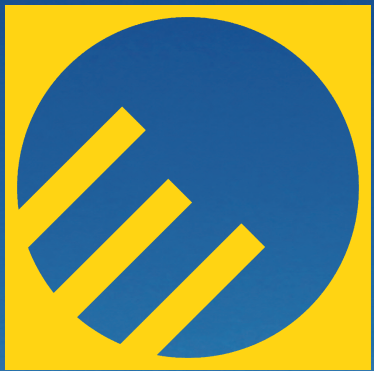

\title{
EuroSun2018
}

$12^{\text {th }}$ International Conference on

Solar Energy for Buildings and Industry

September 10-13, 2018 I Rapperswil, Switzerland

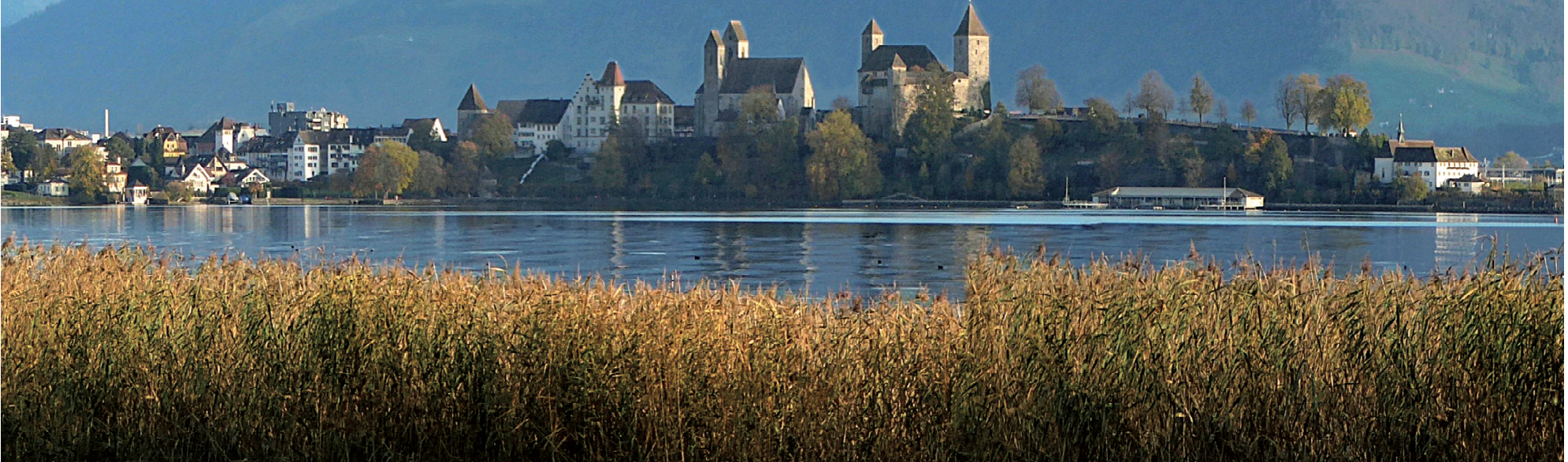

SWISSOLAR 浱 $7^{\text {th }}$ Swissolar

Solar Heating Conference
SIGES $2^{\text {nd }}$ SIGES Conference on the Simulation

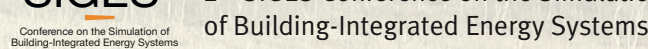

SAC $20188^{8^{\text {th }} \text { International Conference }}$ on Solar Air Conditioning

\section{In cooperation with:}




\title{
Proceedings of the ISES EuroSun 2018 Conference $-12^{\text {th }}$ International Conference on Solar Energy for Buildings and Industry
}

\author{
Editor \\ Dr. Andreas Häberle \\ EuroSun 2018, Chair of the Scientific Committee
}

Copyright (C) 2018 by the International Solar Energy Society and the Authors
International Solar Energy Society
Wiesentalstr 50
79115 Freiburg
Germany
$\begin{array}{ll}\text { Tel } & +4976145906-0 \\ \text { Fax } & +4976145906-99 \\ \text { Email } & \text { hq@ises.org } \\ \text { Web } & \text { http://www.ises.org }\end{array}$

\section{ISBN 978-3-9820408-0-6}

All rights reserved. No part of the publication may be reproduced, transmitted, in any form or by any means, electronic, mechanical, photocopying, recording or otherwise, without permission of the publisher, except in the case of brief quotations embodied in critical articles and review or where prior rights are preserved.

\section{Produced by}

International Solar Energy Society and PSE Conferences and Consulting GmbH

\section{Notice}

The International Solar Energy Society, the HSR Hochschule fur Technik Rapperswil (Technical University of Rapperswil), PSE Conferences and Consulting GmbH or any one of the supporters or sponsors of the EuroSun 2018 makes any warranty, express or implied, or accepts legal liability or responsibility for the accuracy, completeness or usefulness of any information, apparatus, product or process disclosed, or represents that its use would not infringe privately on rights of others. The contents of articles express the opinion of the authors and are not necessarily endorsed by the International Solar Energy Society, the HSR Hochschule fur Technik Rapperswil (Technical University of Rapperswil), PSE Conferences and Consulting $\mathrm{GmbH}$ or by any of the supporters or sponsors of the EuroSun 2018. The International Solar Energy Society, the HSR Hochschule fur Technik Rapperswil (Technical University of Rapperswil) and PSE Conferences and Consulting GmbH do not necessarily condone the politics, political affiliation and opinions of the authors or their sponsors. 


\section{We thank our Sponsors and Supporters!}

\section{Hoval}

\section{polysun \\ SIMULATION \\ SOFTWARE}

\section{HSR}

HOCHSCHULE FÜR TECHNIK

RAPPERSWIL

FHO Fachhochschule Ostschweiz
SWISSOLAR 注

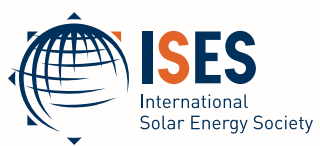

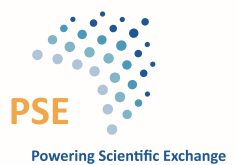

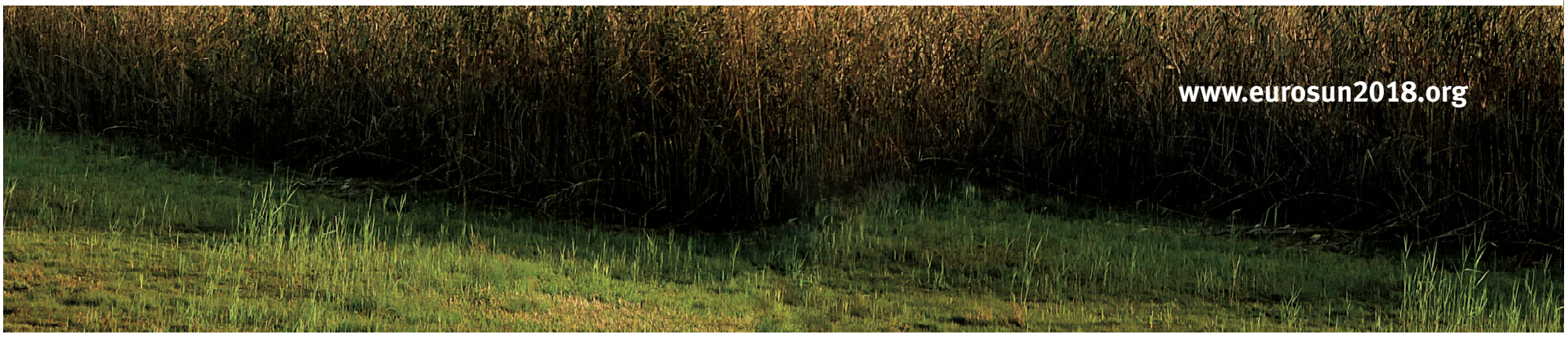




\section{EuroSun2018}

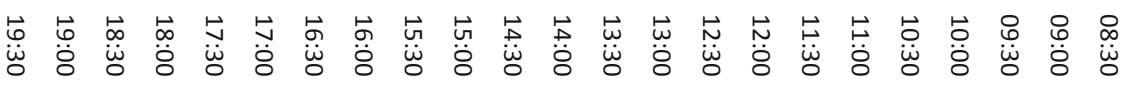
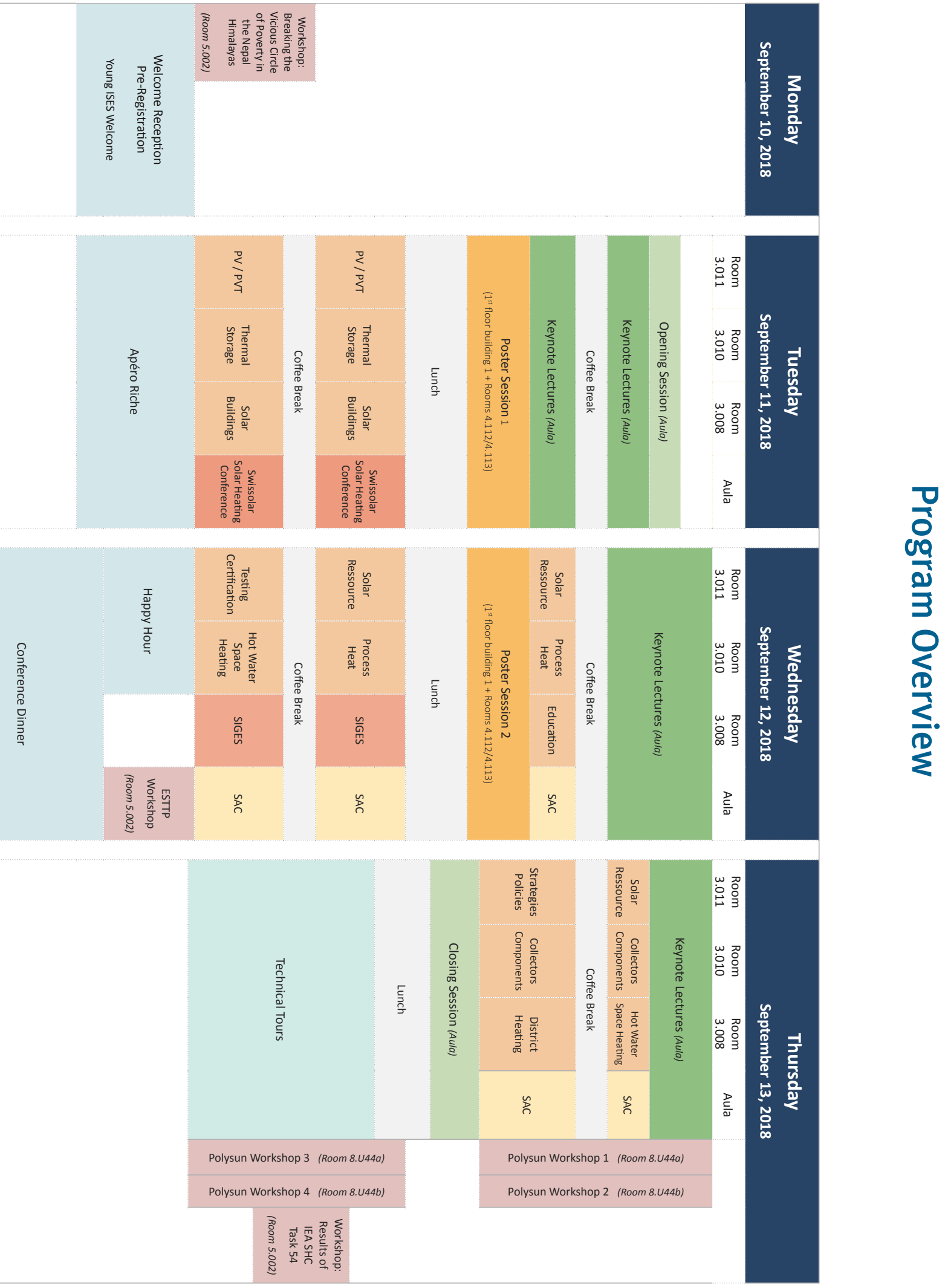


\section{Editorial}

Editorial to the Proceedings of EuroSun 2018

Häberle, A, Stickelberger, D., Streicher, W., Renne, D. . .

\section{Scientific Program}

\section{Solar Buildings}

Evacuated Glazing with Silica Aerogel Spacers

Büttner, B., Beck, A., Buck, D., Heinemann, U., Nauschütz, J., Reichenauer, G.,

Scherdel, C., Weinläder, H., Weismann, S. . .

Radiative Cooling to Cover Cooling Demands of an Earthbag Building in a Training Medical Cernter in Burkina Faso

Castell, A., Carrobé, A., Martorell, I., Medrano, M., Rincón, L., Vall, S.

Definition of a Reference Office Building for Simulation Based Evaluation of Solar Envelope Systems

D'Antoni, M., Bonato, P., Fedrizzi, R., Geisler-Moroder, D., Loonen, R.C.G.M., Magni, M., Ochs, F.E., de Vries, S. . .

Building Integrated Photovoltaic Systems - Energy Production Modelling in Urban Environment

Govehovitch, B., Giroux-Julien, S., Ménézo, C., Peyrol, E. .

The SOLAR DECATHLON Knowledge Platform - Concept and Initial Application

Hendel, S. . . .

Difference in Evaluation of Discomfort Glare from Windows between Middle-Eastern and Japanese Students

Iwata, $T$.

Energy Efficient \& Sustainable Buildings in Qatar \& Integration of Solar Assisted Air-

Conditioning Technology - a Step Towards Grid Free Zero Carbon Living

Khan, M., Hassabou, A., Heithorst, B., Spinnler, M.

Energy Performance Investigation of Energy-Plus Solar House Integrated Renewable Energy Systems

$\mathrm{Kim}, \mathrm{M}$

Control Strategies for a Residential Property with Solar Building, Thermal and Electricity Storages 
Modular Rooftop Building-Integrated Photovoltaic/Thermal Systems for Low-Rise Buildings in India

Kruglov, O., Athienitis, A., Bagchi, A., Ge, H., Lee, B., Rounis, E., Stathopoulos, T.

Semi-Virtual Tests of a System Using Exhaust Air, Grey Water and Solar Heat for Domestic Hot Water and Space Heating Needs of a Multifamily House

Leconte, A., Moureaux, S.

Thermal Monitoring on an Earthbag Building in Mediterranean Continental Climate

Martorell, I., Carrobé, A., Medrano, M., Rincón, L., Solé, C. . .

Solar Seminar Room in the University of Balearic Islands with a New Advanced Radiant System

Moià-Pol, $A$.

bFAST: A Methodology for Assessing the Solar Potential of Façades in Existing Building Stocks

Polo López, C.S., Corti, P., Frontini, F., Polo Lopez, C.S., Saretta, E. . .

High Solar Fraction By Thermally Activated Components

Ramschak, T., Becke, W., Fink, C., Heimrath, R., Lerch, W., Mach, T.

Early Design Stage Consideration of Building Form and BIPVT Energy Performance

Yip, S., Athienitis, A., Lee, B. 140

An Aesthetic Energy Producing Roof with Integration of PV Modules and Solar Thermal Collectors

de Keizer, C., Rindt, C., de Jong, M., van Diemen, R., van Paassen, M., van de Voort, $R$. . . 149

\section{Solar Assisted District Heating and Cooling}

Comparison of Solar District Heating Concepts at Various Land Prices

Best, I., Orozaliev, J., Vajen, K.

Energetic and Economic Analysis of a Solar-Assisted Trigeneration System

D'Antoni, M., Fedrizzi, $R$.

Thermo-Chemical District Networks

Koller, C., Bergmann, T., Danesi, S.

Distributed vs Centralized Solar District Systems. Study Case in Balearic Islands Districts

Moià-Pol, A., Sabater, $P$.

Development of a Software System for Optimal Operation of Heating Networks with Central Solar Plant

Oppelt, T., Frey, H., Göschel, T., Heinrich, I., Otto, S., Schmidt, A., Uhlig, U., Urbaneck, T.

Opportunities for the Integration of Solar Thermal Heat, Photovoltaics and Biomass in a Brazilian Hospital

Pina, E.A., Lozano, M.A., Serra, L.M.

Experimental Plant for Analyzing the Technical Feasibility of Decentralized Solar Heat Feed-In 


\section{Solar Heat for Industrial Processes}

Optical Analysis of an Evacuated Tube Collector with Built-In Semicircular Concentrator for Process Heat Applications

Christodoulaki, R., Drosou, V., Tsekouras, P. . .

Environmental Assessment of Industrial Solar Thermal Systems

Fokaides, P., Ioannides, A., Jurelionis, A., Kalogirou, S., Kylili, A., Souliotis, M., Valancius, R. . . . . . . . . . . . . 229

RESSSPI: The Network of Simulated Solar Systems for Industrial Processes

Frasquet, M., Nel, Y., Silva, M., bannenberg, J.

Cleaning Strategies for Fresnel Linear Concentrator Mirrors in Solar Heating Plants

Gabbrielli, R., Del Medico, F., Di Palo, M., Gulino, G.

Solar Heat in Industrial Processes in Switzerland - Theoretical Potential and Promising Sectors

Guillaume, M., Bunea, M.S., Caflisch, M., Martin, J., Rittmann-Frank, M.H. 257

Solar Heat Integration in Rotational Molding Process: Case Study

Laadel, N.E., Agalit, H., Bennouna, E.G., Mouaky, A. 268

Standardisation of Solar Process Heat Applications to Increase Market Penetration

Schmitt, B., Jesper, M., Pag, F., Ritter, D., Vajen, K., Wimmer, L.

Thermal Analysis and Validation of a Geodesic Dome Dryer for Capsicum Baccatum

Vergara, S., Hadzich, M., Herrera, E., Lopez Vasquez, E., Perez, J., Tipula, R. 290

\section{Domestic Hot Water and Space Heating}

Efficient Design of Solar Assisted Heating Systems for Multi-Family Houses

Backes, K., Adam, M., Eggert, D., Götzelmann, D., Helbig, S., Wirth, H.P. . .

Energetic Behaviour of a Solar Thermal System Producing Domestic Hot Water and Preheating the Ventilation Air

Carbajo Jiménez, P., Fraisse, G., Leconte, A., Ouvrier Bonnaz, O., Wurtz, E.

Comparative Dynamic Performance Tests of Two Real Technology Packages for Buildings

Heating System Retrofit

Chèze, D., Fuligni, F., Nicolas, L., Patric, B.

Drainback Solar Thermal Systems in Switzerland - Market Overview and Main Barriers

Eicher, S., Bony, J., Bunea, M., Citherlet, S., Guillaume, M.

Experimental Analysis of Air-Water Heat Exchanger with Microchannel Coil Exposed to Different Working Parameters

Glazar, V., Kirini, M., Leni, K., Trp, A. .

Hardware-In-The-Loop Tests on Complete Systems with Heat Pumps and PV for the Supply of Heat and Electricity

Haberl, R., Bamberger, E., Haller, M., Reber, A. . .

Sustainability Assessment of Most Relevant Solar Thermal Heat Systems

Kicker, H., Lang, R.W., Wallner, G.M. . . 
Artificial Intelligence for the Efficient Control of Solar Heating Systems

Kramer, W.

Simulation-Based Optimization of Solar Combisystem. Sensitivity Analysis at Optimum

Kusyy, O., Vajen, K. .

Measurement Evaluation and Simulation of an Innovative Drainback Solar Combi-System

Louvet, Y., Orozaliev, J., Vajen, K.

Simulation and Monitoring of PV Heat Pump System with Seasonal Storage

Matuska, T., Broum, M., Sourek, B. . . 409

Towards Automated Continuous Performance Benchmarking of DHW and Combi Systems

Schmelzer, C., Georgii, M., Kusyy, O., Orozaliev, J., Vajen, K.

Single Source "solar Thermal" Heat Pump for Residential Heat Supply: Performance with an Array of Unglazed PVT Collectors

Schmidt, C., Schäfer, A.

Polymer Collectors with Temperature Control - Thermosyphon Valve Development and System Integration

Thür, A., Hauer, N., Schroll, J.

Review of Combined Solar Thermal and Heat Pump Systems Installations in Lithuanian Hospitals

Valancius, R., Cerneckiene, J., Singh, R.M.

Solar Thermal Systems VS. Photovoltaic Systems. Case Study: Single Family Building in Lithuania

Valancius, R., Cerneckiene, J., Fokaides, P., Jurelionis, A., Vaiciunas, J. . . . . . . . . . . . . . . . . . . . . . . . . 449

Space Cooling Application with Unglazed Solar Absorber

Wemhoener, C., Schwarz, R. .

The Development of the Sunridge, an Orientation Independent Thermal Solar System

de Geus, A., de Beijer, H.

Direct Solar Thermal Systems with Thermosiphon Frost Protection and Innovative Control Strategies Using a Thermo-Differential Bypass Valve

\section{Solar Air Conditioning and Refrigeration (8th International Workshop on Solar Air Conditioning)}

Selection of High-Performance Working Fluid for a Solar-Geothermal Absorption Cooling System and Techno-Economic Study in the Northern Mexican Conditions

Altamirano Cundapí, A., Le Pierrès, N., Stutz, B.

Life Cycle Assessment Experiences for Solar Heating and Cooling Systems

Beccali, M., Cellura, M., Cusenza, M.A., Longo, S., Mugnier, D., Selke, T., Vicente Quiles, P.G.

Monitoring and Energy Performance Assessment of the Compact DEC HVAC System "Freescoo

Facade" in Lampedusa (Italy)

Beccali, M., Di Pietra, B., Finocchiaro, P., Motta, M. . 
Modelling of an Absorption Cycle With a Direct Ammonia Vapor Generator Inside a

Concentrating Parabolic Trough Solar Collector

Celik, S.B., Famiglietti, A., Lecuona Neuman, A., Rodrigues Aumente, P.A.

Modelling and Simulation of a PV Driven Refrigerator with Phase-Change Materials in the Internal Walls

Coca-Ortegón, A., Coronas, A., Müller, J., Torres, V.

Simulations of Solar Thermal Cooling System for a Building at Innovation Park Muscat

Cordes, T., Al-Riyami, S., Scheuren, J., Schlatmann, R. .

Simulation of a Solar Fired Absorption System for a Case Study in the Dairy Industry

Correa-Jullian, C., Cortés, F., Crespo, A., Ibarra, M.

Design and Construction of a $\mathbf{1 0}$ KW Sorption Heat Pump Prototype

Daguenet-Frick, X., Gantenbein, P., Haeberle, A., Persdorf, P. . .

Development of a Photovoltaic Driven Thermodynamic Chiller - Application to Solar Air

Conditioning And Cooling Storage

Esparcieux, P., Baup, O., Marvillet, C., Mugnier, D., Weber, C. . .

Measurement Results and Operating Experience of Large-Scale Solar Air Conditioning Plants

Feierl, L., Holter, C., Poier, H. . .

Experimental Investigation on the Dynamic Performance of a Thermally-Driven Adsorption Chiller Integrated with a Gas Boiler

Fuentes, E., Balsells, M., Bellanco, I., Impala, V., Mogro, O., Salom, J., SanJoaquín, S., Sayans, A. . . . . . . . . . 585

PV Driven Dew-Point Cooling for Australia

Goldsworthy, M., Sethuvenkatraman, S.

Experimental Comparison of Scroll and Swash-Plate Compressors for PV Driven Compression Chillers and Heat Pumps

Heithorst, B., Bauer, G., Irrgang, L., Rauscher, B., Sattelmayer, T., Spinnler, M. ...

Design and Practical Validation of a Hybrid Absorption/Compression Chiller Driven by Low-

Grade Heat

Helm, M., Eckert, T.

Modified Solar-Assisted Ejector Cooling System

Huang, B., Ko, H.

Levelised Cost of Thermal Energy Storage and Battery Storage to Store Solar PV Energy for Cooling Purpose

Luerssen, C., Cheong, K.W.D., Gandhi, O., Reindl, T., Sekhar, C.

Comparison of Modeled and Measured Heat and Mass Transfer in a Liquid Desiccant Air-

Conditioning System

Mandow, W., Fleig, D., Jordan, U., Lowenstein, A., Mützel, M., Vajen, K. . .

Development of Solar Assisted Sorption Unit for Extraction of Water from Ambient Air in Desert

Climate

Matuska, T., Sourek, B., Zmrhal, V. . .

Using the Heat of Sun to Cool: A Case Study of 100 TR (350kWth) Solar Air-Conditioning System 
Technical and Economic Performance of Best Practice SHC Plants - A Compilation of IEA SHC Task $\mathbf{5 3}$ Results

Neyer, D., Köll, R., Mugnier, D.

Experimentally Validated Dynamic Model for a Hybrid Cascade System for Solar Heating and Cooling Applications

Palomba, V., Frazzica, A., Große, A., Kühnert, S.

Performance Analysis of a Small Scale Solar Cooling Plant Based on Experimental Measurements

Pellegrini, M., Bianchini, A., Guzzini, A., Saccani, C.

New Water Adsorbent for Adsorption Driven Chillers

Risti, A., Krajnc, A., Zabukovec Logar, N. . .

Efficient Solar Driven Air Conditioning System for Hot Climates: Case Study of Doha

Tamainot-Telto, $Z$.

Performance Investigation of Liquid Desiccant Dehumidification System Integrated with Solar Thermal Energy and Shallow Geothermal Energy

Tseng, C., Chen, S., Liang, J., Yang, L. . .

Application of PCM in Building's Envelope of Lightweight Prefabricated Houses as an addition to a PV driven renovation cooling system by EU project HEART

Zavrl, E., Dovjak, M., Stritih, U., Zupanc, G.

\section{PV and PVT Systems for Buildings and Industry}

Field Test Results of an Innovative PV/T Collector for an Outdoor Swimming Pool

Brottier, L., Bennacer, R. . . . . . . . . . . . . . . . . . . . . . . . . . . . . . . . . . . . . . . . . . . . . . .738

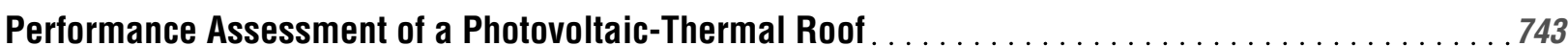

Electrical and Thermal Performance Evaluation of a District Heating System Composed of Asymmetric low concentration PVT Solar Collector Prototypes

Cabral, D., Costeira, J., Gomes, J. . . .

Potential of Covering Electricity Needs of a Flat of a MFH with Decentral Compact Heat Pumps with PV - Simulation Study for Different DHW Profiles and PV Field Sizes

Calabrese, T., Dermentzis, G., Siegele, D.

Assessment of the Suitability of Different Photovoltaic Cell Technologies for Product Development of Building Integrated Solutions Using the Hierarchy Process (ahp)

Haghighi, Z., Isabella, O., Konstantinou, T., Ortiz Lizcano, J.C., Zeman, M., van den Dobbelsteen, A. .

Economic Feasibility of Solar PV System for Buildings

Huang, B., Hsu, P.C.

Comparative Economic Analysis of Single and Dual-Fluid Based Photovoltaic Thermal Systems for Building Energy Needs

Hussain, M.I.

Implementation and Experimental Validation of a Photovoltaic-Thermal (PVT) Collector Model in TRNSYS

Jonas, D., Frey, G., Theis, D. 
Numerical Simulation of the Thermal Performance of Four Prototypes of CPC Collectors That Use Bifacial PV Cells

Lança, M., Gomes, J., Hayati, A.

Organic PVT - A Novel Hybrid Collector Combining Organic Photovoltaics and Polymer

Absorbers

Lämmle, M., Hernandez Gonzalez, H., Li, C., Meir, M., Piekarczyk, A., Pita Bauermann, L., Rekstad, J.

Degradation of photovoltaic systems based on long-term measurements and laboratory tests

Muntwyler, U., Schott, T.

Development and Field Testing of a Novel Hybrid PV-Thermal Solar Collector

Murrell, A., Alonso Alvarez, D., Ekins-Daukes, N., Mellor, A., Povall, S., Williams, C. . .

Study on Distributed MPPT System in Solar EV

Nemoto, Y., Fujisawa, T.

Glazed PVT Collector Integrated Into Façade Module

Pokorny, N., Jirka, V., Matuska, T., Sourek, B. . . 850

Design and Performance Assessment of a Prefabricated BIPV/T Roof System Coupled with a Heat Pump

Rounis, E.D., Athienitis, A., Dumoulin, R., Ioannidis, Z., Kruglov, O., Stathopoulos, T.

Solar Hybrid PVT Coupled Heat Pump Systems Towards Cost-Competitive NZEB

Sanz Martinez, A., Fuente Dacal, R., Martín Miranda, A.J.

Experimental Performance Evaluation of PV/T Panels at Negative Reduced Temperatures

Simonetti, R., Manzolini, G., Molinaroli, L. . .

Experimental Investigation of PVT Collectors with Phase Change Material

Simón, R., Brun, G., Guedea, I., Villén, R. . .

A Techno-Economic Comparison Between PV and PVT Integrated Ground Source Heat Pumps for Multi-Family Houses

Sommerfeldt, N., Madani, H. . .

Multi-Objective Optimization of a Solar Heat Pump System Using PVT and Ice-Based Latent

Storage

Tamasauskas, J., Poirier, M., Zmeureanu, R.

PV Power Production Estimation by Using Radiometric and Meteorological Data

Trigo, M., Alonso-Montesinos, J., Batlles, F.J., Cortés, M., Ferrada, P., Martinez-Durbán, M., Marzo, A., Portillo, C., Rosiek, S. . .

Improvements on the Efficiency of the Photovoltaic Panel by Integrating a Spray Cooling System with Shallow Geothermal Energy Heat Exchanger

Yang, L., Chen, S., Liang, J., Tseng, C. . .

Extended Hottel-Whillier Models for uncovered PVT-Collectors

Zenhäusern, D., Battaglia, M.

An Overview of PVT Modules on the European Market and the Barriers and Opportunities for the Dutch Market

de Keizer, C., Bottse, J., Folkerts, W., de Jong, M. 


\section{Solar Thermal Collectors and Solar Loop Components}

Annual Efficiency - Easy Understanding of Collector Performance

Abrecht, $S$. ...

Assessment of Durability of Solar Absorbers - Performance Criterion

Carvalho, M.J., Diamantino, T., Páscoa, S. . .

Accelerated Aging Tests for Solar Absorber Coatings

Diamantino, T., Carvalho, M.J., Chambino, T., Ferreira, C., Gonçalves, R., Nascimento, I., Páscoa, S. .973

Influence of Using Different SiO2 Antireflective Coatings and Sintering Conditions on the Durability and Optical Performance of the Selective Solar Absorber

Farchado, M., Germán, N., Morales, Á., San Vicente, G.

Testing and Modeling of Direct Steam Generating Parabolic Trough Collectors

Ferchichi, S., Ben Cheikh, R., Bouden, C., Castro, J., Kessentini, H.,

Morales, S., Oliveira, A., Soares, J., Willwerth, L. .

Basic Study on Flow Stabilization of Top-Heat-Type Thermosiphon

Fujisawa, T., Kawaguchi, T. . .

Ray Tracing Method for the Evaluation of Yearly Performance of a Solar Thermal Concentrator

García, H., Delgado, O., Gutierrez, A., Ramirez, C. .

Tailoring Alumina Matrix Optical Properties for Colored Solar Thermal Absorber Coatings

Isac, L., Duta, A., Perniu, D.

Experimental Investigations on the Stagnation Behavior of Thermochromic Flat Plate Collectors

Müller, S., Giovannetti, F., Hafner, B., Reineke-Koch, R. . .

Theoretical Analysis of Combined Solar System Based on Dual Purpose Solar Collector

Pokorny, N., Matuska, T., Shemelin, V., Sourek, B. . .

Solar Flux Map Distribution of a Parabolic-Spheric Dish Based on Photographic Method

Roccabruna, M., Crema, L., Menna, F., Remondino, F. . .

Abrasion and Cleaning Tests on Antireflective and Antireflective/Antisoiling Coatings for Solar Glass Glazing

San Vicente, G., Farchado, M., Germán, N., Morales, Á. . .

Radiative Collector and Emitter: Experimental Results

Vall, S., Medrano, M., Solé, C. .

Surface Modification of AISI 316 Stainless Steel by Oxynitrocarburizing for Solar Collector

Applications

Vargas, G., Chávez, A.F., López, L. .

Electroplating of Selective Surfaces for Concentrating Solar Collectors

Zäll, E., Mossegård, J., Nordenström, A., Wågberg, T. . 
Stratification in Large Thermal Storage Tanks

Battaglia, M., Haller, M.

Thermal Collection and Seasonal Storage Potential of a Mixed-Use Neighborhood

Hachem-Vermette, C., Cellura, M., Guarirno, F.

Experimental Study of a $\mathbf{6 0 0}$ w Seasonal Solar Heat Storage Reactor for the Heating of Buildings

Hennaut, S., André, P., Baiwir, R., Collard, L., Davin, E.

Sensible Thermal Energy Storage in Packed Bed for Industrial Solar Applications

Kocak, B., Paksoy, H.O. .

Encapsulation of Inorganic Phase Change Materials by Sol-Gel Method for Thermal Energy

Storage

Lucio, B., Romero, M.

Preliminary Results for the First Year of Operation of a Seasonal Storage Solar Combisystem for a Single Detached House

Meister, C., Beausoleil-Morrison, I.

Modeling and Validation of Different Heat Exchanger Geometries for Solar Ice Storage Systems

Paulini, S., Brüggemann, D., Plessing, T.

Validation of an Ice Storage Model and Its Integration Into a Solar-Ice System

Philippen, D., Battaglia, M., Carbonell, D., Kunath, L., Thissen, B.

Decentralized DHW Production from Exhaust Air in the Bathroom Prewall

Ruesch, F., Büchel, E., Haller, M., Persdorf, P., Urena, D.

Design and Evaluation of a Compact Thermal Storage System Using River Stones for a Continuous Drying Process of Agricultural Products in Peru

Tipula Ramos, R.R., Hadzich Marin, M.A., Herrera, E., Lopez Vasquez, E., Vergara Dávila, S.G. . .

Development of a Solar Paddy Dryer by Fluidization Technique Using Heat from a Solar Pond

Tundee, S., Rongchai, K.

High Temperature Seasonal BTES for Effective Load Shifting and C02 Emission Reduction

Weber, R., Baldini, L.

Semi Continuous Thermochemical Reactor for Thermal Storage

Wyttenbach, J., Descy, G., Descy, A.

1210

\section{Testing \& Certification}

Optical Properties of Solar Absorbers - Results on Round Robin and Guidelines

Carvalho, M.J., Bohren, A., Fischer, S., Loren, A., Nielsen, J.E.,

Páscoa, S., Sallaberry, F., Wilson, H.R. . .

In Situ Characterization of Thermal Collectors in Field Installations

Fahr, S., Gumbel, U., Kramer, K., Zirkel-Hofer, A. . .

Modelling the Relative Humidity Inside Flat Plate Collectors

Fischer, S., Marquez, F. 
Comparative Analysis of Life-Cycle Assessment Tools (LCA) Using the Example of Different Energy Supply Variants of a Purpose-Built Building

Kastner, R., Reim, M., Weismann, S., Yu, Y. ...

Quasi-Dynamic Testing of a Novel Concentrating Solar Collector According to ISO 9806:2013

Kurdia, A., Gomes, J., Ollas, P., Olsson, O., Pius, G. .

Comparison of Two Whole System Test Methods: CCT and PLPE

Menegon, D., Haberl, R., Haller, M. . .

Analysis of Applicability of PLPE Method for the Test of a Solar Cooling System

Menegon, D.

OTSun: An Open Source Code for Optical Analysis of Solar Thermal Collectors and PV Cells

Pujol-Nadal, R., Bonnín-Ripoll, F., Cardona, G., Hertel, J.D., Martínez-Moll, V.

Ageing Performance of New Solar Cover Materials After Outdoor Exposure

Ruesch, F., Brunold, S.

CFD-Based Development, Testing and Optimization of Flat Plate Collectors

Vetter, B., Drück, H., Fischer, S. . .

\section{System Simulation (2nd SIGES Conference on the Simulation of Building- Integrated Energy Systems)}

An Improved Model for Phase Change Material (PCM) Thermal Storage Tanks

Andrés Chicote, M., Sanz Jimeno, $R$.

Model Predictive Control for Building Automation

Bolt, P., Füchslin, R., Jaeger, C., Maier, O., Ritzmann, R., Zierbart, V. . . . . . . . . . . . . . . . . . . . . . . . . . 1330

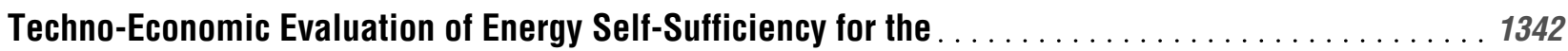

PIPE Network Analysis for Solar Thermal Plants

Eismann, $R$.

Dynamic Modelling of a Hybrid Solar Thermal/Electric Storage System for Application in

Residential Buildings

Frazzica, A., Barz, T., Cabeza, L.F., Emhofer, J., Ferraro, M., Karellas, S.,

Orò, E., Palomba, V., Sergi, F., Varvagiannis, S., Zsembinszki, G.

Potential of Direct Solar Thermal Driven Absorption Heat Pump in Hybrid Systems

Gritzer, F., Neyer, D., Ostheimer, M., Thür, A.

Dynamic Modeling and Optimization of Energy Use in Retrofitted Buildings at District Heating Level

Iturralde, J., Chicote, M.A., Martín, J., Martín, E., Pascual, C., Urra, I., Vasallo, A. ...

BIM Use Case: Model-Based Performance Optimization

Jakobi, M., Stöckli, U., Witzig, A.

From Simulation to Reality: IEC 61499 Compliant Control Applications for Solar Energy Systems Jakobi, M., Meier, L., Quaschning, V., Stöckli, U., Tjaden, T. . . 
Theoretical Analysis of Photovoltaic Panels Using a Spray Cooling System with a Shallow Geothermal Energy Heat Exchanger

Liang, J., Chen, S., Tseng, C., Yang, L.

BIM a Driver for Energy Transition and BIVP Adoption

Nguyen, V.K., Machado, M.

A Comparison of Stratified Heat Storage With and Without Modular PCM Storage Through

Simulation

Pabst, V., Mengedoht, G., Renze, P. . .

Using Behavior Simulation to Synthesize Electromobility Charging Profiles

Pflugradt, N., Muntwyler, U.

Multiobjective Synthesis of a Polygeneration System for a Residential Building Integrating

Renewable Energy and Electrical and Thermal Energy Storage

Pinto, E.S., Serra, L.M.

Quantifying the Potential of Smart Heat-Pump Control to Increase the Self-Consumption of Photovoltaic Electricity in Buildings

Stauffer, Y., Alet, P., Hutter, A., Koch, N., Pflugradt, N.

Integrating Polysun into a Test Bench for Prosumer Hardware

Wienands, S., Pflugradt, N.D., Vezzini, A. . .

1475

\section{Solar Resource and Energy Meteorology}

A First Approach of the Influence of the Forecasting Horizon in the Electricity Generation Simulation of a Solar Tower Plant

Alonso-Montesinos, J... .

Climatic and Global Validation of Daily MODIS Precipitable Water Data at AERONET Sites for Clear-sky Irradiance Modelling

Bright, J.M., Engerer, N.A., Gueymard, C., Killinger, S., Lingfors, D., Sun, X., Wang, P. . .

Brazilian Photovoltaic Potential

Bueno Pereira, E., Ramos Martins, F., Rodrigues Gonçalves, A., Santos Costa, $R$.

Assessing Solar Electricity Potential and Prospective Present Day Costs For A Low Latitude

Caribbean Island: Trinidad

Dookie, N., Chadee, X.T., Clarke, R.M. . .

Accuracy of Solar Resource Assessments on the Basis of Publicly Available GHI Databases

Egler, M.

Solar Irradiation Over a Flat Surface with Different Tracking Strategies

Gonzalez-Cabrera, A.E., Arancibia-Bulnes, C., Estevez, H., Ramirez-Ramirez, A., Valdes-Barron, M., Zarzalejo, F. . . 1532

Validation of Real-Time Solar Irradiance Simulations Over Kuwait Using WRF-Solar

Gueymard, C., Jimenez, $P$.

Progress in Sky Radiance and Luminance Modeling Using Circumsolar Radiation and Sky View Factors

Gueymard, C., Ivanova, S. 
Most Probable Operating Conditions and Performance Assessment of Four PV Technologies at 10 Locations in India

Gupta, N.C., Das, P.K., Giridhar, G.

Short Term PV Forecasting Using Satellite Data for Austria

Kortschak, D., Feichtinger-Hofer, M., Kernitzkyi, M.

The Spatial and Temporal Patterns of the Surface Solar Irradiation in Northeastern Region of

Brazil

Lima, F., Costa, R., Gonçalves, A., Martins, F., Pereira, E., Santos, A.P.

Regression by Integration applied to Angström-Prescott-type Relations

Morf, $H$.

Effect of Solar Position Calculations on Filtering and Analysis of Solar Radiation Measurements

Perez-Astudillo, D., Bachour, D., Martin-Pomares, L.

Urban Climate - Impact on Energy Consumption an Thermal Comfort of Buildings

Remund, J., Grossenbacher, U. .

Evaluation of Solar Radiation from MERRA, MERRA-2, ERA-Interim and CFSR Reanalysis

Datasets Against Surface Observations for Multan, Pakistan

Tahir, Z.u.R., Ahmad, S.U., Ali, M.J., Asim, M., Azhar, M., Hayat, N., Hussain, A.

Evaluation of NCEP-Products (NCEP-NCAR, NCEP-DOE, NCEP-FNL, NCEP-GFS) of Solar

Radiation for Karachi, Pakistan

Tahir, Z.u.R., Ali, H., Asim, M., Azhar, M., Hayat, N., Shahid, H. .

Monthly Solar Irradiance Variability in Brazilian Climate Zones

Weide Luiz, E., Bueno Pereira, E., Gonçalves de Souza, J., J. Lopes de Lima, F.,

Pizzuti Pes, M., Ramos Martins, F., Rodrigues Gonçalves, A., Santos Costa, R.

\section{Solar Education}

On the Importance of Education when Implementing Renewable Energy

Broman, L., Kandpal, T.C., Ott, A. .

A Simple Tool for Assessing Solar and Daylight Access in Urban Canyons

Compagnon, R., Chatzipoulka, C.

Development of a Compact and Didactic Solar Energy Kit Using Arduino

Costeira, J., Cabral, D., Gomes, J., Hayati, A., Vieira, M. . .

Using Heliodon for Solar Building Design Education in the Age of Computer Simulations

Pajek, L., Božiek, D., Dovjak, M., Košir, M., Kuni, R., Potonik, J., Šubic, N. . .

Dialogue Between Research Solar Practices and Training Activities: Interactive Webinar by Integration of ICT in Education

Polo López, C.S., Frontini, F.

Understanding the Dynamics of Solar Energy Systems by Using Simulation Narratives

Witzig, A., Borth, J., Danesi, S. 


\section{Renewable Energy Strategies and Policies}

Indoor Climate Agreements in Energy-Efficiency and Renovation Projects - A Question of Justice?

Henning, A.

Photovoltaics or Solar Thermal -The Winner Takes it All?

Muntwyler, U., Schuepbach, E.

Preliminary Economic Evaluation of the First Grid-Connected Photovoltaic System in the Aysén Region Under the Current Law of Distributed Generation in Chile

Osorio-Aravena, J.C., Muñoz-Cerón, E.

Accompanying Project Owners and Professionals All the Way to Secure Solar Thermal Plants

Porcheyre, E., Mugnier, D.

Research for Compiling a Mandatory National StandardTechnical Code for Energy Efficiency in Buildings and Renewable Energy Application

Zheng, R., He, T., Li, B., Wang, M., Zhang, X.

\section{Author Index}

Index of all Authors 
Editorial 


\section{Editorial to the proceedings of EuroSun 2018, The 12th International Conference on Solar Energy for Buildings and Industry \\ Andreas Häberle, David Stickelberger, Wolfgang Streicher, Dave Renné}

\section{Introduction}

It was our great pleasure to host EuroSun 2018 in Rapperswil, Switzerland.

The worldwide success of renewable energy technologies, and solar energy in particular, is remarkable, and it is what we all work for. In many cases solar technologies are already the most economical way to produce electricity or heat. But there is still a very long way to go to achieve the goal of a 100\% renewable energy supply. Efficiencies must improve and the costs of components and services must be reduced further. We need a shift to thinking in terms of systems and a better understanding of the interaction of the electricity, heat and mobility sectors.

In the last few years we have seen a growing competition between solar thermal technologies and solar electricity in the heating sector. It is not yet clear where that competition will lead us. Most certainly our future energy system will have a higher grade of electrification. On the other hand, it seems likely that energy systems will be more stable and more efficient if a variety of technologies complement each other.

The EuroSun conferences focus on Solar Energy for Buildings and Industry, covering both, heat and electricity.

EuroSun 2018 was organized in cooperation with the Swissolar Solar Heating Conference, the 2nd SIGES Conference on the Simulation of Energy Systems for Buildings and the 8th International Conference on Solar Air Conditioning.

EuroSun 2018 offered a platform to discuss the latest developments with leading solar energy experts as well as policy makers and industry representatives. The program included distinguished keynote speakers in plenary sessions, specialists meetings in breakout sessions and poster exhibitions as well as social events where you had the opportunity to network, meet old friends and to make new ones.

For three days the campus of HSR in Rapperswil hosted the "who"s who" in solar energy for buildings and industry: 344 participants from 49 nations around the world received 116 oral presentations and 156 poster presentations.

\section{Conference Topics}

1. Solar Buildings

2. Solar Assisted District Heating and Cooling

3. Solar Heat for Industrial Processes

4. Domestic Hot Water and Space Heating

5. Solar Air Conditioning and Refrigeration (8th International Conference on Solar Air Conditioning)

6. PV and PVT Systems for Buildings and Industry

7. Solar Thermal Collectors and Solar Loop Components

8. Thermal Storage

9. Testing \& Certification

10. System Simulation (2nd SIGES Conference on the Simulation of Building-Integrated Energy Systems)

11. Solar Resource and Energy Meteorology

12. Solar Education

13. Renewable Energy Strategies and Policies

The proceedings contain 184 manuscripts. We would like to thank all authors for their contributions.

Also many thanks to the EuroSun 2018 scientific committee for the reviewing of abstracts and paper manuscripts as well as the organizing committee for their dedicated support throughout the conference organization. 


\section{Committees}

\section{Scientific Chair}

Andreas Häberle, HSR, Switzerland

\section{Steering Committee}

Christof Biba, HSR, Switzerland

Harald Drück, University of Stuttgart, Germany

Andreas Eckmanns, Swiss Federal Office of Energy,

Switzerland

Sebastian Herkel, Fraunhofer ISE, Germany

Víctor Martínez Moll, University Balearic Islands, Spain

Daniel Mugnier, Tecsol SA, France

Dave Renné, ISES, USA

Christian Schweigler, Munich University of Applied

Sciences, Germany

David Stickelberger, Swissolar, Switzerland

Wolfgang Streicher, University of Innsbruck, Austria

Klaus Vajen, University of Kassel, Germany

Wim van Helden, AEE INTEC, Austria

Andreas Witzig, Zurich University of Applied Sciences,

Switzerland

\section{Organizing Committee}

Stefan Brunold, HSR, Switzerland

Joanna Costello, ISES, Germany

Mihaela Dudita, HSR, Switzerland

Beatrix Feuerbach, PSE, Germany

Felix Flückiger, HSR, Switzerland

Monica Furrer, HSR, Switzerland

Andreas Häberle, HSR, Switzerland

Jasmin Helbling, Swissolar, Switzerland

Stefanie Hermann, PSE, Germany

Arabella Liehr, ISES, Germany

Jennifer McIntosh, ISES, Germany

David Stickelberger, Swissolar, Switzerland

\section{Scientific Committee}

Betsy Agar, Canada

Elsa Andersen, Technical University of Denmark, Denmark

Constantinos A. Balaras, National Observatory of Athens,

Greece

Chris Bales, Högskolan Dalarna, Sweden

Riccardo Battisti, Ambiente Italia, Italy

Marco Beccali, Università degli Studi di Palermo, Italy

Liliana O. Beltran, Texas A\&M University, USA

Nurettin Besli, Harran University, Turkey

Constanze Bongs, Fraunhofer ISE, Germany

Dwipen Boruah, Global Sustainable Energy Solutions India, India

Alessio Bosio, Università Di Parma, Italy

Francois Boudehenn, CEA, France

Christoph Brunner, AEE Intec, Austria

Hüsamettin Bulut, Harran University, Turkey

Marco Calderoni, Politecnico di Milano, Italy

Francesco Calise, University of Naples Federico II, Italy

Maria João Carvalho, LNEG, Portugal

Laltu Chandra, IIT Jodhpur, India

Daniel Chemisana, University of Lleida, Spain

Manuel Collares Pereira, Universidade de Evora, Portugal

Alberto Coronas, Rovira i Virgili University, CREVER,

Spain

Marcelo Cortes-Carmona, University of Antofagasta, Chile

Yanjun Dai, Shanghai Jiao Tong University, China

Henrik Davidsson, Lund University, Sweden

Mathieu Davidsson, Université de la Réunion, Réunion

Samuel Luna de Abreu, Instituto Federal de Santa Catarina, Brazil

Pierre Delmas, NEWHEAT SAS, France
Pedro Dias, ESTIF, Belgium

Vassiliki Drosou, CRES, Greece

Harald Drück, University of Stuttgart, Germany

Jiangtao Du, Liverpool John Moores University, UK

Andreas Eckmanns, BFE, Switzerland

Ursula Eicker, University of Applied Science Stuttgart,

Germany

Yehia Eissa, Khalifa University, United Arab Emirates

Ricardo Enríquez, CIEMAT, Spain

Michael Epstein, Weizmann Institute, Israel

Jianhua Fan, Technical University of Denmark, Denmark

Istvan Farkas, Szent Istvan University, Hungary

Roberto Fedrizzi, EURAC, Italy

Eduardo F. Fernández, University of Jaen, Spain

Christian Fink, AEE Intec, Austria

Stephan Fischer, University of Stuttgart, Germany

Daniela Fontani, CNR, Italy

Francesco Frontini, University of Applied Sciences and Arts

of Southern Switzerland (SUPSI), Switzerland

Simon Furbo, Technical University of Denmark, Denmark

Martín Gaston-Romeo, CENER, Spain

Federico Giovannetti, ISFH, Germany

Daniel González i Castellví, AIGUASOL, Chile

José González-Aguilar, IMDEA, Spain

Chris Gueymard, SolarConsultingServices, USA

Jean-Christophe Hadorn, Switzerland

Michel Haller, SPF, Switzerland

Andreas Hauer, ZAE, Germany

James Hazelton

Zinian He, BSERI, China

Anne Grete Hestnes, NTNU, Norway

Uli Jakob, Green Chiller, Germany

Ulrike Jordan, University of Kassel, Germany

Paul Kaaijk, ADEME, France

Andreas Kazantzidis, University of Patras, Greece

Henner Kerskes, University of Stuttgart, Germany

Christian Kok, Skov PlanEnergi, Denmark

Wolfgang Kramer, Fraunhofer ISE, Germany

Roland Krippner, Nuremberg Institute of Technology,

Germany

Rabindra Kumar, Satpathy Emami Power, India

Chrysovalantou Lamnatou, University of Lleida, Spain

Ana Lázaro, Unizar, Spain

Amandine Le Denn, Tecsol, France

Antonio Lecuona, UC3M, Spain

Florian Lichtblau, Lichtblau Architekten BDA, Germany

Roberto Lollini, EURAC, Italy

Yoann Louvet, University of Kassel, Germany

Tomas Matuska, Czech Technical University, Czech

Republic

Steven Meyers, University of Kassel, Germany

Paulette Middleton, Panorama Pathways, USA

Andreu Moia-Pol, University Balearic Islands, Spain

Mario Motta, Politecnico di Milano, Italy

Daniel Mugnier, Tecsol, France

Urs Muntwyler, Bern University of Applied Sciences BFH,

Switzerland

Les Nelson, IAPMO, USA

Jan Erik Nielsen, SolarKey Int., Denmark

Philip Ohnewein, AEE Intec, Austria

Janybek Orozaliev, University of Kassel, Germany

Philippe Papillon, France

Cedric Paulus, CEA INES, France

Manuel Pérez, Universidad de Almeria, Spain

João Pinho, Universidade Federal do Pará, Brazil

Kaj Pischow, Savo-Solar Oyj, Finland

Jesus Polo, CIEMAT, Spain

Atul Raturi, The University of the South Pacific, Fiji 
Jan Remund, Meteotest, Switzerland

Dave Renne, ISES, USA

Esther Rojas, CIEMAT, Spain

Roberto Román Latorre, Universidad de Chile, Chile

Celestino Ruivo, University of Algarve, Portugal

Radim Rybár, Slovakia

Bastian Schmitt, University of Kassel, Germany

Marion Schroedter-Homscheidt, DLR, Germany

Eva Schüpbach, Bern University of Applied Sciences BFH,

Switzerland

Alessandra Scognamiglio, ENEA, Italy

Luis M. Serra, Universidad de Zaragoza, Spain

Manuel Silva, University of Sevilla, Spain

Manolis Souliotis, University of Western Macedonia, Greece

Gerald Steinmaurer, ASiC, Austria

Wolfgang Streicher, University of Innsbruck, Austria

Uroš Stritih, University of Ljubljana, Slovenia

Christian Tantolin, CEA INES, France

Danjana Theis, htw saar, Germany

Alexander Thür, University of Innsbruck, Austria

Costas Travasaros, Prime Laser Tech, Greece

Alexandra Troi, EURAC, Italy

Kyriakos Tsiftes, University of Cyprus, Cyprus

Klaus Vajen, University of Kassel, Germany

Loreto Valenzuela, CIEMAT, Spain

Wim van Helden, AEE Intec, Austria

Nieves Vela, CIEMAT, Spain

Werner Weiss, AEE Intec, Austria

Stephen White, CSIRO, Australia

Stefan Wilbert, DLR, Germany 
Solar Buildings 


\title{
Evacuated Glazing with Silica Aerogel Spacers
}

\author{
Bastian Büttner ${ }^{1}$, Josephine Nauschütz ${ }^{1}$, Ulrich Heinemann ${ }^{1}$, Gudrun Reichenauer ${ }^{1}$, Christian \\ Scherdel', Helmut Weinläder ${ }^{1}$, Stephan Weismann', Doris Buck², Andreas Beck ${ }^{2}$ \\ ${ }^{1}$ Bavarian Center for Applied Energy Research (ZAE Bayern), Magdalene-Schoch-Str. 3, Germany \\ 2 University of Applied Sciences Stuttgart, Schellingstr. 24, 70174 Stuttgart
}

\begin{abstract}
Glazing has come a long way and are subject to continuous development, especially under the premise of climate change. Highly porous monolithic silica aerogels feature optical transparency at ultra-low thermal conductivity well below the conductivity of free gas. Thus they are excellent candidates even at ambient gas pressure for filling the interpane gap in glass windows. Aerogel glazing is known to exhibit amazing thermal properties $\left(U_{\mathrm{g}}\right.$-values down to $0.5 \mathrm{Wm}^{-2} \mathrm{~K}^{-1}$ ) with the drawback of a high price due to difficulties in large-scale production. An alternative approach is using silica aerogel spacers with an areal coverage of just $10 \%$ in combination with partial evacuation of the interpane volume to suppress convection in between the aerogel spacers and panes. With this, the costs for such a glazing may be greatly reduced; however, the mechanical load on the aerogel is significantly increased.

In this paper, we present silica aerogel for application as spacer in the shape of pillars, investigate their ability to withstand mechanical stress, measure thermal characteristics and perform simulations on how they are expected to perform in a double glazing. With a krypton atmosphere of $1 \cdot 10^{4} \mathrm{~Pa}$ in the interpane gap, $U_{\mathrm{g}}$-values down to $0.5 \mathrm{Wm}^{-2} \mathrm{~K}^{-1}$ are predicted.
\end{abstract}

Keywords: aerogel, glazing, window, thermal performance, FEM simulation, demonstrator, solar buildings

\section{Introduction}

Given the rise in earth's temperature, the reduction of the emission of greenhouse gases is of uttermost importance. Due to that, decisive actions have been taken by many countries. The building sector consumes $40 \%$ of Europe's energy demand with space heating as its main contributor (Artola, 2016). The thermal performance of the building skin is made up by opaque and transparent/translucent elements - the latter so far being the weak spot in terms of energy losses. State-of-the-art developments of triple and even quadruple glazing decreased $U_{\mathrm{g}}$-values down to 0.6 and $0.5 \mathrm{Wm}^{-2} \mathrm{~K}^{-1}$, respectively. However, acceptance for quadruple glazing both, from user and production side, is hindered by its enormous thickness, heavy weight and low total solar transmittance. The internal glass panes serve mainly as an obstacle to prevent convection within the gas-filled space between the single glass panes. The suppression thereof is not only possible by choosing an appropriate interpane gap but also by decreasing the gas pressure. However, even a relatively moderate vacuum involves an enormous stress on the outer glass panes causing them to collapse. This behavior can be prevented by mechanically supporting pillars.

Glazing equipped with monolithic silica aerogel boards in the interpane gap can achieve similar or better $U_{\mathrm{g}}$ values down to $0.5 \mathrm{Wm}^{-2} \mathrm{~K}^{-1}$ (Schultz et al, 2005, 2008) than standard windows and have been underway for a long time (Jensen et al., 2004). Silica aerogels exhibit thermal conductivities of $0.013 \mathrm{Wm}^{-1} \mathrm{~K}^{-1}$ at ambient conditions (Reichenauer, 2012). Until now, the production of full-size, high optical quality aerogel boards is cumbersome and thus its high projected costs prevent the entrance into mass production.

In the present work, we combine both ideas - vacuum to prevent convection and silica aerogel pillars for the mechanical support of the glass panes. The small, pillar-sized aerogels exhibit the advantage of a simplified manufacturing process with decreased material usage. We investigate the application of aerogel pillars with a radius in the cm-range and an areal coverage of $10 \%$ in a partially evacuated double glazing. In this approach, 
the air gap between the panes is evacuated and subsequently filled with krypton up to low pressures to prevent heat transport by convection and to limit the amount of the pricey noble gas. Within the framework of this study, we present the optical, mechanical and thermal characterization of aerogel pillars synthesized and then evaluate their suitability for glazing application by simulations and a demonstrator.

\section{Interpane-gap-dependent $\mathbf{U}_{\mathbf{g}}$-values}

In typical insulation glazing, the width of the interpane gap is chosen depending on the used filling gas. In figure 1, the $U_{\mathrm{g}}$-values are calculated according to the European Standard (DIN EN 673:2011). Starting from low interpane gap distances, the $U_{\mathrm{g}}$-value decreases for increasing gap distances - similar to opaque insulation materials. At a specific distance, however, when convection sets in (solid lines), the $U_{\mathrm{g}}$-values increase again. Convection depends on the properties of the fluid and is thus gas-dependent (Linstrom, NIST Webbook). The higher the density of the gas, the lower is the interpane distance for the onset of convection and the lower are the obtainable $U_{\mathrm{g}}$-values.

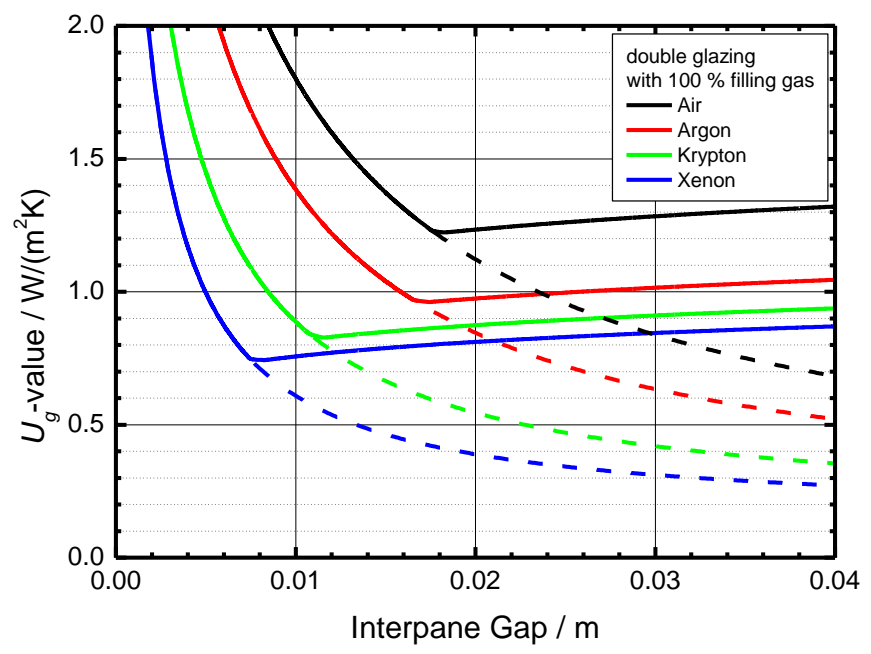

Figure 1: $\mathrm{U}_{\mathrm{g}}$-values of double insulation glazing with different noble gas fillings (filling degree $=100 \%$ ) as a function of the width of the interpane gap; dashed lines are the respective curves for the same insulation component at a respective partial vacuum which is suppressing convection.

When applying a sufficient partial vacuum, the convection is suppressed effectively (dashed lines). In that case, the $U_{\mathrm{g}}$-values keep decreasing for larger interpane gaps. Opposing to standard glazing, the interpane gap can -

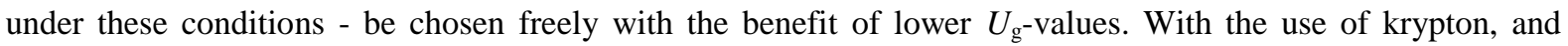
neglecting the pillars' conductivity, $U_{\mathrm{g}}$-values down to below $0.5 \mathrm{~W} /\left(\mathrm{m}^{2} \mathrm{~K}\right)$ are feasible for a double glazing with an interpane gap of $30 \mathrm{~mm}$. The required partial vacuum for the suppression of convection depends on the filling gas and the interpane gap. In the European Standard (DIN EN 673:2011) the gaseous heat transfer is described by

$$
\lambda_{\text {gas }}=N u \cdot \lambda_{0, g a s},
$$

with the Nusselt number $N u=A(G r \cdot \operatorname{Pr})^{n}$ or 1, whichever is higher, with $G r$ and $\operatorname{Pr}$ the Grashoff and Prandtlnumber, respectively, and $\lambda_{0}$, the heat conductivity of the non-convective gas. $A$ and $n$ are parameters which depend on the mounting position. Setting $N u$ to 1 in eq. (1) yields the convection limit for a given system. For horizontal heat transfer (vertically positioned window), the gas pressure versus interpane gap relationship is given by

$$
p=8.2410^{6}\left(\frac{T_{m} \mu \lambda_{0}}{9,81 \Delta T c_{p}}\right)^{1 / 2} \frac{\delta^{-3 / 2}}{\rho_{0}}
$$

for a mean temperature $T_{\mathrm{m}}=283 \mathrm{~K}$, temperature difference $\Delta T=15 \mathrm{~K}$, dynamic viscosity $\mu$, specific heat capacity $c_{\mathrm{P}}$ and density $\rho_{0}$ of krypton at standard conditions $\left(T=298.15 \mathrm{~K}, p=10^{5} \mathrm{~Pa}\right)$ and the interpane gap $\delta$. The interpane-gap-dependent convection limit is depicted in figure 2. The graph reveals that e.g. for an interpane gap of $0.02 \mathrm{~m}$ the krypton gas pressure in between the panes has to be reduced below about $3.510^{4} \mathrm{~Pa}$ to suppress convection. 


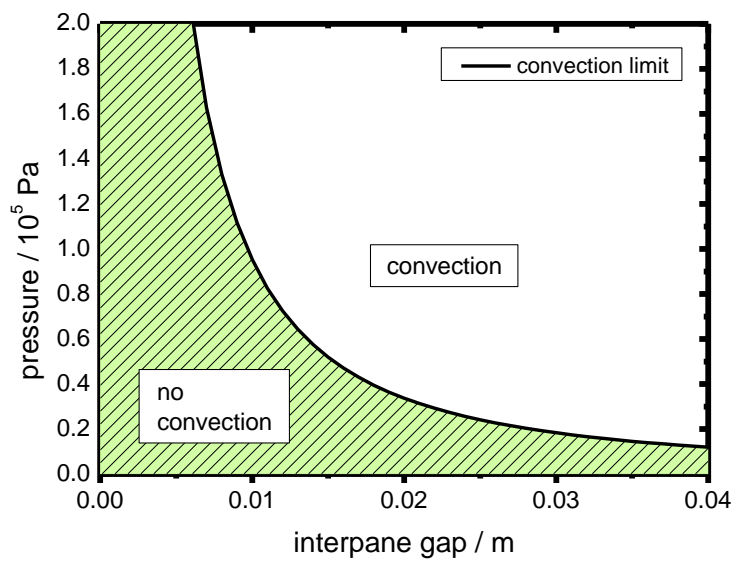

Figure 2: Interpane-gap-dependent convection limiting gas pressure for a vertically mounted window with the filling gas krypton at a mean temperature of $283 \mathrm{~K}$.

\section{Aerogel Synthesis and Characterization}

With an areal coverage of only $10 \%$ and a gas pressure difference of up to $10^{5} \mathrm{~Pa}$ between the outer atmospheric pressure and the gas filling, the aerogel pillars serving as spacers for the two glass panes will be subject to large mechanical stress. The requirements for the aerogel spacer therefore include - besides optical transparency and low thermal conductivity - a sufficient stiffness in order to prevent major compression by the external load of roughly $10^{6} \mathrm{~Pa}$. The physical properties of silica aerogels are usually interdependent and cannot be adjusted separately, thus setting up a challenge in terms of optimization for the given application.

Silica aerogel pillars were synthesized in a sol-gel process with subsequent supercritical $\mathrm{CO}_{2}$-drying of the gels (Wang et al., 1991). No hydrophobization of the inner surfaces of the aerogels was performed. For the given application, the optical transmittance, mechanical strength and heat conductivity are the most important properties. We used a full-factorial experimental design with three factors (synthesis parameters) on two levels with one center point based on design of experiments (DoE). With this approach, the functional dependency and interaction of synthesis parameters were correlated for the relevant output quantities.
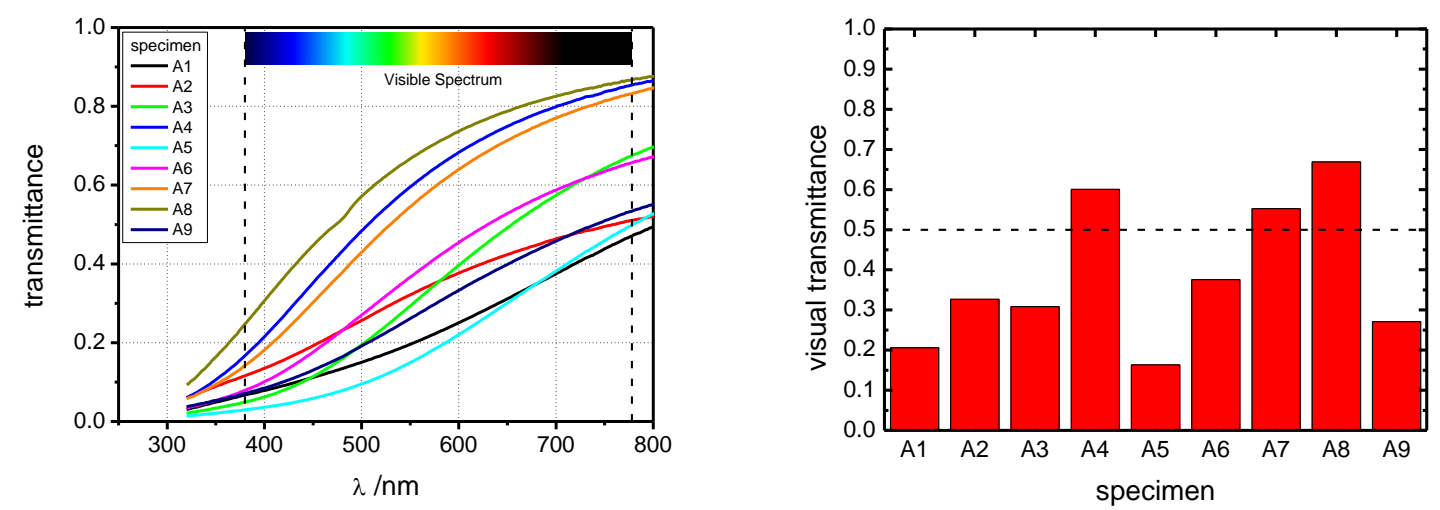

Figure 3: Wavelength-dependent transmittance (left) and visual transmittance according to the European Standard DIN EN 410:2011-04 (right) of the aerogel sample series analyzed in the framework of a DoE study; the dashed line in the right plot shows the set requirement.

The first output quantity is the visual transmittance, determined from the directional hemispherical transmittance value of an $0.02 \mathrm{~m}$ thick sample before drying over the visual spectrum from 380 to $780 \mathrm{~nm}$, weighed with the eye sensitivity curve. By use of a grating spectrometer (Perkin-Elmer Lambda 950 with a wolfram halogen lamp as a light source) the transmission was measured with a photo-multiplier in an integrating sphere. As shown in figure 3 all nine silica aerogels analyzed within the DoE study can be described as "transparent" exhibiting a high transmission. Starting at low wavelengths in the blue spectrum, the transmission is lowest and strongly increases to the red spectrum, giving the aerogel its characteristic bluish haze in reflection due to Rayleigh scattering (Emmerling, 1995). We aimed for a high visual transmittance of more than $50 \%$ for aesthetic reasons, a value which was achieved by samples A4, A7 and A8 (figure 3, right plot). 
Subsequently, the mechanical properties were examined. We measured the Young's Modulus of these aerogel pillars with an ultrasonic test equipment determining the longitudinal ultrasonic speed of each specimen (Gross and Fricke, 1992). The corresponding Young's moduli are depicted in figure 4 (left). Samples with a low transmittance tend to yield higher moduli. The dashed line indicates again the goal set for this value in order to limit the uniaxial compression in the application to $5 \%$. Thus, only samples A4 and A8 meet the two requirements. In addition, for real life stress testing, we used a mechanical testing machine (Zwick Roell TMZ020/TN2S) and exposed the samples A4, A7, and A8, which suffice the set goal for transmittance, to increasing force until rupture or uniaxial compression up to $30 \%$, whichever came first (see figure 4 (right)). The Young's moduli, ascertained from the linear part of the curve are lower compared to the values of the bulk material in the ultrasonic measurement because of their geometric shape. The versatility of the material becomes obvious by seeing the huge differences the pressure-compression curves. The complex flexible structure of the aerogel leads to a deviation of the linear progression while still exhibiting an elastic behavior. All samples are stable beyond the target value of $10^{6} \mathrm{~Pa}$ with concomitant compressions of 4.4, 7.6 and $25 \%$, respectively. However, sample A8 stands out, since it boasts a compression of below $5 \%$ for the maximum application pressure of $10^{6} \mathrm{~Pa}$.
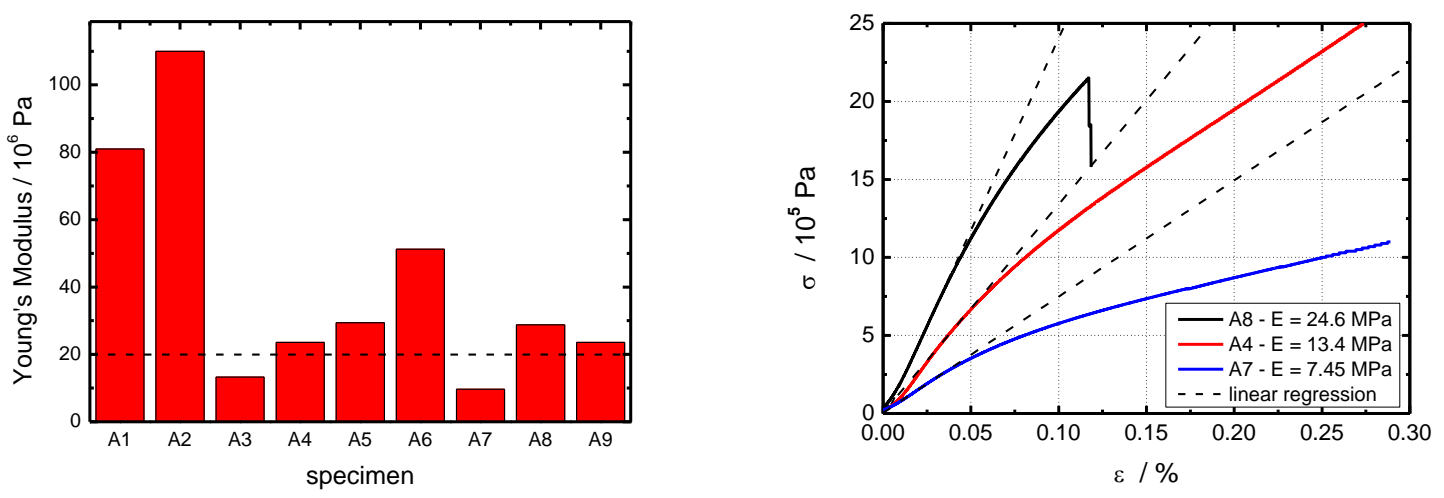

Figure 4: Young's moduli determined by the ultrasonic runtime method (left) and with a mechanical testing machine (right).

In order to minimize the heat transfer via the supporting pillars, the thermal conductivity was determined in a hotwire setup described in (Ebert et al., 1993). All previously tested, mechanical robust aerogel pillars exhibit heat conductivities between 0.016 and $0.025 \mathrm{~W} \mathrm{~m}^{-1} \mathrm{~K}^{-1}$ in an argon atmosphere and reach values down to approx. $0.013 \mathrm{~W} \mathrm{~m}^{-1} \mathrm{~K}^{-1}$ for low gas pressures (figure 5). As the thermal conductivity under application conditions in krypton atmosphere will also be dominated by the solid and radiative heat transfer, the same or slightly lower conductivities as in argon are expected in krypton. All three candidates shown in figure 5 exhibit thermal conductivities below the conductivity of non-convective air and thus surpass the requirements set for the application at $0.04 \mathrm{Wm}^{-1} \mathrm{~K}^{-1}$. In summary, silica aerogel A8 exhibits properties that satisfy all set requirements and is therefore suited to serve as a support pillar in the partially supported insulation glazing.

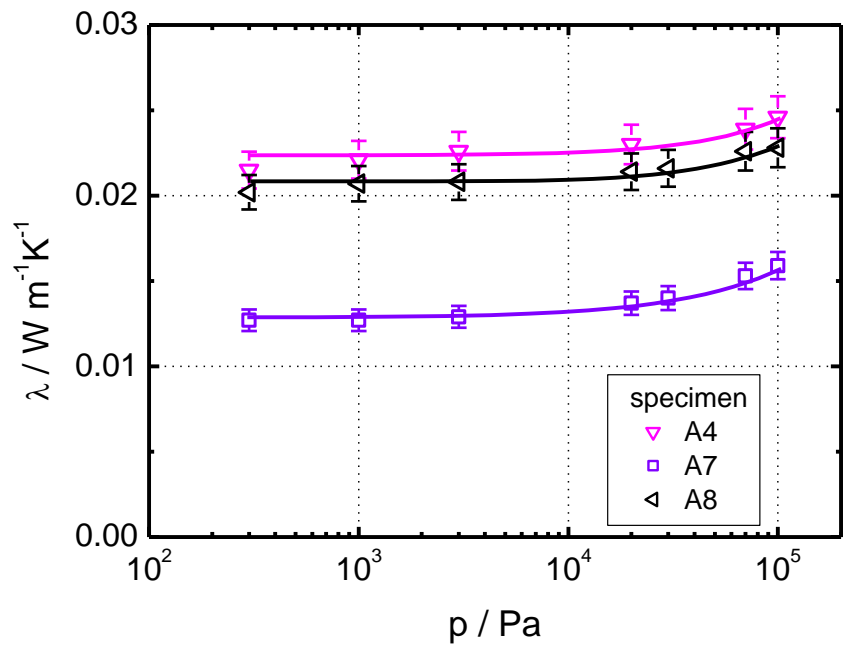

Figure 5: Gas pressure dependent thermal conductivity in argon atmosphere of three different types of silica aerogel pillars at room temperature. 
The long-term stability under ambient conditions and mechanical load is a known issue for the use of silica aerogels in the building sector. In particular in case of non-hydrophobized inner surfaces, ambient humidity leads to creeping under mechanical load. Therefore, sample A8 was subject to a long-term stress test for 7 days - first at zero relative humidity ensured by enclosing the test machine and rinsing the sample volume with dry nitrogen gas. The sample showed no significant deterioration of its mechanical strength (black curve in figure 6). Subsequently, the same test was repeated at a relative humidity of approx. $50 \%$. Here, a constant creep of the aerogel sample became apparent (red curve). Since the concept of the window element includes the usage of a drying agent in the gap volume, the mechanical stability of the silica aerogel under dry conditions proves the suitability of the supporting aerogel pillars over the lifetime of several years.

In summary of the DoE, we evaluated a recipe to synthesize a silica aerogel fulfilling all given requirements for the application in a double insulation glazing. With the knowledge of the material parameters, we determine the achievable $U_{\mathrm{g}}$-value of the respective window in the next section.

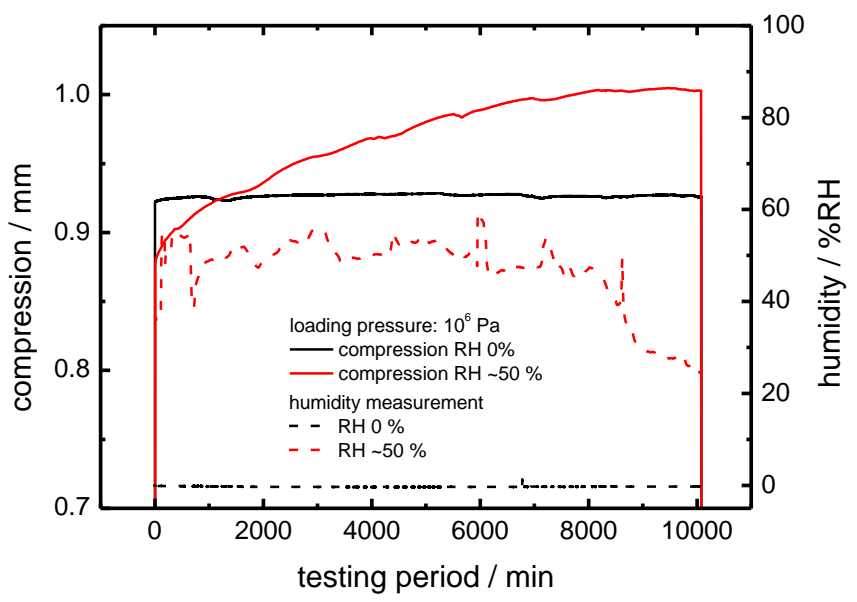

Figure 6: Long-term mechanical stress test on silica aerogel specimen A8; solid lines represent the measured uniaxial compression and dashed lines the measured humidity during the test(right $y$-axis); the black curve is derived at $0 \%$ humidity and shows no creep, the red curve is derived at approx. $50 \%$ relative humidity and shows a significant creeping effect.

\section{3D-simulations of the center-of-pane U-value of the proposed window glazing}

The performance of the glazing is crucial for its suitability in the market. In particular, the $U_{\mathrm{g}}$ value must show a significant improvement over the value of double glazing with comparable weight. Since convection is suppressed, the contributions to the heat transfer are given by conduction and radiation. With the supporting pillars and their high emissivity in between the glass panes, there is a possible shortcut for radiative transport, which needs to be quantified and - in case for a high contribution - reduced by antireflective coatings.

Simulations of the intended double glazing were performed using the FEM simulation software COMSOL Multiphysics ${ }^{\circledR}$ Version 5.3 to quantify their thermal performance considering heat transport by conduction and radiation. The component consists of two glass panes with an interpane air gap of $2 \cdot 10^{-2} \mathrm{~m}$ and $3 \cdot 10^{-2} \mathrm{~m}$. Aerogel pillars with diameters in the cm-range were evaluated. The spacing between the pillars was set according to an areal coverage of $10 \%$. The goal was to determine the influence of the thermal radiation contribution in the window component since, compared to full aerogel boards, the radiative heat transport is not intrinsically suppressed. Multiple simulations were performed for two pillar diameters, different emittances of the components and varied heat conductivities.

The $U_{\mathrm{g}}$-value was first determined for a standard configuration. Subsequently, the effects of different parameters were studied. The standard configuration exhibits an emissivity of the outer pane $\varepsilon_{\mathrm{e}}$ of an untreated float glass (0.837), an aerogel conductivity of $0.035 \mathrm{Wm}^{-1} \mathrm{~K}^{-1}$, an aerogel emissivity of 0.9 (all values for room temperature), and an interpane gap of $0.02 \mathrm{~m}$. The inner pane emissivity $\varepsilon_{\mathrm{i}}$ was set to the state-of-the-art value 0.03 for a lowemissivity (low-e) coating. The $U_{\mathrm{g}}$-value calculated for this parameter set equals $0.91 \mathrm{Wm}^{-1} \mathrm{~K}^{-1}$ and is slightly better than the expected value for conventional double insulation glazing. Better values are limited by the radiative transport between the pillars and the inner pane. 
Table 1: $U_{\mathrm{g}}$-value of the standard configuration and effect of various measures in order to reduce the $U_{\mathrm{g}}$-value. The parameters of the standard model are shown on the left hand, the measures in the middle and the respective effect on the right side.

\begin{tabular}{|c|c|c|c|c|c|}
\hline & & & & $U_{\mathrm{g}}$-value of standard model $\left[\mathrm{Wm}^{-2} \mathrm{~K}^{-1}\right]$ & 0.91 \\
\hline \multicolumn{2}{|c|}{ standard model } & \multicolumn{2}{|c|}{ measure } & \multicolumn{2}{|l|}{$\Delta U_{g}$-value $\left[\mathrm{Wm}^{-2} \mathrm{~K}^{-1}\right]$} \\
\hline$\varepsilon_{\mathrm{e}}$ & 0.837 & $\rightarrow$ & 0.03 & \multicolumn{2}{|l|}{-0.19} \\
\hline Interpane gap $[\mathrm{m}]$ & 0.02 & $\rightarrow$ & 0.03 & \multicolumn{2}{|l|}{-0.12} \\
\hline$\lambda_{\text {pillars }}\left[\mathrm{Wm}^{-1} \mathrm{~K}^{-1}\right]$ & 0.035 & $\rightarrow$ & 0.020 & \multicolumn{2}{|l|}{-0.05} \\
\hline$\emptyset_{\text {pillars }}[\mathrm{m}]$ & $13.110^{-3}$ & $\rightarrow$ & $19.610^{-3}$ & \multirow{2}{*}{\multicolumn{2}{|c|}{-0.05}} \\
\hline spacing $[\mathrm{m}]$ & $36.710^{-3}$ & $\rightarrow$ & $54.910^{-3}$ & & \\
\hline$\varepsilon_{\mathrm{e}} \& \varepsilon_{\mathrm{i}}$ & 0.03 & $\rightarrow$ & 0.01 & \multicolumn{2}{|l|}{-0.04} \\
\hline
\end{tabular}

The application of a low-e coating to the outer pane suppresses the radiative transport strongly thus significantly reducing the $U_{\mathrm{g}}$-value to values below $0.75 \mathrm{~W} \mathrm{~m}^{-2} \mathrm{~K}^{-1}$. The second largest effect is the increase of the interpane gap from 20 to $30 \mathrm{~mm}$ diminishing the $U_{\mathrm{g}}$-value further to $0.60 \mathrm{Wm}^{-2} \mathrm{~K}^{-1}$. Inserting the thermal conductivity for sample A8 from the previous section with its diameter of $19.610^{-3} \mathrm{~m}$ and a corresponding spacing of $54.910^{-3} \mathrm{~m}$ yields a total $U_{\mathrm{g}}$-value of $0.50 \mathrm{~W} \mathrm{~m}^{-2} \mathrm{~K}^{-1}$. A further decrease in the emissivity to 0.01 of both outer and inner pane reduces the $U_{g^{-}}$value down to $0.46 \mathrm{~W} \mathrm{~m}^{-2} \mathrm{~K}^{-1}$. The simulated values for the different configurations are shown in figure 7. The upper set of four curves assumes an uncoated outer pane whereas the next four curves correspond to an outer pane with a low-e coating. The red dashed curve shows values for an interpane gap of $30 \mathrm{~mm}$ with otherwise the same parameters as the blue dashed curve.

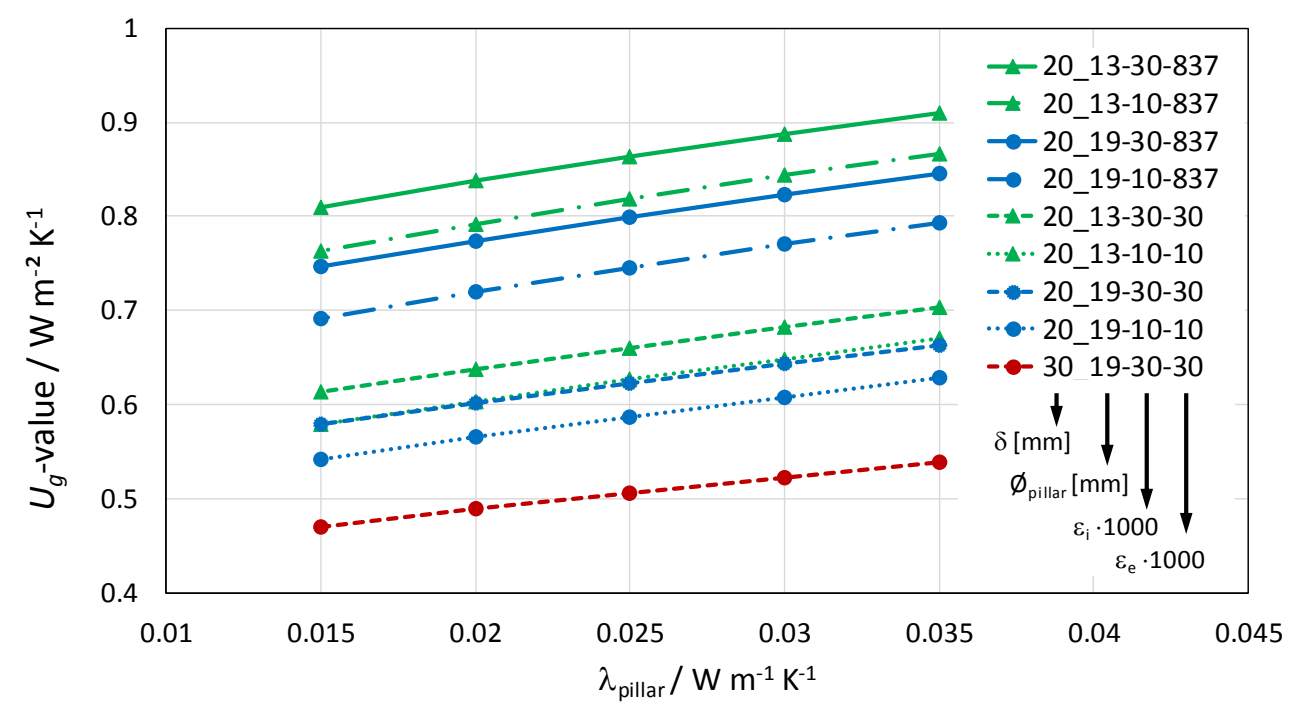

Figure 7: Simulated $U_{\mathrm{g}}$-values for different emissivities, pillar diameters, interpane gaps and thermal conductivities of the pillars.

\section{Demonstrator}

In order to evaluate the appearance and behavior under typical stress conditions due to atmospheric pressure, two test window elements of size $0.25 \mathrm{~m} \cdot 0.25 \mathrm{~m}$ with 16 and 12 pillars, an interpane gas pressure lower than $10^{2} \mathrm{~Pa}$ and a gas-tight edge bond was fabricated (see figure 8). The pillars were ordered in a cubic and hexagonal spacing as two different design solutions. The interpane gaps were evacuated to pressures below $10^{2} \mathrm{~Pa}$; both demonstrators withstood the mechanical stress applied by the atmospheric pressure until the venting of the demonstrator after two weeks of testing. 

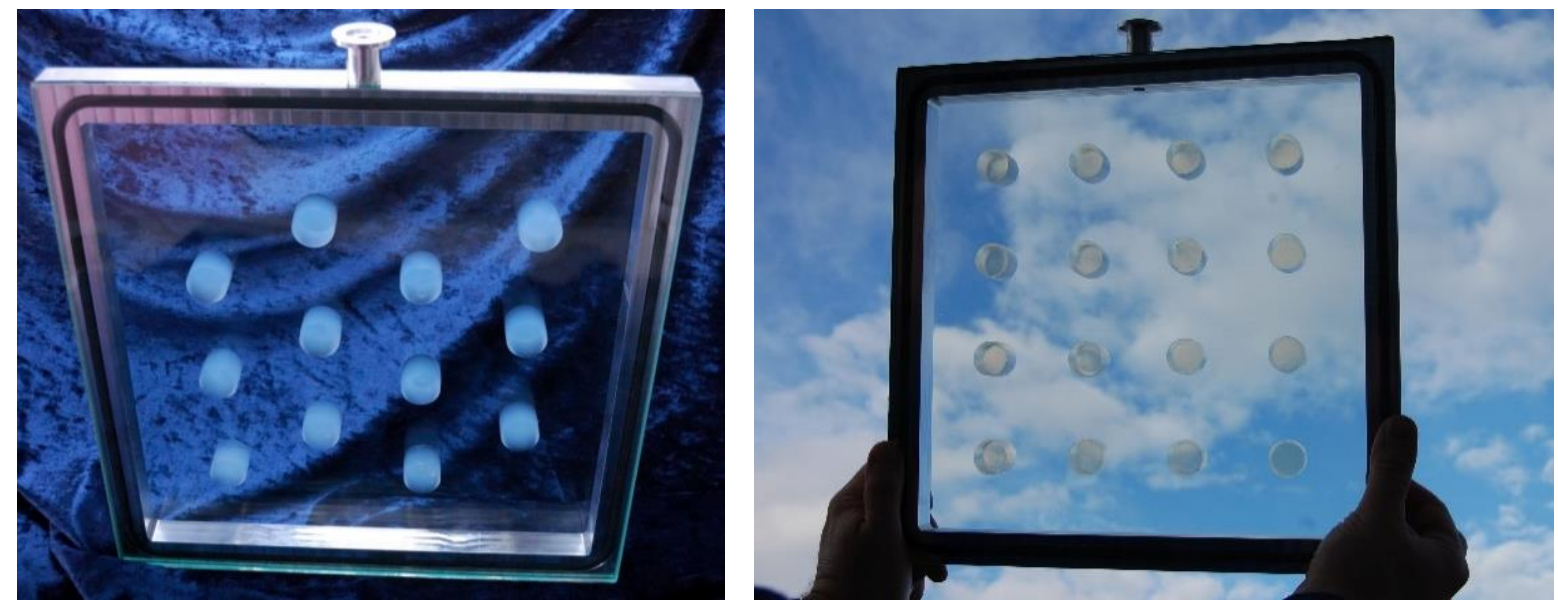

Figure 8: Demonstrators for evacuated double insulated glazing with silica aerogel pillars positioned in hexagonal (left) and cubic (right) arrangement.

\section{Conclusions}

In summary, we developed a process for synthesizing silica aerogel pillars with high optical transmittance, increased mechanical stiffness at a low thermal conductivity of $0.020 \mathrm{~W} \mathrm{~m}^{-1} \mathrm{~K}^{-1}$. Simulations reveal, that the implementation of these silica aerogels as pillars inside a partially evacuated double insulation glazing results in exceptional $U_{\mathrm{g}}$-values down to $0.5 \mathrm{~W} \mathrm{~m}^{-2} \mathrm{~K}^{-1}$. The window element possesses furthermore high transmittance in the visual spectrum and provides high solar gains. For production of the novel window elements, only $10 \%$ of the inter pane volume has to be filled with noble gas, enabling the use of the more expensive krypton, while the standard gas filling process consumes about two times the interpane volume.

\section{Acknowledgements}

The results in this paper are a part of the research project HFV (HFV 2016), which is funded by the german Federal Ministry for Economic Affairs and Energy by resolution of the German Federal Parliament.

\section{References}

Artola, I., Rademaekers, K., Williams, R., \& Yearwood, J. (2016), Directorate General for Energy-European Commission, Boosting Building Renovation: What potential and value for Europe? http://www.europarl.europa.eu/RegData/etudes/STUD/2016/587326/IPOL_STU(2016)587326_EN.pdf.

Accessed online 6 September 2018.

DIN EN 673:2011-04: Glas im Bauwesen; Bestimmung des Wärmedurchgangskoeffizienten (U-Wert); Berechnungsverfahren.

Ebert, H.-P., Bock, V., Nilsson, O., \& Fricke, J. 1993. The hot-wire method applied to porous materials of low thermal conductivity. High Temperatures-High Pressures, 25(4), 391-402.

Emmerling, A., Petricevic, R., Beck, A., Wang, P., Scheller, H., \& Fricke, J. (1995). Relationship between optical transparency and nanostructural features of silica aerogels. Journal of non-crystalline solids, 185(3), 240-248. https://doi.org/10.1016/0022-3093(95)00021-6

Gross, J., \& Fricke, J. (1992). Ultrasonic velocity measurements in silica, carbon and organic aerogels. Journal of Non-Crystalline Solids, 145, 217-222. https://doi.org/10.1016/S0022-3093(05)80459-4

Jensen, K. I., Schultz, J. M., \& Kristiansen, F. H. (2004). Development of windows based on highly insulating aerogel glazings. Journal of Non-Crystalline Solids, 350, 351-357. https://doi.org/10.1016/j.jnoncrysol.2004.06.047

Linstrom, P. J., Mallard, W. G., Eds., NIST Chemistry WebBook, NIST Standard Reference Database Number 69 (National Institute of Standards and Technology); https://webbook.nist.gov/chemistry/. 
Reichenauer, G. 2012. Aerogels: Porous Sol-Gel-Derived Solids for Applications in Energy Technologies, in Lambauer, J., Fahl, U., Voss, A. (Eds.), Nanotechnology and Energy. Science, Promises, and Limits. Pan Stanford, pp. 90-114. ISBN: 97898143108199814310816

Schultz, J. M., Jensen, K. I., \& Kristiansen, F. H. (2005). Super insulating aerogel glazing. Solar energy materials and solar cells, 89(2-3), 275-285. https://doi.org/10.1016/j.solmat.2005.01.016

Schultz, J. M., \& Jensen, K. I. (2008). Evacuated aerogel glazings. Vacuum, 82(7), 723-729.

Hochwärmedämmende Fassadensysteme auf Vakuumbasis (HFV) (2016); FKZ 03ET1324A;

https://projektinfos.energiewendebauen.de/foerderkennzeichen/03et1324a/.

Wang, P., Emmerling, A., Tappert, W., Spormann, O., Fricke, J., \& Haubold, H. G. (1991). High-Temperature and Low-Temperature Supercritical Drying of Aerogels - Structural Investigations with Saxs. Journal of Applied Crystallography, 24, 777-780. https://doi.org/10.1107/S0021889891002327 


\title{
Radiative cooling to cover cooling demands of an Earthbag building in a Training Medical Center in Burkina Faso
}

\author{
Sergi Vall, Ariadna Carrobé, Marc Medrano, Ingrid Martorell, Lídia Rincón, Albert Castell \\ Department of Computer Science and Industrial Engineering, University of Lleida, Edifici CREA, Pere \\ de Cabrera s/n, 25001 Lleida, Spain
}

\begin{abstract}
Comfort conditions in buildings of developing countries are seldom achieved. Moreover, electricity is usually scarce and unreliable. Therefore, the use of a renewable energy source can be a solution. In this paper the use of radiative cooling to achieve human thermal comfort in an Earthbag building of a Training Medical Center in Ouagadougou in Burkina Faso is studied. The building demands are determined by simulation using EnergyPlus, and are compared to the energy production of a Radiative Cooling (RC) system, which is simulated using Trnsys. Peak cooling powers are expected to be around 3.5-4 kW, with a total annual cooling demand of $2081.58 \mathrm{kWh}$. The maximum cooling demands appear during April and May $(567.18 \mathrm{kWh}$ and $554.07 \mathrm{kWh}$ respectively). Different radiative cooling installed surfaces and inlet water temperatures $\left(\mathrm{T}_{\text {in }}\right)$ are analyzed, achieving annual cooling demand coverages of around $35 \%$ for the case of $10 \mathrm{~m}^{2}$ and $\mathrm{T}_{\mathrm{in}}=25{ }^{\circ} \mathrm{C}$. Further research is necessary to determine the interaction between the RC and the HVAC distribution system, which is not considered in this paper.
\end{abstract}

Keywords: Building Energy Simulation, Comfort conditions, Radiative cooling, Earthbag building.

\section{Introduction}

In developing countries, comfort conditions in buildings are usually not achieved, resulting in energy poverty, discomfort, illness, etc. In tropical and arid climates, cooling requirements cannot be achieved by conventional technologies such as compression systems, since electrical energy is scarce and unreliable. Moreover, the installation and operation costs are usually too high. Renewable energies can be a feasible solution to improve human thermal comfort in a reliable and non-expensive way (Kaygusuz 2012).

The most common technology used for space conditioning, especially in hot climate countries, is the reversible heat pump, which consumes a large amount of electrical energy. However, there are other renewable sources capable to produce cooling. Solar cooling is one of the most widely studied ones; however, its use for cooling is limited by the implementation of absorption heat pumps, which are complex, present low overall efficiencies, require high operation temperatures, and need large cooling towers (Hassan and Mohamad 2012).

Radiative cooling is another technology that has been studied to provide cooling from a renewable source. It uses the sky as a heat sink taking advantage of its effective temperature lower than ambient (Bell et al. 1960). Radiative cooling is based on emitting long-wave thermal radiation from a terrestrial body toward space through the infrared atmospheric window between $8-13 \mu \mathrm{m}$ wavelengths. The atmosphere infrared window is the dynamic behavior of earth's atmosphere that allows some infrared radiation pass through the atmosphere without being absorbed and, thus without heating the atmosphere. Therefore, radiative cooling can be useful to provide cooling and improve the comfort conditions in hot climates (Vall and Castell 2017).

Nowadays, a Training Medical Center (TMC) is under construction in Ouagadougou (Burkina Faso). The living quarters for the volunteers are built using an innovative constructive system called Earthbag building. This construction technique consists of introducing an earth mixture of clay, sand, and lime as a binder, inside bags that serve as the formwork and confinement of the filling. Bags are stacked one over the other forming the walls of the house and barwires between rows are used to improve friction and adherence. Rows are disposed in circles to conform a dome shape (Hunter 2004). These structures have been used in the last 25 years in 
emergency situations such as wars or natural disasters, providing quickly, low cost and safe shelters (Khalili, 1999). Although the construction has high thermal inertia and passive strategies, comfort conditions are not achieved due to the extreme weather conditions in Burkina Faso (Peel et al. 2006).

This paper analyzes the potential of radiative cooling to improve the comfort conditions and meet the cooling demand of an Earthbag building located at the Training Medical Center of Ouagadougou in Burkina Faso.

\section{Numerical model}

\subsection{Building model}

The Earthbag building will be the first dwelling of the residential area intended for the sanitary staff that will come as volunteers to Ouagadougou. It consists of four connected domes, two bedrooms of $4 \mathrm{~m}$ of diameter (inner size), one bathroom of $3.5 \mathrm{~m}$, and a central living room of $4.5 \mathrm{~m}$ (Fig. 1), with a net floor area of 12.50 $\mathrm{m}^{2}, 7 \mathrm{~m}^{2}$ and $15.90 \mathrm{~m}^{2}$ respectively, and a height of $4.20 \mathrm{~m}, 3.6$, and $4.70 \mathrm{~m}$ respectively. The walls of the domes are $32 \mathrm{~cm}$ thick and they are reinforced in the lower part with a $64 \mathrm{~cm}$ buttress. An extra roof is added as a shadow device over the central dome. All the windows have wooden frame and simple glazing. The energy simulation has been done with EnergyPlus software, using Open Studio as the graphical user interface. As the program does not allow creating such a circular shape, a polygonal dome was used. The default heat balance algorithm based on the conduction transfer function (CTC) transformation and 6 time steps per hour for the simulation are applied. Whole year simulations have been performed using the EnergyPlus weather data file for Ouagadougou. Ouagadougou is the capital of Burkina Faso (Latitude $12.35^{\circ}$ North, $1.52^{\circ}$ West. Elevation: 316 $\mathrm{m}$ ). Its climate is hot semi-arid, (BSh - Arid Steppe hot arid climate under the Köppen-Geiger climate classification). This climate has a period of 8 months of hot and dry season and 4 months of wet season. During the hottest months, from March to May, day temperatures surpass $40^{\circ} \mathrm{C}$. From November to February the "hermattan" -a fresh and dry wind from the North- produces day temperatures about $25^{\circ} \mathrm{C}$. The annual average precipitation is $788 \mathrm{~mm}$. The number of hours of solar radiation per day is very similar along the year, about 12 hours. The zenit of the sun is $55^{\circ}$ in its lowest point, solstice of December, and $101^{\circ}$ in solstice of June, reaching a perpendicular position respect to the horizontal in the months between both equinox and the solstice of June.
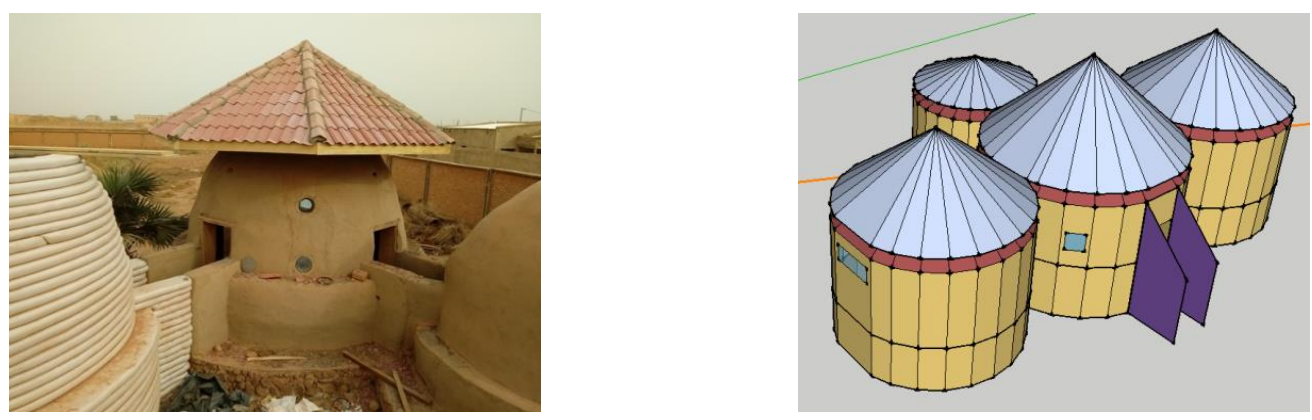

Fig. 1: Construction of the residential area with Earthbag buildings (left), and Earthbag model (right).

\subsection{Radiative Cooler model}

The architecture of the Radiative Cooler (RC) is similar to the architecture of a flat plate solar collector (Fig. 2). A radiator plate (1) collects or emits the radiation heat. A pipe (2) is welded at the back side of the radiator plate to transfer the heat to/from a fluid. The plate is insulated on the back side with insulation foam (3). On the front, it is insulated from the external air with an air gap (a) and a screen (c).

A detailed numerical model to simulate the behavior of the Radiative Cooler was developed in Trnsys (Vall et al. 2018). The model used one dimension (1D) relations based on electrical analogy. The model equivalent resistance network is shown in Fig. 2. The relations between the nodes are based on heat and mass transfer equations. Each node has a thermal capacity and each relation between nodes is represented by a thermal resistance. A radiation balance between the different surfaces is also performed, taking into account the incoming radiation (sun/sky) and the outgoing radiation (emitted, reflected, and transmitted). The model is used to determine the energy production of the Radiative Cooler model in order to cover the cooling demands of the building in Burkina Faso. 

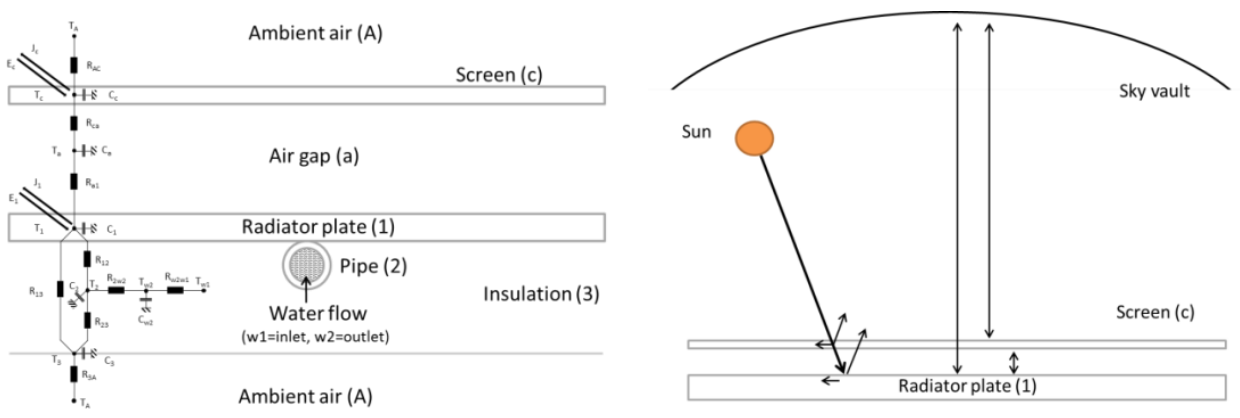

Fig. 2: Sketch of the model and 1D resistor capacitor model (left), and radiation model scheme (right).

Moreover, the radiation balance is done for 4 different wavelength bands $(0-4 \mu \mathrm{m}, 4-7 \mu \mathrm{m}, 7-14 \mu \mathrm{m}$ and $>14 \mu \mathrm{m})$. Thus, the model distinguishes between different wavelength bands, with special care for the infrared atmospheric window $(7-14 \mu \mathrm{m})$.

First order ordinary differential equations in time are used in the model. The backward Euler method (or implicit Euler method) is used to solve the set of equations by using the Gauss-Seidel iterative method.

The model was experimentally validated using empirical data (Vall et al. 2018), comparing the predicted outlet water temperature to the measured one. Experimental and numerical results showed good agreement.

\section{Results and discussion}

Fig. 3 shows the energy demand of the simulated building located in Ouagadougou (Burkina Faso). The simulation assumes that the building is unoccupied during the day. The setpoint for the occupied hours is $27^{\circ} \mathrm{C}$ and the unoccupied hours setpoint is fixed at $30^{\circ} \mathrm{C}$. Cooling demands may increase if occupancy schedules change. Peak cooling powers are expected to be around $3.5-4 \mathrm{~kW}$, with a total annual cooling demand of $2081.58 \mathrm{kWh}$ (Tab. 1). The maximum cooling demands appear during April and May (567.18 kWh and 554.07 $\mathrm{kWh}$ respectively). January and December are the months with lower cooling demands (7.72 kWh and 2.94 $\mathrm{kWh}$ respectively).

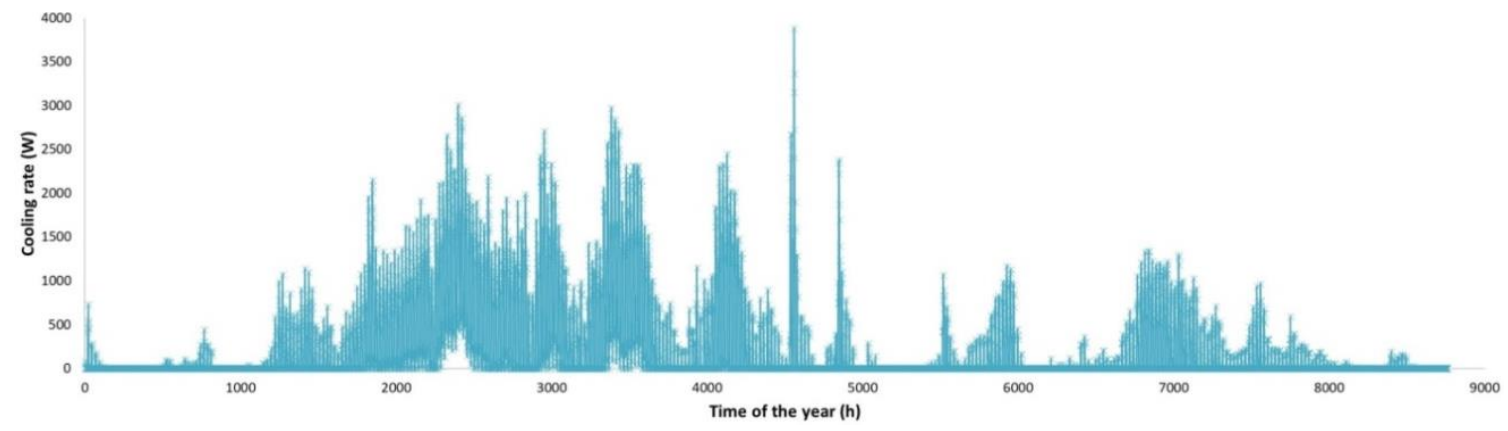

Fig. 3: Cooling rate required to meet comfort conditions in the TMC of Ouagadougou.

Tab. 1 and Tab. 2 present the cooling demands of the building for each month, the Radiative Cooler production for different installed surfaces, and the cooling demand coverage achieved with the RC production. Since the simulations do not consider the HVAC distribution system in the building, Tab. 1 considers an inlet water temperature to the RCE of $20^{\circ} \mathrm{C}$, while Tab. 2 considers a temperature of $25^{\circ} \mathrm{C}$.

The cooling demand coverage increases with the RC installed surface (Fig. 4). Results show the potential of the $\mathrm{RC}$ to cover part of the cooling demand of the building, being able to achieve full coverage for the months with lower demands. However, during the months with higher demands, the coverage is small. Annually, a significant coverage of around $35 \%$ can be achieved with $10 \mathrm{~m}^{2}$ of RC installed surface and an inlet water temperature of $25^{\circ} \mathrm{C}$ (Tab. 2). For this case, the system achieves full coverage during 6 months, while it is below $25 \%$ during 3 months. Even in this partial coverage months, the use of the cold produced by the RC can help significantly reduce the hours and degree-days of thermal discomfort, especially if the adaptive comfort model. ASHRAE Standard 55 Adaptive Comfort model is used to assess comfort conditions (ANSI/ASHRAE Standard 55-2013). This model is especially suited for naturally ventilated buildings with no mechanical cooling systems, such as the one in this study. 
Tab. 1: Cooling demand, $\mathrm{RC}$ production and demand coverage for different installed surfaces of $\mathrm{RC}$ and an inlet water temperature of $20^{\circ} \mathrm{C}$.

\begin{tabular}{|c|c|c|c|c|c|c|c|c|c|c|c|}
\hline & \multirow{3}{*}{$\begin{array}{c}\text { Cooling } \\
\text { Demand } \\
(\mathbf{k W h})\end{array}$} & \multicolumn{10}{|c|}{ Cooling Production - Inlet water temperature $\mathrm{T}_{\mathrm{in}}=\mathbf{2 0}^{\circ} \mathrm{C}$} \\
\hline & & \multicolumn{2}{|c|}{$2 \mathrm{~m}^{2}$} & \multicolumn{2}{|c|}{$4 \mathrm{~m}^{2}$} & \multicolumn{2}{|c|}{$6 \mathrm{~m}^{2}$} & \multicolumn{2}{|c|}{$8 \mathrm{~m}^{2}$} & \multicolumn{2}{|c|}{$10 \mathrm{~m}^{2}$} \\
\hline & & $\begin{array}{l}\text { Prod. } \\
(\mathrm{kWh})\end{array}$ & $\begin{array}{l}\text { Cvg. } \\
(\%)\end{array}$ & $\begin{array}{l}\text { Prod. } \\
\text { (kWh) }\end{array}$ & $\begin{array}{l}\text { Cvg. } \\
(\%)\end{array}$ & $\begin{array}{l}\text { Prod. } \\
\text { (kWh) }\end{array}$ & $\begin{array}{l}\text { Cvg. } \\
(\%)\end{array}$ & $\begin{array}{l}\text { Prod. } \\
\text { (kWh) }\end{array}$ & $\begin{array}{l}\text { Cvg. } \\
(\%)\end{array}$ & $\begin{array}{l}\text { Prod. } \\
(\mathrm{kWh})\end{array}$ & $\begin{array}{l}\text { Cvg. } \\
(\%)\end{array}$ \\
\hline JAN & 7.72 & 37.38 & 100 & 74.76 & 100 & 112.14 & 100 & 149.52 & 100 & 186.90 & 100 \\
\hline FEB & 47.50 & 31.41 & 66 & 62.81 & 100 & 94.22 & 100 & 125.62 & 100 & 157.03 & 100 \\
\hline MAR & 253.18 & 20.98 & 8 & 41.95 & 17 & 62.93 & 25 & 83.91 & 33 & 104.89 & 41 \\
\hline APR & 567.18 & 3.04 & 1 & 6.07 & 1 & 9.11 & 2 & 12.15 & 2 & 15.18 & 3 \\
\hline MAY & 554.07 & 0.90 & 0 & 1.80 & 0 & 2.70 & 0 & 3.59 & 1 & 4.49 & 1 \\
\hline JUN & 241.71 & 1.14 & 0 & 2.28 & 1 & 3.42 & 1 & 4.56 & 2 & 5.70 & 2 \\
\hline JUL & 109.28 & 1.89 & 2 & 3.78 & 3 & 5.67 & 5 & 7.57 & 7 & 9.46 & 9 \\
\hline AUG & 27.16 & 1.97 & 7 & 3.94 & 15 & 5.91 & 22 & 7.88 & 29 & 9.85 & 36 \\
\hline$\overline{\text { SEP }}$ & 46.73 & 3.17 & 7 & 6.34 & 14 & 9.51 & 20 & 12.67 & 27 & 15.84 & 34 \\
\hline OCT & 181.16 & 2.26 & 1 & 4.52 & 2 & 6.78 & 4 & 9.04 & 5 & 11.30 & 6 \\
\hline NOV & 42.97 & 17.25 & 40 & 34.50 & 80 & 51.75 & 100 & 69.01 & 100 & 86.26 & 100 \\
\hline DEC & 2.94 & 32.98 & 100 & 65.96 & 100 & 98.94 & 100 & 131.91 & 100 & 164.89 & 100 \\
\hline ANN & 2081.58 & 154.36 & 4.5 & 308.72 & 7.8 & 463.07 & 10.0 & 617.43 & 11.6 & 771.79 & 13.3 \\
\hline
\end{tabular}

Tab. 2: Cooling demand, RC production and demand coverage for different installed surfaces of $\mathrm{RC}$ and an inlet water temperature of $25^{\circ} \mathrm{C}$.

\begin{tabular}{|c|c|c|c|c|c|c|c|c|c|c|c|}
\hline & \multirow{3}{*}{$\begin{array}{c}\text { Cooling } \\
\text { Demand } \\
(\mathbf{k W h})\end{array}$} & \multicolumn{10}{|c|}{ Cooling Production - Inlet water temperature $T_{\text {in }}=25^{\circ} \mathrm{C}$} \\
\hline & & \multicolumn{2}{|c|}{$2 \mathrm{~m}^{2}$} & \multicolumn{2}{|c|}{$4 \mathrm{~m}^{2}$} & \multicolumn{2}{|c|}{$6 \mathrm{~m}^{2}$} & \multicolumn{2}{|c|}{$8 \mathrm{~m}^{2}$} & \multicolumn{2}{|c|}{$10 \mathrm{~m}^{2}$} \\
\hline & & $\begin{array}{l}\text { Prod. } \\
\text { (kWh) }\end{array}$ & $\begin{array}{l}\text { Cvg. } \\
(\%)\end{array}$ & $\begin{array}{l}\text { Prod. } \\
\text { (kWh) }\end{array}$ & $\begin{array}{l}\text { Cvg. } \\
(\%)\end{array}$ & $\begin{array}{l}\text { Prod. } \\
\text { (kWh) }\end{array}$ & $\begin{array}{l}\text { Cvg. } \\
(\%)\end{array}$ & $\begin{array}{l}\text { Prod. } \\
\text { (kWh) }\end{array}$ & $\begin{array}{l}\text { Cvg. } \\
(\%)\end{array}$ & $\begin{array}{l}\text { Prod. } \\
\text { (kWh) }\end{array}$ & $\begin{array}{l}\text { Cvg. } \\
(\%)\end{array}$ \\
\hline JAN & 7.72 & 61.22 & 100 & 122.43 & 100 & 183.65 & 100 & 244.86 & 100 & 306.08 & 100 \\
\hline FEB & 47.50 & 51.55 & 100 & 103.09 & 100 & 154.64 & 100 & 206.19 & 100 & 257.74 & 100 \\
\hline MAR & 253.18 & 41.44 & 16 & 82.88 & 33 & 124.32 & 49 & 165.77 & 65 & 207.21 & 82 \\
\hline APR & 567.18 & 17.93 & 3 & 35.85 & 6 & 53.78 & 9 & 71.70 & 13 & 89.63 & 16 \\
\hline MAY & 554.07 & 10.30 & 2 & 20.60 & 4 & 30.90 & 6 & 41.20 & 7 & 51.49 & 9 \\
\hline JUN & 241.71 & 10.70 & 4 & 21.39 & 9 & 32.09 & 13 & 42.79 & 18 & 53.48 & 22 \\
\hline JUL & 109.28 & 13.55 & 12 & 27.10 & 25 & 40.65 & 37 & 54.21 & 50 & 67.76 & 62 \\
\hline AUG & 27.16 & 15.41 & 57 & 30.82 & 100 & 46.22 & 100 & 61.63 & 100 & 77.04 & 100 \\
\hline SEP & 46.73 & 17.52 & 38 & 35.04 & 75 & 52.57 & 100 & 70.09 & 100 & 87.61 & 100 \\
\hline OCT & 181.16 & 15.62 & 9 & 31.23 & 17 & 46.85 & 26 & 62.46 & 34 & 78.08 & 43 \\
\hline NOV & 42.97 & 38.79 & 90 & 77.57 & 100 & 116.36 & 100 & 155.15 & 100 & 193.94 & 100 \\
\hline DEC & 2.94 & 56.79 & $100 \%$ & 113.58 & 100 & 170.38 & 100 & 227.17 & 100 & 283.96 & 100 \\
\hline ANN & 2081.58 & 350.80 & $11.5 \%$ & 701.60 & 18.4 & 1052.41 & 24.2 & 1403.21 & 29.5 & 1754.01 & 34.7 \\
\hline
\end{tabular}




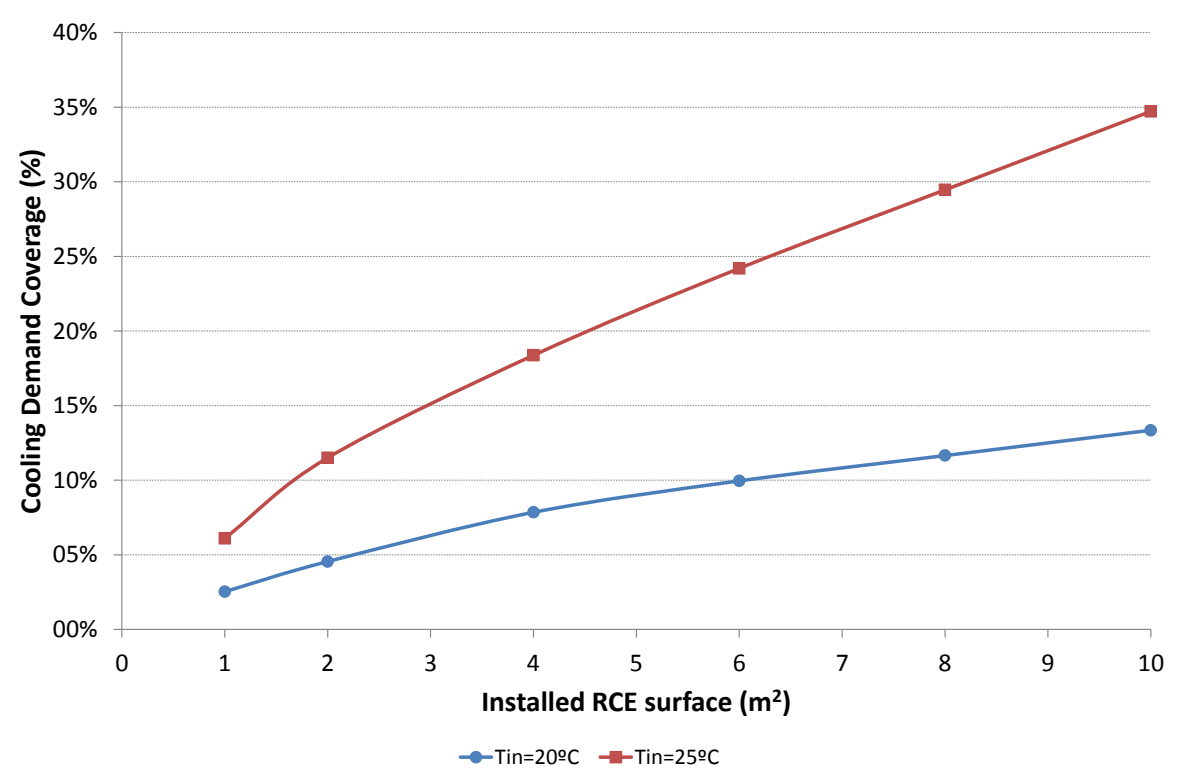

Fig. 4: Cooling demand coverage for different RC installed surfaces and inlet water temperatures.

On the other hand, the HVAC distribution system is not considered in the simulations, which will affect the inlet water temperature. Thus, the interaction of the RC system with the HVAC distribution system of the building must be evaluated in detail. A distribution system which can operate with high water temperatures is advisable in order to take more advantage of the RC system. Otherwise, the combination of the RC with a conventional, non-renewable cooling production system (such as compression heat pumps) would be necessary.

\section{Conclusions}

The potential implementation of a Radiative Cooler (RC) device in a Training Medical Center (TMC) under construction in Ouagadougou (Burkina Faso) is studied in this paper. The TMC is build using an innovative constructive system called the Earthbag building. The residential area of sanitary staff is simulated with EnergyPlus to determine the cooling demands in such extreme weather conditions. A numerical model of the $\mathrm{RC}$ developed in Trnsys is used to determine the cooling production. Different RC installed surfaces and inlet water temperatures are analyzed to determine the cooling demand coverage achievable with such technology. The RC shows potential in covering a significant demand of the cooling loads of the building, with coverage of around $35 \%$ for $10 \mathrm{~m}^{2}$ of installed $\mathrm{RC}$ and an inlet water temperature of $25^{\circ} \mathrm{C}$. Although these results demonstrate the potential of such technology to cover part of the demand, it is not sufficient to cover the full demand during the most demanding months. Further research is required to take into account the interaction between the RC and the HVAC distribution systems.

\section{References}

ANSI/ASHRAE Standard 55-2013, 2013, Thermal Environmental Conditions for Human Occupancy.

Bell E., Eisner L., Young J., Oetjen R. 1960., Spectral-Radiance of Sky and Terrain at Wavelengths between 1 and 20 Microns. II. Sky Measurements. J Opt Soc Am 50, 1313-1320. doi:10.1364/JOSA.50.001313.

Hassan H.Z., Mohamad A.A., 2012. A review on solar cold production through absorption technology. Renew Sustain Energy Rev 16, 5331-5348.

Hunter K., Kiffmeye D., 2004. Earthbag building: the tools, tricks and techniques. 1st ed., New Society Publishers. Gabriola Island, BC, Canada.

Kaygusuz K., 2012. Energy for sustainable development: A case of developing countries. Renew Sustain Energy Rev 16, 1116-1126.

Khalili E.N., Earthquake resistant building structure employing sandbags, US5934027A (1999). https://patents.google.com/patent/US5934027A/en (accessed April 6, 2018). 
Peel M.C., Finlayson B.L., McMahon T.A., 2006. Updated world map of the Köppen-Geiger climate classification. Meteorol Zeitschrift 15, 259-263. doi:10.1127/0941-2948/2006/0130.

Vall S., Castell A., 2017. Radiative cooling as low-grade energy source: A literature review. Renew Sustain Energy Rev 77, 1-18. doi:10.1016/j.rser.2017.04.010.

Vall S., Johannes K., David D., Castell A., 2018. A new flat-plate radiative cooling and solar collector numerical model: evaluation and metamodeling. App Energy, submitted.

\section{Acknowledgements}

The authors would like to thank the Oficina de Desenvolupament i Cooperació de la Universitat de Lleida for its project grants. The authors would like to thank the Catalan Government for the project grant (2017 SGR 659) given to their research group. Sergi Vall would like to thank the Secretaria d'Universitats i Recerca del Departament d'Economia i Coneixement de la Generalitat de Catalunya for its research fellowship. . Ariadna Carrobé would like to thank the Catalan government (AGAUR- Generalitat de Catalunya) for her collaboration grant 2017-2018 in the DIEI Department at UdL. 


\title{
Definition of a reference office building for simulation based evaluation of solar envelope systems
}

\author{
D'Antoni M. ${ }^{1}$, Geisler-Moroder D. ${ }^{2}$, Bonato P. ${ }^{1}$, Ochs F. ${ }^{3}$, Magni M. ${ }^{3}$, de Vries S. ${ }^{4}$, \\ Loonen R.C.G.M. ${ }^{4}$, Fedrizzi R. ${ }^{1}$ \\ 1 Eurac Research, Institute for Renewable Energy, Bolzano (Italy) \\ 2 Bartenbach $\mathrm{GmbH}$, Aldrans (Austria) \\ ${ }_{3}^{3}$ University of Innsbruck, Unit for Energy Efficienct Buildings, Innsbruck (Austria) \\ 4 Eindhoven University of Technology, Eindhoven (The Netherlands)
}

\begin{abstract}
Solar Envelope systems, which represent the technological response for meeting aesthetic requirements and solar renewable energy exploitation on building façades, are gaining rising attention. However, they are still rare on the market. IEA SHC Task 56 focuses on the critical analysis, simulation, laboratory tests and onsite monitoring of market available and near market Solar Envelope systems. Within this framework, reference boundary conditions are required in order to assess the performance of Solar Envelope systems and compare different technologies through numerical simulations.

The present paper reviews the process of defining reference boundary conditions for an office building, listing possible simplifications and required assumptions in order to calculate the impact at whole building level in terms of useful and final energy savings related to the installation of a façade integrated technology. The paper concludes with a comparison of simulation results between TRNSYS and DALEC, a simplified concept evaluation tool, which performs combined thermal and lighting analysis already at early design stages.
\end{abstract}

Keywords: Solar energy; Building façade; IEA

\section{Introduction}

In both residential and tertiary (offices, schools, hospitals) building sectors, solar thermal and PV systems are typically mounted on building roofs with limited attempt to incorporate them into the building envelope, creating aesthetic drawbacks and space availability problems. Building integrated solutions of respective technologies (typically referred as BIST and BIPV) are the technological response for meeting aesthetic requirements and solar renewable energy exploitation.

Daylighting control deeply influences visual and thermal comfort, electrical consumption for lighting as well as heating and cooling loads in buildings. Most of the time, solar control is delegated to individuals' management of internal and external blinds, even though smart lighting controls are nowadays state of the art in particular for the tertiary building sector.

Building integrated solar thermal and PV technologies and daylighting solutions are part of the so-called Solar Envelope systems, which entail elements that use and/or control incident solar energy, having one or more of the following uses:

- To deliver renewable thermal or/and electric energy to the systems providing heating, cooling and ventilation to buildings;

- To reduce heating and cooling demands of buildings, while controlling daylight.

IEA SHC Task 56 focuses on the critical analysis, simulation, laboratory tests and onsite monitoring of market available and near market Solar Envelope systems (http://task56.iea-shc.org/). The strategic objective is to coordinate the research and innovation efforts taking place within the scientific community and the private sector. 
In particular within subtask C, complete Solar Envelope systems are defined based on active and passive components and integrated into the HVAC system of reference buildings. These buildings are considered as virtual case studies, in which specific envelope elements are integrated into.

The performance assessment (in terms of thermal, electric and daylighting behavior) of Solar Envelope elements by means of building and HVAC simulations is key for supporting decision-making processes in a technoeconomic perspective. The comparison of multiple technological solutions should be carried out under the same boundary conditions such as reference climate datasets, user patterns (occupancy profiles), thermal and visual comfort requirements, building geometry and characteristics. The model can be used as a baseline for comparative studies, product rating or educational purposes. Therefore, it is important to find an agreement on a common definition of reference boundary conditions that covers at least a wide range of applications.

The aim of the paper is to provide a detailed description of boundary conditions to adopt for the transient simulation of a reference office building, that enables yearly performance evaluation of different solar active façade technologies. Although TRNSYS software is the tool used for simulation purposes, the description of the reference office boundary conditions aims to be platform independent and to be flexible enough allowing energetic, thermal and daylighting calculations. Most of the times, these tools are too demanding for façade designers and architects and therefore simplified tools are more than welcome. In order to ease the assessment of Solar Envelope systems by means of numerical simulations, within the framework of IEA SHC Task 56 simplified design tools are analyzed. For this purpose, DALEC (Werner et al., 2017), a simplified on-line tool that assesses thermal and daylighting performances of a user-defined façade design, is one of the tools here evaluated.

\section{Definition of the reference zone and weather analysis}

\subsection{Reference climate}

Three reference climatic conditions are selected for simulation purposes: Stockholm (Sweden), Stuttgart (Germany) and Rome (Italy) are chosen as they portray a significant range of European climatic conditions. The weather dataset used for simulation purposes is generated using the Meteonorm 7 database and contains hourly values of meteorological parameters such as ambient air temperature, humidity and solar radiation for a one-year period. For comparison purposes, Table 1 shows the following annual climatic parameters for the three locations. The Mediterranean climate is relatively warm with an annual average ambient temperature around $16{ }^{\circ} \mathrm{C}$ whereas colder climates and higher annual temperature amplitudes are experienced at higher latitudes with especially harsh winters in Stockholm. The annual average relative humidity is instead rather constant among the three climates. The annual solar irradiation decreases with the latitude and is lower on vertical facades than on the horizontal in all climates. The annual solar irradiation is higher for South-oriented façades in comparison to other orientations and varies between $1251 \mathrm{kWh} /\left(\mathrm{m}^{2} \mathrm{y}\right)$ in Rome and $894 \mathrm{kWh} /\left(\mathrm{m}^{2} \mathrm{y}\right)$ in Stockholm.

\subsection{Definition of the reference zone}

Because of the potentially high computational efforts, the energy analysis of high-rise office buildings by means of transient simulations needs adequate simplifications in the development of a numerical model. Since the aim of Subtask C of IEA SHC Task 56 is to carry out an analysis on the energy contribution of different solar active façade technologies in covering building loads and to evaluate indoor comfort conditions, the definition of a detailed architectural building geometry is of less importance. Thus, simplifications and assumptions on building geometry and user behavior are necessary and a good trade-off between accuracy of the model and computational and results analysis efforts has to be found. The reference zone is chosen considering the elementary and most representative modulus of this kind of structures that is a generic office localized in a mid-floor of a high-rise building.

Several attempts in the scientific community have dealt with the definition of reference office buildings (Reinhart et al., 2013; Deru et al., 2011). Geometric and thermophysic properties of the façade and boundary conditions (as internal gains or occupancy profile) are typically functional for the purpose of the simulation analysis to be conducted. When adopted for a simulation analysis that differs from the original scope, users can experience limitations in implementing their desired conditions and need to introduce assumptions that impede a straightforward comparison.

In order to benchmark a Solar Envelope system against a competing technology, the reference office zone could 
require some adaptation. For example, changes could involve the design of the façade assembly (e.g. WWR) or numerical aspects (e.g. simulation time step). In principle, this is possible, but it is requested to include results for the reference set of boundary conditions here presented.

A typical office cell as the one shown in Figure 1 is considered as reference thermal zone. The reference office cell is $6.0 \mathrm{~m}$ long, $4.5 \mathrm{~m}$ wide and $3.0 \mathrm{~m}$ high, resulting into $27 \mathrm{~m}^{2}$ floor surface and $81 \mathrm{~m}^{3}$ gross air volume. The facade is composed of three façade modules with a $60 \%$ window-to-wall ratio (gross value including façade frame), each of which is constituted by a lower spandrel panel and a non-openable window. The office zone is unobstructed from neighborhood buildings. It is assumed that internal walls, floor and ceiling do not exchange heat with adjacent zones, whereas the sole façade is exposed to the exterior environment. Although solar technologies can be theoretically integrated in facades with any azimuthal orientation, the South-oriented facade is considered for reference purposes, as it is the one most commonly exploited for solar applications.
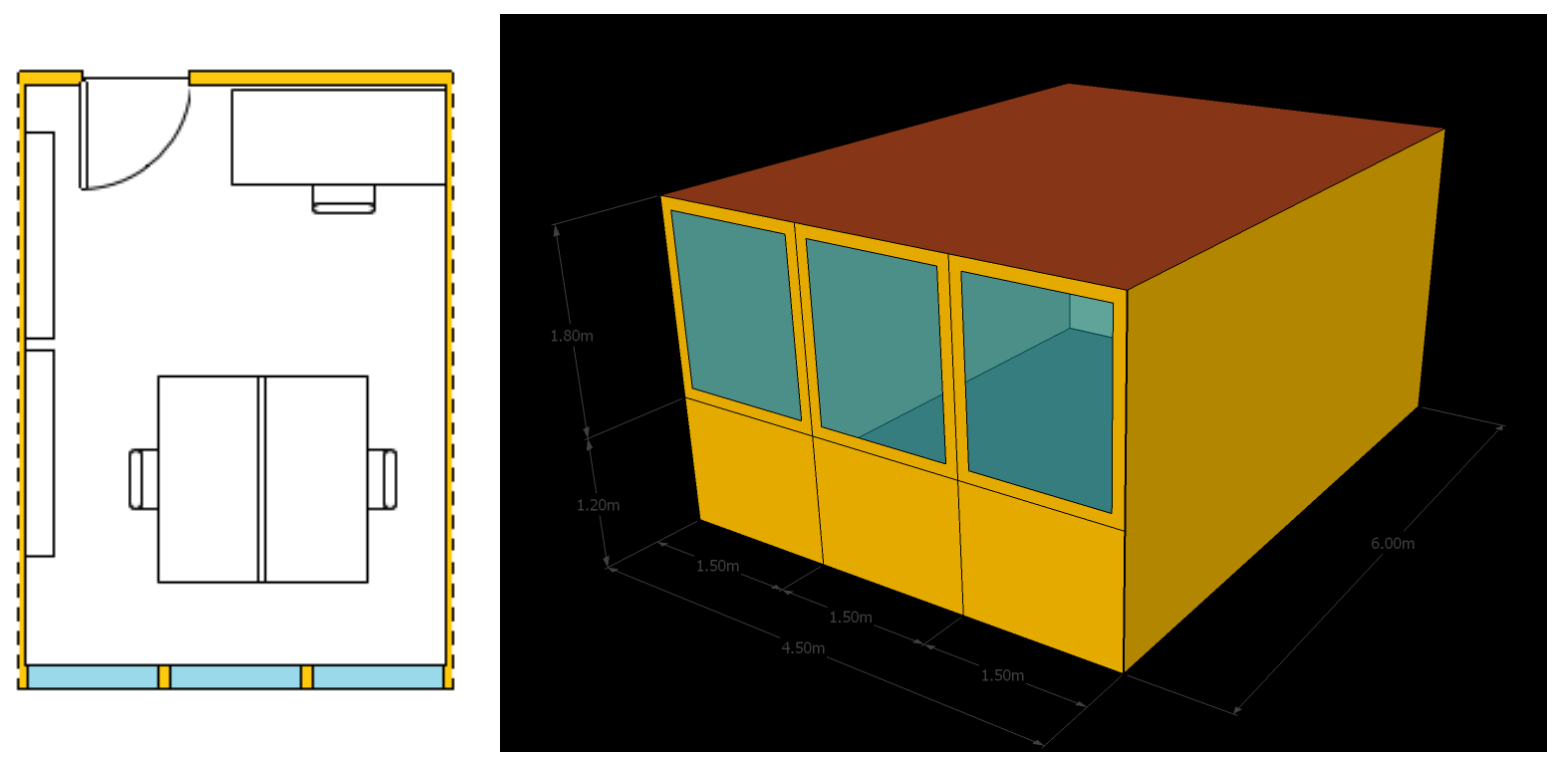

Fig. 1: View of the reference office zone.

The reference zone is modelled with a single-zone single-air node model and a set of parameters is used to characterize the office space in terms of occupancy, internal gains, ventilation, infiltration rate and shading. The optical and thermal properties of the building assemblies as well as the most relevant boundary conditions are listed in Tables 2-7. Envelope characteristics are varied for the different locations, but it should be pointed out that these boundary conditions do not aim to define a building typology for the three reference locations nor a reference energy use for tertiary office buildings.

Fresh air is supplied through a centralized mechanical ventilation system, to which a specific fan power of 0.55 $\mathrm{Wh} / \mathrm{m}^{3}$ is assigned. The ventilation unit is further equipped with a heat recovery unit with a sensible efficiency of $70 \%$ (SIA 2024, 2015), a by-pass strategy and a frost protection by means of an electrical resistance.

The delivery of heating and cooling to the reference office zone is distinguished between air- and water-based emission systems and for both cases sizing criteria and control strategies of the emission system are specified. As reference heating and cooling generation systems, a gas boiler and an electrically driven chiller are considered. Both are assumed to be centralized at building level. Since cooling and heating are in principle possible simultaneously throughout the year, the definition of an annual schedule for switching on and off single units is not necessary. The computation of final energy is carried out using average yearly coefficients of performance, but specifications of these aspects are still to be debated within the IEA SHC Task 56. For an exhaustive description of the boundary conditions and a more detailed description of the modelling approach, the reader is invited to refer to the IEA SHC Task 56 Subtask C activities.

\subsection{Simplification of model inputs and parameters for DALEC simulation}

DALEC (Day- and Artificial Light with Energy Calculation) is an online concept evaluation tool for architects, building engineers, lighting designers and building owners. Although it is easy to use and has short calculation times, the software accounts for the complex thermal and light processes in buildings and allows a simple 
evaluation of heating, cooling and electrical lighting loads. This allows optimizations of the façade settings, the artificial lighting installation and the thermal parameters of a building in an early design phase.

For the reduced inputs into DALEC, the relevant parameters need to be derived from the specified boundary conditions of Appendix I. The following simplifications from TRNSYS to DALEC are necessary:

- Occupancy, appliances and fan power need to be summarized as internal gains. Calculating the gains according to the schedules given in Table 2 of Appendix I, it results in $9.74 \mathrm{~W} / \mathrm{m}^{2}$ of internal gains over the 11 hours of overall occupancy time from 08:00 to 19:00.

- In DALEC, the transparent area of the façade is defined as relative fraction of the overall façade in three areas. In the lower area (below $1 \mathrm{~m})$ no transparent structure is present. For the middle are $(1 \mathrm{~m}-2 \mathrm{~m}$ height) the window size as defined in paragraph 2.2 starting at $1.20 \mathrm{~m}$ height and with $11 \mathrm{~cm}$ frame translates into 0.59 active window area, while for the upper area an active area of 0.76 is obtained.

- Two air exchange rates are considered in DALEC. The general energy-equivalent air exchange rate is the sum of infiltration and energy-effective air exchange rate in terms of ventilation losses. This rate is applied 24/7. The window / night ventilation air exchange rate assumes an additional passive ventilation whenever the indoor temperature exceeds a given threshold and is higher than the outdoor temperature. This strategy also operates the whole day (and not only during occupancy times).

- According to Table 3, the shading device is activated whenever the direct solar radiation incident on the façade exceeds $120 \mathrm{~W} / \mathrm{m}^{2}$. However, in the standard DALEC implementation the overall radiation incident at the façade is used for the solar shading control. To be able to compare the results from DALEC and TRNSYS, the shading control was adapted in the source code of DALEC for these simulations to match the control in TRNSYS.

- In Tables 4-7 the thermal characteristics of the opaque assemblies and building materials are given. The setup matches with a typical medium construction. Thus the value of $165 \mathrm{~kJ} /\left(\mathrm{m}^{2} \mathrm{~K}\right)$ is assumed.

\section{Simulation results}

Numerical simulations are performed using both TRNSYS and DALEC softwares. The key performance indicators presented here, focus on the energy performance of the reference office zone and aim at a preliminary comparison between simulation results calculated by TRNSYS and DALEC. Because of this reason, the following KPIs are considered: annual active space heating (Q $\left.\mathrm{Q}_{\mathrm{HEAT}}\right)$ and cooling (Q $\mathrm{COOL}$ ) energy delivery to the thermal zone; annual total electricity demand of appliances ( $\left.\mathrm{W}_{\mathrm{EL}, \mathrm{APP}}\right)$, artificial lighting ( $\left.\mathrm{W}_{\mathrm{EL}, \mathrm{LIGHT}}\right)$, fans (W $\left.\mathrm{W}_{\mathrm{EL}, \mathrm{FAN}}\right)$ and of the antifreeze resistance ( $\left.\mathrm{W}_{\mathrm{EL}, \mathrm{AF}}\right)$ in the air handling unit.

\subsection{TRNSYS simulation results}

Looking at the TRNSYS energy results, the annual energy flows that characterize the thermal behavior of the office zone are listed in Tables 8-10 for the three reference locations (Rome, Stuttgart and Stockholm). In this regard, the overall energy balance is given by the sum of positive energy contributions (solar gains QsoL, internal gains $\mathrm{Q}_{\mathrm{GINT}}$ and active space heating $\mathrm{Q}_{\mathrm{HEAT}}$ ) and negative contributions (ventilation heat losses $\mathrm{Q}_{\mathrm{VENT}}$, infiltration heat losses $\mathrm{Q}_{\mathrm{INF}}$, transmitted heat $\mathrm{Q}_{\text {TRANS }}$ and active space cooling $\mathrm{Q}_{\mathrm{COOL}}$ ) and shall be equal to zero.

In colder climates, the annual space heating and cooling energy demands increase and decrease, respectively, as expected, even though such effect is mitigated by using more insulated building assemblies and glazing with high solar factor. The space heating demand ranges from $21.3 \mathrm{kWh} /\left(\mathrm{m}^{2} \mathrm{y}\right)$ in Stockholm to $3.5 \mathrm{kWh} /\left(\mathrm{m}^{2} \mathrm{y}\right)$ in Rome, where the space heating is barely used. Concerning space cooling, in modern office buildings it is possible to experience overheating also during mid-season, since the high internal gains cannot be easily dissipated through the well-insulated and air-tight envelope. As a consequence, the resulting space cooling energy demand is relevant also in all the considered locations and ranges from $33.3 \mathrm{kWh} /\left(\mathrm{m}^{2} \mathrm{y}\right)$ in Rome to $23.8 \mathrm{kWh} /\left(\mathrm{m}^{2} \mathrm{y}\right)$ in Stockholm. The internal gains do not vary with the climate $\left(56.5 \mathrm{kWh} /\left(\mathrm{m}^{2} \mathrm{y}\right)\right)$ and are mainly generated by the artificial lighting (55\%), whereas ICT appliances $(24 \%)$ and human presence $(21 \%)$ contribute for smaller shares. The ventilation heat losses amount to a total of $20.2 \mathrm{kWh} /\left(\mathrm{m}^{2} \mathrm{y}\right)$ in Rome, $28.4 \mathrm{kWh} /\left(\mathrm{m}^{2} \mathrm{y}\right)$ in Stuttgart and $30.4 \mathrm{kWh} /\left(\mathrm{m}^{2} \mathrm{y}\right) \mathrm{in}$ Stockholm and are greatly reduced by the use of a high-efficiency heat recovery unit, which is particularly effective at higher latitudes. The solar gains are higher in Stockholm and Stuttgart than in Rome, where a solarcontrol coated glazing is used. The annual solar gains are $32.9 \mathrm{kWh} /\left(\mathrm{m}^{2} \mathrm{y}\right)$ in Rome, $59.9 \mathrm{kWh} /\left(\mathrm{m}^{2} \mathrm{y}\right)$ in Stuttgart 
and $58.0 \mathrm{kWh} /\left(\mathrm{m}^{2} \mathrm{y}\right)$ in Stockholm. The energy demand for humidification ranges from $0.2 \mathrm{kWh} /\left(\mathrm{m}^{2} \mathrm{y}\right)$ in Rome to $5.2 \mathrm{kWh} /\left(\mathrm{m}^{2} \mathrm{y}\right)$ in Stockholm, whereas for dehumidification from $0.1 \mathrm{kWh} /\left(\mathrm{m}^{2} \mathrm{y}\right)$ in Stockholm to 2.1 $\mathrm{kWh} /\left(\mathrm{m}^{2} \mathrm{y}\right)$. Concerning electricity, most of the annual consumption is connected to the artificial lighting system $\left(31.3 \mathrm{kWh} /\left(\mathrm{m}^{2} \mathrm{y}\right)\right)$, whereas the fans of the ventilation unit $\left(7.0 \mathrm{kWh} /\left(\mathrm{m}^{2} \mathrm{y}\right)\right)$ and appliances $\left(13.5 \mathrm{kWh} /\left(\mathrm{m}^{2} \mathrm{y}\right)\right) \operatorname{are}$ responsible for lower shares. The antifreeze resistance integrated in the ventilation unit, which allows to avoid icing in the return section of the heat recovery unit of the ventilation system, is active only in the colder climates of Stuttgart and Stockholm $\left(4 \mathrm{kWh} /\left(\mathrm{m}^{2} \mathrm{y}\right)\right.$ and $7 \mathrm{kWh} /\left(\mathrm{m}^{2} \mathrm{y}\right)$, respectively), whereas it remains un-used in the Mediterranean climate of Rome.

\subsection{DALEC simulation results and comparison with TRNSYS}

The overall agreement between the simulation results is quite good, at least when similar simplified parameter sets (e.g. for internal gains, shading control etc.) are assumed. Figure 1 to Figure 3 shows a comparison between the annual space heating and cooling energy demands calculated with DALEC (dashed fill) and TRNSYS (solid fill) software. The comparison is performed in terms of space heating, space cooling and solar gains, as other energy flows (such as ventilation, infiltration or transmission losses) are not provided as output from DALEC.

Concerning internal gains, the difference between the results of the two software is limited to $6 \%$ (or 3.2 $\left.\mathrm{kWh} /\left(\mathrm{m}^{2} \mathrm{y}\right)\right)$ in all climates and, more specifically, identical results are obtained for the artificial lighting gains. It should be reminded that no advanced artificial lighting control (e.g. dimming) is considered in these simulations. As concerns indoor climate control, deviations up to $30 \%$ (or $7.0 \mathrm{kWh} /\left(\mathrm{m}^{2} \mathrm{y}\right)$ ) are found for space cooling and up to $5.0 \mathrm{kWh} /\left(\mathrm{m}^{2} \mathrm{y}\right)$ in Stockholm for space heating. The overall agreement between the annual and monthly simulation results of TRNSYS and DALEC is relatively good, in spite of the differences in the modeling detail (ventilation, thermal capacity, angular dependent solar gains).

Although the geometric and materials specifications are purposely kept as simple as possible to minimize the opportunity of inputs errors of the part of the user, when a reference zone is modelled, it is likely that deviations from target results occur. From the experience gained from the modelling and comparison of the reference case with the two software, it is also possible to state that deviations in the energy results can be due to a multitude of causes, among which:

- Different simulation inputs (different weather files, schedules, performance of components, time-step);

- Different simulation models (diverse level of detail left to the user in defining the features of their model, physical vs empirical models, different handling of radiative exchange, heat transfer equations or capacitance effects);

- Different convergence algorithms (number of iterations, order resolution of different equation/components, convergence limits and maximum tolerances);

- $\quad$ Different post-processing procedures (time-frame, averaging and integration operations);

- Human mistakes and different sensibility of the modeler to certain issues.
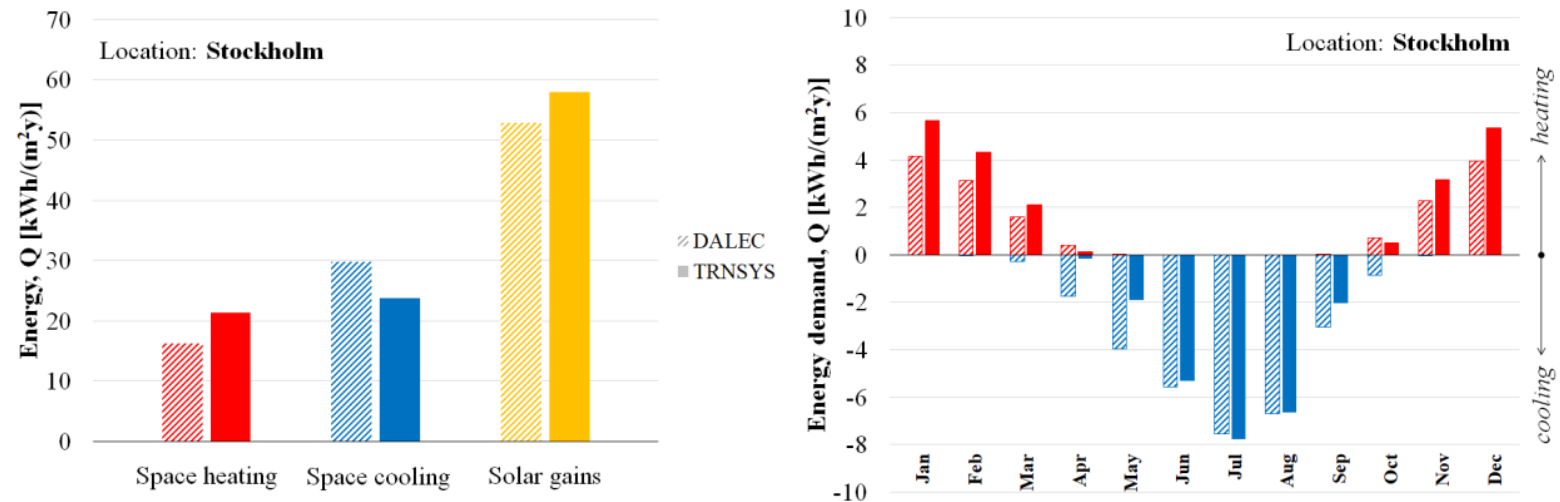

Fig. 1: Comparison of yearly (left) and monthly (right) DALEC (dashed fill) and TRNSYS (solid fill) simulation results for the reference location of Stockholm. 

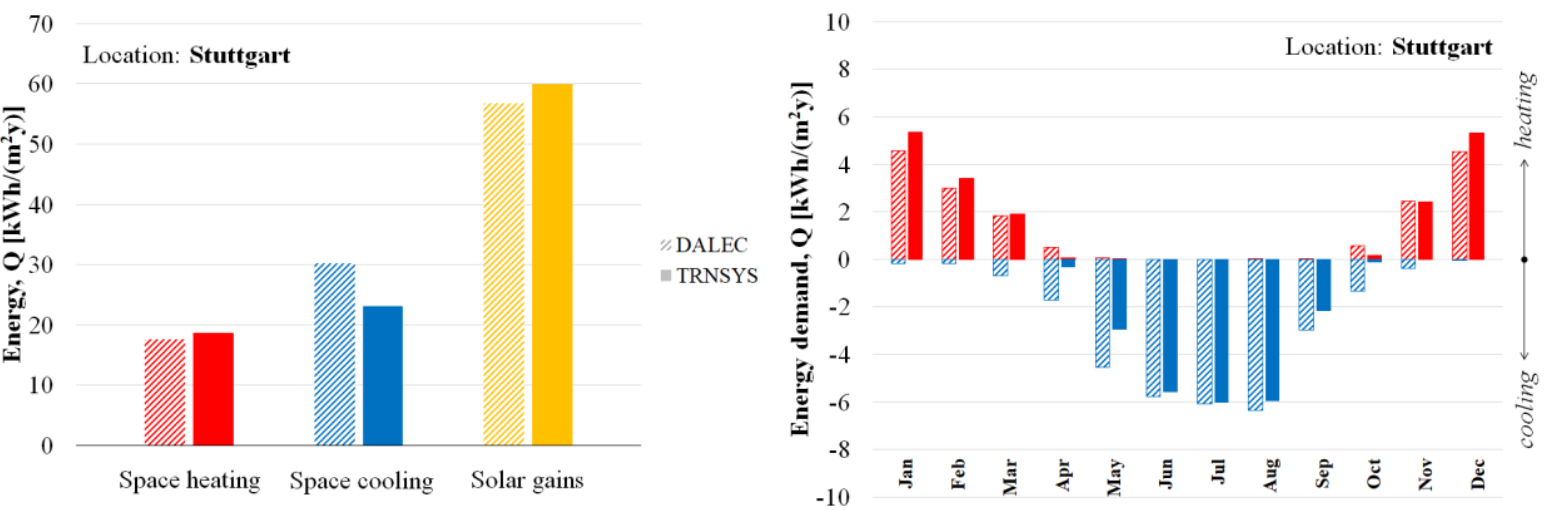

Fig. 2: Comparison of yearly (left) and monthly (right) DALEC (dashed fill) and TRNSYS (solid fill) simulation results for the reference location of Stuttgart.
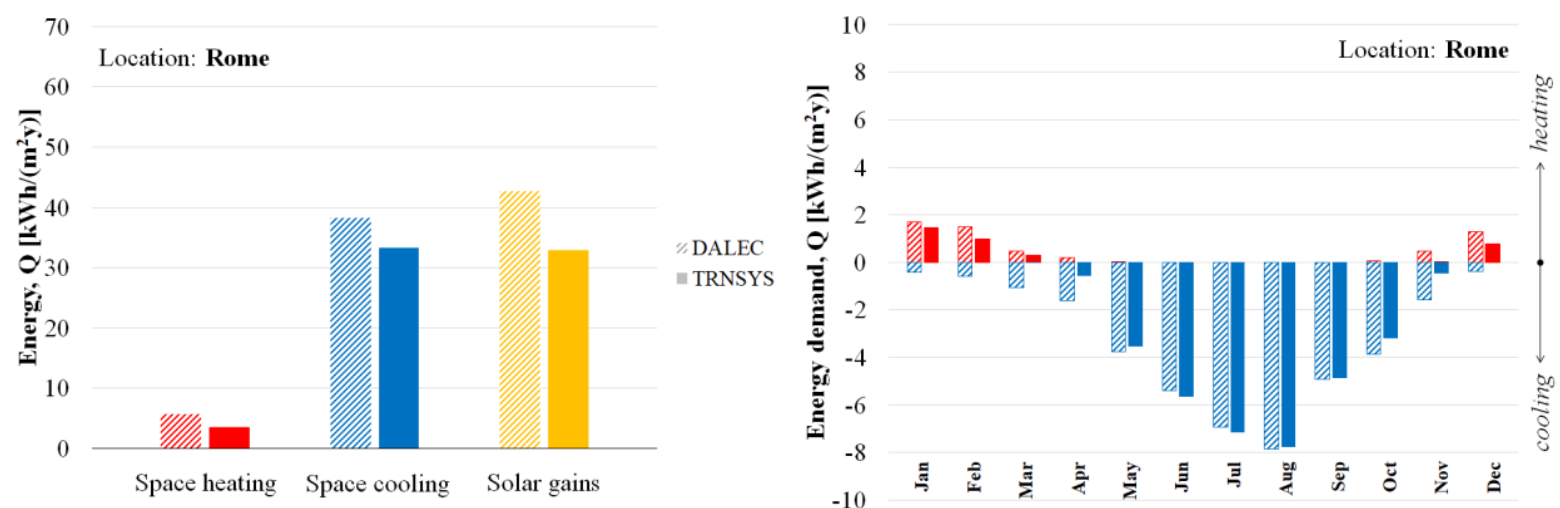

Fig. 3: Comparison of yearly (left) and monthly (right) DALEC (dashed fill) and TRNSYS (solid fill) simulation results for the reference location of Rome.

\section{Conclusions}

The paper focuses on the definition of a reference office zone for numerical simulation purposes of Solar Envelope systems within the framework of IEA SHC Task 56. The model description aims to be exploited by different simulation platform users and for different kind of analysis (thermal, daylighting or a combination of these).

In order to facilitate the evaluation of different Solar Envelopes systems, the adoption of simplified simulation tools is promoted. This allows overcoming typical entry-barriers (e.g. purchasing costs or learning time) in the use of high-resultion softwares. In this regard, DALEC is freely available on-line and easy-to-learn. It proves to be a reliable software to perform preliminary analysis of the energy performance of spaces characterized by simple geometries and façade designs. Undoubtedly, distinct built-in features and code structure characterize different energy simulation applications, making them more or less adequate to the scope of the user. The use of the different tools shall be then fit-to-purpose: simplified simulation software may be preferred for preliminary energy assessment of different façade designs to others that can instead handle more complex problems and may be more suitable for more expert users.

The accuracy of DALEC in predicting yearly energy performance is quite good, despite a set of simplifications in averaging hourly schedules. In the near future, the work within Subtask C of IEA SHC Task 56 will focus on the HVAC system. In high-rise buildings, heating, cooling, hot water and ventilation systems are typically centralized at building level. Façade-integrated solar technologies generate heat or electricity locally, which can be stored or consumed at the production site or shared at building scale. It is then fundamental to define a methodology to assess the impact of Solar Envelope systems on the energy balance of the building, while maintaining an adequate level of detail on the single office zones, guaranteeing thermal and visual comfort as well as indoor air quality. 


\section{References}

Deru, M., Field, K., Studer, D., Benne, K., Griffith, B., Torcellini, P., Liu, B., Halverson, M., Winiarski, D., Rosenberg, M., Yazdanian, M., Huang, J., Crawley, D., 2011. U.S. Department of Energy commercial reference building models of the national building stock.

IEA, 2016. International Energy Agency, Solar Heating and Cooling Programme, IEA SHC Task 56 "Building Integrated Solar Envelope Systems for HVAC and Lighting".

Klein S.A., Beckman W.A., Mitchell J.W., Duffie J.A., Duffie N.A., Freeman T.L., et al., 1979. TRNSYS 17, TRaNsient SY stem Simulation program. University of Wisconsin, Madison, WI, USA.

Reinhart C.F., Jakubiec J.A., Ibarra D. Definition of a reference office for standardized evaluations of dynamics facade and lighting technologies. Proc. of BS2013 $13^{\text {th }}$ Conference of International Building Performance Simulation Association, Chambéry, France, August 26-28.

SIA, SIA 2024:2015: Raumnutzungsdaten für die Energie- und Gebäudetechnik.

Werner M., Geisler-Moroder D., Junghans B., Ebert O., Feist W., 2017. DALEC - A Novel Web-Tool for Integrated Day- and Artificial Light \& Energy Calculation. Journal of Building Performance Simulation, 10(3), 344-363. 


\section{Appendix I: Boundary conditions for the numerical model of the reference office zone}

Table 1: Average climatic parameters.

\begin{tabular}{|c|c|c|c|}
\hline Location & $\begin{array}{l}\text { Rome } \\
\text { (Italy) }\end{array}$ & $\begin{array}{l}\text { Stuttgart } \\
\text { (Germany) }\end{array}$ & $\begin{array}{c}\text { Stockholm } \\
\text { (Sweden) }\end{array}$ \\
\hline \multicolumn{4}{|l|}{$T_{a m b}\left[{ }^{\circ} \mathrm{C}\right]$} \\
\hline - minimum & -1.4 & -12.6 & -16.5 \\
\hline - maximum & 33.1 & 32.4 & 29.7 \\
\hline - average & 15.8 & 10.0 & 7.9 \\
\hline \multicolumn{4}{|l|}{$\phi_{a m b}[\%]$} \\
\hline - average & 71.9 & 73.5 & 73.4 \\
\hline${ }^{I_{g}}\left[\mathrm{kWh} /\left(\mathrm{m}^{2} \mathrm{y}\right)\right]$ & & & \\
\hline - Horizontal & 1637 & 1105 & 954 \\
\hline - East & 1251 & 897 & 894 \\
\hline - South & 980 & 724 & 681 \\
\hline - West & 984 & 679 & 658 \\
\hline
\end{tabular}

Table 2: Reference office schedules during working days: occupancy [SIA, 2015], electrical appliances [SIA, 2015] and artificial lighting.

\begin{tabular}{|c|c|c|c|}
\hline Time $[\mathrm{h}]$ & $\begin{array}{c}\text { Human } \\
\text { occupancy } \\
{[-]}\end{array}$ & $\begin{array}{c}\text { Appliances } \\
{[-]}\end{array}$ & $\begin{array}{c}\text { Artificial } \\
\text { lighting [-] }\end{array}$ \\
\hline 1 & 0.0 & 0.1 & 0.0 \\
\hline 2 & 0.0 & 0.1 & 0.0 \\
\hline 3 & 0.0 & 0.1 & 0.0 \\
\hline 4 & 0.0 & 0.1 & 0.0 \\
\hline 5 & 0.0 & 0.1 & 0.0 \\
\hline 6 & 0.0 & 0.1 & 0.0 \\
\hline 7 & 0.0 & 0.1 & 0.0 \\
\hline 8 & 0.2 & 0.2 & 1.0 \\
\hline 9 & 0.6 & 0.6 & 1.0 \\
\hline 10 & 1.0 & 0.8 & 1.0 \\
\hline 11 & 1.0 & 1.0 & 1.0 \\
\hline 12 & 0.8 & 0.8 & 1.0 \\
\hline 13 & 0.4 & 0.4 & 1.0 \\
\hline 14 & 0.6 & 0.6 & 1.0 \\
\hline 15 & 1.0 & 1.0 & 1.0 \\
\hline 16 & 0.8 & 0.8 & 1.0 \\
\hline 17 & 0.6 & 0.6 & 1.0 \\
\hline 18 & 0.2 & 0.2 & 1.0 \\
\hline 19 & 0.0 & 0.1 & 0.0 \\
\hline 20 & 0.0 & 0.1 & 0.0 \\
\hline 21 & 0.0 & 0.1 & 0.0 \\
\hline 22 & 0.0 & 0.1 & 0.0 \\
\hline 23 & 0.0 & 0.1 & 0.0 \\
\hline 24 & 0.0 & 0.1 & 0.0 \\
\hline
\end{tabular}

Table 3: Boundary conditions of the numerical model of the reference office zone.

\begin{tabular}{|c|c|c|}
\hline \multicolumn{3}{|l|}{ Geometry } \\
\hline Floor area & 27 & $\mathrm{~m}^{2}$ \\
\hline Volume & 81 & $\mathrm{~m}^{3}$ \\
\hline WWR (gross) & 60 & $\%$ \\
\hline \multicolumn{3}{|l|}{ Occupancy } \\
\hline Full occupancy & 3 & pers \\
\hline Crowding index & 11 & pers $/ \mathrm{m}^{2}$ \\
\hline $\begin{array}{l}\text { Contemporaneity factor [SIA, } \\
\text { 2015] }\end{array}$ & 0.8 & \\
\hline $\begin{array}{l}\text { Metabolic rate (office work) [SIA, } \\
\text { 2015] }\end{array}$ & 1.2 & met \\
\hline \multicolumn{3}{|l|}{ Façade building assembly - Glazing } \\
\hline \multicolumn{3}{|l|}{ g-glass } \\
\hline - Rome & 0.33 & - \\
\hline - Stuttgart & 0.59 & - \\
\hline - Stockholm & 0.63 & - \\
\hline \multicolumn{3}{|l|}{ U-value (glass) } \\
\hline - Rome & 1.29 & $\mathrm{~W} /\left(\mathrm{m}^{2} \mathrm{~K}\right)$ \\
\hline - Stuttgart & 1.40 & $\mathrm{~W} /\left(\mathrm{m}^{2} \mathrm{~K}\right)$ \\
\hline - Stockholm & 0.81 & $\mathrm{~W} /\left(\mathrm{m}^{2} \mathrm{~K}\right)$ \\
\hline U-value (frame) & 1.18 & $\mathrm{~W} /\left(\mathrm{m}^{2} \mathrm{~K}\right)$ \\
\hline Frame thickness & 0.11 & $\mathrm{~m}$ \\
\hline \multicolumn{3}{|c|}{ Facade building assembly - Lower infill element } \\
\hline \multicolumn{3}{|c|}{ U-value (glass) } \\
\hline - Rome & 0.80 & $\mathrm{~W} /\left(\mathrm{m}^{2} \mathrm{~K}\right)$ \\
\hline - Stuttgart & 0.40 & $\mathrm{~W} /\left(\mathrm{m}^{2} \mathrm{~K}\right)$ \\
\hline - Stockholm & 0.30 & $\mathrm{~W} /\left(\mathrm{m}^{2} \mathrm{~K}\right)$ \\
\hline \multicolumn{3}{|l|}{ External solar shading } \\
\hline Shading factor & 70 & $\%$ \\
\hline Beam radiation for activation & 120 & $\mathrm{~W} / \mathrm{m}^{2}$ \\
\hline \multicolumn{3}{|l|}{ Internal gains } \\
\hline \multicolumn{3}{|l|}{ Persons [SIA, 2015] } \\
\hline - Latent & 0.08 & $\mathrm{~kg} / \mathrm{h} /$ pers \\
\hline - Sensible & 70 & W/pers \\
\hline Appliances [SIA, 2015] & 7.0 & $\mathrm{~W} / \mathrm{m}^{2}$ \\
\hline Artificial lighting & 10.9 & $\mathrm{~W} / \mathrm{m}^{2}$ \\
\hline \multicolumn{3}{|l|}{ Ventilation } \\
\hline Fresh-air supply & 40 & $\mathrm{~m}^{3} / \mathrm{h} /$ pers \\
\hline Specific fan power & 0.55 & $\mathrm{Wh} / \mathrm{m}^{3}$ \\
\hline Heat recovery unit (HRU) & yes & - \\
\hline Efficiency of the HRU [SIA, 2015] & 70 & $\%$ \\
\hline By-pass & yes & - \\
\hline Frost protection temperature & 0 & ${ }^{\circ} \mathrm{C}$ \\
\hline \multicolumn{3}{|l|}{ Infiltration } \\
\hline Air change rate & 0.15 & $1 / \mathrm{h}$ \\
\hline \multicolumn{3}{|l|}{ Thermal comfort } \\
\hline \multicolumn{3}{|l|}{ Air temperature setpoint } \\
\hline - Heating & 20 & ${ }^{\circ} \mathrm{C}$ \\
\hline - Cooling & 26 & ${ }^{\circ} \mathrm{C}$ \\
\hline - Hysteresis & 1.0 & $\mathrm{~K}$ \\
\hline \multicolumn{3}{|l|}{ Air humidity } \\
\hline - Maximum & 13.5 & $\mathrm{~g}_{\mathrm{v}} / \mathrm{kg}_{\mathrm{a}}$ \\
\hline - Minimum & 4.5 & $\mathrm{~g}_{\mathrm{v}} / \mathrm{kg}_{\mathrm{a}}$ \\
\hline Max. heating power & unlim & nited \\
\hline Max. cooling power & unlim & nited \\
\hline
\end{tabular}


Table 4: Construction assembly of internal walls.

\begin{tabular}{lcccc}
\hline \multicolumn{1}{c}{ Material } & $\begin{array}{c}\mathrm{s} \\
{[\mathrm{m}]}\end{array}$ & $\begin{array}{c}\lambda \\
{[\mathrm{W} /(\mathrm{mK})]}\end{array}$ & $\begin{array}{c}\rho \\
{\left[\mathrm{kg} / \mathrm{m}^{3}\right]}\end{array}$ & $\begin{array}{c}\mathrm{c}_{\mathrm{p}} \\
{[\mathrm{kJ} /(\mathrm{kgK})]}\end{array}$ \\
\hline Plasterboard & 0.024 & 0.160 & 950 & 0.84 \\
Mineral wool & 0.080 & 0.038 & 80 & 0.84 \\
Plasterboard & 0.024 & 0.160 & 950 & 0.84 \\
\hline
\end{tabular}

Table 5: Construction assembly of floor/ceiling.

\begin{tabular}{lcccc}
\hline \multicolumn{1}{c}{ Material } & $\mathrm{s}$ & $\lambda$ & $\rho$ & $\mathrm{c}_{\mathrm{p}}$ \\
& {$[\mathrm{m}]$} & {$[\mathrm{W} /(\mathrm{mK})]$} & $\begin{array}{c}\rho \\
{\left[\mathrm{kg} / \mathrm{m}^{3}\right]}\end{array}$ & $\begin{array}{c}\mathrm{kJ} /(\mathrm{kgK})] \\
\text { Carpet }\end{array}$ \\
Screed & 0.005 & 0.060 & 200 & 1.30 \\
Concrete & 0.120 & 0.080 & 350 & 0.40 \\
\hline
\end{tabular}

Table 6: Construction assembly of external wall.

\begin{tabular}{lcccc}
\hline \multicolumn{1}{c}{ Material } & $\begin{array}{c}\mathrm{s} \\
{[\mathrm{m}]}\end{array}$ & $\begin{array}{c}\lambda \\
{[\mathrm{W} /(\mathrm{mK})]}\end{array}$ & $\begin{array}{c}\rho \\
{\left[\mathrm{kg} / \mathrm{m}^{3}\right]}\end{array}$ & $\begin{array}{c}\mathrm{c}_{\mathrm{p}} \\
{[\mathrm{kJ} /(\mathrm{kgK})]}\end{array}$ \\
\hline Aluminium & 0.003 & 200 & 2700 & 0.86 \\
Mineral wool & var. & 0.038 & 80 & 0.84 \\
Aluminium & 0.003 & 200 & 2700 & 0.86 \\
\hline
\end{tabular}

Table 7: Optical characteristics of indoor surfaces (valid for the overall solar spectrum).

\begin{tabular}{lccc}
\hline \multicolumn{1}{c}{ Material } & $\begin{array}{c}\text { Reflectance } \\
{[-]}\end{array}$ & $\begin{array}{c}\text { Absorptance } \\
{[-]}\end{array}$ & $\begin{array}{c}\text { Emissivity } \\
{[-]}\end{array}$ \\
\hline Plasterboard & 0.707 & 0.293 & 0.900 \\
Mineral wool & 0.384 & 0.616 & 0.900 \\
Plasterboard & 0.850 & 0.150 & 0.900 \\
\hline
\end{tabular}




\section{Appendix II: Monthly energy balance of the reference office zone (TRNSYS)}

Table 8: Monthly energy balance for the reference office zone in Stockholm.

\begin{tabular}{|c|c|c|c|c|c|c|c|}
\hline \multirow{2}{*}{ Month } & QHEAT & QCOOL & Q INF & Qvent & QTRANS & $\mathbf{Q}_{\text {GINT }}$ & QSOL \\
\hline & $\mathrm{kWh} /\left(\mathrm{m}^{2} \mathrm{y}\right)$ & $\mathrm{kWh} /\left(\mathrm{m}^{2} \mathrm{y}\right)$ & $\mathrm{kWh} /\left(\mathrm{m}^{2} \mathrm{y}\right)$ & $\mathrm{kWh} /\left(\mathrm{m}^{2} \mathrm{y}\right)$ & $\mathrm{kWh} /\left(\mathrm{m}^{2} \mathrm{y}\right)$ & $\mathrm{kWh} /\left(\mathrm{m}^{2} \mathrm{y}\right)$ & $\mathrm{kWh} /\left(\mathrm{m}^{2} \mathrm{y}\right)$ \\
\hline January & 5.37 & 0.00 & -2.52 & -1.99 & -7.81 & 4.97 & 1.98 \\
\hline February & 4.14 & 0.00 & -2.34 & -1.90 & -7.33 & 4.33 & 3.10 \\
\hline March & 2.01 & 0.00 & -2.32 & -2.47 & -7.33 & 4.77 & 5.36 \\
\hline April & 0.14 & -0.16 & -1.77 & -3.57 & -5.53 & 4.56 & 6.34 \\
\hline May & 0.00 & -1.85 & -1.40 & -3.83 & -5.09 & 4.97 & 7.24 \\
\hline June & 0.00 & -5.18 & -1.01 & -2.43 & -3.22 & 4.56 & 7.28 \\
\hline July & 0.00 & -7.62 & -0.69 & -1.56 & -2.26 & 4.77 & 7.36 \\
\hline August & 0.00 & -6.47 & -0.80 & -2.13 & -2.51 & 4.97 & 6.94 \\
\hline September & 0.00 & -1.95 & -1.26 & -3.34 & -3.55 & 4.36 & 5.73 \\
\hline October & 0.53 & -0.03 & -1.66 & -3.24 & -4.39 & 4.97 & 3.80 \\
\hline November & 3.09 & 0.00 & -1.94 & -1.85 & -5.67 & 4.75 & 1.62 \\
\hline December & 5.16 & 0.00 & -2.31 & -1.76 & -6.95 & 4.57 & 1.29 \\
\hline Total & 20.43 & -23.25 & -20.02 & -30.08 & -61.64 & 56.52 & 58.04 \\
\hline
\end{tabular}

Table 9: Monthly energy balance for the reference office zone in Stuttgart.

\begin{tabular}{|c|c|c|c|c|c|c|c|}
\hline \multirow{2}{*}{ Month } & $\mathbf{Q H E A T}$ & $\mathbf{Q C O O L}$ & $\mathbf{Q I N F}$ & $\mathbf{Q V E N T}$ & $\mathbf{Q}$ TRANS & $\mathbf{Q G I N T}$ & $\mathbf{Q \text { sOL }}$ \\
\cline { 2 - 8 } & $\mathbf{k W h} /\left(\mathbf{m}^{\mathbf{2}} \mathbf{y}\right)$ & $\left.\mathbf{k W h} / \mathbf{m}^{\mathbf{2}} \mathbf{y}\right)$ & $\left.\mathbf{k W h} / \mathbf{m}^{\mathbf{2}} \mathbf{y}\right)$ & $\mathbf{k W h} /\left(\mathbf{m}^{\mathbf{2}} \mathbf{y}\right)$ & $\mathbf{k W h} /\left(\mathbf{m}^{\mathbf{2}} \mathbf{y}\right)$ & $\left.\mathbf{k W h} / \mathbf{m}^{\mathbf{2}} \mathbf{y}\right)$ & $\mathbf{k W h} /\left(\mathbf{m}^{\mathbf{2}} \mathbf{y}\right)$ \\
\hline January & 5.11 & 0.00 & -2.32 & -2.11 & -8.73 & 4.97 & 3.07 \\
\hline February & 3.27 & 0.00 & -1.95 & -1.98 & -7.47 & 4.33 & 3.81 \\
\hline March & 1.85 & 0.00 & -1.85 & -2.55 & -7.02 & 4.77 & 4.81 \\
\hline April & 0.06 & -0.33 & -1.45 & -3.20 & -5.44 & 4.56 & 5.81 \\
\hline May & 0.02 & -2.89 & -1.12 & -3.09 & -5.14 & 4.97 & 7.31 \\
\hline June & 0.00 & -5.44 & -0.78 & -1.74 & -3.29 & 4.56 & 6.69 \\
\hline July & 0.00 & -5.84 & -0.68 & -1.63 & -2.87 & 4.77 & 6.25 \\
\hline August & 0.00 & -5.78 & -0.70 & -1.81 & -2.96 & 4.97 & 6.28 \\
\hline September & 0.00 & -2.13 & -1.11 & -2.78 & -3.91 & 4.36 & 5.56 \\
\hline October & 0.18 & -0.15 & -1.43 & -3.40 & -4.93 & 4.97 & 4.74 \\
\hline November & 2.40 & 0.00 & -1.79 & -2.15 & -6.25 & 4.75 & 3.03 \\
\hline December & 5.12 & 0.00 & -2.22 & -1.87 & -8.20 & 4.57 & 2.60 \\
\hline Total & $\mathbf{1 8 . 0 1}$ & $\mathbf{- 2 2 . 5 6}$ & $\mathbf{- 1 7 . 4 0}$ & $\mathbf{- 2 8 . 3 2}$ & $\mathbf{- 6 6 . 2 0}$ & $\mathbf{5 6 . 5 2}$ & $\mathbf{5 9 . 9 5}$ \\
\hline
\end{tabular}

Table 10: Monthly energy balance for the reference office zone in Rome.

\begin{tabular}{|c|c|c|c|c|c|c|c|}
\hline \multirow{2}{*}{ Month } & QheAT & QCOOL & QINF & Qvent & QTRANS & QGINT & QSOL \\
\hline & $\mathrm{kWh} /\left(\mathrm{m}^{2} \mathrm{y}\right)$ & $\mathrm{kWh} /\left(\mathrm{m}^{2} \mathrm{y}\right)$ & $\mathrm{kWh} /\left(\mathrm{m}^{2} \mathrm{y}\right)$ & $\mathrm{kWh} /\left(\mathrm{m}^{2} \mathrm{y}\right)$ & $\mathrm{kWh} /\left(\mathrm{m}^{2} \mathrm{y}\right)$ & $\mathrm{kWh} /\left(\mathrm{m}^{2} \mathrm{y}\right)$ & $k W h /\left(m^{2} y\right)$ \\
\hline January & 1.44 & 0.00 & -1.59 & -2.67 & -4.67 & 4.97 & 2.53 \\
\hline February & 0.95 & 0.00 & -1.39 & -2.41 & -3.97 & 4.33 & 2.49 \\
\hline March & 0.27 & -0.04 & -1.31 & -2.83 & -3.88 & 4.77 & 3.04 \\
\hline April & 0.00 & -0.57 & -1.10 & -2.51 & -3.20 & 4.56 & 2.82 \\
\hline May & 0.00 & -3.38 & -0.69 & -1.57 & -2.24 & 4.97 & 2.92 \\
\hline June & 0.00 & -5.51 & -0.33 & -0.56 & -1.00 & 4.56 & 2.84 \\
\hline July & 0.00 & -7.02 & -0.08 & 0.01 & -0.19 & 4.77 & 2.51 \\
\hline August & 0.00 & -7.64 & -0.04 & 0.04 & -0.01 & 4.97 & 2.68 \\
\hline September & 0.00 & -4.74 & -0.48 & -0.88 & -1.16 & 4.36 & 2.90 \\
\hline October & 0.00 & -3.08 & -0.80 & -2.06 & -2.05 & 4.97 & 3.02 \\
\hline November & 0.02 & -0.46 & -1.16 & -2.94 & -2.88 & 4.75 & 2.64 \\
\hline December & 0.72 & 0.00 & -1.44 & -2.47 & -3.90 & 4.57 & 2.52 \\
\hline Total & 3.40 & -32.44 & -10.39 & -20.85 & -29.15 & 56.52 & 32.91 \\
\hline
\end{tabular}




\title{
Building Integrated Photovoltaic (PV) Systems: Energy Production Modeling in Urban Environment
}

\author{
Benjamin Govehovitch ${ }^{1}$, Stéphanie Giroux-Julien ${ }^{1}$, Éric Peyrol ${ }^{2}$ and Christophe Ménézo ${ }^{3}$ \\ ${ }^{1}$ University Claude Bernard Lyon 1, CETHIL UMR CNRS 5008, Villeurbanne (France) \\ ${ }^{2}$ University Claude Bernard Lyon 1, BioDyMIA, Lyon (France) \\ ${ }^{3}$ University Savoie Mont-Blanc, LOCIE UMR CNRS 5271, INES - Le Bourget-du-Lac (France)
}

\begin{abstract}
In the context of urban densification and increased energy consumption, built environment plays an important role by moving from passive to active constructions in terms of energy production, thanks to building integrated photovoltaic (BIPV) systems.
\end{abstract}

Existing power generation modeling results may differ significantly from actual production. This difference is, partly, due to the non-inclusion of the surrounding environment in the modeling approach. The main goal of this study is to highlight, in the context of integrated power generation, the importance of modeling the interaction between the BIPV and the studied building but also its interaction with the immediate environment and the local climatic conditions.

The simulation results presented in this paper are from the Vauban district in Saint-Denis (Reunion Island) modeling, in the framework of the ORCHIDEE project, which is supported by the French Agency of Energy Management (ADEME).

Keywords: transient energy production, photovoltaic (PV) solar collectors, urban environment, CFD modeling, inter-building effects, microclimate simulation

\section{Introduction}

In a world of continuous change, energy consumption and population are rapidly increasing. In most countries, the building sector is the major energy consumer and accounts for over $40 \%$ of the world's total primary energy consumption and for $24 \%$ of greenhouse gas emissions (Hegger et al. (2008)). According to the latest urban population estimated by the United Nations, the population of urban areas has been continually increasing in the last few decades: since 2008, city dwellers account for the majority of the world's population, and this trend will continue. Thus, by $2050,68 \%$ of the world's population is projected to be urban which represents more than 2.5 billion more people living in an urban area.

Combining population and economical growth with energy demand increase whilst limiting the global carbon footprint is then one of the biggest challenges of the $21^{\text {st }}$ century. The building sector could contribute to a sustainable future by turning cities from energy consumers to energy producers. Solar (photovoltaic and thermal) energy has the opportunity to make a major contribution to this transition.

Studies on solar energy production in building sector have been carried out for many years. However, predictive models of energy production consider isolated buildings without considering their urban context. When the urban environment is considered, it is through close mask shadow and ground albedo without any other interaction with the environment. Early studies have shown that the urban environment induces a specific local climate and especially the Urban Heat Island (UHI) effect, which is now well-established (Taha, 1997). More recent studies highlighted the impact of such microclimates on building energy consumption (Kolokotroni et al., (2012)). Regarding radiation potential most studies which are dedicated to solar cadastre focus on roofs, where solar radiation is mostly direct and the surfaces can be considered as horizontal. However in the context of urban densification, it is equally important to take verticality building integration into consideration, as façade/roof ratios are strongly increasing. Considering inter-building effects in terms of heat and mass transfer, especially regarding radiation, is therefore important. Moreover, the operating conditions of solar collectors - that are considered for predictive models - are usually issued from weather stations located outside of cities (typically airport weather stations). All of these hypotheses introduce a bias, especially for solar PV predicted power generation. It is now well-known that the urban climate is specific and that the level of temperature can be $4{ }^{\circ} \mathrm{C}$ to $5{ }^{\circ} \mathrm{C}$ higher than in non-urban environments. Solar PV generation depends on both the solar radiation and the operating temperature 
level. In addition, the higher the temperature, the more premature the ageing and the lower the production yield. Thus, it is essential to take all the phenomena induced by buildings' surroundings into account and to model the local solar resource accordingly, in order to evaluate the feasibility of the system. This represents the ultimate objective which we currently state and present below.

This paper is organized into three parts. Firstly, previous works about solar energy potential at city scale are presented. Secondly, the studied area is described along with the methodology and software used. Finally, the results of the simulations are discussed, as well as future outlooks.

\section{Previous works}

Since the early 1970s, urban heat island (UHI) has been identified through a confrontation between dense and sparse areas of human life and activities. A large amount of studies have been dedicated to its origin and causes (Oke, 1973; Santamouris et al. (2004)) as well as its assessment in reference to substantial cities under both mild and severe climate. These first studies have raised awareness of the need for taking the surrounding environment of buildings into more precise consideration.

This has led to more recent studies on buildings and district energy consumption (Yang et al. (2012), Kolokotroni et al. (2012)). Indeed, a higher ambient temperature can reduce energy loads in winter. However, the needs of airconditioning can be dramatically increased by a higher temperature. Kolokotroni et al. (2012) found that the cooling load in London was $25 \%$ higher than in rural environments, whereas the heating load diminished by $22 \%$.

In the last few years, a focus has been placed on urban districts, not only from the energy consumption perspective but also from the energy production perspective, turning buildings into energy producers and not only energy consumers. Several studies aim to exploit the city solar potential while attempting to bring more accuracy to the evaluation of solar radiation on surfaces. Cheng et al.(2006) and Lobaccaro et al. (2012a, 2012b), highlighted the huge impact of building planning at a district level, but also the envelope of the surrounding buildings and ground radiation characteristics on the PV power generation potential of a building's façade. Redweik et al. (2013) have shown the need to refine the temporal and seasonal analysis. Using a statistical approach, Sarralde et al. (2015) determined that by optimising urban form, the solar irradiation of roofs could be increased by $9 \%$, while that of façades could increase by up to $45 \%$. Thus, an accurate assessment of solar energy potential production is important especially for solar PV on both horizontal and vertical urban surfaces. Such an assessment requires consideration of the building within its environment. Indeed, many inter-building effects can occur and influence the operating conditions of solar collectors, such as shading, reflection, wind channeling, etc.

Regarding urban communities, solar cadastres have been in full expansion all over the world since the early 2010s and mainly treat the solar potential concerning the roofs. These solar potentials are often expressed simply in incident solar energy $\left(\mathrm{kWh} / \mathrm{m}^{2} /\right.$ year), in photovoltaic power of installation $(\mathrm{kWc})$, in possible annual production $(\mathrm{kWh} /$ year), in hours of production to nominal output $(\mathrm{h})$. The relevance of these solar cadastres varies in an important way according to the degree of available and generated information (geographical description, satellite data, digital model 2D or 3D starting from data LiDAR, etc.) as well as the accuracy level of the associated modeling (radiation on horizontal level, taking into account of the slopes, of the masks, estimation of the PV generation starting from the power peak or of a constant ratio of performance, etc.). A very small number of studies are starting to consider the urban microclimate, such as for the town of Vitoria-Gasteiz in Spain. This study evaluates the potential to solar liability and credit (thermal and photovoltaic) starting from a methodology developed by the Technical University of Madrid in the European project POLIS (2012).

\section{Study performed}

\subsection{Modeling tools}

Simulating solar irradiation and photovoltaic energy production at city scale is a considerable technological challenge. Freitas et al. (2015) conducted a review of the most popularly used tools. It appears that each of these softwares relies on specific architecture and assumptions. Thus, some software is based on an all-in-one model (buildings and solar radiation are modeled in a single software, like TOWNSCOPE or SOLENE) whereas some others are plug-ins that can be used along with CAD- or GIS-software (like Autodesk ecotect analysis, SOL or v.sun). CAD software present a higher resolution to GIS software but require high computational power at district scale. 
In this study the simulations have been performed with the version 4.3 of the software ENVI-met. ENVI-met is a prognostic, three-dimensional, high-resolution microclimate model. The model is specifically designed to simulate the urban climate taking into account all the phenomena specific to this type of environment. In the ENVI-met model these phenomena are categorized into five categories: atmosphere, soil, vegetation, ground and buildings (Bruse and Fleer, 1998).

Starting with ENVI-met 4.0 (2010), an improvement of the reflective shortwave model has been incorporated: the Indexed View Sphere (IVS) model. This model, aims to better evaluate the reflected radiation received by building façades from their surrounding environment. The formalism used in previous versions of ENVI-met has not been changed (eq. 1).

$Q_{B l d g, i n}(x, y, z)=\sigma_{B l d g}(x, y, z) \times Q_{B l d g, \text { swrefl }}$

where $Q_{\text {Bldg,in }}\left(\mathrm{W} / \mathrm{m}^{2}\right)$ represents the incoming shortwave radiation and $\sigma_{\text {Bldg,in }}$ the Sky View Factor (SVF), $Q_{B l d g \text {,swrefl }}$ is defined in (eq. 3). But instead of considering the reflected radiation only from a geometrical point of view, it takes into account the thermal and radiative properties of the material that reflects the shortwave radiation to the considered façade. Thus, the sky view factor is calculated as follows (Bruse, 2015):

$\sigma_{B l d g}(x, y, z)=\frac{1}{36} \sum_{a z=0}^{35} \sum_{h=0}^{8}[\sin (10 h+5)-\sin (10 h-5)] \Gamma_{B l d g}$

where $a z$ is the azimuth, $h$ is the height and $\Gamma_{B l d g}$ is a binary flag which is 1 if a building was found in the considered facet for reflection and 0 if no building was found. The reflected radiation coming to the façade from another is evaluated as follows:

$Q_{\text {Bldg,swrefl }}(x, y, z)=\frac{1}{36} \sum_{a z=0}^{35} \sum_{h=0}^{8} \xi(h, a z) Q_{s w, r e f l}^{\text {out }}(h, a z)$

where $Q_{B l d g, s w r e f}\left(\mathrm{~W} / \mathrm{m}^{2}\right)$ is the shortwave radiation reflected by the close surrounding. $\xi(\mathrm{h}, \mathrm{az})$ is the actual shielding factor.

\subsection{Case Studied}

This study is carried out in the framework of ORCHIDEE project, which is supported by the French Agency for Environment and Energy Management (ADEME). The aim of the project is to have a better evaluation and modeling of both thermal comfort and energy consumption in the tropical urban environment. A solar potential in terms of energy generation is considered and may influence - and, in turn, be influenced by - both thermal comfort and energy consumption.

The studied area is the Vauban district, located in Saint-Denis, on the Reunion Island (southern hemisphere). Located in the Indian Ocean, the Reunion Island benefits from a tropical climate with a great number of sunshine hours. The Vauban district is mainly residential, with just a few commercial buildings. In particular, residential buildings are mostly apartments, the rest being detached houses. All buildings have a height of about $12 \mathrm{~m}$. An overview of the district is given on Fig. 1.

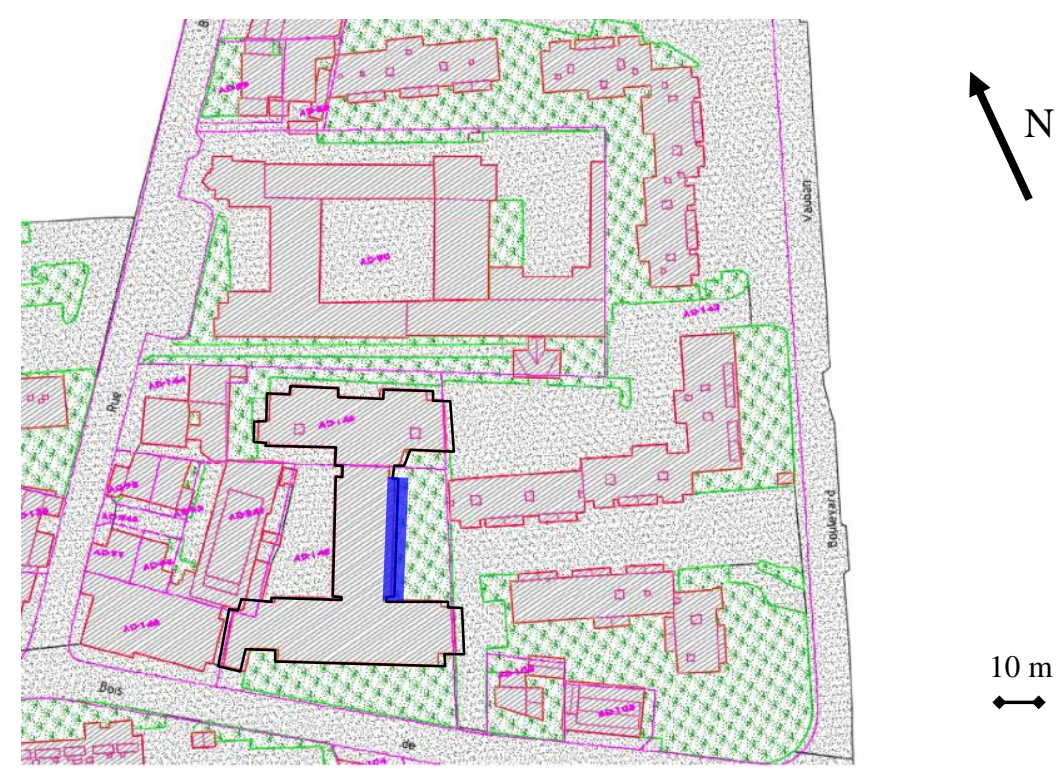

Fig. 1: Overview of the district Vauban 
Local climates may vary on the Reunion Island depending on the location but since the Vauban district is located near the coastline, it benefits from annual temperatures roughly between $20{ }^{\circ} \mathrm{C}$ and $30{ }^{\circ} \mathrm{C}$. Regarding the solar irradiation, the sunniest period lasts from January to March. February $21^{\text {st }}, 2017$ has been selected for the study performed (and described later) as it presents the advantages of being one of the sunniest days of the year along with the drawbacks of being the warmest one.

\subsection{Input data for the model}

The studied day is February $21^{\text {st }}, 2017$ which was the hottest and one of the sunniest days of that year on the Reunion Island (Tab. 1). This day has been considered to provide with a sufficiently high solar potential for energy production. The weather data used were provided by the nearest meteorological station located in the Saint-Denis airport. Thus, the meteorological conditions are entered in the ENVI-met model (Fig. 2).

Tab. 1: Input configuration data applied in the ENVI-met simulation models

\begin{tabular}{|c|c|}
\hline $\begin{array}{l}\text { Position } \\
\text { Longitude }\left({ }^{\circ}\right) \\
\text { Latitude }\left({ }^{\circ}\right)\end{array}$ & $\begin{array}{c}55.45 \\
-20.88\end{array}$ \\
\hline $\begin{array}{c}\text { Start and duration of the model } \\
\text { Date of simulation } \\
\text { Start time } \\
\text { Total simulation time (h) }\end{array}$ & $\begin{array}{c}02 / 20 / 2017 \\
00: 00 \mathrm{am} \\
48\end{array}$ \\
\hline $\begin{array}{c}\text { Initial meteorological conditions } \\
\text { Wind speed measured at } 10 \mathrm{~m} \text { height }(\mathrm{m} / \mathrm{s}) \\
\text { Wind direction }(\mathrm{deg}) \\
\text { Roughness length at measurement site }(\mathrm{m}) \\
\text { Specific humidity at calculation domain upper bound }(2500 \mathrm{mg} / \mathrm{kg}) \\
\text { Relative humidity at } 2 \mathrm{~m} \text { height }(\%)\end{array}$ & $\begin{array}{c}5.1 \\
45 \\
0.01 \\
17.4 \\
78\end{array}$ \\
\hline $\begin{array}{l}\text { Solar radiation and clouds } \\
\text { Adjustment factor for solar radiation } \\
\text { Cover of low clouds (octas) } \\
\text { Cover of medium clouds (octas) } \\
\text { Cover of high cloud (octas) }\end{array}$ & $\begin{array}{l}1.0 \\
0.0 \\
0.0 \\
0.0\end{array}$ \\
\hline $\begin{array}{c}\text { Soil data } \\
\text { Initial temperature in all layers }(\mathrm{K}) \\
\text { Relative humidity upper layer }([0,-20] \mathrm{cm}) \\
\text { Relative humidity middle layer }([-20,-50] \mathrm{cm}) \\
\text { Relative humidity deep layer }(<-50 \mathrm{~cm})\end{array}$ & $\begin{array}{c}293 \\
50 \\
60 \\
60\end{array}$ \\
\hline
\end{tabular}

The roughness length is the height at which the wind speed theoretically becomes zero. The adjustment factor allows the maximum irradiation value to be set between $500 \mathrm{~W} / \mathrm{m}^{2}$ (adjustment factor: 0.5) and $1500 \mathrm{~W} / \mathrm{m}^{2}$ (adjustment factor: 1.5). The cover of clouds is defined on a scale of 8 values. 0 represents a completely clear sky and 8 represents a fully covered sky.

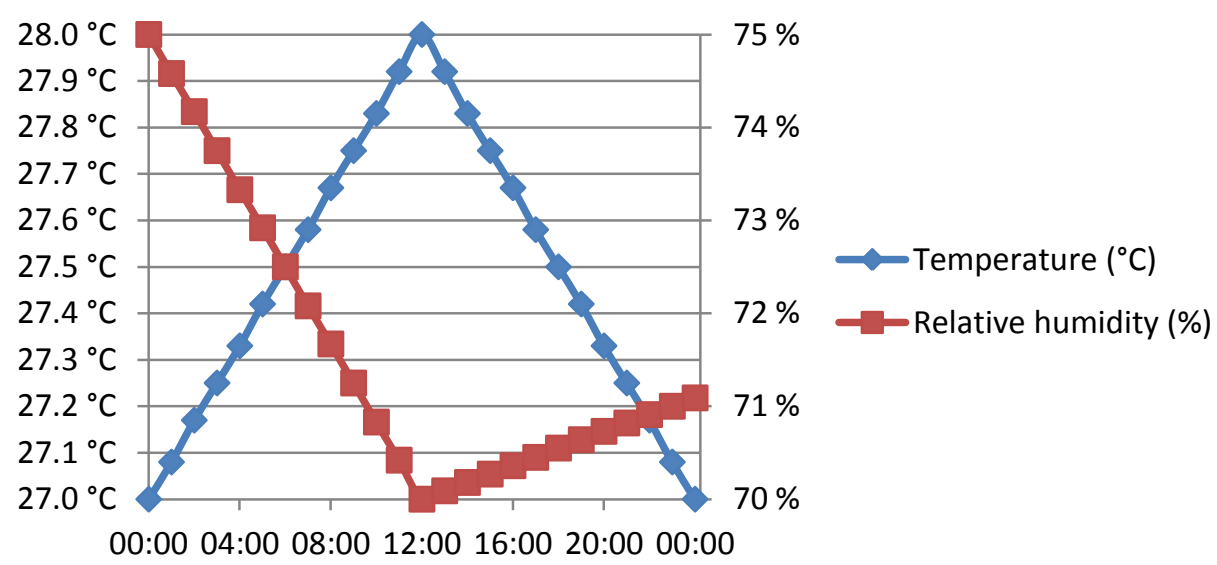

Fig. 2: Evolution of temperature and relative humidity during the day 
B. Govehovitch et. al. / EuroSun 2018 / ISES Conference Proceedings (2018)

The presented evolution is quite unusual and does not have a sinusoidal shape but is based on on-field measurements. Note that those measurements are from the nearest weather-station. Unfortunately it could not represent the aforementioned local UHI.

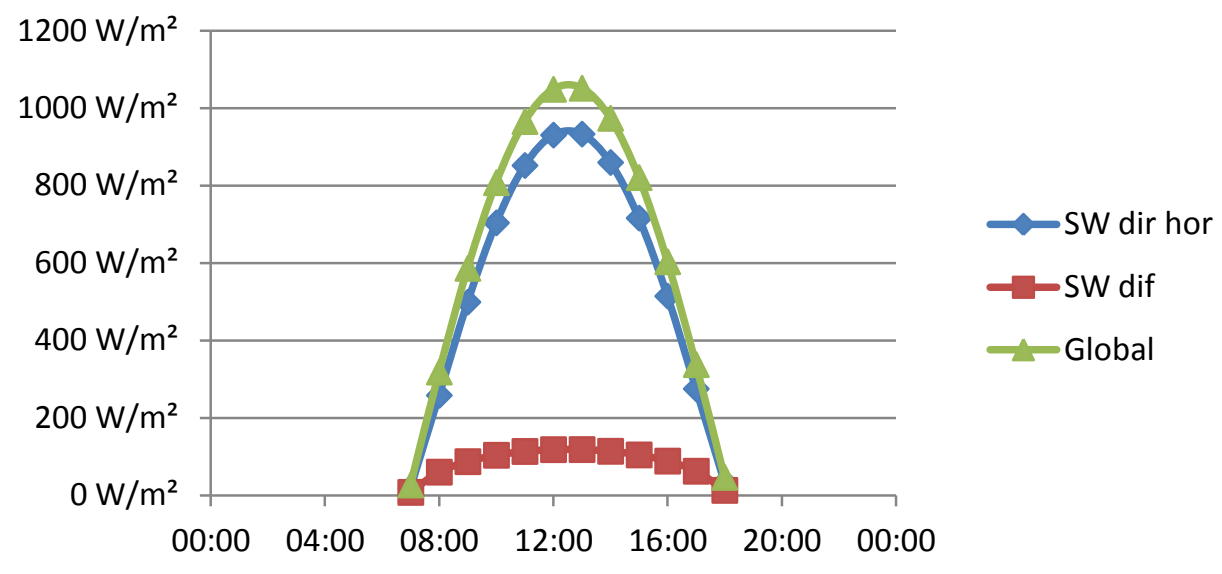

Fig. 3: Evolution of solar radiation density during the day

On Fig. 3, SW dir hor is the shortwave horizontal direct radiation, SW dif is the diffuse shortwave radiation and global is the sum of the two precedents.

The total modeling time was 48 hours. As recommended (Bruse, 2015), the first 24 hours were used to spin up the model in order to get reliable results that would have been influenced by the initialization parameters. Only the last 24 hours were used for the analysis.

\subsection{Time and space discretization}

The district has been modeled with a 3.6-meter resolution in all directions. This is a compromise between the calculation cost and the necessary resolution to get reliable results. The first 3.6 meters above the ground are subdivided into 5 equal heights. This subdivision is used to attain more reliable results by taking into more precise account the different interrelated physic phenomena near the ground (mass and heat transfers at small scales).

Likewise, the upper bound of the calculation domain (see Fig. 4) was set at twice the height of the highest building in order to avoid any numerical influence of the domain of study (Bruse and Fleer, 1998). At the limit of the domain of study, lateral boundary conditions are set at the default values:

- open for temperature and humidity, which corresponds to a zero deviation,

- forced for turbulence, which means that the values of the 1D model are copied to the border.

Regarding the resolution of the equations, they are discretised at the second order on space and at the first order on time. The results are then averaged on every hour.

\subsection{Studied building}

The studied building is hatched on Fig. 1. The composition of its walls is described in Tab. 2.

Tab. 2: Composition of studied building walls

\begin{tabular}{|c|c|}
\hline Property & Value \\
\hline Thickness (m) & 0.3 \\
\hline Absorption (-) & 0.7 \\
\hline Reflection (-) & 0.3 \\
\hline Emissivity (-) & 0.9 \\
\hline Specific heat (J/K/kg) & 840 \\
\hline $\begin{array}{c}\text { Thermal conductivity } \\
\text { (W/m/K) }\end{array}$ & 0.86 \\
\hline
\end{tabular}


\begin{tabular}{|c|c|} 
Density $\left(\mathrm{kg} / \mathrm{m}^{3}\right)$ & 930 \\
\hline
\end{tabular}

Particular focus will be made on the facade outlined in blue on Fig. 1. The interest of this façade lies in the fact it has a direct exposure to sunlight during the first part of the day. However, a small part of the studied wall $(16 \mathrm{~m}$ high) gets partially shaded by the facing wall $(15 \mathrm{~m}$ high). Thus, it is possible to evaluate the heterogeneity and time variability of solar irradiation over this façade.

\section{Results and discussion}

The results presented in this section are issued from simulations run under the version 4.3.2 Summer18 of ENVImet.

\subsection{District irradiance overview}

Fig. 1 presents an overview of the irradiance (direct and diffuse) over the studied district. The spatial heterogeneity of irradiance stands out amongst the results. This may have significant influence on the potential of energy production, as will be discussed in the next sections. Roof values are between about 800 and $1000 \mathrm{~W} / \mathrm{m}^{2}$ whereas façades values are between 0 and $500 \mathrm{~W} / \mathrm{m}^{2}$.

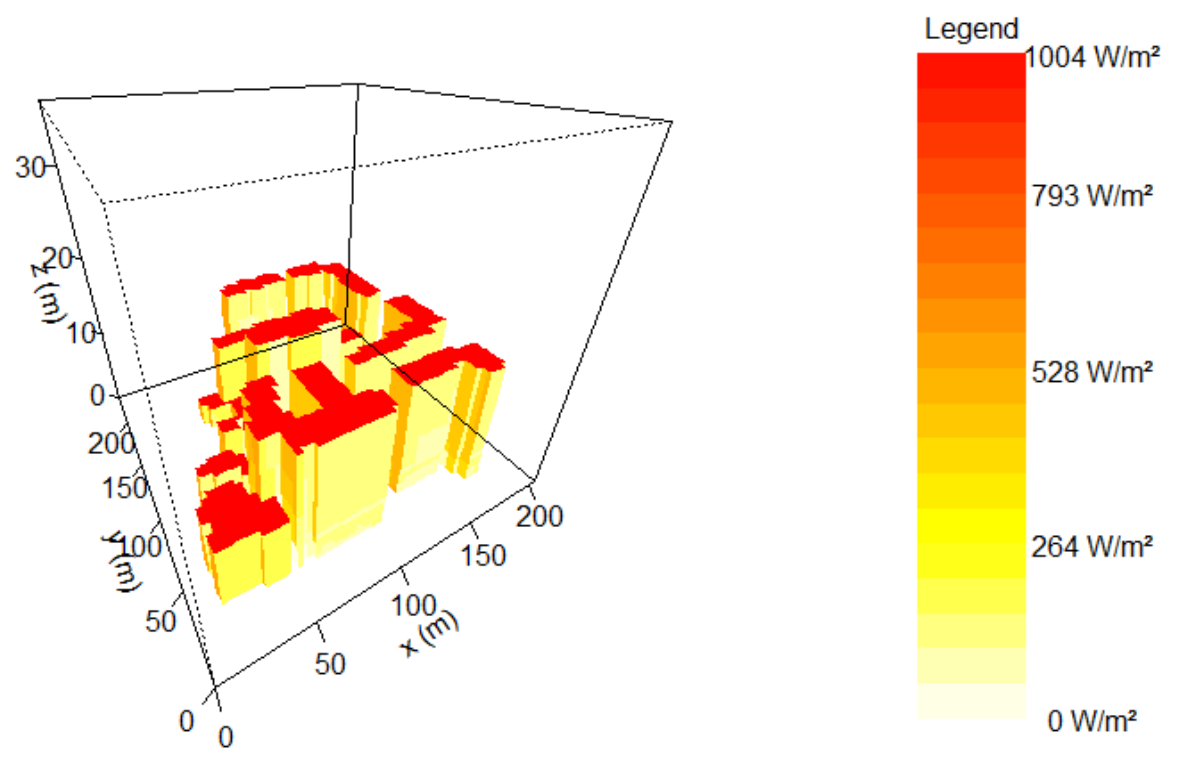

Fig. 4: Domain of study and district irradiance overview on 06/21/2017 at 2:00 pm

\subsection{Building surface temperature}

In this study, the building surface temperature has been considered to be representative of the BIPV panel. Studying this temperature is important in order to characterize the potential of energy production. Indeed, the higher the PV panel temperature, the lower its efficiency.

As can be seen in Fig. 5, the surface temperature is far from uniform. It presents an important spatial heterogeneity and time variability. Indeed, depending on time or on the façade point, the surface temperature range can exceed 20 ${ }^{\circ} \mathrm{C}$. It can represent a PV panel's yield loss of almost $10 \%$.

Regarding the temperature spatial heterogeneity a cooler spot can be observed on the wall. It is due to the drop shadow of the facing building. It highlights the importance of taking into account close environment in predicting energy production. 
Temperature of facade - node $1 /$ outside $\left({ }^{\circ} \mathrm{C}\right)$ at $08: 00$

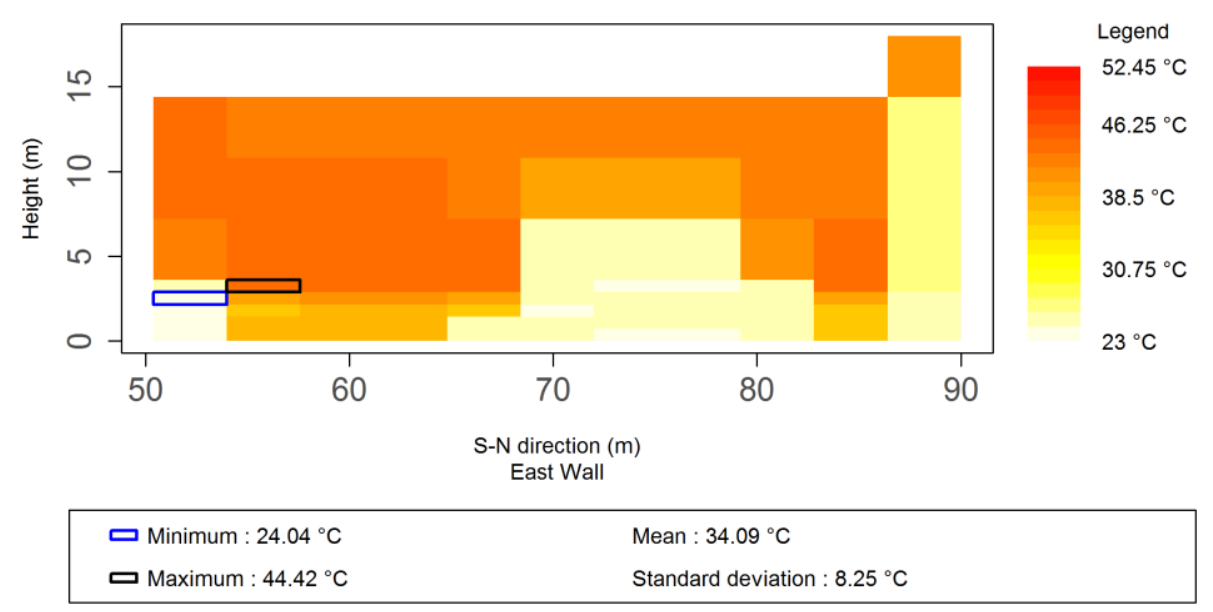

Temperature of facade - node $1 /$ outside $\left({ }^{\circ} \mathrm{C}\right)$ at $12: 00$

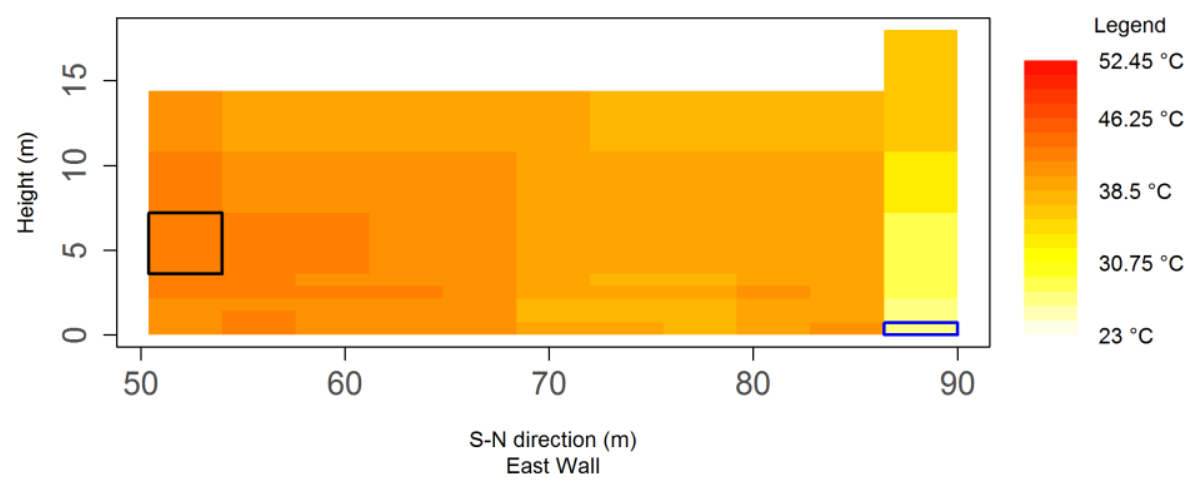

Minimum : $26.75^{\circ} \mathrm{C} \quad$ Mean : $38.99^{\circ} \mathrm{C}$

口 Maximum : $42.8^{\circ} \mathrm{C} \quad$ Standard deviation : $3.5^{\circ} \mathrm{C}$

Temperature of facade - node $1 /$ outside $\left({ }^{\circ} \mathrm{C}\right)$ at $16: 00$

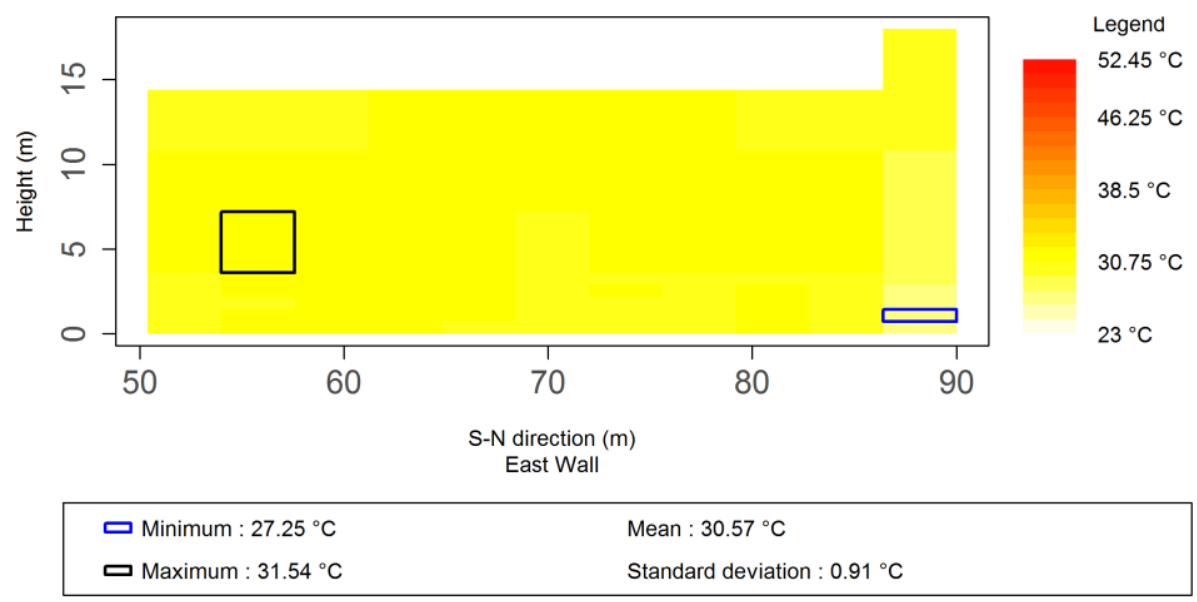

Fig. 5: Evolution of east wall surface temperature during the day

\subsection{Shortwave radiation}

The results for shortwave irradiance façade map resemble those for surface temperature, as can be seen on Fig. 6 . Nonetheless, the spatial heterogeneity is less pronounced. Indeed, vertical heterogeneity is important whereas the horizontal is almost negligible. This result was expected in view of considering mask effects of surrounding buildings.

However, the lighter color spots at 8:00 am reflect the presence of a nearby building that may have a negative 
B. Govehovitch et. al. / EuroSun 2018 / ISES Conference Proceedings (2018)

impact on potential energy production. Because of the sun spot in the sky, darker grid cells at 4:00 pm are due to pure reflection of diffuse radiation on buildings.

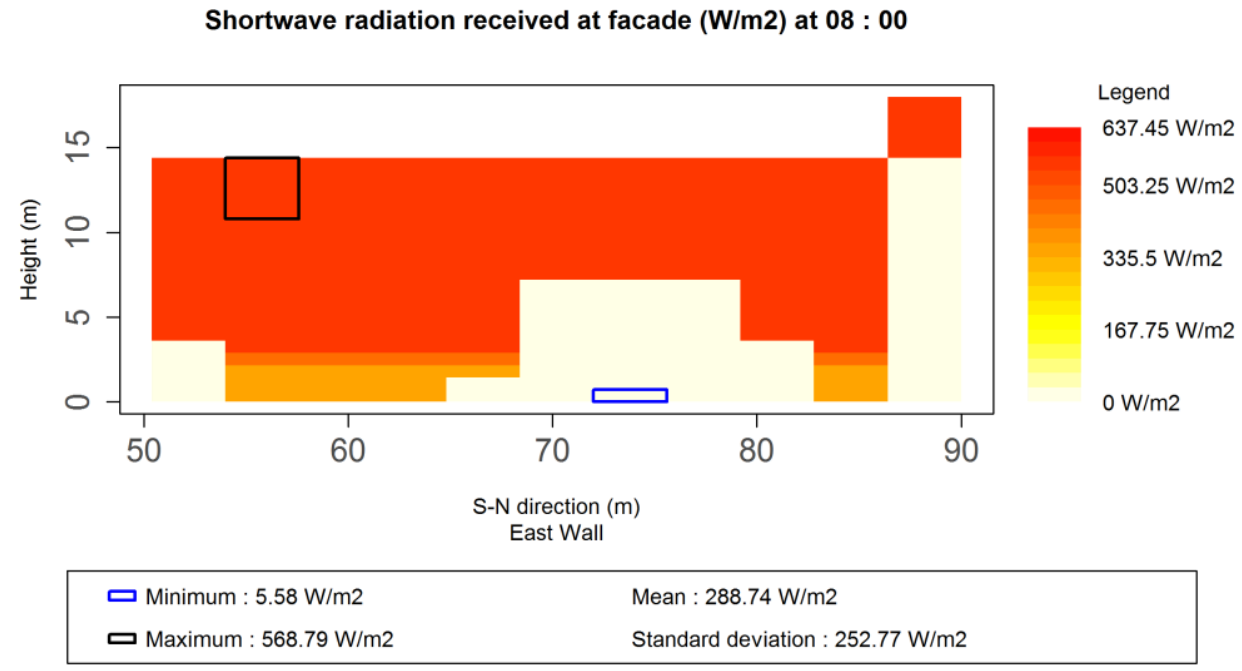

Shortwave radiation received at facade $(\mathrm{W} / \mathrm{m} 2)$ at $12: 00$

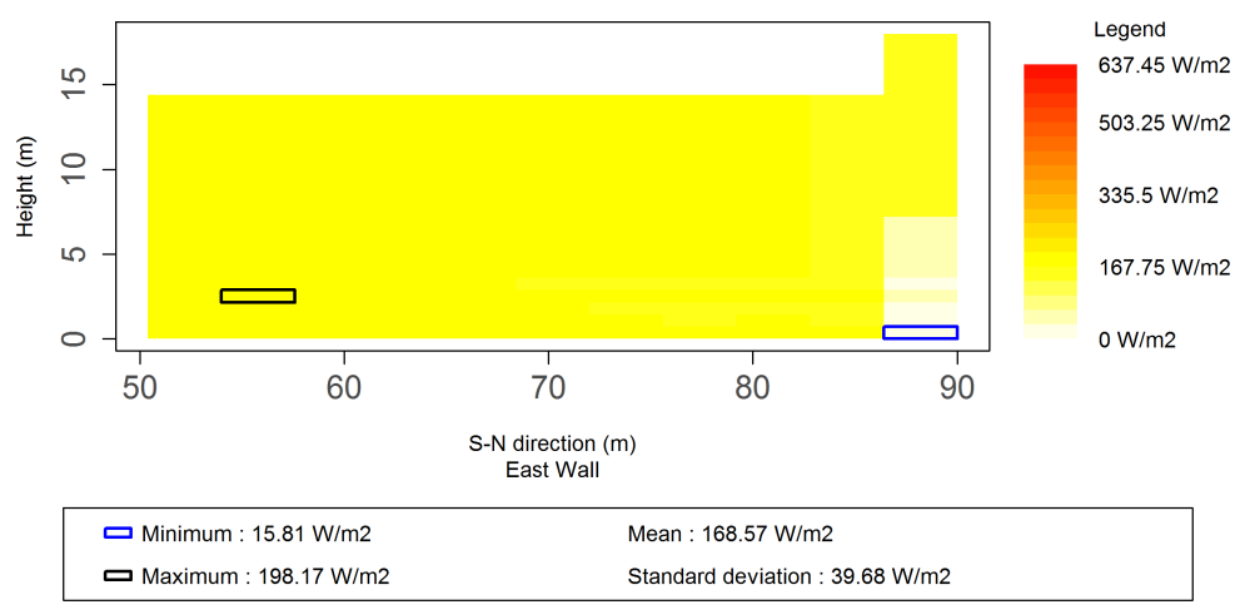

Shortwave radiation received at facade $(\mathrm{W} / \mathrm{m} 2)$ at $16: 00$

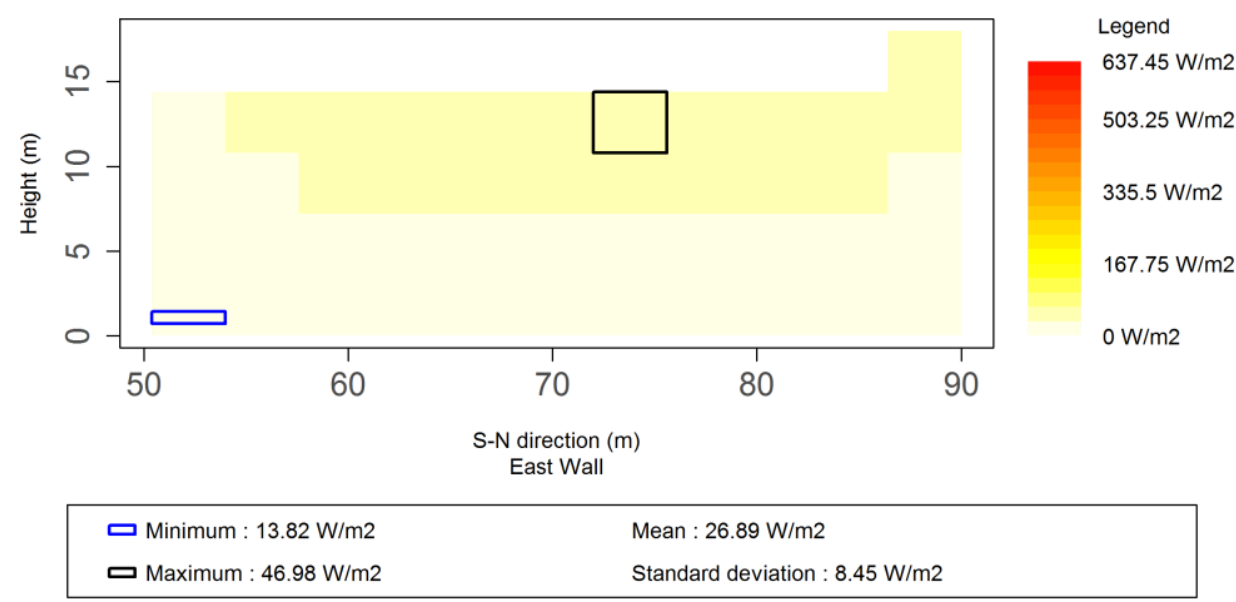

Fig. 6: Evolution of shortwave radiation received at east wall surface during the day 


\subsection{Integrated solar photovoltaic energy production}

A first simple model of photovoltaic energy production has been implemented. A standard photovoltaic panel has been selected. Its technical characteristics are presented in Tab. 4.

Tab. 4: Technical characteristics of the considered photovoltaic panel

\begin{tabular}{|c|c|}
\hline $\begin{array}{c}\text { Electric characteristics } \\
\text { (STC) }\end{array}$ & Value \\
\hline Nominal power $\left(\mathrm{P}_{\text {nom }}\right)$ & $280 \mathrm{Wp}$ \\
\hline $\begin{array}{c}\text { Voltage at nominal } \\
\text { power }\end{array}$ & $31.3 \mathrm{~V}$ \\
\hline $\begin{array}{c}\text { Current at nominal power } \\
\text { Temperature coefficient } \\
(\gamma)\end{array}$ & $-0.42 \% /{ }^{\circ} \mathrm{C}$ \\
\hline
\end{tabular}

STC: Standard Test Conditions, i.e. irradiance at module level $1000 \mathrm{~W} / \mathrm{m}^{2}$, spectrum AM1.5 and cell temperature $25^{\circ} \mathrm{C}$

The predictive energy production model is based on a strong assumption. Indeed, every cell of the modeled area represents a PV panel which operates at the maximum power point all the time. We then consider power generation right after inverters that are considered to be perfect and by neglecting other PV system loss.

As can be seen on Fig. 7, the power output is mainly influenced by the shortwave radiation received at the façade.

The equation 4 gives the output power as a function of temperature and solar irradiation.

$P_{\text {out }}=\min \left(P_{\text {nom }} \times \frac{G}{G_{\text {ref }}} \times\left(1+\gamma \times\left(T-T_{\text {ref }}\right)\right), P_{\text {nom }}\right)$

where $P_{\text {out }}\left(\mathrm{W} / \mathrm{m}^{2}\right)$ is the output power of the PV panel, $P_{\text {nom }}(\mathrm{W})$ the nominal output power of the PV panel, $G$ $\left(\mathrm{W} / \mathrm{m}^{2}\right)$ the irradiance, $T\left({ }^{\circ} \mathrm{C}\right)$ the temperature, $\gamma\left(\% /{ }^{\circ} \mathrm{C}\right)$ the temperature coefficient of $P_{\max }(\mathrm{STC})$ and the subscript ref represents the reference conditions (here STC).

\section{Energy production at 08:00}

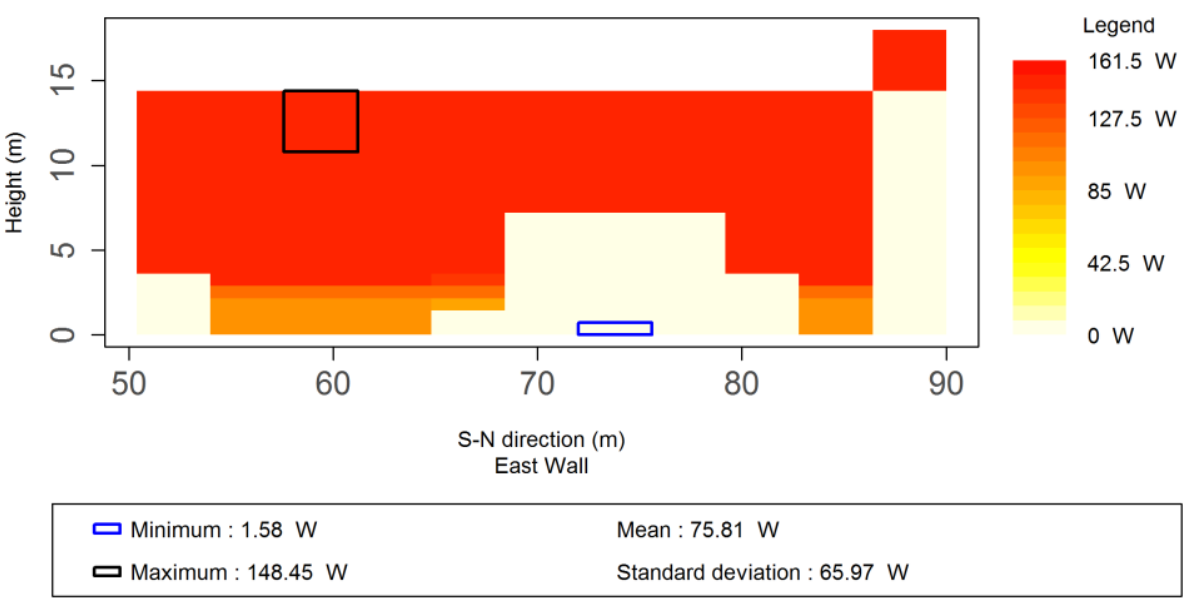




\section{Energy production at 12:00}

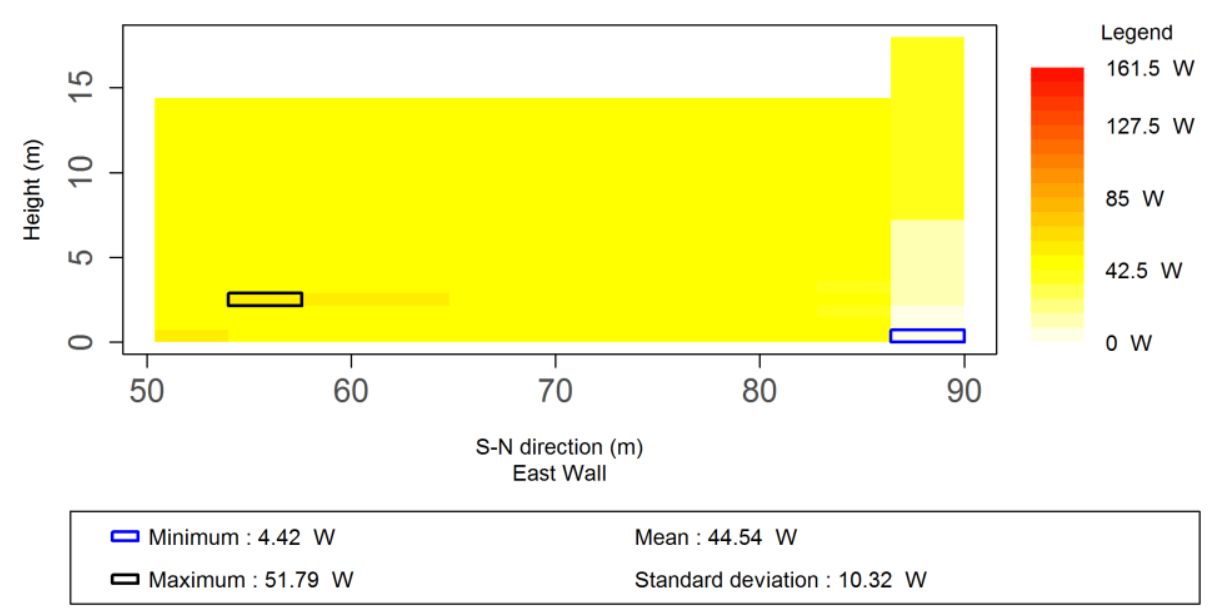

Energy production at 16:00

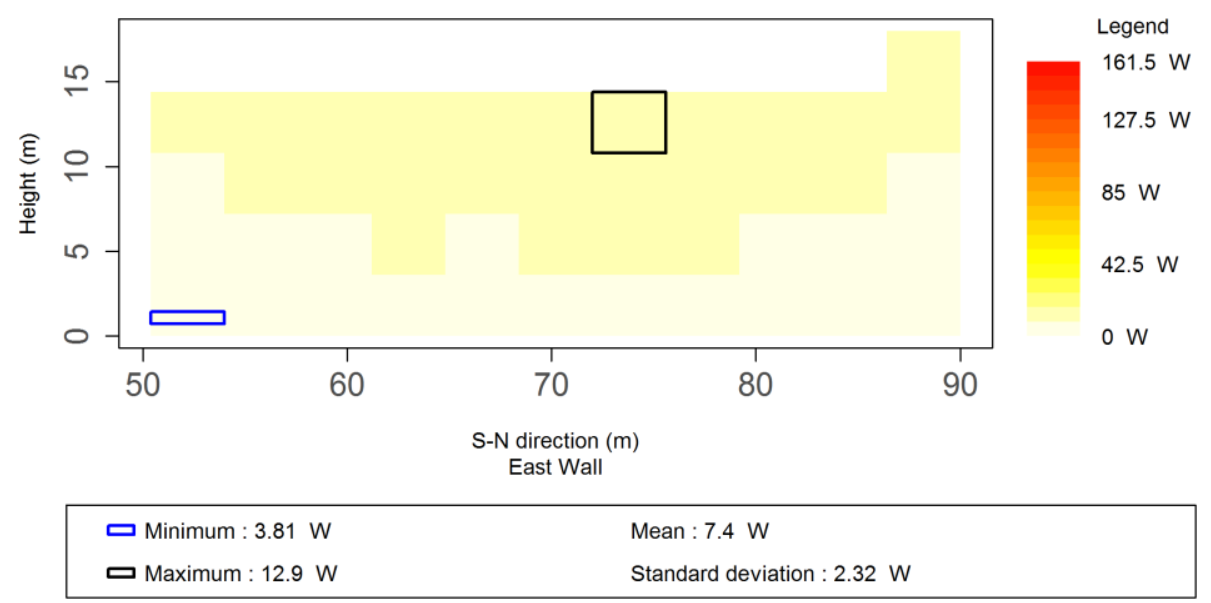

Fig. 7: Evolution of energy production on east wall surface during the day

In order to highlight the importance of taking radiative properties and incident radiation contribution of surrounding buildings into consideration, a simulation has been run while considering those buildings only as masks. The results are presented in Fig. 8 .

It can be noticed that there is locally a maximum discrepancy of $19.7 \mathrm{~W} / \mathrm{m}^{2}$ for shortwave radiation and of local surface temperature of $7{ }^{\circ} \mathrm{C}$. This clearly highlights the impact of inter-building effects especially regarding longwave radiation that induces these important PV surface temperature discrepancies. This induces a power generation discrepancy of $5 \mathrm{~W}$ (on nominal power of a PV panel) corresponding to a decrease of $7 \%$ of local power generation, at mean operating conditions for this location. 


\section{Energy production at 08:00}

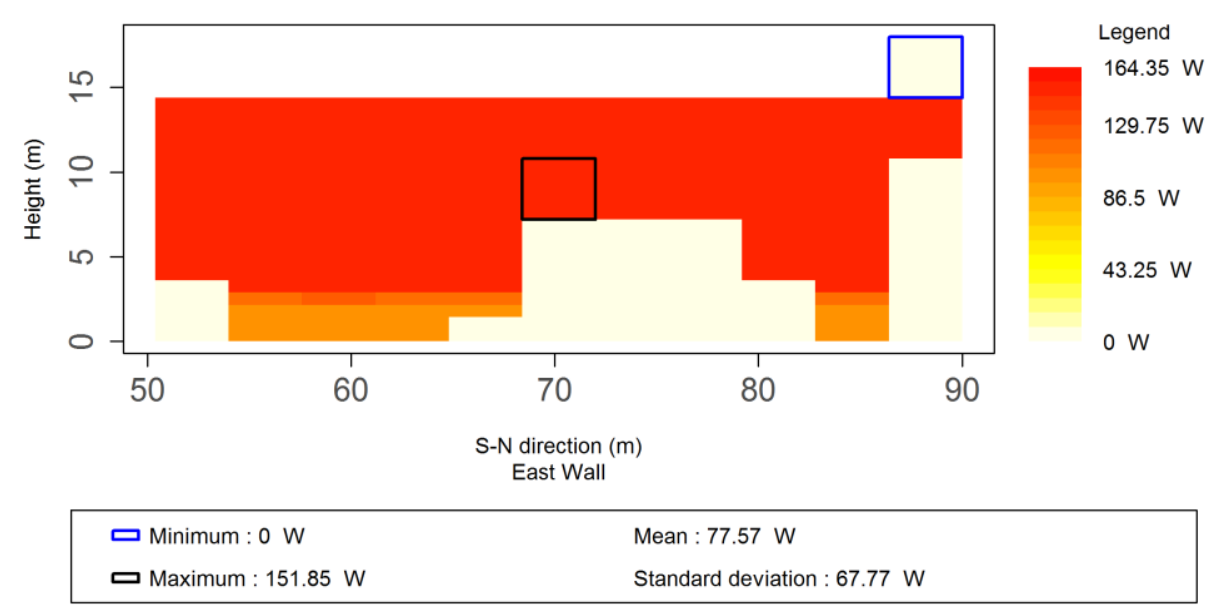

Energy production at 12:00

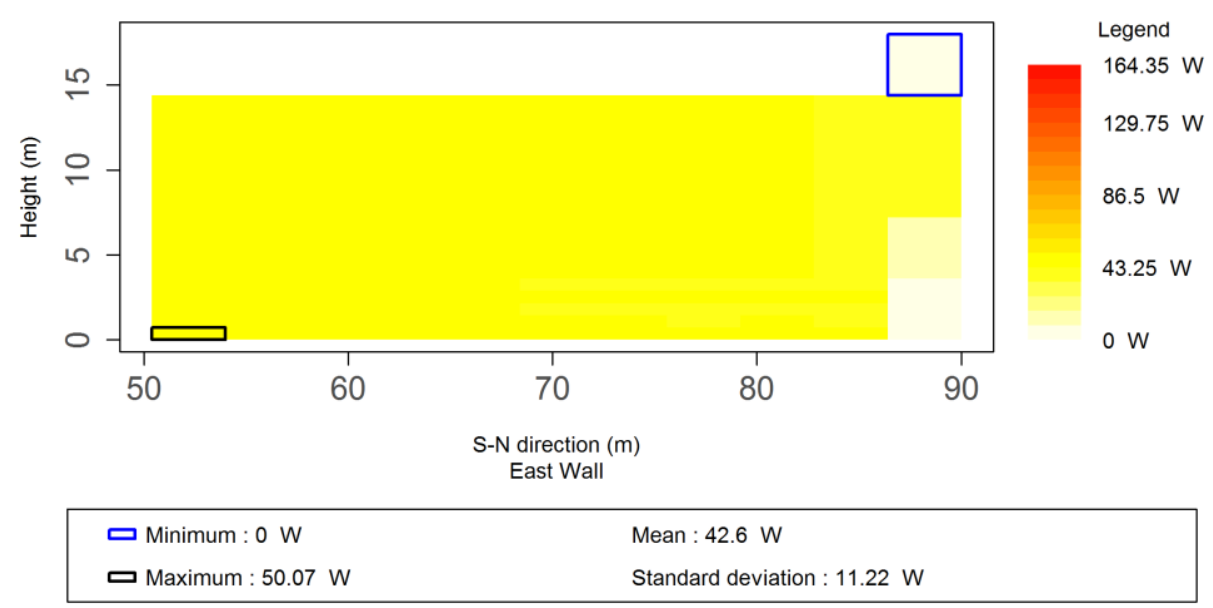

Energy production at 16:00

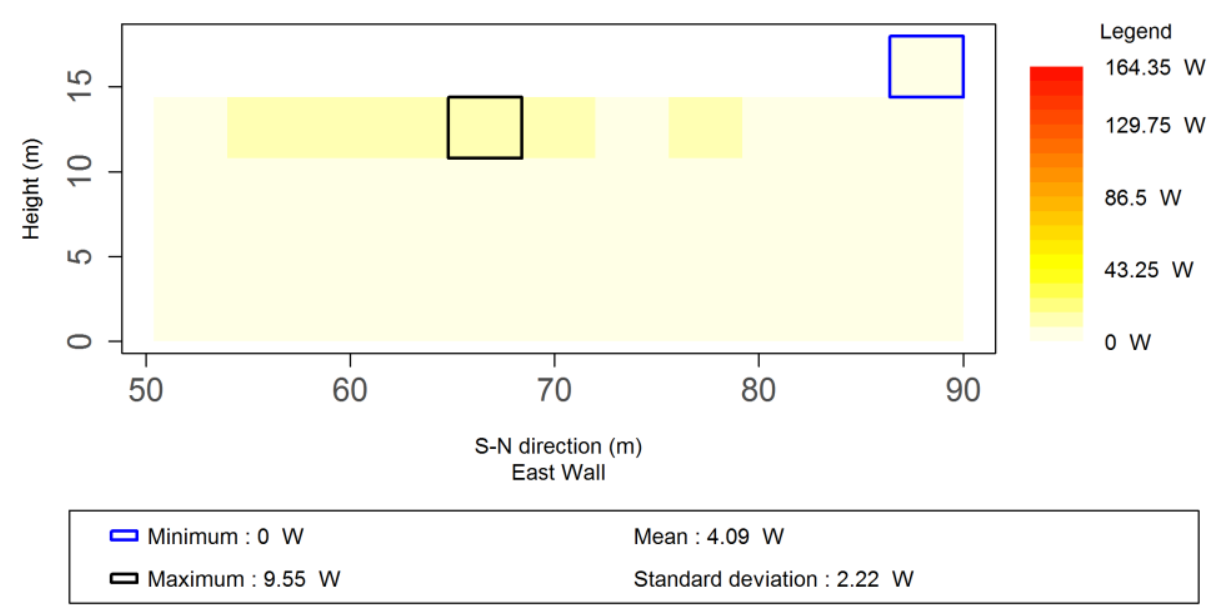

Fig. 8: Evolution of energy production on east wall surface during the day, considering surrounding only as masks

\section{Conclusion}

Local solar energy production at the district scale is a promising contribution toward satisfying increasing global energy demand. Thus, accurate assessment of energy production potential is critical.

As demonstrated in this paper, taking into consideration the close surrounding of buildings has an important influence on the evaluation of their solar energy production potential. So far, models of energy production only 
consider close buildings as masks. However, according to the simple production model presented in this paper, it may lead to a bias in the estimation of potential power generation, up to $7 \%$ for a single PV panel. Nonetheless, this study still needs to be spatially expanded to a whole building and even up to an entire district and temporally to the different characteristics of other days of the year. Moreover these differences would have been greater if the local micro-climate had not been considered especially in terms of temperature. They will undoubtedly be more important when we refine the building façades' composition and the PV generation models in future studies. Future works will also involve a validation and a complexification of the proposed energy production model.

\section{Acknowledgements}

We would like to acknowledge the Energy and Environment Management Agency (ADEME) for funding the ORCHIDEE project (ADEME 1604C0035).

\section{References}

Bruse, M., Fleer, H., 1998. Simulating surface-plant-air interactions inside urban environments with a three dimensional numerical model, Environmental Modelling \& Software. 13, 373-384. 10.1016/S13648152(98)00042-5

Cheng V., Steemer, K., Montavon M., Compagnon R., 2006. The $23^{\text {rd }}$ Conference on Passive and Low Energy Architecture.

Freitas S., Catita C., Redweik P., Brito M.C., 2015. Modelling solar potential in the urban environment: State-ofthe-art review Renewable and Sustainable Energy Reviews. 41, 915-931. 10.1016/j.rser.2014.08.060

Hegger M., Fuchs M., Stark T., Zeumer M., 2008. Energy Manual. Sustainable architecture. Birkhäuser - Edition Detail, Basel.

Kolokotroni M., Ren X., Davies M., Mavrogianni A., 2012. London's urban heat island : Impact on current and future energy consumption in office buildings. Energy and Buildings. 47, 302-311. 10.1016/j.enbuild.2011.12.019

Lobaccaro G., Fiorito F., Masera G., Poli T., 2012. District geometry simulation: a study for the optimization of solar façades in urban canopy layers. Energy Procedia. 30, 1163-1172. 10.1016/j.egypro.2012.11.129

Lobaccaro G., Frontini F., Masera G., Poli T., 2012. SolarPW: A new solar design tool to exploit solar potential in existing urban areas. Energy Procedia. 30, 1173-1183. 10.1016/j.egypro.2012.11.130

Oke T. R., 1973. City Size and the Urban Heat Island. Atmospheric Environment Pergamon Press. 7, 769-779. 10.1016/0004-6981(73)90140-6

Redweik P., C. Catita C., Brito M. 2013. Solar energy potential on roofs and facades in an urban landscape. Solar Energy 97. 332-341. 10.1016/j.solener.2013.08.036

Santamouris M., Adnot J., Alvarez S., Klitsikas N., Orphelin M., Lopes C., Sanchez F., 2004. Cooling the Cities, Presses de l'École des mines de Paris.

Sarralde J. J., Quinn D. J., Wiesmann D., Steemers K., 2015. Solar energy and urban morphology: Scenarios for increasing the renewable energy potential of neighbourhoods in London. Renewable Energy. 73, 10-17. 10.1016/j.renene.2014.06.028

Taha, H., 1997. Urban climates and heat islands: albedo, evapotranspiration and anthropogenic heat. Energy and Buildings. 25, 99-103. 10.1016/S0378-7788(96)00999-1

Yang X., Zhao L., Bruse M., Meng Q., 2012. An integrated simulation method for building energy performance assessment in urban environments Energy and Buildings. 54, 243-251. 10.1016/j.enbuild.2012.07.042

Web references:

Bruse, M., 2015. ENVI-met 4: A Microscale Urban Climate Model. http://envi-met.info - last accessed: $07 / 26 / 2018$

POLIS Methodology for the Identification of the Detailed Solar Potential of Urban Areas. http://www.polissolar.eu/IMG/pdf/tool_box_methodologydetailedsolarpotential.pdf - last accessed 08/20/2018

World Urbanization Prospects: The 2018 Revision, 2018. United Nations.

https://esa.un.org/unpd/wup/Publications/Files/WUP2018-KeyFacts.pdf - last accessed: 07/20/2018. 


\title{
The SOLAR DECATHLON Knowledge Platform -
}

\author{
Concept and Initial Application \\ Susanne Hendel ${ }^{1}$ \\ ${ }^{1}$ University Wuppertal (Germany)
}

\begin{abstract}
The student competition Solar Decathlon (SD) is an established platform to demonstrate and analyze approaches to energy efficiency and solar energy utilization in residential buildings. Its outstandingly unique feature of generating at least 15 to 20 highly comparable houses each competition opens the possibility of being a source for research projects with a lack of case studies. Due to the main goal of previous SD competitions of being a communicative event to educate the general public, how to use renewable energy, the results from previous competitions do not meet scientific demands. Knowledge of the previous results is crucial to influence future SD results to be useful outside the competition for research purposes. This paper evaluates the possibility of using the SD houses as building performance test facilities and shows the need and application of a SD database with harmonized documentation of previous SD houses as well as the possibilities to use the data.
\end{abstract}

Keywords: Solar Decathlon, Student Competition, Knowledge Platform, Case Studies, IEA, Technology Trends

\section{Introduction}

The majority of research projects analyzing building performances lack of a sufficient number of case studies. In particular, projects researching the whole building performance instead of components face significant challenges in finding enough comparable test facilities. The following examples illustrate the difficulties of building performance case study projects. Either a suitable test facility could not be found at all and had to be built specifically for the project, like the Twin houses (link 1) at the Fraunhofer IBP Campus in Holzkirchen Germany, or the analysis had to cover a very long period in order to include a sufficient number of projects were analyzed but over a large timespan, like in the Zaragoza case study (Monzón, López-Mesa, 2017), which lasted from 1945 to 1975 . Only few projects have the time and/or the money to follow such elaborate approaches. Accordingly, also the IEA EBC Annex 58 (Strachan, 2016) described the lack of financial means and time as main reason for the absence of suitable test facilities in building performance case study projects. Another example illustrating the missing comparability of houses in such studies and how the outcome would look like without investing extra time or money is the German initiative for accompanying research of buildings (Voss, 2016). Although the last project phase lasted 10 years and a total of 44 houses could be evaluated, only performance evaluations of components were possible. And even with a focus on components hardly five to ten buildings could be compared to underline the findings. That also reflects in the chapters of the final book publication "EnOB Gebäudeperformance". Addressing the whole building performance within the EnOB context would lead to no comparable houses for such a study. Finally, the ongoing search for comparable test facilities in the building sector within current projects like the Annex 68 and 71. (link 2, link 3) shows the urgent need for the availability of more test objects right now.

For this problem, the Solar Decathlon (SD) with its large number of comparable houses could be the solution.

The SD, with its unique competition concept, challenges international student teams to design, build and operate a sustainable and highly efficient single-family home. Since the first competition in 2002, 15 SDs have been held worldwide. The current boost of interest accelerated by national and international approaches to slow down climate change by improving energy policies has led to seven new SD events being held through the end of 2021 (figure1). With 260 highly comparable SD houses already built, documented and intensely monitored and another approximately 100 new houses on the horizon, now is the right time to think about how the SD could be used as a source for case studies in the future. 


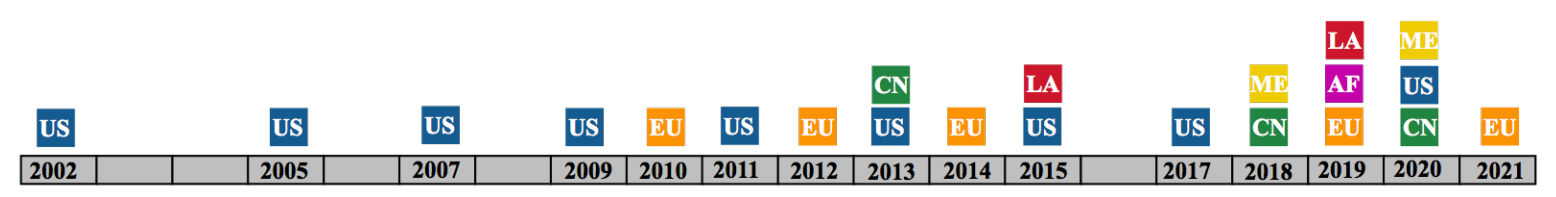

Fig. 1: Global SD Events timeline. US: United States of America; EU: Europe; CH: China; LA: Latin America and Caribbean; ME: Middle East; AF: Africa Source: S. Hendel, Wuppertal University

Some houses were already used as test facilities or were further analyzed besides the competition documentation and monitoring. However, this was limited to studies and projects by the teams who built the respective house or scientist who at least had a direct link to one of the houses. For example, the Energy and Buildings special edition on the findings and research based on the SD 2012 includes numerous studies showing what can be done with SD results (Vega, 2014). From 23 papers published in that edition 18 papers are focused on one specific house and were written by at least one team member who was directly connected to that house. Two of the other five papers in that issue describe the concept of the SD competition or one of the ten contests. The remaining three papers are analyzing all SD houses in that SD EU 2012 competition with a focus on a specific topic, like Building integrated PV (Cronemberge, 2014) and passive technologies (Rodriguez-Ubinas, 2014). These three papers about all SD EU 2012 were only possible because the SD organizers were directly involved in those studies and had a more complete access to the houses data. This shows that case study projects with SD houses are already possible, but generally limited to approaches where no other data is needed than what can be generated by the team's own house. The fact that there is such little research besides the projects of the teams around their own house indicates a problem with the general availability of SD data. This can be confirmed when looking at the existing data. In the past, the enormous amounts of data have been recorded in very different and often confusing way resulting in a significant lack of quality and structure. In addition, the data sets are usually incomplete, lacking for example in general building descriptions, including size, material or technologies used, performance data of the technical building components and descriptions of the monitoring set-up.

Therefore, the first step in order to make the SD feasible as a source for case studies needs to be the preparation of the existing SD data. Based on the knowledge generated by analyzing the existing data, in a second step the documentation of the future SD houses needs to be optimized for research purposes.

This idea was already picked up by the Annex 74 "Competition and Living Lab Platform" (link 4) to ensure the generation of knowledge of the past SD competitions to profoundly influence future SD's to be able to use the houses and data for projects like the above mentioned (Voss, 2016).

For this specific purpose, the Building Competition Knowledge Platform (KP) has been created and will be further developed in close connection with the organization of future SDs. The KP is a high efficient tool to achieve a more scientific output from the SD by making the existing data available and usable for research purposes and can also be employed to optimize the way in which the data will be documented in the future. (link 5)

In the following three chapters, the scientific usability of SD data by implementing the KP will be shown. First, the general features for making the existing data usable and available by applying the KP will be described. Secondly, a further description of the technology tags will be presented which constitute the most important feature of the KP allowing the users to deal with wide spread information like the many different technologies used in the SD houses. Ultimately, by using the KP to analyze the existing SD data, the specific suitability of the $\mathrm{SD}$ houses as test cases for projects outside the competition framework will be proven.

\section{The Knowledge Platform}

The KP is a tool to store and make the existing comprehensive SD data available to potential users. Also with the KP an optimized way of documenting the SD data will be presented. Input and feedback for the setup of the KP was gathered within the Annex 74 (link 4) framework.

The KP is already running and will already be used by the teams participating in the SD Middle East 2018. The combined screenshots in figure 2 illustrate its current set-up. Here it can be seen that the data stored in the KP is organized by editions and competitions. An implemented google map helps to find a house by location. A scoring overview that is linked to the team fact sheets allows users to find a house by competition success. 
Building Competition \& Living Lab Knowledge Platform

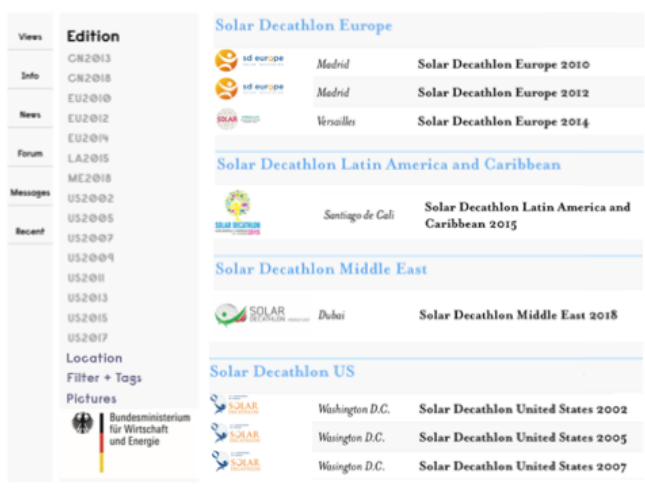

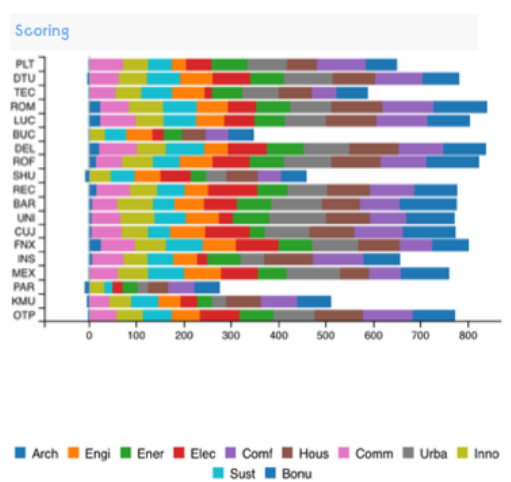

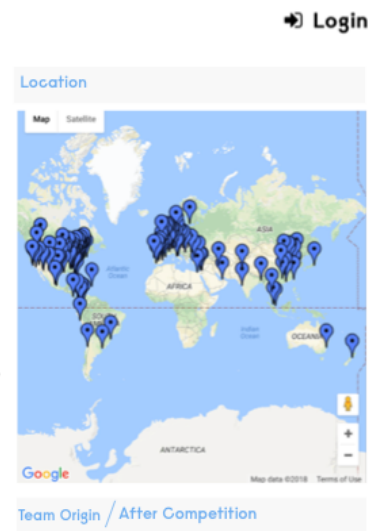

Fig. 2: Illustration of the Building Competition and Living Lab Knowledge Platform. www.building-competition.org

Source: S. Hendel, University of Wuppertal

With every SD competition comes a flood of data. A complete set of existing data would contain competition rules, team project manuals, team project drawings, team jury narratives, jury reports and monitoring description and monitoring data. As far as available, documents from all the past SD competitions are already stored in the KP. However, not once a full set of data could be achieved, mainly because the data was generated but not stored or shared. For example, only the final and one out of 7 or 8 team deliverables could be located. Usually, the final deliverable set contains the "as build" description of the house with detailed of the concept, design and all components. For the SD US and the SD EU at least a full set of team documentation could be located and stored in the KP.

It is to be assumed that the existing team documents contain all the necessary information, but they are usually as voluminous as 1,000 pages per team. Because of the size and the various structure of these team documents, the information they deliver is not easy to access.

The KP not only stores the data in a unified and filtered way to make the existing data usable, it also is online accessible. Team fact sheets were created and filled with general information. The fact sheets are based on information given by the existing team project manuals and are also exportable as an Excel file. Besides house size, envelope quality, team heritage location, scoring, general descriptions of the HVAC system, PV system and an estimated energy balance are also included in the fact sheets. Tags are available to be added to every house documentation and can be used as a filter system for analyses. Tags are set up to identify the technologies or materials used in the houses. The topics addressed by the tags are constantly under development and will be further amended based on the needs of future SDs. Because the tags are a crucial feature of the KP to make the SD output usable for case study research they will be described in detail in chapter "3: Technology tags."

To secure comparability, factsheets and tags are based on global templates. All existing information stored in the fact sheets and tags was researched manually within the German SD research project (cf. Acknowledgement). Fact sheets and tags can be used as a two-layer analysis tool. The tags are for filtering the data and to give an overview of technologies used. The fact sheets provide additional and more descriptive information.

Besides the incomplete data sets available, there is another problem: Even the complete existing documentation as it was recorded and structured within the KP until today would lack information and quality crucial for the use of the data outside the competition. Generally, detailed information about power and performance of applied technologies are not or not completely available. Also, information about control strategies are not included in the majority of the existing documentation, but would be needed for building performance analysis. Monitoring Data of the houses, including indoor temperature, humidity, air quality, energy generation, energy consumption by appliances, light and HVAC are available. But a detailed description of the monitoring set up including descriptions of the sensors, measuring interval and a documentation of the measurement process are missing. Therefore, the monitoring data is useless outside the competition. These here descried missing information can be documented for future SDs. For example, for the SD EU 2014 a template to describe the input for an indoor comfort and energy balance simulation tool was located. That templated is called the "Simulation Input Report" (link 6). The teams in the SD 2014 had to deliver very detailed descriptions about their houses, technical components, materials, control strategies and even usage scenarios. This templates only asked for information that would be needed to feed in a simulation tool., but there was no template to deliver the simulation postprocessing data. Also, the SIR was not part of the final team deliverable. This is reflected on the delivered data from the SD EU 2014 teams. The respective house descriptions contain data partially asked for in the SIR but 
without any useable context or structure. However, it demonstrated that it could be feasible to ask for specific detailed information and to include it in the structured documentation of future SD houses.

Fact sheets and tags are the base for future SD documentation to secure a full set of data that has the quality to be used for building performance case studies. Fact sheets of future SD houses will contain all information that were available of past SD houses and they will be optimized by possible information like presented by templates like the SIR. Another optimization for future documentation is that future teams and organizer will deliver their data directly to the KP. This will to reduce time for editing the documentation and will securing complete data sets. But by allowing teams and SD organizers using the KP and editing certain parts of it a user rights management needs to be in place to still make a fair competition possible. Presently five different user types with specific rights to see and edit the KP are defined and therefore the KP is fully operational. The first teams filling in their house description are the teams of the SD ME 2018, followed by the SD EU 2019, that is possible because the SD organizers are part of the Annex 74 and agreed to this support. Also, SD Organizers should store their data in the KP. Interesting organizer data would be for example background information of rules changes or developments. The log in bound user rights management also offers the possibility to make the information stored in the KP as easy as possible accessible without violating copy rights.

With the improved documentation as suggested here the SD could be a constantly growing source for building performance case study projects.

\section{Technology Tags}

\subsection{Need for tags}

Tags are a feature of the KP to make the SD data effectively usable for building performance case studies, because they allow a broad overview of house specifications. They are used to simply label a house with a large number of non-descriptive single information of any kind. The tags can be used as a filter for specific houses or to get an overview what can be found in the SD houses.

The tags in the KP are currently set for technologies and materials used, because this is the main difference between the houses and the most important part of the building to influence its performance. Besides the technological differences the SD houses are uniquely high comparable because of the competition framework. They have the same user type and a similar size and for each competition at least 15 to 20 houses are located and tested at the same time and the same location.

Tags can be used as a filter but also for trend analysis like, e.g., market studies as published by NREL (Simon, 2017). For that paper, the SD US houses between 2002 and 2015 were analyzed with regards to the questions which technologies were used, how frequent they were applied and whether the SD served as a platform to get certain technologies market ready. This kind of research based on the SD houses and without the KP was only possible because of comparable documentation as a result of the work by a continuous organization team for the SD US between 2002 and 2015. Now the KP also allows analyses of houses other than the SD US houses.

\subsection{Conception of tags}

The tag structure is based on how technologies or materials can be applied to secure indoor and user comfort under certain environmental influences. Therefore, the structure of KP tags is based on the connection between environmental conditions and comfort needs. Comfort conditions for temperature, air quality, humidity and light level always have to be in a certain range to fulfill the user needs. The range of the comfort expectations can vary based on the local climate and cultural influences. Therefore, for each location, a certain comfort range is defined and simplified in the rules for every SD competition. The significance of the environmental conditions at each event location is addressed in figure 3 . 


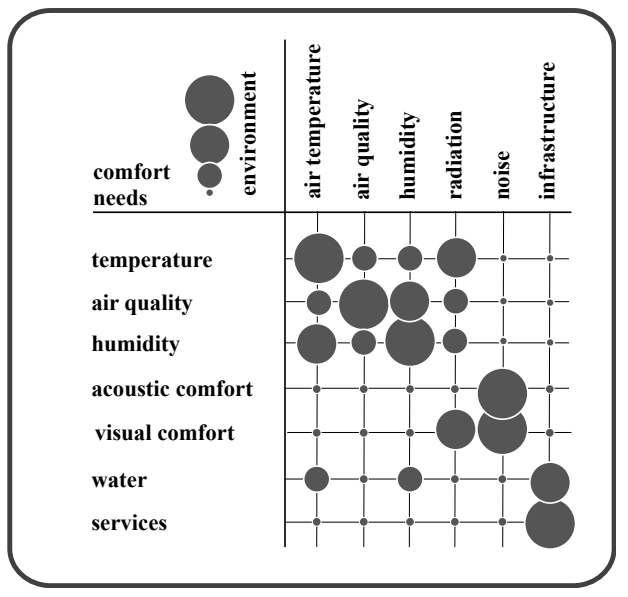

Fig. 3: Connection between the environmental conditions and the user comfort expectations. The size of the dots marks the importance of the relations. The bigger the dot, the stronger the influence of an environmental factor on a comfort need. Source: $S$. Hendel, Wuppertal University

The above-mentioned comfort expectations are complemented by water needs and service needs. The domestic hot water needs and the electricity for house appliances influence the total building energy performance.

The tags set in the KP help to understand the technologies used by the teams to fulfill the competition, comfort and general design expectations and are mainly based on the user needs as described in figure 3 .

The tags are sub-structured based on how they work to ensure a comfortable state (figure 4). If a user need is fulfilled, it can be "protected" from environmental influences. If a comfortable state is not reached, it usually can be by "generation". For instance, heat, cold, service, humidity and energy can be "generated" to satisfy a user need. Everything generated needs to be "distributed" from the place of generation to the place where it is needed. If there was generated more than what was needed, then it can be "stored". The connection between needs, protection, generation, distribution and storage is described by "control".

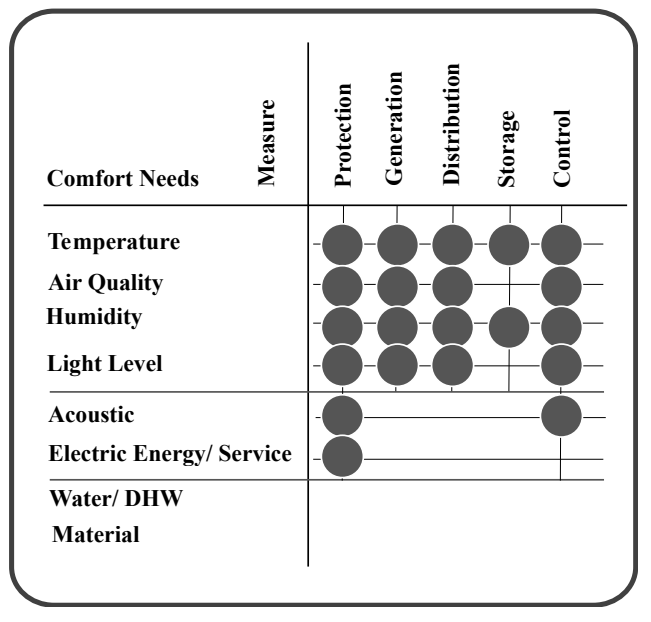

Fig 4: Measures to fulfill comfort needs as a structure base for the technology and material tag list. Source: Wuppertal University; Hendel

As shown in figure 4, some sub-categories need to be skipped, because there is, for example, no storage of light. Based on the experience in researching the SD Europe houses and designing and testing the already implemented fact sheets, it is very likely that the suggested tag structure will withstand all further research (figure 4). A full list of all preconfigured tags can be found at the KP (link 7).

At the moment, 160 tags are already preconfigured and set for the SD EU teams. A finding of tagging the SD EU houses is that the SD houses are particular suitable for building performance case studies, as shown in chapter 4 .

\section{Particular suitability of the SD houses as case studies}

Many current building performance case studies focus on efforts to better understand buildings or components in order to improve them. In this context, improvement mostly means making a contribution to slow down climate change while maintaining at least the same high level of comfort. In addition to energy savings, the use of renewable energies is also of interest in residential construction. All of these projects either need or could profit from case studies. The general suitability of the SD houses for such projects was already established above. Furthermore, they are particular suitable for building performance case study projects, because they are only powered by solar energy and significantly smaller than common houses and that will be presented in this chapter. The following arguments could only be established by applying the two-stage analysis possibility of the $\mathrm{KP}$. The first stage is using the tags to get an overview and filter for specific houses and secondly getting more information about the filtered houses from the fact sheets.

\subsection{Smaller building sizes lead to better test settings}

The SD houses are much smaller than common buildings and are therefor under a stronger environmental influence. However, that stronger influence makes the houses even more suitable for building performance studies, because they function like a lab test under practical conditions. Under extreme boundary conditions, insights about performance can be generated because they are less dependent on small and common disturbances. For example, if an active cooling system has a malfunction, but the need for cooling could be satisfied also by passive systems like shadowing and ventilation, the lack of performance of that active cooling device could be not detected. But if the cooling need is exceptionally high because of high solar irradiation and 
high environmental temperature, then this would increase the probability to find that malfunction.

By looking at the past SD EU houses, a smaller building size means a larger A/V value and also less conditioned floor area per inhabitant than in common homes. The size of the SD houses is a direct result of the competition rules. The maximum conditioned floor area in 2010 was limited to $74 \mathrm{~m}^{2}$, in 2012 limited to $70 \mathrm{~m}^{2}$ and in 2014 limited for a single-story building to $70 \mathrm{~m}^{2}$ and a two-story building to $110 \mathrm{~m}^{2}$. The conditioned floor area of the analyzed SD EU houses is illustrated in figure 5 showing that the majority was smaller than $60 \mathrm{~m}^{2}$.

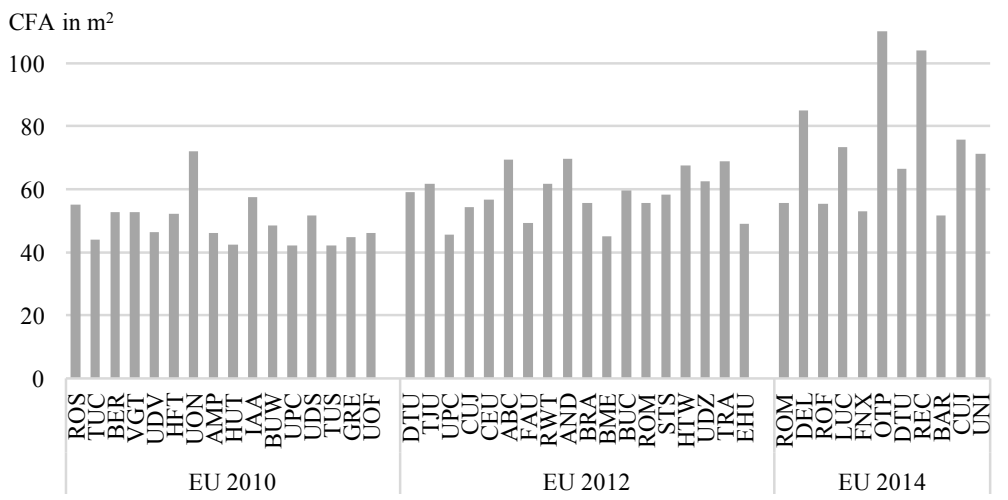

Fig. 5: The conditioned floor area (CFA) is a standard value that is stored in the fact sheets. Conditioned floor area is defined by the SD EU rules as: "Covers and constructed area remaining when walls, columns, stairs shaft, under $1.8 \mathrm{~m}$ high space and closets or any storage or technical element build from floor to ceiling are excluded" (SD EU 2014). Only interior and conditioned spaces are part of this area. Here the CFA of the SD EU houses of 2010, 2012 and 2014 are illustrated.

Source: Wuppertal University; Hendel

A result of the small size and the fact that the SD houses are usually designed for a two-person household is that they offer less living area per inhabitant. The about $70 \mathrm{~m}^{2}$ per house are corresponding to $35 \mathrm{~m}^{2}$ per person. This is significantly less than the common $46.5 \mathrm{~m}^{2}$ per person in Germany (Statistisches Bundesamt, 2017) and less than the European average of $42.6 \mathrm{~m}^{2}$ per person (European Commission, 2011).

More importantly, because of the small sizes, the houses usually have a higher A/V ratio than normal singlefamily homes (SFH) like the two exemplary single-family homes evaluated in a net-zero energy building research project (Voss, Musall, 2012) (figure 6). Their envelope area is therefore significantly higher, which makes the SD houses more exposed to environmental factors like temperature and irradiation. However, the majority of the SD houses achieve comfortable indoor climate conditions with a highly efficient use of solar energy.

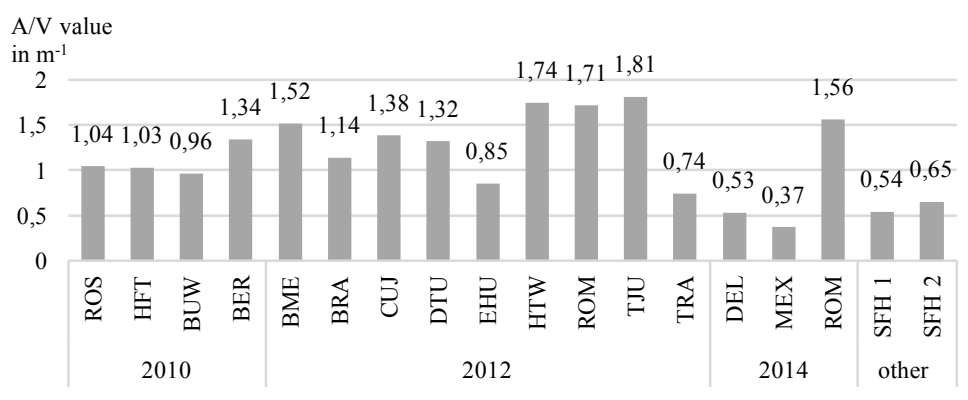

Fig. 6: Surface-to-volume ratio of the SD EU houses of 2010, 2012 and 2014, and, as a comparison, the $A / V$ ratio of two single family homes are illustrated here. The comparison buildings were analyzed in a net zero energy building research project (Voss, Musall, 2012).

Source: Wuppertal University; Hendel

The most important reason why the houses could usually deal well with the stronger environmental influences by using solar energy is, that due to the larger A/V value they have more surface area per conditioned volume available to use for solar energy generation.

\subsection{Extensive use of solar energy in $S D$}

National and international approaches to slow down climate change, among other things, led to a current boost of interest in the SD. The extensive use of renewable energy and especially solar energy in residential buildings with the goal to minimize $\mathrm{CO}_{2}$ emissions is demonstrated by the SD houses. Using their results can give valuable insights also for the building practice. As already explained above, the SD houses achieve a comfortable indoor climate by using only solar energy and that in a highly efficient manner by using a complex and innovative technology set-up. To see with which technologies the houses were equipped to perform best under these boundary conditions the technology tags could be applied. Here the technology tags of the SD EU houses were checked for any frequencies. The biggest variety of technologies was used to secure a comfortable indoor temperature. The three technologies used most frequently in the SD EU context to achieve temperature comfort by heating or cooling are illustrated in figure 7 . The structure shown here is based on the method used to structure the technology tags in the KP. 
Like shown in figure 7, besides solar energy technologies, ventilation systems and strategies are most frequent in the SD houses, what makes them potentially interesting for projects like the above-mentioned Annex 68 "Indoor air quality design and control in low energy residential buildings". (link 2) For the Annex 68 case studies and facilities for field measurements are needed, like described by subtask 5: "field measurements and case studies". "The tests will include studies of new ventilation patterns in highly energy efficient residential buildings based on improved airtightness, increased insulation, use of materials, and possibly also new residential behaviour." (Annex 58, 2015).

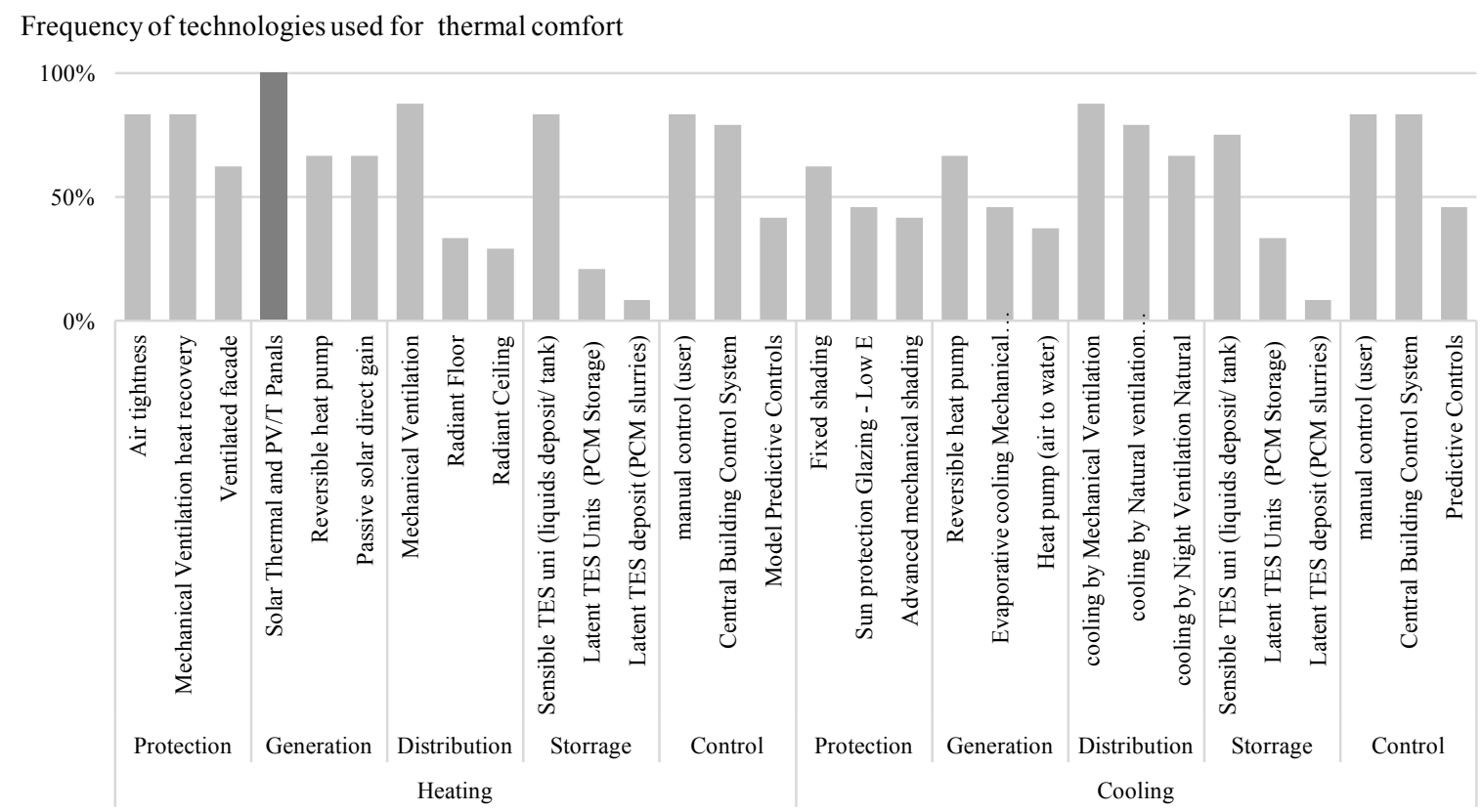

Fig. 7: Frequency of technologies used for temperature control in the Solar Decathlon Europe houses. Because of a lack of information, not all of the 56 SD EU houses could be analyzed and tagged properly. For this research, a total of 46 houses were analyzed.

\section{Source: Wuppertal University; Hendel}

The temporal distribution of solar technologies used in the past SD EU houses shows the function and the cooperation of the fact sheets and tags. The SD EU houses added an average of $6 \mathrm{~m}^{2}$ of solar thermal systems to their building envelope (figure 8). Combined with the average installed size of $55 \mathrm{~m}^{2}$ for the PV systems, this means that the SD houses had more area used for solar energy generation than they had for conditioned floor areas and therefor made the extra envelope area useful to deal with this stronger environmental influence. Also, the range of possible technologies that are photovoltaic, solar thermal or hybrid is to be expected significantly higher than in common buildings. Therefor the possibilities to test even experimental and innovative technical approached lies within the concept of the SD houses. That makes the SD houses even more interesting since many case studies now focus on innovative solar energy solutions.

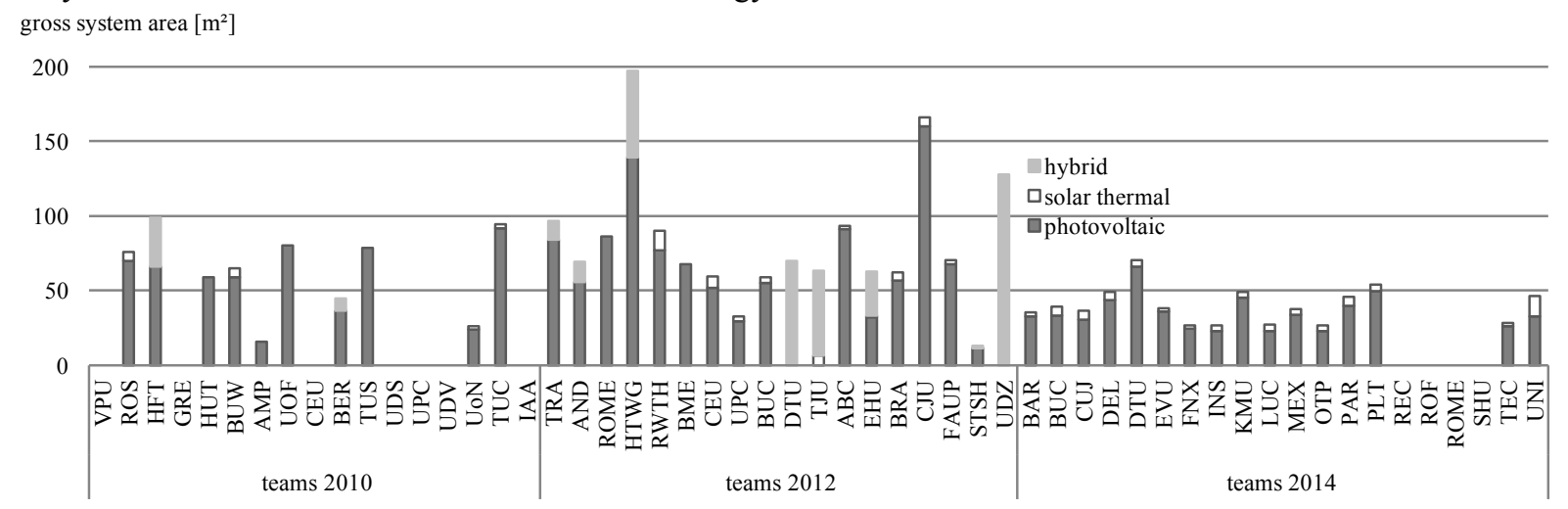

Fig. 8: Use and size of solar thermal, photovoltaic and hybrid systems of the SD EU houses.

Source: Wuppertal University; Hendel

Because the SD houses have a higher energy need for cooling, due to a stronger environmental influence and on the other hand they have a higher potential for solar energy generation, a further look into the data by using the 
KP team fact sheets about the solar systems can give an insight of the common approaches. The solar thermal systems used by the SD EU houses are much smaller than the installed photovoltaic systems (figure 8). This is explained by the higher need for electric energy than in thermal energy. The heat generated by the solar thermal systems was usually used to provide domestic hot water. During all European competitions, there was simply no need to heat the buildings during the event, but to cool the building and therefore electric energy was mainly needed.

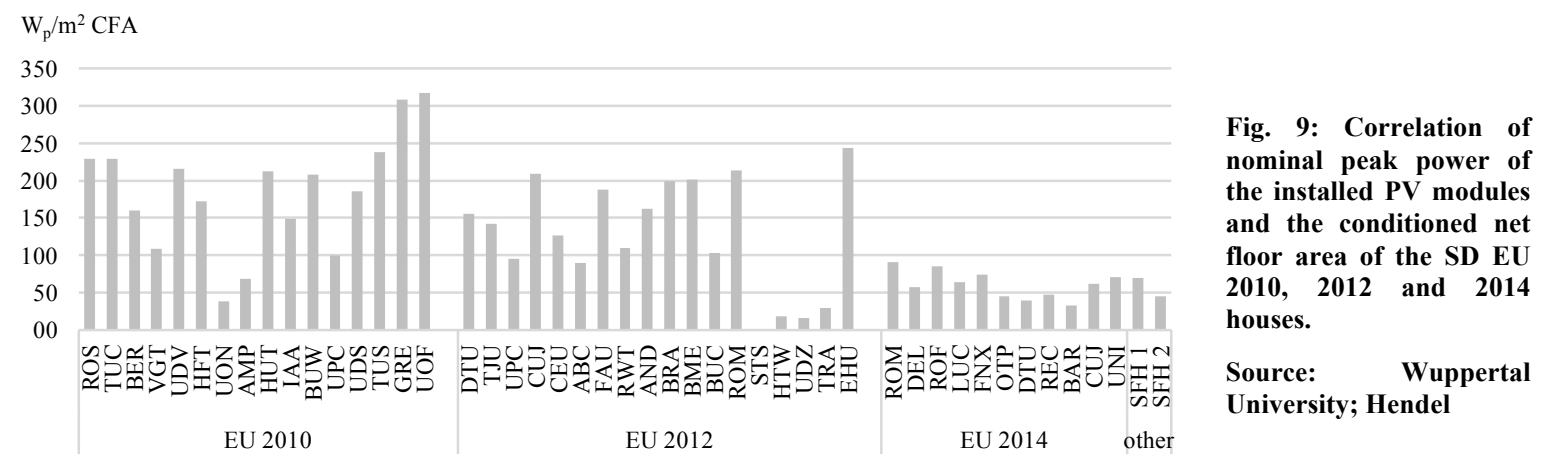

The importance of solar power generation is reflected in the correlation between the installed power and the conditioned net floor area (figure 9). In the three European competitions, the mean ratio is $135 \mathrm{~W}_{\mathrm{p}} / \mathrm{m}^{2} \mathrm{CFA}$. In comparison, the ratio for single family homes in a German research project (BMUB 2014) for plus-energy houses was $69 \mathrm{~W}_{\mathrm{p}} / \mathrm{m}^{2}$, and for zero-energy buildings investigated in the IEA context (Voss, Musall, 2012) the ratio was only $45 \mathrm{~W}_{\mathrm{p}} / \mathrm{m}^{2}$.

Although, the nominal power of the photovoltaic systems was limited to $15 \mathrm{~kW}_{\mathrm{P}}$ in $2010,10 \mathrm{~kW}_{\mathrm{p}}$ in 2012 and $5 \mathrm{~kW}_{\mathrm{p}}$ in 2014 by the competition rules, the potential of solar energy generation is higher than in common buildings. Therefore, it is to be assumed that the houses could cover their energy demands by using solar energy only. This distinction makes them perfectly suitable for studies to evaluate the solar energy use in homes specially to secure indoor comfort during summer conditions. In that way, it is possible to study an energy supply for residential buildings exclusively from renewable energy sources, with all the difficulties and without the usual restrictions. Difficulties would be, for example, the time lag between energy production and energy demand. And because the SD houses are usually free standing and not shadowed they don't have to deal with restrictions like seasonable shadowing.

\section{3. optimization for future scientific use of the $S D$ houses}

For the analysis above, that showed the size of the SD houses and the extensive use of solar energy, the existing documentation of the SD EU houses was filtered by the KP tags and further scrutinized by using the information stored in the fact sheets. Due to a lack of quality and completeness of the existing documentation only 46 out of 56 SD EU houses could be tagged properly and used for this analysis. Also, the existing data cannot be used for a deeper analysis because of a lack of comparability and quality. For all future SDs the KP will secure the needed completeness and quality of the documentation.

Besides the achievement of a complete data set from future SD houses by applying the KP and by setting the standard of completeness based on the existing data, the KP will ask for more information (cf. KP). Because the $\mathrm{SD}$ houses are more exposed to environmental influences and highly equipped with innovative technologies not only the overview of the technologies used and their frequencies and trends of application, but also deeper insights in how they were applied would be interesting. In particular, the control strategies should be also documented to make a scientific use of the data possible. Interesting, for example, are control strategies to deal with hot summer climate and high indoor comfort expectations by only using the amount of energy produced by the installed PV systems.

In addition, building users have a significant influence on the building performance especially in small and highly energy efficient buildings. Users interfere with system controls, opening windows, running appliances or simply by the are present. Therefore, the user presence and behavior also should be a part of the future documentation. This would be needed to interpret and use the monitoring data. The houses are intensely monitored and publicly toured during the event. An event usually lasts 10 to 14 days. During that time, a documentation of the user behavior and the number of people inside the house should be possible without violating the privacy of any inhabitants. 


\section{Conclusion and Outlook}

In building performance projects a lack of suitable case studies is a common obstacle. But the SD houses are particular suitable to serve as case studies in building performance projects. In the past, SD houses were already used for case study projects focusing on the whole building performance or the performance of components. However, because of insufficient documentation these SD house based research projects were only possible by researchers having a direct connection to the analyzed house, like being a team or SD organization member.

The implementation of the KP will significantly optimize the documentation of future SD houses to make them broadly useable for case study based research projects. The core value of the KP is that SD teams have to deliver all information asked in pre-structured templates, that ensures full data sets and absolute comparability of the data. This is the key to have a continuously growing pool of scientific relevant case studies. The KP serves as a documentation platform for the existing and future SD data. In principle, the documentation of the existing houses could be used to analyze the performance of certain building concepts and technical approaches, in particular, because the event monitoring data sets are also available. But the documentation of previous SD's was not structured to meet scientific demands.

The research connected to the design and implementation of the KP led to a full SD EU dataset in the KP. The documentations of the SD US houses from 2009 to 2017 will follow within the next year. Also, the tags set up so far are addressing the topics "Technologies used" and "Materials" and further tags like "building shape and orientation" and "usage and location of the houses after the competition" will follow.

This paper is part of a research project evaluating the potential of the SD. The SD houses, the data generated within the competition and the competition itself have the potential to serve for more than just to be a public event to educate student teams and the general public. As illustrated here, the houses and their documentation can be profitably used for building performance case study research projects.

\section{Acknowledgement}

The project and the resulting online database were funded by the Federal Ministry of Economics and Energy by resolution of the German Bundestag.

The connection to the Annex 74 (Annex 74) and therefore a direct connection to SD organizers from past and present competitions, led to profound feedback that was fundamental to create the KP.

\section{References}

Literature:

Monzón, M, López-Mesa, B, 2017. Simplified model to determine the energy demand of existing buildings. Case study of social housing in Zaragoza, Spain. Paper; Energy and Buildings Journal, 149 https://www.sciencedirect.com/science/article/pii/S0378778816318047

Strachan, P., Svehla, K., Kersken, M., Heusler, I.,2016. Reliable building energy performance characterisation based on full scale dynamic measurements, Annex 58 final report, p.5

Voss, K., Herkel, S., Kalz, D., Lützkendorf, T., Maas, A., Wagner, A., 2016. Performance von Gebäuden. Kriterien - Konzepte - Erfahrungen. Book publication, Fraunhofer IRB Verlag, ISBN-13: 978-3816795834

Vega, S., Rodriguez-Ubinas, E., 2014.Science behind and beyond the Solar Decathlon Europe 2012, Energy and Buildings Special Issue, Vol 83, https://www.sciencedirect.com/journal/energy-and-buildings/vol/83/suppl/C

Cronemberger, J., Almagro Corpas, M., Cerón, I., Caamaño-Martín, E., Vega Sánchez, S., 2014. BIPV technology application: Highlighting advances, tendencies and solutions through Solar Decathlon Europe houses, Energy and Buildings Special Issue, Vol 83, pp 44-56

https://www.sciencedirect.com/science/article/pii/S0378778814003491

Rodriguez-Ubinas, E., Montero, C., Porteros, M., Vega Sánchez, S., Navarro, I., Castillo-Cagigal, M., Matallanas, E., Gutiérrez, A., 2014. Passive design strategies and performance of Net Energy Plus Houses, Energy and Buildings Special Issue, Vol 83, pp. 10-22.

https://www.sciencedirect.com/science/article/pii/S0378778814003430

Voss, K., Hendel, S., Russel, P., 2016. Solar Decathlon Europe and the Energy Endeavour Initiative, Eurosun Conference Paper http://proceedings.ises.org/eurosun2016/EuroSun2016-Proceedings.pdf 
Simon, J., Doris, Farrar, S., 2017.Insights on Technology Innovation - A Review of the U.S. Department of Energy Solar Decathlon Competition Entries 2002-2015, Paper https://www.nrel.gov/docs/fy18osti/70179.pdf

Statistisches Bundesamt, FS 5 R.3, Bautätigkeit und Wohnen, Bestand an Wohnungen, Wiesbaden 2017

European Commission, 2011. Average floor area per person, http://ec.europa.eu/energy/en/content/housingspace-person

Voss, K., Musall, E., 2012. Net Zero Energy Buildings - International projects of carbon neutrality in buildings, Detail book, 2nd edition, ISBN 978-3-920034-80-5

Rode, C., 2015. Indoor Air Quality Design and Control in Low Energy Residential Buildings, Annex 68 description. page 7

http://www.iea-ebc-annex68.org/-/media/Sites/IEA-

EBC/About Annex68/Full Annex Description.ashx?la=da\&hash=FC8567D3AFAD65A08DD71A094550B62 7D5D155A6

BMUB (Federal Ministry for the Environment), 2014. What makes an Efficiency House Plus?, Nature Conservation, Building and Nuclear Safety, brochure

Web links

link 1:

https://www.ibp.fraunhofer.de/en/Press/Research in focus overview/Archives/April 2014 twin research.html

link 2: http://www.iea-ebc-annex68.org

link 3: https://dynastee.info/new-iea-ebc-annex-71-building-energy-performance-assessment-based-on-in-situmeasurements/

link 4: http://www.iea-ebc.org/projects/ongoing-projects/ebc-annex-74/,

link 5: https://building-competition.org,, last visited 25.11.2018

link 6: https://asset.building-

competition.org/EU2014/4 Documents/Eu\%202014\%20Simulation\%20Input\%20Data\%20V2-template.xlsx

link 7: https://building-competition.org/tags-usedlast visited 25.11.2018 


\title{
DIFFERENCE IN EVALUATION OF DISCOMFORT GLARE FROM WINDOWS BETWEEN MIDDLE-EASTERN AND JAPANESE STUDENTS
}

\author{
Toshie Iwata \\ School of Engineering, Tokai University, Hiratsuka (Japan)
}

\begin{abstract}
Recent studies suggest that discomfort caused by glare from windows depends on more factors than the four main variables: the glare source luminance, the background luminance, the angular size of the source, and the relative position of the source. It is possibly affected by climatic conditions to which occupants are accustomed. In this study the difference in glare evaluation between Japanese and Middle-Eastern students was investigated. A simulation using weather data shows that in Riyadh ( $24.71 \mathrm{deg} \mathrm{N}), 70 \%$ of the working hours had more than 4000 $\mathrm{cd} / \mathrm{m}^{2}$ of luminance of the window area including venetian blinds, while in Tokyo (36.18 deg N) it was only $50 \%$. The results of the subjective experiment with an actual window showed no significant difference in glare evaluation between the Japanese subjects and the Middle-Eastern subjects. In the artificial window experiment, when the window had a uniform luminance and the luminance is high, glare evaluation by the Middle-Eastern subjects was lower than that by the Japanese subjects. Glare evaluation by the Japanese subjects showed a higher correlation with PGSV, DGP and DGI mod, while the evaluation by the Middle-Eastern subjects showed a lower correlation.
\end{abstract}

Keywords: Discomfort glare, Daylight, Venetian blinds, Subjective experiment, Climatic conditions

\section{Introduction}

Lighting control strategies using daylight are important for sustainable building designs. However, glare from windows sometimes causes discomfort for occupants. A lot of research has been carried out to develop glare indices for daylighting (Hopkinson, 1972, Wienold and Christoffersen, 2006). The main variables that affect the experience of discomfort glare have been established. They are the luminance of the glare source, the luminance of the background, the angular size of the glare source, and the relative position of the glare source in relation to an observer's focal point. However, studies suggest that window glare depends on more factors than the four main variables (Velds, 2002).

In our previous paper, subjective experiments were carried out to identify the effects of the type of task, the view angle between the line of sight and the window pane, and the view through the window on discomfort glare evaluation (Iwata et al., 2017). The actual window experiment showed no significant difference in glare evaluation between the VDT task and the paper task, between the view angles (perpendicular to the window pane and oblique angle), as well as between the types of view. The results suggested that the view through the windows can relieve discomfort caused by window glare and also increase acceptability.

A recent literature review suggested one of the potential elements influencing discomfort glare perception is the culture (Pierson, et al. 2017). In the study, the culture is defined as the climatic and indoor conditions to which the subject has become accustomed to during the major part of one's life, one's behaviour towards the environment and one's expectations about it. An in-situ study has been conducted in two countries (Belgium and Chile) to study the influence of culture and the results showed that all selected glare predictors (DGP, DGI, CGI, DGI mod, etc.) presented a moderate correlation factor with the Belgian subjective assessments made on a four-point discomfort semantic scale. On the other hand, the correlations of the Chilean assessments with the selected glare predictors 
were either low or non-significant.

Since that was an in-situ study, not only the subjects' background but also the conditions evaluated were different. In this study, in order to identify the effect of culture as background of the subjects on glare evaluation, two subject groups with different climatic background evaluated the same conditions. In this paper the difference between Japanese and Middle-Eastern students was investigated.

\section{Calculation of average window luminance}

\subsection{Methods}

The climate classification of Japan is Cfa (Temperate Rainy climate), while that of Middle-Eastern countries is BWh (Hot desert climate). EnergyPlus weather data was used. Figures 1 and 2 show global illuminance of Tokyo (Hyakuri $36.18 \mathrm{deg} \mathrm{N}$ and $140.42 \mathrm{deg}$ E) and Riyadh (24.71 deg N and $46.68 \mathrm{deg}$ E) and normal direct illuminance of them respectively. The global illuminance of Riyadh is higher than Tokyo all year around.

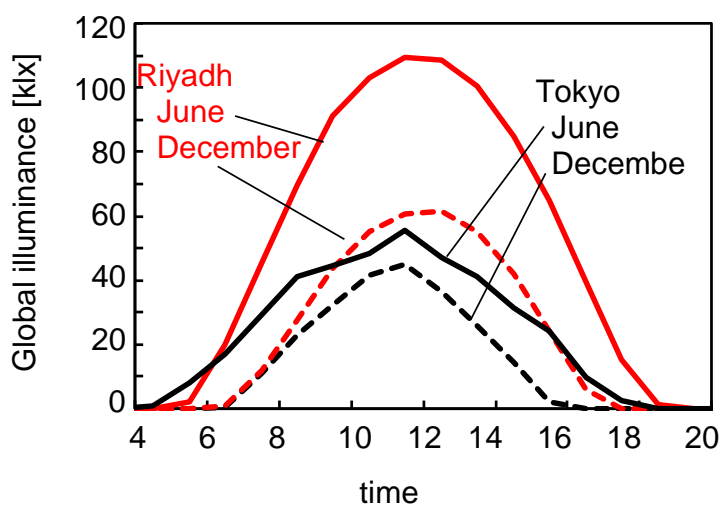

Fig. 1: Global illuminance

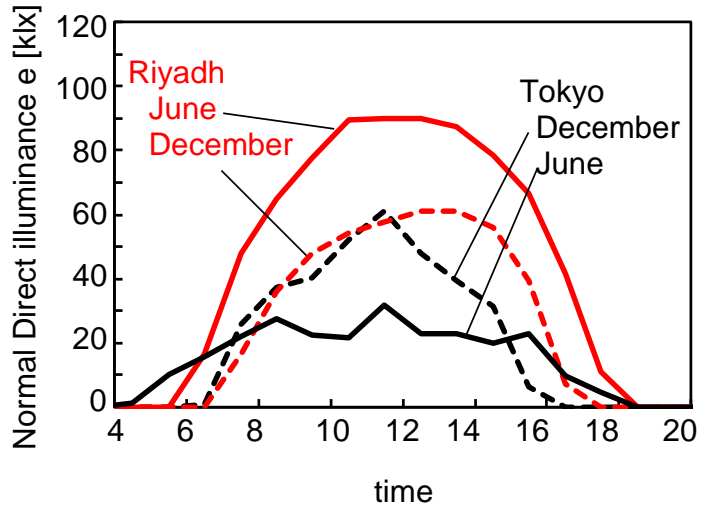

Fig. 2: Normal directl illuminance

Using the data of the normal illuminance of direct sunlight, horizontal illuminance of diffused light from sky and sun position (solar altitude and azimuth), the luminance of window including venetian blinds of each city is calculated. The calculation condition is shown in Table 1.

Tab. 1:Conditions for calculation

\begin{tabular}{|c|c|}
\hline Parameters & Input for calculation \\
\hline Window: orientation and height & South, $1.2 \mathrm{~m}$ from floor $-3.0 \mathrm{~m}$ \\
\hline $\begin{array}{c}\text { Venetian blind: Reflectance } \rho \text { and width of } \\
\text { blind slats and spacing between slats }\end{array}$ & $\rho=0.85$ (Lambertian surface), width $=25 \mathrm{~mm}$, space $=21 \mathrm{~mm}$ \\
\hline Transmittance of glass & 0.8 \\
\hline Calculation point & $3.0 \mathrm{~m}$ from façade, Eye height: $1.2 \mathrm{~m}$ \\
\hline
\end{tabular}

The slat angle of the blinds is controlled to keep the cut-off angle (the slat angle to cut direct sunlight), which can be expressed as a function of the profile angle, the width of the slats and the spacing between the slats as shown in Equations 1 and 2. In this study, the slat angle is set at 0 degrees (horizontal slat position) when the cut-off angle is less than zero to keep the views of outside clear.

$\theta_{\text {cut-off }}=\operatorname{asin}\left(\frac{s}{w} \cos \alpha_{p}\right)-\alpha_{p}$

$\alpha_{p}=\operatorname{atan}\left(\frac{\tan \alpha}{\cos \gamma}\right)$

Where $\theta_{\text {cut-off }}$ is cut-off angle, $\alpha_{\mathrm{p}}$ is solar profile angle, $\mathrm{s}$ is spacing between the slats, $w$ is the width of slats, $\alpha$ is solar altitude and $\gamma$ is solar azimuth to the window plane. 
The average window luminance including both blind area and view seen between the slats was calculated in the same way as described in our previous study (Iwata et al., 2016). To simplify the calculation, it was assumed that desk partitions at eye height did not allow the worker to see the window below eye height. Therefore, only sky could be seen through the window.

\subsection{Results}

Figures 3 and 4 show the hourly change in the angle of the blind slats on the winter solstice, and the cumulated frequency of angle of blind slats, respectively. Since the altitude of the sun in Riyadh is higher than that in Tokyo, the cut-off angle for Riyadh is smaller than that for Tokyo, e.g. $87 \%$ of the working hours need zerodegrees of the cut-off angle (horizontal slat position) in Riyadh, compared to $67 \%$ of the working hours in Tokyo. Figures 5, 6 and 7 show the hourly change in average luminance of window area including the blind and the view seen between the slats in March, June and December, respectively. Figure 8 shows the cumulated frequency of average luminance of window area.

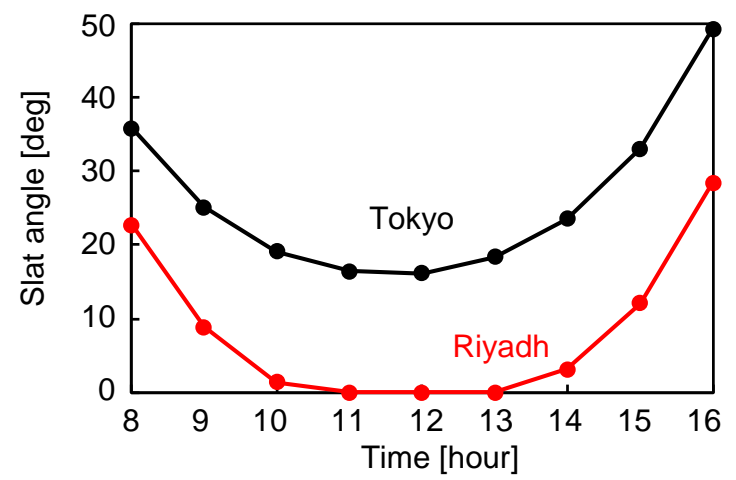

Fig. 3: Change in slat angle on winter soltice

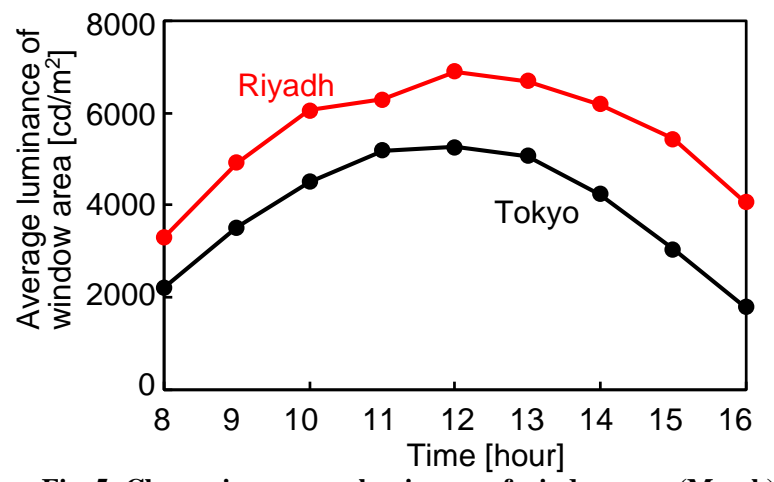

Fig. 5: Change in average luminance of window area (March)

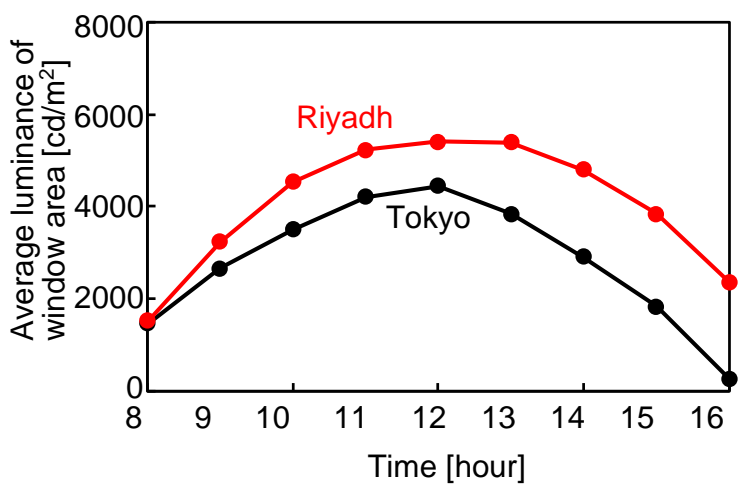

Fig. 7: Change in average luminance of window area (December)

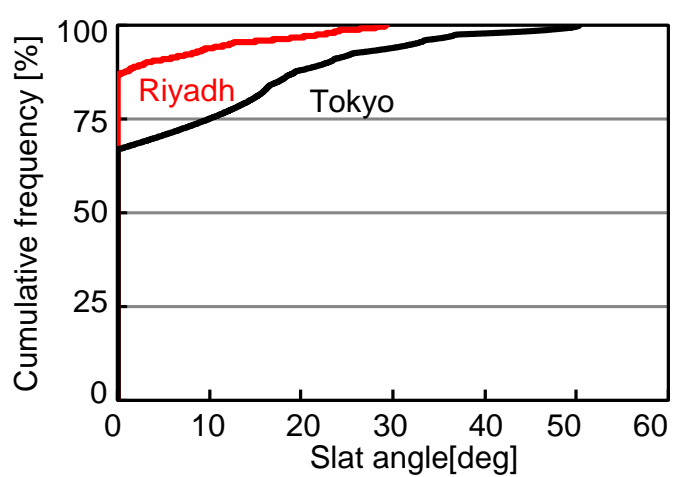

Fig. 4: Cumulative frequency of slat angle ( 8 am to 4 pm)

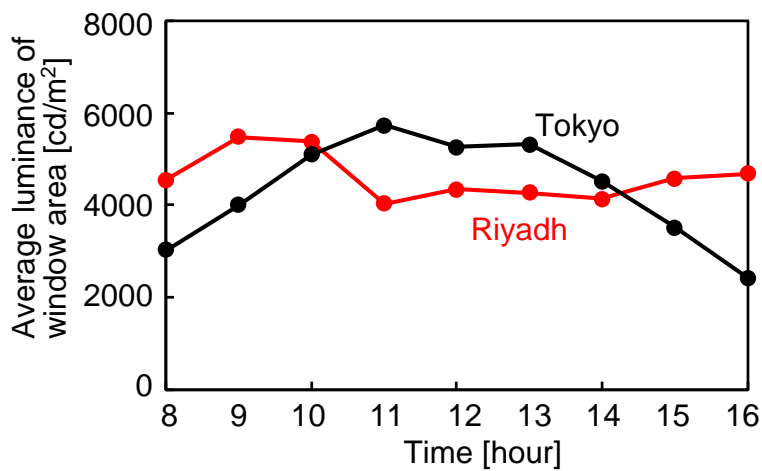

Fig. 6: Change in average luminance of window area (June)

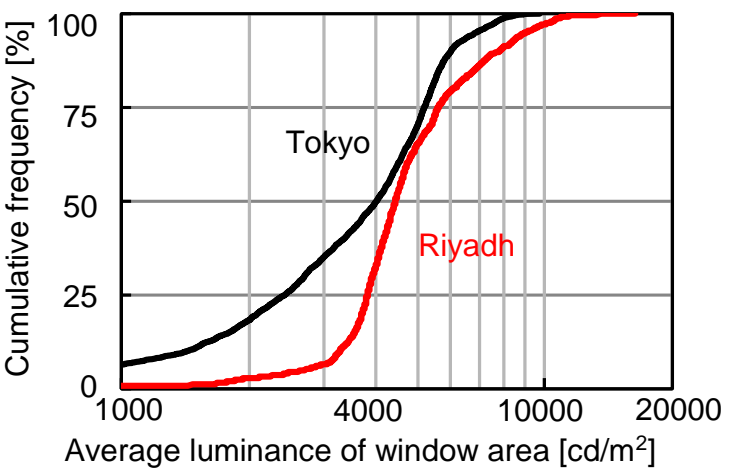

Fig. 8: Cumulative frequency of window luminance (8 am to 4 pm)

The average luminance of the window area in Riyadh is generally higher than that in Tokyo as shown in Figures 5 and 7. In June, the average luminance in Riyadh is lower than that in Tokyo as shown in Figure 6. This is because 
the solar altitude in Riyadh is so high that the amount of direct sunlight reflected on the blind slat is small.

In Riyadh, $70 \%$ of the working hours ( $8 \mathrm{am}$ to $4 \mathrm{pm}$ ) has more than $4000 \mathrm{~cd} / \mathrm{m}^{2}$ of luminance of the window area, compared to $50 \%$ of the working hours in Tokyo, when the cut-off angle is used. Although the simulation conditions shown in Table 1 change the relationship between the luminance of window area and its frequency, generally the luminance of the window area in Riyadh is higher than that in Tokyo.

\section{Subjective experiment with actual windows}

\subsection{Methods}

Subjective experiments were conducted in a room with windows (width: $2000 \mathrm{~mm}$, height: $1200 \mathrm{~mm}$ ) facing south with venetian blinds with reflectance of $69 \%$ on October 10th, 11th and 12th, 2017. There were two different positions of the subject, which provided two angles between the line of sight and the window pane (perpendicular to the window pane and an oblique angle) as shown in Figure 9. The distance between the centre of the window and the eye of the subject was $2 \mathrm{~m}$. The solid angle of the window from the subject was $0.46 \mathrm{sr}$. The slat angle of the venetian blind was set at cut-off angle. Figure 10 shows the view seen from the window.

Twenty-seven Japanese students (with an age range of 20-22 years) and twenty-seven Middle-Eastern students, of whom 67\% were Saudi Arabian, 22\% Qatari, and 11\% Bahraini, (with an age range of 20-28 years) participated as subjects. The subjects entered the room and did a VDT task or a paper task for three minutes. Then, they looked at the window and assessed the glare using the Glare Sensation Vote (GSV) scale (0: just perceptible, 1: just acceptable, 2: just uncomfortable, 3: just intolerable). Each subject evaluated four conditions, two different positions and two different tasks (VDT/paper). From 10:00 am to 2:30 pm, nine sets of experiment (30 minutes for each) were carried out. The air temperature and relative humidity during the experiment were measured at the measurement point shown in Figure 9.

After evaluation, photos were taken by a camera system (Nikon D3300 and Sigma 4.5 mm, 1:2.8 EX DC circular fisheye) to make luminance images from which glare predictors were calculated. In this experiment Predicted Glare Sensation Vote (PGSV) (Tokura et al. 1996) is used as glare predictor which is calculated using the following equation (Eq.3)

$\mathrm{PGSV}=\log \frac{L_{s}^{3.2} \omega^{-0.8}}{L_{b}{ }^{0.61-0.79 \log \omega}}-8.2$

Where $L s$ is luminance of the glare source $\left[\mathrm{cd} / \mathrm{m}^{2}\right], L b$ is luminance of the background $\left[\mathrm{cd} / \mathrm{m}^{2}\right]$ and $\omega$ is solid angle of the glare source [sr].

The values of PGSV are 0: just perceptible, 1: just acceptable, 2: just uncomfortable, 3: just intolerable.

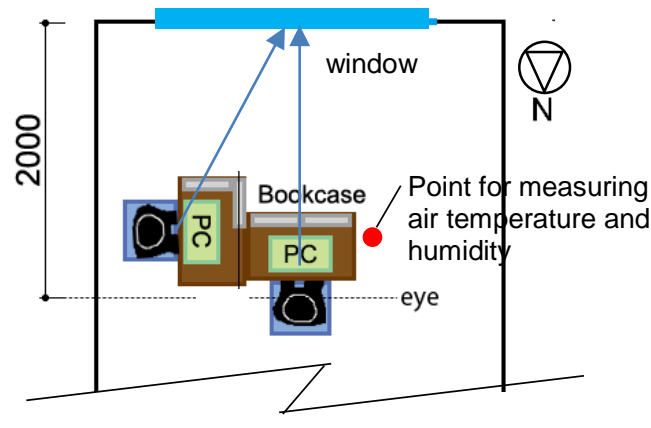

Fig. 9: Positions of subjects

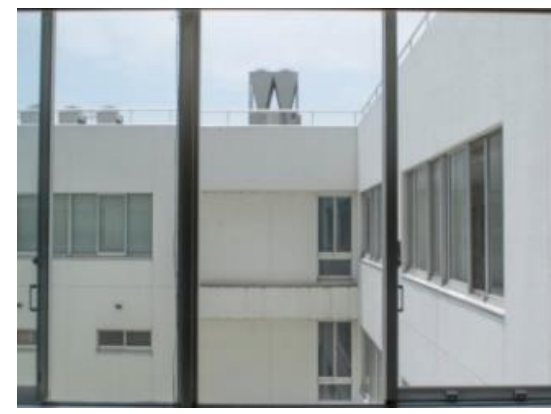

Fig.10: View seen through the window

\subsection{Results}

During the experiment, the air temperature ranged from $27{ }^{\circ} \mathrm{C}$ to $28{ }^{\circ} \mathrm{C}$ while the relative humidity ranged from $49 \%$ to $58 \%$. 
Figure 11shows the change in global illuminance and Figure 12 shows the spectral power distribution (SPD) measured at the position of the subject when the line of sight is perpendicular to the window pane, on October 12 (the third day of the experiment).

Since the individual difference in Glare Sensation Vote judged by the subjects (GSV) was large, the average value of $\mathrm{PGSV}$ in each range $(0 \leq \mathrm{PGSV}<0.5,0.5 \leq \mathrm{PGSV}<1,1 \leq \mathrm{PGSV}<1.5$, and so on $)$ and the average of GSV in each range were calculated. There were no significant difference in the GSV for each range between the VDT task and the paper task. Therefore, this paper used the results with the VDT task. Figure 13 shows the average of PGSV and GSV. The sample numbers were 4, 13 and 9 for the Japanese subjects, and 8, 9 and 6 for the Middle-Eastern subjects with the line of sight perpendicular to the window pane. When the line of sight was oblique to the window pane, the sample numbers were 3,8 and 16 for the Japanese subjects and 6,11 and 9 for the Middle-Eastern subjects.

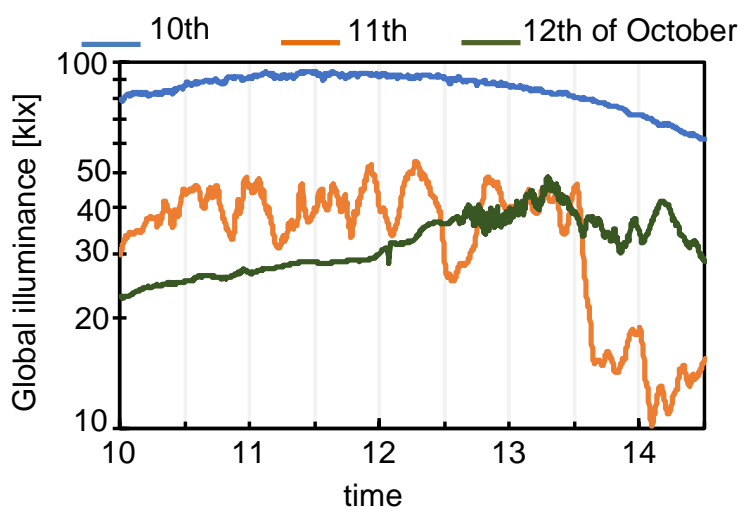

Fig. 11: Change in global illuminance on the experiment days

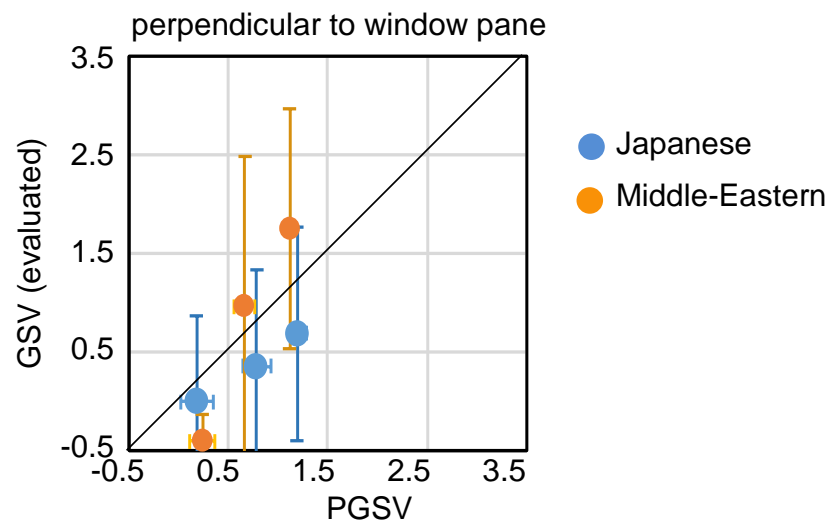

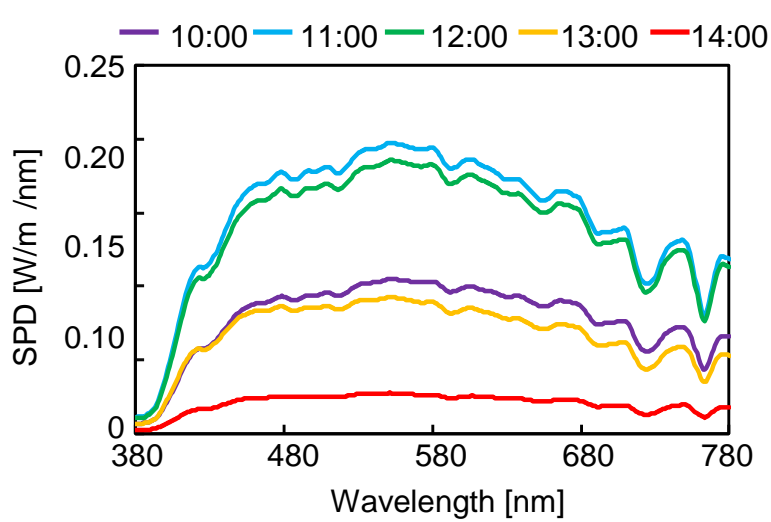

Fig. 12: Spectral power distribution of light at

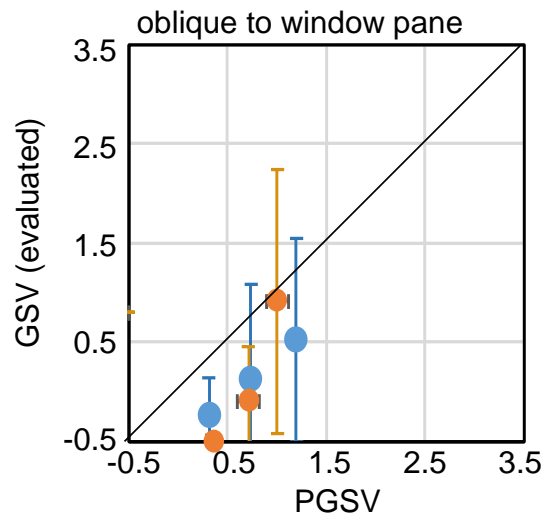

Fig. 13: PGSV vs. GSV (average) for the line of sight perpendicular to window pane (left) and oblique to window pane (right)

The diagonal line means that PGSV can exactly predict GSV. It can be said that GSV judged by the Japanese students was generally lower than PGSV prediction. For both the Japanese subjects and the Middle-Eastern subjects, GSV increases with increments of PGSV.

Increments of GSV judged by the Middle-Eastern subjects were larger than that by the Japanese subjects. The Mann-Whitney U test for each range of PGSV showed no significant difference in GSV between the MiddleEastern and Japanese subjects. No significant difference in GSV was found between the view angles (perpendicular to the window pane and oblique to the window pane) for the Japanese subjects and for the MiddleEastern subjects.

\section{Subjective experiment with artificial windows}

\subsection{Methods}

Subjective experiments were conducted in a test chamber shown in Figure 14 on October 23 to October 24, 2017. 
The test chamber had an artificial window (width: $1200 \mathrm{~mm}$, height: $1200 \mathrm{~mm}$ ) with venetian blinds set at zero degrees. The solid angle of the window from the subject was $0.30 \mathrm{sr}$. Three window views (two kinds of view and no view) with two different luminance levels were evaluated from two different positions.

In order to make a window view, pictures of the view as shown in Figure 15 were printed on the plastic film which were attached to the artificial window. Table 2 shows the luminance distribution of the actual window and the artificial window. For the view 2 in which a building occupying a large area, the luminance distribution of the artificial window was different from that of the actual window due to the low transmittance of the building area printed on the plastic film,
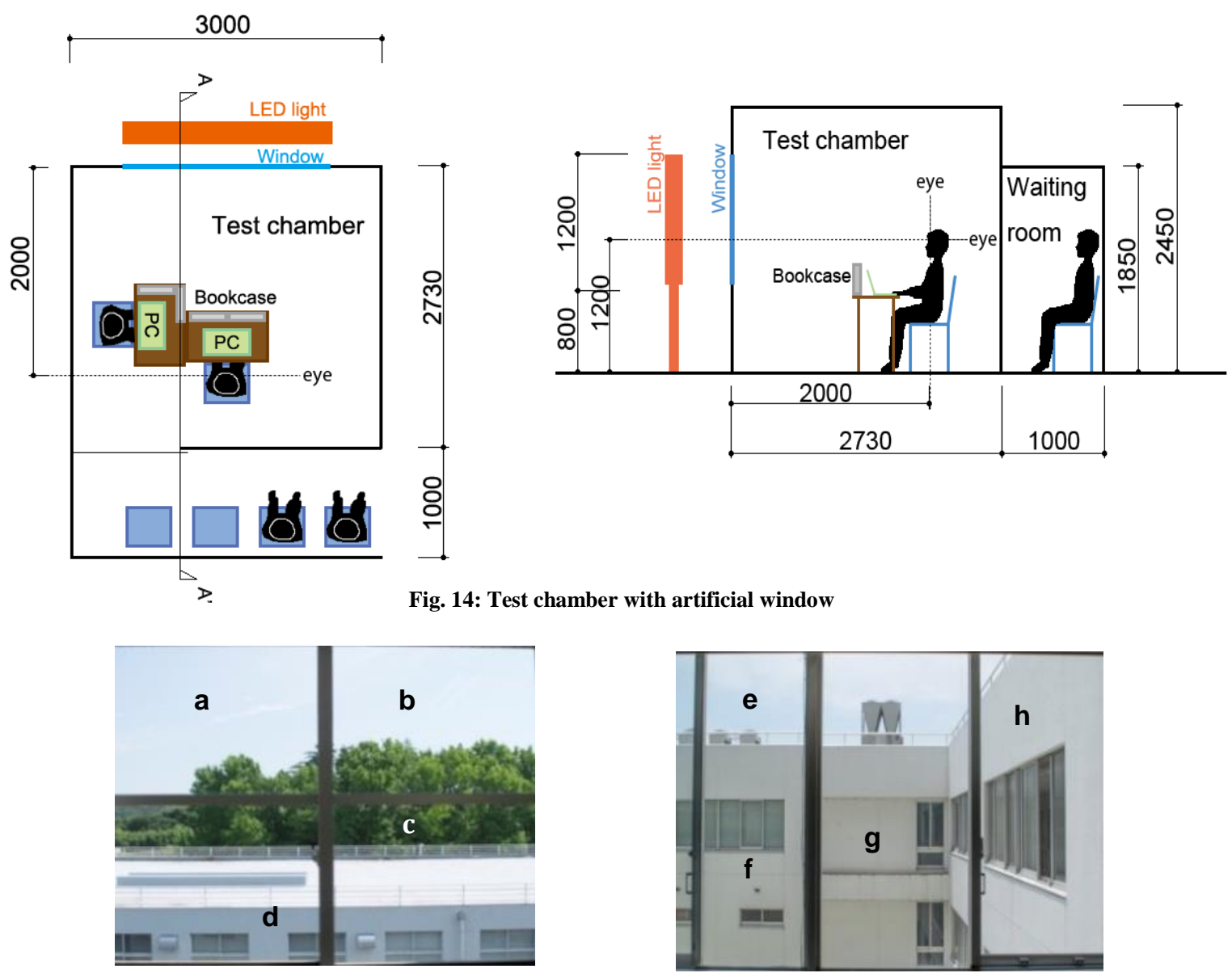

Fig. 15: Views seen from wondow (Left: View 1, Right : View 2)

Tab 2: Luminance of actualwindow andartificail window

\begin{tabular}{|c|c|c|c|c|c|}
\hline & \multirow{2}{*}{$\begin{array}{c}\text { Measurement } \\
\text { point } \\
\text { (symbol in Fig ) }\end{array}$} & \multicolumn{2}{|c|}{ actual window } & \multicolumn{2}{|c|}{ artificial window } \\
\hline & & $\begin{array}{c}\text { Luminance } \\
{\left[\mathrm{cd} / \mathrm{m}^{2}\right]}\end{array}$ & $\begin{array}{c}\text { ratio } \\
{[\%]} \\
\end{array}$ & $\begin{array}{c}\text { Luminance } \\
{\left[\mathrm{cd} / \mathrm{m}^{2}\right]} \\
\end{array}$ & $\begin{array}{c}\text { ratio } \\
{[\%]} \\
\end{array}$ \\
\hline \multirow{4}{*}{ View1 } & a & 6581 & 1 & 5736 & 1 \\
\hline & b & 4073 & 0.62 & 6015 & 1.05 \\
\hline & C & 593 & 0.09 & 216 & 0.04 \\
\hline & d & 602 & 0.09 & 407 & 0.07 \\
\hline \multirow{4}{*}{ View2 } & e & 3930 & 1 & 4793 & 1 \\
\hline & f & 2800 & 0.71 & 186 & 0.04 \\
\hline & g & 2823 & 0.72 & 827 & 0.17 \\
\hline & h & 3141 & 0.8 & 222 & 0.05 \\
\hline
\end{tabular}


Ten Japanese students (with an age range of 20-22 years) and ten Middle-Eastern students (seven Saudi Arabian, two Qatari, and one Bahraini, with an age range of 20-28 years) participated as subjects. The subjects entered the test chamber and did a VDT task for three minutes (Figure 16). They then looked at the window and assessed the glare using the Glare Sensation Vote (GSV) scale. For the window with Views 1 and 2, the preferability of the view was evaluated on 5-point scale (-2: unpreferable, -1:slightly unpreferable , 0 Neither preferable nor unpreferable, 1: slightly preferable, 2 : preferable). The air temperature and relative humidity during the experiment were measured at the centre of the room.

After evaluation, photos were taken by a camera system (Nikon D3300 and Sigma 4.5 mm, 1:2.8 EX DC circular fisheye) to make luminance images from which glare predictors were calculated as shown in Figure 17.

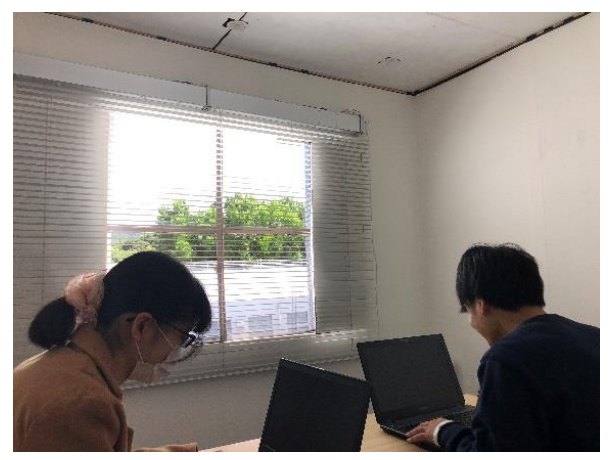

Fig. 16: Subjects doing VDT task during experiment

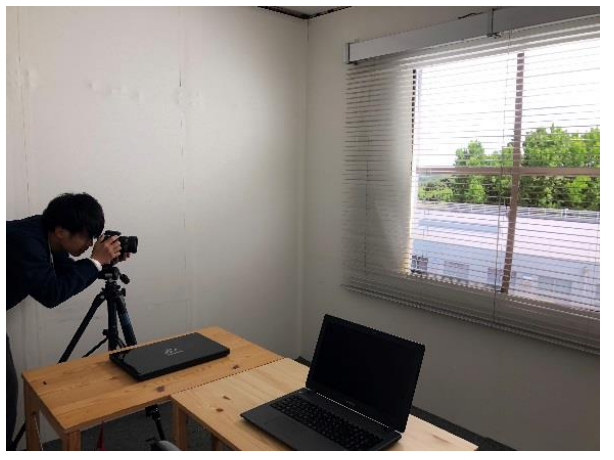

Fig. 17: Experimenter taking photos

\subsection{Results}

During the experiment, the air temperature ranged from $23{ }^{\circ} \mathrm{C}$ to $25^{\circ} \mathrm{C}$ while the relative humidity ranged from $40 \%$ to $68 \%$.

\subsubsection{Distribution of GSV}

Table 3 shows the results of the normality test (Kolmogorov-Smirnov test) showing that for more than $50 \%$ of conditions (shaded cells), the GSV judged by the subjects did not have normal distribution. Therefore, nonparametric tests (the Wilcoxon signed-rank test) were used.

Tab 3: Distribution of GSV and results of a normality test

\begin{tabular}{|c|c|c|c|c|c|c|c|c|}
\hline \multirow[b]{2}{*}{$\begin{array}{l}\text { Window } \\
\text { view }\end{array}$} & \multirow[b]{2}{*}{ position } & \multirow[b]{2}{*}{ Luminance } & \multicolumn{3}{|c|}{ Japanese subjects } & \multicolumn{3}{|c|}{ Middle-Eastern subjects } \\
\hline & & & $\begin{array}{c}\text { Kolmogorov- } \\
\text { Smirnov test } \\
\text { P-value }\end{array}$ & Kurtosis & Skewness & \begin{tabular}{|c|} 
Kolmogorov- \\
Smirnov test \\
P-value
\end{tabular} & Kurtosis & Skewness \\
\hline \multirow{4}{*}{ View 1} & \multirow{2}{*}{$\mathrm{P}$} & $\mathrm{L}$ & $>=0.10$ & 1.579 & 0.031 & 0.0005 & 2.097 & 0.812 \\
\hline & & $\mathrm{H}$ & $>=0.10$ & 1.621 & -0.381 & $>=0.10$ & 3.826 & 0.724 \\
\hline & \multirow{2}{*}{$\mathrm{O}$} & $\mathrm{L}$ & 0.054 & 4.09 & 1.429 & 0.0000 & 8.111 & 2.667 \\
\hline & & $\mathrm{H}$ & $>=0.10$ & 1.952 & 0.318 & $>=0.10$ & 1.899 & 0.143 \\
\hline \multirow{4}{*}{ View 2} & \multirow{2}{*}{$\mathrm{P}$} & $\mathrm{L}$ & 0.001 & 3.025 & 1.361 & 0.0000 & 2.416 & 1.064 \\
\hline & & $\mathrm{H}$ & 0.001 & 2.224 & 0.911 & $>=0.10$ & 1.658 & 0.393 \\
\hline & \multirow{2}{*}{$\mathrm{O}$} & $\mathrm{L}$ & 0.001 & 3.82 & 1.623 & 0.0000 & 5.150 & 1.920 \\
\hline & & $\mathrm{H}$ & 0.064 & 4.67 & 1.585 & 0.0209 & 2.232 & 0.827 \\
\hline \multirow{4}{*}{ No view } & \multirow{2}{*}{$\mathrm{P}$} & $\mathrm{L}$ & $>=0.10$ & 2.63 & -0.579 & $>=0.10$ & 1.688 & 0.240 \\
\hline & & $\mathrm{H}$ & 0.044 & 4.028 & -1.378 & 0.0169 & 4.663 & 1.618 \\
\hline & \multirow{2}{*}{$\mathrm{O}$} & $\mathrm{L}$ & $>=0.10$ & 2.226 & 0.284 & $>=0.10$ & 1.419 & -0.167 \\
\hline & & $\mathrm{H}$ & $>=0.10$ & 3.569 & -1.105 & 0.0418 & 2.572 & -0.920 \\
\hline
\end{tabular}




\subsubsection{Difference between the Japanese subjects and Middle-Eastern subjects}

Figure 18 shows the relationship between PGSV and the median and the quantile of GSV judged by the Japanese subjects and the Middle-Eastern subjects, for the line of sight perpendicular to the window pane and for the line of sight oblique to the window pane. When the window had no view and the luminance of the window was high (PGSV is 1.8), GSV judged by the Middle-Eastern subjects was significantly lower than that by the Japanese subjects for both angles between the line of sight and the window pane. Views 1 and 2 resulted in low window luminance and no significant difference between GSV judged by Japanese and by the Middle-Eastern subjects was found.
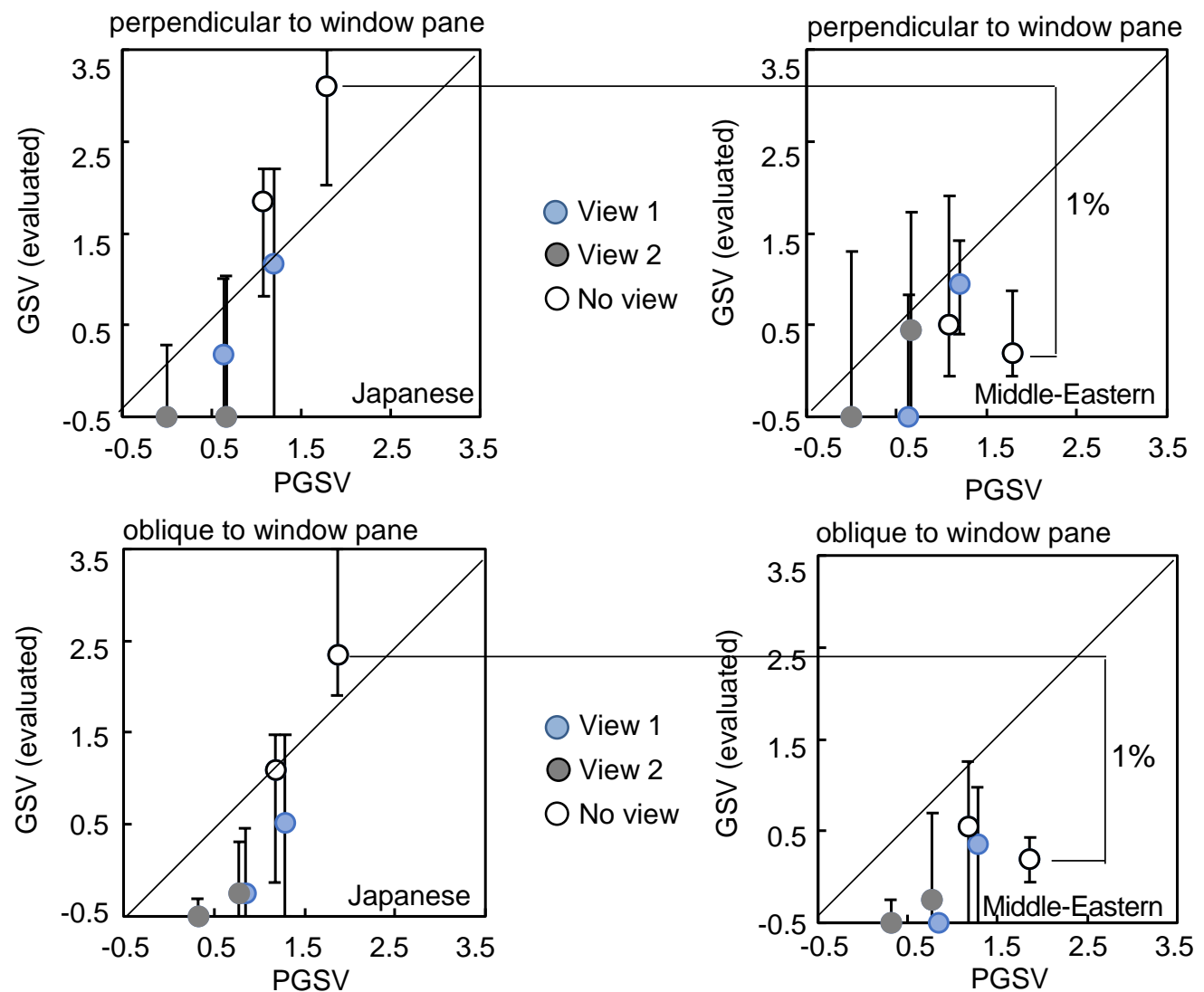

Fig. 18: PGSV vs. GSV (median) judged by the Japanese subjects (Left) andby theMiddle-eastern subjects (Right)

\subsubsection{Preferability of view}

Figure 19 shows preferability judged by the Japanese subjects and by the Middle-Eastern subjects. Significant difference in preferability was found between View 1 and View 2.

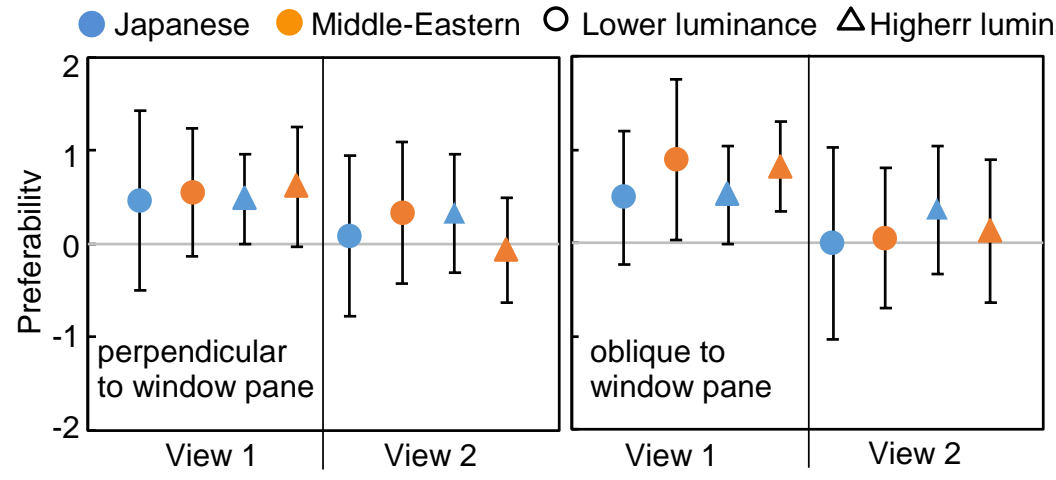

Fig. 19: Preferability of views with line of sight perpendicular to wihdow pane (Left) and oblique to window pane (Right)

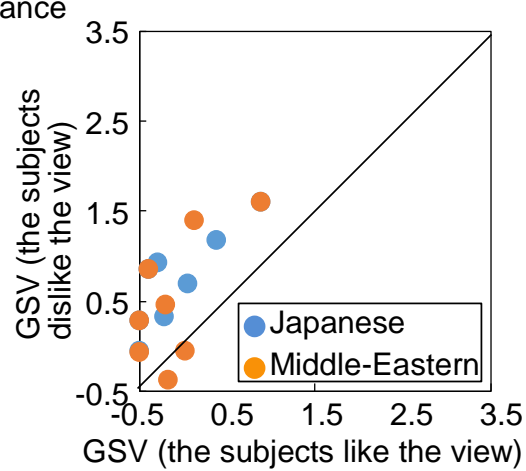

Fig. 20: GSV judged by the subjets who like the view nad who dislike the view 
Both the Japanese subjects and the Middle-Eastern subjects preferred View 1 to View 2. No significant difference was found between the Japanese subjects and the Middle-Eastern subjects. Figure 20 shows a comparison between GSV judged by the subjects who liked the view (preferability was greater than zero) and GSV judged by the subjects who disliked the view (preferability was less than or equal to zero).

Most of the evaluations are above the diagonal line. This means that GSV judged by the subjects who disliked the view was higher than GSV judged by the subjects who liked the view. This result includes the possibility that the subjects who give a positive evaluation for preferability also give a positive evaluation for glare. Therefore, a further experiment is necessary in which subjects evaluate windows with views having the same PGSV or the other glare predictors and different preferability.

\subsubsection{Difference between PGAV, DGP and DGI mod}

When PGSV is replaced by Daylight Glare Probability DGP (Wienold and Christoffersen, 2006) or Modified Daylight Glare Index DGI mod (Fisekis and Davies, 2003), the results are unchanged.

DGP is calculated using the following equation (Eq.4)

$\mathrm{DGP}=5.87 \times 10^{-5} E v+9.18 \times 10^{-2} \log \left(1+\frac{\sum_{i} L_{s, i}^{2} \omega_{s, i}}{E_{v}^{1.87} P_{i}^{2}}\right)+0.16$

DGI $_{\text {mod }}$ is calculated using the following equation (Eq.5)

$\mathrm{DGI}_{\text {mod }}=10 \log 0.478 \frac{L_{s}{ }^{1.6} \Omega^{0.8}}{L_{a}^{0.85}+0.07 \omega^{0.5} L_{s}}$

Where $L s$ is luminance of the glare source $\left[\mathrm{cd} / \mathrm{m}^{2}\right], E v$ is vertical illuminance at eye level [1x], $P$ is Guth's Position Index, $\omega$ is solid angle of the glare source [sr], $L a$ is average luminance of the visual field $\left[\mathrm{cd} / \mathrm{m}^{2}\right]$ and $\Omega$ is modified solid angle $\Omega=\Sigma\left(\omega / P^{2}\right)$. DGP and DGImod are calculate by using Evalglare (2.03) with the default settings.

Figure 21 shows the relationship between PGSV, DGP and DGI mod and GSV. The regression lines and the coefficient of determination are also shown.
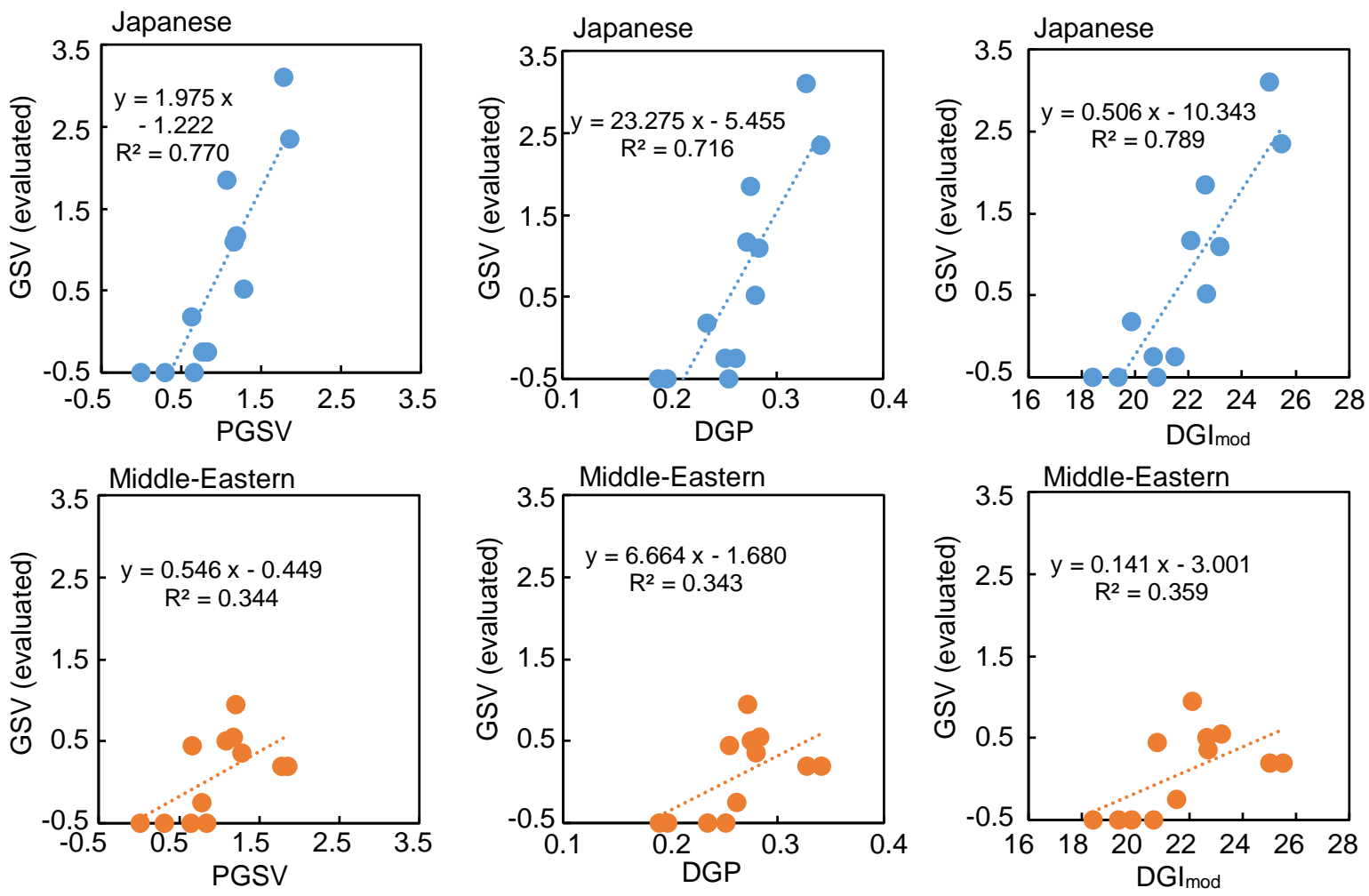

Fig. 21: PGSV, DGP and DGimod vs. GSV (median) judged by Japanese subjects (Upper) and by Middle-Eastern subjects (Lower) 
GSV judged by the Japanese subjects had a higher correlation with those glare predictors, while that by the MiddleEastern subjects had a lower correlation. This shows a similar tendency shown in the study by Pieson et al. (2017) which showed that the correlations of the Chilean glare evaluations with the glare predictors were either low or non-significant and that the Belgian evaluations showed a moderate correlation coefficient with the predictors. The coefficient of determination $\left(R^{2}\right)$ showed DGI $\mathrm{mod}>\mathrm{PGSV}>\mathrm{DGP}$. However, the difference in the coefficient of determination between PGSV, DGP and DGI mod was small.

\section{Conclusions}

In order to identify the effect of climatic conditions on evaluation of discomfort glare from window, the difference between Japanese and Middle-Eastern subjects was investigated.

Simulation using weather data shows that the average luminance of the window area including venetian blind in Riyadh was generally higher than that in Tokyo, when the blind slats were controlled to keep the cut-off angle. In Riyadh, $70 \%$ of the working hours ( 8 am to $4 \mathrm{pm}$ ) had more than $4000 \mathrm{~cd} / \mathrm{m}^{2}$ of luminance of the window area, compared to $50 \%$ of the working hours in Tokyo.

Subjective experiment with actual windows showed no significant difference in glare evaluation by the Japanese subjects and the Middle-Eastern subjects due to a large individual difference. In the artificial window experiment, when the window had a uniform luminance and the luminance was high, glare evaluation by the Middle-Eastern subjects was lower than that by the Japanese subjects. Glare evaluation by the Japanese subjects showed a higher correlation with PGSV, DGP and DGI ${ }_{\text {mod, }}$, while that by the Middle-Eastern subjects showed a lower correlation. The coefficient of correlation $(R)$ ranged from 0.85 to 0.89 for the Japanese subjects and from 0.59 to 0.60 for the Middle-Eastern subjects. The difference in the coefficient of correlation between PGSV, DGP and DGI mod was small.

\section{Acknowledgement}

I would like to thank Mr. Kohei Iida, Mr. Ryotaro Mizukami and Mr. Saad Al-Kwari for conducting the experiments. This work is supported by JSPS KAKENHI Grant-in-Aid for Scientific Research (B) (No. 18H01599).

\section{References}

Fisekis K, Davies M. 2003.Prediction of discomfort glare from windows. Light Res. Tech.; 35: 360-371.

Hopkinson, R.G., 1972, Glare from daylighting in buildings. Appl. Ergon.; 3, 206-215

Iwata, T., Taniguchi, T., Sakuma, R., 2016. Automated blind control based on glare prevention with dimmable light in open-plan offices, Building and Environment, 113, 232-246, DOI:10.1016/j.buildenv.2016.08.034

Iwata, T., et al., 2017, Effects of task and views on discomfort glare from windows, Proc. of CIE mid-term conference, 105-112, DOI:10.25039/X44.2017.OP15

Pierson, C.., et al. , 2017 Discomfort glare from daylighting: influence of culture on discomfort glare perception, Proc. of CIE mid-term conference,83-91, DOI:10.25039/x44.2017.OP12

Tokura M, Iwata T, Shukuya M. 1996. Experimental study on discomfort glare caused by windows, part 3: Development of a method for evaluating discomfort glare from a large light source. J. of Architecture, Planning and Environmental Engineering; 17-25.

Wienold, J., Christoffersen, J.,2006, Evaluation methods and development of a new glare prediction model for daylight environments with the use of CCD cameras. Energy Build. 38, 743-757

Velds, M., 2002, User acceptance studies to evaluate discomfort glare in daylit rooms. Solar Energy 73(2), 95103 


\title{
Energy Efficient \& Sustainable Buildings: Integration with solar assisted air-conditioning technology in Qatar - A Step towards Grid Free Zero Carbon Living. Abdelhakim Mohamed Hassabou', Moazzam Ali Khan' ${ }^{1}$ \\ ${ }^{1}$ Qatar Environment \& Energy Research institute (QEERI), Hamad Bin Khalifa University (HBKU), Qatar Foundation, Doha (Qatar)
}

\begin{abstract}
The air-conditioning systems in hot countries like Qatar consumes around $60-80 \%$ of the total energy demand in buildings. This triggers researchers and industry experts in the built environment to explore new avenues towards reducing the cooling load on buildings to enhance energy efficiency under such extreme conditions. [2] The carbon foot print of buildings can be minimized by reducing cooling load through passive design, using high efficiency equipment and incorporating renewable energy technologies such as solar systems, air and ground source heat pumps, which are few to name among many other concepts and technologies.
\end{abstract}

This paper focuses on optimization of passive house building design alternatives for different blocks of residential buildings as essential components for establishing sustainable and modern agro-industrial communities in Qatar.

Two different designs of multifunctional residential buildings were considered; a block of 3 Apartments (one apartment per floor), as an example of labor housing, and a block of 18 Apartments (six apartments per floor), both spread over three floors, as an example of a community living. Three dimensional (3D) energy models were created for both types of buildings using the IES software (Integrated Environmental Solutions) in virtual environment and thermal analysis was carried out using the Qatar's weather data. Two different criteria were applied to the model of each block of apartments, i.e. Passive house design vs. Conventional design. Energy analysis was carried out to optimize building design, in terms of best thermal comfort and minimum energy consumption to identify/select optimum building materials.

The simulation results revealed that optimized passive house design concepts can significantly reduce the cooling load and lighting loads, which saves 60 to $70 \%$ of the total energy consumption in both small labor residential block and large community residential block respectively. This energy savings can translate into equivalent cost savings and the available flat roof area on top of each block can be utilized for installation of the innovative solar PV cooling plant which has the capacity to meet the cooling and domestic hot water demand of the building. It will also help in achieving grid free zero carbon buildings in future.

Keywords: Passive house design, Building energy efficiency, Solar cooling, Grid free zero carbon building

\section{Introduction}

The building sector consumes more electricity than any other sector worldwide, on average 42 per cent. Most people spend more than 90 per cent of time in buildings, i.e. either at work in the office or at home. Energy used in buildings (residential and commercial) accounts for a significant percentage of a country's total energy consumption. This percentage depends greatly on the usage of electricity, the level of urbanization, the specific building area per person, the surrounding climate, as well as local and national policies to promote energy efficiency [7].

Air-conditioning systems in hot countries like Qatar consumes around $60-80 \%$ of the total energy demand in buildings. This triggers researchers and industry experts to explore new methods and technologies to improve building's energy efficiency in the built environment [2]. 
In industrialized countries, most of the energy consumed in buildings is used for space cooling, ventilation, heating and lighting. This energy usage depends not only on the energy effectiveness of temperature control and lighting system inside the building but also on the design of the building and its outer envelope to minimize heat losses and maximize natural lighting and ventilation to satisfy the human comfort conditions. For a selected set of end uses, the building design and selection of construction materials play a significant role in energy consumption of the building. The purpose of energy efficiency in buildings is to exploit different opportunities and take measures for reducing energy usage in buildings without sacrificing occupant's thermal comfort. [7][8].

Building regulations influence the selection of construction materials for buildings and set appliance standards that have a significant effect on energy efficiency. The Gulf Organization for Research \& Development (GORD) has developed Global Sustainability Assessment System (GSAS) which is a green building certification system developed for the State of Qatar and the GCC region. The primary objective of GSAS is to minimize ecological impact by creating a sustainable built environment while addressing the specific regional needs and environment of Qatar. GSAS has developed star rating system for building's certification. It has six levels of certification to measure the project's environmental impact. Each level of certification corresponds to a star rating from a minimum of 1-star up to a maximum of 6-stars [1].

This work is part of an ongoing research project of Qatar Environment \& Energy Research Institute (QEERI), which is focusing on integration of solar PV power and air cooling system for future buildings in the agroindustrial communities of Qatar. The research project aims to assess the energy consumption of passive house community apartments and agricultural greenhouses in the built environment of Qatar and the feasibility of meeting the building's cooling and domestic hot water demand by integrating with an innovative hybrid solar thermal collector $(\mathrm{PV} / \mathrm{T})$.

The focus of this paper is on an innovative passive house design concept for future residential buildings for establishing modern agro-industrial communities of Qatar. The carbon foot print of buildings can be minimized by reducing the cooling load and energy demand through passive building design. This can be achieved via highly insulated building envelope, lower infiltration rates, effective solar shading, natural ventilation, daylight harvesting system, ventilation heat recovery system, utilizing high efficiency equipment and incorporating renewable energy technologies such as PV panels, air source heat pumps and ground source heat pumps are a few to name that are widely used among many other available renewable energy technologies in the market [3], [4] \& [10].

This research work assess and compare the annual energy consumption of passive house design and conventional design for two different blocks of residential apartments for future agro-industrial communities in Qatar. The passive house design shows significant reduction in cooling load and energy consumption compared to conventional design. The lower cooling loads and the available flat roof area on top of the roof of each block provides an opportunity for future to install the integrated solar PV cooling plant on top of the roof and link the apartments cooling and domestic hot water system with it [5]- [6].

\section{Methodology}

In order to carry out comparative energy analysis, the same building type was simulated with two different designs i.e. passive house design and conventional building design. For this purpose, two different blocks of multifunctional residential apartments were considered; a block of 3-Apartments (one apartment per floor), as an example of labor housing shown on figure $1 \& 2$, and a block of 18-Apartments (six apartments per floor) shown on figure $3 \& 4$, both spread over three floors, as an example of community living. The apartment's floor areas range between $88 \mathrm{~m}^{2}$ and $100 \mathrm{~m}^{2}$ with 2 to 3-bedrooms per apartment and large open plan kitchen, living and dining area. Dynamic energy models were created for both type of buildings using the IES software (Integrated Environmental Solutions) in virtual environment and dynamic thermal analysis was carried out using hourly weather data of Qatar. For each building type, two different criteria were applied to the model, i.e. Passive house design vs. Conventional design. The conventional design was based on the Qatar GSAS (Global Sustainability Assessment System) one star rating, and the passive house design was based on the Qatar Green Building Council (QGBC) passive house design developed for Qatar. Energy analysis was performed to optimize 
Hassabou A. M. Khan et. al. / EuroSun 2018 / ISES Conference Proceedings (2018)

building design, in terms of best thermal comfort and minimum energy consumption to identify/select optimum building materials and design parameters [1], [3] \& [4].

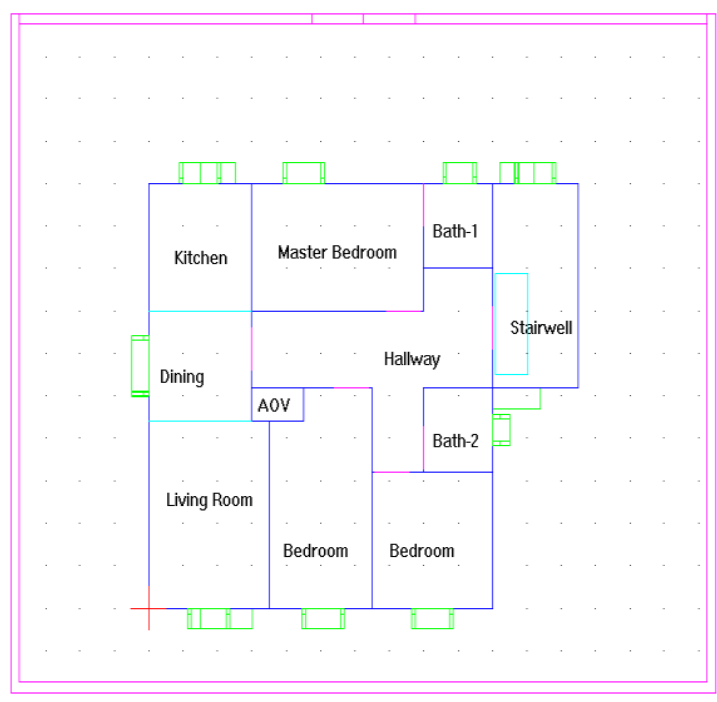

Fig 1: Plan View of Block of 3-Apartments

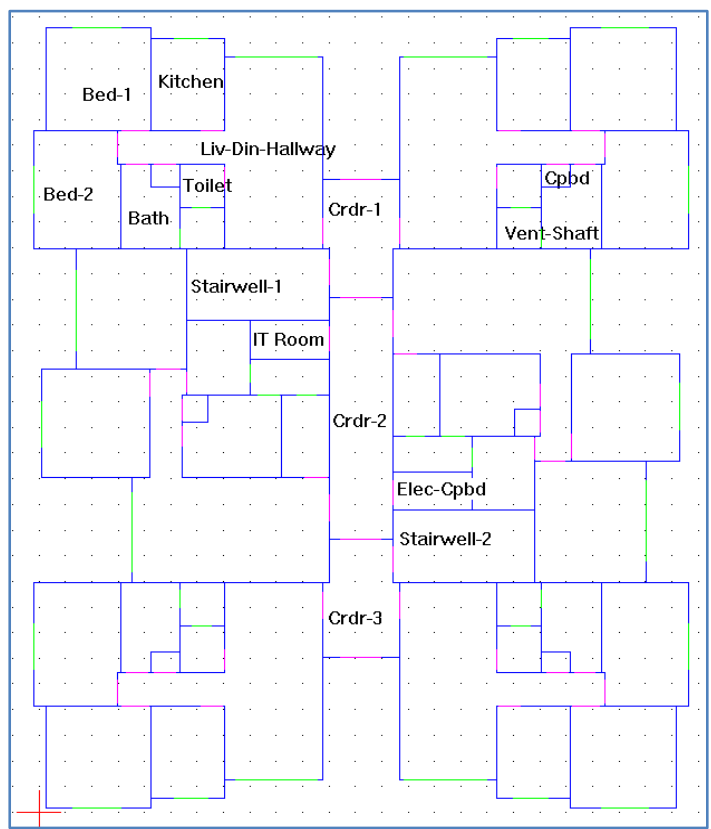

Fig 3: Plan View of Block of 18-Apartments

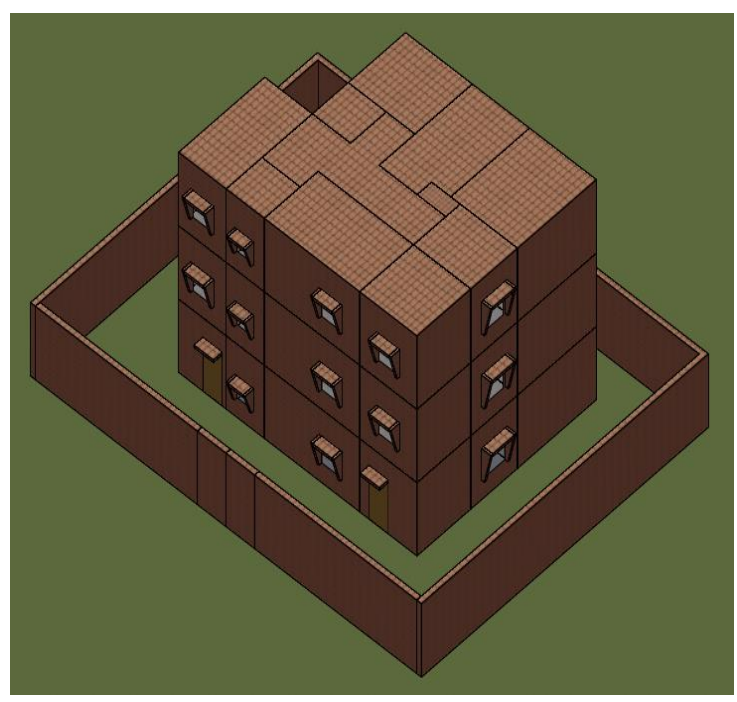

Fig 2: 3D-View of Block of 3-Apartments

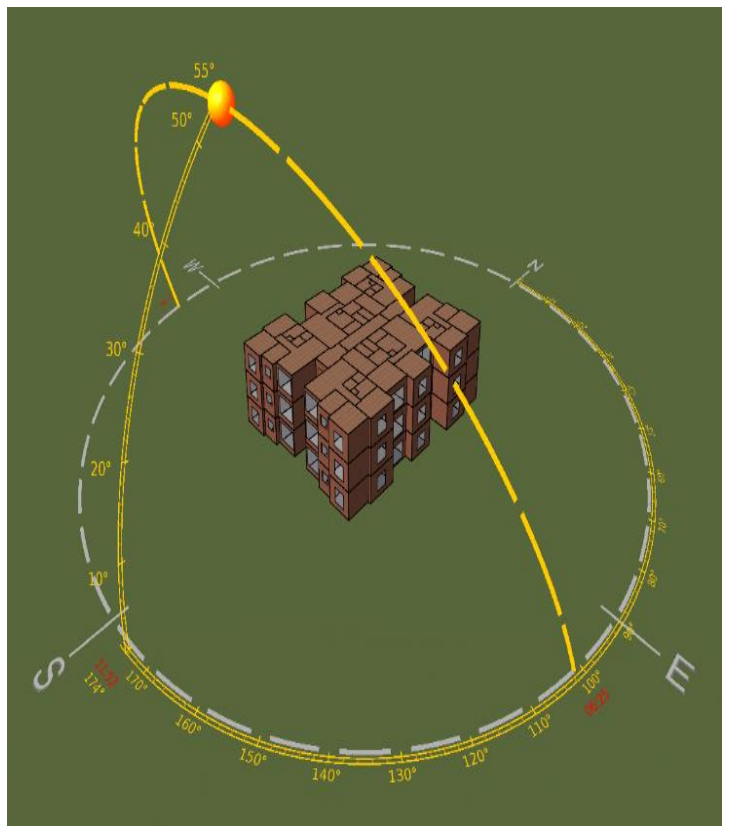

Fig 4: 3D-View of Block of 18-Apartments 
Table 1 below summarizes the input parameters applied to the energy models [1], [3] \& [4].

Tab. 1: Model Input Data

\begin{tabular}{|c|c|c|}
\hline U-Values $\left(\mathrm{W} / \mathbf{m}^{2} . K\right)$ & Passive-house Building* & Conventional Building*** \\
\hline External Walls & 0.083 & 0.35 \\
\hline Internal Partitioning Walls & 1.7 & 1.7 \\
\hline Doors & 2.2 & 2.2 \\
\hline Roof & 0.084 & 0.25 \\
\hline External Windows & 1.17 & 2.84 \\
\hline Glazing g-value & 0.20 & 0.73 \\
\hline Internal Floors/Ceilings & 1.1 & 2.2 \\
\hline Ground/Exposed Floor & 0.11 & 0.25 \\
\hline \multicolumn{3}{|l|}{ Internal Gains } \\
\hline People & \multicolumn{2}{|c|}{$\begin{array}{c}\text { Sensible }-90 \mathrm{~W} / \text { Person } \\
\text { Latent }-60 \mathrm{~W} / \text { Person }\end{array}$} \\
\hline Fluorescent lighting & \multicolumn{2}{|c|}{$8.5 \mathrm{~W} / \mathrm{m}^{2}$} \\
\hline $\begin{array}{l}\text { Miscellaneous gain (Equipment } \\
\text { etc.) }\end{array}$ & \multicolumn{2}{|c|}{$2.90 \mathrm{~W} / \mathrm{m}^{2}$} \\
\hline \multicolumn{3}{|l|}{ Occupancy density } \\
\hline Apartments & \multicolumn{2}{|c|}{$50 \mathrm{~m}^{2} /$ Person } \\
\hline Communal Areas & \multicolumn{2}{|c|}{$25 \mathrm{~m}^{2} /$ Person } \\
\hline Air Permeability $\left(\mathrm{m}^{3} / \mathrm{hr} . \mathrm{m}^{2}\right)$ & 3 & 10 \\
\hline $\begin{array}{l}\text { Cooling set point }\left({ }^{\circ} \mathrm{C}\right) \text { with } 50 \% \\
\text { RH }\end{array}$ & 21 & 21 \\
\hline
\end{tabular}

*QGBC Passive-house Design.

**Based on GSAS one star rating for Conventional/Impassivhaus Design.

A building's energy efficiency is the extent to which the energy consumption per square meter of floor area of the building is compared with the established energy consumption benchmarks for that particular type of building under the defined climatic conditions for that region. Energy consumption benchmarks of buildings are representative values for common building types against which a building's actual performance can be compared. The measure of heat loss or gain through a material, referred to as the U-Value or unit thermal transmittance, is also used as a way of describing the energy performance of a building or any of its structural element. The Uvalue refers to how well a structural element of the building conducts heat from one side to the other by rating how much the heat the component allows to pass through it [9].

The thermal resistance, $\mathrm{R}$, of a structural element can be calculated from:

$\mathrm{R}=\frac{\mathrm{d}}{\lambda}$

Where:

$d=$ thickness of element (m)

$\lambda=$ thermal conductivity of the material $(\mathrm{W} / \mathrm{mK})$

The basic formula for calculating the $\mathrm{U}$-value of an element or structure is:

$U=\frac{1}{R_{T}}$

Where: $\quad R_{T}=\frac{R_{\text {Upper }}+R_{\text {Lower }}}{2}$

Therefore: $U=\frac{2}{R_{L}+R_{U}}$

Where:

$\mathrm{R}_{\mathrm{U}}=$ Upper bound thermal resistance $\left(\mathrm{m}^{2} \mathrm{~K} / \mathrm{W}\right)$

$\mathrm{R}_{\mathrm{L}}=$ Lower bound thermal resistance $\left(\mathrm{m}^{2} \mathrm{~K} / \mathrm{W}\right)$ 
$\mathrm{R}_{\mathrm{T}}=$ Thermal resistance of section $\left(\mathrm{m}^{2} \mathrm{~K} / \mathrm{W}\right)$

$\mathrm{U}=$ Thermal transmittance $\left(\mathrm{W} / \mathrm{m}^{2} \mathrm{~K}\right)$

The U-values are the standards used in building codes for specifying the minimum energy efficiency values for windows, doors, walls and other building components. U-values also rate the energy efficiency of the combined materials in a building component or section, for example a bridged wall. A low U-value indicates good energy efficiency. Windows, doors, walls and skylights can gain or lose heat, thereby increasing the energy required for cooling or heating. For this reason most building codes have set minimum standards for the energy efficiency of these components [9]- [10].

Heat loss equation:

$Q_{t}=\left[F_{1 c u} X \sum(A U)+F_{2 c u} X C_{V}\right] X\left(t_{c}-t_{a o}\right)$

Where:

$\mathrm{Q}_{\mathrm{t}}=$ total heat loss $(\mathrm{W})$

$\mathrm{t}_{\mathrm{c}}=$ dry resultant temperature $\left({ }^{\circ} \mathrm{C}\right)$

$\mathrm{t}_{\mathrm{ao}}=$ outside air temperature $\left({ }^{\circ} \mathrm{C}\right)$

$\mathrm{C}_{\mathrm{v}}$ is the ventilation conductance of the room:

$C_{V}=N V \div 3$

Where:

$\mathrm{Cv}=$ Ventilation Conductance $(\mathrm{W} / \mathrm{K})$

$\mathrm{N}=$ air change per hour $(/ \mathrm{h})$

$\mathrm{V}=$ volume of the room $\left(\mathrm{m}^{3}\right)$

Two correction factors $F_{1 c u}$ and $F_{2 c u}$ are needed to calculate the total heat loss from a space.

$F_{1 C U}=\frac{3\left(C_{V}+6 \sum A\right)}{\sum(A U)+18 \sum A+1.5 R\left(3 C_{V}-\sum(A U)\right)}$

$F_{2 C U}=\frac{\sum(A U)+18 \sum A}{\sum(A U)+18 \sum A+1.5 R\left(3 C_{V}-\sum(A U)\right)}$

Where:

$\mathrm{R}=$ radiant fraction of the heat source

$\sum \mathrm{A}=$ total area through which heat flow occurs $\left(\mathrm{m}^{2}\right)$

$\sum(\mathrm{AU})=$ sum of the products of surface area and corresponding thermal transmittance (W/K) [9]- [10].

The following measures were taken in light of QGBC passive house design and Passivhaus trust to improve the building energy efficiency and reduce the cooling load of both the residential blocks [3]- [4].

- Effective solar shading over external windows with internal blinds

- Triple glazed windows

- Lower infiltration rates

- Supply of natural ventilation linked with external temperature and relative humidity sensor

- Mechanical ventilation heat recovery

- Minimum acceptable U-values for all structural elements (Walls, Doors, Windows, Roof, Ground and partioning walls) 


\section{Simulation Results}

\subsection{Block of 3-Apartments (One apartment per floor)}

Five different cases were simulated to optimize the apartments' design and reduce the cooling loads, increase the energy efficiency and improve the quality of living.

Case A. Impassive/Conventional design with whole house mechanical ventilation

Case B. Impassive/Conventional design without whole house mechanical ventilation

Case C. Passivhaus design without natural and mechanical ventilation

Case D. Passivhaus design with natural ventilation through wind catcher

Case E. Passivhaus design with whole house mechanical ventilation linked with a weather Sensor

Tab. 2: Comparison of cooling load and annual energy consumption of five simulation cases

\begin{tabular}{|c|c|c|}
\hline Reference & $\begin{array}{c}\text { Peak Summer Cooling + } \\
\text { Dehumidification Plant Load (kW) }\end{array}$ & $\begin{array}{c}\text { Annual Cooling +Dehumidification } \\
\text { Plant Load (MWh) }\end{array}$ \\
\hline Case A & 49.86 & 153.23 \\
\hline Case B & 49.86 & 154.13 \\
\hline Case C & 14.8 & 48.07 \\
\hline Case D & 14.8 & 45.85 \\
\hline Case E & 14.4 & 44.18 \\
\hline
\end{tabular}

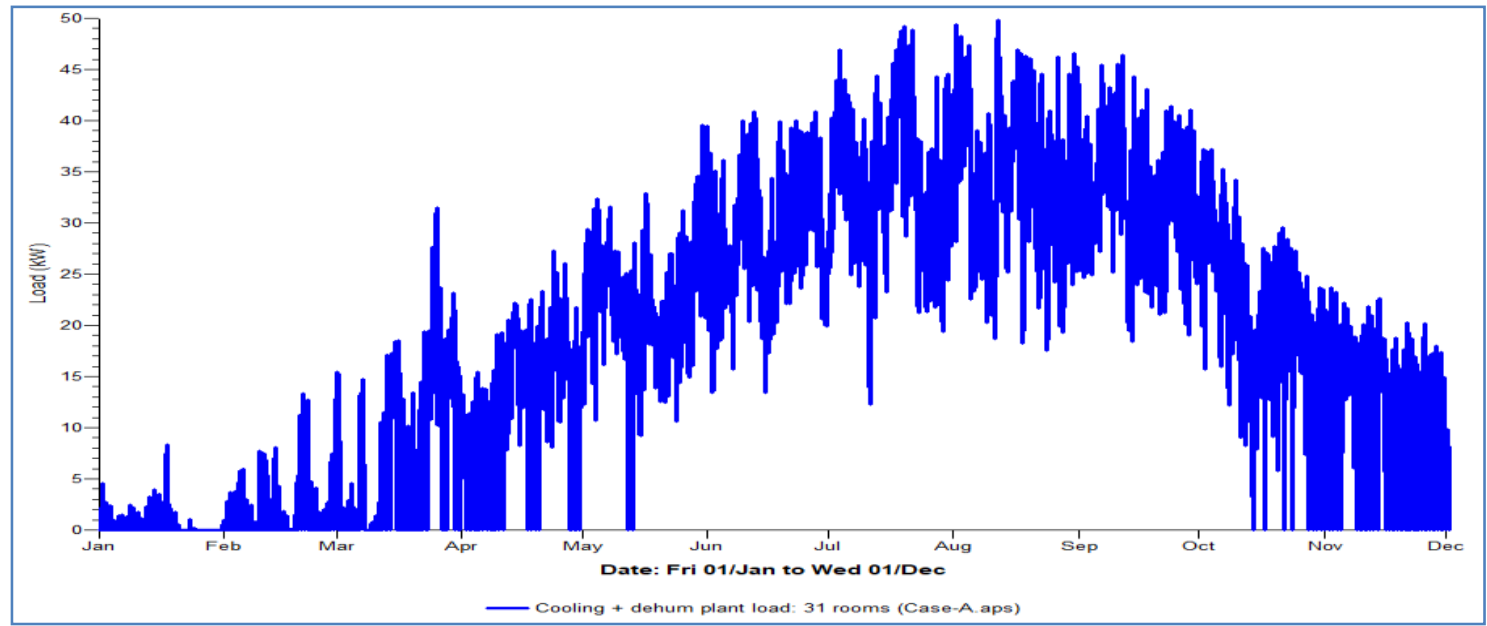

Fig. 5: Case A - Cooling plant annual profile

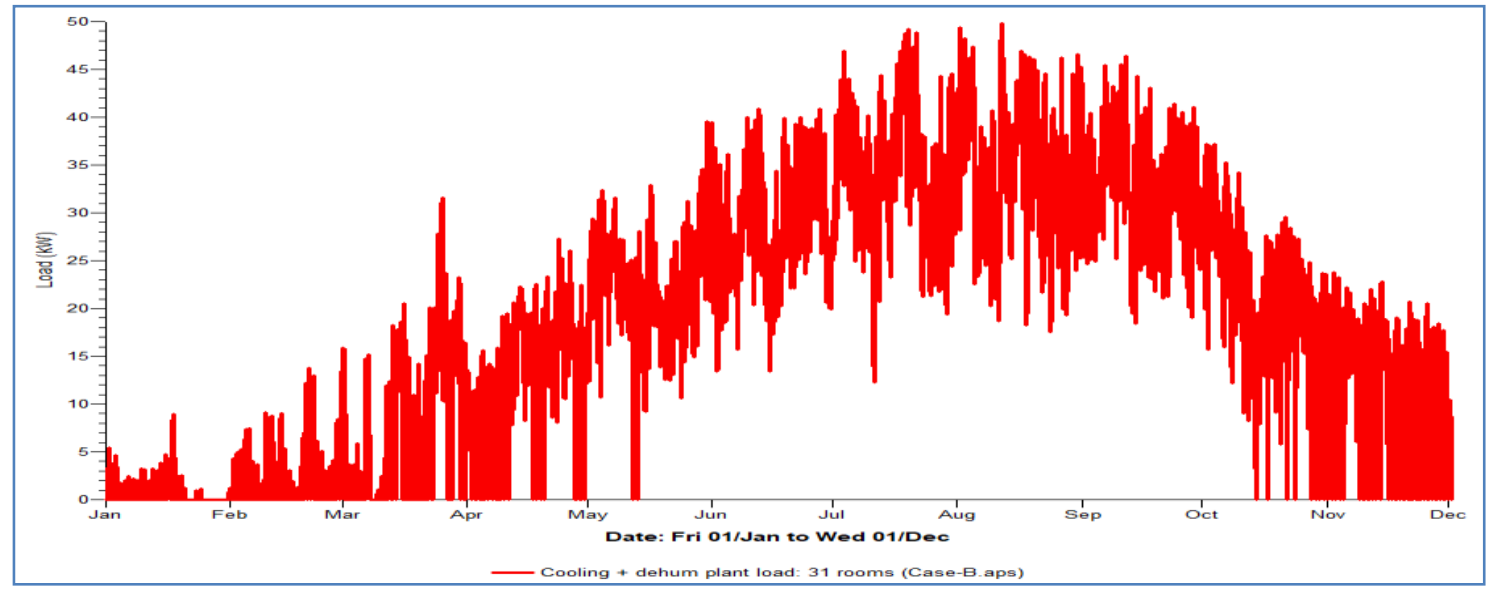

Fig. 6: Case B - Cooling plant annual profile 


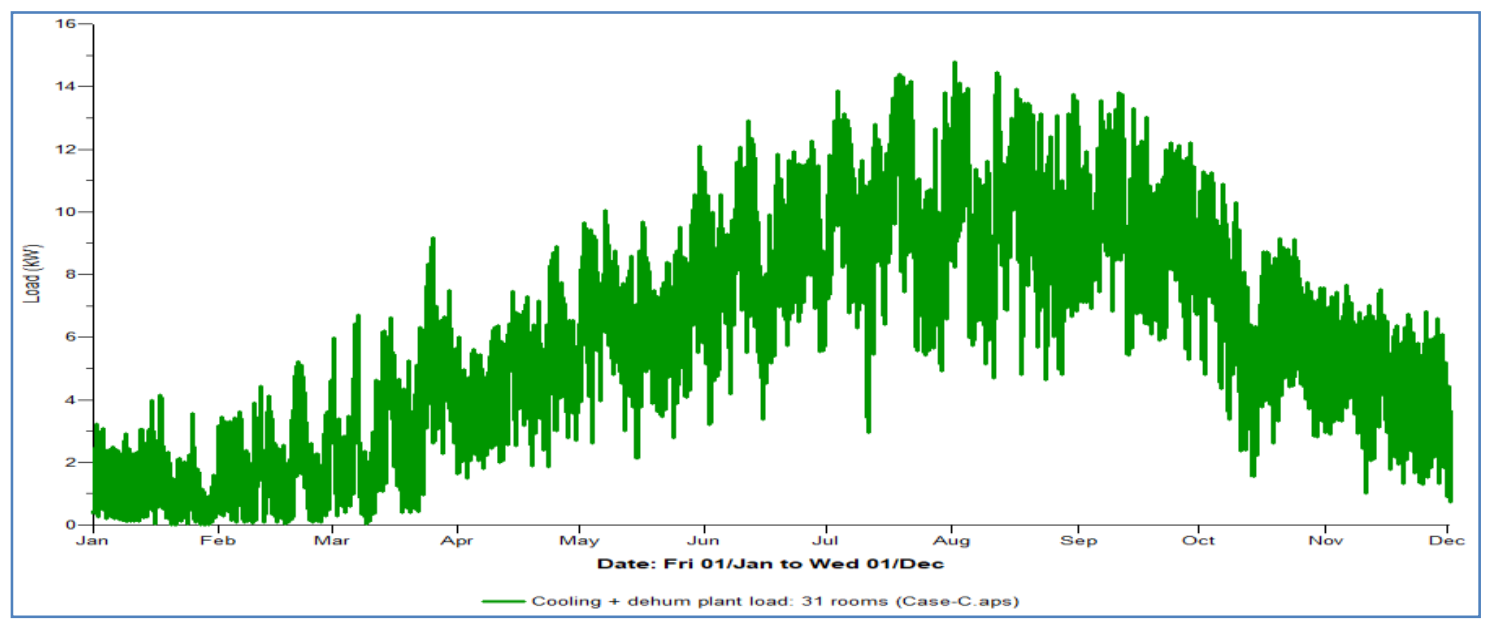

Fig. 7: Case C - Cooling plant annual profile

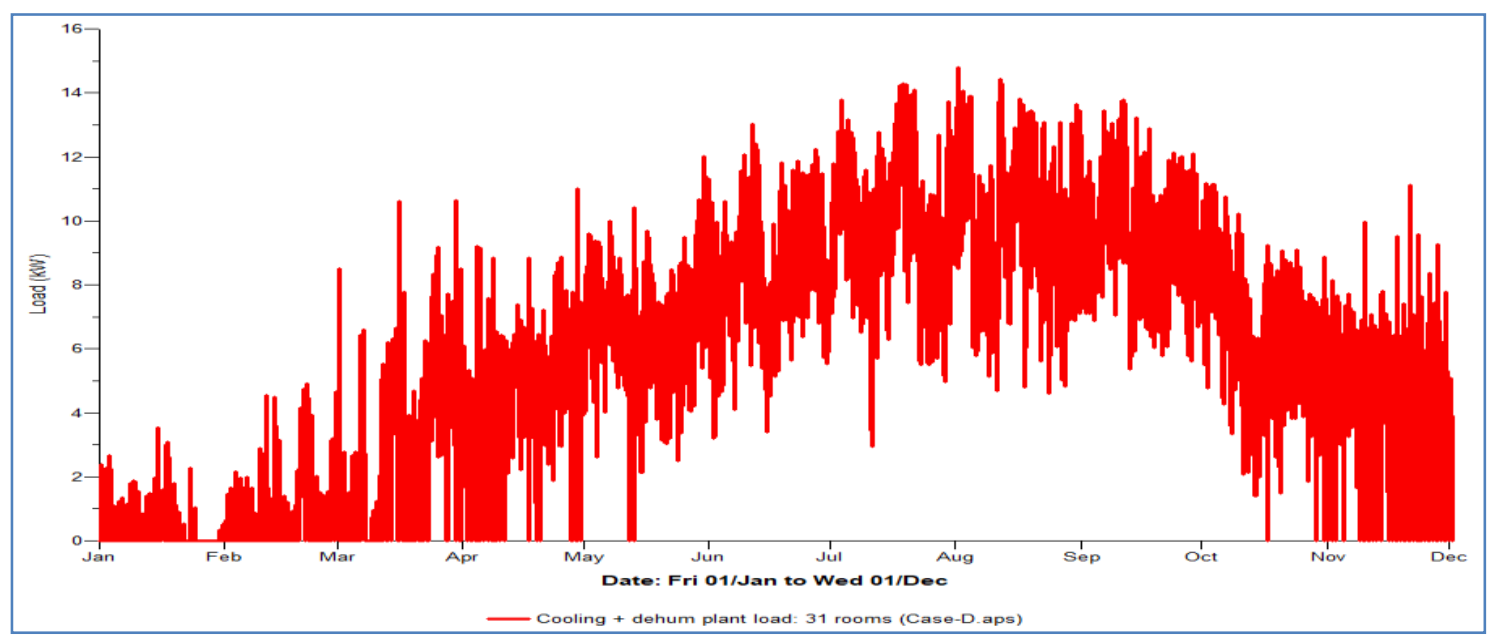

Fig. 8: Case D - Cooling plant annual profile

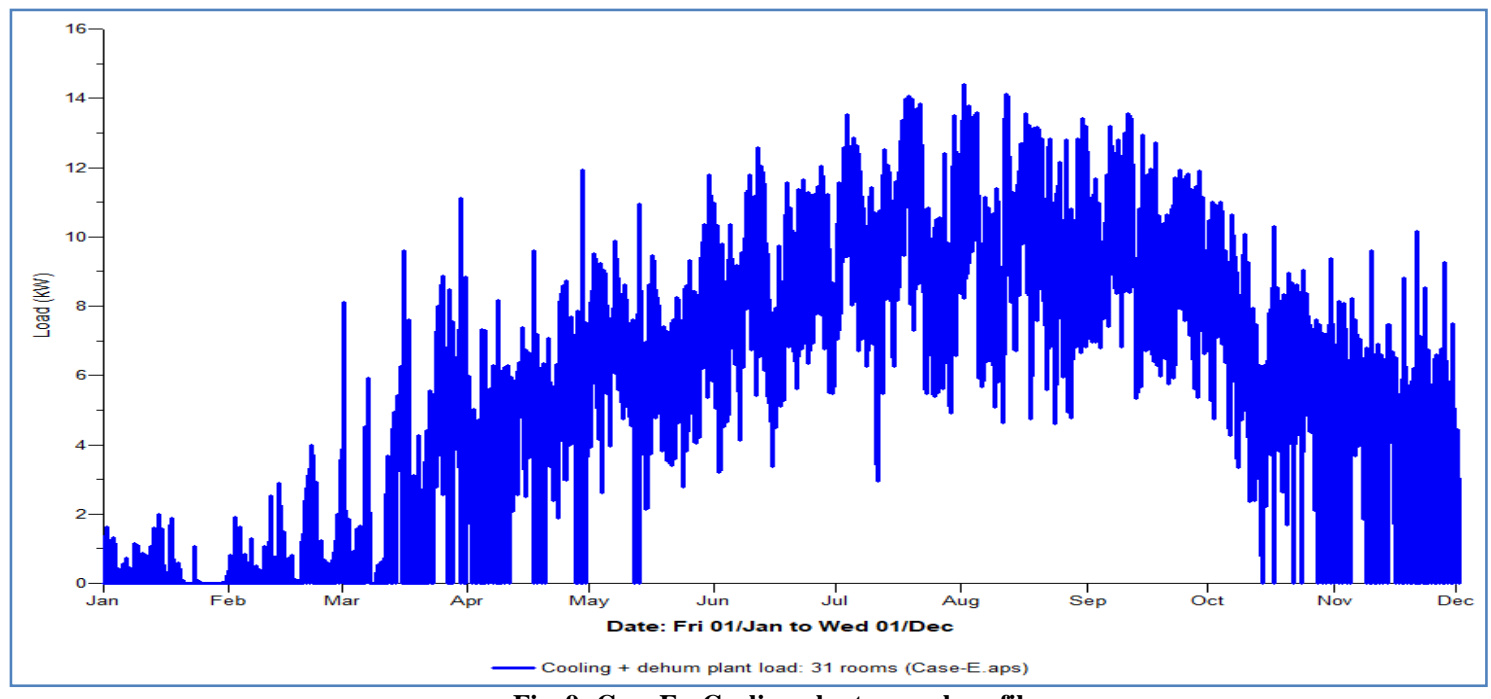

Fig. 9: Case E - Cooling plant annual profile

Case B is the worst and Case E is the best case scenario. Case E not only reduces the cooling load, saves energy but also ensures better living quality via continuous fresh air supply to the building through whole house mechanical ventilation. Case E shows $71.12 \%$ reduction in cooling load compared to Case B.

\subsection{Block of 18-Apartments (six apartments per floor)}

Three different cases were simulated to optimize the community apartments building and reduce the cooling loads, increase the energy efficiency and improve the quality of living. 
Hassabou A.

Case A. Impassive/Conventional design without whole house mechanical ventilation

Case B. Passivhaus design with whole house mechanical ventilation linked with a weather Sensor

Case C. Passivhaus design without mechanical ventilation

Tab. 3: Comparison of cooling load and annual energy consumption of the three simulation cases

\begin{tabular}{|c|c|c|}
\hline Reference & $\begin{array}{c}\text { Peak Summer Cooling }+ \\
\text { Dehumidification Plant Load (kW) }\end{array}$ & $\begin{array}{c}\text { Annual Cooling +Dehumidification } \\
\text { Plant Load (MWh) }\end{array}$ \\
\hline Case A & 329 & 841 \\
\hline Case B & 126 & 296 \\
\hline Case C & 126 & 308 \\
\hline
\end{tabular}

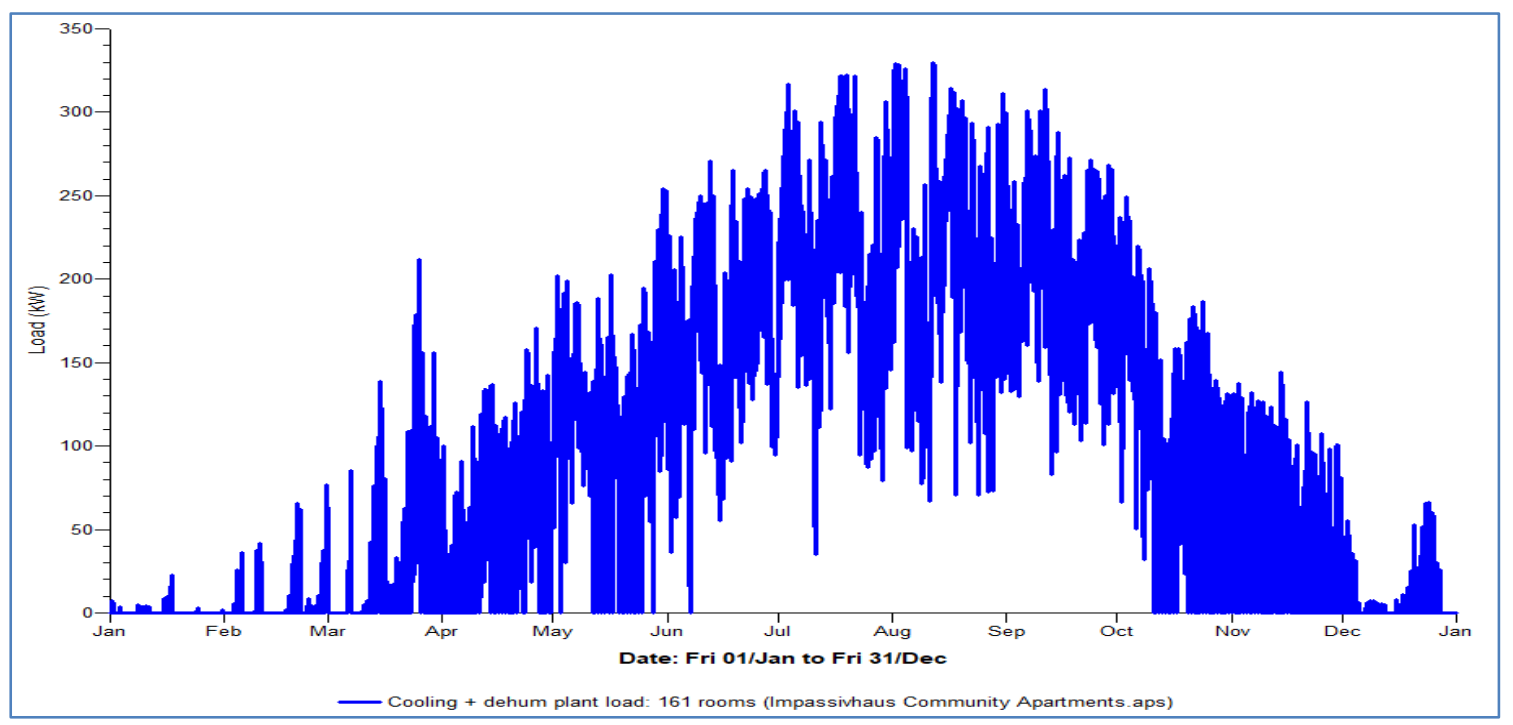

Fig. 10: Case A - Cooling plant annual profile

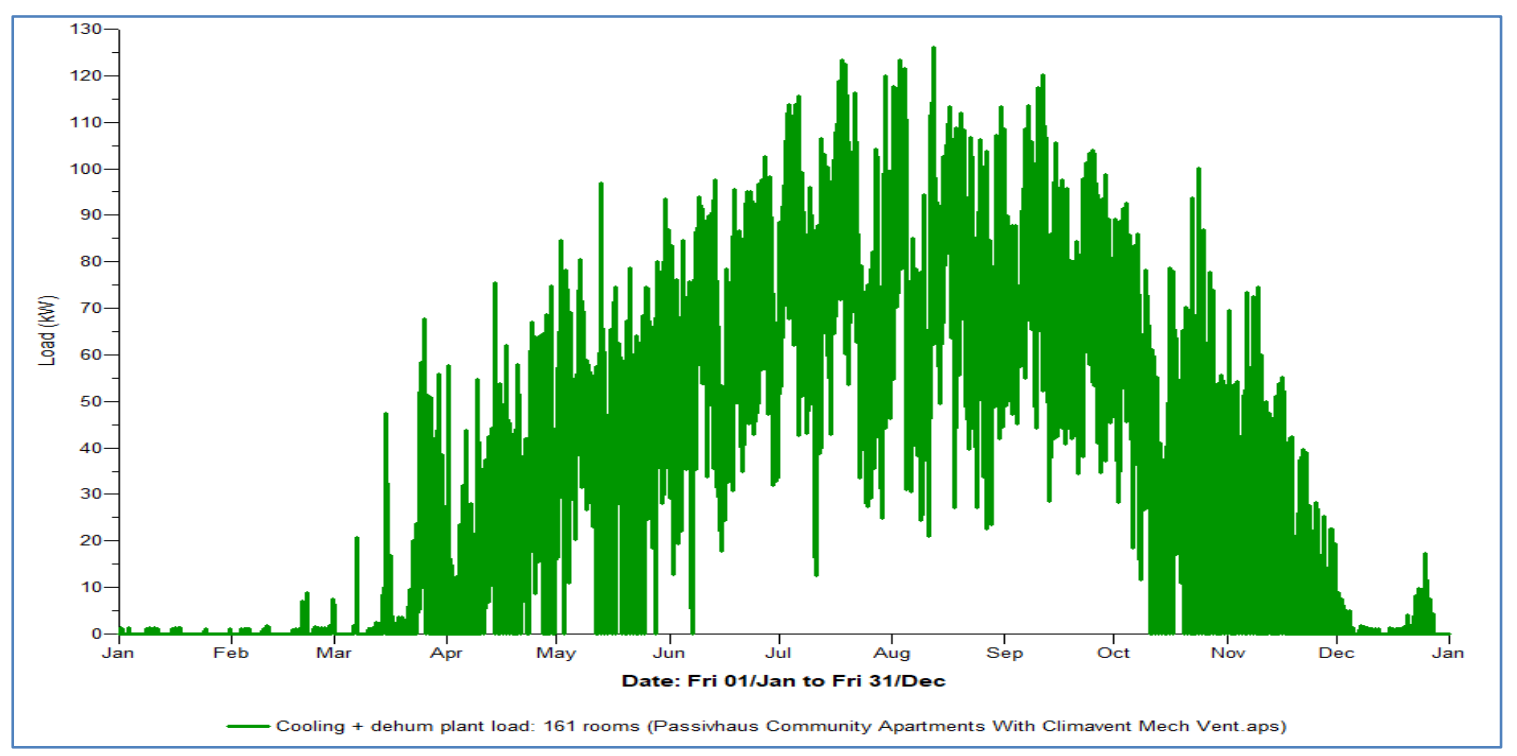

Fig. 11: Case B - Cooling plant annual profile 


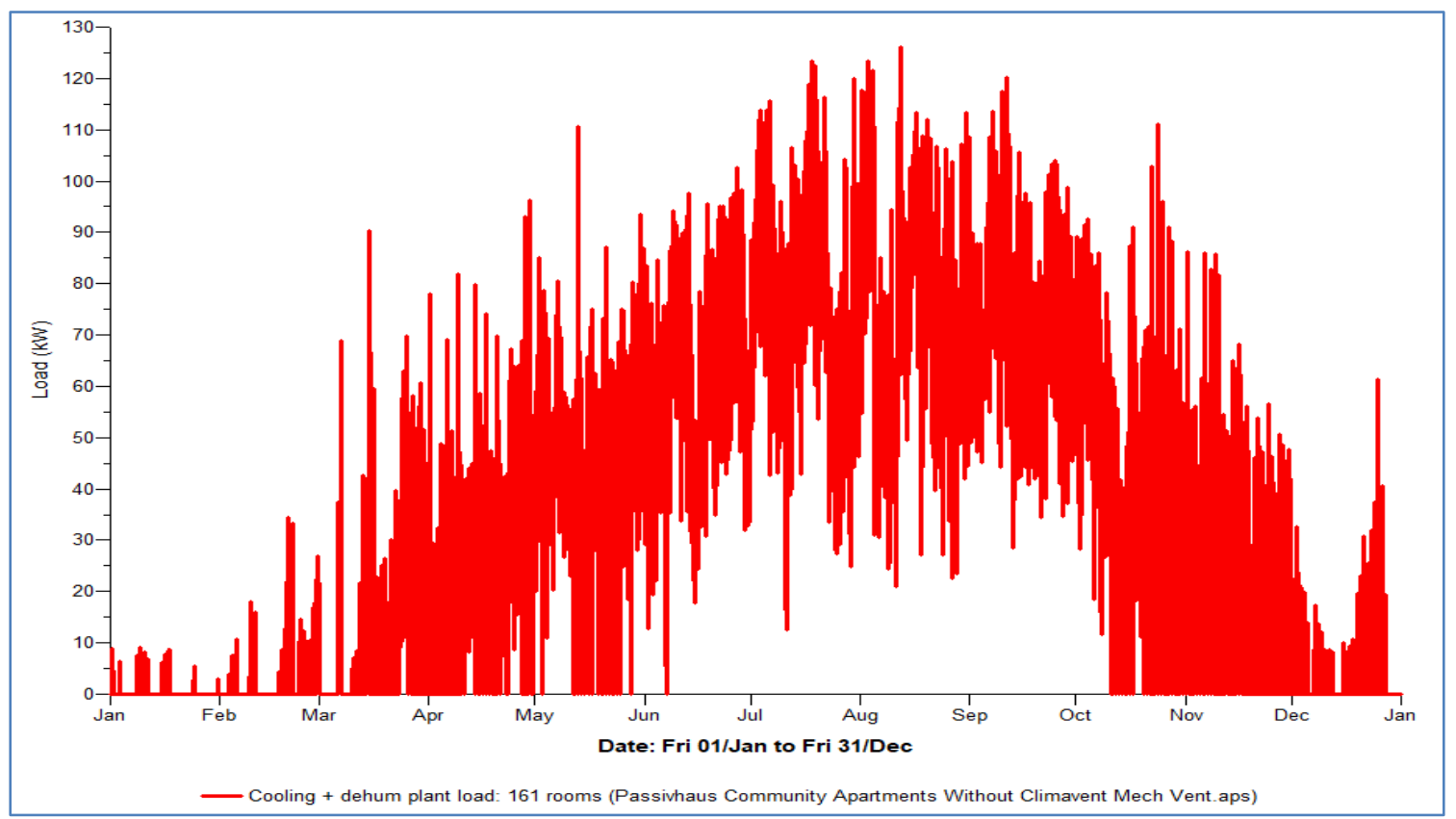

Fig. 12: Case C - Cooling plant annual profile

Case A is the worst and Case B is the best case scenario. Case B not only reduces the cooling load, saves energy but also ensures better quality of living via continuous fresh air supply to the building through whole house mechanical ventilation. Case B (Passivhaus design) shows 65\% reduction in cooling load over Case A (Conventional/Impassive design).

\section{Conclusion}

The simulation results revealed that optimized passive house design can significantly reduce the cooling load and saves 60 to $70 \%$ of the total energy consumption in both small labor residential block and large community residential block respectively. This energy savings can translate into equivalent cost savings and the building' $s$ roof top area can be used for solar system installation that can help to achieve grid free zero carbon buildings in future. This energy saving will also reflect in reducing the as installed cooling plant size and associated infrastructure cost. This will also reduce the annual operational and maintenance cost of the building with just an extra $15 \%$ in construction cost for passive house design compared to conventional design.

For future, the energy model based on passive house design can be improved by application of daylight harvesting system that will help reduce the cooling load of the building and further energy saving. To validate the energy models, QEERI has initiated collaboration with QGBC and discussions are underway to install the innovative hybrid solar thermal collector on top of the roof of passive house villa situated at Barwa city. This will not only provide an opportunity for real life experiment on the passive house villa and hybrid solar thermal collector but will also help validate the buildings simulation models.

This project is funded by the Qatar National Research Funds (QNRF) under NPRP Funds Project \# NPRP81908-2-760 in collaboration with the Institute of Thermodynamics at the Technical University of Munich (TUM), Germany. The financial support of QNRF is gratefully acknowledged. 


\section{References}

1. GSAS TECHNICAL GUIDE 2018, http://www.gord.qa/admin/Content/Link116201825819.pdf (Accessed, December 2017)

2. Qader M. R., Electricity Consumption and GHG Emissions in GCC Countries. Energies 2009, 2(4): 12011213. http://www.mdpi.com/1996-1073/2/4/1201 (Accessed, December 2017)

3. The Passive House Institue, Germany. Passive House requirements. http://www.passiv.de/en/02 informations/02_passive-house-requirements/02_passive-houserequirements.htm (Accessed, February 12, 2018)

4. Qatar Green Bulding Council. The Passivhaus "Baytna" Project".http://qatargbc.org/mediacenter/news/opening-of-passivhaus-baytna-project?backArt=32\&page=15 (Accessed, January 2018)

5. Zhang, X., Zhao, X., Smith, S., Xu, J. and Yu, X. 2012. Review of R\&D Progress and Practical Application of the Solar Photovoltaic/Thermal (PV/T) Technologies. Renewable and Sustainable Energy Reviews. 16, 1 (2012), 599-617. http://centaur.reading.ac.uk/29807/ (Accessed, May 2018)

6. Good, Clara., Chen, Jinfeng., Dai, Yanjun. and Hestnesa, G, Anne. 2015. Hybrid photovoltaic-thermal systems in buildings - a review. Energy Procedia 70 ( 2015 ) $683-690$. https://core.ac.uk/download/pdf/82593934.pdf (Accessed, June 2018)

7. Sustainable energy regulation and policymaking for africa, Module 18: Energy efficiency in buildings. https://www.unido.org/sites/default/files/2009-02/Module18 0.pdf (Accessed, August 2018)

8. The International Energy Agency (IEA), Technology Roadmap: Energy efficient building envelopes. https://www.iea.org/publications/freepublications/publication/TechnologyRoadmapEnergyEfficientBuildin gEnvelopes.pdf (Accessed, July 2018)

9. BSRIA Guide 30/2007. A Guide to Building Services HVAC Calculations. Second edition. https://www.bsria.co.uk/download/product/?file=7rYp1AmF8wE\%3D (Access, July 2018)

10. CIBSE TM54: 2013. Evaluating operational energy performance of buildings at the design stage. https://www.cibse.org/Knowledge/knowledge-items/detail?id=a0q20000008I7f7AAC (Accessed, July 2018) 


\title{
Energy performance investigation of Energy-Plus Solar House integrated renewable energy systems
}

\author{
Min-Hwi Kim ${ }^{1}$ and Jongkyu $\mathrm{Kim}^{1 *}$ \\ ${ }^{1}$ Solar Thermal Convergence Laboratory /Korea Institute of Energy Research, \\ Daejeon (South Korea) \\ *Corresponding author (rnokim@kier.re.kr)
}

\begin{abstract}
In order to realize the climate agenda in terms of reducing $\mathrm{CO} 2$ emission in the buildings, beyond the zero energy house concept is necessary. This paper investigates and proposes the energy-plus solar house. The house has many advantages to add the renewable energy system. For reducing the cooling and heating load of the house, parametric analysis for the building passive design was conducted and optimum passive design was found for minimize the energy consumption. Using the PV and solar thermal system, the optimum renewable energy system design integrated with the HVAC system was investigated. Consequently, the results showed that the proposed house can produce over $40 \%$ more electric energy via the entire energy usage of the house integrating the PV and solar assisted air source heat pump system.
\end{abstract}

Keywords: Energy-plus solar house, air source heat pump, photovoltaic system, solar thermal system

\section{Introduction}

Recently, various efforts has been made in the building sector of each country in order to increase the supplement of energy through the renewable energy sources and reduction of global carbon emissions. (AlAjmi et al., 2016; IEA, 2010). South Korea aims to 20 percent of electricity with renewable energy systems by 2030 for shifting the energy from nuclear to renewable energy. In a circumstance of relatively high land price in South Korea, the buildings are good alternative place rather than the land to place the renewable energy systems. The renewable energy systems, such as photovoltaic (PV), solar thermal system, and fuel cell, can be placed in roof, north side wall, and underground mechanical room of buildings. In order to realize the climate agenda in terms of reducing $\mathrm{CO} 2$ emission in the buildings, beyond the zero energy house concept is necessary to increase the renewable energy portion in Korea's national energy supply. In order to realize the beyond zero energy house, we proposed the Korea Institute of Energy Research (KIER) energy-plus solar house (KePSH). The PV system can be placed at the roof, lover, and windows of the building, and the solar thermal system can be located at the north side wall for the load match as well as roof to collect thermal energy. The loss for transferring the energy from power plant or other sources to the load can be minimize to place the thermal and electricity generation systems, such as fuel cell, located in buildings. If the house produce surplus energy, and it can move to the near load, and house get incomes.

This paper suggested KePSH and energy performance of that was investigated. Using the PV and solar thermal system, the optimum renewable energy system design integrated with the HVAC system was investigated. The basement operating energy of the house is included the cooling and heating energy, ventilation, domestic hot water, lighting and miscellaneous electric load.

\section{Design of KIER energy-plus solar house (KePSH)}

\subsection{Plus Energy House}

In South Korea and EPBD (Energy Performance of Building Directive) in Europe have defined the range of energy usage in the zero energy house as five energies (cooling, heating, hot water supply, ventilation, lighting), and the 
zero energy level is judged based on the primary energy requirement based on the primary energy difference between the produced energy from the renewable energy sources and energy consumption of the house. Meanwhile, the US DOE extends the scope of zero energy houses including the entire energy usage and generation of buildings and land. Plus Zero Energy Building ( + ZEB) is a term that is officially used by the French government. That building produces more energy by the renewable energy system compared with the entire building energy consumption, and the surplus energy can be provided to other sectors, such as other buildings or automobiles.

As shown in Fig. 1, this study defines the positive energy rate in the plus energy house. The zero energy house means that minimizes the thermal load of the house as well as minimizes the energy consumption by utilizing renewable energy systems. Plus energy house extends the concept of the zero energy house to minimize the energy load of buildings as well as maximize the utilization of renewable energy system.

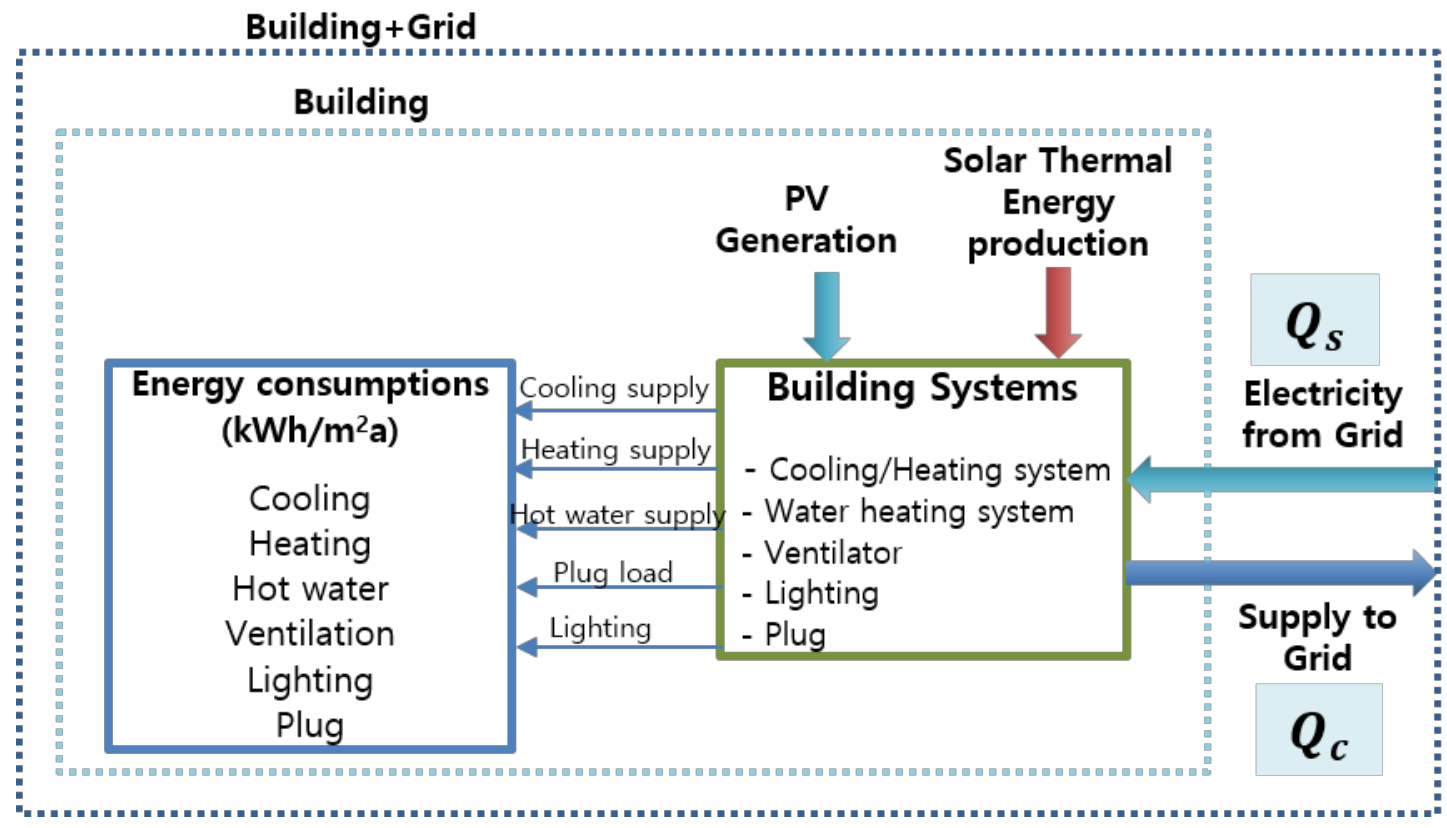

Fig. 1: Definition of Plus Energy Rate (PER)

\subsection{Overview of $\mathrm{KePSH}$}

For the formative approach of the architectural plan, we proposed a mass segment type that separates the public space and the private space with separating the two masses (Figure 2). That mass type can improve the connectivity with the external environment. The public area including the living room and the dining room is formed on the south facing façade, and the private area such as the bedroom, the study room and the toilet, is arranged on the mass form to clearly distinguish the activity line of the family members and ensure the independence of the private space. In addition, the space created between the two masses is composed of a courtyard that provides a contact with stable external environment and atrium that introduce natural conditions such as light and wind. Based on the mass type and floor plan, the plan for new and renewable energy source was established.

\subsection{Overview of Hybrid renewable energy HVAC system}

Among the renewable energy systems, the BIPV and BIST systems were selected for the Plus Energy House. The BIPV and BIST systems were integrated with the heating, ventilation, and air-conditioning (HVAC) system and hot water system. The major HVAC system is composed of the air-source heat pump, and independent dedicated outdoor air system (IDOAS). The space cooling and heating water is served to the fan coil unit (FCU) and radiant heating floor, respectively. In order to maximize the power generation and to secure sufficient roof area, building integrated photovoltaic (BIPV) is planned to have a slope of $32^{\circ}$. Building integrated solar thermal (BIST) has installed a solar collector on the vertical surface of the south faced wall of the first floor as an integral part of the exterior material. In this paper, the two system cases were evaluated (i.e., Case 1 and Case 2). As shown in Figure 3 , Case 1 is the major HVAC system integrated with BIPV system and Case 2 is the major HVAC system integrated with BIPV and BIST system. 
M. Kim / EuroSun 2018 / ISES Conference Proceedings (2018)

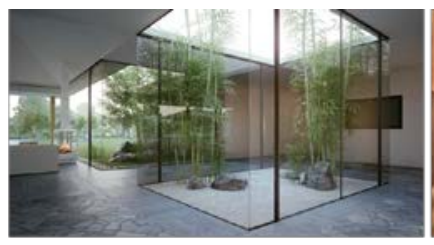

Atrium

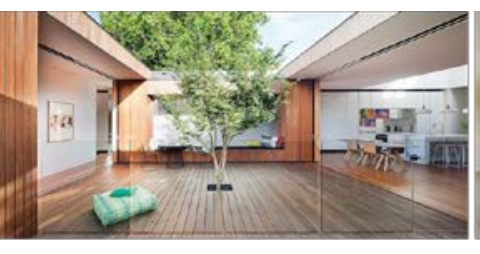

Yard

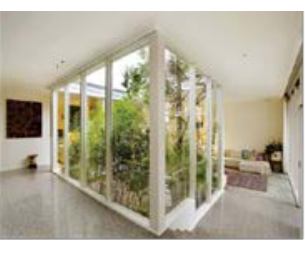

Courtyard

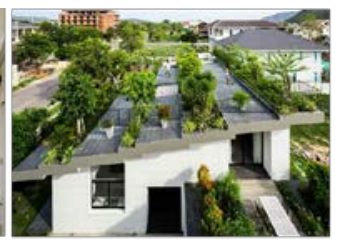

Roof garden

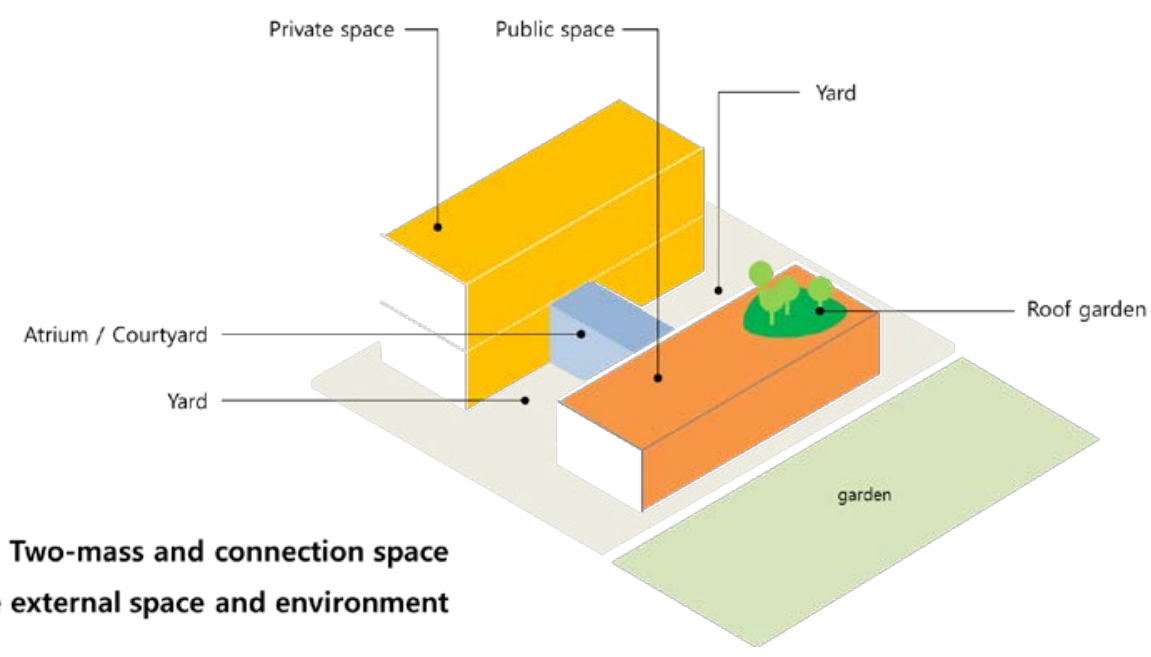

(a) Concept of house

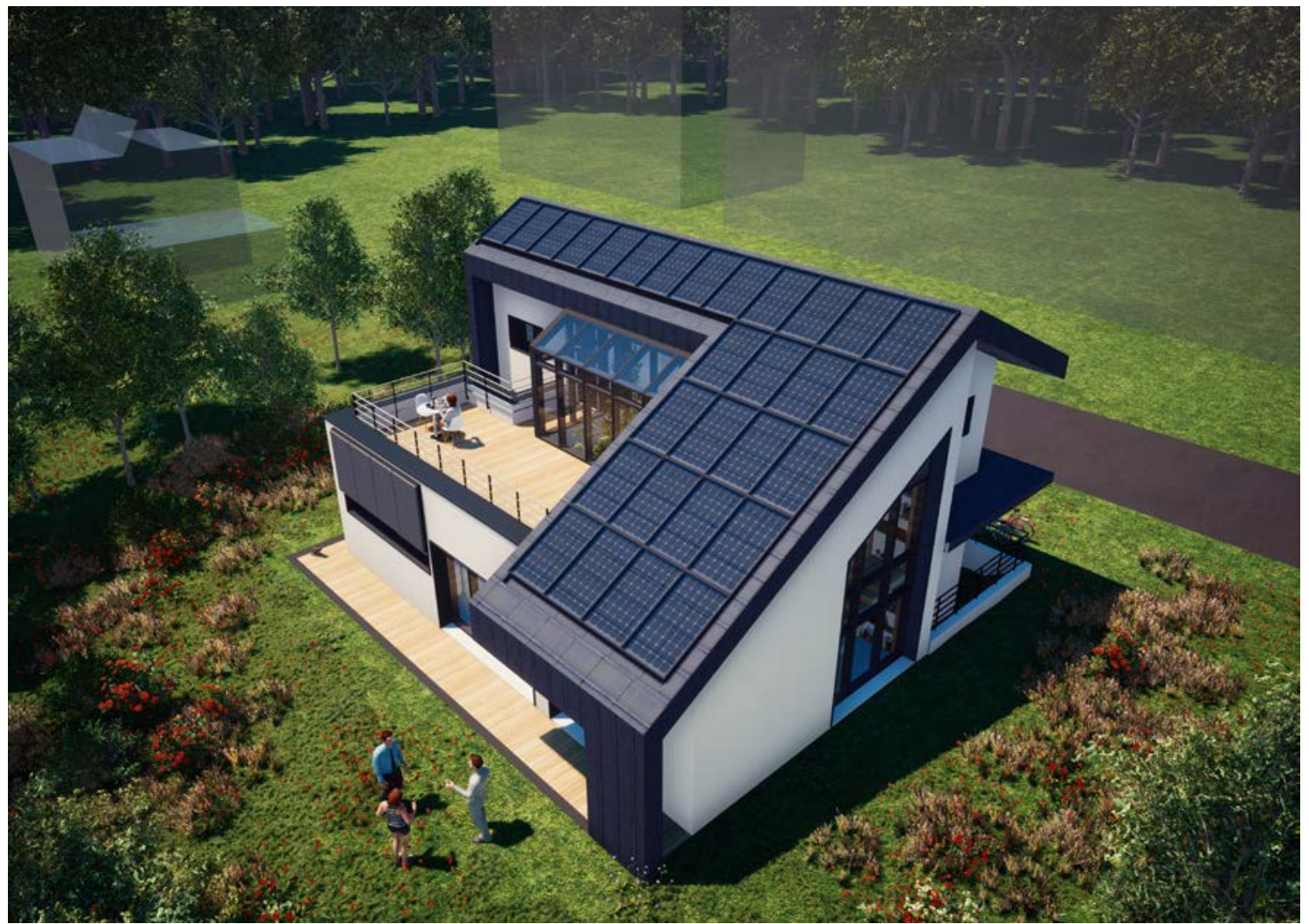

(b) Design overview 

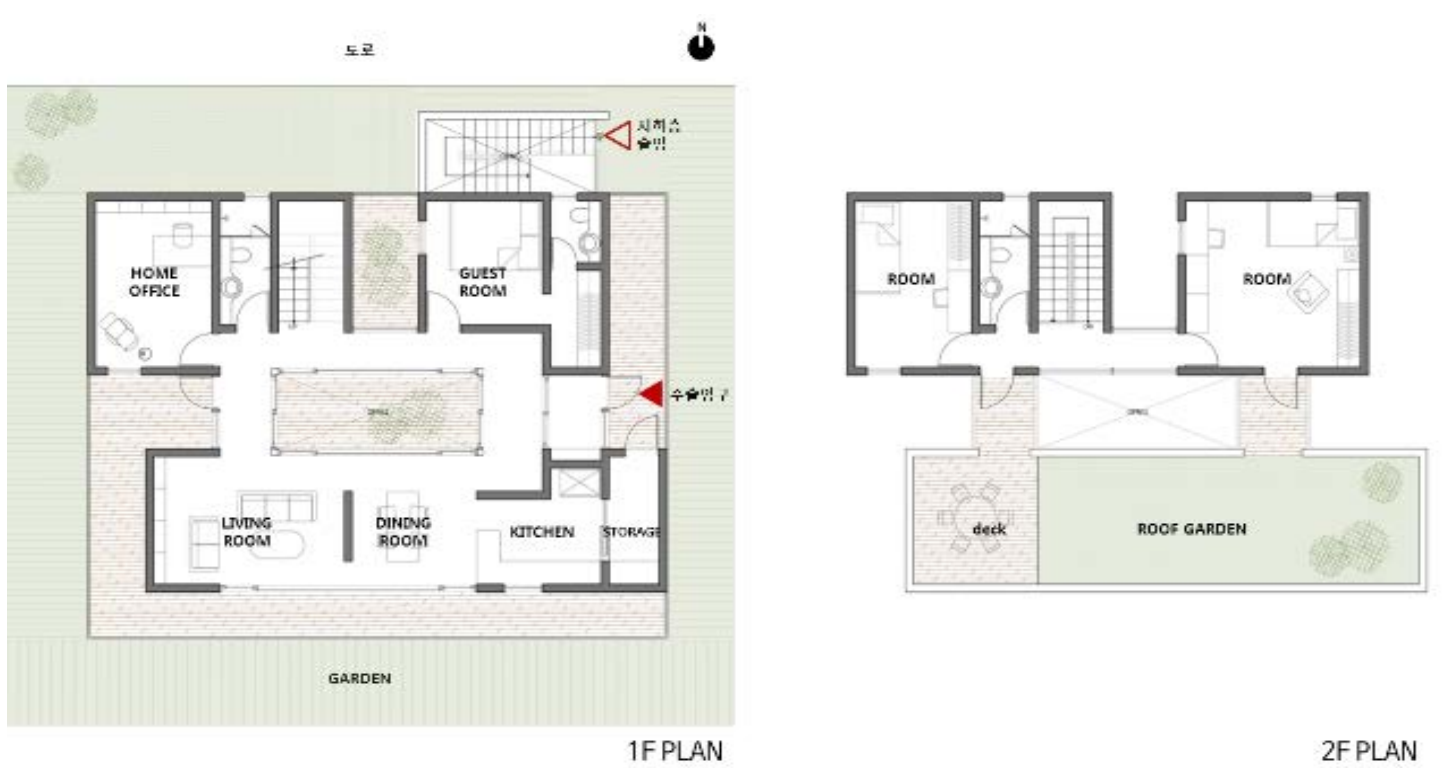

(약 110m, 33py)

2FPLAN (약 55m, 16py)

(c) Floor plan

Fig. 2: KIER energy-plus solar house (KePSH)

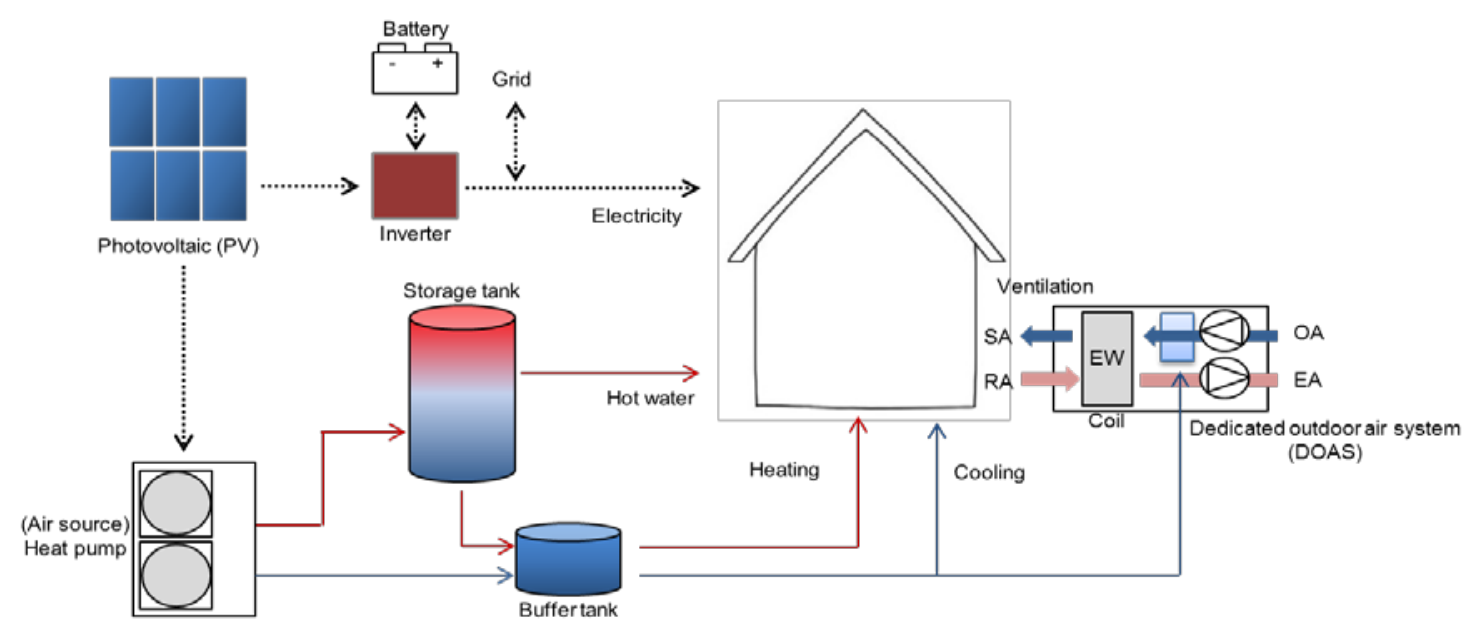

(a) Case 1

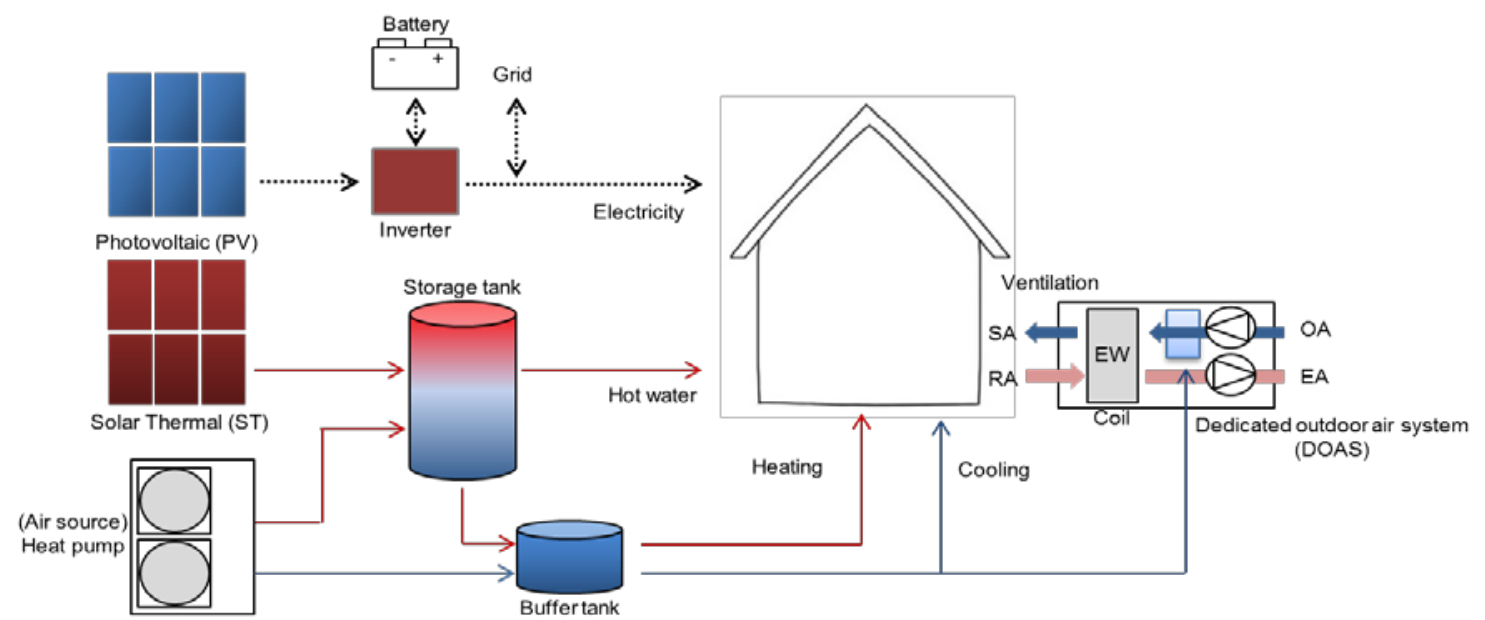

(b) Case 2

Fig. 3: Hybrid renewable energy HVAC system 


\section{Simulation Overview}

To estimate the heating and cooling load of the Plus Energy Solar House, the following input data were used. The meteorological data was obtained from the Daejeon area TMY3 provided by the Korea Research Institute of Standards and Science and the simulation was performed using the TRNSYS 17 program. The building load was estimated using Type 56 and the floor heating was simulated through the Active Layer of TRNBuild. In addition, the cooling and heating set temperature was created by referring to the actual data of the previous paper.

The simulation thermal load profile was obtained the experimental data of the net zero-energy residential house (Lim et al. 2016). The thermal loads of the house was estimated using the TRNSYS 17 program. The floor area of the house was $150 \mathrm{~m}^{2}$, and the floor height was $2.7 \mathrm{~m}$. Table 1 shows the detailed building parameters of the energy-plus solar house. As results of the simulation, the peak sensible and latent cooling load were estimated at $4.0 \mathrm{~kW}$ and $0.7 \mathrm{~kW}$, respectively.

As following the ANSI/ASHRAE Standard 62.2-2016 (2016), the ventilation rates for the residential house was estimated. ASHRAE Standard 62.2 states that the total required ventilation rate is set by depending on the dwelling-unit floor area and number of bedrooms. The energy-plus solar house has six rooms and that rooms were conditioned by the mechanical systems. The dwelling-unit floor area of the house is $172.2 \mathrm{~m}^{2}$ that volume is 644.2 $\mathrm{m}^{3}$, and there are four bedrooms. The required ventilation rates were estimated by 43.3 Liter per second and that indicates 0.24 air change per hour. The detailed simulation parameters of the plus-energy solar house is presented in Table 1.

Tab. 1: Simulation parameters overview

\begin{tabular}{|c|c|c|}
\hline \multicolumn{2}{|c|}{ Location } & Daejeon \\
\hline \multicolumn{2}{|c|}{ Orientation } & South \\
\hline \multicolumn{2}{|c|}{ Occupancy (People/m2) } & 0.047 \\
\hline \multicolumn{2}{|c|}{ Equipment Density (W/m²) } & 32.2 \\
\hline \multicolumn{2}{|c|}{ Lighting Density (W/m²) } & 4.7 \\
\hline \multirow{5}{*}{ U-value $\left(\mathrm{W} / \mathbf{m}^{2} \cdot \mathrm{K}\right)$} & External Wall & 0.10 \\
\hline & Roof & 0.09 \\
\hline & External Floor & 0.09 \\
\hline & Ground Floor & 0.25 \\
\hline & Window & 0.65 \\
\hline \multicolumn{2}{|c|}{ SHGC } & 0.40 \\
\hline \multicolumn{2}{|c|}{ Window-wall-ratio } & $14.6 \%$ \\
\hline \multicolumn{2}{|c|}{ Infiltration (1/h) } & 0.137 \\
\hline \multirow{2}{*}{ Setpoint temperature $\left({ }^{\circ} \mathrm{C}\right)$} & Heating & 22 \\
\hline & Cooling & 26 \\
\hline
\end{tabular}

\section{Results}

Table 2 compares the annual plus energy rate (PER) for houses with CASE 1 (i.e., $6 \mathrm{kWp}$ of BIPV system) and CASE 2 (i.e., $5 \mathrm{~m} 2$ of BIST and $5 \mathrm{kWp}$ of BIPV systems). In CASE 1, annual heat pump energy consumption showed 3,490 kWh, entire house energy consumption also showed 7,283 kWh, and $6 \mathrm{kWp}$ of PV generated 10,320 kWh per year. Consequently, the PER showed 142\%. On the other hand, in Case 2, the $5 \mathrm{~m} 2$ of BIST reduced 591 $\mathrm{kWh}$ of hot water supply energy consumption of the heat pump. However, the $5 \mathrm{kWp}$ of BIPV generated 8,600 $\mathrm{kWh}$, the total energy consumption of the house showed $6,686 \mathrm{kWh}$ with $122 \%$ of PER. In CASE 1 , the entire house energy consumed 7,283 kWh and $6 \mathrm{kWp}$ of BIPV generated 10,320 kWh per year, and the PER showed $142 \%$. On the other hand, in Case 2, the $5 \mathrm{~m} 2$ of BIST reduced $591 \mathrm{kWh}$ of hot water supply energy consumption of the heat pump. However, the $5 \mathrm{kWp}$ of BIPV generated 8,600 kWh, the PER showed 122\%. Consequently, CASE 1 generated 37\% more surplus electricity than CASE 2. 
Tab. 2: Plus energy rate of system cases

\begin{tabular}{|c|c|c|c|c|c|c|c|c|}
\hline \multirow{2}{*}{$\begin{array}{l}\text { System } \\
\text { cases }\end{array}$} & \multicolumn{4}{|c|}{ Heat pump energy consumption* } & \multirow{2}{*}{$\begin{array}{l}\text { Plug } \\
\text { load* }\end{array}$} & \multirow{2}{*}{$\begin{array}{l}\text { Total } \\
\text { consum } \\
\text { ption* }\end{array}$} & \multirow{2}{*}{$\begin{array}{l}\text { BIPV } \\
\text { generati } \\
\text { on rate* }\end{array}$} & \multirow{2}{*}{$\begin{array}{l}\text { Plus } \\
\text { energy } \\
\text { rate (\%) }\end{array}$} \\
\hline & Heating & Cooling & $\begin{array}{l}\text { Hot } \\
\text { water }\end{array}$ & Total & & & & \\
\hline $\begin{array}{l}\text { CASE } 1 \\
\text { (BIPV) }\end{array}$ & 1,270 & 1,267 & 953 & 3,490 & 3,793 & 7,283 & 10,320 & 142 \\
\hline $\begin{array}{l}\text { CASE } 2 \\
\text { (BIPV+ } \\
\text { BIST) }\end{array}$ & 1,266 & 1,265 & 362 & 2,893 & 3,793 & 6,686 & 8,600 & 122 \\
\hline
\end{tabular}

\section{Conclusion}

In this study, the concept for the KePSH was established and the design for that was conducted. The applicability of hybrid HVAC and renewable energy system to the designed KePSH was analyzed through simulation. This research also investigated two simulation cases, which are BIPV system (CASE 1) and BIPV + BIST system (CASE 2) with same installation area. It was found that the $6 \mathrm{~kW}$ of BIPV integrated HVAC system can produce over $40 \%$ of surplus electricity than the entire energy consumption of the KePSH. The CASE 1 generated 3,037 $\mathrm{kWh}$ of surplus energy but the CASE 2 generated 1,914 kWh of surplus energy. It leads that the CASE 1 generated about 37\% more electricity rather than CASE 2.

\section{Acknowledgement}

This work was conducted under framework of the research and development program of the Korea Institute of Energy Research (B8-2424-03).

\section{References}

ASHRAE, 2016. Standard 62.2-2016: Ventilation and Acceptable Indoor Air Quality in Low-Rise Residential Buildings, American Society of Heating, Refrigerating and Air-Conditioning Engineers, Inc., Atlanta. AlAjmi, A., Abou-Ziyan, H. and Ghoneim, A., 2016. Achieving annual and monthly net-zero energy of existing building in hot climate. Applied Energy, 165, 511-521. https://doi.org/10.1016/j.apenergy.2015.11.073 Lim, H., Yoon, J., and Shin, U., 2016. Annual Energy performance Evaluation of Zero Energy House Using Metering Data, Journal of KIAEBS. 16(3), 113-119. https://doi.org/10.12813/kieae.2016.16.3.113

Paiho, S. and Reda, F., 2016. Towards next generation district heating in Finland, Renewable and Sustainable Energy Reviews. 65, 915-924. https://doi.org/10.1016/j.rser.2016.07.049 


\title{
Control strategies for a residential property with solar building, thermal and electricity storages
}

\author{
Timo Korvola ${ }^{1}$, Rinat Abdurafikov' ${ }^{1}$ and Francesco Reda ${ }^{1}$ \\ ${ }^{1}$ VTT Technical research Centre of Finland Ltd, Espoo (Finland)
}

\begin{abstract}
We study the control of an advanced energy system for a residential building. The system includes solar thermal and PV/T collectors, heat storages, a shallow geothermal system with a heat pump and a battery. Two control strategies are evaluated with simulation experiments: a rule-based one and model-predictive control. The rulebased strategy performs quite well in warmer seasons whereas MPC outperforms it in wintertime.
\end{abstract}

Keywords: solar buildings, energy storage, system simulation, model predictive control, control strategy

\section{Introduction}

Global awareness of consequences of climate change, of greenhouse gas emission and of its connection with the energy consumption is driving society to find more energy efficient and clean energy solutions. The EU Energy Performance of Buildings Directive requires all new buildings to be nearly zero-energy by the end of 2020 and the new research $\mathrm{H} 2020$ stream on energy building solutions are supporting the development of innovative smart energy management systems (European Commission, 2010, 2018). With the Strategic Energy Technology plan, the EU aims to aims to accelerate the development and deployment of low-carbon technologies, boosting the penetration of new zero-emissions energy technologies into market (European Commission, 2017). These comprises also renewable energy technologies. The intermittent intrinsic nature of these technologies generates a mismatch between energy production and consumption paving the way to technologies or solutions that are capable of shifting either energy demand or production.

The first section of the paper explores the literature review about building energy system controls in general and, in more detail about model predictive approaches. The second section focuses on the research methodology, emphasizing the approach considered by authors for assessing the performance of the proposed control strategies. The third section introduces the case studied, giving exhaustive detail about main system components and functionalities of the control strategies. Finally, the fourth section presents and discusses the results. The last part of the paper draws the conclusion of the research.

\section{Research background}

As regards demand shifting solution, demand-side management, defined as modification of energy consumption patterns through a behavioural change of end users, has gained some popularity. However, the needed communication infrastructure is not always available and the incentive systems to enable people engagement and proper participation are not mature yet (Pasini, Reda and Häkkinen, 2017). Besides this type of energy management system through behavioural change, another promising approach is to adopt active control of devices by means of actuators and sensors. This energy management approach is supported by the increasing number of smart devices deployed in buildings (Mohammadi et al., 2018). Tools that enable this energy management approach process energy consumption and generation profiles information to manage energy generation and storage, to curtail and/or to shift energy demand in order to meet specific objectives, usually decrease the energy cost (Beaudin and Zareipour, 2015).

Among different active control methods, a recent review identifies model predictive control (MPC) as an appealing approach from many control techniques, due to advancement in processor speed and ability to adapt to 
many applications, including energy management of large PV or wind plant equipped with a battery system (Sultana et al., 2017). MPC application to single building also showed a great potential. E.M. Wanjiru et al. estimated a potential energy saving of $32.24 \%$ during a day when MPC is adopted to control a heat pump and instantaneous shower heater powered using integrated wind and PV energy systems located in South Africa (Wanjiru, Sichilalu and Xia, 2017).

Model predictive control is an advanced control method originally developed in the 1970s and 1980s (Morari and Lee, 1999). The controlled system is modelled as an optimal control problem

$$
\begin{aligned}
\min _{u} J(u) & :=\int_{0}^{t_{h}} r(x(t), u(t)) \mathrm{d} t+g\left(x\left(t_{h}\right)\right) \quad \text { such that } \\
\dot{\mathrm{x}} & =f(x, u), \\
x(0) & =x_{0} .
\end{aligned}
$$

$x$ and $u$ are functions of time that respectively represent the state of the system and the control input. This is a finite horizon problem, optimising the behaviour of the system up to some time $t_{h}$. The state $x$ of the system is subject to dynamics, which also depends on the control input $u$ that is chosen to minimize an objective consisting of costs accumulated over time and another term that evaluates the state that the system is left at the end of the horizon. The second term serves to prevent myopic behaviour, e.g., by assigning value to stored energy in order to prevent MPC from draining storages. There may also be constraints on $x$ and $u$ (not shown). This problem is discretised in time, yielding a finite-dimensional optimisation problem, which is solved numerically with the current state of the system as the initial condition. The control values for the first time step are applied to the actual system. The rest of the solution is discarded: one time step later new optimal controls are computed starting from the state at that time, for time $t_{h}$ ahead (rolling horizon). Thus the procedure repeats.

Problem (1) must allow for reasonably quick solution, much quicker than the time step used, which should be short enough to capture the relevant dynamics. Traditionally this required linear dynamics and a linear or quadratic objective, yielding a linear or quadratic optimisation problem. Compared with classical linear control, such MPC has the advantage of being able to handle constraints. Impressive performance improvements of computer hardware and optimisation algorithms now allow application of MPC also to more complex models.

Since the cost of energy is the main driver in energy saving applications, recently there appeared a notion of an economic MPC (EMPC), which considers the dynamic character of energy prices. The idea is to use an economic objective for MPC directly as opposed to the more traditional process industry approach of first finding an economically optimal steady state, then tracking it with MPC (Zong et al., 2017). A recent study compared the EMPC control with a rule-based control for managing an air conditioner, a water heater, an electric vehicle, a PV system and a battery in a residential building. One year simulation results showed that residential buildings could achieve cost savings up to $26 \%$ under three time of use pricing scheme, $42 \%$ under real time price scheme, and $17 \%$ under hourly pricing scheme, compared to traditional on/off controls (Mirakhorli and Dong, 2018).

In all the above-mentioned studies that focused on EMPC for renewable energy in buildings only solar energy technology was investigated. Up to the authors' knowledge, only one paper has investigated the use of PV and solar collectors (Khakimova et al., 2017). Results of this study are relevant for what concerns the heating season, while cooling has not been considered. Heat pumps, especially ground-source heat pumps, coupled with solar energy technologies are considered one of the most efficient heating and cooling systems (Reda et al., 2015). Solar-assisted heat pump (SAHP) is a relevant choice for achieving high energy performance of buildings and deserves more research on operational control systems in this field. The contribution of this paper is to investigate application of such an EMPC to a more complex system and optimize several solar energy technologies (PV/T and vacuum collectors) connected to energy storages (battery, seasonal and short-term thermal storages) and to a ground source heat pump. The analysed system configuration is in line with the concept of positive energy building (a building that produces more energy than consumes over a timespan of one year), which lately received an increased attention because of the new EU energy 2030 targets (European Commission, 2014).

\section{Methodology}

In this study, the objective of the MPC was to minimize operational costs of the system, which would otherwise be controlled using a set of pre-determined rules. To evaluate the two strategies, we carry out simulation experiments using a detailed model of the energy system and compare the resulting operational costs. In both 
cases we make sure that the model, loads, ambient and initial conditions are the same, and energy demands as well as temperature requirements of heat loads are met at all times. The conceptual scheme of the study is presented on Figure 1.

a)

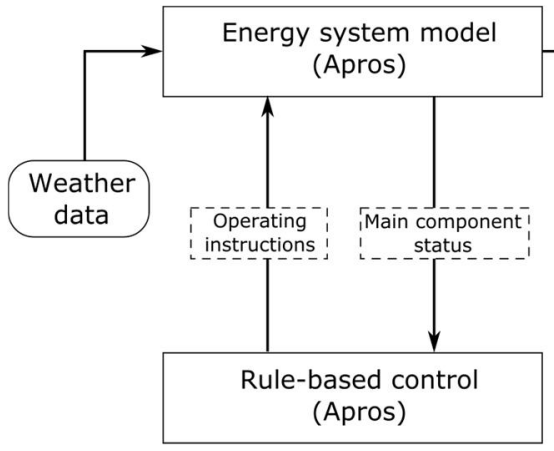

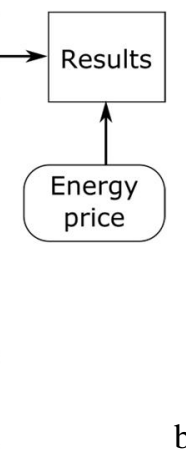

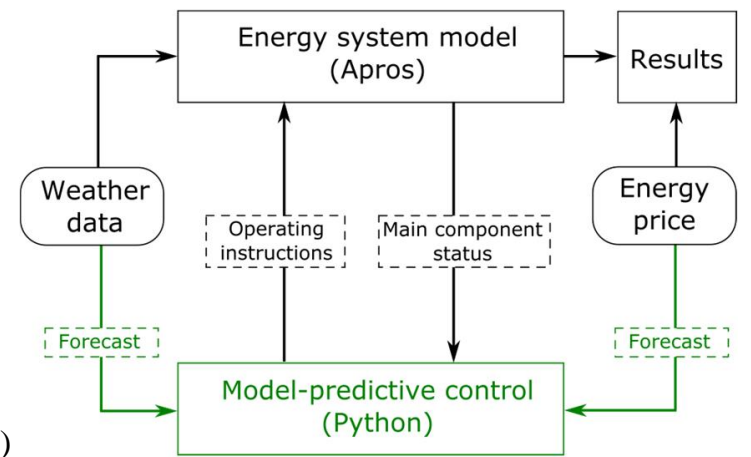

Figure 1 - Conceptual scheme of the study and information flow with rule-based control (a) and model-predictive control (b)

The weather data consists of outdoor air temperature and total solar irradiance incident on the planes of panels of solar energy generation systems. In this study, we used three weeks of a year, determined from one-year weather data for energy simulations as seven consecutive days with the highest, median and lowest values of mean daily outdoor air temperature.

The simulation of the system operation was carried out using the modelling software Apros (Apros, 2018). The detailed model consists of energy generation devices, storages as well as thermal and electrical loads. The most important details of hydraulic system, such as flow capacity values of valves, characteristics of circulation pumps are also modelled in order to take into account pumping costs. The electrical phenomena were not subject of the study and for this reason were not modelled in detail. Instead, the model estimates the electrical loads of equipment controlled by the control system: circulation pumps, heat pump and battery. The thermal and electrical loads associated with demands of the building were pre-simulated using TRNSYS software (TRNSYS Transient System Simulation Tool, 2017) and were considered in the model as independent external inputs. The initial conditions for the test weeks were the same for both rule-based and model-predictive control systems, and were determined from state of the system at the beginning of these weeks during the second consecutive year of simulation using the rule-based control system. More information about the modelled system is provided in Section 4.

The energy system model reports main component status to the control system. This includes temperature measurements in different parts of the system, including thermal storages, as well as battery state of charge. The control system sends operating commands, which include states of pumps and valves, heat output of heat pump, charging or discharging power of the battery.

The rule-based control system operates continuously using measured temperature levels at every time step to identify directions of possible heat transfer and aims to direct heat flows from heat sources to heat loads using a set of rules. The electric power flows is directed using state of charge of the battery and imbalance between the on-site electricity generation and load.

The model-predictive control system operates with one-hour time step, which is significantly larger than that of the rule-based system. The MPC uses the same weather and price data as the simulation model it controls, i.e. we assume that the forecasts are always correct and this allows us to exclude the factors related to forecast inaccuracy when analysing the results. The model-predictive control system uses its own simplified model of the energy system, which differs from the more detailed simulation model. The integrand $r$ of the objective in (1) is the net electric energy cost. Although it is not possible to sell power into the grid at the actual site, we put a small sell price in the MPC model to avoid frivolous power use during excess. In contrast, it is not clear what the final time term $g$ should be. The only externally given price is that of electricity. We valued stored energy at fixed fractions of the electricity price. The fractions depended on the storage and sometimes season (no value for the space heating tank during summer) but were chosen rather arbitrarily. Further simplifications in the model used by MPC are described in Section 4.

The heat system of the site consists of heat sources and storages connected with heat exchangers to circulating fluid loops that transfer heat between them. Heat transfer is proportional to temperature differences and can also 
be controlled with the circulating fluid flow (the whole loop can be turned off by stopping the pump and there are also bypass valves for essentially every component). This is surprisingly difficult to optimise. Assuming complete control, the heat transferred by a heat exchanger is

$$
Q=C z \Delta T,
$$

where $\Delta T$ is the temperature difference, say, between inlets, $C$ is the maximum heat transfer coefficient achievable and $z \in[0,1]$ can be chosen at will. Generally, this is a non-convex constraint. Only if nothing else depends on $z$ and the sign of $\Delta T$ is fixed, e.g., greater or equal to zero, we can eliminate $z$ and replace (2) with $0 \leq Q \leq C \Delta T$. But for storages the sign of $\Delta T$ cannot be fixed.

To get a solvable model we assumed that $z$ is binary (for most cases in the actual system it is). We then replaced (2) with a convex hull relaxation, obtaining a mixed integer linear program (Rubin, 2010). The relaxation is tight when $x$ is binary but allows unphysical heat transfer for fractional $x$ that occur during solution. The MILP was solved with IBM ILOG CPLEX, an advanced branch \& cut solver. It is generally impossible to solve anything but the tiniest MILP to optimum in reasonable time. However, suboptimal but fairly good solutions are often found somewhat quickly. Our model used a one hour time step, which may be long for short-term storages, but fine for the other heat storages, which have vastly larger heat capacity. We gave CPLEX two minutes for solving the MILP and used the best solution it had found in that time. In real time, we could spend a bit longer without wasting a significant part of the one-hour time step, or we could use a shorter time step. However, we want the simulation to run significantly faster than real time. The rolling horizon was 24 hours ahead.

The optimisation model was implemented in Pyomo (Hart et al., 2017), an optimisation modelling library for the Python programming language. Pyomo is a rather high-level framework; a dynamic model can be defined by differential equations and discretized with a transformation from the library. We used the implicit Euler method because it is simple and stable: the optimization problem is solved for all time steps at once, hence an implicit method introduces no additional complexity.

The most important metric should agree with the optimization objective and therefore includes the total cost of electricity from grid during test week:

$$
C_{\text {elec }}=\int_{t 1}^{t 2} P_{\text {elec }}(t) W_{\text {elec }}(t) \mathrm{d} t
$$

where $C_{\text {elec }}$ - is the total cost of purchasing electricity from grid during the test week period (t1, t2), $P_{\text {elec }}(t)$ - is the price of electricity during hour $\mathrm{t}$, and $W_{\text {elec }}(t)$ - is the power drawn from grid during hour $\mathrm{t}$. This corresponds to the term $r$ of the optimization objective (1).

When comparing the two control systems and for further agreement with the optimization objective, there is a need to correct for difference in final states of energy storages, to obtain the operation cost reduction (OCR):

$$
O C R=C_{\text {elec }}^{m p c}-C_{\text {elec }}+\sum_{i} P_{i}\left(E_{i}^{m p c, t 2}-E_{i}^{t 2}\right)
$$

where $C_{\text {elec }}^{m p c}$ and $C_{\text {elec }}$ are the total costs of grid electricity with MPC and rule-based control systems, $P_{i}$ - is price of energy stored in energy storage $i, E_{i}^{m p c, t 2}$ and $E_{i}^{t 2}$ - are the amounts of remaining energy in energy storage $i$ at the end of the test week.

The last summand in (4) corresponds to the term $g$ of the optimization objective in (1), which purpose is to reflect the value of stored energy. We can value energy in the battery at the grid price or some fraction thereof but for the various heat storages value is difficult to quantify.

In addition to operational energy cost savings, we also estimate on-site energy fraction (OEF) and on-site energy matching (OEM) to give a more comprehensive picture of the system performance under the two control approaches. The OEF gives an estimation of the portion of final energy consumption covered by the produced onsite renewable energy. OEM gives an estimation of the portion of the produced on-site renewable energy directly consumed (Cao, Hasan and Sirén, 2013). These indicators have been stated as: 


$$
\begin{array}{cc}
O E F_{e}=\frac{\int_{t 1}^{t 2} \operatorname{Min}\left[G_{\text {elec }}(t)-E S_{\text {on }}(t) ; L_{\text {elec }}(t)\right] \mathrm{d} t}{\int_{t 1}^{t 2}\left[L_{\text {elec }}(t)\right] \mathrm{d} t}, & 0 \leq O E F_{e} \leq 1 \\
O E M_{e}=\frac{\int_{t 1}^{t 2} \operatorname{Min}\left[G_{\text {elec }}(t) ; L_{\text {elec }}(t)+E S_{\text {on }}(t)\right] \mathrm{d} t}{\int_{t 1}^{t 2}\left[G_{\text {elec }}(t)\right] \mathrm{d} t}, & 0 \leq O E M_{e} \leq 1
\end{array}
$$

where $\mathrm{d} t$ is the differential time step, $G_{\text {elec }}$ is on-site electricity generation, $L_{\text {elec }}$ - total electrical loads, and $\mathrm{ES}_{o n}$ electric power to the battery (negative when flow is from the battery).

\section{Case study and modelling}

The simulation study is based on the data and configuration of the EU Story research project demonstration site located in Belgium. The site has a small-scale but rather complex energy system being in implementation phase at a residential property. The system represents a combination of on-site solar heat and electricity generation, long and short-term thermal storages as well as energy conversion (heat pump, PV/T), linking the thermal and electrical subsystems. There is a very well insulated single-family house. Optimal joint operation of equipment installed on site calls for an advanced control method. The main equipment installed on site as well as possible directions of energy transfer are shown on Figure 2.

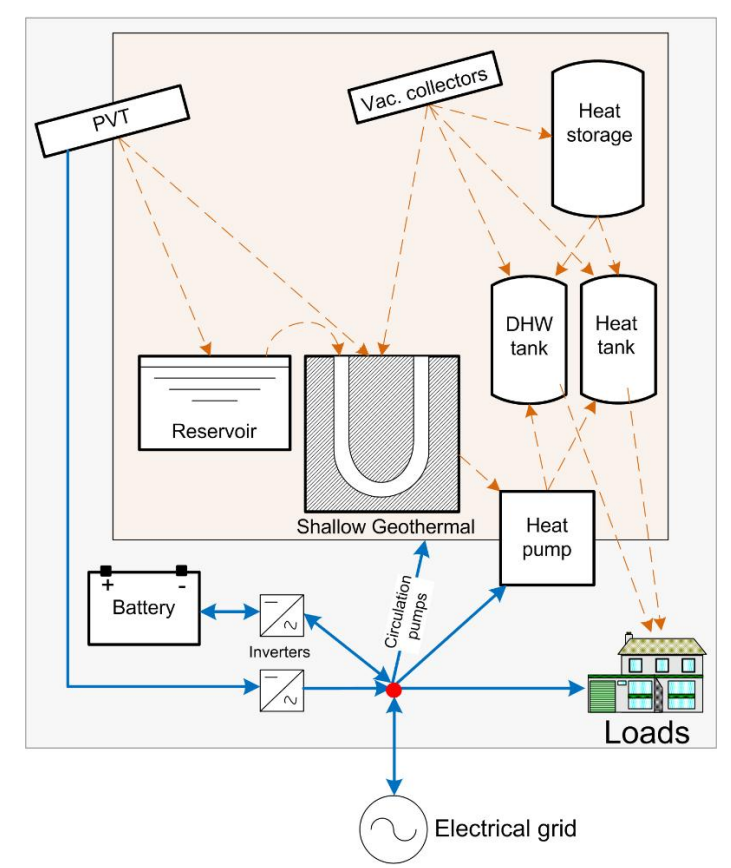

Figure 2 - Main equipment installed on site and paths of possible heat (brown) and electricity (blue) transfer.

The on-site heat generation equipment includes vacuum collectors and a PV/T system. The heat produced by the $\mathrm{PV} / \mathrm{T}$ system is used to warm up a swimming pool water, which cools down the PV/T panels to increase their electrical efficiency; this part of the thermal system has the most significant circulation pump power. The site has a battery system for electricity storage and a bi-directional connection to a local electricity distribution network. The seasonal heat storage consists of two relatively large water tanks buried in the ground. The main sources of heat for the seasonal and short-term heat storages are vacuum solar collectors and a heat pump. The shallow geothermal system represents twelve thermally activated building foundation piles, each 6.5 meters deep. The main technical parameters of the equipment are presented in Table 1. 
Table 1 - The main technical characteristics of the equipment of the case study

\begin{tabular}{cc}
\hline System & Main characteristic \\
\hline PV/T system & $10 \mathrm{kWp}, / 24.3 \mathrm{~kW}$ \\
Vac. collectors system & $3.8 \mathrm{~kW}$ \\
Seasonal heat storage & $2 \times 12 \mathrm{~m}^{3}$ \\
Short-term heat storage & $2 \times 0.2 \mathrm{~m}^{3}$ \\
Heat pump & $1.53 \mathrm{~kW} / 5.8 \mathrm{~kW}$ \\
Reservoir & $42 \mathrm{~m}^{3}$ \\
Shallow geothermal & $312 \mathrm{~m}^{3}$ of activated soil \\
Battery (SoC 30-100\%) & $32.2 \mathrm{kWh}$ \\
\hline
\end{tabular}

A detailed model of the energy system was implemented in the simulation software Apros. The model takes into account the dynamics of the hydraulic system on the heating side with water tanks and circulation pumps. The data for the simulation model included technical data sheets of manufacturers, interviews with the owners as well as online measurement data made available through a cloud service. A hydraulic diagram of the thermal part of the system is shown on Figure 3.

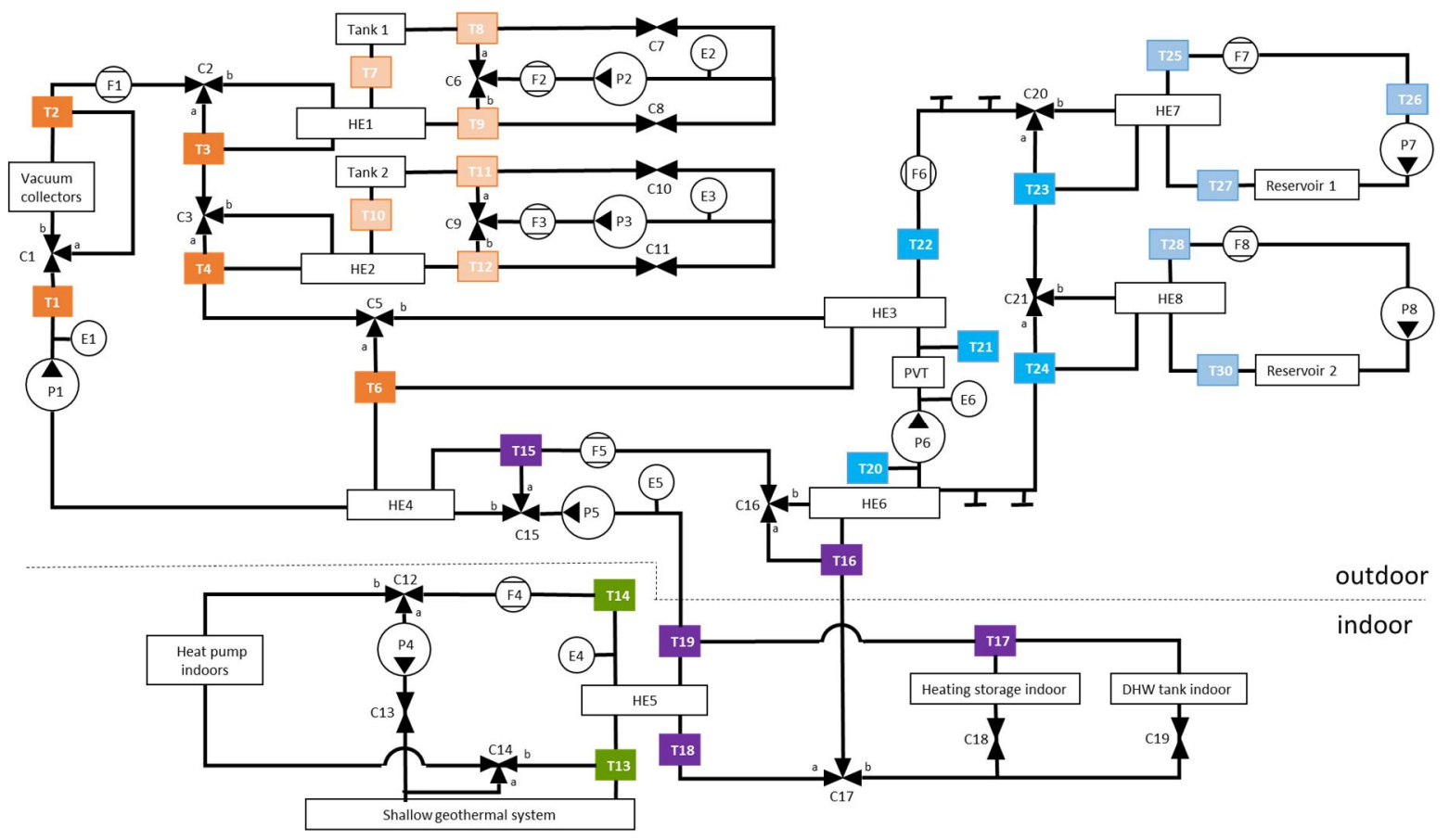

Figure 3 - Hydraulic diagram of the thermal system.

The thermal system, shown in Figure 3, consists of four loops circulating heat transfer fluid through various devices. The loops are interconnected by heat exchangers. Essentially all devices and heat exchangers are equipped with bypass valves. In the model, the loops are assumed lossless: heat transfer occurs only with active devices and heat exchangers along the loop. The short-term heat storages are represented by two indoor hot water tanks both having capacity of 200 litres. As mentioned above, the heat (space heating, domestic hot water) and electricity (appliances, lighting) demands of the building were pre-simulated. The heat demands are modelled as withdrawal of hot water from the corresponding short-term heat storage tanks.

In MPC, the heat storage tanks, the shallow geothermal system and "Reservoir 1" (a swimming pool) are all modelled as simple heat storages; they have a single, uniform temperature, and when active they exchange heat with their loop according to Newton's law of cooling. This affects the storage temperature according to heat capacity. The storages may also have other heat exchanges, e.g., losses to the environment. The "Reservoir 2" is actually a brook, which we model as a heat bath (fixed temperature).

The indoor storage tanks have given loads (space heating and domestic hot water), which in MPC model can be 
extracted from the tank or be produced by the heat pump. The heat pump actually heats the top parts of the tanks, which produces significant stratification that is difficult to model. Having the heat pump heat only the output appears more realistic than having it heat the whole tank. It is assumed that the heat pump has a fixed COP, freely variable power and its output can be directed to the two indoor tanks at will. At least five thermal nodes describe most of the heat storages in the detailed model. The detailed model describes switching of the heat pump between heating the two different tanks.

Solar thermal and PV/T collectors are modelled alike. Incident radiation intensity $I$ perpendicular to the collector is assumed known (weather input). Each collector has an effective area $A$ such that absorbed solar power equals $I A$. The share of this power converted to electricity equals $\epsilon_{0}+\epsilon_{1} T$, where $T$ is the temperature of the solar collector and $\epsilon_{i}$ are known parameters (zero for a pure thermal collector). The rest of the absorbed power becomes heat, which transfers to the fluid loop (if active) and ambient air according to Newton's law of cooling. Heat capacity of the collectors is assumed so small that their temperatures are always at equilibrium.

The battery is modelled as a simple storage: a fixed proportion of charging power is assumed lost; the rest is stored and can be discharged later. Self-discharge and battery wear are not modelled. In addition to storage capacity, there are limits to charging and discharging current.

In the MPC model, the pumps of the heat transfer loops consume a fixed power when active. Individual active devices of the heat system can also consume power. Power consumption from changing controls (e.g., operating bypass valves) is ignored. Uncontrolled pre-simulated domestic electric load is assumed known. Power can be produced by PV/T system, discharged from battery, or bought from the grid at a known (but time-varying) price. The model would also support selling power to the grid, but due to zero feed-in price at the site, this is only reasonable to do in exceptional cases, for example, when storages are full or potentially produced heat is predicted to have no later use. The tariff levels in euro cents/kWh were as follows: 7.685 during the day, 5.988 during the night (21:00 PM - 6:00 AM) and weekends. The rule-based control strategy does not consider the electricity price levels at all - it only attempts to minimize the power drawn from external grid based on state of charge of the battery and imbalance between electricity generation and loads. The battery is only charged when the output of PV/T system exceeds the total electrical loads. The excess electricity, if cannot be entirely used to charge the battery, is exported to the grid. The battery discharges when the loads exceed on-site electricity production until state of charge drops to a minimum of 30 percent. With rule-based control, the battery stores only renewable electricity produced on-site. The rule-based control strategy prioritizes the heat sources according to levels of energy costs and importance of the loads. This means that available output of solar collectors would have higher priority over heat pump and that charging the short-term storage tank of domestic hot water has a higher priority over other heat storages until it reaches a certain high-enough set point temperature. In practice, the heat flows are directed mostly in the following way. The heat output of vacuum solar collectors is transferred to short-term domestic hot water or space heating tanks, and when not possible - to seasonal heat storage. When the temperature levels of water in the seasonal storages allow, and when vacuum collectors are not available, the heat is transferred from seasonal storage to the short-term storages. Finally, the ground-source heat pump ensures the minimum temperatures in both short-term storages.

\section{Results and discussion}

Table 2 summarises the costs of the simulated system operation under the two control strategies. Under MPC, the figures in parentheses are the total direct costs of purchased electricity whereas those outside parentheses are corrected for the difference in stored electricity and heat at the end of corresponding test week as described in Section 3. The differences in stored energy between MPC and rule-based control are also shown. 
Table 2 - Operation energy costs of the system controlled by the two control systems during test weeks and differences in energy content of storages at the end of test weeks.

\begin{tabular}{|l|c|c|c|c|}
\hline \multirow{2}{*}{ Test week } & \multicolumn{2}{|c|}{ Total cost, $€$} & $\begin{array}{c}\text { Difference in stored } \\
\text { electricity, } \mathrm{kWh}\end{array}$ & $\begin{array}{c}\text { Difference in stored } \\
\text { heat, kWh }\end{array}$ \\
\cline { 2 - 3 } & Rule-based & MPC & 7.49 & -34.7 \\
\hline The coldest & 6.44 & $4.39(4.69)$ & 0.61 & -108.7 \\
\hline The warmest & 0.01 & $0.70(0.31)$ & 2.74 & -184.4 \\
\hline Median temperature & 0.01 & $1.24(0.65)$ & \\
\hline
\end{tabular}

It can be seen from Table 2 that at the end of all of the three test weeks, use of model-predictive control resulted in a higher energy content in the battery compared to the case when the system was operated using the rule-based control. In the case of stored heat the result is opposite. The energy content of the battery was directly observable and the price used for valuation of stored electricity was the night electricity tariff. To calculate differences in stored heat we used the difference of total enthalpy of water stored in the tanks as well as heat capacity of activated ground and its average temperature. The prices used for valuation of stored heat were set as fractions of the price of stored electricity. The information about the differences in final states of storages and used prices of stored heat is presented in Table 3.

Table 3 - The differences in content of energy storages, applied prices for valuation of the energy content and resulting corrections to total costs.

\begin{tabular}{|c|c|c|c|c|}
\hline Test week & Energy storage & $\begin{array}{c}\text { Difference in } \\
\text { stored energy, } \\
\mathbf{k W h}\end{array}$ & $\begin{array}{c}\text { Value of energy as fraction of } \\
\text { price of stored electricity } \\
(0.05988 € / \mathrm{kWh})\end{array}$ & $\begin{array}{c}\text { Correction, } \\
€\end{array}$ \\
\hline \multirow[t]{7}{*}{ The coldest } & Battery & 7.5 & 1.0 & 0.45 \\
\hline & Swimming pool & -56.3 & 0.1 & -0.34 \\
\hline & Seasonal tanks & 17.5 & 0.2 & 0.21 \\
\hline & DHW tank & -3.2 & 0.1 & -0.02 \\
\hline & Space heating tank & -0.6 & 0.1 & 0.00 \\
\hline & Geothermal & 0.4 & 0.1 & $\overline{0.00}$ \\
\hline & Total & -34.7 & - & 0.30 \\
\hline \multirow[t]{7}{*}{ The warmest } & Battery & 0.6 & 1.0 & 0.04 \\
\hline & Swimming pool & -146.7 & 0.1 & -0.88 \\
\hline & Seasonal tanks & 40.0 & 0.2 & 0.48 \\
\hline & DHW tank & -4.5 & 0.1 & -0.03 \\
\hline & Space heating tank & 2.0 & 0.0 & 0.00 \\
\hline & Geothermal & -0.1 & 0.1 & 0.00 \\
\hline & Total & -108.7 & - & -0.39 \\
\hline \multirow{7}{*}{$\begin{array}{c}\text { Median } \\
\text { temperature }\end{array}$} & Battery & 2.7 & 1.0 & 0.16 \\
\hline & Swimming pool & -239.2 & 0.1 & -1.43 \\
\hline & Seasonal tanks & 61.7 & 0.2 & 0.74 \\
\hline & DHW tank & -9.5 & 0.1 & -0.06 \\
\hline & Space heating tank & 0.0 & 0.0 & 0.00 \\
\hline & Geothermal & -0.2 & 0.1 & 0.00 \\
\hline & Total & -184.4 & - & -0.59 \\
\hline
\end{tabular}

The value of energy content in the shallow geothermal storage shown in Table 3 was calculated based on the differences in its final average temperatures and thermal capacity of the active ground. The total heat capacity of 
ground expressed in $\mathrm{kWh}$ per Kelvin was 190.7. At the end of the coldest week the ground was on average 2 degrees warmer, and at the end of the warmest and the median temperature week respectively 0.46 and 1.19 degrees colder with model-predictive control compared to rule-based.

The results presented in Table 2 suggest that the best performance of model-predictive control system compared to the rule-based one, both with and without corrections for the final states in heat storages is achieved in the coldest week. During the warmer weeks there is significant on-site electricity generation by the PV/T system and the system is able to store the excess electricity in sufficient amounts to almost entirely cover electrical loads, including operation of heat pump to prepare domestic hot water. This is exactly what happens with rule-based control and can be seen by negative net exchange with electrical grid in Table 4 as well as Figure 5 and Figure 6.

Table 4 - Interaction of the system with electrical grid when controlled by the two control systems during test weeks.

\begin{tabular}{|c|c|c|c|c|}
\hline \multirow{2}{*}{ Test week } & \multicolumn{2}{|c|}{ Consumption (paid), kWh } & \multicolumn{2}{c|}{ Net exchange, $\mathbf{k W}$} \\
\cline { 2 - 5 } & Rule-based & MPC & Rule-based & MPC \\
\hline The coldest & 95.3 & 75.5 & 95.2 & 75.5 \\
\hline The warmest & 0.1 & 4.8 & -127.8 & -110.1 \\
\hline Median temperature & 0.2 & 10.3 & -116.5 & -119.1 \\
\hline
\end{tabular}

The following three figures show consumption of electricity from electrical grid and the values of daily indices of on-site energy fraction and matching for electricity. The indices were calculated from the data having one-minute time resolution and for this reason the values of indices may differ from the expected from hourly presentation of electricity consumption from grid.
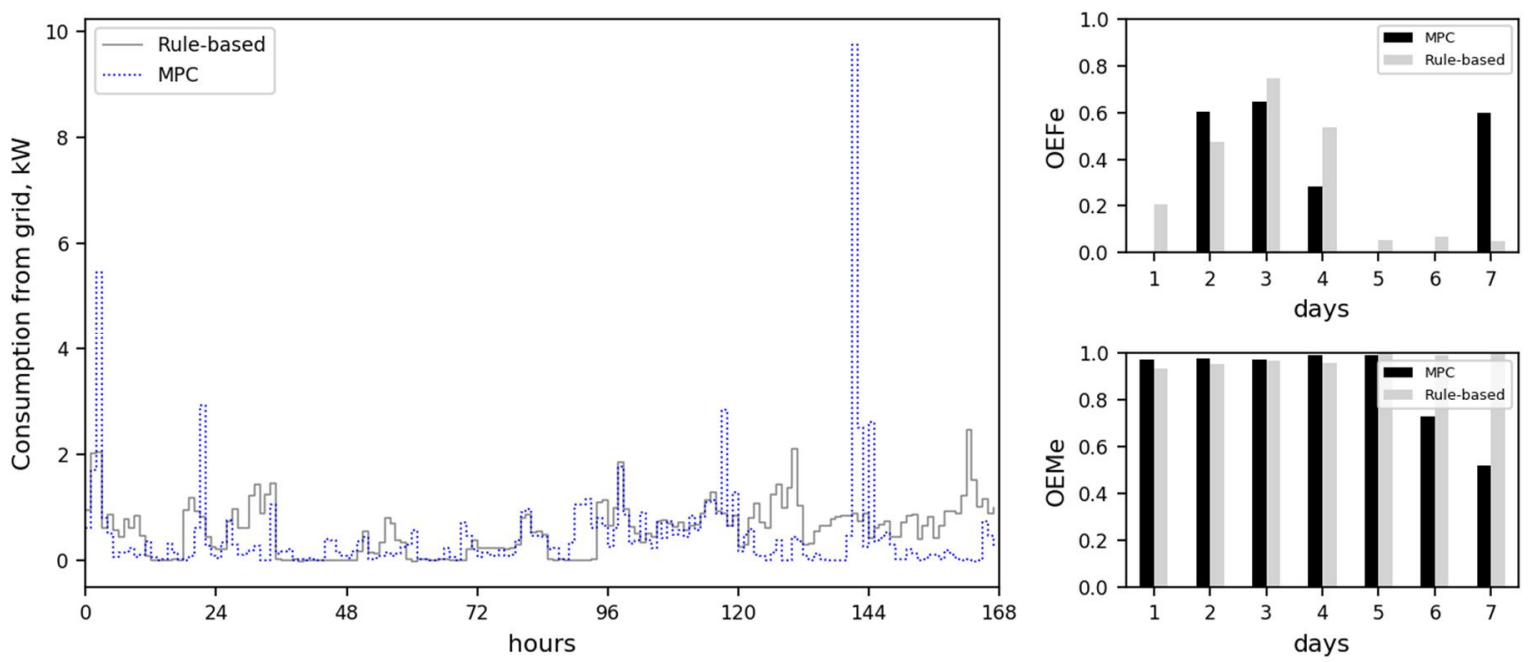

Figure 4 - Electricity consumption from grid and daily on-site energy indices during the coldest week

During the coldest week, the model-predictive control is charging the battery during the night and as a result consumes less electricity from grid during the day when the electricity price is higher. This affects the values of OEFe index on days 5, 6 and 7 . 

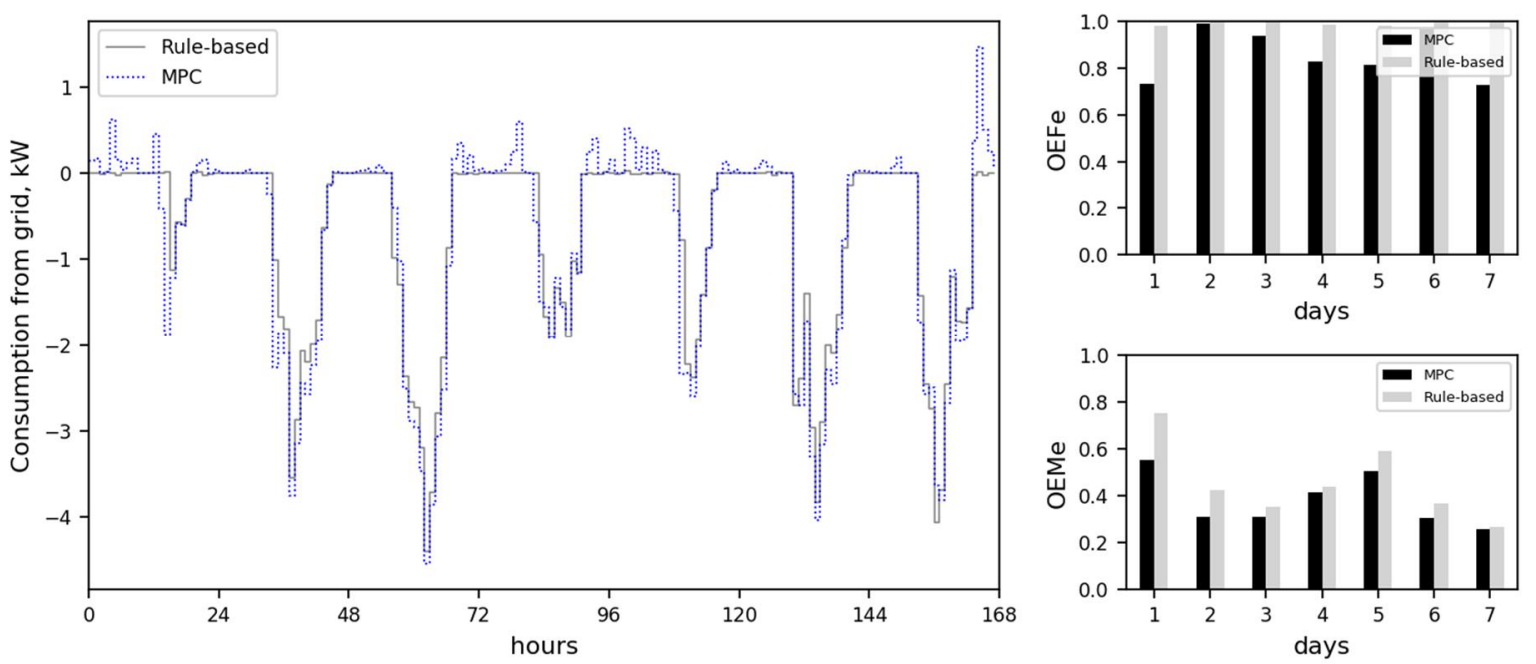

Figure 5 - Electricity consumption from grid and daily on-site energy indices during the median temperature week

During both warmer weeks, due to excess on-site electricity generation the values of OEFe are relatively high for both systems and the values of OEMe are relatively low. Low values of on-site energy matching index is explained by the stress on the external grid caused by feeding the surplus electricity which can't be entirely stored in the battery.
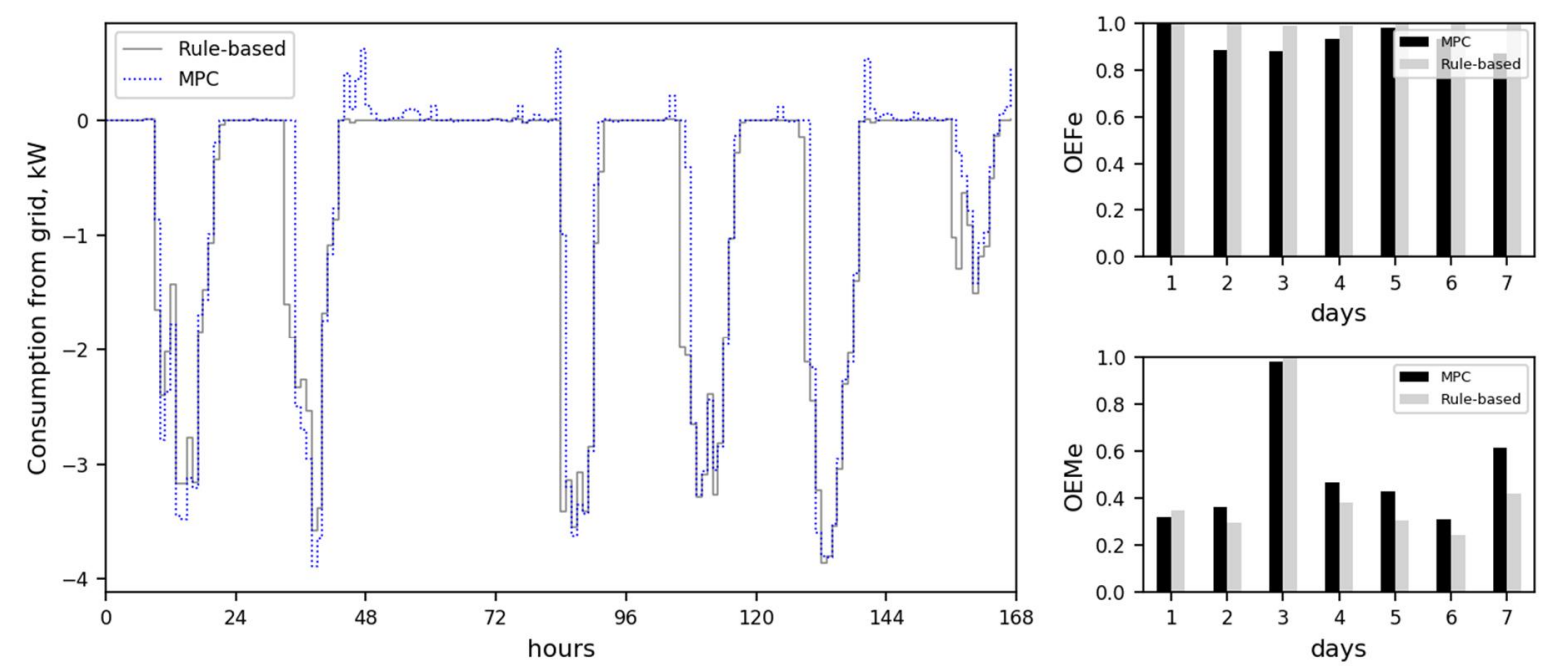

Figure 6 - Electricity consumption from grid and daily on-site energy indices during the warmest week

During the warm weeks, the model-predictive control still causes the system to consume electricity from grid during some hours. This may be due to improperly selected final prices, model mismatches as well as poor optimization solutions due to the short time available for optimization.

The prices used to estimate the value of stored energy were not constant during optimization. The used values were tied to the electricity price at the end of prediction horizon, and therefore it is not entirely clear what values should be used when correcting the total costs. From practical point of view, the most value of stored heat would most likely be attributed to domestic hot water and space heating tanks from which the heat could be used immediately, as well as seasonal storages based on hot water. At the same time, the most influence on the amount of correction is caused by the swimming pool, which main role is being a heat sink.

It should also be noticed that the observed surplus of electricity on the site is intended for charging an electrical vehicle. Charging and discharging the vehicle would most certainly improve the results of model-predictive control system. However, at this time we did not have sufficient data about the vehicle, which is thus completely absent from the models.

\section{Conclusion}

Model-predictive control operates the system reasonably well in the coldest periods, which are the most critical 
from the point of view of thermal systems studied in this work. Its performance in warmer times was less impressive, falling short of the rule-based strategy. MPC has the advantage of being able to buy cheap electricity at night and store it in the battery for later use. This advantage disappears in the sunnier seasons: there is little need to buy power as PV/T tends to cover the demand. Alternative optimisation techniques that would produce better solutions faster than mixed integer programming should be explored. Non-linear optimisation would also allow better modelling of some features of the heat system. The optimisation problem is inherently non-convex though, so only approximate solutions can be expected in limited time.

Determining appropriate prices for valuing the energy content of the different storages at the end of the planning horizon is challenging. They steer the long-term behaviour of MPC and should measure the usefulness of energy to cover the thermal demands while meeting their temperature requirements. This varies by season: to start heating up the seasonal tanks for winter, one should raise their final time price, whereas it can be lowered in the spring, when less use for stored heat is expected. One could also set target levels for the storages. However, it is not clear how to determine them either. A possible approach would be to compute them from an optimisation problem spanning a full year. That would require a much coarser model to be solvable.

\section{Acknowledgements}

The STORY project has received funding from the European Union's Horizon 2020 research and innovation programme under grant agreement No 646426 (Project STORY - H2020-LCE-2014-3). Authors are grateful to Dr. Leen Peeters for the support given in developing the case.

\section{References}

Apros (2018). Available at: http://www.apros.fi/en/ (Accessed: 19 June 2018).

Beaudin, M. and Zareipour, H. (2015) 'Home energy management systems: A review of modelling and complexity', Renewable and Sustainable Energy Reviews. Pergamon, 45, pp. 318-335. doi: 10.1016/j.rser.2015.01.046.

Cao, S., Hasan, A. and Sirén, K. (2013) 'On-site energy matching indices for buildings with energy conversion, storage and hybrid grid connections', Energy and Buildings. Elsevier, 64, pp. 423-438. doi: 10.1016/J.ENBUILD.2013.05.030.

European Commission (2010) Energy Performance of Buildings Directive. Available at: https://eurlex.europa.eu/legalcontent/EN/ALL/ELX_SESSIONID=FZMjThLLzfxmmMCQGp2Y1s2d3TjwtD8QS3pqdkhXZbwqGwlgY9K N!2064651424?uri=CELEX:32010L0031 (Accessed: 18 June 2018).

European Commission (2014) 2030 Energy Strategy - European Commission. Available at: https://ec.europa.eu/energy/en/topics/energy-strategy-and-energy-union/2030-energy-strategy (Accessed: 18 June 2018).

European Commission (2017) Strategic Energy Technology Plan. Available at: https://ec.europa.eu/energy/en/topics/technology-and-innovation/strategic-energy-technology-plan (Accessed: 18 June 2018).

European Commission (2018) HORIZON 2020 -Work Programme 2018-2020 Topics related to Cities and Urban Development. Available at: http://ec.europa.eu/research/environment/pdf/h2020_wp20182020_overview_all_calls_cities_and_urban_development.pdf (Accessed: 18 June 2018).

Hart, W. E. et al. (2017) Pyomo -- Optimization Modeling in Python. Second. Springer (Springer Optimization and Its Applications).

Khakimova, A. et al. (2017) 'Optimal energy management of a small-size building via hybrid model predictive control', Energy and Buildings. Elsevier, 140, pp. 1-8. doi: 10.1016/j.enbuild.2017.01.045.

Mirakhorli, A. and Dong, B. (2018) 'Market and behavior driven predictive energy management for residential buildings', Sustainable Cities and Society. Elsevier, 38, pp. 723-735. doi: 10.1016/j.scs.2018.01.030.

Mohammadi, M. et al. (2018) 'Optimal management of energy hubs and smart energy hubs - A review', Renewable and Sustainable Energy Reviews. Pergamon, pp. 33-50. doi: 10.1016/j.rser.2018.02.035.

Morari, M. and Lee, J. H. (1999) 'Model predictive control: past, present and future', Computers and Chemical 
Engineering, 23(4--5), pp. 667-682. doi: 10.1016/S0098-1354(98)00301-9.

Pasini, D., Reda, F. and Häkkinen, T. (2017) 'User engaging practices for energy saving in buildings: Critical review and new enhanced procedure', Energy and Buildings. Elsevier, 148, pp. 74-88. doi:

10.1016/j.enbuild.2017.05.010.

Reda, F. et al. (2015) 'Energy assessment of solar technologies coupled with a ground source heat pump system for residential energy supply in Southern European climates', Energy. Pergamon, 91, pp. 294-305. doi: 10.1016/j.energy.2015.08.040.

Rubin, P. (2010) Binary Variables and Quadratic Terms. Available at: https://orinanobworld.blogspot.com/2010/10/binary-variables-and-quadratic-terms.html.

Sultana, W. R. et al. (2017) 'A review on state of art development of model predictive control for renewable energy applications', Renewable and Sustainable Energy Reviews. Pergamon, pp. 391-406. doi: 10.1016/j.rser.2017.03.058.

TRNSYS Transient System Simulation Tool (2017). Available at: http://www.trnsys.com/ (Accessed: 18 June 2018).

Wanjiru, E. M., Sichilalu, S. M. and Xia, X. (2017) 'Model predictive control of heat pump water heaterinstantaneous shower powered with integrated renewable-grid energy systems', Applied Energy. Elsevier, 204, pp. 1333-1346. doi: 10.1016/j.apenergy.2017.05.033.

Zong, Y. et al. (2017) 'Challenges of implementing economic model predictive control strategy for buildings interacting with smart energy systems', Applied Thermal Engineering. Pergamon, 114, pp. 1476-1486. doi: 10.1016/j.applthermaleng.2016.11.141. 


\title{
Modular Rooftop Building-Integrated Photovoltaic/Thermal Systems for Low-Rise Buildings in India
}

\author{
Olesia Kruglov, Efstratios Rounis, Andreas Athienitis, Bruno Lee, Ashutosh Bagchi, Hua Ge \\ and Theodore Stathopoulos \\ Concordia University, Montreal (Canada)
}

\begin{abstract}
This study aims to investigate the utilization of the abundant solar resources available in India to provide energy for low-rise mixed use buildings in the city of Chennai. To accomplish this, a modular rooftop building-integrated photovoltaic/thermal (BIPV/T) system is designed, developed and modeled for an archetypical mixed-use building. The BIPV/T system incorporates the production of electricity and useful heat, while considering the building envelope requirements for roof as well as façade applications. These systems can be alternatives to traditional cladding, while retrofitting with BIPV/T can turn unused or semi-conditioned spaces into fully enclosed conditioned spaces. For a roof coverage of $180 \mathrm{~m}^{2}$ and average summer day conditions in Chennai, a typical system with an efficiency of $15 \%$ would have an electrical output of approximately $150 \mathrm{kWh}$ and a thermal output of approximately $230 \mathrm{kWh}$, which can be used for heating through a heat pump, directly, or for cooling through a thermally driven cooling system. For a climate such as the one in India, a BIPV/T application can utilize heat driven technologies such as absorption cooling systems.
\end{abstract}

Keywords: Building-integrated photovoltaic/thermal, modular roofing, building typologies

\section{Introduction}

India is one of the top energy consuming countries in the world, after China, the United States and Russia. However, the country's per capita electricity consumption is less than one third of the world average. In acknowledgement of this as well as the rapid rise of technologies used to harness solar energy, the Indian government has recently initiated policies to encourage the use of photovoltaic (PV) and building-integrated photovoltaic (BIPV) systems for local energy production. While the country does get as many as 300 days of sunshine a year, it is densely populated with little land available for solar parks. Because of this limited land availability and largely accessible unused roof space, rooftop PV systems are especially garnering attention (Shukla et al., 2018).

The Indian government has set goals to produce $100 \mathrm{GW}$ of solar energy by the year 2022 , and $40 \%$ of this will come from rooftops, which is now the fastest growing technology in the clean energy sector, and is cheaper than commercial and industrial power in India ("India Transforms Market for Rooftop Solar," n.d.). The current issue is that while the rooftop projects for commercial buildings are rapidly advancing, solar for residential buildings is falling behind due to large upfront costs and net-metering programs ("Rooftop solar is the fastest-growing segment in India's renewables market — Quartz," n.d.).

This IC-Impacts collaborative project aims to develop novel of rooftop solar concepts for the residential sector. The India-Canada Centre for Innovative Multidisciplinary Partnerships to Accelerate Community Transformation and Sustainability (IC-Impacts) is a center of excellence which focuses on research to improve sustainability within Canadian and Indian communities. The goal of this particular research is to identify optimal configurations of building technologies suitable for the local climate and to aim for the design of a net-zero energy building by utilizing local energy generation from renewable sources. Specifically, the project involves the design and modeling of a low-rise residential building in the city of Chennai, India.

The project conceptualizes a building-integrated photovoltaic/thermal (BIPV/T) cladding for the building which is more efficient than a typical rooftop system and replaces some of the building cladding components, lowering 
the critical up-front cost of material and installation. Since India is one of the leading producers of aluminum, it would be acceptable to use aluminum curtain wall framing to contain the PV panels and enclose the rooftop, converting it into a semi-conditioned space and reducing the solar heating of the roof, which in turn would reduce the energy needed to cool the building.

\subsection{BIPV/T Technology}

Current practices for utilizing PV panels on rooftops mainly include racked systems. BIPV and BIPV/T technologies can be used as alternative to traditional claddings on both roofs and facades. Retrofits with these systems can turn unused spaces into semi-conditioned or fully enclosed spaces.

A BIPV system serves a dual purpose. The PV components not only produce electrical energy but also serve as the exterior cladding of a building envelope, replacing the outer materials that function as walls and roofs. There are many types of BIPV systems, including facades, roofs, fenestration, and sunshades. One way in which the BIPV technology has advanced is the harvesting of excess heat produced by the PV cells and transferring it to a medium for useful energy, further benefitting the electrical production of the system by maintaining lower PV cell temperatures. This variation on the BIPV design is called a building-integrated photovoltaic/thermal (BIPV/T) system and many improvements to this technology have been studied and documented (Yang and Athienitis, 2016). This study focuses on the application of BIPV/T systems (Figure 1) on rooftops.
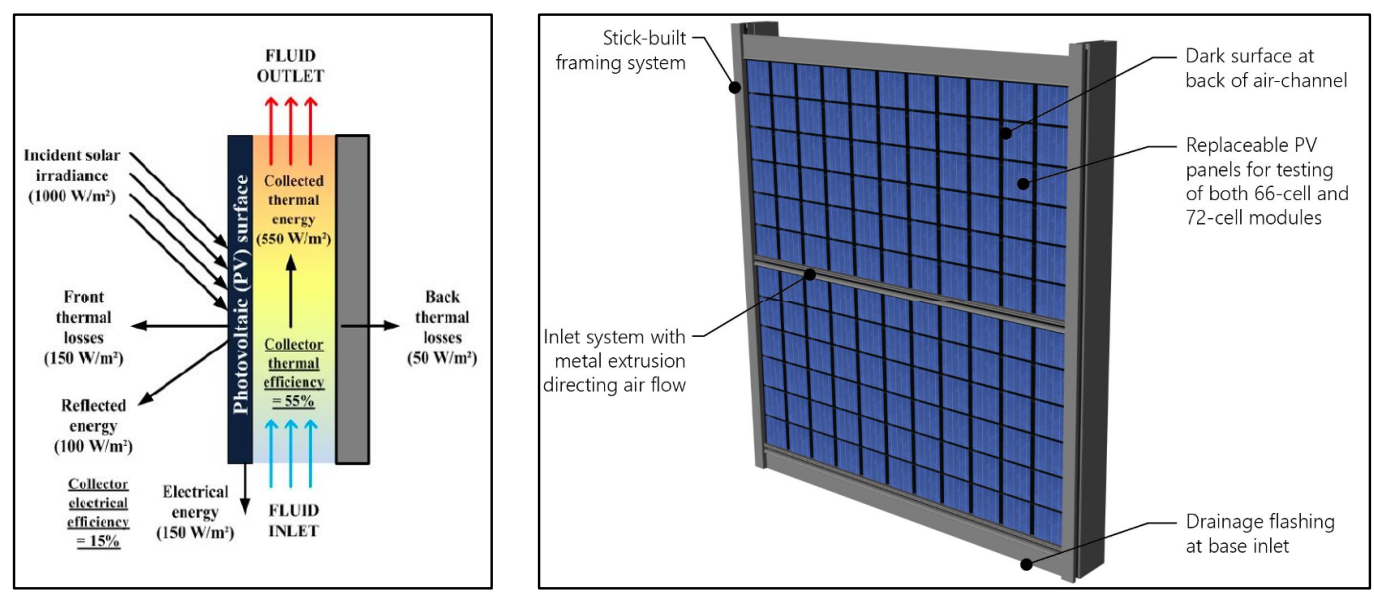

Fig. 1: BIPV/T energy distribution diagram (left) and curtain wall framing design for BIPV/T (right) (Bambara, 2012)

Two examples of built BIPV/T assemblies are shown in Figure 2. The left image shows a modular BIPV/T system assembled with several components. This was used as the roof structure of the Team MTL house for the Solar Decathlon competition in summer of 2018 in Dezhou, China. The image on the right shows a fully integrated BIPV system as the roof of a library building in Quebec. The area of the system is $711 \mathrm{~m}^{2}$ and $173 \mathrm{~m}^{2}$ of this is BIPV/T, producing $220 \mathrm{kWh}$ of solar heat on a cold, sunny day. The slope of this building is $30^{\circ}$ due to the northern latitude, but an even higher slope would have been ideal to prevent snow accumulation.
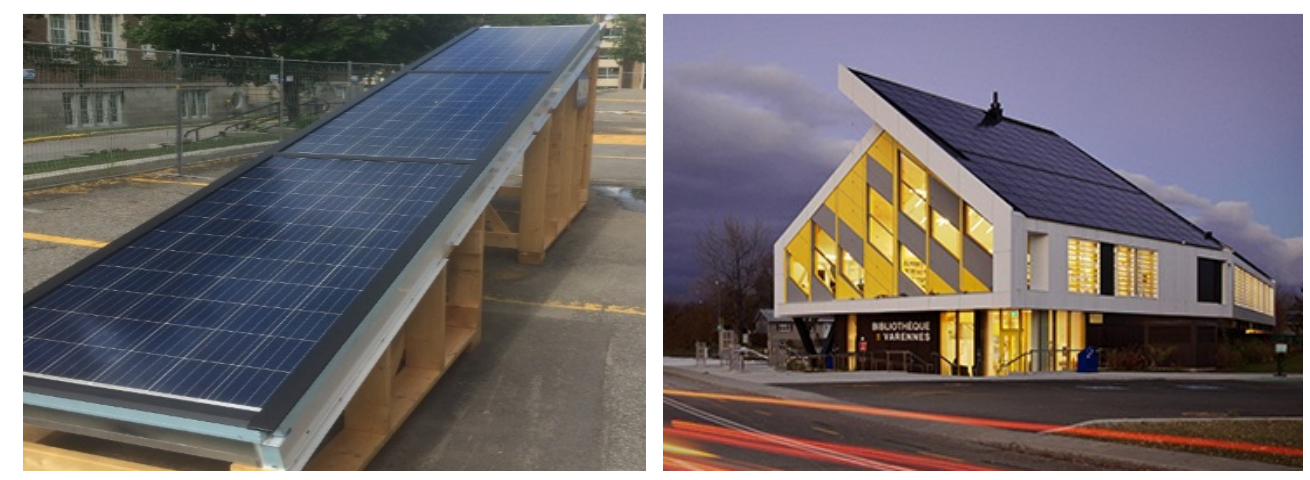

Fig. 2: Modular BIPV/T prototype for the Solar Decathlon (left) and BIPV/T roof on the Varennes library in Quebec, Canada (right) 


\section{Location Analysis: Chennai, India}

Chennai is located in the southern part of India, in the state of Tamil Nadu. At the geographical coordinates $13^{\circ} \mathrm{N}$, $90^{\circ} \mathrm{E}$, this coastal city is close to the equator and has a warm-humid climate. As shown in Figure 3, the annual global horizontal irradiation (GHI) is $1,957 \mathrm{kWh} / \mathrm{m}^{2}$, while the average air temperature is over $28^{\circ} \mathrm{C}$. The annual direct normal irradiation is $1,377 \mathrm{kWh} / \mathrm{m}^{2}$ and the annual diffuse horizontal irradiation is $935 \mathrm{kWh} / \mathrm{m}^{2}$.
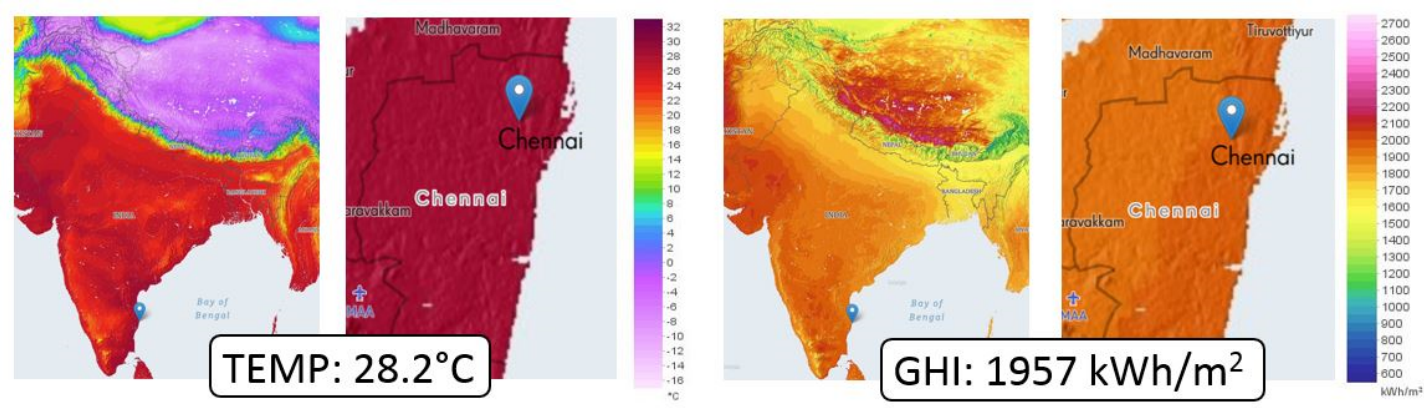

Fig. 3: Radiation and temperature maps of Chennai, India (“Global Solar Atlas,” n.d.)

Average air temperatures for Chennai vary between $24^{\circ} \mathrm{C}$ in the winter months and up to $32^{\circ} \mathrm{C}$ in the summer, making this a cooling dominated climate (Figure 4).

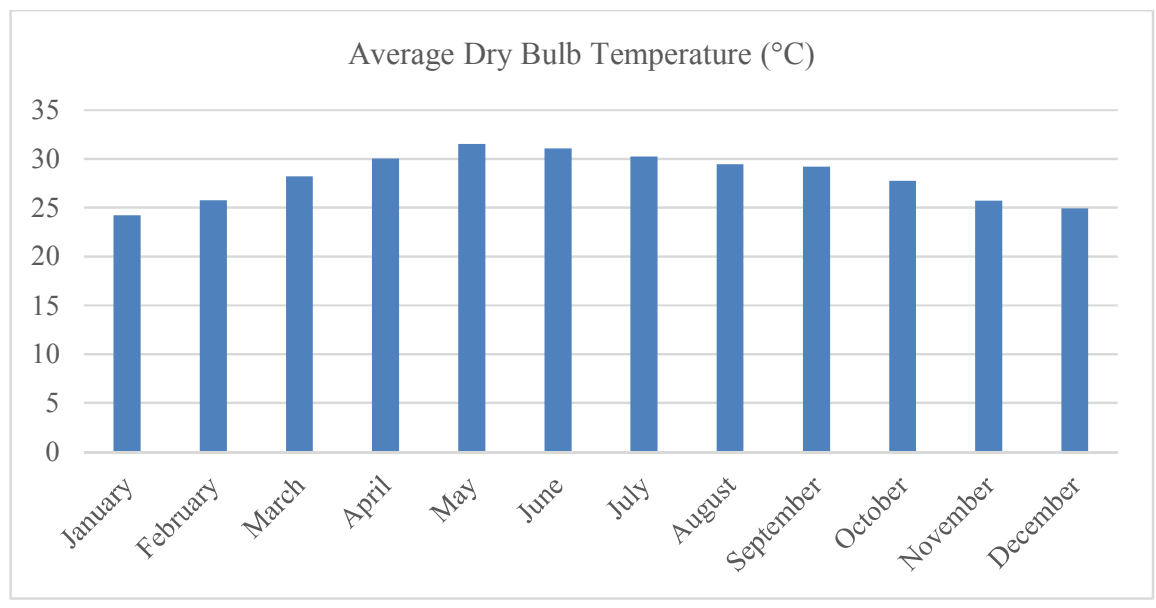

Fig. 4: Monthly averages for air temperatures in Chennai, India

For a location such as Chennai, a PV system would need a low slope to maximize incident radiation. A $13^{\circ}$ slope is favorable, but a lower slope would also be beneficial, due to dominating diffuse radiation. This is due to higher cloud cover in the summer months during the monsoon season. The global horizontal irradiation (GHI) follows a typical pattern throughout the year (Figure 5).

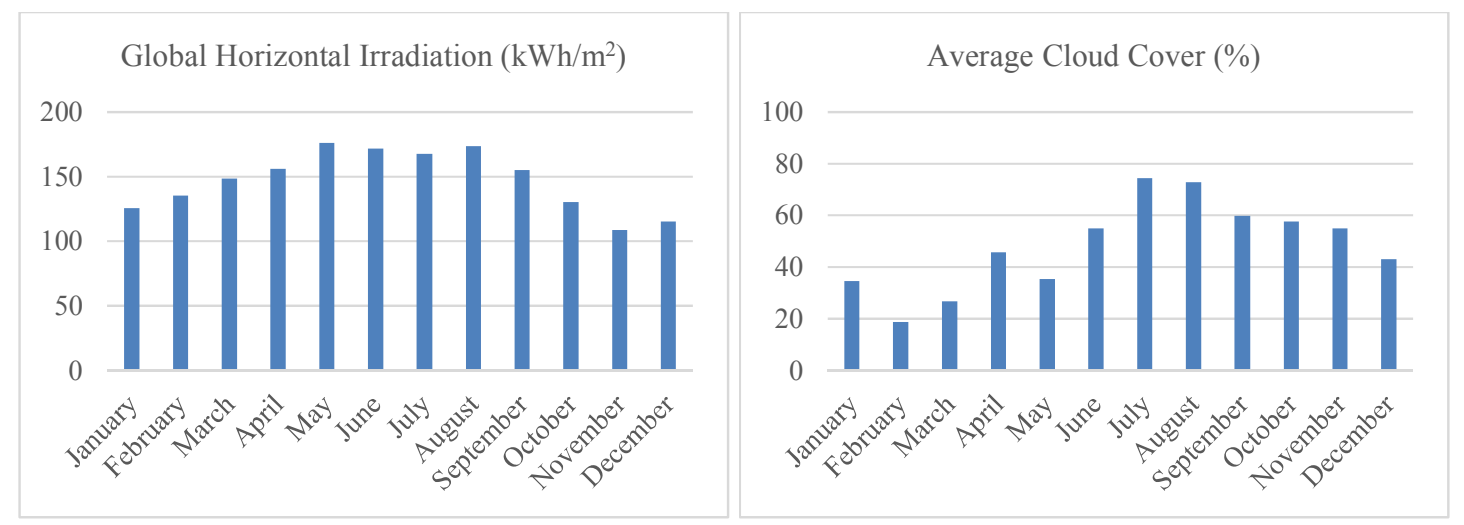

Fig. 5: Monthly total for GHI (left) and percentage of sky covered by clouds (right) 


\subsection{Building Typologies}

Building typologies of the state of Tamil Nadu were studied for patterns in existing residential structures. Among the most common are reinforced concrete structures with non-bearing masonry infill walls. The buildings are often aligned at the front street facade and have narrow plots on which they sit. Several representative buildings are shown in Figure 6.
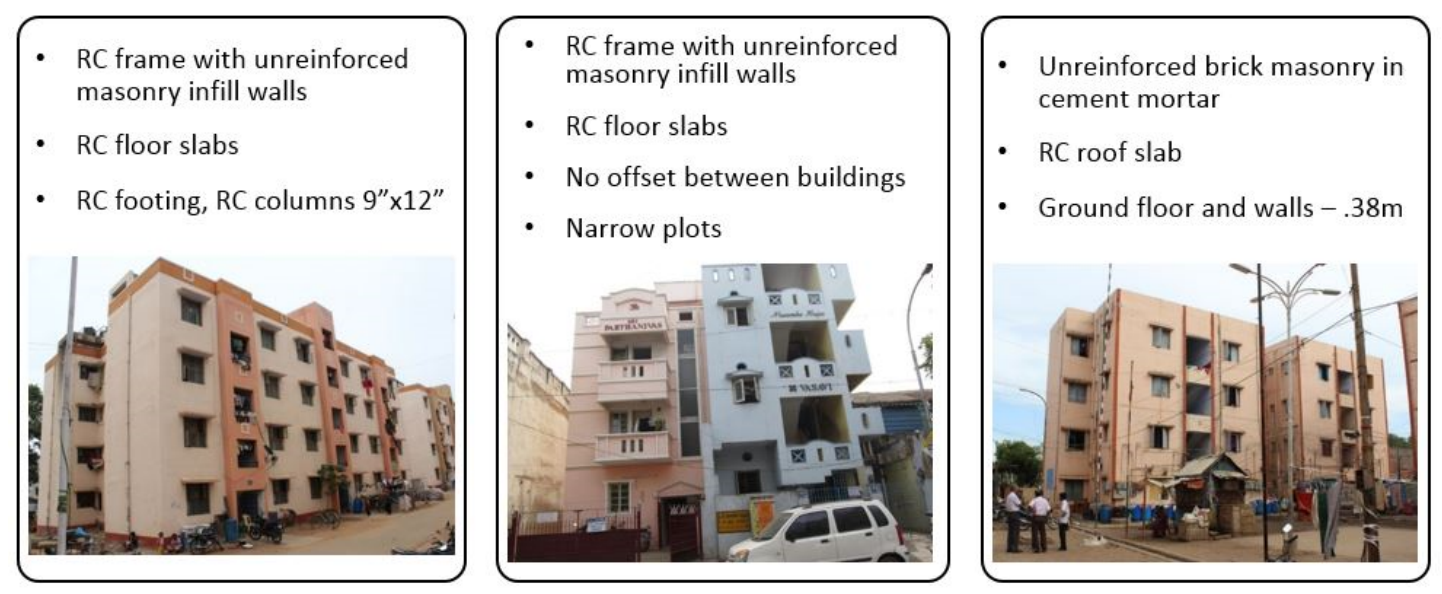

Fig. 6: Building typologies in the state of Tamil Nadu (National Disaster Management Authority, 2013)

A typical reinforced concrete building frame is shown below (Figure 7). This type of structure requires a lightweight BIPV/T framing system with simple attachment methods at the roof.

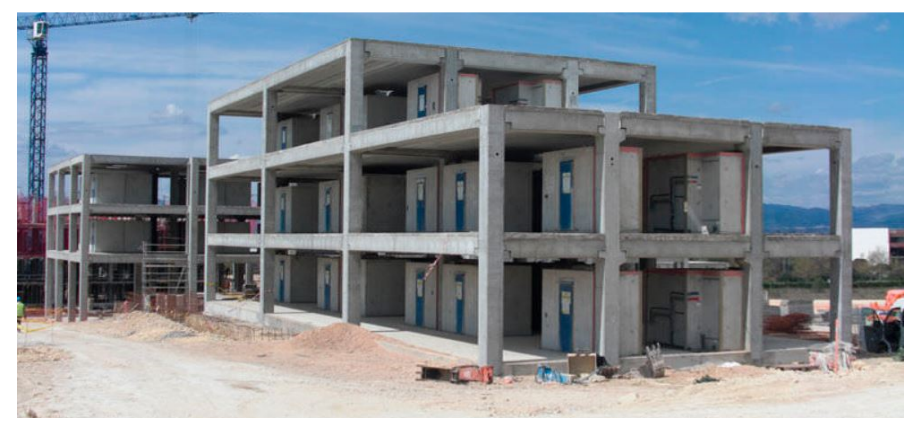

Fig. 7: Reinforced concrete framed building construction ("Reinforced concrete portal frame / prestressed concrete - Pujol," n.d.)

\section{Case Study}

Initially for the study, 4 apartments were selected as representative samples from both Nagpur, which has a composite climate, and Mumbai, which has a warm and humid climate. Specific to the city of Chennai, India, two types of building typologies were reviewed. One is a typical low-rise, 4-story building consisting of 4 apartments and retail or parking spaces on the ground level. Each floor is $55 \mathrm{~m}^{2}$ by $45 \mathrm{~m}^{2}$. The second typology is a 3-story single family home with parking on the ground floor. An energy analysis was performed on the first typology. The building envelope properties for energy analysis were selected based on BEEP (2016) Design Guidelines for Energy-Efficient Multi-Story Residential Buildings: Warm-Humid Climate (Table 1). Results show an average annual energy use intensity of $156 \mathrm{kWh} / \mathrm{m}^{2}$. It is important to note that at this stage, only a base case has been modeled. Improved insulation and an airtight building design will significantly lower the energy use. The energy model is based on ideal control with an assumed constant cooling coefficient of performance (COP) of 2.5 for the heat pump. 
Tab. 1: Building envelope properties for base case

\begin{tabular}{|c|c|}
\hline Design Parameters & $\begin{array}{c}\text { Default Input } \\
\text { Values }\end{array}$ \\
\hline Roof U-value $\left(\mathrm{W} / \mathrm{m}^{2}-\mathrm{K}\right)$ & 3.0 \\
\hline External wall U-value $\left(\mathrm{W} / \mathrm{m}^{2}-\mathrm{K}\right)$ & 2.0 \\
\hline Intermediate floor U-value $\left(\mathrm{W} / \mathrm{m}^{2}-\mathrm{K}\right)$ & 3.4 \\
\hline Window SHGC, VLT & $0.8,0.85$ \\
\hline Window overhang projection factor & 0.6 \\
\hline
\end{tabular}

The available rooftop area is $220 \mathrm{~m}^{2}$ and the western half of the south wall has no windows. For this building design, the application of BIPV/T could extend not just across the roof but also over $97 \mathrm{~m}^{2}$ of the south wall (Figure 8).
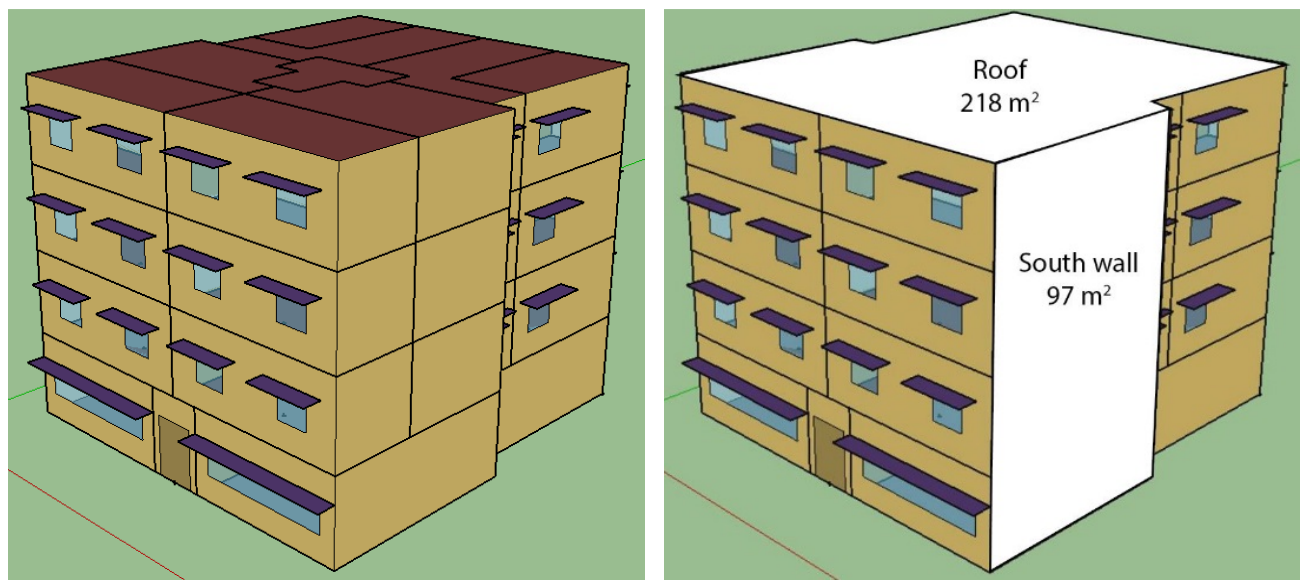

Fig. 8: Building schematic (left) and roof and wall areas available for PV coverage (right)

\subsection{BIPV/T Roof Design}

Different layouts were studied for rooftop PV applications (Figure 9). The first two layouts (left and center) are sawtooth configurations and commonly used, but the BIPV/T layout was determined to not only have maximum area but also receive the most annual radiation, as shown in the radiation maps below each layout.

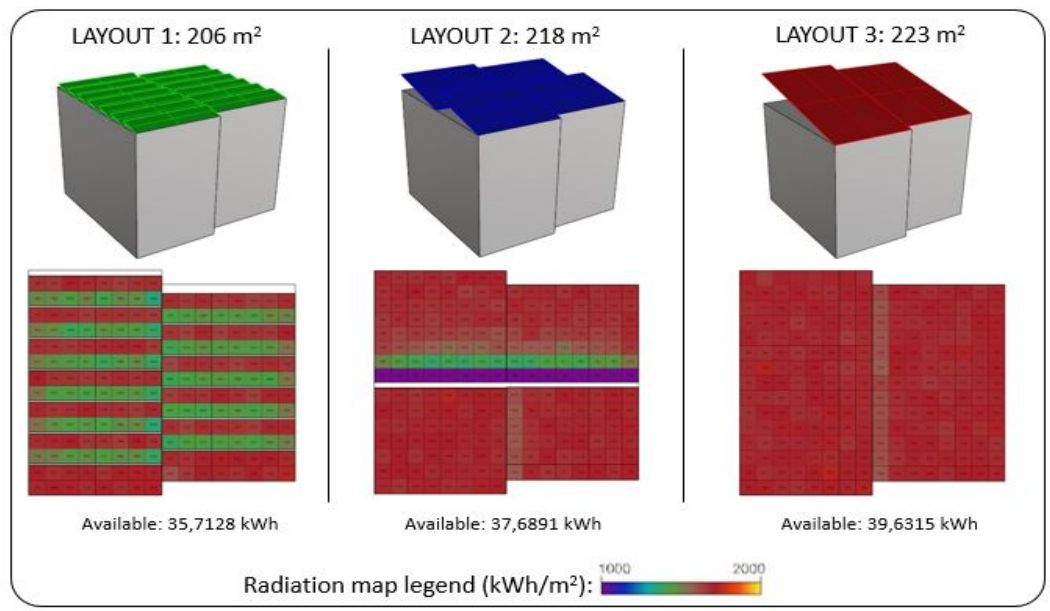

Fig. 9: Rooftop PV configurations and their radiation maps 
Preliminary calculations showed that for the design shown in the bottom right of Figure 9, the annual AC energy production would be approximately $46,781 \mathrm{kWh}$ for a system sloped at $13^{\circ}$. However, it was decided to use only the roof portion available for BIPV/T system.

The project will feature a low-sloped BIPV/T roof of approximately $13^{\circ}$ which is optimal for near equatorial latitudes. The system is based on a prototype developed and constructed in collaboration with curtain wall framing manufacturers. The prototype was assembled with aluminum framing and has been tested for base characterization in the Solar Simulator at Concordia University (Kruglov et al., 2017; Rounis et al., 2017). The design will include an insulated air channel, allowing air to flow through it and cool the PV panels, which serve as the outer layer of the cladding. A manifold will collect the preheated air from the air channel(s) which will then be utilized depending on the coupling with the HVAC system. With a focus on common building practices and the use of local materials for framing design, the potential for modular and unitized rooftop systems to achieve energy savings is even greater for large scale applications. Figure 10 shows the layout and capacity of the designed $\mathrm{BIPV} / \mathrm{T}$ system.
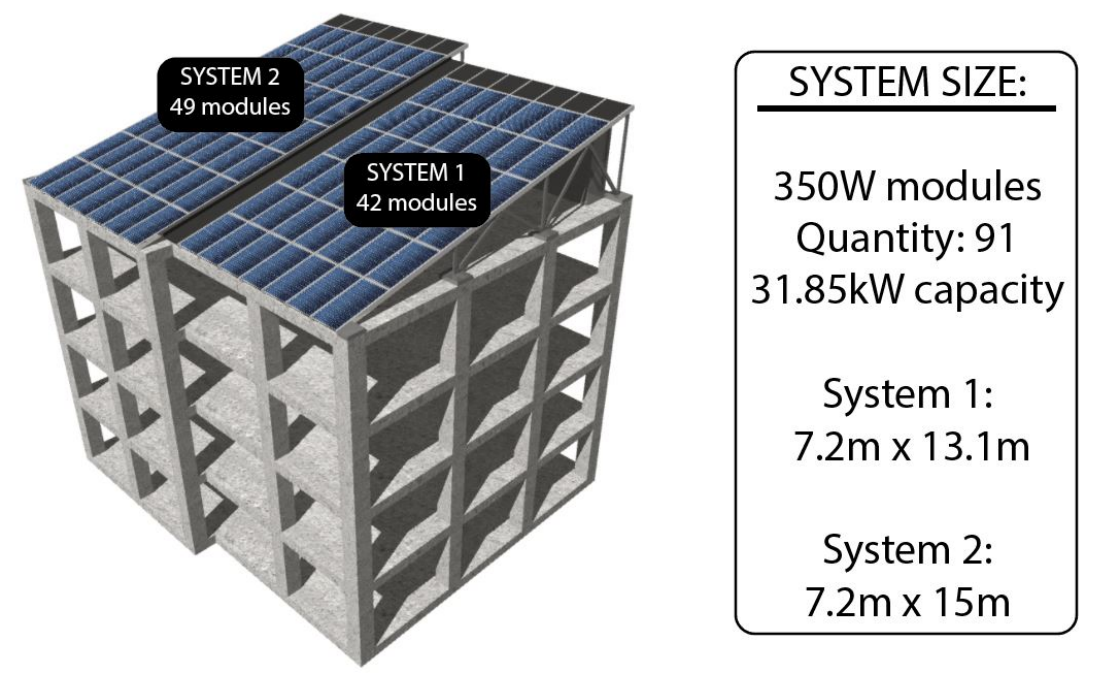

Fig. 10: Size of BIPV/T rooftop system

The focus of this design is on common building practices and previous lack of true integration between façade and PV/T systems. The design offers the potential for modular and unitized designs, primarily for large scale applications, as well as architectural and visual continuity. The mechanical equipment sizing is ongoing, so available area for this was determined under the system (Figure 11).

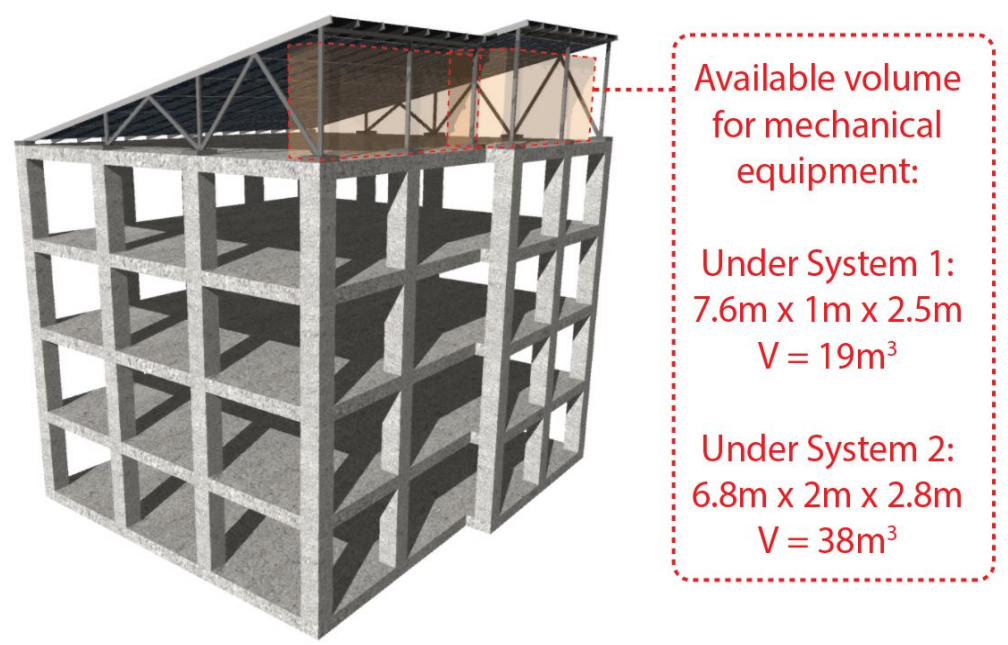

Fig. 11: Available area under BIPV/T system for mechanical equipment 
Figure 12 shows an architectural section through the BIPV/T roof, indicating a simple framing attachment to the reinforced concrete building frame. The sides of the system would be open to allow for some air movement as closing this space with paneling would increase the temperatures between the BIPV/T system and the roof.
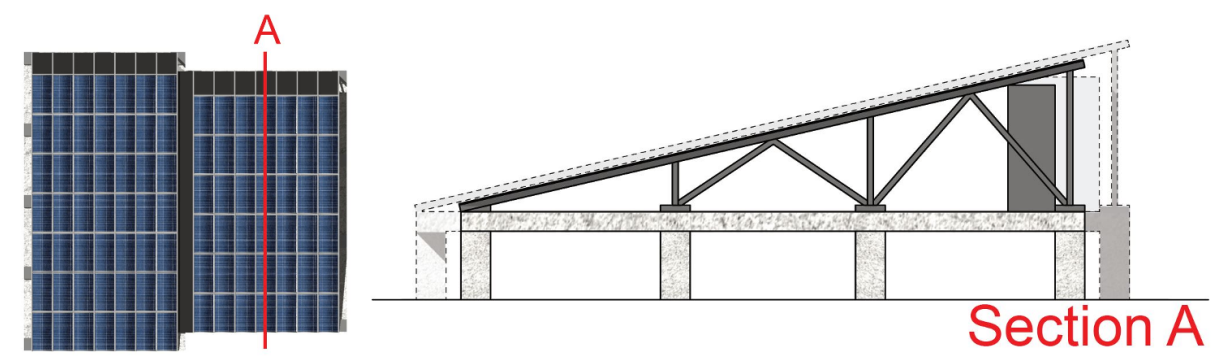

Fig. 12: BIPV/T Plan view (left) and section through the system, framing and building structure (right)

\section{Modeling and Results}

Preliminary performance calculations were performed based on a model validated with the experimental results of prototype testing. For a roof coverage of $180 \mathrm{~m}^{2}$ and average summer day conditions in Chennai, India, a typical system would have an electrical output of $147 \mathrm{kWh}$ and a thermal output of $228 \mathrm{kWh}$. Figure 13 shows the total monthly values of electrical output, with a conservative inverter efficiency of $85 \%$. Maximum outlet temperatures of the air passing through the air channel would be over $60^{\circ} \mathrm{C}$ for more than 5 hours throughout the day. A glazed solar thermal collector added to the end (top) of system could further boost air temperatures to over $70^{\circ} \mathrm{C}$, at which point the air can be used for an absorption cooling system. These values were based on a design that included 9 strings of $10 \mathrm{PV}$ modules each and which had a capacity of $27 \mathrm{kWp}$, less than the final design shown in the previous section.

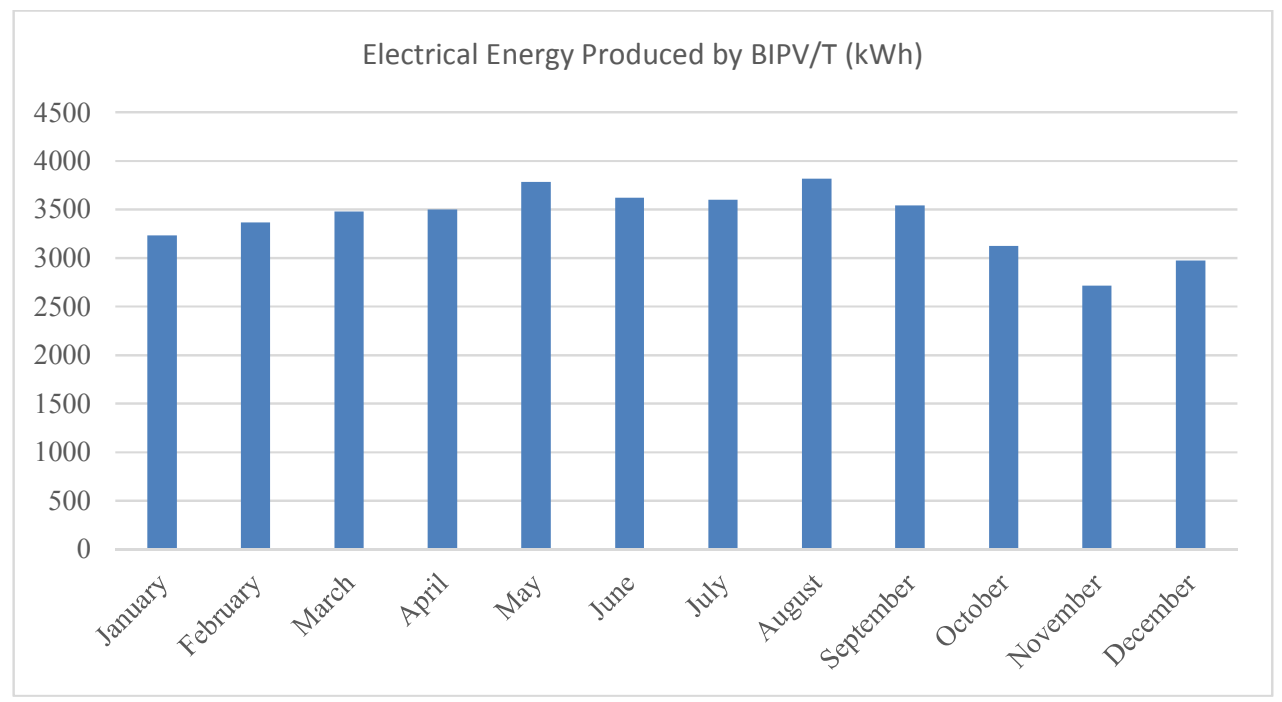

Fig. 13: Monthly electrical production (AC) of the BIPV/T system ("PVWatts Calculator," n.d.)

Figure 14 shows the PV electrical production offset from the initial energy demand of the building. The values shown are for a base case scenario, without improved insulation, fenestration, airtight design, and a properly controlled cooling system. As the project progresses, passive design strategies will be implemented prior to the $\mathrm{BIPV} / \mathrm{T}$ system. 


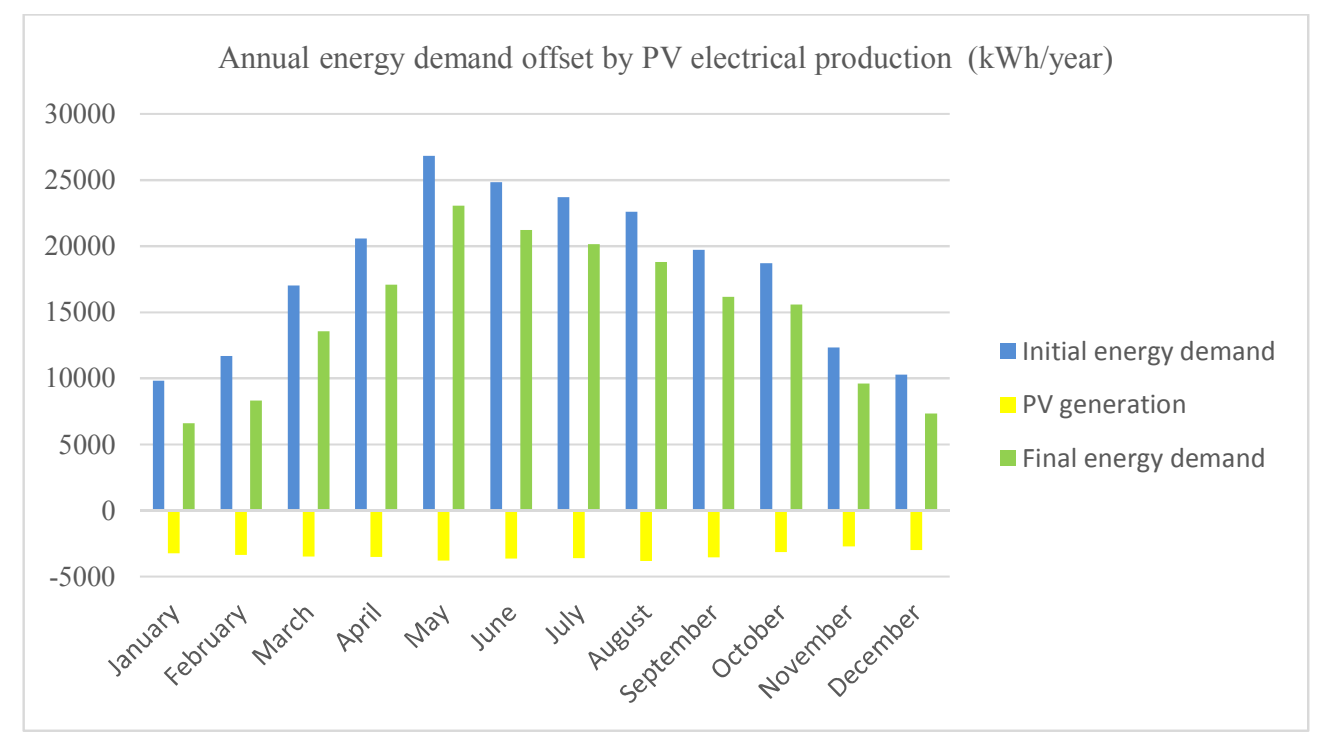

Fig. 14: Monthly totals of building energy demand before (blue) and after (green) addition of BIPV/T electrical energy production (yellow)

\section{Conclusion and Future Work}

A lightweight BIPV/T system has been introduced as a solution to provide local, affordable energy for low-rise, mixed-use buildings in India. A system covering a roof of approximately $180 \mathrm{~m}^{2}$ can produce up to $147 \mathrm{kWh}$ of electrical energy and $228 \mathrm{kWh}$ of thermal energy on a typical summer day. The heat extracted can be used in a thermally driven cooling system. However, it is important to reduce building energy loads by passive design strategies prior to implementing energy generating technologies such as BIPV/T.

The next step for this project is to calculate the annual electrical and thermal performances of the system if it were characterized as a BIPV/T system. The water storage tank (which takes up approximately $20 \%$ of the rooftop), air collecting manifold and heat exchanger must all be positioned in a way that it does not interfere with the continuity of the BIPV/T system. Due to the hot climate, any resulting hot air from the system will best be used in a vapor absorption refrigeration system since the building needs to be cooled far more than heated. Additionally, using preheated air directly in the HVAC system would not work for cooling and would raise the indoor relative humidity. Other heat driven cooling systems are currently being researched.

\section{References}

Bambara, J., 2012. Experimental Study of a Façade-integrated Photovoltaic/thermal System with Unglazed Transpired Collector. Concordia University.

Global Solar Atlas [WWW Document], n.d. URL

http://globalsolaratlas.info/?c=19.890723,81.452637,5\&s=13.09,80.27\&m=sg:ghi (accessed 4.3.18).

India Transforms Market for Rooftop Solar [WWW Document], n.d. URL

http://www.worldbank.org/en/news/feature/2017/12/07/india-transforms-market-for-rooftop-solar (accessed 4.3.18).

Kruglov, O., Rounis, E.D., Athienitis, A.K., Ge, H., 2017. Experimental investigation and implementation of a multiple-inlet BIPV/T system in a curtain wall, in: Proceedings of the 15th Canadian Conference on Building Science and Technology. Vancouver.

National Disaster Management Authority, 2013. Seismic Vulnerability Assessment of Building Types in India.

PVWatts Calculator [WWW Document], n.d. . U.S. Dep. Energy, Off. Energy Effic. Renew. Energy. URL https://pvwatts.nrel.gov/ (accessed 9.7.18).

Reinforced concrete portal frame / prestressed concrete - Pujol [WWW Document], n.d. URL http://www.archiexpo.com/prod/pujol/product-89366-1447649.html (accessed 9.7.18). 
Rooftop solar is the fastest-growing segment in India's renewables market — Quartz [WWW Document], n.d. URL https://qz.com/1148332/rooftop-solar-is-the-fastest-growing-segment-in-indias-renewables-market/ (accessed 4.3.18).

Rounis, E.D., Kruglov, O., Ioannidis, Z., Athienitis, A.K., Stathopoulos, T., 2017. Experimental investigation of $\mathrm{BIPV} / \mathrm{T}$ envelope system with thermal enhancements for roof and curtain wall applications, in: Proceedings of the 34th European PV Solar Energy Conference. Amsterdam. DOI 10.4229/EUPVSEC20172017-6BV.3.50.

Shukla, A.K., Sudhakar, K., Baredar, P., Mamat, R., 2018. Solar PV and BIPV system: Barrier, challenges and policy recommendation in India. Renew. Sustain. Energy Rev. 82, 3314-3322. DOI: 10.1016/j.rser.2017.10.013.

Yang, T., Athienitis, A.K., 2016. A review of research and developments of building-integrated photovoltaic/thermal (BIPV/T) systems. Renew. Sustain. Energy Rev. 66, 886-912.

https://doi.org/10.1016/j.rser.2016.07.011. DOI: 10.1016/j.rser.2016.07.011. 


\title{
Semi-virtual tests of a system using exhaust air, grey water and solar heat for domestic hot water and space heating needs of a multifamily house
}

\author{
Antoine Leconte ${ }^{1}$ and Stéphane Moureaux ${ }^{2}$ \\ 1 Univ Grenoble Alpes, CEA, LITEN, INES, F-38000 Grenoble (France) \\ 2 France Air, F-01708 Beynost (France)
}

\begin{abstract}
This paper presents tests results of a large system on a semi-virtual test bench. The tested system aims to provide the heat needed for domestic hot water and space heating of a building with 19 housing units. The three main thermal sources of the systems are the heat recovery on exhaust air, the heat recovery on grey water and solar thermal collectors. Those sources are combined with a heat pump and terminal auxiliary systems. The core part of the system was set up in the test bench: two $1000 \mathrm{~L}$ storage tanks, a $20 \mathrm{~kW}$ heat pump and the controller of the whole system. This real part interacted with a virtual environment emulating the other parts of the system through hydraulic modules. A realistic test sequence has been defined to study the system operations and to assess its performances. Results are promising and lead to the installation of such a system in a real building.

Keywords: Exhaust air heat, Grey water heat, Solar heat, Domestic Hot Water, Space Heating, Multi Family Houses, Semi-Virtual Tests Bench
\end{abstract}

\section{Background and objectives}

Semi-virtual tests aim to create an interaction between a real system to be tested and a virtual environment, completely controlled and driven by a real-time simulation (TRNSYS in this case). Thus it is possible this way to study the system behavior in various conditions.

The tested system in this paper is a large system that provides heat for Domestic Hot Water (DHW) and Space Heating (SH) needs of a multi-family house with 19 housing units in Strasbourg (France). It is based on 3 heat sources:

- EA: Exhaust air heat recovery (with an air/water heat exchanger).

- GW: Grey water heat recovery (with a grey water buffer store).

- SOL: Solar heat (with solar thermal collectors).

Fig. 1 below globally represents the principle of the system and the tests.

The heat from those sources is stored in central tanks. The source with the highest temperature is used in priority. To do so, temperatures from the solar tank (see Fig. 4 below), the grey water tanks and the exhaust air (see Fig. 8 below) are compared to central tanks temperature (see Fig. 3 for instance).

A Heat Pump (HP) draw the stored energy in order to provide heat at the appropriate temperature for DHW and SH. The HP supplies heat to the DHW tank in priority (see Fig. 5 below): the SH tank is heated up only if the DHW tank temperature is above $50^{\circ} \mathrm{C}$. External classical auxiliary systems give the missing heat if the system can't provide all the needs.

Furthermore, if the temperature of the solar tank is high enough for the needs, solar heat can directly feed up the terminal DHW and SH tanks.

Systems based on grey water or exhaust air to preheat DHW tanks in multi-family house already exists, like the SORAYA® system commercialized by France Air (2018). However, to the knowledge of the authors, there has never been system combining the 3 heat sources mentioned above, for DHW and SH needs. The prototype tested here is probably the first of this kind. 


\section{A. Leconte et. al. / EuroSun 2018 / ISES Conference Proceedings (2018)}

The goal of semi-virtual testing of this system is to study the operation of the core system in near-real conditions and to roughly assess its performances for the Strasbourg climate in order to validate its relevance.

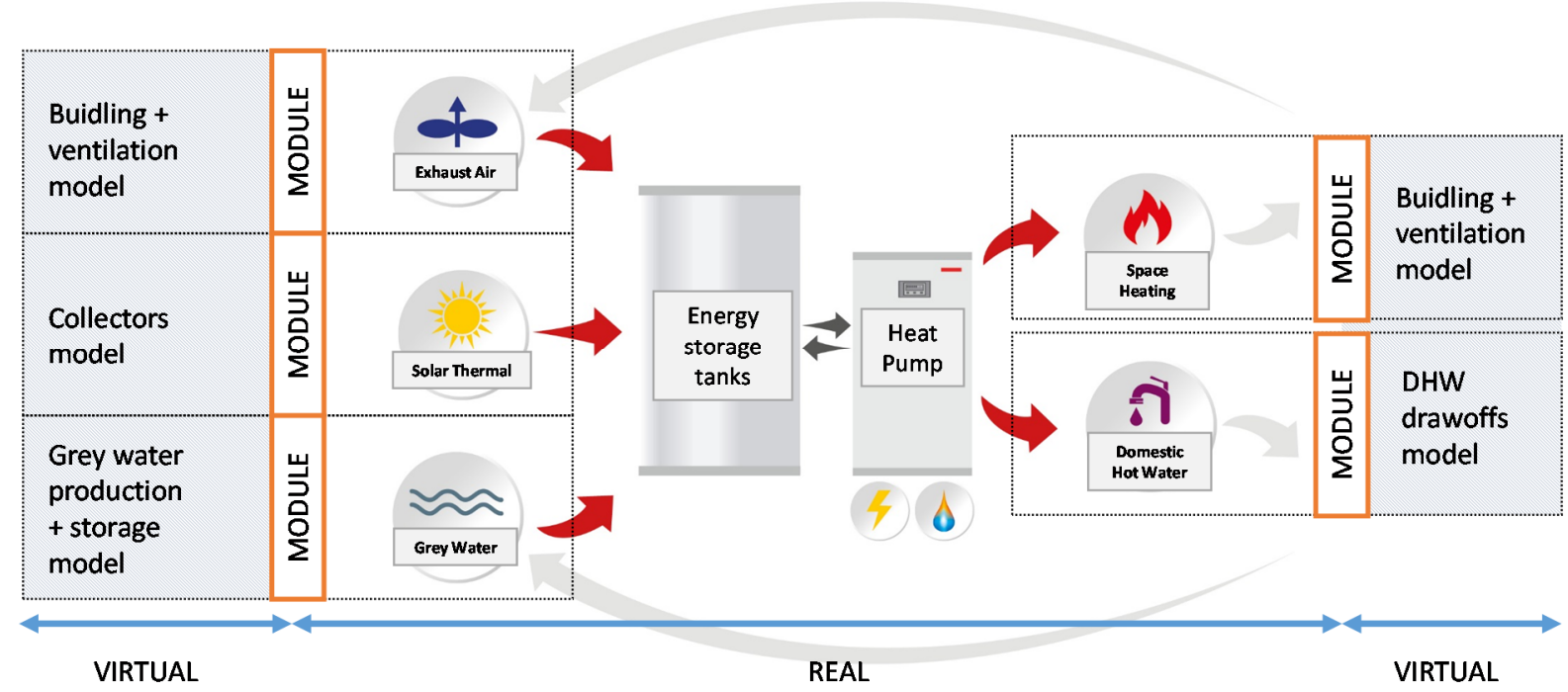

Fig. 1: Global scheme illustrating the principle of the system and of semi-virtual tests

\section{Experimental setup}

For the tests of this system, the core part was set up on the test bench: two 1000L storage tanks, one 20kW heat pump and the controller of the whole system. See Fig. 2 for pictures of the setup.
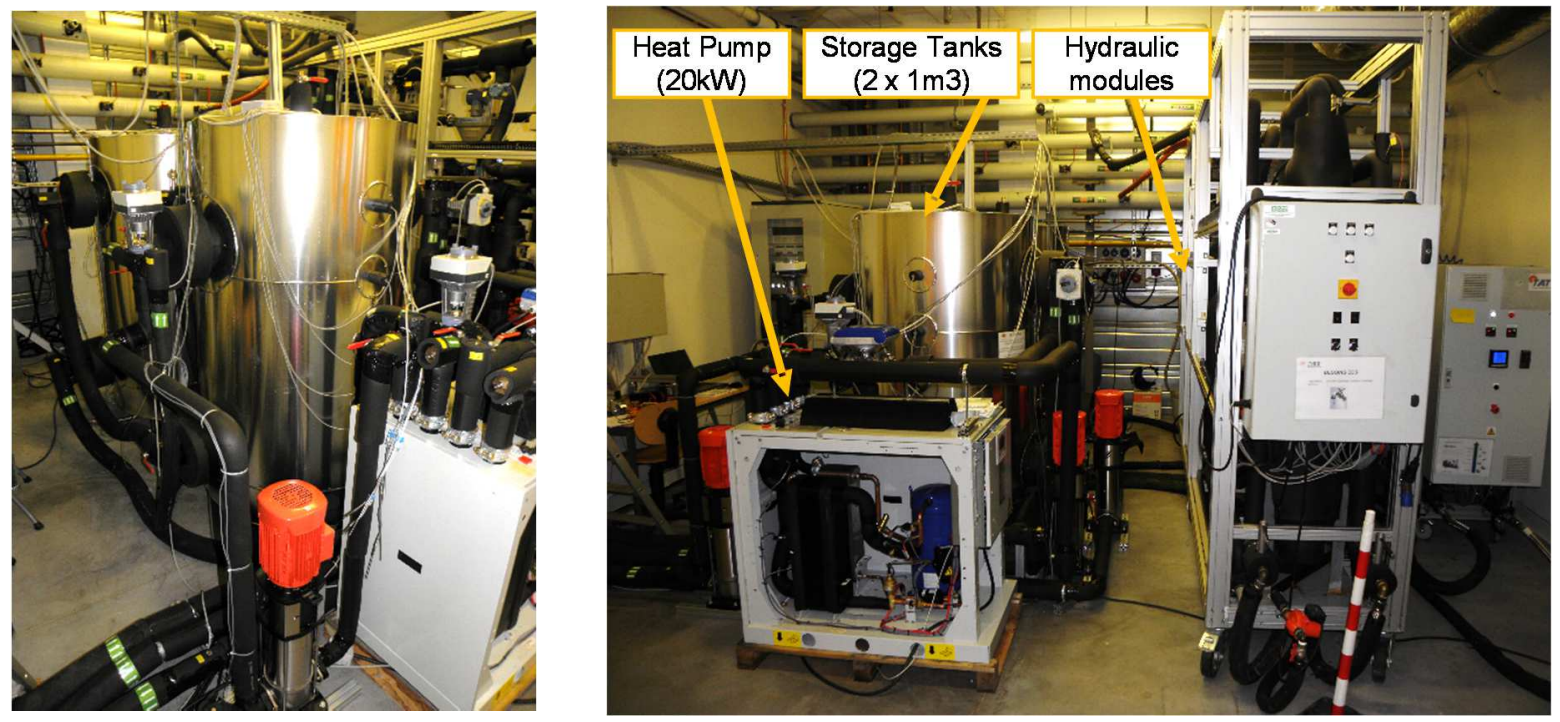

Fig. 2: Pictures of the system tested on the semi virtual test bench

Each hydraulic circuit of the system is connected to modules that reproduce the behavior of the virtual environment as followed:

- At each timestep (1 minute), each module measure the flowrate and the temperature of the fluid coming from the system.

- The values are send to the software that models the virtual environment (TRNSYS in this case, see section 3).

- Based on those values and the assumptions made in the model, the theoretical temperature of the fluid coming back at each circuit is calculated.

- Those results are send as set points to the modules which then provide or withdraw heat from the fluid in order to track the set point temperature. 
- The fluid flows back to the system with the temperatures that it would have had while working with the equipment modeled in the virtual environment.

Hydraulic modules are arranged and combined to meet the power and flowrate specifications of each circuit. The hydraulic diagram and modules specifications are presented on Fig. 3. Considering the foreseen temperature inside the system and for reasons of simplicity, the system was filled with water.

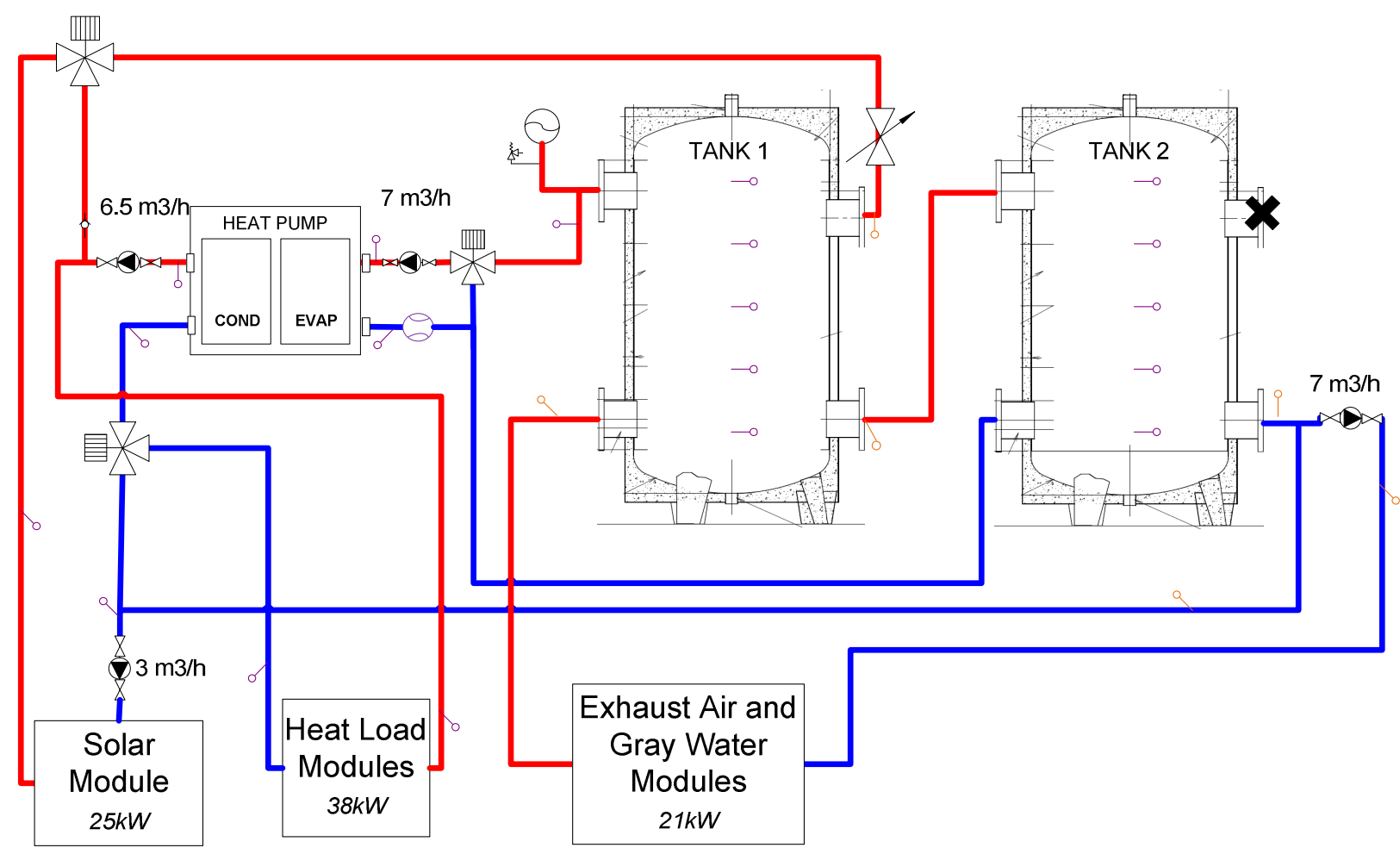

Fig. 3: Hydraulic diagram of the real part of the tested system and modules specifications

Besides, the real controller gathers information from both sides:

- Real measures by its own thermocouples (inside storage tanks and different points of the circuits)

- Measurements from the virtual environment (temperature from additional solar tank and exhaust air for instance) that are reproduced with analog outputs of a resistance box.

Signals and set points from the controller are then:

- Directly transmitted to real actuators (heat pump, pumps, valves)

- Measured and numerically transmitted to actuators of the virtual environment (heat source selection valves and heat load selection valves for instance, see section 3 ).

\section{Definition of the virtual environment}

A detailed TRNSYS model has been developed in order to define the virtual environment of the system during the tests. The goal is to reproduce, through the modules, the behavior of a solar circuit (Fig. 4), the other heat sources circuit (exhaust air and grey water, see Fig. 5) and a heat load circuit (Fig. 8). 


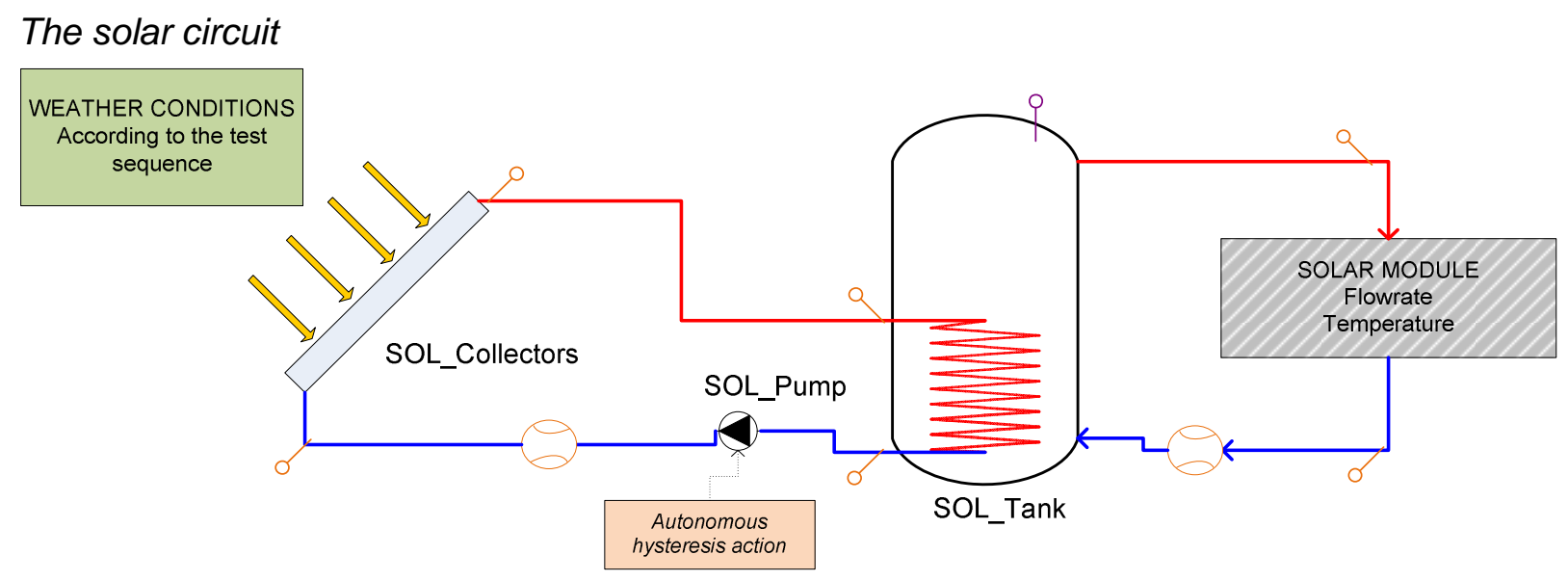

Fig. 4: Hydraulic diagram of the virtual solar circuit

Solar heat is collected thanks to $36 \mathrm{~m}^{2}$ of collectors oriented towards south and tilted of $45^{\circ}$. The performance specification of those collectors are taken from the standard coefficients of the flat plate selective collector defined in the IEA SHC Task 32 (Heimrath and Haller, 2007). The fluid running through the circuit is brine.

A $1.8 \mathrm{~m}^{3}$ tank stores solar heat through an internal heat exchanger, in its lower part, that is characterized by a heat transfer capacity rate of 1800W/K according to (Pelletret R., 1993). The heat losses of the stores are calculated based on the definition of the stand-by heat loss capacity rate in the norm (NF EN 12977-1, 2013).

The heated fluid goes to the system according to the flowrates that are measured on the real setup.

The solar collectors are submitted to the weather variations defined by the selected days (see Section 4). The pump of the collectors loop acts autonomously according to the temperature difference between the collectors and the solar tank (with $[1 \mathrm{~K} 5 \mathrm{~K}]$ as hysteresis thresholds). The fluid flows through the collectors with a fixed flowrate of $1440 \mathrm{~kg} / \mathrm{h}$ when the pump is turned on.

\section{The heat loads circuit}

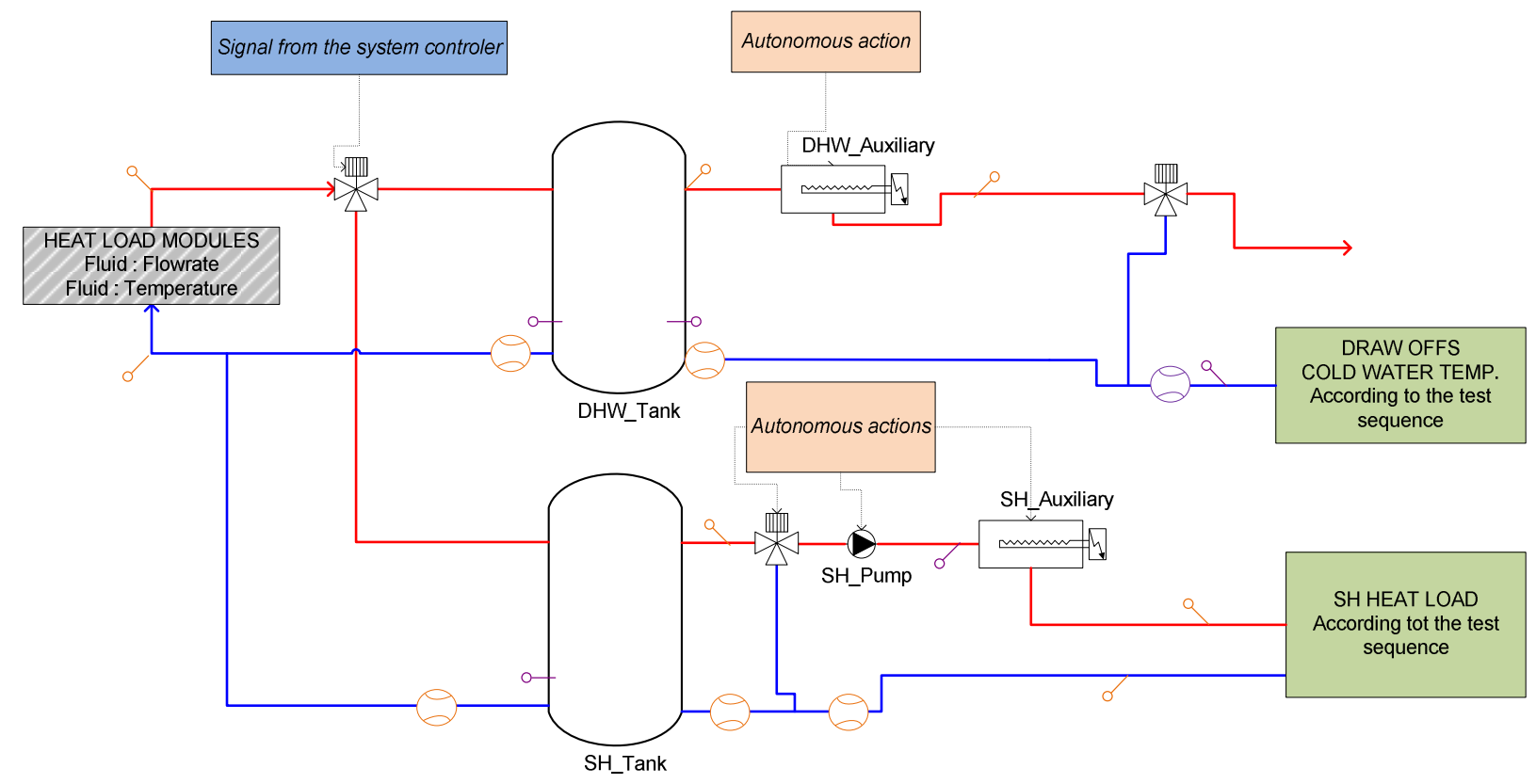

Fig. 5: Hydraulic diagram of the virtual heat loads circuit (DHW and SH)

The heat loads circuit gather the equipment for DHW and SH supplies. The real part of the setup heat up alternately the DHW tank or the SH tanks according to its own controller: the first valve (on the left side of Fig. 5) is oriented in accordance to the controller signals.

The main equipment for the DHW part is a $1 \mathrm{~m}^{3}$ storage tank, a valve that mixes hot and cold water in order to have DHW draw offs at $40^{\circ} \mathrm{C}$ and a theoretical auxiliary system that raises the temperature of the outlet fluid at $40^{\circ} \mathrm{C}$ if needed. As a first simplified approach, neither recirculation loop nor anti-legionella device is considered. 


\section{A. Leconte et. al. / EuroSun 2018 / ISES Conference Proceedings (2018)}

The $\mathrm{SH}$ side is composed of a $1 \mathrm{~m}^{3}$ storage tank, a mixing valve that tracks a heating law and a theoretical auxiliary system that raises the temperature of the outlet fluid if the same heating law is not reached. The heating law is set to have $30^{\circ} \mathrm{C}$ at the heat emitters' inlet when the ambient temperature is $-10^{\circ} \mathrm{C}$. The $\mathrm{SH}$ fluid flows at $3 \mathrm{~m}^{3} / \mathrm{h}$ when there are $\mathrm{SH}$ needs.

The heat load circuit is created to have a model as generic as possible. So, for both sides, the theoretical auxiliary system is considered to be perfect: no heat losses and efficiency of $100 \%$.

DHW needs are derived from the French handbook (ADEME and COSTIC, 2016). The mean daily volume is $2138 \mathrm{~L}$ at $40^{\circ} \mathrm{C}$. A seasonal weight is considered to take into account a seasonal evolution, from 0.72 on day 8 to 1.20 on day 2. The volume is distributed during each day according to a typical MFH draw-offs profile (Fig. 6). The cold water temperature changes every day and is set to the mean temperature of each month suggested for France in the handbook $\left(16^{\circ} \mathrm{C}\right.$ in average over the year).

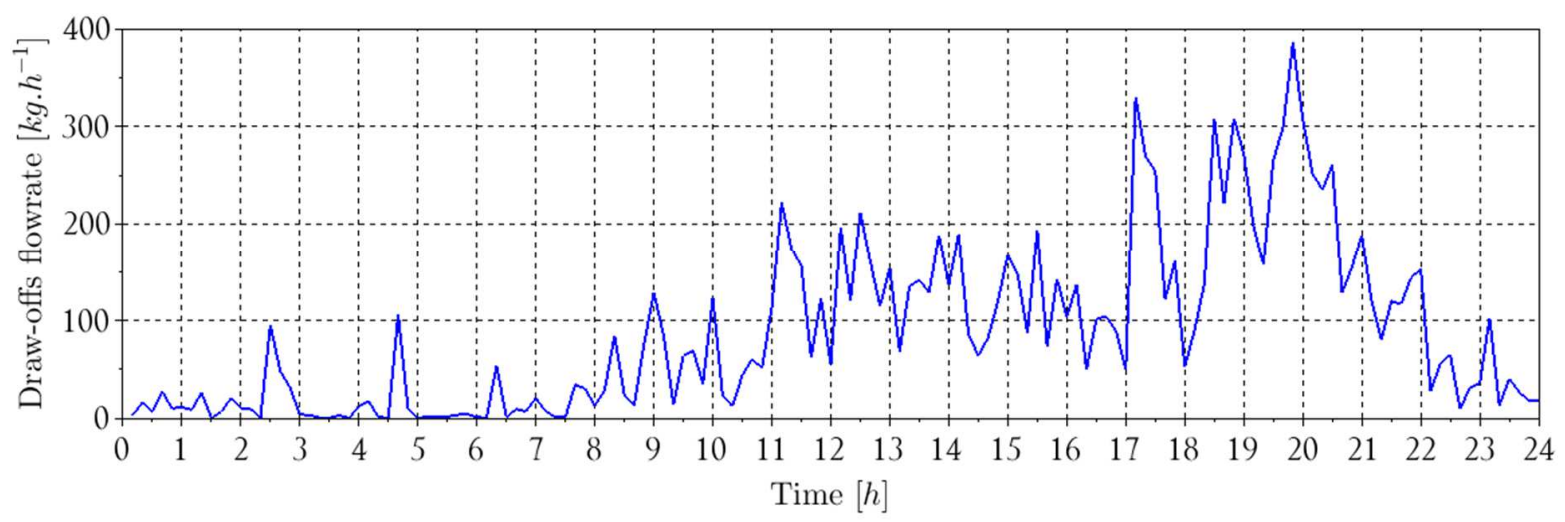

Fig. 6: Reference daily draw offs profile considered in the virtual environment

The SH load profile is defined applying the 12 days climate sequence (see section 4) to the EnergyPlus model of the building that is aimed to host the first prototype of this system (see Fig. 7 below). This building includes 50 housing units. Results are then downsized to fit the test bench specifications (19 housing units).

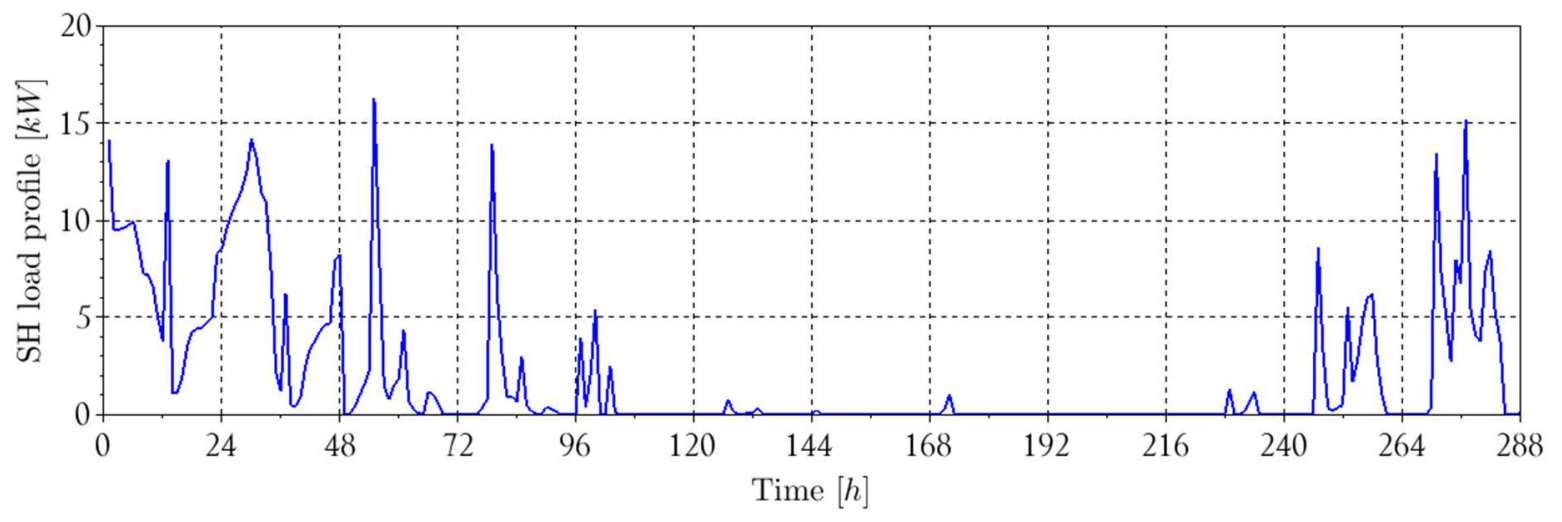

Fig. 7: SH load profile considered in the virtual environment 


\section{The other heat sources circuit}

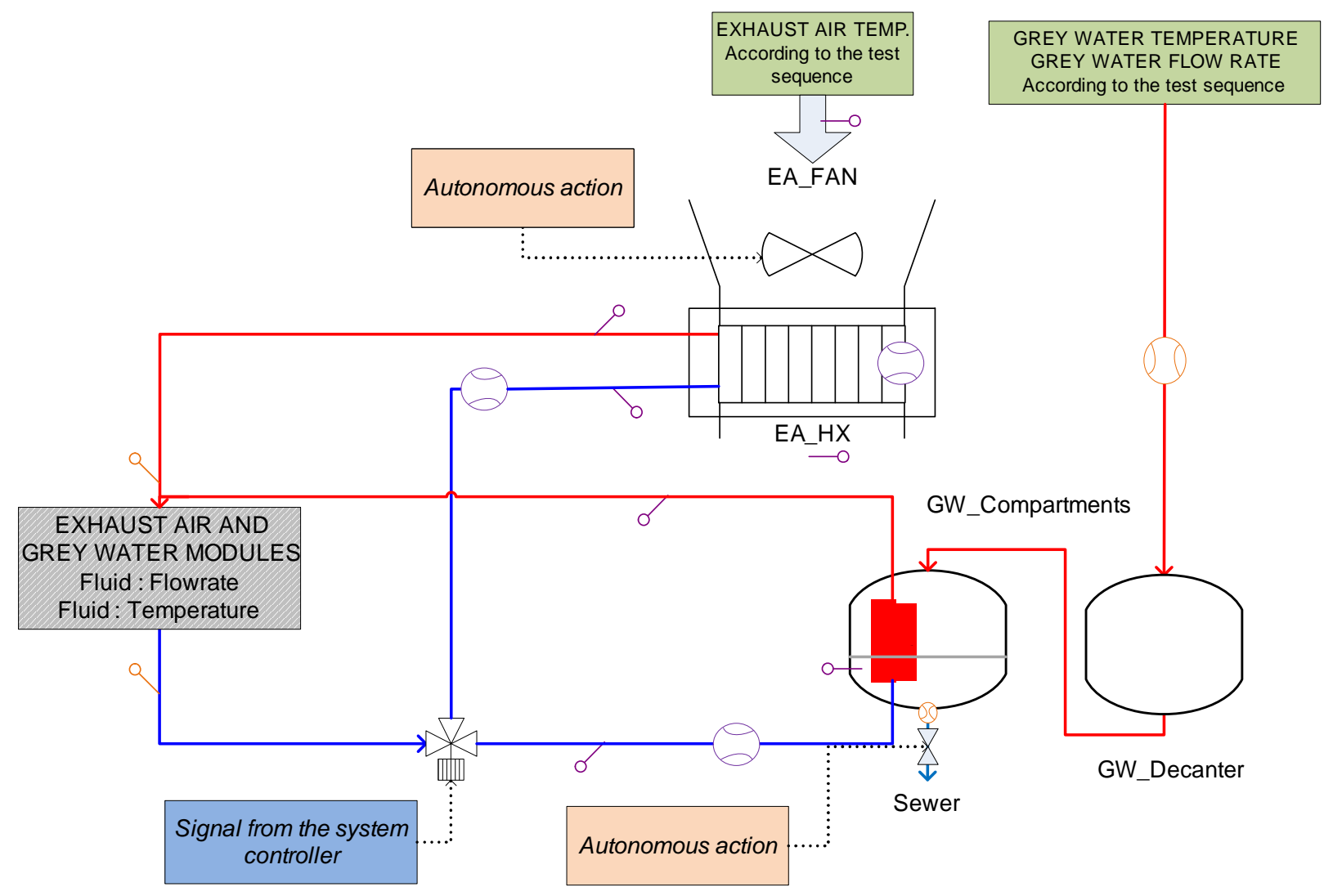

Fig. 8: Hydraulic diagram of the virtual heat sources circuit (Exhaust Air and Grey Water)

The other heat sources enables the real part of the system to withdraw heat alternately from exhaust air flow or gray water tanks. The selection is done according to its own controller: the first valve (on the left side of Fig. 8) is oriented in accordance to the controller signals.

Based on the values of the French thermal regulation for buildings, the total exhaust air of the 19 housing units flows at $844 \mathrm{~m}^{3} / \mathrm{h}$. The heat is withdrawn through a Water/Air heat exchanger that is supposed to be $90 \%$ efficient. The temperature of the exhaust air is taken from the EnergyPlus simulation results, as mentioned above for the definition of SH needs (see results on Fig. 9).

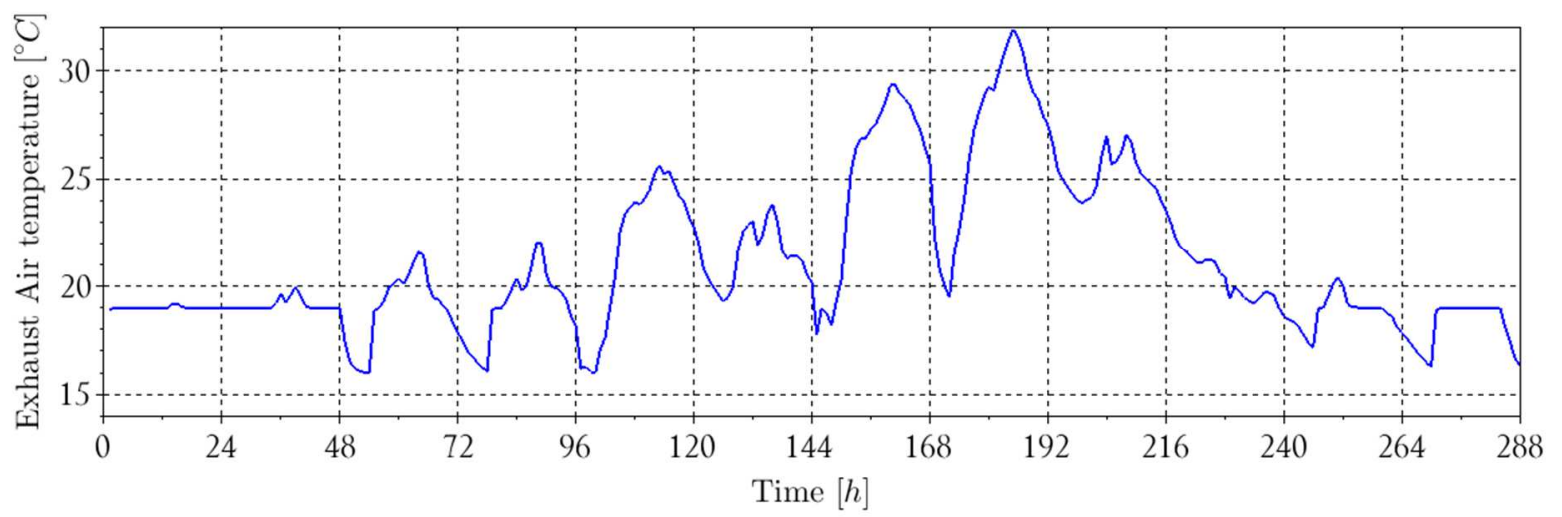

Fig. 9: Exhaust Air temperature profile considered in the virtual environment

The gray water of the building is stored in several tanks with a maximum volume of $0.525 \mathrm{~m}^{3}$ and a total heat loss capacity rate of $11 \mathrm{~W} / \mathrm{K}$. The heat is withdrawn through internal heat exchanger with a maximum heat capacity rate of $908 \mathrm{~W} / \mathrm{K}$. The gray water storage is progressively filled up and flushed once every day. The heat capacity rates are proportional to the filling level of the grey water tanks. According to the expertise of the partners involved in this project, the grey water flowrate is considered as $133 \%$ of the DHW flowrate, at $29^{\circ} \mathrm{C}$. 


\section{Selection of the test days}

During the test, the virtual environment is submitted to weather conditions. So a weather data file had to be created in order to test the whole system. To be appropriate for the objectives of this test, the weather sequence had to be quite short, realistic (with real meteorological evolution), representative of the Strasbourg weather conditions and relevant enough to roughly assess the performance of the system. Thus 12 realistic days had been selected from the Meteonorm weather data file of the "Strasbourg" climate according to the "Short Cycle System Performance Test" method (Albaric et al., 2008).

The SCSPT procedure consists in selecting days from an annual weather sequence in order to make the tested system consume proportionately the same auxiliary energy during the test sequence, as it would consume during a complete year in the same conditions. The selection is based on several simulations of a generic system close to the tested one. The selected 12 days closely matches an annual weather cycle of one precise climate to make the system behave as it usually does over a year.

As a complete generic model of this unusual system has not been developed beforehand, the SCSPT couldn't be properly applied to choose the precise test days for such a system. However, a generic model of a Combisystem with air/water heat pump that provides heat for DHW and SH needs of a Single Family House has been used to select the tests days according to the SCSPT procedure. The modeled system was sized to be proportionately close to the tested system, according to the living area. The selected days for the Strasbourg climate in this case are presented in Tab. 1 below.

Tab. 1: Days selected with the SCSPT method for the Strasbourg climate for a reference Solar Combisystem with air/water heat pump

\begin{tabular}{|c|c|c|c|c|c|c|c|c|c|c|c|c|}
\hline \#Day of the sequence & $\mathbf{1 r}$ & $\mathbf{2}$ & $\mathbf{3}$ & $\mathbf{4}$ & $\mathbf{5}$ & $\mathbf{6}$ & $\mathbf{7}$ & $\mathbf{8}$ & $\mathbf{9}$ & $\mathbf{1 0}$ & $\mathbf{1 1}$ & $\mathbf{1 2}$ \\
\hline \#Day of the year & 20 & 28 & 51 & 88 & 235 & 299 & 184 & 245 & 52 & 309 & 322 & 339 \\
\hline
\end{tabular}

Thus those test days provide realistic weather evolutions that are relevant to analyze the annual behavior of the tested system but the assessed performance in the following sections are only available for this test sequence. The extrapolation of annual performances is not guaranteed here since the method has not been validated for such a system beforehand.

\section{Application of the test sequence and results}

The test sequence has been run for 15 days, with a repeat of the weather data from the $13^{\text {th }}$ day in order to reduce the impact of the initial conditions of the storage tanks on the results.

Firstly the accuracy of the hydraulic modules operations must be assessed. Tab. 2 below represents the global energy difference between the virtual environment and the real system at the bounds of each hydraulic modules. For instance, $-4 \%$ at the "SOLAR" modules means that the module delivered to the real system $4 \%$ less heat than expected by the virtual environment. Those differences are considered acceptable for an appropriate analysis of the system.

Tab. 2: Energy on "virtual" and "real" side of each modules during the test

\begin{tabular}{|c|c|c|c|}
\hline HYDRAULIC MODULES & SOLAR & HEAT LOAD & $\begin{array}{c}\text { EXHAUST AIR AND } \\
\text { GREY WATER }\end{array}$ \\
\hline Energy at the "Virtual" side & $733 \mathrm{kWh}$ & $1216 \mathrm{kWh}$ & $347 \mathrm{kWh}$ \\
\hline Energy at the "Real" side & $705 \mathrm{kWh}$ & $1249 \mathrm{kWh}$ & $335 \mathrm{kWh}$ \\
\hline Global energy difference & $-4 \%$ & $3 \%$ & $-4 \%$ \\
\hline
\end{tabular}

To start the analysis of the system operation, the use of the heat sources (Solar, Exhaust Air, and Grey Water) is presented in Tab. 3 below. For each one of them, a comparison is done between the exploited heat and the maximum heat that could have been collected. The actual collected heat is measured in virtual environments as the heat supposed to be given to the central system. The maximum solar heat collectable is considered as the global solar irradiation on the collector's plane. For the other sources, the maximum heat is calculated considering that all exhaust 
air and grey water were cooled to the minimum reachable temperature in the main stores $\left(11^{\circ} \mathrm{C}\right.$ as set up in the system controller). Results are presented in Tab. 3 below.

Tab. 3: Collected heat and maximum heat for each source during the test

\begin{tabular}{|c|c|c|c|c|}
\hline $\begin{array}{c}\text { HEAT SOURCES } \\
\text { EXPLOITATION }\end{array}$ & SOLAR & GREY WATER & EXHAUST AIR & TOTAL \\
\hline Collected heat & $733 \mathrm{kWh}$ & $231 \mathrm{kWh}$ & $118 \mathrm{kWh}$ & $1082 \mathrm{kWh}$ \\
\hline Maximum heat & $1429 \mathrm{kWh}$ & $715 \mathrm{kWh}$ & $828 \mathrm{kWh}$ & $2972 \mathrm{kWh}$ \\
\hline Energy exploitation rate & $51 \%$ & $32 \%$ & $14 \%$ & $36 \%$ \\
\hline
\end{tabular}

\section{COLLECTED HEAT}

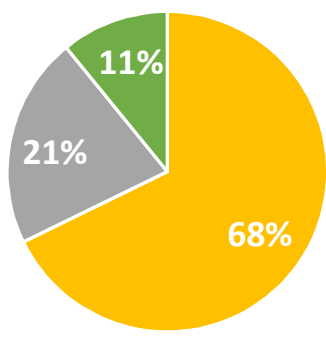

SOLAR

- GREY WATER

EXHAUST AIR

Fig. 10: Share of each source in the global collected heat during the test sequence

As represented by Fig. 10 above, more than 2 thirds of the collected heat is from the solar loop. The solar heat is very well exploited since more than the half of the solar resource is collected. The use of a central heat pump makes the solar heat collected with a quite low temperature level. That increases the solar collectors' efficiency and solicitations. This high global solar efficiency suggests that the collectors' area could even be increased. On the other hand, the other heat sources are less well exploited. Fig. 11 below represents the energy exploitation rates for each day. This figure shows that the use of exhaust air heat and grey water heat is limited by the use of solar heat. In summer days (days 5 to 9), only solar heat is collected. But when no solar heat is available (day 1), more than $70 \%$ of those sources are collected by the system.

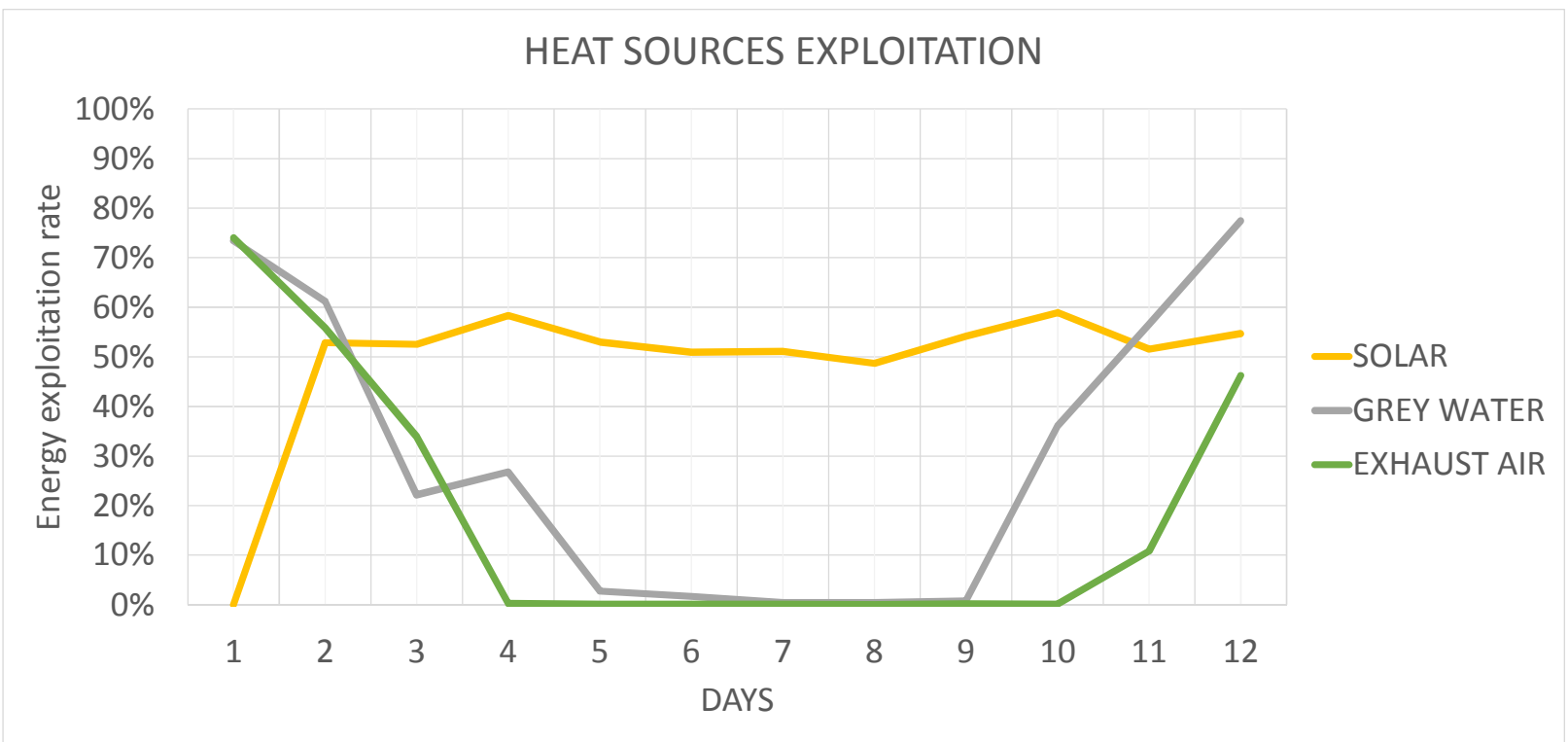

Fig. 11: Evolution of the exploitation rate of each heat source during the test sequence

With the current sizing of the system and its current controller, the solar heat gradually raises the temperature of the central tanks as soon as the heat is available. When tanks temperature is too high (globally above $19^{\circ} \mathrm{C}$ for exhaust air and $29^{\circ} \mathrm{C}$ for grey water), no heat can be collected from the other sources. Fig. 12 below shows that the tanks 
temperature rises up to $30^{\circ} \mathrm{C}$ from the third day thanks to solar heat.

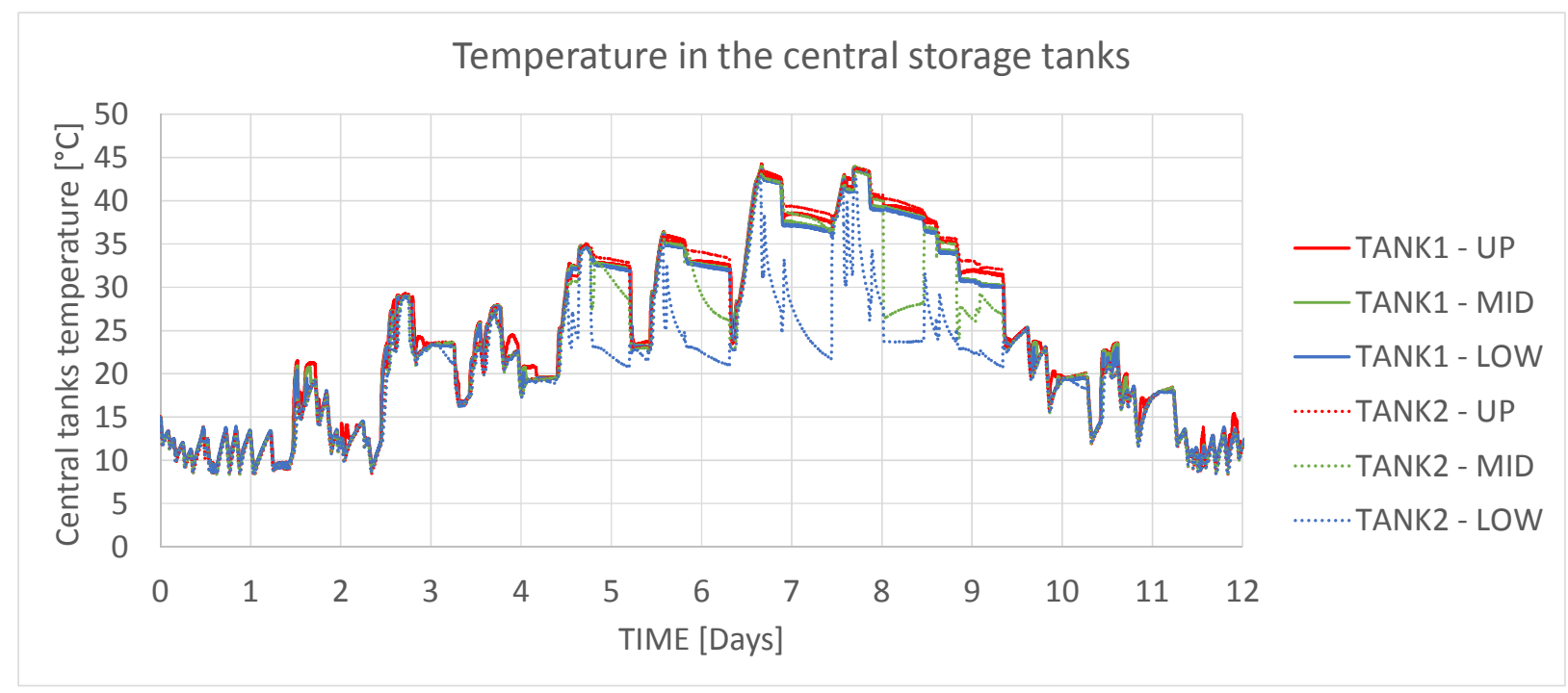

Fig. 12: Evolution of the temperatures measured in the central storage tanks during the test sequence

To complete this analysis, Fig. 13 below shows on the one hand the evolution of the cumulated DHW and SH needs (dotted lines) and, on the other hand, the cumulated energy involved to supply the required needs - i.e. heat collected from the 3 sources (filled area), electricity consumed by the heat pump (dotted area) and theoretical auxiliary energy when the system can't provide the needs (hatched area).

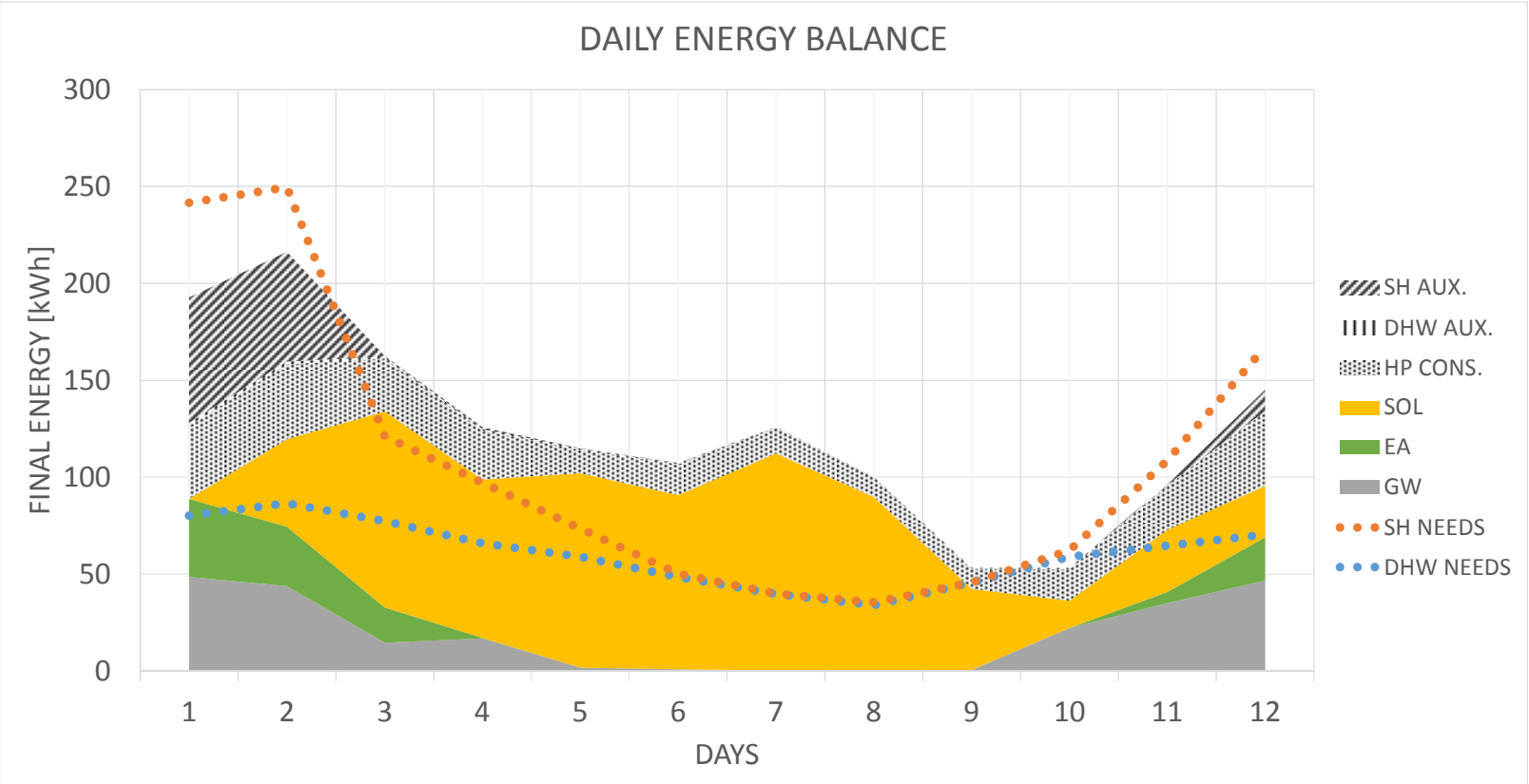

Fig. 13: Daily energy balance during the test

There is a gap between the needs and the global input energy, especially for the first days, that is explained by the initial heat that is stored in the different tanks of the system and the hydraulic modules errors that are a bit larger for these days. The collected heat from the 3 sources during the coldest days, even with a good efficiency, is not enough to meet the energy demand for both DHW and SH. As the heat pump works in priority for the DHW needs, there is almost no need for an external auxiliary in the DHW loop. The SH auxiliary system is mainly requested for days 1 and 2 .

Fig. 13 shows also that the heat pump is requested, even for the summer days with a high solar resource. The system with its actual controller collects a large amount of solar heat but with a low temperature level that is raised by the use of the heat pump. Very few energy is transferred directly from the solar loop to the heat loads tanks.

In those conditions, the heat pump is used with a high Coefficient Of Performance (COP): 4.73 over the whole test sequence. Fig. 14 below represents the daily COP measured during the test. 


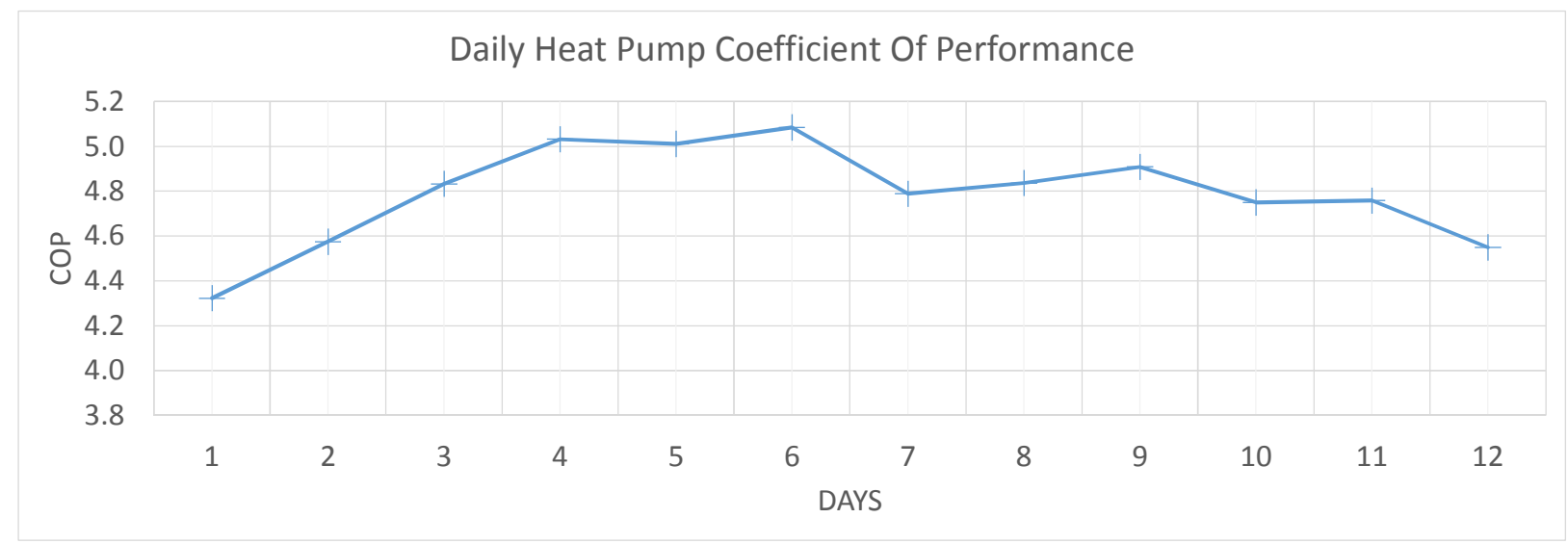

Fig. 14: Daily Heat pump coefficient of performance

Finally, Tab. 4 below focuses on the heat pump consumption, the auxiliary energy and the needs. The heat pump consumption is expressed as a final energy and is split according to its operation mode (SH or DHW mode).

Tab. 4: Final energy consumed by the heat pump and the external auxiliaries compared to the heating needs

\begin{tabular}{|c|c|c|c|}
\hline & SPACE HEATING & $\begin{array}{c}\text { DOMESTIC HOT } \\
\text { WATER }\end{array}$ & TOTAL \\
\hline HEAT PUMP CONSUMPTION & $230 \mathrm{kWh}$ & $39 \mathrm{kWh}$ & $268 \mathrm{kWh}$ \\
\hline EXTERNAL AUXILIARY & $135 \mathrm{kWh}$ & $8 \mathrm{kWh}$ & $143 \mathrm{kWh}$ \\
\hline TOTAL CONSUMPTION & $365 \mathrm{kWh}$ & $47 \mathrm{kWh}$ & $411 \mathrm{kWh}$ \\
\hline NEEDS & $561 \mathrm{kWh}$ & $731 \mathrm{kWh}$ & $1292 \mathrm{kWh}$ \\
\hline
\end{tabular}

On the whole, only $1 \%$ of the heat supplied for DHW needs comes from the theoretical auxiliary. On the SH side, the system can provide $75 \%$ of the heat needed. The other quarter must be provided by an external auxiliary. Considering perfect theoretical auxiliary systems and the global heat pump electrical consumption, the total final energy consumption would represent $32 \%$ of the global needs (see Fig. 15).

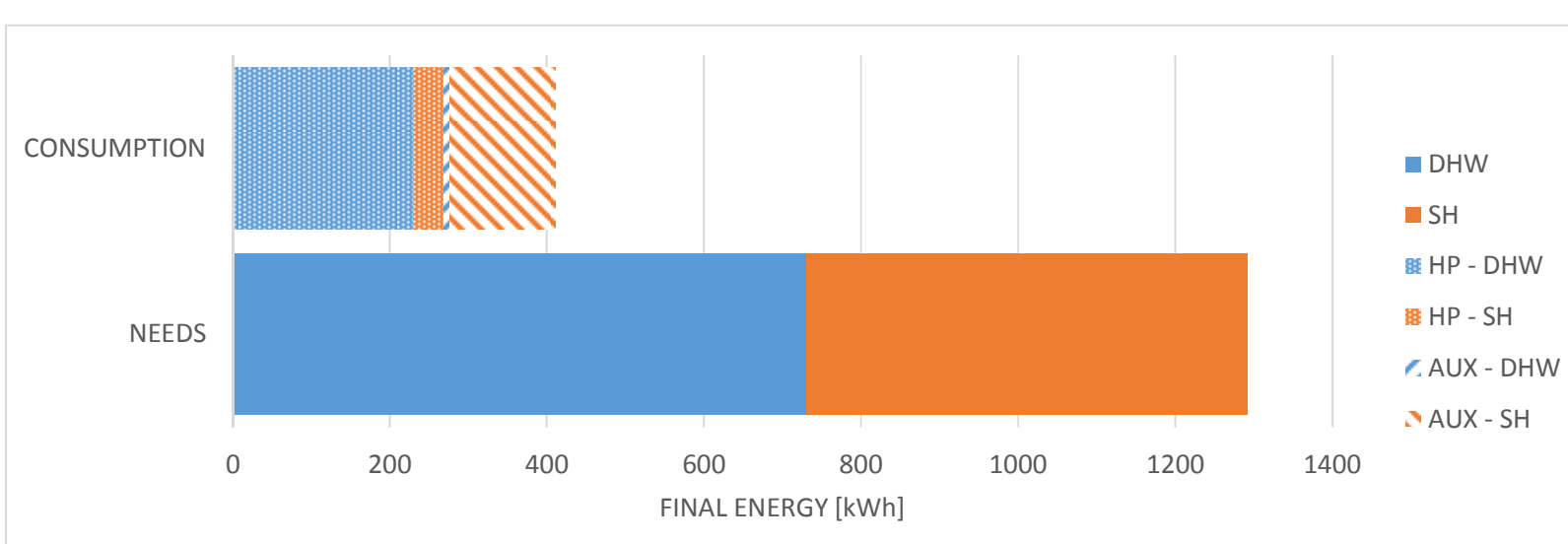

Fig. 15: Comparison between the heating needs and the final energy that would be consumed by the heat pump and the theoretical external auxiliary systems

\section{Conclusion}

A large system based on solar, grey water and exhaust air heat has been set up on a semi-virtual test bench. A 12 days test sequence has been carried on in order to assess the proper functioning of the system.

Based on those tests, the system is deemed relevant and completely operational. The main observations are:

- More than $66 \%$ of the collected heat during the test sequences is from the solar source. Exhaust Air and Gray Water sources are only requested during the coldest days. 
- The heat pump is used with a high Coefficient Of Performance (4.73 over the test sequence).

- Total auxiliary final energy (Heat Pump and theoretical external auxiliary consumption) would represents $32 \%$ of the energy needs.

The observations made through those tests shows also that interesting optimizations can be done like working with higher solar temperatures for instance, in order to favor the use of solar heat directly, and so to avoid the use of the heat pump. That would also leave room for the other heat sources and enhance their exploitation rate.

A larger version of this system will be soon installed on a real multifamily block (50 housing units) in Strasbourg.

\section{Acknowledgements}

This work was supported by the French Agency for the Environment and Energy Management (ADEME).

\section{References}

ADEME, COSTIC, 2016. Les besoins d'eau chaude sanitaire en habitat individuel et collectif - Guide Technique. URL: http://www.costic.com/sites/default/files/upload/telechargements/ECS_MJL_ADEME/besoin-eau-chaudesanitaire-habitat-individuel-et-collectif.pdf (last access: 07/12/2017).

Albaric, M., Nowag, J., Papillon, P., 2008. Thermal performance evaluation of solar combisystems using a global approach. Proceedings Eurosun 2008, October 7-10, Lisbon, Portugal.

France Air, 2018. Système de pré-chauffage ECS-Soraya [On Line]. URL: http://www.france-air.com/secteursdactivite/habitat/habitat-collectif/systeme-de-pre-chauffage-ecs-soraya/ (last access: 27/11/2018).

Heimrath, R., Haller, M.Y., 2007. Project Report A2 of Subtask A : The reference heating system, the template solar system. A report of IEA SHC - Task 32. URL: http://task32.iea-shc.org/Data/Sites/1/publications/task32Reference_Heating_System.pdf (last access: 19/11/2018).

NF EN 12977-1, 2013. Thermal solar systems and components - Custom built systems - Part 1: General requirements for solar water heaters and combisystems.

Pelletret R., 1993. SOLO - Méthode de calcul des performances thermiques des installations solaires de production d'eau chaude sanitaire. CSTB, Valbonne. 


\title{
Thermal monitoring on an earthbag building in Mediterranean continental climate
}

\author{
Lídia Rincón, Ingrid Martorell, Ariadna Carrobé, Cristian Solé, Marc Medrano \\ University of Lleida, Lleida (Spain)
}

\begin{abstract}
Earthbag and superadobe are low-cost and environmentally friendly building techniques that use the raw earth to build structural walls, usually in dome shape. This research analyzes the thermal performance and comfort of an earthbag building located in Mediterranean continental climate by experimentation in real conditions. The monitoring consisted in data collection of air temperature and humidity, horizontal solar radiation, and surface wall temperatures in summer and winter periods, using free floating and controlled temperature experiments. Passive design strategies for winter were tested, such as high thermal inertia of walls and direct solar gain. Natural ventilation was also tested in summer period. Results showed a very stable interior temperature in the earthbag building and the increase of day temperatures due to the direct solar radiation collection through the glassed openings located in the east and south façade. However, the high U-value of the earthbag walls and the lack of internal loads caused the interior temperature to be out from the comfort range, and a heating system was required with an energy consumption of $1-1.7 \mathrm{kWh} / \mathrm{m}^{2}$ per day, in winter. The direct contact of the building with the ground caused a high relative humidity in the dome in both summer and winter periods that could be reduced by using natural ventilation. Night ventilation was a suitable passive strategy in summer period to reduce the average temperature level in the dome.
\end{abstract}

Keywords: Earth building, Thermal comfort, Passive design, monitoring and simulation.

\section{Introduction}

Earthen architecture historically has been widely used for wall construction around the world. According to Minke (Minke, 2012) earth construction has been used for more than 10,000 years. Among the earthen building techniques, adobe is widely spread because is economic, and it is an environmentally friendly and abundantly available building material (Minke, 2000). Adobe construction is associated with low embodied energy, low pollution impacts and low carbon dioxide emissions. This type of construction is also responsible for an indoor air relative humidity beneficial to human health (Ouedraogo, 2012). It is also important to highlight that this type of construction is efficient from a thermal point of view because of the thermal inertia of the earth. Moreover, there is a study (Zhao et al., 2015) which highlights the interest of earthen construction technique as a passive design principle to improve thermal comfort. Earthbag and superadobe count with the advantages of adobe technique but overcome some of the disadvantages. Superadobe is a form of earthbag construction patented and developed by the Iranian architect Nader Khalili who proposed fundamentals rules for the design and building recommendations (Khalili, 1999). Earthbag and superadobe are building techniques that consist in the use of earth-filled sandbags in order to build structural walls, usually in dome shape (Canadell et al., 2016). Among their possible uses, they can be a good solution to temporally emergency housing. Earthbag offers more structural integrity and durability than adobe (Sargentis et al., 2009) and it is four times cheaper compared with conventional techniques (Adegun and Adedeji, 2017). Previous researchs have thermally simulated and monitored raw earthen buildings (Martín et al., 2010, Desogus et al., 2014, Palme et al., 2014 and Serrano et al., 2017), but not earthbag buildings yet. This research analyzes the thermal performance and comfort of an earthbag building located in Mediterranean continental climate by experimentation of a real construction. Passive design strategies are tested, such as the use of high thermal inertia in the enclosure, the capturing of direct solar radiation through the glassed openings and the use of natural ventilation. 


\section{Materials and method}

\subsection{The monitored earthbag building}

The building is constructed with the superadobe technique and dome shape. It has a net floor area of $7.07 \mathrm{~m}^{2}$, a circular plant of $3 \mathrm{~m}$ of diameter and a height of $3.6 \mathrm{~m}$ (Fig. 1). The walls are $32 \mathrm{~cm}$ thick, but the buttress is formed by a double, $64 \mathrm{~cm}$ thick earthbag. The main glass opening is the entrance door, which is facing exactly south $(0.8 \times 2.05 \mathrm{~m})$. Two confronted windows in the east $(0.5 \times 0.7 \mathrm{~m})$ and west $(0.8 \times 0.8 \mathrm{~m})$ facades allow crossed ventilation. The continuous polypropylene bag contains an earthen mixture of on-site earth and construction sand in a 1:1 proportion. Slaked lime in water was used as stabilizer, in approximately $10 \%$ of the total earthen volume. The sieve analysis showed that the earth mixture contained in weight: $0.80 \%$ fine gravel, $92.21 \%$ sand, $3.42 \%$ slime and $3.57 \%$ clay. The earth mixture was manually rammed. The building was exteriorly coated with $4 \mathrm{~cm}$ thick lime mortar.

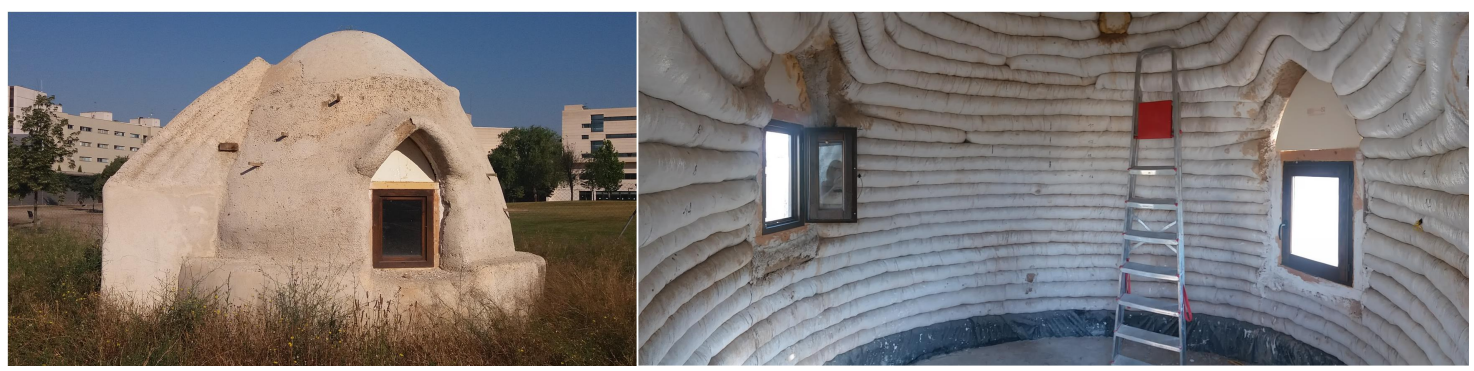

Fig. 1: Earthbag building, University of Lleida Campus, Spain.

\subsection{Experimentation equipment}

The experimental setup consisted of 4 temperature sensors, 1 solar meter, 2 relative humidity sensors and the control and data acquisition systems. Monitoring consisted in data collection of interior and exterior air temperatures as well as interior surface temperatures in both south and north walls. Interior temperature sensor was located in the geometrical center of the dome at $1.50 \mathrm{~m}$ high. North surface wall temperature sensor was located at $1.50 \mathrm{~m}$ high and south surface wall temperature sensor was located at $2.10 \mathrm{~m}$. Temperatures were registered every 5 minutes thanks to a data acquisition system connected to a computer. Air temperature and humidity were measured by Elektronik device model EE210. The experimentation equipment consisted of a data logger (model DIN DL-01-CPU), connected to the adapter data logger-computer (model AC-250). The temperature sensors used were PT100 (TR-M416) for the surface temperature, and for the air temperature are PT-100 class B. The computer software to compile the data was TCS- 01 . When controlled temperature experiments were carried out in winter, a $1500 \mathrm{~W}$ electric radiator was used and its energy consumption was also measured with a Finder E7energy meter. Horizontal solar radiation was measured in all experiments with a KIPP \& ZONEN CMP $6( \pm 2.50 \%$ error).

\subsection{Validation of energy simulation}

Simulated and experimental interior air temperatures in the dome were compared during three weeks of July 2017 for validation purposes (Fig. 2). The energy simulation has been done with Energyplus software and Open Studio. The default heat balance algorithm based on the conduction transfer function (CTC) transformation and 6 time steps per hour for the simulation were applied. The validation showed a good agreement, with an average error along the period of $2 \%$.

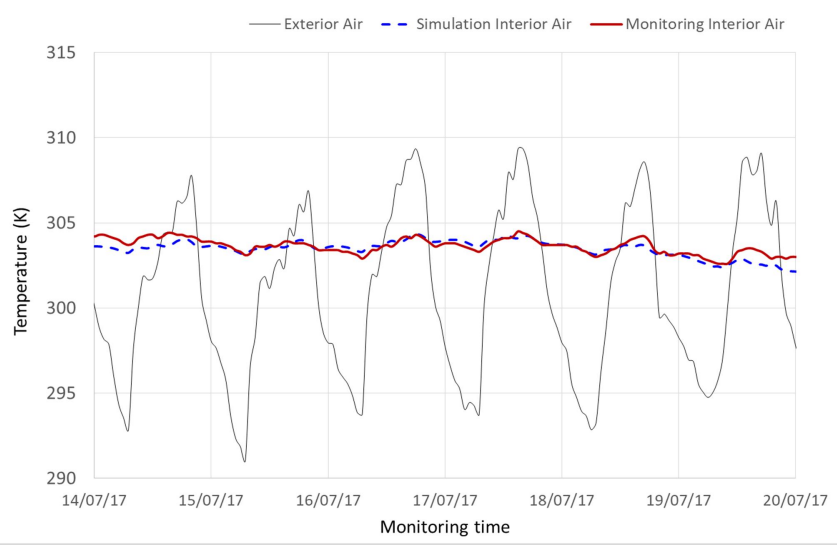

Fig. 2: Simulated and monitored interior air temperatures, free floating in summer period. 


\section{Results}

\subsection{Passive design by using direct capturing of solar radiation}

Experimental free floating temperatures during winter conditions are presented. The daily thermal amplitude is very stable inside the dome of 1.5-3.1 K, while in the exterior the thermal amplitude is much higher ranging from 8.3 to $14.6 \mathrm{~K}$ (Fig. 3). The solar radiation overheats the interior air temperature in the morning, through the east window, and in the midday, through the south glassed door. There is no visible effect in the west window due to the smaller size of that window. The incidence of solar radiation through the glassed openings produces an increase of the maximum temperature even before achieving the maximum temperature in the exterior. That was caused by the greenhouse effect, which increased the thermal amplitude in about $2 \mathrm{~K}$.
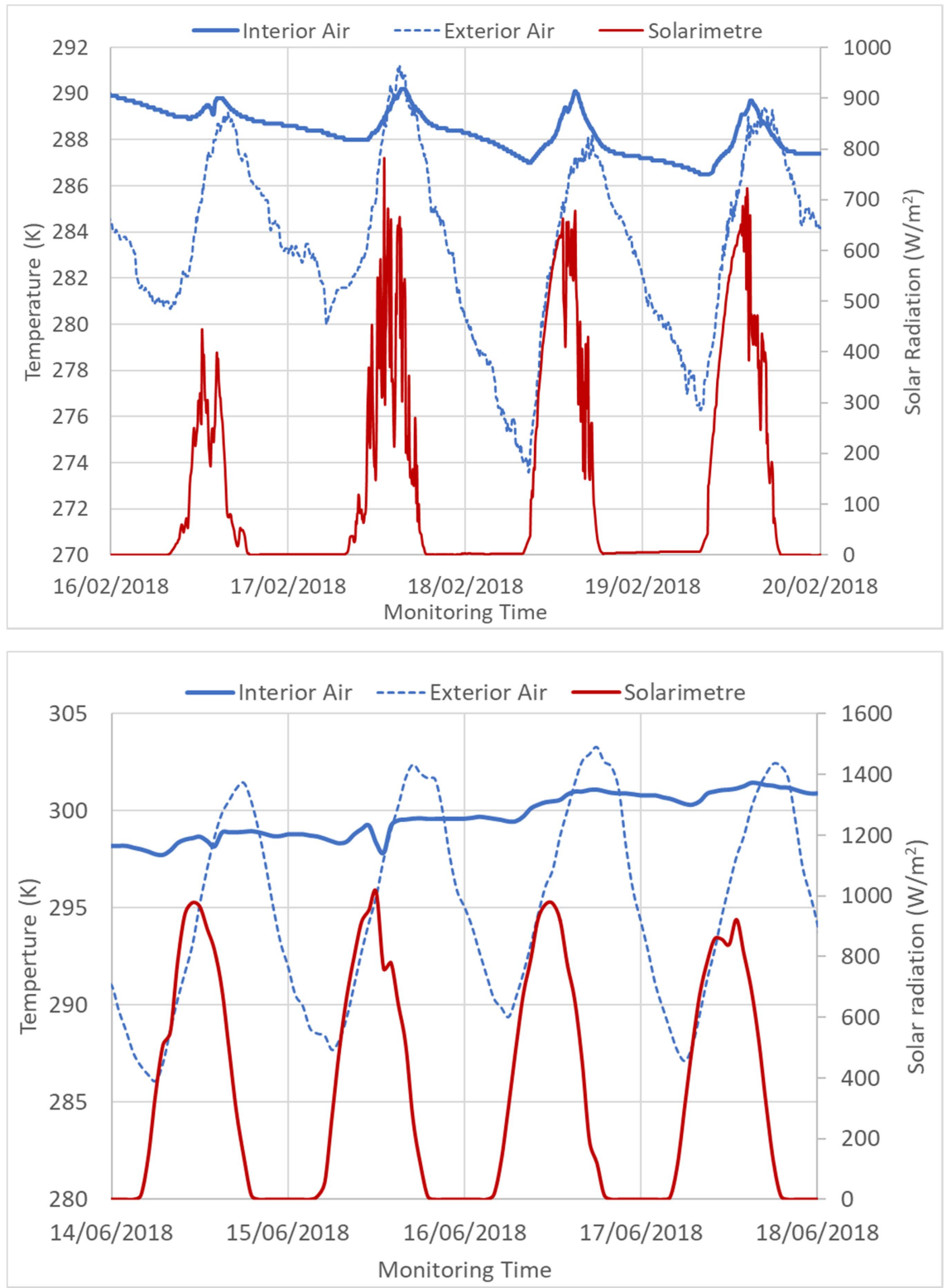

Fig. 3: Interior and exterior air temperature and solar radiation in winter period (above) summer period (bottom).

\subsection{Humidity level in summer and winter conditions}

The humidity level was all year above the comfort range. In summer time, it reached around $76 \%$ of relative humidity and in winter time around $67 \%$ (Fig. 4). It was caused by the direct contact of the building with the ground, which transferred the subsoil humidity to the interior of the dome. In summer period, the humidity level reached a value within the comfort range when natural ventilation was applied. 

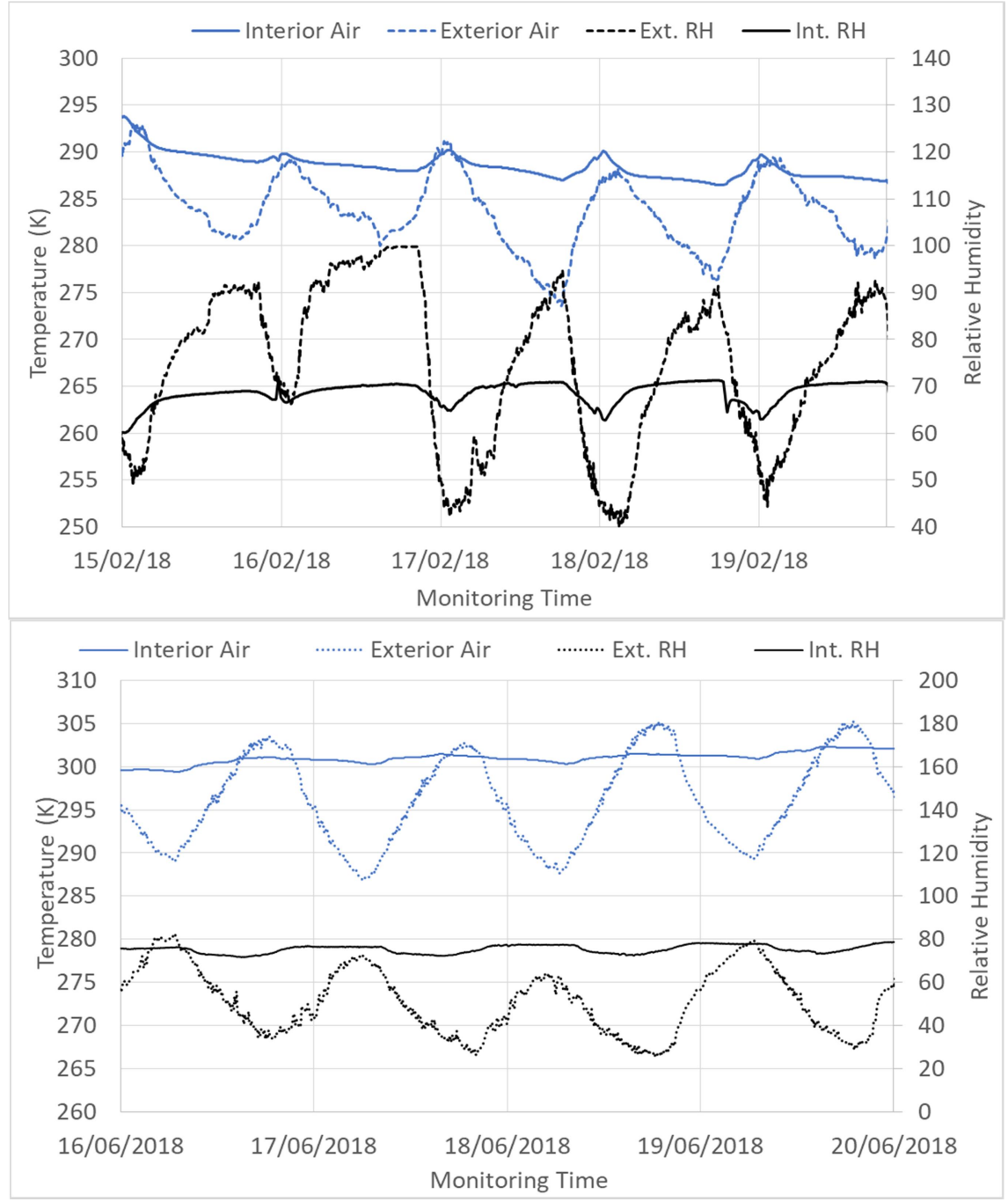

Fig. 4: Humidity and interior air temperature in winter (above) period and summer period (bottom).

\subsection{Effect of natural crossed ventilation}

Two experiments were set up in summer period; one with all day ventilation (Fig. 5) and another with just night ventilation, from 8 PM to 7:30 AM (Fig. 6). Night ventilation decreased the night temperatures over the expected minimum peak night temperature with no ventilation. When the dome is ventilated during all day in summer period, interior temperatures are closer to the exterior temperatures than when it is not ventilated, what produces a higher daily thermal amplitude in the dome, and more hours of discomfort along the day.

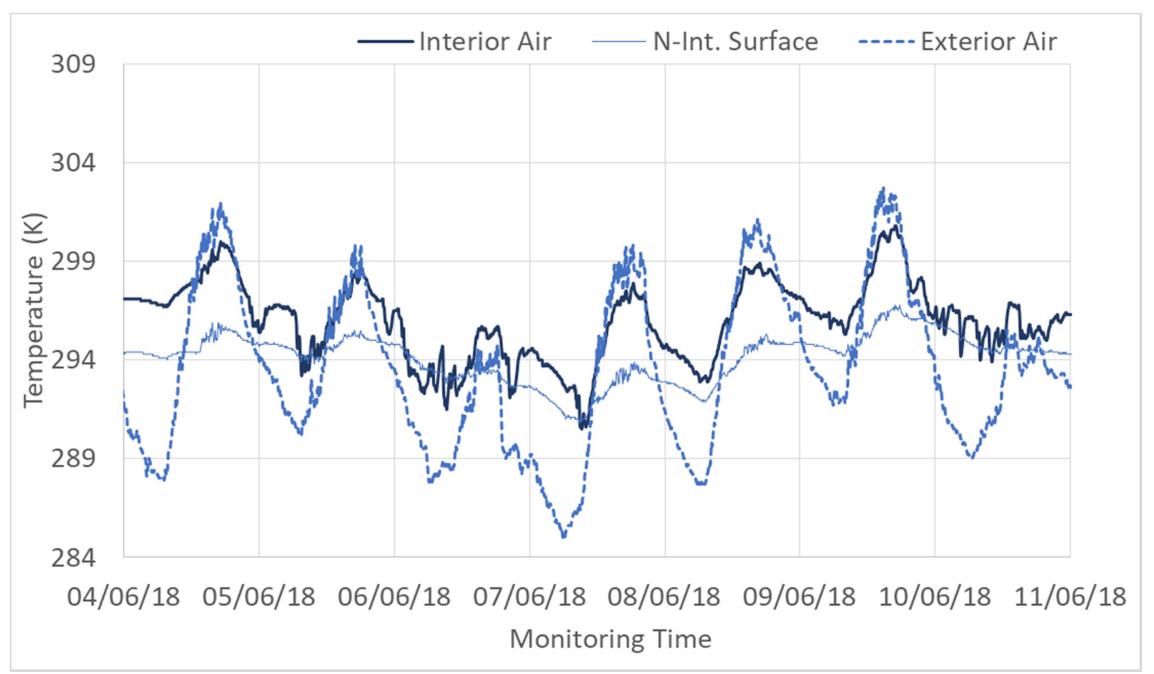

Fig. 5: Interior air temperature during all day ventilation experiment in summer period. 


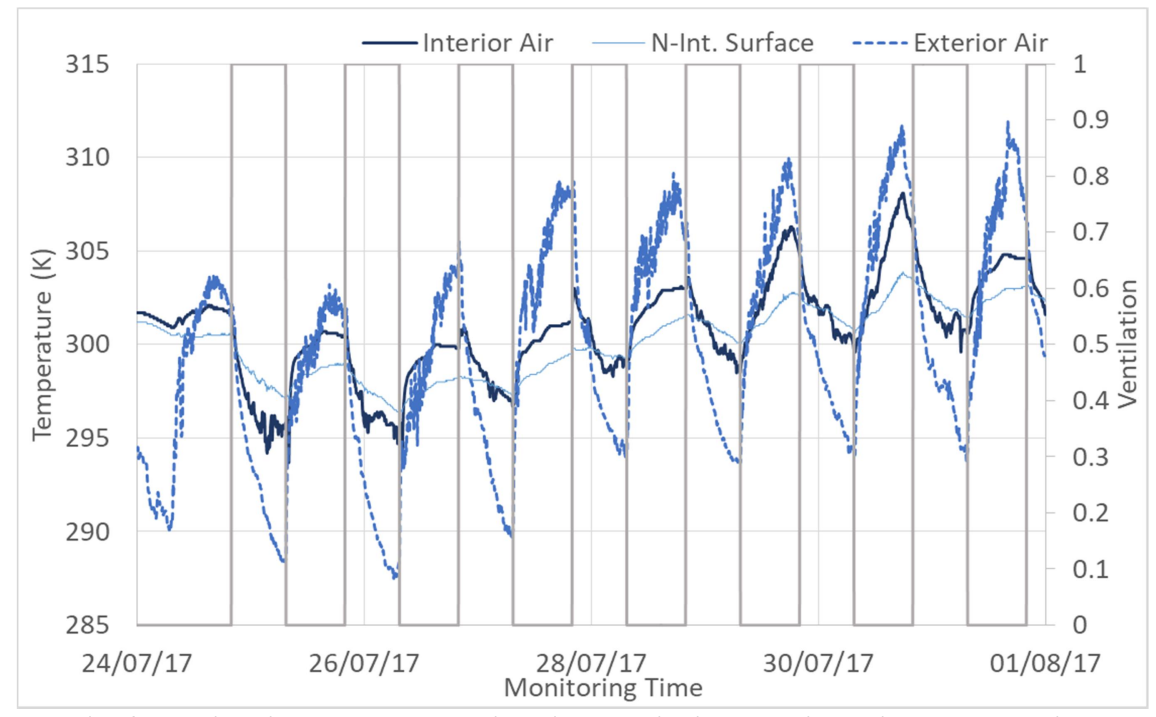

Fig. 6: Interior air temperature during night ventilation experiment in summer period.

\subsection{Heating consumption}

A controlled temperature experiment with a set point of $294 \mathrm{~K}$ was performed during one week in winter conditions. The daily energy consumption for heating ranged between $1-1.7 \mathrm{kWh} \mathrm{m}^{-2}$. It increased proportionally the days with lower temperature and lower solar radiation (Fig. 7).

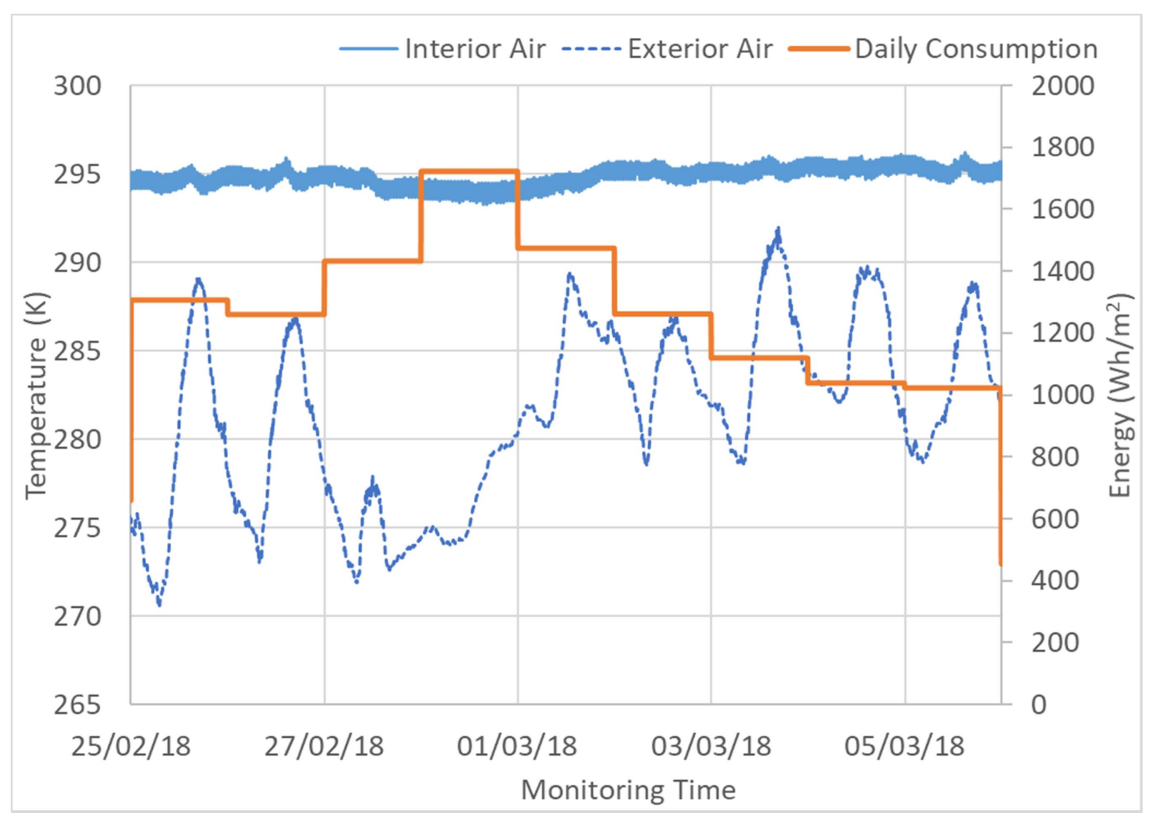

Fig. 7: Controlled temperature in winter period.

\subsection{U-value calculation}

During winter period, 3 foggy days in December 2017 with exterior air constant temperature and controlled temperature with a set point of $294 \mathrm{~K}$ allowed to calculate the overall heat transfer coefficient of the earthbag walls (TESTO 2017) (Fig. 8). According to eq. 1 and considering an interior surface thermal resistance of $0.13 \mathrm{~m}^{2} \mathrm{~K} \mathrm{~W}^{-1}$ (CTE 2013), it resulted in a U-value of $2.7 \mathrm{~W} \mathrm{~m}^{-2} \mathrm{~K}^{-1}$. This result is within the conventional U-value range of a rammed earth wall.

$U=\frac{\left(T_{i}-T_{s i}\right)}{\left(T_{i}-T_{e}\right)} * \frac{1}{R_{s i}}$

$\mathrm{T}_{\mathrm{i}}$ : Interior temperature

$\mathrm{T}_{\mathrm{si}}$ : Interior surface temperature

$\mathrm{T}_{\mathrm{e}}$ : Exterior temperature

$\mathrm{R}_{\mathrm{si}}$ : Surface thermal resistance 


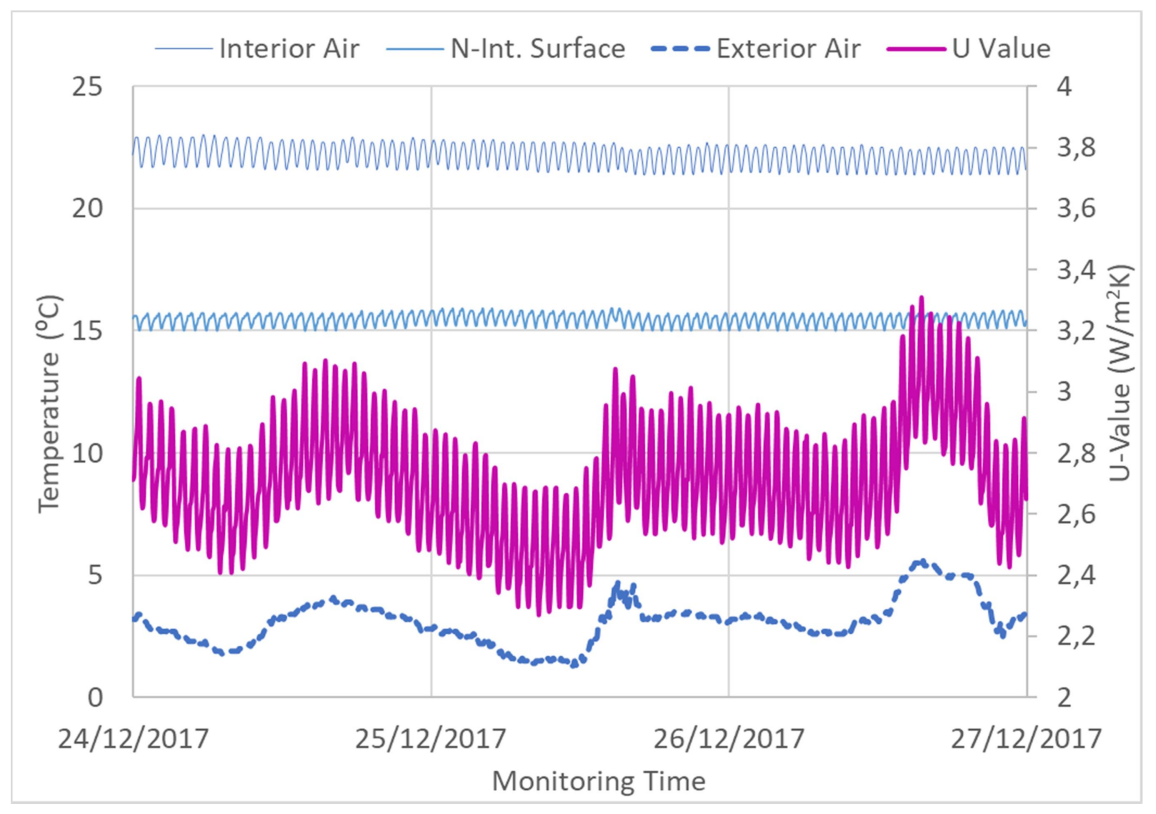

Fig. 8: Monitored temperatures and $U$-value calculation during winter period.

\section{Conclusions}

Passive design strategies in the earthbag building contributed to achieve the thermal comfort in the dome, despite the high U-value of the earthbag walls. Those strategies were, for winter period, the use of high thermal mass to store thermal energy and the capturing of direct solar radiation, and, in summer period, the use of night natural ventilation.

The use of high thermal mass in the building envelope caused a stable interior air temperature along the year, reducing the exterior thermal oscillation from $14.6 \mathrm{~K}$ to $3.1 \mathrm{~K}$ in winter period. Low shape factor and the thermal inertia of the dome floor in contact with the ground would also cause this result.

Direct solar radiation through the east and south glazed openings produced an increase in the interior air temperature, especially during the midday in winter period, what made increase the maximum interior temperature in about $2 \mathrm{~K}$ in winter.

The humidity level in the dome was in winter and summer period over the comfort range and it was caused by the direct contact with the ground, which should be avoided by placing a waterproofing layer.

Night ventilation in summer period was a suitable passive strategy to achieve a lower average temperature inside the dome and reduce the humidity level to a comfort range. However, all day ventilation cannot be recommended because the high exterior day temperatures increase the average temperatures inside the dome.

Despite the passive design strategies, the earthbag building requires in winter period a heating system to achieve thermal comfort levels because the U-value $\left(2.7 \mathrm{~W} \mathrm{~m}^{-2} \mathrm{~K}^{-1}\right)$ of the $32 \mathrm{~cm}$ earth wall is well above the Spanish building code threshold $\left(0.66 \mathrm{~W} \mathrm{~m}^{-2} \mathrm{~K}^{-1}\right)$. In the case of the analyzed building, to achieve a comfort temperature of $294 \mathrm{~K}$, energy consumption in the range $1-1.7 \mathrm{kWh} \mathrm{m}^{-2}$ per day was required.

\section{References}

Adegun, O.B., Adedeji, Y.M.D., 2017. Review of economic and environmental benefits of earthen materials for housing in Africa, Front. Archit. Res. 6, 519-528.

Canadell, S., Blanco, A., Cavalaro, S.H.P., 2016. Comprehensive design method for earthbag and superadobe structures. Mater Design Volume. 96, 270-282.

de la Edificación, Código Técnico. "Documento básico HE Ahorro de energía." CTE, DB-HE (2013).

Guía rápida para determinar el valor U. TESTO 435. www.testo.es Accessed on December 2017.

Sargentis G.F., Kapsalis V.C., 2009. Symeonidis N., Earth building. Models, technical aspects, tests and 
environmental evaluation, 11th Int Con Environ Sci Technol, Chania, Crete, Greece.

Serrano, S., Rincón, L., González, B., Navarro, A., Bosch, M., Cabeza, L.F., 2017. Rammed earth walls in Med. climate: Material charact. and thermal behavior. I. J of Low-Carbon Tech. Open Access, 12, 281-288.

Minke G, Building with Earth: Design and Technology of a Sustainable Architecture, Walter de Gruyter, ISBN: 978-3-7643-7873-8 (2012).

Ouedraogo B.I., Climate change, renewable energy and population impact on future energy demand for Burkina Faso built environment (2012). https://www.escholar.manchester.ac.uk/jrul/item/?pid=uk-ac-man-scw:179799 (accessed May 31, 2018).

Minke G., Earth construction handbook: the building material earth in modern architecture, Wit Press (2000).

Zhao Z., Lu Q., Jiang X., An Energy Efficient Building System Using Natural Resources-Superadobe System Research, Procedia Eng. 121, 1179-1185 (2015). doi:10.1016/j.proeng.2015.09.133.

Martín S., Mazarrón F.R., Cañas I., Study of thermal environment inside rural houses of Navapalos (Spain): The advantages of reuse buildings of high thermal inertia, Constr. Build. Mater. 24 (2010) 666-676. doi:10.1016/j.conbuildmat.2009.11.002.

Desogus G., Di Benedetto S., Grassi W., Testi D., Environmental monitoring of a Sardinian earthen dwelling during the summer season, J. Phys. Conf. Ser. 547 (2014) 012009. doi:10.1088/1742-6596/547/1/012009.

Palme M., Guerra J., Alfaro S., Thermal Performance of Traditional and New Concept Houses in the Ancient Village of San Pedro De Atacama and Surroundings, Sustainability. 6, 3321-3337 (2014). doi:10.3390/su6063321.

Khalili E.N., Earthquake resistant building structure employing sandbags, US5934027A (1999). https://patents.google.com/patent/US5934027A/en (accessed April 6, 2018).

\section{Acknowledgements}

The authors would like to thank the "Oficina de Desenvolupament i Cooperació (ODEC)" of the University of Lleida (UdL), Spain, for the grant projects of 2014, 2015, 2016 and 2017, the "Escola Politècnica Superior" of UdL, the "Consell Social" of UdL for their donatives, Domoterra association and all the students that participated in the construction of the earthbag building. The authors would like to thank the Catalan Government for the project grant (2017 SGR 659) given to their research group. Ariadna Carrobé would like to thank the Catalan government (AGAUR- Generalitat de Catalunya) for her collaboration grant 2017-2018 in the DIEI Department at UdL. 


\title{
Solar seminar room in the University of Balearic Islands with a new advanced radiant system
}

\author{
A. Moià-Pol ${ }^{1}$ \\ ${ }^{1}$ Balearic Island's University- Engineering Group of Building and Energy Management \\ Carretera Valldemossa km 7,5, 07122 Palma de Mallorca (Spain) \\ Phone/Fax number:+34971171374, e-mail: andreu.moia@uib.es
}

\begin{abstract}
The use of Solar Energy in the Solar Seminar Room became more efficient with the combination with radiant systems for the highest renewable fraction, where solar thermal, photovoltaic, geothermal and auxiliary energy with heat pump systems (HP) have been used. The renewable energy is capable to cover all the energy consumption of the year. The net zero energy building needs low embodied energy in the materials with a high insulation. New radiant systems with capillary tube mats and clay in combination with calcium silicate has been used with solar heating and a geothermal system for buildings has been designed to achieve different values of the fraction of a primary energy saving using the Flat Plate Collectors (FPC) for Solar Thermal (ST) and other supply energies like solar photovoltaic (PV) or wind technology, and having the higher efficiency of the system with net zero energy.
\end{abstract}

Keywords: Solar energy, radiant system, Heat Pump, net zero energy building

\section{Introduction}

Radiant heating and cooling systems require considerably less energy consumption than conventional cooling systems. The radiant systems are ideal systems to replace heating and air conditioning in existing buildings or monument-protected buildings, because they have a lower cost in the retrofit and low impact on the construction of such buildings. The solar energy used in the project referred to in table 2. Results below are Flat Plate Collectors (FPC) and a Photovoltaics panel's polycrystalline (PV). FPC is working with less than $40^{\circ} \mathrm{C}$ and arrives to high efficiency with high and sufficient comfort in the room. This became possible not only through the progress made in new renewable energy and advanced combisystems, but it has also been significantly improved by construction technologies and techniques. According to the thermal necessities and the weather conditions, the design has to be adapted in each area. Radiant cooling (floor, walls and/or ceiling) is not so often used but with the appearance of high efficiency aerothermal systems they have started to be installed with more frequency, though new constructions cover all thermal necessities (hot water, heating and cooling) with one system, especially at southern countries. The seminar room referred to below was built in the late 80 s, and this new system has been tested in three more places, in a duplex residence in Mallorca and in a monumentprotected building (the "Old Forge") in Ottersburg, Germany, and now in a flat in Palma. 
Table 1. Description of the composition of conventional materials (Hammond \& Jones 2006).

\begin{tabular}{|l|c|c|c|c|r|}
\hline \multicolumn{1}{|c|}{ Material } & $\begin{array}{c}\text { Embodied energy } \\
\mathbf{M J} \text { per kg }\end{array}$ & $\mathbf{\epsilon} / \mathbf{m}^{\mathbf{2}}$ & $\begin{array}{c}\mathbf{C O} \mathbf{~ p e r ~} \mathbf{~ k g} \\
\mathbf{~ k g} / \mathbf{k g}\end{array}$ & $\begin{array}{c}\text { Density } \mathbf{~ k g} \\
/ \mathbf{m}^{\mathbf{3}}\end{array}$ & $\boldsymbol{\lambda} \mathbf{W} / \mathbf{m ~ K}$ \\
\hline Cement Mortar & 1.09 & 18 & 0.18 & 1360 & 0.55 \\
\hline Expanded polystyrene & 88.6 & 18 & 2.55 & 20 & 0.04 \\
\hline Autoclaved aerated concrete & 1.3 & 33 & 0.7 & 1000 & 0.67 \\
\hline Plasterboard & 6.75 & 4.4 & 0.38 & 900 & 0.25 \\
\hline Expanded polystyrene & 88.6 & 6.8 & 2.55 & 20 & 0.04 \\
\hline Gypsum/ plaster & 1.8 & 10 & 0.12 & 1120 & 0.3 \\
\hline & $\mathbf{1 8 8 . 1}$ & $\mathbf{9 0 . 2}$ & $\mathbf{6 . 4 8}$ & $\mathbf{4 4 2 0}$ & \\
\hline
\end{tabular}

Table 2. Description of the composition of alternative materials (Hammond \& Jones 2006)(Rossello-Batle et alt 2016)(skamol).

\begin{tabular}{|l|c|c|c|c|r|}
\hline \multicolumn{1}{|c|}{ Material } & $\begin{array}{c}\text { Embodied } \\
\text { energy } \mathbf{M J} \\
\text { per } \mathbf{~ k g}\end{array}$ & $\mathbf{\epsilon} / \mathbf{m}^{\mathbf{2}}$ & $\begin{array}{c}\mathbf{C O} \mathbf{~ p e r ~} \mathbf{~ k g} \\
\mathbf{~ k g} / \mathbf{k g}\end{array}$ & $\begin{array}{c}\text { Density } \mathbf{~ k g} \\
/ \mathbf{m}^{\mathbf{3}}\end{array}$ & $\boldsymbol{\lambda} \mathbf{W} / \mathbf{m ~ K}$ \\
\hline Mortar of lime and clay & 1.8 & 90 & 0.13 & 1600 & 0.24 \\
\hline Straw bale & 0.91 & 18 & 0 & 100 & 0.18 \\
\hline Clayboard & 0.35 & 26.3 & 0.03 & 1500 & 0.18 \\
\hline Calcium Silicate & 2 & 19 & 2.5 & 300 & 0.06 \\
\hline Clay & 0.3 & 31 & 0.021 & 1900 & 0.59 \\
\hline & $\mathbf{5 . 4}$ & $\mathbf{1 8 4 . 3}$ & $\mathbf{2 . 6 8}$ & $\mathbf{5 4 0 0}$ & \\
\hline
\end{tabular}

The systems with clay and straw are being used again in the construction, within the framework of the search for more sustainable systems, the use of ecological and traditional materials of $\mathrm{km} 0$ and little embodied energy. They are very hygroscopic materials, so they keep the indoor humidity very stable throughout the year. Different radiant systems and materials could be used, in our case an assessment of the embodied energy variations was studied, but finally we have used the lowest impact in the materials to achieve similar insulation with low embodied energy. The proposed materials have 35 times less embodied energy, a $50 \%$ less of $\mathrm{CO}_{2}$ emissions. These materials need more time to be installed and because they are not standard they became more expensive, but in the future the prices will be similar. The calcium silicate is more expensive than the polystyrene but has a high fire resistance and is more hygroscopic, helps to the system to be used for cooling without dehumidification system as recently has been shown ( Moià et alt 2016).

\section{Results}

The system has been installed in the seminar room at the university campus in September 2015. It is composed of the new radiant systems with capillary tube mats in the room (figure 1), a well (geo-cooling system), Flat Plate Collectors, Air-Water Heat Pump, Storage Tank of 300L, PV with a Heat Pump, a ventilation system, the control and data logger systems, as showed at figure 4 (Moià et alt 2016).

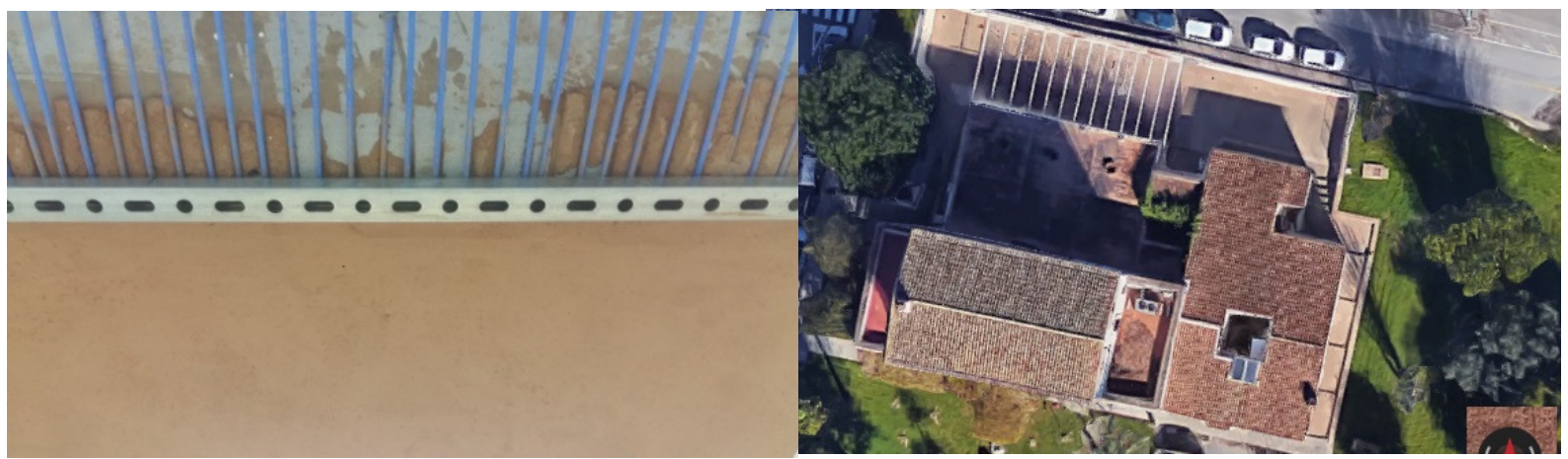

Fig. 1: View of the capillary radiant system and top view of the seminar room

The results have been validated during a two-year data collection. These results are very promising and confirm the simulated results. The most important result is that during all the meetings and conferences the system has 
managed to keep the comfort temperature and control the humidity of the room (about $18^{\circ} \mathrm{C}$ in winter and $26^{\circ} \mathrm{C}$ at summer with $65 \%$ of relative humidity). The heat pump and solar system at winter never work more $40^{\circ} \mathrm{C}$. The large surface of the capillary tube mats helps that the system transfers heating and cooling with temperatures of the ceiling near to $18^{\circ} \mathrm{C}$.

Table 3. - Approximate embodied energy and $\mathrm{CO}_{2}$ emissions for the described ensemble.

\begin{tabular}{|c|c|c|}
\hline & $\mathbf{E E ~}\left(\mathbf{k W h} / \mathbf{m}^{\mathbf{2}}\right)$ & $\mathbf{E C O} \mathbf{2}\left(\mathbf{k g} / \mathbf{m}^{\mathbf{2}}\right)$ \\
\hline Expanded clay concrete & 61,6 & 18,1 \\
\hline Calcium silicate board & 3,9 & 1,3 \\
\hline & $\mathbf{E E ~}\left(\mathbf{k W h} / \mathbf{m}^{\mathbf{2}}\right)$ & $\mathbf{E C O} \mathbf{2}\left(\mathbf{k g} / \mathbf{m}^{\mathbf{2}}\right)$ \\
\hline Polypropylene tubes & 3,3 & 1,7 \\
\hline
\end{tabular}

Table 4: Energy Consumption and $\mathrm{CO}_{2}$ emissions

\begin{tabular}{|c|c|c|}
\hline & Before & New system \\
\hline Electricity kWh/year & 3507 & 330 \\
\hline Kg CO$/$ year & 1708 & 0 \\
\hline Solar Thermal used & 0 & 748 \\
\hline
\end{tabular}

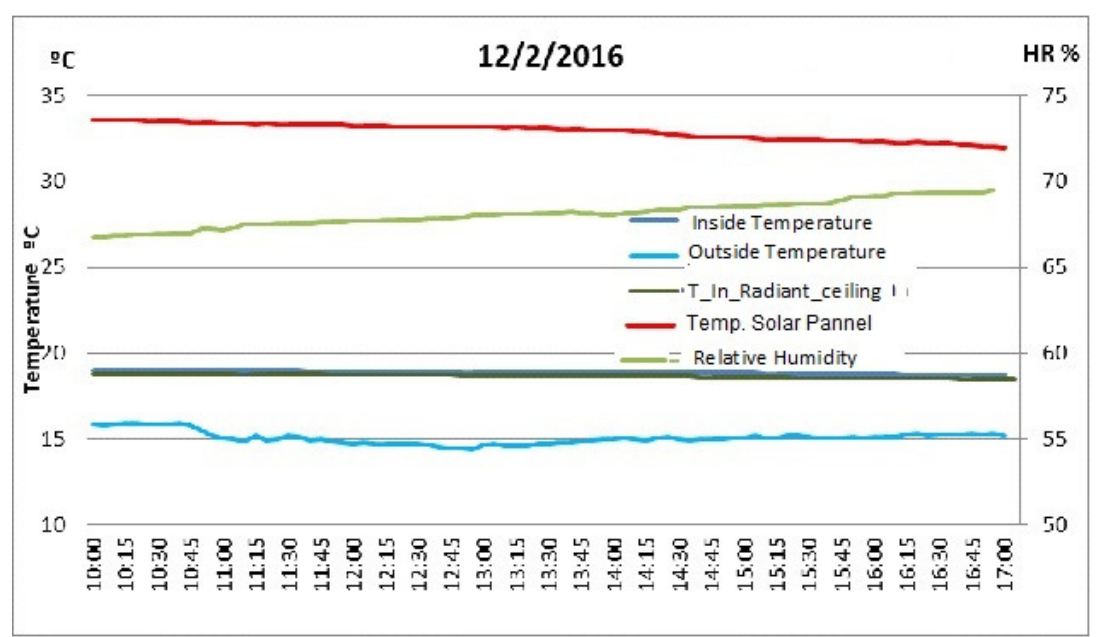

Fig. 2a: Temperatures of the system Heating-winter (12/2/2016)

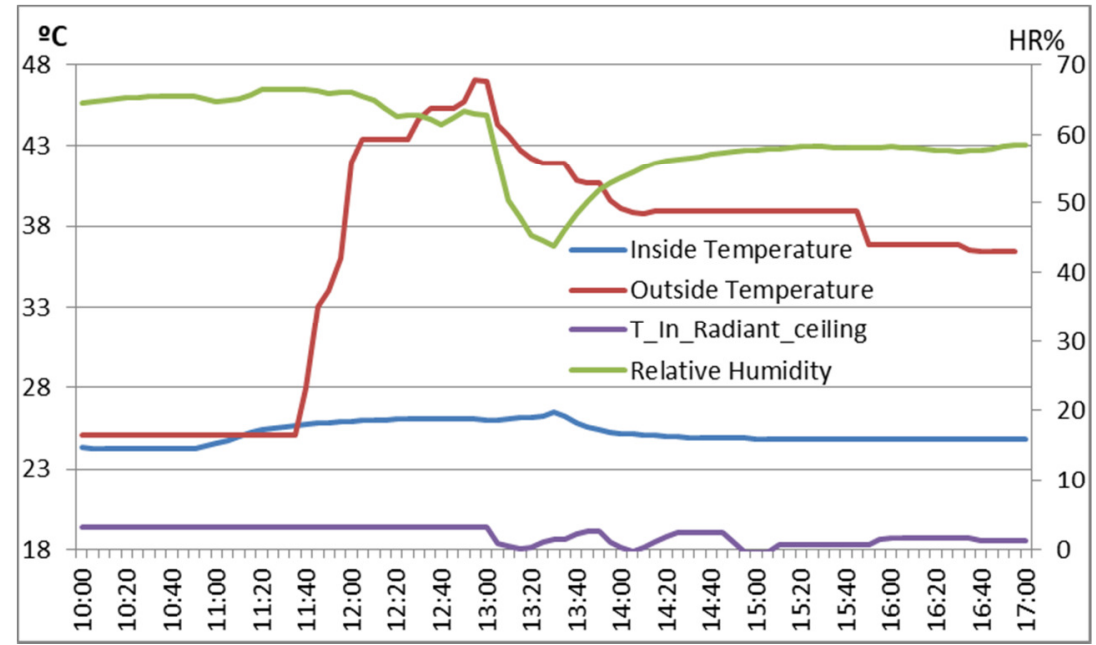

Fig. 2b: Temperatures of the system for Cooling-summer (21/7/2016) 


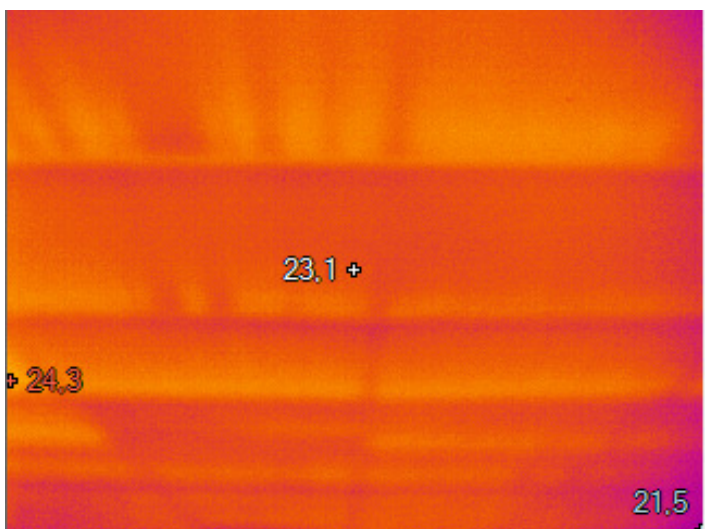

Fig. 3. Thermographic view of the radiant system in autumn

The heat transfer is very uniform in all the room (see figure 3), if the hydraulic circuits are well regulated; each panel has a capillary pipe every $2 \mathrm{~cm}$, with a total of 50 capillaries. Each capillary has a diameter of $3.4 \mathrm{x}$ $0.55 \mathrm{~mm}$, round distribution tube $20 \times 2.0 \mathrm{~mm}$. The new system uses renewable energies during all the year, and a small quantity of electricity is needed for pumps and auxiliary systems. There are more components in the system but a good control and design allows a high reduction of the electric consumption, compared with the old system. As can be seen in Table 3 and Table 4, the installed power of the new system is $50 \%$ lower than before, including the chiller, only necessary for extreme external temperatures (less than $7^{\circ} \mathrm{C}$ or higher than $32^{\circ} \mathrm{C}$ ). In this case the reduction is about the $85 \%$ at summer and $95 \%$ at winter.

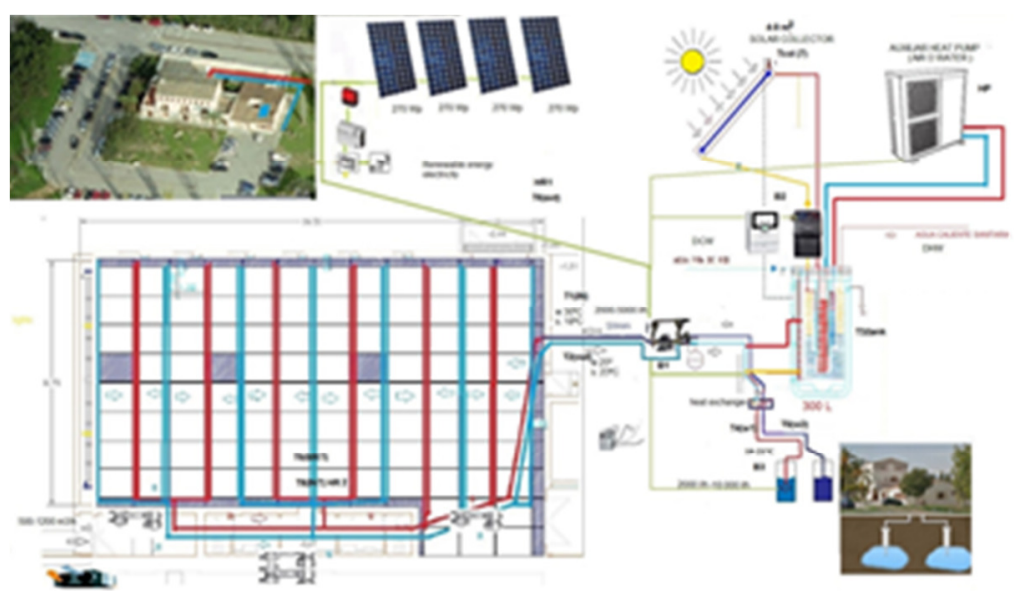

Fig. 4. Design of the system

The radiant system reduces the working temperatures of the system $\left(17-22^{\circ} \mathrm{C}\right.$ in summer and $18-33^{\circ} \mathrm{C}$ in winter $)$ and don't need any fan to transfer the heat, if we compare this with the fan coil, they work with temperatures lower at summer and higher in winter, the design temperatures of the fancoils usually are $7-12^{\circ} \mathrm{C}$ in summer and $40-45^{\circ} \mathrm{C}$ in winter. Only this fact makes increasing the efficiency of the normal FPC and the heat pump about $30 \%$. The new system uses renewable energies during all the year and the little auxiliary energy will be covered by a PV Heat Pump system. 


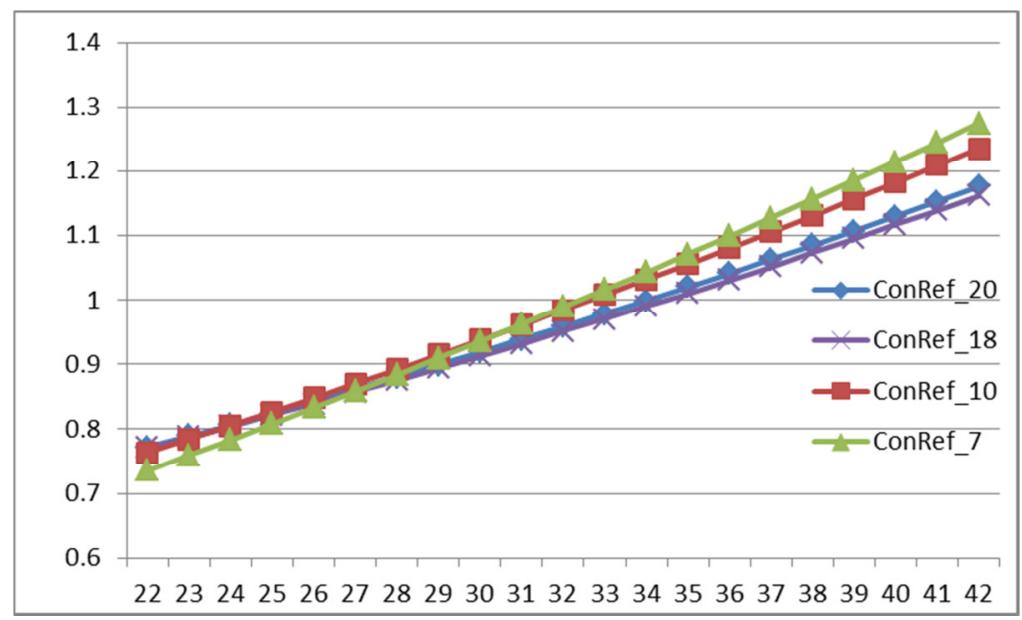

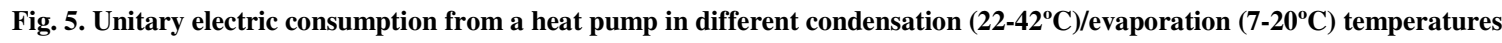
(Moià et alt 2016).

From the real results from October until April, the FPC is used for the heating system, with some support of a heat pump during the coldest days (January-February). The only problem is at summer when the solar thermal collectors have an over production, during 3 months they have stagnation problems. In order to avoid this in the future there will be installed a seasonal storage, according to the results it will be dimensioned for storage of the energy for the winter.

The cooling ceiling is working with $17^{\circ} \mathrm{C}$ and doesn't need any dehumidification, due to the calcium silicate, which avoids condensation when it is working below the dew point and recovers all the latent moisture, once the system is off and the ventilation on.

\section{Conclusions}

With the new system a $90 \%$ of the energy costs have been reduced. Radiant cooling energy savings have per se a 30\% saving compared to conventional systems (Fan coils or split) and can work with optimal temperatures for geothermal and Solar thermal energy. PV will provide the little energy consumption of the new system.

- The system cools with a minimum impulse temperature of $17^{\circ} \mathrm{C}$, so the savings compared to systems with fan coils $\left(7^{\circ} \mathrm{C}\right)$ are also proven.

- The system heats the room with a flow temperature of $18^{\circ} \mathrm{C}$, so in winter the savings are much higher than other systems and the system is therefore ideal to combine with solar thermal energy.

- The system maintains greater comfort in the relative humidity inside, helping to regulate it both in winter and in summer.

- The materials used have lower embodied energy than the conventional materials.

\section{References}

Andreu Moià-Pol, Beatriz Rosselló, Benito Mas Garcia. Estudio de un Sistema de Climatización Radiante con un material higroscópico. Proceedings CYTEF 2016. Coimbra. Portugal.

Rossello-Batle, B., Moià, A., Ribas, C. .Towards a nearly zero-emissions dwelling in Majorca. Proceedings EUROSUN 2016. Palma de Mallorca. Spain. doi:10.18086/eurosun.2016.01.0.

M. Van Belleghem, M. Steeman, A. Janssens, M. De Paepe. Drying behaviour of calcium silicate. Construction and Building Materials 65 507-517. 2014 
NadineWalikewitz, BrittaJänicke, Marcel Langner, Fred Meier, Wilfried Endlicher. The difference between the mean radiant temperature and the air temperature within indoor environments: A case study during summer conditions. Building and Environment. Volume 84, Pages 151-161, January 2015.

G.P.Hammond ,C.I.Jones. Embodied energy and carbon footprint database, Department of Mechanical Engineering, University of Bath, UK 2006

www.hippokrates-clima.com.

$\underline{\text { www.skamol.com }}$ 


\title{
bFAST: a methodology for assessing the solar potential of façades in existing building stocks
}

\author{
Pierluigi Bonomo', Cristina S. Polo López', Erika Saretta ${ }^{1,2}$, Paolo Corti ${ }^{1}$, Francesco Frontini ${ }^{1}$ \\ 1 ISAAC-SUPSI, Campus Trevano, CH 6952, Canobbio, Lugano (Switzerland)
}

2 Department of Architecture, Built environment and Construction Engineering, Politecnico di

Milano, Italy

\begin{abstract}
The research presented in this paper proposes a new approach to assess the solar potential for photovoltaic (PV) integration in façades of existing buildings, by evaluating both energy and building features of the built environment. Since the feasibility of a BIPV plant, especially in façade, is strictly related to the construction compatibility and not only to the energy exploitability of surfaces, a key-part of the project focuses on the definition of a methodology to move the assessment from a "theoretical solar potential", actually provided by solar mapping tools, to a "more realistic" estimation considering the building with its typological and technical/constructive constraints together with urban morphology. The implementation of the main project results, developed within the project bFAST co-financed by Fondo Energie Rinnovabili (FER) of the Canton of Ticino, can be replicated in order to create the impact to support the transfer and implementation of integrated PV (BIPV) in the renovation of the built environment in the next years. The article provides an overview of this research by presenting the main motivations, methodological aspects and discussion on results.
\end{abstract}

Keywords: building integrated photovoltaics- BIPV, solar potential, solar mapping, energy retrofit, façade

\section{Introduction}

The Swiss Federal Energy Strategy 2050, implemented at local level in the building sector (MuKEn/MoPEC, 2014), emphasizes the key role of combining energy efficiency and integration of renewable solar energy (RES) for a sustainable refurbishment of the existing building stock. At cantonal level, the expected potential for the coming years, as targeted on the Cantonal Energy Plan (PEC), is to achieve a production of $280 \mathrm{GWh}$ per year of electricity through PV, representing the 7\% of electricity production expected (Cereghetti and Pampuri, 2013). Even though the goal to reach $99 \mathrm{MW}$ by 2035 is already achieved at 45\% (Impianti fotovoltaici in Ticino, 2017), there is a great potential not yet exploited in the façades of existing buildings, mostly of which will require an energy retrofit in the coming years. According to the policy to use the built environment as a strategic priority for solar integration, this topic calls into considerations greater complexity than PV roofs, opening up also the role of façades in the solar exploitation as well as the need of an integrated assessment of energy, architectural and technological-constructive aspects of the built environment. As solar map of Canton of Ticino (www.oasi.ti.ch) is already implemented as a decision making tool for supporting the preliminary estimation of solar potential in roofs, Sonnenfassade for Swiss buildings (www.uvek-gis.admin.ch/BFE/sonnenfassade/) represents one of the unique examples of solar maps for building vertical surfaces. However, such an existing solar mapping platforms quantify the potential of the building surfaces by mainly considering the gross area and the incident solar radiation. Their purpose is not to quantify the "real" solar potential in an urban context as it would be required in a project phase (Mavromatidis et al. 2015; Peronato G. et al. 2016), but rather to provide an indicative scenario by displaying the expected suitability degree based on the available irradiation of the building surfaces (Kanters, et al. 2014). It emerges as typological elements such as windows, balconies, volumes or eaves, which typically have a strong impact and create barriers reducing the solar potential of the building skin, are not taken into consideration. Within the research we introduced building criteria in the procedure of evaluation of the solar potential for building façades, developing a new methodology for the identification of solar PV/BIPV potential on façades in the Canton of Ticino. 


\section{Method}

As explained in Figure 1, a first phase of the work concerned an analysis of the cantonal building stock with the goal to define the main potentials for solar integration at urban level (e.g. most relevant categories according to building uses, year of construction, energy and refurbishment needs, etc.) and to define alternatives representing the most frequent façade archetypes (1, in Fig.1). Afterwards, reference parameters conditioning PV integration have been identified, by including both quantitative and qualitative typological "indicators". For each façade type, the relative ranges of variability (e.g. reduction factors due to overhang or balconies projection or length, window surfaces, etc.) have been analyzed and synthetized with reference to relevant scenarios (2, in Fig.1); these "indicators", considered as positive or negative aspects affecting PV integration, have been adopted as the basic input for the methodology to calculate the final value closer to the real solar potential through the equation of solar potential introduced in the project (3, in Fig.1) and then validated through real case studies (4, in Fig.1).
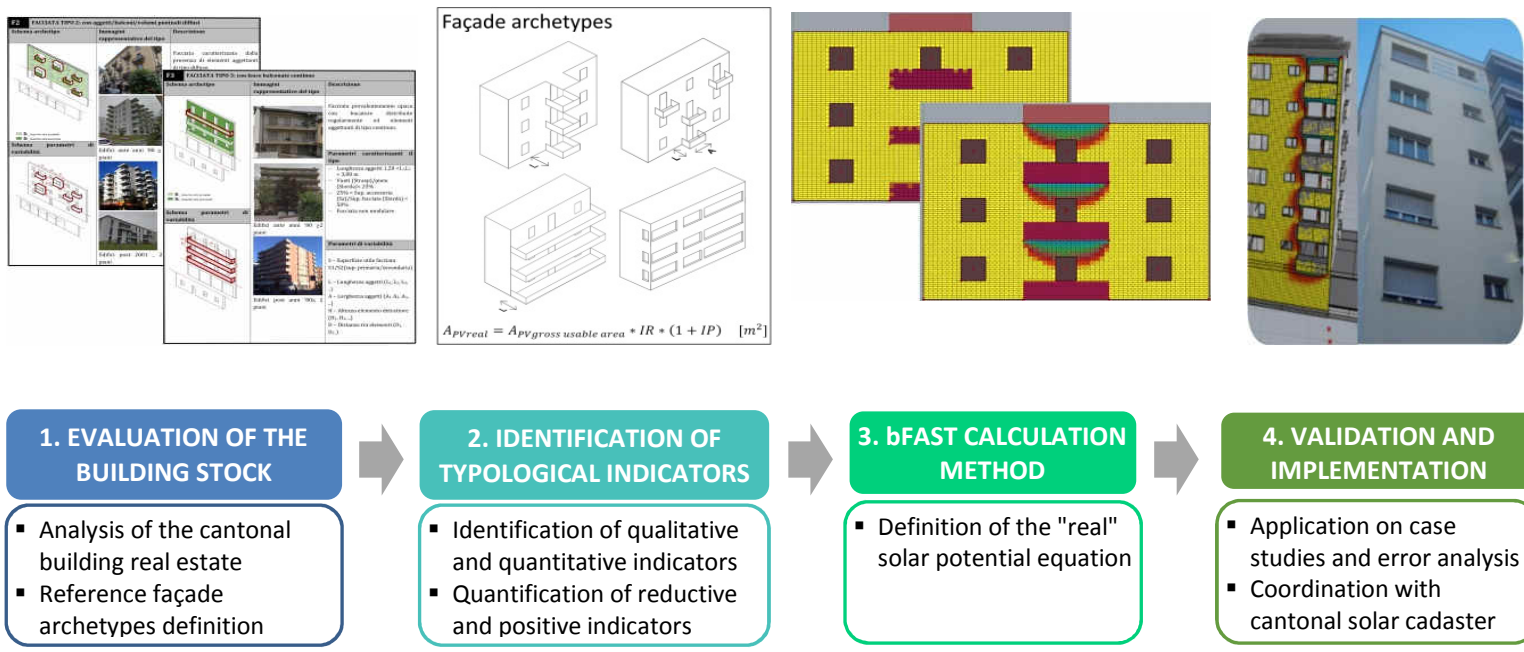

4. VALIDATION AND IMPLEMENTATION

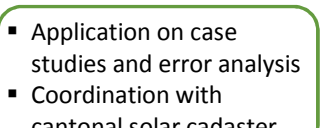

Fig. 1: Methodological process of bFAST research project

The evaluation and statistical analysis of the buildings in Ticino has also been useful to characterize the building stock and to select different façade archetypes as representative of architectural and typological parameters affecting solar potential. BIPV technological solutions were collected and a technical-economic estimation of the BIPV façade systems corresponding to significant types were carried out as case studies.

\subsection{Evaluation of the building stock}

The first analysis, on the basis of statistical evaluations made on different available datasets, such as the federal Register of Buildings and Dwellings RBD, the Building Programme data (2010-2016) for energy retrofit of buildings and the Cantonal Energy Certificate of Buildings (CECE®) data since 2009, the Canton Ticino building stock consists mainly of residential buildings (96.28\% that's account for 108'817 of a total of 113'023 buildings analyzed), as seen in Figure 2.a and Figure 2.b. The most relevant part (up to 70\%) was built before 1980 thus figuring out the need for an energetic retrofit in the coming years (e.g. $45.2 \%$ with low thermal insulation, on a sample of 1'520 buildings, see Figure 3.a). However, from the data processed in the annual reports of the Building Incentives Program, it appears that only a small percentage of buildings $(2.9 \%$ if we consider the analyzed Ticino real estate) have requested financing for the renovation. Of the former (see Figure 3.b), only $8.9 \%$ refers to the request for financing for the rehabilitation of façades, while the highest percentage of applications was for the rehabilitation of roofs and windows. Most of the buildings (78\% in residential, 52\% in commercial / service buildings and $49 \%$ in industrial buildings) are between two and three storeys; In multi-family buildings a high percentage is represented by buildings with heights of more than four and five floors ( see Figure 3.c). On the other hand, if we consider only multi-family residential buildings, the requests made so far (for energy renovation represent only $3.5 \%$. This means that $96.5 \%$ of the multi-family buildings are yet to be rehabilitated and can benefit from a combined intervention including both facade energy retrofit and the use of active solar systems. This is relevant also considering that multi-family buildings (category I) are characterized by a high energy consumption rate, essentially twice the energy consumed by single-family houses (category II), as showed in Figure 4.a).

The study also confirms a significant potential for the use of solar systems in façades at the cantonal/regional level: considering only residential buildings, the total estimated gross usable façade area is about $41.67 \mathrm{~km}^{2}$ as presented in Figure 4.b. If only the $5 \%$ of all theoretical gross façade area available was used to integrate solar systems (which corresponds to $2.24 \mathrm{~km}^{2}$ for the total of buildings and $0.99 \mathrm{~km}^{2}$ only for multi-family houses), considering a 
PV exploitation factor of $1 \mathrm{kWp} / 10 \mathrm{~m}^{2}$ and an average energy yield of $500 \mathrm{kWh} / \mathrm{kWp}$, this could generate about $112 \mathrm{GWh} /$ year at Cantonal level, namely configuring a realistic contribution of facades for about $43 \%$ to the Cantonal Energy Plan. The total estimated economic value for the construction of these photovoltaic façades could be around CHF 1.43 billion (Table 1).

\begin{tabular}{|c|c|c|c|c|c|c|c|c|}
\hline \multirow[b]{3}{*}{ ' } & \multicolumn{8}{|c|}{$\begin{array}{l}\text { Percentage of residential, industrial and trade/services buildings by } \\
\text { construction period }\end{array}$} \\
\hline & & \multicolumn{2}{|c|}{$\begin{array}{l}\text { R_before } 1980 \\
\text { T/S+Ind_1980-2000 }\end{array}$} & \multicolumn{2}{|c|}{$\begin{array}{l}\text { T/S+Ind_before } 1980 \\
\text { R_after } 2000\end{array}$} & \multicolumn{2}{|c|}{$\begin{array}{l}\text { R_1980_2000 } \\
\text { - T/S+Ind_after } 2000\end{array}$} & \multirow{2}{*}{\begin{tabular}{|l|l} 
N. buildings \\
113.023
\end{tabular}} \\
\hline & Total C. Ticino & $96.0 \%$ & $4.0 \%$ & $97.1 \%$ & $2.9 \%$ & $97.3 \%$ & $2.7 \%$ & \\
\hline$\infty$ & VALLEMAGGIA & $97.3 \%$ & $2.7 \%$ & $97.7 \%$ & $2.3 \%$ & $98.0 \%$ & $2.0 \%$ & 5.221 \\
\hline r & RIVIERA & $95.7 \%$ & $4.3 \%$ & $97.5 \%$ & $2.5 \%$ & $97.3 \%$ & $2.7 \%$ & 4.545 \\
\hline 6 & MENDRISIO & $94.2 \%$ & $5.8 \%$ & $98.0 \%$ & $2.0 \%$ & $98.1 \%$ & $1.9 \%$ & 12.841 \\
\hline in & LUGANO & $94.7 \%$ & $5.3 \%$ & $95.7 \%$ & $4.3 \%$ & $97.2 \%$ & $2.8 \%$ & 39.045 \\
\hline+ & LOCARNO & $97.4 \%$ & $2.6 \%$ & $98.1 \%$ & $1.9 \%$ & $98.1 \%$ & $1.9 \%$ & 25.746 \\
\hline$m$ & LEVENTINA & $97.9 \%$ & $2.1 \%$ & $98.3 \%$ & $1.7 \%$ & $97.2 \%$ & $2.8 \%$ & 6.351 \\
\hline n & BLENIO & $98.2 \%$ & $1.8 \%$ & $98.9 \%$ & $1.1 \%$ & $96.9 \%$ & $3.1 \%$ & 5.623 \\
\hline-1 & BELLINZONA & $95.5 \%$ & $4.5 \%$ & $97.5 \%$ & $2.5 \%$ & $96.2 \%$ & $3.8 \%$ & 13.651 \\
\hline
\end{tabular}

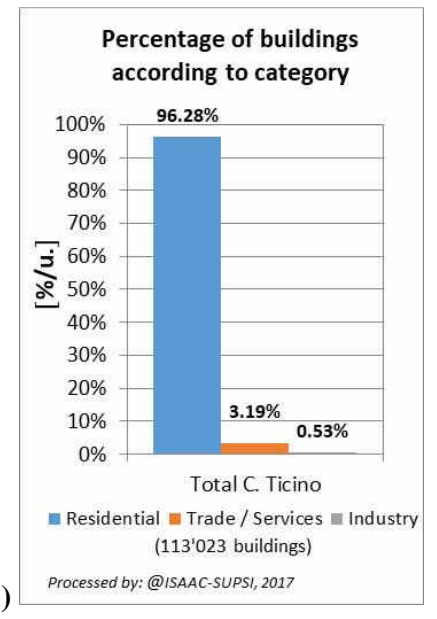

Fig. 2: Share of buildings [\%] residential, industrial and trade / services by construction period (total percentage of the number of buildings in each district. Source: RDB, processed by SUPSI).
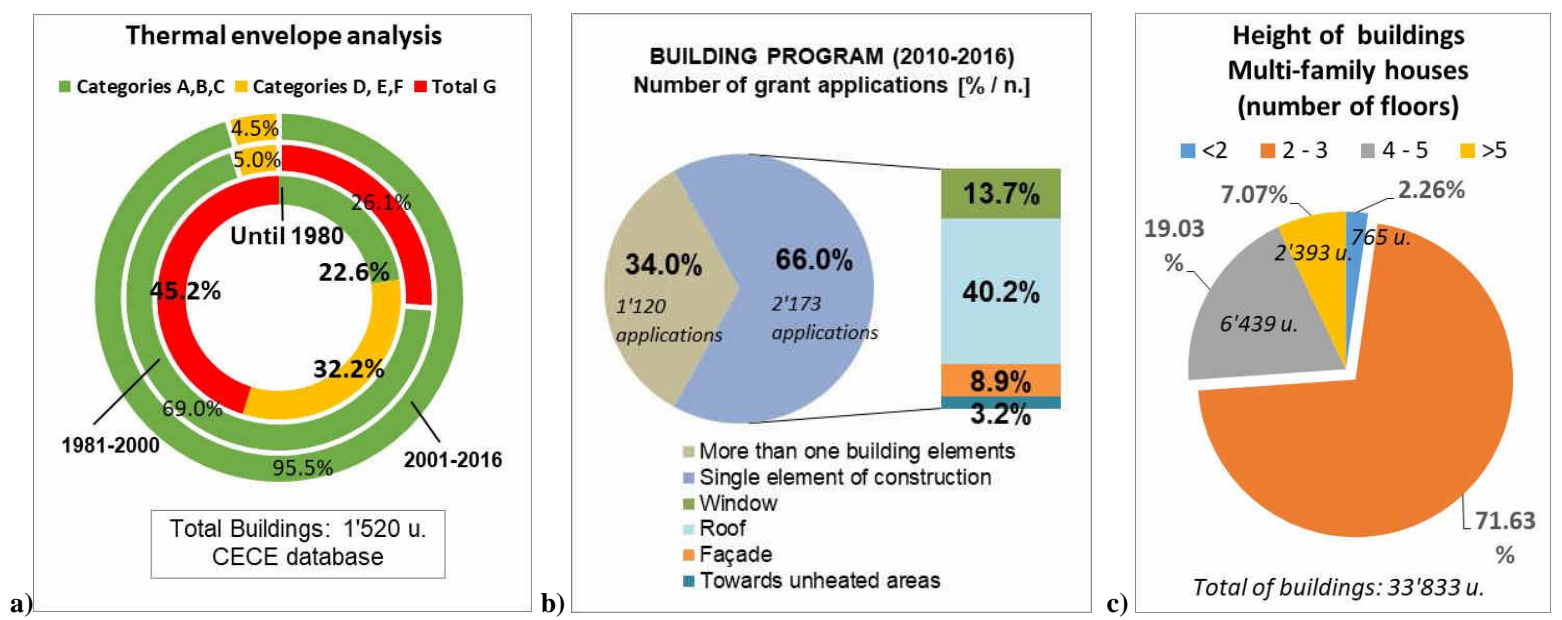

Fig. 3: Statistical data processed for Ticino: a) Evaluation of the thermal envelope, in the different building construction periods (before 1880, from 1981 to 2000 and from 2001 to 2016) and distribution for efficiency classes (Categories A, B, C and D, E, F and G). Source: CECE®, processed by SUPSI; b) Buildings Program, number of requests for funding [\% / $\mathbf{n}$.] carried out in the Canton of

Ticino, in the period 2010-2016 and percentage distribution for individual elements of construction refurbished; c) Height of buildings in Ticino [num. plans], in residential buildings (multi -family houses). Source: Building Program, processed by SUPSI
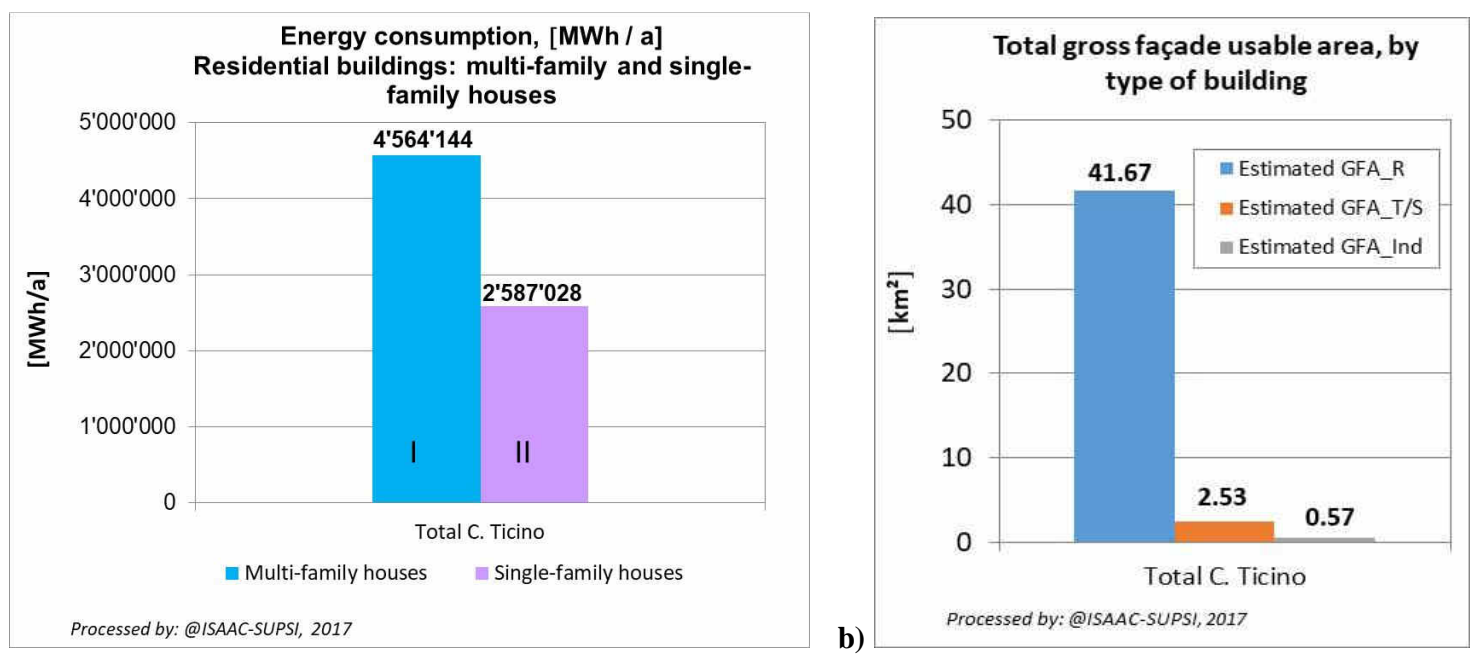

Fig. 4: a) Energy consumption [MWh / year] of residential buildings: multi-family (I) and single-family (II) houses; b) Estimated gross façade usable area by typologies (R, Residential buildings; T/S, trade and services; Ind, Industry buildings). Source: RDB, processed by SUPSI 
Tab. 1: Estimated gross area available on façades, calculated active PV power [MWp], annual energy production [MWh] and estimated economic value of the installation $[\mathrm{CHF}]$

\begin{tabular}{|c|c|c|c|c|c|}
\hline $\begin{array}{c}\text { Canton of Ticino } \\
\text { Building Stock }\end{array}$ & $\begin{array}{c}\text { Estimated } \\
\text { Gross } \\
\text { Façade Area } \\
\text { (GFA) }\end{array}$ & $\begin{array}{c}\text { Estimated } \\
\text { active PV } \\
\text { area on } \\
\text { façades }\end{array}$ & $\begin{array}{c}\text { Estimated } \\
\text { active PV } \\
\text { power }\end{array}$ & $\begin{array}{c}\text { Estimated } \\
\text { annual energy } \\
\text { produced by } \\
\text { façades }\end{array}$ & $\begin{array}{c}\text { Estimated } \\
\text { economic value }\end{array}$ \\
\cline { 2 - 6 } & (GFA) & {$\left[\mathrm{Km}^{2}\right]$} & {$[\mathrm{MWp}]$} & {$[\mathrm{GWh}]$} & {$[\mathrm{CHF}$ millions] } \\
\hline Total Buildings $^{1}$ & 44.77 & 2.24 & 224 & 112 & $1^{\prime} 456$ \\
\hline $\begin{array}{c}\text { Residential buildings } \\
\text { - Multi-family houses }\end{array}$ & 41.67 & 2.08 & 208 & 104 & 1 '352 \\
\hline
\end{tabular}

${ }^{1}$ Residential, Trade/Services and Industry buildings

${ }^{2}$ Corrective factor: $5 \%$ of $G F A$

${ }^{3}$ Assumptions: PV exploitation factor of $1 \mathrm{kWp} / 10 \mathrm{~m}^{2}$ and an equivalent average energy yield of $500 \mathrm{kWh} / \mathrm{kWp}$

\subsection{Identification of typological indicators}

The analysis and evaluation of reference typological archetypes, representing the local settlements, was used to define a catalog of main facade types. Reference typological façade archetypes were identified among all residential real estate of Ticino (see Figure 5 and Figure 6), in order to define quantitative and qualitative typological "indicators" by determining their relative ranges of variability (e.g. overhang or balconies projection or length, window surfaces, etc.), as positive or negative aspects for solar PV integration.

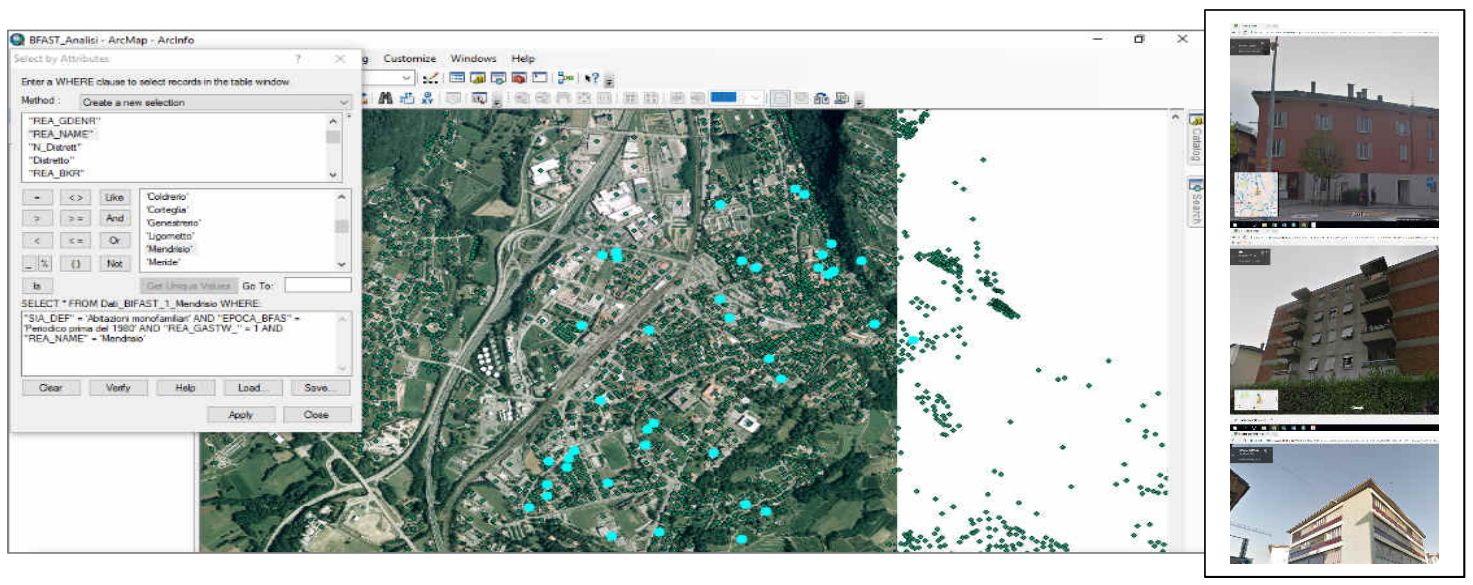

Fig. 5: GIS platform used for research on the cantonal territory of the typological classes to be further analyzed.

The method adopted, therefore, as a consequence of a systematic analysis of the Ticino real estate, is based on the definition of a typological abacus of the facades which characterize the type of building analyzed. Ten different types of façades were identified and then analyzed, with particular reference to the multi-family residential category, identified as a strategic intervention areas.
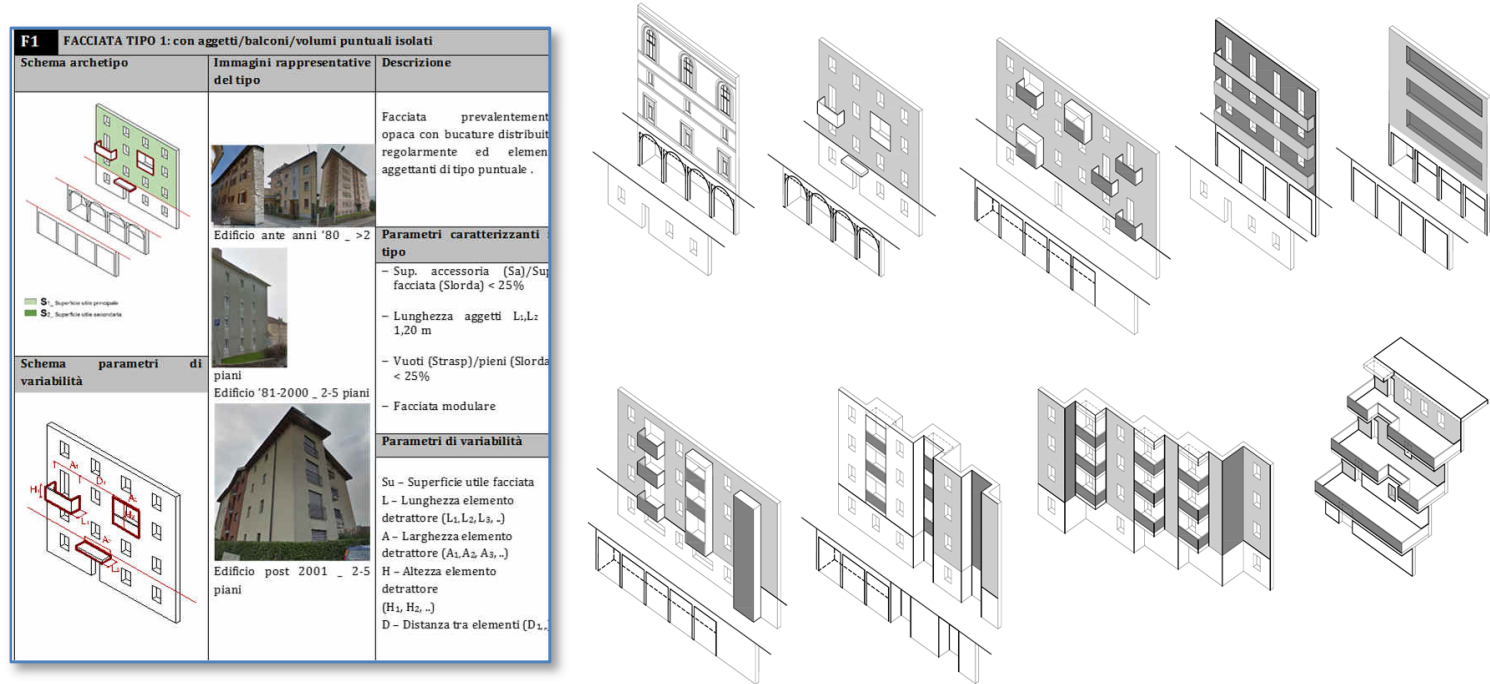

Fig. 6: Façade archetypes defined (source: ISAAC-SUPSI). 
Each type of façade is therefore distinguished and evaluated on the basis of some parameters defined as "indicators" useful for estimating the solar potential (quantitative parameters), such as the relationship between opaque and transparent surface, the reduction due to protruding elements, technological systems in facade, accessory elements). Other criteria, in relation to the greater / less ease of integration of solar systems, defined in the study as qualitative parameters (e.g. construction type, modularity of the façade, surface finishing envelope), have not been evaluated but only indicated since they were not the main aim of the research.

The set of parameters considered for each type of façade will result in a global indicator with the aim of expressing, through a synthesis quantity (e.g. a numerical coefficient through which to reduce the available gross surface of the façade), the largest or lower applicability of a solar system, for each type of façade assessed.

\section{3 bFAST calculation method}

The calculation method presented in this study has been developed starting from the existing solar cadaster of facades for Swiss buildings, named Sonnenfassade (Figure 7).
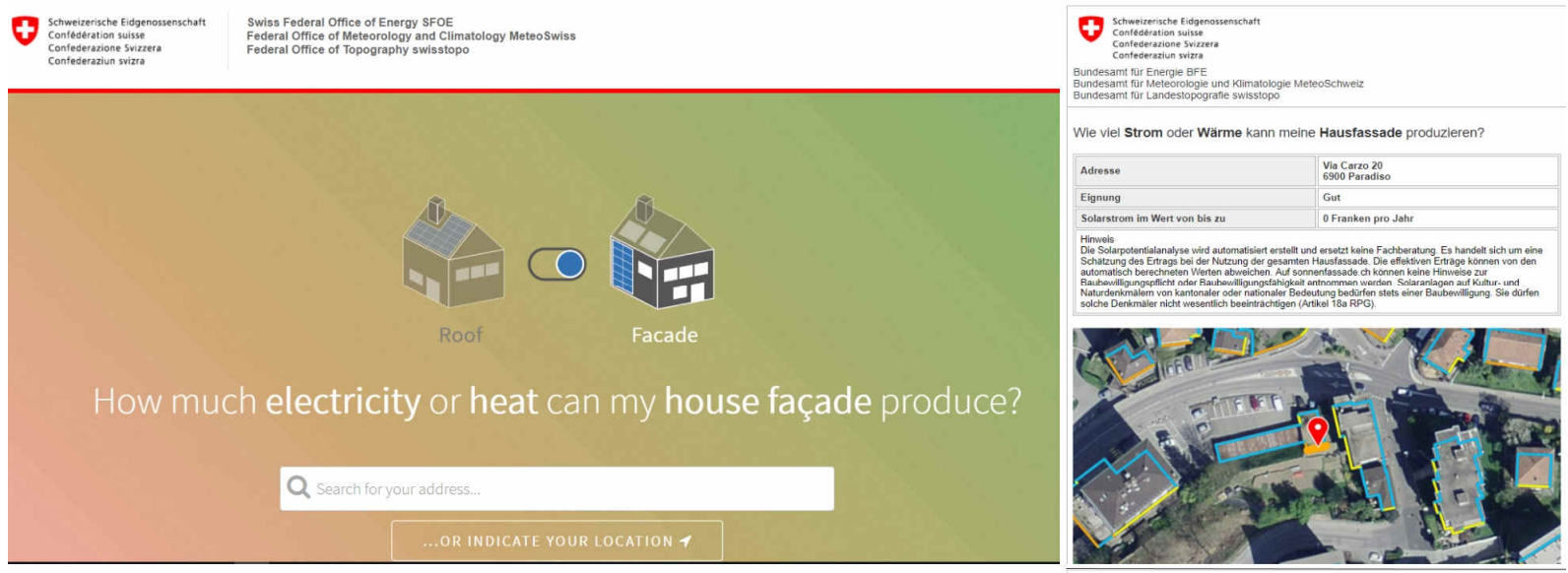

Fig. 7: Swiss Sonnenfassade Web platform for calculating solar façades potential throughout the country (www.uvekgis.admin.ch/BFE/sonnenfassade).

In the current Web platform (Figure 7), it is possible to obtain, for individual geometric sub-sections in which the façade is discretized according to the geometric survey, the solar potential of the selected surface. In detail, this solar cadaster provides the annual solar potential for every façade of each building, as described in the following Eq. 1.

$$
\text { Solar Potential }[k W h / y]=S_{g r}\left[m^{2}\right] \cdot I R R_{\text {avg }}\left[k W h / m^{2} y\right]
$$

Where " $S_{g r}$ " and "IRR avg" represent respectively the gross surface of a façade as reported by swissBUILDING3D 2.0 and the average yearly irradiation value, calculated in the middle point of the façade (SFOE, 2016).

Even though this solar cadaster is one of the more advanced, it approximates the façade area considering the gross surface, thus not including the presence of architectural elements (e.g. openings, balconies...), which significantly affect the solar potential. Hence, the calculation method developed by authors aims at taking into account typical façade elements of archetypes by means of reduction/ additional indicators (Equation 2), which are multiplied to the gross surface of the façade to obtain the "real" opaque area suitable for BIPV (Equation 3). Therefore, the equations for the calculation of the BIPV potential of facades are the following ones:

$$
\text { BIPV Potential }[k W h / y]=S_{B I P V}\left[m^{2}\right] \cdot I R R_{\text {avg }}\left[k W h / m^{2} y\right]
$$

$$
S_{B I P V}\left[m^{2}\right]=S_{g r}\left[m^{2}\right] \cdot I R \cdot(1+I P)
$$

Where "S $\mathrm{BIPV}_{\mathrm{B}}$ " represents the real opaque area suitable for BIPV with irradiation values greater than $600 \mathrm{kWh} / \mathrm{m} 2 \mathrm{y}$ and IR and IP indicate respectively reduction indicators (e.g. due to openings) and additional indicators (e.g. presence of balcony parapets), which are calculated for each façade archetypes, previously indicated. 
Specifically, real opaque area suitable for BIPV can be also described as Equation 4, by means of indicators described in Table 2.

$$
S_{B I P V}\left[m^{2}\right]=S_{g r}\left[m^{2}\right] \cdot I R_{A C C} \cdot I R_{1} \cdot I R_{2} \cdot I R_{3} \cdot I R_{3} \cdot\left(1+I P_{A C C}\right)
$$

Tab. 2: Reduction and additional indicators

\begin{tabular}{|c|c|c|}
\hline Indicators & Description & Equation \\
\hline $\mathrm{IR}_{\mathrm{ACC}}$ & $\begin{array}{l}\text { Reduction indicator due to the presence of extra architectural } \\
\text { elements such as balconies and/or protruding volumes }\end{array}$ & $I R_{A C C}=\frac{S_{g r}-S_{A C C}}{S_{g r}}$ \\
\hline $\mathrm{IR}_{1}$ & Reduction indicator due to the presence openings & $I R_{1}=\frac{S_{g r}-S_{\text {open }}}{S_{g r}}$ \\
\hline $\mathrm{IR}_{2}$ & Reduction indicator due to the shadows of balconies & $I R_{2}=\frac{S_{g r}-S_{\text {shadow,balc }}}{S_{g r}}$ \\
\hline $\mathrm{IR}_{3}$ & Reduction indicator due to the shadow of the roof overhang & $I R_{3}=\frac{S_{g r}-S_{\text {shadow }, \text { roof }}}{S_{g r}}$ \\
\hline $\mathrm{IR}_{4}$ & $\begin{array}{l}\text { Reduction indicator due to the presence of technological elements } \\
\text { (e.g. lifts, air conditioner devices...) }\end{array}$ & $I R_{4}=\frac{S_{g r}-S_{t e c h n}}{S_{g r}}$ \\
\hline $\mathrm{IP}_{\mathrm{ACC}}$ & $\begin{array}{l}\text { Additional indicator due to the presence of extra architectural } \\
\text { elements such as balconies and/or protruding volumes that can be } \\
\text { totally or partially used for BIPV }\end{array}$ & $I P_{A C C}=1-\frac{S_{A C C}}{S_{g r}}$ \\
\hline
\end{tabular}

In particular, indicators have been calculated using an experimental method for each façade archetype. As shown in Figure 8, the method is based on the setting-up of a Rhino-Grasshopper ${ }^{\circledR}$ model capable to combine the parametric geometric façade archetype and the simulation of solar radiation by means of the tool DIVA (McNeil \& Lee, 2012). In such a way, for each parameter variation, the incident solar radiation on the façade has been evaluated and the portion with annual irradiation greater than $600 \mathrm{kWh} / \mathrm{m}^{2} \mathrm{y}$ (in accordance with the threshold set in the solar cadaster) has been detected to calculate reduction and/or additional factors.

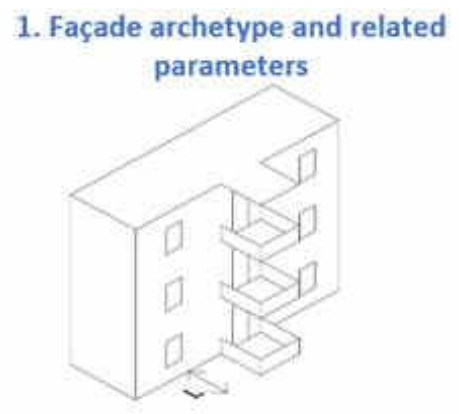

4. Definition of indicators

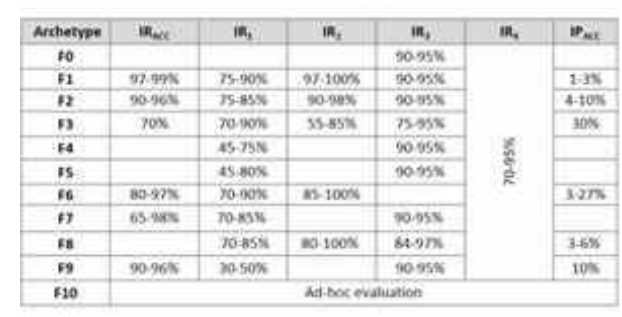

2. Rhino-Grasshopper modelling

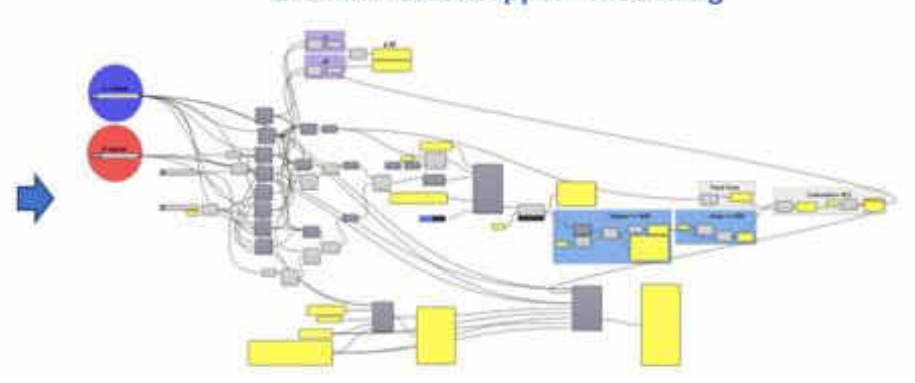

3. Evaluation of BIPV area (values $\geq 600 \mathrm{kWh} / \mathrm{m}^{2} \mathrm{y}$ )

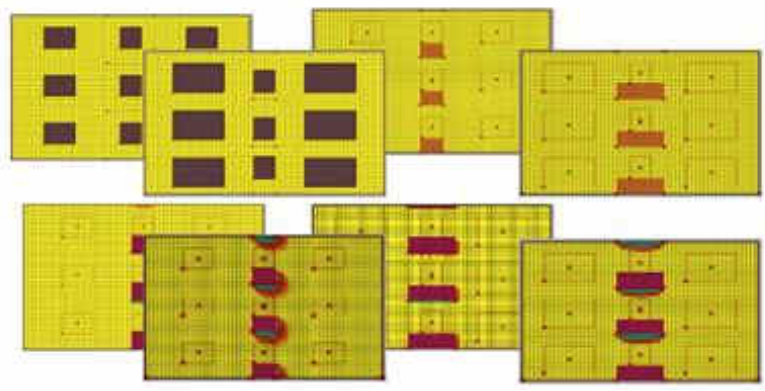

Fig. 8: Phases of the bFAST method to calculate the suitable facade area for BIPV. 


\subsection{Validation and implementation}

It is important to note that this calculation method has been developed in accordance with an archetypal approach that allows dealing with the complexity and the heterogeneity of the building facades by identifying the main recursive characteristics. As a consequence, through the application of indicators, it is possible to estimate the BIPV potential even though it can be not accurate as a professional analysis on a real case study. For this reason, the method has been validated through real case studies for which the following values have been compared: area provided by Sonnenfassade (Sgr), area useful for BIPV calculated using the bFAST method ( $\left.\mathrm{S}_{\mathrm{BIPV}}\right)$, through the application of the corrective factors associated with the type of façade corresponding and useful area obtained through an accurate "design" simulation of the real building ( $\left.\mathrm{S}_{\mathrm{PVSIM}}\right)$.

Specifically, the error of the area supplied by Sonnenfassade with respect to the accurate area from simulation ( $\varepsilon 1)$ and the error of the area calculated with the bFAST method with respect to t the real area from simulation $(\varepsilon 2)$ have been calculated and compared. Therefore, when $\varepsilon 1$ results lower than $\varepsilon 2$, the method is validated. In particular, the validation is carried out by the evaluation of three real case studies of multi-family buildings for which the geometric data are available and, in this case, the method is always verified with $\varepsilon 1$ in the range $8-151 \%$ and $\varepsilon 2$ in the range $2-27 \%$. One case study is shown in Figure 9.

\begin{tabular}{|c|c|c|}
\hline Real Simulation & Sonnenfassade & Archetype $\mathrm{F} 5$ \\
\hline $\mathrm{S}=198 \mathrm{~m}^{2}$ & $\mathrm{~S}_{\mathrm{GR}}=449 \mathrm{~m}^{2}$ & $\mathrm{~S}$ \\
\hline & & \\
\hline
\end{tabular}

Fig. 9: Example of the calculation of errors for the method validation.

\section{Technical solutions, analysis and assessment of case-studies and scenarios}

As part of analysis on real case-studies, we analyzed some reference real scenarios for the PV integration in the building envelope by assessing architectural, technological and economical features of the technical solutions. The first step permitted to identify different technical possibilities related to the construction of an active building skin. Reference examples related to the defined scenarios were identified. The second step identified design examples and reference products. In particular, different PV applications on façade have been evaluated and analyzed for each related technological solutions through the use of real case-studies. In the Table 3 the map of the BIPV technical solutions for the vertical envelope is shown.

Tab. 3: Classification of technical solutions for the BIPV envelope

\begin{tabular}{|l|}
\hline 1) Building integration \\
\hline (F) Façade system \\
(F.a) Warm Façade /Curtain Wall \\
- F.a.1 Stick system \\
- F.a.2 Unitized curtain wall \\
$\quad-$ F.a.3 Structural / semi-structural glass façades \\
$\quad-$ F.a.4 Point-fixed or suspended façade \\
(F.b) Opaque Cold Façade \\
- F.b.1 Added/Attached solutions (BAPV/BAST) \\
- F.b.2 Ventilated facade (BIPV/BIST)
\end{tabular}


(F.c) Multifunctional façade and innovative

- F.c.1 Double skin semi-transparent façade

- F.c.2 Interactive and dynamic façade

(F.d) Ready-made system

- F.d.1 Prefab and multifunctional systems

(F.e) Accessory elements

- F.e.1 Shading and solar protection

F.e.2 Balconies and railings

\section{2) Technology}

(Ac) Active

(Pa) Passive

(Ib) Hybrid

(In) Innovative

3) Purpose of the BIPV system

(E) Electric production

(T) Hybrid electrical and thermal production

(C) Constructive and multifunctional: thermal insulation, soundproofing, ventilation, protection (wind/rains), solar control, safety and structural function.

\section{4) Application / Integration}

(Pu) Punctual - Specific or regular application

(Pa) Partial - Non complete or partial/linear surface

(To) Total - Complete façade/roof surface

(Mi) Mixed

Thanks to this analysis it was possible to identify five different façade systems, the related reference techniques of BIPV integration and design solutions. From the case-study analysis the effectiveness, in term of energy and cost, was shown for a vertical BIPV system, despite the yield losses due to non-optimal exposition and shading of facades thanks to the self-sufficiency, self-consumption, final yield and limited extra-cost of the BIPV system compared with a traditional cladding. Particular attention was given to the economical assessment of BIPV systems, where the active cladding replaces an equivalent non-active system whose economic value is expressed in term of extra-cost compared with the similar traditional system (SUPSI-SEAC report 2017, available on the website www.bipv.ch - Bonomo, 2017). Figures 10 and 11 show a cost comparison in $\mathrm{CHF} / \mathrm{m}^{2}$ between the traditional envelope claddings and the PV claddings ${ }^{1}$. Figure 10 shows the cost variation of different claddings, including two PV typologies (horizontal and vertical black lines) while Figure 11 shows the cost of different PV modules compared with a traditional cladding. If the BIPV cost is higher than the traditional system is identified with the colour red, if is lower with a green texture. Further analyses were carried out on case-studies with an indepth analysis on the design, energy, technology and economy aspects. In the Table 4 an example of case-study referred to a BIPV cold façade for a retrofit on a residential building in Chiasso (Ticino, Switzerland).

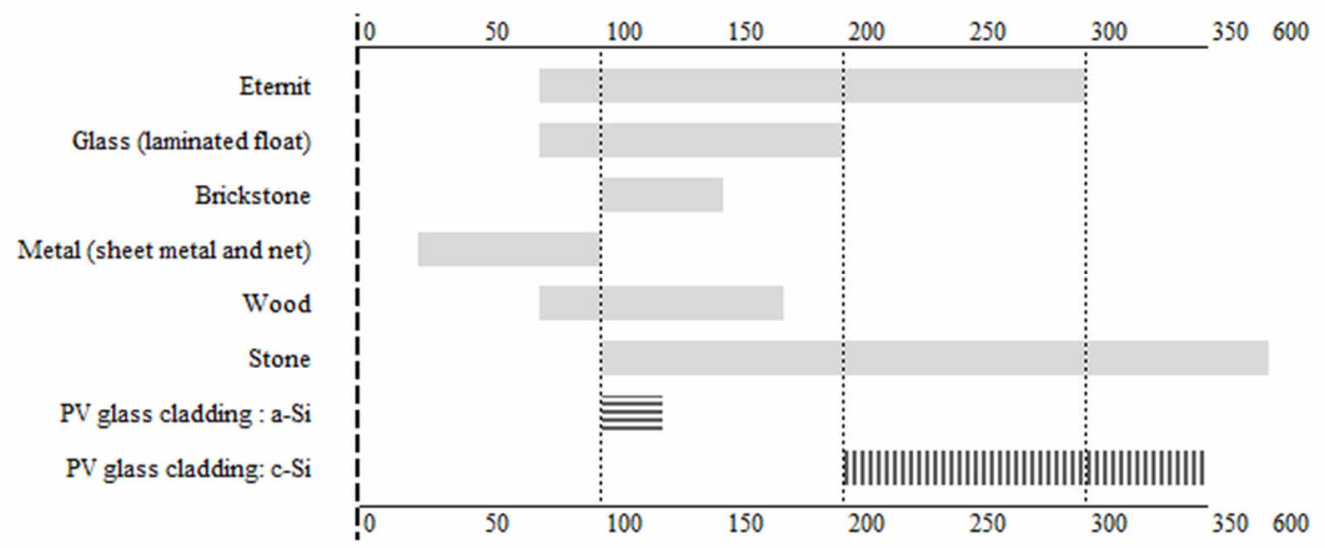

Fig. 10: Cost of material $\left(\mathrm{CHF} / \mathrm{m}^{2}\right)$

\footnotetext{
${ }^{1}$ Values are evaluated on a not complete record; they should be considered just as an example. Values do not assume design binding value. A specific offer should be request before the project starts. Substructures and insulation are not considered.
} 


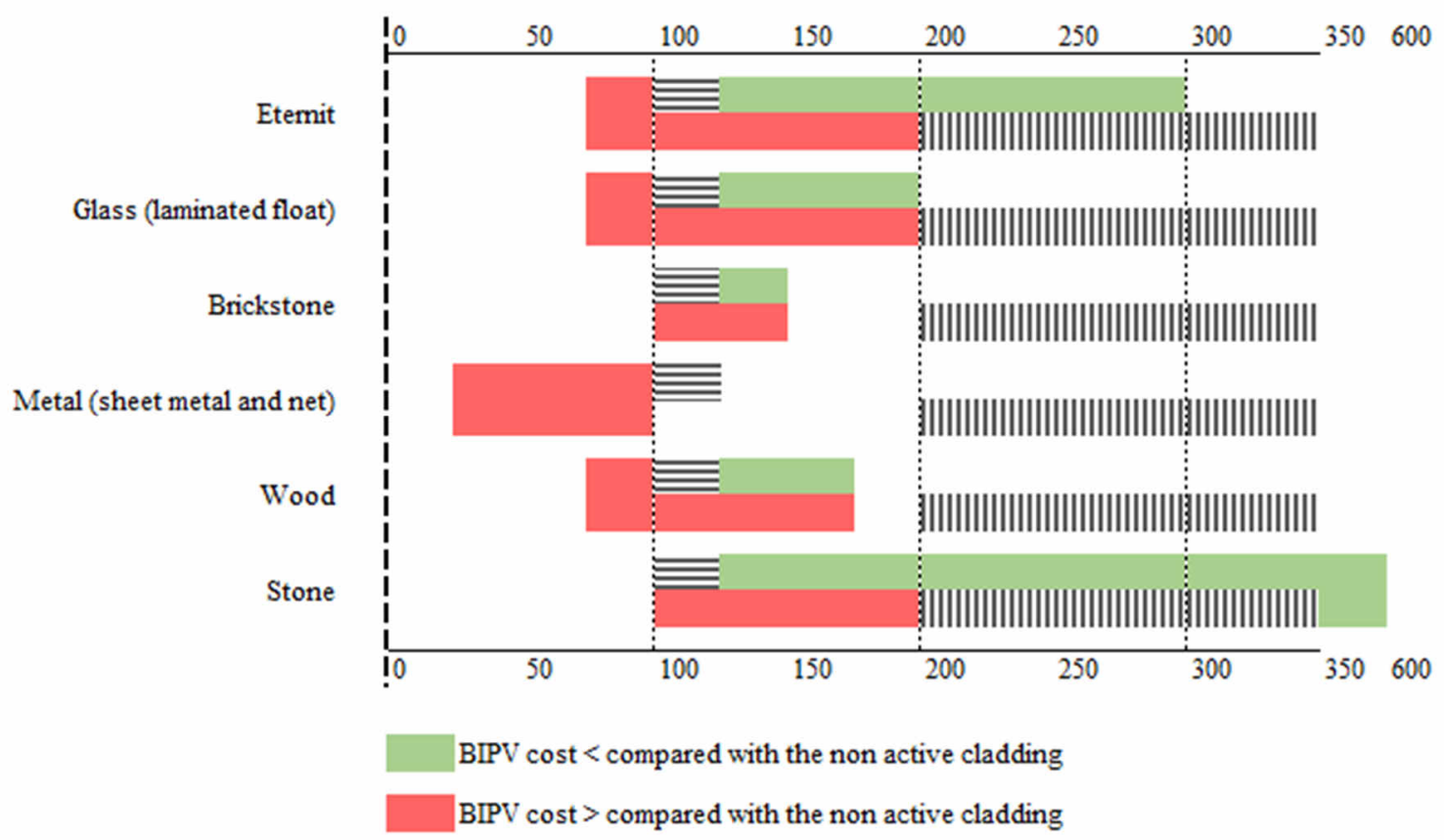

Fig. 11: Extra-cost BIPV compared with the material $\left(\mathrm{CHF} / \mathrm{m}^{2}\right)$

\section{Conclusions, scientific innovation and relevance}

Energy policies at local emphasize the importance of increasing the supply of energy from renewable sources, by also reducing energy demand with new solutions for the sustainable refurbishment of the existing building stock. The bFAST provided a methodology to define the information base to integrate data into the energy mapping, with more detailed indications on the typological-building features of the facades. Through the research, the critical definition of information was prepared, to be made available and functional for implementation within existing spatial information models and those in preparation for the coming years.

The solar potential of the facades is very promising in Ticino for the next few years, evaluating the characteristics and nature of the existing building heritage and its high attractiveness to rehabilitation and redevelopment. A multidisciplinary approach such as that of the bFAST project is essential to grasp the features and building factors that are essential for estimating the potential for real integration of solar systems in the built environment.

The percentage of residential buildings is significantly higher than other types of buildings (industry and trade / services) and in multi-family buildings a high percentage is represented by buildings with heights greater than four and five floors. In all the districts the buildings built before 1980 are predominant, which in the case of housing is more than $65 \%$ in all districts. The buildings that have so far required a financial contribution for rehabilitation within the Buildings Program represent only $2.9 \%$ of the canton's building stock, for which a potentially important market emerges for the coming years. According to the hypotheses mentioned above and to case studies and simulations, the overall assessment of the report estimates that the total photovoltaic façade surfaces potentially available at the cantonal level are over $2 \mathrm{~km}^{2}$, which, although deriving from exploitation of only $5 \%$ of the total (taking into account the potential impact of the different typological, geometric, technical and local climatic factors) could contribute about $43 \%$ to the Cantonal Energy Plan (about 208 MWp installable on the facades for approx. 104GWh/year).

The defined methodology and the information developed through the project (such as the building indicators in the definition of the "realistic" solar potential of the facades for multi-family buildings) can be replicated on the remaining part of the building stock (e.g. in other contexts or on other typologies). In this sense, the methodology set in this project could lead to the improvement of the current digital territorial systems for the evaluation of urban solar potential, through the implementation of data in the Swiss solar cadaster, with the perspective to encourage an optimal management of the building stock for production of solar renewable energy. 


\begin{tabular}{|c|c|c|c|c|c|}
\hline & \multicolumn{5}{|c|}{ Palazzo Positivo Chiasso $(\mathrm{CH})$ - Case study } \\
\hline Description & \multicolumn{5}{|c|}{$\begin{array}{l}\text { The project concerns a complete refurbishment of a MFH with the aim to reach the passive } \\
\text { house standard. The main feature of this intervention is the installation of a PV system as re- } \\
\text { cladding of the building envelope for each orientation. In this case study are evaluated the } \\
\text { PV elements installed on the facades (no balconies and roof). }\end{array}$} \\
\hline \multicolumn{6}{|l|}{ Imagines } \\
\hline \multirow{5}{*}{$\begin{array}{r}\text { BIPV } \\
\text { system }\end{array}$} & Typology & MFH & \multirow{3}{*}{$\begin{array}{r}\text { Electric } \\
\text { production }\end{array}$} & \multirow{2}{*}{\begin{tabular}{|l|} 
Nominal power \\
Active surface \\
\end{tabular}} & $45.9 \mathrm{kWp}$ \\
\hline & \multirow{2}{*}{$\begin{array}{l}\text { Year of } \\
\text { construction }\end{array}$} & \multirow[t]{2}{*}{2013} & & & $583 \mathrm{~m}^{2}$ \\
\hline & & & & Annual production & $14 ' 268 \mathrm{kWh}$ \\
\hline & Modules & \multicolumn{2}{|c|}{$\mathrm{a}-\mathrm{Si}$} & Cladding cost unit & $100 \mathrm{CHF} / \mathrm{m}^{2} \mathrm{a}-\mathrm{Si}$ \\
\hline & \multicolumn{3}{|l|}{ Façade typology } & Cladding cost total & $\begin{array}{l}200 \mathrm{CHF} / \mathrm{m}^{2} \mathrm{c}-\mathrm{Si} \\
65^{\prime} 480 \mathrm{CHF}\end{array}$ \\
\hline \multirow{12}{*}{$\begin{array}{c}\text { Economic } \\
\text { assessment }\end{array}$} & \multicolumn{2}{|l|}{ Location } & Chiasso & $\begin{array}{l}16,0 \\
140.0\end{array}$ & \\
\hline & \multicolumn{2}{|l|}{ Orientation } & $\mathrm{S} / \mathrm{E} / \mathrm{O} / \mathrm{N}$ & 12.0 & \\
\hline & \multicolumn{2}{|l|}{ Tilt } & $90^{\circ}$ & $\begin{array}{l}20.0 \\
e^{2}\end{array}$ & \\
\hline & \multicolumn{2}{|c|}{ Nominal power } & $78.73 \mathrm{Wp} / \mathrm{m}^{2}$ & 50.0 & \\
\hline & \multicolumn{2}{|c|}{ Electric production } & $24^{\prime} 473 \mathrm{Wh} / \mathrm{m}^{2} / \mathrm{y}$ & & \\
\hline & \multicolumn{2}{|c|}{ Final yield (average for facade) } & $311 \mathrm{Wh} / \mathrm{Wp} / \mathrm{y}$ & 0.0 & \\
\hline & \multicolumn{2}{|c|}{ Electric production in 20 years } & $489 \mathrm{kWh} / \mathrm{m}^{2}$ & & \\
\hline & \multicolumn{2}{|c|}{ Interest rate } & $1 \%$ & The energy demand & e $29^{\text {th }}$ of June 2017 \\
\hline & \multicolumn{2}{|c|}{ Annual energetic demand } & $66^{\prime} 022 \mathrm{kWh} / \mathrm{y}$ & is shown by the or & e profile. The blue \\
\hline & \multicolumn{2}{|c|}{ Self-consumption rate } & $88 \%$ & profile represents & Ie BIPV energy \\
\hline & \multicolumn{2}{|c|}{ Self-sufficiency rate } & $19 \%$ & production during th & ame day. The area \\
\hline & \multicolumn{2}{|c|}{$\begin{array}{l}\text { Extra-cost BIPV compared with a } \\
\text { cotto tile ventilated facade }\end{array}$} & $0 \mathrm{CHF} / \mathrm{m}^{2}$ & $\begin{array}{l}\text { subtended both profi } \\
\text { consumed energy. }\end{array}$ & represents the self- \\
\hline \multirow{6}{*}{$\begin{array}{r}\text { Analysis of } \\
\text { consumption }\end{array}$} & \multicolumn{2}{|c|}{ Self-consumption rate } & $88 \%$ & SELF-CONSUMPTI & RATE (SCR), kWh \\
\hline & & $2^{\prime} 976 \mathrm{Wh} / \mathrm{m}^{2} / \mathrm{y}$ & & \\
\hline & \multicolumn{2}{|c|}{ Self-consumption } & $21^{\prime} 497 \mathrm{Wh} / \mathrm{m}^{2} / \mathrm{y}$ & & \\
\hline & \multicolumn{2}{|c|}{ Yearly revenues $^{[1]}$} & 4.29 CHF $/ \mathrm{m}^{2} / \mathrm{y}$ & & \\
\hline & \multicolumn{2}{|c|}{ ROI extra-cost of facade } & 0 years & & \\
\hline & $\begin{array}{l}\text { [1] The energy wit } \\
\mathrm{CHF} / \mathrm{kWh} \text {, the ener } \\
\mathrm{CHF} / \mathrm{kWh} \text {. In this a } \\
\text { the yearly increase }\end{array}$ & $\begin{array}{l}\text { wh from the } \\
\text { jected into } t \\
\text { sis are not } \\
\text { he energy pr }\end{array}$ & $\begin{array}{l}\text { rrid has a price of } 0,19 \\
\text { grid has a price of } 0,07 \\
\text { nsidered subsidies and } \\
\text { e. }\end{array}$ & & \\
\hline Comments & $\begin{array}{l}\text { BIPV Modules } \\
\text { The orientation } \\
\text { cladding in a-S } \\
\text { typology, it is } \\
\text { gain given by tl }\end{array}$ & $\begin{array}{l}\text { the façade } \\
\text { PV modul } \\
\text { this spec } \\
\text { sible to no } \\
\text { V product }\end{array}$ & $\begin{array}{l}\text { Palazzo Positivo } \\
\text { is not optimal, hov } \\
\text { ic case is comparab } \\
\text { ce the economic fe } \\
\text { ind enhanced by } t\end{array}$ & $\begin{array}{l}\text { a-Si or in monoc } \\
\text {, considering that } \\
\text { ith a traditional c } \\
\text { lity of the system } \\
\text { ossible self-consur }\end{array}$ & $\begin{array}{l}\text { stalline silizium. } \\
\text { e cost of the PV } \\
\text { ding similar for } \\
\text { d the economic } \\
\text { tion. }\end{array}$ \\
\hline & $\begin{array}{l}\text { Disclaimer: the } \\
\text { from the monito } \\
\text { demand and rea } \\
\text { analysed hereaft }\end{array}$ & $\begin{array}{l}\text { omic/eners } \\
\text { of the } P V \\
\text { sts. The val }\end{array}$ & $\begin{array}{l}\text { tic assessment within } \\
\text { stem and assuming } r \\
\text { es do not represent th }\end{array}$ & $\begin{array}{l}\text { research activities } \\
\text { from real hourly } p \\
\text { al data of the build }\end{array}$ & $\begin{array}{l}\text { ng available data } \\
\text { files of the energy } \\
\text { and they will be }\end{array}$ \\
\hline
\end{tabular}




\section{Acknowledgments}

This work was carried out within the framework of Project "bFAST" supported by the Fondo Energie Rinnovabili (FER) of the Canton Ticino.

\section{References}

Cereghetti, N., Pampuri, L., 2013. Fotovoltaico in Ticino: situazione, potenziale e obiettivi. Dati - statistiche e società, 13 (2). pp. 37-43

Impianti fotovoltaici in Ticino, 2017. Report 2016 ISAAC-SUPSI. SPAAS December 2017

Kanters, J., Wall, M., \& Kjellsson, E. (2014). The Solar Map as a Knowledge Base for Solar Energy Use. Energy Procedia, 48(0), 1597-1606. DOI: 10.1016/j.egypro.2014.02.180

Mavromatidis G., Orehounig K., Carmeliet J., 2015. Evaluation of solar energy integration potential in a neighborhood. Proceedings of BS2015, Hyderabad, India, Dec. 7-9, 2623-2630

Peronato G., Rey E., Andersen M., 2016. 3D-modeling of vegetation from LiDAR point clouds and assessment of its impact on façade solar irradiation. Int. Arch. Photogramm. Remote Spatial Inf. Sci., XLII-2/W2, 67-70, 2016. https://doi.org/10.5194/isprs-archives-XLII-2-W2-67-2016

McNeil, A., Lee, E.S. (2012). A validation of the Radiance three-phase simulation method for modelling annual daylight performance of optically complex fenestration systems. J. Build. Perform. Simul. 6, 24-37. http://dx.doi.org/10.1080/19401493.2012.671852.

Bonomo, I. Zanetti, F. Frontini, M.N. van den Donker, F. Vossen, W. Folkerts, BIPV PRODUCTS OVERVIEW FOR SOLAR BUILDING SKIN, EU PVSEC 2017, Amsterdam

SFOE - Swiss Federal Office of Energy (2016). Solarpotentialanalyse für Sonnendach.ch. Retrieved from http://www.bfe.admin.ch/geoinformation/06409/index.html?lang=en\&dossier_id=06527 (late accessed: 2018, September) 


\title{
High solar fraction by thermally activated components Thomas Ramschak ${ }^{1}$, Walter Becke ${ }^{1}$, Christian Fink ${ }^{1}$, Werner Lerch ${ }^{2}$, Richard Heimrath ${ }^{2}$ and Thomas Mach ${ }^{2}$ \\ ${ }^{1}$ AEE - Institute for Sustainable Technologies (AEE INTEC), Gleisdorf (Austria) \\ ${ }^{2}$ Institute of Thermal Engineering (TU-Graz), Graz (Austria)
}

\begin{abstract}
Thermally activated building elements (TABs) are employed successfully in the building sector in recent years. From an energetic point of view, such low temperature systems are especially beneficial when combined with solar thermal installations or heat pumps. Within the scope of national funding programs and R\&D projects the intensive use of thermally activated building elements is investigated, as main thermal storage in different buildings, with focus on the combination with solar technologies (thermal, photovoltaic) for energy supply. Investigations based on measuring data from realised buildings and on a theoretical approach, various technical system concepts with solar thermal or photovoltaic in combination with thermally activated components for single- (SFH) and multifamily houses (MFH) were analysed under technical, economic and ecological criteria. The results show that through the activation and use of the thermal storage potential contained in the building mass, high solar fractions up to $100 \%$ of the building's heat demand can be achieved.
\end{abstract}

Keywords: high solar fraction, thermal activation, concrete slabs, technical economic and ecologic analysis

\section{Introduction}

The Renewable Energy Directive of the EU requires buildings to fulfill at least $20 \%$ of its total energy needs with renewables by 2020. An efficient integration of fluctuating renewable energy from solar thermal and photovoltaic systems into the heating infrastructure of a building is a big challenge. However, compensating for these fluctuations with the assistance of batteries and big thermal storages at the level of the heat supply is very cost-intensive. On the other hand, thermally activated building systems (TABs) have been shown to enable an efficient and cost effective integration of renewable energy. With TABs, the large thermal capacities of the building structure - such as massive floors and ceilings - are used as heat storage and they are as such integrated into the overall energy system of the building. By absorbing heat from internal or external passive gains through radiation, conduction and convection or by releasing stored energy, the slabs provide respectively cooling and heating to the rooms. The thermal activation of the building mass enables it to store more heat, providing inertia against temperature fluctuations and allowing it to be heated or cooled in hours with renewable energy production. Moreover, the large areas of the thermo-active surfaces allow for substantial heat flux between room and structure, even with relatively low temperature differences. For these reasons, TABs are predestined for the application of solar thermal and low temperature heating sources, such as near-surface geothermal, ground water and outside air.

The goal of the research project solSPONGEhigh is the detailed analysis of this approach. On the basis of numerical models and several case studies the project and its results contribute to a better understanding of the energy-related processes in and the design of such systems.

\section{Method}

For two prototype buildings, a one-family house and an apartment building, different system concepts for heating and preparation of domestic hot water are being developed. In addition to small buffer storage tanks, the system concepts mainly include thermally activated components (story ceilings) as heat storage and heat dissipation system. The energy source is provided by building-integrated solar-thermal or solar-electric systems combined with heat pumps. The system concepts are numerically modeled in different configurations, supplemented with control strategies and used to cover the heat requirements of different heat demand levels of 
the considered buildings.

In the first step, the single-family house ( $120 \mathrm{~m}^{2}$ floor space) and the multi-family house ( $540 \mathrm{~m}^{2}$ floor space), in each case with two different heat demand levels, were modeled in the simulation environment TRNSYS. The heat demand level "Low Energy Building" (LEB) meets the current state of thermal protection in new buildings in Austria and the heat demand level "Nearly Zero Energy" is equivalent to the heat consumption of a passive house. With regard to the four different heat demand profiles, different heat supply systems were developed in the second step (see chapter 3). The system A is supplied in a monovalent way via an air-water heat pump, the systems B, C, D are additionally equipped with building-integrated thermal solar systems and the systems E and F include a photovoltaic system. In addition, variations in the type of heat pump and the thermal charging of the story ceiling are defined and modeled in TRNSYS. In the case of "solar overheating", an increase of the upper temperature limit by 2 Kelvin is allowed in the component (Fig. 2). Systems B to F are equipped with three differently sized solar systems (SFH: $20 \mathrm{~m}^{2}$ (a), $40 \mathrm{~m}^{2}$ (b), $60 \mathrm{~m}^{2}$ (c); MFH: $25 \mathrm{~m}^{2}$ (a), $125 \mathrm{~m}^{2}$ (b) $200 \mathrm{~m}^{2}$ (c)).

Tab. 1: Overview of the established systems for the heat supply of the considered buildings

\begin{tabular}{|c|c|c|c|c|c|}
\hline & solar plant & heatpump & storage tank & solar charging & $\begin{array}{l}\text { activated structural } \\
\text { elements }\end{array}$ \\
\hline system A & - & air-water & domestic hot water & - & ceiling slab \\
\hline system B & solar thermal & air-water & domestic hot water & - & ceiling slab \\
\hline system C & solar thermal & air-water & domestic hot water & +2 Kelvin & ceiling slab \\
\hline system D & solar thermal & soil-water & domestic hot water & +2 Kelvin & ceiling slab \\
\hline system E & photovoltaic & air-water & domestic hot water & - & ceiling slab \\
\hline system F & photovoltaic & air-water & domestic hot water & +2 Kelvin & ceiling slab \\
\hline
\end{tabular}

In the third step, the models of the systems (A to F) were combined with the building models in both heat demand levels, equipped with control systems and simulated as overall system models on an annual basis. Step four was the definition of characteristic figures for the assessment of the systems, with the aim of being able to assess both the energy-related performance, the economic and the ecological performance. In the fifth step, the simulation results were evaluated, compared and analyzed with regard to the defined energetic, economic and ecological assessment figures.

\section{CONSIDERED SYSTEMS}

At the start of the project, different heat supply concepts were defined to cover as much heat as possible through the solar thermal and solar electrical system by the additional activation of the storage mass in the building (primarily concrete). The considered Systems are described in Tab. 2.

Tab. 2: Considered systems for the heat supply of the buildings

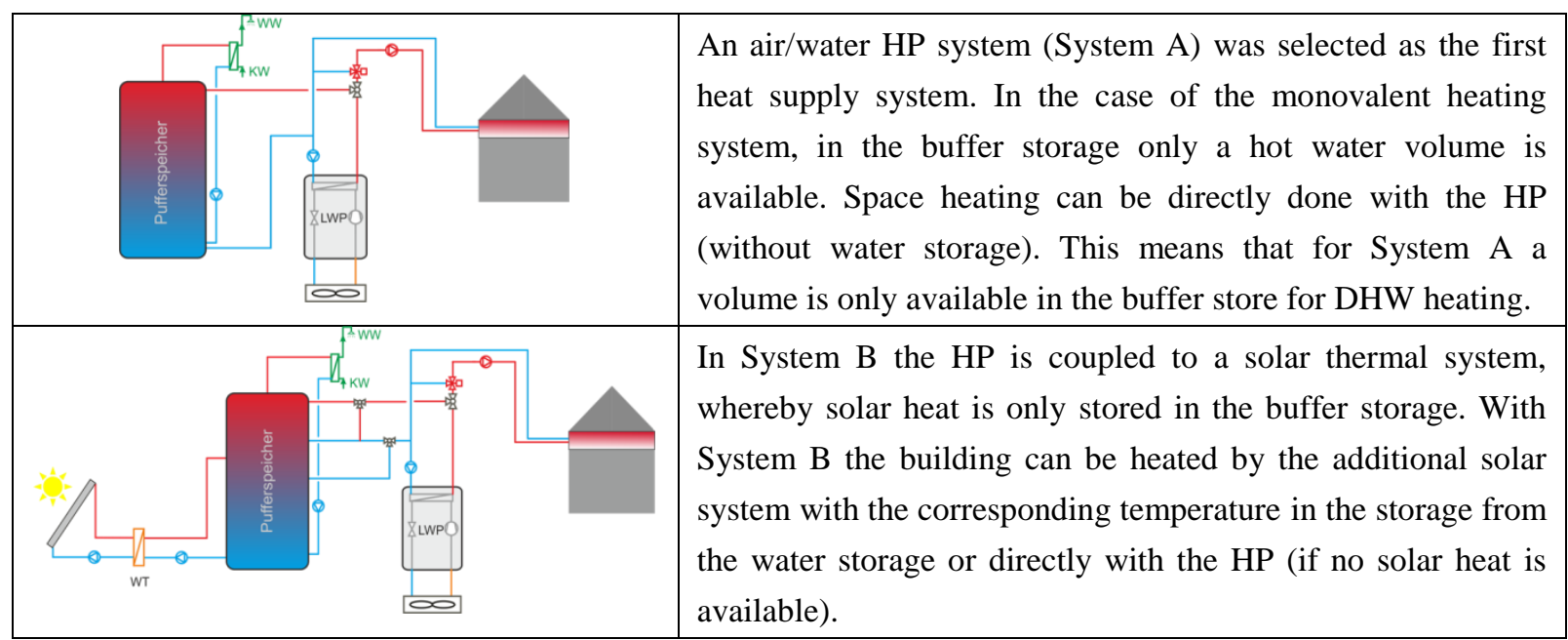




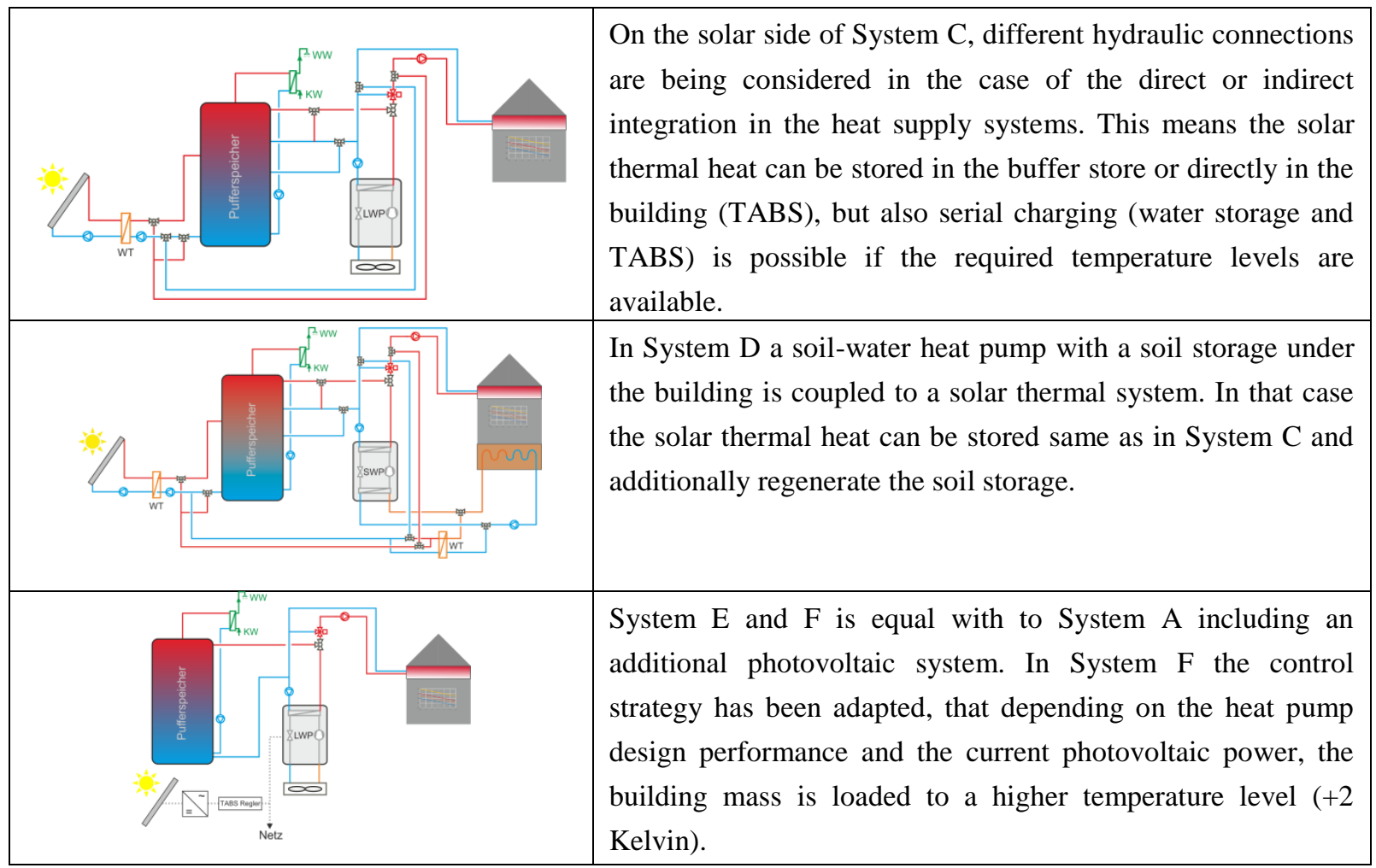

\section{Building}

Concerning the climatic conditions the city of Graz (Austria) was chosen for the building location. For the thermal building and system simulations a mean climatic data set (over 10 years) is used (Tmean ambient: 10.7 ${ }^{\circ} \mathrm{C}$, heating degree days: $3102 \mathrm{Kd}$, global hor. radiation: $1206 \mathrm{kWh} / \mathrm{m}^{2} \mathrm{a}$, diffuse hor. radiation: $616 \mathrm{kWh} / \mathrm{m}^{2} \mathrm{a}$ ). The building designs (insulation standards) are based on the building guidelines OIB-RL 6 for the minimum requirement and for a very ambitious case a nearly zero energy building (including controlled ventilation with air heat recovery) was defined. The specific head demand of the two different considered buildings amounts for the low energy building (LEB) $37 \mathrm{kWh} /\left(\mathrm{m}^{2} \mathrm{a}\right)$ and for the net zero energy building (NZEB) $17 \mathrm{kWh} /\left(\mathrm{m}^{2} \mathrm{a}\right)$.

The dimensioning of the required heating capacity of the backup system was based on a heating load calculation. For the nearly zero energy building the same design criteria were chosen for the backup systems as for the low energy building. The dynamic heat load calculation (simulations in TRNSYS) for the low energy buildings for a room air temperature of $22{ }^{\circ} \mathrm{C}$ during the heating period are summarized in Tab. 2. Since the solar thermal systems are compared with an air heat pump system (System A), the backup system has to be dimensioned to ensure the coverage of the heat requirements for the DHW heating and space heating without solar support.

Tab. 3: Heating load of the LEB and heating capacity for heat pumps

\begin{tabular}{llll}
\hline LEB & Heating load & air-water heat pump (A-12W35) & soil-water heat pump (S0W35) \\
\hline SFH & $4.3 \mathrm{~kW}$ & $5.4 \mathrm{~kW}$ & $5.8 \mathrm{~kW}$ \\
MFH & $20.4 \mathrm{~kW}$ & $19.8 \mathrm{~kW}$ & -
\end{tabular}

In addition to the various heat-supply systems, the heat dissipation system is also considered and analyzed. The systems and ceiling constructions is shown in Fig. 1 for the ground floor of the building. The largest difference to an underfloor heating system $(\mathrm{FH})$ is the positioning of the insulation layer. In the case of the underfloor heating system, the heat dissipation system is installed in the screed, and the concrete is separated by the insulation layer in order to limit its activation. If the building is heated through the ceiling (TABS), where the heat transfer system is installed directly in the concrete, more storage mass can be activated. The next difference is that the pipes of the heat dissipation system are positioned much deeper in the concrete in the TABS system 
than in the FH system and the heat transfer coefficients of the heat output surfaces (ceiling or floor) are also be different and calculated through the building model in TRNSYS dependent on the room air temperature and the surface temperature of the heat transfer surface.

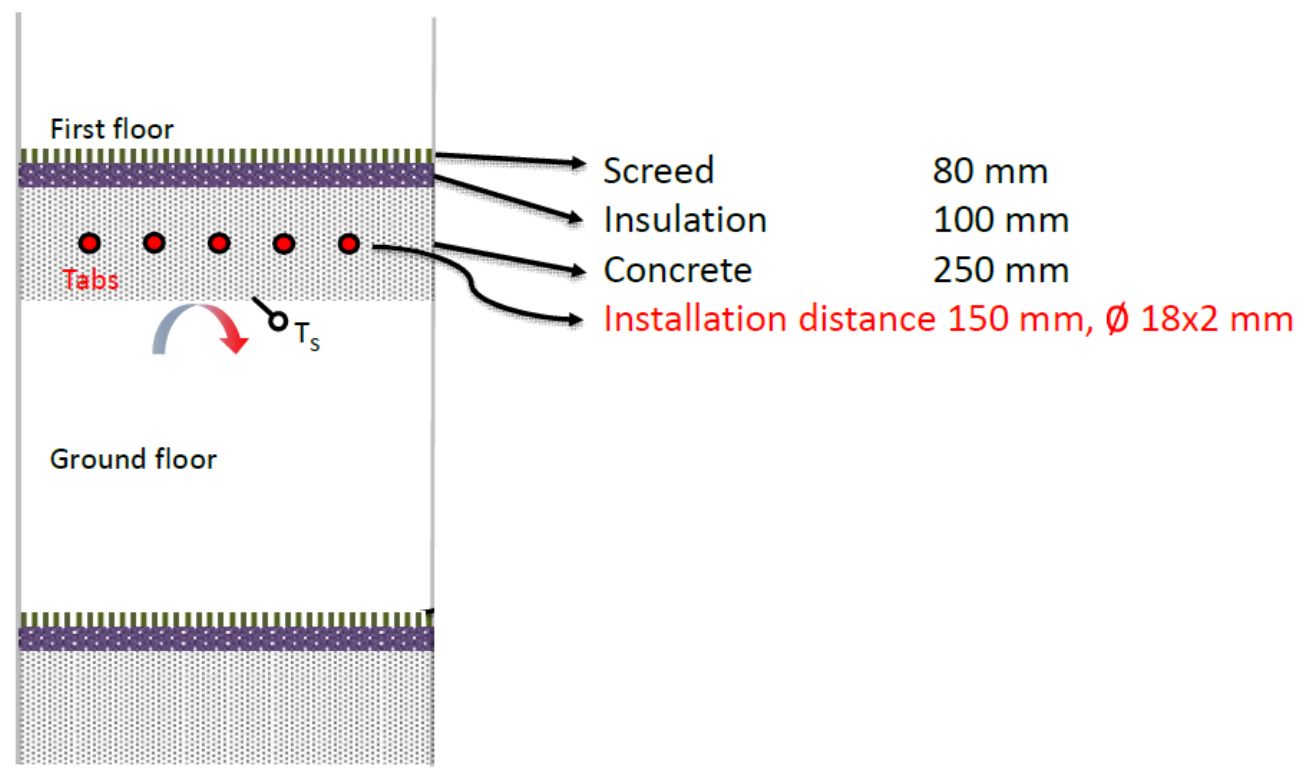

Fig. 1 Ceiling construction for the concrete core activation (TABS)

\section{Control strategy}

On the basis of the evaluations of the different simulation data of the various types of control temperatures that were tested, the surface temperature (Ts) was chosen for the control variable for the room heating. The building model of the considered building consists of multiple thermal zones. Each thermal zone can be charged independently of one another, whereby the control variable (surface temperature of the thermally activated component) is dependent on the outside air temperature. The required control surface temperature changes with the outside air temperature. In addition, depending on the heat source (solar or HP), the temperature hysteresis for the charge controller changes (Fig. 2). If heat is required to charge the thermal zone and no solar heat is available, the backup system is charging to a surface temperature hysteresis of $2 \mathrm{~K}$ (Tsurf Heat ON, Tsurf HP $\mathrm{OFF}$ ). If solar heat is available, the hysteresis is increased by $2 \mathrm{~K}$ to $4 \mathrm{~K}$, so that the storage mass is charged to a higher average temperature level.

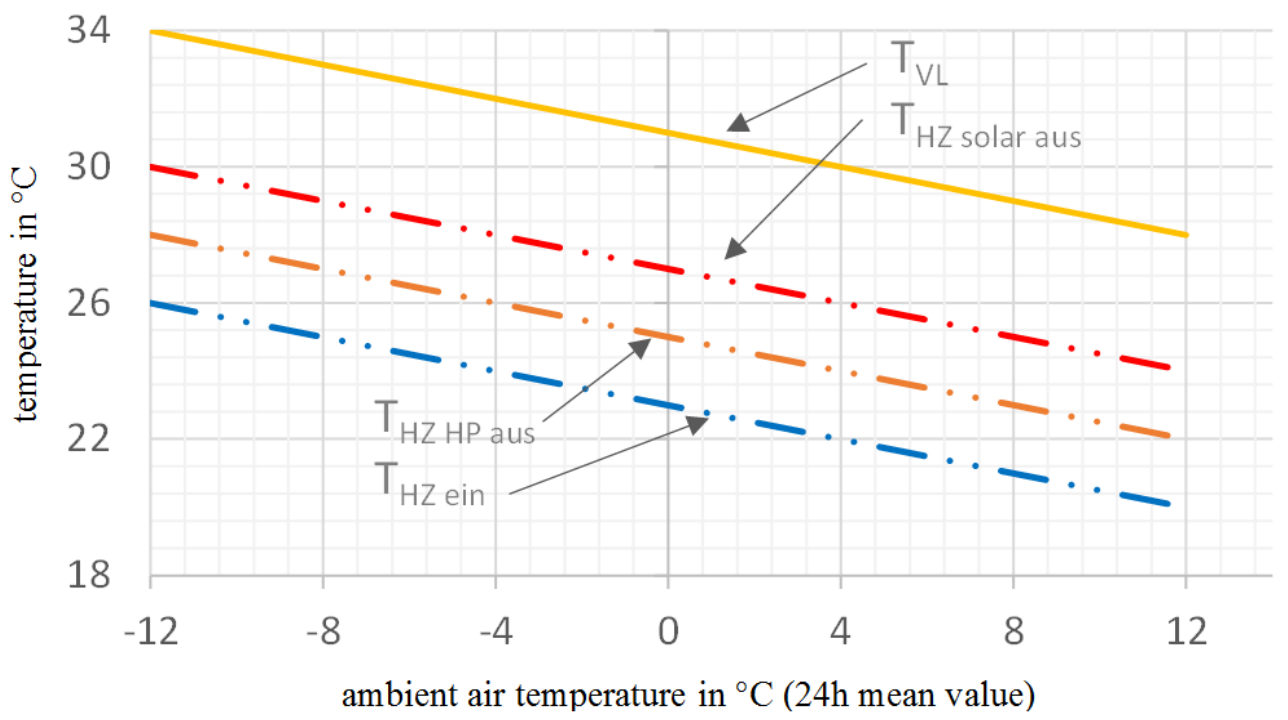

Fig. 2: Control strategy 


\section{Results}

At the centre of the considerations is the question of the achievable degree of self-sufficiency with heat for the reference buildings. The solar coverage SD, as a measure of the self-sufficiency, depends both on the ratio of solar heat provided to the heat consumption, and on the possibilities for storing heat.

Due to the storage capacity of the story ceilings, a single-family house in low energy level can achieve a solar fraction of approx. SD $=50 \%$ even with the smallest considered solar thermal collector area $20 \mathrm{~m}^{2}$ (a) and a small buffer storage $\left(1.5 \mathrm{~m}^{3}\right)$. With using all considered possibilities for improvement, reduction of heat consumption to the level Nearly Zero Energy, plus solar overheating, plus use of the soil, plus covering of the entire roof area and the entire south façade with thermal collectors $60 \mathrm{~m}^{2}$ (c), the solar coverage is $\mathrm{SD}=91 \%$. Thus, over $90 \%$ of the heat demand in the assumed single-family home can be covered in a decentral way and the heat pump has to contribute only about $10 \%$ to a full thermal supply.

Thermal and electrical energy demand in $\mathrm{kWh} / \mathrm{a}$

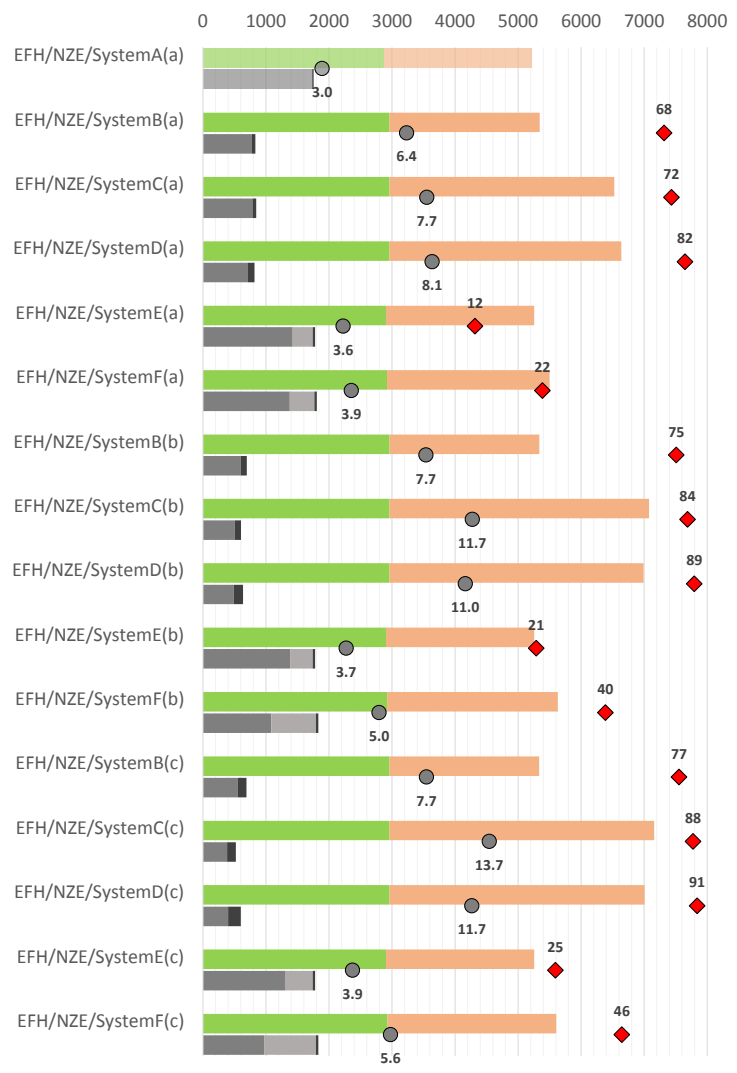

Thermal and electrical energy demand in $\mathrm{kWh} / \mathrm{a}$

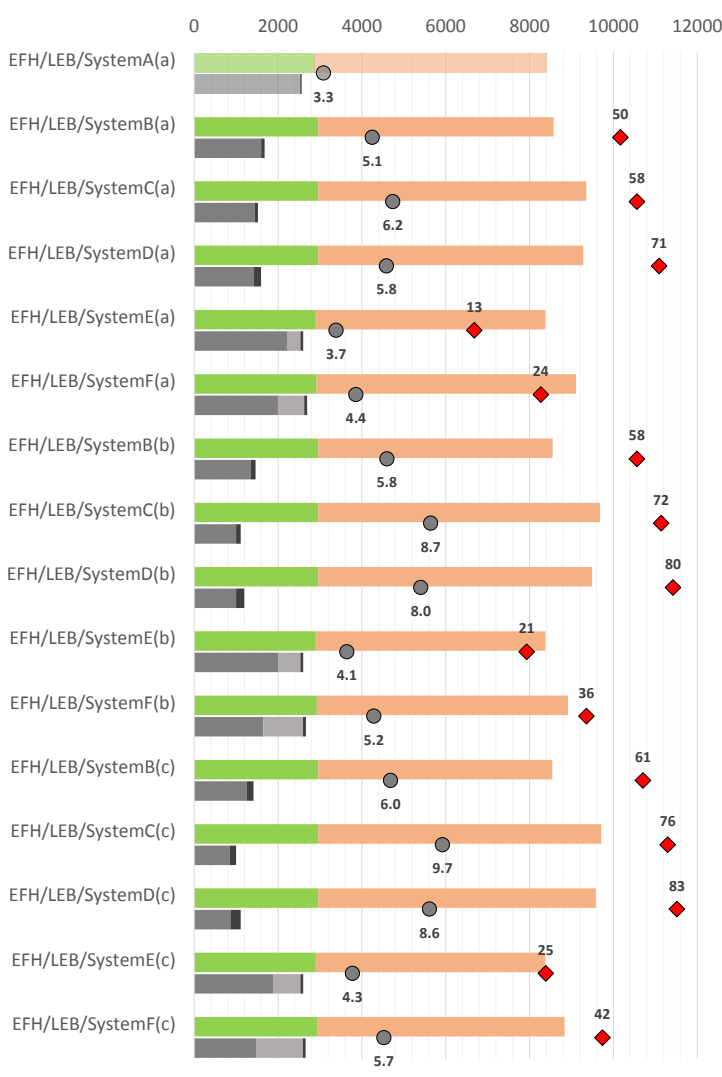

heat demand for hot water preparation [kWh/a]

heat demand for space heating [kWh/a]

electrical energy consumption heat pump (grid) $[\mathrm{kWh} / \mathrm{a}]$

- electrical energy consumption heat pump (PV) [kWh/a]

electrical energy consumption of pumps, controller, etc. [kWh/a]

- solar fraction [\%]

system efficiency (SPFsys) [-]

Fig. 3: Energetic results for the single-family house

For the multi-family building, the prerequisites for high solar fractions are less pronounced than for singlefamily dwellings. Due to the higher compactness of the building the specific heating demand is slightly lower, but in relation to the heated volume significantly less external surfaces are available for solar use. These circumstances are evident in the achievable solar fractions. In the heat demand level Low Energy Building with a compact energy storage $\left(30 \mathrm{l} / \mathrm{m}^{2}\right.$ collector area) and with the smallest considered collector area of $25 \mathrm{~m}^{2}$, a solar fraction of approx. SD $=25 \%$ can be achieved. The full utilization of all examined possibilities of improvement leads to a maximum achievable solar fraction of approx. SD $=75 \%$. 
Thermal and electrical energy demand in $\mathrm{kWh} / \mathrm{a}$

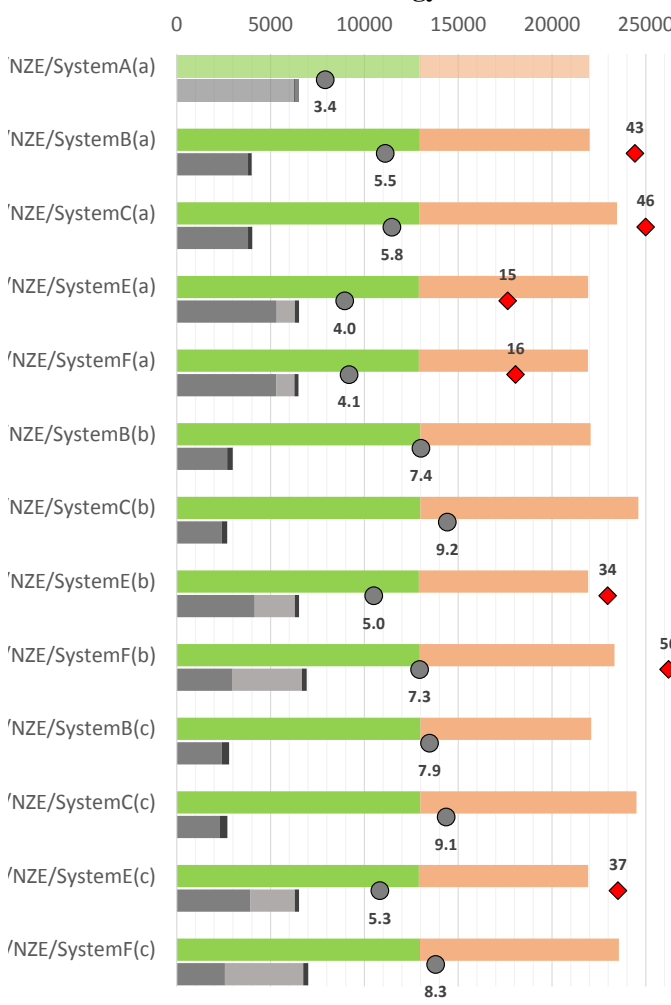

Thermal and electrical energy demand in $\mathrm{kWh} / \mathrm{a}$

500010000150002000025000300003500040000

30000 LEB/SystemA(a)

'LEB/SystemB(a)

LEB/SystemC(a)
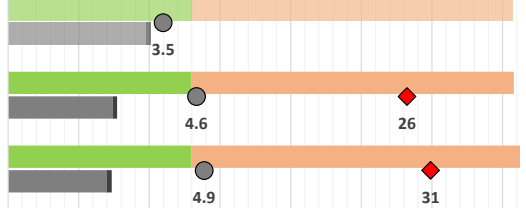

'LEB/SystemE(a)

'LEB/SystemF(a)

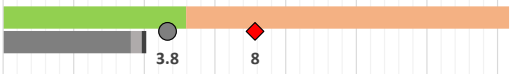

LEB/SystemB(b)
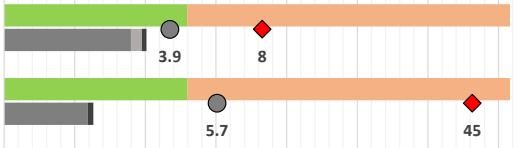

LEB/SystemC(b)

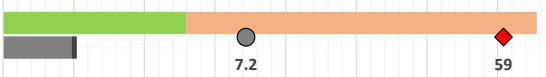

'LEB/SystemE(b)

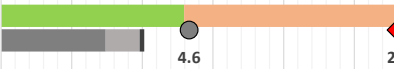

'LEB/SystemF(b)

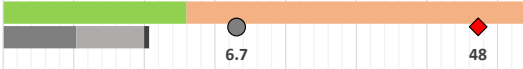

LEB/SystemB(c)

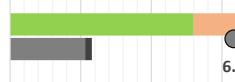

'LEB/SystemC(c)

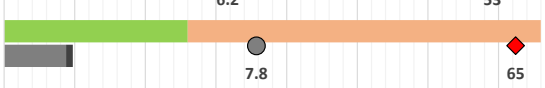

'LEB/SystemE(c)

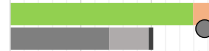

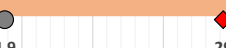

'LEB/SystemF(c)

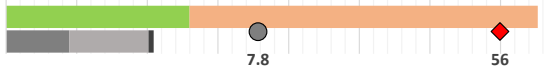

- heat demand for hot water preparation [kWh/a]

heat demand for space heating $[\mathrm{kWh} / \mathrm{a}]$

- electrical energy consumption heat pump (grid) [kWh/a]

- electrical energy consumption heat pump (PV) [kWh/a]

electrical energy consumption of pumps, controller, etc. [kWh/a]

- solar fraction [\%]

system efficiency (SPFsys) [-]

Fig. 4: Energetic results for the multi-family house

Besides the solar fraction a number of additional assessment parameters were analyzed for the considered scenarios. With regard to the costs of the energy concepts, it can be seen that the solar thermal concepts cause high additional investment costs. However, even small collector areas cause a significant reduction of the energy demand and thus also the operating costs. The solar-electric concepts have lower additional investment costs, whereby the solar electricity yields that cannot be directly utilized can be offset against the operating costs considering a feed-in tariff into the electricity grid.
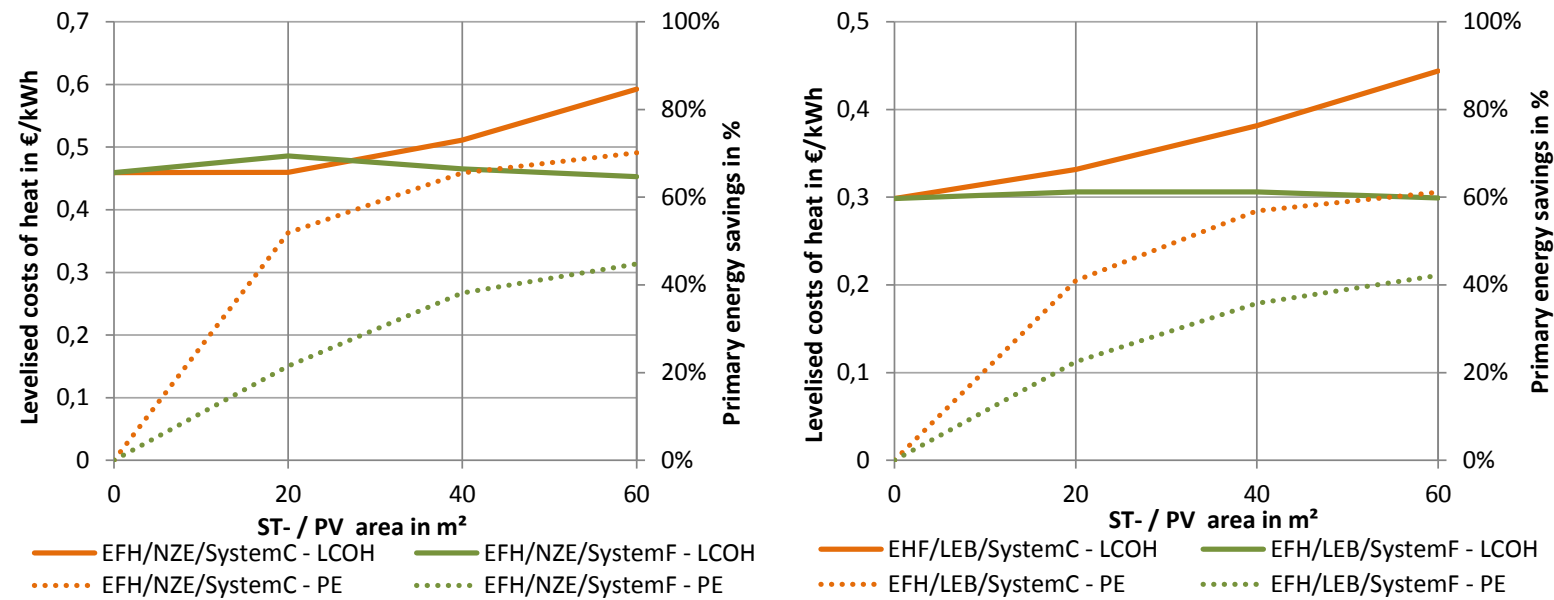

Fig. 5: Economical and ecological results for the single-family house 

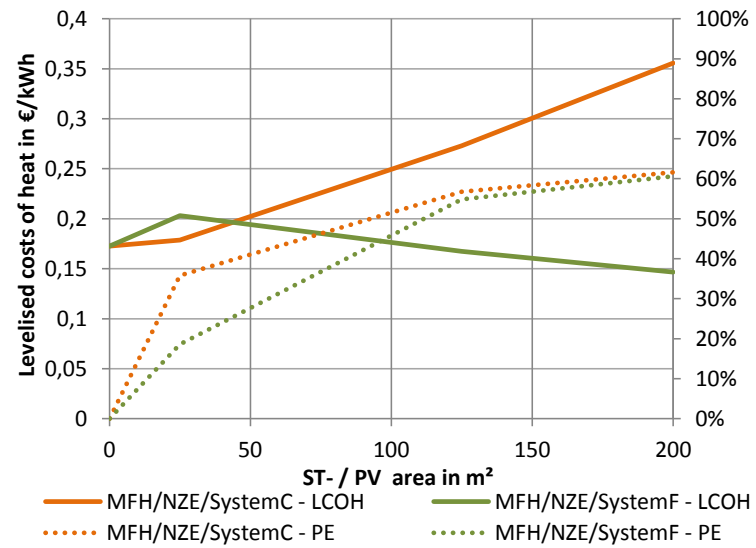

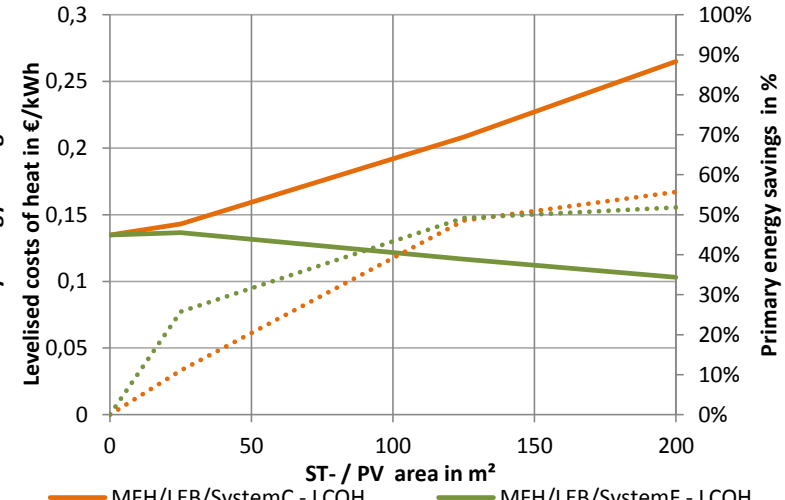

$\mathrm{MFH} / \mathrm{LEB} /$ SystemC - LCOH $\longrightarrow \mathrm{MFH} / \mathrm{LEB} /$ SystemF - LCOH $\ldots$ MFH/LEB/SystemF - PE $\quad \ldots$ MFH/LEB/SystemC - PE

Fig. 6: Economical and ecological results for the multi-family house

When interpreting the presented results, it should be considered that the heat supply systems combined with the reference buildings are simulated using extensive and complex models based on a number of assumptions. The presented results are valid only in relation to these assumptions.

\section{Acknowledgements}

The reported research has been conducted within the framework of the Austrian project solSPONGEhigh" (FFG Project-No.: 845182), funded by the Austrian Ministry for Transport, Innovation and Technology.

\section{References}

Heimrath et al. (2018): Final Project Report: Hohe solare Deckungsgrade durch thermisch aktivierte Bauteile im urbanen Umfeld (in German), Austrian Klima- und Energiefond, Project number: 845182

\section{Conclusion}

Due to the mismatch in time between the solar supply and the energy demand, usually only a part of the solar energy can be used to cover the energy needs of a building. The larger the solar energy system is dimensioned, the more important is the integration of an energy storage. In order to achieve high solar fractions, the short to medium term storage of larger amounts of heat is essential. This raises the question of alternative solutions for heat storage in buildings.

One way to increase the heat storage capacity of a building has been analyzed in the research project solSPONGEhigh. The thermal activation of solid components such as ceilings and foundations (used as sensible heat storage elements), with solar-thermal or solar-electric systems shows a huge energy saving potential. The results show that through the activation and use of the thermal storage potential contained in the building mass, high solar fractions up to $100 \%$ of the building's heat demand can be achieved.

A general picture across the analysis of the different systems, buildings and insulation standards showed that that a solar thermal concepts shows a better system efficiency and thereby a higher primary energy- and CO2reduction potential in comparison with solar-electrical concepts but also higher levelised costs of heat for bigger collector areas. For solar thermal concepts it makes sense to realize to realize rather small collector areas and for solar-electric concepts a larger solar-electric area should be preferred.

In general terms, it can be said that the use of renewable energy sources and the building as thermal storage makes heat supply systems with adequate investment costs, low operating costs, a significant reduction in the dependency. 


\title{
Early Design Stage Consideration of Building Form and BIPVT Energy Performance
}

\author{
Samson Yip ${ }^{1}$, Andreas Athienitis ${ }^{1}$ and Bruno Lee ${ }^{1}$ \\ ${ }^{1}$ Centre for Zero Energy Building Studies, Concordia University, Montreal (Canada)
}

\begin{abstract}
Building form can be an influencing factor on the energy performance of solar net-zero energy buildings. While previous studies have examined the effects of building form on the energy demand of buildings and energy generation through the use of building-integrated photovoltaics (BIPV), fewer exist for the newer buildingintegrated photovoltaics with thermal heat recovery (BIPVT) system. Therefore this study analyzes the relationship between building form and BIPVT energy performance to provide guidance for commercial and institutional building design at the early design stage. Through TRNSYS simulations, different building plan shapes are analyzed in a heating dominated climate to determine the balance between energy demand and PV electricity generation and thermal heat recovery. Results indicate that configurations of each of the form families studied were able to reach net-zero energy depending on different enclosure parameters, BIPVT tilt angle, and building orientation, offering different pathways to net zero energy for building designers.
\end{abstract}

Keywords: BIPVT, design support, building form, building typology, net-zero energy building, TRNSYS

\section{Introduction}

\subsection{NZEB, energy performance, tools for building designers}

There is growing interest in the building sector for high performance buildings such as net zero energy buildings (NZEBs) as a means to reduce overall energy consumption. One of the common renewable energy technologies integrated into NZEBs is photovoltaic (PV) technology. While PV can be mounted on racking on building facades and roofs - for so-called building-applied PV (BAPV) - the full integration of PV as a component in the building enclosure - for building-integrated PV (BIPV) - offers the potential for better enclosure and architectural integration.

Since, in BIPV, the PV system is now an integral part of the building enclosure, building form will have an influence on the energy-generating performance of the BIPV as well as the overall energy performance of the NZEB. Previous performance studies have examined the effects of building form on the energy demand of buildings and energy generation using BIPV (Hachem, Athienitis et al. 2011; Youssef, Zhai et al. 2016).

Recent research focus has been on an enhancement of BIPV, the building-integrated PV/thermal (BIPVT) system, which includes thermal heat recovery as a means to extract additional benefit from the sun's energy at the building enclosure. Typically, when generating electricity, in a BIPV design, the heat at the panel backface is evacuated to the outside to cool down the PV panel and to prevent heat damage to proximate building materials. In the case of a BIPVT system, this heat is recovered for building use. Delisle and Kummert (2016) have examined building form and BIPVT in the context of cost-benefits for residential buildings. Athienitis et al (2018) have produced a BIPVT case study for commercial/institutional buildings, but the BIPVT application was limited to vertical facades. Therefore, this study analyzes the relationship between building form and roofmounted BIPVT performance to provide guidance for commercial/institutional building design at the early design stage when major design decisions are yet to be made.

More specifically, the objective of this study is to determine the benefit of the thermal heat recovery in addition to the PV electric generation potential in a BIPVT system depending on building form, whilst maintaining an annual net-zero energy balance between energy demand and energy generation. 


\section{Methodology}

\subsection{Building typology}

The building type proposed in this study is 2 storey commercial/institutional, with a floor plate of $1500 \mathrm{~m}^{2}$, for a total useable floor area of $3000 \mathrm{~m}^{2}$. The floor plan is for an open-plan office space with a depth of $15 \mathrm{~m}$ to maximize the potential for daylighting that can be used in the space. Other locations will have different maximum building depths for daylighting depending on climate (Guglielmetti, Pless et al. 2010, Yip, Chen et al. 2015). The roof is pitched symmetrically about the longitudinal axis of each building wing to function as the BIPVT surface. Roof surfaces that are oriented between $90^{\circ}$ and $270^{\circ}$ azimuth are clad with BIPVT. While this makes for unequal total surface areas of BIPVT between building configurations, it represents realistic tradeoffs inherent in design choices. Using the bar plan shape (RE) as a reference point, several plan shapes were used to generate the 2-storey building configurations of equal floor area. These are simplified representations of common building plan types in the urban environment. The L- and U-shapes are further defined by a plan rotation angle from $15^{\circ}$ to $75^{\circ}$ to denote the rotation of a wing of the building vis-à-vis the other wings. (See Figure 1). The study uses weather conditions for the heating-dominated climate of Montreal, Canada (ASHRAE zone 6A).

All the building configurations tested use the same occupancy density, set point temperatures, and operating schedules.

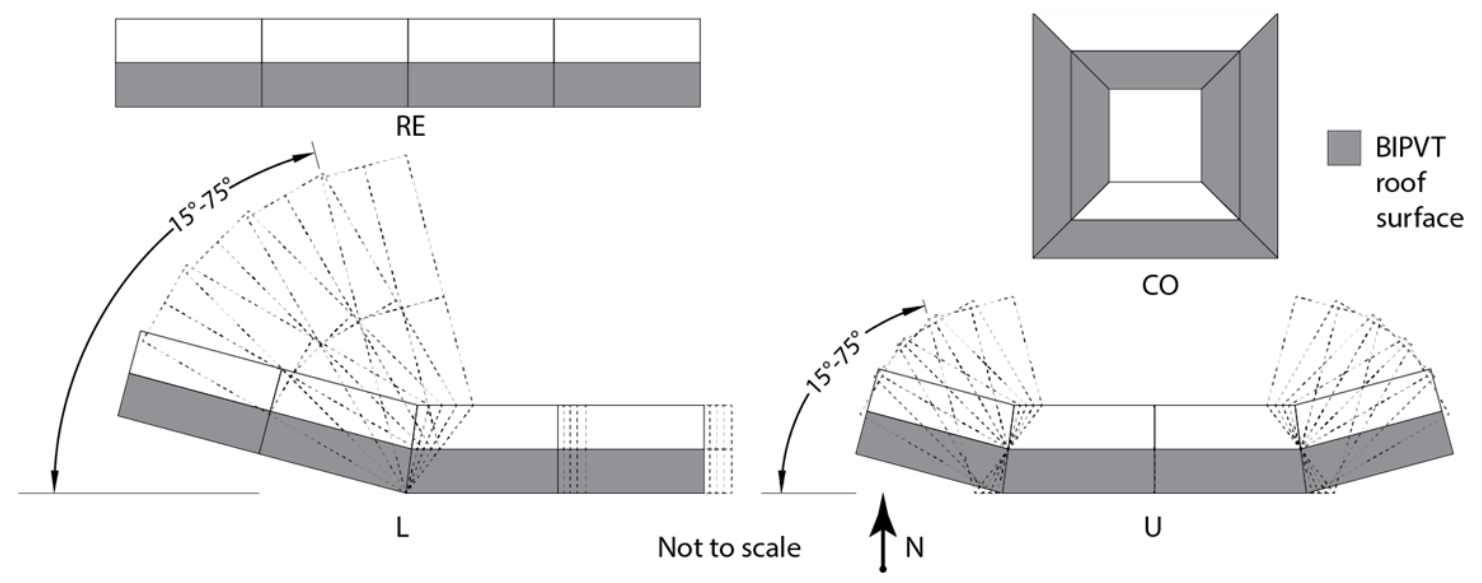

Figure 1: Plan shape families; grey shading indicates BIPVT surfaces; and the L- and U-shape plan rotation angles

\subsection{Roof surface shape efficiency}

The BIPVT surface area calculations do not account for potentially unusable, residual area due to possible mismatches between overall roof surface dimensions and total PV module dimensions since actual PV module sizes and layout are usually not yet known at early design stage. However, all triangular surface areas are excluded from usable BIPVT surface area. (See Figure 2). This represents the inherent inefficiency for roofs depending on the angle of intersection of the adjoining roofs.

Aside from ensuring daylighting penetration through the entire floor plate, the other reason to limit the depth of the building is to limit the height of the roof due to its pitch. For medium-sized commercial/institutional buildings, the roof is the principal surface for PV application. In a BIPV or BIPVT rooftop application, the PV tilt angle is the roof tilt angle; and the PV plane is the roof plane. For northern climates (latitudes), a balance must be achieved between providing a large surface area at a useful tilt angle for PV electricity generation and minimizing interior ceiling volume and space that must be conditioned and assigned a productive function or use.

This is a constraint that does not exist for BAPV rooftop applications. The deeper building is at best beneficial (at worst indifferent) for BAPV because the tilt angle and tiling of the BAPV is independent of roof slope or orientation due to the racking systems. 


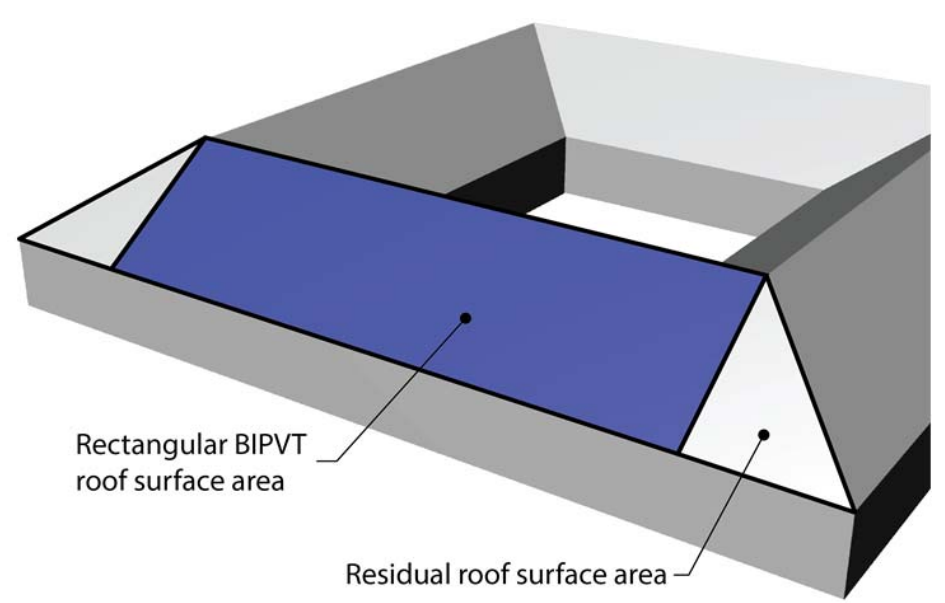

Figure 2: Detail of roof volume showing BIPVT surface (in blue) and residual area (in light grey)

\subsection{TRNSYS model}

TRNSYS 18 is used to simulate the building energy performance as well as the BIPVT electricity generation and thermal heat recovery. The three-dimensional building form derived from the plan shapes is used in the TRNSYS Type56 along with semantic variables such as thermal insulation quantities, window characteristics, building occupancy, setpoints, and schedules. Since this study is concerned with conditions for the early stage of a building design, ideal heating and cooling loads are calculated at hourly time steps based on a simplified heat pump with a heating coefficient of performance of 2.5, and a cooling coefficient of performance of 3.0. The minimum insulation values represent the minimum required under the National Energy Code of Canada for Buildings (Canadian Commission on Building and Fire Codes and Construction 2015) for Montreal. (See Table 1 for a summary of the main variables and values used in the simulations).

Table 1: Model inputs

\begin{tabular}{|c|c|}
\hline Parameter & Value(s) \\
\hline Location & Montreal, Canada \\
\hline Azimuth & $135^{\circ}-225^{\circ}$ \\
\hline Floor plate / storeys & $1500 \mathrm{~m}^{2} / 2$ \\
\hline Total floor area & $3000 \mathrm{~m}^{2}$ \\
\hline Roof pitch & $25^{\circ}-45^{\circ}$ \\
\hline PV nominal efficiency & 0.16 \\
\hline BIPVT channel height & $0.025 \mathrm{~m}^{\circ}$ \\
\hline Total roof surface area & $827-1591 \mathrm{~m}^{2}$ \\
\hline $\begin{array}{c}\text { Total BIPVT surface } \\
\text { area }\end{array}$ & $827-1233 \mathrm{~m}^{2}$ \\
\hline
\end{tabular}

\begin{tabular}{|c|c|}
\hline Parameter & Value(s) \\
\hline Wall insulation & $1.0-1.5(\mathrm{~h} / \mathrm{kJ}) \mathrm{m}^{2} \mathrm{~K}$ \\
\hline Roof insulation & $1.5-2.0(\mathrm{~h} / \mathrm{kJ}) * \mathrm{~m}^{2} \mathrm{~K}$ \\
\hline Window (see Table 2) & WinID 300,500 \\
\hline WWR(S, E, W, N) & $0.1-0.9$ \\
\hline Heating Setpoint & $\begin{array}{c}2{ }^{\circ} \mathrm{C}, 15^{\circ} \mathrm{C} \text { night } \\
\text { setback }\end{array}$ \\
\hline Cooling Setpoint & $26^{\circ} \mathrm{C}$ \\
\hline Heating COP & 2.5 \\
\hline Cooling COP & 3.0 \\
\hline Schedule (occupancy) & $\begin{array}{c}\text { M-F: } 07 \mathrm{~h}-20 \mathrm{~h} ; \\
\text { Sa-Su: } 09 \mathrm{~h}-18 \mathrm{~h}\end{array}$ \\
\hline
\end{tabular}

The BIPVT system is represented by TRNSYS Type 568; uses a simple PV efficiency of $16 \%$, and is connected to Type 56 to access the Type 56 roof inside surface temperature. Type 568 uses this as the collector back surface temperature to calculate the lower air channel surface temperature. Type56 in turn uses this as the roof outside temperature to calculate the roof inside surface temperature. This process repeats until convergence is reached. 


\subsection{Windows}

The sizes of fenestration are described by a window to wall ratio (WWR) variable. A separate WWR is calculated for each vertical building surface orientation. Two triple-glazed window types are used: one with a relatively high solar heat gain coefficient (SHGC) and daylight transmittance and the other with a lower SHGC and daylight transmittance. (See Table 2). Both window types are selected from the Window v7.4.6.0 database incorporated in TRNSYS 18.

Table 2: Window properties

\begin{tabular}{|c|c|c|}
\hline Parameter & Window 1 & Window 2 \\
\hline Description & $\begin{array}{c}\text { High SHGC, high Tvis- } \\
\text { daylight }\end{array}$ & $\begin{array}{c}\text { Low SHGC, low Tvis- } \\
\text { daylight }\end{array}$ \\
\hline Description & $\begin{array}{c}\text { Triple-glazed, argon- } \\
\text { filled, low-e }\end{array}$ & $\begin{array}{c}\text { Triple-glazed, argon- } \\
\text { filled, low-e }\end{array}$ \\
\hline WinID & 300 & 500 \\
\hline U-value & $0.61 \mathrm{~W} /\left(\mathrm{m}^{2} \mathrm{~K}\right)$ & $0.73 \mathrm{~W} /\left(\mathrm{m}^{2} \mathrm{~K}\right)$ \\
\hline g-value & 0.5 & 0.3 \\
\hline Tsol & 0.425 & 0.256 \\
\hline Tvis-daylight & 0.72 & 0.54 \\
\hline
\end{tabular}

Solar heat gain is managed through the use of an internal sunshade that is activated when incident solar radiation is above $140 \mathrm{~W} / \mathrm{m}^{2}$, blocking $70 \%$ of the solar radiation, and is deactivated when incident solar radiation is below $120 \mathrm{~W} / \mathrm{m}^{2}$.

\subsection{Parametric model}

Each building configuration is generated from a parametric model using a Python script which draws from the plan-shape families described in section 2.1 along with values for other parameters within the ranges listed in Table 1. The Python script then calls the TRNSYS executable to run the simulation of building energy demand, and BIPV/T electricity generation and thermal heat recovery. The simulation results are collected and stored using modeFRONTIER.

\subsection{Evaluation criteria (NZEB)}

The current study uses only one locale and uses site energy calculations to compare the relative performance of the different building configurations. The convention used in this study is that energy demand is a positive number; renewable energy generated is a negative number.

At each time step, the heating demand is first reduced by whatever amount of BIPVT heat that is recovered; the surplus BIPVT heat is exhausted to the exterior. Then, the net energy demand is calculated by summing the remaining heating demand along with the cooling demand, plug-loads, electrical lighting, and the BIPVTgenerated electricity. The net energy demand is integrated over the whole year to obtain the annual net energy performance of the building. If this annual quantity is negative, the building will have achieved net zero energy (NZE) for the year.

\section{Results and discussion}

The results show that many of the building configurations from each family of plan shapes are able to reach NZE for Montreal. Figure 3 maps the net annual energy balance versus plan shape, BIPVT slope, and azimuth. These results are broken down further by plan shape in Figures 4 to 7 . The dominating factor is the BIPVT roof tilt angle. Without exception, the best NZE performing configuration for each of the plan shapes is for a BIPVT roof tilt angle of $45^{\circ}$, which corresponds well to the angle of the site latitude $\left(45.5^{\circ}\right)$ and the general rule-of- 
thumb optimal tilt angle for annual solar radiation being equal to the site latitude (Duffie and Beckman 2013). Across all plan shapes, NZE was attained for roof tilt angles of $35^{\circ}$ to $45^{\circ}$. Each of the different variants of each family of plan shapes (shapes 0 to 11) was able to reach NZE.

Since orientation refers to the nominal direction of the building plan on a site, the plan shapes with wing rotations result in BIPVT surface areas with different orientations. This ensures that the building can capture solar radiation at different times of day even though it may not be optimal. For example, the courtyard shape reaches NZE in a diamond configuration at azimuth $225^{\circ}$. Since this is a study for the early design stage, this particular configuration can be refined to adjust the quantity and placement of the BIPVT surfaces as the design progresses.

With the exception of the BIPVT tilt angle, each of the other input variables was able to reach NZE in configurations using all values from the entire input value range. As mentioned before, for the BIPVT tilt angle, NZE was reached only when the tilt angle was between $35^{\circ}$ and $45^{\circ}$. Therefore, aside from the BIPVT tilt angle, choosing input values for reasons other than for net annual energy demand reduction, such as choosing a plan shape for architectural space planning reasons, will not compromise the NZEB goal.

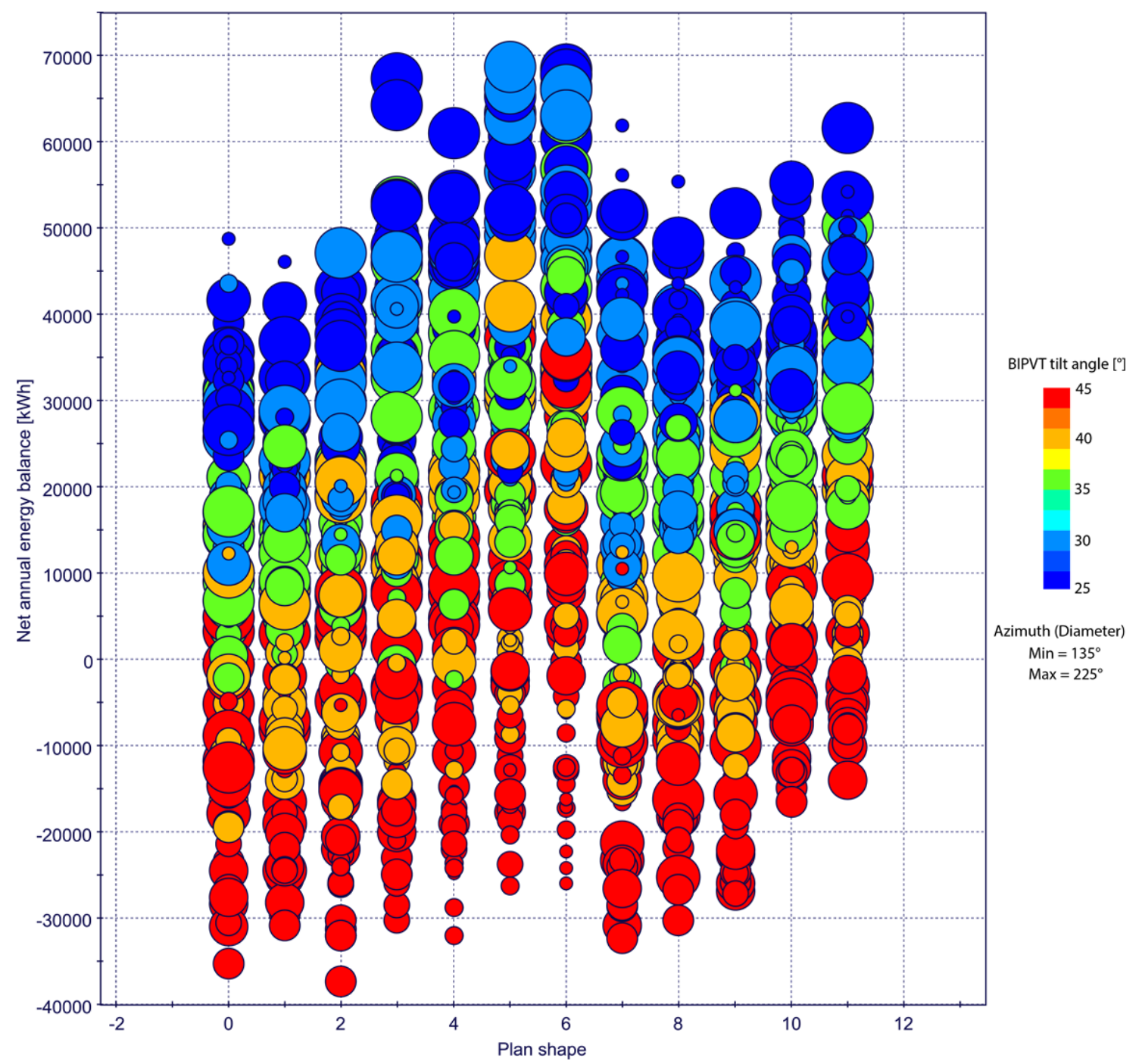

Figure 3: 4D plot of net energy balance versus plan shape, NZEB, BIPVT tilt angle, and azimuth (negative net annual energy means NZE reached) 

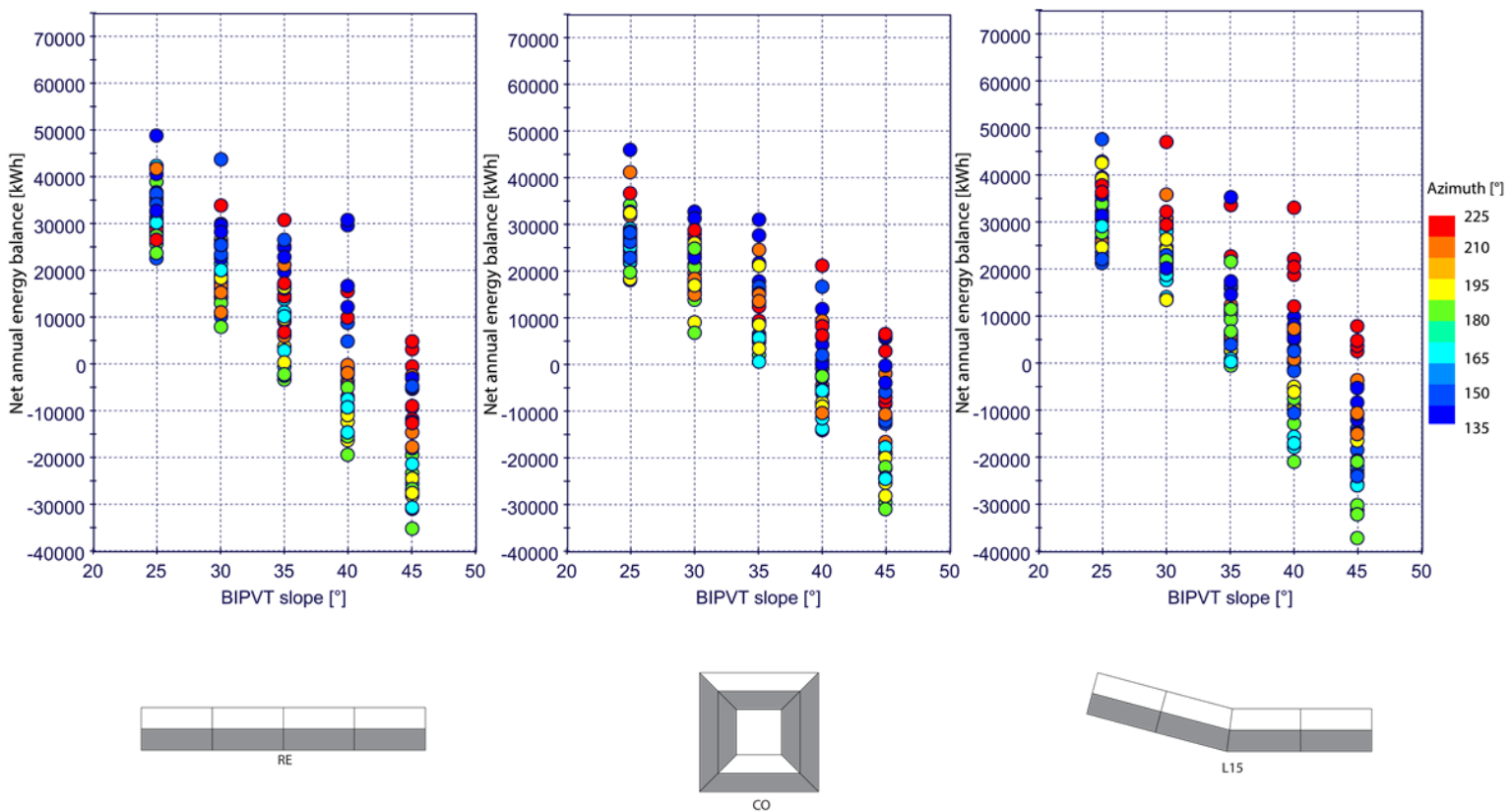

Figure 4. Plan shapes 0, 1, 2; net annual energy balance versus BIPVT slope and azimuth (negative net annual energy means NZE reached)
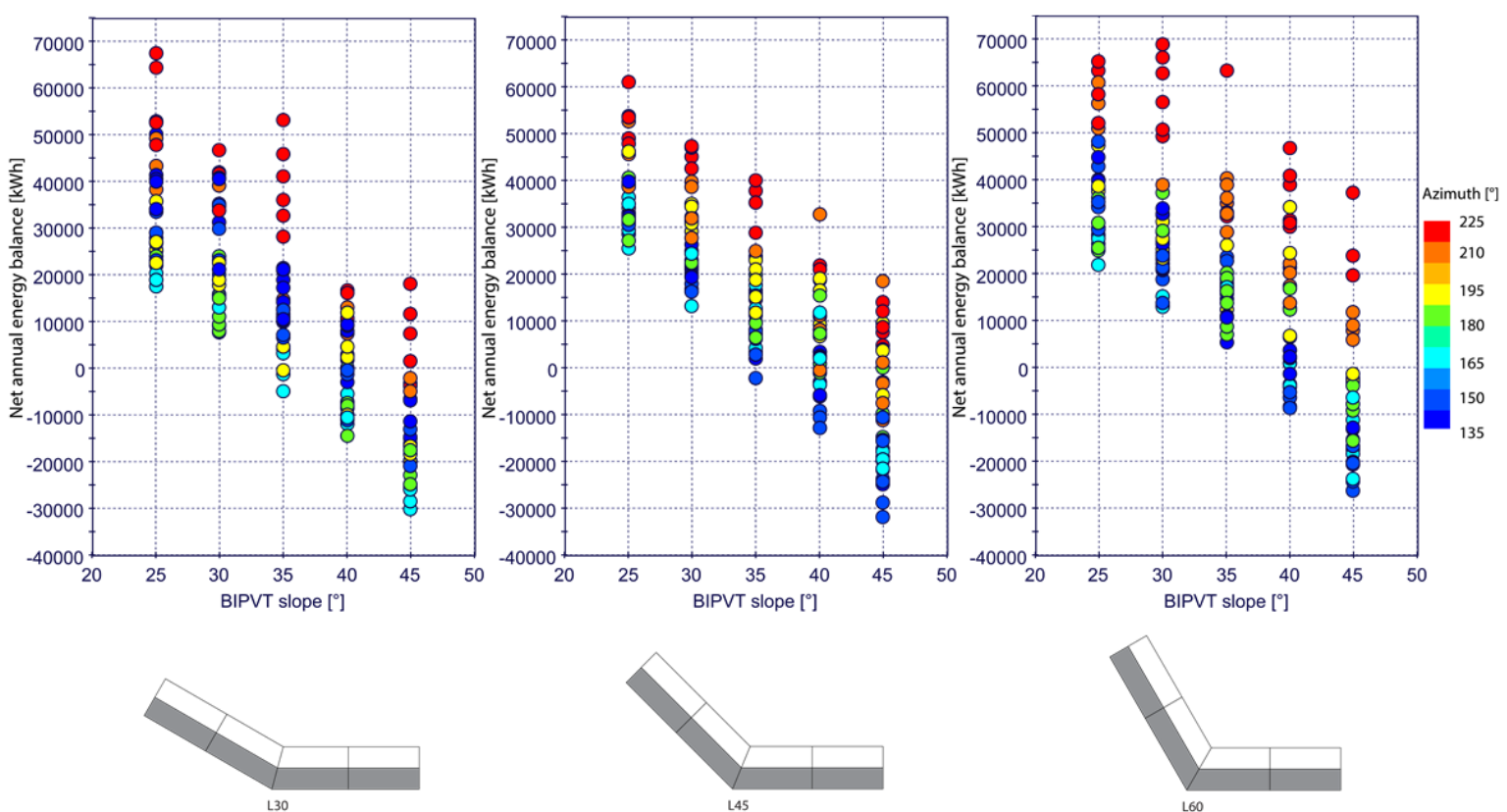

Figure 5: Plan shapes 3, 4, 5; net annual energy balance versus BIPVT slope and azimuth (negative net annual energy means NZE reached) 

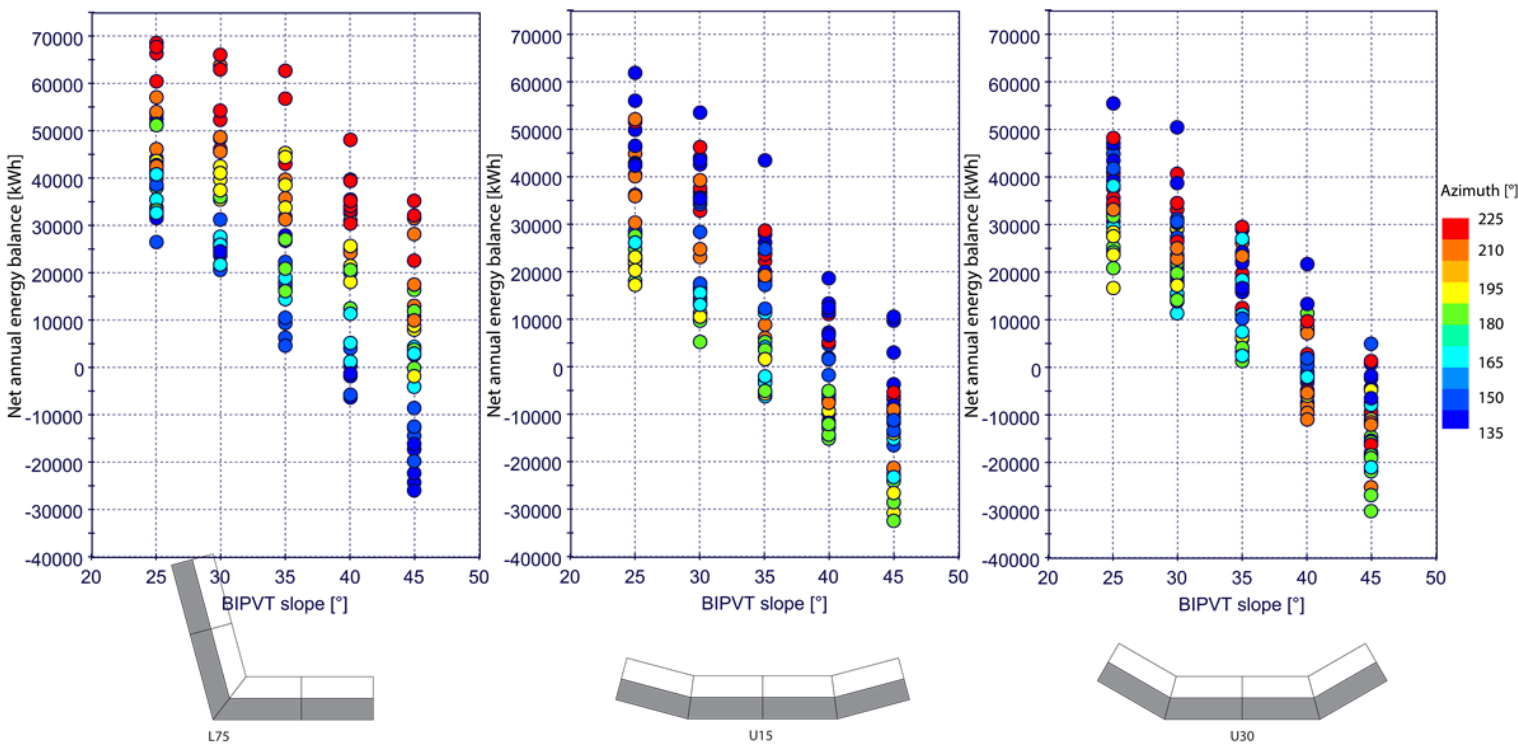

Figure 6: Plan shapes 6, 7, 8; net annual energy balance versus BIPVT slope and azimuth (negative net annual energy means NZE reached)
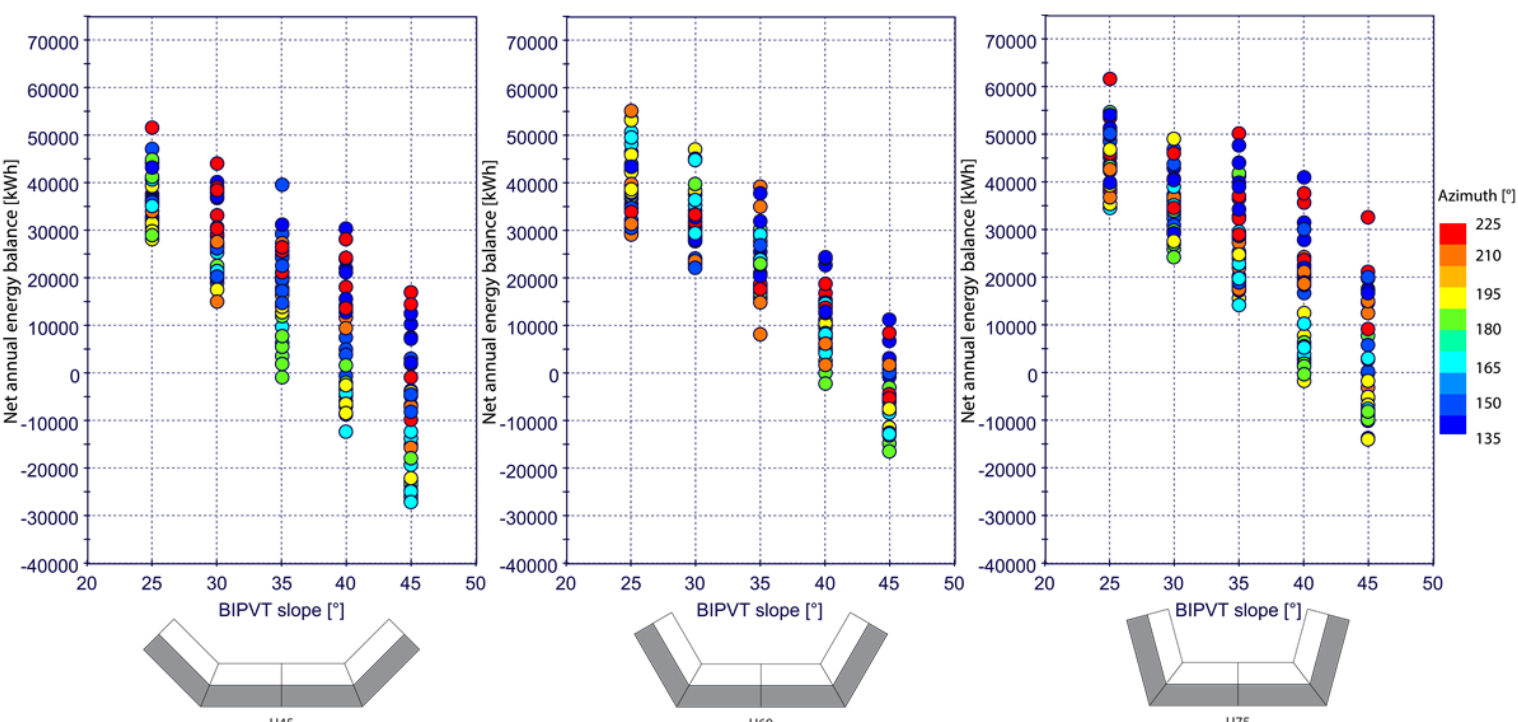

Figure 7: Plan shapes 9, 10, 11; net annual energy balance versus BIPVT slope and azimuth (negative net annual energy means NZE reached)

From Table 3, the CO, L, and $\mathrm{U}$ shape configurations with the best NZE performance compared to the RE reference shape share the same south orientation (azimuth $=180^{\circ}$ ) and root tilt angle $\left(45^{\circ}\right.$ ) but have notably lower cooling demands due to the combination of using the lower SHGC window, different WWRs, and smaller South-facing surface area.

Of particular note is the CO shape which manages to have an EUI that is only $0.35 \%$ greater than that of the reference RE shape. Its electricity and heat recovery is $2.70 \%$ and $2.67 \%$, respectively, less than the reference RE shape but is achieved using more BIPVT surface area than the other configurations. On the other hand, its building footprint is more compact than any of the other plan shapes studied. This highlights the conflicting demands inherent in the building design process. In exchange for more BIPVT surface area at less optimal East/West orientation to achieve NZE, the CO shape provides a better internal plan for space use and circulation patterns and a semi-protected outdoor courtyard. 
Table 3: Best net annual energy performance per plan shape family; $Q \mathrm{~h}=$ annual heating demand; $\mathrm{Qc}=$ annual cooling demand; $\mathbf{P V}=$ annual electricity generation; $\mathrm{T}=$ annual thermal heat recovery

\begin{tabular}{|c|c|c|c|c|c|c|c|c|c|c|c|c|c|c|c|}
\hline \multicolumn{4}{|c|}{ RE (Reference) shape } & \multicolumn{4}{|c|}{ CO shape } & \multicolumn{4}{|c|}{ L shape } & \multicolumn{4}{|c|}{ U shape } \\
\hline & & & & & & & & & & & & & & & \\
\hline \multicolumn{16}{|c|}{ Annual totals (MWh); negative indicates energy generated or recovered } \\
\hline Qh & Qc & PV & $\mathrm{T}$ & Qh & Qc & PV & $\mathrm{T}$ & Qh & Qc & PV & $\mathrm{T}$ & $\mathrm{Qh}$ & Qc & PV & $\mathrm{T}$ \\
\hline 125 & 54 & -222 & -371 & 139 & 40 & -216 & -361 & 150 & 35 & -221 & -369 & 147 & 45 & -221 & -369 \\
\hline \multicolumn{16}{|c|}{ Relative performance with respect to RE (reference) shape (\%) } \\
\hline Qh & Qc & PV & $\mathrm{T}$ & Qh & Qc & PV & $\mathrm{T}$ & Qh & Qc & PV & $\mathrm{T}$ & Qh & Qc & PV & $\mathrm{T}$ \\
\hline- & - & - & - & 10.75 & -25.97 & -2.70 & -2.67 & 19.74 & -35.04 & -0.26 & -0.34 & 17.58 & -16.50 & -0.44 & -0.48 \\
\hline \multicolumn{16}{|c|}{ Energy use intensity without renewables $\left(\mathrm{kWh} /\left(\mathrm{m}^{2} * \mathrm{y}\right)\right)$} \\
\hline \multicolumn{4}{|c|}{71.01} & \multicolumn{4}{|c|}{71.26} & \multicolumn{4}{|c|}{72.22} & \multicolumn{4}{|c|}{72.96} \\
\hline \multicolumn{16}{|c|}{ Net annual energy balance ( $\mathrm{kWh})$; negative indicates energy surplus } \\
\hline \multicolumn{4}{|c|}{-35249} & \multicolumn{4}{|c|}{-30851} & \multicolumn{4}{|c|}{-37318} & \multicolumn{4}{|c|}{-32353} \\
\hline \multicolumn{16}{|c|}{ Total PVT surface area $\left(\mathrm{m}^{2}\right)$} \\
\hline \multicolumn{4}{|c|}{1061} & \multicolumn{4}{|c|}{1233} & \multicolumn{4}{|c|}{1061} & \multicolumn{4}{|c|}{1061} \\
\hline \multicolumn{16}{|c|}{ Roof tilt angle $\left(^{\circ}\right)$} \\
\hline \multicolumn{4}{|c|}{45} & \multicolumn{4}{|c|}{45} & \multicolumn{4}{|c|}{45} & \multicolumn{4}{|c|}{45} \\
\hline \multicolumn{16}{|c|}{ Azimuth $\left({ }^{\circ}\right)$} \\
\hline \multicolumn{4}{|c|}{180} & \multicolumn{4}{|c|}{180} & & & & & & & & \\
\hline & & & & & & nsulat & $\mathrm{a}-\mathrm{Wa}$ & $1 \mid$ roof & $(\mathrm{h} / \mathrm{kJ})^{*}$ & $\left.{ }^{2} \mathrm{~K}\right)$ & & & & & \\
\hline & & & & & & & & & & & & & & & \\
\hline & & & & & & & WR (E & $\mathrm{N}, \mathrm{S}, \mathrm{V}$ & $(\%)$ & & & & & & \\
\hline 60 & 20 & 20 & 20 & 10 & 30 & 40 & 20 & 60 & 10 & 10 & 40 & 10 & 60 & 30 & 30 \\
\hline & & & & & & & & dow ID & & & & & & & \\
\hline & & & & & & & & & & & & & & & \\
\hline
\end{tabular}

\section{Conclusions}

The results show that each of the plan shapes studied is able to reach net zero energy using different combinations of input parameters and with the requirement of a BIPVT roof tilt angle of $35^{\circ}$ to $45^{\circ}$.

Orientation is a misleading indicator of performance when using L, CO, and $\mathrm{U}$ shapes because they are not adversely affected as rectangular shapes to orientations oblique to the sun. 
The CO courtyard plan shape is particularly interesting because its best NZE configuration performs almost as well as the reference RE rectangular shape while offering a compact footprint that has benefits to architectural space planning and urban planning.

Altogether, this shows that through different plan shapes and the other input parameters, there are different pathways to net zero energy that can satisfy architectural and engineering design requirements at the same time. Thus, these results can provide valuable insight into creating design guidelines and a methodology at the earliest stages of the building design process when there is the greatest opportunity to influence the energy profile, solar energy utilization, and form of a building.

\section{Acknowledgements}

This work was supported by the Natural Sciences and Engineering Research Council of Canada (NSERC)/Hydro-Québec Industrial Research Chair in Optimized Operation and Energy Efficiency: Towards High Performance Buildings, and le Fonds de recherche du Québec (FRQNT).

\section{References}

Athienitis, A., Barone, G., Buonomano, A., Palombo, A., 2018. Assessing active and passive effects of façade building integrated photovoltaics/thermal systems: Dynamic modelling and simulation. Applied Energy. 209, 355-382. https://doi.org/10.1016/j.apenergy.2017.09.039

Canadian Commission on Building and Fire Codes and Institute for Research in Construction, 2015. National Energy Code of Canada for Buildings. Ottawa, ON, National Research Council.

Delisle, V., Kummert, M., 2016. Cost-benefit analysis of integrating BIPV-T air systems into energy-efficient homes. Solar Energy. 136, 385-400. https://doi.org/10.1016/j.solener.2016.07.005

Duffie, J. A., Beckman, W. A., 2013. Solar engineering of thermal processes. Hoboken, Wiley.

Guglielmetti, R., Pless, S., Torcellini, P., 2010. On the use of integrated daylighting and energy simulations to drive the design of a large net-zero energy office building. Fourth National Conference of IBPSA-USA, New York, NY. https://buildingdata.energy.gov/cbrd/resource/824

Hachem, C., Athienitis, A., Fazio, P., 2011. Parametric investigation of geometric form effects on solar potential of housing units. Solar Energy. 85(9), 1864-1877. https://doi.org/10.1016/j.solener.2011.04.027

Yip, S., Chen, Y., Athienitis, A., 2015. Comparative Analysis of a Passive and Active Daylight Redirecting Blind in Support of Early Stage Design. CISBAT 2015, Lausanne, Switzerland. https://doi.org/10.5075/epflcisbat2015-229-234

Youssef, A. M. A., Zhai, Z. J., Reffat, R. M., 2016. Genetic algorithm based optimization for photovoltaics integrated building envelope. Energy and Buildings. 127, 627-636. https://doi.org/10.1016/j.enbuild.2016.06.018 


\title{
An Aesthetic Energy Producing Roof with Integration of PV Modules and Solar Thermal Collectors
}

\author{
Corry de Keizer ${ }^{1}$, Minne de Jong ${ }^{1}$, Camilo Rindt ${ }^{2}$, Robbert van Diemen ${ }^{3}$, Martijn van Paassen ${ }^{3}$ \\ and Ruud van der Voort ${ }^{4}$ \\ 1 SEAC - TNO, Eindhoven (Netherlands) \\ 2 TU Eindhoven, Eindhoven (Netherlands) \\ ${ }^{3}$ HRsolar, de Lier (Netherlands) \\ ${ }^{4}$ SCX Solar, Someren (Netherlands)
}

\begin{abstract}
Aesthetic integration of solar energy products in the roofs of dwellings is important to achieve a good social acceptance and a high market potential. Several solutions for building integrated PV (BIPV) are available on the market, however, a very limited number of solutions for covered solar thermal collectors are available. Currently, covered solar thermal collectors are much thicker and often much larger than PV modules, which complicates aesthetic integration of both PV and solar thermal collectors in the same roof. Therefore, a Dutch collector producer developed a solar thermal collector with the same dimensions and thickness as a framed PV module. The aim was to also achieve the same efficiency parameters. Eight collectors, eleven PV modules and a window were integrated into a dummy roof and measured extensively in a field test.
\end{abstract}

Keywords: Building integration, solar thermal

\section{Introduction}

Dutch policy aims to realize a more sustainable built environment in the Netherlands. To achieve a reduction of $49 \%$ of greenhouse gas emissions in 2030 (with reference to 1990), a large reduction of greenhouse gas emissions in the built environment is required. Because of a limitation of the available space in the Netherlands, application of solar energy products on buildings is very interesting. When the number of solar energy systems in the built environment increases, aesthetic integration of those systems becomes more important for social acceptance and a higher market potential. It is expected that Building Integrated PV (BIPV) will show a strong growth in the upcoming years. Many BIPV products have been developed in the last five years (Zanetti et al., 2017), however, the number of building integrated solar thermal collectors are very limited. Especially for newly built dwellings with a high insulation, the share of the domestic hot water (DHW) demand can be over $50 \%$ of the total heat demand of a dwelling. The DHW demand is at higher temperatures and a large share of it can be supplied by a simple domestic hot water system with covered solar thermal collectors.

The research presented in this paper is part of the 'Building Integrated Solar Thermal and PV (Building STeP)' project. The goal of this project is the development of a multifunctional roof, which includes PV modules, a PVsized solar thermal collector and an integrated window. The focus is mainly on the development of the thinner solar thermal collector, since that was not yet available.

In this paper, we will present the current results regarding the development of the collector. Within the project a field test is carried out with the integration of PV modules, a window and the solar thermal collector in a multifunctional roof. The results of the field test will be presented as well as some simulation results. 


\section{Nero solar thermal collector}

The Dutch solar thermal collector company HRsolar had been producing a high performing solar thermal collector with an area of $1.6 \mathrm{~m}^{2}$, called HPC-1.6, since 2013. Though the HPC-1.6 collector was easier to include in a sideby-side installation together with PV modules than a standard solar thermal collector, with 94 mm thickness, it was still too thick for the standard PV mounting frames.

The goal of the development of the new collector was to create a thinner and lighter collector with a similar collector performance. The thickness of the collector was set to be a maximum of $40 \mathrm{~mm}$, the same as a framed PV module. Furthermore, the collector should have the same look as an all-black PV module. Therefore, a different absorber coating is used. It was a challenge to decrease the thickness and similar heat losses. To reach this, the insulation on the back of the collector was replaced by insulation with a higher Rc value. Furthermore, instead of air, a noble gas mixture was used between the absorber plate and the glass cover. Also double coated glass was used.

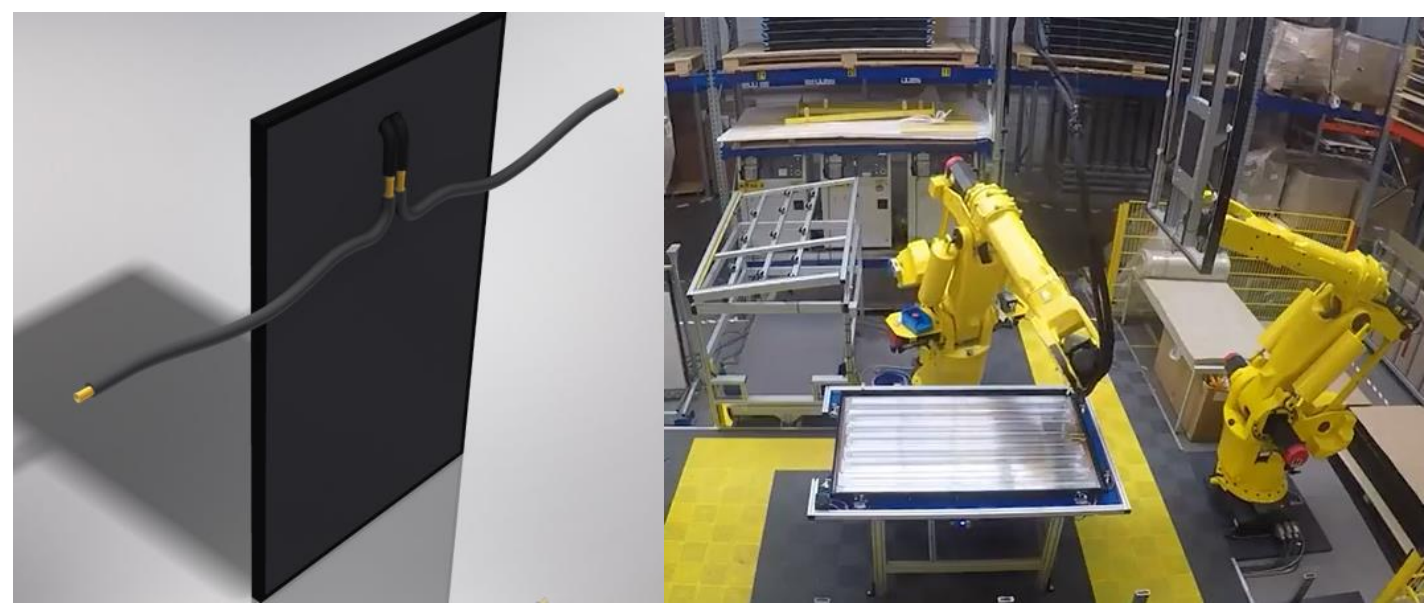

Fig. 1: Left: New solar thermal Nero collector, Right: automated production process (HRsolar, 2018)

Table 1 shows a comparison between some key characteristics of the HRsolar Nero and HPC-1.6 collectors. The heat loss factors $\mathrm{a}_{1}$ and $\mathrm{a}_{2}$ are in the same range. The incidence angle modifier is higher. The zero-loss efficiency is lower, probably due to the black absorber coating.

Table 1: Comparison of old and new collector characteristics based on data sheets and Solar Keymark certificates

\begin{tabular}{|l|l|l|}
\hline & Nero (new) & HPC-1.6 (old) \\
\hline Gross area & $1.62 \mathrm{~m}^{2}$ & $1.63 \mathrm{~m}^{2}$ \\
\hline Thickness & $40 \mathrm{~mm}$ & $94 \mathrm{~mm}$ \\
\hline Weight & $23.8 \mathrm{~kg}$ & $25 \mathrm{~kg}$ \\
\hline$\eta_{0}$ & $0.692($ gross area, Solar Keymark) & $\begin{array}{l}0.750 \text { (gross area, calculated) } \\
0.837 \text { (aperture area, Solar Keymark)) }\end{array}$ \\
\hline $\mathrm{a}_{1}$ & $4.503 \mathrm{~W} / \mathrm{m}^{2} \mathrm{~K}$ (gross area) & $4.61 \mathrm{~W} / \mathrm{m}^{2} \mathrm{~K}($ gross area) \\
\hline $\mathrm{a}_{2}$ & $0.022 \mathrm{~W} /\left(\mathrm{m}^{2} \mathrm{~K}^{2}\right)($ gross area) & $0.017 \mathrm{~W} /\left(\mathrm{m}^{2} \mathrm{~K}^{2}\right)$ (gross area) \\
\hline IAM at $50^{\circ}$ & 0.96 & 0.91 \\
\hline
\end{tabular}

The collector is commercially available with the name Nero (HRsolar, 2018) and has a Solar Keymark certification since January 2018. 


\section{Field test building integrated PV and solar thermal roof}

\subsection{Field test specification and installation}

The multifunctional building integrated roof was installed on SolarBEAT, the experimental outdoor research facility of SEAC, as shown in Figure 2. The outdoor facility is located on the roof of one of the buildings of the Technical University of Eindhoven and includes a solar measurement station that measures direct, diffuse and global horizontal irradiance, as well as wind speed and direction and ambient temperature.

The following setup was installed:

- $11260 \mathrm{Wp}$ mono-crystalline PV modules in SCX Solar Soloroof mounting structure, one string of 11 modules is connected to an SMA Sunnyboy 3600 TL inverter.

- 8 HRsolar solar thermal collectors type Nero (zero-series, 4 with one sided anti reflection coating, 4 with double coating), two series of four collectors.

- Integrated roof window

Furthermore, a thermal loop was designed and installed to allow for measurements on solar thermal collectors and PVT systems. Excess heat produced by the thermal systems is dumped in the university's aquifer. The liquid is preconditioned to the specified temperature. The input temperature for the systems can be set between 15 and $80^{\circ} \mathrm{C}$. A $49 \%$ glycol solution is used.

The following measurement equipment is installed:

- Meteorological measurements: Global tilted irradiance (secondary standard pyranometer), pyrgeometer, in-plane wind speed and direction, ambient temperature.

- $\quad$ PV performance measurements: DC and AC string voltage and current are measured, the PV module temperature is measured with T-type thermocouples.

- $\quad$ Thermal performance measurements: input and output temperature of each collector (Pt100, 1/3B) and flow rate (Electromagnetic sensor, one per series of collectors).

- Datalogging: All sensors are connected to a Yokogawa MW100 datalogger. Data is recorded every minute and uploaded every night to a database.

The field test is running from November 2017.

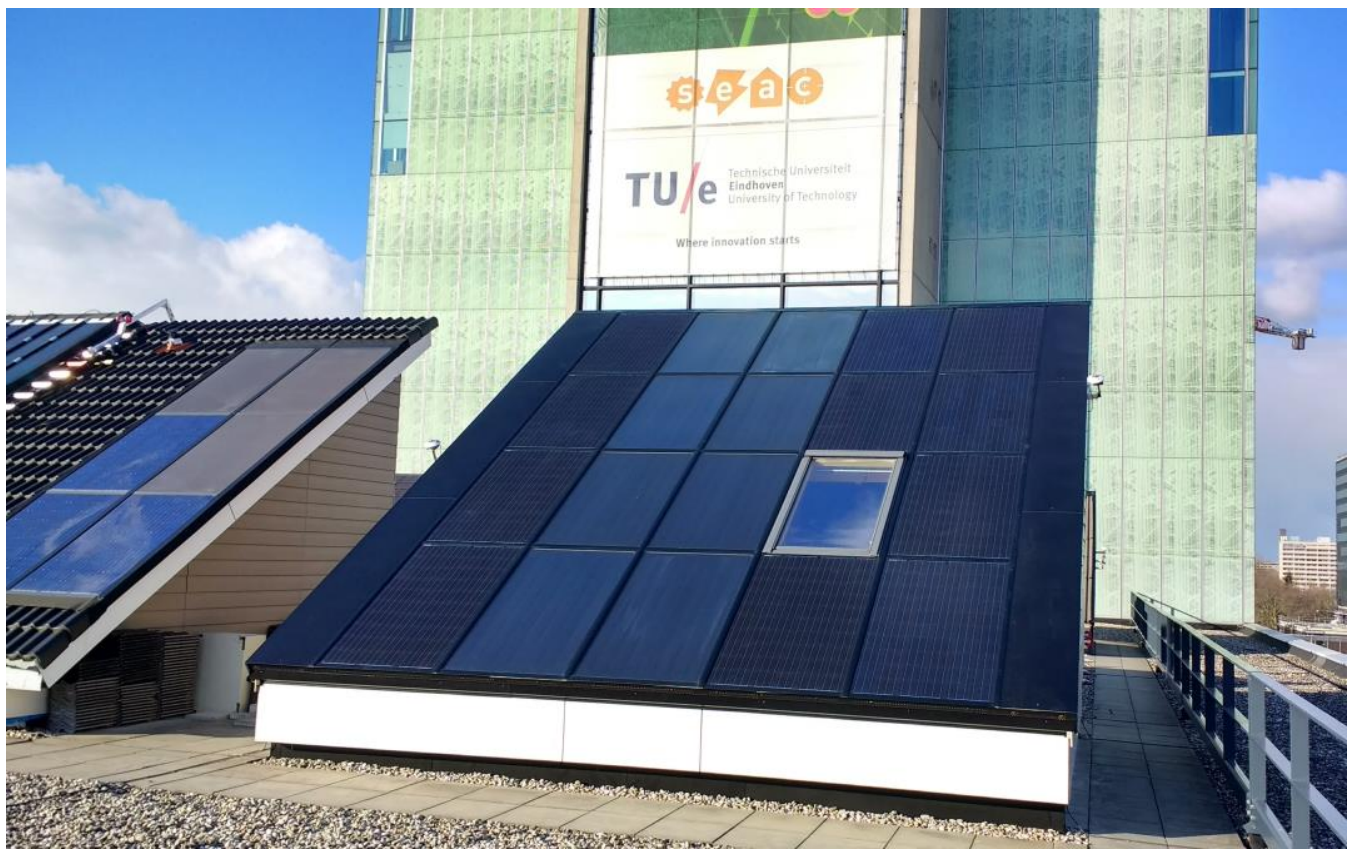

Fig. 2: Field test on the SolarBEAT location 


\subsection{Thermal performance results}

The thermal analysis was carried out for all solar thermal collectors individually. We present the results here of one of the collectors with the quasi-dynamic approach. Since it is a covered collector we only fit the zero-loss collector efficiency factor $\left(\eta_{0}\right)$, the heat loss coefficient $\left(c_{1}\right)$, the temperature dependent heat loss coefficient $\left(c_{2}\right)$ and the effective thermal capacity of the collector $\left(c_{5}\right)$ (see equation 1 ). The $b_{0}$ coefficient is derived from the solar keymark tests.

$$
\begin{aligned}
& \dot{Q} / A_{g}=\eta_{0} K_{0 b}(\theta) G_{b}+\eta_{0} K_{0 d} G_{d}-c_{1}\left(T_{m}-T_{a}\right)-c_{2}\left(T_{m}-T_{a}\right)^{2}-c_{5} \frac{d T_{m}}{d t} \\
& \text { Where } K_{0 b}(\theta)=1-b_{0}\left(\frac{1}{\cos \theta-1}\right)
\end{aligned}
$$

The coefficients (Table 1) are in the same range as the ones in the Solar Keymark certificate with a few differences. The zero-loss efficiency is slightly lower, this might be caused by some pollution on the panel, the use of a propylene-glycol mixture as well as a single reflection coating. Figure 3 shows the measured efficiency points versus the reduced temperature. The blue curve is the collector curve where only the zero-loss efficiency and $c_{1}$ (of $4.3 \mathrm{~W} / \mathrm{m}^{2} \mathrm{~K}$ ) are taken into account. The red curves also include $\mathrm{c}_{2}$ where the reduced temperature is calculated with respectively 500 or $1000 \mathrm{~W} / \mathrm{m}^{2} \mathrm{~K}$. Incidence angle related losses as well as differences due to the thermal capacity of the collector, are not shown in the graph.

\begin{tabular}{|c|c|}
\hline & Parameters \\
\hline $\boldsymbol{\eta}_{\mathbf{0}}$ & $0.66[-]$ \\
\hline $\mathbf{c}_{1}$ & $4.3 \mathrm{~W} / \mathrm{m}^{2} \mathrm{~K}$ \\
\hline $\mathbf{c}_{2}$ & $0.024 \mathrm{~W} /\left(\mathrm{m}^{2} \mathrm{~K}^{2}\right)$ \\
\hline $\mathbf{c}_{5}$ & $2.4 \mathrm{~kJ} / \mathrm{m}^{2} \mathrm{~K}$ \\
\hline
\end{tabular}

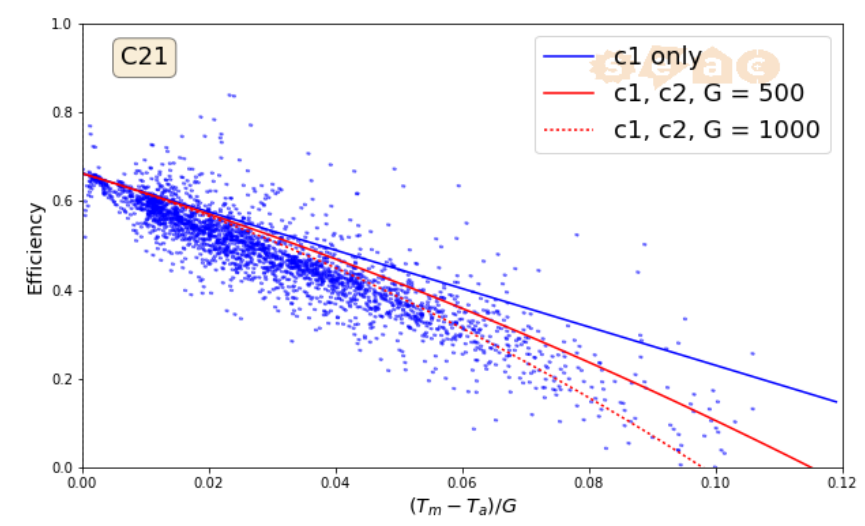

Table 2: Fitted collector parameters

Fig. 3 Collector curve with only c1 from table 2 and $\mathrm{c} 2=0$ and at $\mathbf{G}=500$ or $1000 \mathrm{~W} / \mathrm{m}^{2}$

\subsection{PV performance}

The performance of the $11 \mathrm{PV}$ modules is characterized by the Performance Ratio (PR). The performance ratio is defined in Equation 3. The performance ratio is a measure of the realized energy yield in comparison to the performance under Standard Test Conditions. Both AC and DC performance is measured. Using DC or AC output power $\mathrm{P}$ we can calculate the performance ratio $(\mathrm{PR})$ and efficiency $\left(\mathrm{\eta}_{\mathrm{e}}\right)$ of the PV modules using

$$
P R=\frac{G_{\mathrm{STC}}}{G} \frac{P_{\text {measured }}}{P_{\text {rated }}}
$$

where $\mathrm{P}_{\text {measured }}$ is the measured AC or DC power output, $\mathrm{G}$ is the measured irradiance in the plane of the modules, $\mathrm{G}_{\text {STC }}$ is the irradiance under standard test conditions and $\mathrm{P}_{\text {rated }}$ is the rated power of the PV module under standard test conditions (in Wattpeak or Wp).

The performance ratio is usually lower than $100 \%$ due to inverter losses, reflection losses, cabling losses and a higher PV temperature than the module temperature under Standard Test Conditions. Figure 4 shows the DC and 
AC performance ratio of the system over the measured months (in blue and cyan). The average with irradiance weighted temperature is shown in orange. It can be seen that there is a clear correlation between module temperature and the PV performance ratio. The average PR over the measured period is $83 \%$ (DC) and $79 \%$ (AC).

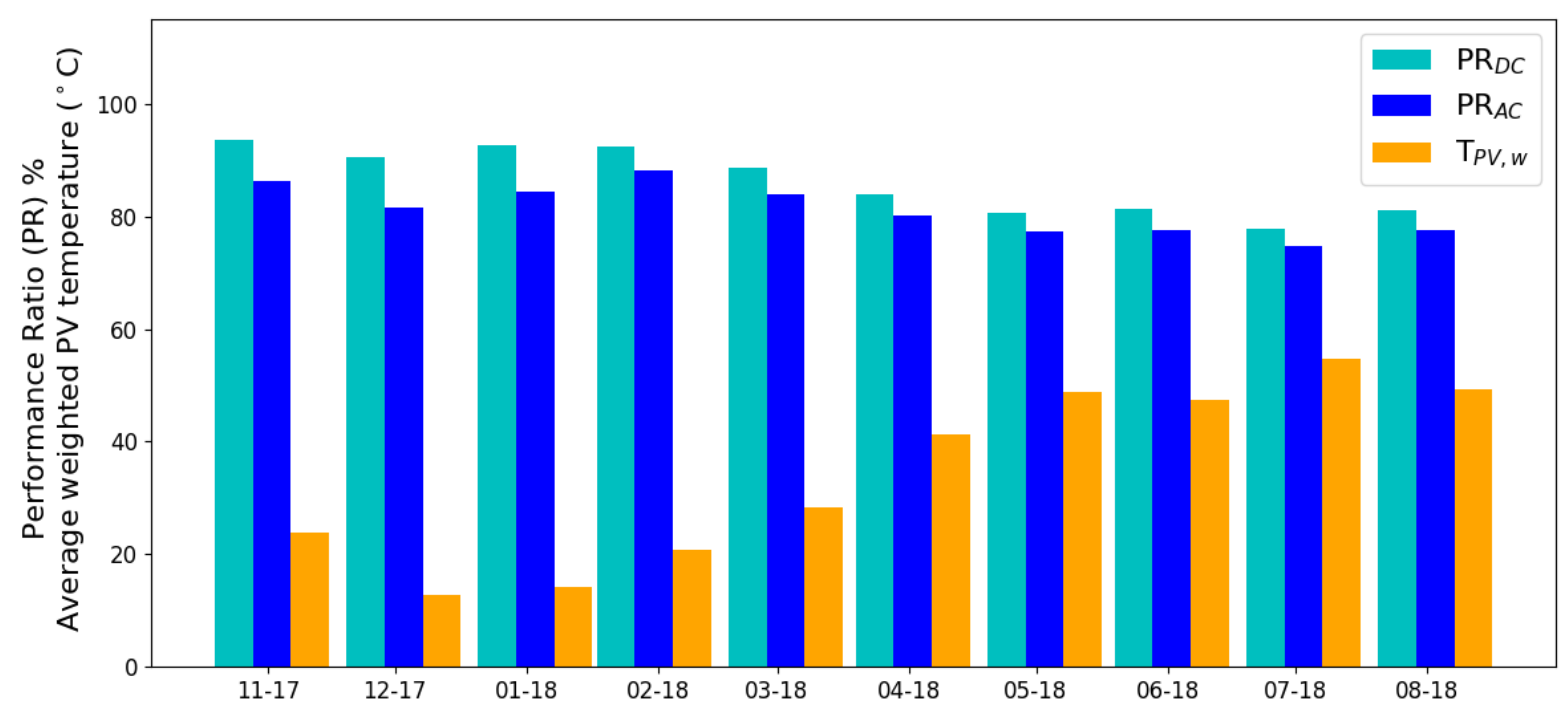

Fig. 4: Monthly PV DC and AC performance ratio and weighted average PV module temperature

\section{Simulation of building integrated solar roof}

The simulation was carried out for a roof with space for $20 \mathrm{PV}$ modules, thermal collectors or windows. The thermal collector yield for a typical domestic hot water system was simulated with TRNSYS. A DHW profile of 9 GJ (2486 kWh) of the Dutch norm NEN7120 is used with a variation in the number of collectors (1 to 3), the size of the storage (120 or 2001$)$ and the temperature level of the hot water $\left(45\right.$ or $\left.60^{\circ} \mathrm{C}\right)$.

The thermal yield is shown in Figure 5 and is between 292 and $530 \mathrm{kWh} / \mathrm{m}^{2}$ collector area.

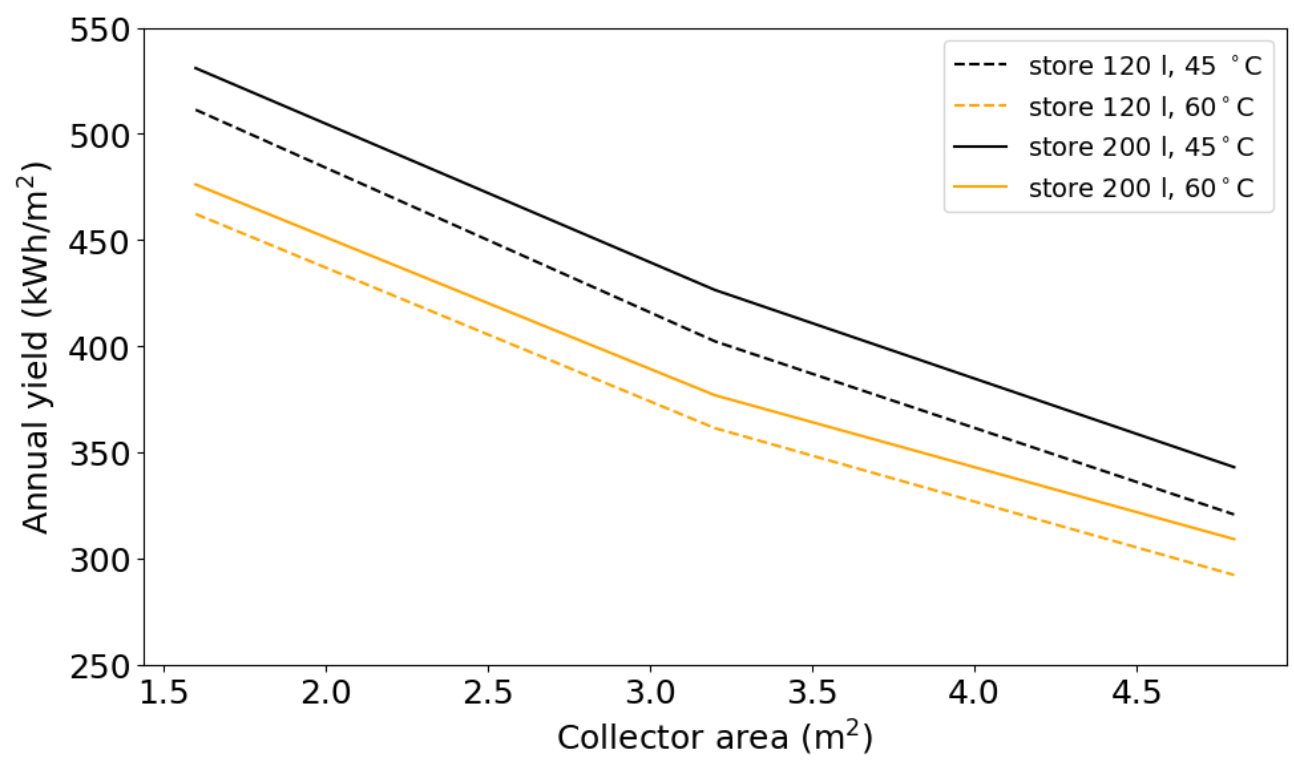

Fig. 5: Annual collector yield for a DHW system with one, two or three collectors, a 120 or 2001 storage and a DHW demand temperature of 45 or $60^{\circ} \mathrm{C}$

The PV yield is calculated with an annual AC Performance ratio of $80 \%$ and an STC power of $300 \mathrm{~W}$ per module. 
Furthermore, it is assumed there is one roof window. The annual irradiation at the location is $1100 \mathrm{kWh} / \mathrm{m}^{2}$.

Table 3: Annual energy yield of a multifunctional roof

\begin{tabular}{|c|c|c|c|c|}
\hline \#PVmodules & \#collectors & Thermal yield & Solar Fraction & Electrical yield \\
\hline 18 & 1 & $0.85 \mathrm{MWh}$ & $32 \%$ & $4.7 \mathrm{MWh}$ \\
\hline 17 & 2 & $1.4 \mathrm{MWh}$ & $51 \%$ & $4.5 \mathrm{MWh}$ \\
\hline 16 & 3 & $1.6 \mathrm{MWh}$ & $61 \%$ & $4.2 \mathrm{MWh}$ \\
\hline
\end{tabular}

\section{Conclusion}

In this project, we showed that it is possible to produce a collector that is the same size and thickness as a standard crystalline silicon PV module. We demonstrated the easier integration of the thermal collectors in a building integrated solar roof. The performance was measured over an eight month period. The collector shows a slightly lower zero-loss efficiency than the previous thick PV sized solar thermal collector due to a different aesthetic coating that was used. Heat loss parameters are in a similar range.

\section{References}

Zanetti, I., Bonomo, P., Frontini, F., Saretta, E., Van den Donker, M., Vossen, F., Folkerts, W., 2017. Building Integrated Photovoltaics: Product overview for solar building skins Status Report 2017, SUPSI-SEAC, Online available: https://www.seac.cc/wp-content/uploads/2017/11/171102_SUPSI_BIPV.pdf.

HRsolar, Nero Solar Collector, https://www.hrsolar.nl/en/nero-solar-collector/ accessed 29 August 2018. 
Solar Assisted District Heating and Cooling 


\section{Comparison of Solar District Heating Concepts at Various Land Prices \\ Isabelle Best, Janybek Orozaliev, and Klaus Vajen \\ University of Kassel, Institute of Thermal Engineering, Kassel (Germany)}

\section{Abstract}

Two solar district heating concepts for an exemplary new housing development at different supply temperature levels were examined in terms of economic and energy efficiency aspects. Both district heating-based heat supply systems were designed to meet a renewable heat share of $80 \%$. Afterwards, the systems were compared within a detailed economic analysis. Key issue is, under which boundary conditions a central solar district heating system is more beneficial than a district heating system with distributed solar thermal systems for very low demand density areas in Germany. Thereby, the impact of land prices due to land use for ground-mounted solar collectors and seasonal storages on the system feasibility was evaluated.

Keywords: solar district heating, fourth generation district heating, low linear heat density, heat generation costs

Abbreviations
\begin{tabular}{|l|l|}
\hline BTES & Borehole Thermal Energy Storage \\
\hline DH & District Heating \\
\hline DHW & Domestic Hot Water \\
\hline GSHP & Ground Source Heat Pump \\
\hline HP & Heat Pump \\
\hline PTES & Pit Thermal Energy Storage \\
\hline SH & Space Heating \\
\hline TTES & Tank Thermal Energy Storage \\
\hline B / W & Brine /Water \\
\hline rm & Route meter \\
\hline we & Water equivalent \\
\hline
\end{tabular}

\section{Introduction}

Future smart thermal energy systems must show a high rate of renewable energies along with residual resources to meet the heat demand (Lund et al., 2014). District heating infrastructures and large thermal storages already play an important role in integrated energy systems as demonstrated by various projects in Denmark in recent years (SDH solar district heating, 2017). However, central heat supply systems risk to lose competitiveness the lower the heat demand density of a district is. This applies especially for new building developments with a high share of single family houses in sub-urban and rural areas. High distribution heat losses of $20 \%$ and even higher can occur in case of conventional low-temperature district heating of $70^{\circ} \mathrm{C} / 40^{\circ} \mathrm{C}$ (supply/return). The district heating operating temperatures affect significantly the distribution losses as well as the integration of renewable technologies. Regarding solar heat integration high land prices and competition of land use can hinder the realization of large ground-mounted solar collector fields according to the Danish example. Thus, a broad implementation of large scale solar collector fields is missing currently in Germany. Individual solar thermal systems are dominating the German market. Key issue is, under which boundary conditions a central solar district heating system is more beneficial than a district heating system with distributed solar thermal systems for very low demand density areas in Germany. 


\section{Boundary Conditions}

\subsection{Description of the New Housing Development}

The planned new housing development "Zum Feldlager" (Kassel, Germany) comprises of 131 buildings on a land area of $115,000 \mathrm{~m}^{2}$. The housing development will consist mainly of single family houses, resulting in a low building density with a plot ratio of 0.25 according to (Persson and Werner, 2011)(Persson and Werner, 2011). The buildings were calculated to meet the requirements of the German KfW-70 low-energy building standard according to the Energy Saving Ordinance 2016 (GRE Gesellschaft für Rationelle Energieverwendung e. V., 2016). This means that the buildings were designed to have a specific heating demand below $50 \mathrm{kWh} /\left(\mathrm{m}^{2} \cdot \mathrm{a}\right)$. The space heating demand of each building was calculated according to the German standard DIN V 4108-6 (Deutsches Institut für Normung e. V., 2003). Additionally, the peak heating load for every building was computed according to DIN EN 12831 (Deutsches Institut für Normung e. V., 2012). Regarding the domestic hot water demand, demand profiles were generated by using a stochastic modelling tool developed by Jordan et al. for IEA SHC-Task 26, which takes into consideration the Gaussian-Distribution and different time scales to generate various load profiles (Jordan and Vajen, $2001)$. The total heat demand was calculated to amount $\approx 1,656 \mathrm{MWh} / y r$, that comprises of one quarter DHW $(\approx$ $380 \mathrm{MWh} / \mathrm{a})$ and of three quarter for space heating $(\mathrm{SH})(\approx 1,285 \mathrm{MWh} / \mathrm{a})$. It represents a heat demand sparse area with a low linear heat demand density of around $580 \mathrm{kWh} /(\mathrm{rm} \cdot \mathrm{a})$ assuming a total district heating $(\mathrm{DH})$ pipe length of $2.89 \mathrm{~km}$.

\subsection{Generation of Heat Load Profile}

Within the framework of the joint research project "Geosolare Nahwärmeversorgung für die Siedlung Zum Feldlager" the new building development and the corresponding semi-decentralized solar DH system was modelled with the software TRNSYS. Dynamic simulations were conducted in cooperation with the Fraunhofer Institute of Building Physics from Kassel. The model consists of all heat supply units, a simplified distribution infrastructure, and clustered consumers. The distribution infrastructure was simplified calculating the average pipe diameter of the district heating network branches and the corresponding pipe length. The characteristics of standard plastic jacket compound pipes with standard insulation were assumed. The 131 buildings were clustered in 22 building typologies and then displayed as single thermal zone models. According to design characteristics of each building type, there were various possibilities for the number of consumers of domestic hot water. These possibilities were sub-grouped into three main cases: typical single family houses, double single family houses and multi-family houses. All other possibilities were realized by taking into account multiplication factors for each case. Precise and realistic domestic hot water systems consisting of all system engineering components were designed in accordance to VDI 6002 (Verein Deutscher Ingenieure e. V., 2014) and VDI 2067 Blatt 12 (Verein Deutscher Ingenieure e. V., 2000). The resulting annual heat load profile is shown in Fig. 1. The space heating (SH) demand is depicted in blue, while the domestic hot water (DHW) demand is displayed in red. The heat load profile is taken as a base for system design and calculation of the central solar DH system (see section 3.1).

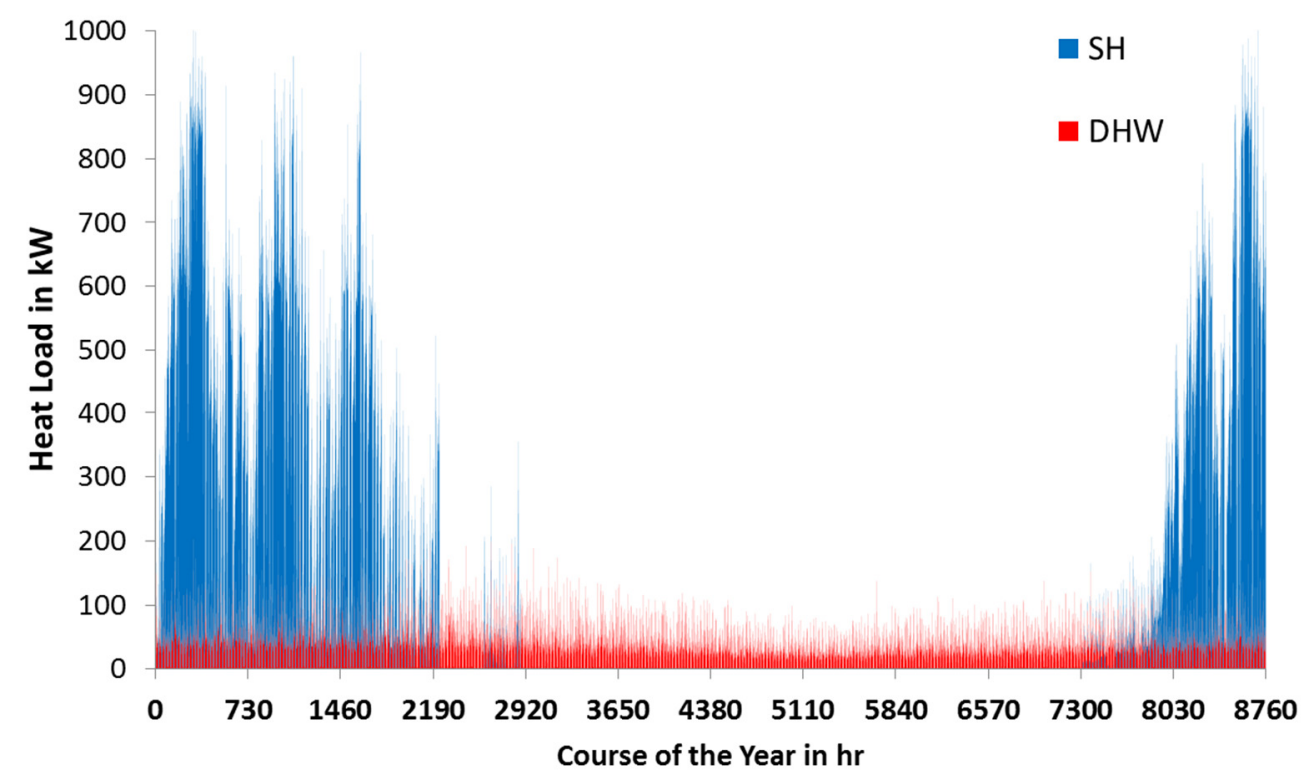

Fig. 1: Calculated hourly heat load profile of the housing development "Zum Feldlager", in blue the space heating demand, in red the domestic hot water demand 


\subsection{Design Requirements and Basis of Comparison}

Both solar DH systems presented were designed to achieve a renewable heat supply of $\approx 80 \%$ of the total heat demand of the new building development. Considering that the renewable energy already covered roughly $29 \%$ of gross electricity generation (total volume of electricity generated in Germany) in 2016, the electricity consumption of each solar DH system had to be below $427 \mathrm{MWh} / \mathrm{a}$. The number of buildings and inhabitants, as well as the DH geometry and pipe length were kept constant. Depending on the required temperature level of the heat supply concept the components' design differs. Also, the heat distribution network design (pipe diameters, pumps) was adapted according to the distribution temperatures. The central solar DH system is compared to the semi-decentralized DH system for low heat density housing developments in Germany taking following criteria into account:

- Investment for heat supply components (decentralized versus central solar thermal system, heat pump, electric peak load heater, borehole thermal energy storage, pit thermal energy storage, tank thermal energy storage)

- Investment for the distribution infrastructure (material and burring costs for pipes)

- Prices for land area

- Maintenance and service costs

- Operating costs (variable costs).

The discounted present value of capital costs, service and maintenance costs, and operating costs was calculated on a base period of 30 years including proportional reinvestments after 15 operating years (central heat pump, decentralized hot water storages, electric back-up heater, components of the uncovered collector field) with an interest rate of $5.6 \%$. All heat supply components, the DH infrastructure, pumps, the energy centre (centre building with utilities), site development costs, connection, and commissioning costs were considered. Furthermore, the characteristic operating costs were computed at the base of the results from dynamic simulations and static calculations. The maintenance and service costs were evaluated according to VDI 2067 Blatt 1, which recommends fixed rates of investment to calculate the maintenance and service costs depending on the technology used (Verein Deutscher Ingenieure e. V., 2012).

\section{System Design}

\subsection{Central Solar District Heating System}

The first concept introduced in this paper is similar to Danish systems like the DH system in Braedstrup and the German DH system in Crailsheim (Nußbicker-Lux, 2010; SDH solar district heating, 2017). The supply temperature of $70^{\circ} \mathrm{C}$ ensures DHW preparation and SH supply via a low-temperature district heating network. The heat supply system consists of (see Fig. 2):

- A central large-scale, ground-mounted collector field,

- A central heat pump supplemented by an electric peak load heater,

- A Pit Thermal Energy Storage (PTES),

- And a low-temperature district heating network of $70^{\circ} \mathrm{C}$ supply and $40{ }^{\circ} \mathrm{C}$ return temperature.

The shown functional diagram of the heat supply concept shows only the main components and does not include heat exchangers, pumps, valves etc. for reason of simplicity (see Fig. 2). The district heating network is simplified and represented by a supply line and a return line. The DH network is operated throughout the year with a fixed supply temperature. A linear heat demand density of $576 \mathrm{kWh} /(\mathrm{rm} \cdot \mathrm{a})$ was determined. The solar thermal system was designed with the free software ScenoCalc Fernwärme 2.0 (Solites, 2017). The heat demand profile shown above served as a basis for the system design. The seasonal PTES is dimensioned in order to achieve a high solar fraction and at the same time low solar heat surplus. A specific storage volume of $3.3 \mathrm{~m}^{3} / \mathrm{m}^{2}$ collector area was found to be reasonable (via parameter variations) resulting in the lowest solar heat surplus. The collector field is connected through a heat exchanger to the PTES (heat exchanger temperature difference $5 \mathrm{~K}$ ). 


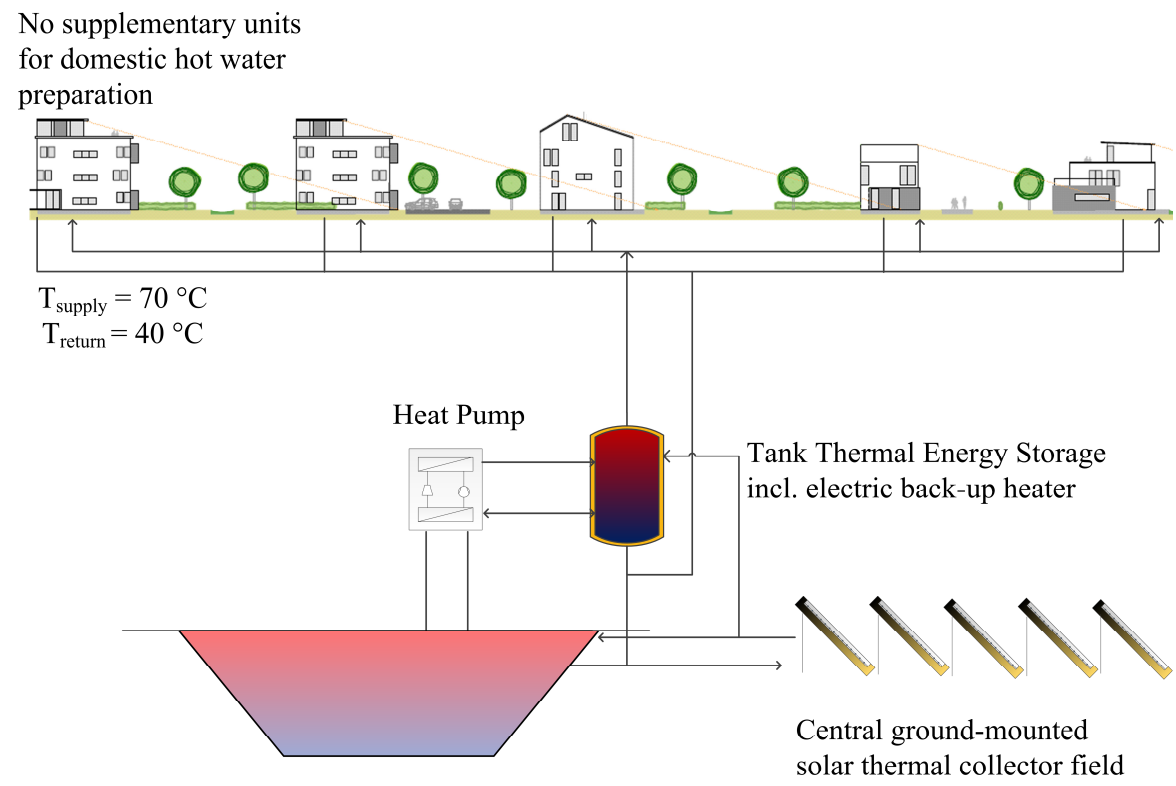

Pit Thermal Energy Storage

Fig. 2: Central solar district heating based on low-temperature district heating network

An additional heat exchanger is assumed between the PTES and the DH network (heat exchanger temperature difference $5 \mathrm{~K}$ ). In order to meet the requirements of renewable heat share of $80 \%$, the system was designed as follows:

Tab. 1: System design of the central solar district heating system

\begin{tabular}{|l|l|}
\hline \multicolumn{1}{|c|}{ Component } & \multicolumn{1}{c|}{ Size } \\
\hline Flat plate collectors (ground mounted) & $2,400 \mathrm{~m}^{2}$ gross \\
\hline PTES & $8,000 \mathrm{~m}^{3}$ \\
\hline Heat Pump & $593 \mathrm{~kW}_{\text {th }}($ at W0/W35) / SPF 3.8 \\
\hline Tank Thermal Energy Storage (TTES) & $100 \mathrm{~m}^{3}$ \\
\hline Electric peak load heater & $740 \mathrm{~kW}$ nominal power \\
\hline DH operating Temperatures & Summer: $70^{\circ} \mathrm{C} / 40{ }^{\circ} \mathrm{C}$ Winter: $70{ }^{\circ} \mathrm{C} / 30^{\circ} \mathrm{C}$ \\
\hline Software for design and calculation & TRNSYS and ScenoCalc Fernwärme 2.0 \\
\hline
\end{tabular}

\subsection{Semi-decentralized solar district heating system}

The second concept is a semi-decentralized concept based on an ultra-low-temperature district heating network. The supply temperature of $40^{\circ} \mathrm{C}$ ensures space heating. However, supplementary components for Domestic Hot Water (DHW) preparation are needed. A linear heat demand density of $432 \mathrm{kWh} /(\mathrm{rm} \cdot \mathrm{a})$ has been determined, as only space heating is provided by the district heating.

The heat supply consists of (see Fig. 3):

- Distributed solar thermal systems (mounted on the building roofs) for DHW preparation,

- Uncovered solar thermal collector fields for thermal ground regeneration,

- A central Ground Source Heat Pump (GSHP) supplemented by an electric peak load heater,

- A Borehole Thermal Energy Storage (BTES),

- And an ultra-low-temperature district heating network with $40{ }^{\circ} \mathrm{C}$ supply and $25^{\circ} \mathrm{C}$ return temperature.

Furthermore, a seasonal operating strategy is applied in order to keep distribution losses low. The heat network is operated during the space heating period from October to April only and distributed solar thermal systems on the building roofs combined with electrical back-up heaters ensure DHW preparation throughout the year. The GSHP and the DH is offline in the period of May to September. Only the thermal ground generation is operated through one DH branch. The uncovered solar collector field supplies the BTES with low temperature heat. Thus, the ground temperature is kept constant over the calculated 30 operating years. Also here, the shown functional diagram of the heat supply concept shows only the main components and does not include heat exchangers, pumps, valves etc. for reason of simplicity (see Fig. 3). The district heating network is simplified and represented by a supply line and a return line. 


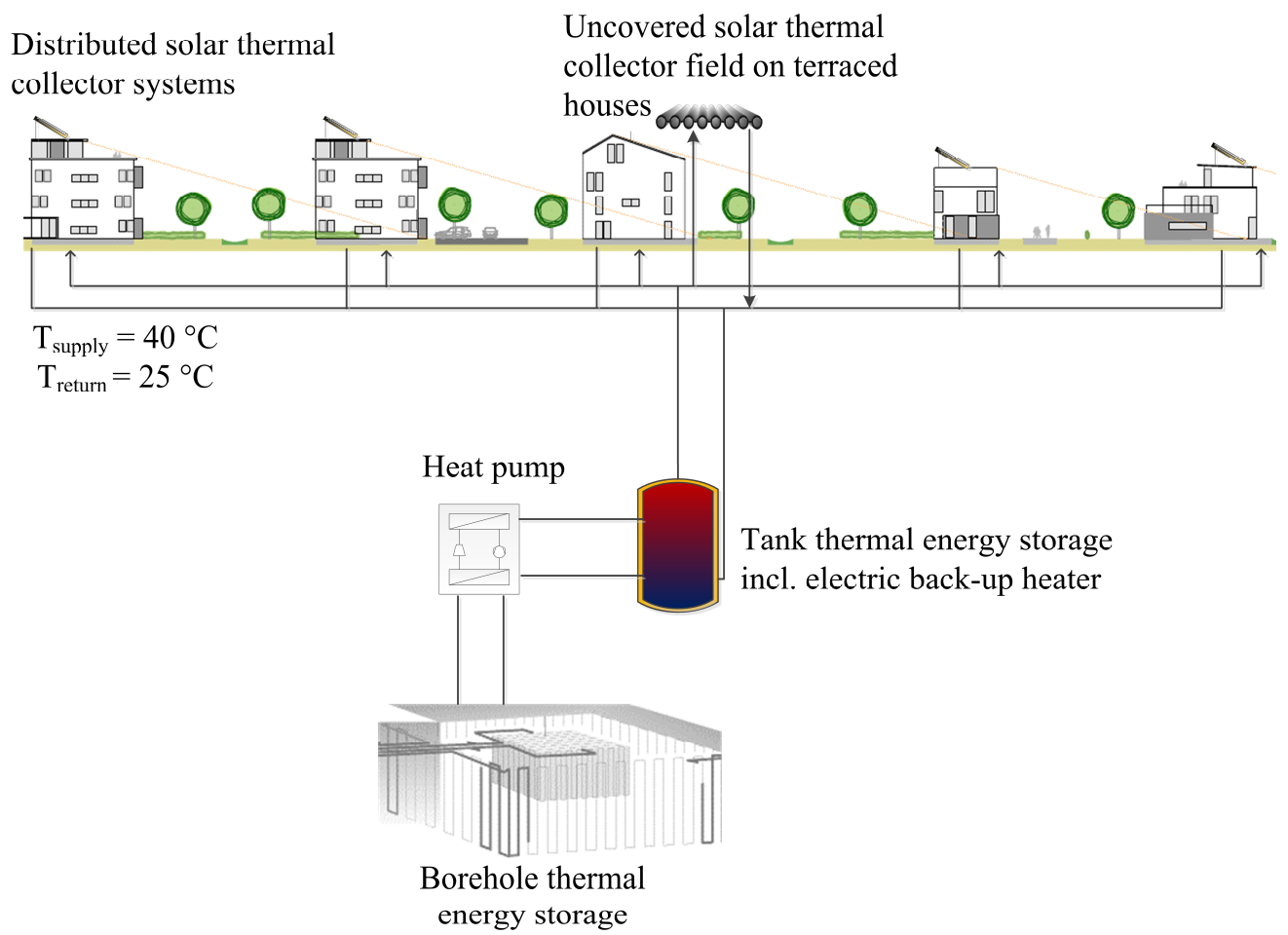

Fig. 3: Semi-decentralized solar district heating based on an ultra-low-temperature district heating network

The semi-decentralized solar DH system was modeled with the software TRNSYS (see section 2.2). The GSHP was designed to meet $60 \%$ of the maximum heat load. The distributed solar collector systems are determined to ensure a solar fraction $f_{\text {sol in }}$ of $\approx 70 \%$ (average solar fraction of the energy input into the hot water storage).

Tab. 2: System design of the semi-decentralized solar district heating system

\begin{tabular}{|l|l|}
\hline \multicolumn{1}{|c|}{ Component } & \multicolumn{1}{c|}{ Size } \\
\hline Distributed solar DHW systems & $820 \mathrm{~m}^{2}$ (on the buildings roofs) \\
\hline $\begin{array}{l}\text { Distributed hot water storage tanks in buildings with } \\
\text { electrical back-up heaters }\end{array}$ & $\begin{array}{l}3001 \text { (for single family houses) to } 1,7001 \text { (for } \\
\text { large multifamily houses) }\end{array}$ \\
\hline BTES & 92 boreholes, $120 \mathrm{~m}$ depth \\
\hline Heat pump & $593 \mathrm{~kW}$ th (at W0/W35) / SPF 4.6 \\
\hline Tank Thermal Energy Storage (TTES) & $20 \mathrm{~m}^{3}$ \\
\hline Electrical peak load heater & $740 \mathrm{~kW}$ nominal power \\
\hline $\begin{array}{l}\text { Uncovered solar collectors } \\
\text { for thermal ground regeneration }\end{array}$ & $1,800 \mathrm{~m}^{2}$ on several large building roofs \\
\hline DH operating temperatures & Summer: $-\mathrm{C} /{ }^{\circ} \mathrm{C}$ Winter: $40^{\circ} \mathrm{C} / 25^{\circ} \mathrm{C}$ \\
\hline Software for design and calculation & TRNSYS \\
\hline
\end{tabular}

\subsection{Network Design}

The housing development has been sub-divided in three parts that are supplied by three DH branches. The DH network geometry was kept constant. For each building a connection capacity was determined. The piping network was designed for the maximum heat load. Depending on the heat supply system, it has been differentiated between two design temperature levels: for $70{ }^{\circ} \mathrm{C}$ supply and $40{ }^{\circ} \mathrm{C}$ return (temperature difference $\Delta \mathrm{T}=30 \mathrm{~K}$ ) as well as for $40{ }^{\circ} \mathrm{C}$ supply and $25^{\circ} \mathrm{C}$ return $(\Delta \mathrm{T}=15 \mathrm{~K})$. Additionally, the piping manufacturer's recommendation (ISOPLUS) for maximum flow velocities were applied (Nussbaumer and Thalmann, 2014; Nussbaumer and Thalmann, 2016). According to the connected capacity a volume flow and the corresponding pipe diameter were computed for each branch. The resulting pipes sums up to $2.89 \mathrm{~km}$ pipe length. The connecting pipes were defined to have $1.71 \mathrm{~km}$, while the transportation pipes were calculated to have $1.18 \mathrm{~km}$. The following bar chart depicts the sum of supply and return pipe length (including the connecting pipes) broke down into nominal pipe diameter (see Fig. 4). 


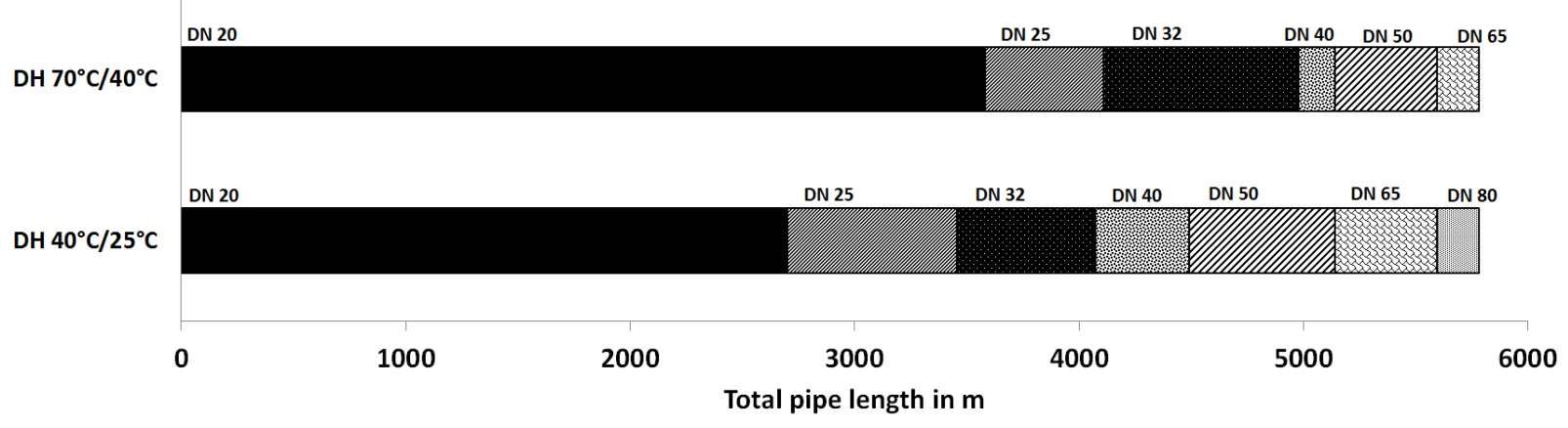

Fig. 4: Nominal pipe diameter distribution showing the sum of supply and return pipes

Based on the nominal pipe diameter (DN) distribution, the network costs were determined with a medium cost approach for new building developments for unmade terrain and rigid pipes after (Nast et al., 2009). The network construction costs range from $190 € / \mathrm{rm}$ (DN 25) to $410 € / \mathrm{rm}$ (DN 150). This medium cost approach was also approved by (Klöpsch et al., 2009) and can still be considered valid in 2018. Nevertheless, there is an optimization potential according to Manderfeld, who showed that specifically in rural areas the specific network construction costs can be reduced using for example flexible pipes (Manderfeld et al., 2008). This data applies only for Germany, they may differ in other countries. In operation a DH network shows a characteristic heat loss rate that depends mainly on the pipe type, pipe diameter, insulation, and the temperature gradient between the pipe and the surrounding ground. The relative heat distribution losses increase, the lower the linear heat demand density is. Consequently, the operating costs are affected. For this reason, the heat losses have been calculated and modeled for the two different heat supply systems taking single rigid pipes as a basis (Arbeitsgemeinschaft QM Fernwärme: Nussbaumer, Thomas et al., 2017).

\section{System Efficiency}

The central solar DH network was designed to meet the requirement of $\approx 80 \%$ renewable heat supply of the total heat demand of the new building development. Thus, the electricity consumption has to be below $427 \mathrm{MWh} / \mathrm{a}$. On the basis of the designed DH network $\approx 18 \%$ distribution heat losses occur within one operating year (see section 3.3). The HP was assumed discharging the PTES from $40^{\circ} \mathrm{C}$ to $10^{\circ} \mathrm{C}$, which results in a seasonal performance factor $S P F$ of 3.8. The corresponding maximum electricity consumption of the HP was calculated to be $\approx 310 \mathrm{MWh} / \mathrm{a}$. taking distribution heat losses and auxiliary energy demand of the system into account. According to these assumptions, the solar collector field needs to ensure $\approx 40 \%$ solar fraction of the total heat demand (fraction of solar energy that meets the heat demand including distribution heat losses). Thus, a large collector field of $2,400 \mathrm{~m}^{2}$ of flat plat collector gross area was determined. This corresponds to a solar heat supply of $\approx 800 \mathrm{MWh} / \mathrm{a}$. to the $\mathrm{DH}$ network. The remaining $\approx 60 \%$ of the heat demand are met by the HP. The seasonal storage, which consists of $8,000 \mathrm{~m}^{3}$, causes $\approx 14 \%$ heat losses, which are already subtracted from the yearly solar heat supply. The electrical peak load heater was assumed to supply only $4 \%$ of the heat demand which shall be covered by the HP.

In contrast to the central DH system, the distributed solar collector systems were designed only for the DHW preparation. They were calculated to meet fully the DHW demand during the non-SH period, which allows keeping the DH network and the HP offline during this period. The simulation's results demonstrated a solar fraction of DHW demand $f_{\text {sol out }}$ of $\approx 58 \%$ (average solar fraction of the DHW net energy). Besides this, the DHW is preheated via DH network during space heating period up to $\approx 29 \%$ (fraction of the DHW net energy). The remaining $\approx 13 \%$ are covered by electrical back-up heaters. Regarding the HP design, the approach was to keep supply temperatures of the DH network as low as possible in order to achieve a high seasonal performance of the HP and at the same time to avoid heat losses through the network. The calculations showed that a $S P F$ of 4.6 (without peak load heater) is achieved following this approach (supply $40{ }^{\circ} \mathrm{C}$ return $25^{\circ} \mathrm{C}$ ). Add to this, only $5.5 \%$ heat distribution losses occur through the DH network, due to the low operating temperatures and the seasonal operating strategy. The uncovered solar collectors (roof top installation) fully ensure thermal regeneration of the BTES during the non SH period. This means, the BTES is charged or rather regenerated with the amount of energy which was subtracted during space heating period. The total electricity consumption amounts to $413 \mathrm{MWh} / \mathrm{a}$., thus it meets the requirement of $80 \%$ renewable heat supply. The resulting total electricity consumption of the different solar DH system is listed in the following table: 
Tab. 3: Comparison of Electricity Consumption

\begin{tabular}{|l|c|c|}
\hline \multicolumn{1}{|c|}{ Component } & $\begin{array}{c}\text { Central Solar DH system } \\
\text { Electricity Consumption in MWh/a. }\end{array}$ & $\begin{array}{c}\text { Semi-decentralized Solar DH system } \\
\text { Electricity Consumption in MWh/a. }\end{array}$ \\
\hline Heat Pump, DH heat losses & 55 & 16 \\
\hline Heat Pump operating & 251 & 294 \\
\hline $\begin{array}{l}\text { DHW electrical back-up } \\
\text { heaters }\end{array}$ & - & 50 \\
\hline $\begin{array}{l}\text { Central electrical peak load } \\
\text { heater }\end{array}$ & 47 & 16 \\
\hline $\begin{array}{l}\text { Sum without auxiliary } \\
\text { energy demand }\end{array}$ & $\mathbf{3 5 3}$ & $\mathbf{3 7 6}$ \\
\hline $\begin{array}{l}\text { Auxiliary Energy demand } \\
\text { (pumps) }\end{array}$ & 54 & 37 \\
\hline Total Sum & $\mathbf{4 0 7}$ & $\mathbf{4 1 3}$ \\
\hline
\end{tabular}

\section{Economic Evaluation}

Hereafter, the results of the economic evaluation are presented. This section presents the full-cost accounting without subsidies and examines the resulting net annual costs of the two different solar DH systems. Thereby, specific costs of the components are discussed. Also, the maintenance and service costs as well as the operating costs (variable costs) are considered. Additionally, the impact of land prices and the land requirements for ground-mounted solar collector systems are highlighted.

\subsection{Net Annual Costs of the Central Solar DH System}

The specific investment for each component was evaluated. First, the DH network costs for transportation pipes were calculated on the basis of the computed DN distribution of the network. The network was characterized by a majority of small diameters of DN 20 and DN 32. This results in an average $226 € / \mathrm{m}$ pipe length (Nast et al., 2009) (see section 3.3) Together with costs for substations, house-lead-in costs, and network pumps, they build total investment for the central distribution infrastructure. Secondly, the central flat plate collector field was calculated based on a gross collector area of $2,400 \mathrm{~m}^{2}$. Taking the economy of scale into account, specific collector costs of $380 € / \mathrm{m}^{2}$ were assumed. Furthermore, the pit storage (PTES) was examined. It was designed according to the Danish principle. The Danish pit storages are typically without surface sealing and only covered by insulation material and a canvas cover. Thus, costs of only $45 € / \mathrm{m}^{3}$ water equivalent (we) incur. However, as a result the seasonal storage cover is not usable as leisure space for example. Consequently, costs for land use for the PTES installation and the collector field incurred (blue parts in the pie chart, see Fig. 5). Land prices for green areas and for solar system installations were assumed according to standards in Kassel. The specific net investment for each component is listed in the following table:

Tab. 4: Specific net investment of the central solar DH system's components

\begin{tabular}{|l|l|l|}
\hline Network construction costs & $226 € / \mathrm{m}_{\text {tr }}$ & (Nast et al., 2009) \\
\hline Costs for substations & $4,000 € /$ unit & (Stuible et al., 2016) \\
\hline House-lead-in costs & $3,600 € /$ unit & (Stuible et al., 2016) \\
\hline Network Pumps & $3,350 € /$ unit & (wilo, 2017) \\
\hline Solar System Collector Costs & $380 € / \mathrm{m}^{2}$ gross & $\begin{array}{l}\text { (Verein Deutscher Ingenieure e. V., } \\
2017)\end{array}$ \\
\hline $\begin{array}{l}\text { Ratio of construction area to gross } \\
\text { collector area }\end{array}$ & 3.5 & - \\
\hline PTES & $45 € / \mathrm{m}^{3}$ water equivalent & $\begin{array}{l}\text { (Solites, 2016; Freistaat Thüringen } \\
\text { Ministerium für Umwelt, Energie und } \\
\text { Naturschutz, 2016) }\end{array}$ \\
\hline Land area & $\begin{array}{l}\text { (BORIS Hessen, 2016) } \\
\text { installations }\end{array}$ & $\begin{array}{l}\text { (Lambauer et al., 2008; Wolf et al., } \\
\text { 2014) }\end{array}$ \\
\hline HP & $195 € / \mathrm{kW}_{\text {th }}$ & \\
\hline
\end{tabular}




\begin{tabular}{|l|l|l|}
\hline Peak load heater & $100 € / \mathrm{kW}$ & Assumption, expert knowledge
\end{tabular}

According to the specific investment the total annual investment was determined based on the system components design. The following figure shows the results of the detailed economic evaluation of the central solar DH system (see Fig. 5). The net annual heat costs comprise of operating costs, maintenance and service costs, as well as the investment. The bar chart shows the net annual costs without taken subsidies into account. In absolute values the total annual system costs are $\approx 415 \mathrm{k} € / \mathrm{a}$. Thereof $61 \%$ are investment $(252 \mathrm{k} € / \mathrm{a}$.), $22 \%$ result from maintenance and service and only $18 \%$ are caused by system operating. Thus, the fixed cost rate is $83 \%$.

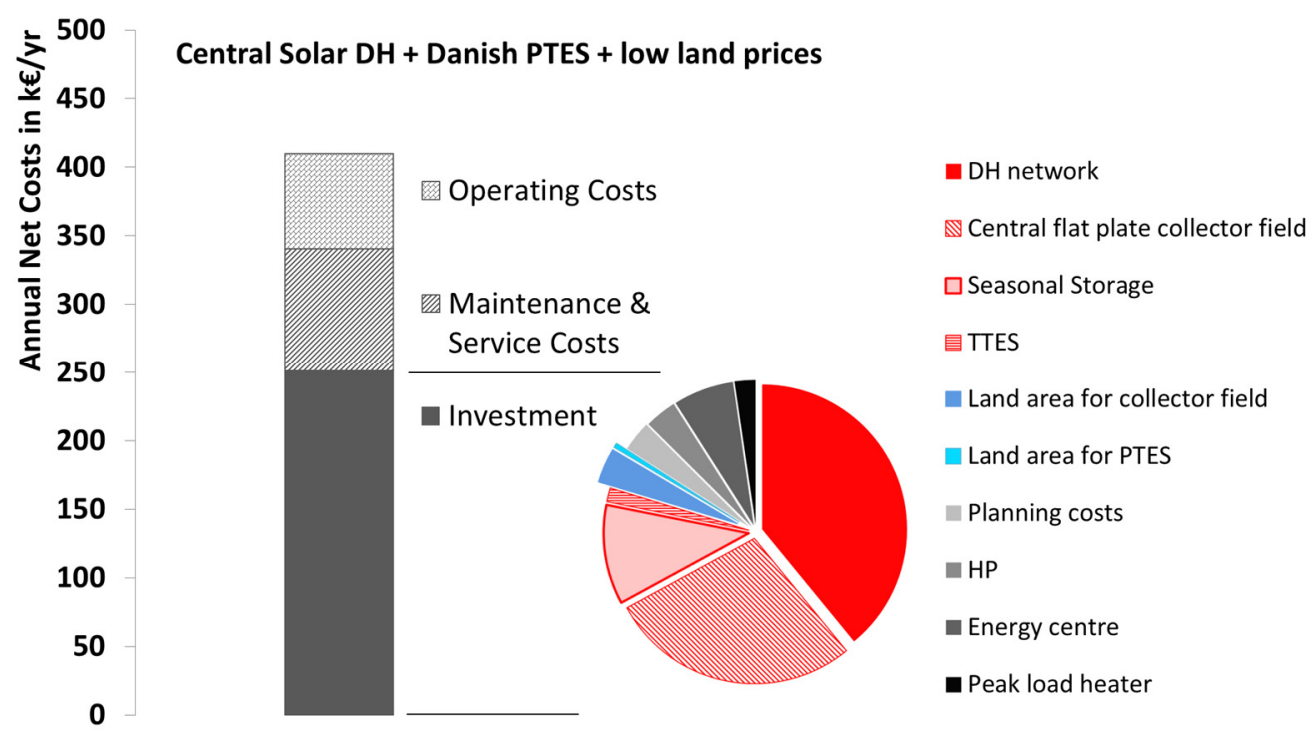

Fig. 5: Net annual costs for a central solar district heating system (left) and the breakdown of the investment (right) at a base period of 30 years

The break-down of investment demonstrates the three most cost-intensive system components: the DH network (39\%), the central collector field (28\%), and the pit storage PTES (11\%). The pie chart shows also several other points of expenses marked in grey. They are considered to be nearly constant through the different heat supply systems. They comprise of planning costs, the heat pump, the peak load heater, and the energy centre. Together they amount to $16 \%$ of the investment. The land use costs represent an ideal situation and can be seen as a low cost approach. Nevertheless, they amount to $4 \%$ of the total investment (marked in blue).

On top of the investment, maintenance \& service costs and operating costs are added. The maintenance and service costs were evaluated according to fixed rates recommended by VDI 2067, whereas the operating costs represent the system operating characteristic. Here, the operating costs result only from the yearly electricity consumption, which mainly reflects the HP performance and secondly the auxiliary energy demand of pumps (see section 4). The HP achieves a SPF of 3.8 and supplies $60 \%$ of the total heat demand. To sum up, the net annual costs amount to $415 \mathrm{k} € / \mathrm{a}$. This results in specific net heat generation costs of $249 € / \mathrm{MWh}$ for a total heat demand of 1,665 MWh/a. without subsidies.

\subsection{Net Annual Costs of the Semi-decentralized Solar DH system}

Similar to the economic evaluation of the central solar DH system, the calculations were conducted for the semidecentralized solar DH. First the specific costs for system components were investigated. The DH network costs resulted to be only slightly higher as the costs of the central solar DH network, despite the lower temperature level and the smaller temperature difference of $15 \mathrm{~K}$ between supply and return. The DH network transportation pipes amount of average $233 € / \mathrm{rm}$ (Nast et al., 2009), which is an increase of $3 \%$ compared to the central solar DH system. The costs for substations as well as house-lead-in costs were assumed to be the same as previously shown. In contrast to the central solar DH system, distributed flat plate collector systems of $820 \mathrm{~m}^{2}$ were planned in order to supply the DHW demand during non-space heating period. Thus, higher specific solar thermal system costs incur of $742 € / \mathrm{m}^{2}$ (Stuible et al., 2016). The BTES was designed in cooperation with the Institute of Geotechnics of the University Kassel, which computed the BTES to have 92 boreholes of $120 \mathrm{~m}$ depth. Specific costs of $98 € / \mathrm{m}$ borehole depth were determined. The land area above the BTES was assumed to be still usable as green space, because the boreholes are installed $1 \mathrm{~m}$ under the surface. Consequently, no additional costs for land area occur.

The specific investment for each component is listed in the following table: 
I. Best et. al. / EuroSun 2018 / ISES Conference Proceedings (2018)

Tab. 5: Specific investment of the semi-decentralized solar DH system's components

\begin{tabular}{|l|ll|}
\hline Network construction costs & $233 € / \mathrm{m}_{\text {tr }}$ & (Nast et al., 2009) \\
\hline Costs for substations & $4,000 € /$ unit & (Stuible et al., 2016) \\
\hline House-lead-in costs & $3,600 € /$ unit & (Stuible et al., 2016) \\
\hline Network Pumps & $3,490 € /$ unit & (wilo, 2017) \\
\hline Solar System Collector Costs & $742 € / \mathrm{m}^{2}$ & (Stuible et al., 2016) \\
\hline BTES & $98 € / \mathrm{m}^{2}$ borehole depth & $\begin{array}{l}\text { (Solites, 2016; Freistaat Thüringen } \\
\text { Ministerium für Umwelt, Energie und } \\
\text { Naturschutz, 2016) }\end{array}$ \\
\hline Land area & & \\
\hline HP & - & (Lambauer et al., 2008; Wolf et al., \\
& $195 € / \mathrm{kW}$ th & 2014) \\
\hline Peak load heater & $100 € / \mathrm{kW}$ & assumption \\
\hline
\end{tabular}

The central solar DH system shall be compared with a semi-decentralized solar DH system, which was designed especially for the new building development "Zum Feldlager". Therefore, the net annual costs were examined similarly to the central solar DH system. The results are shown in the following diagram. Fig. 6 displays the net annual costs of the semi-decentralized solar DH system. The net annual costs consist of $64 \%$ investment ( $284 \mathrm{k} € / \mathrm{a})$. Furthermore, maintenance and service costs amount to $22 \%$ of the total heat generation costs, which can be summed up to a fixed cost rate of $86 \%$. The investment is dominated also by three main system components: the DH network (37\%), followed by the BTES (31\%), and the distributed solar collector systems (17\%). In case of the semidecentralized solar DH system the operating costs were determined via dynamic simulations (see section 2.2). Similar to the central solar DH system analyses, the specific electricity costs were assumed to be $0.17 € / \mathrm{kWh}$, which applies to large consumers. Regarding DHW preparation, the electricity consumption of the electrical back-up heaters was rated with $0.21 € / \mathrm{kWh}$, which applies to small consumers in Germany. The HP performance, thus the $S P F$ has the largest impact on the operating costs. The electricity consumption of the HP is $310 \mathrm{MWh} / \mathrm{a}$. $(S P F=4.6)$ that generates costs of $68 \%$ of total operating costs. This implies the distribution heat losses through the network already. To sum up, the net annual costs amount to $443 \mathrm{k} € / \mathrm{a}$.. This results in specific net heat generation costs of $265 € / \mathrm{MWh}$ for a total heat demand of 1,665 MWh/a. without subsidies.

In conclusion the semi-decentralized DH system shows $7 \%$ higher net heat generation costs than the central solar DH system. However, this applies only for the given boundary conditions. Specifically, this applies for sites with very low land prices and for the assumed seasonal storage type. In order to investigate the impact of land prices and land requirements on the total net heat generation costs, a parameter study was conducted.

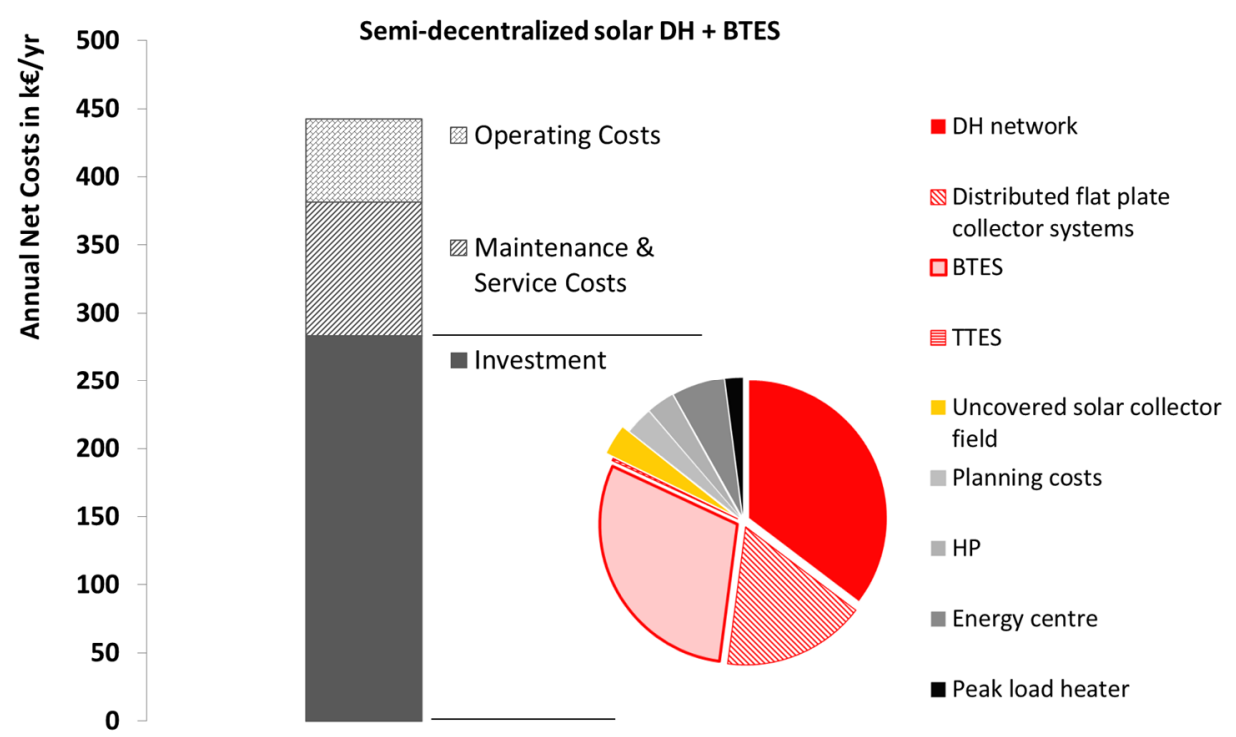

Fig. 6: Net annual costs of the semi-decentralized solar DH system for the new housing development „Zum Feldlager“" at a base period of 30 years 


\subsection{Variation of land prices for central solar $\mathrm{DH}$}

In Germany the availability of open space is restricted, which results in high land prices. In order to demonstrate the upper limit of heat generation costs, the maximum land price was set to $180 € / \mathrm{m}^{2}$. This represents the land value of the district, where the new housing development "Zum Feldlager" will be build. However, the land prices as well as the land requirements can differ depending on the boundary conditions. In consequence, the resulting heat generation costs were calculated for land prices in the range of $10 € / \mathrm{m}^{2}$ to $180 € / \mathrm{m}^{2}$. Additionally, the ratio of land requirements for ground-mounted solar collector installation (construction area) to the gross collector area. The following diagram shows the heat generation costs as a function of land price and ratio of construction area to gross collector area (see Fig. 7). Thereby the solar yield was kept constant over the varying ratio of construction area to gross collector area.

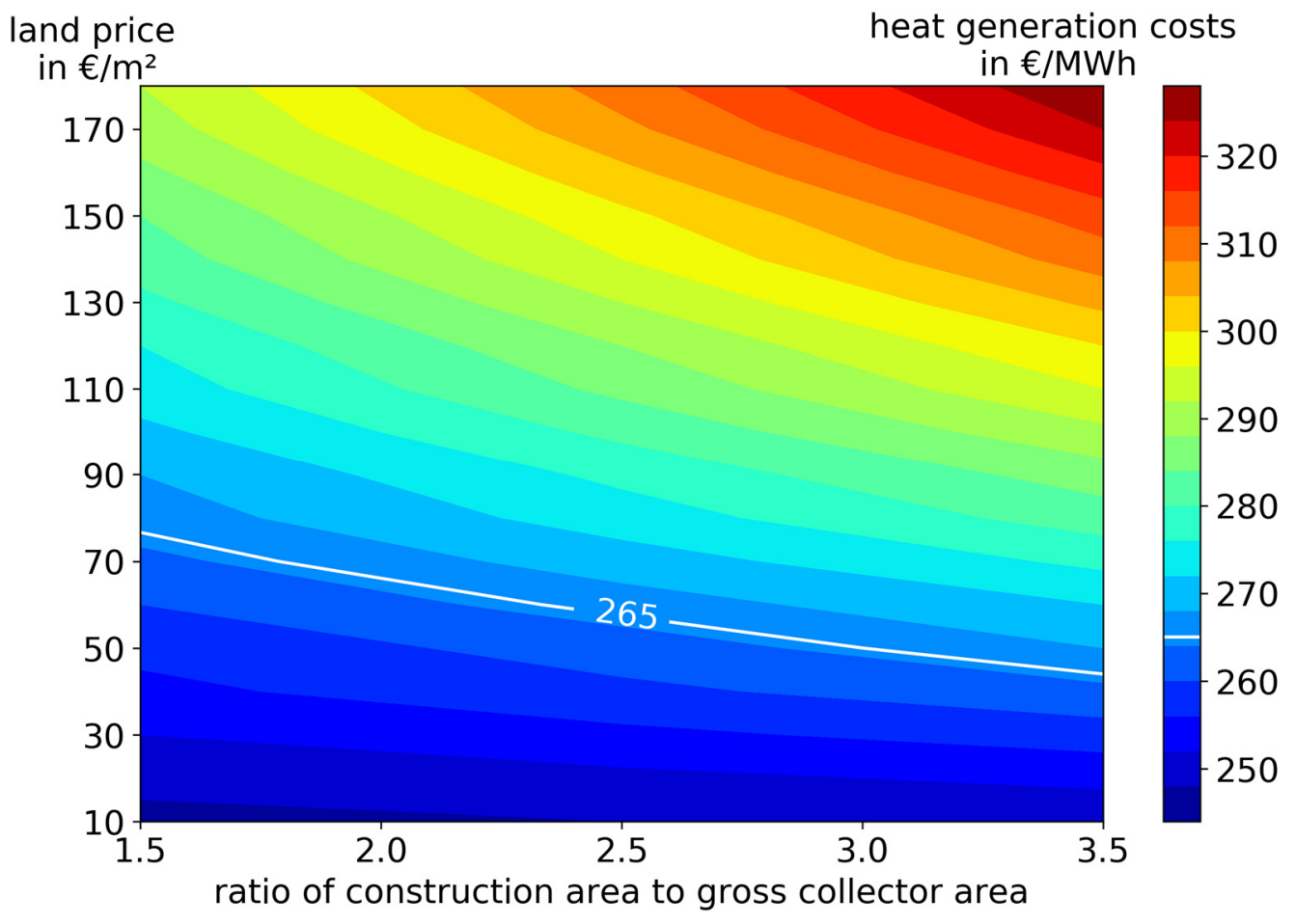

Fig. 7: Heat generation costs for central solar DH as a function of land price and ratio of construction area to collector area

The contour plot shows, that at a ratio of construction area to collector area of 3.5 the total heat generation costs of central solar DH increase about $32 \%$ from very low land price of $10 € / \mathrm{m}^{2}$ to the maximum land price of $180 € / \mathrm{m}^{2}$. At a ratio of construction area to collector area of 1.5 this effect is reduced; the heat generation costs increase about $18 \%$ within the given land price range. Cost parity between semi-decentralized solar DH and central solar DH is achieved at heat generation costs of $265 € / \mathrm{MWh}$ (marked by the white line, see Fig. 7). Below the white line the central solar DH system is more economic than the semi-decentralized solar DH. Above the white line the semidecentralized solar DH is more economic. This means at land prices greater equal than $75 € / \mathrm{m}^{2}$, the semidecentralized solar DH is more economic than central solar DH regardless of the ratio of construction area to collector area at chosen assumptions. Thus, land prices have a high impact on the system feasibility and have to be considered within economic analyses.

\section{Discussion}

Two different solar district systems have been designed for the new building development "Zum Feldlager", which represents a low heat density area. Both developed heat supply systems were designed under the precondition to achieve a renewable heat supply of $\approx 80 \%$. Key issue was to identify the preferable system from the economic point of view. Detailed economic analyses were conducted via a full-cost accounting in order to determine the net heat generation costs of each system comprising of investment, maintenance and service as well as operating costs (variable costs). A medium cost approach was chosen. The specific costs for solar thermal collectors were considered conservatively. The maintenance costs are determined applying fixed percentages of investment according the German VDI 2067, which might be overestimating the costs in case of large systems. In conclusion, the economic analyses showed that the central solar district heating system is favorable under specific boundary conditions: at land prices lower than $75 € / \mathrm{m}^{2}$ and low costs for the seasonal pit thermal energy storage of around $45 € / \mathrm{m}^{3}$ we. In case of 
lack of open space, the semi-decentralized solar DH system represents an energy efficient, sustainable and economic alternative to the central solar DH system.

\section{Acknowledgment}

The project partners greatly acknowledge the financial support of the project by the German Federal Ministry of Economic Affairs and Energy. (FKZ: 03ET1336C)

\section{References}

Arbeitsgemeinschaft QM Fernwärme: Nussbaumer, Thomas, Thalmann, S., Jenni, A., Ködel, J., 2017. Planungshandbuch Fernwärme ISBN 3-90870505-30-4. www.verenum.ch/Dokumente/PLH-FW_V1.0.pdf. Accessed 26 June 2017.

BORIS Hessen, 2016. Hessische Verwaltung für Bodenmanagement und Geoinformation. https://hvbg.hessen.de/immobilienwerte/boris-hessen. Accessed 9 October 2017.

Deutsches Institut für Normung e. V., 2003. Thermal protection and energy economy in buildings Part 6: Calculation of annual heat and annual energy use. https://www.beuth.de/de/vornorm/din-v-4108-6/63939447. Accessed 18 December 2017.

Deutsches Institut für Normung e. V., 2012. Heating system in buildings - Method for calculation of the design heat load - Supplement 2: Simplified method for calculation of the design heat load and the heat generator capacity. Beuth Verlag GmbH.

Freistaat Thüringen Ministerium für Umwelt, Energie und Naturschutz, 2016. Zukunft Sonne! Solarthermie und Fernwärme: Ein Wegweiser für die Praxis. Solites - Steinbeis Forschungsinstitut für solare und zukünftige thermische Energiesysteme, Stuttgart.

GRE Gesellschaft für Rationelle Energieverwendung e. V., 2016. Energieeinsparverordnung 2016. Bau+Technik $\mathrm{GmbH}$, Düsseldorf.

Jordan, U., Vajen, K., 2001. Realistic Domestic Hot Water Profiles in Different Time Scales. Universität Marburg.

Klöpsch, M., Besier, R., Wagner, A., 2009. Reicht für Kunststoffmantelrohre die Standarddämmung? Wirtschaftliche Dämmung von KMR. Euro Heat \& Power (12), 46-54.

Lambauer, J., Fahl, U., Ohl, M., Blesl, M., Voß, A., 2008. Industrielle Großwärmepumpen - Potenziale, Hemmnisse und Best-Practice Beispiele. Institut für Energiewirtschaft und Rationelle Energieanwendung (IER).

Lund, H., Werner, S., Wiltshire, R., Svendsen, S., Thorsen, J.E., Hvelplund, F., Mathiesen, B.V., 2014. 4th Generation District Heating (4GDH). Integrating smart thermal grids into future sustainable energy systems. Energy 68, 1-11: 10.1016/j.energy.2014.02.089.

Manderfeld, M., Jentsch, A., Pohlig, A., Dötsch, C., Richter, S., Bohn, K., 2008. Abschlussbericht Forschungsvorhaben Fernwärme in der Fläche RDH (Rural District Heating) . Ermittlung des Fernwärmepotentials unter Berücksichtigung der neuester Verlegeverfahren und unterschiedlicher Energiedargebote in der Fläche der Bundesrepublik Deutschland. Accessed 18.12.17.

Nast, M., Ragwitz, M., Schulz, W., Bürger, V., Leprich, U., Klinski, S., 2009. Ergänzende Untersuchungen und vertiefende Analysen zu möglichen Ausgestaltungsvarianten eines Wärmegesetzes. Ausarbeitung im Auftrag des Bundesministeriums für Umwelt, Naturschutz und Reaktorsicherheit. DLR, Fachhochschule für Wirtschaft Berlin (FHW), Öko-Institut, IZES, ISI, BEI.

www.dlr.de/tt/Portaldata/41/Resources/dokumente/institut/system/publications/Endbericht_Waermegesetz11.pdf. Accessed 18 December 2017.

Nussbaumer, T., Thalmann, S., 2014. Sensitivity of System Design on Heat Distribution Cost in District Heating. ISBN 3-908705-27-4. verenum and Swiss Federal Office of Energy, Zürich. www.ieabcc.nl/publications/IEA_Task32_DHS_Cost_Analysis.pdf. Accessed 18.12.17.

Nussbaumer, T., Thalmann, S., 2016. Influence of system design on heat distribution costs in district heating 101, 496-505: 10.1016/j.energy.2016.02.062.

Nußbicker-Lux, J., 2010. Simulation und Dimensionierung solar unterstützter Nahwärmesysteme mit ErdsondenWärmespeicher. Dissertation.

Persson, U., Werner, S., 2011. Heat distribution and the future competitiveness of district heating. Applied Energy 88 (3), 568-576: 10.1016/j.apenergy.2010.09.020.

SDH solar district heating, 2017. Ranking List of European Large Scale Solar Heating Plants. http://solar-districtheating.eu. Accessed March 2017.

Solites, 2016. saisonalspeicher.de. Das Wissensportal für die saisonale Wärmespeicherung. Solites Steinbeis Forschungsinstitut für solare und zukunftsfähige thermische Energiesysteme. http://www.saisonalspeicher.de/. Accessed 9 October 2017.

Solites, 2017. ScenoCalc Fernwärme 2.0. SDH tools. Solites - Steinbeis Forschungsinstitut für solare und zukünftige thermische Energiesysteme. http://solar-districtheating.eu/ServicesTools/SDHcalculationtools.aspx. Accessed 9 October 2017.

Stuible, A., Zech, D., Wülbeck, H.-F., Sperber, E., Nast, M., Hartmann, H., Reisinger, K., Budig, C., Orozaliev, J., Pag, F., Vajen, K., Erler, R., Janczik, S., Kaltschmitt, M., Niederberger, M., 2016. Evaluierung von 
Einzelmaßnahmen zur Nutzung erneuerbarer Energien im Wärmemarkt (Marktanreizprogramm) für den Zeitraum 2012 bis 2014. Evaluierung des Förderjahres 2014.

Verein Deutscher Ingenieure e. V., 2000. Economic efficiency of building installations - Effective energy requirements for heating service water Blatt 12. https:/www.beuth.de/de/technische-regel/vdi-2067-blatt12/32138558. Accessed 19 December 2017.

Verein Deutscher Ingenieure e. V., 2012. Economic Efficiency of building - Fundamentals and economic calculation VDI 2067 Blatt 1. Beuth Verlag GmbH.

Verein Deutscher Ingenieure e. V., 2014. Solar heating for potable water - Basic principles - System technology and application in residential buildings Part 1/2. https://www.vdi.de/technik/fachthemen/bauen-undgebaeudetechnik/fachbereiche/technische-gebaeudeausruestung/richtlinienarbeit/vdi-6002/. Accessed 18 December 2017.

Verein Deutscher Ingenieure e. V., 2017. Gründruck VDI 3988 Solarthermische Prozesswärme.

wilo, 2017. high efficiency pumps: Stratos 40/ 1-16 PN 6/10, Stratos GIGA 50/ 1-20/1,2, operating mode dp-v. Accessed 2017.

Wolf, S., Fahl, U., Blesl, M., Voß, A., Jakobs, R., 2014. Analyse des Potenzials von Industriewärmepumpen in Deutschland. Institut für Energiewirtschaft und Rationelle Energieanwendung (IER). 


\title{
Energetic and economic analysis of a solar assisted trigeneration system \\ D'Antoni Matteo', Fedrizzi Roberto and Simone De Luca \\ ${ }^{1}$ Eurac Research, Institute for Renewable Energy, Bolzano (Italy)
}

\begin{abstract}
The aim of this paper is to present the simulation activities carried out for the energy and economic assessment of a solar-assisted trigeneration system within the framework of EU FP7 BRICKER project. The system comprises a parabolic trough collectors field, an Organic Rankine Cycle unit and an adsorption chiller. It is installed in a hospital building in Aydin (Turkey). TRNSYS system simulations are used for the evaluation of the yearly performance.
\end{abstract}

This work shows that the economic feasibility of the trigeneration layout concept is limited by low energy tariffs and by the low electricity generation efficiency of the small-scale ORC unit. For the system and application here presented, the operation of the trigeneration system should be driven by heating and cooling working modes, having the priority on a pure electricity generation.

Keywords: Solar energy, Trigeneration, Heating and cooling; TRNSYS

\section{Introduction}

Today, cogeneration (also termed as Combined Heat and Power - CHP) has become an energy efficient, economically viable and mature technology and it is being addressed on a very large scale. According to 2016 REN21 Global Report (REN21, 2016), about 8\% of world's electricity generating capacity is in CHP facilities, with a total installed capacity of $325 \mathrm{GW}$ and an average overall efficiency of $75-90 \%$. Trigeneration systems, also known as Combined Cooling, Heating, and Power (CCHP) systems, are a technical extension of CHP systems, which use thermally activated chilling technologies to produce cooling using the discarded thermal energy by the power generator. The concept of trigeneration has come up since a few decades, in the same time when CHP system began to be applied for residential consumers, usually involving large units with district heating. Typically, CCHP systems are considered in large-scale centralized power plants and industrial applications (Jradi and Riffat, 2014) as an energy efficiency measure to recover high-temperature heat losses.

In the last years, CCHP has attracted considerable interest for small-scale decentralized applications $\left(<1 \mathrm{MW}_{\mathrm{el}}\right)$ with the development of different options regarding cooling technologies and cogeneration units. Potential trigeneration users might be multi-residential dwellings and communities, large tertiary and commercial buildings. Small-scale CCHP systems could be effectively exploited within district heating and cooling networks (EU H2020 FLEXYNETS, 2015).

Different heat and power generating technologies have been considered in literature to serve as prime movers for CCHP applications. Some of these technologies are commercially mature with wide availability in the market (combustion engines and turbines), while others are still in a development stage such as Stirling, ORC and fuel cell based units.

The ORC modules with higher evaporator inlet temperatures result in better performances, producing more electricity and achieving better cycle efficiencies. Commercially available capacities of ORC range from 0.2-2 $\mathrm{MW}_{\mathrm{el}}$, which cost between 1000-4000 €/ $\mathrm{kW}_{\mathrm{el}}$ depending on capacity and manufacturer (Velez et al., 2012). Technical feasibility of ORCs as a prime movers in trigeneration systems applied to buildings has been actively researched (Buonomano et al., 2014) and possible combinations of ORC modules and renewable sources have been studied (Tchanche et al., 2011). 
Within this technological trend, the aim of the paper is to discuss energy and economic results of a novel solarassisted trigeneration system where a small small-size Organic Rankine Cycle (ORC) unit is used as prime mover. The CCHP system is installed in the city hospital of Aydin (Turkey) and is part of the demonstration activities of EU FP7 BRICKER project (EU FP7 BRICKER, 2013). The goal of the project is to develop the layout of a smallscale CCHP system that can exploit solar heat to cover the heating and cooling loads of buildings while generating electricity. System performance is evaluated by means of TRNSYS numerical simulations (Klein S.A. et al., 2010).

\section{Description of the energy system}

In the proposed energy system, the ORC unit is assisted by a PTC field and a gas boiler. An operationally flexible system layout supporting different working mode configurations is proposed. Figure 1 shows the layout of the CCHP system. Energy generation units, namely the PTC field and the gas boiler, deliver high-temperature heat to the ORC unit or to the heat exchangers (HX1 and HX2). In this loop, Therminol SP is used as heat transfer medium. The ORC unit generates electricity and rejects heat to the secondary side of the CCHP system for covering heating loads or for trigeneration purposes in combination with an adsorption chiller (ADCH).

One of the advantages of this CCHP concept is the flexibility in covering thermal heating loads at high (radiators), medium (heating and ventilation coils) or low (radiant system) distribution temperatures. Beneath to these, a series of challenges should be mentioned:

- The integration of the new energy system into the existing one, not only from a mere electro-mechanical installation perspective but mainly in the control and regulation of systems operation priorities and strategies;

- The mismatch between energy consumption and generation through stochastic solar energy sources should be solved in order to maximize the renewable energy exploitation;

- The optimization of the thermal cascade exploitation in heating and cooling processes;

- The definition of cost-optimal scenarios in which final energy savings make the higher upfront costs as effective as state-of-the-art alternatives.

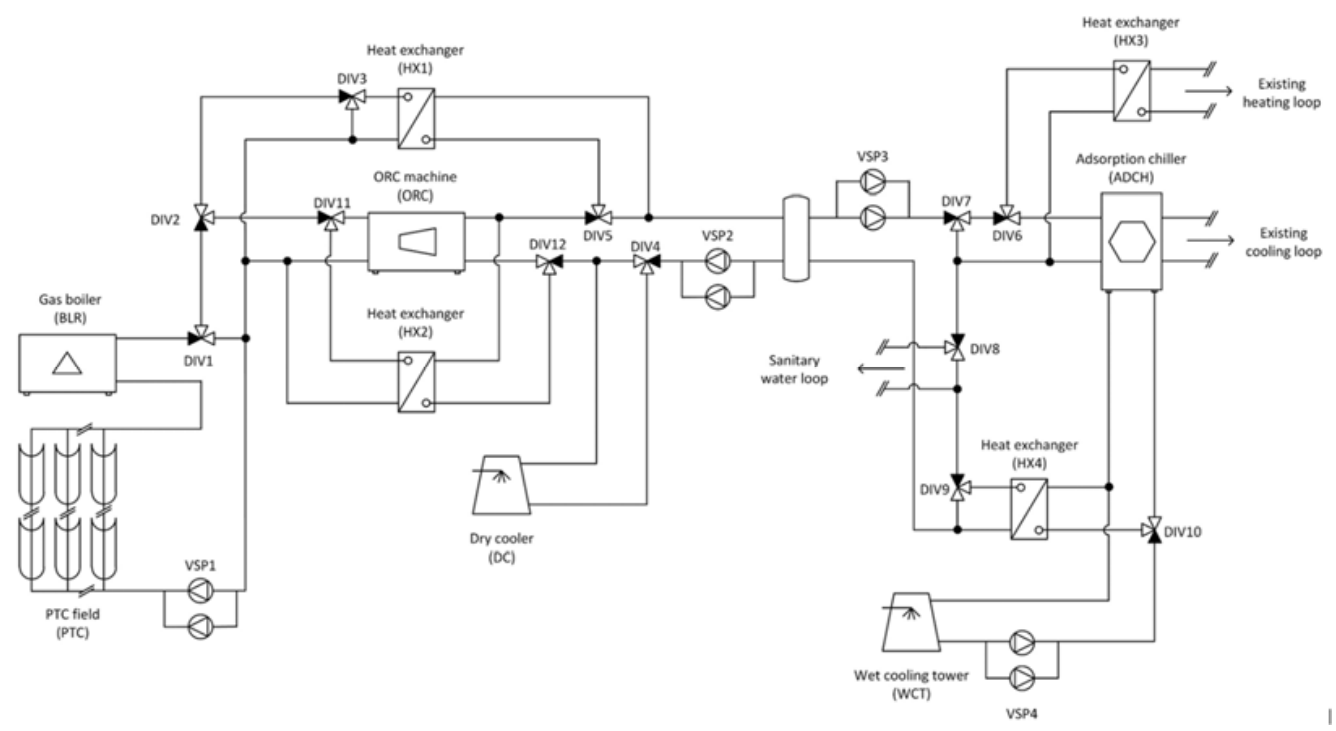

Fig. 1: Layout of the CCHP system developed within BRICKER project.

\subsection{Building description and system integration into the existing energy system}

The CCHP is installed in the hospital building of the Adnan Menderes University in the province of Aydin (Turkey). The hospital has three building blocks with an overall conditioned are of about $43200 \mathrm{~m}^{2}$. Most of the building blocks areas are used with a $7 / 24$ schedule. The indoor air temperature is kept to $24^{\circ} \mathrm{C}$ during the heating season whereas to $25^{\circ} \mathrm{C}$ during the cooling season. The technical staff performs manually the switch from heating to cooling working mode. For the sake of simplicity, the heating season schedule is defined from $1^{\text {st }}$ of November, 
to $15^{\text {th }}$ of March, whereas the cooling season is complementary.

The hot water for heating purposes is generated by two natural gas boilers $(6500 \mathrm{~kW}$ each, model: Buderus SB825). The set point temperature of the boilers is manually imposed by the operator and is usually kept at $70{ }^{\circ} \mathrm{C}$ during typical winter days, but it might be increased up to $80{ }^{\circ} \mathrm{C}$ during extraordinarily cold days and down to $60^{\circ} \mathrm{C}$ when mild heating is required. The cooling water is produced through a centralized system composed of three centrifugal chillers (2x $4650 \mathrm{~kW}$ each and 1x $2326 \mathrm{~kW}$, model: Carrier 19XR). As condensing unit, a dedicated open cycle wet cooling tower is installed for each chiller. Heating and cooling thermal energy is provided to the air-conditioned spaces in the hospital through wall-mounted fan coil units. The HVAC system of the building includes 19 air-handling units, which operate with $100 \%$ fresh air without any heat recovery system.

Mass flow rates, temperature set points and performance characteristics of existing HVAC system components are fragmented or missing. On-site measurements were not feasible as the interruption of building's services (heating, cooling or hot water delivery) would have been required. For these reasons, the development of a detail numerical model of the existing energy system was not possible.

The installation of the new CCHP system aims to drastically improve the environmental performance of the existing heating and cooling system. The approach used in the evaluation of the BRICKER system is typical of an energy potential analysis. In other words, constant return temperatures from heating and cooling distribution loops $\left(50^{\circ} \mathrm{C}\right.$ and $15^{\circ} \mathrm{C}$, respectively) are imposed as boundary temperatures to the CCHP system. Since heating, cooling and electricity loads of the hospital are much greater than the installed capacity of the CCHP system, it is assumed that $100 \%$ of energy outputs (heating, cooling and electricity production) are consumed in the building.

\subsection{Description of main system component}

The solar technology employed in the CCHP system consists of a field of parabolic trough collectors $\left(1632 \mathrm{~m}^{2}\right.$ of net collecting area) with an automatic controlled sun-tracking motion that allows the continuously adjusts the position of the mirrors to concentrate the solar beams onto the receiver tube. Performance and dimensional parameters are based on the data provided by the manufacturer of the PTC (Soltigua, model "PTMx-36"). The installation includes 20 concentrating collectors arranged in five rows of four collectors each for a total estimated thermal power of overall estimated thermal power of the PTC field is about $950 \mathrm{~kW}$.

The gas boiler (Babcock Wanson, model "TPC-H400) has a capacity of $465 \mathrm{~kW}$ and uses thermal oil. It is a horizontal thermal oil boiler with an average thermal efficiency of about $86 \%$. The gas boiler modulates between $10 \%$ and $100 \%$ of its capacity in order to reach a set point outlet temperature of $225^{\circ} \mathrm{C}$.

The CCHP is built around the ORC unit, a prototype developed by RANK with R245a as working fluid. The rated electrical generation capacity ranges between $99.2 \mathrm{~kW}$ and $70.8 \mathrm{~kW}$ according to evaporator/condenser inlet temperature respectively, whereas the thermal power extracted from the oil loop ranges from $562.9 \mathrm{~kW}$ to 455.7 $\mathrm{kW}$.
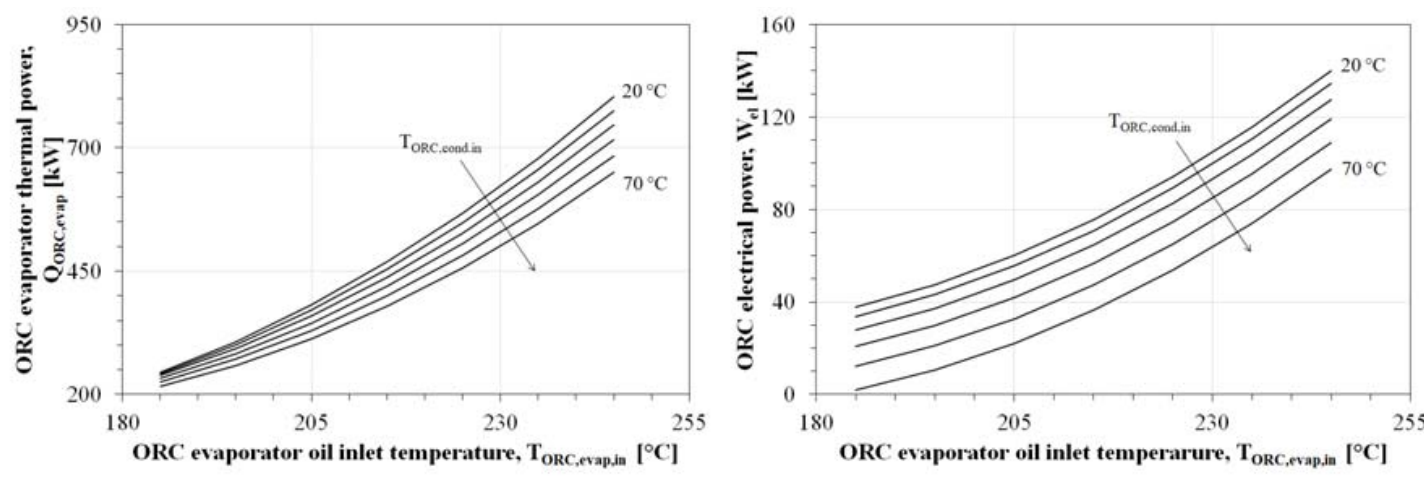

Fig. 2: Dependency of the evaporator thermal power (left side) and of the electrical power (right side) of the ORC unit from the inlet oil temperature (evaporator side) and the inlet water temperature (condenser side).

The ADCH model "ECO-MAX D-75" manufactured by PPI is considered for installation. It includes two beds of silica gel and water as refrigerant fluid. Its rated capacity and $\mathrm{COP}_{\text {th }}$ are $267 \mathrm{~kW}$ and 0.55 , respectively. However, these performance values are achieved in different operating condition than the BRICKER system nominal 
condition, with the main difference represented by the nominal source mass flow, which is reduced by a half in the BRICKER system. Subsequently, the ADCH will work in off-design condition to match the real inlet condition. Figure 3 shows the dependency of $\mathrm{COP}_{\text {th }}$ and cooling capacity to hot water and chilled water inlet temperatures for the selected model.
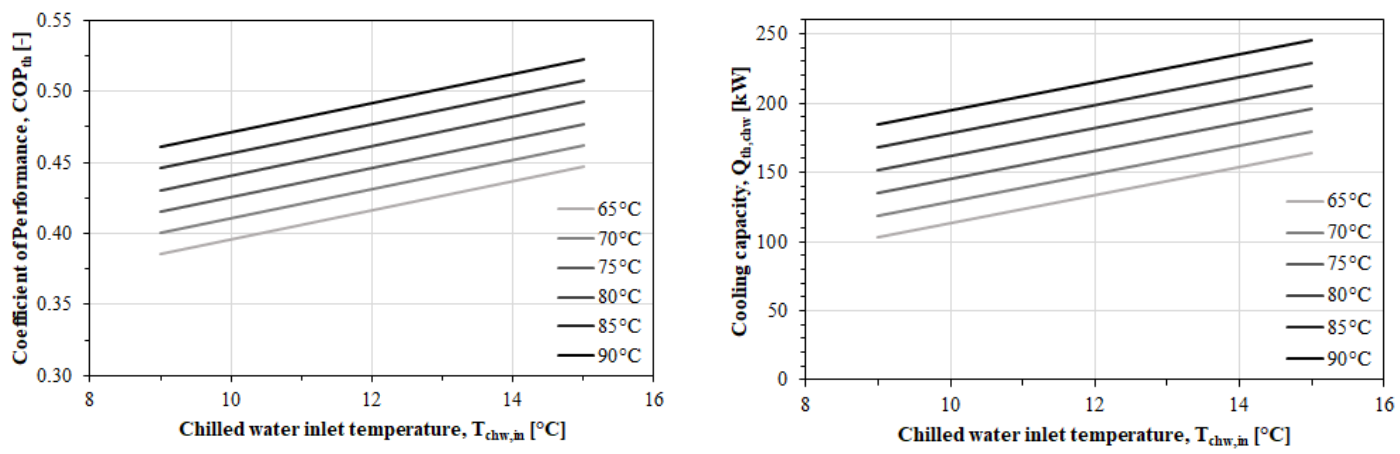

Fig. 3: Dependency of the $\mathrm{COP}_{\text {th }}$ (left side) and of the cooling capacity (right side) of the ADCH unit from the chilled water inlet temperature for a cooling water inlet temperature of $30^{\circ} \mathrm{C}$.

\subsection{Operation strategies}

The ORC unit is activated through high-temperature heat (in the operative range of $185-245{ }^{\circ} \mathrm{C}$ ) generated by the PTC field and the gas boiler. The PTC field is activated when the Direct Normal Irradiation (DNI) on the collector surface exceeds the threshold of $250 \mathrm{~W} / \mathrm{m}^{2}$. When the DNI ranges between $250-300 \mathrm{~W} / \mathrm{m}^{2}$, the solar pump recirculates the oil into the solar loop performing a pre-heating of the circuit. This working scheme is necessary since the ORC evaporator requests at least $500 \mathrm{~kW}$ and the gas boiler has a limited capacity of $465 \mathrm{~kW}$. Under these circumstances, the gas boiler is shut off. The flow rate in the thermal oil loop is set at such constant value $\left(21 \mathrm{~m}^{3} / \mathrm{h}\right)$, avoiding overheating of the transfer fluid. When the DNI on the collector surface rises above $300 \mathrm{~W} / \mathrm{m}^{2}$, the solar harvesting mode starts and heat is delivered for ORC activation. Such threshold was derived from a preliminary set of simulations that aimed to assess which conditions must be maintained to avoid overheating in the high-temperature loop for the specific demo installation. The PTC operational limits have a crucial influence on the design of the entire oil loop. The flow rate in the PTC field is modulated between a minimum $\left(13 \mathrm{~m}^{3} / \mathrm{h}\right)$ and a maximum $\left(26 \mathrm{~m}^{3} / \mathrm{h}\right)$ value. The lower limit is due to the necessity of keeping an uniform flow inside the receiver pipe, avoiding localized increases of temperature that can lead to a degradation of the oil. The upper limit is set in order to limit fluid pressure losses while flowing in the solar collector absorber.

The gas boiler is activated only in solar harvesting mode and if the inlet temperature is lower than the inlet set point temperature of ORC $\left(225^{\circ} \mathrm{C}\right)$. When the oil temperature is higher than $225^{\circ} \mathrm{C}$, cogeneration/trigeneration is fed only by the PTC field.

The ORC unit is designed as the core of the trigeneration system. It produces simultaneously thermal and electrical energy, and the relative energetic output and system efficiency are dependent to its optimal working conditions. The activation of the ORC is restricted to the following conditions: (1) evaporator inlet oil temperature between $185-245^{\circ} \mathrm{C}$; (2) consender inlet water temperature between $20-70{ }^{\circ} \mathrm{C}$; (3) presence of heating/cooling demands from the building. The operation in cogeneration / trigeneration modes is prioritized against electricity generation mode.

Working schemes for both heating and cooling are activated only when there is a solar output from the hightemperature oil loop. If the outlet temperature from the gas boiler is compatible with the operation of the ORC unit, the simultaneous generation of thermal energy and electricity is possible. Being the nominal oil volumetric flow rate of the ORC equal to $13 \mathrm{~m}^{3} / \mathrm{h}, \mathrm{ORC}$ and $\mathrm{HX} 1$ are operated together when the solar pump is modulated up to $26 \mathrm{~m}^{3} / \mathrm{h}$. An alternative heating scheme is used when inlet oil and water temperature restrictions are not met. Under these conditions, the ORC operation is not possible and HX1 and HX2 are considered.

Preheating of the ORC's condenser water loop during the cooling season is required in order to achieve the minimum source temperature for the ADCH's operation, set at $65^{\circ} \mathrm{C}$. As long as the inlet source temperature to 
the chiller is below the minimum threshold value, the hot water flow is recirculated and cooling and chilled water circuit pumps are not activated. Those conditions lead to a rather quick pre-heating of the loop, as no thermal load is being covered. During this operation, the ORC unit produces electricity with a variable efficiency, depending on the temperature of the condensing water.

The main cooling scheme is activated when the minimum required temperature for sorption chilling is achieved and the ORC is working in cogeneration mode. The adsorption chiller generator is then fed with the water exiting the condenser of the ORC unit, which can be also further heated up by HX1, depending on availability of solar radiation. Similarly to the main heating scheme, also the main cooling working scheme allows the generation of electrical power. If ORC inlet condensing temperature is greater than $70{ }^{\circ} \mathrm{C}$ (maximum allowed value for ORC operation), a dry cooler rejects the excess of heat.

The alternative cooling scheme is used during summer season when the ORC is in out of operation conditions. In this case, HX2 performs the heat transfer usually done by ORC working fluid condensation, in conjunction with HX1. Similarly to the alternative heating working scheme, no electricity is generated under this scheme. In this case, the amount of cold water produced by the adsorption chiller and delivered to the existing cooling system is slightly higher than in the case of cooling through ORC wasted heat, since no heat rejection is required.

Whenever the return temperature from the CCHP heating/cooling units is greater than $60{ }^{\circ} \mathrm{C}$, there is the possibility to reject part of the heat for the production of domestic hot water. This additional operating scheme allows to reach constantly the nominal inlet water temperature to either the ORC condenser or to HX2 load side. This operation scheme permits to optimize the thermal cascade of the system, replacing the operation of the dry cooler in the ORC condensing loop.

\section{System performance by means of transient simulation}

\subsection{Definition of KPIs and energy tariffs}

The performance analysis of any energy system starts with the definition of appropriate system boundaries. With respect to the installation at the demo building, system boundary $\Sigma_{2}$ is considered (see Figure 4). At this boundary, it is possible to identify:

- energy inputs: useful energy provided by the solar field (P1) and the gas boiler (P2), electricity inputs for water and oil pumps and ORC operation;

- energy outputs: heating (P18) and cooling (P12) production supplied to the building and electricity generated by the ORC unit;

- thermal losses from hydraulic components like pipes, buffers, storages and hydraulic junctions.

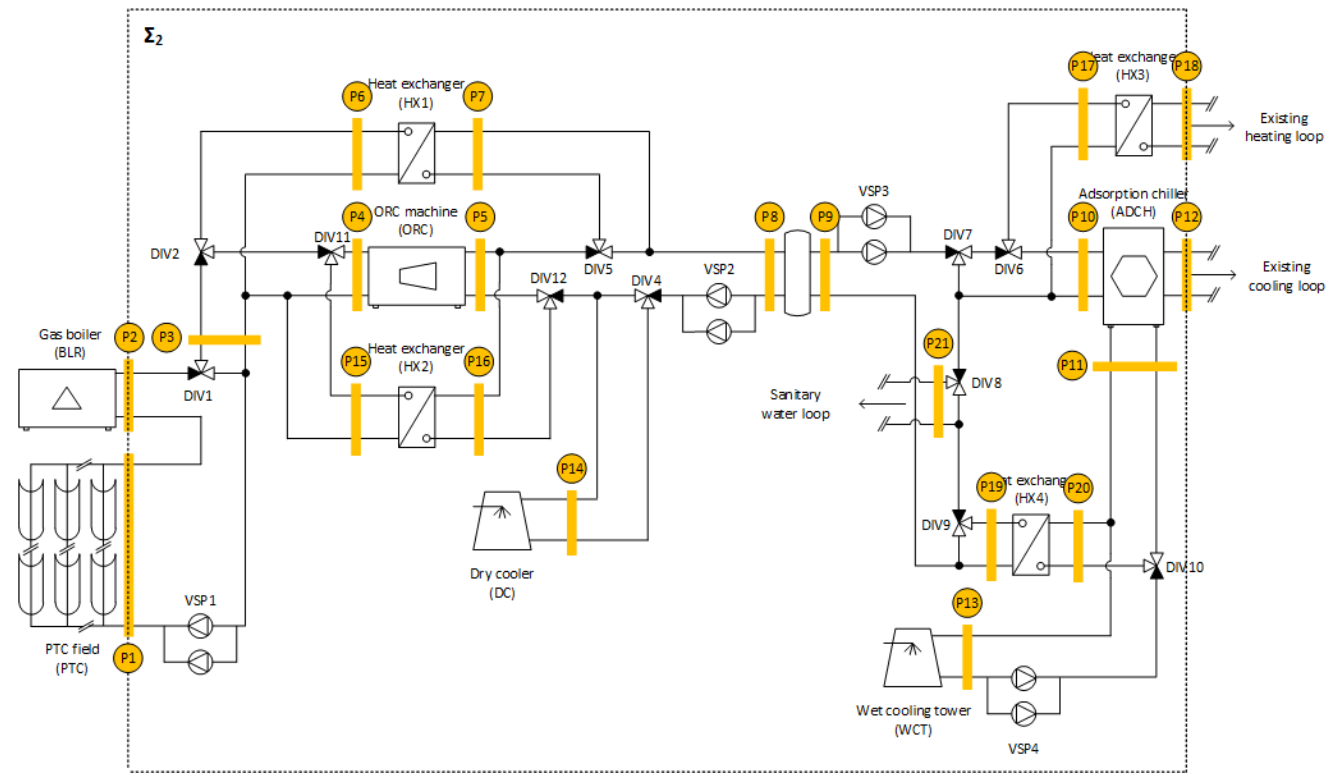

Fig. 4: CCHP system layout showing system boundaries in yellow. 
Since the performance characteristics of the existing energy system are not available, it assumed that gas boilers have an average thermal efficiency of $90 \%$ and that the compression chillers have a SEER of 3.5. With respect to this system (also defined reference system), the energy savings in terms of lower electricity and gas consumptions are calculated from the amount of heating and cooling energy delivered by the CCHP.

\subsection{Simulation results}

The yearly amount of heating energy provided by the CCHP system amounts to $541 \mathrm{MWh}$, while the overall cooling energy generation amounts is $318 \mathrm{MWh}$. The gas final energy consumption amounts to $247 \mathrm{MWh} / \mathrm{year}$ equivalent to about $22570 \mathrm{Sm}^{3}$ of gas, whereas electricity final energy consumption is $570 \mathrm{MWh} / \mathrm{year}$. The electricity generated by the system during an annual operation period is $194 \mathrm{MWh}$.

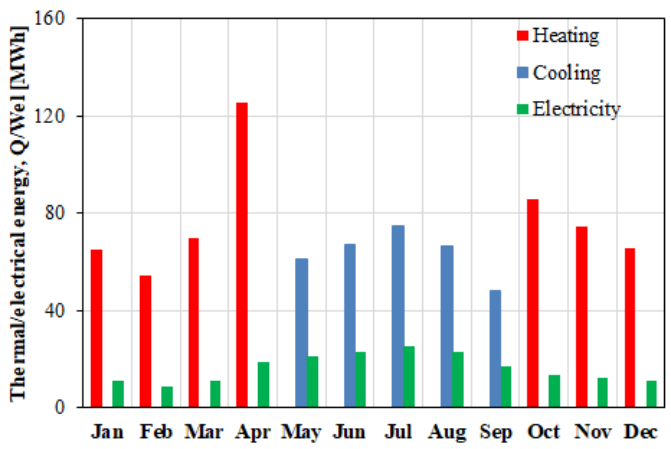

Fig. 5: Monthly thermal and electrical energy production.

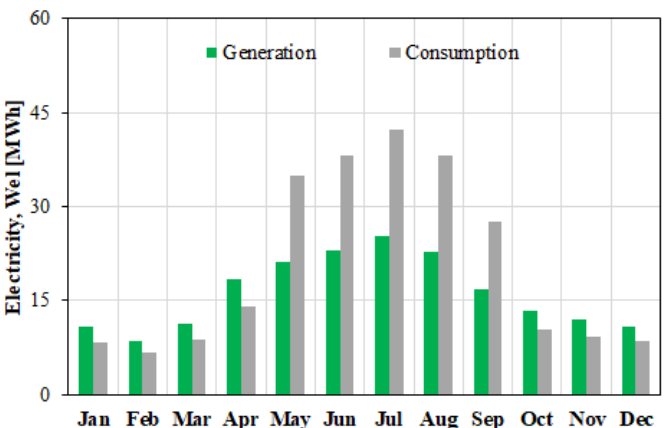

Fig. 6: Monthly electricity generation and consumption.

The yearly DNI available on the collectors surface is about $1696 \mathrm{kWh} /\left(\mathrm{m}^{2} \mathrm{y}\right)$. The average thermal efficiency of the solar field is about $41 \%$ on yearly basis, whereas the Gross Solar Yield amounts to $687 \mathrm{kWh} /\left(\mathrm{m}^{2} \mathrm{y}\right)$. As mentioned before, the gas boilers compensate the solar field output in order to achieve a constant oil temperature at the evaporator of the ORC unit. Defining Solar Fraction (SF) as the relative share of the solar yield on the total heat provided by the high-temperature oil loop (gas + solar), this figure varies from winter to summer from 54\% and $79 \%$, respectively.

The working hours of the CCHP system are calculated as follows:

- Winter season: 1201 hours (all working days, according to sun radiation), with an average value of 5 hours and 40 minutes per day;

- Summer season: 1691 hours (all working days, according to sun radiation), with an average value of 11 hour per day.

- Year: 3030 hours, including the preheating scheme of the solar loop, with an average of 8 hours and 20 minutes per day.

\subsection{Economic analysis}

For the economic analysis, average electricity and gas costs of $0.0845 € / \mathrm{kWh}$ and $0.0253 € / \mathrm{kWh}$, respectively, are retrieved from demo owner tariffs. Electricity prices for consumed and generated electricity are considered equal, since electrical energy is completely self-consumed by either the CCHP system or the users of the hospital. Net energy costs are computed as the net electricity and gas consumptions multiplied by the respective specific energy costs. The calculation of the specific costs for heating and cooling leads to $11.7 € / \mathrm{MWh}$ and $39.6 € / \mathrm{MWh}$, respectively, whereas the specific energy costs of the reference system (gas boilers + electrically driven chillers) for heating and cooling amount to $28.1 € / \mathrm{MWh}$ and $24.1 € / \mathrm{MWh}$, respectively.

The overall investment costs of the CCHP system (purchase of technologies, without installation) for this specific layout and application is of about $1.42 \mathrm{M} €$. The unitary specific cost of the ORC is about $1500 € / \mathrm{kW}_{\mathrm{el}}$, which is actually a low value for small-scale ORC units, but still high if compared to other prime mover technologies (internal combustion engines: $340-1600 € / \mathrm{kW}_{\mathrm{el}}$; micro gas turbines: $900-1500 € / \mathrm{kW}_{\mathrm{el}}$ ). The unitary specific cost for PTC is $381 € / \mathrm{m}^{2}$, which together with the ORC represent $58 \%$ of the total capital costs.

With respect to the reference system, yearly total savings are quantified in $3960 €$. With such conditions and in 
order to achieve a Return of Investment (ROI) of 20 years, the overall investment costs of the system should be $79.2 \mathrm{k} €$.

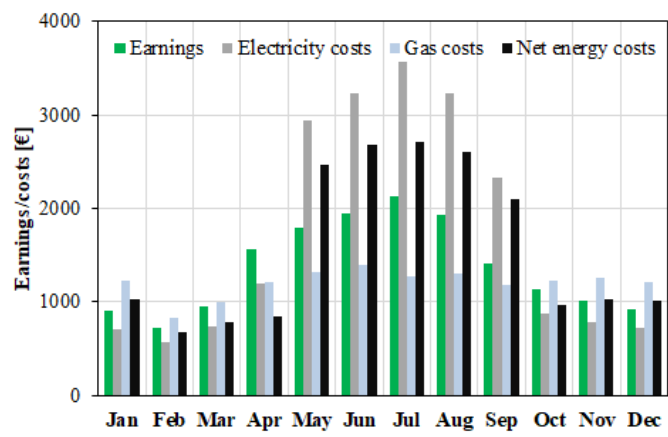

Fig. 7: Monthly earning and energy costs.

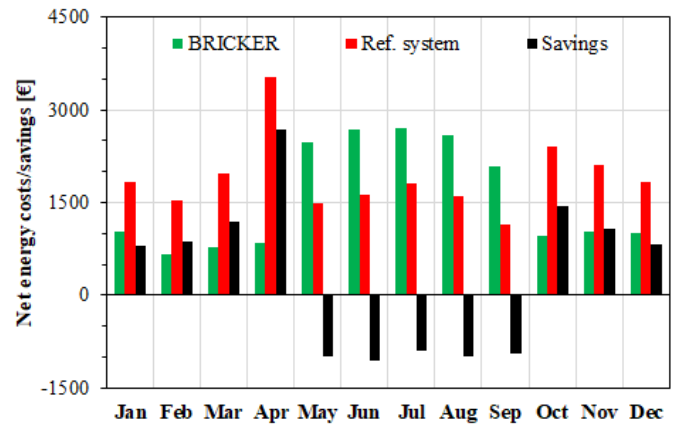

Fig. 8: Monthly energy savings of the CCHP system compared with a reference system.

\subsection{Parametric analysis}

A parametric analysis is carried out to investigate the dependency of system performance to a variation of some key parameters. For the sake of brevity, only a selection of the evaluated cases are here presented.

The first analysis focuses on the PTC field. The number of collector in each row is varied in order to understand the impact of the solar energy input on the yearly system performance. In the initial layout, 4 strings with 5 collectors each are considered. Here, the cases with 3 (15 collectors) and 5 ( 25 collectors) strings of 5 collectors each is further evaluated. In terms of yearly outputs, increasing the overall number of PTCs leads to a higher heating production in winter, whereas cooling production and electricity generation remain nearly the same (Figure 9). Consequently, energy provided by gas reduces $36.7 \mathrm{kWh} / \mathrm{m}^{2}$ PTC. The solar fraction goes from a minimum of $62 \%$ to a maximum of $76 \%$. Final and primary energy savings are proportional to gas savings. The impact in terms of net energy costs is a consequence of gas savings but in specific terms is almost negligible and estimated in $1.0 € / \mathrm{m}^{2}$ PTC.
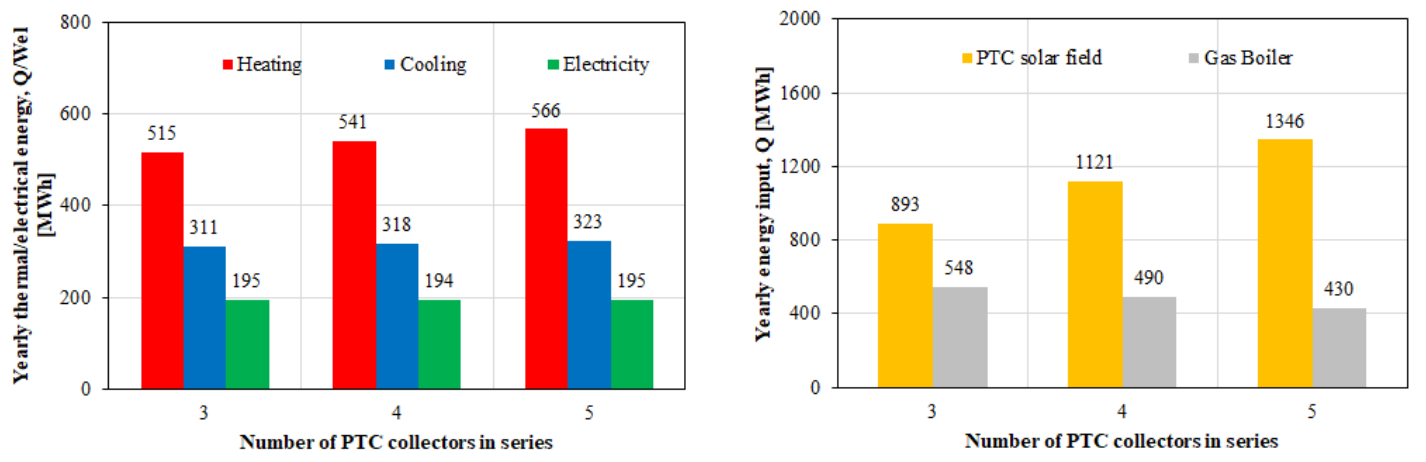

Fig. 9: Yearly thermal and electrical energy output and inputs for different solar field sizes.

In a second place, the set point temperature is varied from a value of $205^{\circ} \mathrm{C}$ to the maximum inlet oil temperature for the selected ORC unit $\left(245^{\circ} \mathrm{C}\right)$. Herein, the goal is to study the trade-off between higher set point values and consequent higher heating, cooling and electricity productions, and the higher fuel consumption. This effect is shown in Figure 10. In general, higher oil set point temperatures lead to a proportional increase in heating, cooling and electricity production, but conversely increase the gas consumption at a similar raising rate. The energy delivery from gas boiler is in average $160 \mathrm{MWh}$ for a variation of $10 \mathrm{~K}$ in the set point oil temperature, whereas the variation on solar energy input is null. Looking at the balance on electricity consumption, it can be seen from Figure 11 that higher oil set point temperatures lead to a conditions where the energy production is about twice the consumption in winter, while a complete self-consumption is almost achieved during summer. 

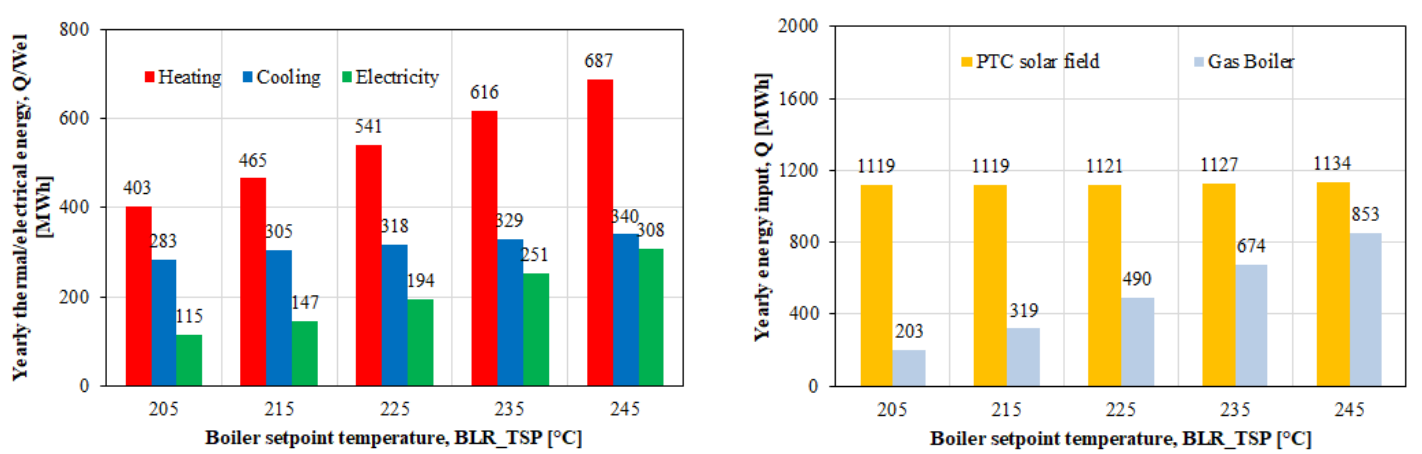

Fig. 10: Yearly thermal / electrical energy outputs and inputs for different setpoint temperature of the gas boiler.
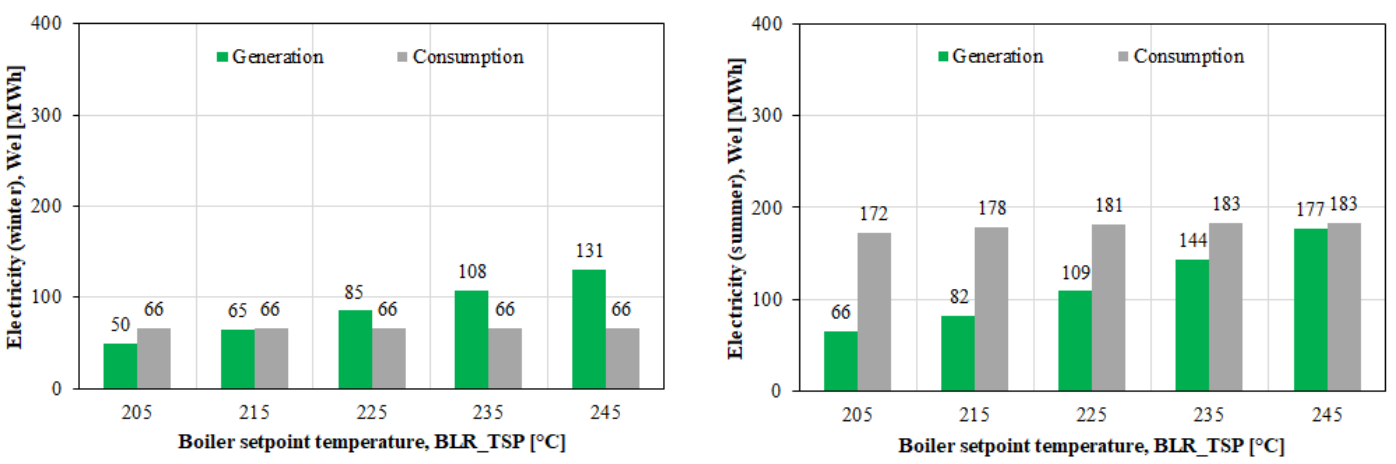

Fig. 11: Seasonal (winter - left, summer - right) electricity balance for different set point temperature of the gas boiler.

Finally, it is interesting to evaluate the performance of the system with and without the operation of the ORC unit. Without the ORC unit, the heating production is reduced by $7 \%$, while the cooling production results increased $(+19 \%)$ thanks to the higher $\mathrm{COP}_{\mathrm{th}}$ achieved in the adsorption chiller. The impact in terms of earnings and energy costs is shown below. Although the lack of the ORC allows to reduce the electricity cost of about $19 \%$, the gas consumption is increased of only $5 \%$. In global terms, the lack of earnings from electricity generation increases the energy costs of $62 \%$ with respect to the case with ORC.

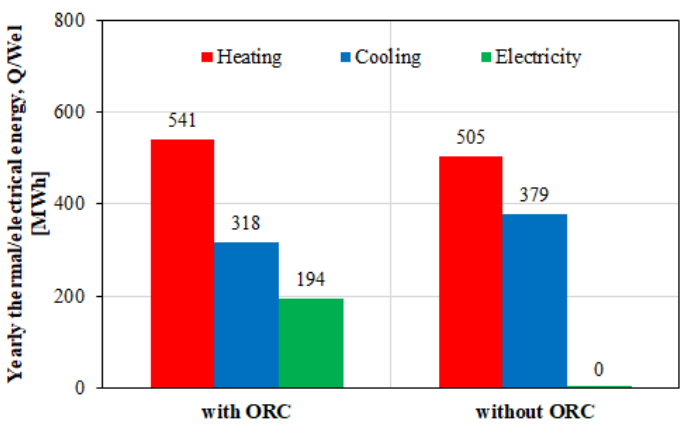

Fig. 12: Yearly energy outputs (heating, cooling and electricity) of the system with and without the ORC unit.

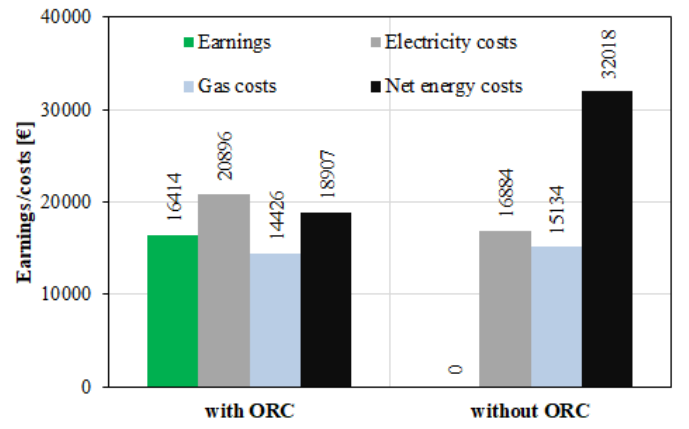

Fig. 13: Yearly earning and energy costs of the system with and without the ORC unit.

The results of this parametric analysis have contributed in defining an optimized system layout, characterized by a larger PTC solar field area with an improved control strategy for pump modulation and a set point inlet temperature into ORC's evaporator of $245^{\circ} \mathrm{C}$. The heating production increases of $23 \%$, while the cooling production achieves an improvement of only $5 \%$. The electrical efficiency of the ORC unit largely improves and the electricity generation is increased of about $61 \%$. These figures have a positive impact on the net energy costs, with an overall reduction of about $36 \%$ with respect to the initial layout. The net energy savings increase from about $4000 € /$ year to $14700 € /$ year. 


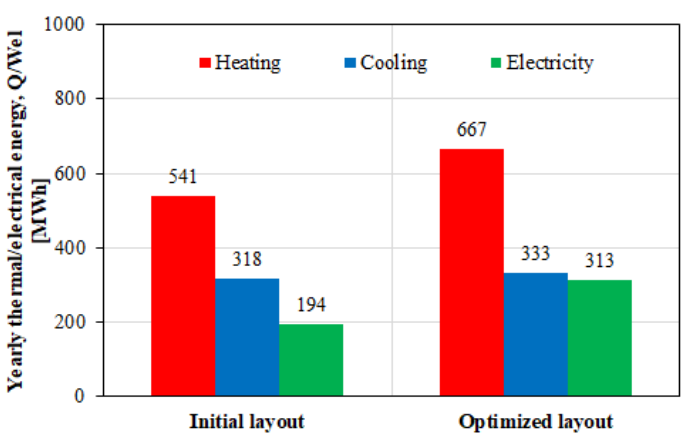

Fig. 14: Comparison of yearly energy outputs (heating, cooling and electricity) between initial and optimized layouts.

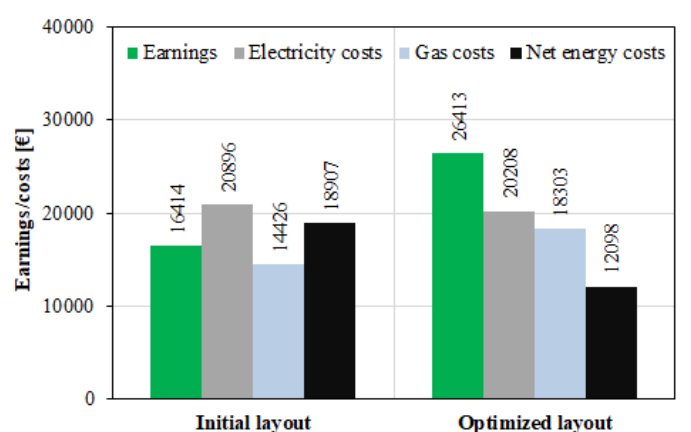

Fig. 15: Comparison of yearly earning and energy costs between initial and optimized layouts.

\section{Conclusions}

This paper has presented simulation results and economic analysis on the profitability of a small-scale CCHP system installed in the hospital of Aydin (Turkey). The CCHP system is built around a $51 \mathrm{~kW}_{\mathrm{el}} \mathrm{ORC}$ unit assisted by a $1632 \mathrm{~m}^{2}$ PTC solar field. The priority of the system is directed on the production of heating and cooling throughout the year, whereas electricity generation has a secondary relevance. The work has been conducted within the framework of the EU FP7 BRICKER project that aimed to develop new solutions for the renovation of public-owned residential buildings.

The trigeneration system covers only a fraction of the energy demand of the hospital building, since its limited capacity is not able to cover neither the heating demand in winter, nor the cooling demand in summer. The electrical output is completely self-consumed by either the CCHP system or the existing system.

The yearly amount of heating provided by the trigeneration systems per $\mathrm{kW}$ of installed solar thermal capacity is $0.54 \mathrm{MWh} / \mathrm{kW}_{\text {sol, }}$, while the total cooling energy generation amounts to $0.32 \mathrm{MWh} / \mathrm{kW}_{\text {sol }}$. The electric energy generated by the system during an annual operation period is $0.19 \mathrm{MWh} / \mathrm{kW}_{\text {sol }}$, while final electricity and gas energies are $0.25 \mathrm{MWh} / \mathrm{kW}_{\text {sol }}$ and $0.57 \mathrm{MWh} / \mathrm{kW}_{\text {sol }}$, respectively.

Since the gas boiler is in series to the PTC field and no thermal energy storage is included, the working hours of the CCHP system are strictly dependent on weather condition and cannot fulfil any variable energy demand. Because of this, such CCHP system is particularly suitable for applications where the energy demand is much larger than the trigeneration system capacity, such as large tertiary and commercial buildings or District Heating and Cooling networks preferably working at low or neutral temperatures.

Actual Turkish gas and electricity tariffs are used to calculate the net energy cost related to system operation. This calculation results in a specific space heating cost of $11.7 € / \mathrm{MWh}$ and a cooling specific cost of $39.6 € / \mathrm{MWh}$. The total initial investment cost is estimated around $1.42 \mathrm{M} €$, while yearly energy savings obtained by cogenerating energy through this small-scale system with respect to a reference system are limited to approximately $4000 €$. An optimized design of the CCHP is derived from the parametric analysis on key system parameters. Although the energy savings increase to $14700 €$ /year, the attractiveness of the system is still limited.

From a technological perspective, the replication of the system has to deal with a deep standardization of the CCHP layout. The efficiency of the ORC is limited by the small-scale of the unit. Compared to the ORC units available on the market with sizes in the order of $1 \mathrm{MW}_{\mathrm{el}}$, the efficiency in electricity generation mode of the prototype here considered is half.

Looking at economic conditions, speculative approaches prioritizing electricity generation in place of thermal energy outputs, should be carefully considered. From a simplified analysis, a preliminary conclusion is that they can be only partly justified (1) through solar energy resource exploitation, (2) for larger capacity installations and (3) for high electricity and gas tariffs. Future works will investigate closer such aspects in quantitative terms. 


\section{Acknowledgement}

The result presented in this paper is part of the BRICKER project (www.bricker-project.com). This project has received funding from the European Union's Seventh Framework Programme for research, technological development and demonstration under grant agreement No 609071. The information reflects only the author's view and the Commission is not responsible for any use that may be made of the information it contains.

\section{References}

REN21, 2016. Renewables 2015 Global Status Repot, Paris: REN21 Secretariat.

Jradi, M., Riffat, S., 2014. Tri-generation systems: Energy policies, prime movers, cooling technologies, configurations and operation strategies. Renewable and Sustainable Energy Reviews 32, 396-415.

EU FP7 BRICKER, 2013. Total Renovation Strategies for Energy Reduction in Public Building Stock. Grant agreement no: 609071. Webpage: www.bricker-project.com

EU H2020 FLEXYNETS, 2015. Fifth generation, Low temperature, high EXergY district heating and cooling NETworkS. Grant agreement no: 649820. Webpage: www.flexynets.eu

Buonomano, A., Calise, F., Ferruzi, G., Vanoli, L., 2014. A novel renewable polygeneration system for hospital buildings: Design, simulation and thermo-economic optimization. Applied Thermal Engineering 67, 43-60.

Klein S.A. et al, 2010, TRNSYS 17: A Transient System Simulation Program, Solar Energy Laboratory, University of Wisconsin, Madison, USA, http://sel.me.wisc.edu/trnsys

Velez, F., Segovia, J.J., Martin., M.C., Antolin, G., Chejne, F., Quijano, A., 2012. A technical, economical and market review of organic rankine cycles for the conversion of low-grade heat for power generation. Renewable and Sustainable Energy Reviews 16, 4175-4189.

Tchanche, B.F., Lambrinos, G., Frangoudakis, A., Papadakis, G., 2011. Low-grade heat conversion into power using organic Rankine cycles - A review of various applications. Renewable and Sustainable Energy Reviews 15, 3963-3979. 


\title{
Thermochemical district networks
}

\section{Claudio Koller ${ }^{1}$, Serena Danesi ${ }^{1}$ and Thomas Bergmann ${ }^{1}$}

\author{
${ }^{1}$ Institute of Energy Systems and Fluid Engineering / Zurich University of Applied Science, Winterthur
}

(Switzerland)

\begin{abstract}
Thermo-chemical networks are a new technology for district networks, which can provide heating, cooling and drying in one heat loss-free multiservice network. The innovation is the use of thermo-chemical fluids as transport medium, e.g. in the form of concentrated salt solutions, rather than water. Due to the hygroscopic characteristics of the salt solutions, a chemical potential is transported and not thermal energy as in conventional networks. The chemical potential is used to generate useful heat or cold from ambient heat at the place and time of demand or to dehumidify air for drying or air conditioning processes. An important advantage of this novel technology is that the technology is heat loss-free, which means the thermochemical potential stored in the fluids degrade neither in the piping infrastructures nor in storages. In comparison to conventional district heating networks, thermo-chemical networks can be realized with less investment (no insulation is required) and over longer distances (no heat losses occur). The aspect of heat loss-free storage is also interesting for applications of seasonal thermal storage. In particular with solar energy, allowing shifting the energy available in summer to the wintertime. Thermo-chemical district networks and the possibility of long-term storages will improve the efficiency and profitability of the use of solar energy in district heating networks. The demonstrators, realised in Canton Zurich, are part of the project "HDisNet" funded by the European Program Horizon2020 (Agreement No. 695780).
\end{abstract}

Keywords: thermochemical network, liquid desiccant, syn- disproportion, absorption, desorption, anergy, exergy, chemical potential

\section{Introduction}

The statement of the first law of thermodynamics initiated a debate which continues till today - energy cannot be created nor destroyed. This statement does not mention the quality and form of energy, which is then part of the second law of thermodynamics. The conversion of energy requires a state of non-equilibrium (potential difference). Another aspect for the energy is also the availability at the right place and time. The energy storage became more important due to the increase demand of renewable energy.

In the last years, the district heating networks became more popular especially in densely populated areas. Heat losses during the transport are generally accepted up to $20 \%$, whereby the losses can be reduced depending on the consumer density (local component) (Jenni, 2013 [1]).

Thermochemical networks can be an alternative to conventional district heat networks. They can also be integrated in conventional district heating network. They transport a chemical potential, e.g. in the form of concentrated salt solutions instead of thermal energy in form of hot/warm water. This chemical potential can be transported over long distances as well as stored for long time without losses (of course energy is required for the transport). Thermochemical networks can also be used to recover excess heat that cannot be economically used with conventional systems. Another advantage of thermochemical networks is the high energy density of the transport medium. Approximately ten times higher than in conventional systems (Gaegauf, 2016 [2]). 


\section{Fundamentals of heat transformation}

To raise a material flow from a lower to a higher temperature, another one has to balance out the reduction of entropy. Heat transformation is given, if the reduction of one potential (temperature) is raising another potential. Such heat transformation processes can be classified into syn- and disproportionation (Hebcker, 2000 [3]). Figure 1 shows examples of synproportion processes, such as the absorption heat pump and the compression heat pump, and of disproportion processes, such as the thermal power plant and the heat transformer.

If mechanical work and electrical energy are interpreted as heat of infinite temperature, the electrical drive of a compression heat pump or the mechanical work of a turbine can be integrated into this approach.

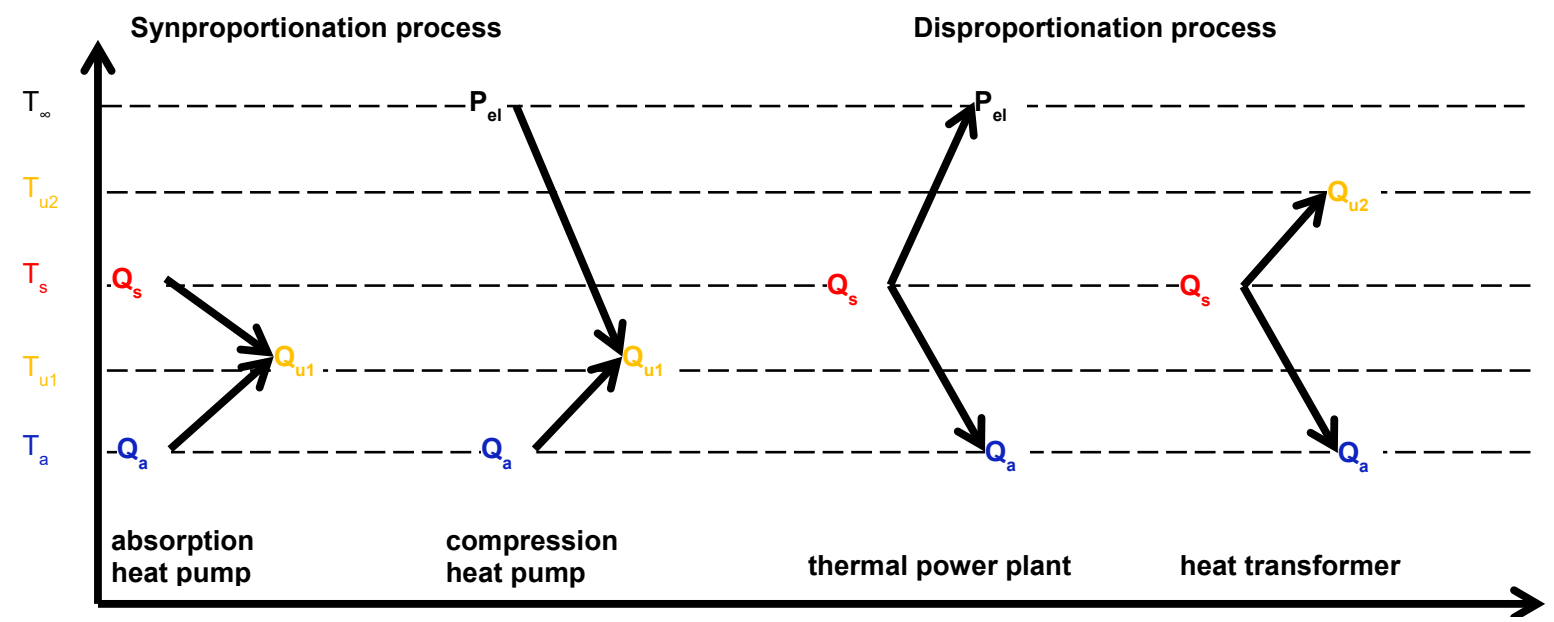

Figure 1: Different energy transformation processes. Parameter for : Tu/Qu users ; Ts/Qs source ; Ta/Qa ambient

Figure 2 shows an absorption heat pump process (synproportion). This process can be divided in to two partial processes (fig. 3): synproportion process (consumer of the chemical potential) and disproportionation process (producer of the chemical potential). The synproportion process combines low-temperature heat and exergy (chemical potential) to produce useable heat at a higher temperature. The disproportion process generates exergy by converting heat from high temperature to low temperature heat. A thermo-chemical network can be considered as an absorption heat pump process (or, as a heat transformer if the pressure levels are reversed). (fig. 4)
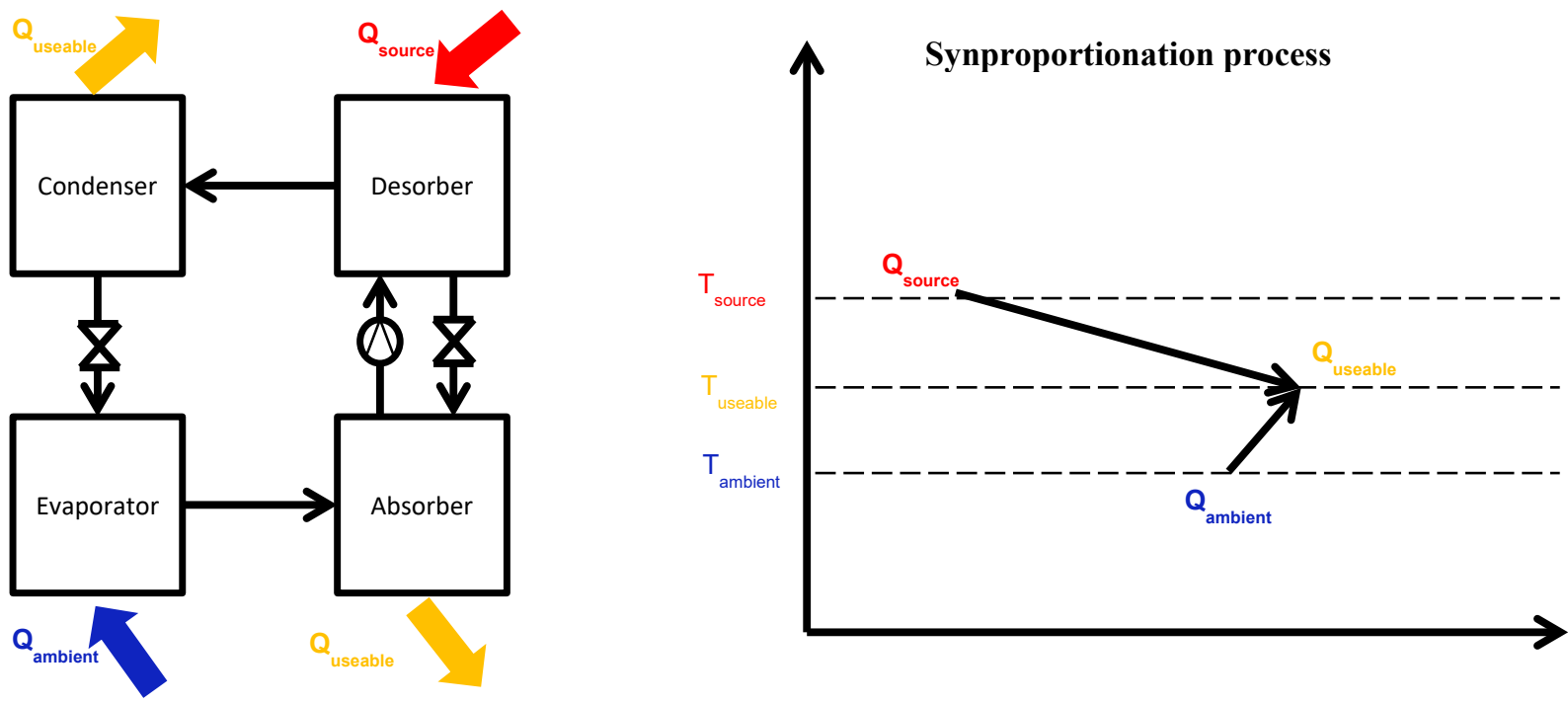

Figure 2: Simplified process of an absorption heat pump

The producers of the chemical potential (source) in the thermochemical network are the sub-system desorbercondenser (transformation of heat into chemical potential) and the generators of useful heat (users) are the sub-system evaporator-absorber (transformation of chemical potential into heat). Many applications can utilise this concept.

\section{Applications in thermochemical networks}




\section{Generation of chemical potential in an open process:}

If excess heat is available at a low temperature level (above approx. $50^{\circ} \mathrm{C}$ ), desorption can be realised as an evaporation process. The condensation heat cannot be used and is transferred to the environment as anergy. Instead of using process excess heat, this process can also be driven by solar thermal energy or excess electrical energy from renewable energy sources (PV, wind).

\section{Generation of chemical potential in a closed process:}

In a close system, the salt solution is regenerated by evaporation of a part of its water (pure water vapour is produced, no humid air). Heat is then released with the subsequent condensation of the water vapour. In the desorption process, a temperature above $100^{\circ} \mathrm{C}$ is required (at atmospheric pressure). In a close system, unlike the open desorption, no thermal energy is required to concentrate the salt solution, since the heat supplied to the desorber is then almost completely recovered in the condenser: the temperature difference between heat utilisation (warm-water circuit temperature) and the available heat is used. An application for a close system could be realized in motor-driven cogeneration unit (CHP), since the exhaust gas normally has a temperature of approx. $500^{\circ} \mathrm{C}$ and the warm-water circuit usually is operating at a temperature of approx. $90^{\circ} \mathrm{C}$.
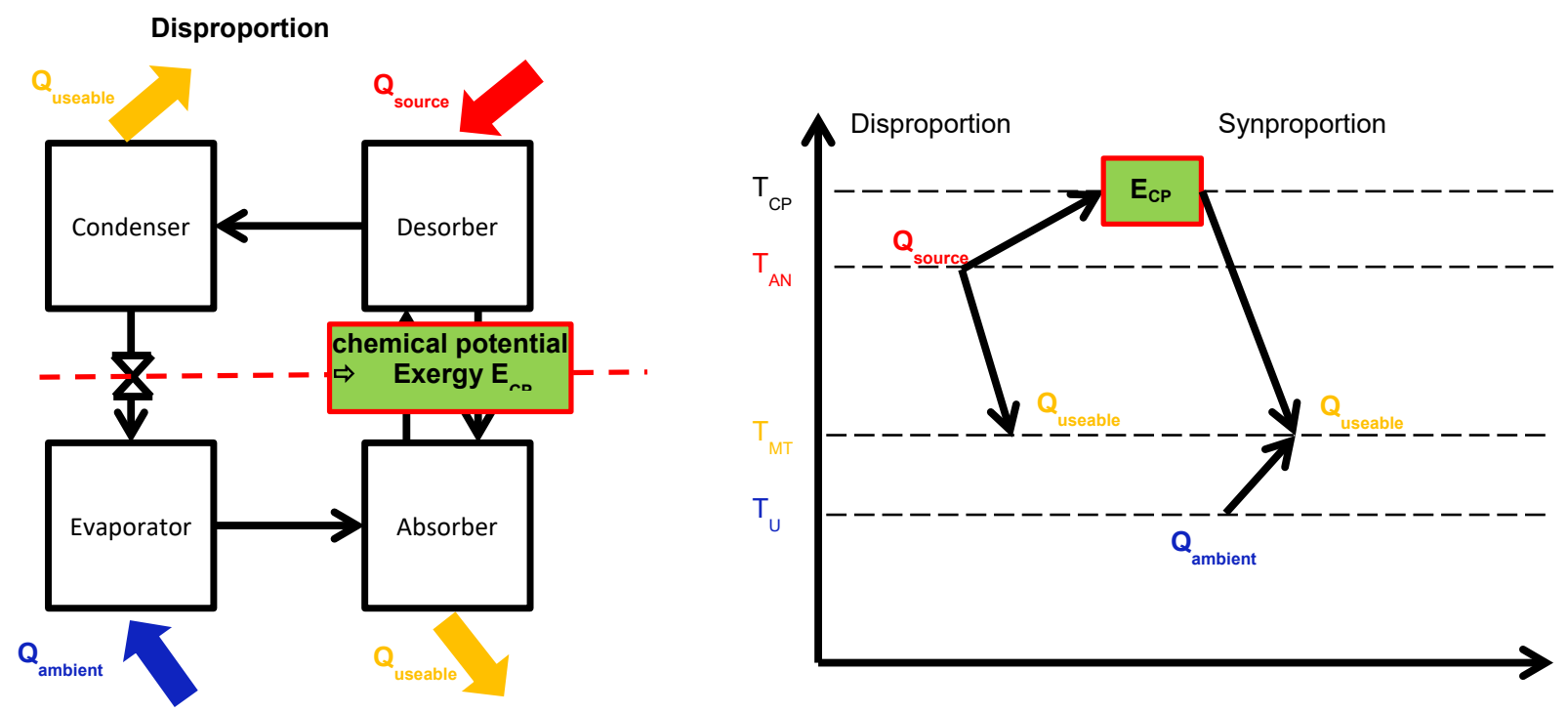

Synproportion

Figure 3: Dis- and synproportion process in a absorption heat pump

\section{Use of chemical potential in open process:}

Open sorption processes are a good alternative to support air conditioning systems (e.g. DEC systems: Dessicative and Evaporative Cooling) (Hebecker, 1988; Dai, 2006; Kessling, 1997 [4, 5, 6]). They have a good energy efficiency but require a simultaneous regeneration of the desiccant which can be difficult to realize. This disadvantage can be eliminated by combining the system into a thermo-chemical network. The possibility of accurate air conditioning (temperature and humidity) through an open sorption process is, in addition to building-air-conditioning, particularly interesting for special applications where the air conditions must be strictly adhered. Examples include greenhouses, museums, archives and laboratories. An open absorption process can also be used in industrial drying processes (e.g. low-temperature drying of spices to protect the aromas). The exhaust air leaving the dryer is dehumidified in an absorption scrubber and simultaneously heated by the heat released during absorption. Such a drying process could theoretically be operated energy self-sufficient, i.e. without the supply of additional heat energy.

Open sorption processes are also used to recover excess heat in industrial processes increasing the condensation temperature of combustion gases (Danesi, 2015; Weber, 2008 [7, 8]). 


\section{Use of chemical potential in closed process:}

The possibility of loss-free storage makes thermo-chemical fluids a promising opportunity for seasonal heat storages in solar-heated buildings. Sodium hydroxide solution is recommended as a suitable storage medium in various publications (Weber, 2008; Hui, 2008; Goetz, 2001; [9, 10, 11]), but cannot be used in open processes: the reaction of sodium hydroxide with the carbon dioxide of the air forms a poorly soluble sodium carbonate, which precipitates in solid form during cooling processes and therefore clog pipes and plant components. The plant components for regeneration (desorber-condenser) as well as those for utilisation of the chemical potential (evaporator-absorber) shall operate at a negative pressure specified by the temperature level (vapour pressure of the water). However, the transport and storage of the fluid can be decoupled and can operate at atmospheric pressure allowing the integration to the network (the decoupling can be realised e.g. using a hydrostatic height difference to the storage tank/pipeline of the network).

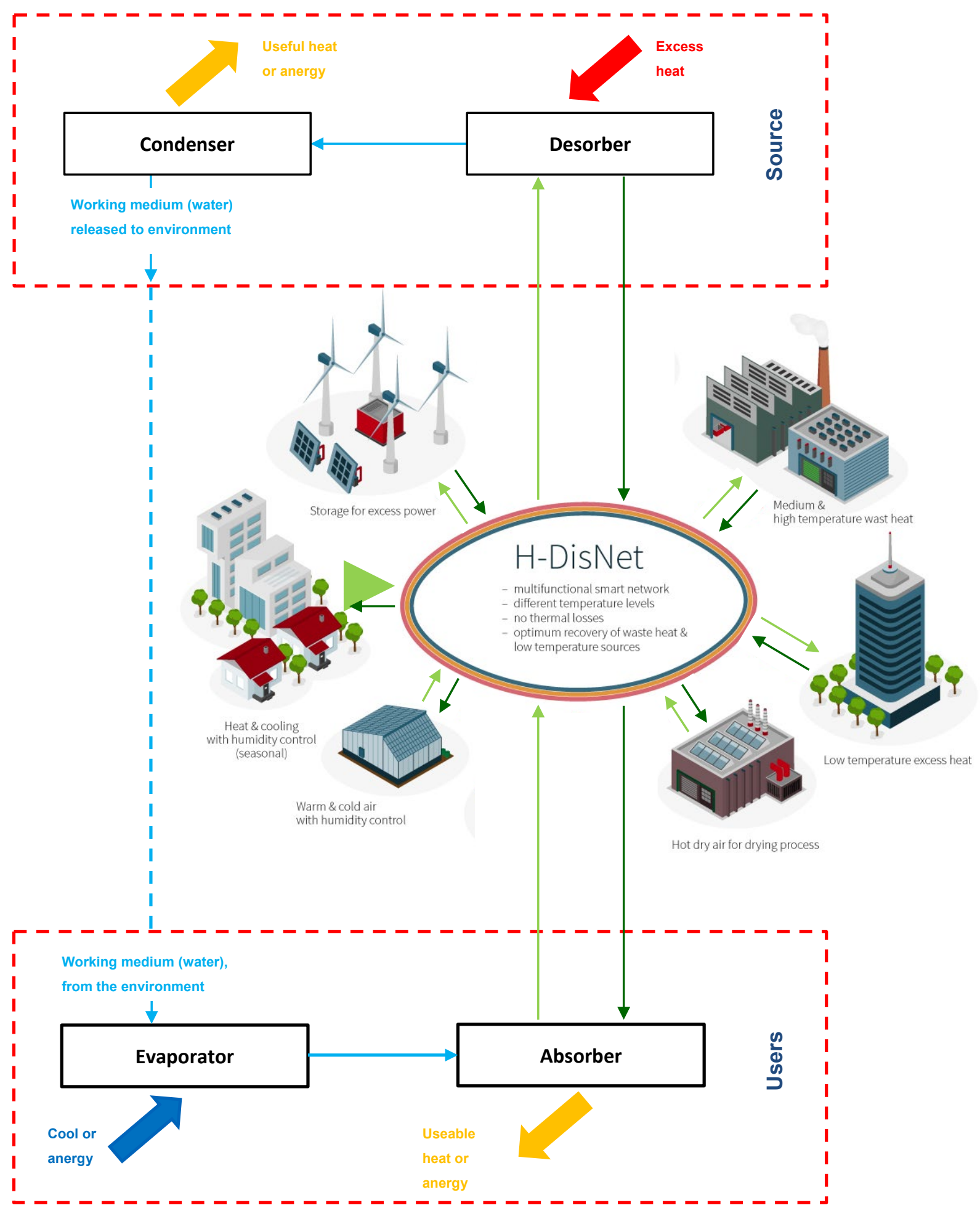

Figure 4: Thermo-chemical network 


\section{Thermo-chemical fluids}

Only water-based fluids are considered in this paper. Different groups of substances such as salts, alkalis, acids, organic compounds and ionic liquids can be used as absorbents (Bittrich, 2001; [12]).

In addition to thermodynamic properties, the following criteria must be considered for the selection of the thermoschemical fluid:

Availability / Price

Environmental compatibility / Recyclability / Toxicity

Chemical stability

Aspects of secondary importance in stand-alone application such as absorption chillers (price, availability, toxicity) can have a huge impact in thermo-chemical networks which requires a massive volume of these fluids. As a result of these circumstances, the following fluids were investigated as transport fluid in thermo-chemical networks:

Table 1: Selection of different desiccant

\begin{tabular}{|l|l|}
\hline \multicolumn{1}{|c|}{ Desiccant } & \multicolumn{1}{c|}{ Comments } \\
\hline Lithium bromide $(\mathrm{LiBr})$ & $\begin{array}{l}\text { common in absorption plants (chillers), but not suitable in thermo- } \\
\text { chemical network due to the high price. Used as reference }\end{array}$ \\
\hline Lithium chloride $(\mathrm{LiCl})$ & $\begin{array}{l}\text { common in dehumidification systems, but not suitable in thermo- } \\
\text { chemical network due to the high price. Used as reference }\end{array}$ \\
\hline Calcium chloride $\left(\mathrm{CaCl}_{2}\right)$ & High efficiency \\
\hline Magnesium chloride $\left(\mathrm{MgCl}_{2}\right)$ & High efficiency \\
\hline Calcium nitrate $\mathrm{Ca}\left(\mathrm{NO}_{3}\right)_{2}$ & $\begin{array}{l}\text { Not corrosive. Low efficiency at low temperatures and high efficiency at } \\
\text { high temperatures. }\end{array}$ \\
\hline Sodium hydroxide $(\mathrm{NaOH})$ & Very high efficiency. Not suitable in open processes. \\
\hline
\end{tabular}

Coefficients have been defined to describe the properties of interest for thermo-chemical networks in the entire range of solubility as function of mass fraction of the absorbent $(\xi)$ and the temperature $(T)$. The following substance properties were considered:

Table 2: Desiccant properties

\begin{tabular}{|l|l|l|l|}
\hline Solubility & $\mathrm{T}^{\mathrm{SL}}(\xi)$ & Density & $\rho(\xi, \mathrm{T})$ \\
\hline Phase equilibrium & $\mathbf{p}^{\mathrm{LV}}(\xi, \mathrm{T}) / \mathrm{T}^{\mathrm{LV}}(\xi, \mathrm{p})$ & Dynamic viscosity & $\eta(\xi, \mathrm{T})$ \\
\hline & & & \\
\hline Specific enthalpy & $\mathrm{h}(\xi, \mathrm{T})$ & Thermal conductivity & $\lambda(\xi, \mathrm{T})$ \\
\hline & & Surface tension & $\delta(\xi, \mathrm{T})$ \\
\hline
\end{tabular}

An open-access database has been created for the aqueous solutions of the salts in table 2 and is available on the website $^{1}$ of the Institute of Energy Systems and Fluid Dynamics (IEFE) of the Zurich University of Applied Sciences $(\mathrm{ZHAW})$. The database provides material data functions for Excel $^{\mathrm{TM}}$ and Matlab ${ }^{\mathrm{TM}}$.

The diagram of the phase equilibrium $(\log (\mathrm{p})-1 / \mathrm{T})$ (fig. 5) reports the crystallisation line as function of temperature and vapour pressure. Furthermore, the humidity of the air is plotted. The diagram is a valid instrument for the selection of fluid for specific applications.

For example, in an open sorption process with the calcium nitrate absorbent it is not possible to achieve a relative humidity less than $50 \%$ at a temperature of $20^{\circ} \mathrm{C}$, while it would be possible with the other thermo-chemical fluids. In general, the lowest temperature in the entire network limits the concentration. With the information about the aimed air quality and the tempeture of the network, the maximum and minium concentration can be determined. The

\footnotetext{
${ }^{1}$ (https://www.zhaw.ch/de/engineering/institute-zentren/iefe/energiespeicher-und-netze/thermische-speicher/)
} 
transport quantity is defined according to the network and process boundaries conditions.

The density and viscosity determinate the energy required for the transport. A high concentration difference between supply and return line means a high energy density and therefore a small fluid quantity has to be transported. Considering the viscosity, which increases as a function of the concentration, a high concentration can be detrimental, because the energy required for the transport is increasing also.

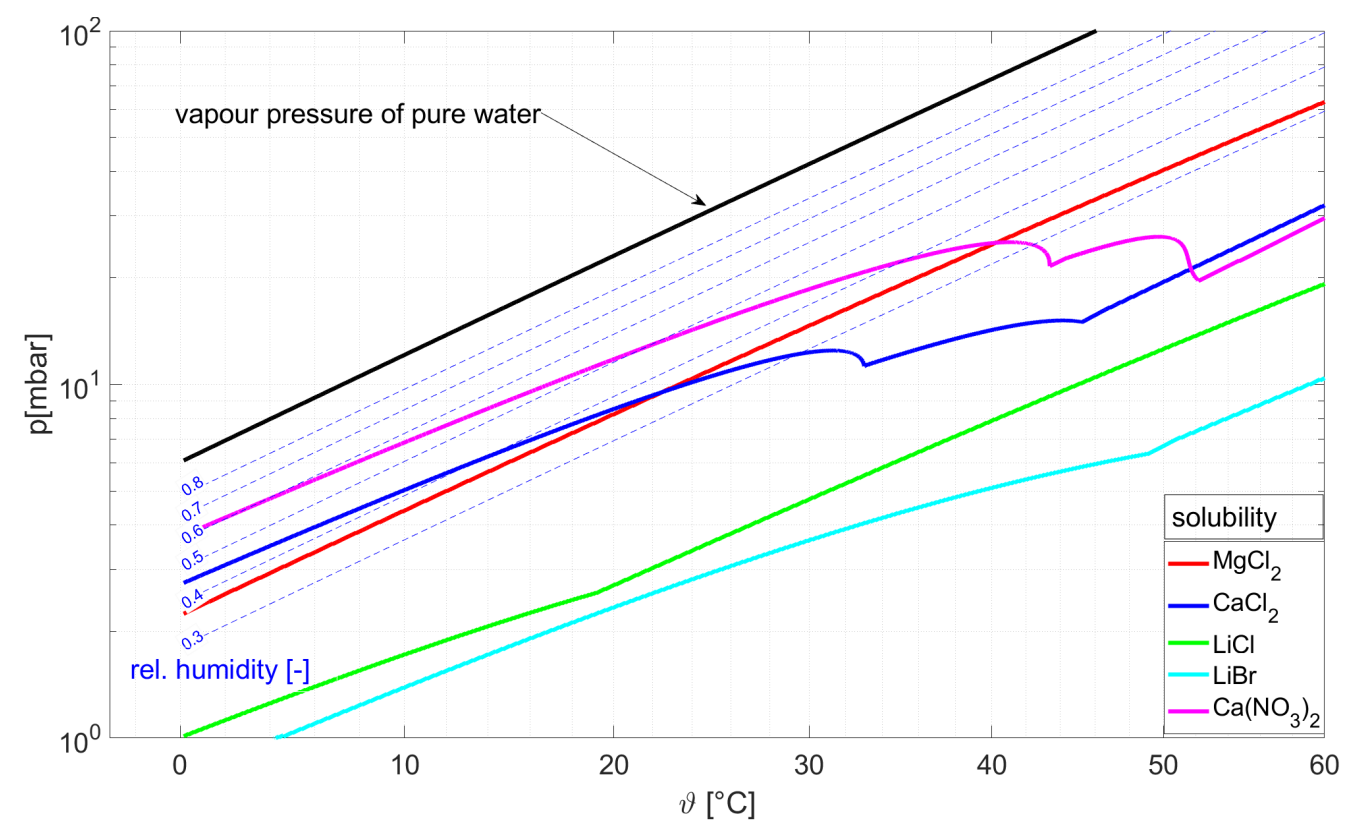

Figure 5: Different desiccant and their solubility boundaries within the $\log (p)-1 / T-$ diagram

The efficiency of the system ("energy storage density" of the transport medium) is given by the caloric material properties, while the parameters for the design of the ab-/desorber are the thermal conductivity, surface tension and diffusion coefficients.

\section{Characteristic Numbers}

The usable heat $(\Delta \mathrm{H})$ of the network is defined through the mass balance between the concentrated and diluted solution, since the difference is proportionally to the absorbed water $\left(\Delta \mathrm{m}_{\mathrm{w}}\right)$. In relation to the mass of the concentrated solution $\left(m_{s o l, 1}\right)$ a mass specific "energy density" $\left(\mathbf{k}_{\mathbf{E}}\right)$ is given.

$$
\mathbf{k}_{\mathbf{E}}=\frac{\Delta H}{m_{s o l, 1}}=\frac{\Delta m_{w} \Delta h_{v}}{m_{s o l, 1}}=\frac{\xi_{2}-\xi_{1}}{\xi_{2}} \Delta h_{v}
$$

The formula (1) is valid for an isothermal process, mixing effects were neglected.

The heat of vaporization $\left(\Delta \mathrm{h}_{\mathrm{v}}\right)$ can be assumed as constant within the temperature range of application. Therefore, the dimensionless number $\left(\mathbf{k}_{\mathbf{e}}\right)$ can be defined:

$$
\mathbf{k}_{\mathbf{e}}=\frac{k_{E}}{\Delta h_{v}}=1-\frac{\xi_{1}}{\xi_{2}}
$$

The kinematic viscosity $v$ (dynamic viscosity divided by density) is a function of temperature and concentration and can be used as a reference for energy required for the transport $\left(\mathbf{k}_{\mathbf{T}}\right)$.

$$
\mathbf{k}_{\mathbf{T}}=v=\frac{\eta}{\rho}
$$




\section{Demonstrator}

The absorption process will be tested as air conditioning system in the Horizon2020 project H-DisNet. A demonstrator is installed in Switzerland in a greenhouse (approx. $600 \mathrm{~m}^{2}$ ), owned by Meyer Orchideen AG. Here a new air distribution system will be also tested. The conditioned air is injected direct under the plant tables. The advantage of this new air distribution system is that only the air around the plants is heated or cooled and not the air of the entire greenhouse. A considerable energy saving is expected, which will be validated during the project. Orchids are cultivated in different growth phases, which require different climatic conditions (leaf growth approx. $30^{\circ} \mathrm{C}$ and flower formation approx. $20^{\circ} \mathrm{C}$ at $65 \%$ humidity each). The energy balance over one year shows a positive energy demand (heat). However, on warm days with high solar radiation, heat must be dissipated. Based on measurements in the greenhouse, a heating and cooling load of $75 \mathrm{~kW}$ was determined.

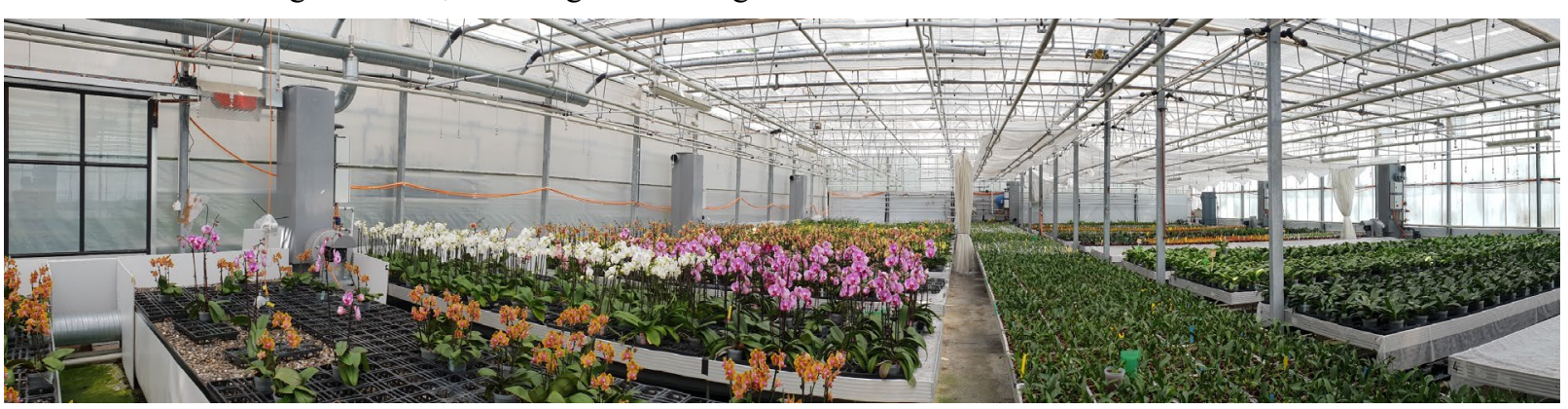

Figure 6: Application in the greenhouse

\section{Air-conditioning}

The absorbers are counter-flow with random packings. The air is simultaneously tempered (cooled or heated) and humidified or dehumidified by a hygroscopic salt solution. The temperature $\vartheta_{Z}$ and the humidity $\varphi_{Z}$ of the conditioned air (point 2 in figure 7 and figure 8 ) can be set exactly through the temperature $\vartheta_{\mathrm{L}}$ and the salt concentration $\xi_{\mathrm{L}}$ of the solution, because the thermodynamic equilibrium is nearly reached at the top of the absorber.

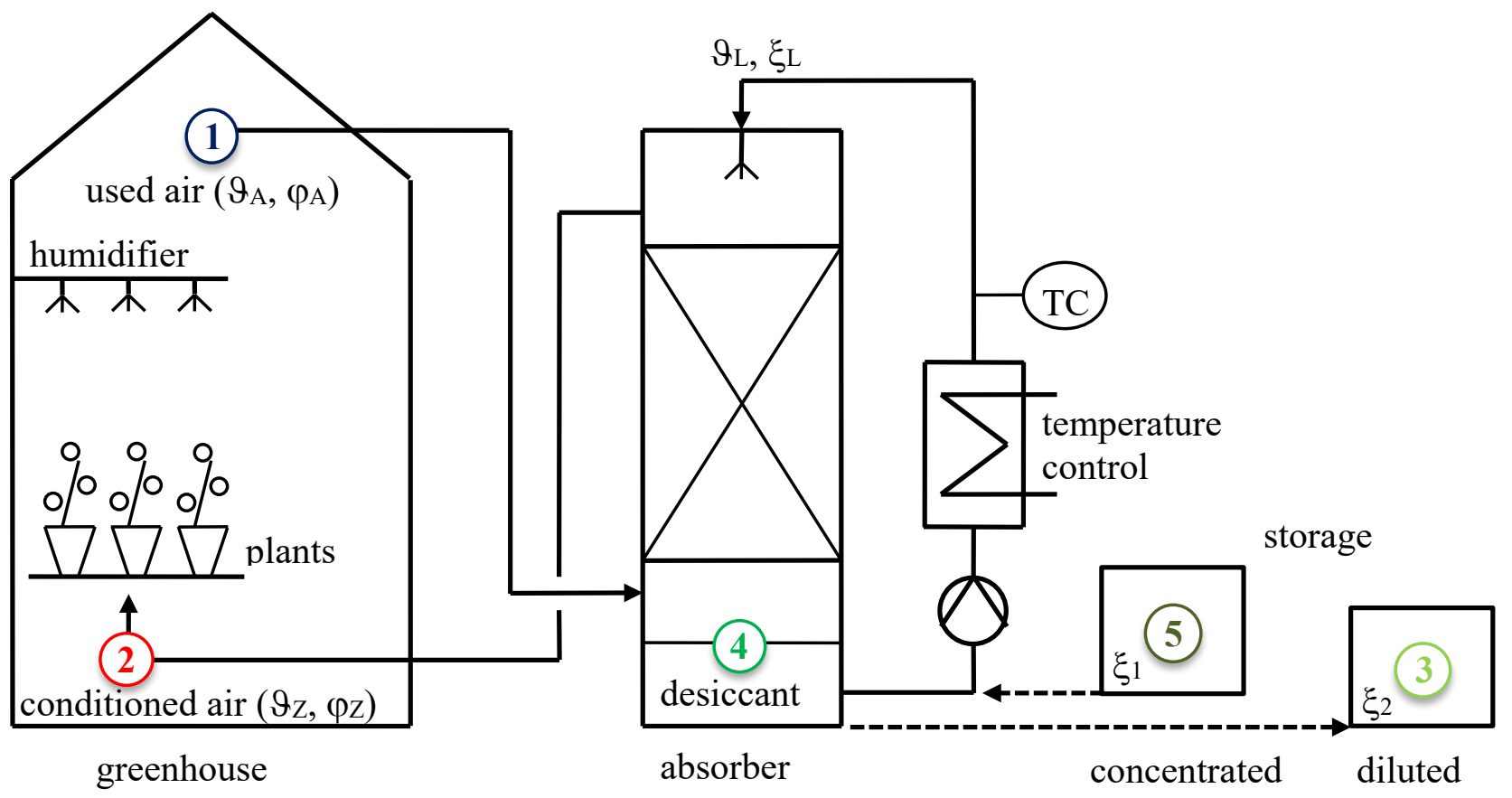

Figure 7: climate-concept within the greenhouse

An exact climate condition can be realised with minimum technical effort. The absorption process for cooling in the greenhouse is illustrated in the $\log (\mathrm{p})-1 / \mathrm{T}$ diagram with calcium chloride as working fluid (figure 8). The measurements have been carried on in laboratory for an absorption scrubber. They show a maximum deviation of 
the conditioned air (point 2) from the desired target value (phase equilibrium) of $\pm 1 \mathrm{~K}$ and $\pm 5 \%$ relative humidity.

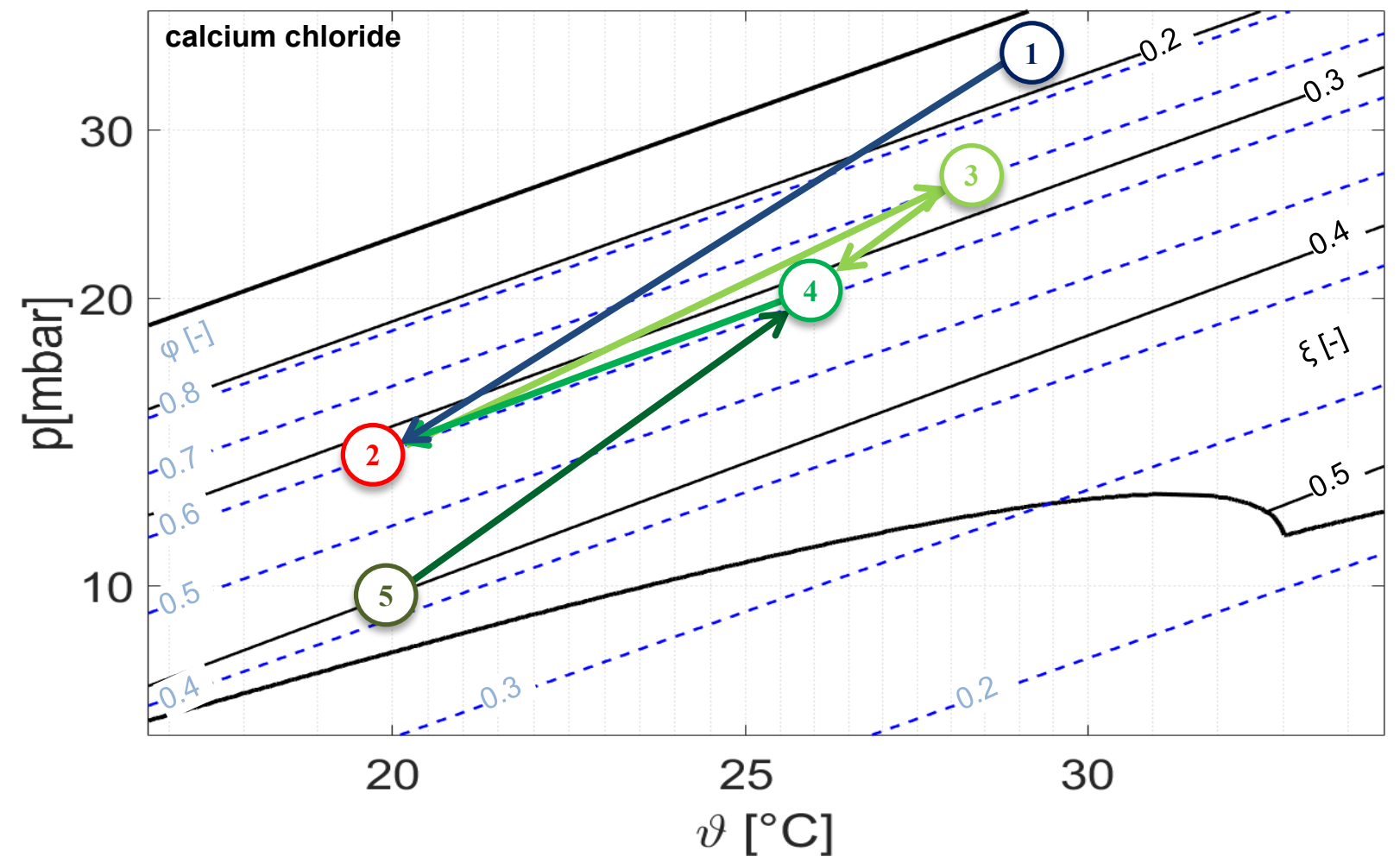

Figure 8: climate process in the greenhouse (cool load)

The tolerance range of the optimum growth conditions of the plants are $\pm 2.5 \mathrm{~K}$ and $\pm 15 \%$ relative humidity.

The analysis shows that $\mathrm{CaCl}_{2}$ and $\mathrm{MgCl}_{2}$ have different characteristic numbers, even though they share the same difference in concentration. This is a result to the different position $\left(\xi_{2}\right)$ of the diluted solution in the solution field. For a high benefit/effort ratio, the position of the diluted solution is much more important than the difference in concentration. Since these properties are in no way linear, each process must be considered and evaluated separately.

Table3: Assessment of the working materials using the greenhouse as an example of application

\begin{tabular}{|c|c|c|c|c|c|}
\hline Salt solution & $\xi_{\mathbf{1}}[-]$ & $\xi_{2}[-]$ & $\mathbf{k}_{\mathbf{E}}[\mathbf{k J} / \mathbf{k g}]$ & $\mathbf{k}_{\mathbf{e}}[-]$ & $\mathbf{k}_{\mathbf{T}}\left[\mathbf{m m} \mathbf{m}^{2} / \mathbf{s}\right]$ \\
\hline Lithium bromide $(\mathrm{LiBr})$ & 0.59 & 0.30 & 2450 & 1.00 & 2.2 \\
\hline Lithium chloride $(\mathrm{LiCl})$ & 0.43 & 0.19 & 3062 & 1.25 & 5.6 \\
\hline Calcium chloride $\left(\mathrm{CaCl}_{2}\right)$ & 0.40 & 0.28 & 1470 & 0.42 & 6.7 \\
\hline Magnesium chloride $\left(\mathrm{MgCl}_{2}\right)$ & 0.35 & 0.23 & 1283 & 0.52 & 9.1 \\
\hline Calcium nitrate $\mathrm{Ca}\left(\mathrm{NO}_{3}\right)_{2}$ & 0.53 & 0.45 & 544 & 0.18 & 7.1 \\
\hline
\end{tabular}

\section{Conclusions}

The technology is already under test in the greenhouse which is the Swiss demonstrator of the H-DisNet project. The plan is to extend the demonstrator in future projects with a fully automatic control system and with the integration in a small district network.

The absorption technology is also very promising for other application as for example in drying process in food industry and for the climatization of museums and historic archives, where self-sufficient systems can be designed using renewable energy or excess heat as driving source for the regeneration.

\section{References}

[1] Thalmann, S., Nusssbaumer, Th., Jenni, A., 2013. Analyse und Optimierung von Fernwärmenetzen. 
Bundesamt für Energie.

[2] Gaegauf, Ch., et al., 2016. SPEQUA - Thermische und elektrische Speicher in Gebäuden und Quartieren. Bundesamt für Energie.

[3] Hebecker, D., 2000. Technische Möglichkeiten der Wärmetransformation in: Strategien zur Abfallenergieverwertung - ein Beitrag zur Entropiewirtschaft, Hrsg. Fratzscher, W.; Stephan, K.,Verlag Vieweg, S. 59 - 71

[4] Hebecker, D., 1988. Energietransformation. Wiss. Zeitschr. THLM 30 S.495-508

[5] Mei, L., Dai, Y.J., 2006. A technical review on use of liquid-desiccant dehumification for air-conditioning application. Renewable \& sustainable energy reviews.

[6] Kessling, W., 1997. Luftentfeuchtung und Energieseicherung mit Salzlösungen in offenen Systemen. Fortschrittberichte VDI. Reihe 3: Verfahrenstechnik, Nr. 509

[7] Bittrich, P., Hebecker, D., Bergmann, Th., 1997. Entwicklung eines Hochtemperatur-Brennwert-kessels, VDI Bericht 1321 Fortschrittliche Energiewandlung und -anwendung Bd. I, S. 327-340

[8] Wartig, G., Bergmann, Th., Danesi, S., 2015. Blockheizkraftwerk nutzt Hochtemperatur-Brennwerttechnik, BWK Bd. 67 Nr. 9, S. $55-57$

[9] Weber, R., et al., 2008. Saisonale Wärmespeicher mit Natronlauge (NaOH). 15.Schweizerisches StatusSeminar «Energie und Umweltforschung im Bauwesen»

[10] Hui, L. et al., 2008. Seasonal storage of solar energy for house heating by different absorption couples.

[11] Mugnier, D., Goetz, V., 2001. Energy storage comparison of sorption systems for cooling and refrigderation. Solar Energy. Vol. 71, pp. 47-55

[12] Bittrich, P., 2001. Energietransformation. Shaker Verlag

\section{Appendix: Unites and Symbols}

Table 1: Symbols

\begin{tabular}{|c|c|c|}
\hline Quantity & Symbol & Unit \\
\hline Specific enthalpy & $h$ & $\mathrm{~J} \mathrm{~kg}^{-1}$ \\
\hline Thermal conductivity & $\lambda$ & 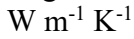 \\
\hline Mass concentration & $\xi$ & - \\
\hline Density & $\rho$ & $\mathrm{kg} \mathrm{m}^{-3}$ \\
\hline Surface tension & $\sigma$ & $\mathrm{mNm}^{-1}$ \\
\hline Heat flux & $Q$ & W \\
\hline Thermal diffusivity & $\alpha$ & $\mathrm{m}^{2} \mathrm{~s}^{-1}$ \\
\hline Dynamic Viscosity & $\eta$ & $\mathrm{Pa} \mathrm{s}$ \\
\hline Vapour pressure & $p^{L V}$ & mbar \\
\hline Mass & $M$ & $\mathrm{Kg}$ \\
\hline Kinematic viscosity & $v$ & $m^{2} s^{-1}$ \\
\hline
\end{tabular}




\title{
Distributed vs centralized solar District systems. Study case in Mediterranean districts
}

\author{
Andreu Moià-Pol ${ }^{1}$, Pere Sabater ${ }^{1}$ \\ ${ }^{1}$ University of Balearic Islands, Physics department, P. Mallorca (Spain)
}

\begin{abstract}
Balearic Islands have a few renewable energy facilities in the buildings like the rest of Spain. The combination of District Heating with solar thermal centralized and decentralized systems can provide all the thermal energy for the buildings and share the excess of energy during the summer. Solar heating in a central plant and distributed in buildings has been designed to achieve different values of the solar fraction, comparing $100 \%$ centralized system and decentralized system with the Spanish Building Code and having the higher efficiency of the system with net zero energy in thermal production.
\end{abstract}

Keywords: Solar Thermal, Photovoltaic, District Heating, Solar District

\section{Introduction}

District heating is installed in all over the world, especially in countries with higher thermal demand all the year. Solar heating has obtained increased interest all over Europe in recent years. District heating is one major approach to increase the overall energy efficiency in urban areas, either by refurbishment of existing systems or by the introduction of new systems in existing or new building establishments. On the other hand, solar heat is available practically anywhere all over Europe. A prevailing success factor of the realized plants is the involvement of local actors and policy makers with interest and knowledge to develop and demonstrate the new technologies.

The Solar thermal energy has lost installed power lately against other technologies, like photovoltaics (PV). The electricity has a better perspective, for two reasons, the simplicity of the systems and the excess could be sent to the grid. The thermal systems need not only more support from the public administration using of Large Solar Energy Centralized plants. They need as well new concepts of energy systems with decentralized systems and sell the energy with District Heating Systems, where the bigger facilities (like hotels and building residents) can buy or sell energy according to their occupancy. Mallorca has a high amount of tourist areas where the quantity of tourists during the period when there is more solar radiation makes even more interesting to create District Heating and Cooling combined with large Solar Plants, and share thermal resources between buildings. In different countries, different concepts have been developed for solar district heating. The two main variables are:

The way the solar plant is connected to the net (distributed vs centralized). Distributed solar district heating plant: The solar collectors are placed at suitable locations and connected directly to the district heating primary circuit on site. Often these plants use the district heating network as storage.

The goals of Solar Thermal System are an energy thermal reuse, the challenge of which is how to store thermal energy in the cheapest way, the threshold of power installation between solar thermal generation and green renewable generation to obtain electric power and thermal power and the known objectives basically are energy sustainability for environment purposes and energy efficiency for saving resources purposes. The size of the heat net in which the solar thermal heat is fed-in has to be optimized before installing it. It ranges from small net systems to supply a few buildings to systems destined to supply new construction areas or villages and lastly systems to be connected to large district heating nets supplying large cities. In this paper has been studied a District heating system with several scenarios from completely centralized without solar thermal energy in the buildings to distributed systems with solar thermal energy in each building at the Balearic Islands. 


\section{Description of the system}

Large Solar Energy Centralized plants can sell the energy with District Heating Systems, where the tertiary buildings and residents can buy energy according to their necessities. Mediterranean towns have few heating necessities, and sometimes larger cooling necessities, only the Domestic Hot Water is the most constant throughout the year, that makes even more interesting the creation of District Heating and Cooling combined with large Solar Plants, and share thermal resources between buildings. The maximum distance considered is 5 kilometers, there will be different scenarios studied, one installing one Large Solar Plant in the center and another with distributed generation (roofs, and public areas). In all the cases flat plate collectors have been considered. We have studied different Buildings, with different necessities (Education, Hotel, Multi-family, city block, single houses, commercial, Municipal, Hospital,) for the Balearic Islands. There has been developed a simulation program from the conclusions and detailed analysis from other studies (Wolfgang Streicher 2006) using the typical meteorological year (TMY). The result will be presented with very few days of overheating, and using all the energy throughout the year for Domestic Hot Water (DHW). The solar policies are different in each country, according to the IEA Members. In our case the Spanish Technical Building Code is promoting the solar energy in two different ways. For each new building a demand limitation is imposed through simulation taking into account passive solar issues. In a second stage, the energy footprint is calculated, where active solar systems are directly involved in the simulation. In the new buildings or big upgrade, a minimum DHW contribution from 2006 is imposed and it will be revised in the upcoming years to include district heating and cooling system characteristics. This imposition requires a minimum quantity of solar panels to produce the DHW, between 0,5-1 square meter per person, to produce a solar fraction between the 30-70\%, according to the solar radiation and external temperatures. At the Balearic Islands this is between the 50-70\% according to the size of the system. In existing districts, the less than the $10 \%$ of the houses are made with the new code, and from the existing there is a $15 \%$ with solar energy. In new districts all the buildings will have solar energy, and in 2020 they will almost be zero energy buildings.

\section{$\underline{\text { DATA }}$}

Demand of Domestic Hot Water: according to the Spanish Technical Building Code.

Demand of Heating: space of $20 \mathrm{~m}^{2} 24 \mathrm{~h}$ for heating, the rest according to real simulation

Surface of FPC to cover de \% of DHW: according to the Spanish Technical Building Code.

The occupancy factor has been contemplated in each building.

Simulating the whole year system we reach different solar fractions depending on the efficiency of the system and the working temperature of the storage system.

$$
\begin{gathered}
\text { ST Collector Efficiency } \eta=0,807-3,075\left(\mathrm{~T}_{\mathrm{m}}-\mathrm{T}_{\mathrm{a}}\right) / \mathrm{G}-0,022\left(\left(\mathrm{~T}_{\mathrm{m}}-\mathrm{T}_{\mathrm{a}}\right) / \mathrm{G}\right)^{2}(\text { eq. } 1)(\mathrm{e}) \\
Q_{D H W}=m_{e} \cdot c_{p e} \cdot\left(T_{H O T}-T_{C O L D}\right) \quad \mathrm{m}=\mathrm{n}^{\mathrm{o}} \text { people } \cdot \text { water-person } \cdot \text { density of water } T_{H O T}=60^{\circ} C[8] \\
Q_{\text {transfer }}=U \cdot A_{r} \cdot\left(\Delta T_{A}-\Delta T_{B}\right) /\left(\ln \Delta T_{A}-\ln \Delta T_{B}\right) \text { with heat exchanger } \\
Q_{\text {Transfer }}=m_{\text {district }} \cdot c_{p e} \cdot\left(T_{\text {in_D }_{-}}-T_{\text {out_D }}\right)=m_{\text {builiding }} \cdot c_{p e} \cdot\left(T_{\text {in_b }}-T_{\text {out_b } b}\right)
\end{gathered}
$$

Without heat exchanger the solar policies are different in each country, according to the IEA Members [9], most of them they give tax deduction or helps and others they have in their technical building code. 


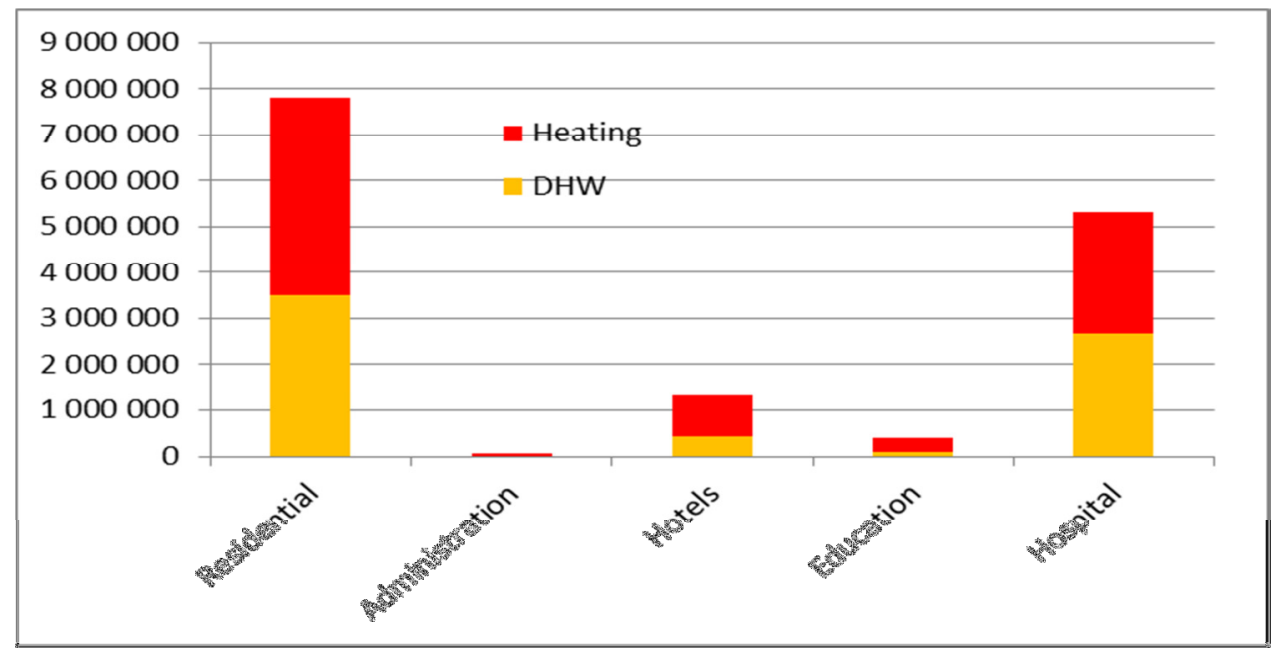

Figure 1. Annual Thermal consumption for uses and buildings in Balearic Islands district

Tab. 1: Demand according to the Spanish Code and solar fraction per year.

\begin{tabular}{lcc} 
& Liters/day person at $60^{\circ} \mathrm{C}$ & Solar Fraction \\
\hline Residential & 28 & $50-70 \%$ \\
Administration & 2 & $70 \%$ \\
HOTEL & 55 & $70 \%$ \\
Education & 21 & $70 \%$ \\
Hospital & 55 & $70 \%$
\end{tabular}

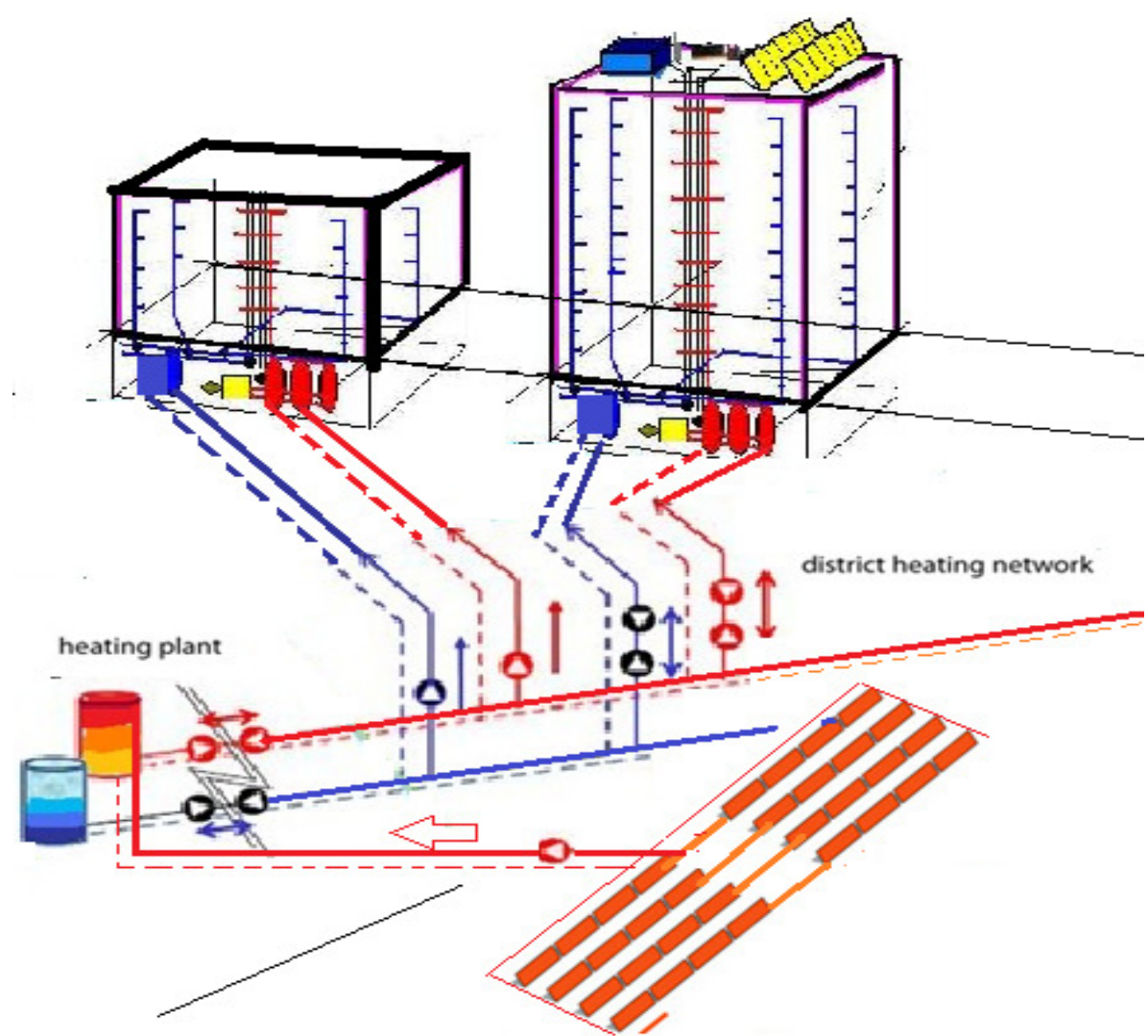

- Figure 2. District heating and cooling decentralized network. Unidirectional buildings and bidirectional buildings. 


\section{Results}

We can see five different scenarios, comparing a completely centralized system (Figure 3) without solar energy in the buildings, to a system with a $100 \%$ of the buildings with a solar system providing the $70 \%$ of the DHW provided by their FPC (figure 6), and sharing the excess of energy to the District Heating. Other scenarios have been simulated, from $25 \%$ to $75 \%$ of the building with solar energy. We set a number of buildings for each scenario according the actual situation, and after that we obtain a random normalized number with the average of people on these buildings. Besides we obtain a random number with the \% of solar thermal installation deployed with the reference target. So once established, these random values are going to be constant during the whole simulation for each building changing the $\%$ of occupation, obtained by another variable in each loop of 8760 cycles averaged by days. In order to run the whole simulation by Visual Basic (VBA), it has been necessary to run that by parts or by buildings.

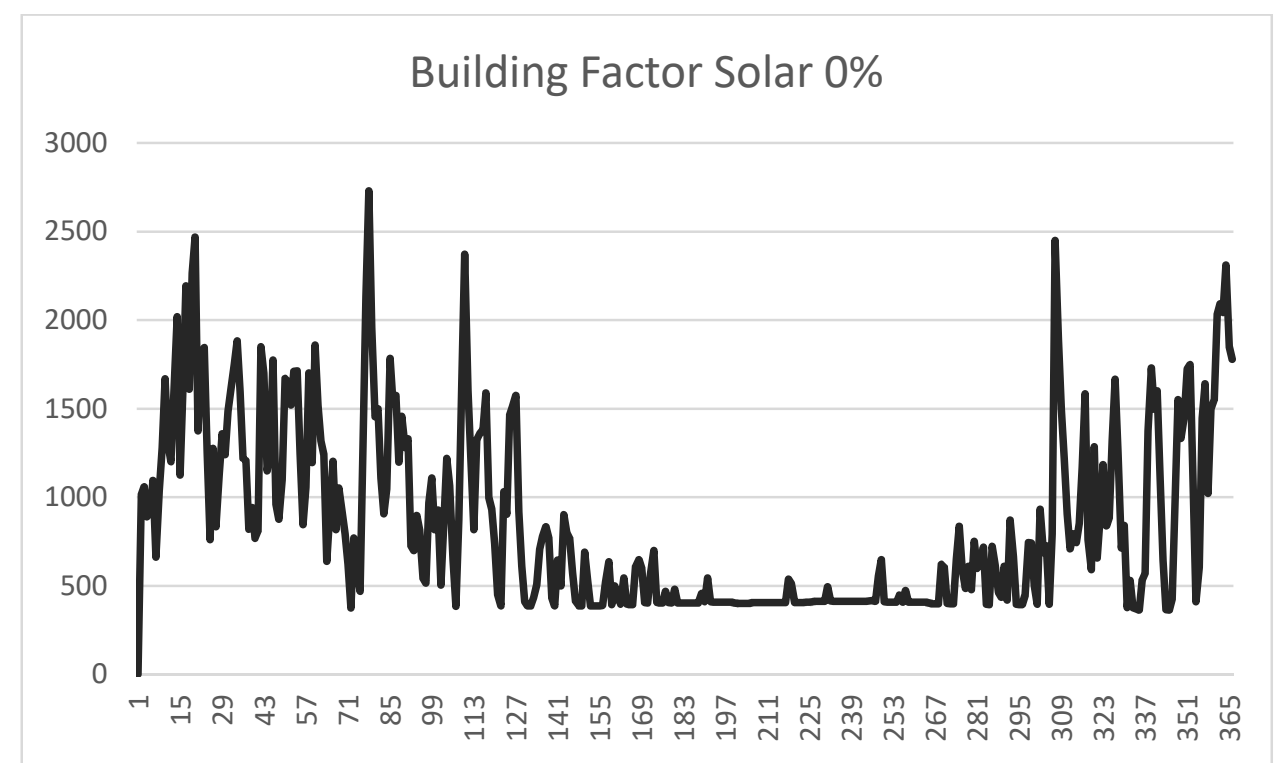

Figure 3. Annual Thermal consumption in a completely centralized District heating network.

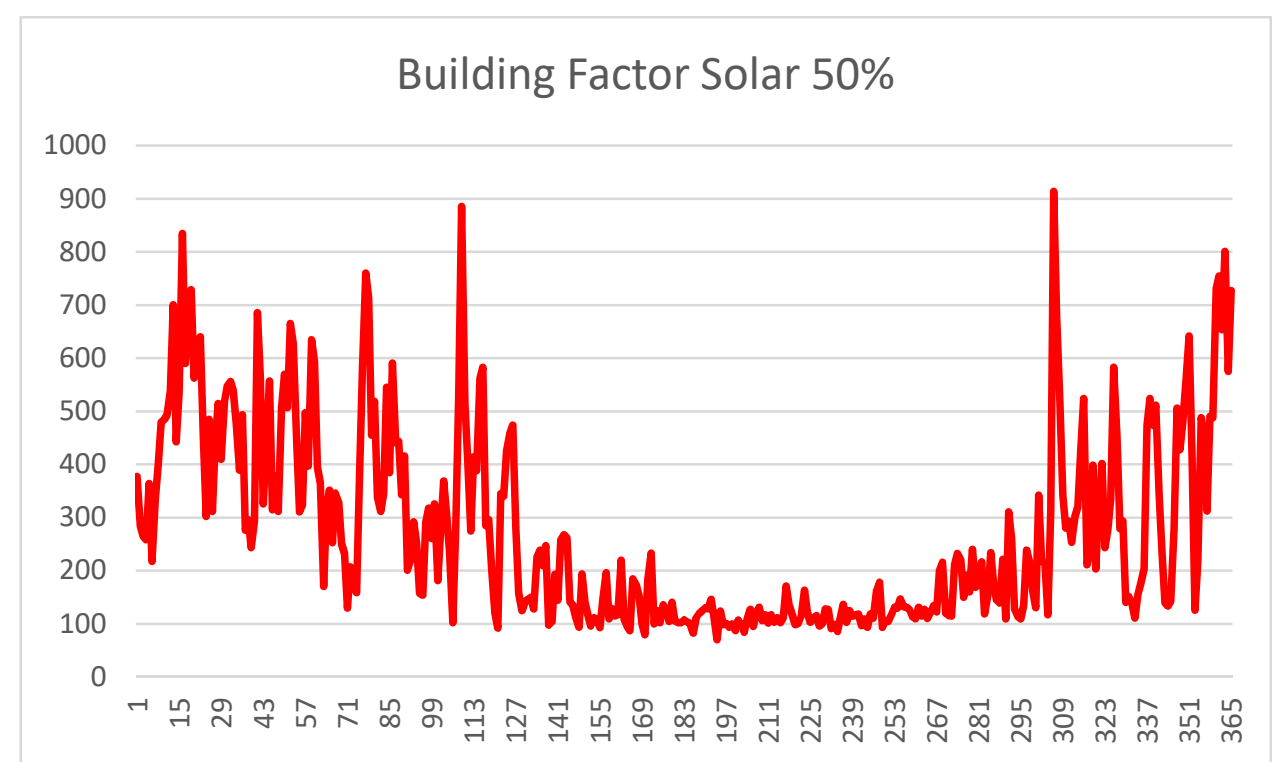

Figure 4. Annual Thermal consumption in a 50\% distributed Solar District heating network 


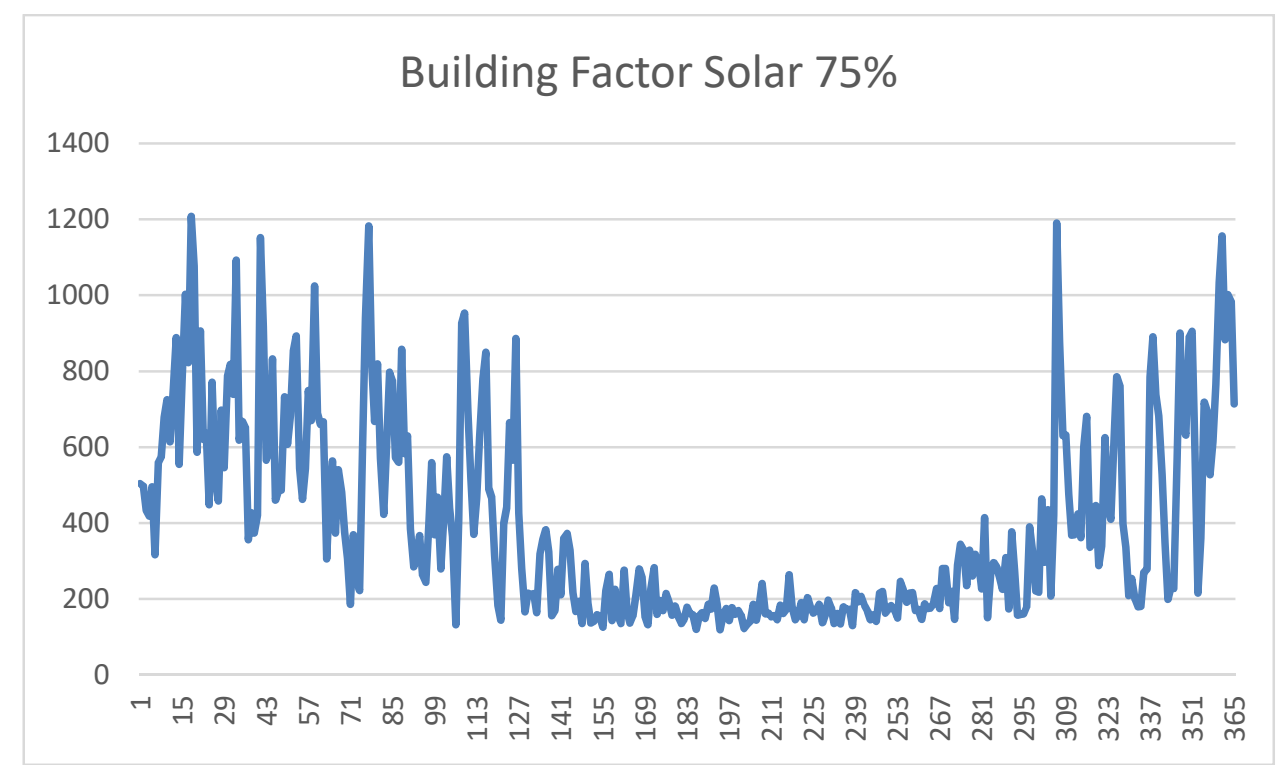

Figure 5. Annual Thermal consumption in a 75\% distributed Solar District heating network

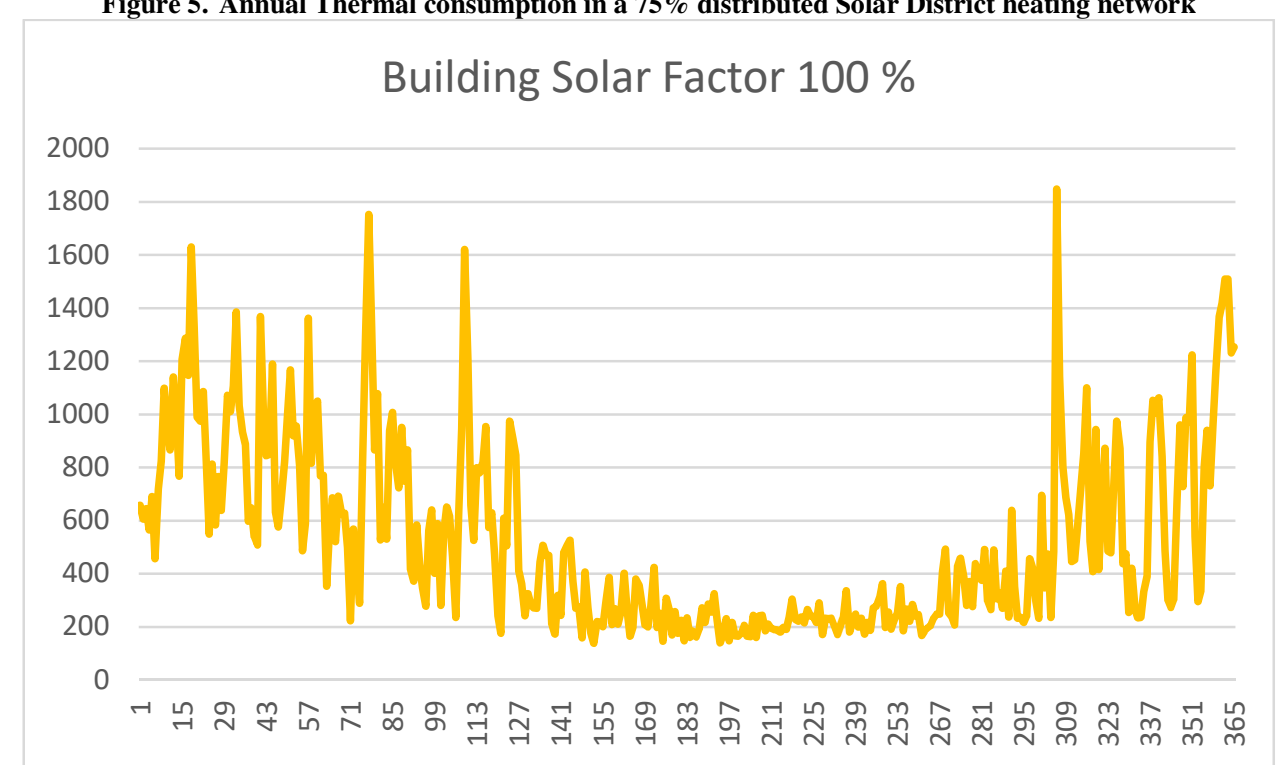

Figure 6. Annual Thermal consumption in a $\mathbf{1 0 0 \%}$ distributed Solar District heating network

The decentralized systems with the actual laws will be better than the conventional solar district. Solar Photovoltaic - Thermal Technology is an interesting solution for micro thermal generation as well micro electric generation to compensate electric demand of pumps by net zero balance. Heating and cooling solar district is the way in southern locations to thermally efficient buildings with high thermal demand as residential and hospital locations should have an absorption chiller for their micro thermal installation.

As the majority of solar irradiation is in most regions (especially in southern countries) not produced during heating season, summer time operation is crucial for financial effects of a solar thermal plant (Streicher \& Fink 2006). The centralized systems have the advantage of not having thermal excess, according to the production system and the storage systems, but they need larger dimension of pipes and pumping consumption. 
A. Moià-Pol et. al. / EuroSun 2018 / ISES Conference Proceedings (2018)

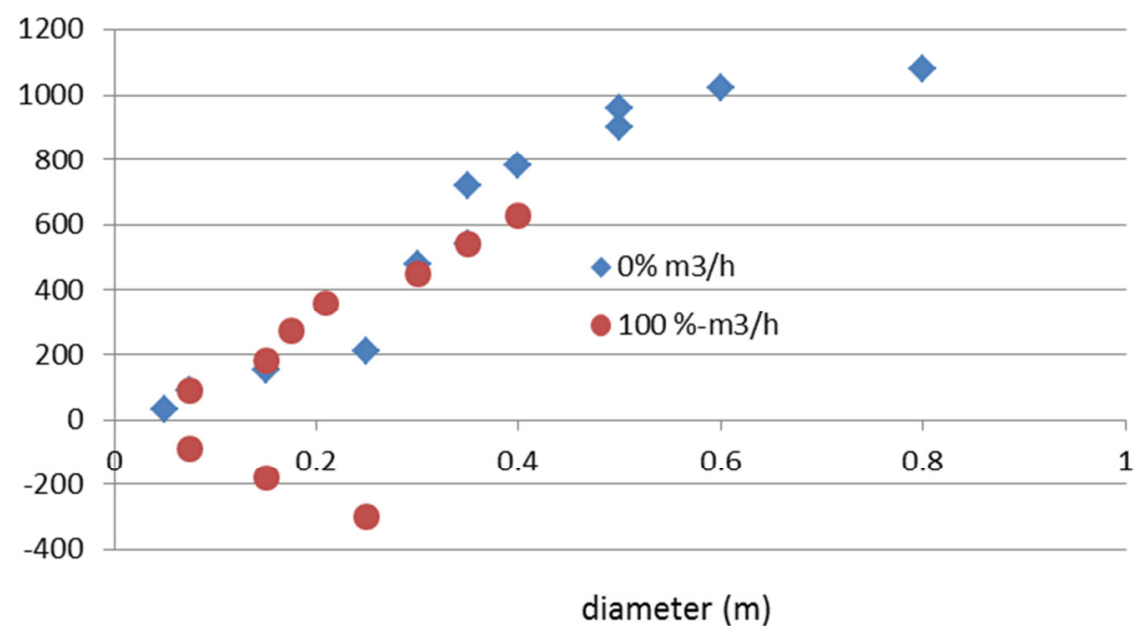

Fig. 7 : Peak Flow vs. diameter in a centralized (0\%) vs. distributed(100\%) Solar District heating network

\section{Thermal losses in the pipes (kWh)}

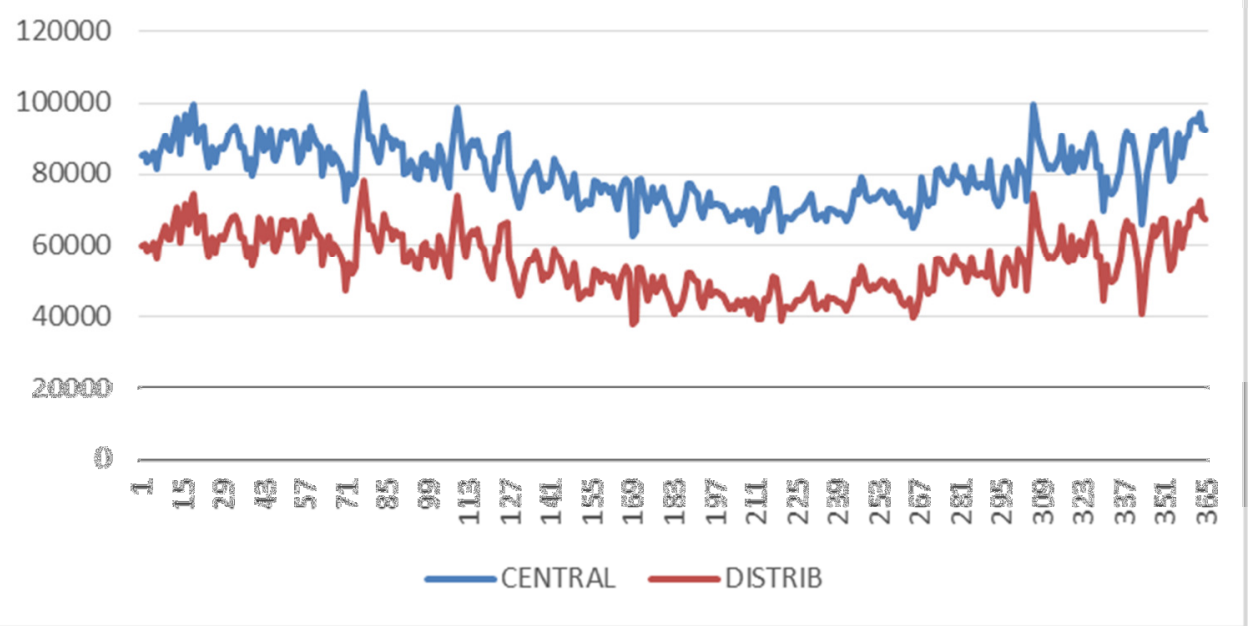

Fig. 8 : Thermal losses of the Pipes of a Centralized vs. distributed Solar District heating network

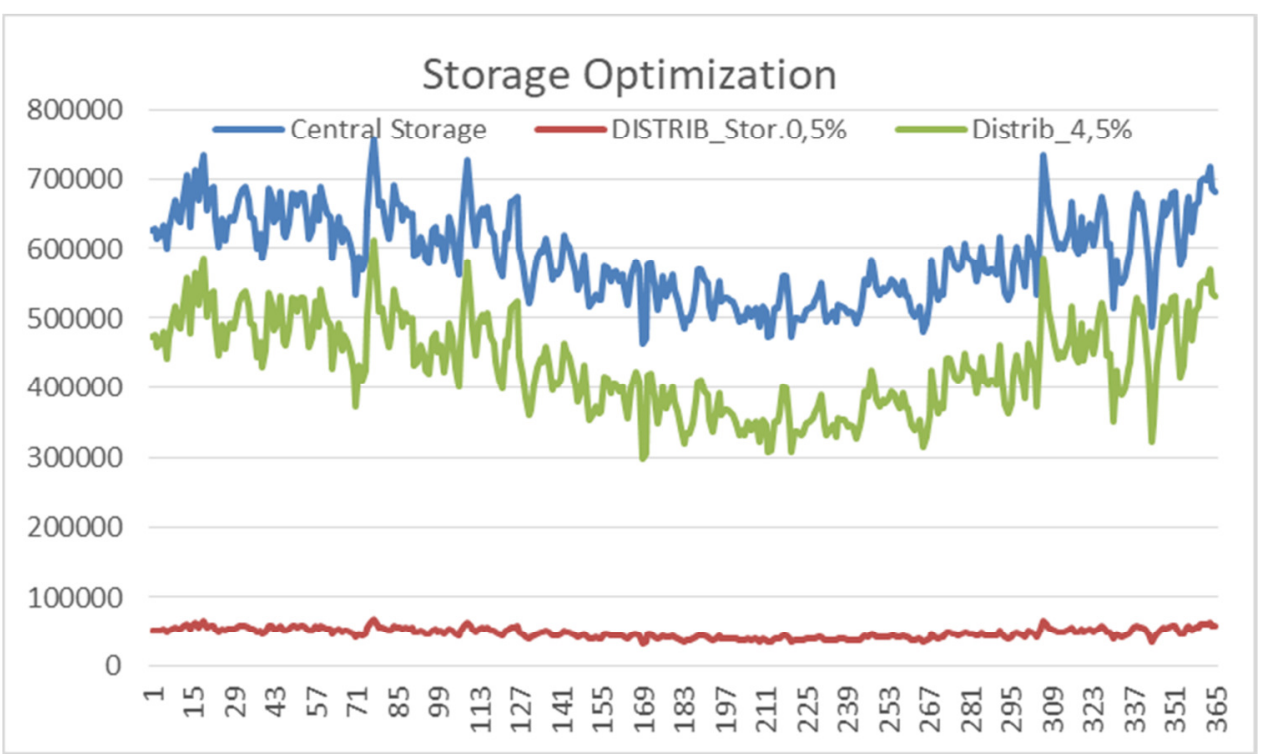

Fig. 9 : Thermal losses of a Storage Centralized vs. distributed Solar District heating network 
Some scenarios of storage have been studied, the thermal losses of a distributed system are higher due to the surface of the tank, but in the distributed system the storage is necessary to reduce the thermal losses of the pipes. The optimal storage of the central tank vs. the distributed tank have to be studied from another point of view, like safety reasons, and have thermal safety in each building. The engineers usually put the volume of one day of DHW consumption. Figure 9, which shows the storage thermal losses, makes it clear that it's better to have a large centralized tank with small tanks distributed, the 4,5\% $\left(220 \mathrm{~m}^{3}\right)$ of the storage has almost the same losses than a central tank with the $95,5 \%$ of the volume $\left(4900 \mathrm{~m}^{3}\right)$. Some storage is needed in each building for have more reliability and safety for the distributed FPC.

If we center on distributed systems with a high fraction of solar thermal energy, with the radiation of a southern country, like Balearic Islands, we achieve districts where we need storage systems, seasonal storage or design to be improved, but the best in these cases will be found in other uses, like cooling systems (absorption or adsorption technologies) in the biggest buildings, where the cost of the devices is similar to the compression machines.

These systems are necessary in southern countries where tertiary buildings usually have more cooling necessities than heating (Moià-Pol et alt 2014). The distributed systems have another advantage: smaller dimension of pipes and less pumping consumption, because only peak demands are needed to pump to the grid. The diameter of the distributed system is almost a 50\% smaller than the centralized systems. Strategies of flow and Delta $\mathrm{T}$ can be designed in order to control the pumps from the maximum flow to the minimum flow (figure 7). The usage of bidirectional substations reduces the centralized heat production for the DHW of all the consumers of the District Heating Network, even during summer ( Lamaison et alt 2017).

It is planned to install this system in a District of the Balearic Islands, however it will be necessary in order to have real testing results, to improve the simulation program and algorithms and find new technologies, materials and systems. According to the actual Spanish law the maxim solar fraction for all the thermal uses will be less than the $21 \%$. In the future with the NZEB directive these fraction could be 2 or 3 times bigger, depending of the District and the local laws. With bigger fraction, the dimension of the pipes could be even smaller, and have lower pay-backs for the biggest facilities, where each building could sell the over production, with the same rules that the PV systems.

The cooling demand has to be included in future studies, with higher solar fraction, and has to be included in the algorithm so as to improve the mix of the central plant, in order to arrive to zero emissions districts. For areas with more tourism, where in summer there is an increase of the DHW the system could arrive to a perfect balance.

\section{Energy consumption}

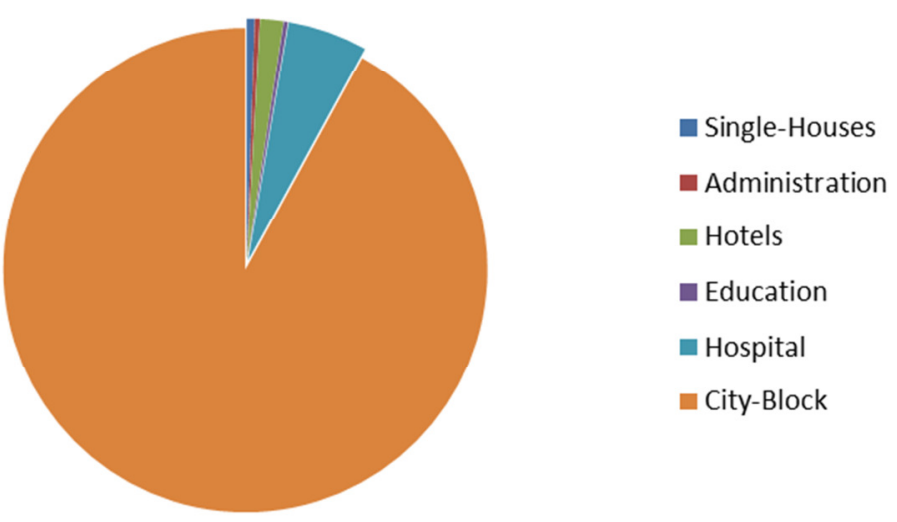

Figure 10. Annual Thermal consumption for buildings

\section{Conclusions}

The decentralized systems with the actual laws will be better than the conventional solar district, with fewer dimensions of pipes and pumping consumption. Thermal solar energy systems must be increased at the 
legislative level to reach zero-emission buildings (Heating fraction). District networks are essential if we want solar thermal energy to compete with photovoltaics.

\section{References}

Andreu Moià-Pol, Víctor Martínez-Moll, Ramon Pujol Nadal, Josep M. Rigo Serra. Solar thermal potential for collective systems in Palma Beach(Balearic Island's). Energy Procedia 48 ( 2014 ) 1118 - 1123. SHC 2013, Freiburg, Germany.

Lozano, M. A., Anastasia, A., Palacín, F., and M. Serra, L.,(2010) Simulation study and economic analysis of large-scale solar heating plants in Spain, Zaragoza.

Wolfgang Streicher, Christian Fink: Einspeisung von Solaranlagen in (bestehende) FW-Netze, Gleisdorf Solar 2006.

IEA Solar Heating and Cooling Programme - Country Members http://www.iea-shc.org.

http://solar-district-heating.eu/

Technical Code of the Building of Spain http://www.codigotecnico.org/

Nicolas Lamaison, Roland Bavière, David Chèze, Cédric Paulus. A multi-criteria analysis of bidirectional solar district heating substation architecture. SWC 2017 / SHC 2017, 2017. AbuDhabi, UAE 


\title{
Development of a software system for optimal operation of heating networks with central solar plant
}

\author{
Thomas Oppelt ${ }^{1}$, Thorsten Urbaneck ${ }^{1}$, Sebastian Otto ${ }^{2}$, Ingrid Heinrich ${ }^{2}$, Andreas Schmidt ${ }^{2}$, \\ Thomas Göschel ${ }^{3}$, Ulf Uhlig ${ }^{3}$, and Holger Frey ${ }^{3}$ \\ ${ }^{1}$ Chemnitz University of Technology, Faculty of Mechanical Engineering, \\ Professorship Technical Thermodynamics, 09107 Chemnitz, Germany \\ 2 Ingenieurbüro Last- und Energiemanagement LEM-Software, Nordplatz 6, 04105 Leipzig, Germany \\ 3 inetz GmbH, Augustusburger Straße 1, 09111 Chemnitz, Germany
}

\begin{abstract}
More and more district heating systems contain a central solar thermal plant in addition to the conventional CHP plant as heat source. In most cases, a short-term thermal energy storage is applied for balancing load and heat generation. The optimal operation of such complex systems regarding operational costs, high share of renewable energy sources, supply safety, etc. is difficult due to mutual influences of the different components as well as fluctuating loads, solar gain and electricity prices. In a current research project, a new software system named Heating Network Navigator is developed which will help the operators of solar district heating systems to reach optimal operation. The approach of the project is to combine an intelligent deterministic optimization scheme based on a system model with predictive control using forecasts of network load, solar yield and electricity price. Based on current and historical measured data and forecasts for the boundary conditions, the Heating Network Navigator will generate suggestions for the process control system on when to charge and discharge the thermal energy storage, which set-point to define for the collector output temperature in matched-flow operation, etc. during the optimization horizon of several hours to some days.
\end{abstract}

Keywords: solar district heating, combined heat and power, optimization, operation software, forecasting

\section{Background}

Heating supply to buildings is an important point when striving for the reduction of primary energy demands and $\mathrm{CO}_{2}$ emissions. Larger settlement areas, e.g. city centers or neighborhoods with multiple dwelling units, can be supplied $\mathrm{CO}_{2}$-neutrally with heat only via district heating (DH) (BSW, 2007). Integrating solar thermal plants into such central heating supply systems is a promising approach for using the sun as a renewable energy source. Solar heat is often paired with combined heat and power plants (CHP). With short-term heat storage, achieved solar coverage rates mostly lie in the range from $10 \%$ to $25 \%$ (BSW, 2007).

In Germany and Austria, several solar district heating systems have been built during the last years. For example, the solar district heating system in the Brühl quarter at Chemnitz, Germany with a collector area of $2100 \mathrm{~m}^{2}$ was put into operation in 2016 (Urbaneck et al., 2014; Shrestha et al., 2018).

In order to utilize the huge potential of solar thermal energy, a quarter-based approach seems to be favorable (quarter level in contrast to town level). By transfiguring the heat supply on quarter level, existing DH systems as existing e.g. in most of the large German cities can be adapted to conditions that have been changing during the last decades. These are i.a. declining heat demands due to building insulation and climate change as well as the claim for low primary energy factors with heat prices being competitive at the same time. Thus, the project "Heating network navigator - software for extensively optimizing the operation of heating networks on town and quarter level" being presented here spatially concentrates on heating systems for quarters where solar thermal systems are combined with CHP and a thermal energy storage (TES). The following system types are considered:

- Quarter heating systems within larger heating systems (e.g. Chemnitz Brühl system),

- small district heating systems for residential quarters,

- district heating systems for small towns and villages (common in Denmark and Austria).

Figure 1 shows the schematic configuration of such a quarter heating system with short-term storage for the example of Brühl, Chemnitz. This solar DH system is connected to the town level DH system and the CPH plant, but decoupled hydraulically from these and operated independently. The system components in a quarter heating system 
create a complex structure of mutual influences:

- Quarter heating network:

- requires a certain supply temperature, i.e. depending on the current load, the technical equipment of the buildings and heat losses in the network,

○ a return temperature results e.g. depending on load, supply temperature and building equipment;

- Solar thermal plant:

- efficiency depends on the return temperature (from the network or storage), the required supply temperature (depending on required network supply temperature etc.) and the ambient conditions,

○ auxiliary energy demand (circulation pumps) depending on collector flow rate;

- CHP plant:

- profitability depends on the fluctuating electricity price,

- current electricity price is influenced by load and supply of renewable energy (especially wind and PV power) into the national power grid,

○ the flexibility of the CHP plant depends on the technology and operational mode (constant or variable power-to-heat ratio);

- TES:

- link between the network, the solar plant and the CHP plant,

○ the storage capacity depends on the supply and return temperatures in the network and heat losses,

- losses are influenced by the temperature level in the storage as well as ambient conditions,

- stratification quality has an influence on the temperatures at the top (supply temperature) and the bottom (return temperature to collector field) of the storage

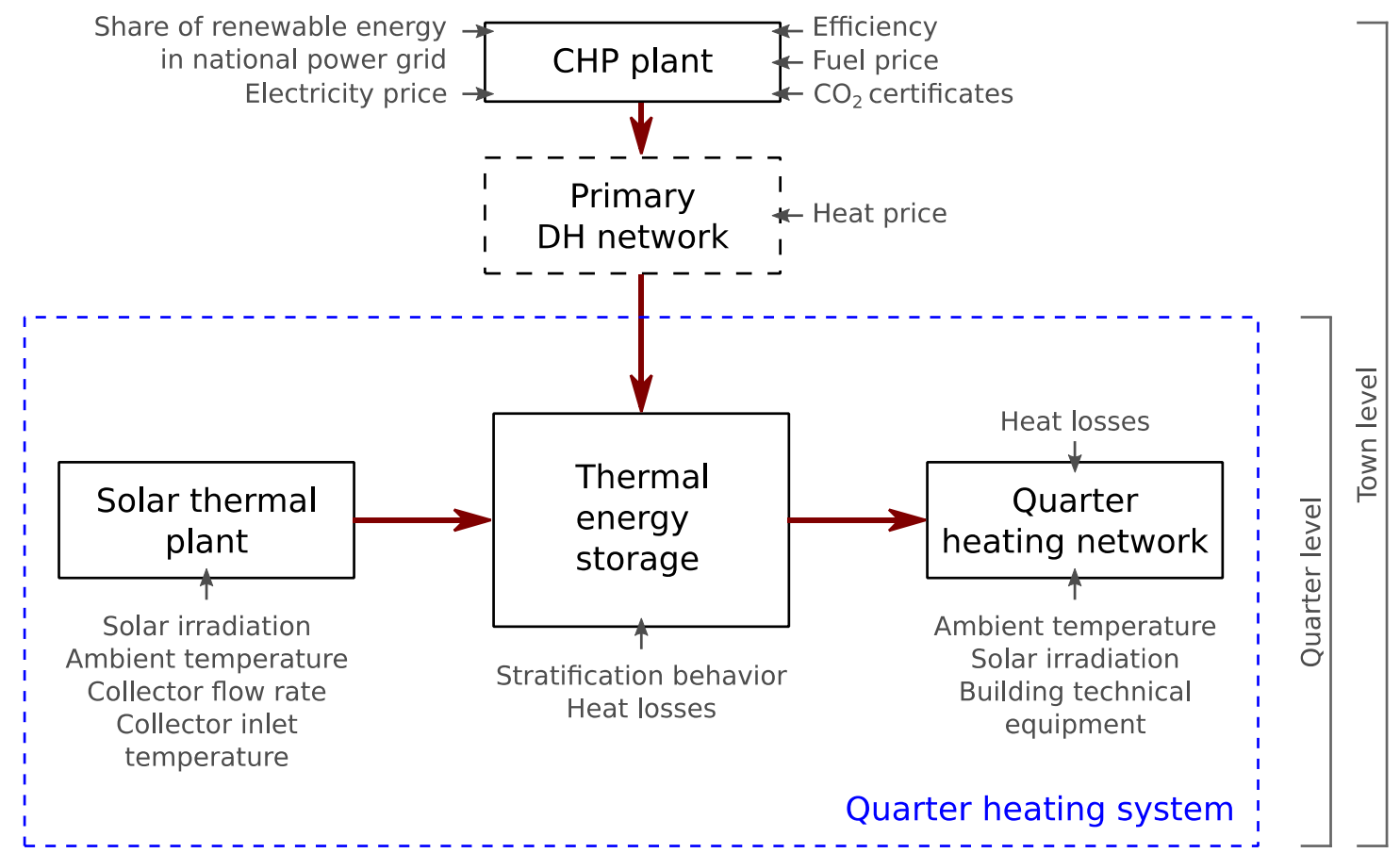

Figure 1: Scheme of a quarter heating system with solar plant, important influences on the system components (example system: Brühl, Chemnitz)

The manifold mutual influences between the system components, combined with external influences like economic boundary conditions and natural ambient conditions, make an optimal operation impossible to reach without special effort. For example, today solar plants often are controlled independently from the other components of the system or the storage is charged with CHP heat without taking into account the current heat demand and electricity price. It makes sense from the point of view of the operators as well as society to holistically optimize the system operation.

\section{Project goals}

The main goal of the research project which has been running since July 2017 is to develop a software system named Heating Network Navigator for heating network operators which will help them in reaching optimal system operation 
despite of difficult boundary conditions (integration of fluctuating renewable energy sources, varying electricity prices, etc.) and complex technical demands. This optimal operation can be characterized by the following target criteria:

- High share of renewable energy sources in heat supply,

- low operating costs,

- low primary energy factor in district heating (high product quality even under varying boundary conditions),

- security of supply.

The Heating Network Navigator is supposed to cover the following demands simultaneously (as far as possible):

- Optimal application of the short-term storage, e.g. avoid charging under unfavorable conditions for generation,

- best possible exploitation of solar irradiation, e.g. by minimizing the collector input temperature, avoiding unnecessarily high set-point values for the collector output temperature in matched-flow operation,

- minimizing the competition between solar thermal energy and CHP by avoiding unnecessary CHP charging of the storage based on forecasting solar yields on the one hand and using the storage capacity for CHP flexibility when low solar yields are expected on the other hand,

- minimizing the network supply temperature, thus reducing losses and providing good conditions for the solar system,

- maximizing the temperature difference in the network for maximizing the storage capacity, reaching a low collector input temperature and reducing the auxiliary energy demand for water circulation.

\section{Approach}

In order to reach holistic optimization of operation, the Heating Network Navigator should involve the following features:

- Intelligent deterministic optimization scheme (underlying model of the supply system as abstracted as possible and as detailed as required),

- predictive control algorithms (forecasting of load, solar yieldsolar and electricity price),

- learning software, e.g. autonomous adaption of the load forecast to changing boundary conditions like the occupancy rate in the quarter,

- adaptivity, e.g. flexibility facing different system configurations,

- integrated error identification, e.g. recognition of slow effects as calcification of heat exchangers.

Figure 2 schematically shows the planned integration of the Heating Network Navigator software system into the town quarter DH system (example: Brühl quarter, Chemnitz). The software receives measured data from the process control system, creates forecasts using mathematical models and generates an advice for the optimal operation based on the current measured data, the forecasts, time series (historical data) as well as "learned" information on previous operating conditions. This advice for a defined future horizon is sent to the process control system in order to be considered. Additionally, the Heating Network Navigator permanently compares operational data from past and present in order to detect errors in the system (error identification).

The mathematical-numerical optimization will be based on a model of the heating system which is included in the Heating Network Navigator. Based on a complex reference model, submodels for the different system components (e.g. storage, collector field) are developed during the project. These should reflect reality adequately on the one hand, but be as simple as possible on the other hand. Different types of models are applied:

- Physical models which are based on equations describing reality, e.g. energy conservation law, heat equation,

- blackbox models with mathematical regression equations which describe the correlation between input and output values without considering real physical effects,

- ANN models which determine output values from given input values by means of artificial neural networks (ANN). 


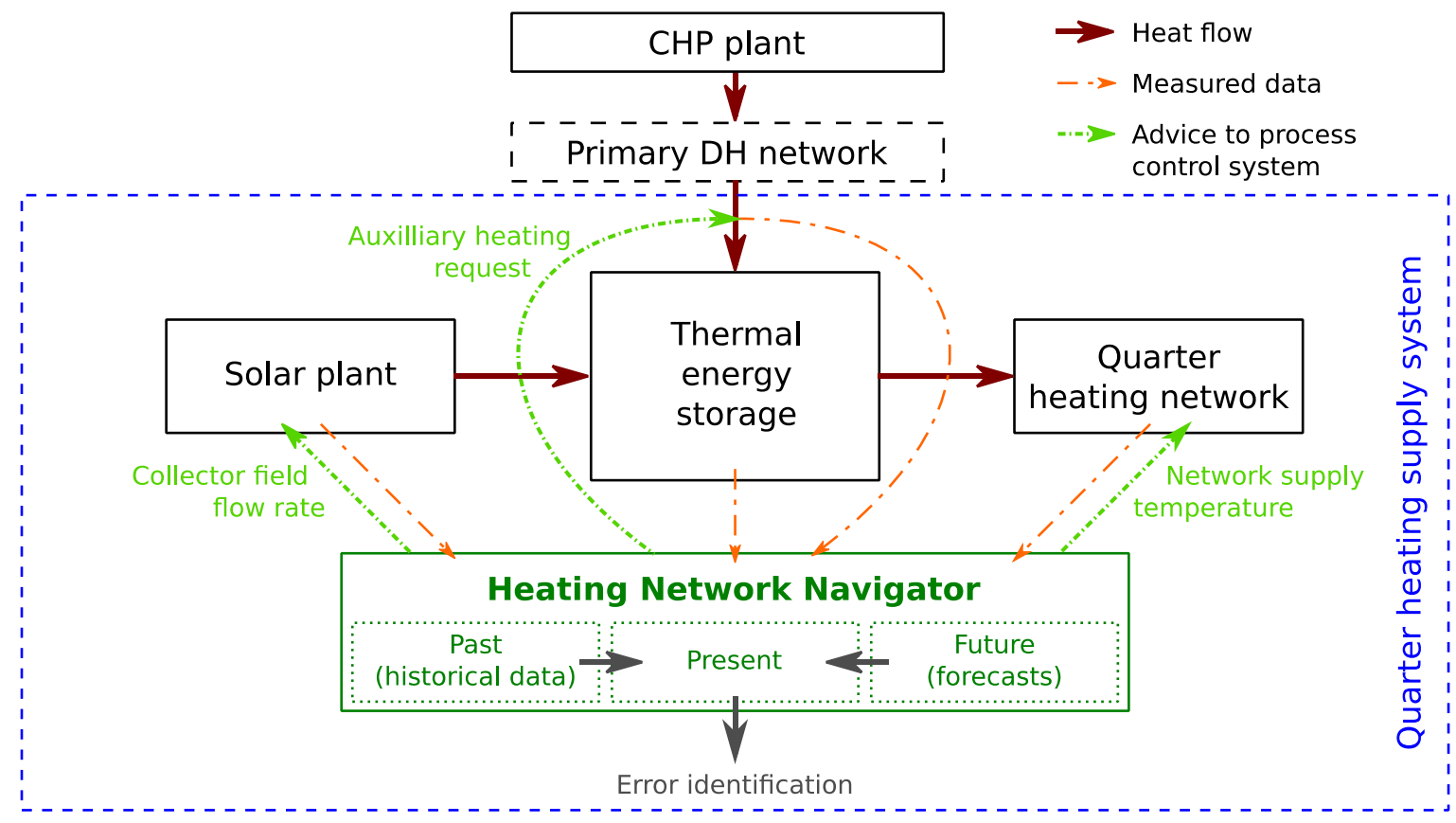

Fig. 2: Integration of the Heating Network Navigator into a quarter heating system

For each of the subsystems, one of these model types is especially suitable. For example, the TES requires a physical model because only such a model can represent the storage's complex transient stratification behavior with sufficient accuracy. Whereas, a blackbox model seems promising for the collector field and the load behavior of the heat customers is predestinated for applying an ANN model due to the stochastic effects.

Some of the authors where involved in the RenewIT European project (RenewIT, 2016; Salom et al., 2017) where metamodels (blackbox models) could be applied successfully for abstracting complex cooling supply systems. In the project presented here, the method established in the RenewIT project is developed further by combining blackbox models with physical models and ANN models. The abstracted overall model built from the different submodels is supposed to be applied during real operation for simulating different operation scenarios for the following period (optimization horizon about several hours to some days). Combined with the boundary conditions (current and historical measured data of the system, forecasted network load, solar irradiation/yield and electricity price), the Heating Network Navigator can thus generate control suggestions for the process control system which will lead to holistically optimal system operation. Control suggestions are the optimal operation parameters like when to charge or discharge the TES, which set-point temperature to specify for the matched flow operation of the collector field etc.

\section{Project stages and outlook}

During the project, the Heating Network Navigator will be pre-developed and tested. The project is subdivided into three stages of development:

1. Basic developments: In this first stage, simulation and forecasting models are developed and abstracted for application in the Heating Network Navigator.

2. Lab testing: The Heating Network Navigator is tested in a Hardware-in-the-loop (HIL) environment.

3. Real-life testing: Supported by the network operator inetz, the software system is tested in practice in the Brühl solar DH system at Chemnitz.

The project is running until end of 2019. Results will be published continuously on the project website (Oppelt and Urbaneck, 2018). At present, the project partners are in the first stage of development dealing with the models of the system components, the required forecasting algorithms and the optimization method. 


\section{Acknowledgements}

The project underlying this paper is funded by the German Federal Ministry for Economic Affairs and Energy under the codes ZF4389101ST7/ZF4147602ST6 following a decision by the German parliament. Special thanks also go to the AiF Projekt GmbH for supporting the project. The sole responsibility for the report's contents lies with the authors.

\section{References}

BSW, 2007. GroSol - Studie zu großen Solarwärmeanlagen [GroSol - Study on large solar thermal systems]. Bundesverband Solarwirtschaft e.V.

Oppelt, T., Urbaneck, T., 2018: Project website Heating Network Navigator. http://www.wn-navi.de

RenewIT, 2016: RenewIT Project - Renewable Energy Simulation Tool for IT Data Centres. http://www.renewitproject.eu

Salom, J., Urbaneck, T., Oró, E., 2017. Advanced concepts for renewable energy supply of data centres. Delft: River Publishers. ISBN: 9788793519428.

Shrestha, N. Lal, Urbaneck, T., Oppelt, T., Platzer, B., Göschel T., Uhlig, U., Frey, H., 2018. Implementation of large solar thermal system into district heating network in Chemnitz (Germany). In: International Solar Energy Society (ed.): ISES Solar World Conference 2017 and the IEA SHC Solar Heating and Cooling, 322-332. doi:10.18086/swc.2017.06.08.

Urbaneck, T., Oppelt, T., Platzer, B., Frey, H., Uhlig, U., Göschel, T., Zimmermann, D., Rabe, D., 2015. Solar district heating in East Germany - Transformation in a cogeneration dominated city. International Conference on Solar Heating and Cooling for Buildings and Industry, SHC 2014. In: Energy Procedia 70, 587-594. doi:10.1016/j.egypro.2015.02.090. 


\title{
Opportunities for the Integration of Solar Thermal Heat, Photovoltaics and Biomass in a Brazilian Hospital
}

\author{
Eduardo A. Pina, Miguel A. Lozano, Luis M. Serra \\ GITSE-I3A, Department of Mechanical Engineering, University of Zaragoza, Zaragoza (Spain)
}

\begin{abstract}
The present study assesses the technical, economic and environmental feasibility of integrating renewable energy technologies (photovoltaic panels, solar thermal collectors, and biomass boilers), thermal energy storage units, absorption chillers, mechanical chillers, natural gas boilers, and power exchange with the grid in a university hospital located in Campinas (Brazil). The proposed design procedure combines mathematical programming techniques, such as a mixed integer linear programming model, addressing the synthesis, operational planning and dynamic operation conditions, with process integration techniques, such as the problem table algorithm (the algebraic tool of Pinch Analysis). The methodology is applied considering actual local data (energy demands, energy prices, climatic data), investment costs, and $\mathrm{CO}_{2}$ emissions factors. The results show that under the conditions considered herein, biomass is economically the most appropriate fuel for heat production, displacing the deployment of natural gas; cooling production, on the other hand, is made entirely with electricity purchased from the grid. From the solar energy technologies, only the photovoltaic panels were included as a result of the condition that the annual electricity sold to the grid must be equal to the annual electricity purchased.
\end{abstract}

Keywords: Biomass, CSP, energy storage, optimization, photovoltaics, renewable energy, solar thermal.

\section{Introduction}

Renewable energy sources (RES), along with high-efficiency cogeneration systems, play a fundamental role in the transition towards sustainable energy systems. Renewable energy technologies (RETs) based on solar (e.g. photovoltaic and solar thermal collectors), wind (e.g. wind turbine generator), and biomass (e.g. biomass boiler) resources, among others, can be used to cover multiple energy demands directly, such as solar heat for space heating, and/or effectively coupled to heating/cooling technologies, such as solar heat to drive an absorption chiller. These systems, in which two or more energy services are produced from common resources, may be referred to as polygeneration systems. Owing to an appropriate energy integration between the constituting devices, polygeneration systems can achieve higher energy efficiency, lower primary energy consumption, lower unit costs of the final products, and lower environmental burdens relative to the conventional separate production (Mancarella, 2014; Rong and Lahdelma, 2016; Serra et al., 2009).

Despite having been applied in the industrial sector for decades, there is still very limited deployment of polygeneration systems in the buildings sector. Hospitals are great candidates for the application of such systems due to their long operating hours, regular occupation, large amounts of thermal energy required, and varied energy services demand, which typically include electricity, steam, space heating, domestic hot water, and chilled water (Biglia et al., 2017; Santo, 2014; Gimelli and Muccillo, 2013; Lozano et al., 2009). The multi-faceted nature of polygeneration systems (multiple energy resources, multiple energy products, multiple technology options) requires a design procedure that provides flexible, efficient and reliable energy systems. The design is further complicated as new factors are taken into account, such as the normative for power exchange with the electric grid, the decreasing investment costs of photovoltaic panels and solar thermal collectors, subsidies to the deployment of renewables, and the increased opportunity for biomass.

In this regard, mathematical optimization techniques based on mixed integer linear programming (MILP) models are suitable tools to address the synthesis (installed technologies and capacities, etc.) and operational planning (strategy concerning the operational state of the equipment, energy flow rates, purchase/selling of electricity, etc.) of polygeneration systems, as well as dynamic operation conditions, such as the intermittent behavior of solar resource, daily and annual fluctuations in energy demands and energy prices, interactions with the electric grid. 
The issue is that, in general, studies have considered fixed layouts for the heat recovery between the equipment supplying and demanding heat. As a result, there is a thermodynamic oversimplification in which both the heat flow's temperature and use are set before the optimization procedure even begins.

In a previous paper (Pina et al., 2018), we have proposed a first approach to this problem by introducing in the superstructure a heat integration subsystem, in which the hot flows supplied by generation technologies (e.g. natural gas boilers) and the cold flows associated with technologies that produce energy services (e.g. absorption chillers, domestic hot water network) can be integrated through a virtual heat exchangers network, providing flexibility for the model to optimally couple the heat offer and demand in both quantity and quality (temperature). Thus, the Pinch Analysis, by means of the problem table algorithm, and mathematical programming, based on a MILP model, were combined to achieve a more realistic and efficient process integration. The methodology was applied to a university hospital located in Campinas (Brazil), demonstrating that cogeneration was by far the most economically interesting option to attend the hospital's energy demands; solar energy technologies, however, were only included under highly advantageous conditions.

Therefore, the present study continues the work started in the previous paper, aiming at a $100 \%$ renewable energy system. To this end, cogeneration was removed from the previous model and biomass was introduced, along with additional RETs (parabolic trough concentrators and biomass boilers). Also, the environmental impacts of installing and operating the system were assessed through the $\mathrm{CO}_{2}$ emissions factors. The improved optimization model is applied to the same university hospital as considered in Pina et al. (2018), evaluating the technical, economic, and environmental feasibility of integrating RETs, thermal energy storage (TES) units, thermally activated technologies (TATs), mechanical chillers, natural gas boilers, and power exchange with the electric grid.

\section{Renewable-based energy system}

The synthesis of energy systems begins with the definition of the superstructure (Iyer and Grossmann, 1998; Lozano et al., 2010; Yokoyama et al., 2015). The first step in defining the superstructure is to identify the design targets, which correspond to the types and quantities of the energy demands of the consumer center and the energy resources available. Then, the superstructure can be established, considering potential technologies and the feasible connections between them, based on appropriate process integration. Once the superstructure is defined, additional and more specific data must be collected and elaborated, including technical, economic, and environmental data. This step plays an essential role in the synthesis problem since the quality of the data used directly affects the validity of the results of the optimization model. These steps are described in the following subsections.

\subsection{Consumer center's energy demands}

The consumer center considered herein corresponds to a medium size university hospital with $65,000 \mathrm{~m}^{2}$ constructed area located in the city of Campinas (latitude $\left.-22.9^{\circ}\right)$, Brazil. The hospital's energy demands consist of electricity, steam (saturated steam, $180^{\circ} \mathrm{C}$ ), hot water $\left(60^{\circ} \mathrm{C}\right)$, and chilled water $\left(7^{\circ} \mathrm{C}\right)$. It should be noted that the electricity demand accounts for lighting, elevators and other devices, thus excluding the consumption for thermal energy production (e.g. electricity consumption to produce cooling). The energy demands are assumed to be known beforehand, their values have been originally presented by Santo (Santo, 2014).

Local climatic data for Campinas was obtained from the software METEONORM (METEOTEST, 2018). These data include the hourly ambient temperature $T_{a}$, hourly global solar radiation on a surface tilted $20^{\circ}$ facing north $Q_{r}$, and hourly normal direct solar radiation $Q_{B n}$.

The analysis has been carried out for the period of one year, which is divided into 24 representative days $d$ (one working day $w d$ and one weekend/holiday we for each month of the year), each one composed of 24 consecutive periods $h$ of 1-hour duration. Table 1 shows the number of representative days type $d$ per year NRY.

Table 1: Number of representative days type $d$ per year $N R Y$

\begin{tabular}{|c|c|c|c|c|c|c|c|c|c|c|c|c|}
\hline Day & Jan & Feb & Mar & Apr & May & Jun & Jul & Aug & Sep & Oct & Nov & Dec \\
\hline$w d$ & 21 & 19 & 22 & 20 & 20 & 21 & 23 & 21 & 21 & 21 & 19 & 22 \\
\hline$w e$ & 10 & 9 & 9 & 10 & 11 & 9 & 8 & 10 & 9 & 10 & 11 & 9 \\
\hline
\end{tabular}


The annual energy demands of the hospital are: electricity 9,633.5 MWh, hot water 518.7 MWh, steam 4,660.3 MWh, and chilled water 4,755.7 MWh. Table 2 shows the hospital's daily energy demands grouped by the season of the year. An example is provided in Figure 1, which depicts the hourly energy demands for a working day in January (summer, maximum electricity and cooling demands) and in July (winter, maximum hot water demand).

Table 2: Hospital's daily energy demands, $\mathrm{kWh} / \mathrm{day}$

\begin{tabular}{|c|r|r|r|r|r|r|r|r|}
\hline \multirow{2}{*}{ Energy demand } & \multicolumn{2}{|c|}{ Summer (Jan-Mar) } & \multicolumn{2}{c|}{ Autumn (Apr-Jun) } & \multicolumn{2}{c|}{ Winter (Jul-Sep) } & \multicolumn{2}{c|}{ Spring (Oct-Dec) } \\
\cline { 2 - 9 } & $\boldsymbol{w d}$ & \multicolumn{1}{c|}{$\boldsymbol{w} \boldsymbol{e}$} & $\boldsymbol{w d}$ & $\boldsymbol{w} \boldsymbol{e}$ & $\boldsymbol{w d}$ & $\boldsymbol{w} \boldsymbol{e}$ & \multicolumn{1}{c|}{$\boldsymbol{w d}$} & $\boldsymbol{w} \boldsymbol{e}$ \\
\hline Electricity $E_{d}$ & 31,614 & 25,503 & 27,262 & 21,384 & 25,375 & 20,840 & 28,273 & 22,996 \\
\hline Steam $V_{d}$ & 16,257 & 15,037 & 10,947 & 11,858 & 10,393 & 12,868 & 12,236 & 14,206 \\
\hline Hot water $Q_{d}$ & 1,178 & 889 & 1,788 & 1,077 & 2,039 & 1,225 & 1,438 & 822 \\
\hline Chilled water $R_{d}$ & 18,321 & 16,412 & 12,116 & 11,580 & 8,424 & 7,896 & 14,788 & 13,205 \\
\hline
\end{tabular}
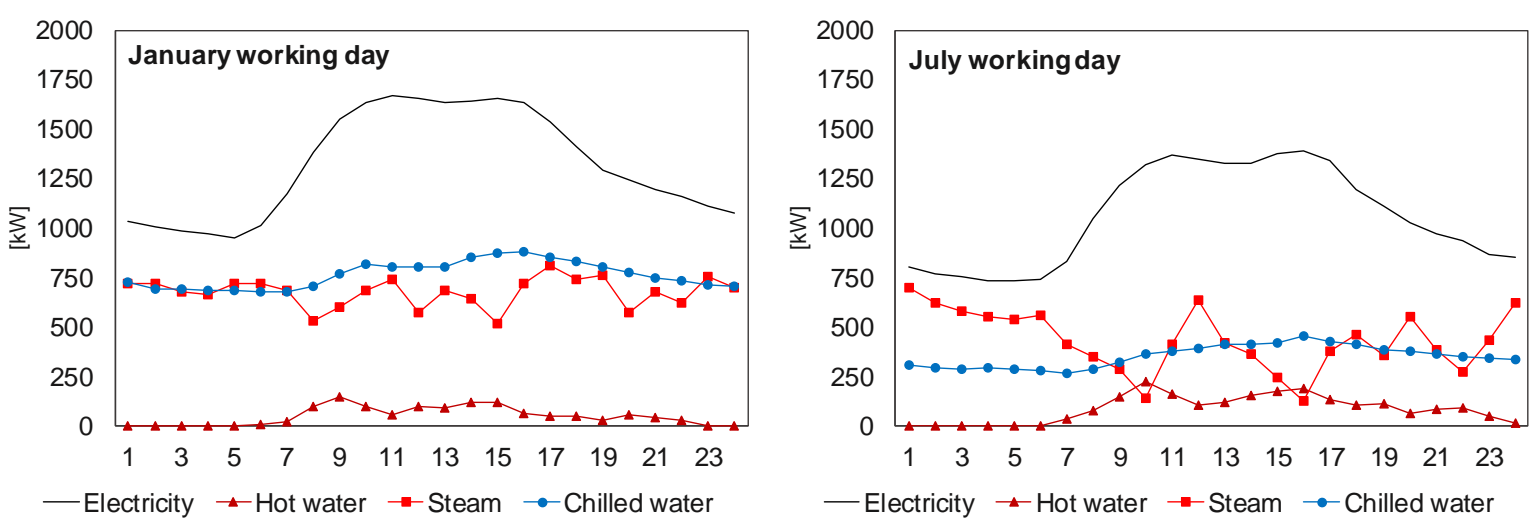

Figure 1: Hourly energy demands for a representative working day in January (left) and July (right)

\subsection{Superstructure and thermal integration subsystem}

The superstructure of the renewable-based energy system is depicted in Figure 2. The energy resources available to the system include both renewable (solar radiation and biomass) and conventional (natural gas and electricity purchased from the grid) resources. The energy system must attend the consumer center's energy demands, namely electricity $E_{d}$, steam $V_{d}$, hot water $Q_{d}$, and chilled water $R_{d}$. It is considered that a part of the electricity produced by the system can be sold to the grid. Also, an auxiliary electricity consumption was considered for most of the candidate technologies.

The candidate technologies in the superstructure can be divided into three groups:

- Generation: These technologies convert the energy resource into intermediate or final products. When the technology consumes a renewable energy resource, it may be referred to as a RET. Considering the energy resource's availability, the generation technologies may be classified as dispatchable (biomass hot water boiler $\mathrm{BH}$, biomass steam boiler BV, natural gas hot water boiler $\mathrm{GH}$, and natural gas steam boiler GV) and non-dispatchable or intermittent (photovoltaic panel PV, flat-plate solar thermal collector ST, and parabolic trough concentrator PT);

- Transformation: These technologies convert an energy product into a different one. The transformation technologies in the superstructure are the electric chiller EC, the single-effect absorption chiller AS, and the double-effect absorption chiller AD;

- Storage: These technologies store the energy product for later use. A hot water storage tank HS and a chilled water storage tank CS have been included in the superstructure.

The only exception to this classification is the cooling tower CT, which is a heat rejection technology that must be installed to dissipate to the ambient air the heat from the transformation technologies and from the thermal integration subsystem. 


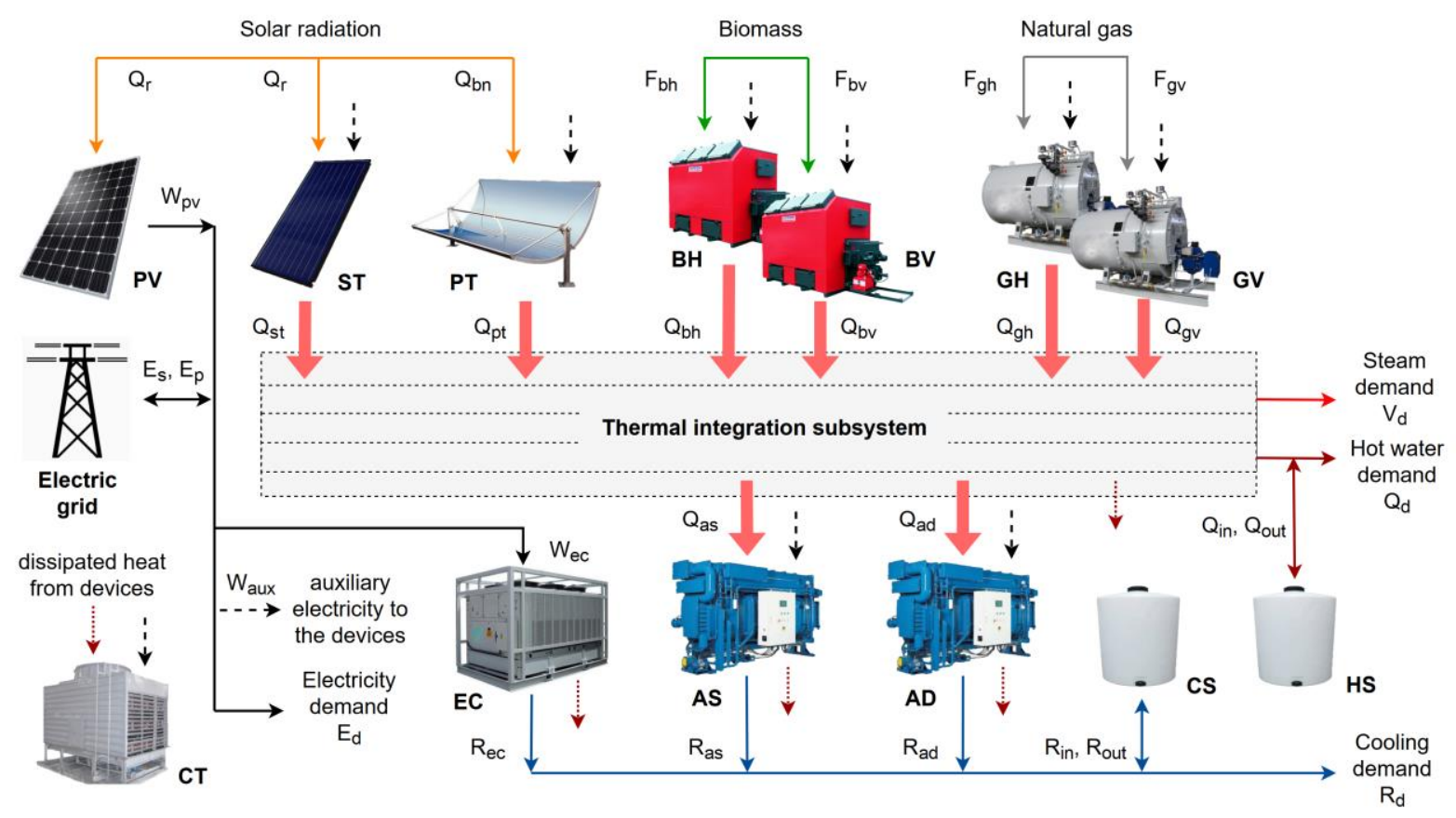

Figure 2: Superstructure of the renewable-based energy system

An appropriate thermal integration requires that the thermal energy flows be evaluated in terms of quantity ( $\mathrm{kWh}$ produced) and quality (temperature levels). In this regard, Figure 3 (a) shows the thermal integration of the hot and cold flows in the energy system (Figure 2), providing their initial (supply) and final (target) temperatures, and the unit flow production or consumption in $\mathrm{kg} / \mathrm{s}$ per MW of operating capacity; six temperature intervals were identified, the first being the hottest. The heat balance in a general temperature interval $k$ is shown in Figure 3 (b).

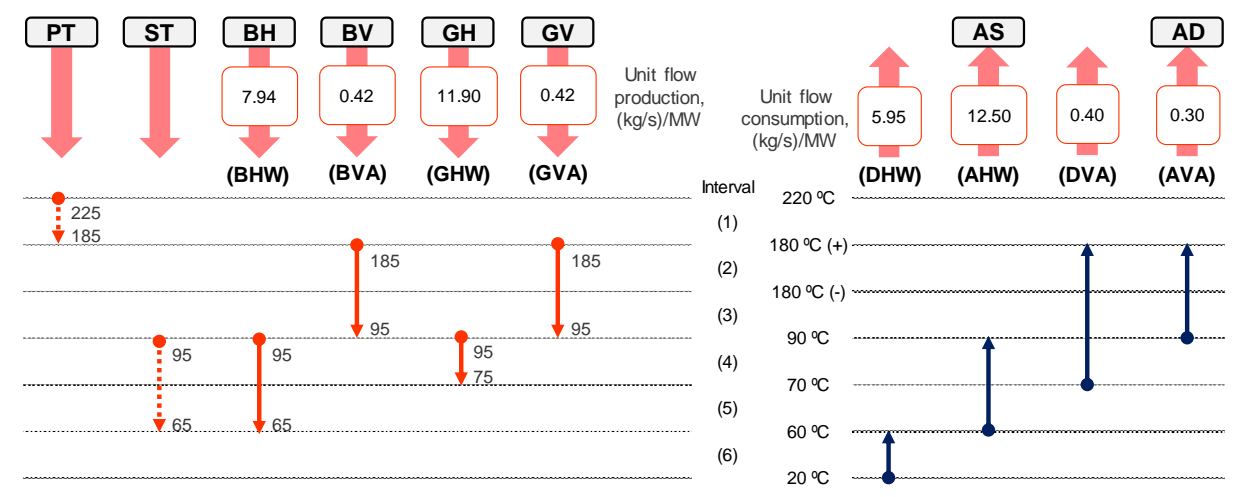

(a)

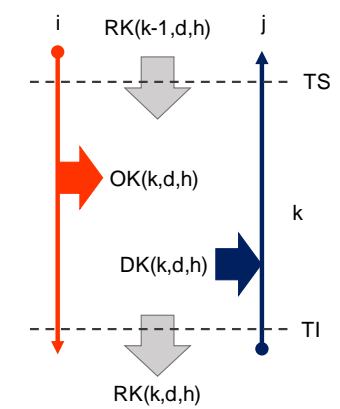

(b)

Figure 3: (a) Thermal integration subsystem, and (b) heat balance in a general temperature interval $k$

Originally introduced in a previous paper (Pina et al., 2018), the superstructure's thermal integration subsystem connects the generation technologies to the transformation technologies and to the steam and hot water energy demands. In other words, it serves as interface between the heat supply and the heat demand through a virtual network of heat exchangers. The generation technologies are associated with the following hot flows: (i) the $\mathrm{BH}$ supplies hot water $Q_{b h}$ at $95^{\circ} \mathrm{C}$ from hot water at $65^{\circ} \mathrm{C}$ (flow BHW); (ii) the BV supplies saturated steam $Q_{b v}$ at $185^{\circ} \mathrm{C}$ from hot water at $95^{\circ} \mathrm{C}$ (flow BVA); (iii) the $\mathrm{GH}$ supplies hot water $Q_{g h}$ at $95^{\circ} \mathrm{C}$ from hot water at $75^{\circ} \mathrm{C}$ (flow GHW); (iv) the GV supplies saturated steam $Q_{g v}$ at $185^{\circ} \mathrm{C}$ from hot water at $95^{\circ} \mathrm{C}$ (flow GVA); (v) the PT supplies heat $Q_{p t}$ directly into the first (hottest) temperature interval; and (vi) the ST supplies heat $Q_{s t}$ directly into the fourth temperature level. The transformation technologies are associated with the following cold flows: (i) the AS produces chilled water $R_{a s}$ at $7{ }^{\circ} \mathrm{C}$, consuming hot water at $90^{\circ} \mathrm{C}$ and discharging it at $60{ }^{\circ} \mathrm{C}$ (flow $\mathrm{AHW}$ ); and (ii) the $\mathrm{AD}$ produces chilled water $R_{a d}$ at $7{ }^{\circ} \mathrm{C}$, consuming saturated steam at $180{ }^{\circ} \mathrm{C}$ and discharging hot water at $90{ }^{\circ} \mathrm{C}$ (flow AVA). Cold flows can also be directly related to the energy demands: steam $V_{d}$ at $180{ }^{\circ} \mathrm{C}$ returning as hot water at $70{ }^{\circ} \mathrm{C}$ (flow DVA), and hot water $Q_{d}$ at $60^{\circ} \mathrm{C}$ returning at $20^{\circ} \mathrm{C}$ (flow DHW). The minimum temperature difference of $5^{\circ} \mathrm{C}$ was adopted in the thermal integration subsystem. 


\subsection{Data collection and elaboration}

All candidate technologies included in the superstructure (Figure 2) are commercially available. The technologies can modulate up to nominal load, except for the intermittent RETs (PV, PT, and ST). Table 3 presents the main technical, economic, and environmental parameters of the technologies, obtained from the manufacturers' catalogues and from the literature. The unit auxiliary electricity consumption cue is given per unit of operation capacity, while the bare module cost $C I$ and the unit $\mathrm{CO}_{2}$ emissions $C O 2 U$ are given per unit of installed capacity. It is assumed that no energy losses take place in the TES units $\left(\eta_{T E S}=1\right)$.

Table 3: Technical, economic, and environmental parameters of the technologies in the superstructure

\begin{tabular}{|c|c|c|c|c|}
\hline $\begin{array}{c}\text { Technology } \\
t\end{array}$ & $\begin{array}{c}\text { Technical } \\
\text { parameters }\end{array}$ & $\begin{array}{c}\text { Unit electricity } \\
\text { consumption cue } \\
\qquad \mathbf{k W}_{\mathrm{el}} / \mathbf{k W} \\
\end{array}$ & $\begin{array}{c}\text { Bare module } \\
\text { cost } C I \\
€ / \mathbf{k} \mathbf{W}_{\text {nom }} \\
\end{array}$ & $\begin{array}{c}\text { Unit } \mathrm{CO}_{2} \\
\text { emissions } \mathrm{CO} 2 U \\
\mathrm{~kg} \mathrm{CO} / \mathrm{kW} \text { nom }\end{array}$ \\
\hline PV & $\begin{array}{c}P_{p v}=0.34 \mathrm{kWp}, A_{m, p v}=1.94 \mathrm{~m}^{2} \\
\operatorname{Rap} P V=5.707 \mathrm{~m}^{2} / \mathrm{kWp} \\
\eta_{p v}=0.1752, \mu_{T}=0.0038^{\circ} \mathrm{C}^{-1}\end{array}$ & - & 1300 & 1840 \\
\hline ST & $\begin{array}{c}A_{m, s t}=12 \mathrm{~m}^{2}, \operatorname{RapST}=1.4286 \\
\mathrm{~m}^{2} / \mathrm{kWp}, \eta_{0}=0.806, k_{l}=2.580 \\
\mathrm{~W} /\left(\mathrm{m}^{2} \cdot \mathrm{K}\right), k_{2}=0.009 \mathrm{~W} /\left(\mathrm{m}^{2} \cdot \mathrm{K}^{2}\right)\end{array}$ & 0.0050 & 500 & 140 \\
\hline PT & $R a p P T=1.5172 \mathrm{~m}^{2} / \mathrm{kW}$ & 0.0164 & 425 & 130 \\
\hline $\mathrm{BH}$ & $\eta_{b h}=Q_{b h} / F_{b h}=0.85$ & 0.0050 & 310 & 15 \\
\hline $\mathrm{BV}$ & $\eta_{b v}=Q_{b v} / F_{b v}=0.85$ & 0.0050 & 375 & 20 \\
\hline $\mathrm{GH}$ & $\eta_{g h}=Q_{g h} / F_{g h}=0.92$ & 0.0050 & 55 & 10 \\
\hline GV & $\eta_{g v}=Q_{g v} / F_{g v}=0.93$ & 0.0050 & 120 & 10 \\
\hline AS & $C O P_{a s}=R_{a s} / Q_{a s}=0.635$ & 0.0050 & 260 & 165 \\
\hline $\mathrm{AD}$ & $C O P_{a d}=R_{a d} / Q_{a d}=1.41$ & 0.0050 & 260 & 165 \\
\hline $\mathrm{EC}$ & $C O P_{e c}=R_{e c} d Q_{e c}=6.11$ & - & 105 & 160 \\
\hline $\mathrm{CT}$ & $\eta_{c t}=1$ & 0.0050 & 30 & 25 \\
\hline $\mathrm{HS}$ & $\eta_{T E S}=1$ & - & 40 & 150 \\
\hline CS & $\eta_{T E S}=1$ & - & 80 & 300 \\
\hline
\end{tabular}

The PT has been modeled using the System Advisor Model (SAM) (NREL, 2018). The SAM is a free software package which contains hourly performance and economic models for concentrating solar power (CSP) systems, photovoltaic, solar hot-water, and generic fuel-use technologies. An in-depth explanation of the model can be found in Wagner and Gilman (2011). Only a few key parameters have been changed in the basic model, leaving the rest with their default values. The considerations were the following: On the model's first page, Location and Resource, METEONORM's weather file for Campinas was imported; System Design is the model's second page, in which the system's nominal ratings are defined; it was considered that (i) the direct normal irradiance available at design point was equal to $950 \mathrm{~W} / \mathrm{m}^{2}$; (ii) the target solar multiple (ratio of the target receiver thermal power and heat sink power) was equal to 1; (iii) the loop inlet and outlet heat transfer fluid (HTF) temperatures were 185 and $225^{\circ} \mathrm{C}$, respectively; (iv) the heat sink power was equal to $1.5 \mathrm{MWth}$; and (v) the hours of storage at design point were zero. Following to the next page, Solar Field, it was necessary to choose a different HTF to match the operation temperatures previously set; thus, the Downtherm RP field HTF fluid was selected. Finally, on the next two pages, Collectors (SCAs) and Receivers (HCEs), the collector SkyFuel SkyTrough and the receiver Schott PTR80 were chosen from their respective libraries.

From the model's results, the following data are given as input to the optimization model developed herein: (i) the area to power ratio RapPT of $1.5172 \mathrm{~m}^{2} / \mathrm{kW}$; and (ii) the unit production per $\mathrm{m}^{2}$ installed of PT, $x_{p t}(d, h)$, for each hourly period $h$ of each representative day $d$.

The bare module costs $C I$ in Table 3 were obtained from various references: Guadalfajara (2016), IEA (2017), Kurup and Turchi (2015), Lazard (2016), and Ramos (2012). The CI is the purchase cost multiplied by a simple module factor, which accounts for transportation, installation, connection costs, etc. Additional economic data include the amortization and maintenance factor fam, equal to $0.15 \mathrm{yr}^{-1}$, and the indirect costs factor fic, equal to 0.20 (Ramos, 2012). The plant's operational lifetime nyr was considered to be 20 years. 
Regarding the unit $\mathrm{CO}_{2}$ emissions values $\mathrm{CO} 2 \mathrm{U}$ in Table 3, they were obtained from Burkhardt et al. (2011), Carvalho (2011), Guadalfajara (2016), Ito et al. (2009), Raluy et al. (2014), and WEC (2016).

Local energy prices are required for the assessment of the system's annual operation cost: (i) the natural gas purchase price is pgncon $=0.035 € / \mathrm{kWh}(\mathrm{LHV})(\mathrm{COMGAS}, 2018)$; (ii) the purchase price of the pellets is pcebio $=0.026 € / \mathrm{kWh}$ (LHV) (Delgado et al., 2018); and (iii) two billing periods apply for the electricity: on-peak tariff pcepta $=0.136 € / \mathrm{kWh}$ (between hours 18 and 20 from March to October and hours 19 and 21 for the remaining months) and off-peak tariff pcevle $=0.094 € / \mathrm{kWh}$ (for the rest of the hours of the year) (CPFL, 2018); additionally, the electricity selling price was assumed to be the purchase price at the corresponding hour minus a penalization of penven $=0.012 € / \mathrm{kWh}$.

In terms of $\mathrm{CO}_{2}$ emissions, the environmental impact associated with the consumption of energy resources is assessed through: (i) the natural gas emission factor $\mathrm{kgCO} 2_{\text {con }}=0.2020 \mathrm{~kg} \mathrm{CO}_{2} / \mathrm{kWh}$ (Rupp and Lamberts, 2017); (ii) the pellets emission factor $\mathrm{kgCO} 2_{\text {bio }}=0.0506 \mathrm{~kg} \mathrm{CO}_{2} / \mathrm{kWh}$ (Delgado et al., 2018); and (iii) the emission factor of the electricity available in the national electric grid $\mathrm{kgCO} 2 e$, which varies hourly and daily. The hourly $\mathrm{kgCO} 2_{e}$ are available for the whole year in (MCTIC, 2018); for the present study, we have processed the data for 2016 to obtain the average hourly $\mathrm{CO}_{2}$ emissions for each representative day $d$. The annual average is $0.6228 \mathrm{~kg} \mathrm{CO} / \mathrm{kWh}_{\text {. }}$

\section{Mathematical model}

A MILP model was developed to determine the optimal cost configuration and operational planning of the renewable-based energy system analyzed herein. The model is composed of decision variables representing: (i) the existence and size of the technologies; (ii) the operation load of each technology in each time interval; (iii) the energy resources exchanged with the economic market (electricity, natural gas, and biomass) and the solar radiation; (iv) the capacity of the TES units and the corresponding energy stored in each time interval; (v) the heat supply and demand in each temperature interval; and (vi) the heat surplus from a temperature interval to the next (heat cascade). The existence of technologies and external (legal) restrictions, such as the permission to sell electricity to the grid, are represented by binary variables, while all other variables are continuous.

The objective function is explained in Section 3.1. The environmental aspects of installing and operating the system are incorporated in the model, as described in Section 3.2. Section 3.3 presents the methodology employed to determine the hourly productions per $\mathrm{m}^{2}$ of PV and ST installed. Finally, Section 3.4. presents the model's constraints.

\subsection{Objective function: Economic criterion}

The objective function to be minimized is the total annual cost $C T E_{t o t}$, which consists of the annual fixed cost $C T E_{f i x}$ and the annual variable cost $C T E_{\text {var }}$.

Min $C T E_{\text {tot }}=C T E_{f i x}+C T E_{\text {var }}$

The annual fixed cost is expressed by Eq. 2, where $\operatorname{PIN}(t)$ is the installed capacity of the technology $t$.

$C T E_{f i x}=f a m \cdot(1+f i c) \cdot \sum_{t} C I(t) \cdot P I N(t)$

The annual variable cost $C T E_{v a r}$ corresponds to the sum, for each hourly period $h$ of each representative day $d$, of the costs of purchasing natural gas $C T E_{\text {gas }}(d, h)$, biomass $C T E_{b i o}(d, h)$, and electricity $C T E_{\text {ele }}(d, h)$ :

$$
\begin{aligned}
& C T E_{\text {var }}=\sum_{d, h} N R Y(d) \cdot\left(C T E_{g a s}(d, h)+C T E_{\text {bio }}(d, h)+C T E_{\text {ele }}(d, h)\right) \\
& C T E_{\text {gas }}(d, h)=\operatorname{pgncon} \cdot\left(F_{g h}(d, h)+F_{g v}(d, h)\right) \\
& C T E_{\text {bio }}(d, h)=\operatorname{pcebio} \cdot\left(F_{b h}(d, h)+F_{b v}(d, h)\right) \\
& C T E_{\text {ele }}(d, h)=\operatorname{pelcom}(d, h) \cdot E_{p}(d, h)-\operatorname{pelven}(d, h) \cdot E_{s}(d, h)
\end{aligned}
$$

where, in each time interval, pelcom $(d, h)$ is the electricity purchase price (on-peak pcepta or off-peak pcevle, as defined in Section 2.3) and pelven $(d, h)$ is the electricity selling price (purchase price pelcom $(d, h)$ minus the penalization penven defined in Section 2.3). 


\subsection{Environmental criterion}

Analogous to the economic criterion (objective function), the total annual $\mathrm{CO}_{2}$ emissions $\mathrm{CO}_{\text {tot }}$ consists of the annual fixed emissions $C O 2_{f i x}$ and the annual variable emissions $C O 2_{v a r}$.

$\mathrm{CO} 2_{\text {tot }}=\mathrm{CO}_{\text {fix }}+\mathrm{CO} 2_{\text {var }}$

The $C O 2_{f i x}$, annualized over the plant's operational lifetime $n y r$ is expressed by Eq. 8 .

$C O 2_{\text {fix }}=\sum_{t} \operatorname{CO2U}(t) \cdot \operatorname{PIN}(t) /$ nyr

The $C O 2_{\text {var }}$ consists of the terms relative to the consumption of natural gas $C O 2_{\text {gas }}(d, h)$, biomass $C O 2_{b i o}(d, h)$, and electricity $\mathrm{CO} 2_{\text {ele }}(d, h)$ :

$$
\begin{aligned}
& C O 2_{\text {var }}=\sum_{d, h} N R Y(d) \cdot\left(\operatorname{CO2}_{g a s}(d, h)+C O 2_{b i o}(d, h)+C O 2_{\text {ele }}(d, h)\right) \\
& C O 2_{\text {gas }}(d, h)=\operatorname{kgCO2} \operatorname{con} \cdot\left(F_{g h}(d, h)+F_{g v}(d, h)\right) \\
& C O 2_{b i o}(d, h)=\operatorname{kgCO2bio} \cdot\left(F_{b h}(d, h)+F_{b v}(d, h)\right) \\
& C O 2_{\text {ele }}(d, h)=\operatorname{kgCO2e}(d, h) \cdot\left(E_{p}(d, h)-E_{s}(d, h)\right)
\end{aligned}
$$

\subsection{PV and ST solar productions}

The performances of the solar technologies are dependent on the local climatic conditions, which vary hourly and daily. Taking the climatic data for the city of Campinas, obtained from METEONORM as explained in Section 2.1, and the technical parameters given in Table 3, the unit production per $\mathrm{m}^{2}$ of installed PV and ST were calculated. As explained in Section 2.3, the unit production per $\mathrm{m}^{2}$ of PT was obtained through the SAM software.

For each hourly period $h$ of each representative day $d$, the unit electricity production per $\mathrm{m}^{2}$ of PV installed $x_{p v}(d, h)$ is determined by Eq. 13, according to the methodology by Duffie et al. (2013). The maximum power $P_{p v}$, surface area $A_{m, p}$, module efficiency $\eta_{p v}$, and temperature coefficient of power $\mu_{T}$ are given in Table 3. Irradiation and cell temperature at SRC conditions are $Q_{r, S R C}=1 \mathrm{~kW} / \mathrm{m}^{2}$ and $T_{c, S R C}=25{ }^{\circ} \mathrm{C}$, respectively. Irradiation, cell temperature and ambient temperature at NOCT conditions are $Q_{r, N O C T}=0.8 \mathrm{~kW} / \mathrm{m}^{2}, T_{c, N O C T}=45^{\circ} \mathrm{C}$ and $T_{a, N O C T}=$ $20{ }^{\circ} \mathrm{C}$, respectively. The efficiency of power-conditioning equipment $\eta_{\mathrm{e}}=0.9$. The hourly cell temperature $T_{c, p v}(d, h)$ and the hourly temperature correction factor $F_{\text {top }}(d, h)$ are obtained by solving Eqs. 14 and 15.

$$
\begin{aligned}
& x_{p v}(d, h)=\frac{P_{p v}}{A_{m, p v}} \cdot \frac{Q_{r}(d, h)}{Q_{r, S R C}} \cdot F_{t o p}(d, h) \cdot \eta_{e} \\
& F_{t o p}(d, h)=1-\mu_{T} \cdot\left(T_{c, p v}(d, h)-T_{c, S R C}\right) \\
& T_{c, p v}(d, h)=T_{a}(d, h)+\left(T_{c, N O C T}-T_{a, N O C T}\right) \cdot \frac{Q_{r}(d, h)}{Q_{r, N O C T}} \cdot\left(1-\frac{\eta_{p v} \cdot F_{t o p}(d, h)}{0.9}\right)
\end{aligned}
$$

The unit production per $\mathrm{m}^{2}$ of ST collector $x_{s t}(d, h)$ is calculated by Eq. 16, in which the performance coefficients $k_{0}, k_{l}$ and $k_{2}$ are found in Table 3, and $\Delta T$ is the temperature difference between the collector $T_{c, s t}=95^{\circ} \mathrm{C}$ and the ambient $T_{a}(d, h)$, according to Eq. 17. Only the positive values of collected heat are considered.

$$
\begin{aligned}
& x_{s t}(d, h)=\operatorname{Max}\left(k_{0} \cdot Q_{r}(d, h)-k_{1} \cdot \Delta T(d, h)-k_{2} \cdot \Delta T(d, h)^{2} ; 0\right) \\
& \Delta T(d, h)=T_{c, s t}-T_{a}(d, h)
\end{aligned}
$$

\subsection{Model constraints}

The objective function is subject to the following types of constraints:

(i) Equipment constraints: Include capacity limits and production restrictions for each technology $t$. Capacity limits are inequality constraints that limit the installed capacity $P I N(t)$ to the maximum installable capacity $\operatorname{PIN}_{M A X}(t)$. The binary variable $Y I N S(t)$ expresses the permission to install the technology $t$.

$P I N(t) \leq Y I N S(t) \cdot \operatorname{PIN}_{M A X}(t)$ 
Production restrictions limit the production of a technology $t$ to its installed capacity and relate the technology's energy consumption to its production. An example is provided herein for the flat-plate solar thermal collector ST:

$Q_{s t}(d, h) \leq x_{s t}(d, h) \cdot \operatorname{RapST} \cdot \operatorname{PIN}(S T)$

An auxiliary electricity consumption has been considered for most technologies. For example, the BV auxiliary electricity consumption $W_{a u x, b v}(d, h)$ is calculated according to Eq. 20.

$W_{a u x, b v}(d, h)=\operatorname{cue}(B V) \cdot Q_{b v}(d, h)$

(ii) Energy balances: For each energy service, in each time interval. Taking the electricity as an example, in each time interval, the following energy balance must hold true:

$E_{p}(d, h)+W_{p v}(d, h)=E_{d}(d, h)+E_{s}(d, h)+W_{e c}(d, h)+W_{a u x}(d, h)$

(iii) Electric grid constraints: A binary variable is used to express the permission to sell electricity to the grid.

(iv) Thermal integration constraints: As explained in Pina et al. (2018), the heat cascade depicted in Figure 3 (a) has been modeled based on the transshipment model of Papoulias and Grossmann (1983). As explained in Section 2.2 , temperature intervals $k$ were defined, in which hot $i$ and cold $j$ flows exchange heat. The heat balance in each temperature interval and time interval is expressed by Eq. 23, in accordance with Figure 3 (b).

$R K(k, d, h)+D K(k, d, h)=R K(k-1, d, h)+O K(k, d, h)$

where $R K(k, d, h)$ is the surplus heat of the temperature interval $k, R K(k-1, d, h)$ is the surplus heat from the previous temperature interval $k-1, O K(k, d, h)$ is the heat supplied by the hot flows $Q I K$ plus the ST and PT solar heat (Eq. 23) and $D K(k, d, h)$ is the heat consumed by the cold flows $Q J K$ (Eq. 24). The fundamental requirement of the Second Law of Thermodynamics is that $R K(k) \geq 0$.

$$
\begin{aligned}
& O K(k, d, h)=Y S K(k) \cdot Q_{s t}(d, h)+Y P K(k) \cdot Q_{p t}(d, h)+\sum_{i} Q I K(i, k, d, h) \\
& D K(k, d, h)=\sum_{j} Q J K(j, k, d, h)
\end{aligned}
$$

As explained in Section 2.3, the ST and the PT supply heat directly into the corresponding temperature interval; this is done through the binary variables $Y S K(k)$ and $Y P K(k)$, which express the temperature interval in which the solar heat $Q_{s t}(d, h)$ and $Q_{p t}(d, h)$ are delivered, respectively.

For each time interval, each of the thermal flows entering $\left(Q_{s t}, Q_{p t}, Q_{b h}, Q_{b v}, Q_{g h}, Q_{g v}\right)$ and leaving $\left(Q_{d}+Q_{i n}-Q_{o u t}\right.$ $V_{d}, Q_{a s}, Q_{a d}$ ) the thermal integration subsystem (Figure 2 and Figure 3 (a)) can be determined as the sum of the total heat supplied or demanded throughout the temperature intervals. An example is provided below for the $\mathrm{BH}$ :

$Q_{b h}(d, h)=\sum_{k} Q I K(B H W, k, d, h)$

\section{Results}

The optimization model has been solved using the software LINGO (Schrage, 1999). Different system configurations have been evaluated considering different structural and operational conditions. Structural conditions involved the permission to install the candidate technologies from the superstructure depicted in Figure 2, while operational conditions concerned the different approaches to the interconnection with the electric grid.

First, the reference system (Configuration A) was obtained by removing the permission to install the RETs and TES units. The optimal economic cost solution (Configuration B) was then evaluated, in which all candidate technologies could be installed, and the system could purchase as much electricity from the grid as necessary. Based on the optimal economic solution, an additional system configuration (Configuration C) was obtained by imposing the condition of a zero annual balance with the electric grid (throughout the year, the system must inject back into the electric grid the same amount of purchased electricity). The main results obtained for each system are shown in Table 4 and Table 5. Moreover, the configuration and annual energy flows of the reference and optimal economic cost configurations are depicted in Figure 4; the thermally integrated technologies are found enclosed in the dashed line. 
Table 4: Installed technologies in the reference and optimal economic configurations.

\begin{tabular}{|c|c|c|c|c|c|c|c|c|c|}
\hline \multirow[b]{2}{*}{ Technology } & \multicolumn{3}{|c|}{ Configuration A } & \multicolumn{3}{|c|}{ Configuration B } & \multicolumn{3}{|c|}{ Configuration $\mathrm{C}$} \\
\hline & $\begin{array}{l}P I N, \\
\text { kW }\end{array}$ & $\begin{array}{c}\text { Investment, } \\
€\end{array}$ & $\begin{array}{c}f u, \\
\%\end{array}$ & $\begin{array}{l}P I N, \\
\text { kW }\end{array}$ & $\begin{array}{c}\text { Investment, } \\
€\end{array}$ & $\begin{array}{r}f u, \\
\%\end{array}$ & $\begin{array}{l}P I N, \\
\text { kW }\end{array}$ & $\begin{array}{c}\text { Investment, } \\
€\end{array}$ & $\begin{array}{r}f u, \\
\%\end{array}$ \\
\hline PV & $\mathrm{x}$ & $\mathrm{x}$ & $\mathrm{x}$ & 0 & 0 & 0 & 6,344 & $9,896,792$ & 18.8 \\
\hline $\mathrm{ST}$ & $\mathrm{x}$ & $\mathrm{x}$ & $\mathrm{x}$ & 0 & 0 & 0 & 0 & 0 & 0 \\
\hline PT & $\mathrm{x}$ & $\mathrm{x}$ & $\mathrm{x}$ & 0 & 0 & 0 & 0 & 0 & 0 \\
\hline $\mathrm{BH}$ & $\mathrm{x}$ & $\mathrm{x}$ & $\mathrm{x}$ & 0 & 0 & 0 & 0 & 0 & 0 \\
\hline BV & $\mathrm{x}$ & $\mathrm{x}$ & $\mathrm{x}$ & 533 & 239,714 & 96.7 & 533 & 239,714 & 96.7 \\
\hline $\mathrm{GH}$ & 76 & 5,047 & 1.6 & 27 & 1,808 & 2.0 & 27 & 1,808 & 2.0 \\
\hline GV & 780 & 112,356 & 75.6 & 248 & 35,648 & 30.6 & 248 & 35,648 & 30.6 \\
\hline AS & 0 & 0 & 0 & 0 & 0 & 0 & 0 & 0 & 0 \\
\hline $\mathrm{AD}$ & 0 & 0 & 0 & 0 & 0 & 0 & 0 & 0 & 0 \\
\hline $\mathrm{EC}$ & 879 & 110,781 & 61.7 & 871 & 109,726 & 62.3 & 854 & 107,616 & 63.6 \\
\hline CT & 1,023 & 36,833 & 61.7 & 1,013 & 36,482 & 62.3 & 994 & 35,781 & 63.6 \\
\hline $\mathrm{HS}, \mathrm{kWh}$ & $\mathrm{x}$ & $\mathrm{X}$ & $\mathrm{x}$ & 49 & 2,356 & - & 49 & 2,356 & - \\
\hline $\mathrm{CS}, \mathrm{kWh}$ & $\mathrm{x}$ & $\mathrm{x}$ & $\mathrm{x}$ & 8 & 804 & - & 42 & 4,019 & - \\
\hline
\end{tabular}

Table 5: Main results for the reference and optimal economic configurations.

\begin{tabular}{|l|r|r|r|}
\hline & Configuration A & Configuration B & Configuration C \\
\hline Natural gas, $\mathrm{MWh} / \mathrm{yr}$ & 5,567 & 719 & 719 \\
Biomass, $\mathrm{MWh} / \mathrm{yr}$ & 0 & 5,304 & 5,304 \\
Purchased electricity, $\mathrm{MWh} / \mathrm{yr}$ & 10,466 & 10,466 & 5,215 \\
Sold electricity, MWh/yr & 0 & 0 & 5,215 \\
\hline Natural gas, $€ / \mathrm{yr}$ & 194,851 & 25,152 & 25,152 \\
Biomass, $€ / \mathrm{yr}$ & 0 & 137,904 & 137,904 \\
Purchased electricity, $€ / \mathrm{yr}$ & $1,021,641$ & $1,021,626$ & 527,973 \\
Sold electricity, $€ / \mathrm{yr}$ & 0 & 0 & 427,603 \\
Annual variable cost, $€ / \mathrm{yr}$ & $1,216,492$ & $1,184,682$ & 263,425 \\
Annual fixed cost, $€ / \mathrm{yr}$ & 39,753 & 63,981 & $1,548,560$ \\
Total annual cost, $€ / \mathrm{yr}$ & $1,256,245$ & $1,248,662$ & $1,811,985$ \\
\hline Investment cost, $€$ & 265,017 & 426,537 & $10,323,732$ \\
\hline Natural gas, $\mathrm{kg} \mathrm{CO} / \mathrm{yr}$ & $1,124,568$ & 145,164 & 145,164 \\
Biomass, $\mathrm{kg} \mathrm{CO} / \mathrm{yr}$ & 0 & 268,223 & 268,223 \\
Purchased electricity, $\mathrm{kg} \mathrm{CO} / \mathrm{yr}$ & $6,508,147$ & $6,508,152$ & $3,254,982$ \\
Sold electricity, $\mathrm{kg} \mathrm{CO}_{2} / \mathrm{yr}$ & 0 & 0 & $3,239,618$ \\
Annual variable $\mathrm{CO}_{2}$ emissions, $\mathrm{kg} \mathrm{CO}_{2} / \mathrm{yr}$ & $7,632,715$ & $6,921,540$ & 428,752 \\
Annual fixed $\mathrm{CO}_{2}$ emissions, $\mathrm{kg} \mathrm{CO}_{2} / \mathrm{yr}$ & 8,741 & 9,397 & 593,398 \\
Total annual $\mathrm{CO}_{2}$ emissions, $\mathrm{kg} \mathrm{CO} / \mathrm{yr}$ & $7,641,456$ & $6,930,937$ & $1,022,150$ \\
\hline
\end{tabular}

As can be seen from Table 4, the only technologies installed in the reference system (Configuration A) include hot water GH and steam GV natural gas boilers, the electric chiller EC, and the cooling tower CT. The GV operates with a high load factor (75.6\%), while the GH only covers occasional heat peak demands; in fact, the $\mathrm{GH}$ is virtually irrelevant to the system as it only covers $0.2 \%$ of the total annual heat production. In the case of the Configuration B, there is a shift from natural gas to biomass: a biomass steam boiler BV is installed to the detriment of the GV and GH, whose capacities are reduced by $65 \%$. The BV operates with a very high load factor reaching the $97 \%$ figure, while the $\mathrm{GV}$ is responsible for covering heat peak demands (load factor $30.6 \%$ ). By contrast, the cooling production remains entirely based on electricity from the electric grid in the EC. Even though this solution includes a hot water HS and a chilled water CS storage tanks, their capacities are extremely low. Configuration $\mathrm{C}$ is practically equal to the optimal economic cost, however with $6,344 \mathrm{~kW}$ of photovoltaic panels $\mathrm{PV}$. It should be mentioned that the PV load factor has been calculated considering its nominal module power and whole year operation. 

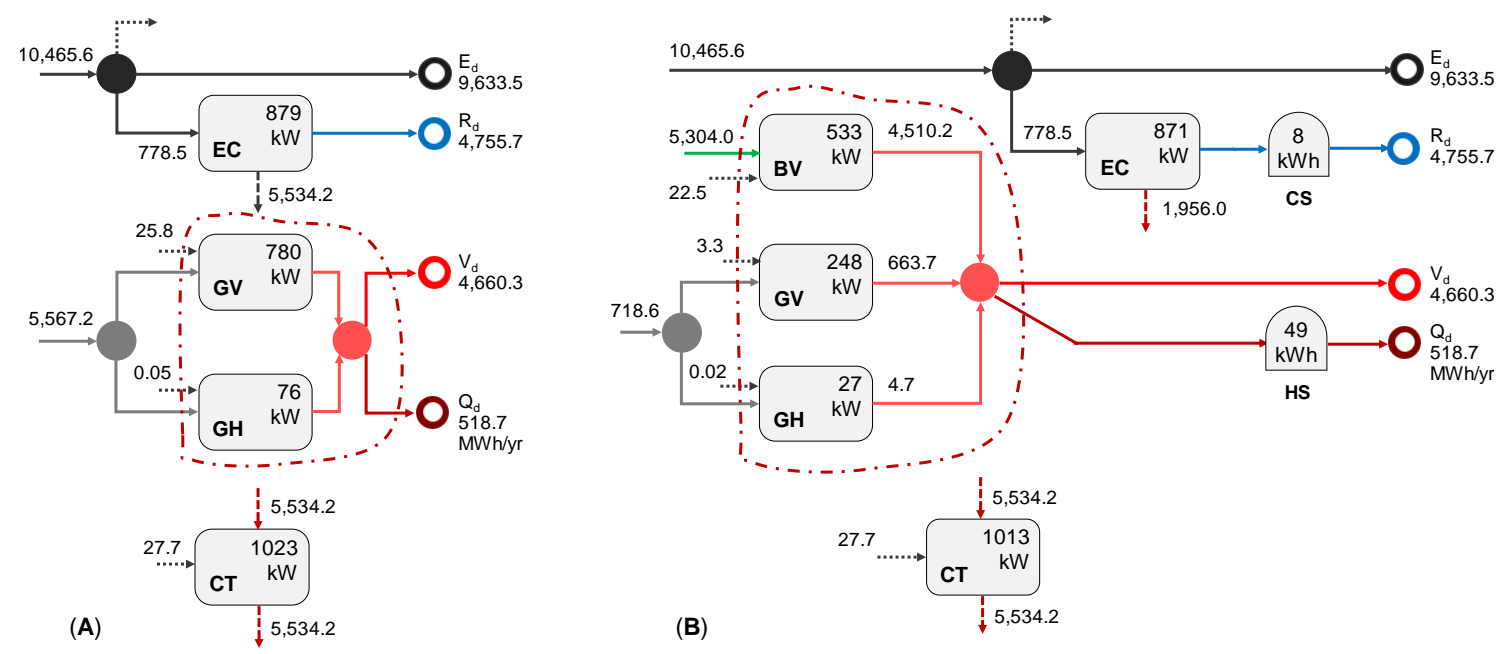

Figure 4: Configurations A and B with annual energy flows in MWh.

The results presented in Table 5 show that Configuration B has a total annual cost only $0.6 \%$ smaller than Configuration A; the fixed and the variable terms, on the other hand, are not the same: the annual installation and amortization cost in the optimal economic cost solution is about $61 \%$ higher than that of the refence system, while the annual variable cost is $2.6 \%$ lower. The increased investment $\operatorname{cost}(\Delta \operatorname{Inv}=426,537-265,017=161,520$ $€)$ is compensated by a reduction in the annual variable costs $\left(\triangle C T E_{v a r}=1,216,492-1,184,682=31,810 € / \mathrm{yr}\right)$, thus resulting in a Payback Period of 5 years. Regarding the total annual $\mathrm{CO}_{2}$ emissions, Configuration $\mathrm{B}$ achieves a $9 \%$ reduction in the total annual $\mathrm{CO}_{2}$ emissions relative to Configuration $\mathrm{A}$; this is due to: (i) the shift from natural gas to biomass, which allowed the $\mathrm{CO}_{2}$ emissions associated with the thermal energy production to be reduced from $1,124 \mathrm{tCO}_{2} / \mathrm{yr}$ to $413 \mathrm{tCO}_{2} / \mathrm{yr}$; and (ii) the increase in the annual fixed $\mathrm{CO}_{2}$ emissions from 8.7 to $9.4 \mathrm{tCO}_{2} / \mathrm{yr}$.

The obligation to compensate, throughout the year, every kWh of purchased electricity with another kWh of sold electricity results in the installation of $6,344 \mathrm{~kW}$ of PV in Configuration C. This has a twofold effect: On the one hand, there is a dramatic increase in the investment cost of the system from $426,537 €$ to $10,323,732 €, 96 \%$ of which is attributed to the PV; on the other hand, the annual operation costs are sharply reduced by $78 \%$, as now the system buys only a half of the electricity consumed $(5,215 \mathrm{MWh} / \mathrm{yr}$ ) and is able to sell the same amount, generating an income of $427,603 € / \mathrm{yr}$. As a consequence, the total annual cost of Configuration $\mathrm{C}$ is $45 \%$ higher than that of the Configuration $\mathrm{B}$, with a Payback Period of 11 years. By contrast, the total annual $\mathrm{CO}_{2}$ emissions are drastically reduced (86\%), as the annual operation $\mathrm{CO}_{2}$ emissions drop by $92 \%$, compensating the increase in the emissions relative to the manufacturing of the PV.

Based on the previously discussed Configurations, removing the permission to install natural gas boilers in Configurations B and C led to the no fossil fuels and the $100 \%$ renewable Configurations D and E, respectively. The total annual costs and total annual $\mathrm{CO}_{2}$ emissions for all Configurations are shown in the graph of Figure 5. As can be seen, natural gas did not play a significant role in neither of the optimal solutions.

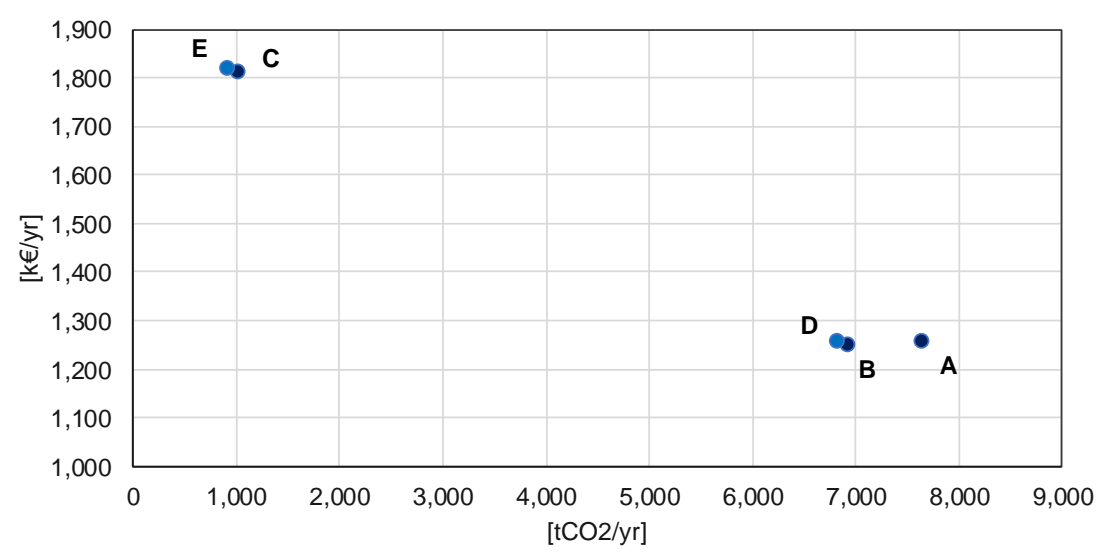

Figure 5: Total annual cost and total annual $\mathrm{CO}_{2}$ emissions of different Configurations. 


\section{Conclusions}

The present work was a follow-up to the previous study by Pina et al. (2018), in which a MILP model was developed to determine the optimal cost configuration and hourly operation strategy of a polygeneration system that must attend the energy demands of a Brazilian university hospital. Under the conditions considered in that study, it was evident from the results obtained that cogeneration gas engines were the most economically interesting option; consequently, the solar energy technologies, such as photovoltaic panels and solar thermal collectors, were never included in the optimal solutions except under highly advantageous conditions.

In order to continue in the direction of a $100 \%$ renewable energy system, it was proposed herein to improve the optimization model by: (i) removing the cogeneration gas engines altogether; (ii) incorporating an additional renewable energy resource, biomass, so that the system has both intermittent and dispatchable RES available; and (iii) providing RETs capable of producing thermal energy at higher temperature levels, such as the parabolic trough concentrators and the biomass steam boiler. The thermal integration subsystem originally introduced by Pina et al. (2018) was adjusted accordingly, thus allowing the optimization model to optimally match the heat supply and demand considering both quantity and quality (temperature). Moreover, the environmental aspects of installing and operating the energy system were taken into account in the improved optimization model.

In the present work, the results obtained for the case study of the Brazilian university hospital showed that biomass was economically the most appropriate fuel for heat production, displacing deployment of natural gas and reaching a share of $87 \%$ of the total thermal energy produced. The same cannot be said about the cooling production, which was made entirely with electricity purchased from the electric grid, thus proving that electricity was more appropriate for cooling production in the electric chiller than heat in the absorption chillers. Despite the shift from natural gas to biomass, the optimal economic system was rather similar to the reference system.

Solar energy technologies (both photovoltaic and solar thermal) remained elusive. Photovoltaic panels were only included when the system was required to achieve a zero annual balance with the electric grid. Thus, it would be interesting to carry out a sensitivity analysis to better understand the conditions in which these technologies become feasible in relation to other energy resources (e.g. natural gas and biomass) and to the interaction of the system with the electric grid. Likewise, it would be interesting to perform a sensitivity analysis concerning the use of absorption chillers for cooling production, as opposed to the mechanical chillers consuming electricity.

\section{Acknowledgements}

This work was developed in the frame of the research projects ENE2014-57262-R and ENE2017-87711-R, partially funded by the Spanish Government (Energy Program), the Government of Aragon (Spain) and the EU Social Fund (FEDER Program). Eduardo Pina acknowledges financial support from the Brazilian Federal Government and CNPq Science Without Borders Program.

\section{References}

Biglia, A., Caredda, F.V., Fabrizio, E., Filippi, M., Mandas, N., 2017. Technical-economic feasibility of CHP systems in large hospitals through the Energy Hub method: The case of Cagliari AOB. Energy Build. 147, 101-112. doi:10.1016/j.enbuild.2017.04.047.

Burkhardt, J.J., Heath, G.A., Turchi, C.S., 2011. Life cycle assessment of a parabolic trough concentrating solar power plant and the impacts of key design alternatives. Environ. Sci. Technol. 45, 2457-2464. doi:10.1021/es1033266.

Carvalho, M., 2011. Thermoeconomic and environmental analyses for the synthesis of polygeneration systems in the residential-commercial sector. PhD Thesis - University of Zaragoza. https://zaguan.unizar.es/record/5744/files/TESIS-2011025.pdf (accessed 16.11.18).

COMGAS, 2018. Natural gas rates. https://www.comgas.com.br/tarifas/ (accessed 6.9.18).

CPFL, 2018. Electricity rates. CPFL Paul. https://www.cpflempresas.com.br/institucional/tarifas.aspx?emp=CPFL (accessed 6.9.18).

Delgado, D., Carvalho, M., Moreira, L., Junior, C., 2018. Analysis of Biomass-fired Boilers in a Polygeneration System for a Hospital. Front. Manag. Res. 2, 1-13. doi:10.22606/fmr.2018.21001.

Duffie, J.A., Beckman, W.A., Worek, W.M., 2013. Solar Engineering of Thermal Processes, 4th ed, Wiley. doi:10.1115/1.2930068. 
Gimelli, A., Muccillo, M., 2013. Optimization criteria for cogeneration systems: Multi-objective approach and application in an hospital facility. Appl. Energy 104, 910-923. doi:10.1016/j.apenergy.2012.11.076.

Guadalfajara, M., 2016. Economic and environmental analysis of central solar heating plants with seasonal storage for the residential sector. PhD Thesis - University of Zaragoza. https://zaguan.unizar.es/record/56714/files/TESIS-2016-196.pdf (accessed 16.11.18).

IEA, 2017. District Energy Systems in China. https://www.iea.org/publications/freepublications/publication/ DistrictEnergySystemsinChina.pdf (accessed 16.11.18).

Ito, M., Komoto, K., Kurokawa, K., 2009. A comparative LCA study on potential of very-large scale PV systems in Gobi desert. Conf. Rec. IEEE Photovolt. Spec. Conf. 000729-000732. doi:10.1109/PVSC.2009.5411180.

Iyer, R.R., Grossmann, I.E., 1998. Synthesis and operational planning of utility systems for multiperiod operation. Comput. Chem. Eng. 22, 979-993. doi:10.1016/S0098-1354(97)00270-6.

Kurup, P., Turchi, C.S., 2015. Parabolic Trough Collector Cost Update for the System Advisor Model (SAM). Tech. Rep. NREL/TP-6A20-65228 Natl. Renew. Energy Lab. 1-40. doi:10.2172/1227713.

LAZARD, 2016. Lazard's Levelized Cost of Energy Analysis 10.0, 1-21. https://www.lazard.com/media/438038/levelizedcost-of-energy-v100.pdf (accessed 16.11.18).

Lozano, M.A., Ramos, J.C., Carvalho, M., Serra, L.M., 2009. Structure optimization of energy supply systems in tertiary sector buildings. Energy Build. 41, 1063-1075. doi:10.1016/j.enbuild.2009.05.008.

Lozano, M.A., Ramos, J.C., Serra, L.M., 2010. Cost optimization of the design of CHCP (combined heat, cooling and power) systems under legal constraints. Energy 35, 794-805. doi:10.1016/j.energy.2009.08.022.

Mancarella, P., 2014. MES (multi-energy systems): An overview of concepts and evaluation models. Energy 65, 1-17. doi:10.1016/j.energy.2013.10.041.

MCTIC, 2018. Fatores de emissão da margem de operação pelo método da análise de despacho. http://www.mctic.gov.br/mctic/opencms/ciencia/SEPED/clima/textogeral/emissao_despacho.html (accessed 7.2.18) [In Portuguese].

METEOTEST, 2018. METEONORM. http://www.meteonorm.com/ (accessed 6.9.18).

NREL, 2018. System Advisor Model (SAM) . https://sam.nrel.gov/ (accessed 6.9.18).

Papoulias, S.A., Grossmann, I.E., 1983. A structural optimization approach in process synthesis-II: Heat recovery networks. Comput. Chem. Eng. 7, 707-721. doi:10.1016/0098-1354(83)85023-6.

Pina, E.A., Lozano, M.A., Serra, L.M., 2018. Optimal design of polygeneration systems supported with renewable energy sources and energy storage for a Brazilian hospital, in: Proceedings of ECOS 2018. Guimaraes, Portugal.

Raluy, R.G., Serra, L.M., Guadalfajara, M., Lozano, M.A., 2014. Life cycle assessment of central solar heating plants with seasonal storage. Energy Procedia 48, 966-976. doi:10.1016/j.egypro.2014.02.110.

Ramos, J.C., 2012. Optimización del diseño y operación de sistemas de cogeneración para el sector residencial comercial. PhD Thesis - University of Zaragoza. https://zaguan.unizar.es/record/9901/files/TESIS-2012-136.pdf (accessed 16.11.18).

Rong, A., Lahdelma, R., 2016. Role of polygeneration in sustainable energy system development challenges and opportunities from optimization viewpoints. Renew. Sustain. Energy Rev. 53, 363-372. doi:10.1016/j.rser.2015.08.060.

Rupp, R.F., Lamberts, R., 2017. Fatores de conversão de energia elétrica e térmica em energia primária e em emissões de dióxido de carbono a serem usados na etiquetagem de nível de eficiência energética de edificações [In Portuguese]. http://cb3e.ufsc.br/sites/default/files/RI_61_2017_RelatorioFatoresDeConversaoEnergiaEletricaTermica_EnergiaPrimaria_E missoesCO2_paraPBEEdifica\%20\%28corrigido\%29_0.pdf (accessed 16.11.18).

Santo, D.B., 2014. An energy and exergy analysis of a high-efficiency engine trigeneration system for a hospital: A case study methodology based on annual energy demand profiles. Energy Build. 76, 185-198. doi:10.1016/j.enbuild.2014.02.014.

Schrage, L., 1999. Optimization modeling with LINGO. Lindo Systems.

Serra, L.M., Lozano, M.A., Ramos, J., Ensinas, A. V., Nebra, S.A., 2009. Polygeneration and efficient use of natural resources. Energy 34, 575-586. doi:10.1016/j.energy.2008.08.013.

Wagner, M.J., Gilman, P., 2011. Technical manual for the SAM physical trough model, NREL/TP-55 Technical report. https://www.nrel.gov/docs/fy11osti/51825.pdf (accessed 16.11.18).

World Energy Council [WEC], 2016. World Energy Resources: Solar 2016. World Energy Counc. https://www.worldenergy.org/wp-content/uploads/2013/10/WER_2013_8_Solar_revised.pdf (accessed 6.9.18).

Yokoyama, R., Shinano, Y., Taniguchi, S., Ohkura, M., Wakui, T., 2015. Optimization of energy supply systems by MILP branch and bound method in consideration of hierarchical relationship between design and operation. Energy Convers. Manag. 92, 92-104. doi:10.1016/j.enconman.2014.12.020. 


\title{
Experimental plant for analyzing the technical feasibility of decentralized solar heat feed-in
}

\author{
Kai Schäfer and Thomas Schmidt \\ Solites - Steinbeis Research Institute for Solar and Sustainable Thermal Energy Systems, \\ Meitnerstraße 8, 70563 Stuttgart, Germany
}

\begin{abstract}
To investigate the decentralized feed-in of solar heat into district heating networks, an experimental plant was built in Düsseldorf. This plant is composed of a collector field with $218 \mathrm{~m}^{2}$ Aperture and a prototype feed-in substation. The setup is installed in a multi-family building, which is supplied by district heat from Stadtwerke Düsseldorf AG. The following publication focuses on three main parts:
\end{abstract}

1. Technical challenges for solar thermal plants with decentralized feed-in into district heating networks.

2. The hydraulic design of the experimental plant.

3. First monitoring results of the solar heat feed-in.

Keywords: decentralized feed-in, solar heat, district heat, experimental plant

\section{Introduction}

The research project "Decentralized integration of heat from renewable energies into the CHP district heating system of Stadtwerke Düsseldorf AG" (short title SWD.SOL) started in May 2015. Five project partners are involved: the utility Stadtwerke Düsseldorf AG, the German district heating association AGFW, the housing company Rheinwohnungsbau GmbH Düsseldorf, the environmental agency of the state capital (Umweltamt Landeshauptstadt Düsseldorf) and the Steinbeis Research Institute Solites.

The objective of the project is to analyze the technical feasibility of decentral heat feed-in based on the example of a mid-large solar thermal plant. For this purpose, an experimental plant composed of a prototype feed-in substation and a collector field with $218 \mathrm{~m}^{2}$ Aperture $\left(232 \mathrm{~m}^{2}\right.$ Gross $)$ was installed in a multi-family building supplied by district heat. The experimental plant is located in Düsseldorf.

The operational behavior of the plant is monitored and evaluated. These measurement data deliver the base for a simulation study, whose aim is to optimise the controlling and operational management concept of the feed-in station. The following publication focuses on three main aspects. At first, the technical challenges for solar thermal plants with decentralized feed-in into district heating networks are discussed. At second, the hydraulic design of the experimental feed-in station is presented. As third aspect, first monitoring results of the solar heat feed-in are shown.

\section{Bases}

The section addresses the technical boundary conditions at the feed-in and extraction location of solar thermal plants with decentralized heat feed-in into a district heating network. See Fig. 2 for an illustration of the terms.

All in all, the technical boundary conditions at the feed-in and extraction location are determined by the hydraulic pressure and the temperature of the fluid inside the DH network. The following part contains a description of the boundary conditions, which are relevant within the context of decentralized heat feed-in. This part is considering the return to supply feed-in variant only (RF/SF feed-in).

- Temperature level

The temperature level at the feed-in location is determined by the supply temperature of the central heat feed- 
in unit. For that, an adjustment depending on the ambient temperature is very common. This leads to variations in the temperature level at the feed-in location, which can be classified as slow according to time. Based on the DH network and the position in this network, supply flow temperatures between $70{ }^{\circ} \mathrm{C}$ to $100{ }^{\circ} \mathrm{C}$ are common during summer.

- $\quad$ Temperature difference

Like the temperature level, the temperature difference between the feed-in and extraction location is also subject to changes during the year. Usual values for the summer period vary between $20 \mathrm{~K}$ and $30 \mathrm{~K}$. During the transitional periods (spring and autumn), the temperature difference continues to rise. With respect to a variety of DH systems, values of over $40 \mathrm{~K}$ are fairly common in the winter period.

- Differential pressure

The differential pressure between the feed-in and the extraction location is substantially determined by the position in the DH network. Values vary between the amount at the hydraulic critical net-point of the DH network (often approx. 1 bar) and the one at the central pump for increasing the network pressure (sometimes larger than 10 bar). Furthermore, the temporal profile of the differential pressure can be subject to very dynamic changes. As the analyses form Lennermo [Lennermo 2015 a] show, network operators are quite often not correctly informed about the real fluctuations of the differential pressure at potential feed-in locations. For example, Fig. 1 shows a section of a measurement series. The specified results relate to the differential pressure between the supply and return pipe at a certain position within the DH system of Malmö at which the heating network operator assumed mostly constant differential pressures.

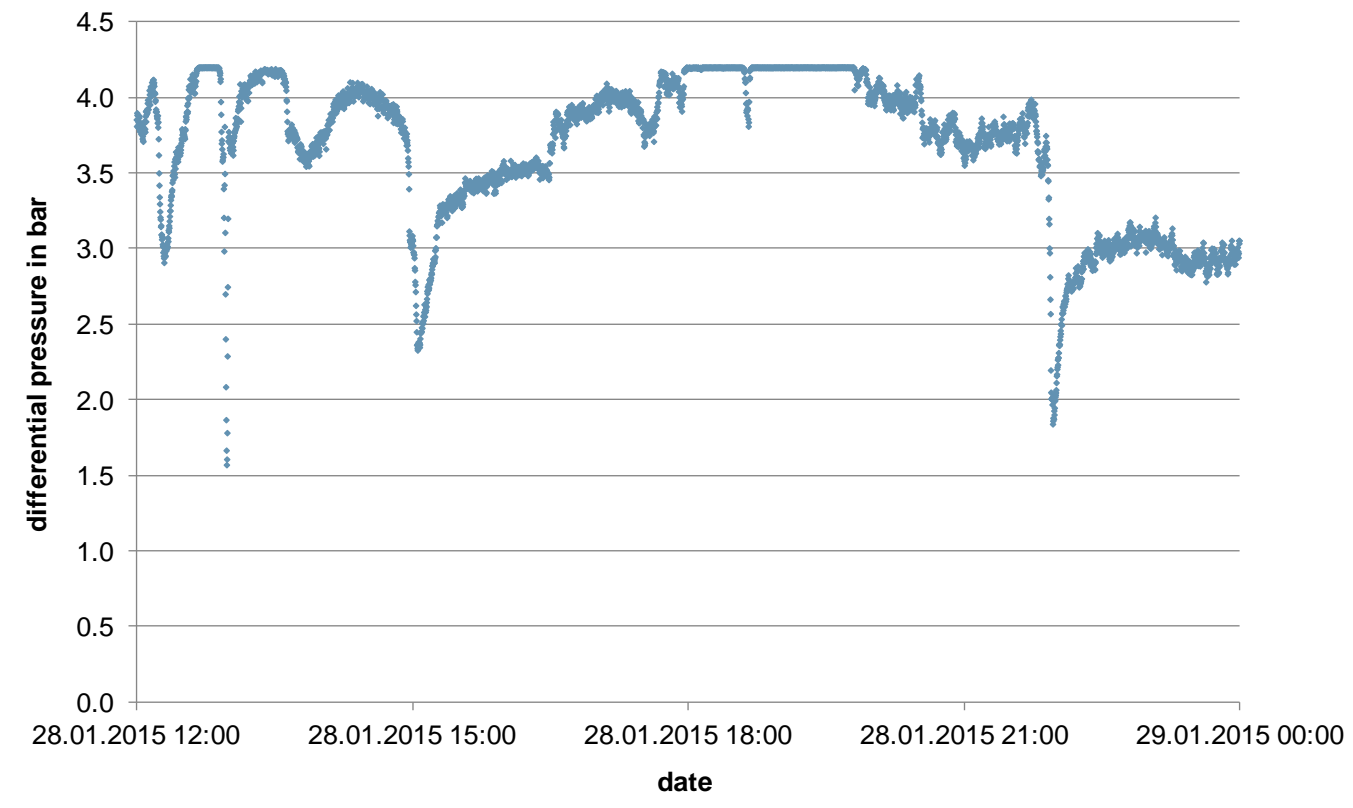

Fig. 1: Instantaneous values of the differential pressure between supply and return pipe; measurement has been done at a potential feed-in location in the DH network system of Malmö, Sweden; time step of measurement 10 s; source [Lennermo 2015 b] 


\section{Technical challenges}

Fig. 2 shows a schematic illustration of a solar thermal plant connected decentrally to the district heating network. The setup can be divided in (i) a collector loop and (ii) a feed-in loop. In the following, the technical challenges for solar thermal plants with decentralized feed-in are summarized. A separation according to the hydraulic loops of the example in Fig. 2 is done.

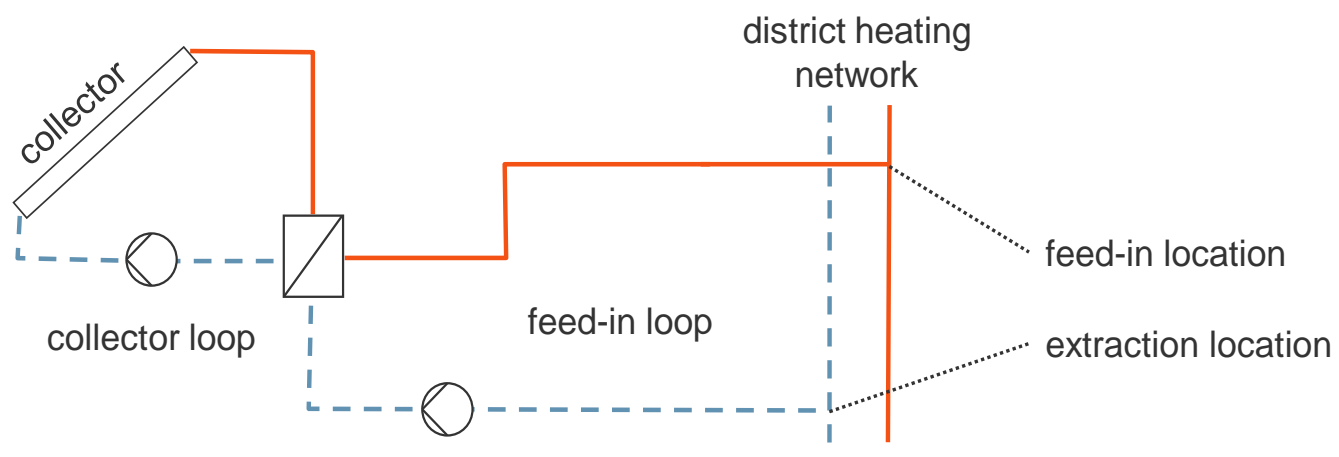

Fig. 2: Schematic representation of a solar thermal plant variant for decentralized feed-in; for way of example the RF/SF feed-in is shown

\subsection{Feed-in loop}

The plant engineering in the feed-in loop basically has to solve two different tasks. On the one hand, the variable differential pressure between the feed-in and the extraction location must be exceeded to generate a flow rate in the feed-in loop. On the other hand, the flow rate must be adjusted to observe the required target temperature in accordance with the variable solar heat output available at the heat exchanger.

If both influencing parameters (differential pressure and solar heat output to be fed-in) present quick changes over time (which is often the case), it represents a very demanding control task.

However, if just one of the two specified influencing parameters present changes, the required target temperature control can be classified as unproblematic. For example this situation can be compared with solar thermal plants in which the collector loop is connected to a heat storage. In such a plant configuration the differential pressure in the corresponding hydraulic loop (storage charging loop) is almost constant. The almost constant pressure is only influenced by control demands for the pump, due to varying solar irradiation to keep the targeted DH network supply temperature.

Besides, every period without solar heat feed-in leads to a decrease of temperature within the connection pipes between the net heat exchanger and the feed-in location. Consequently, each start-up procedure of decentralized feed-in involves the risk of generating a cold node in the supply pipe of the DH network. To avoid this, technical measures are available (comparable to the solutions existing for conventional substations).

\subsection{Collector loop}

Compared with the conventional application range of solar thermal plants the temperature conditions in large DH networks are fairly uncommon. Both the temperature level and the temperature difference must be classified as high. In addition the requirement for a low number of start-up procedures of decentralized feed-in (expressed by AGFW) complicates the operation situation. According to this requirement, the temperature differences in the collector loop (classified as high) are to be maintained even during times with medium to low solar irradiation and relatively high temperature levels.

There are limitations for the variation of the flow speed inside the collector loop. The upper limit is defined by the tolerable maximum pressure drop in the hydraulic loop, the lower limit by the behavior of the fluid inside the collectors. According to physics, the degree of flow turbulence decreases in case of reduced flow speed and constant fluid temperature. For thermal and hydraulic reasons, a change of the flow state inside the collectors into the laminar flow range must be avoided during plant operation. Otherwise considerable reduction of the collector efficiency and the hydraulic friction pressure would occur. The latter may result in an unequal flow distribution through the single collector rows within the field since their hydraulic balancing is commonly carried out for turbulent flow conditions. 


\section{Experimental plant}

This chapter gives some general information about the experimental plant and presents the hydraulic design.

\subsection{General information about the experimental plant}

In May 2017 the experimental plant was taken into operation. Different companies were involved in the implementation of the plant. The collector field was planned and mounted form the company Wagner Solar GmbH, which used a double-glazed flat plate collector for the project. The detailed hydraulic planning as well as the construction of the feed-in substation was done by Kring TWT GmbH. The plant control and the monitoring system were setup by Samson AG as a subcontractor of Kring TWT GmbH. Fig. 3 and Fig. 4 show the collector field and the feed-in substation.

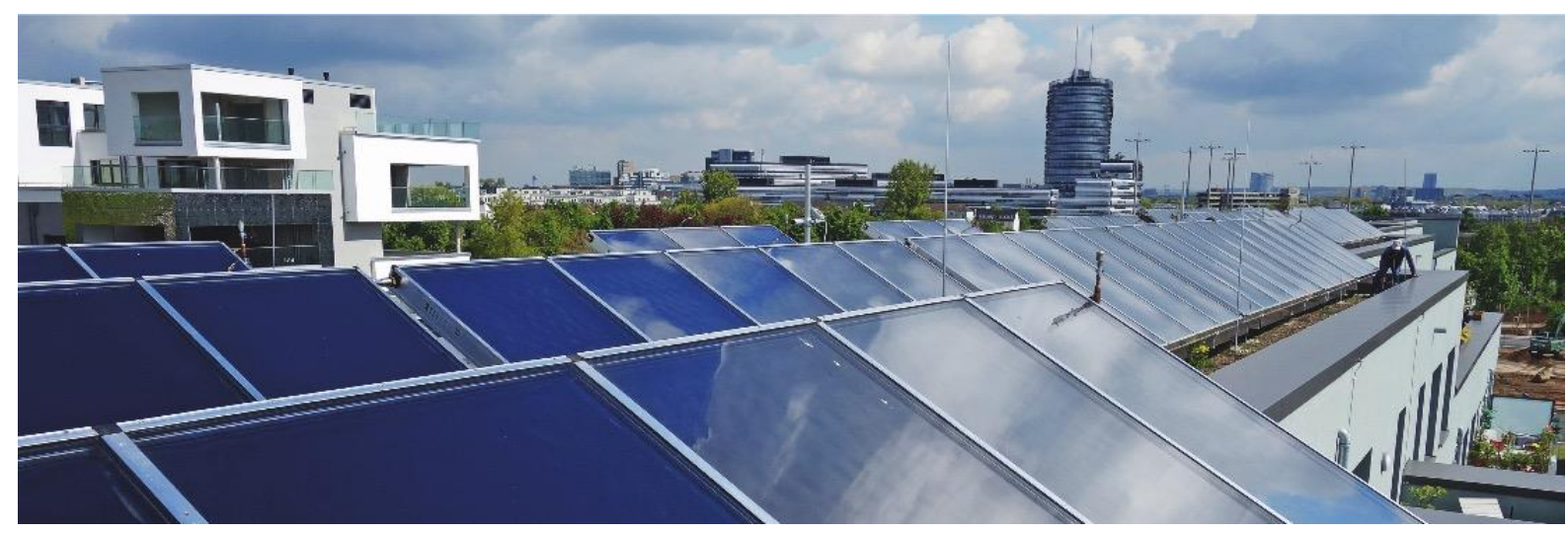

Fig. 3: Solar collector field of the experimental plant

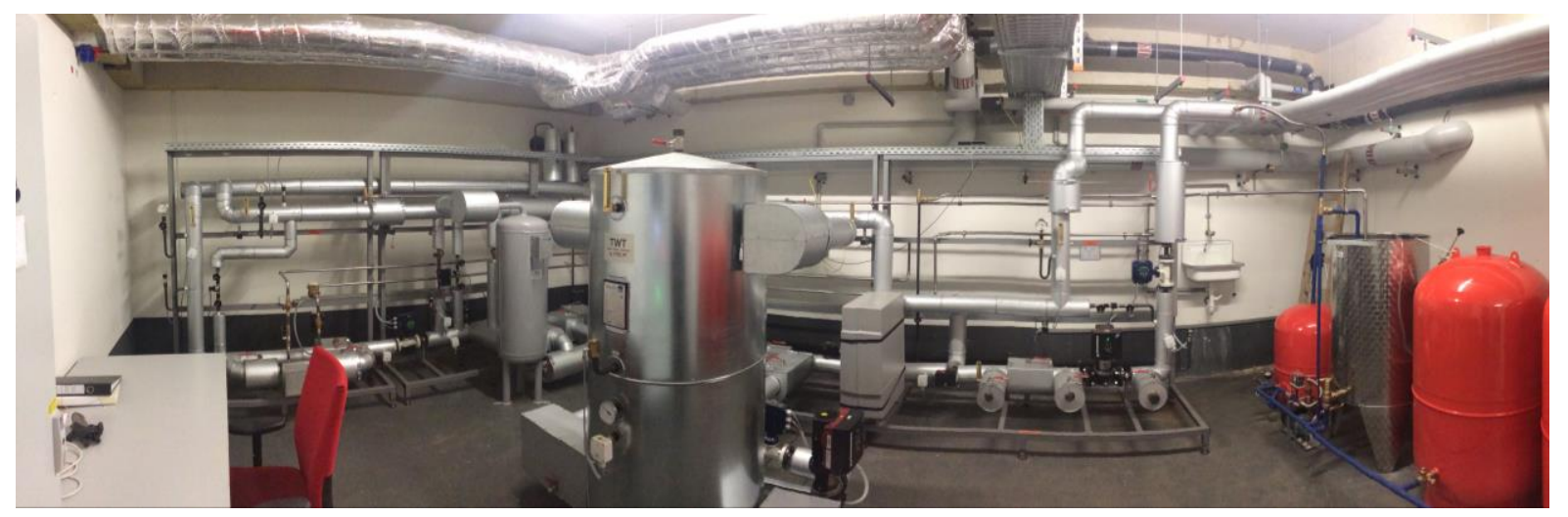

Fig. 4: Feed-in substation of the experimental plant (deformed panoramic view) [AGFW 2018]

\subsection{Hydraulic design of the experimental feed-in substation}

One objective of the project SWD.SOL is to analyze different hydraulic solution approaches for feeding-in solar heat under comparable boundary conditions. In this regard, four hydraulic solution approaches were realized in the setup of the experimental plant. These approaches are presented below. The hydraulic design of the experimental plant is shown in Fig. 6. 


\section{Hydraulic solution approaches for decentralized feed-in of solar heat}

To solve the presented technical challenges (see chapter 3) different concepts exist. A review of 33 decentral solar thermal feed-in plants (realized in different European countries) shows four basic solution approaches [Schäfer 2014]. These four approaches are implemented in the feed-in loop of the experimental plant. Fig. 5 illustrate the four solution approaches in a schematically way. An individually description of the approaches is given below.

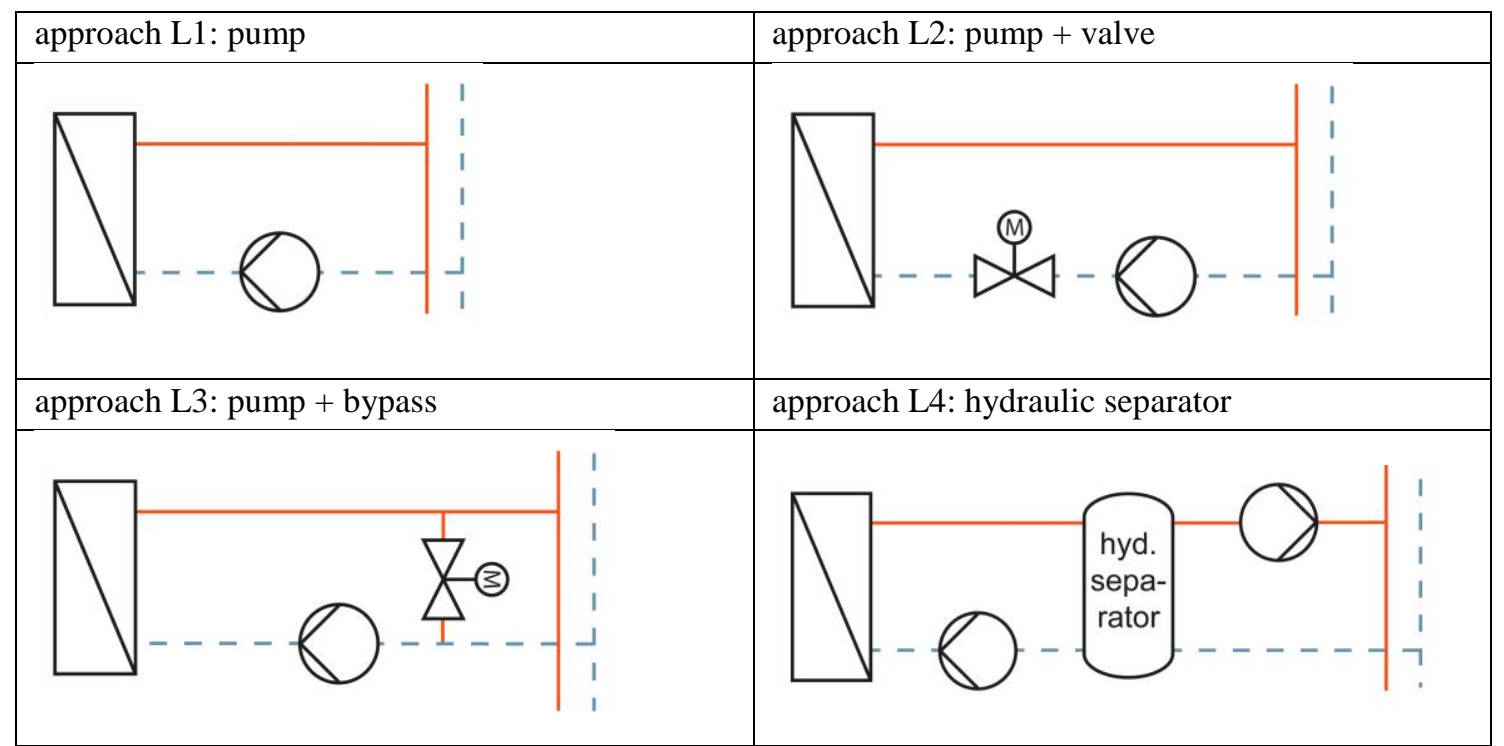

Fig. 5: Schematic representation of the technical solution approaches within the feed-in loop of realized plants (M: motor control)

- Solution approach L1: pump

Function: Only the pump in the feed-in loop is used as control device. Depending on the operation conditions, the pump must be able to respond to very quick variations of the following parameters:

a) solar heat to be fed-in

b) differential pressures to be exceeded between the feed-in and extraction location

Characteristic: On one hand, the control of the approach requires small effort. On the other hand, the solution approach is only productive in case of connection points without strong gradients of the differential pressures between the feed-in and extraction location. Otherwise, a large number of start-up and shut-down procedures of the pump is necessary to maintain the required target temperature range within the feed-in loop.

- Solution approach L2: pump + valve

Function: In this context, the control function of the pump is supported by a fast-acting control valve. The pump is primarily used for exceeding the differential pressure. In order to observe the required target temperature during times with fast variations of heat flows inside the collector loop, the fine control of the volume flow is carried out using the control valve.

Characteristic: Even if the differential pressure between the feed-in and extraction location changes quickly, a very good observance of the required target temperature within the feed-in loop combined with a low number of start-up procedures of the pump can be achieved. On the other hand, the resulting increase in flow resistance caused by the control valve leads to higher demand in electrical energy for the pump.

- Solution approach L3: pump + bypass

Function: The use of a bypass in the feed-in loop enables the proportionate circulation of the pump's flow rate. The division between the flow rates (fed-in flow rate and circulated flow rate) is carried out in a continuous way. Accordingly, the limitation of the pump's minimum volume flow (reason: self-cooling) does not lead to any restriction with respect to the fed-in flow rates.

Characteristic: The resulting extension of the variation range of fed-in flow rates can reduce the number of start-up and shut-down procedures of the pump especially during conditions with medium and low irradiation. However, if the differential pressure between the feed-in and extraction location changes quickly the same problems as in solution approach L1 occurs. 
- Solution approach L4: hydraulic separator

Function: The feed-in loop is divided into two hydraulic loops by means of a hydraulic separator. This measure clearly simplifies the control task of solar heat feed-in. The pump in the hydraulic loop located between collector loop and hydraulic separator can be regulated just focusing on the required target temperature. To exceed the varying differential pressure between the feed-in and extraction location, the additional pump is used (hydraulic loop between hydraulic separator and connection point in the DH network). Characteristic: The solution approach obtains very good results in observing the target temperature. This also applies to the case of strongly varying differential pressure between the feed-in and extraction location. However, the total costs of the system increase because of the additional components and the number of starts and stops of the feed-in pump can be high. Furthermore, there is a risk of mixing supply and return temperature levels in the hydraulic separator.

\section{Hydraulic design of the experimental plant}

A section of the hydraulic structure from the experimental plant is shown in Fig. 6. For reasons of clarity, the diagram does not contain the full collector circuit and the measurement sensors. To indicate the optional combination of single hydraulic elements in the test setup, they are identified using L1), L2), L3) and L4). The alphabetical designation is in line with the solution approaches presented in the section above. Apart from testing the individual solution approaches, the test setup enables to analyze different combinations of them.

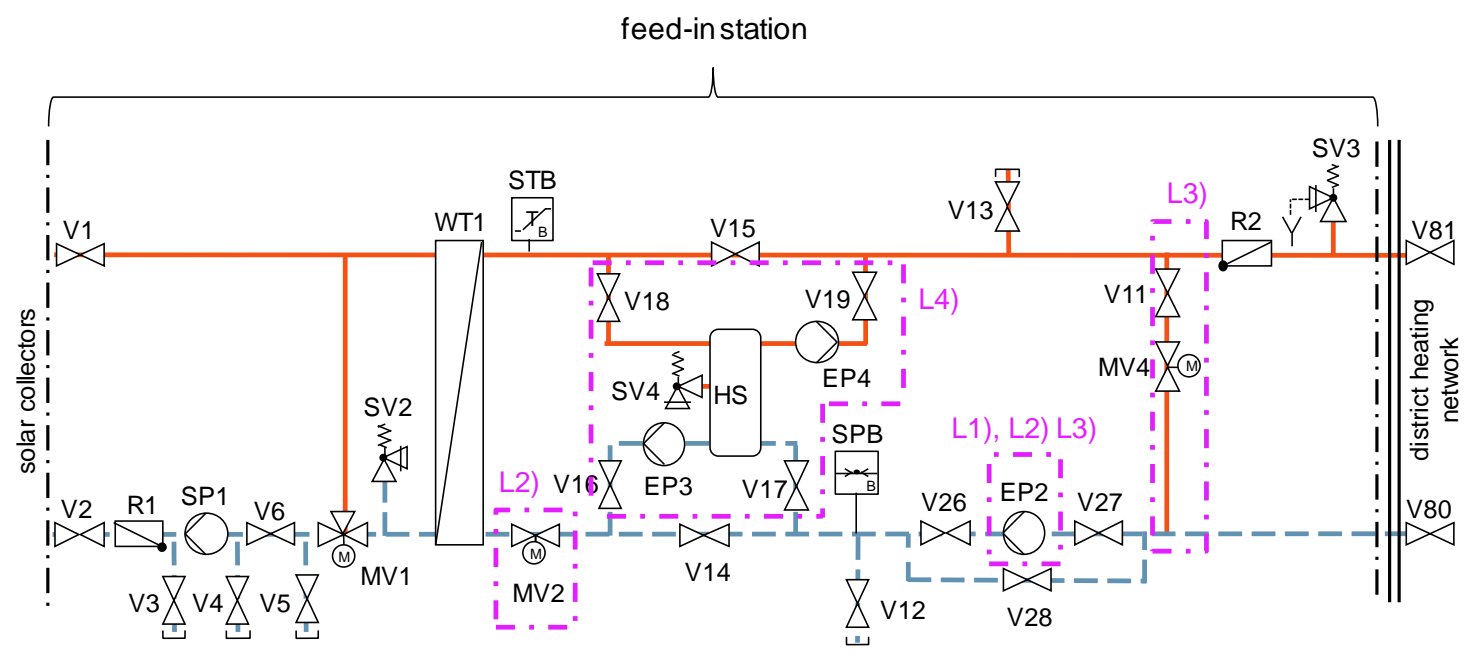

Fig. 6: Schematic representation of the hydraulic structure of the experimental plant (HS: hydraulic separator) 


\section{First monitoring results}

This chapter contains first measurement results, which will be followed by an elaboration of possible improvements. The discussed results are based on the hydraulic operation mode L3 (see Fig. 5).

\subsection{Presentation of measurement results}

The following Figure 7 shows measurement results of the solar heating plant for an example day in August 2018. During this day the sky was clear, which results in a smooth curve of increasing and decreasing solar radiation throughout the day. Therefore, no dynamics in the system caused by clouds can be seen. For the following discussion, Figure 7 is separated by vertical dash-dotted lines in five sections (corresponding numbers are located above the figure).

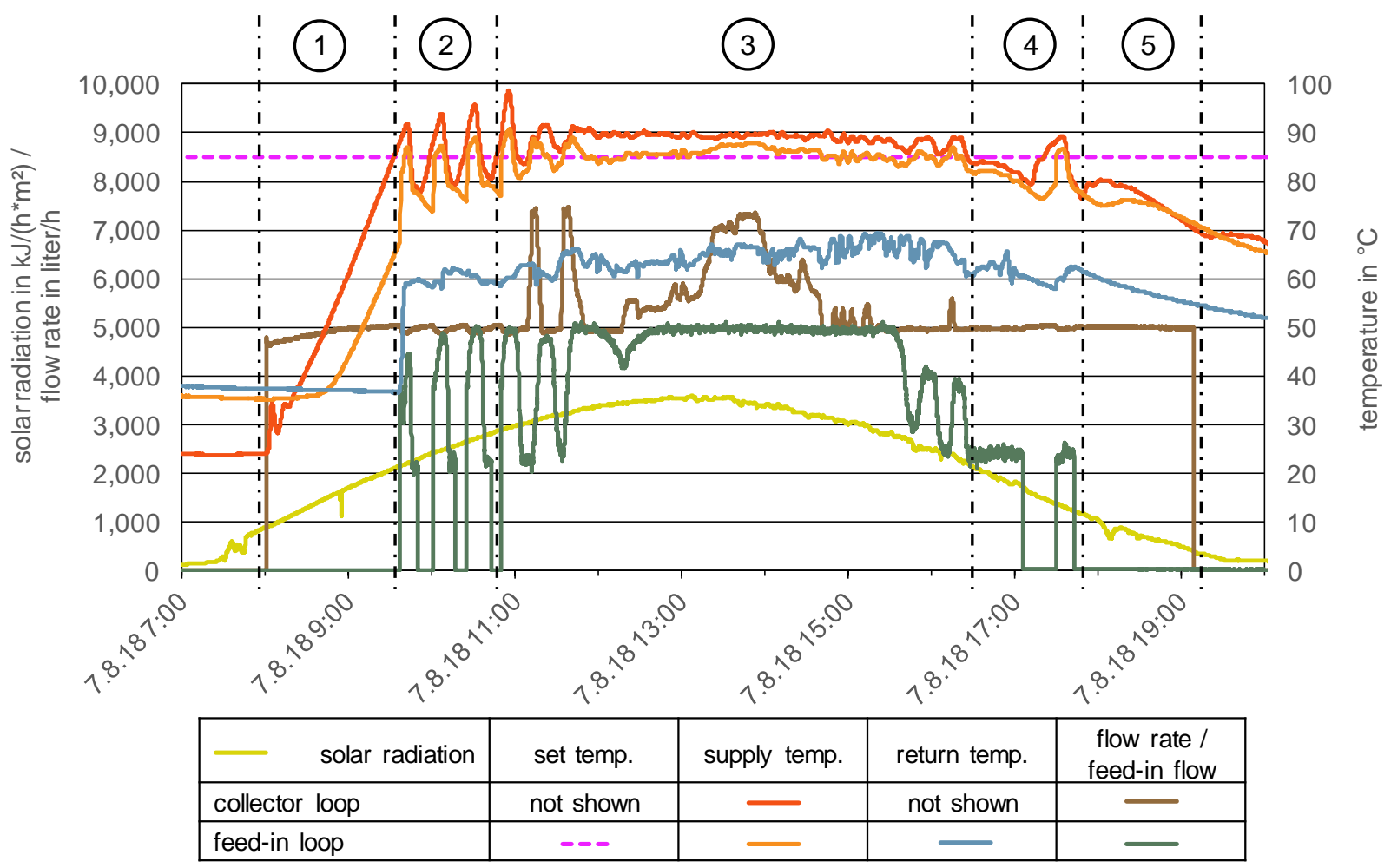

Fig. 7: Measurement results for one selected summer day; plant configuration: solution approach L3 (pump + bypass)

\section{Discussion of the operating results}

Phase 1: First heating phase of the collector loop

Generally, the pump in the collector loop starts operation depending on a characteristic curve that uses the irradiation as an input. On the specific example day, the start of the pump is triggered about 8:00 am. In this first phase, the volume flow created by the pump is constant in the collector loop. The feed-in pump is not yet in operation. As the volume flow in the collector loop is constant and heat is not yet transferred to the feed-in loop, the fluid temperature in the collector loop rises continuously.

Phase 2: Operation start of the feed-in loop pump

Once the fluid temperature in the collector loop exceeds the pre-defined threshold of $88{ }^{\circ} \mathrm{C}$, the start of the pump in the feed-in loop is triggered. The speed of the pump within the feed-in loop is in case of the operation mode L3 solely based on the pressure difference between the feed-in and extraction location of the DH network. Accordingly, the volume flow generated by the pump is just based on the conditions in the DH network. In order to achieve the required feed-in temperature, liquid in the feed-in loop is recirculated through the bypass. The volume flow in the bypass is regulated by a motor-driven valve, which uses the temperature difference between the feed-in target temperature and the current feed-in temperature as an input. This mode of control allows varying the feed-in flow between 2,200 and 5,000 liters $/ \mathrm{h}$. If the feed-in target temperature is not reached, even though the feed-in flow is on its minimum (maximal flow through the bypass), the pump in the feed-in loop stops operation. An interruption of the pump 
operation was provoked at 9:50 am, 10:15 am and 10:40 am. These interruptions result in an intermitted feed-in to the DH network and indicate potential for improvement of the control.

Phase 3: Continuous supply to the DH network

The solar radiation during phase 3 is sufficiently high to allow a continuous supply to the DH network with the given possible variation of the feed-in flow. Between 10:50 am and 11:50 am high variations in the feed-in temperature cause an adaptation of the volume flow in the collector loop and feed-in loop. This adaptation in volume flow allows keeping the supply temperature in a range of $\pm 5 \mathrm{~K}$ from the set point temperature of $88^{\circ} \mathrm{C}$. From 12:00 am onwards, the mismatch between required and currently supplied feed-in temperature is, to the largest extend, insignificant. The only exception is an increase of the feed-in temperature at about 1:50 pm. At this time, the feed-in loop would need a higher volume flow, which was not intended and is therefore not permitted for the given example day.

Phase 4: Falling stage of the pump operation in the feed-in loop

After 4:30 pm, the solar radiation is too low to allow for a supply of the required feed-in temperature, even though the collector and feed-in loop operates with the lowest possible flow. At about $5 \mathrm{pm}$, the temperature in the feed-in loop is below the threshold of $80^{\circ} \mathrm{C}$. Therefore, the pump in the feed-in loop stops operation. Because of this stop, the fluid temperature in the collector loop increases again, which triggers another short operation of the feed-in loop pump in the end of phase 4.

Phase 5: Falling stage of the pump operation in the collector loop

With the continuous decrease of solar irradiation on the collector field, the thermal losses of the collector field exceed the energy gains at 6:15 pm, which in turn results in a decrease of the fluid temperature in the collector loop. At $7: 10 \mathrm{pm}$, the pump in the collector loop finally stops operation due to the irradiation, which is below the control characteristic curve for the pump operation.

\subsection{Potential for improvement and outlook}

Especially phase 2 as well as the beginning and the end of phase 3 offer potential for improvement. Simulations in TRNSYS have shown that depending on the technical possibilities, the intermittent pump operation during phase 2 can be avoided completely. For this avoidance of intermittency, a lower feed-in flow of about $1000 \mathrm{liter} / \mathrm{h}$ is required. As the possible lowest feed-in flow of the plant is $2200 \mathrm{liter} / \mathrm{h}$, this cannot be achieved with the current setup. Therefore, suggestions for improvements have been prepared, which shall be implemented and tested in a potential follow-up project of SWD.SOL.

Furthermore, the variation of the feed-in temperature in the beginning of phase 3 implicates improvement potential. Performed simulations point out that on the one hand the minimal and maximal allowed temperature mismatch of the feed-in temperature can be reduced and on the other hand the period to achieve the target feed-in temperature (Fig. 7 between 10:50 am and 11:50 am) can be shortened. To achieve these improvements, a faster variation of the feed-in flow is required. In how far the increased variation speed of the feed-in flow via adjusted values for the PIDcontrol unit is possible will also be elaborated in a potential follow up project of SWD.SOL.

Additionally the relatively early end of phase $3(4: 30 \mathrm{pm})$ could be delayed. To achieve this delay, the minimum volume flow within the collector loop (currently 5,000 liter/h) has to be reduced. This measure of lowering the pump flow would enable the plant to supply the feed-in target temperature with lower irradiation than in the current control configuration.

\section{Conclusion}

The decentralized feed-in of solar heat into district heating networks is linked to technical challenges. These challenges were identified and summarized. On this base, an experimental plant with a collector field of $218 \mathrm{~m}^{2}$ was developed and realized in Düsseldorf. First monitoring results of the experimental plant show that the plant is able to supply the generated solar heat to the district heating network. During the evaluated feed-in processes, the temperature of the solar heat is equal to the supply temperature of the district heating network or higher (in this case $85^{\circ} \mathrm{C}$ ). Furthermore, different options to improve the feed-in processes were determined and shall be investigated during the upcoming summer period. 


\section{References}

AGFW | Der Energieeffizienzverband für Wärme, Kälte und KWK e.V.; 2018; German district heating assosiation

Lennermo G., Lauenburg P.; 2015; Variation in differential pressure at a district heating prosumer substation; Mälardalen University and Lund University; Sweden; Publication, published at the $3^{\text {rd }}$ SDH-Conference in Toulouse

Lennermo G. 2015; Variation in differential pressure at a district heating prosumer substation; Mälardalen University; Sweden; Presentation, presented at the $3^{\text {rd }} \mathrm{SDH}-$ Conference in Toulouse

Schäfer K., Schlegel F., Pauschinger T.; 2014; Decentralized feed-in of solar heat into district heating networks - a technical analysis of realized plants; Solites - Steinbeis Research Institute for Solar and Sustainable Thermal Energy Systems; Stuttgart, Germany; Publication, published at the $2^{\text {nd }} \mathrm{SDH}-$ Conference in Hamburg

Disclaimer: The research project SWD.SOL is funded by the German Federal Ministry for Economic Affairs and Energy (BMWi, FKZ 03ET1269) by reason of a decision of the German Parliament. The authors gratefully acknowledge this support. The sole responsibility for the content of this publication lies with the authors. It does not necessarily reflect the opinion of the supporting authorities. The supporting authorities are not responsible for any use that may be made of the information contained therein. 


\section{Solar Heat for Industrial Processes}




\title{
Optical Analysis of an Evacuated Tube Collector with Built-In Semicircular Concentrator for Process Heat Applications
}

\author{
Rosa Christodoulaki ${ }^{1}$, Panagiotis Tsekouras ${ }^{2}$ and Vassiliki Drosou ${ }^{1}$ \\ ${ }^{1}$ Solar Thermal Systems Department / Center for Renewable Energy Sources and Saving, Pikermi \\ (Greece) \\ ${ }^{2}$ Laboratory of Solar Energy, Thermal Engineering Section, School of Mechanical Engineering / \\ National Technical University of Athens, Athens (Greece)
}

\begin{abstract}
The aim of this study is to evaluate the optical performance of an Evacuated Tube solar thermal Collector with Semi-Circular concentrator (ETC-SC). An optical simulation model is developed in a ray-tracing software and its consistency is proven through experimental data from the literature. A parametric analysis is then performed to investigate the impact of the absorber's radius, the absorber's position and the acceptance angle of the semicircular mirror on the optical efficiency of the collector. The results of this study show that the variation of the absorber's radius slightly affects the optical performance of the collector. Regarding the absorber's position, the greatest distance studied presented the best results for all incident angles studied. In terms of acceptance angle, it was shown that for small incident angles, the best performance is shown from the smallest acceptance angle studied, but for greater incident angles, this relationship is reversed. The results of this study are valuable for the design, simulation and performance analysis of the evacuated tube collectors.
\end{abstract}

Keywords: Evacuated tube collector, ray tracing, optical efficiency.

\section{Introduction}

To date, insufficient attention has been paid to the potential of renewable energy resources in industrial applications. An analysis (Taibi et al., 2012) suggests that up to $21 \%$ of final energy demand and feedstock use in the manufacturing industry sector could be of renewable origin by 2050, a five-fold increase over current levels in absolute terms. In addition, if a 50\% share of renewables in power generation is assumed, the share of direct and indirect renewable energy use rises to $31 \%$ in 2050 . Yet, the substantial potential for solar heat is not reflected to the installations number. While low-temperature solar process heat can reach cost effectiveness today in locations with good radiation as in Mediterranean region, in early 2014 there were only 130 solar thermal plants for industrial process heating worldwide, producing $93 \mathrm{MW}_{\mathrm{th}}$ (IEA SHC, 2014).

Process temperatures found in the industrial sector range from low $\left(\mathrm{T}<100^{\circ} \mathrm{C}\right)$, medium $\left(100^{\circ} \mathrm{C}<\mathrm{T}<250^{\circ} \mathrm{C}\right)$ to high $\left(\mathrm{T}>250^{\circ} \mathrm{C}\right)$ level (IRENA, 2015, Horta et al., 2016). Whereas low temperature applications are already addressed by well-established flat plate solar thermal collector technologies, the approach to medium temperature applications relies on a range of more sophisticated thermal collector technologies, such as the evacuated tube collectors (Aguilar-Jiménez et al., 2018). The effectiveness of the evacuated tube collectors and subsequently, their capacity to produce medium temperature level heat is closely related to their optical performance.

In the literature there are many studies discussing the optical and thermal properties of the evacuated tube collectors. Back in 1974, Winston (1974) studied a collector with a trough-like reflecting wall light channel that had a concentration factor of 10 and did not need diurnal sun tracking. More recently, all-glass vacuum tube collector was the objective of the study of Li et al. (2010). They developed a heat transfer model, then validated it with a physical model and found reasonable deviations. Buttinger et al. (2010) developed a new non-tracking, low concentrating collector that aimed specifically at delivering process heat at temperatures $120-150^{\circ} \mathrm{C}$. They showed efficiencies around $50 \%$ at a temperature of $150^{\circ} \mathrm{C}$ with a radiation of $1000 \mathrm{~W} / \mathrm{m}^{2}$. Nkwetta and Smyth (2012) analyzed two profiles of concentrated evacuated tube heat pipe solar collectors made of single-sided and double sided absorber. The concentrated double-sided absorber evacuated tube heat pipe proved better 
compared to the concentrated single-sided absorber evacuated tube heat pipe solar collector due to higher outlet temperature with greater temperature differential and improved thermal performance. They also evaluated the optical performance of an internal low-concentrating evacuated tube heat pipe solar collector for medium temperature applications. Their raytracing analysis resulted in an optical efficiency of $79.13 \%$ for transverse angles $0-20^{\circ}$. Another study (Kumar et al., 2017) investigated theoretically the performance of heat pipe solar collectors and found that they are sensitive to the solar radiation, the ambient temperature as well as to the length of evaporator. A study targeted at the calculation of the potential of solar process heat to specific industrial sectors in Germany was recently published (Lauterbach et al., 2012). It was found that the theoretical potential of solar heat for industrial processes below $300^{\circ} \mathrm{C}$ in Germany accounts for $134 \mathrm{TWh}$ per year and the technical potential is $3.4 \%$ of the overall industrial heat demand.

The Evacuated Tube solar thermal Collector with Semi-Circular concentrator (ETC-SC) considered in the present study consists of a row of evacuated receiver tubes connected in series. Inside each receiver tube, there is an absorber tube coated with a special absorption layer. In this configuration, a semicircular concentrator is placed inside the evacuated tube and underneath the absorber tube with the scope to direct the solar radiation onto the absorber tube (Fig. 1). This study aims at evaluating the effect of adding the semicircular mirror component on the optical efficiency of the ETC-SC.

\section{Methodology}

\subsection{Description of the Evacuated Tube solar thermal Collector with Semi-Circular concentrator}

The components and the design features of the ETC-SC are shown in Fig. 1. This ETC-SC collector converts energy from the sun into usable heat under solar thermal technology principles. The heat produced can be then used for sanitary hot water use and for industrial process heat. The ETC SC composed of three main parts: a)The evacuated tubes, that consist of two glass tubes, one inside the other. The inner tube, in which the heat transfer fluid flows, is coated with a selective paint on its external surface. There is vacuum in the annulus space to minimize heat losses. In the inner side of the outer glass tube, a semicircular mirror is positioned facing the sun to direct the radiation into the inner glass tube. b) The manifold that is an insulated box containing the header pipe. c) The mounting frame. It is out of the scope of this study to evaluate the manifold and the frame, since this study focuses on the optical performance of the evacuated tubes.

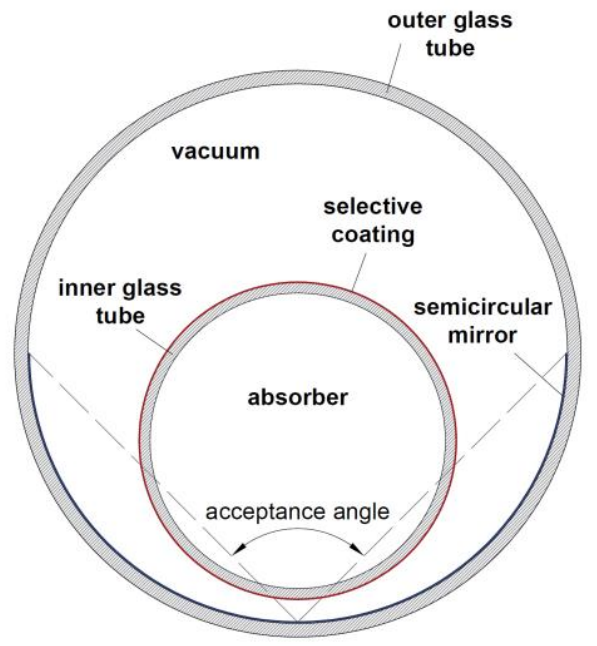

Fig. 1: ETC-SC design configuration

The optical analysis of the ETC SC is performed using the Tonatiuh ray-tracing software developed by CENER (Tonatiuh, 2012). Considering that all tubes comprising the solar collector are identical, the optical analysis was performed for one tube only, with an indicative length of $1 \mathrm{~m}$. Fig. 2 depicts the developed model that consists of three elements; outer glass, absorber and mirror. The glass envelope is built as two concentric surfaces, but it is not clearly shown due to its transparency feature. 
The optical analysis is implemented in terms of the Incidence Angle Modifier (IAM). When the Sun rays hit the collector from an angle the performance changes and this is what the IAM provides; an angular performance factor. A value of 1 is achieved when the collector receives the maximum radiation. For evacuated tube collectors that employ reflective components and are affected by reflection off neighboring tubes, the IAM may exceed 1. The two types of IAMs are:

- Transversal IAM, that measures the change in performance as the Sun angle changes in relation to the collector, through the day.

- Longitudinal IAM, that measures the change in performance as the Sun angle changes in relation to the collector, through the year.

The value of most concern for fixed collectors is the transversal IAM, as this reflects the change in performance throughout the day. Therefore, in this study the transversal IAM is calculated and evaluated.

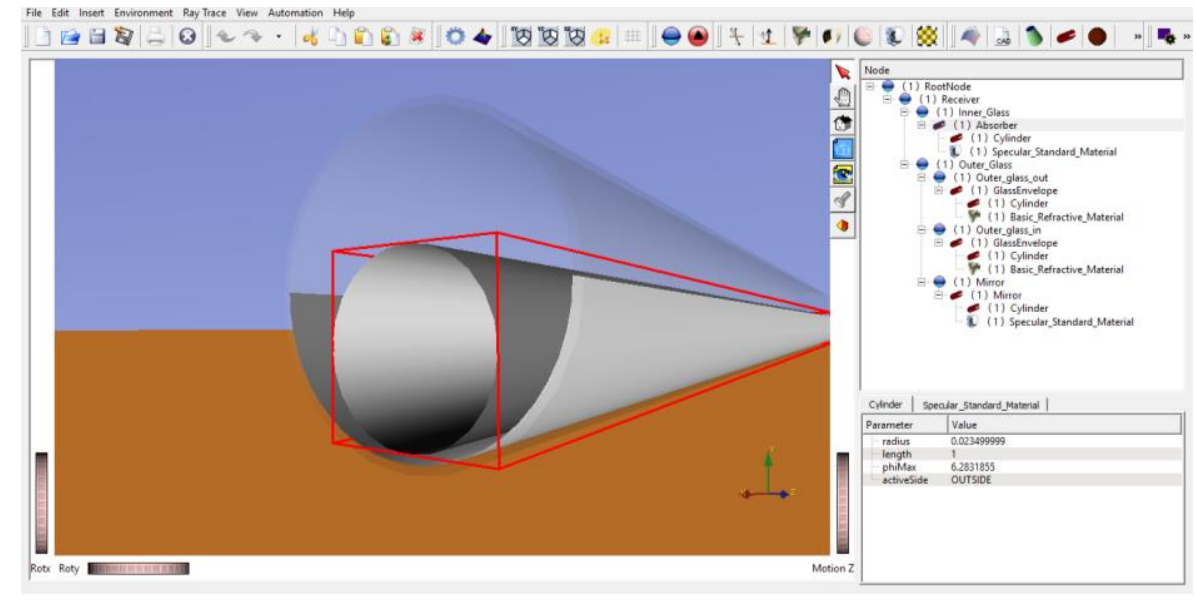

Fig. 2: Print screen of the optical model developed in Tonatiuh.

The geometrical and material properties of the elements of the tube that were used to the Tonatiuh model are shown in Table 1.

Table 1: Geometrical and material properties used in Tonatiuh

\begin{tabular}{|c|c|c|c|c|}
\hline & Glass outer & Glass inner & Absorber & Mirror \\
\hline Geometry & $\begin{array}{l}\text { Radius } 0.042 \mathrm{~m} \\
\text { Length } 1 \mathrm{~m}\end{array}$ & $\begin{array}{l}\text { Radius } 0.040 \mathrm{~m} \\
\text { Length } 1 \mathrm{~m}\end{array}$ & $\begin{array}{l}\text { Radius } 0.0245 \mathrm{~m} \\
\text { Length } 1 \mathrm{~m}\end{array}$ & $\begin{array}{l}\text { Radius } 0.0396 \mathrm{~m} \\
\text { Length } 1 \mathrm{~m}\end{array}$ \\
\hline Material & $\begin{array}{l}\text { Basic refractive } \\
\text { material } \\
\text { Transmissivity } 0.96\end{array}$ & $\begin{array}{l}\text { Basic refractive } \\
\text { material } \\
\text { Transmissivity } 0.96\end{array}$ & $\begin{array}{l}\text { Specular standard } \\
\text { material } \\
\text { Reflectivity } 0\end{array}$ & $\begin{array}{l}\text { Specular standard } \\
\text { material } \\
\text { Reflectivity } 0.96\end{array}$ \\
\hline
\end{tabular}

Fig. 3 shows the raytracing analysis implemented for the ETC-SC solar collector, under various Sun deviations from the transversal plane.

When looking at the tubes from above $\left(0^{\circ}\right)$ each tube's surface is exposed to the maximum amount of sunlight with no gaps between them and no overlap. At this angle, the amount of rays lost between the tubes is neglected and therefore this angle is used as the reference point for the IAM value of 1 . Indeed, with 500 rays selected to be showed, at $0^{\circ}$ Sun deviation, most of the sun rays actually hit the absorber and the concentrator produces $787 \mathrm{~W}$ per $\mathrm{m}^{2}$ of absorber's aperture area. For greater Sun angles, the tubes start to overlap, shading each other. They are still facing the Sun, but the actual surface area of the receiver exposed to the sunlight is reduced. For the collector under investigation and at $20^{\circ}$ zenith angle, the production is reduced by only $1 \%\left(778 \mathrm{~W} / \mathrm{m}^{2}\right)$. For zenith angles beyond $40^{\circ}$ (early morning or late afternoon), only a small amount of rays reaches the tubes and so, this period has minimal influence on the total daily energy output of the collector. At $40^{\circ}$, the loss in power production becomes evident at $17 \%$ with the concentrator now producing $651 \mathrm{~W} / \mathrm{m}^{2}$. Fig. 4 shows the incidence flux distribution in the surface of the absorber, at zenith $0^{\circ}$. 

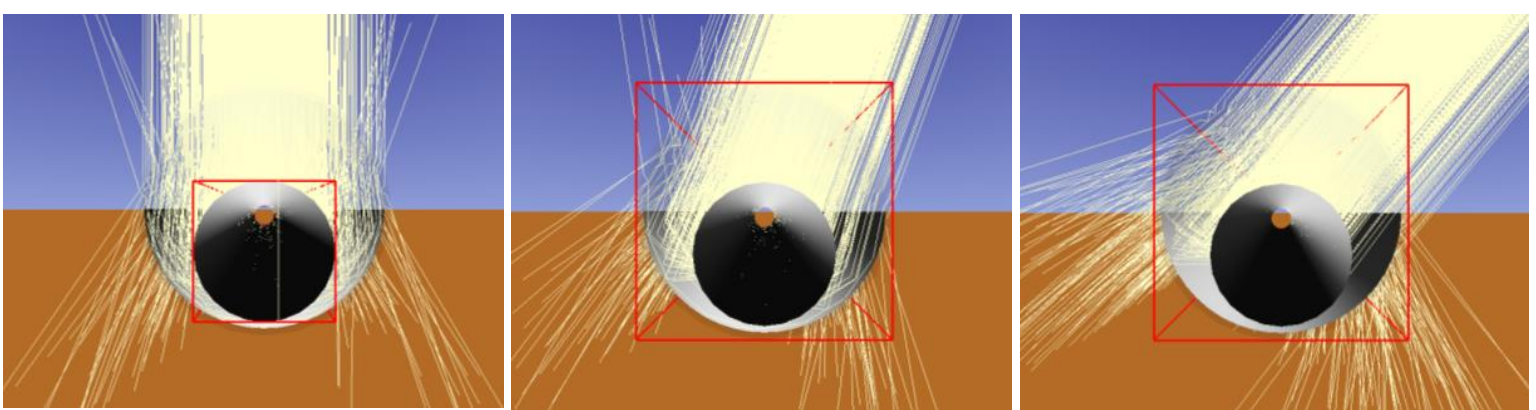

Fig. 3: Ray tracing figures for the ETC-SC collector under investigation, zenith $0^{\circ}$ (left), $20^{\circ}$ (middle) and $40^{\circ}$ (right).

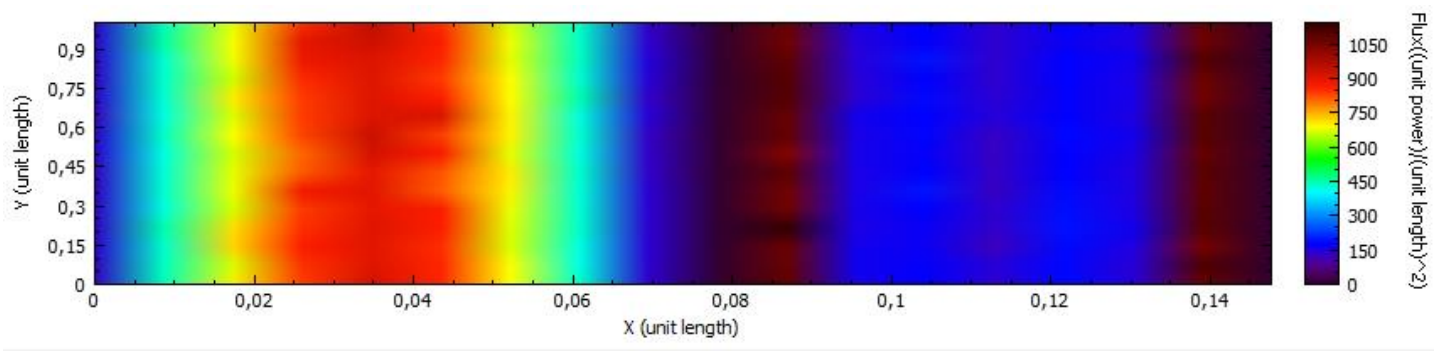

Fig. 4: Incidence flux distribution in the surface of the ETC-SC absorber, with zenith $0^{\circ}$.

\subsection{Validation of optical model}

The model is validated towards accredited performance data, taken from the Solar Rating and Certification Corporation SRCC (SRCC, 2017). Sun angles beyond $40^{\circ}$ are not considered in the model validation, since the solar radiation is very low at that period (early morning and late afternoon) and the impact on the total daily energy output of the collector is negligible. As such, the deviation between the optical model and experimental data from the literature does not exceed $11 \%$ and the average deviation of all cases considered is $2.8 \%$, so the model is considered as valid and consistent.

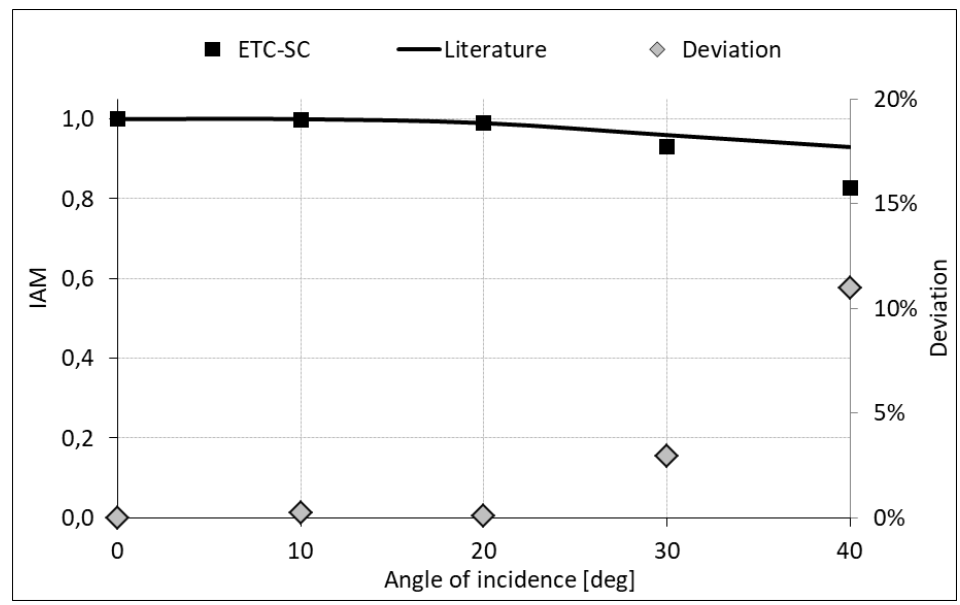

Fig. 5: Left axis: IAM points (black points) of ETC-SC collector under investigation, IAM curve (black line) of the reference collector in the literature. Right axis (grey points): \% deviation between those two values.

Following the validation of the optical model, the transversal IAM curve of the ETC-SC collector under investigation is drawn (Fig. 6), by varying the angle of incidence, from $0^{\circ}$ to $70^{\circ}$, with a step of $5^{\circ}$. 


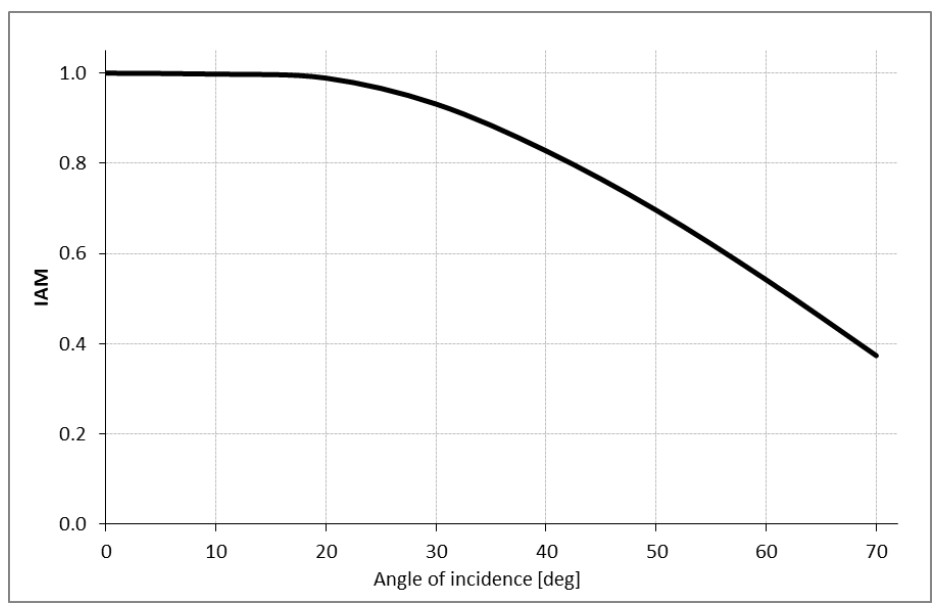

Fig. 6: IAM curve of ETC-SC collector under investigation.

The shape of the transversal IAM curve is due to the cylindrical absorber area and the presence of the semicircular mirror, which passively tracks the sun throughout the day. The IAM values drop away from 1, as the angle increases and as such, solar conversion efficiency is maximum at midday. For angles of incidence higher than $50^{\circ}$, there are rays lost between the tubes, tube overlap and reflection of neighboring tubes, hence the IAM drops at a faster pace. These angles correspond to early morning or late afternoon, when solar radiation levels are already very low, so this efficiency drop is of minor importance.

\section{Parametric analysis}

\subsection{Absorber radius}

Three different values for the absorber radius, namely $0.0235 \mathrm{~m}, 0.021 \mathrm{~m}$ and $0.0185 \mathrm{~m}$, are compared towards the IAM curve (Fig. 7). In general, this study shows that the variation of the absorber radius has a marginal effect on the collector performance. More specifically, reducing the absorber radius by $12 \%$ and $14 \%$ reduces the power production by $0.6 \%$ and $0.9 \%$, respectively. This is owned to the limited range of change; possibly, a greater change in the radius is expected to have a greater effect on the collector performance.

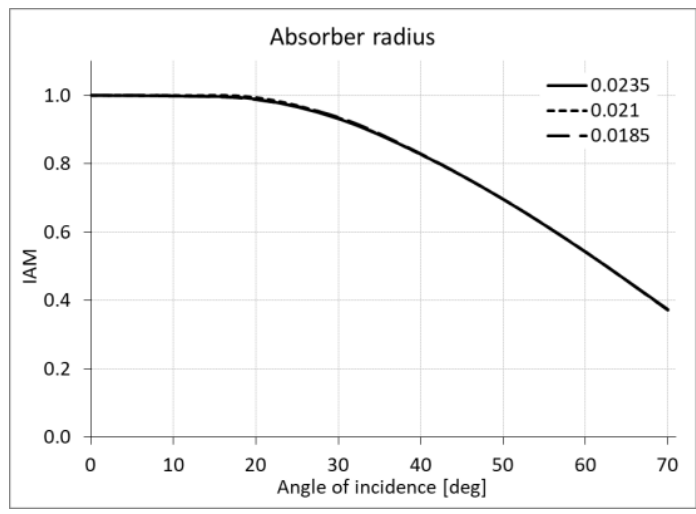

Fig. 7: IAM curve of the ETC-SC collector, for three absorber radiuses

\subsection{Absorber position}

The second investigated parameter is the position of the absorber tube, in relation to the outer glass tube. Three different positions are studied, namely $0.007 \mathrm{~m}, 0.005 \mathrm{~m}$ and $0.003 \mathrm{~m}$ distance between the lower part of the absorber and the lower part of the semicircular mirror. Fig. 8 shows the results of this analysis and reveals that at the $0.007 \mathrm{~m}$ distance the absorber has a better performance, for all incident angles up to $70^{\circ}$. Fig. 9 shows the effect of the absorber's position on the intercept factor of the solar collector; the intercept factor of the $0.003 \mathrm{~m}$ distance is $13.6 \%$ greater than that of the $0.007 \mathrm{~m}$. At this point, it should be noted that the zero distance option was not studied, due to the practical and construction limitations that this option would have. 


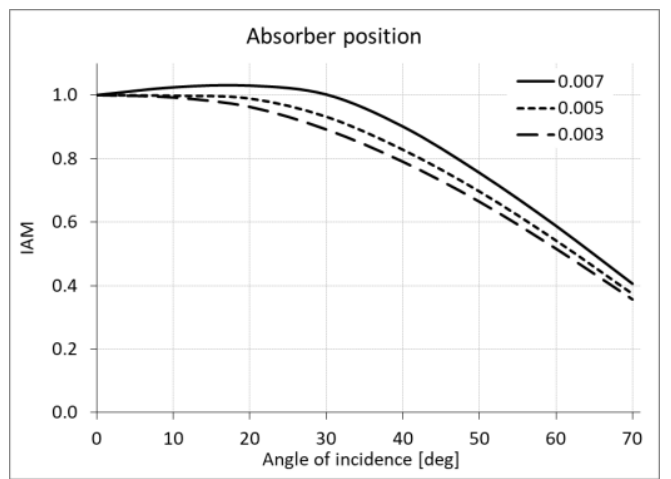

Fig. 8: IAM curve of the ETC-SC collector, for three absorber positions

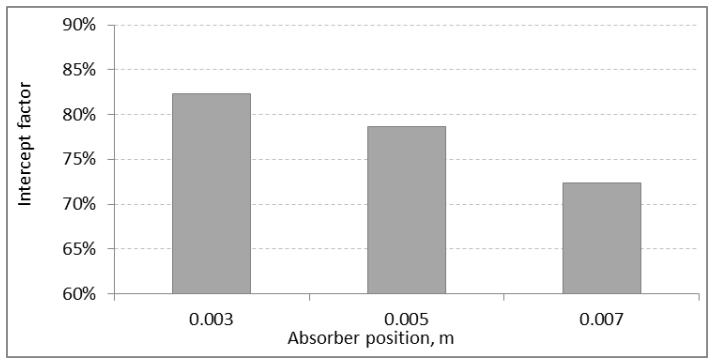

Fig. 9: Intercept factor of the ETC-SC collector, for three absorber positions

\subsection{Acceptance angle}

Three different acceptance angles were investigated, namely $90^{\circ}, 105^{\circ}$ and $120^{\circ}$. Fig. 10 depicts the IAM curve towards the angle of incidence for the three acceptance angles studied. The results show that for incident angles up to $40^{\circ}$, the best performance is shown from $90^{\circ}$ acceptance angle. This is relationship is also reflected in the power production curve. For greater incident angles, there is the reverse phenomenon; the solar collector with $120^{\circ}$ acceptance angle shows better IAM curve. This is owned to the fact that for greater incident angles, the $120^{\circ}$ acceptance angle allows more rays to reach the absorber and has less blocking losses.

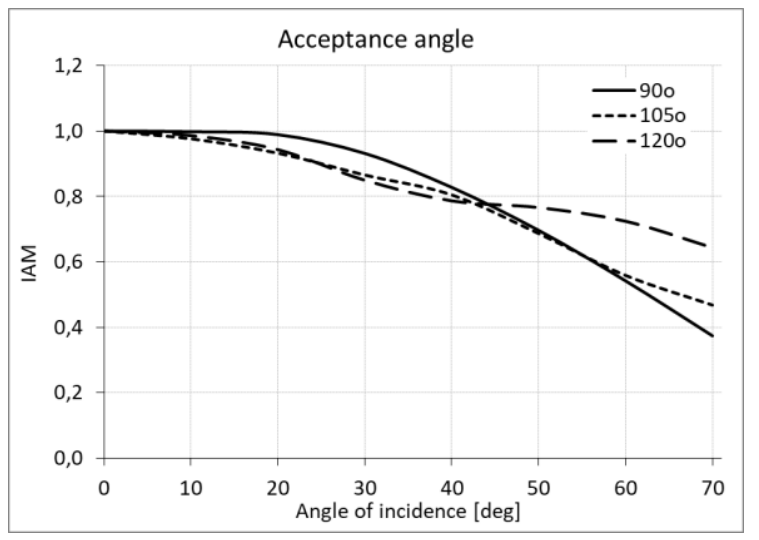

Fig. 10: IAM curve of the ETC-SC collector, for three acceptance angles

\section{Conclusions}

The optical performance of an Evacuated Tube Collector with Semi-circular Concentrator was investigated, in terms of transversal IAM curve. An optical simulation model was initially developed and validated with literature data. The impact of the absorber's radius, absorber's position and acceptance angle on the optical efficiency were evaluated, in the range of $0.0185 \mathrm{~m}-0.0235 \mathrm{~m}, 0.003 \mathrm{~m}-0.007 \mathrm{~m}$, and $90^{\circ}-120^{\circ}$ respectively. It was found that the variation of the absorber radius at the selected range had marginal effect on the IAM. In terms of distance between the absorber tube and the glass tube, the greatest distance studied $(0.007 \mathrm{~m})$ presented the best outcome throughout all day. Finally, the parametric analysis of the acceptance angle showed that for incident angles up to $40^{\circ}$, the best outcome is shown from the $90^{\circ}$ acceptance angle. For greater incident angles though, the best performance was shown from the $120^{\circ}$ acceptance angle. This study revealed the importance of 
considering the IAM effect when calculating the performance of solar collectors. The results are valuable for the design and performance analysis of evacuated tube collectors.

\section{Acknowledgements}

This research work was implemented in the framework of the EU H2020 LCE-33-2016 (RIA) project INSHIP Integrating National Research Agendas on Solar Heat for Industrial Processes, GA 731287, duration 01.01.2017 - 31.12.2020, https://www.inship.eu/.

\section{References}

Aguilar-Jiménez, J.A., Velázquez, N., Acuña, A., López-Zavala, R., González-Uribe, L.A., 2018. Effect of orientation of a CPC with concentric tube on efficiency, Applied Thermal Engineering, 130, 221-229.

Buttinger, F. Beikircher, T. Proll, M. Scholkopf, W. 2010. Development of a new flat stationary evacuated CPCcollector for process heat applications, Solar Energy, 84, 1166-1174

CENER National Renewable Energy Centre, Tonatiuh ray-tracing software, version 2.2.4, iatcener.github.io/tonatiuh/, 2012

Horta, P., Brunner, C., Kramer, K., Frank, E., 2016. IEA/SHC T49 activities on process heat collectors: available technologies, technical-economic comparison tools, operation and standardization recommendations, Energy Procedia, 91, 630-637.

International Energy Agency Solar Heating and Cooling Programme IEA-SHC, 2014. Solar Heat Worldwide. Market and Contribution to the Energy Supply 2012. http://www.iea-shc.org/data/sites/1/publications/SolarHeat-Worldwide-2014.pdf, accessed 18/7/2018.

International Renewable Energy Agency IRENA, 2015. Renewable Energy Options For The Industry Sector: Global And Regional Potential Until 2030, Background to "Renewable Energy in Manufacturing" Technology Roadmap. http://www.irena.org//media/Files/IRENA/Agency/Publication/2014/Aug/IRENA_RE_Potential_for_Industry_BP_2015.pdf?la=en\& hash=F9B495F78DB624BC6A546F15D90C216FDE09DBAD, accessed 18/7/2018.

Kumar, S.S., Kumar, K.M., Kumar, S.R.S., 2017. Design of Evacuated Tube Solar Collector with Heat Pipe, Materials Today: Proceedings, 4, 12641-12646.

Lauterbach, C., Schmitt, B., Jordan, U., Vajen, K., 2012. The potential of solar heat for industrial processes in Germany, Renewable and Sustainable Energy Reviews, 16, 5121-5130.

Li, Z., Chen, C., Luo, H., Zhang, Y., Xue, Y., 2010. All-glass vacuum tube collector heat transfer model used in forced-circulation solar water heating system, Solar Energy, 84, 1413-1421.

Nkwetta, D.N., Smyth, M., 2012. Performance analysis and comparison of concentrated evacuated tube heat pipe solar collectors, Applied Energy, 98, 22-32.

Nkwetta, D.N., Smyth, M., Zacharopoulos, A., Hyde, T., 2012. Optical evaluation and analysis of an internal low-concentrated evacuated tube heat pipe solar collector for powering solar air-conditioning systems, Renewable Energy, 39, 65-70.

SRCC Solar Rating and Certification Corporation, 2017, https://secure.solarrating.org/Certification/Ratings/RatingsReport.aspx?device=7514\&units=METRICS, accessed 02/07/2018.

Taibi, E., Gielen, D., Bazilian, M., 2012. The potential for renewable energy in industrial applications, Renewable and Sustainable Energy Reviews, 16, 735-744.

Winston, R., 1974. Principles of solar concentrators of a novel design, Solar Energy, 16, 89-95. 


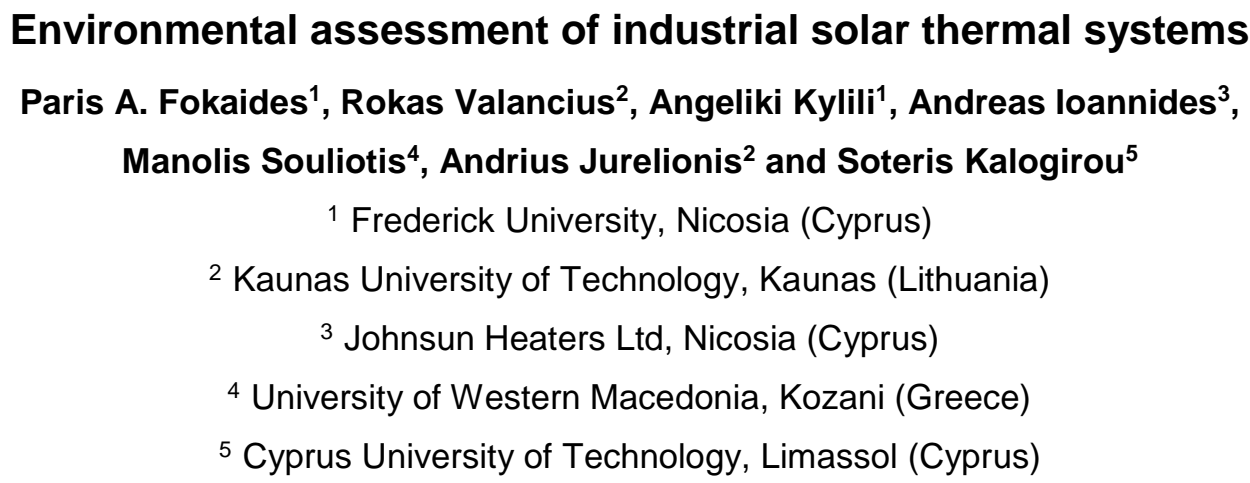

\begin{abstract}
European figures indicate that the deployment of solar thermal technologies for the supply of hot water is limited to the domestic sector, leaving untapped a large potential that could be exploited by the industrial sector. This work aims to describe the development of industrial solar thermal system penetration scenarios, in an effort to inform about the magnitude of this unexploited potential for Europe. For this purpose, the environmental performance of large-scale industrial solar thermal systems was quantified through the use of life cycle assessment (LCA) tools. A parametric LCA for two European locations allowed the definition of the relationship between solar potential and the system's environmental performance. The results concerning the carbon-saving potential of the industrial application of solar thermal systems were assessed, with reference to the European Emissions Trading System for the development of European penetration scenarios, as well as appropriate country-based incentives for encouraging their deployment in the industrial sector.
\end{abstract}

Keywords: Solar thermal system, flat plate collector, industrial sector, Life Cycle Assessment, Emissions Trading System

\title{
1. Introduction
}

While solar thermal technologies are widely used in domestic applications across Europe, their application in the industrial sector is still at a low level. The generation of process heat from solar thermal systems has enormous potential, which can satisfy a substantial amount of heat demand for industrial processes. In fact, there is technical potential to provide around $15 \mathrm{EJ}$ of solar thermal heat by 2030, while the share of solar thermal deployed in the industrial sector could reach 33\% (IRENA, 2014). This potential is also anticipated to significantly support the industrial sector in achieving its greenhouse gas (GHG) emissions mitigation, under the European Union Emissions Trading System (EU ETS), and could also contribute to meeting Europe's 2020 energy and climate targets. At present in Europe, however, only a small percentage of installations for process heat have collector areas exceeding $1000 \mathrm{~m}^{2}$ (ESTIF, 2015).

The main focus of this study was the implementation of the life cycle assessment (LCA) of industrial solar thermal systems (ISTSs), with the purpose of quantifying and monetising their carbon-saving potential. The findings of the environmental performance of ISTSs, considering geographic location and solar potential, were assessed in relation to the EU ETS for the development of scenarios of ISTS penetration into the industrial sector. In conclusion, this work suggests appropriate incentives for the successful deployment of these systems in Europe.

\section{Background information}

\subsection{Industrial application of solar water heating}

Solar thermal systems for water heating are predominantly suitable for application in industries that utilise water in the low-temperature range of $40^{\circ} \mathrm{C}$ to $80^{\circ} \mathrm{C}$ and that have low energy requirements. Such industries include the food industry, agro-industries, textiles, the chemical industry and the beverage industry (Karagiorgas et al., 2001; 
Kalogirou, 2002). Due to their low cost and simple construction, Muneer et al. (2006) proposed the introduction of built-in-storage water heaters, units that combine a flat-plate collector and a storage tank in one system, for application in the textile industry. Using the model of an Austrian dairy plant, Schnitzer et al. (2007) demonstrated that a solar field of $1000 \mathrm{~m}^{2}$ can achieve annual natural gas savings of $85,000 \mathrm{~m}^{3}$ and carbon savings of 170 tonnes of $\mathrm{CO}_{2}$, with a return on the investment in less than three years. Kalogirou and Tripanagnostopoulos (2007) introduced a new hybrid photovoltaic/thermal system for low-temperature industrial application, which proved to cover a great percentage of the thermal energy required for the industrial process, as well as generating electricity.

Beyond this application, potential has also been identified for solar thermal energy at medium and medium to high temperatures that would satisfy the temperature requirements of industrial solar process heat applications $\left(60^{\circ} \mathrm{C}\right.$ to $260^{\circ} \mathrm{C}$ ) (Kalogirou, 2002, 2003, 2004). It has been indicated that using parabolic trough collectors can satisfy half of the annual load, achieving annual energy savings of $896 \mathrm{GJ}$ and carbon savings of 208 tonnes of $\mathrm{CO}_{2}$ equivalent (Kalogirou, 2002). The same study also revealed that greater savings were achieved with larger loads. In addition, Kalogirou (2003) assessed a variety of solar thermal systems for providing industrial process heat with energy generation ranging between 550 and $1100 \mathrm{kWh} / \mathrm{m}^{2} / \mathrm{a}$, depending on the type of solar collector. A novel methodology - a design space approach - was proposed by Kulkarni et al. $(2007,2008)$ for the design and optimisation of flat-plate solar-collector-based systems and concentrating-solar collector-based systems for both low- and medium-temperature industrial applications. The proposed methodology was demonstrated through a case study of a dairy plant, where a $23 \%$ reduction in total system costs could be realised, compared to the existing design.

\section{2. $L C A$ of solar water heating}

Solar thermal systems exploit a renewable energy source whilst essentially emitting zero emissions during their life-cycle operation phase. This has led to the implementation of a considerable number of LCA studies, the focus of which has been on quantification of the environmental impact of such systems throughout their life-cycles. In a recent study, the use of biomass as fuel for the auxiliary system in solar water heating systems demonstrated the best performance, in terms of kilograms of $\mathrm{CO}_{2}$-equivalent, among 32 different types of solar water heating systems (Zambrana-Vasquez et al., 2015). Several studies have employed LCAs related to the environmental impact of two types of solar thermal systems that have traditionally been used for domestic water heating - flatplate and evacuated-tube collectors (Hang et al., 2012; Carlsson et al., 2014; Greening and Azapagic, 2014). Hang et al. (2012) indicated that the flat-plate solar water heating system, using a natural gas auxiliary heater, was the best performing system among all the investigated types of auxiliary systems and locations, while Greening and Azapagic (2014) indicated a better performance of evacuated-tube collectors in regions with low solar irradiation, such as the UK. Additional studies also exist that have investigated the environmental performance of novel solar thermal collector concepts through LCA methodologies (Otanicar and Golden, 2009; Lamnatou et al., 2014, 2015; Comodi et al., 2014; Carnevale et al., 2014).

Researchers have also investigated the life-cycle performance of solar thermal systems from an environmental perspective, using the life cycle costing (LCC) methodology. Hang et al. (2012) calculated the LCC payback for solar water heating systems, finding it to vary from four to 13 years, depending on geographical location and type of solar collector, using the conventional electrical water heating system as the reference case. In Carlsson et al. (2014), where a solar heating system with polymeric solar collectors was compared to two equivalent solar heating systems (with flat-plate and evacuated-tube solar collectors), using both LCA and LCC, the economic analysis indicated that, despite the environmental advantage of the novel system, in terms of costs per amount of solar heat collected, the differences between the three types of collector systems were small, considering the given energy prices and environmental tax rates.

\subsection{European policy on support schemes for the promotion of RES and Energy Efficiency}

The EU is taking action in several areas to meet its climate and energy targets under the 2020 package. The main objective of the Renewable Energy Directive (2009/28/EC) for a 20\% RES contribution to the EU's total energy demand will be achieved through the fulfilment of national renewable targets, as set out in the National Action Plan (NAP). In acknowledging that each Member State has different renewable energy potentials, tailored support schemes and measures have to be developed to meet national targets. In several cases, RES support schemes that have been successfully implemented in one country, have failed in another (Kylili and Fokaides, 2015; Pyrgou et al., 2016). The rationalisation of national support schemes is also considered important, so that investor confidence 
is maintained and schemes are effectively implemented.

As far as the contribution of the industrial sector to meeting the climate and energy targets is concerned, the EU has established the EU ETS (2003/87/EC, 2009/29/EC). This is the EU's key tool for cutting GHG emissions from large-scale facilities in the power, industrial and aviation sectors, involving a 'cap and trade' system, where the total volume of GHG emissions from the aforementioned sectors that are responsible for $45 \%$ of European GHG emissions, is capped. The relevant legislation creates allowances, which are essentially rights to emit GHG emissions equivalent to the global warming potential of 1 tonne of $\mathrm{CO}_{2}$-equivalent. The scheme allows the trading of emission allowances, with the purpose of keeping the total emissions of the installations and aircraft operators below the cap, which tightens over time, and ensuring that emissions are reduced where it is most cost-effective. As a result, the trading allows the carbon price to meet the desired target.

\section{Methodology}

\subsection{Methodology overview}

The methodology followed in this work was based on the implementation of a LCA on an ISTS for environmental assessment of the different components that make up the systems, including the flat-plate collectors, storage tank and other auxiliary components. Definition of the environmental impact of ISTSs allows its comparison to conventional water heating systems (CWHS), as well as the conduction of a parametric analysis for specific European locations of diverse solar potential. Taking into consideration the quantified carbon savings from the application of ISTSs, and in relation to the EU ETS, scenarios of ISTS penetration and monetisation in the industrial sector were developed. In light of that, the study included the definition of appropriate incentives for ISTS penetration for diverse locations in Europe. The methodology followed in this study is illustrated in Figure 1.

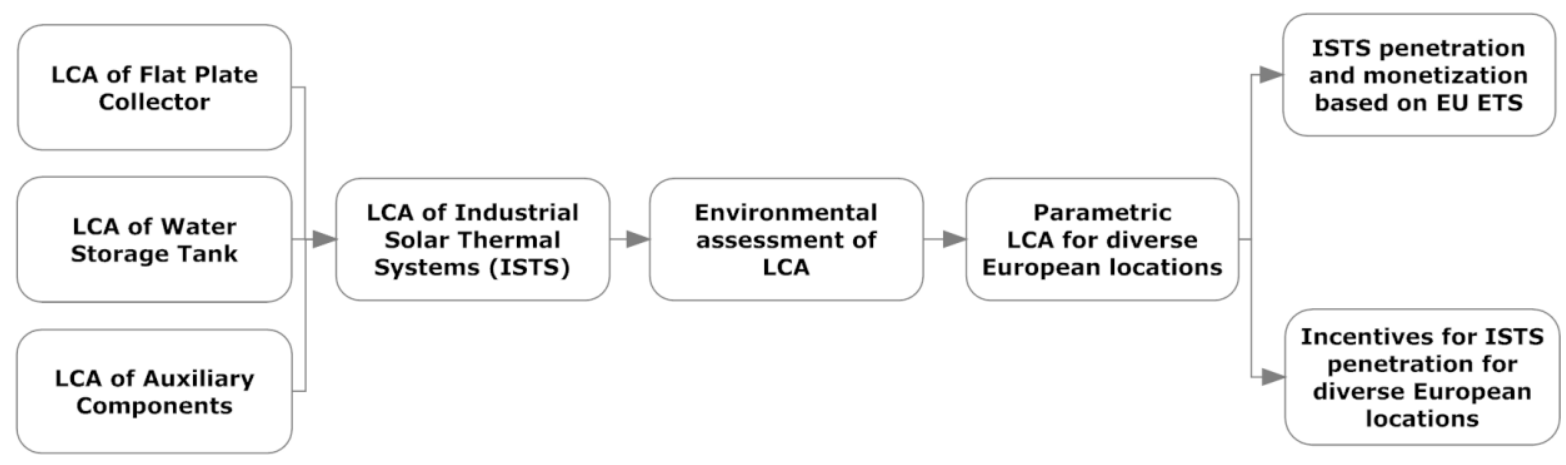

Fig. 1: Graphic representation of the methodology of the study

\subsection{Life Cycle Assessment Scope and Inventory}

The definition of the environmental performance of solar thermal water heating systems for industrial applications is achieved through the adoption of the standardized LCA approach, provided by the ISO 14040 series, and the employment of one of the most well- established LCA tools currently available - GaBi software (ISO 14040:2006; Thinkstep GaBi., 2017). The investigated solar thermal water heating systems were pre-engineered to satisfy the temperature requirements of industrial processes concerning low temperature hot water up to 100 ${ }^{\circ} \mathrm{C}$ (Kalogirou, 2004). Taking into consideration the installed capacity of existing ISTS which exploit flat plate collector technology for water heating purposes (IEA, 2016), the functional unit (FU) has been defined (Table 1). The functional units included the system which is comprised from the solar collectors, storage tanks, mounting equipment, pipes, hydraulic components, auxiliary heating and the solar fluid. The data for the development of the LCI has been obtained from the manufacturers and/ or importers of the components that make up the solar thermal systems; whereas for those components primary data were not available, secondary data from wellestablished LCI databases has been used. In this study, a cradle to use analysis was implemented; the system boundaries are illustrated in Figure 2. 
Tab. 1: Functional unit (FU) employed for the LCA of Industrial Solar Thermal System (ISTS)

\begin{tabular}{|c|c|c|c|c|}
\hline $\begin{array}{c}\text { Installed thermal } \\
\text { power }[\mathbf{k W t h}]\end{array}$ & $\begin{array}{c}\text { Installed collector } \\
\text { area }\left[\mathbf{m}^{\mathbf{2}}\right] \text {, gross }\end{array}$ & $\begin{array}{c}\text { Aperture area } \\
{\left[\mathbf{m}^{\mathbf{2}}\right]}\end{array}$ & $\begin{array}{c}\text { Number of solar } \\
\text { collectors }\end{array}$ & $\begin{array}{c}\text { Number of water } \\
\text { storage tanks }\end{array}$ \\
\hline 70 & 100 & 92 & 41 & 9 \\
\hline
\end{tabular}

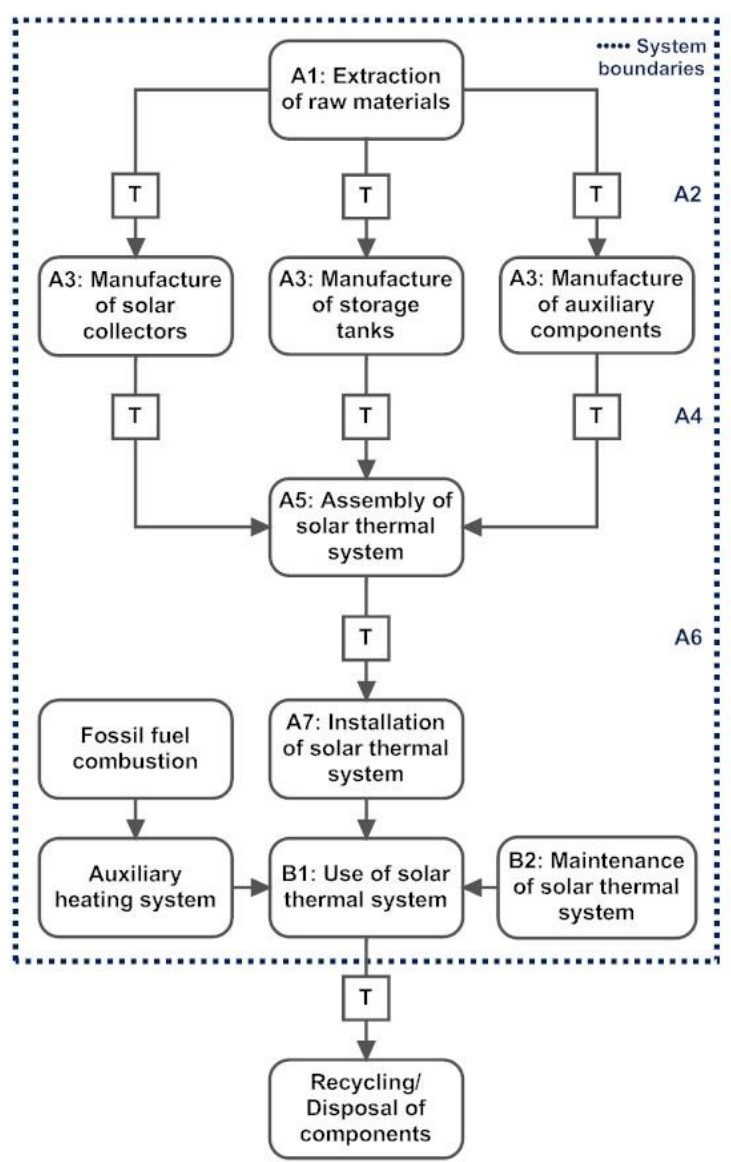

Fig. 2: Life Cycle Assessment - System Boundaries (T: Transportation - A2, A4, A6
The assumptions made for the environmental analysis are the following:

Cyprus is the reference geographical area for the manufacturing of the solar thermal system. The origin of the different system components was considered as follows (Johnsun Heaters Ltd, 2016):

- Absorber Plate: Germany

- Back cover and framework: Egypt

- Headers and risers: Bulgaria

- Glass wool and tempered glass: Greece

- EPDM: Cyprus

- A parametric investigation of the impact of the distance between the assembly and the installation point was not considered as a requirement, as the impact of this parameter was found to be negligible.

- The life span of the solar thermal system was assumed to be 20 years.

- The use phase of the system included the fossil fuel combustion for auxiliary heating, while its maintenance included the annual drainage and refilling of the solar fluid over its lifetime.

- Propylene glycol was considered as the solar fluid.

- The auxiliary heating was assumed to be through fossil-fuelled boiler, representing a CWHS. The manufacturing of the auxiliary heating source (boiler) was also considered.

The findings of the LCA on the environmental impact of the investigated ISTS were evaluated with respect to the environmental performance of equivalent capacity of CWHS, ie., fossil-fueled boilers. The performance of the ISTS was also assessed under two climatic conditions — warmer (Athens) and colder climates (Frankfurt aM) given that its performance would be affected by the solar potential of the installation location. The annual energy contribution of the ISTS and the auxiliary hot water system per kWth for each considered location was defined through the employment of the TSOL software (Valentin software, 2017) (Table 2).

Tab. 2: Energy contributions of the ISTS and the auxiliary conventional water heating systems in investigated sites

\begin{tabular}{|l|c|c|}
\hline \multicolumn{1}{|c|}{ Location } & \multicolumn{2}{|c|}{ System energy contribution per kW per annum } \\
\hline & ISTS & Auxiliary CHWS \\
\hline Athens (37.9 ${ }^{\circ}$ lat.) & 879 & 229 \\
\hline Frankfurt aM (50.1 ${ }^{\circ}$ lat.) & 552 & 557 \\
\hline
\end{tabular}

\subsection{Life Cycle Costing and Support Schemes}

In terms of this study, the potential support schemes, in the form of investment aids, were defined by considering the equivalent cost of carbon savings from the application of ISTS and in relevance to the EU ETS. For the calculation of the carbon monetary value, the price of carbon was set at $10.32 € /$ tn $\mathrm{CO}_{2}$, representing the average cost for carbon since January 1st, 2008 (Investing.com, 2017). The costing of the investigated ISTS was performed based on price indicators retrieved from ESTIF (2015), as well as based on LCC principles described in Kalogirou 
(2013) and Fokaides and Kylili (2014). For the development of the scenarios of ISTS penetration and the implementation of the LCC, actual data of the total final consumption of the industrial sector for each of the investigated locations has been retrieved from the International Energy Agency (EIA, 2017). This concludes to incentives' recommendations for the development of support schemes of ISTS in the considered energy mixes.

\section{Results and Discussion}

\subsection{Life Cycle Impact Assessment (LCIA) of Industrial Solar Thermal Systems (ISTS)}

The LCIA results, illustrated in Figure 3 for Athens, reveal the percentage contribution of each life-cycle stage on the total environmental impact of ISTSs. In both locations, the results demonstrate that the life-cycle phases of the investigated ISTSs that are the most detrimental to the environment are the raw material extraction, the system manufacturing phase and the use phase. In terms of impact, the raw material extraction and system manufacturing phases contribute to more than $84 \%$ of the total in the categories of ozone and element depletion, as well as the ecotoxicity to human health and the marine and terrestrial environments. As a result of fossil fuel combustion (natural gas) in the auxiliary heating system for the generation of hot water, the use phase is presented as having a principal contributing role in the potential for global warming and ocean acidification and eutrophication, depletion of fossil fuels, and the creation of photochemical ozone in the troposphere, amounting to $67 \%$ to $81 \%$. The installation of such systems is also worth noting, contributing $9 \%$ to the ocean acidification potential, $6 \%$ to the terrestrial ecotoxicity potential, and $5 \%$ to the photochemical ozone creation potential. Regarding the rest of the phases included in the system boundaries of this work - transportation of the system and system components, and maintenance of the system - their contribution to the totals are negligible.

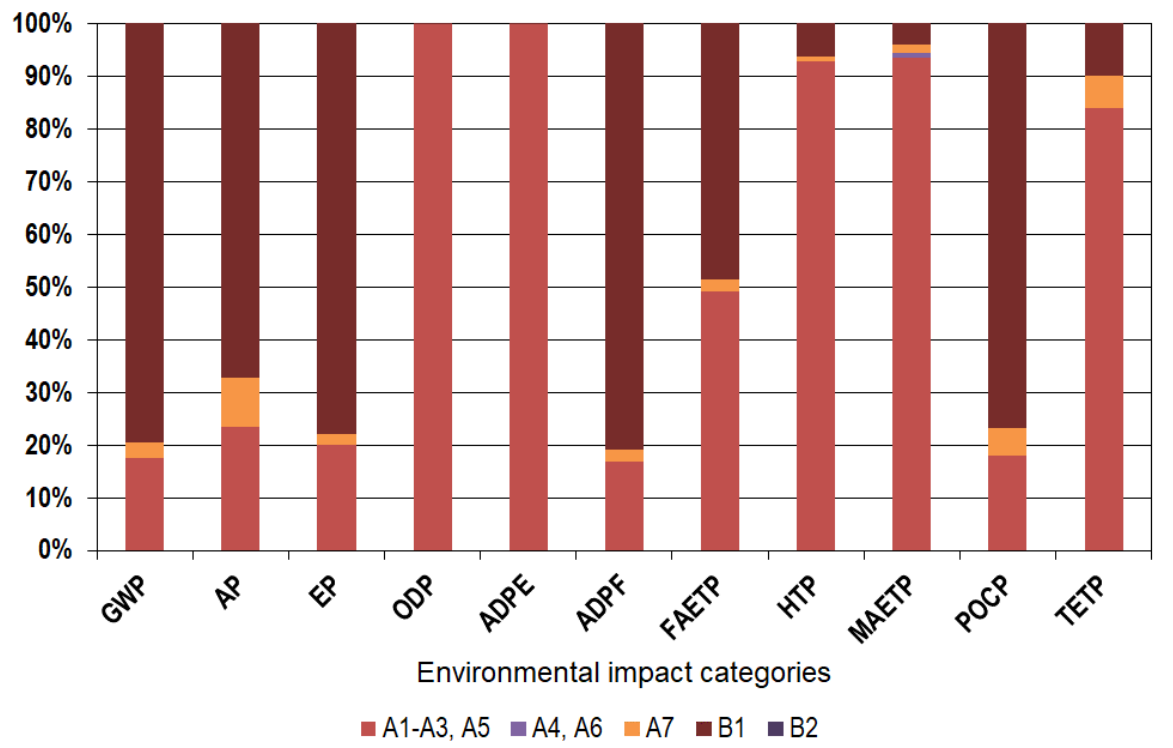

Fig. 3: Life Cycle Impact Assessment of ISTS located in Athens per life cycle stage

The environmental impact of ISTSs was also comparatively assessed against the CWHS of equivalent system output, taking into consideration the same system boundaries. The potential of ISTSs is less than one-third of the conventional equivalent system for the categories of climate change, ocean acidification and eutrophication, depletion of fossil fuels and photochemical ozone creation. The potential in the respected categories for the conventional system can be largely related to the fossil fuel combustion during its manufacturing and use phases; however, the comparative analysis results also revealed significant pressure on the environment caused by manufacturing of the ISTSs, especially in terms of the abiotic depletion of elements and ecotoxicity to human health. For these specific categories, the potential of ISTSs is considerably higher than its conventional equivalent system, by a factor of 400 and 30, respectively. By taking into consideration the life-cycle phases in the defined system boundaries, the non-renewable energy sources and $\mathrm{CO}_{2}$ balances for both systems were also extracted using GaBi software. 


\subsection{Parametric Life Cycle Impact Assessment (LCIA) results for diverse locations}

The parametric LCA analysis indicated that the environmental burden of ISTSs found in locations of lower solar potential was higher in the majority of environmental categories than systems located at southern latitudes (Table 3). The reasoning directs to the use phase of the system, and the fact that ISTSs located in areas of high solar potential (i.e., Athens) can generate higher energy yields for the supply of hot process water, while the use of the auxiliary system, along with the fossil fuel consumption, is substantially reduced.

Tab. 3: Life Cycle Impact Assessment (LCIA) results per kWth of ISTS for the two investigated locations

\begin{tabular}{|c|c|c|}
\hline Environmental impact categories & Athens & Frankfurt aM \\
\hline GWP & $1,82 \mathrm{E}+03$ & $3,75 \mathrm{E}+03$ \\
\hline AP & $5,44 \mathrm{E}+00$ & $5,10 \mathrm{E}+00$ \\
\hline EP & $5,10 \mathrm{E}-01$ & $5,92 \mathrm{E}-01$ \\
\hline ODP & $9,81 \mathrm{E}-03$ & $1,05 \mathrm{E}-02$ \\
\hline ADPE & $6,54 \mathrm{E}-02$ & $6,55 \mathrm{E}-02$ \\
\hline ADPF & $2,46 \mathrm{E}+04$ & $5,14 \mathrm{E}+04$ \\
\hline FAETP & $1,24 \mathrm{E}+01$ & $2,41 \mathrm{E}+01$ \\
\hline HTP & $8,54 \mathrm{E}+02$ & $8,99 \mathrm{E}+02$ \\
\hline MAETP & $4,00 \mathrm{E}+05$ & $4,29 \mathrm{E}+05$ \\
\hline POCP & $4,55 \mathrm{E}-01$ & $5,54 \mathrm{E}-01$ \\
\hline TETP & $3,42 \mathrm{E}+00$ & $3,29 \mathrm{E}+00$ \\
\hline
\end{tabular}

The overall non-renewable energy sources and $\mathrm{CO}_{2}$ emissions for the considered sites, as well as the savings that can be achieved when compared to the CWHS, are presented in Table 4. In agreement with the LCIA results, location also has a decisive effect on the energy and carbon savings that can be achieved by large-scale ISTS applications.

Tab. 4: Life-Cycle energy and carbon emissions savings per kWth of ISTS for the two investigated locations

\begin{tabular}{|l|c|c|c|c|}
\hline \multicolumn{1}{|c|}{ Site } & $\begin{array}{c}\text { Non-renewable } \\
\text { energy consumption } \\
{[\mathbf{G J}]}\end{array}$ & $\begin{array}{c}\text { Energy Savings } \\
\text { [GJ] }\end{array}$ & $\begin{array}{c}\text { Carbon Emissions } \\
{\left[\text { ton } \mathbf{C O}_{2} \text { ] }\right.}\end{array}$ & $\begin{array}{c}\text { Carbon Savings } \\
{\left[\text { ton } \mathbf{C O}_{2} \text { ] }\right.}\end{array}$ \\
\hline Athens & 27,21 & 75,32 & 1,74 & 4,95 \\
\hline Frankfurt aM & 56,14 & 44,04 & 3,62 & 2,93 \\
\hline
\end{tabular}

For the establishment of the relationship between latitude and ISTS energy performance, the same methodology was followed for four additional European locations - Barcelona, Milan, Copenhagen, and Oslo. This allowed the development of a 'life-cycle produced to consumed energy' ratio, where the impact of location on the energy performance of ISTS application was more profound (Figure 4). For the latitudinal range of $35^{\circ}$ to $60^{\circ}$, Figure 4 illustrates a strong inverse relationship between latitude and the ratio, with a higher ISTS location latitude equating to a lower 'life-cycle produced to consumed energy' ratio, and consequently a reduced system energy lifetime performance.

\subsection{Scenarios of Industrial Solar Thermal Systems (ISTS) penetration}

The results of the LCC of the considered ISTSs are provided in Table 5, where the saved carbon monetary value and the required number of ISTS applications of $700 \mathrm{kWth}$ per penetration percentage are indicated. The values differentiate depending on the total final consumption of the industry of each country, as well as the potential energy saving per installed $\mathrm{kW}$ th. Greece has a lower (numerically) required capacity for ISTS applications of $700 \mathrm{kWth}$ to satisfy national demand, as well as the lowest saved carbon monetary value per percentage of ISTS contribution to its energy mix. By considering the findings of Table 5, policy-makers can be guided towards providing appropriate financial incentives for large-scale ISTS applications, depending on the chosen national support scheme. 


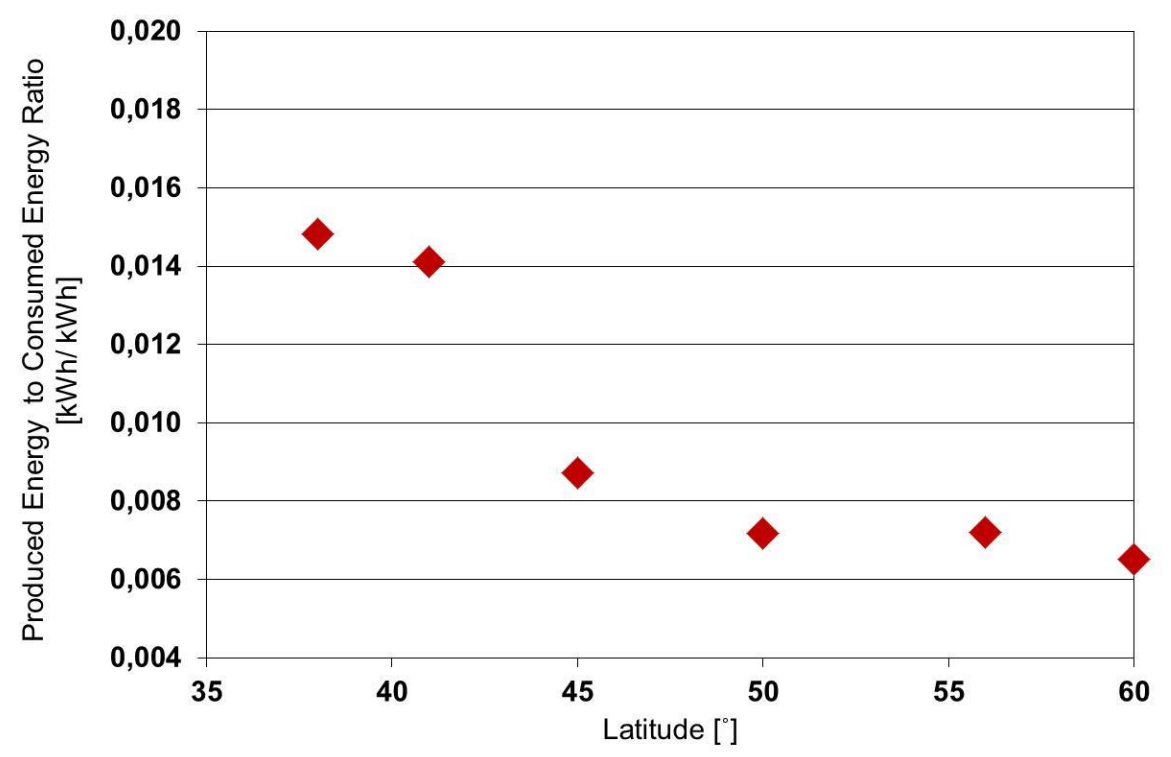

Fig. 4: 'Life-Cycle Produced to Consumed Energy' Ratio' for diverse European locations

Tab. 5: Number of $700 \mathrm{kWth}$ installations and saved carbon monetary value per percentage of ISTS penetration into considered energy mixes

\begin{tabular}{|c|c|c|}
\hline Country & Number of installations & Saved Carbon monetary value [M€] \\
\hline Greece & 188 & 46,74 \\
\hline Germany & 3343 & 831,02 \\
\hline
\end{tabular}

\section{Concluding remarks}

While solar thermal technologies are widely used in domestic applications across Europe, solar heat for industrial processes is still a niche market. The key objective of this work was to quantify the untapped potential of solar thermal in industrial applications, and provide recommendations for the development of financial incentives for the promotion of the technology. For this purpose, the environmental performance of ISTSs was defined through the implementation of LCA.

The LCA results demonstrated that the life-cycle phases of the investigated solar thermal systems that are the most detrimental to the environment include the raw material extraction and system manufacturing phases, as well as the use phase. The raw material extraction and system manufacturing phases contributed more than $85 \%$ of the total impact in the categories of ozone and element depletion, and ecotoxicity to human health and marine and terrestrial environments. The use phase was found to be the main contributor to the depletion of fossil fuels and the creation of photochemical ozone impact categories, as a result of fossil fuel combustion in the auxiliary heating system for the generation of hot water. The implementation of a parametric assessment on the environmental performance of ISTSs for specific European geographical locations with diverse solar potential allowed the development of a 'life-cycle produced to consumed energy' ratio, which indicated that applications located at lower latitudes (in the Northern Hemisphere) can achieve greater life-cycle energy and carbon savings than ISTS applications located at higher latitudes.

Lower-latitude locations have higher solar potential, generating higher energy yields for the supply of hot process water, whereas the use of an auxiliary system is substantially reduced. In particular, large-scale ISTS applications in Athens were found to achieve energy savings of $75 \mathrm{GJ}$ and carbon savings of 5 tonnes of $\mathrm{CO}_{2}$ per $\mathrm{kW}$ th, while the respective values for Frankfurt aM were $44 \mathrm{GJ}$ and 3 tonnes of $\mathrm{CO}_{2}$ per $\mathrm{kWth}$. The ratio can also be used to support decision-making by policy-makers throughout the process of renewable energy support scheme development. In particular, in the case of large countries or unions that extend through several climatic zones, the 'life-cycle produced to consumed energy' ratio can provide significant guidance in setting realistic incentives in relation to local available potential.

The parametric analysis also enabled the development of scenarios of ISTS penetration into the industrial sector in relation to the EU ETS, as well as definition of the carbon monetary value for the selected Member States. 
Evaluation of the required capacity of large- scale ISTS applications to satisfy the desired percentage of national industrial demands for hot water is supported by taking into consideration the carbon monetary value and geographical location of the application. The findings of this work can be exploited by European policy-makers as a guideline for the development of national strategic plans and investment aids for the promotion of large-scale solar heat water generation applications for industrial processes.

\section{References}

Carlsson, B., Persson, H., Meir, M., Rekstad, J., 2014. A total cost perspective on use of polymeric materials in solar collectors-Importance of environmental performance on suitability. App. Energy, 125, 10-20.

Carnevale, E., Lombardi, L., Zanchi, L. 2014. Life Cycle Assessment of solar energy systems: Comparison of photovoltaic and water thermal heater at domestic scale. Energy, 77, 434-446.

Comodi, G., Bevilacqua, M., Caresana, F., Pelagalli, L., Venella, P., Paciarotti, C., 2014. LCA analysis of renewable domestic hot water systems with unglazed and glazed solar thermal panels. Energy Procedia, 61, 234237.

Directive 2003/87/EC of the European Parliament and of the Council of 13 October 2003 establishing a scheme for greenhouse gas emission allowance trading within the Community and amending Council Directive 96/61/EC.

Directive 2009/28/EC of the European Parliament and of the Council of 23 April 2009 on the promotion of the use of energy from renewable sources and amending and subsequently repealing Directives 2001/77/EC and 2003/30/EC.

Directive 2009/29/EC of the European Parliament and of the Council of 23 April 2009 amending Directive 2003/87/EC so as to improve and extend the greenhouse gas emission allowance trading scheme of the Community.

European Solar Thermal Industry Federation (ESTIF), 2015. Solar Thermal Markets in Europe Trends and Market Statistics 2014. Last accessed 17 May 2017. Available from: http://www.estif.org/home/

Fokaides, P. A., Kylili, A., 2014. Towards grid parity in insular energy systems: The case of photovoltaics (PV) in Cyprus. Energy Policy, 65, 223-228.

Greening, B., Azapagic, A., 2014. Domestic solar thermal water heating: A sustainable option for the UK?. Renewable Energy, 63, 23-36.

Hang, Y., Qu, M., Zhao, F., 2012. Economic and environmental life cycle analysis of solar hot water systems in the United States. Energy and Build., 45, 181-188.

IEA (International Energy Agency) Solar Heating \& Cooling Programme, 2016. Solar Heat Worldwide Markets and Contribution to the Energy Supply 2014. Last accessed 17 May 2017. Available from: www.iea-shc.org/

International Energy Agency (IEA) World Energy Balance, 2017. Last accessed 17 May 2017. Available from: http://www.iea.org/sankey/

Investing.com, Carbon Emissions Futures Historical Data Last accessed 17 May 2017. Available from: https://www.investing.com/commodities/carbon-emissions-historical-data

IRENA (International Renewable Energy Agency), 2014. REmap 2030: A Renewable Energy Roadmap, June 2014, Abu Dhabi. Last accessed 17 May 2017. Available from: http://www.irena.org/remap/IRENA_REmap_Report_June_2014.pdf

ISO (International Organization for Standardization), 2006. ISO 14040:2006. Environmental Management- Life Cycle Assessment- Principles and Framework.

ISO (International Organization for Standardization), 2006. ISO 14044:2006. Environmental Management- Life Cycle Assessment- Requirements and guidelines.

Johnsun Heaters Ltd. Personal Communication. December 2016. 
Kalogirou, S. A., 2002. Parabolic trough collectors for industrial process heat in Cyprus. Energy, 27(9), 813830.

Kalogirou, S. A., 2003. The potential of solar industrial process heat applications. Appl. Energy, 76(4), 337361.

Kalogirou, S. A., 2004. Solar thermal collectors and applications. Prog. Energy Combust.Sci., 30(3), 231-295.

Kalogirou, S. A., 2013. Solar energy engineering: processes and systems. Academic Press.

Kalogirou, S. A., \& Tripanagnostopoulos, Y., 2007. Industrial application of PV/T solar energy systems. Appl. Therm. Eng., 27(8), 1259-1270.

Karagiorgas, M., Botzios, A., Tsoutsos, T., 2001. Industrial solar thermal applications in Greece: economic evaluation, quality requirements and case studies. Renewable Sustainable Energy Rev., 5(2), 157-173.

Kulkarni, G. N., Kedare, S. B., Bandyopadhyay, S., 2007. Determination of design space and optimization of solar water heating systems. Sol. Energy, 81(8), 958-968.

Kulkarni, G. N., Kedare, S. B., Bandyopadhyay, S., 2008. Design of solar thermal systems utilizing pressurized hot water storage for industrial applications. Sol. Energy, 82(8), 686-699.

Kylili, A., Fokaides, P. A., 2015. Competitive auction mechanisms for the promotion renewable energy technologies: The case of the 50MW photovoltaics projects in Cyprus. Renewable Sustainable Energy Rev., 42, 226-233.

Lamnatou, C., Notton, G., Chemisana, D., Cristofari, C., 2014. Life cycle analysis of a building-integrated solar thermal collector, based on embodied energy and embodied carbon methodologies. Energy Build., 84, 378-387.

Lamnatou, C., Notton, G., Chemisana, D., Cristofari, C., 2015. The environmental performance of a buildingintegrated solar thermal collector, based on multiple approaches and life-cycle impact assessment methodologies. Build. Environ., 87, 45-58.

Muneer, T., Maubleu, S., Asif, M., 2006. Prospects of solar water heating for textile industry in Pakistan. Renewable Sustainable Energy Rev., 10(1), 1-23.

Otanicar, T. P., Golden, J. S., 2009. Comparative environmental and economic analysis of conventional and nanofluid solar hot water technologies. Environ. Sci. Technol., 43(15), 6082-6087.

Pyrgou, A., Kylili, A., Fokaides, P. A., 2016. The future of the Feed-in Tariff (FiT) scheme in Europe: The case of photovoltaics. Energy Policy, 95, 94-102.

Schnitzer, H., Brunner, C., Gwehenberger, G., 2007. Minimizing greenhouse gas emissions through the application of solar thermal energy in industrial processes. J. Cleaner Prod., 15(13), 1271-1286.

Thinkstep GaBi. (2017). GaBi's website. Available from: http://www.gabi-software.com/international/index/

Valentin software (2017). T*SOL Dynamic thermal Simulation Program for Designing and Optimizing Solar Thermal Systems. Last accessed 17 May 2017. Available from: www.valentin-software.com/en

Zambrana-Vasquez, D., Aranda-Usón, A., Zabalza-Bribián, I., Janez, A., Llera-Sastresa, E., Hernandez, P., Arrizabalaga, E., 2015. Environmental assessment of domestic solar hot water systems: a case study in residential and hotel buildings. J. Cleaner Prod., 88, 29-42. 
P. Fokaides et. al. / EuroSun 2018 / ISES Conference Proceedings (2018)

\section{Appendix: Nomenclature}

\begin{tabular}{|c|c|c|}
\hline Abbreviation & Description & Unit \\
\hline ADPE & Abiotic Resource Depletion Potential for elements & [kg Sb- equiv.] \\
\hline ADPF & Abiotic Resource Depletion Potential of Fossil Fuels & {$[\mathrm{MJ}]$} \\
\hline AP & Acidification Potential & [kg SO S- equiv. $]$ \\
\hline CWHS & Conventional Water Heating Systems & - \\
\hline EP & Eutrophication Potential & [kg phosphate- equiv.] \\
\hline ESTIF & European Solar Thermal Industry Federation & - \\
\hline EU ETS & European Emission Trading System & - \\
\hline FAETP & Fresh-Water Aquatic Ecotoxicity Potential & [kg DCB- equiv.] \\
\hline GHG & Greenhouse Gases & - \\
\hline GWP & Global Warming Potential & [kg CO 2 - equiv.] \\
\hline HTP & Human Toxicity Potential & [kg DCB- equiv.] \\
\hline IEA & International Energy Agency & - \\
\hline ISTS & Industrial Solar Thermal Systems & - \\
\hline LCA & Life Cycle Assessment & - \\
\hline LCC & Life Cycle Costing & - \\
\hline LCIA & Life Cycle Impact Assessment & - \\
\hline LCI & Life Cycle Inventory & - \\
\hline MAETP & Marine Aquatic Ecotoxicity Potential & [kg DCB- equiv.] \\
\hline NAP & National Action Plan & - \\
\hline ODP & Ozone Depletion Potential & [kg R11- equiv.] \\
\hline POCP & Photochemical Oxidant Creation Potential & [kg ethene- equiv.] \\
\hline RES & Renewable Energy Sources & - \\
\hline TETP & Terrestric Ecotoxicity Potential & [kg DCB- equiv.] \\
\hline
\end{tabular}




\title{
ReSSSPI: The network of simulated solar systems for industrial processes
}

\author{
Miguel Frasquet ${ }^{1}$, Joey Bannenberg ${ }^{2}$, Yago N. Vila ${ }^{3}$ and Manuel Silva ${ }^{4}$ \\ 1 Solatom CSP S.L, Valencia (Spain) \\ ${ }^{2}$ Fontys University of applied sciences, Eindhoven (Netherlands) \\ ${ }^{3}$ ETH, Zürich (Switzerland) \\ ${ }^{4}$ University of Sevilla, Sevilla (Spain)
}

\begin{abstract}
During 2017, the Spanish Ministry of Economy, Industry and Competitiveness through the technology platform "Solar Concentra", launched a field study to identify the one hundred Spanish industries with the highest potential of using concentrating solar collectors to meet their thermal energy demand. In order to evaluate both the energy and economic performance in each case, an open-source solar simulator for industrial processes called ReSSSPI has been developed during this study. ReSSSPI is an online calculator (OC) written in Python 3 that estimates the economic and energy performance of solar process heat applications. ReSSSPI's performance model is based on SHIPcal code, one of the earliest OCs for solar heat applications in industrial processes. In one year, ReSSSPI has performed more than 267 simulations from Spanish industry users, creating a network of simulated solar plants across the Spanish territory.
\end{abstract}

Keywords: RESSSPI; solar; simulator; industrial; process; SHIPcal; online; calculator

\section{Introduction}

During 2017, the Spanish Ministry of Economy, Industry and Competitiveness through the Spanish technology platform for Solar Concentration "Solar Concentra", launched a field study to assess the use of concentrated solar technologies for heat generation in industrial processes (Frasquet, 2017). The goal of this study aimed to identify the Spanish industries with the highest potential to use concentrated solar collectors to meet their thermal energy demand. To assess the potential of every industry, a detailed set of information was obtained from industries in 8 different sectors. A total of two hundred industries were studied. In most cases, the information needed was gathered through telephone interviews and field visits.

In order to establish a common framework with which benchmark every case, an open-source solar simulator called ReSSSPI was developed during the study. ReSSSPI is an online calculator (OC) written in Python 3 capable of estimating both the energy performance, and the financial aspects of a large range of solar process heat applications.

\section{Online calculators as benchmarking tool}

When simulating solar thermal applications for industrial processes, there are several tools available in the market. These tools range from very simple Excel sheets, to quite complex but detailed software such as TRNSYS or PolySun. Due to time constrains, and the diversity of integration concepts found during the project, the ideal solution was a compromise between the flexibility of commercial software like the ones mentioned before, in which users are not limited to use pre-designed models, and the speed and simplicity of Excel sheets. In addition, since the goal of the project is to identify the industries with the highest potential, rather than to perform very 
accurate simulations of every one of them, certain degree of uncertainty in the results is considered acceptable. Upon these considerations, the use of an OC was the final decision.

The use of OCs has a long tradition in more mature sectors like photovoltaic industry (PV). Nowadays hundreds of PV calculators can be found online (e.g NREL's PVWatts (Dobos, 2013) or SolarCalculator website https://solarcalculator.com.au ). Although it is possible to find some OCs for solar heat for industrial processes (SHIP), such as SHIP Design Tool or Appsol. All of them proved to be inadequate for this study due to the limited integrations concepts available, and the lack of solar radiation sources regarding the Spanish territory.

SHIPcal code was released in 2015 (Frasquet, 2016) as an open source OC for solar heat applications in industrial processes. This tool came with an extensive data base of meteorological files for the Spanish territory, and some of the integration concepts proposed by the IEA SHC Task 49 (Muster et al., 2015). The results of SHIPcal were validated using TRNSYS, showing discrepancies in the energy production up to $10 \%$ during cloudy days (cumulative values), and 3\% during sunny conditions. Although this level of accuracy made SHIPcal unsuitable to be used as a design program, is enough for the purpose of this project. Unfortunately, since the development of SHIPcal ceased one year after its release due to financial constraints, only the backend code (not the fully working tool) was available. Therefore a new OC called ReSSSPI, was developed during the project, using a completely new front-end and most of the SHIPcal's backend.

\section{ReSSSPI online calculator}

ReSSSPI has been the OC used as benchmarking tool during the project. Due to the size and heterogeneity of the group of industries studied, ReSSSPI has been designed to provide simple yet flexible simulations, of cost and energy performance, in a reasonable time span. To facilitate its use, during and after the project, ReSSSPI runs over a user-friendly website available online at www.ressspi.com.

\subsection{Improvements over SHIPcal original approach}

In addition to be tailored to fulfill the requirements of the project, ReSSSPI has also solved some of the limitations of the original SHIPcal approach.

SHIPcal was conceived as open-source initiative, in order to boost the collaboration of all stakeholders in the SHIP business. For these matters, the code was fully written in GNU Octave. Since Octave is a free and opensource programming language compatible with Matlab, the initial idea was to allow an easy transition from licensed software such Matlab (very popular in the scientific community), to free and compatible alternatives. However, this decision proved to be counterproductive due to the low popularity of Octave. In fact, based on the PYLP index 2018 (http://pypl.github.io/PYPL.html), an index that ranks the popularity of programming languages based on Google Trends, Matlab ranks in tenth position, while Octave is not even in the top 50. In ReSSSPI, all the code has been translated from Octave into Python, which not only ranks the first one in the PYLP index, it is free and open-source like Octave.

Another decision that significantly limited the development of SHIPcal, was the version control system used for tracking changes in the code. SHIPcal relied on a simple mailing list in which all the researchers contributing to the development of the code, posted their changes. This quickly spiraled out of control generating inefficiencies and overlaps. ReSSSPI however uses Git as version control system. Git was created by Linus Torvalds in 2005 for managing the collaborative development of the open-source software Linux, and since then, it has successfully managed the changes in the source code, applied by more than 15600 external contributors (Corbet et al., 2010). The source code of ReSSSPI is freely available at GitHub (https://github.com/mfrasquet/), a public repository of open-source projects using Git. From there, any interested user can clone the source code and start collaborating in its development.

\subsection{ReSSSPI input form}

As in most OCs, ReSSSPI uses a simple online form to gather the data needed for the simulation. This input form has 5 primary variables, and 19 secondary ones. Although all the variables are needed to perform a simulation, ReSSSPI can suggest default values for the secondary variables, as long as the primary variables are provided by the user. The primary variables are: Industry sector, size of the industry, type of fossil fuel currently used in the 
industry, annual thermal energy demand, and location. The same way SHIPcal suggested values from the "Matrix of Industrial Process Indicators" of the Greenfood platform (http://www.green-foods.eu/) when some variables were left blank, once the primary variables are provided in ReSSSPI, it suggests default values for the missing secondary variables. But instead of using external sources like in SHIPcal, it generates default values using similar projects in its database.

ReSSSPI comes with meteorological and solar radiation data for 50 cities in Spain and several international locations. When data is not available for a specific location, it can be requested using the online website. Although the main source of the meteo and solar database is Meteonorm 7.2, in particular cases (like in the case of some Spanish cities) another sources have also been used. More information regarding meteo source can be found in ReSSSPI manual (Frasquet, 2018).

Once the input form is filled, and before the simulation starts, ReSSSPI checks the input set using a precautionary firewall. This firewall checks if the variables introduced are technically and/or thermodynamically feasible. If the user provides an outlet temperature lower than the input temperature, or the fluid chose is not compatible with the integration concept, for example, ReSSSPI stops the process avoiding a potential convergence problem when simulating.

\subsection{Design process and simulation}

ReSSSPI implements two design methods: Manual and Automatic. In the manual mode, the user introduces the design parameters manually (i.e. Number of loops, number of collectors per loop, integration concept and storage capacity if needed), whereas in the automatic mode, ReSSSPI finds the optimal configuration by itself. At the time of writing, ReSSSPI offers the possibility of choosing between 7 different industrial integration concepts proposed by Muster et al. (2015). It also enables the use of thermal storage depending on the integration concept selected, and some other specific integration concepts, found recursively during the project. Table 1 show the characteristics and the current development of the integration concepts available in ReSSSPI.

Tab. 1: Current development of integration concepts available in ReSSSPI

\begin{tabular}{|c|c|c|c|c|c|}
\hline $\begin{array}{l}\text { Solar heat integration } \\
\text { concept (* not } \\
\text { included in Muster et } \\
\text { al. (2015)) }\end{array}$ & $\begin{array}{c}\text { Level of } \\
\text { integration }\end{array}$ & $\begin{array}{l}\text { Heat } \\
\text { transfer } \\
\text { medium }\end{array}$ & Integration description & Storage & $\begin{array}{l}\text { Current status } \\
\text { in ReSSSPI }\end{array}$ \\
\hline SL_L_P & Supply & Water/Oil & Parallel integration (Direct) & No & Operative \\
\hline SL_L_PS & Supply & Water/Oil & Parallel integration (Direct) & Yes & Operative \\
\hline SL_L_RF & Supply & Water/Oil & Return flow boost & No & Operative \\
\hline SL_L_S & Supply & Water/Oil & Heating of storages & Yes & Operative \\
\hline SL_S_PD & Supply & Steam & Parallel integration (Direct) & No & Operative \\
\hline SL_S_PI & Supply & Steam & Parallel integration (Indirect) & No & Being tested \\
\hline SL_S_FW & Supply & Steam & Heating of feedwater & No & Operative \\
\hline SL_S_FWS & Supply & Steam & $\begin{array}{l}\text { Heating of feedwater with } \\
\text { intermediate storage }\end{array}$ & Yes & Operative \\
\hline SL_S_MW & Supply & Steam & Heating of make-up water & No & Operative \\
\hline PM_E_PM & Process & Water/Oil & Heating of process medium & No & Operative \\
\hline PM_E_PM_Past* & Process & Water & $\begin{array}{l}\text { Integration for pasteurizators } \\
\text { with intermediate storage }\end{array}$ & Yes & Being tested \\
\hline PM_E_PM_Sew* & Process & Water/Oil & $\begin{array}{l}\text { Integration for Sewage plants } \\
\text { with intermediate storage }\end{array}$ & Yes & Operative \\
\hline
\end{tabular}


During the project the manual mode was used in the vast majority of the cases, since the users of the code were solar specialists. However, since ReSSSPI is meant to be used by public with all types of technical background, an automatic design method was needed.

When the automatic method is chosen, ReSSSPI creates a list of potential configurations depending on the input received. For example, if the process introduced in the form requires the use of steam, it creates potential configurations using all the possible alternatives: SL_S_PD, "Direct solar steam generation" and SL_S_FW, "solar heating of boiler feed water". If the process uses hot water/thermal oil as working fluid, it creates the list of candidates combining the following integration concepts: SL_L_RF, "solar return flow boost", SL_L_P, "parallel integration" and PL_E_PM, "external HEX for heating of product or process medium”. Once the list of potential configurations is generated, it performs a generic annual simulation for every configuration and selects the one which delivers the minimum Levelized Cost of Thermal Energy (LCOE ${ }_{t h}$ ) (IRENA, 2012). The LCOE th is calculated using eq. 1 .

$$
L C O E=\frac{\sum_{t=1}^{n} \frac{I_{t}+M_{t}+F_{t}}{(1+r)^{t}}}{\sum_{t=1}^{n} \frac{E_{t}}{(1+r)^{t}}}
$$

The configuration with the lowest $\mathrm{LCOE}_{\text {th }}$ is then simulated on an hourly-basis, combining different solar field designs (number of collectors in series per loop, and number of loops in the plant), with different sizes of thermal storage (if the selected configuration allows thermal storage).

Only one annual simulation is performed when the manual simulation procedure is used, thus it gives short simulation times (aprox. 30 seconds). In automatic simulations however, ReSSSPI needs to simulate every configuration listed as a potential candidate. And once the configuration is proved to deliver the lowest $\mathrm{LCOE}_{\mathrm{th}}$, ReSSSPI still needs to optimize the solar field and the size of the storage (if available). Currently, this process takes almost 23min and limits its potential application as real time online calculator. During the first half of 2018, a collaboration with Fontys University of Applied Sciences studied the use of different optimization algorithms to speed up the design optimization process. The following optimization algorithms were tested: Greedy search algorithms such as local search (Michiels, et al. 2007) and hill-climbing (Romeo, 1984), non-greedy search algorithms that use cooling schedules such as simulated annealing (Du and Swamy, 2016) and threshold accepting (Dueck and Scheuer, 1990), non-greedy search algorithm that use memorizing strategies such as Tabu search (Gendreau, 1995) and late acceptance hill-climbing (Burke and Bykov, 2012), and combinations of these algorithms. This research led to several conclusions, where the most important conclusions are that the non-greedy algorithm local search is preferred when searching the minimum LCOE $_{\text {th }}$ in search spaces where it is known that only one minimum exists, while the tabu search and the hill climbing algorithms are preferred to find the global minimum for search spaces that contain several local minima for small and large search spaces respectively.

\subsection{Generic vs third party libraries}

Although ReSSSPI source code comes with generic libraries for the solar collector optics and economics, it is prepared to include third-party libraries. When using the generic library, the collector data needed in the simulation (Aperture area, length of collector, IAM, etc.) comes from publicly available literature (Schenk, 2014). In a similar way, the required economic data in the generic libraries has been gathered from different sources (IDEA, 2010). When using third-party libraries however, both solar optics and economic data are provided by companies with commercial collectors in operation.

The solar energy yield is calculated following the guidelines developed during Guismo project (Eck, et al., 2013), in which the energy output of the solar field is obtained using eq. 2 and eq.3:

$$
\begin{aligned}
& \dot{Q}_{\text {solar }}=A_{\text {net }} \cdot D N I \cdot \eta_{\text {opt }, 0} \cdot \operatorname{IAM}(\theta) \cdot \eta_{\text {clean }} \\
& \eta_{\text {opt }, \theta}=\rho \cdot \tau \cdot \alpha \cdot \gamma_{I C}
\end{aligned}
$$

Where IAM is the incidence angle modifier which describes the collector losses depending on the incidence angle 
$\theta$ (eq.4). Note that in the case of linear Fresnel two IAM must be evaluated to take into consideration both transversal and longitudinal incidence angle.

$$
\operatorname{IAM}(\theta)=\frac{\eta_{o p t(\theta)}}{\eta_{o p t, 0(\theta=0)}}
$$

In this project, a third-party library provided by Solatom has been used to perform all simulations. Solatom's collector uses linear Fresnel optics, and comes in modules of $6 \mathrm{~m}$ long, see Figure 1. This third-party library is also the default library in the front-end version available on-line.

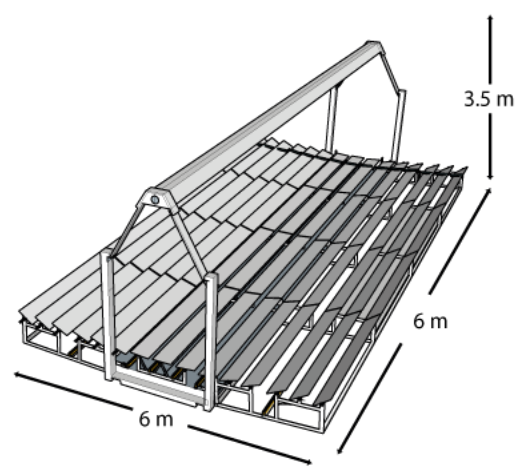

Fig. 1: Geometric dimensions of Solatom's linear Fresnel collector used in ReSSSPI

\subsection{Finance model}

ReSSSPI currently includes two finance models: turnkey and ESCO. In both cases, the model provides the total investment needed, annual savings, free cash flows and return of investment. ReSSSPI coniders a set of hypotheses needed for the financial calculation such as interest rate, mid-term evolution of fossil fuel price, price of $\mathrm{CO}_{2}$ ton, etc. These variables can be modified or leave fixed on their default values (see Frasquet, (2018))

\subsection{Output of results}

Once the simulation is completed, ReSSSPI outputs the results obtained through a plain text summary and a set of images grouped in 3 categories: Solar plant, energy production and economics. In the solar plant category, ReSSSPI shows a scheme of the integration concept selected, and the characteristics of the process fluid. When water or steam is used, ReSSSPI outputs T-s and h-s diagrams with the fluid evolution. When thermal oil is used, only the oil's property graphs are provided. See Figure 2
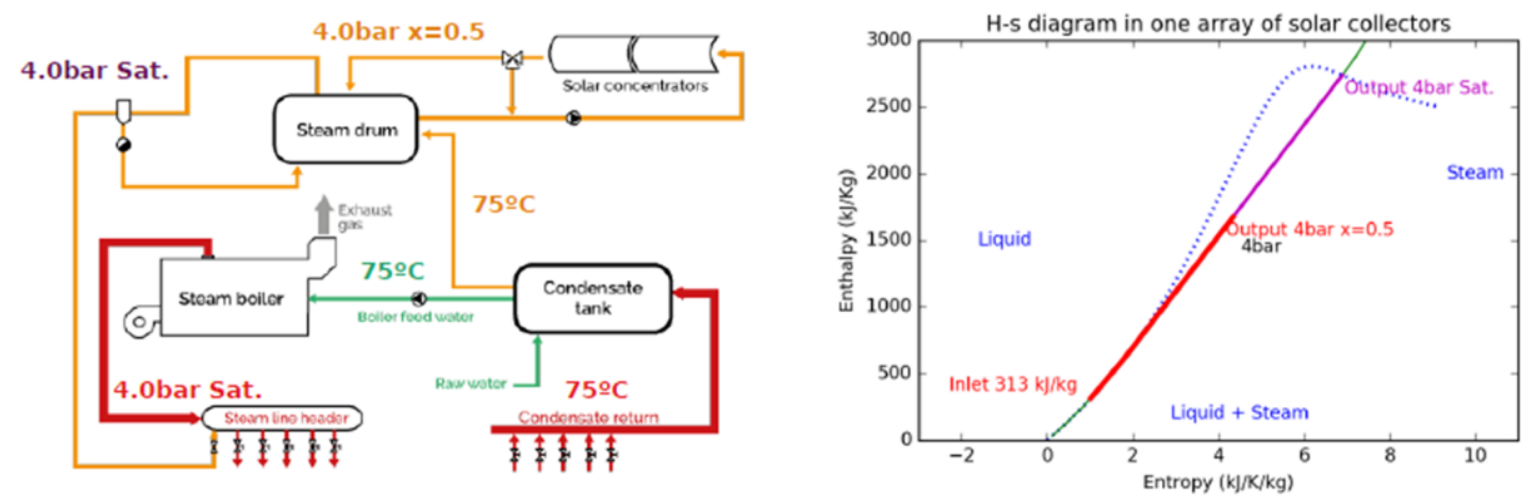

Fig. 2: (Left) Example of diagram ReSSSPI provides when the SL_S_PD configuration concept is used in the simulation (Right) Example of one h-s process diagram provide as output 
Initiallly ReSSSPI only plotted monthly energy production. But during the project, after meeting with many industry managers, it was clear their difficulties understanding the role of thermal storage in the output yield of the solar system. For that reason, the evolution of the state of charge during the first week of summer/winter, has been included. As Figure 3 shows, the plot also provides information regarding the amount of energy going into the storage (Charging) and going out of the system (Discharging).

Regarding the financial aspects, ReSSSPI provides a visual image of how the sum of free cash flows generated by the energy savings breaks even when it equals the initial investment.

As in the case described before, where solar collectors could be determined using generic or third-party libraries, ReSSSPI is also capable of using modules written by third-parties when printing the results. In fact, the online website has the possibility of using a module written by Solatom capable of generating pdf templates with all the images and results that ReSSSPI provides.
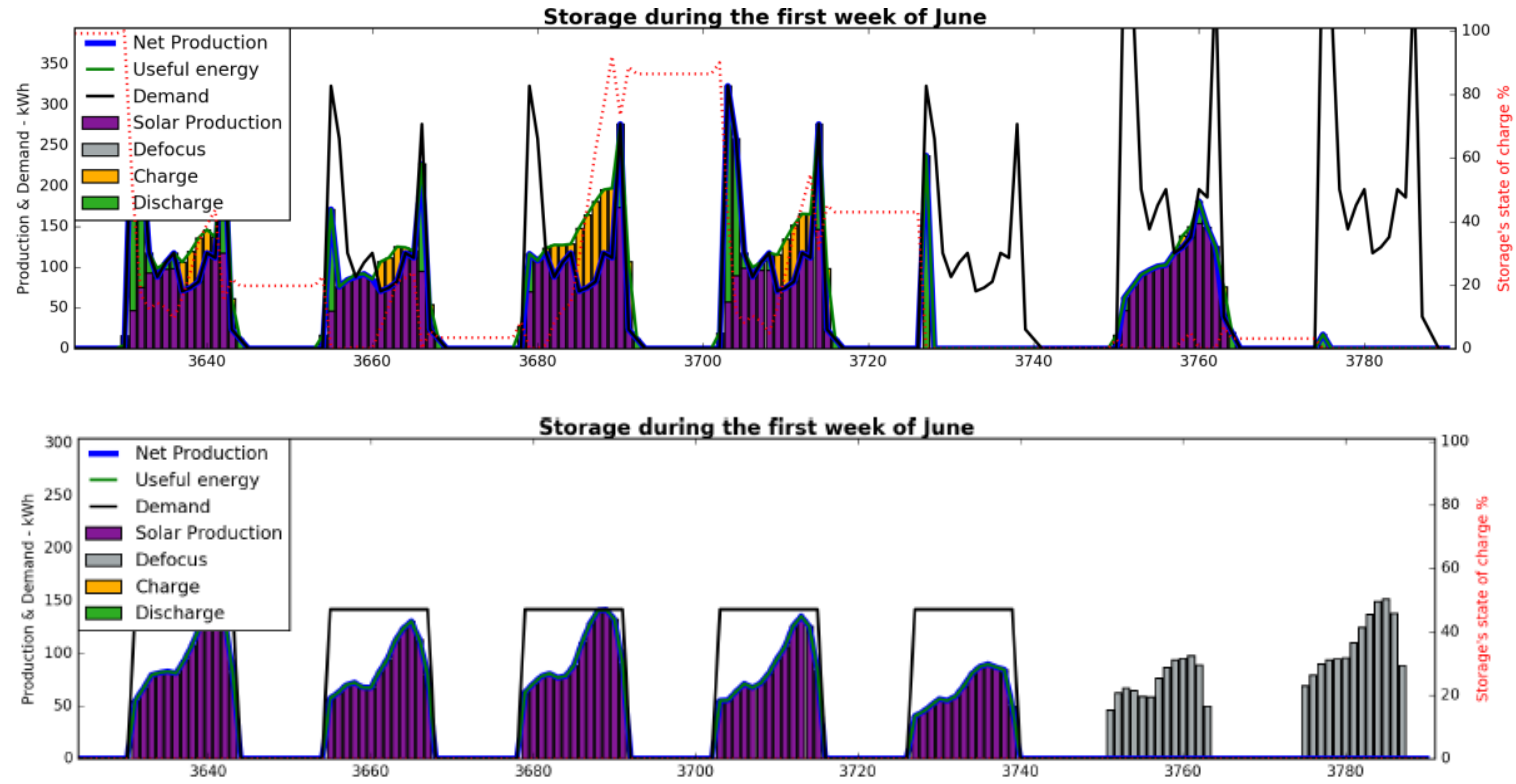

Fig. 3: State of the Charge of the thermal storage and energy inputs/outputs in the system. (Top) Solar plant with storage and demand during the whole week. (Bottom) Solar plant without storage and demand only the first 5 days of the week (Industry has no process during the weekends)

\section{Results and validation}

ReSSSPI code was developed during 2017 as the benchmarking tool needed to assess the potential of the industries studied during the project. From there, it has performed more than 267 simulations creating a significant data base of simulated solar projects. Figure 4 shows the location of the simulations performed since the origin of the tool. In June 2018, ReSSSPI included the automatic design method to allow users with no solar background to perform simulations through its website. Currently, every interested stakeholder can perform an annual simulation and benchmark the results against its database. 

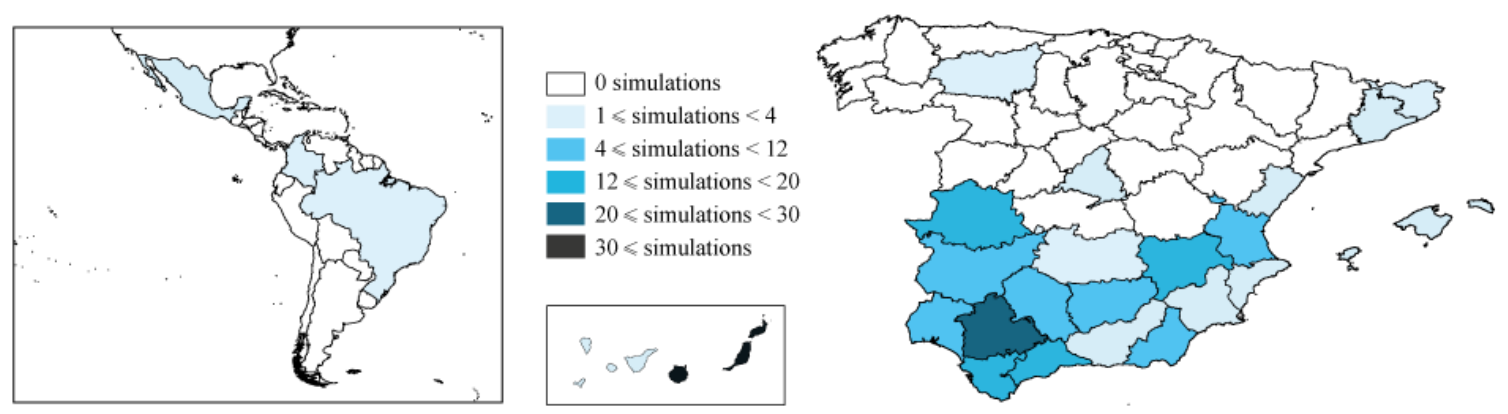

Fig. 4: State of the Charge of the thermal storage and energy inputs/outputs in the system

Although ReSSSPI still relays in SHIPcal original code, and this one has only been validated using theoretical simulations in TRNSYS, the validation with real operation data is already taking place on a Spanish agrochemical factory called Dadelos. Dadelos (Figure 5) is using a small linear Fresnel solar field $\left(72 \mathrm{~m}^{2}\right)$ to provide pressurized hot water to its chemical reactors. The test campaign will be completed during the first quarter of 2019, so data during both summer and winter will be obtained.

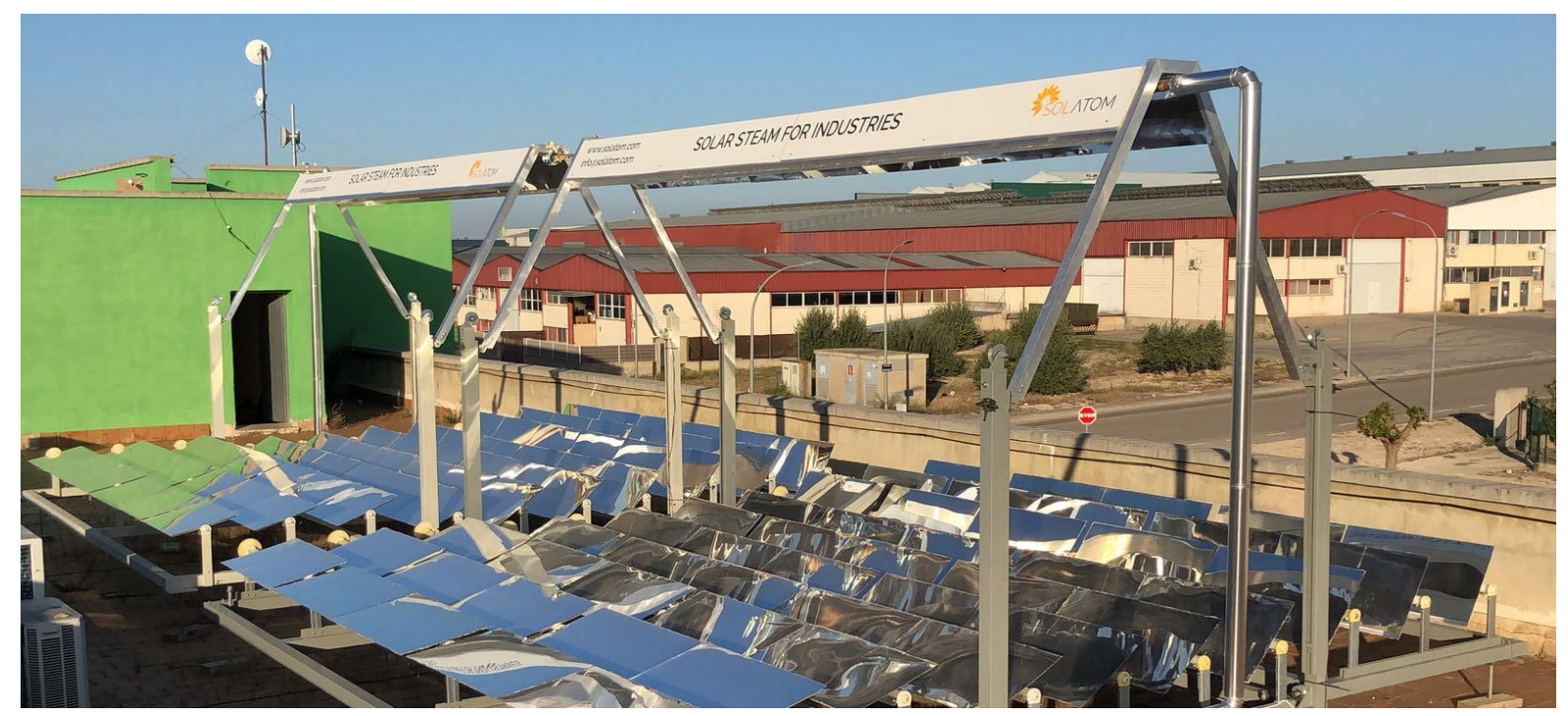

Fig. 5: Linear Fresnel solar field where the validation of ReSSSPI is being carried out

\section{Conclusions}

Online calculators have proven to be a useful tool for performing quick calculations of solar energy projects. Due to the characteristics of the study lead by Solar Concentra, in which two hundred Spanish industries were analyzed, current OCs were not flexible enough, and a new code called ReSSSPI, was developed. Initially based on SHIPcal's engine, ReSSSPI has solved some of SHIPcal's original limitations, and added more integration concepts to gain flexibility. Since its release in 2017, it has performed more than 267 simulations, creating a significant data base of simulated solar projects. Both the source code and the front-end are available online and open to the general public, which now can perform annual simulations and benchmark the results against its database.

\section{Acknowledgements}

The author would like to thank the support of the Spanish technology platform for concentrating solar power (Solar Concentra) and all the researchers and students involved in the development of ReSSSPI. 


\section{References}

Burke E.k., Bykov Y., 2012. The Late Acceptance Hill-Climbing Heuristic.

Corbet J., Kroah-Hartman G., McPherson A., 2010. Linux Kernel Development. The Linux Foundation. <https://www.static.linuxfound.org/docs/lf_linux_kernel_development_2010.pdf> (accessed 13.06.18)

Dobos, A. 2013. PVWatts Version 1 Technical Reference. NREL Technical Report NREL/TP-6A20-60272

Du K., Swamy M.N., 2016. Search and Optimization by Metaheuristics. Springer.

Dueck, G., Scheuer T., 1990. Threshold Accepting. A General Purpose Optimization Algorithm Superior to Simulated Annealing. Journal of Computational Physics 90, 161-175.

Eck M., Hirsch T., Feldhoff F., Kretchmann D., Dersch J., Gavilan Morales A., Gonzalez-Martinez L., Bachelier C., Platzer W., Riffelann K.-J., Wagner M., 2013. Guidelines for CSP yield analysis -optical losses of line focusing systems; definitions, sensitivity analysis and modeling approaches. SolarPaces 2013. Energy Procedia 49 (2014) $1318-1327$

Frasquet M., 2016 SHIPcal: Solar Heat for Industrial Processes Online Calculator, Energy Procedia, Volume 91, 2016, Pages 611-619, ISSN 1876-6102

Frasquet M., 2017. Estudio geolocalizado del potencial de aplicaciones de calor solar de proceso en media temperature. Solar Concentra. Madrid <http://www.solarconcentra.org/estudio-geolocalizado-del-potencial-deaplicaciones-de-calor-solar-de-proceso-en-media-temperatura/> (accessed 01.06.18)

Frasquet M., 2018. ReSSSPI reference manual. <http://www.ressspi.com/static/documentation/manual.pdf>

Gendreau M., 1995. An Introduction to Tabu Search. Handbook of Metaheuristics. Springer, Boston, MA

IDAE (Instituto para la Diversificación y Ahorro de Energía), 2010. Evaluación del potencial de la energía solar térmica en el sector industrial. <http://www.idae.es/uploads/documentos/documentos_11227_e8_ST_industria_bf2e9296.pdf> (accessed 25.06.18)

IRENA (International Renewable Energy Agency), 2012. Renewable Energy Technologies: Cost Analysis Series. Concentrating Solar Power. <http://www.irena.org/documentdownloads/publications/re_technologies_cost_analysis-csp.pdf $>$ (accessed 25.06.18)

Michiels W., Aarts E., Korst J., 2007. Theoretical Aspects of Local Search. Springer Science \& Business Media. Berlin

Muster B., Ben Hassine I., Helmke A., Heß S., Krummenacher P., Schmitt B., Schnitzer H., 2015. Solar Process Heat for Production and Advanced Applications. Integration Guideline. IEA

Romeo F. I., 1984. Probabilistic hill climbing algorithms: Properties and applications. Unknown

Schenk H., Hirsch T., Feldhoff F., Wittman M., 2014. Energetic comparison of linear Fresnel and parabolic trough collector systems. Journal of Solar Energy Engineering. < http://www.idae.es/uploads/documentos/documentos_11227_e8_ST_industria_bf2e9296.pdf> (accessed 25.06.18) 


\section{Appendix: Unites and Symbols}

Table 1: Units and symbols for $\mathrm{LCOE}_{\text {th }}$ calculation

\begin{tabular}{lcc}
\hline Quantity & Symbol & Unit \\
\hline Investment expenditures in & $I_{t}$ & $€$ \\
$\quad$ year t & & \\
O\&M expenditures in year t & $M_{t}$ & $€$ \\
Fuel expenditures in year t & $F_{t}$ & $€$ \\
Energy generation in year $\mathrm{t}$ & $E_{t}$ & $\mathrm{kWh}$ \\
Discount rate & $r$ & \\
Life of the system & $n$ & years \\
\hline
\end{tabular}

Table 2: Units and symbols for energy yield calculation

\begin{tabular}{lcc}
\hline Quantity & Symbol & Unit \\
\hline Neat area of mirrors & $A_{\text {net }}$ & $\mathrm{m}^{2}$ \\
Dirext Normal Irradiation & $D N I$ & $\mathrm{~W} \mathrm{~m}^{-2}$ \\
Peak Optic Efficiency & $\eta_{\text {opt }, 0}$ & \\
Receiver tube solar absorptivity & $\alpha$ & \\
Mirrors solar reflectivity & $\rho$ & \\
Geometric intercept factor of the & $\gamma I C$ & \\
$\quad$ collector & & \\
Glass envelope solar & $\tau$ & \\
$\quad$ transmissivity & & \\
Incidence angle & $\theta$ & \\
Optic Efficiency & $\eta_{o p t}$ & \\
Incidence Angle Modifier & IAM & \\
Efficiency due to soiling of & $\eta_{\text {clean }}$ & \\
$\quad$ mirrors. & & \\
\hline
\end{tabular}




\title{
Cleaning strategies for Fresnel Linear Concentrator Mirrors in Solar Heating plants
}

\author{
Roberto Gabbrielli', Michelangelo Di Palo ${ }^{1}$, Francesco Del Medico ${ }^{2}$ and Giovanni Gulino ${ }^{2}$ \\ ${ }^{1}$ Dipartimento di Ingegneria Civile e Industriale, University of Pisa, Pisa (Italy) \\ ${ }^{2}$ Glayx srl, Pontedera (Italy)
}

\begin{abstract}
A deep investigation on mirror dust deposition for a Fresnel Linear Concentrator System has been developed in order to elaborate an optimized cleaning strategy to be used in several conditions. The model was built on the accurate expected production of the solar system and enables the choice of required cleaning interventions per year, based on their specific cost compared to improved production. A rain-cleaning model based on historical precipitation data for specific location was developed and optimized intervention date has been defined.
\end{abstract}

\section{Introduction}

The present work concerns the determination of several cleaning strategies on full scale Fresnel Linear Concentrator Mirrors (FLCM) using both an analytical predictive model and experimental data. The aim of the work is the determination of an optimized strategy based on specific plant, environmental conditions, cleaning cost (Fernández-García et al., 2014) and technical specification of collectors including number of cleaning per year as well as best days during the year.

The model is based on solar system expected hourly production along the year determined through the assessment of FLCM in accordance with EN ISO 9806 (European Code EN ISO 9806, 2013). Reduction of cleanliness due to dust accumulation on mirrors should be measured in specific location since it shows a different time drop due to typical environment. Experimental data have been collected in Lucca (central area of Italy, with coordinates $43.82^{\circ}$ north, $10.56^{\circ}$ east) where an industrial FLCM system coupled with solar-cooling and a peak thermal power of $125 \mathrm{~kW}$ is installed.

Two different cleaning strategies have been defined in order to consider a wider range of plant management. First approach (Case 1) enables the determination of optimized number of cleanings per year and specific execution date for a plant whose cleanliness curve has been estimated without rain polish effect (i.e. mirrors are always in protection mode during precipitation). Optimized intervention number is a direct function of cleaning cost compared to relative expected production improvement, based on historical data. This approach can be profitable in every case where no direct monitoring of the optical performances is applicable (i.e. small scale process heating solar thermal systems). In the second approach (Case 2) cleaning effect due to rain precipitation has been added assuming a reference value of improved cleanliness. Such model can be applied in those systems with no protection position or with specific devices for the recognition of rain, hail and snow.

\section{Cleaning operation description}

The cleaning operation and cleanliness drop assessment have been carried out on FLCM coupled with Solar Heating and Cooling for office facilities located in Lucca, Italy. The Solar Plant is provided by the company Glayx srl, that proposes a proprietary technology based on solar concentration through linear Fresnel mirrors for the industrial heat, solar cooling and power generation. In Fig. 1 a view of FLCM Solar Plant is shown. 


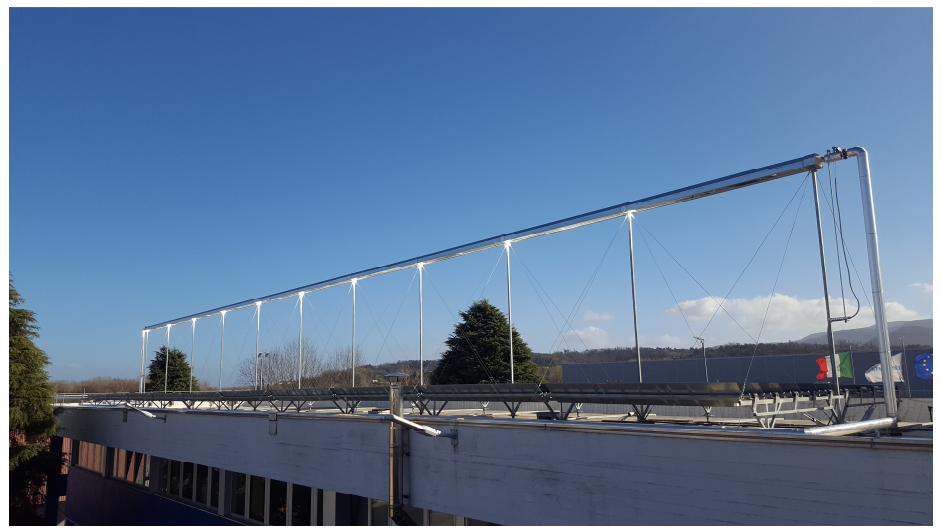

Fig. 1: FLCM Solar Plant in Lucca, Italy.

The main features of the Solar Plant are summarized in Tab. 1.

Tab. 1: FLCM Solar Plant main features

\begin{tabular}{|c|c|}
\hline \multicolumn{2}{|c|}{ FLCM Solar Plant in Lucca (Italy) } \\
\hline Peak Power & $125 \mathrm{kWt}$ \\
\hline Net reflective surface & $187.5 \mathrm{~m}^{2}$ \\
\hline Gross Area & $287 \mathrm{~m}^{2}$ \\
\hline Heat Transfer Fluid & Water \\
\hline Outlet temperature & $<90^{\circ} \mathrm{C}$ \\
\hline
\end{tabular}

The company has developed a proprietary technology for automatic cleaning of primary reflector mirror surface. The system has been designed to minimize water consumption and make it easy to use in several kind of installations, both on land and on the building, directly by the plant operator. The cleaning robot, based on rover kinematics (rover with articulated suspension linkage (Tarokh and McDermott, 2005)), can drive the whole line of the solar field unmanned, preserving the reflecting surface from any damage. Due to the high degree of automation and low power consumption, the system requires limited labor intensity by the operator with a consequent reduction of the operating costs. Driving, cleaning, dust removal, sensors and alarms are managed by a dedicated integrated control system. The cleaning operation is carried out through spraying water and rubber blade sliding. At the end of each single mirror line the machine is moved on the adjacent line or on the nearest plant row. In Fig. 2 a view of the Cleaning Robot is shown.
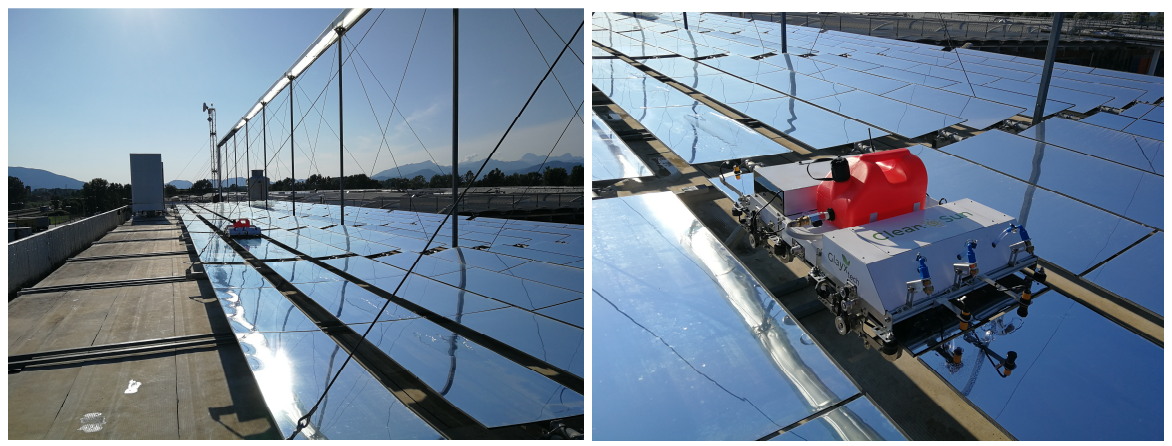

Fig. 2: Cleaning Robot provided by Glayx 
The main features of the Cleaning Robot are summarized in Tab. 2.

Tab. 2: Cleaning robot main features

\begin{tabular}{|c|c|}
\hline \multicolumn{2}{|c|}{ Cleaning Robot } \\
\hline Dimension & $80 \mathrm{~cm}$ length, $50 \mathrm{~cm}$ large, 21 cm height \\
\hline Weight & $17 \mathrm{~kg}$ (empty tank, including battery) \\
\hline Water consumption & $0.21 \mathrm{l} / \mathrm{m}^{2}$ \\
\hline Cruise speed & $80 \mathrm{~mm} / \mathrm{s}$ \\
\hline Duration of the battery & $50 \mathrm{~min}$ at operative full load \\
\hline Water tank capacity & 61 \\
\hline
\end{tabular}

\section{Cleaning cost operation}

The cleaning cost operation strictly depends on the specific site installation and plant scale. The whole operation cost is given from the sum of manpower, depreciation charge of Cleaning Robot and water cost. The transfer cost of operator, water and equipment on site is not considered.

The overall cleaning operation involves the following step: water and machine stowing on site installation, machine preparation and setting, single row cleaning, line replacing. The stowing operation strictly depends on the site installation. In rooftop installation with complicated accessibility (i.e. rooftop installation with vertical ladder) the stowing time (for both water and machine) may be significant and remarkable respect to overall operation. The cleaning time of single row depends on the dust accumulation for the specific location, given multiple cleaning for highly soiled surfaces. Since every plant row is composed by different mirror line, at the end of each line the Cleaning Robot must be moved on to the adjacent line, at end of the plant row the machine must be moved to the close row. For small scale plant (with short rows) or improper aspect ratio (high number of rows respect to total length) the replacing time may affect considerably the overall time. The refill time and the battery change are strictly proportional to the plant net surface.

Considering only manpower and water cost, the trend of intervention cost is shown in Fig. 3. Each dot of the graph represents a specific plant design with a given aspect ratio (number of mirror lines and mirror line length). So, the trend is not perfectly a straight line.

The plant considered in the present work is a small scale plant (single row with 10 mirror lines) and a rooftop installation with an easy access through metal staircase. For small scale Solar Plant the stowing time has a great impact on overall cost, especially for a rooftop with hard accessibility. In Solar Plant smaller than $300 \mathrm{~m}^{2}$, the cleaning cost might be double respect to ground installation. 


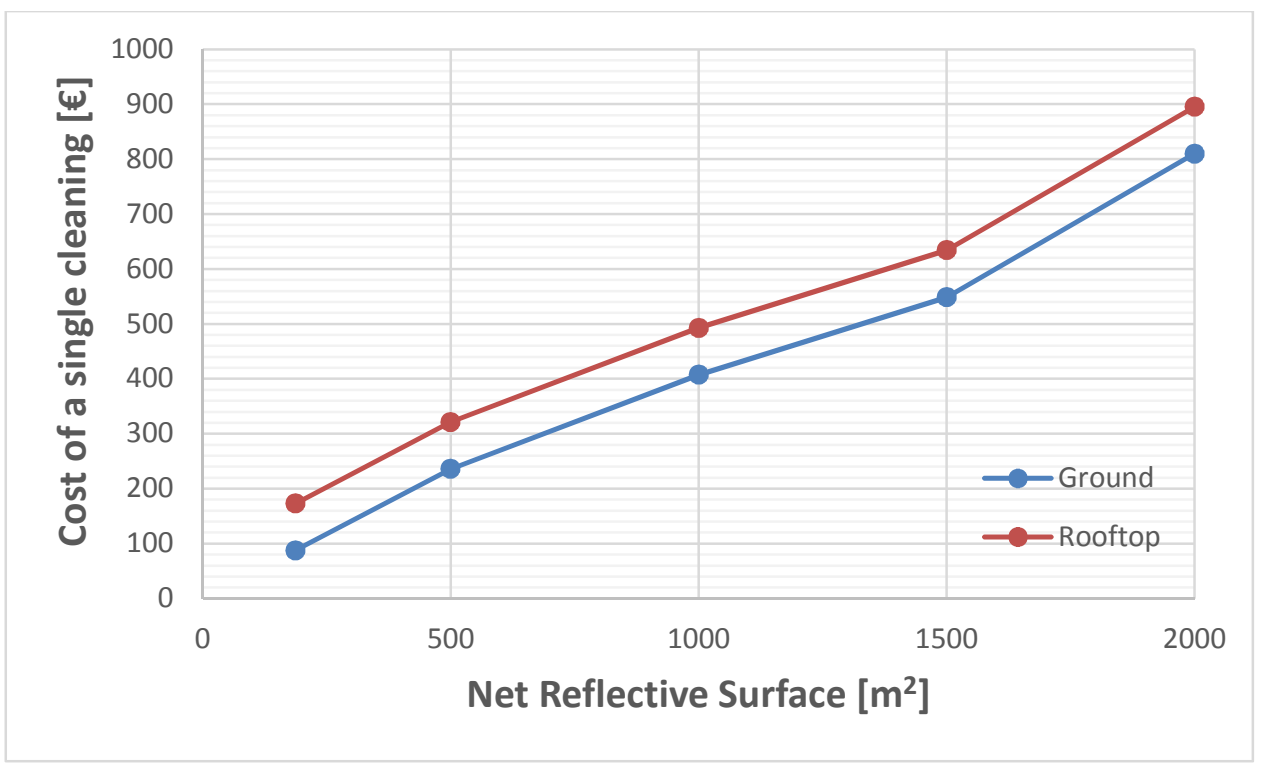

Fig. 3: Cleaning cost vs Net Reflective Surface using Cleaning Robot

\section{Model description and experimental tests}

The computational model has been developed based on EN ISO 9806 (European Code EN ISO 9806, 2013) efficiency curve experimentally determined for the specific Fresnel Linear Concentrator Mirror system and expressed in the following form:

$$
\eta=I A M_{L} \cdot I A M_{T} \cdot \eta_{0}+a_{1} \frac{T_{m}-T_{a}}{G_{b}}+a_{2} \frac{\left(T_{m}-T_{a}\right)^{2}}{G_{b}}
$$

where $T_{m}=\frac{T_{i}+T_{e}}{2}$ and $I A M_{L}$ and $I A M_{T}$ stand for solar system Incidence Angle Modifier on longitudinal and transversal direction, $\eta_{0}$ is optical efficiency with clean mirrors, $G_{b}$ is Direct Normal Irradiance (beam), $T_{i}, T_{e}, T_{a}$ are temperatures at inlet, outlet and ambient, $a_{1}, a_{2}$ are efficiency curve parameters defined according to EN ISO 9806 (European Code EN ISO 9806, 2013).

Dust deposition upon mirror surface yields reduction on reflectivity that can be immediately associated with lower $\eta_{0}$. In particular, the parameter used to measure the effect of dust on reflecting surfaces is called cleanliness and defined as:

$$
C l=\frac{\rho_{d}}{\rho_{c}}=\frac{\eta_{0, C l}}{\eta_{0}}
$$

where $\rho_{d}$ and $\rho_{c}$ are mirrors reflectivity in dusty and clean condition respectively and $\eta_{0, C l}$ is the optical efficiency associated to dusty condition.

Mirror cleanliness behavior has been assumed as shown in Figure 4: starting from hypothetic clean condition (mirror immediately after cleaning) $\mathrm{Cl}$ drops with constant time rate achieving baseline value (Guan et al., 2015; Alami et al., 2015; Bouaddi et al., 2018). This model is representative for solar system without direct rain exposure (blue line in Figure 3) because in these operating conditions rain cleaning effect cannot be considered. Such systems activate safety positioning on rainfall to prevent any damage to reflective surfaces. Otherwise, several FLCM are exposed to precipitation effects and related cleaning effects can be considered proportional to water amount; in particular, the amount of rain precipitation $R$ in $[\mathrm{mm}]$ has been associated to an increase of $\mathrm{Cl}$ value based on direct measure on site, assuming that maximum $\mathrm{Cl}$ achievable with rain polishment cannot overcome 0.9 due to customary impurity content. An estimated behavior of yearly based cleanliness value is shown in Figure 3 in red line. 


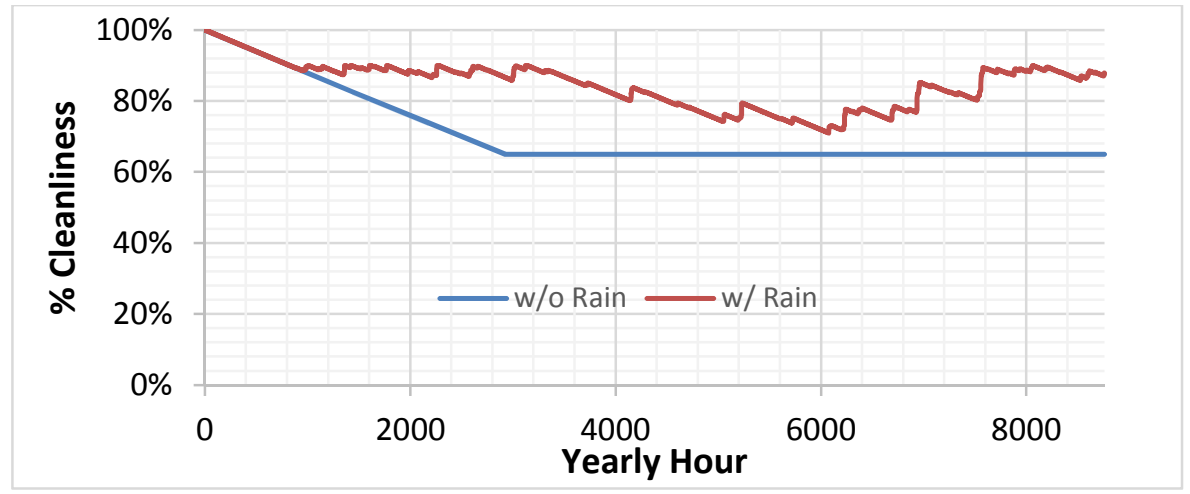

Fig. 4: Cleanliness curves with and without the polish effect of the rain (maximum effectiveness of the rain cleaning equal to $90 \%$ of the initial cleanliness, $\mathrm{Cl}$ baseline $65 \%$ )

Experimental tests are required to determine Cleanliness baseline in each plant since it can be affected by specific environmental condition. The value can be determined by managing dedicated tests according to EN ISO 9806 (European Code EN ISO 9806, 2013) where the inlet and outlet temperatures, DNI, and mass flow are accurately measured during steady state condition (i.e. at least $\pm 0,1 \mathrm{~K}$ variation on $T_{i}, T_{e}$ and maximum $\pm 5 \%$ DNI variation along the test). It can be assumed that Cleanliness baseline doesn't change across time for the single site and is determined once after installation.

Every test execution provides a value of measured efficiency $\eta_{m}$ defined as:

$$
\eta_{m}=I A M_{L} \cdot I A M_{T} \cdot \eta_{0} \cdot C l+a_{1} \frac{T_{m}-T_{a}}{G_{b}}+a_{2} \frac{\left(T_{m}-T_{a}\right)^{2}}{G_{b}}
$$

Thus enabling determination of Cleanliness. Figure 5 shows test results achieved for FLCM in Lucca site during several performance tests developed along three different days, each during morning and afternoon (for a total of 6 performance tests). Average cleanliness value in this case resulted to be equal to $77 \%$.

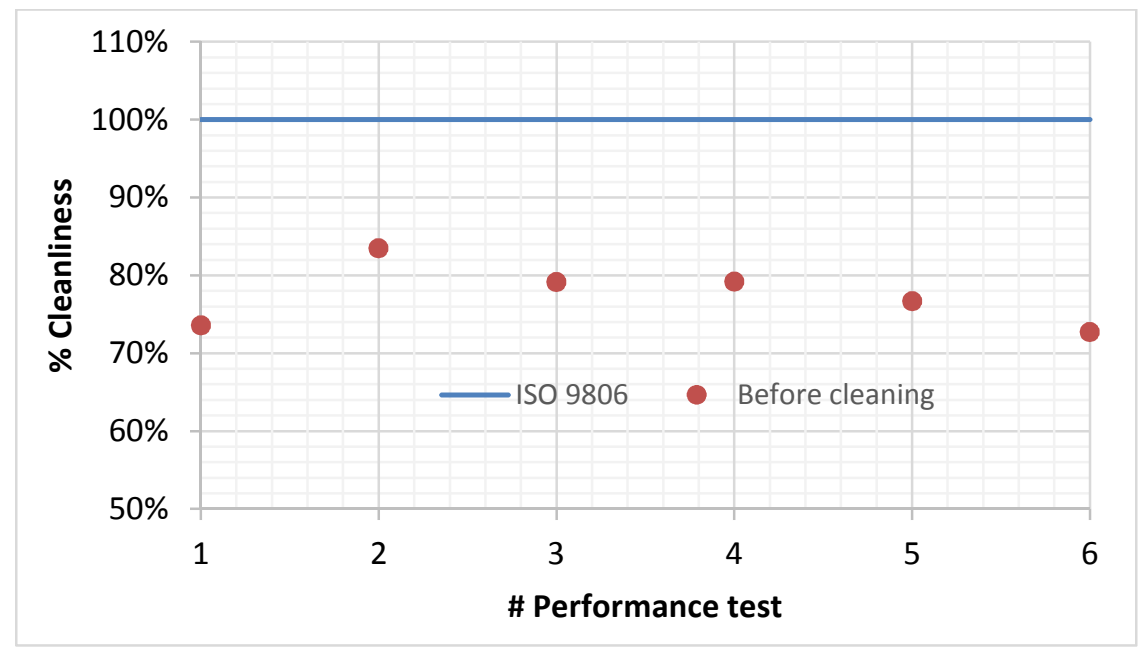

Fig. 5: Cleanliness points from performance tests before cleaning action

Model validation has been obtained repeating performance test in the hours immediately after completion of full mirror cleaning using the robot. In this case, five performance points have been found out and the results are shown in Figure 6. Average cleanliness after cleaning resulted equal to $99 \%$, thus confirming the value of efficiency curve determined according to EN ISO 9806 (European Code EN ISO 9806, 2013) in order to estimate dust effects. The resulting yearly cleanliness curve for the specific site is shown in Figure 7. 


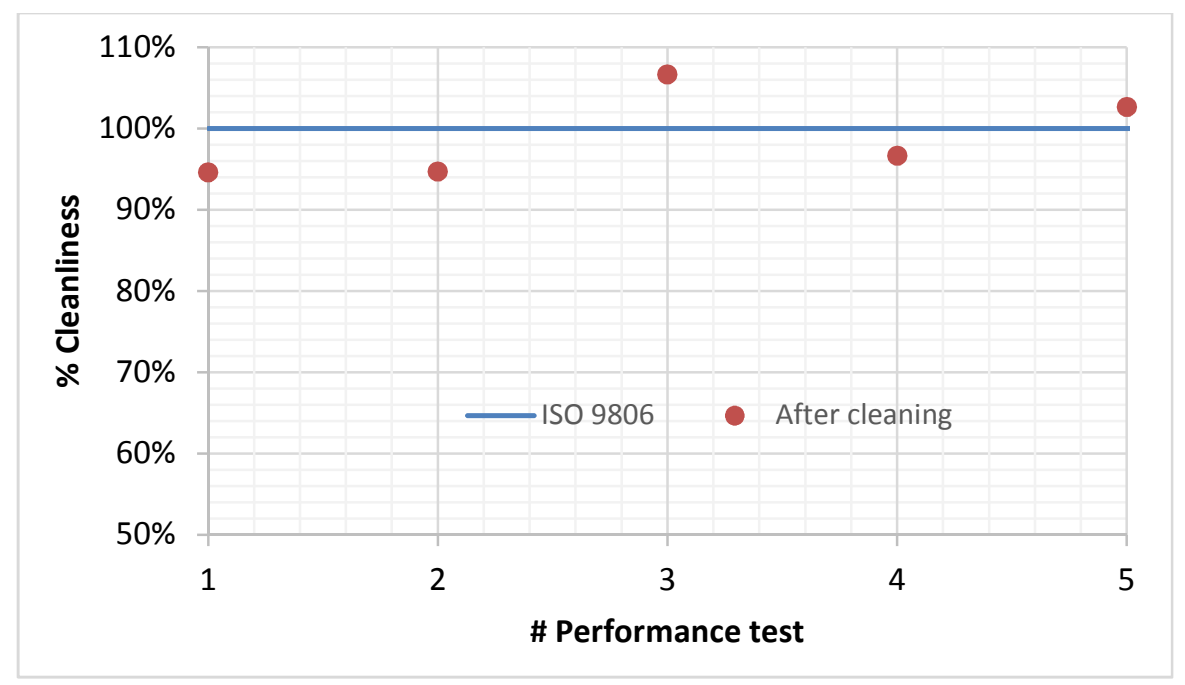

Fig. 6: Cleanliness points from performance tests after cleaning action

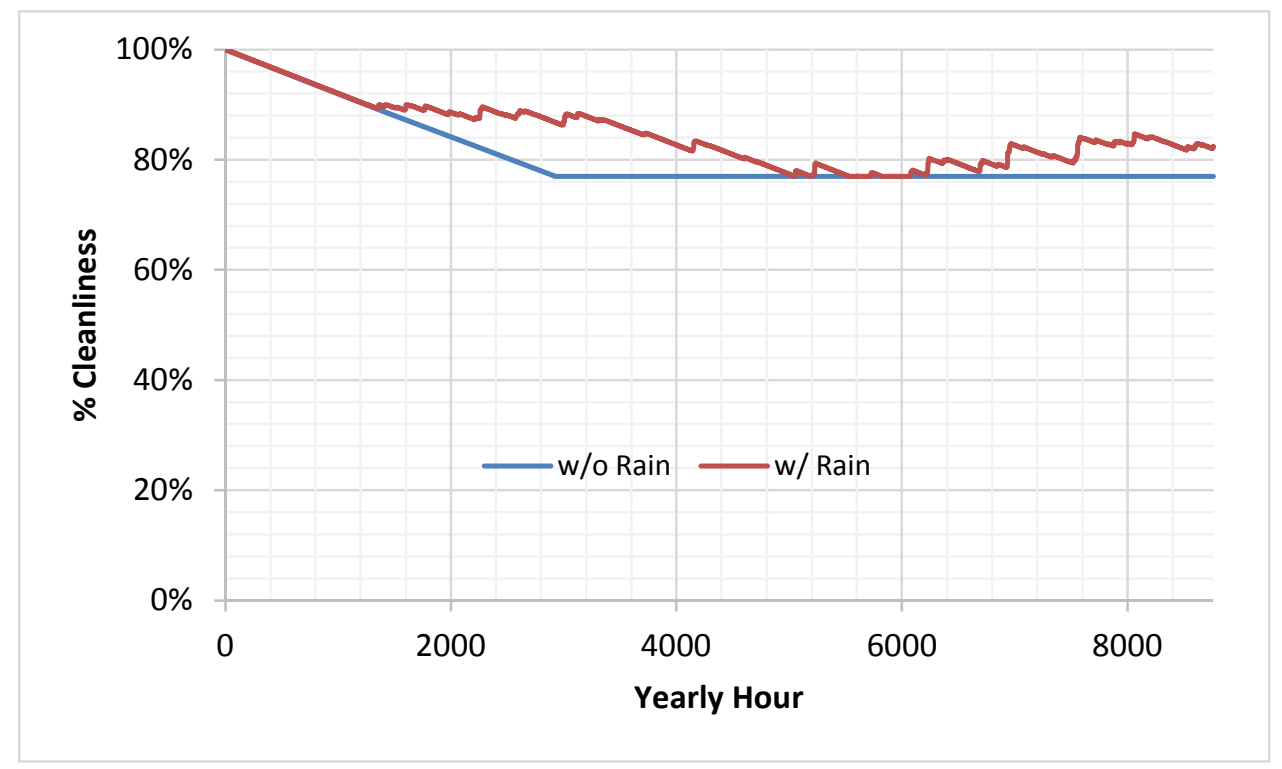

Fig. 7: Cleanliness curves with and without the polish effect of the rain (maximum effectiveness of the rain cleaning equal to $90 \%$ of the initial cleanliness, $\mathrm{Cl}$ baseline $77 \%$ )

Once cleanliness baseline has been determined for the single system, an optimization study can be developed in order to determine the number of the cleaning interventions and their distribution across the whole year.

In particular, expected production based on efficiency determined at Eq.1, DNI hourly values for the site and operating temperature can be combined within an hourly based simulation code with decreasing cleanliness both in Case 1 (without any rain effect) and in Case 2 (considering rain cleaning effect based on average measured precipitation).

Such computation has been coupled with a self-built genetic algorithm (Goldberg, 1989) to determine optimized number of cleaning per year and distribution in order to maximize the yearly production. The evolution starts from a population of 100 randomly generated combinations of yearly days of cleaning (a combination of $n$ number between 1 and 365, where $\mathrm{n}$ is the cleaning number). In each generation, the fitness of every individual in the population is evaluated basically on expected yearly production; the combination showing major fitness are stochastically selected from the current population and each is modified through recombination and randomly mutated to form a new generation. The new generation of candidate solutions has been then used in the next iteration of the algorithm. The algorithm automatically stops when no improvement on best available 
combination has been found over 30 following generations. A mutation rate (probability) equal to 0.075 has been added, thus at each generation stage a small amount of day number has been redefined randomly. For each solution, the algorithm has been run twice in order to verify numerical convergence. Figure 8 shows the effect of increasing cleanings on total yearly energy production. Of course number of interventions must be established comparing specific economical value of FLCM production (heat, cooling or power) with increase in expected production.

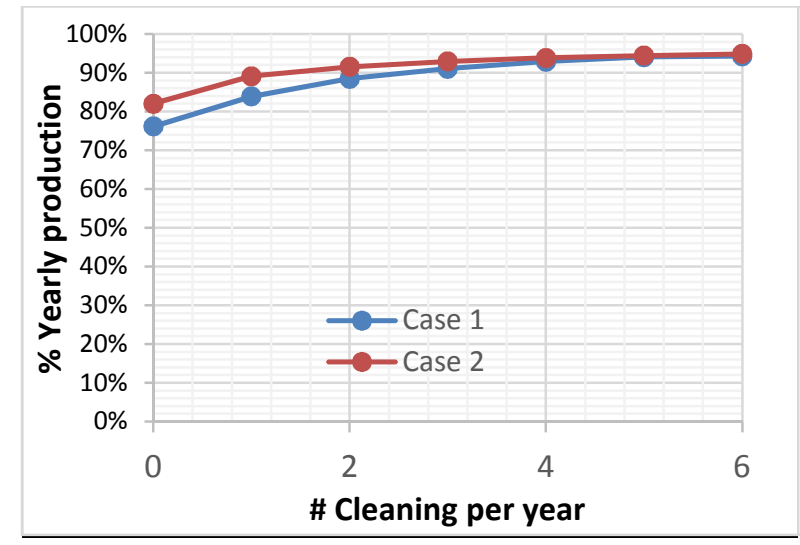

(a)

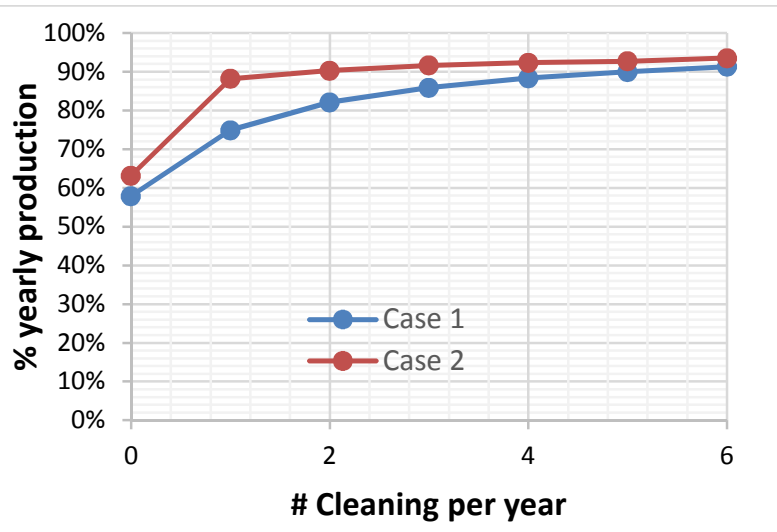

(b)

Fig. 8: Effect of cleaning intervention on yearly production with $\mathrm{Cl}$ baseline $77 \%$ (a) and $65 \%$ (b)

Once the optimized number of intervention is determined, a fixed time plan must be applied to achieve the expected results. As shown in Figure 9, cleaning intervention are usually optimized before the periods of greatest yearly irradiation.

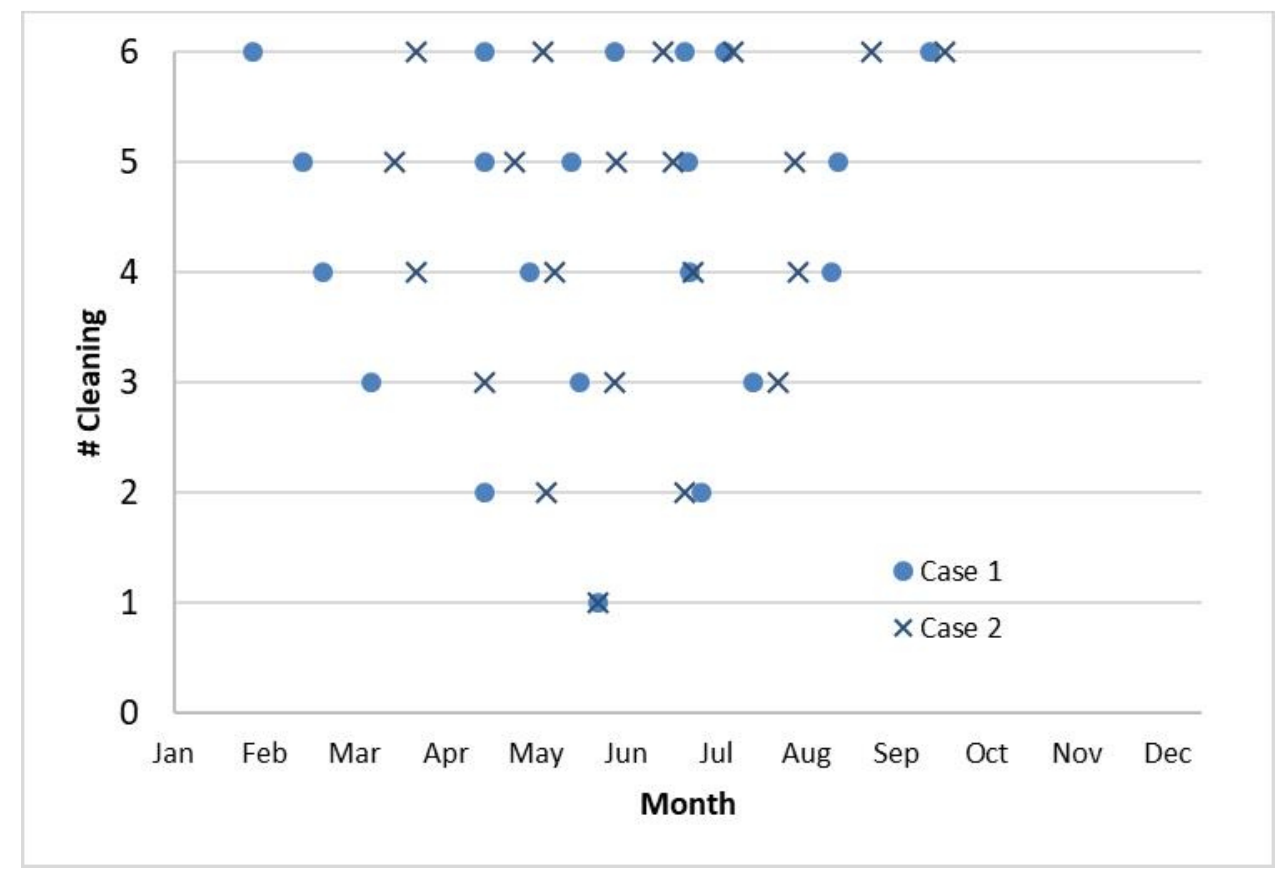

Fig. 9: Optimized days of execution for reference site in Case 1 and Case 2

\section{Conclusions}

The present work is addressed to find out a computational model enabling a technical and economical evaluation of dust effects on FLCM systems production. Looking at results achieved during performance tests, a 
relevant effect of the dust deposition on mirrors has been confirmed considering the difference between efficiency obtained before and after mirror cleaning. Besides, it has been assumed that efficiency drop does not overtake baseline value reached approximately within four months of dust exposition (without rain effect).

In addition, it should be considered that the weight of efficiency drop must be determined case by case since site exposition is relevant on value of final baseline. For this reason, an effective cleaning strategy should be based upon performance tests directly developed on single site for the determination of key parameter.

After the technical assessment has been achieved, economical matter should be considered within the whole strategy: as shown in Figure 10, the effect of an increasing number of cleaning interventions is different for Case 1 and Case 2 and depends on assumed baseline. Production benefits due to each intervention must be compared with their economic value on one side and specific intervention cost on the other side.

Optimized number of cleanings is then determined comparing yearly production increase associated to addictive cleaning intervention. Once determined optimized intervention number, time distribution is relevant to match expected production increase. As shown in Figure 9, independently on the total number, mirror cleanings should be concentrated preferably in summer season.

In case the solar plant is fully equipped for performance monitor, the proposed methodology can be applied dynamically through continuous monitoring of the optical efficiency. As a consequence, cleanliness values can be continuously updated.

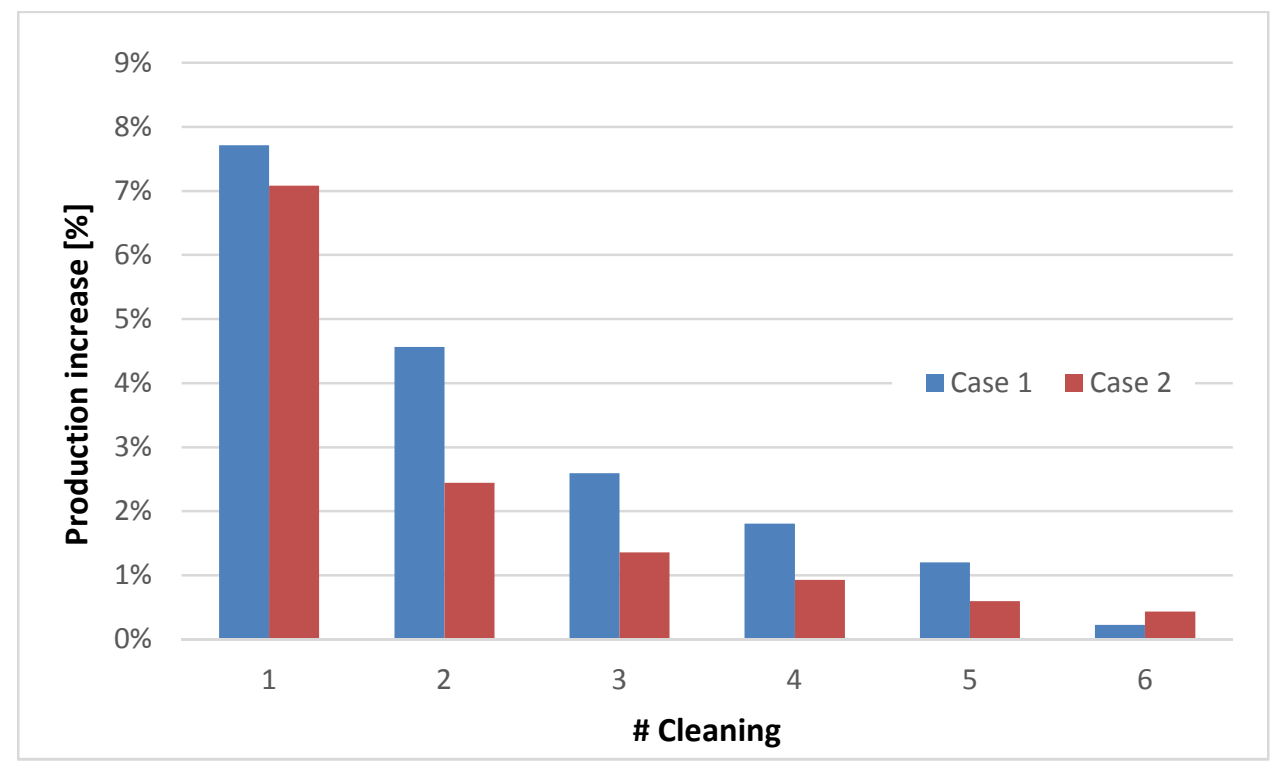

Fig. 10: \% increase on yearly production for each cleaning intervention

\section{References}

Alami Merrouni, A., Wolfertstetter, F., Mezrhab, A., Wilbert S., Pitz-Paal, R., 2015. Investigation of soiling effect on different solar mirror materials under Moroccan climate. Energy Procedia. 69, 1948-1957, doi.org/10.1016/j.egypro.2015.03.194.

Bouaddi, S., Fernández-García, A., Ihlal, A., Ait El Cadi, R., Álvarez-Rodrigo, L., 2018. Modeling and simulation of the soiling dynamics of frequently cleaned reflectors in CSP plants. Solar Energy, 166, 422-431, doi.org/10.1016/j.solener.2018.03.070.

European code, EN ISO 9806: 2013 Solar energy - Solar thermal collectors - Test methods.

Fernández-García, A., Álvarez-Rodrigo, L., Martínez-Arcos, L., Aguiar, R., Márquez-Payés, JM., 2014. Study of different cleaning methods for solar reflectors used in CSP plants. Energy Procedia, 49, 80-89, SolarPACES 
2013, doi: 10.1016/j.egypro.2014.03.009.

Goldberg, D.E., 1989. Genetic Algorithms in Search, Optimization and Machine Learning, Addison-Wesley Longman Publishing Co., Inc. Boston, USA.

Guan, Z., Yu, S., Hooman, K., Gurgenci, H., Barry, J., 2015. Dust characterization for solar collector deposition and cleaning in a concentrating solar thermal power plant. Proceedings of International Conference on Heat Exchanger Fouling and Cleaning, June 07-12, 2015, Enfield (Dublin), Ireland.

Tarokh, M., McDermott, G., 2005. Kinematics Modeling and Analyses of Articulated Rovers. IEEE Transactions on robotics. 21, No. 4, 539-553, doi:10.1109/TRO.2005.847602. 


\title{
Solar Heat in Industrial Processes in Switzerland - Theoretical Potential and Promising Sectors
}

\author{
Martin Guillaume ${ }^{1}$, Mircea Bunea', Marco Caflisch², Mercedes H. Rittmann-Frank², José Martin ${ }^{3}$ \\ ${ }^{1}$ Laboratory of Solar Energetics and Building Physics (LESBAT), HES-SO/HEIG-VD, Route de \\ Cheseaux 1, CH-1401 Yverdon-les-Bains (Switzerland) \\ 2 Institut für Solartechnik SPF, Hochschule für Technik HSR, Oberseestrasse 10, CH-8640 \\ Rapperswil-Jona (Switzerland) \\ ${ }^{3}$ Swissolar, Neugasse 6, CH-8005 Zürich (Switzerland)
}

\begin{abstract}
The aim of this work is to identify the potential of conventional solar systems for industrial process heating and determine the most suitable Swiss industrial sectors for its implementation. For this purpose, a detailed study of the Swiss industry energy consumption is carried out in order to obtain the amount of thermal energy consumed by process heating. Subsequently, this amount of energy is analysed for each industrial sector and those for which the energy demand could be provided by conventional solar thermal systems are sorted out. The theoretical potential for conventional solar thermal systems in the Swiss industry is therefore, estimated taking into account the most promising industrial sectors revealing an important implementation potential. Finally, the study also assese the potential for the implementation of solar process heat systems for different regions and cantons in Switzerland.
\end{abstract}

Keywords: Solar thermal collectors, industrial process heating, potential, Switzerland

\section{Introduction}

According to the International Energy Agency (IEA), the final energy consumption in the world reached 9384 Mtoe, equivalent to $392.8 \mathrm{EJ}$, in 2015 . In the same year, the industry sector represented nearly $30 \%$ of this worldwide energy consumption, with fossil fuels being the main energy vector (International Energy Agency (IEA), 2018). The IEA balance sheet shows that electricity represented only $27 \%$ of the industry energy consumption while fossil fuels, which include oils, coal and natural gas, represented $61 \%$.

In Switzerland, the final energy consumption represented $855 \mathrm{PJ}$ in 2016 for which the industry sector accounted for 18\% during the same year (Swiss Federal Office of Energy, 2017). The largest part of the energy consumed by the industry is used directly in process heating applications. Integration of solar thermal (ST) systems as energy source for industrial processes is a research area that has seen a growing interest last decade. According to Horta (2017), around $30 \%$ of the total industrial heat demand is required at temperatures below $150{ }^{\circ} \mathrm{C}$ and could theoretically be met with conventional solar thermal technologies, such as flat-plate and evacuated tube collector.

Some ST systems have been set up in Switzerland to supply process heating applications in different industrial sectors such as in dairy products manufacturing, machinery products manufacturing or bitumen production (Bunea et al., 2017). Some of them use conventional solar thermal system such as that used to heat the pretreatment washbasins of coating device (Rittmann-frank et al., 2017). A large spectrum of industrial processes can benefit from the integration of solar thermal technologies and important energy savings can occur as well as greenhouse gas reductions but the potential of this type of system is so far largely unexploited.

In this work, only the potential of conventional solar thermal systems for process heating is studied, including flat plate collectors and evacuated tube collectors. These systems have proven their efficiency and reliability in the residential sector. As these systems provide efficiently heat up to $130^{\circ} \mathrm{C}$, only the share of heat consumption for process heating with operating temperatures in this range is consided here. Industrial sectors having a large share 
of heat demand for process heating occurring at low temperature are therefore selected as promising sectors for the implementation of conventional ST systems and the theoretical potential is calculated for these sectors.

\section{Methodology}

In order to identify the potential of conventional ST systems for industrial process heating in Switzerland, a detailed analysis of the energy consumption of the Swiss industry was performed considering separately the total energy consumption (electricity and heat) and the thermal energy consumption (heat only). Data on industry energy consumption was obtained from the Swiss Overall Energy Statistics GEST, established by the Swiss Federal Office of Energy (SFOE) and corresponding to the year 2016.

The GEST calculation respects the territory principle and only takes into account the energy consumed inside the Swiss territory in the form of an energy balance sheet presenting and detailing the gross energy consumption and the final energy consumption. All data on energy consumption presented here corresponds to the final energy consumption as provided by Swiss Federal Office of Energy (2017). With these data it is possible to differentiate final consumption between thermal and electrical energy. Another advantage is the possibility to identify the energy vectors from which the final consumption of thermal energy is issued. Finally, it is possible to identify the final energy consumption of the Swiss industry sector and its distribution by energy vector

Industry sectors have been defined according to the NOGA 2008 classification, used by the Swiss Federal Office of Statistics (SFOS) and the SFOE, which groups the Swiss companies in 88 economic divisions, including 37 for the industry. For this study, these economic divisions of the industry are grouped into 12 sectors to facilitate the analysis. These 12 industrial sectors have been defined according to the SFOS and are identical to the classification structure used in the study of Swiss Federal Office of Energy (2012).

The SFOS, through its database STAT-TAB (Swiss Federal Office of Statistic, 2017), allows obtaining different statistics about the industry in Switzerland. In this study, the distribution of the industrial sectors is used to identify the cantons where industry energy consumption is largest. The variable chosen for this distribution is the full time equivalent (FTE) employment which leads to the energy consumption by canton for each industrial sector.

\section{Swiss Industry Energy Consumption}

In 2016, industry sector consumed around 155PJ, accounting for $18 \%$ of the total Swiss final energy consumption (see Figure 1). The industry electricity consumption accounted for only $7 \%$ of the total energy consumption in Switzerland and $30 \%$ of the total Swiss electricity consumption.. Regarding the industry heat consumption, it accounted for $11 \%$ of the total energy consumption in Switzerland and represented $14 \%$ of the total heat consumption in Switzerland.

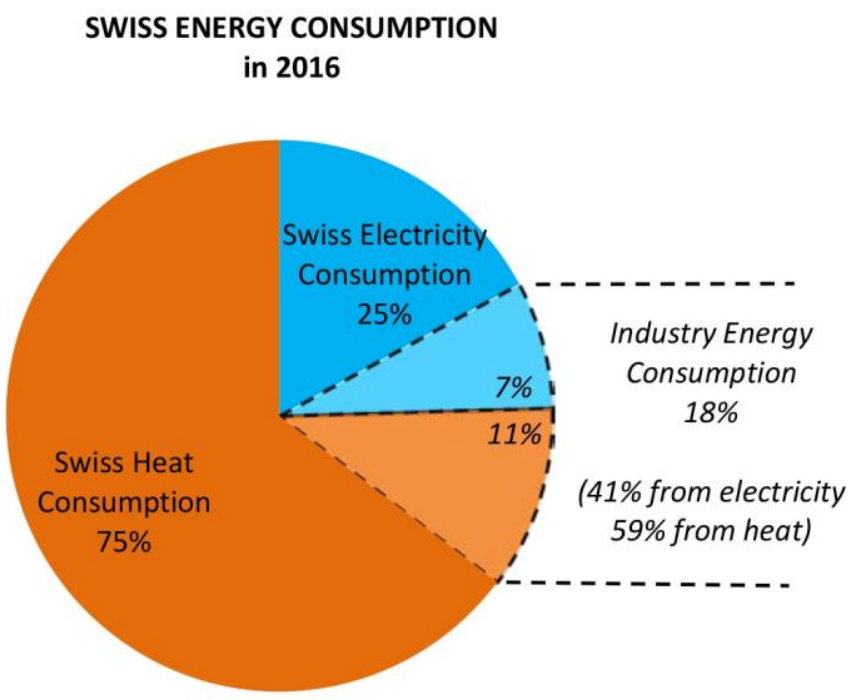

Fig. 1: Swiss energy consumption and share of the industry (own calculation based on Swiss Federal Office of Energy (2017)) 
The share of heat consumption in relation to the total energy consumption of the industry represented $59 \%$, whereas it represented $41 \%$ in the case of electricity consumption, in 2016. This distribution shows that heat consumption is more important than electricity consumption, but the latter still accounts for a large part of the energy consumption of the industry sector in Switzerland.

Various energy vectors provide the heat consumed by the industry. Fossil fuels accounted for about $66 \%$ of the industry thermal energy consumption. The part of renewable energies (RE), wood and others renewables energies, represented $14 \%$ of the industry heat consumption which is still much lower than the part of fossil fuels. There is still a high potential for solar thermal systems to replace the high share of fossils fuels used in the energy mix.

Energy-intensive industries represent a great potential for integrating solar thermal systems as energy source to improve RE share and avoid fossil fuels utilisation. To identify the Swiss major energy consuming industries, the energy consumption shares of each industrial sectors are presented as a percentage of the total industrial sector energy consumption and the corresponding percentages in terms of industry thermal demand, in 2016 (see Figure 2).

\section{INDUSTRY TOTAL ENERGY CONSUMPTION by INDUSTRIAL SECTOR in 2016}
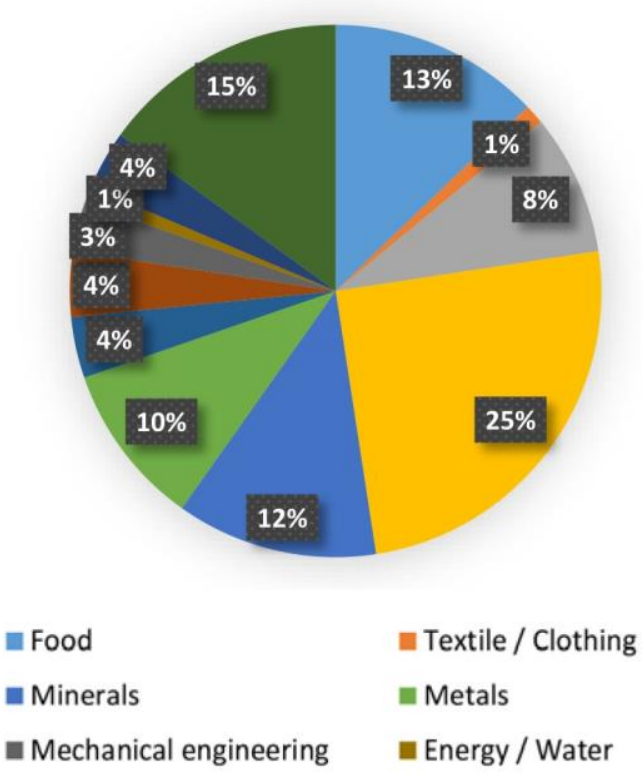

\section{INDUSTRY THERMAL ENERGY CONSUMPTION by INDUSTRIAL SECTOR in 2016}

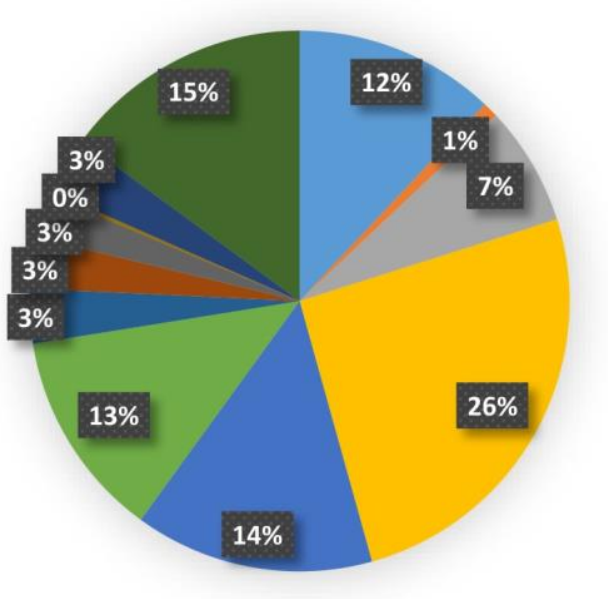

$$
\begin{aligned}
& \text { - Paper } \\
& \text { - Metal products } \\
& \text { - Construction }
\end{aligned}
$$

“ Chemistry / Pharma

Electrical engineering

ather industry

Fig. 2: Energy consumption shares of industry sectors in 2016 (own calculation based on Kemmler et al. (2017))

Among the different industry sectors, the largest consumer is the chemistry/pharma sector, followed by food, minerals, metals and paper industries. All these equate to about $68 \%$ of the industry total energy consumption and for $72 \%$ of the industry thermal energy consumption in 2016.

In 2016, the amount of energy consumed by the chemistry/pharma sector reached $39 \mathrm{PJ}$, accounting for $25 \%$ of the industry total energy consumption. The thermal energy consumed by this sector reached $23 \mathrm{PJ}_{\mathrm{th}}$, representing $26 \%$ of the industry thermal energy consumption.

The second largest industrial energy consumer in Switzerland, accounting for $13 \%$ of the industry total energy consumption in 2016, is the food sector, which includes manufacturing food, beverages and tobacco. The energy consumption for this sector is as follows: $54 \%$ for heat and $46 \%$ for electricity. The heat consumption of the food industry reached $11 \mathrm{PJ}_{\text {th }}$ in 2016 , which represented $12 \%$ of the industry thermal energy consumption.

Other energy-intensive industries are those of the minerals sector, which includes non-metallic mineral products other than rubber and plastic products such as cement or ceramic industries. This is followed by the metals industry, which includes industries of smelting and refining ferrous and non-ferrous metals, and finally the paper industry, which includes the manufacture of pulp, paper and converted paper products. These three industrial sectors represent respectively $12 \%, 10 \%$ and $8 \%$ of the industry total energy consumption, and $14 \%, 13 \%$ and $7 \%$ of the industry thermal energy consumption. 
The Other industry category is not considered because it includes different industries that are not bound, adding extra difficulties in to the energy consumption behaviour analyse. Nevertheless, it accounts for a large amount of the industry energy consumption in 2016 , representing $15 \%$ of the industry total energy consumption and $15 \%$ of the industry thermal energy consumption.

This analysis has highlighted the industries that accounted for most of the Swiss industry energy consumption. The five industrial sectors, mentioned above, represented together almost three-quarter of the industry thermal energy consumption. Overall, the industrial sector breakdown of total energy consumption (electricity and heat) and thermal energy consumption (heat only) are nearly identical. This means that industrial sectors with large energy consumption have large heat demand.

\section{Industrial Process Heat Consumption}

\subsection{Industry Energy Consumption by Application}

To understand energy usage within the different industrial processes and how solar thermal systems could be potentially implemented, the evaluation of the process heat demand is performed. Kemmler et al. (2017) provides the distribution of the industry energy consumption by application and compares the share of heat and electricity consumption for each application. Figure 3 shows the total energy consumed by each application and the share of electricity and heat consumption compared to the industry total energy consumption, for 2016.

APPLICATION ENERGY CONSUMPTION

by ENERGY VECTOR in 2016

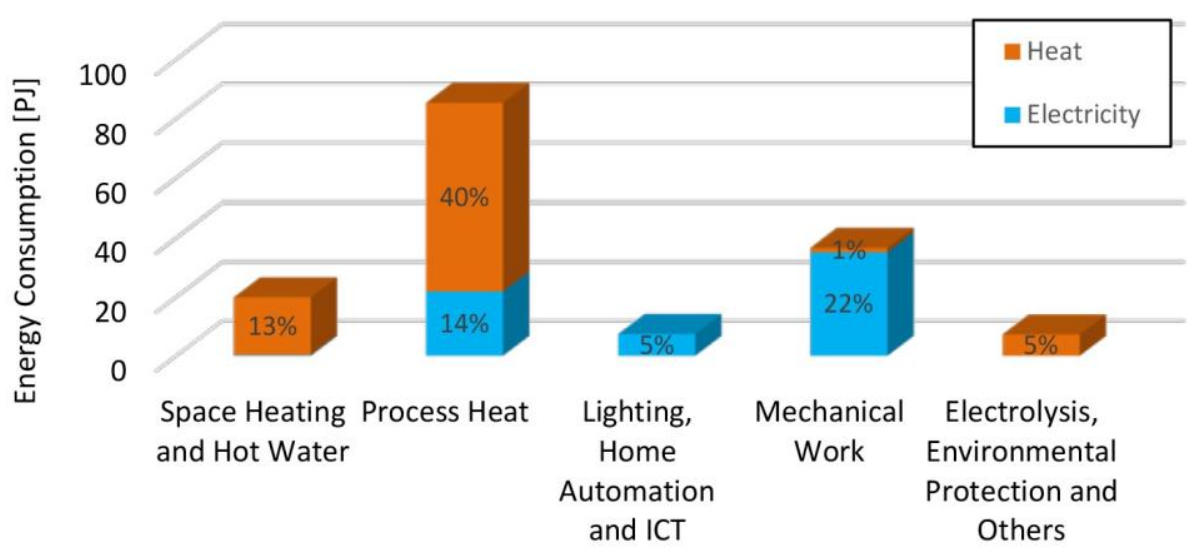

Fig. 3: Industrial application energy consumption by energy source in 2016 (own calculation based on Kemmler et al. (2017))

The amount of energy consumption for hot water, space heating and process heat applications is mostly provided by thermal energy whereas lighting, home automation, ICT (Information and Communication Technologies) and mechanical work applications is almost totally provided by electricity. The last group of applications, regrouping electrolysis, environmental protection and others processes is also totally provided by thermal energy. However, this last category will not be considered in this study because it includes processes for which no information is available. Consequently, mechanical work and lighting, home automation and ICT were not considered as potentially suitable to ST systems implementation because their demand is essentially in electricity.

Because the purpose of this study is the integration of ST systems in process heat, hot water and space heating applications are excluded in the analysis of the potential of solar thermal systems in Swiss industry, but they still represent interesting applications. Indeed, all the energy consumed by these applications is in the form of thermal energy and accounts for $13 \%$ of the industry total energy consumption. In addition, the suitability of these applications to benefit from solar is even larger because the thermal demand occurs at temperatures below $60^{\circ} \mathrm{C}$.

In terms of industrial energy consumption, it can be seen that process heating is the largest energy consumer in the industry sector. This application consumed 85 PJ during the year 2016, representing 54\% of the total energy consumption of the Swiss industry. A closer look into industrial process heating, shows that the share of energy consumed by process heat application is $75 \%$ from heat and $25 \%$ from electricity. Electricity demand for process 
heating is excluded from this study because it will involve consistent changes in the heat distribution system (additional hydraulic pipes, pumps, heat exchangers, etc.) raising considerably the global cost of the system and implicitly reduce the financial performance of the global system. Nevertheless, in some cases, electric heaters could also be effectively replaced by solar thermal systems.

For all these reasons, only the potential of solar thermal systems to provide the thermal energy consumption for process heating is considered in this work. This amount of energy represented $40 \%$ of the industry energy consumption in 2016.

\title{
INDUSTRY THERMAL ENERGY CONSUMPTION by APPLICATION in 2016
}

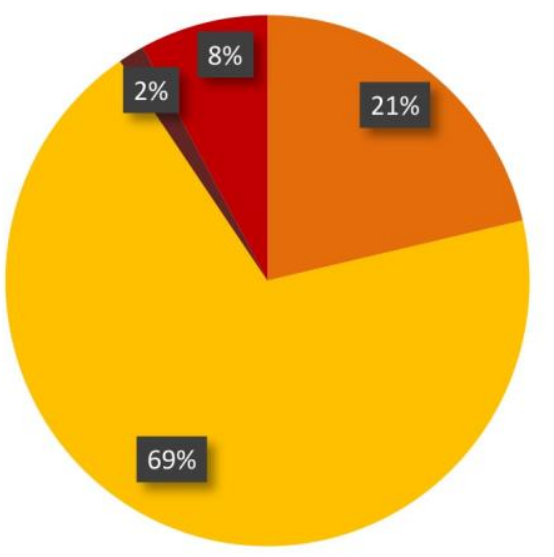

\author{
Space Heating and Hot \\ Water \\ Process Heat \\ Mechanical Work \\ Electrolysis, \\ Environmental \\ Protection and Others
}

Fig. 4: Industry energy consumption by application in 2016 (own calculation based on Kemmler et al. (2017))

As shows in the industrial application breakdown of Swiss thermal energy consumption (Figure 4), process heating is the largest consumer. The heat demand for this application reached $63 \mathrm{PJ}_{\mathrm{th}}$, representing $69 \%$ of the industry thermal energy consumption in 2016, thus more than two-thirds. As demonstrated above, this amount of energy is mostly provided by fossil fuels. It therefore represents a great potential for renewable energies, such as ST, to reduce the greenhouse gas emissions of the Swiss industry.

\subsection{Process Heat Consumption by Industrial Sector}

To identify the promising industrial sectors where integration of ST systems may have a significant impact on the reduction of fossils fuels consumption, the distribution of the thermal energy consumption for process heating by industrial sector is displayed in Figure 5.

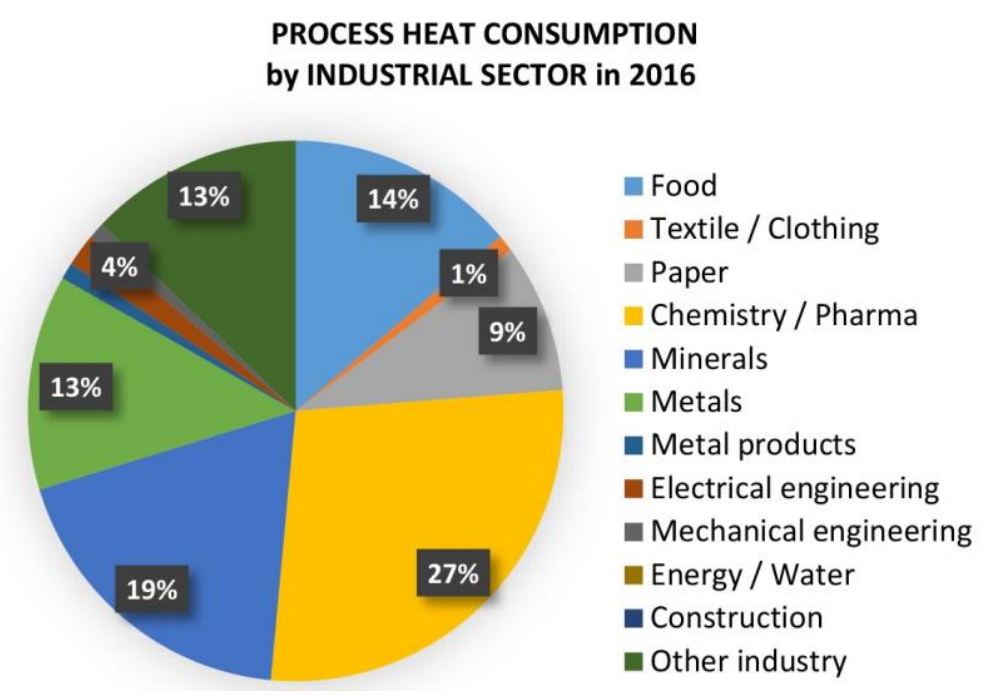

Fig. 5: Thermal energy consumption for process heat application by industrial sector in 2016 (own calculation based on Kemmler et al. (2017) and on Swiss Federal Office of Energy (2017)) 
The chemistry/pharma industry, which is the highest energy consumer sector in terms of total energy consumption (see Figure 2), is also the sector with the largest part of thermal energy use for process heating. The amount of thermal energy consumed for this purpose reached $18 \mathrm{PJ}_{\mathrm{th}}$ for this sector, accounting for $27 \%$ of the thermal energy consumption for this application. The second largest consumer of thermal energy for industrial process heating in Switzerland, accounting for $19 \%$, is the minerals industrial sector, where the amount of thermal energy consumed for this purpose, in 2016, reached $12 \mathrm{PJ}_{\mathrm{th}}$. The thermal energy consumption for process heat reached $9 \mathrm{PJ}_{\mathrm{th}}$ for the food industry sector, representing $14 \%$ of the thermal energy consumption use for this application. In the case of the metals sector, the amount of energy consumed for this purpose reached $8 \mathrm{PJ}_{\text {th }}$, representing $13 \%$ of the thermal energy consumption used for this application in the Swiss industry. Another high thermal energy consumer sector is the paper sector, where the amount of thermal energy consumed for process heat reached $6 \mathrm{PJ}_{\text {th }}$ in 2016 , representing $9 \%$ of the industry thermal energy consumption used for process heating.

Others industrial sectors do not account a lot in the thermal energy consumption used for process heating in the Swiss industry. The textile/clothing sector represented $1 \%$ with less than $1 \mathrm{PJ}_{\mathrm{th}}$ consumed. The electrical, mechanical, energy/water and construction sector represented together $4 \%$ in 2016 . As mentioned previously, the Other industry category groups various industrial sectors and is not considered in this study. Nevertheless, this category account for a large part of the thermal energy consumed for process heat in 2016, representing $13 \%$.

Regarding only the thermal energy consumption for process heating in 2016, the distribution trend between the different industrial sectors appears to be similar to the thermal energy consumption distribution considering all applications. As shown previously, this is because process heating is the higher thermal energy consuming application in the Swiss industry, so that industrial sectors, having a large part of heat process applications, consume more than the others.

Promising sectors for implementation of ST systems are those that have process heating application representing a large part of their thermal energy consumption. Figure 6 presents the distribution of thermal energy consumption by application for each industrial sector.

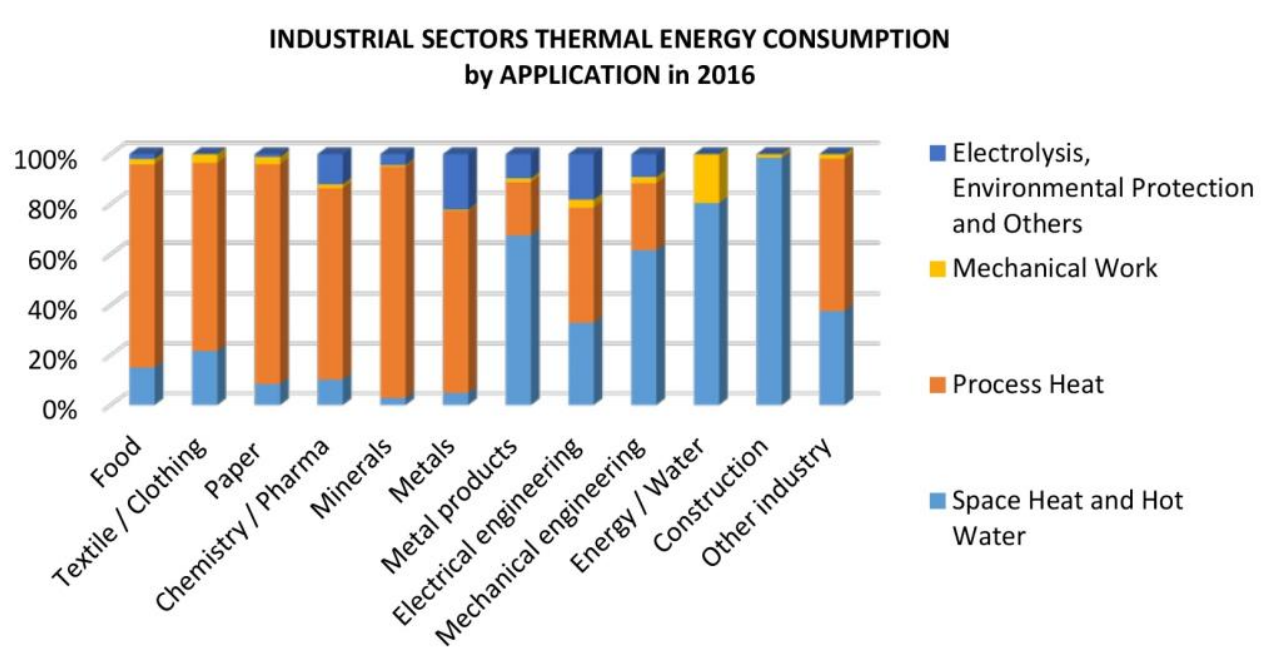

Fig. 6: Thermal energy consumption distribution by application for each industrial sectors in 2016 (own calculation based on Kemmler et al. (2017) and on Swiss Federal Office of Energy (2017))

The industrial sectors representing the largest share of thermal energy consumption in Switzerland in 2016, are also those that have a high thermal energy consumption in process heating. Therefore, these are the more interesting sectors to consider for solar thermal systems implementation. These sectors are the food sector, the paper sector, the chemistry/pharma sector, the minerals sector and the metals sector where process heating application represented respectively $81 \%, 88 \%, 76 \%, 92 \%$ and $73 \%$ of their thermal energy consumption.

For the five industrial sectors mentioned above, representing the largest consumers of thermal energy, the share of energy consumption for process heating represents an important part of their heat demand. Therefore, these industrials sectors are pre-selected as potentially suitable for implementation of solar thermal systems in process heating applications. The textile/clothing sector despite its small part in the industry thermal energy consumption is also pre-selected due to the share of its heat consumption for process heating, representing $75 \%$. 
The amount of heat consumption for process heating in these six sectors reaches $53 \mathrm{PJ}_{\text {th }}$ in 2016 , representing $57 \%$ of the industry thermal energy consumption and 33\%, thus a third, of the industry total energy consumption (electricity and heat).

\section{Solar Heat Potential for Industrial Processes}

\subsection{Promising Industrial Sectors}

Heat demand for process heating occurs at different temperature levels depending on the industry sector. In order to determinate the real potential of conventional solar systems in the pre-selected industrial sectors, it is necessary to identify the temperature level at which the heat processes occur. To our knowledge, no studies are available on the distribution of the heat demand according to the temperature level for the Swiss industry. However, there are many studies dealing with this subject in Europe and abroad. Since, there is no study on the specific distribution of the heat delivery by temperature range for Switzerland, this distribution is assumed to be similar to that of other European countries.

Distribution of the heat demand by temperature range is obtained from the data of the European study (Pardo et al., 2012). This study provides the distribution of the heat demand by temperature range for different industrial sectors in the EU-27 countries. The definition of industrial sectors considered in the latter is almost the same that those used in the present study. The only difference is the paper industry sector, which also includes the printing sector in the European study.

The distribution of the industry heat demand is divided into three temperature levels. The low temperature range (LT) corresponds to temperatures below $100^{\circ} \mathrm{C}$ and is the temperature range required for conventional solar system applications. The medium temperature range (MT) corresponds to temperatures between $100^{\circ} \mathrm{C}$ and $400^{\circ} \mathrm{C}$. The high temperature range $(\mathrm{HT})$ corresponds to temperatures higher than $400^{\circ} \mathrm{C}$.

Figure 7 presents the distribution of the heat demand for the pre-selected industrial sectors according to the three temperature levels.

INDUSTRY HEAT CONSUMPTION in EU-27

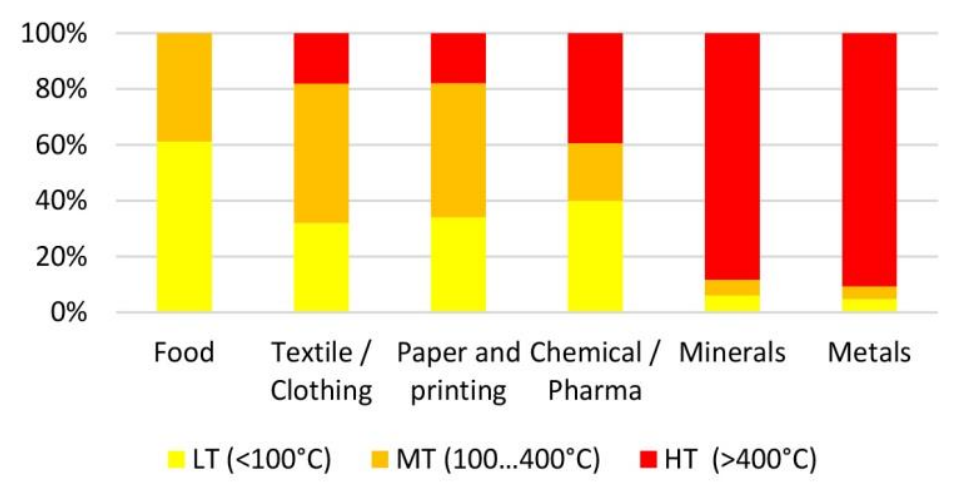

Fig. 7: Distribution of the industry heat demand by temperature level in EU-27 (own calculation based on Pardo et al. (2012))

Significant differences between the heat consumption behaviour of the pre-selected industry sectors can be observed. The food sector has heat consumption only at low and medium temperature ranges. Textile/clothing and paper sectors have more than $80 \%$ of their heat demand at these same temperature ranges. The chemical/pharma sector also has its largest part of heat demand occurring at low and medium temperature ranges. As this study focuses on low temperature ranges $\left(<130^{\circ} \mathrm{C}\right)$ for the implementation of conventional solar thermal systems, it clearly appears that the more promising sectors are:

- food

- textile/clothing

- paper

- chemical/pharma 
The share of heat consumption in the low temperature range for these industrial sectors represents a minimum of $30 \%$, reaching more than $60 \%$ in the case of the food industry (percent of total heat demand for process heating).

In the minerals and metals sectors some process heating occurs at low temperatures, e.g. pickling; metal surface treatment; mineral cleaning, but the largest part of their heat demand is at high temperatures. For this reason, they are not considered as promising industry sectors for the implementation of conventional ST collectors.

The food industry sector, which includes manufacturing of food products, beverages and tobacco products, appears to present an important potential for solar technology. According to the Euroheat \& Power study (Werner and Constantinescu, 2006), more than half of the heat demand for its processes is in the low temperature range with the remaining in the medium temperature range. As far as this study is concerned, it appears that almost $61 \%$ of the heat demand for process heating falls into the low temperature range.

The textile/clothing industry sector includes the manufacturing of textiles, wearing apparel and leather and related products. It appears that this industry has $32 \%$ of its thermal energy consumption at low temperature ranges and almost $50 \%$ at medium temperature ranges.

The paper sector includes the manufacturing of paper and paper products. According to Lauterbach (2014), twothirds of the heat demand in the paper sector is at temperatures below $200^{\circ} \mathrm{C}$. Concerning heat demand at temperature below $100^{\circ} \mathrm{C}$, its share represents $34 \%$, almost as for the textile/clothing industry.

The chemical/pharma sector includes the manufacturing of chemicals and chemical products, basics pharmaceutical products and pharmaceutical preparations. This is an extremely important sector because, it accounts for a large part of the Swiss industry thermal energy demand as already demonstrated in Figure 2 within the Swiss industrial context. According to Pardo et al. (2012) the share of thermal energy consumption used for process heating at temperatures below $100^{\circ} \mathrm{C}$ represents $40 \%$.

\subsection{Theoretical Potential in Swiss Industry}

The amount of thermal energy consumed by the four industrial sectors selected, presenting the greatest potential for conventional solar thermal systems, reached $41.4 \mathrm{PJ}_{\text {th }}$ in 2016 . This accounts for $26 \%$ of the industry total energy consumption (electricity and heat) and $46 \%$ of the industry thermal energy consumption. As far as process heating is concerned, the amount of energy consumed by these four industrial sectors represented $33 \mathrm{PJ}$ th, which accounted for $35 \%$ of the industry thermal energy consumption.

The theoretical potential for conventional thermal solar systems depends on the share of low temperature heat demand of each industrial sector. As explained in the Pardo et al (2012) study, the LT range includes the heat demand for process heating and also the heat demand for space heating $(\mathrm{SH})$ and hot water $(\mathrm{HW})$. In the context of this study, these applications are excluded in the analysis of the potential of ST systems. Then the amount of energy consumed by these applications is excluded in the final theoretical potential.

To identify this theoretical potential, the total amount of thermal energy consumed for process heating, hot water and space heating applications by each selected industrial was calculated. The share of heat demand occurring at low temperature is identified using the share of LT from the Pardo et al (2012) study. Finally, the theoretical potential for ST system for LT process heating application is calculated by subtracting the heat demand for space heating and hot water applications. Table 1 presents the theoretical potential for each selected industrial sector.

Tab. 1: Theoretical potential at low temperature operation for each industrial sector

\begin{tabular}{|c|c|c|c|c|c|}
\hline \multirow[b]{2}{*}{ Industrial Sector } & \multicolumn{2}{|c|}{$\begin{array}{l}\text { Thermal Energy } \\
\text { Consumption }\end{array}$} & \multirow{2}{*}{$\begin{array}{l}\text { Low Temperature } \\
\text { Demand }\left(<100^{\circ} \mathrm{C}\right)\end{array}$} & \multirow{2}{*}{$\begin{array}{c}\text { Low } \\
\text { Temperature } \\
\text { Heat Demand } \\
\text { [PJ] }\end{array}$} & \multirow{2}{*}{$\begin{array}{c}\text { Theoretical } \\
\text { Potential } \\
\text { [PJ] }\end{array}$} \\
\hline & $\begin{array}{c}\text { SH and HW } \\
{[\mathrm{PJ}]}\end{array}$ & $\begin{array}{c}\text { Process } \\
\text { Heating } \\
{[\mathrm{PJ}]}\end{array}$ & & & \\
\hline \multirow{4}{*}{$\begin{array}{c}\text { Food } \\
\text { Textile/Clothing } \\
\text { Paper } \\
\text { Chemistry/Pharma }\end{array}$} & 1.6 & 8.8 & $61 \%$ & 6.3 & 4.7 \\
\hline & 0.2 & 0.6 & $32 \%$ & 0.3 & 0.1 \\
\hline & 0.5 & 5.7 & $34 \%$ & 2.1 & 1.6 \\
\hline & 2.3 & 17.7 & $40 \%$ & 8.0 & 5.7 \\
\hline
\end{tabular}


The theoretical potential for conventional thermal solar system in these four industrial sectors accounts for 12.1PJ. This represents $13 \%$ of the industry thermal energy consumption and $8 \%$ of the industry total energy consumption (electricity and heat) during the year 2016. This value represents the estimation of thermal energy used for process heating that would be entirely provided by conventional solar thermal systems.

This theoretical potential for conventional solar thermal systems to provide heat in industrial processes is equivalent to more than 8 Million $\mathrm{m}^{2}$ installed ST collectors considering an annual yield of $400 \mathrm{kWh} / \mathrm{m}^{2}$. However, to estimate the real technical potential is necessary to take into account more consideration such as available space for systems installation, profile load of the processes energy consumption, energy storage opportunities, etc...

In the context of this study, it was chosen to identify the specific potential of solar thermal systems for process heating. However, the potential for these systems is more important considering that they can equally provide energy for hot water production, space heating and also to replace part of the electricity used for process heating. In this case, the theoretical potential for the selected industrial sectors represents 16.7PJ, equivalent to $10 \%$ of the industrial total energy consumption. Considering all the industrial sectors, the thermal energy consumption for hot water production and space heating reached $18 \mathrm{PJ}$ in 2016, then the theoretical for conventional ST system is even greater.

The electricity consumption of industrial process heating, which represented 22 PJ in 2016 for all Swiss industry, could also been of interest for the potential of solar thermal systems. Indeed, depending on the temperature requirements, the heat could be provided by conventional solar thermal systems and replace the use of electricity.

This shows that the real potential for conventional solar systems is greater than highlighted in this study. Moreover, as the conventional solar systems can provide heat up to $130^{\circ} \mathrm{C}$, it can be added the heat requirement that occurs at temperature between $100^{\circ} \mathrm{C}$ and $130^{\circ} \mathrm{C}$. Nonetheless, this energy consumption is not considered in this study because of the lack of data on the proportion of industrial processes taking place at this temperature range.

More recent developments as the concentrating technologies or the ultra-high vacuum fat plate collectors could also cover temperatures ranges up to $400^{\circ} \mathrm{C}$ efficiently and could contribute to a considerable raise of the energy delivered to the industrial process heat. Nevertheless, this range is not taken into account because these technologies are often more difficult to install and are more costly. Therefore, the potential announced above represents only the heat that could be covered by ST collectors easily and at a competitive price compared to the actual price of fossil fuels.

This result together with data from the distribution of these sectors across Switzerland (Swiss Federal Office of Statistic, 2017), makes it is possible to obtain the potential of each canton for the implementation of conventional solar thermal systems for process heating. Figure 8 shows the distribution of the theoretical potential, considering the four selected industrial sectors by canton.

THEORETICAL POTENTIAL FOR CONVENTIONAL SOLAR THERMAL SYSTEM by CANTON

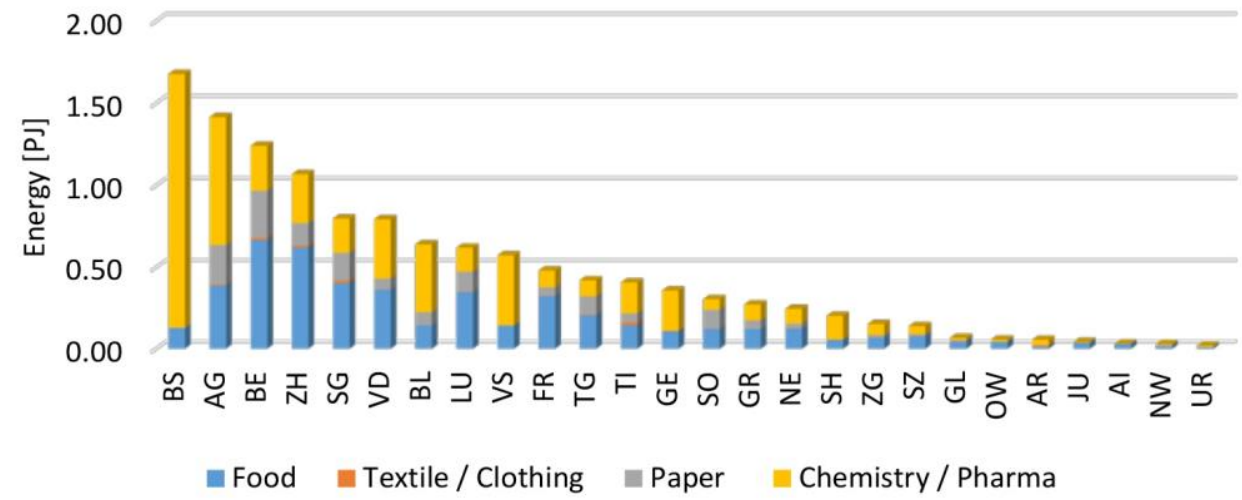

Fig. 8: Potential for conventional thermal solar systems for heat process in Switzerland (own calculation based on Swiss Federal Office of Statistic (2017)) 
The canton of Basel-City is where the theoretical potential is most important with an amount greater than 1.7PJ. It follows the canton of Aargau with a potential of 1.4PJ. The cantons of Bern, Zurich, St. Gallen and Vaud present a potential of $1.2 \mathrm{PJ}, 1.1 \mathrm{PJ}, 0.8 \mathrm{PJ}$ and $0.8 \mathrm{PJ}$, respectively.

\section{Conclusion}

A deep screening of the Swiss energy consumption was made in this work with a focus on the industry sector. The heat demand is carefully analysed depending on the industrial sector, energy vector, application and temperature level. Because of the Swiss organisation with different specifications for each canton, a geographical classification of the energy industrial demand was also carried out in order to highlight the potential of ST systems in each canton.

According to the Swiss Overall Energy Statistics GEST, the Swiss industry consumed 156 PJ in the year 2016, accounting for $18 \%$ of the final energy consumption in Switzerland. The main energy-consuming application in the industry resulted to be process heating. This application consumed 85PJ. The share energy demand for this application supplied by electricity was not taken into account in this study reducing the investigated energy consumption to 63PJ or about $40 \%$ of the Swiss industry energy demand.

Food, textile and clothing, paper, chemistry and pharma sectors are interesting for solar thermal systems implementation because they have a high thermal energy consumption in process heating and a high share of low operating temperature. These four industrial sectors have together an amount of heat demand for process heating reaching 33PJ, which accounted for $21 \%$ of the Swiss industry energy consumption in 2016.

Out of this demand, the share of heat demand for process heating application that occurs at low temperature $\left(<100^{\circ} \mathrm{C}\right)$ is estimated at $12.1 \mathrm{PJ}$ representing the theoretical potential for conventional thermal solar system in these four industrial sectors. This value represents $8 \%$ of the final energy consumption made by the Swiss industry during the year 2016 and $1.4 \%$ of total energy consumption in Switzerland. Several assumptions have been made in this work in order to identify processes where ST could easily replace fossil fuels. Therefore, it is important to mention that the theoretical potential energy supplied by ST conventional technologies can considerably increase with taking into account all industry sectors, other applications than process heat (e.g. space heat and HW) or the part of process heat supplied by electricity. Furthermore, processes occurring at higher temperature levels, up to $400^{\circ} \mathrm{C}$ could also be partly covered by different ST technologies such as concentrating or the ultra-high vacuum fat plate collectors.

This study highlights the important potential of conventional ST technologies to cover low temperature process heat in the Swiss Industry. It indicates the most favorable industrial sectors for ST implementation, the most suitable processes and also the regions where it is more likely to install such systems. Therefore it provides basic elements for different actors (industrials, ST manufacturers, planners/installers and policy makers) in order to help them increase energy efficiency in this sector and implicitly reduce greenhouse gas emissions which will greatly contribute to meet the targets of the Swiss Energy Strategy 2050. 


\section{References}

Bunea, M., Eicher, S., Bony, J., Duret, A., Citherlet, S., 2017. Medium Temperature Solar Thermal Installation for Industrial Thermal Storage of Bituminous Products, in: Proceedings of SWC2017/SHC2017. International Solar Energy Society, Freiburg, Germany, pp. 1-10. https://doi.org/10.18086/swc.2017.26.01

Horta, P., 2017. Solar Heat for Industrial Processes - Available Technologies, Design Procedures, Upcoming Innovations.

International Energy Agency (IEA), 2018. Energy Balance Flows 2015 [WWW Document]. URL http://www.iea.org/Sankey/

Kemmler, A., Koziel, S., Wüthrich, P., Benedikt, N., Keller, M., Martin, J., Catenazzi, G., 2017. Analyse des schweizerischen Energieverbrauchs 2000 - 2016 nach Verwendungszwecken, Bundesamt für Energie. Bern, Switzerland.

Lauterbach, C., 2014. Potential, system analysis and preliminary design of low-temperature solar process heat systems. Kassel Univ. Press. Kassel University.

Pardo, N., Vatopoulos, K., Krook-Riekkola, A., Moya, J.A., Perez, A., 2012. Heat and cooling demand and market perspective. Publications Office of the European Union. https://doi.org/10.2790/56532

Rittmann-frank, M.H., Möllenkamp, J., Caflisch, M., Häberle, A., 2017. Evaluation of Solar Process Heat projects in Switzerland Potential for Solar Process Heat in Switzerland, in: Proceedings of SolarPaces2017.

Swiss Federal Office of Energy, 2017. Schweizerische Gesamtenergiestatistik 2016 Statistique globale suisse de l'énergie 2016, Bundesamt für Energie. Bern, Switzerland.

Swiss Federal Office of Energy, 2012. Die Energieperspektiven für die Schweiz bis 2050, Bundesamt für Energie. Basel, Switzerland.

Swiss Federal Office of Statistic, 2017. STAT-TAB [WWW Document]. URL https://www.pxweb.bfs.admin.ch

Werner, S., Constantinescu, N., 2006. EcoHeatCool WP1: The European heat market, Euroheat \& Power. Brussels, Belgium. 


\title{
Solar Heat Integration in Rotational Molding Process: Case Study
}

\author{
Nour Eddine Laadel ${ }^{1}$, Ammar Mouaky ${ }^{1}$, Hassan Agalit ${ }^{1}$ and El Ghali Bennouna ${ }^{1}$ \\ 1 Institut de Recherche en Energie Solaire et Energies Nouvelles, IRESEN, 16, Avenue S.A.R. \\ Sidi Mohamed, Rabat 10090
}

\begin{abstract}
Rotational molding process (RMP) is conventionally used to manufacture plastic products. This process is based on the use of considerable amounts of heat in order to reach the required operating temperature $\left(300^{\circ} \mathrm{C}\right)$ for plastics melting. As fossil fuels are the primary source of the required heat in industrial processes, RMP suffers from their drawbacks (e.g. $\mathrm{CO}_{2}$ emissions, and instable cost of the used fossil fuels). One promising way to reduce these negative impacts is the use of solar thermal technologies as source of energy. Thus, the main objective of this paper is to study the potentiality of the integration of solar heat into Rotational Molding process, as well as its environmental and economic benefits. For this purpose, a real case study of a plant located in Casablanca city in Morocco was simulated in EBSILON ${ }^{\circledR}$ Professional software. The obtained numerical simulation results show that up to $26 \%$ of cost-effective solar share could be achieved with a reasonable payback time (around 6 years).
\end{abstract}

Keywords: Solar Heat for Industrial Process, Rotational Molding Process, EBSILON Professional, Annual Life Cycle Savings, Payback time.

\section{Introduction}

Among several applications of solar energy, solar heat for industrial process (SHIP) is a promising field. In fact, industrial sector accounts for approximatively $32 \%$ of total final energy consumption worldwide, and it's projected to grow by 56\% in 2040 (Philibert, 2017). In most of industries, three quarters of the energy demand are for process heat supplying, which is important to attain materials transformation required in the manufacture of industrial products such as heating, drying, cooking, etc. Generally, the conventional combustion of fossil fuels (oil, coal and natural gas) is the primary source providing the required heat for industries. Greenhouse gas emissions from fossil fuel combustion in industrial processes contribute undoubtedly to global warming (Schnitzer et al., 2007). Thus, reducing the consumption of fossil fuels in the industry sector is one of the big challenges of the energy transition worldwide. Therefore, integrating renewable energy sources and particularly solar heat into industrial processes is a clean and suitable alternative to fossil fuels, which can fulfill a considerable amount of heat demand in the sector.

In Morocco, the energy system is very dependent on imported fuels to meet the energy demand of the Kingdom, and primary energy sources are: Petroleum $(67,6 \%)$, coal $(16,1 \%)$ and natural gas $(5,7 \%)$ (Energy Policies Beyond IEA Countries - Morocco 2014,). Fortunately, the country has an important solar potential, which creates favorable conditions for exploitation of solar into the reduction of its energy bill. In this context, the industrial sector has a considerable energetic consumption, which represents around $26 \%$ of the national energy consumption. This value is going to grow up, as this sector has known recently a strong development. Thus, the importance of SHIP for improving the local energetic situation. However, to convince the local stakeholders to go into this promising vison, many real case studies should be performed. In this scope, the aim of this work is to study the feasibility of SHIP in rotational molding process, which is used conventionally to manufacture different plastic products in the desired forms. To fulfill this study, real data related to this process were obtained from a plant located in the region of Casablanca city, Morocco. Currently, the needed heat demand is provided by a gas burner in order to achieve the required process temperature of $300{ }^{\circ} \mathrm{C}$. Linear Fresnel Collector (LFR) technology was selected as suitable to attain this temperature levels, and a 
solar thermal plant was optimally designed to supply the process with maximum feasible solar thermal energy to reduce the manufactory gas consumption. All the simulations related to this study were performed in EBSILON Professional software in order to select the best configuration based on two economical indicators, namely Annual Life Cycle Savings (ALCS) and the Payback time.

\section{Overview of solar heat in industrial processes}

Integration of solar heat in industrial process has a promising outlook as demonstrated by several feasibility studies. The concept of SHIP consists at providing the required heat in the process through a solar thermal plant. The solar field is usually coupled with a thermal energy storage system and installed parallel to a conventional boiler system to ensure a continuous thermal energy supply. The design of SHIP systems consists at defining the most technically and economically suitable solar technology and the most suitable integration point in the process (Baniassadi et al., 2018). Selection of these parameters is totally depending on the process key parameters (fluid medium process, heat supply and distribution networks, working temperature, heat demand, industry location etc.). Generally, different integration concepts are possible and the chosen one for this present study is the most used by previous SHIP investigations (see Fig.1). This concept uses a solar heat exchanger between the solar field and the supply line of the process medium (e.g. hot water, steam, air) in order to integrate efficiently the solar heat into the process.
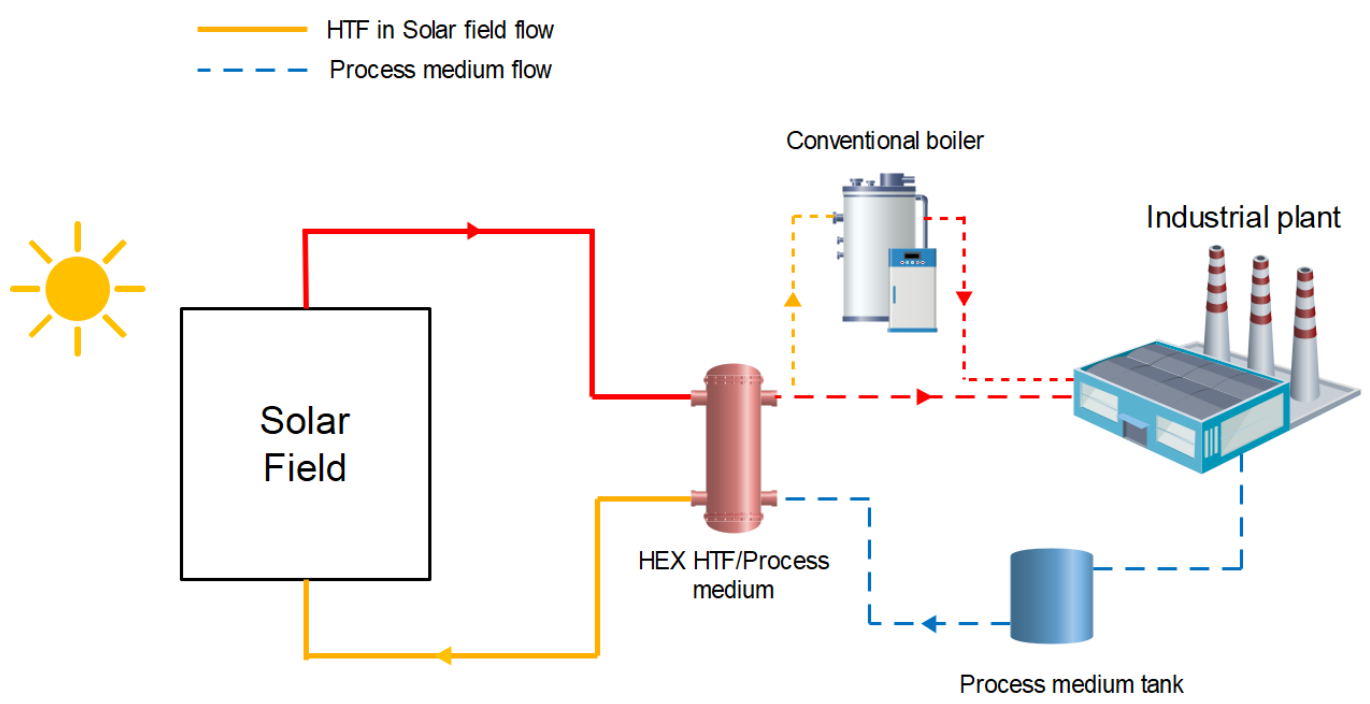

Fig. 1: Integration of solar heat in an existing industrial plant

\section{Rotational molding process}

Several industrial sectors have been identified with favorable conditions for the integration of solar heat into their processes. In the present work, the study is related to the rotational molding process. The latter is used to manufacture hollow plastic products such as plastic tanks, separators and vessels. Essentially, the process consists of four main operations (see Fig. 2). Firstly, a quantity of plastic powder is introduced into a mold (a: charging). Then, the mold is heated and rotated continuously until the plastic material forms a layer on the mold surface (b: heating). Thirdly, the mold rotation continues during the cooling phase (c: cooling). Finally, when the plastic is sufficiently rigid, the plastic product is demolded to get the final product (d: demolding) (Crawford et al., 2001). 


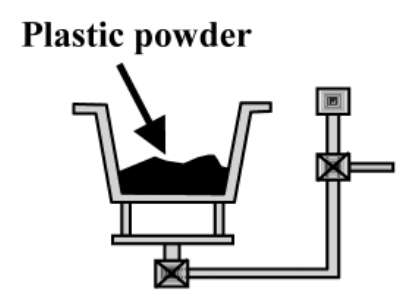

(a) Charging

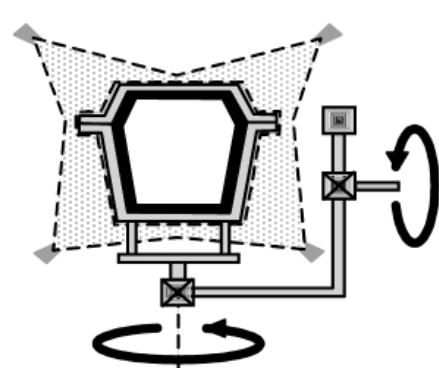

(c) Cooling

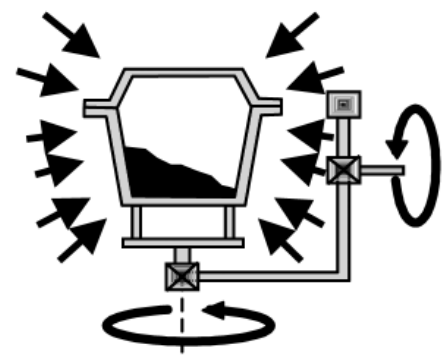

(b) Heating

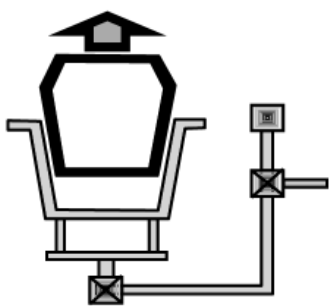

(d) Demolding

Fig. 2: Steps of rotational molding process (Crawford et al., 2002)

Currently, the majority of local RMP industries use polyethylene as plastic raw material in its several forms. It accounts for approximatively $85 \%$ to $90 \%$ of all polymers used in the process (Crawford et al., 2001). The real processing program of the studied case of study is presented in Fig. 3, where the second (heating) and third (cooling) steps of the RMP are illustrated. The duration of one cycle of heating/cooling inside the furnace takes approximately about $35 \mathrm{~min}$. in the same figure are presented also the temperature variations of the mold and the plastic as function of time. With respect to this real heat demand curve, the solar heat plant would be designed.

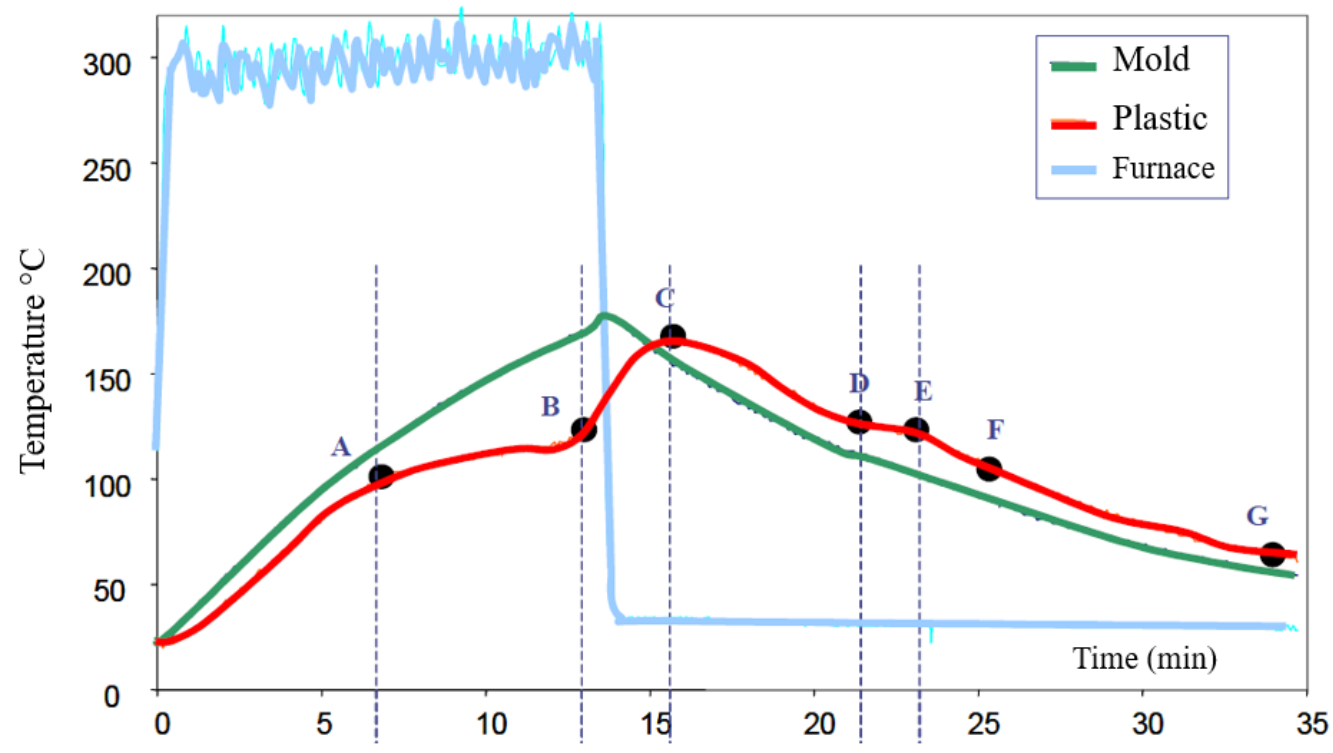

Fig. 3: Temperature variation during a rotational molding cycle (Pérot, 2006) 


\section{Modeling and simulation}

\subsection{Proposed integration system}

The proposed scheme of the integration is illustrated in Fig. 4. The solar field was designed to supply the required heat during the curing period of the process through a heat exchanger between the heat transfer fluid (HTF) circulating in the solar plant and the air used as a process medium. During the operation of the plant, he air takes the maximum heat from the solar field. In the case where the air temperature is below $300{ }^{\circ} \mathrm{C}$, which is the working temperature of the process, the gas burner, installed in serie with the solar field, is activated in order to heat up the air to attain the targeted temperature inside the process mold.

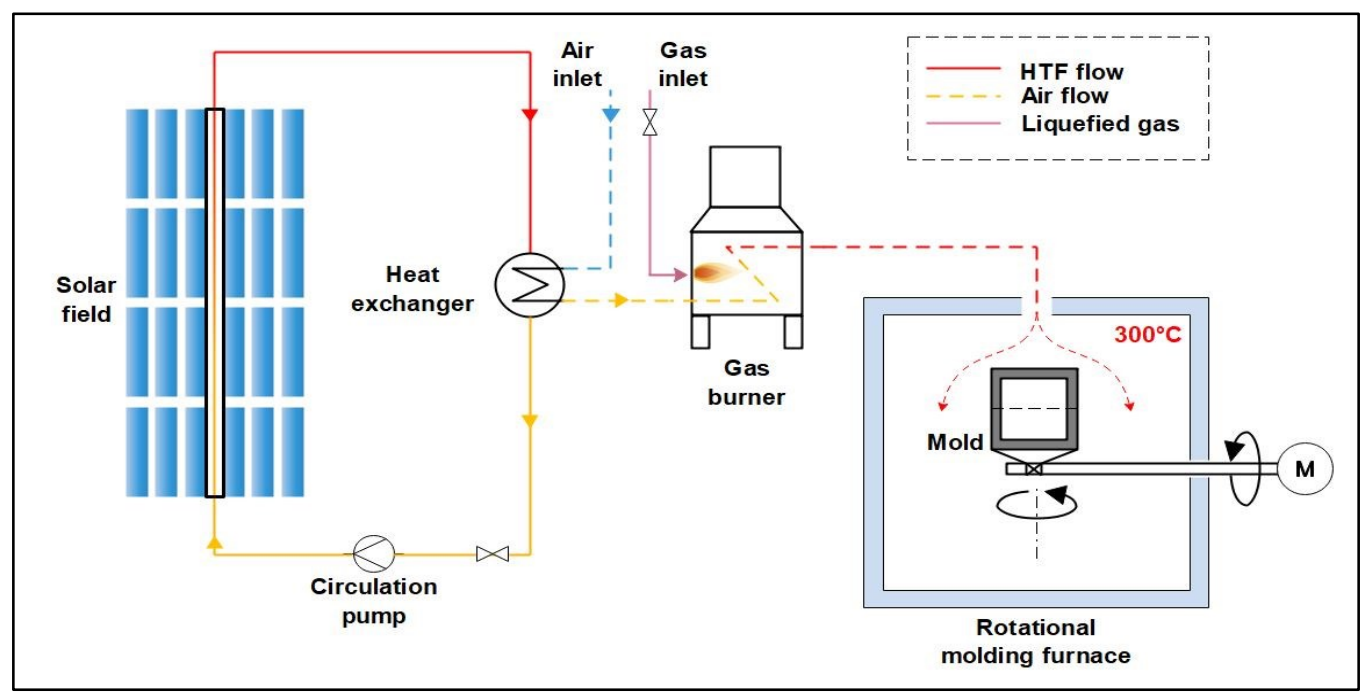

Fig. 4: scheme of the proposed solar heat integration in RMP

In the case of the unavailibility of the solar radiation, the existing gas burner is supplying the additional or the total heat demand in the process. The implementation of a thermal energy storage system was not taken into consideration during this study.

\subsection{Process load profile}

In the present real case investigation, the solar plant was designed to supply heat for two RM machines. As indicated previously, the duration of each cycle accounts for approximatively $40 \mathrm{~min}$. Since the thermal energy is needed only during the curing phase of each cycle, which takes about $20 \mathrm{~min}$, and in order to simplify the conducted numerical study, the two machines have been supposed to work alternately. In other words, the curing phase of one is corresponding to the cooling phase of the other machine. In this case, the supplying of hot air will be continuously. The heat power required in the process can be computed by using the following equation:

$Q_{\text {process }}=\dot{m}_{\text {air }} c_{p}\left(T_{\text {out }}-T_{\text {in }}\right)$

Where $\dot{m}_{\text {air }}$ is the mass flow of the hot air, $c_{p}$ is the specific heat of the air, $T_{\text {out }}$ and $T_{\text {in }}$ indicate respectively the outlet and inlet temperature of the air in the process.

Fig. 5 depicts the heat demand profile considered during 24 hours. Furthermore, the hot air mass flow required by the process is also presented in the same figure. The demand in the factory is supposed constant during all the days of the year. 


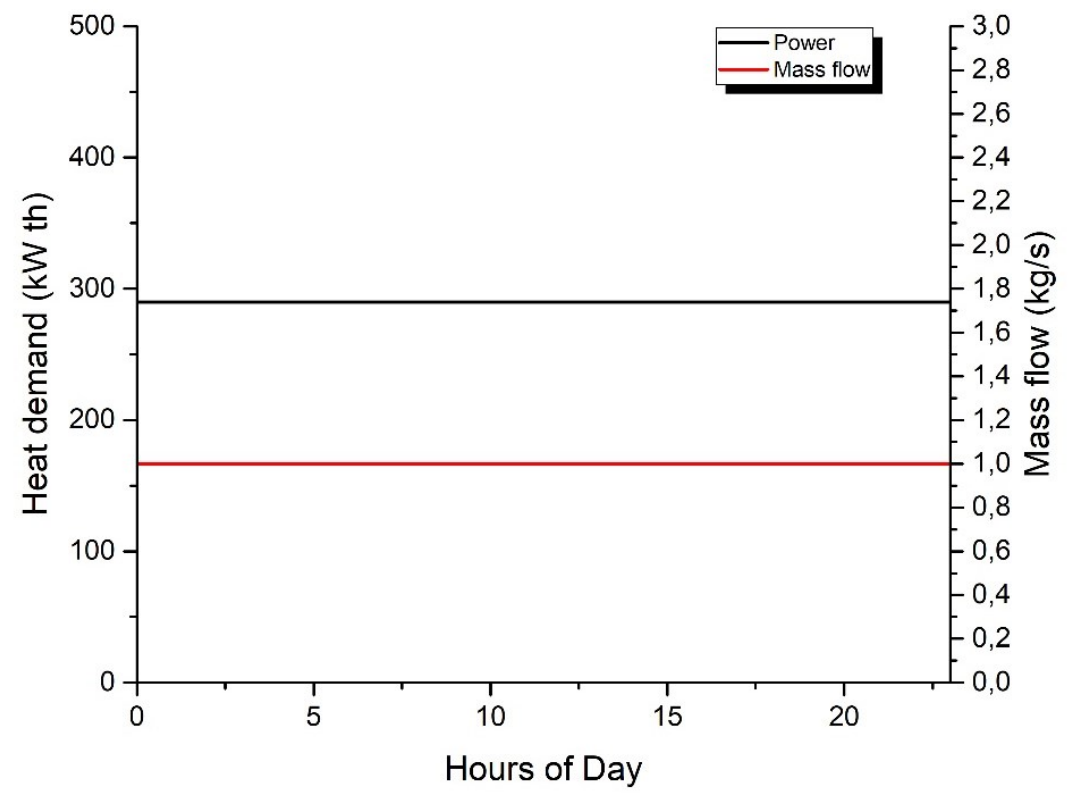

Fig. 5: Heat demand profile of the process

\subsection{Solar collectors}

According to published studies (Kalogirou, 2003; Pulido-Iparraguirre et al., 2019), line focusing systems, i.e., parabolic-trough collectors (PTCs) and linear Fresnel reflectors (LFRs), are typically the suitable concentrated solar technologies for SHIP in medium temperature applications (up to $300^{\circ} \mathrm{C}$ ). For the purpose of this work, LFR collectors are selected since the technology presents some economic advantages compared with PTC in this range of temperature (Sait et al., 2015). Therefore, Soltigua's Linear Fresnel collectors re exploited in the present simulation work. Technical characteristics of collectors used in the study are listed in Table. 1 ("Soltigua - PV trackers, Solar Tracker Manufacturers, parabolic trough and linear Fresnel collectors,").

Tab 1. Technical characteristics of solar collectors

\begin{tabular}{|c|c|c|c|c|}
\hline Collector type & $\begin{array}{c}\text { Net collecting } \\
\text { surface } \mathbf{( m}^{\mathbf{2}} \mathbf{)}\end{array}$ & $\begin{array}{c}\text { Reference } \\
\text { thermal capacity } \\
\mathbf{( k W t )}\end{array}$ & $\begin{array}{c}\text { Working } \\
\text { temperature }\left({ }^{\circ} \mathbf{C}\right)\end{array}$ & $\begin{array}{c}\text { Heat transfer } \\
\text { fluid }\end{array}$ \\
\cline { 1 - 3 } FLT10v-48 & 297,0 & 166 & \multirow{2}{*}{$\begin{array}{c}T_{\text {outlet }}=300, \\
T_{\text {inlet }}=180\end{array}$} & $\begin{array}{c}\text { DelcoTerm } \\
\text { Solar E } 15\end{array}$ \\
\cline { 1 - 3 } FLT10v-60 & 371,3 & 207 & \\
\hline FLT10v-72 & 445,5 & 249 & \\
\hline
\end{tabular}

\subsection{Plant location}

The studied RMP plant is located in Casablanca city in Morocco. The city is considered as the commercial capital of the country and the hub of its industry. As the majority of the industrial cities worldwide, and according to statistics published by the World Health Organization ("WHO | World Health Organization,"). The city suffers from air pollution due to the greenhouse gas emissions caused by the industrial activities. With regard to the weather conditions, Casablanca has a hot and humid Mediterranean climate. The main meteorological characteristics related to the city are presented in Table 2 (Ouammi et al., 2012). 
Tab. 2: Characteristics of Casablanca city

\begin{tabular}{|c|c|c|c|}
\hline City & Coordinates & Altitude (m) & $\begin{array}{c}\text { Annual Solar } \\
\text { Irradiation } \\
\text { (Wh/m } / \mathbf{d a y})\end{array}$ \\
\hline Casablanca & $33^{\circ} 35^{\prime}{ }^{\prime} \mathrm{N} 7^{\circ} 36^{\prime} \mathrm{W}$ & 22 & 5832 \\
\hline
\end{tabular}

\subsection{Model in EBSILON Software}

To simulate the performances of the proposed system, a numerical study was conducted using EBSILON Professional Software. This commercial program is widely used in modeling, simulation and evaluation of thermodynamic cycle processes. Fig. 5 presents the studied model using available components in the software component libraries.

The sun
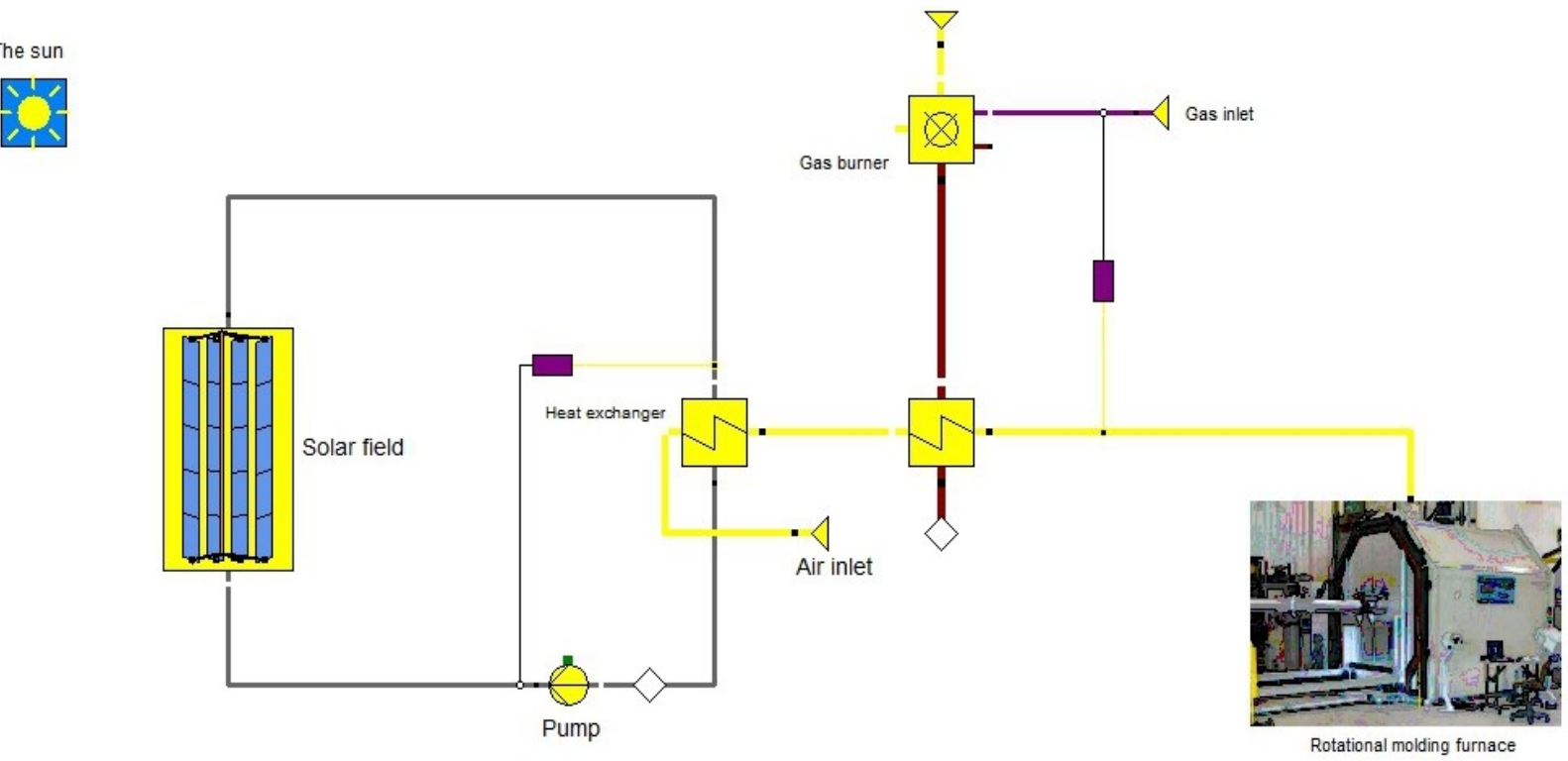

Fig. 6: Layout of the proposed model in EBSILON

As it's indicated previously, the solar field based on LFR collectors was implemented to heat up the process medium (air) through a heat exchanger. The process heat demand was modeled by the determination of the hot air flow rate in the output of the heat exchanger. Depending on the temperature of the extracted air, the gas flow in the inlet of the gas burner varies in order to provide the required heat to meet the recommended temperature of the process. In the considered model, the component "Sun" serve to calculate the parameters related to the solar incident radiation using meteorological data of the plant location. The "Solar field" component simulates the performances of the used LFR collector taking into account the variation of the meteorological data provided by the component "Sun". The absorbed heat by the collector is calculated by the following expression:

$Q_{\text {solar }}=D N I \times A_{S F} \times \eta_{o p t, 0} \times I A M \times f \times C l \times \eta_{\text {endloss }} \times \eta_{\text {shading }}$

Where DNI is the direct normal irradiation, $A_{S F}$ is the net aperture area, $\eta_{o p t, 0}$ is the optical efficiency for perpendicular sun on collector, IAM is the incidence angle modifier, $f$ is the focus state of the collector, $C l$ is the cleanliness factor, $\eta_{\text {endloss }}$ and $\eta_{\text {shading }}$ are the end loss effects factor and shading losses factor respectively. In the present work, the cleanliness factor is not considered in the performed simulations.

The useful thermal output of the collector is given by:

$Q_{\text {eff }}=Q_{\text {solar }}-Q_{\text {loss }}$

(eq. 3) 
Where $Q_{\text {loss }}$ presents the thermal losses in the tube receiver. Heat losses are varying as function of the outlet temperature according to the manufacturer instructions datasheet.

For each collector, the HTF flow rate is varying as function of the DNI to maintain $300^{\circ} \mathrm{C}$ outlet temperature of the thermal oil using the component "Internal controller" in EBSILON. In the case where the solar radiation are insufficient to attain the nominal operating conditions in the solar field, the "Gas burner" component is implemented in serie to supply the additional heat needed to meet the process conditions. As function of the solar thermal power obtained, the component calculates the additional heat to supply by varying the gas flow rate using the "internal controller" component based on the following expression:

$Q_{\text {g.u }}^{\cdot}=\dot{m}_{\text {air }} \times\left(h_{\text {process }}-h_{\text {solar }}\right) \quad$ (eq. 4$)$

Where $Q_{g . u}^{\cdot}$ is the useful heat produced by the gas burner, $h_{\text {process }}$ being the enthalpy of the air needed in the process, $h_{\text {solar }}$ being the enthalpy of hot air obtained through the solar field heat exchanger.

\section{Results and discussion}

\subsection{Solar field sizing}

For the sizing of the solar system, the method followed is based on the optimization of solar field surface. Six configurations were chosen accordingly to the Solar Multiple coefficient (SM) expressed by the following equation:

$$
S M=\frac{Q_{\text {demand }}}{Q_{S F}}
$$

Where $Q_{\text {demand }}$ being the required thermal power in the process and $Q_{S F}$ is the reference thermal capacity of the solar field.

The technical characteristics of each selected configuration are resumed in Table 3.

Table 3. Technical characteristics of selected configurations

\begin{tabular}{|c|c|c|c|}
\hline Configuration & $\begin{array}{c}\text { Qsf (Reference } \\
\text { thermal } \\
\text { capacity (kWt)) }\end{array}$ & $\begin{array}{c}\text { Number of } \\
\text { collectors }\end{array}$ & Solar multiple \\
\hline 1 & 166 & FLT10v-48 $\times 1$ & 0,57 \\
\hline 2 & 207 & FLT10v-60 $\times 1$ & 0,72 \\
\hline 3 & 249 & FLT10v-72 $\times 1$ & 0,86 \\
\hline 4 & 332 & FLT10v-48 $\times 2$ & 1,15 \\
\hline 5 & 414 & FLT10v-60 $\times 2$ & 1,44 \\
\hline 6 & 498 & FLT10v-72 $\times 2$ & 1,73 \\
\hline
\end{tabular}

\subsection{Selection of the optimal solar field size}

The optimal solar field size can be determined based on an economical analysis. For this purpose, a financial evaluation of the six investigated configurations is carried out based on two economical indicators, Annual Life Cycle Savings (ALCS) and Payback time (PB). These parameters are decisive to evaluate the economics of solar systems. The aim of this methodology is to obtain the optimal design corresponding to the maximum life cycle net energy savings and the minimum payback time. The ALCS can be expressed by the following equations (Duffie and Beckman, 2013; Kalogirou, 2013):
$A L C S=A L C C_{g a s}-A L C C_{\text {sol }}$
(eq. 6) 
Where $\mathrm{ALCC}_{\mathrm{gas}}$ and $\mathrm{ALCC}_{\text {sol }}$ are the annual life cycle cost related to the conventional system (gas burner) and solar one respectively. The latter one is taking into account the cost of the fuel used when the solar system is not available. The $\mathrm{ALCC}_{\text {gas }}$ is given by:

$A L C C_{\text {gas }}=C_{\text {gas }} \times Q_{\text {load }} \times P W F$

Where $C_{g a s}$ is the natural gas cost, $Q_{l o a d}$ is the total thermal energy required by the process and $P W F$ is the present worth factor, which is expressed by:

$P W F=\frac{1}{d-i}\left[1-\left(\frac{1+i}{1+d}\right)^{n}\right]$

Where $\mathrm{d}$ is the market discount rate, I is the inflation rate and $\mathrm{n}$ the number of years.

The annual life cycle cost related to the solar system is approximated by:

$$
A L C C_{\text {sol }}=I C+\left(M C+C_{g a s} \times Q_{g . u}\right) \times P W F \text { (eq. 9) }
$$

Where IC represents the initial investments covering the cost of solar collectors and installation, MC refers to the maintenance costs and $Q_{g . u}$ is the total thermal energy used by the conventional burner during the unavailability of the solar system.

The payback time is a widely used financial indicator to evaluate projects. It corresponds to the number of necessary years for the undiscounted accumulated fuel saving to commensurate the initial solar plant investments. It is given by the following formula:

Payback time $=\frac{\ln \left(\frac{I C \times i}{f \times \frac{Q_{l o a d}}{\eta_{b}} \times C}+1\right)}{\ln (1+i)}$

All the terms in the above expression are already given previously, with the exception of the term $f$ which refers to the annual solar fraction related to the proposed solar system and $\eta_{b}$ which represents the efficiency of the gas burner. Estimation of all the previous parameters are listed below based on Moroccan market considerations (Allouhi et al., 2017; Otanicar et al., 2012) and the results of the conducted simulations in EBSILON software:

- Natural gas cost is considered as $0.1 € / \mathrm{kwh}$.

- Total annual thermal load of the process is $Q_{\text {load }}=2528110 \mathrm{kwh}$.

- Natural gas cost inflation rate is considered $2.5 \%$ per year.

- Annual market discount rate in Morocco is 5\%.

- Specific cost of solar field is estimated as $300 € / \mathrm{m}^{2}$.

- Installation cost and maintenance cost are taken as $1 \%$ and $2 \%$ of IC respectively.

Table. 4 indicates the obtained simulation results related to further parameters for each solar size combination. Furthermore, Fig. 6 presents the calculation results obtained for the six configurations. It can be seen that as the solar multiple is increased the ALCS indicator increases as well to reach a maximum value for the fifth configuration ( $\mathrm{SM}=1.44)$. Then, after this point, the increasing of SM is unnecessary, as the investment, cost is more important than the extracted solar heat. On the other hand, the PB increases with respect to SM due to the subsequent increase in the investment cost. The best-achieved annual solar fraction was obtained for configuration No. 6 as it involve the biggest solar field. However, the optimal configuration is the fifth one as it has the maximum ALCS and reasonable PB, while it achieve an important SF. This configuration was used to perform the annual simulations in the upcoming sections. 
Table 4.Simulation results of the selected configurations

\begin{tabular}{|c|c|c|}
\hline Configuration & ALCC $_{\text {sol }}(\mathbf{\epsilon})$ & Annual solar fraction \\
\hline 1 & 3305 & $6 \%$ \\
\hline 2 & 3286 & $7.4 \%$ \\
\hline 3 & 3267 & $9 \%$ \\
\hline 4 & 3228 & $11.7 \%$ \\
\hline 5 & 3216 & $14 \%$ \\
\hline 6 & 3228 & $15.6 \%$ \\
\hline
\end{tabular}

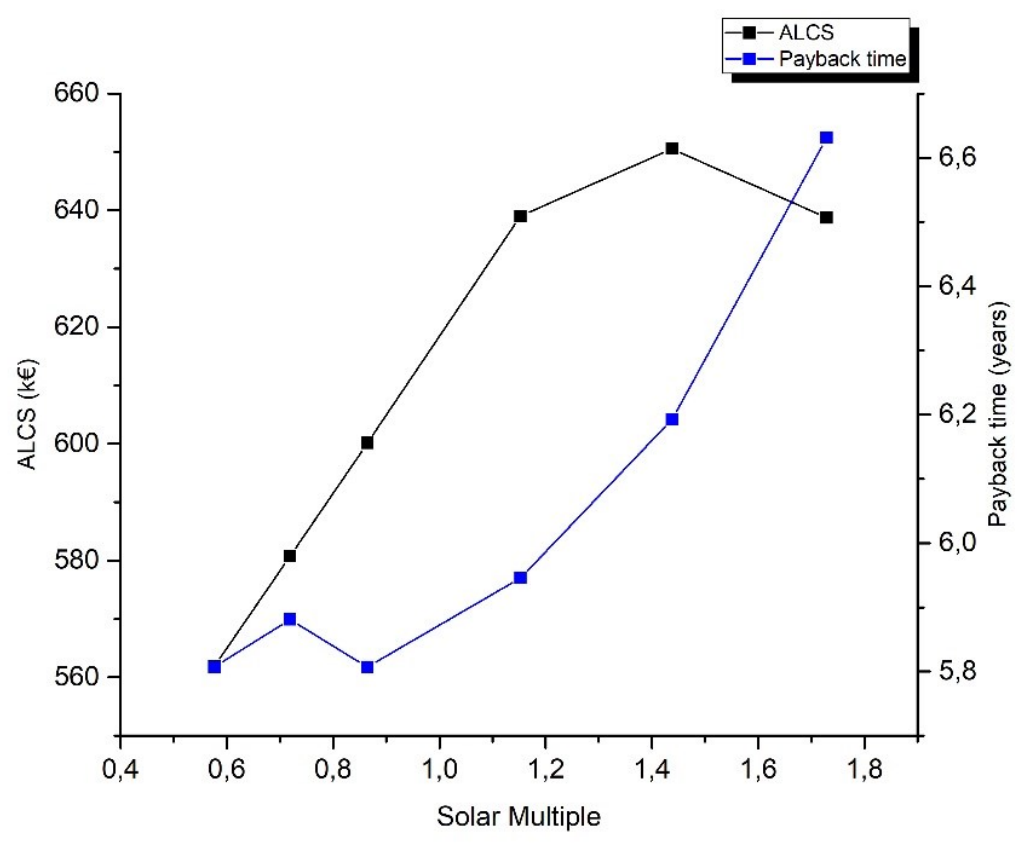

Fig. 7: ALCS and payback time with respect to SM

\subsection{Annual results of the optimal configuration}

As it has been shown in the previous section, the optimal design corresponds to the maximal annual life cycle saving with a payback time of 6,2 years. To investigate the performances of this configuration, annual simulation considering an hourly time step were conducted. As shown in Fig. 8, the solar field output varies between 7,67 (December) and 55,85 MWh (August), while the gas burner output varies between 154,37 (August) and 210,13 MWh (December). Consequently, high solar fraction values are obtained during summer period. In fact, the highest solar fraction value obtained is $26 \%$ (August), and it was reached during August month. It can be explained by the high solar irradiation available in this month. Furthermore, the monthly variation of solar fraction is following the trend the DNI variation. Finally, these obtained results indicate the potential of SHIP for the RMP. Further, work including thermal energy storage component needs to be done in order to increase the potentiality of SHIP and reach higher cost-effective solar share while reducing the energy bill and the $\mathrm{CO} 2$ footprint of the RMP. 


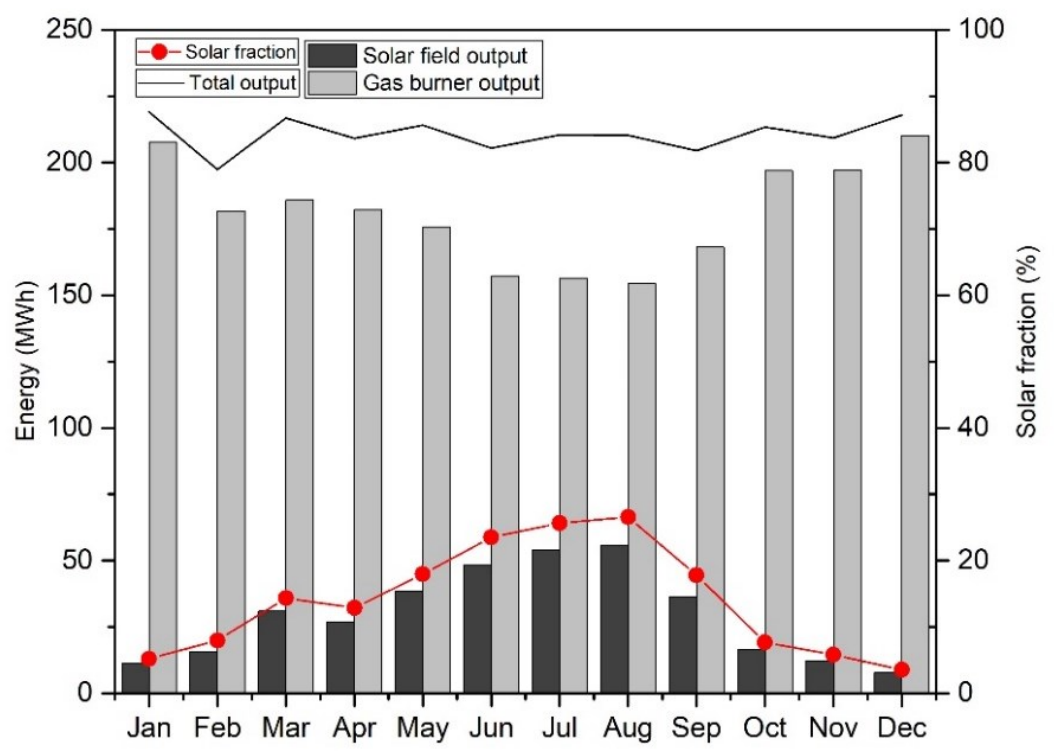

Fig. 8: Monthly solar fraction for the optimal configuration

\section{Conclusions}

In this effort, a real case of study of solar heat integration (SHIP) into the rotational molding process (RMP) was investigated in order to demonstrate its feasibility and help in increasing the awareness of the local industrial stakeholder for the importance of SHIP for the nowadays-energetic situation of Morocco. Six configurations of solar thermal field based on Linear Fresnel collectors were studied in order to select the most optimal one. To fulfill this, two critical indicators were used and they are namely ALCS and Payback time. The obtained result suggested that the configuration No. 5 performs the best as it achieves the highest ALCS $(650 \mathrm{k} €)$ with a reasonable payback time (6.2 years) and an important annual solar share. Moreover, this optimal configuration were used to perform the annual simulation and the obtained results have shown a great potential of SHIP for RMP. Actually, it reached up to $26 \%$ of solar fraction during August month. This value could be increased more if a thermal energy storage system is implemented in the integration scheme.

\section{References}

Allouhi, A., Agrouaz, Y., Amine, M.B., Rehman, S., Buker, M.S., Kousksou, T., Jamil, A., Benbassou, A., 2017. Design optimization of a multi-temperature solar thermal heating system for an industrial process. Applied Energy 206, 382-392.

Baniassadi, A., Momen, M., Amidpour, M., Pourali, O., 2018. Modeling and design of solar heat integration in process industries with heat storage. Journal of Cleaner Production 170, 522-534.

Crawford, R.J., Crawford, R.J., Throne, J.L., 2001. Rotational molding technology. William Andrew.

Duffie, J.A., Beckman, W.A., 2013. Solar engineering of thermal processes. John Wiley \& Sons.

Energy Policies Beyond IEA Countries - Morocco 2014 [WWW Document], n.d. . IEA webstore. URL https://webstore.iea.org/energy-policies-beyond-iea-countries-morocco-2014.

Kalogirou, S., 2003. The potential of solar industrial process heat applications. Applied Energy 76, 337-361.

Kalogirou, S.A., 2013. Solar energy engineering: processes and systems. Academic Press. 
Otanicar, T., Taylor, R.A., Phelan, P.E., 2012. Prospects for solar cooling-An economic and environmental assessment. Solar Energy 86, 1287-1299.

Ouammi, A., Zejli, D., Dagdougui, H., Benchrifa, R., 2012. Artificial neural network analysis of Moroccan solar potential. Renewable and Sustainable Energy Reviews 16, 4876-4889.

Pérot, E., 2006. Optimisation et modélisation du procédé de rotomoulage. École doctorale : École doctorale matériaux de Lyon - L’institut national des sciences appliquées de Lyon.

Philibert, C., 2017. Renewable Energy for Industry. Paris: International Energy Agency. URL https://www.iea.org/publications/insights/insightpublications

Pulido-Iparraguirre, D., Valenzuela, L., Serrano-Aguilera, J.-J., Fernández-García, A., 2019. Optimized design of a Linear Fresnel reflector for solar process heat applications. Renewable Energy 131, 1089-1106.

Sait, H.H., Martinez-Val, J.M., Abbas, R., Munoz-Anton, J., 2015. Fresnel-based modular solar fields for performance/cost optimization in solar thermal power plants: a comparison with parabolic trough collectors. Applied Energy 141, 175-189.

Schnitzer, H., Brunner, C., Gwehenberger, G., 2007. Minimizing greenhouse gas emissions through the application of solar thermal energy in industrial processes. Journal of Cleaner Production 15, 1271-1286.

Soltigua - PV trackers, Solar Tracker Manufacturers, parabolic trough and linear Fresnel collectors. URL http://www.soltigua.com/.

WHO | World Health Organization. URL http://www.who.int. 


\title{
Standardization of Solar Process Heat Applications to Increase Market Penetration
}

\author{
Bastian Schmitt, Dominik Ritter, Felix Pag, Mateo Jesper, Lukas Wimmer, and Klaus Vajen \\ University of Kassel, Institute of Thermal Engineering, Kassel (Germany)
}

\begin{abstract}
Based on the necessity to decarbonize future energy systems, the market uptake of solar process heat has to be accelerated. Currently, the market development is underwhelming, not only in Germany. However, numerous solar process heat plants have been realized, focusing on a few specific applications outside the traditional industry sector. These applications, namely rearing of animals, cleaning of vehicles and drying of biomass cover approx. two third of the German solar process heat market. Since Industry is often characterised by slow hierarchal decision structures, near-term planning horizons, and short payback times it seems promising to standardize the named popular applications outside the traditional industry sector and therefore, accelerate the market development and increase the visibility of solar process heat. Based on the evaluation of planning documents from 174 solar process heat plants, standardized systems concepts for the three applications were developed including hydraulic, key facts for dimensioning of collector area and storage as well as typical turn-key costs. These concepts will enable the market entry of new solar project developers and installers and therefore help to develop the large potential of low hanging fruits in the short term and for solar process heat in general.
\end{abstract}

Keywords: Solar process heat, low hanging fruits, standardization, planning guidelines

\section{Introduction}

While the German Energiewende is stalling at the moment in case of renewable electricity, the transition to a wide spread renewable heat supply has not really started yet at all. Like residential buildings, the heat consumption in Industry and Commerce allocates the major share of the overall energy demand (Fig. 1). Despite the significant lower $\mathrm{CO} 2$-factor for heat generation in contrast to electricity generation, more than half of the energy caused $\mathrm{CO} 2$-emissions in Industry and Commerce is based on fossil fuels for heat supply. With respect to the necessary decarbonisation it has to be underlined that the electricity caused $\mathrm{CO} 2$-load of companies is reduced by itself without any activities by the companies itself through the (slow) expansion of wind and PV capacities. This is completely different for the heat supply, since every company independent of its size has its own infrastructure being itself responsible for modernization and decarbonisation. If a fossil boiler has to be changed, it is usually replaced by a new gas boiler without even considering possibilities for decarbonisation. Following, there are no significant changes in the heat supply infrastructure for the next 20 years.

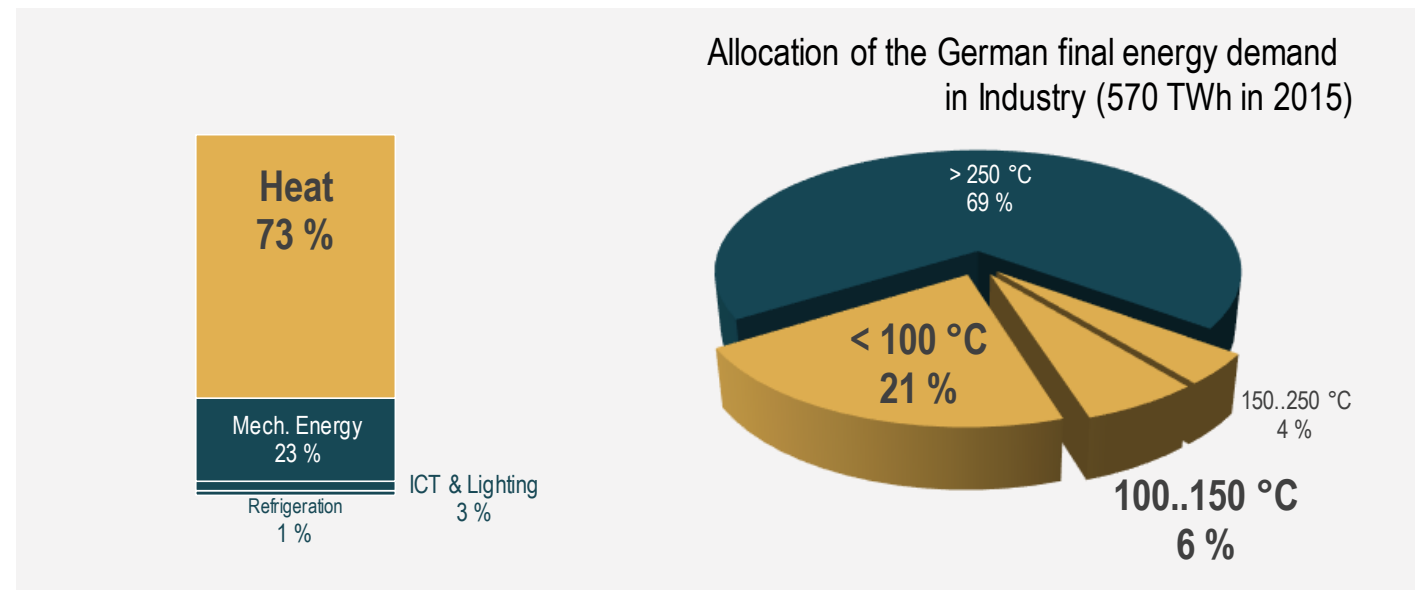

Fig. 1: Distribution of German final energy demand in Industry with respect to use and temperature level, based on BMWi (2018) 
Different potential studies state a huge market potential for solar collectors in Industry and Commerce. About one quarter of the industrial heat demand in Germany needs temperatures below $100{ }^{\circ} \mathrm{C}$ and thus can be provided by solar thermal systems. In consequence, there is a market potential of up to 150 Million $\mathrm{m}^{2}$ collector area, that has to be developed in the upcoming years (VDI 3988, 2018). The market exploitation should focus on new stakeholders to speed up the dissemination of the potential for solar process heat. Therefore, simple concepts for the use of solar process heat are needed, which can also be applied by inexperienced planners and (energy) consultants. So far, in the German market there are several applications which dominate the emerging solar process heat market. Within this paper, standardized concepts for the integration of solar process heat into the conventional infrastructure are described for these applications with high potential for multiplication.

\section{Solar process heat market in Germany}

In the first two years after the introduction of the Market Incentive Program (MAP) for solar process heat systems with funding of $50 \%$ of the overall investment costs, the market developed well. Whereas the market startet with nearly 2,000 $\mathrm{m}^{2}$ in 2013, the approved collector area more than doubled in 2014. In 2015 and 2016, the market declined significantly, as oil prices dropped over $50 \%$ (Ritter at al., 2017). Since 2017, a positive market development with a noteworthy growth reaching the level of 2014 can be registered again. Likewise, the first months of 2018 are promising. This growth cannot only be traced back to a growing number of applied systems but especially to an increased collector area of these systems. Currently, the largest solar process heat plant is used for drying of woodchips and hay with $1,313 \mathrm{~m}^{2}$ of air-collectors. The largest water-based solar process heat plant with nearly $1,000 \mathrm{~m}^{2}$ of vacuum tubes is currently installed at the Rothaus Brewery close to Freiburg while an even larger system with almost $1,300 \mathrm{~m}^{2}$ of vacuum tubes for the cleaning of road trains is granted and in the detailed planning phase.

Overall, about 15,000 $\mathrm{m}^{2}$ of collector area in more than 230 solar process heat systems were installed since 2012 and in addition more than $5,000 \mathrm{~m}^{2}$ are planned or installed right now. Including the known systems installed before August 2012, about 25,000 $\mathrm{m}^{2}$ of solar thermal collectors will efficiently produce $\mathrm{CO} 2$-free process heat for industry, commerce, agriculture and forestry in Germany at the end of 2018. Although it is a very small share compared to the large market potential, these systems will increase the visibility and can be the basis for a further growth of the German market for solar process heat.

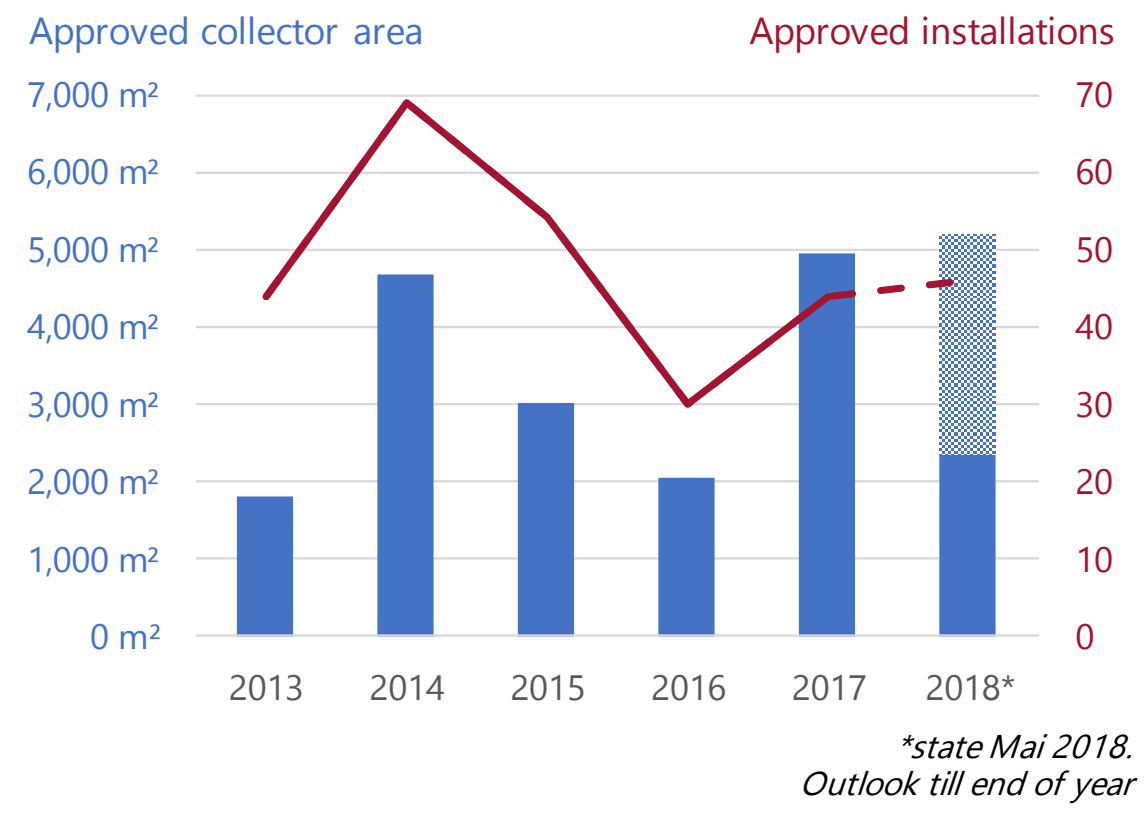

Fig. 2: Market development in Germany. Yearly approved collector area in $\mathbf{m}^{2}$ (blue) and number of systems (red)

Till now, mainly flat plate collectors are used and account for $55 \%$ of the installed collector area, vacuum tube collectors and air collectors are both a bit over $22 \%$. However, the share of air collectors and vacuum tube collectors increased continuously in the last years to the disadvantage of flat plate collectors, whose share dropped below $20 \%$ in 2017. 


\section{Economic aspects}

Similar to other efficient or renewable technologies, the main barrier for the implementation of solar process heat in Germany is the amortization period. Although funded systems reach high single-digit returns on invest over their life time of at least 20 years the market development is rather slow. Despite the fact that short amortization periods are not suitable for installations with a life time of 20 years or even longer, many companies simply do not accept amortization periods longer than two or three years.

Another barrier is that the turnkey cost can vary significantly, depending on the conventional process technology, collector type, selected hydraulics or even on the chosen supplier. Instead of a generalized amount for the turnkey costs of solar process heat systems comparable with photovoltaic systems it is only possible to communicate a possible range such as 350 to $900 € / \mathrm{m}^{2}$ with a large variance especially for small systems below $100 \mathrm{~m}^{2}$. This leads to a reduced transparency and hinders economic feasibility assessments of potential customers.

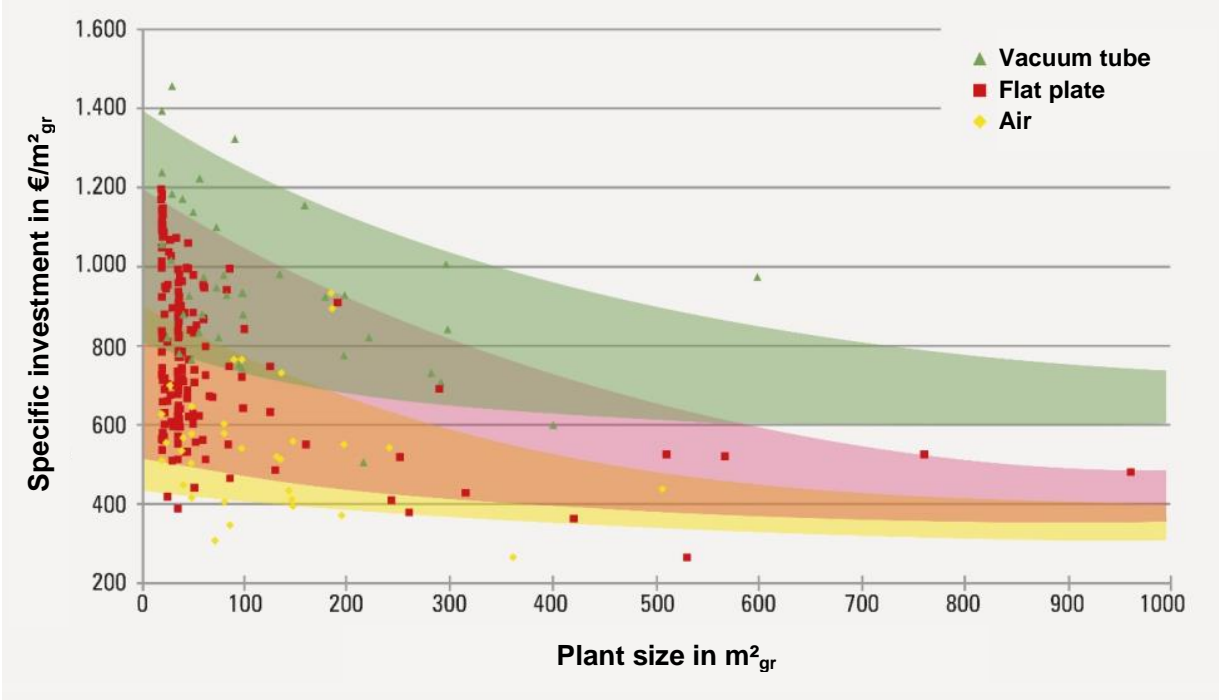

Fig. 3: Specific net investment costs (before funding) of realized solar process heat systems different sizes in Germany using different collector types (www.solar4industry.com)

\section{Relevance of solar process heat outside the traditional industry sector}

Having a look at the different applications, the German solar process heat market shows the importance of other sectors outside Industry such as commerce and services, agriculture, and forestry. About $80 \%$ of the overall collector area is installed within these sectors (Ritter et al., 2017). Compared to Industry, a successful realization within these sectors is fostered by four important facts: 1. Typically, higher energy costs, 2. Less complex company structures and therefore smoother decision routines, 3. Higher payback times are accepted, and 4. Less complex energetic situation by means of number of heat sinks and potential integration points for solar heat.

With respect to the most popular applications, the market analysis showed some dominating fields. About $80 \%$ of the systems realized since August 2012 are producing renewable heat for the rearing of animals (mainly piglets), the cleaning of vehicles, the drying of biomass with a focus on wood chips and hay, and for cleaning processes in industry and commerce. With more than $100 \mathrm{~m}^{2}$ per system, the drying applications with air collectors are in average the largest systems, whereas the average collector field size in the other named application fields are in the range of $50 \mathrm{~m}^{2}$. These low hanging fruits show, that even with the given low fossil energy prices there are some branches where systems can be realized successfully. Some companies are even installing solar process heat systems at each of their facilities step by step. These easy to access applications are the foundation for the solar process heat market in Germany increasing the visibility, helping to decrease costs and therefore are the basis to realize systems in larger industrial applications in the near future. Despite these main applications, there is a large variety like galvanization, brewing processes, gas pressure regulation, paint shops, meat and milk processing, and others like tanning and breeding of insects for biological pest control. 


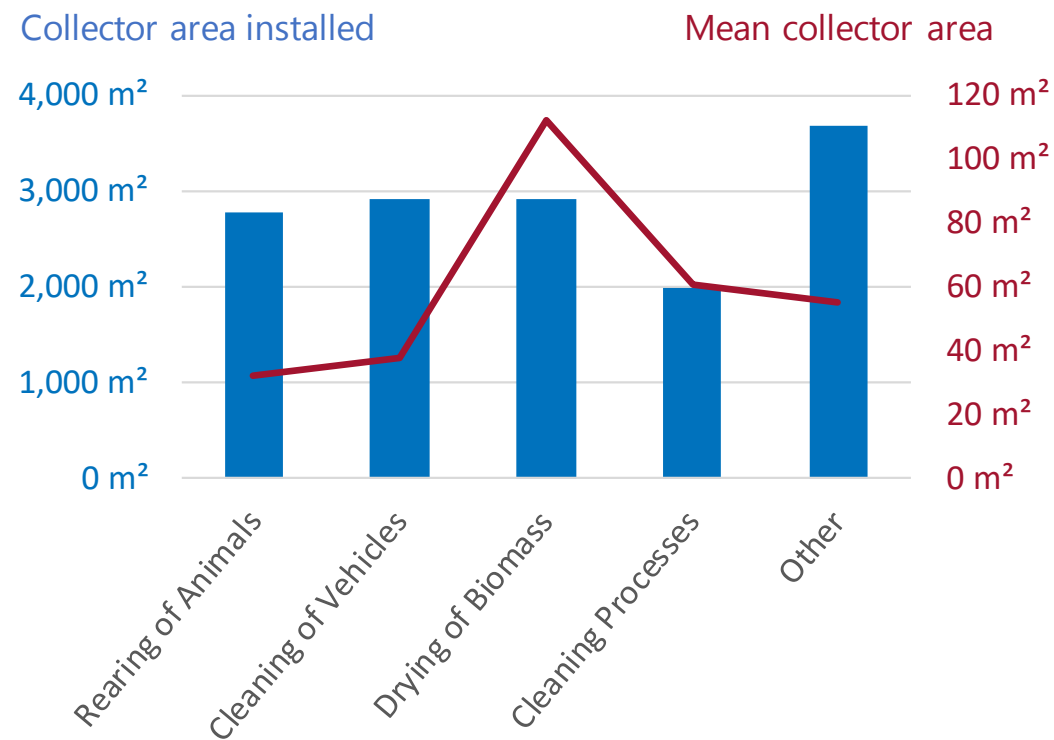

Fig. 4: Installed collector area and average collector field size for the different main applications in Germany

Whereas cleaning and washing processes may differ significantly in terms of temperature level, conventional heating equipment and suitable integration points, the three other dominating applications of solar process heat seem very promising with respect to standardization. So far, there are only a few installations, but the following analysis demonstrates that there still is a huge potential for further installations where standardized system concepts can enhance the market penetration.

In 2017 one fourth of the worldwide pig meat was produced in Europe (USDA, 2017). Within the European Union, Germany and Spain are the biggest producers of pig meat with a share of $24 \%$ and $17 \%$ (Eurostat, 2018). Just the livestock in Germany accounted for 28 Mio. pigs. They were kept in about 23.500 companies and used to produce about 6 Mio. tons of pig meat (Destatis, 2018a). Because more and more companies specialise either on rearing or fattening, the number of rearing companies is assumed to be lower. Furthermore, in addition to the hot water heating of piglet rearing nests, various other heating methods like electric floor heating, electric infrared heating or gas-fired infrared heating are used (Beckert et al., 2012). However, in comparison to the piglet rearing companies that are using solar process heat so far, the total number of companies that are suitable for solar process heat is adequate high to point out the assumed potential for solar process heat in this branch. The same applies to car cleaning and biomass drying systems. The total number of car cleaning companies in Germany accounted for 2.700 companies in 2016 (Destatis, 2018b). In 2014, 0,5 million $\mathrm{m}^{3}$ solid of wood chips were used just in private households in Germany that have to potential to be dried with solar energy (Döring et al., 2016). Of course, not every car cleaning company or technical wood drying system will be suitable for solar process heat supply, but in comparison to the realised systems the potential seems to be more than sufficient.

\section{Analysis of most popular solar process heat applications}

Due to the relevance of the three applications rearing of animals, cleaning of vehicles and drying of biomass in the German solar process heat market, the paper focuses on the development of standardized concepts for these applications, which could further enhance the market uptake. As it has been demonstrated before, the potential for further implementations is significant and should be addressed. Therefore, the different hydraulic concepts and integration points for solar heat are evaluated and transferred into standardized concepts (up to three, based on the specific application - cf. 4.1). In addition, these systems have been analyzed in terms of specific costs, solar yield, specific collector area (with respect to annual heat demand) and specific storage size ${ }^{1}$ (with respect to collector area). In total, planning documents of 174 solar process heat plants were used for the analysis

\footnotetext{
${ }^{1}$ The solar process heat plants for drying biomass predominantly use air collectors. Thus, apart from singular innovative exceptions no storage is installed.
} 


\subsection{Standardized solar process heat concepts}

The detailed analysis of hydraulics and integration concepts showed a wide range of different concepts. The largest variety can be found for systems for the rearing of animals. Here, 12 different concepts could be identified. The application of cleaning vehicles still shows eight. Only the drying of biomass shows two different concepts in practise. Nevertheless, all concepts show a lot of similarities and only differ in detail. Within this paper, two or three standard concepts have been derived for each application combining the advantages of the different analysed concepts.

\section{Rearing of animals}

Farm animals need constant temperatures to reach a satisfying growth. Therefore, so-called "nests" are typically kept at temperature around $30{ }^{\circ} \mathrm{C}$ by floor heating systems. Similar to domestic applications, supply temperatures of $60{ }^{\circ} \mathrm{C}$ are used for this application. In order to avoid too high flow temperatures and a low return temperature, the return flow is fed partially into the flow as shown in Fig. 5. The solar heat is fed into buffer storage. The return of the heating circuit feeds into the bottom of the storage. The storage is heated by the collector field via an external heat exchanger whereby the height of the feed-in is controlled by a three-way valve. Thereby, the solar heat can be integrated at middle height (preheating) or in the top area (set temperature). As auxiliary heater the conventional boiler saves the set temperatures in the upper area of the storage.

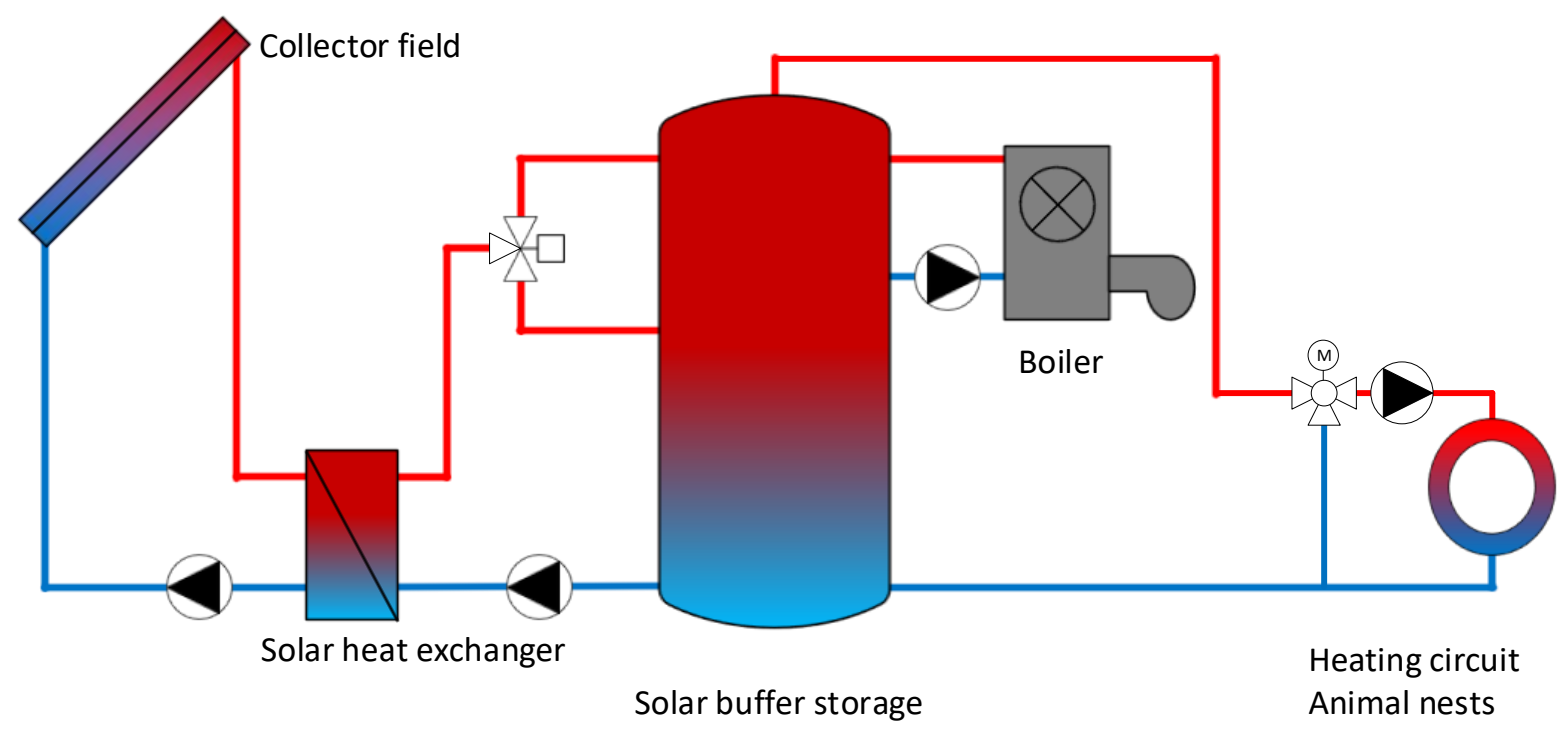

Fig. 5: Standardized solar concept for animal rearing stations with the heating circuit as heat sink

Very often, not only space heating for the animal nests but also hot water for food preparation or cleaning processes is needed. Therefore, a second integration concept is needed (Fig. 6). The hot water generation should be arranged in parallel to the heating circuit. The hot water is heated by a fresh water station which must be sized with respect to peak loads during cleaning. This concept has the advantage that all heat sinks can be provided with solar heat. Still, the set temperature for the upper area of the storage must be chosen with respect to the hot water temperature. Furthermore, it its important to have a good control of the system in a way that low return temperatures in the bottom part of the storage can be reached. That is also why the return flows are fed separately into the storage. The return of the fresh water station can reach lower temperatures than the return of the floor heating system. Latter is plugged above the storage connection of the return of the fresh water station. 


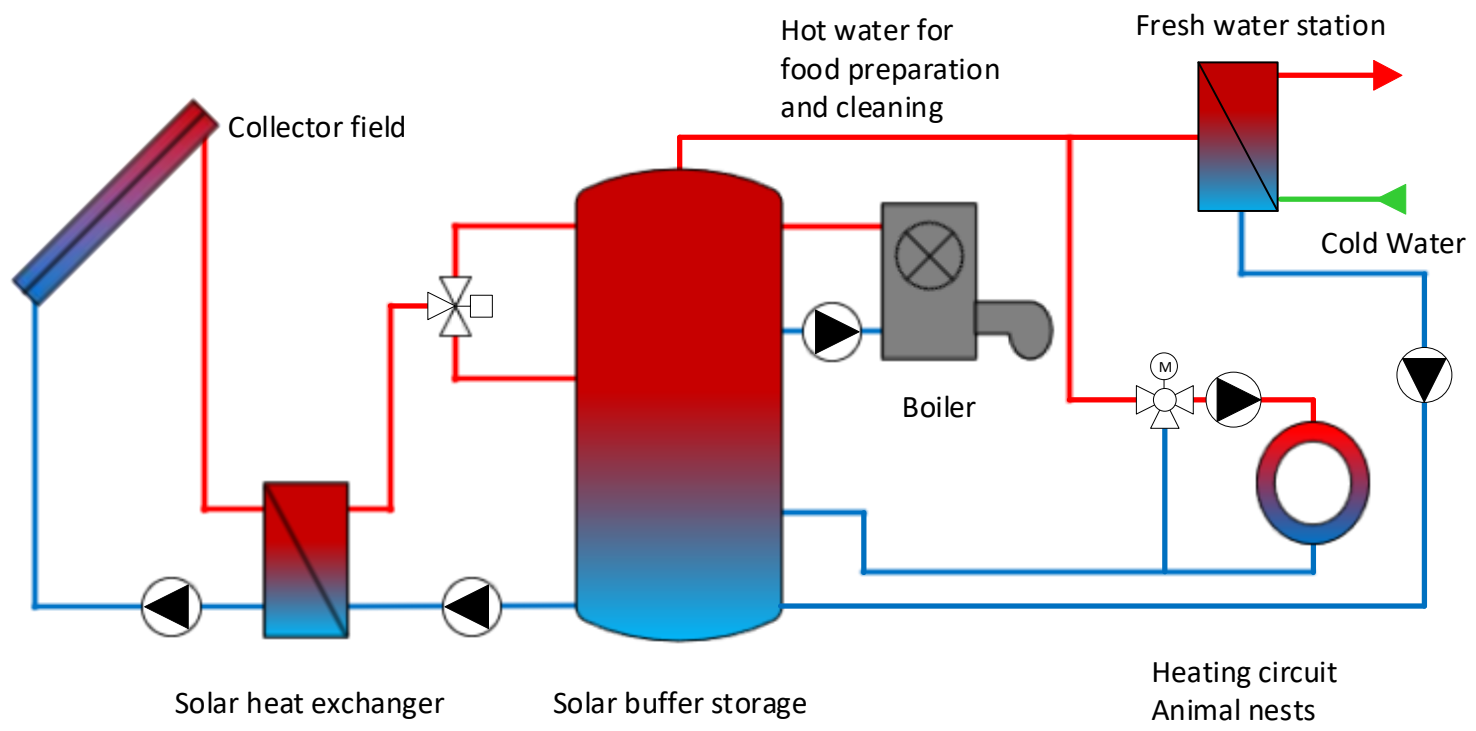

Fig. 6: Standardized solar concept for animal rearing stations with heating circuit and hot water generation as heat sinks

\section{Cleaning of vehicles}

The cleaning of vehicles consumes a lot of hot water and can be generally divided into self-service washing stations and car-wash plants, with the latter typically using cold water for cleaning. To reach a good cleaning result the hot water can be heated up to $60^{\circ} \mathrm{C}$ (typically $50{ }^{\circ} \mathrm{C}$ ), based on the way of cleaning and amount of cleaning agents. Besides the hot water generation for self-service washing stations, the washing area has to be kept free of ice in in winter time, which is another potential heat sink for a solar process heat plant. Therefore, floor heating systems below the cleaning areas are installed. In those cases, heating circuit and hot water preparation are connected in parallel (Fig. 7). The flow temperatures of the floor heating systems can be set very low because only icing should be prevented. Consequently, very low return temperatures are reached. So, it is suitable to mix it with the return of the fresh water station providing the hot water for cleaning and to refeed the mixed flow into the bottom area of the storage. This is the only difference to concept 2 for animal rearing stations where the return flows are kept separately. This concept is mainly used if the heat supply is going to be redesigned or if a car cleaning station is going to be built newly by itself.

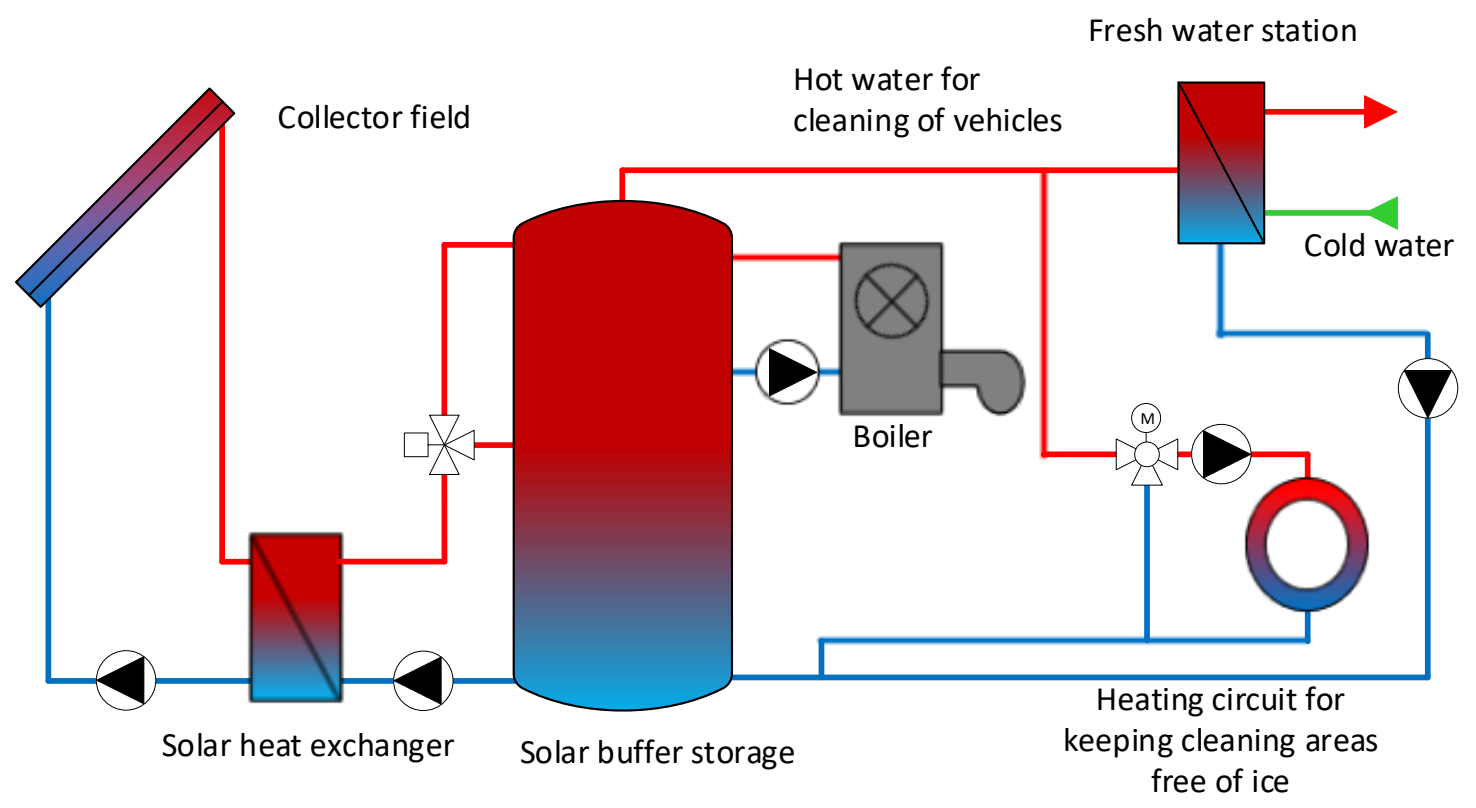

Fig. 7: Standardized solar concept for the cleaning of vehicles with one storage (new building) 
If the solar heating plant is going to be integrated in the existing heat supply, another concept should be preferred which is presented in Fig. 8. The conventional system has a hot water storage to cover the typical peak loads. The heating circuit is connected to the bottom of the storage using low temperatures. The storage is heated by a fossil burner via an external heat exchanger. The hot water for cleaning is taken directly from the top of the storage. The solar thermal system is installed in serial as a preheating system. The auxiliary heating storage is fed by preheated water which is taken from the solar hot water storage. This differs to all other concepts presented where the solar storage always acts as a buffer storage. Hence, this system concept has the disadvantage that the solar heating plant can only provide heat to the overall system if there is a hot water demand. In case of no hot water is desired but the floor heating system is working, the bottom area of the auxiliary storage has to be reheated by the fossil boiler. Due to the fact that the heat demand for hot water generation is dominating and the floor heating system is only active if the cleaning places are opened this seems to be feasible.

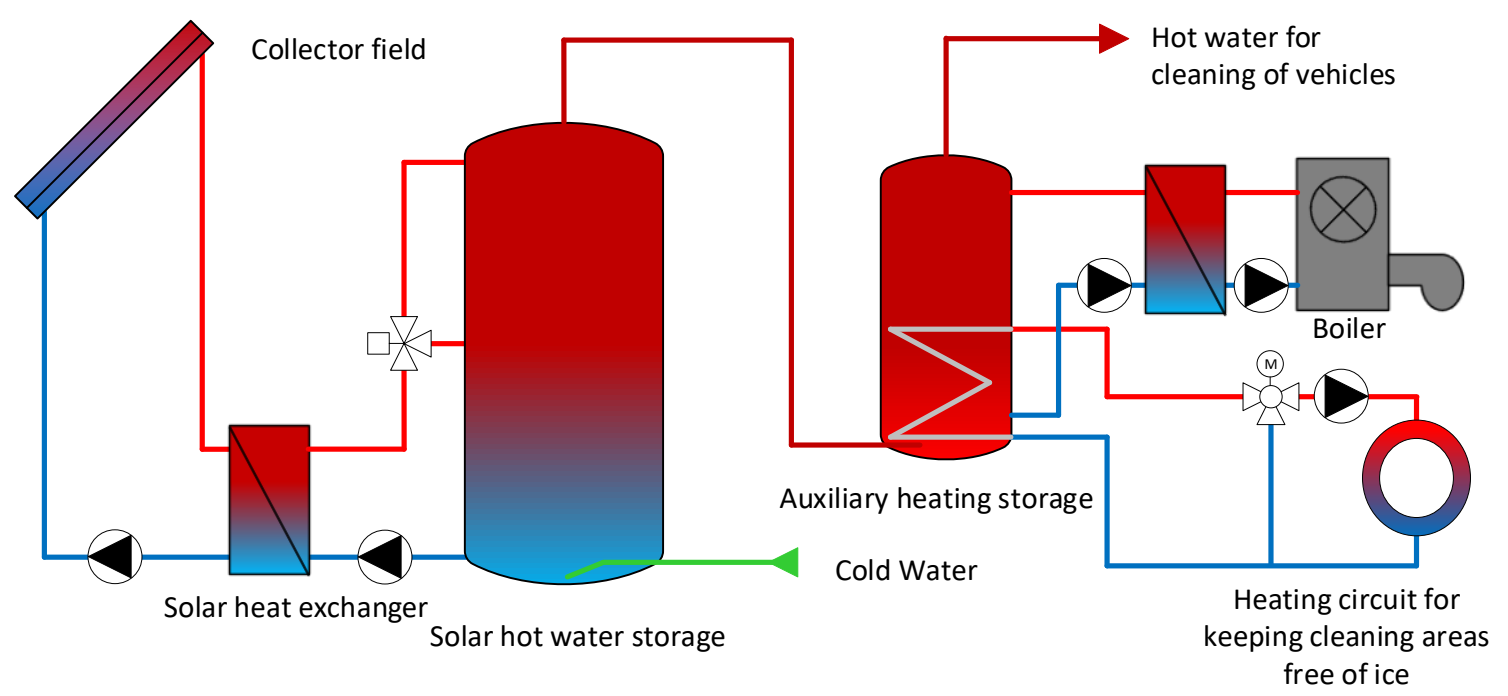

Fig. 8: Standardized solar concept for the cleaning of vehicles with one storage (old building)

\section{Drying of biomass}

Drying of agricultural products to increase or guarantee quality or for preservation reasons is an important market for solar process heat. Due to fact that air is the dominating process medium, solar air collectors play a major role for this application. Air collector fields are easier in terms of integration and control. In general, the air collectors preheat ambient air while the conventional system ensures the set temperature. Often, there is even no need for a conventional system because of the congruence of heat demand and solar radiation. Then, the products are only dried if there is sufficient solar radiation. Fig. 9 shows a typical solar drying system. Ambient air is sucked through the collector field by a ventilation system and thereby heated up. Since the collector output temperature cannot be controlled exactly the heat air can be mixed with ambient air by a mixing valve and the air temperature reduced by this means. How much additional ambient air is sucked in to reduce the drying temperature is controlled by the second fan just before entering the drying area. The drying products are placed on a grate which can be inclined in some cases. The hot air is blown in from the bottom and pushed through the raised biomass material (e.g. wood chips). In general, not heat recovery system is installed because the exhaust air is very humid and relatively cool. 


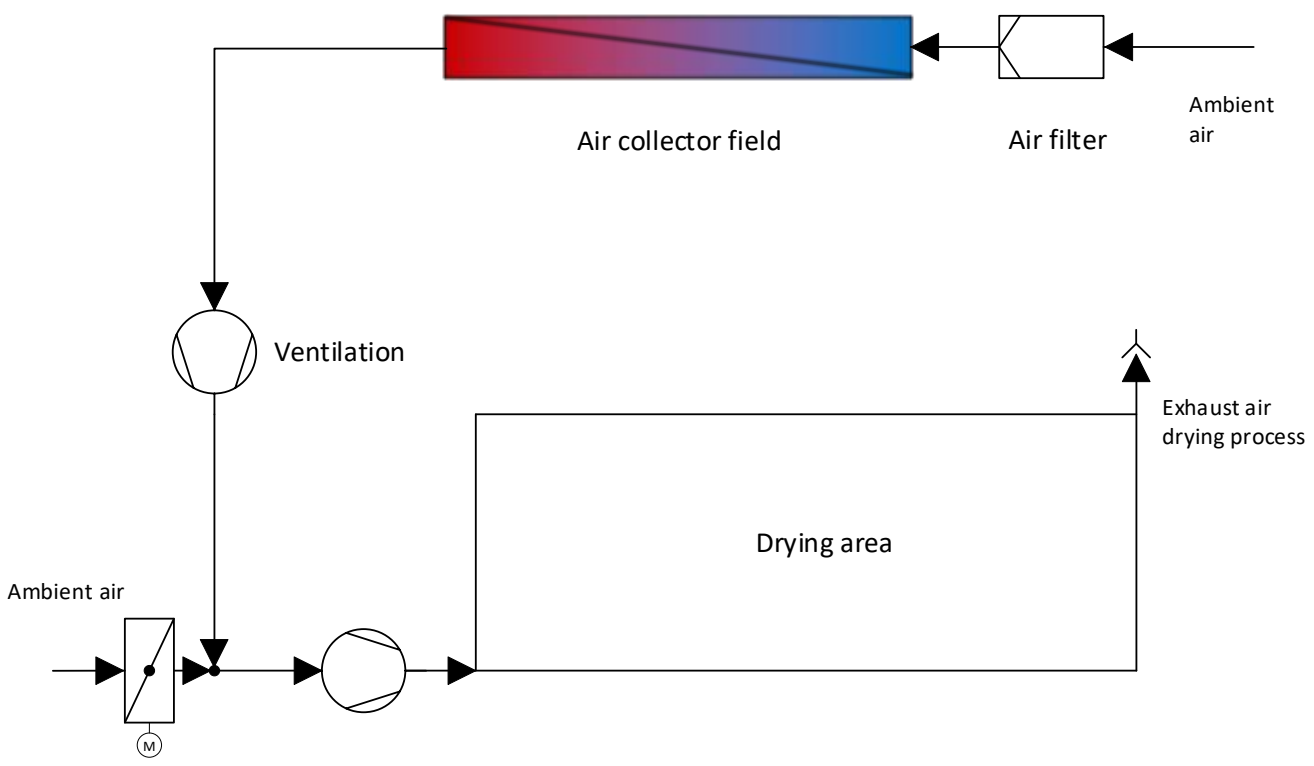

Mixing flap ambient air

Fig. 9: Standardized concept for drying of bulk materials in (inclined) grates

In many cases, different products have to be dried with different maximum temperatures that can be accepted due to product protection. Fig. 10 demonstrates this concept for two different set temperatures. The output air stream of the collector field is cooled down by ambient air with a first mixing flap (upper left) to the set temperature which is needed in the drying containers (e.g. for wood chips). A share of the mixed stream is sucked by a second fan which is feeding the drying area (centre of Fig. 10). A second mixing flap before the fan enables to further reduce the air temperature for this drying area (e.g.in case of hay drying). Throttle flaps control the input flow of heated air into the different containers.

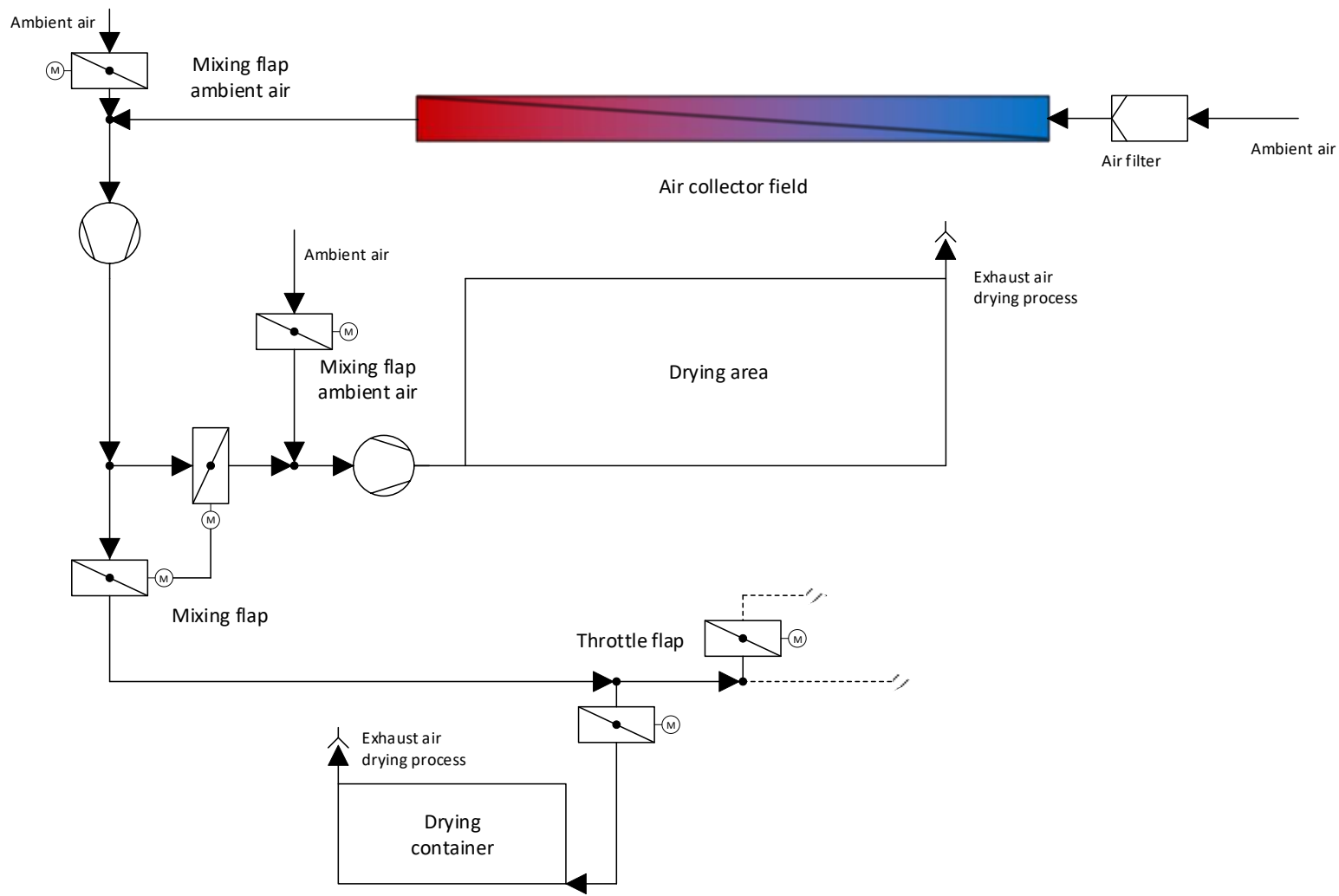

Fig. 10: Standardized concept for drying of biomass for several products with different maximum temperatures 


\subsection{Dimensioning, solar yield and system costs}

Fig. 11 shows the results of the analysis of the dimensioning strategies for the three applications. Looking at the average collector area for "rearing of animals" shows that the specific collector area in relation to the annual heat demand is smaller compared to the other applications. As shown above, the rearing of animals predominantly needs heat for space heating. In consequence, the load profile shows a strong decrease of heat demand in summer which leads to smaller collector areas. In contrast, the heat demand for cleaning of vehicles is more constant over the year and in most cases correlated to the solar irradiation. Thus, larger collector areas in relation to the annual heat demand are possible, leading to higher solar fractions. With $601 / \mathrm{m}^{2}$ the storage size for this application is lower than for rearing of animals, which is also based on the fact that heat demand and solar irradiation is correlating. The range of storage sizes in animal rearing stations is clearly higher which traces back on the different concepts for the use of solar heat. If heat is provided only for space heating but not for cleaning water the storage can be sized much smaller.

The application of biomass drying shows significant higher specific collector area. Similar to car washing, this application benefits from the simultaneity of heat demand (e.g. for hay drying) and solar radiation which enables larger collector areas. Additionally, these kinds of solar heating plants can be operated already with a few Kelvins of temperature difference, which increases the effect. Even so, the standard deviation is in the same range as in the other two applications the systems can be designed very differently.

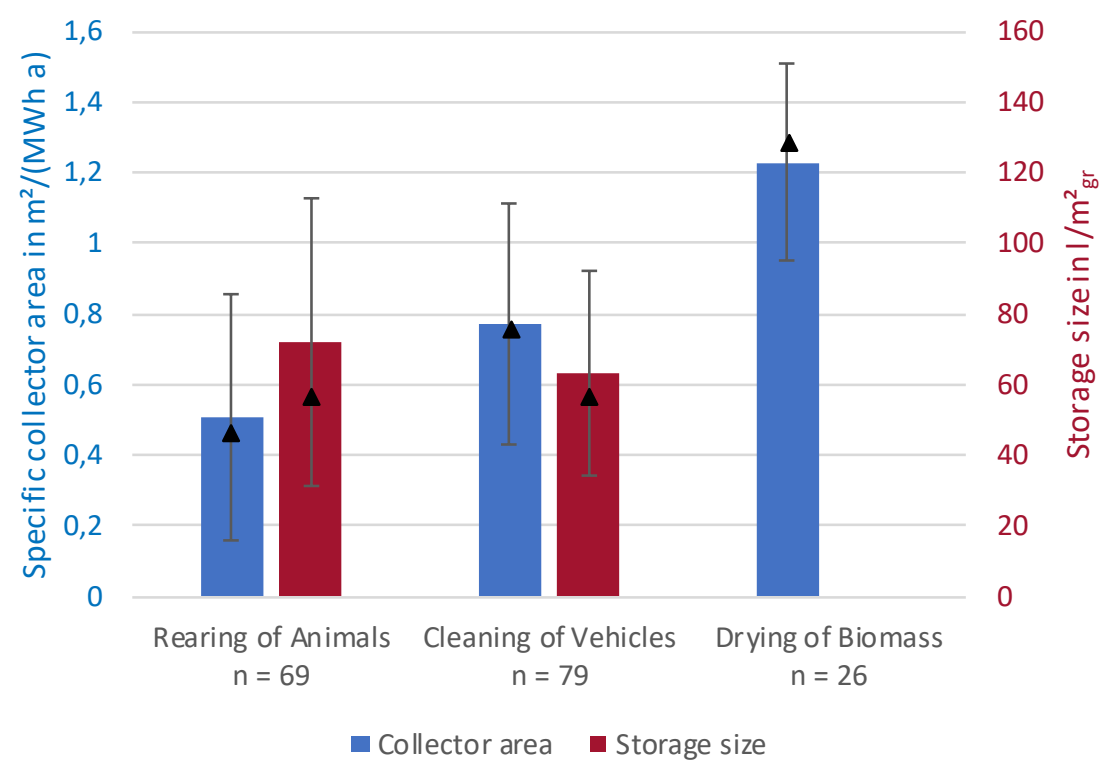

Fig. 11: Mean specific collector area and storage size for the installed systems within the three applications, error bars represent standard deviation, drying systems using air collectors without storage

As it can be seen in Fig. 12 the specific costs do not only vary between the applications but also between the installations within the same application. This leads back to differences in the conventional heating equipment and the consequent different efforts needed for the integration of solar heat. Additionally, there can be differences by the used collector technology or also by the commissioned company. Air collector systems prove to be most cost effective. These systems are less complex and easy to install by the use of air as heat medium. The systems do not need any stagnation protection or heat exchanger because air is the heat carrier and process medium rolled into one. The cheapest system reached costs below $400 € / \mathrm{m}^{2}$. In addition, the air collector systems generate high solar yields because generally all the produced heat can be used (heat demand is available every day) and the temperature level of the heat demand is very low with max. $60^{\circ} \mathrm{C}$. Due to the lack of any heat exchangers, the solar collectors do not need to work above process temperature. Depending on the material to be dried and the actual humidity even lower temperature than $60{ }^{\circ} \mathrm{C}$ are sufficient. Taking the funding into account, levelized costs of heat in the order of $10 € / \mathrm{MWh}_{\text {th }}$ or even below can be reached. 
The cleaning of vehicles shows higher specific costs with approximately $1,000 € / \mathrm{m}^{2}$ on average. As shown before, two heat sinks, hot water for cleaning and floor heating to keep the cleaning area free of ice, typically have to be provided with heat. The demand of hot water is not continuous showing high peaks in the demand. This affects the design of the whole system. All components have to be sized in order to be able to cover peak loads which results in higher costs. The costs for a solar process heat installation for animal rearing is in the range of $730 € / \mathrm{m}^{2}$ on average. With more than $400 \mathrm{kWh} / \mathrm{m}^{2} \mathrm{a}$, the specific solar yield is in a suitable range with respect to the temperature level that has to be provided. Systems for the cleaning of vehicles reach even higher yields $\left(450 \mathrm{kWh} / \mathrm{m}^{2} \mathrm{a}\right)$ because the preheating of water on a low temperature level and the simultaneity of heat demand and solar irradiation results in a more efficient operation of the solar process heat installation.

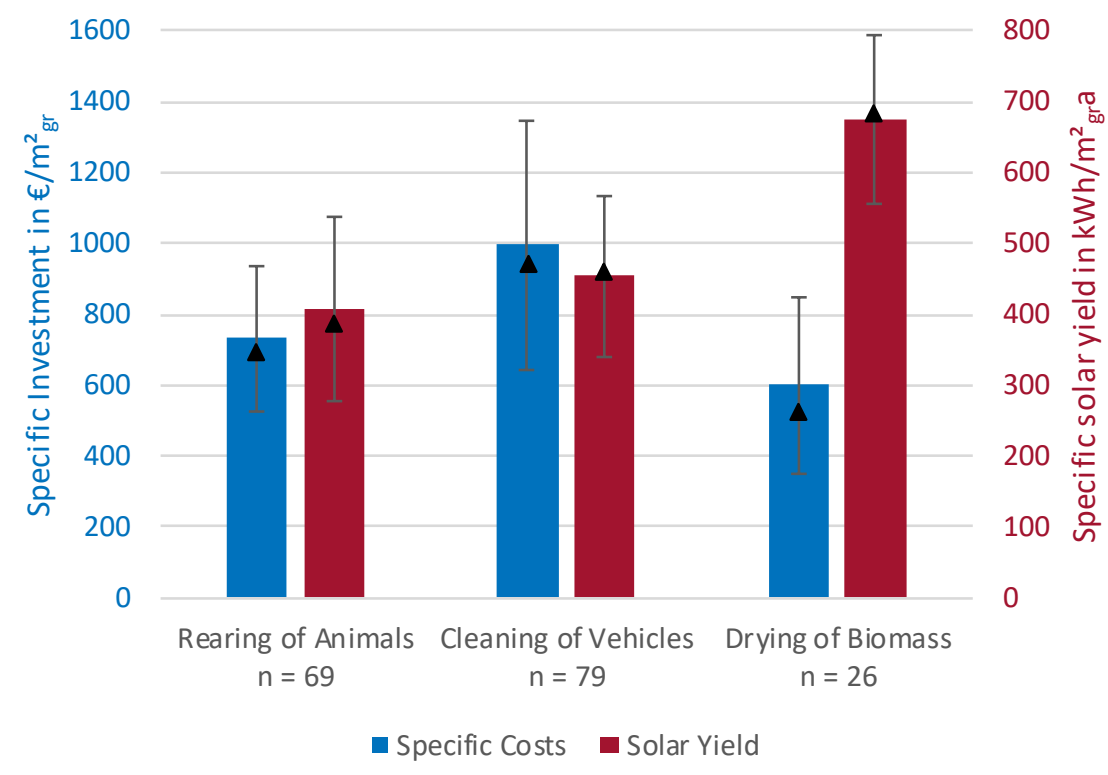

Fig. 12: Mean specific costs and solar yield for the installed systems within the three sectors, error bars represent standard deviation

\section{Summary and Outlook}

The solar process heat market in Germany shows a promising development after critical years in 2014 and 2015. Based on the strong funding within the Market Incentive Program, solar process heat systems can be competitive to heat generated by fossil fuels. So far, there are a few applications (Rearing of animals, cleaning of vehicles and drying of biomass) that dominate the market so far. Within this paper, standardized concepts for the use of solar heating plants for these applications have been derived by a detailed analysis of implemented systems. These standardized concepts are transferred into fact sheet that are used to facilitate the market entry of new stakeholders by providing all relevant information such as dimensioning, energetic key facts and economics. Those concepts will be available free of charge at www.solar.4industry.com and will help to tap the potential of low hanging fruits in the field of solar process heat. In future, the market is going to be monitored continuously to derive further standardized concepts for other applications e.g. for heated baths or handling units. Next to these standardized systems concepts and general information that are provided by the website, the new VDI standard 3988 "Solar thermal process heat" is a very important step to support the market by standardizing the planning and installation of solar process heat systems. Currently this standard is available in green print, the final version is expected to be published early 2019 . 


\section{References}

BMWi, 2018: Energy data - complete edition. Federal Ministry for Economic Affairs and Energy, Berlin, Germany. https://www.bmwi.de/Redaktion/DE/Binaer/Energiedaten/energiedaten-gesamtxls.xlsx?_blob=publicationFile\&v=85

Destatis, 2018 a: Fachserie 3 Reihe 4.1 -Agriculture and forestry, fisheries - livestock (in German language). Federal Office of Statistics, Wiesbaden, Germany.

https://www.destatis.de/DE/Publikationen/Thematisch/LandForstwirtschaft/ViehbestandTierischeErzeugung/Vi ehbestand2030410175324.pdf?_blob=publicationFile

Destatis, 2018 b: Fachserie 14 Reihe 8.1 - Finance and taxes -VAT statistics (in German language). Federal Office of Statistics, Wiesbaden, Germany.

https://www.destatis.de/DE/Publikationen/Thematisch/FinanzenSteuern/Steuern/Umsatzsteuer/Umsatzsteuer214 0810167004.pdf?__blob=publicationFile

Beckert, I. et al., 2012: DLG leaflet 378 - piglet rearing nests - design and heating options (in German Language). DLG e.V., 1st edition. https://www.dlg.org/fileadmin/downloads/merkblaetter/dlgmerkblatt_378.pdf

Döring, P. et al., 2016: Raw material monitoring wood - Fuel wood use in private households 2014 - Market volume and used wood assortments (in German Language). Final report, Ident. No. 22021614. Department of economics of wood and forestry, University of Hamburg, Hamburg, Germany. http://www.seemla.eu/wpcontent/uploads/2016/03/Energieholzverw_Privathaushalte_2014_Mantau_Feb2016-1.pdf

Ritter et al., 2017: Analysis and development of the market for solar process heat in Germany (in German Language). Final Report, Ident. No. 03MAP286. Institute of Thermal Engineering, University of Kassel, Kassel, Germany. http://solar-publikationen.umwelt-unikassel.de/uploads/1521186181_170630_Abschlussbericht_03MAP286.pdf

USDA, 2017: Livestock and Poultry: World Markets and Trade, United States Department of Agriculture Foreign Agricultural Service, Washington, USA. http://usda.mannlib.cornell.edu/usda/fas/livestock-poultry$\mathrm{ma} / / 2010 \mathrm{~s} / 2017 /$ livestock-poultry-ma-10-12-2017.pdf

VDI 3988, 2018: Solar thermal process heat (in German language). Beuth Verlag GmbH, Berlin. www.solar4industry.com 


\title{
Thermal analysis and validation of a geodesic dome dryer for Capsicum baccatum
}

\author{
Sandra Vergara ${ }^{1}$, Miguel Hadzich ${ }^{1}$, Ronald Tipula ${ }^{1}$, Juan Pablo Perez ${ }^{1}$, Evelyn Lopez ${ }^{2}$, Esteban \\ Herrera $^{3}$ \\ ${ }^{1}$ Grupo de Apoyo al Sector Rural, Pontificia Universidad Católica Del Perú, Lima (Peru) \\ 2 Instituto Tecnológico y de Estudios Superiores de Monterrey, Estado de México (Mexico) \\ ${ }^{3}$ Centro de Innovación Tecnológica de Industrias Alimentarias, Lima (Peru)
}

\begin{abstract}
Today, Peru is among the first countries with the largest non-conventional agroexports worldwide. One of the most representative products is the Capsicum baccatum, which is mostly exported as frozen, pasta and sauces because the traditional process used for drying is not optimal. Given this, a geodesic dome type dehydrator, that uses solar thermal energy, was developed to contribute to the process of drying a variety of Capsicum baccatum. This research has been developed in the project "Design and development of a portable dehydrator for the transformation and conservation of pickled chili in Mórrope Lambayeque using renewable energies", which has the sponsorship of the National Program of Agricultural Innovation (PNIA) of the Ministry of Agriculture of Peru, the World Bank and the Inter-American Development Bank. The results using the dome dryer are a temperature of around $43^{\circ} \mathrm{C}$ has been obtained for a day with global irradiance at midday of $780 \mathrm{~W} \mathrm{~m}^{-2}$ and an air flow velocity of $1.1 \mathrm{~m} \mathrm{~s}^{-1}$; in addition, for a load of $50 \mathrm{~kg}$ of chili the dome is able to reduce its moisture content from $89.5 \%$ to $15 \%$ in 20 days
\end{abstract}

Keywords: geodesic dome, Capsicum baccatum, solar thermal energy, drying, dehydration, aji escabeche, productive uses

\section{Introduction}

Peru is the fourth exporter of chili (genus Capsicum) in the world, among them, the aji escabeche or Capsicum baccatum is being increasingly valued especially due to the gastronomic boom nationally and internationally. The product that is exported dehydrated presents limitations due to a rudimentary drying process used. After harvest, the product is spread on the ground to be dehydrated by the sun. As a result, the product ends up contaminated, rotten or with other problems, reaching losses of up to $50 \%$ of the initial production. It should be noted that the project also seeks to maintain the carotenoids, organic pigments, which give the characteristic color to the chilies. The general consensus is that there is sufficient evidence to support increased consumption of carotenoid-rich food (Rodriguez-Amaya, 2018) since many health benefits has been attributed to carotenoids: eye health, brain-cognitive function, heart health, cancer prevention, skin-UV protection, fertility, immune modulation (Eggersdorfer and Wyss, 2018). Therefore it is important to optimize heating treatments to minimize carotenoids loss. Saini et al. (2014), assessed different types of drying processes for M.oleifera fresh leaves, finding that drying at $50^{\circ} \mathrm{C}$ in cabinet trays had the best performance preserving carotenoids and Direct solar drying (exposed to the sun) was the worst. Fratianni et al. (2018), evaluated 3 different temperatures for drying goji berries $\left(50,60,70^{\circ} \mathrm{C}\right)$ finding no significant difference in carotenoids loss. Multari et al. (2018), found that $60^{\circ} \mathrm{C}$ was the best drying temperature for carotenoids contents in quinoa seeds. Considering this problem and that the level of global irradiance in Lambayeque is around $5 \mathrm{~kW} \mathrm{~h} \mathrm{~m}^{-2}$, according to the Solar Atlas of Peru, it was proposed to optimize the drying process based on solar thermal energy in order to be used for the product transformation. The research has been developed in the project "Design and development of a portable dehydrator for the transformation and conservation of chili in Mórrope Lambayeque using renewable energies" for which it was considered to develop a geodesic dome dryer coupled to a thermal storage system that allow to standardize the parameters for optimal drying. The geodesic dome has been built and installed for tests in Cieneguilla, Lima, Peru with coordinates $12^{\circ} 04^{\prime} 10.0^{\prime \prime} \mathrm{S} 76^{\circ} 45^{\prime} 15.5^{\prime \prime} \mathrm{W}$. 
The following images, in figure 1, show the transition in the appearance of chilies through the drying process.
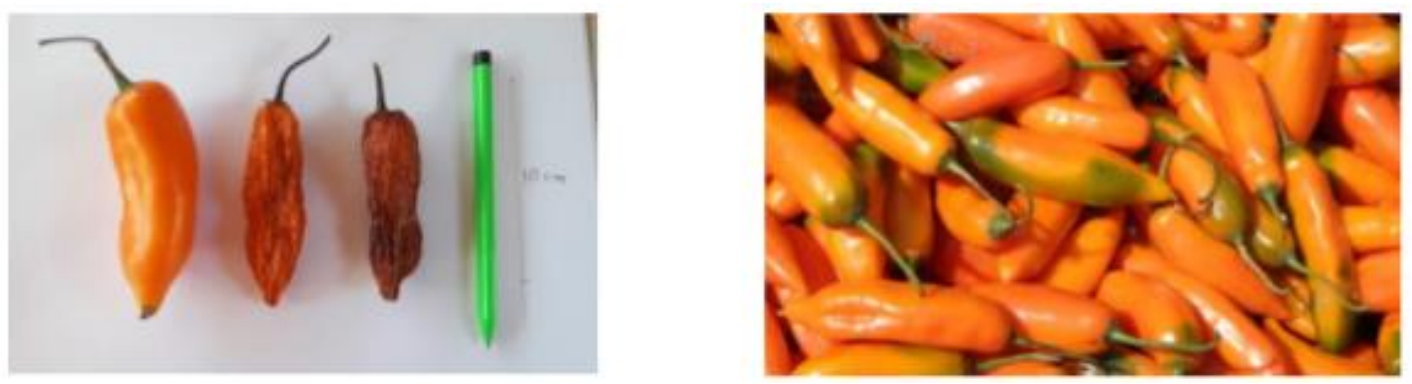

Fig. 1:. Left: Photograph of Capsicum Baccatum. Fresh, dried into the dome and dried outdoors. Right: Fresh chili pepper.

\section{Methodology}

Based on the research of "Analysis of a geodesic dome solar fruit dryer" (Goswami, 2007) and considering the structural and homogeneity of temperatures advantages, a geodesic dome type dryer was developed consisting of a single dome and wind extractor. The dryer was designed to extract the moisture content from $90 \%$ to around $15 \%$ of chili. For this, a geodesic dome type dryer of 5 meters in diameter and 3 meters high was developed to obtain a homogeneous drying of the product. The dome was built with accessible materials in areas of agricultural activities. Polyvinyl chloride (PVC) tubes were used for the structure, a layer of Linear lowdensity polyethylene (LLDPE) was made using the heat-sealing process and a common plastic was placed on the floor.

It was used a datalogger specially designed to measure temperature and relative humidity in 11 different points distributed inside the dome. According to the figures 2 and 3, the elements with a DHT\# nomenclature were the sensors that measured temperature and relative humidity and were located on the floor, on the top and on the sides inside the dome; whereas those with a $B \#$ nomenclature only measured the temperature which were on the trays. These measurements were taken every minute.

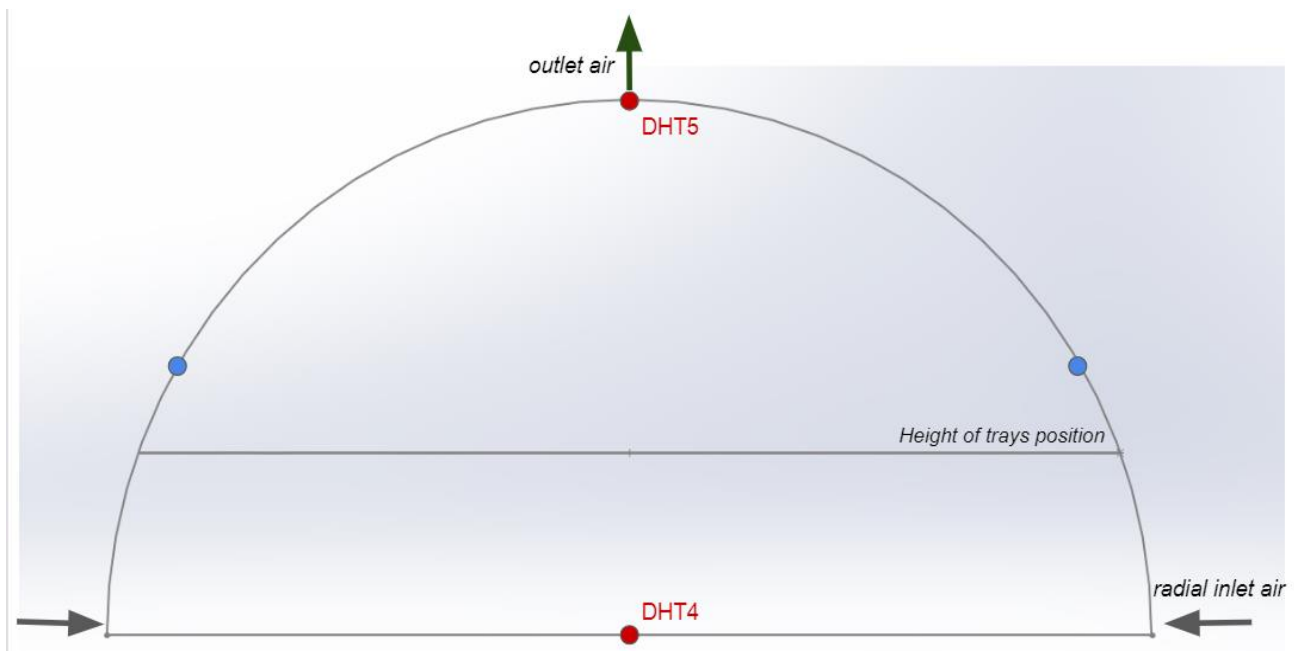

Fig. 2: Side view of a schematic diagram of a geodesic dome solar dryer. Distribution of the sensors which measures temperature and humidity. 


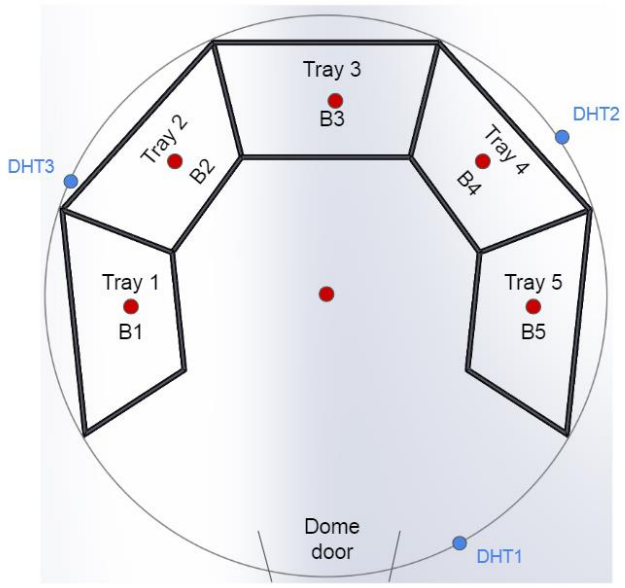

Fig. 3: Top view of a schematic diagram of a geodesic dome solar dryer. Distribution of the sensors that measures temperature and humidity.

Outside, weather conditions were measured with a Davis Portable Weather Station (figure 4) in which temperature, relative humidity, radiation and precipitation measurements were taken every 10 minutes to transmit them to a remote console.
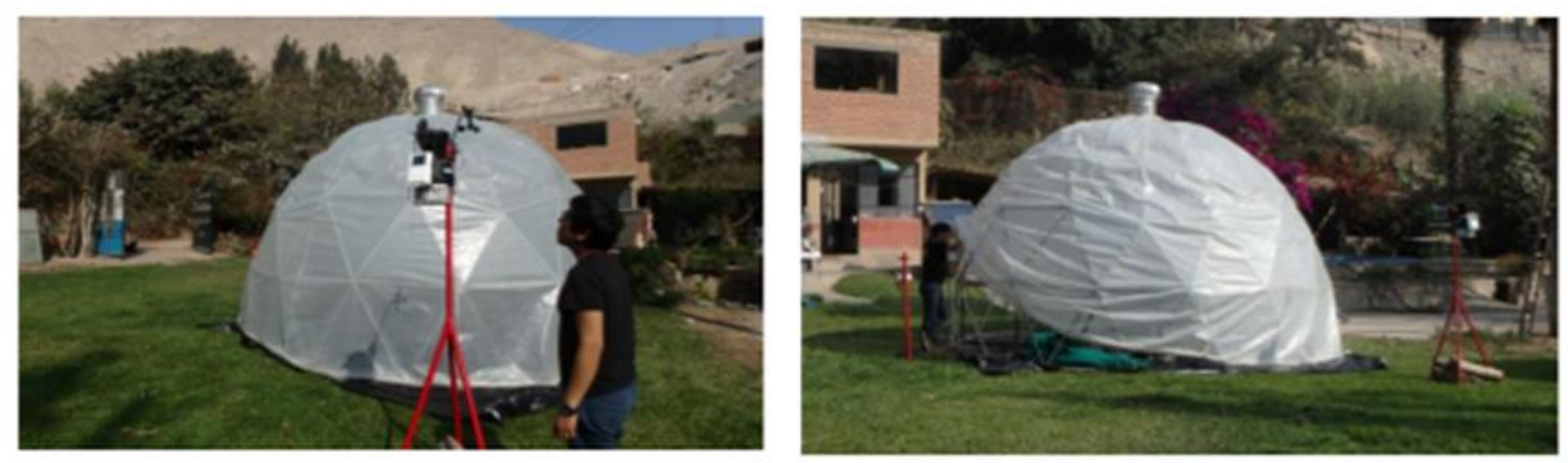

Fig. 4: Left: Photographs of weather station DAVIS. Right: Panoramic view of the dome.

\section{Results and discussion}

Then, the graphs of the behavior of the dome's temperature and humidity during the month of August are presented for a solar energy average of $4.3 \mathrm{~kW}$ h per day. In the first graph you can see the cover's average temperature calculated with the average of DHT1, DHT2, DHT3, the floor center's temperature measuring in the point DHT4, the outlet temperature measuring in the point DHT5 and the inlet temperature using the ambient temperature of the Weather Station. 


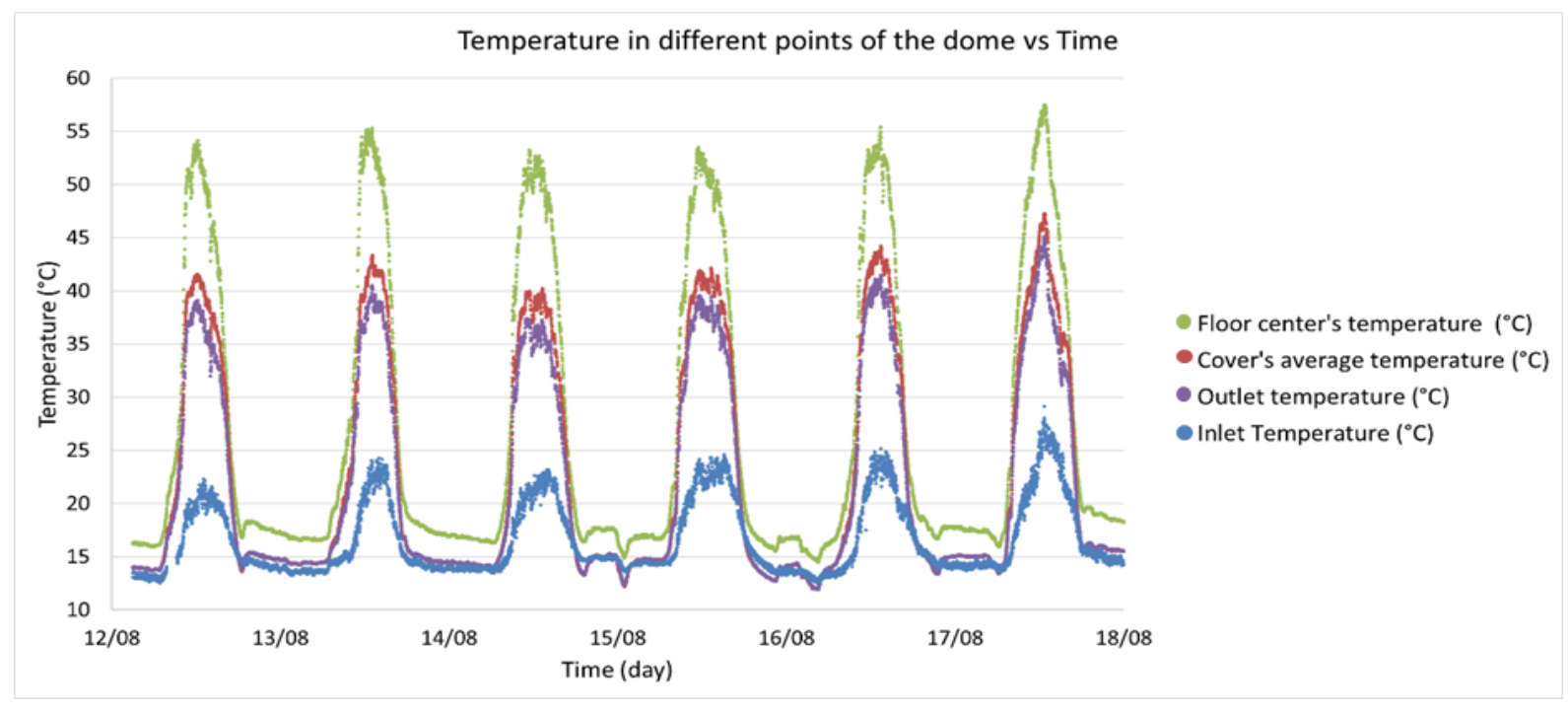

Fig. 5: Temperature in different points of the dome vs. Time.

It can be seen in the graph (figure 5), that the maximum difference temperature between floor and inlet temperature is around $31^{\circ} \mathrm{C}$ during the day and $2.8{ }^{\circ} \mathrm{C}$ in the night . The floor of the dome has been covered with a thick black plastic.

Floor temperature rises very quickly up to a maximum of $55^{\circ} \mathrm{C}$ in the mornings and decreases up to a minimum of $16.5^{\circ} \mathrm{C}$ even with an ambient temperature of $13^{\circ} \mathrm{C}$.

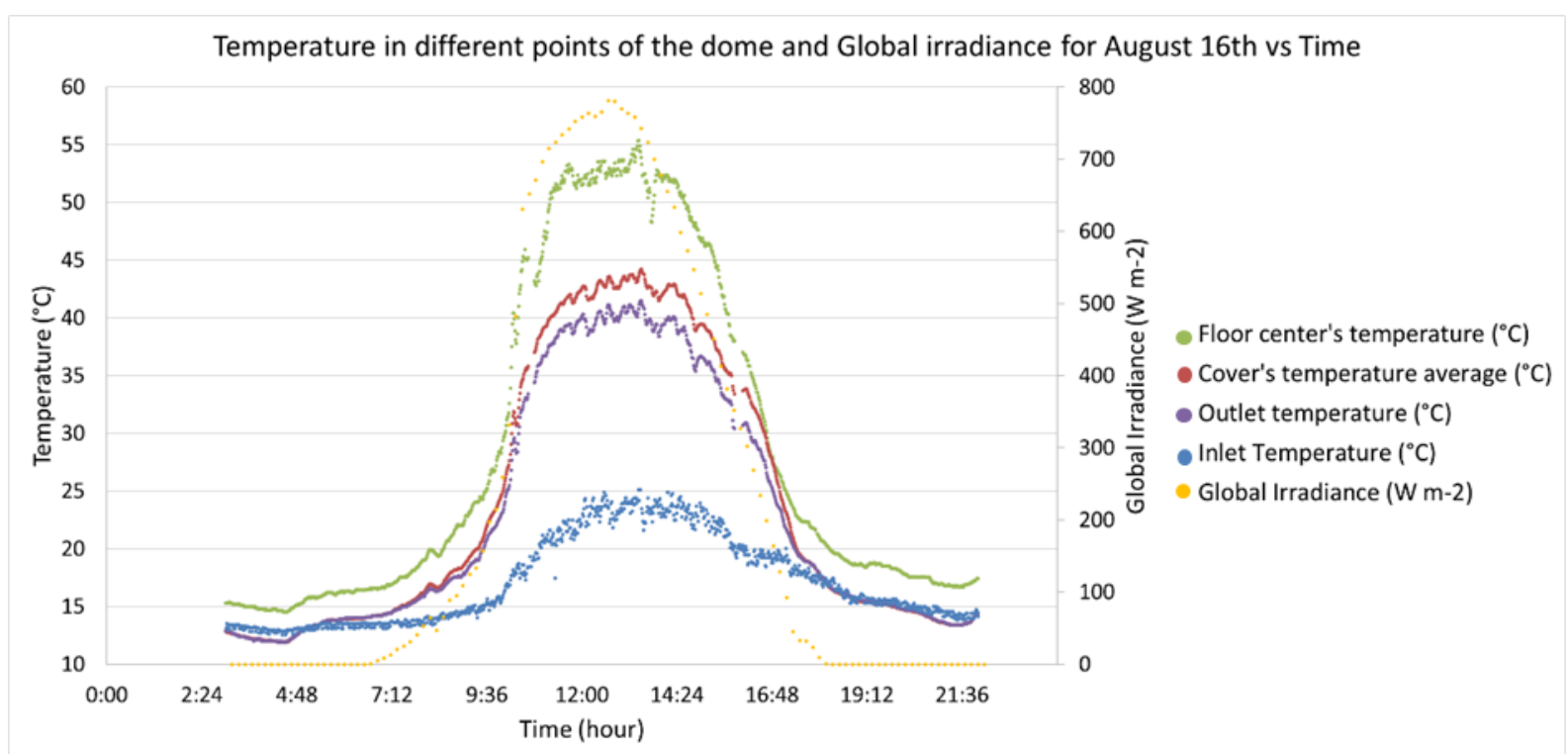

Fig. 6: Graphing of temperatures in different points of the dome on an average day of August 2018.

As is to be expected, it can be seen in the figure 6 that the increase of temperature in all the points is proportional to the irradiation during the day. Outlet air temperature of the dome is almost the same than in the dome cover, with a slight difference of $3^{\circ} \mathrm{C}$ in the peak hour at 1:00 pm.

It is worth mentioning that the temperature at dome exit $\left(35^{\circ} \mathrm{C}\right.$ to $40^{\circ} \mathrm{C}$ in four hours of sun) does not affect the properties of the chili owing to the maximum temperature allowed to a good drying, that is $60^{\circ} \mathrm{C}$. Despite the above, the exit temperature can be modified by 3 ways:

- Increasing the input area of the air. 
- Increasing the airflow of the extractor.

- Increasing the amount of product.

All these variables are currently being worked and can be grounds for future documents.

For the following graphs (figures 7 and 8), it was measured the average temperature using DHT 1 to DHT 5 and B1 to B2, the average of relative humidity (\%) using DHT 1 to DHT 5, and the Inlet temperature using the ambient temperature of the Weather Station.

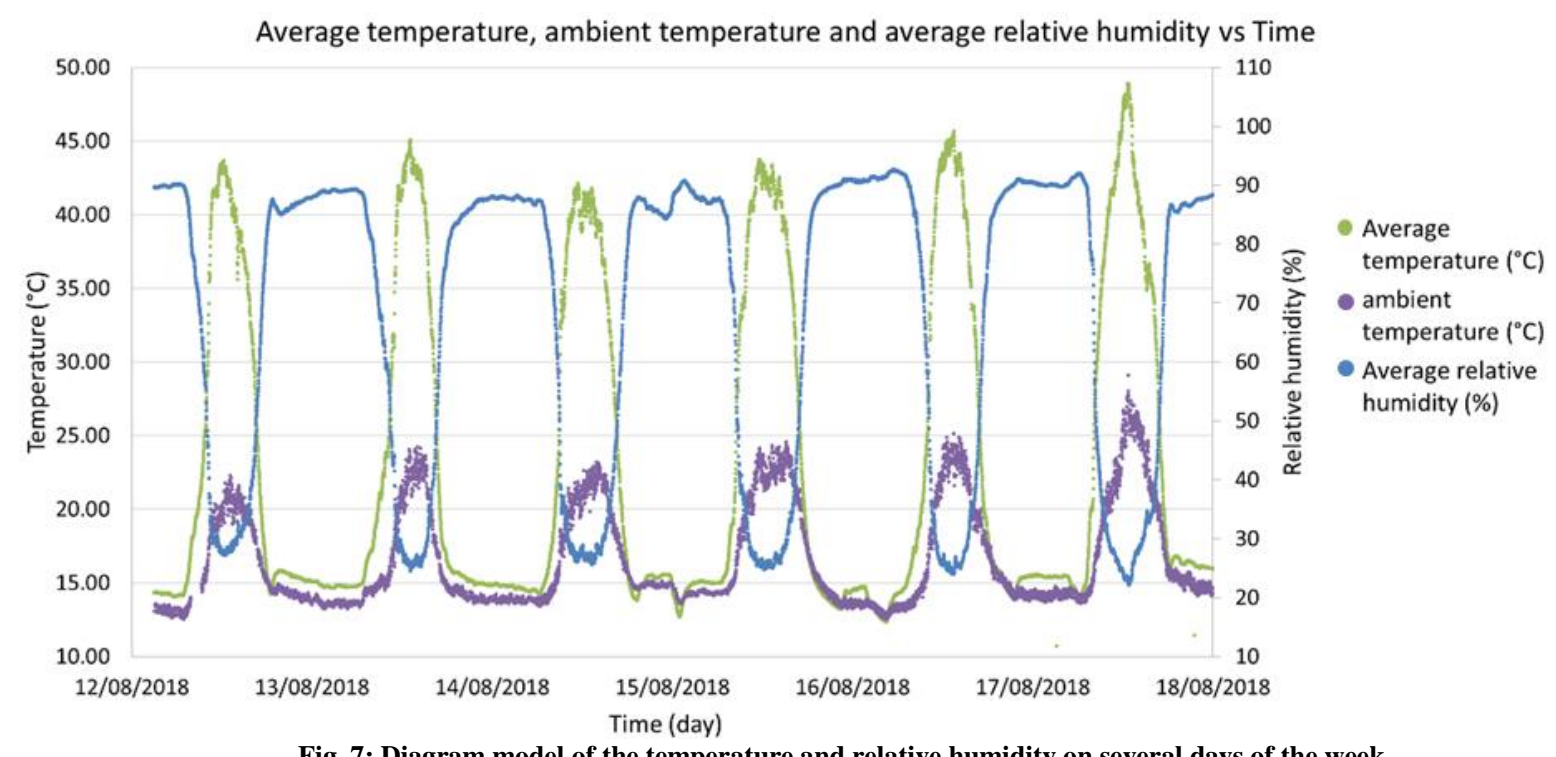

It can be observed, in the previous graph, the uniformity of the measurements over time, which lead us to predict a steady and uniform dome behavior to drying process with better precision.

Average temperature, ambient temperature and avergare relative humidity for August 16 th vs Time

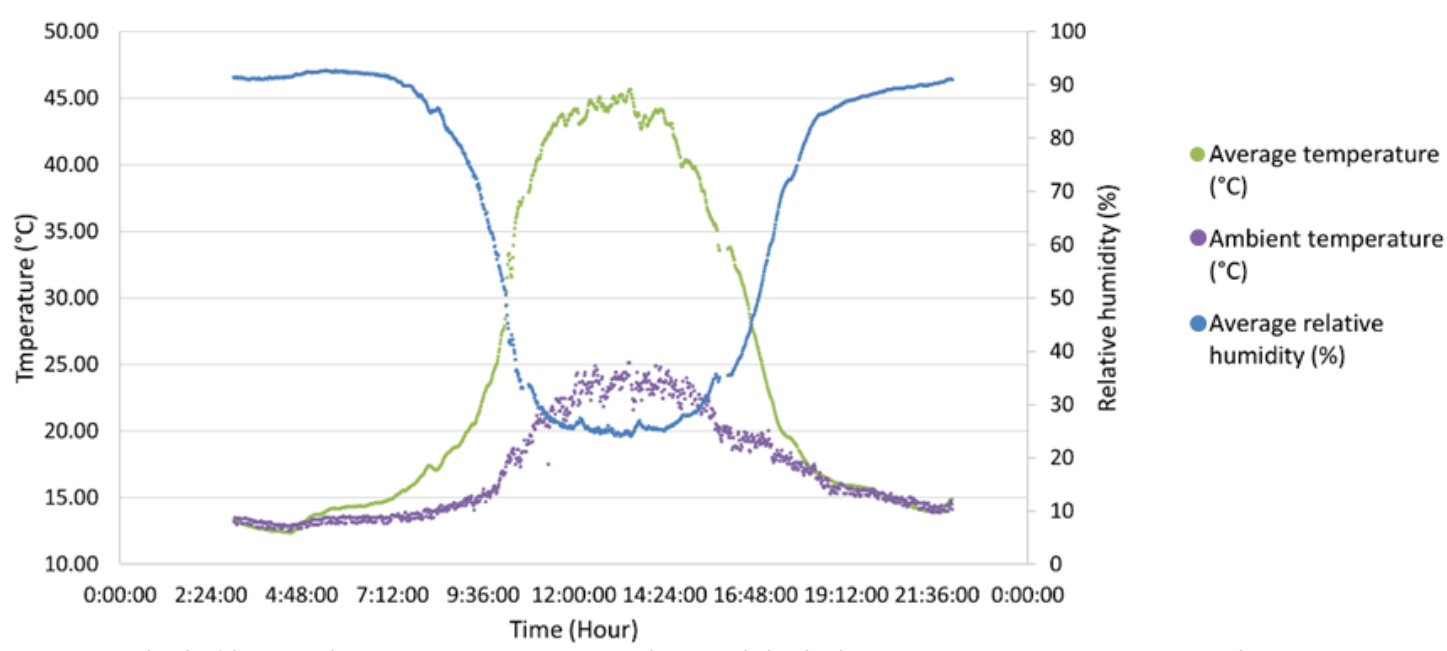

Fig. 8: Air behavior. Temperature and relative humidity inside the dome on an average day with respect to the environment.

In the figure 8 , it can be observed how the dome affects the inside temperature and relative humidity, reaching a maximum of $45^{\circ} \mathrm{C}$ and a $25 \%$ of relative humidity. 


\subsection{Chili behavior}

The tests were done with $50 \mathrm{~kg}$ of fresh chili. Each tray contains $10 \mathrm{~kg}$ of chili. The methodology used to measure the loss of moisture content was through the weight control of a sample of 5 chilies per tray. For which an electronic scale with resolution of $1 \mathrm{~g}$ inside the dome was used. Three times a day we proceeded to weigh the samples.

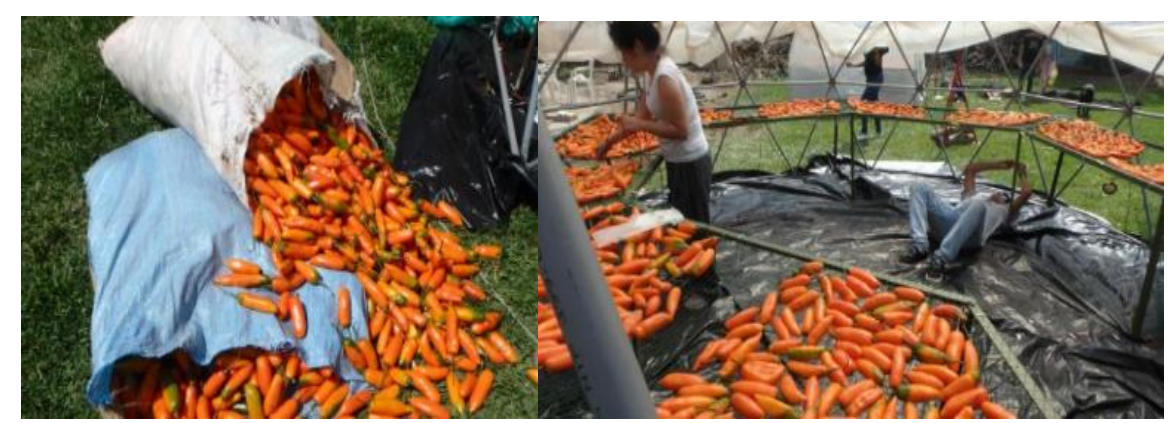

Fig. 9: From left to right. Photographs of the chili in sacks and their distributions inside the dome.

Figure 9 shows the distribution of peppers in the 5 trays inside the dome. The trays were constructed of steel and with a metal mesh with plastic coating.

By making use of the sensors B1- B5 located in tray 1- tray 5, we can show the homogeneity of the tray temperatures.

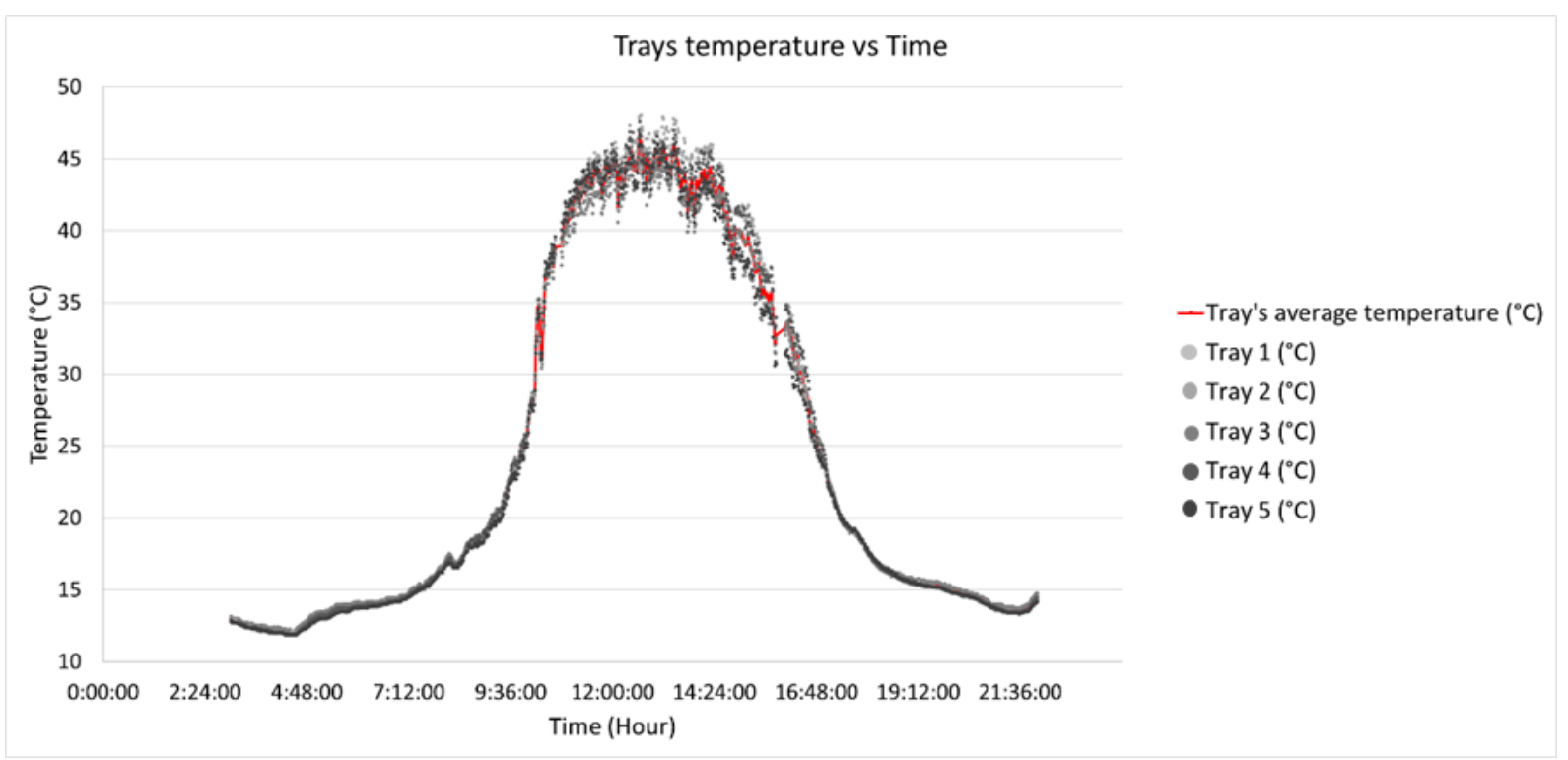

Fig. 10: Temperature in the five trays at a height of one meter above ground level.

In figure 10 is appreciated the uniformity in the measurements of the temperatures in the five trays distributed inside the dome. It was calculated an average standard deviation per day using temperatures of 0.368.

The loss of moisture content during the 20 days of the test can be observed in the figure 11 . 


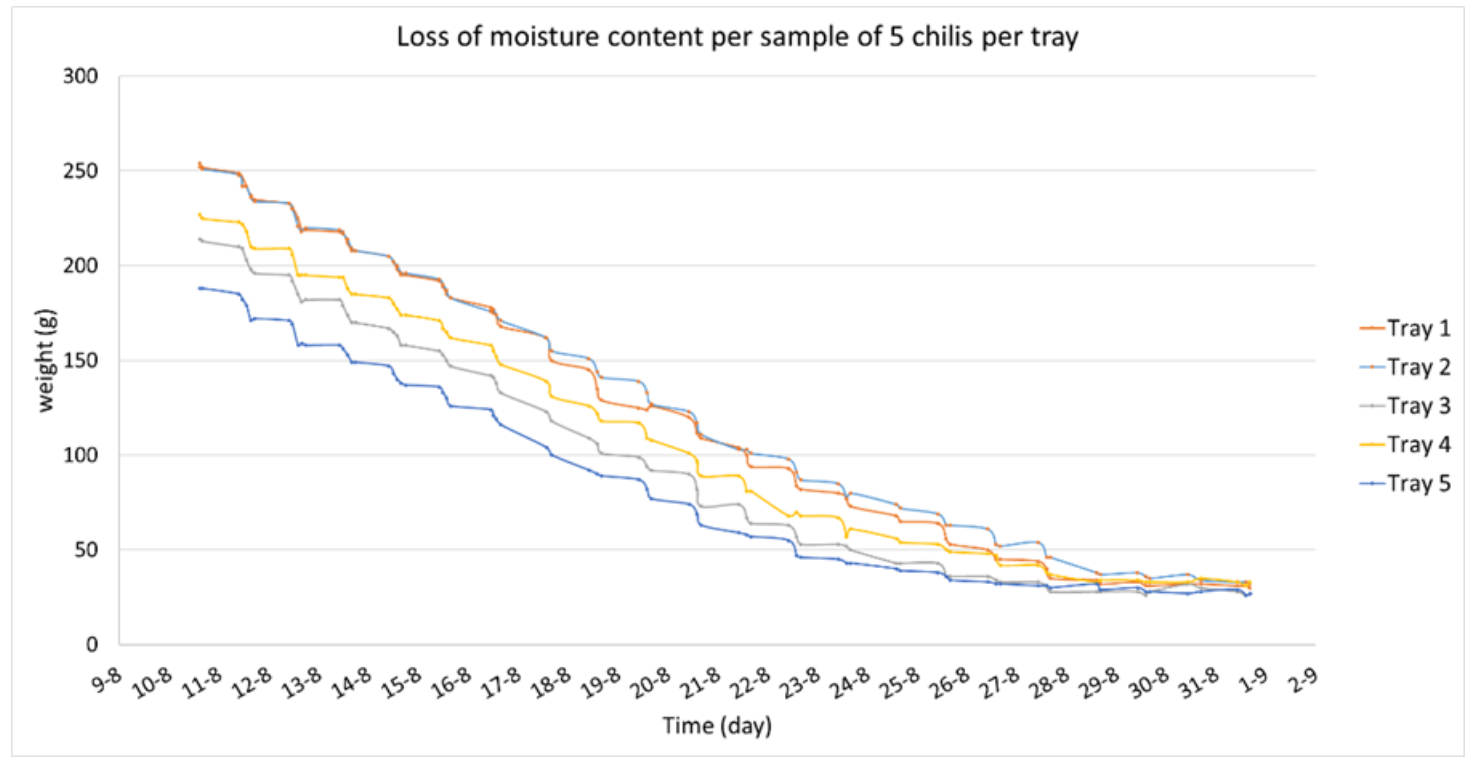

Fig. 11: Loss of weight per sample of 5 chilies per day.

The samples of tray 1, tray 2, tray 3, tray 4 and tray 5 had an initial weight of 254, 252, 214, 227 and 188 grams respectively. After 20 days of drying with an average daily radiation of $4.3 \mathrm{~kW}-\mathrm{h} \mathrm{m}^{-2}$, a final weight of 30,31 , 26, 29 and 24 grams respectively was obtained.

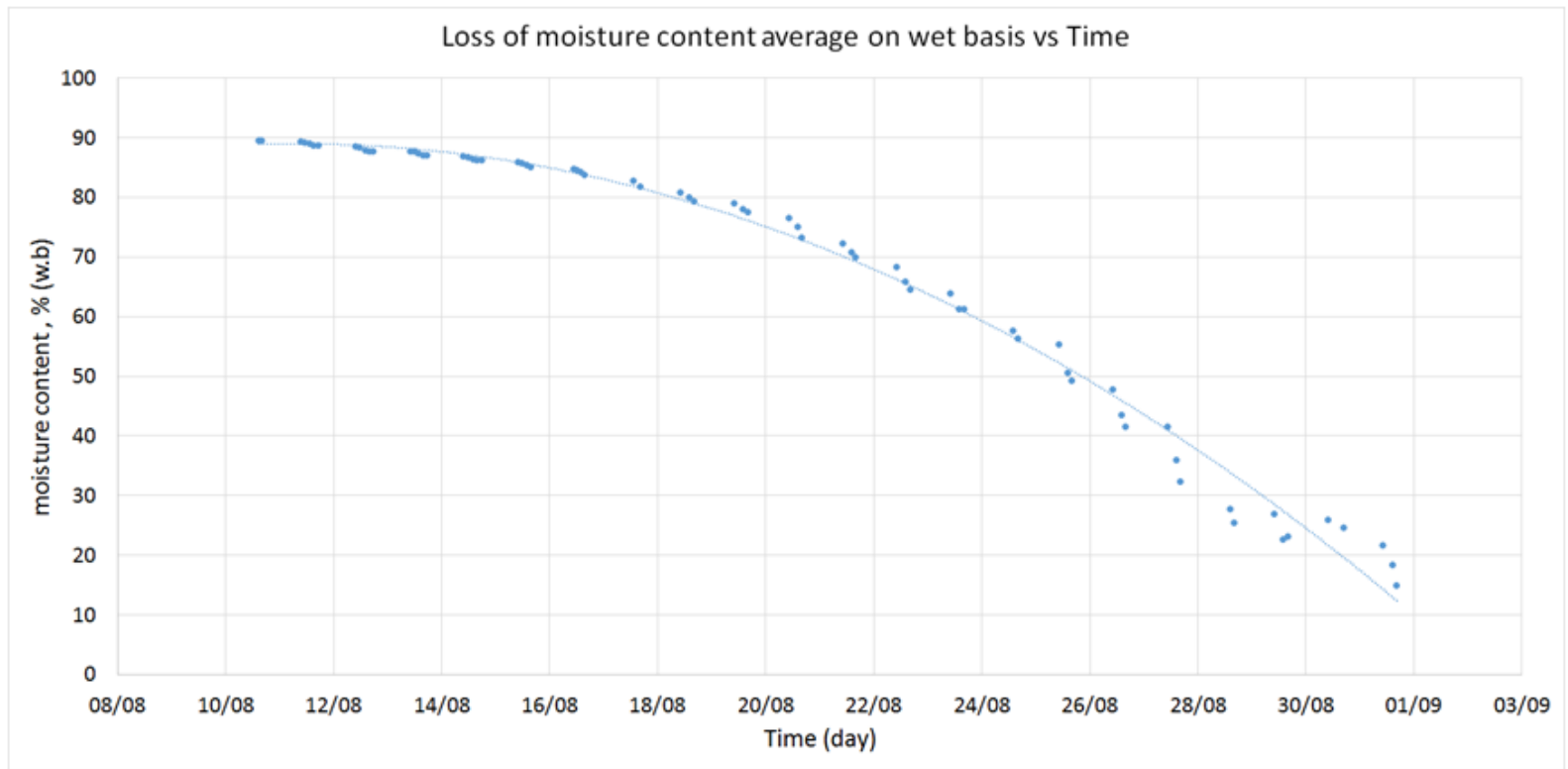

Fig 12: Loss of moisture content average on wet basis 
S. Vergara et. al. / EuroSun 2018 / ISES Conference Proceedings (2018)

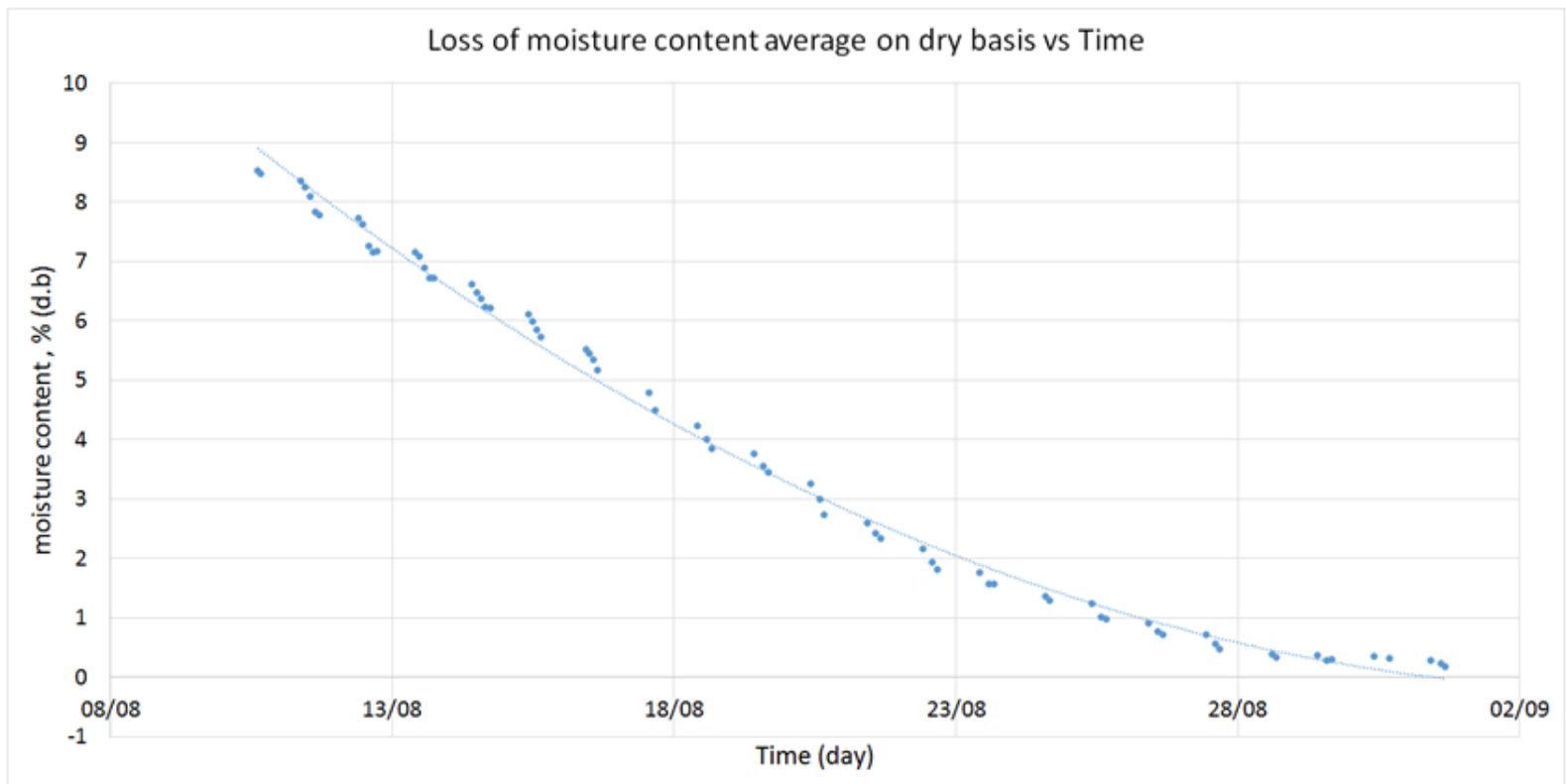

Fig 13: Loss of moisture content average on wet dry

As shown in figures 12 and 13, the moisture content on a dry basis reached its ideal weight of drying with a moisture content of $15 \%$ in 20 days.

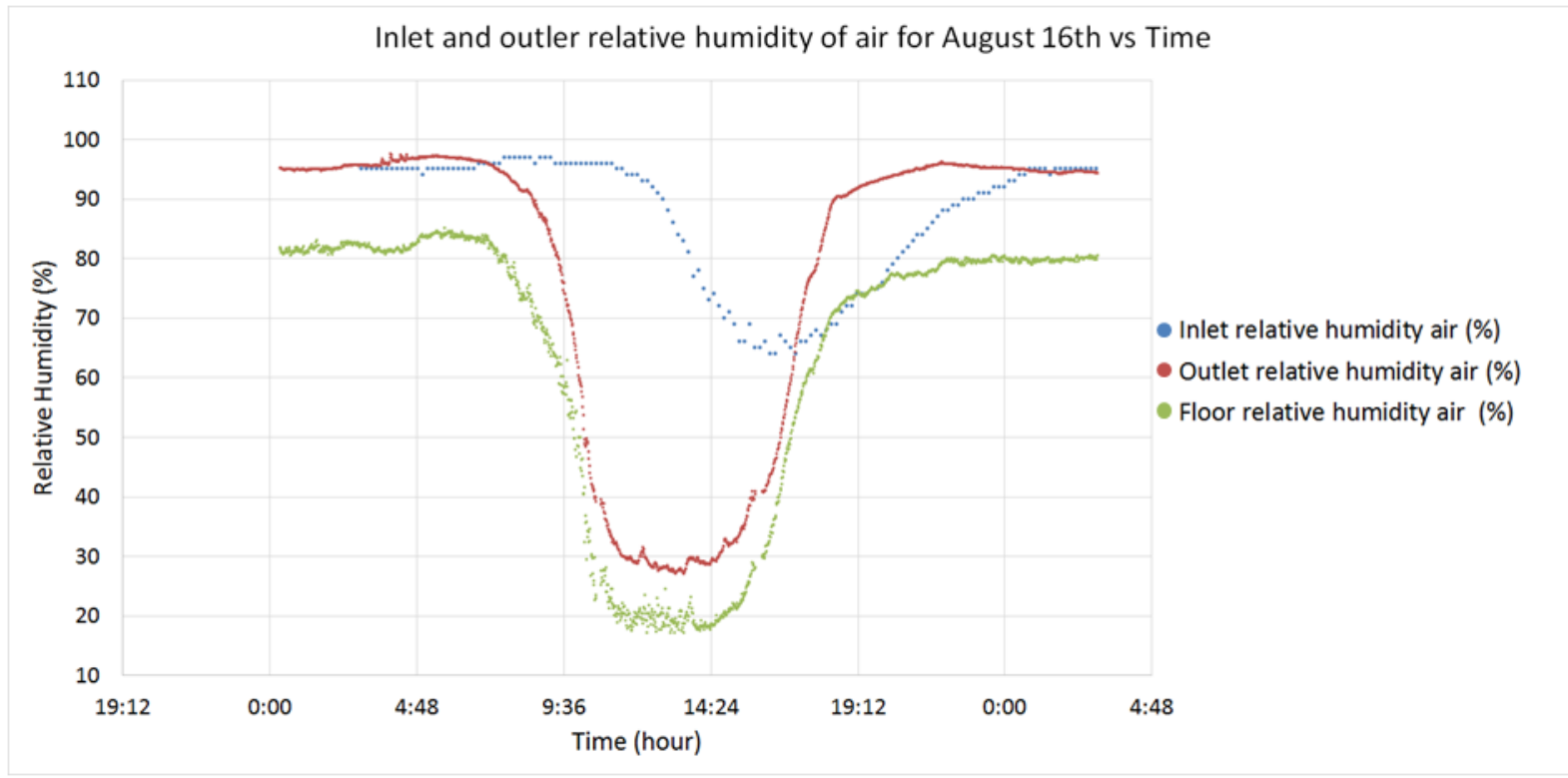

Fig.14: Inlet and outlet relative humidity vs. time in a specific day.

In figure 14, the differences in the percentage of relative humidity between the inlet and outlet air; the data was obtained from the DHT 5 sensor and the weather station. As it is revealed in the graph, a difference around 37\% is observed in an average day. And, the differences in the percentage of relative humidity between the floor air and outlet air were $10 \%$. 


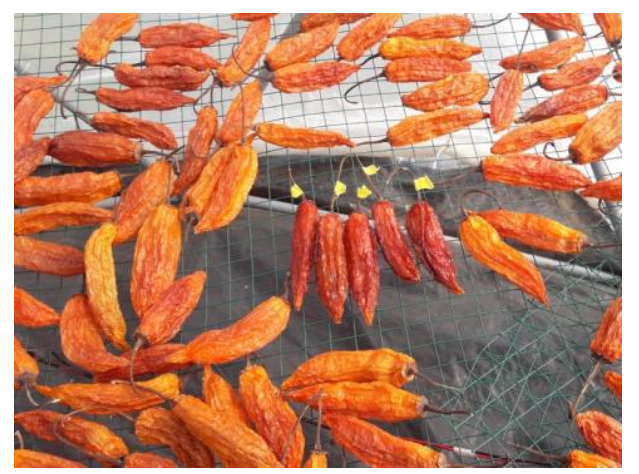

Fig.15. Color of the product dried

Finally, during the experimentation it was observed that the chili that had not been manipulated presented their characteristic color, while the chili peppers of sample showed a dark orange color.

\section{Conclusions}

The system shows that there is a maximum temperature reached per day corresponding to the maximum radiation delivered by the sun and the efficiency of the system based on the losses of the equipment itself.

A temperature of around $43^{\circ} \mathrm{C}$ has been obtained for a day with global irradiance at midday of $780 \mathrm{~W} \mathrm{~m}^{-2}$ and an air flow velocity of $1.1 \mathrm{~m} \mathrm{~s}^{-1}$. The reached temperature allows carry out the process of drying the chili. In addition, for a load of $50 \mathrm{~kg}$ of chili the dome is able to reduce its percentage of humidity by $15 \%$ in 20 days

It can be concluded, the dome as a solar dryer for agricultural products can works efficiently for daily irradiations greater than $4 \mathrm{~kW}-\mathrm{h} \mathrm{m}^{-2}$. That uniformity of the temperature makes the dome design affordable to any velocity and direction of outside wind, hence suitable for drying any other product.

More research is still necessary on the dome behavior in other places of higher and lowers daily irradiances than $4 \mathrm{kWh} \mathrm{m}^{-2}$. Additionally, it is needed to do more tests changing variables for different products like modifying the amount of product to dry for example. Furthermore, it is important to research about the behavior of the materials of the dome.

Nowadays, the Grupo Rural de Apoyo al sector Rural and the Centro de Innovación Tecnológica de Industrias Alimentarias continue working on the subject to achieve the optimal design of the dome, as well as attain the automatic functioning of all the processes.

Another application for this system is in the line of thermal comfort research for homes or others. Likewise, the system can be used for the replication of microclimates with an automated control.

\section{References}

Eggersdorfer, M., Wyss, A., 2018. Carotenoids in human nutrition and health. Archives of biochemistry and biophysics 652: 18-26.

Fratianni, A., Niro, S., Alam, M., Cinquanta, L., Di Matteo, M., Adiletta, G., Panfili, G., 2018. Effect of a physical pre-treatment and drying on carotenoids of goji berries (Lycium barbarum L.) LWT 92, 318-323. DOI:10.1016/j.lwt.2018.02.048

Goswami, D. Y., L. A., 1991. Analysis of a geodesic dome solar fruit dryer. Drying Technology, 677-691. DOI:10.1080/07373939108916703

Kürklü, A., Bilgin, A., Özkan, B., 2003. A study on the solar energy storing rockbed to heat a polyethylene tunnel type greenhouse. Renewable Energy, 683-97. DOI:10.1016/s0960-1481(02)00109-x

Multari, S., Marsol-Vall, A., Keskitalo, M., Yang, B., Suomela, J., 2018. Effect of different drying temperatures on the content of phenolic compounds and carotenoids in quinoa seeds (chenopodium quinoa) from Finland. Journal of composition and Analysis. 72, 75-82. DOI:10.1016/j.jfca.2018.06.008

Intawee, P., Janjai, S., 2011. Performance Evaluation of a Large-Scale Polyethylene Covered Greenhouse Solar 
Dryer. International Energy Journal, 39-52.

Rodriguez-Amaya, D., 2018. Update on natural food pigments - a mini review on carotenoids, anthocyanins, and betalains. Food research international. In press. DOI:10.1016/j.foodres.2018.05.028

Saini, R., Shetty, N., Prakash, M., Giridhar, P., 2014. Effect of dehydration methods on retention of carotenoids, tocopherols, ascorbic acid and antioxidant activity in Moringa oleifera leaves and preparation of a RTE product. J Food Sci Tech. 51(9), 2176-2182. DOI:10.1007/s13197-014-1264-3

Tunde-Akintunde, T.Y., 2011. Mathematical modeling of sun and solar drying of chilli pepper. Renewable Energy, pp. 2139-2145. DOI:10.1016/j.renene.2011.01.017 
Domestic Hot Water and Space Heating 


\title{
Efficient Design of Solar Assisted Heating Systems for Multi-Family Houses
}

\author{
K. Backes ${ }^{1}$, M. Adam ${ }^{1}$, H. Wirth ${ }^{1}$, D. Götzelmann ${ }^{1}$, S. Helbig ${ }^{2}$, D. Eggert ${ }^{2}$ \\ ${ }^{1}$ University of Applied Sciences (HSD), ZIES Center of Innovative Energy Systems, \\ Düsseldorf (Germany) \\ ${ }^{2}$ Institute for Solar Energy Research (ISFH), Hamelin (Germany)
}

\begin{abstract}
Summary
Hydraulic concepts for solar heat appliances to support heating and domestic hot water in multi-family houses (solar combisystems) are investigated and compared by means of simulations and hardware-in-the-loop tests. The aim is to find best-practice solutions.

The standard for new constructions of multi-family housing is a central buffer storage system with fresh water station, but hot water storage systems are also used. Hydraulic concepts found in market research are compared concerning their efficiency, costs and complexity. Solar combisystems with fresh water stations are not very complex, offer high energy savings and the lowest heat generation cost: $0,19 € / \mathrm{kWh}$. This makes it the best practice concept for solar combisystems in multi-family houses.
\end{abstract}

Keywords: solar thermal system, hydraulic concept, multi-family houses, solar combisystems, fresh water station, solar assisted heating, hardware in the loop, simulations, domestic hot water, buffer storage

\section{Acknowledgement}

The project presented in this paper is funded by the German Federal Ministry for Economic Affairs and Energy based on a decision of the German Federal Parliament (reference number: 03ET1212). The authors are grateful for the financial support and responsible for the content.

\section{Introduction}

The market in Germany for solar thermal systems is almost completely (97\%) restricted to detached and semidetached houses, but 53\% of all apartments are located in multi-family housing (IWU 2010). In order to supply more solar energy to multi-family housing and better penetrate this market, the different designs of solar assisted heating systems were evaluated - to help planners and installers identify the advantages and disadvantages of the hydraulic concepts and find the best concept.

The aim is to define best-practice solutions. The concept which offers the best compromise between lower overall costs, high energy savings and low equipment complexity is considered to be the best one. Methods used are market research, Hardware-in-the-loop-tests (HIL) and simulations (using TRNSYS and MATLAB)

\section{Classification of concepts}

The concepts are classified using 3 criteria: centrality (of the equipment), energy provision for domestic hot water (DHW) and energy provision for heating. The first criterion "centrality" in figure 1 refers to three functions of the concept: DHW- production, conventional heating and heat storage. How are these three carried out - separately (decentral) in each apartment or in one central place?

In figure 1, from left to right the concepts are getting more decentral: If the heating and hot water production is done centrally (concepts 1 to 7), a 4-pipe network is used distributing DHW and heating water in separate flow and return lines. 


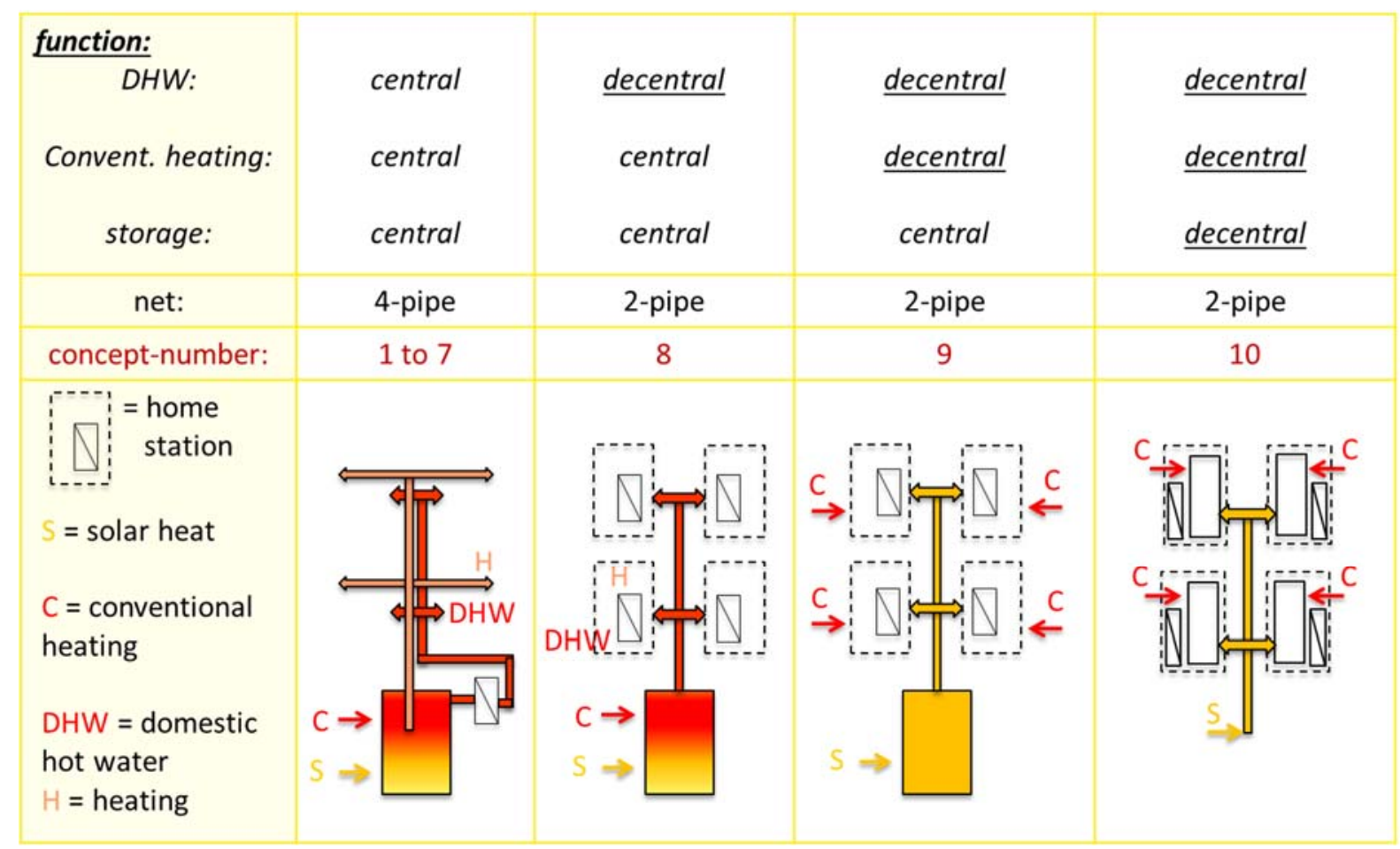

Fig. 1: Criterion Centrality: Solar-supported central and decentral concepts for heating and DHW in MFH

If the DHW is produced decentrally in the apartments (by a home station), only two pipes are needed (concept 8). If the hot water production and the conventional reheating takes place decentrally in the apartments, also a 2-pipe network is used and all network losses are solar losses (concept 9). If, additionally, heat is stored decentral, it is concept 10. (Wirth 2018)

\begin{tabular}{|l|c|c|c|}
\hline $\begin{array}{c}\text { conv. heating to } \\
\text { bival. DHW storage }\end{array}$ & $\begin{array}{c}\text { conventional heating to } \\
\text { buffer storage }\end{array}$ & $\begin{array}{c}\text { conventional heating to } \\
\text { monov. DHW storage }\end{array}$ & $\begin{array}{c}\text { conv. heating in boiler } \\
\text { flow }\end{array}$ \\
$\begin{array}{l}\mathrm{C}=\text { solar energy } \\
\text { heating }\end{array}$ & $\mathbf{1}$ fresh water station \\
$\mathrm{CW}=$ fresh water station + & $\begin{array}{l}3 \text { conv. heating in } \\
\text { boiler flow+ preheat } \\
\text { heat exchanger } \\
\text { monovalent } \mathrm{DHW}\end{array}$ \\
$\begin{array}{l}\text { storage } \\
\text { hot water }\end{array}$ &
\end{tabular}

Fig. 2: the central concepts that transfer solar heat to DHW in the flow

The second criterion for classification is "energy provision for domestic hot water" and defines if the transition of solar heat to the hot water is "in the flow" (figure 2) or by charging a storage (figure 3). The four columns of both figures (2 and 3) separate different concepts and are defined by the different kind of storages the conventional heating is transferred to.

In the columns far right of figure 2 and 3 (concepts 3 and 7) it is not really a storage, but the conventional heating of DHW is in boiler flow. However, these concepts 3 and 7 will not be further investigated, because in reality they cannot be found in multi-family houses - among others for the reason that they require a very high thermal output of the conventional heating, only to cover the (maximum) DHW-demand. 
Concepts 1, 1c and 2 in figure 2 are concepts with freshwater station. Concept 1 is the standard concept. Concept 1c uses an additional heat exchanger for heating up the DHW-circulation return flow separately - and not mixing warm circulation return with incoming cold water. This also prevents the lower part of the storage from being heated by the constant (24 hours) DHW-circulation.

With an additional monovalent DHW-storage (concept 2) higher DHW-comfort can be achieved and the buffer storage is only heated by solar energy.

This also applies to concept 4 and 6 in figure 3, concept 4 using a bivalent DHW-storage and concept 6 using two monovalent DHW storages. The first (cold) DHW storage is the solar preheat storage. Concepts 5 and 6 are used if the solar thermal system has to be integrated into an existing DHW-installation.

\begin{tabular}{|l|l|l|l|}
\hline $\begin{array}{c}\text { conv. heating to } \\
\text { bival. DHW storage }\end{array}$ & $\begin{array}{c}\text { conventional heating to } \\
\text { buffer storage }\end{array}$ & $\begin{array}{c}\text { conventional heating to } \\
\text { monov. DHW storage }\end{array}$ & $\begin{array}{c}\text { conv. heating in } \\
\text { boiler flow }\end{array}$ \\
$\begin{array}{l}5 \text { bivalent } \mathrm{DHW} \\
\text { storage }\end{array}$ & $\begin{array}{l}5 \text { monovalent } \\
\mathrm{DHW} \text { storage }\end{array}$ & $\begin{array}{l}6 \mathrm{DHW} \text { preheat } \\
\text { storage }\end{array}$ \\
\hline
\end{tabular}

= solar energy, $\mathrm{C}=$ conventional heating, $\mathrm{CW}=$ cold water, $\mathrm{DHW}=$ domestic hot water

Fig. 3: the central concepts that transfer solar heat to DHW by charging a storage

\section{Market research}

For this market research 60 manufacturers were surveyed. They were asked for a system for a building with 8 apartments. Finally, 58 hydraulic systems of 28 manufacturers were taken into account. 13 of these are decentral hydraulic concepts in addition to 45 central concepts. Half of the central concepts included a fresh water station. A central buffer storage with fresh water station is standard in multi-family housing. For the future, manufacturers forecast more systems with home stations.

\section{Concepts tested on the HIL test stand}

As the market research suggests, a focus of the study is on systems with fresh water stations (concept 1), which are tested on the hardware-in-the-loop test bench in four variations:

a) Fresh water station (and a valve for stratified solar loading)

b) Fresh water station with „cold water preheating“, (the incoming cold water is pre-heated by the circulation return flow)

c) Fresh water station with additional heat-exchanger for circulation (concept 1c in figure 2)

d) fresh water station with additional heat-exchanger for circulation and ultrafiltration module (ultrafiltration module provides a mechanical legionella treatment so that the hot water feed temperature can be lowered from $60^{\circ} \mathrm{C}$ to just above the desired tap temperature, for example $47^{\circ} \mathrm{C}$ )

Another focus of the study is on decentral concepts: concept 8 and concept 10 (figure 4) were also tested. Concept 10 is the most decentral one, with only the solar collectors left central. 


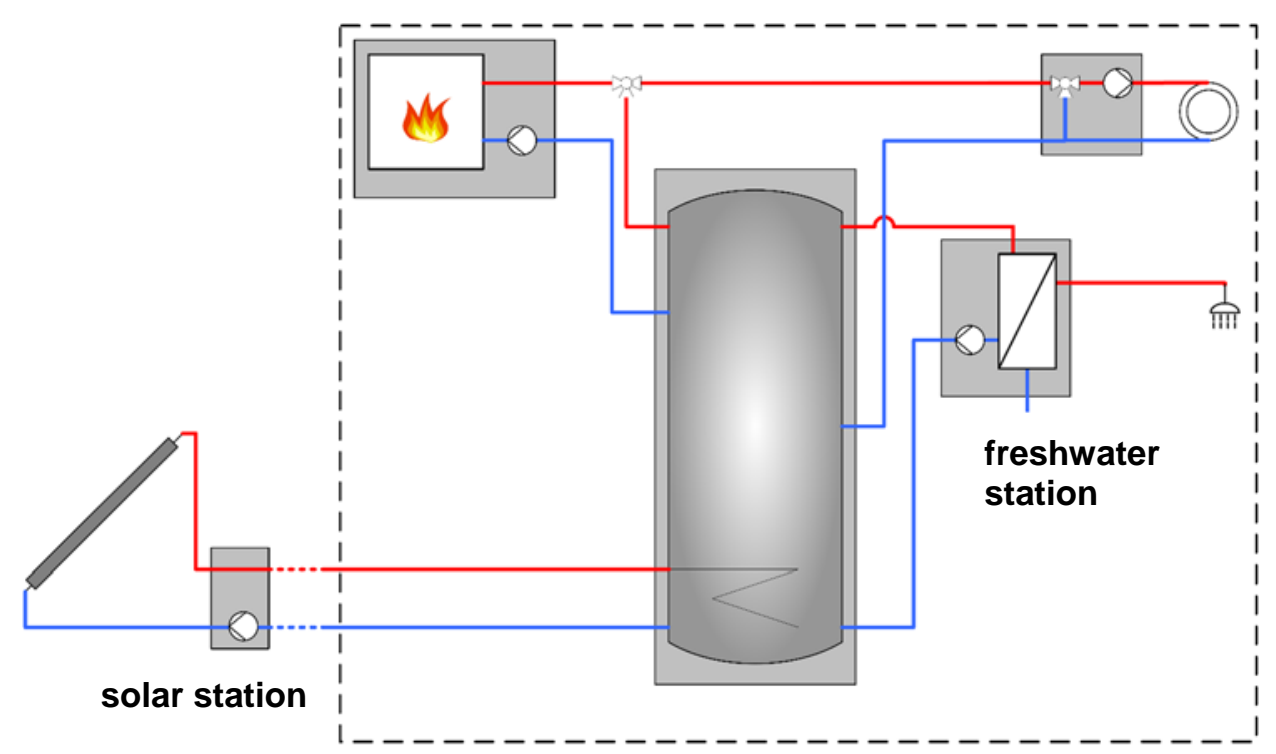

Fig. 4: decentral concept 10, all decentral facilities (in one apartment) in dotted lines

Concept 8 is tested first with a buffer storage with integrated boiler and second with decentral electrical reheating of DHW. The central concept 2 was also tested, the other concepts $(4,5,6,9)$ are only investigated by simulation.

The solar collectors, the weather and the building with its space heat demand, DHW-load and DHW-circulation do not exist in reality at the test bench, so they are simulated / emulated and parameterized as follows:

- Weather: Meteonorm (version 5), weather datasets from Zürich, Switzerland. Eight typical days were selected, so each measurement lasted $8 \times 24$ hours.

- Collector: aperture area $24 \mathrm{~m}^{2}$, inclination $45^{\circ}$, orientated south, total pipe length $53.5 \mathrm{~m}$

- DHW: $60^{\circ} \mathrm{C}, 55$ liter per apartment and day, profile generated by the program DHWcalc (Jordan 2014)

- Circulation: $24 \mathrm{~h}$ DHW-circulation, maximum temperature difference of $5 \mathrm{~K}$ leading to a circulation volume flow of $150 \mathrm{l} / \mathrm{h}$.

- Building: 4-storey multi-family house with 8 apartments each at a size of $65 \mathrm{~m}^{2}$, heated by radiators.

\section{Simulations}

The HiL measurement data was used as the basis for the simulation models of all concepts, which are then run through annual simulations. All concepts from 1 to 10 (except 3 and 7) were simulated and compared - using one example system per concept. Then the following variations were simulated:

- solar plant aperture area: $\mathrm{A}_{\text {collector }}=14 \mathrm{~m}^{2}$ to $33 \mathrm{~m}^{2}$,

- building from the 1960s not renovated - with a space heat demand of $173 \mathrm{kWh} / \mathrm{m}^{2} \mathrm{a}$ / building renovated according to German energy saving regulations "EnEV 2009” - with a space heat demand of $41 \mathrm{kWh} / \mathrm{m}^{2 a}$

The system has to meet the loads of the DHW production, the DHW-circulation and the heating. $\mathrm{Q}_{\mathrm{L}}$ is the sum of these loads. The load-related specific collector area adsc was used in the simulations:

$$
a_{d s c}=\frac{A_{\text {collector }}}{Q_{L}}\left[\mathrm{~m}^{2} / M W h\right]
$$

\section{Results}

Solar combisystems (concepts 1, 2, 8 and 10) are measured on representative days and their functions are checked. All concepts from 1 to 10 (except 3 and 7) are simulated and their annual efficiencies are compared. Costs are added from real offers. Finally, the complexities of the concepts are assessed and compared. 


\section{Function}

The real, (HiL-)tested systems are commercially available solar combisystems such as the systems for concept 1 and 2. The measured systems of concepts 8 and 10 are prototypes, system 10 in particular still has great optimization potential. Several discrepancies have been found in the functionality of the commercially available systems, concerning the system hydraulics, the selection of components and also the system control. One system has a mixing valve that is too slow. Another system is not optimally adapted to a 24-hour circulation period, whereby the correct integration of the circulation return (or the return flow of the fresh water station) is extremely important for an efficient system in a multi-family house (Adam 2017).

The solution approach of "cold water preheating” (concept $1 \mathrm{~b}$ in chapter 5) could not yet be implemented profitably on the test stand. However, the simulation suggests energy savings of $2.2 \%$ (for a variant of this preheating with a pipe heat exchanger for the cold water) compared to the standard concept 1.

\section{Energy}

In the following figures the final energy savings of all (solar) concepts are shown in comparison to a system without solar support, called reference system. The final energy saving fsav.EE is defined as follows:

$$
\begin{array}{lll}
f_{\text {Sav.EE }}= & 1-\frac{E_{\text {final }}}{E_{\text {final.ref }}} & \\
\text { where: } & E_{\text {final }}: & \text { final energy consumption }[\mathrm{kWh}] \\
& E_{\text {final.ref }}: & \text { final energy consumption of the reference system }[\mathrm{kWh}]
\end{array}
$$

For the definition of the reference system the DIN V 4701-10 "Energetische Bewertung heiz- und raumlufttechnischer Anlagen" has been the guideline. This reference system is a central concept for DHW and heating

\begin{tabular}{|c|c|}
\hline General description & $\begin{array}{l}\text { central generation of DHW- and heating: gas condensing boiler } \\
\text { gas: } 1,1 \\
\text { usable area of the building: } 500 \mathrm{~m}^{2} \\
\text { room heating requirements: } 40 \mathrm{kWh} / \mathrm{m}^{2} / \mathrm{a} \text { (renovated building), } 170 \mathrm{kWh} / \mathrm{m}^{2} / \mathrm{a} \text { (not } \\
\text { renovated building) } \\
\text { DHW requirement: } 12,5 \mathrm{kWh} / \mathrm{m}^{2} / \mathrm{a}\end{array}$ \\
\hline Room heating & $\begin{array}{l}\text { Transfer: free heating surfaces with } 1 \text { Kelvin spreading } \\
\text { Distribution: horizontal distribution pipes outside the thermal envelope and all } \\
\text { other pipes inside the thermal envelope. } \\
\text { Heating design: } 55 / 45^{\circ} \mathrm{C} \text { (renovated) and } 70 / 55^{\circ} \mathrm{C} \text { (not renovated). Controlled } \\
\text { heating circuit pump } \\
\text { Storage: none } \\
\text { Generation: Gas condensing boiler outside the thermal envelope }\end{array}$ \\
\hline Domestic hot water & $\begin{array}{l}\text { Distribution: 24-hour DHW circulation with distribution outside the thermal } \\
\text { envelope } \\
\text { Storage: indirectly heated storage with installation outside the thermal envelope } \\
\text { Generation: Gas condensing boiler outside the thermal envelope }\end{array}$ \\
\hline Ventilation & No consideration. \\
\hline primary energy factor & natural gas: 1,1 ; electricity: 1,8 \\
\hline
\end{tabular}
generation with gas condensing boiler. Table 1 shows the boundary conditions:

Tab. 1: Definition and boundary conditions for the reference system (DIN V 4701-10)

Figure 5 and 6 show the final energy savings of all concepts over the load-related specific collector area $\mathrm{a}_{\mathrm{dsc}}$.

The annual simulations show that concept 8 with decentral electrical DHW reheating and concept 10 have clear energy advantages, especially due to their low system and distribution losses. For a collector area of $1.1 \mathrm{~m}^{2} / \mathrm{MWh}$ which corresponds to a collector area of $33 \mathrm{~m}^{2}$ for the renovated building, there is a final energy saving of $42 \%$ to $45 \%$ for the concepts 8 and 10 in figure 5 . 


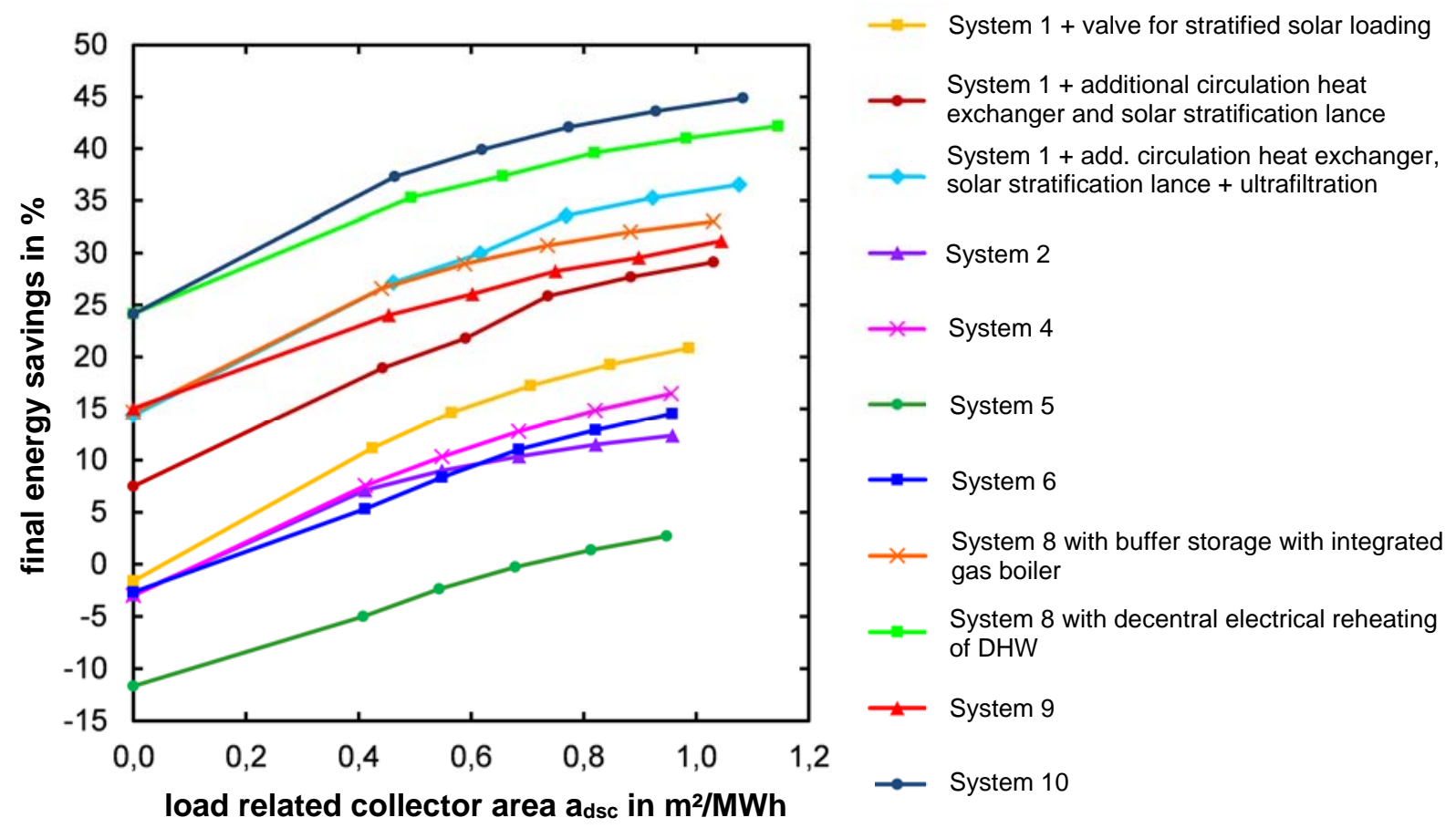

Figure 5: simulated final energy savings of all concepts for the renovated building

Within the central concepts, examples of concept 1 are the most energy-efficient.

A similar order of concepts applies to the non-renovated building in figure 6. But concept 8 with decentral electrical DHW reheating and concept 1 with ultrafiltration have a higher gradient than other concepts. So it becomes clear that both systems can make particularly effective use of solar heat because of (the higher heating loads of the non-renovated building and) the lower temperature level of the distribution lines - due to their concept. Therefore, for these concepts a larger design of the collector field is particularly noticeable.

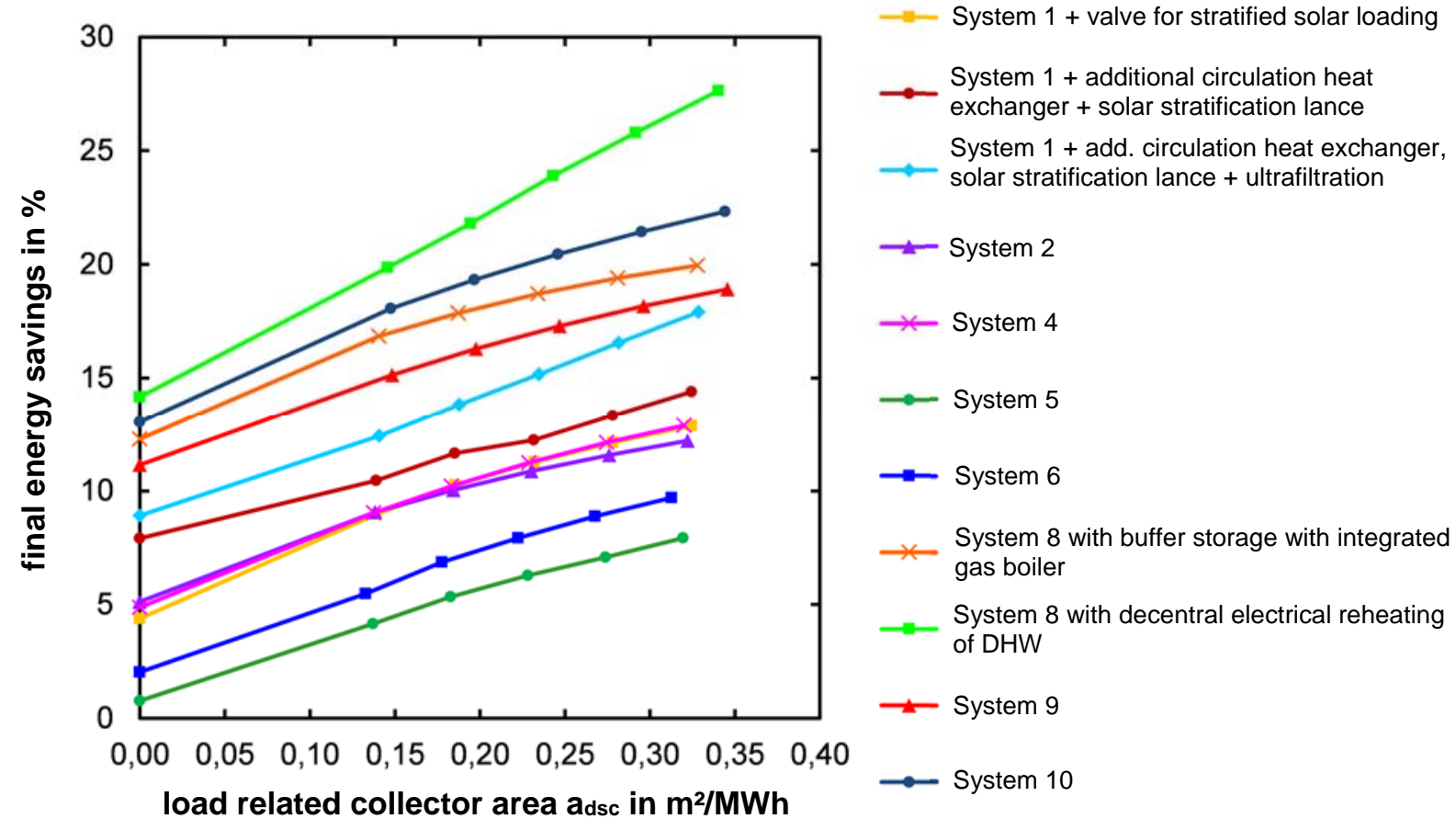

Figure 6: simulated final energy savings of all concepts for the non-renovated building

A benchmark procedure was developed to determine the potential of the concepts. Using simulations, individual causes of losses were analysed-in comparison to an ideal system. Efficiency is increased by keeping the temperature stratification in the storage, reducing heat distribution losses in the building and by compact installation. 


\section{Costs}

Decentral concepts are energy-efficient, but their costs are high, especially for the concepts 9 and 10 (figure 7 and 8). So central concepts prove to be more economical: For the renovated building, the systems of concept 1 with fresh water station (without ultrafiltration) are the most cost-effective, often in the variant with separate circulation heat exchanger and lance for stratified loading. For the non-renovated building, concept 4 is also a cost-efficient system with low "levelized cost of heat” (LCOH, eq.3). The LCOH describes the cost for one heat unit in $€ / \mathrm{kWh}$.
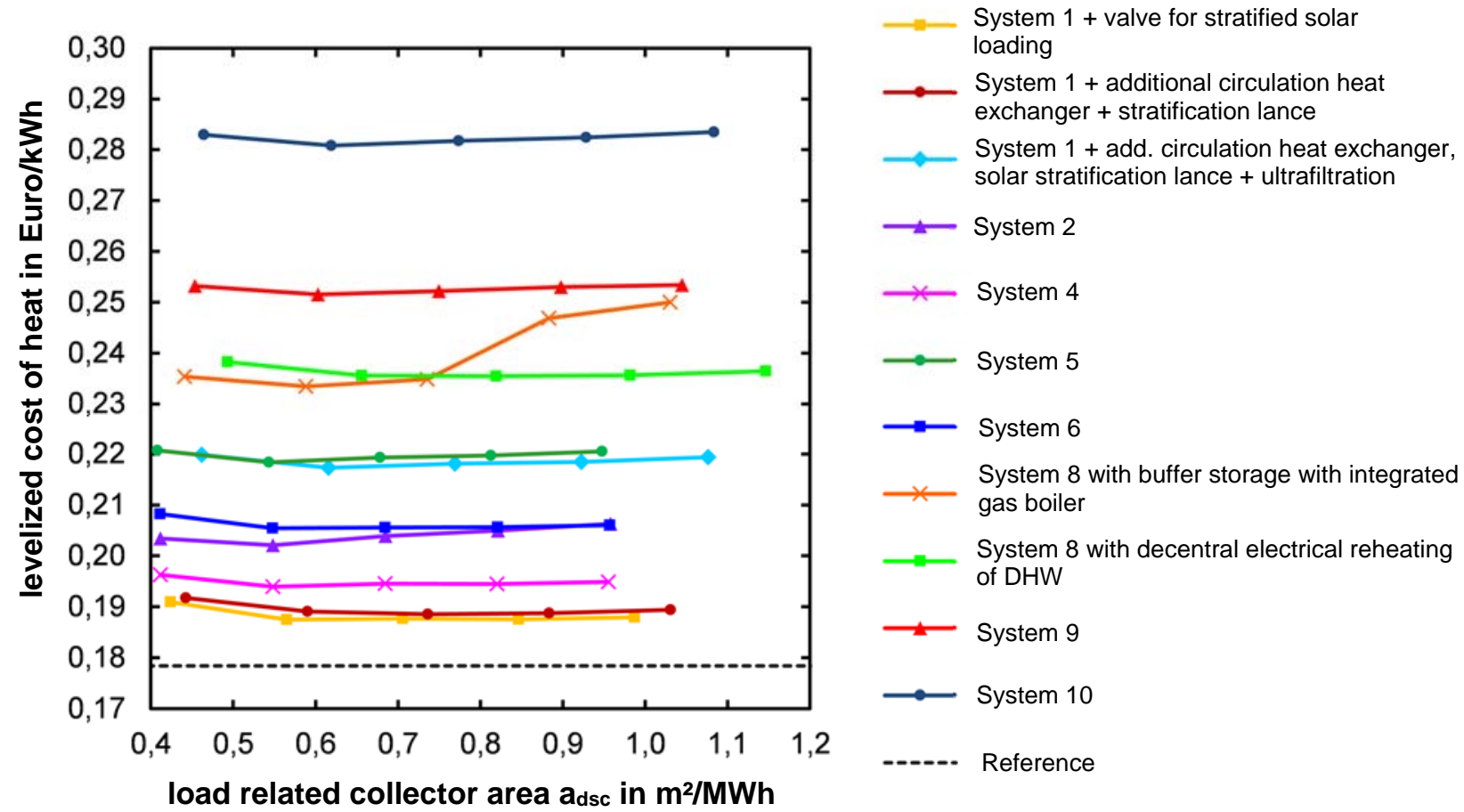

Figure 7: levelized cost of heat over the load-related specific collector area $a_{\text {dsc }}$ for the renovated building

The LCOH is gained by dividing the equivalent annual costs EAC by the annual useful energy of the system $\mathrm{Q}_{\text {use: }}$ :

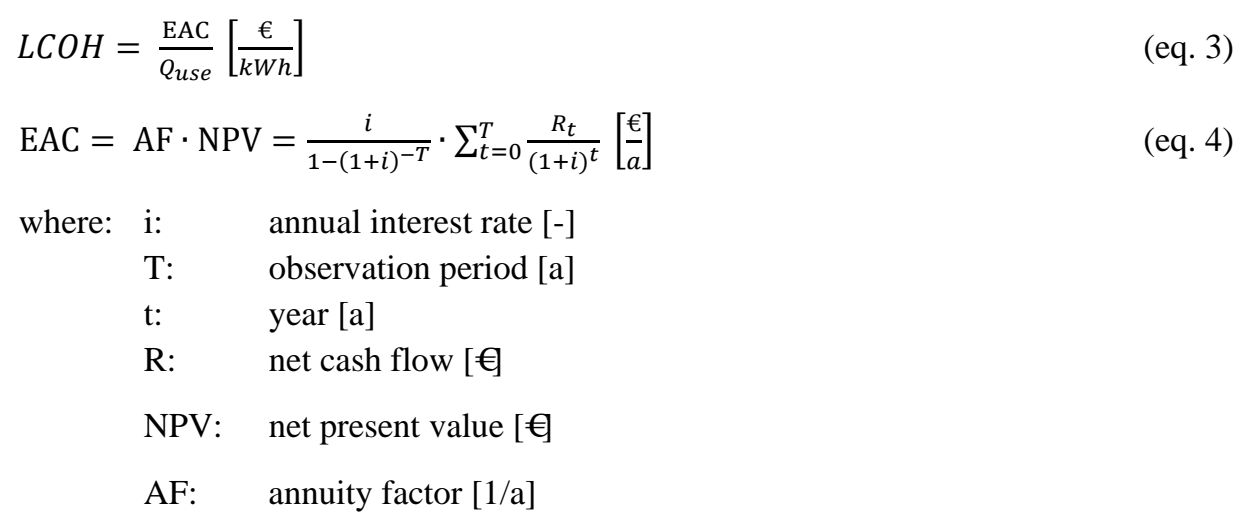

Tab. 2: Applied boundary conditions for the economic efficiency analysis

\begin{tabular}{|c|c|}
\hline annual interest rate & $0,4 \%$ \\
\hline prices for energy & electricity: $29,7 €$-Cent/kWh and natural gas: 6,1 Cent/kWh \\
\hline price change factors & $\begin{array}{l}\text { capital-related: } 1,4 \% / \mathrm{a} \text { and salary: } 2,2 \% / \mathrm{a} \\
\text { electricity: } 3,6 \% / \mathrm{a} \text { and natural gas: } 3,7 \% / \mathrm{a}\end{array}$ \\
\hline observation period & 20 years \\
\hline
\end{tabular}

In contrast to the variation of the collector area, the variation of the heat demand (building renovated / not 
renovated) has a noticeable effect on the costs. Generally, the costs are higher in the renovated building and the distances between the concepts are higher.
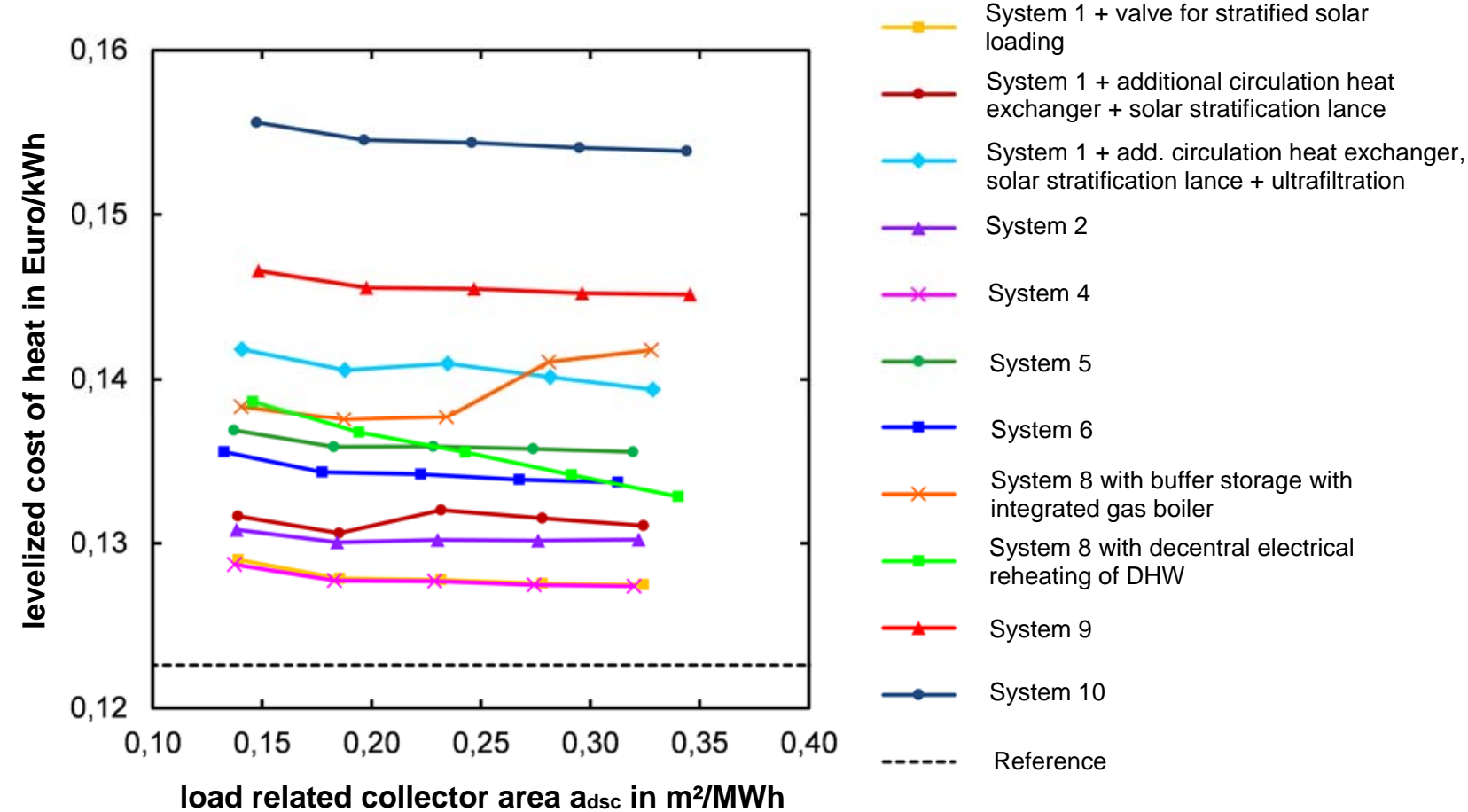

Figure 8: levelized cost of heat over the load-related specific collector area adsc for the non-renovated building

The LCOH of the most economical concepts, including the BAFA support, is still approx. $5 \%$ higher than that of a conventional reference heating installation without solar part. This results in carbon abatement costs of less than $200 € / \mathrm{tCO}_{2}$ for concept 1 (Helbig Et al. 2017). With more realistic assumptions than in VDI 2067 for the maintenance costs of the storage tank and the lifetime of the collector and the storage, concept 1 is more costefficient than the reference.

The following optimizations of concept 1 are economical: a stratification valve in the return flow of the fresh water station with $2.4 \%$ energy savings or a separate circulation heat exchanger with $4.0 \%$ energy savings (Helbig et al 2018). In combination with a solar charging lance, both optimizations work better and yield energy savings of 3.9 and $6.0 \%$, respectively.

To determine the costs of a concept, two offers were requested and the average costs were used as a basis. The cost differences between the individual offers are sometimes high and of the same scale as the cost differences between the concepts.

\section{Complexity}

The number of hydraulic components and the number of control sensors were counted to compare the degree of complexity of the concepts. There were no significant differences between the central concepts. Within the decentral concepts, concept 9 showed a very high level of complexity. The other concepts are simpler and therefore more reliable.

\section{Conclusion}

According to market research, hydraulics with fresh water station according to concept 1 are currently the most frequently offered in new constructions. The concept is not very complex, offers high energy savings and the lowest heat generation cost. This makes it the best practice concept for solar combisystems in multi-family houses.

Decentral concepts offer the highest energy savings. But the more decentral the concepts get, the more expensive they are. However, the investigated decentral concepts 8a, 8b and 10 are still in prototype condition and offer great potential for more compact design and cost reduction. In addition, the costs of the decentral conventional heating may not be attributed to the concept if they already exist or are mandatory for billing reasons. 


\section{References}

Adam, M., Backes, K., Eggert, D., 2017. Symposium Thermische Solarenergie, Energetischer Vergleich verschiedener Zirkulationseinbindungen bei einer solaren Wärmezentrale mit Frischwasserstation.

DIN (Deutsches Institut für Normung e.V.): DIN V 18599-1, 2016 (Vornorm). Energetische Bewertung von Gebäuden - Berechnung des Nutz-, End- und Primärenergiebedarfs für Heizung, Kühlung, Lüftung, Trinkwarmwasser und Beleuchtung, Teil 1: Allgemeine Bilanzierungsverfahren, Begriffe, Zonierung und Bewertung der Energieträger, Berlin.

Helbig, S., Steinweg, J., Eggert, D., Adam, M., 2017. Energetic and Economic Efficiency Evaluation of Solar Assisted Heating Systems for Multi-Family Houses. SHC, International Conference on Solar Heating and Cooling for Buildings and Industry, Conference proceedings, Abu Dhabi.

Helbig, S., Eggert, D., Adam, M., 2018. Einfluss von Speicheranschlusshöhen und geschichteter Speicherbe- und -entladung auf die Effizienz solarer Kombisysteme im Mehrfamilienhaus, Solarthermie-Symposium 2018.

IWU (Institut Wohnen und Umwelt), 2010. Datenbasis Gebäudebestand - Datenerhebung zur Energetischen Qualität und zu den Modernisierungstrends im deutschen Wohngebäudebestand, Darmstadt, http://www.datenbasis.iwu.de/dl/Endbericht_Datenbasis.pdf

Jordan, U., Vajen, K., 2014. Manual DHWcalc - Tool for the Generation of Domestic Hot Water (DHW) Profiles on a Statistical Basis, Version 1.20, Universität Kassel, Institut für thermische Energietechnik.

Wirth, H., Backes, K., Adam, M., Helbig, S., Eggert, D., 2018. Best-Practice-Lösungen für Mehrfamilienhäuser mit Solaranlage, Solarthermie-Symposium 2018. 


\title{
ENERGETIC BEHAVIOUR OF A SOLAR THERMAL SYSTEM PRODUCING DOMESTIC HOT WATER AND PREHEATING THE VENTILATION AIR
}

\author{
Patricia Carbajo Jiménez ${ }^{1,2}$, Antoine Leconte ${ }^{2}$, Gilles Fraisse ${ }^{1}$, Ophélie Ouvrier Bonnaz ${ }^{2}$, Etienne \\ Wurtz ${ }^{2}$
}

1 Univ. Grenoble Alpes, Univ. Savoie Mont Blanc, CNRS, LOCIE, 73000 Chambéry, France.

2Univ. Grenoble Alpes, CEA, LITEN, INES, 73375 Le Bourget-du-Lac, France.

\begin{abstract}
As a result of the evolution of the thermal regulation in Europe, buildings are better isolated and more airtight, thereby reducing their heating needs. Efficient systems from the energetic point of view, using preferably renewable sources, must cover the new distribution of needs. Indeed, domestic hot water (DHW) becomes a more important load than space heating in residential buildings. In this context, solar thermal systems are appropriate for supplying a significant part of the heat demand in energy efficient housing. Thus, this paper focuses on an innovative solar thermal system producing DHW and preheating the ventilation air. A co-simulation between Dymola (Modelica language) and EnergyPlus forecasts the energy performance of the system in a low-energy individual house for different French cities. The results show an improved collector efficiency as well as a higher solar productivity in comparison to a classical solar domestic hot water system. Although energy savings are achieved for the majority of the studied climates with the studied system, a different control strategy may be interesting in order to improve the distribution of the collected solar energy. To this end, a parametric analysis provides some clues for increasing the energy performance of the innovative system when modifying the design and control parameters.
\end{abstract}

Keywords: solar thermal system, air preheating, DHW, low-energy building, Modelica, EnergyPlus, FMU

\section{Introduction}

The building sector represents a major axis of the European energetic policy. Indeed, it is responsible for almost $40 \%$ of the final energy consumption and for about $36 \%$ of the greenhouse emissions in the European Union (European Commission, 2013). Consequently, many efforts have been done in order to decrease energy consumption and, at the same time, increase the use of renewable energy sources in buildings.

For existing residential buildings, about 55\% of the final energy demand is used for comfort heat (space and water heating) (IEA-ETSAP and IRENA, 2015). In recent high-performance houses, space heating needs have been considerably reduced by improving the building envelope (isolation and air-tightness) and by increasing passive gains during the cold season (Ionescu et al., 2015). Thus, air renewal losses constitute an important part of the space heating needs in efficient buildings and can also be decreased by using heat recovery systems or natural thermal sources for fresh air conditioning. In this context, domestic hot water (DHW) needs become a large portion of the heat demand in buildings and may even be more important than space heating needs (Faninger, 2010).

Since solar thermal systems are a mature and competitive technology for DHW production (IEA, 2012), this paper studies an innovative solar domestic hot water system which can also preheat the supplied fresh air. Indeed, when using supply ventilation systems, the air blown into the building can be filtered and preheated during the heating season, thus improving indoor air quality and providing thermal comfort in efficient buildings (Rahmeh, 2014).

\section{A solar thermal system producing DHW and preheating the ventilation air}

\subsection{Presentation of the studied system}

The studied solar system produces DHW, by heating the cold water (CW) that enters the tank, and preheats the ventilation air regarding the scheme in Fig. 1. To do this, the heat transfer fluid flowing in the solar loop delivers the collected solar energy into the storage tank by using the $\mathrm{C} 1$ circulator or directly to the air in the hot water coil with the $\mathrm{C} 2$ circulator. During the periods where solar energy cannot be collected, the air can also be preheated by using the stored energy if needed. In this case, a three-way valve (V3V) allows the fluid to change its flowing path through the heat exchanger in the tank first and then through the hot water coil. Both in the storage tank as well as in the 
supply air flow, auxiliary heaters, Aux Sto and Aux $x_{\text {Air }}$, may be needed to reach the respective set point temperatures of the tank $\left(T_{\text {SetSto }}\right)$ and of the preheated air $\left(T_{\text {SetAir }}\right)$. The preheating temperature $T_{\text {SetAir }}$ is set so that thermal comfort is guaranteed during the heating season.

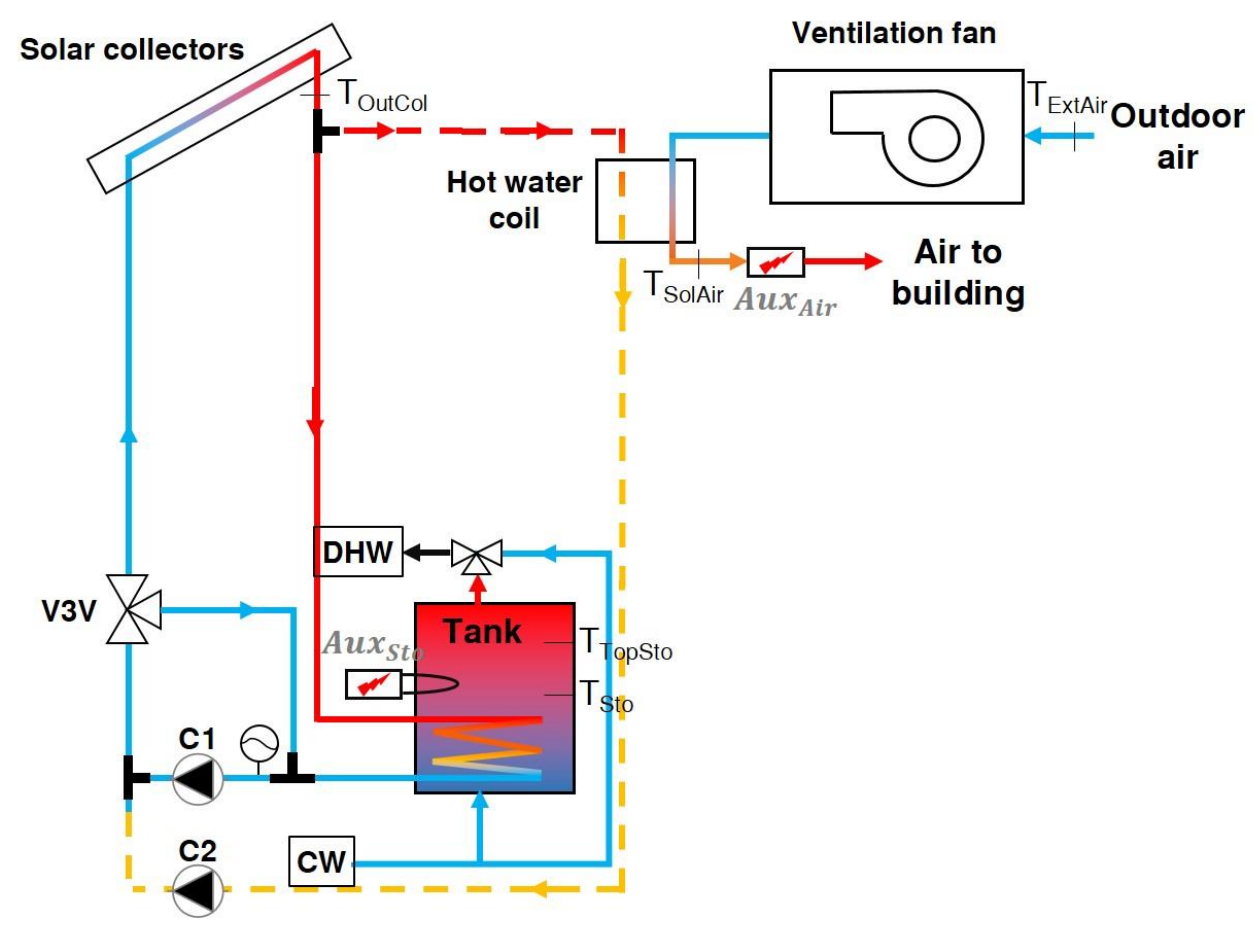

Fig. 1. Scheme of the studied solar thermal system for DHW production and ventilation air preheating.

\subsection{Control algorithm}

\section{Solar energy distribution}

Tab. 1 represents the algorithm for distributing the collected solar energy in the storage tank and/or the hot water coil by controlling the 3-way valve (V3V), the $\mathrm{C} 1$ and the $\mathrm{C} 2$ circulators. The rows in Tab. 1 describe the different conditions used in the control algorithm. The last four columns correspond to the four possible operation modes of the system, which are activated if the conditions of the respective column are fulfilled. The temperatures needed for control are represented in Fig. 1.

First, the orientation of the 3-way valve (V3V) is defined. On the one hand, if the solar energy can be collected and either stored in the tank or used immediately to heat the air in the hot water coil, the V3V guides the heat transfer fluid through the solar collectors. Then, if the collected solar energy is enough for heating the tank and if the temperature of the stored water is lower than its maximal temperature $T_{\text {Maxsto }}$, the $\mathrm{C} 1$ circulator is switched on. At the same time, during the season where air preheating is appropriate, if the outdoor air temperature $T_{\text {ExtAir }}$ is lower than the set air temperature $T_{\text {SetAir }}$ and if solar energy can heat the air, the $\mathrm{C} 2$ circulator is turned on, controlling that the air temperature $T_{\text {SolAir }}$ is under its maximal temperature $\mathrm{T}_{\text {MaxAir. }}$. The DT1 and DT2 parameters represent the threshold for defining if the collected energy is enough for heating the tank or the air respectively, and both include hysteresis. The «Heating_Season» function defines the necessity of air preheating regarding the average outdoor air temperature over 4 weeks $\bar{T}_{E x t A i r}$. The end of the preheating season is defined when the average outdoor temperature $\bar{T}_{\text {Ext Air }}$ is over $15^{\circ} \mathrm{C}$ and the beginning when $\bar{T}_{\text {ExtAir }}$ is below $12^{\circ} \mathrm{C}$.

On the other hand, if it is not appropriate to circulate the heat transfer fluid through the solar collectors, the V3V is oriented towards the submerged heat exchanger in the tank, allowing the air to be preheated by using the stored energy. The $\mathrm{C} 2$ circulator is then switched on during the heating season if the tank temperature is higher than a minimal temperature $T_{\text {MinStoAir }}$ and higher than the outdoor air temperature $T_{\text {ExtAir }}$, keeping the preheated air temperature under the limit temperature $\mathrm{T}_{\text {MaxAir. }}$

\section{Supplied auxiliary energy}

The auxiliary systems in the tank, in the air flow as well as in the building for covering the space heating demand, are switched on if the respective set point temperatures $T_{\text {SetSto }}, T_{\text {SetAir }}$ and $T_{\text {SetBuil }}$ are not reached. The auxiliary heater in the tank works the whole year while the auxiliary systems concerning the air flow and space heating are only used during the heating season. 
Tab. 1. Control algorithm defining the solar energy distribution between the storage tank and air preheating in simulation.

\begin{tabular}{|c|c|c|c|c|c|}
\hline & & \multicolumn{3}{|c|}{ V3V towards collectors } & V3V towards tank \\
\hline & & \multicolumn{2}{|c|}{ C1 ON } & \multicolumn{2}{|r|}{ C1 OFF } \\
\hline Conditions & Meaning & C2 OFF & \multicolumn{3}{|c|}{$\mathrm{C2} \mathrm{ON}$} \\
\hline$T_{\text {OutCol }}-T_{\text {Sto }}>D T 1$ & $\begin{array}{l}\text { Enough solar energy is available } \\
\text { for heating the stored water. }\end{array}$ & TRUE & TRUE & $\begin{array}{l}\text { ONE } \\
\text { OR }\end{array}$ & ONE OR MORE \\
\hline$T_{\text {Topsto }}<T_{\text {MaxSto }}$ & $\begin{array}{l}\text { The temperature of the water in } \\
\text { the tank is lower than its maximal } \\
\text { temperature } T_{\text {Maxsto }} \text {. }\end{array}$ & TRUE & TRUE & $\begin{array}{l}\text { MORE } \\
\text { FALSE }\end{array}$ & FALSE \\
\hline$T_{\text {OutCol }}-T_{\text {ExtAir }}>D T 2$ & $\begin{array}{l}\text { Enough solar energy is available } \\
\text { for heating the air in the coil. }\end{array}$ & \multirow{3}{*}{$\begin{array}{c}\text { ONE } \\
\text { OR } \\
\text { MORE } \\
\text { FALSE }\end{array}$} & TRUE & TRUE & FALSE \\
\hline Heating_Season & $\begin{array}{l}\text { The period is defined as cold, } \\
\text { involving air preheating and space } \\
\text { heating. }\end{array}$ & & TRUE & TRUE & TRUE \\
\hline$T_{\text {ExtAir }}<T_{\text {SetAir }}$ & $\begin{array}{l}\text { The outdoor air temperature is } \\
\text { under the set point temperature } \\
T_{\text {Set Air. }} \text {. }\end{array}$ & & TRUE & TRUE & TRUE \\
\hline$T_{\text {SolAir }}<T_{\text {MaxAir }}$ & $\begin{array}{l}\text { The temperature of the preheated } \\
\text { air } T_{\text {SolAir }} \text { is under its maximal } \\
\text { temperature } T_{\text {MaxAir }} \text {. }\end{array}$ & $\begin{array}{l}\text { TRUE } \\
\text { OR } \\
\text { FALSE }\end{array}$ & $\begin{array}{l}\text { TRUE } \\
\text { OR } \\
\text { FALSE }\end{array}$ & $\begin{array}{l}\text { TRUE } \\
\text { OR } \\
\text { FALSE }\end{array}$ & TRUE \\
\hline $\begin{array}{c}T_{\text {Sto }}>T_{\text {MinStoAir }} \\
\text { AND } \\
T_{\text {Sto }}>T_{\text {ExtAir }}\end{array}$ & $\begin{array}{l}\text { The energy stored in the tank is } \\
\text { over a limit defined by a threshold } \\
\text { temperature } T_{\text {MinSto Air and is }} \\
\text { enough for heating outdoor air. }\end{array}$ & $\begin{array}{l}\text { TRUE } \\
\text { OR } \\
\text { FALSE }\end{array}$ & $\begin{array}{l}\text { TRUE } \\
\text { OR } \\
\text { FALSE }\end{array}$ & $\begin{array}{l}\text { TRUE } \\
\text { OR } \\
\text { FALSE }\end{array}$ & TRUE \\
\hline
\end{tabular}

\section{Model development}

\subsection{Modelling the system}

The innovative solar system as well as the control algorithm are modelled using the Modelica language in the Dymola environment. The acausal and object-oriented features of the Modelica language are well-adapted to multiphysical model development in buildings (Wetter et al., 2016). The involved components in the modelling come from the " Buildings » library, the " Modelica » library or from the works of Bois (2017). The Dassl solver is used in Dymola, keeping a variable time step during the simulation.

\subsection{Parameters characterising the main components}

\section{Hot water coil}

The parameters characterising the hot water coil are experimentally calibrated under real conditions. A solar thermal system for DHW production and air preheating was installed in a test house located in the INCAS platform at CEA INES (Le Bourget-du-Lac, France). The heat exchanger between the fresh air flow and the heat transfer fluid is the BTC-C-160 model from Tuvaco, a cross-flow heat exchanger. The heat transfer fluid is a mix between water (75\% vol.) and mono-propylene glycol (25\% vol.). The temperatures of the air and the heat transfer fluid are measured at the inlet and outlet of the hot water coil.

Numerically, the model Fluid.HeatExchangers.DryEffectivenessNTU from the "Buildings » library is used for representing the heat exchanger. The experimental air flow, heat transfer fluid flow and inlet temperatures of the air and of the water/glycol mixture constitute the inputs of the model. The standard deviation between the experimental and numerical air temperatures at the coil outlet is minimised for calibration by using Brent's algorithm from 6 to 12 April 2018. The value of the standard deviation is $0,68 \mathrm{~K}$ for the studied period. The delivered energy to the air in the exchanger is 3,03 kWh experimentally and 3,07 kWh numerically, obtaining a difference of 1,3\% in the same period. Only the nominal inlet temperature is calibrated, the other parameters come from the data sheet. Tab. 2 presents all the parameters used in simulation. 
Tab. 2. Parameters involved in the modelling of the hot water coil.

\begin{tabular}{|l|c|}
\hline Nominal power $(\mathbf{W})$ & 1500 \\
\hline Nominal air flow $\left(\mathbf{m}^{\mathbf{3}} \cdot \mathbf{s}^{\mathbf{1}}\right)$ & 0,11 \\
\hline Nominal air inlet temperature $\left({ }^{\circ} \mathbf{C}\right)$ & 20 \\
\hline Nominal heat transfer fluid flow $\left(\right.$ litre $\left.\cdot \mathbf{s}^{-1}\right)$ & 0,018 \\
\hline Nominal heat transfer fluid inlet temperature $\left({ }^{\circ} \mathbf{C}\right)$ & 70 \\
\hline
\end{tabular}

Storage tank

Similarly, the parameters characterising the model of the storage tank are obtained from the data sheet. Only the ratio between the external and internal convective coefficients ( $\mathrm{r}$ ) is experimentally calibrated under real conditions. The tank used is the SC1Z model from SolisArt, with a volume of 400 litres. The heat exchanger fluid is also a mix between water and mono-propylene glycol. The temperature of the heat transfer fluid is measured at the inlet and outlet of the submerged heat exchanger as well as the temperature of the hot water leaving the tank.

The model representing the tank is the component Storage.StratifiedEnhancedInternalHex from the "Buildings " library. The heat transfer fluid and the water flow rates as well as the inlet heat transfer fluid and water temperatures are the inputs for calibration. The standard deviation between the experimental and numerical temperature of the water leaving the tank is minimised with Brent's algorithm from 16 to 22 June 2018. All the water contained in the tank was renewed with cold water on the $15^{\text {th }}$ of June in order to set the initial conditions of the tank in the simulation. The standard deviation between the experimental and numerical hot water temperatures is $0,40 \mathrm{~K}$ for the studied period. The energy delivered by the heat transfer fluid to the water in the tank is $25,04 \mathrm{kWh}$ experimentally and 24,14 $\mathrm{kWh}$ numerically, obtaining a difference of 3,6\%. The parameters involved in tank modelling are shown in Tab. 3 .

Tab. 3. Parameters involved in the modelling of the 400-litre storage tank.

\begin{tabular}{|l|c|}
\hline Height without isolation $(\mathbf{m})$ & 1,56 \\
\hline Thickness of the isolation $(\mathbf{m})$ & 0,055 \\
\hline Thermal conductivity of the isolation $\left(\mathbf{W} \cdot \mathbf{m}^{-\mathbf{1}} \cdot \mathbf{K}^{-\mathbf{1}}\right)$ & 0,023 \\
\hline Number of layers & 20 \\
\hline Lower heat exchanger position $(\mathbf{m})$ & 0,305 \\
\hline Upper heat exchanger position $(\mathbf{m})$ & 0,860 \\
\hline Nominal power $(\mathbf{W})$ & 53000 \\
\hline Tank nominal temperature $\left({ }^{\circ} \mathbf{C}\right)$ & 10 \\
\hline Heat transfer fluid nominal temperature $\left({ }^{\circ} \mathbf{C}\right)$ & 80 \\
\hline Heat transfer fluid nominal mass flow rate $\left(\mathbf{k g} \cdot \mathbf{s}^{-\mathbf{1}}\right)$ & 0,37 \\
\hline Ratio between the external and internal convective coefficients for the heat exchanger $(\mathbf{r})$ & 0,34 \\
\hline
\end{tabular}

Solar collectors

The component Fluid.SolarCollectors.EN12975 from the «Buildings » library is used for modelling the solar collectors following the European test standard EN 12975. The parameters of a generic collector defined in Task 32 of the IEA (Heimrath and Haller, 2007), shown in Tab. 4, are used in simulations.

Tab. 4. Parameters involved in the modelling of solar collectors.

\begin{tabular}{|c|c|}
\hline Optical efficiency $\eta_{0}$ & 0,8 \\
\hline Loss coefficient $\mathbf{a}_{1}\left(\mathbf{W} \cdot \mathbf{m}^{-2} \cdot \mathbf{K}^{-1}\right)$ & 3,5 \\
\hline Loss coefficient $\mathbf{a}_{2}\left(\mathbf{W} \cdot \mathbf{m}^{-2} \cdot \mathbf{K}^{-2}\right)$ & 0,015 \\
\hline Incident angle modifier over the direct radiation $b_{0}$ & 0,18 \\
\hline Incident angle modifier over the diffuse radiation $K_{\theta \text {,dif }}$ & 0,9 \\
\hline
\end{tabular}




\subsection{A co-simulation for coupling the system model to the building model}

Although Modelica is well-adapted to complex model development, a well-known and robust program as EnergyPlus (Crawley et al., 2001) is appropriate for building modelling, offering a good compromise between the detailed description of the envelope and the computation time when predicting heating needs. Consequently, the system model developed with the Modelica language is coupled to a building model using EnergyPlus with a co-simulation. Indeed, a « Functional Mockup Interface » (FMI) (Blochwitz et al., 2011) is created, meaning that the building model is encapsulated as a «Functional Mockup Unit» (FMU) and imported into Dymola. The communication time step is 10 minutes, corresponding to the EnergyPlus constant time step used for the building simulation. The air flow rate and the preheated air temperature are sent to the building model, while the system model receives the indoor temperatures of the house. The computing time for simulating one year is 27 minutes with a Intel Xeon processor W3520 (2,66 GHz and 16 GB RAM).

The modelled building is the test house where the real system used for calibration was installed, which is a lowenergy individual house. The inside dimensions are 7,5 $\mathrm{m} \mathrm{x} \mathrm{6,5} \mathrm{m,} \mathrm{with} \mathrm{a} \mathrm{height} \mathrm{under} \mathrm{ceiling} \mathrm{of} \mathrm{2,7} \mathrm{m}$ in the ground floor and 2,4 $\mathrm{m}$ in the first floor, obtaining a living area of $89 \mathrm{~m}^{2}$. The model considers four thermal zones (basement, ground floor, first floor and roofspace), where only the ground and first floors are heated areas. Ventilation air is supplied in two points: one in the ground floor and the other in the first floor. The used scenario for internal heat gains and occupancy considering a 4-person family come from the PhD thesis of Spitz (2012).

\section{Numerical study}

This section presents the numerical study of the innovative solar thermal system producing DHW and preheating the ventilation air, and is compared to a classical solar domestic hot water (SDHW) system.

\subsection{Hypothesis}

\section{$\underline{\text { Studied climates }}$}

Seven French cities are studied: Bordeaux, Brest, Lyon, Marseille, Nantes, Paris and Strasbourg. The weather files used for simulation are obtained from the EnergyPlus database. The main variables of these files are summarized in Tab. 5, characterizing the weather conditions of each studied city as well as the air preheating period obtained from the « Heating_Season » function defined in Tab. 1.

Tab. 5. Minimal, maximal and average temperature (T), global horizontal radiation (GHI), direct normal radiation (BNI), diffuse horizontal radiation (DHI) and simulated heating period for the studied climates in a typical year.

\begin{tabular}{|c|c|c|c|c|c|c|c|}
\hline & Bordeaux & Brest & Lyon & Marseille & Nantes & Paris & Strasbourg \\
\hline Minimal T $\left({ }^{\circ} \mathrm{C}\right)$ & $-8,2$ & $-4,0$ & $-8,5$ & $-4,0$ & $-5,3$ & $-6,0$ & $-9,6$ \\
\hline Maximal T $\left({ }^{\circ} \mathrm{C}\right)$ & 34,0 & 29 & 33,6 & 34 & 32 & 30 & 31 \\
\hline Average T $\left({ }^{\circ} \mathrm{C}\right)$ & 13,2 & 11,2 & 11,9 & 14,8 & 12,2 & 11,1 & 10,3 \\
\hline GHI $\left(k W h \cdot m^{-2}\right)$ & 1264,6 & 1085,4 & 1203,5 & 1545,4 & 1184,1 & 1068,1 & 1091,1 \\
\hline BNI $\left(\mathrm{kWh} \cdot \mathrm{m}^{-2}\right)$ & 929,9 & 661,3 & 861,5 & 1503,8 & 885,4 & 678,9 & 721,9 \\
\hline DHI $\left(\mathrm{kWh} \cdot \mathrm{m}^{-2}\right)$ & 712,0 & 688,5 & 666,2 & 615,4 & 665,1 & 668,8 & 650,4 \\
\hline Preheating start & Late Oct & Mid-Oct & Mid-Oct & Early Nov & Late Oct & Early Oct & Early Oct \\
\hline Preheating end & Mid-May & Late June & Mid-May & Late April & Late May & Late May & Late May \\
\hline
\end{tabular}

\section{Control variables}

The control variables used in simulation, appearing in section 2.2, are presented in Tab. 6 . The two values of the DT1 and DT2 parameters represent the bottom and upper limits of the hysteresis. The maximal air temperature of $50{ }^{\circ} \mathrm{C}$ is defined in order to avoid the risk of dust carbonization in the air, which is dangerous for health (Feist et al., 2005).

\section{Design parameters}

The collector surface used in the modelling is $4 \mathrm{~m}^{2}$ for all the studied climates, the collectors having an inclination of $33^{\circ}$. The tank has a volume of 400 litres and the ventilation air flow is set to $0,0375 \mathrm{~m}^{3} \cdot \mathrm{s}^{-1}\left(135 \mathrm{~m}^{3} \cdot \mathrm{h}^{-1}\right)$. The domestic hot water (DHW) demand is set to 200 litres per day at $45^{\circ} \mathrm{C}$ for a 4-person family. The water drawing pattern is obtained from Task 26 (Jordan and Vajen, 2000) with a 1-hour time step. 
Tab. 6. Values of the parameters involved in the control algorithm in simulation.

\begin{tabular}{|l|c|}
\hline Temperature differential for activating the $\mathbf{C 1}$ circulator DT1 $(\mathbf{K})$ & $4-10$ \\
\hline Temperature differential for activating the $\mathbf{C}$ circulation DT2 (K) & $2-6$ \\
\hline Maximal water temperature allowed in the tank $\boldsymbol{T}_{\text {MaxSto }}\left({ }^{\circ} \mathbf{C}\right)$ & 50 \\
\hline Maximal air temperature allowed $\mathbf{T}_{\text {MaxAir }}$ & 30 \\
\hline Minimal water temperature in the tank for air preheating $\boldsymbol{T}_{\text {MinStoAir }}\left({ }^{\circ} \mathbf{C}\right)$ & 55 \\
\hline Set point temperature for water stored in the upper part of the tank $\boldsymbol{T}_{\text {SetSto }}\left({ }^{\circ} \mathbf{C}\right)$ & 15 \\
\hline Set point temperature for air preheating $\boldsymbol{T}_{\text {SetAir }}\left({ }^{\circ} \mathbf{C}\right)$ & Occupation: 19 \\
\hline Set point temperature in the building $\boldsymbol{T}_{\text {SetBuil }}\left({ }^{\circ} \mathbf{C}\right)$ & No occupation: 16 \\
\hline
\end{tabular}

\subsection{Performance indicators}

The following indicators are defined in order to analyse the energetic behaviour of the studied solar system.

- Collector efficiency $\left(\eta_{\mathrm{Col}}\right)$ : represents the ratio between the energy recovered by solar collectors and the radiation arriving to the total collector tilted surface.

- Solar productivity (SP): is defined as the collected solar energy per unit of collector surface, in $\mathrm{kWh} \cdot \mathrm{m}^{-2}$.

- Storage efficiency $\left(\eta_{\text {Sto }}\right)$ : represents the ratio between the useful energy delivered by the storage tank and the total supplied energy (solar and auxiliary) to the tank.

- DHW solar fraction $\left(\mathrm{F}_{\mathrm{DHW}}\right)$ : represents the ratio between the useful solar energy participating in the DHW production and the DHW needs.

- Air preheating solar fraction $\left(\mathrm{F}_{\mathrm{Air}}\right)$ : represents the part of the heat needed to raise the fresh air temperature $T_{\text {ExtAir }}$ to the set point temperature $T_{\text {SetAir }}$ covered by the solar energy collected with the solar system.

- System solar fraction $\left(\mathrm{F}_{\text {System }}\right)$ : represents the part of DHW and air preheating needs covered by the solar energy collected with the solar system.

- Global solar fraction $\left(\mathrm{F}_{\mathrm{T}}\right)$ : represents the part of DHW, air preheating and space heating needs covered by the solar energy collected with the solar system.

\subsection{Annual performance results in Lyon}

The studied system is simulated and compared to the «reference » system, a typical solar domestic hot water (SDHW) heater where the set point temperature of the air is reached only by using the electric auxiliary heater in the air flow. Fig. 2 represents the annual indicators defined in the section 4.2 .

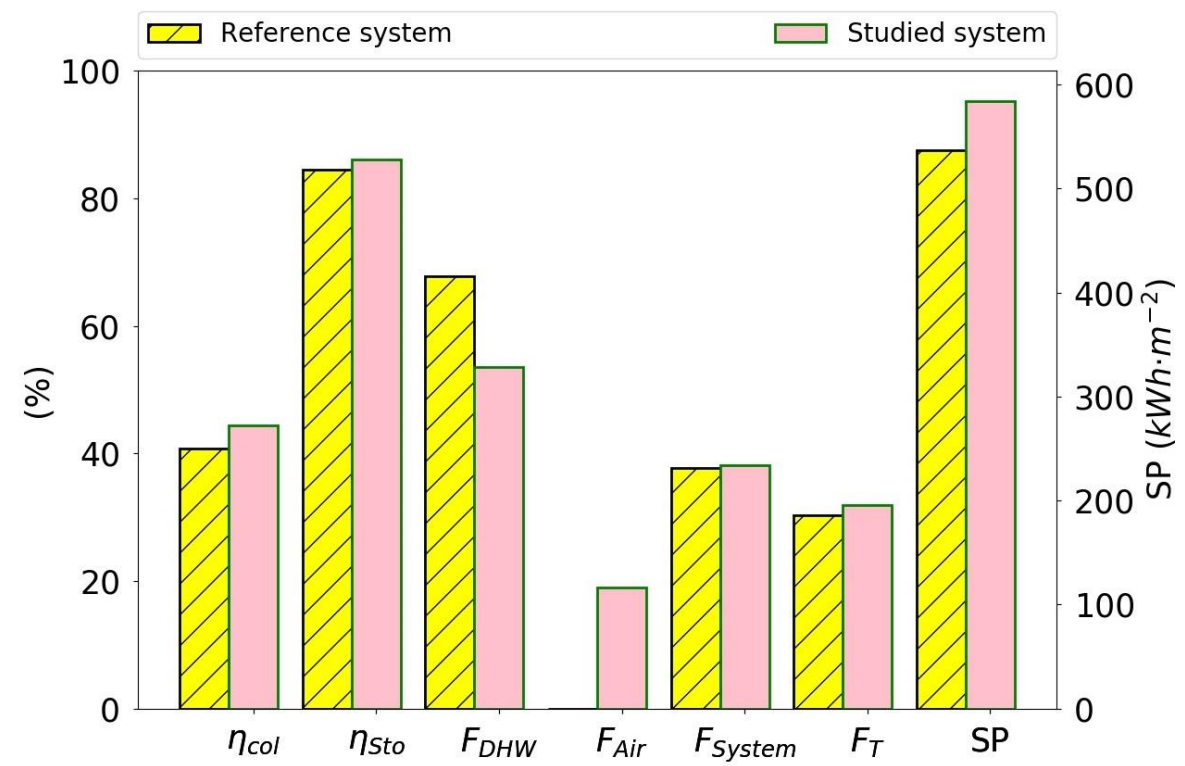

Fig. 2: Annual performance indicators obtained numerically for the studied system producing DHW and preheating the ventilation air and compared to a classical SDHW heater (reference system), both coupled to the modelled building for the climate of Lyon. 
The collector efficiency $\eta_{\mathrm{Col}}$ increases from $40,8 \%$ for the reference system to $44,3 \%$ for the innovative system since more solar energy can be collected thanks to air preheating, increasing the collector solar productivity SP by about $8,8 \%$. The air preheated by using the energy stored in the tank leads to an improved tank efficiency $\eta_{\text {Sto }}$ since a part of the tank losses are converted into useful energy. Regarding solar fractions, since less solar energy is supplied for covering DHW needs, the DHW solar fraction $\mathrm{F}_{\mathrm{DHW}}$ decreases. On the contrary, a part of the total supplied energy

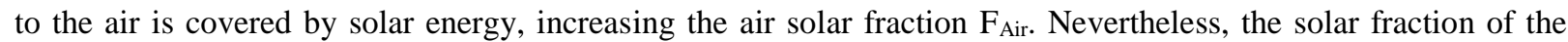
system $\mathrm{F}_{\text {System }}$ is almost the same in both cases, meaning that the auxiliary energy savings achieved in air preheating are needed for heating the tank. The additional solar energy recovered with the studied system is mostly used for heating the air over the set point temperature $\mathrm{T}_{\text {SetAir }}$, decreasing space heating consumption. Thus, the global solar fraction increases from $30,3 \%$ with the reference system to $31,9 \%$ with the studied system.

Fig. 3 shows, on the one hand, the energy entering the storage tank as well as the hot water coil (IN) for the reference and the studied systems. On the other hand, the delivered energy uses (OUT) are presented. As explained before, the sum of the auxiliary energy consumption in the tank and in the air flow is almost the same for both cases. However, energy savings are achieved when considering space heating. The total energy delivered (OUT) is higher with the studied system due to air overheating.

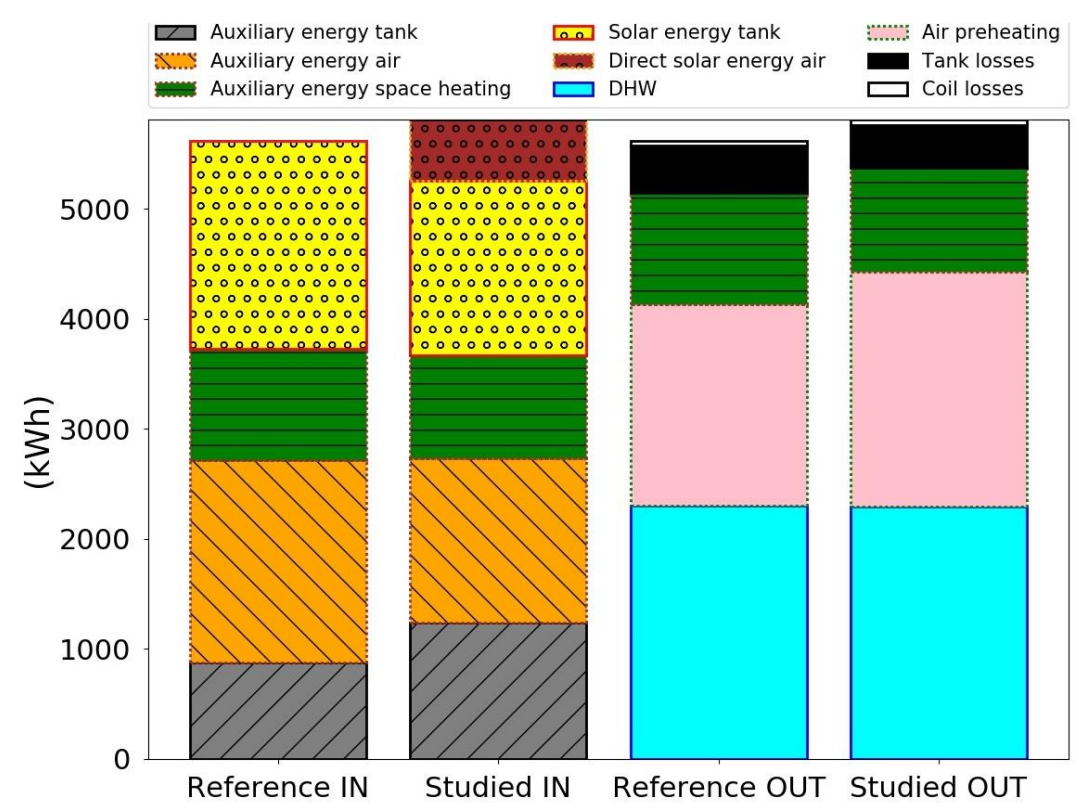

Fig. 3. Annual solar and auxiliary energies supplied for covering the DHW, air preheating and space heating needs for the reference and the studied systems for the climate of Lyon.

Fig. 4 shows a histogram of the temperature of the preheated air supplied to the building during the heating season for the studied and reference systems in order to illustrate air overheating when using the innovative system. The histogram of the outdoor air temperature during the heating season is also represented. Indeed, thermal comfort is improved when preheating the ventilation air by preventing cold air from blowing on the occupants. Fig. 4 also shows that the air is mostly preheated to the set point temperature $T_{\text {SetAir }}$ of $15^{\circ} \mathrm{C}$ for both systems but the studied system supplies a warmer air than the reference system during about 800 hours. A zoom of the air temperatures between -8 and $44^{\circ} \mathrm{C}$ shows closely the different distributions.

Higher supply air temperatures result in higher indoor temperatures for the studied system, as presented in Fig. 5. Consequently, the auxiliary energy consumption for space heating decreases about $6,5 \%$ and the total auxiliary energy concerning DHW, air preheating and space heating also decreases about $1,5 \%$ when using the innovative system, as shown before in Fig. 3. Indeed, air overheating is sometimes useful for reducing space heating consumption but, in other cases, it only increases indoor temperature when space heating is not needed, as shown in Fig. 5. For a building set point temperature of $19^{\circ} \mathrm{C}$ during occupation and $16^{\circ} \mathrm{C}$ with no occupation, temperatures in the ground floor are over $22^{\circ} \mathrm{C}$ for a longer time when using the innovative system. Fig. 5 also shows that air preheating provides a better thermal comfort, with higher indoor air temperatures, regarding a case without ventilation air preheating 


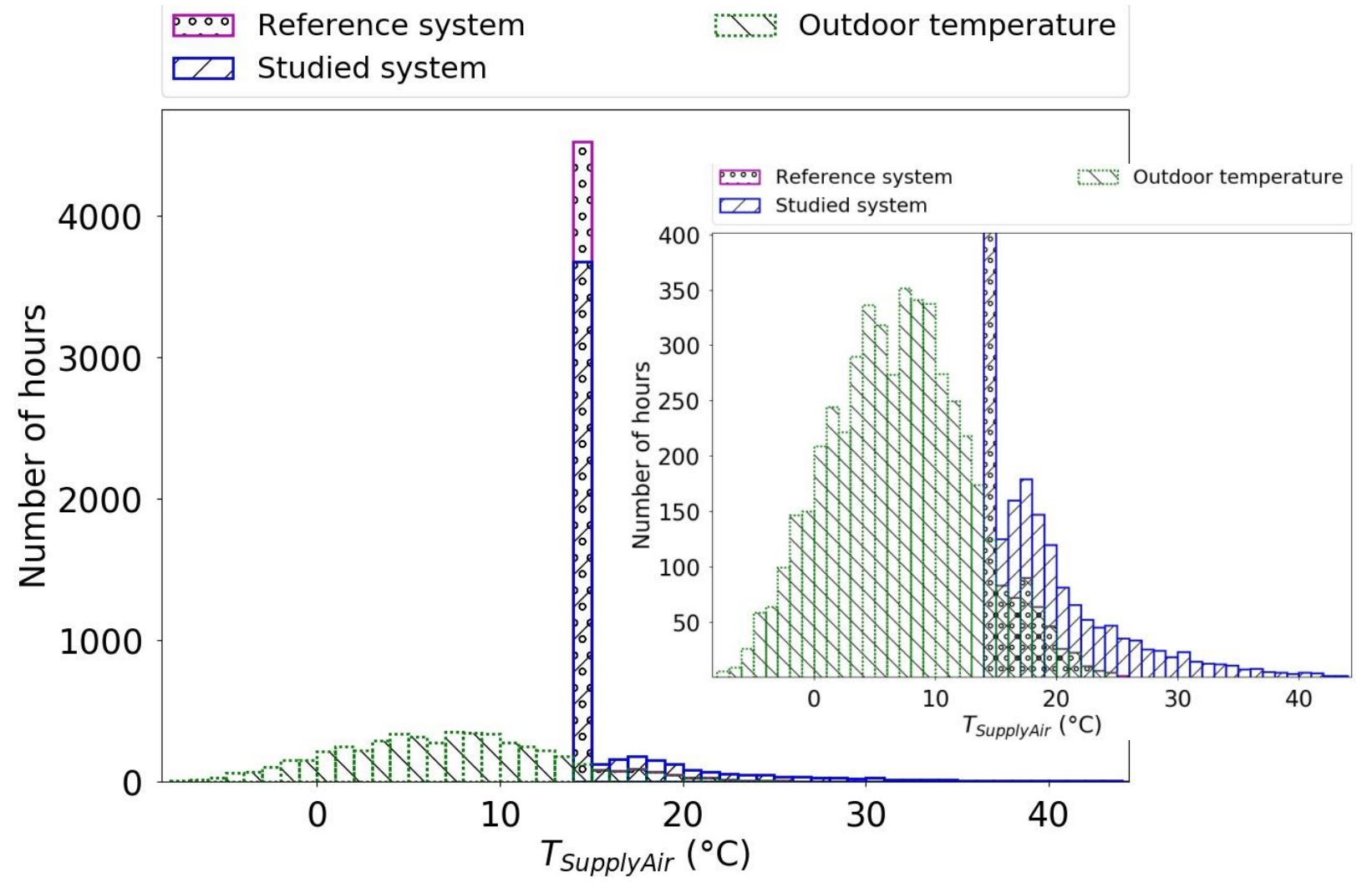

Fig. 4. Histogram of the supply air temperature when using the reference or the studied system and outdoor temperature during the preheating season in Lyon, including a zoom for air temperatures between -8 and $44^{\circ} \mathrm{C}$.

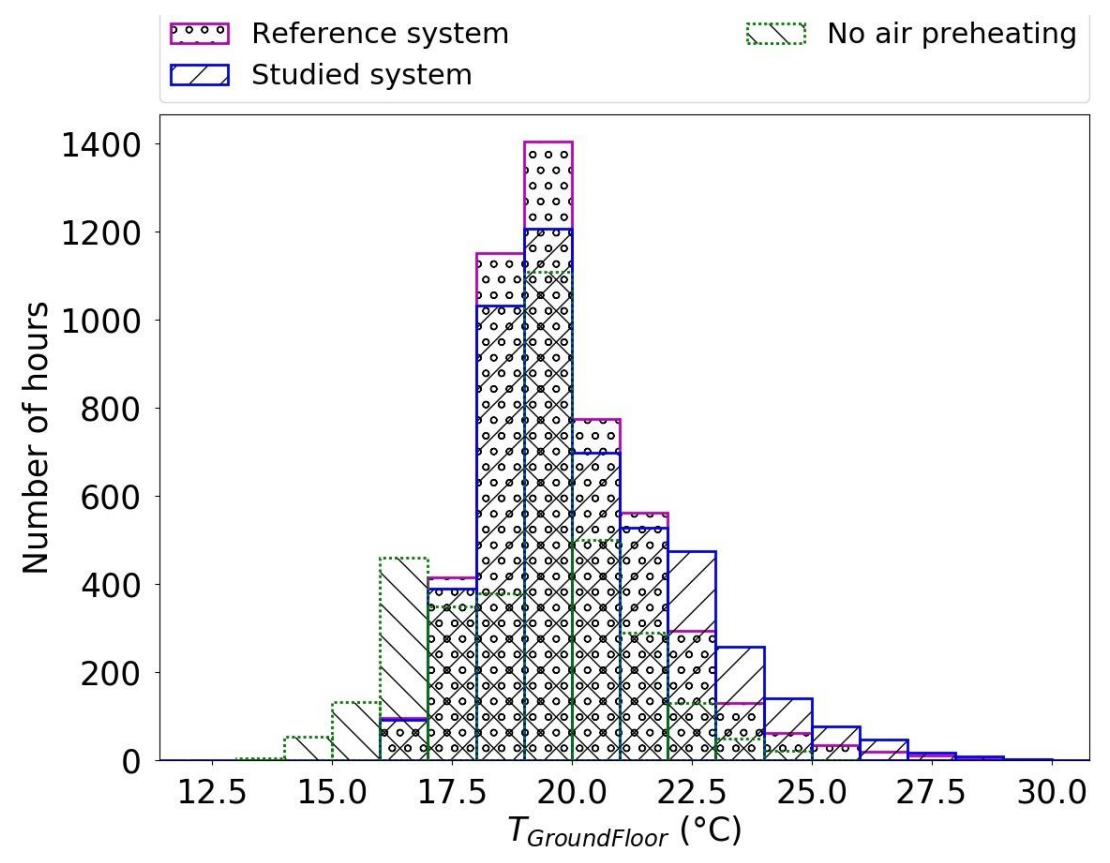

Fig. 5. Histogram of indoor temperatures of the ground floor during the heating season for the studied and the reference systems as well as for a case without air preheating, for the climate of Lyon.

\subsection{Parametric analysis}

\section{Variation of the climate}

The innovative system is studied hereafter for the different climates introduced in section 4.1. Fig. 6 shows the solar productivity SP for the reference and the innovative systems depending on the climate. There is a significant increase of the SP in all the studied cities thanks to air preheating, the SP improvement varying from 12,0\% in Paris to 22,3\% in Brest, the latter presenting a longer period for air preheating (Tab. 5) which allows the system to collect a higher quantity of solar energy. Nevertheless, the auxiliary energy consumption for heating the tank and for preheating the air is higher for all the studied climates when using the studied system, with the exception of Strasbourg where this auxiliary energy consumption decreases about $1,1 \%$. The auxiliary energy consumption used for DHW, air 
preheating and space heating is slightly reduced in the majority of climates with the innovative system, between 0,7 $\%$ in Brest and 2,3\% in Strasbourg, except for the warmer climates, Bordeaux and Marseille, where the total auxiliary energy consumption increases. In these cases, even if more solar energy is collected with the innovative system as shown in Fig. 6, the additional solar energy is mostly used to overheat the building instead of producing DHW. Thus, solar energy must be better distributed with a different control strategy.

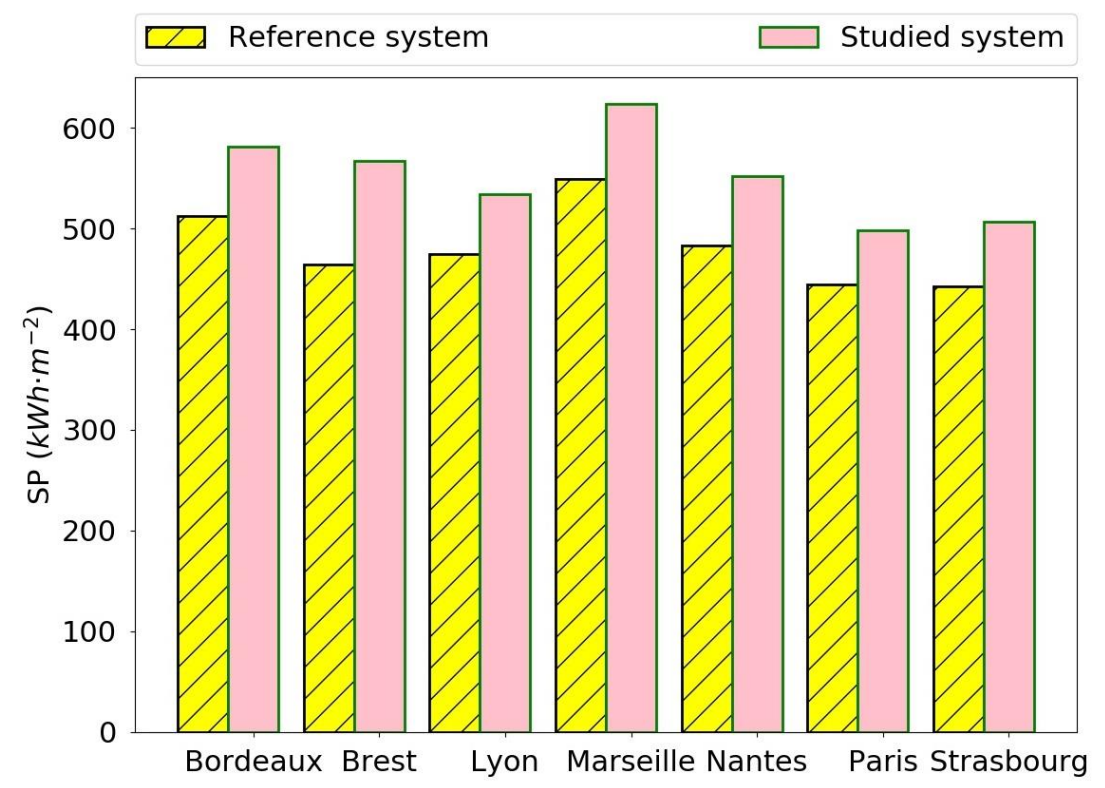

Fig. 6. Annual comparison of the solar productivity SP for the reference system and the innovative systems depending on the climate.

\section{Variation of the collector surface}

Collector surfaces $\left(\mathrm{S}_{\mathrm{Col}}\right)$ from 2 to $10 \mathrm{~m}^{2}$ are simulated for the climate of Lyon for the studied system. As shown in Fig. 7, the solar productivity SP decreases when increasing the collector surface. However, the global solar fraction $\mathrm{F}_{\mathrm{T}}$ increases with surface. Consequently, an important collector surface is more interesting from the energetic point of view, while keeping an appropriate solar productivity.

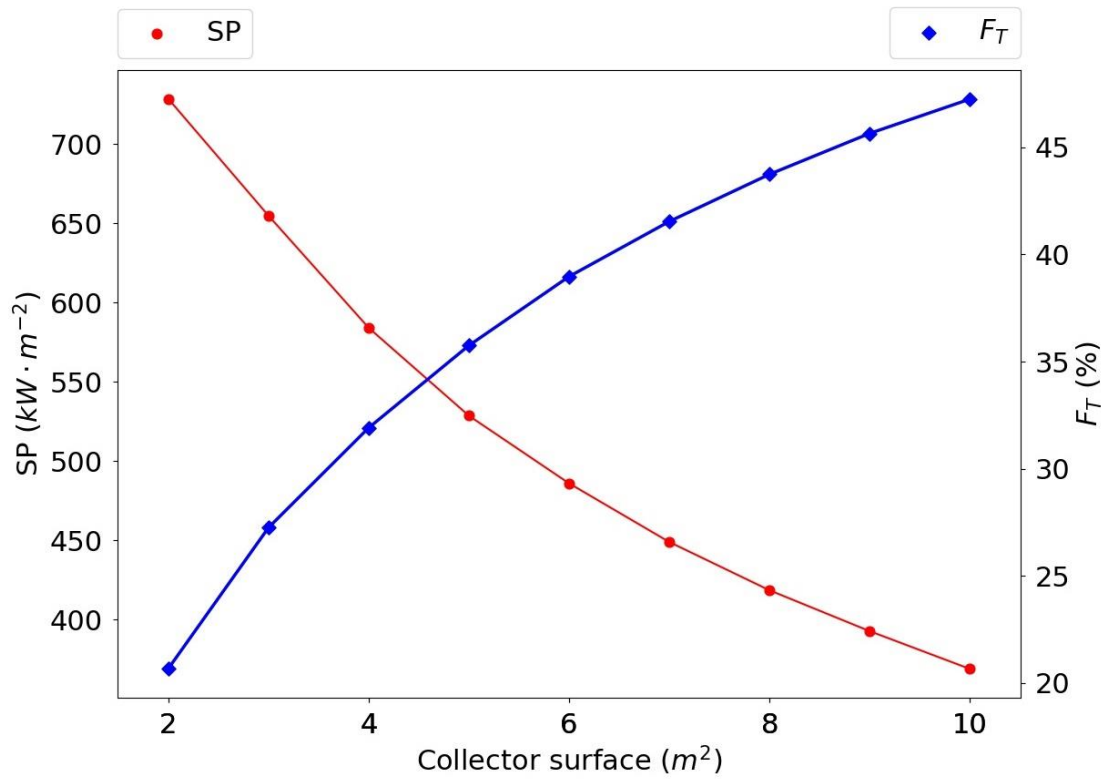

Fig. 7. Annual USP and global solar fraction for the climate of Lyon when using the innovative system for different collector surfaces.

\section{Variation of the tank volume}

Three tank volumes $\left(\mathrm{V}_{\text {Sto }}\right)$ of 300, 400 and 500 litres are simulated for the climate of Lyon. As the tank thermal losses are reduced when decreasing the tank volume, the storage efficiency $\eta_{\text {Sto }}$ is also reduced as observed in Fig. 8 . The total auxiliary energy consumption for DHW production, air preheating and space heating does not vary significantly when changing the tank volume. Thus, the volume of 300 litres seems appropriate for collecting and using the solar energy arriving to a collector surface of $4 \mathrm{~m}^{2}$, with less thermal losses and a lower price than bigger tanks. 


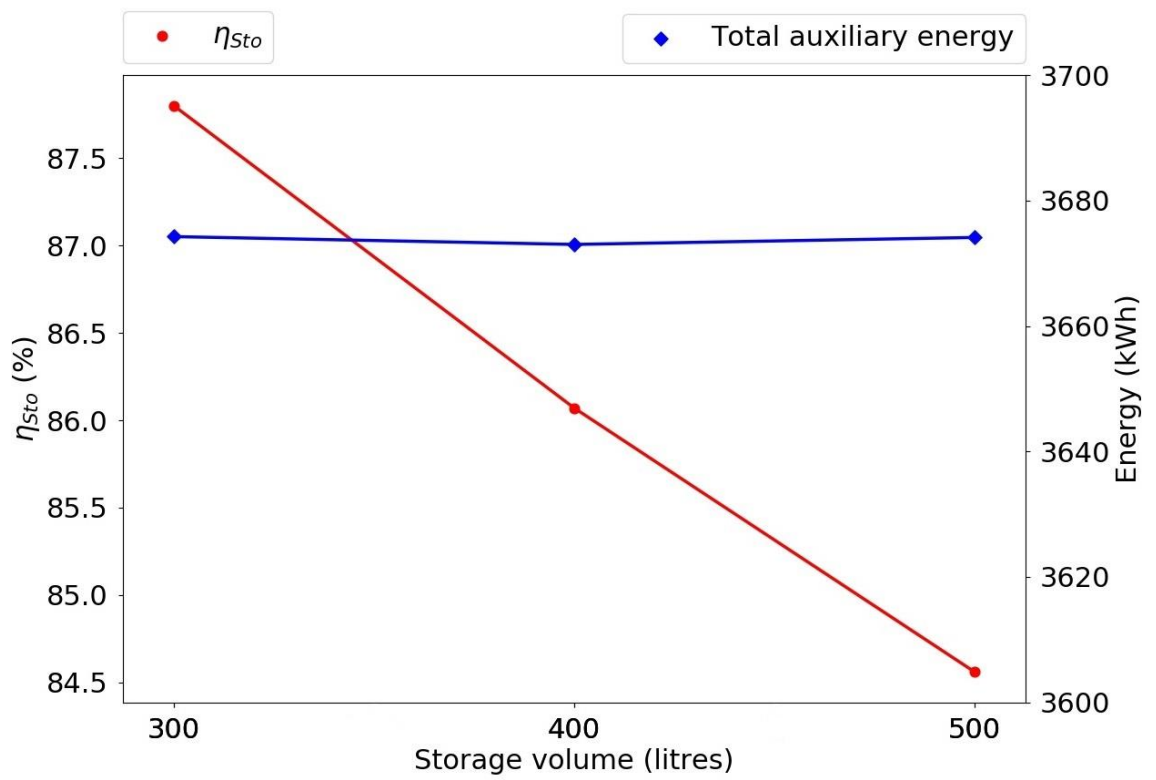

Fig. 8. Annual storage efficiency and total auxiliary energy consumption for DHW production, air preheating and space heating for the climate of Lyon when using the innovative system with different storage volumes.

Variation of the minimal temperature to enable air preheating with the stored energy

Five temperatures ( $\mathrm{T}_{\text {MinstoAir }}$ ): $10,20,30,40$ and $120^{\circ} \mathrm{C}$ are simulated for the studied system for the climate of Lyon and compared in Fig. 9. The case of $120^{\circ} \mathrm{C}$ represents a system where the air preheating by using the storage is not possible. The storage efficiency $\eta_{\text {sto }}$ increases when decreasing $\mathrm{T}_{\text {MinstoAir }}$, meaning that a part of the tank thermal losses are transformed into useful solar energy. Nevertheless, the air preheating by using the energy stored in the tank is not enhanced neither with the involved control algorithm nor with the selected collector surface of $4 \mathrm{~m}^{2}$. Consequently, the differences in energy savings concerning the total auxiliary energy consumption are not significant. In any case, the lowest temperature of $10^{\circ} \mathrm{C}$ is recommended for improving the energetic performances of the system. DHW comfort was checked and it is not deteriorated for the different temperatures $\mathrm{T}_{\text {MinstoAir. }}$.

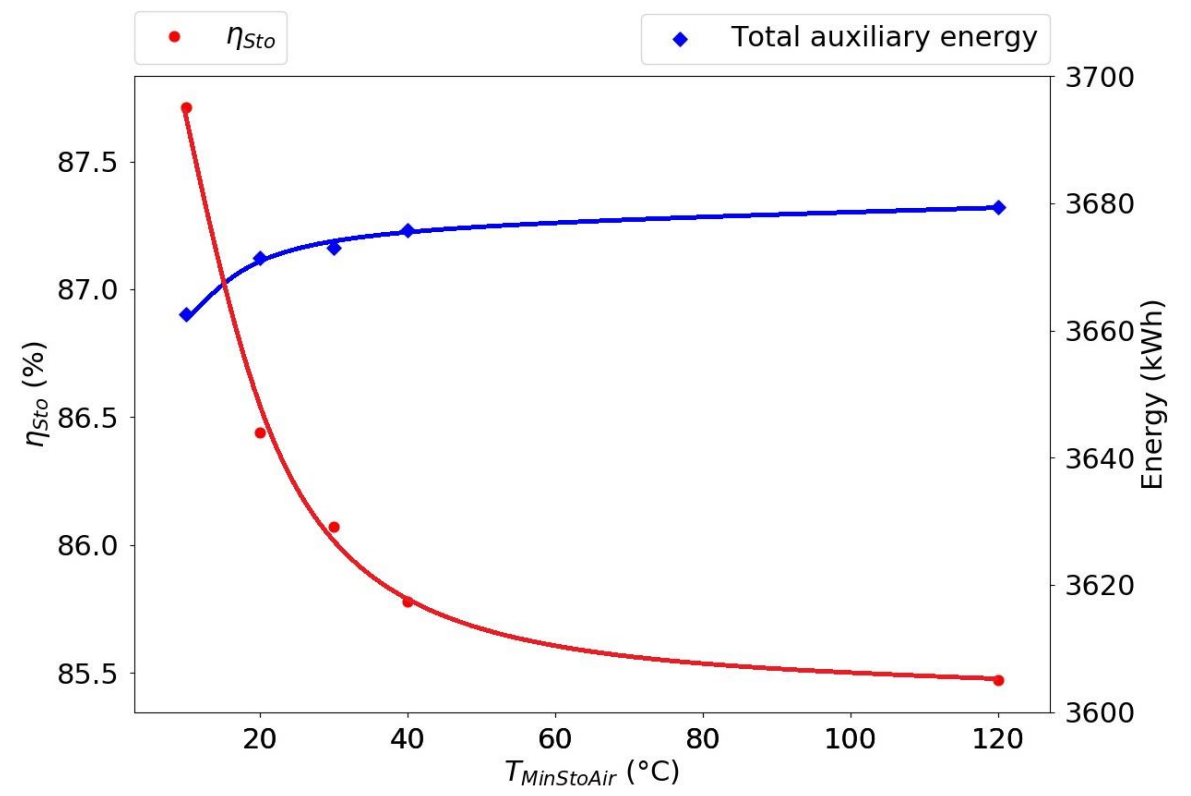

Fig. 9. Annual storage efficiency and total auxiliary energy consumption for DHW production, air preheating and space heating for the climate of Lyon when using the innovative system with different minimal temperatures in the tank for allowing air preheating.

\section{Variation of the air preheating set temperature}

Three set temperatures $\left(\mathrm{T}_{\text {SetAir }}\right)$ of 12,15 and $18^{\circ} \mathrm{C}$ are simulated and compared for the climate of Lyon in Fig. 10. These values are the typical air preheating temperatures in France. Although a higher set air temperature $\mathrm{T}_{\text {SetAir }}$ increases the solar productivity SP, the total auxiliary energy consumption for DHW production, air preheating and space heating also increases for a higher $\mathrm{T}_{\text {SetAir. }}$. Indeed, a higher set point temperature for air preheating requires outdoor air be preheated to a higher temperature, even when space heating is not necessary, thus increasing the total energy consumption. Consequently, the lower temperature $\mathrm{T}_{\text {SetAir }}$ of $12^{\circ} \mathrm{C}$ is recommended. 


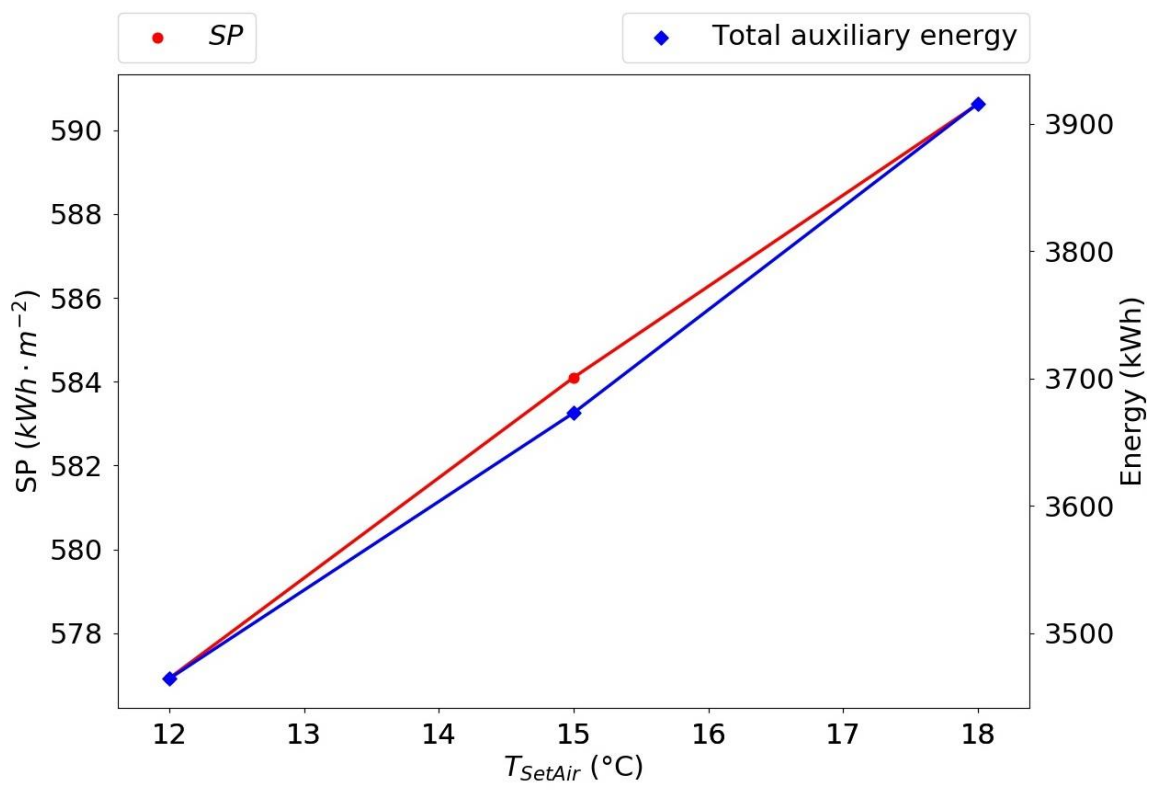

Fig. 10. Annual solar productivity and total auxiliary energy consumption for DHW production, air preheating and space heating for the climate of Lyon when using the innovative system with different set air temperatures.

\section{Conclusions}

This paper presents the numerical study of a solar thermal system producing DHW and preheating the ventilation air to a minimal temperature of $15^{\circ} \mathrm{C}$, using a collector surface of $4 \mathrm{~m}^{2}$ and a storage tank volume of 400 litres. The analysis is mainly done for the French city of Lyon, including the comparison with other French climates.

When comparing the innovative system with a classical SDHW system that only produces DHW, preheating the air with an independent auxiliary heater, the innovative system improves the collector efficiency and the solar productivity for all the studied climates. Thus, air preheating allows the system to collect and deliver more solar energy. Nevertheless, as part of the solar energy used for heating the storage tank in a classical SDHW system is now used for air preheating, more auxiliary energy must be supplied to the tank. Consequently, the auxiliary energy consumption for DHW production and for air preheating is increased for the majority of the studied climates when using the innovative system with a $4-\mathrm{m}^{2}$ collector surface and a 400 -litre tank. This is due to air overheating, meaning that a significant part of the solar energy supplied to the air results in a temperature of the preheated air higher that its set point temperature $T_{\text {SetAir }}$, thus reducing the space heating energy consumption. Regarding the total auxiliary energy consumption for DHW production, air preheating and space heating, energy savings between 0,7 and 2,3\% are achieved depending on the climate, except for Bordeaux and Marseille, the warmer climates, where the total auxiliary energy consumption increases with the studied system. Consequently, particularly for the climates of Bordeaux and Marseille but also for the other climates where energy savings are not significant, the control strategy should enhance the storage of solar energy when air overheating is not useful for reducing space heating consumption. In general, when dimensioning the solar system for a typical DHW application, there is no much extra solar energy available for air preheating. Thus, the control algorithm is essential for optimising energy performance. Even if energy gains are limited, they are interesting as they can be achieved easily, only by adding a heat exchanger coupling the solar loop and the ventilation network.

Finally, a parametric analysis for the climate of Lyon provides some clues for improving the energy performance of the studied system. Increasing the collector surface results in a higher global solar fraction and a lower solar productivity. Thus, the collector surface can be increased while keeping an acceptable solar productivity. The studied tank volumes do not show a significant impact of the energy savings provided by the innovative system. Consequently, the lower studied volume of 300 litres is recommended in order to increase the tank efficiency and decrease its price. The system also allows the air to be preheated indirectly by using the energy stored in the tank. Although this option provides some energy savings regarding the case without indirect air preheating, the implemented control strategy do not deliver enough energy to the tank to obtain significant energy savings with a collector surface of $4 \mathrm{~m}^{2}$. Finally, a higher set point temperature for air preheating $T_{\text {SetAir }}$ results in a higher total auxiliary energy consumption regarding DHW production, air preheating as well as space heating. Consequently, it is not recommended to increase the set point temperature $\mathrm{T}_{\text {SetAir. }}$ 
The next step of this study consists in optimising the control algorithm of the presented innovative system in order to improve the solar energy distribution and so, energy performance. A previous sensitivity analysis will differentiate the most influential variables over the energy performance indicators that should be optimised.

\section{References}

ADEME, 2012. Feuille de route stratégique solaire thermique.

Blochwitz, T., Otter, M., Arnold, M., Bausch, C., Clauß, C., Elmqvist, H., Junghanns, A., Mauss, J., Monteiro, M., Neidhold, T., Neumerkel, D., Olsson, H., Peetz, J.-., Wolf, S., Gmbh, A.S., Berlin, Q., Scai, F., Augustin, S., 2011. The Functional Mockup Interface for Tool independent Exchange of Simulation Models, in: Proceedings of the 8th International Modelica Conference.

Bois, J., 2017. Aide à la conception de maisons à énergie positive à forte ouverture solaire (PhD thesis). Université de Bordeaux.

Crawley, D.B., Lawrie, L.K., Winkelmann, F.C., Buhl, W.F., Huang, Y.J., Pedersen, C.O., Strand, R.K., Liesen, R.J., Fisher, D.E., Witte, M.J., Glazer, J., 2001. EnergyPlus: creating a new-generation building energy simulation program. Energy and Buildings 33, 319-331.

European Commission, 2013. Energy, transport and environment indicators, 2013 edition. Publications Office of the European Union, Luxembourg.

Faninger, G., 2010. The potential of solar heat in the future energy system. Faculty for Interdisciplinary Research and Continuing Education, IFF-University of Klagenfurt, Austria 20.

Feist, W., Schnieders, J., Dorer, V., Haas, A., 2005. Re-inventing air heating: Convenient and comfortable within the frame of the Passive House concept. Energy and Buildings, Research That Inspires 125 Years of EMPA 37, $1186-1203$.

Heimrath, R., Haller, M., 2007. Project Report A2 of Subtask A: The Reference Heating System, the Template Solar System (No. Task 32). IEA SHC.

IEA, 2012. Technology Roadmap Solar Heating and Cooling.

IEA-ETSAP, IRENA, 2015. Solar Heating and Cooling for Residential Applications.

Ionescu, C., Baracu, T., Vlad, G.-E., Necula, H., Badea, A., 2015. The historical evolution of the energy efficient buildings. Renewable and Sustainable Energy Reviews 49, 243-253.

Jordan, U., Vajen, K., 2000. Realistic Domestic Hot-Water Profiles in Different Time Scales (No. Task 26). IEA SHC, Universität Marburg, FB Physik, Marburg, Germany.

Rahmeh, M., 2014. Etude expérimentale et numérique des performances de la ventilation mécanique par insufflation : qualité de l'air intérieur dans les bâtiments résidentiels (Phd thesis). Université de La Rochelle.

Spitz, C., 2012. Analyse de la fiabilité des outils de simulation et des incertitudes de métrologie appliquée à l'efficacité énergétique des bâtiments (PhD thesis). Université de Grenoble.

Wetter, M., Bonvini, M., Nouidui, T.S., 2016. Equation-based languages - A new paradigm for building energy modeling, simulation and optimization. Energy and Buildings 117, 290-300. 


\title{
Comparative Dynamic Performance Tests of Two Real Technology Packages for Buildings Heating System Retrofit
}

\author{
David Chèze ${ }^{1}$, Nicolas Lamaison ${ }^{1}$, Patric Breitenbach ${ }^{2}$ and Federica Fuligni ${ }^{3}$ \\ 1 Univ Grenoble Alpes, CEA, LITEN, DTS, INES, F-38000 Grenoble (France) \\ 2 Bosch Thermotechnik, Wernau (Germany) \\ ${ }^{3}$ Exergy, Coventry (England)
}

\begin{abstract}
This work is performed within the framework of the THERMOSS EU project. The main objective of the project is to foster the deployment of advanced heating and cooling technologies with high replication potential, enabling 20-30\% primary energy consumption reduction through thermal solar combination, model predictive control and storage strategy. The efficient match between supply and demand of energy is ensured by real-time management of thermal energy at building level and at district level for District Heating and Cooling (DHC) connected buildings. Before installing the systems in real THERMOSS demonstration sites by the end of 2018, the whole system test of two heating technologies (hybrid solar heat pump and interface unit to heat network) from the industrial partner has validated some recent features while assessing the performance of these technologies with dynamic reproducible boundary conditions (small residential buildings, Western European climate). The results assessed the primary energy savings in the range $9.7-36 \%$ and revealed its high sensitivity to control parameter settings related to the use of indoor temperature sensor. The realistic dynamic test also emphasized the major influence on the standby heat losses of thermal inertia of the system components combined with flow temperature control. For both technologies, the realistic radiator thermostatic valve emulation enabled to keep the deviation of the space heat load below $1.8 \%$ compared to the reference individual gas boiler.
\end{abstract}

Keywords: solar thermal, hybrid air source heat pump, heat network interface, building retrofit, experimental dynamic performance test, primary energy indicators, control validation, radiator thermostatic valve

\section{Introduction}

This work was performed in the framework of H2020 Thermoss project (Fuligni and Centeno 2016). It aims at the demonstration of efficient heating technologies recently arrived or arriving on the market that reduce primary energy consumption for heating or cooling of building, thanks to renovation of the heating/cooling system. A few technologies have been proposed for demonstration in real demo sites with real users and the performance of two others are to be demonstrated through test results in realistic operating conditions. This work focused on two technology packages for Space Heating (SH) and Domestic Hot Water (DHW) supply, at small residential building scale, abbreviated in this article as:

- SHP: Solar and air source split Heat Pump combisystem with gas backup and thermal storage.

- HIU: Heat Interface Unit in replacement of individual heating systems in apartments block by centralized highly efficient heat generators and distributed compact units in the dwellings.

In Thermoss perspective, the heating system test objective is to get experimental, reproducible evaluation of the overall system behaviour in realistic operating conditions, including real control. The subgroup of solar combisystems (here referring to heating systems providing both DHW and space heating by mean of solar thermal collector and with flexible heat backup like fuel boiler or electrical heater) test was investigated in the past by several research teams. In Albaric et al., 2010 the authors analysed two approaches to evaluate the system behaviour/performance either as extrapolated system behaviour from previous component tests or as direct whole system test. The findings were that the extrapolation approach based on components tests is limited in accuracy by the missing knowledge of the full components details and inter-connections, in particular regarding the control implementation. For this reason the comparison of performances of hybrid system packages including confidential 
developments of their manufacturers (blackbox systems) appears more straightforward with a 'whole system test' approach in specific reproducible test conditions. This latter approach was used for Thermoss work and its principles, main characteristics, new development (as the radiator thermostatic valve emulation) and comparison of primary energy figures are presented in the second section of this article. The description of the tested systems, installations on the test bench, test results and discussions are presented successively in the following sections.

\section{Methodology of dynamic system test}

\subsection{Overview}

A comparison of specific methodologies based on 'whole system test' are given in Haller et al. 2013. In particular, the authors categorized the findings based on the heating load as fixed heating load file or as dynamic models of the heating load. Among the studies relying on fixed load file, the recent work of Menegon et al., 2017, investigated the characterization of HeatingVentilationAirConditionning (HVAC) systems and the methodology to generate a customized test sequence for a given HVAC system. While it allows direct comparison of systems performance test results since the method ensures the systems are providing the same heat loads, it doesn't account for specific dynamic behaviors of the radiator and buildings that are influenced by the characteristic behavior of the real system control during the test. As a consequence, there's a discrepancy between the results from such test compared to those obtained in fully real operating conditions.

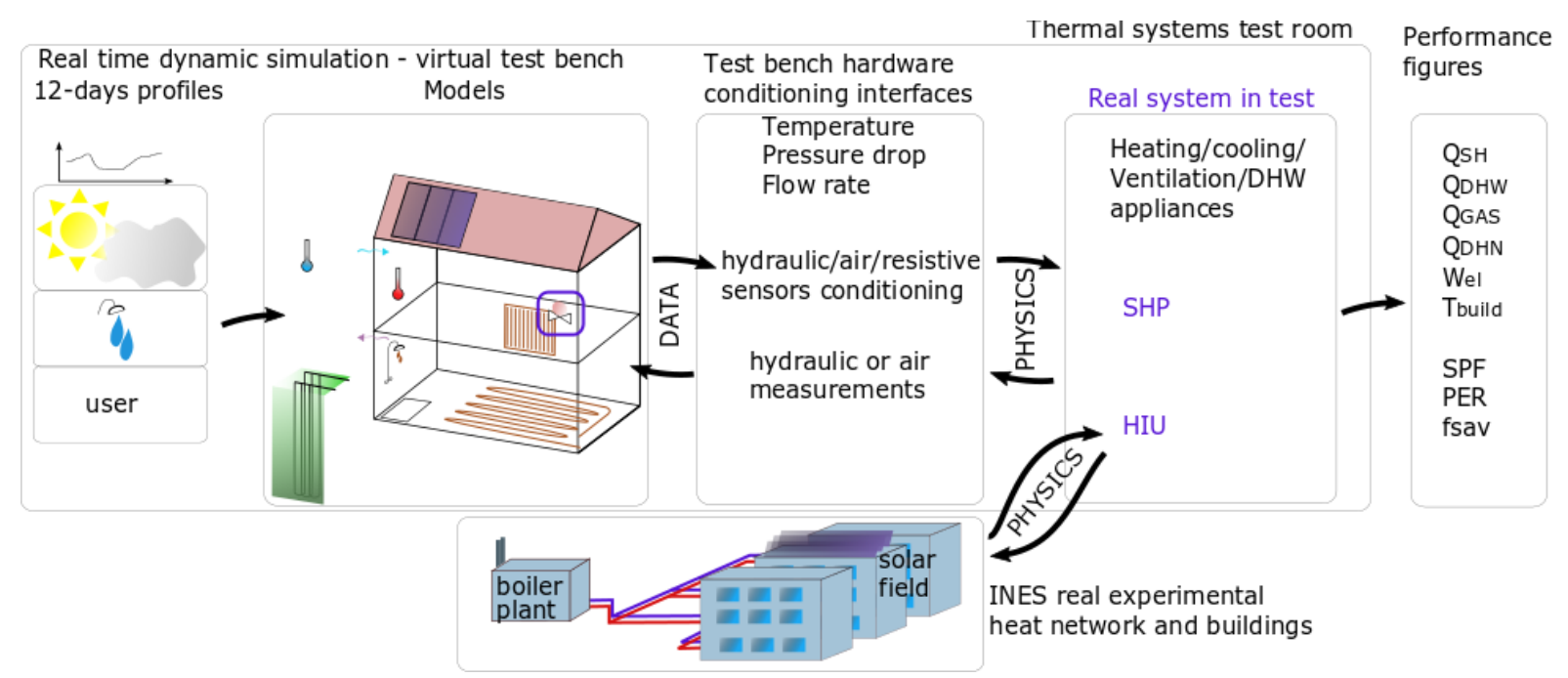

Fig. 1: Principle of semi-virtual dynamic performance test of HVAC systems at CEA INES ; illustrated by SHP and HIU test cases with performance figures defined in $\$ 2.3$

A dynamic whole system test methodology using real time dynamic models of the heating load, called SCSPT test (Short Cycle System Performance Test), was originally developed for solar gas boilers combisystems (Albaric, M. et al., 2008) by CEA INES team. It consists in real-time hardware in the loop dynamic system test (including all thermal and control parts) for thermal systems during 12 days. It relies on TRNSYS 17 dynamic simulation system to cover the typical working conditions during 12 months of operation, as illustrated in Fig. 1. The test conditions are representative of annual variations of the Zurich climate $(\mathrm{CH})$. The heat demand of the Single Family House simulated building is $60 \mathrm{kWh} / \mathrm{m}^{2} /$ year (SFH60) to maintain constant $20^{\circ} \mathrm{C}$ indoor temperature at the same location. The SFH60 building consists in a two storeys building of $140 \mathrm{~m}^{2}$ total floor heated area and $350 \mathrm{~m}^{3}$ volume. Further details about the building are contained in International Energy Agency Solar Heating and Cooling (IEA SHC) Task 32 work (Heimrath and Haller, 2007). During the 12-days test the total global horizontal radiation is $33.9 \mathrm{kWh} / \mathrm{m}^{2}$, the average outdoor temperature is $8.4^{\circ} \mathrm{C}$ and the total water draw-off reaches $2436 \mathrm{~L}$, about $200 \mathrm{~L} /$ day with maximum flowrate of $8 \mathrm{~L} / \mathrm{min}$ and minimum of $3 \mathrm{~L} / \mathrm{min}$. The simulated climate and draw-off profiles are applied in real time (no virtual time acceleration), with 1 minute time step operation, to the real tested appliance in the test room. Fig. 2 shows an outlook of the 12-days test conditions variations. The INES experimental Heat Network shown in Fig. 1 comprises a $280 \mathrm{~kW}$ condensing gas boiler, $300 \mathrm{~m}^{2}$ of thermal solar panels, a hot tank storage of $40 \mathrm{~m}^{3}$ and a two-tubes distribution network (see Fig. 3). It supplies heat to several consumers, including real buildings and the aforementioned semi-virtual test-bench. In the HIU work described in section 4 we used the SFH60 building referred as 'Emulated Building' in Fig. 3. 


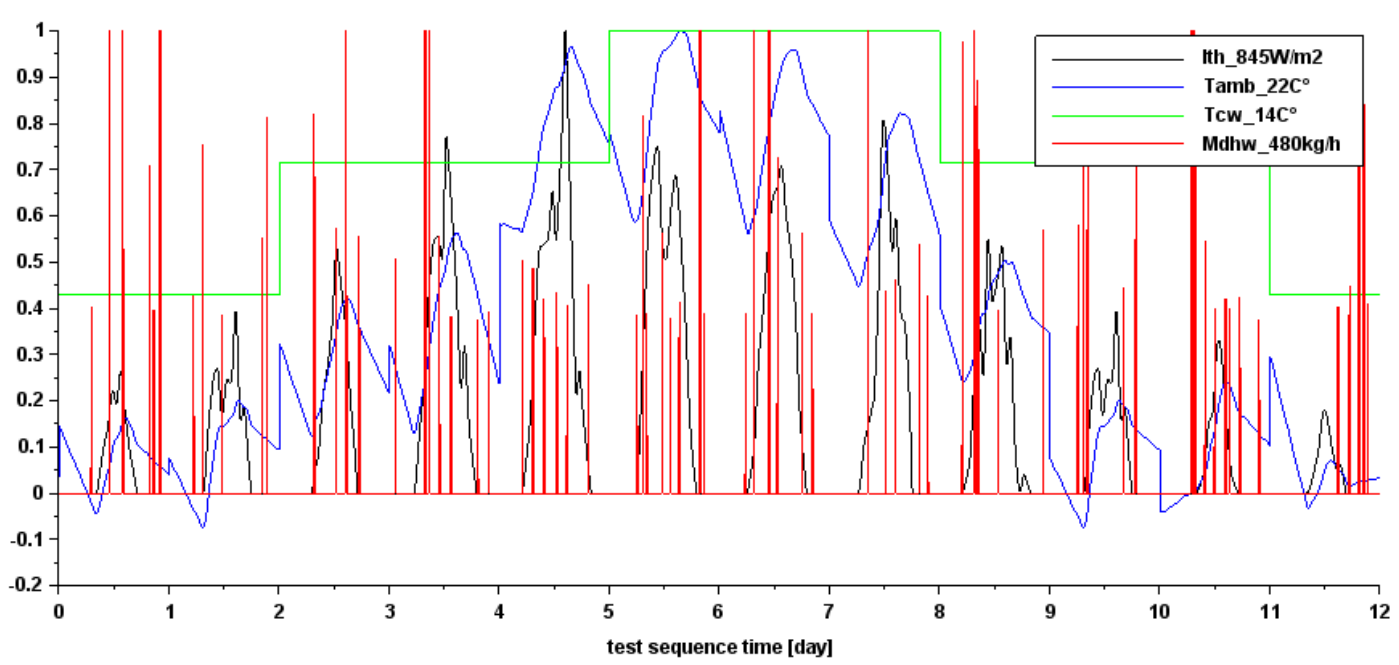

Fig. 2: Normalized total horizontal radiation, outdoor and cold water temperature and water draws flow rates along the 12-days test sequence

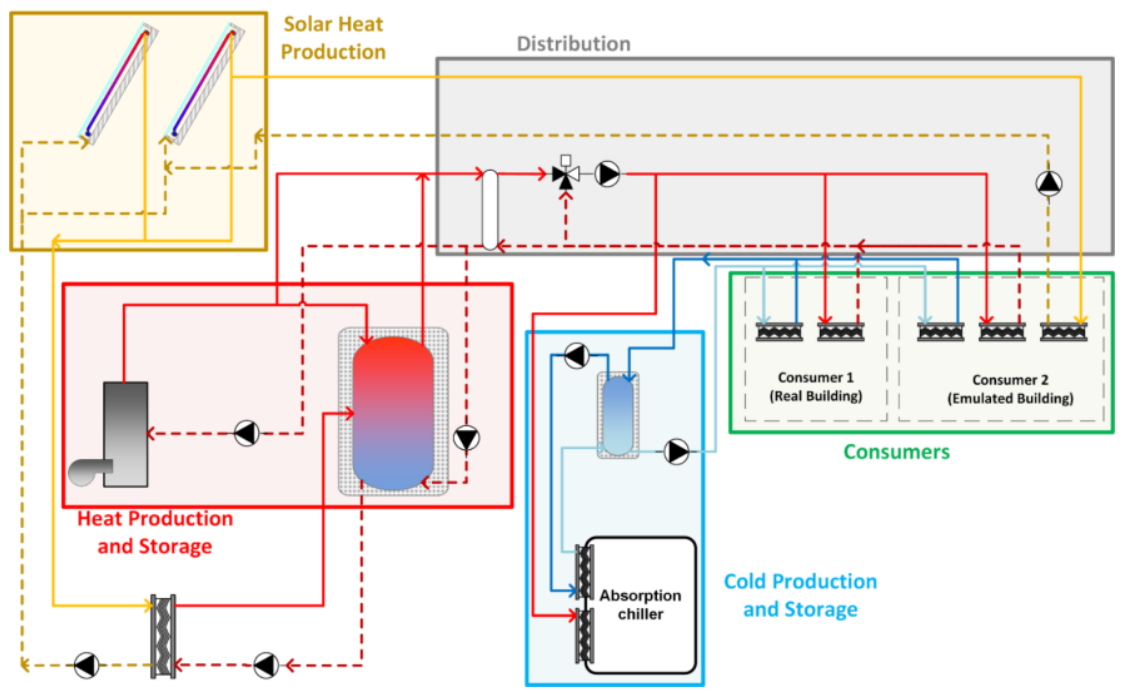

Fig. 3: Principles of micro District Heat Network (DHN) at CEA-INES

The dynamic whole system test methodology was recently improved by the testing institutes SPF, SERC, CEA INES as part of the MacSheep EU project (Chèze et al. 2014) regarding the control of space heating and DHW loads (with climate conditions selection for solarcombi systems relying on water heat pump) and the duration of the test sequence (reduced to 6 days). In this approach the fixed space heating load is achieved by combination of radiator dynamic model and a 1-minute-profile of authorized maximum load during the 6 days of simulation.

In the THERMOSS project, we used this approach to provide new results with the specific 6-days test sequence for the Solar Heat Pump (SHP) in section 3. We also performed the test following the SCSPT 12-days test procedure in order to compare the new SHP test results with those of the hybrid systems previously tested at CEA INES under different project and circumstances using the same test conditions.

\subsection{Radiator thermostatic valve emulation}

Within the THERMOSS framework, the SCSPT test method was upgraded with robust real dynamic pressure drop emulation of a thermostatic valve in the virtual radiator circuit. The aim is to evaluate the heat load behavior 
with a fully realistic emulation of the radiator thermostatic valve compared to previous developments within the MacSheep project to ensure a fixed heat load (Chèze et al., 2015) and (Haberl et al., 2015). So far most of the tested heating systems' controllers are using an indoor temperature sensor (an emulated one for the test bench experiments) to optimize flow temperature in the heating circuit. The emulated temperature sensor accounts for passive solar gains, electric devices and human occupancy gains. However, the emulated sensor is not able to operate for the case of thermostatic valve (THV) on radiators and without automatic heating curve adjustments, which is a very frequent type of installation. This happens even with the more recent appliances that can modulate the flow rate via variable speed pumps. When the emulated sensor is not able to operate, the supply flow temperature from the heating appliance is purely based on the outdoor temperature and occupancy schedules. Therefore, how to evaluate the performance of such a system? How to compare the performance test results between systems with/without indoor sensor information? In this study, we proposed to emulate a THV in order to observe realistic dynamic variable flows and pressure drop at the system boundaries. THV dynamic was approximated as ProportionalIntegral-controlled motorized valve instead of Proportional-controlled thermostatic actuators to ensure that the flow rate is actually reduced down to its minimal value, until the setpoint temperature is reached. This behavior is similar to the one of existing electronic thermostat embedded in the radiator valve head. The practical implementation is $100 \%$ on test bench side and consists of:

- Real controllable motorized valve in test bench;

- $\quad 20.5^{\circ} \mathrm{C}$ virtual indoor set point for PI control in TRNSYS dynamic simulation, similar dynamic as a radiator thermostatic valve, $0.5 \mathrm{~K}$ is a common dead-band accuracy for room thermostat;

- $\quad 5 \%$ minimal opening level of the valve on the test bench (similar effect to these of safety differential pressure valve in heating circuit).

The influence of this emulated THV on the space heating flow rate was visible during SHP test $\mathrm{n}^{\circ} 3$ as illustrated in Fig. 4. A constant nominal flow rate about $800 \mathrm{~kg} / \mathrm{h}$ in space heating loop is observed with the default settings of the space heating pump for the emulated building. In Fig. 4, when the emulated indoor temperature rises above $20.5^{\circ} \mathrm{C}$, we see as expected that the valve progressively reduces the flow rate only for small periods in emulated 'cold season' (0 to $6000 \mathrm{~min}$. or 14000 to $17000 \mathrm{~min}$.) and for a long duration in 'hot season'(11500 to 14000 min.). The space heating pump is halted by the SHP controller when the daily average outdoor temperature rises above $16^{\circ} \mathrm{C}$.

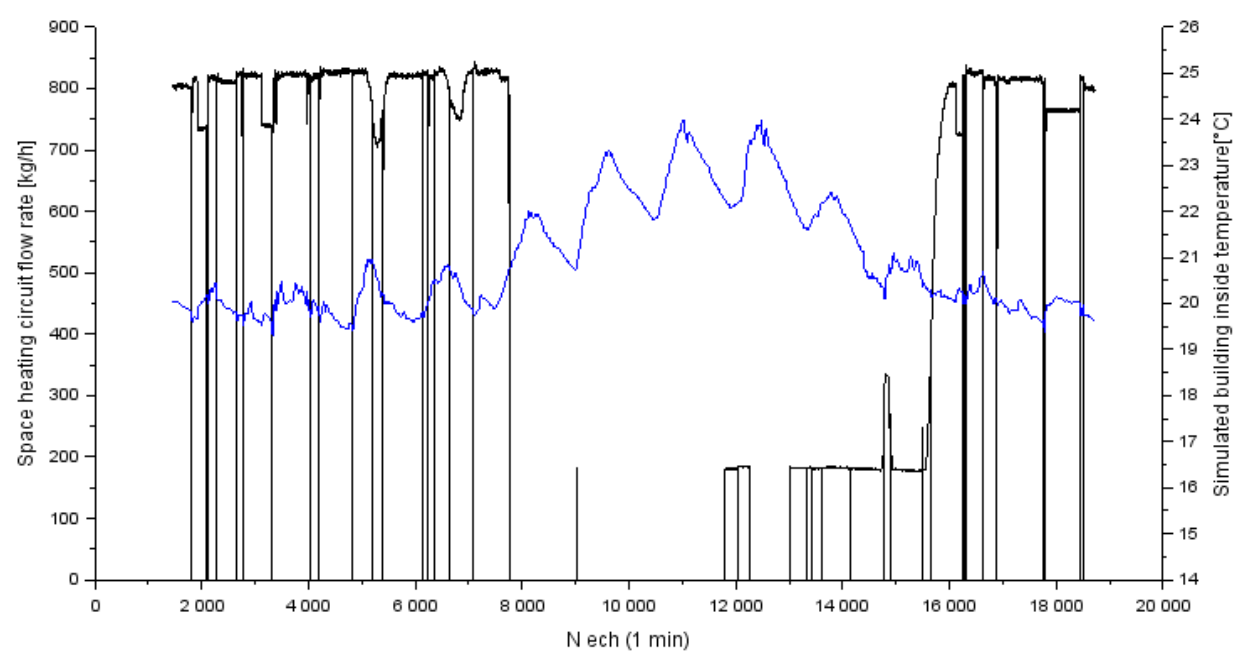

Fig. 4: Actual realistic space heating flow rate variations for a 12-days test with THV and indoor temperature emulation

\subsection{Reference systems and indicators}

Thermoss Project methodology relies on the primary energy savings approach for the comparison of the performance of several type of heating technology packages, as described in Deliverable 3.1 (Chèze et al., 2017). The methodology is based on the calculation of the fuel (gas and/or electricity) consumed by the testing systems compared to that of the R1 reference heating system, a condensing gas boiler with $85 \%$ average annual efficiency 
for space heating and DHW (including a 200L tank), single family house context. This reference has also been used in Task 26 (Streicher and Heimrath, 2003) and Task 32 (Heimrath and Haller, 2007). The indicators used in the test are:

- $I_{\text {hor }}$, total irradiation on horizontal plane over the period

- $T_{a m b}$, mean ambient outdoor temperature over the period

- $T_{\text {build }}$, mean building indoor temperature over the period

- $\int P_{S H} \cdot d t=Q_{S H}$, heat delivered to the building by the heating circuit over the period

- $\int P_{D H W} \cdot d t=Q_{D H W}$, heat delivered to the user as DHW over the period

- $\int P_{C O L} \cdot d t=Q_{C O L}$, heat from the emulated solar collector delivered to the real system under test over the period

- $\int P_{e l} . d t=E_{e l}, \int P_{e l H P} . d t=E_{e l H P}$ total absorbed electricity resp. by the whole system and by Heat Pump only when present over the period

- $\int P_{a u x} . d t=Q_{a u x}$, heat produced by the HP

- $\int P_{g a s} \cdot d t=Q_{g a s}$, fuel energy consumption as lower heat content

- $Q_{P E}=1 * Q_{g a s}+2.5 * E_{e l}$, total primary energy consumed by the tested system over the period. By convention in the calculation for each system test performed in this work, the conversion factors from natural gas consumption to primary energy and from electricity consumption to primary energy are taken as 1 and 2.5 respectively. It is not specific to any country and there's still no agreement on common figures usable across Europe.

- $\quad N_{H P}, N_{B U R}$, respective number of starts of HP and burner when present over the period

- $\quad P F_{S Y S}=\frac{Q_{S H}+Q_{D H W}}{E e l}$, performance factor of the whole system over the period, ratio of useful heat over total electricity consumption for heat pump systems (nb: when the period is one year, it is commonly named Seasonal Performance Factor (SPF) )

- $\quad P E R_{S Y S}=\frac{Q_{S H}+Q_{D H W}}{Q_{P E}}$, primary energy ratio of the whole system over the period

- $f S a v_{P E, S Y S}=1-\frac{Q_{g a s}+2.5 * E_{e l}}{Q_{g a s, r e f}+2.5 * E_{e l, r e f}}$, the primary energy savings over the period compared to the reference case, introduced in THERMOSS Deliverable 3.1.

The main performance values for the $\mathrm{R} 1$ reference case (residential context) are reported in Tab. 1 .

Tab. 1: Reference system performance figures R1

\begin{tabular}{|l|l|l|l|l|l|l|l|}
\hline Reference R1 & Qsh & Qdhw & Eel & Qloss & Qgas & QPE & PER \\
\hline kWh & 279 & 100 & 22 & 21 & 471 & 526 & 0.72 \\
\hline
\end{tabular}

In a heat network context, a reference heating system R2 is introduced that considers a network with a condensing gas boiler, a piping system and a pump to connect to a user with a heating system and a DHW tank. A density of $8 \mathrm{MWh} / \mathrm{m} / \mathrm{yr}$ (usually range between 1.5 and $15 \mathrm{GWh} / \mathrm{m} / \mathrm{yr}$ ), a supply and return temperature of $60^{\circ} \mathrm{C}$ and $40^{\circ} \mathrm{C}$ and an average diameter of the piping of $100 \mathrm{~mm}$ is considered for the network. That density led to an equivalent piping of $1.5 \mathrm{~m}$ which was used to calculate yearly heat losses and pump consumption. Heat losses for a DHW tank of 501 were also calculated. Finally, the condensing gas boiler efficiency (101.9\%) was obtained from traditional manufacturers' datasheet and based on the average network temperature. Tab. 2 summarizes the R2 system performance figures.

Tab. 2: R2 Reference system performance figures

\begin{tabular}{|l|l|l|l|l|l|l|l|}
\hline Reference R2 & Qsh & Qdhw & Eel & Qloss & Qgas & QPE & PER \\
\hline kWh & 279 & 100 & 24.4 & 20.1 & 391.7 & 454.6 & 0.83 \\
\hline
\end{tabular}




\section{SHP testing}

\subsection{Tested systems description}

The Solar Heat Pump System (SHP) is based on existing components. It is a new hybrid combination for Compact pre-fabricated Bosch products Cerapur solar tank with gas boiler and Supraeco air source heat pump as main heat generators. An architecture with relay interaction between gas boiler and heat pump controllers exists but with less compact/pre-mounted integration of solar installation with either the gas boiler or the air source heat pump. In this context the control principle is that the solar combisystem controller manages the heat delivery to the user; it requests heat from the gas burner when the buffer tank temperature doesn't reach the setpoint temperature calculated from the current user demand (either SH or DHW demand). The heat pump is operating in space heating mode only of the top of the buffer tank following the same outdoor heating curve as the solar combisystem without indoor temperature sensor correction.

The SHP test comprises:

- Solar combisystem Cerapur JUPA SHU10 GC9000,

- HDS 400L buffer tank,

- emulated $8 \mathrm{~m}^{2}$ standard flat plate solar collectors (performance coefficients according to EN $12975-2: \eta 0=0.8, \mathrm{a} 1=3.5 \mathrm{~W} / \mathrm{m}^{2} . \mathrm{K}, \mathrm{a} 2=0.015 \mathrm{~W} / \mathrm{m}^{2} \cdot \mathrm{K}^{2}$; south oriented, $45^{\circ}$ tilted),

- $25 \mathrm{~kW}$ gas boiler backup is integrated and combined with SUPRAECO A SAS 4-2 ASE heat pump (R410a, $4.5 \mathrm{~kW}$ heating capacity, $\mathrm{COP}=3.5$ for space heating at $\mathrm{A} 2 / \mathrm{W} 35$ ) with outdoor split unit (in INES climatic test chamber).

Fig. 5 shows the installed SHP system on the dynamic thermal test bench of CEA INES facilities. It comprises four compact blocks of hardware appliances (flagged by the blue arrows on the top) connected to each other by two pairs of customized installation pipes and a proprietary communication bus. The complex hydraulic connections between the buffer storage tank and the gas boiler unit (manager of heat distribution to the heating demand circuits) relies only on pre-fabricated pipes with failure-proof designs to avoid installation errors.

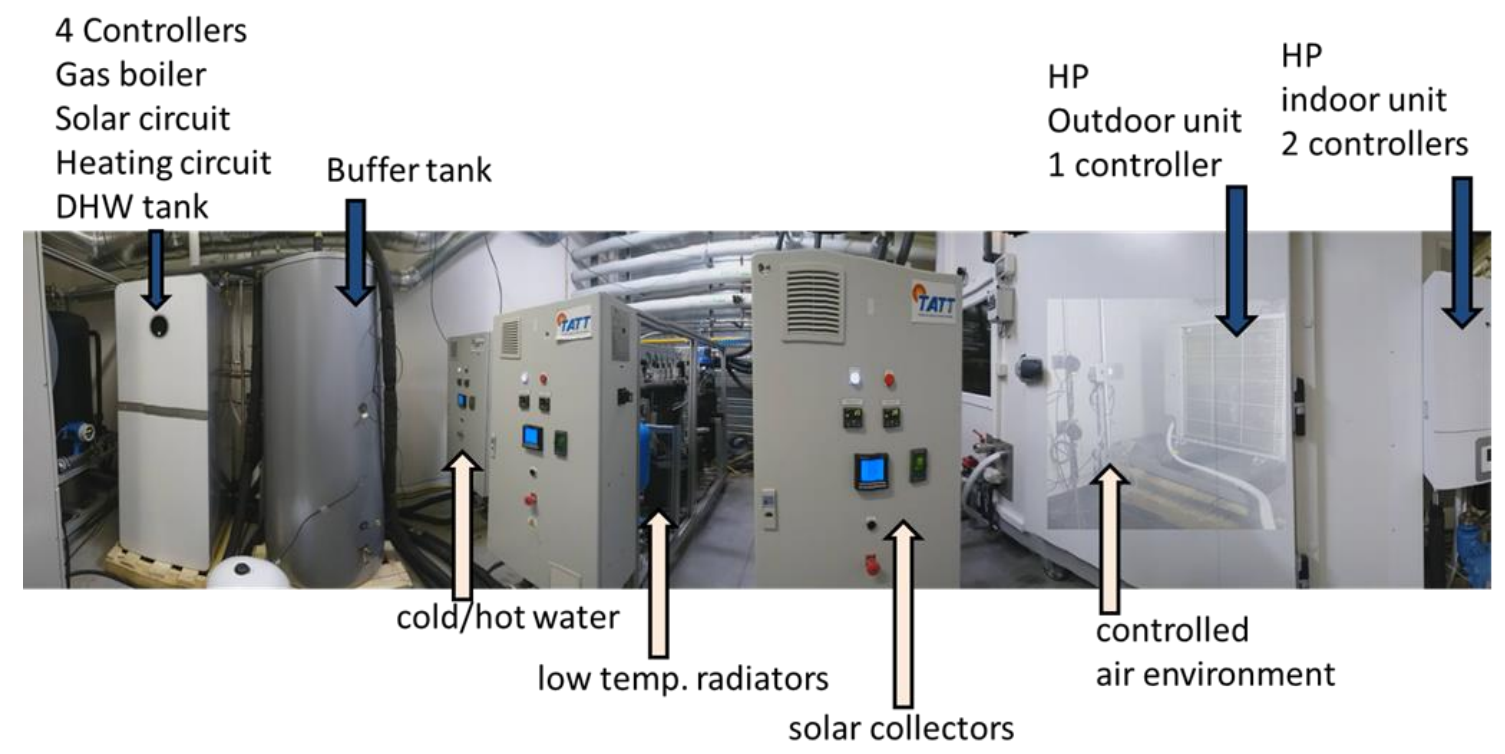

Fig. 5: Picture of the real SHP system under dynamic test process

The SHP system internal and external connections are summarized on Fig. 6. The names of the main energy flows of the tested system are introduced for further reference. 


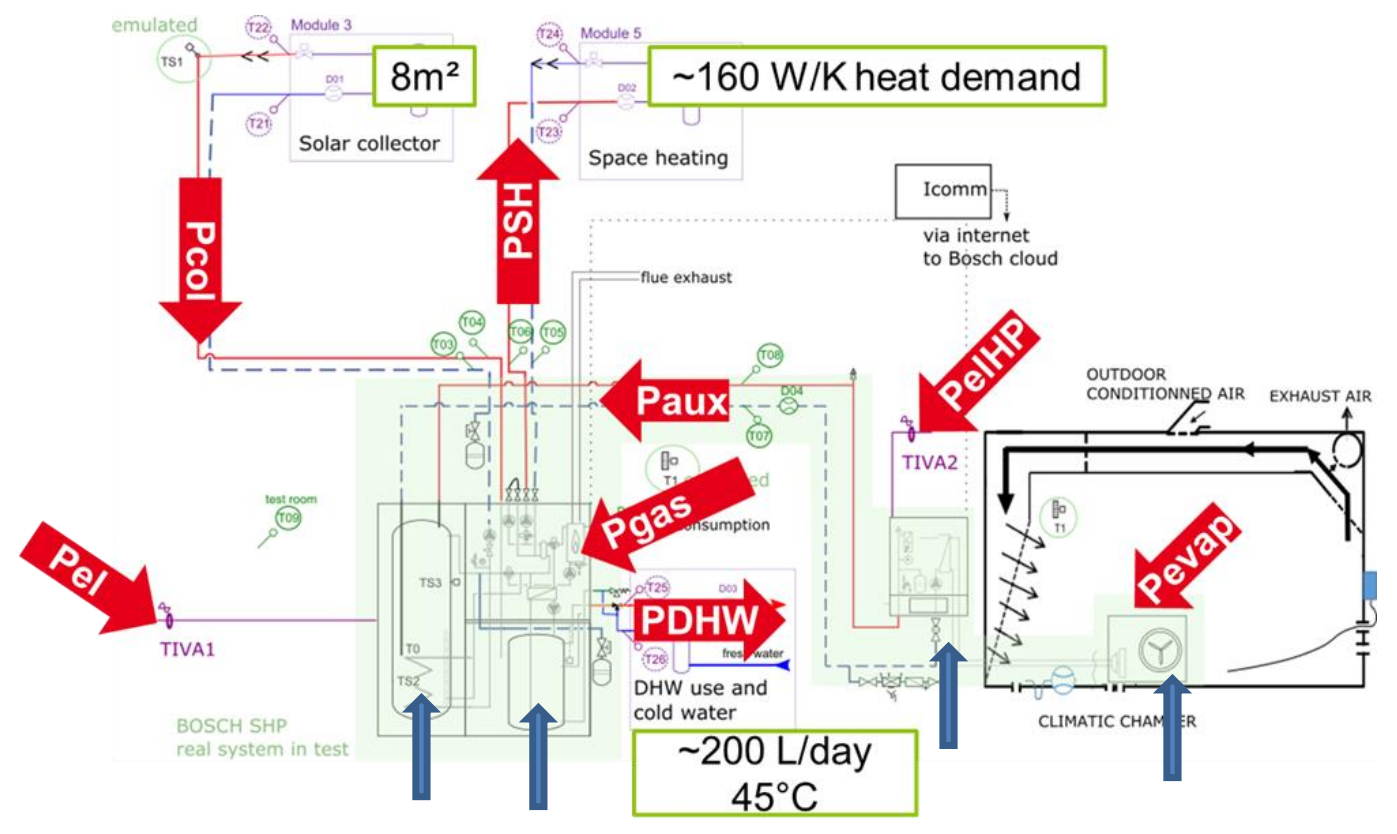

Fig. 6: Connections diagram of SHP installed on dynamic test bench

\subsection{Test results}

Three incremental performance tests were performed while changing the parameters of the SHP control system and/or the test procedure parameters as summarized in Tab. 3. The overall measurements from the three scenarios are reported in Tab. 4, performance figures in Tab. 5 while Tab. 6 provides an insight of daily measurements and performance.

Tab. 3: SHP test plan

\begin{tabular}{|c|c|c|}
\hline SHP test $\mathbf{n}^{\circ}$ & SHP configuration & Test procedure \\
\hline 1 & $\begin{array}{c}\text { Adjusted outdoor temp. heating curve, no indoor temperature } \\
\text { sensor nor room thermostat }\end{array}$ & 12-days, no THV \\
\hline 2 & $\begin{array}{c}\text { Adjusted outdoor temp. heating curve, ON/OFF heating } \\
\text { controlled by indoor temperature sensor }\end{array}$ & $\begin{array}{c}\text { 6-days MacSheep test procedure with } \\
\text { specific THV load control }\end{array}$ \\
\hline 3 & $\begin{array}{c}\text { Adjusted outdoor temp. heating curve with influence of indoor } \\
\text { temperature sensor room thermostat }\end{array}$ & 12-days, THV \\
\hline
\end{tabular}

The optimal settings of the SHP installation (fine control of the heat demand and heating curve looking at the building's indoor sensor) combined with the emulated of thermostatic valve on the radiators (described in Section 2.2) during the SHP test $n^{\circ} 3$ led to $36 \%$ of realistic primary energy savings compared to R1 reference gas condensing boiler under the same testing conditions. The solar thermal and heat pump technology from industrial partner outperformed the 20-30\% primary energy savings goal of Thermoss for the three tests as shown by the figures from Tab. 5. The primary energy ratio (PER) is 1.11, including the electricity consumed by the whole system with a primary energy factor of 2.5. The average Seasonal Performance Factor of the heat pump during the whole test sequence is 2.98 and the solar fraction of the total heat demand is $22 \%$ with $8 \mathrm{~m}^{2}$ of flat plate solar collector.

Tab. 4: Overall three SHP tests measurements

\begin{tabular}{|c|c|c|c|c|c|c|c|c|c|c|c|}
\hline SHP tests & Ihor & Tamb & Tbuild & QSH & QDHW & Qcol & EelHP & Eel & Qaux & Qgas & QPE \\
\hline $\mathrm{n}^{\circ}$ & $\mathrm{kWh} / \mathrm{m}^{2}$ & $\mathrm{C}^{\circ}$ & $\mathrm{C}^{\circ}$ & $\mathrm{kWh}$ & $\mathrm{kWh}$ & $\mathrm{kWh}$ & $\mathrm{kWh}$ & $\mathrm{kWh}$ & $\mathrm{kWh}$ & $\mathrm{kWh}$ & $\mathrm{kWh}$ \\
\hline 1 & 34 & 8.4 & 21.7 & 343 & 96 & 98 & 113 & 121 & 296 & 105 & 419 \\
\hline 2 & 17 & 7.0 & 20.3 & 142 & 48 & 44 & 19 & 23 & 36 & 150 & 209 \\
\hline 3 & 34 & 8.4 & 20.9 & 277 & 96 & 83 & 86 & 91 & 256 & 103 & 337 \\
\hline
\end{tabular}


Tab. 5: Overall three SHP tests performance

\begin{tabular}{|c|c|c|c|c|c|c|}
\hline $\begin{array}{c}\text { SHP tests } \\
\mathbf{n}^{\circ}\end{array}$ & COPHP & NHP & NbUR & PERsys & fsavpesys & SF \\
\hline $\mathbf{1}$ & 2.63 & 69 & 37 & 1.06 & 0.20 & 0.22 \\
\hline $\mathbf{2}$ & 1.87 & 22 & 129 & 0.91 & 0.21 & 0.23 \\
\hline $\mathbf{3}$ & 2.98 & 74 & 78 & 1.11 & 0.36 & 0.22 \\
\hline
\end{tabular}

Looking at Tab. 4 test $\mathrm{n}^{\circ} 1$ space heating load $343 \mathrm{kWh}$, we notice a large overshoot above the R 1 reference 279 $\mathrm{kWh}$ while the heat load from test $\mathrm{n}^{\circ} 2(284 \mathrm{kWh}$, with factor 2 to scale-up from 6-days to 12-days period) and test $\mathrm{n}^{\circ} 3$ deviated by less than $1.8 \%$. It shows the efficiency of the THV emulation to observe realistic system behavior and performance while keeping the heating load close to the $\mathrm{R} 1$ reference. The $16 \%$ increased savings between tests $\mathrm{n}^{\circ} 2$ and 3 emphasizes the savings sensitivity to fine tuning of the space heating control parameters: to maximize the real operation efficiency of the HP (COPHP) and to reduce the gas boiler use (NBUR). As the real HP operating conditions during tests $n^{\circ} 1,2,3$ differ from those used in Standards testing, the measured COP differs.

Despite the $36 \%$ savings from test $n^{\circ} 3$ are significant, it deviates from the $46 \%$ savings estimations for SHP in R1 context in D3.1. This could be due mainly to the thermal inertia of the components (thermal capacity from boiler burner, HeatPump (HP) heat exchangers, pipes, water vessels etc...) and actual controllers that are actually influencing the standby heat losses of any real thermal systems, losses that are not accounted for the monthly sizing method relying only on measured efficiencies in steady state (even considering part load efficiencies of the heat generators).

Tab. 6 : SHP test $\mathbf{n}^{\circ} 3$, daily results summary

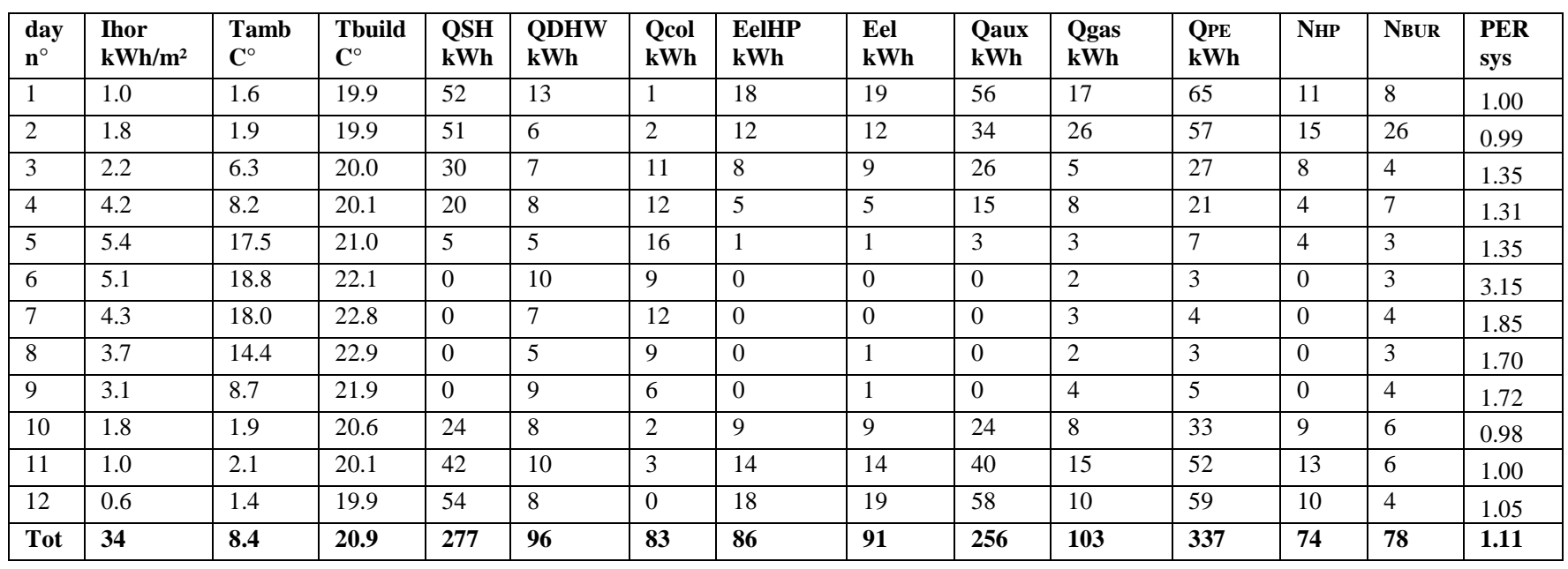

\section{HIU testing}

\subsection{Tested systems description}

The Heat Interface Unit (HIU) tested is the Greenstar HIU-E-PLUS model from Bosch. Recalling from Bosch website, the HIU is "the perfect solution for district heating and applications with a centralised plant room, providing both domestic hot water and heating" (Worcester-bosch.co.uk). HIU-E-PLUS model exhibits a nominal DHW output power of $39 \mathrm{~kW}$ for a temperature rise of $40^{\circ} \mathrm{C}$ and a $\mathrm{SH}$ output range from 1.5 to $15 \mathrm{~kW}$. It is an indirect-indirect HIU with the separation of the DHW performed on the primary side. The specificity of this HIU is to be able to handle very low flow rate on the primary side with accuracy (suitable for renovated envelope building) and thus reducing the primary return temperature. The latter allows decreasing the heat losses on the building primary heat network while increasing the efficiency of the heat generator in case of a condensing gas boiler for example. 


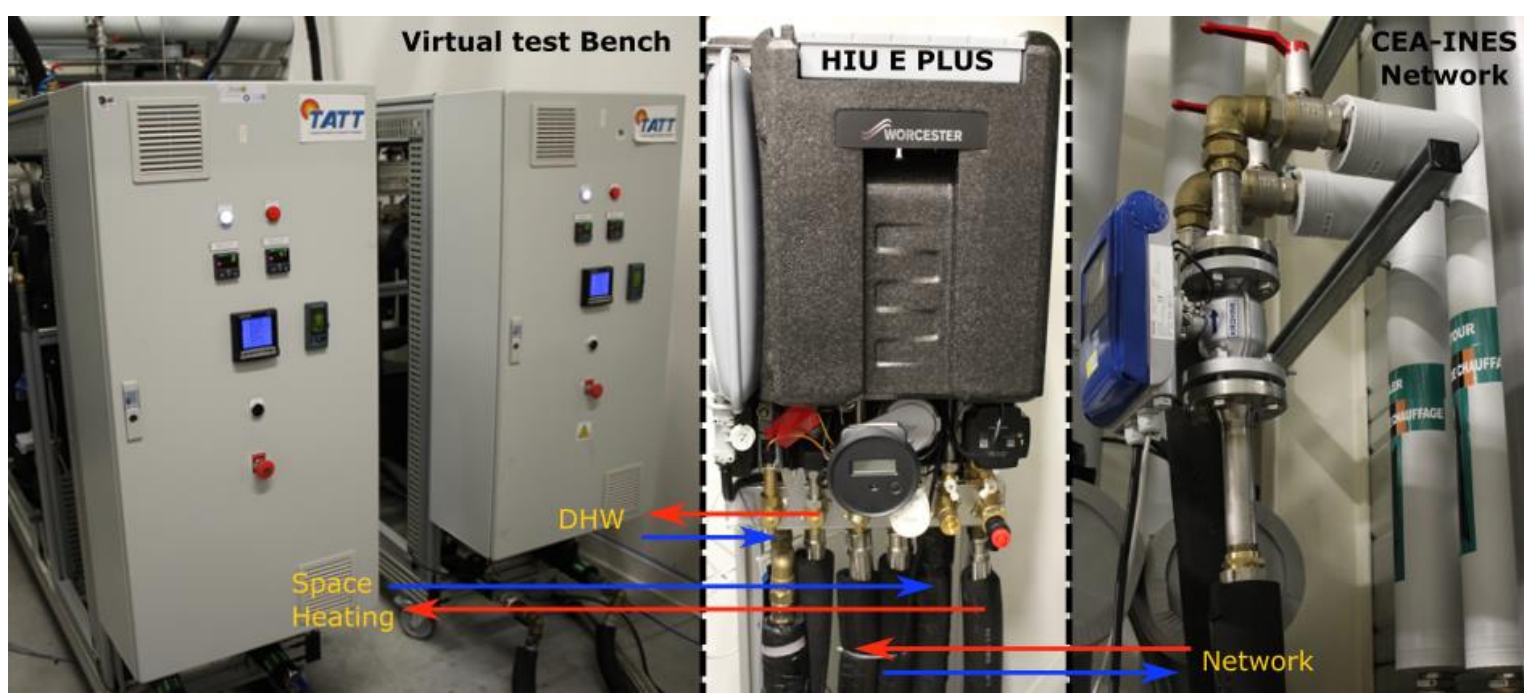

Fig. 7: CEA-INES test setup picture for the HIU testing

The Heat Interface Unit (HIU) tested is connected on one end to the micro District-Heating Network of CEAINES and to the same semi-virtual test bench as for the SHP testing on the other end. Fig. 7 and Fig. 8 respectively present a picture and the schematic of the tests performed in the frame of the Thermoss project at CEA-INES. In Fig. 8, the HIU on the left, the network on the right and the Space Heating (SH) and Domestic Hot Water (DHW) modules from the semi-virtual test bench are highlighted. The different energy flows are also shown.

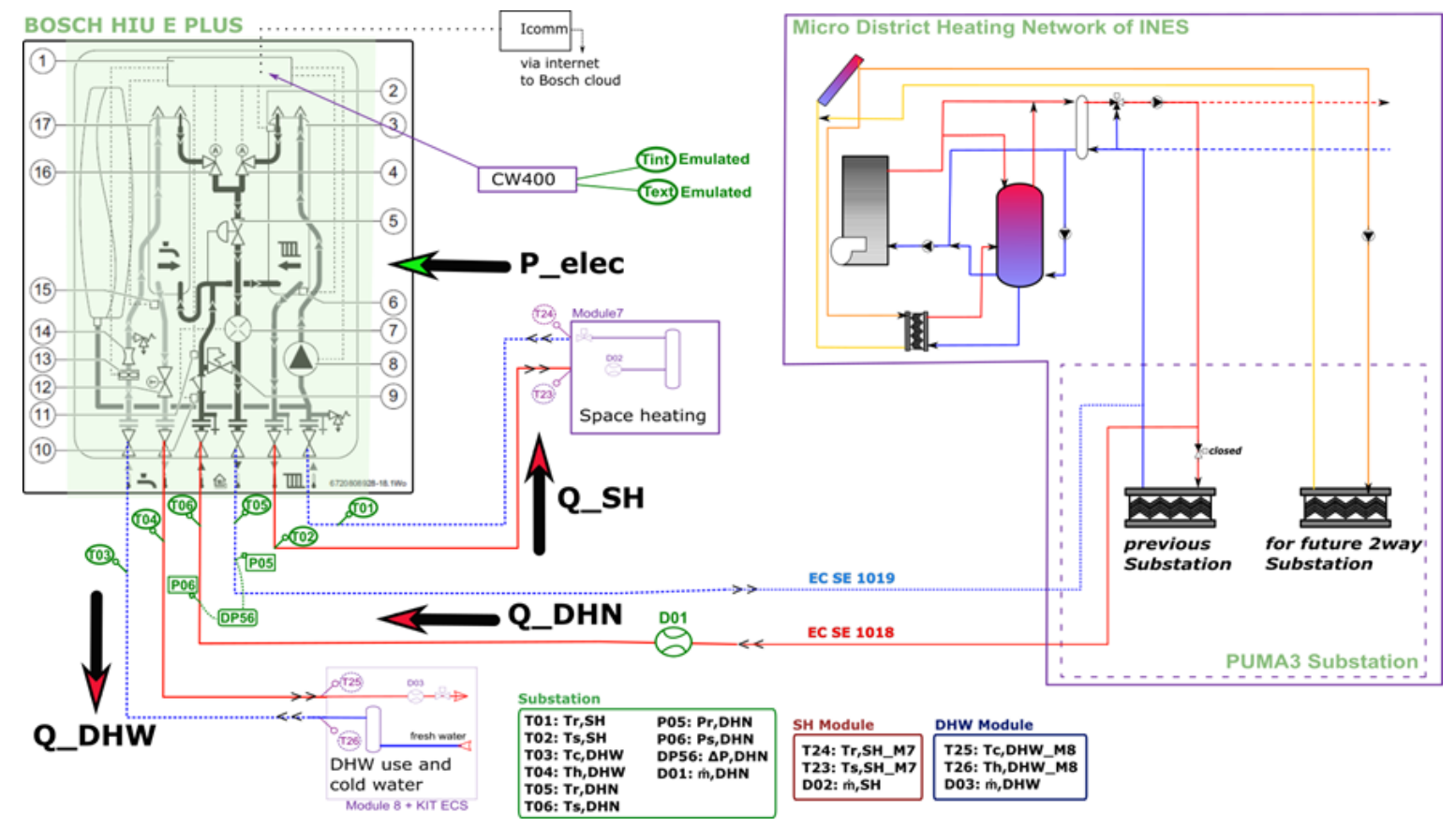

Fig. 8: CEA-INES test setup schematic for the HIU testing

\subsection{Tests results}

\section{- Tests Description and Reference Cases Presentation}

Tab. 7 presents the 3 tests that were performed with varying control strategies and network temperatures. 
Tab. 7: HIU test plan

\begin{tabular}{|l|l|l|l|}
\hline $\begin{array}{l}\text { HIU Test } \\
\mathbf{n}^{\circ}\end{array}$ & Type & Control Strategy & $\begin{array}{l}\text { Network Supply } \\
\text { Temperature }\end{array}$ \\
\hline $\mathbf{1}$ & 12-days, THV & Outside Temperature & 60 \\
\hline $\mathbf{2}$ & 12-days, THV & Outside + Inside Temperatures & 60 \\
\hline $\mathbf{3}$ & 12-days, THV & Outside + Inside Temperatures & 50 \\
\hline
\end{tabular}

Compared to the other technologies tested usually on the semi-virtual test bench, the HIU does not convert heat from any chemical fuel or electrical source; it is merely a hydraulic and thermal interface. Thus, in addition to the residential context reference case R1, a specific reference case referred as R2 was established to compare the impact of a situation with and without HIU, as described in section 2.3.

\section{- Tests Results Summary}

Besides giving the opportunity to meter and control the heat consumption of each dwelling, the HIU also allows for reduction of the return temperature, with consequent disposal of the DHW tank usually found at consumers (as in reference case R2). The former leads to lower network pump power consumption (due to the larger dT obtained), lower piping heat losses (due to the lower average temperature of the network) and higher gas boiler efficiency (due to fumes condensation), while it eliminates the heat losses inherent to the DHW tank.

Tab. 8 summarizes the results obtained for the 3 different HIU tests. First, it is observed that for Test 1 , the controlled strategy using a heating curve based only on the external temperature leads to a higher building internal temperature than the set point. The latter was also observed with the closing of the THV valve at $95 \%$ for a long time during the test underlining the fact that the building was not needing that much heat. The closing of this valve also results in higher pump consumption for the HIU. This over-production of heat for space heating is not observed for the other control strategy based on internal temperature. For the 3 tests, the DHW needs are slightly lower than the theoretical needs $(100 \mathrm{kWh})$ because of the small delay between the thermo-hydraulic modules and the theoretical demand.

Tab. 8: Summary of HIU performance tests measurements

\begin{tabular}{|c|c|c|c|c|c|c|c|c|c|c|c|}
\hline Tests & Tamb & Tbuild & QSH & QDHW & EelHIU & EelDHN & Qgas & QPE & Treturn & $\boldsymbol{f s a v}_{\boldsymbol{P E}, \boldsymbol{R} 1}$ & $\boldsymbol{f s a}_{\boldsymbol{P E}, \boldsymbol{R} 2}$ \\
\hline $\mathrm{n}^{\circ}$ & ${ }^{\circ} \mathrm{C}$ & ${ }^{\circ} \mathrm{C}$ & $\mathrm{kWh}$ & $\mathrm{kWh}$ & $\mathrm{kWh}$ & $\mathrm{kWh}$ & $\mathrm{kWh}$ & $\mathrm{kWh}$ & ${ }^{\circ} \mathrm{C}$ & - & - \\
\hline 1 & 8.4 & 21.6 & 304.5 & 91.5 & 2.3 & 2.4 & 398.5 & 410.5 & 33.6 & 21.9 & 9.7 \\
\hline 2 & 8.4 & 20.8 & 280.2 & 92.2 & 1.9 & 2.3 & 374.0 & 384.7 & 37.0 & 26.9 & 15.4 \\
\hline 3 & 8.4 & 20.8 & 281.9 & 91.9 & 2.0 & 2.3 & 371.3 & 382.3 & 36.9 & 27.3 & 15.9 \\
\hline
\end{tabular}

In comparison with reference case R1, the main differences of the three different tests are i) the lower DistrictHeatNetwork (DHN) return temperature that reduces the DHN heat loss but most importantly leads to an increase of the DHN production unit efficiency and ii) the lower auxiliary electricity use of the heating component because of higher pump efficiency.

In comparison with reference case $\mathrm{R} 2$, the main differences of the three different tests are i) again a much lower auxiliary electricity consumption of the HIU pump with regards to the reference pump and ii) a much higher DHN boiler efficiency with regards to the R1 reference case boiler. The efficiency of the latter is much smaller $(85 \%$ estimated seasonal efficiency of gas condensing boiler in individual dwellings from in-situ measurements campaigns (D3.1) vs about 104\% coming from datasheets relying on steady state measurements in lab) because it exhibits much more frequent ON/OFF cycles and thus higher standby heat losses than the DHN boiler that is assumed in the HIU performance calculations to run continuously (because of other consumer needs). At this stage it's the documented optimistic choice that is made in the analysis. As a consequence, the experimental savings of HIU in R1 context are theoretical maximum since the seasonal efficiency of DHN boilers is likely lower than the value assumed. The DHN boiler efficiency assumption has to be investigated further in the future with real in-situ seasonal measurements of DHN condensing gas boilers.

\section{- Detailed Results for Test 3}

Fig. 9 and Fig. 10 presents respectively the dynamic measurements of powers and temperatures during 12 days (real time) test. The main conclusions to draw from these graphs are:

- The good tracking of the internal temperature set point;

- The DHW priority can be observed as peaks in network power with no space heating power. The latter 
leads to return temperature reduction peaks;

- The increase of return temperature during summer days due to the low demand.

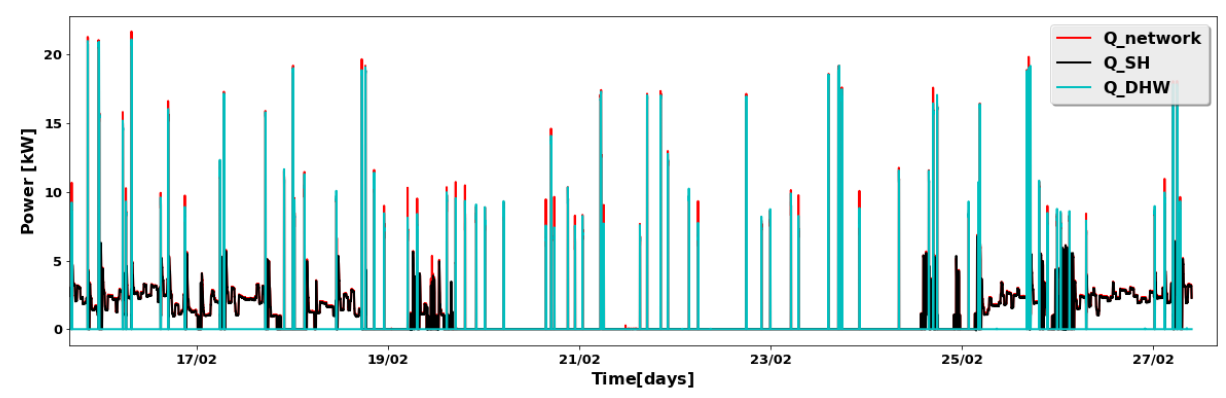

Fig. 9: Heat Power for the DHN, the space heating (SH) and the domestic hot water (DHW) loops for Test 3
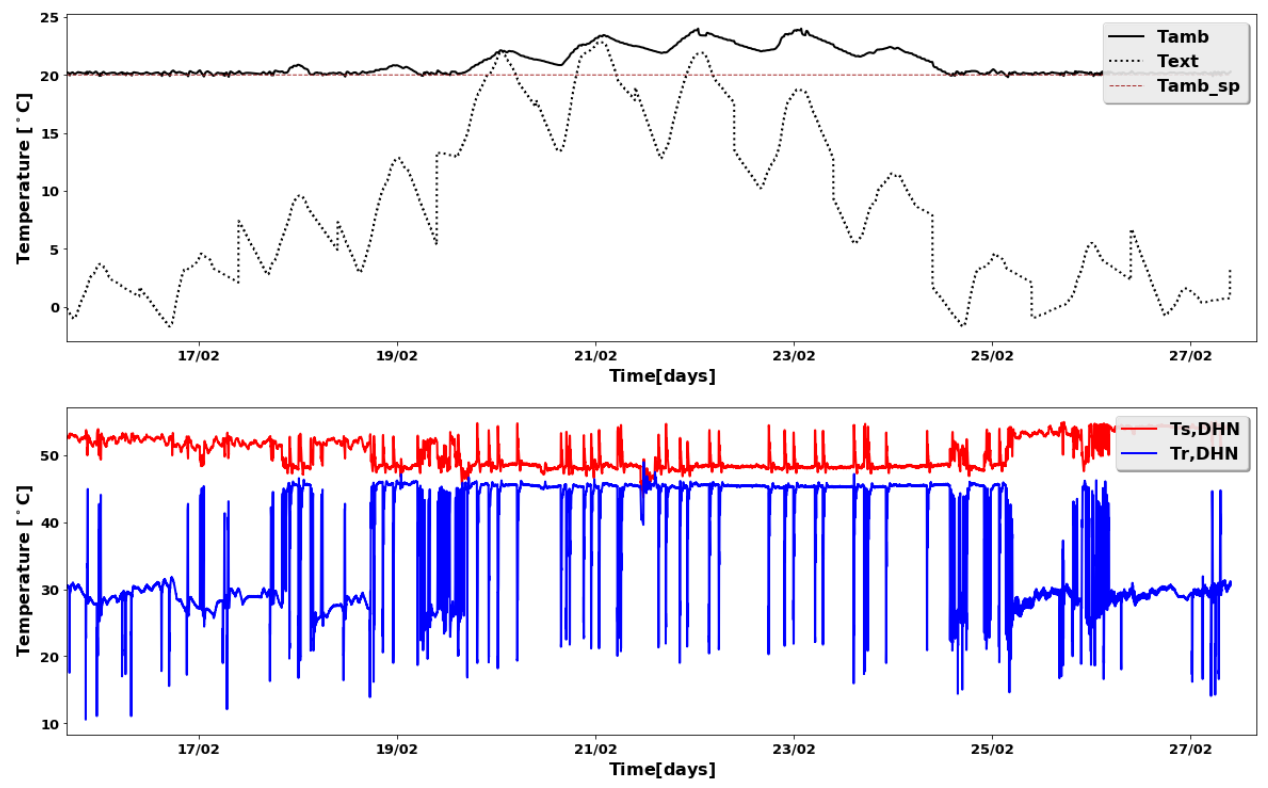

Fig. 10: Ambient and external temperature and network temperatures for Test 3

Tab. 9 summarizes the integrated results on a daily basis. As expected, the integrated results over the 12 days period are the same as the last line of Tab. 8. The Primary Energy Ratio is very high for the HIU. The latter is expected since this equipment is transferring heat in a very efficient manner.

Tab. 9: Daily summary of HIU performance tests

\begin{tabular}{|c|c|c|c|c|c|c|c|c|c|}
\hline Day & Tamb & Tbuild & QSH & QDHW & EelHIU & EelDHN & Qgas & QPE & PERsys \\
\hline $\mathbf{N}^{\circ}$ & ${ }^{\circ} \mathbf{C}$ & ${ }^{\circ} \mathbf{C}$ & $\mathbf{k W h}$ & $\mathbf{k W h}$ & $\mathbf{k W h}$ & $\mathbf{k W h}$ & $\mathbf{k W h}$ & $\mathbf{k W h}$ & - \\
\hline $\mathbf{1}$ & 1.6 & 20.2 & 54.7 & 12.7 & 0.3 & 0.4 & 66.2 & 68.0 & 0.99 \\
\hline $\mathbf{2}$ & 2.0 & 20.2 & 50.3 & 5.9 & 0.3 & 0.3 & 55.1 & 56.7 & 0.99 \\
\hline $\mathbf{3}$ & 6.3 & 20.3 & 30.5 & 6.1 & 0.2 & 0.2 & 36.5 & 37.7 & 0.97 \\
\hline $\mathbf{4}$ & 8.2 & 20.3 & 19.5 & 7.6 & 0.2 & 0.2 & 27.2 & 28.1 & 0.97 \\
\hline $\mathbf{5}$ & 17.6 & 21.1 & 3.8 & 4.5 & 0.1 & 0.0 & 8.5 & 8.8 & 0.94 \\
\hline $\mathbf{6}$ & 18.8 & 22.2 & 0.0 & 9.9 & 0.1 & 0.1 & 10.1 & 10.4 & 0.95 \\
\hline $\mathbf{7}$ & 18.0 & 22.8 & 0.0 & 6.5 & 0.1 & 0.0 & 6.9 & 7.2 & 0.91 \\
\hline $\mathbf{8}$ & 14.4 & 22.9 & 0.0 & 4.6 & 0.1 & 0.0 & 5.1 & 5.3 & 0.87 \\
\hline $\mathbf{9}$ & 8.7 & 21.9 & 0.0 & 8.8 & 0.1 & 0.1 & 9.3 & 9.6 & 0.92 \\
\hline $\mathbf{1 0}$ & 1.9 & 20.2 & 17.1 & 7.5 & 0.1 & 0.1 & 24.6 & 25.4 & 0.97 \\
\hline $\mathbf{1 1}$ & 2.1 & 20.1 & 47.5 & 10.1 & 0.3 & 0.3 & 56.5 & 58.0 & 0.99 \\
\hline $\mathbf{1 2}$ & 1.4 & 20.1 & 58.5 & 7.7 & 0.3 & 0.4 & 65.3 & 67.1 & 0.99 \\
\hline Total & 8.4 & 21.0 & 281.9 & 91.9 & 2.0 & 2.3 & 371.3 & 382.3 & 0.97 \\
\hline
\end{tabular}

\section{Conclusions}

Two heating technologies have been tested during 12 days in realistic operating conditions that are covering typical annual 12 months variations. For the SHP technology, the savings assessments from measurements are in the range $20-36 \%$ in R1 individual gas boiler context. The maximum theoretical primary energy savings of the HIU derived from the experimental results are in the ranges $22-27 \%$ in R1 individual gas boiler context and 10- 
$16 \%$ in R2 reference DHN context since it relies on DHN boiler efficiency evaluated in steady state. In both technology cases it revealed the high sensitivity of the performance to the control parameter settings related to indoor temperature sensor use. The realistic dynamic test also emphasized the major influence of thermal inertia of the system components combined with flow temperature control on the standby heat losses. Therefore the 20$30 \%$ primary energy savings goal of Thermoss is achieved by both SHP and HIU technologies. For both technologies, the realistic radiator THV emulation enabled to keep the deviation of the space heat load below $1.8 \%$ compared to the reference individual gas boiler. The detailed HIU test results also enabled the validation of components simulation models currently used in THERMOSS to develop a solar bi-directional substation connected to a district heat network.

This work was performed thanks to EU funding, H2020 program, under the grant agreement $\mathrm{n}^{\circ} 723562$.

\section{References}

Albaric, M., Nowag, J., Papillon, P., 2008. Thermal performance evaluation of solar combisystems using a global approach, in: Eurosun 2008, 1st International Congress on Heating, Cooling and Buildings. Lisbon, Portugal.

Albaric, M., Mette, B., Ullmann, J., Drück, H., Papillon, P., 2010. Comparison of two Different Methods for Solar Combisystems Performance Testing. International Solar Energy Society, pp. 1-8. https://doi.org/10.18086/eurosun.2010.15.01

Chèze, David, Philippe Papillon, Antoine Leconte, Michel Y. Haller, Robert Haberl, Tomas Perrson, and Chris Bales. 2015. 'Towards an Harmonized Whole System Test Method for Combined Renewable Heating Systems for Houses'. In , 1-10. International Solar Energy Society. 10.18086/eurosun.2014.03.06.

Chèze, D., Benett, G., Li, Y., Hyppolite, J.-L., Macciò, C., Porta, M., Lamaison, N., Fuligni, F., James, P., Anero, A., 2017. Heating and Cooling Technology Assessment Report (THERMOSS task 3.1 Deliverable No. D3.1). THERMOSS project. https://thermoss.eu/download/d3-1heating-and-cooling-technology-assessment-report/

Fuligni, Federica, and Fernando Centeno. 2016. 'THERMOSS'. European Union's Horizon 2020 research and innovation. G.A. $\mathrm{n}^{\circ}$ 723562. https://thermoss.eu/.

Haberl, R., Haller, M.Y., Papillon, P., Chèze, D., Persson, T., Bales, C., 2015. Testing of combined heating systems for small houses: Improved procedures for whole system test methods (Delivrable No. D2.3), MacSheep project.

Haller, M.Y., R. Haberl, T. Persson, C. Bales, P. Kovacs, D. Chèze, and P. Papillon. 2013. 'Dynamic Whole System Testing of Combined Renewable Heating Systems - The Current State of the Art'. Energy and Buildings 66 (November): 667-77. https://doi.org/10.1016/j.enbuild.2013.07.052.

Heimrath, R., Haller, M., 2007. Project Report A2 of Subtask A, the Reference Heating System, the Template Solar System. A Report of the IEA-SHC Task32.

Lamaison, N., Bavière, R., Chèze, D., Paulus, C., 2017. A Multi-Criteria Analysis of Bidirectional Solar District Heating Substation Architecture. International Solar Energy Society, pp. 1-11. https://doi.org/10.18086/swc.2017.10.02

Menegon, D., Soppelsa, A., Fedrizzi, R., 2017. Development of a new dynamic test procedure for the laboratory characterization of a whole heating and cooling system. Applied Energy 205, 976-990. https://doi.org/10.1016/j.apenergy.2017.08.120

Streicher, W., Heimrath, R., 2003. Structure of the Reference Buildings of Task 26, Task 26. IEA SHC. 


\title{
Drainback Solar Thermal Systems in Switzerland - Market Overview and Main Barriers
}

\author{
Sara Eicher, Mircea Bunea, Martin Guillaume, Jacques Bony and Stéphane Citherlet \\ University of Applied Sciences and Arts Western Switzerland \\ HEIG-VD, LESBAT, Yverdon-les-Bains (Switzerland)
}

\begin{abstract}
During the last years, solar thermal systems have lost in attractiveness mostly due to their high initial installation costs, higher complexity compared to photovoltaic systems and a regular need of maintenance to avoid overheating and freezing problems, e.g. control of glycol mixture properties. Drainback (DB) solar thermal systems may overcome some of these issues and contribute to the market recovery as it prevents overheating and freezing of the solar system components even when pure water is used as the heat carrier fluid. It also needs less components than classical pressurised systems, which leads to less complex, lower system costs. Nevertheless, this type of system has not been very successful in Switzerland, only accounting for a small part of the market. In order to identify the barriers preventing the wide Swiss acceptance of DB systems, a literature review was performed and an online survey conducted and addressed to the different actors of the solar thermal sector. The aim is to understand the reasons of low market penetration of DB systems in Switzerland and to clearly identify the main barriers to its spreading. Results show that investments in research, product development, technology demonstration and market deployment in the form of professional training and technology information are essential to promote the DB in Switzerland.
\end{abstract}

Keywords: solar thermal, drainback, Switzerland, barriers

\section{Introduction}

In Switzerland, solar thermal systems have lost their attractiveness because the initial investment is high and they are in competition with other renewable energy solutions. Erreur! Source du renvoi introuvable. shows the decrease in solar thermal collector sales in Switzerland over the past years. This decline in the Swiss solar thermal market is also evident in the European market, which has again declined for the eighth consecutive year (EurObserv'ER, 2017). The development of the solar thermal market is also hampered by the increased attraction of individuals and investors for photovoltaic systems.

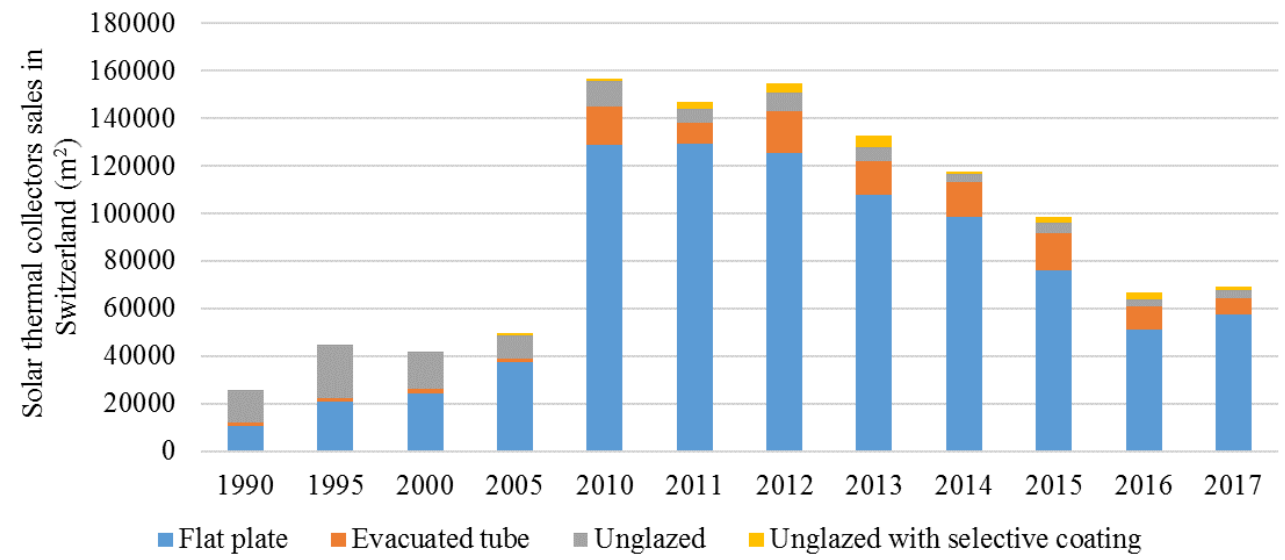

Fig. 1 Solar thermal collectors sales in Switzerland in $\mathbf{m}^{2}$ (Office fédéral de l'énergie OFEN, 2018)

Conventional solar thermal systems have been used in Switzerland for many years, mainly in the residential sector 
and mainly for domestic hot water production. The operating principle is simple: the solar energy is absorbed by the collectors installed on the roof and transported by an antifreeze mixture of water and glycol to the domestic water tank. A heat exchanger transfers the heat energy to the water in the tank. If the circulation of the heat transfer medium is interrupted, for example due to a pump failure or because the tank has reached its maximum temperature, the heat transfer medium remains in the collectors, vaporises and deteriorates over time. More frequent in summer, this phenomenon of overheating can damage the installation over time by subjecting it to extremes of expansion and contraction and technically limits the sizing of the installation to solar fractions that are not too high. The systematic degradation of the heat transfer fluid by repeated overheating of the collector also reduces its performance and weakens its antifreeze properties. These installations must therefore be subject to regular monitoring of the heat transfer fluid in order to avoid serious damage to the system due to freezing or formation of solid particles in the heat transfer fluid.

However, there is an alternative technology, historically not much used in Switzerland, in contrast to other European countries, which prevents overheating while offering freezing protection, making the solar installation more reliable, simpler and, in principle, more economical; it is the Drainback (DB) system. This paper presents the barriers that hinder the diffusion of DB systems in Switzerland and provides solutions for a better dissemination of this technology to help solar thermal professionals and ultimately the Swiss legislator to better support solar thermal energy within the Swiss 2050 Energy Strategy vision.

\section{Methodology}

The analysis of the barriers to the diffusion and the potential of DB systems in Switzerland was based on: (1) literature review and (2) online survey of 380 Swiss professionals of the solar thermal branch. The review presents the studies and developments carried out as well as the technological solutions present on the Swiss market in the field of DB systems. The questionnaire, designed to be administered over the internet, covered the following topics: current product range, Swiss DB market, feedback from experience and perception of the DB technology by solar thermal professionals. Questions were specially designed for each actor of the solar thermal sector: manufacturers/distributors, installers and planners. Thirty-one solar thermal professionals completed the survey.

\section{Literature review}

\subsection{Solar thermal in Switzerland}

Today, solar thermal energy is a technically mature technology available on the Swiss market primarily for domestic hot water production. However, it still accounts for a relatively small share of the country's total consumption (Office fédéral de l'énergie OFEN, 2018). The potential of solar heat is nevertheless high in Switzerland, and could cover a large proportion of these thermal needs, particularly in the temperature range from 10 to $60{ }^{\circ} \mathrm{C}$ (Office fédéral de l'énergie OFEN, 2016). According to the Office fédéral de l'énergie OFEN (2018): "If all existing buildings were to be optimally improved in terms of energy efficiency, it would be possible to meet the heating requirements of all Switzerland's households through the use of solar collectors".

But since 2008 the global solar thermal sector has been facing development problems and slower growth, which has not spared Switzerland. The reasons for this downward trend are the low price level of fossil fuels which affects the competitiveness of solar heat prices as well as increasing competition with technologies that are easier to install and less costly to invest. This has led industry professionals to less prescribe this type of technology causing destruturing of the sector (EurObserv'ER, 2017). At the technical level, the idea of having temperatures above $200^{\circ} \mathrm{C}$ on their roofs poses a real problem of acceptance for many people seeking solar heating technologies (Meyer, 2016).

Uncertainties regarding the energy strategy in 2016 have also contributed to a contraction of the Swiss market, but the current lack of cantonal coordination in energy policy and the expectation of appropriate implementation of subsidy policies inevitably continue to affect the dynamics of solar thermal in the residential market (Stickelberger, 2018). 
In order to reverse this trend and make solar systems more attractive in Switzerland, the market is looking to offer systems that are more reliable, simpler, less expensive and with improved performance. Research has therefore focused on these themes to offer more competitive solutions capable of reviving the Swiss solar thermal market.

\subsection{Drainback technology}

By its operating principle, DB technology offers an interesting alternative to conventional solar thermal systems. Unlike the latter, the DB allows the solar collectors to drain naturally, by gravity, into a drainage tank every time the circulation pump stops. In this way, the system is in safe mode, protected from overheating and freezing even at stand-by. Because of this drainage, it is possible to use pure water in the DB without antifreeze as heat transfer fluid. However, this unique feature of emptying and refilling the solar collectors requires a specific hydraulic design for proper operation.

This three-step operating mode: (1) filling the circuit, (2) system operation and (3) emptying the circuit has many advantages in addition to those often indicated regarding overheating and freezing. For example, without the risk of overheating, no expansion vessel or non-return valve required. Fewer components also make installation easier. As previously mentioned, another advantage is the possibility of using water instead of an antifreeze as a heat transfer fluid. Water has a better heat transfer and higher thermal capacity. Its low viscosity makes pumping easier than antifreeze mixing and requires less maintenance. However, attention must be paid to disadvantages such as the need for adequate slope of the piping and the use of appropriate components to ensure that no water will remain in the installation when the circulation pump stops. A summary of the advantages and disadvantages of DB systems can be found in (Botpaev et al., 2016).

\subsection{Classification of DB systems}

A DB system consists of three basic components: the solar collectors, the drainback vessel and the storage tank. The different types of drainback containers have made it possible in the past to establish simplified basic configurations for domestic applications. DB systems are often classified between a closed circuit and a circuit open to the atmosphere. They can also be classified according to the type of heat transfer fluid: water and antifreeze. More recently, another classification has been proposed according to the type of drainback vessel: additional drainback tank, heat storage or oversized heat exchanger, as shown in Figure 2.

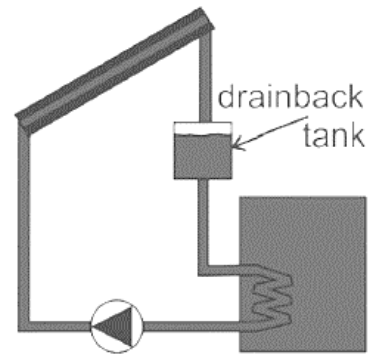

a

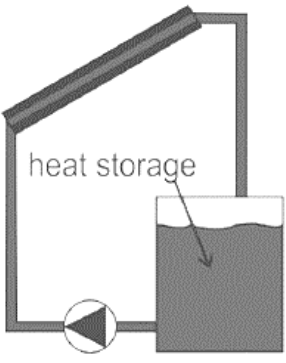

b

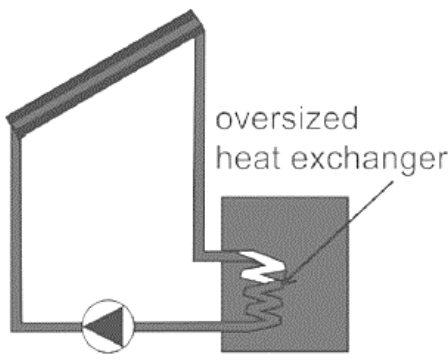

C

Fig. 1 Classification of DB systems in terms of type of drainback vessel (Botpaev, 2017)

Closed-loop, pressurized antifreeze systems with an additional drainback tank, Figure 2a, represent the current state of the art in most countries (Suter et al., 2003). For more information on the different advantages and applications of these three DB concepts, please refer to Botpaev (2017).

\subsection{Swiss DB market}

Although DB systems have been used in Europe for some decades, their advantages do not seem to have convinced the Swiss market yet and only a few manufacturers offer this system at national level. A market study conducted in 2014 shows that despite dominance in some countries such as the Netherlands, Belgium and Norway (over 70\% of the market), the market share in Switzerland is estimated to be less than $10 \%$ as in other Mediterranean countries 
(Botpaev and Vajen, 2014). This same study shows that despite a large domination by German manufacturers in Europe, the DB remains almost unknown in Germany, by far the largest European solar thermal market.

While in the Netherlands the commercial success of the DB technology in the 1980s was linked to drinking water quality regulations, the major barrier in Europe seems to be the lack of qualified professionals capable of properly system installation (Suter et al., 2003). In Germany, for example, DB related failures in the past or poorer than expected performances have left some mistrust in the adoption of this technology (Berner, 2004) and today, the so-called conventional solar thermal installations are still primarily promoted. On the basis of information found on the market, three Swiss manufacturers are still offering drainback tank type of systems as in Figure 2a. Although not exhaustive, this research shows that the current offer of Swiss DB products is small and therefore not much visible.

\subsection{Research \& development}

Very few scientific studies concerning DB technology have been recorded in the public domain. The contributions encountered are mainly technology and DB market reviews (Berner, 2008, 2004; Botpaev et al., 2016; Botpaev and Vajen, 2014). The technology is often presented as safe in stand-by, frost protected, low maintenance and easy to install. The most mentioned disadvantages are the need for careful assembly, greater pumping power and the need for components that drain properly (Berner, 2007). The work carried out under Task 26 on combined systems and their findings on the state of the art of DB systems also revealed some problems for a wide dissemination of the DB in Europe. The most important is the lack of qualified professionals (Suter et al., 2003.

Combined systems using DB technology with evacuated solar collectors have been studied experimentally and by simulation. Recommendations have thus been drawn up for a correct installation of this type of system: assembly of pipes on a continuous slope; rapid filling/starting of the installation is advantageous in order to reduce pumping energy; the risk of frost formation of the external pipes is important only under certain extreme temperature conditions (Perers et al., 2014, 2015). More recently, Botpaev, (2017) conducted a series of experimental work on the fundamental principles of DB systems working with water. These results have been used to make similar recommendations regarding the operation of DB systems.

Other studies in Switzerland concern a Pilot \& Demonstration project on a solar thermal DB installation placed in a residential house (Programme P\&D, 2002). Some engineering offices and DB distributors have also provided DB integration references on their websites. For example, in Switzerland the largest installation $\left(300 \mathrm{~m}^{2}\right)$ operating on the DB principle is located in Geneva in a low income housing for hot water production, as mentioned in (cooltec.ch, 2018).

Overall, the lack of scientific publications indicates that research and development in this field is needed not only in Switzerland but also abroad. However, the few examples of DB systems in Switzerland show that the technology has an important market potential. For this, higher investments should be made and priorities set for training of professionals, the development of DB products, as well as in providing the public with more information on this type of technology. Thus, a regain in the confidence of the various players in the field: installers, planners and users, could be achieved.

\section{Survey}

This study seeks to establish the current state of the DB technology in Switzerland and to target the reasons for its low dissemination, despite its advantages. To this end, a survey on DB installations was conducted among solar thermal professionals. The survey was conducted from late April to late May 2018. More specifically, the questionnaire was designed around the following topics:

- the current product range in Switzerland ;

- $\quad$ the Swiss DB market

- feedback from experience 
- perception of the DB technology by all professionals

To reach as much Swiss professionals as possible and avoid any misunderstandings due to language barriers, the questionnaire was available in two official Swiss languages: German and French. The questionnaire was implemented in SurveyMonkey (SurveyMonkey Inc., 2018), a low cost online survey service offering easy question implementation, the ability to collect data in a consistent and quick manner and with mobile-friendly capabilities.The time required to complete this survey was approximately 10 minutes. Please refer to (Eicher et al., 2018) for the French version of the questionnaire.

Invitations to participate in the survey were sent by e-mail to nearly 380 actors involved in solar thermal energy in Switzerland, namely manufacturers, distributors, installers and engineering office, in partnership with the Swiss leading solar thermal association (Swissolar) through their extensive network of professionals. A total of 31 professionals completed the survey, 14 of whom deal currently with DB systems or dealt with it in the past.

\section{Results and Discussion}

Figure 3 provides the profile of the 31 respondents. As would be expected, installers are the best represented category. Among the 31 respondents, 14 are concerned by the DB (light colour of each category): 3 manufacturers, 1 distributor, 7 installers and 3 planners.

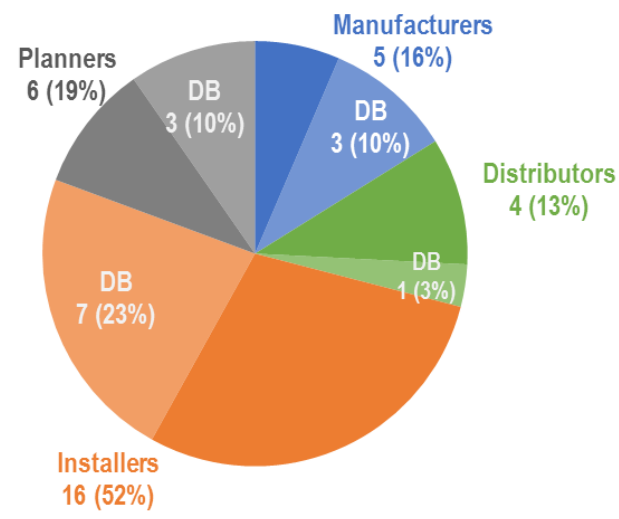

Fig. 3 Breakdown by professional category and percentage concerned by the DB (light colour)

The following three subsections present the responses only from professionals concerned by the DB. It is important to notice that for some limited cases, invalid responses were detected and not all 14 responses could be obtained. In order to clearly indicate the number of responses obtained for each question a value $n$ is provided. In multi-choice questions (indicated with MC), respondents were allowed to select one or more options from a list.

\subsection{Current product range in Switzerland}

Table 1 shows the list of DB products identified in the survey. It can be seen that five of the listed DB products fall into the additional drainback tank category (see Figure 2a), already mentioned to be the most widespread configuration. 
Tab. 1 List of DB products identified in the survey

\begin{tabular}{|c|c|c|c|}
\hline DB products & $\begin{array}{c}\text { Type of system } \\
(\text { refer to Fig.2) }\end{array}$ & $\begin{array}{c}\text { Origin } \\
(\boldsymbol{n}=\mathbf{1 0})\end{array}$ & $\begin{array}{c}\text { Heat transfer fluid } \\
(\boldsymbol{n}=\mathbf{1 2})\end{array}$ \\
\hline 1 & Drainback tank & $\mathrm{CH}$ & Water \\
\hline 2 & Drainback tank & $\mathrm{CH}$ & Glycol \\
\hline 3 & Drainback tank & $\mathrm{CH}$ & Glycol or water \\
\hline 4 & Heat storage & EU & Water \\
\hline 5 & Drainback tank & EU & Glycol \\
\hline 6 & Drainback tank & Outside EU & Glycol or water \\
\hline
\end{tabular}

In terms of product origin, 3 out of the 6 listed DB products are Swiss made. These come from the three Swiss manufacturers already identified in the literature review. The survey also shows that DB products from EU and outside EU are also available to Swiss customers. 6 out of the 10 respondents reported to use Swiss DB products.

Although DB systems can be used with water, glycol remains de most widely used heat transfer fluid, in particular by installers as shown in Fig. 44. Of the tree Swiss DB products, only one takes full advantage of using water as heat transfer carrier. This corroborates the idea that past failures related to safety and reliability of this type of technology led professionals to stay safe by prescribing glycol operating DB systems.

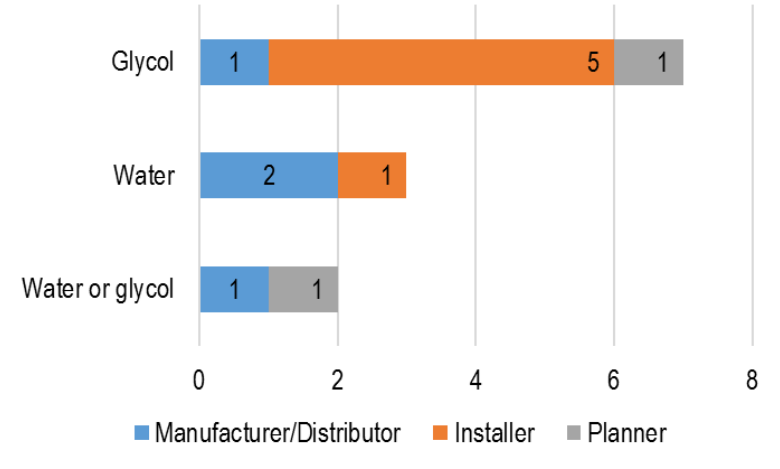

Fig. 4 Type of heat transfer fluid used in the listed DB products $(n=12)$

The top three major differences between a DB and a conventional solar thermal system are presented in Figure 5.

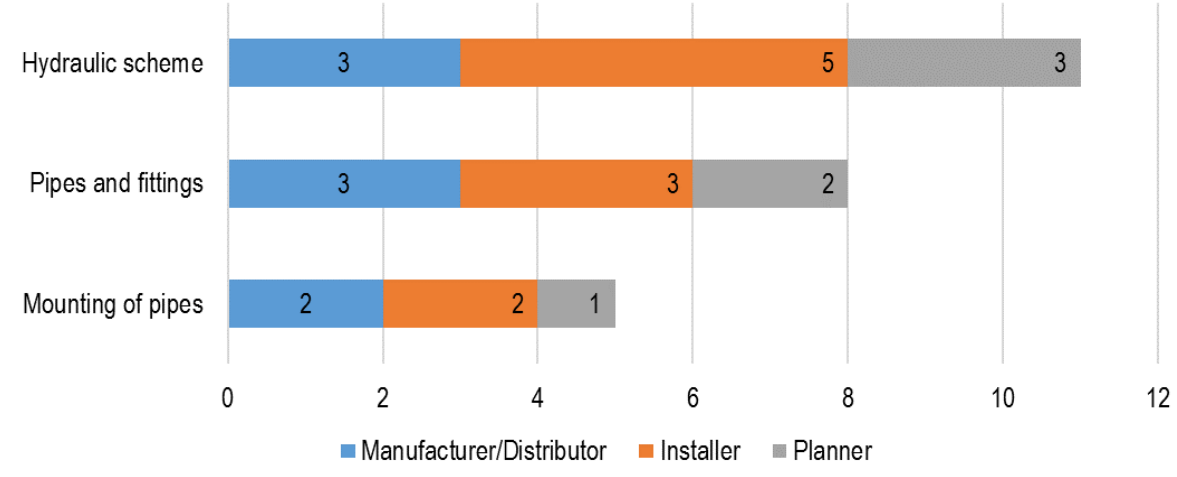

Fig. 5 Major differences between a DB and a conventional solar thermal installation (MC, $n=14)$

Due to their different operating mode, the hydraulic scheme stands out as the first major difference between these two types of systems. Some important technical aspects such as adequate pipes and fittings as well as mounting considerations, essential to guarantee complete drainage of the heat transfer carrier, follow this. These differences 
seem to indicate that professionals working with DB system are aware of the main aspects to consider for a proper DB operation.

The estimated price of a DB system is shown in Figure 6, based on the values provided by respondents. As for any type of solar thermal installation, the prices depend on: the price of the components of the installation, the number of hours required to install, the size and type of installation. The indicated values correspond to the total estimated prices of a DB facility with and without installation costs. This latter comprises only the components costs. Note that values with and without installation costs do not come from the same respondents. In addition, more prices were obtained from installers which explains the wider discrepancies between installation and components only values.

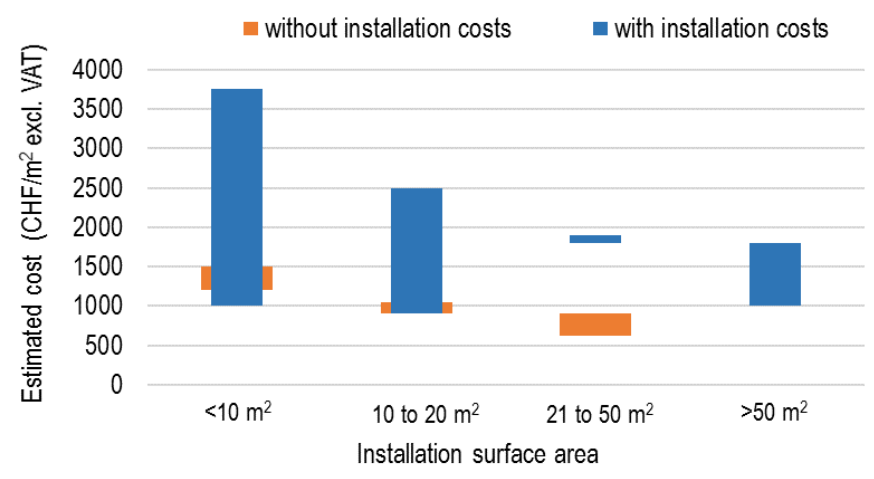

Fig. 6 Price range of a DB installation $(n=10)$

For small size installations $\left(<10 \mathrm{~m}^{2}\right)$, representing about $80 \%$ of the Swiss solar thermal installations (SHC, 2017), the price range communicated by manufacturers, on the basis of their price list, varies from 1200 to $1500 \mathrm{CHF} / \mathrm{m}^{2}$ (components only). When considering the installation costs provided by installers, these values change from 1000 to $3750 \mathrm{CHF} / \mathrm{m}^{2}$. The price per hour charged by the installer plays a role in the calculation of the latter values. It is also observed that the price decreases as the size of the installation is increased. For installations larger than 50 $\mathrm{m}^{2}$, the price ranges from 1000 to $1800 \mathrm{CHF} / \mathrm{m}^{2}$.

Pricing of solar thermal installations is, as for many other products, an important decision factor for buyers. Respondents stated that there is no difference in price between installing a DB against a conventional solar thermal system. This seems to indicate that it is not the economic factor that is preventing Swiss customers from buying DB installations.

\subsection{Swiss DB market}

Responses have shown that 10 over 14 respondents have sold/installed DB systems in the last two years. However, the sales of DB systems have remained stable or decreased in comparison to previous years, as presented in Figure 7. This result is not surprising as it follows the decreasing trend observed in the current solar thermal market.

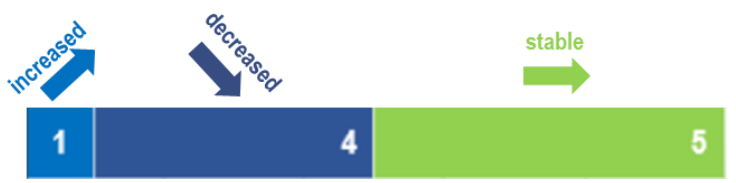

Fig. 7 Sales evolution in the last two years $(n=10)$

The size of the DB installations performed in the last two years is shown in Figure 8. It can be seen that the majority of the installations are less than $20 \mathrm{~m}^{2}$. As previously mentioned in the paper, this reflects the dominance in Switzerland, of small size solar thermal installations for single-family houses. 


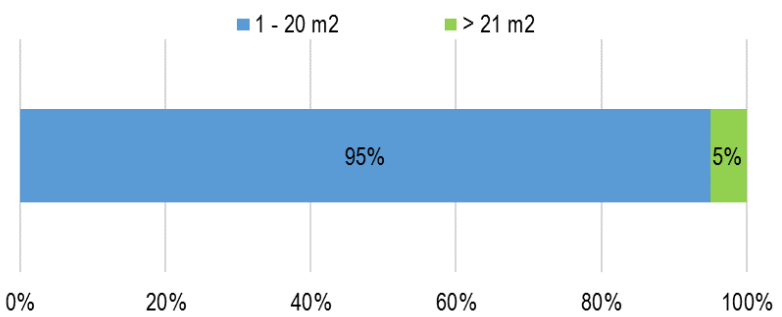

Fig. 8 Estimated percentage of small and large DB installations realised in the last two years $(n=6)$

As earlier referred in the paper, conventional solar thermal systems are primarily used for domestic hot water production. In contrast, survey results show that DB systems have been installed, on an equal basis, for both hot water production as well as for hot water coupled to space heating, see Figure 9. It is clear that by avoiding overheating, DB systems can be designed larger to achieve much larger solar fractions and consequently, cover more important heating demands. Properly installed, DB system are clearly more appropriate for combined heating demands and this advantage seems to have been considered by half of the respondents.

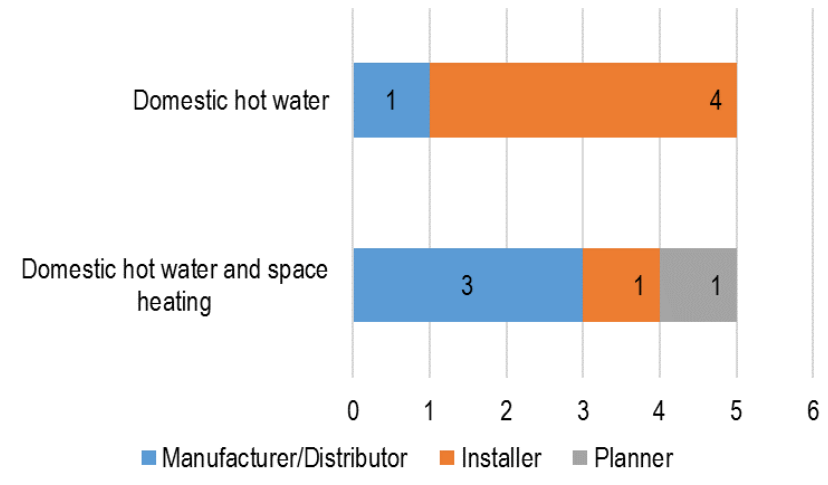

Fig. 9 Top selling applications in the last two years $(n=10)$

According to respondents, the top selling arguments for purchasing a DB installation, see Figure 10, are all related to the advantages of the system earlier mentioned in the paper. The arguments put forward by professionals clearly show a willing to present different benefits that a conventional solar thermal system is not able to provide.

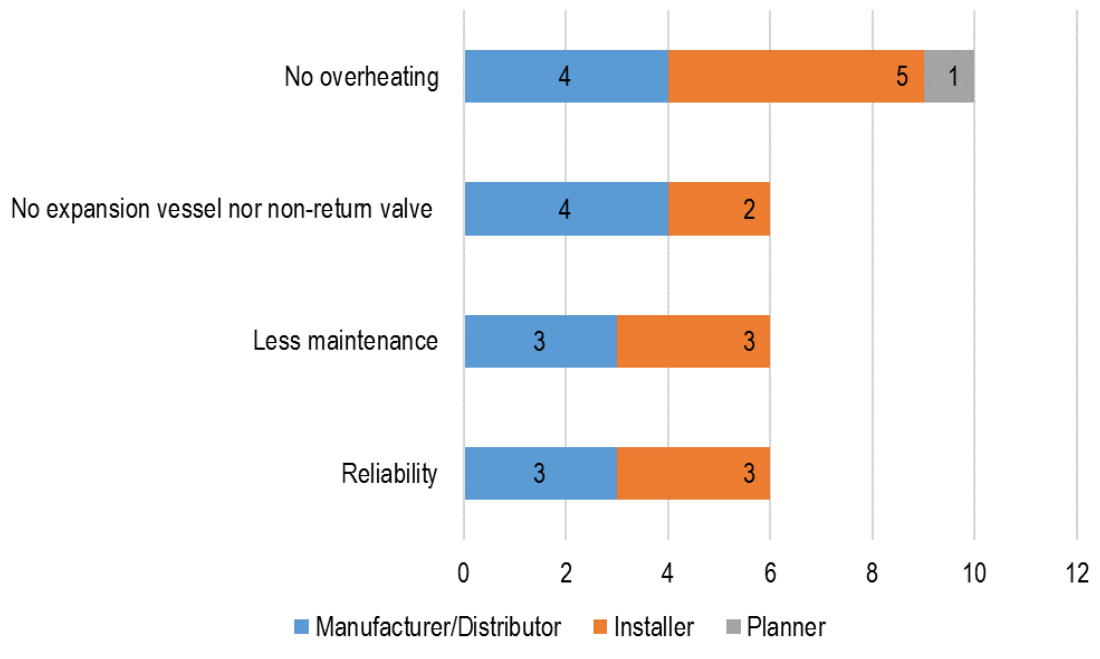

Fig. 10 Top four DB selling arguments $(M C, n=14)$

\subsection{Feedback from experience}

As previously mentioned, DB system requires special attention to mounting of pipes and choice of components to guarantee the complete drainage of the system. It has also been referred that past failures due to incorrect installation of DB system have create a profound mistrust in the technology. The need for training to regain trust in the technology is necessary and the survey shows in Figure 11 that 9 out of 14 respondents acknowledge the 
need for a specific training on DB systems. Nevertheless, only 6 out of 9 have actually followed one.

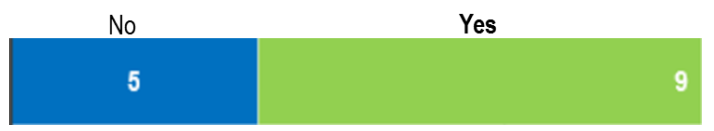

Fig. 11 Need for a specific training to install DB systems $(n=14)$

8 out of 14 respondents have not encountered any major problems with DB systems, as indicated in Figure 12.

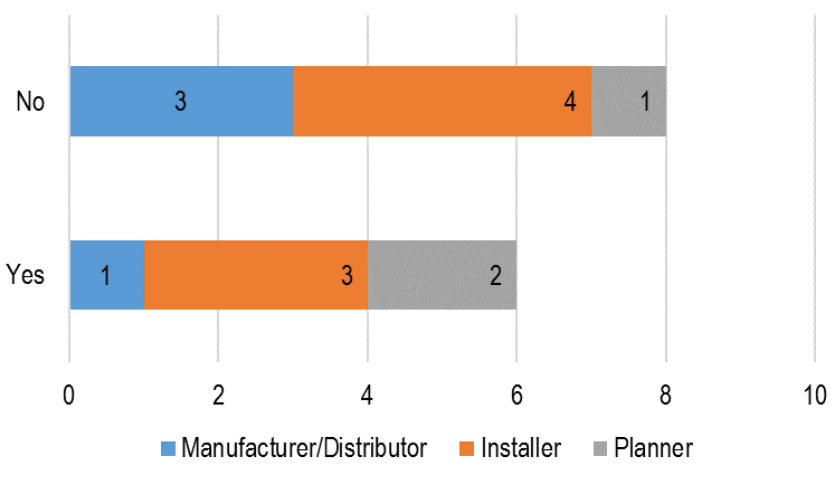

Fig. 12 Problems encountered with the DB system $(n=14)$

The main challenges encountered by respondents with DB systems are stated in Figure 13. The major challenge indicated is the mounting of pipes with the necessary slope for complete drainage of the installation. It follows pump aspects as appearing on the top two challenges. Two respondents indicated to have faced noise, freezing and control system problems of the DB installation. It is clear that training of professionals is essential to clarify technical aspects of design and installation of DB systems.

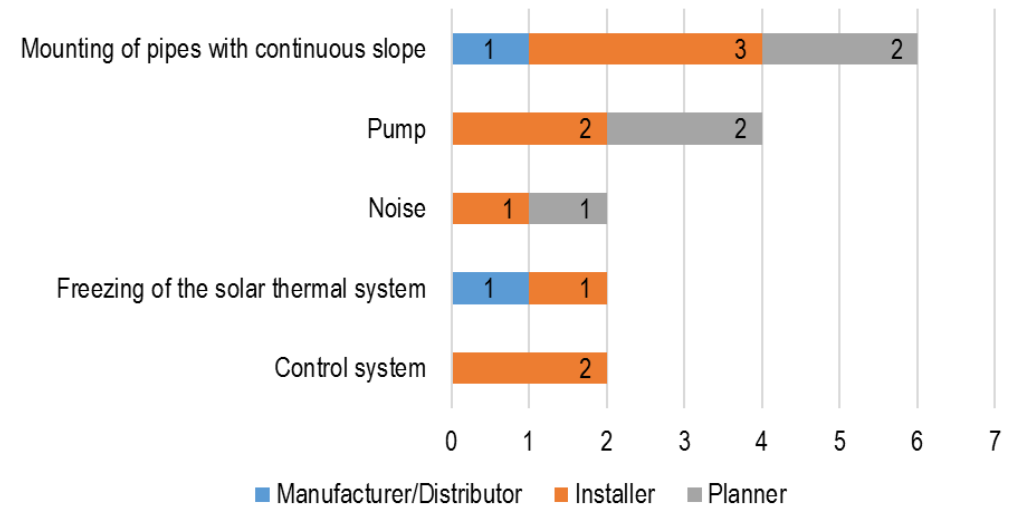

Fig. 13 Main challenges encountered with DB systems $(M C, n=14)$

\subsection{Perception of $D B$ technology by all professionals}

The changes required to promote the spreading of the DB technology in Switzerland are presented in Figure 14 and take into consideration all views from all respondents of the survey, concerned or not by the DB. As would be expected, training of professionals followed by a wider promotion and information of this type of system are seen as the main axes to explore. This would certainly result in improved reliability of the technology, also on the top four of the change factors list. 


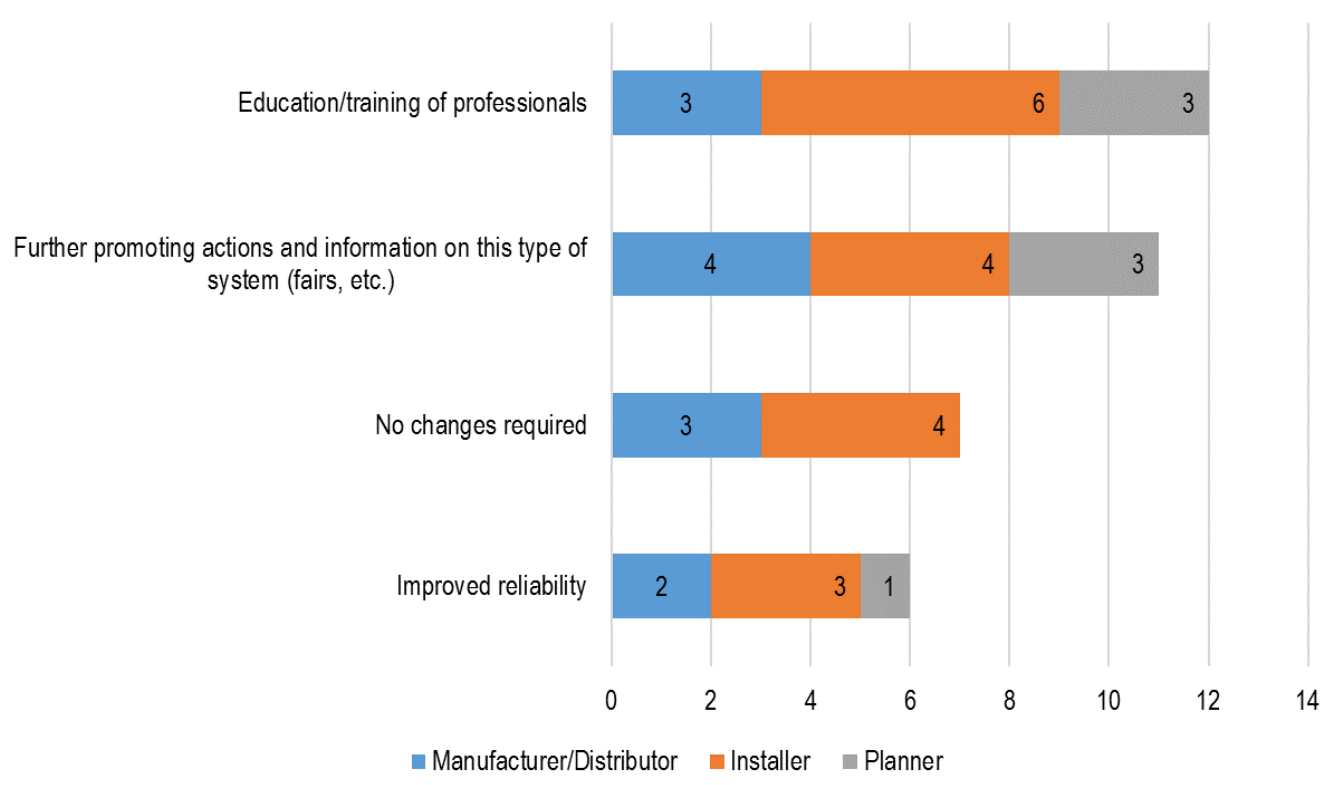

Fig. 14 Top four changes that would promote the spreading of the DB in Switzerland ( $n=31)$

\section{Conclusions}

The barriers that prevent the diffusion of DB solar thermals systems in Switzerland have been identified. The literature review highlights a lack of visibility of the technology in Switzerland and worldwide. Apart a few European countries, the market share of this type of technology remains low in Switzerland. German manufacturers are the most present on the European market but the technology remains unknown in Germany, by far the largest solar thermal market in Europe. The main reason is a mistrust in the DB technology mainly due to failures of the past often linked to the lack of qualified professionals. Current research shows a lack of scientific work in the field of DB.

The survey shows that despite available in Switzerland for more than twenty years, the DB remains almost invisible in the solar thermal market. The use of water as a heat transfer fluid is not promoted despite thermal, financial and ecological advantages. Concerns of improper installation with a potential freezing risk and its negative consequences for the installation seem to drive professionals to prescribe the use of glycol instead. DB installations were seen to have the same price as conventional installations, so the economic factor is not an issue when it comes to purchase decisions. The professionals concerned by the DB are generally satisfied with the technology but suggest that investments in the training of installers and greater information and demonstration of the technology are needed to boost confidence in the DB technology and thus promote its wider dissemination in Switzerland.

Overall, the potential of the DB in Switzerland is great. The challenge of relaunching the solar thermal market requires solutions such as DB but it is clear that investments in research, product development, technology demonstration and market deployment in the form of professional training and technology information are essential.

\section{References}

Berner, J., 2004. Drain Back for export. Sun \& Wind 2, 32-37.

Berner, J., 2007. Drain back: full protection with empty collectors. Sun \& Wind 1, 60-65.

Berner, J., 2008. Drainback systems : empty and safe. Sun \& Wind 5, 48-53.

Botpaev, R., 2017. Experimental investigations of water filled drainback systems, PhD Thesis, Uni-Kassel. 
Botpaev, R., Vajen, K., 2014. Drainback Systems : Market Overview, in: Gleisdorf 2014.

Botpaev, R., Louvet, Y., Perers, B., Furbo, S., Vajen, K., 2016. Drainback solar thermal systems : A review. Sol. Energy 128, 41-60.

Cooltec, URL cooltec.ch (access July 2018).

Eicher, S., Bunea, M., Bony, J., Guillaume, M. and Citherlet, S., DrainBiS - Drainback in Stwizerland. Final report 2018. SuisseEnergie.

EurObserv'ER, 2017. État des énergies renouvelables en Europe.

Meyer, J.-P., 2016. Pushing down stagnation temperature. Sun \& Wind 6, 16-19.

Office fédéral de l'énergie OFEN - Energie solaire, URL bfe.admin.ch (access July 2018).

Office fédéral de l'énergie OFEN, 2016. Plan directeur de la recherche énergétique 2013-2016.

Office fédéral de l'énergie OFEN, 2018. Le recensement du marché de l'énergie solaire en 2017.

Perers, B., Furbo, S., Fan, J., Kong, W., Chen, Z., 2014. Drain Back, Low Flow Solar Combi Systems: Design , Monitoring and Simulation, in: EuroSun 2014 - International Solar Energy Society.

Perers, B., Furbo, S., Fan, J., Kong, W., Chen, Z., 2015. Drain back systems in laboratory and in practice. Energy Procedia 70, 300-310.

Programme P\&D domaine solaire actif: AccaDueO: Installation solaire sans antigel, 2002.

SHC, Status of the market for solar thermal systems - Switzerland. Country report 2017.

Stickelberger, D., Evolution du marché de l'énergie solaire boom mondial, stagnation en Suisse, URL swissolar.ch (access July 2018).

Suter, J-M, Kovács, P., Hausner, R., Visser, H. and Peter, M., 2003. Durability and reliability of solar combisystems, in: Weiss W. (Eds) Solar Heating Systems for Houses - A Design Handbook for Solar Combisystems. James \& James Ltd., London, pp. 182-190.

SurveyMonkey Inc, URL surveymonkey.com (access July 2018). 


\title{
Experimental Analysis of Air-Water Heat Exchanger with Microchannel Coil Exposed to Different Working Parameters
}

\author{
Vladimir Glazar, Anica Trp, Kristian Lenic, Mateo Kirincic \\ University of Rijeka, Faculty of Engineering, Department of Thermodynamics and Energy \\ Engineering, Vukovarska 58, Rijeka, HR-51000, Croatia
}

\begin{abstract}
In this study experimental analysis of heat exchanger with microchannel coil (MCHX) has been done. MCHX have already been proven as key for improvement of outdoor condenser units in domestic space cooling systems. Many questions still exist in case of their implementation as evaporating unit, or in case of both single and multiphase fluid flow. In this study MCHX is used as air-water heat exchanger. An open circuit wind tunnel has been used for testing the MCHX in this non-standard application. The experimental analysis has been performed for a range of various water/air velocities and temperatures. Water temperatures and velocities, as well as air temperatures, velocities and pressure drops, were measured using data acquisition system with developed application in Labview software. Influence of water/air inlet temperatures and velocities on heat transfer in the heat exchanger with microchannel coil has been investigated.
\end{abstract}

Keywords: Microchannel heat exchanger, open circuit wind tunnel, experimental analysis

\section{Introduction}

Development of heat exchangers and search for higher heat transfer rate per volume brought new group of compact heat exchangers: the heat exchangers with microchannel coil (Kandlikar et al., 2016). The heat exchanger with microchannel coil (further in text: MCHX) consists of flat tubes and folded fins that are connected to the manifolds. In last decades, mostly used as automotive radiators and condensers, they have a great potential in a field of domestic space heating and cooling systems. MCHX have already been applied as a standard part of air conditioning units, refrigeration systems, transport cooling systems, and even as high efficient chilled water coils for air conditioning and process cooling (Danfoss, 2018). Better performance, lower weight compared to standard copper fin-and-tube heat exchangers, minimal use of refrigerant and easier handling are just some of advantages and reasons for their larger implementation. Consequently, increased savings can be obtained by use of MCHX as a unit in single phase heat exchange, or in processes where phase change occurs. However, all aluminium MCHX still lack broader appliance in case when they should be applied as evaporators where refrigerant maldistribution should be taken with special caution. Liquid/gas separation, control of the refrigerant flow direction, secondary openings to spread out the refrigerant evenly across the length of the manifold, are just some of designs developed to make possible this use of MCHX (Kaltra Inovativtechnik, 2018).

Large number of research papers about MCHX can be found with different topics that deal with both single phase or with phase change processes (Asadi et al., 2014). Al-Zaidi et al. (2018) made experimental investigation to study the effect of refrigerant flow rate, local vapour quality, coolant flow rate and its inlet temperature on the local condensation heat transfer coefficient. They compared their experimental results with the existing correlations for the heat transfer rate. Dalkilic et al. (2017) published results of their experimental study of heat transfer characteristics of single-phase flow. In paper, they investigated single-phase turbulent flow of R-134a refrigerant in a rectangular multi-micro channel heat sink. Their finding demonstrated that well-known correlations for heat transfer could be used to predict heat transfer in multiport microchannel heat sink. This is very important, as in last decade of twentieth century respectable number of papers with experimental data for friction factor and Nusselt number in microchannel disagreed with conventional theories. Morini $(2004,2006)$, and later Rosa (2009), concluded that when dealing with microchannels, standard theory and correlations can be used but with inclusion of scaling effects that are often neglected. Dalkilic et al. (2018) investigated flow boiling 
of refrigerant R134a inside a multi-microchannel heat sink. They developed the copper test section that consisted of 27 parallel rectangular channels with all dimensions smaller than $0.5 \mathrm{~mm}$. Using data collected by the experiments they proposed new correlation to calculate the heat transfer coefficients for R134a flow boiling inside the multi-microchannel at high mass flow and high heat fluxes. Application in single phase process has been given by Robles et al. (2014). In paper, authors examined aluminium minichannel solar water heater performance under year-round weather conditions. In case of solar water heaters, increase of the heat transfer efficiency can be obtained using a more compact design of heat exchangers with microchannel technology (Garcia et al., 2011). Bhuiyan and Sadrul Islam (2016) have done review of research papers about heat exchangers geometry. They explored thermal and hydraulic performance of finned-tube heat exchangers under different flow regimes. Knourek et al. (2012) showed by detail set up and procedures that they used for measurement of thermal characteristics of the heat exchangers in their laboratory. They showed measured results for common automotive water-air heat exchanger by mean of normalized heat exchanged at the coolant side and by normalized heat exchanged at the air side.

In this paper, experimental analysis of the water-air heat exchanger with microchannel coil, that has been installed and tested in wind tunnel in its non-standard application, has been presented. Single-phase heat transfer characteristics have been measured and analysed. Thus, the influence of water/air inlet temperatures and influence of different velocities on heat transfer has been investigated. For purpose of this experimental investigation, previously developed open circuit wind tunnel (Glazar et al., 2011; Glazar et al., 2015) has been modified and upgraded. Description of experimental facility setup, test conditions and methods, with measurement results and final conclusions follows.

\section{Experimental Facility}

\subsection{Open circuit wind tunnel}

The experimental measurements have been done in open circuit wind tunnel, shown on Figure 1, which is used to prepare air and bring it towards measuring zone.

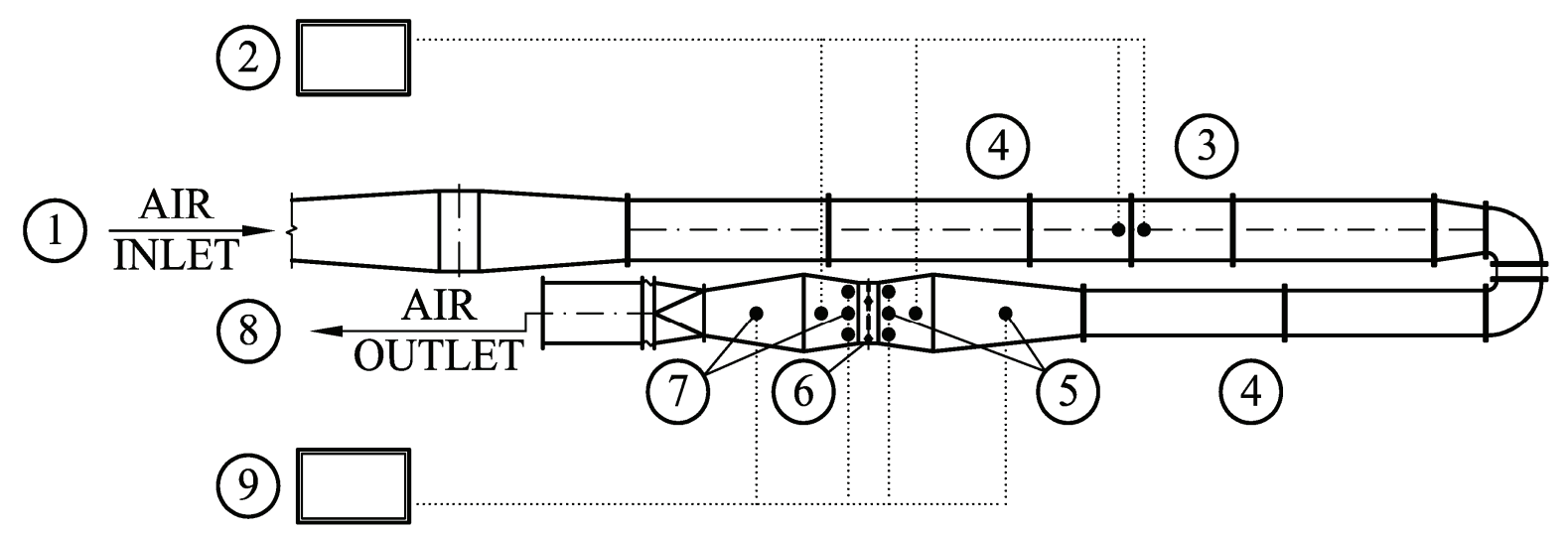

LEGEND: 1. air inlet (from air handling unit), 2. data acquisition system for pressure drops, 3. orifice, 4. air settling ducts, 5. air inlet temperature and air inlet velocity sensors, 6. MCHX (with installed water temperature in/out sensors), 7. air outlet temperature and velocity sensors, 8 . air outlet, 9. data acquisition system for velocities and temperatures

Fig. 1: Schematic view of experimental facility (wind tunnel)

The main components of the system are air supply unit with centrifugal fan, measuring orifice, heat exchanger with microchannel coil, instrumentations and data acquisition systems. The open circuit wind tunnel system, containing air-handling unit with heating and cooling section, is used to draw air over the tested heat exchanger. The air flow rate can be adjusted by pressure relief damper from approximately 20 to $100 \%$ of maximal air flow rate. The upper part of tunnel is composed of circular ducts with diameter of $600 \mathrm{~mm}$ and the lower part consists of rectangular ducts of appropriate size, $550 \times 450 \mathrm{~mm}$. 


\subsection{Water-based heating/cooling loop}

The hot/cold water supply section is divided in two separate loops. Primary loop with hot/cold water is connected to water/water heat pump with capacity of $50 \mathrm{~kW}$ and to the building heating installation. Secondary water loop is connected to the primary water loop with plate heat exchanger as shown on Figure 2. Secondary loop is used to prevent possible creation of lime scale in micro channels and it is filled with demineralized water. Lime scale is extremely damaging for channels with hydraulic diameter smaller than $1 \mathrm{~mm}$ and could cause undesired obstructions on water side of heat exchanger if not carefully treated.

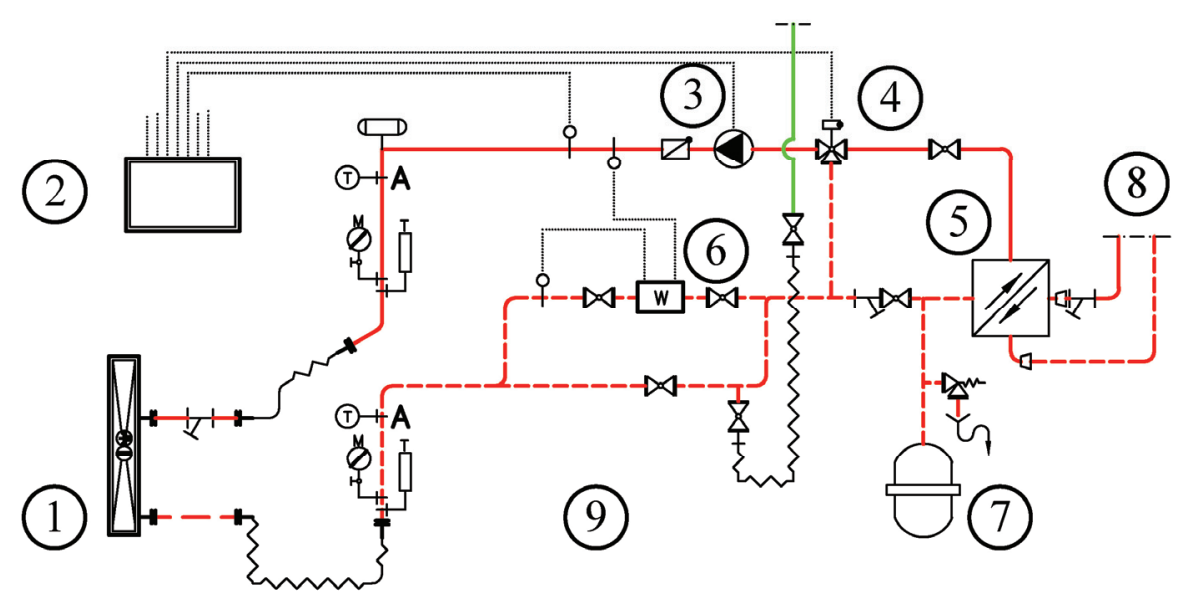

LEGEND: 1. test heat exchanger (MCHX), 2. hot/cold water control unit, 3. water pump, 4. three-way regulating valve, 5. plate heat exchanger between primary and secondary water loops, 6. ultrasonic flow meter, 7. expansion vessel, 8. connection to primary water loop, 9. secondary water loop filled with demineralized water

Fig. 2: Schematic view of water loop filled with demineralized water

\subsection{Temperature and flow measurements}

The air inlet and air outlet temperatures were measured with two thermocouple fields each placed before and after MCHX. Thermocouple field placed before MCHX was composed of three $K$ type thermocouples. Thermocouple field placed after MCHX was composed of twelve $K$ type thermocouples. Water inlet and outlet temperatures were measured with two thermocouples. Used thermocouples were pre-calibrated with an accuracy of $\pm 0.15^{\circ} \mathrm{C}$. Signals obtained from all temperature sensors were recorded and then processed. Figure $3 \mathrm{a}$ shows measuring station of wind tunnel with installed data acquisition system and part of secondary water loop with pipes filled with demineralized water. Figure $3 \mathrm{~b}$ shows thermocouples' displacement.

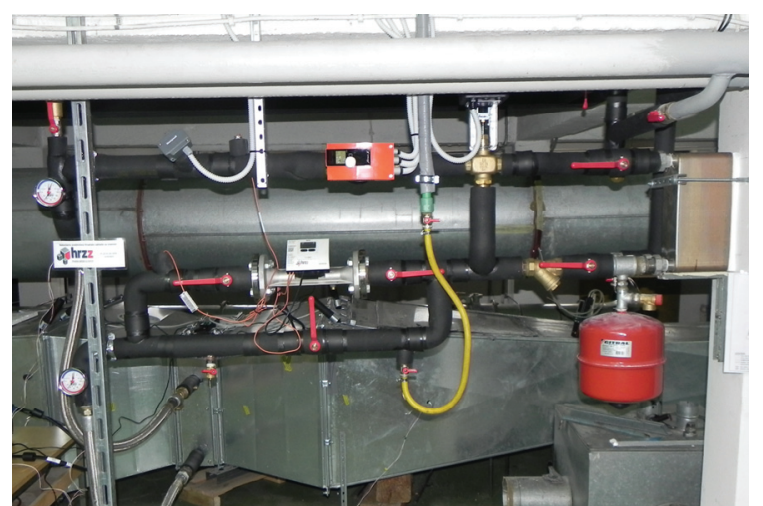

(a)

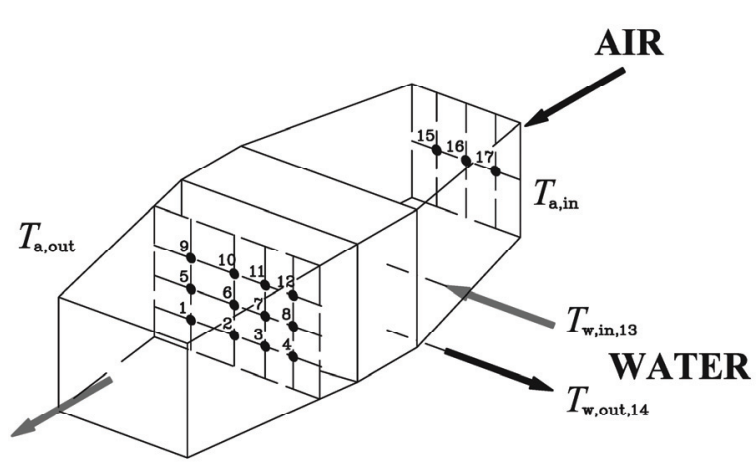

(b)

Fig. 3: Measuring station of wind tunnel (a) and layout of thermocouples' fields (b) 
Measuring orifice was used to determine air volume flow rate in orifice opening. Air passing through an orifice construction creates pressure drop in system. Pressure drop was measured with portable measuring system. Following equation has been used to calculate volume flow rates for each measurement setup:

$$
\dot{V}_{\mathrm{a}}=\alpha \cdot \varepsilon \cdot A \cdot \sqrt{\frac{2 \cdot \Delta p}{\rho_{\mathrm{a}}}}
$$

where used variables represent:

$$
\begin{array}{ll}
\dot{V}_{\mathrm{a}} & \text { - air volume flow rate, } \mathrm{m}^{3} \mathrm{~s}^{-1}, \\
\alpha & \text { - pipe orifice flow coefficient, }, \\
\varepsilon & \text { - coefficient of discharge, }-, \\
A & \quad \text { - cross-sectional area of the orifice hole, } \mathrm{m}^{2}, \\
\rho_{\mathrm{a}} & \text { - air density, } \mathrm{kg} \mathrm{m}^{-3} \text { and } \\
\Delta p & \text { - measured pipe orifice pressure drop, } \mathrm{Pa} .
\end{array}
$$

Corresponding average air velocity in ducts and air mass flow rate have then been calculated according to acquired air volume flow rate. Additionally, four hotwire anemometer probes (Figure 4a) were used to measure air velocities at appropriate cross-section of the tunnel. These data have been used to validate previously calculated air mass and volume flow rates. Time-wise air velocities, measured for three measuring points, have been shown on figure $4 b$.

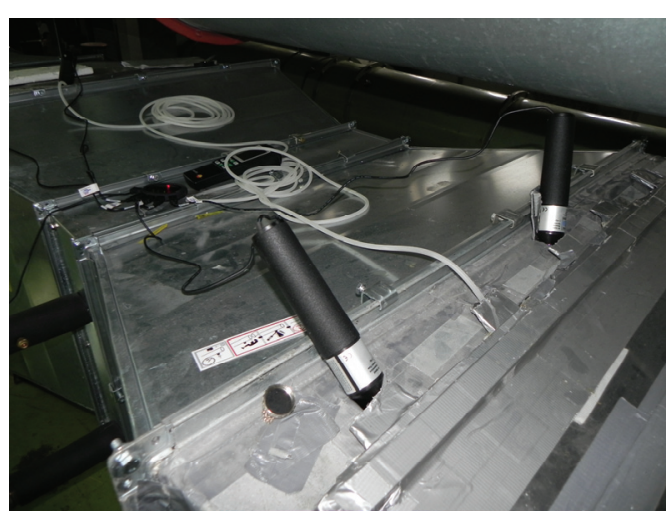

(a)

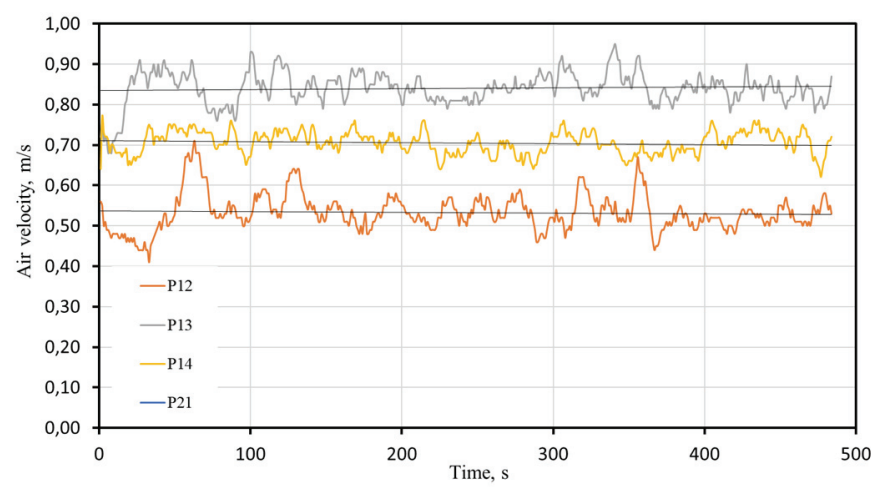

(b)

Fig. 4: Set up of hotwire anemometer probes (a) and graph-chart with measured air velocities at three points (b)

Water volume flow rate inside secondary water loop was measured with ultrasonic water flow meter. Appropriate water velocities and water mass flow rates were calculated according to previously measured water volume flow rates. Required water flows were obtained by change of water pump rotor speed.

\subsection{Data acquisition system}

The National Instruments SCXI data acquisition, automation and control module system was used. Connection to personal computer has been done by National Instruments USB-6251 adapter. All virtual instruments were developed in LabVIEW. Figure 5a shows data acquisition system connected to personal computer and Figure $5 \mathrm{~b}$ shows user interface developed for purpose of these measurements. 


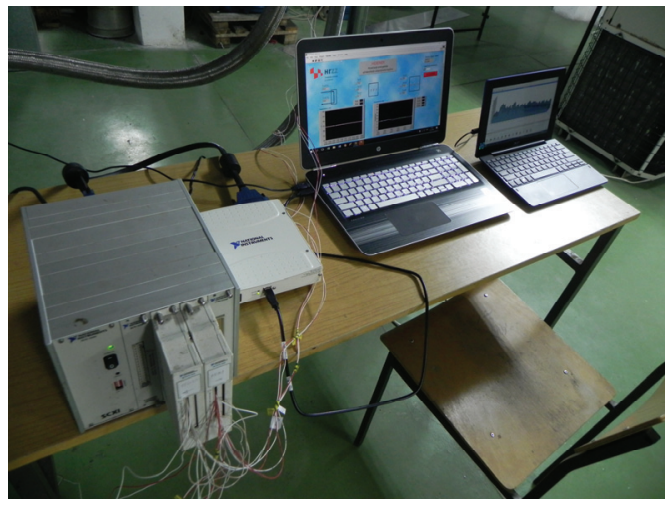

(a)

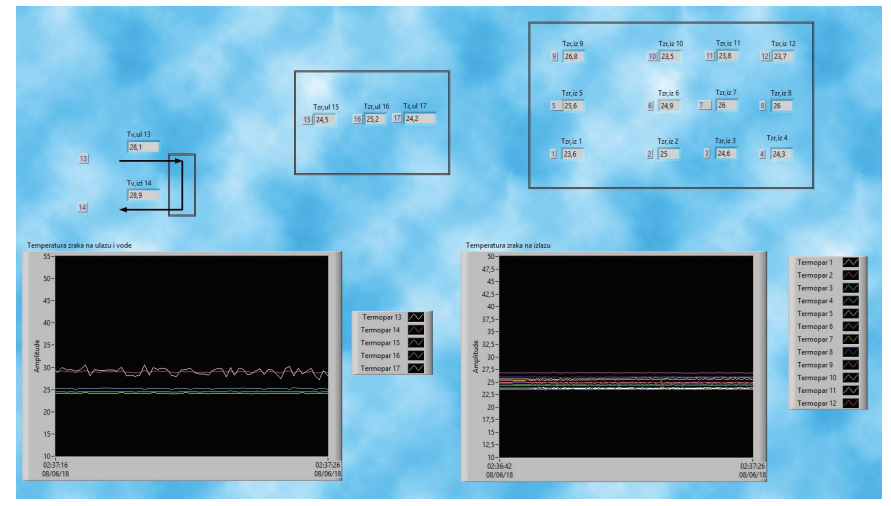

(b)

Fig. 5: Data acquisition system (a) and graphical user interface (b)

Experimental data are automatically saved to data file for further analyses. Block diagram section of developed virtual instrument in LabView is shown on Figure 6.

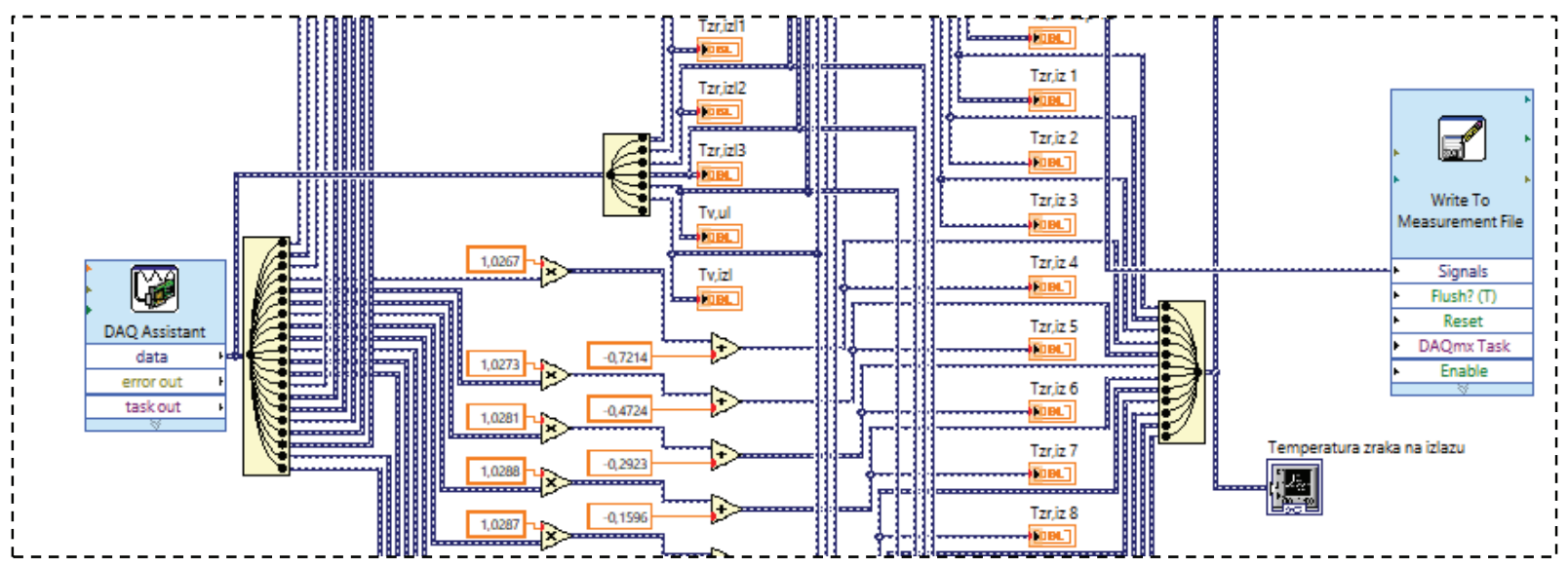

Fig. 6: Section of virtual instrument's block diagram developed in LabView

\subsection{Test heat exchanger}

The MCHX used in this investigation consist of 47 parallel flat tubes connected with louvered fins. Flat extruded tubes contains multiple small rectangular channels, each with hydraulic diameter smaller than $1 \mathrm{~mm}$. Outer overall dimensions of tested heat exchanger are $860 \times 600 \mathrm{~mm}$. MCHX has two passes. The first pass includes approximately $3 / 4$ of all tubes and the second pass is made of remaining tubes. Figure 7 a shows heat exchanger before it was installed in measuring station and figure $7 \mathrm{~b}$ shows thermogram of MCHX surface temperatures distribution during steady state condition. 


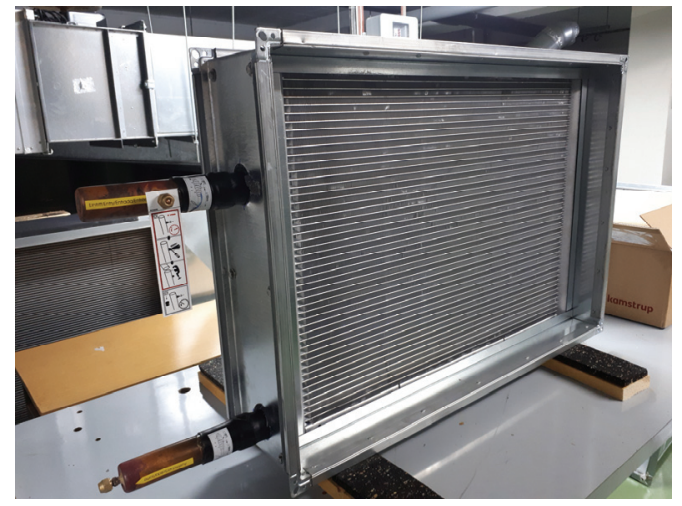

(a)

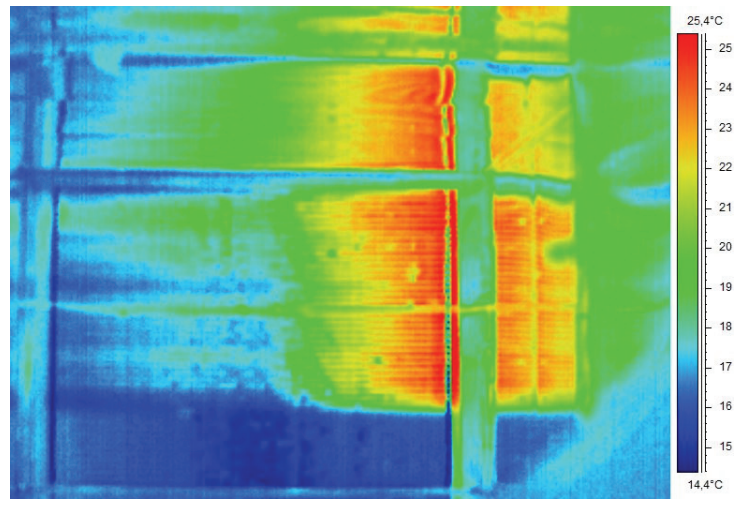

(b)

Fig. 7: MCHX (a) and thermogram of MCHX surface (b)

Thermogram of MCHX surface, made by infrared camera during experiment, gives clear insight in water flow through heat exchanger tubes. Division of water flow from first to second passage can be well noticed through MCHX surface temperature distribution because of extensive water-cooling. In this work, thermograms were used for qualitative assessment of heat exchanger's surface temperature distributions.

\section{Measurement conditions and results}

\subsection{Test conditions}

Measurements were performed for a wide range of air and water velocities and temperatures. Air inlet velocities were in a range from 0.5 to $5 \mathrm{~m} \mathrm{~s}^{-1}$. Water velocities entering in heat exchanger were in a range from 0.05 to $1 \mathrm{~m}$ $\mathrm{s}^{-1}$. Both air and water temperatures were in range from 2 to $67^{\circ} \mathrm{C}$. A series of experimental measurements have been done in order to analyse heat transfer in the heat exchanger with microchannel coil. Set of different parameter setups have been created according to measurement plan. Two major groups of measurement setups have been performed: first with air inlet temperatures in the range from 10 to $15^{\circ} \mathrm{C}$, and second with air inlet temperatures in the range from 20 to $25^{\circ} \mathrm{C}$. Time wise air and water temperatures for test conditions: $T_{\mathrm{w}, \text { in }}=50^{\circ} \mathrm{C}, T_{\mathrm{a}, \text { in }}=20^{\circ} \mathrm{C}$, $u_{\mathrm{w}, \text { in }}=0.1 \mathrm{~m} \mathrm{~s}^{-1}$ and $u_{\mathrm{a}, \text { in }}=0.7 \mathrm{~m} \mathrm{~s}^{-1}$, are shown on Figure $8 \mathrm{a}$ (startup procedure) and Figure $8 \mathrm{~b}$ (steady state). Data acquisition frequency in all measurements was set to $1 \mathrm{~Hz}$.
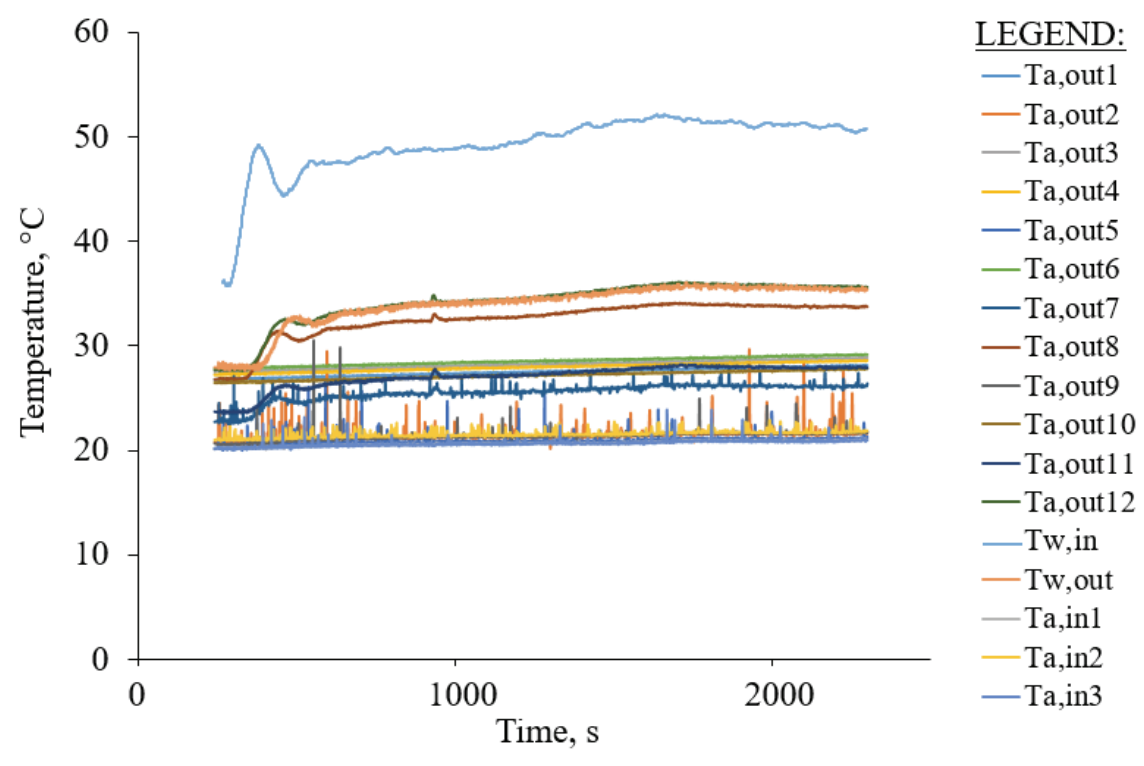


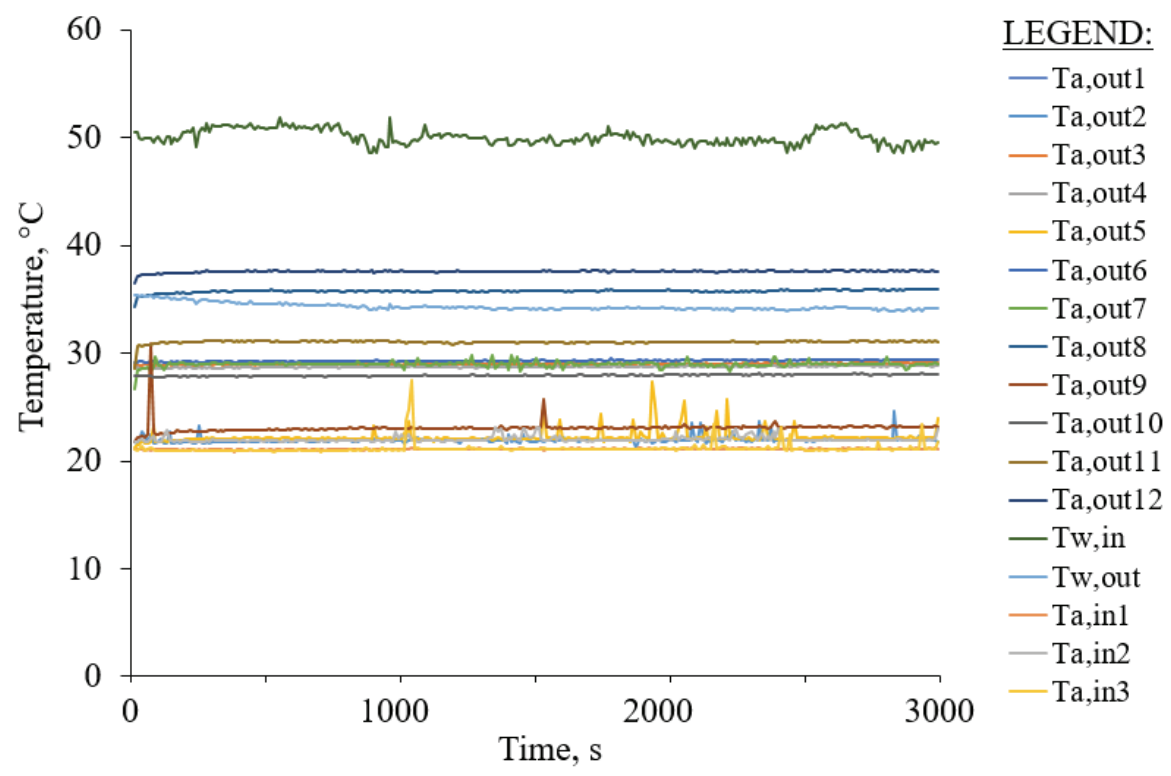

(b)

Fig. 8: Air and water temperatures for heating startup procedure (a) and after steady state achieved (b)

All measuring data were collected for steady-state conditions. Error analysis has been done according to standard procedures. As a part of the analysis, the balance of measured exchanged heat fluxes on water and air side has been checked.

\subsection{Average temperatures and exchanged heat fluxes}

Measurement results have been given by corresponding exchanged heat fluxes. Heat fluxes were calculated using average air and water temperatures as well as air and water velocities acquired by experimental measurements. Average temperatures of air were calculated from multiple temperature measuring points using following equations:

$$
\begin{aligned}
& T_{\mathrm{a}, \mathrm{in}}=\frac{\sum_{i=1}^{3} T_{\mathrm{a}, \mathrm{in \textrm {i }}}}{3} \\
& T_{\mathrm{a}, \text { out }}=\frac{\sum_{i=1}^{12} T_{\mathrm{a}, \text { out } \mathrm{i}}}{12}
\end{aligned}
$$

Average exchanged heat flux can be expressed as:

$$
\dot{Q}_{\mathrm{m}}=\frac{\dot{Q}_{\mathrm{w}}+\dot{Q}_{\mathrm{a}}}{2}
$$

where air side and water side heat fluxes can be calculated by:

$$
\dot{Q}_{\mathrm{w}}=\dot{m}_{\mathrm{w}} \cdot c_{\mathrm{w}} \cdot \Delta T_{\mathrm{w}}
$$




$$
\dot{Q}_{\mathrm{a}}=\dot{m}_{\mathrm{a}} \cdot c_{\mathrm{P}, \mathrm{a}} \cdot \Delta T_{\mathrm{a}}=\rho_{\mathrm{a}} \cdot \dot{V}_{\mathrm{a}} \cdot c_{\mathrm{P}, \mathrm{a}} \cdot \Delta T_{\mathrm{a}}
$$

In previous equations used variables are:

$$
\begin{array}{ll}
c_{\mathrm{P}, \mathrm{a}} & \text { - specific heat capacity of air, } \mathrm{J} \mathrm{kg}^{-1} \mathrm{~K}^{-1}, \\
c_{\mathrm{w}} & \text { - specific heat capacity of water, } \mathrm{J} \mathrm{kg}^{-1} \mathrm{~K}^{-1}, \\
\dot{m}_{\mathrm{a}} & \text { - mass flow rate of air, } \mathrm{kg} \mathrm{s}^{-1}, \\
\dot{m}_{\mathrm{w}} & \text { - mass flow rate of water, } \mathrm{kg} \mathrm{s}^{-1}, \\
\rho_{\mathrm{a}} & \text { - air density, } \mathrm{kg} \mathrm{m} \mathrm{m}^{-3}, \\
\dot{Q}_{\mathrm{a}} & \text { - air side heat flux, } \mathrm{W}, \\
\dot{Q}_{\mathrm{m}} & \text { - average exchanged heat flux, } \mathrm{W}, \\
\dot{Q}_{\mathrm{w}} & \quad \text { - water side heat flux, W, } \\
\Delta T_{\mathrm{a}} & \text { - air temperature difference, } \mathrm{K}, \\
\Delta T_{\mathrm{w}} & \text { - water temperature difference, } \mathrm{K}, \\
T_{\mathrm{a}, \text { in }} & \text { - air inlet temperature, } \mathrm{K} \text { and } \\
T_{\mathrm{a}, \text { out }} & \text { - air outlet temperature, } \mathrm{K} .
\end{array}
$$

\subsection{Measurement results}

Results are given for heat exchanger with microchannel coil in single-phase heat transfer conditions. Calculated heat fluxes on air and water side, combined with average exchanged heat flux for range of different water velocities are shown on Figure 9. Test conditions for this measurements were: $T_{\mathrm{w}, \text { in }}=35^{\circ} \mathrm{C}, T_{\mathrm{a}, \text { in }}=24^{\circ} \mathrm{C}$ and $u_{\mathrm{a} \text {,in }}$ $=0.7 \mathrm{~m} \mathrm{~s}^{-1}$

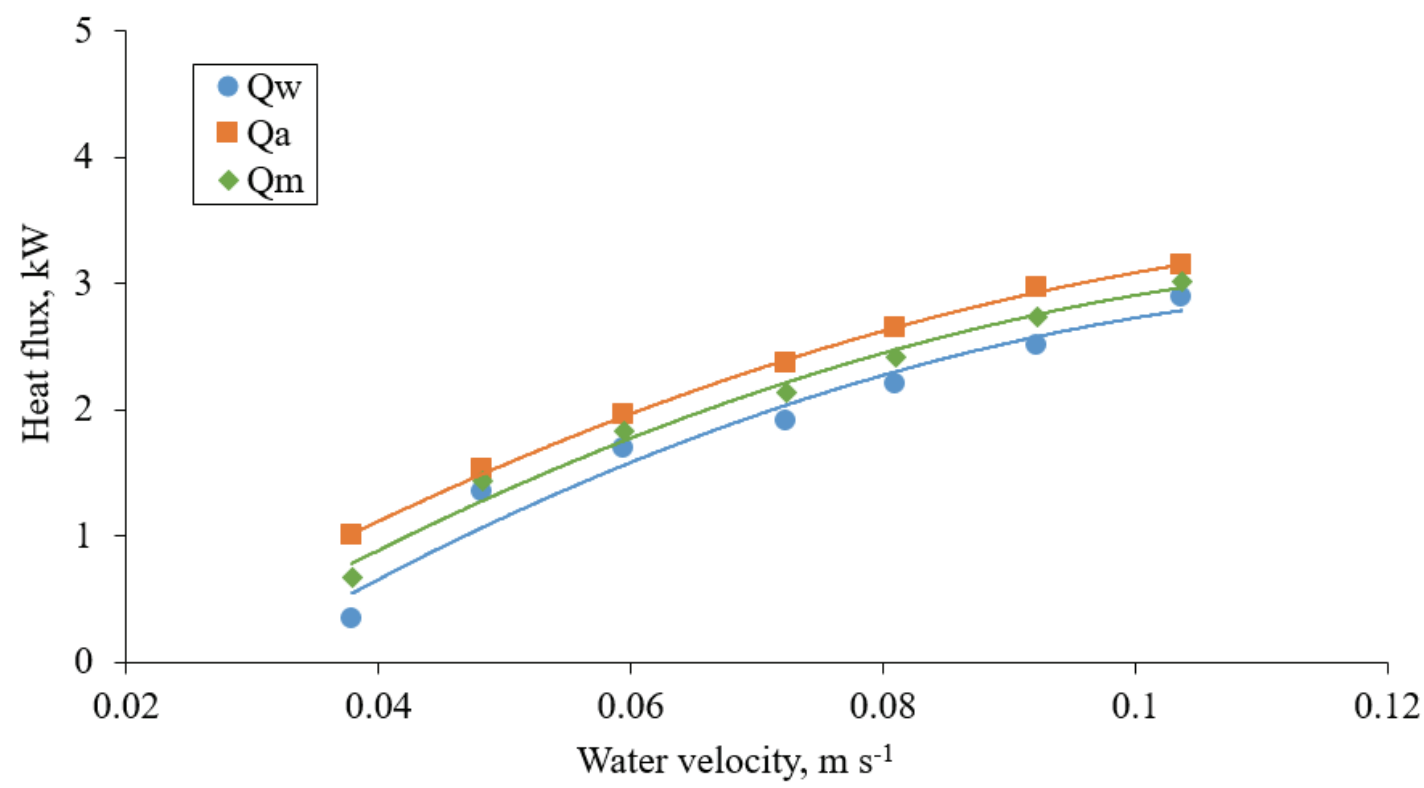

Fig. 9: Exchanged heat fluxes on air and water side combined with average exchanged heat flux for different water velocities. Test conditions: $T_{w, i n}=35^{\circ} \mathrm{C}, T_{a, \text { in }}=24^{\circ} \mathrm{C}$ and $u_{a, \text { in }}=0.7 \mathrm{~m} \mathrm{~s}^{-1}$ 
Average air inlet and air outlet temperatures were used to calculate heat fluxes on air side and measured water inlet and outlet temperatures were used to calculate heat fluxes on water side. Heat fluxes, both on air and water side, were higher at higher water inlet velocities. In this measurement setup, calculated air heat fluxes were higher than water heat fluxes for all water velocities as can be seen from Figure 9.

Air outlet temperatures and average exchanged heat fluxes for the range of water inlet velocities from 0.03 to 0.12 $\mathrm{m} \mathrm{s}^{-1}$ are shown on Figures 10a and 10b. Corresponding water flow rates were from 150 to $480 \mathrm{l} \mathrm{h}^{-1}$. Air inlet temperature was $22^{\circ} \mathrm{C}$, air inlet velocity was $1.58 \mathrm{~m} \mathrm{~s}^{-1}$ and water inlet temperatures were $35,40,45$ and $50^{\circ} \mathrm{C}$.

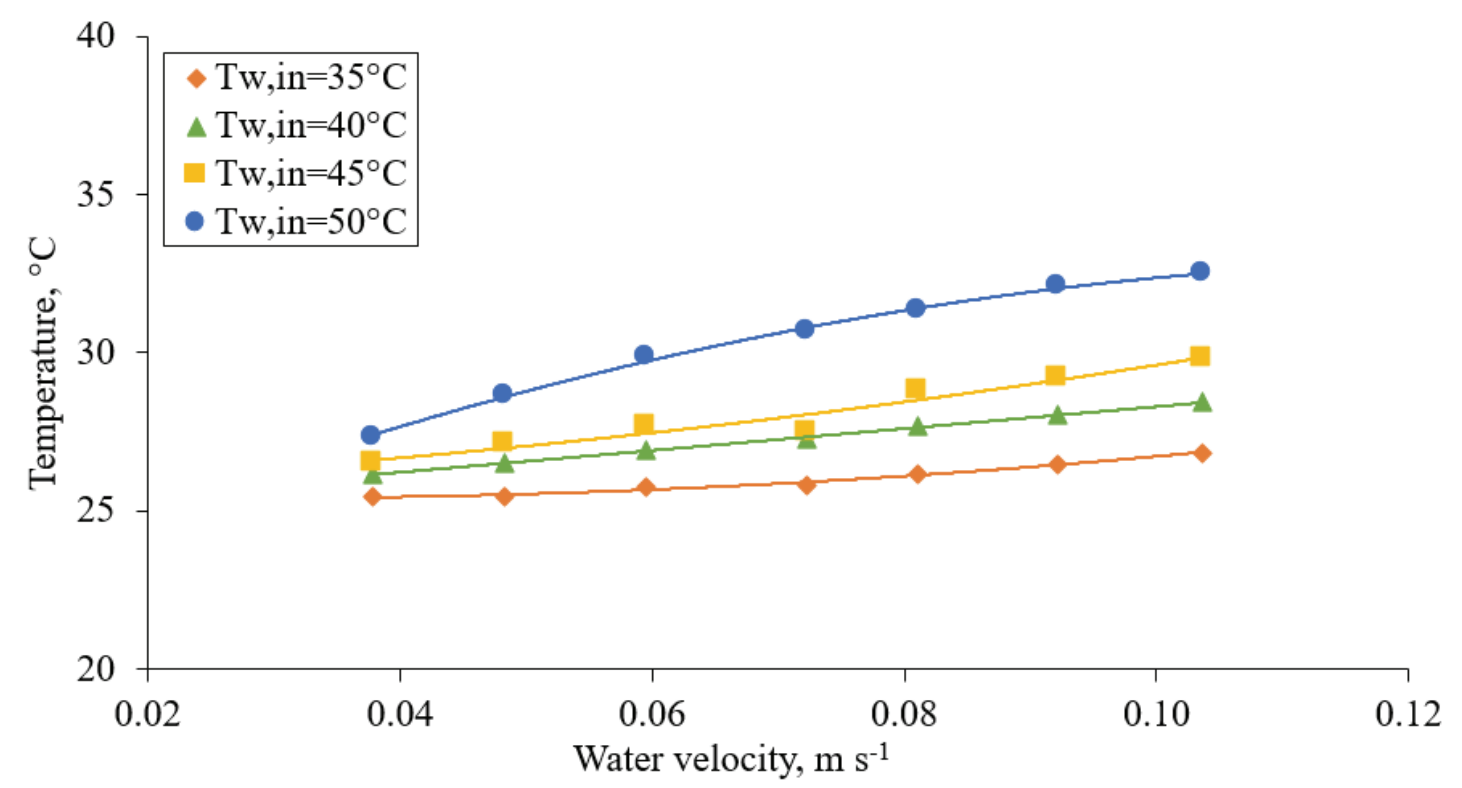

(a)

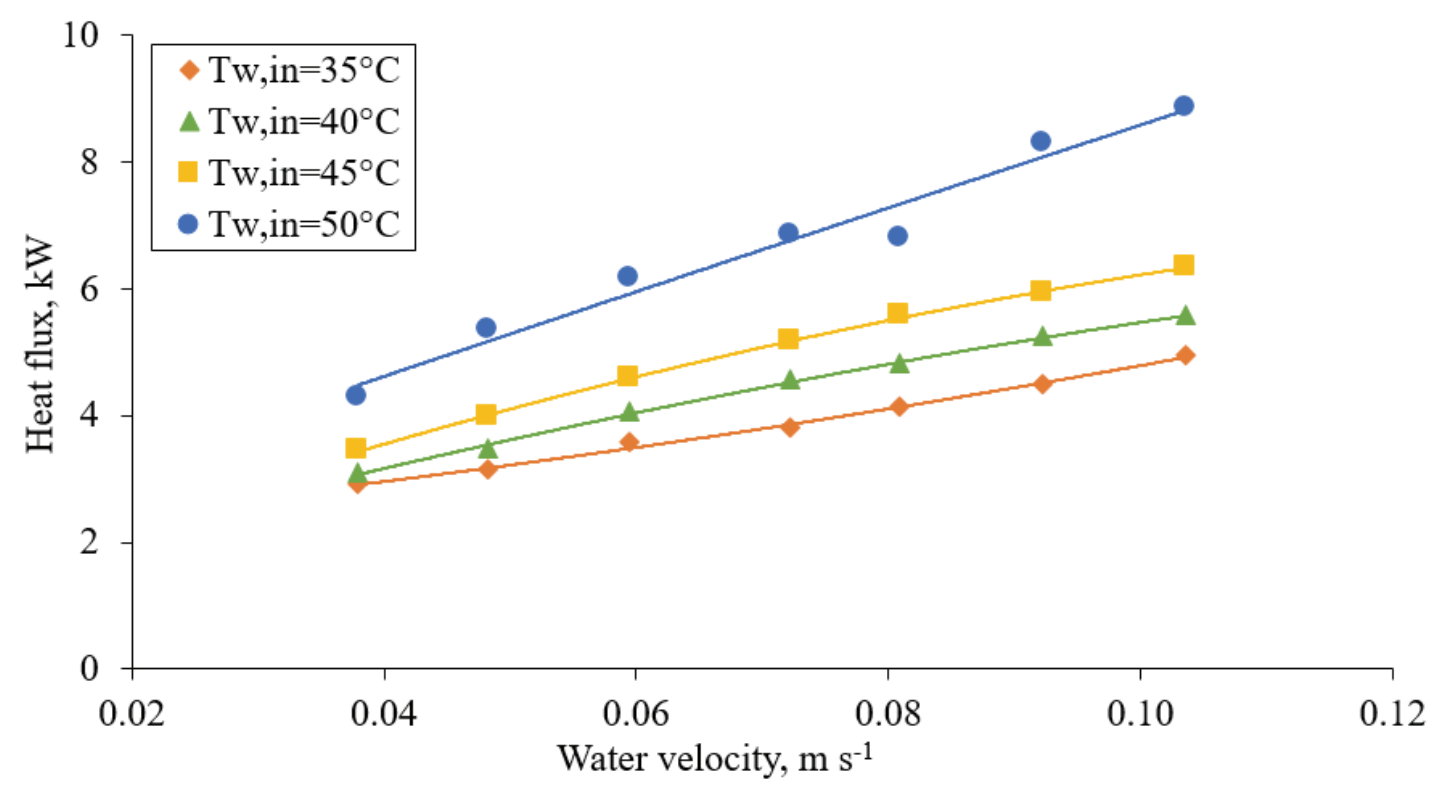

(b)

Fig. 10: Air outlet temperatures (a) and average exchanged heat fluxes (b) for different water velocities and water inlet temperatures. Test conditions: $T_{a, \text { in }}=22^{\circ} \mathrm{C}, u_{a, i n}=1.58 \mathrm{~m} \mathrm{~s}^{-1}$

Higher water velocity gives higher heat flux for constant water inlet temperature. In case of lower water velocities, the differences between heat fluxes for different water temperatures are relatively small and they increase with higher water velocities. 
Figure 11 gives insight in temperature and heat flux changes depending on water velocity for two different air inlet velocities. In this measurements air inlet temperature was $22^{\circ} \mathrm{C}$ and water inlet temperature was $40^{\circ} \mathrm{C}$.

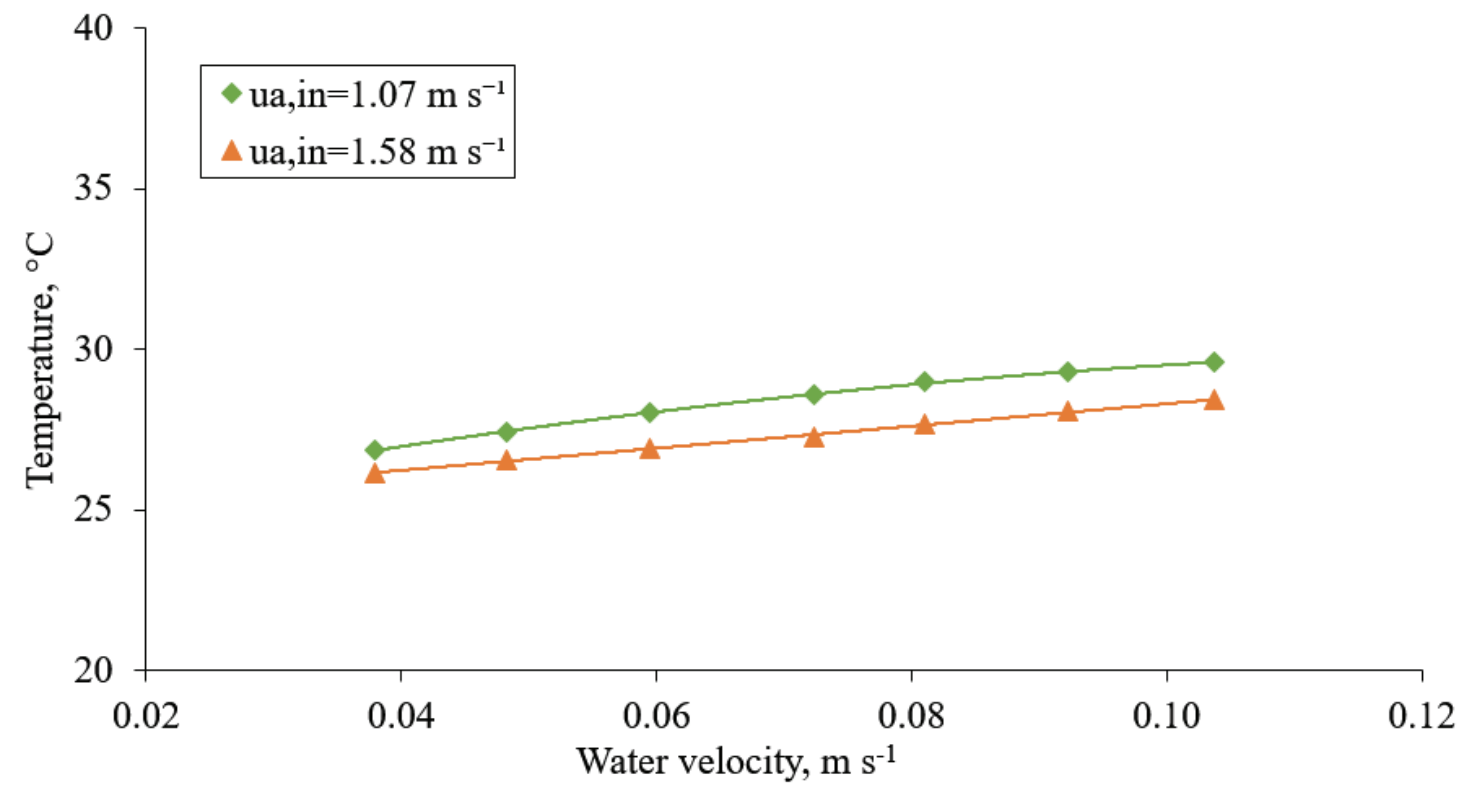

(a)

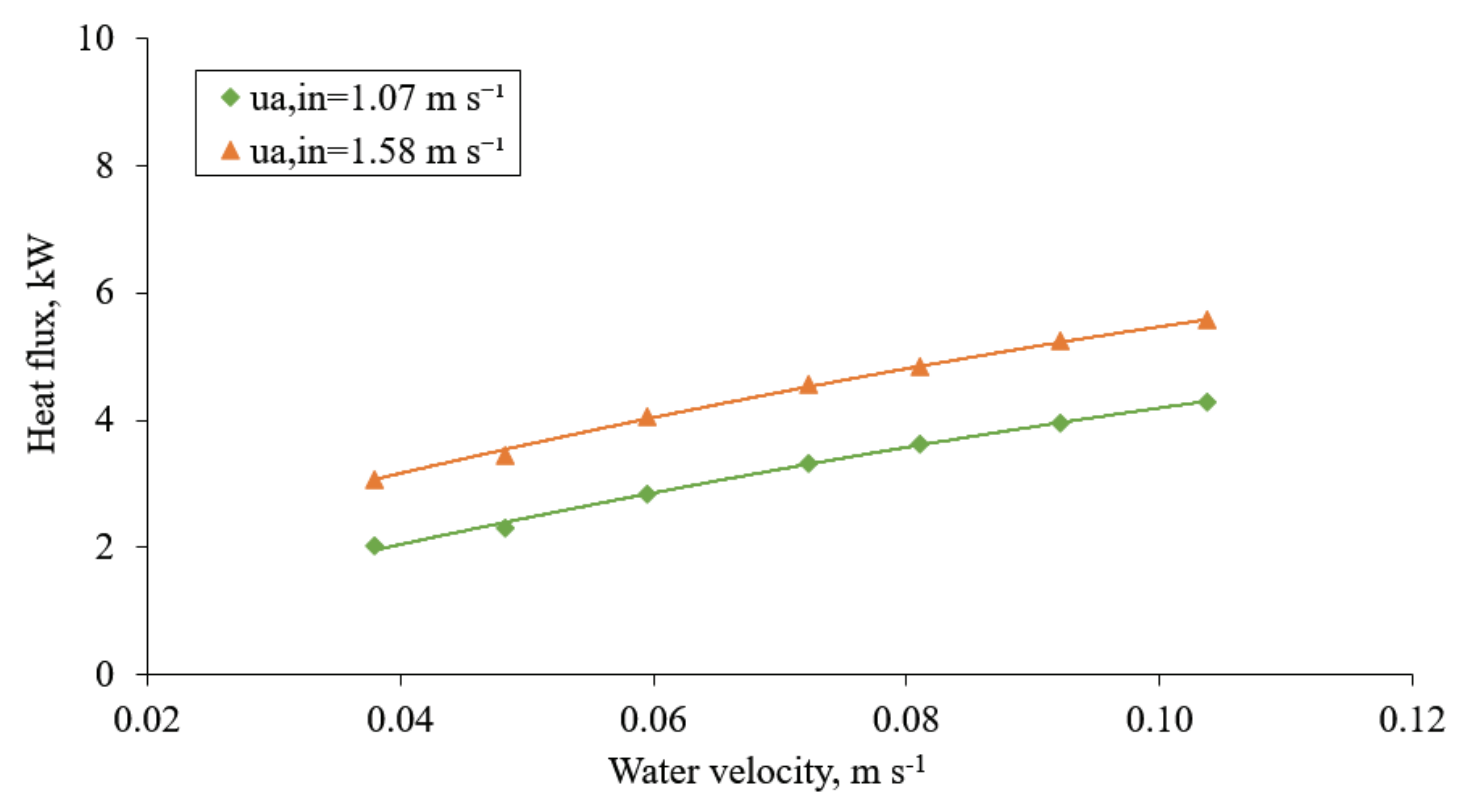

(b)

Fig. 11: Air outlet temperatures (a) and average exchanged heat fluxes (b) for different water and air velocities and inlet temperatures. Test conditions: $\mathrm{T}_{\mathrm{a}, \mathrm{in}}=22^{\circ} \mathrm{C}, \mathrm{T}_{\mathrm{w}, \mathrm{in}}=40^{\circ} \mathrm{C}$

Measured air outlet temperatures are lower in cases of higher air velocities. Heat fluxes have higher values with increasing of air and water velocities.

Heat fluxes for measured range of water inlet temperatures are shown for two different water inlet velocities (Figure 12a) and for two different air inlet velocities (Figure 12b). Air inlet temperature was $12^{\circ} \mathrm{C}$, air inlet velocities were $1.16 \mathrm{~m} \mathrm{~s}^{-1}$ and $1.43 \mathrm{~m} \mathrm{~s}^{-1}$, and water inlet velocities were 0.05 and $0.07 \mathrm{~ms}^{-1}$. Water inlet temperatures were in range from 28 to $70^{\circ} \mathrm{C}$. 


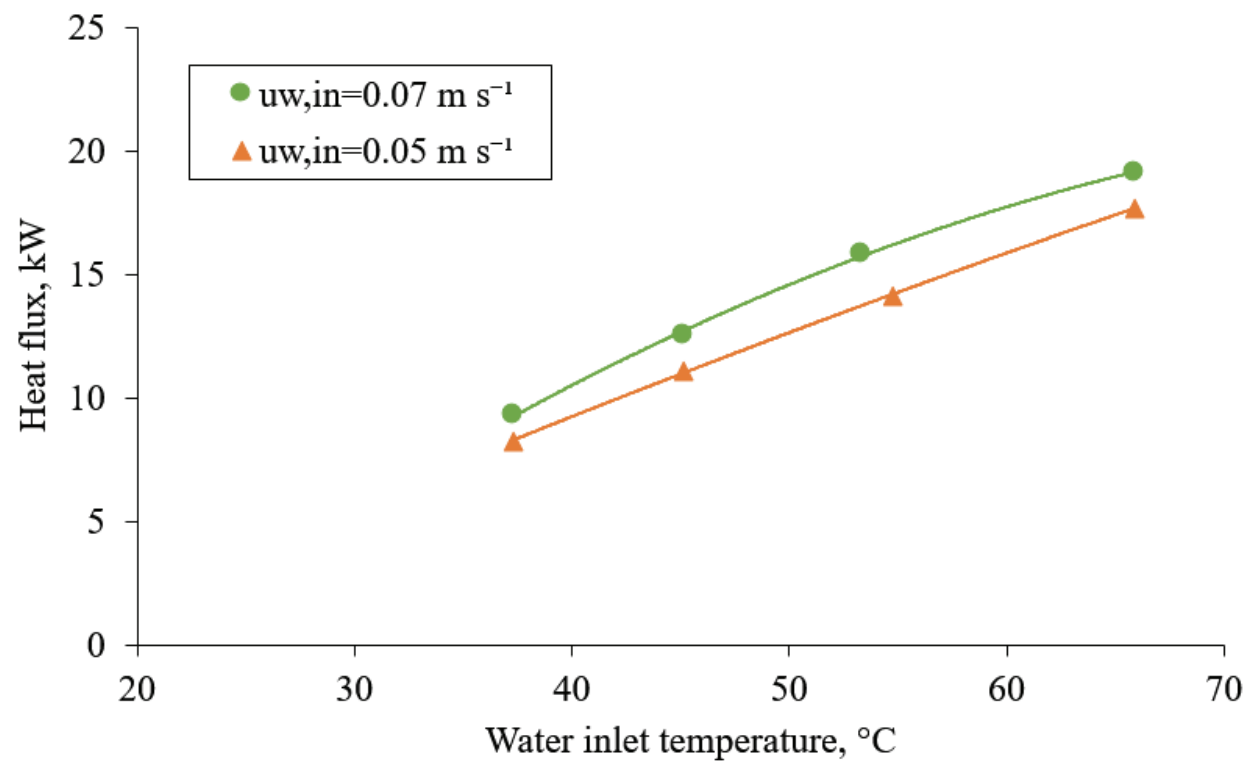

(a)

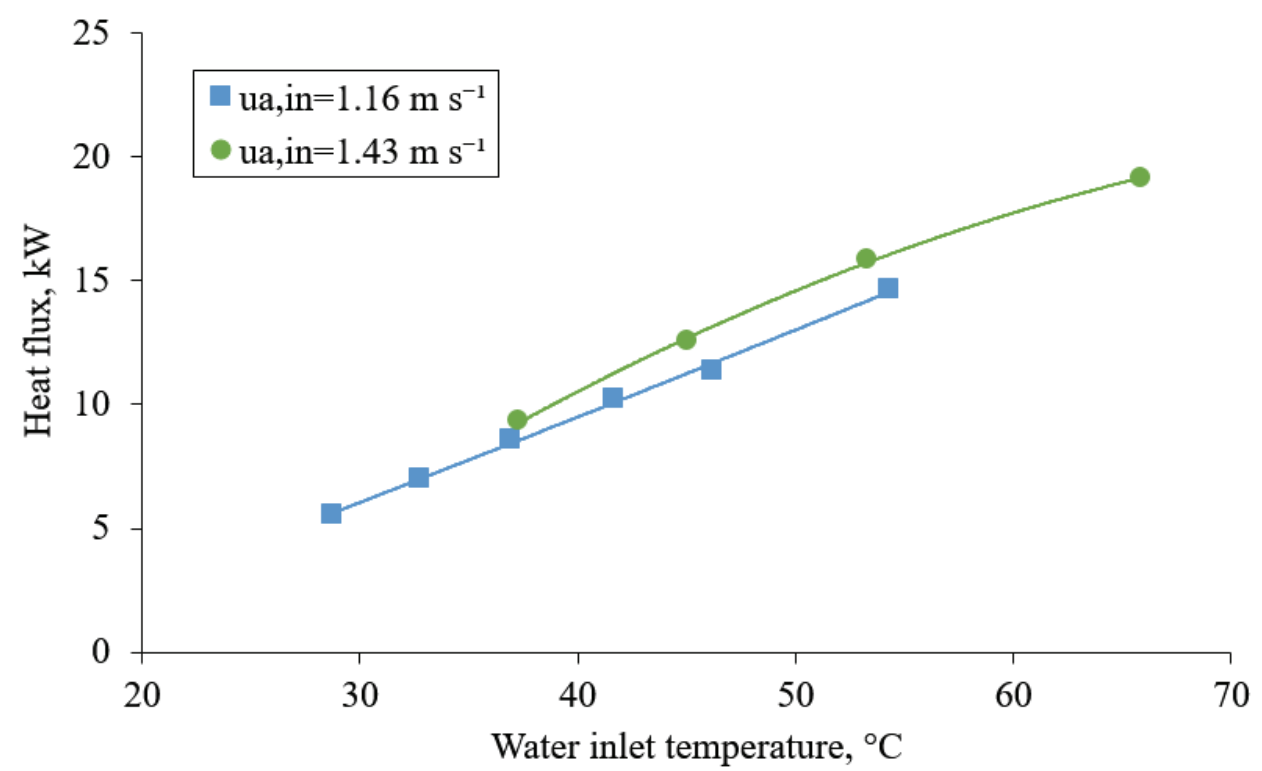

(b)

Fig. 12: Average exchanged heat fluxes for different water inlet temperatures in case of different water inlet velocities with test conditions: $T_{a, i n}=12^{\circ} \mathrm{C}, u_{a, i n}=1.43 \mathrm{~m} \mathrm{~s}^{-1}$ (a) and different air inlet velocities with test conditions: $T_{a, i n}=12^{\circ} \mathrm{C}, u_{w, i n}=0.07 \mathrm{~m} \mathrm{~s}^{-1}(\mathrm{~b})$

For whole range of water inlet temperatures, average heat flux is lower in cases of lower water inlet velocities and in cases of lower air inlet velocities.

\section{Conclusion}

Heat exchanger with microchannel coil has been installed in an open wind tunnel and measurements with different air and water flow and temperature regimes have been done. Measurements were performed in following range of air and water velocities and temperatures: air inlet velocities were from 0.5 to $5 \mathrm{~m} \mathrm{~s}^{-1}$, water inlet velocities were in a range from 0.05 to $1 \mathrm{~m} \mathrm{~s}^{-1}$, air and water inlet temperatures were in range from 2 to $68^{\circ} \mathrm{C}$. Various parameter setups have been set and measurements were performed. Appropriate dependences of temperatures and exchanged heat fluxes on water and air inlet velocities have been shown. This paper presents a part of measurement results performed using modified and upgraded open circuit wind tunnel, with installed heat exchanger with microchannel coil. Main aim of this paper was to experimentally analyse the heat exchanger with microchannel coil in an air-water heat exchange application. 
Goals of further work will be to improve heat balance in system and to make analysis of heat transfer efficiency. Acquired data from these measurements will be applied for validation of numerical model that will be used for optimization of heat exchanger with microchannel coil geometrical parameters.

*Acknowledgement: This work has been fully supported by Croatian Science Foundation under the project HEXENER (IP-2016-06-4095).

\section{References}

Al-Zaidi, A.H., Mahmoud, M.M., Karayiannis, T.G., 2018. Condensation flow patterns and heat transfer in horizontal microchannels. Exp. Therm. Fluid. Sci. 90, 153-173,

https://doi.org/10.1016/j.expthermflusci.2017.09.009

Asadi, M., Xie, G., Sunden, B., 2014. A review of heat transfer and pressure drop characteristics of single and two-phase microchannels, Heat Mass Transfer. 79, 34-53,

https://doi.org/10.1016/j.ijheatmasstransfer.2014.07.090

Bhuiyan, A.A., Sadrul Islam, A.K.M., 2016. Thermal and hydraulic performance of finned-tube heat exchangers under different flow ranges: A review on modeling and experiment, Heat Mass Transfer. 101, 38-59, https://doi.org/10.1016/j.jhheatmasstransfer.2016.05.022

Bosnjakovic, F., 2012. Nauka o toplini, Graphis d.o.o., Zagreb (on Croatian).

Dalkilic, A.S., Mahian, O., Yilimaz, S., Sakamatapan, K., Wongwises, S., 2017. Experimental investigation of single-phase turbulent flow of R-134a in a multiport microchannel heat sink. Heat Mass Transfer. 89, 47-56, https://doi.org/10.1016/j.icheatmasstransfer.2017.09.023

Dalkilic, A.S., Özman, C., Sakamatapan, K., Wongwises, S., 2018. Experimental investigation on the flow boiling of R134a in a multi-microchannel heat sink. Heat. Mass. Transfer. 91, 125-137, DOI: 10.1016/j.icheatmasstransfer.2017.12.008

Danfoss, http://files.danfoss.com/technicalinfo/dila/24/DKQBPB400A402_Sep2014_LR.pdf, accessed on $6^{\text {th }}$ of July, 2018.

Garcia, A., Wong, J., Diaz, G., Balkoski, K., Rico, K., 2011. Solar water heater utilizing mini-channel technology, The 2011 UC Solar Research Symposium, http://cast.ucmerced.edu/home/2011-solar-symposium, accessed on 6th of July, 2018.

Glazar, V., 2011. Compact Heat Exchanger Geometry Optimization. PhD thesis. Faculty of Engineering University of Rijeka, Croatia (in Croatian).

Glazar V., Frankovic B., Trp A., 2015. Experimental and numerical study of the compact heat exchanger with different microchannel shapes. Int. J. Refrig. 51 (1), 144-153, https://doi.org/10.1016/j.ijrefrig.2014.06.017

Kaltra Innovativtechnik, https://www.kaltra.de/microchannel-evaporators, accessed on $6^{\text {th }}$ of July, 2018.

Kandlikar, S., Garimella, S., Li, D., Colin, S., King, M.R., 2016. Heat Transfer and Fluid Flow in Minichannels and Microchannels. Butterworth-Heinmann, United States of America.

Knourek, J., Kus, M., Syka, T., 2012. Measuring thermal characteristics of the heat exchanger. EPJ Web of Conferences 25, 01041, DOI: 10.1051/epjconf/20122501041.

Morini. G.L., 2004. Single-phase convective heat transfer in microchannels: a review of experimental results, Int. J. Therm. Sci. 43, 631-651, https://doi.org/10.1016/j.jithermalsci.2004.01.003

Morini. G.L., 2006. Scaling Effects for Liquid Flows in Microchannels, Heat. Transfer Eng. 27, 64-73, https://doi.org/10.1080/01457630500523865Robles, A., Duong, V., Martin, A.J., Guadarrama, J.L., Diaz, G., 2014. Aluminum minichannel solar water heater performance under year-round weather conditions. Sol. Energy. 110, 356-364, https://doi.org/10.1016/j.solener.2014.09.031

Rosa, P., Karayiannis, T.G., Collins, M.W., 2009. Single-phase heat transfer in microchannels: The importance of scaling effects, Appl. Therm. Eng. 29, 3447-3468, https://doi.org/10.1016/j.applthermaleng.2009.05.015 


\title{
Hardware-in-the-Loop Tests on Complete Systems with Heat Pumps and PV for the Supply of Heat and Electricity
}

\author{
Robert Haberl, Andreas Reber, Evelyn Bamberger, Michel Haller \\ SPF Institut für Solartechnik, Hochschule für Technik Rapperswil
}

\begin{abstract}
Four "smart control" heat pump (HP) heating systems have been tested and evaluated as a whole by detailed measurements in the laboratory with a hardware in the loop approach. The complete systems were installed on a test rig that emulated a building with photovoltaic (PV) electricity production as well as the heat demand for domestic hot water and space heating and the electricity demand for household appliances. The test bench also emulated the environmental heat (air or ground source) as the source of the heat pump. The measurement focused on the capability of the tested systems to deal with solar power in excess to household needs and with different types of energy storage (thermal or electrochemical). In addition to insights into the behavior and performance of the tested systems, insights into the advantages and disadvantages of various key performance factors for these kind of systems were gained. It is found that self-sufficiency and self-consumption are not suitable optimization parameters. The grid purchase ratio is proposed instead.
\end{abstract}

Keywords: PV, heat pump, hardware in the loop, thermal energy storage, battery, self-consumption, selfsufficiency, control strategies, grid purchase ratio

\section{Introduction}

Single-family houses are no longer just energy consumers, but also energy producers. The combination of heat pump and PV systems reflects this very well. Corresponding products are already on the market: Heat pump systems whose control is designed for an increased self-consumption.

This work shows test results of four systems that aim to increase self-sufficiency and decrease electricity costs for households.

\section{Methods}

The Concise Cycle Test (CCT) is a test method for testing complete heating systems under realistic conditions. Originally developed to test systems with thermal collectors in combination with oil, gas and pellet boilers (Haberl et al. 2009; Haller et al. 2013), the method and the associated test infrastructure have meanwhile been expanded. This means that heat pumps and PV systems can now also be tested using the hardware-in-the-loop method (Haberl et al. 2014). The test method has thus developed from a test method for heating systems that provide space heat and domestic hot water to a test method for systems that supply heat and electricity for buildings. A description of the test method (in German) can be found in Haberl et al. 2018.

On the test bench the realistic operation of a complete heating system in the hardware-in-the-loop method is being enabled. During the test cycle, the test bench simulates and emulates a complete building whose heat and power requirements must be covered. This emulation also includes the building envelope with a photovoltaic system, the environmental heat as a source of a heat pump (ambient air or geothermal borehole probes) and the electric energy demand of home appliances (household electricity). The applied loads for space heating, hot water and household electricity are pre-defined to ensure an identical load and thus allow a direct comparison of the tested systems.

The procedure for simulation and emulation can be described as follows: The test bench software transfers current measured values to the simulation software at the end of each time step. In the simulation, the behavior of the respective component is calculated according to the input data and communicated to the test bench software. 
During each time step, the test bench software controls the emulation while the simulation software pauses. Only at the end of the time step are the new measurement data transferred to the simulation software, and the control target variables for the next time step are determined by the simulation software.

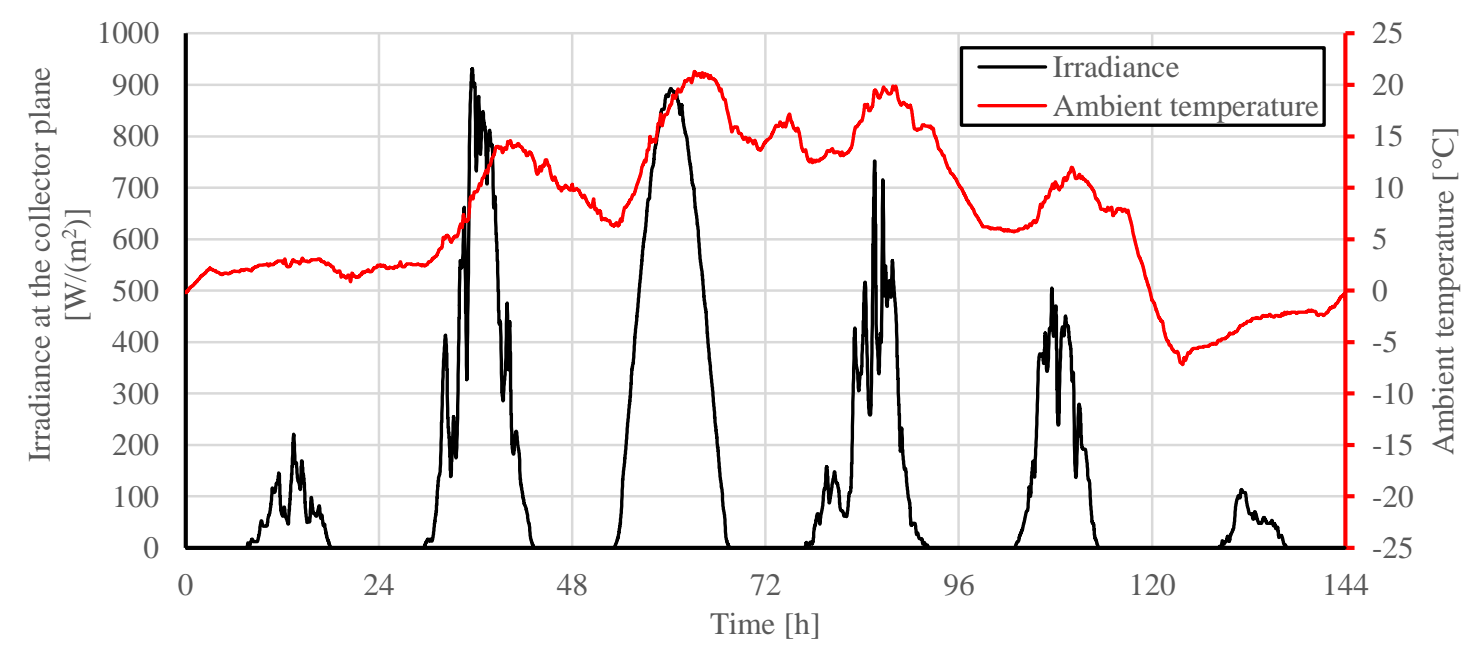

Figure 1: Weather data of the 6-day test cycle for the CCT.

Figure 1 shows the weather data of the 6-day test cycle of the CCT, which are representative to a whole year (Battaglia et al. 2017). Further boundary conditions of the test method are:

- $\quad$ PV system: 2 x 12 modules, $5.76 \mathrm{kWp}$, orientation south, tilt angle $45^{\circ}$

(Max Power: $240 \mathrm{~W}$; Open circuit voltage: $52.4 \mathrm{~V}$; Short Circuit Current: $5.85 \mathrm{~A}$ )

- Space heating: Heating floor $140 \mathrm{~m}^{2}, 7.4 \mathrm{MWh} / \mathrm{a}$ respectively $120 \mathrm{kWh}$ in a 6-day test

- Domestic hot water: 4 persons, $3 \mathrm{MWh} / \mathrm{a}$ respectively $50 \mathrm{kWh}$ in a 6-day test, max. flow rate $18 \mathrm{l} / \mathrm{min}$

- Household appliances: 4 persons, 3.3 MWh/a respectively $55 \mathrm{kWh}$ in a 6-day test; Profile resolution 1 min.; max. power $5 \mathrm{~kW}$

Both, thermal and electrical power, are measured in the system test. The thermal output is measured at the interface to the test bench via immersed temperature sensors in the flow and return lines and a volumetric flow meter.

The electrical power is measured at several positions during the test. The important variables for the energy balance are measured galvanically integrated. These are:

$E_{P V-y i e l d} \quad$ Produced PV electricity. The measurement is carried out on the DC and AC lines; the AC current measurement is used for the energy balance.

$E_{H H}$ : Household electricity (without heat pump).

$E_{\text {grid-purchase }}$ Electric energy from the grid.

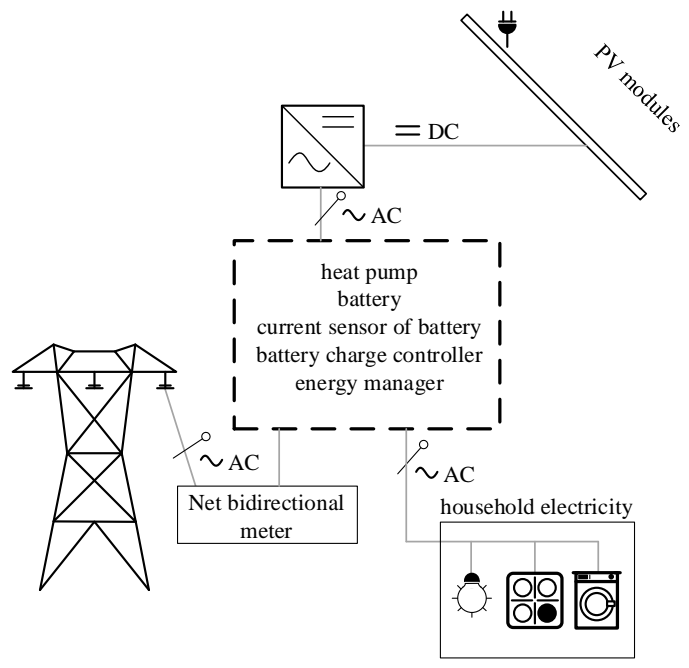

Figure 2: Fixed (galvanically integrated) measuring points. In addition, non-contact measurements are carried out within the tested system.

$E_{\text {grid-feed-in }}$ Electric energy supplied to the grid.

Various key figures are determined from the measurement data of the system test. The self-consumption ratio $\left(R_{\text {self-con }}\right)$ indicates the share of locally produced PV that is being used on-site (eq. 1$)$. The level of independence from the external power grid is described by the degree of self-sufficiency ( $R_{\text {suff }}$, eq. 2 ). The PV generation ratio 
( $R_{\text {gen }}$, eq. 3) describes the ratio of PV yield to total electrical energy consumption. A system with $\mathrm{R}_{\text {gen }}=1$ corresponds to a net-zero energy building. Due to the different efficiencies of the different systems tested and thus different values for the total energy consumption $\left(E_{\text {consumption }}\right)$, the $\mathrm{PV}$ generation ratio can vary despite the same size of PV system and the same useful energy demand in terms of heat for space heating and DHW and electricity for the household. The grid purchase ratio $\left(R_{\text {net }}\right.$, eq. 4$)$ describes the ratio of energy purchased from the grid to total useful energy demand $\left(E_{u s e}\right)$ for household electricity, domestic hot water $\left(Q_{D H W}\right)$ and space heating $\left(Q_{S H}\right.$, eq. 5). In this way, a mixed calculation of thermal and electrical energy is used. The advantage, however, is that all variables are defined by the test method and are identical for all tests.

$$
\begin{aligned}
& R_{\text {self-con }}=\frac{E_{\text {consumption }}-E_{\text {grid-purchase }}}{E_{P V-\text { yield }}} \\
& R_{\text {suff }}=\frac{E_{\text {consumption }}-E_{\text {grid-purchase }}}{E_{\text {consumption }}} \\
& R_{\text {gen }}=\frac{E_{P V \text {-yield }}}{E_{\text {consumption }}} \\
& R_{\text {net }}=\frac{E_{\text {grid-purchase }}}{E_{u s e}} \\
& E_{\text {use }}=E_{H H}+Q_{S H}+Q_{D H W}
\end{aligned}
$$

\section{Tested Systems}

Four different systems were installed and tested on the test bench. The installation includes all hydraulic components as well as a complete electrical installation to supply the building with electricity. The tested systems had to work autonomously to meet the building's heat and electricity requirements. This also includes determining the current surplus of PV electricity and a strategy to utilize this energy.

The common feature of all tested systems is a $5.8 \mathrm{kWp}$ PV system and a heat pump. The PV system size has been chosen such that its annual electricity yield corresponds roughly to the annual electricity consumption for the heat pump heating system and the household appliances. Thus, a net-zero energy balance may be achieved.

The concepts of the different tested systems differ considerably. Table 1 gives an overview about the storage concepts and the type of heat pumps of the tested systems.

Table 1: Storage capacities of the tested systems (thermal and electric) and source of the heat pump.

\begin{tabular}{ccccc}
\hline Tested systems: & 2TankBrine & CombiBatAir & CombiAir & CombiBatBrine \\
\hline Thermal Energy Store & $\begin{array}{c}\text { DHW storage tank } \\
+ \text { heating buffer } \\
\text { Volume }\end{array}$ & Combistore & Combistore & Combistore \\
\hline $\begin{array}{c}5001+3001 \\
\text { Electrical Storage Device }\end{array}$ & No & 6001 & 9001 & 9001 \\
Useable capacity & - & Yes & No & Yes \\
\hline Source of the heat pump & Brine & Air & Air & Brine \\
\hline
\end{tabular}

\section{Results}

The systems that were tested in this project aimed to increase self-sufficiency and decrease electricity costs for the household. This was done by a smart handling of the PV surplus and the storage capacities available in the system ${ }^{1}$.

Figure 2 shows the PV yield and PV surplus, which are identical to all systems since they are the result of the yield that is predefined by the $\mathrm{PV}$ plant and weather and the equally predefined household electricity consumption (without heat pump). In the evaluation shown, the surplus is calculated on a per-minute basis, and shows the potential that is available for increasing self- consumption. Figure 4 shows how much of this PV surplus was fed

\footnotetext{
${ }^{1}$ The use of the thermal mass of the building is excluded in the presented measurements.
} 
to the grid by the different systems that were tested. Figure 5 shows the electric energy consumption from the grid for the same systems.

With $60 \mathrm{kWh}$ in total, the CombiAir-System has the highest feed-in to the grid, followed by the 2TankBrineSystem (compare Figure 4). Both are systems without electrical storage and thus with a lower total storage capacity and no means for electric load shifting of household appliances.

- PV yield (AC) $\quad$ household electricity $\quad$ PV surplus

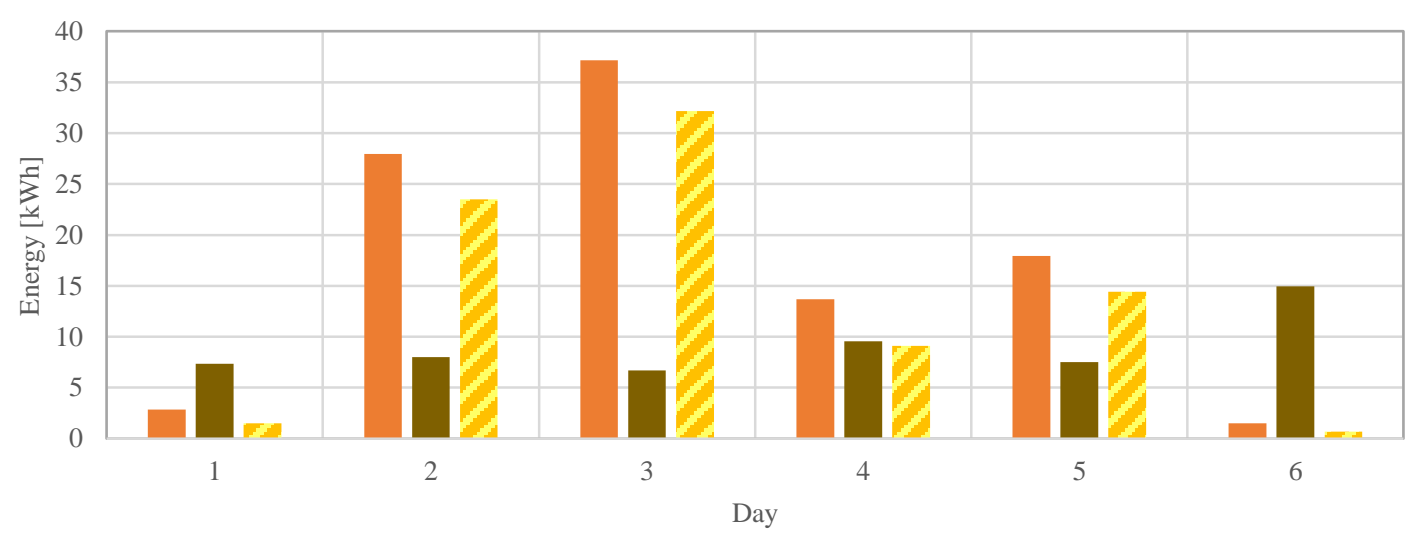

Figure 3: PV yield and household electricity and PV surplus per day. The calculation of PV surplus is based on minutes.

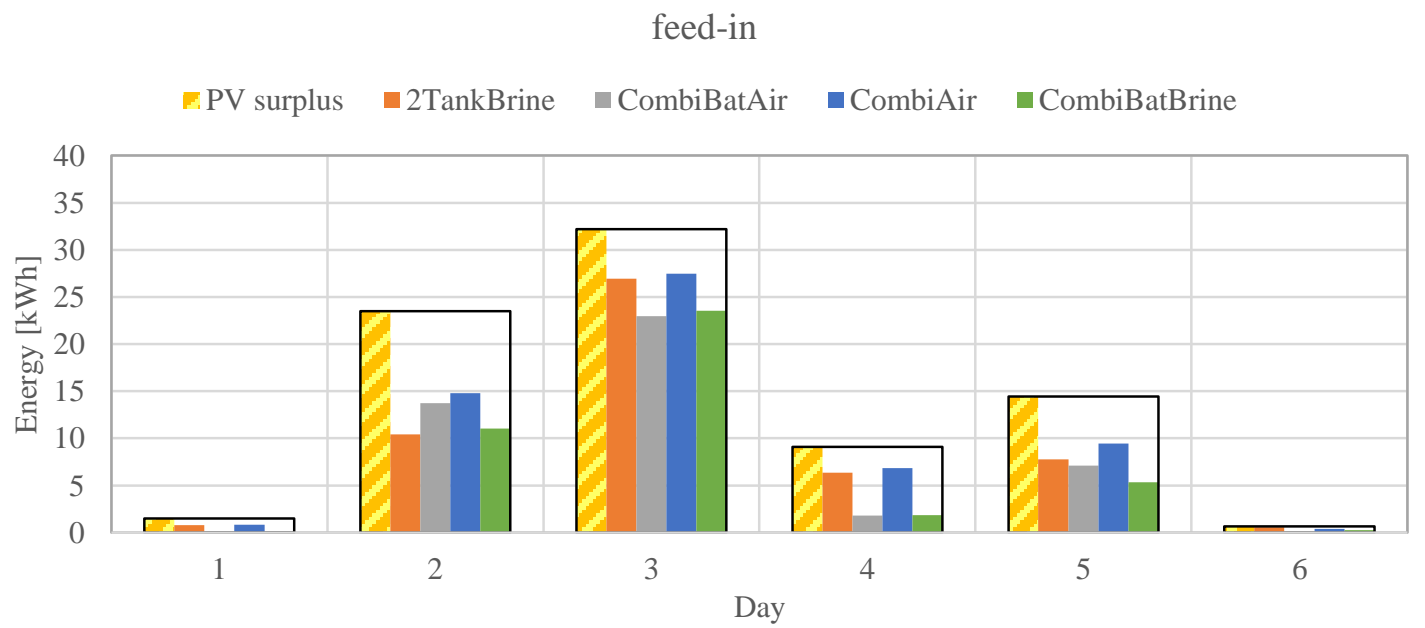

Figure 4: Electric energy supplied to the grid per day.

purchase

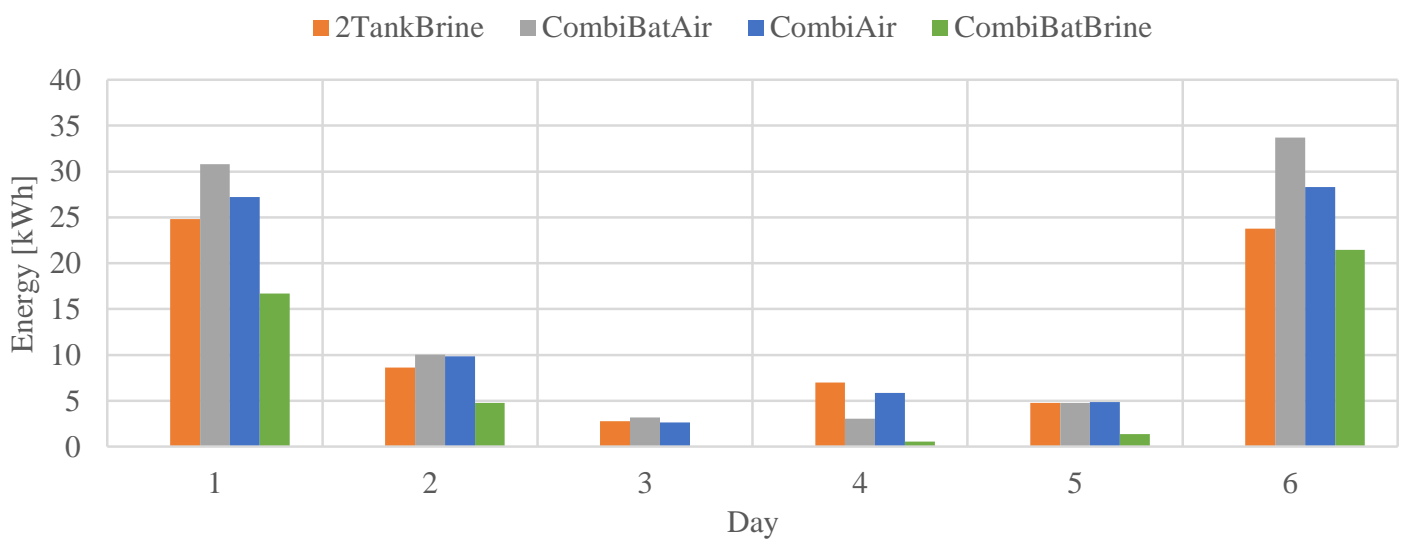

Figure 5: Electric energy from the grid per day. 
The CombiBatBrine-System uses the least electricity from the grid (45 kWh in total, Figure 5). The further order is: 2TankBrine, CombiAir and CombiBatAir. It is remarkable on the one hand that the 2TankBrine-System (with brine-source heat pump) is only slightly better than the CombiAir-System (with air-source heat pump) and on the other hand that the highest value for purchased electricity from the grid results from a system with a battery.

Due to the test method, the loads of space heating, domestic hot water and household electricity are equal for all systems. For this reason, the key figures of the tested systems can be compared directly with each other. The CombiBatBrine-System reaches in all categories shown in Figure 6 the highest value: Well above $50 \%$ in both, self-consumption ratio and self-sufficiency rate and close to 1 in PV generation ratio.

The CombiBatAir-System achieves a comparatively high self-consumption ratio. However, the selfconsumption ratio increases with higher overall consumption, and the purchase of electricity from the grid was thus also highest for the CombiBatAirSystem, which shows the weakness of selfconsumption and self-sufficiency as KPIs.

The PV generation ratio was described in chapter 2 . It was mentioned, that this value can vary despite an identical PV system and identical useful energy demand. The results show that the CombiBatBrineSystem achieves the highest yield ratio due to its lowest total consumption. A PV generation ratio of 1 indicates a Net Zero Energy building. In this case, internal consumption and self-sufficiency must be identical. The measurements confirm this mathematical law.

Figure 7 shows another key performance factor: The grid purchase ratio. This value shows what proportion of total useful energy demand (the addition of DHW delivered, space heat delivered, and household electricity) had to be covered by electricity from the grid. This value should be as low as possible. The System CombiBatBrine achieves the lowest and thus the best value. The CombiAir system should also be noted positively in this case, since it achieves a comparatively good, i.e. low, value with relatively simple means (air-water heat pump, no battery). A grid purchase ratio of $20 \%$ means that compared to the total useful energy demand, only $20 \%$ of electricity input from the grid was necessary.

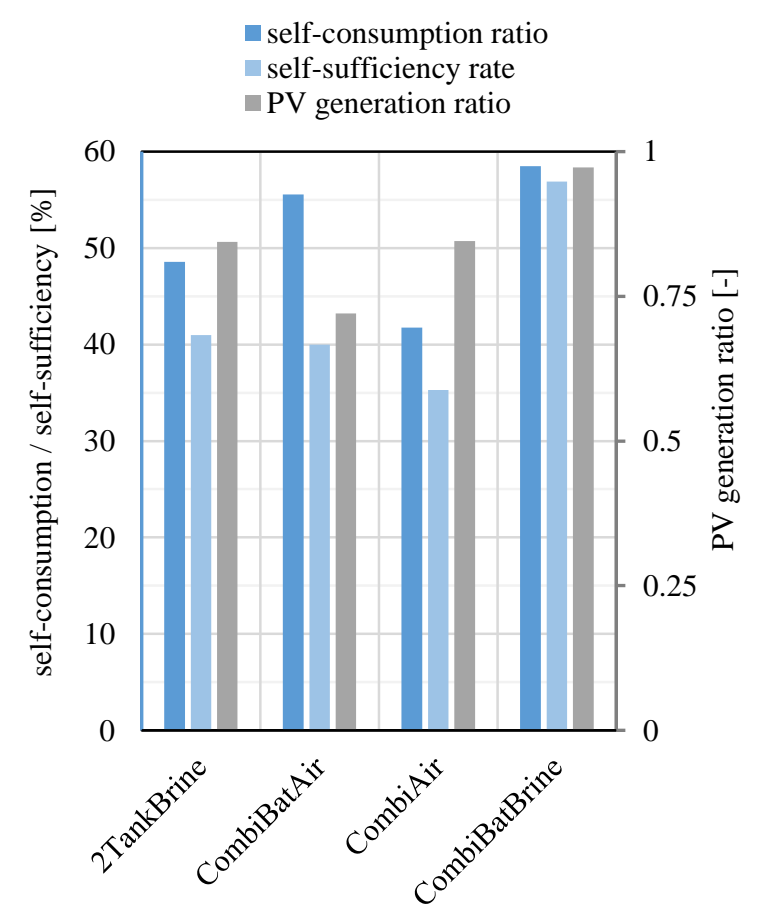

Figure 6: Operating figures of the tested systems.

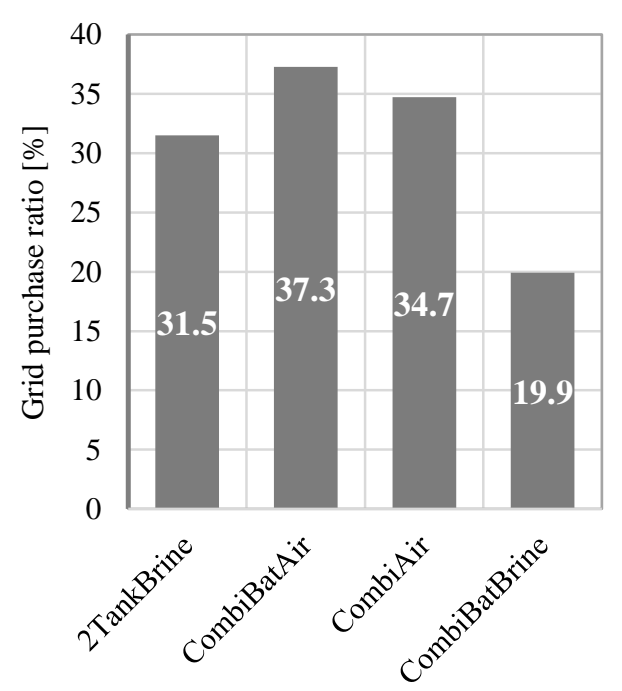

Figure 7: Grid purchase ratio of the tested systems.

With other words, the system delivered five times more useful energy than it consumed electricity from the grid.

\section{Discussion}

\section{Thermal energy storages}

In addition to comparing the systems with each other, valuable insights into the operating behavior of the individual systems were gained. The visualization of the temperature profile in the thermal storage tank or the power of electrical sources and sinks provide information on the quality of control strategies. Figure 8 gives an 
overview of the temperatures in the thermal energy storages. The highest temperatures are reached in the DHW storage tank of the 2TankBrine-System, which was to be expected. The days 2 and 3 of the test sequence are the days with the highest PV yield (and PV surplus). At these two days the average storage tank temperature reaches $60{ }^{\circ} \mathrm{C}$. After the maximum temperature in the domestic hot water tank has been reached, the temperature in the space heating buffer starts to rise. In this way, the system achieves a very high self-consumption value without the use of a battery.

The System CombiBatBrine shows also a rise in the temperature of the combistore, but on a much lower level. The average temperature of the tank during winter days (day 1 and day 6 ) is around $30^{\circ} \mathrm{C}$. The maximum average temperature reaches $40{ }^{\circ} \mathrm{C}$ on days with a high solar yield. The comparably low average temperatures are the result of a good temperature stratification within the storage, since the comfort requirements for domestic hot water were always met. Figure 9 shows the measurement of electric power during the test. It can be seen that the use of PV surplus to heat the storage tank by heat pump was limited. In this case, the hydraulic system (storage tank connections and position of the temperature sensors) inhibited charging of the storage tank to a higher temperature.

The course of temperatures in the CombiBatAir-System shows that there was no temperature increase on days with high PV yield. In this system, the heat pump was not controlled according to the PV yield but only according to the heat demand.

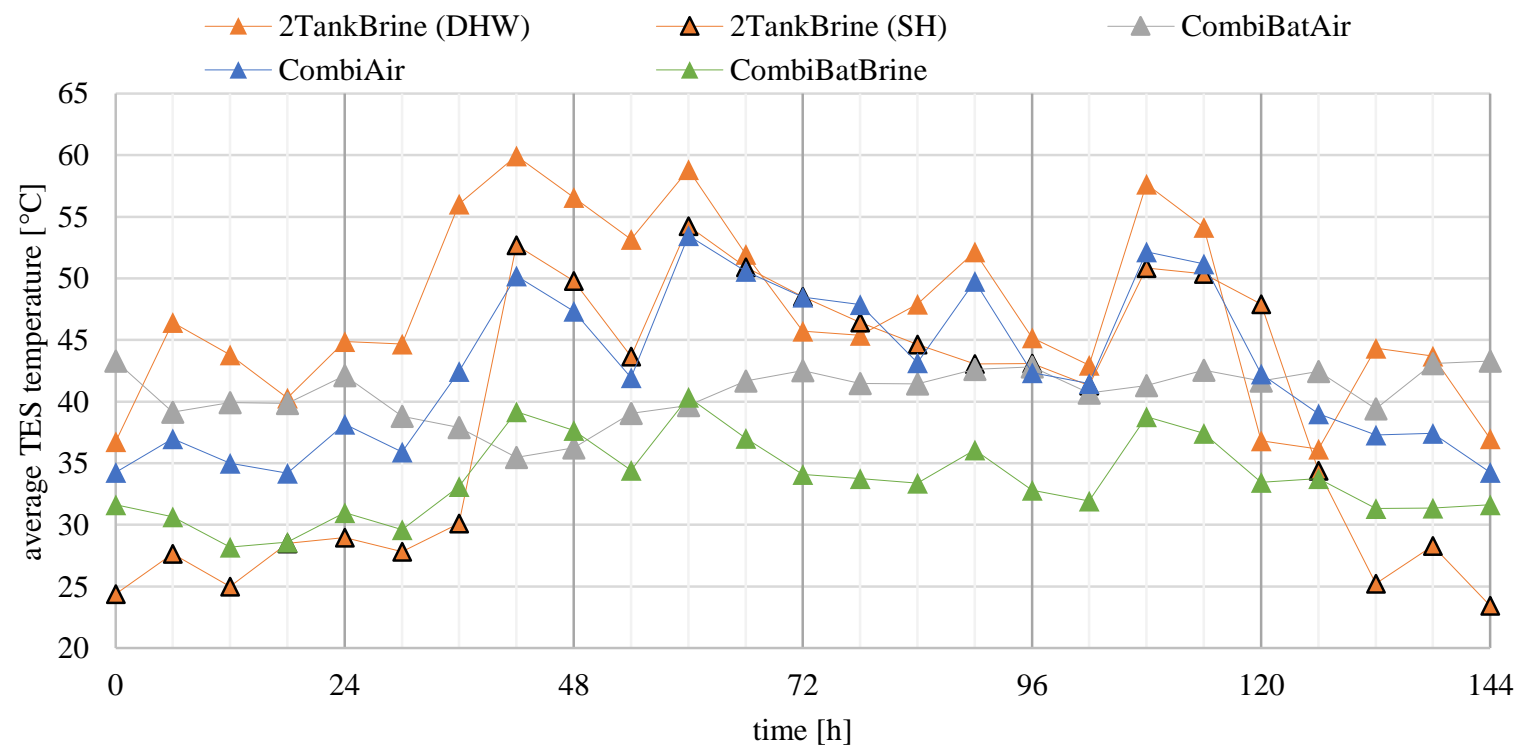

Figure 8: Average temperature of the TES-tanks during the 6-day system test.

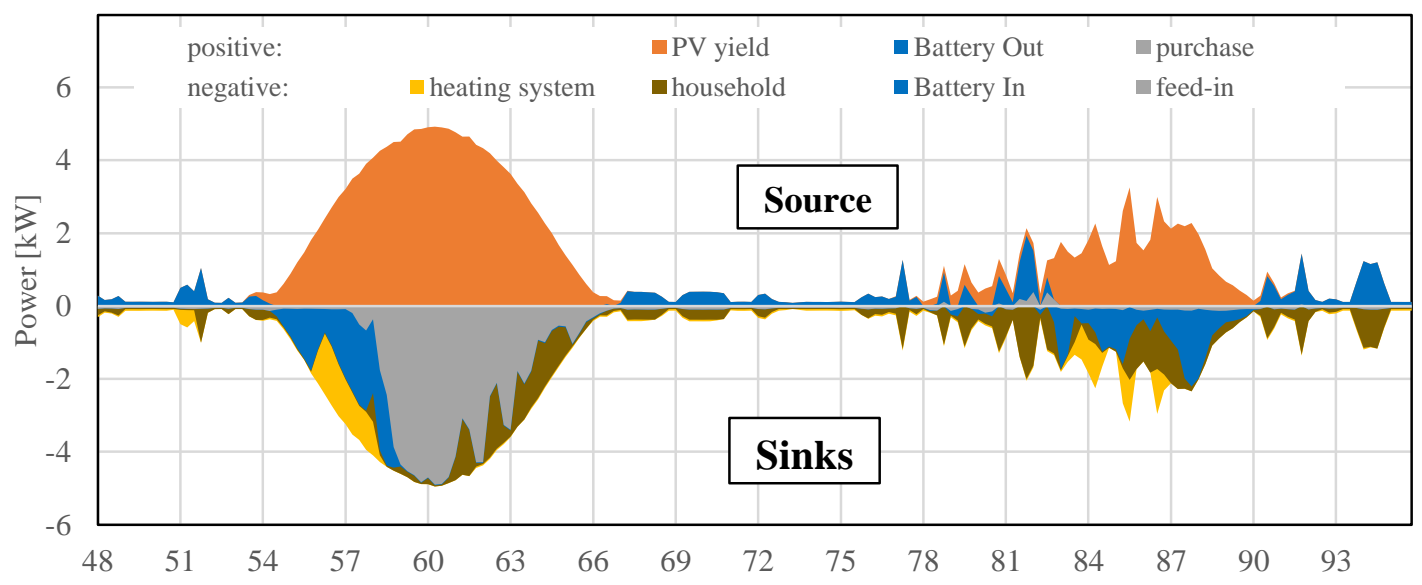

Figure 9: Excerpt of the measurement of System CombiBatBrine: Measurement of electric power during the days 3 and 4 of the 6day test sequence. 


\section{Electrochemical energy stores}

Two of the tested systems use an electrochemical storage device in addition to the thermal energy storage. The table describing the tested systems (Table 1) shows that the storage capacity of the batteries used is of a similar size.

The charging and discharging strategy of the batteries was simple: PV surplus that was not converted to heat by the heat pump is charged into the battery. As soon as the demand for household electricity and the heating system is higher than the available PV electricity, the battery is discharged again. Neither system differentiated between household electricity and the demand of the heating system during discharge.

Figure 10 and Figure 11 show the electrical power of the charging and discharging of the batteries and the cumulative energy during the 6-day test. The state of charge of the batteries has been checked on an hourly basis. It was in both cases identical at the beginning and the end of the test. It is therefore clear that the final value of the energy balance corresponds to the losses of the battery. These losses consist of the conversion losses in the inverter, the losses of the cells and a standby consumption of the battery system including its controller. The cycle efficiency of the batteries was 74\% (CombiBatAir) and 65\% (CombiBatBrine).

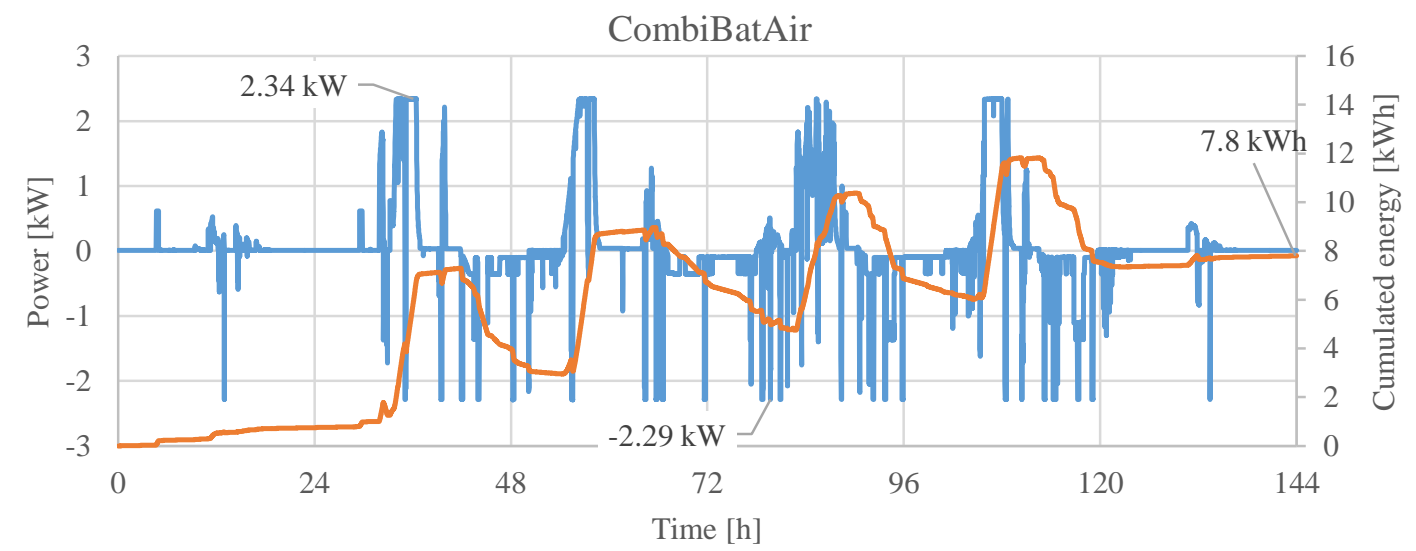

Figure 10: Electrical power of the charging and discharging of the battery as well as the cumulative energy during the 6-day test.

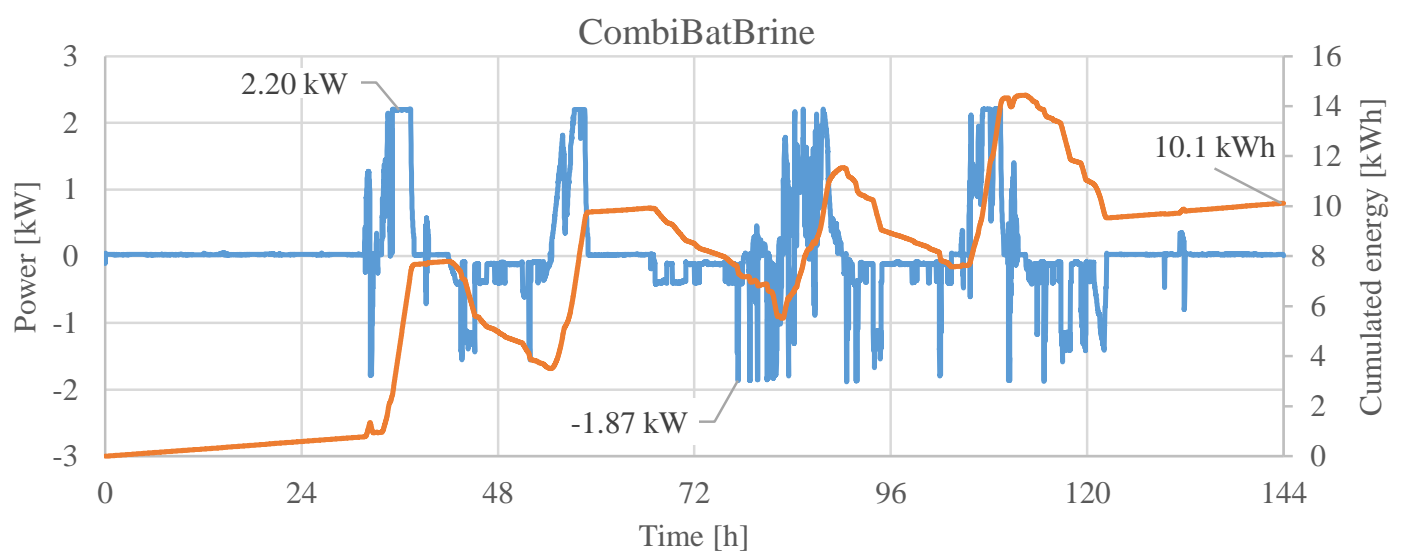

Figure 11: Electrical power of the charging and discharging of the battery as well as the cumulative energy during the 6-day test. 


\section{Benefit to the grid}

The increasing use of PV systems may lead to a stress on the grid on days with high solar radiation. Heating systems with heat pumps and batteries have the potential to cut the feed-in peaks. However, these feed-in peaks are not cut with the control strategies implemented in the tested systems. Figure 12 shows exemplary for two of the tested systems that the PV power is completely fed into the grid at peak times. This is due to the fact that the storages are already full at this point in time.

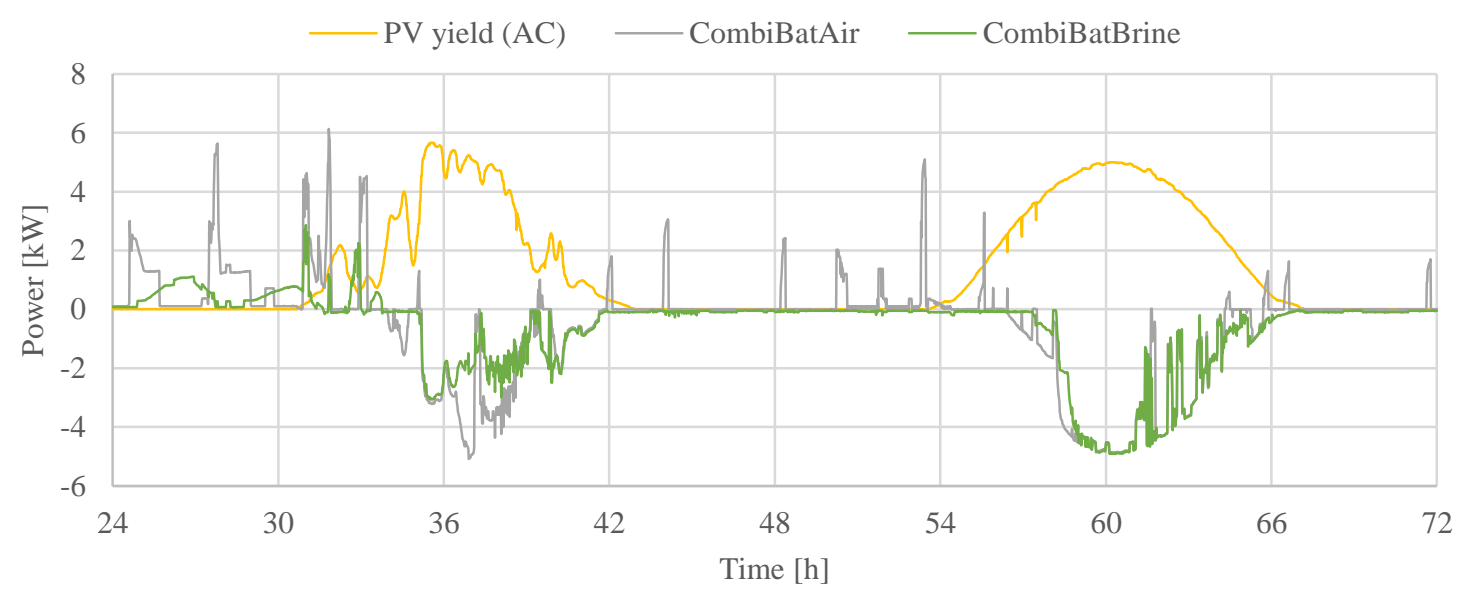

Figure 12: Excerpt of two system tests: PV yield (yellow) and the grid purchase (positive values green or grey) and feed-in (negative values) during a period of two days within the 6-day test.

\section{Key Performance Indicators}

The weakness of self-consumption and self-sufficiency as key performance indicators (KPIs) becomes apparent when electric or thermal storages are introduced with their respective losses. Losses of electric or thermal storages that are charged predominantly with PV electricity or with heat produced from PV electricity in combination with the heat pump, inevitable increase both KPIs. Therefore, a new KPI, the grid purchase ratio, has been introduced. This new KPI sets electricity purchase in proportion to useful energy demand. It has proven to be a more reliable indicator for the quality of the system and its control, and it allows for a fairer comparison of the different systems. 


\section{Conclusion}

\section{Test method}

The whole system test method CCT proved to be a valuable tool both for system development as well as for performance evaluation. The advantage of this kind of system test is that non-ideal component interactions and the influence of hydraulics and control under transient operating conditions can be detected and evaluated precisely. The test delivers within 6 days information about all operating conditions that may occur during a whole year and is thus much faster than field testing. Compared to field testing, the amount (number of sensors installed) and precision (high precision laboratory equipment used) of information that is obtained is much higher. Moreover, the results can be compared with tests of other systems that were performed under the same boundary conditions.

\section{Test results}

The test results show that the maximum self-consumption as a target function for the control of the systems does not lead to efficient solutions. The entire energy balance must always be taken into account in the analysis. For this purpose, it is better to consider the grid purchase ratio. However, economic aspects or grid friendly operation are not taken into account with this solution either. Tariffs for energy purchases and feed-in as well as aspects of grid friendliness also play an important role for end customers and grid operators.

The evaluation of the individual systems revealed significant differences:

2TankBrine: The control of the heat pump according to the current PV surplus works very well, and higher temperatures are reached in the storage tank in this operation mode as intended. A negative aspect was the inadequate implementation of a desuperheater during space heating operation that lead to poor storage stratification and increased energy consumption in normal operation. This prevented the system from achieving a better overall result.

CombiBatAir: In this system the stratification of the combistore while being charged by the heat pump must be criticized. It lead to unnecessary high flow temperatures of the heat pump and correspondingly low efficiency. A thermal storage with good stratification behavior is essential for reaching high efficiencies in combination with a heat pump. Especially with the particularly high volume flow rates that are advantageous for heat pumps, this is a special challenge. The cycle efficiency of the battery was higher than for the other system with battery, which was mainly due to less stand-by electricity consumption.

CombiAir: Implementing the CombiAir concept in the field does not require any special investment on the part of the user: no geothermal probes or batteries are required. Although the degree of self-sufficiency of $35 \%$ is the lowest value of the various candidates, a good value is nevertheless achieved for the grid purchase ratio.

CombiBatBrine: This system shows a very good overall behavior. Good values are achieved for most key figures. The purchase of electricity from the grid was by far the lowest. Nevertheless, there is still room for improvement: The efficiency of the battery remained below expectations. Especially the standby consumption of the battery was too high (around $24 \mathrm{~W}$ ). The thermal storage showed a good stratification and enabled an efficient operation of the heat pump. However, the hydraulic connection missed potential for storing excess PV as heat in the storage tank. 


\section{Acknowledgment}

The authors acknowledge gratefully the financial support of the Swiss Federal Office of Energy (SFOE) within the project CombiVolt (project nr. SI/501336-01) as well as the contributions of companies that provided their systems for testing and energy service providers that contributed to the project.

\section{References}

Battaglia, M., Haberl, R., Bamberger, E. \& Haller, M., 2017. Increased self-consumption and grid flexibility of $P V$ and heat pump systems with thermal and electrical storage. Energy Procedia, 135(Supplement C), p.358-366.

Haberl, R., Frank, E. \& Vogelsanger, P., 2009. Holistic System Testing - 10 Years of Concise Cycle Testing. In: proceedings of the SWC 2009, Johannesburg, South Africa.

Haberl, R., Haller, M. \& Frank, E., 2014. Hardware in the loop tests on eleven solar and heat pump heating systems. In: Proceedings Eurosun, Aix-les-bains, France.

Haberl, R., Reber, A., Carbonell, D. \& Haller, M.Y., 2018. SolProof - Kompaktheit und Fehlerresistenz von Solaren Heizsystemen auf dem Prüfstand. Report SE/501234-01, Bern, Switzerland.

Haller, M.Y., Haberl, R., Persson, T., Bales, C., Kovacs, P., Chèze, D. \& Papillon, P., 2013. Dynamic whole system testing of combined renewable heating systems - The current state of the art. Energy and Buildings, 66, p.667-677. 


\title{
Sustainability Assessment of Most Relevant Solar Thermal Heat Systems
}

\author{
Harald Kicker ${ }^{1}$, Gernot M. Wallner ${ }^{1}$ and Reinhold W. Lang ${ }^{1}$ \\ 1 Institute of Polymeric Materials and Testing / Johannes Kepler University, Linz (Austria)
}

\begin{abstract}
Solar thermal heat systems are of high relevance and interest for the supply of low temperature heat for different purposes. Especially, hot water systems are dominating the solar-thermal market with non-pumped systems gaining more and more importance. The main objective of this paper is to assess most relevant small and medium sized as well as large scale district solar-thermal heat systems as to their sustainable development metrics. While 2017 about $94 \%$ of the energy provided by solar thermal systems was used for domestic hot water, currently a trend to larger solar thermal systems with seasonal storage coupled to district heating networks is discernible. Solar thermal at present contributes about $1 \%$ to total heat consumption. The share of solar district heating and solar process heat applications is steadily increasing despite it is still only representing $3 \%$ of the global market (Weiss and Spörk-Dür, 2018). The potential contribution is much larger. Many national governments seek to realize this potential by offering subsidies and feed-in-tariffs. Assessing sustainable development for solar thermal heat systems is a complex discipline. The best heat system depends to a large extend on the climate region. If solar heat is intermittent, seasonal, economic storage of heat is advantageous. Significant cost reductions of solar thermal systems and a shift towards polymeric materials to regain market growth and to improve ecological performance is required. For the assessment a 5-step methodology developed by Ashby et al. (2016) is used.
\end{abstract}

Keywords: thermal heat system; all-polymeric, sustainable development; assessment.

\section{Introduction}

Solar thermal heat systems are of high relevance and interest for the supply of low temperature heat for different purposes. Especially, hot water systems are dominating the solar-thermal market with non-pumped systems gaining more and more importance (Mauthner et al., 2016). Alternatives to the small hot water systems are medium-sized combi-systems allowing also for space heating or large systems for district heating and cooling or process heat. The current work is a follow-up of Kicker et al. 2017. The main objective of this paper is to assess most relevant solar-thermal heat systems as to their sustainable development metrics.

In recent years attempts have been made to open up a mass market for solar thermal energy and thereby promote the use of renewable energies with novel, more cost-effective materials and production processes. An alternative to metals is the use of cheaper plastics. Investigations showed that the use of proven methods of polymer processing can reduce the costs of manufacturing solar thermal systems by up to $50 \%$. To assess the costs of the heat generated by solar thermal systems recently the levelized cost of heat (LCOH) evaluation procedure has been implemented. Buchinger [3] shows that $\mathrm{LCOH}$ for an all polymeric pumped flat plate collector system can go down to $2 € \mathrm{ct} / \mathrm{kWhth}$. The LCOH for conventional, fossil oil based hot water preparation for a single family house (SFH) in Austria amounts to $10 € \mathrm{ct} / \mathrm{kWhth}$. The $\mathrm{LCOH}$ for conventional, metal based, pumped flat plate collector systems for a single family house are ranging from 12 to $15 € \mathrm{ct} / \mathrm{kWhth}$ (Fischer, 2017). It is a clear fact allpolymeric solar thermal systems entail a high cost reduction potential for heat generation.

The holistic view of solar thermal systems in terms of sustainability opens up marketing possibilities of solar thermal heat systems based on novel all-polymeric materials. 


\section{Methodology and approach}

The much-quoted definition of sustainable development by the Brundtland Commission tells: 'Sustainable development is development that meets the needs of the present without compromising the ability of future generations to meet their own needs' (The Brundtland Report of the World Council on Economic Development, WCED 1987). But how is sustainable development to be achieved? The definition lacks of concrete guidance how to reach the goals.

Ashby et al. (2016) developed a 5-step analysis methodology for assessing sustainability of complex systems and multi-dimensional problems. The approach is to split the problem into layers and to follow a five-step strategy for assessing. The 5-step analysis includes:

1. the definition of the prime objective as well as the size and time scale,

2. the identification of the stakeholders,

3. the fact-finding step to research both the factual background of the articulations and the validity of the concern expressed by the stakeholder,

4. the synthesis of the facts for examination of how the facts influence human, natural and manufactured capital, and

5. the reflection step assessing the picture that has emerged and considering priority changes.

The current work is a follow-up of Kicker et al. 2017, where the focus was given to solar thermal systems for hot water preparation and the first three of the five above steps. In this paper the focus is to assess most relevant solarthermal heat systems as to their sustainable development metrics. The range of investigated systems extends from systems for hot water preparation for single family houses, passing through hot water preparation for multifamily houses and small district heating up to large collector fields with seasonal storage for district heat providers. Step one, two and three are restated within this broader context.

\section{Main results and conclusions}

The layered approach to assess solar thermal collector systems as to their sustainable development metrics and the key findings are elucidated in the following.

\subsection{Background information, prime objective and scale}

To meet carbon-reduction targets heat generation from renewable sources is of utmost importance. Direct conversion of sunlight via solar thermal collectors has many attractions. Mean solar irradiance varies between 150 and $250 \mathrm{~W} / \mathrm{m}^{2}$ dependent on the world region. In the use phase, solar thermal systems emit negligible $\mathrm{CO}_{2}$ and they reduce dependence on imported energy. Historically solar thermal has grown at $15 \%$ per year for the last 15 years. Worldwide a capacity of $410 \mathrm{GW}_{\text {th }}$ was installed corresponding to a total of 586 million $\mathrm{m}^{2}$ of collector area. The annual collector yield of water-based systems in operation by end of 2014 was about 1.2 exajouls saving about 0.1 gigatonnes of $\mathrm{CO}_{2}$ (Mauthner et al., 2016). While 2014 about $94 \%$ of the energy provided by solar thermal systems was used for domestic hot water, currently a trend to larger solar thermal systems coupled to district heating networks is discernible (Weiss and Spörk-Dür, 2018). Solar thermal at present contributes about $1 \%$ to total heat consumption. The potential contribution is much larger. Many national governments seek to realize this potential by offering subsidies and feed-in-tariffs.

In Europe targets for a $20 \%$ reduction in carbon emissions by 2020 and an $80 \%$ reduction by 2050 were defined. To which extent are these targets achievable by solar thermal? Is it a sustainable development?

Solar heat is intermittent. Most of the solar heat is generated in summer. However, the heating demand is significantly higher in winter. Hence, seasonal storage of heat is required. Economic storage is work-in-progress, yet just rather limited available. Large-scale investment is required. Furthermore, a significant drop in the growth rates of solar thermal are discernible, especially in Europe. Hence, efforts are put on significant cost reductions of solar thermal systems to regain market growth. While solar thermal heat systems based on novel all-polymeric materials find their way to hot water preparation for single family houses, they are still not considered for application in large collector fields or applications for industrial process heat generation. 


\subsection{Stakeholders and their concerns}

Contemporary news headlines suggest a range of stakeholders. Many current newslines are dealing with large systems. Only less can be found on the currently most important field of application which is domestic hot water preparation.

- "Drake Landing: A ray of sunshine for solar thermal energy”. Monty Kruger from CBC News posted that 2 or 3 sunny summer days are enough to heat homes throughout cold seasons in Alberta town's solar community. (CBC News, February 14, 2016).

- “Gigantic Danish Solar Heating System Completed”. The world's biggest solar heating system, completed in less than a year after signing the contract, consists of $156,694 \mathrm{~m}^{2}$ of collectors and will provide $20 \%$ of the total heat consumption in Silkeborg. (Energy Supply, January 17, 2017).

- "Italy: new subsidy scheme for solar thermal up to $1000 \mathrm{~m}^{2}$ ". Large solar thermal plants will receive an incentive of $55 € / \mathrm{m}^{2}$ per year, over a period of 5 years. (solar district heating, February 6, 2013).

- "First Solar Civic Participation Project". Crowdfunding participation model for solar thermal plants has reached $€ 1.5$ Mio. (EuroHeat\&Power Industry News, November 2014).

- "Weltgrößter Solarspeicher soll Grazern einheizen". Günter Pilch and Markus Zotter note that $20 \%$ of the district heating demand in Graz could be covered by solar thermal in 2019. (Kleine Zeitung, February 27, 2016).

- "ECREE begins move to exploit solar thermal energy potential in Ghana" The ECOWAS Center for Renewable Energy and Energy Efficiency (ECREE), has began processes to help Ghana exploit the abundant solar thermal energy potential for domestic and industrial use. (ghanaweb.com, September 26, 2017).

- "The sleeping giant is waking up" Bhoo Thirumalai, the Chief Executive Officer of Aspiration Energy and a solar aficionado, is a busy man these days. For years, the man who co-founded the successful IT company had been trying to rev it up with limited success. But suddenly things seem to be falling in place. (thehindubusinessline.com, August 29, 2017)

- "Clean Energy Isn't Just the Future-It's the Present" Solar power geysers to heat hot water sit on the roofs of a residential shack in the Alexandra township outside Johannesburg, South Africa (Bloomberg, April 19, 2017)

Based on these quotes and the value creation chain of the solar thermal industry the following key stakeholders are suggested:

- Government: Solar thermal could provide a contribution to meeting renewable energy commitments. Government has the power to make it happen through subsidies and feed-in tariffs.

- Heat providers: Solar thermal and large-scale storages allow for the substitution of economically inefficient fossil fuel co-generation plants with the by-product electricity, which is hard to sell economically due to the low electricity market prices.

- Heat system industry: Solar thermal is an interesting alternative in their product portfolio. Some of them already invested in collector manufacturing facilities.

- Collector makers: Many small- or medium-sized collector makers are on the market. Their profit margins are diminishing due to large enterprises established in China offering cheap products mainly for hot water preparation.

- Installers: Current system technologies for hot water preparation or space heating are not easy-to-install. More reliable system designs are needed for small-sized installers. Large-scale systems offer interesting market opportunities for more specialized companies.

- $\quad$ Property owners: They are attracted by subsidies. In some regions solar thermal systems allow for independent hot water supply and improvement in comfort (especially in less industrialized countries).

- NGOs: are campaigning for decentralized, renewable energy to halt climate change.

- $\quad$ R\&D: Solar thermal is an attractive research field with open issues (e.g., thermal energy storage; function-oriented design and simulation of systems). Funding for research on solar thermal systems is stimulating.

- Investors: Crowdfunding initiatives are attracting general public. Large-scale systems are of interest for investors. To meet carbon-reduction targets heat generation from renewable sources is of utmost importance. 
The relationship between the stakeholders for small and medium sized systems is displayed in Figure 1 reflecting also their specific influence / power and their interests. Figure 2 displays the shift of interest and influence of Heat Providers and Investors for large collector fields with seasonal storage by the example of district heat providers in Denmark.

Significant concerns for solar thermal heat is that this technology is in many cases to expensive. In contrast to photovoltaic power, there is still a lack of transparency and continuity regarding subsidies for solar thermal collector systems. Furthermore the intermittency of heat generation and the problem that heat storage is seen challenging, especially for domestic hot water systems with high performance collectors and poor performance storages. PV for hot water preparation (supplemented by heat pumps) is supposed by some as the smarter and cheaper solution and is a serious competitor especially in the small- and medium-size system segment for hot water preparation with or without combined space heating.

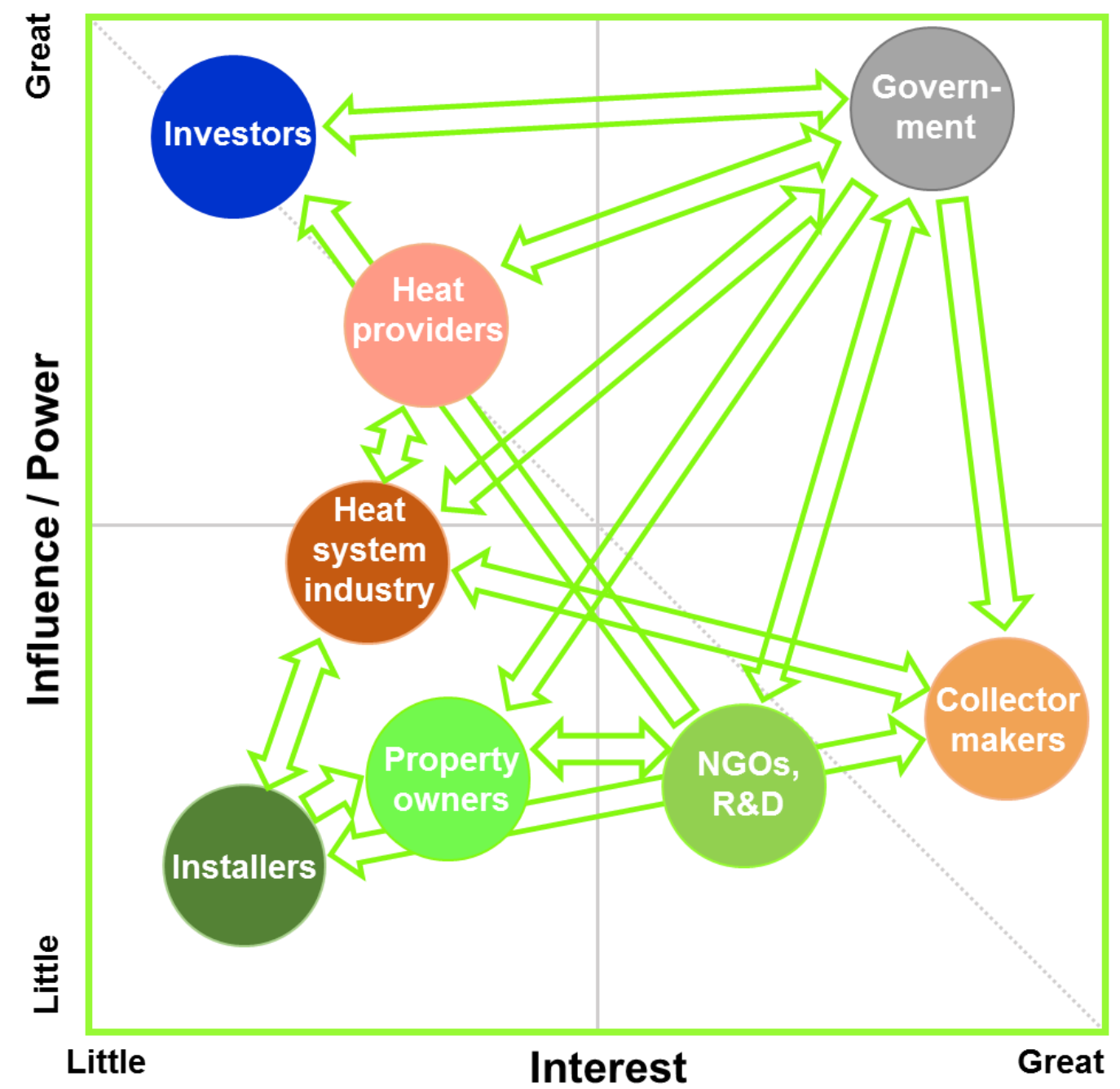

Fig. 1: Stakeholder matrix reflecting their influence and interest for small and medium size systems.

\subsection{Fact-finding}

To research the factual background of the articulations and the validity of the concerns expressed by stakeholders a comprehensive approach considering materials, environment, society, economics, legislation and energy issues was used.

In terms of sustainable development the overall question is, if solar collector systems can make a substantial contribution to carbon reduction targets in the next decades. Figure 3 summarizes the issues needing research.

(a) Materials. State of the art solar thermal collector systems are mainly based on metals like copper, aluminum 
or steel and silicate glass for the collector, piping and storage. As evident in many other fields of application, a transformation to mass technologies and full market penetration is often associated with a material substitution towards polymeric materials. Interestingly, also for solar thermal systems major research efforts are put on the development of all polymeric collectors, piping and storages. Here, two different approaches are discernible. On the one hand, high performance plastics and related processing technologies are developed for space heating systems. On the other hand, affordable, overheating protected solar thermal collector systems made from commodity polymeric materials are developed. Research work focuses on failsafe overheating protection measures and novel material formulations with improved long term performance in the temperature range between 80 and $95^{\circ} \mathrm{C}$. For both issues adequate solutions have been developed, so that the main issue is now the industrial implementation and transformation (Bradler et al., 2017; Fischer et al., 2016; Grabmann et al., 2016a, 2016b; Geretschläger and Wallner, 2016; Kahlen et al., 2010a, 2010b, 2010c, 2010d; Köhl et al., 2012; Kurzböck et al., 2012; Olivares et al., 2010a, 2010b; Povacz et al., 2014, 2016; Wallner et al., 2016). Therefore, investors and venture capital is needed to successfully implement polymer based alternatives, especially for often poor.

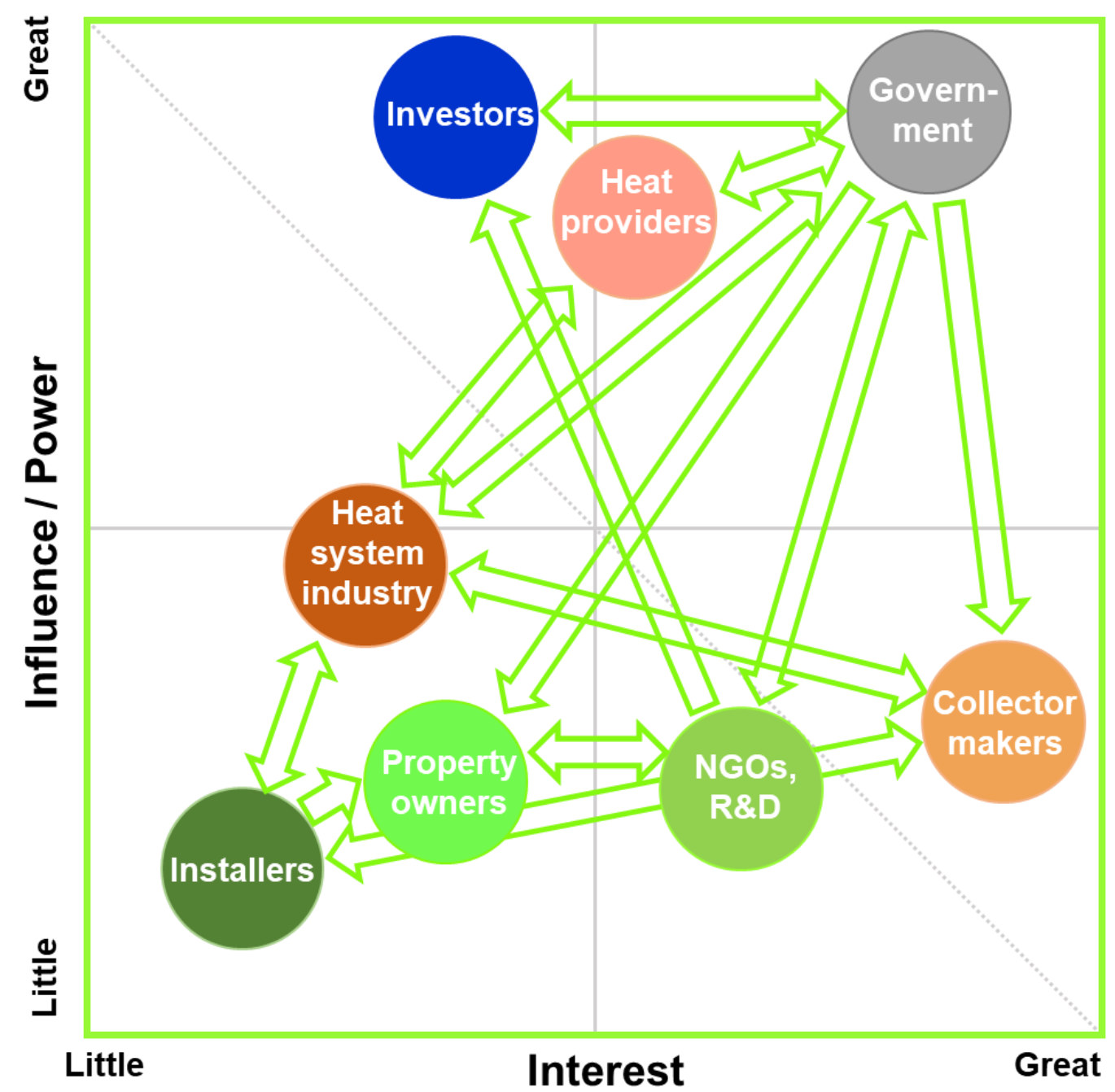

Fig. 2: Stakeholder matrix reflecting their influence and interest for large collector fields with seasonal storage by the example of district heat providers in Denmark.

(b) Energy. Weiss and Spörk-Dür (2018) have shown that the annual collector yield of all water-based solar thermal systems in operation by the end of 2017 worldwide was 388 TWh corresponding to a final energy savings equivalent of 41.7 million tons of oil and 134.7 million tons of $\mathrm{CO}_{2} .94 \%$ of the provided energy by solar thermal collector systems was used for domestic hot water heating. This is dominated by small-scale systems in single- 
family houses $(63 \%)$ and larger applications $(28 \%)$ for multi-family houses, schools, hotels etc. Swimming pool heating adds $6 \%$ and $2 \%$ of the energy supply and $\mathrm{CO}_{2}$ reduction is contributed by solar combi systems for hot water preparation and heating. Regarding hot water preparation the most important issue is to replace electric hot water power systems in less-industrialized countries in sub-tropical and tropical climate zones. So far, no comprehensive investigation has been carried out to which extent this measure could contribute to fossil-based energy savings.

(c) The Environment. It is a well-known fact, that the use of metals, especially aluminum, for solar thermal collector systems has a significantly higher environmental impact than the use of polymeric materials (Arnaoutakis et al., 2017; Battisti and Corrado, 2005; Carlsson et al., 2014; Kicker, 2009; Kicker 2018; Koroneos and Nanaki, 2012; Singh et al., 2016; Weiss et al., 2015; Zambrana-Vasquez et al., 2015). In case of polymers a worse environmental effect was deduced for high performance polymers compared to commodity plastics such as polyolefins. Nevertheless, solar thermal systems reveal energetic and environmental amortization times ranging from 0.5 to 1.5 years depending on the system type and the location (Buchinger, 2017; Carlsson et al., 2014; Kicker, 2009; Weiß et al., 2015).

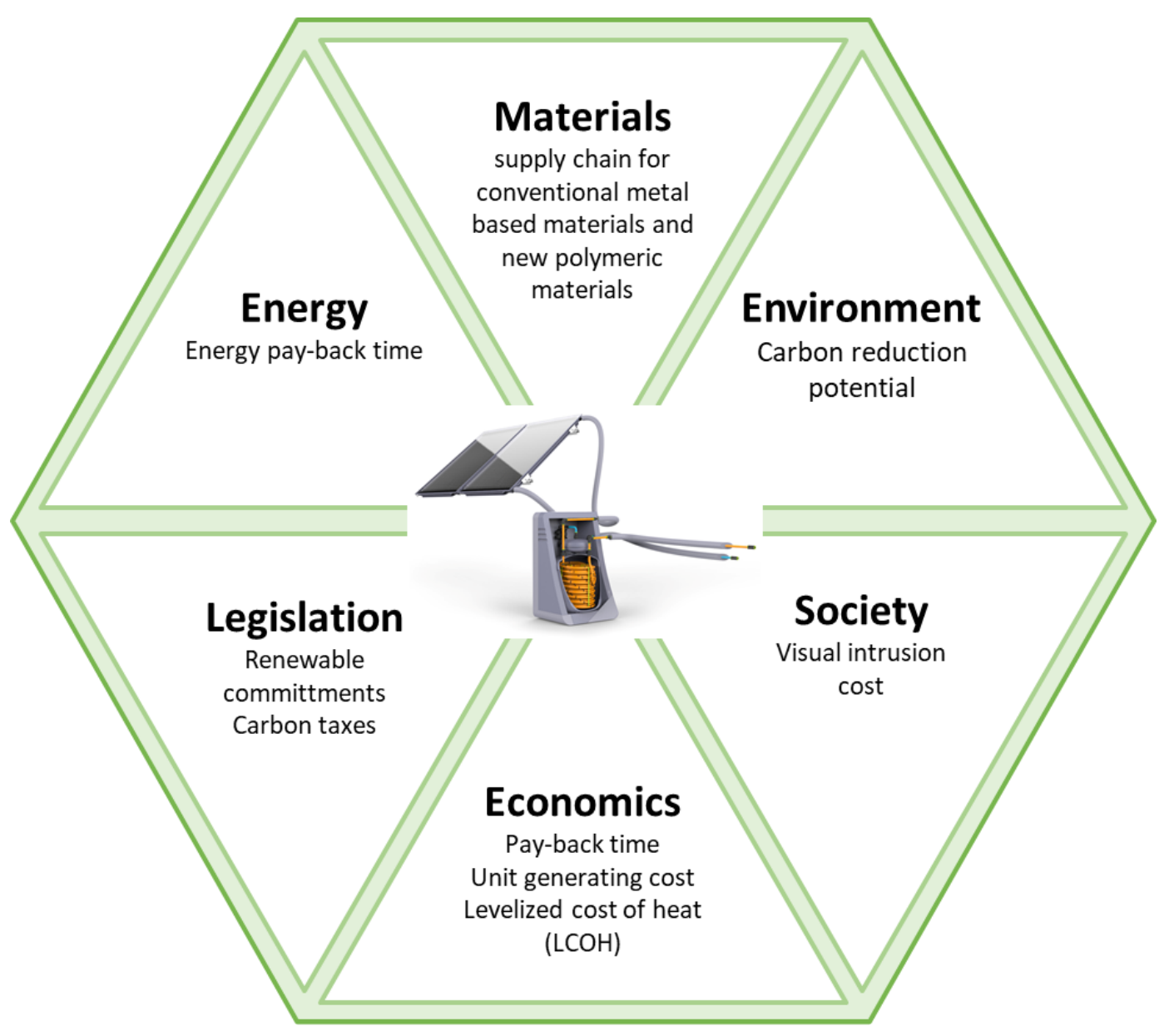

Fig. 3: Fact-finding summary.

(d) Legislation. The production of heat accounts for more than $50 \%$ of global final energy consumption. At present $75 \%$ of global energy use for heat (129 exajouls) is met with fossil fuels. About 1/3 of global energyrelated carbon dioxide emissions ( 10 gigatonnes of $\mathrm{CO}_{2}$ ) is related to the production of heat (Eisentraut and Brown, 2014). In 2015 many nations have agreed to hold global temperatures well below $2^{\circ} \mathrm{C}$ above pre-industrial levels and to pursue efforts to limit the temperature increase to $1.5^{\circ} \mathrm{C}$. This implies that global $\mathrm{CO}_{2}$ emissions have to peak as soon as possible and that rapid emission reductions must follow (Streck, 2015). This agreement is a clear commitment to a sustainable development. However, this commitment still lacks a regulatory framework and is often not subject to public law. Moreover, current standardization procedures for solar thermal systems are 
dominated by individual countries and by the copper and glass industry.

(e) Economics. To assess the costs of the heat generated by solar thermal collector systems recently the levelized cost of heat $(\mathrm{LCOH})$ evaluation procedure has been implemented. Important parameters affecting the LCOH are depicted in equation 1. Of significant importance are investment costs, the saved final energy and the lifetime (Fischer, 2017; Louvet et.al, 2017; Mauthner et al., 2016, Weiss and Spörk-Dür (2018).

$$
L C O H=\frac{l_{0}-S_{0}+\sum_{t=1}^{T} \frac{C_{t}(1-T R)-D E P_{t} * T R}{(1+r)^{t}}-\frac{R V}{(1+r)^{T}}}{\sum_{t=1}^{T} \frac{E_{t}}{(1+r)^{t}}}
$$

Where:

\author{
$L C O H$ : levelized cost of heat in $€ / \mathrm{kWh}$ \\ $I_{0}$ : initial investment in $€$ \\ $S_{0}$ : subsidies and incentives in $€$ \\ $C_{t}$ : operation and maintenance costs (year $\mathrm{t}$ ) \\ $T R$ : corporate tax rate in $\%$
}

\author{
$D E P_{t}$ : asset depreciation (year $\mathrm{t}$ ) in $€$ \\ $R V$ : residual value in $€$ \\ $E_{t}$ : saved final energy (year $\mathrm{t}$ ) in $\mathrm{kWh}$ \\ $r$ : discount rate in $\%$ \\ $T$ : period of analysis in year
}

Fischer (2017) has shown that the LCOH for conventional, fossil oil based hot water preparation for a single family house (SFH) in Austria amounts to $10 € \mathrm{ct} / \mathrm{kWh}_{\mathrm{th}}$. The $\mathrm{LCOH}$ for conventional, metal based, pumped flat plate collector systems for a single family house are ranging from 12 to $15 € \mathrm{ct} / \mathrm{kWh}_{\mathrm{th}}$. It is a clear fact that the costs for solar hot water preparation with conventional flat plate collectors in SFH is too high and needs significant reduction. On the other hand, Buchinger (2017) shows that LCOH for an all polymeric pumped flat plate collector system can go down to $2 € \mathrm{ct} / \mathrm{kWh}_{\mathrm{th}}$, if the performance and the degree of utilization is high, which is especially achieved for small systems in hot climate regions. Weiss and Spörk-Dür (2018) have shown that analysis of Danish large-scale solar district heating (SDH) systems shows that economies of scale enable a huge potential for cost reduction: while the average $\mathrm{LCOH}$ for small domestic applications in Denmark ranges between 18.5 $€ \mathrm{ct} / \mathrm{kWh}$ for COMBI-single family houses and $12.1 € \mathrm{ct} / \mathrm{kWh}$ for domestic hot water for multi family houses, the average $\mathrm{LCOH}$ for large-scale systems $\left(>10,000 \mathrm{~m}^{2}\right)$ including the cost for a diurnal storage goes down to 3.6 $€ \mathrm{ct} / \mathrm{kWh}$. For even larger systems $\left(>50,000 \mathrm{~m}^{2}\right)$ with seasonal storage attached a $\mathrm{LOH}$ of $4.9 € \mathrm{ct} / \mathrm{kWh}$ is achieved. The low LCOH in combination with a tax on natural gas makes large-scale solar thermal a commercial business case for district heating (con sumer) cooperatives all over Denmark.

(f) Society. The news-quotes show that present solar thermal collector systems are widely seen as large-scale installations for district heating. Although the market is dominated by systems for hot water preparation the stakeholders do not recognize this fact. Presumably, the situation is different for China.

For domestic hot water preparation in Europe solar thermal collector systems for single family houses are widely accepted by the public, but seen as much too expensive for an auxiliary source of heat for summer season. In this region solar thermal collectors are commonly replaced by photovoltaic modules and electric heaters. Interestingly, solar thermal hot water preparation for multi-family houses, which is already more economic than fossil based technologies or much more efficient than PV based systems, is of limited acceptance in society. Most likely, the outstanding advantages of this system type have not been communicated to the people, the building developers and the investors.

\subsection{Synthesis of the facts}

It is a clear fact that the costs for solar hot water preparation with conventional flat plate collectors in single family houses is too high and needs significant reduction. State of the art solar thermal collector systems are mainly based on metals like copper, aluminum or steel and silicate glass for the collector, piping and storage. As evident in many other fields of application, a transformation to mass technologies and full market penetration is often associated with a material substitution towards polymeric materials. It is a well-known fact, that the use of metals, especially aluminum, for solar thermal collector systems has a significantly higher environmental impact than the 
use of polymeric materials. While solar thermal heat systems based on novel all-polymeric materials find their way to hot water preparation for single family houses, they are still not considered for application in large collector fields or applications for industrial process heat generation.

\subsection{Reflection and conclusions}

While 2017 about $94 \%$ of the energy provided by solar thermal systems was used for domestic hot water, currently a trend to larger solar thermal systems with seasonal storage coupled to district heating networks is discernible. Solar thermal at present contributes about $1 \%$ to total heat consumption. The share of solar district heating and solar process heat applications is steadily increasing despite it is still only representing $3 \%$ of the global market (Weiss and Spörk-Dür, 2018).

The potential contribution is much larger. Many national governments seek to realize this potential by offering subsidies and feed-in-tariffs.

Assessing sustainable development for solar thermal heat systems is a complex discipline. The best heat system depends to a large extend on the climate region. If solar heat is intermittent, seasonal, economic storage of heat is advantageous. Significant cost reductions of solar thermal systems and a shift towards polymeric materials to regain market growth and to improve ecological performance is required.

\section{Acknowledgements}

This research work was performed in the platform project IEA SHC Task 54 "Cost Reduction of Solar Thermal Systems" (www.iea-shc.org). The Austrian participation in the project is funded by the Austrian ministry of traffic, innovation and technology (bmvit).

\section{References}

Arnaoutakis, N., Souliotis M., Papaefthimiou, S., 2017. Comparative experimental Life Cycle Assessment of two commercial solar thermal devices for domestic applications, Renewable Engergy, 111, 187-200 (doi:10.1016/j.renene.2017.04.008).

Ashby, M. F., Ferrer- Balas, D., Coral, J. S., 2016. Materials and Sustainable Development, Oxford (doi:10.1016/C2014-0-01670-X).

Battisti, R., Corrado, A., 2005. Environmental assessment of solar thermal collectors with integrated water storage, Journal of Cleaner Production, 13/2005, 1295-1300 (doi:10.1016/j.jclepro.2005.05.007).

Buchinger, R., 2017. One World Solar System. Presentation at IEA SHC Task 54 Meeting 10/4/17, Linz, AT

Bradler, P. R., Fischer, J., Pohn, B., Wallner, G. M., Lang, R. W., 2017. Effect of stabilizers on the failure behavior of glass fiber reinforced polyamides for mounting and framing of solar energy applications, Energy Procedia, 119, 828-834 (doi: 10.1016/j.egypro.2017.07.108).

Carlsson, B., Persson, H., Meir, M., Rekstad, J., 2014. A total cost perspective on use of polymeric materials in solar collectors - Importance of environmental performance on suitability, Applied Energy, 125, 10-20 (doi: 10.1016/j.apenergy.2014.03.027).

Eisentraut, A., Brown, A., 2014. Heating without global warming - Market Developments and Policy Considerations for Renewable Heat, International Energy Agency, Paris. Available at https://www.iea.org/publications/freepublications/publication/FeaturedInsight_HeatingWithoutGlobalWarming_ FINAL.pdf [accessed 2018.09.13].

Fischer, J., Bradler, P. R., Schlaeger, M., Wallner, G. M., Lang, R. W. 2016. Novel Solar Thermal Collector Systems in Polymer Design - Part 5: Fatigue Characterization of Engineering PA Grades for Pressurized Integrated Storage Collectors, Energy Procedia, 91, 27-34 (doi:10.1016/j.egypro.2016.06.167).

Fischer, S., 2017. Die LCOH-Methode zur Berechnung von Wärmegestehungskosten, Presentation at IEA SHC Task 54 Meeting 10/4/17, Linz, AT

Geretschläger, K. J., Wallner, G. M., 2016. Aging characteristics of glass fiber-reinforced polyamide in hot water and air, Polymer Composites, 9 pages (doi:10.1002/pc.23945). 
Grabmann, M. K., Wallner, G. M., Ramschak, T., Buchinger, R., Lang R. W., 2016. Global Aging and Lifetime Prediction of Polymeric Materials for Solar Thermal Systems - Part 1: Polypropylene Absorbers for pumped Systems, Proceedings EuroSun 2016, International Solar Energy Society, 6 pages (doi:10.18086/eurosun.2016.06.06).

Grabmann, M. K., Wallner, G. M., Ramschak, T., Ziegler, G., Lang R. W., 2016. Global Aging and Lifetime Prediction of Polymeric Materials for Solar Thermal Systems - Part 2: Polyamid 66 Glass-fiber Reinforced Absorbers for Integrated Storage Collectors, Proceedings EuroSun 2016, International Solar Energy Society, 6 pages (doi:10.18086/eurosun.2016.04.03).

Kahlen, S., Wallner, G. M., Lang, R. W., Meir, M., Rekstad, J., 2010. Aging behavior of polymeric solar absorber materials: Aging on the component level, Solar Energy, 84, 3, 459-465 (doi:10.1016/j.solener.2010.01.003).

Kahlen, S., Wallner, G. M., Lang, R. W., 2010. Aging behavior and lifetime modeling for polycarbonate, In Solar Energy, 84, 5, 755-762 (doi:10.1016/j.solener.2010.01.021).

Kahlen, S., Wallner, G. M., Lang, R. W., 2010. Aging behavior of polymeric solar absorber materials-Part 1: Engineering plastics, Solar Energy, 84, 9, 1567-1576 (doi:10.1016/j.solener.2010.03.021).

Kahlen, S., Wallner, G. M., Lang, R. W., 2010. Aging behavior of polymeric solar absorber materials-Part 2: Commodity plastics, Solar Energy, 84, 9, 1577-1586 (doi:10.1016/j.solener.2010.04.007).

Kicker, H., 2009. Vergleichende Ökobilanzierung von solarthermischen Kollektoren, Bachelor Thesis, University of Leoben, A

Kicker, H., Wallner, G. M., Lang, R. W., 2017. Sustainability Assessment of Solar Thermal Collector Systems, Proceedings SWC 2017, International Solar Energy Society (doi:10.18086/swc.2017.34.02)

Kicker, H., Wallner, G. M., Lang, R. W., Ramschak, T., 2018. Life Cycle Assessment of a Novel All-Polymeric Pumped Solar Thermal Collector System for Hot Water Preparation, in Universidade do Minho. Departamento de Engenharia Mecânica Campus Azurém, Guimarães Portugal:ECOS 2018 - Proceedings of the 31st International Conference on Efficiency, Cost, Optimisation, Simulation and Environmental Impact of Energy Systems, 6-2018, ISBN: 978-972-99596-4-6.

Köhl, M., Meir, M. G., Pappilon, P., Wallner, G. M., Saile, S., 2012. Polymeric materials for solar thermal applications, Wiley-VCH, Weinheim (doi:10.1002/9783527659609)

Koroneos, C. J., Nanaki, E. A., 2012. Life cycle environmental impact assessment of a solar water heater, Journal of Cleaner Production, 37, 154-161 (doi:10.1016/j.jclepro.2012.07.001).

Kurzböck, M., Wallner, G. M., Lang, R. W., 2012. Black pigmented polypropylene materials for solar absorbers, Energy Procedia, 30, 438-445 (doi:10.1016/j.egypro.2012.11.052).

Louvet, Y., Fischer, S., Furbo, S., Giovanetti, F., Mauthner, F., Mugnier, D., Philippen, D., 2017. LCOH for Solar Thermal Applications, IEA SHT Task 54 INFO Sheet A.2. Available at http://task54.ieashc.org/Data/Sites/54/media/info-sheets/170306-IEA-SHC_Task\%2054-Info_Sheet_LCOH.pdf [accessed 2018.09.13].

Mauthner, F., Weiss, W., Spörk-Dür, M., 2016. Solar Heat Worldwide - Markets and Contribution to the Energy Supply 2014 - 2016 Edition 2017, IEA-SHC, bmvit, Gleisdorf. Available at http://www.ieashc.org/Data/Sites/1/publications/Solar-Heat-Worldwide-2017.pdf [accessed 2018.09.13].

Olivares, A., Rekstad, J., Meir, M., Kahlen, S., Wallner, G. M., 2010. A test procedure for extruded polymeric solar thermal absorbers, Solar Energy Materials and Solar Cells, 92, 4, $445-452$ (doi:10.1016/j.solmat.2007.10.006).

Olivares, A., Rekstad, J., Meir, M., Kahlen, S., Wallner, G. M., 2010. Degradation model for an extruded polymeric solar thermal absorber, Solar Energy Materials and Solar Cells, 94, 6, 1031-1037 (doi:10.1016/j.solmat.2010.02.001). 
Streck, C., 2015. The Paris Agreement - Briefing Note, ClimateFocus, Amsterdam. Available at https://climatefocus.com/sites/default/files/20151228\%20COP\%2021\%20briefing\%20FIN.pdf [accessed 2018.09.13].

Povacz, M., Wallner, G. M., Lang, R. W., 2014. Black-pigmented polypropylene materials for solar thermal absorbers-Effect of carbon black concentration on morphology and performance properties, Solar Energy, 110, 420-426 (doi:j.solener.2014.09.024).

Povacz, M., Wallner, G. M., Grabmann, M. K., Beißmann, S., Grabmayer, K., Buchberger, W., Lang, R. W., 2016. Novel solar thermal collector systems in polymer design-Part 3: aging behavior of PP absorber materials, Energy Procedia, 91, 392-402 (doi:10.1016/j.egypro.2016.06.280).

Singh, R., Lazarus,I. J., Souliotis, M., 2016. Recent developments in integrated collector storage (ICS) solar water heaters: A review, Renewable and Sustainable Energy Reviews, 54, 270-298 (doi:10.1016/j.rser.2015.10.006).

United Nations, 1987. Our Common Future - Brundtland Report. Oxford University Press, Page 41. Available at http://www.un-documents.net/our-common-future.pdf [accessed 2018.09.13].

Wallner, G. M., Povacz, M., Hausner, R., Lang, R. W., 2016. Lifetime modeling of polypropylene absorber materials for overheating protected hot water collectors, Solar Energy, 125, 324-331 (doi:10.1016/j.solener.2015.12.035).

Weiß, R., Piekarczyk, A., Ramschak, T., Preiß, D., Lutschounig, K., Kicker, H., Wallner, G. M., Meir, M., Weiss, K-A., Köhl, M. 2015. Ökobilanz von polymerbasierten solarthermischen Kollektoren im Vergleich zu konventionellen Kollektoren, Proceedings 25. Symposium Termische Solarenergie, 9 pages.

Weiss, W., Spörk-Dür, M., 2018. Solar Heat Worldwide - Markets and Contribution to the Energy Supply 2018 Edition, IEA-SHC, bmvit, Gleisdorf. Available at http://www.iea-shc.org/Data/Sites/1/publications/Solar-HeatWorldwide-2018.pdf [accessed 2018.09.13].

Zambrana-Vasquez, D., Aranda-Uson, A., Zabalza-Bribian, I., Janez, A., Llera-Sastresa, E., Hernandez, P., Arrizabalaga, E., 2015. Environmental assessment of domestic solar hot water systems: a case study in residential and hotel buildings, Journal of Cleaner Production, 88, 29-42 (doi:10.1016/j.jclepro.2014.06.035). 


\title{
Artificial Intelligence for the Efficient Control of Solar Heating Systems
}

\author{
Wolfgang Kramer \\ Fraunhofer Institute for Solar Energy Systems, Freiburg (Germany)
}

\begin{abstract}
Artificial Neural Networks (ANN) are the basis of a new intelligent control concept for residential heating systems developed at Fraunhofer ISE. This artificial intelligence based concept is able to predict thermal behavior of a building and load level of a thermal storage based on measured data without using any physical model based simulation tool. This allows to improve energy efficiency and simplicity of control devices at the same time. The focus of the concept is simplicity of application, thus enabling low cost model predictive control. Up to $12 \%$ gain of energy efficiency was calculated for a current 1950's building in Southern Germany. This gain is reached without any interaction of installer or user. The ANN control approach proved to work in a real building, too.
\end{abstract}

Keywords: Artificial Neural Networks, Artificial Intelligence, Solar Thermal, Control, Heating System, Energy Efficiency

\section{Introduction}

Similar to biological Neural Networks (brains), Artificial Neural Networks (ANN) are able to automatically develop strategies of operation based on experience in the past. The structure of ANN is motivated by the knowledge of research in Neural Science. For an introduction to Neural Networks see for example Gurney (1997). It is obvious that such structures could be very beneficial for technical control tasks. For solar thermal heating applications ANNs seem to be useful for learning the individual thermal dynamics of a building including fossil fuel heating, the effects of passive solar heating (i.e. heating by sunlight hitting the building surface and passing window surfaces), shading and heat losses to the ambient, thus enabling the prediction of future temperature development in the building. A second application is the prediction of storage temperature distribution of the installation. These predictions do not need any physical model based simulation. The ANN is able to perform these predictions based on training from past measurement data, only. It is able to handle nonlinear static and dynamic systems.

Thus, ANNs provide the back bone of a new self-learning control concept for solar thermal systems based on simple and cheap prediction methods. Local climate data, individual thermal behavior of buildings, solar passive and active gains can easily be forecasted without costly and tedious simulation. This allows not only a significant improvement of energy efficiency but also cost reduction installation and set-up of controllers.

This paper presents the description of the ANN method for the prediction of room temperatures of the building and the storage temperature development of the installation on a real building equipped with a solar thermal supported heating system. The second part shows, how ANN is used in order to control a heating system. Results on the application in a virtual environment and a real application are also shown. 


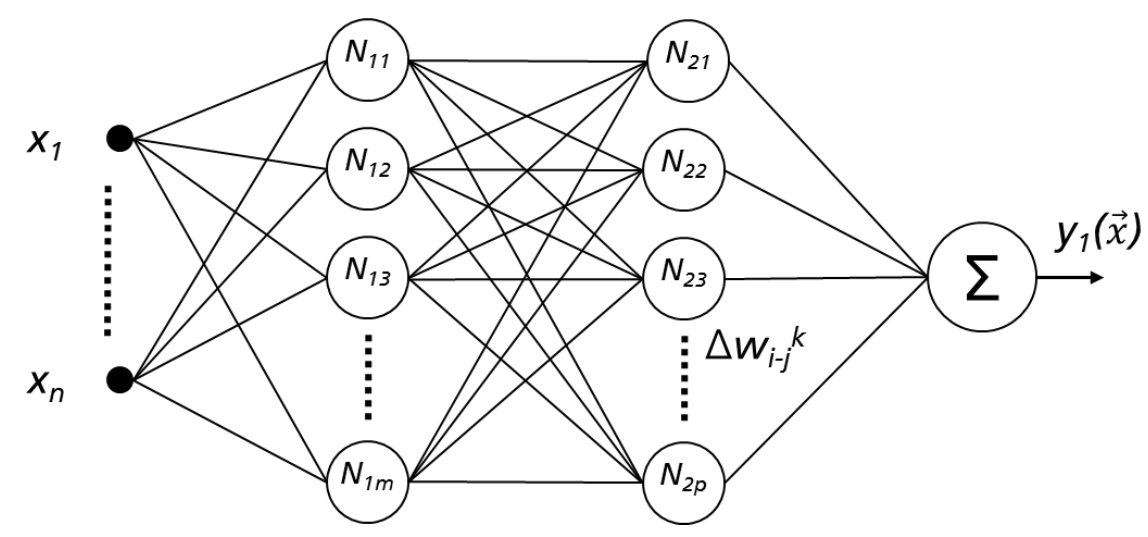

Fig. 1: 4-layer ANN Network with one input layer, 2 hidden layers and one output layer

\section{Prediction using ANN Structures}

ANN structures for the prediction of room temperatures and storage temperature development have been developed at the authors' institution. The ANN models consist of a 4-layer ANN structure (figure 1) including one input layer, two hidden layers and one output. Input data $x_{1}-x_{m}$ is normalized to $+/-1$ before being transferred to the first hidden layer $N_{11}-N_{1 n}$. The calculation procedure in each neuron $\mathrm{N}$ is presented in figure 2 . Each normalized input value is multiplied by a weight $W_{i}$ and summed up. An offset is added and the sum is passed through a transfer function. In our case this is hyperbolic tangent (tanh). The calculation scheme for the second layer is identical. In the last layer, which is the output layer, the output of the second hidden layer $N_{21}{ }^{-}$ $N_{2 p}$ is summed up and extended in order to get the output value $y_{1}(\vec{x})$. Figure 1 shows the ANN.

A program code was developed to do training of the ANN. This means to determine the most suitable values of $W_{i}$ for each neuron in order to get the best fit between measured input and output training data of the ANN. Main challenges of the training process are overfitting, convergence, termination method, being trapped in local minima, required processing power to perform an epoch of training and required RAM to perform an epoch of training.

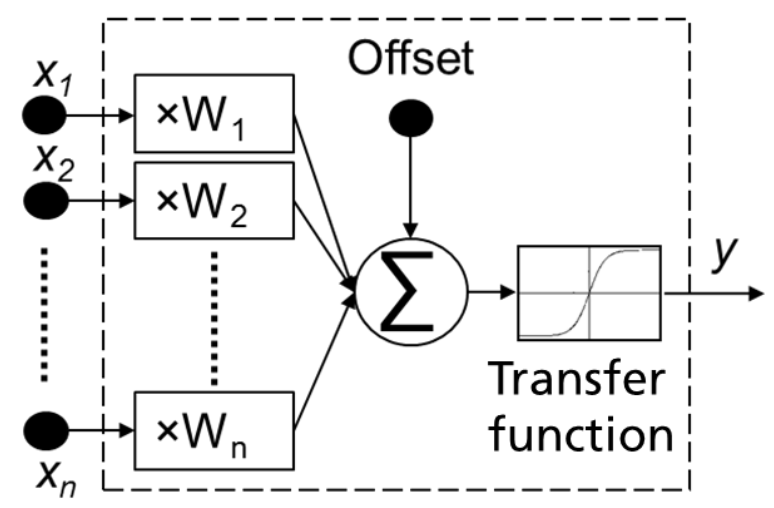

Fig. 2: Mathematical description of a neuron $\mathbf{N}_{\mathrm{ij}}$

Based on the local conditions of weather data and a real individual building construction a trial and error approach was used to choose the most suitable topology. The most important criteria were accuracy of prediction, robustness of the training result and computation time. Overfitting can be avoided by minimizing the size of the ANN. A maximum of 2 hidden layers with not more than 15 neurons each proved to be appropriate for the application presented in this paper. The trials carried out showed that at least for the data that was available a simple termination rule could be defined by stopping the training after a fixed number of training epochs. The developed algorithm follows a supervised training approach and incorporates several training 
features including weight correction, momentum modification and temperature as described by Haykin (2005) in order to avoid being trapped in local minima. Required processing power and RAM does not seem to be a problem for the presented dynamic ANNs.

\subsection{Prediction of Room Temperature and Storage Load Status}

Control of the heating system of a building is normally based on the measurement of the local temperature outside the building. A heating curve which has to be adjusted to the thermal behavior of the building defines the temperature of the heating circuit. Sometimes, on top of that some limited correction to the heating circuit temperature is made by taking into account the current room temperature of a reference room representing the typical behavior of the building.

Experience shows, that the optimum adjustment is hard to find and takes a lot of time. Therefore, in very many cases the applied heating curve does not reach the most efficient status. Besides this, the control approach is only based on the current status of outside temperature (and possibly room temperature). This means, that the future development of the room temperature is not taken into account. Effects like future passive solar gains, change of outside temperature or reduced heating demand due to the approaching night temperature reduction are neglected.

However, the ANN control approach is able to account for all these effects. Using internet based weather forecast data, it is based on the future prediction of the room temperature development. It accounts for effects like passive solar gains, shading of the building, microclimatic influences and position of the sun.

It is important to state, that the ANN is able to account for all these effects implicitly. That means, it is sufficient to deliver the time dependent necessary raw input data to the system which show an influence on the room temperature and the measured room temperature in the building. No separate calculation of energy flow, irradiation reaching the building or other physical data is done. The system is able to correlate this data which results in a black box dynamic model for the room temperature forecast.

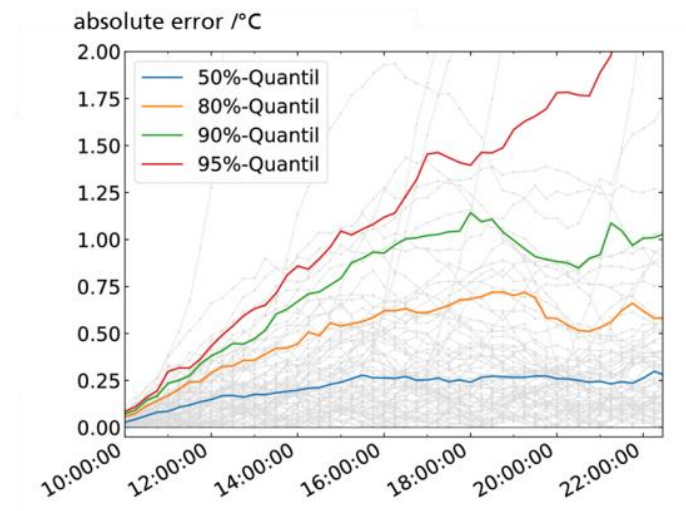

Fig. 3: Prediction of the room temperature using a rolling prediction based on 4 weeks historical data

Figure 3 shows the capability of an ANN to predict the room temperature of a real building. The building is situated in Marburg, Germany. It has a low specific heat demand of $45 \mathrm{kWh} / \mathrm{m}^{2} \mathrm{a}$.

The dynamic ANN consisted of 8 inputs (figure 4). Date, time, day of the week, surface temperature of a wood stove, heating circuit temperature and from a weather forecast (data by meteoblue 2017) hourly local outside temperature, global normal irradiation and cloudiness factor. Output is the room temperature. The back propagation of the room temperature transforms the system into a dynamic one. Time step is 15 minutes. The ANN network consists of 2 hidden layers with 12 neurons each. The ANN algorithm has been combined with a Linear System Approach (LSI) as described by Chen (1999) in order to be able to handle non-linear (ANN) and linear (LSI) behavior of the building. 


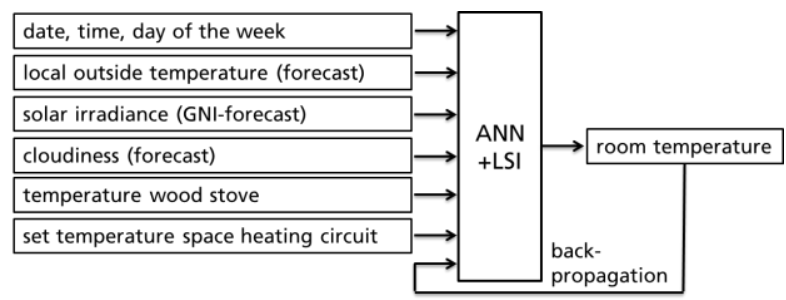

Fig. 4: Dynamic ANN+LSI Module with backpropagation for the prediction of room temperature development

First the LSI is applied to identify the linear part of the behavior. The residues are treated with the ANN. In the analyzed building, the behavior was mainly linear. However, short trials on other buildings showed, that nonlinear behavior can also be significant. The combined non-linear - linear approach using ANN and LSI seems to be robust and universal for a general application in buildings.

Continuous rolling learning using the measured data from the 4 last weeks was applied every day during the heating period. The graph shows the results for 100 days. Every day the forecast starts a 9:00h in the morning and is done for the next 13.5 hours. Prediction for the first hours is good. For more than $95 \%$ of data the accuracy is better than $0.5 \mathrm{~K}$ for the first 3 hours. This is a very good value, since there are always some unpredictable additional heat sources or sinks like for example opening of the windows or unexpected cooking or ironing.

Prediction of the storage load status is done in a similar way. Prediction quality is lower than for the room temperature. Deviation from the real temperature is better than $15 \mathrm{~K}$ for $90 \%$ of the predictions during the first 4 hours. This is due to non-predictable hot water tapping. However this prediction quality is still sufficient for an efficient operation of the ANN control algorithm.

\section{Control Approach using ANN}

A new approach for controlling the heating system in buildings using ANN has been developed. This approach relies on the strong performance of ANN combined with a Linear System Identifier approach (LSI) predicting room temperature and storage load status. The control approach is based on the ANN+LSI prediction shown in figure 4. Output of the prediction is the room temperature development in the future hours. The only input parameter which can be varied by the control system is the heating circuit temperature. Changing this temperature leads to a different room temperature development. The task of the control system is to find the lowest heating circuit temperature leading to the future desired room temperature. The desired room temperature is defined by the user and described by a temperature-time table. Deviation from the desired temperature is calculated for 1, 2, 3 and 4 hours in advance. Each deviation is weighted by a factor in order to differentiate the importance of sooner and later deviations. The algorithm determines the heating circuit temperature allowing the lowest sum of weighted deviations.

Switch on/off of the boiler is also done by an ANN+LSI approach. ANN+LSI forecast is used to predict the development of the different storage temperatures. If the future storage temperatures are in line with the calculated needed heating circuit temperatures in the future, there is no need to switch on the boiler. The prediction of the future storage temperature includes solar gains, reduced heat demand if the wood stove is delivering additional heat or due to demanded nightly room temperature reduction. The boiler is switched on in order to deliver the minimum storage temperature to keep the calculated future heating circuit temperatures.

\section{Results of a Real Building Tests}

The ANN controller approach was tested in a real building. The question to be answered was whether the ANN approach can cope with a real control environment. The building is shown in figure 5. It is equipped with a 18 $\mathrm{m}^{2}$ flat plate collector field, a $1000 \mathrm{~L}$ thermal storage, a $10 \mathrm{~kW}$ Pellet Boiler. The heated surface area is $200 \mathrm{~m}^{2}$, the yearly heat demand is $45 \mathrm{kwh} / \mathrm{m}^{2}$. It is located in Marburg, (Germany) 

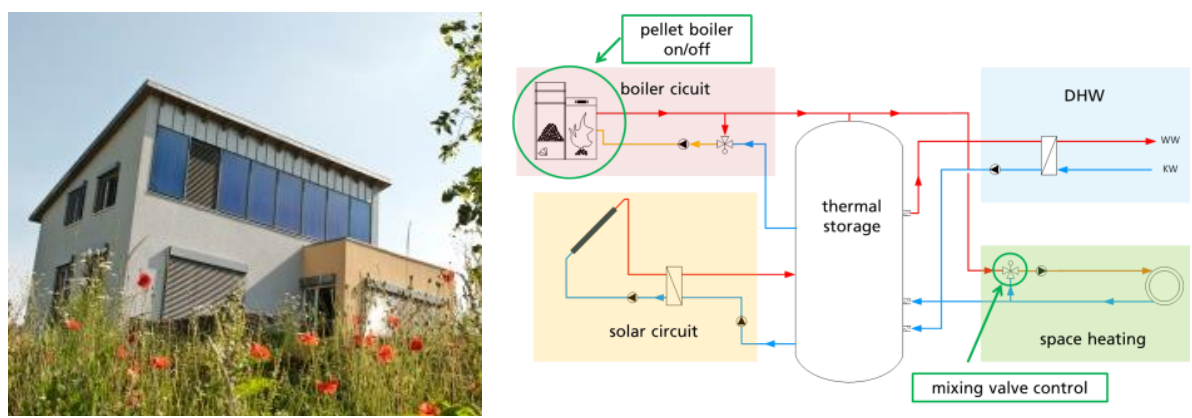

Fig. 5: Test building and simplified hydraulic scheme. ANN-controlled actuators control the mixing valve of the space heating circuit and the on/off switch of the pellet boiler

The ANN controller controls the mixing valve of the space heating circuit and the on/off switch of the pellet boiler. All other control actions are taken by the conventional controller already implemented in the building. This means in particular control of the fresh water heat exchanger. The ANN controller was tested during the heating period 2017/2018. Some typical results are shown in Figure 6. The top graph shows the heating circuit temperature defined by the ANN controller. For comparison the heating circuit temperature which would be defined by the conventional controller of the building is also shown. The second graph shows the time dependent set-value of the room temperature and the measured room temperature. The third graph shows the collector temperature representing solar irradiation.

The heating circuit temperature of the ANN differs significantly from the conventional controller. Although the conventional controller also takes into account the real room temperature there is only a small reduction, when the room temperature exceeds the desired value. When the room temperature is significantly below the desired value, the ANN rises the temperature of the heating circuit to its limit of $60^{\circ} \mathrm{C}$. This allows for fast reaching of the desired room temperature after for example a holiday period with reduced heating (i.e. 3.4.2018). When passive solar gains help to reach the room temperature, ANN reduces the heating circuit temperature or even switches completely off the heating circuit (i.e. 6.4. and 7.4.2018), which reduces heat demand of the boiler.

temperature $/{ }^{\circ} \mathrm{C}$
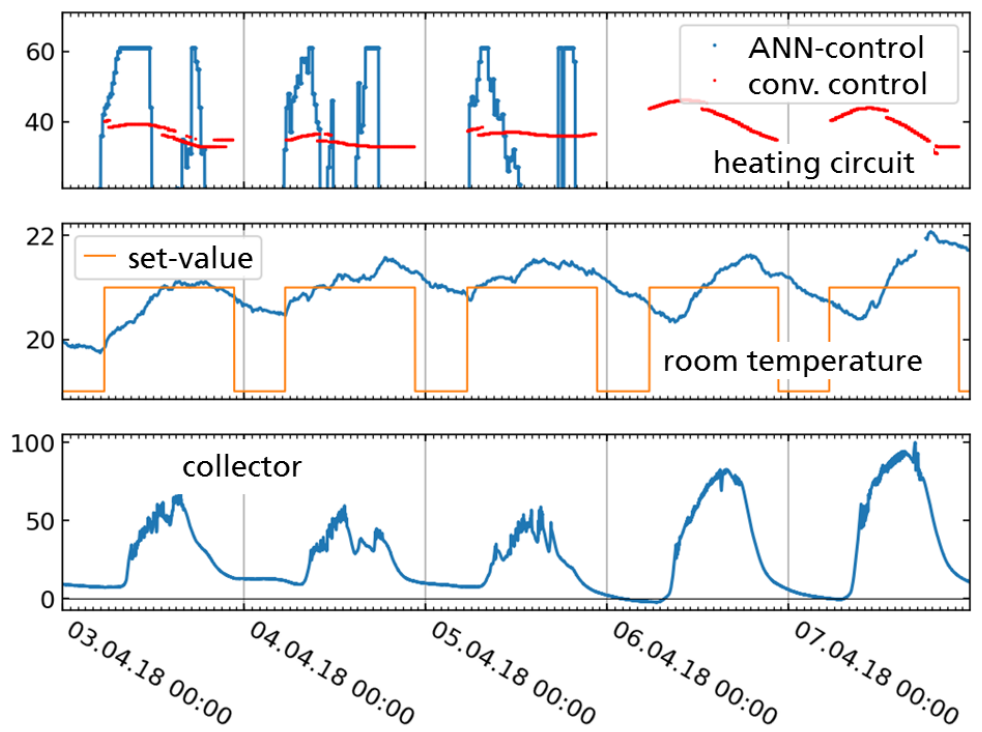

Fig. 6: ANN-controller acting in a real building (typical example) 


\section{Results of a Virtual Building Test}

The test in the real building was mainly meant to see whether the ANN algorithm is able to run in a real environment without problems. However, the question of energy savings was answered by simulating different buildings with ANN-Controller. The basis for the comparison were two building types. One close to the building which was used for the real building test. This means a modern well insulated building with low heat demand (i.e. $45 \mathrm{kWh} / \mathrm{m}^{2} \mathrm{a}$ ) and a rather high heat demand building corresponding to the building stock of the 1950's in Germany (i.e. $150 \mathrm{kWh} / \mathrm{m}^{2} \mathrm{a}$ ). For both buildings three simulations where conducted. On with the heating curve independent from outside temperature at constant temperature (worst case, if the heating curve is not adapted), a second one with optimized conventional heating curve and a third one with ANN-Controller approach. Both simulations were done with climatic data of Freiburg, Germany. Heat transfer to the building is by radiators. The optimization of the conventional heating curve was done in such a way, that more than $80 \%$ of the daytime in the heating period is within a limit of maximum $2 \mathrm{~K}$ below set-value. Approximately the same comfort was reached by the ANN Controller.

Figure 7 shows that in a modern building with low heat demand the effect of either optimizing a conventional heating system or using an ANN controller is low. However, existing buildings with higher heat demand can gain significant energy efficiency by optimization. Optimizing a conventional heating curve can improve the system by up to $5 \%$. ANN improves efficiency even more significantly by up to $12 \%$ under Freiburg climatic conditions.

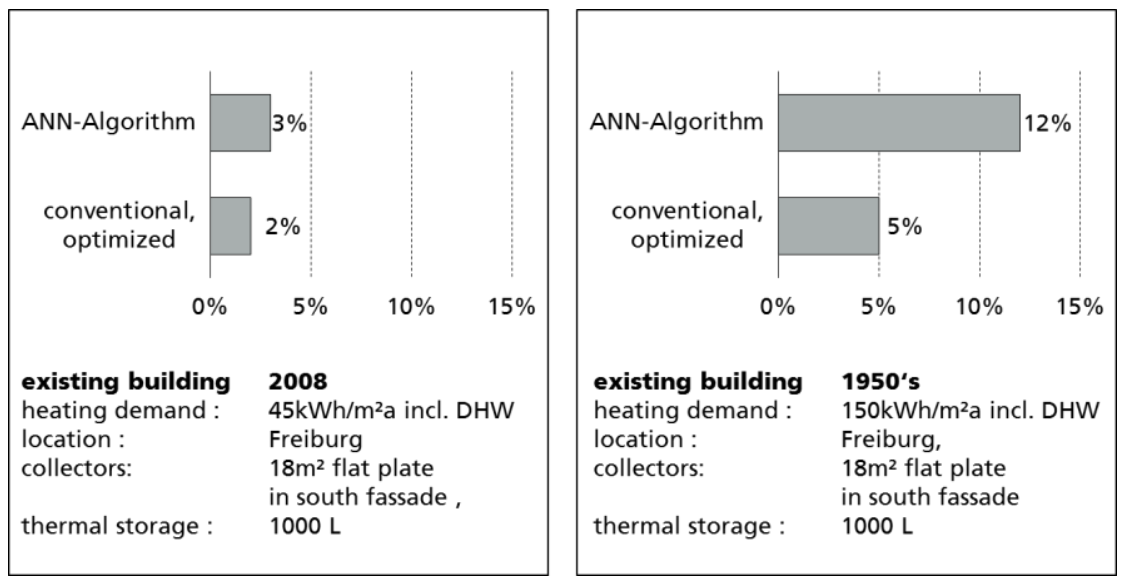

Fig. 7: Energy savings by using the ANN controller approach for 2 different applications

\section{Discussion of the Results and Conclusion}

A new artificial intelligence control approach using Artificial Neural Networks provides a powerful concept which can significantly improve energy efficiency and reduce implementation cost at the same time. Higher improvements of energy efficiency can be reached in the existing building stock than in new buildings with low heat demand. This due to the fact that modern buildings normally show a higher thermal capacity to heat demand ratio than old buildings. Therefore, temporary overheating can be stored more efficiently in the thermal building capacity. Old buildings with a less favorable thermal capacity to heat demand ratio are more sensitive to unnecessary heat supply to the building.

Up to $12 \%$ gain in energy efficiency was calculated for existing 1950 's buildings under southern Germany climatic conditions. Other climatic conditions and other low thermal capacity buildings might lead to even higher savings. This has to be further investigated.

Besides the benefit of energy savings the ANN approach allows for automatic adjustment of the heating controller to the individual buildings. Its strength is its simplicity in application by relying on local measured and simple weather forecast data, only. This is a very big advantage, since optimization of current heating controllers demand a high labor cost. The installer has to come at least twice at different periods of the heating season in order to minimize the necessary heating circuit temperatures. ANN does not need such an effort since 
it automatically adapts to the individual conditions of the building and the environment.

\section{Acknowledgment}

This research was conducted within the project „Neuronale Netzwerke für die Anwendung in der Solarthermie“ (Neural Networks for the application in solar Thermal ) (ANNsolar) and is supported by the German Ministry of Economics (Bundesministerium für Wirtschaft, BMWi) under the grant number FKZ 325548 and supported by the project executing organization PTJ Jülich. The responsibility for the content of this paper lies completely with the authors.

\section{References}

Chen, C., 1999. Linear system theory and design. Oxford, GB: Oxford University Press.

Gurney, K., 1979. An Introduction to Neural Networks, UCL Press Limited, London.

Haykin, S., 2005. Neural Networks - A Comprehensive foundation, Pearson Prentice Hall, $2^{\text {nd }}$ Edition.

Meteoblue, 2017. http://www.meteoblue.com, accessed 201701 16, [Online]. 
W. Kramer / EuroSun 2018 / ISES Conference Proceedings (2018) 


\title{
Simulation-based Optimization of Solar Combisystem Sensitivity Analysis at Optimum
}

\author{
Oleh Kusyy and Klaus Vajen \\ Institute of Thermal Engineering, University of Kassel, Kassel (Germany) \\ Abstract
}

In this paper, a solar thermal combisystem is optimized for minimal solar energy costs at specified extended fractional energy savings by applying hybrid genetic $\mathrm{CHC}-$ binary search optimization algorithm. An optimization potential of around 13\% in terms of solar energy costs or 19 percent points in terms of extended fractional energy savings can be achieved when compared to the system configuration planned by experts. A Pareto front is built showing the optimal solar energy costs at desired energy savings of the system, or vice versa. The influence of variations of domestic hot water and space heating demand as well as geographical location on course and position of the Pareto front and optimal combisystem configuration is investigated. To determine the most important parameters and quantify their influence on the solar energy costs, methods of global sensitivity analysis are applied near the optimum.

Keywords: Numerical optimization, hybrid genetic algorithm, Pareto front, sensitivity analysis

\section{Introduction}

Since operation of a solar thermal combisystem consisting of many interacting components is complex, dynamic system simulations are often required to investigate the system behaviour. Proper dimensioning of the system components as well as efficient controller settings depend on changing boundary conditions as weather, domestic hot water and space heating demand. In addition to the energetic performance, the dimensioning of combisystem must be justified economically. All this makes finding the combisystem configuration optimally designed in terms of cheapest solar energy costs for given location and demand rather challenging. After the optimal configuration is found, further investigation is required showing how sensitive it is to variations of the boundary conditions or single system parameters.

In this paper the reference solar combisystem proposed in the IEA-SHC Task 32 (Heimrath and Haller, 2007) is numerically optimized for minimal solar energy costs by a hybrid genetic CHC - binary search optimization algorithm. It is shown to be reliable and efficient for finding optimal system configuration (Kusyy et al., 2010). As a result of several optimization runs, each with different constraints on extended fractional energy savings of the combisystem, the Pareto front between solar energy costs and fractional energy savings is built. It shows minimal energy costs at desired fractional energy savings or, vice versa, maximal fractional energy savings that are possible to achieve at given energy costs. Further, the influence of boundary conditions on the Pareto front and optimal combisystem configuration is investigated. This allows estimating the performance decrease of the solar combisystem optimized for given initial conditions but operated at changed conditions.

The influence of combisystem parameters and two boundary conditions (DHW demand and collector price) on solar energy costs is accessed by application of global sensitivity methods in the parameter space near the optimum. Parameters having much influence on the solar energy costs must be handled carefully, and less influential parameters may deviate from their optimal values with only insignificant increase of solar energy costs. This might be helpful if, for example, components of particular optimal sizes are not accessible on the market.

All numerical simulations of the solar combisystem are carried out by TRNSYS simulation software (Klein et al., 2007) and the coupling with the optimization algorithm is done by GenOpt generic optimization program (Wetter, 2008) 


\section{Optimization problem formulation}

\subsection{Description of solar combisystem}

The reference solar combisystem (Figure 1) proposed in IEA-SHC Task 32 is the object of investigation in the present paper. The combisystem is planned to cover domestic hot water consumption and space heating demand of a single family house. Solar thermal collectors are connected via an external heat exchanger to a store which is the central system component. A conventional heater is intended to heat up an auxiliary volume at the top of the store when the energy supplied by solar collectors is not enough to cover the demand. On the consumption side, the tap water is prepared via fresh water station and space heating is supplied directly from the store.

For simulation of the Task 32 combisystem the locations Stockholm, Zurich and Madrid are chosen representing a wide range of the European climates. The yearly profile for domestic hot water demand with a 6 minute time resolution is generated using the DHWcalc tool (Jordan and Vajen, 2005) as a typical profile for a single family house. According to the profile, the consumption of the domestic hot water is stochastically distributed over the days having main peaks in the morning and late afternoon. Three reference buildings (two-storey, $140 \mathrm{~m}^{2}$ of the living area) with the same architectural design but different wall insulation and window thermal quality resulting in different heating demand (30, 60 and $100 \mathrm{kWh} / \mathrm{m}^{2} a$ for Zurich climatic conditions) are defined in Task 32.

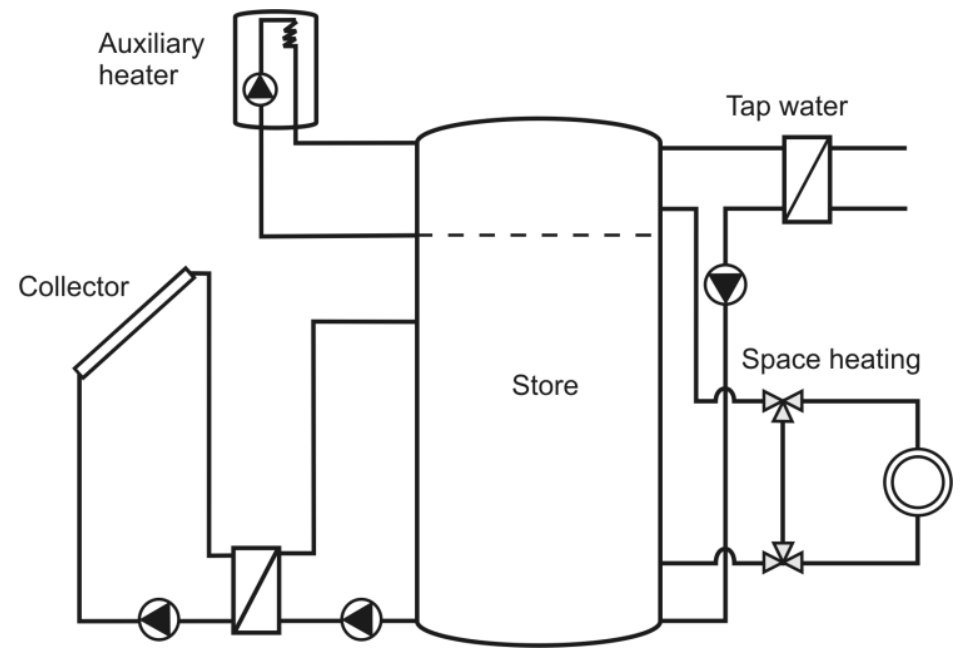

Fig. 1: Schematics of investigated solar combisystem

\subsection{Target function}

In this study the solar combisystem is optimized for minimum costs per $k W h$ of saved auxiliary final energy. The target function dependent on the set of the optimization parameters $X=\left\{x_{1}, \ldots, x_{N}\right\}$ which are listed in Table 1 below, installer margin $m$ and interest rate $r$, is constructed as follows:

$$
F_{\text {target }}(X, c, m, r)=\frac{F_{\text {cost }}(X, m, r)}{E_{\text {ref }}-E_{\text {sol }}(X)+\widehat{F}_{\text {penalty }}\left(f_{\text {sav }, \text { ext }}(X), c\right)}
$$

The energetic performance of the combisystem is described by the denominator of the target function, where $E_{r e f}$ is the auxiliary final energy consumption of the reference heating system, $E_{\text {sol }}(X)$ is the energy consumption of the solar combisystem and $E_{r e f}-E_{s o l}(X)$ is the amount of auxiliary final energy saved by the solar combisystem over the year. The third term $\widehat{F}_{\text {penalty }}$ in the denominator of (1) is the penalty added to the target function if the extended fractional energy savings $f_{\text {sav,ext }}$ defined as

$$
f_{\text {sav }, e x t}(X)=1-\frac{E_{\text {sol }}(X)+F_{\text {pen,DHW }}(X)+F_{\text {pen }, S H}(X)}{E_{\text {ref }}}
$$

are less than a given value $c$. The term $\hat{F}_{\text {penalty }}$ is needed only if the extended fractional energy savings $f_{\text {sav,ext }}$ of the optimized combisystem must be kept larger than $c$. It determines how much solar gains are missing in order to reach $f_{\text {sav,ext }}=c$. The terms $F_{p e n, D H W}$ and $F_{p e n, S H}$ in (2) describe the penalties are applied when the required tap hot water temperature $\left(45^{\circ} \mathrm{C}\right)$ cannot be supplied or the room temperature drops below the 
desired set temperature $\left(19.5^{\circ} \mathrm{C}\right)$.

To determine the costs of the combisystem described by the function $F_{\text {cost }}$ in (1), a comprehensive market study is required. It is connected with large uncertainties due to the variety of solar thermal components of different quality on the market. Furthermore, the prices of the system components, transportation costs, interest rates, etc., are noticeably time dependent, different special offers may influence the cost function. All this together with non-transparency of the installer price margins makes an exact determination of the costs quite difficult.

In this study a simple calculation of the prices of individual system components is attempted. If any optimization parameters from Table 1 below have an impact on the price of a certain system component, then the price function for this component is built which is a dependency of the component market price from the magnitude of these parameters. The price functions are built for each component based on the offers of online discounters. Dependency of the price from the optimization parameters is chosen as a polynomial up to the second degree and the unknown coefficients of the polynomial are determined by performing linear or multilinear regression. Offers of the online discounters, taken as the regression data, seem to be the cheapest retail prices on the market accessible for the end user and probably they are the best approximate for the wholesaler prices. The component prices offered by the installers most likely already include their margins which might be different for different components and also vary from installer to installer. For example, one installer might add $30 \%$ to the price of collectors and 50\% to the store price offered by the wholesaler whereas another installer might do vice versa. From this reason the component prices offered by the discounters and not the installer prices are chosen to be appropriate for building the cost function of the solar combisystem.

On the other hand, however, it seems unlikely that the end user will be able to hire the installer to build up the combisystem out of the user's own components bought by the discounter. Therefore, to estimate the final price for each component $C_{i}, i=1, \ldots, N$ for the end user, the discounter prices $F_{\text {cost,disc }}\left(C_{i}\right)$ are corrected by the factor $m$ representing expected installer margin, supposed to be the same for all components. To get the final capital costs $F_{\text {cost,cap }}$ the installation costs equal to $20 \%$ of the price for solar combisystem are added.

$$
F_{\text {cost }, \text { cap }}(X, m)=1.2 \cdot m \cdot \sum_{i=1}^{N} F_{c o s t, d i s c}\left(C_{i}\right)
$$

The final capital costs $F_{\text {cost,cap }}$ depend implicitly (through the functions $F_{\text {cost,disc }}\left(C_{i}\right)$ ) on at least some of the optimization parameters $X$. In the present implementation the capital costs include German value added tax equal to $19 \%$

Following the annuity method, the annual payments due each year over the lifetime of the solar combisystem at the given interest rate $r$ are calculated as follows:

$$
F_{\text {cost }}(X, m, r)=\frac{(1+r)^{20} \cdot r}{(1+r)^{20}-1} \cdot F_{c o s t, c a p}(X, m)+0.007 \cdot F_{c o s t, c a p}(X, m)
$$

The lifetime of the combisystem is set to 20 years and it is not varied in any of the following optimizations. Second term in (4) describes annual maintenance and insurance costs. These costs discounted to the installation year, are taken to be equal around $11 \%$ of the capital costs $F_{\text {cost,cap }}$ for the lifetime of the combisystem and the interest rate of $2.5 \%(r=0.025)$.

The cost function $F_{\text {cost }}(X)$ with interest rate of $2.5 \%$ and $m=1.5$, meaning that $50 \%$ is added to the discount component prices as an installer margin, is used in the target function $F_{\text {target }}(X, c)$ from (1) in the following optimizations. Other annuities $F_{\text {cost,contr }}(X)=F_{\text {cost }}(X, 1,0.025)$ and $F_{\text {cost,contr }}^{0}(X)=F_{\text {cost }}(X, 1,0)$ both representing the costs with different interest rates of $2,5 \%$ and $0 \%$, respectively, for the company which installs the solar thermal systems $(m=1)$, are calculated as well. After subtracting the added value tax, the costs $\hat{F}_{\text {cost,contr }}^{0}(X)$ for the installation company doing, for example, an energy contracting are obtained. The cost function $F_{\text {cost }}^{0}(X)=F_{\text {cost }}(X, 1.5,0)$, that is the cost function for the end user $(m=1.5)$ investing its own savings $(r=0)$ in a solar combisystem, is presented in the results below as well.

After substituting the annuity cost functions into (1) the corresponding target functions, are obtained. Since all the cost functions derived here do not change the weighting of the capital costs $F_{\text {cost,disc }}\left(C_{i}\right)$ of single 
components under the sum sign in (3) but only modify the sum as the whole, the optimal system configuration $X=X_{\text {opt }}$ received for one of the functions is also the optimum for all others.

\subsection{Optimization parameters}

Before the optimization algorithm may start, the parameters of the system must be specified, especially values of which are believed to be not optimal and should be adjusted in order to improve the existing system. Not only the parameters themselves, but also the variation ranges in which the parameter values can be varied during the optimization are to be chosen. Too wide variation ranges will most likely slow down the optimization whereas too narrow ranges may cause missing the optimum when the optimal parameter value lies beyond the specified variation range. For any two parameters which are involved in interactions with regard to the target function (f.e. flow rate and pipe diameter), the variation ranges should be chosen such that none configuration of the values (f.e. flow rate chosen large and pipe diameter - small) will cause the system simulation to fail.

In this study, 18 parameters of the solar heating combisystem are adjusted in the process of optimization in order to get the optimal value of the target function (1). All optimization parameters with their variation ranges are listed in Table 1. In several optimizations below, the variation ranges of certain parameters are modified so that the optimum lies within the variations ranges.

Tab. 1: List of parameters with variation ranges for optimization ("optimization range") and for calculation of parameter influence on solar energy costs $\boldsymbol{F}_{\text {target }}$ near optimum ("sensitivity range"). Resolution $\boldsymbol{N}$ for optimization parameters is given in bits meaning that each parameter may take any of $2^{N}$ values equidistantly distributed between endpoints of its optimization range

\begin{tabular}{|c|c|c|c|c|}
\hline Parameter & Notation & $\begin{array}{l}\text { Optimization } \\
\text { range }\end{array}$ & Resolution & $\begin{array}{l}\text { Sensitivity } \\
\text { range }\end{array}$ \\
\hline \multicolumn{5}{|l|}{ Optimization parameters } \\
\hline 1. Collector area, $m^{2}$ & $A_{\text {col }}$ & {$[5 ; 36]$} & 5 & {$[14 ; 21]$} \\
\hline 2. Store volume, $m^{3}$ & $V_{\text {store }}$ & {$[0.5 ; 2.0]$} & 4 & {$[1.2 ; 1.8]$} \\
\hline 3. Number of auxiliary nodes & $N_{\text {aux }}$ & {$[5 ; 20]$} & 4 & {$[8 ; 12]$} \\
\hline 4. Store insulation thickness, $m$ & $D_{i s o}$ & {$[0.05 ; 0.8]$} & 4 & {$[0.2 ; 0.3]$} \\
\hline 5. Pipe inner diameter, $\mathrm{mm}$ & $D_{\text {pipe }}$ & {$[10 ; 40]$} & 4 & {$[10 ; 15]$} \\
\hline 6. Specific collector flow rate, $\mathrm{kg} / \mathrm{m}^{2} \mathrm{~h}$ & $m_{\text {flow }}$ & {$[5 ; 36]$} & 5 & {$[11 ; 16.5]$} \\
\hline 7. $\Delta \mathrm{T}$ controller upper dead band, $K$ & $\Delta T_{\text {col,up }}$ & {$[4 ; 11.5]$} & 4 & {$[4 ; 6]$} \\
\hline 8. $\Delta \mathrm{T}$ controller lower dead band, $K$ & $\Delta T_{\text {col, low }}$ & {$[0.1 ; 4.0]$} & 4 & {$[4 ; 6]$} \\
\hline 9. $\Delta \mathrm{T}$ controller sensor pos. in store & $H_{c o l, s e n s}$ & {$[0.01 ; 0.3]$} & 4 & {$[0.14 ; 0.21]$} \\
\hline 10. UA value of solar $\mathrm{hx}, W / K$ & $U A_{c o l}$ & {$[1000 ; 5500]$} & 4 & {$[1000 ; 1500]$} \\
\hline 11. UA value of DHW hx, $W / K$ & $U A_{D H W}$ & $1000 ; 10300]$ & 4 & {$[0.4 ; 0.8]$} \\
\hline 12. Collector inlet position in store & $H_{c o l, \text { in }}$ & {$[0 ; 1]$} & 5 & {$[0.07 ; 0.105]$} \\
\hline 13. SH outlet position in store & $H_{S H, \text { out }}$ & $\begin{array}{l}{\left[1-V_{\text {aux }} /\right.} \\
\left.V_{\text {store }} ; 1\right]\end{array}$ & 4 & {$[0.15 ; 0.3]$} \\
\hline 14. SH inlet position in store & $H_{S H, \text { in }}$ & {$[0.07 ; 0.3]$} & 4 & {$[6580 ; 9870]$} \\
\hline 15. Set temperature of aux. heater, ${ }^{\circ} \mathrm{C}$ & $T_{a u x, \text { set }}$ & {$[50 ; 70]$} & 4 & {$[52 ; 78]$} \\
\hline 16. Aux. controller upper dead band, $K$ & $\Delta T_{\text {aux }, u p}$ & {$[4 ; 16]$} & 4 & {$[7.2 ; 10.8]$} \\
\hline 17. Aux. controller lower dead band, $K$ & $\Delta T_{\text {aux }, \text { low }}$ & {$[0.5 ; 4]$} & 4 & {$[2.1 ; 3.2]$} \\
\hline 18. Collector slope ${ }^{\circ}$ & sl & {$[40 ; 71]$} & 5 & {$[53 ; 79]$} \\
\hline \multicolumn{5}{|l|}{ Boundary condition parameters } \\
\hline 19. DHW demand multiplier & $D H W$ & & & {$[1.0 ; 1.5]$} \\
\hline 20. Collector price, Eur $/ \mathrm{m}^{2}$ & Price $_{\text {col }}$ & & & {$[300 ; 450]$} \\
\hline
\end{tabular}

\subsection{Optimization algorithm}

The algorithm solving the optimization problem is a sequence of operations, usually repeated iteratively, which are performed on the set of optimization parameters. The solution found by the optimization algorithm is the 
system configuration optimal with regards to a chosen target function. Whether the found solution is really the optimal one and how efficient the performed operations are, are the questions of reliability and efficiency of the algorithm. In this study, the solar combisystem is optimized by the hybrid genetic CHC - binary search optimization algorithm. It belongs to hybrid optimization algorithms which are an attempt to make the reliable global optimization algorithms faster by coupling them with computationally less expensive local algorithms.

To speed up the optimization, the proposed hybrid algorithm is parallelized for simultaneous solar combisystem simulations on multi-core CPUs or in the computer network using HTC Condor (High Throughput Computing) distributed computing software. The hybrid CHC - binary search algorithm was started 6 times in a row for chosen optimizations in order to test its reliability. All the optima found by the algorithm differed less than $1-2 \%$ from their mean value, depending on the number of optimization parameters, boundary conditions and system configurations. This means that most probably the global optimum was found each time and the algorithm might be seen as a reliable one.

The parallelized version of the hybrid genetic CHC - binary search optimization algorithm is implemented in GenOpt (Generic Optimization software) which is the open source framework for the numerical optimization. For more details on the hybrid algorithm refer to (Kusyy et al., 2010).

\section{Optimization results}

\subsection{Pareto front}

The proposed hybrid CHC - binary search optimization algorithm is applied to optimization of the solar combisystem (Figure 1) located in Zürich, Switzerland. The single family house has space heating demand of $60 \mathrm{kWh} / \mathrm{m}^{2} a(8,4 \mathrm{MWh} / \mathrm{a})$ and domestic hot water consumption is set to $200 \mathrm{l} / \mathrm{d}(2,93 \mathrm{MWh} / \mathrm{a})$. Optimization parameters varied during the optimization are listed in Table 1 and the target function $F_{\text {target }}$ is defined by (1).

The solar combisystem is optimized for different extended fractional energy savings $f_{\text {sav } \text {,ext }}$. Seven optimizations are carried out with respect to $F_{\text {target }}$ with corresponding constraints $c$ with $c=0.3,0.35, \ldots, 0.6$ on the $f_{\text {sav,ext }}$, and one optimization is started without any constraint, that is, with $c=0$. Optimal values of $F_{\text {target }}$ plotted versus $f_{\text {sav,ext }}$ build the Pareto front, that is, the minimal costs per saved auxiliary energy for each given extended fractional energy savings $f_{\text {sav,ext }}$ (Figure 2).

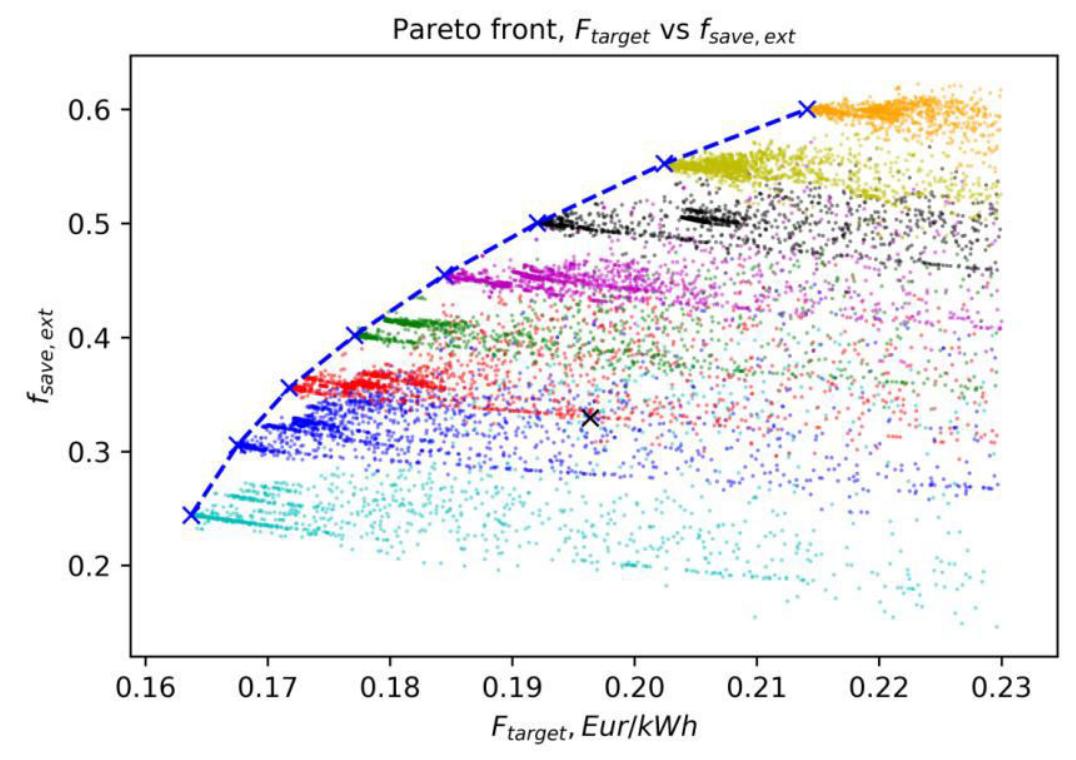

Fig. 2: Interpolation of Pareto front: optimal $F_{\text {target }}$ versus $\boldsymbol{f}_{\text {sav, ext }}$ for combisystem with DHW consumption $200 l / d$ and SH demand $60 \mathrm{kWh} / \mathrm{m}^{2} a$, located in Zürich. Results of 8 optimizations are shown by blue crosses. Colored points depict non-optimal configurations $\left(F_{\text {target }}, f_{\text {sav,ext }}\right)$ calculated in progress of optimizations. Each color represents different optimization. Black cross shows properties $\left(F_{\text {target }}, f_{\text {sav,ext }}\right)$ of base combisystem. The turnkey-cost on the $x$-axis include $19 \%$ VAT, but no subsidies 
Each point $\left(F_{\text {target }}, f_{\text {sav } \text {,ext }}\right)$ located to the left of the Pareto front is not reachable, that means, under the given boundary conditions, no combisystem can be built having such properties. On the other hand, each combisystem with the properties $\left(F_{\text {target }}, f_{\text {sav,ext }}\right)$ to the right of the Pareto front is realizable but not optimal.

The optimum of each optimization corresponding to a given constraint $c$ with $c=0.3,0.35, \ldots, 0.6$ is marked by a blue cross. Colored points depict the properties $\left(F_{\text {target }}, f_{\text {sav,ext }}\right)$ of intermediate non-optimal system configurations which are calculated by the algorithm before the optimum is reached. Colors of the points correspond to the values of constraint $c$, for example, red color means $c=0.35$, black $-c=0.5$, etc. Higher density of the points is observed near optimum, where the algorithm converges and performs more calculations. Only the points corresponding to combisystem configurations with $F_{\text {target }}<0.23 \mathrm{Eur} / \mathrm{kWh}$ are shown for better visibility. Blue dashed line connecting the optima shows interpolation of the Pareto front.

\subsection{Optimization potential. Comparison to Task 32 reference combisystem}

The base configuration of the solar combisystem from IEA Task 32 has extended fractional energy savings $f_{\text {sav,ext }} \approx 0.33$ and solar energy costs of 0.196 Eur per $k W h$ of saved final auxiliary energy. This point is depicted by the black cross in Figure 2. The minimal costs for the combisystem with the same fixed $f_{\text {sav,ext }}$ are nearly $0.17 \mathrm{Eur} / \mathrm{kWh}$ what is around $13.5 \%$ cheaper than those for the base configuration. On the other hand at nearly the same $F_{\text {target }}$ as for the base system, it is possible to construct the combisystem with noticeably higher fractional energy savings $f_{\text {sav,ext }}=0.52$.

Optimal values of optimization parameters, target function $F_{\text {target }}$, corresponding $f_{\text {sav,ext }}$, energy amounts such as solar yield, auxiliary energy $Q_{a u x}$, measured at the store doubleports, store losses, various capital and annuity costs for end user and installer / energy contractor both with interest rate of $2.5 \%$ and when investing own capital, are listed in Table 2 for all eight optimized combisystems along with the base case.

It is seen from Table 2 that the Task 32 reference combisystem is more expensive than the optimal combisystem with approximately the same fractional energy savings. It is mostly due to larger collector area and store volume. The auxiliary heating volume is also slightly larger but the store insulation is thinner. The store losses are with $2.3 \mathrm{MWh} / \mathrm{a}$ noticeably larger than those for the optimal combisystem (only around $1.3 \mathrm{MWh} / \mathrm{a}$ ). The systems significantly differ also in specific flow rates, set temperatures of the auxiliary heater, collector inlet positions, etc. However it is not obvious which parameters except, probably, collector area and store volume, make the most contribution to the deviation between target functions of the both combisystems. The results of sensitivity analysis from Section 5 below might be used for a rough estimation.

The optimal combisystem with similar solar energy costs $F_{\text {target }}$ as the reference system reaches almost $19 \%$ higher $f_{\text {sav, ext }}$. It has significantly larger solar collectors $\left(38 \mathrm{~m}^{2} \mathrm{vs} 20 \mathrm{~m}^{2}\right)$ and therefore higher solar yield. The store volume remains nearly the same; the store losses are still smaller due to better store insulation and lower auxiliary set temperature.

Tab. 2: Properties of solar combisystem optimized for different target extended energy savings $c=0,0.3,0.35, \ldots, 0.6 .0$. Otimal values of parameters being varied, energy demands, solar yield and store losses for both reference heating system and optimized solar combisystems followed by differently defined capital and annuity costs and resulting target functions are showed together with reached fractional energy savings. First column shows properties of base case combisystem defined in framework of Task 32

\begin{tabular}{|c|c|c|c|c|c|c|c|c|c|}
\hline & $\begin{array}{l}\text { base case } \\
\text { Task } 32\end{array}$ & $\begin{array}{l}\text { opt } 1, \\
c=0\end{array}$ & $\begin{array}{l}\text { opt } 2, \\
c=0.3\end{array}$ & $\begin{array}{l}\text { opt3, } \\
c=0.35\end{array}$ & $\begin{array}{l}\text { opt4, } \\
c=0.4\end{array}$ & $\begin{array}{l}\text { opt5, } \\
c=0.45\end{array}$ & $\begin{array}{l}\text { opt6, } \\
c=0.5\end{array}$ & $\begin{array}{l}\text { opt7, } \\
c=0.55\end{array}$ & $\begin{array}{l}\text { opt } 8, \\
c=0.6\end{array}$ \\
\hline \multicolumn{10}{|c|}{ Optimization parameters } \\
\hline Collector area, $m^{2}$ & 20 & 10 & 14 & 19 & 24 & 30 & 38 & 45 & 54 \\
\hline Store volume, $m^{3}$ & 2 & 0.8 & 1.2 & 1.5 & 1.9 & 2 & 2.1 & 2.5 & 3.1 \\
\hline Aux. volume, $m^{3}$ & 0.2 & 0.14 & 0.16 & 0.14 & 0.12 & 0.2 & 0.12 & 0.16 & 0.18 \\
\hline Store insulation, $m$ & 0.15 & 0.2 & 0.2 & 0.2 & 0.15 & 0.25 & 0.2 & 0.25 & 0.25 \\
\hline Pipe diameter, $\mathrm{mm}$ & 13 & 14 & 10 & 12 & 12 & 14 & 14 & 14 & 16 \\
\hline Flow rate, $\mathrm{kg} / \mathrm{m}^{2} \mathrm{~h}$ & 15 & 36 & 11 & 10 & 10 & 9 & 10 & 9 & 8 \\
\hline$\Delta \mathrm{T}$ upper $\mathrm{db}, K$ & 7 & 4.5 & 4.0 & 4.0 & 4.0 & 4.5 & 9.5 & 5.5 & 6.5 \\
\hline$\Delta \mathrm{T}$ lower $\mathrm{db}, K$ & 4 & 0.7 & 4.0 & 1.9 & 2.1 & 1.0 & 2.1 & 0.7 & 1.7 \\
\hline$\Delta \mathrm{T}$ sensor pos., $\%$ & 0.1 & 0.15 & 0.15 & 0.15 & 0.15 & 0.15 & 0.07 & 0.13 & 0.07 \\
\hline
\end{tabular}




\begin{tabular}{|c|c|c|c|c|c|c|c|c|c|}
\hline UA solar hx, $W / K$ & 2100 & 1000 & 1000 & 1300 & 1900 & 2200 & 2500 & 3100 & 3400 \\
\hline UA DHW hx, $W / K$ & 5333 & 5340 & 6580 & 5340 & 6580 & 5960 & 7200 & 7200 & 6580 \\
\hline Coll. inlet pos., $\%$ & 0.4 & 0.65 & 0.81 & 0.84 & 0.81 & 0.84 & 0.87 & 0.84 & 0.68 \\
\hline SH outlet pos., \% & 0.96 & 0.85 & 0.88 & 0.91 & 0.94 & 0.91 & 0.95 & 0.94 & 0.95 \\
\hline SH inlet pos., \% & 0.15 & 0.28 & 0.30 & 0.30 & 0.27 & 0.27 & 0.27 & 0.26 & 0.18 \\
\hline$T_{\text {set }}$ aux. heater, ${ }^{\circ} \mathrm{C}$ & 63 & 55 & 52 & 55 & 55 & 54 & 54 & 51 & 51 \\
\hline Aux. upper db, $K$ & 8 & 9.6 & 7.2 & 7.2 & 10.4 & 11.2 & 10.4 & 8.0 & 8.8 \\
\hline Aux. lower db, $K$ & 2 & 2.6 & 2.1 & 2.8 & 3.8 & 2.6 & 3.8 & 2.6 & 3.5 \\
\hline Collector slope, ${ }^{\circ}$ & 45 & 51 & 53 & 56 & 57 & 61 & 60 & 60 & 61 \\
\hline \multicolumn{10}{|c|}{ Energy quantities, $M W h / a$} \\
\hline Aux. demand, $Q_{a u x}$ & 7.82 & 8.84 & 8.08 & 7.45 & 6.89 & 6.24 & 5.68 & 5.02 & 4.43 \\
\hline Solar yield (spec.) & $5.89(294)$ & $3.54(353)$ & $4.51(322)$ & $5.34(281)$ & $6.50(270)$ & $6.68(222)$ & $7.58(199)$ & $8.17(181)$ & $9.09(168)$ \\
\hline Store losses & 2.30 & 1,00 & 1.22 & 1.41 & 1.99 & 1.50 & 1.82 & 1.74 & 2.05 \\
\hline Ref. demand, $E_{r e f}$ & 14.72 & 14.7 & 14.7 & 14.7 & 14.71 & 14.71 & 14.72 & 14.72 & 14.72 \\
\hline Solar demand, $E_{\text {sol }}$ & 9.88 & 11.11 & 10.21 & 9.47 & 8.80 & 8.02 & 7.36 & 6.59 & 5.88 \\
\hline \multicolumn{10}{|c|}{ Capital costs, $k E u r\left(E u r / m^{2}\right)$} \\
\hline End user $F_{\text {cost }, c a p}$ & $13.3(663)$ & $8.2(819)$ & $10.5(749)$ & $12.5(659)$ & $14.6(608)$ & $17.2(573)$ & 19.7(519) & $23.0(510)$ & $26.4(488)$ \\
\hline Contractor $F_{\text {cost }, \text { cap }}$ & $8.9(442)$ & $5.5(546)$ & $7.0(499)$ & $8.4(439)$ & $9.7(405)$ & $11.5(382)$ & $13.2(346)$ & $15.3(340)$ & $17.6(325)$ \\
\hline \multicolumn{10}{|c|}{ Solar energy costs (Annuity costs), Eur / $k W h(E u r / a)$} \\
\hline $\begin{array}{l}\text { End user, rate } 2.5 \% \\
F_{\text {target }}\left(F_{\text {cost }}\right)\end{array}$ & $\begin{array}{l}0.196 \\
(951)\end{array}$ & $\begin{array}{l}0.164 \\
(587)\end{array}$ & $\begin{array}{l}0.168 \\
(752)\end{array}$ & $\begin{array}{l}0.172 \\
(898)\end{array}$ & $\begin{array}{l}0.177 \\
(1046)\end{array}$ & $\begin{array}{l}\mathbf{0 . 1 8 4} \\
(1234)\end{array}$ & $\begin{array}{l}0.192 \\
(1414)\end{array}$ & $\begin{array}{l}0.202 \\
(1645)\end{array}$ & $\begin{array}{l}0.214 \\
(1891)\end{array}$ \\
\hline $\begin{array}{l}\text { End user, own cap. } \\
F_{\text {target }}^{0}\left(F_{\text {cost }}^{0}\right)\end{array}$ & $\begin{array}{l}0.158 \\
(763)\end{array}$ & $\begin{array}{l}0.131 \\
(471)\end{array}$ & $\begin{array}{l}0.134 \\
(603)\end{array}$ & $\begin{array}{l}0.138 \\
(721)\end{array}$ & $\begin{array}{l}0.142 \\
(840)\end{array}$ & $\begin{array}{l}0.148 \\
(990)\end{array}$ & $\begin{array}{l}0.154 \\
(1134)\end{array}$ & $\begin{array}{l}0.162 \\
(1320)\end{array}$ & $\begin{array}{l}0.172 \\
(1517)\end{array}$ \\
\hline \multicolumn{10}{|l|}{ Contractor, rate $2.5 \%$} \\
\hline $\begin{array}{l}F_{\text {target, contr }}, \\
\left(F_{\text {cost }, \text { contr }}\right)\end{array}$ & $\begin{array}{l}0.131 \\
(634)\end{array}$ & $\begin{array}{l}0.109 \\
(391)\end{array}$ & $\begin{array}{l}0.112 \\
(501)\end{array}$ & $\begin{array}{l}0.115 \\
(598)\end{array}$ & $\begin{array}{l}0.118 \\
(697)\end{array}$ & $\begin{array}{l}0.123 \\
(822)\end{array}$ & $\begin{array}{l}0.128 \\
(942)\end{array}$ & $\begin{array}{l}0.135 \\
(1096)\end{array}$ & $\begin{array}{l}0.143 \\
(1260)\end{array}$ \\
\hline \multicolumn{10}{|l|}{ Contractor, own cap. } \\
\hline $\begin{array}{l}F_{\text {target }, \text { contr }}^{0} \\
\left(F_{\text {cost }, \text { contr }}^{0}\right)\end{array}$ & $\begin{array}{l}0.105 \\
(509)\end{array}$ & $\begin{array}{l}0.088 \\
(314)\end{array}$ & $\begin{array}{l}0.090 \\
(402)\end{array}$ & $\begin{array}{l}0.092 \\
(480)\end{array}$ & $\begin{array}{l}0.095 \\
(560)\end{array}$ & $\begin{array}{l}0.099 \\
(660)\end{array}$ & $\begin{array}{l}0.103 \\
(756)\end{array}$ & $\begin{array}{l}0.108 \\
(880)\end{array}$ & $\begin{array}{l}0.115 \\
(1011)\end{array}$ \\
\hline \multicolumn{10}{|c|}{ Extended fractional energy savings } \\
\hline$f_{\text {sav,ext }}$ & 0.329 & 0.244 & 0.305 & 0.356 & 0.402 & 0.455 & 0.500 & 0.552 & 0.600 \\
\hline
\end{tabular}

\subsection{Profitability of optimized solar combisystem}

Any solar combisystem lying on the Pareto front is optimal with respect to the pair $\left(F_{\text {target }}, f_{\text {sav,ext }}\right)$. However, only one configuration might be optimal when taking into account its profit over the lifetime. To calculate the profitability of the solar combisystem solar energy costs and reference fuel price, for example gas price, should be at hand for the lifetime period of the system. In Figure 3 profit over 20 years compared to reference fuel price taken constant at $0.10 \mathrm{Eur} / \mathrm{kWh}$ is shown versus extended fractional savings of the system for five different solar energy costs functions. The reference fuel price is chosen constant for simplicity, any price trend can be taken as well. According to the figure, different size (fractional energy savings) of the combisystem is optimal for each solar energy costs. For example, for the private person investing its own capital (curve in magenta) solar combisystem of any size would be unprofitable. Only for the contractor investing own money (no tax) the solar combisystem remains bringing small profit of maximally around $2.4 \mathrm{kEur}$ at $f_{\text {sav,ext }}=0.40$.

It is obvious that the profit calculation and consequently the best size of the solar combisystem depends on the the reference fuel price to much extent. Changing this price to $0.16 \mathrm{Eur} / \mathrm{kWh}$ makes the combisystem profitable for four out of five cost calculations. For the private person investing its own capital the solar combisystem with $f_{\text {sav,ext }}=0.35$ would be the most profitable and it would bring around $2.3 \mathrm{kEur}$ over 20 years. For the contractor investing own capital and paying no tax, the solar combisystem with $f_{\text {sav,ext }}=0.55$ would be the best, bringing 11.2 kEur profit. 


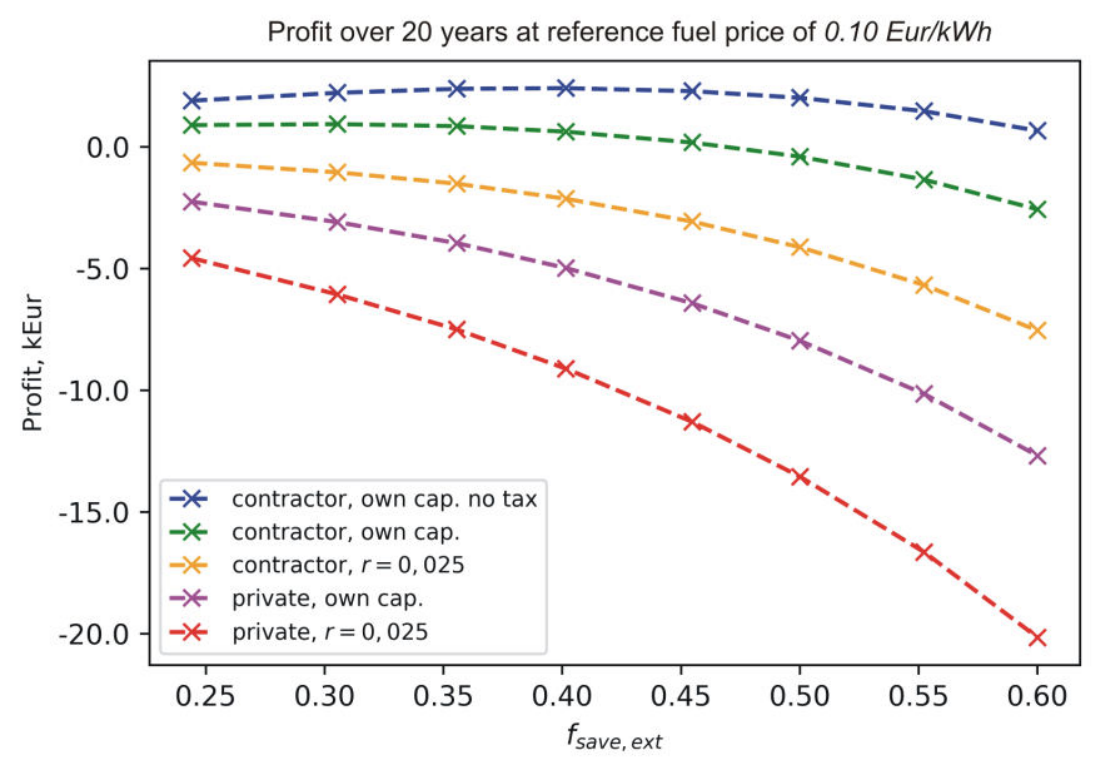

Fig. 3: Profit calculation over 20 years versus extended fractional savings (system size) for five variations of the cost function. Reference fuel price is set constant to $0.10 \mathrm{Eur} / \mathrm{kWh}$ for the whole lifetime period

\section{Influence of boundary conditions on optimization results}

\subsection{Influence of domestic hot water demand}

To estimate the influence of DHW demand, the demand is changed proportionally - the DHW profile is multiplied by a factor. The combisystem is optimized for $\pm 50 \%$ change in DHW consumption, that is, for $100 \mathrm{l} / \mathrm{d}$ and $300 \mathrm{l} / \mathrm{d}$ at $45^{\circ} \mathrm{C}$. The corresponding Pareto fronts are shown in Figure 4. Light blue dashed lines show $-10 \%,+10 \%$ and $+20 \%$ with respect to $F_{\text {target }}$ of the Pareto front for the combisystem with the base DHW demand of $200 l / d$ (blue curve).

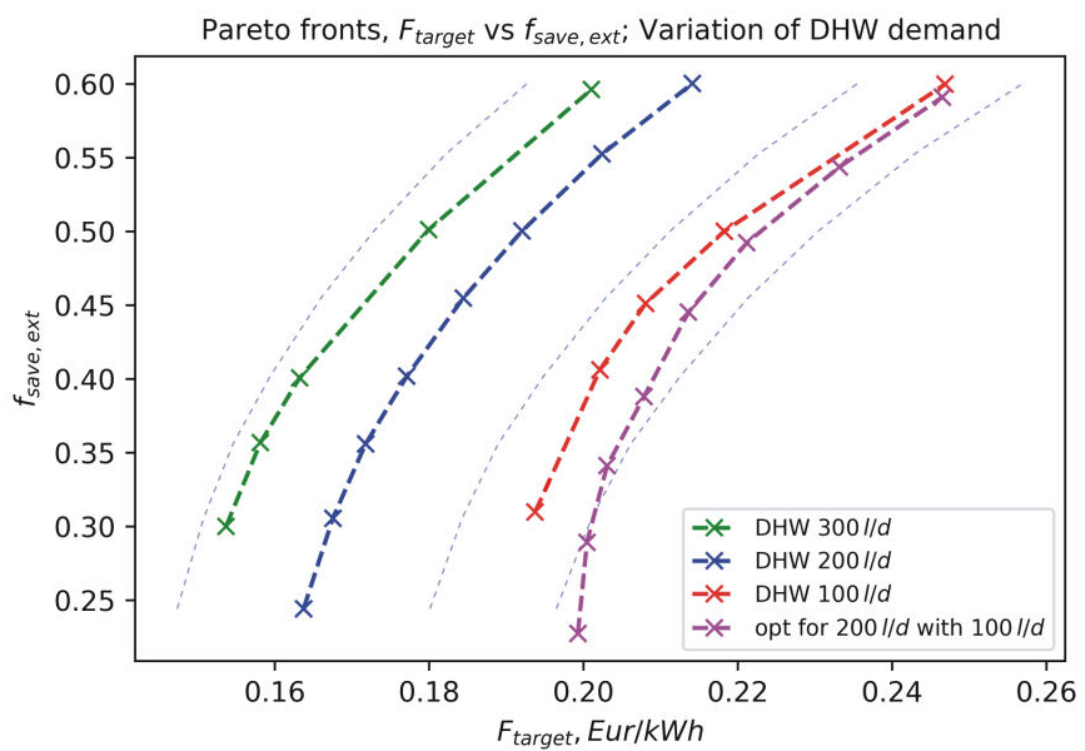

Fig. Fehler! Verweisquelle konnte nicht gefunden werden.: Pareto fronts for combisystem with $\pm \mathbf{5 0} \%$ changed DHW demand. Light blue dashed lines show $-\mathbf{1 0} \%,+\mathbf{1 0} \%,+\mathbf{2 0} \%$ solar costs levels with respect to combisystem with base DHW demand of $200 \mathrm{D} / \mathrm{d}$ (blue line). Pareto front for combisystem optimized for DHW demand of $200 l / d$, but then used with $100 l / d$, is shown in magenta

If the DHW consumption decreases by $50 \%$ to $100 \mathrm{l} / \mathrm{d}$, then the solar costs of the combisystem optimized for this consumption increase by around 15\% depending on the point on the Pareto front. The solar heat from the combisystem optimized for $50 \%$ larger DHW demand will be around $5-8 \%$ cheaper. 
The quality of the solar combisystem optimized for the base DHW demand of $200 l / d$ but used with reduced demand of $100 l / d$ is shown by the magenta curve in Figure 4. It is seen that although the energy costs are increased by around $18-20 \%$ in comparison to the base demand, the combisystem optimized for the base demand but used with the reduced demand is not significantly worse (only around $1-5 \%$ ) than the combisystem optimized for the reduced demand.

\subsection{Influence of space heating demand}

The influence of the space heating demand is estimated in a similar way. Three building envelopes are defined within IEA Task 32 having space heating demand of 30,60 and $100 \mathrm{kWh} / \mathrm{m}^{2} a$. Pareto fronts for the optimal combisystems for all three buildings located in Zurich are shown in Figure 5. The curves lie close to each other, differing in less than $5 \%$. A closer look at the data behind the curves shows more distinctions. For example, to reach $f_{\text {sav,ext }}=0.50$ by the combisystem optimized for the SH demand of $30 \mathrm{kWh} / \mathrm{m}^{2} a$, collector area of $20 \mathrm{~m}^{2}$ is required, for $60 \mathrm{kWh} / \mathrm{m}^{2} a-38 \mathrm{~m}^{2}$ and for $100 \mathrm{kWh} / \mathrm{m}^{2} a-57 \mathrm{~m}^{2}$. The fact that the green curve corresponding to $\mathrm{SH}$ demand of $30 \mathrm{kWh} / \mathrm{m}^{2} a$ lies to the right of the blue one can be explained by good house insulation - SH demand is shifted to the colder months with less solar yield.

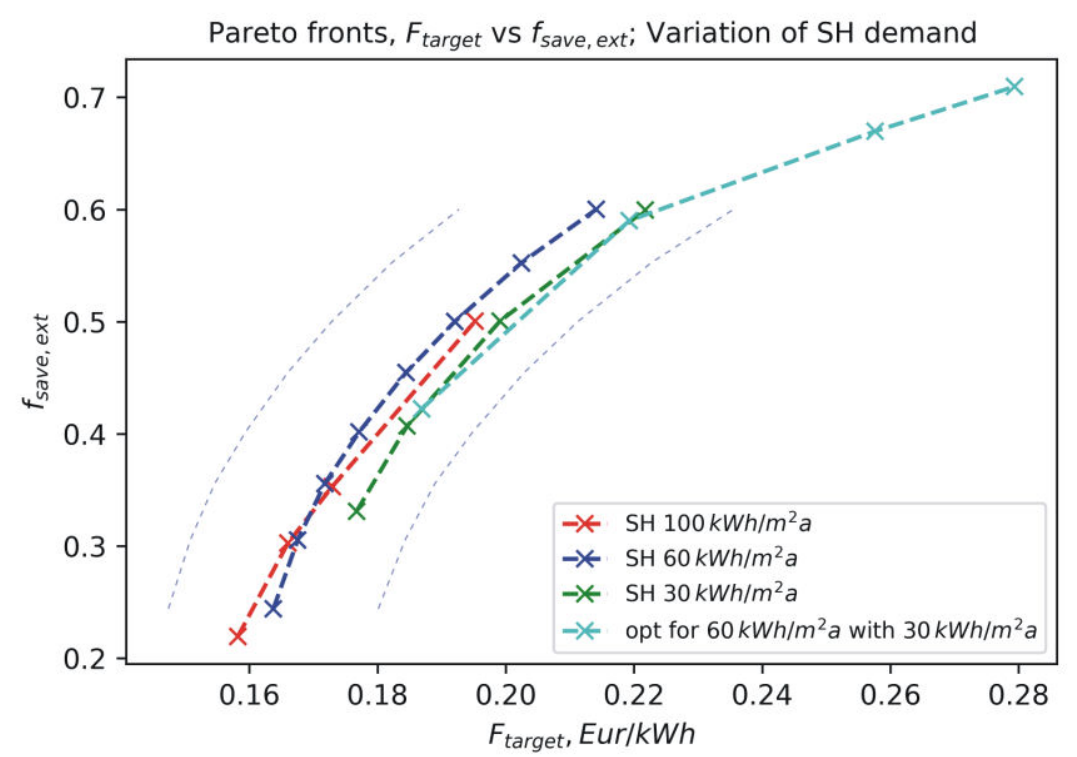

Fig. 5: Pareto fronts for combisystem with changed SH demand. Light blue dashed lines show $-10 \%,+10 \%$ with respect to combisystem with SH demand of $60 \mathrm{kWh} / \mathrm{m}^{2} a$ (blue line). Pareto fronts for combisystems with changed SH demand lie close to each other but system configurations differ significantly. Combisystem optimized for SH demand of $60 \mathrm{kWh} / \mathrm{m}^{2} a$ and then applied to better insulated house with $30 \mathrm{kWh} / \mathrm{m}^{2} a$ (in cyan) remains optimal but each point on base Pareto front is shifted to a point located higher on this line.

The combisystem optimized for the SH demand of $60 \mathrm{kWh} / \mathrm{m}^{2} a$ but operated with $30 \mathrm{kWh} / \mathrm{m}^{2} a$ is almost as good as the combisystem optimized for $30 \mathrm{kWh} / \mathrm{m}^{2} a$. This is shown by the cyan curve in Figure 5 built through only the selected points (cyan crosses) which do not induce large DHW penalty. The curve is shifted up with respect to the base Pareto front, meaning that, for example, the combisystem with $f_{\text {sav,ext }}=0.30$ optimized for the base SH demand of $60 \mathrm{kWh} / \mathrm{m}^{2} a$ obviously has significantly higher $f_{\text {sav, ext }}=0.42$ when applied to better insulated house with only $30 \mathrm{kWh} / \mathrm{m}^{2} a$ heating demand.

\subsection{Influence of weather conditions}

To estimate the influence of weather conditions, the combisystem is optimized for two additional locations, Stockholm and Madrid. The corresponding Pareto fronts are shown in Figure 6. The combisystem in Madrid is optimized with a less insulated house having larger space heating demand of $100 \mathrm{kWh} / \mathrm{m}^{2} a$ if located in Zurich, but still needs only around $42 \mathrm{kWh} / \mathrm{m}^{2} a$ in Madrid. The minimal solar energy costs are nearly equal for the combisystems built in Stockholm and Zurich for $f_{\text {sav,ext }}<0.35$; For higher $f_{\text {sav, ext }}$ (up to 0.50) the comibsystem in Stockholm is up to $12 \%$ more expensive whereas the combisystem built in Madrid is around $40 \%$ cheaper than in Zurich. Similarly as for variation of space heating demand, the combisystem remains to be 
nearly optimal when its location is changed (simultaneous variation of solar gain and space heating demand), at least when moving the combisystem from Stockholm to Zurich as it is shown by cyan curve in Figure 6.

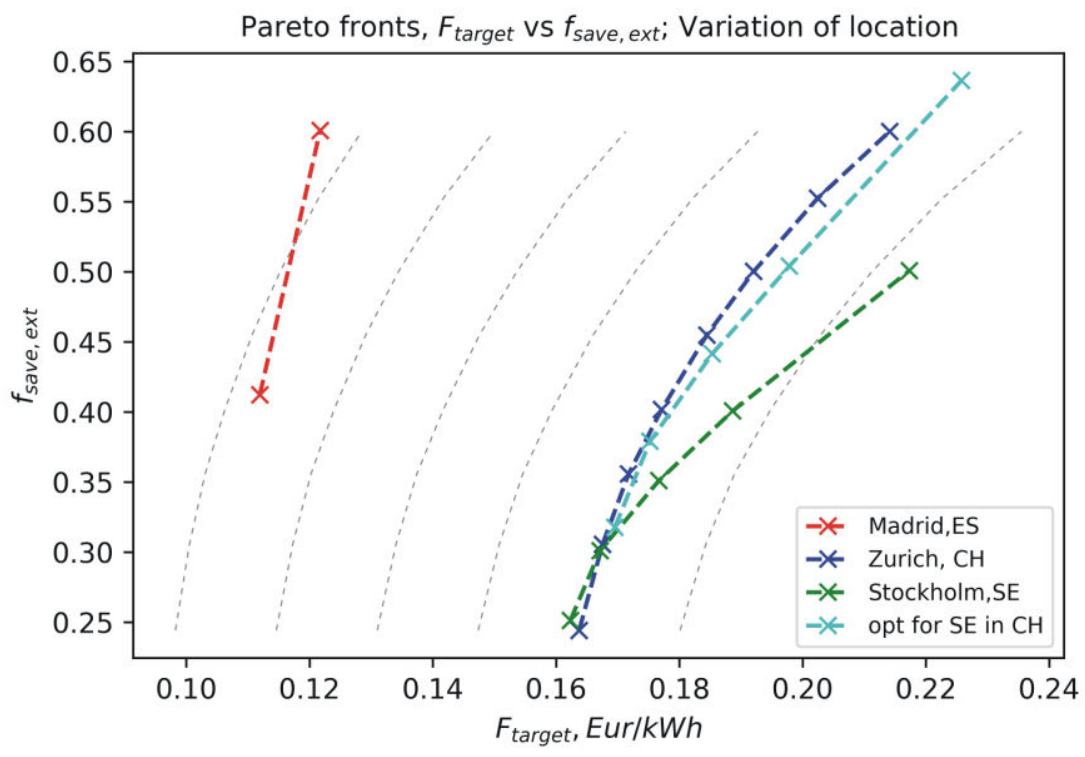

Fig. 6: Pareto fronts for combisystems optimized for different locations. Gray dashed lines show in $10 \%$ steps solar costs levels with respect to Zurich location. Combisystem built in Madrid is around $40 \%$ cheaper. For $f_{\text {savext }}<0.35$, combisystem built in Stockholm is comparably expensive as that located in Zurich but it is more expensive for larger $f_{\text {sav,ext }}$. Combisystem optimized for Stockholm location and then built in Zurich is almost optimal but with similar shift as for variation of SH demand

\section{Parameter influence near optimum}

The estimation of the sensitivity of the solar energy costs $F_{\text {target }}$ upon single parameters varied in a larger parameter space containing the optimum point is carried out by global sensitivity analysis: Multiple Linear Regression (MLR) and Morris methods. The sensitivity analysis is applied to the solar combisystem already optimized for the reference boundary conditions defined above in subsection 2.1. No constraints are applied to $f_{\text {sav,ext }}$ in the calculations.

The influence of all 18 optimization parameters together with 2 boundary conditions is investigated. Since the sensitivity analysis requires many simulations with parameter values independently varying near the optimum point, the probability is large that the DHW and SH demands cannot be fully covered by certain combisystem configurations and the respective penalties apply. Thus, the variation range for each parameter is defined as either $[-50 \% ; 0 \%]$ or $[0 \% ;+50 \%]$ depending on where less penalty is anticipated due to not meeting DHW or SH comfort requirements. In this way, the sensitivity of the optimization parameters in a "half space" with the optimum lying on the boundary is to be investigated. The optimization and boundary condition parameters with corresponding sensitivity ranges are listed in Table 1.

\subsection{MLR Method}

The MLR method attempts to model the relationship between $k$ independent variables $x_{j}, j=1, \ldots, k$ (parameters) and dependent variable $y$ (target function) in the linear form:

$$
y_{i}=\beta_{0}+\sum_{j=1}^{k} \beta_{j} x_{i j}+\varepsilon_{i}, \quad i=1, \ldots, n,
$$

where $y_{i}$ are $n$ measurements of the target function for corresponding parameter vectors $\left(x_{i 1}, \ldots x_{i k}\right)$, that is, system configurations $x_{i} ; \varepsilon_{i}$ denote the model errors. The estimates of the coefficients $\beta_{j}$, denoted as $b_{j}, j=$ $0, \ldots, k$, are calculated by minimizing the least-squares error, that is, from $\sum_{i=1}^{n} \varepsilon_{i}^{2} \rightarrow$ min. The coefficients $b_{j}$ are the influence measures for corresponding parameters over the variation space. They represent the averaged change of the target function $y$ due to the unit increase in the corresponding parameters $x_{j}$ when all other 
parameters are fixed. To determine the quality of the model, that is, to check how well the measured values $y_{i}$ are described by the fit, the determination coefficient $R^{2}$ is used.

The "measured" data required as an input for the MLR are obtained as follows. First $n=500$ parameter sets (combisystem configurations) are chosen by random sampling of the Latin Hypercube what gives the uniform distribution with respect to each parameter, and then the "measured" $F_{\text {target }}$ is calculated for each combisystem configuration. The size $n$ of the "measured" data has influence on the accuracy of the model, $n=500$ is turned out to be fairly enough.

The MLR model is built using the simulated "measured" data for the solar combisystem described above. The determination coefficient $R^{2}$ for the model with all parameters from Table 1 equals 0.97 meaning that $97 \%$ of the variance in measured data is explained by the MLR model. It justifies application of the MLR. If only the optimization parameters are taken as independent variables, then $R^{2}=0.93$. It can be explained by large linear impact of the two boundary conditions - DHW demand and collector price. Influence of single parameters on the solar energy costs $F_{\text {target }}$ is shown in Figure 7.

\subsection{Morris Method}

In contrast to the MLR, the Morris method (Morris, 1991) can be successfully applied to the problems having significantly non-linear relationships between the target function and parameters. However, the Morris method can identify the parameter importance only qualitatively providing no reliable quantification of its influence. Another drawback is lack of the self-verification indicator similar to the MLRs coefficient of determination $R^{2}$.

In the Morris method two quantities are used as sensitivity measures for each parameter; the measure $\mu^{*}$ estimates the overall, linear effect of the parameter on the target function, and the measure $\sigma$ accounts for the second and higher order effects, including interaction effects in which the parameter is involved. The Morris method varies one parameter at a time. Each parameter may take only a set of discrete values, the so-called levels, fixed within the parameter variation range. The elementary effects are calculated for each parameter by changing it over $55 \%$ of its variation range defined in Table 1 . Number of trajectories, that is, at how many points elementary effects are evaluated for each parameter is set to 80 .

In Figure 7 the investigated parameters are presented in descending order regarding their Morris sensitivity measures $\mu^{*}$. The larger $\mu^{*}$ for the parameter the more linear influence it has on $F_{\text {target }}$. The values of $\mu^{*}$ can be recalculated into mean values of absolute change of $F_{\text {target }}$ by simple relation $\overline{\left|\Delta F_{\text {target }}\right|}=\mu^{*} \cdot 0.55$ or in its relative change with respect to the optimal $F_{\text {target }}$ which is shown on the left $y$ - axis in Figure 7 . The $95 \%$ confidence intervals of the mean values $\mu^{*}$ are shown by black lines for each parameter. It is seen that the both boundary condition parameters - collector price and domestic hot water demand have large influence followed by the optimization parameters as boiler set temperature, slope, collector area, collector input height, auxiliary volume, etc.

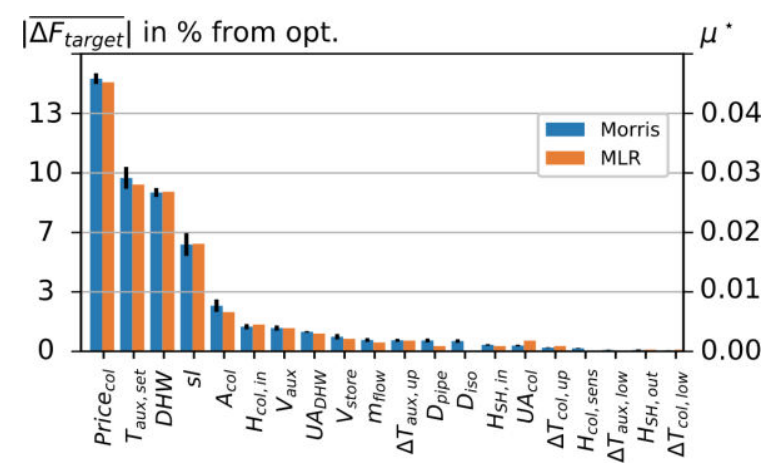

Fig. 7: Results of sensitivity methods applied in parameter variation space as from Table 1. Morris measure $\mu^{*}$ and recalculated $\left|\overline{\Delta F_{\text {target }}}\right|$ are shown along with results obtained by MLR. Black lines denote $95 \%$ confidence interval

Besides the Morris sensitivity measure, similar sensitivities calculated from estimates of the regression coefficients of the MLR method are shown in orange. Although being completely different, the both methods deliver very similar results. It might be considered as a kind of justification of both of them. 


\section{Conclusions}

In the presented paper, the IEA Task 32 solar combisystem is optimized with the hybrid genetic CHC - binary search algorithm for several extended fractional savings and the Pareto front - optimal solar energy costs vs. extended fractional savings - is obtained. It is shown that improvement of either by around $13 \%$ in terms of solar costs or 19 percent points in terms of energy savings is reachable compared to the parametrization of the standard IEA Task 32 solar combisystem.

The influence of the domestic hot water and space heating demands as well as the climate conditions (location of the combisystem) on the Pareto front is investigated showing much impact of the DHW demand. It is shown that the combisystem optimized for the base conditions but operated under the changed conditions is not significantly worse than the combisystem optimized for the changed conditions.

The influence of variations of each optimization parameter as well as two boundary condition parameters on the solar energy costs is accessed near the optimum point by application of MLR and Morris methods. Good coincidence of the results of both methods and large value of the determination coefficient of the MLR justify their application.

\section{References}

Heimrath, R., Haller, M., 2007. Project Report A2 of Subtask A: The Reference Heating System, the Template Solar System. http://task32.iea-shc.org/Data/Sites/1/publications/task32-Reference_Heating_System.pdf, Graz University of Technology, Graz, Austria

Jordan, U., Vajen, K., 2005. DHWcalc: Program to generate Domestic Hot Water Profiles with Statistical Means for User Defined Conditions, Proc. ISES Solar World Congress, Orlando, USA, DOI: 10.1.1.560.350

Klein, S. A., Beckman, W. A., Mitchell, J., Duffie, J. A., Duffie, N., 2009. TRNSYS 17: A Transient System Simulation Program. http://sel.me.wisc.edu/trnsys, University of Wisconsin, Madison, USA

Kusyy, O., Kuethe, S., Vajen, K., Jordan, U., 2010. Simulation-based optimization of a solar water heating system by a hybrid genetic - binary search algorithm, EuroSun 2010, Graz, Austria, DOI: 10.18086/eurosun.2010.04.08

Morris, M. D., 1991. Factorial Sampling Plans for Preliminary Computational Experiments, Technometrics 33, 161-174

Wetter, M., 2008. GenOpt. Generic Optimization Program, User Manual v.2.1.0, https://simulationresearch.lbl. gov/GO/download/manual-2-1-0.pdf, Lawrence Berkeley National Laboratory, University of California, USA

\section{Nomenclature}

\begin{tabular}{lll}
\hline Quantity & Symbol & Unit \\
\hline Collector area & $A_{\text {col }}$ & $\mathrm{m}^{2}$ \\
Store volume & $V_{\text {store }}$ & $\mathrm{m}^{3}$ \\
Auxiliary volume & $V_{\text {aux }}$ & $\mathrm{m}^{3}$ \\
Number of aux. nodes & $N_{\text {aux }}$ & - \\
Store insulation & $D_{\text {iso }}$ & $\mathrm{m}$ \\
Pipe inner diameter & $D_{\text {pipe }}$ & $\mathrm{mm}$ \\
Spec. coll. flow rate & $m_{\text {flow }}$ & $\mathrm{kg} / \mathrm{m}^{2} \mathrm{~h}$ \\
$\Delta$ T controller upper db. & $\Delta T_{\text {col,up }}$ & $\mathrm{K}$ \\
$\Delta$ T controller lower db. & $\Delta T_{\text {col,low }}$ & $\mathrm{K}$ \\
$\Delta$ T controller sensor pos. & $H_{\text {col,sens }}$ & - \\
UA value of solar hx. & $U A_{\text {col }}$ & $\mathrm{W} / \mathrm{K}$ \\
UA value of DHW hx, & $U A_{D H W}$ & $\mathrm{~W} / \mathrm{K}$ \\
Coll. inlet pos. in store & $H_{\text {col,in }}$ & - \\
SH outlet pos. in store & $H_{S H, o u t}$ & - \\
SH inlet pos. in store & $H_{S H, \text { in }}$ & - \\
Set temp. of aux. heater, & $T_{\text {aux,set }}$ & ${ }^{\circ} \mathrm{C}$ \\
Aux. controller upper db. & $\Delta T_{\text {aux }, u p}$ & $\mathrm{~K}$ \\
Aux. controller lower db. & $\Delta T_{\text {aux }, l o w}$ & $\mathrm{~K}$ \\
Collector slope & sl & ${ }^{\circ}$ \\
\hline
\end{tabular}

\begin{tabular}{lll}
\hline DHW demand multiplier & DHW & - \\
Collector price & Price $_{\text {col }}$ & $\mathrm{Eur} / \mathrm{m}^{2}$ \\
Solar energy costs & $F_{\text {target }}$ & $\mathrm{Eur} / \mathrm{kWh}$ \\
Aux. energy, ref. combisystem & $E_{\text {ref }}$ & $\mathrm{kWh}$ \\
Aux. energy, solar combisystem & $E_{\text {sol }}$ & $\mathrm{kWh}$ \\
Extended fractional energy savings & $f_{\text {sav,ext }}$ & $\mathrm{kWh}$ \\
Penalty function & $\widehat{F}_{\text {penalty }}$ & $\mathrm{kWh}$ \\
Penalty function, DHW & $F_{\text {pen,DHW }}$ & $\mathrm{kWh}$ \\
Penalty function, SH & $F_{\text {pen,SH }}$ & $\mathrm{kWh}$ \\
Cost function & $F_{\text {cost }}$ & $\mathrm{Eur}$ \\
Capital costs & $F_{\text {cost,cap }}$ & $\mathrm{Eur}$ \\
Discount component price & $F_{\text {cost,disc }}$ & $\mathrm{Eur}$ \\
Contractor costs & $F_{\text {cost,contr }}$ & $\mathrm{Eur}$ \\
Component & $C_{i}$ & - \\
Installer margin & $\mathrm{m}$ & - \\
Interest rate & $r$ & - \\
Vector of opt. parameters & $X$ & - \\
Constrain on $f_{\text {sav,ext }}$ & $\mathrm{c}$ & - \\
Measurements of $F_{\text {target }}$ & $y_{i}$ & $\mathrm{Eur} / \mathrm{kWh}$ \\
\hline
\end{tabular}




\title{
Measurement Evaluation and Simulation of an Innovative Drainback Solar Combi-System
}

\author{
Yoann Louvet ${ }^{1}$, Janybek Orozaliev ${ }^{1}$ and Klaus Vajen ${ }^{1}$ \\ ${ }^{1}$ University of Kassel, Institute of Thermal Engineering, Kassel (Germany)
}

\begin{abstract}
This paper presents an innovative drainback solar combi-system constructed in a new building during the year 2016. The system is unpressurized, and the same heat transfer fluid circulates from the solar collectors to the airhandling unit delivering the heat to the building. The number of heat exchangers is thereby minimized. The first measurement data show a lower system performance than expected, which can be explained on the one hand by differing heat demand compared to what was originally planned and on the other hand by improvement potentials, especially regarding the control strategies. TRNSYS simulations highlight that simple modifications of the control strategy could more than double the saved final energy. Detailed calculations nevertheless show that heat costs $\left(\mathrm{LCoH}_{\mathrm{ov}, \mathrm{fin}}\right)$ still remain between 24.5 and $30 \%$ higher compared to a conventional heating system.
\end{abstract}

Keywords: combi-system, drainback system, passive house

\section{Nomenclature}

$\Delta \mathrm{Q}_{\mathrm{st}}$ : variation of the store internal energy in $\mathrm{kWh}$

$\mathrm{A}, \mathrm{B}, \mathrm{C}$ and $\mathrm{D}$ : fit parameters of the sigmoid function $\mathrm{h}\left(\mathrm{T}_{\mathrm{amb}}\right)$

$\mathrm{A}_{\mathrm{a}}$ : collector aperture area in $\mathrm{m}^{2}$

$\mathrm{A}_{\mathrm{G}}$ : collector gross area in $\mathrm{m}^{2}$

$\mathrm{f}_{\text {sav,ext }}$ : extended fractional energy

$\mathrm{f}_{\text {sav,ext }}$ : extended fractional energy savings

$\mathrm{f}_{\mathrm{sav}, \mathrm{th}}$ : fractional thermal energy savings

$\mathrm{I}_{0}$ : investment costs in $€$

$\mathrm{LCoH}_{\text {ov,fin }}$ : levelized cost of heat of the entire system based on final energy in $€ c t / \mathrm{kWh}$

$\mathrm{Q}_{\text {bal: }}$ store energy balance in $\mathrm{kWh}$

$\mathrm{Q}_{\text {boil }}$ : energy delivered by the boiler to the store in $\mathrm{kWh}$

\section{Introduction}

The reduction of the costs of solar thermal systems is a key issue to limit the reduction of the market which is currently faced in Europe. One approach to achieve this target is to simplify the design of solar thermal systems to reduce the number of components, therefore reducing investment costs and the resulting maintenance. The drainback design without heat exchanger in the collector loop is for this purpose an appropriate solution. An extensive analysis of the advantages and drawbacks of drainback systems (DBS) can be found in Botpaev et al. (2016). The combi-system presented in this study is an attempt to push the drainback concept at its limit, by placing the heat storage in the attic directly below the collectors. This allows getting rid of most of the issues linked to the drainback design. It furthermore allows an unpressurized boiler operation, further reducing the number of heat exchangers in the system.

In a first step the hydraulic configuration and the control strategy of the studied system are described in the details. A reference conventional system, without solar assistance is also defined. The evaluation of the monitoring campaign carried over one and a half year is then presented. The energy balance as well as the load profiles are analysed. Several issues hampering a proper functioning are identified and solutions proposed. 
Based on these measurement, a simulation model was developed in TRNSYS (Klein et al., 2006). The impact of several control and design improvement measures on the system performance is assessed. The impact of varying load profiles is also evaluated. In a last step, the heat costs $\left(\mathrm{LCoH}_{\mathrm{ov} \text {,fin }}\right)$ are calculated and compared to the ones of the reference conventional heating system.

\section{Description of the studied system}

The studied solar combi-system consists of a $13.8 \mathrm{~m}^{2}$ (aperture area) evacuated tubular collector field with heat pipes (VITOSOL 200-T from Viessmann) and a $1 \mathrm{~m}^{3}$ polypropylene (PP) heat storage (from Enersolve GmbH). The collectors, presenting a total aperture area $\left(\mathrm{A}_{\mathrm{a}}\right)$ of $13.84 \mathrm{~m}^{2}$, are directly installed on the roof with a slope of $20^{\circ}$ and an azimuth of $553^{\circ} \mathrm{W}$. It is equipped with a $35 \mathrm{~kW}$ gas condensing boiler (VITODENS $300-\mathrm{W}$ from Viessmann) as back-up heater and provides space heating (SH) and domestic hot water (DHW) to a new multifunctional building, used as boathouse, changing room as well as seminar room by the University of Kassel. The building has a total floor area of $268 \mathrm{~m}^{2}$ and is built as passive building. During the planning phase, a primary energy need of 8.6 MWh/a for space heating and 6.9 MWh/a for DHW were foreseen.

The hydraulic scheme of the system is depicted in Fig. 1. Its innovative character lies in the fact that it is an open, i.e. non-pressurised system with very few heat exchangers, thereby saving costs and increasing the system efficiency. The same heat transfer fluid (HTF), water with a corrosion inhibitor, circulates from the solar collectors to the air-handling unit delivering most of the heat to the building. Some additional radiators are installed, also supplied by the same HTF. DHW is provided by a fresh-water unit. The solar collector loop is designed according to the drainback principle in order to avoid freezing of the water in winter. The heat storage, the boiler, the fresh-water unit and the air-handling unit (AHU) are all located directly below the roof in the attic. This is an advantage for the DBS as the apex of the solar collector loop is located approximately $1 \mathrm{~m}$ higher than the water level in the store. This avoids the need for pump oversizing for filling at start-up and also minimizes underpressure in the collectors during operation. The air volume of the heat storage is directly connected to the atmosphere. It was necessary to adapt the internal control strategy of the boiler in order to allow non-pressurised operation.

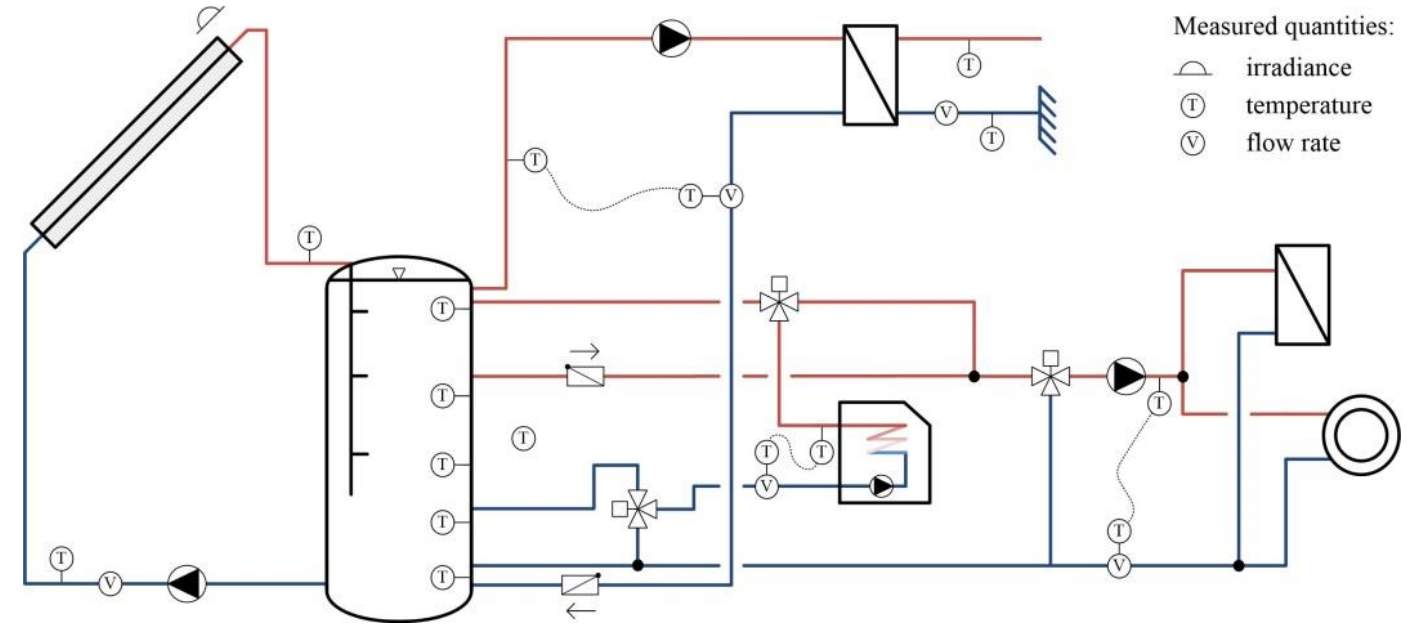

Fig. 1: Schematic hydraulic drawing of the unpressurised combi-system studied with the installed measurement instrumentation.

Concerning the control strategy, several improvements were achieved during the monitoring period. From the initial parametrisation several points have to be noticed. The solar collector loop pump starts when the temperature difference between the bottom of the tank and the collector exceeds $12 \mathrm{~K}$ and stops when it falls below $3 \mathrm{~K}$. To avoid too high stresses which could reduce its lifetime the store temperature is limited $\left(\mathrm{T}_{\mathrm{st}, 1}\right.$ limited to $70{ }^{\circ} \mathrm{C}$ and $\mathrm{T}_{\mathrm{st}, 4}$ limited to $85{ }^{\circ} \mathrm{C}$ ). Regarding the load, a DHW volume of 370 litres (until the $4^{\text {th }}$ temperature sensor in the store, $\left.\mathrm{T}_{\mathrm{st}, 4}\right)$ is kept at a set temperature of $60{ }^{\circ} \mathrm{C}( \pm 2 \mathrm{~K})$, and the motor valve situated in the return pipe of the boiler allows the preparation of a larger DHW volume on-demand; a button to be pushed manually is located in the changing rooms for this purpose. Finally the set-point temperature for space heating depends on the ambient air temperature. It is determined by the controller of the AHU and communicated to the boiler. On weekdays between 7:00 and 22:00 the set-point temperature has a fixed value of $57.5^{\circ} \mathrm{C}$ during the heating season. 


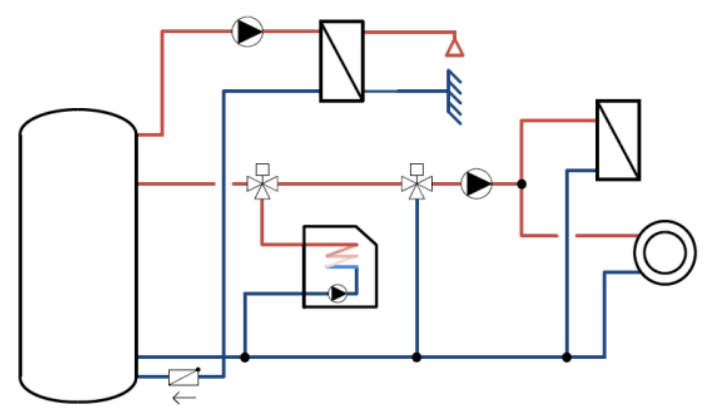

Fig. 2: Hydraulic scheme of the reference conventional system

A reference heating system without solar assistance was also defined to assess the performance of the innovative drainback concept. Its hydraulic scheme is presented in Fig. 2. The volume of the storage was determined according to CEN (2012) to 2501 . The reference storage is assumed being in the middle of the energy efficiency class D with a standing loss of $103.8 \mathrm{~W}$ (European Commission, 2013) which corresponds to a UA-value of $2.3 \mathrm{~W} / \mathrm{K}$, for a temperature difference of $45 \mathrm{~K}$ (DIN, 2016). The entire volume is kept at $60{ }^{\circ} \mathrm{C}( \pm 2 \mathrm{~K})$ as the DHW volume of the solar thermal system.

\section{Measurement results}

\subsection{Issues encountered along the monitoring period}

The system was commissioned in June 2016, and the monitoring period started in November 2016. After this date several issues impacting the system performances and the measurement data have been detected and corrected one after the other. They are detailed in Tab. 1, sorted according to their origin. Five different categories are identified.

Tab. 1: Summary of the issues detected on the combi-system installed at the boathouse classified by origin and related solutions proposed.

\begin{tabular}{|c|c|c|c|}
\hline No & Issue related to & Brief description & Solution \\
\hline 1 & Design & $\begin{array}{l}\text { Mixing of the upper layers of the store } \\
\text { during operation of the solar collector loop. }\end{array}$ & $\begin{array}{c}\text { Improve the design of the stratification } \\
\text { lance. }\end{array}$ \\
\hline 2 & Design / Control & $\begin{array}{l}\text { Short on/off boiler cycles and overheating } \\
\text { when the SH load is low. }\end{array}$ & $\begin{array}{l}\text { Install a smaller boiler or modify the } \\
\text { hydraulic configuration or adapt the } \\
\text { control strategy of the SH loop. }\end{array}$ \\
\hline 3 & Construction & $\begin{array}{l}\text { Presence of an unwanted siphon in the } \\
\text { collector loop preventing a proper draining. }\end{array}$ & $\begin{array}{l}\text { Add more fixing points or use rigid } \\
\text { piping instead of flexible ones in } \\
\text { horizontal sections. }\end{array}$ \\
\hline 4 & Construction & $\begin{array}{l}\text { Lack of two check-valves, one preventing } \\
\text { thermosiphoning effect in the DHW loop } \\
\text { and one preventing direct heating of the } \\
\text { store from the boiler. }\end{array}$ & $\begin{array}{l}\text { Careful check of the hydraulic } \\
\text { components at commissioning. }\end{array}$ \\
\hline 5 & Control & $\begin{array}{l}\text { The boiler delivers heat to the } \mathrm{SH} \text { loop even } \\
\text { though } \mathrm{T}_{\mathrm{st}, 4}>\mathrm{T}_{\mathrm{SH}, \text { set }}\end{array}$ & Stop the boiler when $T_{\text {st, } 4}>T_{\mathrm{SH}, \text { set }}$. \\
\hline 6 & Control & $\begin{array}{c}\text { The set point temperature of the boiler is } \\
\text { constant }\left(57.5^{\circ} \mathrm{C}\right) \text { during weekdays } \\
\text { between 07:00 and 22:00. }\end{array}$ & $\begin{array}{l}\text { Adapt } \mathrm{T}_{\text {boil,set }} \text { to the required inlet } \\
\text { temperature to the SH loop. }\end{array}$ \\
\hline 7 & Control & $\begin{array}{l}\text { The boiler delivers heat with an offset } \\
\text { compared to its set point temperature. }\end{array}$ & $\begin{array}{l}\text { Compensate the offset in the control of } \\
\text { the boiler. }\end{array}$ \\
\hline 8 & Control & $\begin{array}{l}\text { Wrong conversion coefficients for the data } \\
\text { exchanged between the air handling unit } \\
\text { and the heat production unit. }\end{array}$ & $\begin{array}{l}\text { Careful check of the exchanged data } \\
\text { when different control units are } \\
\text { communicating with each other. }\end{array}$ \\
\hline 9 & Control & $\mathrm{T}_{\mathrm{st}, 1}$ limited to $70^{\circ} \mathrm{C}$. & Increase $\mathrm{T}_{\mathrm{st}, 1}$ upper boundary. \\
\hline
\end{tabular}




\begin{tabular}{|c|c|c|c|}
\hline 10 & $\begin{array}{c}\text { Measurement } \\
\text { devices }\end{array}$ & $\begin{array}{c}\text { Presence of air bubbles in the flow metre of } \\
\text { the HFM. }\end{array}$ & $\begin{array}{c}\text { Move flow meter from the flow side to } \\
\text { the return side of the boiler. }\end{array}$ \\
\hline 11 & $\begin{array}{c}\text { Measurement } \\
\text { devices }\end{array}$ & $\begin{array}{c}\text { Accurracy and reliability of the Grundfos } \\
\text { Vortex VFS sensors. }\end{array}$ & Prefer other types of sensor. \\
\hline 12 & $\begin{array}{c}\text { Measurement } \\
\text { devices }\end{array}$ & Incoherent storage temperatures. & Use longer immersion sleeves. \\
\hline 13 & Maintenance & $\begin{array}{c}\text { One valve forgotten in close position, } \\
\text { preventing DHW use. }\end{array}$ & $\begin{array}{c}\text { Careful check of the manipulated } \\
\text { hydraulic components after } \\
\text { maintenance. }\end{array}$ \\
\hline
\end{tabular}

\subsection{Energy balances}

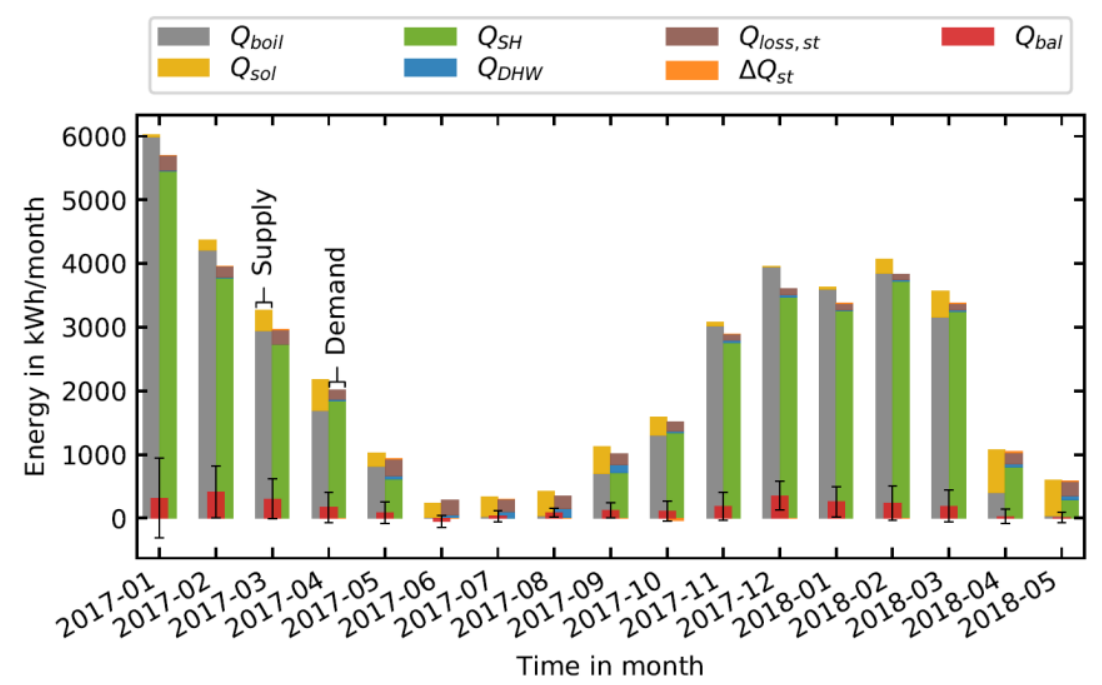

Fig. 3: Monthly energy supply and demand at the boathouse for heating as well as monthly balance including measurement uncertainties (95\% confidence). Data between January 2017 and May 2018.

The heating energy input and output of the system are presented on a monthly basis over the monitoring period in Fig. 3. Because of the issues above-mentioned, the following points have to be clarified:

- Due to the problem with the heat metre in the boiler loop, the energy delivered by the boiler could not be directly measured until the beginning of June 2017. The energy delivered by the boiler before this date is estimated from the measured gas consumption. A boiler utilization ratio of $90.2 \% \pm 5.5 \%$-point (95\% confidence) is calculated for the heating season. This value is used to calculate the monthly $\mathrm{Q}_{\text {boil }}$ between January and May 2017.

- Until the 11th of July 2017 the DHW demand was only measured on the secondary side of the heat exchanger of the fresh water unit. Due to the heat exchanger losses but mainly to the thermosiphonic circulation observed and described before, the actual heat delivered by the storage to the DHW loop is expected to be significantly higher than the energy measured on the secondary side of the heat exchanger. Due to the lack of better data, the energy delivered to the DHW loop until this date was set equal to the energy measured on the secondary side of the heat exchanger. Over this period, the heat loss coefficient of the heat storage was however corrected to include the losses due to the thermosiphonic circulation, as explained in the next point.

- The heat loss coefficient of the heat storage is estimated based on measured data. During the period when thermosiphonic circulation occurred, before the check-valve was installed, two heat loss coefficients were calculated, one including the losses from the thermosiphonic circulation and one excluding them, respectively $9.3 \mathrm{~W} / \mathrm{K} \pm 2.0 \mathrm{~W} / \mathrm{K}$ and $6.9 \mathrm{~W} / \mathrm{K} \pm 1.1 \mathrm{~W} / \mathrm{K}(95 \%$ confidence $)$.

The monthly values show a typical profile for a combi-system, where most of the demand occurs during the winter months for space heating. During the summer months, the supply is almost exclusively covered by the 
solar thermal system. Over the studied period, the DHW needs represented $2.0 \%$ of the total energy demand, while the SH needs accounted for more than $90 \%$ of the total. On the supply side, most of the energy was delivered by the gas boiler ( $88 \%$ ). Compared to the energy demand foreseen during the design phase of the building, one can notice that for the year 2017 the DHW needs are far below the expected values (10.4 times lower), and on the contrary the space heating demand is 2.9 times higher than originally planned. A primary energy factor of 1.1 is assumed to compare the foreseen primary energy needs with the measured consumptions (Deutscher Bundestag, 2016). The unexpected demands are discussed more in details in the following sections.

\subsection{Space heating demand}

The daily space heating demand of the building is shown in Fig. 4 as a function of the average ambient temperature. The sigmoid function used to approximate the scatterplots is described in Hellwig (2003) and is presented in eq. (1). The average ambient temperature considered is a geometric construction, as recommended by BDEW (2015) and expressed in eq. (2).

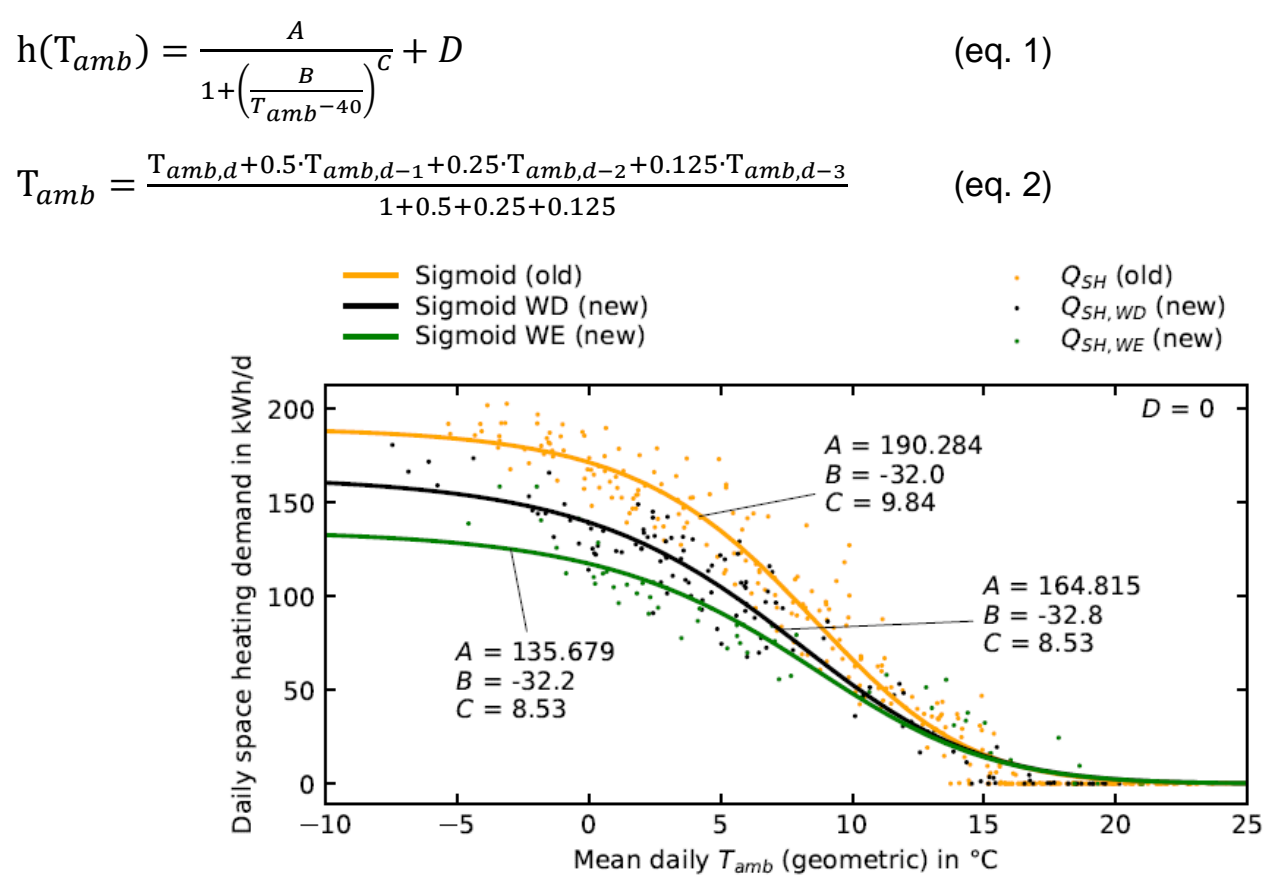

Fig. 4: Measured daily space heating demand between November 2016 and Mai 2018 and sigmoid functions approximating the demand with their coefficients.

In the interpolated curves $\mathrm{D}$ is set to zero as only the space heating demand is considered for the boathouse, while eq. (1) represents the total heat demand including the DHW needs. The measured data shows a clear difference of the SH demand before (old) and after (new) correction of the issues which caused high inlet temperatures to the SH loop; No. 6 and 7 notably (Tab. 1). The daily SH needs are impacted by the corrections in two ways: (a) the daily needs are generally lower than before the correction (orange data), and (b) weekdays (black data) and weekend days (green data) present differentiated profiles. Point (a) can be explained by the fact that the inlet temperature to the SH loop was always higher than required. After correction, the boiler reaches its lower power threshold much more often (especially at night and during the weekends when the set-point temperature is low) which causes repeated on/off boiler cycling. For this reason, the AHU receives a fluctuating inlet temperature, which drops cyclically for a few minutes (with a typical frequency of 15 minutes) a few degrees below the set temperature. As a consequence, the measurements show that during nights and weekends, the rooms do not keep a temperature of $21^{\circ} \mathrm{C}$ as it was the case before the correction, and their temperature drop depending on the outside temperature (room temperatures close to $18{ }^{\circ} \mathrm{C}$ were measured as a minimum during winter 2017-2018). Point (b) is a consequence of (a) and the differentiated set-point temperatures during weekends and weekdays. An insufficient number of measurement points were available to properly estimate the new heating curve on the weekends. For this reason, it was decided to constrain some of the parameters of eq. (1) for its calculation. As mentioned in Hellwig (2003), the sigmoid plateaus for the extreme cold temperatures due to the dimensioning of the heating system, which corresponds to A. In the case of the boathouse, the orange and black heating curves highlight that this threshold is also impacted by the control 
strategy of the heating system as illustrated hereinabove. It is hence not realistic to fix A. However the flattening of the old and new weekday sigmoid curves expressed by the coefficient $\mathrm{C}$ is similar. For the new heating curve on weekend days $\mathrm{C}$ is hence set equal to the new heating curve on weekdays. Finally due to the shape of the sigmoid curve, a residual daily space heating demand is always present even at high mean ambient temperature. This is not realistic, especially during the summer months and it can be clearly seen on the graph that there is often no SH demand when the ambient temperature exceeds $15^{\circ} \mathrm{C}$. To avoid this effect, the daily space heating demand is set to zero outside of the heating season (from May 15 to Sep. 15) when the geometric mean ambient temperature is higher than $15^{\circ} \mathrm{C}$. The daily $\mathrm{SH}$ demand calculated with the new sigmoid curves is then compared to the measured consumption in Fig. 5. Both curves follow a similar trajectory, nevertheless the model shows less rapid oscillations than the measured curve. For this reason, peaks of demand often have lower amplitude in the model compared to the reality.

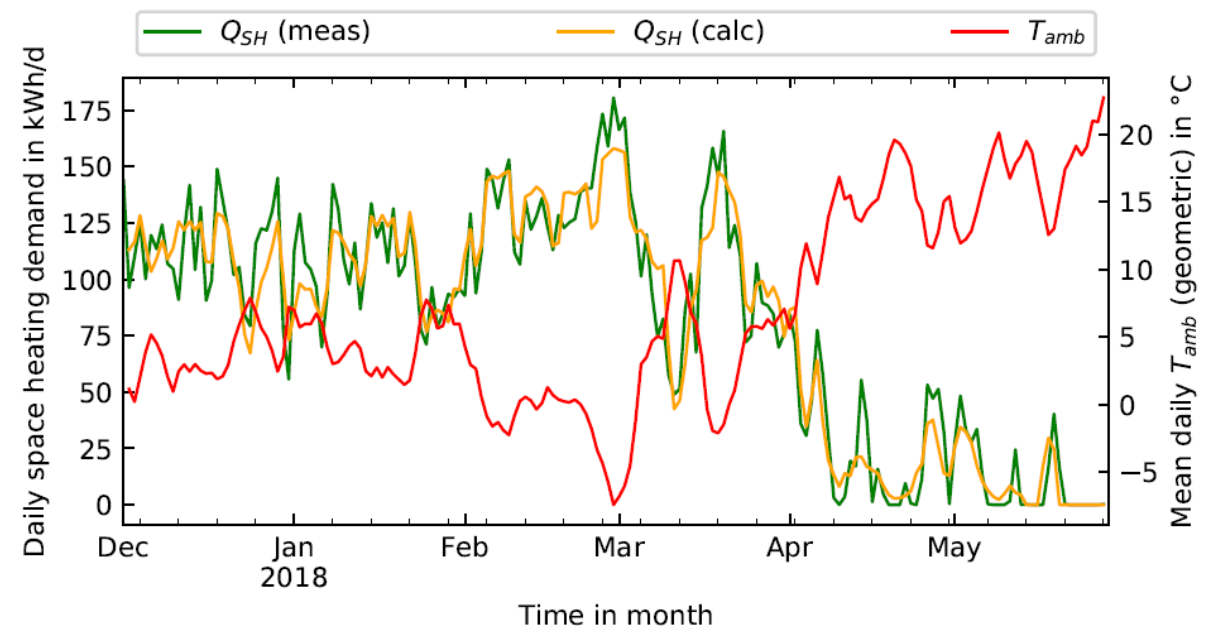

Fig. 5: Comparison of the measured and calculated daily SH demand and geometric mean daily temperature.

During the year 2017, the space heating demand was almost 3 times higher as foreseen during the planning phase despite $2 \%$ less degree days compared to the long-term average ${ }^{1}$. A detailed analysis of additional data from the AHU shows high air exchange rates with the outside through the AHU during the heating season, even at night or when the building is not occupied, which explains despite the air heat recovery unit the high losses to the ambient.

\subsection{Domestic hot water demand}

The DHW demand was surprisingly low over the studied period compared to what was foreseen during the planning of the building. After questioning supervisors of the people utilizing the building (for sports training), came out several reason for this low DHW demand:

- most people come to the boathouse with bikes, therefore prefer not to shower there but rather at home

- the two locker rooms are too small and only 5 to 6 people can change per room at the same time (while four showers per room are available)

- $\quad$ so far only few activities take place at the boathouse, more are planned in the future.

On top of that, during the first months of 2017 hot water was not available during several weeks. The confidence of the users in the possibility to shower was for this reason reduced. However the supervisors mentioned that users should currently be aware that the system is functioning.

The low DHW demand is responsible for the poor performance of the solar thermal system during the summer months. Between June and August 2017 (3 months) collector stagnation occurred 53 days. Overall in 2017 the

\footnotetext{
${ }^{1}$ Degree days calculated with the Excel tool provided by IWU (2018) for the weather station Fritzlar, data for Kassel not been available. The method Gradtagzahl is selected for an internal temperature of $20{ }^{\circ} \mathrm{C}$ and a heating threshold-temperature of $12{ }^{\circ} \mathrm{C}$. The long-term average refers to the period 2002-2017.
} 
solar energy yield delivered to the heat storage amounts to $212.6 \pm 17.4 \mathrm{kWh} / \mathrm{m}^{2}\left(\mathrm{~A}_{\mathrm{a}}\right) / \mathrm{a}$, which is a quite low value for a combi-system.

Because of the low demand, it appeared unnecessary to maintain a 370 litres DHW volume at $60{ }^{\circ} \mathrm{C}$ all the time. The DHW volume was thus reduced to 110 litres, corresponding to the position of the $5^{\text {th }}$ temperature sensor in the tank. It should be noticed that no DHW volume was foreseen in the original planning. Instead the users should have manually activated DHW preparation before their sport activities so that they could shower one or two hours later. The building operator finally decided not to retain this solution and to always maintain a DHW volume in the store.

\section{System simulations and improvement potential}

The following simulations are carried out with TRNSYS 16.01 (Klein et al., 2006). The measured load profiles are replaced with synthetic load profiles to allow variations. The SH profile is generated on an hourly basis with the data presented in the previous section. For DHW, the software DHWCalc allowing the generation of random load profiles is applied with a daily consumption of 401 at $45{ }^{\circ} \mathrm{C}$ approximately corresponding to the measured yearly DHW consumption (Jordan and Vajen, 2005). These profiles result in a total simulated yearly consumption of 19.68 MWh/a for SH and 0.58 MWh/a for DHW. Concerning the weather file the measured data from the year 2017 are used as model input. The yearly solar irradiation in the collector plane amounts to $1022 \mathrm{kWh} / \mathrm{m}^{2} / \mathrm{a}$ and the yearly mean ambient temperature to $10.7^{\circ} \mathrm{C}$. The results of the simulations were compared with the measured values over the first four months of 2018 and showed a good agreement.

\subsection{Impact of various parameters on the system performance}

A reference solar thermal heating system is first of all defined. All issues related to the design and control of the system (except No. 8) as they are presented in Tab. 1 are considered as part of the reference. The parameters listed in Tab. 2 are then varied one after the other to assess their potential for system performance improvement. Parameters related to the control strategy range from $a$ to $f$, while the ones from $g$ to $j$ are linked to the system design. Concerning the control strategies, store prioritisation $(a)$ is achieved by decreasing the boiler settemperature to a low value (below $10^{\circ} \mathrm{C}$ ) when $\mathrm{T}_{\mathrm{st}, 4}>\mathrm{T}_{\mathrm{SH}, \text { set }}$, which prevents it from running. A reduction of the size of the DHW volume ( $e$ and $f$ ) is furthermore tested as it better suits the low demand. The simulation without DHW volume $(f)$ reproduces the behaviour foreseen in the real system. The boiler heats up the heat storage during 30 minutes before a drawing, as long as $\mathrm{T}_{\mathrm{st}, 2}$ does not exceed the set-point. With regards to the design of the system, higher collector tilt angles $(i)$ are simulated as $20^{\circ}$ seems relatively low for a combi-system. The impact of improved storage insulation is also assessed $(j)$. Finally the impact of the simultaneous variation of several parameters is also evaluated.

Tab. 2: List of the modifications implemented in TRNSYS to assess their impact on the system performance.

\begin{tabular}{|c|c|c|}
\hline No. & Parameter modified & Addressed issue \\
\hline$a$ & Boiler stops delivering to the DHW loop when $\mathrm{T}_{\mathrm{st}, 4}>\mathrm{T}_{\mathrm{SH}, \mathrm{set}}$ & 5 \\
\hline$b$ & $\mathrm{~T}_{\text {boil,set }}$ reduced when low SH demand during the day & 6 \\
\hline$c$ & Boiler outlet temperature corrected from offset & 9 \\
\hline$d$ & $\mathrm{~T}_{\mathrm{st}, 1, \mathrm{max}}$ increased from $70^{\circ} \mathrm{C}$ to $80^{\circ} \mathrm{C}$ & \\
\hline$e$ & Size of the DHW volume reduced till the height of the $5^{\text {th }}$ (top) temperature sensor & 1 \\
\hline$f$ & No DHW volume, only one button for DHW on demand & 2 \\
\hline$g$ & Smaller boiler $(19 \mathrm{~kW}$, minimum power of $1.7 \mathrm{~kW})$ & \\
\hline$h$ & Collector tilt increased $\left(i 1: 25^{\circ}, i 2: 30^{\circ}, i 3: 35^{\circ}\right)$ & \\
\hline$j$ & Store insulation improved $(j 1:$ class $\mathrm{D}, j 2:$ class $\mathrm{C}, j 3:$ class B) & \\
\hline
\end{tabular}

The outcome of the simulations is summarized in Fig. 6. The two fractional energy savings are presented, as well as the yearly collector yield (directly between the collector field inlet and outlet), the store losses and the pipe losses in the solar collector loop. Energies are given as specific values, relative to the collector aperture area. The results are presented by issue type (control / design) and ranked by rising $\mathrm{f}_{\text {sav,ext }}$. 
The reference conventional heating system against which all solar thermal systems are compared present store losses of $51 \mathrm{kWh} / \mathrm{m}^{2}\left(\mathrm{~A}_{\mathrm{a}}\right) / \mathrm{a}$ and the total heat delivered by the boiler amounts to $21.82 \mathrm{MWh} / \mathrm{a}$. It is first of all to notice that as one could expect, the multiple issues above mentioned significantly hamper the performance of the reference solar thermal system. It reaches an extended $\mathrm{f}_{\mathrm{sav}}$ of $7.0 \%$. As highlighted in the figure, most of the solar collector yield is compensated by heat losses through the store and the piping. This situation can be nevertheless easily improved with modifications of the control.

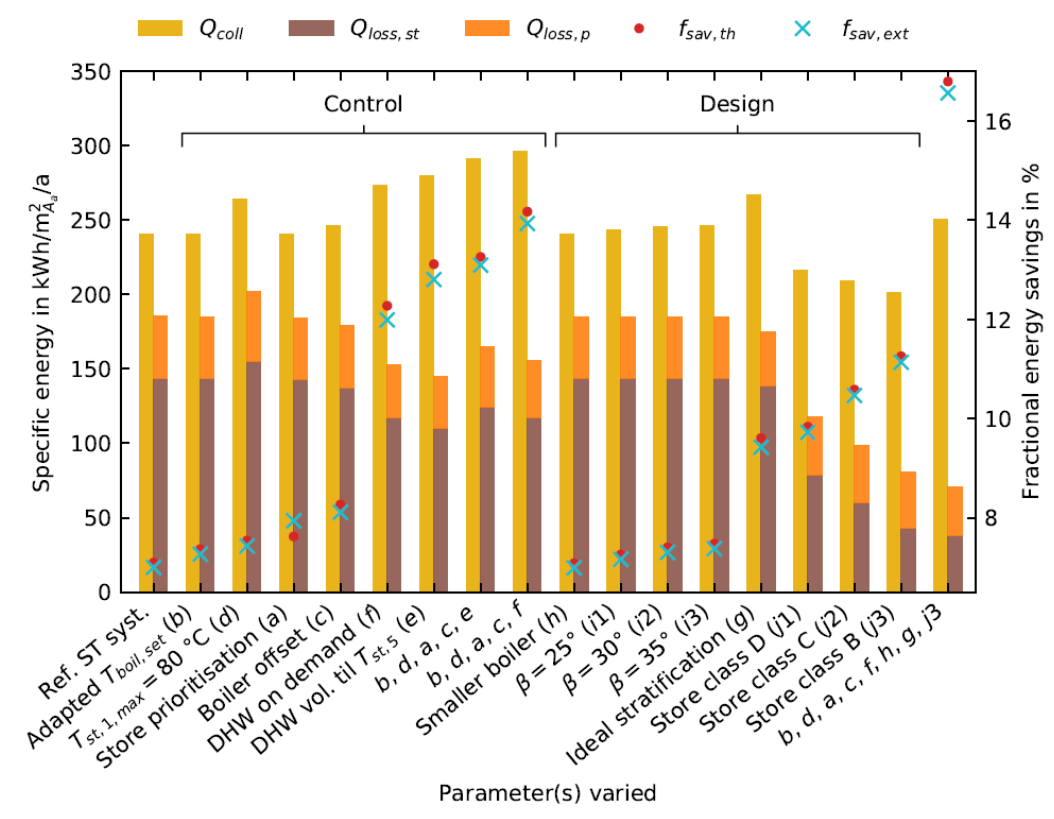

Fig. 6: Results of the TRNSYS simulations of the boathouse for several parameter variations and combinations.

The reduction of the boiler set-point $(b)$ has a minor impact as it only slightly reduces the pipe losses in the $\mathrm{SH}$ loop. However an advantage that the simulation does not show is that in the real system this measure should avoid boiler overheating when the SH demand is very low, i.e. when the actually required SH inlet temperature is low (between 20 and $30{ }^{\circ} \mathrm{C}$ ), by preventing the boiler from starting up. The boiler entered several times in error mode during the winter 2017/2018 because of overheating as the SH demand was very low but the setpoint temperature still had a value of $57.5^{\circ} \mathrm{C}$. The increase of the maximum store bottom temperature $\mathrm{T}_{\mathrm{st}, 5, \mathrm{max}}$ $(d)$ improves as expected the collector yield, but most of the gains occur outside of the heating season when the system enters daily in stagnation due to the low DHW demand. They are thus lost through higher store losses.

Giving priority to the store over the boiler ( $a$ ) for SH also has a small impact. Indeed the store outlet to the space heating loop is located inside the DHW volume, which means that heat is delivered to the SH exclusively through the store. This contributes to reduce the running time of the boiler significantly as it does not continuously delivers to the space heating loop, but rather warms up the DHW volume when the minimal threshold is reached. This explains the improvement of $\mathrm{f}_{\text {sav,ext }}$ seen in the figure. On the contrary, the short on/off boiler cycles might reduce its efficiency, which is however not assessed in the simulations. Taking into account the boiler offset $(c)$ has a slightly higher impact on the performance thanks to the subsequent reduction of the DHW volume temperature which in turns reduces the yearly store losses.

The most impacting single measures are the ones reducing the size of the DHW volume ( $e$ and $f)$ as they significantly reduce the store losses and leave more space for storing the heat from the solar collector loop. The worst $\mathrm{f}_{\text {sav,ext }}$ in both cases is caused by a longer running time of the boiler, as it is the main direct supplier for the SH loop contrary to the previous cases when the supply is partly covered by the store (via the store outlet to the SH loop which was kept at a high temperature level as part of the DHW volume). As mentioned before however, the reduction of the number of boiler on/off cycles might improve the boiler efficiency but is not considered here. The DHW on demand only $(f)$ performs worse than reducing the size of the DHW volume $(e)$. It is the consequence of having the boiler offset not corrected in $(f)$, which contribute to heating up a store volume at a higher temperature than simply keeping a smaller volume at the DHW set-point. The combination of $e$ and $f$ with the improvement of the control strategy shows on the contrary that DHW on demand is indeed the best solution compared to having a DHW volume, even a smaller one (110 litres). 
All in all by simply modifying the control strategy, i.e. without any additional material cost, a doubling $\left(f_{\text {sav,ext }}=13.9 \%\right)$ of the performance can be fulfilled.

The impact of the design of the system is also assessed. The reduction of the boiler size $(h)$ does not bring any quantified improvement. Nevertheless, it contributes to lower the number of short boiler on/off cycles. Even though all fast oscillations of the outlet temperature are not completely avoided with a smaller boiler a significant reduction of their number and amplitude is noticeable. This should in the real system improve the boiler efficiency, but is not quantified in the present simulations. The tilt angle of the collector is also modified $(i)$. However no real performance improvement is seen and this measure is hence not further considered as it would in the present case have led to additional costs for the mounting system without significant gains. The tiny improvement can be explained by the orientation of the boathouse (S53 $\left.{ }^{\circ} \mathrm{W}\right)$ which only leads to a $3.1 \%$ increase of the total irradiation in the collector plane during the heating season (mid Sep. mid May) when the tilt angle rises from $20^{\circ}$ to $35^{\circ}$. With regards to system design, modifications of the store would bring the most significant improvements. A perfect stratification $(g)$ plays an important role especially as in the boathouse case, the mixing occurs in the DHW volume (in its initial reference configuration of 3701 ). Consequently the boiler needs to start-up in order to compensate for the cooling of the DHW volume. The heat content of the store increases therefore faster than without mixing, reducing the efficiency of the collectors (due to higher temperatures) but also decreasing the storage capacity available for the heat from the solar collector field. The reduction of the heat losses from the store is an additional way of increasing the fractional energy savings. This could be achieved through thicker insulation but also with reduction of the losses at the location of piping connections and temperature sensors. Finally combining the best assessed corrections of both control and design parameters would raise the extended fractional energy savings to $16.8 \%$. This is mainly achieved through a strong reduction of $74 \%$ of the store losses and a minor $4 \%$ increase of the solar collector gains compared to the reference solar thermal system.

\subsection{Impact of the load profiles}

As it was already mentioned in the previous sections, apart from the several issues detected during the monitoring phase, the major discrepancy between the actual system and the planned one is the incorrect assessment of the heat demand both for SH and DHW. In order to assess to which extent this affects the performance of the solar heating system, the profiles are varied. The resulting total yearly heat demands are detailed in Tab. 3.

Tab. 3: DHW and SH yearly energy needs for the different profiles simulated.

\begin{tabular}{|c|c|c|}
\hline Profile name & DHW demand in MWh/a & SH demand in MWh/a \\
\hline Ref. ST syst. Improved & 0.58 & 19.68 \\
\hline DHW 80 1/d & 1.16 & 19.68 \\
\hline DHW 120 1/d & 1.76 & 19.68 \\
\hline DHW 160 1/d & 2.33 & 19.68 \\
\hline DHW 200 1/d & 2.93 & 19.68 \\
\hline $0.75 \mathrm{SH}$ & 0.58 & 14.76 \\
\hline $0.5 \mathrm{SH}$ & 0.58 & 9.84 \\
\hline
\end{tabular}

All simulated variations bring the demands closer to the values foreseen during the planning phase compared to the actual ones. For DHW new profiles are randomly generated with DHWCalc with the indicated daily tapped volume at a temperature of $45{ }^{\circ} \mathrm{C}$. The $\mathrm{SH}$ profiles are generated by multiplying the coefficient $\mathrm{A}$ from the measured sigmoid curves (eq. (1)) by the coefficient indicated in the profile name. Multiplying A by 0.5 for instance halves the total yearly heat demand when the other coefficients are kept constant. The calculation of the fractional energy savings also requires additional simulations of the reference conventional heating system with the varied load profiles. The results of the simulations are presented in Fig. 7. The solar heating system taken as reference on the left hand side of the figure corresponds to the system improved with modifications of the control strategy (variation " $b, d, a, c, f$ " in Fig. 6), as these can be realistically implemented in the existing system contrary to the measures linked to the system design. 


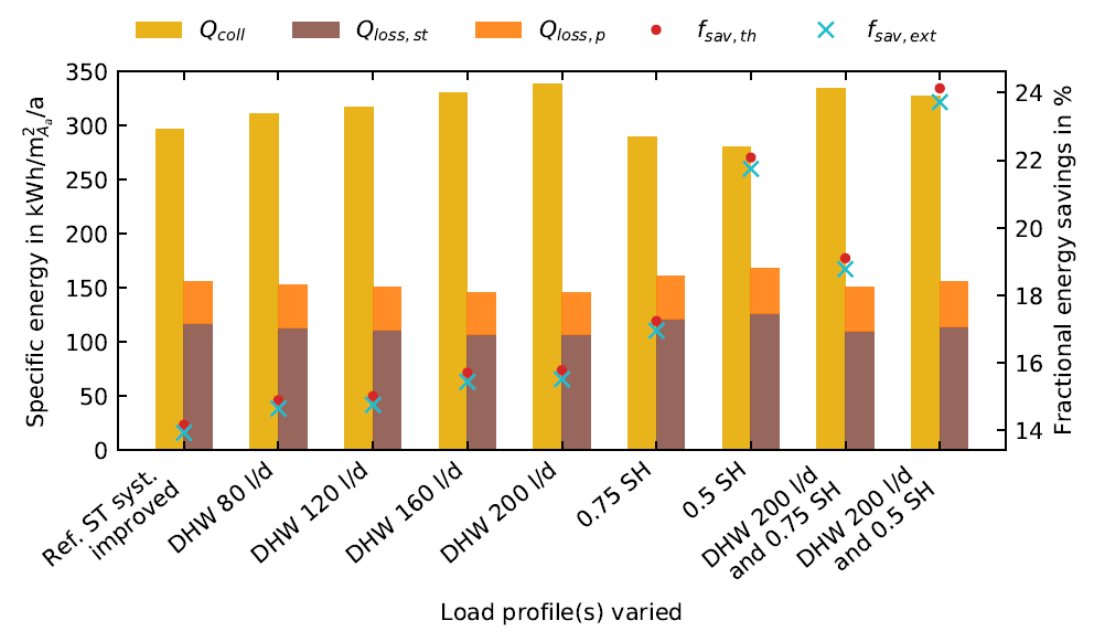

Fig. 7: Results of the TRNSYS simulations for the boathouse when varying the yearly DHW and SH demands.

It is first of all to notice that all simulated variations are increasing the savings. The rise of the DHW demand has the lowest impact but contributes to raise the contribution of the solar collector field, as it delivers more heat especially during summer time. A tapped volume of $200 \mathrm{l} / \mathrm{d}$ corresponds approx. to half of the foreseen yearly hot water needs. Further increase is not simulated as it does not seem very realistic that it will ever be reached given the current consumption level. Reducing the SH demand should be easier to fulfil with modifications of the control strategy of the AHU as highlighted before. Fig. 7 shows that it has the highest potential for increasing the fractional energy savings, even though the savings are lower in absolute values, which explains the lower solar thermal yield and slightly higher store losses compared to the reference. On top of increasing the fractional savings, the decrease of the SH demand obviously strongly reduces the needs for back-up energy and should be implemented in priority to lower the carbon footprint of the building. In the most favourable case simulated, with a halving of the SH needs and 5 times higher DHW demand, $\mathrm{f}_{\text {sav,ext }}$ could reach $23.7 \%$, compared to $13.9 \%$ with current consumption levels and at the same time the yearly energy delivered by the boiler would be reduced from $18.7 \mathrm{MWh} / \mathrm{a}$ to $10.9 \mathrm{MWh} / \mathrm{a}$.

\section{Costs analysis}

The heat costs $\left(\mathrm{LCoH}_{\mathrm{ov}, \mathrm{fin}}\right)$ are also estimated. For this purpose, the methodology described in Louvet et al. (2018) is used. All prices mentioned here are net prices, without VAT. The period of analysis is 25 years and the real discount rate is taken equal to zero. No subsidy is considered. The investment $\left(I_{0}\right)$ for the heating system is based on actual prices including both material and installation. The material prices for the boiler $(3000 €)$, collectors $\left(200 € / m^{2}{ }_{A_{G}}\right.$ ), collector connections ( $20 € /$ piece) and collector mounting system (40€/m ${ }_{A_{G}}$ ) were unknown from the project and the value given in parenthesis are estimated from average component prices found on the internet. With the same method a price of $250 €$ is taken for the buffer store of the reference conventional heating system with additional installation costs of $500 €$. Under these assumptions, the total investment for the solar part of solar assisted heating system amounts to $15131 €$ (including the credit of $750 €$ from the store of the reference conventional system) and $13485 €$ for the conventional part. The breakdown of the costs is shown in Fig. 8. The maintenance costs are calculated at the component level, with the values given in VDI (2012). The yearly maintenance cost for each component is the sum of the yearly effort for maintenance, servicing and inspection indicated in the reference. The replacement costs are also added for each component depending on their given depreciation period (VDI, 2012) and equally spread over the period of analysis. The rest value is deduced from the replacement costs if the component (or replaced component) depreciation period exceeds the period of analysis. As additional assumption, the total yearly maintenance effort for the PP storage were reduced from $2 \%$ to $1 \%$ of the investment as less maintenance is required than for conventional metallic buffer stores. Under these assumptions, the total maintenance costs for the solar part of the solar assisted heating system amount to $253 €\left(1.7 \%\right.$ of $\left.I_{0}\right)$ and $295 €$ for the conventional part $\left(2.2 \%\right.$ of $\left.I_{0}\right)$. 

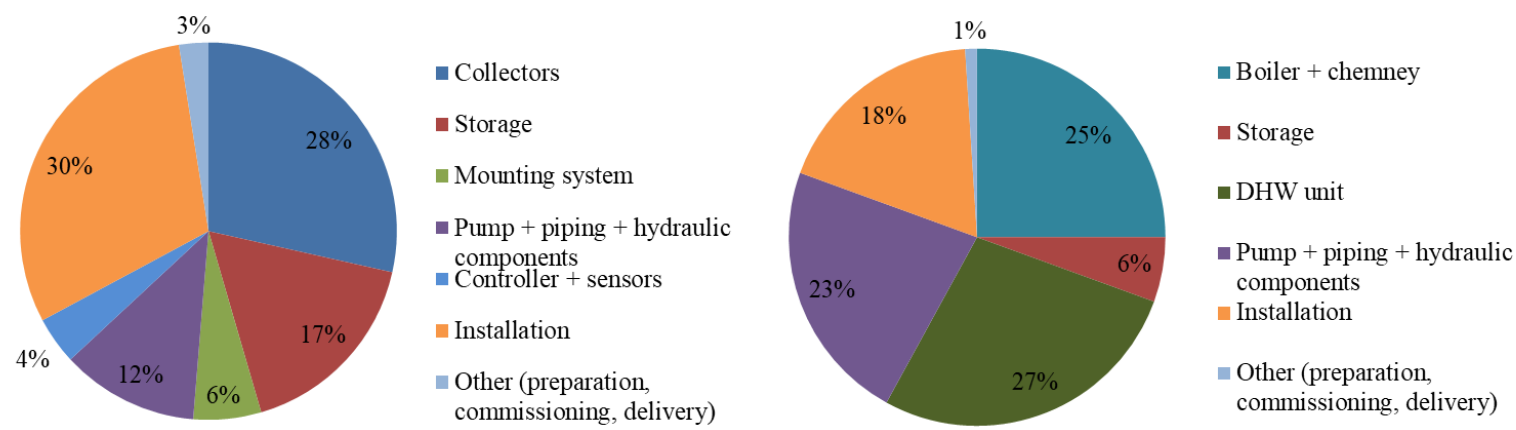

Fig. 8: Breakdown of the investment costs for the solar part (left) and conventional part (right) of the solar assisted heating system installed at the boathouse.

The calculated heat costs are presented in Fig. 9 and one can notice that they are in all cases higher for the solar assisted heating system compared to the reference conventional system. Without any improvement, the heating system with solar assistance has a $\mathrm{LCoH}_{\mathrm{ov} \text {,fin }} 30 \%$ higher than the reference conventional system, which drops to $26 \%$ with the improvement of the control and decreases further to $24.5 \%$ with additional design improvements (Fig. 9, left). This example also highlights that despite a more than doubling of the saved final energy between the worst (Ref. ST syst.) and the best (b, d, a, c, f, h, g, j3 $)$ cases investigated, the $\mathrm{LCoH}_{\mathrm{ov}, \mathrm{fin}}$ faces a slight reduction of only $4.5 \%$. This is a consequence of the small share of the total energy supply which is covered by the solar heating system.

The load profiles have as expected an important impact on the heat costs. For both systems (solar and reference), the rise of the heat consumption decreases the heat costs and vice-versa. In the former case indeed, the weight of the investment costs per unit of energy is reduced which explains the lower heat costs. Moreover, while the increase of the DHW consumption has a positive impact in bringing closer the $\mathrm{LCoH}_{\mathrm{ov} \text {,fin }}$ of both systems, the reduction of the SH load has the opposite effect.
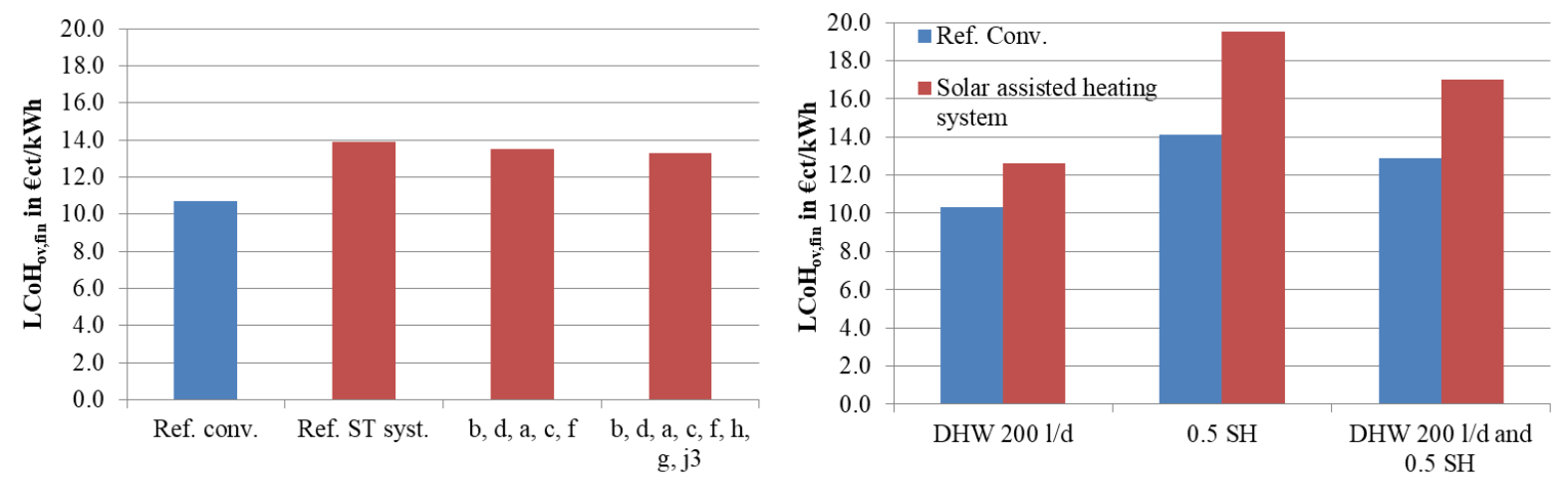

Fig. 9: $\mathrm{LCoH}_{\text {ov,fin }}$ for different parameter configuration of the solar assisted heating system compared to one of the reference conventional system (left) and comparison of the $\mathrm{LCoH}_{\text {ov,fin }}$ of solar assisted heating system (with improvements b, $\mathrm{d}$, a, c, f) and the reference conventional system for varying load profiles.

\section{Discussion and conclusion}

The analysis revealed a poor performance of the system after commissioning but showed that most of the issues identified could be solved through an adapted control strategy, already significantly raising the performance. The unusual usage of the building contributes to the specificity of the most energy efficient control strategy determined with the simulations. Indeed no DHW volume should be kept in the store and DHW only prepared on-demand. This would however require that the building users adapt to this uncommon situation and this solution was not adopted for this reason. In addition to the control strategy, additional care in the system design, notably regarding store stratification and heat losses could further improve the system performance. A smaller boiler would also be more adapted and avoid overheating and short on/off cycles.

The measurements have shown that the solar thermal system with current DHW consumption level is overdimensioned which also partly explains the low specific collector yields. Beyond this fact the drainback design 
appears as an appropriate technical solution for such a building with very low consumption during summer time causing collector stagnation almost every day. A conventional pressurized system would result in a much higher stress on the components of the solar collector loop due to high temperatures and pressures and lead to a fast degradation of the HTF. This would in turn lead to higher maintenance efforts especially as antifreeze mixtures might account for most of the required maintenance (Schiebler, 2018).

On top of preventing damaging stagnation cycling, the chosen drainback design is perfectly suited for heating systems as the one installed at the boathouse. Indeed, as it is notably highlighted in R. Botpaev et al. (2016) and Ruslan Botpaev (2017), DBS require additional care by planning and installation in order to ensure proper filling, operation and draining. At the boathouse, the heat storage, which is also the drainback tank, is located directly under the roof in the attic. The collector loop can thus be filled without the need to over-dimension the pump. Moreover a reduction of the water boiling point due to underpressure is also avoided. The risk associated with an incorrect installation of outside piping nevertheless remains. The boathouse highlights the necessity to avoid using flexible pipes with drainback systems in (almost) horizontal sections. Rigid piping should be installed instead.

Despite the apparent simplicity of such system, due to fewer components thanks to the drainback design in the solar collector loop and the reduction of the number of heat exchangers, the costs analysis showed that with the current consumption level the heat costs are between 24.5 and $30 \%$ higher with the solar assistance than without, depending on the control and design improvements considered. This can be partly explained by the very low DHW-consumption which limits the solar yield outside of the heating period. A better estimation of the needs is therefore a key to reduce the heat costs. It nevertheless also appears that further reductions of the investment costs are required to increase the competitiveness of combi-systems.

\section{References}

BDEW, 2015. BDEW/VKU/GEODE Leitfaden - Abwicklung von Standardlastprofilen Gas. BDEW, VKU, GEODE, Berlin.

Botpaev, R., Louvet, Y., Perers, B., Furbo, S., Vajen, K., 2016. Drainback solar thermal systems: A review. Sol. Energy, Special issue: Progress in Solar Energy 128, 41-60. https://doi.org/10.1016/j.solener.2015.10.050

CEN, 2012. EN 12977-2:2012 Thermal solar systems and components - Custom built systems - Part 2: Test methods for solar water heaters and combisystems. European Committee for Standardization (CEN), Brussels, Belgium.

Deutscher Bundestag, 2016. Sachstand - Primärenergiefaktoren (No. WD 5-3000-103/16). Wissenschaftliche Dienste - Deutscher Bundestag.

DIN, 2016. DIN EN 12897 - Wasserversorgung - Bestimmung für mittelbar beheizte, unbelüftete (geschlossene) Speicher-Wassererwärmer. Deutsches Institut für Normung, Berlin.

European Commission, 2013. Commission delegated regulation (EU) No 812/2013 of 18 February 2013 supplementing Directive 2010/30/EU of the European Parliament and of the Council with regard to the energy labelling of water heaters, hot water storage tanks and packages of water heater and solar device. Brussels, Belgium.

Hellwig, M., 2003. Entwicklung und Anwendung parametrisierter Standard-Lastprofile (PhD Thesis). TU München, Munich.

IWU, 2018. IWU-Tools / Werkzeuge - Gradtagszahlen in Deutschland [WWW Document]. URL http://www.iwu.de/downloads/tools/ (accessed 14.02.2018).

Jordan, U., Vajen, K., 2005. DHWcalc: Program to generate domestic hot water profiles with statistical means for user defined conditions, in: Proceedings of the 2005 Solar World Congress Bringing Water to the World. Orlando, Florida, USA.

Klein, S.A., Beckman, W.A., Mitchell, J.W., 2006. TRNSYS 16 a TRaNsient SYstem Simulation program.

Louvet, Y., Fischer, S., Furbo, S., Giovannetti, F., Köhl, M., Mauthner, F., Mugnier, D., Philippen, D., Veynandt, F., 2018. LCOH for Solar Thermal Applications (No. Info Sheet A01). IEA SHC - Task 54 Price Reduction of Solar Thermal Systems. URL http://task54.iea-shc.org/info-sheets (accessed 15.11.2018).

Schiebler, B., 2018. Cost reduction by temperature limitation. SHC Solar Academy Webinar. URL https://www.youtube.com/watch?v=5aNeDR6bfHY (accessed 15.11.2018).

VDI, 2012. VDI 2067, Blatt 1 - Wirtschaftlichkeit gebäudetechnischer Anlagen Grundlagen und Kostenberechnung. Verein Deutscher Ingenieure (VDI), Düsseldorf, Germany. 


\title{
Simulation and Monitoring of PV Heat Pump System with Seasonal Storage
}

\author{
Tomas Matuska ${ }^{1}$, Borivoj Sourek ${ }^{1}$ and Michal Broum ${ }^{2}$ \\ 1 UCEEB, Czech Technical University in Prague (Czech Republic) \\ 2 Regulus, Prague (Czech Republic)
}

\begin{abstract}
PV and heat pump system with a seasonal storage has been proposed and investigated. Specific components have been developed (ground-air source heat pump with variable speed compressor and desuperheater, combined storage tank with a division plate, low cost seasonal storage), built and installed in experimental family house. System simulations have shown a potential to achieve a very low need for external electricity from the grid and to reach strict requirements for nearly zero energy building. The long-term monitoring of the system has started in October 2017 and results representing the system functionality are presented.
\end{abstract}

Keywords: heat pump, photovoltaic system, seasonal storage

\section{Introduction}

European Directive on Energy Performance of Buildings (2010) has brought a clear vision and an opportunity to transform the building stock to nearly zero energy buildings (NZEB). There is a number of measures to increase the energy performance of modern buildings today. Space heating demand could be minimized to limits of technical and economical possibilities in case of passive houses (envelope insulation, triple glazing, ventilation with heat recovery, etc.). Domestic hot water systems could use energy saving showers, insulation of hot water piping, time and temperature control of hot water circulation run, etc. Further savings can be expected with use of heat recovery from the waste water. Electricity demand has been continuously reduced with an introduction of appliances with energy class A and better and implementation of modern daylighting principles together with proper control of LED artificial lighting.

Logical step ahead to decrease the energy demand in buildings is an application of renewable energy sources. Heat pumps use the renewable energy from ambient environment, however they also need grid electricity to valorize the renewable heat to useful temperature level for space heating and hot water preparation. However, the grid electricity in Europe in general has high primary energy conversion factors (Molenbroek, 2011) dependent on the share of renewables in the grid in each country. The grid electricity in Czech Republic originates from nonrenewable fuels (brown coal and nuclear power plants) which disqualifies the use of electricity in heating applications within the frame of building certification (primary energy factor $P E F=3.0$ ).

To improve the balance, combination of the PV systems and heat pumps represents a trend to nearly zero energy buildings with minimized non-renewable energy demand. European Commission has recommended for oceanic climate area (also Czech Republic) specific values of non-renewable energy demand at level $30 \mathrm{kWh} / \mathrm{m}^{2}$.a in annual energy balance (European Commission, 2016). Despite the fact that calculation of the non-renewable criterion is generally based on simple annual balance between imported and exported energy, it is an ambitious target. However, the export of local renewable electricity production to external grid has been already complicated in number of countries by significant reduction of feed-in tariffs. New PV installations focus on the local use of renewable electricity in buildings. Coupling of PV and heat pump system with low cost seasonal storage could significantly increase the local use of PV electricity in summer, reduce the electricity use from external grid in winter and achieve the target values of NZEB also with realistic evaluation of usability of locally produced electricity. 
Paper shows the results of simulation and monitoring of energy system which has been developed and demonstrated with the motivation mentioned above. The system combines the PV system and heat pump for family house to achieve high share of renewable energy for space heating and hot water, to increase the selfsufficiency and to meet the strict goals defined for NZEB.

\section{Description of the system}

The presented energy system for space heating and hot water preparation in a family house is based on the combination of PV system with an advanced heat pump, photovoltaic (PV) system and the low cost ground heat storage built within the foundation perimeter under the house. The system concept and function is shown in Fig. 1 with the main components used. The heat pump, in addition to usual components, has a variable speed compressor and desuperheater to use effectively heat from superheated refrigerant at high temperature. Heat pump in the case of sufficient PV power production in summer season adapts its power input to PV system power output and extracts the heat from the ambient air by heat exchanger (6) and rejects it to the building for hot water production with higher set-point in combined storage tank (overcharges the volume of storage tank to $55^{\circ} \mathrm{C}$ ) or to ground seasonal heat storage (at low condensation temperature 25 to $40^{\circ} \mathrm{C}$ ) while heat from the desuperheater (2) can be used for hot water preparation in the top part of water storage tank (hot water zone). Such a function of PV heat pump system could be achieved without any grid electricity input (see Fig. 1).
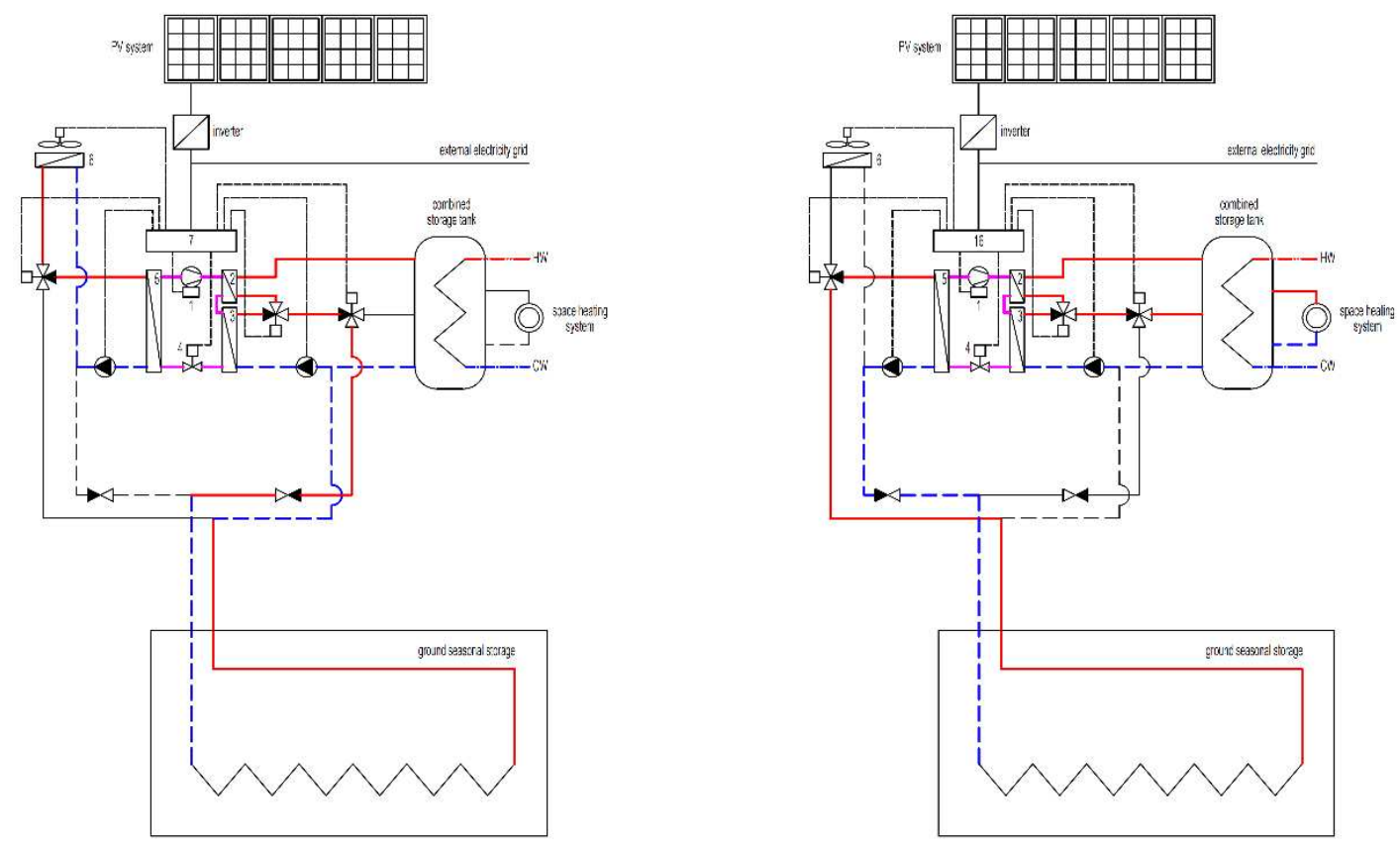

Fig. 1: Scheme of the PV heat pump system concept: summer operation (left), winter operation (right)

If the building requires the heat but PV system power has decreased under threshold electric power, i.e. during winter time or during the night, the electric demand for heat pump system operation is automatically covered from the external grid. Then, the heat pump extracts the heat stored in the seasonal ground storage at higher temperature (from $10{ }^{\circ} \mathrm{C}$ to $35^{\circ} \mathrm{C}$ ) than ambient air temperature or conventional ground borehole and thus system operates with higher efficiency (see Fig. 1, right).

This concept reduces the grid electricity use and simultaneously increases the usability of available PV system production within the whole year. Compared to conventional PV and heat pump systems the proposed energy system has a several advantages:

- application of desuperheater for hot water preparation at high temperature without increased electricity demand - increase of usable energy and effectivity of the heat pump;

- use of excess renewable electricity for heat pump system to charge the storage tank to higher setpoint and increase of stored heat to bridge the daily load peaks - coverage of hot water energy demand mostly by renewables in summer; 
- use of excess renewable electricity to charge the ground heat storage by transformed ambient heat increase of heat pump energy efficiency in winter season by use of stored heat at higher temperature;

- power input control for heat pump according to power output of PV system - operation of the heat pump completely without need of external electricity for a large part of the year;

- operation of ground heat storage with water instead of antifreeze mixture.

The energy system has been designed, simulated and demonstrated for a specific family house in Hamry (Hlinsko, Czech Republic). Family house has two floors with a space volume of $935 \mathrm{~m}^{3}$ and total living floor area $190 \mathrm{~m}^{2}$. Family house was designed in low energy house concept, $U$-values of individual envelope constructions meet the recommended values for such high performance buildings. Foundations has been realized by sacrificial formwork insulated by extruded polystyrene of thickness $160 \mathrm{~mm}$. Base floor has been assembled from concrete slabs, upper insulation has been realized from extruded polystyrene with a thickness of $240 \mathrm{~mm}$ and floor heating system layer. Envelope brick system is based on cellular clay blocks filled with insulation and external mineral insulation system of thickness $180 \mathrm{~mm}$. Saddle roof has a slope of $40^{\circ}$ with south-north orientation and roof thermal insulation layer thickness is $240 \mathrm{~mm}$.

Design heat loss of the house is $4.5 \mathrm{~kW}$ for design ambient temperature $-15{ }^{\circ} \mathrm{C}$. Low temperature floor space heating system has been used with design flow/return water temperatures $40 / 35^{\circ} \mathrm{C}$. Ventilation is provided by air handling unit with maximum flowrate $275 \mathrm{~m}^{3} / \mathrm{h}$ using a heat recovery. The proposed system consists of the advanced heat pump with heat output $5.5 \mathrm{~kW}$ at B0/W35 $(50 \mathrm{~Hz})$ and combined storage tank of volume 9001 with internal heat exchanger with surface area $9 \mathrm{~m}^{2}$. Investor considered the large PV system installation with peak power $6 \mathrm{~kW}_{\mathrm{p}}$ to increase the energy independency of the house operation.

During the construction stage the seasonal ground heat storage has been realized with use of pipe heat exchanger (see Fig. 2) with size of $14.4 \mathrm{~m} \times 8.0 \mathrm{~m}$ within the foundations of the house, which are $1.5 \mathrm{~m}$ deep and thermally insulated at external surface. Internal perimeter of the ground storage volume is also thermally insulated but only to depth of $0.5 \mathrm{~m}$ in order to eliminate the thermal bridges from the charged storage to interior through the envelope and foundations. Heat exchanger is made of plastic piping DN32 burried in the trenches $300 \mathrm{~mm}$ deep filled with cement and silicate sand mixture to provide a good thermal contact between the pipe and ground. Distance of pipes in the heat exchanger is $0.6 \mathrm{~m}$. Heat exchanger has been realized in two loops, each of length $100 \mathrm{~m}$. Two loops have been designed to reduce the auxiliary demand of circulation pumps. Redundant thermal insulation with thickness $100 \mathrm{~mm}$ has been applied between the seasonal storage volume and the floor concrete slabs.

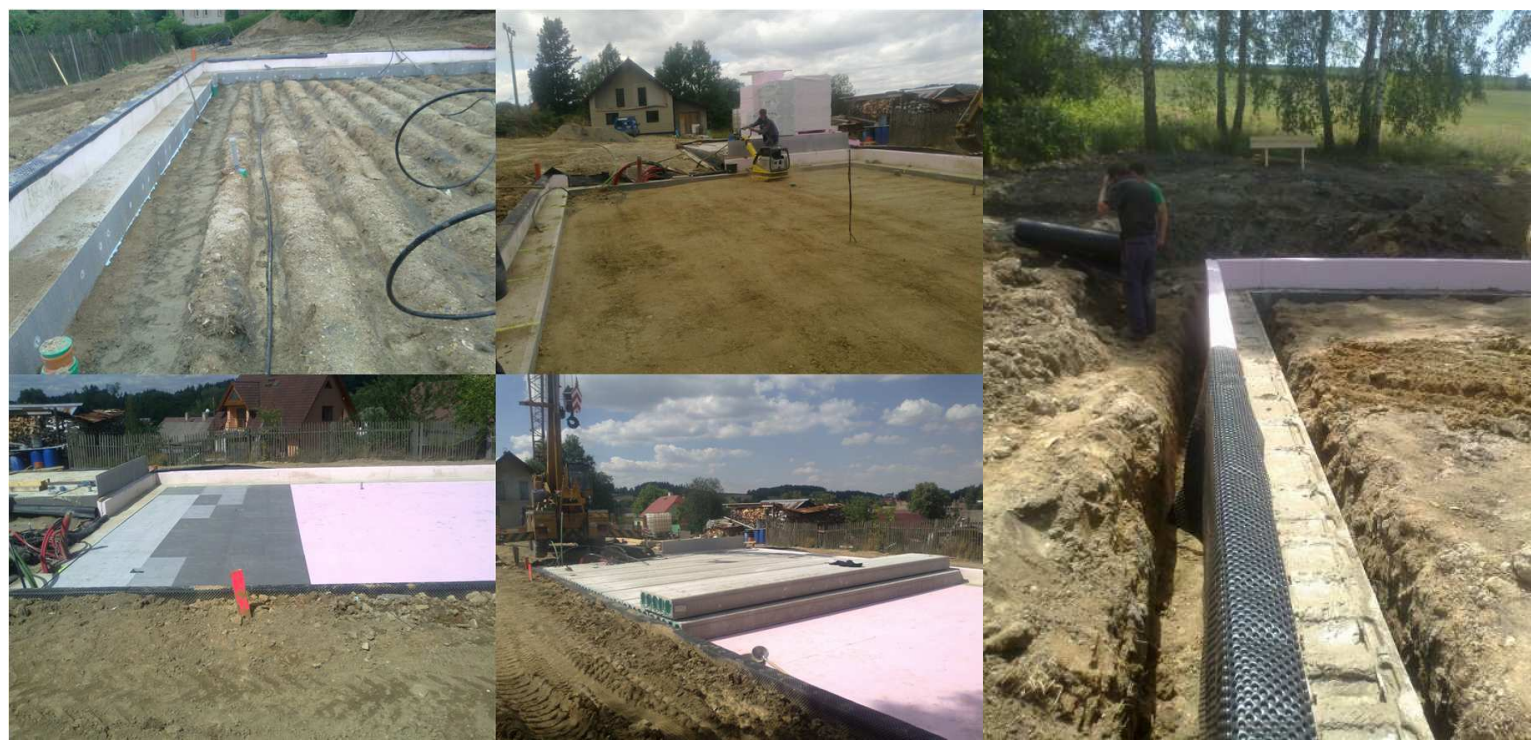

Fig. 2: Realization of simple and low cost ground seasonal storage

\section{System simulation}

The building and the system simulation has been performed in TRNSYS environment. The objective of the 
analysis was to proof the functionality of the system concept and to compare the performance with the conventional PV and heat pump system. Computer simulations have been performed with a time step of 2 minutes and always two years of operation have been simulated because of ground massive use in both proposed and conventional heat pump system. Results have been evaluated from the second year of simulation. Building model has been built also in TRNSYS based on construction plans and used for separate simulations to reduce the calculation time. Results for the space heating and hot water load have been used as inputs to system simulations. Space heating demand is $3400 \mathrm{kWh} / \mathrm{a}$ and hot water demand is $3060 \mathrm{kWh} / \mathrm{a}$.

Conventional heat pump system with a borehole heat exchanger $(75 \mathrm{~m})$, standard combined water storage tank (900 1) and PV system $\left(6 \mathrm{~kW}_{\mathrm{p}}\right)$ has been modelled for given house as a reference case. Total grid electricity use of the conventional system is $2200 \mathrm{kWh} / \mathrm{a}$ and the system operates with seasonal performance factor $S P F=2.9$. Monthly values of system SPF ranges around this value (see Fig. 3). The main reason of low operation effectiveness for the conventional reference case is large share of hot water heat demand in general combined with necessity of charging the hot water zone in the storage tank to temperature of $55^{\circ} \mathrm{C}$ to eliminate the electric backup heater operation. Despite the high installed power of PV system, there is high external electricity use and low utilization of PV electricity production by the heat pump system. The reason is the mismatch between hot water peak loads (morning, evening), space heating peak loads (winter season, night time) and PV electricity production (summer season, daytime). PV system covers annually only $420 \mathrm{kWh}$ from total $2620 \mathrm{kWh}$ system electricity demand, despite the installed power $6 \mathrm{~kW}_{\mathrm{p}}$ produces about $6020 \mathrm{kWh} / \mathrm{a}$ of electricity.

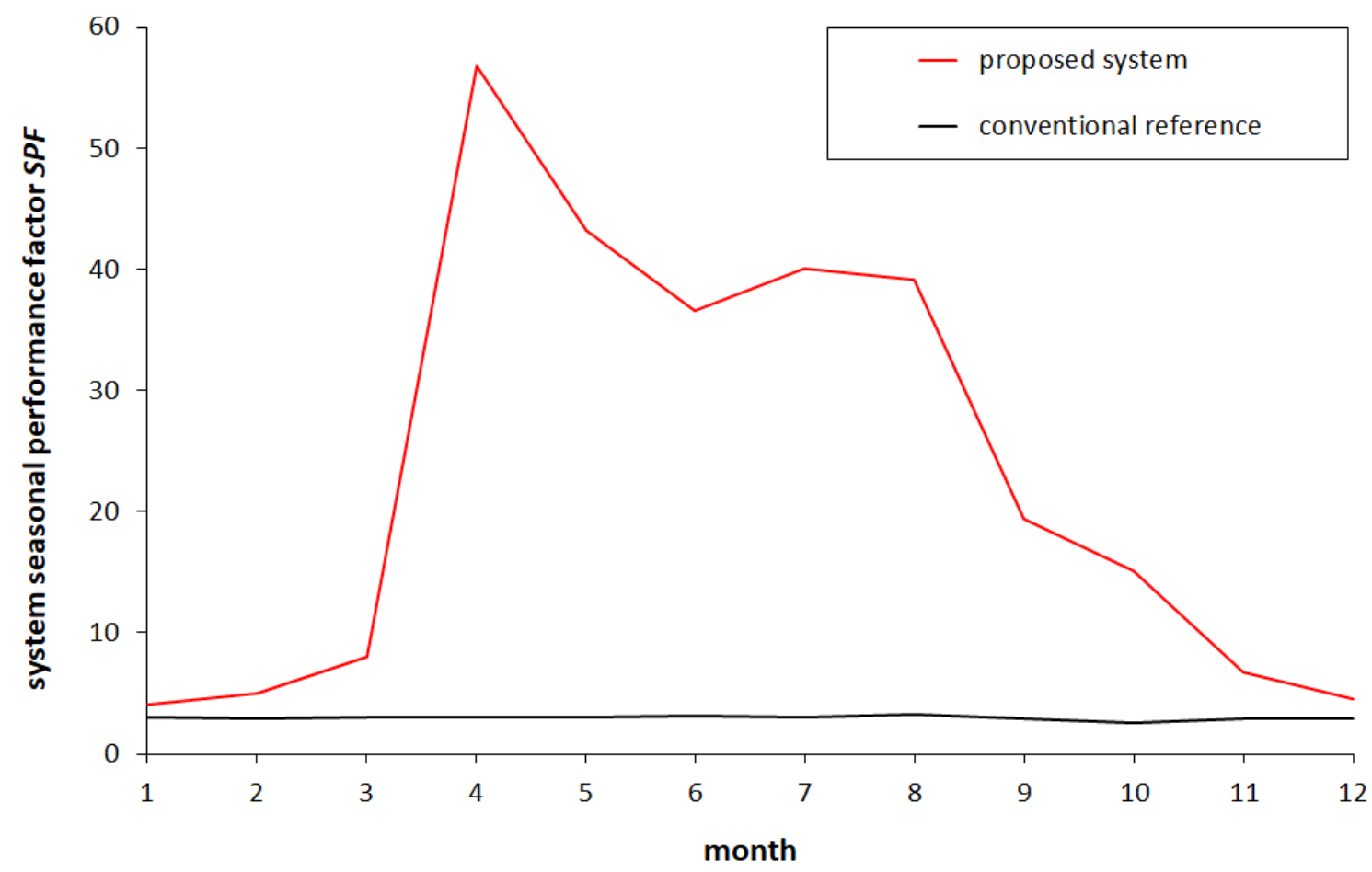

Fig. 3: Seasonal performance factor of the proposed system compared with conventional system

The developed system concept has been modelled with use of both newly developed models (variable speed heat pump with desuperheater) and standard models (storage tank, seasonal storage). The models of critical system components have been calibrated by results from testing. Total electricity demand (heat pump, circulation pumps, auxiliary heater, external air cooler) with subtracted PV production used for system is $1069 \mathrm{kWh} / \mathrm{a}$ and the system operates with seasonal performance factor $S P F=6.1$. The system operates with very low energy demand outside the heating season and monthly SPF values are above 30 (see Fig. 3). Advanced control of compressor allows the operation of system completely with use of PV electricity for charging of combined storage tank and for charging of ground storage. Coverage of energy demand for system operation by renewable energy achieves about $83 \%$. Thus the specific demand of non-renewable primary energy for the space heating and hot water preparation for given family house is under limit of $20 \mathrm{kWh} / \mathrm{m}^{2}$.a and house reaches reliably NZEB requirements for oceanic climate zone. Moreover, this value results from realistic balance of energy utilization, not from fictive balance of PV electricity export to the external electric grid and annual electricity import. 

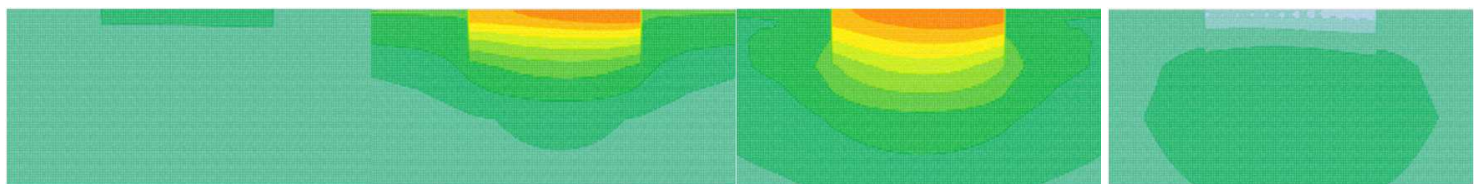

Fig. 4: Charging and discharging of ground seasonal storage during the year (March, June, September, December)

Fig. 4 shows the simulation results for the ground storage charging/discharging during the year. The highest temperature in the ground storage occurs in September, lowest in December. The thermally insulated foundations are clearly visible in the figures. Fig. 5 shows the course of average temperature in the ground storage mass within foundations during the year.

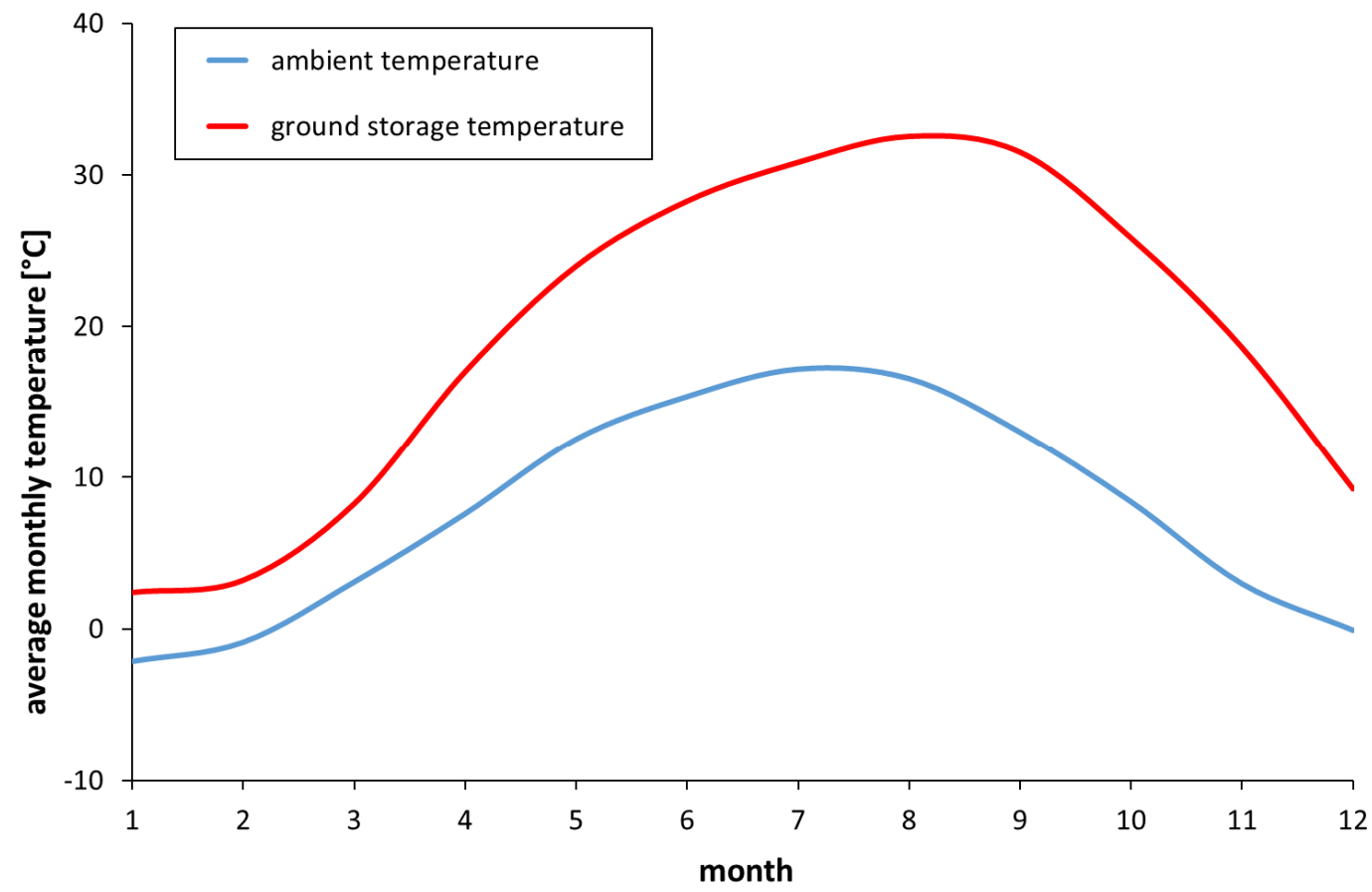

Fig. 5: Temperature in the ground storage during the year

\section{Demonstration and monitoring}

The main components of the energy system: heat pump with desuperheater and varable speed compressor, combined storage tank with division plate and underground storage have been developed, built, tested and installed in respected family house in Hamry (Hlinsko, CZ) during season 2016 / 2017. Whole system has been connected to intelligent controller and monitoring system. With a respect to demonstration nature of the energy system, specific components were installed in addition to proposed system to allow the experiments, further development and optimization of critical components. Central water storage tank and back-up ground loop has been applied. Scheme of realized demonstration system is shown in Fig. 6.

Heat pump installed in machinery room of the house (see Fig. 7) extracts the heat from air cooler or central water storage to which heat from seasonal ground storage and back-up loop (in case of insufficient temperature in ground storage) is delivered. Controller automatically runs the ground heat sources according to priority and set temperature difference (winter season). Surplus electricity production from PV system is converted to heat by a heating element in central water storage in summer season and heat is be delivered to evaporator of heat pump or to ground storage. Simultaneously, the heat from ambient air can be pumped through combined storage tank to charge the seasonal ground storage. Space heating, ventilation and hot water heating loops are connected to combined storage tank. Heat pump is connected to combined storage tank by 4 pipes for separate charging of hot water zone and space heating zone. Controller allows charging of the space heating zone by condensation heat while hot water zone is charged by heat from desuperheater to high temperature (more than $60{ }^{\circ} \mathrm{C}$ ). Controller evaluates required setting of compressor speed according to measured PV system power and power input of the compressor, in order that heat pump is not consuming any external grid electricity during the ground storage 
charging. Similar strategy is used in case of overheating of combined storage tank above standard set-point in case of sufficient PV power.

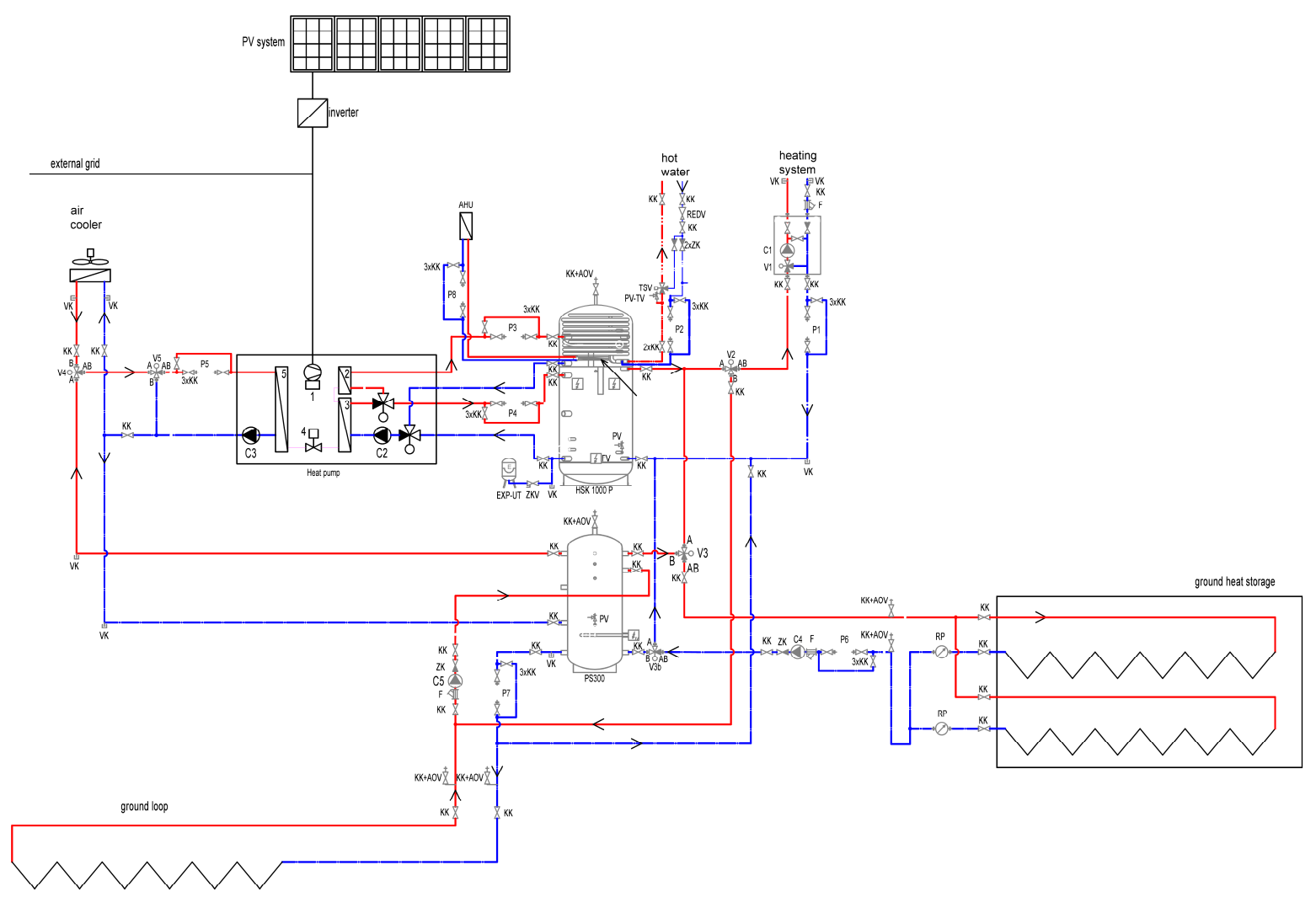

Fig. 6: Scheme of realized demonstration system

PV system has been commissioned in October 2017. Charging of seasonal ground storage has started late and it was not possible to reach sufficiently high temperature for winter operation. Therefore the system was running during winter in emergency regime with use of back-up ground loop periodically alternating with seasonal ground storage. Because both the back-up loop and loops for ground storage are operated with water (not antifreeze), controller precisely evaluates operation temperatures at evaporator and central water tank, in order not to go under freezing temperature. Controller starts the heat pump with minimum rotations $20 \mathrm{~Hz}$ to avoid sudden coolingdown at evaporator.
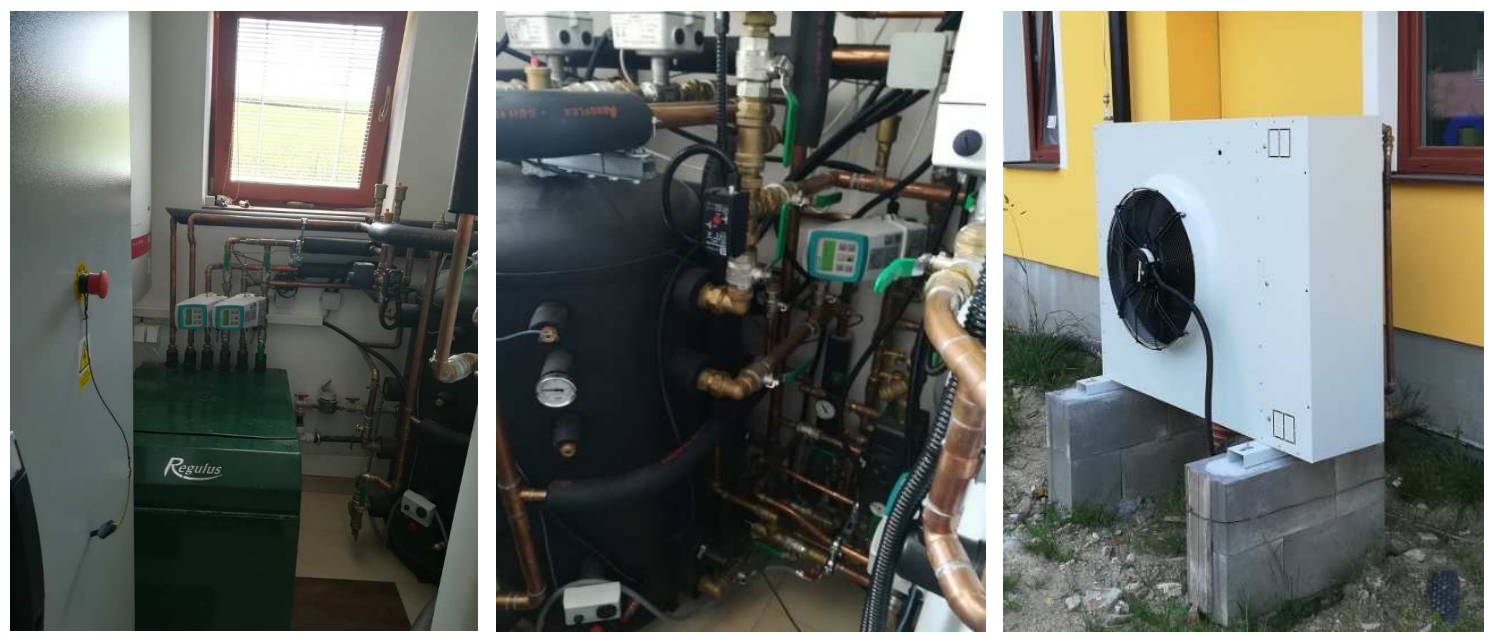

Fig. 7: Heat pump, storage tanks and external air unit for heat pump

The whole energy system is monitored and evaluated. The monitoring system includes the energy balance of PV system, heat pump, hot water and space heating system. Flowrates and temperatures are monitored in each of operation loops and storage tanks. Temperature field in seasonal ground storage is monitored by 5 vertical 
borehole probes with temperature sensors in 5 heights with $1 \mathrm{~m}$ distance. The probe \#1 is located in the centre of the ground storage. Moreover, the heat pump has own monitoring of internal refrigerant loop. Measured data are saved and accessible via webserver of Regulus company for the research purposes.

Fig. 8 includes the graph with main quantities to show the function of ground storage charging by heat pump during one selected day (April 2018). Heat pump delivers heat into combined storage tank, from which it is extracted and fed into ground storage. From the comparison of PV power and heat pump power input during charging, there is an evident speed control of the compressor and adaptation of compressor power input to PV power output with a certain provision, that the heat pump will never use external grid electricity when charging the ground storage by extracted ambient heat. Electric power input of the heat pump slightly increases during the charging, which is associated with increase of operation temperature.

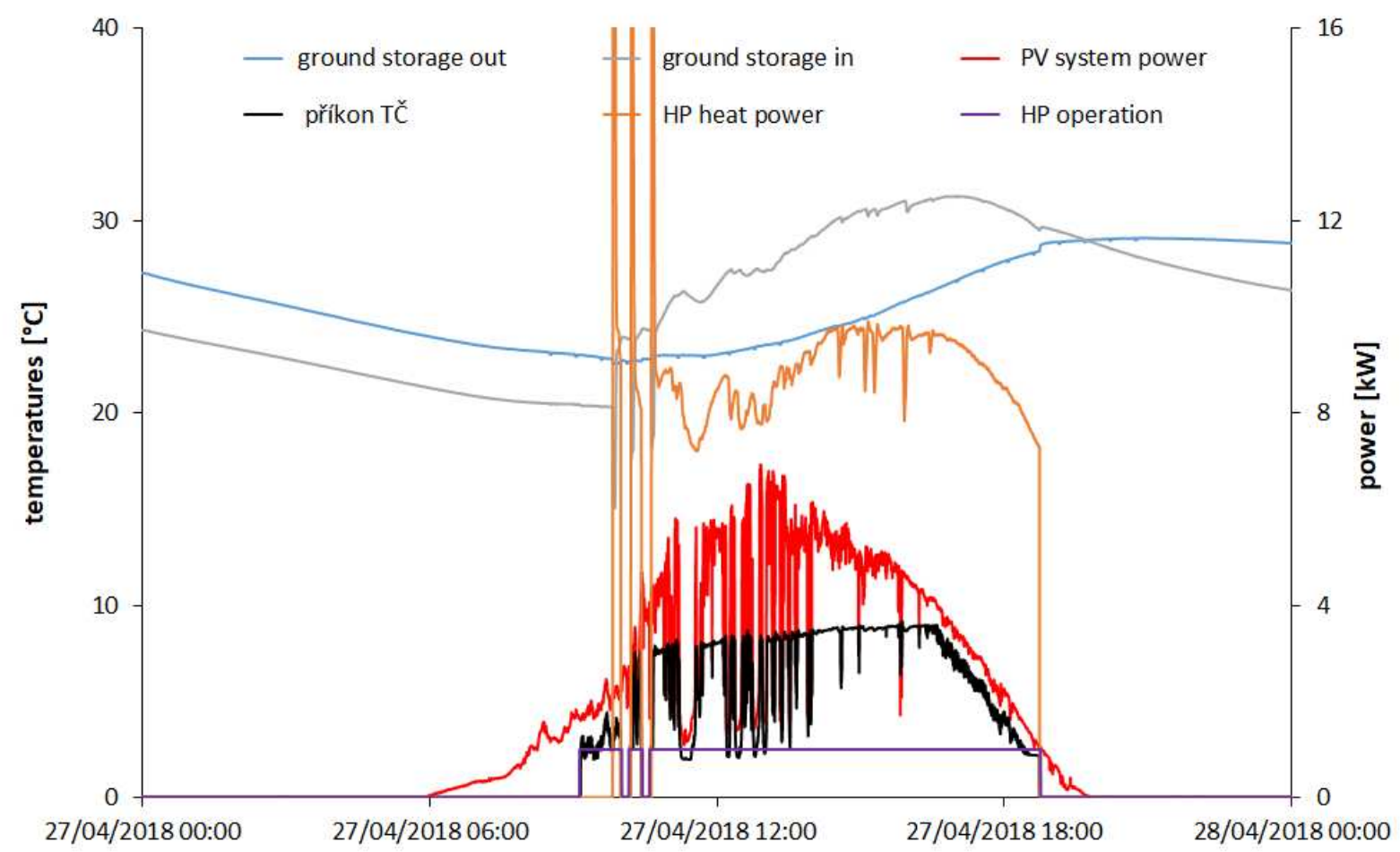

Fig. 8: Adaptation of heat pump power input according to PV system output during ground storage charging

For the same day, Fig. 9 shows the function of desuperheater. While condenser output temperature during the ground storage charging is maintained at low value close to condensing temperature, three-way valve integrated in the heat pump controls the flowrate from condenser output to desuperheater by PID algorithm. Output from desuperheater has then significantly higher temperature than the condenser output. While condenser output is supplied into ground storage through space heating zone of combined storage tank, desuperheater output is led into hot water zone of storage tank. Temperature of the water in hot water zone is about $65{ }^{\circ} \mathrm{C}$ at the end of heat pump operation.

The graph in Fig. 10 represents the time course of the temperatures in seasonal ground storage in period of October 2017 to end of August 2018 for a borehole probe \#1 located in the central part, in the layers of 1, 2, 3, 4 a 5 meters under the base slab. While the temperature is varying during charging and discharging in the upper layer with installed pipe heat exchanger, the temperature increase is supressed in deep layers. There are also visible the fallouts of the monitoring during the season. Temperature in upper layer of seasonal ground storage has decreased down to $7{ }^{\circ} \mathrm{C}$. Back-up ground loop and seasonal storage was a heat source for the heat pump during winter. From the beginning of March 2018 the charging of the seasonal storage has been started again and achieve at the end of August almost $30^{\circ} \mathrm{C}$, which is in good correlation with a simulation. 
T. Matuska et. al. / EuroSun 2018 / ISES Conference Proceedings (2018)

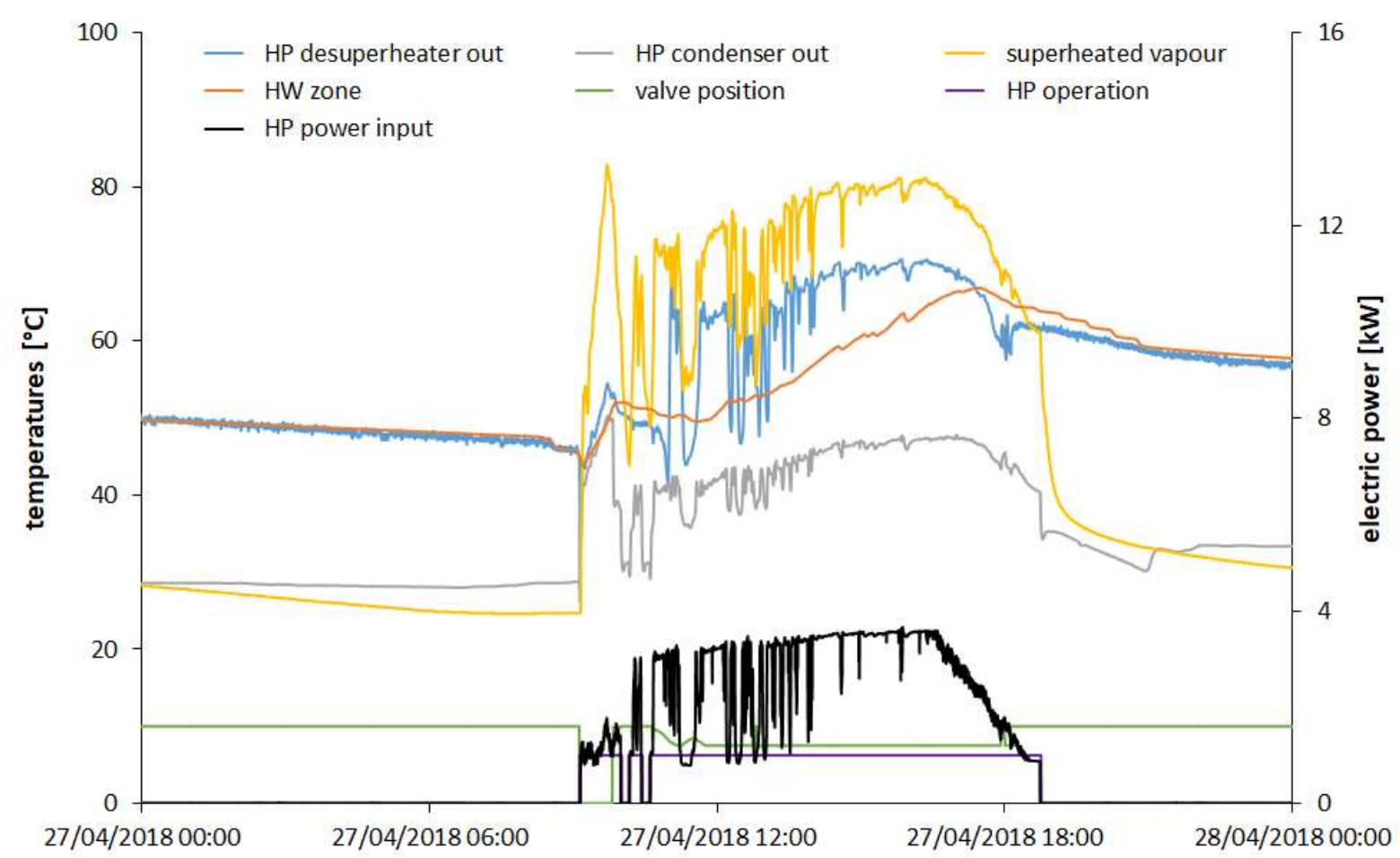

Fig. 9: Desuperheater function for hot water preparation during the charging of ground storage

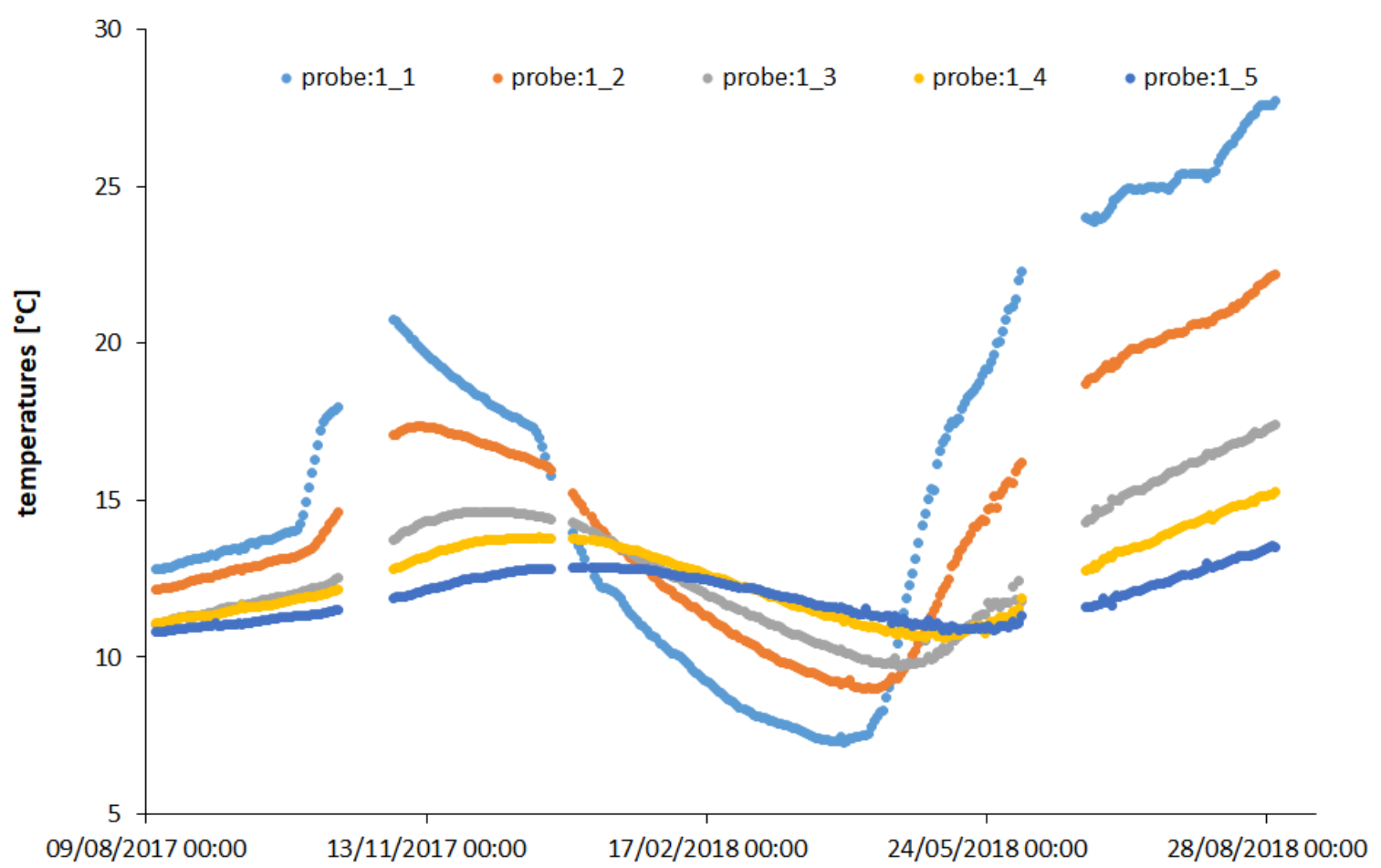

Fig. 10: Temperatures in the central part of the ground storage

\section{Conclusion}

The energy system combining the advanced heat pump, PV system and low cost seasonal ground storage under the house has been proposed. The simulations have shown significantly reduced electricity demand from external grid. Coverage of energy demand for system operation by renewable energy achieves about $83 \%$ and the specific demand of non-renewable primary energy for the space heating and hot water preparation for given family house 
fall far under NZEB requirements.

The system has been demonstrated and the monitoring of functionality runs for the first season. The system has been operated in "emergency" mode during the first winter because ground storage was insufficiently charged due to late installation of PV system. However, the experience was positive, the ground water loops delivered enough energy for the house without freezing even in the climate area of highlands. The new charging cycle has started in spring 2018 and at the end of August almost reaches the predicted value (about $2 \mathrm{~K}$ lower). Results of monitoring has also shown the function of advanced components as charging of the ground heat storage by heat pump with adapting of power input to PV system power output or use of desuperheater for hot water preparation in storage tank at high temperatures without increase of electricity consumption.

\section{References}

Directive 2010/31/EC (EPBD), of European Parliament and of the Council of 19 May 2010 on the energy performance of buildings (recast).

Molenbroek, E., Stricker, E., Boermans, T., 2011. Primary energy factors for electricity in buildings. Toward a flexible electricity supply. Ecofys.

Commission Recommendation (EU) 2016/1318 of 29 July 2016 on guidelines for the promotion of nearly zeroenergy buildings and best practices to ensure that, by 2020 , all new buildings are nearly zero-energy buildings, C/2016/4392.

Transient System Simulation Tool - TRNSYS 17.1, 2014, The University of Wisconsin, Madison, http://sel.me.wisc.edu/trnsys.

This work has been supported by the Ministry of Education, Youth and Sports within National Sustainability Programme I, project No. LO1605. 


\title{
Towards Automated Continuous Performance Benchmarking of DHW and Combi Systems
}

\author{
Christoph Schmelzer ${ }^{1}$, Matthias Georgii ${ }^{1}$, Oleg Kusyy ${ }^{1}$, Janybek Orozaliev ${ }^{1}$ and Klaus Vajen ${ }^{1}$ \\ 1 Institute of Thermal Engineering, University of Kassel, Germany
}

\begin{abstract}
Aiming at automated continuous performance benchmarking of domestic hot water (DHW) and combi systems, a performance control method based on FSC correlations is presented in this paper. The main influencing quantities on the scattering of the underlying FSC correlations are investigated, discussing the practicability of the method and evaluating possibilities to improve it.
\end{abstract}

Keywords: Solar heating, yield control, function control, monitoring

\section{Introduction}

Solar thermal systems for single family houses are usually equipped with an auxiliary heating system which is able to cover the whole heat demand on its own. Hence, faulty design or operation of the solar part of the heating system often remains undetected by the end user, at least for a longer period. To avoid increased consumption of auxiliary heat and to enhance the trust of the users in solar thermal systems, an automated function and yield control is desirable. However, only measuring the solar yield is not sufficient, as design and operation faults outside the solar loop may affect the overall system performance. For example, a faulty installation or controller setting may lead to a situation where too much of the storage is heated by the auxiliary heater, significantly reducing the amount of energy the solar collector can contribute. Therefore, it makes sense to rate the overall system performance. But even if the actual heat demand is measured and the fractional auxiliary energy savings $\mathrm{f}_{\text {save }}$ are calculated (with an appropriate reference auxiliary heat), these values cannot be used directly to compare different systems with each other. Furthermore, one still misses the evaluation whether the yielded $\mathrm{f}_{\text {save }}$ values are in the expected range, since they also depend on the operating conditions like actual load and irradiance. Therefore, it is the goal to develop a performance benchmarking method, which can rate the system performance and allows the comparison between different systems.

\section{Basic Method}

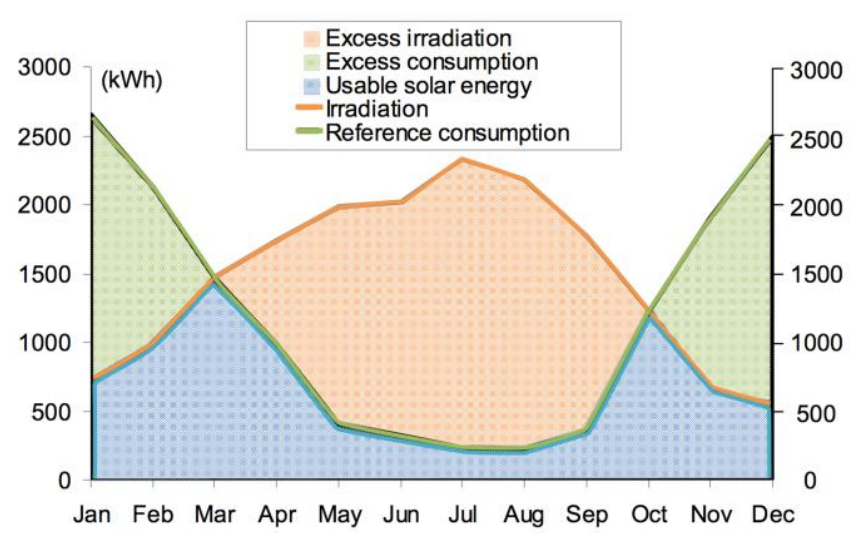

Fig. 1: Monthly energy consumption in contrast to usable and excess solar radiation for a specific building, dhw demand, collector area, slope and tilt (Letz, 2002)
Starting point for the performance benchmarking method is the Fractional Solar Consumption (FSC) method that was developed in IEA SHC task 26 to compare solar combi systems with different system designs and between different locations in Europe (Letz, 2002). Fig. 1 shows the underlying principle of the calculation. To define a usable solar energy ( $E_{\text {sol,use, blue area), the total }}$ irradiation on the collector area (orange area) is compared to the load (green area) on a monthly basis, hence taking into account that solar excess radiation in summer cannot be use.

FSC does not depend on any system design aspects except the collector area, but on the total irradiation on the collector area and the load. Therefore, it describes the energetic boundary conditions for the system. Effects of storage are not considered in FSC. For every system type, a correlation can be seen between $\mathrm{f}_{\text {save }}$ and FSC. This means that 
the expected fractional energy savings $\mathrm{f}_{\text {save,expected }}$ for a system can be derived in dependence of its actual irradiation (location) and actual load without an expensive individual simulation, allowing to compute a comparable performance indicator that relates the measured auxiliary energy savings to the expected values.

To calculate FSC, first the monthly energy sums are compared to each other, to determine the maximum usable solar energy:

$E_{\text {sol, use }}=\sum_{i=1}^{12} \min \left[\left(A_{c o l} \cdot H_{t, i}\right), Q_{r e f, i}\right]$

The heat demand $Q_{r e f, i}$ is calculated as a fossil reference heating system considering domestic hot water demand $(d h w)$, space heating $(s h)$ and storage losses (loss) for each month $(i)$ :

$Q_{\text {ref }}=\sum_{i=1}^{12} \frac{Q_{d h w, i}+Q_{s h, i}+Q_{\text {loss }, i}}{\eta_{\text {boiler }, \text { ref }}}$

Eventually, the Fractional Solar Consumption is calculated by dividing the useful solar energy by the reference energy demand:

$F S C=\frac{Q_{\text {sol,use }}}{Q_{\text {ref }}}$

The FSC value therefore depends on collector area, location (e.g. solar radiation) and reference energy demand but is independent of system design, etc. It describes the energetic boundary conditions under which a system works.

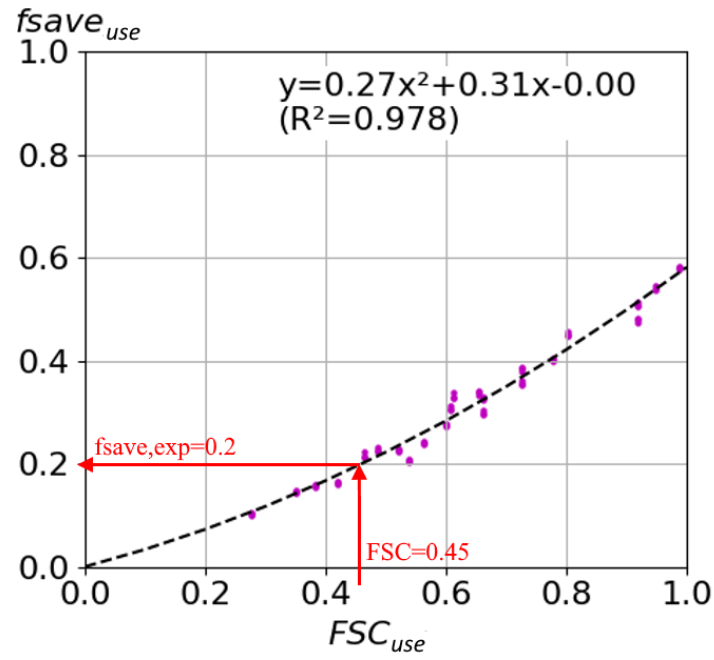

Fig. 2: FSC-fsave-correlation for a specific solar combi system $\left(\mathbf{e x t}_{\text {sol }}+\mathbf{e x t}_{\mathrm{dhw}}\right.$, see below), every dot represents an annual simulation with different boundary conditions
For every system type, a correlation is found between $\mathrm{f}_{\text {save }}$ and FSC. As fig. 2 shows, this relationship can be used to directly estimate the expected yearly $\mathrm{f}_{\text {save }}$ value for a given FSC value, without the need for dynamic system simulations.

To determine the FSC, the heat demand for space heating and domestic hot water and the solar radiation must be measured. Comparing the expected $f_{\text {save }}$ to the measured one, the actual system performance can be benchmarked. By including the heat delivered by the (fossil) boiler and the heat demand into the calculations, the whole system is evaluated and not just the solar circuit.

It should be noted, that former publications concerning the FSC method always calculate their key figures using final energy, given as gas or oil consumption. The current approach for expanding the method for fault detection is based on usable energies, taking into consideration only the energies really delivered to or taken from the storage. In this way, no assumption concerning the boiler efficiency has to be made.

\section{FSC correlations for solar combi systems}

\subsection{Modeling}

Starting point for the simulation-based approach was the TRNSYS deck for solar combi systems developed in IEA task 32. This system, shown in fig. 3, was slightly adjusted and then used as starting point for every new hydraulic scheme, to ensure the comparability. 


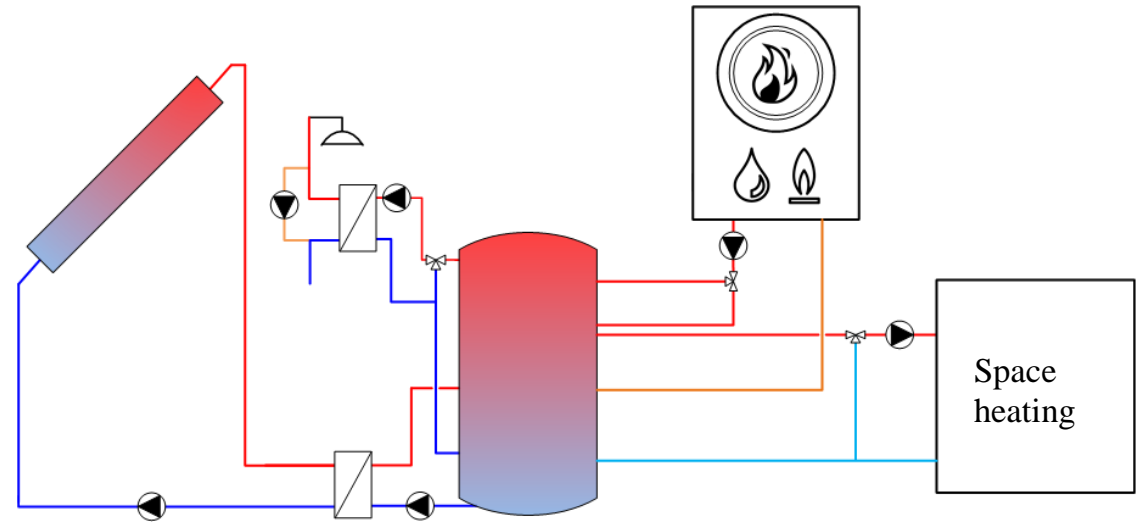

Fig. 3: Hydraulic scheme of system $\left(\mathbf{e x t}_{\text {sol }}+\mathbf{e x t}_{\text {dhw }}\right)$

System (ext $\left.\mathrm{sol}_{\mathrm{s}}+\mathrm{ext}_{\mathrm{dhw}}\right)$ consists of a central buffer storage. The solar system provides energy via an external heat exchanger, while the boiler is directly connected to the storage. Domestic hot water preparation is implemented using a fresh water station, while the space heating loop is directly connected. More details especially concerning the control strategy for the different circuits can be found in (Heimrath \& Haller, 2007).

The second standard combi system (ext sol $^{+}$ ext $_{\text {dhw }}+\mathrm{RLA}$ ) uses the principle of return flow boosting. As shown in fig. 4, solar system and dhw preparation did not change, but the space heating circuit is not directly connected to the storage any more. If the space heating loop is in operation and the storage exceeds the return flow temperature (+hysteresis), the return flow is sent through the storage. Following, the auxiliary heater only needs to provide the additional heat demand to reach the desired flow temperature.

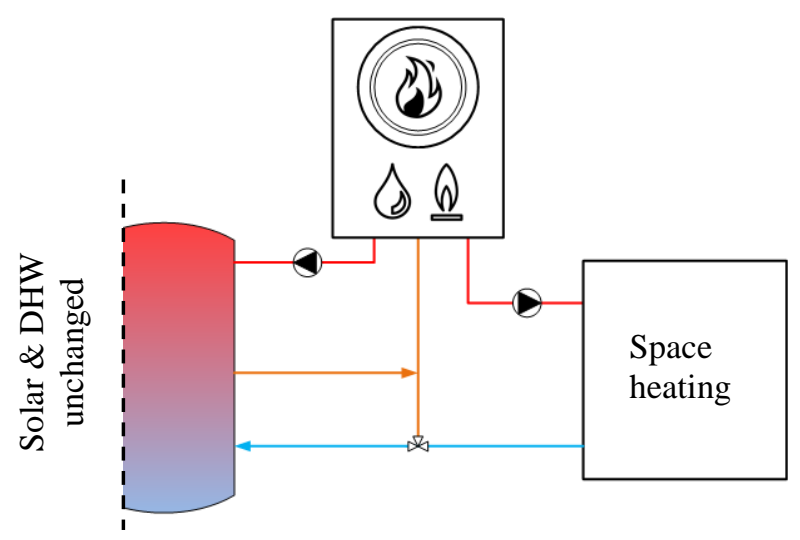

Fig. 4: Hydraulic scheme of system $\left(\mathrm{ext}_{\mathrm{sol}}+\mathrm{ext}_{\mathrm{dhw}}+\mathrm{RLA}\right)$

The last standard combi system (int sol + int $_{\mathrm{dhw}}$ ) uses internal heat exchangers in the solar circuit and for domestic hot water preparation (fig. 5). The solar heat exchanger is located in the lower part of the storage while the dhw heat exchanger runs through the whole tank. In contrast to the other combi systems, system $\left(\right.$ int $_{\text {sol }}+$ int $_{\text {dhw }}$ ) does not have a dhw circulation. This would cause a mixing of the thermal storage, reducing the solar gains (see below, application example).

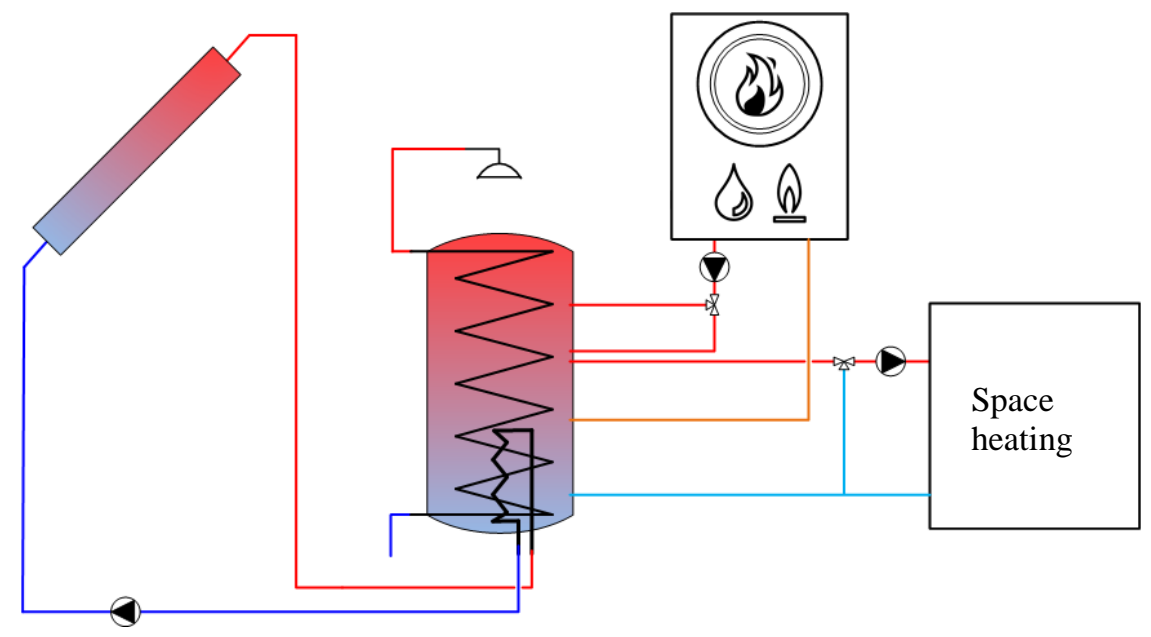

Fig. 5: Hydraulic scheme of system (int sol $_{\text {oint }}+\mathrm{dhw}_{\text {}}$ ) 


\subsection{Correlation and influencing factors (ext $\left.t_{s o l}+e x t_{d h w}\right)$}

On this basis, parametric studies were performed, varying important system and operation parameters like:

- Location: Stockholm (Sweden), Würzburg (Germany), Madrid (Spain)

- Space heating demand (building type): $30,60,100 \mathrm{kWh} /\left(\mathrm{m}^{2} \mathrm{a}\right)$ [calculated for Germany], special buildings for Spain

- Collector area: $5 . .50 \mathrm{~m}^{2}$

- Collector tilt: $30,45,70^{\circ}$

- $\quad$ Specific mass flow rate in solar loop: $10 . .30 \mathrm{l} /\left(\mathrm{m}^{2} \mathrm{hr}\right)$

- Boiler supply temperature: $63 . .75^{\circ} \mathrm{C}$

- Specific storage size: $40 . .100 \mathrm{l} / \mathrm{m}^{2}$ coll

- Domestic hot water profile and demand: $100 . .400 \mathrm{l} / \mathrm{d}$

- Auxiliary heated storage volume: 50,100, 1501

This results in about 3.500 system simulations for each hydraulic scheme, producing $>10 \mathrm{k}$ simulation outputs to be analyzed. This broad approach was chosen, to make sure, that the important and influential parameters are identified in the process.

Fig. 6 shows a selection of simulation results to illustrate the total scattering caused by the broad approach of the parametric study. As indicated by the dotted lines and the black arrows, a performance benchmarking is not reasonable on this basis. For a fixed FSC, there would be a bandwidth of expected energy savings of 18 to $30 \%$. Fortunately, many of the influencing parameters can be fixed. The boiler supply temperature can be easily measured while in operation and the dhw demand must be measured/calculated anyway. Moreover, the storage size should be one easy parameter to be known (e.g. given by the installer/plumber). If these parameters are fixed, the scattering decreases significantly, as shown in fig. 7. For the remaining points, correlation parameters for the quadratic regression can be found, that depict the relationship quite good.

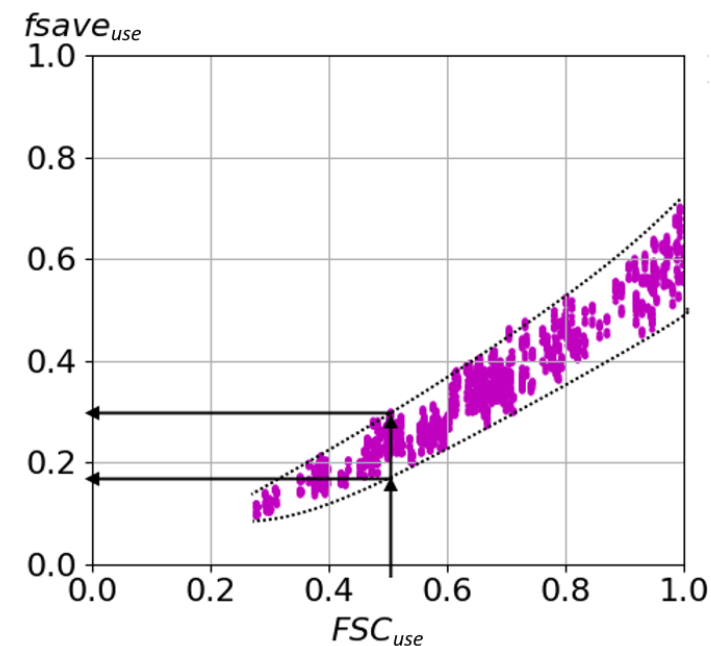

Fig. 6: FSC-fsave-correlations for system $\left(\operatorname{ext}_{\text {sol }}+e x_{\text {dhw }}\right)$, total scattering of parametric study

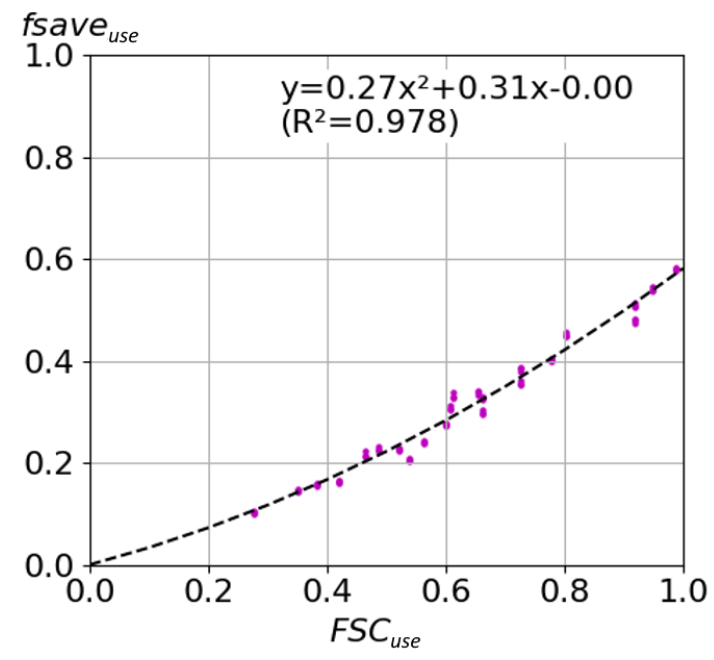

Fig. 7: FSC-fsave-correlations for system $\left(\mathbf{e x t}_{\text {sol }}+\operatorname{ext}_{\text {dhw }}\right)$, filtered by influencing factors

Unfortunately, it turned out, that the auxiliary heated storage volume and the storage heat loss rate also have a significant influence on the scattering, which are unlikely to be known. Other parameters, like location (weather), collector area, specific flowrate (solar), tilt and azimuth have proven to be unproblematic and only shift the points along the quadratic correlation curve. 


\subsection{Joint correlation for combi systems}

Comparing the different combi systems to each other, the correlations turned out to be sensitive to the same parameters. If these influencing parameters remain fixed and key figures are calculated with the same reference heating system, the combi systems can be described by the same correlation as shown in fig. 8. The figure shows the expected $f_{\text {save }}$ plotted against the FSC for each system simulation. It is to be mentioned, that the simulation results for system $\left(\right.$ int $_{\text {sol }}+$ int $_{\text {dhw }}$ ) tend to be slightly higher. This is caused by the absence of dhw circulation. As the figure shows, there is only little scattering among the different combi system designs. In comparison to the scattering caused by variation of influencing parameters, e.g. the boiler supply temperature, the scattering caused by different system design is negligible.

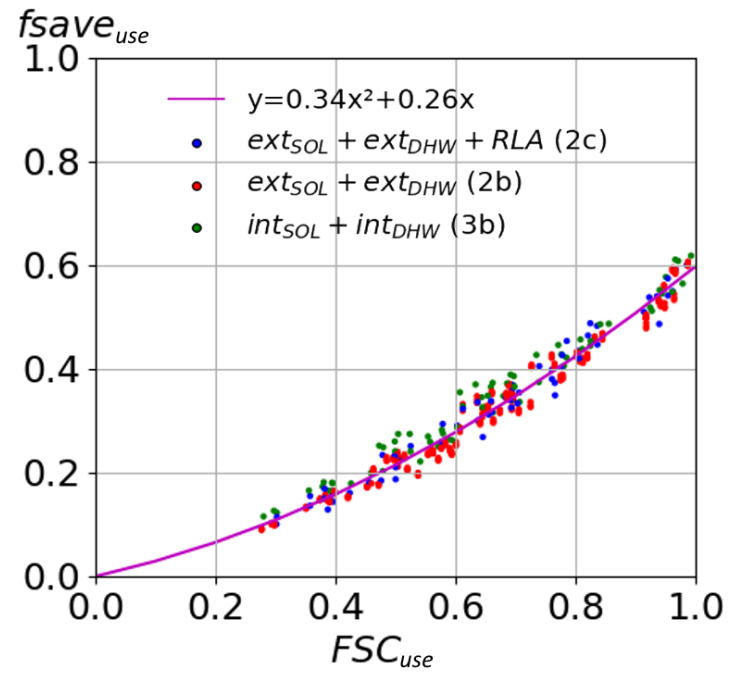

Fig. 8: Joint FSC-fsave-correlations for all investigated solar combi systems

\section{Application for automated performance benchmarking}

To illustrate the basic principle, fig. 9 shows the correlation for the combi system design (int sol + int $_{\text {dhw }}$, see above): Solar heat is transferred to the heat storage by means of an internal heat exchanger, and domestic hot water (DHW) is also prepared via an internal heat exchanger that spreads over the whole storage height. Dots in fig. 9 show the system performance at different loads, collector areas and tilts and at different locations, where the storage size is adapted to the collector area. The blue dots represent normal operation and they are close to the expected performance described by a correlation curve (magenta line). The red triangles represent faulty systems with an installed domestic hot water circulation, so that the circulating hot water always heats the lower part of the storage, thereby decreasing the amount of energy the collectors can contribute. The red triangles lie well below the correlation curve and the FSC-based performance benchmarking method can identify these systems as faulty.

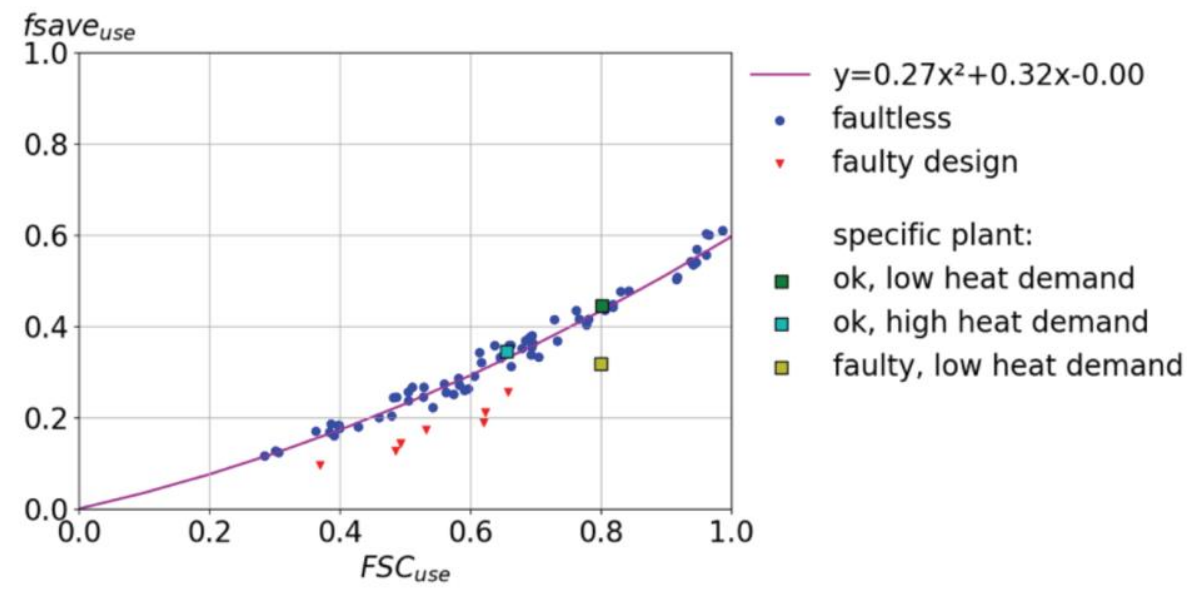

Fig. 9: Correlation for system with internal heat exchangers for solar input and DHW preparation (blue dots), and operating points for faulty designs that implement a DHW circulation that continuously heats the whole storage

To further illustrate the procedure, fig. 9 shows the performance of a certain combi system at three conditions. The green square represents a faultless combi system for a building with space heat demand of $30 \mathrm{kWh} / \mathrm{m} 2$. If the space heat demand is rather $60 \mathrm{kWh} / \mathrm{m} 2$, both fsave and FSC change, but the resulting point (cyan) still lies on the correlation. Otherwise, if the space heat demand actually is $30 \mathrm{kWh} / \mathrm{m} 2$, but a DHW circulation was installed (= overheated storage), a substantially lower fsave for the same FSC value is obtained (yellow square). The performance benchmarking method will recognize that there is no fault in the first case despite the reduced fsave and that there is a fault in the second case. 


\section{Applicability to solar system for dhw preparation (SDHW)}

FSC was originally developed for solar combi systems. Looking at the market for solar thermal systems (in Germany), the majority of systems is installed in single family houses to support the dhw preparation and not for space heating. Thus, it had to be investigated whether the method is applicable for this SDHW systems as well.

Fig. 10 shows the standard SDHW system that was designed and modeled in TRNSYS. It consists of a small dhw storage with two internal heat exchangers for solar (bottom) and conventional boiler (top). The space heating loop is directly supplied by the boiler. Dhw preparation also includes a circulation pipe.

To ensure a common starting point for all systems this system was also developed using the modified task 32 deck.

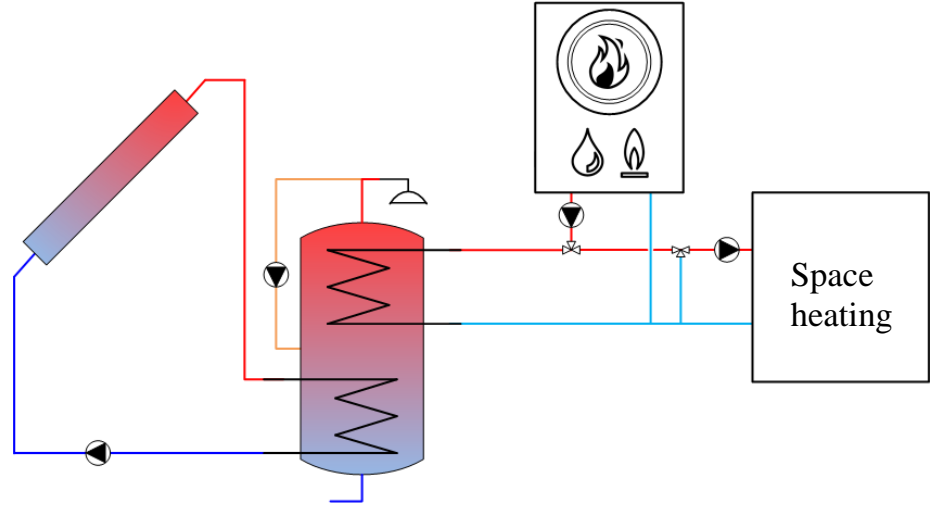

Fig. 10: Hydraulic scheme of SDHW system

To check applicability of the method and to identify influencing parameters, about 3.000 annual simulations were conducted in a first parametric study. Hereby the following parameters were varied:

- $\quad$ Location: Sweden, Germany, Spain

- $\quad$ Collector area: $2.8 \mathrm{~m}^{2}$

- $\quad$ Collector tilt: $30,45,60^{\circ}$

- Boiler supply temperature: $55 . .75^{\circ} \mathrm{C}$

- $\quad$ Specific storage size: $35 . .601 / \mathrm{m}^{2}$ coll

- $\quad$ Domestic hot water profile and demand: $100 . .400 \mathrm{l} / \mathrm{d}$

- $\quad$ Auxiliary heated storage volume: 50, 100, 1501

To illustrate the influences of the different parameters, the following four figures show the scattering of the annual simulations. For each figure, another influencing parameter is fixed to reduce the scattering.

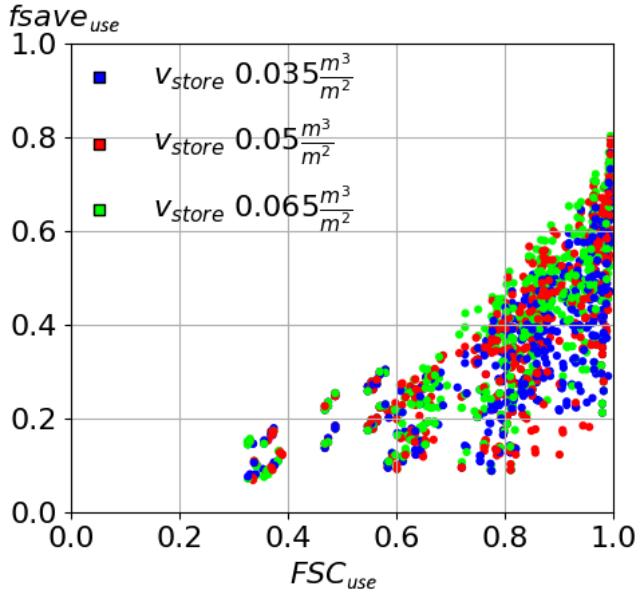

Fig. 11: FSC-fsave-correlations for SDHW system, total scattering of parametric study, $\mathrm{UA}_{\text {store }}$ fixed

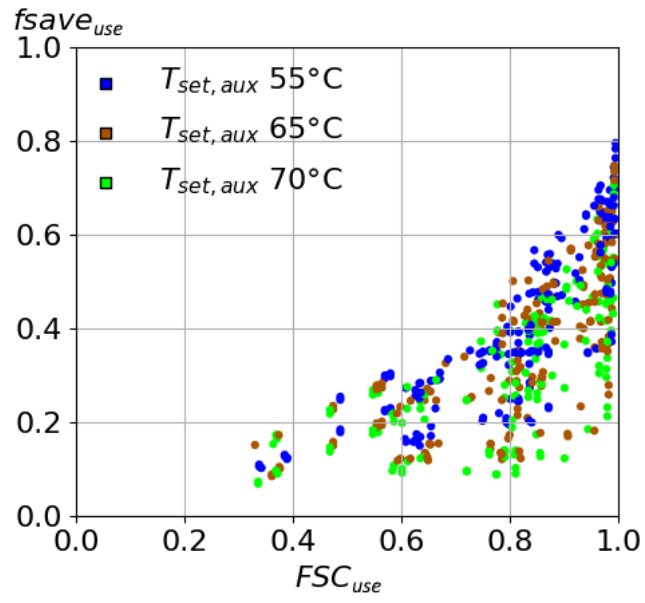

Fig. 12: FSC-fsave-correlations for SDHW system, fixed: $\mathbf{U A}_{\text {store }}, \mathbf{v}_{\text {store }}=\mathbf{5 0} \mathbf{~} / \mathrm{m}^{2}$ coll

Fig. 11 shows the initial bandwidth with all parameters varied. Directly compared to the total scattering for combi systems (fig. 6), the bandwidth here is much wider. This can be explained by the reduced total demand (only dhw instead of dhw and space heating). Even if the absolute effects of certain parameter changes are smaller compared to combi systems, the relative changes are significantly higher, causing a wider scattering. The storage size per $\mathrm{m}^{2}$ collector area is marked with different colors to show the dependency. It can be seen that systems with higher storage 
capacities (50 and $65 \mathrm{l} / \mathrm{m}^{2}$ coll) have a tendency towards higher energy savings. But still there are too many free parameters to build certain clusters. For fig. 12 the storage size was fixed to $501 / \mathrm{m}^{2}$ coll and the boiler supply temperature is marked in three different colors. As expected, systems with a higher boiler supply temperature show a lower fractional energy saving, at least for larger systems with FSC values $>0.5$. For small systems this effect does not seem to be present, which could be explained with significantly undersized solar systems.

For fig. 13, the boiler supply temperature was fixed to $55^{\circ} \mathrm{C}$ and with the daily dhw demand marked in different colors, there are three clusters to be seen. The highest dhw demand leads to higher energy savings and vice versa. The figure shows furthermore, that the scattering is greater if the demand is reduced. While the results for higher demand start at a FSC of about 0.3 , the low heat demand only creates FSC of 0.7 and higher. This can be explained with the definition of FSC and the chosen collector areas (and storage sizes). For the systems with low dhw demand, the radiation on a collector plane of $2 \mathrm{~m}^{2}$ already covers $70 \%$ of the needed energy.

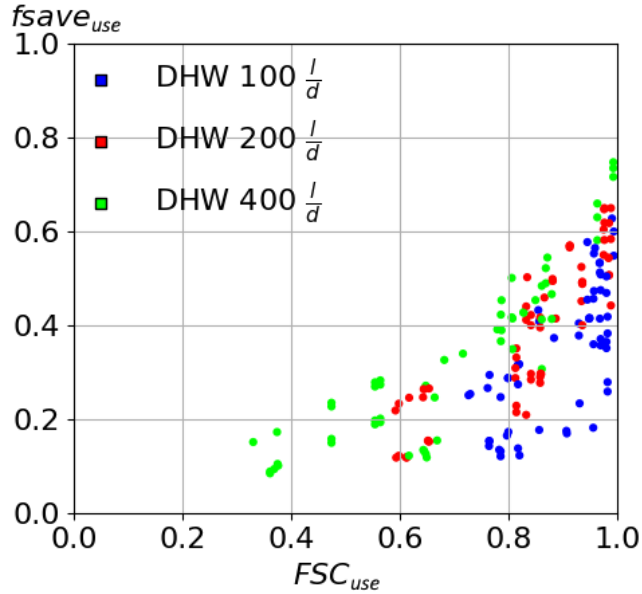

Fig. 13: FSC-fsave-correlations for SDHW system, fixed: $U A_{\text {store }}, \mathbf{v}_{\text {store }}=50 \mathrm{l} / \mathrm{m}^{2}$ coll,,$T_{\text {set,aux }}=55^{\circ} \mathrm{C}$

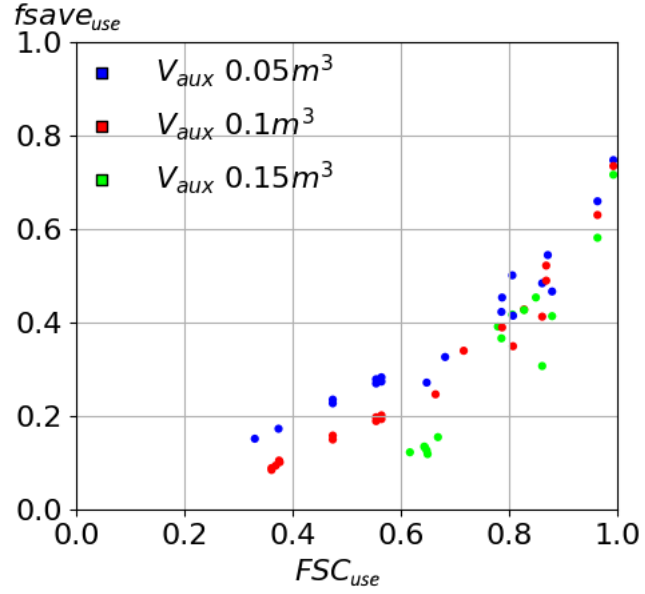

Fig. 14: FSC-fsave-correlations for SDHW system, fixed: $U A_{\text {store }}, v_{\text {store }}=50 \mathrm{l} / \mathrm{m}^{2}$ coll, $T_{\text {set,aux }}=55{ }^{\circ} \mathrm{C}$, dhw $400 \mathrm{l} / \mathrm{d}$

Fig. 14 shows the remaining annual simulations if in the dhw demand is fixed to $400 \mathrm{l} / \mathrm{d}$. The scattering has been reduced significantly, but still there are clusters visible for the different auxiliary heated storage volume. Smaller volumes lead to higher energy savings, because there is a larger part of the storage available for solar energy. In contrast to the tendency before, here the scattering seems to increase for lower FSC values, while the points to the upper right are close to each other. This can at least be partially caused by the overall storage volume. For the smaller systems to the left, the influence of the auxiliary heated volume is bigger, because it makes up a larger part of the storage itself. Towards higher FSC values the collector area and storage size increase and the proportion of auxiliary heated volume decreases, reducing the influence and therewith the scattering.

The overall tendency for SDHW systems, that a lower heat demand leads to more scattering, can be seen in fig. 15 as well. The figure shows a direct comparison of the simulated dhw demands, while the other influencing parameters are fixed.

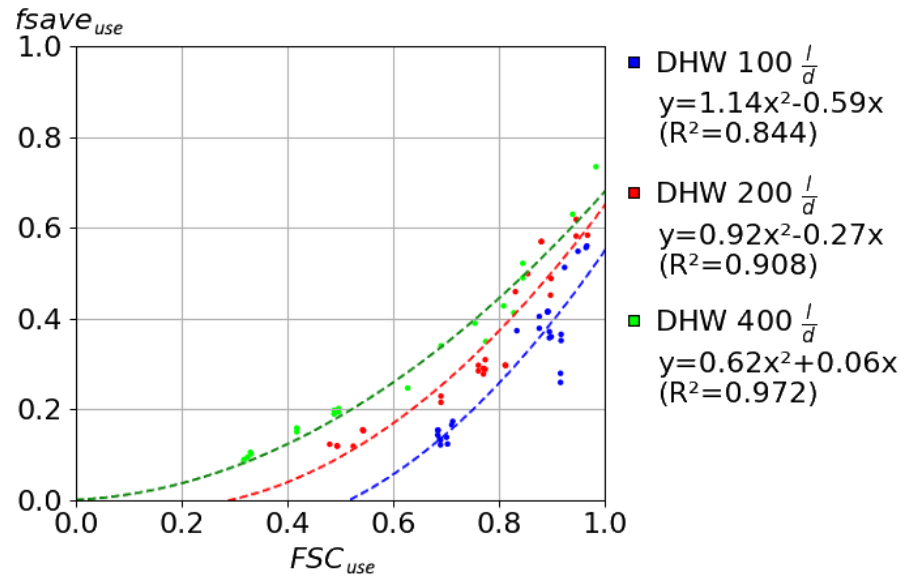

Fig. 15: Different FSC-fsave-correlations for SDHW system depending on the daily dhw demand, fixed: $\mathrm{UA}_{\text {store }}, \mathrm{v}_{\text {store }}=50 \mathrm{l} / \mathrm{m}^{2}{ }_{\text {coll }}, \mathrm{T}_{\text {set,aux }}=55^{\circ} \mathrm{C}, \mathrm{v}_{\text {aux }}=0.1 \mathrm{~m}^{3}$ 


\section{Limitations and outlook}

To benchmark a system performance using the describe method, measurement data of a whole year must be available. Since the FSC method compares energies monthly and the analyzed time period comprises 12 months, this is the starting point of every benchmarking. Subsequently the key figures can be calculated every month to detect decreasing performance, but still 12 months of data must be used. This means that even a total failure of a previously working solar loop has only slow effect on $\mathrm{f}_{\text {save }}$, because over the whole evaluation period of a year, the fault-free operation times dominate initially. Since the idea of FSC is based on seasonal distribution of irradiation and heat demand, the evaluation period cannot be just shortened. Just choosing a shorter period of one month would for example lead to a constant FSC $=1$ for the whole summer. Furthermore, the correlation with $\mathrm{f}_{\text {save }}$ was only shown for yearly evaluation periods. When aiming for shorter evaluation periods, it also has to be taken into account that the effects/state of the heat storage and also the amount of excess heat in summer become more important. To address this issue, new key figures have to be defined and tested.

Concerning the system correlations, it is planned to include the influencing parameters into the calculation via correction functions. Since the combi systems all react sensitive to the same parameters, it is reasonable to assume, that correction functions will affect their correlations in a similar way. If so, the combi systems can be described by just one correlation, which would simplify the necessary steps for performance benchmarking significantly and lead to an easily understandable, unified performance indicator.

For SDHW systems, while FSC correlations can be retrieved with some effort and the definitive need of correction functions, FSC might not be the best parameter to start with when estimating the expected $\mathrm{f}_{\text {save }}$. The underlying reasons are that the proportions of the involved energy flows are quite different, and that the systems typically are not oversized with respect to the average summer demand. Therefore, methods to describe the performance in other parameter spaces are to be investigated.

\section{Conclusion}

The described approach for automated continuous performance benchmarking offers reasonable advantages over other state of the art methods. With the FSC-derived performance indicator a meaningful standalone key figure can be calculated. While other quantities like the saved $\mathrm{kWh} / \mathrm{a}$ or $\mathrm{f}_{\text {save }}$ can only be interpreted by experts or with in depth knowledge of the according system, the performance indicator is self-explanatory. In contrary to the other key figures, it can be used to compare the performance of different systems to each other. Using the FSC-derived performance indicator, the (easy) question, whether a system works well or not can be answered with a simple yes or no. Thus, making the performance benchmarking more attractive to system operators. The FSC based approach offers the benefits of a dynamically calculated key figure, without the need for costly dynamic system simulations.

\section{Acknowledgements}

The research project "SolarCheck" (project number 0325870A) is funded by the Federal Ministry for Economic Affairs and Energy (BMWi). We want to thank the BMWi and the Project Management Jülich (PtJ) for their support. Also, we want to thank our project partners from industry and science: Bosch Solarthermie GmbH, Enertracting GmbH, SOLVIS GmbH, RESOL - Elektronische Regelungen GmbH, Vaillant GmbH, Viessmann Werke GmbH \& Co. KG, WILO SE, Institute of Thermodynamics and Thermal Engineering (ITW) of the University of Stuttgart, INES (Institut National de l'Energie Solaire, France).

\section{References}

Heimrath, R., Haller, M., 2007. Report A2 of Subtask A: The Reference Heating System, the Template Solar System of Task 32. A Report of IEA Solar Heating and Cooling program - Task 32 "Advanced storage concepts for solar and low energy buildings", URL: http://task32.iea-shc.org/Data/Sites/1/publications/task32-Reference_Heating_System.pdf (last accessed 20.11.2018)

Letz, T., 2002. Validation and background information on the FSC procedure. A Report of IEA SHC Task 26 - Solar Combisystems. URL: http://task26.iea-shc.org/Data/Sites/1/publications/task26-validation_and_background_information.pdf (last accessed 20.11.2018) 


\title{
Single Source "Solar Thermal" Heat Pump for Residential Heat Supply: Performance with an Array of Unglazed PVT Collectors
}

\author{
Christian Schmidt, Arim Schäfer, Korbinian Kramer \\ Fraunhofer-Institute for Solar Energy Systems ISE, Freiburg, Germany
}

\begin{abstract}
This work deals with the results of experimental measurements of a novel solar heat pump based heating supply concept for residential heat supply. The constructed load case aims at supplying heat for a single-family house with a moderate heat demand of $45 \mathrm{kWh}$ per $\mathrm{m}^{2}$ and year. An extreme system design case was measured comprising an array of rear insulated uncovered photovoltaic thermal (PVT) collectors, a brine/water heat pump with deactivated resistance heaters and extended temperature range on the evaporator side, and a two-zone combi storage. The main innovation is to operate the PVT array as the sole heat source for the heat pump and accordingly with extended collector loop temperatures below the freezing point. Performance analysis was carried out on two characteristic cold winter test days. Measurement results show that the present system configuration is able to cover the heat demand comprising domestic hot water and space heating. Analysis of the cold winter test days reveal that insignificant icing occurred on the surface of the collectors, and heat demand was met completely. Temperature comfort levels were reached for space heating and with few limitations for domestic hot water delivery. Improper system design was detected, discussed and several concrete optimization potential measures were identified. One was illustrated for a particular night time heat exchange operation on a test day in spring: A significant source temperature increase of $10 \mathrm{~K}$ can be expected, if an array of rear non-insulated PVT collectors would be used instead. For a summer test day with electricity data available, component and system performance figures were calculated.
\end{abstract}

Keywords: solar thermal, heat pump, solar only, single source, photovoltaic thermal collector, PVT

\section{Introduction to solar thermal heat pump systems}

\subsection{System concepts}

In residential heating systems comprising domestic hot water preparation, solar thermal collectors are usually combined with a fossil back up. Replacing the fossil boiler with a heat pump provides the possibility to boost the renewable share of these heating systems. In such a solar and heat pump (SHP) system, solar thermal collectors and the heat pump supply energy for space heating and/or hot water independently of the source(s) of the heat pump. Heating systems with this kind of operation mode were defined as "parallel" within the work of the Task 44/Annex 38 "Solar and Heat Pump" of the Solar Heating and Cooling program of the International Energy Agency (T44A38). In the "serial" configuration the solar thermal collector acts as a source of the heat pump, either exclusively or additionally (Hadorn, 2015). In general, in SHP systems, both, parallel and serial operation modes can be realized within one system (Fig. 1, left). The SHP system investigated in this work is a combined parallel/serial solar thermal heat pump system (Fig. 1, right) with an array of unglazed PVT collectors.

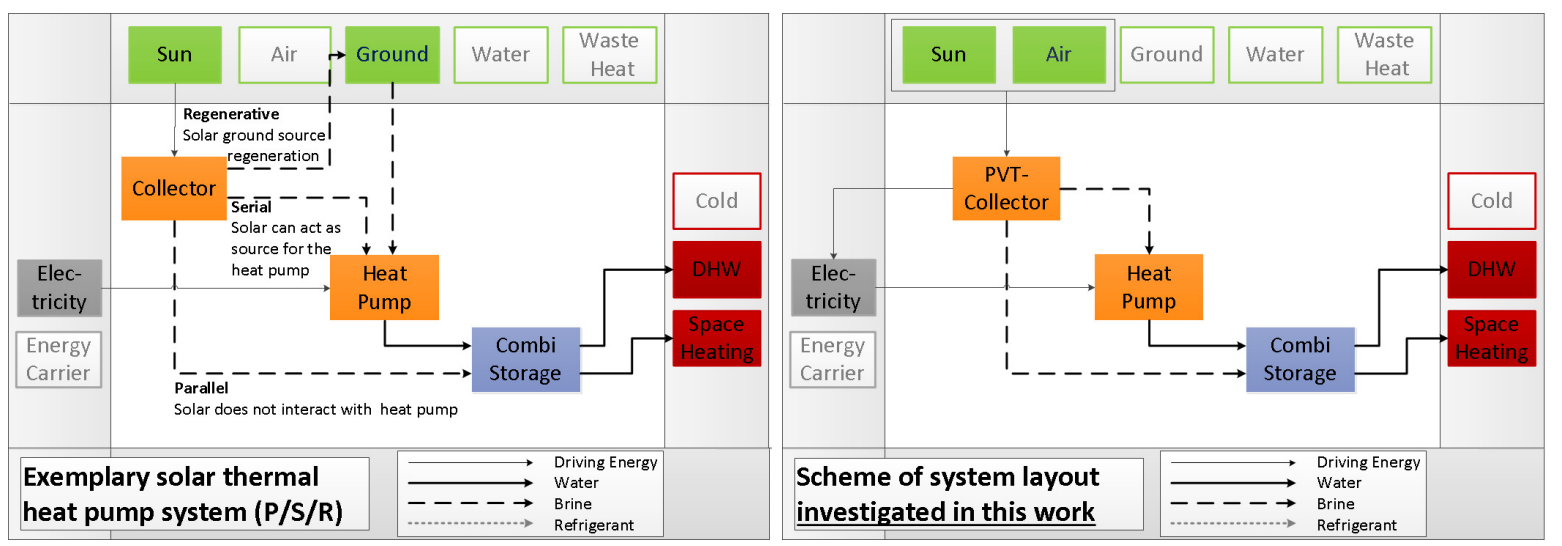

Fig. 1: The left scheme shows an exemplary parallel/serial solar thermal heat pump system according to T44A38 visualization scheme with costly energy sources on the left bar, free energy sources on the top bar, and useful energy sinks on the right bar. The right 
scheme shows the combined parallel/serial solar thermal heat pump system investigated in this work. Similar to the example on the left, this system has access to two heat sources via the PVT collector array.

\subsection{Market barriers}

The T44A38 market research conducted in 2011/2012 found 135 solar thermal heat pump system configurations offered by different suppliers and manufacturers (Ruschenburg, Herkel et al., 2013). Results of T44A38 have shown that there are promising systems in terms of energy performance in both, serial and parallel (and regenerative) configurations (Hadorn, 2015). For illustration purposes, Fig. 2 shows the operating temperatures of the main components, solar part and heat pump with either air or ground source, of said SHP configurations ("state of the art"). It can be seen that in (regenerative and) serial SHP configurations, controller and system design rule out operation temperatures below zero degrees in the solar loop. Manufacturers may shy away from the risk of formation of ice. On the one hand, the performance of unglazed solar collectors under operating conditions below the frost point was investigated in the past i.e. in (Massmeyer and Posorski, 1982) or more recently in (Bunea, Perers et al., 2015), but studies with operation of entire systems are still rare. Hence, a second heat source is required to cover the remaining (high) heat demand during cold weather periods. A consequence is that the utilization ratio of the solar array is greatly reduced by limiting the operating temperatures of the collector field above the freezing point (i.e. $<2{ }^{\circ} \mathrm{C}$ ). As a result, the solar fraction of these systems would be in a similarly (low) range as for conventional solar thermal combi systems with fossil back up heater.

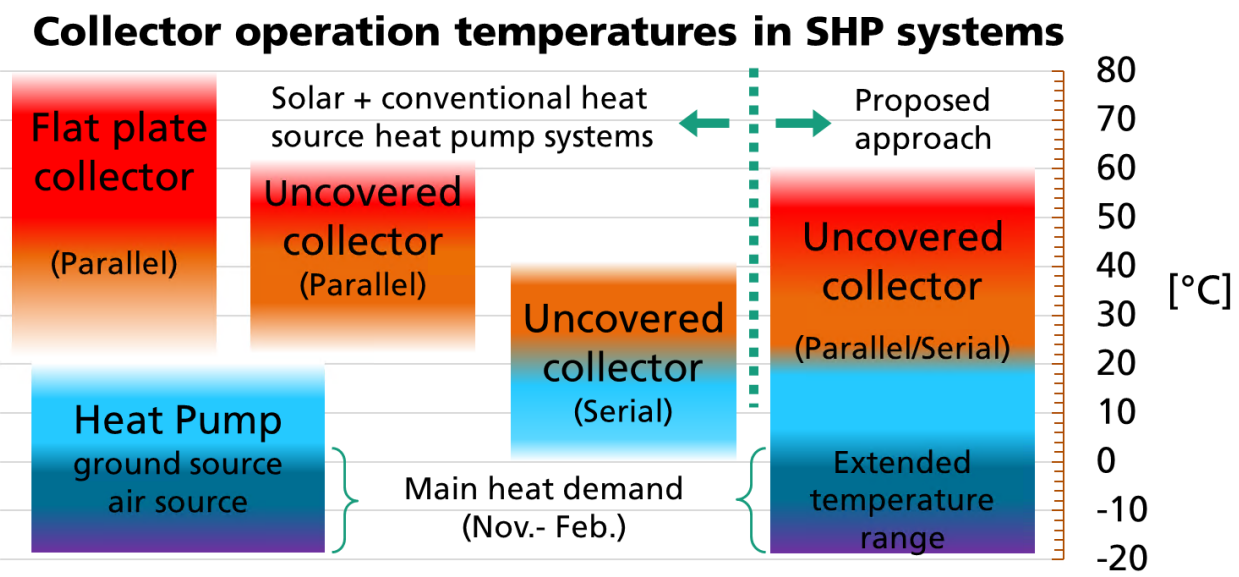

Fig. 2: Most SHP configurations investigated within T44A38 (i.e. market study) do not substitute a conventional heat source. Hence, solar does not cover the main heat load: This design approach limits the solar utilization ratio, thus leading to low fractional energy savings.

Whereas improved system performance can be achieved, the additional investment cost for the solar thermal part (solar collector array, hydraulics and pump group, installation and initial operation, etc.) forms a market barrier: Considering the extra cost of the "optional solar thermal add-on" and its limited saving potential, investors might question its meaningfulness. To date, solar thermal and heat pump systems - if at all - play a niche role in the national heat pump markets. In order to improve the cost efficiency solar thermal heat pump systems, it seems in the nature of the case to substantially increase the utilization ratio of the solar part by extending its temperature operation range below zero degrees Celsius, hence, making the conventional heat pump heat source and cost for its activation obsolete (Fig. 2, "Proposed approach").

\section{Single source SHP systems}

\subsection{Solar thermal and PVT: Previous developments}

Only six out of 135 configurations of said T44A38 market study can be called single source SHP systems employing an array of solar collectors as sole source of the heat pump (Tab. 1). All systems but one use unglazed solar collectors to operate below ambient temperatures. The majority of systems allow for operation below the frost point. All but two systems rely on smaller or larger source side storages, mostly using water as a phase change material, which results in additional cost. None of the systems use PVT collectors. On the one hand, PVT collectors in T44A38 system configurations are only employed as additional low-temperature heat and electricity source for space heating and DHW or to regenerate a heat pump source (ground probe or brine storage). On the other hand, the prospect of a heat pump heating system with a single component PVT collector as heat and electricity generator for the heat pump seems attractive. 
Tab. 1: Overview of collector types, operation temperatures and storage types of all identified single source solar thermal "only" heat pump system configurations of T44A38 market study. Only systems providing space heating and domestic hot water (DHW) are listed. For comparison, the system investigated in this work is shown at the end.

\begin{tabular}{|c|c|c|c|c|c|c|}
\hline \multirow[t]{2}{*}{$\#$} & \multirow{2}{*}{$\begin{array}{l}\text { Available } \\
\text { modes }\end{array}$} & \multirow[t]{2}{*}{ Collector type } & \multicolumn{2}{|c|}{ Collector array operated } & \multicolumn{2}{|c|}{ Storage on heat pump ... side } \\
\hline & & & $\begin{array}{c}\text { as ambient heat } \\
\text { exchanger }\end{array}$ & $\begin{array}{c}\text { below } \\
\text { freezing point }\end{array}$ & source & $\sin k$ \\
\hline 1 & $\begin{array}{c}\text { Parallel/ } \\
\text { Serial }\end{array}$ & Flat plate & Presumably not & - & $\begin{array}{l}\text { wet sand (large, } \\
\text { outdoor) }\end{array}$ & DHW \\
\hline 2 & Serial & Absorber & yes & yes & - & DHW \\
\hline 3 & Serial & Absorber & yes & $?$ & $\begin{array}{l}\text { ice (large, } \\
\text { outdoor) }\end{array}$ & DHW \\
\hline 4 & Serial & Absorber & yes & yes & ice $(3201)$ & $\begin{array}{l}\text { Combi } \\
\text { storage }\end{array}$ \\
\hline 5 & Serial & Absorber & yes & yes & - & DHW \\
\hline 6 & Serial & $\begin{array}{l}\text { Flat plate with } \\
\text { integrated fan }\end{array}$ & yes & yes & ice (320 l) & $\begin{array}{l}\text { Combi } \\
\text { storage }\end{array}$ \\
\hline $\begin{array}{l}\text { This } \\
\text { work }\end{array}$ & $\begin{array}{l}\text { Parallel/ } \\
\text { Serial }\end{array}$ & PVT & yes & yes & - & $\begin{array}{l}\text { Combi } \\
\text { storage }\end{array}$ \\
\hline
\end{tabular}

While in R\&D, the heat supply concept of PVT collectors applied as sole heat source for a heat pump gained increased interest (Zhang, Zhao et al., 2012), especially for DHW applications (Wang, Guo et al., 2017), efficient application in combined space heating and DHW still seems to pose a challenge. To date, the authors are aware of only one single source PVT heat pump system configuration for space heating application which is about to enter the market (Leibfried, 2018).

\subsection{Objectives of the study}

The objective of this study was therefore to check the principal meaningfulness and furthermore the potential of the single source PVT heat pump as a heat supply concept for residential buildings.

1. Is the array of PVT collectors able to sufficiently supply heat for the heat pump during cold weather periods, including extreme cold and snowfall?

2. To what extent can icing be expected due to the continuous low-temperature operation?

3. Which optimization potential can be derived?

4. How to integrate the electric benefit of PVT into established performance figures?

\section{Experimental setup}

\subsection{Single source PVT heat pump system configuration}
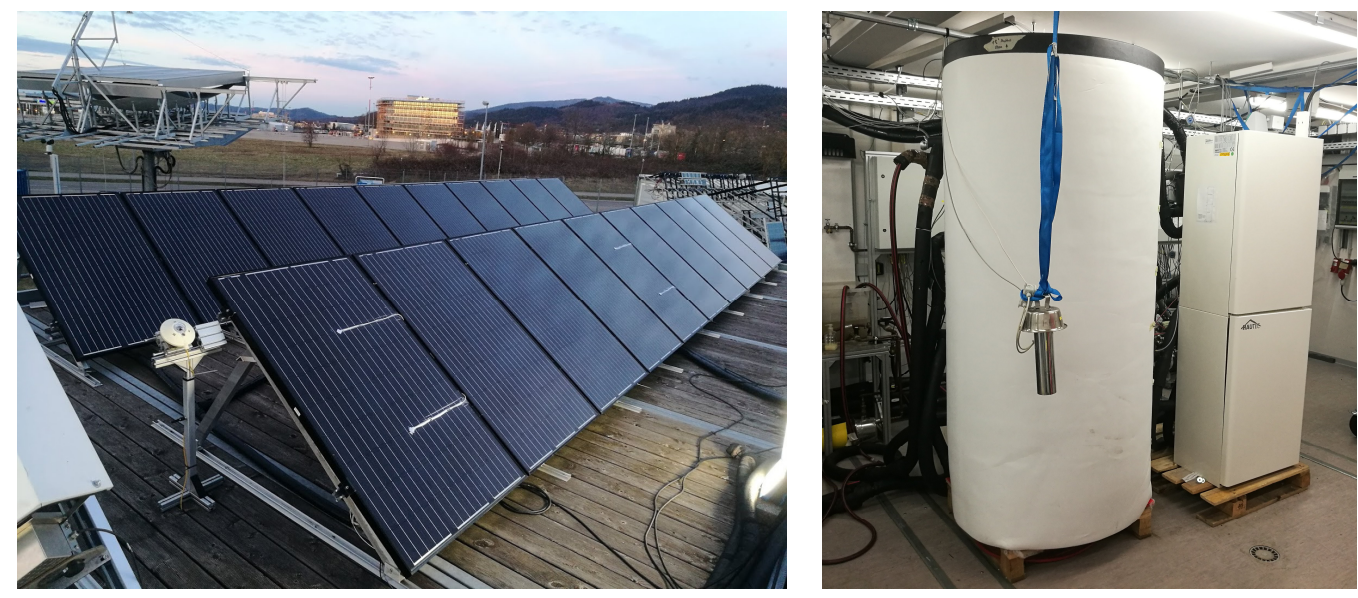

Fig. 3: Investigated single source SHP system with an array of PVT collectors in two rows totaling 20 collectors installed on top of the system test stand at Fraunhofer ISE (left). The photo on the right shows the installed combi storage and the heat pump including a hydraulic unit. The power inverter is installed as well (not shown in the photo). 
A parallel/serial solar thermal heat pump system with an array of PVT collectors, power inverter, combi storage, heat pump, and hydraulics was installed at the system test rig at Fraunhofer ISE in Freiburg, Germany and put into operation in December 2017 (Fig. 3). The main system components are described in further detail in Tab. 2.

Tab. 2: Description of the main components of the measured solar thermal heat pump system.

\begin{tabular}{|c|c|c|}
\hline Component & Subcomp. & Description \\
\hline \multirow{4}{*}{$\begin{array}{l}\text { Solar PVT } \\
\text { array } \\
31,4 \mathrm{~m}^{2} \\
5,2 \mathrm{kWp}\end{array}$} & $\begin{array}{l}\text { Collector } \\
\text { type }\end{array}$ & $\begin{array}{l}\text { The array consists of } 20 \text { rear-insulated uncovered and therefore infrared and } \\
\text { wind-dependent PVT collectors (" } 2 \text { Power HM } 1000,1 \text { Power } 260 \text { Mono } \\
\text { Black"). Rated power is } 260 \mathrm{Wp}(\mathrm{PV}) \text {, area is } 1,57 \mathrm{~m}^{2} \text {. }\end{array}$ \\
\hline & Electric side & $\begin{array}{l}\text { The modules are connected to an SMA inverter, which is connected to the grid. } \\
\text { The inverter is powered only by the PV array. }\end{array}$ \\
\hline & Thermal side & $\begin{array}{l}\text { The array is subdivided into four arrays with five modules each. The hydraulic } \\
\text { connectors of the modules are connected according to the Tichelmann system; } \\
\text { hence all collectors are flowed through in parallel. }\end{array}$ \\
\hline & Control & $\begin{array}{l}\text { The parallel mode is set as first priority. Charging is triggered if the temperature } \\
\text { of the solar array is above the lower storage tank temperature. Serial mode is } \\
\text { triggered by heat pump control settings based on heat demand. }\end{array}$ \\
\hline \multirow[t]{3}{*}{$\begin{array}{l}\text { Heat pump } \\
\mathrm{P}_{\text {rated: }} 5,1 \mathrm{~kW}\end{array}$} & Type & $\begin{array}{l}\text { Brine-water heat pump with extended temperature operation range on the source } \\
\text { side from }-20^{\circ} \mathrm{C} \text { to }+30^{\circ} \mathrm{C} \text {. }\end{array}$ \\
\hline & Heating rods & $\begin{array}{l}\text { Resistance heaters (backup) on source/sink side deactivated during } \\
\text { measurements. }\end{array}$ \\
\hline & Control & $\begin{array}{l}\text { Storage tank temperatures trigger the serial heat pump operation using the solar } \\
\text { array. After parallel mode, serial mode is second priority: The heat pump should } \\
\text { provide temperatures above } 48^{\circ} \mathrm{C} \text { in the DHW section of the combi storage. If } \\
\text { this criterion is fulfilled, the space heating section of the combi storage is } \\
\text { charged. The required temperature depends on the ambient temperature. }\end{array}$ \\
\hline Storage & Type & $\begin{array}{l}850 \text { liter combi storage provided with a permeable partition plate to avoid } \\
\text { temperature mixing of space heating and domestic hot water zones. Inner outlets } \\
\text { in the space heating zone are provided with diffusors (cf. Fig. 4). }\end{array}$ \\
\hline
\end{tabular}

\subsection{Description of load emulation and measurement equipment}

Fig. 4 shows the experimental setup of this work comprising the solar thermal heat pump system (equipment under test), with its main thermal components and hydraulics as well as the interface to the test rig. In total, almost 60 sensors were installed, of which 41 were calibrated for the characterizing measurements, the remaining form part of the equipment under test. Tab. 3 and Fig. 4 refer to (and show) selected sensors relevant to this work only: Tab. 3 shows the applied sensor types and accuracies; Fig. 4 shows the denominations of the sensors used in result diagrams (Fig. 5) in chapter 4.

Tab. 3: Properties of selected sensors used for the measurements and presented in this work.

\begin{tabular}{|c|c|c|c|}
\hline Sensor & Manufacturer & Type & Accuracy \\
\hline Temperature (fluid) & TMH & PT 100 & $0,1 \mathrm{~K}$ \\
\hline Flow Rate & Krohne/Siemens & $\begin{array}{c}\text { magnetic inductive (Optiflux } \\
5000 / \text { Sitrans FM MAG 1100) }\end{array}$ & $0,5 \%$ \\
\hline Solar radiation & Kipp\&Zonen & CMP 11 & $2 \%$ \\
\hline Relative humidity & $\begin{array}{c}\text { B\&B Thermo- } \\
\text { Technik GmbH }\end{array}$ & HA-ANA-10V & $2 \%$ \\
\hline Electricity (summer test day only) & EMU & Allrounder 3/75 & $1 \%$ \\
\hline
\end{tabular}

Fig. 4 shows the load side on the right side of the dashed line, comprising a space heating loop (radiator) and domestic hot water loop with a freshwater station (heat exchanger and shower head symbol). In both cases, hot water tapping from the combi storage is realized by directly connected hydraulic loops with eccentric worm pumps. Details of the volume flow control specifications are given in Tab. 4. 


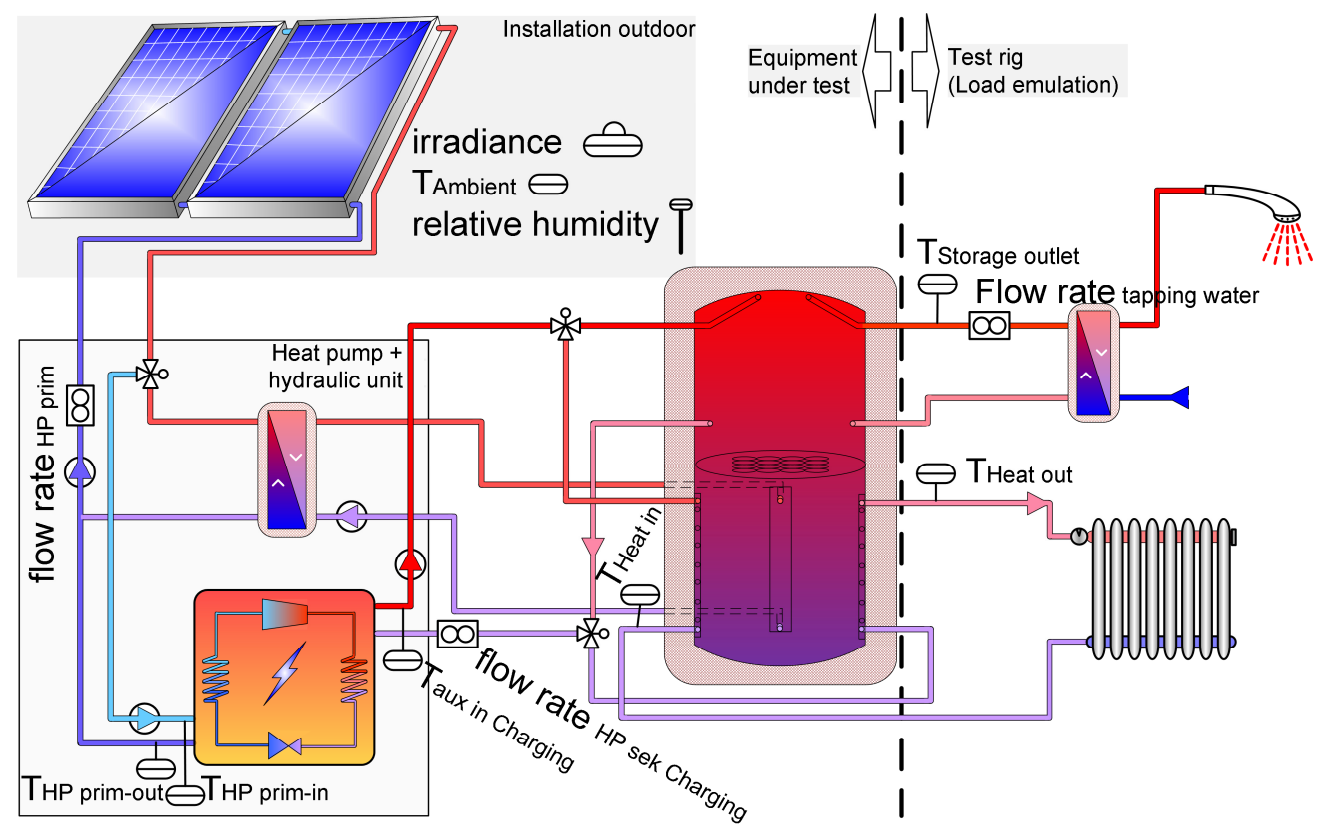

Fig. 4: Experimental setup of this work comprising the solar thermal heat pump system, with its main thermal components and hydraulics, interface to the test rig and sensor positions. The electric side of the solar array is connected to a power inverter (not shown). Sensor denominations given in this illustration are used in Fig. 5 of the next chapter.

Tab. 4: Set up for the domestic hot water (DHW) and space heating heat loads.

\begin{tabular}{|c|c|}
\hline Type & Load description \\
\hline $\begin{array}{l}\text { DHW } \\
\text { load: }\end{array}$ & $\begin{array}{l}\text { 7,7 kWh at } 45^{\circ} \mathbf{C} \text { carried out in } 23 \text { draw offs (shower, small draw offs, dishwashing, bathtub). } \\
\text { The load profile is equal for every day and based on the EU tapping cycle "M" with } 23 \text { draw-offs, } \\
\sim 5,8 \mathrm{kWh} \text { (Ecodesign Regulation } 814 / 2013,2013 \text { ). The following T44A38 modifications according to } \\
\text { (Haller, Dott et al., 2013) were adopted: } \\
\text { - Since a daily } 3,6 \mathrm{kWh} \text { "bathtub" draw off was added to the EU tapping cycle, the energy } \\
\text { demand for the other draw-offs was reduced (Total: } 7,7 \mathrm{kWh} \text { instead of } 9,4 \mathrm{kWh} \text { ). } \\
\text { - Required draw off temperatures were set to } 45^{\circ} \mathrm{C} \text {. } \\
\text { - The bathtub draw-off is every day (not every } 7 \text { th day) } \\
\text { - The dishwasher draw-off is as well at } 45^{\circ} \mathrm{C} \text { (instead of } 55^{\circ} \mathrm{C} \text { ) } \\
\text { The temperature loss of the freshwater station was assumed } 3 \mathrm{~K} \text {. Hence, the heat pump control was } \\
\text { set to provide temperatures of least } 48^{\circ} \mathbf{C} \text { in the DHW zone of the combi storage. }\end{array}$ \\
\hline & $\begin{array}{l}\text { 65 kWh "Winter peak case" for winter and spring test days based on SFH45 building with } \\
\text { underfloor heating }(\Delta \mathbf{T}=\mathbf{4 K}) \text { in the climate of Strasbourg. } \\
\text { A maximum heating load "winter load case" was defined for all test days except summer. The load is } \\
\text { based on T44A } 38 \text { simulation results for an "SFH } 45 \text { " building with an underfloor heating in the } \\
\text { climate of Strasbourg }\left(45 \mathrm{kWh} / \mathrm{m}^{2} \mathrm{a}\right) \text { and a heated area of } 140 \mathrm{~m}^{2} \text {. Based on simulated monthly values } \\
\text { given in (Dott, Haller et al., } 2013) \text {, the mean daily heat demand for the coldest months December and } \\
\text { January was obtained }(51 \mathrm{kWh} / \mathrm{d} \text { and } 54 \mathrm{kWh} / \mathrm{d}) \text {. Since there are positive (and negative) deviations } \\
\text { from these mean values throughout these months, an increased daily space heat load of } 65 \mathrm{kWh} \text { was } \\
\text { chosen for said winter load case. The temperature of the space heating zone of the combi storage } \\
\left.\text { (hence, indirectly } \mathrm{T}_{\text {Heat out }}\right) \text { is controlled dynamically by a heating curve dependent on ambient } \\
\text { temperature, as usual in heating systems. The heat load of } 65 \mathrm{kWh} \text { is achieved as follows: Underfloor } \\
\text { heating loops are often operated without night setback because of their inertia; accordingly, the } \\
\text { eccentric worm pump operates } 24 \mathrm{~h} \text { with a (constant) volume flow of } 10 \mathrm{l} / \mathrm{min} \text {. Assuming a } \\
\text { temperature difference of } 4 \mathrm{~K} \text { between } \mathrm{T}_{\text {Heat out }} \text { and } \mathrm{T}_{\text {Heat in }}, \sim 65 \mathrm{kWh} \text { is discharged from the combi } \\
\text { storage within } 24 \mathrm{~h} . \mathrm{T}_{\mathrm{Heat}} \text { in was set dynamically to } \mathrm{T}_{\mathrm{Heat}} \text { out }-4 \mathrm{~K} \text { with a minimum temperature admitted } \\
\text { by the thermostat at } 20^{\circ} \mathrm{C} \text {. }\end{array}$ \\
\hline
\end{tabular}

\subsection{Test days}

In response to the questions raised in section 2.2 (Objectives of the study), characteristic test days were selected from the measurement period and analyzed accordingly. Refer to the next chapter for test day description and 
system performance analysis.

\section{Results: Performance analysis on test days and optimization potential}

\subsection{Presentation of measurement results on test days}

1st winter test day $\mathbf{- 2 8 . 0 2}$.

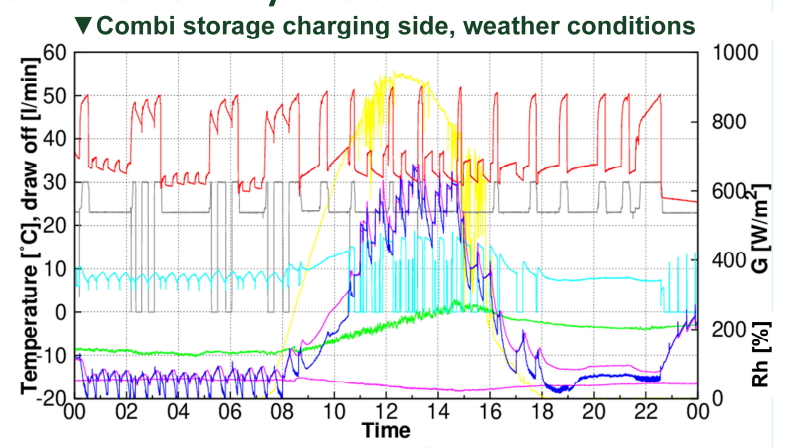

2nd winter test day - 03.03 .

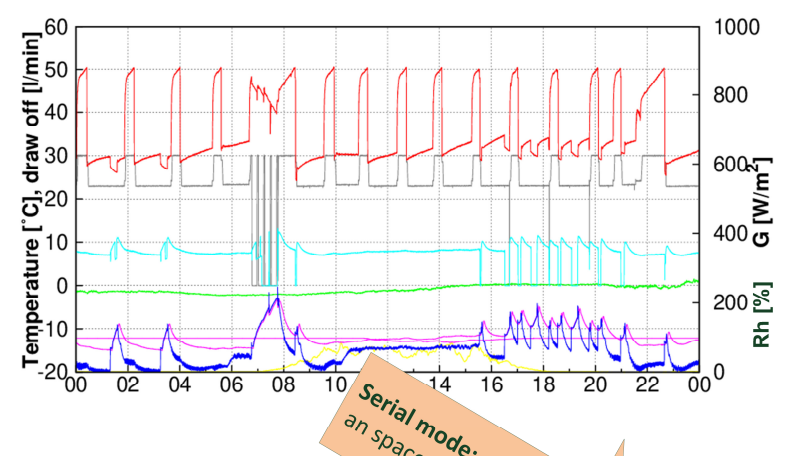

Spring test day - 09.04.

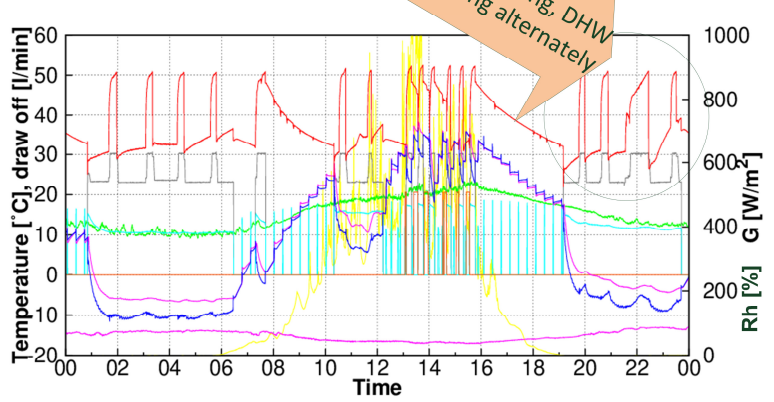

Summer test day -18.08 .
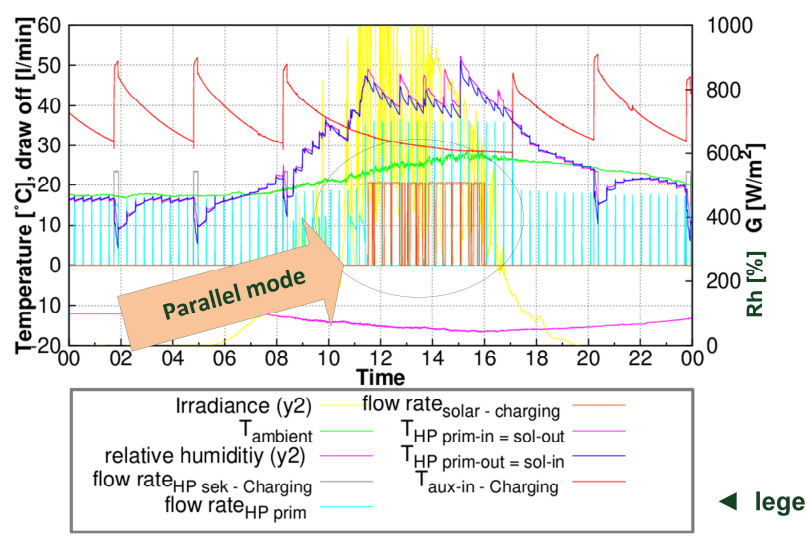
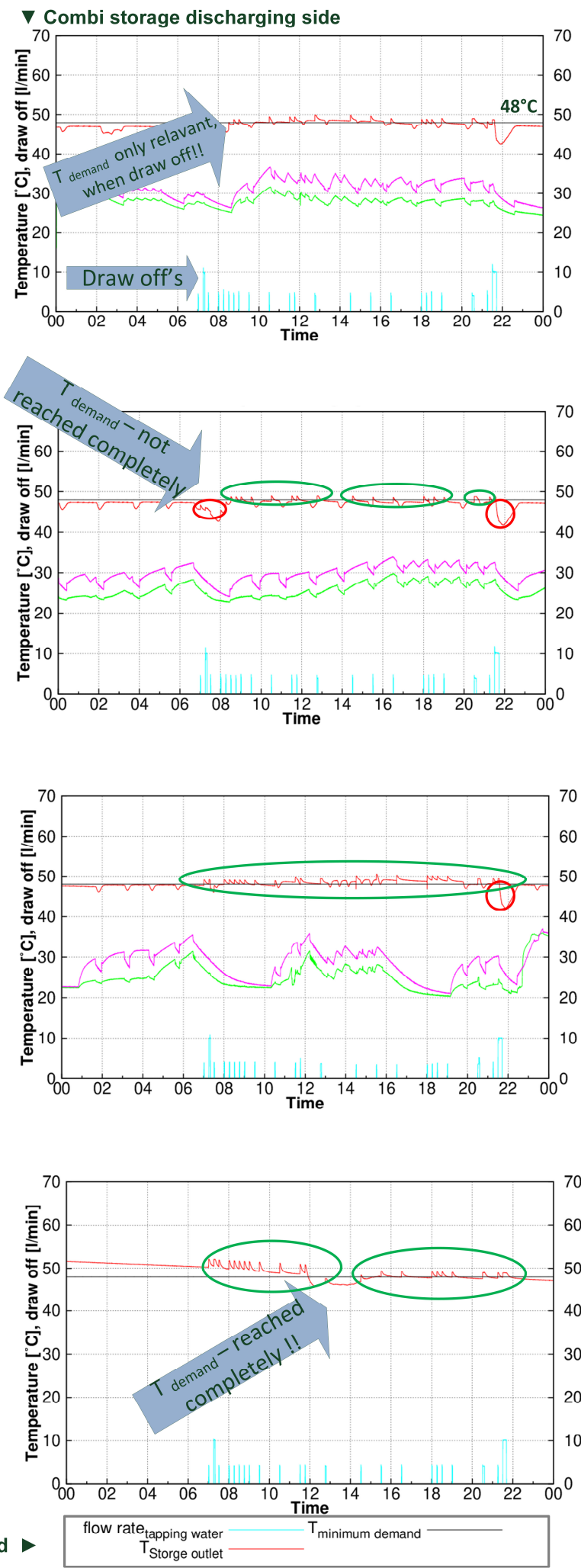

Fig. 5: Diagrams of the following test days: Winter $\left(1^{\text {st }}: \mathbf{2 8 . 0 2 . 1 8}\right.$ and $2^{\text {nd }}$ : 03.03.18), Spring (09.04.18) and Summer (18.08.18). Diagrams on the left show the charging side of the combi storage, diagrams on the right show the discharging side of the combi storage. Legend applies to all diagrams above. Refer to Fig. 4 for positions of the sensors within the system. 
Result diagram description: Result diagrams of all test days are shown in Fig. 5. The characteristic operating behavior of the system is shown by pairs of diagrams showing the key sensor values of the charging (left) and discharging (right) side of the combi storage. Discharging is carried out via the domestic hot water and/or the space heating loop. Refer to Fig. 4 of the previous chapter for sensor positions. Irradiance and ambient temperature are shown on the left side.

Load side - DHW tapping emulation: 23 draw offs were performed on every test day, with the desired characteristics. Energy quantities as provided by the test rig are presented (Tab. 5). DHW tapping was carried out as intended: The targeted energy load of $7,7 \mathrm{kWh}$ was either met or slightly surpassed presumably due to a temperature level above $48^{\circ} \mathrm{C}$ in the DHW zone of the combi storage on test days spring and summer.

Load side - space heating load emulation: Due to inappropriate control settings of the thermostat, which in turn lead to temperature differences lower than $4 \mathrm{~K}$ between $\mathrm{T}_{\text {Heat out }}$ and $\mathrm{T}_{\text {Heat in }}$, the targeted "winter peak case" heat demand of $65 \mathrm{kWh}$ was met only on the second winter test day (03th of March), caused by the control of the test rig. Nevertheless, heat demand is still appropriate: $57.2 \mathrm{kWh}$ is still above the mean heat demand of December $(51 \mathrm{kWh} / \mathrm{d})$ and January $(54 \mathrm{kWh} / \mathrm{d}$, cf. Tab 4, "heating load").

Tab. 5: Measured heat loads for DHW and space heating for given test days. Measurements were carried out in 2018.

\begin{tabular}{|l|c|c|c|c|}
\hline $\begin{array}{c}\text { Unit } \\
{[\mathbf{k W h}]}\end{array}$ & $\begin{array}{c}\mathbf{1}^{\text {st }} \mathbf{w i n t e r} \text { day } \\
\mathbf{2 8}^{\text {th }} \mathbf{F e b .}\end{array}$ & $\begin{array}{c}\mathbf{2}^{\text {nd }} \text { winter day } \\
\mathbf{0 3}^{\text {th }} \text { Mar. }\end{array}$ & $\begin{array}{c}\text { Spring day 09 } \\
\text { Apr. }\end{array}$ & $\begin{array}{c}\text { Summer day 19 } \\
\text { Aug. }\end{array}$ \\
\hline DHW: Total & 7.6 & 7.5 & 8.1 & 9.1 \\
\hline DHW: Tapping, shower & 4.1 & 4.0 & 4.6 & 5.4 \\
\hline DHW: Bathtub & 3.6 & 3.6 & 3.6 & 3.7 \\
\hline Space heating: Total & $\mathbf{5 7 . 2}$ & $\mathbf{6 6 . 9}$ & 55.7 & 0.0 \\
\hline
\end{tabular}

General remarks regarding the system behavior - combi storage charge: Charging is carried out either via the heat pump (serial mode) or via the solar plate heat exchanger (parallel mode). In serial mode, the heat pump is charging the DHW and space heating zone of the combi storage alternately (cf. $\mathrm{T}_{\text {aux-in - charging). Depending on the }}$ heat demand, this occurs continuously, as on the $2^{\text {nd }}$ winter test day, or with interruptions when the combi storage is fully charged (cf. spring test day from ca. 07:30). During these periods, it can be seen that the heat pump control "checks" the source temperature level three times per hour, sending a volume flow of about one minute to the source side pump. On the summer test day, the occurrence of the parallel mode can be observed, starting at about 11:30 (cf. flow rate solar - charging, $\mathrm{T}_{\mathrm{HP} \text { prim-in }=\text { sol out }} \mathrm{T}_{\mathrm{HP} \text { prim-out }=\text { sol in }}$ ).

General remarks regarding the system behavior - combi storage discharge: Regarding the achieved temperatures of the space heating temperatures, the two winter test days are relevant only (Refer to the following section 4.2). Regarding the achieved DHW temperatures, a general problem can be observed which concerns the heat pump charging behavior: DHW temperature comfort level $\left(\mathrm{T}_{\text {Minimum demand }}=48^{\circ} \mathrm{C}\right)$ is generally met for all draw offs apart from the bathtub where discharge temperatures always drop to about $43-44{ }^{\circ} \mathrm{C}$. That this is a heat pump specific issue can be seen on the summer day, where the combi storage is fully charged by the solar array in parallel mode. The heat demand for the entire bathtub is met without any temperature drop. Further malfunctions due to bad control or system layout are discussed in chapter 4.4, Tab 5.

\subsection{Performance under cold weather conditions}

This section deals with the question, whether the array of PVT collectors is able to sufficiently supply heat for the heat pump during cold weather periods, including extreme cold, snowfall, and icing. In response, system performance on two typical winter situations is analyzed.

- $1^{\text {st }}$ winter day (28.02.) Clear sky day/night with ambient temperature ranging from $-5{ }^{\circ} \mathrm{C}$ to $-10^{\circ} \mathrm{C} .27^{\text {th }}$ and $28^{\text {th }}$ of February 2018 were the coldest days of the entire winter period 2017/2018 in Freiburg (Fig. 5,6).

- $2^{\text {nd }}$ winter day (03.03.) Cloudy day/night with an ambient temperature between $-2^{\circ} \mathrm{C}$ to $1{ }^{\circ} \mathrm{C}($ Fig. 5,7$)$.

Icing: Fig. 6 shows the maximum level of ice formation at 04:53 the early hours of the $1^{\text {st }}$ winter test day. The layer of ice is in places and superficially only $(<1 \mathrm{~mm})$. Similar behavior was observed during measurements of other cold days, as well as in the climate chamber (Schmidt, Schäfer et al., 2018). "Ice-production" on the module surfaces did not exceed $1 \mathrm{~cm}$ of thickness (precipitation) on the front side during the entire system measurement phase (Dec. '17 to Aug. '18). No slipping of ice could be detected (tilt angle of $35^{\circ}$ ). The 
comparably low ice formation can be explained due to the low flow of humidity being transported to the surface of the PVT collectors by means of natural convection. In contrast, icing occurs usually in external air units, where humidity is permanently supplied by means of a forced air flow to the compact heat exchanger of the external unit. In consequence, significant amounts of icing on the PVT collector array should only be expected if transport of humidity is assured in large quantities (i.e. precipitation). It could also be observed, that surface ice would melt within a few minutes under direct solar irradiation.

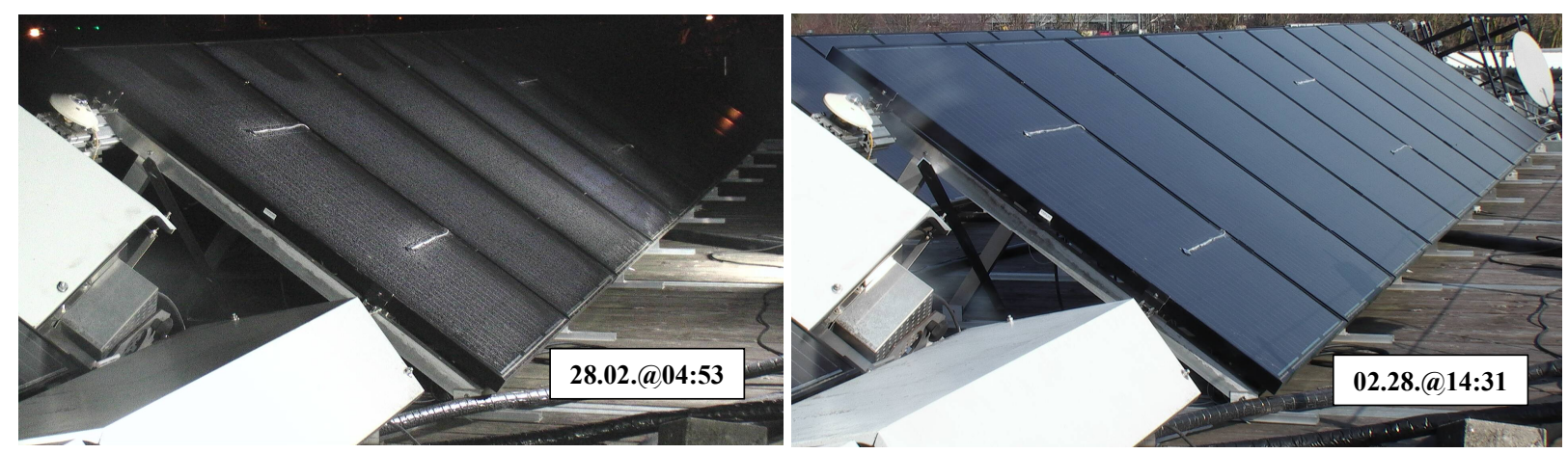

Fig. 6: Maximal observed ice cover on the surface of the solar array in the clear sky night from $27^{\text {th }} / 28^{\text {th }}$ of February with a thickness approximately below one millimeter (left). On the coldest two days of the winter 2017/2018, the solar array reached operation temperatures above $20^{\circ} \mathrm{C}$ from noon to the early afternoon.

The layer of snow on the solar array on the $2^{\text {nd }}$ winter test day (Fig. 7) originates from snowfall on the previous day. It persisted for the entire test day on the solar array due to: low irradiance, the cooled PVT collectors operating as ambient heat exchanger and ambient air temperatures close to the freezing point. As explained below, such a layer of snow still allows for ambient heat exchange with the collector fluid. Measurements on absorbers under comparable conditions (Bunea, Perers et al., 2015) revealed that heat exchange can be increased due to the "naturally" increased collector surface. The heat pump allows for manual reversing the heat pump cycle to heat the collector with energy by cooling the space heating zone of the combi storage. The mechanism was successfully tested on a layer of snow $(+5 \mathbf{~ c m})$ on the solar array: The layer of snow started melting on the side touching the collector array and slipped afterwards to the test rig floor.
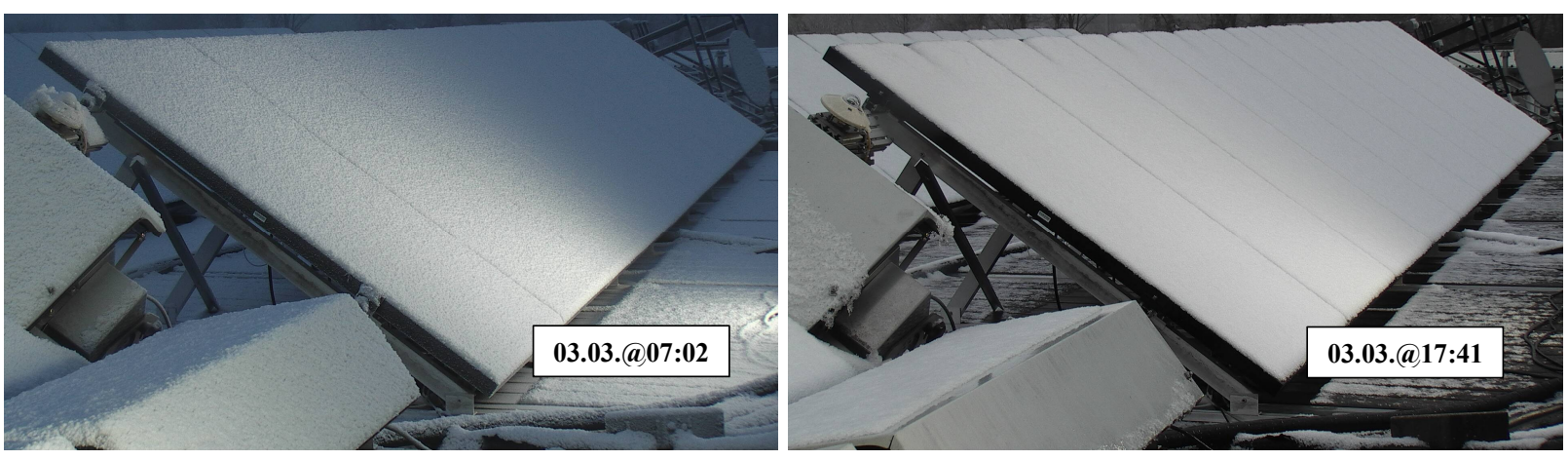

Fig. 7: The solar array was covered with a layer of snow with a thickness of $\sim 2 \mathrm{~cm}$ on the solar array for the period of $24 \mathrm{~h}$ of the first winter test day (03.03.). The photos show the first row of the solar array in the morning (07:02) and in the evening (17:41).

System performance on the $1^{\text {st }}$ winter day (cf. Fig. 5): On the second coldest day of the winter period $2017 / 2018$, a space heat demand of $57.2 \mathrm{kWh}$ is covered. Mean temperatures of the space heating loop $\left(\mathrm{T}_{\text {heat }}+\right.$ $\mathrm{T}_{\text {heat out }} / 2$ range from $26^{\circ} \mathrm{C}$ to $33^{\circ} \mathrm{C}$. DHW energy demand is met as well; comfort levels are met with exceptions in the morning and in the evening (cf. section 4.2, last paragraph and section 4.5, Tab. 6, Area "DHW").

Throughout the day, the heat pump is operating most of the time in serial mode (cf. flow rate $\mathrm{HP}_{\mathrm{HP}} \mathrm{Se}-\mathrm{Charging}$ ). Due to the cold ambient temperatures, when the evaporator outlet temperature $\mathrm{T}_{\mathrm{HP}}$ prim-out reaches $-20{ }^{\circ} \mathrm{C}$, the heat pump switches to frost protection mode and combi storage charging is interrupted. This occurs frequently from midnight to about $8 \mathrm{am}$ in the morning. During this time, it can be seen how space heating loop temperatures decline gradually. Interestingly, during the sunny day, mean evaporator temperatures $\left(\mathrm{T}_{\mathrm{HP}}\right.$ prim-in $+\mathrm{T}_{\mathrm{HP} \text { prim-out }} / 2$ increasing along with the sunrise to peak values above $20^{\circ} \mathrm{C}$ between 12:00 and 15:00 and decreasing back to low night time values after sunset. Hence, on clear sky days, the single source heat pump can play out its advantage by means of high source temperatures compared to air or ground source heat pumps.

System performance on the $2^{\text {nd }}$ winter day (cf. Fig. 5): On this cloudy winter day, where a layer of snow covers 
the solar array, a space heat demand of $66.9 \mathrm{kWh}$ is covered. Mean temperatures of the space heating loop ( $\mathrm{T}_{\text {heat in }}+$ $\mathrm{T}_{\text {heat out }} / 2$ range from ca. $26^{\circ} \mathrm{C}$ to $30^{\circ} \mathrm{C}$. DHW energy demand is met as well; comfort levels are met with exceptions due to an unknown charging interruption of the heat pump between ca. 7:45 to 8:45 (see also section 4.2, last paragraph and section 4.5, Tab. 6, Area "DHW").

Likewise, to the first winter day, the heat pump is operating most of the time in serial mode (cf. flow rate $\mathrm{HP}_{\mathrm{HP}}$ Se Charging), charging DHW and space heating zone alternately (cf. $\left.\mathrm{T}_{\text {aux-in }- \text { charging }}\right)$. Mean evaporator temperatures $\left(\mathrm{T}_{\mathrm{HP}}\right.$ prim-in $+\mathrm{T}_{\mathrm{HP}}$ prim-out $/ 2$ are below $-10^{\circ} \mathrm{C}$ during the whole day reaching minimum values at night time between $-15^{\circ}$ and $-18^{\circ} \mathrm{C}$. Apart from two frost protection cycles (at about 01:15 and 03:15), the solar array provides lowtemperature energy to the heat pump at all times.

Assessment of system performance under cold weather conditions: Heat demand was met completely. The heat was delivered at the required temperature levels for space heating and with few limitations for domestic hot water.

\subsection{Suggested performance indicator}

Fig. 8 shows the equation for the suggested performance figure "SPF $F_{S H P}$, incl PV" for the investigated single source PVT heat pump system. Equations were derived from the performance figures developed in T44A38 (cf.

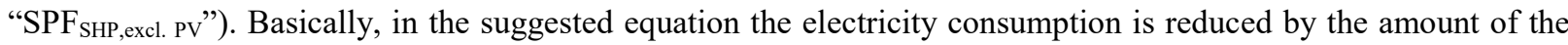
PV generator. Electricity fed to the grid is an important evaluation indicator but should be disregarded for this particular performance figure to avoid confusion.

Boundaries and values for $\mathrm{SPF}_{\mathrm{SHP} \text {,incl PV, }} \mathrm{SPF}_{\mathrm{SHP}, \text { excl. PV }}, \mathrm{SPF}_{\mathrm{HP}}$ for the summer test day are shown. From Fig. 5 it can be seen, that the heat pump charged the combi storage DHW zone five times. Remaining significant electricity consumption was caused by the circulation pumps which also charged the combi storage. This explains why the $\mathrm{SPF}_{\mathrm{SHP} \text {,excl. PV }}$ is higher than $\mathrm{SPF}_{\mathrm{HP}}$. By comparing the values of $\mathrm{SPF}_{\mathrm{SHP} \text {,incl PV }}$ with $\mathrm{SPF}_{\mathrm{SHP}, \text { excl. PV }}$, the energetic performance benefit of the integrated PV generator for the heat production of the PVT collectors becomes tangible.

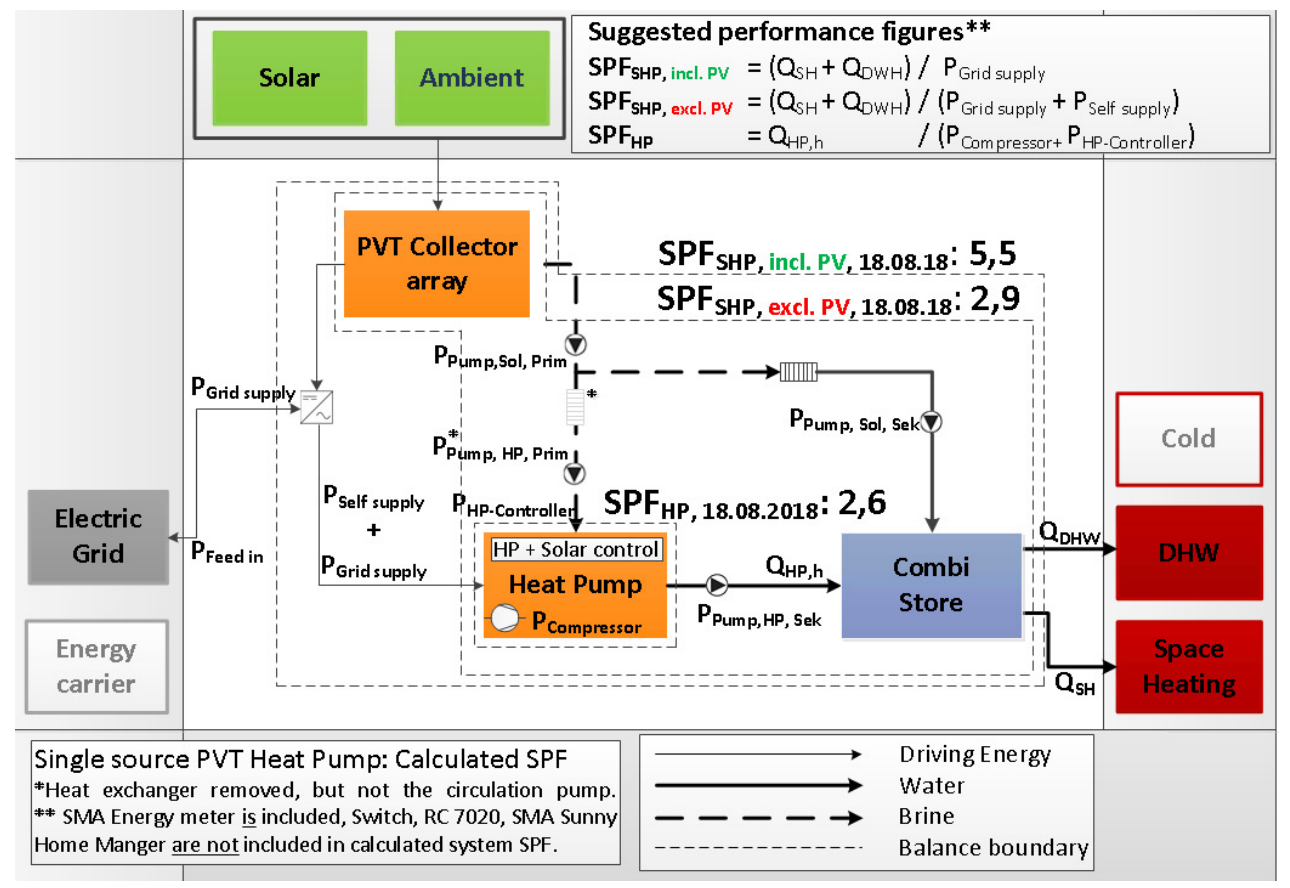

Fig. 8: Upper left corner shows the equation for the suggested performance figure "SPF PVT heat pump system. Equations derived from the performance figures developed in T44A38. Boundaries and values for $\mathrm{SPF}_{\mathrm{SHP}}$, incl PV SPF $\mathrm{SHP}$, excl. PV $\mathrm{SPF}_{\mathrm{HP} \text { PV }}$ for the summer test day are shown.

\subsection{Optimization potential}

Before looking at the actual optimization potential of the investigated system, Tab. 6 summarizes the unintended system behavior observed during measurements, i.e. due to control settings and/or system layout. Subsequently optimization measures are listed in the order of impact in Tab. 7.

Tab. 6: Discussion of malfunctions of the investigated equipment under test due to bad control or system layout.

\begin{tabular}{|c|l|l|l|}
\hline Area & \multicolumn{1}{|c|}{ Problem observed } & Cause & Solution \\
\hline DHW & Shower and bathtub temperature & In principle, the DHW zone of the combi & Fixed continuous \\
\hline
\end{tabular}




\begin{tabular}{|c|c|c|c|}
\hline & $\begin{array}{l}\text { comfort level could not be reached } \\
\text { totally. DHW charging of the heat } \\
\text { pump very frequently ( } 15 \text { to } 21 \text { times } \\
\text { in winter and spring test days). }\end{array}$ & $\begin{array}{l}\text { storage is large enough to cover the heat } \\
\text { demand. Most likely reason is } \\
\text { inappropriate charging of the DHW zone } \\
\text { eventually in combination with mixing } \\
\text { while either charging DHW or tapping. }\end{array}$ & $\begin{array}{l}\text { DHW charging } \\
\text { window during } \\
\text { daytime (cf. } \\
\text { optimization). }\end{array}$ \\
\hline $\begin{array}{l}\text { Heat } \\
\text { pump }\end{array}$ & $\begin{array}{l}\text { Periods with inactive heat pump but } \\
\text { active circulation pump, hence, } \\
\text { removing heat from the storage. }\end{array}$ & To be clarified with the manufacturer. & - \\
\hline $\begin{array}{l}\text { Heat } \\
\text { pump }\end{array}$ & Frequent heat pump cycling. & To be clarified. & - \\
\hline $\begin{array}{c}\text { Solar } \\
\text { thermal }\end{array}$ & $\begin{array}{l}\text { Parallel mode operation puts DHW } \\
\text { comfort level at risk. }\end{array}$ & $\begin{array}{l}\text { Using the solar array for the parallel mode } \\
\text { (direct combi storage heating) prevents the } \\
\text { heat pump to charge DHW when needed. }\end{array}$ & $\begin{array}{l}\text { Fixed DHW } \\
\text { charging window } \\
\text { or remove parallel } \\
\text { mode. }\end{array}$ \\
\hline $\begin{array}{l}\text { Solar } \\
\text { thermal }\end{array}$ & $\begin{array}{l}\text { Further evaluations showed } \\
\text { significantly reduced power output } \\
\text { from the solar plate heat exchanger }\end{array}$ & $\begin{array}{l}\text { Plate heat exchanger capacity too small for } \\
\text { the PVT collector array. }\end{array}$ & $\begin{array}{l}\text { Increase capacity } \\
\text { or remove parallel } \\
\text { mode. }\end{array}$ \\
\hline
\end{tabular}

Tab. 7: Suggested optimization measures for of the investigated equipment under test.

\begin{tabular}{|c|c|c|}
\hline Area & Motivation for measure & Suggested optimization measure \\
\hline $\begin{array}{l}\# 1 \\
\text { Solar } \\
\text { array }\end{array}$ & $\begin{array}{l}\text { Substantially increase } \\
\text { source side temperatures of } \\
\text { the heat pump }\end{array}$ & $\begin{array}{l}\text { Use of rear non-insulated PVT-collectors in the solar array. The } \\
\text { measure has further consequences: The parallel operation mode } \\
\text { could also be removed, saving invest for related components and } \\
\text { installation. Motivation to remove the parallel mode includes } \\
\text { - A non-insulated PVT collector will achieve lower temperature } \\
\text { levels due to increased heat losses when operated above } \\
\text { ambient, resulting in reduced overall operation time of the } \\
\text { parallel mode. } \\
\text { - The parallel mode will run during times of high irradiance. In } \\
\text { this case, the electricity demand of the heat pump could be } \\
\text { met by the PV generator } \\
\text { In order to prevent unwanted shutdown of the heat pump when the } \\
\text { solar loop temperatures exceed the upper temperature threshold of } \\
\text { the heat pump evaporator side, a bypass cooling loop with a } \\
\text { mixing valve would have to be designed. }\end{array}$ \\
\hline $\begin{array}{l}\# 2 \\
\text { Storage }\end{array}$ & $\begin{array}{l}\text { The heat pump operates } \\
\text { "demand driven"; acting } \\
\text { according to the temperature } \\
\text { needs of the combi storage; } \\
\text { Overall estimated yearly heat } \\
\text { pump operation time is less than } \\
20 \% \text {. Accordingly, there is a } \\
\text { high likelihood that the system } \\
\text { will not operate during favorable } \\
\text { operation conditions. }\end{array}$ & $\begin{array}{l}\text { - Implement a source side storage in the system layout. } \\
\text { A cheaper option could be to use the available thermal } \\
\text { storages on the sink side, such as said combi storage or the } \\
\text { capacity of the underfloor heating loop. In order to activate } \\
\text { sink side storages, the target temperature set value for } \\
\text { storage/underfloor heating should be increased temporarily. } \\
\text { Trigger for such control activities could be the current power } \\
\text { output of the PV generator. With such an approach the } \\
\text { increased heat demand of extremely cold but clear and sunny } \\
\text { periods ( } 1^{\text {st }} \text { winter test day) can be met more efficiently. }\end{array}$ \\
\hline $\begin{array}{l}\text { \#3 } \\
\text { Heat } \\
\text { pump } \\
\text { control }\end{array}$ & $\begin{array}{l}\text { Avoid problems associated } \\
\text { with DHW charging in } \\
\text { combi storages } \\
\text { - Higher source temperatures } \\
\text { during daytime, use "free" } \\
\text { PV electricity for heat pump }\end{array}$ & $\begin{array}{l}\text { Define a charging window for the DHW zone, ideally during } \\
\text { daytime, for example between } 12 \mathrm{~h} \text { and } 14 \mathrm{~h} \text {. Fixed daily DHW } \\
\text { charging time windows for combined solar thermal and heat } \\
\text { pumps systems with combi storages were also recommended by } \\
\text { (Haller, Haberl et al., 2014) }\end{array}$ \\
\hline $\begin{array}{l}\text { \#4 } \\
\text { Heat } \\
\text { pump } \\
\text { control }\end{array}$ & $\begin{array}{l}\text { Avoid reoccurring source } \\
\text { side pump operation, when } \\
\text { heat pump is off. }\end{array}$ & $\begin{array}{l}\text { As usual in solar thermal systems, the solar array usually provides } \\
\text { a collector temperature sensor to "inform" the system controller } \\
\text { about potential energy harvest. The heat pump could eventually } \\
\text { adopt this mechanism; hence avoiding flow driven source } \\
\text { temperature checks for the heat pump controller. }\end{array}$ \\
\hline
\end{tabular}


System performance estimation with an improved solar heat exchanger: In order to get an idea of optimization measure \#1 (Tab. 7, "Substantially increase source side temperatures of the heat pump"), the potential mean collector loop temperature increase of an alternative solar array with rear non-insulated PVT collectors was estimated for a particular situation, namely the spring test day from 02-04 am.

\begin{tabular}{|c|c|}
\hline \multicolumn{2}{|c|}{$\begin{array}{l}\text { 09.04. spring day: } \\
\text { conditions@02-04am }\end{array}$} \\
\hline $\mathrm{T}_{\mathrm{amb}}$ & $11^{\circ} \mathrm{C}$ \\
\hline G & $0 \mathrm{~W} / \mathrm{m}^{2}$ \\
\hline$E$ & $-40 \mathrm{~W} / \mathrm{m}^{2}$ \\
\hline$v_{- \text {wind }}$ & $0,5 \mathrm{~m} / \mathrm{s}$ \\
\hline $\mathrm{RH}$ & $65 \%$ \\
\hline
\end{tabular}

Collector array
Elevated, tilted $35^{\circ}$

$\begin{array}{ll}A_{\text {array }} & 31,4 \mathrm{~m}^{2} \\ P_{\text {array, set }} & 2,7 \mathrm{~kW} !\end{array}$

\section{Estimated achievable mean source temperatures $\mathbf{T}_{\mathbf{m}}$ for different collector types}

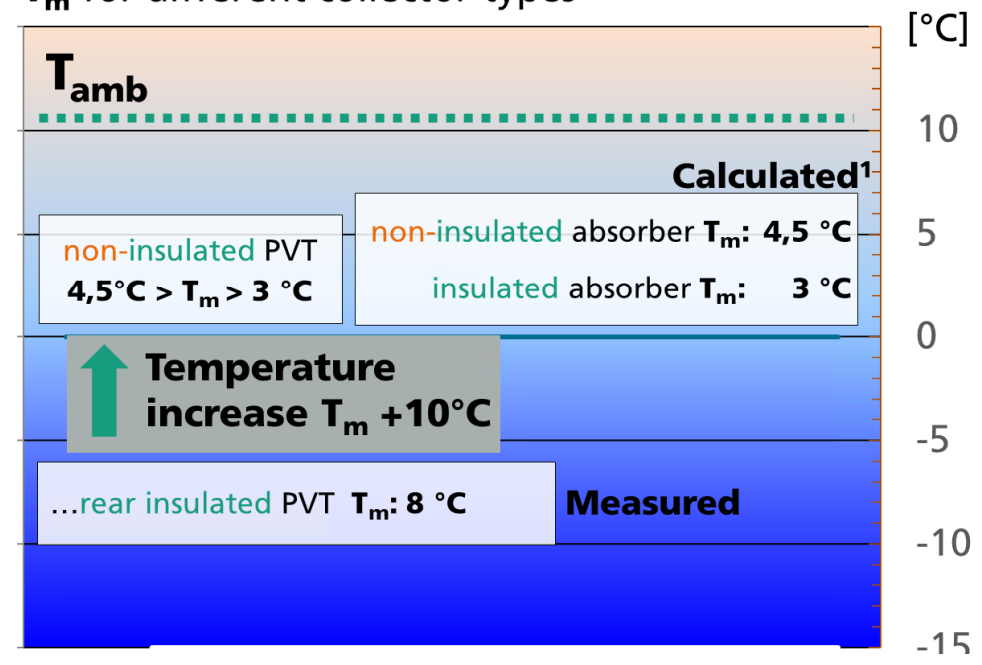

Fig. 9: Results of the system performance estimation with an array of rear non-insulated PVT collectors. A significant temperature increase of $10 \mathrm{~K}$ of the source temperature for the heat pump can be expected for the given boundary conditions.

The estimation is based on the assumption, that a rear non-insulated PVT should - when operated as ambient heat exchanger - perform "better" than a rear insulated absorber, but "worse" than non-insulated absorber. This can be expected when considering that the rear non-insulated PVT basically consists of a non-insulated absorber - with a small insulation due to the PV module. Hence, the achievable collector loop/evaporator temperature $\left[\mathrm{T}_{\mathrm{m}}=\mathrm{T}_{\mathrm{HP}}\right.$ prim-in=sol-out $\left.\left.+\mathrm{T}_{\mathrm{HPprim}-\mathrm{out}=\mathrm{sol}-\mathrm{in}}\right) / 2\right]$ of such a rear non-insulated PVT should supposedly be significantly lower than the one of the non-insulated absorber and slightly above the one of the rear insulated absorber (Fig. 9.).

Collector loop temperatures for the two absorbers were calculated using absorber parameters and the equation developed in (Bunea, Perers et al., 2015). Input values for the equation (weather data) are given in the table in Fig. 9. A measured value for the wind velocity was not measured; it was therefore assumed $0,5 \mathrm{~m} / \mathrm{s}$. As a result, the temperature increase amounts to about $10 \mathrm{~K}$ when switching from rear insulated PVT array to a non-insulated PVT array of the same size providing the same power $(\sim 2,7 \mathrm{~kW})$. It should be noted, that the achievable $\mathrm{T}_{\mathrm{m}}$ of $3{ }^{\circ} \mathrm{C}$ to $4,5^{\circ} \mathrm{C}$ is close to the $\mathrm{T}_{\mathrm{m}}$ of an external air source unit (rated power $5 \mathrm{~kW}$ ), which can be in the range of the noninsulated absorber at fan speeds of $\sim 50 \%$. Results are achievable only if the PVT collectors are naturally ventilated on their rear side similar to the investigated setup. A non-insulated PVT installed closely attached to a roof surface will perform "worse".

\section{Conclusion}

Up to date, combined solar thermal heat pump (SHP) systems form a niche in the national heat pump markets. The hypothesis is raised that an ineffective integration of the solar collector array forms a market barrier due to increased cost but little-added value, because solar thermal collectors are inactive during the cold periods of a year when heat demand is large. While such inactivity is inevitable in a conventional solar thermal system with a fossil backup heater, the solar array of a SHP system should be active, operating as heat exchanger to ambient during low irradiation conditions and night time. Hence, in order to exploit the full saving potential in SHP systems, it is suggested to substitute other conventional heat pump sources entirely by the solar thermal array. To date, such single source SHP systems typically rely on solar absorbers. The objective of this work was to check the principal meaningfulness and potential of an array of photovoltaic thermal (PVT) collectors in a single source SHP system configuration with a residential heat demand: On the one hand, a PVT collector can provide electricity for the heat pump. On the other hand, the thermal performance is lower compared to a solar thermal absorber. 
Results suggest that the single source SHP with PVT collector array is a promising heat supply concept for residential buildings. An extreme case with an array of rear-insulated PVT collectors was investigated. A brine/water heat pump with extended temperature range on the evaporator side and deactivated resistance heaters as well as two-zone combi storage form the other components of the SHP system configuration. The analysis of two cold winter test days reveals that insignificant icing occurred on the surface of the collectors and heat demand was met completely. Temperature comfort levels were also met for space heating and with few limitations for domestic hot water delivery. Improper system design was detected and discussed and concrete optimization potential measures identified. The most obvious measure is to replace the solar array with rear non-insulated PVT collectors. A significant temperature increase of source temperatures can be expected. Estimated for a particular night time heat exchange operation of the solar array in spring; the increase amounts to $10 \mathrm{~K}$. For the summer test day with electricity data available, component and system performance figures were calculated exemplarily. Concerning autumn and winter situations, corresponding performance figures will be measured in the period of $10 / 2018$ to $02 / 2019$.

\section{Acknowledgements}

This work was supported by the Federal Ministry for Economic Affairs and Energy (0325854A). Support is gratefully acknowledged.

\section{References}

Bunea, M., Perers, B., Eicher, S., Hildbrand, C., Bony, J., Citherlet, S., 2015. Mathematical modelling of unglazed solar collectors under extreme operating conditions. Sol Energy 118, 547-561. DOI: 10.1016/j.solener.2015.06.012

Dott, R., Haller, M., Ruschenberg, J., 2013. The Reference Framework for System Simulations of the IEA SHC Task 44 / HPP Annex 38 Part B: Buildings and Space Heat Load A technical report of subtask C - Report C1 Part B. URL: http://www.taskx.iea-shc.org/data/sites/1/publications/T44A38_Rep_C1_B_ReferenceBuildingDescription_Final_Revised_ 130906.pdf.

Ecodesign Regulation 814/2013, 2013. Commission regulation (EU) No 814/2013 of 2 August 2013 implementing Directive 2009/125/EC of the European Parliament and of the Council with regard to ecodesign requirements for water heaters and hot water storage tanks. Official Journal of the European Union. URL: https://eur-lex.europa.eu/LexUriServ/LexUr iServ.do?uri=OJ:L:2013:239:0162:0183:EN:PDF.

Hadorn, J.-C. (Ed.), 2015. Solar and Heat Pump Systems for Residential Buildings, 1st ed. Ernst, Wilhelm \& Sohn, Berlin, Online-Ressource. ISBN: 978-3-433-03040-0.

Haller, M., Dott, R., Ruschenberg, J., Ochs, F., Bony, J., 2013. The Reference Framework for System Simulations of the IEA SHC Task 44 / HPP Annex 38 Part A: General Simulation Boundary Conditions. A technical report of subtask C Report C1 Part A. URL: http://www.taskx.iea-shc.org/data/sites/1/publications/T44A38_Rep_C1_B_Ref erenceBuildingDescription_Final_ Revised_130906.pdf.

Haller, M.Y., Haberl, R., Carbonell, D., Philippen, D., Frank, E., 2014. SOL-HEAP Solar and Heat Pump Combisystems. URL: https://www.researchgate.net/publication/272093420_SOL-HEAP_Solar_and_Heat_Pump_Combisystems

Leibfried, U., 2018. Energieschub für Wärmepumpen. Innovatives PVT-Energieversorgungssystem für Heizungstechnik in Verbindung mit Sole-Wasser-Wärmepumpen. Sonnenenergie: Offizielles Fachorgan der Deutschen Gesellschaft für Sonnenenergie e.V. (02/2018), 54-55. URL: http://www.sonnenenergie. de/sonnenenergie-redaktion/SE-2018-02/Layoutfertig/PDF/Einzelartikel/SE-2018-02-s054-Innovationen-Energies chub_fuer_Waermepumpen.pdf.

Massmeyer, K., Posorski, R., 1982. Wärmeübergänge am Energieabsorber und deren Abhängigkeit von meteorologischen Parametern. Zentralbibliothek d. Kernforschungsanlage, Jülich, II, 155 S. ISSN 0343-7639. URL: https://www.researchgate.net/profile/Klaus_Massmeyer/publication/318901737_Warmeubergange_am_Energieabsorber_und_d eren_Abhangigkeit_von_meteorologischen_Parametern/links/59a9714d458515d09ccfed2d/Waermeuebergaenge-am-

Energieabsorber-und-deren-Abhaengigkeit-von-meteorologischen-Parametern.pdf

Ruschenburg, J., Herkel, S., Henning, H.-M., 2013. A statistical analysis on market-available solar thermal heat pump systems. Sol Energy 95, 79-89. DOI: 10.1016/j.solener.2013.06.005.

Schmidt, C., Schäfer, A., Thoma, C., Rajkiran Jayachandran, E., Lämmle, M., Geimer, K., Kramer, K., 2018. Quellenseitig in Wärmepumpen-Heizsystem integrierte PVT Kollektoren - Experimentelle Messungen am Einzelmodul und am Gesamtsystem., Thermische Solarenergie, 10. bis 12. Juni 2018, Kloster Banz, Bad Staffelstein.

Wang, Z., Guo, P., Zhang, H., Yang, W., Mei, S., 2017. Comprehensive review on the development of SAHP for domestic hot water. Renewable and Sustainable Energy Reviews 72, 871-881. DOI: https://doi.org/10.1016/j.rser. 2017.01.127.

Zhang, X., Zhao, X., Smith, S., Xu, J., Yu, X., 2012. Review of R\&D progress and practical application of the solar photovoltaic/thermal (PV/T) technologies. Renewable and Sustainable Energy Reviews 16 (1), 599-617. DOI: https://doi.org/10.1016/j.rser.2011.08.026. 


\title{
Polymer Collectors with Temperature Control Thermosyphon Valve Development and System Integration
}

\author{
Alexander Thür, Johann Schroll and Norbert Hauer \\ University of Innsbruck, Unit of Energy Efficient Building, Innsbruck (Austria)
}

\begin{abstract}
The goal of several projects in Europe is to develop and design collectors made out of polymers. A main boundary condition for such polymer collectors is the possibility to use as cheap as possible polymer material, which can typically withstand temperatures only up to about $95^{\circ} \mathrm{C}$. Therefore solutions for limiting the temperatures during stagnation are looked for. One possible solution is a collector with integrated thermosiphon cooling, which limits the temperature during stagnation, but also allows the design of a collector with highest possible efficiency during operation. Based on this collector type also solar domestic hot water systems (SDHW) and solar combisystems (SCS) as well can be developed and operated under different boundary conditions in a new way. In a single family house a solar combisystem with overheat controlled polymer collector in combination with building mass activation can achieve a solar fraction which is comparable with conventional high performing flat plate collector systems coupled only to a water storage. In solar domestic hot water systems a polymer collector system with thermosiphon cooling can avoid stagnation periods, which allows restarting at any time also after a high insulation period during noon. This gives the potential to reduce the disadvantage of reduced efficiency during operation by longer operation periods in comparison to standard flat plat collectors.
\end{abstract}

Keywords: Solar Thermal, Solar Collector, Polymer Collector, Simulations

\section{Introduction}

Within the Austrian research project SolPol-4/5 it is the goal to find solutions for solar thermal systems based on cheap polymer materials but with low temperature limits in order to realize significant cost reduction potentials. Therefore one major point is to keep the temperature of the solar collector (and the complete system) below the material limits which means below $100^{\circ} \mathrm{C}$ for cheap polymer materials. For this, several possibilities are under investigation in many research projects. One solution is to design the collector in such a way, that the performance does not allow stagnation temperatures above $100^{\circ} \mathrm{C}$ (temperature limited collector $-\mathrm{TLC}$ ). Other solutions try to keep the collector performance highest possible during operation and reduce the performance during stagnation by different technical solutions (overheat controlled - OHC) like reduction of absorption characteristic at high temperatures (Föste et.al., 2015), reduction of transmission of the transparent cover or increasing the heat losses by activating cooling processes like internal ventilation of the collector (Harrison et.al., 2004).

Within this project the concept using a thermosyphon driven backcooler (Thür, 2014; Thür and Maslikova, 2016) was further developed and improved.

The main idea is to design a best possible collector for operation and to integrate a thermosiphon cooling element for stagnation periods which is intrinsically save and keeps the temperature within acceptable limits. This concept enables highest possible collector efficiency and also the possibility to switch on and off the collector loop at any time without evaporation of the collector fluid. Fig. 1 shows the principle concept of the thermosiphon cooling concept. In fact it works like a solar thermal thermosiphon heating system, but instead of the hot water tank an additional absorber is mounted on the rear and operates as a cooler. Depending on the collector temperature and/or the operational status of the solar heating system a special valve activates or closes the connection to the backcooler. Otherwise the collector operates as an ordinary flat plate collector in a pumped solar heating system. 


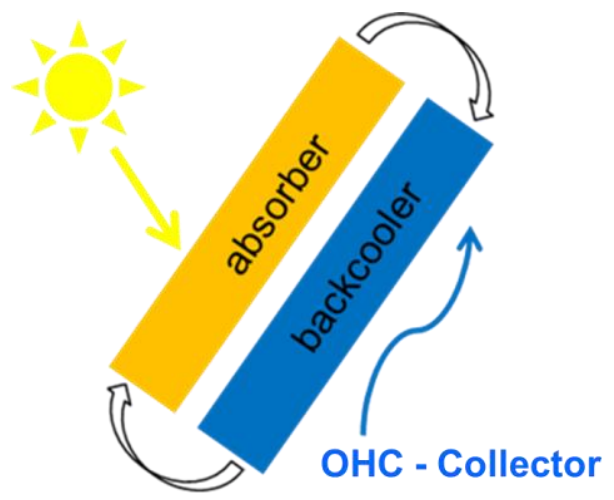

Fig. 1: Principle of a OHC-collector with a thermosyphon driven backcooler

Beside component testing simulation studies were performed with this advanced collector type for solar domestic hot water systems (SDHW) and solar combisystems (SCS) under Austrian climate conditions.

\section{Collector development}

Based on an existing polymer collector as a basis, a thermosiphon driven back cooler was added and the performance of the collector was increased in order to develop an overheat controlled (OHC) collector which has higher performance during operation but still keeps the limit of less than $100^{\circ} \mathrm{C}$ maximum material temperature during stagnation. A main part of this collector concept is a new developed valve which ensures a fail save switching between operation and stagnation of the collector. This collector was tested at the outdoor test facility of University of Innsbruck.
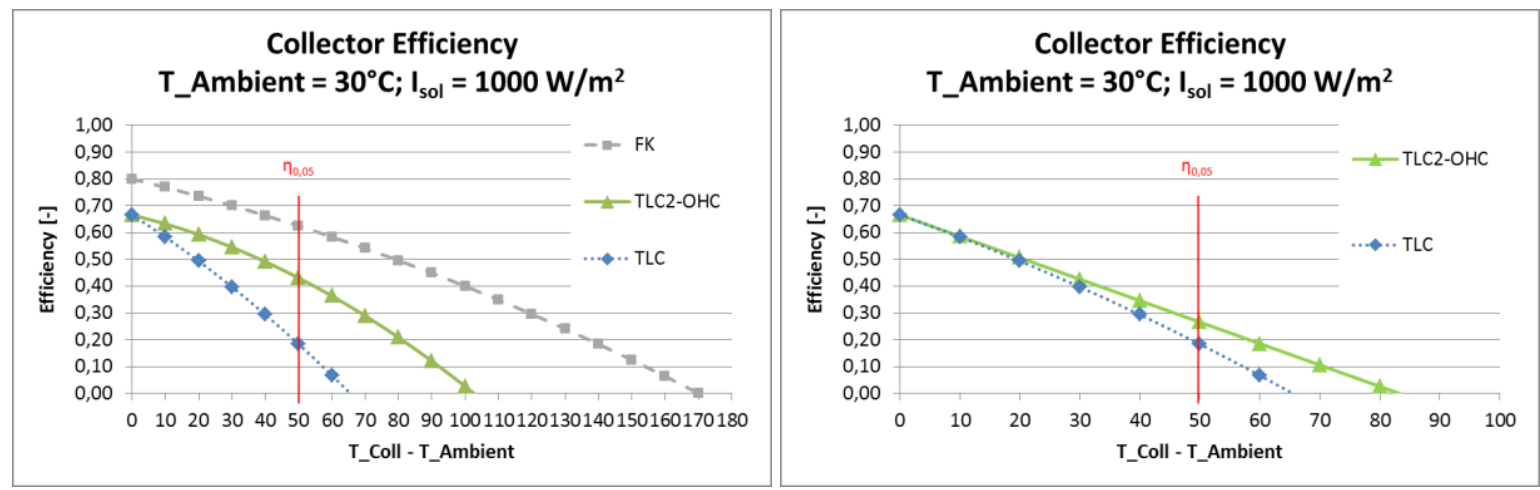

Fig. 2: LEFT: Theoretical Collector Efficiency Curve for TLC-Collector with $95^{\circ} \mathrm{C}$ Stagnation Temperature and TLC2-OHC Collector with $135^{\circ} \mathrm{C}$ Stagnation Temperature as theoretically calculated (but limited to $95^{\circ} \mathrm{C}$ due to backcooler) and a Standard Flat Plate Collector (FK) as Reference. RIGHT: Status of tested TLC2-OHC which does not completely reach the theoretical calculated efficiency of TLC2-OHC in left graph.

The difference in stagnation temperatures is demonstrated comparing Fig 3 (without back-cooling) and Fig 4 (with back-cooling). The maximum material temperatures due to back-cooling can be reduced from about $120^{\circ} \mathrm{C}$ (dotted red lines in Fig 3) to slightly less than $100^{\circ} \mathrm{C}$ (dotted red lines in Fig 4). 


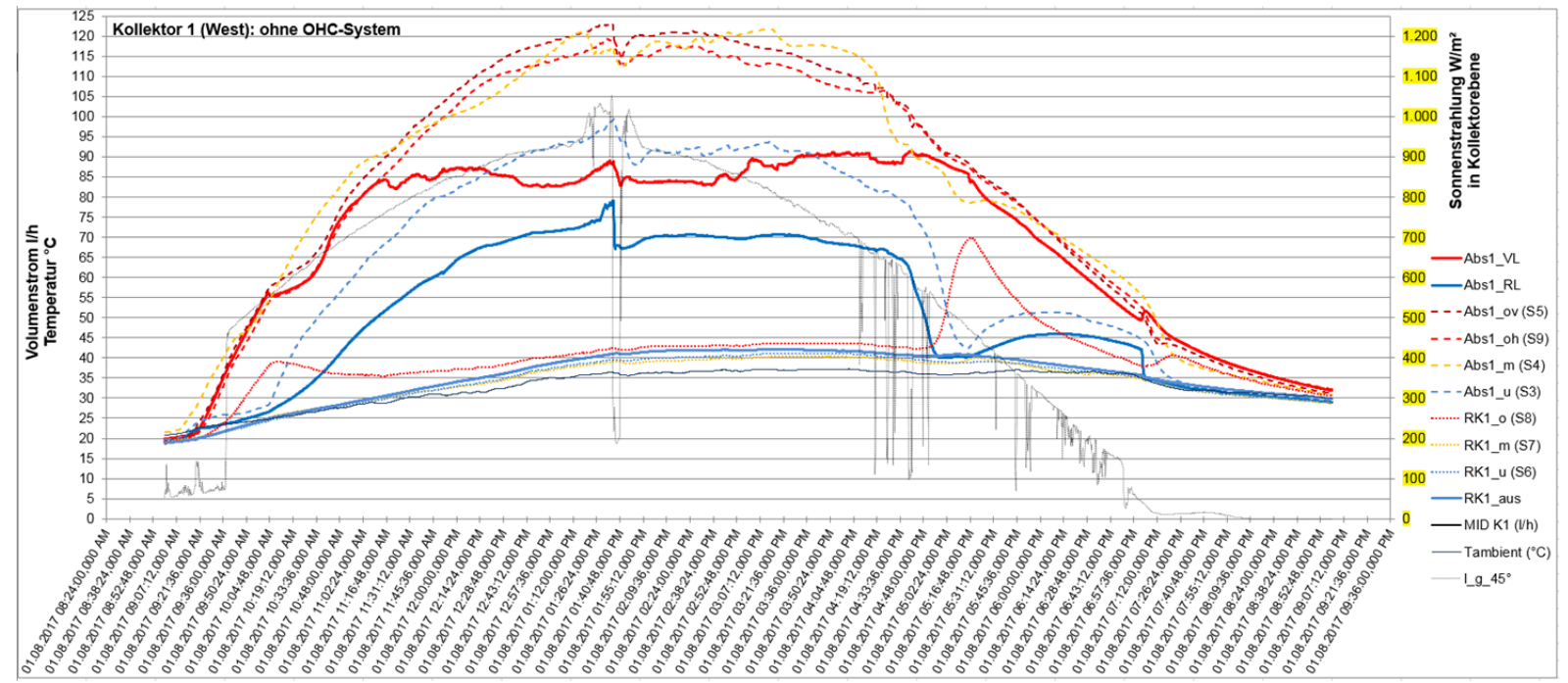

Fig. 3: Stagnation test without back-cooling (absorber inlet temperature "Abs1_RL" is around $7^{\circ}{ }^{\circ} \mathrm{C}$ where back-cooler outlet temperature "RK1_aus" is close to "Tambient" which indicates that there is no thermosiphonal mass-flow; also all temperatures of the back-cooler "RK1_o,m,u" are around ambient temperatur "Tambient")

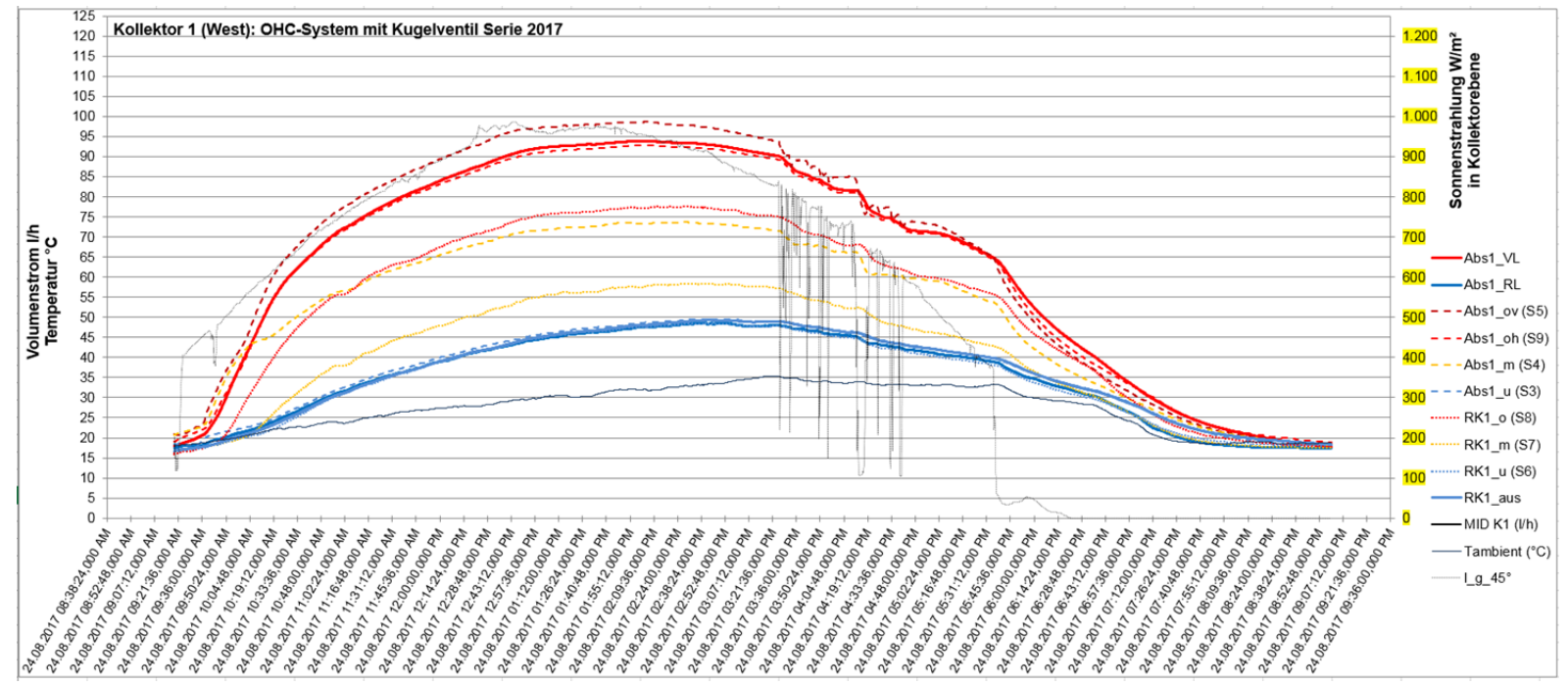

Fig. 4: Stagnation test with back-cooling (absorber inlet temperature "Abs1_RL" is around 50 ${ }^{\circ} \mathrm{C}$ as maximum and identical to backcooler outlet temperature "RK1_aus" which indicates that there is a thermosiphon mass-flow; also all temperatures of the backcooler "RK1_o,m,u" show a clear gradient from top ("RK1_o" $\left.=77^{\circ} \mathrm{C}\right)$ to middle ("RK1_m" $\left.=57^{\circ} \mathrm{C}\right)$ and bottom ("RK1_u" $\left.=50^{\circ} \mathrm{C}\right)$ )

A more advanced back-cooler with about 3 times more volume and therefore lower velocity in the thermosiphon back-cooling flow showed potential to further reduction of stagnation temperatures by additional $8^{\circ} \mathrm{C}$; maximum temperatures in Fig 4 therefore would reach about $90^{\circ} \mathrm{C}$.

\section{System simulation - Solar Domestic Hot Water (SDHW)}

Fig. 5 shows the simulation results of a SDHW system located in Innsbruck (Austria) with a 295 Liter DHW-tank and hot water consumption of 200 Liter per day. The system with TLC2-OHC collector ( $6 \mathrm{~m}^{2}$ collector area) can achieve around $25 \%$ higher solar fraction $(\mathrm{SF}=50 \%)$ compabred to the TLC collector $(\mathrm{SF}=40 \%)$. 


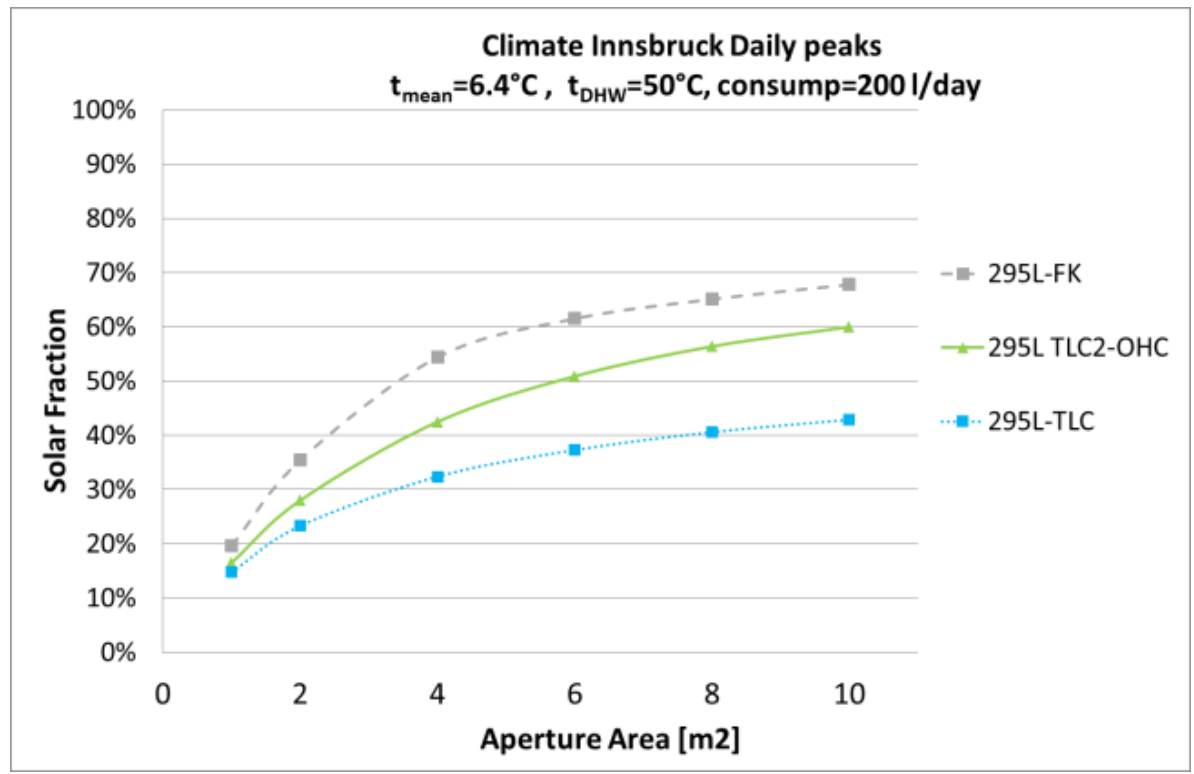

Fig. 5: Simulation results of a solar domestic hot water system with significant higher solar fraction of the system with TLC2-OHC compared to TLC collector.

\section{System simulation - Solar combisystem (SCS)}

For SCS systems a conventional flat plate collector with thermal energy storage (TES) was compared with TLC and TLC2-OHC collectors which also use the building mass via concrete core activation as heat storage (BUI+TES). The heat load of the investigated single family house is $6700 \mathrm{kWh}$ for space heating and $2175 \mathrm{kWh}$ for domestic hot water. Fig 6 shows the concept of possible solar thermal heat flows:

1. from solar thermal collector to thermal energy storage (TES) heating up to $60^{\circ} \mathrm{C}$ in winter and up to $90^{\circ} \mathrm{C}$ in summer.

2. from solar thermal collector direct to the building via the floor heating system using the building mass as thermal storage (BUI) by heating up to a room temperature of $23^{\circ} \mathrm{C}$ as a maximum.

3. as auxiliary a heat pump (HP) is heating the TES up to $50^{\circ} \mathrm{C}$ or directly the floor heating system to keep the room temperature at $21 \pm 0.5^{\circ} \mathrm{C}$

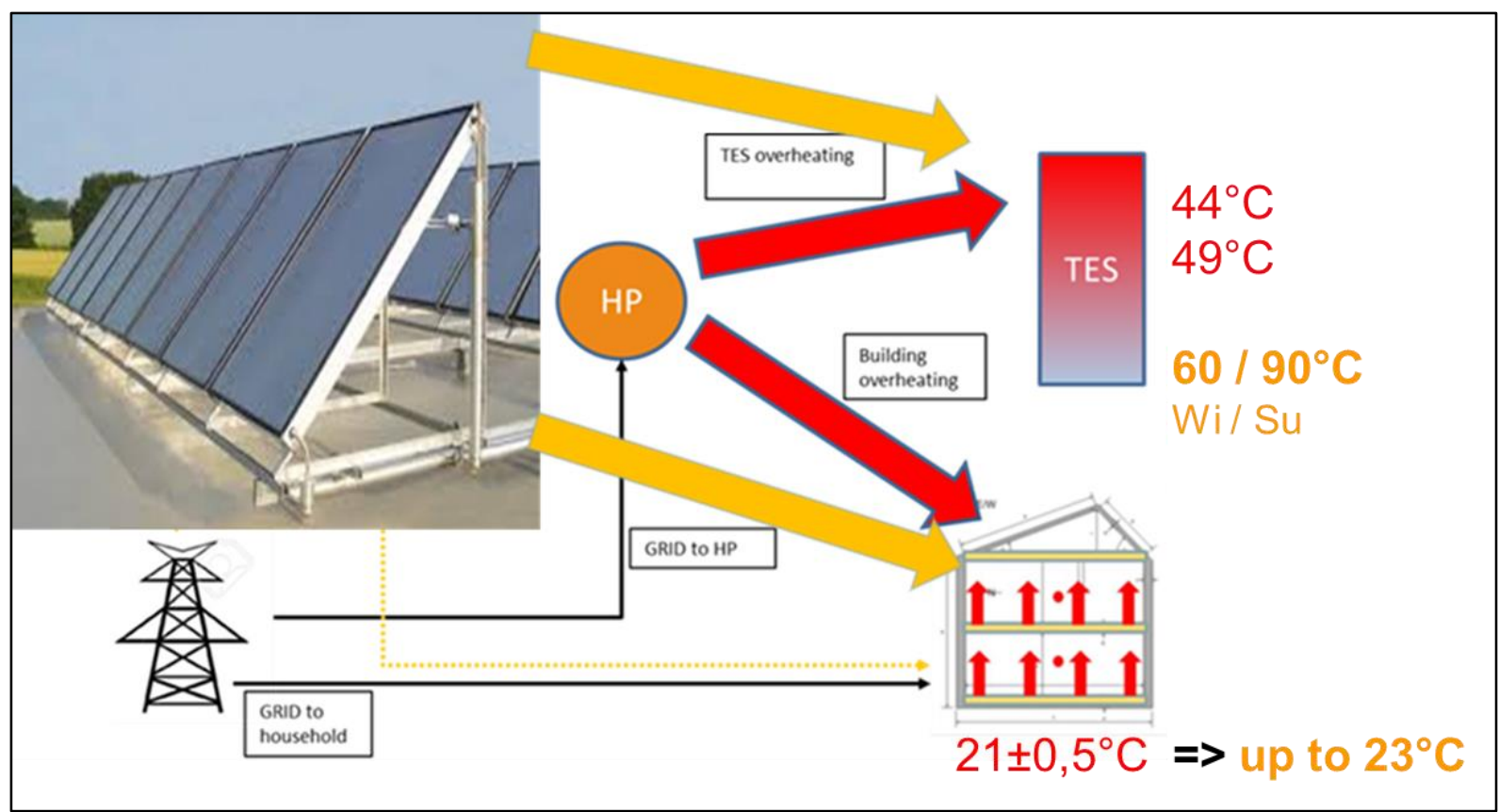

Fig. 6: Possible heat flows from solar thermal collector to TES and to the building directly. 
As shown in Fig. 7 a solar combisystem (SCS) with TLC2-OHC combined with BUI+TES can achieve about the same solar fraction as a conventional system (FK with TES), where just the TLC shows a significant reduced solar fraction.
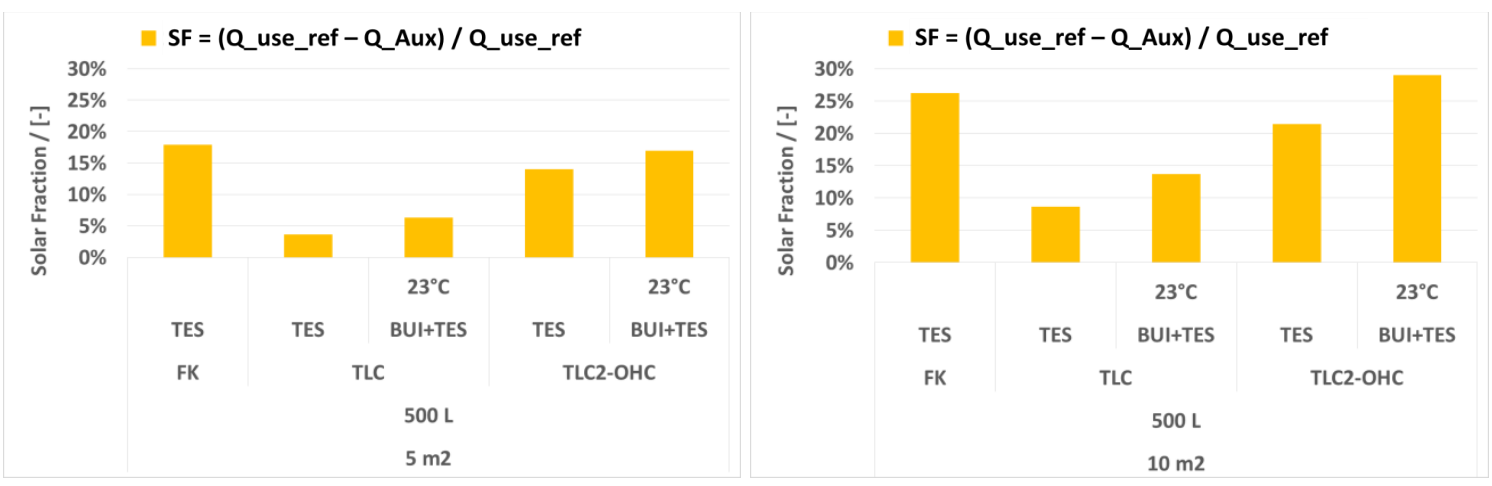

Fig. 7: Solar fraction of solar combisystems with 500 liter water storage combined with 5 and $10 \mathbf{m}^{2}$ collector area respectively.

As shown in Fig 8 the TLC2-OHC collector in combination with building mass activation also shows a high potential to achieve high solar fraction with increasing collector area but keeping the water storage very small. This gives to possibility to place the water storage inside the living area with minimized pipe length and useful heat loss during winter season.

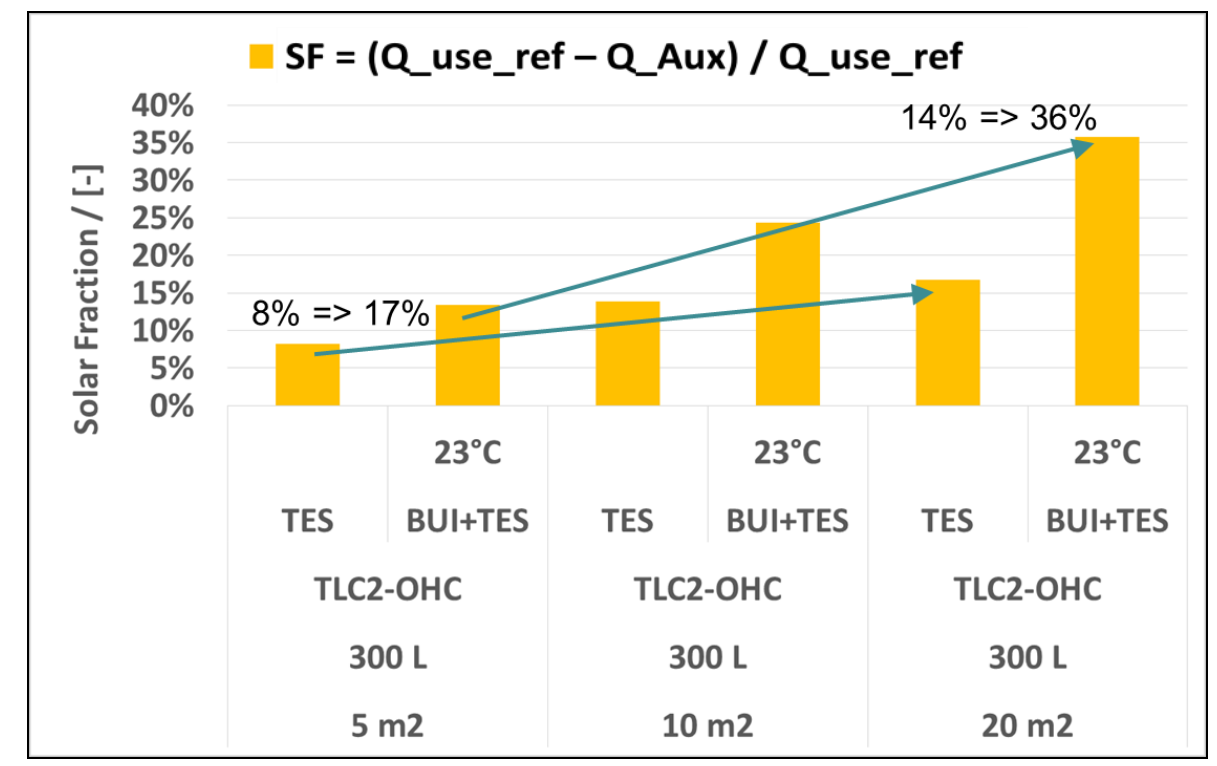

Fig. 8: Solar fraction of solar combisystems with 300 liter water storage combined with 5,10 and $20 \mathrm{~m}^{2}$ collector area respectively.

\section{Summary}

In a single family house a solar combisystem with overheat controlled polymer collector in combination with building mass activation can achieve a solar fraction which is comparable with conventional high performing flat plate collector systems coupled only to a water storage.

In solar domestic hot water systems a polymer collector system with thermosiphon cooling can avoid stagnation periods, which allows restarting at any time also after a high insulation period during noon. This gives the potential to reduce the disadvantage of reduced efficiency during operation by longer operation periods in comparison to standard flat plat collectors.

\section{References}

Föste, S., Pazidis, A., Reineke-Koch, R., Giovannetti, F., Hafner, B., Mercs, D., Delord, C., Leconte, A., Papillon, P., 2015. Leistungsfähigkeit und Stagnationsverhalten von Kollektoren mit thermochromen Absorberbeschichtungen. Tagungsband 25. Symposium Thermische Solarenergie, OTTI e. V., Regensburg. 
A. Thür et. al. / EuroSun 2018 / ISES Conference Proceedings (2018)

Harrison, S.J., Lin, Q., Mesquita, L.C.S., 2004. Integral stagnation temperature control for solar collectors. SESCI 2004 Conference. University of Waterloo.

http://citeseerx.ist.psu.edu/viewdoc/download?doi=10.1.1.618.9962\&rep=rep1\&type=pdf

Thür, A., 2014. Collector Efficiency Calculation Tool for Polymer Collectors with Temperature Limitation. Eurosun 2014. http://proceedings.ises.org/?conference=eurosun2014

Thür, A., Maslikova, K., 2016. Polymer Collectors with Temperature Control - Potentials for System Integration. Gleisdorf Solar 2016. https://www.aee-intec.at/download-centre-11 


\title{
Review of Combined Solar Thermal and Heat Pump Systems Installations in Lithuanian Hospitals
}

\author{
Rokas Valancius ${ }^{1}$, Jurgita Cerneckiene ${ }^{1}$ and Rao Martand Singh ${ }^{2}$ \\ ${ }^{1}$ Kaunas University of Technology, Faculty of Civil Engineering and Architecture, Kaunas (Lithuania) \\ 2 University of Surrey, Department of Civil and Environmental Engineering, Surrey (United Kingdom)
}

\begin{abstract}
One of the major part of energy demand of a building goes to heating and hot water in countries with a cold climate. It is now clearly recognised that modernization of public buildings must be a mix of measures and not only cover the renovation of building components (e.g. roof, walls, windows etc.), but also HVAC systems and heating sources. Aim of any renovation of a public building is to improve the physical aesthetic, the microclimate in the building and reduce primary energy demands. Seventeen projects with solar thermal systems and heat pumps were implemented in Lithuanian hospital buildings by using Swiss and Lithuanian state funding in 2016.

This paper presents the cases and monitoring data of three different integrated solar thermal and heat pump systems in Lithuanian hospitals and prospect of solar thermal and heat pump systems in relation to traditional energy prices, technical barriers and government policy as well as potential of these systems.
\end{abstract}

Keywords: renewable energy sources, solar thermal systems, heat pumps

\section{Introduction}

Heating and hot water is the main energy consumption of a building in countries with cold climate such as Lithuania. Big part of sustainable energy measures is directed to the buildings as they are one of the largest energy consumers. Combined solar thermal (ST) and heat pumps (HP) systems constitutes as one of the solutions and its implementation can considerably influence sustainable energy usage and economy.

The building sector accounts for $40 \%$ of the total energy consumption and $36 \%$ of $\mathrm{CO}_{2}$ emissions in Lithuania and EU countries (Eurostat, 2017). Space heating and hot water accounts for about $26 \%$ of all final energy consumption in the EU. In the recent years, the European Commission has set the new target of reducing the $\mathrm{CO}_{2}$ emissions by $90 \%$ for the building sector by the year 2050 (Eurostat, 2017). More than 17\% of the primary energy savings potential of the EU is related to the building retrofit for 2050 as reported in the 2014/15 European work program (European Commission, 2015).

Lithuanian building heating sector is quite unique where district heating network occupies more than $55 \%$ of the total thermal market and the average price in Lithuanian cities is $0.057 € / \mathrm{kWh}$ (LSTA, 2018). The other thermal energy sources used for building heating systems are natural gas (11.9\%), bio fuel (25\%), coal (5.2\%) and in some cases electricity $(0.22 \%)$ (EHPA, 2017). Natural gas prices in Lithuania in 2017 varied from 0.38 to $0.64 € / \mathrm{m}^{3}$ for residents, depending on total gas consumption per calendar year. Electricity prices varied from 0.077 to $0.124 € / \mathrm{kWh}$, depending on selected tariff (Regula, 2017). Despite of small fluctuation in recent years, the prices of traditional energy are slowly growing.

The number of medium-scale ST systems in Lithuania is still relatively low and represents the potential for development of these systems. There is a number of medium-scale ST systems installed in the country varying from 50 to $250 \mathrm{~m}^{2}$ of total solar panel area. Most of these systems are installed within the past few years in public buildings, hospitals and industrial facilities. The oldest still operating ST system with $77 \mathrm{~m}^{2}$ of total solar panel area was installed in 2002 in children sanatorium "Zibute" (in Kacergine town). However, it took 10 years for the first ST system to be installed in multi-family building, as the first ST system in this type of building was launched only in 2012 (Katinas et al., 2013; Karbauskaite and Perednis, 2011; Valancius et al., 2015a; Valancius et al., 2015b).

Only about $14800 \mathrm{~m}^{2}$ (10360 kWth) of glazed solar collectors were installed by the end of 2016 in Lithuania, and the applications were mostly limited to single-family buildings (ESTIF, 2017). Only in recent years the trend continued towards larger ST systems for multifamily buildings, hospitals, hotels and other large complexes, due to the support from the government, EU and other funds. More than $1500 \mathrm{~m}^{2}$ of solar collectors in over 17 hospitals was installed in 2016 (Valancius et al. 2016). 
Because of relatively low traditional energy prices, infrastructure (such as usage of district heating network) of Lithuania market and cold climatic conditions the HP market in Lithuania started to develop only at the beginning of this century and is growing slowly. Despite government subsidies only 1660 units of different HPs were sold in Lithuanian market in 2016. In total there are already over 7000 HP's in Lithuania, which has a population of about 3 million people. HP is by far the most popular source of heating for single-family houses, and HPs are slowly replacing gas and solid fuel boilers as well as district heating in existing buildings. Compared to 2015 the sales of air source HP increased by $48.3 \%$ and of ground source HP and water source HP decreasing slowly (EHPA, 2017). That is because of increased efficiency of aerothermal HPs and lower investments compared to other HP types.

The price of thermal energy and other energy needs for buildings are the most important factors that influence the renewable energy market. The growth of this market depends on subsidies in most cases. In Lithuania, some limited subsidy systems and funds for renewable energy installations exist since 2005. Depending on a project, it is possible to apply for a subsidy covering from 30 to $100 \%$ of initial costs. For example, it is possible to get a subsidy up to $30 \%$ for single family building, up to $40 \%$ for multifamily building and up to $100 \%$ for hospitals.

Nevertheless, that ST and HP systems have been installed in Lithuania for over 20 years there is still a lack of performance reviews and economic analysis of these systems. The aim of this study is to review three existing combined ST and HP systems in Lithuanian hospitals in relation to traditional energy prices and environmental aspects as well as future potential of these systems.

\section{Review and analysis of solar thermal and heat pump systems in hospitals}

Three different combined ST (from 24 to $95 \mathrm{~m}^{2}$ ) and air source HP's (from 19 to $74 \mathrm{~kW}$ ) systems in different hospitals were evaluated in this study. Two of these systems were designed for domestic hot water (DHW) applications and one for DHW and swimming pool heating. All of these systems are in operation for up to 2 years. All systems are equipped with heat meters, electrical meters and monitoring systems. All of these systems are operating fully automatically. The primary energy source is ST systems, HP operates only when the ST systems are not working (cloudy days) or when the power of ST system is too low. In most cases ST systems operates all-round the year, HP systems operates only till the temperature of $-10^{\circ} \mathrm{C}$. When the temperature is lower than $-10^{\circ} \mathrm{C}$ it is more efficient to use district heating or gas boiler energy. Technical and economical characteristics of the analyzed ST and HP systems are presented in Table 1. The subsidy from Swiss and Lithuanian state funds for these projects covered $100 \%$ of the total investments and only a technical supervision was paid by hospitals.
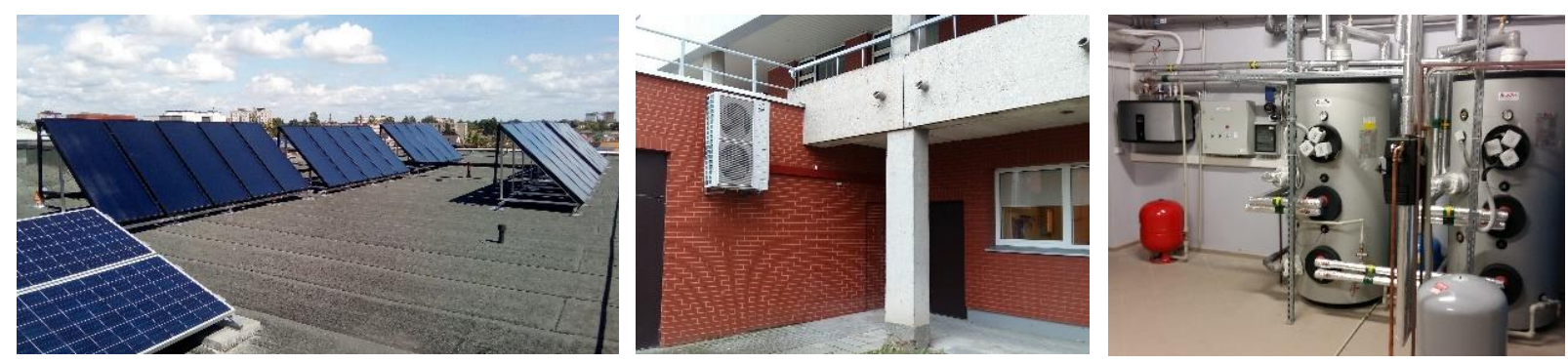

Fig. 1: View of combined ST and HP system in one of the hospitals.

The measurements were performed in 2017 and the performance of these systems was compared to the theoretical values obtained by means of simulation software. All technical parameters of the systems, such as inclination angle of solar collectors, orientation, building energy demands and characteristics of the installed equipment, were used as boundary conditions for the simulations.

Table. 1: Technical and economical characteristics of the analysed ST and HP systems.

\begin{tabular}{|c|l|c|c|c|}
\hline No. & \multicolumn{1}{|c|}{ Description of ST and HP systems } & $\begin{array}{c}\text { ST total } \\
\text { gross / } \\
\text { absorber } \\
\text { area, } \mathbf{~ m}^{2}\end{array}$ & $\begin{array}{c}\text { HP heating } \\
\text { capacity } \\
\mathbf{k W} / \mathbf{C O P} \\
\text { (A2/W35) }\end{array}$ & $\begin{array}{c}\text { Total } \\
\text { investments, } \\
\text { Eur }\end{array}$ \\
\hline 1 & $\begin{array}{l}\text { System for DHW, with secondary traditional energy } \\
\text { source - natural gas }\end{array}$ & $24 / 22$ & $33 / 3.4$ & 55877 \\
\hline 2 & $\begin{array}{l}\text { System for DHW and recirculation, with secondary } \\
\text { traditional energy source - district heating }\end{array}$ & $60 / 55$ & $19 / 3.5$ & 68300 \\
\hline 3 & $\begin{array}{l}\text { System for DHW and swimming pool heating, with } \\
\text { secondary traditional energy source - district heating }\end{array}$ & $95 / 88$ & $74 / 3.5$ & 112190 \\
\hline
\end{tabular}


According to Lithuanian norms of hygiene (HN 24:2003) temperature of DHW in system must range from 50 to 60 ${ }^{\circ} \mathrm{C}$ in order to avoid legionella bacteria breed. Due to this condition air source HP's seasonal coefficient of performance (SCOP) cannot reach high values (especially in cold climates). The results of the analysis showed that ST systems with solar flat plate type collectors can produce from 263 to $433 \mathrm{kWh} / \mathrm{m}^{2}$ per year, but almost the whole solar energy (approximately 80\%) can be collected during the warm period of the year. Experimental data shows that air source HP system used for DHW preparation operated with an average SCOP from 2.42 to 2.61 in the Lithuanian climate. Despite the lower SCOP than expected (>3.5), customers are content with these systems (see Table 2).

Table 2. Results of analysis of ST and HP systems.

\begin{tabular}{|c|c|c|c|c|c|}
\hline \multirow{2}{*}{ No. } & \multicolumn{2}{|c|}{$\begin{array}{c}\text { ST annual energy production, } \\
\text { kWh }\end{array}$} & \multirow{2}{*}{$\begin{array}{l}\text { HP annual energy } \\
\text { production, } \mathrm{kWh}\end{array}$} & \multirow{2}{*}{ SCOP of HP } & \multirow{2}{*}{$\begin{array}{l}\text { Average price o } \\
\text { HP produced } \\
\text { energy, Eur }\end{array}$} \\
\hline & Total & $\begin{array}{c}\text { Per } 1 \mathrm{~m}^{2} \text { gross } \\
\text { area }\end{array}$ & & & \\
\hline 1 & 6320 & 263 & 13320 & 2.42 & 4.54 \\
\hline 2 & 21981 & 366 & 19150 & 2.48 & 4.43 \\
\hline 3 & 41240 & 433 & 26350 & 2.61 & 3.83 \\
\hline
\end{tabular}

The gap between measured and simulated data of thermal energy produced by ST systems is approx. $7 \%$ in the analyzed cases. It can either be caused by differences in actual solar irradiation compared to the standard average data, or some discrepancies (heat losses in the piping system, hydronic misbalance, dirty collector surface etc.) in the design and maintenance of the ST systems.

Simulations showed that analysed ST systems in Lithuania can reduce greenhouse gas emissions from 49 to $232 \mathrm{~kg}$ $\mathrm{CO}_{2} / \mathrm{m}^{2}$ absorber per year. However, $\mathrm{CO}_{2}$ reduction can vary a lot depending on the type of the system and alternative source of energy production.

\section{Potential of solar thermal and heat pumps systems in Lithuania}

District heating networks are well developed in Lithuania and other Baltic countries since the end of 20th century. District heating network in Lithuania occupies more than 55\% of total thermal market. ST and HP systems integration in to district heating networks as well as ST and HP systems for industrial processes can play an important role in the energy transition of the heat sector in Baltic countries.

The refurbishment of district heating system or integrating new systems into existing or new building establishments is one of the major approaches to increase the overall energy efficiency in urban areas. Beside the good examples of technologies used in Denmark (Trier, 2015; Rama and Mohammadi, 2017), Norway, Sweden (Winterscheid et al. 2017), Austria, Germany (Bauer et al. 2010; Lauterbach et al. 2012) and other European countries (Hugo and Zmeureanu, 2012) further markets are developing or emerging. In recent years the solar district heating market boomed in Denmark, not because of subsidies but due to its competitive price in comparison to biomass and gas (Trier, 2015; Flynn and Siren, 2015). A study performed in Finland and Denmark (Rama and Mohammadi, 2017), showed that centralized ST system can provide cost savings from 7 to $21 \%$ and the pay-back times between 10 to 11 years for centralized systems were recorded.

The largest ST district systems are installed in Denmark, with the biggest one in 2016 in Silkeborg city, with aperture are of $156694 \mathrm{~m}^{2}$ and total capacity of $110000 \mathrm{kWth}$. A study in Latvia (Soloha et al. 2017) in municipality with 20000 inhabitants showed that with ST district system would be possible to supply $10 \%$ to $78 \%$ of the total heat demand. Study presented in 2017 (Ge et al. 2017) showed that large scale district water heating systems and hybrid solar photovoltaic and thermal systems are the most promising solutions that attract extensive attentions.

ST and HP energy market development can have the following advantages:

- decrease the consumption of primary fuels and save resources that can be redirected to other sectors;

- minimal environmental impact during whole life cycle;

- flexibility to combine ST and HP systems with all types of auxiliary heat supply systems;

- energy independence as most of fossil resources are imported;

- increase in local employment as ST and HP systems can be installed and produced by the local market participants and thus can have positive influence on the country economics. 
In parallel with growing interest about HP systems, photovoltaic systems (PV) producing electrical energy are also gaining bigger interest. Electricity is used for operation of the HP compressor and the circulation pump in the HP system. The implementation of the HP as a heat source significantly improves the overall efficiency of the energy sector so it is being promoted by the European Union (Directive 2009/28 / EC of the European Parliament and of the Council, EU heating and cooling strategy 2016). According to Lithuanian legislation, the HP is rated as an effective source for compulsory certification of the energy performance of new buildings. When installing a HP for building heating and DHW the only external energy source that is necessary for the household is electrical energy so alternative electricity generation significantly reduces the household's operating costs.

As long as in Lithuania individual consumers were not able to "store" excess energy in distribution networks, the prospective of the combined HP and PV power plant was poor, as the thermal energy needs of the building are almost the opposite to the potential of solar electricity. As this option is currently being offered for Lithuanian consumers, the possibilities of payback of the combination HP and PV systems came into the field of interest. The calculations carried out by Rupeika (2018) shows that the payback period of the combined HP and PV system for individual house in Lithuania is relatively long ( 20 years), therefore these types of systems could be implemented after the decrease in installation costs or additional financial support from the government.

\section{Discussions and conclusions}

Combined ST and HP systems claim to become the solution and its implementation can considerably influence energy and economy. However, the performance of these systems depends on the type of energy users, design solutions, equipment used and maintenance of these systems.

In analysed cases SCOP of HP's vary from 2.42 to 2.61 , because of requirements of high temperature $\left(50 \div 60^{\circ} \mathrm{C}\right)$ of DHW. ST systems produced from 263 to $433 \mathrm{kWh} / \mathrm{m}^{2}$ of thermal energy per year, depending on equipment used. ST and HP system for DHW and swimming pool heating was the most efficient.

The renewable energy market growth in Lithuania and other countries strongly depends on the government policy. The payback period of renewable energy sources installation in most cases is too long to ensure the stable market growth without the governmental grants. Despite the long payback period the market of renewable energy sources in buildings is slowly growing and the trend continues towards larger systems for multifamily buildings, hospitals, hotels, swimming pools and other large complexes.

With a good development district heating neatwork's Lithuania and other Baltic States have a huge potential in ST and HP's integration in to district heating networks. ST and HP's for industrial processes can equally play an important role in the energy transition of the heat sector in Baltic countries.

\section{References}

Bauer, D., Marx, R., Nußbicker-Lux, J., Ochs, F., Heidemann, W., Müller-Steinhagen, H. German central solar heating plants with seasonal heat storage. Solar Energy 2010 (84), 612-623. DOI: 10.1016/j.solener.2009.05.013

EHPA 2017. European heat pump market and statistics report 2017.

European commission 2015. Draft horizon 2020 work programme 2014-2015 in the area of secure, clean and efficient energy.

Eurostat 2017. European commission. Consumption of energy [accessed 8 November 2017]. Available at: https://ec.europa.eu/energy/en/topics/energy-efficiency/buildings

ESTIF, 2017. European heat thermal industry federation. Solar thermal markets in Europe. Trends and market statistics 2016. November 2017.

Flynn, C., Sirén, K., 2015 Influence of location and design on the performance of a solar district heating system equipped with borehole seasonal storage. Renewable Energy 81, 377-388. DOI: https://doi.org/10.1016/j.renene.2015.03.036

Ge, T., Wang, R., Xu, Z., Pan, Q., Du, S., Chen, X. et al. 2017. Solar heating and cooling: Present and future development. Renewable Energy 93, 466-483. DOI: 10.1016/j.energy.2015.08.098 
Hugo, A., Zmeureanu, R., 2012. Residential solar-based seasonal thermal storage systems in cold climates: building envelope and thermal storage. Energies 5, 3972-3985. DOI: 10.3390/en5103972

HN 24:2003 "Geriamojo vandens saugos ir kokybės reikalavimai". Lithuanian legislative system, 2003.

Katinas, V., Karbauskaitè, J., Perednis, E., Valančius, R., 2013. Efficiency analysis of combined biomass and solar energy in Lithuania. Clean Techn. Environ. Policy 15(4), 667-676. DOI: https://doi.org/10.1007/s10098-012-0534$\mathrm{x}$

Karbauskaitė, J., Perednis E., 2011. Kačerginės vaikų sanatorijos šilumos energijos vartojimo mažinimo galimybės. Energetika 57(1), 20-25. DOI: https://doi.org/10.6001/energetika.v57i1.2040

Lauterbach, C., Schmitt, B., Jordan, U., Vajen, K., 2012. The potential of solar heat for industrial processes in Germany. Renew. Sustain. Energy. Rev. (16), 5121-5130. DOI: 10.1016/j.rser.2012.04.032

LSTA 2018. Lietuvos šilumos tiekèjų asociacija. Vidutinè šilumos kaina gyventojams (po perskaičiavimų) [accessed 15 February 2018]. Available from Internet: http://lsta.lt/lt/pages/apie-silumos-uki/silumos-kainos

Rämä M, Mohammadi S., 2017. Comparison of distributed and centralised integration of solar heat in a district heating system. Energy (137), 649-660. DOI: http://dx.doi.org/10.1016/j.energy.2017.03.115

Regula 2017. Valstybinè kainų ir energetikos kontrolès komisija. Visuomeniniai tarifai AB "Energijos skirtymo operatorius" nuo $2017 \mathrm{~m}$. sausio 1 d. [accessed 9 January 2018]. Available at: https://www.regula.lt/elektra/Puslapiai/tarifai/visuomeniniai-tarifai-ab-ENERGIJOS-SKIRSTYMO-

OPERATORIUS-nuo-2017-m--sausio-1-d.aspx

Rupeika I., 2018. Hibridinès šilumos siurblio oras-vanduo ir saulès elektrinès sistemos gyvenamajam namui tyrimas, Master's thesis. Kaunas university of technology, Faculty of electrical and electronics engineering.

Soloha, R., Pakere, I., Blumberga, D., 2017. Solar energy use in district heating systems. A case study in Latvia. Energy (137), 586-594. DOI: 10.1016/j.energy.2017.04.151

Trier D., 2015. Towards solar district heating with more than 70\% solar fraction. Energy Procedia 70, 580-586. DOI: 10.1016/j.egypro.2015.02.16

Valančius, R., Jurelionis, A., Jonynas, R., Katinas, V., Perednis, E., 2015a. Analysis of medium-scale solar thermal systems and their potential in Lithuania. Energies 8(6), 5725-5737. DOI: https://doi.org/10.3390/en8065725

Valančius, R., Jurelionis, A., Vaičiūnas, J., Perednis, E., 2015b. Dimensioning of solar thermal systems for multifamily buildings in Lithuania: an optimisation study. Journal of sustain. architec. civil eng. 11(2), 32-40. DOI: 10.5755/j01.sace.11.2.12459

Valancius, R., Jurelionis, A., Vaiciunas, J., 2016. Review of solar thermal systems and their potential in Lithuania. Proceedings of EuroSun 2016 Conference of ISES Europe, October 11-14, 2016, Palma de Mallorca, Spain. DOI: 10.18086/eurosun.2016.04.15

Winterscheid, C., Dalenbäck, J., Holler, S., 2017. Integration of solar thermal systems in existing district heating systems. Energy (137), 579-585. DOI: https://doi.org/10.1016/j.energy.2017.04.159 


\title{
Solar Thermal Systems vs. Photovoltaic Systems. Case study: Single Family Building in Lithuania
}

\author{
Rokas Valancius, Jurgita Cerneckiene, Juozas Vaiciunas, Andrius Jurelionis, Paris Fokaides \\ Kaunas University of Technology, Faculty of Civil Engineering and Architecture, Kaunas (Lithuania)
}

\begin{abstract}
Solar thermal systems have been installed in Lithuania for over 20 years, and the main trend is to use them on a small scale. Large-scale solar photovoltaic systems only blossomed in 2013 due to a very good feed-in tariff. Small-scale (up to $10 \mathrm{~kW}$ ) solar photovoltaic systems became more attractive after the national energy distribution operator offered the possibility of electrical energy 'storage' in the grid after 2015. Only in recent years have photovoltaic system prices dropped significantly, and a subsidy system been started for renewable energy sources in single-family buildings. This has increased interest in these renewable energy sources.

The popularity of renewable sources is growing because of increasing traditional energy prices and the support of government policies. In certain cases, however, the renewable energy systems are competing with each other. This is noticeable in the single-family building sector, where solar thermal systems are often in competition with photovoltaic systems. There is no unambiguous answer to which system is more profitable for the owner of the building, as this depends on many aspects, which are discussed below. Herein, also, an analysis of the annual balance of various forms of energy used in building engineering systems is presented, which allows us to make an economic comparison between the systems, and to determine the ecological effects of produced green energy.
\end{abstract}

The aim of this study was to compare solar thermal and photovoltaic systems in technical, energy production, environmental and payback time aspects for the single-family building case in Lithuania.

Keywords: single-family building, renewable energy, solar thermal systems, photovoltaic systems, energy prices

\section{Introduction}

The renewable energy share has continued to grow worldwide in recent years, alongside increasing global energy consumption, decreasing investment in many renewable energy sources and declining global fossil fuel prices. Furthermore, in a lot of countries the fluctuating price of fossil fuels has had a serious impact on energy security. There are several alternative resources that can provide clean, continuous and renewable energy, such as solar, wind, biomass, hydro and geothermal.

Solar systems are one part of the environmentally-friendly technologies that produce renewable energy. Solar thermal (ST) systems first started being installed in Lithuania over 20 years ago. The solar photovoltaic (PV) market only blossomed in 2013 due to a very good feed-in tariff $(0.472 € / \mathrm{kWh})$. Only in recent years have PV systems prices dropped significantly, and a subsidy system been started for renewable energy sources in single-family buildings, which has increased their popularity.

The cost of PV systems has dropped by more than $50 \%$ in the last few years, and is expected to continue dropping (Chung et al. 2015). From 2009 to 2015, there was a 56\% reduction in the total cost, $77 \%$ in PV modules, $45 \%$ in inverter costs, and 44\% in installation-related costs (Malinowski et al. 2017). In 2018, the price of small (up to 10 $\mathrm{kWp}$ ) domestic rooftop PV systems in Lithuania has dropped below $1100 € / \mathrm{kWp}$ (ESO 2018; TERMA 2018). On the other hand, the price of ST systems has not change much in the last decade. Analysis in 2016 showed that the average price of a medium-sized $\left(25-166 \mathrm{~m}^{2}\right) \mathrm{ST}$ system, with a flat plate solar collector, was $527 € / \mathrm{m}^{2}, 657 € / \mathrm{m}^{2}$ with evacuated tube solar collectors (Valancius et al. 2016).

Studies on PVs currently concentrate on their improvement, presenting solutions for a higher efficiency and lower price of the panels and systems, and extracting the maximum possible amount of energy from the PV panels. The best-performing monocrystalline silicon models have about 26.7\% efficiency (Photovoltaics Report, 2018). Highconcentration multijunction solar cells have achieved up to $46 \%$ efficiency in the laboratory, and there is still much research and development needed in this direction (Photovoltaics Report 2018). On the other hand, ST systems have well-developed collectors, and the efficiency of these collectors has not changed much in the last decade. 
The Lithuanian energy market is quite unique. The district heating network in Lithuania occupies more than 55\% of the total thermal market, and the average price in Lithuanian cities is $0.057 € / \mathrm{kWh}$ (LSTA 2018). Quite frequently, natural gas $(11.9 \%)$, biofuels $(25 \%)$, coal $(5.2 \%)$ or, in some cases, electricity $(0.22 \%)$ are used for building heating systems (EHPA 2018). In 2017, the prices of natural gas varied from 0.38 to $0.59 € / \mathrm{m}^{3}$ for citizens in Lithuania, depending on the total consumption per calendar year. Electricity prices currently vary from 0.078 to $0.122 € / \mathrm{kWh}$, depending on the selected tariff (ESO 2018a). Despite small fluctuations in recent years, it is noticeable that traditional energy prices are slowly growing.

The cost of energy for heating and electricity needed for buildings is the most important factor that influences the renewable energy market. In Lithuania, some limited subsidy systems and funds for renewable energy installations have existed since 2005 .

Depending on the project, subsidies covering from 30 to $100 \%$ of the initial costs are available. For example, it is possible to get a subsidy of up to $30 \%$ for a single-family building. On the other hand, if you want to get a subsidy for an ST system, heat pump or other renewable energy source for heating, your house must be older than five years. The maximum subsidy cannot exceed 14,500 $€$. Subsidies available in 2018 for different renewable energy sources in single-family buildings are presented in Table 1. In 2018, the subsidy system for single-family buildings was so popular that 3.3 million $€$ was distributed in under five working days. Based on information from the Ministry of the Environment, Lithuanian subsidies for renewable energy sources in single-family buildings should stay the same for the next two years.

Table 1. Subsidies for renewable energy sources in single family buildings (APVA, 2018)

\begin{tabular}{|c|c|c|}
\hline Technology and/or equipment & Unit & $\begin{array}{c}\text { Fixed subsidy } \\
\text { EUR/m² or EUR/kW }\end{array}$ \\
\hline ST system with flat plate collectors & $\mathrm{m}^{2}$ total area & 160 \\
\hline ST system with evacuated tube collectors & $\mathrm{m}^{2}$ total area & 128 \\
\hline PV system without batteries & $\mathrm{kW}$ (peak power) & 336 \\
\hline Vertical axis wind turbine without batteries & $\mathrm{kW}$ (peak power) & 683 \\
\hline Horizontal axis wind turbine without batteries & $\mathrm{kW}$ (peak power) & 557 \\
\hline Heat pump "soil to water" & $\mathrm{kW}$ (nominal power) & 343 \\
\hline Heat pump "air to water" & $\mathrm{kW}$ (nominal power) & 193 \\
\hline Heat pump "air to air" & $\mathrm{kW}$ (nominal power) & 121 \\
\hline Biofuel boiler, rate of class 5 (EN 303-5) & kW (nominal power) & 41 \\
\hline
\end{tabular}

It is noticeable that, in Lithuania, increasingly more users in the single-family building sector are choosing PV systems over ST systems. This is because of their shorter payback time, easier maintenance, and better combination with heat pumps and other systems. In fact, customers who had installed ST systems in the past have, in recent years, also been installing PV systems (see Fig. 1.). There is evidence that ST and PV systems are competing in the market not only with traditional energy sources, but also with each other and other renewable energy sources.

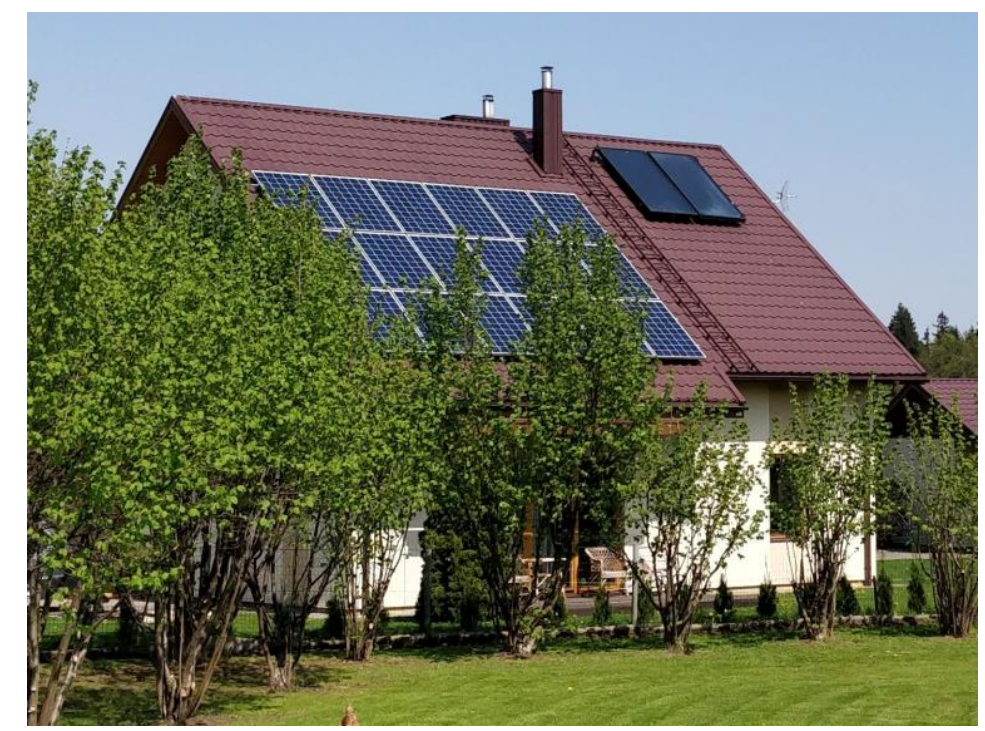

Fig. 1: Single family house with ST $\left(5 \mathrm{~m}^{2}\right)$ and PV $(5 \mathrm{kWp})$ systems. 
The aim of this study was to compare ST and PV systems in terms of technical, energy production, environmental and payback time aspects for in the case of single-family buildings in Lithuania.

\section{Methods}

The average global solar irradiation in Lithuania is similar to that in such countries as Germany, Austria, Denmark and Poland, with average annual solar irradiation of $1000 \mathrm{kWh} / \mathrm{m}^{2}$, but with almost all the irradiated solar energy being collected between April and the end of October (Valancius et al. 2015).

Analysis of the Lithuanian market at the end of 2017 showed that the size of ST systems in single-family buildings vary between 2 and $20 \mathrm{~m}^{2}$ in total area, and that the power of PV systems is from 1.2 to $10 \mathrm{kWp}$ (ESO 2018; TERMA 2018). It is difficult to install a larger than $5 \mathrm{kWp}$ grid-connected PV system in a single-family building in the Lithuanian market because of strict regulations. The maximum allowed PV system power for a single-family building cannot exceed $10 \mathrm{kWp}$. It is also not allowed to produce more electrical energy than a single-family building consumes per year. The use of network services ('upkeep') in low-voltage distribution networks is $0.0389 € / \mathrm{kWh}$ for each $\mathrm{kWh}$ retrieved.

The most popular solar systems for three to five-person single-family buildings are:

- An ST system with flat plate collectors of $5 \mathrm{~m}^{2}$ in total area, a domestic hot-water boiler with a 300-litre volume, and additional equipment. Average investment in such systems is $3360 €$;

- A grid-connected $5 \mathrm{kWp}$ (three-phase) PV system with polycrystalline modules. Most single-family electricity energy needs are up to $5000 \mathrm{kWh} / \mathrm{year}$, with power consumption of up to $40 \%$. Average investment in such systems is $6720 €$.

These two systems where selected for detailed analysis. The simulation software $T * \mathrm{SOL}$ and $\mathrm{PV} * \mathrm{SOL}$ and data from exiting systems were used to compare the systems in terms of their energy production, environmental and payback time aspects.

It was also assumed that the entire cost of the system was covered during the installation. The lifespan of both systems was considered to be 25 years. The parameters used for financial assessment of the systems are presented in Tables 1 and 2 .

Table 2. Energy prices and other parameters used for economic calculations.

\begin{tabular}{|l|c|}
\hline The lifespan of the system, years & 25 \\
\hline Specific energy from district heating (average), $€ / \mathrm{kWh}$ & 0.056 \\
\hline Specific energy from natural gas price (consumption from $501 \mathrm{~m}^{3}$ to $\left.20000 \mathrm{~m}^{3}\right), € / \mathrm{m}^{3}$ & 0.390 \\
\hline Specific energy from solid fuel or wood pellets (average), $€ / \mathrm{kWh}$ & 0.040 \\
\hline Specific electricity costs (standard), $€ / \mathrm{kWh}$ & 0.113 \\
\hline Index for energy prices, \% per year & 2.0 \\
\hline Running costs, \% & 0.5 \\
\hline
\end{tabular}

\section{Results of systems analysis}

The results of the analysis showed that a typical $5 \mathrm{~m}^{2} \mathrm{ST}$ system for a single-family building can cover approximately $50 \%$ of the domestic hot-water (160 litres/day) needs. A $5 \mathrm{kWp} \mathrm{PV} \mathrm{system} \mathrm{can} \mathrm{produce} \mathrm{electrical} \mathrm{energy} \mathrm{of} \mathrm{up} \mathrm{to}$ $4700 \mathrm{kWh} /$ year. In most cases, the payback time of a PV system is shorter than that of a ST system (see Table 3).

Table 3. Results of analysis of ST systems.

\begin{tabular}{|c|c|c|c|c|c|}
\hline $\begin{array}{l}\text { Main energy } \\
\text { source }\end{array}$ & $\begin{array}{c}\text { Cost of ST } \\
\text { energy } \\
\text { production } \\
\text { (without } \\
\text { subsidy), } \\
€ / \text { kWh } \\
\end{array}$ & $\begin{array}{l}\text { Savings in } \\
\text { first year, } €\end{array}$ & $\begin{array}{c}\mathrm{CO}_{2} \text { emissions } \\
\text { avoided, } \mathrm{kg}\end{array}$ & $\begin{array}{l}\text { Amortization } \\
\text { period, years }\end{array}$ & $\begin{array}{l}\text { Amortization } \\
\text { period with } \\
\text { subsidy, years }\end{array}$ \\
\hline District heating & \multirow{4}{*}{0.091} & 93 & 360 & \multirow{3}{*}{$>25$} & 22.6 \\
\hline Natural gas & & 82 & 447 & & 25.0 \\
\hline $\begin{array}{l}\text { Solid fuel or } \\
\text { wood pellets }\end{array}$ & & 66 & 929 & & 25.0 \\
\hline Electricity & & 93 & 1098 & 14.8 & 11.9 \\
\hline
\end{tabular}


The amortisation period of the analysed PV systems was 13.9 years (see Table 4), whereas the ST systems' amortization period, in most cases, was over 14 years (see Table 4) when potential subsidies (see Table 1) were not included. The payback period with possible subsidies in Lithuania (see Table 1) averaged three years less, although that is too long to ensure the stable growth of solar applications.

The analysed ST system can produce approximately $350 \mathrm{kWh} / \mathrm{m}^{2}$ of thermal energy, and reduce greenhouse gas emissions from 360 to $1098 \mathrm{~kg} \mathrm{CO} /$ year. A $5 \mathrm{kWp} \mathrm{PV} \mathrm{system} \mathrm{can} \mathrm{produce} \mathrm{approximately} 156 \mathrm{kWh} / \mathrm{m}^{2}$, or $940 \mathrm{kWh}$ with a $1 \mathrm{kWp}$ system, and can reduce greenhouse gas emissions by approximately $2790 \mathrm{~kg} /$ year (see Tables 3 and 4). Calculations of energy related $\mathrm{CO}_{2}$ emissions was done with $\mathrm{T} * \mathrm{SOL}$ and $\mathrm{PV} * \mathrm{SOL}$ software.

Table 4. Results of analysis of solar PV system.

\begin{tabular}{|c|c|c|c|c|c|}
\hline PV system & $\begin{array}{c}\text { Cost of PV } \\
\text { electricity } \\
\text { production } \\
\text { (without } \\
\text { subsidy), } \\
\boldsymbol{\epsilon} / \mathbf{k W h}\end{array}$ & $\begin{array}{c}\text { Savings in } \\
\text { first year, } €\end{array}$ & $\begin{array}{c}\mathbf{C O}_{2} \text { emissions } \\
\text { avoided, kg }\end{array}$ & $\begin{array}{c}\text { Amortization } \\
\text { period, years }\end{array}$ & $\begin{array}{c}\text { Amortization } \\
\text { period with } \\
\text { subsidy, years }\end{array}$ \\
\hline $\begin{array}{c}\text { Grid connected 5 } \\
\text { kWp PV System }\end{array}$ & 0.08 & 512 & 2790 & 13.9 & 10.5 \\
\hline
\end{tabular}

\section{The influence of the solar thermal systems and photovoltaic systems to the energy efficiency of the building}

In Lithuania, the energy performance class of buildings that had a building permit issued after 1st January 2016 should not be lower than A, after 1st January 2018, not lower than A+, and after 1st January 2021, the energy performance class must be in the A++ class (STR 2.01.02:2016).

In buildings rated as energy efficiency class A++, the biggest share of energy consumed should be generated from renewable sources, therefore the implementation of renewable energy sources in such buildings will be mandatory. The renewable energy sources for A and A+ buildings are not formally obligatory, but their implementation improves complex building energy efficiency indicators, and gives more freedom in implementing different architectural solutions. For buildings with a certain architecture (mostly with big areas of glass partitions), renewable energy sources must also be integrated in order to meet the requirements of energy efficiency classes A or A+.

According to Lithuanian legislation (STR 2.01.02:2016), when evaluating the energy efficiency of a building, the use of solar energy will influence the value of the energy efficiency indicator, $\mathrm{C}_{1}$, which describes the efficiency of primary, non-renewable energy used for heating, ventilation, cooling and lighting, and the value of the energy efficiency indicator, $\mathrm{C}_{2}$, describing the efficiency of primary, non-renewable energy consumption for the preparation of domestic hot water. The $\mathrm{C}_{1}$ and $\mathrm{C}_{2}$ indicators are two of seven (for classes $\mathrm{A}$ and $\mathrm{A}+$ ) or eight (for $\mathrm{A}++$ ) that must be met by a building of a certain energy efficiency class. Other criteria influencing the building energy efficiency class are:

- The specific heat loss of the building, $\mathrm{W} / \mathrm{K}$;

- If the building is equipped with mechanical ventilation with a recuperator, the efficiency of the recuperator and the amount of energy used by the recuperator in $\mathrm{Wh} / \mathrm{m}^{3}$;

- The thermal properties of the inner walls and overlays between the parts of the building having independent autonomic heating;

- The tightness of the building; and

- The annual consumption of thermal energy for building heating in $\mathrm{kWh} / \mathrm{m}^{2}$.

The values of $\mathrm{C}_{1}$ and $\mathrm{C}_{2}$ for different energy performance classes are given in Table 5 .

Table 5. Values of $C_{1}$ and $C_{2}$ indicator for buildings with different energy performance classes

\begin{tabular}{|c|c|c|}
\hline Energy performance class & \multicolumn{2}{|c|}{ Indicator value } \\
\hline $\mathrm{A}++$ & $\mathrm{C}_{1}<0,25$ & $\mathrm{C}_{2} \leq 0,70$ \\
\hline $\mathrm{A}+$ & $0,25 \leq \mathrm{C}_{1}<0,375$ & $\mathrm{C}_{2} \leq 0,80$ \\
\hline $\mathrm{A}$ & $0,375 \leq \mathrm{C}_{1}<0,5$ & $\mathrm{C}_{2} \leq 0,85$ \\
\hline $\mathrm{B}$ & $0,5 \leq \mathrm{C}_{1}<1$ & $\mathrm{C}_{2} \leq 0,99$ \\
\hline
\end{tabular}


As an example, in a randomly-chosen $120 \mathrm{~m}^{2}$ single-apartment residential building, with partitions that meet the requirements of energy efficiency class $\mathrm{A}$, by installing a PV system of $5 \mathrm{kWp}$ power (with a modules area of approximately $30 \mathrm{~m}^{2}$ ), as described above, with $45^{\circ}$ south-facing, effectively-ventilated polycrystalline modules, the energy efficiency indicators of the building would be $\mathrm{C}_{1}=0.1314, \mathrm{C}_{2}=0.1314$; i.e., both would meet the A++ requirements. This system should be used for building heating, hot water and electrical appliances, and should be able to store excess electricity in distribution networks.

In order to simply improve energy efficiency indicators $C_{1}$ and $C_{2}$ for the same building, in order to reach energy efficiency class A++ $\left(\mathrm{C}_{1}<0.25, \mathrm{C}_{2} \leq 0.70\right)$, a PV system power of $1.32 \mathrm{kWp}$ (with modules area of $\left.8.6 \mathrm{~m}^{2}\right)$ would be sufficient.

If a ST system with a $5 \mathrm{~m}^{2}$ area of flat panels and an accumulation tank of 300 litres was to be installed in the same building, using this system for general heating and preparing domestic hot water, the building's energy efficiency indicators would be $\mathrm{C}_{1}=0.3145, \mathrm{C}_{2}=0.4096$; i.e., the heating performance indicator $\mathrm{C}_{1}$ would meet the requirements of $\mathrm{A}+$, and the domestic hot water indicator, $\mathrm{C}_{2}$, would meet the requirements of A++. In order to meet the requirements of the A++ class with both indicators, it would be necessary to install a ST system of $28 \mathrm{~m}^{2}$, where $\mathrm{C}_{1}=0.249, \mathrm{C}_{2}=0.4294$.

\section{Discussions and conclusions}

The main factor hindering market growth is still the high initial cost of solar systems. In the last few years, the cost of PV systems has dropped by more than $50 \%$, and is expected to continue to drop in the near future. The national energy distribution operator in Lithuania has offered the possibility for electrical energy 'storage' in the grid, which has helped in promoting this technology. On the other hand, the cost of ST systems has not changed much over the last decade, and it is difficult to see the price reducing in the next few years.

The implementation of PV systems is also increasing with the growing popularity of heat pumps. The implementation of heat pumps as a heat source that can significantly improve the overall efficiency of the energy sector is encouraged by the EU.

Despite the long payback period and decreasing popularity of ST systems in single-family buildings, the market is slowly growing, and the trend continues towards larger systems in multifamily buildings, hospitals, hotels and other large complexes, due to support from the Lithuanian government, the EU and other sources of funding.

\section{References}

APVA, 2018. Lietuvos respublikos aplinkos ministerijos aplinkos projektų valdymo agentūra [accessed 2 August 2018]. Available from Internet: https://www.apva.lt/kaip-apskaiciuojama-kompensacine-ismoka-fiziniamsasmenims/

Chung, D., Davidson, C., Ardani, R. F. K., Margolis. R., 2015. U.S. Photovoltaic prices and cost breakdowns: Q1 2015 Benchmarks for residential, commercial, and utility-scale systems," NREL, Golden, CO, USA, Tech. Rep., 2015.

EHPA, 2018. European heat pump market and statistics report 2017 [accessed 20 February 2018]. Available from Internet: http://www.ehpa.org/about/news/article/european-heat-pump-market-and-statistics-report-2017-isavailable-now/

ESO, 2018a. Energijos skirstymo operatorius [accessed 20 February 2018]. Available from Internet: http://www.eso.lt/lt/namams.html

ESO, 2018b. Energijos skirstymo operatorius [accessed 28 May 2018]. Available from Internet: http://www.eso.lt/lt/namams/elektra/paslaugos_1723/saules-jegaines-irengimas.html

LSTA, 2018. Lietuvos šilumos tiekẻjų asociacija. Vidutiné šilumos kaina gyventojams (po perskaičiavimų) [accessed 12 February 2018]. Available from Internet: http://lsta.lt/lt/pages/apie-silumos-uki/silumos-kainos

Malinowski, M., Leon, J. I., Abu-Rub, H., 2017. Solar photovoltaic and thermal energy systems: current technology and future trends. Proceedings of the IEE, vol. 105, No. 11. DOI: 10.1109/JPROC.2017.2690343

Photovoltaics report, 2018. Fraunhofer institute for solar energy systems, ISE with support of PSE conferences \& consulting GmbH Freiburg, 26 February, 2018. 
R. Valancius et. al. / EuroSun 2018 / ISES Conference Proceedings (2018)

STR 2.01.02:2016 „Pastatų energinio naudingumo projektavimas ir sertifikavimas““

TERMA, 2018. Saules electrines [accessed 28 May 2018]. Available from Internet: http://www.terma.lt/Sauleselektrines [accessed 28 May 2018].

Valancius, R., Jurelionis A., Jonynas J., Katinas V., Perednis E., 2015. Analysis of medium-scale solar thermal systems and their potential in Lithuania. Energies. 8 (6), 5725-5737. DOI: https://doi.org/10.3390/en8065725

Valancius, R., Jurelionis, A., Vaiciunas, J., 2016. Review of solar thermal systems and their potential in Lithuania. Proceedings of EuroSun 2016 Conference of ISES Europe, October 11-14, 2016, Palma de Mallorca, Spain. DOI: 10.18086/eurosun.2016.04.15 


\title{
Space Cooling Application with Unglazed Solar Absorber Carsten Wemhoener, Roman Schwarz \\ Institute of Energy Technologies IET, HSR Rapperswil (Switzerland)
}

\begin{abstract}
Increasing outdoor air temperatures, rising number of electric devices and higher comfort requirements lead to significantly rising cooling demands. Free-cooling measures reach high efficiencies, which are limiting the electricity demand for cooling. In the SCCER EIP WP4 the reuse of treated wastewater for evaporative cooling is investigated. On the building level a system configuration with integrated evaporative cooling by outer building surfaces is developed, which can for instance be realized by unglazed solar absorbers or PV/T collectors and also cover the space heating and domestic hot water demand, enabling a cost-effective integration of the cooling operation. Simulations with boundary conditions according to the Swiss guidelines SIA 2024 and SIA 2028 for a single- and multi-family house as well as an office building according to the Swiss building directive MuKEn 2014 or better in Zurich yield high free-cooling fractions of $100 \%$ in residential application and from $80 \%$ to $100 \%$ in office use depending on the boundary conditions. By wetting the absorber the cooling capacity can be notably increased. Overall system performance is in the range of 4.5-6, which corresponds to ground-coupled heat pump system performance. The paper focuses on results of the multi-family house simulation.
\end{abstract}

Keywords: Space cooling, unglazed collector, multi-functional system layout, simulation study

\section{Introduction}

Currently, residential buildings are seldom cooled actively in central Europe, while in office buildings, there is already a cooling demand due to higher internal gains. However, recent studies indicate, that due to increasing outdoor air temperatures, rising number of electric devices and higher comfort requirements also in residential buildings, the cooling demand will increase significantly until the mid of the $21^{\text {st }}$ century. In Settembrini et al. (2017) an increase of the cooling demand in residential buildings in Switzerland of $300 \%$ to $700 \%$ has been evaluated by simulations in the reference year of 2060. Since buildings have a long life cycle it is thus important to consider changes of the boundary conditions already in the planning phase. In addition to purely passive measures regarding the design of the building envelope, efficient cooling processes must also be developed and established in order to maintain comfort conditions, but to limit the electrical expenditure for cooling.

Passive cooling methods, often also denoted as free-cooling, have already been introduced, but more in the application of non-residential buildings. In residential buildings, free cooling methods are often limited to nighttime ventilation or ground-coupled free-cooling when a ground-coupled heat pump is used as heat generator. A possibility of free-cooling in residential buildings, which is not much applied so far, is the heat dissipation by activated outer surfaces of the building envelope, e.g. those installed with solar thermal components. These components, which are designed to generate heat, can also reject heat to the ambiance during nighttime operation, provided that there is a good thermal connection to the ambiance. In addition to pure heat dissipation to the outside air by convection, heat dissipation by infrared radiosity to the ambiance and particularly to the sky can be used, since a cloudless night sky has a significant lower equivalent sky temperature that is up to $20 \mathrm{~K}$ colder than the outdoor air temperature. Fig. 1 shows the cooling mechanisms that can be used for night-time cooling on the outer surfaces of buildings. The heat emission is especially favorable for uncovered solar components, which are in direct contact to the ambiance. An increase in the cooling capacity of these components can be achieved by an additional evaporative cooling, if the surface of the components is wetted with water. In order to have a sustainable water source, reuse of decentralized treated grey- and wastewater is investigated as water for wetting the absorber. 


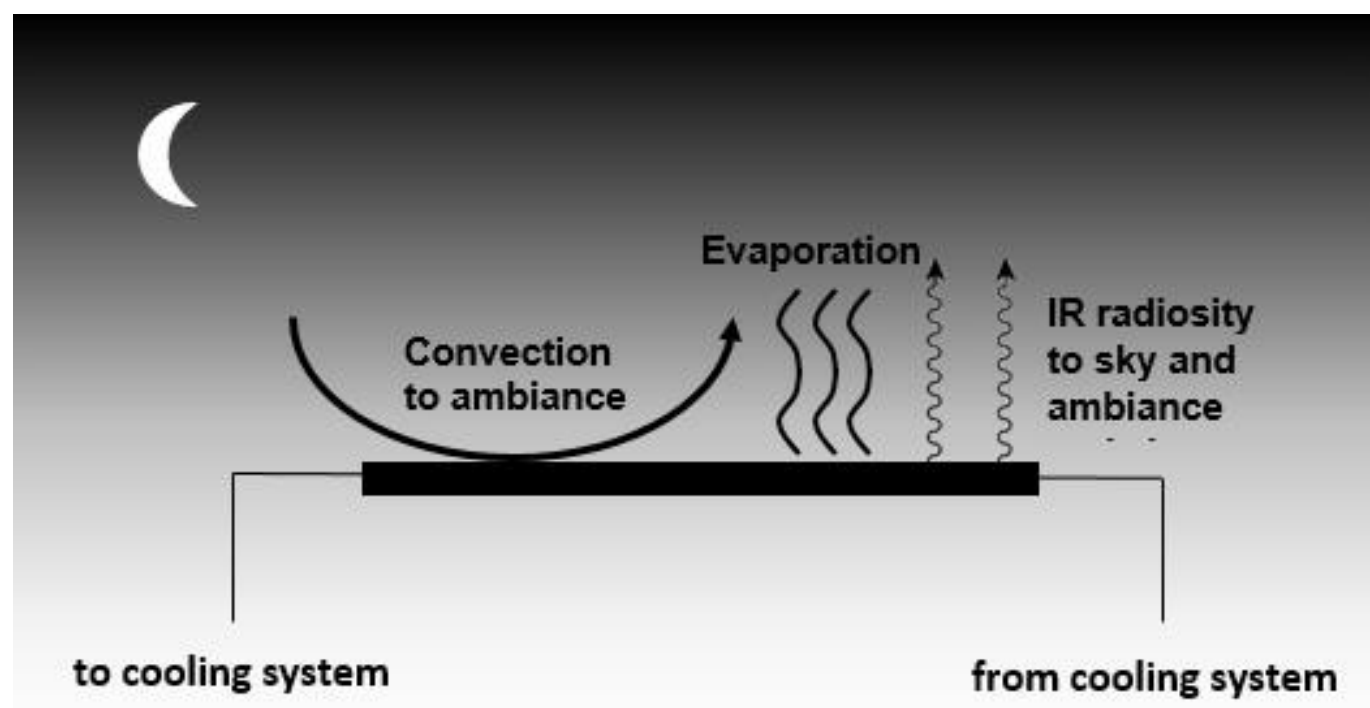

Fig. 1: Different cooling mechanisms on building outer surfaces

\section{Method}

In order to evaluate the feasibility of free-cooling by the outer building surfaces, simulation studies were carried out for residential and office buildings. In this publication, the investigations of the residential buildings, in particular in multi-family building, are presented. Results for the office buildings examined show that high freecooling rates of $80 \%$ to almost $100 \%$ can be achieved for Zurich Meteoschweiz weather station according to the Swiss guideline SIA 2028 (2018) and boundary conditions of use according to SIA 2024 (2015), depending on comfort requirements and properties of the outer building surface.

The simulations for residential buildings were carried out for a single- and multi-family house. For both types of buildings, energy-efficient new buildings have been considered that meet the requirements of the Swiss building directive MuKEn 2014 (2015).

\subsection{Building parameters}

The single-family house has an energy reference area of $200 \mathrm{~m}^{2}$. The $\mathrm{U}$-value of the outer walls with $\mathrm{U}_{\mathrm{AW}}=0.17$ $\mathrm{W} \mathrm{m}{ }^{-2} \mathrm{~K}^{-1}$ corresponds to the requirements of the Swiss building directive MuKEn 2014 (2015). The window fraction of $40 \%$ is evenly distributed across all façade orientations. The windows are triple glazed with an $U_{g^{-}}$ value of $1.0 \mathrm{~W} \mathrm{~m}^{-2} \mathrm{~K}^{-1}$ and a low fraction of the frame of only $10 \%$. The g-value of 0.5 is in the typical range for triple glazing. For shading, variants are calculated that are to reflect the user behavior. With optimal shading, from $200 \mathrm{~W} \mathrm{~m}^{-2}$ irradiance and a room temperature of $23.5^{\circ} \mathrm{C}$, the total energy transmission is reduced to a g-value of $\mathrm{g}=0.1$. Irradiance of $400 \mathrm{~W} \mathrm{~m}^{-2}$ and $600 \mathrm{~W} \mathrm{~m}^{-2}$ are considered as variants for non-optimal shading and $1000 \mathrm{~W}$ $\mathrm{m}^{-2}$ as unshaded case. For the hot water consumption, 1501 or 37.51 person $^{-1}$ with a useful temperature of $55{ }^{\circ} \mathrm{C}$ were used constantly throughout the year, which corresponds to an energy consumption of $2900 \mathrm{kWh}$ or $14.5 \mathrm{kWh} \mathrm{m}^{-2} \mathrm{a}^{-1}$.

The multi-family building has 5 stories with a total of 10 flats. The total energy reference area is $1500 \mathrm{~m}^{2}$, resulting in approx. $150 \mathrm{~m}^{2}$ per flat. The $\mathrm{U}$-value of the outer wall is with $\mathrm{U}_{\mathrm{AW}}=0.185 \mathrm{~W} \mathrm{~m}^{-2} \mathrm{~K}^{-1}$ just above the limit value according to MuKEn 2014 (2015), and the U-value of the triple-glazed window with a frame proportion of $10 \%$ with $\mathrm{U}_{\mathrm{g}}=1.2 \mathrm{~W} \mathrm{~m}^{-2} \mathrm{~K}^{-1}$ is also slightly higher than the requirement. The g-value is 0.5 , which is reduced to 0.14 when shading is activated. Shading is controlled dependent on the façade orientation. The activation of the shading of 200/400/600 W m $\mathrm{W}^{-2}$ irradiance is also varied for multi-family houses in order to model different user behavior. The occupancy of the flats with 5 persons or a person area of $30 \mathrm{~m}^{2}$ person ${ }^{-1}$ is higher than in a single-family house with a person specific area of $50 \mathrm{~m}^{2}$ person $^{-1}$. Hot water consumption is assumed to be a slightly lower consumption of 301 person $^{-1}$ at a hot water temperature of $55^{\circ} \mathrm{C}$. 
The residential buildings are equipped with mechanical ventilation and heat recovery, which has a temperature change coefficient of $80 \%$. In summer mode, heat recovery is reduced to $10 \%$ for modelling a summer bypass. The residential buildings are also both equipped with floor heating, which corresponds with $0.1 \mathrm{~m}$ pipe spacing to a rather large dimensioned floor heating, which enables low flow temperatures and thus creates favorable conditions for renewable energy use. The floor heating serves as a transfer system for both heating and freecooling operation.

\subsection{System configuration}

The building technology consists of a solar absorber, which is connected to a water-glycol source storage tank and serves as the only heat source for the heat pump, which extracts the source heat from the source storage tank. The heat pump operates in both heating and hot water mode. If the temperature level of the solar absorber is high enough, the hot water generation can also be switched over to the absorber and be carried out directly with the solar absorber. In this study a selective absorber is considered, which can reach the hot water temperatures in summer operation due to the reduced radiative losses at higher temperatures. Furthermore, both a buffer tank for heating operation and the hot water tank are integrated. In cooling mode, the source storage is used as a cold storage. Then, the absorber circuit is operated during the night for heat losses to the ambiance in order to cool down the storage tank. When charging the storage tank with the heat extracted from the building by the floor heating, the comfort limit of a floor surface temperature of at least $19{ }^{\circ} \mathrm{C}$ must be considered. Tab. 1 summarizes the parameters of the single-family and multi-family house.

Tab. 1: Building and system parameters for the single-and multi-family building

\begin{tabular}{|c|c|c|}
\hline Building and system parameters & Single-family house & Multi-family house \\
\hline Residents/People & 4 & 50 \\
\hline Window fraction & $40 \%$ & $40 \%$ \\
\hline Energy reference area $(\mathrm{ERA})\left[\mathrm{m}^{2}\right]$ & 200 & 1500 \\
\hline Annual heating demand $\left[\mathrm{kWh} \mathrm{m}{ }^{-2}\right.$ ERA $]$ & 25 & 15 \\
\hline Annual hot water demand $\left[\mathrm{kWh} \mathrm{m}^{-2}\right.$ ERA $]$ & 14.5 & 19.5 \\
\hline Annual cooling demand $\left[\mathrm{kWh} \mathrm{m}^{-2}\right.$ ERA $]$ & $4-6$ & $4-6$ \\
\hline Absorber area $\left[\mathrm{m}^{2}\right.$ abs] & $11-18$ & $71-178$ \\
\hline Source-/cold storage $\left[1 \mathrm{~m}^{-2}\right.$ ERA $]$ & 5.0 & 3.3 \\
\hline
\end{tabular}

The hot water demand of the multi-family building exceeds the heating energy demand (see Tab. 1) due to a low space heating demand of $15 \mathrm{kWh} \mathrm{m}^{-2} \mathrm{a}^{-1}$ on average between the flat, ranging from $9.3 \mathrm{kWh} \mathrm{m}^{-2} \mathrm{a}^{-1}$ of a flat on the third floor in south orientation to $27.4 \mathrm{kWh} \mathrm{m}^{-2} \mathrm{a}^{-1}$ of a flat in north orientation on the top floor. The low space heating demand is due to the lower area volume ratio of the multi-family house. In addition, the multi-family house has a higher occupancy with $30 \mathrm{~m}^{2}$ person $^{-1}$, which increases the hot water requirements and also lowers the space heating needs due to about two-thirds higher internal gains compared to the single-family house. However, the loads for equipment and lighting remain the same. The cooling requirement is with an average of $4 \mathrm{kWh} \mathrm{m}^{-2} \mathrm{a}^{-1}$ still moderate and ranges from 2.6 to $4.8 \mathrm{kWh} \mathrm{m}^{-2} \mathrm{a}^{-1}$. It is slightly lower than for a single-family house, partly for similar reasons as for heating, e.g. due to the smaller outer surface area compared to the energy reference area and also due to slightly smaller window area.

\section{Results}

In the following, the results for the multi-family building are discussed in more detail. Variation carried out for the multi-family house are

- Variation of the absorber area $71 \mathrm{~m}^{2}$ (40 absorbers), $107 \mathrm{~m}^{2}$ (60 absorbers), $142 \mathrm{~m}^{2}$ (80 absorbers), $178 \mathrm{~m}^{2}$ (100 absorbers)

- Variation of shading activation of $200 / 400 / 600 \mathrm{~W} \mathrm{~m}^{-2}$. Additionally, an unshaded case (activation at $1000 \mathrm{~W} \mathrm{~m}^{-2}$ ) is considered.

- Variation of the weather boundary condition of the weather station "Zurich Meteoschweiz" normal and warm annual data sets 


\subsection{Seasonal performance factors of the heat pump in multi-family house}

Fig. 2 shows the seasonal performance factors (SPF) of the heat pump both in space heating and domestic hot water (DHW) mode and the combined SPF. In space heating mode, the SPF of the heat pump is in the range of 4.3 and can be increased to a value of almost 5, if the absorber area is increased. A larger absorber area increases the source temperature for the space heating operation, which leads to higher performance factors. The SPF of the heat pump in DHW mode lies between 2.8 and 3.0. The increase of the SPF in the DHW mode is only moderate, since with higher absorber area, the fraction of direct DHW production by the absorber is increased, so that the heat pump has to produce the higher DHW temperature levels, which compensates the better source temperatures. The overall SPF for space heating and DHW operation is between 3.5-3.8 which approaches the SPF of ground source heat pumps, which lie in the range of 4 in recent field monitoring projects (Guenther et al., 2014). For a change of the weather conditions to Zurich Meteoschweiz warm year, the SPF of the heat pump is slightly increased by 0.1 due to the better source temperature conditions.

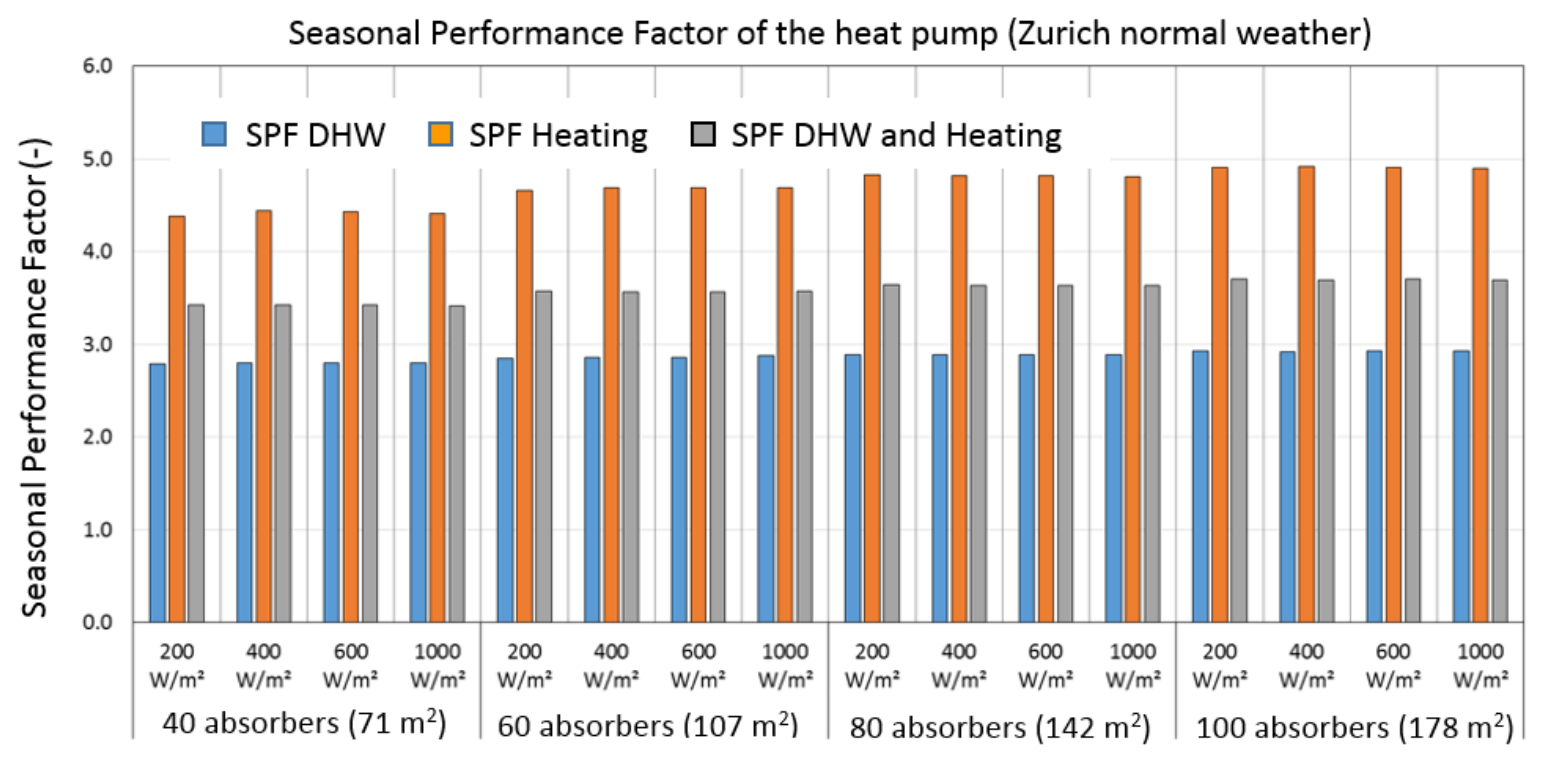

Fig. 2: Seasonal performance factors for the different operation modes, activation of shading and absorber areas

\subsection{Seasonal performance factors generator in multi-family house}

Fig. 3 shows the seasonal performance factors SPF generator, with includes both generator systems, the heat pump and the direct solar DHW operation of the absorber. The figure is split-up into the DHW mode only and a combined SPF for all operation modes including also a free-cooling operation by the absorbers. Due to the direct solar DHW operation, the SPF generator in the DHW mode is notably increased. For the smaller absorber area, a SPFgen of 4.0 is reached, which increase with higher absorber areas to 4.6 in comparison to 3.0 of the SPF of the heat pump.

The overall SPF of the system of all operation modes including also the free-cooling operation of the absorber is notably increased, as well. The effect of the cooling mode can be seen in the variation of the shading. The higher the cooling load the higher the overall seasonal performance, since the cooling demand can be covered very efficiently with the free-cooling operation. The efficiencies in cooling mode are in the range of 20 depending on the nighttime weather conditions. With the largest absorber area, an SPF of 5 is reached compared to an SPF of 3.8 of the heat pump. Direct solar DHW shares are in the range of $40 \%$.

The change of the SPF generator for a change to Zurich Meteoschweiz warm year is more distinct than for the heat pump. Due to a higher solar DHW yield, a higher fraction of cooling demand and better source temperatures, the overall SPF generator is in the range of 6. 


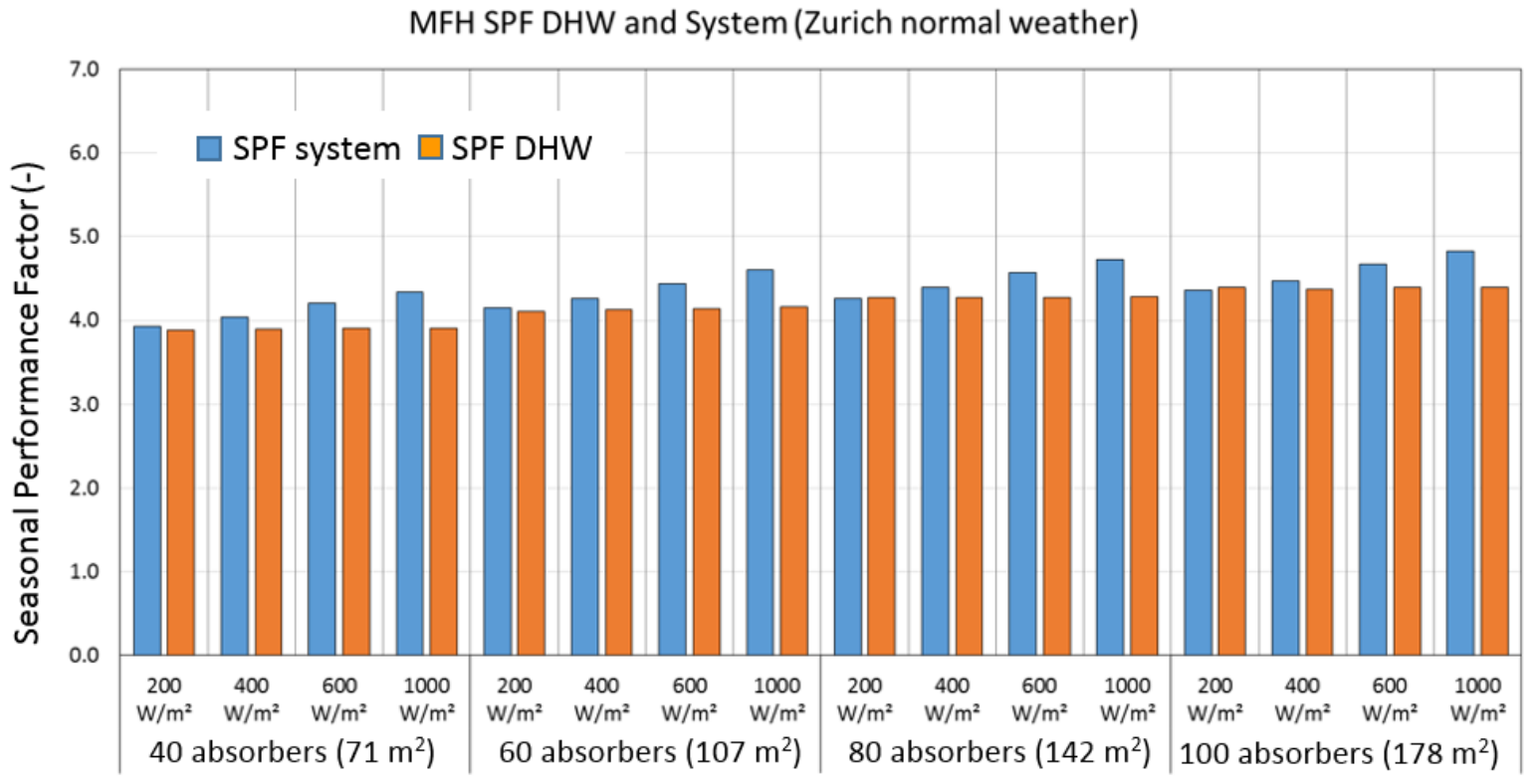

Fig. 3: Seasonal performance factors generator for the different operation modes, activation of shading and absorber areas

\subsection{Comfort multi-family house}

The comfort evaluation presented is based on the operative room temperature and the smallest absorber area of $107 \mathrm{~m}^{2}$, since relative humidity cannot be influenced by the cooling operation and a smaller absorber area limits the cooling capacity. Fig. 4 shows the hourly operative temperature within the limits of SIA 180 (2014) for airconditioned buildings, even though no active cooling or air-conditioning is applied in the buildings. However, the criteria are stricter than for window ventilated buildings, where adaptive comfort criteria apply.

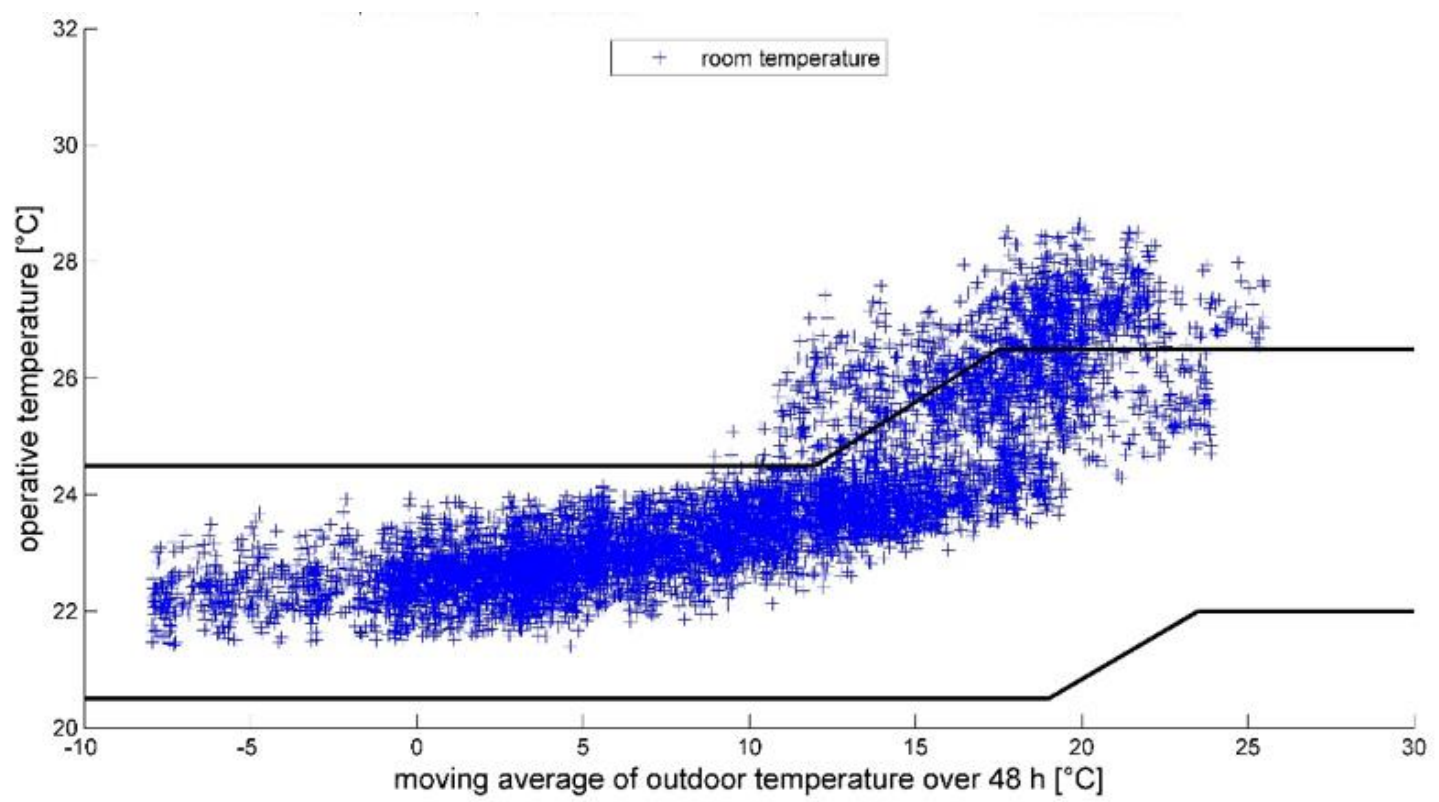

Fig. 4: Operative temperature for optimally shaded building without free-cooling according to SIA 180 (2014)

In Fig. 4, the variant with optimal shading operation at $200 \mathrm{~W} \mathrm{~m}^{-2}$, but without free-cooling operation is depicted. In the winter operation the building is kept in the temperature range between $22{ }^{\circ} \mathrm{C}-23{ }^{\circ} \mathrm{C}$, which is in the middle of the range of comfortable temperatures and often found as winter temperature range in field monitoring projects. However, in the summer operation, the shading cannot avoid violation of the comfort range. Already in the transitional period overheating occurs, while in the summer, the temperature reaches values above $28^{\circ} \mathrm{C}$. 


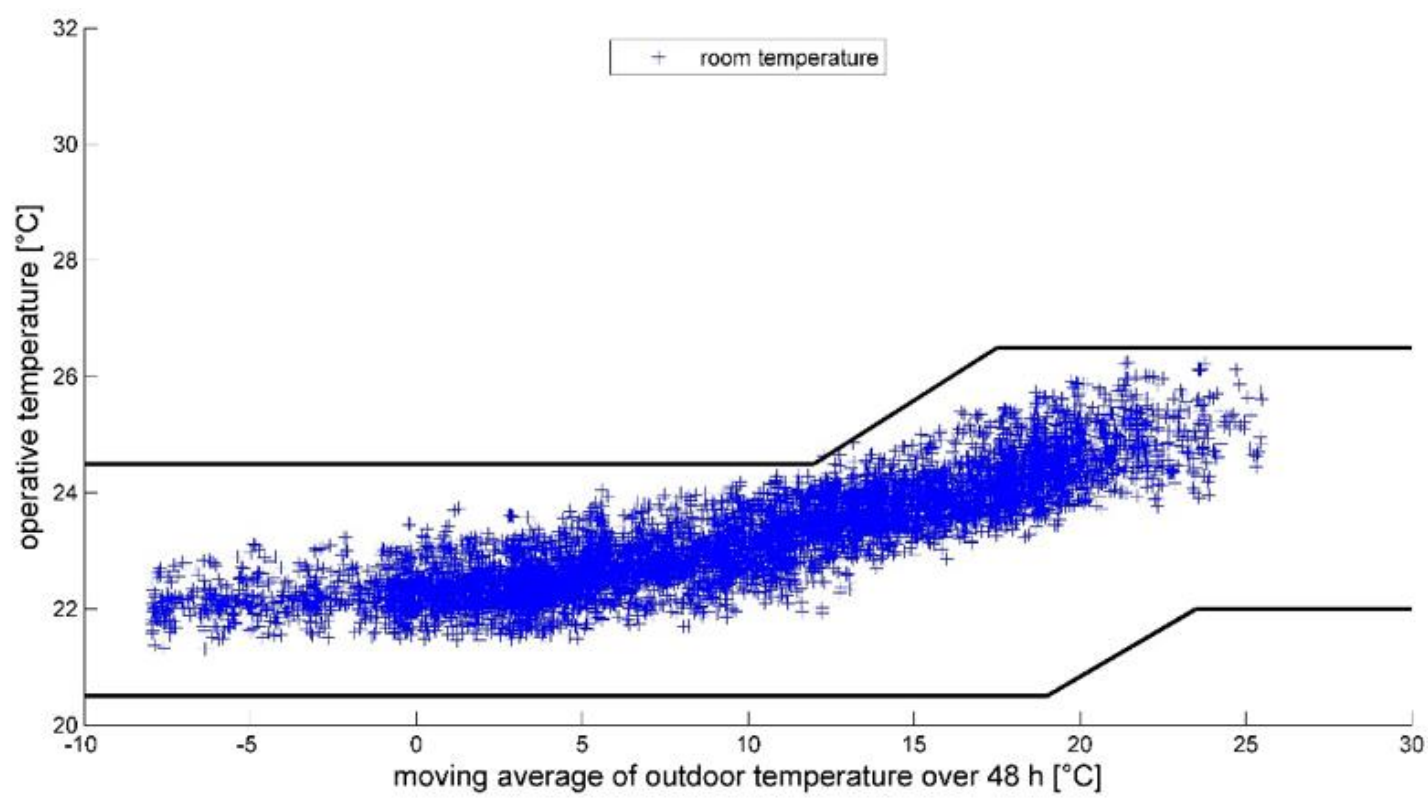

Fig. 5: Operative temperature for optimally shaded building with free-cooling range according to SIA 180 (2014)

Fig. 5 shows the variant with optimal shading and additional free-cooling operation. The overheating can be notably reduced, so that all hourly operative temperatures are in the comfortable range. The critical temperatures, which are approaching the comfort limit, are rather in the transitional period, i.e. in the summer operation, there is even a distance to the comfort limit. Thus, the free-cooling operation can compensate within limits a nonoptimal shading without violation of the comfort range.

\subsection{Results for the single family house}

The results for the single family house resemble the results of the multi-family house. So, only a brief overview is given in the frame of this publication. Performance values vary slightly from the multi-family building due the different loads and design values. The seasonal performance of the heat pump reaches an SPF of 4 in space heating operation and an SPF of 3 in DHW operation, leading to an overall performance factor between 3.5-3.8 dependent on the absorber size. The overall SPF of the generator including the direct solar DHW production and the freecooling operation reaches values up to 5 depending on the absorber size.

The comfort in terms of the operative temperature in the single family house is also similar to the multi-family house. In summer, the shading alone is not enough to stay entirely inside the comfort boundary, 340 overheating hours occur in summer with maximum temperatures around $28.5^{\circ} \mathrm{C}$. With additional free-cooling, however, the overheating can be completely avoided and there is a remaining temperature difference to the upper comfort limit. However, free-cooling only without any shading (shading activation at $1000 \mathrm{~W} \mathrm{~m}^{-2}$ ) also leads to 260 overheating hours, of which, though, only 110 occur in the summer. The other 150 overheating hours occur in the transitional period, which implies an optimization potential of the control of the free-cooling operation, since the potential of heat rejection to the ambiance should be high enough in the transitional period. Operative temperatures in winter are around $22{ }^{\circ} \mathrm{C}$ and thereby around the optimal winter temperature. Different to the design of the absorber in the multi-family house, in the single family house at low absorber size, source temperatures below the operation limit of the heat pump can occur at cold outdoor air temperatures. With a larger design of the absorber, though, source temperatures are increased and stay above the operation limit of the heat pump. With the absorber design for the multi-family building, no problems with the lower operation limit of the heat pump were observed.

\section{Discussion}

Both in single family and in multi-family buildings the feasibility of the system operation including the freecooling is confirmed. The systems reach good performance values in the range of an overall performance between $3.5-3.8$ for the heat pump and up to 6 with absorber operation and higher cooling demand. The comfort conditions according to SIA 180 (2014) for air-conditioned buildings can be kept with a combination of shading and freecooling operation. In the following, different aspects are discussed in more detail. 


\subsection{System configuration}

The system configuration is chosen in a way that all system components can be applied in multifunctional operation, both for space heating and the space cooling. The absorber is used as heat source in winter and heat sink in summer. The heat pump is used for the heat production for space heating and DHW operation, but can also be used in back-up operation for the space cooling mode, although this operation mode has not been applied in this study. The heat emission in winter and heat extraction in summer is both accomplished by the floor heating and the source storage is used as heat storage in winter and cold storage in summer. There are even synergies between the operation mode, e.g. in DHW mode, the source storage is cooled down by the heat pump. In winter operation, this enables a longer operation time for the solar absorber, in summer operation, the heat extraction of the evaporator in DHW mode is used as back-up cooling for the source storage. However, in summer operation, a large fraction of $70-90 \%$ of the DHW demand can be covered directly by the absorber and the efficiency of the free-cooling operation is higher than the efficiency in simultaneous operation of the heat pump, which leads to high overall performance factors.

\subsection{System performance}

The seasonal performance factor of the heat pump operation is in the range of ground-coupled heat pumps, which reaches a value of 4.15 on average according to current field monitoring (Guenter et al., 2014). Depending on the DHW share the combination with solar DHW production even reaches higher performance factors. The high performance values of the free-cooling operation in the range of 20 can further increase the overall efficiency at higher cooling fractions. The given performance and comfort evaluations, though, refer to a distinct design of the systems, which has not been varied in the frame of this study. Design changes in the system components can thus improve the performance and comfort reached by the system configuration. For this study the design of the source and the DHW storage were kept constant. With larger design of the source storage, for instance, more energy can be stored to overcome adverse weather conditions. By better source temperatures, also the system performance can be improved. In fact, if the source storage is designed too small, problems with the operation limit of the heat pump may occur. There are also system improvements regarding the control, so optimization on different levels are possible.

\subsection{Free-cooling operation}

By the free-cooling operation, the comfort according to SIA 180 (2014) can be kept efficiently, which would not be possible with shading only. Despite the building is not actively cooled the comfort requirements for air conditioned buildings can be achieved. Thereby, the free-cooling operation reaches high performance values in the range of 20. Cooling capacities reached with the absorber are in the range of $50 \mathrm{~W} \mathrm{~m}^{-2}-200 \mathrm{~W} \mathrm{~m}^{-2}$ depending on the weather conditions at nighttime. In order to maximize the DHW operation, a selectively coated absorber with an IR emittance of $\varepsilon_{\mathrm{IR}}=0.15$ has been used for this study. Typically, a selectively coated absorber is not well suited for a cooling operation, since the IR-emission to the sky during nighttime operation is strongly inhibited by the selectivity. However, in this case, a wetting of the absorber has been considered, which significantly increases the IR emittance to that of water, and additionally contributes to the cooling capacity by evaporative cooling. Simulation results show an increase of the cooling capacity by about $50 \%$ of the wet absorber. While in the considered residential buildings, the space heating operation is dominant and the cooling demand can be entirely covered by free-cooling, if shading is adequately operated, in office buildings, cooling may become the predominant load.

\section{Perspective}

In the frame of the feasibility study the capacity of the system integration has been approved for the application in residential buildings. In the research project as part of the Swiss Competence Center of Energy Research on Efficiency of Industrial Processes Work package 4 (SCCER EIP WP4) further investigations on the operation of the evaporative cooling with treated grey-/wastewater are planned. Thereby, requirements on the water quality with regard to scaling, fouling, odors and hygienic requirements are investigated and necessary water flows for the prevention of the above issues are assessed. Moreover, investigation for an optimized wetting of the outer surface as well as capacity and performance evaluation shall be accomplished, and also other components like $\mathrm{PV} / \mathrm{T}$ collectors shall be investigated, which are delivering also electrical energy besides the thermal yield. However, with PV/T, there may be limitations regarding the reachable temperature level for DHW operation. 
The research project is financially supported by the Swiss Innovation Agency Innosuisse and is part of the Swiss Competence Center for Energy Research SCCER EIP.

\section{References}

Conference of cantonal energy directors EnDK, 2015. MuKEn 2014. Model rules of the cantons in the field of energy, Swiss cantonal building directive, Version 2014, Berne

Guenther, D., Miara, M., Langner, R., Helmling, S. and Wapler, J., 2014. HP Monitor - Field monitoring of heat pump systems, Final report, Fraunhofer Institute for Solar Energy Systems, Freiburg (Brsg.)

Settembrini, G., Domingo-Irigoyen, S., Heim, Th., Jurt, D., Zakovorotnyi, A., Seerig, A., Zweifel, G., Menti, U. 2017. ClimaBau - Planning with regard to climate change, Energy demand and thermal comfort of present residential buildings until the year 2100, Final report SFOE resarch program buildings and cities, IGE, University of Applied Sciences and Arts Lucerne, Horw

Swiss Engineers and Architects Association, 2015. SIA 2024. Room utilization data sets for the energy and building technology, Zurich

Swiss Engineers and Architects Association, 2014. SIA 180. Heat protection, moisture protection and indoor environment in buildings, Zurich

Swiss Engineers and Architects Association, 2010. SIA 2028. Climate data for building physics, energy and building system technologies, Zurich 


\title{
The development of the Sunridge, an orientation independent thermal solar system
}

\author{
Aart de Geus ${ }^{1}$ and Henk de Beijer ${ }^{2}$ \\ ${ }^{1}$ ArtEnergy BV, Delft, The Netherlands \\ 2 De Beijer RTB, Duiven, The Netherlands
}

\begin{abstract}
For near zero energy dwellings an easy to integrate and install, efficient thermal solar system is essential. Moreover, the main disadvantage of thermal solar energy systems, i.e. the required south orientation on tilted roofs, needs to be tackled to increase the applicability of such systems. Furthermore, the competition on the roof with PV systems should be avoided. This will be tackled with the Sunridge solar energy system, a ridge integrated solar thermal system. The system characteristics are designed, tested and the blue print for the industrial manufacturing process has been made. The first prototypes are produced and are tested for performance, durability, fail safe overheating and freezing. The system will be ready for market implementation end 2018.

Keywords: ICS, solar thermal system, ridge integration, SDHW system, orientation independent.
\end{abstract}

\section{Introduction}

In order to realize Nearly Zero Energy Buildings not only renewable electricity has to be produced, but also the energy consumption needs to be reduced. Moreover, renewable heat needs to be generated and used effectively. The heat demand of existing and new buildings is about 1.5 to 3 times higher than the electricity demand. Thermal solar energy systems can reduce the demand for conventional fuels. On the roof there is competition between solar photo voltaic systems and solar thermal systems. Moreover, if the orientation of the roof is not favorable for solar energy, for instance east-west orientated houses, no economic possibilities for solar energy exists. Solar domestic hot water systems are smaller and can be placed as integrated system on the ridge of the roof. In this way, some of the called disadvantages will be solved.

For this application an easy to integrate and install, efficient thermal solar system is under development (fig 1). In Figures. 2 to 4 CAD views of the Sunridge system are presented.

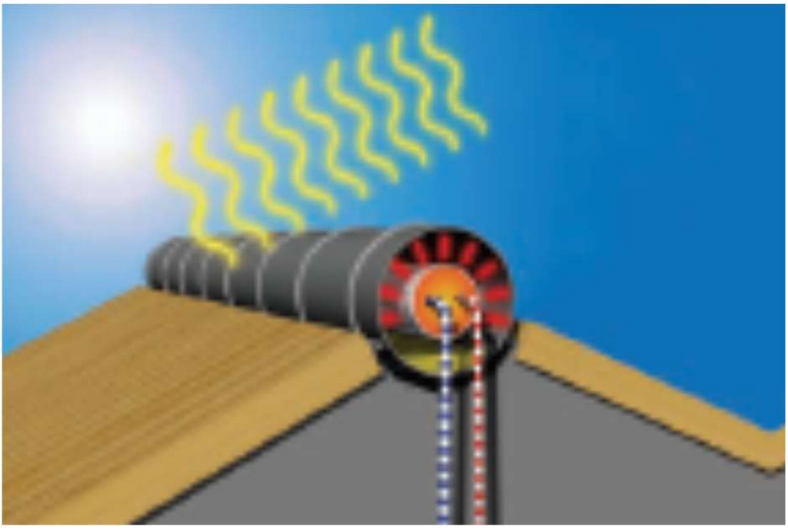

Fig. 1: Schematic presentation Sunridge

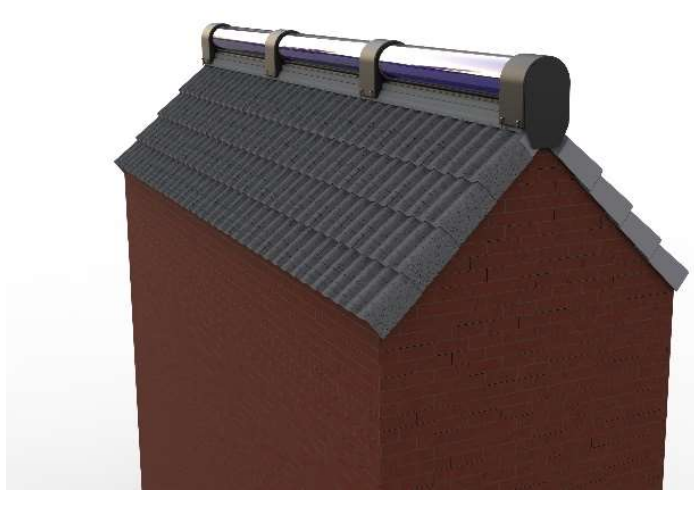

Fig. 2: CAD views of the Sunridge system on the roof. 


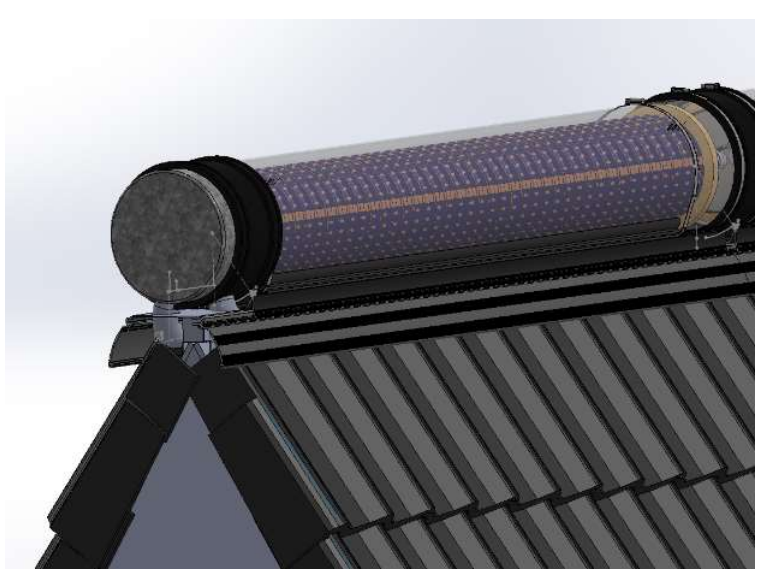

Fig. 3: Detail of the Sunridge system integrated in the ridge.

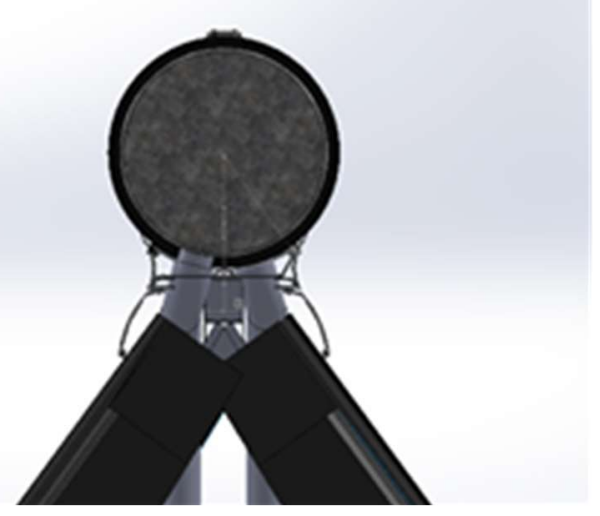

Fig. 4: View at the end of the roof.

This development of the Sunridge system, a ridge integrated solar domestic hot water system is further described in the paper. The Sunridge system offers the integration of a solar product at a place of the building (the ridge) which has a low attention factor (aesthetics), is not in competition with other energy systems at that place, integrates also the water tank (no extra space in the building needed) and is scalable to fit the ridge length. From street level the system is almost invisible. The developed concept is a tube in tube concept placed on the ridge of the roof. (Figure 3.). The Sunridge system will be very well suited for the new to build and the existing one family buildings. For this reason, the market potential is high. There are approximately 120 million existing dwellings across Europe which are suited for the Sunridge. The energy performance measurements show that more than $50 \%$ of the energy consumption needed for hot water can be produced by the Sunridge system. This performance will, of course, vary according to the climate.

\section{Technology of the Sunridge system}

The Sunridge product is an integrated solar domestic hot water system. The absorber for solar energy and the

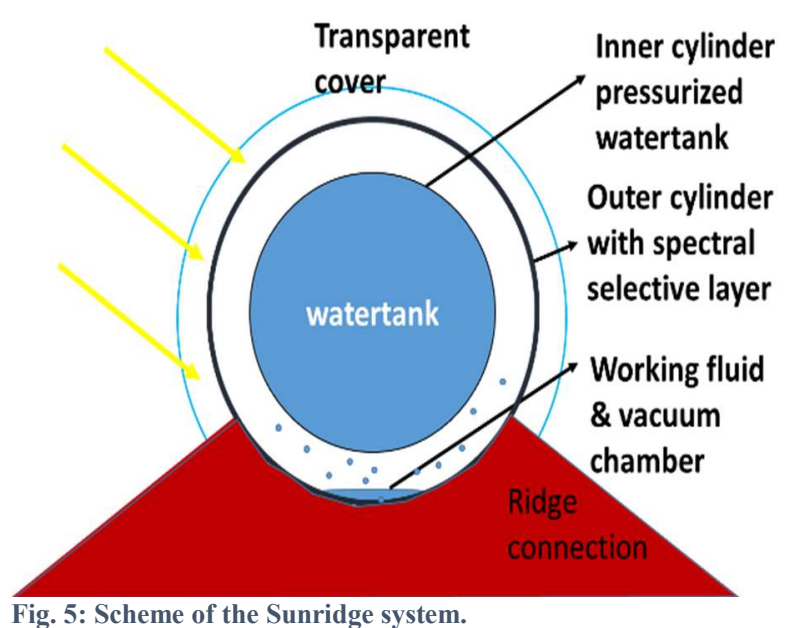
storage tank, for the hot water, have been merged into one unit (see Figure 5). The product consists of two tubes whereby one tube is assembled into the other. The inner tube is the container for (hot) tap water. The outer tube is provided with a spectral selective layer. Demineralized water is placed in the space under low pressure between the inner and outer tube in order to transport the solar heat form the outer tube to the inner tube. When the outer tube is heated by solar energy, the water evaporates. The evaporated water condenses at the inner tube and transfers in this way the heat from the outer tube to the inner tube. The inner tube containing the tap water is heated. The condensed water drips of the inner tube and the whole process of evaporation and condensing starts again. In case of absence of solar energy and during nights the heat transfer from the inner tube to the outer tube is only possible through radiation and some convection. The evaporation/condensing process is not possible then. In this way the heat losses are low.

The inner tube serves as storage tank for the hot water. In this way the solar heat is efficiently transported to the storage tank.

The Sunridge product is placed on the ridge of the dwelling and several modules can be connected in series in order to reach the required volume for storing the hot water. The modules have a length of $1,8 \mathrm{~m}$ and can store 351 of hot tap water. Up to 5 modules can be connected together, which gives 1751 of hot tap water. For a typical Dutch single one family house three modules are connected and placed of the ridge of the roof. Due to the characteristic of the tubular Sunridge system and the placement of the system at the ridge of the roof, the system performance is 
almost independent of the orientation of the dwelling. Another advantage of the integrated system is the fact that in this concept an extra storage tank for hot water is not needed inside the dwelling, but is integrated at the roof. In this way a large market for SDHW systems now becomes available especially in refurbishment sector.

\section{The Industrial Design}

The previous version of the Sunridge system, the so-called Econok, was for a short time on the market around 2004. This working and set-up of the Econok was based on the same working principles, but experienced some draw-backs. The system did not have a spectral selective layer, was time consuming to install and the transparent outer tube was a polymeric material deteriorating quicker than foreseen. This resulted in a lower performance and higher installation costs than designed. At that point of time there was not market party interested in further product development.

With the help of InnoEnergy (Knowledge Innovation Community of European Institute of Technology) the redevelopment was supported through an innovation project. The Sunridge product is since end 2014 under development to realize a competitive product for the market by 2019 .

Furthermore, the goal of the development in this InnoEnergy innovation project is to develop the pilot prototype production line, showing the manufacturing process at small scale, proving the realistic end price of the system and showing the high performance under realistic conditions.

The program of requirements for the redesign of the old Econok system looks as follows:

- Price / performance of the systems market conform;

- Esthetic, simple and scalable ridge integration for new and existing dwellings;

- Inherent safe product for overheating and freezing;

- The product has to withstand all the tests according to the standard and internal Monier standards for roofing product, such as wind, ventilation, hail, durability and safety.

- The product must be easy adaptable to different widths of the roof.

- Product should be easy to install by roofing companies

- Robust and quick connection for the modules.

- Installation process: only at one place of the roof connection through the roof for connection the water pipes to the auxiliary heater and the mains water supply.

Based on these requirements the industrial design of the Sunridge system was made, leading to the following important systems parts to be further developed and tested. These are:

- The transparent outer cover. The choice has been made to use glass tubes.

- Stainless steel as the material for the inner tank containing the drinking water.

- Copper as material for the outer tank

- Spectral selective layer applied on the outer copper tank.

- Water under low pressure between the outer and inner tank enabling the boiling condensation process for heat transfer from the outer to the inner tube.

- Supporting construction for quick installation between the ridge and the system, in the form of dedicated aluminum profiles.

In the following Figures 6 to 10 the results of the industrial design are showed.

Besides the solar and thermal performance, the durability, safety and ecological performance must be excellent. And of course, last but not least the price performance ratio must be competing with normal solar domestic hot water system.

The roofing company Monier is participant in this project and has the rights for the first market introduction. For this reason, the systems overall performance and the integration in the roof should fulfill all the requirement of the quality of products which are standard at Monier. For this reason, the durability and safety tests will be performed by Monier in their roof testing center in Heusenstamm, Germany. 


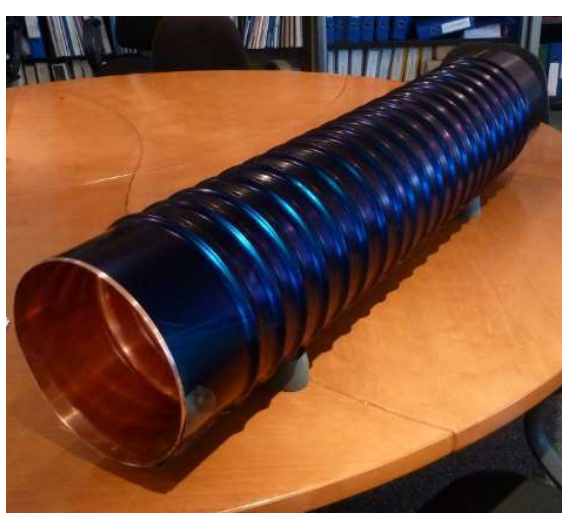

Fig. 6: Spectral layer on copper tube

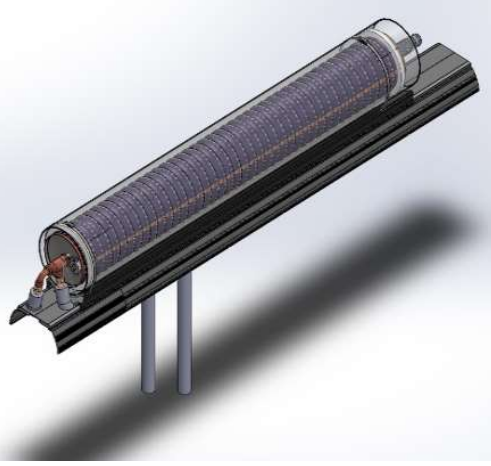

Fig. 8: Ridge profile, upper for the system, under profile to the beam of the ridge

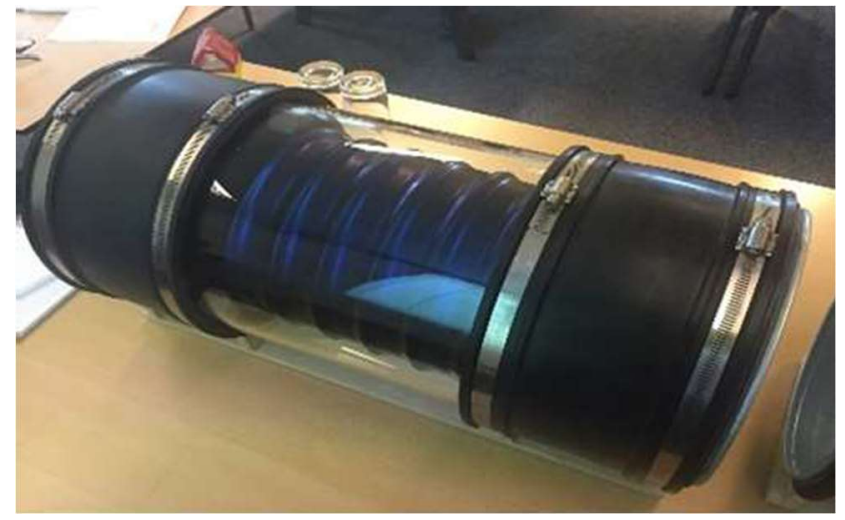

Fig. 7: Mock-up of the Sunridge

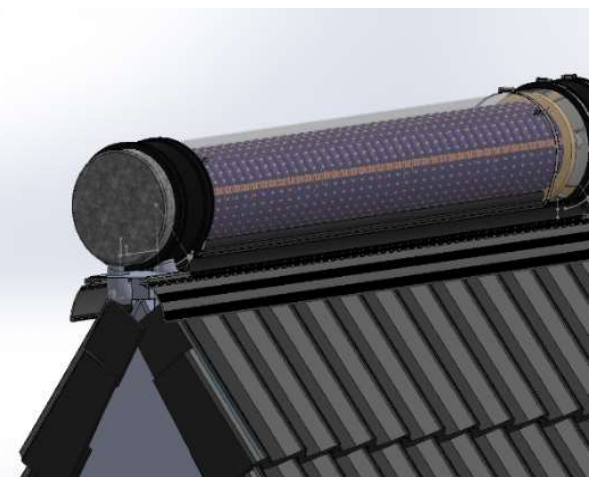

Fig. 9: End cap for the module

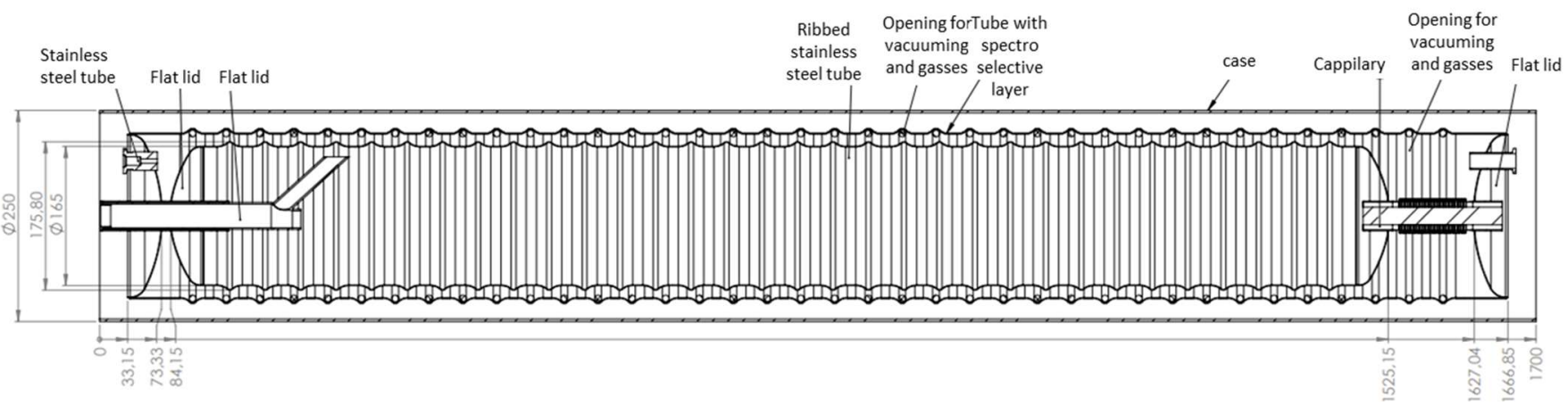

Fig. 10: Designed module with end caps.

\section{First tests results with the Sunridge system}

\subsection{Performance test}

In the spring of 2017 one module of the Sunridge system consisting of the spectral selective layer and glass transparent layer was delivered at IREC, for outdoor performance testing. In Figure 11 the system placed at the testing roof at IREC is shown. The system was tested according to the Dynamic System Test method (DST method). In Figure 12 the outcome of the new module is presented and compared to the old module (Econok). The results shown are for one module. For typical one family conditions about 3-4 modules will be used. 


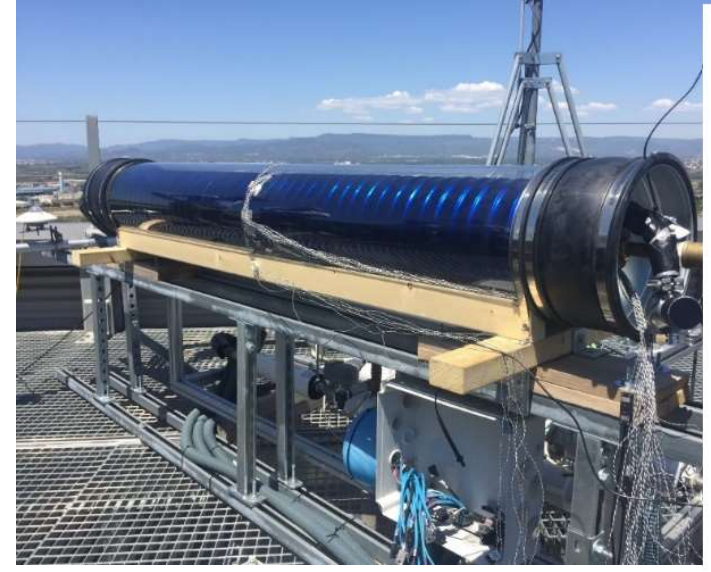

Fig. 11: The Sunridge system at test facility at IREC (Taragona Spain)

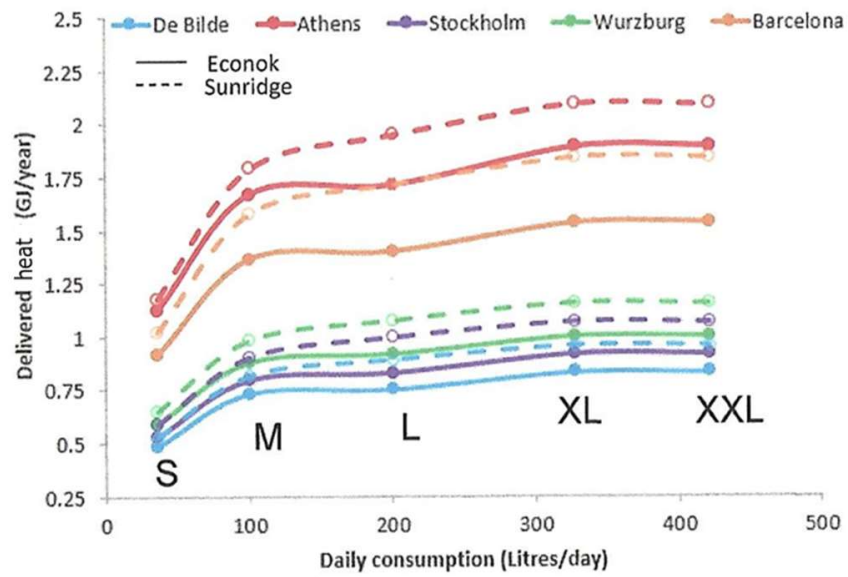

Fig. 12: Results from the DST test. Yearly energy output for one module for various climatic zones and different daily hot water consumptions. Comparison between the old Econok module and the new Sunridge module.

\subsection{Overheating and freezing test}

In the case of long period of absence (holiday) and high solar radiation the temperature in the tank of the Sunridge system can be very high, even higher than $100^{\circ} \mathrm{C}$. for this reason, a safety control will always be a part of the installed installation.

Since the complete system is place outside freezing during winter conditions can occur. For this reason, the Sunridge will be equipped with an electrical tracer. The typical vulnerable aspects in the design are in the inlet and outlet tap water piping and the connecting pipes between the modules (see Figure 13 and 14).

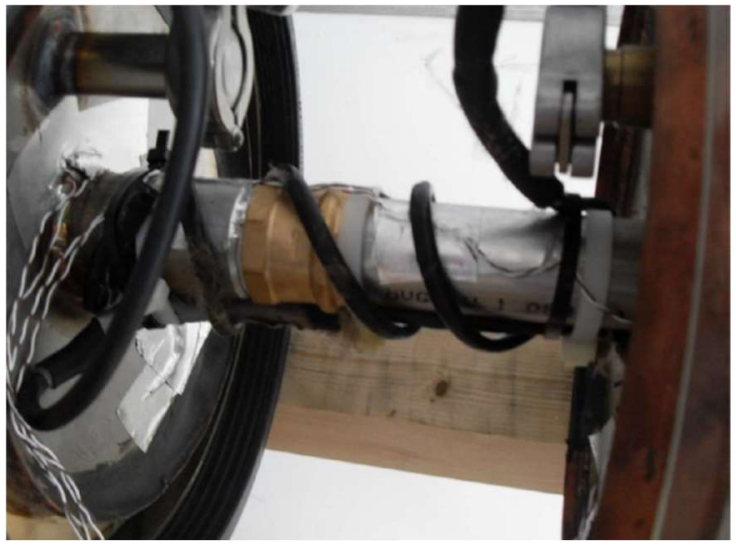

Fig. 13: Tracer on the connection pipe between the modules

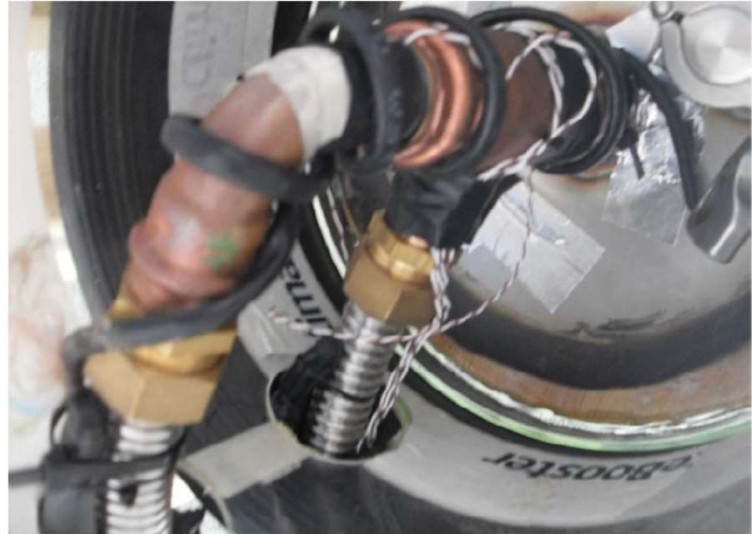

Fig. 14: Electrical tracer to the inlet and outlet pipe of the module.

In a freezing cabinet at TNO the Sunridge system including the installed electrical tracers were tested according the requirements of EN 12976-2. The complete system has to withstand an outdoor temperature of $-20^{\circ} \mathrm{C}$ during a period of 12 hours with a start temperature of the tap water of $5^{\circ} \mathrm{C}$. In Figure 15 the location of the temperature sensors is shown and in Figure 16 the test results.

The system was tested under $-20^{\circ} \mathrm{C}$ for more than 30 hours. The temperatures of T203, T204 and T205 are around $0^{\circ} \mathrm{C}$, but the more critical temperatures of the connecting pipes are above $15^{\circ} \mathrm{C}$. The temperatures $\mathrm{T}$ deep and $\mathrm{T}$ shallow drop to a still safe level of slightly below $3{ }^{\circ} \mathrm{C}$.

The conclusion from the test was that the Sunridge system equipped with the electrical traces and the temperature sensor placed on the right position, fulfills the EN12975-2 requirements with respect to withstanding freezing. Moreover, the freezing tests have made clear that the highest energy losses are at the beginning and the end of the Sunridge module. This cold bridge can be avoided by changing the hydraulic connections. 


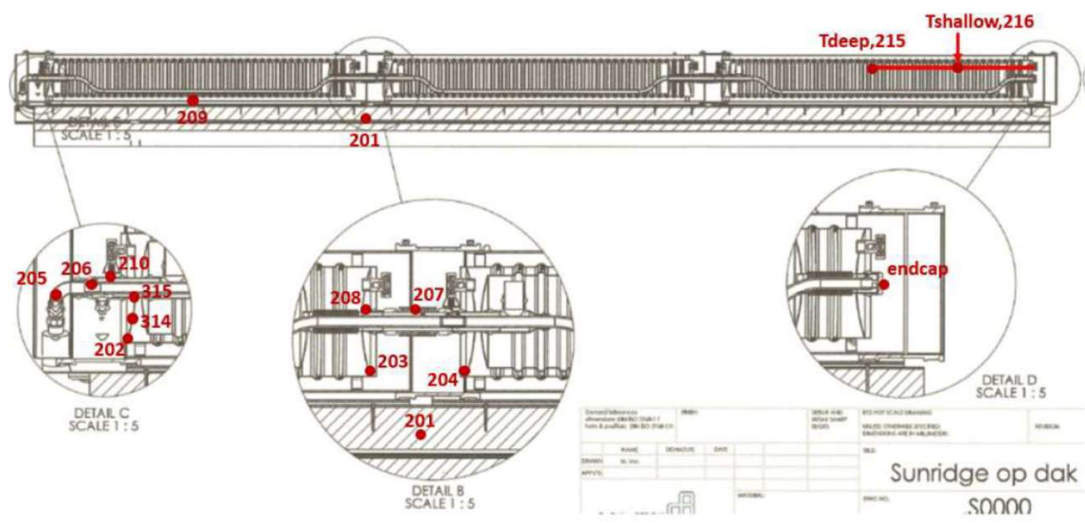

Fig. 15: The location of the temperature sensors in and around the Sunridge system.

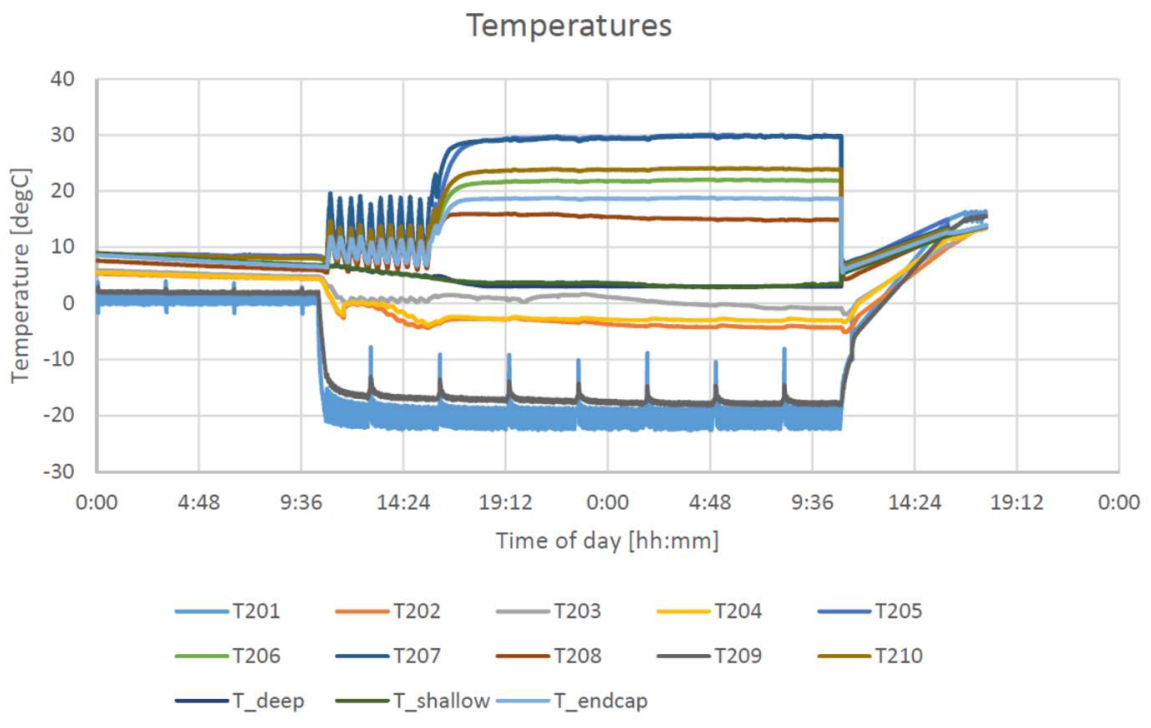

Fig. 16. Temperatures in the and around the Sunridge water tank during the freeze testing

\section{3}

\section{Heat loss test}

As part of the freezing tests carried out the heat loss coefficient of the module was measured and calculated with the detailed model. As follow up, a thermal loss test was performed by first heating the water in the module, and

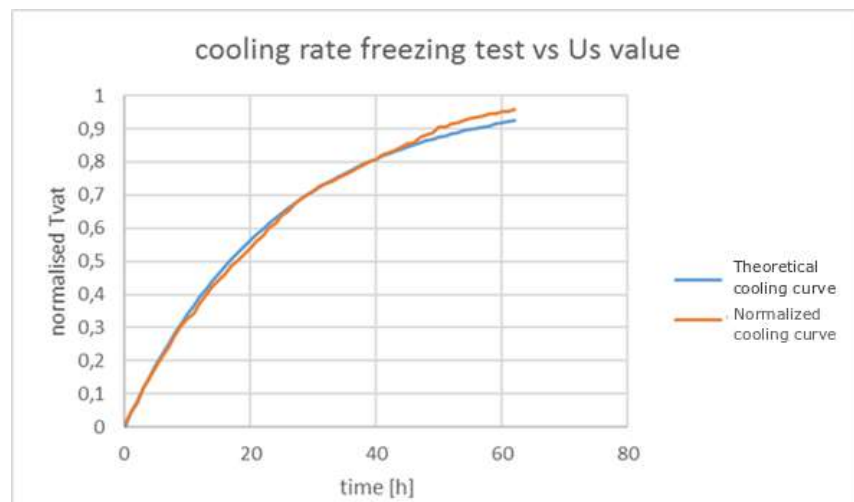

Fig. 17: Normalized cooling curve as measured (red) and calculated (blue). number of modules. The result is shown in Figure 18. subsequently measuring the water temperature during free cooling down to ambient temperature. The normalized cooling curve is shown in Figure 17 (red line), together with a fit based on a theoretical cooling curve (blue line). The resulting loss coefficient equals $1,5 \mathrm{~W} / \mathrm{m}^{2} \mathrm{~K}$. During the DTS test the heat loss coefficient was determined as $1,37 \mathrm{~W} / \mathrm{m}^{2} \mathrm{~K}$. Based on the test results and calculations, it was concluded that the thermal loss coefficient is mainly determined by the connections to the modules, and not by the modules themselves

From the results shown in Figure 17 it is concluded that the thermal loss coefficient is a system parameter, rather than a module parameter: the loss coefficient will depend on the be made of the loss coefficient as a function of the 


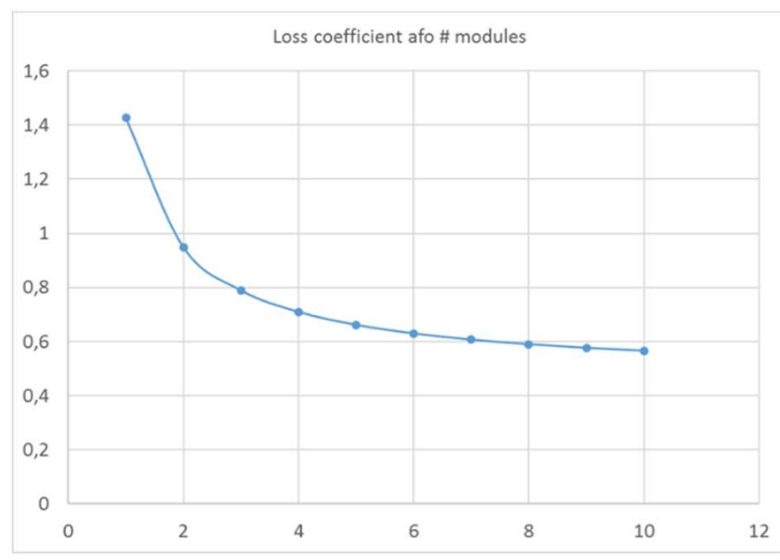

Figure 18 shows that the loss coefficient decreases with an increasing number of modules in a system, ranging from approx. $1,4 \mathrm{~W} / \mathrm{m} 2 \mathrm{~K}$ for a single module to approx. $0,6 \mathrm{~W} / \mathrm{m} 2 \mathrm{~K}$ for large systems. Improvement in the heat loss coefficient can be obtained by redesigning the inlet and outlet connection to the modules and a better insulation of the end of the first and last module.

Fig. 18:. Calculated loss coefficient as a function of the number of modules, based on the DST test result (one module) and additional data and calculations from the freezing test

\subsection{Wind load design}

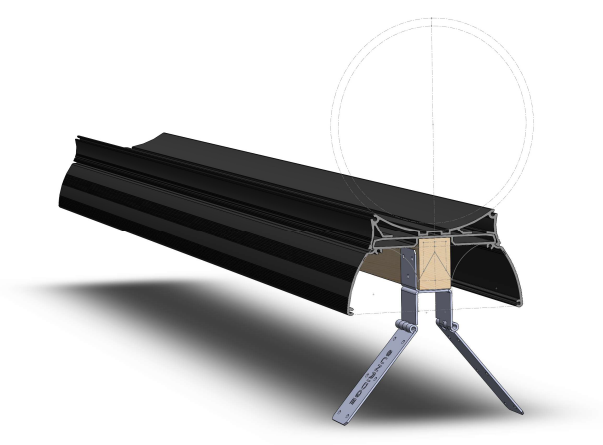

Fig.19:. The aluminum profile connected to the beam and the clamp for holding the wooden beam for connection to the roof plates.
The Sunridge system is mounted on an aluminum profile. This profile clicks into a profile that is connected to the ridge. The wooden beam for the ridge is connected to the roof plates by means of a number of clamps. Wind loads will come on the glass tube of the Sunridge system. These forces will generate momentum to the roof. The connection from the system to the roof plates have to withstand severe wind loads. For this the most severe conditions from the standards are taken. In this case that is the British Standard for wind loads on roofs. The glass tube is mounted on the aluminum support profile. The profile is screwed on the beam of the ridge. This is a new wooden beam mounted with ridge batten holders on the roof plates. A dedicated design has been made for the ridge batten because they form a constructive unit with profiles. In order to withstand the extreme wind load, the place and thickness of the screws was calculated. Moreover, this was also carried out for the clamps and ridge batten holder. Hereafter this was manually tested at the test roof set-up at Monier. A first quite simple tests showed that the steel support for the beam were not strong enough. Redesign for strengthening the steel support is needed

\section{Redesign}

Based on the outcome of the testing and the cost price analysis a number of improvements were taken into account. These are:

- Improvement of the heat loss coefficient of the modules

- Reducing the mixing during draw-off

- Cost reduction for the outer copper tube

- $\quad$ Redesign of the end caps and intermediate caps

- $\quad$ Redesign of the steel ridge support

\subsection{Improving the heat loss of the Sunridge system}

Based on the analysis of the heat loss of the Sunridge modules a redesign of the hydraulic connections of the modules was carried out. In Figure 20 and 21 the solution for this is presented. Based on the outdoor testing at IREC and the heat loss test at TNO, it was concluded that the heat losses were much lower than in the old version. Analysis showed room for improvement. The heat losses at the end caps could be further reduced. The improvement given in the redesign of the hydraulic connections reduces the cold bridge at the end /beginning of 
a 3-module system. Furthermore, well insulating the end/beginning caps of the system will further reduces the heat losses. Moreover, this also applies for the interconnection between the modules

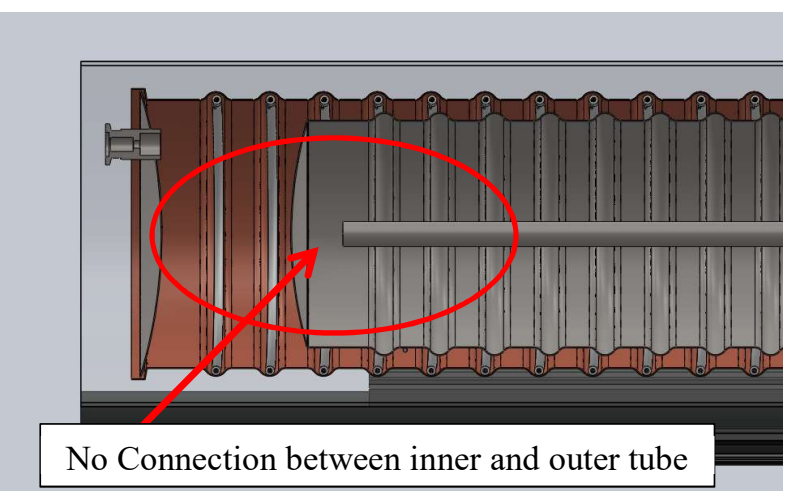

Fig. 20: Redesign absorber tube without cold bridge

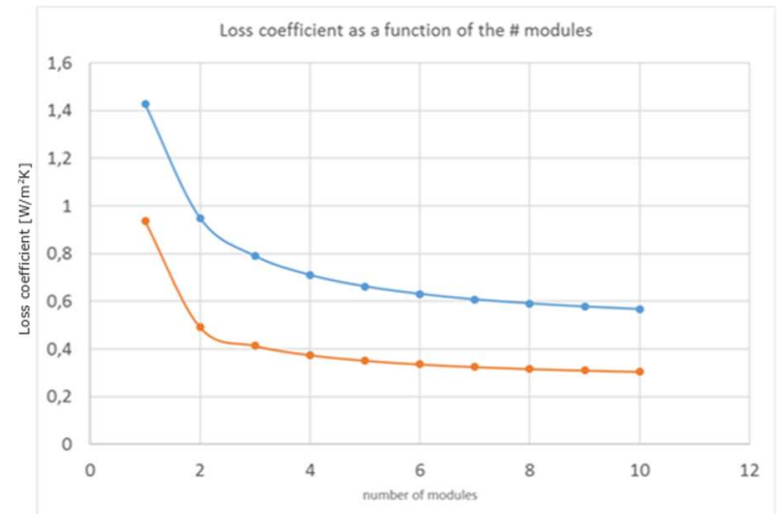

Fig. 22: Calculated effect of improvements in the insulation of the end caps and connections.

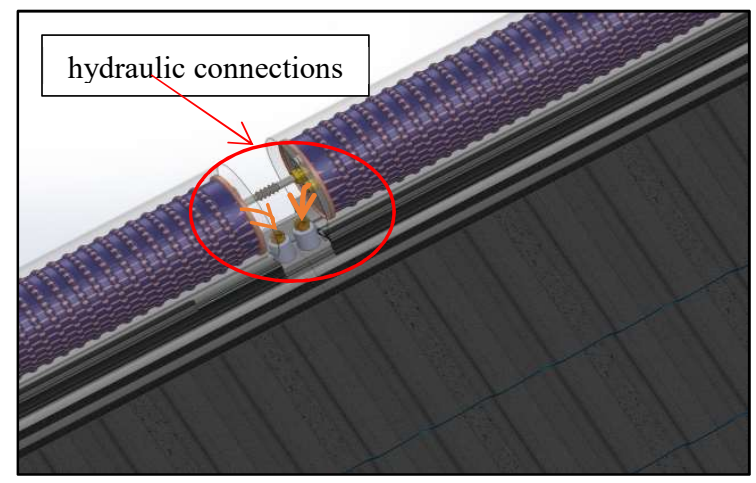

Fig. 21: Hydraulic connections through roof between modules

In Figure 22 it is shown, based on simulations, that the heat losses of the Sunridge system can be much lower and that the heat losses are dependent on the number of modules.

\subsection{The draw-off mixing}

Dynamic System Testing and modeling by IREC indicates an additional improvement in the energy performance of up to $12 \%$ in simulations, when the mixing during draw-off is similar to the previous system (Econok), depending on hot water consumption \& climate conditions. Experiments have taken place on two types of modules of the Sunridge system, which are foreseen. To be more precise: a middle module and an end module. Various tests are carries out for a number of different flow-stratifiers for both modules. The flow patters are visualized by using a test circuit and inject ink into the pipeline. A transparent tube in combination with a camera allows to visually capture flow profiles over time. For this test a PMMA tube with flanges has been designed. By opening the flanges, the internal configuration can be changed and tested.

The solution which comes the closest to the theoretically ideal block-response will be industrialized to the final solution for Sunridge.The Sunridge system is designed for the so-called highest comfort class. Therefore, the experiments are carried out for a water draw off flow rate of 14 1/min (higher than the best comfort class of 12 $1 /$ min in The Netherlands).

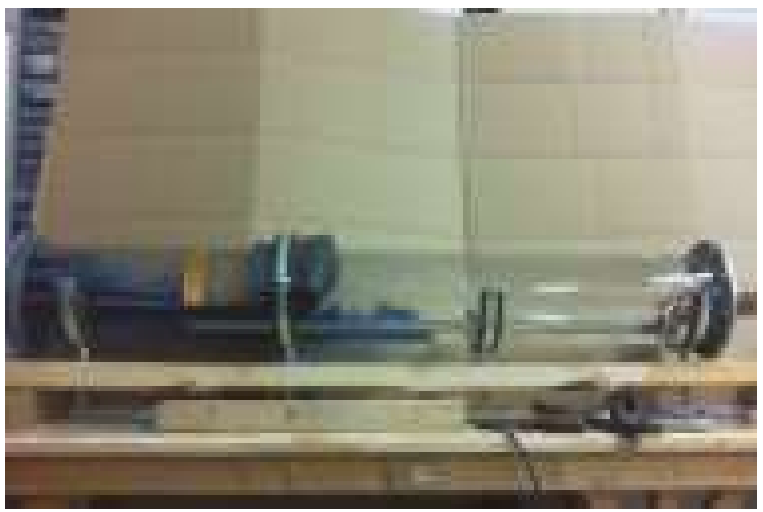

Fig. 23: Transparent module with ink injection.

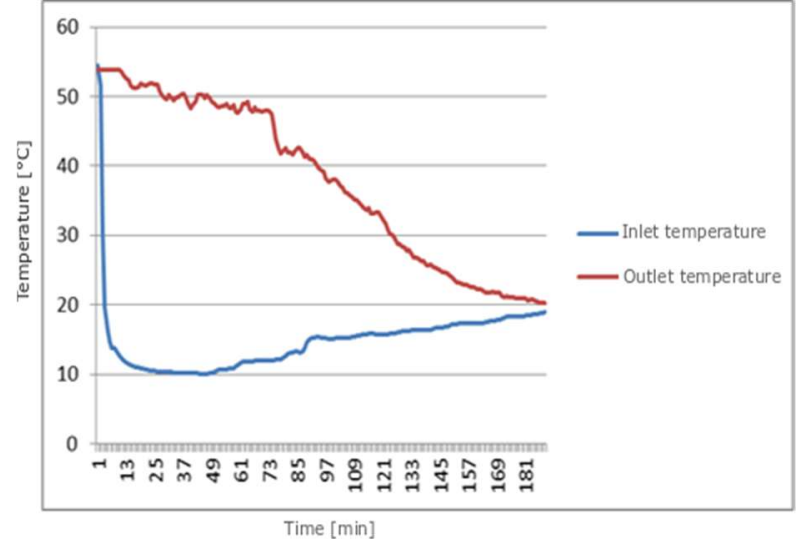

Fig.24: Inlet (blue) and outlet (red)t temperature of the module over time. 
Based on the analysis of the measurements and visualization the best configuration is chosen and presented in the following Figures.

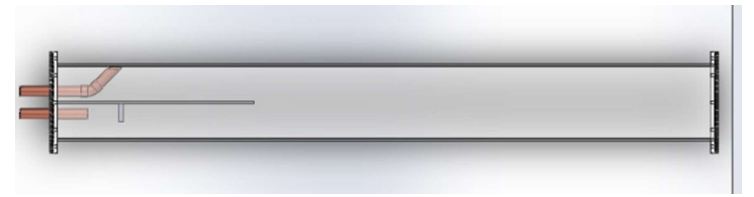

Fig. 25: Inlet-outlet solution end modules

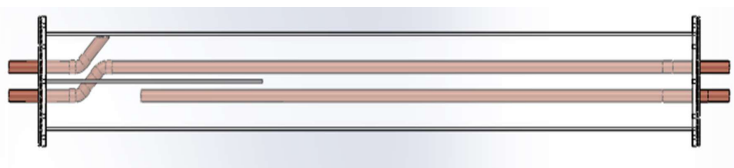

Fig. 26: Flow solution middle module

Combination of the modules leads to the final system set-up as shown the Figure 27.

In this Figure the Sunridge configuration for 3 modules is given, two end-modules and a middle-module.

The solution of applying the two type of modules with different internal flow coupling leads to a situation which comes the closest to the theoretically ideal block-response for tapping of the hot water of the storage tank. In this way the mixing of cold and hot tap water during draw-off is strongly reduced. This solution will be industrialized for the final solution for Sunridge.

\section{[1] [III}

Fig. 27: The Sunridge system coupling of modules

\subsection{Cost Reduction}

The first prototype of the Sunrise modules consisted of a copper absorber tube, covered with a spectral selective layer on a thin $(0,12$ or $0,20 \mathrm{~mm})$ copper carrier.

The use of a copper tube has two disadvantages:

- copper is expensive;

- Ensuring vacuum tightness of the copper/stainless-steel welding at the end-caps of the tube is difficult and requires skilled workers.

For this reason, the use of a stainless- steel absorber tube was proposed by the consortium.

The use of stainless-steel has two advantages:

- A cost reduction in materials of EUR 40 per module, plus a reduction in labour cost;

- Easier to achieve vacuum-tight welding at the end-caps of the tube.

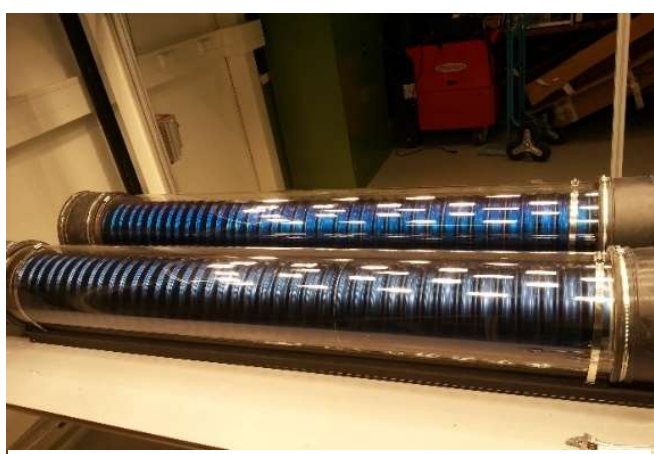

Fig. 28: Two Sunridge prototypes, as-received for testing
The thermal conductivity of stainless-steel however is lower than for copper, which might influence the thermal gain of the solar energy system. Therefore, the thermal performance of a module was investigated in the lab, where a comparison was made between a prototype with a copper absorber tube and a prototype with a stainless-steel absorber tube.

The investigation was performed at the HVAC- and Solar Energy lab of TNO in Delft, using an indoor solar simulator delivering close to $1000 \mathrm{~W} / \mathrm{m} 2$ of power.

Both the prototype with the copper absorber tube and the prototype with the stainless-steel absorber tube were tested using the solar simulator. The tests were done simultaneously. In Figure 28 the two different prototypes are shown, as-received int he lab. In Figure 29, the prototypes are shown, mounted in

the solar simulator. Four Tests were carried out in to determine difference in the performance of the modules. Type 1: Static heating test. In this test, both prototypes are filled with cold water. All valves are closed, and the solar simulation is switched on.

Type 2: Dynamic heating test. In this test, both prototypes are filled with cold water. The valves are adjusted, to apply a flow (e.g. $1 \mathrm{dm} 3 / \mathrm{min}$ ) to the system. The flows are measured by Q1 and Q2. The temperature differences T4 - T1 and T5 - T1 are measured. The thermal power is calculated from the flow and the temperature difference. 
Type 3: Static cooling test. This test usually follows a Type 1 test. All valves are closed, and the solar simulation is switched off.

Type 4: Stagnation test. This test closely resembles a Type 1 test. All valves are closed, and the solar simulation is switched on. The temperatures in the inner tube with the tap water is measured by T2 and T3.

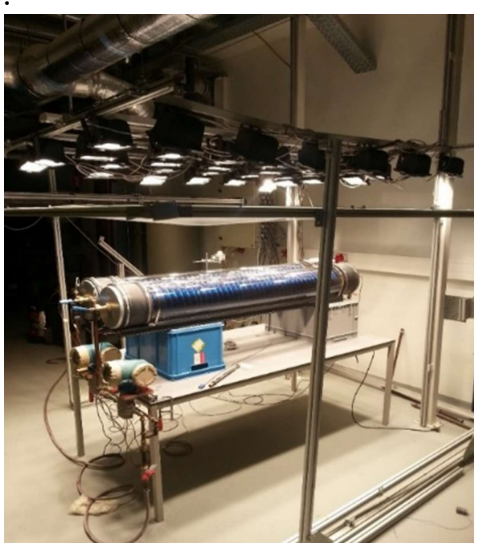

Fig. 29: Two Sunridge prototypes, mounted in the solar simulator

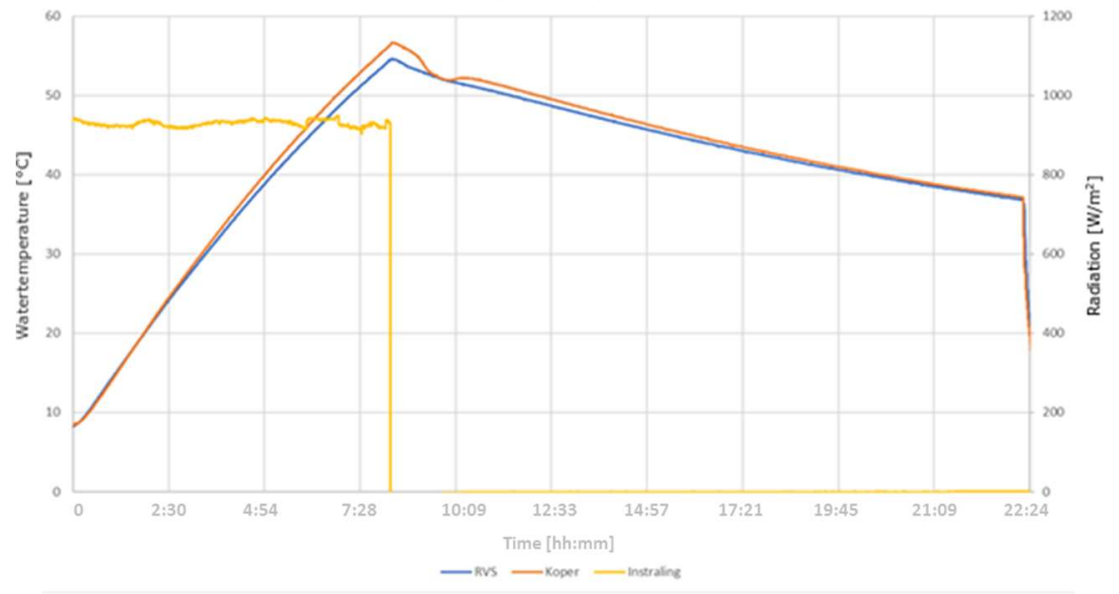

Fig. 30: Measurement results of the copper and stainless-steel tube

Tab. 1: Comparison of the prototypes using a dynamic measurement

\begin{tabular}{|l|l|l|}
\hline & $\begin{array}{l}\text { stainless-steel outer } \\
\text { tube }\end{array}$ & copper outer tube \\
\hline Supply temperature $\left[{ }^{\circ} \mathrm{C}\right]$ & 9,8 & 9,8 \\
\hline Delivery temperature $\left[{ }^{\circ} \mathrm{C}\right]$ & 13,5 & 15,0 \\
\hline Measured flow $[\mathrm{dm} 3 / \mathrm{min}]$ & 1,39 & 0,90 \\
\hline $\begin{array}{l}\text { Measured irradiation } \\
{[\mathrm{W} / \mathrm{m} 2]}\end{array}$ & \multicolumn{2}{|c|}{928} \\
\hline Thermal power $[\mathrm{W}]$ & 363 & 330 \\
\hline Difference & $+9 \%$ & \\
\hline
\end{tabular}

The thermal performance (gains and losses) of both prototypes were measured.

In static measurements, differences of $5 \%$ or less were measured in the advantage of the stainless-steel outer tube. The measured difference is comparable with the overall accuracy of the measurement, which is determined as $4 \%$. In a dynamic measurement, the thermal gain of the prototype with the stainless-steel outer tube was $9 \%$ higher. This result seems to be significant.

In a stagnation test, the stagnation temperature of the prototype with the stainless-steel absorber tube was 103 ${ }^{\circ} \mathrm{C}$, while the stagnation temperature of the prototype with the copper absorber tube was $106{ }^{\circ} \mathrm{C}$. This difference is within the accuracy of the measurement.

In view of the different test results, the thermal performance of the prototype with the stainless-steel absorber tube was not significantly lower than the thermal performance of the prototype with the copper absorber tube. Since the stainless-steel absorber tube is significantly cheaper as compared to the copper absorber tube, it is concluded that using a stainless-steel absorber tube will result in a better business case: lower production costs at the same energy (cost) savings.

The prototype with the stainless-steel absorber tube will therefore be produced for the field test

\section{Conclusions}

In this paper the development of the ridge integrated solar water heating system, Sunridge is described. The Sunridge system consist of a number of modules coupled and placed on the ridge of the roof. With this flexible design for the system, the solar energy contribution to the hot tap water can be tuned to the demand, the climate and the dwelling. The first development started during 2015-2016. Test results and production analysis showed a competitive performance. Based on the test a number of improvements are carried out. The inlet and outlet configuration for the tap water was changed from the beginning and end of the Sunridge system to the middle of the system. This change reduces the heat losses considerably. Moreover, the installation costs will be 
reduced by this measure. Next the mixing of the tap water during draw-off is prevented by designing a socalled stratifier in the modules.

An important step in the design is the replacement of the expensive copper tube by a tube of stainless-steel. Experiments showed little difference between the materials. The big advantage of using the stainless-steel tube is first a reduction in the material cost and secondly a reduction in the manufacturing cost. Welding copper with stainless steel is more complicated than only stainless steel.

The energy performance of the ridge integrated system can be about $50 \%$ of the energy demand for hot tap water and most important this is orientation independent. Moreover, the ridge integration enables the roof of the dwelling being used for other purposes, such as photo voltaic panels and/or roof windows.

The Sunridge system is a preheater for hot tap water with the tap water storage tank placed outside the dwelling, on the roof. The design of the system enables an inherent safe product, easy to install and to connect to the hot water system in the dwelling.

The industrial production process is designed in order to produce the system at high quality in a professional way. The overall cost price including installation is expected to be competitive with the standard solar thermal domestic hot water systems. In 2019 the Sunridge product will be introduced in the market in The Netherlands.

\section{Acknowledgements}

This development is supported by InnoEnergy a Knowledge Innovation Community through the funding of the Sunridge project. InnoEnergy is supported financially by European Institute of Technology. In this project the following parties are cooperating:

- Monier roof and tiles manufacturer,

- TNO research Institute in The Netherlands,

- IREC Renewable Energy laboratories,

- $\quad$ RTB de Beijer bv innovative SME company

- ArtEnergy bv SME company

\section{References}

De Geus, A., De Beijer, H., 2018. The development of the Sunridge ICS System: An Orientation Independent Solar System. Proceedings ISES Solar World Congress 2017 IEA SHC International Conference on Solar Heating and Cooling for Buildings and Industry.

Fuentes, E., Salom, J., 2017. Characterization of the thermal performance of a novel roof ridge solar hot water system. Journal of Façade Design and Engineering.

Web references:

www.innoenergy.com , EIT - InnoEnergy, sun-RISE, Ridge Integrated Solar Energy system, innovation project 2014-2018. 


\title{
Direct solar thermal systems with (thermosiphon) circulation frost protection using a Thermo-Differential Valve
}

\author{
Nico J.L. van Ruth', Paul Kratz' \\ 1 Conico Valves bv, Veldhoven (Netherlands)
}

\begin{abstract}
This research involves a direct solar (combi-)system for use in cool climates, based on vacuum-tube collectors, that uses night-circulation for frost protection, which doesn't just rely on pumped circulation, but also provides frost protection through thermosiphon circulation as a back-up in case of power/control failures. Furthermore, this direct solar system does not use a collector sensor or storage tank sensor, but instead has both the temperature sensors integrated into the pumping station. These features are achieved by using a Thermo-Differential Valve (TDV), which is installed on the storage tank at the solar inlet, and which only opens when the solar supply temperature is higher than the storage tank temperature and bypasses the storage tank when the supply temperature is lower than the storage tank temperature. Novel strategies for operating the circulating pump have been developed and tested, that are designed to optimize the efficiency of the system using the TDV in low-intensity conditions, such as overcast conditions, and to create a system that can focus on generating high temperature heat, without significantly compromising efficiency, by using multiple collector passes to achieve the desired temperature, before directing the flow into the storage tank.
\end{abstract}

Keywords: Thermo-Differential Valve, Direct Solar System, Solar frost protection

\section{Introduction}

The use of the self-actuating Thermo-Differential Valve (TDV) has been previously reported for the application of promoting stratification in solar combi systems ${ }^{1}$, where the TDV is used to direct the solar supply flow to the appropriate height in a (combi-)storage tank for solar systems. In this work the same valve is used, except that the valve is used to bypass the storage tank completely). The use of the TDV isolates the solar circuit from the storage tank when the temperature of the solar supply flow is lower than the temperature inside the storage tank (at the height where the TDV is installed) and allows circulation in the solar circuit without potential heat loss from the storage tank. This feature is used to position all the sensors for the controller inside the solar pumping station, using circulation to detect the temperature of the collector and the storage tank temperature. This periodic circulation will be referred to as 'sampling' in this article, and the waiting period between sampling is referred to as the 'rest'. The system switches to continuous pumping if at the end of the sampling period there is a significant temperature difference between the supply and return temperature (indicating that the TDV is in the open position), or if a maximum threshold temperature is reached during sampling. In continuous pumping operation, it is expected that in many circumstances the temperature increase in the collector, at minimum pumping speed, will not be sufficient to achieve a temperature high enough for the TDV to open, in which case multiple passed through the solar circuit will be made to achieve the necessary temperature for the TDV to open. At night, if the temperature in the solar circuit drops below a lower limit, a thermostatic frost protection valve opens, allowing a small amount of heat from the tank to flow into the solar circuit, just enough to maintain it at the preset minimum temperature, preventing frost damage. When there is a power failure and the periodic pumped circulation no longer takes place, thermosiphon flow starts circulating when the collector is cold and at risk of freezing (with the collector positioned at the highest point in the solar circuit), and in this case also the thermostatic frost protection valve adds heat to the solar circuit to maintain the preset minimum temperature.

In the research presented in this paper, supported by the EU's OP-Zuid program for regional development, the system arrangement shown in Figure 1 was used, which has the TDV positioned in the center of the storage tank, and the thermostatic frost protection valve connected to the upper section of the storage tank. 


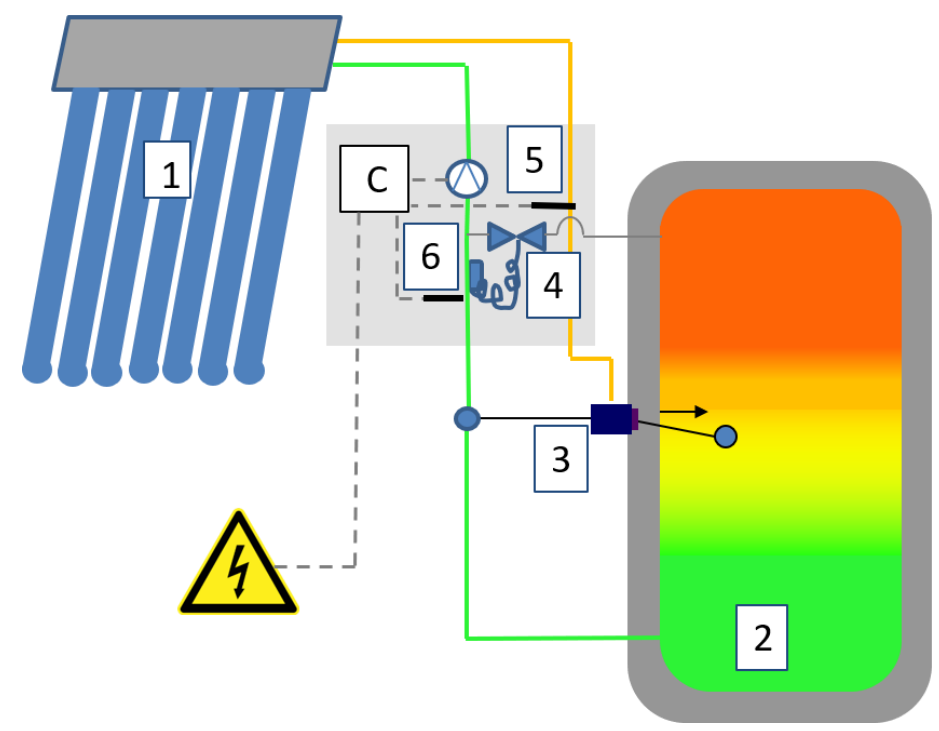

1) Vacuum tube collector

2) Combi-tank for hot water and heating

3) Thermo-Differential Switching Valve

4) Thermostat frost protection valve

5) Solar supply Tsensor

6) Solar return Tsensor

Fig. 1: System arrangement, only solar circuit depicted

The operation of the system in sampling mode, in low intensity conditions, is explained graphically in Figure 2.

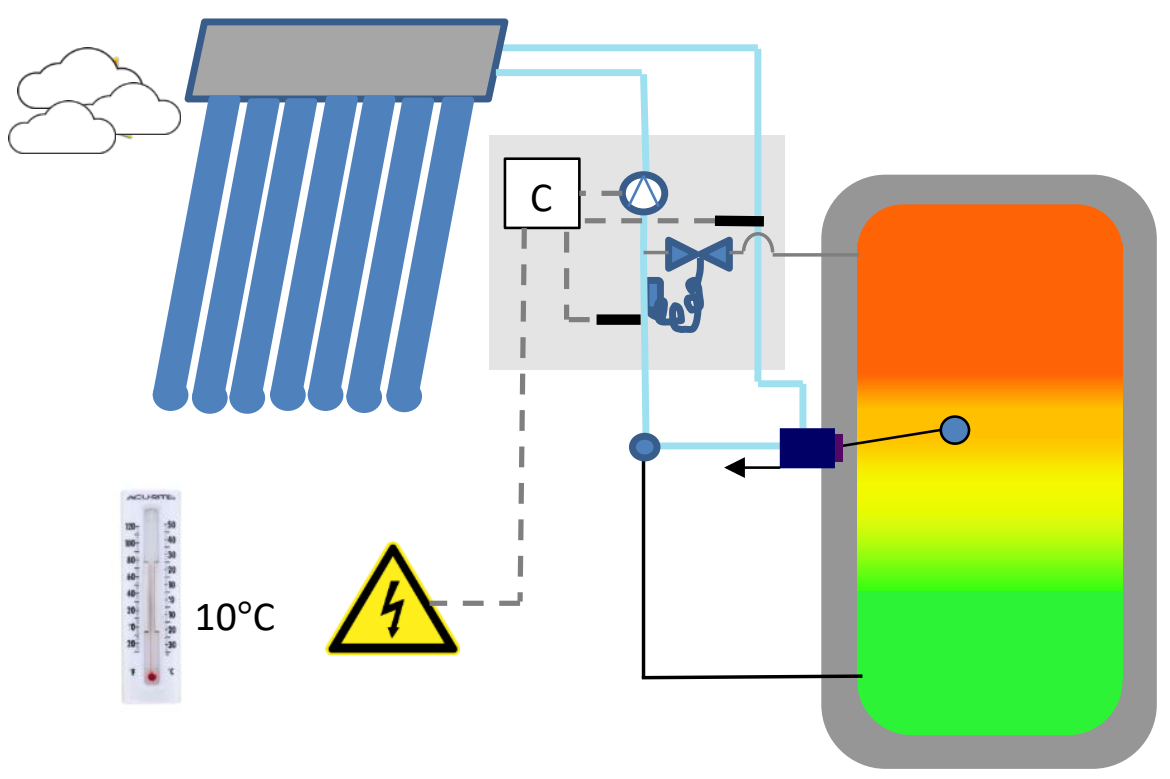

Fig. 2: Operation of the system arrangement in sampling mode, in low intensity conditions

In Figure 2 the solar collector does not generate enough heat for the TDV to switch to open position during sampling, so the TDV remains in the bypass position, and the system returns to the rest state after sampling

The expected operation of the system in continuous mode, in high intensity conditions, is depicted in Figure 3.

In the high intensity conditions of Figure 3, the vacuum tube collector can reach the high temperature of the center of the storage tank, and the controller switches to continuous mode. The system can achieve the necessary increase in temperature in one pass through the collector (as depicted), in which case the TDV stays in the open position, or in multiple passes, in which case the TDV switched between bypass and open position. The controller allows a post-run period in the continuous mode before switching back to sampling mode to allow the multiple passes. 


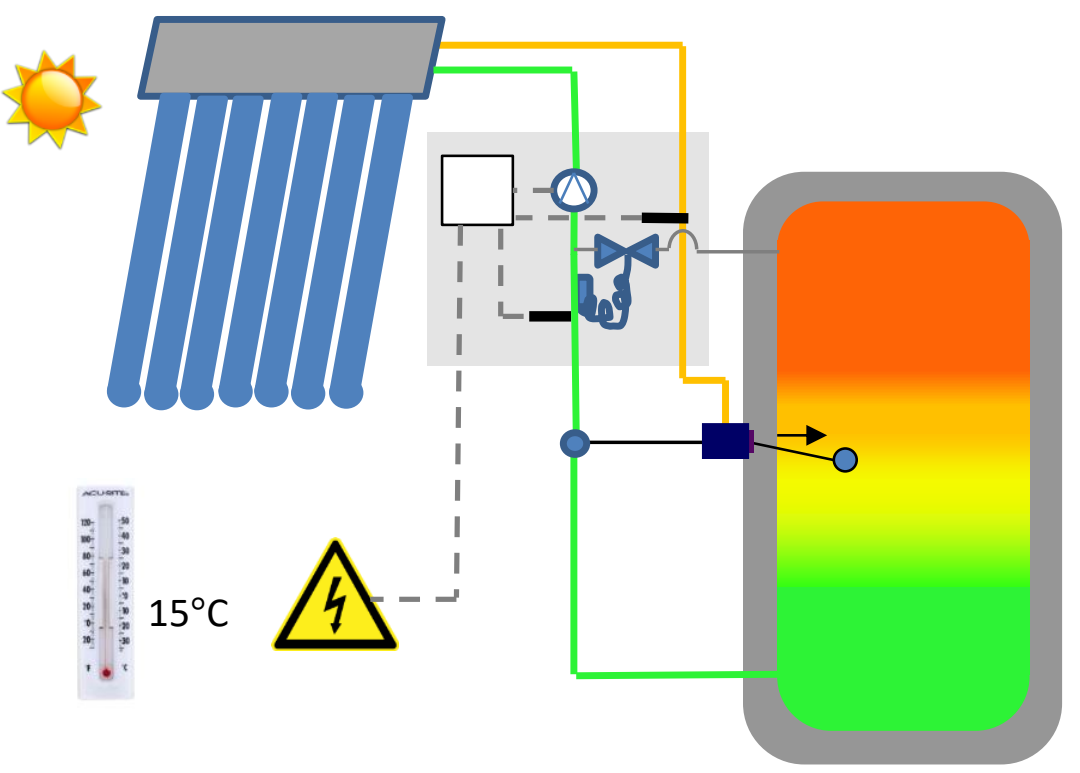

Fig. 3: Operation of the system in continuous mode, in high intensity conditions

The expected operation of the system during night-time is depicted in Figure 4.

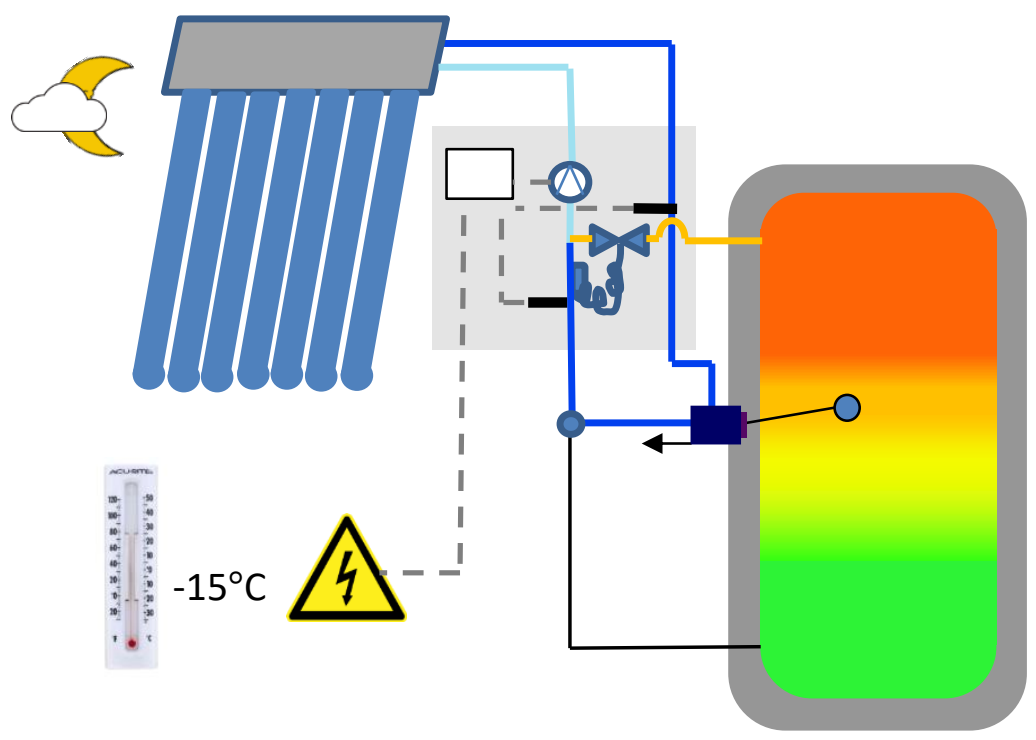

Fig. 4: Operation of the system in night-time mode, with periodic pumped circulation

At night the periodic circulation of the sampling mode continues. When the temperature in the circuit drops below a preset value, the frost protection valve opens and allows heat into the solar circuit, to prevent frost damage to the collector and/or the tubing.

The expected operation of the system during night-time, in case of a power black-out, is depicted in Figure 5.

Figure 5 depicts a power blackout during freezing conditions, in which case pumped circulation stops, and thermosiphon flow is allowed to take place, to prevent frost damage also during power outages (or pump/controller failure). 


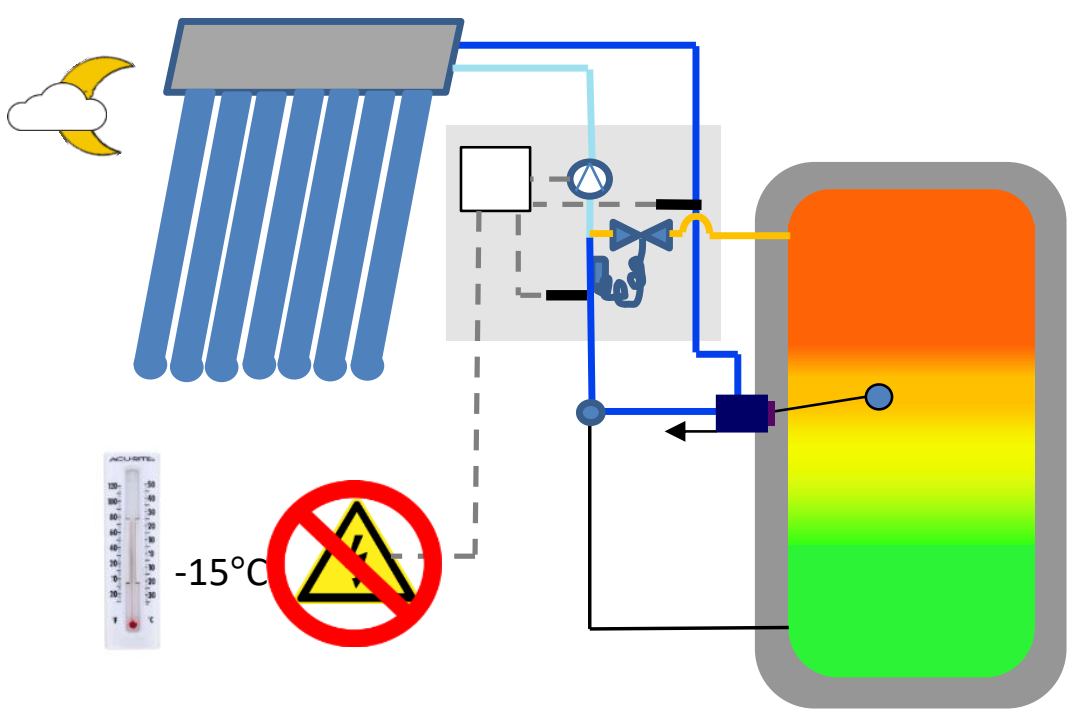

Fig. 5: Operation of the system during night-time, during a power black-out

\section{Experimental}

To test and further develop the direct solar system, a prototype was built at our location in Veldhoven, the Netherlands. Some basic details about this prototype are given in table 1:

Tab. 1: Selected details of direct solar system prototype

\begin{tabular}{|c|c|}
\hline Collector array: & $2 \times$ TWL HLK-30, vacuum tube (Sydney), heat pipe \\
\hline Orientation: & South, $45^{\circ}$ inclination \\
\hline Collector array area: & Gross: $9.98 \mathrm{~m} 2$, Aperture: $5.56 \mathrm{~m} 2$ \\
\hline Collector parameters: & $\eta_{0}=0.761, \mathrm{a}_{1}=2.299, \mathrm{a}_{2}=0.010$ \\
\hline Storage tank: & 900 litre steel buffer-tank, height: $208 \mathrm{~cm}$, diameter $79 \mathrm{~cm}$ \\
\hline Tank connections: & TDV: 0.5 rel. height, Thermostat valve: 0.8 rel. height, return: 0 rel. height \\
\hline Solar tubing: & $2 \times 15$ meter DN16 corrugated stainless steel \\
\hline
\end{tabular}

The circulation pump used in the solar circuit is a Wilo Yonos Para ST15.0/7.0 PWM controlled pump, controlled by an Arduino-based controller, that uses the solar supply temperature and return temperature (measured close to the storage tank) in various algorithms to determine the PWM signal for the circulation pump. To study the thermosiphon behavior in different and realistic conditions, negative loops were introduced into the tubing (see also Figure 6). The first negative loop is on the flat roof, where the tubing runs along the roof floor, before rising $25 \mathrm{~cm}$ into the roof passage (also, the tubing on the roof was installed symmetrically $-2 \times 2.5$ meter of outside tubing - to create a worst-case-scenario for thermosiphon flow starting up), the second negative loop is indoors, and is variable, dipping up to 1 meter. The top of the collector is positioned 9.5 meters above bottom of the tank.
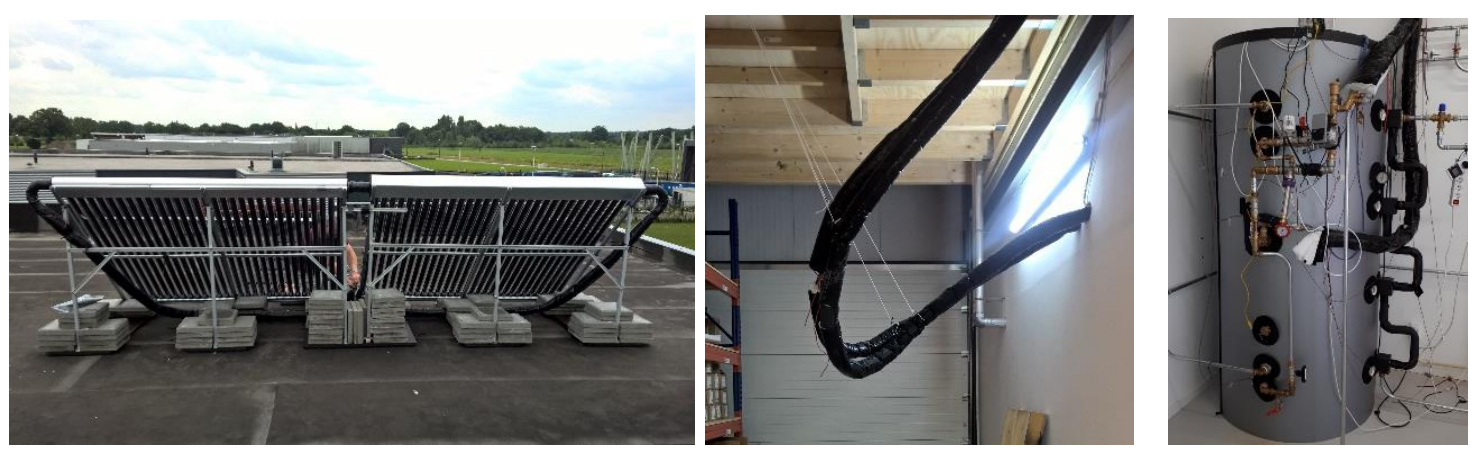

Fig. 6: Images of direct solar system with TDBV; collector array (left), adjustable negative loop (middle) and the storage tank (right) with TDV installed at 0.5 relative height, and thermostat valve at 0.8 relative height 
The system is monitored using 18 T-type thermocouple temperature sensors connected to a datalogger, the temperatures that are measured and used in the results are:

\begin{tabular}{|c|c|}
\hline Temperature measurement position & Line type/color used for graphs \\
\hline Solar supply temperature, measured just before TDV & Bold line, Red \\
\hline Solar return temperature, measured just after pump & Bold line, Blue \\
\hline Collector outlet temperature & Fine line, Red \\
\hline Collector inlet temperature & Fine line, blue \\
\hline Temperature inside vacuum tube & Bold line, Green \\
\hline Temperature of tubing just before thermostat frost protection valve & Long-dash line, Pink \\
\hline Temperature of storage tank at frost protection valve connection & Short-dash, Grey \\
\hline Temperature of storage tank at TDV & Long-dash, Grey \\
\hline Outside ambient temperature & Fine line, Purple \\
\hline Inside ambient temperature at storage tank & Fine-dash, Brown \\
\hline
\end{tabular}

Tab. 2: Details of temperature measurement positions, based on pumped flow direction

\section{Results}

To analyse the frost protection behavior, a measurement was performed on a cold night, where the power supply was interrupted for several hours, test the thermosiphon behavior. The results are presented in Figure 7.

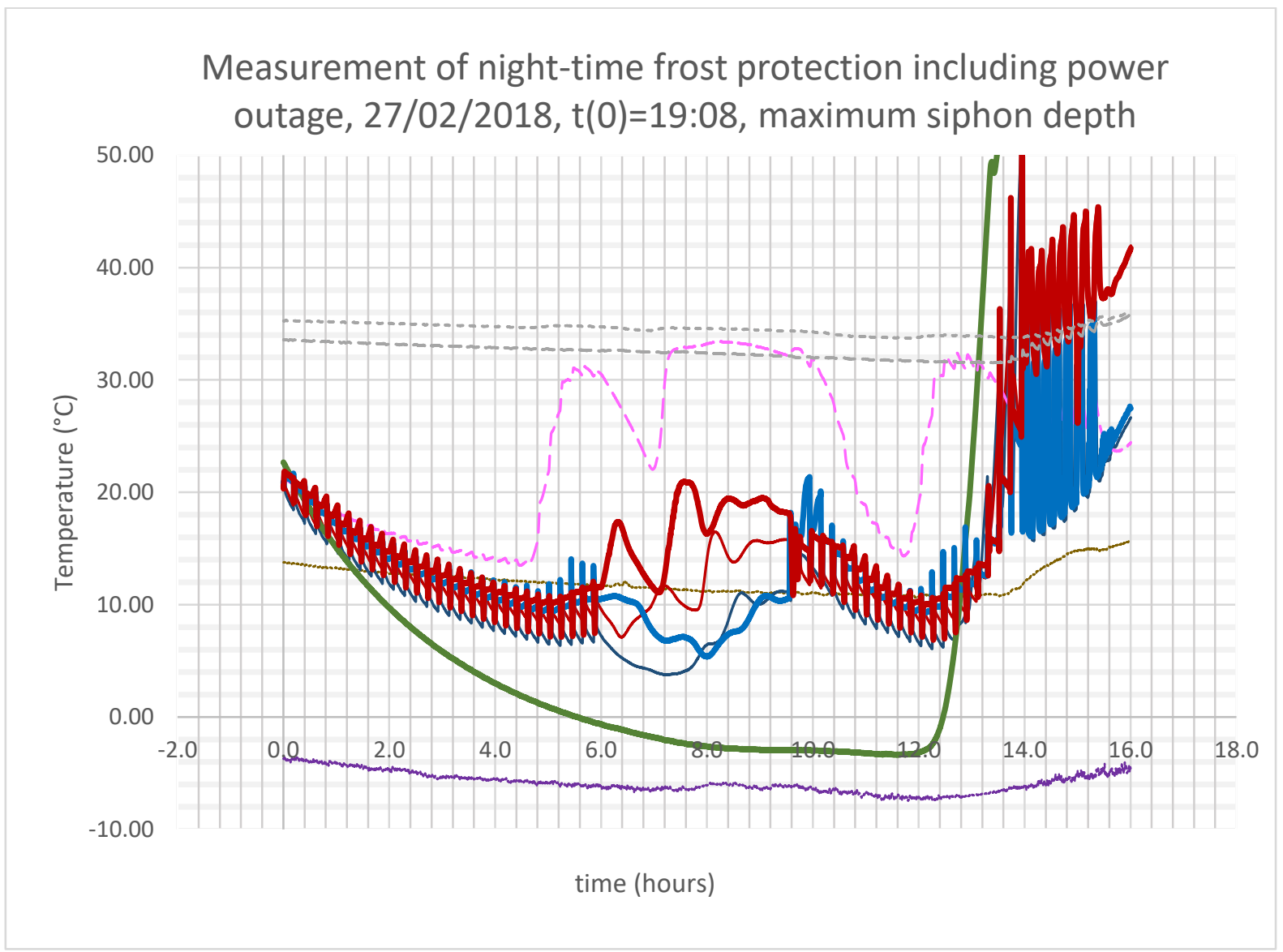

Fig. 7: Results obtained from the prototype solar system from 7 p.m. February $27^{\text {th }} 2018$ to 11 a.m. February 28th

The measurement was performed with a maximum dip in the negative loop (maximum siphon depth). Going through the results presented in Figure 7 chronologically; the system is in regular sampling mode in the evening, with a rest period of 10 minutes. As the solar circuit cools down, after roughly 4.5 hours the temperature reaches the preset temperature at which the frost protection valve starts opening, being $10^{\circ} \mathrm{C}$, which is evident from the 
sudden increase in the temperature of the piping before the frost protection valve, and from the gradual increase of the solar circuit supply and return temperature after the 4.5 hours point. At 6.0 hours into the measurement, the power is switched off for 3.5 hours, to simulate a black-out. For the first 25 minutes after the power is switched off, there is no thermosiphon flow, which is evident from both the collector inlet and outlet temperature decreasing at the same rate. After 25 minutes thermosiphon flow starts up, noticeable from the sudden decreasing of the solar supply temperature and increasing of the collector outlet temperature, which is taking place in the opposite direction of the pumped flow direction. At this point the flow through the frost protection valve is almost zero; it opened during the pumped circulation, but only slightly, just enough to allow enough flow through under pumped conditions, but with the very low pressure-differences in the case of thermosiphon flow this slight opening does not let through a significant flow. The thermosiphon flow causes the return temperature of the solar circuit to start decreasing at around $\mathrm{t}=7 \mathrm{hrs}$, and this decrease leads to the further opening of the frost protection valve at $\mathrm{t}=7.5$ hrs, which causes the thermosiphon flow to accelerate, and which also causes the collector inlet temperature to start increasing. The observed minimum temperature in the collector is $4^{\circ} \mathrm{C}$, which is still safely above frost damage risk The thermosiphon stabilizes around $\mathrm{t}=8.5-9 \mathrm{hrs}$, with a temperature difference of around $10 \mathrm{~K}$ between supply and return temperatures. At $\mathrm{t}=9.5 \mathrm{hrs}$ the pumped sampling starts again as power is restored, and this leads to an increase in supply and return temperatures, as the frost protection valve has opened to a relatively large extent during thermosiphoning. This increase leads to the frost protection valve closing, which causes temperatures in the solar circuit to cool down again, until $t=11.7 \mathrm{hrs}$, when the frost protection valve opens again, as temperatures in the solar circuit have fallen back to the $10^{\circ} \mathrm{C}$ preset limit again. From $\mathrm{t}=12 \mathrm{hrs}$ the sun comes up, as can be observed from the sudden increase of the measured temperature inside the vacuum tube. From just before $\mathrm{t}=14 \mathrm{hrs}$ onwards heat is collected by the storage tank, first while in sampling mode, in which case the TDV switches to open and back to bypass within the sampling period, and from $\mathrm{t}=15.5 \mathrm{hrs}$ in continuous circulation mode.

\section{Conclusions \& Discussion}

From the results it appears that with the frost protection valve set to start dosing heat from the tank at $10^{\circ} \mathrm{C}$, the collector temperature stays above $6^{\circ} \mathrm{C}$, with an ambient temperature of $-5^{\circ} \mathrm{C}$ and a rest period of 10 minutes between sampling. With an assumed scenario of ambient temperatures of $-20^{\circ} \mathrm{C}$, the heat loss of the collector during the rest period will be twice a large, so the collector can be expected to cool down to $2^{\circ} \mathrm{C}$ during the rest period. It also appears that the frost protection valve only needs to open slightly during the tested conditions, even with the top of tank at very moderate temperature levels of around $35^{\circ} \mathrm{C}$, so it can be concluded that providing sufficient heat for frost protection is not a problem using this configuration.

From the results with the power switched off, it appears the critical aspect of the thermosiphon frost protection circulation is the start-up. Once the thermosiphon has established and stabilized, it achieves sufficient flow to maintain the collector at $10^{\circ} \mathrm{C}$, far above critical levels, with a temperature difference between supply and return of $10 \mathrm{~K}$. Since this temperature difference could rise a lot further if necessary, and the collector temperature is allowed to fall well below $10^{\circ} \mathrm{C}$ it can be concluded that the thermosiphon can provide enough heat also in conditions of ambient temperatures of $-20^{\circ} \mathrm{C}$.

One of the important questions that remain is whether the thermosiphon will always start up quickly enough to prevent freezing before sufficient flow is established. The start-up of the thermosiphon depends, to a great extent, on the level of symmetry in the temperature profiles of the supply and return lines. During the sampling in this experiment the circuit fluid was circulated exactly once around, and after sampling it was observed that temperature differences between the supply and return tubing were small, which presents the worse case for the thermosiphon starting up. Creating a situation where there is an a-symmetry between supply and return tubing during the rest period will likely improve the start-up behavior of the thermosiphon flow.

\section{References:}

1) Van Ruth, N.J.L., 2016. New Type of Valve for Solar Thermal Storage Tank Stratification. Energy Procedia https://www.sciencedirect.com/science/article/pii/S1876610216303101 
Solar Air Conditioning and Refrigeration (8th International Workshop on Solar Air Conditioning) 


\title{
Selection of High-Performance Working Fluid for a Solar-Geothermal Absorption Cooling System and Techno-Economic Study in the Northern Mexican Conditions
}

\author{
Amín Altamirano*, Benoît Stutz, Nolwenn Le Pierrès \\ LOCIE Laboratory, Université Savoie Mont Blanc, CNRS UMR5271, Savoie Technolac, 73376 Le \\ Bourget Du Lac (France)
}

\begin{abstract}
The global energy demand is increasing at alarming rates. This increase is expected to be twice as big in developed countries like Mexico, and until 2040, most of this energy will still be coming from fossil fuels, which generate pollution and global warming, increasing even more the energy demand and creating a vicious circle. Absorption systems represent a possibility to contribute to the reduction of fossil fuels consumption and $\mathrm{CO}_{2}$ emissions. These systems can run on renewable energies like solar energy, however, they possess until now high initial investment costs. Two studied methods to improve these system's effectiveness are new refrigerants and heat sink sources. The present article proposes the study of a small-capacity geothermally cooled absorption system in the Monterrey city (Mexico) climate conditions comparing the two more conventional working fluids $\left(\mathrm{NH}_{3}-\mathrm{H}_{2} \mathrm{O}\right.$ and $\mathrm{H}_{2} \mathrm{O}-\mathrm{LiBr}$ ) and an innovative working fluid $\left(\mathrm{NH}_{3}-\mathrm{LiNO}_{3}\right)$. The work is divided into three parts: The first section studies the specific climatic conditions of Monterrey and their impact on the operating temperatures in the system. The second section compares the thermodynamic cycles of the three proposed working fluids in these conditions. Finally, the dimensioning of the components of the system and an economic viability study for the three working pairs is presented to see if it is cost-effective.
\end{abstract}

Keywords: Absorption system, ammonia, water, lithium bromide, lithium nitrate, HGHE

\section{Introduction}

The global energy demand is increasing at alarming rates. According to the International Energy Agency, the increase in the global energy demand between 2000 and 2040 is expected to be of around $70 \%$, and from the total energy consumed in 2040, 74\% will still be coming from fossil fuels, whose combustion generates pollution and global warming (IEA, 2016). Moreover, due to human activity, there is an expected increase in the global average temperature in the range of 1.4 to $5.8^{\circ} \mathrm{C}$ for 2100 compared to 1990 (Aliane et al., 2016), which will impact even more the biggest contributor to world energy consumption and greenhouse emissions: the building sector (Allouhi et al., 2015). This increase in the cooling demand due to global warming generates even more energy consumption, generating a vicious circle that can only be stopped with the transition to clean energies. Nowadays, in the US, $40 \%$ of electricity during the summer is consumed by commercial buildings for air conditioning (AC) purposes (Agrouaz et al., 2017). New international agreements require the development of systems that contribute to the fight against climate change and global warming (Calm, 2008).

Absorption systems replace the mechanical compression of standard refrigeration systems by chemical compression. These systems are still more expensive than common vapor compression systems. However, they will be of great interest in the coming years because they are able to run from renewable heat and waste heat (Dube et al., 2017), which could importantly contribute to the reduction of fossil fuel consumption and harmful emissions to the environment (Wu et al., 2014a). When solar driven, the need for cooling coincides with the time of higher irradiation levels. Moreover, absorption systems are gaining acceptance and seem like a real alternative for cooling residential, light commercial and industrial applications ( $\mathrm{Zhu}$ and $\mathrm{Gu}, 2010$ ). Their low operating cost has made them more attractive in recent years (Wu et al., 2014a). The main advantage of absorption cooling systems over the other heat driven cooling technologies is their higher COP (Hassan and Mohamad, 2012). 


\begin{tabular}{|c|c|c|c|}
\hline \multicolumn{2}{|c|}{ Nomenclature } & \multicolumn{2}{|c|}{ Greek letters } \\
\hline A & solar thermal collector area $\left(\mathrm{m}^{2}\right)$ & $\eta_{0}$ & solar thermal collector optical efficiency \\
\hline$a$ & thermal diffusivity $\left(\mathrm{m}^{2} \mathrm{~s}^{-1}\right)$ & $\eta_{\text {col }}$ & solar thermal collector efficiency \\
\hline & linear coefficient of the solar thermal & $\theta$ & inclination angle of the solar thermal panel $\left(^{\circ}\right)$ \\
\hline$a_{1}$ & collector & $\omega$ & annual pulse $(\mathrm{rad} / \mathrm{s})$ \\
\hline$a_{2}$ & $\begin{array}{l}\text { quadratic coefficient of the solar } \\
\text { thermal collector }\end{array}$ & & \\
\hline $\mathrm{COP}$ & coefficient of performance & & \\
\hline $\mathrm{CR}$ & circulation ratio & \multicolumn{2}{|l|}{ Subscripts } \\
\hline$G^{*}$ & solar irradiation $\left(\mathrm{Wm}^{-2}\right)$ & a & absorber \\
\hline h & specific enthalpy $(\mathrm{kJ} \mathrm{kg}-1)$ & $\mathrm{c}$ & condenser \\
\hline$k(\theta)$ & solar thermal collector tilt angle factor & col & collector \\
\hline $\mathrm{m}$ & mass flow rate $\left(\mathrm{kg} \mathrm{s}^{-1}\right)$ & $\mathrm{e}$ & evaporator \\
\hline$\dot{Q}$ & exchanged heat $(\mathrm{kW})$ & $\mathrm{i}$ & in 1 \\
\hline $\mathrm{T}$ & temperature $(\mathrm{K})$ & int & intermediate \\
\hline & yearly amplitude of the ground-level & $\mathrm{g}$ & generator \\
\hline$I_{a m p}$ & temperature $(\mathrm{K})$ & $\mathrm{p}$ & pump \\
\hline$T_{a}$ & ambient temperature $(\mathrm{K}$ & o & out \\
\hline$T_{\text {mean }}$ & mean ground temperature $(\mathrm{K})$ & & \\
\hline$T_{m}$ & $\begin{array}{l}\text { average temperature of the fluid in the } \\
\text { solar collector }(K)\end{array}$ & & \\
\hline$t$ & observed day of the year (s) & \multicolumn{2}{|c|}{ Accentuation } \\
\hline$t_{c}$ & coldest day (s) & $\sim$ & undisturbed by the exchanger \\
\hline$\dot{W}$ & $\begin{array}{l}\text { mechanical work transfer to or from } \\
\text { the component }(\mathrm{kW})\end{array}$ & & \\
\hline $\mathrm{x}$ & absorbent solution mass fraction & & \\
\hline $\mathrm{z}$ & depth $(m)$ & & \\
\hline
\end{tabular}

Considering their thermodynamic cycle arrangement, absorption refrigeration systems can be divided into three categories: single effect, half-effect and double effect (or multi-effect) cycles. The single-effect cycle requires lower temperatures compared to the multi-effect cycles (Aliane et al., 2016) and is the most advantageous in terms of cost and simple configuration (Hassan and Mohamad, 2012). At the same time, it is the most commercially available. Two absorption pairs are commonly encountered: $\mathrm{H}_{2} \mathrm{O}-\mathrm{LiBr}$ (Water-Lithium Bromide) and $\mathrm{NH}_{3}-\mathrm{H}_{2} \mathrm{O}($ AmmoniaWater).

Nowadays, different research teams focus on improving absorption systems to reduce the manufacturing costs, complexity, maintenance, and environmental concerns. One challenge is the search for the ideal refrigerant, for which, besides of good thermal properties, special attention to its environmental impact has gained attention in recent years (Calm, 2008). Other research groups are investigating alternative heat sink possibilities, as cooling towers present some disadvantages like high water consumption, high maintenance needs, electricity consumption, and there have been reported cases of legionella bacteria development (Bailo et al., 2010; Monné et al., 2011). Air-cooled systems have been investigated and experimented. However, these systems require higher driving temperatures and get closer to the crystallization line in the case of the $\mathrm{H}_{2} \mathrm{O}-\mathrm{LiBr}$ working pair. Moreover, their performance is influenced by the highly variable ambient temperature (Chen et al., 2017). Geothermal heat exchangers (GHE) have recently been proposed as heat sinks for absorption systems. They possess some advantages compared to the conventional ones in terms of efficiency, operating costs, and maintenance (Noorollahi et al., 2018). Borehole heat exchangers are the most common GHE, while other options like pile GHE or horizontal loop GHE also exist, all of which present disadvantages in terms of cost or surface required (Moch et al., 2014). Helical geothermal heat exchangers (HGHE) have recently been proposed as they offer a good compromise between borehole heat exchangers and horizontal loops in terms of required surface and cost. However, there are very few studies that investigate their operation (Moch et al., 2015).

The present work proposes the study of a small-capacity geothermally cooled absorption system for hot climates (Figure 1). To be more precise, the climatic and economic conditions taken into account for the present study are the ones from the Monterrey city, in northern Mexico, as it is a representative city of this region in which the need for AC and the irradiation levels are both very high. The study is divided into three parts. In the first part, the study of the specific climatic conditions and determination of the underground temperature profile of the Monterrey zone is done. This information is used to determine the operating equilibrium intermediate and generator temperatures in the absorption system and a comparison of the thermodynamic cycle performances of three working fluids is performed in a second section. Two of the compared working fluids are the conventional $\mathrm{NH}_{3}-\mathrm{H}_{2} \mathrm{O}$ and $\mathrm{H}_{2} \mathrm{O}-\mathrm{LiBr}$ pairs, while 
the third working fluid is the recently studied $\mathrm{NH}_{3}-\mathrm{LiNO}_{3}$ working pair. Finally, in the third part, the dimensioning of the components of the system is done for the three selected working fluids. An economic assessment is presented at the end to analyze the economic viability of the proposed systems.

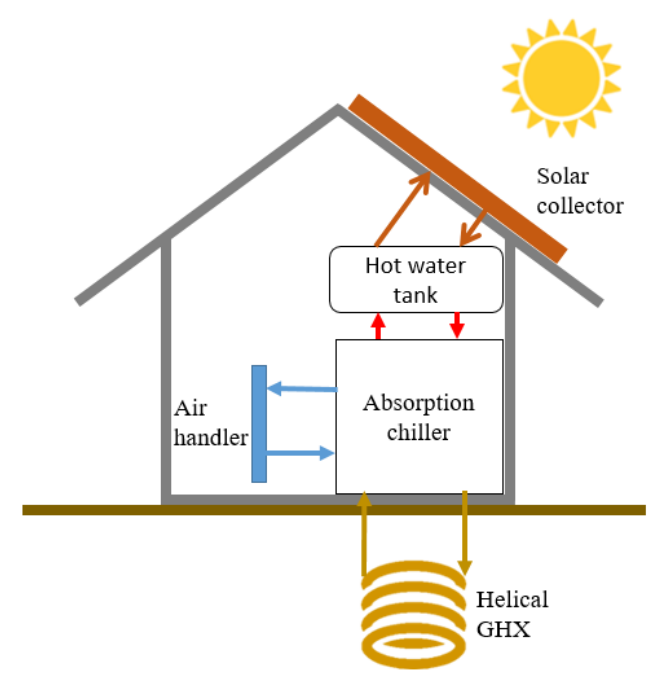

Fig. 1: Diagram of the proposed solar-geothermal absorption cooling system.

\section{Climatic conditions and ground temperature profiles}

Monterrey is the $3^{\text {rd }}$ largest metropolitan area in Mexico. To determine the operating temperature profiles of the machine, data from the Mexican National Meteorological System (SMN, 2018) and the Integral System of Environmental Monitoring (SIMA, 2018) were used. This data is illustrated in Figure 2.

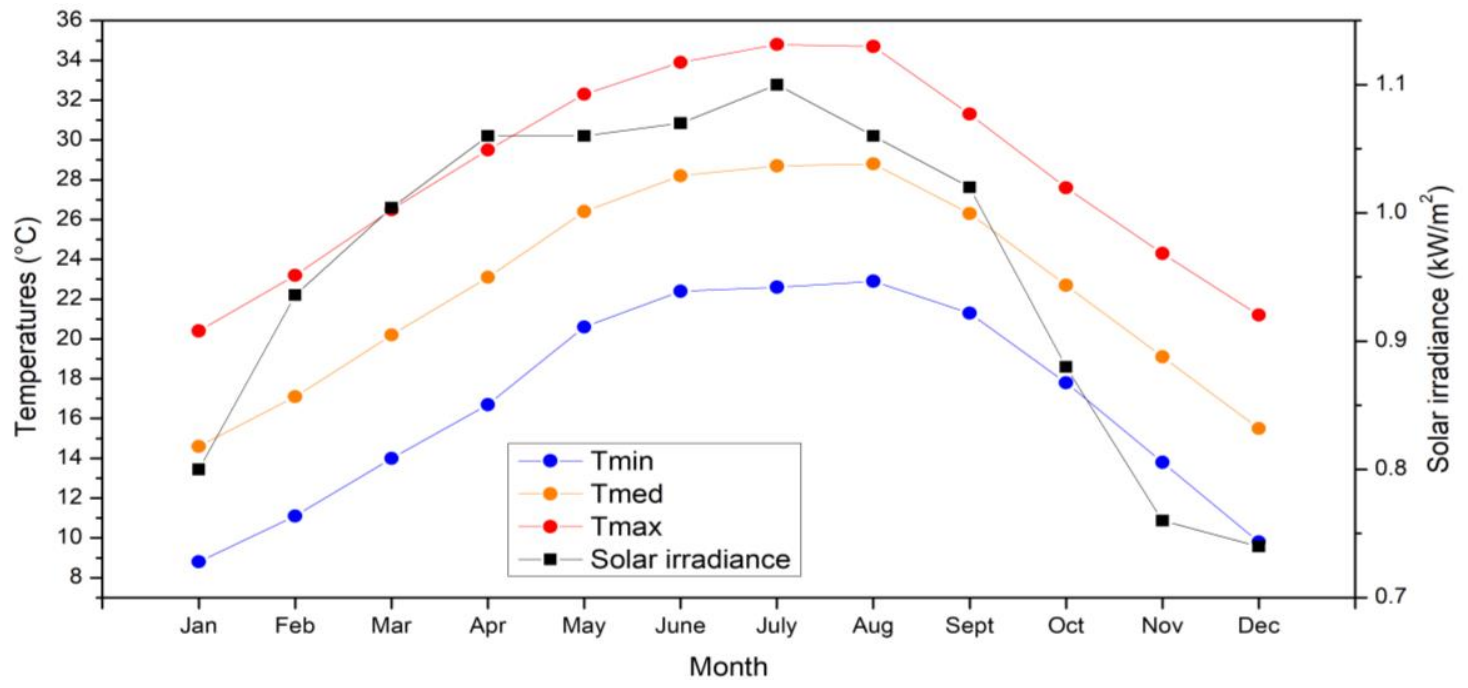

Fig. 2: Monterrey city maximum solar irradiance in 2017 (SIMA, 2018) and temperature profiles from 1981 to 2010 (SMN, 2018).

Considering the underground as a semi-infinite solid, spatially homogeneous, with thermal transfers only occurring by conduction, the underground undisturbed temperature profile can be obtained by equation 1 (Doughty et al., 1991). This equation allows to represent graphically the undisturbed underground temperature profiles in Monterrey for the different seasons, as observed in Figure 3.

$\tilde{T}(z, t)=T_{\text {mean }}-T_{a m p} \exp \left(z \sqrt{\frac{\omega}{2 a}}\right) \cos \left(\omega\left(t-t_{c}\right)+z \sqrt{\frac{\omega}{2 a}}\right)$ 
Temperature $\left({ }^{\circ} \mathrm{C}\right)$

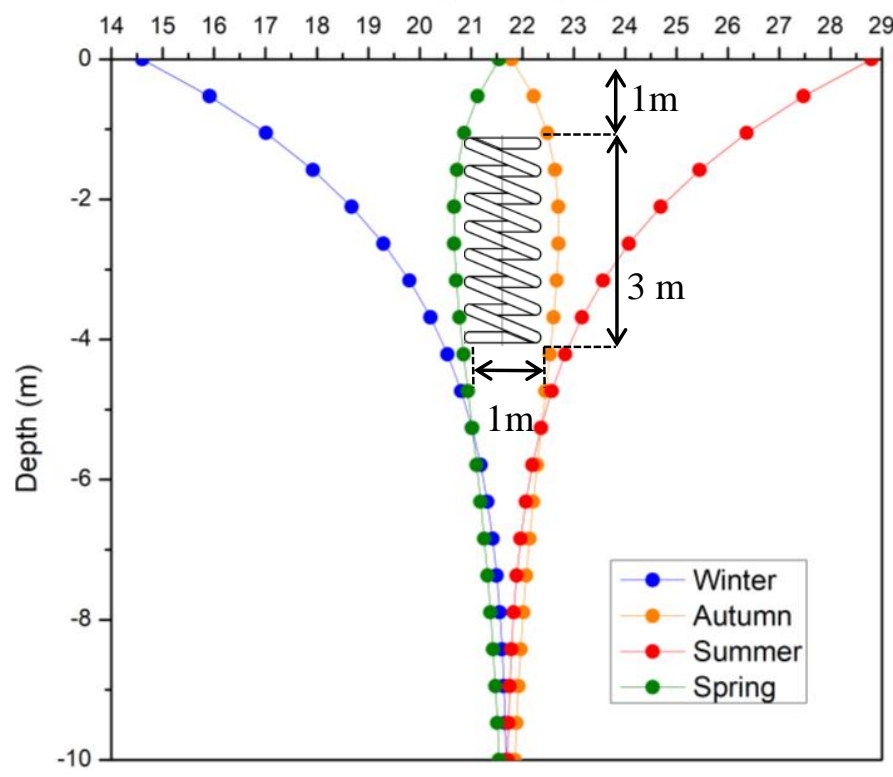

Fig. 3: Underground temperature profile of Monterrey city for different seasons.

Models available in the literature often don't take into account the effect of the distance between the HGHE coils and the local variations in temperature due to the heat transfer between the heat exchangers and the ground, which usually leads to unrealistic calculations (Agbossou et al., 2018). In the present study, these effects are taken into account to obtain more realistic results. HGHE usually have heights between 2 and $6 \mathrm{~m}$, and diameters between 0.35 and $2 \mathrm{~m}$. Their upper part generally being placed at $1 \mathrm{~m}$ below the ground level (Moch et al., 2014). In the present study, HGHE coils of $1 \mathrm{~m}$ diameter and $3 \mathrm{~m}$ height inserted in a $4 \mathrm{~m}$ deep were selected. Considering the hottest days during summer, the average undisturbed underground temperature is about $24^{\circ} \mathrm{C}$ (the temperature of the undisturbed ground being enclosed between $26.3^{\circ} \mathrm{C}$ at $1 \mathrm{~m}$ depth and $22.7^{\circ} \mathrm{C}$ at $4 \mathrm{~m}$ depth). The increase of the underground temperature due to the heat released by the absorption system is estimated to be of around $9^{\circ} \mathrm{C}$ during the hottest day using transient simulations (see Section 4.1). Considering a temperature difference of $2^{\circ} \mathrm{C}$ between the underground and the heat transfer fluid, and a difference of $5^{\circ} \mathrm{C}$ between the heat transfer fluid and the fluids in the absorption machine, an equilibrium outlet intermediate temperature for the absorption system of around $40^{\circ} \mathrm{C}$ is assumed (see Figure 4). While thanks to the irradiation levels during sunny days, equilibrium outlet generator temperatures in the range of $70-90^{\circ} \mathrm{C}$ (see Figure 4) can be achieved with flat solar collectors and a non-pressurized water tank for the hot source.

\section{Thermodynamic comparison of the working fluids}

\subsection{Description of the system}

The simulated geometry is illustrated in Figure 4. It consists of an evaporator, a condenser, an absorber, a generator, a solution pump, a solution heat exchanger ( $\mathrm{SHX}$ ) and two valves. In the case of the $\mathrm{NH}_{3}-\mathrm{H}_{2} \mathrm{O}$ system, a rectifier is needed after the generator, however, in the case of the $\mathrm{NH}_{3}-\mathrm{LiNO}_{3}$ and $\mathrm{H}_{2} \mathrm{O}-\mathrm{LiBr}$ working pairs, the rectifier is eliminated of the diagram and points 11 and 12 disappear. The solution in the generator is heated and desorbs refrigerant vapor. This vapor is condensed at the condenser before passing through an expansion valve and being vaporized again at a lower pressure and a lower temperature in the evaporator. The evaporation heat is taken from the cold source. The vapor produced at the evaporator is absorbed by the highly concentrated solution in the absorber. The resulting diluted solution is pumped from the absorber to the generator, where the cycle starts again (Best and Rivera, 2015). A Solution Heat Exchanger (SHX) is added between the absorber and the generator to increase the efficiency of the machine by recovering internal heat. 


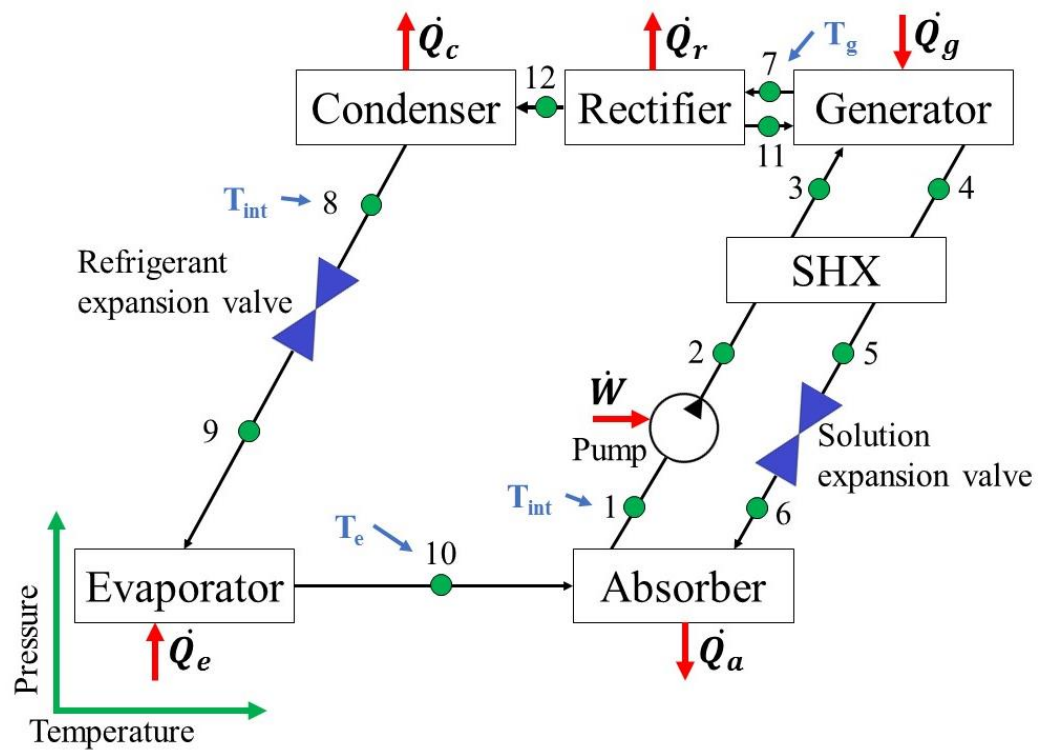

Fig. 4: Studied geometry of $\mathrm{NH}_{3}-\mathrm{H}_{2} \mathrm{O}$ single stage absorption cooling system (for the $\mathrm{NH}_{3}$ - $\mathrm{LiNO}$ and $\mathrm{H}_{2} \mathrm{O}$-LiBr working fluids, the rectifier is eliminated and points 11 and 12 disappear).

For this study, the two most conventional working fluids in absorption systems $\left(\mathrm{NH}_{3}-\mathrm{H}_{2} \mathrm{O}\right.$ and $\left.\mathrm{H}_{2} \mathrm{O}-\mathrm{LiBr}\right)$ and one innovative working fluid $\left(\mathrm{NH}_{3}-\mathrm{LiNO}_{3}\right)$ were selected. Water as refrigerant presents different advantages like a high enthalpy of vaporization, high availability, low-cost, and environmental friendliness. The $\mathrm{H}_{2} \mathrm{O}-\mathrm{LiBr}$ solution offers a high purity of refrigerant at the exit of the generator and high COP compared to the $\mathrm{NH}_{3}-\mathrm{H}_{2} \mathrm{O}$ system. However, there are some disadvantages of using water as refrigerant. For example, it is restricted to positive cooling and it operates in vacuum conditions, which requires special expensive components. Moreover, there are some corrosion and crystallization risks. $\mathrm{NH}_{3}$ also possesses a high enthalpy of evaporation. Moreover, this refrigerant allows negative cooling and moderate working pressures, however, it is toxic. In the case of the $\mathrm{NH}_{3}-\mathrm{H}_{2} \mathrm{O}$ pair, the properties and materials compatibility are well documented and there are no crystallization risks. However, a supplementary component is required (a rectifier, Figure 4) to improve the refrigerant purity (Ullah et al., 2013). The system has a lower COP compared to the $\mathrm{H}_{2} \mathrm{O}-\mathrm{LiBr}$ working pair, and it is also an alkaline and corrosive solution. Finally, the $\mathrm{NH}_{3}-\mathrm{LiNO}_{3}$ is a recently studied working pair, which eliminates the disadvantages of the $\mathrm{NH}_{3}-\mathrm{H}_{2} \mathrm{O}$ solution, as it does not require a rectifier, it has a higher COP than the $\mathrm{NH}_{3}-\mathrm{H}_{2} \mathrm{O}$ working pair, and there are very low crystallization risks. Moreover, it is non-corrosive to steel. However, experimental results have shown a limited performance due to an elevated viscosity (Cera-Manjarres et al., 2018; Wu et al., 2014a).

\subsection{Assumptions for the thermodynamic analysis}

The assumptions that were taken into account to develop the simulations and analysis for the studied systems are as follows:

- The system operates under steady conditions.

- $\quad$ Pressure losses due to friction in the components and pipes are considered negligible.

- The refrigerant at the outlet of the condenser and evaporator (points 8 and 10 in Figure 4) is under saturated conditions.

- The solution at the outlet of the generator and the absorber (points 1 and 7 in Figure 4) is under equilibrium conditions.

- The heat losses to the surroundings are considered negligible.

- The cooling capacity remains constant at $\dot{Q}_{e}=5 \mathrm{~kW}$.

- The evaporator outlet temperature remains constant at $\mathrm{T}_{\mathrm{ev}}=10^{\circ} \mathrm{C}$ (point 10 in Figure 4).

- $\quad$ The SHX effectiveness is fixed at 0.8 .

- For the $\mathrm{NH}_{3}-\mathrm{H}_{2} \mathrm{O}$ working pair, an ideal rectifier (thermodynamically reversible) was considered, which in simple terms leads to $T_{11}=T_{7}$ and $x_{11}=x_{3}$. 


\subsection{Thermodynamic analysis}

Thermophysical properties of the studied working pairs are needed to calculate the performance of the proposed absorption refrigeration cycle. The thermophysical properties of pure ammonia were obtained from Tillner-Roth et al. (1993). In the case of the $\mathrm{NH}_{3}-\mathrm{LiNO}_{3}$ solution, the last correlations for the equilibrium pressure and isobaric specific heat were presented by Hernández-Magallanes et al. (2017), and the specific enthalpy was obtained from Farshi et al. (2014). The $\mathrm{H}_{2} \mathrm{O}-\mathrm{LiBr}$ properties were obtained from Pátek and Klomfar (2006). Finally, the thermodynamic properties of the $\mathrm{NH}_{3}-\mathrm{H}_{2} \mathrm{O}$ solution were obtained from Ibrahim and Klein (1993).

A mathematical model was developed based on the mass and energy balances for each component in the absorption cycle. The main equations used in the model were the total mass conservation (equation 2), the absorbent conservation (equation 3), the energy balance for each of the components (equation 4), the coefficient of performance (equation 5), and the circulation rate (equation 6).

$\sum m_{i}=\sum m_{o}$

$\sum\left(m_{i} x_{i}\right)=\sum\left(m_{o} x_{o}\right)$

$\sum\left(\left(m_{i} h_{i}\right)-\left(m_{o} h_{o}\right)\right)+\sum\left(\dot{Q}_{i}-\dot{Q}_{o}\right)+\dot{W}=0$

$C O P=\frac{\dot{Q_{e}}}{\dot{Q_{g}}+\dot{W_{p}}}$

$C R=\frac{m_{3}}{m_{9}}$

An important parameter is the cut-off temperature of the cycle, which is the minimum generator temperature needed for the system to operate at given conditions. Two parametric studies were developed: the first one considering that the equilibrium temperature at the outlet of the absorber and condenser $\left(T_{1}\right.$ and $\left.T_{8}\right)$, called intermediate temperature $\left(T_{\text {int }}\right)$, is fixed at $40^{\circ} \mathrm{C}$. The second case assumes two fixed generator outlet temperatures $\left(T_{7}=T_{g}\right): 75^{\circ} \mathrm{C}$ and $85^{\circ} \mathrm{C}$.

\subsection{Results and discussion}

The comparison of COP vs $T_{\text {int }}$ for the $\mathrm{NH}_{3}-\mathrm{H}_{2} \mathrm{O}, \mathrm{NH}_{3}-\mathrm{LiNO}_{3}$, and $\mathrm{H}_{2} \mathrm{O}-\mathrm{LiBr}$ working pairs can be observed in Figure 5. As the intermediate temperature increases, the COP decreases. In the case of the outlet generator temperature of $75^{\circ} \mathrm{C}$, the machine is able to operate at maximum intermediate temperatures $T_{\text {int }}$ of $40^{\circ} \mathrm{C}, 41^{\circ} \mathrm{C}$, and $40.5^{\circ} \mathrm{C}$ for the $\mathrm{NH}_{3}-\mathrm{H}_{2} \mathrm{O}, \mathrm{NH}_{3}-\mathrm{LiNO}_{3}$, and $\mathrm{H}_{2} \mathrm{O}-\mathrm{LiBr}$ working fluids, respectively. As the intermediate temperature gets close to its higher limit, the COP decreases drastically. Hence, it is recommended to limit the operating intermediate temperatures to keep acceptable COP values (of around 0.6) at $T_{\text {int }}$ of $37^{\circ} \mathrm{C}, 39^{\circ} \mathrm{C}$, and $40^{\circ} \mathrm{C}$ or less for the $\mathrm{NH}_{3}-\mathrm{H}_{2} \mathrm{O}, \mathrm{NH}_{3}-\mathrm{LiNO}_{3}$, and $\mathrm{H}_{2} \mathrm{O}-\mathrm{LiBr}$ cycles, respectively.

An increase in the generator temperature leads to higher allowable intermediate temperatures. When the generator temperature is increased to $85^{\circ} \mathrm{C}$, the machine is able to operate at maximum intermediate temperatures $T_{\text {int }}$ of $44^{\circ} \mathrm{C}$, $46^{\circ} \mathrm{C}$, and $45^{\circ} \mathrm{C}$ for the $\mathrm{NH}_{3}-\mathrm{H}_{2} \mathrm{O}, \mathrm{NH}_{3}-\mathrm{LiNO}_{3}$, and $\mathrm{H}_{2} \mathrm{O}-\mathrm{LiBr}$ working fluids, respectively. Moreover, in order to maintain a COP of at least 0.6 , a $T_{\text {int }}$ of $39^{\circ} \mathrm{C}, 42^{\circ} \mathrm{C}$, and $44^{\circ} \mathrm{C}$ or less is required for the $\mathrm{NH}_{3}-\mathrm{H}_{2} \mathrm{O}, \mathrm{NH}_{3}-\mathrm{LiNO}_{3}$, and $\mathrm{H}_{2} \mathrm{O}-\mathrm{LiBr}$ cycles, respectively. For both generator temperatures, the $\mathrm{H}_{2} \mathrm{O}-\mathrm{LiBr}$ working fluid is the working pair that can operate at highest intermediate temperatures with acceptable COP values. Moreover, as observed in Figures 1 and 2, a generator operating temperature higher than $75^{\circ} \mathrm{C}$ would be recommended, as lower generator temperatures limit the intermediate temperature to conditions that might not be achievable in real applications. In the optimum operating temperature conditions of $T_{i n t}=40^{\circ} \mathrm{C}$ and $T_{g}=85^{\circ} \mathrm{C}$, the $\mathrm{H}_{2} \mathrm{O}-\mathrm{LiBr}$ working fluid shows the highest COP. 


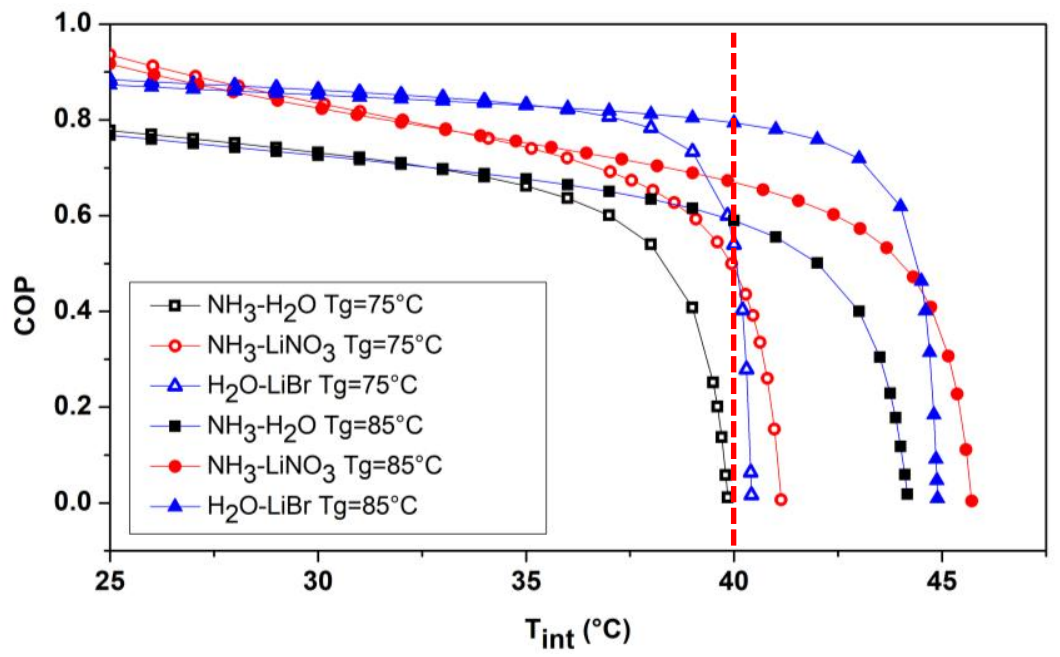

Fig. 5: Effect of $T_{\text {int }}$ on COP at $T_{e}=10^{\circ} \mathrm{C}$ and two different generator temperatures $\left(T_{g}=75^{\circ} \mathrm{C}\right.$ and $\left.T_{g}=85^{\circ} \mathrm{C}\right)$.

Figure 6 shows the effect of the intermediate temperature on the circulation ratio (CR) at two different outlet generator temperatures $\left(75^{\circ} \mathrm{C}\right.$ and $\left.85^{\circ} \mathrm{C}\right)$. As the generator temperature increases, the circulation ratio also increases, and a higher circulation ratio requires more pumping capacity. Therefore, it is not recommended to operate the system at high intermediate temperatures. In the range of low intermediate temperatures, $\mathrm{NH}_{3}-\mathrm{LiNO}_{3}$ possesses the highest circulation ratios, and $\mathrm{NH}_{3}-\mathrm{H}_{2} \mathrm{O}$ the lowest.

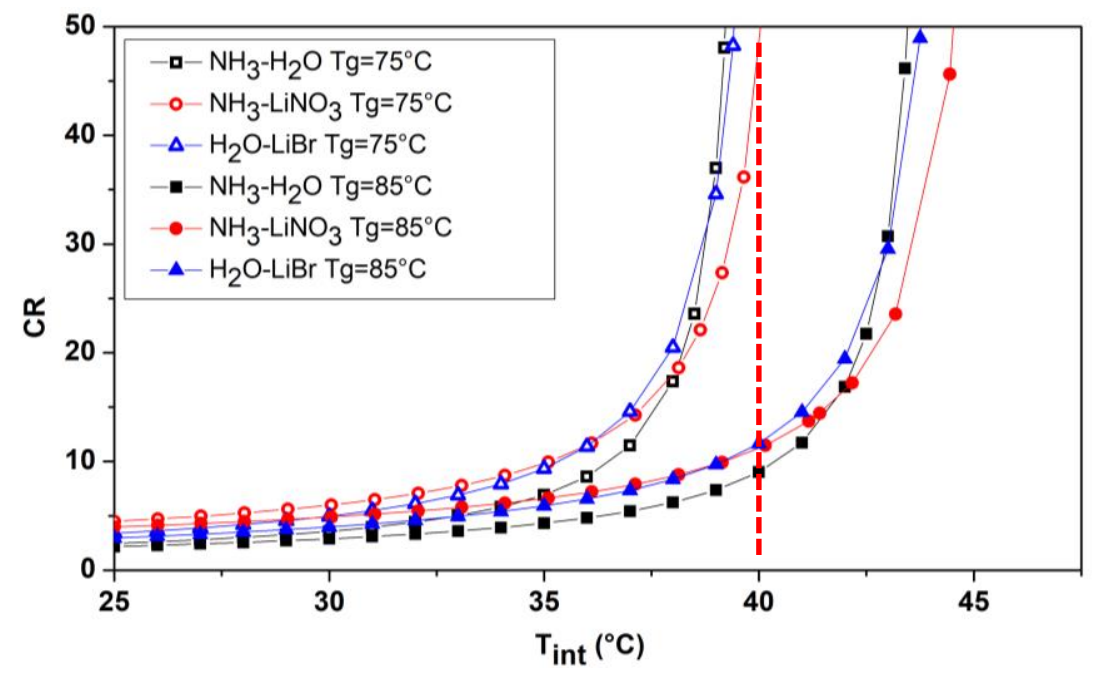

Fig. 6: Effect of $T_{i n t}$ on Circulation Ratio at $T_{e}=10^{\circ} \mathrm{C}$ and two different generator temperatures $\left(T_{g}=75^{\circ} \mathrm{C}\right.$ and $\left.T_{g}=85^{\circ} \mathrm{C}\right)$.

Figure 7 shows the COP variations comparison against generator temperatures, considering an intermediate temperature of $40^{\circ} \mathrm{C}$. The hot water storage unit is able to provide heat transfer fluid in the range of $70-100^{\circ} \mathrm{C}$. The compared systems have different cut-off temperatures. In the case of the $\mathrm{NH}_{3}-\mathrm{H}_{2} \mathrm{O}$ system, its cut-off temperature is of $75^{\circ} \mathrm{C}$, while for $\mathrm{H}_{2} \mathrm{O}-\mathrm{LiBr}$ it is of $74^{\circ} \mathrm{C}$. Finally, $\mathrm{NH}_{3}-\mathrm{LiNO}_{3}$ possesses the lowest cut-off temperature of $72^{\circ} \mathrm{C}$. However, it does not necessarily mean that it is the most convenient working fluid in the studied case, as the COP values of the three fluids increase dramatically just above the cut-off temperature. The value of the generator temperatures for which the system starts to operate at acceptable performances (COP values higher than 0.6) is about $75.5^{\circ} \mathrm{C}$ for the $\mathrm{H}_{2} \mathrm{O}-\mathrm{LiBr}$ pair, $78^{\circ} \mathrm{C}$ for $\mathrm{NH}_{3}-\mathrm{H}_{2} \mathrm{O}$, and $87^{\circ} \mathrm{C}$ for $\mathrm{NH}_{3}-\mathrm{H}_{2} \mathrm{O}$. Moreover, the $\mathrm{H}_{2} \mathrm{O}-\mathrm{LiBr}$ system reaches and maintains the highest $\mathrm{COP}$ values for the rest of the generating temperatures. This indicates that if a good control over the generating temperatures is maintained, the $\mathrm{H}_{2} \mathrm{O}-\mathrm{LiBr}$ working fluid would be the most convenient for the studied case in terms of performance. 


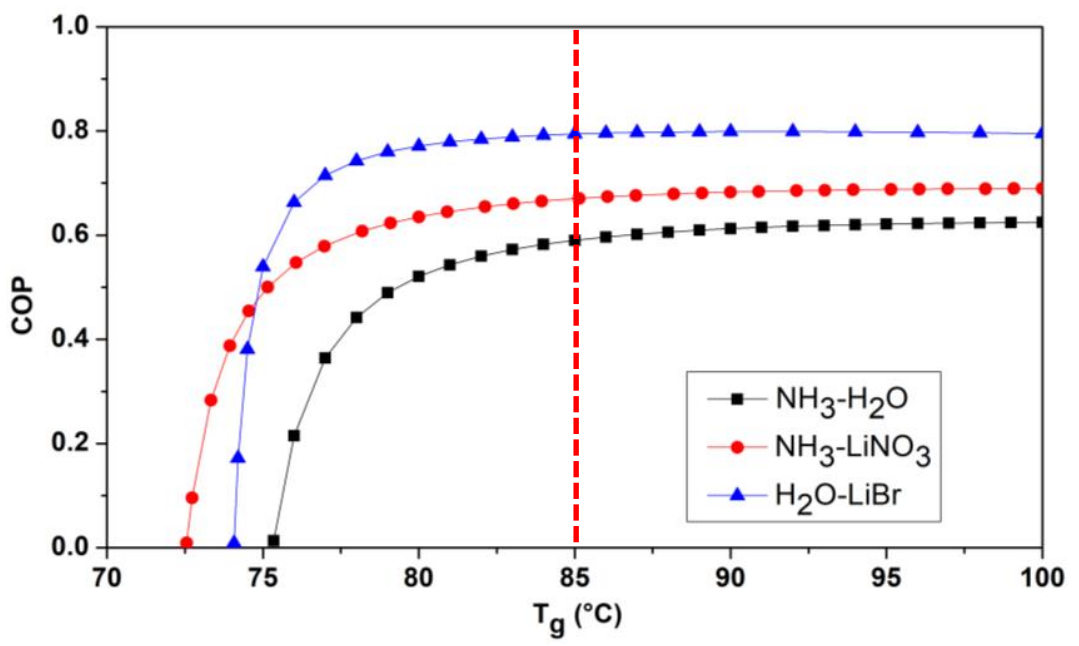

Fig. 7: Effect of $T_{g}$ on COP at $T_{e}=10^{\circ} \mathrm{C}$ and $T_{i n t}=40^{\circ} \mathrm{C}$.

Figure 8 illustrates the impact of the generator temperature on the circulation ratio at $T_{\text {int }}=40^{\circ} \mathrm{C}$ and $T_{e}=10^{\circ} \mathrm{C}$. In the lower limit conditions of the generator temperatures, the circulation ratio increases drastically. Hence, higher generator temperatures are recommended. At high generator temperatures, the $\mathrm{NH}_{3}-\mathrm{H}_{2} \mathrm{O}$ working pair has the lowest circulation ratios, and $\mathrm{NH}_{3}-\mathrm{LiNO}_{3}$ has the highest, but very close to the ones of $\mathrm{H}_{2} \mathrm{O}-\mathrm{LiBr}$.

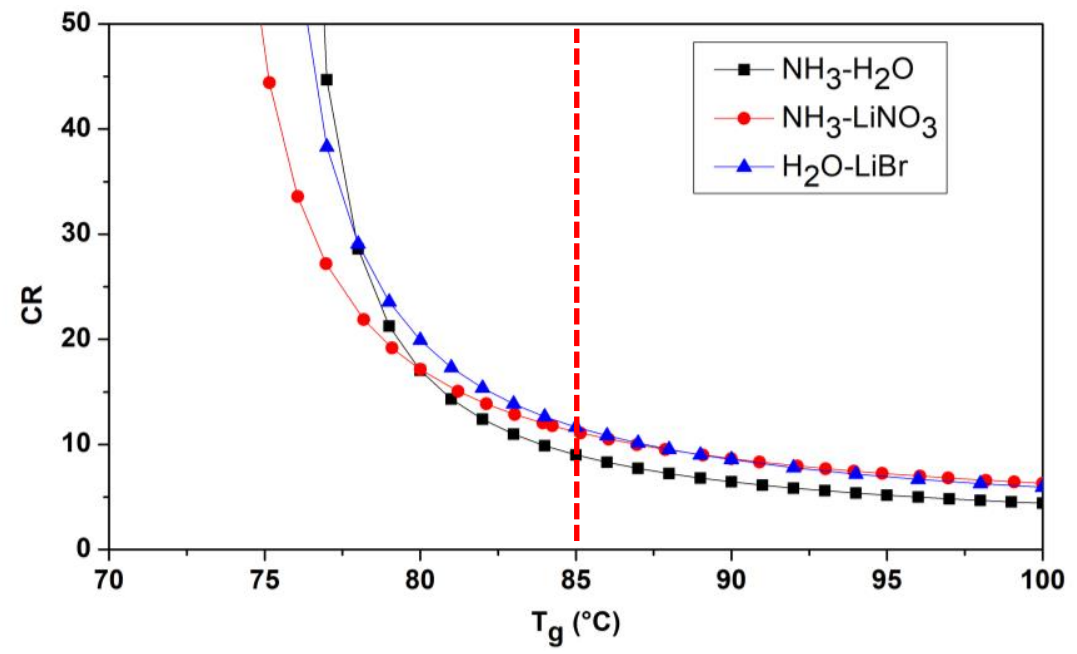

Fig. 8: Effect of $T_{g}$ on COP at $T_{e}=10^{\circ} \mathrm{C}$ and $T_{\text {int }}=40^{\circ} \mathrm{C}$.

\section{Integrated solar-geothermal absorption cooling system and economic feasibility study}

\subsection{Solar-geothermal absorption cooling system and dimensioning}

Following the study of the cycle performances, the integration of the absorption cycle with the solar driving heat source and the geothermal heat sink source can be performed. The proposed configuration is the one illustrated in Figure 1. The system consists of a solar thermal evacuated tubes collector system, a hot water storage tank, the absorption chiller, the air handler, and a HGHE. In order to make an objective comparison of the proposed working fluids, an evaporator average power of $5 \mathrm{~kW}$ is fixed for the cooling system eight hours a day during the 6 hottest months in Monterrey (Apr-Sept), and an average solar irradiance of $1 \mathrm{~kW} / \mathrm{m}^{2}$ (which is acceptable according to Figure 2) was taken into account for these conditions. The total power to be put into the ground would be approximately $\dot{Q}_{i n t}=\dot{Q}_{a}+\dot{Q}_{c}$, while the power of the evacuated tube collectors is approximately $\dot{Q}_{g}$ if we consider that there is a good match between the solar irradiation availability and the cooling need, therefore, the influence of the hot water storage tank over the system's thermal components would be negligible. These values depend on the performance of the different absorption working fluids. In order to evaluate the solar collector area (in $\mathrm{m}^{2}$ ) required for the system, the equations presented hereafter were used.

$A=\frac{\dot{Q_{g}}}{G^{*} \eta_{\text {col }}}$ 


$$
\begin{aligned}
& \eta_{\text {col }}=k(\theta) \cdot \eta_{0}-a_{1} \frac{T_{m}-T_{a}}{G^{*}}-a_{2} \frac{\left(T_{m}-T_{a}\right)^{2}}{G^{*}} \\
& k(\theta)=1-0.239\left(\frac{1}{\cos \theta}-1\right)
\end{aligned}
$$

In the calculations, a tilt angle of the collector of $25^{\circ}$ and south orientation were considered, which is the recommended tilt angle for Monterrey's $25^{\circ} 4^{\prime}$ north latitude. While the collector's characteristics are the ones of the Thermomax - Mazdom vacuum tube solar collectors $\left(\eta_{0,}=0.804, a_{1}=1.15 \frac{{ }^{\circ} \mathrm{C} \cdot \mathrm{m}^{2}}{\mathrm{~kW}}\right.$ and $\left.a_{2}=0.0064 \frac{{ }^{\circ} \mathrm{C} \cdot \mathrm{m}^{2}}{\mathrm{~kW}}\right)$. In the case of the hot water storage tank, 60 liters were considered for every square meter of collector (Mateus and Oliveira, 2009). The work on the characterization and dimensioning of HGHE was presented in Moch's thesis (2013) and was followed by other papers on the subject (Agbossou et al., 2018; Moch et al., 2015, 2014). This study concerns geothermal heat pumps, and more precisely the impact of the heat transfers on the underground temperature near the HGHE and the temperature provided to the heat pump. The transient calculations were performed considering coils of standard size ( $1 \mathrm{~m}$ diameter and $3 \mathrm{~m}$ height) inserted in a $4 \mathrm{~m}$ deep well and assuming a quasi-constant heat flux along the day, whereas in the present study, the absorption heat pump operates only during eight hours a day, which somewhat underestimates the underground temperature even if the energy exchanges per day are the same for the two studies. Considering a heat exchange during the 6 hottest months of the year (Apr-Sept) with no phase change and a dry underground (worst case scenario for the thermal transfers), Moch's model leads to a capacity of $500 \mathrm{~W}$ for every helicoidal GHX and a separation of 4 meters between them to maintain a soil temperature perturbation under $9{ }^{\circ} \mathrm{C}$, that means a temperature of $33^{\circ} \mathrm{C}$ at the HGHE position (see Section 2). To calculate the surface area required for the HGHE, the number of coils has to be multiplied then twice by $4 \mathrm{~m}$. The final values for the different systems requirements are shown in Table 1.

Tab. 1: Requirements and dimensioning for the studied conditions and the three studied working fluids.

\begin{tabular}{|l|c|c|c|}
\cline { 2 - 4 } \multicolumn{1}{c|}{} & $\mathbf{N H}_{3}-\mathbf{H}_{2} \mathbf{O}$ & $\mathbf{N H}_{3}-\mathrm{LiNO}_{3}$ & $\mathbf{H}_{2} \mathrm{O}-\mathrm{LiBr}$ \\
\hline COP & 0.59 & 0.67 & 0.794 \\
\hline$\dot{\boldsymbol{Q}}_{\text {int }}(\mathbf{k W})$ & 13 & 12.68 & 11.39 \\
\hline Number of HGHE coils & 26 & 26 & 23 \\
\hline Surface required for the $\mathbf{G H X}\left(\mathbf{m}^{\mathbf{2}}\right)$ & 416 & 416 & 368 \\
\hline$\dot{\boldsymbol{Q}}_{\boldsymbol{g}}(\mathbf{k W})$ & 8.5 & 7.46 & 6.35 \\
\hline Solar collector area $\left(\mathbf{m}^{\mathbf{2}}\right)$ & 15 & 13 & 11 \\
\hline Size of the hot water storage tank $\left(\mathbf{m}^{\mathbf{3}}\right)$ & 1 & 1 & 1 \\
\hline
\end{tabular}

\subsection{Economic assessment}

In spite of their low operating costs, the historical problem with solar absorption air conditioning has been the elevated initial investment. Therefore, an analysis of the initial investment costs and economic benefits of the system becomes fundamental. Three fundamental economic parameters were selected to evaluate the economic performance of the selected system: The Net Present Value (NPV), the payback period (PB), and the Return On Investment (ROI). In order to be a profitable system, the NPV should be positive, the PB should be at least half of the product lifetime, and the ROI should be higher than one. The parameters used for the economic study are shown in Table 2.

Tab. 2: Economic data for the initial investment of the solar-geothermal absorption cooling system.

\begin{tabular}{|l|c|}
\hline \multicolumn{1}{|c|}{ Concept } & Data \\
\hline Lifetime of absorption systems (years) & 20 (Tsoutsos et al., 2003) \\
\hline Inflation rate for the year 2017 (\%) & 6.77 ("Banco de México," 2018) \\
\hline Price of electricity (USD/kWh) & 0.1484 ("CFE," 2018) \\
\hline Average energy inflation in Mexico from 2006 to 2017 (\%) & 2.62 ("CFE," 2018) \\
\hline
\end{tabular}

The Mexican pesos - USD exchange rate considered was $1 \mathrm{MXN}=0.053$ USD. The system's cost of installation (not including the GHX) was considered to be $30 \%$ of the cost of the chiller and the hot storage tank was priced at $2600 \mathrm{USD} / \mathrm{m}^{3}$ (Viñas et al., 2016). The solar collectors were priced at $200 \mathrm{USD} / \mathrm{m}^{2}$ and the absorption chiller at 572 
USD/kW (Vargas Bautista et al., 2011). The electricity consumption by the pumps and auxiliary elements was neglected considering the orders of magnitude of the other economic parameters. Finally, regarding the geothermal installation, a cost of 1,500 USD for every $100 \mathrm{~m}^{2}$ of $4 \mathrm{~m}$ depth GHE was calculated (Acuña et al., 2017). Taking the presented economic parameters and the chillers operating conditions presented in Section 4.1, the annual economic benefits were calculated by considering the energy savings and the operational costs. With the new energy reform in Mexico, new programs are being implemented to promote the use of renewable energies in the country. This is why for the economic evaluation; two scenarios were considered. In the first one, the user would cover the entire investment costs of the system, and in the second scenario, the government would subsidize $40 \%$ of it. The considered costs for the initial investment are presented in Table 3.

Tab. 3: Considered costs for the initial investment of the solar-geothermal absorption cooling system and economic analysis considering two scenarios.

\begin{tabular}{|c|c|c|c|c|}
\hline & & $\mathrm{NH}_{3}-\mathrm{H}_{2} \mathrm{O}$ & $\mathrm{NH}_{3}-\mathrm{LiNO}_{3}$ & $\mathrm{H}_{2} \mathrm{O}-\mathrm{LiBr}$ \\
\hline \multirow{10}{*}{$\begin{array}{c}\text { Initial } \\
\text { investment }\end{array}$} & Absorption chiller & $\$ 2,860.00$ & $\$ 2,860.00$ & $\$ 2,860.00$ \\
\hline & GHX construction and installation & $\$ 6,240.00$ & $\$ 6,240.00$ & $\$ 5,520.00$ \\
\hline & Solar evacuated tube collectors & $\$ 3,000.00$ & $\$ 2,600.00$ & $\$ 2,200.00$ \\
\hline & Hot storage tank & $\$ 2,600.00$ & $\$ 2,600.00$ & $\$ 2,600.00$ \\
\hline & System installation costs & $\$ 2,000.00$ & $\$ 2,000.00$ & $\$ 2,000.00$ \\
\hline & Required pumps & $\$ 604.00$ & $\$ 604.00$ & $\$ 604.00$ \\
\hline & Air handling unit & $\$ 1,500.00$ & $\$ 1,500.00$ & $\$ 1,500.00$ \\
\hline & Accessories & $\$ 1,200.00$ & $\$ 1,200.00$ & $\$ 1,200.00$ \\
\hline & TOTALS & $\$ 20,004.00$ & $\$ 19,604.00$ & $\$ 18,484.00$ \\
\hline & TOTALS WITH SUBVENTION 40\% & $\$ 12,002.40$ & $\$ 11,762.40$ & $\$ 11,090.40$ \\
\hline \multirow{3}{*}{ SCENARIO 1} & $N P V$ & $-\$ 2,985.57$ & $-\$ 2,585.57$ & $-\$ 1,465.57$ \\
\hline & $P B$ & 18.08 & 17.72 & 16.71 \\
\hline & ROI & 1.10 & 1.13 & 1.19 \\
\hline \multirow{3}{*}{ SCENARIO 2} & NPV & $\$ 5,016.03$ & $\$ 5,256.03$ & $\$ 5,928.03$ \\
\hline & $P B$ & 10.86 & 10.64 & 10.03 \\
\hline & ROI & 1.84 & 1.88 & 1.99 \\
\hline
\end{tabular}

From the results in Table 3, the scenario 1 would not be economically viable, as the NPV results negative and the payback period is almost the same as the system's lifetime. As observed by the ROI, at the end of the product lifetime, there is almost no economic gain. On the other hand, the second scenario seems economically viable, as the systems pay themselves after around 10 or 11 years of operation and their NPV is positive. In order to make use of the system in other than hot months in Mexico, its use for domestic hot water production should be considered. Finally, the application of a solar-geothermal system like the one presented here in Mexico could only be viable in the current market conditions if new green subsidies are offered to the families, otherwise, the implementation is possible, but seems like not economically viable.

\section{Conclusion and perspectives}

A small-capacity geothermally-cooled absorption system for hot climates has been proposed. The functioning of this system in the Monterrey city (Mexico) climate conditions has been analyzed. Three working fluids were studied as possible candidates, the two conventional $\mathrm{NH}_{3}-\mathrm{H}_{2} \mathrm{O}$ and $\mathrm{H}_{2} \mathrm{O}-\mathrm{LiBr}$ working fluids and a third innovative working fluid $\left(\mathrm{NH}_{3}-\mathrm{LiNO}_{3}\right)$. In a first section, the climatic conditions of Monterrey were studied to see how they impact the operating temperatures of the system. In a second section, the thermodynamic cycle performances for the three proposed working fluids were compared. Finally, the dimensioning of the components of the solar-geothermal system and an economic viability study was performed, to see if the proposed system could be cost-effective. A characteristic of the present study is that for the heat sink, a recently studied helical geothermal heat exchanger was considered, and the effects of the heat transfers on the underground temperature profiles were taken into account in the dimensioning to maintain a soil temperature perturbation under $9^{\circ} \mathrm{C}$.

In terms of thermodynamic performance, the $\mathrm{H}_{2} \mathrm{O}-\mathrm{LiBr}$ resulted to be the most performant working pair for the nominal conditions. However, from the economic point of view and under the hypothesis considered for the present study, the choice of the working fluid seems to have a relatively low impact on the initial investment cost of a smallcapacity solar-geothermal absorption system. On the other hand, the proposed system would be technically feasible, 
but seems like not economically viable in the Mexican conditions. The geothermal system strongly impacts the already high initial investment cost of the solar absorption system. One option to increase the system's economic viability would be to take into account the use of the solar thermal collectors and the hot water storage tank as domestic hot water because, in arid regions like northern Mexico, the need for heating is also important during winter. However, other aspects in terms of security and technical requirements must be compared for the different working fluids to observe if there is one with the most ideal conditions for the Mexican climate requirements. In the context of the recently implemented Mexican energy reform, there is a big expectation and new implementation of programs to transit to a more sustainable energy market. New green subsidies could be an important factor to boost this transition and engage Mexicans in the challenge. The present study aims to provide the orders of magnitude of the technical and economic perspectives of a solar-geothermal absorption cooling system implemented in the northern region of Mexico. A more complex analysis would have to be developed before the implementation of a real machine with real quotations and more detailed calculations of its operation.

\section{Acknowledgements}

The present work was supported by the Sectorial Fund "CONACYT - SENER - SUSTENTABILIDAD ENERGÉTICA”.

\section{References}

Acuña, A., Lara, F., Rosales, P., Suastegui, J., Velázquez, N., Ruelas, A., 2017. Impact of a vertical geothermal heat exchanger on the solar fraction of a solar cooling system. Int. J. Refrig. 76, 63-72. https://doi.org/10.1016/j.ijrefrig.2017.02.007

Agbossou, A., Souyri, B., Stutz, B., 2018. Modelling of helical coil heat exchangers for heat pump applications: Analysis of operating modes and distance between heat exchangers. Appl. Therm. Eng. 129, 1068-1078. https://doi.org/10.1016/j.applthermaleng.2017.10.089

Agrouaz, Y., Bouhal, T., Allouhi, A., Kousksou, T., Jamil, A., Zeraouli, Y., 2017. Case Studies in Thermal Engineering Energy and parametric analysis of solar absorption cooling systems in various Moroccan climates. Case Stud. Therm. Eng. 9, 28-39. https://doi.org/10.1016/j.csite.2016.11.002

Aliane, A., Abboudi, S., Seladji, C., Guendouz, B., 2016. An illustrated review on solar absorption cooling experimental studies. Renew. Sustain. Energy Rev. 65, 443-458. https://doi.org/10.1016/j.rser.2016.07.012

Allouhi, A., Fouih, Y. El, Kousksou, T., Jamil, A., Zeraouli, Y., Mourad, Y., 2015. Energy consumption and efficiency in buildings : current status and future trends. J. Clean. Prod. 109, 118-130. https://doi.org/10.1016/j.jclepro.2015.05.139

Bailo, C.M., Garcés, S.A., Arizón, F.P., 2010. Analysis of a New Dissipation System for a Solar Cooling Installation. J. Thermodyn. 2010, 1-6. https://doi.org/10.1155/2010/750675

Banco de México [WWW Document], 2018. . Inflación. URL http://www.anterior.banxico.org.mx/portalinflacion/inflacion.html

Best, R., Rivera, W., 2015. A review of thermal cooling systems. Appl. Therm. Eng. 75, 1162-1175. https://doi.org/10.1016/j.applthermaleng.2014.08.018

Calm, J.M., 2008. The next generation of refrigerants - Historical review, considerations, and outlook. Int. J. Refrig. 31, 1123-1133. https://doi.org/10.1016/j.ijrefrig.2008.01.013

Cera-Manjarres, A., Salavera, D., Coronas, A., 2018. Vapour pressure measurements of ammonia/ionic liquids mixtures as suitable alternative working fluids for absorption refrigeration technology. Fluid Phase Equilib. https://doi.org/10.1016/j.fluid.2018.01.006

CFE [WWW Document], 2018. . Tarifas. URL https://app.cfe.mx/aplicaciones/ccfe/tarifas/tarifas/tarifas_casa.asp

Chen, J.F., Dai, Y.J., Wang, R.Z., 2017. Experimental and analytical study on an air-cooled single effect LiBr-H2O absorption chiller driven by evacuated glass tube solar collector for cooling application in residential buildings. Sol. Energy 151, 110-118. https://doi.org/10.1016/j.solener.2017.05.029

Doughty, C., Nir, A., Tsang, C.-F., 1991. Seasonal Thermal Energy Storage in Unsaturated soil : Model Development and Field Validation Soils:

Dube, E., Cha, A., Agboola, O.P., Or, J., Fakeeha, A.H., Al-fatesh, A.S., 2017. Energetic and exergetic analysis of solar-powered lithium bromide- water absorption cooling system. J. Clean. Prod. 151, 60-73.

https://doi.org/10.1016/j.jclepro.2017.03.060 
Farshi, L.G., Infante Ferreira, C.A., Mahmoudi, S.M.S., Rosen, M.A., 2014. First and second law analysis of ammonia/salt absorption refrigeration systems. Int. J. Refrig. 40, 111-121. https://doi.org/10.1016/j.ijrefrig.2013.11.006

Hassan, H.Z., Mohamad, A.A., 2012. A review on solar cold production through absorption technology. Renew. Sustain. Energy Rev. 16, 5331-5348. https://doi.org/10.1016/j.rser.2012.04.049

Hernández-Magallanes, J.A., Rivera, W., Coronas, A., 2017. Comparison of single and double stage absorption and resorption heat transformers operating with the ammonia-lithium nitrate mixture. Appl. Therm. Eng. 125, 53-68. https://doi.org/10.1016/j.applthermaleng.2017.06.130

Ibrahim, O.M., Klein, S.A., 1993. Thermodynamic Properties of Ammonia-Water Mixtures. ASHRAE Trans. 99, 1495-1502.

IEA, 2016. World energy outlook.

Mateus, T., Oliveira, A.C., 2009. Energy and economic analysis of an integrated solar absorption cooling and heating system in different building types and climates. Appl. Energy 86, 949-957. https://doi.org/10.1016/j.apenergy.2008.09.005

Moch, X., 2013. Étude théorique et expérimentale d'échangeurs géothermiques hélicoïdaux: Production de chaud et de froid par pompe à chaleur, et dimensionnement d'installations. Université de Grenoble.

Moch, X., Palomares, M., Claudon, F., Souyri, B., Stutz, B., 2015. Geothermal helical heat exchangers: Coupling with a reversible heat pump in Western Europe. Appl. Therm. Eng. 81, 368-375. https://doi.org/10.1016/j.applthermaleng.2015.01.072

Moch, X., Palomares, M., Claudon, F., Souyri, B., Stutz, B., 2014. Geothermal helical heat exchangers: Comparison and use of two-dimensional axisymmetric models. Appl. Therm. Eng. 73, 689-696. https://doi.org/10.1016/j.applthermaleng.2014.06.051

Monné, C., Alonso, S., Palacín, F., Serra, L., 2011. Monitoring and simulation of an existing solar powered absorption cooling system in Zaragoza (Spain). Appl. Therm. Eng. 31, 28-35. https://doi.org/10.1016/j.applthermaleng.2010.08.002

Noorollahi, Y., Saeidi, R., Mohammadi, M., Amiri, A., Hosseinzadeh, M., 2018. The effects of ground heat exchanger parameters changes on geothermal heat pump performance - A review. Appl. Therm. Eng. 129, 1645-1658. https://doi.org/10.1016/j.applthermaleng.2017.10.111

Pátek, J., Klomfar, J., 2006. A computationally effective formulation of the thermodynamic properties of LiBr$\mathrm{H} 2 \mathrm{O}$ solutions from 273 to $500 \mathrm{~K}$ over full composition range. Int. J. Refrig. 29, 566-578. https://doi.org/10.1016/j.ijrefrig.2005.10.007

SIMA, 2018. Reportes mensuales de calidad del aire.

SMN, 2018. Información Climatológica por Estado.

Tillner-Roth, R., Harms-Watzenberg, F., Baehr, H.D., 1993. Eine neue fundamentalgleichung für ammoniak. Dkvtaungsbericht 20, 167-181.

Tsoutsos, T., Anagnostou, J., Pritchard, C., Karagiorgas, M., Agoris, D., 2003. Solar cooling technologies in Greece. An economic viability analysis. Appl. Therm. Eng. 23, 1427-1439. https://doi.org/10.1016/S13594311(03)00089-9

Ullah, K.R., Saidur, R., Ping, H.W., Akikur, R.K., Shuvo, N.H., 2013. A review of solar thermal refrigeration and cooling methods. Renew. Sustain. Energy Rev. 24, 499-513. https://doi.org/10.1016/j.rser.2013.03.024

Vargas Bautista, J.P., García Cuéllar, A.J., Rivera Solorio, C.I., 2011. Design and economic analysis of a solar airconditioning system: case of study in Monterrey, Mexico, in: EUROSUN 2011.

Viñas, E., Best, R., Lugo, S., 2016. Simulation of solar air conditioning systems in coastal zones of Mexico. Appl. Therm. Eng. 97, 28-38. https://doi.org/10.1016/j.applthermaleng.2015.09.104

Wu, W., Wang, B., Shi, W., Li, X., 2014a. An overview of ammonia-based absorption chillers and heat pumps. Renew. Sustain. Energy Rev. 31, 681-707. https://doi.org/10.1016/j.rser.2013.12.021

Wu, W., You, T., Wang, B., Shi, W., Li, X., 2014b. Evaluation of ground source absorption heat pumps combined with borehole free cooling. Energy Convers. Manag. 79, 334-343. https://doi.org/10.1016/j.enconman.2013.11.045

Zhu, L., Gu, J., 2010. Second law-based thermodynamic analysis of ammonia/sodium thiocyanate absorption system. Renew. Energy 35, 1940-1946. https://doi.org/10.1016/j.renene.2010.01.022 


\title{
Life Cycle Assessment experiences for solar heating and cooling systems
}

\author{
Marco Beccali ${ }^{1}$, Maurizio Cellura ${ }^{1}$, Maria Anna Cusenza ${ }^{1}$, Sonia Longo ${ }^{1}$, Daniel Mugnier ${ }^{2}$, Tim \\ Selke ${ }^{3}$ and Vicente Quiles Pedro Gines ${ }^{4}$ \\ ${ }^{1}$ University of Palermo - Department of Energy, Information Engineering and Mathematical Models \\ (DEIM), Palermo (Italy) \\ 2 TECSOL, Perpignan (France) \\ ${ }^{3}$ AIT Austrian Institute of Technology $\mathrm{GmbH}$, Vienna (Austria) \\ ${ }^{4}$ Universidad Miguel Hernandez, Elche (Spain)
}

\begin{abstract}
Solar heating and cooling systems can significantly contribute to the energy and climate European goals. A complete assessment of this contribution needs the analysis of these systems from a life-cycle perspective, in order to estimate the energy and environmental costs of their manufacturing and end-of-life, and to compare these costs with the benefits obtained during operation. A well-established methodology to fulfil this task is the Life Cycle Assessment (LCA). The paper describes some LCA experiences of solar heating and cooling systems, developed within the Task 53 "New generation solar cooling \& heating systems (PV or solar thermally driven systems)" of the International Energy Agency. The results of these analyses can be useful to orientate manufacturers, researchers and decision makers for a more sustainable use of solar technologies.
\end{abstract}

Keywords: solar heating and cooling, life cycle assessment, sustainability, environmental impacts

\section{Introduction}

Solar heating and cooling (SHC) systems can significantly contribute to the energy and climate European goals (European Commission, 2014; European Commission, 2011) by reducing the use of fossil fuels and the related environmental impacts for building air-conditioning (Beccali et al., 2016; Bukoski et al., 2014; Longo et al., 2017).

The SHC systems mainly use energy from renewable sources during operation. However, they consume energy and cause environmental impacts during the whole life cycle (manufacturing, operation and end-of-life) (Beccali et al., 2014). Thus, to correctly assess the real benefits due to the installation of SHC technologies, their life cycle energy and environmental impacts should be estimated (Beccali et al., 2012a; Finocchiaro et al., 2016).

A useful tool to assess resource use, energy and environmental burdens related to the full life cycle of products and services is the Life Cycle Assessment (LCA) methodology (ISO, 2006a, 2006b).

In this paper, some experiences of LCA applied to SHC systems are described, developed within the Task 53 "New generation solar cooling \& heating systems (PV or solar thermally driven systems)" of the International Energy Agency (IEA) (Mugnier et al., 2015).

\section{Description of the examined systems}

The SHC systems examined in this study are the following:

- a PV - air conditioner unit (S1);

- a PV cooling system based on an air to water compression chiller (working fluid: propane) (S2);

- a compact desiccant evaporative cooling system, called "Freescoo" (S3).

The system $\mathrm{S} 1$ is designed to operate by using the electricity produced by a photovoltaic plant. The main components of the PV - air conditioner system are the PV panels and the air conditioning unit (Fig. 1). 


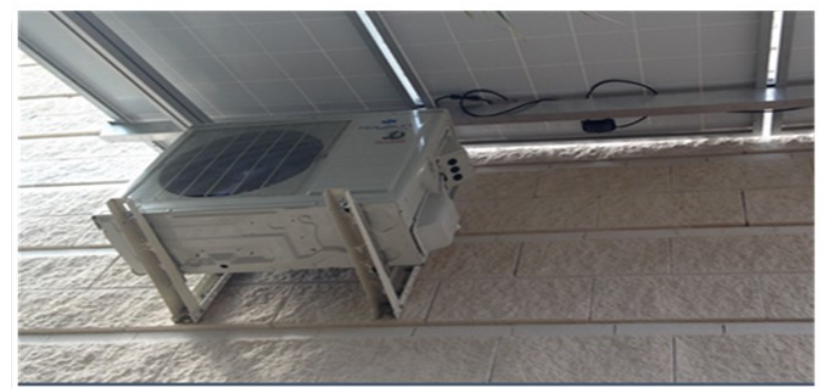

a) PV - Air conditioner: external unit

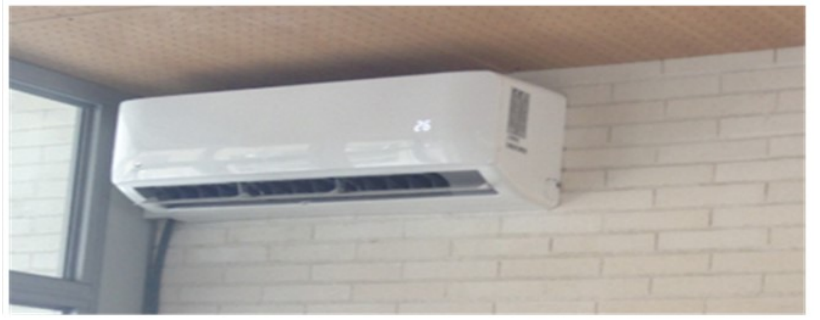

b) PV - Air conditioner: internal unit

Fig. 1: PV - air conditioner system

The system S2 is a PV cooling designed to operate by using the electricity produced by a photovoltaic power plant. The main components of S2 are the PV system, the heat pump and the chilled water circuit (Fig. 2).

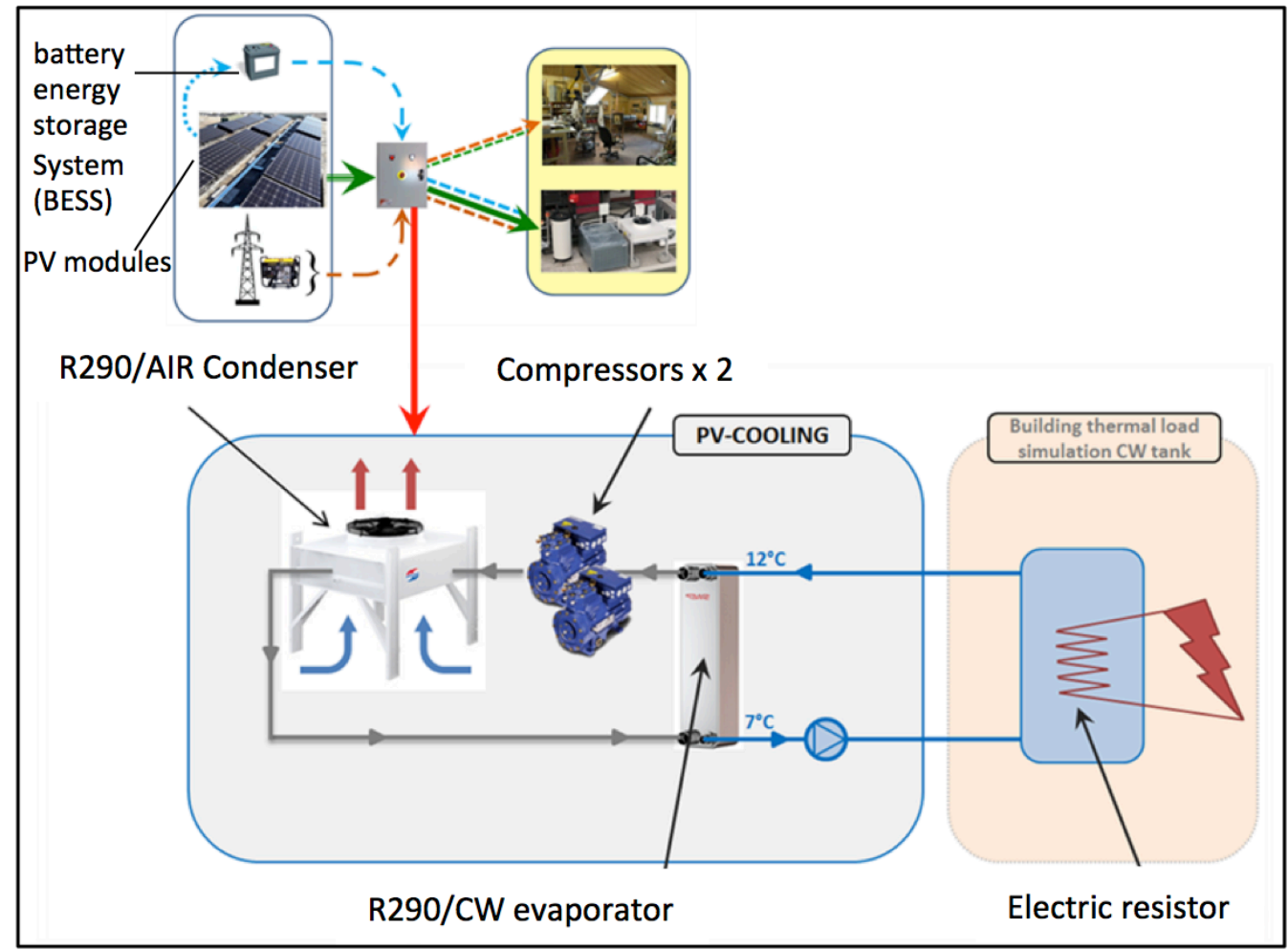

Fig. 2: PV - cooling system scheme

The system S3 (Fig. 3) is designed for air-conditioning in buildings and it is composed by a solar photovoltaic/thermal air collector, two adsorption beds, an integrated cooling tower, two wet heat exchangers, fans, batteries and all other auxiliaries needed to perform the air handling process also in stand-alone operation. 


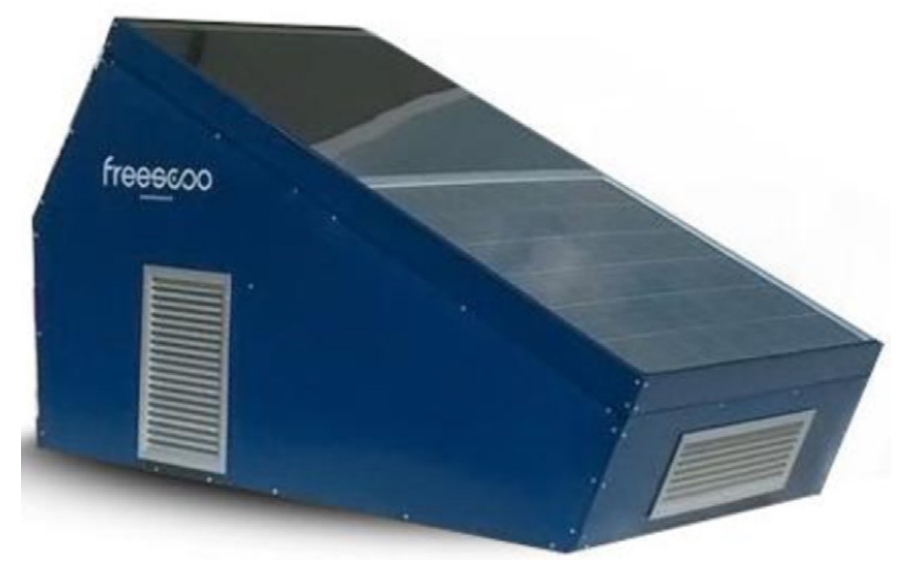

Fig. 3: Compact desiccant evaporative cooling system

\section{Life Cycle Assessment of the three systems}

The LCA is a standardized methodology widely adopted by the scientific community to assess the environmental impacts of products and services from a life cycle perspective (i.e. including extraction of raw materials, transports, manufacturing process, use and end-of-life) (ISO, 2006a, 2006b).

The LCA consists of four steps, briefly described in the following:

- Goal and scope definition. In this step the intended application(s) and the object of the study (i.e. the exact product or other system(s) to be analysed) are described and defined in detail (European Commission - Joint Research Centre - Institute for Environment and Sustainability, 2010). This step also includes the identification of system boundaries (unit processes that are part of a product system), functional unit (quantified performance of a product system for use as a reference unit), allocation procedures, selected impact categories and impact assessment methodologies, etc.

- Life Cycle Inventory (LCI) analysis. This step involves data collection and calculation procedures to quantify the resources consumption, the air, water and soil emissions, and the waste production.

- Life Cycle Impact Assessment (LCIA). This step is aimed at evaluating the significance of potential environmental impacts using the LCI result.

- Life cycle interpretation. In the final step of the LCA the results of a LCI and/or a LCIA are summarized and discussed as a basis for conclusions, recommendations and decision-making in accordance with the goal and scope definition.

The LCA methodology allows to capture the complexity hidden behind a product/service and to identify opportunities to improve its environmental performance at various phases of the life cycle preventing the risk to shift the impacts from one life cycle phase to another (i.e. from use phase to manufacturing one) and/or from one impact category to another.

\subsection{Goal and scope definition}

The goal of the study was to assess the energy and the environmental impacts caused by three different SHC systems and to highlight the potentials of the LCA methodology in evaluating the performance of this kind of systems in terms of impacts associated to a wide range of environmental categories.

The selected functional units (FUs) are:

- $\quad$ For the $\mathrm{S} 1$ system, the $\mathrm{PV}$ - air conditioner $\left(\mathrm{FU}_{1}\right)$;

- $\quad$ For the S2 system, the PV cooling $\left(\mathrm{FU}_{2}\right)$;

- For the S3 system, the FU is represented by a system with a useful life of 15 years that provides cooling and heating for the building, considering a cooling solar fraction of about $0.85\left(\mathrm{FU}_{3}\right)$.

The system boundaries include the manufacturing step for the S1 and S2 systems, while the whole life cycle was investigated for the last one, including the raw materials supply, the manufacturing of the system, its operation and end-of-life. The transports, installation and maintenance steps were not taken into account due to data unavailability. However, their impact on global energy consumption and the environment can be considered likely negligible (Kalogirou, 2009). 
The following energy and environmental indexes are selected to illustrate the energy and the environmental performance of the examined system:

- $\quad$ Global energy requirement (GER);

- $\quad$ Global warming potential (GWP);

- $\quad$ Ozone depletion potential (ODP);

- Human toxicity, non-cancer effects (HT-ce);

- Human toxicity, cancer effects (HT-nce);

- $\quad$ Particulate matter (PM);

- $\quad$ Ionizing radiation, HH (IR-hh);

- $\quad$ Ionizing radiation, $\mathrm{E}$;

- $\quad$ Photochemical ozone formation (POFP);

- Acidification (AP);

- $\quad$ Terrestrial eutrophication (T-EU);

- Freshwater eutrophication (F-EU);

- Marine eutrophication (M-EU);

- $\quad$ Freshwater ecotoxicity (F-E);

- $\quad$ Land use (LU);

- Water resource depletion (WRD);

- $\quad$ Mineral, fossil \& renewable resource depletion (MFRRD).

The characterization models used for the impact calculations are the Cumulative Energy Demand (CED) (Frischknecht et al., 2007) method for the energy impacts, and ILCD 2011 Midpoint method for the environmental impacts (European Commission and Joint Research Centre, 2012).

The eco-profiles of materials and energy sources used to produce the main components of the analysed FUs are based on the Ecoinvent database (Frischknecht et al., 2005; Wernet et al., 2016) Impacts of end-of-life, only for $\mathrm{FU}_{3}$, are calculated by using the following databases:

- Buwal 250 in the case of recycling (BUWAL250, 1998);

- Ecoinvent for landfilling (Frischknecht et al., 2005):

- $\quad$ Eth-Esu for the end of life of the solar panels (E.U.ESU Group, 1996);

- $\quad$ European Reference Life Cycle Database (ELCD) for the iron metals (Joint Research Center, 2016).

\subsection{Life Cycle Inventory}

This step was finalized to the first hand data collection (primary data) concerning the main inputs and outputs in terms of materials, components, energy sources and waste production. In addition, specific energy and environmental impacts (secondary data) of the above inputs and outputs were identified by using environmental databases (Wernet et al., 2016).

In the following, the authors describe the data collection related to each investigated SHC system.

$\underline{\text { Data collection }- \text { S1 system }}$

The data are collected from the PV - air conditioner data sheet provided by the manufacturer.

The PV system consists of three modules made of polycrystalline silicon cells. The modules are connected in parallel. The nominal power of each panel is $235 \mathrm{~W}$ and the area $1.67 \mathrm{~m}^{2}$. The PV modules are covered by a 3.3 $\mathrm{mm}$ tempered glass.

The air conditioner system has a cooling power of $3.7 \mathrm{~kW}$ and a heating power of $3.8 \mathrm{~kW}$. The Seasonal Energy Efficiency Ratio (SEER) and the Seasonal Coefficient of Performance (SCOP) are, respectively, 7.5 (energy efficiency class A++ in cooling mode) and 4 (energy efficiency class A+ in heating mode).

Data collection - S2 system

The data are referred to the data sheet provided by the manufacturer. The PV system consists in 18 mono- 
crystalline photovoltaic modules and in a battery energy storage system (BESS). The modules are connected in parallel. The nominal power of each panel is $280 \mathrm{Wp}$. The overall nominal capacity is $5.04 \mathrm{kWp}$. Each panel has an area of $1.62 \mathrm{~m}^{2}$, a frame made of anodized aluminium and it is covered with a transparent tempered glass of 3.2 $\mathrm{mm}$. The BESS is constituted by four lead acid batteries. The nominal energy capacity is $28.8 \mathrm{kWh}$.

The heat pump consists in:

- Two semi - hermetically compressors. The cooling power ranges from 2.38 to $5.38 \mathrm{~kW}$. The Coefficient of Performance (COP) is 3.56 .

- Refrigerant (Propane, R290);

- Refrigerant tank (2.8 1);

- Filter drier for refrigerant;

- Sight glass for refrigerant circuit;

- Electronic pressure switch;

- Low and high security pressure switch;

- Solenoid valves and coil for solenoid valves;

- An air-cooled condenser (micro-channel type condenser);

- An evaporator (brazed plate heat exchangers);

- A super-heater (brazed plate heat exchangers);

- Pump with a mass flow ranging from 2 to $12 \mathrm{~m}^{3} / \mathrm{h}$;

- Expansion tank (steel);

- Electronic expansion valve;

- An effective circuit oil, including a filter drier, a sight glass for oil circuit, isolation valves for oil level regulation, a mechanical oil level regulator, an oil tank valve, an oil tank, an oil separator);

- Frame and various panels of the heat pump box.

The chilled water circuit consists in a 10001 thermal storage tank and in a 2001 thermal storage tank with an electrical resistance to simulate the building loads (which was not considered in the inventory). Finally, a monitoring system is included to control the performance of the system. The chilled water consists in a mix of water and methyl propylene glycol (30\% glycol).

Data collection $-\mathrm{S} 3$ system

Data were obtained from the direct measurement of the size and mass of each component and technical datasheets of each component of the system.

The data collection process involved the following equipments:

- Two adsorbent beds filled with silica-gel;

- Two Pb-Ca solar batteries, $12 \mathrm{~V}-65 \mathrm{Ah}$;

- Air ducts connecting the evaporative cooling module and the evaporative tower;

- Electric components, including electric wires and junction boxes;

- Two $38 \mathrm{~W}$ circulation pumps;

- Solar photovoltaic panel (power $170 \mathrm{~W}$, height per length $1150 \mathrm{~mm} * 966 \mathrm{~mm}$ ) and solar thermal panel

(aluminium based, $\mathrm{TiNO}_{\mathrm{X}}$ coating $(0.3 \mu \mathrm{m})$, and quartz glass $(0.3 \mu \mathrm{m})$ );

- Two electrovalves;

- Three polyester-based air filters;

- Ethylene propylene diene monomer (EPDM) thermal insulation;

- Evaporative cooling module, including hydraulics components and two heat evaporative heat exchangers;

- Galvanized steel bars utilized for the case;

- Fuse box;

- Control board with micro-controller governing all the electricity driven equipment; 
- Servo-motor for rolling shading devices;

- Internal frame;

- Steel frame;

- Evaporative tower;

- Hydraulic components;

- Four ways air valve displaced among the two adsorbent beds;

- Two fans with 190 and $300 \mathrm{~mm}$ diameter.

In the operation phase (Tab.1-2) a heating period of 121 days and a cooling period of 90 days were considered to assess yearly impacts. Average monitored data are used to extrapolate seasonal performance for the whole heating (12 $\mathrm{h}$ a day) and cooling ( $8 \mathrm{~h}$ a day) season length. For the whole year, $113.4 \mathrm{kWh}$ of total electricity consumption is considered for the yearly use phase calculation, of which only $24.9 \mathrm{kWh}$ are imported from the grid. 2,590 1 of water have been considered as well. A useful life of 15 years is expected for the system.

Tab. 1: Cooling season, use phase data for system S3

\begin{tabular}{|c|c|c|}
\hline Consumption & Unit of measure & Value \\
\hline $\begin{array}{c}\text { Cooling energy delivered } \\
\text { to the building }\end{array}$ & $\mathrm{kWh} /$ day & 13.32 \\
\hline $\begin{array}{c}\text { Electricity consumed } \\
\text { (cooling mode) }\end{array}$ & $\mathrm{kWh} /$ day & 1.04 \\
\hline $\begin{array}{c}\text { Electricity from the grid } \\
\text { (cooling mode) }\end{array}$ & $\mathrm{kWh} /$ day & 0.26 \\
\hline Water consumption & $1 /$ day & 28.78 \\
\hline
\end{tabular}

Tab. 2: Heating season, use phase data for system S3

\begin{tabular}{|c|c|c|}
\hline Consumption & Unit of measure & Value \\
\hline $\begin{array}{c}\text { Solar heat produced } \\
\text { (including ventilation) }\end{array}$ & $\mathrm{kWh} /$ day & 6.1 \\
\hline $\begin{array}{c}\text { Electricity consumed } \\
\text { (heating mode) }\end{array}$ & $\mathrm{kWh} /$ day & 0.17 \\
\hline $\begin{array}{c}\text { Electricity from the grid } \\
\text { (heating mode) }\end{array}$ & $\mathrm{kWh} /$ day & 0.01 \\
\hline $\begin{array}{c}\text { Sensible heating energy } \\
\text { delivered to the building }\end{array}$ & $\mathrm{kWh} /$ day & 2.34 \\
\hline Water consumption & 1/day & 0 \\
\hline
\end{tabular}

In the end-of-life phase it has been considered the recycling for glass based materials, landfill disposal for the solar $\mathrm{PV} /$ thermal modules and silica based components, rock wool and paints. No credit for recycling is associated to the end-of-life phase.

\subsection{Life Cycle Impact Assessment: results and interpretation}

In the following, the impacts on GER of each examined SHC system are indicated.

Concerning the $\mathrm{S} 1$ system, the GER of the $\mathrm{PV}$ - air conditioner manufacturing is $2.60 \mathrm{E}+04 \mathrm{MJ}_{\text {primary }}$ of which $86 \%$ is non - renewable primary energy. The PV panels manufacturing is responsible for the highest primary energy consumption. In detail, this component causes $88 \%$ of the GER (Fig. 4).

The GER of manufacturing phase of the PV - cooling unit (S2) is $2.86 \mathrm{E}+05 \mathrm{MJ}_{\text {primary }}$ of which $88 \%$ is non renewable primary energy. The PV panels manufacturing and the chilled water circuit are responsible for the 
highest primary energy consumptions (Fig. 5). In detail, they account, respectively, for $71 \%$ and $16 \%$ of the GER.

The impact on GER of the system S3 is $3.59 \mathrm{E}+04 \mathrm{MJ}_{\text {primary }}$, of which $75.7 \%$ is caused during the construction phase, $11.2 \%$ during operation and the remaining $13.1 \%$ during the end-of-life (Fig. 6).

The environmental impacts associated to the examined SHC systems are shown in Tab. 3.

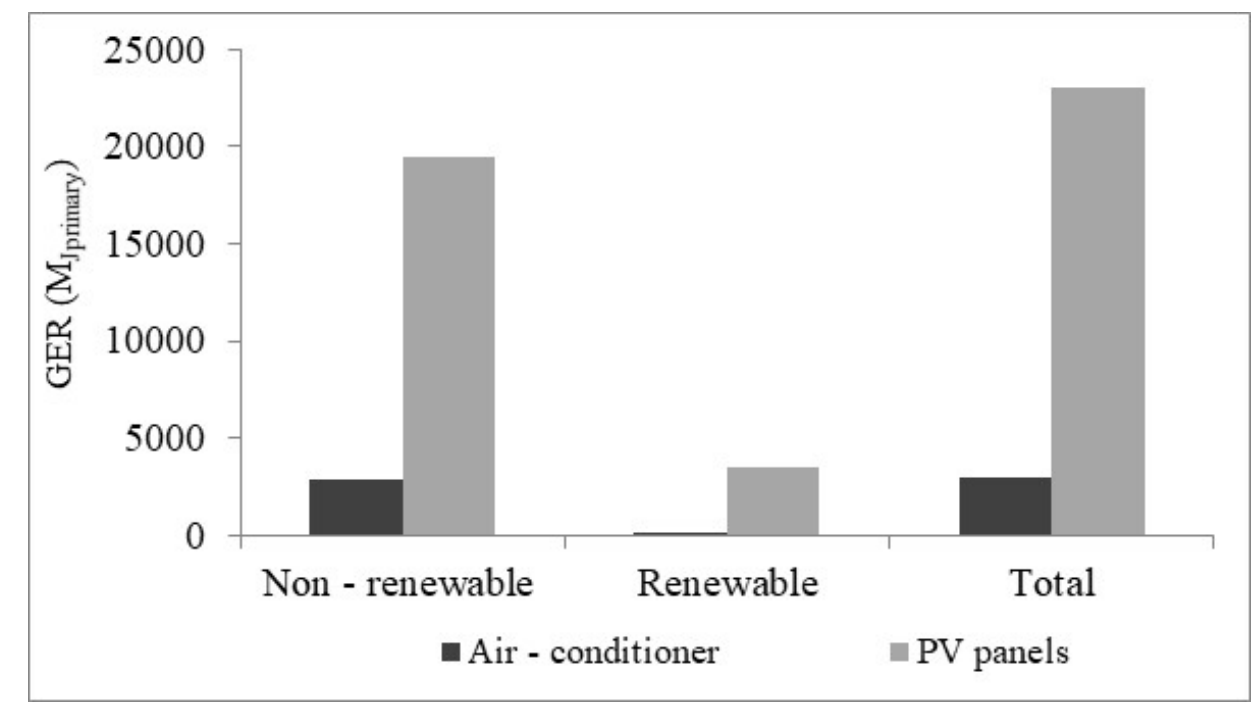

Fig. 4: GER processes contribution of the manufacturing phase - S1

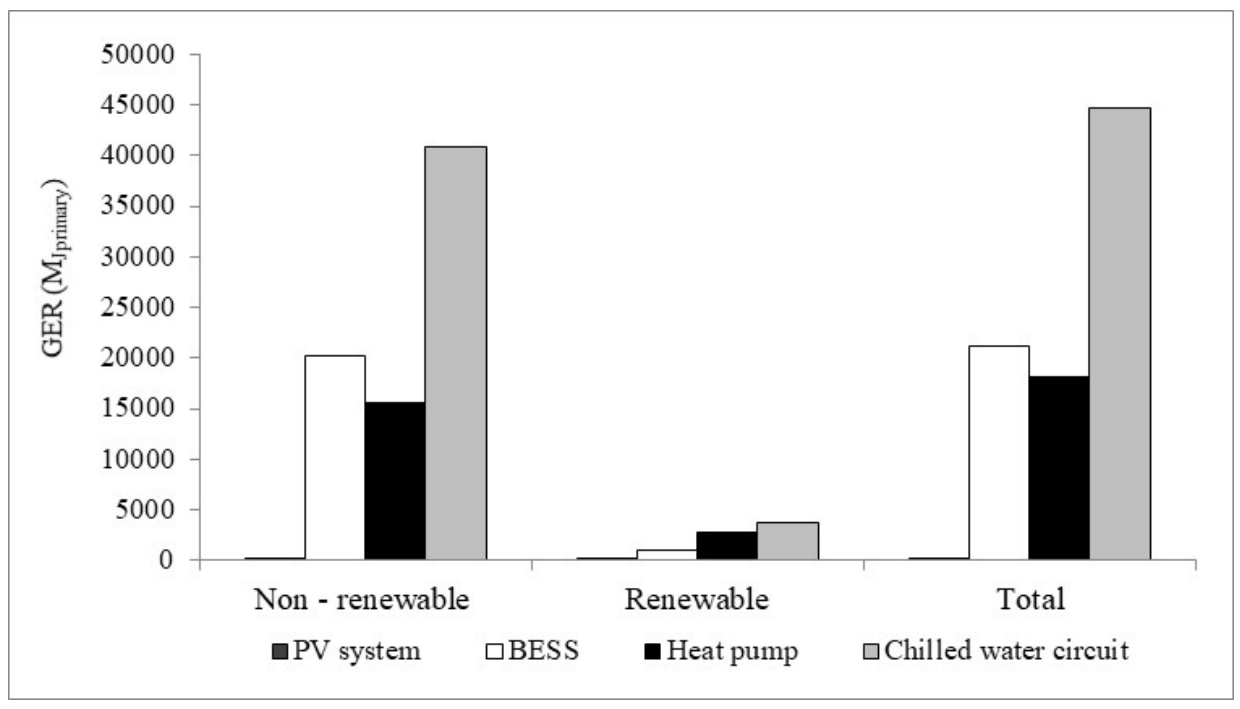

Fig. 5: GER processes contribution of the manufacturing phase - S2 


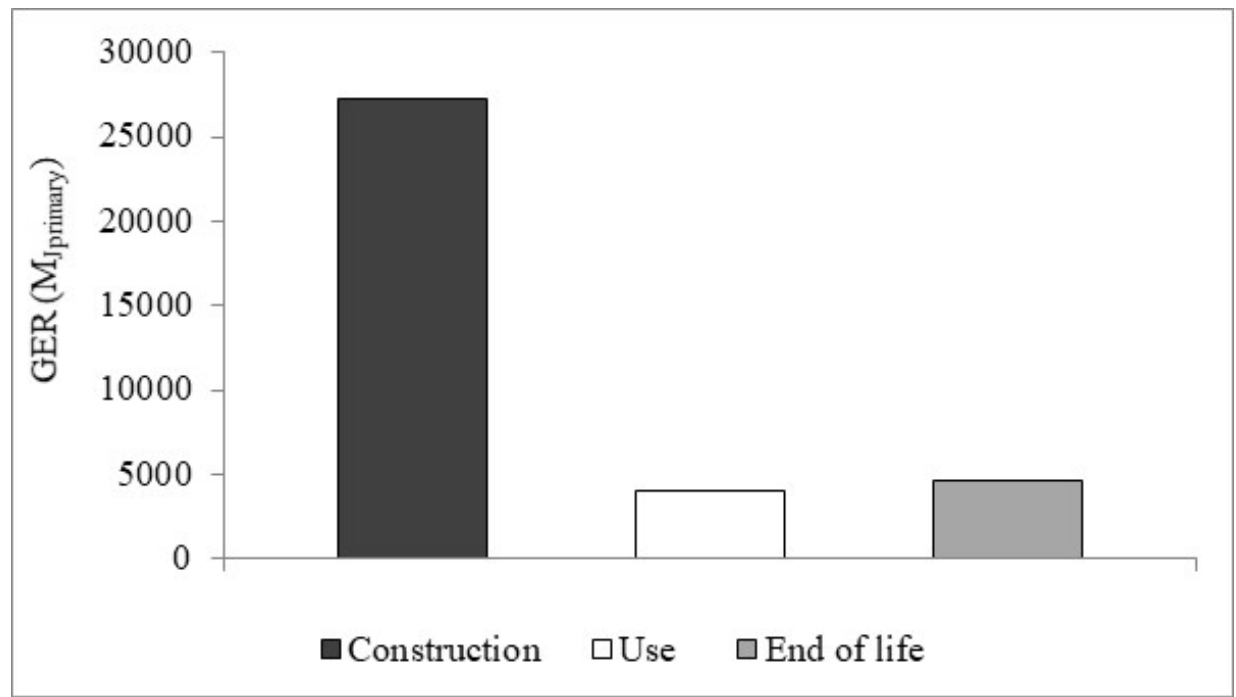

Fig. 6: GER processes contribution of each life cycle phase - S3

Tab. 3: Environmental impacts of the examined SHC systems

\begin{tabular}{|c|c|c|c|}
\hline Impact category & S1 & $\mathbf{S 2}$ & S3 \\
\hline $\mathrm{GWP}\left(\mathrm{kg} \mathrm{CO} \mathrm{CO}_{2 \mathrm{eq}}\right)$ & $1.87 \mathrm{E}+03$ & $4.57 \mathrm{E}+03$ & $2.15 \mathrm{E}+03$ \\
\hline ODP (kg CFC-11 $\left.1_{\mathrm{eq}}\right)$ & $1.21 \mathrm{E}-02$ & $1.28 \mathrm{E}-02$ & $2.19 \mathrm{E}-04$ \\
\hline HT-ce (CTUh) & $2.66 \mathrm{E}-04$ & $8.85 \mathrm{E}-03$ & $7.10 \mathrm{E}-04$ \\
\hline HT-nce (CTUh) & $2.26 \mathrm{E}-03$ & $2.22 \mathrm{E}-03$ & $2.36 \mathrm{E}-03$ \\
\hline PM (kg PM2.5eq & 7.63E-01 & $5.43 \mathrm{E}+00$ & $5.32 \mathrm{E}+02$ \\
\hline IR-hh $\left(\mathrm{kBq} \mathrm{U}^{235}{ }_{\mathrm{eq}}\right)$ & $3.96 \mathrm{E}+02$ & $4.91 \mathrm{E}+02$ & $4.12 \mathrm{E}+02$ \\
\hline IR-e (CTUe) & $1.21 \mathrm{E}-03$ & $1.59 \mathrm{E}-03$ & $1.25 \mathrm{E}-03$ \\
\hline POFP (kg NMVOC $\left.{ }_{\text {eq }}\right)$ & $5.13 \mathrm{E}+00$ & $1.71 \mathrm{E}+01$ & $6.84 \mathrm{E}+00$ \\
\hline $\mathrm{AP}\left(\right.$ molc $\left.\mathrm{H}_{\text {eq }}^{+}\right)$ & $8.90 \mathrm{E}+00$ & $3.74 \mathrm{E}+01$ & $1.45 \mathrm{E}+01$ \\
\hline T-EU (molc $\left.\mathrm{N}_{\mathrm{eq}}\right)$ & $1.43 \mathrm{E}+01$ & $5.50 \mathrm{E}+01$ & $2.22 \mathrm{E}+01$ \\
\hline F-EU $\left(\mathrm{kg} \mathrm{P} \mathrm{P}_{\mathrm{eq}}\right)$ & $1.50 \mathrm{E}+00$ & $5.76 \mathrm{E}+00$ & $1.63 \mathrm{E}+00$ \\
\hline M-EU $\left(\mathrm{kg} \mathrm{N}_{\mathrm{eq}}\right)$ & $1.50 \mathrm{E}+00$ & $6.25 \mathrm{E}+00$ & $2.13 \mathrm{E}+00$ \\
\hline F-E (CTUe) & $5.32 \mathrm{E}+04$ & $2.30 \mathrm{E}+05$ & $5.64 \mathrm{E}+04$ \\
\hline LU (kg C $\mathrm{deficit})$ & $1.20 \mathrm{E}+03$ & $9.07 \mathrm{E}+03$ & $2.05 \mathrm{E}+03$ \\
\hline WRD $\left(\mathrm{m}^{3}\right.$ water $\left._{\mathrm{eq}}\right)$ & $4.80 \mathrm{E}+03$ & $8.87 \mathrm{E}+00$ & $4.86 \mathrm{E}+03$ \\
\hline $\operatorname{MFRRD}\left(\mathrm{kgSb}_{\mathrm{eq}}\right)$ & $6.35 \mathrm{E}-01$ & $5.87 \mathrm{E}+00$ & $3.13 \mathrm{E}-01$ \\
\hline
\end{tabular}

Fig. 7 shows the process contribution of the manufacturing phase of S1 on the examined impact categories. The highest impacts are observed for the PV panels in all the examined environmental categories, the only exception is the ODP for which the air conditioner manufacturing contribution is $98 \%$, mainly related to the refrigerant R134a 
production.

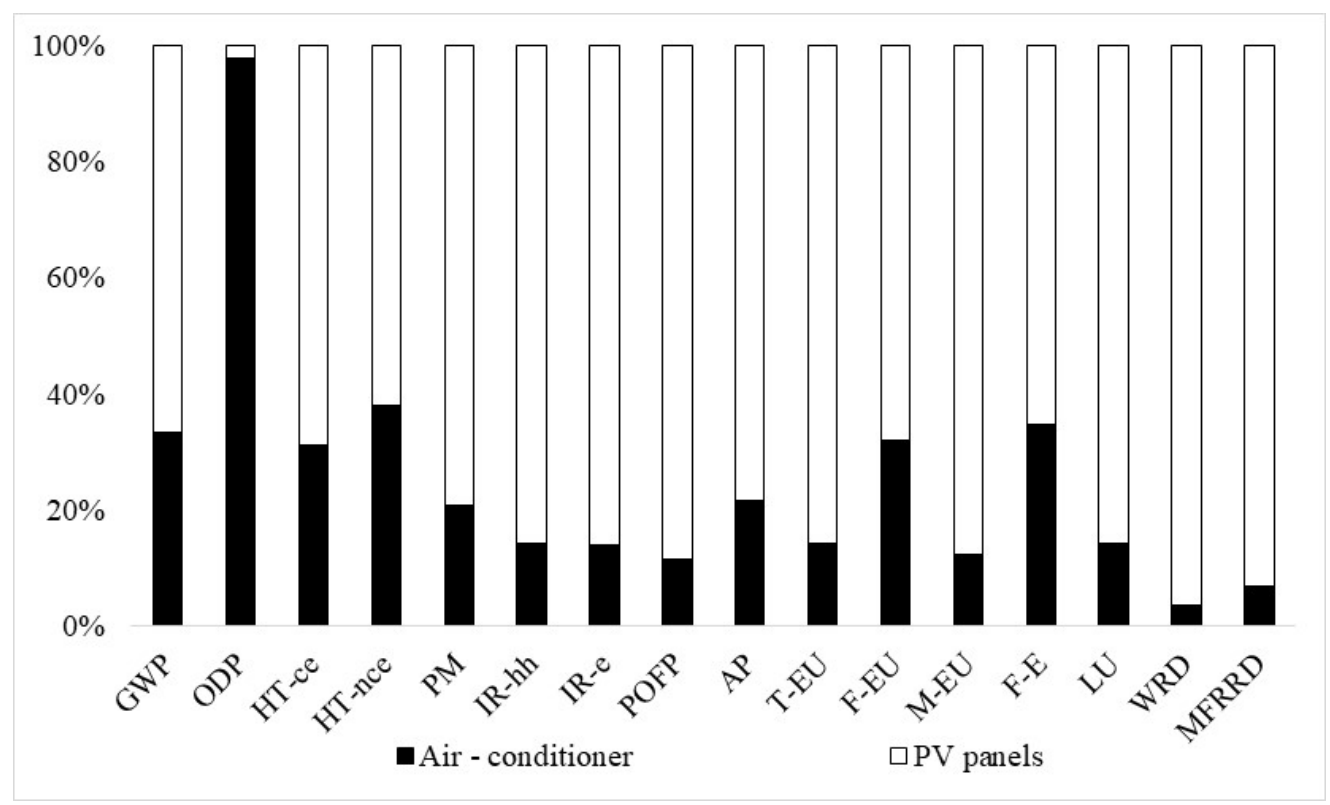

Fig. 7: Environmental impacts processes contribution - S1

Fig. 8 illustrates the contribution of each component of the S2 system to the examined impact categories. The PV panels account for the highest impact in all the examined impact categories. The only exceptions are the ODP and MFRRD, for which they represent about $12 \%$ and $40 \%$ of the overall impact, respectively. The contribution of the PV in the other impact categories ranges from $40.7 \%$ (for HT-nce) to $93 \%$ (for WRD). The BESS contributions range from a minimum of about $0.9 \%$ in ODP up to $50.4 \%$ for MFRRD. The heat pump is responsible for the highest contribution to the ODP (about 86\%) due to the refrigerant R134a production, used as a proxy for the refrigerant R290. The chilled water circuit gives an impact variable from $0.8 \%$ for ODP to $35.6 \%$ for HT-nce.

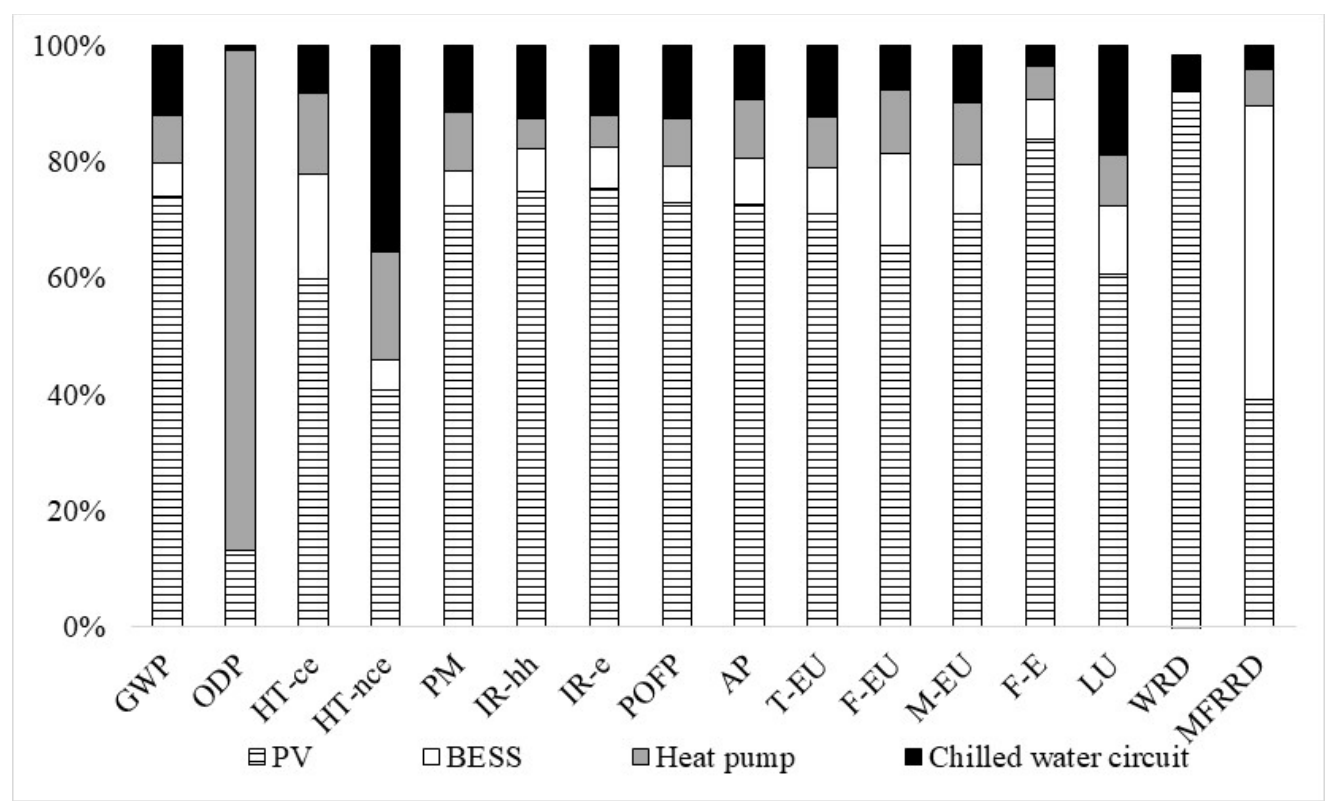

Fig. 8: Environmental impacts processes contribution - S2

With reference to the S3 system, Fig. 9 illustrates the share of each life cycle impact on the total impacts. 


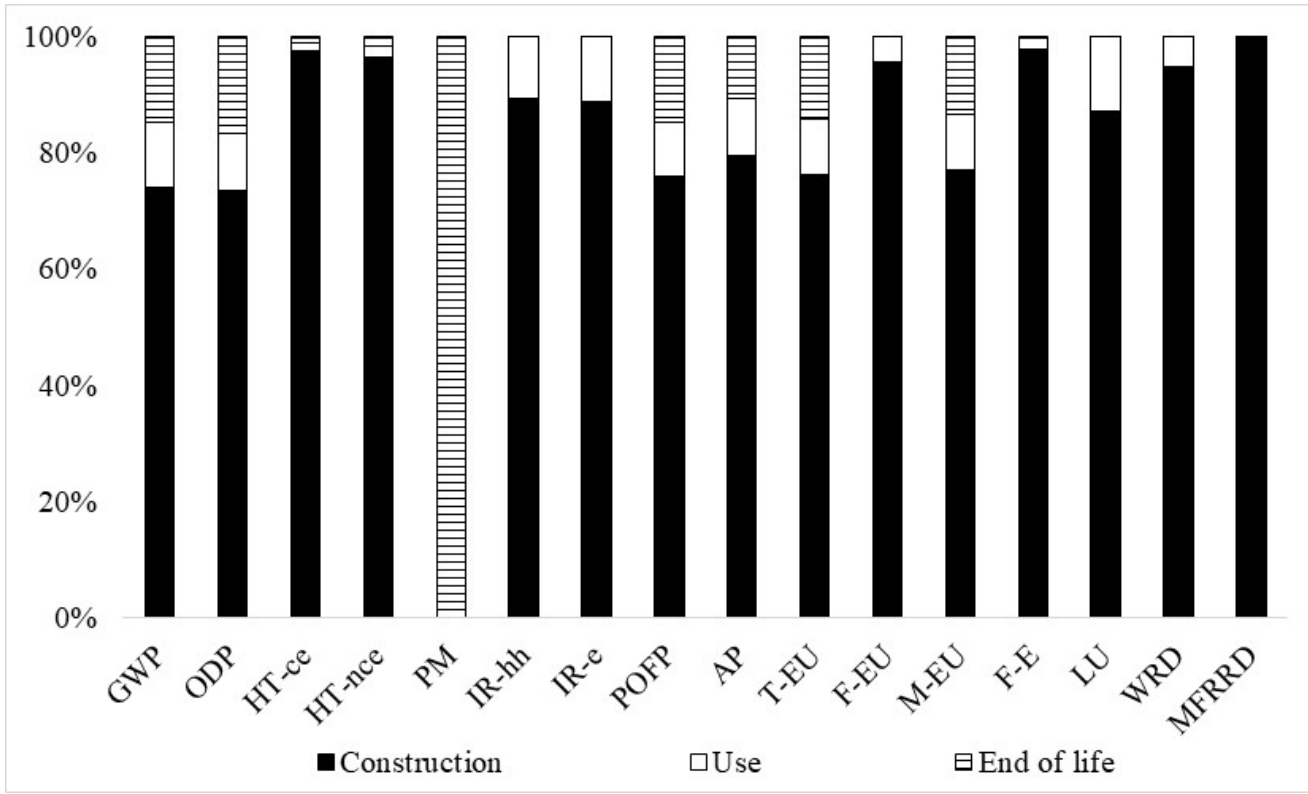

Fig. 9: Environmental impacts share of each life cycle phase - S3

The manufacturing phase has a predominant weight in most of the indicators, reaching values above or close to $95 \%$ in the case of the indicators WRD, F-E, F-EU, HT-nce, HT-ce. Moderately lower impacts are reported and always higher than $70 \%$ for all other impacts, the lowest being ODP at $73.55 \%$. Since the manufacturing phase is largely the most relevant among all the others, some further insights will be discussed on this phase. The most impacting components are the adsorbent bed, the solar batteries, the PV/thermal system, the air filters, the evaporative cooling module, the external, internal and steel frames. The sum of the impacts for these components is higher than $85 \%$ of the total impacts for all the indicators, the only exception being ODP reaching $79.91 \%$.

A detailed analysis of the manufacturing phase was carried out and the main outcomes are briefly discussed in the following bullet points:

- the highest share of impacts in DEC based processes is associated to the adsorbent beds, ranging from the $5.53 \%$ of the ODP and the $22.85 \%$ of the LU;

- for solar batteries the most relevant indicators are HT-nce (48.39\%), F-EU (43.72\%) and F-E (46.06\%). The other indicators range between the $10.80 \%$ of the HT-ce to the $27.85 \%$ of the AP;

- the photovoltaic-thermal system impacts share varies between $13.27 \%$ of the indicator HT-nce and $21.67 \%$ of M-EU. HT-nce (7.73\%), F-E (7.14\%) and ODP (37.40\%) are outside the overall trend;

- the air filters have a less relevant role, since their impact would range in most cases between the $4.35 \%$ (ODP) and 6.70\% (GER). HT-nce, F-UE and F-E would fall below the lower threshold;

- the evaporative cooling modules impacts the total between the $9.18 \%$ of the POFP to the 13.19 of IR-e. Only some indicators, such as HT-nce (3.81\%), F-EU (5.92\%) and F-E (5.51\%) are below 6\%;

- in systems using PV collectors:

○ the external frames impacts are variable between the $3.18 \%$ of HT-nce to the $10.34 \%$ of HT-ce;

- the internal frames result variation range is included between $3.48 \%$ of ODP and $7.08 \%$ of the GER;

- the steel frames impacts vary between the $2 \%$ of WRD to the $5 \%$ of GWP. The only indicator outside the trend is the HT-ce, reaching the $10.87 \%$ of the overall impact.

\section{Conclusions}

The results of the LCA analyses allowed identifying the main energy and environmental "hot spots" to be taken into account for improving the environmental sustainability of the SHC systems. In detail, the results showed that the PV panels account for the highest impact caused during the manufacturing of the PV cooling system and the PV - air conditioner unit. The only exception is for ODP mainly caused by the heat pump (about $86 \%$ ) in the first system and by the air conditioner (about $98 \%$ ) in the second one. Referring to the compact desiccant evaporative cooling system (S3), the manufacturing step has a predominant weight in most of the impact categories, reaching values above or close $95 \%$ in the case of the freshwater ecotoxicity, freshwater eutrophication and human toxicity. 
The most impacting components to the above impact categories are the solar batteries (about 40\%).

The results of the research can represent a "knowledge basis" to assess the real advantages arising from the installation of SHC technologies for reducing the energy and environmental impacts of buildings air-conditioning and to orientate manufacturers, researchers and decision makers for a more sustainable use of solar technologies.

\section{References}

Beccali, M., Cellura, M., Longo, S., Nocke, B., Finocchiaro, P., 2012a. LCA of a solar heating and cooling system equipped with a small water-ammonia absorption chiller. Sol. Energy 86, 1491-1503. https://doi.org/10.1016/j.solener.2012.02.010Beccali, M., Cellura, M., Longo, S., Nocke, B., Finocchiaro, P., 2012a. LCA of a solar heating and cooling system equipped with a small water-ammonia absorption chiller. Sol. Energy 86, 1491-1503. https://doi.org/10.1016/j.solener.2012.02.010

Beccali, M., Finocchiaro, P., Nocke, B., 2012b. Energy performance evaluation of a demo solar desiccant cooling system with heat recovery for the regeneration of the adsorption material. Renew. Energy 44, 40-52. https://doi.org/10.1016/j.renene.2011.12.021

Beccali, M., Cellura, M., Finocchiaro, P., Guarino, F., Longo, S., Nocke, B., 2014. Life Cycle performance assessment of small solar thermal cooling systems and conventional plants assisted with photovoltaics. Sol. Energy 104, 93-102, https://doi.org/10.1016/j.solener.2013.10.016

Beccali, M., Cellura, M., Longo, S., Guarino, F., 2016. Solar heating and cooling systems versus conventional systems assisted by photovoltaic: Application of a simplified LCA tool. Sol. Energy Mater. Sol. Cells 156, 92-100. https://doi.org/10.1016/j.solmat.2016.03.025

Bukoski, J., Gheewala, S.H., Mui, A., Smead, M., Chirarattananon, S., 2014. The life cycle assessment of a solarassisted absorption chilling system in Bangkok, Thailand. Energy Build. 72, 150-156. https://doi.org/10.1016/j.enbuild.2013.12.034

BUWAL250, 1998. Bundesamt für Umwelt, Wald und Landschaft, Ökoinventar für Energie systeme, Berne, Switzerland.

E.U.ESU Group, 1996. ETH-ESU96 Okoinventare von Energie systemen.

European Commision, 2014. A policy framework for climate and energy in the period from 2020 to 2030. https://Ec.Europa.Eu/Energy/En/Topics/Energy-Strategy/2030-Energy-Strategy Brussels.

European Commission, 2011. COMMUNICATION FROM THE COMMISION: A Roadmap for moving to a competitive low carbon economy in 2050. COM(2011) 112 Final 34, 1-34.

European Commission - Joint Research Centre - Institute for Environment and Sustainability, 2010. International Reference Life Cycle Data System (ILCD) Handbook - General guide for Life Cycle Assessment - Detailed guidance. First edition March 2010. EUR 24708 EN. Luxembourg. Publications Office of the European Union; 2010.

European Commission, Joint Research Centre, 2012. Characterisation factors of the ILCD Recommended Life Cycle Impact Assessment methods: database and supporting information, European Commission.

Finocchiaro, P., Beccali, M., Cellura, M., Guarino, F., Longo, S., 2016. Life Cycle Assessment of a compact Desiccant Evaporative Cooling system: The case study of the "Freescoo." Sol. Energy Mater. Sol. Cells 156, 83-91. https://doi.org/10.1016/j.solmat.2016.03.026

Frischknecht, R., Jungbluth, N., Althaus, H., Bauer, C., Doka, G., Dones, R., Hischier, R., Hellweg, S., Köllner, T., Loerincik, Y., Margni, M., 2007. Implementation of Life Cycle Impact Assessment Methods. Am. Midl. Nat. $150,1-151$.

Frischknecht, R., Jungbluth, N., Althaus, H.J., Doka, G., Dones, R., Heck, T., Hellweg, S., Hischier, R., Nemecek, T., Rebitzer, G., Spielmann, M., 2005. The ecoinvent database: Overview and methodological framework. Int. J. Life Cycle Assess. 10, 3-9.

ISO, 2006a. ISO 14040: Environmental management — Life Cycle Assessment — Principles and Framework, International Organization for Standardization.

ISO, 2006b. ISO 14044: Environmental management - Life cycle assessment — Requirements and guidelines, International Organization for Standardization.

Joint Research Center, 2016. EPLCA - European Reference Life-Cycle Database. 〈http://eplca.jrc.ec.europa.eu/ELCD3/index.xhtml〉. 
Kalogirou, S., 2009. Thermal performance, economic and environmental life cycle analysis of thermosiphon solar water heaters. Sol. Energy 83, 39-48. https://doi.org/10.1016/j.solener.2008.06.005

Longo, S., Palomba, V., Beccali, M., Cellura, M., Vasta, S., 2017. Energy balance and life cycle assessment of small size residential solar heating and cooling systems equipped with adsorption chillers. Sol. Energy 158, 543-558. https://doi.org/10.1016/j.solener.2017.10.009

Mugnier, D., Fedrizzi, R., Thygesen, R., Selke, T., 2015. New Generation Solar Cooling and Heating Systems with IEA SHC Task 53: Overview and First Results. Energy Procedia 70, 470-473. https://doi.org/10.1016/j.egypro.2015.02.149

Samuel, D.G.L., Nagendra, S.M.S., Maiya, M.P., 2013. Passive alternatives to mechanical air conditioning of building: Areview. Build. Environ. 66, 54-64. https://doi.org/10.1016/j.buildenv.2013.04.016

Santamouris, M., Kolokotsa, D., 2013. Passive cooling dissipation techniques for buildings and other structures: The state of the art. Energy Build. 57, 74-94. https://doi.org/10.1016/j.enbuild.2012.11.002

Wernet, G., Bauer, C., Steubing, B., Reinhard, J., Moreno-Ruiz, E., Weidema, B., 2016. The ecoinvent database version 3 (part I): overview and methodology. Int. J. Life Cycle Assess. 21, 1218-1230. https://doi.org/10.1007/s11367-016-1087-8 


\title{
Monitoring and energy performance assessment of the compact DEC HVAC system "freescoo facade" in Lampedusa (Italy)
}

\author{
Marco Beccali ${ }^{1}$, Pietro Finocchiaro ${ }^{2}$, Biagio Di Pietra ${ }^{3}$, Mario Motta ${ }^{4}$ \\ ${ }^{1}$ University of Palermo, Palermo (Italy) \\ ${ }^{2}$ Solarlnvent srl, Catania (Italy) \\ ${ }^{3}$ ENEA, Palermo (Italy) \\ ${ }^{4}$ Polytechnic of Milan, Milan (Italy)
}

\begin{abstract}
This work addresses the energy performance of a solar DEC HVAC system working with the freescoo technology coupled with DHW tank for hot water preparation. Freescoo is a patented solar air conditioning concept for ventilation, cooling, dehumidification and heating of buildings for residential and tertiary sectors.

The work presents monitoring results of a system installed at the ENEA Research Center in Lampedusa island. The monitoring of the system started in 2017 and here results for cooling operation are presented. Global seasonal electrical COP of about 10 have been registered.
\end{abstract}

Keywords: compact DEC system, freescoo;

\section{Description of the system}

In the framework of a project between the Italian Research Institution ENEA and the University of Palermo, novel and efficient HVAC systems have been investigated with the aim to reduce power absorbed and electricity consumption for cooling in small islands such Lampedusa in Sicily.

In this work, the energy performances of a solar DEC HVAC system working with the freescoo technology coupled with DHW production have been investigated.

The operation of the system in summertime can be described as following:

- $\quad$ Outside air (high humidity and high temperature) is drown through an innovative cooled packed adsorption bed to be strongly dehumidified

- Afterwards the air is cooled down in an indirect evaporative cooling heat exchanger without increasing its humidity

- When the adsorption material gets saturated, solar heat is used for its regeneration $\left(50-60^{\circ} \mathrm{C}\right)$

- The adsorption heat is rejected to the ambient using an internal rejection heat exchanger

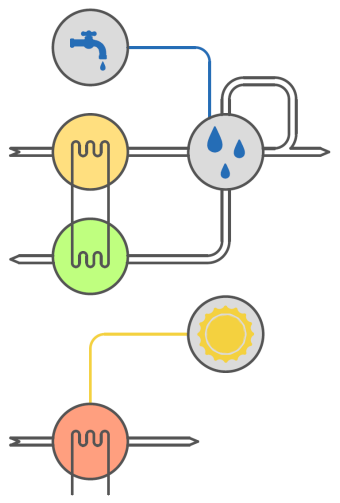

The system investigated has a maximum air flowrate of $500 \mathrm{~m}^{3} / \mathrm{h}$, rated cooling power of $2.5 \mathrm{~kW}$ and can be operated in ventilation mode $\left(350 \mathrm{~m}^{3} / \mathrm{h}\right.$ of fresh air) or in partial recirculation mode (typical $40-60 \%$ of fresh air and $60-40 \%$ of recirculated air flow rate). Design supply air conditions in summertime are $19-21^{\circ} \mathrm{C}$ and $8-11 \mathrm{~g} / \mathrm{kg}$ of humidity ratio with ambient conditions of $35^{\circ} \mathrm{C}$ and $16 \mathrm{~g} / \mathrm{kg}$.

In the wintertime, the system can provide heat recovery and heating to the room when the sun shines. The system is driven by three X-RAY10 evacuated tube collectors by Pleion connected in series and needs about $200 \mathrm{~W}$ of power for driving fans and small pumps. Solar heat is also used to prepare DHW in a $300 \mathrm{lt}$ tank connected in series to the freescoo HVAC. This permits to take advantage of higher regeneration temperatures of the desiccant and higher efficiency of the solar collectors. In case of no need for regeneration, solar heat is used only for DHW. 


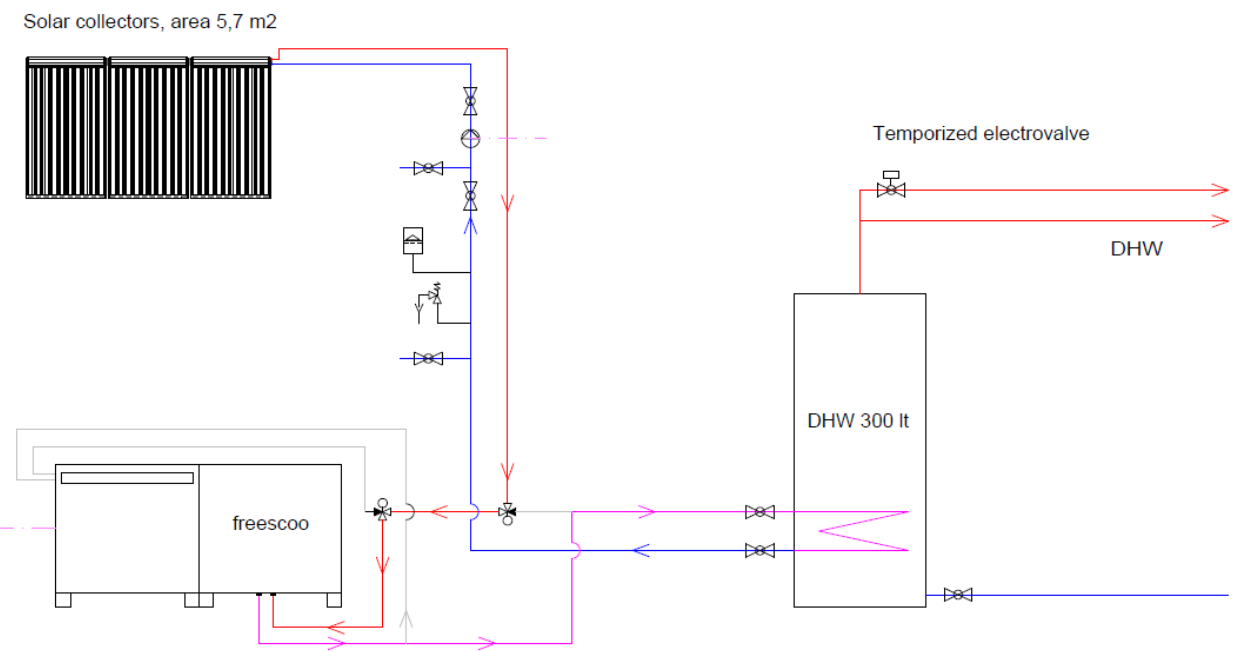

Fig. 1: Scheme of the freescoo system for air conditioning and DHW production

Main system parameters and performance characteristics are summarized in the table 1 while a simple sketch of it is shown in figure 1 .

Tab. 1: Main characteristics of the system and rated performance at design summer conditions $\left(T_{\text {ambient }}=35^{\circ} \mathrm{C} x_{\text {ambient }}=16 \mathrm{~g} / \mathrm{kg}\right.$, $T_{\text {building }}$ $\left.=27^{\circ} \mathrm{C} \mathbf{x}_{\text {building }}=10.5 \mathrm{~g} / \mathrm{kg}\right)$

\begin{tabular}{|c|c|c|}
\hline Description & Value & Unit \\
\hline Volume of the conditioned space & 140 & {$\left[\mathrm{~m}^{3}\right]$} \\
\hline Supply air flow rate & $0-500$ & {$\left[\mathrm{~m}^{3} / \mathrm{h}\right]$} \\
\hline Rate of fresh air & $30-50$ & {$[\%]$} \\
\hline Total max cooling power & 2.5 & {$[\mathrm{~kW}]$} \\
\hline Heating power required for the regeneration & 2.5 & {$[\mathrm{~kW}]$} \\
\hline Max Power absorbed & 200 & {$[\mathrm{~W}]$} \\
\hline Rated EER for cooling & 12.5 & {$[-]$} \\
\hline Solar collector area & $3 \times 1.91$ & {$\left[\mathrm{~m}^{2}\right]$} \\
\hline Installed solar collector power (including DHW production) & 3.6 & {$[\mathrm{~kW}]$} \\
\hline Volume of DHW storage tank & 300 & {$[\mathrm{lt}]$} \\
\hline
\end{tabular}

For more detailed descriptions of the working principle of the freescoo concept, please refer to previous works of the same authors (Finocchiaro P, et al. 2013, 2014, 2015). Figure 2 shows some picture of the components installed at Lampedusa.

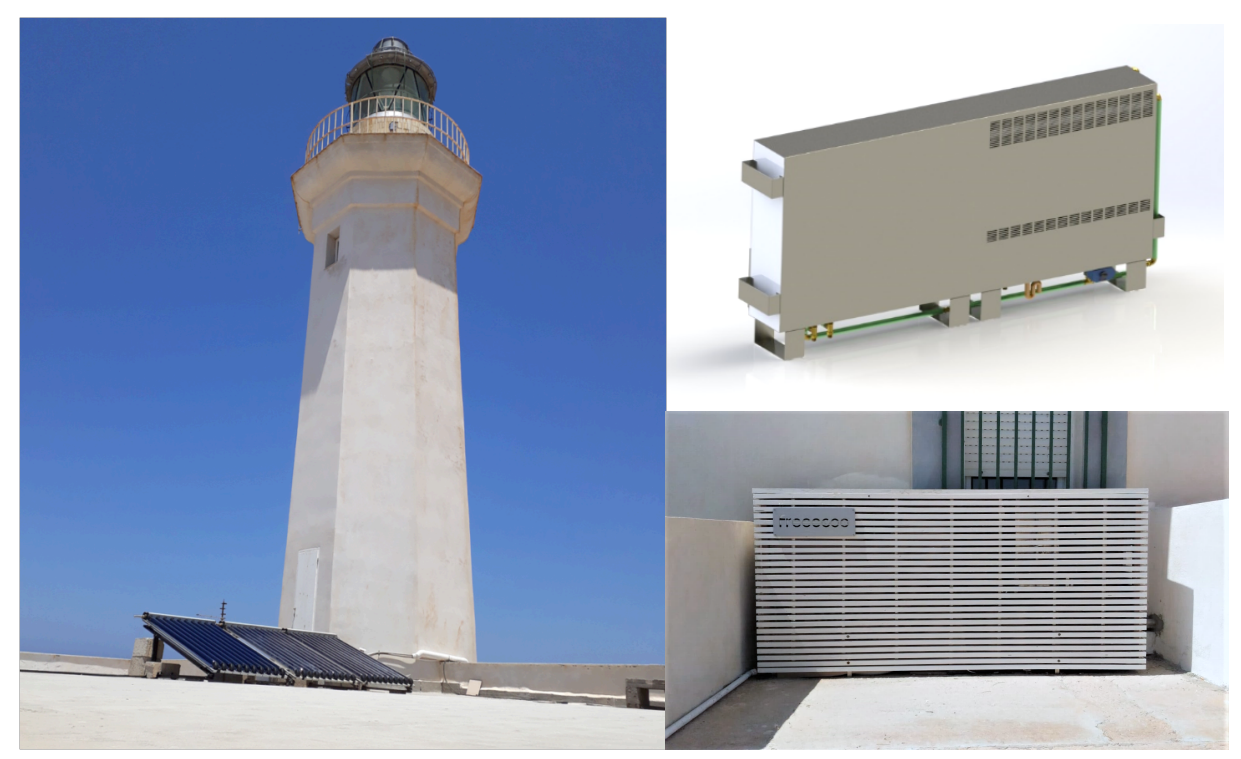

Fig. 2: Picture of the freescoo system for facade integration monitored at ENEA Research Center in Lampedusa 


\section{Results and discussion}

In order to assess the cooling energy performance of the system, an extended monitoring campaign has been performed from June to the end of August 2018. In the following pages, 23 days of operation during August of 2018 will be presented and analysed.

Various measurements of temperature (accuracy $\pm 0.3^{\circ} \mathrm{C}$ ), humidity (accuracy $\pm 2.5 \%$ of measured value), air velocity (at supply, return, adsorption beds), accuracy of $\pm(0.5 \mathrm{~m} / \mathrm{s}+3 \%$ of measured value), electricity consumption (accuracy $\pm 0.5 \%$ ), solar radiation ( $2^{\circ}$ class according to ISO9060), and water flowrates (accuracy \pm $3 \%$ ) have been conducted at inlet and outlet of the main components. Data acquisition has been performed with a time step of one minute, using the GPRS 2 16-bit acquisition platform from SENECA together with $4 \times 8$ input analogue modules and $4 \times$ RTD modules. Energy performances have been evaluated according to the monitoring procedure for solar cooling systems developed by the Task 38 and 48 of the International Energy Agency experts.

In the first graph (figure 3), ambient conditions for one selected day of operation are reported. Mean daily temperature and humidity ratio registered are respectively $29.8^{\circ} \mathrm{C}$ and $15.5 \mathrm{~g} / \mathrm{kg}$ with peaks over $32^{\circ} \mathrm{C}$ and 17 $\mathrm{g} / \mathrm{kg}$. Solar irradiation is high reaching $7 \mathrm{kWh} / \mathrm{m}^{2}$ on the collector plane.

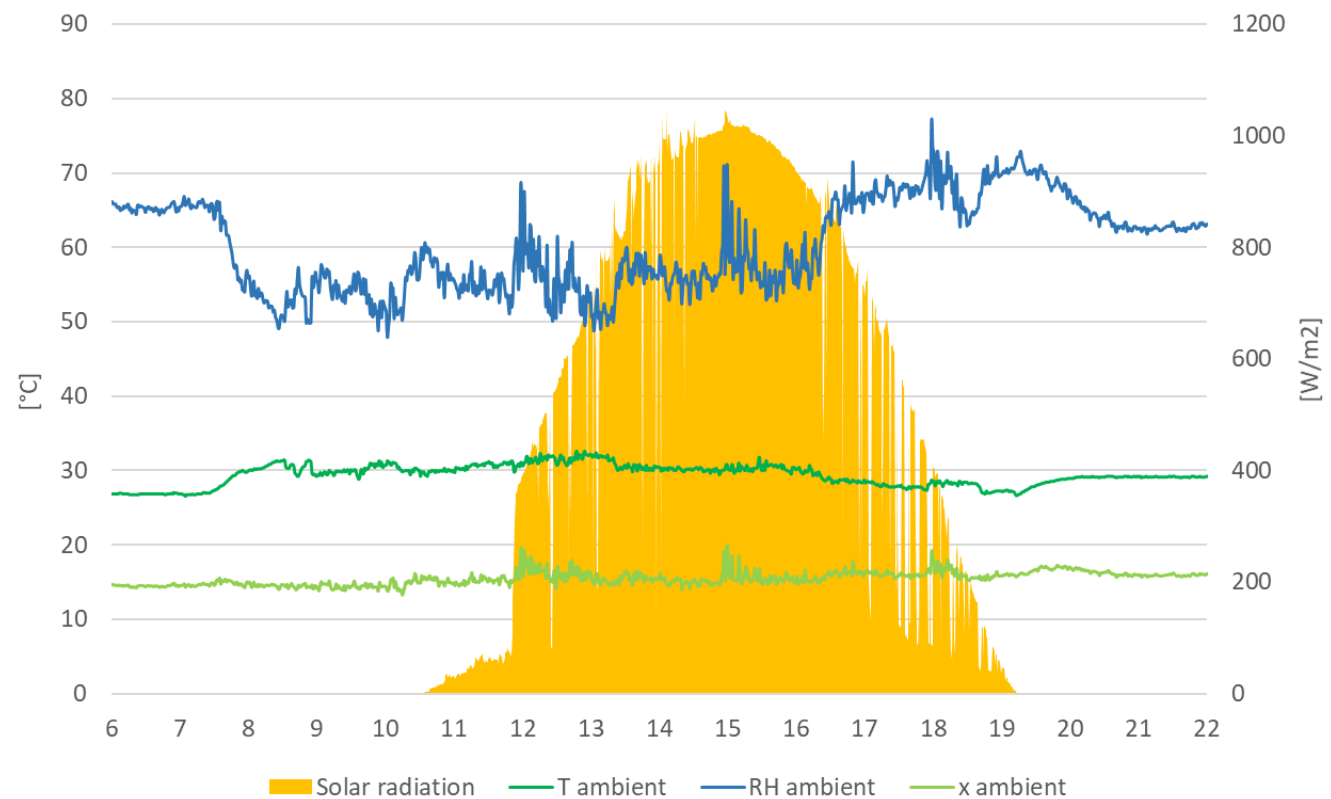

Fig. 3: Ambient conditions for the presented day of operation - Day 17

The behaviour of the system under these conditions is described in the pictures below. In particular, Fig. 4 describes temperature and humidity ratio profiles in the building, at the outlet of the adsorption bed and at the supply point.

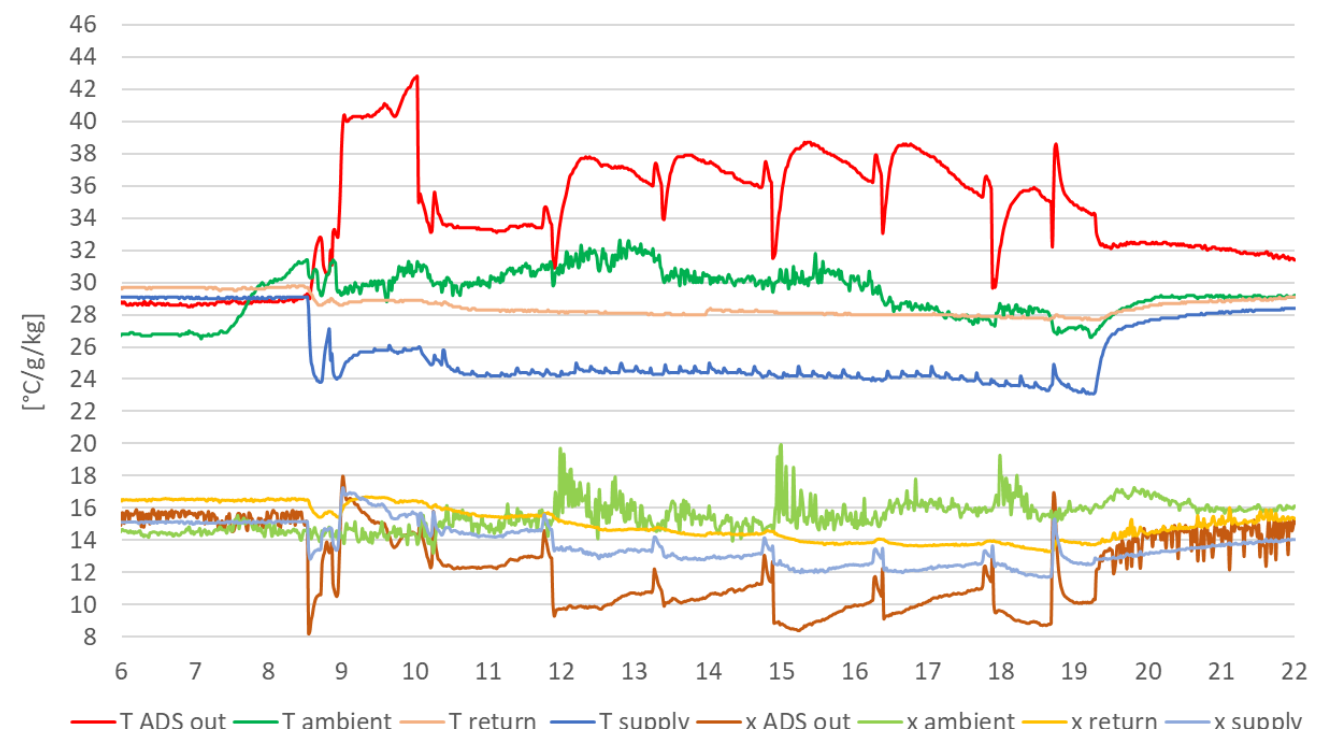


Fig. 4: Temperature and humidity ratio for one day of operation - Day 17

In Fig. 5 instantaneous energy performances such as cooling power, electricity absorbed, and thermal energy used for regeneration and DHW preparation are depicted. It can be noted that, with these conditions, the system has maximum continuous cooling power of about $1.9 \mathrm{~kW}$ with only some peaks over $2 \mathrm{~kW}$. Power absorbed is quite constant and about $180 \mathrm{~W}$. Although the cooling power of the system is reasonably high, it can be clearly noted that temperature in the building cannot be maintained at comfort level (Fig.4). This was due mainly to the building cooling loads which are higher than expected and at a lower rate to the lower cooling performance of the system.

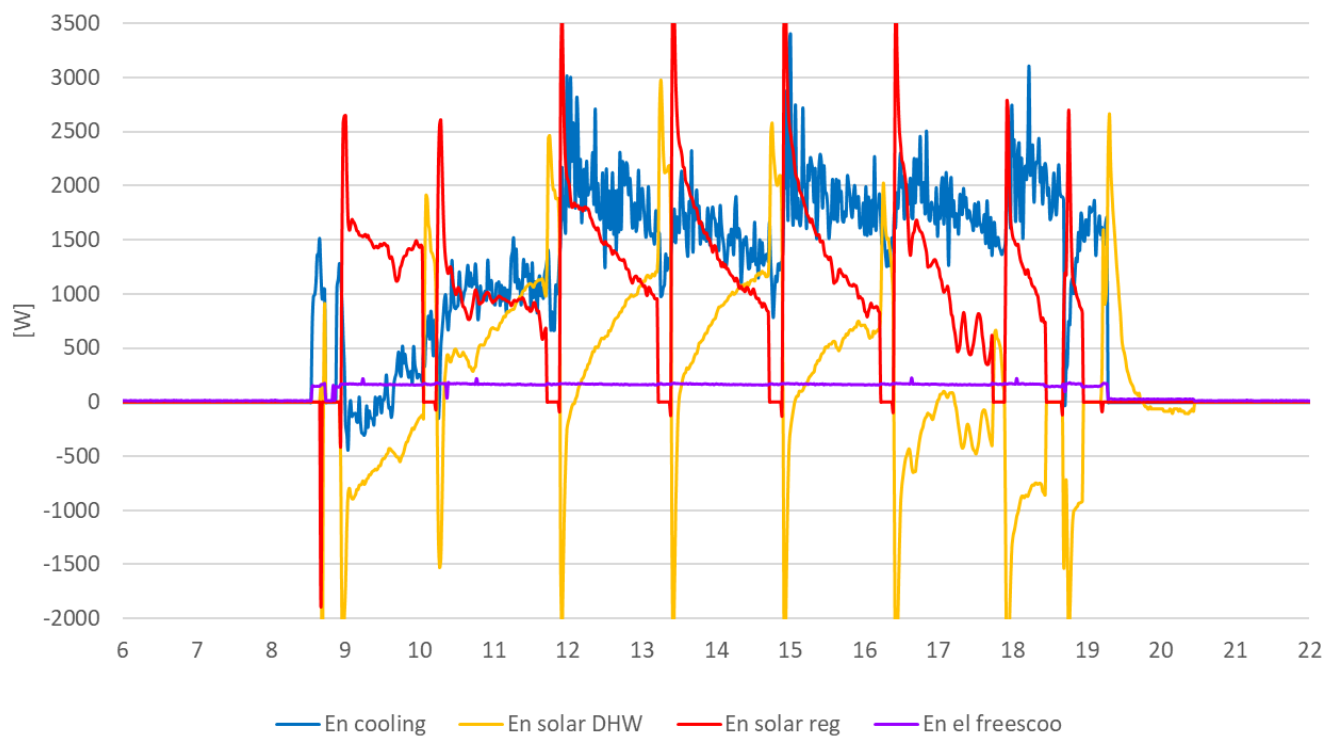

Fig. 5: Energy performance for one day of operation - Day 17

Energy efficiency ratio range mainly from 8 to 12 whereas thermal COP of the desiccant cycle is normally higher than one with some peaks over 2 as reported in Fig. 6. In the calculation of the thermal COP, only the solar heat used for the regeneration has been considered, whereas for the EER the whole cooling energy, including the ambient air handling process, has been considered.

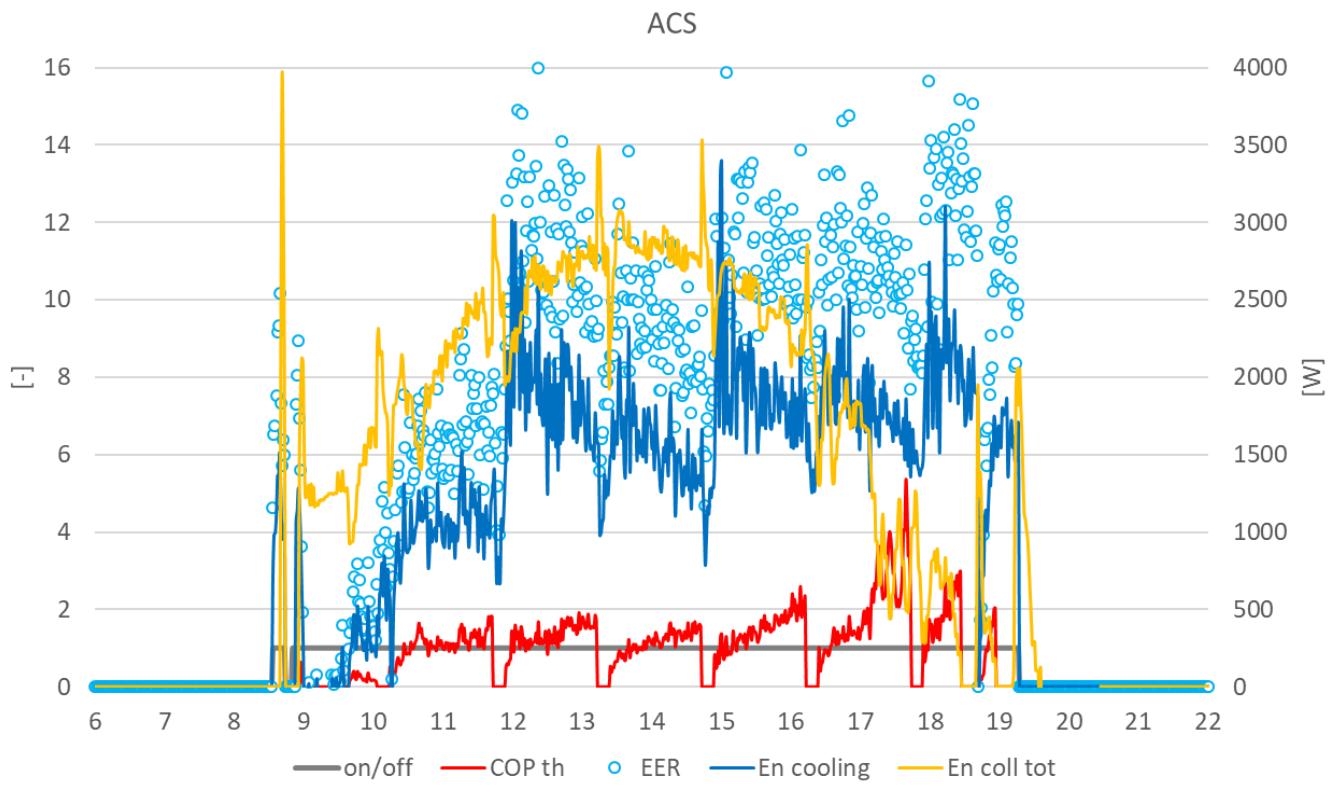

Fig. 6: Temperature and humidity ratio for one day of operation - Day 17

Main energy performance results also including DHW preparation are summarized in the table below for the considered day of operation. Results clearly show the good efficiency of the air handling process, even if it can be stated that there is a lack of performance in terms of cooling power. With these conditions, the adsorption beds are indeed not able to dehumidify enough the air stream before the air enters the indirect evaporative process. This causes a lack of sensible cooling power at the outlet of the HVAC unit. 
M. Beccali et. al. / EuroSun 2018 / ISES Conference Proceedings (2018)

Tab. 2: Monitored daily performance of the HVAC + DHW for one day - Day 17

\begin{tabular}{|l|l|l|}
\hline Description & Value & Unit \\
\hline Cooling energy - due to air handling & 15.1 & {$[\mathrm{kWh}]$} \\
\hline Cooling energy - to the building & 10.3 & {$[\mathrm{kWh}]$} \\
\hline Incident solar radiation & 41.1 & {$[\mathrm{kWh}]$} \\
\hline Solar collector heat & 19.9 & {$[\mathrm{kWh}]$} \\
\hline Electricity consumed & 1.9 & {$[\mathrm{kWh}]$} \\
\hline Total water consumption for cooling & 26.8 & {$[1]$} \\
\hline Total hours of operation & 10.6 & {$[\mathrm{~h}]$} \\
\hline Total DHW consumption & 155 & {$[1]$} \\
\hline Global electrical COP (HVAC + DHW) & 10.7 & {$[-]$} \\
\hline EER (freescoo HVAC) & 7.9 & {$[-]$} \\
\hline COP th (freescoo HVAC) & 1.3 & {$[-]$} \\
\hline Solar collector efficiency & 48 & {$[\%]$} \\
\hline
\end{tabular}

In the following pages, longer-term energy performances will be presented ( 23 days of operation). In these days the system has been operated for about 10 hours but under different control conditions. In order to test the behavior of the adsorption beds, different flow rates and ratio between ambient and recirculated air flows have been investigated. In particular, from day 6 to day 15 the system has been operated at half of the nominal flow rate.

It can be noted how the cooling energy delivered is strongly dependent by the humidity ratio of the considered day of operation. For example, considering the days from 16 to 23 , the cooling energy line is almost opposite to the one of the humidity ratio. This is due to the fact that, in correspondence to very humid air conditions, system performances fail since the adsorption bed are not able to sufficiently remove the moisture from the ambient air. As result, the indirect evaporative cooling process can only be operated at high wet bulb temperatures and the supply temperature rise then in the range of $24-27^{\circ} \mathrm{C}$. The cooling performances are also influenced by the solar heat collected and used for the regeneration of the desiccant. For example, in day 8 the system has a poor performance mainly due to a combination of lack of regeneration heat and high humidity ratio of the ambient air. The dependence from the ambient temperature is indeed less strong. The best performance is reached at day 4 where the system delivers up to $20 \mathrm{kWh}$ of cooling energy.

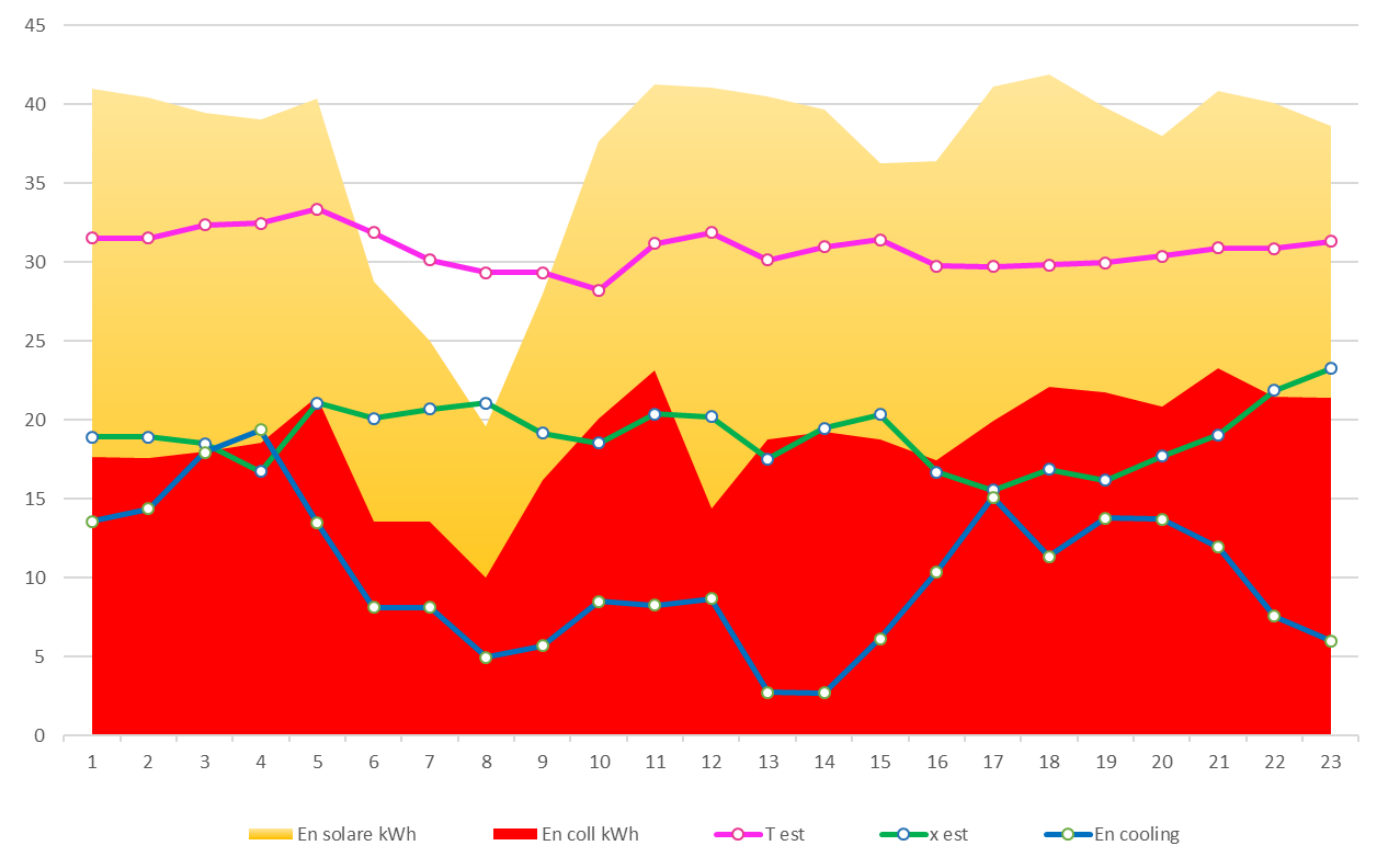

Fig. 7: Ambient conditions for the considered days

More detailed information are also reported in Fig. 8 where EER, efficiency of the solar collectors, and global electric COP are also depicted. Global electric COP is calculated as the sum of cooling energy delivered and heat for DHW divided by the total electricity consumed. 


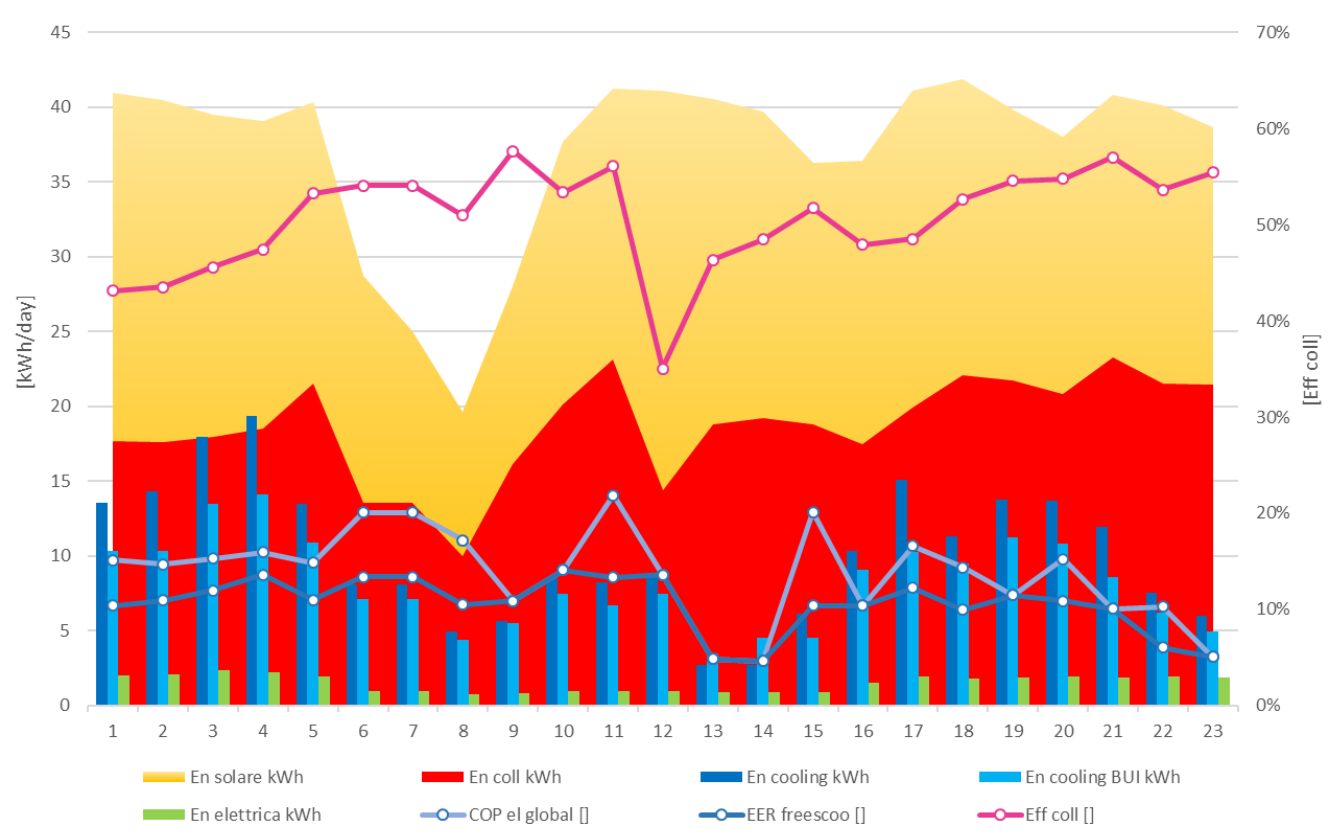

Fig. 8: Energy performance of the freescoo HVAC + DHW preparation for the considered days

Fig 9. describes the heat distribution between DHW preparation and the regeneration of the adsorption beds in the freescoo HVAC together with the heat losses of the circuit and DHW tank. The average share for the regeneration of the desiccant amounts to $46 \%$ of the total heat produced by the solar collectors, $24 \%$ is used for DHW preparation and about $30 \%$ are lost in the ambient. With this regard, it has to be noted that the instantaneous flow rate of DHW could be controlled automatically according to a given profile with an average daily consumption of about 150 liters and in some days it was decided to have no DHW consumption.

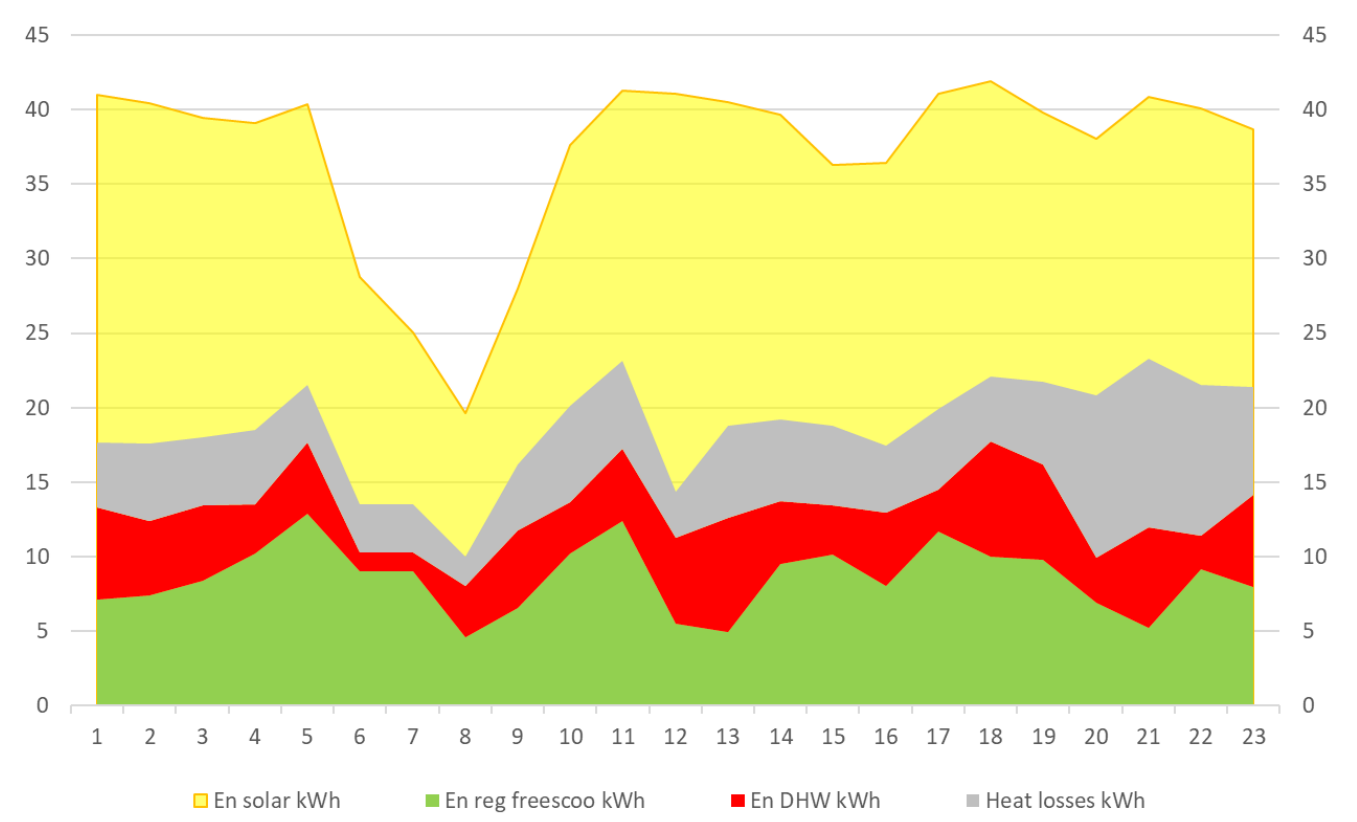

Fig. 9: Temperature and humidity ratio for one day of operation

Delivered hot water temperature at the outlet of the tank ranged from 50 to $60^{\circ} \mathrm{C}$ whereas the entering water temperature was in the range of $24-26^{\circ} \mathrm{C}$. 


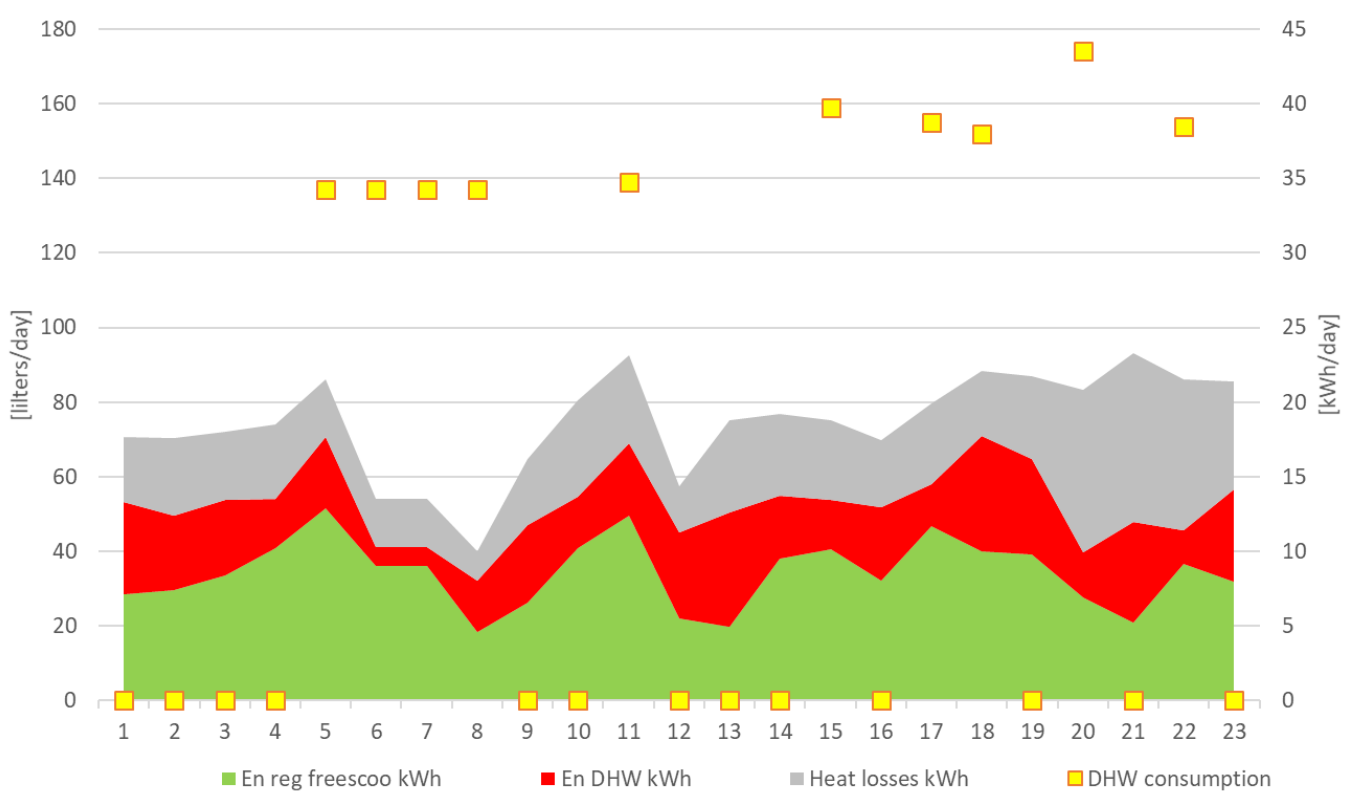

Fig. 10: DHW consumption in liters/day

In Tab.3 global performance results are reported.

Tab. 3: Global performance results for the considered days

\begin{tabular}{|l|l|l|}
\hline Description & Value & Unit \\
\hline Cooling energy - due to air handling & 232 & {$[\mathrm{kWh}]$} \\
\hline Cooling energy - to the building & 188 & {$[\mathrm{kWh}]$} \\
\hline Incident solar radiation & 855 & {$[\mathrm{kWh}]$} \\
\hline Solar collected heat & 429 & {$[\mathrm{kWh}]$} \\
\hline Solar heat used for regeneration of the desiccant & 197 & {$[\mathrm{kWh}]$} \\
\hline Solar heat used for DHW preparation & 105 & {$[\mathrm{kWh}]$} \\
\hline Electricity consumed & 34 & {$[\mathrm{kWh}]$} \\
\hline Total water consumption for cooling & 450 & {$[1]$} \\
\hline Mean daily water consumption & 19.5 & {$[\mathrm{l} / \mathrm{day}]$} \\
\hline Total hours of operation & 230 & {$[\mathrm{~h}]$} \\
\hline Mean daily hours of operation & 10 & {$[\mathrm{~h}]$} \\
\hline Total DHW water consumption & 1480 & {$[1]$} \\
\hline Global electrical COP $($ HVAC + DHW) & 9.8 & {$[-]$} \\
\hline EER (freescoo HVAC) & 6.8 & {$[-]$} \\
\hline COP th (freescoo HVAC) & 0.96 & {$[-]$} \\
\hline Solar collector efficiency & $50.2 \%$ & {$[-]$} \\
\hline
\end{tabular}

\section{Conclusions}

In this work the energy performance of a DEC HVAC working with the freescoo concept and coupled with DHW preparation has been presented. The system has been monitored in summer cycle, showing good results in terms of high energy saving potential with global COP of about 10. However, a lack of cooling performance has been also registered mainly due to the extreme humid ambient conditions of Lampedusa island.

Under these conditions, the adsorption process is not able to efficiently dehumidify the air stream before the air enters the indirect evaporative process, this causing supply temperatures not sufficiently low to meet the sensible loads of the building. 


\section{Acknowledgements}

The mentioned project has been realized with the support of the Italian ENEA Research Institution in the framework of the research project "Ricerca di Sistema Elettrico".

\section{References}

Finocchiaro $\mathrm{P}$, et al. Investigation of adsorption performances of an heat exchanger packed with silica gel for application in solar desiccant cooling systems. Proceedings of OTTI 5th Solar Air-Conditioning Conference, Black Forest: $25-27$ p. $210-215$, Sept 2013

Finocchiaro P, Beccali M, Innovative compact solar air conditioner based on fixed and cooled adsorption beds and wet heat exchangers. Energy Procedia 819:827-48 2014;

Finocchiaro P, et al. Monitoring results and energy performances evaluation of freescoo solar DEC systems. SHC 2015 International Conference on Solar Heating and Cooling for Buildings and Industry Energy Procedia 2015; 


\title{
Modelling of an Absorption Cycle with a Direct Ammonia Vapor Generator Inside a Concentrating Parabolic Trough Solar Collector
}

\author{
Sitki Berat Celik ${ }^{1,2}$, Antonio Lecuona-Neumann1, Pedro A. Rodriguez-Aumente ${ }^{1}$, Antonio \\ Famiglietti ${ }^{1}$ \\ 1 University of Carlos III, Madrid (Spain) \\ 2 Middle East Technical University, Ankara (Turkey)
}

\begin{abstract}
A desorber-separator for an absorption machine using a parabolic through solar collector has been recently suggested (Lecuona-Neumann et al. 2016). It significantly reduces the complexity and cost of an absorption-cycle based Solar Heating and Cooling facility. A complex flow develops inside the receiver tube: a two-phase, gravity driven and gravity stratified opposite direction currents including boiling of a liquid-solid dissolution, actually $\mathrm{NH}_{3}-\mathrm{LiNO}_{3}$. This mixture is both the heat absorbing medium and the working fluid of the absorption cycle. The comprehension of the mutual interactions between cycle and solar direct desorber is necessary in order to unveil the potential of this innovative layout. In the current work, simplified assumptions of the complexity are suggested and implemented in a mathematical model of its integration with a single-effect absorption cycle. The performance of the proposed design has been investigated. Results indicate the importance of the subcooled length and the improvement obtained with lower mass fluxes.
\end{abstract}

Keywords: Absorption, Solar cooling, Parabolic Trough Solar Collector

\section{Introduction}

The most promising sorption cycles from the point of view of sustainability are those converting the solar energy to pump heat, forming part of the so called solar heating and cooling (SHC) technology. Market competiveness seems difficult owing to the nowadays complexity of a purposely designed fully available facility and the variability of the solar energy. It needs storage and/or a backup system for cloudy intervals. With the nowadays technology, a primary circuit of a Heat Transfer Fluid (HTF, typically water or a thermal oil) receives the solar heat and transports it to the storage and/or directly to the absorption machine, implying complexity, cost, bulk and weight. Elimination of any extraneous HTF can be achieved by heating directly the absorption machine working fluid inside the solar collector with the result of a simpler layout. Moreover, the cost of the facility could be amortized faster by supplying solar heat in winter, cold in summer and even producing electricity as a complement when neither cold nor heat are demanded. Moreover, the absorption machine could implement electricity consumption for boosting the solar energy to satisfy the user demand; this way, energy storage could be reduced and even eliminated as well as the backup electrical inverse Rankine cycle machine, such as proposed by (Vereda, et al. 2012; Vereda, et al. 2014).

The refrigerant ammonia is a low impact natural substance. The usage of $\mathrm{NH}_{3}-\mathrm{LiNO}_{3}$ dissolution as the working fluid is a choice of various advantages. It enables eliminating the rectifier in the cycle and thanks to the chemical properties of $\mathrm{NH}_{3}$ subzero ${ }^{\circ} \mathrm{C}$ can be achieved (Wu, et al. 2014). After all, the HTF has been eliminated because the solution directly circulates inside the solar collectors. That avoids an extra heat exchanger, heat transfer fluid, piping, control valves and pumps. According to (Lazzarin and Noro 2018) the energy spent in pumping the HTF could be more than the gain from the whole system. Here, the dissolution pump from the absorption machine can also serve for propelling the working fluid through the solar collector field.

The layout proposed in (Lecuona-Neumann, et al. 2016) uses a set of parabolic trough collectors (PTCs) with an inclination (tilting) towards the Equator. This enables direct refrigerant vapor, in this case $\mathrm{NH}_{3}$, generation and separation inside the collector receiver tubes, although other types of concentrating linear solar collectors can be used, such as Linear Fresnel Collectors (LFCs). Due to the tilted orientation, the generated vapor and the weak solution leave the tube at either ends. Inside the tube, a non-well studied flow is produced. It is a two-phase, both 
driven and stratified by gravity, flowing at low velocities $\sim 1 \mathrm{~m} / \mathrm{s}$ in opposite directions with a boiling liquid dissolution, Fig. 3. The flow might be subcooled or saturated at the inlet, while it is expected to be saturated and boiling downstream. The absorption process can be observed in the subcooled length. (Famiglietti, et al. 2018) simulated the complex physics inside the tube under the steady-state 1D regime and (López, et al. 2017; López, et al. 2018) under 1D transient conditions. In (Lecuona-Neumann, et al. 2016) the heating of the tube was investigated concluding that the heat received by the vapor is negligible in comparison with the heat received by the liquid as a result of the conductivity of the wall and the much higher heat conductance of the liquid flow. Moreover, the heat interchanged at the interphase is also negligible in comparison with the heat received by the descending liquid stream.

Among other issues, in this study, we estimate the undesired length of the subcooled zone in the receiver tube as a result of the thermodynamic cycle functioning and its impact on other performance parameters. The time profile of the production, here only cold production, is highly valuable for its integration with the user demand. For compactness of the paper, here no electric boosting neither electricity production is considered.

Due to high costs and time-consuming nature of experiments, it seems reasonable to start the investigation with a simulation using a physical model of the whole system beforehand, revealing its performance and limitations and propose design parameters. The herewith simulations involve the meteorological data measured in Madrid, Spain, subjected to a Mediterranean continental climate. Four representative clear days have been selected for the four seasons. The characteristic behaviors include $C O P$ and capacity of the design, in addition to the subcooled length.

\section{Theory}

A single effect absorption cycle incorporates two different flows, refrigerant and dissolution (solution from now on), and uses five main heat exchangers, Fig. 1. The absorber and the desorber (vapor generator plus vapor separator) are where the fluids are respectively joining and separating whereas condenser and evaporator are heat exchangers with the refrigerant alone. Beside all, the system is completed with a pump and two expansion valves, for refrigerant and solution which divide the cycle into high and low pressure parts. Due to the fact that adding a solution heat exchanger to the system significantly increases the efficiency, it is highly preferred to do so. A schematic drawing of the machine is demonstrated in Fig. 1.

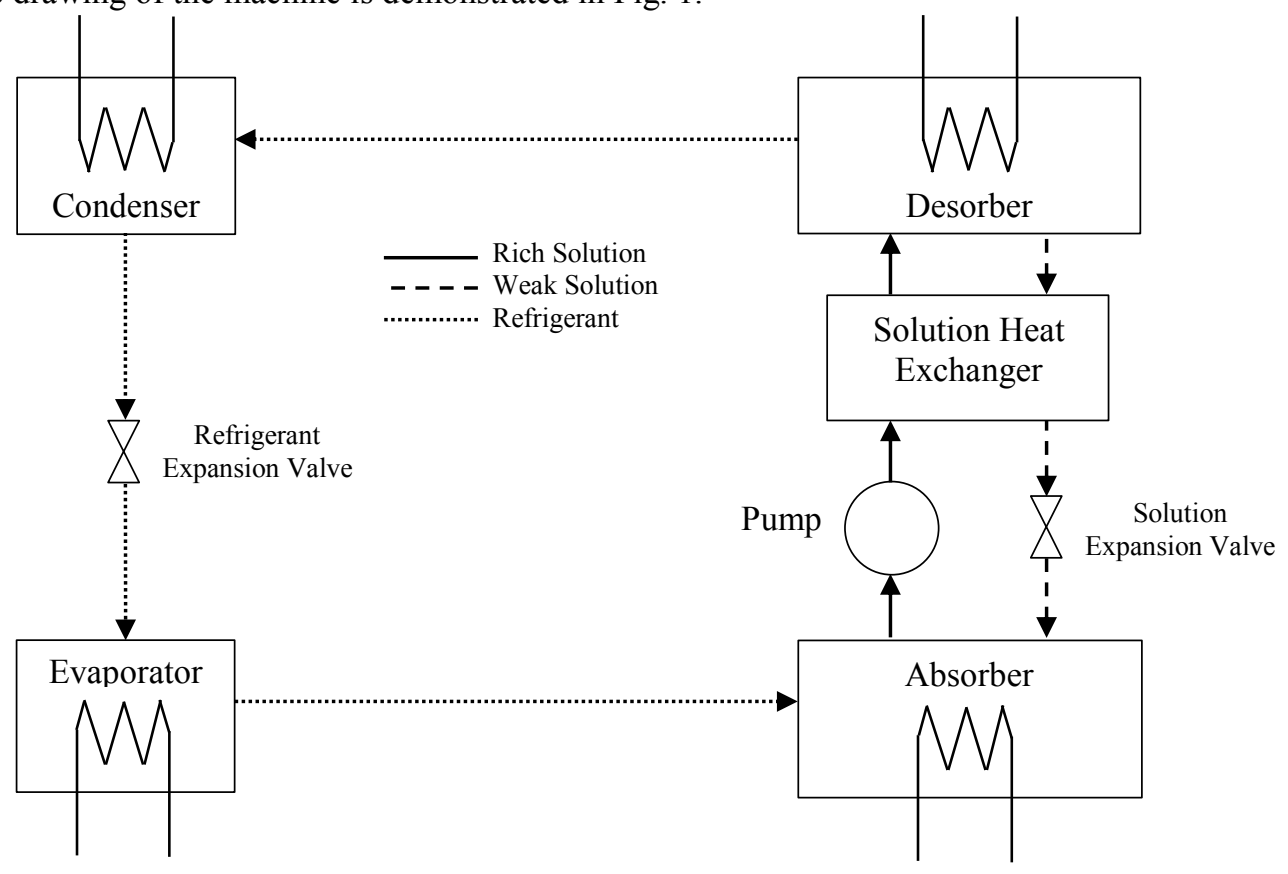

Fig. 1: Single effect absorption cycle

The heat input to the system is through the desorber and the cooling effect is obtained in the evaporator. Heat is rejected from both absorber and condenser. The proposed design replaces the classical desorber and implements a tilted parabolic trough solar collector directly, as shown in Fig. 2. Inside the receiver tube of the parabolic trough 
solar collector, the solution is separated into weak solution and refrigerant with the help of heat input by the sun action. The weak solution is in liquid phase whereas the refrigerant is in gaseous phase. Due to tilted position of the tube the liquid is evacuated from the lower exit, as it flows freely, and lets the upper exit of the tube open so that the gas has only the upper exit to leave the tube.

Inside the tube there is a stratified counter-current flow. The liquid solution is driven by gravity and the refrigerant is driven by the evaporation pressure. The low velocities involved assures an almost flat interphase. The solution at the entrance of the tube could be subcooled or saturated with a null quality or positive owing to the performance of the solution heat exchanger. The solution is expected to be saturated at the exit in regular working conditions owing to the effective heat addition as well as for the large contact area with the vapor, small depth as a consequence of the small liquid angle $\varphi<\pi$, Fig. 4 , and the turbulent regime experienced.

The cycle has two pressure levels: the condenser, solution heat exchanger and the tube of the parabolic trough contain a high pressure flow, the rest contain a lower pressure flow. As a result, the whole tube has a fairly constant pressure along its longitudinal axis equal to the condenser saturation pressure. The parabolic trough mirror is reflecting the solar radiation uniformly along the tube. However, some portion of it can go to the solution and some other by the refrigerant. That portion varies with the position of the sun, although (Lecuona-Neumann, et al., 2016) explain that the heat fraction going to the vapor flow can be neglected in a first approximation. There, the flowing regime is explained as stratified separated flow with an essentially flat interphase, eventually wavy if a large tilting angle is selected. Possible hydraulic jumps at the exit can be neglected for the purposes of this study.

The mass ratio, $Y$, of the solution inside the tube is defined as the ratio of the mass flow rate $\dot{m}$ of the dissolved refrigerant $(r)$ to that of the solution $(s)$, both taken $>0$.

$Y=\frac{\dot{m}_{r}}{\dot{m}_{s}}$

$Y$ is decreasing with the amount of separation of refrigerant from the solution when it is flowing downstream along the longitudinal $z$ axis. As a result, the mass ratio at the inlet of the tube is higher of that at the exit. The temperature of the solution $T_{s}$ is a function of mass ratio $Y$ and pressure $P$ where the former one varies and the latter one is assumed constant along $z$ although a negligible pressure drop is necessary for the vapor upward flow.

$T_{s}=f\langle Y, P\rangle$ or $T_{s} \rightarrow T_{s}\langle z\rangle$

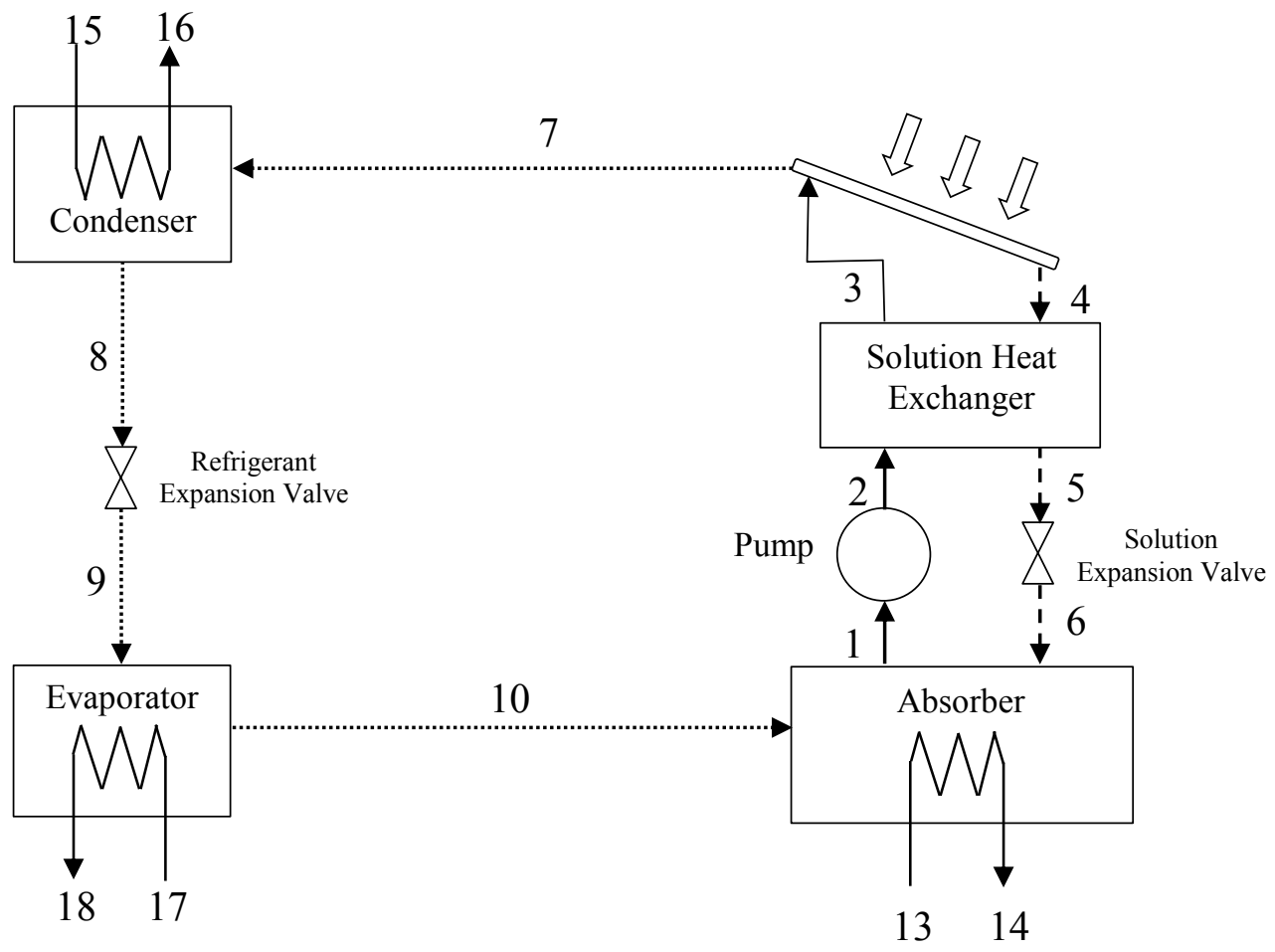

Fig. 2: Proposed design and cycle points nomenclature 


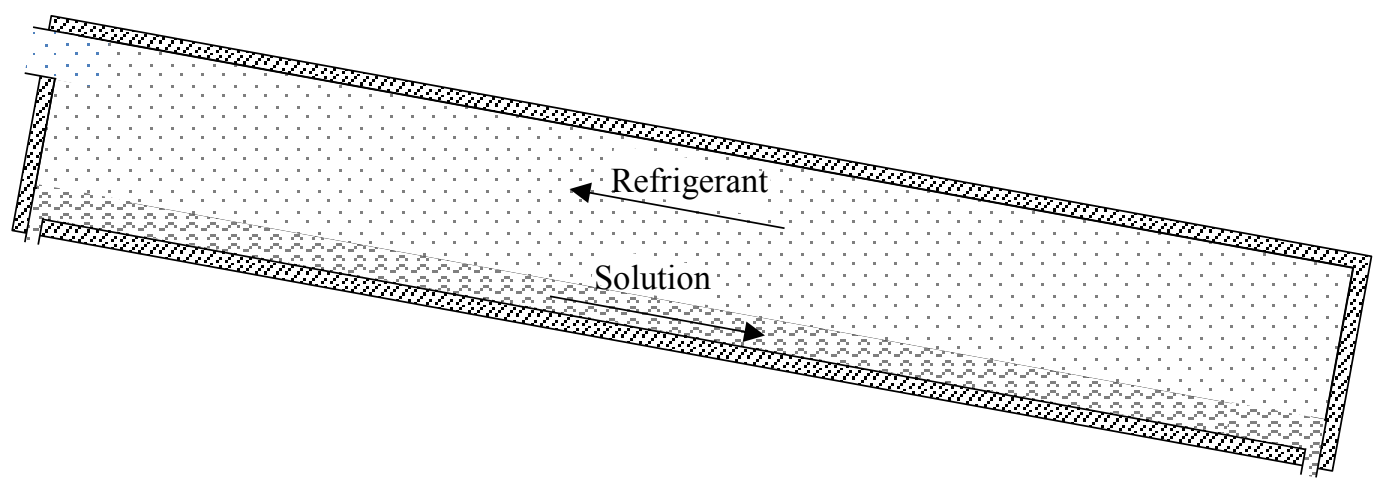

Fig. 3: Fluid flow inside the tube

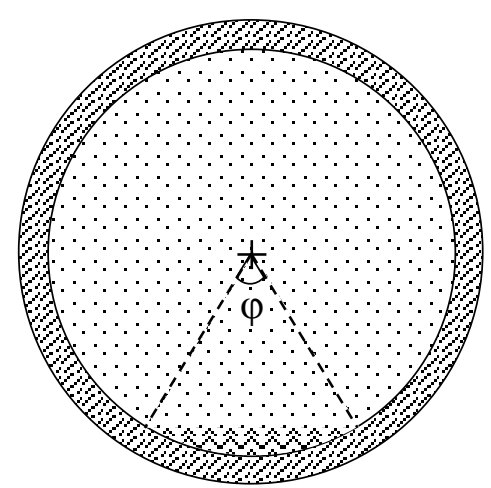

Fig. 4: Cross section of the tube indicating liquid flow angle $\varphi$

The bulk flow velocity of refrigerant vapor at the lower end of the tube is null and is increasing toward the upper part as a result of boiling. Even though the refrigerant is generated along the tube, some portion can be absorbed upon meeting a possible subcooled solution at the upper part. The subcooled liquid flow reaches its saturation condition in a lower part of the tube and leaves the tube boiling. Consequently, in the tube, three critical liquid temperatures can be identified; inlet, onset of saturation and exit temperatures where $T_{\text {in }} \leq T_{\text {sat }}<T_{\text {exit }}$. If the solution is already saturated while entering the tube, inlet and saturation temperature for the highest mass ratio are the same. If absorption occurs when the refrigerant meets the subcooled solution, the mass ratio at the inlet and at the onset of the saturation may differ. In Fig. 5 the flow is visualized and $Y^{-}$represents the mass ratio at the exit, $Y>Y^{-}$. Wavy arrows represent the production of refrigerant.

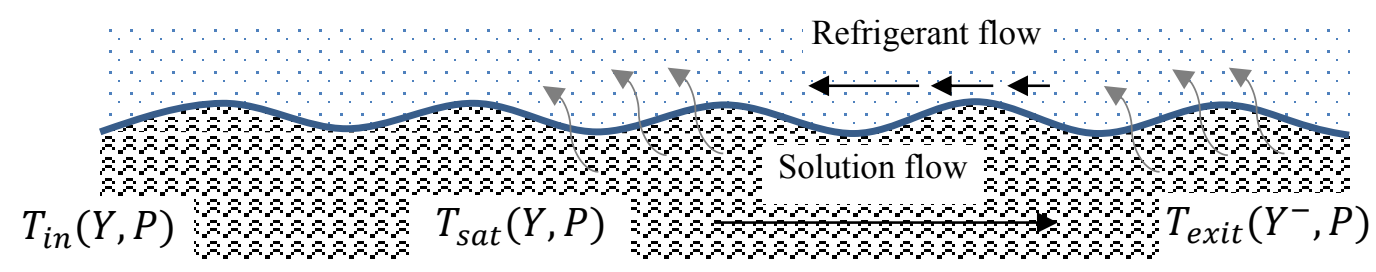

Fig. 5: Critical temperatures for the solution flow

The energy balance of the tube in a $0 \mathrm{D}$ representation with either streams perfectly mixed can be formulated as:

$\dot{H}_{s}^{\text {in }}-\dot{H}_{s}^{\text {exit }}-\dot{H}_{r}^{\text {exit }}+\dot{Q}_{\text {in }}-\dot{Q}_{\text {loss }}=0$ 
There, $s$ and $r$ stand for solution and refrigerant respectively. The energy of flow is calculated by their mass flow rates and enthalpies, $\dot{H}=\dot{m} h$, where $h=h\langle T, Y\rangle$. $Y$ is the refrigerant mass fraction of the solution.

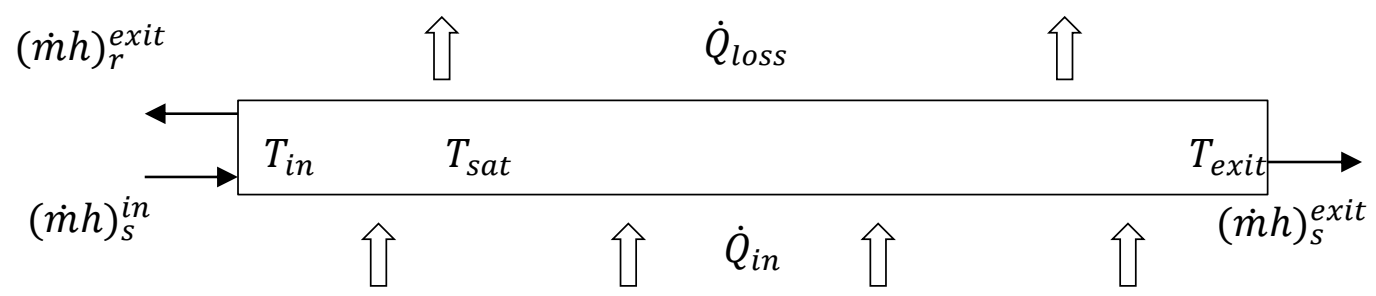

Fig. 6: Heat balance of the tube

Detailed calculation of heat losses is troublesome for such systems due to the complex physics involved. Rather than that, empirical formulas for overall heat transfer coefficients is of common use representing commercial absorber tubes. The overall standardized characteristic equation of the tube estimates the heat losses (ISO, 2017). For a higher accuracy, heat losses are here separated into two distinct zones: Subcooled and saturated. The heat loss formula for a tube of diameter $D$ and length $L$ is:

$\dot{Q}_{\text {loss }}=\pi D L\left[c_{1}\left(T_{\text {ave }}-T_{a}\right)+c_{2}\left(T_{\text {ave }}-T_{a}\right)^{2}+c_{3}\left(T_{\text {ave }}-T_{a}\right) V_{\text {wind }}\right]$

$c_{1}=0.358\left[\mathrm{~W} \mathrm{~m}^{-2} \mathrm{~K}^{-1}\right]$

$c_{2}=0.0019\left[\mathrm{~W} \mathrm{~m}^{-2} \mathrm{~K}^{-2}\right]$

$c_{3}=0.116\left[\mathrm{~J} \mathrm{~m}^{-3} \mathrm{~K}^{-1}\right]$

$T_{a v e}$ is the flow average temperature of the zone of interest. $T_{a}$ is the ambient temperature, $V_{\text {wind }}$ is the wind speed. Due to the two different temperature zones, heat losses are calculated separately for those zones of length $L_{s u b}$ and $L_{\text {sat }}$.

\section{Mass Balance of the Absorption cycle}

The vapor $(r)$ is generated from the rich solution and the remaining is called the weak solution. One has to consider that the amount of salt in the solution does not change. The superscript "_" indicates that the property belongs to the weak solution.

$\Sigma \dot{m}=0$

$\dot{m}_{r}=\dot{m}_{\mathrm{s}}-\dot{m}_{s}^{-}$

$\dot{m}_{r}=x_{3} \dot{m}_{s}+Y\left(1-x_{3}\right) \dot{m}_{s}-Y^{-} \dot{m}_{s}^{-}$

Where $\dot{m}_{r}=x_{3} \dot{m}_{s}+Y\left(1-x_{3}\right) \dot{m}_{s}-Y^{-} \dot{m}_{s}^{-}$(eq. 7) is evaluated at the boundary of the desorber tube. The first term on the right hand side of the equations $Y=\frac{\dot{m}_{r}}{\dot{m}_{s}}$ (eq. 1) is the contribution of gas phase at the inlet, second term is the amount of the refrigerant in the liquid phase at the inlet and the last one is the refrigerant mass in the weak solution leaving the tube. Note that the inlet condition of the tube can be single phase or two-phase. Which, in other words, means that the solution inlet condition can be subcooled $(\mathrm{sub})$ or saturated liquid (sat) with quality.

\section{Energy Balance of the Absorption Cycle}

The first law of thermodynamics is applied to the individual components of a single effect absorption cycle for steady-state conditions.

$\Delta H=Q-W$

The detailed form of the first law is demonstrated in Tab. 1 as a set of governing equations, according to the numbering of Fig. 2 where $L m t d$ is the logarithmic mean temperature difference, $v$ is the specific volume, $U A$ is the thermal conductance and $G_{b t}$ the tilted beam irradiance on the aperture with $W_{a}$. 
Tab. 1: Application of the first law of thermodynamics to individual components

\begin{tabular}{|c|c|}
\hline Component & Equations \\
\hline Absorber & $\begin{array}{l}\dot{m}_{10} h_{10}+\dot{m}_{6} h_{6}-\dot{Q}_{a b s}-\dot{m}_{1} h_{1}=0 \\
\dot{Q}_{a b s}=\dot{m}_{13}\left(h_{14}-h_{13}\right) \\
L m t d_{a b s}=\left[\left(T_{6}-T_{14}\right)-\left(T_{1}-T_{13}\right)\right] / \ln \left[\left(T_{6}-T_{14}\right) /\left(T_{1}-T_{13}\right)\right] \\
\dot{Q}_{a b s}=L m t d_{a b s} U A_{a b s}\end{array}$ \\
\hline Pump & $h_{2}=h_{1}+\frac{W_{\text {pump }}}{\dot{m}_{1}}, W_{\text {pump }}=\dot{m}_{1} v\left(P_{\text {high }}-P_{\text {low }}\right)$ \\
\hline Solution Heat Exchanger & $\begin{array}{l}\dot{Q}_{\text {hex }}=\dot{m}_{1}\left(h_{3}-h_{2}\right)=\dot{m}_{4}\left(h_{4}-h_{5}\right) \\
L m t d_{\text {hex }}=\left[\left(T_{4}-T_{3}\right)-\left(T_{5}-T_{2}\right)\right] / \ln \left[\left(T_{4}-T_{3}\right) /\left(T_{5}-T_{2}\right)\right] \\
\dot{Q}_{\text {hex }}=\operatorname{Lmtd}_{\text {hex }} U A_{\text {hex }}\end{array}$ \\
\hline Solution Expansion Valve & $m_{6} h_{6}=m_{5} h_{5}$ \\
\hline Desorber Tube & $\begin{array}{l}x \dot{m}_{3} h_{3, r}+(1-x) \dot{m}_{3} h_{3, s}-\dot{m}_{4} h_{4}-\dot{m}_{7} h_{7}+\dot{Q}_{\text {in }}-\dot{Q}_{\text {loss }}=0 \\
\dot{Q}_{\text {in }}=G_{b T} W_{a} L_{\text {sub }} \eta_{\text {op }} \\
\dot{Q}_{\text {in }}-Q_{\text {loss }, \text { sub }}=m_{1} c_{p}\left(T_{\text {sat }}-T_{3}\right) \\
\dot{Q}_{\text {loss }}=\dot{Q}_{\text {loss }, \text { sub }}+\dot{Q}_{\text {loss }, \text { sat }} \\
\dot{Q}_{\text {loss }, \text { sub }}=\pi D L_{\text {sub }}\left(c_{1}\left(T_{\text {ave }, \text { sub }}-T_{a}\right)+c_{2}\left(T_{\text {ave }, \text { sub }}-T_{a}\right)^{2}+\right. \\
\left.c_{3}\left(T_{\text {ave }, \text { sub }}-T_{a}\right) V_{\text {wind }}\right) \\
\dot{Q}_{\text {loss }, \text { sat }}=\pi D L_{\text {sat }}\left(c_{1}\left(T_{\text {ave }, \text { sat }}-T_{a}\right)+c_{2}\left(T_{\text {ave }, \text { sat }}-T_{a}\right)^{2}+\right. \\
\left.c_{3}\left(T_{\text {ave }, \text { sat }}-T_{a}\right) V_{\text {wind }}\right) \\
T_{\text {ave }, \text { sub }}=\left(T_{3}+T_{\text {sat }}\right) / 2, T_{\text {ave }, \text { sat }}=\left(T_{\text {sat }}+T_{4}\right) / 2 \\
L=L_{\text {sub }}+L_{\text {sat }}\end{array}$ \\
\hline Condenser & $\begin{array}{l}\dot{Q}_{c o n}=\dot{m}_{7}\left(h_{7}-h_{8}\right)=\dot{m}_{15}\left(h_{16}-h_{15}\right) \\
L m t d_{c o n}=\left[\left(T_{8}-T_{15}\right)-\left(T_{8}-T_{16}\right)\right] / \ln \left[\left(T_{8}-T_{15}\right) /\left(T_{8}-T_{16}\right)\right] \\
\dot{Q}_{c o n}=L m t d_{\text {con }} U A_{c o n}\end{array}$ \\
\hline Refrigeration Expansion Valve & $\dot{m}_{9} h_{9}=\dot{m}_{8} h_{8}$ \\
\hline Evaporator & $\begin{array}{l}\dot{Q}_{e v a}=\dot{m}_{9}\left(h_{10}-h_{9}\right)=\dot{m}_{17}\left(h_{17}-h_{18}\right) \\
L m t d_{e v a}=\left[\left(T_{17}-T_{10}\right)-\left(T_{18}-T_{10}\right)\right] / \ln \left[\left(T_{17}-T_{10}\right) /\left(T_{18}-\right.\right. \\
\left.\left.T_{10}\right)\right] \\
\dot{Q}_{\text {eva }}=\operatorname{Lmtd}_{\text {eva }} U A_{\text {eva }}\end{array}$ \\
\hline
\end{tabular}

Besides the mass and energy balance equations some complementary equations and assumptions are necessary in order to equate the number of equations to the number of variables. The higher pressure is set to the condensation saturation pressure in the condenser and the lower pressure is set to evaporation saturation pressure in the evaporator. Saturation is also assumed at the exit of the desorber. The refrigerant temperature leaving the desorber tube is assumed to be at the local saturation temperature at the solution exit. The flow regime may be two-phase 
depending on the condition at the exit of the expansion valves and at the inlet of the desorber tube (points 6,9 and 3 respectively in Fig. 2). This condition enables the inlet of the desorber tube to incorporate immediately vapor to the exit stream. As a result, subcooled and saturated flows can be observed inside the whole tube at the same moment.

The simulation requires several input data in two categories. The first one relies on assumptions and the second one relies on measured data. The optical efficiency of the parabolic trough collector is taken to be a constant value, $\eta_{o p}=0.765$ which is a typical value for reflectors with high optical quality (Lovegrove and Stein 2012). Beside those, the length $(L=3 \mathrm{~m})$ and aperture area $\left(L W_{a}=3.42 \mathrm{~m}^{2}\right)$ of the single PTC and the diameter of the desorber tube $(D=0.03 \mathrm{~m})$ are measured data from a real experimental setup. The direct solar irradiance on a $40^{\circ}$ tilted, east-west tracking surface and the temperature values are measured data for every 10 minutes on representative days in Madrid, Spain. The solution composes of $\mathrm{NH}_{3}$ and $\mathrm{LiNO}_{3}$ with equal masses which results in a mass ratio of 0.5 . Two test cases have been taken for the mass flow rate of rich solution, 0.01 and $0.02 \mathrm{kgs}^{-1}$.

The solution in the modelling is a mixture of $\mathrm{NH}_{3}$ and $\mathrm{LiNO}_{3}$. The thermodynamic properties of the solution are evaluated from Ferreira (Infante Ferreira, 1984) and the refrigerant $\left(\mathrm{NH}_{3}\right)$ ones are from Tillner-Roth (TillnerRoth, et al., 1993). The set of governing equations is non-linear so that an iterative method is used for its resolution. The mathematical tool that is used to solve those equations iteratively at once is called Engineering Equation Solver, EES (F-Chart Software, 2018).

\section{Results}

In this paper, the simulation runs are oriented to calculate the quasi-steady time evolution of the machine cooling COP $=\dot{Q}_{e} / \dot{Q}_{i n}$, the cooling power $\dot{Q}_{e}$ and the length of the subcooled zone in the desorber tube $L_{\text {sub }}$. The cycle is cooling down a water stream of $4{ }^{\circ} \mathrm{C}$ inlet constant temperature with a flow rate of $0.6 \mathrm{~kg} \mathrm{~s}^{-1}$. The representative days are clear days with an average of $1 \mathrm{~m} / \mathrm{s}$ wind speed. The characteristic values are summarized in Tab. 2 . Sunrise and sunset times are the local times. The irradiance is measured for a E-W tracking with $40^{\circ}$ constant inclined surface. The irradiation values are plotted in Fig. 7 which the x-axis demonstrates the hour of the day.

Tab. 2: Properties of representative days

\begin{tabular}{llllcllll}
\hline & Sunrise & Sunset & \multicolumn{2}{c}{ Temperature, ${ }^{\circ} \mathrm{C}$} & \multicolumn{2}{c}{ Irradiance, $\mathrm{kWm}^{-2}$} & \multicolumn{2}{c}{${\text { Insolation, } \mathrm{kWh}^{-2}}^{2}$} \\
& & & & Min. & Max. & Min. & Max. & Ave. \\
& & & & & & & & \\
\hline January & $8: 50$ & $17: 50$ & 5 & 10 & 0.10 & 0.87 & 0.69 & 6.09 \\
April & $8: 20$ & $20: 30$ & 11 & 18 & 0.10 & 1.00 & 0.84 & 10.09 \\
July & $7: 40$ & $21: 30$ & 22 & 32 & 0.10 & 0.89 & 0.74 & 10.13 \\
October & $9: 10$ & $19: 10$ & 14 & 20 & 0.10 & 0.97 & 0.81 & 7.90 \\
\hline
\end{tabular}




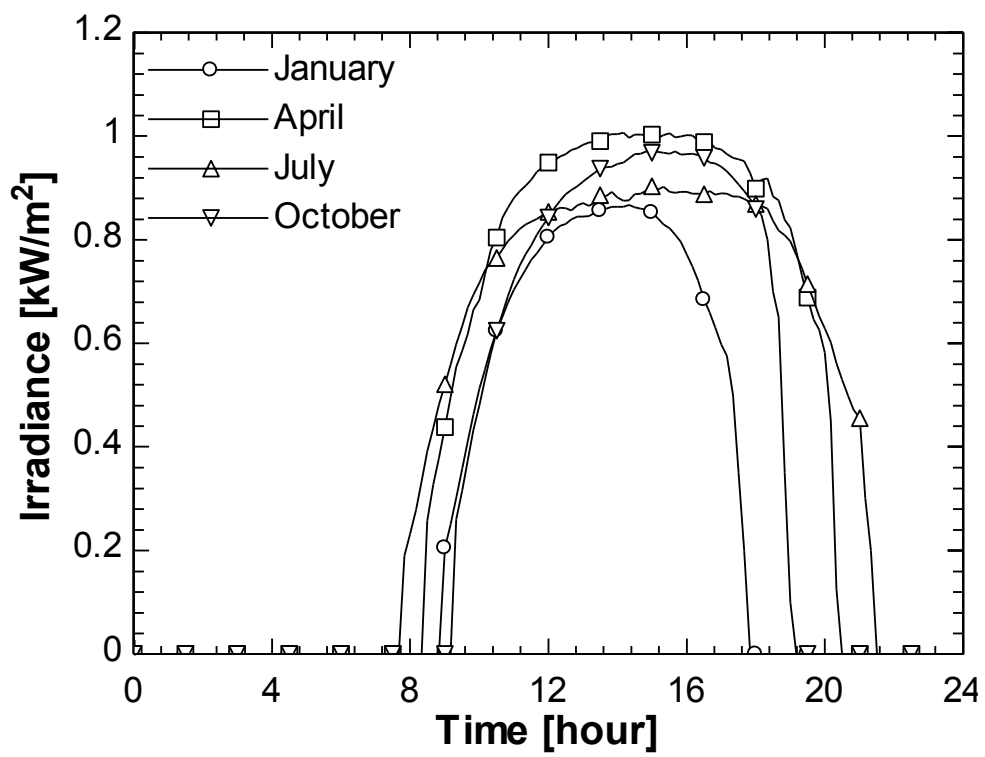

Fig. 7: Daily solar power of the representative days

There are four different days representing four different months with two different mass flowrate conditions through the pump of the cycle. Fig. 8 and Fig. 9 show the COP and cooling power $\dot{Q}_{e}$ of the cycle for each 10 minutes of the days. The time axes of the plots span between sunrise and sunset which are represented by 0 and 1 respectively. Similarly, 0.5 stands for the solar noon. The plots show that the highest efficiencies are observed in January whereas the highest cooling power is in April. The average COPs and cooling power as well as total cooling energy are summarized in Tab. 3. The average values are calculated from the sunrise to the sunset.
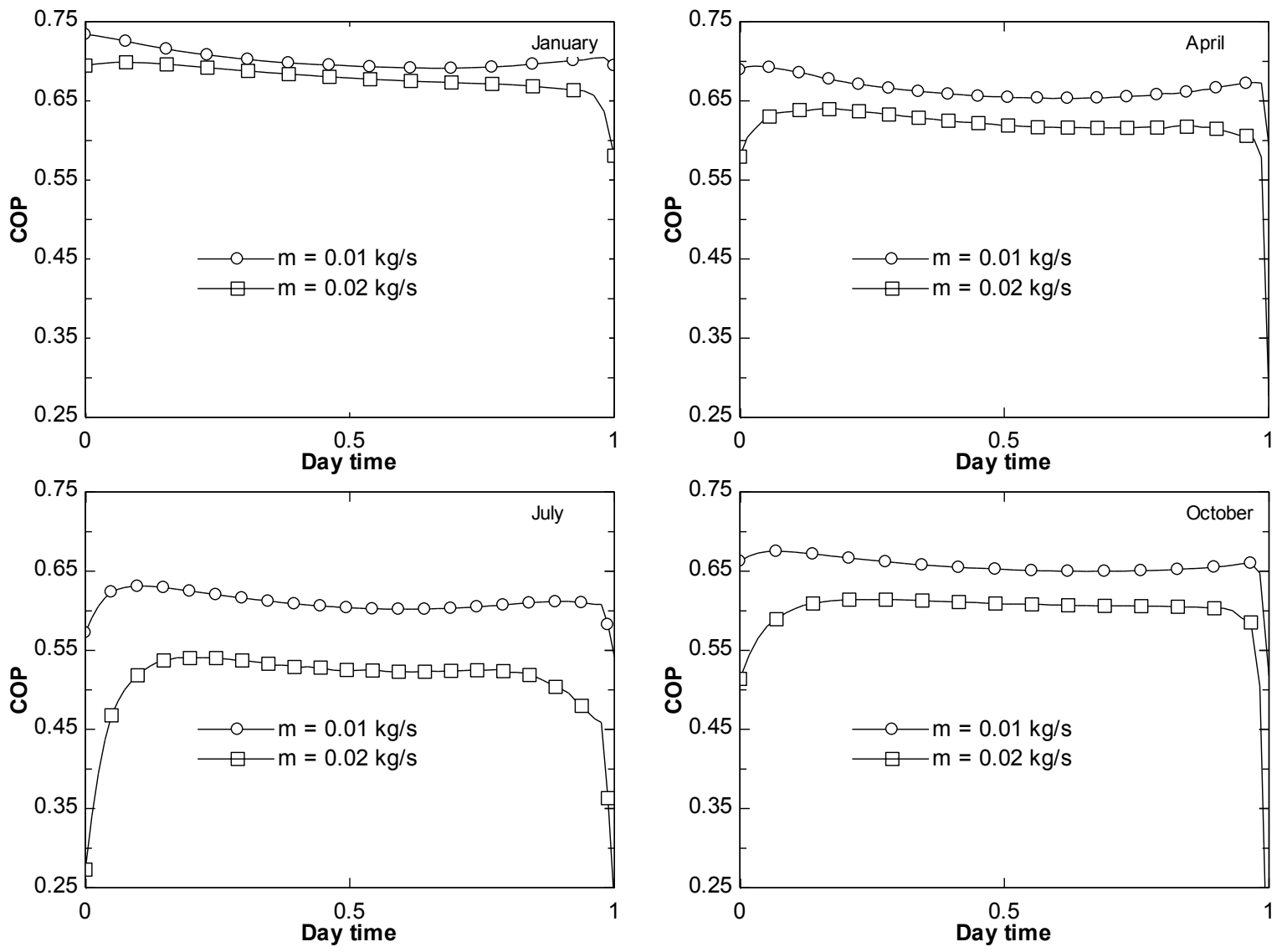

Fig. 8: Time evolution of refrigeration $C O P$ along the representative days of each month 

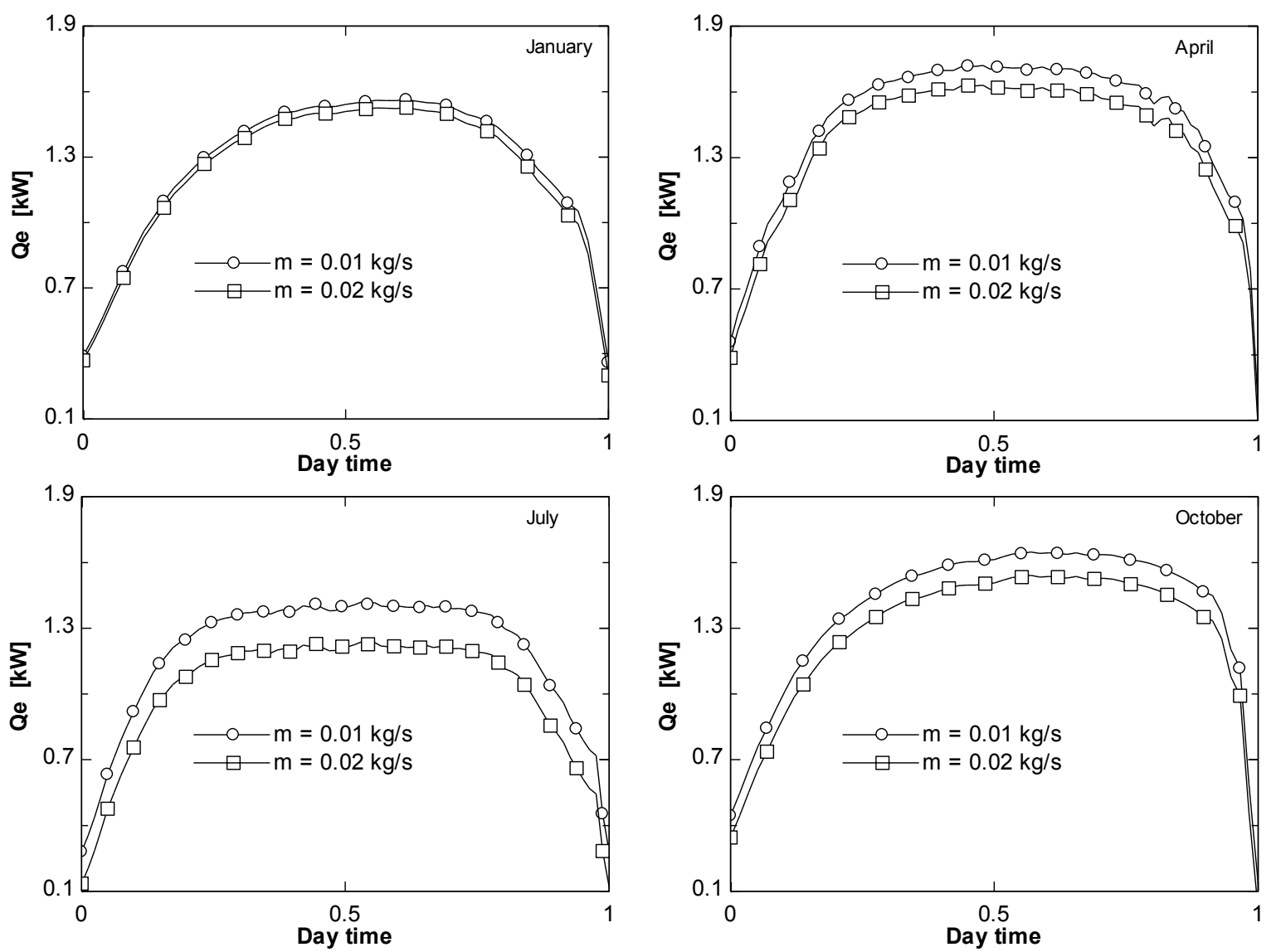

Fig. 9: Time evolution of cooling power $\dot{Q}_{e}$ along the representative days of each month

Tab. 3: Summary of results

\begin{tabular}{lccccc}
\hline & $\dot{\boldsymbol{m}}\left[\mathrm{kgs}^{-1}\right]$ & January & April & July & October \\
\cline { 3 - 6 } Ave. $\boldsymbol{C O P}$ & 0.01 & 0.702 & 0.665 & 0.610 & 0.658 \\
& 0.02 & 0.678 & 0.617 & 0.508 & 0.595 \\
\hline Ave. cooling & 0.01 & 1.263 & 1.457 & 1.182 & 1.424 \\
power [kW] & 0.02 & 1.226 & 1.366 & 1.007 & 1.239 \\
\hline Total cooling & 0.01 & 11.16 & 17.48 & 16.15 & 12.89 \\
energy [kWh ] & 0.02 & 10.78 & 16.36 & 13.74 & 13.11 \\
\hline
\end{tabular}

The solar integrated cycle reveals that it yields a higher $C O P$ and cooling power with the lower mass flow rate of the two ones considered. On the other hand, in terms of $C O P$, the cycle performs better in January than the rest of the months. The reason is that the ambient temperature is relatively lower and hence the high pressure of the cycle is moderated by the lower ambient temperatures. That makes the separation of the refrigerant easier. Also it is worth mentioning that the representative day in January (and each of the others too) is a clear day. Besides performing the highest $C O P$, it has a good average daily cooling power of more than $1.2 \mathrm{~kW}$ for $A_{a}=3.42 \mathrm{~m}^{2}$ PTC. The total heat extracted from the cooling water stream in a whole day has the lowest value despite the high $C O P$ and cooling power due to the fact that the day time is lower than the rest of the months studied here. The total cooling energy is calculated by integrating data in Fig. 9 along time. The day in April yields also high $C O P \mathrm{~s}$ compared to the other months and yields the highest cooling power and total energy values. The reason is that the ambient temperatures are still not at the highest levels as in July and the incidence angle to the PTC has the minimum value during this month. The solar panel is east-west tracking but has constant tilt angle of 40 degrees 
and located in Madrid at a latitude of 40.333 degrees. The cycle performs the worst values in the July day when the ambient temperatures are the highest and the incidence angle is already high even though there is the highest incoming insolation. The total energy value is fairly good enough thanks to the longer day time in the northern hemisphere. Lastly, the cycle seems to produce fairly good results in October too.

The length where the solution is subcooled, $L_{s u b}$, is plotted in Fig. 10. With a higher mass flow rate $\dot{m}$, it is more likely to have a subcooled zone in the tube. Also, near sunrises and sunsets where irradiance is minimum, the length of the subcooled zone is performing its maximum. In January, due to low internal pressure values, the solution inlet is almost always saturated. In April and October for a mass flow rate of $0.02 \mathrm{~kg} \mathrm{~s}^{-1}$, the subcooled length $L_{\text {sub }}$ is observed to have nonzero values at low irradiance period, yet for the lower mass flow rate it is zero all the time of the days. In July, the subcooled length is calculated to be zero for both flow rates, yet only for the higher flow rate the length is around $0.25 \mathrm{~m}$ except near sunrise and the sunset. All in all, apart from sunrise and sunset times, the subcooled length is usually very short. In other words, the solution reaches saturation temperature immediately after entering the desorber tube.
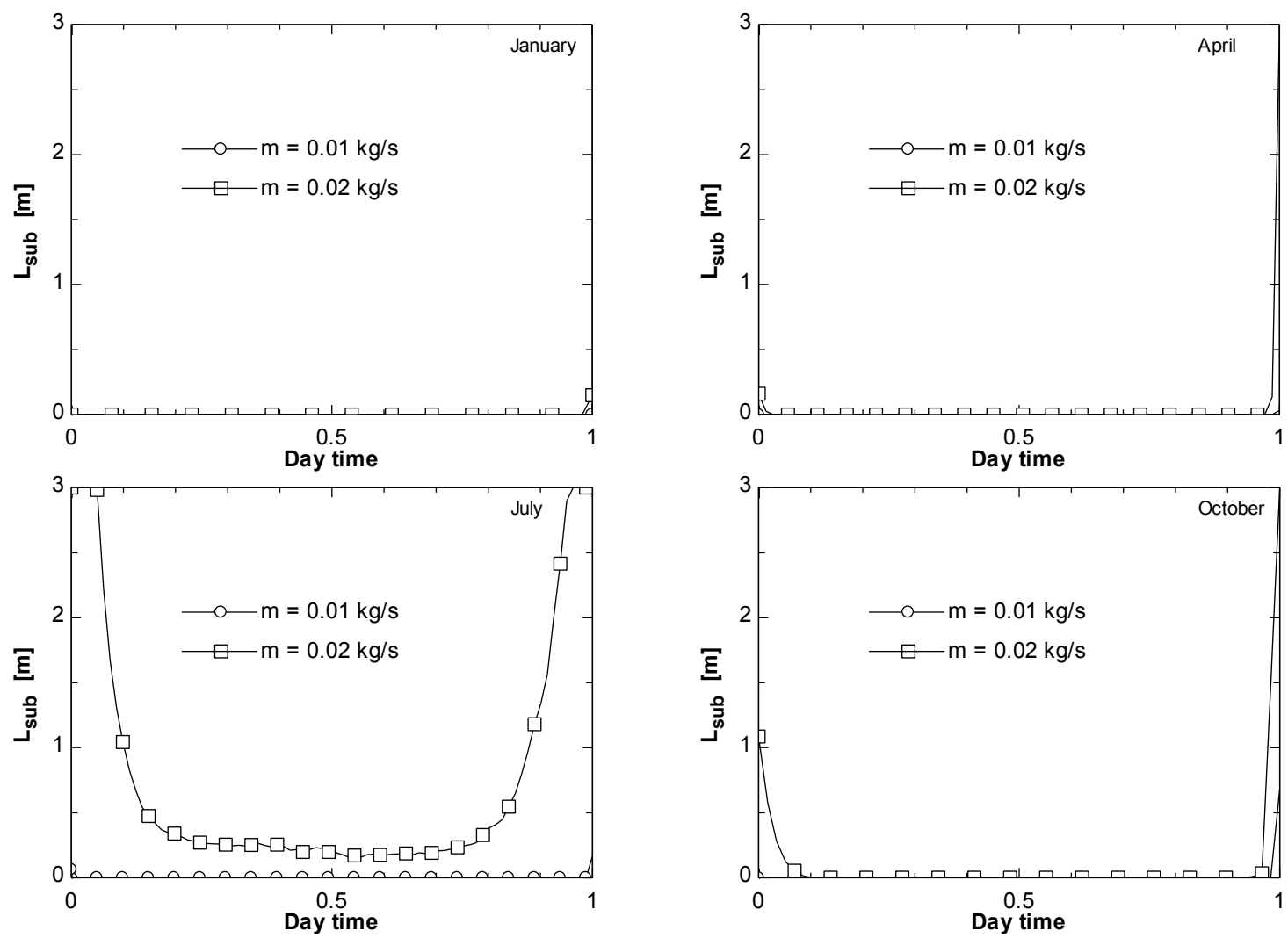

Fig. 10: Time evolution of subcooled zone length $L_{s u b}$ along the representative days of each month

\section{Conclusions}

A single-effect absorption cycle has been integrated with a parabolic trough collector drawing inside it the inner working solution of the absorption machine. That mainly enabled to avoid the HTF and an extra heat exchanger. Also using the solution pair $\mathrm{NH}_{3} / \mathrm{LiNO}_{3}$, the solution rectifier that is necessary for the $\mathrm{NH}_{3} / \mathrm{H}_{2} \mathrm{O}$ pair is avoided too. All of those result in an absorption machine with a smaller footprint, lower in price and simpler in design. Besides, that it is placed outdoors makes it safer to use and benefits of not occupying space inside the buildings. The thermodynamic simulation of the absorption machine integrated with the solar collector is performed in order to anticipate the behavior of the proposed design. The simulations are done along four representative days of the four seasons in Madrid, Spain. The PTC is set to be east-west tracking with a constant tilt angle, year-round optimum in this location. The properties of the PTC are taken from a real one and the irradiance and temperature values are measured in Madrid, Spain for clear days. The cycle is set to cool down $4{ }^{\circ} \mathrm{C}$ inlet water stream with a 
$0.6 \mathrm{~kg} \mathrm{~s}^{-1}$ mass flow rate. The results reveal the cooling $C O P$ and cooling power of the absorption machine along the day. A maximum of $0.42 \mathrm{~kW} \mathrm{~m}^{-2}$ of average cooling power has been reached. Also the subcooled length of the desorber tube has been calculated which has a vital role in the performance of the proposed solar integrated cycle. Results show that this length is small for the application data, thus supporting the viability of the technology proposed.

\section{Acknowledgements}

This work has been partially supported by The Scientific and Technological Research Council of Turkey with the program number 2214/A. The funding of the research project "Tecnologias energéticas térmico-solares y de aprovechamiento de calores residuales a baja y media temperatura integradas en la red eléctrica", ENE201345015-R from the Spanish Ministerio de Economía y Competitividad is greatly appreciated.

\section{References}

Famiglietti, Antonio, Lecuona-Neumann.Antonio, J. I. Nogueira, and Sitki Breat Celik. "Direct ammonia vapor generation inside a concentrating parabolic trough solar collector for an ammonia/lithium nitrate absorption machine. Theoretical study." Valencia, 2018.

F-Chart Software. 2018. http://www.fchart.com/ees/ (accessed May 21, 2018).

Infante Ferreira, C. A. "Thermodynamic and physical property data equations for ammonia-lithium nitrate and ammonia-sodium thiocyanate solutions." Solar Energy 32, no. 2 (1984): 231-236. https://doi.org/10.1016/S0038-092X(84)80040-7

ISO. International Standards Office, Solar thermal collectors -- Test methods. Geneva Patent ISO 9806:2017(en) Solar energy. 2017.

Lazzarin, R., and M. Noro. "Past, present, future of solar cooling: Technical and economical considerations." Solar Energy, 2018. https://doi.org/10.1016/j.solener.2017.12.055

Lecuona-Neumann, A., M. Rosner, and R. Ventas-Garzón. "Transversal temperature profiles of two-phase stratified flow in the receiver tube of a solar linear concentrator. Simplified analysis." ISES. Palma de Mallorca, 2016. DOI:10.18086/eurosun.2016.04.17.

Lecuona-Neumann, A., R. Ventas-Garzón, Vereda-Ortiz, and M. Legrand. "Linear tube solar receiver as stratified flow vapor generator/separator for absorption machines using NH3/LiNO3." ISES. Palma de Mallorca, 2016. DOI: 10.18086/eurosun.2016.04.11

López, R., A. Lecuona, J. Nogueira, and C. Vereda. "Numerical solution of one-dimensional transient, twophase flows with temporal fully implicit high order schemes: Subcooled boiling in pipes." Nuclear Engineering and Design, 2017: 319-329. https://doi.org/10.1016/j.nucengdes.2016.12.027.

López, R., A. Lecuona-Neumann, R. Ventas, and J. Nogueira. "1-D transient numerical modeling of countercurrent two-phase stratified flow inside a medium temperature solar linear collector." Energy Conversion and Management, 2018: 218-229. https://doi.org/10.1016/j.enconman.2017.10.066

Lovegrove, K., and W. Stein. Concentrating Solar Power Technology: Principles, Developments and Applications. 1st Edition. Woodhead Publishing, 2012. ISBN: 9780857096173

Machiels, Olivier, S. Erpicum, B. J. Dewals, P. Archambeau, and M. Pirotton. "Continuous formulation for bottom friction in free surface flows modelling." WIT Transactions on Ecology and the Environment 124 (2009): 81-92. doi: 10.2495/RM090081

Tillner-Roth, R, F Harms-Watzenberg, and H D Baehr. "Eine neue Fundamentalgleichung fur Ammoniak." DKV-Tagungsbericht 20 (1993): 167-181. ISSN: 0172-8849.

Vereda, C., R. Ventas, A. Lecuona, and M. Venegas. "Study of an ejector-absorption refrigeration cycle with an adaptable ejector nozzle for different working conditions." Applied Energy, 2012: 305-312. https://doi.org/10.1016/j.apenergy.2011.12.070.

Vereda, C., R. Ventas, A. Lecuona, and R. López. "Single-effect absorption refrigeration cycle boosted with an ejector-adiabatic absorber using a single solution pump." International Journal of Refrigeration, 2014 : 22-29. https://doi.org/10.1016/j.ijrefrig.2013.10.010.

Wu, W., B. Wang, W. Shi, and X. Li. "Absorption heating technologies: A review and perspective." Applied Energy, 2014: 51-71. https://doi.org/10.1016/j.apenergy.2014.05.027. 


\title{
Modelling and Simulation of a PV-Driven Refrigerator with Phase Change Materials in the Internal Walls
}

\author{
Adriana Coca-Ortegón', Victor Torres-Toledo², Joachim Müller², Alberto Coronas' \\ 1 Universitat Rovira i Virgili, Department of Mechanical Engineering, Tarragona (Spain) \\ 2 Universität Hohenheim, Agricultural Engineering Institute, Stuttgart (Germany)
}

\begin{abstract}
Refrigeration systems driven by photovoltaic energy are a useful solution for those regions of developing countries in which there is no electrical supply, or this supply is unreliable. These systems usually store energy through use of electrical lead-acid batteries. However, other energy storage options, with lower environmental effects, such us thermal energy storage, can be applied.

This study presents a model and simulation of a horizontal direct-current, compression refrigerator, which is driven by a photovoltaic sub-system. The system has latent thermal energy storage, through the incorporation of a slab with phase-change materials, next to the evaporator-wall, inside the refrigerator.

System performance was analysed with a product temperature of $11^{\circ} \mathrm{C}$, and includes three materials. One was water, and the others were phase-change materials, with average melting temperatures of $5^{\circ} \mathrm{C}$ and $9^{\circ} \mathrm{C}$, respectively. Results indicate that the lead-acid battery capacity in such a PV-driven refrigerator can be reduced between $16 \%$ and $78 \%$, in accordance with system operating conditions and the phase change material selected for the studied application.
\end{abstract}

Keywords: PV-refrigerator, thermal energy storage, phase change materials.

\section{Introduction}

Compression refrigeration systems driven by Photovoltaic (PV) energy are a useful alternative for those regions of developing countries in which there is no electrical supply, or there are frequent electrical outages (Pedersen and Katic, 2016). This type of systems usually store energy through electric lead-acid batteries. However, alternative energy storage options, with lower environmental effects, can also be applied. These options include Thermal Energy Storage (TES), based on Phase Change Materials (PCMs).

Main environmental effects of electrical batteries are related to the toxicity of the substances they content, like lead and sulphuric acid, which can be harmful to water, land and human health, and imply high costs of handling and recycling processes (Schaddelee-Scholten and Tempowski, 2017; Sørensen, 2015). On the other hand, thermal energy storage based on PCMs, for cold applications, use materials such as hydrated salts and paraffin (Oró et al., 2012), without any toxic substances and lower environmental effects.

PCM integration in refrigerators has been analysed in several studies throughout the past decade (Azzouz et al., 2009; Cheng et al., 2017; Marques et al., 2014). Generally, PCMs have been installed in contact with the evaporator surface or with the condenser. The most relevant effects pointed out in these studies are: 1) An increase in compressor cycle time, 2) higher product temperature stability, and 3) A decrease in electrical consumption for single speed compressors, owing to lower compressor starts during global system operation.

Despite these reported studies, there are still few focused on PCM integration into PV-refrigerators. In order to fulfil this gap, this study presents a model and simulation of a horizontal PV-refrigerator, which includes latent thermal storage, by incorporating a TES slab, in contact to the evaporator wall. A case was analysed, in which the product temperature was $11^{\circ} \mathrm{C}$, and the simulation included three different materials, one was water, and the other two were PCMs, with average melting temperatures of $5^{\circ} \mathrm{C}$ and $9^{\circ} \mathrm{C}$, respectively.

The objective of this study is to select the most suitable PCM for the required product temperature, and analyse its main effects on system performance, in order to improve PV sub-system integration. Specifically, a parametric study was performed, in order to evaluate the influence of TES slab thickness, insulation thickness, and compressor velocity on system performance. The revised output variables included product temperature, TES temperature, PV field size, and battery size. 


\begin{tabular}{|c|c|c|c|}
\hline \multicolumn{4}{|c|}{ Nomenclature } \\
\hline$h$ & Specific enthalpy $\left[\mathrm{kJ} \mathrm{kg}^{-1}\right]$ & \multicolumn{2}{|c|}{ Subscripts } \\
\hline$q$ & Heat flow rate $[\mathrm{W}]$ & air & Air \\
\hline$T$ & Temperature $[\mathrm{K}]$ & com & Compressor \\
\hline$W$ & Electrical power $[\mathrm{W}]$ & Int & Internal equipment \\
\hline$V$ & Voltage [V] & $\operatorname{Inf}$ & Infiltration \\
\hline$I$ & Current $[\mathrm{A}]$ & $\operatorname{los}$ & Losses \\
\hline$R$ & Resistance [Ohm] & $P C M$ & Phase change material \\
\hline$x$ & Space dimension $[\mathrm{m}]$ & TES & Thermal energy storage \\
\hline$t$ & Time $[\mathrm{s}]$ & $p r$ & Product \\
\hline$k$ & Thermal conductivity $\left[\mathrm{W} \mathrm{m}^{-1} \mathrm{~K}^{-1}\right]$ & $\mathrm{D}$ & Diode \\
\hline$p$ & Density $\left[\mathrm{kg} / \mathrm{m}^{3}\right]$ & $S$ & Series \\
\hline$a$ & Parameter "a" of photovoltaic model [-] & $P$ & Parallel \\
\hline C & Coefficient polynomial compressor curves & $h$ & Horizontal \\
\hline COP & Coefficient of Operation $[-]$ & $v$ & Vertical \\
\hline
\end{tabular}

\section{System description and experimental setup}

The analysed system (Fig. 1) consists of a horizontal direct current refrigerator, driven by electricity produced by a photovoltaic (PV) sub-system. The refrigeration cell has an upper door with a useful area of $0.59 \mathrm{~m}^{2}$, and a volume capacity of 350L. The refrigeration sub-system is equipped with a direct current compressor (Danfoss, Secop, 35BD), an evaporator wall, and a natural air-cooled condenser. This sub-system uses a simple vapour compression refrigeration cycle with refrigerant R134a.

Electricity required by the refrigeration subsystem is produced in a PV sub-system, with multi-crystalline silicon modules (Peak power of 100W). In this sub-system, the energy is stored in electric lead acid batteries, and the charger controller permits to take the electricity from battery or directly from PV modules according to the system conditions.

The TES slab was located in contact with the evaporator wall, covering all internal walls of refrigeration cell. When the compressor starts (ON), the TES slab and the stored product start to be cooled. Once the product reaches the required set temperature, the compressor stops (OFF). In this way, during the compressor ON time, the TES slab is charged and stores cold thermal energy (sensible and latent). After this, during the compressor OFF time, the TES slab is discharged and contributes to remove heat from the stored product.

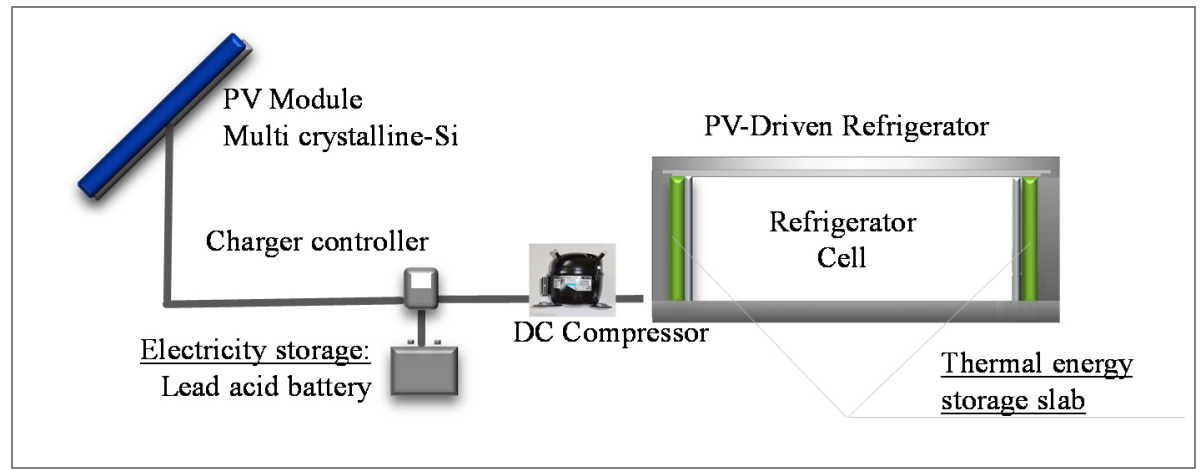

Fig. 1: System scheme

The system was modelled and simulated with three materials, with different average melting temperatures $\left(0^{\circ} \mathrm{C}, 5^{\circ} \mathrm{C}\right.$ and $\left.9^{\circ} \mathrm{C}\right)$. In order to validate the model, the refrigeration cell was tested at the laboratory in a climatic room for 2 scenarios: 1) Refrigerator without TES and 2) Refrigerator with TES. The material used for TES during the test was RT5HC, manufactured by Rubitherm with average melting temperature of $5^{\circ} \mathrm{C}$

Fig. 2 shows the main elements included in the experimental setup: the direct current refrigerator (a); the climatic room, in which the temperature and humidity were controlled by an air conditioning system (b); steel sheets with encapsulated PCM, to install in contact to evaporator-wall of the refrigerator (c), a standard electrical panel, used for supplying AC electricity (d), a regulated direct current source which converts AC to $\mathrm{CC}$ and provides electricity at $12 \mathrm{~V}$ to the compressor (e), a data acquisition system (f), a hall sensor for measuring the CC current and complementary elements $(\mathrm{g})$. The measurements were carried out according to the European Norm EN 62552 (IEC, 2013). More details in relation to the experimental setup were reported in a previous study (Coca-Ortegón et al., 2017). 


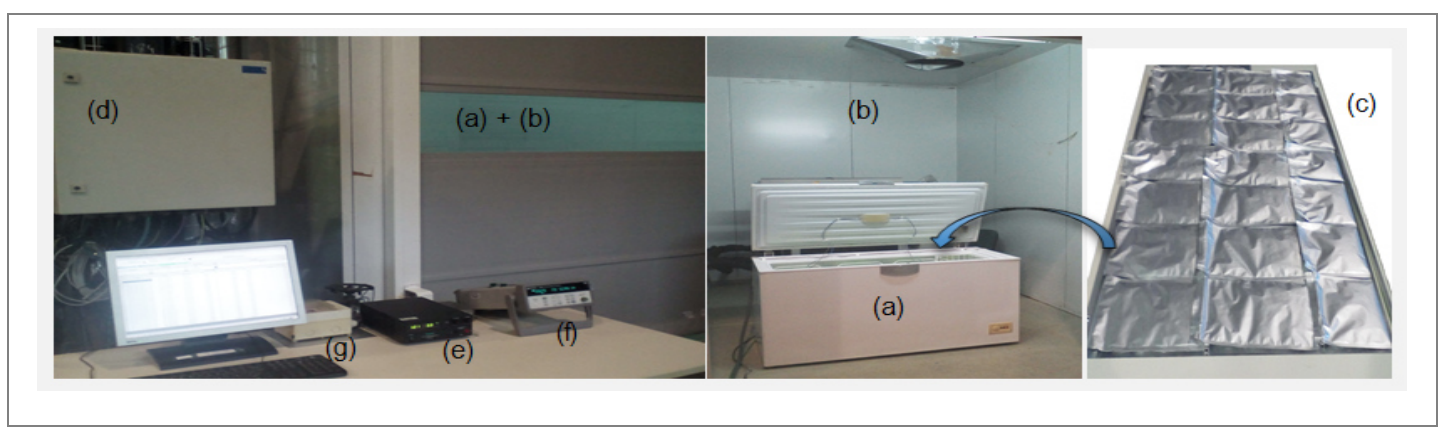

Fig. 2: Main elements of the experimental setup: (a) Refrigerator, (b) Climatic Room, (c) Encapsulated PCM in steel sheets, (d) AC Electrical panel, (e) DC source, (f). Data acquisition system, (g) Current sensors

\section{Modelling and simulation}

The general model was implemented in Matlab, and as a complementary tool was used the dynamic simulation software TRNSYS, in order to simulate the PV sub-system. The model includes four main blocks: the refrigerated cell or cabin (a), the energy thermal storage (TES) (b), the refrigeration sub-system (c), and the photovoltaic sub-system (d), with electrical storage using lead-acid batteries (See Fig.3).

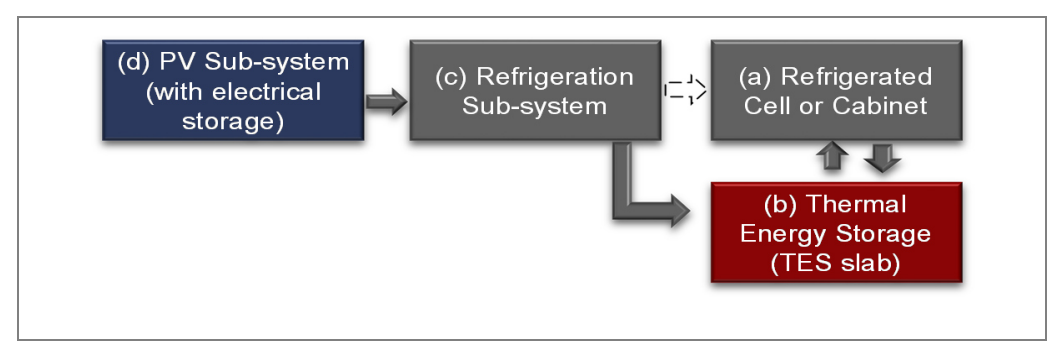

Fig. 3: Main blocks of developed model

The simulation was carried out for three different materials in the TES slab; Table 2 presents the main characteristics of them. The first material is distilled water; which was included in the study due to the low cost and the high sensible thermal storage capacity. The second and third materials are PCMs, which can store sensible and latent thermal energy. These PCMs are organic materials (paraffin's), manufactured by Rubitherm (references RT-5HC and RT-9). The main advantage of paraffin's is that they do not need to be sub-cooled for getting the crystallization, as occurs with water and hydrated salts.

Tab. 1: Main characteristics of phase change materials used in the simulation

\begin{tabular}{|c|c|c|c|c|}
\hline Material & Units & $\begin{array}{l}\text { Distilled } \\
\text { Water }\end{array}$ & $\begin{array}{c}\text { Rubitherm } \\
\text { RT5HC }\end{array}$ & $\begin{array}{c}\text { Rubitherm } \\
\text { RT9 }\end{array}$ \\
\hline Class & - & Inorganic & Organic & Organic \\
\hline Subclass & - & - & Paraffin & Paraffin \\
\hline Phase change temperature & {$\left[{ }^{\circ} \mathrm{C}\right]$} & 0 & 4 to 6 & 7 to 11 \\
\hline Heat storage capacity & {$[\mathrm{kJ} / \mathrm{kg}]$} & 334 & 250 & 175 \\
\hline Specific heat capacity (solid) & {$\left[\mathrm{kJ} \mathrm{kg}^{-1} \mathrm{~K}^{-1}\right]$} & 2.09 & 2.0 & 2.0 \\
\hline Specific heat capacity (liquid) & {$\left[\mathrm{kJ} \mathrm{kg}^{-1} \mathrm{~K}^{-1}\right]$} & 4.18 & 2.0 & 2.0 \\
\hline Density (solid) ${ }^{1}$ & {$\left[\mathrm{~kg} \mathrm{~m}^{-3}\right]$} & 900 & 880 & 880 \\
\hline Density (liquid) ${ }^{2}$ & {$\left[\mathrm{~kg} \mathrm{~m}^{-3}\right]$} & 1000 & 760 & 760 \\
\hline Thermal conductivity (solid) & 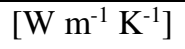 & 1.8 & 0.2 & 0.2 \\
\hline Thermal conductivity (liquid) & {$\left[\mathrm{W} \mathrm{m} \mathrm{m}^{-1} \mathrm{~K}^{-1}\right]$} & 0.4 & 0.2 & 0.2 \\
\hline
\end{tabular}

${ }^{1}$ Value at $-15^{\circ} \mathrm{C} .{ }^{2}$ Value at $20^{\circ} \mathrm{C}$

\subsection{Heat transfer in the PCM}


As previously mentioned, the TES slab is arranged in contact to the evaporator wall (Fig 4). In this way, when the stored product needs to be cooled, the removed heat is transferred first from stored product to the air inside of refrigerator, second from air to the TES slab, and third, from the TES slab to the evaporator-wall.

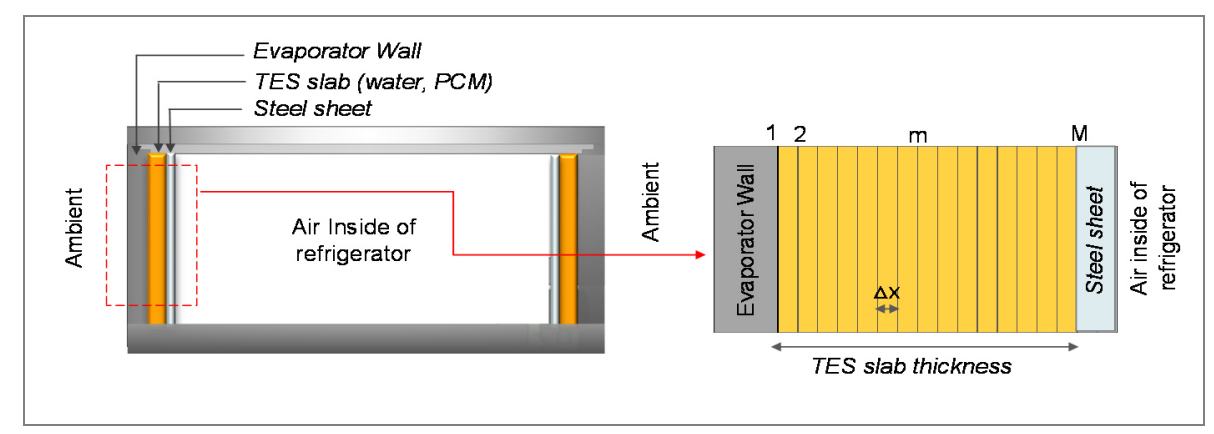

Fig. 4: Layout of the TES slab in the refrigerated cell and scheme of spatial discretization

For the analysed product temperature $\left(11^{\circ} \mathrm{C}\right)$, "Water" is a particular case of PCM in which the process of phase change does not occur. Therefore, to model the TES slab with water, it is possible to apply the same procedure described for the heat transfer for the PCM slab described below.

Heat transfer in the PCM can be modelled, with a good accuracy, by a one-dimensional model, applying either the moving boundary method, developed by Stefan or the enthalpy method. Stefan's method (Fleischer, 2015) assumes that the PCM has a single phase change temperature, as occurs with pure crystalline and eutectic substances, while the enthalpy method (Ozisik, 1993) is suitable for PCMs that have a temperature region for the change phase process, as it happens with fatty substance and alloys.

In this study we used the enthalpy method, because the PCMs selected for the study are not pure substances and do not have a single phase change temperature. In this case, heat transfer in the PCM internal nodes is governed by the general 1-dimensional heat transfer equation (eq. 1), in which the PCM Temperature $\left(T_{P C M}\right)$ and the PCM specific enthalpy $\left(h_{P C M}\right)$ vary in the spatial dimension $(x)$ and in the time dimension $(t)$. In this equation the PCM thermal conductivity $\left(k_{P C M}\right)$ and density $\left(p_{P C M}\right)$ are considered constant in the liquid phase and in the solid phase, while in the phase change region, these properties are calculated by interpolation as previous studies indicate (Ozisik, 1993).

$$
\frac{\partial}{\partial x} k_{P C M} \cdot \frac{\partial T_{P C M}}{\partial \mathrm{x}}=\rho_{P C M} \cdot \frac{\partial h_{P C M}}{\partial \mathrm{t}}
$$

To solve the differential equation, we used the finite difference method. In this method, equation 1 was discretized, dividing the TES slab in the spatial dimension, with a $\Delta \mathrm{x}$ of $1 \mathrm{~mm}$, and an appropriate $\Delta \mathrm{t}$ value, in order to maintain the convergence conditions. Fig. 4 shows a scheme of the spatial division of the TES slab, in which the node " 1 " is in contact with the internal evaporator-wall, while the node " $M$ " is in contact with the steel sheet arranged between the TES slab and the air inside of refrigerator. The system equations obtained after the discretization, were solved by applying the explicit method (Bergman et al., 2011; Patankar, 1980)

\subsection{Refrigerated cell}

Average temperature inside the refrigerated cell was calculated through energy balance equation (eq. 2), which takes into account the thermal load components, as well as the heat transfer rate between the TES slab and the air inside of refrigeration cell $\left(q_{T E S-a i r}\right)$

$$
q_{\text {TES-air }}=q_{\text {los }}+q_{p r}+q_{\text {Int }}+q_{\text {Inf }}
$$

The thermal load components were calculated according to ASHRAE standards. These components include: Transmission heat gains or losses through the refrigerator enclosures $\left(q_{l o s}\right)$, Product thermal load $\left(q_{P r}\right)$, heat gains due to internal equipment $\left(q_{I n t}\right)$, and infiltration heat gains $\left(q_{I n f}\right)$. (ASHRAE, 2010).

In relation to transmission heat gains, the model considers the transmission heat gains through the vertical enclosures $\left(q_{l o s, v}\right)$, which were taken into account in the boundary conditions at the external node of PCM , as well the transmission heat gains through the horizontal enclosures $\left(q_{l o s, h}\right)$, which were included in the energy balance of the refrigerated cell. 


\subsection{Refrigeration sub-system}

Refrigeration sub-system model is based on a simple mechanical compression refrigeration cycle, which uses $\mathrm{R} 134 \mathrm{a}$ as refrigerant. The refrigerator has an evaporator-wall, made of a copper tube circuit, with external diameter of $7.92 \mathrm{~mm}$; the heat transfer mode is forced convection. The condenser is wire on tube type, made of copper with external diameters of 4.75 and $1 \mathrm{~mm}$ for tubes and wires respectively, and dissipates the heat by natural convection. The compressor is alternative hermetic type, manufactured by Danfoss-Secop, BD35F. Table 2 presents the main characteristics of these components.

Tab.2: Main characteristics of refrigeration sub-system components

\begin{tabular}{|l|l|}
\hline Element & Characteristics \\
\hline $\begin{array}{l}\text { Cell or } \\
\text { cabinet }\end{array}$ & $\begin{array}{l}\text { - Length x Width x Depth: } 1.36 \times 0.44 \times 0.63 \mathrm{~m}^{3} \\
\text { - Net Volume: } 0.350 \mathrm{~m}^{3}\end{array}$ \\
\hline Compressor & $\begin{array}{l}\text { - Type: Reciprocating, hermetic } \\
\text { - Manufacturer: Danfoss, Model:BD35F, Voltage 12V DC } \\
\text { - Refrigerant: R134a, Swept volume: } 2 \mathrm{~cm}^{3}\end{array}$ \\
\hline Evaporator & $\begin{array}{l}\text { - Heat transfer mode: Forced convection (adapted) } \\
\text { - Type: Evaporator-wall, area: } 2.033 \mathrm{~m}^{2}\end{array}$ \\
\hline - Tube: External diameter tube $7.92 \mathrm{~mm}$, thickness $0.813 \mathrm{~mm}$, length $30.29 \mathrm{~m}$ \\
\hline $\begin{array}{l}\text { Condenser } \\
\text { element }\end{array}$ & $\begin{array}{l}\text { - Heat transfer mode: Natural convection } \\
\text { - Type: Wire on tub (Cooper). } \\
\text { - Tube: External diameter } 4.75 \mathrm{~mm}, \text { thickness } 0.762 \mathrm{~mm}, \text { length } 13.90 \mathrm{~m}\end{array}$ \\
\hline
\end{tabular}

The simulation of this refrigeration sub-system is based on the performance curves of the compressor, provided by the manufacturer, according to the European Norm EN-12900 (AENOR, 2014). This standard characterizes compressors performance through cubic regression curves, in which the cooling capacity $\left(q_{\text {com }}\right)$ and the electrical power consumption $\left(W_{c o m}\right)$ are expressed as a function of the evaporation $\left(T_{e}\right)$ and condensation $\left(T_{c}\right)$ temperatures, according to the following equation.

$$
Y_{=} C_{1}+C_{2} \cdot T_{e}+C_{3} \cdot T_{c}+C_{4} \cdot T_{e}^{2}+C_{5} \cdot T_{e} \cdot T_{c}+C_{6} \cdot T_{c}^{2}+C_{7} \cdot T_{c}^{3}+C_{8} \cdot T_{e} T_{c}^{2}+C_{9} \cdot T_{e} T_{c}^{2}+C_{10} \cdot T_{c}^{3}
$$

The coefficients of the polynomial curves corresponding to the compressor used in the refrigeration sub-system were provided by the manufacturer, using the software Coolselector®2.

\subsection{Photovoltaic sub-system}

The dynamic simulation software Trnsys was used for simulating the PV sub-system; the components used in this simulation were: type 194 for the PV module, type 47a for electrical batteries, type 48b for the regulator, type $14 \mathrm{~h}$ for power load profiles, and type 15.3 for the weather file.

In particular, the simulation of the photovoltaic module was based on the well-known "five parameters model", whose equivalent circuit is shown in Fig. 5. This circuit is integrated by a direct current source, which simulates the photovoltaic production, a diode connected in parallel, which represents the semiconductor material of the photovoltaic cells, a resistor connected in series and a resistor connected in parallel (De Soto et al., 2006; Duffie and Beckman, 2013; Eckstein, 1990; Surith et al., 2013). 


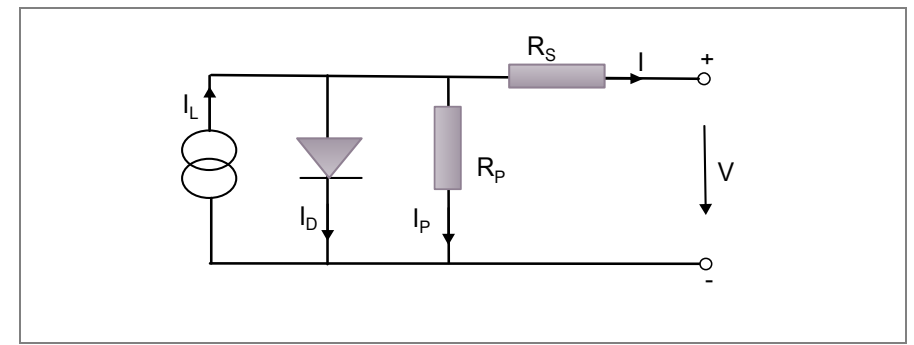

Fig. 5: Equivalent circuit model of 5 parameters photovoltaic module

The relation between the voltage $(V)$ and the intensity $(I)$ of the current supplied by the photovoltaic module is expressed by equation 4 , in which it is necessary to know the five parameters of the model: the light current $\left(I_{L}\right)$, the inverse saturation current of the diode $\left(I_{D}\right)$, the series resistance $\left(R_{S}\right)$, Parallel Resistance $\left(R_{P}\right)$, and the "a" factor (De Soto et al., 2006). These parameters are calculated for reference conditions, using the manufacturer's datasheet.

$$
I=I_{L}-I_{D} \cdot\left(e^{\frac{V+I \cdot R_{S}}{a}}-1\right)-\frac{V+I \cdot R_{S}}{R_{P}}
$$

\subsection{Base simulation conditions and performance indicators}

The simulation was performed under the following base simulation conditions: ambient temperature at $25^{\circ} \mathrm{C}$, since the refrigerator will be installed in a conditioned process area; product set temperature at $11 \pm 2{ }^{\circ} \mathrm{C}$, insulation of polyurethane with a thickness of $80 \mathrm{~mm}$, compressor velocity of $3000 \mathrm{Rpm}$, internal air speed of $0.2 \mathrm{~m} / \mathrm{s}$, and air renewal rate of $0.25 / \mathrm{h}$.

As case studied we selected a ripening cheese at $11^{\circ} \mathrm{C}$ for a small scale cheese processing process. Other application at this temperature can be some fruits and vegetables. The application was evaluated for the implementation in the region of Nyanza (Kenya).

A parametric analysis was carried out by varying the values of TES slab thickness, insulation thickness and compressor velocity. The revised output variables were the product temperature evolution, the TES materials temperature evolution, PV field size and the battery size. The battery was sized for a total autonomy time of the refrigerator without electricity supply of $24 \mathrm{~h}$.

As performance indicators we used the compressor cycle time, the daily electricity consumption, and the mismatch between electricity production and power loads.

\section{Results and Discussion}

The simulation was carried out under the base conditions previously described. The analysis includes three materials: The first material was distilled water, which only store sensible thermal energy, and the others were PCMs (RT5HC and RT9) with average phase change temperatures of $5^{\circ} \mathrm{C}$ and $9^{\circ}$ respectively, which store latent and sensible thermal energy. Detailed properties of these materials were already presented in Table 2.

The influence of the TES on the system, first considers effects of TES slab thickness variation, making simulations with thickness values between 5 and $12 \mathrm{~mm}$. According to the results, the most suitable material was selected for the simulation base conditions.

Subsequently the influence of other two variables was considered: insulation thickness and compressor velocity. For these variables additional simulations were carried out, with insulation thickness values between 40 and $120 \mathrm{~mm}$, and compressor velocity values of 2000, 2500, 3000 and $3500 \mathrm{~min}^{-1}$.

Taking into account the relevance of the TES slab thickness, this study presents a more detailed analysis for this variable. In this case, we revise the TES slab thickness effects on the product temperature, TES materials temperature, electricity consumption, compressor cycle time, photovoltaic field size and the electrical battery size. For the other variables the analysis is centred only in the compressor cycle time, and the battery size. 


\subsection{Temperature evolution for stored product and studied materials}

The evolution of product temperature in the refrigerator "Without TES" and refrigerator With TES, using different materials (water, RT5HC and RT9) are presented in Fig. 6, under simulation base conditions, with a TES slab thickness of $8 \mathrm{~mm}$ and a product set-point temperature of $11 \pm 2^{\circ} \mathrm{C}$. The duration of analysed period was 48 hours.

During the maintenance cycles, the refrigerator "Without TES" maintains the product temperature between the required values $\left(9\right.$ to $\left.13^{\circ} \mathrm{C}\right)$. When the TES slab is installed, the maximum product temperature remains at the desired value $\left(13^{\circ}\right)$; however, the minimum product temperature drops slightly $1.4^{\circ} \mathrm{C}, 2.2^{\circ} \mathrm{C}$, and $1.8^{\circ} \mathrm{C}$ below to the desired value $\left(9^{\circ} \mathrm{C}\right)$, for water, RT5HC and RT9 respectively.

This is because the TES slab is charged when the compressor is ON and discharged while the compressor is OFF, removing additional heat from the product during the OFF time. This behaviour must be taken into account in the final control strategy definition, since it is necessary to control the allowed product sub-cooling

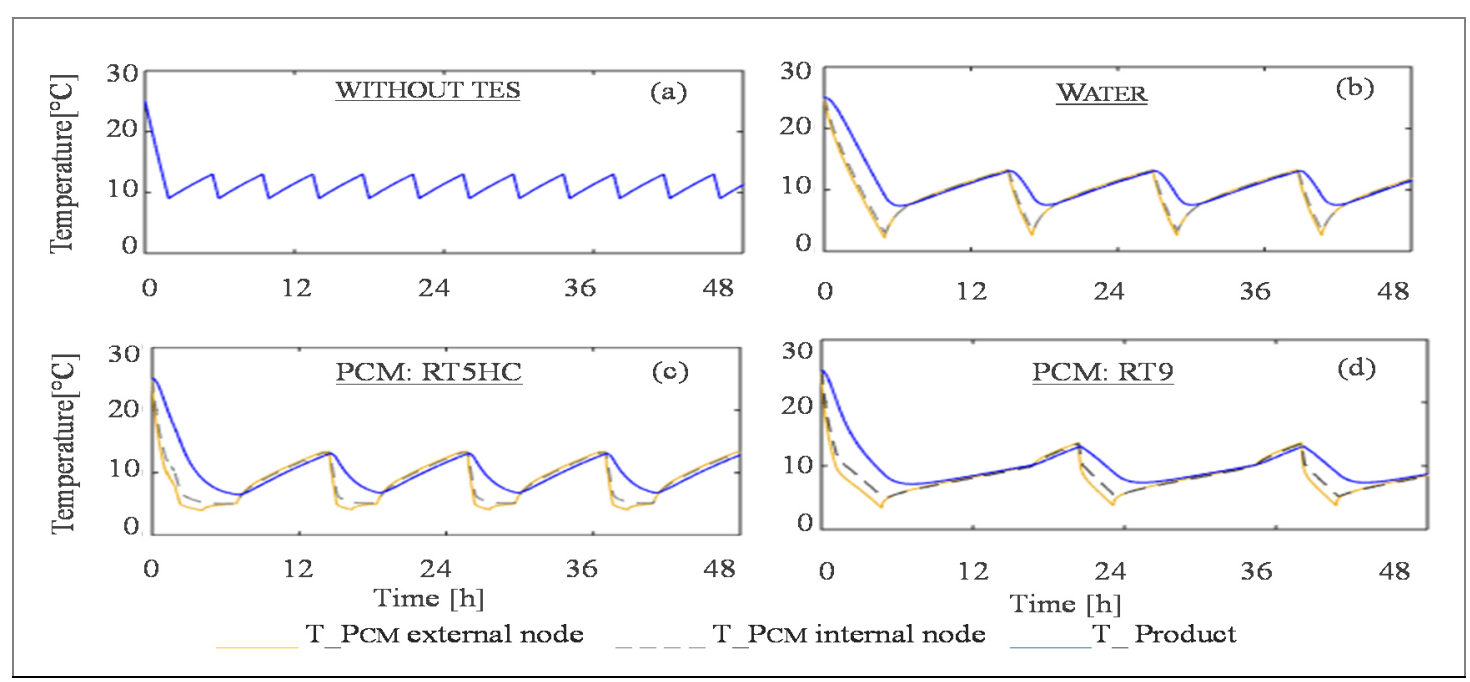

Fig. 6: Product and TES materials temperature evolution under simulation base conditions with a TES Slab thickness of $8 \mathrm{~mm}$

Fig. 6 also shows the TES materials temperature evolution, including the external node of the TES slab which is in contact with the evaporator-wall, as well as the internal node, which is closer to the indoor air of the refrigerated cell.

For Water, the minimum temperatures were $2.5^{\circ} \mathrm{C}$ and $3.4^{\circ} \mathrm{C}$, at the external and internal nodes respectively; therefore, as it is expected, this material only store sensible thermal energy.

For the PCM RT5HC, the minimum temperatures were $4.2^{\circ} \mathrm{C}$ and $5.1^{\circ} \mathrm{C}$ at the external and internal node respectively. Since in this $\mathrm{PCM}$, the phase change process was not completed, because the melting temperature region is between $4^{\circ} \mathrm{C}$ and $6^{\circ} \mathrm{C}$; so this PCM took advantage from the latent thermal storage in a partial way.

For the PCM RT9, the minimum temperatures were $3.4^{\circ} \mathrm{C}$ at the external node, and $4.9^{\circ} \mathrm{C}$ at the internal node. In this case, the phase change process was completed because the melting temperature range is between $7^{\circ} \mathrm{C}$ and $10^{\circ} \mathrm{C}$; therefore it was possible to take full advantage from the latent thermal storage.

These results indicate that the phase change process takes place in a complete way, when the phase change temperature of the PCM is closer to the set-temperature in the inside of the refrigerator, for the analysed case.

\subsection{Effect of TES slab thickness on the compressor cycle time}

Incorporation of a TES slab gives more inertia to the refrigerator and reduce the total number of compressor cycles. A compressor cycle include two parts, one in which the compressor is ON and the other in which the compressor is OFF. 
For a better integration of the refrigerator with the PV sub-system, the number of compressor cycles per day should be near to one; that implies a minimum duration cycle of 24 hours. In this way it is easier to supply the electricity required by the system during the day, attend the thermal demand, and charge the TES slab. Later, during the night, the TES slab can be discharged and attend thermal demand without any electricity supply.

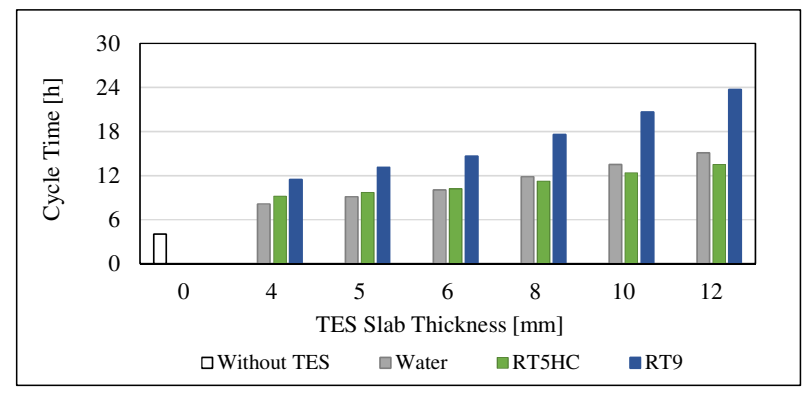

Fig. 7: Cycle time for different TES slab thickness

Taking into account the importance of the cycle duration, we simulated the system for several TES slab thickness values, and calculated the cycle duration time for the three analysed materials. Results under base simulation conditions, are presented in Fig.7. When the refrigerator does not have a TES slab, the cycle time is only $4.03 \mathrm{~h}$.

If the TES slab thickness is about $4 \mathrm{~mm}$, the cycle time increases to 8.1, 9.2 and 11.5h for water, the PCM RT5HC y the PCM RT9 respectively. If the slab thickness is $12 \mathrm{~mm}$ this cycle time increases to 15.1, 13.5, y $23.7 \mathrm{~h}$ for the same PCMs. These results indicate that the PCM RT9 is the most suitable for the analysed application because the longer cycle time, makes easier the integration of PV sub-system.

\subsection{Effect of TES slab thickness on the electricity consumption}

Despite the fact the TES slab gives more inertia to the system and improves the integration with the PV subsystem, the results show that the electricity consumed by the system also increases. Fig. 8 shows the electrical consumption for different TES slab thickness, under simulation base conditions and assuming that only maintenance cycles take place during the system operation.

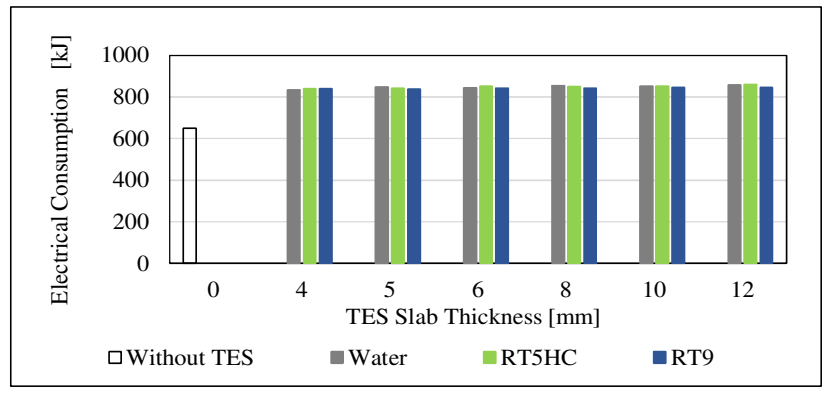

Fig. 8: Daily electricity consumption for different PCM slab thickness

When the refrigerator does not have TES, the daily electricity consumption is $649 \mathrm{~kJ}$. There is an important variation when the refrigerator has a TES Slab, with increments between $28.5 \%$ and $32.1 \%$ for Water, between $29.5 \%$ and $32.4 \%$ for the PCM RT5HC, and between $29.4 \%$ and $30.5 \%$ for the PCM RT9. We can see that the thicker TES slab, the more electricity consumption there is, and the PCM RT9 has lower increments.

Regarding to PV sub-system design, a higher consumption may imply an increment in the photovoltaic field size. On the other hand, the incorporation of the TES slab also increases the cycle time, thanks to this increment, it is possible to improve the use of solar resource and to reduce the electrical battery size.

Therefore, in the following items these two points are analysed, the size of the photovoltaic field, as well as the size of the electrical batteries, when the TES slab is installed in the refrigerator. 


\subsection{PV field size and mismatch between PV production and power load profiles}

At the location of the analysed application (region of Nyanza, Kenya, with a latitude of $0.08^{\circ} \mathrm{N}$, and longitude of $35.06^{\circ} \mathrm{E}$ ), the minimum electricity production of the photovoltaic field takes place during November. Therefore, this month was taken as the reference period for the analysis.

Taking into account the daily electricity consumption of the system, as well as the power demand, it is possible to size the photovoltaic field. For both cases: Refrigerator without and with TES slab, the electricity required by the system can be supplied by a small multi-crystalline silicon module, with a peak power of 100W STC. During the analysed month, this PV module has an average daily production of $1533 \mathrm{~kJ} / \mathrm{day}$, with minimum and maximum values of 1215 and $1807 \mathrm{~kJ} /$ day, respectively.

As usually occurs in this type of systems, there is a mismatch between PV production and power load. Fig. 9 illustrates this mismatch for the refrigerator without TES, and the refrigerator with TES (PCM RT9). In general, the thicker TES slab, the lower the number of cycles are, and the smaller the mismatch between the PV production and the power load is.

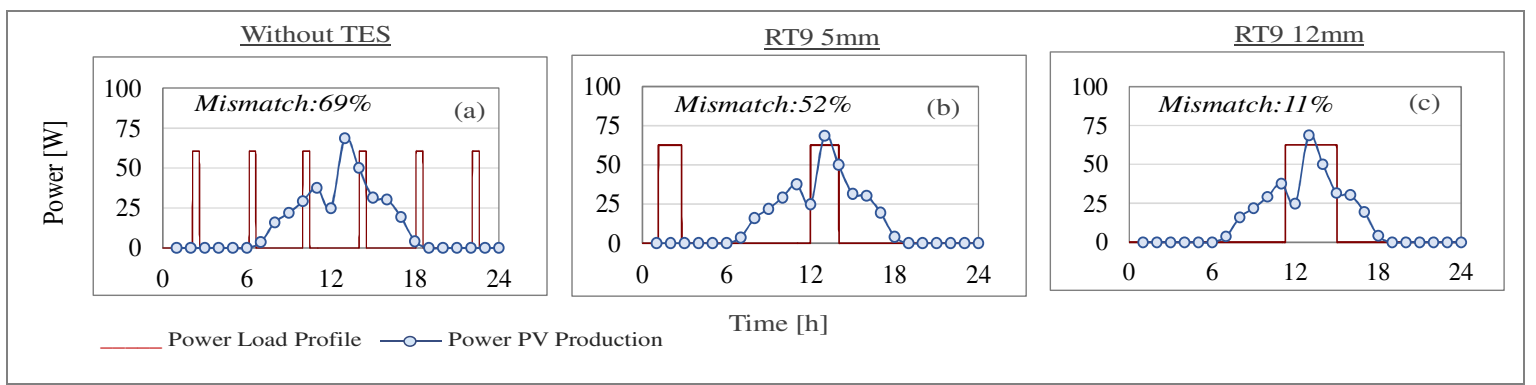

Fig. 9: Mismatch between Power PV Production and Power Load Profiles: (a) Refrigerator without TES

(b) Refrigerator with PCM RT9 slab thickness of 5mm, (c) Refrigerator with PCM RT9 slab thickness of 12mm

Table 3 summarizes the mismatch obtained for the three materials considered in the study, with different TES slab thicknesses. The refrigerator without TES has an average mismatch of $72 \%$; while the refrigerator with TES, this mismatch can be reduced up to $37 \%, 44 \%$ and $11 \%$ for water, the PCM RT5HC and the PCM RT9, respectively, when the TES slab thickness is $12 \mathrm{~mm}$.

Tab.3 Mismatch between power PV production and power load profiles for studied materials and different TES slab thickness

\begin{tabular}{|c|c|c|c|c|c|c|c|}
\hline \multirow{2}{*}{ Material } & \multicolumn{7}{|c|}{ TES Slab Thickness [mm] } \\
\cline { 2 - 8 } & 0 & 4 & 5 & 6 & 8 & 10 & 12 \\
\hline Distilled Water & $69 \%$ & $57 \%$ & $55 \%$ & $55 \%$ & $49 \%$ & $44 \%$ & $37 \%$ \\
\hline RT5HC & $69 \%$ & $57 \%$ & $55 \%$ & $52 \%$ & $48 \%$ & $46 \%$ & $44 \%$ \\
\hline RT9 & $69 \%$ & $55 \%$ & $52 \%$ & $46 \%$ & $34 \%$ & $21 \%$ & $11 \%$ \\
\hline
\end{tabular}

\subsection{Effect of TES slab thickness on the battery size}

The electrical battery was sized taking into account the mismatch between the PV production and the power load profiles calculated previously. Other factors applied for battery sizing were the battery discharge efficiency (0.85) and the maximum depth of discharge (0.70). Fig. 10 shows the results under the simulation base conditions, for the three materials included in the analysis and different TES slab thickness.

The battery size for the refrigerator without TES is $209 \mathrm{Wh}$. The best results are obtained for the PCM RT9, in which the battery size is reduced to $44 \mathrm{Wh}$ (when the TES slab thickness is $12 \mathrm{~mm}$ ). For water and the PCM RT5HC the effects on the battery size are smaller, with final values of 148 and $175 \mathrm{Wh}$, respectively for the same simulation conditions. This results shows that the reduction of battery size can be between 16 and $78 \%$ according to the material selected for the TES Slab.

Better results of the PCM RT9 are mainly due to the fact this material has a complete phase change process, 
and therefore it takes better advantage of the latent thermal energy storage, as was exposed in 4.1, in which the evolution of the temperature of the TES slabs was revised.

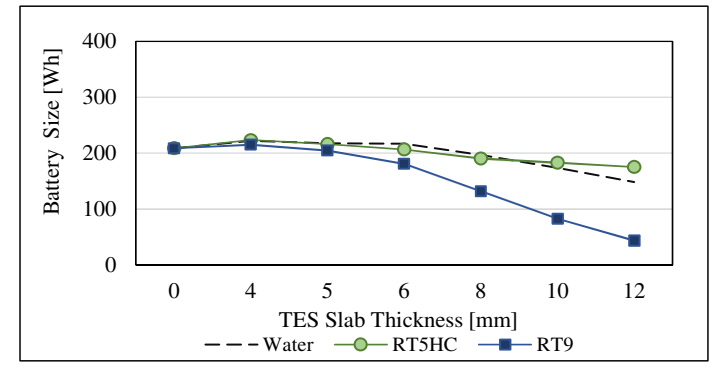

Fig. 10: Battery size for different PCM slab thickness

\subsection{Effects of insulation thickness}

Thermal loads due to transmission losses through the enclosures is highly important in the overall thermal load of the refrigerator. Therefore, insulation thickness has been widely analysed in numerous literature studies. ASHRAE recommends, among different types of insulation, polyurethane with a minimum thickness of 50 $\mathrm{mm}$ when the set product temperature is between 10 and $16{ }^{\circ} \mathrm{C}$ (ASHRAE, 2010).

Due to the importance of this variable, in this section we analysed the effects of insulation thickness on the duration of the compressor cycle, as well as on the electrical battery size. Since the most significant effects on the system were obtained for the PCM RT9, the simulations were performed with this material with TES slab thickness values of 8 and $10 \mathrm{~mm}$.
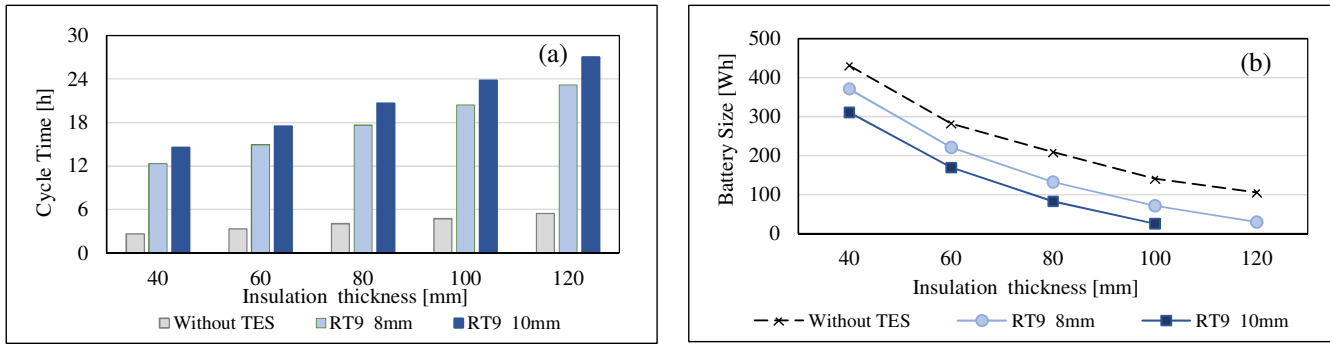

Fig. 11: Compressor cycle time and battery size for different insulation thickness

The refrigerator without TES, has a compressor cycle time between 2.6 and 5.4 hours, while in the refrigerator with the PCM RT9, the cycle time is closer to 24 hours, when insulation thickness is greater than $100 \mathrm{~mm}$ (Fig 11 (a)). Through the combination of $100 \mathrm{~mm}$ of insulation thickness and a TES slab thickness of $10 \mathrm{~mm}$, with the PCM RT9, this cycle time can increase up to $23.9 \mathrm{~h}$.

Regarding the electrical battery size (Fig. 11 (b)), the effects are important in both cases: Refrigerator without TES and Refrigerator with TES. For the Refrigerator without TES, the electrical battery size has a reduction of $49 \%$, when the insulation thickness changes from 80 to $120 \mathrm{~mm}$. On the other hand, for the Refrigerator with TES, with the PCM RT9, the electrical battery size can be reduced up to $78 \%$ when insulation thickness also changes from 80 to $120 \mathrm{~mm}$.

For the operation conditions analysed, the positive effects of increasing the insulation thickness on the size of the battery, are very important. This is because the transmission thermal losses represent $89 \%$ of the total thermal loads in the system. However, it is expected that at higher the internal thermal and infiltration loads, the PCMs will be more relevant.

\subsection{Effects of compressor velocity}

Table 4 summarizes the effects of the variation of compressor velocity on the system; these results are presented for a TES Slab thickness of 10mm and the PCM RT9. The faster compressor velocity, the shorter cycle time is, for instance, when the compressor velocity changes from 2000 to $3500 \mathrm{~min}^{-1}$, the cycle time increases from 
$19.2 \mathrm{~h}$ to $21.0 \mathrm{~h}$. In addition, the "Time ON" for the compressor decreases from $4.4 \mathrm{~h}$ to $2.9 \mathrm{~h}$, and this reduction has a positive effect on the compressor useful life.

Tab.4 Results for different compressor velocities for the PCM RT-9 with slab thickness of 10mm

\begin{tabular}{|c|c|c|c|c|c|}
\hline \multirow{2}{*}{ Description } & \multirow{2}{*}{ Units } & \multicolumn{4}{|c|}{ Compressor Velocity $\left(\mathrm{min}^{-1}\right)$} \\
\cline { 3 - 6 } & & 2000 & 2500 & 3000 & 3500 \\
\hline Cycle Time & {$[\mathrm{h}]$} & 19.2 & 19.9 & 20.7 & 21.5 \\
\hline Time ON & {$[\mathrm{h}]$} & 4.4 & 3.7 & 3.2 & 2.9 \\
\hline Time OFF & {$[-]$} & 14.8 & 16.2 & 17.4 & 18.5 \\
\hline Ratio Time ON / Time OFF & {$[-]$} & 0.296 & 0.225 & 0.185 & 0.158 \\
\hline Average Power & {$[\mathrm{W}]$} & 36.7 & 48.3 & 58.6 & 68.9 \\
\hline Electricity consumption & {$[\mathrm{Wh} / \mathrm{day}]$} & 223 & 231 & 235 & 239 \\
\hline COP System & {$[-]$} & 3.42 & 3.24 & 3.17 & 3.12 \\
\hline Electrical batteries size & {$[\mathrm{Wh}]$} & 94 & 86 & 83 & 63 \\
\hline
\end{tabular}

On the other hand, this increase of compressor velocity, also produces a slight increment of $7 \%$ in the daily electricity consumption, and a strong increment of $88 \%$ in the power demand. Despite this effect, it was found that PCM charging process is more effective, since there is a reduction of $33 \%$ for the electrical battery size. This means that the PCM takes more advantage from the thermal energy storage (sensitive and latent), when the compressor velocity is higher.

This performance must be taken into account in the definition of system control strategy. It is recommended to regulate the compressor at high velocity when the solar radiation is also high, and at low velocity when the solar radiation is also low.

\section{Conclusions}

A PV-refrigerator was modelled and simulated, under base operating conditions, at $11 \pm 2^{\circ} \mathrm{C}$ product temperature and $25^{\circ} \mathrm{C}$ ambient temperature. Three materials were included in the simulations: one was water, and the others were PCM with average phase change temperatures of $5^{\circ} \mathrm{C}$ and $9^{\circ} \mathrm{C}$, respectively. The analysis considered the effects of three relevant variables: TES slab thickness, insulation thickness, and compressor velocity.

The thicker the TES slab, the longer the cycle duration is. For improving PV sub-system integration, compressor cycle time had to be a minimum of 24 hours. In this regard, longer cycle times were obtained for the PCM whose average phase change temperature was $9^{\circ} \mathrm{C}$, with slab thickness greater than $8 \mathrm{~mm}$.

On the other hand, the TES slab installed in contact with the evaporator-wall, in the internal side of the refrigerator, increased the daily electricity consumption. In light of this, the effects on PV field size and electrical battery size in the analysed operation conditions should be evaluated.

In the present study, the final selected PV module had 100W of peak power, under standard test conditions. The electricity required by the system provided for this PV module in both cases: Refrigerator without TES and the Refrigerator with TES. In regards to electrical battery size, the best results are obtained with the PCM RT9, manufactured by Rubitherm, as this material took more advantage of latent storage, in comparison to the other analysed materials.

Insulation thickness also influenced system performance. Under the operation conditions analysed, this impact was especially important because almost the entirety of the thermal load was due to transmission losses through refrigerator enclosures. However, this impact may be lower when the internal and infiltration thermal loads increase, and in that case TES with PCM will get more relevant.

A higher compressor velocity helped to reduce the electrical batteries size, but it did increase the power demand. This behaviour must be taken in to account, in order to define a system control strategy. It is it is recommended that the compressor operates at higher velocity when solar irradiation is high, and at lower velocity when solar irradiation is low. 


\section{Acknowledgement}

The authors are grateful to URV-Solidaria, and AGAUR (FI-DGR 2017), program co-financed by the European Social Funds.

\section{References}

AENOR, 2014. UNE-EN 12900. Refrigerant compressors. Rating conditions, tolerances and presentation of manufacturer's performance data. doi:M 27527:2014

ASHRAE, 2010. Handbook of Refrigeration. American Society of Heating, Refrigerating and AirConditioning Engineers (ASHRAE), Atlanta (US).

Azzouz, K., Leducq, D., Gobin, D., 2009. Enhancing the performance of household refrigerators with latent heat storage: An experimental investigation. Int. J. Refrig. 32, 1634-1644. doi:10.1016/j.ijrefrig.2009.03.012

Bergman, T.L., Lavine, A.S., Incropera, F.P., DeWitt, D.P., 2011. Introduction to heat transfer, Sixth Edit. ed. John Wiley \& Sons, US.

Cheng, W. long, Ding, M., Yuan, X. dong, Han, B.C., 2017. Analysis of energy saving performance for household refrigerator with thermal storage of condenser and evaporator. Energy Convers. Manag. 132, 180188. doi:10.1016/j.enconman.2016.11.029

Coca-Ortegón, A., Torres-Toledo, V., Müller, J., Coronas, A., 2017. Assessment of a Solar Powered Refrigerator Equipped with Thermal Storage for a Dairy Application. Proc. SWC2017/SHC2017 1-12. doi:10.18086/swc.2017.28.02

De Soto, W., Klein, S.A., Beckman, W.A., 2006. Improvement and validation of a model for photovoltaic array performance. Sol. Energy 80, 78-88. doi:10.1016/j.solener.2005.06.010

Duffie, J., Beckman, W., 2013. Solar engineering of thermal processes, 4th Editio. ed. John Wiley \& Sons, Wisconsin-Madison.

Eckstein, J.H., 1990. Detailed modelling of photovoltaic system components. University of Wisconsin Madison.

Fleischer, A.S., 2015. Thermal energy storage using phase change materials. Fundamentals and applications. Springer, US. doi:10.1007/978-3-319-20922-7

IEC, 2013. EN 62552 Household refrigerating appliances - Characteristics and test methods.

Marques, A.C., Davies, G.F., Maidment, G.G., Evans, J. a., Wood, I.D., 2014. Novel design and performance enhancement of domestic refrigerators with thermal storage. Appl. Therm. Eng. 63, 511-519. doi:10.1016/j.applthermaleng.2013.11.043

Oró, E., De Gracia, A., Castell, A., Farid, M.M., Cabeza, L.F., 2012. Review on phase change materials (PCMs) for cold thermal energy storage applications. Appl. Energy 99, 513-533. doi:10.1016/j.apenergy.2012.03.058

Ozisik, M.N., 1993. Heat Conduction, Second Edi. ed. John Wiley \& Sons, Inc., New York. doi:10.1002/9781118411285

Patankar, S., 1980. Numerical Heat Transfer and Fluid Flow. Ser. coputational methods Mech. Therm. Sci.

Pedersen, H., Katic, I., 2016. Direct drive solar coolers, in: 12th IIR Gustav Lorentzen Natural Working Fluids Conference. Papaer ID 1070. Edinburgh, p. 8. doi:10.18462/iir.gl.2016.1070

Schaddelee-Scholten, B., Tempowski, J., 2017. Recycling used Lead-Acid Batteries: health considerations, 1st ed. World Health Organization, Geneve (Switzerland).

Sørensen, B., 2015. Chapter 11 - Environmental Issues Associated with Solar Electric and Thermal Systems with Storage, in: Sørensen, B. (Ed.), Solar Energy Storage. Elsevier Inc /Academic Press, United Kingdom, pp. 247-271. doi:10.1016/B978-0-12-409540-3.00011-6

Surith, N., Vishnu, V., Raam, K., Sai, P., Ramya, K., 2013. Photovoltaic Driven Dual Purpose Thermoelectric Refrigerator for Rural India. Int. J. Adv. Res. Technol. 2, 111-117. 


\title{
Simulations of Solar Thermal Cooling System in the Oman climate: Case study for a Building at Innovation Park Muscat
}

\author{
Tom Cordes ${ }^{1,3}$, Sausan AI Riyami ${ }^{2,3^{*}}$, Jörn Scheuren ${ }^{1}$ and Rutger Schlatmann ${ }^{1,3}$ \\ ${ }^{1}$ HTW Berlin - University of Applied Sciences, Renewable Energy Systems, Berlin, Germany \\ ${ }^{2}$ Institute of Advanced Technology Integration (IATI)/ The Research Council (TRC), Muscat, Oman \\ ${ }^{3}$ Helmholtz-Centre Berlin, PVcomB, Berlin, Germany
}

\begin{abstract}
An increasing demand in space cooling and thus in electricity is not only a challenge for the public electricity supply in Oman, but also leads to an increase of $\mathrm{CO} 2$-emission, as the electricity production in Oman relies almost completely on fossil fuels. This work aims to investigate different options of a solar cooling system for a nonresidential building at Innovation Park Muscat in Oman with the target autarky from the public electricity grid. Therefore, the two main principles of solar cooling, thermally driven with solar thermal systems and electrically driven with photovoltaics, are modelled in a dynamic simulation environment. The solar thermal system contains double covered flat plate collectors, a s hot water tank storage and an absorption chiller with aquifer cooling for heat rejection. The electrically driven systems consist out of a PV system with batteries and a compression chiller. The results of the simulations show the suitability of solar cooling and give the optimised dimensions for each system. A high correlation between the cooling load and the solar radiation makes the full coverage even at small storage sizes possible, where the PV driven system has an advantage in terms of required space.
\end{abstract}

Keywords: weather data, solar irradiation, cooling demand, solar thermal collectors

"corresponding author: $\underline{\text { sausan.alriyami@trc.gov.om }}$

\section{Introduction}

The worldwide demand for space cooling, mostly covered through electrical energy, is increasing and is expected to double within the next 40 years [1]. This also applies for the countries in the Middle East like Oman, where $97 \%$ of electricity is generated from the $\mathrm{CO}_{2}$-emmiting conversion of fossil fuels [2]. Apart from the international climate objectives, which force a reduction of the use of fossil fuels, the electricity demand for space cooling causes peak loads in the electricity networks. This might become an issue in Oman, as almost half of the electric energy for residential living is used for cooling [3]. The need for climate friendly technologies makes solar cooling a promising technology for space cooling, as solar energy is available almost the same time when cooling is needed.

There are two main principles of solar cooling. The first implies the conversion of the solar energy into electricity, using photovoltaic cells (PV), to drive a vapour compression chiller. The other one uses heat, produced through solar thermal systems, to drive a sorption chiller. Both technologies have advantages and disadvantages, depending on the targets and system boundaries. However, in terms of autonomy from electricity grid, interaction with additional heat sources or sinks and lager variety of storage technologies, solar thermal cooling systems are offering the better options for this project. Hence, different options of solar thermal cooling will be investigated and compared to a PV driven system in this work.

With the goal of minimal grid interaction, the most suitable option will be realized as a demonstrator to provide space cooling for a building at the Innovation Park Muscat (IPM) in the Sultanate Oman. A consortium of the German Research Centre for Geosciences (GFZ), the Technical University Berlin (TUB), the Helmholtz Centre Berlin (HZB), the University of applied sciences Berlin (HTW-Berlin) and the Omani Institute for Advanced Technology 
Integration (IATI) is cooperating closely and couple their expertise in the fields of geosciences, thermally driven chillers and solar energy. This project is supposed to not only create an example of environmentally friendly space cooling, but also to transfer the knowledge to Oman.

\section{Methodology}

Basis of this study is the annual weather profile and the cooling load of the building. A Typical Meteorological Year (TMY) by Meteonorm dataset of Seeb in Muscatis used as a weather file, after a detailed comparison with historical weather data provided by the Public Authority of Civil Aviation (PACA) in Oman. Some key values of the system are listed in Table 1.

Table 1: Climate data of the location

\begin{tabular}{|c|c|}
\hline Max. ambient temperature & $50^{\circ} \mathrm{C}$ \\
\hline Annual mean temperature & $28.6^{\circ} \mathrm{C}$ \\
\hline Annual solar radiation & $1990 \mathrm{kWh} / \mathrm{m}^{2} / \mathrm{a}$ \\
\hline Mean annual sunshine hours & $3,493 \mathrm{~h} / \mathrm{a}$ \\
\hline
\end{tabular}

To gain the cooling load profile, the target building was modelled based on the architectural databy Dr. Saleh Al Saadi from college of Engineering at Sultan Qaboos University. The single-storey building hosts a restaurant, a gym and other facilities. Some key values are listed in Table 2.

Table 2: Key data of the target building 'Social Centre'

\begin{tabular}{|c|c|}
\hline Space area & $1500 \mathrm{~m}^{2}$ \\
\hline Max. cooling load & $280 \mathrm{~kW}$ \\
\hline Annual cooling demand & $391 \mathrm{kWh} / \mathrm{a}$ \\
\hline
\end{tabular}

After selecting the components and system configuration of the solar thermal cooling system, the system is modelled in the simulation environment TRNSYS. In a parameter variation the collector slope, the specific collector mass flow, the storage size, the nominal cooling power of the absorption chiller and the collector area are optimized for the lowest investment costs and land consumption for different solar shares. For each option the auxiliary electrical energy was calculated and recorded in an electrical load profile. Based on this load profile, the sizing of a PV-Battery system, to cover the electrical demand, was carried out in a developed programme in Matlab. The results are compared to a purely electrically driven system. This system was modelled with the PV-Battery system in Matlab and optimised for the lowest investment costs.

\section{Concepts and modeling}

\subsection{Electrically driven system}

As a reference, an electrically driven system is developed. It consists of a PV-Battery system, a compression chiller and a dry cooling tower (dry cooler) with the option of a grid connection, as shown in Fig.1. This system with all its components is modelled in Matlab. The key parameters are stated in Table 3

Table 3: Parameters of PV Module used in the simulations

\begin{tabular}{|c|c|}
\hline Cell type & Poly-si \\
\hline $\boldsymbol{\eta}$ (STC) & $15.2 \%$ \\
\hline Temperature coefficient & $-0.43 \% / \mathrm{K}$ \\
\hline
\end{tabular}

The chiller and dry cooler comply with the highest market available energy efficiency. The generated electricity is calculated with respect to the module temperature, the incidence angle and losses at the inverter. The battery system 
with its periphery is modelled as a lithium-ion battery. Losses are respected for charging and discharging, controls and cooling.

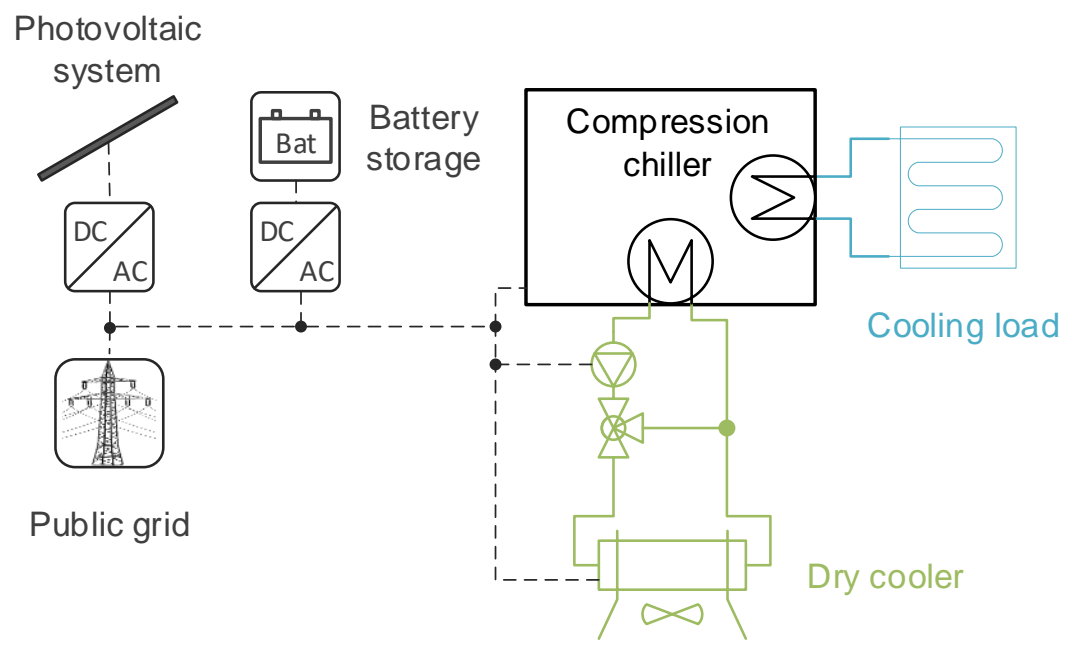

Figure 1: Design of the electrically driven system

\subsection{Thermally driven system}

Absorption chillers with the working pair Lithium-Bromide/Water are the most efficient absorption chillers at relatively low costs and they are environmental harmless. They require hot water temperatures between $70^{\circ} \mathrm{C}$ and $120^{\circ} \mathrm{C}$ and a heat rejection temperature below $40^{\circ} \mathrm{C}$ to provide chilled water at a temperature of $5.5^{\circ} \mathrm{C}$. To produce heat at this temperature level, double covered flat plate collectors (see Table 4) are used in a combination with a pressurized insulated hot water tank storage ( $30 \mathrm{~cm}$ at $\lambda=0.04 \mathrm{~W} / \mathrm{m} / \mathrm{K})$.

Table 4: Performance data of the solar thermal collector used in the simulations with reference to the aperture area

\begin{tabular}{|c|c|}
\hline Collector type & Double covered flat plate \\
\hline$\eta_{0}$ & 0.77 \\
\hline$a_{l}$ in $W / \mathbf{m}^{2} / \mathbf{K}$ & 2.89 \\
\hline$a_{2}$ in $W / \mathbf{m}^{2} / \mathbf{K}^{2}$ & 0.006 \\
\hline
\end{tabular}

A heat exchanger between the solar thermal collectors and the storages is not necessary, because the ambient temperature is always above $0^{\circ} \mathrm{C}$. As the dry cooler is not able to maintain the cooling water temperature below $40^{\circ} \mathrm{C}$ all year and a water consuming wet cooling tower is excluded, an aquifer is used to reject the heat at high ambient temperatures. The auxiliary energy of pumps, absorption chiller and heat rejection are covered by a grid connected PV-Battery system. All the components, pumps and pipes are implemented in a simulation model in TRNSY according to the scheme in Fig. 2. 


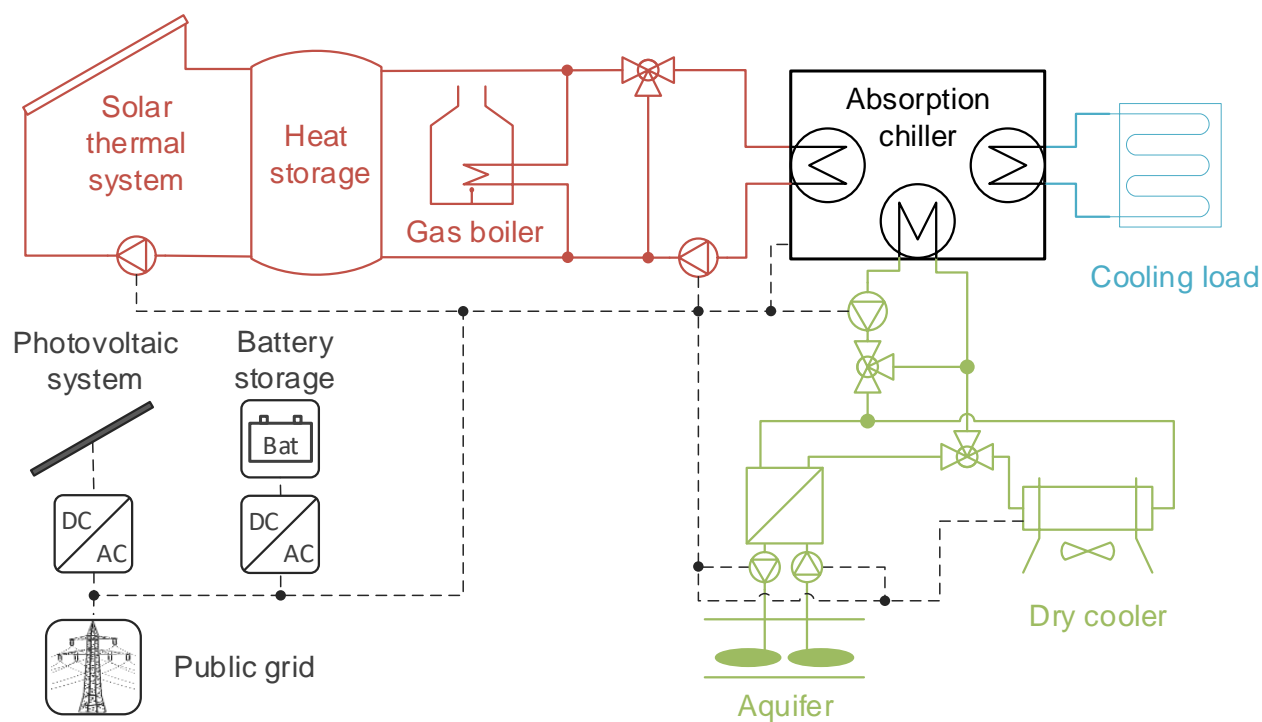

Figure 2: Design of the thermally driven system

\section{Results}

The results of the simulations show that the high sun radiation makes solar cooling a suitable way to provide space cooling for buildings in Oman. For both cases studied, the autarkic operation, without electricity grid connection or external gas supply, is possible, but will not present the optimal solution in all respects. In the following, the results of the best options in terms of sustainability, complexity, maintenance and investment costs are shown in more detail.

\section{Electrically driven system}

Figure 3 shows the degree of autarky as a function of the installed PV power. It can be seen that without any battery storage, the degree of autarky (DOA) levels of at a maximum of about 60\%, irrespective of installed PV power. The electrically driven system contains an optional grid connection to the public electricity grid, which functions as backup. Depending on the installed PV power and the battery capacity, the share between electricity used from PV and electricity used from the public grid varies. To reach grid independency (an autarky of $100 \%$ ) the battery storage has to have a size of at least $900 \mathrm{MWh}$. On the other hand, a larger storage than $1000 \mathrm{kWh}$ can reduce the required PV capacity only slightly.

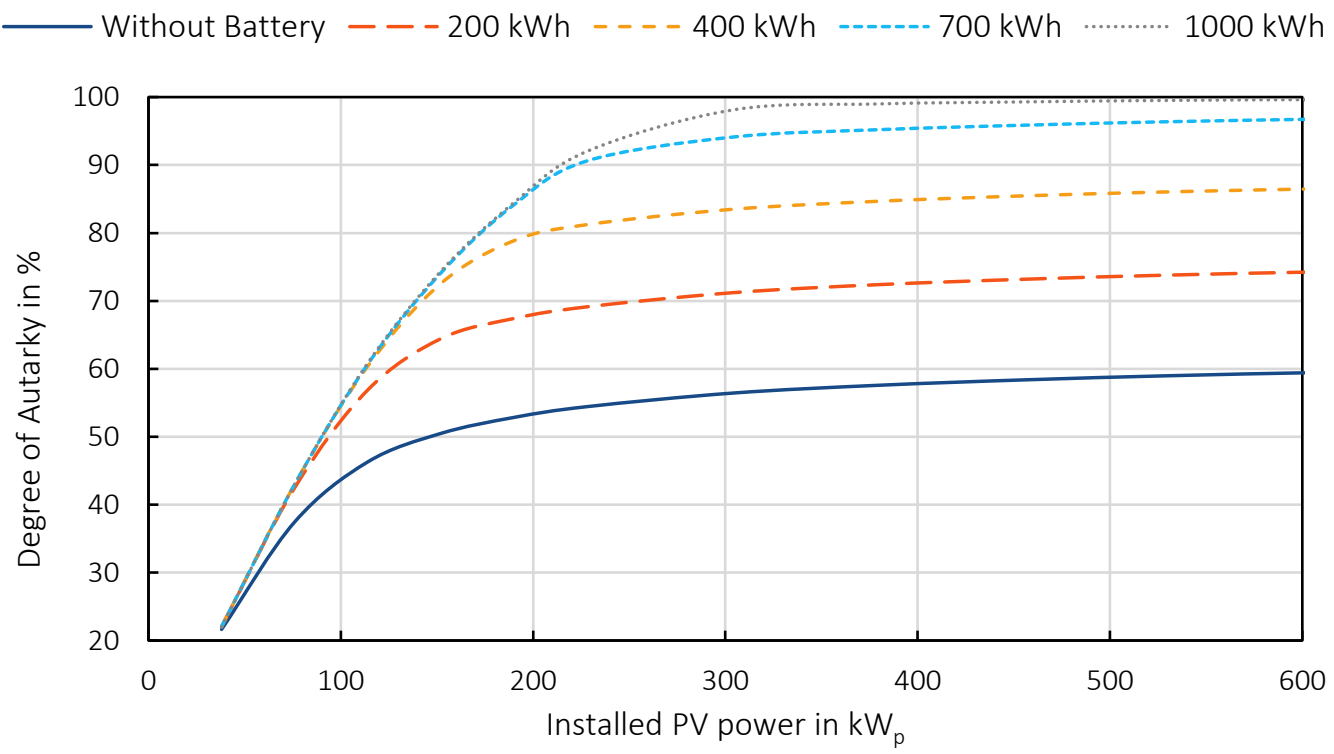

Figure 3: Share of PV-generated energy on the energy demand for space cooling over the installed PV power at different battery capacities

The option with the lowest investment costs to reach almost full autarky (99 \%), is a $440 \mathrm{~kW}_{\mathrm{p}} \mathrm{PV}-\mathrm{System}$ with 
$1000 \mathrm{kWh}$ battery storage. A reduction to $300 \mathrm{~kW}_{\mathrm{p}}$ and $800 \mathrm{kWh}$ can reduce the investment costs significantly, while the degree of autarky is still at $95 \%$. In this case a grid connection is needed and to support the electricity supply mostly in the early morning before sun rise when the battery storage is exhausted.

\section{Thermally driven system}

The analysis and evaluation of the established simulation model is performed for an annual simulation with the parameter settings shown in Table 5.

Table 5: Optimzed parameters for the the solar thermal system

\begin{tabular}{|c|c|}
\hline Collector slope & $20^{\circ}$ \\
\hline Specific collector mass flow & $20 \mathrm{~kg} / \mathrm{h} / \mathrm{m}^{2}$ \\
\hline
\end{tabular}

Figure 3 shows the degree of autarky as a function of the installed solar thermal collector area, for different size of the thermal storage tank. It can be seen that even without very modest storage, the degree of autarky (DOA) levels can reach very much higher levels than are usually seen in more moderate climates. The thermal energy, needed to drive the absorption chiller, can be either provided by the solar thermal system or the optional back-up gas boiler. Both operate without significant interaction with the electricity grid. Thus it is not necessary to cover the whole demand of driving heat through the solar thermal system to meet the main goal of grid independency. The cheapest option to reach a full coverage ( $99 \%$ ), without using the gas boiler, requires a solar thermal system with a collector area of $2740 \mathrm{~m}^{2}$ and a storage of $200 \mathrm{~m}^{3}$. As shown in Fig. 4, a reduction of the solar fraction to $95 \%$ can reduce the required collector area by more than $25 \%$.

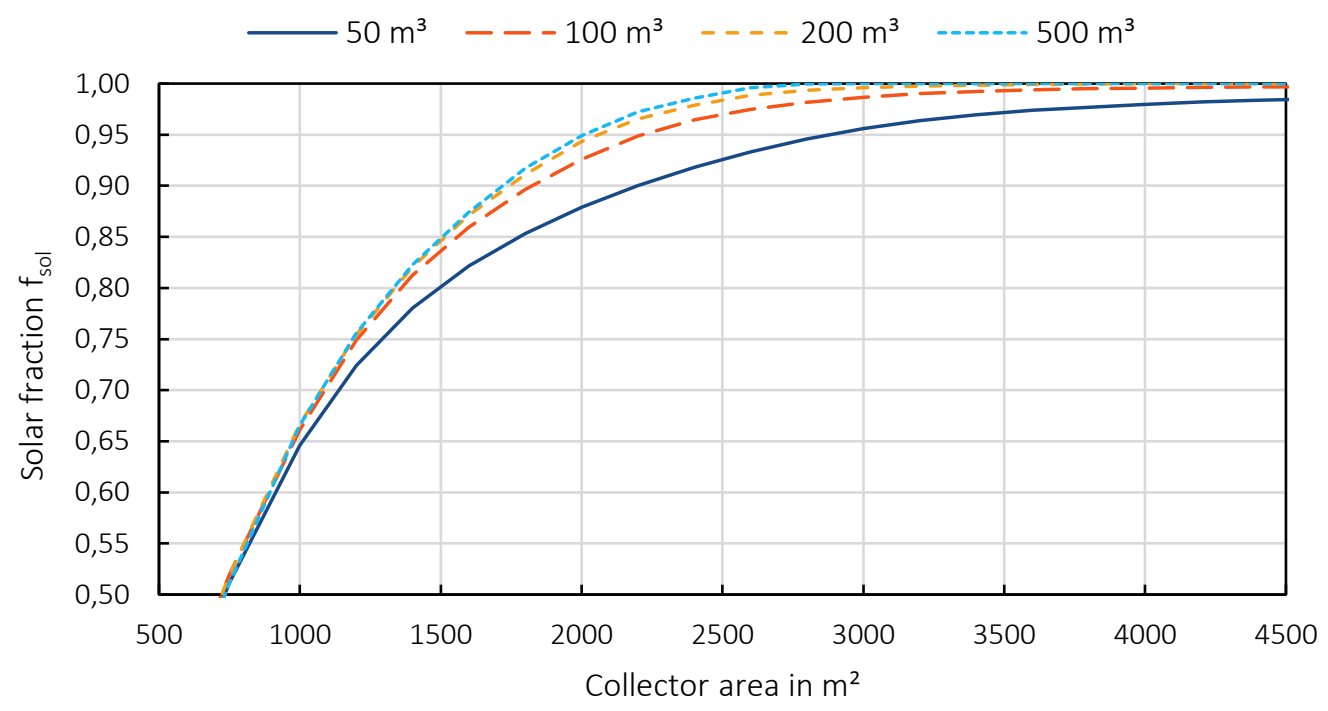

Figure 4: Share of solar thermal energy on the driving heat demand of the absorption chiller versus solar thermal collector area at different storage sizes

Due to the low seasonal differences in the profile of cooling load and solar radiation, the storage only has to cover the daily mismatches. This makes the full coverage of the cooling load with the solar thermal system even at relatively small storage sizes possible. A storage larger than $500 \mathrm{~m}^{3}$ has only a small effect on the required collector area, but increases the investment costs.

In addition to the thermal energy needed to drive the chiller, electrical energy is needed for pumps, fans and other electrical applications. The required driving heat amounts $1214 \mathrm{MWh}_{\mathrm{th}} / \mathrm{a}$ and the electrical energy $115 \mathrm{MWh}_{\mathrm{el}} / \mathrm{a}$. Figure 5 shows the expected annual electricity consumption of the different devices in the cooling system. 


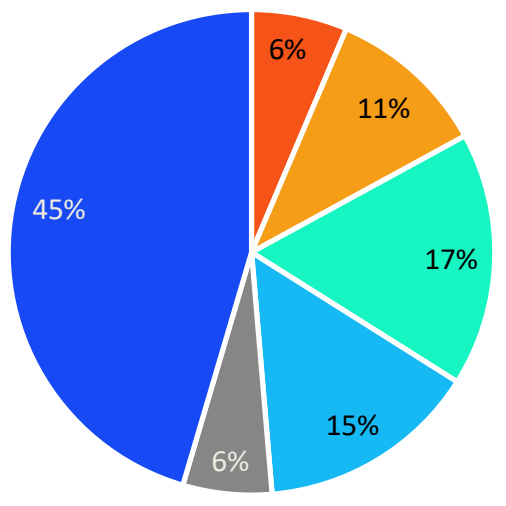

Total: $115 \mathrm{MWh}_{\mathrm{el}}$

- Solar Pumps

- Cooling Water Pumps

$$
\begin{aligned}
& \text { - Hot Water Pumps } \\
& \text { - Dry Cooler }
\end{aligned}
$$

- Absorption Chiller

- Aquifer Pumps

Figure 5: Percentage of electrical consumption for different devices on the annual electricity demand of the cooling system

A share of $45 \%$ of the annual electricity consumption for the cooling system is expected to be consumed by the aquifer pumps, as shown in Fig. 5. This value mostly depends on the permeability of the rocks at the location and might reduce after the results of the drilling are available.

Figure 6 shows the resulting total land consumption required to cover the whole electricity demand of the cooling system at different shares of solar thermal energy on the driving heat at with the respective storage volume to obtain the lowest investment costs.

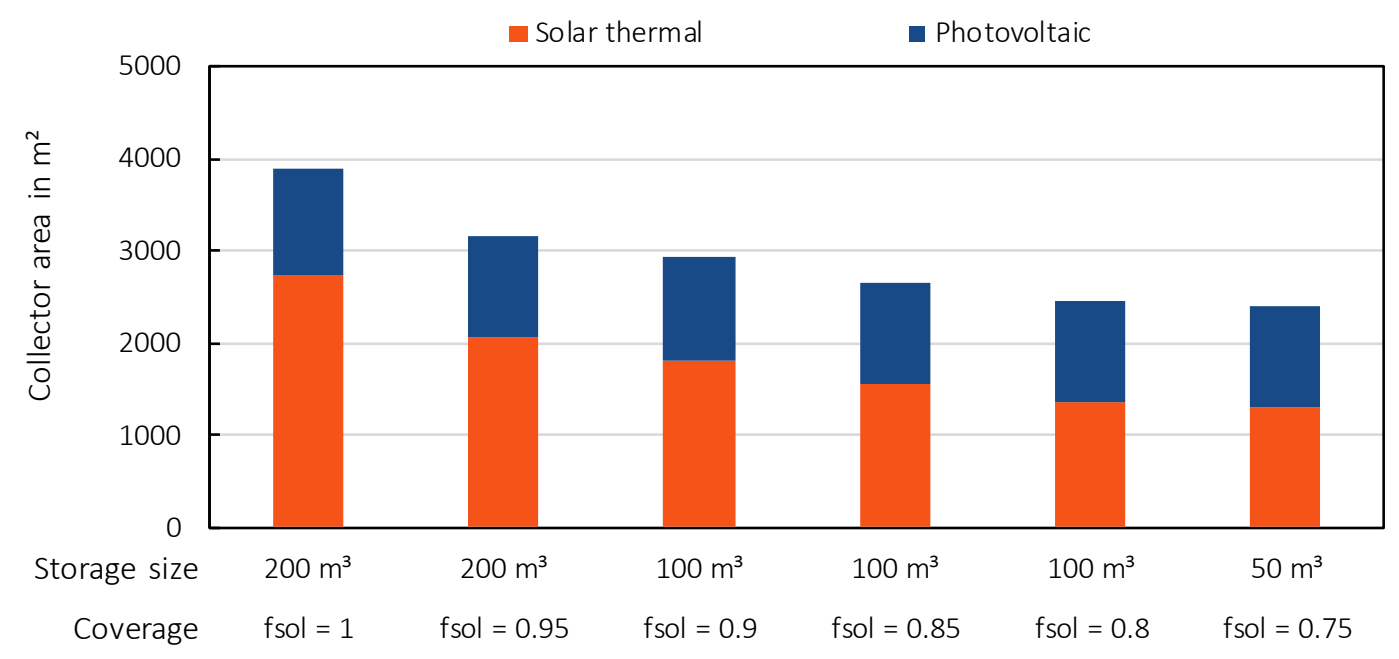

Figure 6: Comparison of land consumption for the thermally driven systems with the required PV area to cover the auxiliary electrical energy demand at different solar shares and storage sizes.

For a full coverage of the cooling system in terms of thermal and electrical energy, a total area of solar thermal collectors and PV modules of $3890 \mathrm{~m}^{2}$ is required. Reducing the share of solar thermal energy reduces the required solar thermal collector area, while the PV area almost stays the same, because the percentage of electrical energy for the solar pump is relatively small. 


\section{Comparison}

A comparison of the thermally driven system with the electrically driven system as a reference can be carried out for various aims like the costs, degree of autarky, the complexity, sustainability, primary energy consumption and $\mathrm{CO}_{2}$ emission. In this project the main goal was to develop an electrically autarkic system with a high degree of sustainability and reliability at low land consumption. Fig. 7 shows the land consumption of thermally driven systems and electrically driven systems at different coverage rates. The thermally driven system uses a gas boiler to cover the remaining part of thermal energy in the options with a solar share below 1, while the electrically driven system uses the public electricity grid to cover the residual energy.

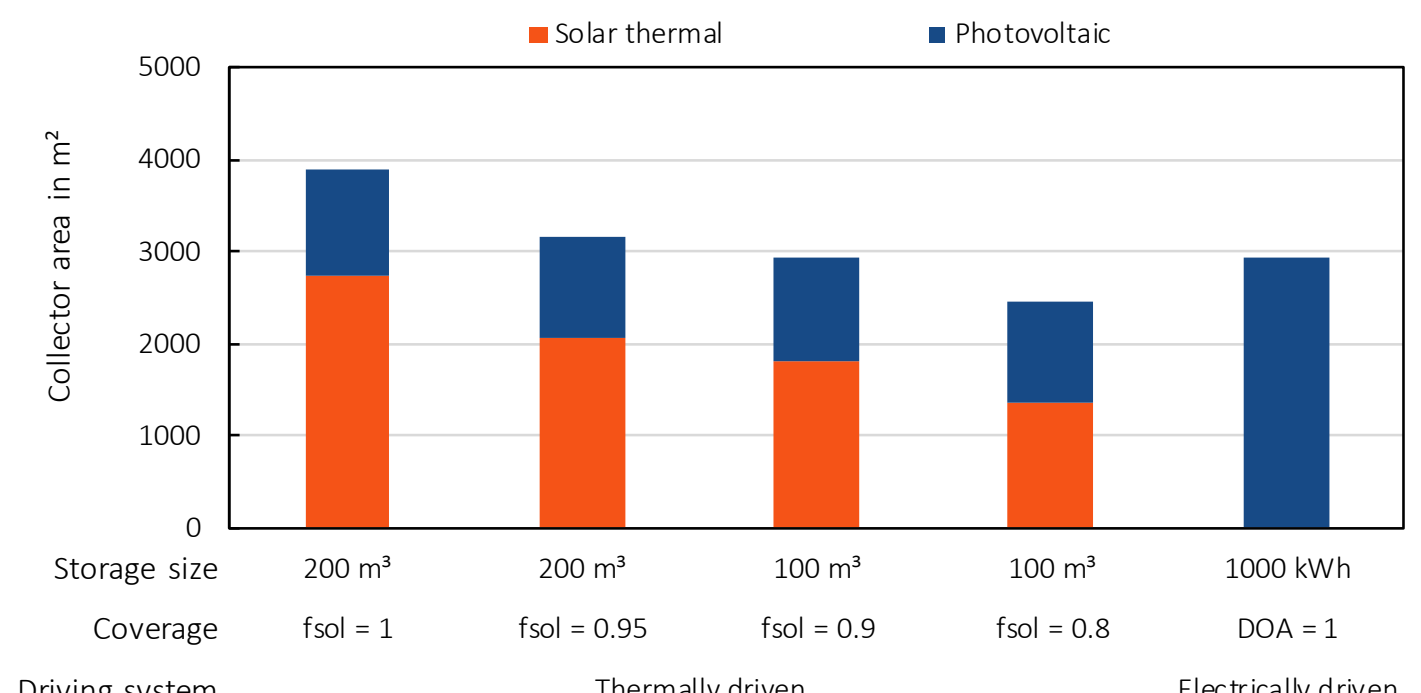

Driving system

Thermally driven

Electrically driven

Figure 7: Comparison of land consumption of solar thermally driven systems and electrically driven systems at different coverage rates.

The energy autarkic thermally driven system, with a full coverage of thermal energy from solar thermal and electrical energy from PV, has a land consumption with the total area of $3890 \mathrm{~m}^{2}$. The autarkic electrically driven system requires an area of PV modules of $2895 \mathrm{~m}^{2}$. Using the gas-boiler as a backup and for peak-loads, reduces the required solar thermal collector area, while the goal of electrical grid autarky can be obtained. The total area for a thermally driven system is the same as the area needed for an autarkic electrically driven system when $10 \%$ of the thermal energy is covered through the gas boiler.

Besides the land consumption, the complexity, reliability and costs have to be considered too. While the investment costs of both systems are in the same range, the lifetime and reliability of the components of the PV-Battery system in the desert-like region could be expected to be lower and thus lead to higher operating costs. On the other hand, the surplus electrical energy, produced by a PV-System can be used to cover a part of the electricity demand of the building. These aspects will be studied in more detail as a next step in the project.

\section{Conclusion}

A thermally driven and an electrically driven design of a solar cooling system could be developed and optimised for a non-residential building in Oman and the study has shown that both are suitable for space cooling. Due to the extreme climatic situation in Oman, it is worthwhile to note that with both options one can achieve full solar coverage at relatively modest storage sizes. Depending on the objectives, one or the other principle has advantages and disadvantages. To reach autarky from the electricity grid, the thermally driven system has the option to use a gas boiler and has hence the potential to reduce the solar thermal area and thus requires less space. When considering the auxiliary electrical energy of the thermally driven system too, the electrically driven systems requires less totals 
space if a $100 \%$ renewable system is desired. The additional PV area to cover the electricity demand, which is mostly traces back to the heat rejection, amounts more than one third of the area needed for solar thermal collectors. This highlights the facts, that auxiliary energy demand cannot be neglected when comparing solar thermal cooling and $\mathrm{PV}$ assisted cooling and that the heat rejection is a big issue in countries with high ambient temperatures. The future work in this project will include a detailed economic study and the comparison with other technologies for heat rejection.

\section{Acknowledgments}

The authors are grateful to our colleagues from German Research Centre for Geosciences (GFZ), Technical University of Berlin, Innovation Park Muscat (IPM), and Public Authority for Civil Aviation (PACA) for their support and constructive discussions. All the detailed cooling load calculations building at Innovation Park Muscat (IPM) was performed by Dr. Saleh Al Saadi from Sultan Qaboos University (SQU). The Research leading to these results has received funding from Institute of Advanced Technology Integration (IATI) under The Research Council (TRC) of the Sultanate of Oman. TRC Research contract No. TRC/RCP/15/003.

\section{References}

[1] International Energy Agency report. 2012. Technology Roadmap: Solar Heating and Cooling. Fig. 17, p. 28. https://www.iea.org/publications/freepublications/publication/Solar_Heating_Cooling_Roadmap_2012_WEB.pdf ,June 2018.

[2] $\underline{w w w . i e a . o r g / s t a t i s t i c s / ? c o u n t r y=O M A N \& y e a r=2016 \& \text { category=Electricity\&indicator }=E l e c G e n B y F u e l \& m o d e=}$ chart\&categoryBrowse=false \&dataTable=ELECTRICITYANDHEAT\&showDataTable=false, June 2018.

[3] Sweetman, T., et.al, 2014. Residential energy use in Oman: a scoping study. Oman final report v8. http://discovery.ucl.ac.uk/1425280/ , January 2014. 


\title{
Simulation of a Solar Fired Absorption System for a Case Study in the Dairy Industry
}

\author{
Camila Correa $^{1}$, Alicia Crespo ${ }^{2,3}$, Felipe Cortés ${ }^{2}$ and Mercedes Ibarra ${ }^{2}$ \\ ${ }^{1}$ Mechanical Engineering Department, University of Chile, Santiago (Chile) \\ ${ }^{2}$ Center for Solar Energy Technologies, Fraunhofer Chile Research, Santiago (Chile) \\ ${ }^{3}$ Faculty of Environmental and Natural Resources. Albert-Ludwigs-Universität Freiburg, Freiburg im \\ Breisgau (Germany)
}

\begin{abstract}
The aim of this study is to evaluate the performance of a single effect hot water-fired Water/LiBr absorption chiller that supplies the cooling demands in the dairy industry sector in Chile. The high levels of radiation of the Chilean center regions enhance solar absorption as a viable alternative to electrically driven mechanical vapor compression systems. Different plant configurations were simulated with TRNSYS 18 for a designed cooling fraction covered by the absorption chiller in a range of $14 \%$ to $20 \%$. Areas of a solar field between $80-230 \mathrm{~m}^{2}$ of evacuated tube collectors coupled with an auxiliary gas system provided heat for the absorption system. The results showed a solar fraction for the studied cooling system of values between $30 \%$ to $66 \%$ and COPs between 0.40 to 0.51 . A LCOC varying from 0.164 to $0.22 \mathrm{USD} / \mathrm{kWh}$ was obtained. The configurations of solar absorption system for the different studied collector's area obtain a negative NPV. However, a reduction in the collector's prices, different storage capacities or different system configurations may improve the results of the economic study.
\end{abstract}

Keywords: Solar absorption refrigeration system, solar integration to dairy industry, economic evaluation

\section{Introduction}

Traditional power generation methods based on fossil fuels and hydroelectric dams still dominate the Chilean power grid. At the end of 2017, only $18 \%$ of the energy sources in the country were renewable, where solar photovoltaic and wind technologies designed for electricity generation have had the greatest growths in the last years. Reducing the dependency on fossil fuel-obtained electricity and on conventional refrigeration fluids are both serious concerns regarding global warming and the need to pursue more sustainable energy sources.

In the Chilean manufacturing industry, food and beverages production represents nearly a third of the annual electricity consumption $(1,220 \mathrm{GWh})$, from which between $30 \%$ and $50 \%$ of the electricity demand is used for refrigeration purposes (Instituto Nacional de Estadisticas (INE), 2014). Most of the time, refrigeration demands are supplied by vapor compressor systems or conventional chillers, which require a large amount of electricity to operate, therefore explaining the high electricity consumption values for refrigeration purposes.

Thermally driven chillers or absorption chillers are an alternative to traditional vapor compressor systems, supplying chilled water for air conditioning and dehumidification processes or for water cooling applications in industry. Closed absorption cycles operate with a pair of fluids which work as a heat removal solution, in an evaporation-condensation process which can be divided into three stages: Evaporation, Absorption and Regeneration. To extract heat, the liquid refrigerant is evaporated in a low partial pressure environment, and then is absorbed in gaseous form by the other liquid, transferring the heat from its surroundings to it. Finally, the solution is heated by an external source and thus, the refrigerant is evaporated and then condensed to reutilize it in the cycle. Special care must be taken to maintain the absorption chiller within nominal conditions, to avoid crystallization or corrosion issues caused by the selected working pairs (Akhtar et al., 2015). Water and lithium-bromide is a frequently used working pair, in particular for applications where sanitary conditions must be guaranteed, as in the food industry. Other materials can be used for similar purposes, such as a refrigerant and a highly porous solid in an adsorption cycle, however these are much bulkier and expensive than absorption systems, which are also more efficient and have greater cooling capacities (Zhai and Wang, 2009).

Thermally driven chillers need an external source to heat the solution in the absorption cycle. This source can be of different nature, such as, a fossil fuel boiler or solar thermal collectors. The temperature range required from the 


\section{Correa et.al}

heat source, around 70 to $100{ }^{\circ} \mathrm{C}$, matches perfectly the temperatures reached by solar thermal collectors, such as flat plate collectors or evacuated tube collectors. Therefore, there is a great opportunity for integrating solar thermal heat together with absorption chillers (solar absorption systems) in order to supply refrigeration demand in industrial processes without a high electricity consume.

Solar absorption systems have been previously studied, however in most of the cases for air-conditioning systems for residential and commercial buildings and in a few cases for industrial applications. A number of simulations have been carried out for $\mathrm{LiBr}$-water absorption cycles, such as systems coupled with evacuated tube collectors in Malaysia (Assilzadeh et al., 2005) and parabolic trough collectors in Iran (Mazloumi et al., 2008). Experimental studies in Madrid with flat-plate collectors for $35 \mathrm{~kW}$ (Syed et al., 2005) and $4.5 \mathrm{~kW}$ (Lizarte et al., 2012) cooling capacities were carried out, obtaining mean COP values of 0.42 and 0.53 , respectively. In Thailand, a solar fraction of $81 \%$ was reached by evacuated tube collectors for a 10 ton absorption system (Pongtornkulpanich et al., 2008).

In Sun et al. (2015) a solar and gas fired absorption system for joint cooling and heating in a commercial building is presented. The need to combine a sustainable source such as solar thermal energy with a stable traditional gas to operate the absorption cycle was highlighted. As a result, gas consumption was reduced in 49,7 \% for the chiller. In Akhtar et al., (2015) a feasibility study of solar-driven absorption cooling cycle for air-handling applications was presented for Tetrapak Lahore, Pakistan. The studied variables for the economic analysis were the solar collector area and type, cooling capacity and cooling area. The estimated payback period was of 4.1 years for a solar fraction of $69 \%$. In Mexico, solar cooling potential was studied in the food industry (Best B. et al., 2013) for an air cooled ammonia-water absorption chillers driven by a Fresnel solar field. Here, a $19 \%$ reduction of electricity consumption was obtained in simulations for a subsystem in a large-scale pork processing plant with operating temperatures between $-2-2{ }^{\circ} \mathrm{C}$.

Food and beverage production industries in Chile represent a high refrigeration demand. Furthermore, most of the industries are located in the center of the country where high radiations levels are available (GHI yearly average of $2015 \mathrm{kWh} / \mathrm{h}$ ). Hence, the industry selected for this work is the food and beverage industry. This study focused on the economic and thermal performance assessment of a solar assisted absorption systems in a sub-sector from the food and beverage industry in Chile.

The following sections will contain: In Section 2 the context of the Chilean diary industry is presented, along with a description of the proposed system. In Section 3, configurations and design parameters of the simulations will be summarized. Section 4 contains the results of these simulations, the thermal and economic evaluation. As a conclusion, an assessment of the different configurations is made.

\section{Dairy industry and production process}

Food industry was selected as the focus for potential solar cooling integration due to an analysis of the most commonly utilized thermal processes and their required operation temperatures. In Tab. 1, Chilean electricity consumption has been extracted from the Annual National Industrial Survey of 2014 (Instituto Nacional de Estadisticas (INE), 2014) and expressed in its relative weight for the main industrial sectors. This survey does not include information of the mining sector, where thermal demands are also important. Furthermore, cooling demands are negligible in this industry. The food and beverage industry are the second most energy-consuming manufacturing sector in the country, preceded by wood and paper industry, which is exclusive to the southern regions and whose refrigeration needs are also small in comparison to the food sector. Hence, the focus of this work is on the food industry.

Tab. 1: Electric consumption of selected industrial sectors in Chile.

\begin{tabular}{|c|c|c|}
\hline Sector & Electric yearly consumption (MWh) & Relative weight (\%) \\
\hline Food and beverages & 1.220 .000 & $27,3 \%$ \\
\hline Textiles & 65.400 & $1,46 \%$ \\
\hline Wood and paper & 1.475 .000 & $33,0 \%$ \\
\hline Chemicals and pharmaceutics & 914.000 & $20,5 \%$ \\
\hline
\end{tabular}


C. Correa et.al

\begin{tabular}{|c|c|c|}
\hline Plastics & 325.400 & $7,28 \%$ \\
\hline Non-metallic minerals & 409.000 & $9,15 \%$ \\
\hline
\end{tabular}

Dairy and meat companies represented the biggest energy consumption for refrigeration areas in the industry. Tab. 2 shows the estimated refrigeration demands for the biggest sub-sectors in the food industry, where dairy and met represent $24 \%$ and $21 \%$, respectively. Although dairy industry is mainly located in the south region of Chile, the largest processing plants are close to Santiago, which is in the center of the country. Additionally, the industrial processes are highly standardized and require refrigeration temperatures over $0{ }^{\circ} \mathrm{C}$, allowing the use of commercially available, non-toxic Water/LiBr absorption chillers to supply the cooling demand. Both reasons make the dairy industry a better alternative to integrate solar refrigeration, which also is reflected in the number of case studies of solar driven plants in other countries (Farjana et al., 2018).

Tab. 2: Estimated refrigeration demands for sub-sectors in the food and beverage industry.

\begin{tabular}{|c|c|c|c|c|c|}
\hline $\begin{array}{c}\text { Sub- } \\
\text { sector }\end{array}$ & $\begin{array}{c}\text { Electric yearly } \\
\text { consumption } \\
\text { [MWh] }\end{array}$ & $\begin{array}{c}\text { Electricity } \\
\text { destined for } \\
\text { refrigeration } \\
\text { purposes [\%] }\end{array}$ & $\begin{array}{c}\text { Electricity } \\
\text { destined for } \\
\text { refrigeration } \\
\text { purposes [MWh] }\end{array}$ & $\begin{array}{c}\text { Main } \\
\text { refrigerati } \\
\text { on process }\end{array}$ & $\begin{array}{c}\text { Relative } \\
\text { refrigeration } \\
\text { demand [\%] }\end{array}$ \\
\hline Meat & 242.039 & $54 \%$ & 130.701 & Freezing & $21 \%$ \\
\hline Fish & 167.936 & $17 \%$ & 28.549 & Freezing & $8 \%$ \\
\hline $\begin{array}{c}\text { Fruit \& } \\
\text { vegetables }\end{array}$ & 124.418 & $16 \%$ & 19.907 & Storage & $3 \%$ \\
\hline Dairy & 128.882 & $41 \%$ & 52.842 & $\begin{array}{c}\text { Process } \\
\text { cooling }\end{array}$ & $24 \%$ \\
\hline Wine & 47.462 & $58 \%$ & 27.528 & $\begin{array}{c}\text { Process } \\
\text { cooling }\end{array}$ & $12 \%$ \\
\hline $\begin{array}{c}\text { Non- } \\
\text { alcoholic } \\
\text { beverages }\end{array}$ & 80.727 & $45 \%$ & 36.327 & $\begin{array}{l}\text { Process } \\
\text { cooling }\end{array}$ & $11 \%$ \\
\hline Bakery & 118.362 & $60 \%$ & 71.017 & Storage & $21 \%$ \\
\hline
\end{tabular}

In the typical Chilean dairy plant in the central region, the main products are milk (53\%) and yoghurt (37\%). The thermal demand for their production derives from several processes: cooling for storage $\left(4^{\circ} \mathrm{C}\right)$, preheating for secondary processes (e.g.: cream extraction by standardization at 40-60 ${ }^{\circ} \mathrm{C}$ ), pasteurization (LTLT, HTST, UHT at 60-72-130 ${ }^{\circ} \mathrm{C}$, respectively) and process cooling (4-30 ${ }^{\circ} \mathrm{C}$ ) (Bylund, 2015). These processes are summarized in Tab. 3. Assuming typical and standardized plant processes, it has been identified most energy-consuming refrigeration process is the post-pasteurization cooling process, followed by cooled storage (Masanet et al., 2014).

Tab. 3: General heating and cooling processes in dairy production.

\begin{tabular}{|c|c|c|}
\hline General Process & $\begin{array}{c}\text { Operational } \\
\text { Temperature }\left[{ }^{\circ} \mathrm{C}\right]\end{array}$ & Function \\
\hline $\begin{array}{c}\text { Cooling for } \\
\text { storage }\end{array}$ & $4{ }^{\circ} \mathrm{C}$ & $\begin{array}{c}\text { Cool milk entering the storage and maintain } \\
\text { constant temperature. }\end{array}$ \\
\hline Preheating & $40-60{ }^{\circ} \mathrm{C}$ & E.g.: Standardization \\
\hline Pasteurization* & $60-72-130{ }^{\circ} \mathrm{C}$ & $\begin{array}{c}\text { Heat treatment to reduce unwanted bacterial } \\
\text { concentration in dairy products. }\end{array}$ \\
\hline Process cooling & $4-30^{\circ} \mathrm{C}$ & $\begin{array}{c}\text { E.g.: As part of the pasteurization process or } \\
\text { intermediate states between other dairy products. }\end{array}$ \\
\hline
\end{tabular}

*Operational temperatures and times depend on the heat treatment applied (LTLT, HTST, UHT, etc.) 


\section{Correa et.al}

From the Office for Agricultural Studies and Policies (Oficina de Estudios y Políticas Agrarias (ODEPA), 2014) information of dairy sub-products production of every industrial plant is recollected, as well as their reception of fresh milk from regional farms. This was crucial to determine average production levels. For the simulations, the average regional production of 15200 ton/year was taken as the base case. Also, with the purpose of evaluating the integration of solar refrigeration for big companies (representing more than $50 \%$ of the regional production) a high-level production of 47.200 ton/year was assessed. For both cases, a constant monthly demand was considered, as the year-round variation is less than $10 \%$.

Production of dairy sub-products varies from type, country and processes applied. This study focused on the performance of an absorption solar refrigeration system that supplies part of the thermal need to the postpasteurization process and part of the cooling demand required for milk storage $\left(\right.$ at $\left.4{ }^{\circ} \mathrm{C}\right)$ due to the match between required process temperatures and chiller working temperatures. In Fig. 1 a scheme of the solar integration to the process is presented, where the solar field and auxiliary heating source is connected to an absorption chiller coupled to the post-pasteurization cooling for storage. Other integration points have been identified, such as reception storage cooling, additional pre-heating and/or pre-cooling of pasteurization and even pasteurization al low temperatures. However, a bigger investment and alteration to standardized processes must be made and escapes the proposed scope.

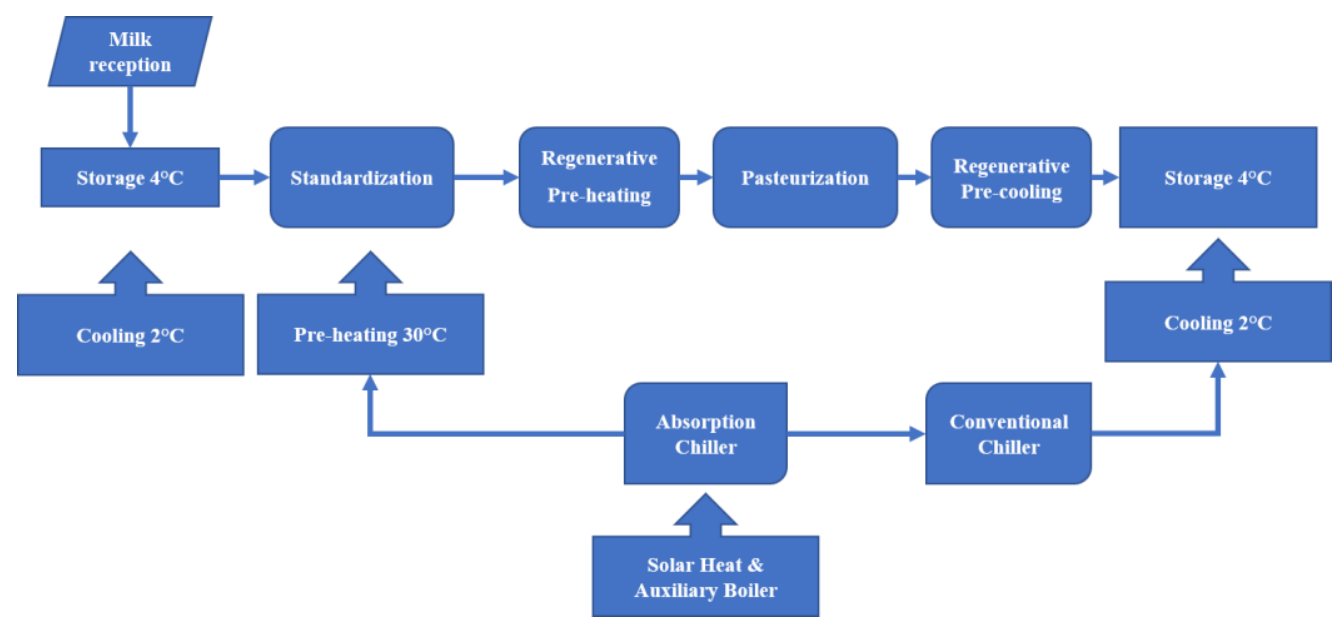

Fig. 1: Scheme of solar integration to dairy process

\section{Simulation design}

The simulated system was designed to satisfy between $14 \%$ to $20 \%$ of total cooling demand by the absorption chiller assisted by a conventional chiller. The analyzed demands for the cooling were based on two levels of dairy production, constant throughout the year:

- Model 1: Average regional production amounts to 15.200 ton/year. Operation time of 10 hours daily. The absorption system was designed to satisfy around $20 \%$ of the cooling demand.

- Model 2: High level production plant is 47.200 ton/year. Operation time of 8 hours daily. The absorption system was designed to satisfy around $14 \%$ of the cooling demand.

Moreover, two plant configurations were analyzed: configuration A (see Fig. 2), focused on the chilled water production and using a preheating section to reduce the cooling water outlet temperature. The cooling water outlet temperature will preheat the milk from $4{ }^{\circ} \mathrm{C}$ to maximum values of $28{ }^{\circ} \mathrm{C}$ (Model 1) to $34{ }^{\circ} \mathrm{C}$ (Model 2). In configuration B (see Fig.3), the solar field, in addition to heat the water to feed the absorption chiller, uses the excess hot water in the collector circuit for a second preheat of the milk up to $60{ }^{\circ} \mathrm{C}$ before returning to the solar field. In the absorption chiller, the milk is cooled down from 24 to $13{ }^{\circ} \mathrm{C}$ in configuration A and from 19 to $12{ }^{\circ} \mathrm{C}$ in configuration $\mathrm{B}$.

The hot thermal energy required for the absorption chiller is supplied by solar energy with assistance of a gas boiler. The absorption chiller considered in the simulations is a single effect water/LiBr absorption system with working 
C. Correa et.al

temperatures of hot water $88 / 83^{\circ} \mathrm{C}$, cooling water $31 / 35^{\circ} \mathrm{C}$ and chilled water $12 / 7^{\circ} \mathrm{C}$. The chiller provides the pasteurization cooling with the chilled water produced. A small conventional chiller has been integrated in the system to support the absorption chiller and maintain the operational temperatures within $12-7^{\circ} \mathrm{C}$, however it is used in less than $0.5 \%$ of the energy. For the cooling water circuit, a cooling tower is considered to support the absorption chiller when the water is not cold enough to enter the absorption chiller.

Different areas of solar collector field $\left(80-230 \mathrm{~m}^{2}\right)$ coupled to the refrigeration system were considered in the TRNSYS 18 simulation. Evacuated tube collectors have been chosen for this configuration to reduce ambient heat and efficiency loss due to the great daily thermal oscillation present in the center regions of the country. Type 71 of the TESS Library of TRNSYS was selected. The Incidence Angle Modifier (IAM) data of the collector was obtained from commercially available evacuated solar collectors (Apricus).

The absorption chiller was simulated based on a Maya-Yazaki model using the type 107 of TRNSYS. The main data parameters of this absorption chiller are shown in Tab. 4.

Tab. 4: Inlet and outlet temperatures simulated in hot water-fired absorption chiller (Maya-Yazaki).

\begin{tabular}{|c|c|c|c|c|c|}
\hline Model & SC10 & SC20 & \multicolumn{2}{|c|}{ Inlet Temperature ${ }^{\circ} \mathbf{C}$} & Outlet Temperature ${ }^{\circ} \mathbf{C}$ \\
\hline Power (kJ/hr) & 126.720 & 253.080 & Min. & Max. & 83 \\
\hline Hot water (kg/hr) & 8.640 & 17.280 & 70 & 95 & 35 \\
\hline Cooling water (kg/hr) & 18.360 & 36.720 & 29,5 & 31 & 7 \\
\hline Chilled water (kg/hr) & 5.472 & 10.980 & 12 & 15,5 & 7 \\
\hline
\end{tabular}

Moreover, an automatic control is incorporated to the system. First, pumps, auxiliary heater and both chillers' operation hours are limited to a six day-week and 8 to 10 hours a day for the different configurations. The pasteurized milk will first be cooled with the conventional chiller from $60{ }^{\circ} \mathrm{C}$ (estimated outlet temperature from regenerative cooling section) to $24{ }^{\circ} \mathrm{C}$ (Model 1) or $19{ }^{\circ} \mathrm{C}$ (Model 2), then it will be cooled down by the chilled water of the absorption chiller with help of the conventional chiller.

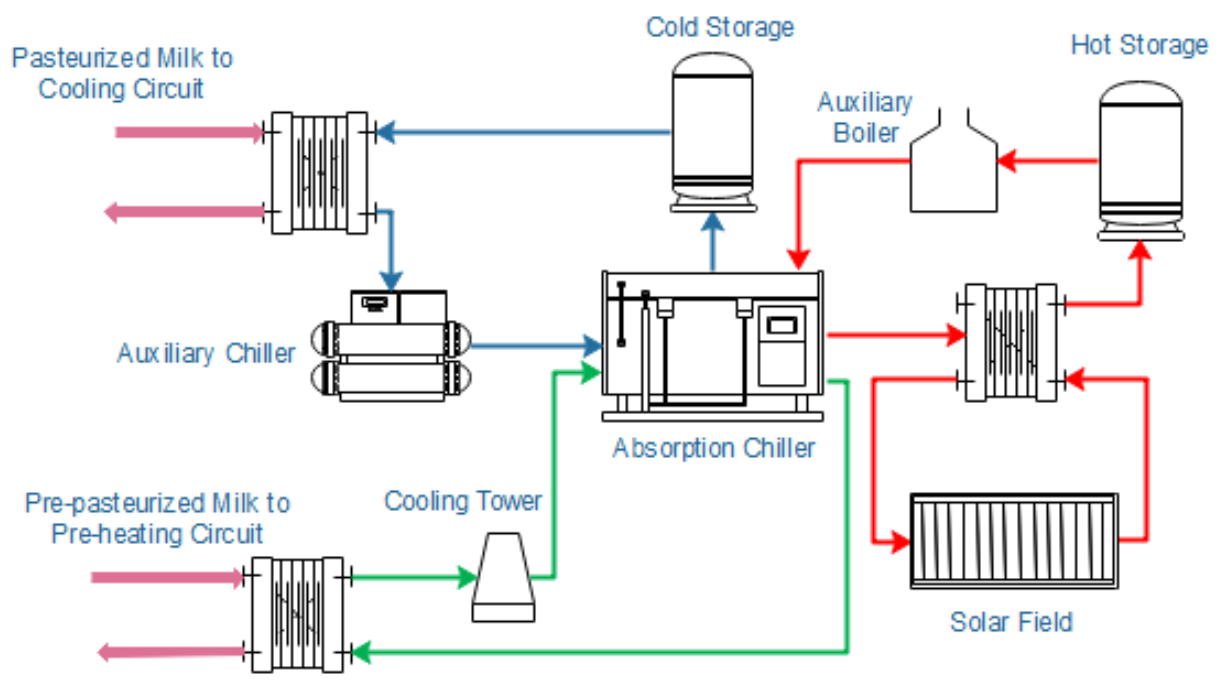

Fig. 2: Scheme of solar refrigeration integration for configuration A 
C. Correa et.al

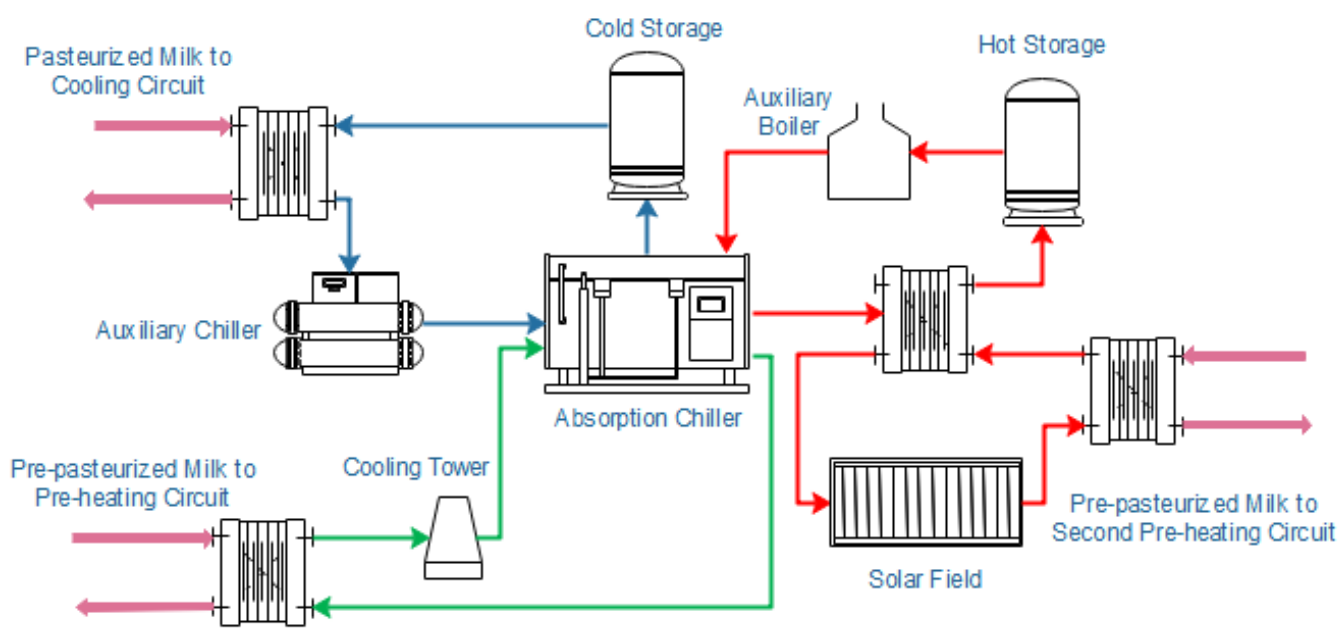

Fig. 3: Scheme of solar refrigeration integration for configuration B

\section{Results conclusions}

In Tab. 5 the results of the simulations are presented: the chilled water energy produced by the solar absorption chiller and the conventional chiller, the heat produced by the solar field and the gas boiler and the energy supplied by refrigeration towers to cool down the water for the medium temperature circuit of the absorption chiller.

The results show that for the considered solar collector's area a considerable amount of energy from the boiler was necessary to supply the thermal energy to the absorption chiller. However, the larger the area of the collector's field was, the lower was the amount of energy required by the boiler. The medium temperature circuit of the absorption chiller must be also supported by a cooling tower to reach the $31{ }^{\circ} \mathrm{C}$ necessary to enter the chiller. Nevertheless, the chilled circuit worked almost completely without support from the conventional chiller.

Tab. 5: Results of the simulations for the different configurations.

\begin{tabular}{|c|c|c|c|c|c|c|c|}
\hline Simulation & $\begin{array}{l}\text { Collector's } \\
\operatorname{area}\left(\mathbf{m}^{2}\right)\end{array}$ & $\begin{array}{c}\text { Absorption } \\
\text { chiller } \\
\text { power } \\
(\mathbf{k W})\end{array}$ & $\begin{array}{c}\text { Cooling } \\
\text { supplied by } \\
\text { convention } \\
\text { al chiller } \\
\text { (kWh/year) }\end{array}$ & $\begin{array}{c}\text { Cooling } \\
\text { supplied by } \\
\text { absorption } \\
\text { chiller } \\
\text { (kWh/year) }\end{array}$ & $\begin{array}{c}\text { Cooling } \\
\text { energy } \\
\text { supplied by } \\
\text { refrigeratio } \\
\text { n towers } \\
\text { (kWh/year) }\end{array}$ & $\begin{array}{c}\text { Solar } \\
\text { thermal } \\
\text { energy } \\
\text { (kWh/year) }\end{array}$ & $\begin{array}{c}\text { Thermal } \\
\text { energy } \\
\text { supplied by } \\
\text { boiler } \\
\text { (kWh/year) }\end{array}$ \\
\hline $1 \mathrm{~A}$ & 80 & 35.2 & 171 & 88,946 & 45,555 & 58,760 & 122,280 \\
\hline $1 \mathrm{~A}$ & 105 & 35.2 & 171 & 88,946 & 45,555 & 76,425 & 104,250 \\
\hline $1 \mathrm{~A}$ & 130 & 35.2 & 171 & 88,947 & 45,555 & 93,100 & 82,012 \\
\hline $1 \mathrm{~A}$ & 155 & 35.2 & 171 & 88,947 & 45,575 & 106,176 & 66,463 \\
\hline $1 \mathrm{~B}$ & 80 & 35.2 & 210 & 88,915 & 45,237 & 66,749 & 157,781 \\
\hline $1 \mathrm{~B}$ & 105 & 35.2 & 210 & 88,915 & 45,237 & 86,153 & 134,625 \\
\hline $1 \mathrm{~B}$ & 130 & 35.2 & 210 & 88,915 & 45,237 & 104,874 & 113,078 \\
\hline $1 \mathrm{~B}$ & 155 & 35.2 & 210 & 88,915 & 45,237 & 122,293 & 93,304 \\
\hline $2 \mathrm{~A}$ & 150 & 70.3 & 1,897 & 148,312 & 11,252 & 80,947 & 228,537 \\
\hline $2 \mathrm{~A}$ & 180 & 70.3 & 1,896 & 148,312 & 11,252 & 93,802 & 211,759 \\
\hline $2 \mathrm{~A}$ & 200 & 70.3 & 1,896 & 148,312 & 11,248 & 106,637 & 195,390 \\
\hline $2 \mathrm{~A}$ & 230 & 70.3 & 1,896 & 148,312 & 11,254 & 120,347 & 177,445 \\
\hline $2 \mathrm{~B}$ & 150 & 70.3 & 2,409 & 141,313 & 34,061 & 133,898 & 159,323 \\
\hline $2 \mathrm{~B}$ & 180 & 70.3 & 2,409 & 141,311 & 34,058 & 151,391 & 132,415 \\
\hline $2 \mathrm{~B}$ & 200 & 70.3 & 2,409 & 141,310 & 34,058 & 170,252 & 113,376 \\
\hline $2 \mathrm{~B}$ & 230 & 70.3 & 2,409 & 141,309 & 34,059 & 188,509 & 97,640 \\
\hline
\end{tabular}


C. Correa et.al

The solar fraction of the system was calculated as the solar energy used for the chiller versus the total thermal energy required for the chiller. The results showed that the larger the solar collector's area was, the higher the solar fraction was. The same happened for the COP of the absorption chiller of the different cases. However, the collector's area had less impact in the COP of the absorption chiller than in the solar fraction. The COP and the solar fraction for studied configurations (1A, 1B, 2A or 2B) and collector's areas $\left(80,105,130\right.$ and $\left.155 \mathrm{~m}^{2}\right)$ are shown in Fig. 4.

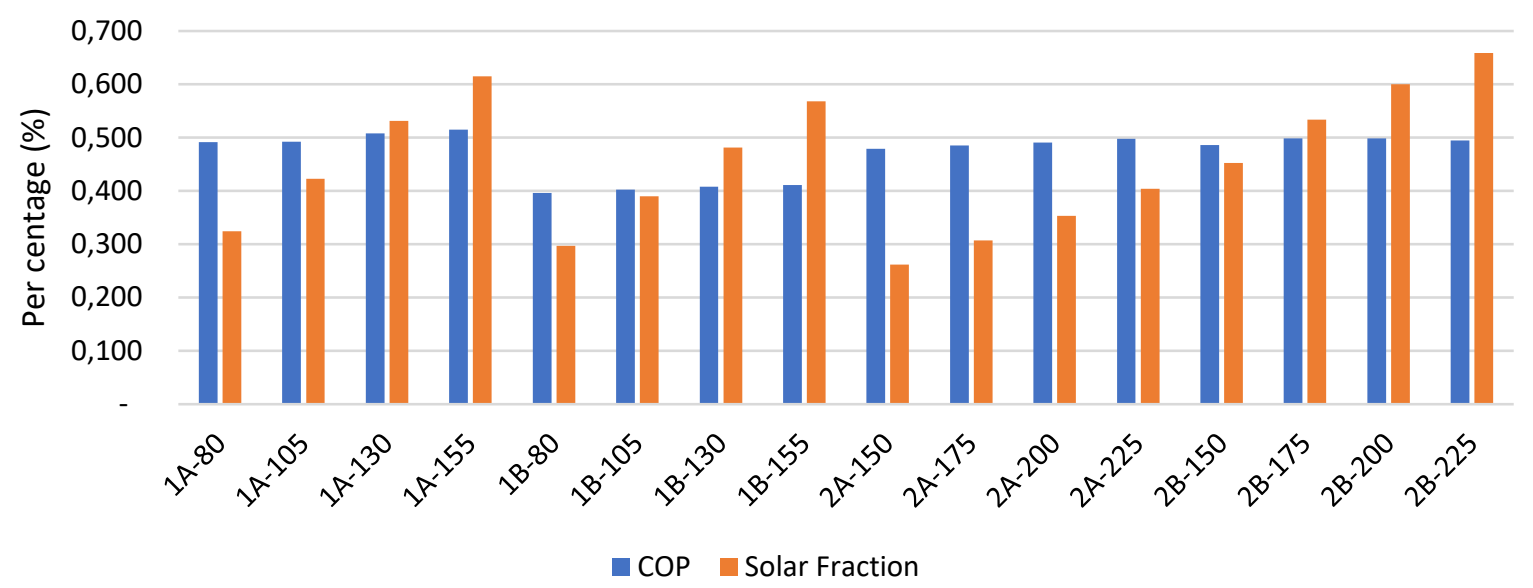

Fig. 4: COP and Solar Fraction.

In the plant configuration B, the solar field, in addition to provide heat for the absorption chiller, preheats the milk. In order to compare which configuration was more efficient regarding the milk pre-heating for the same collector's area, the total fossil fuel energy required (see Fig. 5) to heat up the milk from 4 to $60{ }^{\circ} \mathrm{C}$ has been obtained. The results showed that the configuration $\mathrm{B}$ required less fossil-fuel energy to heat up the same amount of milk.
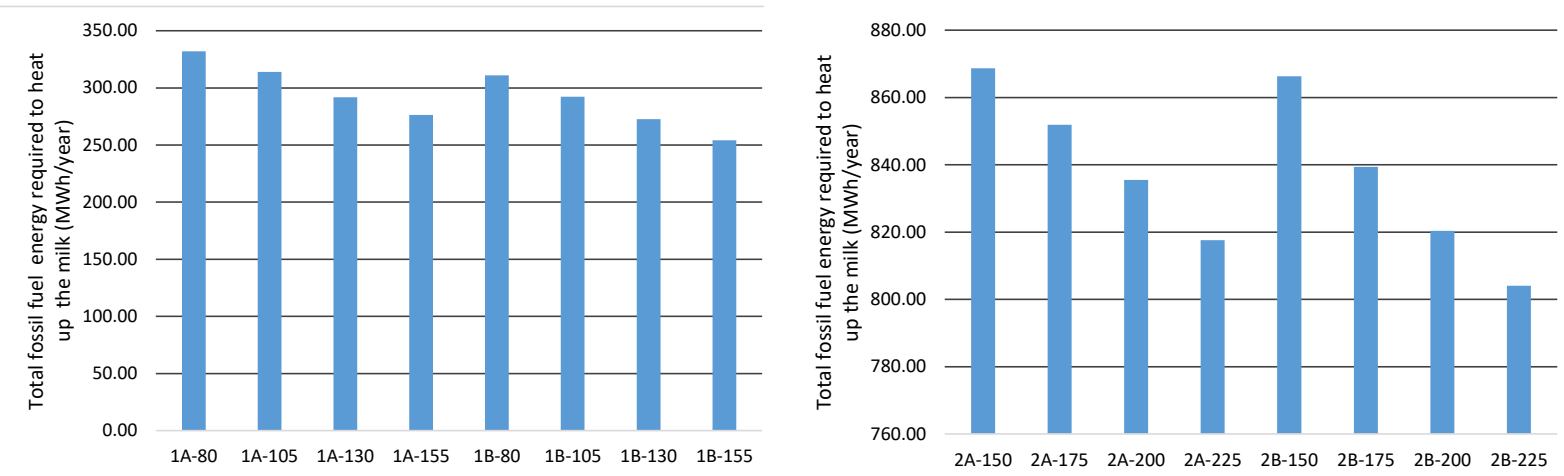

Fig. 5: Total fossil fuel energy required to heat up the milk from 4 to $60{ }^{\circ} \mathrm{C}$ for the studied cases $(1 \mathrm{~A}, 1 \mathrm{~B}, 2 \mathrm{~A}$ or $2 \mathrm{~B})$ and collector's areas $(80,105,130$ and $155 \mathrm{~m} 2)$.

Furthermore, an economic-analysis of the configurations presented has been also performed. The investment and operational cost and other economic parameters considered in the study are shown in Tab. 6.

Tab. 6: Parameters for the economic analysis.

\begin{tabular}{|c|c|}
\hline Name & Cost \\
\hline Absorption chiller & $800 \mathrm{USD} / \mathrm{kW}$ cooling \\
\hline Solar field & $250 \mathrm{USD} / \mathrm{m}^{2}$ \\
\hline O\&M Chiller & $2 \%$ investment cost \\
\hline O\&M Solar & $2 \%$ investment cost \\
\hline Electricity & $0.13 \mathrm{USD} / \mathrm{kWh}$ \\
\hline Natural Gas & $0.03 \mathrm{USD} / \mathrm{kWh}$ \\
\hline
\end{tabular}


C. Correa et.al

\begin{tabular}{|c|c|}
\hline Additional components & $10 \%$ of total inversion cost \\
\hline Discount rate & $10 \%$ \\
\hline Lifetime of the systems & 20 years \\
\hline
\end{tabular}

The results of the LCOC for the different cases are shown in Fig. 6. The LCOC for configuration A is lower than for configuration $\mathrm{B}$, reaching the lowest value at $0.164 \$ / \mathrm{kWh}$ for the configuration $2 \mathrm{~A}$ with a collector area of $150 \mathrm{~m}^{2}$. Moreover, in this case, the larger the collector's area is, the lowest the LCOC is. The cases with higher milk process demand (case 2) obtained also lower LCOC.

$L C O C=\frac{I_{0}+\sum_{t=1}^{T} \frac{C_{t}}{(1+r)^{t}}}{\sum_{t=1}^{T} \frac{E}{(1+r)^{t}}}$

Where $\mathrm{I}_{0}$ are the investment costs, $\mathrm{C}_{\mathrm{t}}$ the operation and maintenance costs, $\mathrm{r}$ the escalation rate, $\mathrm{T}$ is the lifetime of the system in years, $\mathrm{t}$ is every year considered and $\mathrm{E}$ is the cooling energy produced by the absorption chiller.

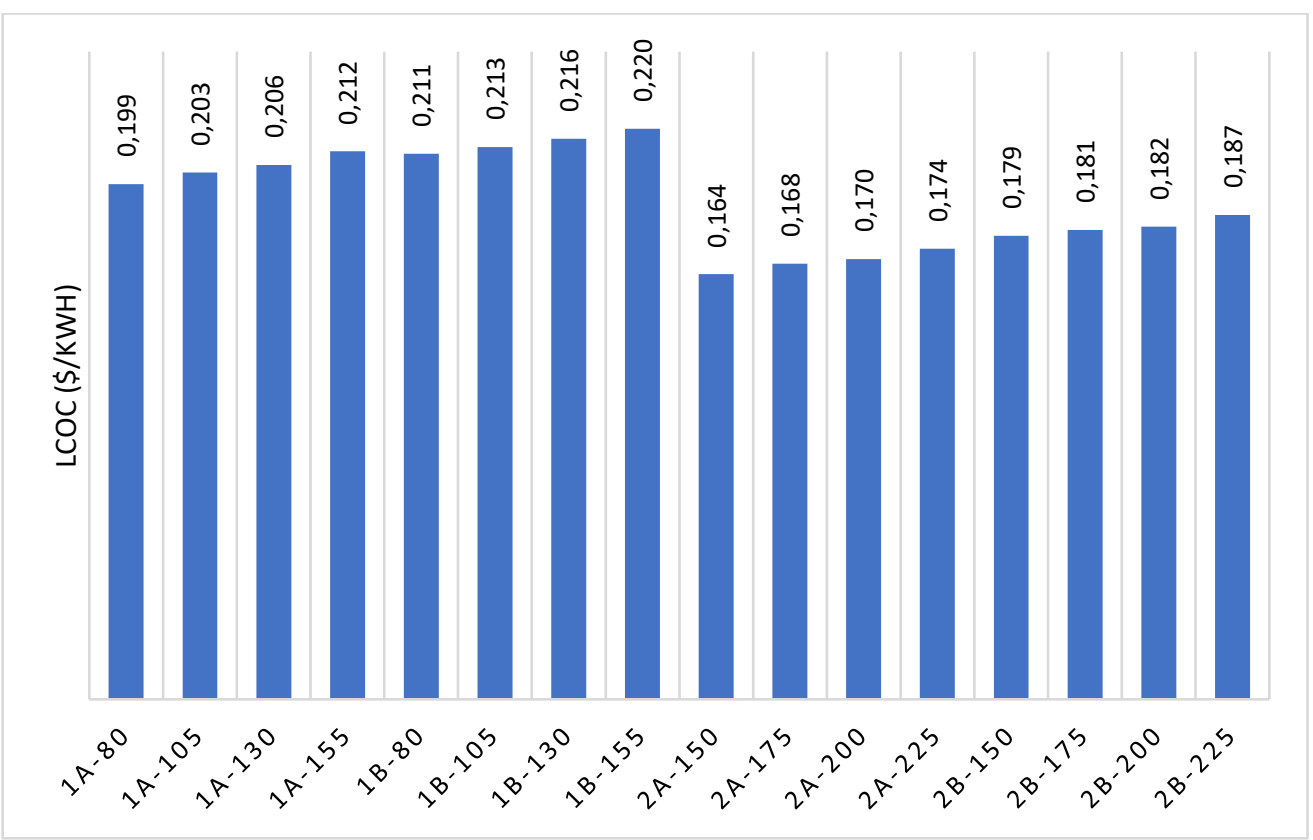

Fig. 6: Levelized Cost of Cooling of the different configurations in USD/kWh.

A negative NPV was obtained for all configurations presented. This is mainly due to the high investment costs of the collector and absorption chiller and the operational costs of the boiler and refrigeration towers in comparison with the savings in cooling energy produced by the absorption chiller. Nevertheless, a decrease in the collector's prices, different storage capacities or system configurations and the possibility to cool down completely the cooling water circuit with a process stream may improve the results of the economic study.

\section{Conclusions}

A set of 16 simulations with different collector's area, process demand and system configurations for a designed cooling fraction covered by an absorption chiller in a range of $14 \%$ to $20 \%$ has been performed. The analysis showed that the higher the collector's area is, the higher is the solar fraction of the cooling system and the COP of the absorption chiller. However, the solar fraction is more sensible to variations in the collectors' area than the COP. The results showed a solar fraction for the studied cooling system of values between $30 \%$ to $66 \%$ and COPs between 0.40 to 0.51 . A LCOC varying from 0.164 to $0.22 \mathrm{USD} / \mathrm{kWh}$ was obtained. Configuration A provides better LCOC values in comparison to configuration B in a range between 4 to $9 \%$ lower. Nevertheless, configuration A requires more external fossil fuel consume to heat up the milk from 4 to $60{ }^{\circ} \mathrm{C}$ in a range from 0.3 to $8 \%$ more energy is required by configuration $\mathrm{A}$ in comparison to configuration $\mathrm{B}$. Although a combined economic analysis of the whole system considering all heating and cooling demands of the milk process has not 
C. Correa et.al

been performed, configuration A seems to be more cost-effective, since electricity to supply cooling demand is more expensive than the fossil fuels such as natural gas, required to supply the thermal demand. Moreover, configuration $\mathrm{B}$, requires of an extra heat exchanger and a complex control system.

The studied configuration of absorption chiller power by solar thermal energy with the considered collector's area obtains a negative NPV. However, a reduction in the collector's prices, different storage capacities, different system configuration and the possibility to cool down completely the cooling water circuit with a process stream may improve the results of the economic study.

\section{References}

Akhtar, S., Khan, T.S., Ilyas, S., Alshehhi, M.S., 2015. Feasibility and Basic Design of Solar Integrated Absorption Refrigeration for an Industry, in: Energy Procedia. Elsevier, pp. 508-513. https://doi.org/10.1016/j.egypro.2015.07.441

Appricus, http://www.apricus.com/html/solar_collector.htm\#.W4_oBFVKhhE. Last visit: 08/07/2018.

Assilzadeh, F., Kalogirou, S.A., Ali, Y., Sopian, K., 2005. Simulation and optimization of a LiBr solar absorption cooling system with evacuated tube collectors. Renew. Energy 30, 1143-1159. https://doi.org/10.1016/J.RENENE.2004.09.017

Best B., R., Aceves H., J.M., Islas S., J.M., Manzini P., F.L., Pilatowsky F., I., Scoccia, R., Motta, M., 2013. Solar cooling in the food industry in Mexico: A case study. Appl. Therm. Eng. 50, 1447-1452. https://doi.org/10.1016/j.applthermaleng.2011.12.036

Bylund, G., 2015. CTETRA PAK INTERNATIONAL S.A.Dairy Processing Handbook by Tetra Pak, 2nd ed. Tetra Pak Processing Systems AB, Lund.

Dincer, I., Ratlamwala, T.A.H., 2016. Integrated Absorption Refrigeration Systems: Comparative Energy and Exergy Analyses, 1st ed. Springer International Publishing. https://doi.org/10.1007/978-3-319-33658-9

Farjana, S.H., Huda, N., Mahmud, M.A.A.P., Saidur, R., 2018. Solar process heat in industrial systems - A global review. Renew. Sustain. Energy Rev. https://doi.org/10.1016/j.rser.2017.08.065

Instituto Nacional de Estadisticas (INE), 2014. Encuesta Nacional Industrial Anual (ENIA) [WWW Document]. Dep. Estadísticas Económicas Estructurales. URL http://www.ine.cl/estadisticas/economicas/manufactura?categoria=Encuesta Nacional Industria Anual ENIA (accessed 1.12.18).

Lizarte, R., Izquierdo, M., Marcos, J.D., Palacios, E., 2012. An innovative solar-driven directly air-cooled LiBrH2O absorption chiller prototype for residential use. Energy Build. 47, 1-11. https://doi.org/10.1016/J.ENBUILD.2011.11.011

Maya Yazaki, http://www.maya-airconditioning.com/eng/assorbitori-ad-acqua.html. Last visit: 07/07/2018.

Masanet, E., Brush, A., Worrell, E., 2014. Energy efficiency opportunities in the U.S. dairy processing industry. Energy Eng. J. Assoc. Energy Eng. 111, 7-34. https://doi.org/10.1080/01998595.2014.10876999

Mazloumi, M., Naghashzadegan, M., Javaherdeh, K., 2008. Simulation of solar lithium bromide-water absorption cooling system with parabolic trough collector. Energy Convers. Manag. 49, 2820-2832. https://doi.org/10.1016/J.ENCONMAN.2008.03.014

Oficina de Estudios y Políticas Agrarias (ODEPA), 2014. Recepción y Elaboración de la Industria Láctea [WWW Document]. Estadísticas Product. URL https://www.odepa.gob.cl/avance-mensual-y-series-de-tiempo-deproductos-por-planta-o-region-de-la-industria-lactea (accessed 1.29.18).

Pongtornkulpanich, A., Thepa, S., Amornkitbamrung, M., Butcher, C., 2008. Experience with fully operational solar-driven 10-ton $\mathrm{LiBr} / \mathrm{H} 2 \mathrm{O}$ single-effect absorption cooling system in Thailand. Renew. Energy 33, 943-949. https://doi.org/10.1016/J.RENENE.2007.09.022

Sun, H., Xu, Z., Wang, H., Wang, R., 2015. A Solar/gas Fired Absorption System for Cooling and Heating in a Commercial Building, in: Energy Procedia. Elsevier, pp. 518-528. https://doi.org/10.1016/j.egypro.2015.02.156

Syed, A., Izquierdo, M., Rodríguez, P., Maidment, G., Missenden, J., Lecuona, A., Tozer, R., 2005. A novel 
C. Correa et.al

experimental investigation of a solar cooling system in Madrid. Int. J. Refrig. 28, 859-871. https://doi.org/10.1016/J.IJREFRIG.2005.01.007

Zhai, X.Q., Wang, R.Z., 2009. A review for absorption and adsorption solar cooling systems in China. Renew. Sustain. Energy Rev. 3-15. 


\title{
Design and construction of a $10 \mathrm{~kW}$ sorption heat pump prototype
}

\author{
Xavier Daguenet-Frick, Paul Gantenbein, Patrick Persdorf and Andreas Haeberle
}

Institute for solar technology SPF, University of applied science Rapperswil, Rapperswil (Switzerland)

\begin{abstract}
The cooling power of a closed adsorption system is depending on the thermo-physical properties of the sorbent/sorbate material combination. A good adaption by synthetic measures of the material properties to the temperature levels and mass flow rates of the external heating and cooling hydraulic loops has to be done consequently. Based on experimental results gained on a single vacuum chamber $1 \mathrm{~kW}$ average cooling power closed adsorption-desorption laboratory test rig, a scale-up to a four chamber $10 \mathrm{~kW}$ cooling power demonstrator was carried out. This scaling comprised the water sorbate evaporator and water vapour condenser design and the two combined fin-tube fixed sorbent bed adsorber/desorber heat and mass transfer units. The heat transfer fluid mass flow rates from the external heat sources and heat sinks was determined though simulation with an experimental results based model and is described for the mid temperature loop. In this paper, the design of the $10 \mathrm{~kW}$ prototype is described and technical decisions that were done as well as component choices are documented.
\end{abstract}

Keywords: sorption, thermally driven heat pump, cooling

\section{Introduction}

In solid adsorption heat pump systems, solar thermal energy or waste heat can be used for the sorbate desorption, enabling significant saving of $\mathrm{CO}_{2}$ emissions. For the design of such heat pumps, the challenge is - like in all thermo-physical processes - the scale up from the experimental $\mathrm{W}$ (Watt) power range to the application $\mathrm{kW}$ power range. The aim of the presented work was to design a $10 \mathrm{~kW}$ adsorption cooling machine using in a first step Fuji Silica Gel RD-Type sorbent in a fixed bed arrangement and water as a sorbate. In a further step it is planned to replace the Fuji Silica Gel and use any other available sorbent materials (Aristov, 2014) - coatings or fixed bed etc. - as an alternative in the same machine.

The designed heat pump is based on a four chambers concept, comprising two Adsorption/Desorption (A/D) units as well as an evaporator (E) and a condenser (C) unit enabling a quasi-continuous operation (Ruch and Ammann, 2016). Fig. 1 shows a cross section view of the four chambers heat pump depicting two working phases.
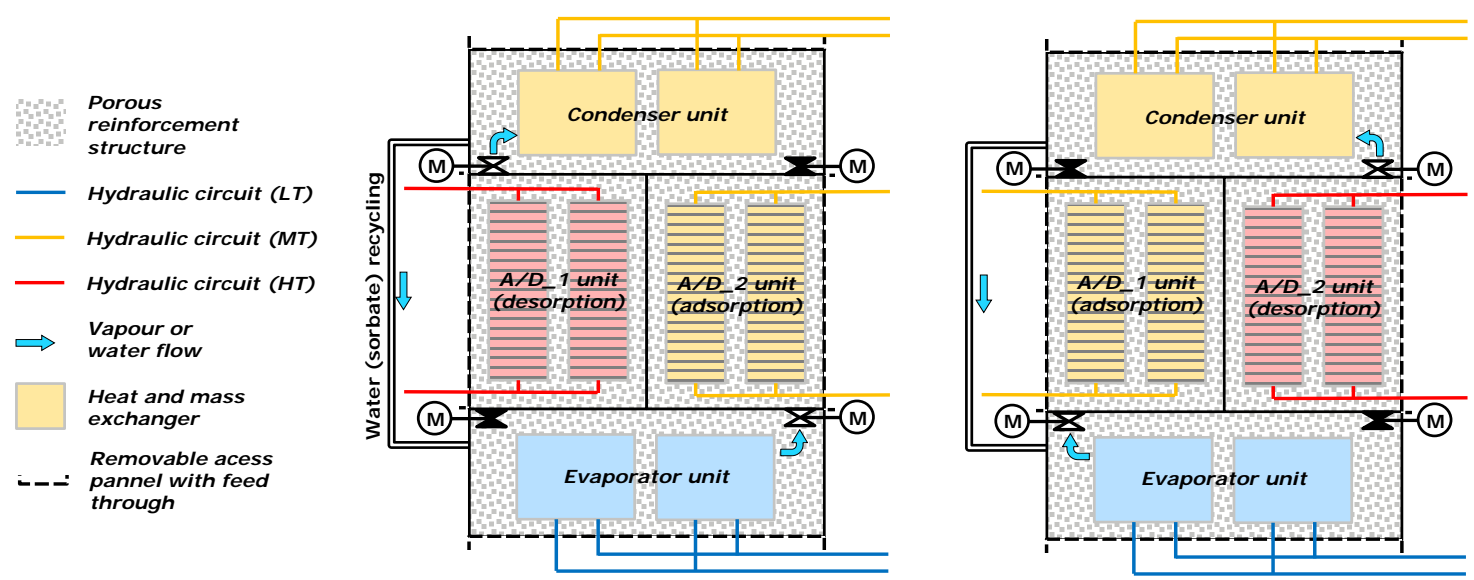

Fig. 1: Schematic of the $10 \mathrm{~kW}$ thermally driven Adsorption Heat Pump (AdHP) comprising Adsorber-Desorber heat exchangers (A/D 1 \& A/D 2) and the Evaporator and Condenser units.

On this schematic, internal controlled vapour valves as well as the liquid water recycling drain back tube are also depicted. The sorbate flow direction as vapour (upward arrows) and as liquid (downward arrows) is shown in the figure 1 . 
A quasi continuous operation of the adsorption machine is reached though switching the motor ( $\mathrm{M}$ in the figure) driven vapour valves and the temperature levels in the A/D units from high (desorption) to mid (adsorption) and vice versa. For a good performance optimized temperature differences from the units - A/D, condenser and evaporator - to the heat transfer fluid in the external loops and their flow rates are essential. In the following sections 2.1 the characterization of the sorbate immersed evaporator by determining the location of the onset of evaporation is described. The section 2.2 describes the A/D design. In section 2.3 the mid temperature loop flow rate modelling is shown. After power scaling considerations in this section 2 section 3 comprises the design and manufacturing of the sorption heat pump.

\section{Experimental based modelling}

Design of the $10 \mathrm{~kW}$ prototype is based on modelling results. To establish the models, experimental measurement campaigns were carried out on both $\mathrm{E} / \mathrm{C}$ as well as $\mathrm{A} / \mathrm{D}$ heat and mass exchangers.

\subsection{Preliminary characterisation of one E/C heat and mass exchanger}

For the E/C heat and mass exchanger, the first investigations were focused on the localization of the nucleation sites on the evaporator (limiting element). The experimental setup consists in two spiral heat and mass exchangers depicted on Fig. 10 (one used as evaporator, the other as condenser) placed in glassed containers and linked together on one side with a butterfly valve (vapour feed through) and on the other side by a small flexible tube (ID = $6 \mathrm{~mm}$ ) shaped in a siphon (condensate return flow). Temperature and mass flow of both Heat Transfer Fluid (HTF) loops flowing respectively through the evaporator and the condenser can be controlled and measured. Incondensable gases were removed from the vacuum tight containers so that only water in equilibrium with its vapor is present round the heat and mass exchangers.

Imaging of the evaporator was carried out for four water levels $(\mathrm{H}$, in $\mathrm{mm})$ and several temperature differences between HTF inlet of the evaporator and condenser. One of the post treated image is presented on Fig. 2, left. On this figure, the warm colours betrays the high reflection areas (mainly linked with the presence of vapour bubbles). According to the graph presented on the right of Fig. 2, nucleation occurs on the entire heat exchanger height only by strong temperature differences (i.e. overheating). Furthermore, when the evaporator is not completely immersed, splashes issued from the vapour bubbles are wetting the tubes above leading to the formation of a film and an evaporation at the pressure of the evaporator chamber (limited overheating required).
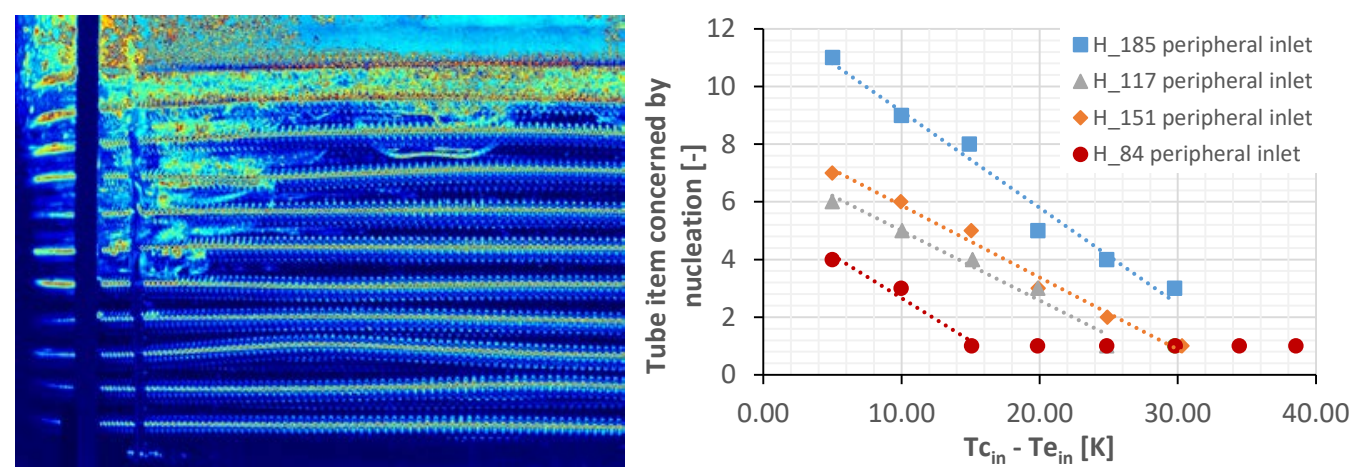

Fig. 2: Localization of the nucleation sites on the Evaporator in warm colours (posttreatment of a set of 1000 images @ $2 \mathrm{~Hz}$, $7.5 \mathrm{~ms}$ exposure time) $\Delta \mathrm{T}=25 \mathrm{~K}, \Delta \mathrm{P}=9.5 \mathrm{mbar}, \mathrm{Q}=4300 \mathrm{~W}$ (left) and localisation of the nucleation depth for different water level in function of the temperature differences between HTF inlet of the evaporator and condenser (right).

Finally, it was found out that higher exchanged power were reached when the HTF inlet is placed in the centre of the exchanger. In fact, the HTF inlet matches with the most overheated area which also is the location where nucleation mainly occurs. Furthermore, the vapour bubbles originated at the centre of the heat exchanger have more probability to wet the overhanging tubes and to trigger further nucleation that the vapour bubbles at the periphery. 


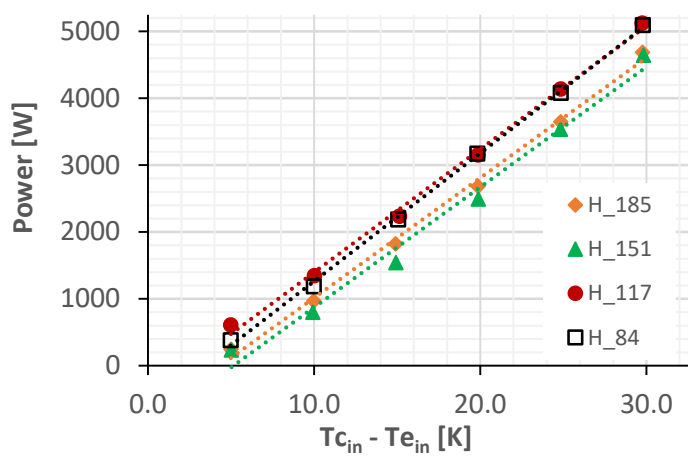

Fig. 3: Exchanged power for different water levels in the evaporator in function of the temperature differences between HTF inlet of the evaporator and condenser.

According to the results presented on Fig. 3, the evaporator is working in the best conditions when less than half immersed. Furthermore, up to $10 \mathrm{~kW}$ of heat was exchanged on a single module (by a temperature difference of $50 \mathrm{~K}$ ). For the evaporator unit of the $10 \mathrm{~kW}$ AdHP Prototype, this experimental measurement campaign has shown that the number of heat exchangers can be reduced from 6 to 5 modules.

\subsection{A/D unit: adsorption-desorption measurement and results}

For the upscaling of A/D heat and mass exchanger extended experimental measurements were carried out in a single vacuum chamber $1 \mathrm{~kW}$ cooling power setup (Gantenbein et al., 2017). This double jacket single chamber experimental facility can be equipped with an A/D module as well as a combined Evaporator/Condenser (E/C) module.

For the A/D geometrical design a cubic shaped $6.6 \mathrm{~m}^{2}$ fin-tube all-aluminium adsorption-desorption module was used to carry solid sorbent beads (Freni et al., 2016), see Figure 4. This unit has a surface to volume ratio of $0.54 \mathrm{~m}^{2} / \mathrm{l}$. The vapour flow is towards the four sides of the cube (arrows in figure 4) while the front ends of the $\mathrm{A} / \mathrm{D}$ are aluminium plates impermeable for water vapour. The A/D consists of 6 tube columns and 9 of these in parallel. Measurements with two fin pitches $(\mathrm{s}=3 \mathrm{~mm}$ and $5 \mathrm{~mm}$ ) were carried out, a fin thickness of $0.18 \mathrm{~mm}$ and a particle beads size $\mathrm{d}_{\mathrm{p}}$ of $0.85 \mathrm{~mm}<\mathrm{d}_{\mathrm{p}}<1.7 \mathrm{~mm}$. The spherical shaped Fuji RD-Type Silica Gel particles filling amounts of $7.5 \mathrm{~kg}$ and $8.4 \mathrm{~kg}$ for the $3 \mathrm{~mm}$ and the $5 \mathrm{~mm}$ fin spacing A/D units were used, respectively.
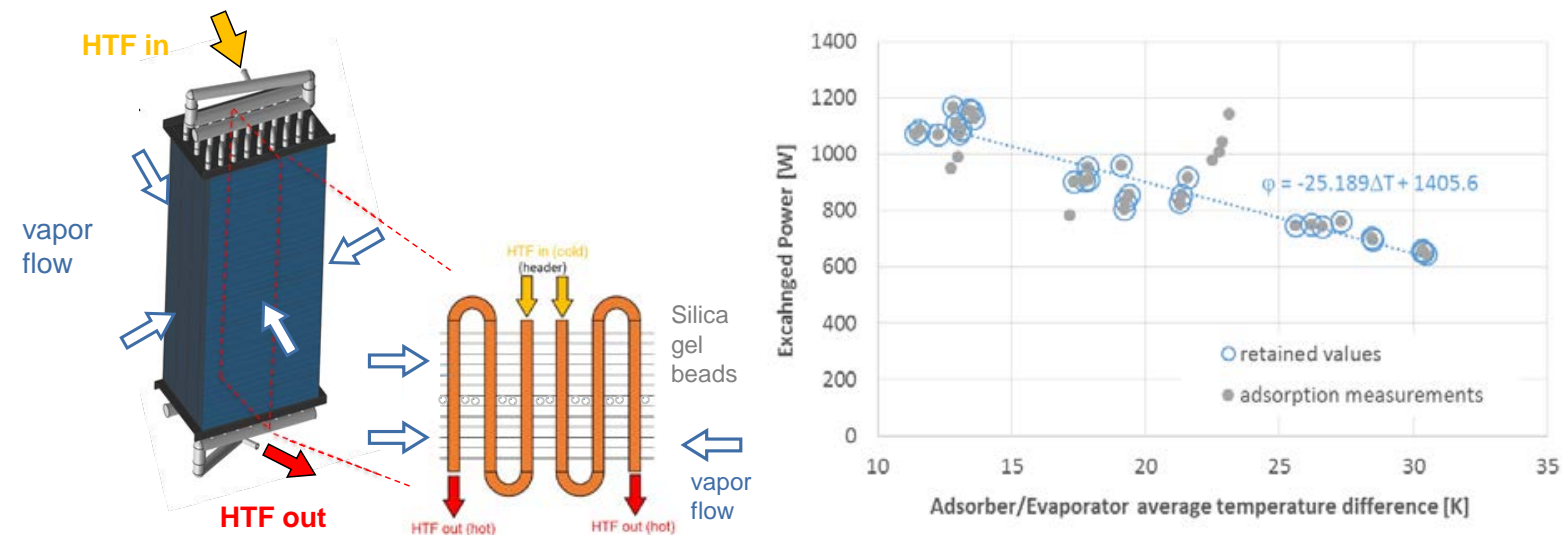

Fig. 4: $1 \mathrm{~kW}$ average A/D module installed in the single vacuum chamber with heat transfer fluid (HTF) flow direction in the adsorption mode and cross section view of the "crossed counter" current vapour and HTF flow A/D module (left); aggregated measurement data of time-averaged power measurements for the adsorption process (right).

Measurements were achieved with external fluid loop temperatures in the range of 30 to $50^{\circ} \mathrm{C}$ for the adsorption process (mid temperature loop) and between 70 and $95^{\circ} \mathrm{C}$ for the desorption process (high temperature loop), while adsorption and desorption cycle length $\mathrm{t}_{\mathrm{c}}$ from $900 \mathrm{~s}$ up to $3600 \mathrm{~s}$ were performed. The peak cooling power reached values up to $2.2 \mathrm{~kW}$. Figure 4 (right) shows power measurement time averaged results $\left(\mathrm{t}_{\mathrm{c}}=900 \mathrm{~s}\right)$ for the evaporation/adsorption (E/A) process in function of the average heat transfer fluid (HTF) temperature difference in the adsorber and in the evaporator. Similar measurement data post processing was carried out for the Desorbtion/Condensation (D/C) processes. 
Based on the experimental measurements with A/D heat and mass exchangers of different fin spacing, a numerical model (Daguenet-Frick et al., 2017) was defined to assess the heat pump behaviour depending on the boundary conditions, i.e. temperature levels of the external heat sources and sinks and the mass flow rates (power) in the hydraulic loops. This model includes pumping power (in function of pressure drop) calculations in the external heat transfer fluid loops. Based on the results, a parallel hydraulic connection of the adsorption unit(s) and condenser unit is advantageous, see next section. A fin spacing of $3.0 \mathrm{~mm}$ should be preferred for the A/D heat and mass exchangers. An optimized heat transfer fluid (HTF) mass flow rate was also determinate.

Focusing on a $10 \mathrm{~kW}$ cooling power machine, the scale up task was carried out in two steps. As a first step from the lab setup of $1 \mathrm{~kW}$ to $1.6 \mathrm{~kW}$, a linear increase of the A/D length was defined, keeping its cubic structure. For the further upscaling (reaching the power of $10 \mathrm{~kW}$ ), a hydraulic parallel arrangement of 6 such A/D modules was designed and manufactured.

\subsection{A/D unit: external fluid loop modelling and upscaling}

Temperature levels as well as volume flow rate of the three external fluid loop are defining the $10 \mathrm{~kW}$ adsorption heat pump boundary conditions. Based on the linear approximation of the power in function of the temperature differences for both $\mathrm{E} / \mathrm{A}$ and $\mathrm{D} / \mathrm{C}$ processes (see paragraph above), a numerical model was set up. Calculations are done in steady state and an ideal efficiency of the machine is assumed (i.e. the power transferred during E/A and $\mathrm{D} / \mathrm{C}$ processes are identical). Based on the temperature boundary conditions, the heat transfer are calculated by the model for the E/A process and defines the power exchanged for the D/C process as well as the output HTF temperatures. Looping stops as soon as no significant power variation are noticed. For the medium temperature source HTF loop two configurations are investigated: adsorber module hydraulically connected either in serial or in parallel with the condenser unit. For the HTF loops, pressure drop as well as pumping power are calculated. Figure 5 shows some results of a parametrical study carried out on the external fluid loops. According to simulation, a volume flow rate higher $2.4 \mathrm{~m}^{3} / \mathrm{h}$ will dramatically increase the pumping power with only a minor increase of the heat exchanged. At this volume flow rate, a serial connection (--) of the A (A/D in adsorption) and C (condenser) units will enhance the heat $\Phi_{\mathrm{a},--}$ exchanged by $3 \%$ but with $39 \%$ higher pumping power $\mathrm{W}_{\mathrm{pp},--}$ compared to $\mathrm{W}_{\mathrm{pp}, / /}$ in a parallel connection. Figure 5 shows that using $3 \mathrm{~mm}$ fin spacing increases the exchanged power ( $+6 \%$ in comparison to the $5 \mathrm{~mm}$ spacing) and that a theoretical minimal pumping power $\mathrm{W}_{\mathrm{pp}}$ is reached for a distribution ratio of 0.57 (flow rate A to flow rate $\mathrm{C}$ ).
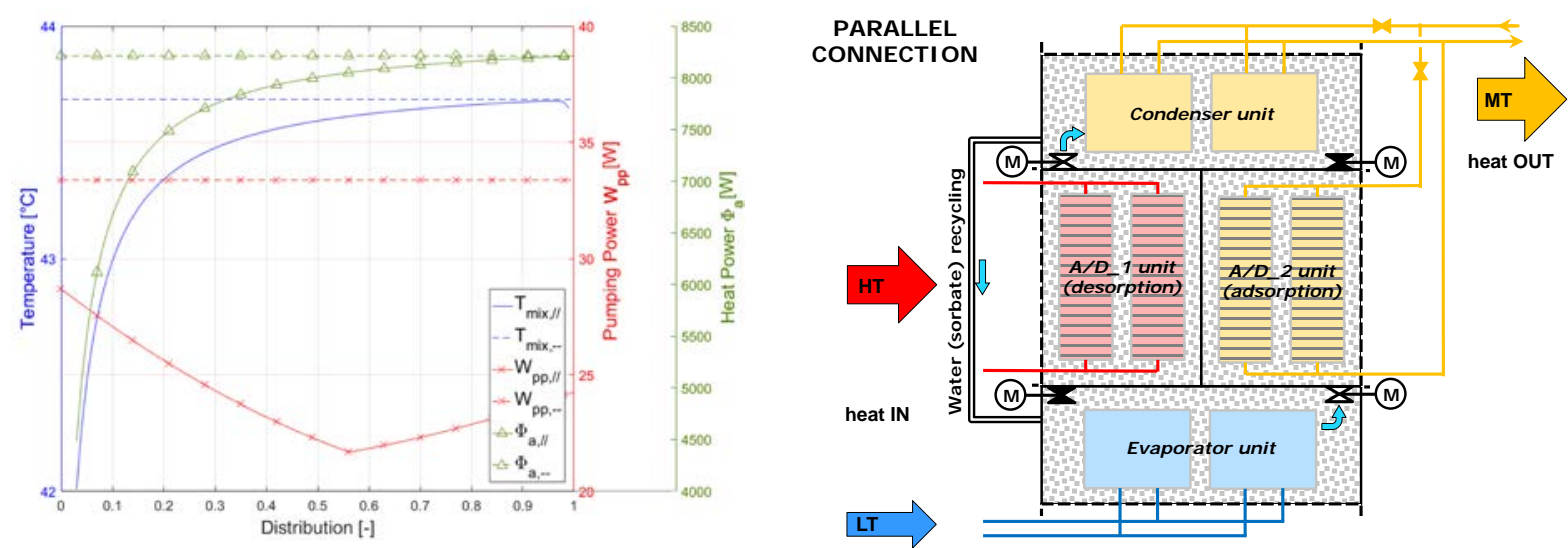

Fig. 5: Temperature at the outlet of the mid temperature HTF loop $\left(T_{\text {mix }}, / /, T_{\text {mix, }}--\right)$, pumping power $\left(W_{p p, / /}, W_{p p,--}\right)$ and heat power exchanged ( $\Phi_{\mathrm{a}, / /}, \Phi_{\mathrm{a},--)}$ by the adsorber depending on the distribution factor for a $3 \mathrm{~mm}$ and $5 \mathrm{~mm}$ fin spacing (left); A and $\mathrm{C}$ units connected in parallel (right).

\section{Heat pump design and construction}

\subsection{General design}

For the design of the heat pump, a mechanically self-supported concept was retained (cf. Fig. 6); the thin stainless steel envelop insuring the vacuum tightness is indirectly supported by the heat and mass exchangers. Below this welded container envelop, reinforcement walls (in grey on Fig. 6) are foreseen to equalize the mechanical constrains. This structure as well as the ceramic foam (in white) placed between the heat and mass exchangers are porous in order to distribute the sorbate vapour flow to the heat exchangers modules (in blue for the condenser 
unit and in red for the A/D units). The first generation A/D modules are using silica gel beads placed in a fin-tube all-aluminium heat exchanger whereas the $\mathrm{E}$ and $\mathrm{C}$ modules are based on spiral coiled stainless steel corrugated tubes.

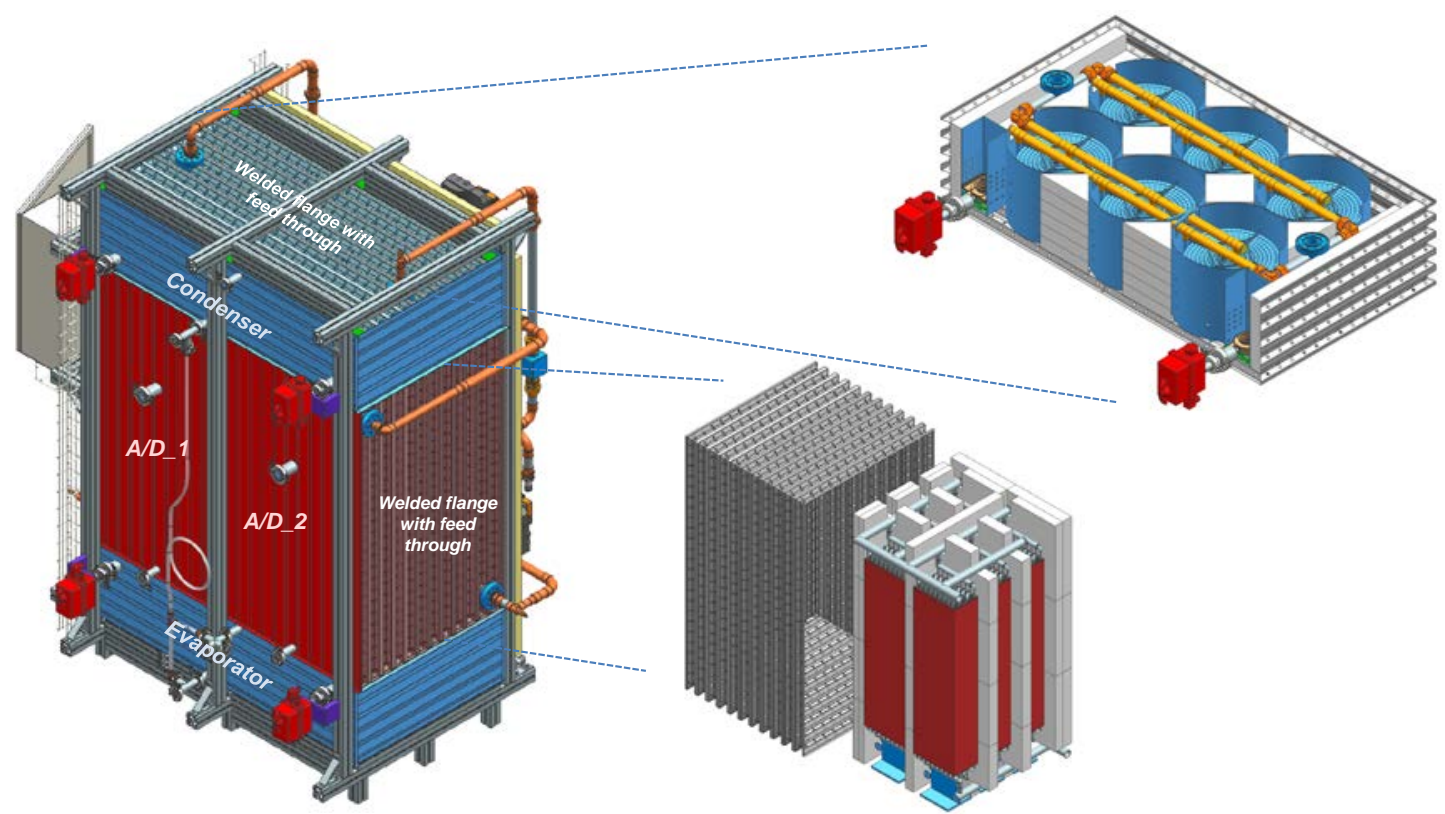

Fig. 6: CAD view of the four chamber adsorption heat pump with exploded view of the Condenser unit (top right) and of an A/D unit (bottom right).

Aiming to test a second generation of optimized sorbent, the whole concept is based on dismountable welded flanges (depicted on Fig. 6) enabling to replace the A/D heat and mass exchanger units.

\subsection{AdHP hydraulics \& connections}

For the case of a replacement of the A/D heat and mass exchanger units, dismountable feed through have been inhouse designed, manufactured and vacuum leakage tested (see Fig. 7). These feed through have to ensure tightness on the heat transfer fluid loop side as well as on the container side (vacuum) and allow to remove the door prior to the heat and mass heat exchanger replacement.
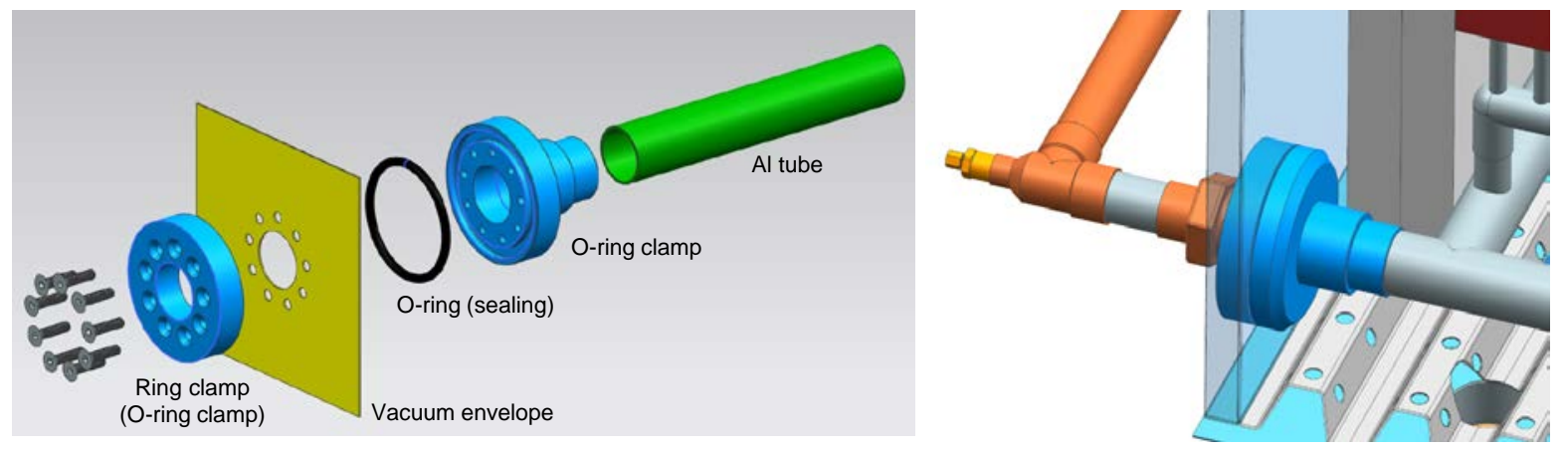

Fig. 7: CAD view of the feed-through exploded (left) and assembly connected to the AD unit (right).

The rear side of the AdHP (shown on Fig. 8) is constituted of a panel comprising tubing, motorised valves and magnetic inductive flow sensors as well as temperature sensors. These motorised valves are ensuring the distribution of the heat transfer fluid between the three heat sources/sinks (see Fig. 1) and the four heat and mass exchangers. The fluid distribution factor between the condenser and the absorber (see paragraph 2.3) can be controlled and optimised. This panel also includes a fluid pump ensuring heat recovery between the two A/D units (from regenerated and hot desorber to the saturated absorber). A heat recovery mode (depicted on Fig. 9) can be activated between each adsorption/desorption cycling. 

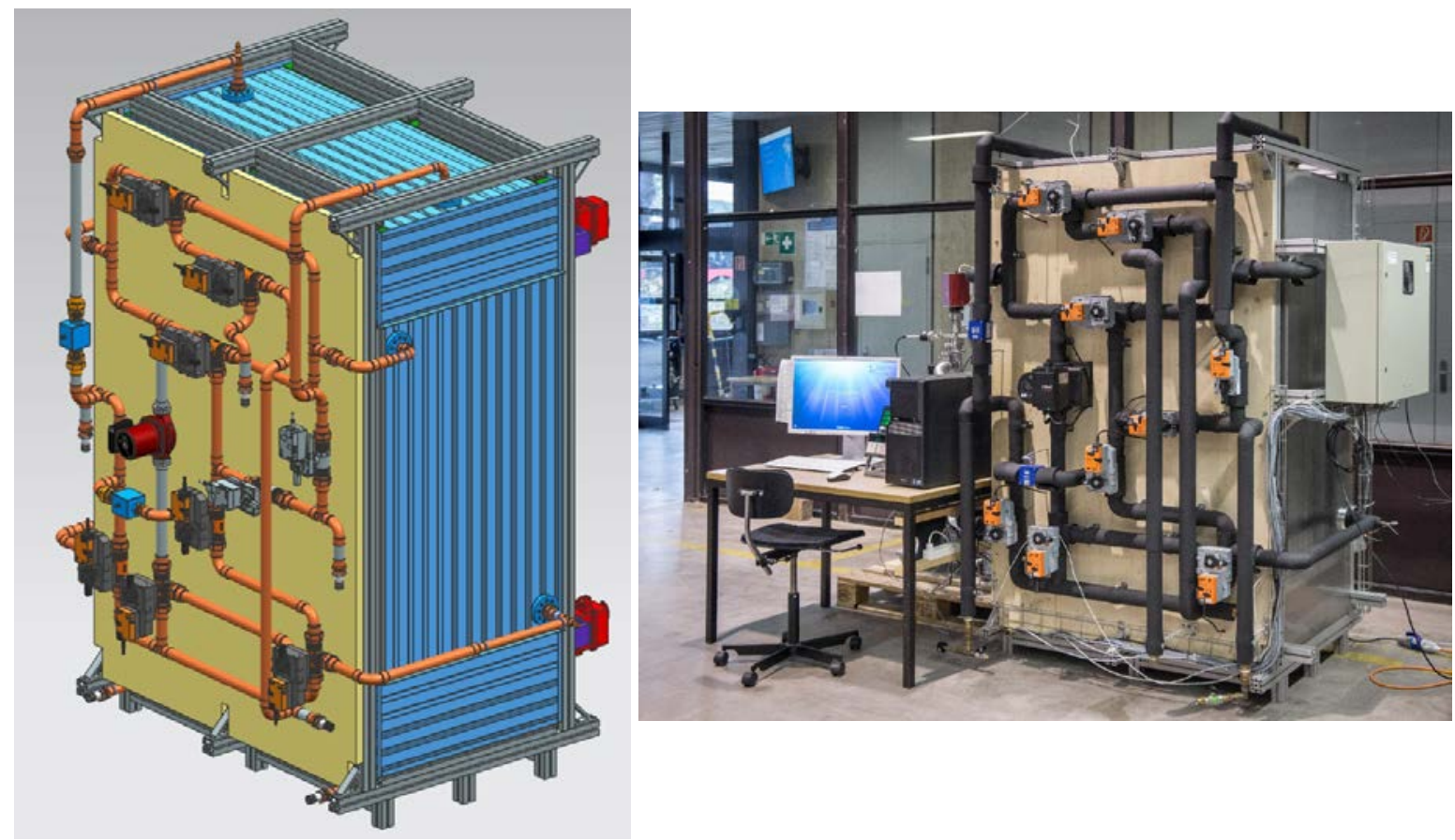

Fig. 8: AdHP rear side: tubing and connecting interfaces to the internal components; heat recovery pump (CAD left, real facility right).

Fig. 9 shows the Graphical User Interface (GUI) of the National Instruments LabVIEW ${ }^{\circledR}$ Software. Thanks to this interface, different machine internal measured values like temperature, mass flow rate and pressure inside of the AdHP chambers can be measured and stored to analyse and assess the operation of the machine.

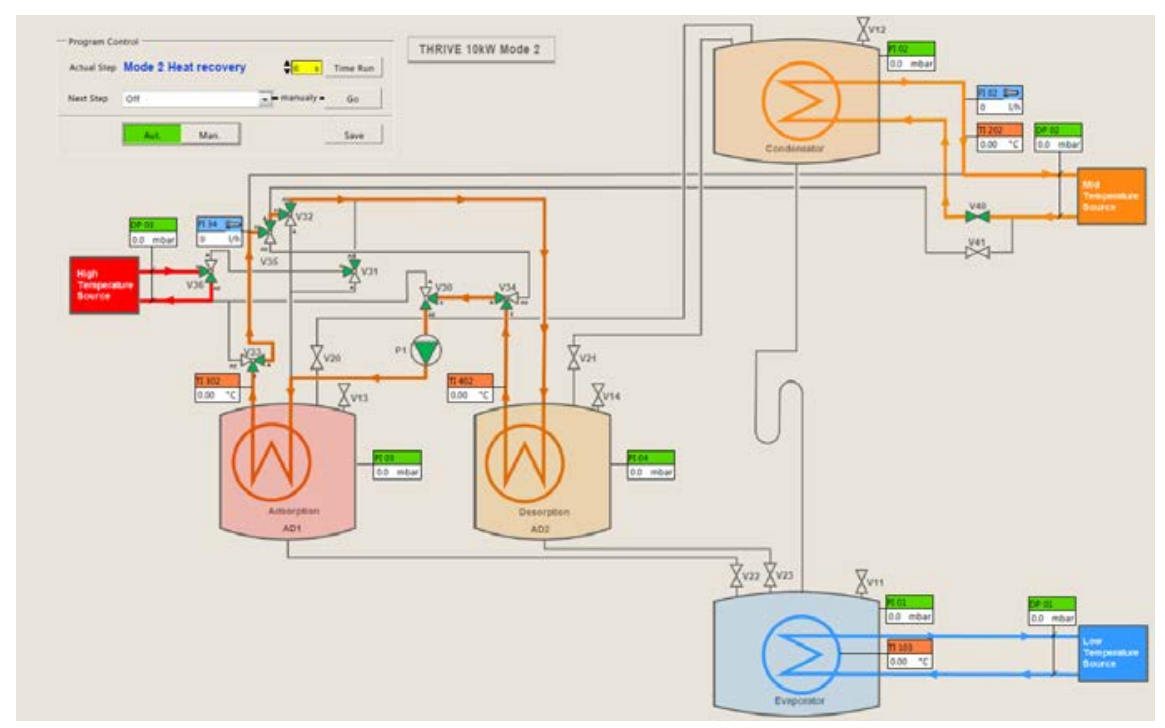

Fig. 9: Graphical User Interface (GUI) of the AdHP; heat recovery mode.

Self-learning PID modulators are implemented to control the flow distribution in the Medium Temperature (MT) loop. A control of the adsorption/desorption cycle length either with a timer or on the basis of a pressure differences measurement or heat power calculation is foreseen.

\subsection{E/C design and manufacturing}

As shown on Fig. 6, an evaporator and a condenser unit are implemented in the AdHP prototype. These units are made of spiral formed heat and mass exchanger modules, modules themselves constituted of eleven coiled corrugated stainless-steal hoses. These corrugated tubes are in parallel connected to copper inlet and outlet manifolds which are designed and hydraulic configured in Tichelmann arrangement (see Fig. 10, left). 


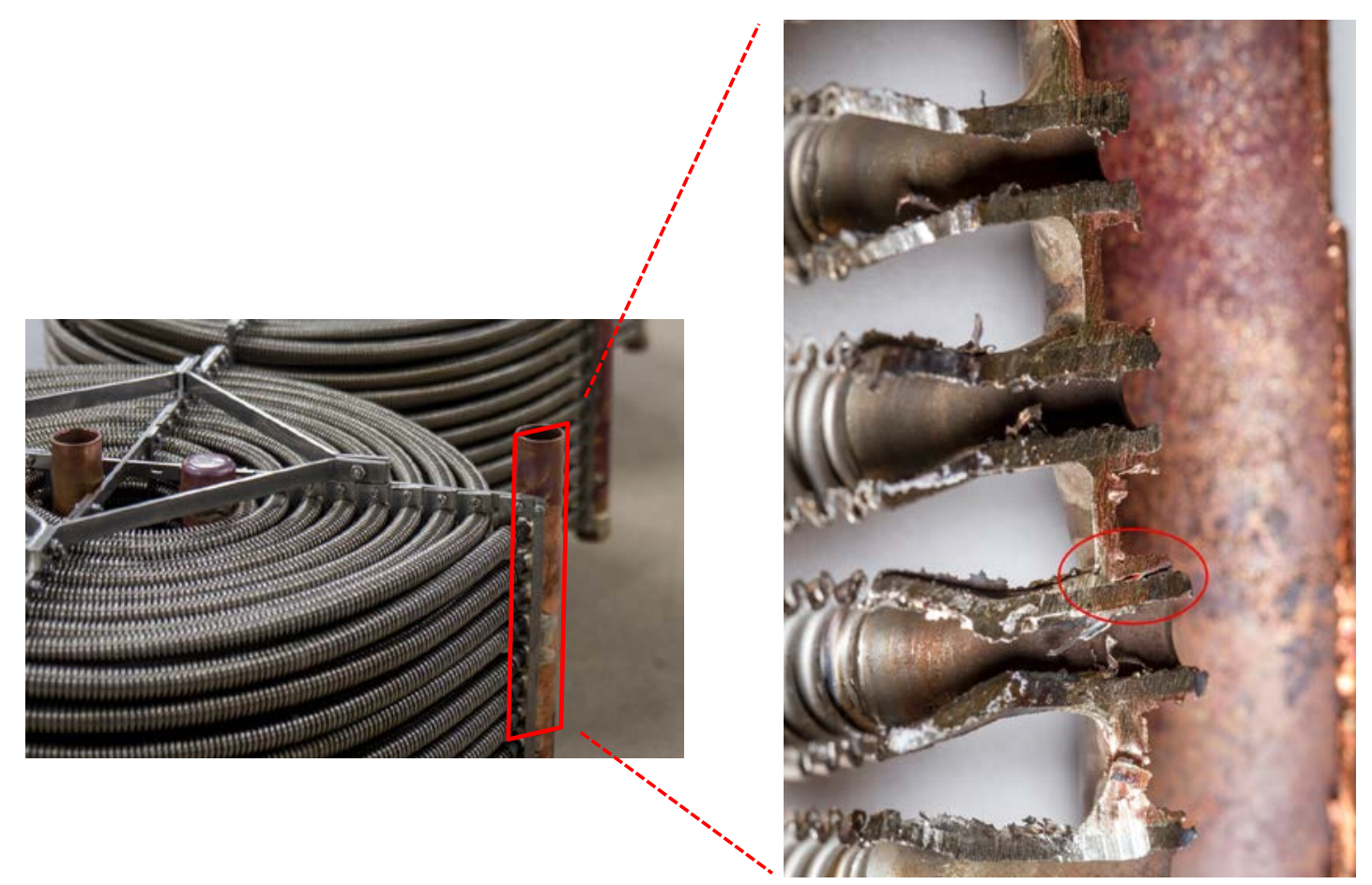

Fig. 10: E/C spiral heat and mass exchanger module (left) and cut of its manifold showing the copper/stainless-steal junction with one crack (right).

Considerable mechanical stability issues (spring effect of the tubes) were experienced on the copper / stainless steel junction. They were evidenced during the leakage tests each part was submitted prior to implementation in the $10 \mathrm{~kW}$ AdHP prototype. One heat and mass exchanger had to be sacrificed (see manifold cut shown on Fig. 10, right) in order to find out the origin of the leakages and thus for an improvement of the soldering/brazing process.

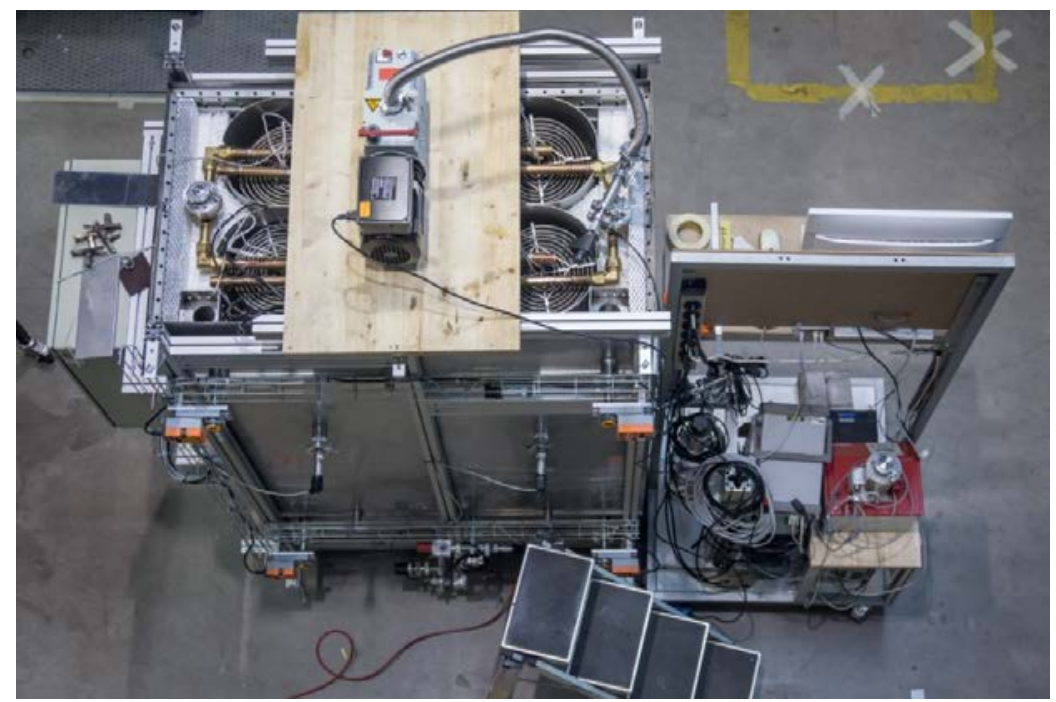

Fig. 11: Implementation of the condenser heat and mass exchanger unit in the container and leakage test (generally performed by pressure increase followed by a Helium leakage test with mass spectrometer).

Fig. 11 shows the top of the AdHP prototype with implemented condenser unit during a leakage test. This picture was taken before the implementation and welding of the container top wall.

\subsection{A/D manufacturing}

In the same way as the $\mathrm{E}$ and $\mathrm{C}$ units, two A/D units were implemented in the AdHP prototype (see Fig. 6). On Fig. 12, one of these two units is shown before (left) and during (right) the implementation into the container (arrow). On this last picture, the white porous ceramic foam enabling the assembly to be mechanically selfsupported can be seen. 

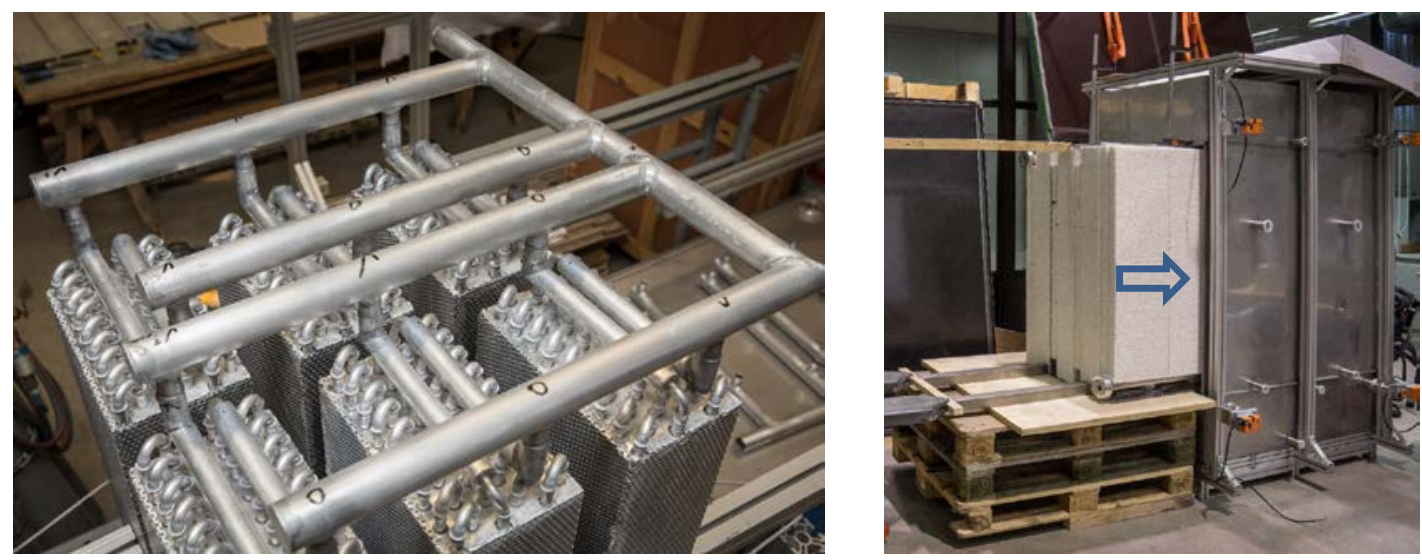

Fig. 12: All-aluminium A/D $10 \mathrm{~kW}$ module with brazed manifold (left), dragging of the AD1 into the vacuum envelope (right).

\section{Outlook}

The sorption heat pump demonstrator is set up and Helium leakage tests were performed. An assessment through measurements of the machine with A/D containing Fuji Silica Gel RD-Type is planned. Further measurements with fixed sorbent bed or coated A/D or any other structure of the sorbent can be performed. The improvement of the evaporator and the condenser is planned.

\section{Acknowledgements}

The funding by the Swiss National Science Foundation SNSF in the frame of the National Research Program NRP 70 and by the University of Applied Sciences Rapperswil is highly acknowledged. Franz Steiner and Albert Trudel, supporting engineers, are also gratefully acknowledged.

\section{References}

Aristov Y., 2014. Concept of adsorbent optimal for adsorption cooling/heating. Applied Thermal Engineering 72, pp. 166-175, doi: 10.1016/j.applthermaleng.2014.04.077.

Ruch, P., Ammann, J., 2016. Materials and System design for adsorption heat pumps. 12th International Conference on the Fundamentals of Adsorption, Friedrichshafen Germany.

Daguenet-Frick, X., Moullet, Y., Gantenbein, P., Persdorf, P. and Notter, D., 2017. Adsorption heat pump upscaling from $1 \mathrm{~kW}$ to $10 \mathrm{~kW}$ of cooling power: experimental based modelling, International Sorption Heat Pump Conference, Tokyo Japan.

Gantenbein, P., Daguenet-Frick, X., Bont, F., Persdorf, P. and Notter, D., 2017. Cooling power determination by measuring the adsorbed vapour mass variations, International Sorption Heat Pump Conference, Tokyo Japan.

A. Freni, G. Maggio, A. Sapienza, A. Frazzica, G. Restuccia, S. Vasta, 2016. Comparative analysis of promising adsorbent/adsorbate pairs for adsorptive heat pumping, air conditioning and refrigeration. Applied Thermal Engineering 104, pp. 85-95, doi: 10.1007/s40243-018-0131-y. 


\title{
Development of a photovoltaic driven thermodynamic chiller Application to solar air conditioning and cooling storage
}

\author{
Philippe Esparcieux ${ }^{1}$, Olivier Baup ${ }^{1}$, Daniel Mugnier ${ }^{2}$, \\ Christophe Weber ${ }^{3}$, Christophe Marvillet ${ }^{3,4}$ \\ ${ }^{1}$ Atisys Concept, Toulon (France) \\ ${ }^{2}$ Tecsol, Perpignan (France) \\ ${ }^{3}$ NeoTherm Consulting, Le Bourget du Lac (France) \\ ${ }^{4}$ CNAM/IFFI, Paris (France)
}

\begin{abstract}
This paper presents a smart design named PV COOLING to produce solar cooling using low GWP heat pump system coupled with a standard photovoltaic plant. A maximum of self-consumption is promoted by means of a light bank of batteries and chilled water tank. For this, a test bench has been installed on the building roof in the south of France with the originality to be entirely controllable in terms of building load injected. Thereafter, this new system aims to be used for air-conditioning and/or dehumidification in the tertiary sector and positive cold storage in the industrial sector in countries where climatic, regulatory and technical conditions are suitable. PV COOLING potential is developed within a market study. The aim of this study is to assess the thermal / electrical performances of our test bench with the purpose to airconditioning a building by means of several sensors and meters.
\end{abstract}

Keywords: solar cooling, air-conditioning, cold storage, food preservation photovoltaic, heat pump, selfconsumption, batteries, thermal tank, glycol water, low GWP, R290,

\section{Introduction}

Until now, traditional PV economic model was based on feed-in tariff. However this trend is currently moving toward on-site self-consumption. PV self-consumption can be used in a straightforward manner for domestic purposes: lighting, heating, domestic hot water heating (DHW), cooking, domestic appliances, etc.

An example of application consists in using solar power to directly drive a thermodynamic device with a target to produce cooling or refrigeration. It can be noted that PV production perfectly matches cooling needs during the day. Besides, in many countries all over the world, the summer comfort in buildings becomes necessary in order to allow employees to work in good condition.

The use of renewable energy for powering heat pumps can solve environmental problems due to the ways of producing energy (e.g. $\mathrm{CO} 2$ emissions by coal thermal plants in China). Even if the energy problem is settled, it remains the issue of refrigerant fluid leakage which represents a non-negligible share of the greenhouse effect. Therefore, the use of low global warming potential (GWP) fluid in thermodynamic system allows to reduce the device carbon footprint.

\section{The adopted strategy}

At first glance, compressor power shall be adapted with PV output power. This may work within a certain range until a minimum threshold where chiller compressor has to be stopped. When PV output power is back, the main issue is to be sure that power remains sufficiently stable and reliable to start compressor again and avoid short-cycle. Indeed, the problem of driving a chiller compressor with PV lies in the fact that it may happen that irradiation may be temporary obstructed by some peculiar clouds. 
Using variable-frequency drive can solve the problem of high inrush current during compressor run-up. For the intermittent energy problem, storage using batteries or other electricity supply can easily sort this problem out. It's also possible to mix with thermal storage system which is a shorter-term storage mode. Both electricity and thermal storage allow to store a sufficient energy when the PV production exceeds and use it when the need becomes higher than the PV production.

To contribute to an environmentally friendly device, propane (R290) has been chosen as refrigerant for this project. This very low GWP refrigerant (GWP < 10) combined with an original configuration allows a significant reduction of refrigerant amount. To maximize the self-consumption, the inverter has to allow both electric powers issued from PV and batteries.

This research aims to study a test bench using PV cooling, installed on the building roof in the south of France. For a better understanding of the system behaviour, instead of cooling the building, cooling is distributed into a chilled water tank in which is fitted a power controlled heating resistor which simulated all sorts of building thermal load configurations.

\section{Promoting solar photovoltaic on new market segments}

\subsection{Air-conditioning for the tertiary sector}

To avoid an unfair competition with cheap traditional heat pump produced at ten millions samples yearly, PV cooling will be suitable for medium / high power in the tertiary sector and according to certain criteria. The criteria to lead the market study are classified into three main contextual families (climatic, economic and regulatory) and are summarized through a "bubble chart" (Fig. 1). These criteria are expressed inside the chart as:

- The cooling demand expressed in cooling degree days (CDD) on the $\mathrm{x}$-axis.

- The annual global horizontal irradiation (GHI) per square meter on the y-axis.

- The market size of mid-sized / large heat pump in the tertiary sector is expressed by the percentage of the worldwide unit demand through the surface size of the bubble.

- The electricity price in the tertiary sector as a driver of renewable investment is expressed by the colour of the country, with cheap costs in light and high costs in black.

- Finally, self-consumption policy and fiscal incentives which are positive for renewables (e.g. feed-intariffs, subsidies, solar obligations) are marked with (+); others with (-) and unclear situation with (?).

Figure 1 shows only the final result of an ambitious market study. Indeed, several countries have been removed from previous "bubble charts" because of following weaknesses. First of all, many countries in Europe have an insufficient radiation like Germany and even if the radiation is enough like in South Europe, the cooling needs are only present during summer. Among countries which gather good natural conditions (both radiation and cooling needs), the low electricity price doesn't allow for photovoltaic to be profitable (e.g. Saudi Arabia).

Countries that appear qualitatively as the most mature to accommodate a short-term photovoltaic airconditioning system according to Figure 1 are mainly countries with a tropical climate. Indeed, under this kind of climate, the cooling needs are constant during the full year. Electricity price appears as an important criterion which participates to have a return on investment the most quickly possible. 
The market size is not an essential criterion because PV COOLING can find its place in a market niche where the tertiary sector is not developed like high-income countries (for instance, the air-conditioning for a cybercafe in Africa which doesn't have access to a reliable electrical grid). Indeed, more and more African cities have the means to propose services moving towards European standard for a category of population which are increasingly financially secure.

The self-consumption policy and fiscal incentives are the last criterion which may help PV solutions to be more attractive especially the right to self-consume. But it is difficult to be entirely exhaustive in each country because the PV policy changes quickly. PV outlooks show that each government will pass laws to tend towards a smarter way to consume photovoltaic which is self-consumption model. Besides, a lot of PV self-consumption projects take place in countries where no PV policy exists particularly in Western Africa. That means PV policy is not a necessary criterion to have the right to self-consume.

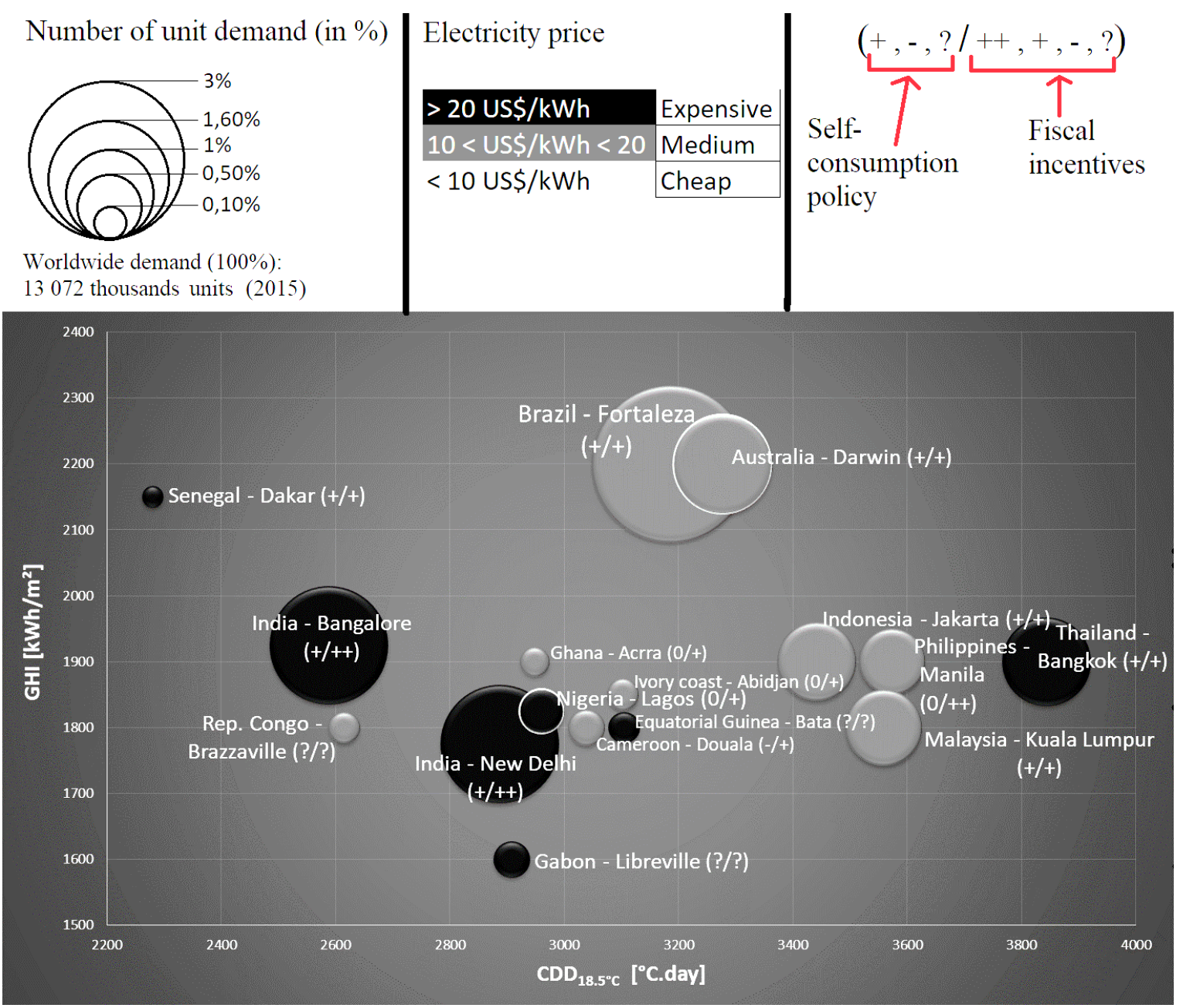

Fig. 1: Graph illustrating the attractiveness of cooling markets for PV COOLING

\subsection{Cold room for perishables foods in industrial sector}

The industrial sector which matches quite well with the natural condition is agri-food industry and more specifically storage for perishable food items with positive cold storage or refrigerated warehouse. The perishable foodstuffs which require positive cold storage to maintain a longer lifetime are mostly fruits \& vegetables and roots \& tubers. Countries with tropical climate appear to be regions where food harvest are significant and represent a considerable share of GDP. The majority of countries with tropical climate are low or middle-income, so the food cold chain is not developed as high-income countries. This is why due to 
economic and climate problems (hot and damp), tropical climate regions have a significant food losses share caused by a lack of cold storage (Gustavsson et al., 2011).

As the air-conditioning study market, the "bubble chart" underlines the fact that tropical countries appear to be the most attractive for PV COOLING usage for positive cold storage food.

We can notice all the same a slight difference, with the apparition of very low-income countries in Africa in the "bubble chart" owing to the fact that agriculture is the only source of revenue.

\section{4. $R \& D$ carried out for a properly sized system}

Actual PV COOLING innovation mainly consists of setting together in a clever way, components which actually are highly improved, but never have been set together in a single goal system: PV plant dedicated to driving a thermodynamic fluid chiller as shown in Figure 2.

This is the fruit of two years co-operation with four French companies, with several decades' expertise in solar energy (Tecsol), heat exchangers technology \& design (NeoTherm Consulting), designing special thermodynamic equipment (EED) and designing \& implementing innovative systems (Atisys).

Besides, the R\&D project has also an academic dimension in France with an expert in cold industry from the Conservatoire National des Arts \& Métiers (CNAM-Paris).

\subsection{Overall PV COOLING architecture}

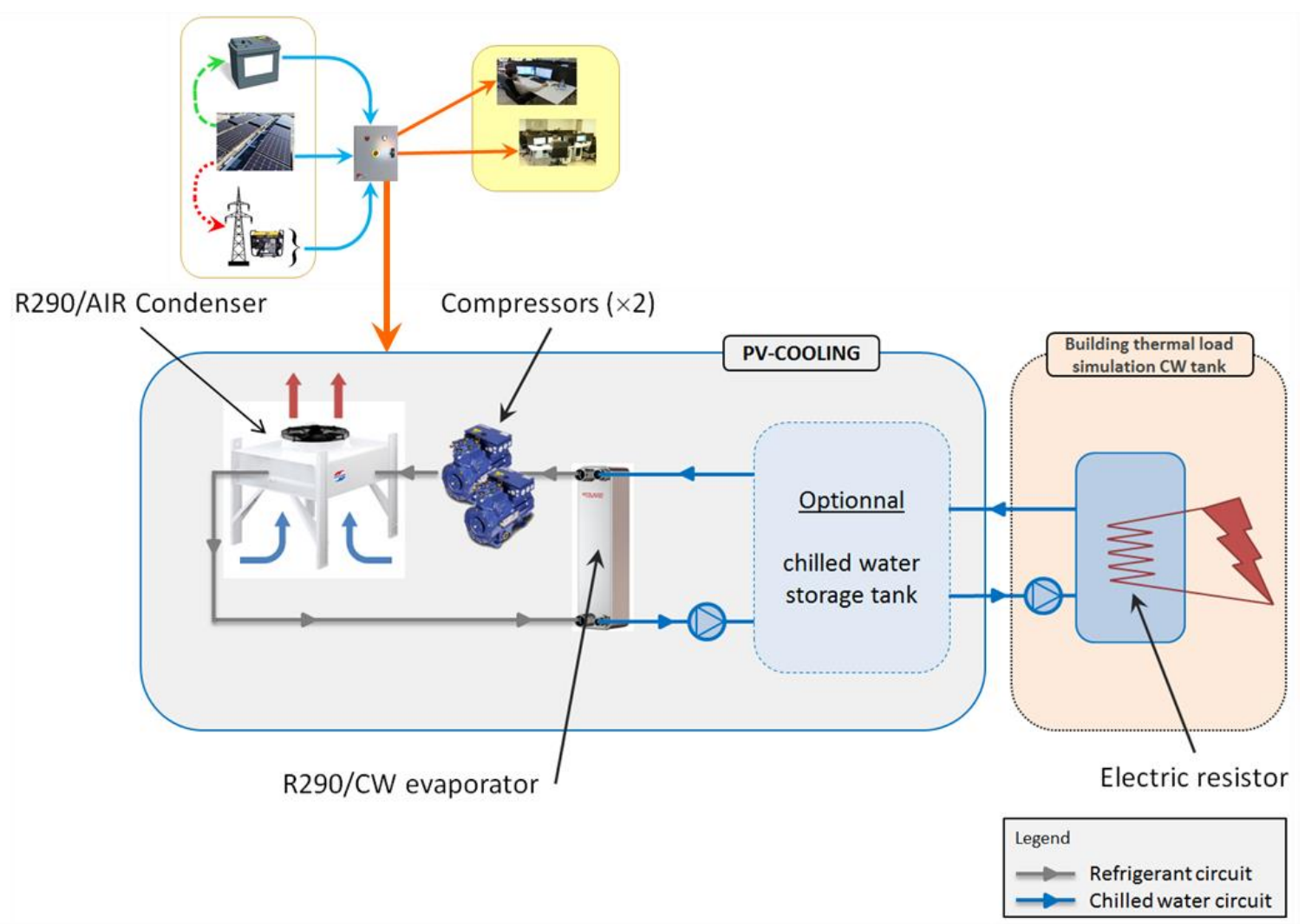

Fig. 2: Schematic architecture of PV-COOLING system 


\subsection{Layout description}

The first test bench, installed on the ATISYS head-office roof-top, is located in Toulon area (South East of France, lovely site in French Riviera).

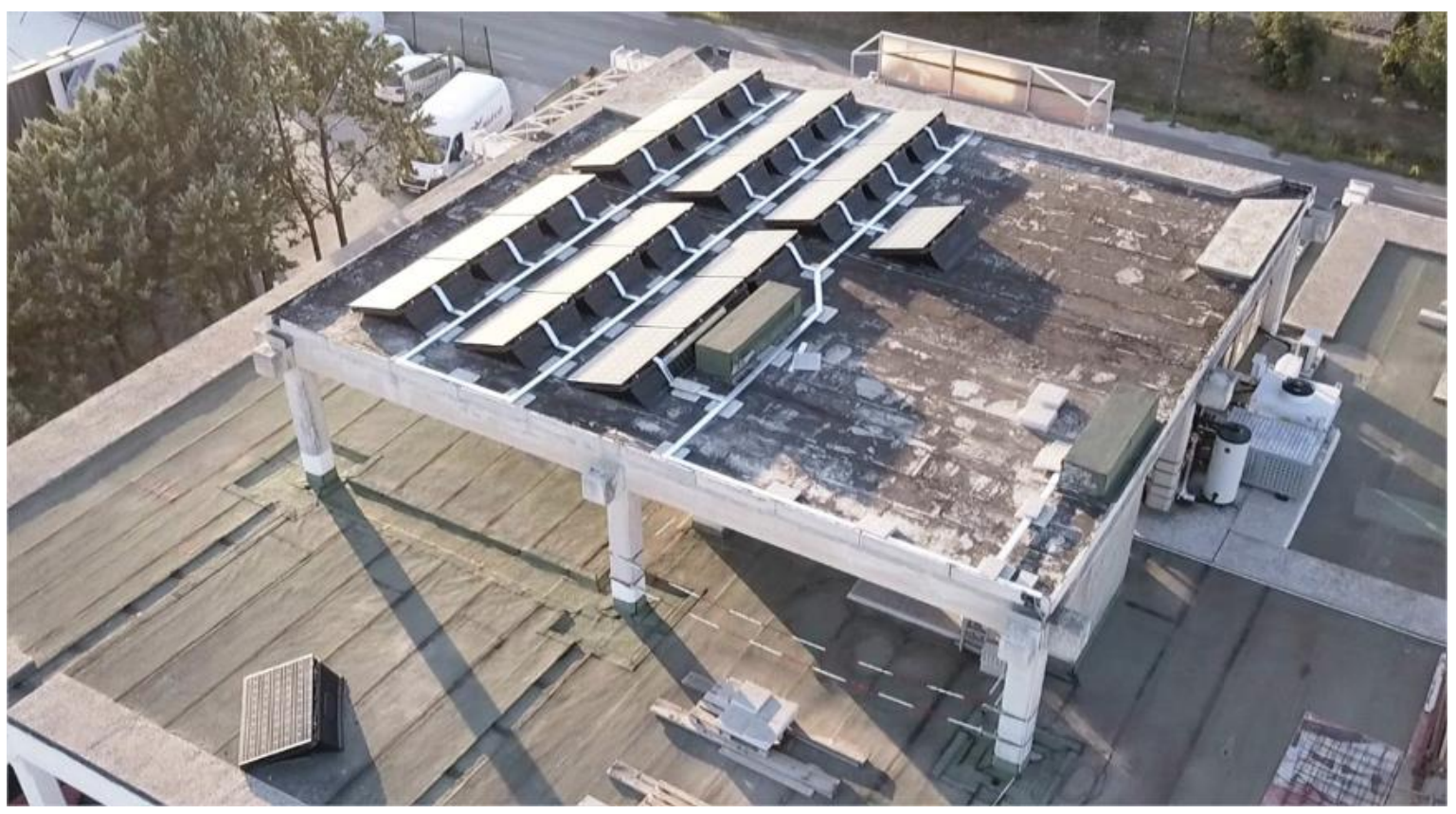

Fig. 3: Global view of 18 mono-crystalline PV plant and chiller unit on ATISYS roof

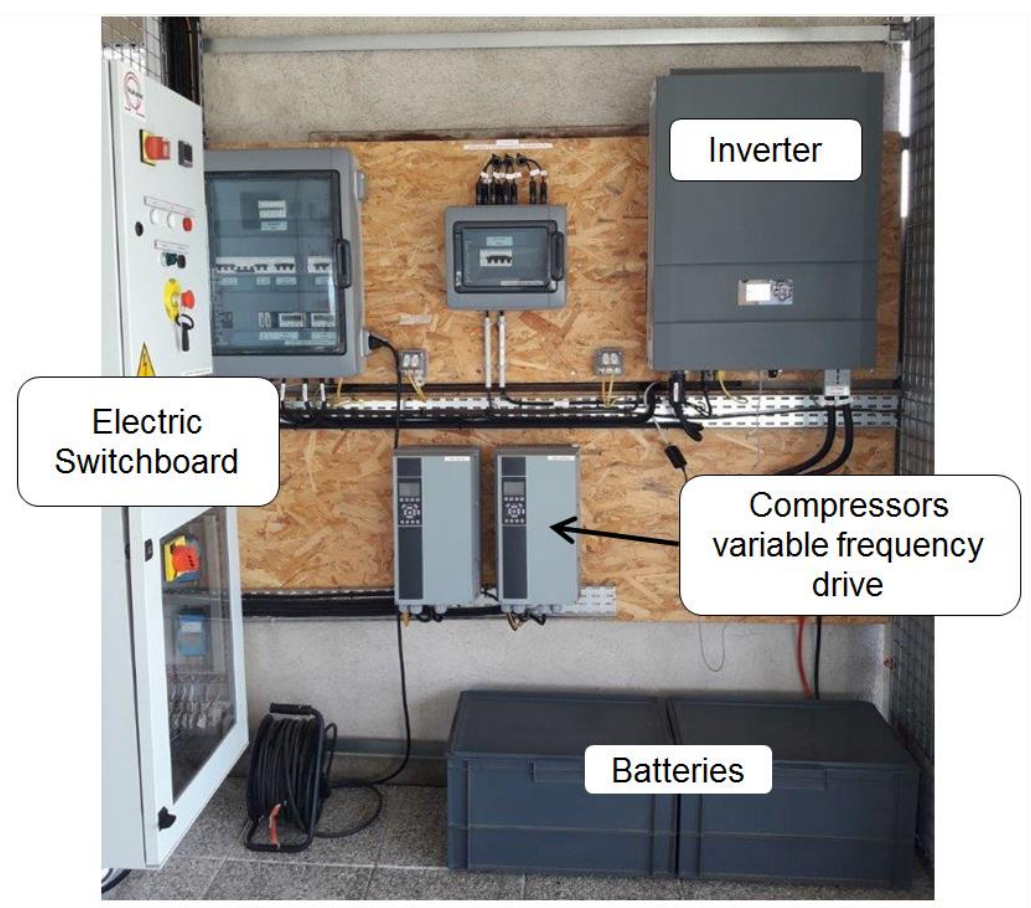

Fig. 4: PV COOLING control and management system

In the pilot testing system, electrical production is delivered by 18 mono-crystalline photovoltaic modules (280 Watts peak (Wp) for each module) as illustrated on Figure 3, which represents a total power of $5.0 \mathrm{~kW}_{\mathrm{p}}$. This power is quite enough for driving chiller compressors and all ancillary equipment dimensioned for 10 $\mathrm{kW}_{\mathrm{th}}$ chilling power (condenser fan and chilled water circulation pump). 
These photovoltaic panels are connected to a three-phase wired inverter along with batteries bank. The four selected $12-$ Volt batteries are connected in series to obtain a voltage of $48 \mathrm{~V}$. Their $150 \mathrm{Ah}$ capacity each with a $50 \%$ depth of discharge (DOD) allows to obtain a useful electrical storage energy about 3.6kWh. This is enough to drive the full load power installation at least for one hour.

For a real operational system, battery capacity may be chosen according to actual need.

In order to limit the inrush current during compressor run-up, a variable-frequency drive has been installed downstream from the inverter which makes possible to divide the inrush current by 6 .

Figure 4 presents the complete electrical setting.

Two parallel-mounted semi-hermetic compressors were selected and adapted for propane. Each compressor can provide from 2.4 to $5.4 \mathrm{~kW}$ of cooling by varying its rotation frequency from 30 to $70 \mathrm{~Hz}$. This allows a cooling capacity between 2.4 and $10.8 \mathrm{~kW}$. For the future, commercial PV cooling systems will be able to reach high cooling power till $300 \mathrm{~kW}$ using bigger compressors. It is enough to size the other equipment accordingly.

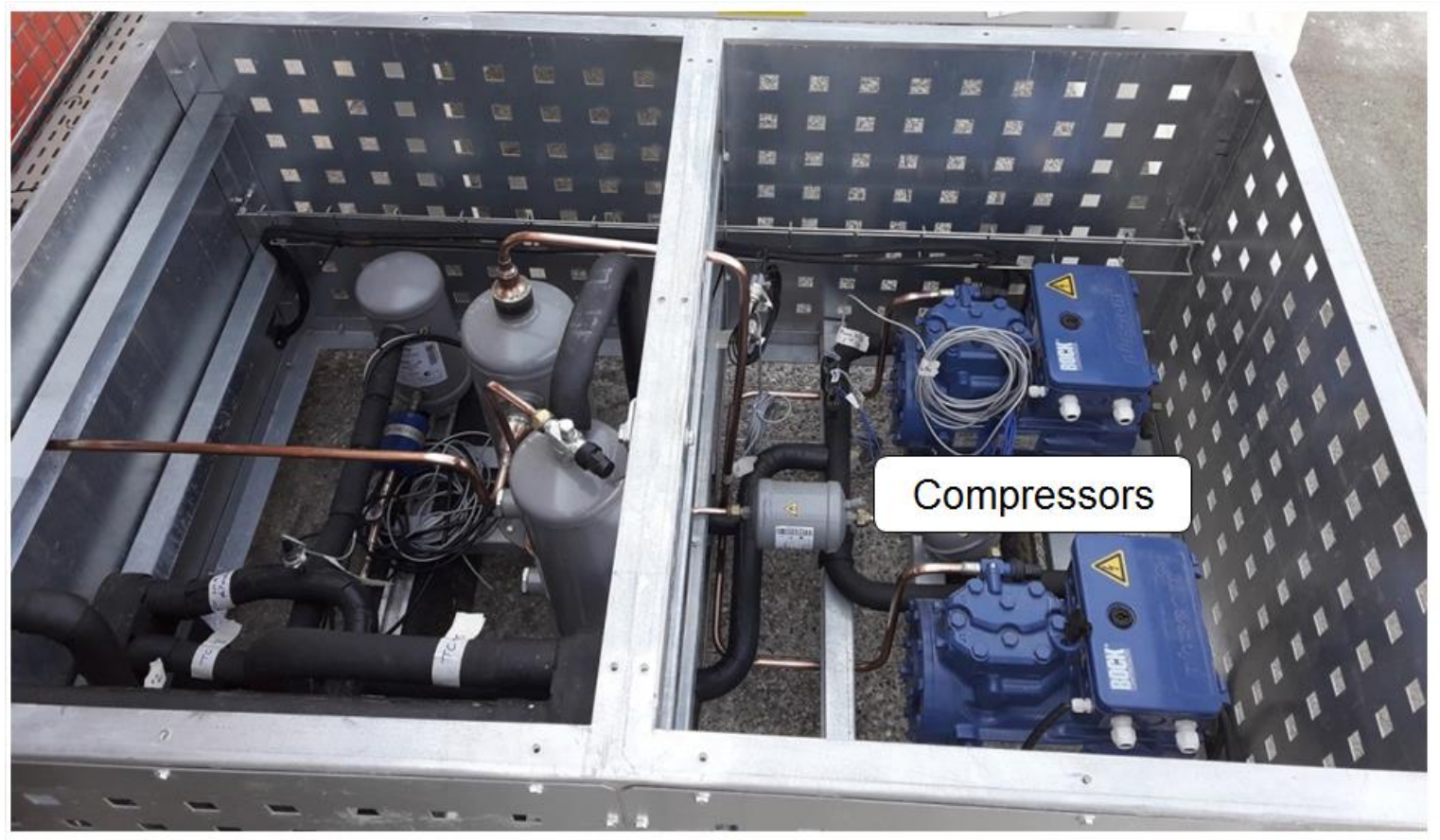

Fig. 5: Picture of the Two parallel-mounted semi-hermetically compressors

The condenser is an air/R290 type heat exchanger, also called air-cooled condenser. In order to reduce refrigerant load, a microchannel type condenser has been chosen.

The evaporator selected for the project is brazed plate heat exchangers, also suitable for propane.

The major innovation regarding the heat pump system lies in the use of low Global Warming Potential (GWP) refrigerant.

The choice fell on propane (R290) with $(<10)$ GWP, which is considerably low compared to a common refrigerant (e.g. 1300 GWP for R134a).

The only drawback with using propane is the necessity of additional security due to propane flammability. In our case and according with French safety regulation, setting the chiller outdoor (see Fig. 6) is considered as sufficient. Thus, no additional security is necessary.

The fluid that transports the refrigerating capacity from the cold unit to the chilled water tank is water/methyl propylene glycol (MPG) mixture, so as to avoid any freezing risk. 


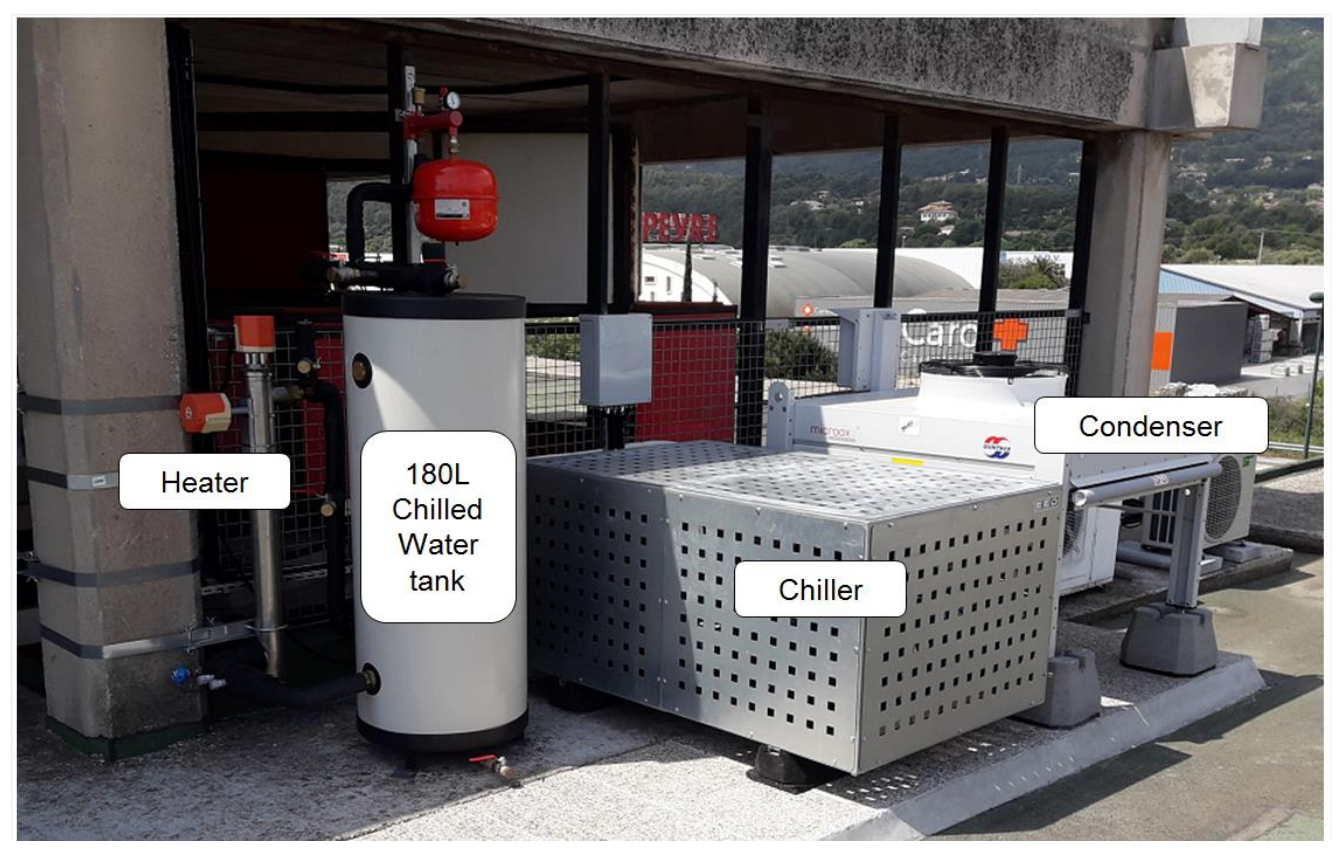

Fig. 6: Picture of the global chiller installation installed on the Atisys top roof

For this test bench, the chilled water tank is representative of a typical building whose thermal load is simulated with an electrical resistor heating the 180L chilled water tank (see heater on Fig. 6). That gives the advantage to fully control the building loads and consequently simulate several conditions which correspond to different building utilization/insulation and climate conditions.

A monitoring system has been set up with a view to monitoring performances of the system according to the needs throughout the year. Monitoring is powered by PV-COOLING itself.

\subsection{PV COOLING management}

Building thermal load is estimated as follows:

$$
P_{\text {Build-Load }}(t)=G \times V \times\left[T_{\text {ext }}(t)-T_{\text {set }}(t)\right]+K \times S_{\text {Build }} P_{\text {Sol.Ir }}(t) * \delta(t-\tau)
$$

With:

- $\mathrm{T}_{\text {ext }}$ : outdoor temperature

- $\mathrm{T}_{\text {set }}$ : indoor set point temperature

- $\mathrm{G}$ : volume heat loss coefficient $\left[\mathrm{W} / \mathrm{m}^{3} .{ }^{\circ} \mathrm{C}\right]$ chosen as $\mathrm{G}=2.5$ (poorly insulated building in our case)

- V: the cooled volume. $\mathrm{V}=325 \mathrm{~m}^{3}$

- $\mathrm{P}_{\text {Sol.Ir }}$ : Power of solar irradiation $\left[\mathrm{W} / \mathrm{m}^{2}\right]$

- $\mathrm{S}_{\text {Build }}$ : time average wall surface of building exposed to solar irradiation (chosen to $40 \mathrm{~m}^{2}$ )

- K: solar power absorption sensitivity of building walls [non-dimensional, $0 \leq \mathrm{K} \leq 1$ ], chosen to 0.20

$-\delta(\mathrm{t}-\tau)$ : delay function (Dirac), corresponds to thermal inertia of building to solar irradiation $(\tau=1$ hour)

For the automatic control of heat pump management, several approaches are tested between two main paradigms.

The first one is the economy mode (also designated as "eco" mode) in which compressor driving power is adapted to PV output power.

The second one is the comfort mode in which set point value consists in keeping constant chilled water feedback temperature $\left(12^{\circ} \mathrm{C}\right)$ and if necessary take complementary power from the grid when both PV and batteries power are insufficient. 


\section{Results and discussion}

PV COOLING test bench has been tested during several months with monitoring sequences of several days from June to September 2017. The electrical resistance of the heater has been controlled to model a $350 \mathrm{~m}^{3}$ building (i.e. $135 \mathrm{~m}^{2}$ with a high ceiling of $2.60 \mathrm{~m}$ ). To correspond to reality, an outside temperature sensor has been installed.

PV COOLING major monitoring data and performance results are presented hereby, for both "eco" and "comfort" modes, and under both sunny and intermittently disrupted sunny/cloudy conditions.

On graphical displays of fig. 7 to 11 , negative values of grid electric powers means that power in injected by PV system into the grid (red curve). For battery (black curve), it is the opposite (this was done for legibility).

Data and performances results are obtained on a daily basis, from 8 a.m. up to 7 p.m. Those data may permit one to appreciating PV COOLING efficiency (fig. 12), especially EER (ratio of thermal energy produced to grid energy consumption, from 8 a.m. up to 7 p.m.).

\section{1. "eco" mode}

Figure 7 below shows PV COOLING monitoring data captured on Sept $5^{\text {th }}$. Although this was a very sunny day, weather was quite windy due to a northern dry and cold wind, designated as "Mistral" (quite typical of south of France) : Mistral blows clouds away and also pushes Mediterranean sea thermocline offshore, such that sometimes even in summer, swimming on the French Riviera is a matter of bravery !

That explains why despite of sunny conditions, thermal load is far below classical figure in this period of the year. Therefore, PV-COOLING power remains far below PV power until late afternoon (5:30 p.m.) and no any external source is required. This case gives $\mathbf{E E R}=\mathbf{1 0 6 . 3}$ ! (see fig. 12).

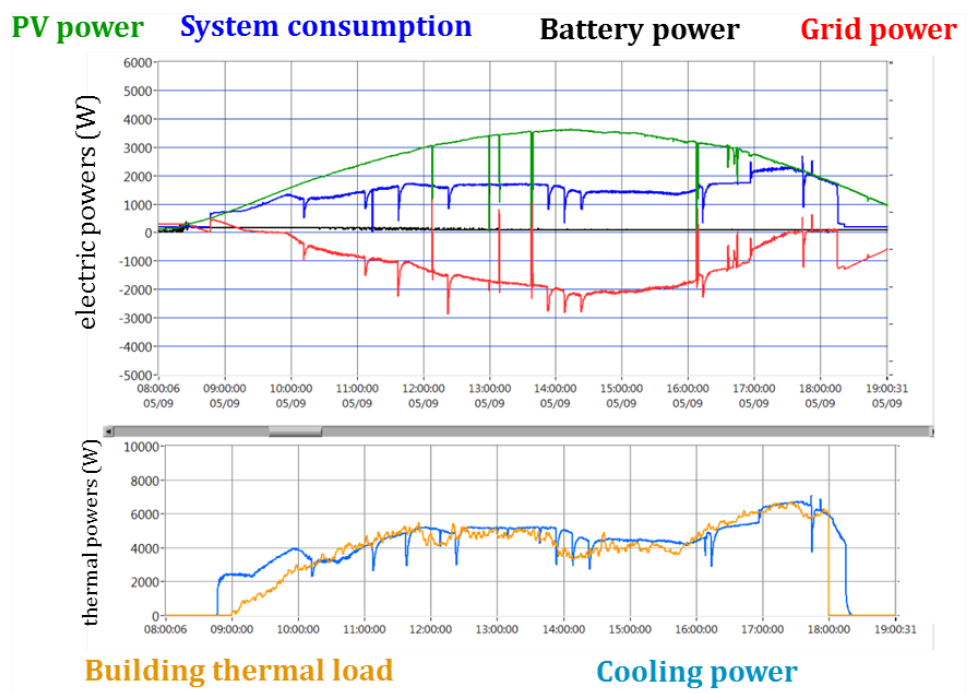

Fig. 7: Electric and thermal powers time history (Sept $5^{\text {th }} 2017$ - TOULON) - "eco" mode

It can be noticed that if PV-COOLING manager was configured as "comfort" mode, results would have been identical.

Figure 8 displays a much more significant case of "eco" mode efficiency : Sept $6^{\text {th }}$ was quite a disrupted sunny/cloudy day until 4:00 p.m. and in can be seen that system consumption (and thus cooling power) is limited by both PV power and thermal load.

One can notice that despite disrupted conditions, Sept $6^{\text {th }}$ conditions show a much higher building thermal load than eve, and even in "eco" mode, cooling power matches quite well thermal load history. This case gives EER = 44 (see fig. 12). 


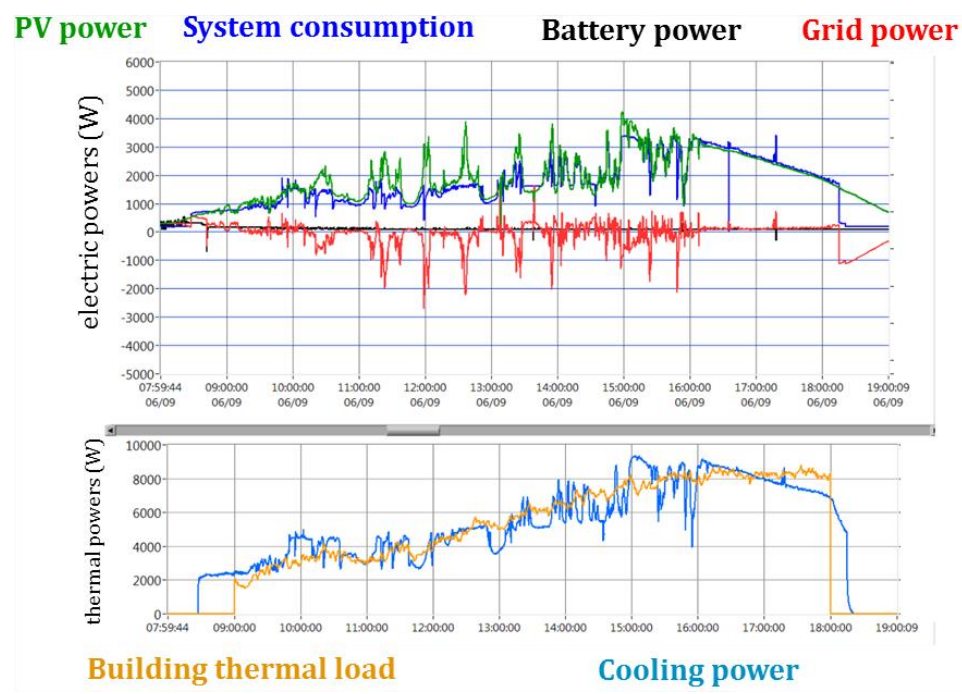

Fig. 8: Electric and thermal powers time history (Sept $6^{\text {th }} 2017-$ TOULON) - "eco" mode

\section{2."comfort" mode}

Figure 9 displays PV-COOLING results obtained on Aug. $28^{\text {th }}$ 2017, quite a sunny day and with high thermal load $(71.15 \mathrm{kWh})$, a high cooling production $(75.46 \mathrm{kWh})$ and a low grid consumption $(0.47 \mathrm{kWh})$ which yields to $\mathbf{E E R}=\mathbf{1 6 1 . 9 3}$ (see fig. 12).

Figure 10 displays following day (Aug $29^{\text {th }}$ ) which much more disrupted than previous example and still exhibits high thermal load $(72.04 \mathrm{kWh})$ a high cooling production $(75.14 \mathrm{kWh})$ and a low grid consumption $(0.78 \mathrm{kWh}$ ). Here EER = 95.82 (see fig. 12).

Similar comments can be done regarding Aug. $30^{\text {st }}$ (fig. 11) where cooling power matches quite well building thermal load history. One may notice that battery power was limited to $1.5 \mathrm{~kW}$ as a security barrier set up to save battery lifetime, which yields to grid consumption $(3.15 \mathrm{kWh})$ and consequently degrades performances to $\mathbf{E E R}=\mathbf{2 4 . 7 1}$ (see fig. 12).

On all those examples, one can see that priority is given to battery as external supply (at the condition that battery charge level is sufficient).

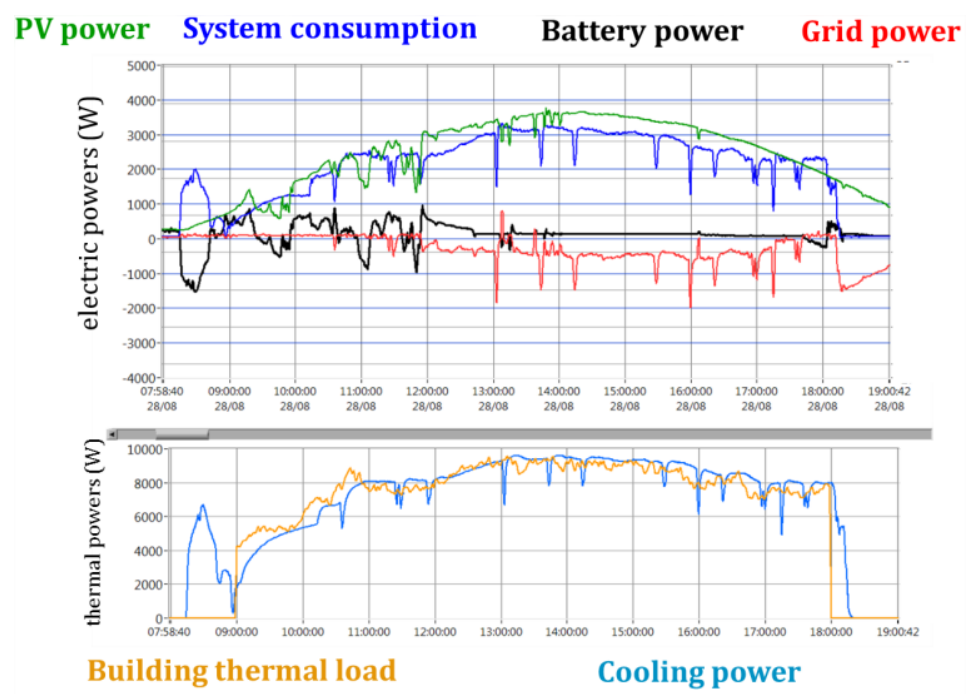

Fig. 9: Electric and thermal powers time history (Aug. $28^{\text {th }} 2017$ - TOULON) - "comfort" mode 


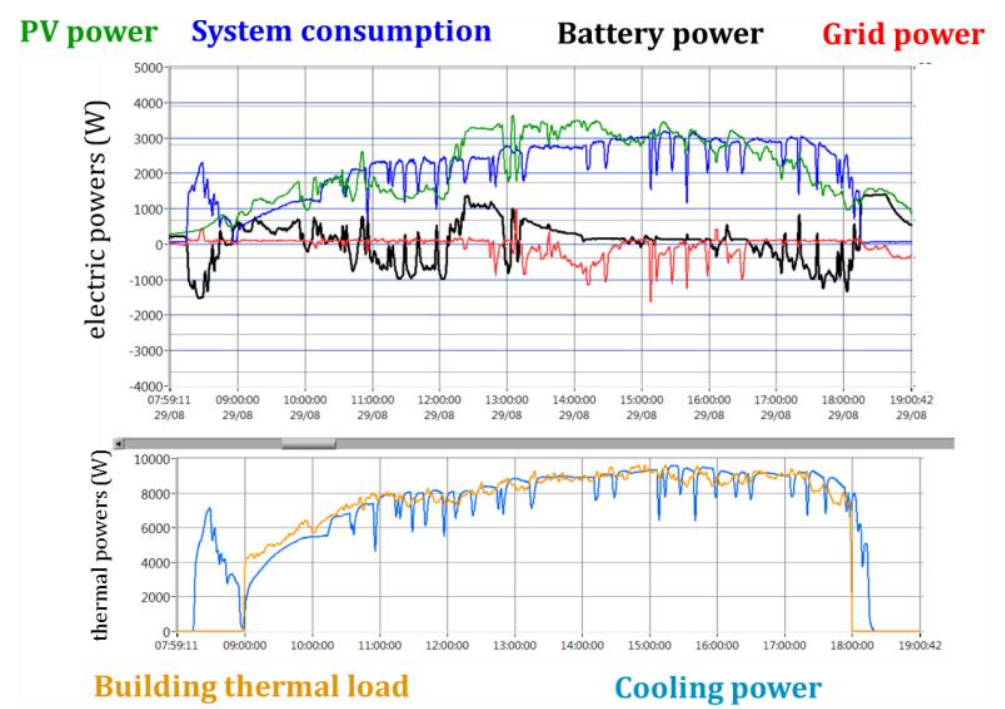

Fig. 10: Electric and thermal powers time history (Aug. $29^{\text {th }} 2017$ - TOULON) - "comfort" mode

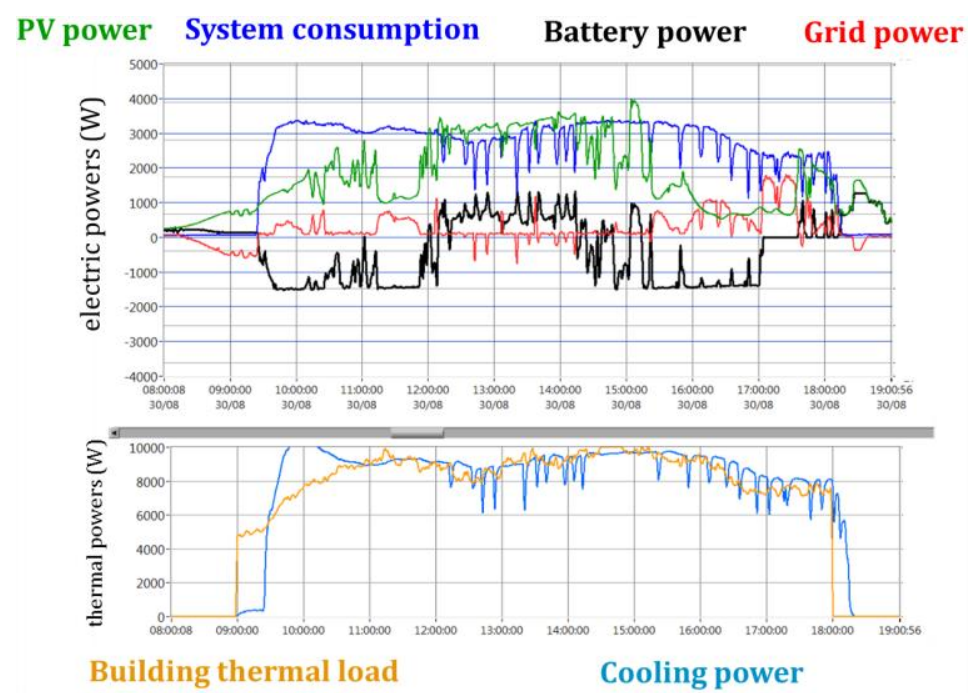

Fig. 11: Electric and thermal powers time history (Aug. 30 ${ }^{\text {th }} 2017$ - TOULON) - "comfort" mode

Fig. 12 below is a synthetic table of significant values which permit one to appreciating PV-COOLING performances.

\begin{tabular}{|l|c|c|c|c|c|}
\cline { 2 - 7 } \multicolumn{1}{c|}{} & \multicolumn{2}{c|}{ "ECO" mode } & \multicolumn{3}{c|}{ "COMFORT" mode } \\
\hline overall electric consumption(kWh) & sept 5th & sept 6th & Aug. 28th & Aug. 29th & Aug. 30th \\
\hline PV electric consumption $(\mathrm{kWh})$ & 14,52 & 17,87 & 22,62 & 22,22 & 25,24 \\
\hline PV energy production $(\mathrm{kWh})$ & 26,56 & 16,64 & 21,29 & 19,26 & 15,95 \\
\hline consumption from battery $(\mathrm{kWh})$ & 0,00 & 0,01 & 25,88 & 22,94 & 18,72 \\
\hline $\mathbf{Q}_{\text {grid }}$ : consumption from GRID $(\mathrm{kWh})$ & $\mathbf{0 , 4 0}$ & $\mathbf{1 , 2 2}$ & $\mathbf{0 , 4 7}$ & $\mathbf{0 , 7 8}$ & $\mathbf{3 , 1 5}$ \\
\hline building thermal load $(\mathrm{kWh)}$ & 38,64 & 51,74 & 71,15 & $\mathbf{7 2 , 0 4}$ & $\mathbf{7 5 , 9 9}$ \\
\hline $\mathbf{Q}_{\text {th }}$ : cooling production $(\mathrm{kWh})$ & $\mathbf{4 3 , 0 3}$ & $\mathbf{5 3 , 8 7}$ & $\mathbf{7 5 , 4 6}$ & $\mathbf{7 5 , 1 4}$ & $\mathbf{7 7 , 8 9}$ \\
\hline compressor COP & 3,40 & 3,36 & 2,91 & 2,96 & 2,82 \\
\hline "PV COOLING" COP & 2,96 & 3,02 & 2,72 & 2,76 & 2,64 \\
\hline PV COOLING "EER" $\left(\mathbf{Q}_{\text {th }} / \mathbf{Q}_{\text {grid }}\right)$ & $\mathbf{1 0 6 , 3 4}$ & $\mathbf{4 4 , 1 1}$ & $\mathbf{1 6 1 , 9 3}$ & $\mathbf{9 5 , 8 2}$ & $\mathbf{2 4 , 7 1}$ \\
\hline SELF CONSUMPTION RATE (\%) & $\mathbf{5 3}$ & $\mathbf{8 3}$ & $\mathbf{8 2}$ & $\mathbf{8 4}$ & $\mathbf{8 5}$ \\
\hline SELF PRODUCTION RATE (\%) & $\mathbf{9 7}$ & $\mathbf{9 3}$ & $\mathbf{9 4}$ & $\mathbf{8 7}$ & $\mathbf{6 3}$ \\
\hline
\end{tabular}

Fig. 12: Summary off significant values for different weather and management conditions 
Surprisingly high values of EER are the result of very low grid consumption and have to be interpreted with humility: in fact, comparing EERs on Aug. $28^{\text {th }}$ and $29^{\text {th }}$ (respt. 162 and 96) is only du to $0.31 \mathrm{kWh}$ difference in 11 hours !

However, as a result of those examples, it may be concluded that PV-COOLING concept can be considered as efficient and quite acceptable values of EER were obtained which demonstrate possibility to run PVCOOLING independently from grid.

\subsection{Estimate of environmental and economic benefit}

From 2017 summer measurements, an attempt has been done with a view to estimating environmental and economic benefit due to PV COOLING. This was done considering thermal cooling need for days when cooling is required, and the monthly rate of days of for which cooling is needed. This yields to monthly cooling energy $(\mathrm{kWh})$.

\begin{tabular}{|l|c|c|c|r|c|c|}
\hline & $\begin{array}{c}\mathbf{k W h}(\mathrm{th}) \\
\text { per day }\end{array}$ & $\begin{array}{c}\mathbf{N b} \\
\text { days }\end{array}$ & $\begin{array}{c}\text { rate of use } \\
(\%)\end{array}$ & $\begin{array}{c}\mathbf{k W h} \\
\text { (thermal) }\end{array}$ & $\begin{array}{c}\mathbf{k g} \mathbf{C O 2} / \mathbf{k W h} \\
\text { (elec) }\end{array}$ & $\begin{array}{c}\text { CO2 benefit } \\
\text { (kg) }\end{array}$ \\
\hline april & 20 & 30 & $20 \%$ & 120 & 0,09 & 4 \\
\hline may & 40 & 31 & $50 \%$ & 620 & 0,09 & 19 \\
\hline june & 60 & 30 & $85 \%$ & 1530 & 0,09 & 46 \\
\hline july & 75 & 31 & $100 \%$ & 2325 & 0,09 & 70 \\
\hline aug. & 65 & 31 & $90 \%$ & 1814 & 0,09 & 54 \\
\hline sept. & 50 & 30 & $70 \%$ & 1050 & 0,09 & 32 \\
\hline oct. & 30 & 31 & $30 \%$ & 279 & 0,09 & 8 \\
\hline & & & & & & \\
\hline
\end{tabular}

(a)

\begin{tabular}{|l|c|c|r|r|r|c|}
\hline & $\begin{array}{c}\mathbf{k W h}(\text { th) } \\
\text { per day }\end{array}$ & $\begin{array}{c}\mathbf{N b} \\
\text { days }\end{array}$ & $\begin{array}{c}\text { rate of use } \\
(\%)\end{array}$ & $\begin{array}{c}\mathbf{k W h} \\
\text { (thermal) }\end{array}$ & $\begin{array}{c}\mathbf{k g ~ C O 2 / k W h} \\
\text { (elec) }\end{array}$ & $\begin{array}{c}\text { CO2 benefit } \\
\text { (kg) }\end{array}$ \\
\hline april & 30 & 30 & $30 \%$ & 270 & 0,32 & 29 \\
\hline may & 50 & 31 & $70 \%$ & 1085 & 0,32 & 116 \\
\hline june & 80 & 30 & $100 \%$ & 2400 & 0,32 & 256 \\
\hline july & 95 & 31 & $100 \%$ & 2945 & 0,32 & 314 \\
\hline aug. & 80 & 31 & $100 \%$ & 2480 & 0,32 & 265 \\
\hline sept. & 75 & 30 & $80 \%$ & 1800 & 0,32 & 192 \\
\hline oct. & 50 & 31 & $60 \%$ & 930 & 0,32 & 99 \\
\hline & & & & & & \\
\hline
\end{tabular}

(b)

Fig. 13: Elements of estimate of the environmental and economic benefit (a): in southern France (French Riviera) ; (b): in southern Europe (southern Italy)

Figure 13(a) above shows the result in terms of cooling energy $(\mathrm{kWh})$ and electricity induced $\mathrm{CO}_{2}(\mathrm{~kg})$ during the period from april to September for our $135 \mathrm{~m}^{2}$ office building in south of France (French riviera): $232 \mathrm{~kg}$; although Figure 13(b) produces same results considering southern Italy : $1270 \mathrm{~kg}$.

A transposition is done considering a $1000 \mathrm{~m}^{2}$ office building over a 15 years duration, and by considering 2 hypothesis : (1) PV COOLING COP $=3$ and (2) one may expect a $3 \%$ annual increase in electric energy cost.

In France (fig.13(a)), the required 7.7 MWh induces $232 \mathrm{~kg} \mathrm{CO}_{2}$ and in southern Italy (fig.13(b)), $12 \mathrm{MWh}$ correspond nearly to 1.3 ton of $\mathrm{CO}_{2}$.

Transposition to a $1000 \mathrm{~m} 2$ office building shows the following:

- $\mathrm{CO}_{\mathrm{a}}$ saving of 25,8 tons in France and 141 tons in Italy

- Energy saving cost of $30 \mathrm{k} €$ in France and $121 \mathrm{k} €$ in Italy.

The disparity is due to the fact that in Italy, as a lot of Europeans countries (and unkike France), grid power rests upon embodied energy and consequently carbon footprint is much higher than in France.

Similar remarks may be done and for the same reasons regarding cost considerations where PV COOLING may induce $121 \mathrm{k} €$ in Italy although the same PV COOLING may only induce $30 \mathrm{k} €$ in southern France. 


\section{Conclusion}

To conclude, the developed and tested PV-COOLING concept allows bringing following conclusions:

- PV-COOLING demonstrates that it is possible to combine improved technologies which are photovoltaic (PV) power plant to drive vapor compression thermodynamic system for the sake of producing cooling energy ;

- Securing PV plant with external power supply to drive thermodynamic system was successfully demonstrated ;

- Part of efficiency results in possibility to real-time adapting cooling power to solar irradiation ;

- EER obtained values shows that only a limited amount of grid supply is necessary and consequently, external generator may efficiently be substituted to grid ;

- Proper management permits one to consider fully autonomous systems disconnected from grid ;

Technically, existing system is planned to further investigate clever ways of using PV excessive power. This concerns mainly investigating cold storage (as shown on fig.2), but also electric storage and compare which is better to improve autonomy of PV-COOLING.

Comparison of Italy vs France benefits of PV COOLING shows that energy cost and current grid power carbon footprint is a drastic parameter for environmental and economic efficiency. In this respect, France is far from holding the best position for developing a renewable energies policy.

The marketing plans carried out target PV COOLING as a development tool in sunny and/or tropical regions for both air-conditioning system and positive food storage. Eventually, PV-COOLING concept open wide perspective for insulated areas and may constitute a tool for land-use planning, and especially in the developing world.

\section{References}

Gustavsson J., Cederberg C., Sonesson U., van Otterdijk R., Meybeck A., 2011. Global food losses and food waste - Extent, causes and prevention. Report of Food and Agriculture Organization of the United Nations (FAO). 


\title{
Measurement Results and Operating Experience of Large-Scale Solar Air Conditioning Plants
}

\author{
Lukas Feierl'1, Hannes Poier ${ }^{1}$, Christian Holter ${ }^{1}$ \\ 1 SOLID GmbH, Graz (Austria)
}

\begin{abstract}
The demand for air-conditioning has increased in the past years and is expected to rise even further. As an alternative to conventional air-conditioning systems, solar cooling may be used to reduce electricity peak loads and at the same time delivering environmentally-friendly cooling. This paper aims to analyze the monitoring data of four of the currently largest solar air-conditioning systems in order to show the potential of solar cooling systems and outline trends. This is done by calculating key performance indicators considering the boundary conditions, financials as well as solar and chiller performance of each system.

All solar systems performed as planned during the 7-month long calculation period, yielding more than $5.1 \mathrm{GWh}$ total solar energy yield, with an average solar conversion factor of $34.6 \%$ and electric efficiency ratios of up to 26. The results also show increased performance of the solar collectors of the recently build (2017) solar system compared to the older ones commissioned in 2011 and 2014, with up to 46\% higher solar conversion factors. Additionally, specific system costs decreased by approximately $70 \%$. Even though the paper only could analyze four different solar systems with different boundary conditions, the sheer magnitude of performance and construction-cost improvements clearly supports the hypothesis that both costs and performance improved.
\end{abstract}

Keywords: solar cooling, large-scale solar thermal system, measurement results,

\section{Introduction}

In the past years the demand for air-conditioning and electric energy consumption has increased and is expected to rise even further (OECD/IEA 2018). Especially in hot tropical or subtropical countries increasing population and urbanization is expected to accelerate cooling demand (OECD/IEA 2018, Waite et al. 2017).

Conventionally, cooling is done with vapor compression refrigeration machines which are driven by electrical energy. However, to reduce the resulting high electricity peak loads and at the same time provide environmentally friendly cooling, solar thermal air-conditioning proved to be a good alternative. The combination of a solar system and a heat powered absorption chiller is especially beneficial as cooling demand perfectly aligns with available solar irradiation. Even though the technology is market-ready (SHC Task 48 2015), system designers are often faced with a lack of awareness and confidence for solar thermal cooling (Olsacher and Schnitzer 2016).

Therefore, this paper aims to show the potential of solar thermal air conditioning systems and tries to outline system-price and performance trends by analyzing the monitoring data of four of the currently largest solar thermal cooling systems worldwide. All of them were designed, installed and are operated by the company SOLID, which is a pioneer in this field of knowledge. The range of selected solar plants covers different climate conditions and systems with long monitoring periods as well as newly installed state-of-the-art systems. Furthermore, extensive monitoring equipment is installed at the different systems used for collecting and analyzing the monitoring data.

\section{Selected Solar Systems}

In this section a short overview of each selected solar system is given. From here on the systems are symbolized by their abbreviations: UWC, DMHS, MANAGUA and IKEA.

\subsection{United World Collage (UWC)}

At the United World Collage, Singapore, $3872 \mathrm{~m}^{2}$ of flat plate collectors were commissioned by SOLID in August 2011. The solar heat is used mainly for cooling the building, which encompass about $60000 \mathrm{~m}^{2}$ of air-conditioned 


\section{Feierl Lukas}

space, but also to satisfy $100 \%$ of the domestic hot water demand. With a total of $2200 \mathrm{MWh} /$ year of heat produced by the solar collectors supplying a $1475 \mathrm{~kW}$ lithium bromide single effect absorption chiller, this solar plant was the largest solar cooling system worldwide until 2014 (Schubert et al. 2011, Olsacher and Schnitzer 2016). The collectors are positioned on the roof of the building facing different directions (see Fig. 1 left). This way, the usage of available space and thus the solar fraction was optimized as collector orientation is less important due to Singapore's location near the equator. Furthermore, two storage tanks with $30 \mathrm{~m}^{3}$ each, together with a smaller $7 \mathrm{~m}^{3}$ hot water tank were installed to store the solar heat (see Fig. 1 right). The larger storage tanks are positioned next to each other in series and are used for both supplying the chiller with heat and feeding into the smaller domestic hot water tank if needed.
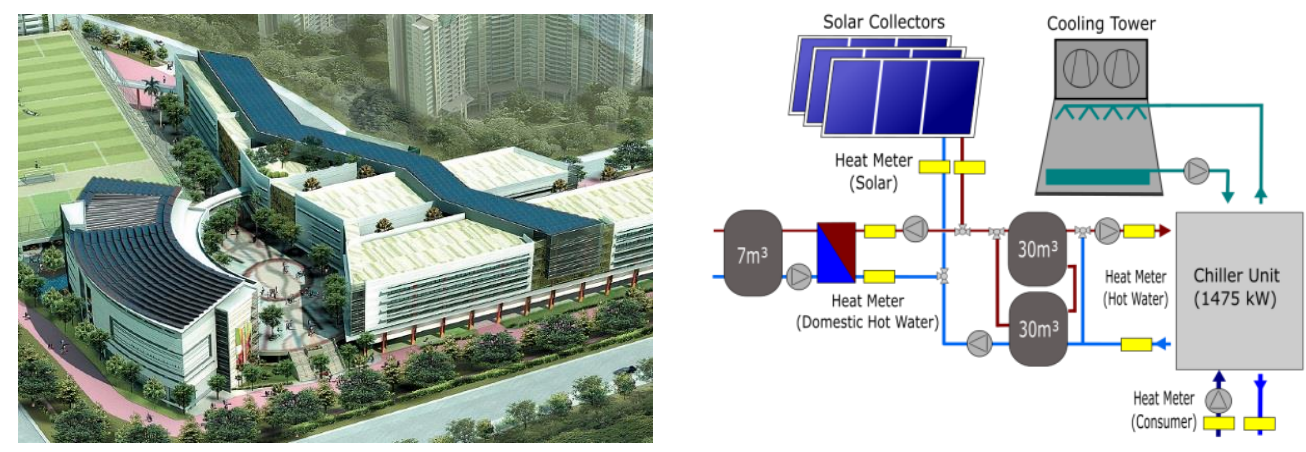

Fig. 1: Design view of the UWC campus with collector arrays in blue (left) and simplified hydraulic schema of UWC (right).

The school building with approximately 5000 enrolled students is located in the west of Singapore, near the Payar Lebar Air Base and the Bedok Reservoir. Situated in the tropical rainforest climate, there are no typical seasons as winter or summer, but constant high humidity, hot temperature and frequent and heavy rainfall. Average temperatures are in the range of $20^{\circ} \mathrm{C}$ to $34^{\circ} \mathrm{C}$ which lead to high cooling demands. However, high relative humidity of $80 \%$ throughout the year and the heavy rainfalls are a challenge for heat rejection at the cooling tower and for delivering heat at rainy days.

\subsection{Desert Mountain High School (DMHS)}

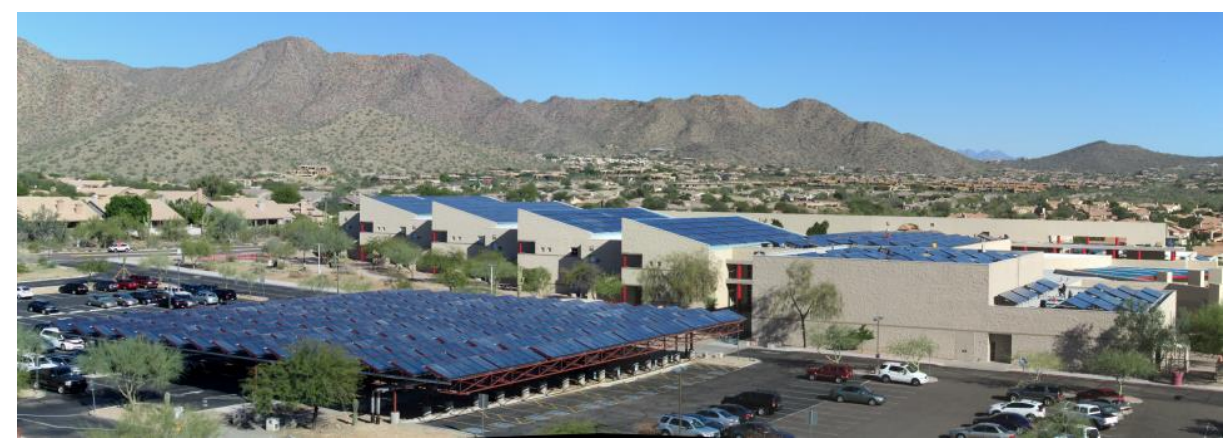

Fig. 2: Panorama view of DMHS.

In February 2014, SOLID commissioned a solar cooling system at the Desert Mountain High School in Scottsdale, Arizona (see Fig.2). With a gross collector area of $4935 \mathrm{~m}^{2}$ and a $1750 \mathrm{~kW}$ lithium bromide absorption chiller, the solar system is currently the most powerful solar cooling system worldwide (Weiss and Spörk-Dür 2018) and has therefore also been previously studied by various authors (Schubert et al. 2011, 2014) (Buchinger et al. 2012) (Olsacher and Schnitzer 2016).

The school for over 2600 pupils has $55000 \mathrm{~m}^{2}$ of air-conditioned space, which is cooled with a solar driven lithium bromide single effect absorption chiller in combination with three conventional vapor compression chillers. The double-glazed flat plate solar collectors are positioned on different roofs of the building and are mainly tilted at 20 degrees, while some were installed with a 14 degrees tilt. For buffering the solar load, a $34.5 \mathrm{~m}^{3}$ storage tank is used to connect the solar and chiller circuit (see Fig.3). As there are no accommodations for students, the solar heat is solely used for air conditioning during school operation. 


\section{Feierl Lukas}

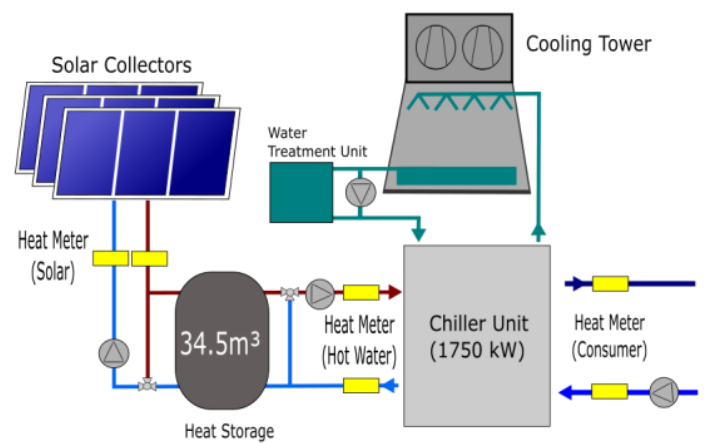

Fig. 3: Simplified hydraulic schema of DMHS.

DMHS is located in the arid desert climate and thus faces high ambient temperature, dry air and low precipitation. Ambient temperature ranges from over $45^{\circ} \mathrm{C}$ in July to low temperatures just above the freezing point in cold winter nights in January. Nevertheless, no anti-freeze protection has been used for the collector circuit as small amounts of water from the storage tank can be pumped through the collectors at these rare events to prevent freezing (Schubert et al. 2014). However, even in the winter high temperature maxima can occur during the day, resulting in cooling demand for approximately 12 months. In combination with the dry air, the climate is beneficial for the operation of the chiller and the cooling tower.

\subsection{Hospital Managua (MANAGUA)}

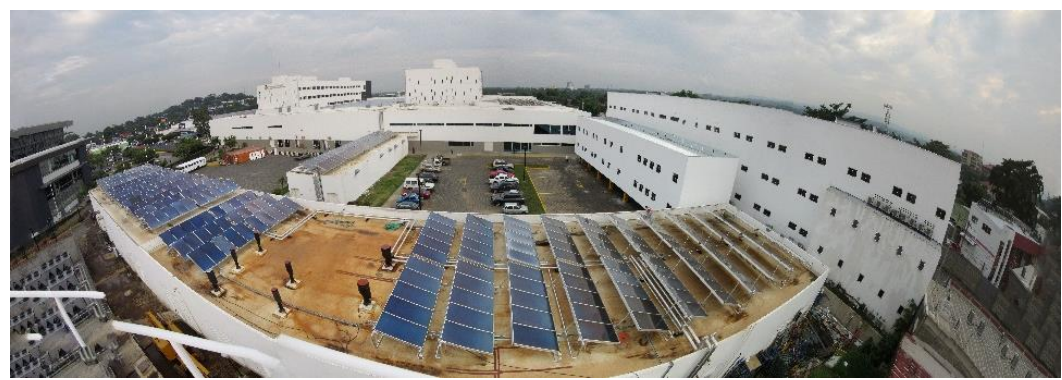

Fig. 4: Panorama view of $4450 \mathrm{~m}^{2}$ collector area installed at Managua Hospital, Nicaragua.

The third of the selected solar systems was commissioned by SOLID in December 2017 at the Hospital Militar Escuela Dr "Alejandro Dávila Bolaños" in Managua, Nicaragua, with a collector area of $4450 \mathrm{~m}^{2}$ of high performance collectors (see Fig.4). Same as at UWC, the solar heat is not only used for cooling the building, but also for domestic heat for the laundry and the hospital. Therefore, a $75 \mathrm{~m}^{3}$ storage tank is used to store the solar yield and to provide heat for the $1023 \mathrm{~kW}$ lithium bromide single effect absorption chiller, the $2 \mathrm{~m}^{2}$ laundry tank and the $3.75 \mathrm{~m}^{3}$ domestic hot water tank (see Fig.5).

MANAGUA has a tropical wet and dry climate, with a dry season between November and April and lots of rainfall between May and October. Nevertheless, ambient temperature is constantly high throughout the year with averages above $26^{\circ} \mathrm{C}$. Relative humidity ranges between approximately $60 \%$ during the dry seasons to $80 \%$ during the rainy season. 


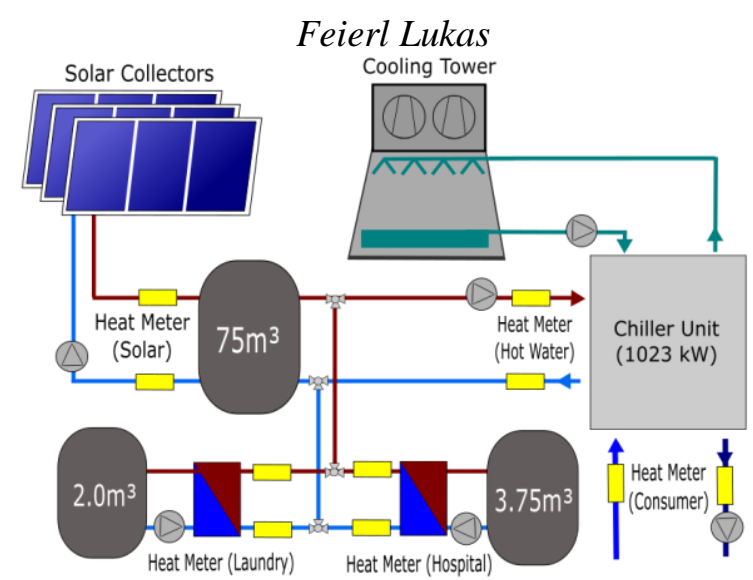

Fig. 5: Simplified hydraulic schema of MANAGUA.

\subsection{Ikea Alexandra (IKEA)}

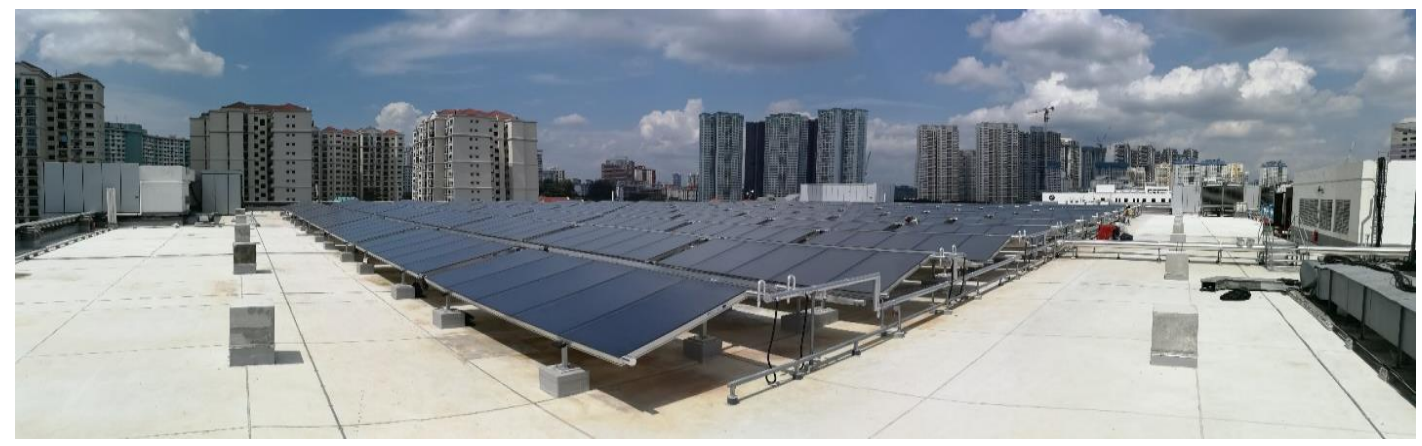

Fig. 6: Panorama view of $2472 \mathrm{~m}^{2}$ collector area installed at IKEA.

Recently in December 2017, SOLID commissioned a solar cooling system with a collector area of $2472 \mathrm{~m}^{2}$ and an $880 \mathrm{~kW}$ lithium bromide single effect absorption chiller at the Swedish furniture giant IKEA in Alexandra, Singapore (see Fig.6). Together with three conventional compression chillers, the solar powered chiller unit is used to cool the facility. The solar system with its $15 \mathrm{~m}^{3}$ buffer storage reduces power consumption significantly and also helps to reduce expensive electricity costs. Due to Singapore's location near the equator, the solar collectors have been positioned at the top of the building facing southwest and northeast in turns to optimize annual solar yield and to minimize shading effects.

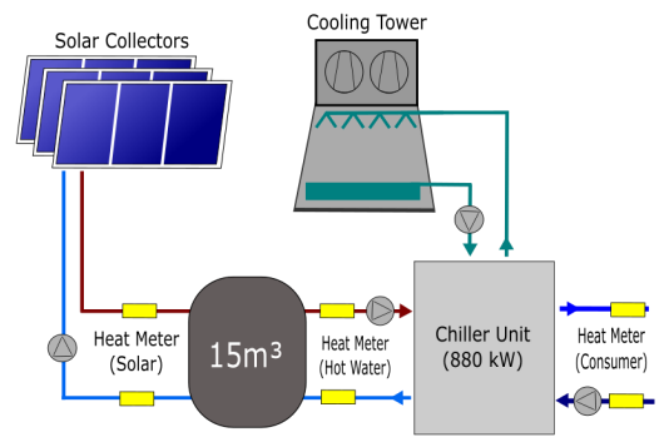

Fig. 7: Simplified hydraulic schema of IKEA.

Located in the same city as UWC, the solar system at IKEA faces the same tropical climate conditions as previously described. In contrast to UWC however, the cooling demand is not based on school operation, but almost constant throughout the year - determined by the opening hours and especially the number of visitors of the warehouse. Similar to DMHS, the solar heat is solely used for chilled water production (see Fig.7). 


\section{Method}

\section{Feierl Lukas}

Various key performance indicators can be calculated to analyze solar thermal cooling systems. To get a better overview, all considered key indicators are categorized into four different main categories, each describing a key section of a solar thermal air-conditioning plant: Boundary Conditions, Solar Circuit, Chiller Circuit and Financials (see Fig.8).

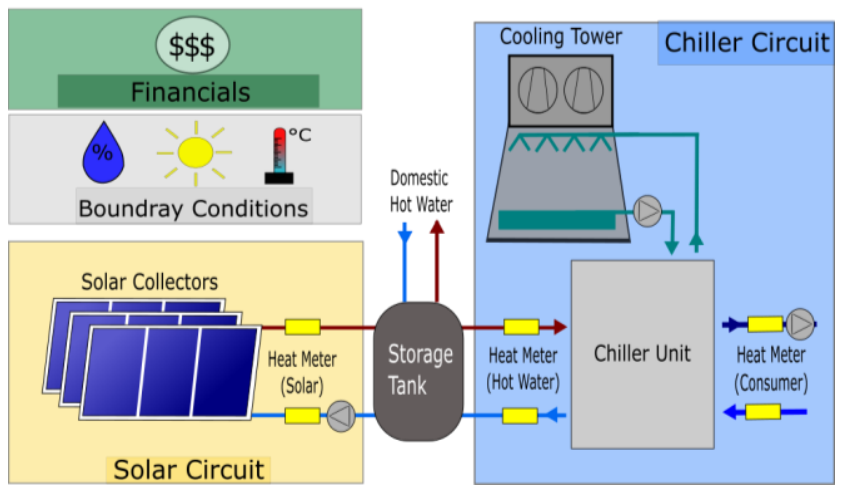

Fig. 8: Symbolic visualization of the key performance indicator categories: Boundary Conditions, Solar Circuit, Chiller Circuit and Financials.

To carry out this analyzation the monitoring data of each plant has been used, which is recorded in a one-minute interval and stored and pre-processed in SOLID's METHODIQA Database (Ohnewein et al 2016). For further analysis and visualization, the programming language Python has been used. The types of measurement devices used for collecting the monitoring data are shown in Tab.1. The calculation period is from 01.01.2018 to 31.07.2018, data from IKEA and MANAGUA is available since February and March 2018, respectively.

Tab. 1: Types of measurement devices installed at the selected solar systems.

\begin{tabular}{|c|c|c|c|}
\hline Plant & Measurement Device & Brand & Description/Type \\
\hline UWC & Radiation Sensor & MESA & MS-020VM \\
\hline UWC & Temperature Sensors & TGH & PT1000 (1/3 DIN Class B, Silicone Cable) \\
\hline UWC & Heat Meter & KAMSTRUP & ULTRAFLOW 54 + MULTICAL 602 \\
\hline UWC & Electric Power Meter & SCHRACK & Digital Industry Meter DIZ Generation G \\
\hline DMHS & Radiation Sensor & MESA & MS-020VM \\
\hline DMHS & Temperature Sensors & TGH & PT1000 (1/3 DIN Class B, Silicone Cable) \\
\hline DMHS & Heat Meter & KAMSTRUP & ULTRAFLOW 54 + MULTICAL 602 \\
\hline DMHS & Electric Power Meter & SCHRACK & Digital Industry Meter DIZ Generation G \\
\hline MANAGUA & Radiation Sensor & MESA & MS-020VM \\
\hline MANAGUA & Temperature Sensors & TGH & PT1000 (1/3 DIN Class B, Silicone Cable) \\
\hline MANAGUA & Heat Meter & KAMSTRUP & ULTRAFLOW 54 + MULTICAL 602 \\
\hline MANAGUA & Electric Power Meter & SCHRACK & NA 96 \\
\hline IKEA & Radiation Sensor & MESA & MS-020 VM (tilt: $0^{\circ}$ ) \\
\hline IKEA & Temperature Sensors & TGH & PT1000 (1/3 DIN Class B, Silicone Cable) \\
\hline IKEA & Heat Meter & KAMSTRUP & ULTRAFLOW 54+ MULTICAL 602 \\
\hline IKEA & Electric Power Meter & SCHRACK & Digital Industry Meter DIZ Generation G \\
\hline
\end{tabular}




\subsection{Boundary Conditions}

\section{Feierl Lukas}

The environmental boundary conditions such as ambient temperature, humidity, radiation and energy demand of the consumers are important to bear in mind when analyzing other key indicators, as they are strongly influencing the performance of a solar system. Radiation is the main energy source of a solar thermal plant and thus is critical for comparing solar- or chilled-water energy yield. Ambient temperature also plays a vital role concerning heat losses and cooling demand. Humidity on the other hand strongly influences the heat rejection at the cooling tower. Therefore, average daily irradiation $\langle H\rangle$ and average ambient temperature $\left\langle T_{a}\right\rangle$ are calculated for each month, to show the potentials and challenges of solar cooling in these regions. As no measurement devices for humidity are installed at the systems, average relative humidity values are extracted from (Weatherbase) for each location.

\subsection{Solar Circuit}

The performance of the solar collectors and the produced solar heat are key to any solar thermal cooling system. To get comparable values, the specific solar yield $\tilde{Q}_{s}$ can be calculated by norming the solar energy yield $Q_{s}$ by the gross collector area $A_{c o l}$ of the considered system:

$$
\tilde{Q}_{s}=\frac{Q_{s}}{A_{c o l}}
$$

For calculating the efficiency of the solar collectors, the solar conversion factor can be used, which characterizes the ratio of solar specific yield $\tilde{Q}_{S}$ to solar radiation $\mathrm{H}$ :

$$
\eta_{\text {col }}=\frac{\tilde{Q}_{s}}{H}
$$

For both of these indicators daily averages are calculated. As indicated by Fig.8, produced solar heat $Q_{s}$ is defined as heat supplied to the first (main) storage tank to consider different system designs regardless of whether domestic hot water is produced or not and whether the hot water tank is used as buffer or as storage device.

\subsection{Cooling Circuit}

To analyze the performance of a solar driven chiller unit, daily values for the electric- and thermal energy efficiency ratio $\left(E E R_{e l}\right.$ and $\left.E E R_{t h}\right)$ can be calculated:

$$
\begin{aligned}
& E E R_{t h}=\frac{Q_{c}}{Q_{s u p}} \\
& E E R_{e l}=\frac{Q_{c}}{Q_{e l}}
\end{aligned}
$$

Here, $Q_{\text {sup }}$ is the energy provided by the solar circuit that is supplied to the chiller unit, $Q_{c}$ is the cooling energy that is transferred to the consumer and $Q_{e l}$ is the total electric energy used at the solar system for operating various pumps and the cooling tower. These indicators are often used for characterizing the performance of a chiller and are sometimes also called daily coefficient of performance (COP), or daily seasonal performance factor (SPF). However, SOLIDs solar systems are never optimized in terms of chiller efficiency but in terms of providing useful energy. Therefore, the solar powered chiller will be in operation even if there are not full-load conditions as long as the electrical efficiency outnumbers the vapor compression chillers installed at these systems. Hence, this reduces the daily energy efficiency ratio, even though the system performs well during the day.

As the cooling tower at IKEA was preinstalled and is not only used by the solar thermal system, no electric meter to measure its electricity demand was installed. Therefore, its electric consumption corresponding to the solar absorption chiller is estimated by $80 \%$ of the remaining electric energy consumption, which is a benchmark derived as upper bound from data of the other selected solar systems.

\subsection{Financials}

Unfortunately, financial data is hard to compare due to various influencing factors such as different environmental conditions, the amount and quality of preinstalled equipment, customs, the availability of area and other specific construction-site dependencies. However, SOLID can provide rough benchmarks for the construction-costs of solar systems similar in terms of supply but not equal to the real solar systems, not taking into account any 
Feierl Lukas

beneficial nor unfavorable influencing factors. Their values are based on SOLIDs vast experience for designing and installing various solar systems. For better comparison, these estimated total system-costs are normed by the gross collector area $A_{c o l}$ and weighed by the solar conversion factor:

$$
\text { specific costs }=\frac{\text { costs }}{A_{\text {col }} \cdot \eta_{s}}
$$

\section{Monitoring Results}

\subsection{Boundary Conditions}

At DMHS a seasonal pattern can be seen both for the average ambient temperature and the solar irradiation (see Fig.9, and Fig.10). With its maxima in May and minimum in January the irradiation at DMHS is very high compared to the other solar systems, with an average of $6.7 \mathrm{kWh} / \mathrm{m}^{2} /$ day during the calculation period. Especially in the summer months, average daily solar irradiation reaches $8.0 \mathrm{kWh} / \mathrm{m}^{2} /$ day. Ambient temperature shows high fluctuations - visualized by the black whiskers in Fig. 10 - with measurements ranging from $5^{\circ} \mathrm{C}$ in the winter to $46^{\circ} \mathrm{C}$ in the summer. However, even during cold months high temperatures of over $25^{\circ} \mathrm{C}$ were not uncommon, yielding cooling demand also during winter-season. Compared to other solar systems, average relative humidity is very low with about $40 \%$ throughout the year (see Fig.12).

\section{Daily Irradiation 2018}

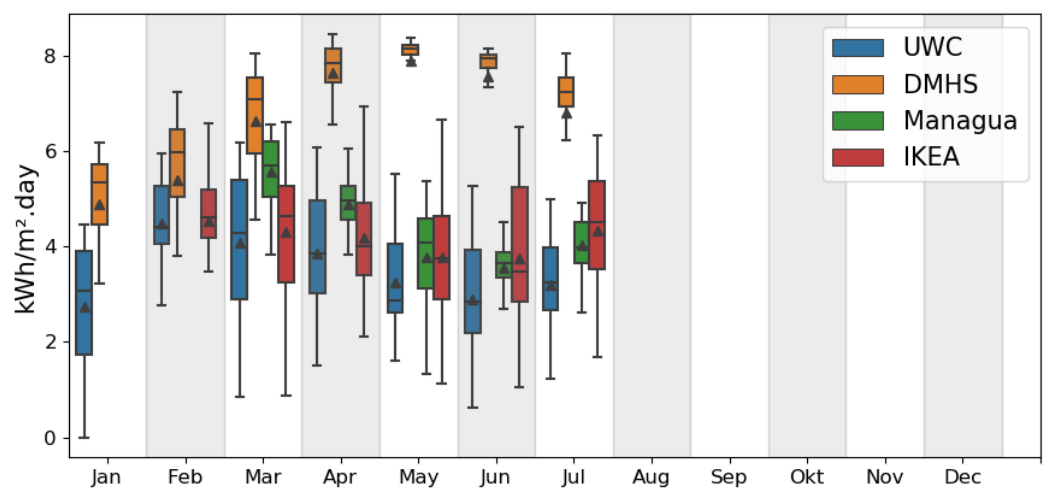

Fig. 9: Daily average irradiation per day for each month at each solar system in 2018. Black lines mark the median, the border of the colored boxes mark the quartile and the whiskers mark the range of the measured data. Averages are displayed as black triangles.

In contrast to DMHS, there are no clear seasonal patterns visible for UWC and IKEA, located in Singapore's tropical rainforest climate. Both face high ambient temperatures of about $30^{\circ} \mathrm{C}$ and high relative humidity with an average value of about $80 \%$. Due to its heavy rains occurring randomly throughout the year, daily irradiation values show high fluctuations from one day to the next. This leads to an average daily irradiation of $3.8 \mathrm{kWh} / \mathrm{m}^{2} /$ day during the calculation period. Interestingly, there are differences between solar irradiation at IKEA and UWC, even though they are in the same city. This can be explained by the different orientation of the radiation sensors, but is also caused by different neighborhood settings (fog, clouds, reflection of buildings) as UWC is located near a lake while IKEA is surrounded by skyscraper buildings. Similarly, ambient temperature is slightly higher at IKEA than UWC for the same reason (see Fig.11).

MANAGUA shows similar results to UWC and IKEA: Average irradiation is at $4.4 \mathrm{kWh} / \mathrm{m}^{2} /$ day during the calculation period, average temperatures are ranging from $25^{\circ} \mathrm{C}$ to $35^{\circ} \mathrm{C}$ and average relative humidity ranges between $40 \%$ and $90 \%$. Due to its rainy season in May to October, relative humidity is rising and irradiation is a little bit lower during these months. 
Feierl Lukas

Ambient Temperature 2018

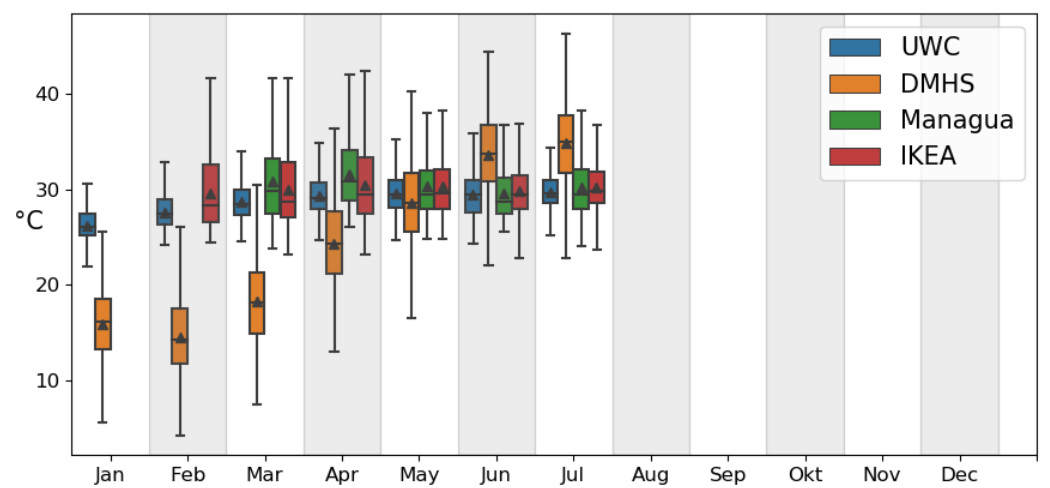

Fig. 10: Ambient temperatures at each system in 2018. Black lines mark the median, the border of the colored boxes mark the quartile and the whiskers mark the range of the measured data. Average values are displayed by black triangles.
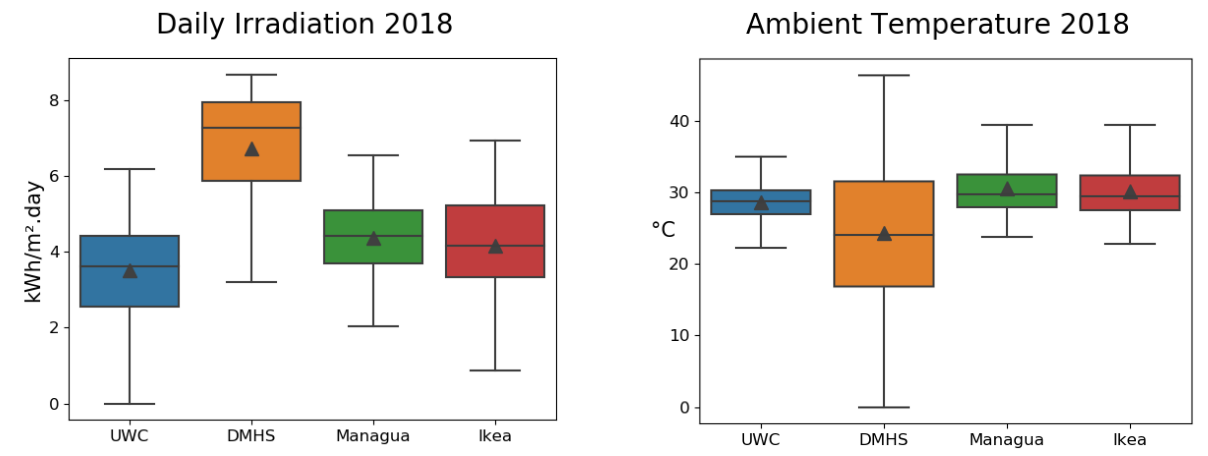

Fig. 11: Average daily radiation per day (left) and average ambient temperature (right) for each system in 2018 . Black lines mark the median, the border of the colored boxes mark the quartile and the whiskers mark the range of the measured data. Average values are displayed by black triangles.

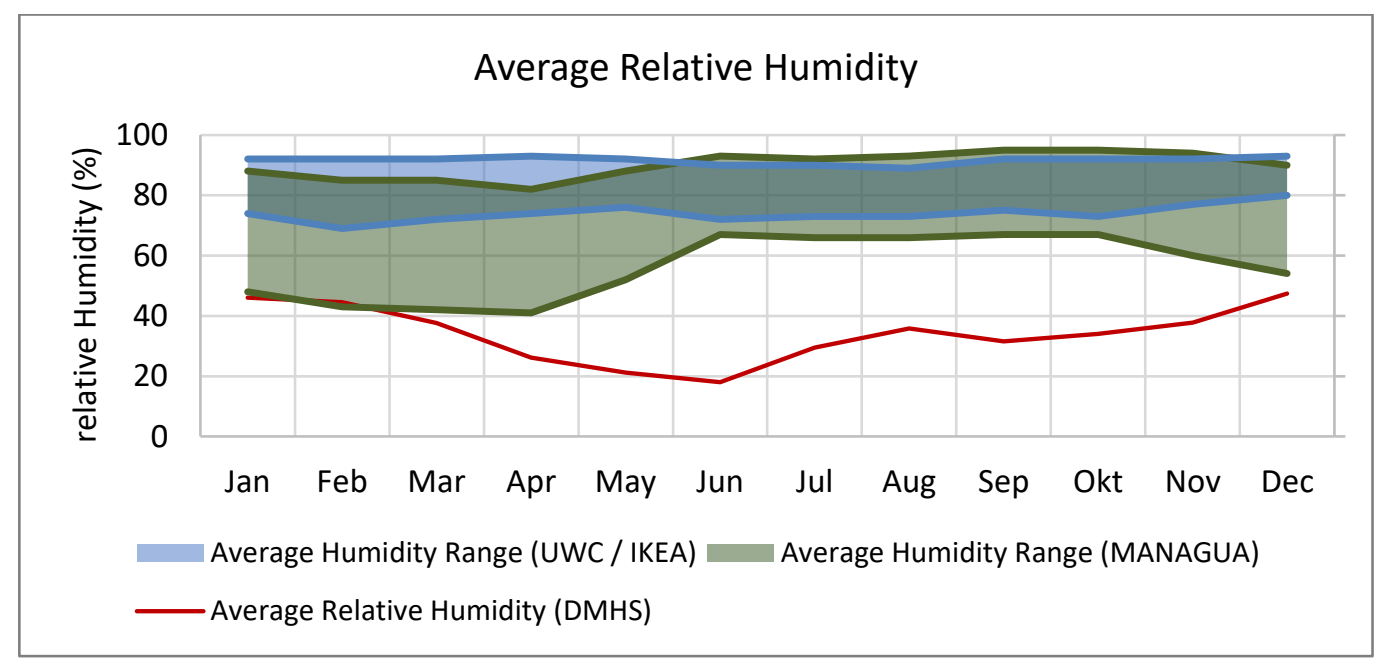

Fig. 12: Average relative humidity for each plant. Source: www.weatherbase.com.

\subsection{Solar Circuit}




\section{Feierl Lukas}

All solar thermal systems performed very well during the calculation period from January to August 2018, with a total of $5.1 \mathrm{GWh}$ of solar energy yield produced by the four solar systems. Fig.13 shows the average specific solar yield (left) and the solar conversion factor (right) of each plant, calculated by eq. 1 and eq. 2 .

It can be seen that DMHS shows the highest average specific solar yield with $2.23 \mathrm{kWh} / \mathrm{m}^{2} /$ day followed by MANAGUA with $1.80 \mathrm{kWh} / \mathrm{m}^{2} /$ day and IKEA with $1.62 \mathrm{kWh} / \mathrm{m}^{2} /$ day. However, this is due to DMHS's favorable climate conditions with its high solar irradiation. In contrast, when looking at the solar conversion factor $\eta_{s}$, it can be seen that MANAGUA and IKEA perform much better than DMHS. Another observation is that the solar conversion factor correlates with the time of commission of the solar systems. Compared to UWC (commissioned 2011) with an average solar conversion factor of 0.28, the performance of IKEA (commissioned 2017, $\left\langle\eta_{s}\right\rangle=$ 0.38 ) and MANAGUA (commissioned 2017, $\left\langle\eta_{s}\right\rangle=0.40$ ) improved by $36 \%$ and $46 \%$, respectively. Compared to DMHS (commissioned in $2014,\left\langle\eta_{s}\right\rangle=0.32$ ) the improvement is still $17 \%$ to $25 \%$.
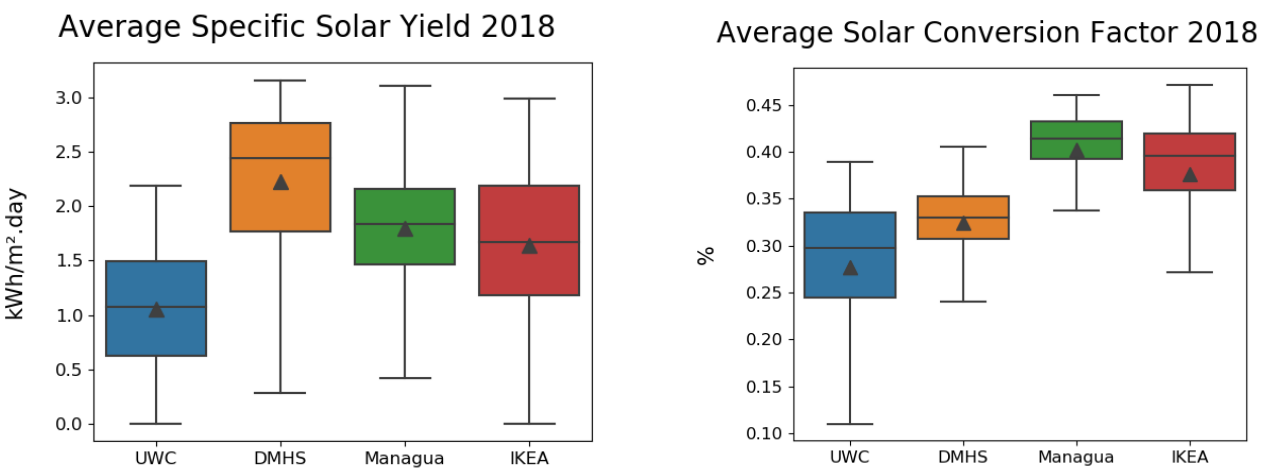

Fig. 13: Average specific solar yield (left) and average solar conversion factor (right) of each solar system in 2018. Median are displayed by a solid black line, quartiles are marked by colored boxes and the range of the measured data is displayed by the black whiskers. Averages are marked by black solid triangles.

\subsection{Chiller Circuit}

For analyzing the chiller circuit, the thermal and electrical energy efficiency ratio $\left(E E R_{t h}\right.$ and $\left.E E R_{e l}\right)$ have been calculated with Equation 3 and 4.

The results in Fig.14 show that the average $E E R_{t h}$ is about $60 \%$ to $75 \%$ at all of the selected solar systems. Although located in the same climate region, IKEA thermal efficiency ratio is approximately $2 \% /$ day higher compared to UWC, indicating some performance improvements.

However, the highest values for $E E R_{t h}$ can be observed at DMHS with daily averages ranging up to $80 \%$, especially in the summer season. During the winter however, days with low cooling demand lead to lower thermal efficiencies, which in terms lead to the large value range visualized by the whiskers in Fig.14.

In comparison to the thermal efficiency ratio, there are more differences between the various systems when looking at the $E E R_{e l}$. DMHS clearly stands out with average daily thermal efficiency ratios of 15.6 compared to UWC $\left(E E R_{e l}=4.8\right)$, MANAGUA $\left(E E R_{e l}=6.9\right)$ and IKEA $\left(E E R_{e l}=8.9\right)$. Similar to the thermal efficiency, DMHS also shows the biggest range for average electric efficiency ratios. As described previously, this is caused by the low cooling demand in the winter season. However, during summer when the chiller operates in steady state, daily $E E R_{e l}$ of 25 were reached. These high electric efficiency values might be the effect of the dry desert climate at DMHS, where average relative humidity is at low $40 \%$, which contributes to the cooling tower efficiency. 


\section{Feierl Lukas}

Average Thermal Energy Efficiency Ratio 2018
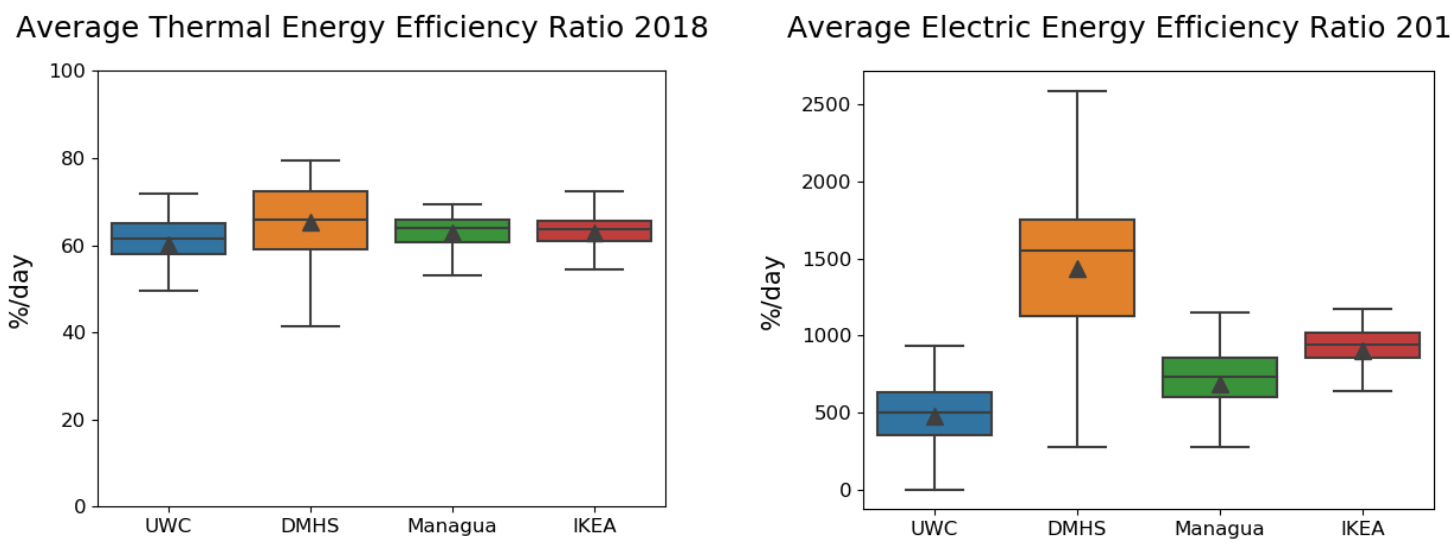

Fig. 14: Thermal (left) and Electrical Energy Efficiency Ratio (right) of each plant in 2018. Average values are displayed by black triangles, the median is displayed as horizontal line, the quartiles are marked by the colored boxes and the range of the calculated data is marked by the black whiskers.

Both UWC and MANAGUA show lower efficiency values compared to DMHS and IKEA. However, electrical meter installed at these plants only measure overall energy consumption - not only the consumption of chilled water related components. Therefore, and due to their system design, also electrical consumption contributing to the domestic hot water are included in the electric energy efficiency ratios. This way, their values can only be taken as lower boundaries of their actual performance. In addition, as mentioned in section 3, the solar cooling systems are optimized for maximizing cooling energy and not for optimizing efficiency and thus chiller are in operation as long as its performance is better than the vapor compression chillers installed at the system.

\subsection{Financials}

Estimated costs for solar systems with similar scope of supply and performance compared to the actual systems are shown in Fig.15. As described in section 3, these values are derived by standard-costs approximations not including any beneficial or unfavorable boundary factors (see eq.4). The results show major cost savings of the recently build systems with approximately $0.23 \mathrm{Mio} . \$ / \eta_{\mathrm{s}} \mathrm{m}^{2}$ in comparison to the older ones $(0.62$ and 0.75 Mio. $\$ / \eta_{\mathrm{s}} \mathrm{m}^{2}$ ). Most of the improvements have been realized by decreasing component costs, but also by reducing the costs for design and commission, as SOLID has standardized various design and construction steps and increasing knowledge about solar cooling let to better dimensioning.

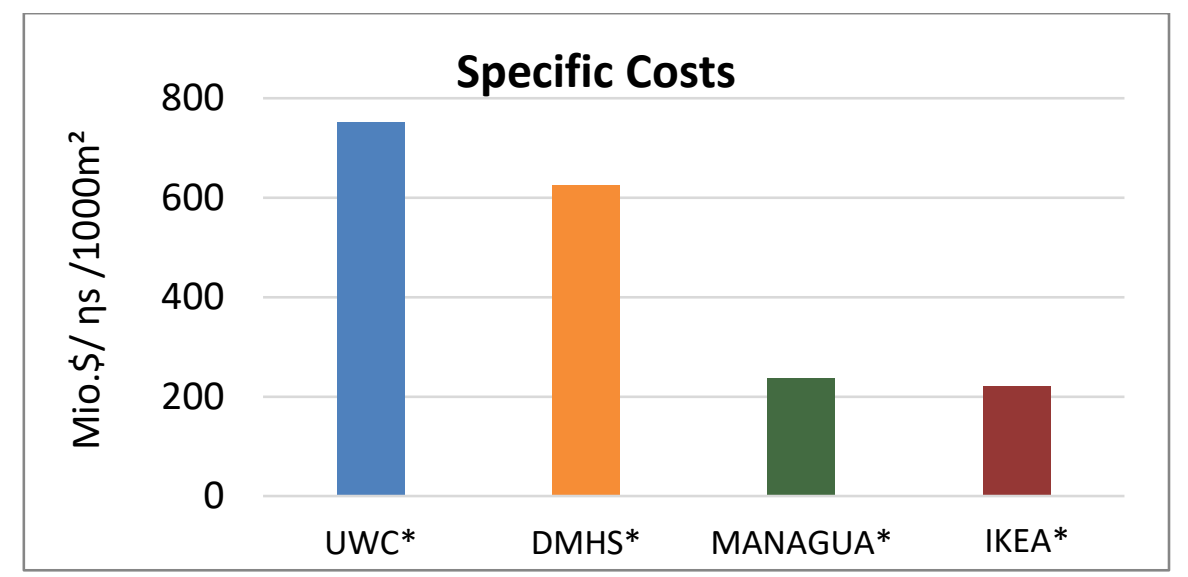

Fig. 15: (*) Estimated values for the specific costs of solar systems similar but not equal to the real commissioned solar systems. 


\section{Discussion}

Feierl Lukas

Various key performance factors of the selected solar systems have been calculated and analyzed. The results show the great potential of solar cooling at the considered regions, as high solar irradiation is available and high ambient temperatures lead to high cooling demand. With an average daily solar irradiation of $6.7 \mathrm{kWh} / \mathrm{m}^{2} / \mathrm{day}$, ambient temperatures up to $45^{\circ} \mathrm{C}$ and dry air, DMHS shows most favorable climate conditions for solar cooling. On the other hand, irradiation at IKEA, UWC and MANAGUA is lower, but cooling demand is higher due to constant high temperatures throughout the year.

All solar systems performed well during the 7-month long monitoring period, yielding more than $5.1 \mathrm{GWh}$ total solar energy yield, with an average solar conversion factor of $34.6 \%$ and electric efficiency ratios of up to 26 . Furthermore, thermal efficiency ratios of about $60 \%$ to $70 \%$ were reached for the absorption chillers. Comparison to previous analysis of UWC and DMHS from 2011 to 2014 show similar results, indicating that these systems still perform as expected. The high solar conversion factors enable even smaller solar systems to produce enough solar yield for supplying powerful absorption cooling machines. Together with the high electrical efficiency ratios of the system (> 4.8) and long technical lifespan this proves the potential of solar cooling as alternative to the conventional vapor compression technology.

Finally, both construction costs and performance of the solar systems seem to have improved. For example, the solar conversion factor of the recently build (2017) solar systems are up to $47 \%$ higher compared to the older ones commissioned in 2011 and 2014 and specific cost decreased by approximately 70\% (Fig.15). Even though the paper could only analyze four different solar systems with different boundary conditions, the shear magnitude of performance- and construction-cost improvements clearly support these hypotheses. Additionally, the comparison of UWC and IKEA - both located in the same city - also show the same trend.

\section{References}

Buchinger, J., Holter, C., Blazek, H., 2012. Financing of large solar thermal systems for cooling and process heat. Energy Procedia 2012, Vol.30, 1372-1379. DOI: 10.1016/j.egypro.2012.11.151

Ohnewein, P., Schrammel, H., Tschopp, D., Krammer, S., Poier, H., Gerardts, B., Köstinger, A., Weinhappl, A., 2015. METHODIQA - Development of a quality assurance methodology for renewable heat systems based on intelligent operational monitoring. Energy Procedia 2016, Vol.91, 376-383. DOI: 10.1016/j.egypro.2016.06.285

OECD/IEA, 2018. The Future of Cooling - Opportunities for energy-efficient air conditioning. IEA Publishing, License: $\underline{w w w . i e a . o r g / t \& c}$

Olsacher, N., Schnitzer, H., 2016. Solar Heating and Cooling for Tropical Countries Experiences, Chances, Hurdles. Proceedings of the International Conference 2016 ICENR - ILTER-EAP, 390-394.

Schubert, M., Holter, C., Luttenberger, J., 2011. Solar Cooling with Cooling Power Beyond One Megawatt - new Installations in Singapore and USA, in: OTTI $4^{\text {th }}$ International Conference Solar Air-Conditioning, Larnaca, 269271.

Schubert, M., Holter, C., Blazek, H., 2014. First operation months of world's most powerful solar cooling system in the USA at Desert Mountain High School (DMHS), Scottsdale, AZ. ISES Conference Proceedings 2014, 654656. DOI: 10.18086/eurosun.2014.07.15

Waite, M., Cohen, E., Torbey, H., Piccirilli, M., Tian, Y., Modi, V., 2017. Global trends in urban electricity demands for cooling and heating. Energy, Vol.127, 782-802. DOI: 10.1016/j.energy.2017.03.095

\section{Web-References:}

SHC Task 48, 2015. Quality Assurance and Support - Measures for Solar Cooling. Solar Cooling Positioning Paper. URL: https://www.iea-shc.org/data/sites/1/publications/IEA-SHC_Solar-Cooling-PositionPaper_Sep2015.pdf, last accessed: 20.08.2018

Weatherbase. URL: www.weatherbase.com, last accessed: 20.08.2018.

Weiss, W., Spörk-Dür, M., 2018. Solar Heat Worldwide. URL: https://www.iea-

shc.org/Data/Sites/1/publications/Solar-Heat-Worldwide-2018.pdf, last accessed: 24.08.2018 


\title{
Experimental investigation on the dynamic performance of a solar thermally-driven adsorption chiller integrated with a gas boiler
}

\author{
Elena Fuentes ${ }^{1}$, Veronica Impala ${ }^{1}$, Ivan Bellanco${ }^{1}$, Jaume Salom ${ }^{1}$, Alejandra Sayans ${ }^{2}$, Miquel \\ Balsells ${ }^{2}$, Silvia Sanjoaquín² and Oscar Mogro ${ }^{3}$ \\ ${ }^{1}$ Catalonia Institute for Energy Research, IREC, Barcelona (Spain) \\ 2 Naturgy, Barcelona (Spain) \\ 3 BDR Thermea Group, Barcelona (Spain)
}

\begin{abstract}
The present study investigates the dynamic performance of a state-of-the-art adsorption chiller to provide useful cooling for a residential and a tertiary building. The equipment was tested at a hardware-in-the-loop configuration in a laboratory setting under the dynamic loads of two simulated building models at two climatic zones in Spain. The adsorption chiller was connected to a hot tank of $760 \mathrm{~L}$ volume used to store the heat from an emulated solar collector array. In addition, a gas boiler was used as an auxiliary source of heat to the storage tank. Summertime dynamic experiments of 24 hours were performed at the two building and climate scenarios. The efficiency of the system was analysed in terms of coefficient of performance, coverage of cooling demand and primary energy savings with respect to a reference system.
\end{abstract}

Keywords: solar cooling, adsorption, gas boiler.

\section{Introduction}

In the last decades, a great effort has been made to improve cooling technologies based on renewable energy sources. The use of solar energy is one of the most interesting solutions for climatization applications and air conditioning, as availability of solar radiation and cooling loads is largely coincidental. Currently, the vast majority of the cooling demand in buildings is covered with the use of traditional heat pump systems. The disadvantage of these systems is that they use refrigerants that contribute to greenhouse emissions and that the increasing installed capacity of heat pumps leads to the overload of electric grids and consequent black-outs, especially during warm periods (Palomba et al., 2017). For solar cooling, efforts are made to improve the efficiency of conventional solar thermal cooling technologies based on adsorption and absorption. While existing technologies are increasingly modified to improve their performance, the development of methods for the efficient integration of solar renewable equipment in different types of buildings is one of the main research and development directions for solar building climatization systems (Ge et al., 2018).

Adsorption is a proven technology able to harness the potential of solar heat and low grade waste heat for producing useful cooling. Generally, this type of adsorption chiller can be driven with waste heat with temperatures as low as $55^{\circ} \mathrm{C}$ (Wuang et al., 2005). Adsorption machines are a promising technology for implementation in southern Europe, where a consistent source of solar energy is available during the warm season. However, there is a lack of studies aiming at optimizing the integration and analyzing the behavior of these systems when operating under dynamic conditions. In this study it is presented a laboratory experimental investigation on the performance of a 2-bed adsorption chiller of $10 \mathrm{~kW}$ nominal cooling capacity and a thermal nominal COP of 0.65 , operated under the dynamic loads of virtual buildings at quasi-realistic conditions. 


\section{Methodology}

\subsection{System concept and case scenarios}

The system under study consists of a virtual building that is conditioned by means of a solar cooling system comprising an adsorption machine coupled to an air heat rejection unit, a solar thermal array of 8 panels and a gas boiler. The aim of the adsorption chiller is to cover the cooling needs of either a virtual residential or a tertiary building provided with a fancoils cooling distribution system that works at a chilled water set point of $15^{\circ} \mathrm{C}$.

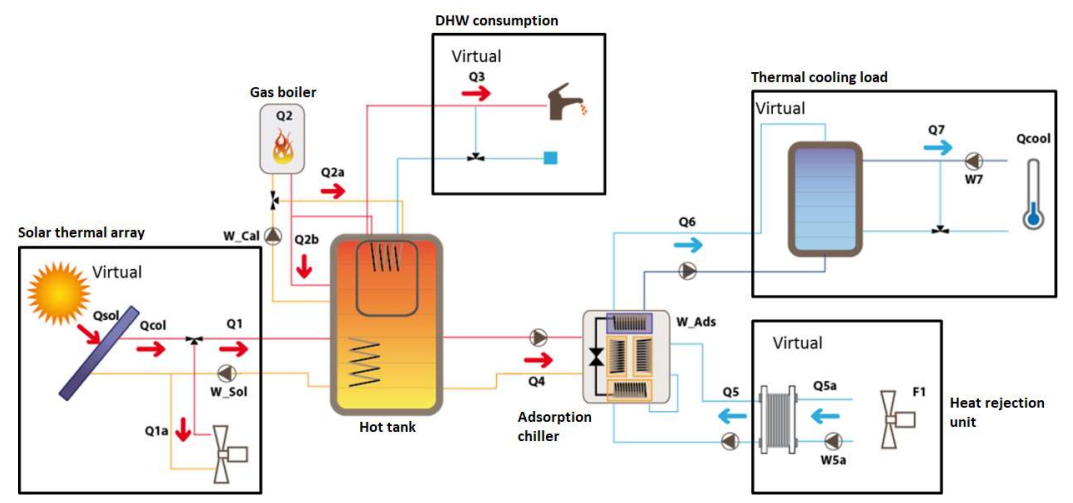

Fig. 1: Solar cooling system concept

The driving circuit of the adsorption machine was connected to a hot tank of $760 \mathrm{~L}$ used to store the heat from an emulated 8 collector solar thermal array and an auxiliary domestic gas boiler. The system was tested in a hardware-in the-loop configuration in which the adsorption chiller, the hot storage tank and the gas boiler were real laboratory components while the rest of the elements: solar array, cooling load and adsorption machine rejection unit were virtual components emulated by means of the laboratory thermal test benches according to the output from a simulation model (TRNSYS) that reproduced the behavior of the virtual systems (Fig. 1). The real and virtual components are listed in Tab. 2, along with the technical characteristics that were adopted using data from equipment technical datasheets.

Typical days of the summer were selected in order to test the performance of the system for two different climates in Spain and two different building scenarios: a single family dwelling and a small tertiary building (office). Statistical methods were applied for the selection of the case days, using typical climatic data of the geographic zones of interest. The days selected for the study are indicated in Tab. 1 . The virtual building chosen for the climate of Salamanca (Mediterranean continental climate) is a single-family dwelling of $200 \mathrm{~m}^{2}$ area and annual cooling demand of $15.6 \mathrm{kWh} / \mathrm{m}^{2}$, while the scenario for Bilbao (oceanic climate) is an office building of $250 \mathrm{~m}^{2}$ with an annual cooling demand of $7.5 \mathrm{kWh} / \mathrm{m}^{2}$.

Tab. 1. : Scenarios considered for the summer day case studies

\begin{tabular}{|c|c|c|c|}
\hline City (climate) & $\begin{array}{c}\text { Building } \\
\text { type }\end{array}$ & Day selected & Characteristic of selected day \\
\hline \multirow{3}{*}{$\begin{array}{c}\text { Salamanca } \\
\text { (Mediterranean } \\
\text { continental) }\end{array}$} & \multirow{2}{*}{ Residential } & $21^{\text {st } J u l y ~}$ & Warmest day \\
\cline { 3 - 4 } & & $31^{\text {st }}$ August & Lowest radiation day \\
\cline { 3 - 4 } & & $15^{\text {th }}$ June & Average day \\
\cline { 3 - 4 } & & $22^{\text {nd }}$ May & Average day \\
\hline \multirow{2}{*}{ Bilbao (Oceanic) } & \multirow{2}{*}{ Office } & $11^{\text {st }}$ July & Warmest day \\
\cline { 3 - 4 } & & $7^{\text {th }}$ August & Average day \\
\cline { 3 - 4 } & & $7^{\text {th }}$ September & Lowest radiation day \\
\hline
\end{tabular}


Tab. 2. : Main technical characteristics of real and virtual components comprising the studied system

\begin{tabular}{|c|c|c|}
\hline System & Type & Technical characteristics/model \\
\hline $\begin{array}{l}\text { Distribution system } \\
\text { and cooling load }\end{array}$ & virtual & $\begin{array}{l}\text { Cold water tank: } 750 \text { L (TRNSYS type 534) } \\
\text { Fancoil system (TRNSYS type 682). } \\
\text { Mixing valve (TRNSYS type } 812 \text { ) to control the supply water } \\
\text { temperature to fancoils. }\end{array}$ \\
\hline Solar array & virtual & $\begin{array}{l}8 \text { solar panels, parallel arrangement } \\
\text { Total aperture surface: } 11.4 \mathrm{~m}^{2} \text {; Flow rate: } 30 \mathrm{l} / \mathrm{h} \mathrm{m}^{2} \\
\text { Optical efficiency: } 0.817 \\
\text { Thermal loss coefficient: } 3.716 \mathrm{~W} / \mathrm{m}^{2} \mathrm{~K} \\
\text { Orientation: } 40^{\circ}\end{array}$ \\
\hline Heat rejection unit & virtual & $\begin{array}{l}\text { Air rejection unit (TRNSYS type } 511 \text { ) } \\
\text { Water nominal flow rate: } 5.93 \mathrm{~m}^{3} / \mathrm{h} \\
\text { Air nominal flow rate: } 15005 \mathrm{~m}^{3} / \mathrm{h} \\
\text { Electrical power consumption: } 0.3 \mathrm{~kW}\end{array}$ \\
\hline DHW consumption & virtual & $\begin{array}{l}\text { Tapping profiles as defined in standard EN 12976; cycles L, M } \\
\text { Mains water temperature as defined in standard DBHE-2013 }\end{array}$ \\
\hline Adsorption chiller & real & $\begin{array}{l}\text { Nominal COP:0.65; Nominal cooling capacity: } 10 \mathrm{~kW} \\
\text { Cold water set point temperature: } 14^{\circ} \mathrm{C}\end{array}$ \\
\hline Gas boiler & real & $\begin{array}{l}\text { Saunier-Duval Thema condens F25: thermal power } 19.5 \mathrm{~kW} \\
\text { heating/25 kW DHW } \\
\text { Baxi Platinum } 24 \mathrm{AF} \text { : thermal power } 24 \mathrm{~kW} \text { heating } / 24 \mathrm{~kW} \\
\text { DHW }\end{array}$ \\
\hline Hot storage tank & real & $\begin{array}{l}\text { Tank-in-tank design } \\
760 \text { L volume }\end{array}$ \\
\hline
\end{tabular}

\subsection{Experimental set up}

The laboratory test benches are provided with a set of sensors and control loops that allow the monitoring and control of the temperature and water flow of the fluid circuits in the system. The temperatures are measured with PT100 type A sensors, calibrated in the working temperature range. The return temperatures from the solar array, the cooling load and the adsorption rejection system were emulated according to the output obtained from the simulation model by using individual heat exchangers through which secondary refrigeration and heating fluids are circulated for temperature control. In addition, for the control of the water flow and temperatures the test benches are equipped with two magnetic-inductive flow meters and two precision valves. 


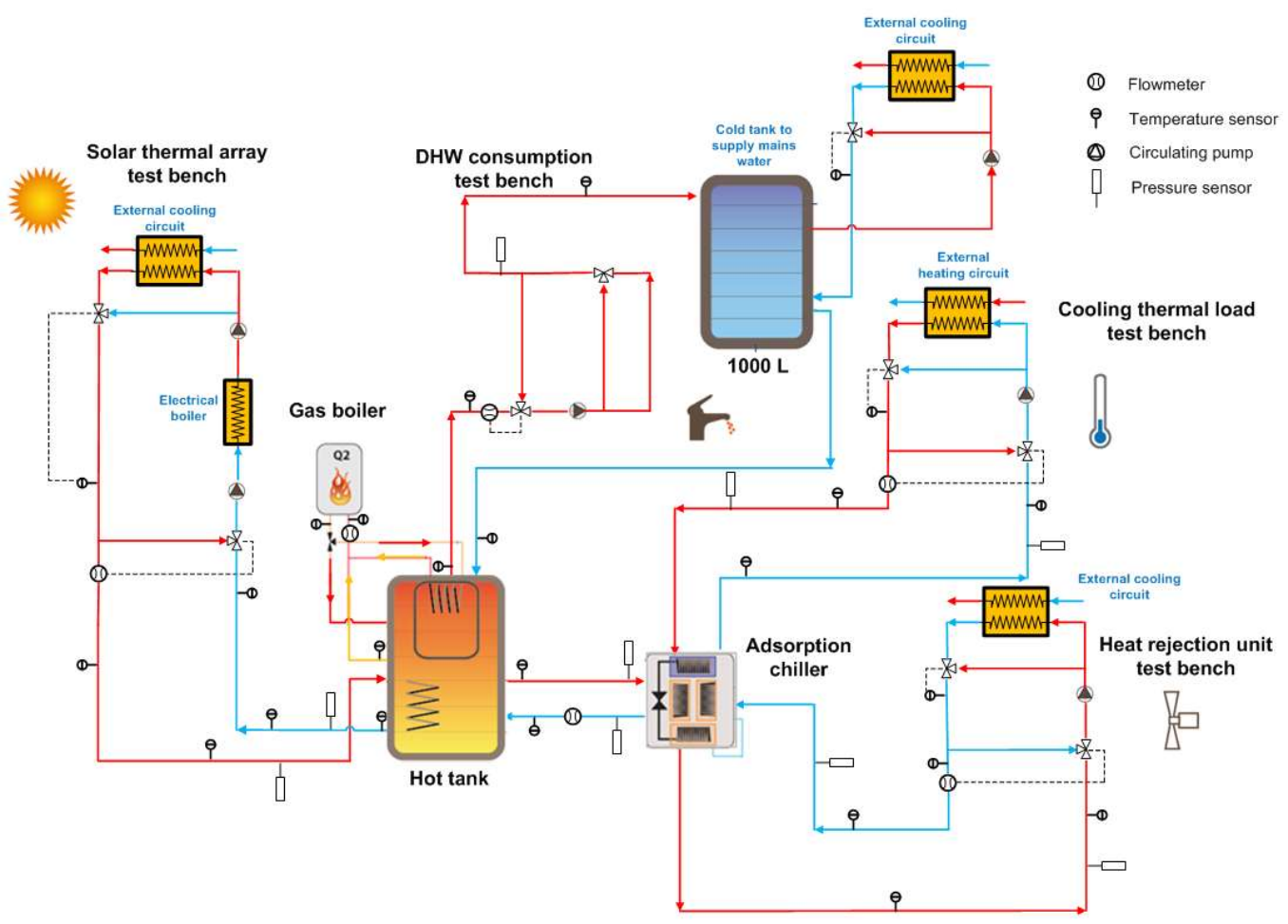

Fig. 2: Laboratory experimental set up

The gas consumption of the installation is measured at the gas inlet of the boiler with a digital flow meter. For reproducing the mains water temperature for DHW (domestic hot water), a $1000 \mathrm{~L}$ volume storage tank was used to store cold water that was conditioned according to the climate and period of the year under study.

Three series of experiments with a different control strategy for the auxiliary gas boiler were conducted, namely, set 1,2 and 3 . The control strategies were based on the operation of the gas boiler as a function of the hot tank temperatures (Tab. 3) at the exit tubing towards the boiler for heat production and at the immersed tank for DHW. The control strategies were sequentially proposed and tested in order to improve the results obtained from the previous control strategy evaluated, aiming at reducing the gas consumption while covering the cooling demand.

\subsection{Performance of solar cooling system in different climates and typical days}

In this section the behaviour of the components integrating the solar cooling system in different summer days is illustrated for the set of measurements corresponding to the first control strategy (set 1). For this control strategy the hot tank set point control temperature was set between $60-75^{\circ} \mathrm{C}$ for heat production and $47^{\circ} \mathrm{C}$ for $\mathrm{DHW}$, while the set point temperature for the hot water produced by the boiler was $75^{\circ} \mathrm{C}$ (Table 3). Fig. 3 shows the evolution of the inlet and outlet temperatures of the solar collector circuit for the 4 selected days, Salamanca scenario. These results show that the days with the highest hot water temperature from the solar array are July 21st (day with highest outdoor temperatures) and June 15th (average day). The days with the lowest temperatures are the average day May $22^{\text {nd }}$ and the day of lowest radiation, August $31^{\text {st }}$. Water circulation through the solar circuit activates from 10:30 am to 7:00 pm on the days with the highest temperatures, while for lower temperature days the solar circuit is active in a smaller time window, from approximately $11.00-12: 00$ to $17.00-18.00 \mathrm{~h}$.

The activation of the adsorption chiller heat rejection unit is illustrated in Fig.4 in which the temperatures and the flow rate are shown. Very significant differences are observed regarding the time of activation and deactivation of the chiller among the different days under study. On July $21^{\text {st }}$ the chiller starts at 8.45 am and stops at 11.30 am, with a shutdown interval between 11.30 am and $12.15 \mathrm{pm}$. 

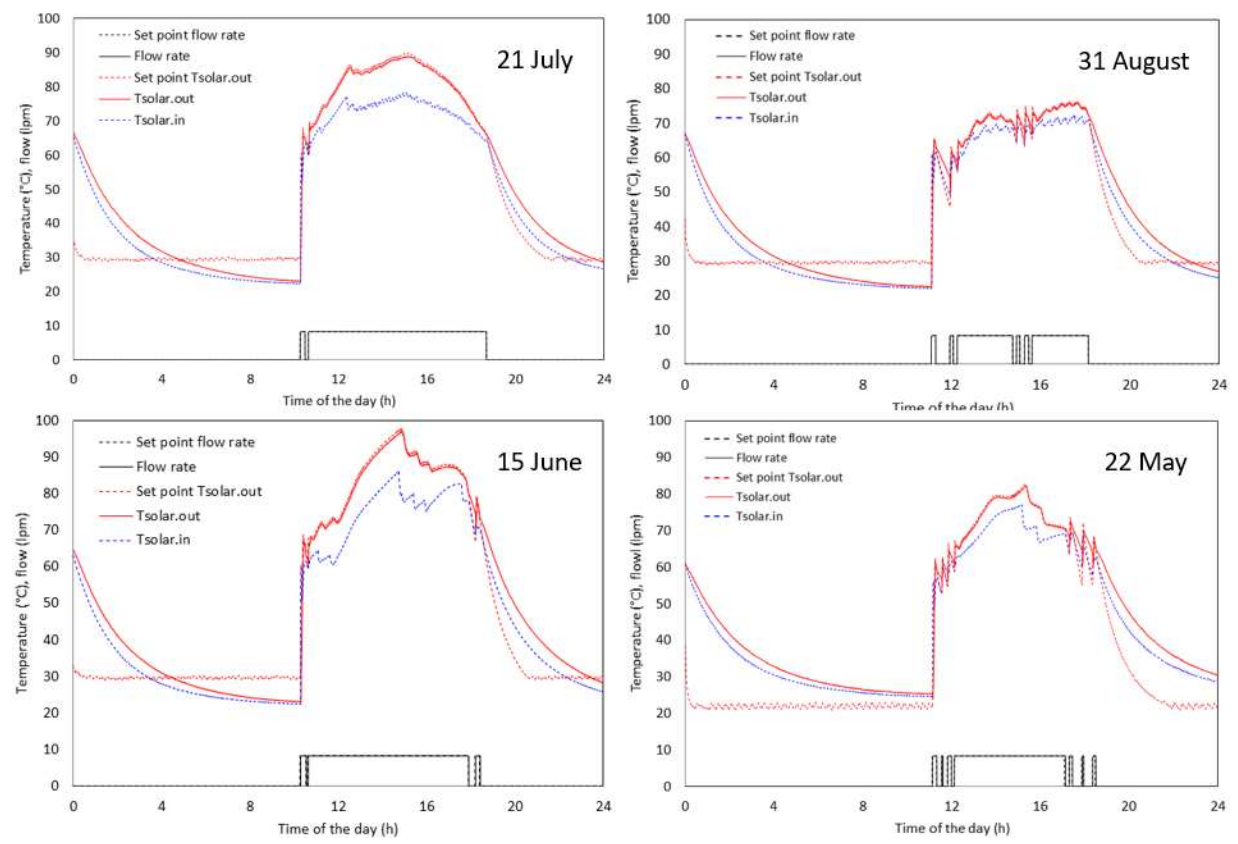

Fig.3 Comparison of solar array performance during different dynamic tests, Salamanca, set 1
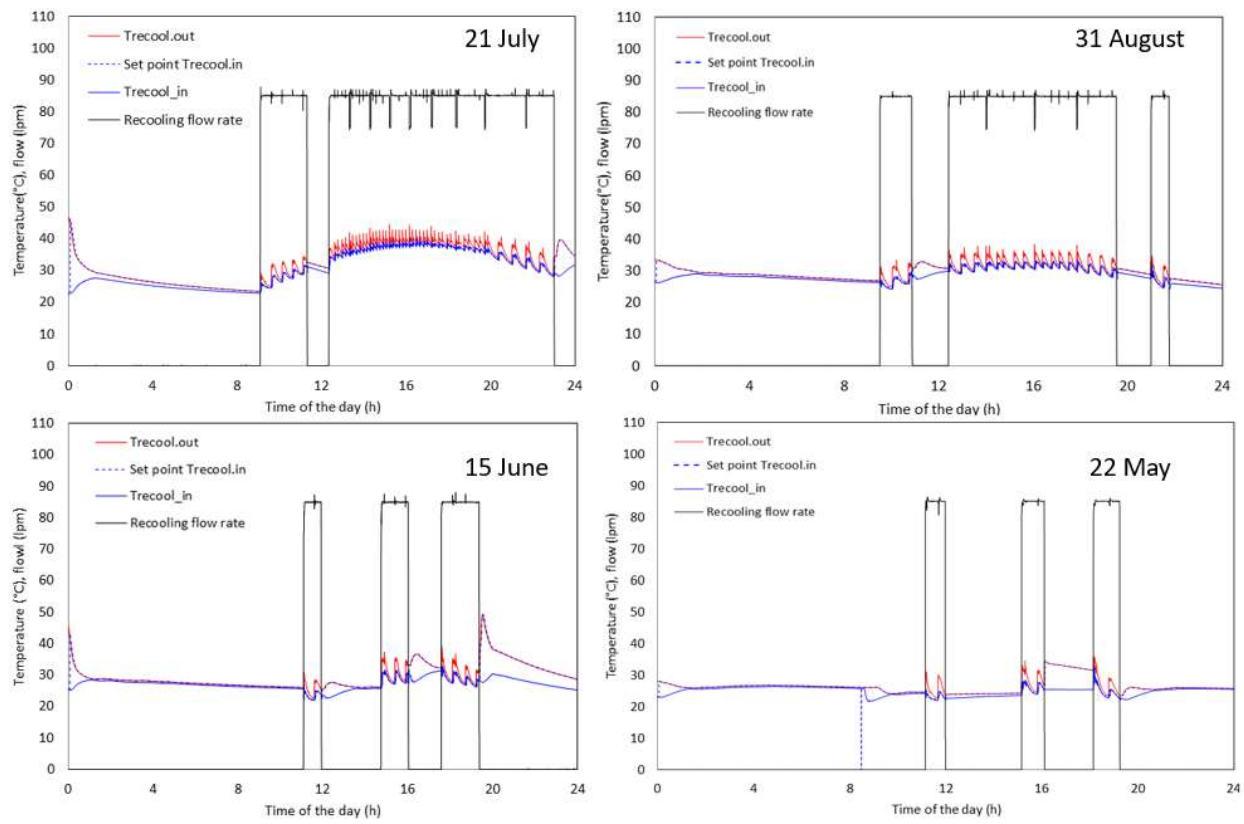

Fig.4 Comparison of recooling circuit (heat rejection unit) during different dynamic tests, Salamanca, set 1

For the warmest day, the inlet temperature to the chiller from the heat rejection unit is high, reaching values up to $37^{\circ} \mathrm{C}$. During the periods of high temperatures from the recooling circuit, the maximum cooling capacity achieved by the chiller is $4 \mathrm{~kW}$. On the average days, June $15^{\text {th }}$ and May $22^{\text {nd }}$, the machine is active for a shorter period of time, operating only during three intervals during the day and switching off before 8:00 pm. For the two average case days, the inlet temperature from the rejection unit is below $32{ }^{\circ} \mathrm{C}$ and a higher average cooling capacity of 7 $\mathrm{kW}$ is achieved. As most summer days will be represented by the average day, it is only on the extreme temperature days that the cooling capacity will be significantly reduced.

The effect of the external temperature on the cooling capacity is presented in Fig.5 where it is shown that during the periods of activation of the machine the temperature of the chilled water rises up to $22{ }^{\circ} \mathrm{C}$ for warmest day, while it remains below $18{ }^{\circ} \mathrm{C}$ and close to the $14{ }^{\circ} \mathrm{C}$ set point for the rest of the case days considered for Salamanca. The control strategy applied is able to maintain the hot water in the tank at a temperature above $60{ }^{\circ} \mathrm{C}$ in all cases 
(Fig.6). However, the activation of the auxiliary boiler to keep these temperature levels is rather intensive for the highest temperature ( $\left.21^{\text {st }} \mathrm{July}\right)$ and the lowest solar radiation ( $31^{\text {st }}$ August) case days, while it is considerably lower for the average days.
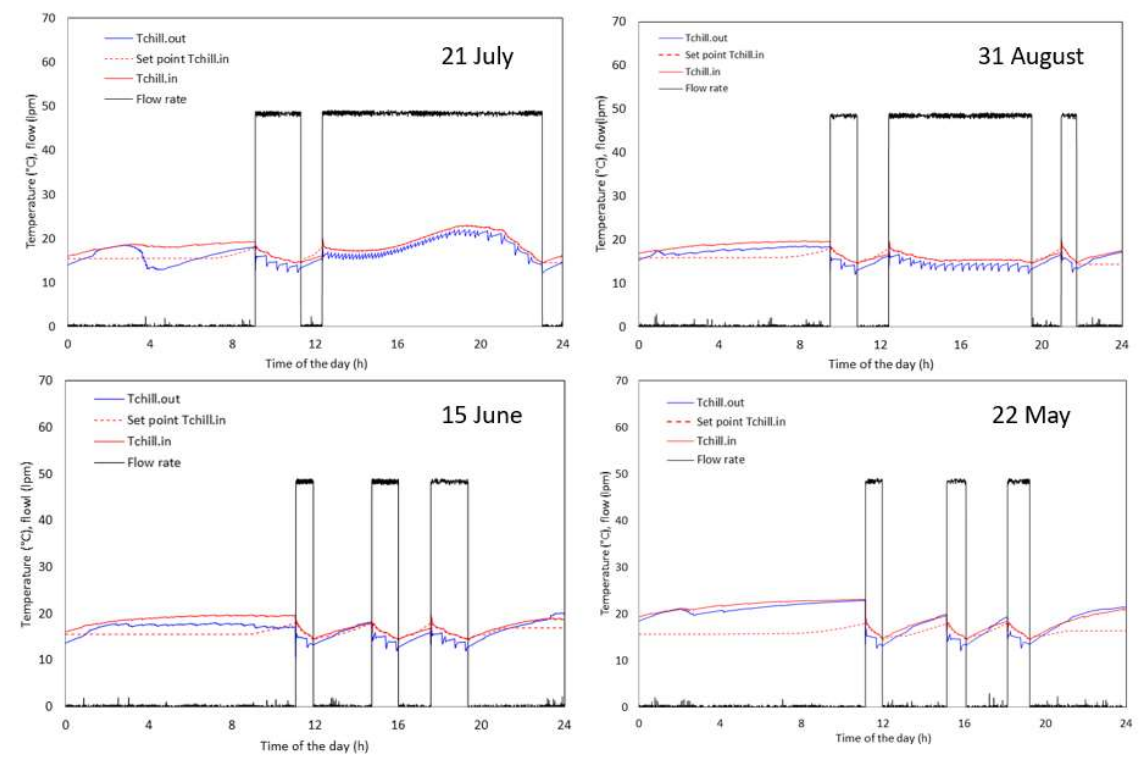

Fig.5 Comparison of cooling circuit during different dynamic tests, Salamanca, set 1

The ability of the solar cooling system to cover the cooling load for the Salamanca case with the control strategy 1 is illustrated in Fig.7, which shows the supply water temperature from the cold storage tank (T1) and the supply (T3) and return water temperatures (T2) of the fancoils distribution system. FR1 and FR2 are the water flows through the cold tank and the fancoils, respectively. The supply water to the fancoil (T3) is below $19^{\circ} \mathrm{C}$ for all the scenarios but for the warmest case day $\left(21^{\text {st }}\right.$ July). Considering a maximum supply temperature to the fancoils of $22{ }^{\circ} \mathrm{C}$ required to cover the cooling demand, it is not possible to fully cover the cooling needs on the warmest day.
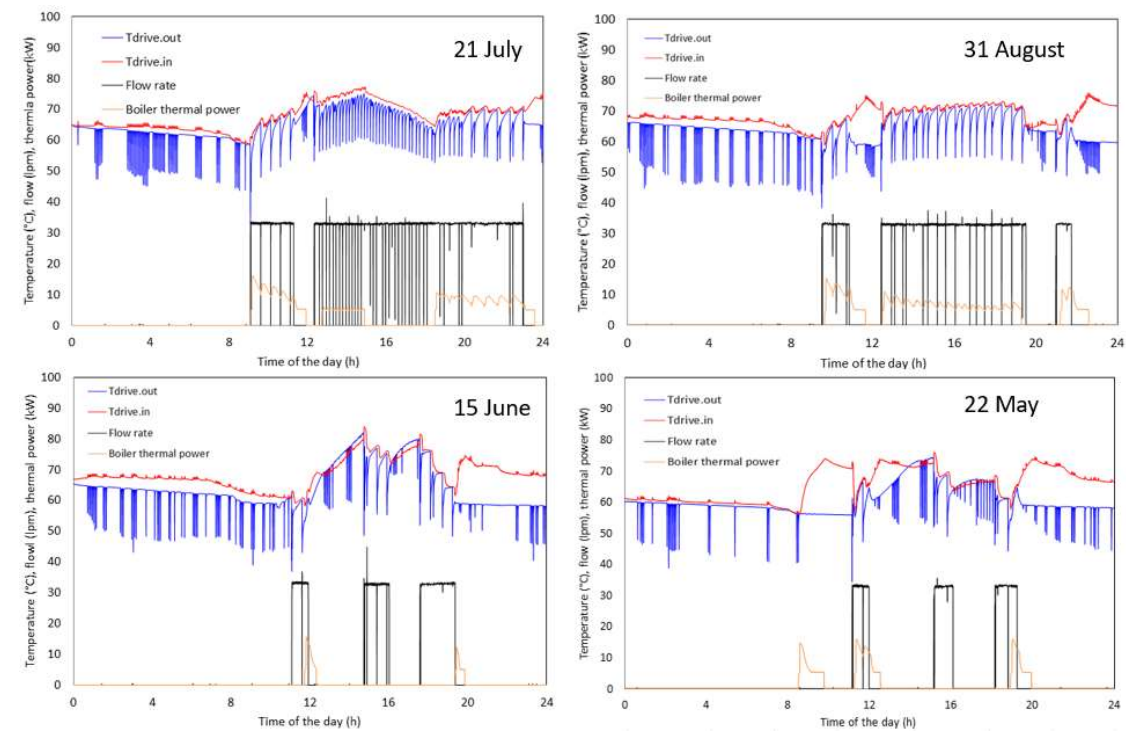

Fig.6 Comparison of driving circuit during different dynamic tests, Salamanca, set 1

The results indicate that the outdoor temperature is a dominant variable on the cooling load and the resulting performance of the system, since for Salamanca, both for the cloudiest and warmest day, an intensive activation of the boiler is needed to cover the cooling demand. When comparing with the Bilbao case (Fig. 8) the highest temperature case day ( $21^{\text {st }}$ July) also exhibits the longest operation hours for the adsorption chiller ( 11 hours), as compared to the average and lowest radiation case days, in which the machine is activated between 3 and 4.4 hours 
in the period of maximum external temperatures from 12-13 to 4 p.m. As in the case of Salamanca, the inlet temperature to the machine from the heat rejection unit reaches values up to $37^{\circ} \mathrm{C}$ on the warmest day, whereas for the other case days this temperature remains below $32{ }^{\circ} \mathrm{C}$ during the whole period. Because of the lowest cooling capacity of the system on the warmest day, the temperature of the chilled water produced by the adsorption chiller rises up to $20^{\circ} \mathrm{C}$ in the extreme temperature scenario, while it remains below $18{ }^{\circ} \mathrm{C}$ for the other case days.
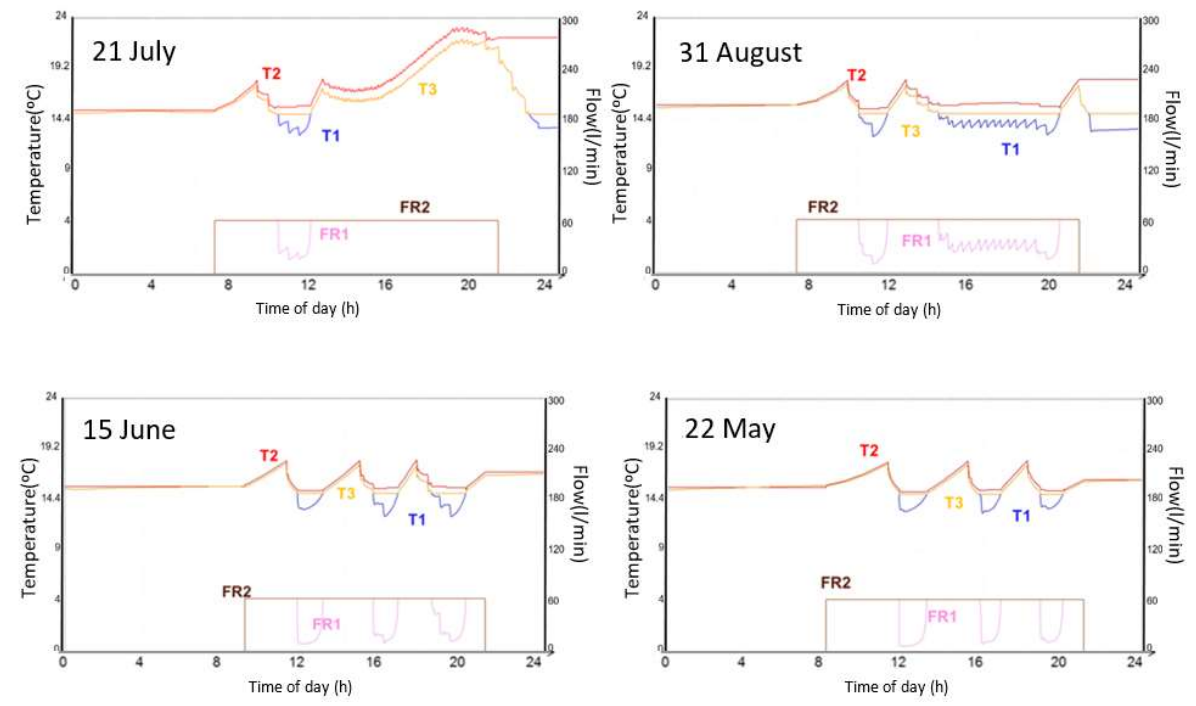

Fig.7 Comparison of distribution cooling system outlet temperature and flow profiles for different days, Salamanca, set 1.

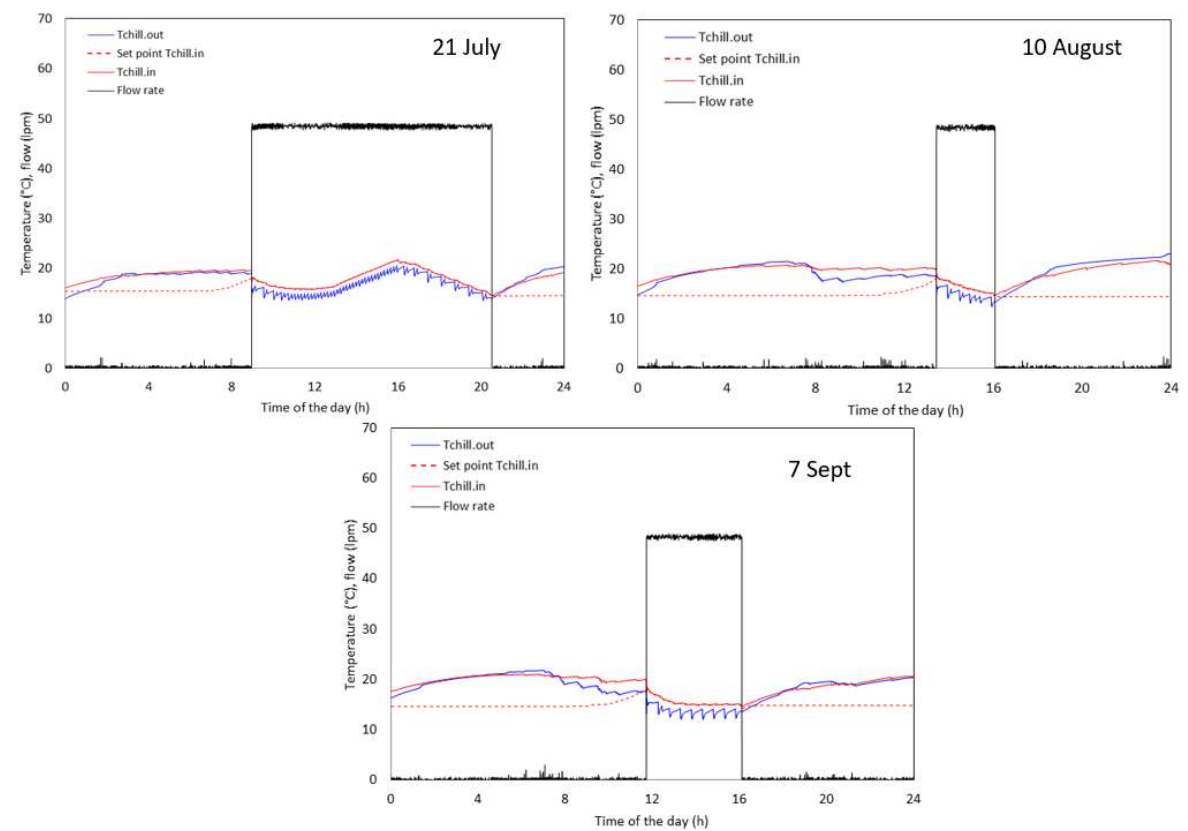

Fig. 8 Comparison of adsorption machine cooling circuit temperature and flow profiles for different days, Bilbao, set 1

In general, it is found that the daily activation of the boiler is mainly driven by the drop of the water tank temperatures that occurs when the chiller starts and it progressively returns cold water back into the tank. In the Bilbao scenario, similarly to the Salamanca case, the chiller is operative for long periods on the warmest day and it requires the support of the boiler to maintain the required temperatures in the hot tank (Fig.9). Regarding the influence of the cloudiness, it is seen that it is less influential than the temperature on the activation of the boiler, since on the cloudiest day ( $7^{\text {th }} \mathrm{Sept}$ ) the auxiliary boiler is not needed to sustain the tank temperatures, whereas it operates intensively on the day with the highest cooling load (warmest day, $21^{\text {st }} \mathrm{July}$ ).

Analogously to findings for Salamanca, the outlet temperature to the fancoils (Fig.10) in Bilbao is the highest for the warmest day, however it is still below the maximum temperature of $22{ }^{\circ} \mathrm{C}$ considered necessary to cover the 
cooling demand. On the other hand, for the average and low radiation case days the temperature to the fancoils is considerably low, with a maximum value of $17^{\circ} \mathrm{C}$, thus fulfilling the requirements to cover the cooling load.

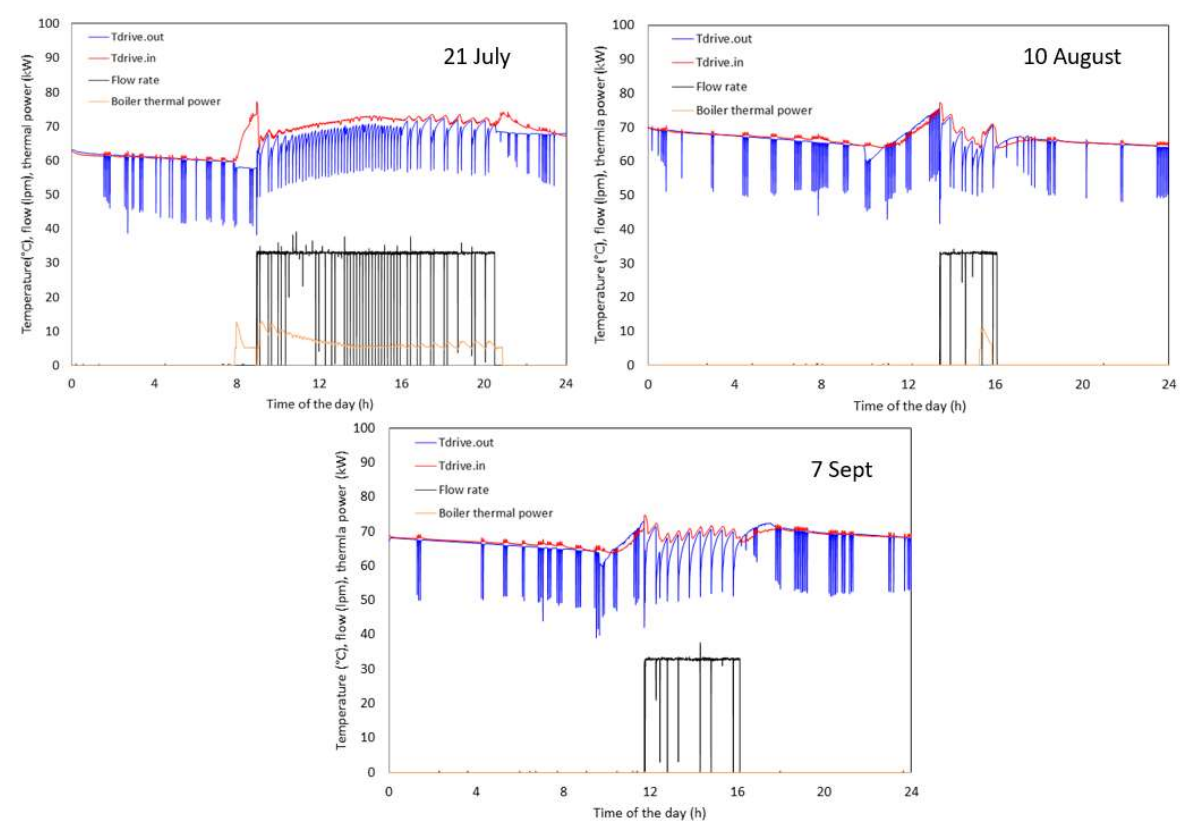

Fig.9 Comparison of driving circuit during different dynamic tests, Bilbao, set 1
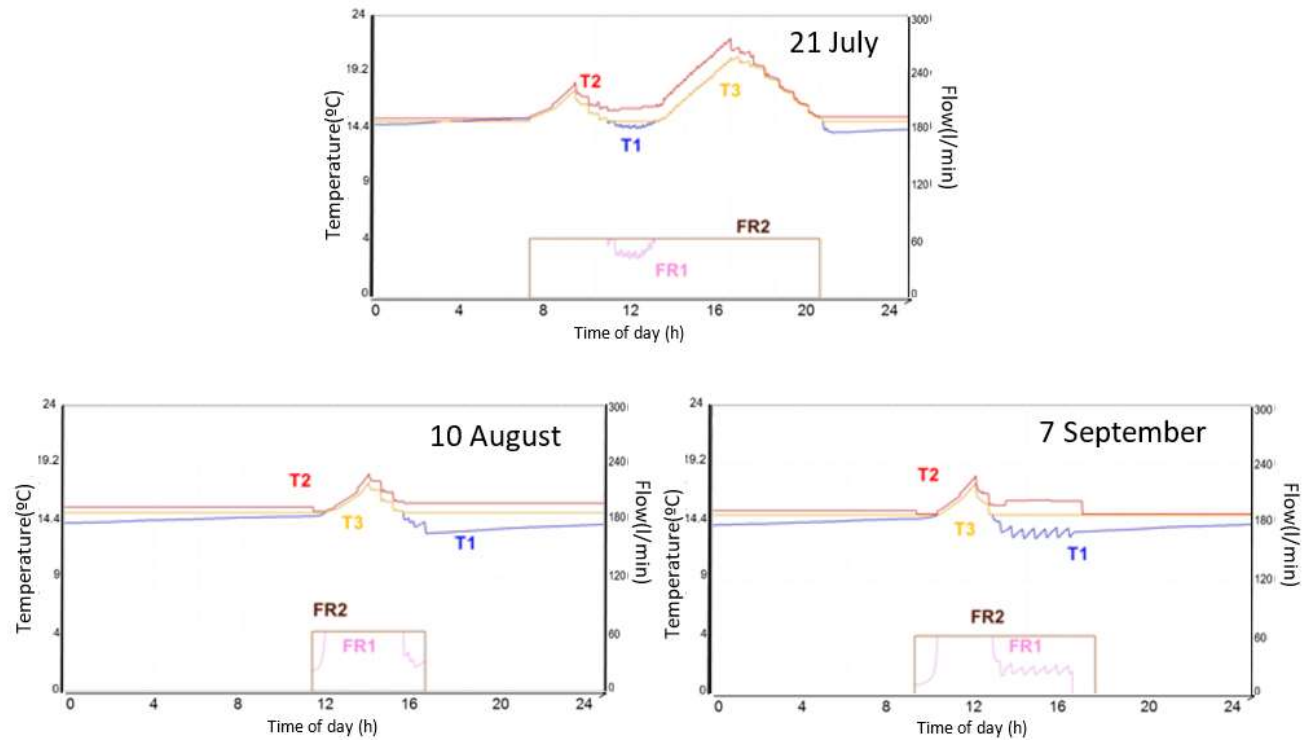

Fig.10 Comparison of distribution cooling system outlet temperature and flow profiles for different days, Bilbao, set 1

Significant operation differences for the adsorption chiller were obtained for the two climate and building scenarios studied (Fig.11). On the warmest case day, the chiller operated for at least 11 hours for both cases. Although the Salamanca scenario has higher temperatures and cooling load, the operating time for the boiler is $2.5 \mathrm{~h}$ longer on the warmest day for Bilbao, as this climate presents more cloudiness and lower solar radiation. For Salamanca, the operating times for the adsorption chiller and the gas consumption are $69-77 \%$ and $60-88 \%$ lower on an average day, respectively, than those in the warmest day. In the Bilbao scenario there is an even larger difference between the warmest and the average days. The operating hours of the chiller drop $77 \%$ from the warmest to the average case day, whereas the gas consumption drops a $94 \%$. 
Salamanca (mediterranean continental climate)

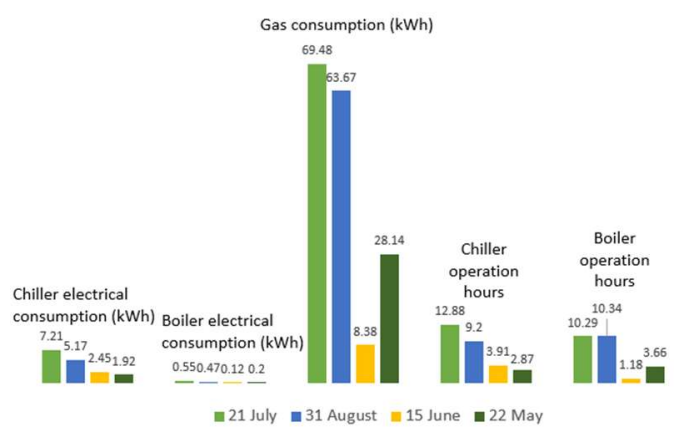

Bilbao (oceanic climate)

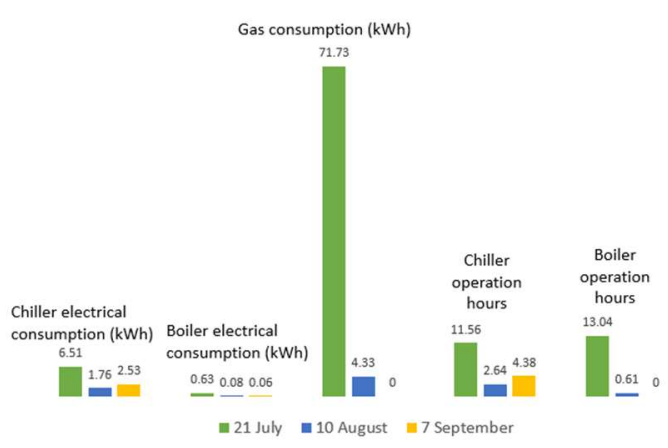

Fig.11 Comparison of daily electrical and gas energy consumption and number of operation hours for the gas boiler and adsorption chiller, Salamanca and Bilbao scenarios, set 1

The results shown in this section are for the first strategy (set 1) that was explorative and not optimized to cover the energy demand in all cases. Two more strategies (set 2 and set 3) were further proposed and applied sequentially in order to improve the system performance, aiming at covering the cooling demand while minimizing the auxiliary gas consumption. The performance results of the other two strategies applied is presented in the following section.

\subsection{Performance of solar cooling system under different control strategies}

Three control strategies were sequentially applied in order to optimize the performance of the solar cooling system to cover the cooling demand with a minimum of energy usage of the auxiliary gas boiler. In the different strategies applied, the boiler was started to reach a set point temperature in the hot tank (Tset_heating) by producing hot water with a set value (Tset_boi_heating). The control would also ensure that a set-point temperature (Tset_DHW) is maintained in the immersed tank of the storage in order to cover the DHW demand.

Tab. 3. : Summary of strategies tested for control of the gas boiler. Tset_heating: hot tank set point temperature, Tset_boi_heating: boiler set point outlet temperature for heating, Tset_DHW: immersed tank set point temperature, Tset_boi_DHW: boiler set point outlet temperature for DHW, Tamb: outdoor temperature, Tamb_max: maximum reference outdoor temperature used for control strategy.

\begin{tabular}{|c|c|c|c|c|}
\hline Parameter & \multicolumn{2}{|c|}{$\operatorname{Tamb}<\mathbf{2 0}{ }^{\circ} \mathrm{C}$} & $20^{\circ} \mathrm{C}<$ Tamb $<$ Tamb_max ${ }^{\circ} \mathrm{C}$ & Tamb $>$ Tamb_max ${ }^{\circ} \mathrm{C}$ \\
\hline \multirow{3}{*}{ Tset_heating $\left({ }^{\circ} \mathrm{C}\right)$} & Set 1 & \multirow{3}{*}{$60{ }^{\circ} \mathrm{C}$} & $\mathrm{Tamb}+40$, with Tamb_max $=35^{\circ} \mathrm{C}$ & 75 \\
\hline & Set 2 & & $2 \mathrm{Tamb}+20$, with Tamb_max $=30^{\circ} \mathrm{C}$ & 80 \\
\hline & Set 3 & & 1.5 Tamb +30 , with Tamb_max $=30^{\circ} \mathrm{C}$ & 75 \\
\hline \multirow{3}{*}{$\begin{array}{l}\text { Tset_boi heating } \\
\left({ }^{\circ} \overline{\mathrm{C}}\right)\end{array}$} & Set 1 & 75 & 75 & 75 \\
\hline & Set 2 & \multirow{2}{*}{\multicolumn{3}{|c|}{ Minimum (82,Tset_heating+15) }} \\
\hline & Set 3 & & & \\
\hline \multirow{3}{*}{ Tset_DHW $\left({ }^{\circ} \mathrm{C}\right)$} & Set 1 & \multirow{3}{*}{47.5} & \multirow{3}{*}{47.5} & \multirow{3}{*}{47.5} \\
\hline & Set 2 & & & \\
\hline & Set 3 & & & \\
\hline \multirow{3}{*}{ Tset_boi_DHW $\left({ }^{\circ} \mathrm{C}\right)$} & Set 1 & \multirow{3}{*}{75} & \multirow{3}{*}{75} & \multirow{3}{*}{75} \\
\hline & Set 2 & & & \\
\hline & Set 3 & & & \\
\hline
\end{tabular}


In addition, the boiler used in the first experiment series (set 1) was replaced by a different model. The boiler used in set 2 and 3 allows external modulating control of the output set point temperature while the first one was used with a fixed set point of $75{ }^{\circ} \mathrm{C}$ for both heating and DHW operation modes. Tab. 3 shows the different strategies (set 1, set 2 and set 3) used for operating the gas boiler as a function of the temperature in the hot storage tank. These strategies were tested on the warmest and average days of the two case scenarios under study in Salamanca and Bilbao, by performing laboratory experiments following the methodology described previously. The results of the strategies applied were evaluated with a number of indicators related to the energy performance and energy consumption of the system. The results were also compared with the energy usage from a reference system comprising a standard heat pump to cover the cooling demand and a gas boiler to cover the DHW needs.
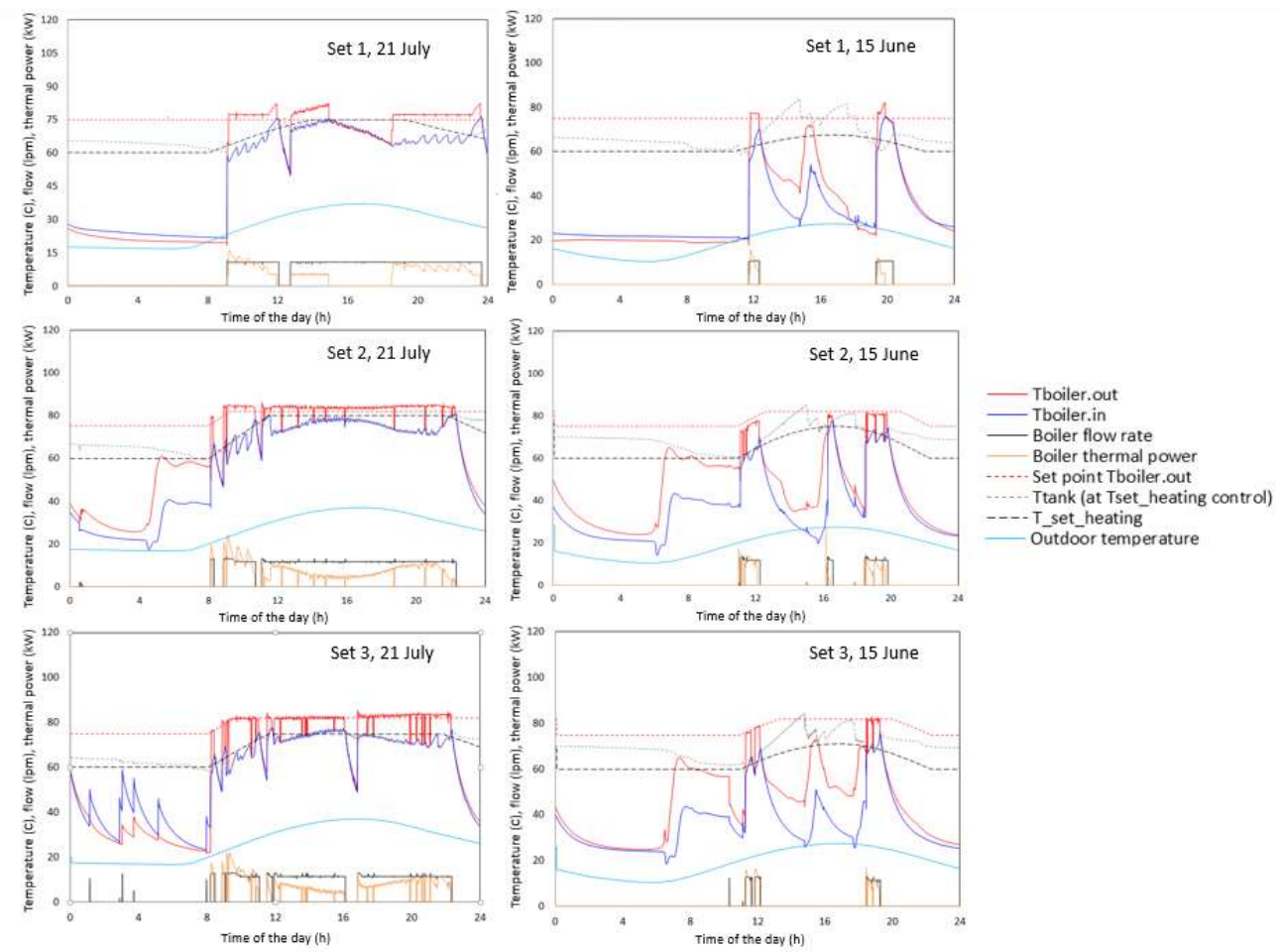

Fig.12 Comparison of gas boiler operation for the three control strategies applied (set 1 , set 2 and set 3) on the warmest case day $\left(21^{\text {st }} \mathrm{July}\right)$ and the average case day $\left(15^{\text {th }} \mathrm{June}\right)$, Salamanca scenario.

Fig.12 shows the operation of the boiler under the different strategies for the warmest and the average case days for the Salamanca scenario. The objective of all strategies is to maintain the temperature at the tank (Ttank_boiler) as close as possible to the set point (Tset_heating), which is defined as a function of the ambient temperature (Tamb). When the boiler is active, for the first strategy (set 1) a fixed set point output temperature of $75{ }^{\circ} \mathrm{C}$ is used. The first strategy used (set 1) was explorative and was not optimized to cover the energy demand in all cases. The application of this strategy on the warmest case day (A, set 1) results in a discontinuous operation of the gas boiler during the period of highest cooling demand with tank temperatures between 62 and $75{ }^{\circ} \mathrm{C}$ (Fig.12). The discontinuous operation of the boiler is due to an internal control operation that protects the system and prevents the boiler from starting until the temperatures have dropped below certain value. The result of using this control strategy is that the cooling load of the warmest day in Salamanca cannot be fully covered, although it is sufficient to cover the energy needs for the warmest day in Bilbao. For the Bilbao scenario, this strategy is suitable since this location has milder climate conditions than Salamanca.

Strategy 2 was next proposed as an improvement to strategy 1, with the aim of covering the cooling demand in all cases by using higher tank set point temperatures (Table 3). With the application of the second strategy (set 2) the temperatures in the tank are maintained above $65{ }^{\circ} \mathrm{C}$ for longer periods, since the boiler is active during most of the time that the chiller is operating. With this strategy, it is possible to cover the cooling demand in all scenarios at the expense of an increase in the gas consumption (Tab. 4), which leads to a reduction of primary energy savings 
with respect to the reference system (reference to solar cooling system primary energy ratio), particularly for the average case day (Tab. 5). In order to achieve better energy savings for the average case days, strategy 3 (set 3 ) was further proposed as an improvement to strategy 2 , to reduce the gas consumption while the load is still covered. For that, strategy 3 applies a moderate reduction of the set point tank temperatures with respect to those in set 2 . Although when changing from strategy 2 to 3 no substantial change is seen on the warmest case day in terms of primary energy savings, a significant improvement is achieved for the average case days (Tab. 5), with an increase of $26-32 \%$ in the primary energy savings ratio.

For set 3 , the results show that the daily COP remains at a relatively high value between 0.52 and 0.63 during the average and the warmest days, while the primary energy savings ratio in the average day ranges from 0.67 to 0.85 . The daily average COP values obtained are influenced by the inlet temperatures to the adsorption chiller. The inlet temperatures from the recooling and heat source circuits are higher for the warmest day with respect to the other days for both the Salamanca and Bilbao scenarios, which produces a lower COP than in the average days. When comparing the COP of the warmest day, Salamanca presents COP values that are slightly lower than in Bilbao, which can be due to the higher temperatures in the recooling circuit in the Salamanca warmest day with respect to the Bilbao case.

Although strategy 3 provides the best performance results it should be noted that there is a potential for improvement that could be achieved with alternate control strategies for the adsorption chiller as a function of the temperatures in the cold tank, with changes in the control settings of the gas boiler and by optimizing the solar collectors array configuration and panels number (Chekirou et al, 2016). Although the primary energy savings ratio of the solar cooling system in the summer yield values below 1, annual performance calculations considering both winter and summer periods leads to primary energy annual savings of the solar cooling system of $19 \%$ with respect to the reference system.

Tab. 4. : Summary of results obtained for the day with highest external temperatures (21st July) for Salamanca and Bilbao climate and building scenarios, under the 3 considered control strategies. Ref. indicates reference case. (Primary energy factors for Spain: 2.5 (electricity) and 1.1 (gas))

\begin{tabular}{|c|c|c|c|c|c|c|}
\cline { 2 - 7 } \multicolumn{2}{c|}{} & \multicolumn{3}{|c|}{ Salamanca } & \multicolumn{3}{c|}{ Bilbao } \\
\hline Parameter & Set 1 & Set 2 & Set 3 & Set 1 & Set 2 & Set 3 \\
\hline Thermal COP & 0.56 & 0.50 & 0.52 & 0.55 & 0.55 & 0.55 \\
\hline Collector efficiency & 0.39 & 0.35 & 0.36 & 0.33 & 0.29 & 0.30 \\
\hline Boiler efficiency & 1.03 & 1.01 & 0.98 & 1.07 & 1.00 & 0.98 \\
\hline Solar gain to driving heat + DHW energy ratio & 0.37 & 0.29 & 0.30 & 0.28 & 0.25 & 0.25 \\
\hline Solar cooling electrical energy use (kWh) & 13.74 & 12.23 & 12.92 & 12.5 & 10.81 & 12.21 \\
\hline Solar cooling gas thermal energy use (kWh) & 78.16 & 103.5 & 101.2 & 80.69 & 97.46 & 101.0 \\
\hline Solar cooling primary energy use (kWh) & 120.3 & 144.4 & 143.6 & 120.0 & 134.2 & 141.6 \\
\hline Ref. electrical energy use $(\mathrm{kWh)}$ & 19.05 & 19.00 & 19.00 & 17.55 & 17.56 & 17.56 \\
\hline Ref. Gas thermal energy use $(\mathrm{kWh})$ & 4.4 & 4.4 & 4.4 & 1.7 & 1.7 & 1.7 \\
\hline Ref. Primary energy use, $(\mathrm{kWh})$ & 52.5 & 52.4 & 52.4 & 45.7 & 45.8 & 45.8 \\
\hline Reference to solar cooling primary energy ratio & - & 0.36 & 0.36 & 0.38 & 0.34 & 0.32 \\
\hline Fraction of cooling load covered (\%) & 77 & 100 & 100 & 100 & 100 & 100 \\
\hline Fraction of DHW load covered (\%) & 100 & 100 & 100 & 100 & 100 & 100 \\
\hline
\end{tabular}


Tab. 5. : Summary of results obtained for the average case day for Salamanca (15th June) and Bilbao (10th August) climate and building scenarios, under the 3 considered control strategies. Ref. indicates reference case.

\begin{tabular}{|c|c|c|c|c|c|c|}
\cline { 2 - 7 } \multicolumn{2}{|c|}{} & \multicolumn{3}{c|}{ Salamanca } & \multicolumn{3}{c|}{ Bilbao } \\
\hline Parameter & Set 1 & Set 2 & Set 3 & Set 1 & Set 2 & Set 3 \\
\hline Thermal COP & 0.62 & 0.52 & 0.63 & 0.62 & 0.60 & 0.63 \\
\hline Collector efficiency & 0.36 & 0.34 & 0.35 & 0.31 & 0.29 & 0.29 \\
\hline Boiler efficiency & 0.95 & 0.93 & 0.89 & 0.95 & 0.97 & 0.92 \\
\hline Solar gain to driving heat plus DHW energy ratio & 0.96 & 0.75 & 0.97 & 1.06 & 0.95 & 1.01 \\
\hline System electrical energy usage $(\mathrm{kWh})$ & 4.79 & 4.94 & 4.63 & 3.22 & 3.21 & 3.24 \\
\hline System thermal energy, gas usage $(\mathrm{kWh})$ & 9.42 & 24.3 & 16.2 & 4.87 & 15.1 & 10.4 \\
\hline System primary energy usage $(\mathrm{kWh})$ & 22.30 & 39.09 & 29.34 & 13.40 & 24.66 & 19.58 \\
\hline Ref. electrical energy usage $(\mathrm{kWh})$ & 7.98 & 7.95 & 7.91 & 4.52 & 4.51 & 4.51 \\
\hline Ref. Thermal energy, gas usage $(\mathrm{kWh})$ & 4.7 & 4.7 & 4.7 & 1.66 & 1.70 & 1.70 \\
\hline Ref. Primary energy usage, $(\mathrm{kWh})$ & 25.1 & 25.0 & 25.0 & 13.11 & 13.15 & 13.15 \\
\hline Reference to solar cooling primary energy ratio & 1.13 & 0.64 & 0.85 & 0.98 & 0.53 & 0.67 \\
\hline Fraction of cooling load covered (\%) & 100 & 100 & 100 & 100 & 100 & 100 \\
\hline Fraction of DHW load covered (\%) & 100 & 100 & 100 & 100 & 100 & 100 \\
\hline
\end{tabular}

\section{Summary and conclusions}

The dynamic performance of a solar cooling system integrated with a gas boiler has been tested for two different buildings (residential and tertiary) and climate scenarios (continental mediterranean and oceanic) under a laboratory hardware-in-the-loop configuration. The system was tested on case days that represented average and extreme climate conditions, under different control strategies. The adsorption chiller was able to cover the cooling demand in all case days, with primary energy ratios between the solar cooling system and a reference system of $0.67-0.85$. Although the energy savings for the solar cooling system in the summer are below 1 , annual calculations considering both winter and summer yield primary energy annual savings of $19 \%$ with respect to the reference system. This energy savings could be further enhanced by increasing the number of solar panels to provide heat.

\section{References}

Ge, T.S., Wang, R.Z., Xu, Z.Y., Pan, Q.W., Du, S., Chen, X.M., Ma, T., Wu, X.N. , Sun, X.L., Chen, J.F., 2018. Solar heating and cooling: Present and future development. Renew. Energy, 126, 1126-1140.

Palomba, V., Vasta, S., Freni, A., Pan, Q.W., Wang, R.Z., Zhai, X., 2017. Increasing the share of renewables through adsorption solar cooling: a validated case study; Renew. Energy, 110, 126-140.

Wuang. X., Chua, H. T., Choon, Ng. K., 2005. Experimental Investigation of silica gel-water adsorption chillers with and without a passive heat recovery scheme. Int. J. Refrig., 28, 756-765.

Chekirou, W., Boukheit, N., Karaali, A., 2016. Performance improvement of adsorption solar cooling system. Int. J. Hydrogen Energ. 41, 7169-7174. 


\title{
PV driven dew-point cooling for Australia
}

\author{
Mark J. Goldsworthy ${ }^{1}$ and Subbu Sethuvenkatraman ${ }^{2}$ \\ ${ }^{1}$ CSIRO Energy, Newcastle (Australia)
}

\begin{abstract}
Dew-point cooling devices use the principles of evaporative cooling to provide air-conditioning with very high electrical efficiency. Although commercial products are available, they are yet to gain mainstream acceptance in the residential cooling market. One factor has been a lack of clarity around the climates for which they're suitable. This is undoubtedly complicated by the fact that cooling demand varies greatly between different buildings even within the same climate. In addition, the economic benefit due to lower running costs may be off-set by a higher initial purchase price. If dew-point coolers (DPC) are to compete on price alone, any economic benefit needs to be very clearly communicated. A complicating factor is the advent of dedicated solar PV driven, and PV-battery driven air-conditioners. Given that DPC's require less electricity to provide the same cooling, this should translate to a reduction in the required PV-battery system size. Here we analyse the ability of DPC's to provide complete comfort in different combinations of Australian climates and buildings, both for grid-connected and off-grid PVbattery applications, as well as the economics of both these systems in comparison to conventional vapourcompression air-conditioners. Results show that a DPC can provide complete comfort for approximately half the Australian population; that a $5 \mathrm{~kW}$ grid-connected cooler is economic in key climates at an installed cost of $\$ 2000$, and that an off-grid PV-battery driven DPC is currently not economically viable.
\end{abstract}

Keywords: dew point cooling, air-conditioning, solar cooling

\section{Introduction}

In Australia, rising energy prices have resulted in a $69 \%$ increase in residential electricity expenditure during the last decade (Coleman, 2017). Use of residential air conditioners during hot summer afternoons is the main contributor to network peak demand periods (Energy Networks Association, 2014). HVAC energy consumption in residential buildings is estimated to contribute nearly $18 \%$ of total emissions $\left(\mathrm{CO}_{2}\right.$-e) from the built environment sector (ClimateWorks, 2016).Heat stress is the largest cause of fatalities due to natural hazards in Australia with recent evidence suggesting that the number and severity of such events may be increasing (Steffen \& Hughes, 2014). Energy efficient, cost effective cooling solutions that can address these problems would be very valuable to Australian consumers, network utilities and the community in general.

Dew point indirect evaporative coolers (DPC's) can deliver temperatures to the building as low as the dew-point temperature of the incoming air and use only a fraction of the energy required by a conventional vapourcompression air conditioner. In addition, unlike compression air conditioners, whose capacity and efficiency are decreased due to reduced heat rejection capacity on hot summer days, DPC's can operate with higher capacity and efficiency during these periods. Their low energy use also gives them a greater potential to be integrated with a PV energy source and small battery to operate as standalone cooling delivery system. A grid independent PV DPC solution can take the cooling load off the electricity grid and reduce peak energy demand. However, DPC's provide only sensible cooling, they do not remove any humidity from the indoor space and hence may not be appropriate for certain combinations of climates and building heat loads.

The laboratory and in-situ performance of various DPC's has been studied by a number of researchers (see for example (Jradi, 2014) (Ham, 2016) (Pandelidis \& Anisimov, 2015) (Bruno, 2011)) and ongoing development is targeted at incremental improvements to the cooling performance, overall efficiency, and in particular, the size and cost, for example through the use of new heat exchange surfaces and manufacturing methods (see for example (Lee., 2013) (Xu, Ma, \& Zhao, 2016)). An overview of the fundamentals of indirect evaporative cooling may be 
found in (Glanville, Kozlov, \& Maisotsenko, 2011).

Worldwide there are several commercial suppliers of DPC's. Commercially available systems have been, in the most part, targeted at larger scale applications such as warehouses, manufacturing facilities and offices. However, residential scale systems are also beginning to enter the market. In Australia, residential scale DPC systems are yet to reach any measureable penetration into the air-conditioning market which is dominated by the annual sale of approximately 1 million vapour-compression systems (E3 Committee, 2016).

Undoubtedly one of the reasons why DPC's are yet to become more than a novelty for residential buildings is the fact that their performance over a wide range of climates and building designs is still yet to be described. The extent to which they can expand the historical operating range of direct evaporative (swamp) coolers from dry climates to more humid and even tropical locations, given typical occupant comfort levels, is of particular interest.

The second aspect of interest stems from the fact that typical electricity efficiencies of DPC's are 2 to 3 times higher than vapour-compression systems. Obviously by itself this results in a direct saving of electricity and any associated emissions. However, it may be more important for households with a photovoltaic system (either with or without batteries) where purchasing energy from the grid is particularly undesirable (for example due to high electricity costs and low prices paid for excess PV generation fed back to the grid) given that significant cooling use for many households occurs in the late afternoon and early evening. For households not connected to the electricity grid, a small saving in air-conditioner energy use may have big implications for the required size of the electricity generation system; be it a PV-battery system or other form of generation. However, the size of the dedicated PV-battery system required to run a DPC in different climates is highly dependent on the coupling between the pattern of solar availability, the weather, the building physics and the occupant requirement for cooling. There is no common 'rule-of-thumb'.

Thus, this study aims to address three questions;

1. For what combination of Australian climates and residential buildings can a commercial DPC provide complete annual (cooling) comfort if connected to the electricity grid?

2. What size PV-battery system is required to operate a stand-alone (grid independent) DPC in different combinations of Australian climates and buildings?

3. What is the maximum installed cost of a DPC to be cost neutral with a vapour-compression system in different climates and buildings?

For the off-grid PV-battery driven system we focus on economics as the primary performance parameter since theoretical measures such as annual efficiencies and PV utilization have little relevance to the overall viability which is ultimately governed by the economics. The modelling method used is described in Section 2 . The three questions above are addressed in Sections 3.1, 3.2 and 3.3 respectively. Section 4 discusses the results including the market potential of DPC's in Australia.

\section{Modelling method}

The simulation model as described in (Goldsworthy M. , 2017) was used with selected modifications. This model simulates the combined building and cooling system over a year at intervals of 10 minutes using representative climate data for locations across Australia. It consists of i) a building model based on a uniform temperature and humidity air node coupled to transfer function models of external walls, ceiling and roof cavity; ii) a photovoltaic and lithium ion battery charge/discharge model, iii) a vapour-compression air-conditioner model based on performance curves (Cutler, 2013) and using the Bypass Factor approach, and iv) weather and radiation data processing models. To this model a dew-point cooler sub-model was implemented as described below.

\subsection{Dew-point cooler model}

The dew-point cooler (DPC) performance model is based on curve fit of data from experimental tests of a commercial DPC in the Controlled Climate Test Facility at CSIRO Energy Technology (Brandenburger, 2017). Tests were conducted with inlet air dry and wet bulb air temperatures in the ranges 32 to $40^{\circ} \mathrm{C}$ and 20 to $28^{\circ} \mathrm{C}$ such that the inlet air wet-bulb depression was between 5 and $17^{\circ} \mathrm{C}$. The resulting performance was characterised in terms of two quantities; the dew-point effectiveness and electrical coefficient of performance (COP), given by; 


$$
\begin{aligned}
& \varepsilon_{d p}=0.364+0.0172 T_{i n_{-} w b} \\
& C O P=-0.665+1.09\left(T_{i n}-T_{i n_{w b}}\right)
\end{aligned}
$$

where dew-point effectiveness is defined according to;

$$
\varepsilon_{d p}=\frac{T_{\text {in }}-T_{S}}{T_{\text {in }}-T_{\text {in_ } d p}}
$$

$T_{i n}, T_{i n \_w b}$ and $T_{i n_{-} d p}$ are the inlet air dry bulb, wet bulb and dew-point temperatures respectively and $T_{S}$ is the supply air temperature to the building. The Root Mean Square Error over the test range was 0.014 for the dewpoint correlation and 0.203 for the COP correlation.

These correlations are based on a fixed secondary exhaust mass flow fraction of 0.4. Higher exhaust fractions typically result in lower supply air temperatures which is off-set by the lower supply air flow rate. Hence there is a trade-off between cooling capacity and supply air temperature. The presence of an exhaust air stream means that the DPC cannot operate with $100 \%$ recirculation of building air without also drawing outside air into the building. Thus, here a fixed fresh air flow rate equal to the secondary exhaust flow rate was used for all simulations. Hence the inlet air to the DPC was a mixture of return air and ambient air. A fixed supply air flow rate of $1500 \mathrm{~kg} / \mathrm{hr}$ corresponding to a $5 \mathrm{~kW}$ (sensible) cooling capacity at air inlet conditions of $T_{i n}=35^{\circ} \mathrm{C}, T_{i n \_w b}=24^{\circ} \mathrm{C}$ was used for all simulations.

\subsection{Control strategy}

The cooling control strategy is summarised in Figure 1. This consisted of 3 temperatures levels each for day cooling and night cooling. For day-cooling (awake hours) the highest temperature level $\left(27^{\circ} \mathrm{C}\right.$ in the figure), referred to here as the 'trigger temperature' $T_{t}$, was compared to the indoor apparent temperature $\widetilde{T}_{b}$. Apparent temperature combines both temperature and humidity and gives a better indicator of thermal comfort. Here the method of Steadman (Steadman, 1984) was used to calculate apparent temperature. If $\tilde{T}_{b}>T_{t}$, then cooling was activated and the cooler cycled on/off to maintain the building temperature between the upper and lower apparent temperature set-points $\widetilde{T}_{u}$ and $\widetilde{T}_{l}$. The signal that indicates that cooling has been 'tripped' was reset at 6am each day. This models, in effect, a 'resetting' of the occupant memory of air-conditioner use. (Note though that the cooler could still turn off prior to this if the indoor temperature was within the set-points.)

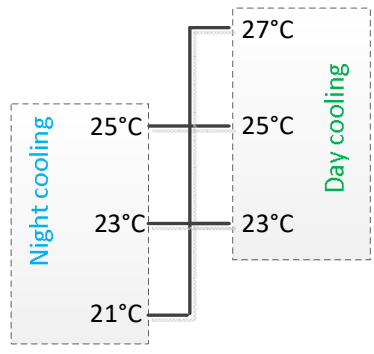

Figure 1 Apparent temperature threshold levels for air-conditioning control.

\subsection{Residential building models}

To assess the ability of the DPC to provide cooling for different combinations of climate and buildings, multiple building models were developed by varying the thermal characteristics of the building envelope. The 'building' models were based on a single room with fixed floor area of $50 \mathrm{~m}^{2}$, pitched roof, and a single window with external eave shading on one of the four walls. The thermal characteristics of this single room were varied to construct 2000 different building models composed from a random selection of the parameter values in Table 1.

These parameter values are the same as those described in (Goldsworthy, 2017) and, with the exception of orientation and wall construction type, were chosen to correspond to a notionally 'above average' value and a notionally 'below average' value for Australian houses. These values are not intended to represent the extrema, but rather plausible ranges that cover the majority of residential buildings. As outlined in (Goldsworthy, 2017), these parameter values were selected with reference to the published literature where possible.

For each climate zone, three annual simulations were run for each building model; one for the building with dew- 
point evaporative cooler, one for the same building with a grid-connected vapour-compression air-conditioner with the same total cooling capacity, and one for the building without any air-conditioning. In addition, for the off-grid DPC cases simulations with varying PV and battery sizes were also run. Typical Meteorological Year weather data files for the 69 climate zones (Department of Environment and Energy, 2018) that cover all of Australia were employed. As described in Section 2.4, the model predictions from each building simulation were weighted according to the estimated proportions of the different building types in each climate zones based on a housing stock model.

Tab. 1: Building model thermal parameter values and distribution

\begin{tabular}{|c|c|c|}
\hline Variable & Parameter values & Frequency of parameter value in a given climate \\
zone
\end{tabular}

\subsection{Building model weighting factors}

Here we applied a weighting factor to the simulation results to reflect the estimated distribution of actual buildings with the various characteristics in each climate zone. That is, for a specific performance metric $\mathrm{Y}$, the weighted average of the performance metric for a given climate zone $c z$ was calculated according to;

$$
\left.\langle Y\rangle_{c z}=\sum_{b=1}^{N_{b}} Y_{c z} W_{b, c z} \quad \text { (eq. } 4\right)
$$

Where $W_{b, c z}$ is the weight factor for a building model $b$ and climate zone $c . W_{b, c z}$ was calculated according to; 


$$
W_{b, c z}=\frac{N_{b}}{\sum_{b} \Pi_{v} W_{v, b}} \prod_{v} W_{v . b} \quad \text { (eq. 5) }
$$

where $W_{v, b}$ is the weight factor for the specific building parameter value $v$ for the building $b$. The building parameter weight factor $W_{v, b}$ was calculated differently for each building parameter as described below.

For the internal thermal capacitance, internal load profile, building aspect ratio, window orientation, wall and roof solar absorptivity and window to floor area ratio, a uniform weighting factor $\left(W_{v, b}=1\right)$ was applied. That is, we assumed a uniform distribution of buildings with parameter values as listed for these variables. With the exception of roof solar absorptivity and window orientation, this assumption was made in the absence of other information on the distributions of these variables in actual buildings. For roof solar absorptivity and window orientation a recent study using satellite data to investigate the possible impact of building regulations on roof colour and house orientation found no consistent evidence for a difference between buildings built pre and post introduction of more stringent energy efficiency standards (Whitsed, 2013). While this does not necessarily mean that window orientation and roof colour are uniformly distributed across buildings and locations, in the absence of detailed data describing these parameter variations, here we assume uniform distributions of these parameters also.

For ceiling insulation, wall insulation and wall construction, data from a National Housing Stock model (DEWHA, 2008) was used to calculate the fraction of buildings with and without ceiling and wall insulation for three different base construction types; lightweight, medium-weight and heavyweight in each climate zone for the year 2020. The proportions of buildings in each classification for each climate zone were used to calculate the weight factors $W_{v, b}$ for a given building model ensuring that the weights for each variable were normalized to have a maximum of 1 over all the building models.

For natural infiltration rate and window type, the proportion of 'performance' buildings (i.e. buildings built post the introduction of more stringent energy efficiency standards in each state) in each climate zone was used to calculate the weight factors. Higher weightings were assigned to the building models with the lower infiltration rate and with double glazed windows based on the proportion of performance buildings in the climate zone.

\subsection{Comfort performance metrics}

Since we expect that the DPC will not provide complete comfort in all building and climate combinations, we define an occupant discomfort metric as follows. The annual degree of discomfort $\left(d d_{c}\right)$ is calculated as the cumulative difference between the indoor apparent temperature $\widetilde{T}_{b}$ and the upper temperature threshold $\widetilde{T}_{u}$ for the given time of day.

$$
d d_{c}=\sum \max \left(\widetilde{T}_{b}-\widetilde{T}_{u}, 0\right) \Delta t / 24 \quad \text { (eq. 6) }
$$

Here $\Delta t$ is the time interval of the simulation in units of hours. We use $\widetilde{T}_{u}=25^{\circ} \mathrm{C}$ for awake hours (6am to $\left.10 \mathrm{pm}\right)$ and $\widetilde{T}_{u}=23^{\circ} \mathrm{C}$ for sleeping hours (10pm to $\left.6 \mathrm{am}\right)$.

Comparison of the $d d_{c}$ metric with the conditioning control strategy described in Section 2.2 reveals that even a cooling system with unlimited capacity generally will not lead to a precisely zero discomfort metric over the year because of the use of the trigger temperature. In practice this could be attributed to the accumulated periods of time over a year between the onset of some mild occupant discomfort and the action of switching on cooling. Because of this, if the DPC system achieves $d d_{c}<100$ we considered this to correspond to full (cooling) comfort for that particular case.

\subsection{Economics}

Economic comparisons were based on the estimated maximum purchase cost of the DPC $\left(C_{D P C_{-} \max }\right)$ to achieve net zero cost over the lifetime of product, assuming a cooling device needed to be purchased. For a grid connected DPC this is calculated by solving the following equations;

$$
\begin{gathered}
A_{t}=A_{t-1}(1+i)^{t}-\left(R C_{V C}-R C_{D P C}\right)(1+r p i)^{t} \\
A_{0}=C_{D P C_{-} \max }-C_{V C}, \quad A_{10}=0
\end{gathered}
$$

where $i=5 \%$ is the investment interest rate, $r p i=1 \%$ is the real retail electricity annual price increase, $t$ is the year sense installation, $R C_{V C}$ and $R C_{D P C}$ are the calculated annual running costs of the grid connected vapour compression and dew-point cooler respectively, and $C_{V C}$ is the purchase cost of the vapour-compression system. This equation models an initial loan required to purchase the DPC with annual electricity cost savings used to 
make repayments. The maximum size of the initial loan (i.e. the purchase cost of the DPC) that achieves payback after 10 years is calculated.

For the off-grid comparison a similar approach was used. The maximum purchase cost of the DPC to achieve payback over the lifetime is calculated by solving the equation;

$$
\begin{gathered}
A_{t}=A_{t-1}(1+i)^{t}-R C_{V C}(1+r p i)^{t}+\left(0.5 C_{B}+C_{D P C \_ \text {max }}-C_{V C}\right) \delta(t-10) \\
A_{0}=C_{P V}+C_{B}+C_{D P C_{-} \max }-C_{V C}, A_{20}=0
\end{gathered}
$$

This equation also assumes a cooling device needs to be purchased and models an initial loan to purchase the DPC and PV-battery system with annual electricity cost savings used to make repayments. However, in this case the payback is calculated over 20 years with purchase of a replacement DPC and battery after 10 years.

Additional economic parameters used in the model are summarized in Table 1.

Tab. 2: Summary of economic parameters used

\begin{tabular}{|c|c|c|}
\hline Category & Value & Details \\
\hline Electricity tariff & $\begin{array}{c}\text { Peak/off-peak/shoulder: } \\
47 \mathrm{c} / \mathrm{kWh} / 11 \mathrm{c} / \mathrm{kWh} / \\
20 \mathrm{c} / \mathrm{kWh}\end{array}$ & $\begin{array}{c}\text { Peak: M-F 2pm-8pm } \\
\text { Off-peak: 10pm-7am 7 days }\end{array}$ \\
\hline $\begin{array}{c}\text { Real retail electricity price increase } \\
5 \mathrm{~kW} \text { vapour-compression system } \\
\text { installed cost }\end{array}$ & $\begin{array}{c}\$ \% \text { per annum } \\
\text { (Jacobs Pty Ltd., 2016) }\end{array}$ & $\begin{array}{c}\text { Compiled from multi- } \\
\text { sources }\end{array}$ \\
\hline Vapour-compression system lifetime & 10 years & (BIS Shrapnel, 2014) \\
\hline DPC lifetime & 10 years & Estimated \\
\hline PV installed cost & $\begin{array}{c}\$ 1.5 \text { to } \$ 3.4 / \mathrm{Watt} \text { (State } \\
\text { dependent) }\end{array}$ & $\begin{array}{c}\text { (Solar Choice, 2018) } \\
2 \mathrm{~kW} \text { system }\end{array}$ \\
\hline $\begin{array}{c}\text { Battery system installed cost } \\
\text { (Solar Choices, 2018) } \\
3 \mathrm{kWh} \text { system }\end{array}$ \\
\hline $\begin{array}{c}\text { PV-battery lifetime } \\
\text { Battery system 10 year replacement } \\
\text { cost reduction }\end{array}$ & $\begin{array}{c}20 \text { year }(\mathrm{kV}), 10 \text { years } \\
\text { (battery) }\end{array}$ & $\begin{array}{c}\text { (SolarQuotes, 2017) } \\
\text { (Brinsmead, 2015) }\end{array}$ \\
\hline
\end{tabular}

\section{Results}

\subsection{Comfort delivery (grid connected DPC)}

The question of whether the DPC can maintain comfort conditions inside the building in different climates if sufficient electricity is available was considered first. That is, the ability to create comfortable conditions with no constraint on available electricity given that the DPC provides sensible cooling only.

Figure 2 shows a map of Australia with capital cities locations marked. The tropic of Capricorn is located at approximated $23.4^{\circ} \mathrm{S}$ latitude; areas north of this line typically have tropical climates though far inland areas often have low humidity and may be arid. Areas south of this line have more temperate climates though inland areas generally have hot, dry summers.

The diagonal hatched region indicates the climates where the DPC provides complete cooling comfort over the year for less than $20 \%$ of residential dwellings. In this region, complete comfort was achieved in only a small fraction of buildings and so DPC's operating in this region are deemed unlikely to provide a complete cooling comfort solution for most occupants, almost regardless of the building design. The cross-hatched region indicates the climates where the DPC provided a complete cooling comfort solution for more than $20 \%$ of residential dwellings. Whether complete comfort is achieved depends on the particular thermal design of the building, internal heat loads, local climate and, in practice, the occupant comfort tolerance. This region includes most of the major population centres. Overall the DPC is estimated to be able to provide a complete cooling solution for $45 \%$ of Australian households or over 10.5 million people. 


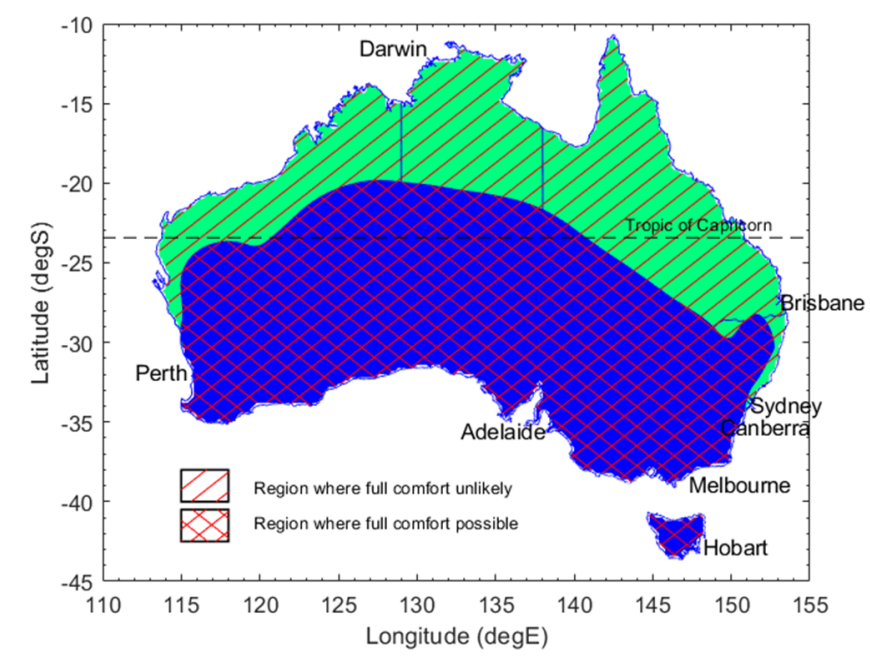

Figure 2 Regions where complete cooling comfort using the DPC are unlikely (lines) and possible (cross hatch) based on $<20 \%$ and $>\mathbf{2 0} \%$ (respectively) of the simulated buildings achieving complete cooling comfort.

Although complete comfort was not achieved for certain building and climate combinations, this does not necessarily mean that comfort levels were not substantially improved by the DPC for these cases. Figure 3 compares the number of daytime operating hours as a function of internal apparent for one particular building for the sub-tropical climate of Brisbane (left) and the temperate climate of Melbourne (right). The internal temperatures are shown for the building with the DPC operating, and also for the building with no cooling at all. The particular building chosen had an annual degree of discomfort with the DPC very close to the median for all of the buildings in both Brisbane $(d d=520)$ and Melbourne $(d d=25)$. It had an insulated brick veneer construction, was relatively well sealed, and had a North-East facing double glazed window. The number of hours corresponding to each apparent outside temperature is also shown.

In both climates the DPC substantially improved the comfort level in the building over the case with no cooling. However, for Brisbane there were a considerable number of hours where the daytime comfort level remained above the upper threshold of $25^{\circ} \mathrm{C}$ apparent temperature. This resulted from the inability of the DPC to provide building supply air temperatures low enough to result in comfortable indoor conditions when the outside relative humidity was high. Whether or not these conditions are acceptable of course depends upon the individual occupant preferences. The analysis here assumes that such conditions are unacceptable.
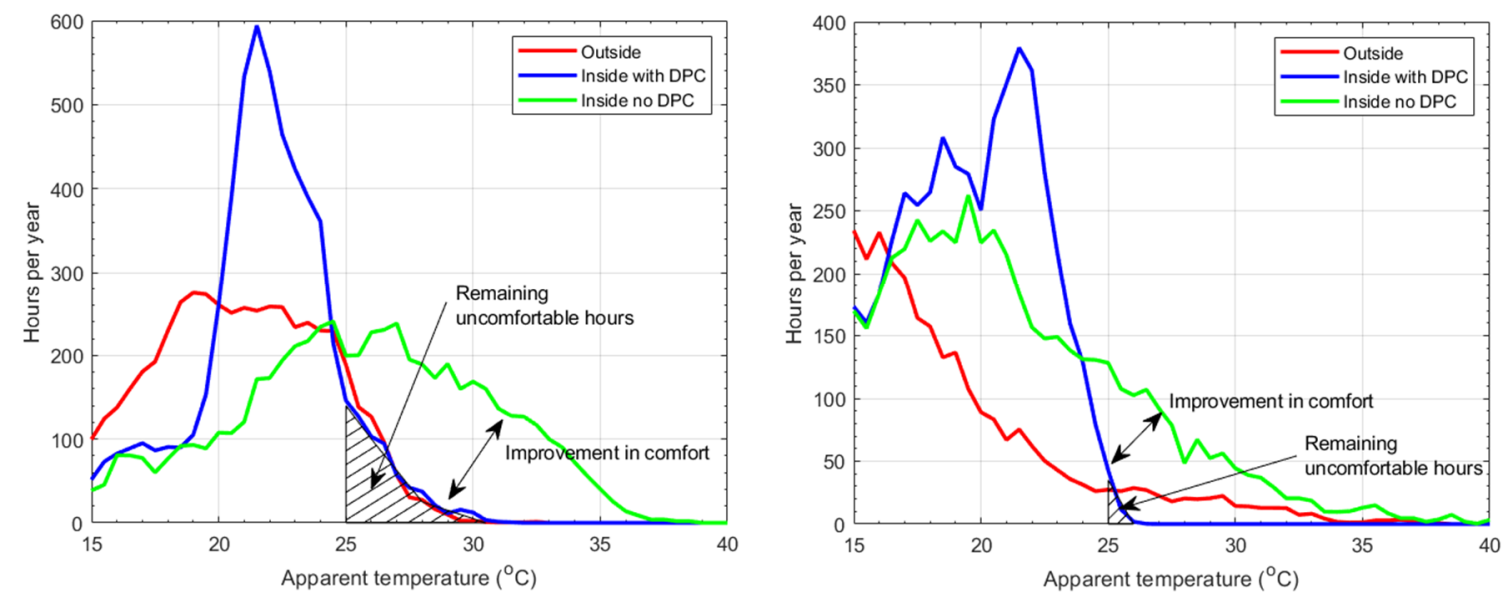

Figure 3 Apparent temperature frequency histogram showing outside temperature and inside temperature in the building with and without DPC for 1 selected building for sub-tropical climate of Brisbane (left) and temperate climate of Melbourne (right).

\subsection{PV-battery system sizing for off-grid DPC}

The second question of interest is the size (i.e. generation and storage capacities) of the PV-battery system required to operate the DPC independent of the grid in different climates and buildings. Simulations were run with combinations of three different PV array rated output (300W, 600W and 900W) corresponding to 1, 2 or 3 standard 
crystalline silicon modules, and 5 different battery storage capacities between $0.2 \mathrm{kWh}$ and $3 \mathrm{kWh}$.

At the nominal rated condition the DPC has a $5 \mathrm{~kW}$ capacity and $\mathrm{COP}=11.3$, hence an electrical power draw of $440 \mathrm{~W}$. Thus, for the case with a single PV module operation relied on battery discharge to operate at full capacity at the rated condition. These battery capacities correspond to between 20 minutes and 5 hours of operation with $75 \%$ discharge.

The lowest overall cost PV-battery system that allowed the DPC to satisfy the comfort criteria was determined for each combination of building and climate zone. The resulting weighted fraction of buildings with different combinations of PV and battery system are shown in stacked bar charts in Figure 4 for selected climate zones.

For example, for the Perth climate zone, approximately $32 \%$ of buildings reached comfort with a $600 \mathrm{~W}$ PV system and $35 \%$ with a $900 \mathrm{~W}$ system. Approximately $28 \%$ of buildings required a $3 \mathrm{kWh}$ battery, another $17 \%$ a $1.5 \mathrm{kWh}$ battery, a further $14 \%$ a $1 \mathrm{kWh}$ battery and $7 \%$ a battery of $500 \mathrm{Wh}$ or smaller.

Where the total height of the bar is less than 1, the missing fraction of buildings corresponds to those buildings where none of the modelled combinations of DPC and PV-battery system achieved the required comfort conditions. This may have been due to either insufficient electrical power available, or the inability of the DPC to provide comfort conditions for those buildings in the given climate.

While the required number of PV modules and battery system capacity is of general interest (for example from the perspective of the physical space required for these devices), ultimately it is the economics of the overall system that is the main consideration. This is discussed below.
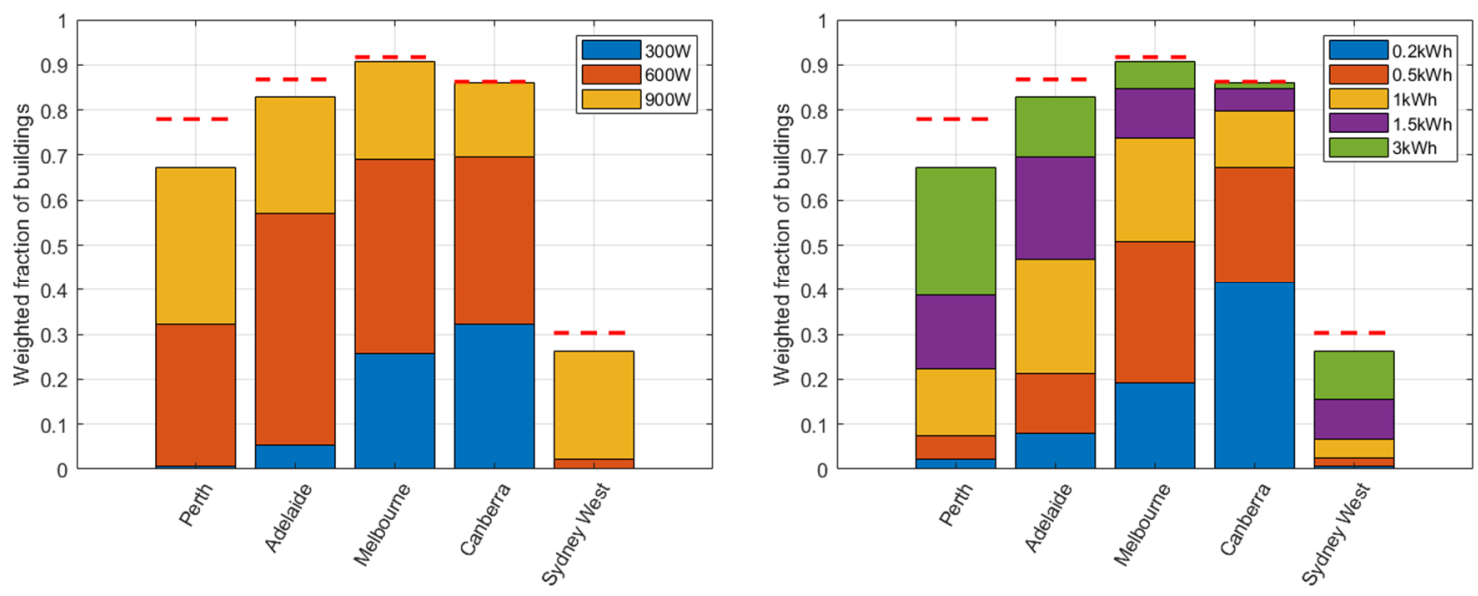

Figure 4 Weighted fraction of buildings and corresponding required PV (left) and battery (right) size to achieve equivalent comfort to grid-connected DPC for selected locations. Where totals sum to less than 1 , the missing fraction corresponds to buildings that required a PV-battery system larger than modelled or where comfort could not be achieved with the DPC.

\subsection{Economics}

The third question of interest is the economics of both the grid-connected and the off-grid PV-battery DPC in different climates and buildings. The economic viability can be calculated in comparison to different baselines and using different methods. Here we use a grid-connected vapour-compression system as the baseline for both cases. As noted above, for the off-grid system the PV-battery is sized to satisfy the comfort conditions (if possible); for climate-building combinations where the comfort conditions are not met, the economics were not calculated.

To evaluate economic viability the lifetime cost including the capital for the initial investment and the operating costs are compared to calculate the maximum installed cost of the DPC that achieves break even (or cost neutrality) with the reference system over the operating life. For the grid-connected DPC, the operating life was taken as 10 years while for the off-grid system, twice this period was assumed allowing for battery and cooling system replacement at the 10 year mark. Economic parameters used are listed in Table 2.

Figure 5 (left) shows a boxplot of the maximum installed cost of the grid-connected DPC to achieve breakeven with the grid-connected vapour-compression air-conditioner over the operating life for the buildings that achieve full comfort and for selected climates. Higher costs are preferable sense these indicate that the DPC can cost more to purchase and still deliver savings over the lifetime. In all cases the maximum cost is at least greater than the 
cost of the vapour-compression air-conditioner; this simply confirms that the DPC costs less to run than the vapour-compression air-conditioner.

The most favorable locations from an economic perspective are Perth, Adelaide and Western Sydney. This is despite the fact that a significant proportion of buildings in Western Sydney did not reach full comfort with the DPC. That is, for those buildings where full comfort was met, the economics were more favourable if the location (and building) required more cooling.

Figure 5 (right) shows the average maximum installed cost of the grid-connected DPC as a function of the annual apparent temperature cooling degree days for each climate zone. Blue circles represent climate zones where more than $50 \%$ of buildings reached full comfort with the DPC; red crosses climates zones where fewer than $50 \%$ of buildings reached full comfort. The installed cost of the DPC can be higher and the system still achieve cost neutrality over the lifetime for climates with a large cooling demand; though if the demand is too high, the DPC struggles to provide comfort for many buildings.

The distinction between climates where the DPC can provide full comfort for the majority of buildings and those where it cannot is not clear cut in terms of the number of cooling degree days. This is because additional factors such as the timing of the cooling demand, the relative portion of the load due to irradiance, as well as the ambient humidity levels, all affect the ability of the DPC to provide full comfort.
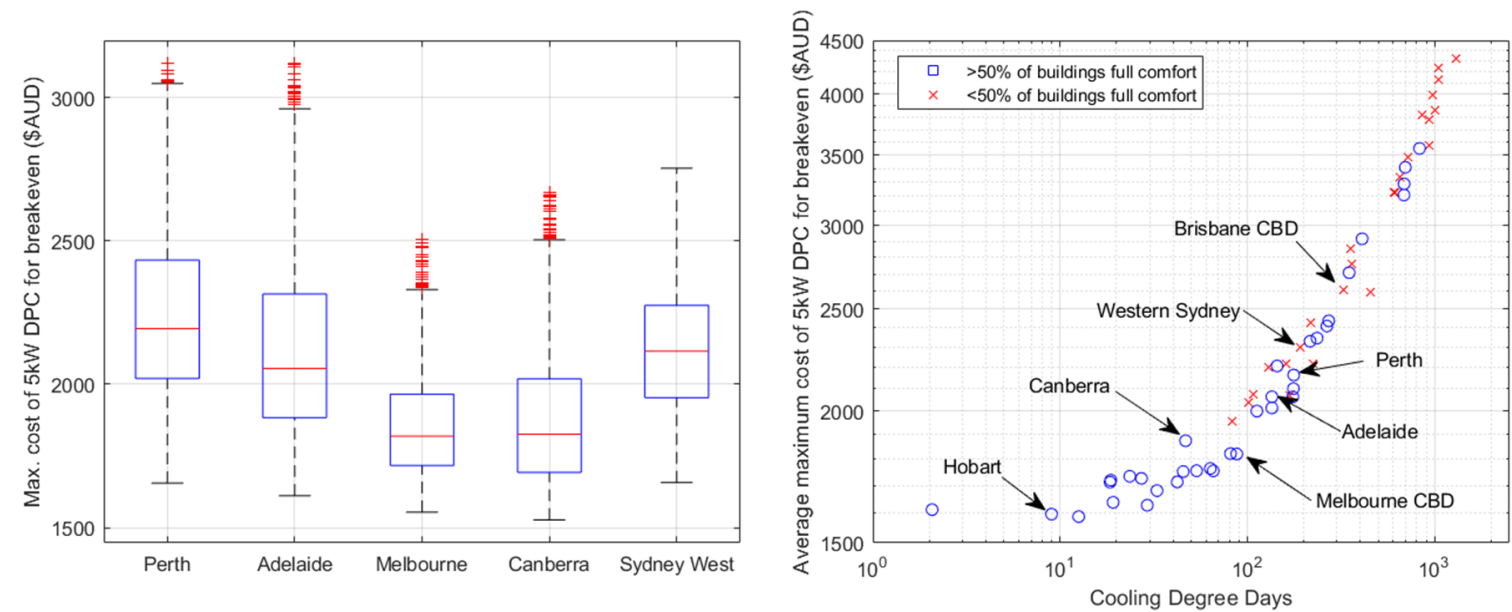

Figure 5 Left: Boxplots showing maximum purchase price of a $5 \mathrm{~kW}$ DPC to achieve net zero cost over the lifetime of the product for selected locations for buildings reach full comfort assuming financing at $5 \%$ interest. Right: Weighted average maximum purchase price as a function of the number of apparent temperature cooling degree days in the climate zone.

For the of the off-grid PV-battery driven DPC case economics were also calculated in comparison to the gridconnected vapour-compression air-conditioner. Figure 6 shows boxplots of the maximum installed cost of the offgrid DPC to achieve breakeven over the lifetime. Note that the installed cost is only that of the DPC; the PVbattery purchase costs were already factored into the calculation. Similarly to above, results are only shown for buildings where the off-grid DPC could provide full comfort.

In this case, for the vast majority of buildings the maximum installed cost of the DPC must be less than $\$ 1500$ which is the cost of the vapour-compression system. For example, for Canberra, if the DPC was to cost between $\$ 450$ and $\$ 1100$, then for $50 \%$ of buildings (the region covered by the blue box in the figure) an off-grid PVbattery driven DPC system would be cost neutral with a grid-connected vapour-compression system. In some cases the maximum installed cost is negative. This means that the cost of the PV-battery system alone is too high to achieve cost neutrality, regardless of the cost of the DPC.

Based on these results, at present an off-grid PV-battery driven DPC for residential cooling is not economic. This is essentially due to the number of operating hours where cooling is required in a residential building for the locations where the DPC can provide full comfort, and the relatively high cost of the PV-battery system. Key factors likely to improve the economic prospect include decreasing the cost of battery storage, increasing the hours of operation, and any financial incentives that offset the purchase cost of the system. 


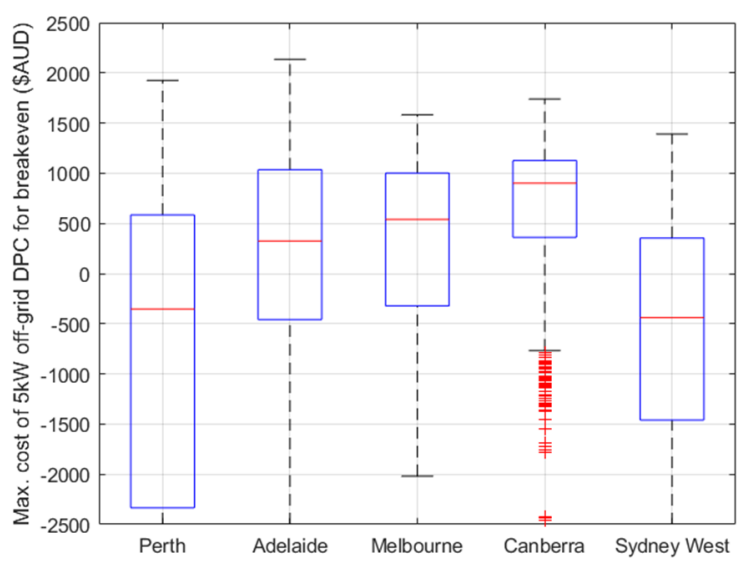

Figure 6 Boxplots showing maximum purchase price of a $5 \mathrm{~kW}$ DPC in an off-grid PV-battery driven system to achieve net zero cost over the lifetime of the product for selected locations for buildings reach full comfort assuming financing at $5 \%$ interest. (Note: battery and PV costs are considered separately.)

\section{Discussion}

The analysis describe here was based on simulations of a single year using Typical Meteorological Year climate data derived from long term meteorological records covering the period 1967-2012. The economic analysis then assumed the single year simulation results applied for the 10 and 20 year operating lifetimes. However, evidence shows that climate change is increasing the daytime maximum and overnight minimum temperatures across most of Australia (Bureau of Meteorology, 2018). This is resulting in an increase in the required operating hours of cooling systems and hence is likely to improve the economics of the DPC; both because of the greater potential for running cost savings, but also because, under hotter conditions, the comparative performance of the DPC improves relative to vapour-compression systems, provided humidity does not also increase. Unfortunately projections on future humidity levels are uncertain with no clear consensus between various climate models (Climate change in Australia; projections for Australia's NRM regions, 2018). A future topic of research is to assess the impact of climate change on DPC suitability and economics through the use of future climate data in the simulations.

An important factor in the economic comparison that was not considered here is the fact that many conventional air-conditioners are reverse cycle, hence they provide a heating function as well. In most of the less humid, southern climates where the DPC could provide a complete (cooling) comfort solution for the majority of buildings, winter heating would also be required. To properly account for this in the economic analysis it would be necessary to assume a combined heating system with the DPC. We have not done this here since there are no such systems currently available commercially for residential buildings. However, the impact of climate change is relevant here also. For example (Wang, Chen, \& Zhengen, 2010) estimate that under a 'moderate' climate change scenario (A1B), the annual heating load will reduce by 36\% in Melbourne and 74\% in Sydney by 2050 . At the same time, the cooling load is predicted to increase by $90 \%$ in Melbourne and $120 \%$ in Sydney. The reduction in heating demand is expected to have the most impact on the economics if it means heating is no longer required at all, but it may also be relevant in cases where it becomes economic to provide the small amount of heating required using a low purchase cost device such as a convection heater.

The suitability and economic viability of dew-point cooling is essentially guided by the interaction between three factors, the climate, the building and the occupants. The analysis here considered varying climates and building thermal parameters. However, the occupants play a central role in determining the overall energy use of a building, as well as the energy use for air-conditioning. Variations in energy use can arise due to fundamentally different comfort preferences, but they can also be strongly influenced by other considerations such as the financial cost of using air-conditioning. In seeking to assess a relatively new, efficient technology for providing comfort, here our interest is in occupants ideal comfort levels, not actual current air-conditioning usage behaviors. We have used fixed day and night-time apparent temperature comfort thresholds of $25^{\circ} \mathrm{C}$ and $23^{\circ} \mathrm{C}$ respectively. Some occupants may find these conditions uncomfortable, either too hot or too cold. By way of comparison, at $60 \%$ relatively humidity, an apparent temperature of $25^{\circ} \mathrm{C}$ corresponds to an air temperature of $24^{\circ} \mathrm{C}$. According to the ASHRAE comfort standard (ASHRAE, 2010), for a seated person with summer clothing, at the same humidity the air temperature corresponding to the lowest percentage of persons dissatisfied is $25.3^{\circ} \mathrm{C}$ (neglecting the effects of radiant temperature and wind speed). Hence the value we used is likely toward the cooler end of most individual's ideal for comfort. 
Finally we have used data from laboratory testing of a commercial DPC. In operation it is possible that performance may be slightly reduced, for example we have not considered ducting heat losses or performance degradation over time. On the other hand similar effects are also likely to apply to the conventional technology as well. Characterisation of the long term performance of DPC in residential installations is a topic of future investigation.

\section{Conclusion}

A commercially available dew-point cooling system with a rated electrical efficiency over 10 can provide complete (cooling) comfort in most residential buildings in the southern region of Australia covering the capital cities of Perth, Adelaide, Canberra and Melbourne. This corresponds to $46 \%$ of households or over 10 million people. In the sub-tropical and tropical locations DPC can provide significantly improved comfort, but higher humidity levels mean that complete comfort is unlikely for most buildings in these climates.

The economics of a grid-connected DPC varying across climates and buildings, but are most favourable in Perth, Adelaide and Western Sydney where a 5kW DPC with an installed cost of $\$ 2000$ or less would be cost competitive at present with a vapour-compression cooler for the majority of households.

For an off-grid PV-battery driven DPC, the required size of the PV array and battery system also varies across climates and buildings. However, the relatively high cost of the PV-battery system and the relatively small number of operating hours over a year in a residential application mean that the economics of an off-grid DPC system are not favourable at present.

\section{References}

BIS Shrapnel. (2014). The household appliances market in Australia. Australia: BIS Shrapnel.

Brandenburger, A. (2017). Experimental investigation into the design of an indirect evaporative cooler. Newcastle: CSIRO.

Brinsmead, T. G. (2015). Future energy storage trends: an assessment of the economic viability, potential uptake and impacts. Australia: CSIRO.

Bruno, F. (2011). On-site experimental testing of a novel dew point evaporative cooler. Energy and Buildings, 43, 3475-3483.

Bureau of Meteorology. (2018, July). Climate change and variability. Retrieved from http://www.bom.gov.au/climate/change/

Climate change in Australia; projections for Australia's NRM regions. (2018, July). Retrieved from https://www.climatechangeinaustralia.gov.au/

ClimateWorks. (2016). Low carbon, high performance. ClimateWorks Australia.

Coleman, S. (2017). Australia State of the Environment 2016; Built Environment. Canberra: Department of Environment and Energy.

Cutler, D. e. (2013). Improved modeling of residential air conditioners and heat pumps for energy calculations. Colorado: NREL.

DEWHA. (2008). Energy use in the Australian residential sector. Canberra: Australian Government.

E3 Committee. (2016). Consultation Regulation Impact Statement - air conditioners and chillers. Canberra: Department of Industry, Innovation and Science.

Energy Networks Association. (2014). Towards a national approach to electricity network tariff reform. ENA.

Goldsworthy, M. (2017). Building thermal design for solar photovoltaic air-conditioning in Australian climates. Energy and Buildings, 135, 176-186.

Goldsworthy, M. (2017). Comfort versus energy saving; the effect of building parameters on heating and cooling 
for Australian climates. Australasian Building Simulation Conference (p. 12). Melbourne: AIRAH.

Ham, S. a. (2016). DPHX (dew point evaporative heat exchanger): System design and performance analysis. Energy, 132-145.

Jacobs Pty Ltd. (2016). Retail Electricity Price History and Projections - Public. AEMO.

Jradi, M. (2014). Experimental and numerical investigation of a dew-point cooling system. Applied Energy, 524535 .

Lee., J. a. (2013). Experimental study of a counter flow regenerative evaporative cooler with finned channels. Int. J. of Heat and Mass Transfer, 65, 173-179.

Pandelidis, D., \& Anisimov, S. a. (2015). Performance of the Maisotsenko Cycle heat exchangers in different airconditioning applications. Int. J. of Heat and Mass Transfer, 81, 207-221.

Solar Choice. (2018, June). Residential Solar PV price index - June 2018. Retrieved from https://www.solarchoice.net.au/blog/residential-solar-pv-price-index-june-2018/

Solar Choices. (2018, June). Battery storage price index - June 2018. Retrieved from https://www.solarchoice.net.au/blog/battery-storage-price-index-june-2018/

SolarQuotes. (2017, September). Solar Battery Storage Comparison Table. Retrieved from https://www.solarquotes.com.au/battery-storage/comparison-table/

Steadman, R. (1984). A universal scale of apparent temperature. J. App. Met., 23(12), 1674.

Steffen, W., \& Hughes, L. a. (2014). Heatwaves : Hotter, Longer, More often, Climate council of Australia. Climate Council of Australia.

Wang, X., Chen, D., \& Zhengen, R. (2010). Assessment of climate change impact on residential building heating and cooling energy requirement in Australia. Building and Environment, 1663-1682.

Whitsed, R. a. (2013). Remote assessment of factors influencing housing thermal efficiency in NSW using GIS and aerial photography. Urban policy and research, 31(4), 473-492.

Xu, P., Ma, X., \& Zhao, X. a. (2016). Experimental investigation on performance of fabrics for indirect evaporative cooling applications. Building and Environment, 104-114. 


\title{
Experimental Comparison of Scroll and Swash-Plate Compressors for PV Driven Compression Chillers and Heat Pumps

\author{
Bernd Heithorst ${ }^{1}$, Gregor Bauer ${ }^{1}$, Benedikt Rauscher ${ }^{1}$, Ludwig Irrgang ${ }^{1}$, Markus Spinnler ${ }^{1}$, \\ Thomas Sattelmayer ${ }^{1}$ \\ 1 Institute of Thermodynamics, Department of Mechanical Engineering, Technical University of \\ Munich, Munich (Germany)
}

\begin{abstract}
A scroll and a swash-plate compressor are compared with each other, regarding their capability to operate in a PV-driven vapor cycle. Compressors for PV driven applications need a wide operation range and a dynamic control behavior. The comparison is performed in three steps: Firstly, the performance in steady-state operation, secondly, the controllability in dynamic operation and, thirdly, the operation under realistic boundary conditions. It is shown that the swash-plate compressor has a wider operation range with low part-load capability down to 18.9\%. Regarding the controllability, the swash-plate compressor shows severe oscillations after a sudden decrease of the power signal. Finally, both compressor types are operated in a hardware in the loop simulation considering the generated PV power as well as electric and thermal demand of a single-family house in Munich to evaluate their applicability in PV driven applications.
\end{abstract}

Keywords: Solar Cooling, Solar Heating, PV, Scroll Compressor, Swash-Plate Compressor

\section{Introduction}

For small-scale solutions in solar cooling, photovoltaic (PV) plants coupled with compression chillers (CC) are more economic than ad- or absorption processes coupled with solar-thermal collectors (Lazzarin and Noro, 2018). Due to decreasing PV-panel prices, heat pumps (HP) coupled with PV become a more and more promising alternative for solar heating compared to fossil-fired boilers combined with solar-thermal collectors (Poppi et al., 2018, Tjaden et al., 2013).

If feed-in-tariffs are lower than the electricity prices, a high self-consumption ratio is required to achieve an economically reasonable system. This is especially important if the ratio between generated PV power and annual electricity demand is high (Luthander et al., 2015; Poppi et al., 2018). A HP or CC is one of the major electricity consumers in a building. Thus, the coupling between PV and HPs or CCs can lead to both, a high self-consumption and self-supply ratio.

Generally, state-of-the-art PV driven systems are equipped with a variable frequency drive (VFD) to ensure a flexible compressor operation to respond to fluctuating PV power. The main focus in research is currently on improving the control strategy of the HP or CC regarding the considered energy system (e.g., Fischer et al., 2017; Sichilalu et al., 2017; Tygessen and Karlsson, 2016). To the knowledge of the authors, there is no recent research to adapt the compressor, which is the main component of the vapor cycle, to the needs of a PV driven HP or CC. The requirements for a PV-driven vapor cycle are:

- High flexibility to respond to fluctuations in PV power and electricity demand.

- Wide operation range to make use of PV power generated in times of low solar irradiation (morning and evening hours).

Spinnler et al. (2014) introduced a system using a swash-plate compressor that is mainly used in the automotive industry instead of the usually applied scroll compressors in residential applications. The advantage of the swashplate compressor is a lower part load capability of about $10 \%$ of the maximum power. Furthermore, Spinnler et al. (2014) write that the power of swash-plate compressors can be adjusted by two degrees of freedom, namely varying the rotational speed and the cylinder stroke. In contrast to that, in common scroll compressors only the rotational speed can be varied to control the compressor power (Spinnler et al., 2014). 
The aim of this paper is to compare both compressor types regarding the aforementioned needs of PV driven HPs or CCs. In the first step, the efficiency of both compressor types in steady state operation is compared with each other. Subsequently, the dynamics of both compressors are evaluated and finally both compressors are operated under realistic boundary conditions in a hardware in the loop (HIL) simulation.

\section{Working Principle of the Compared Compressor Types}

Both compressor types investigated in this study are displacement compressors. These compressors increase the refrigerant pressure by reducing the compression chamber's volume (ASHRAE, 2012). Compressors are also distinguished regarding their drive enclosure. In case of hermetic compressors, a gastight casing contains the motor and the compression unit. Semi-hermetic casings also contain both the motor and compressor but are accessible for later service or repair. Generally, semi-hermetic compressor designs are made in a bolted construction. In contrast, open compressors are driven by a shaft that is connected to an external motor. Thus, a gas-tight sealing is needed between shaft and compressor crankcase (ASHRAE, 2012).

\subsection{Scroll Compressor}

Scroll compressors are based on an orbiting compression mechanism (ASHRAE, 2012). They consist of two spiral-shaped scrolls. One scroll is fixed in the compressor casing while the other one rotates on an orbital path around the shaft center. Illustrations and a more profound description can be found in literature e.g. in ASHRAE (2012), p. 38.24 or Wang et al. (2000), p. 11.45. The gas pockets formed between the contact lines of the orbiting and the fixed scroll and their respective baseplates are sealed by lubricating oil. During the rotation, the contact lines move along the scroll flanks. Thus, the gas pockets are reduced in size and the refrigerant is compressed (Wang et al., 2000).

Different approaches are used to control the refrigeration capacity beside a trivial on/off control. A method that is frequently applied is rapid-cycling, where the distance between the two baseplates of the scroll is increased in times of thermal demand (e.g., Poort and Bullard, 2006). This basically results in a decreased volumetric efficiency of the compressor and thus is not favorable for an energy efficient capacity control. Another possibility is to adjust the rotational speed of the compressor. Here, the voltage and frequency of the alternating current (AC) of the motor are modified in a variable frequency drive. Then the capacity of the compressor is nearly proportional to the rotational speed (ASHRAE, 2012).

\subsection{Swash-Plate Compressor}

Swash-plate compressors are a subcategory of piston-compressors. They are mainly used in the automotive industry with the aim of generating a constant refrigerant volume flow at varying revolution numbers of the combustion motor (Stulgies et al., 2009). This is achieved through a variable cylinder stroke.

The cylinder stroke is adjusted by the inclination angle of the swash-plate. A sketch of an exemplary swash-plate geometry can be found e.g. in Tian et al. (2005). This inclination angle cannot be modified directly. It results from a force balance in the compressor's kinematics and depends on the rotational speed, the pressure on the suction and on the discharge side as well as on the pressure in the swash-plate chamber. The latter is adjusted by a mass flow compensation control valve that separates the swash-plate chamber from the discharge- and suction gas chamber (Tian et al., 2005). The valve is controlled with a voltage applied on the valve's coil $U_{\text {swash }}$. Thus, the voltage $U_{\text {swash }}$ is the control variable of the compressor.

\section{Methodology}

In order to generate the required measurement results, both compressors are integrated in parallel in the same test rig. Thus, their performance can be compared under identical boundary conditions. To operate the compressors in a HIL-simulation, the test rig is embedded in a simulation environment. Both the test rig and the simulation environment are explained in more detail in the following.

\subsection{Test Rig}

\section{Main Structure and Components}

Figure 1 shows the hydraulic system sketch of the test rig. For the steady-state experiments, the installed swash- 


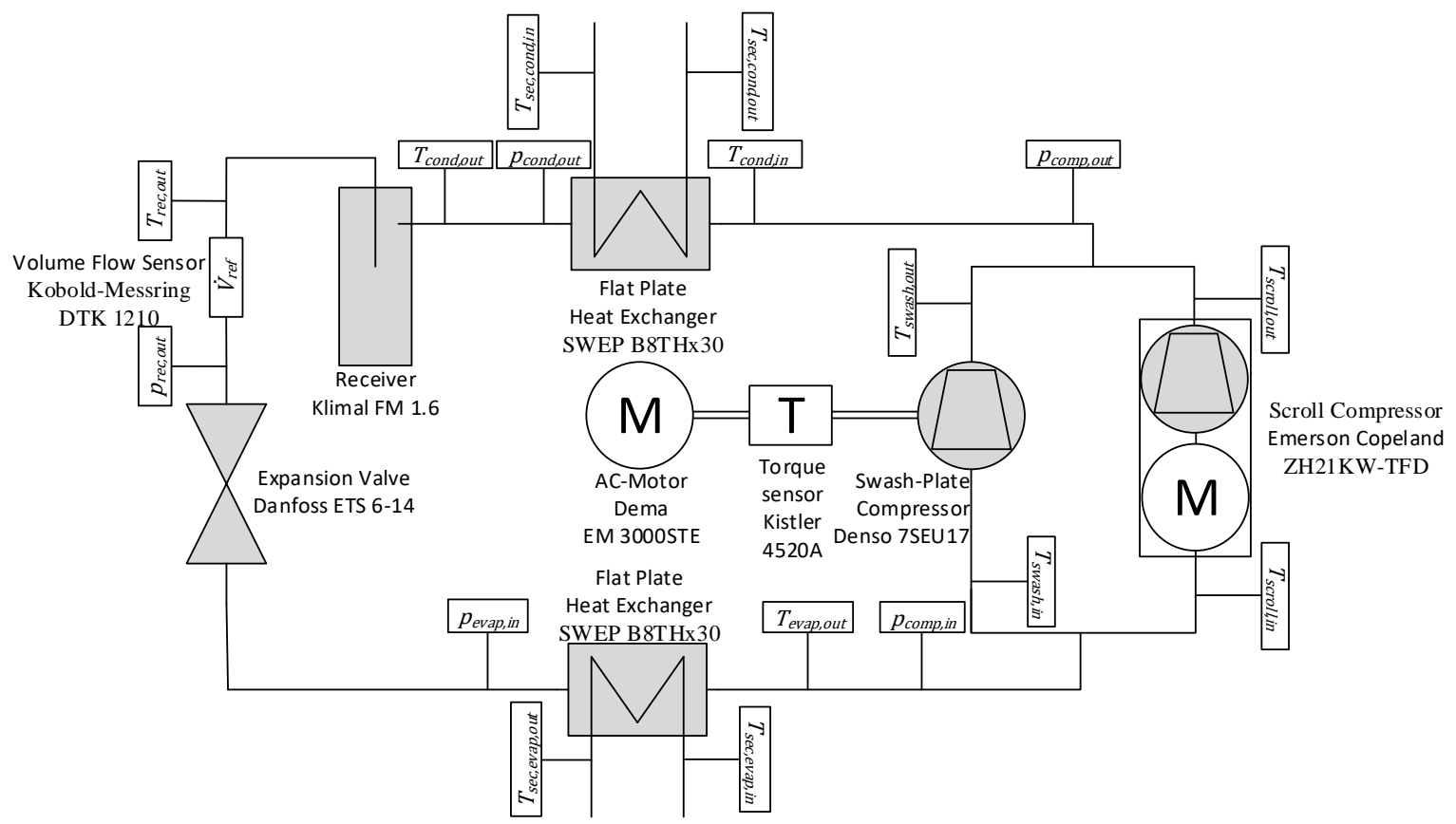

Fig. 1: Sketch of the test rig's hydraulics

plate compressor is a Denso 6SEU14 with 6 cylinders and a maximum displacement volume of $140 \mathrm{~cm}^{3}$. For the dynamic experiments, a Denso 7SEU17 with a maximum displacement volume of $170 \mathrm{~cm}^{3}$ and 7 cylinders was used. The swash-plate compressor is driven by an external air-cooled asynchronous motor. To calculate the mechanical power transferred to the compressor, a sensor for torque and rotational speed (Kistler 4520A) is installed between the AC-motor and the compressor. The installed scroll compressor is a hermetic Emerson Copeland ZH21KW-TFD with a displacement volume of $45 \mathrm{~cm}^{3}$. Due to the hermetic design it is not possible to measure the mechanical power transferred to the scroll compressor. The AC-motors of both compressors are driven by a Danfoss VLT 3500 VFD with a maximum power of $3000 \mathrm{~W}$. The main components are listed in table 1 in the appendix.

Condenser and evaporator consist of equal flat plate heat exchangers. The secondary circuit of the heat source is filled with a water-glycol mixture to allow operation below the freezing point. Water is used in the secondary circuit of the heat sink. For both heat exchangers, the mass flow rate and temperature of the incoming volume flow can be controlled. The accuracy of the temperature control is $+/-0.5 \mathrm{~K}$ for the evaporator and $+/-0.3 \mathrm{~K}$ for the condenser in steady state operation.

\section{Measurement Devices, Data Acquisition and Post Processing}

As shown by figure 1, the test rig is equipped with different measurement devices. Table 2 in the appendix lists the different sensors and their measurement accuracy. To obtain the measured signals, the test rig is equipped with a National Instruments cFP-1808 data acquisition (DAQ) system. For process control and data processing, the digitalized signals are processed in a real-time MATLAB Simulink routine. The electric power consumed by the motors is measured in the VFD. The sample time of the power value is $1.3 \mathrm{~s}$. The frequency of the generated ACcurrent is measured with a sample time of $0.29 \mathrm{~s}$.

To obtain the performance data of the compressors in the test rig, it is necessary to calculate the specific enthalpy $h$, specific entropy $s$ and the density $\rho$ of the refrigerant using the measured state variables: pressure $p$ and temperature T. For this purpose, the open source MATLAB plugin CoolProp (Bell et al., 2014) is used. Since the refrigerant volume flow rate $\dot{V}_{\text {ref }}$ is measured between the receiver and expansion valve, the mass flow is calculated with the density at the respective position:

$$
\dot{m}_{\text {ref }}=\rho\left(T_{\text {rec }, \text { out }}, p_{\text {rec }, \text { out }}\right) \cdot \dot{V}_{\text {ref }}
$$

The obtained values for mass flow rate $\dot{m}_{r e f}$ and specific enthalpy $h$ are subsequently used to calculate the coefficient of performance (COP), the main parameter of the efficiency comparison of both compressor types. 


\section{Parameters for Performance Comparison}

The performance of compressors is usually expressed in form of the COP. The COP is calculated using the capacity $\dot{Q}$ and the input power $P$ of the compressor (ASHRAE, 2012):

$$
C O P=\frac{\dot{Q}}{P}
$$

In heat pumps, the capacity $\dot{Q}$ is the condenser heat flow $\dot{Q}_{\text {cond }}$. The heat flow $\dot{Q}_{\text {cond }}$ for a system in steady-state can be calculated as follows:

$$
C O P=\frac{\dot{Q}_{\text {cond }}}{P}=\frac{\dot{m}_{r e f}\left(h_{\text {cond }, \text { in }}-h_{\text {cond }, \text { out }}\right)}{P}
$$

Here, $\dot{m}_{r e f}$ is the refrigerant mass flow rate and $h_{\text {cond,in }}$ and $h_{c o n d, o u t}$ are the enthalpy at the condenser inlet and outlet, respectively.

In case of hermetic or semi-hermetic compressors, the input power $P$ is the electrical power $P_{e l}$ of the motor, while the input power for open compressors is the mechanical power $P_{m}$ of the driving shaft (ASHRAE, 2012). Since the drive enclosure of the considered scroll compressor is hermetic and the swash-plate compressor is an open-type, a common basis for the input power $P$ of the COP-calculation is required. In preliminary experiments, it was found that the AC-motor of the swash plate compressor has a poor efficiency. This would cause an inappropriate disadvantage of the swash plate compressor when comparing the COP based on the electrical motor input power $P_{e l}$. Using the mechanical power $P_{m}$ of the compressor shaft is also not possible because the compressor shaft of the scroll compressor is not accessible. Therefore, the heat flow from the compressor into the refrigerant cycle $\dot{Q}_{\text {comp }}$ was chosen as the common basis. This heat flow can be calculated neglecting heat losses of the compressor crankcase to the ambient:

$$
\dot{Q}_{c o m p}=\eta_{e l} \cdot \eta_{m} \cdot P_{e l}=\dot{m}_{r e f} \cdot\left(h_{c o m p, o u t}-h_{c o m p, i n}\right)
$$

with the efficiency of the AC-motor, $\eta_{e l}$, the mechanical efficiency of the compressor drive train and the compressor itself $\eta_{m}$, and the enthalpies at the compressor inlet $h_{c o m p, \text { in }}$ and outlet $h_{\text {comp,out }}$. The modified, thermal coefficient of performance, $C O P_{t h}$, can then be expressed as:

$$
C O P_{t h}=\frac{\dot{Q}_{\text {cond }}}{\dot{Q}_{\text {comp }}}=\frac{h_{\text {cond,in }}-h_{\text {cond,out }}}{h_{\text {comp }, \text { out }}-h_{\text {comp }, \text { in }}}
$$

Thus, the relation between the original COP and thermal COP is (again, neglecting heat losses of the compressor crankcase):

$$
C O P=\frac{C O P_{t h}}{\eta_{e l} \cdot \eta_{m}}
$$

The derived thermal COP is used to compare the efficiency of both compressors in the steady-state experiments.

\subsection{Control for Dynamic Experiments}

The HP or CC considered in this study is not intended to work in an off-grid system. Therefore, the system is not self-adjusting, and a control algorithm had to be designed that ensures that the compressor runs on the desired electric power. The designed controller consists of a PI-controller with integrated feed-forward control. A schematic diagram of the control system is depicted in figure 2. Li et al. (2009) and Lin et al. (2011) described similar approaches for controlling a variable speed compressor.

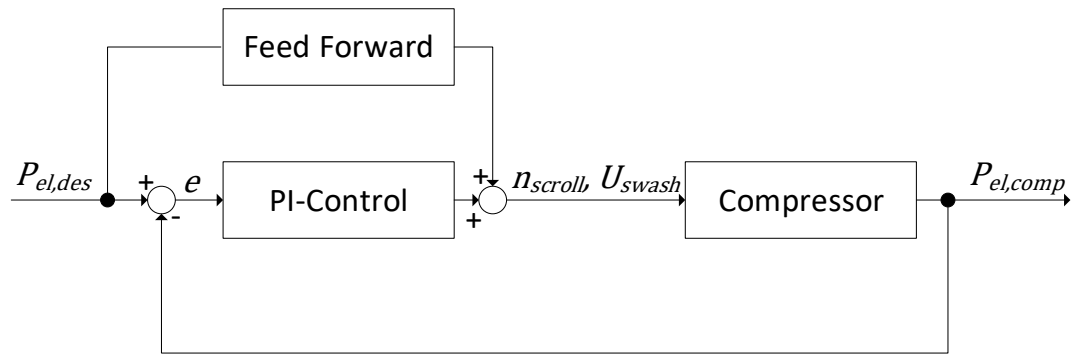

Fig. 2: Control system of the compressor 
In this figure, the output value is the electric power consumption $P_{e l, c o m p}$ of the AC-motor driving the compressor. The input value is the desired electric power consumption $P_{e l, d e s}$. The control variables of the system for the two compressors differ: for the scroll compressor the control variable is the rotational speed of the compressor shaft $n_{\text {scroll }}$. The swash-plate compressor has two control variables: the rotational speed $n_{\text {swash }}$ and the control voltage for the cylinder stroke $U_{\text {swash }}$, as explained in chapter 2.2. The control voltage $U_{\text {swash }}$ is the main control variable, as it is shown in section 4.1 and is determined in the control scheme as described above. The rotational speed $n_{\text {swash }}$ is controlled with the aim to run the motor at the lowest possible speed above the breakdown torque.

The principle idea of feed-forward controls is to measure disturbances and act before the disturbance interacts with the system (Seborg et al., 2010). The feed-forward control contains an inverse model of the process. Thus, the output of the feed-forward is an estimate for the control variable corresponding to the system's state based on the inverse model. The task of the PI-controller is finally to correct the error between the real system and the model incorporated in the feed-forward control.

\subsection{Hardware in the Loop Simulation}

In order to operate the compressor under realistic boundary conditions, the test-rig is embedded in a HILsimulation. For the present study, it was decided to operate the vapor cycle as a heat-pump under mid-European boundary conditions. The elements of the HIL-simulation are depicted in figure 3.

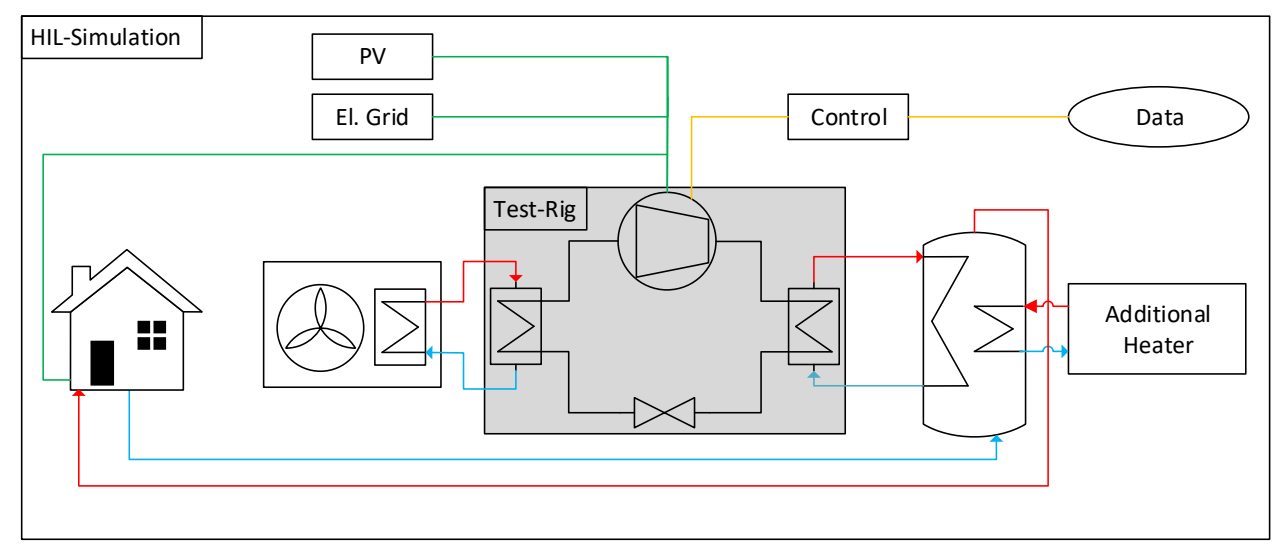

Fig. 3: Scheme of the considered system for the hardware in the loop simulation

It takes into account the thermal and electrical demand of a single-family house, the PV plant, the space heating and domestic hot water demand. This system consists of the heat pump, implemented in the test rig, a thermal storage, an additional ohmic heater to cover peak loads on cold winter days and a brine / air heat exchanger, serving as a heat source. The interfaces between the test rig (marked in gray) and the HIL-simulation are the liquid-inputs for condenser and evaporator. The temperature of the water entering the condenser $T_{\text {sec,cond,in }}$ is controlled to the simulated thermal storage temperature. Regarding the heat source, the temperature of the brine entering the evaporator $T_{\text {sec,evap,in }}$ is controlled to the ambient air temperature. In both, the heat exchanger with the ambient air and the heat exchanger inside the thermal storage, a temperature difference of $3 \mathrm{~K}$ is assumed between the fluid output temperature and the storage medium temperature or the ambient air temperature.

In order to resolve the dynamics in PV power generation and the electrical user demand, a fine resolution of the simulation and the necessary input data are required. In the following, the single elements are described in more detail:

- PV plant: For the PV plant measurements with a high temporal resolution of $1 \mathrm{~s}$ provided by Solarenergieförderverein Bayern e.V. are used to resolve the transient behavior of the PV power generation. The plant located in Munich is inclined at an angle of $28^{\circ}$ in southern direction and has a capacity of $1 \mathrm{MW}_{\mathrm{p}}$. For this study, the power was scaled to a size of $5 \mathrm{~kW}_{\mathrm{p}}$. The error in scaling a largescale plant to the size of a typical single-family house rooftop plant was accepted because of the beneficial temporal data-resolution.

- Electrical demand: To consider the electric demand of the building's inhabitants without the demand of the heat pump, the data of HTW-Berlin (Tjaden et al., 2015) is used. The resolution of the electrical loadprofile is $1 \mathrm{~s}$. 
- Thermal demand: The thermal demand of the $122 \mathrm{~m}^{2}$ single family house with an annual energy demand of $40 \mathrm{kWh} /\left(\mathrm{m}^{2} \mathrm{a}\right)$ is modeled with the Building-Simulation-Tool introduced in a previous study (Heithorst et al., 2016). For this study, a day in November (Nov, 01 ${ }^{\text {th }}$ 2008) was chosen since it shows significant solar irradiation and relatively low environmental temperatures. Temperature and solar irradiation of the dataset of Solarenergieförderverein Bayern e. V. were used as well. The thermal energy demand for space heating during this day was $33.9 \mathrm{kWh}$.

- Domestic hot water demand: The energy demand for the domestic hot water supply was modeled with the tool DHWcalc (Jordan et al., 2017). As hot water demand and generation are decoupled by the thermal storage, a high temporal resolution is not as crucial as for the electricity demand.

- Thermal storage: The thermal storage is modelled as an ideally stirred vessel by a simple exergy balance since more advanced models e.g. for stratified storages showed problems in the real-time operation required for a HIL simulation. The volume of the storage is 4001.

- Control: The system control calculates a desired compressor power $P_{e l, d e s}$ to completely use the generated PV power $P_{P V}$ in the building. In this study a basic rule-based approach is used to determine the power the compressor should utilize. It is based on two restrictions:

1. Thermal storage temperature: If the thermal storage temperature exceeds the upper limit of $60^{\circ} \mathrm{C}$, the compressor is shut off. If the temperature falls below a value of $38^{\circ} \mathrm{C}$, the compressor is operated at $P_{e l, d e s}=2500 \mathrm{~W}$ to ensure that the system covers the thermal demand of the building and domestic hot water.

2. Available PV power: If the storage temperature is between the aforementioned limits, the compressor is operated with the PV power that remains after covering the electric demand of the inhabitants:

$$
P_{e l, \text { des }}= \begin{cases}P_{P V}-P_{D e m}, & \text { if } P_{P V}-P_{D e m}>0 \\ 0 & , \text { if } P_{P V}-P_{D e m} \leq 0\end{cases}
$$

\section{Results \& Discussion}

\subsection{Steady State Results}

In total, 201 experiments with the swash-plate and 105 experiments with the scroll compressor were conducted in steady-state. The state of the experiment was assumed to be steady when variations in the heat sink temperature were below +/- $0.3 \mathrm{~K}$, variations in the heat source temperature below $+/-0.5 \mathrm{~K}$ and the hot gas discharge temperature reached a steady level. Subsequently, a time series of 5 minutes was tracked. Finally, the measured and calculated state variables were averaged over the tracked time series and postprocessed.

Figure 4 shows the relation between the control variables of the swash plate compressor: the rotational speed $n$ of the compressor shaft and the voltage $U_{\text {swash }}$ applied to the pressure control valve.
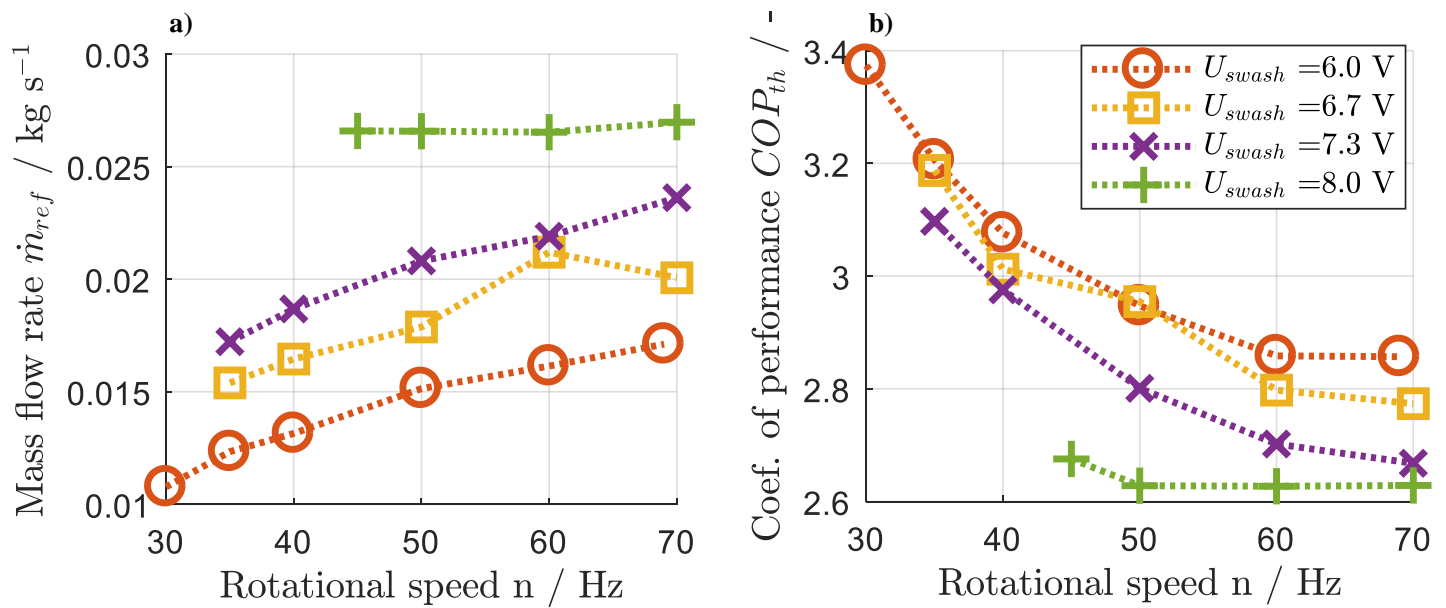

Fig. 4: a) Mass flow rate over rotational speed and b) thermal COP over rotational speed for swash-plate compressor experiments with a heat source temperature of $10^{\circ} \mathrm{C}$ and a heat sink temperature of $55^{\circ} \mathrm{C}$

It can be seen in figure 4a) that a rise in the rotational speed $n$ only leads to slight changes in the measured mass 
flow rate and thus in the compressor's capacity. In the range of high compressor powers, the capacity is nearly constant. In contrast, the valve voltage $U_{\text {swash }}$ shows a larger influence on the compressor capacity. The reason for this behavior is the original automotive application, where the aim is to minimize the influence of the variing rotational speed of the combustion motor on compressor capacity and thus on passenger comfort.

If the rotational speed $n_{\text {swash }}$ is increased at a constant valve voltage $U_{\text {swash }}$, the force balance on the swash-plate is modified leading to a smaller displacement volume. Therefore, the dead volume at the top dead center of the compression rises and thus the efficiency of compression is reduced. Additionally, the friction losses inside the compressor rise at increasing rotational speed. The combination of both effects lead to a decrease of the thermal COP for increasing rotational speed, shown in figure $4 \mathrm{~b}$ ). Therefore, it is favorable to operate the swash-plate compressor at the lowest possible rotational speed. The AC-motor reaches its breakdown-torque if it is operated at low rotational speed and high loads. Therefore, it was decided to operate it at a fixed-speed $n_{\text {swash }}=50 \mathrm{~Hz}$ and variable valve voltage $U_{\text {swash }}$ in the following steady-state experiments to be able to operate the compressor over the complete power range.

Figure 5 shows the performance comparison of the two compressor types.
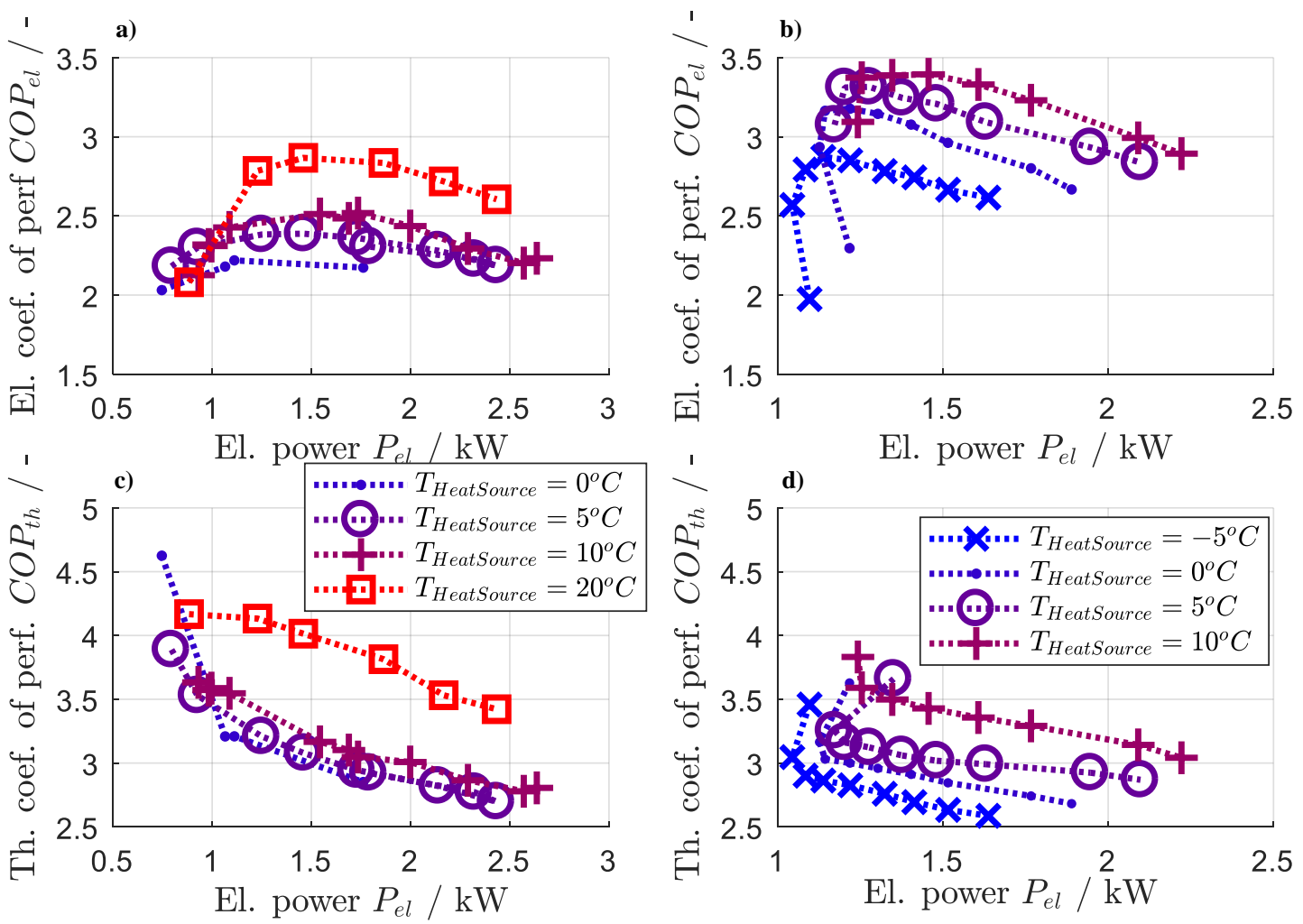

Fig. 5: COP based on electrical power of a) the swash-plate compressor and b) the scroll compressor. COP based on heat flow from c) the swash-plate compressor and d) the scroll compressor over the electrical motor power for steady-state experiments with a heat sink temperature of $45^{\circ} \mathrm{C}$

The figures 5a) and 5b) show the COP based on the electrical power for the swash-plate compressor (figure 5a) ) and the scroll compressor (figure 5b) ). Here, the inferior quality of the swash-plate compressor's AC motor becomes visible. In the figure $5 \mathrm{~b}$ ), a sharp decrease in the COP at low electrical powers $P_{e l}$ can be seen. Here, the AC-motor of the compressor advances towards its breakdown-torque. This leads to increasing electrical power consumption and decreasing mechanical power output. Thus, the operation in this regime should be avoided, also to prevent damages of the AC-motor.

The thermal COP based on equation 5 is shown in figure 5c) for the swash-plate compressor and in figure 5d) for the scroll compressor. Both compressors show a decreasing thermal COP with rising loads due to increasing friction losses. This effect is more prominent for the swash plate compressor. Additionally, the maximum electric power decreases with decreasing heat source temperature. In this regime, the maximum power of the scroll compressor is limited by the maximum allowable discharge gas temperature. The swash-plate compressor, in 
contrast, is limited by the low suction pressure, as the control valve is adjusted to work at higher heat source temperatures due to the original application in automotive air conditioning. All in all, the thermal COP of the scroll compressor is slightly higher than for the swash-plate compressor for identical operation conditions.

It is also visible that the minimal electrical power of the swash-plate compressor is much lower than for the scroll compressor which is limited by the motor's breakdown-torque. The minimum part load values achieved are listed in table 1 for all combinations of heat source and heat sink temperatures.

Tab. 1: Minimum part load values determined for combinations of heat sink and heat source temperatures

\begin{tabular}{|c|c|c|c|c|c|c|c|c|c|}
\hline & & \multicolumn{4}{|c|}{ Swash-Plate } & \multicolumn{4}{|c|}{ Scroll } \\
\hline \multicolumn{2}{|c|}{$\boldsymbol{T}_{\text {Heat Source }} /{ }^{\circ} \mathbf{C}$} & 0 & 5 & 10 & 20 & -5 & 0 & 5 & 10 \\
\hline \multirow{3}{*}{ 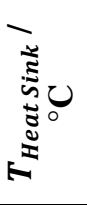 } & 35 & 54.7 & 36.7 & 43.1 & 20.4 & 52.7 & 50.7 & 50.9 & 49.4 \\
\hline & 45 & 42.4 & 28.9 & 25.7 & 18.9 & 63.8 & 59.6 & 55.9 & 55.95 \\
\hline & 55 & 55.9 & 24.5 & 31.2 & 26.8 & 69.1 & 52.5 & 57.2 & 30.1 \\
\hline
\end{tabular}

Table 4 shows that the minimum part load of the scroll compressor is always higher than $50 \%$ with an exception for the combination of a heat sink temperature of $55^{\circ} \mathrm{C}$ and a heat source temperature of $10^{\circ} \mathrm{C}$. As the maximum power of the swash-plate compressor strongly depends on the heat source temperature and the minimum electric power is relatively constant (cf. figure 5a), the minimum operation range is wider for higher heat source temperatures. Due to the relatively high idle power of the swash-plate compressor, the minimum part load measured in the experiments is $18.9 \%$. This is higher than the $10 \%$ expected by Spinnler et al. 2014, but it is obvious that the operation range of the swash-plate compressor can be much wider compared to the scroll compressor if the maximum power is not limited due to low heat source temperatures.

\subsection{Results of Dynamic Operation}

Different experiments were performed to evaluate the dynamic behavior of the two compared compressor types. The response of different controller types to a square wave signal with an amplitude of $1000 \mathrm{~W}$ and a step length of $10 \mathrm{~s}$ is demonstrated in more detail. As shown in figure 6, the DAQ-system leads to a delay between the rising or falling edges of the signal and the system response. The dead time of the DAQ-system was determined to be $375 \mathrm{~ms}$.
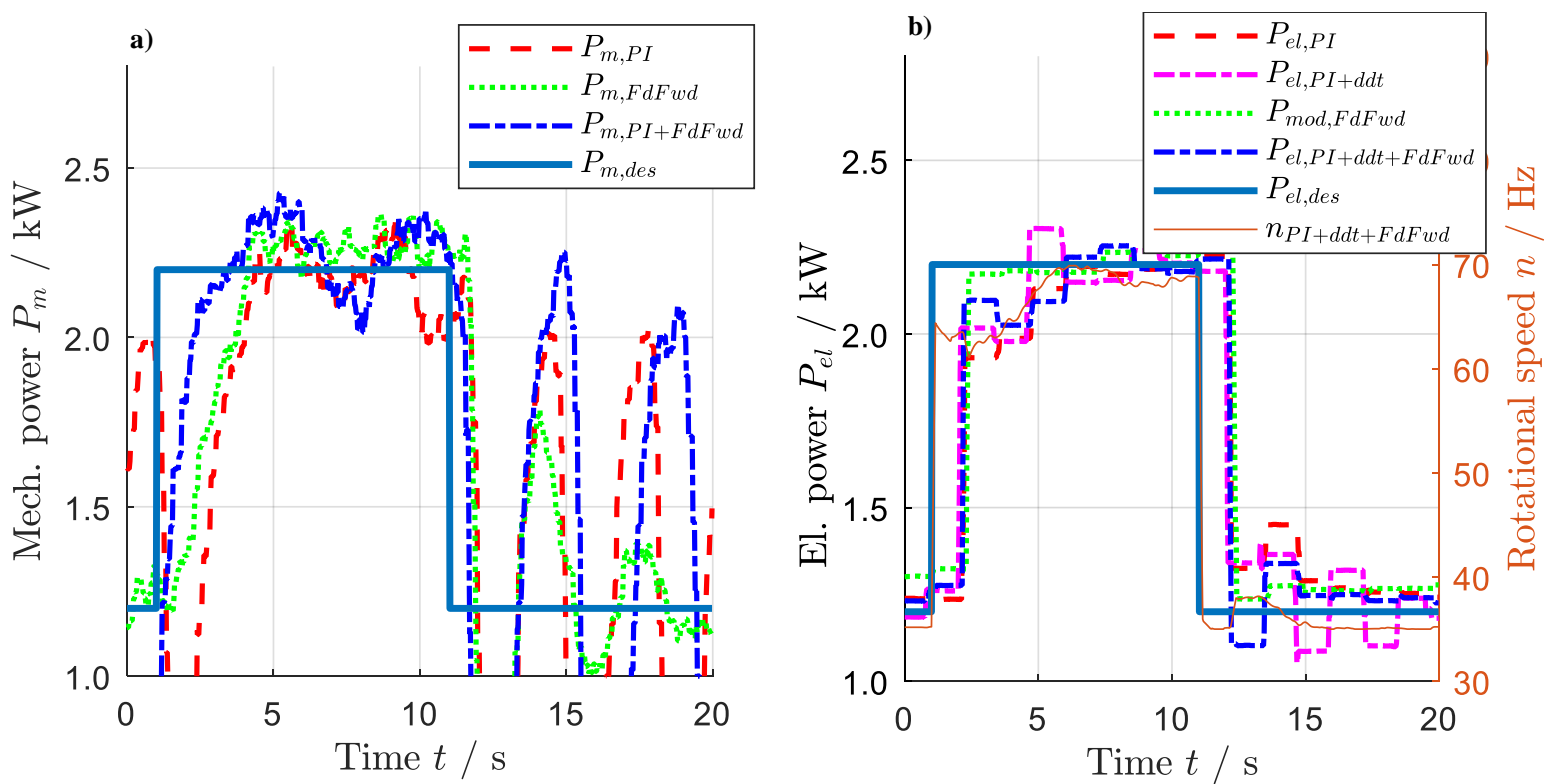

Fig. 6: Response of the compressors to a square wave signal with sample time $10 \mathrm{~s}$ and amplitude of $1000 \mathrm{~W}$. a) swash-plate compressor: mechanical power over time b) scroll compressor: electrical power over time

The plot of the scroll compressor in figure 6b) shows a coarse temporal resolution of the electrical power $P_{e l}$ due 
to the low temporal resolution of the power signal output at the VFD. Therefore, the rotational speed $n$ of the compressor is depicted on the right $\mathrm{y}$-axis as it has a better temporal resolution and proves that the signal does not show strong oscillations. Thus, even a simple control architecture using a PI-controller (red line) leads to good results showing only a small damping impact on the square wave signal. A controller using only the feed-forward control without an PI controller (green line) shows the fastest response on the rising edge, but also a constant offset after the downward edge because of the imperfections of the incorporated model. To avoid this offset, both controllers are coupled and a dead time compensation (ddt) is added. This combined controller (blue dash-dotted line) shows satisfactory results and is slightly damping the target signal with a settling time of $4.5 \mathrm{~s}$.

In contrast to the scroll compressor, the swash-plate compressor, depicted in figure 6a) shows severe oscillations following on the falling signal edge for all considered control architectures. This oscillating behavior is caused by the complex control mechanism, where the power controller, the pressure controlling valve and the complex kinematics of the driving shaft, the swash-plate and the reciprocating cylinders interact. The response using only the feed-forward control shows the best damping behavior after the downward step. Therefore, the integral term of the PI-controller was made dependent on the valve voltage $U_{\text {swash }}$. For $U_{\text {swash }}<5.5 \mathrm{~V} K_{I}$ is set to 0 . As it is shown later in the results of the HIL-simulation (figure 7), this improves the compressor control. However, complete damping could not be achieved.

From a dynamics point of view, the scroll compressor is more advantageous for a PV driven HP or CC, especially if the strong dynamics of an electric load profile must be taken into account.

\subsection{Results of the Hardware in the Loop Simulation}

Figure 7 shows the result of the HIL-simulation. Figure 7a) shows the desired power $P_{e l, d e s}$ of the control (brown line). Especially at about 11:30 am the transient behavior of the electrical demand due to high load changes is visible. At the beginning of the day, the target power signal $P_{e l, d e s}$ rises to a value of $2500 \mathrm{~W}$ when the storage temperature falls below the minimum limit (c.f. figure $7 b$ ) ).

a)

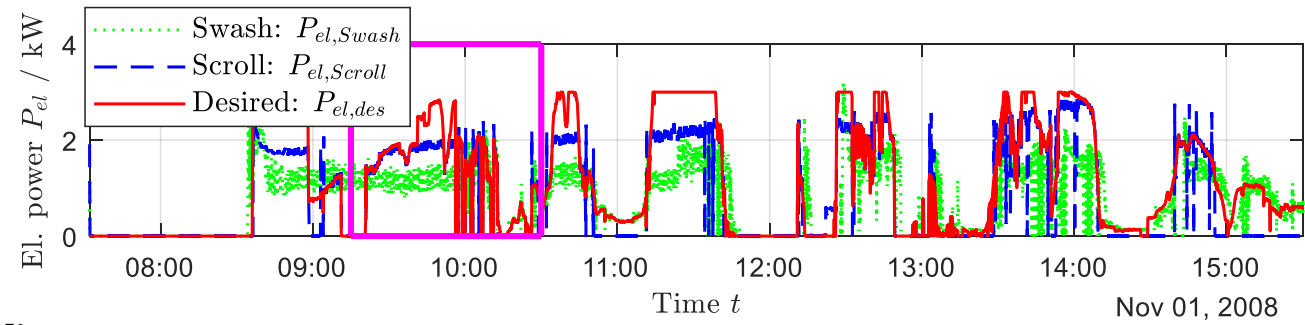

b)

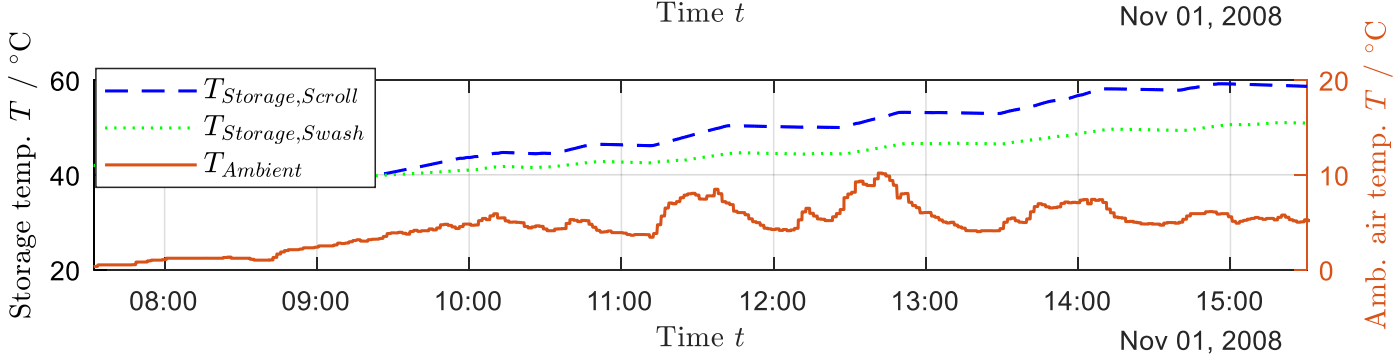

Fig. 7: Results of the HIL-simulation. a) desired and actual power of scroll and swash-plate compressor over time. b) thermal storage temperature development for scroll and swash-plate compressor operation and ambient temperature over time

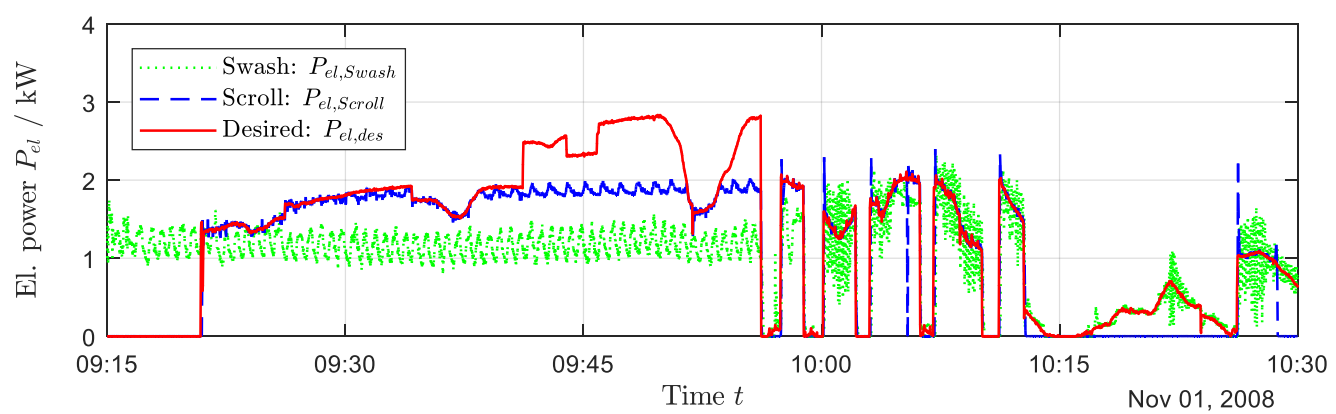

Fig. 8: Detail of figure 7a) (area marked in red) desired and actual power of scroll and swash-plate compressor over time 
The swash-plate compressor (green line) shows the oscillations known from the square wave experiments. Furthermore, especially in the morning, it does not reach the required power due to the low outside temperatures which are between $3{ }^{\circ} \mathrm{C}$ and $10^{\circ} \mathrm{C}$, as it was also observed in the steady-state experiments in section 4.1. This problem is also visible but less dominant for the scroll compressor (blue line).

The advantage of the wide operation range of the swash-plate compressor is visible in figure 7a), e.g., at 14:30 hrs or between 10:15 hrs and 10:30 hrs (see additionally figure 8). While the scroll compressor must be switched off because the target power $P_{e l, d e s}$ is lower than the minimum operation power, the swash-plate compressor continues working. Figure 8 shows the reduction of the compressor oscillations following a falling edge achieved by the adjustment of the integral gain $K_{I}$ of the PI controller. However, at higher operation powers the oscillations are prevalent.

Furthermore, figure 8 shows, beginning at 09:55 hrs, that both compressor types follow the step gradients induced through the electric demand. It is visible that the scroll compressor follows the target signal accurately, when it is in its operation range. In contrast, the swash-plate compressor shows an oscillating behavior especially at higher electrical powers, but it is qualitatively following the target power signal.

To overcome the limited capacity of both compressor types at low ambient temperatures, a second shorter experiment between 11 am and $3 \mathrm{pm}$ of the same day was conducted at fixed heat source and heat sink temperatures of $10^{\circ} \mathrm{C}$ and $50^{\circ} \mathrm{C}$, respectively. Here, both compressors achieved the maximum capacity. The resulting self-consumption ratio of this experiment can be found in table 2 :

Table 2: Comparison of the self-consumption ratio of experiment without HP, with scroll-compressor and with swash-plate compressor driven HP

\begin{tabular}{|c|c|c|c|}
\hline Compressor & Only El. Demand & El. Demand + Scroll & El. Demand + Swash \\
\hline Self-consumption ratio & $31.5 \%$ & $85.1 \%$ & $91.4 \%$ \\
\hline
\end{tabular}

Table 2 shows, that the self-consumption ratio rises about $53.5 \%$ if a common variable speed HP is used. The implementation of a swash-plate compressor leads to an improvement of $6.3 \%$ regarding the self-consumption ratio compared to the scroll compressor.

\section{Conclusion}

In the present study, a swash-plate and a scroll compressor were compared with each other regarding their applicability in PV driven heat pumps. In the steady-state experiments the scroll compressor showed a slightly better thermal COP but has a limited part load capability. The operation range of the swash-plate compressor is much wider (minimum part load $18.9 \%$ ). Regarding the dynamic experiments the swash-plate compressor showed severe oscillations of the compressor power after a sudden decrease in the desired power signal. In contrast, the scroll compressor showed a satisfactory control behavior. Finally, both compressors were operated under realistic boundary conditions in a HIL-simulation with a duration of one day. Despite its limited part-load capability, the scroll compressor used the generated PV power more efficiently than the swash-plate compressor. This is caused by the limited maximum power of the swash-plate compressor and its oscillating operation in the present control mode. If both compressors work in a regime where they can reach their maximum capacity, the swash-plate compressor shows an improvement of $6.1 \%$ regarding the self-consumption ratio compared to the scroll compressor.

In conclusion, the presented study showed that the swash-plate compressor is difficult to control in a PV driven HP or CC. A possible solution to achieve both, a higher self-consumption ratio and a good controllability, could be an adapted scroll compressor with a reduced part load capability.

\section{Acknowledgements}

The project is funded by the Qatar National Research Funds (QNRF) under NPRP Funds Project \#NPRP8-19082-760 and conducted in collaboration with the Qatar Environment and Energy Institute (QEERI). The authors thank Solarenergieförderverein Bayern e.V. for providing the PV-data. 


\section{Nomenclature}

\begin{tabular}{lll}
\hline Quantity & Symbol & \multicolumn{1}{c}{ Unit } \\
\hline Coefficient of performance & $C O P$ & \\
Specific enthalpy & $h$ & $\mathrm{~J} \mathrm{~kg}^{-1}$ \\
Mass flow rate & $\dot{m}$ & $\mathrm{~kg} \mathrm{~s}^{-1}$ \\
Rotational speed & $n$ & $\mathrm{~Hz}$ \\
Pressure & $p$ & $\mathrm{~Pa}$ \\
Power & $P$ & $\mathrm{~W}$ \\
Heat flow & $\dot{Q}$ & $\mathrm{~W}$ \\
Temperature & $T$ & $\mathrm{~K}$ \\
Voltage & $U$ & $\mathrm{~V}$ \\
Volume flow rate & $\dot{V}$ & $\mathrm{~m}^{3} \mathrm{~s}^{-1}$ \\
Efficiency & $\eta$ & \\
Density & $\rho$ & $\mathrm{kg} \mathrm{m}^{-3}$
\end{tabular}

\section{References}

American Society of Heating, Refrigerating and Air-Conditioning Engineers, Inc., 2015. ASHRAE Handbook Heating, Ventilation, and Air-Conditioning Systems and Equipment (SI Edition). Knovel.

Bell, I.H., Wronski, J., Quoilin, S., Lemort, V., 2014. Pure and pseudo-pure fluid thermophysical property evaluation and the open-source thermophysical property library CoolProp. Ind. Eng. Chem. Res. 53, 2498-2508. https://doi.org/10.1021/ie4033999

Fischer, D., Bernhardt, J., Madani, H., Wittwer, C., 2017. Comparison of control approaches for variable speed air source heat pumps considering time variable electricity prices and PV. Appl. Energy 204, 93-105. https://doi.org/10.1016/j.apenergy.2017.06.110

Jordan, U., Vajen, K., 2017. DHWcalc Werkzeug zur Generierung von Trinkwasser-Zapfprofilen aus statistischer Basis. Universität Marburg, Marburg.

Lazzarin, R.M., Noro, M., 2018. Past, present, future of solar cooling: Technical and economical considerations. Sol. Energy. https://doi.org/10.1016/j.solener.2017.12.055

Li, H., Jeong, S.-K., You, S.-S., 2009. Feedforward control of capacity and superheat for a variable speed refrigeration system. Appl. Therm. Eng. 29, 1067-1074. https://doi.org/10.1016/j.applthermaleng.2008.05.022

Lin, Z., Wang, J., Howe, D., 2011. A Learning Feed-Forward Current Controller for Linear Reciprocating Vapor Compressors. IEEE Trans. Ind. Electron. 58, 3383-3390. https://doi.org/10.1109/TIE.2010.2089948

Luthander, R., Widén, J., Nilsson, D., Palm, J., 2015. Photovoltaic self-consumption in buildings: A review. Appl. Energy 142, 80-94. https://doi.org/10.1016/j.apenergy.2014.12.028

Poort, M.J., Bullard, C.W., 2006. Applications and control of air conditioning systems using rapid cycling to modulate capacity. Int. J. Refrig. 29, 683-691. https://doi.org/10.1016/j.ijrefrig.2005.12.007

Poppi, S., Sommerfeldt, N., Bales, C., Madani, H., Lundqvist, P., 2018. Techno-economic review of solar heat pump systems for residential heating applications. Renew. Sustain. Energy Rev. 81, 22-32. 
https://doi.org/10.1016/j.rser.2017.07.041

Seborg, D.E., Mellichamp, D.A., Edgar, T.F., III, F.J.D., 2010. Process dynamics and control. John Wiley \& Sons.

Sichilalu, S., Mathaba, T., Xia, X., 2017. Optimal control of a wind-PV-hybrid powered heat pump water heater. Appl. Energy, Clean, Efficient and Affordable Energy for a Sustainable Future 185, 1173-1184. https://doi.org/10.1016/j.apenergy.2015.10.072

Spinnler, M., Hörth, L., Böing, F., Wolf, S., Sattelmayer, T., 2014. Novel heat pump system for highly transient PV operation, in: 29th European Photovoltaic Solar Energy Conference and Exhibition. pp. 3562-3567.

Stulgies, N., Gräber, M., Tegethoff, W., Försterling, S., 2009. Evaluation of different compressor control concepts for a swash plate compressor, in $7^{\text {th }}$ Modelica Conference, Como, Italy. pp. $299-303$. https://doi.org/10.3384/ecp09430035

Thygesen, R., Karlsson, B., 2016. Simulation of a proposed novel weather forecast control for ground source heat pumps as a mean to evaluate the feasibility of forecast controls' influence on the photovoltaic electricity selfconsumption. Appl. Energy 164, 579-589. https://doi.org/10.1016/j.apenergy.2015.12.013

Tian, C., Liao, Y., Li, X., 2006. A mathematical model of variable displacement swash plate compressor for automotive air conditioning system. Int. J. Refrig. 29, 270-280. https://doi.org/10.1016/j.ijrefrig.2005.05.002

Tjaden, T., Krien, U., Breyer, C., 2013. Simulation und techno-ökonomischer Vergleich von solarthermischen Heizungskonzepten und Photovoltaik-Wärmepumpen-Kombinationen im Wohnungssektor, in: 23. Symposium Thermische Solarenergie. Bad Staffelstein.

Tjaden, T.; Bergner, J.; Weniger, J.; Quaschning, V., 2015. Repräsentative elektrische Lastprofile für Einfamilienhäuser in Deutschland auf 1-sekündiger Datenbasis, Datensatz, Hochschule für Technik und Wirtschaft HTW Berlin

Wang, S.K., 2000. Handbook of air conditioning and refrigeration, 2nd ed. McGraw-Hill, New York.

\section{Appendix: Test Rig Components and Measurement Equipment}

Table 1: Main components of the test rig

\begin{tabular}{|l|l|l|}
\hline Component & Manufacturer / Type & Specifications \\
\cline { 1 - 2 } Swash-plate compressor & Denso 6SEU14 / Denso 7SEU17 & $140 \mathrm{~cm}^{3} / 170 \mathrm{~cm}^{3}$ disp. vol., open casing \\
\cline { 1 - 2 } Scroll compressor & Emerson Copeland ZH21KW-TFD & $45 \mathrm{~cm}^{3}$ disp. volume, hermetic casing \\
\cline { 1 - 2 } Condenser & SWEP B8THx30/1P-SC-M & Flat plate heat exchanger; Surface $0.63 \mathrm{~m}^{2}$ \\
\cline { 1 - 2 } Evaporator & Danfoss ETS 6-14 & \\
\cline { 1 - 2 } Expansion valve & Danfoss EKD 316 & Volume 1.61 \\
\hline Superheat controller & Klimal FM 1.6 & Max. power: $3000 \mathrm{~W}$ \\
\hline Receiver & Dema EM 3000 STE & Max. power 3000 W, max. frequency $80 \mathrm{~Hz}$ \\
\hline AC-motor for swash-plate comp. & Danfoss VLT 3505 HV AC & \\
\hline Variable frequency drive & R134a & \\
\hline Refrigerant & &
\end{tabular}

Table 2: Measurement Equipment

\begin{tabular}{|l|l|l|l|}
\hline Component & Manufacturer / Type & Measurement Range & $\begin{array}{l}\text { Accuracy } \\
\text { Time / s }\end{array}$ \\
\hline Temperature sensors & PT1000 elements & $-200-600$ C & 1.13 \\
\hline $\begin{array}{l}\text { Pressure transducers } \\
\text { Volume flow sensor }\end{array}$ & KLCO PT5-30M & $1-31 \mathrm{bar}$ & 0.25 \\
\hline $\begin{array}{l}\text { Torque and rotational } \\
\text { speed sensor }\end{array}$ & Kistler 4520A050 & $\begin{array}{l}0-50 \mathrm{Nm} ; \\
0-10000 \mathrm{rpm}\end{array}$ & $+/-2 \%(\mathrm{FS})$ \\
\hline
\end{tabular}




\title{
Design and Practical Validation of a Hybrid Absorption/Compression Chiller Driven by Low-Grade Heat
}

\author{
Martin Helm, Thomas Eckert, Christian Schweigler \\ CENERGIE Competence Center Energieeffiziente Gebäude und Quartiere \\ Munich University of Applied Sciences, Lothstraße 34, 80335 Munich, Germany
}

\begin{abstract}
For all applications of sorption chillers or heat pumps strict limits have to be met, arising from the physical properties of the working fluids. A minimum temperature of the driving heat source has to be provided and the temperature lift of the cycle is limited. As a consequence, the chiller has to be oversized for application in solar cooling or tri-generation systems in order to adapt for low-grade driving heat. Due to the limited temperature lift of the working pair water as refrigerant and lithium bromide as sorbens the use of dry cooling towers is not feasible and in heat pumps systems only moderate heating supply temperatures can be provided.
\end{abstract}

When a mechanical compressor is integrated in the internal cycle of a sorption chiller, flexibility is obtained for a more compact and cost-efficient design and for adaptation to challenging operating conditions.

Design and first experimental results of a hybrid absorption/compression cycle are presented. An electrically driven high-speed turbo compressor is directly integrated in the sorption process of a single-stage water/ $\mathrm{LiBr}$ cycle providing a variable share of the required pressure rise between evaporator and condenser. The system shall be operable in pure sorption mode and in hybrid absorption/compression mode, offering a boost of cooling capacity or increased flexibility for operation with low-grade driving heat or increased temperature of heat rejection.

Keywords: absorption chiller, vapor compression, hybrid cycle, turbo compressor, low-grade heat, temperature lift

\section{Introduction}

In the field of thermally driven cooling by absorption chillers based on the working pair water/lithium bromide substantial improvements have been achieved during the last decades concerning compactness, reliability, system performance and overall efficiency. But still, limitations in temperature lift due to the danger of crystallization of the sorbent solution, high required driving temperature and weak peak load capability at raised ambient temperatures narrow their field of application. To overcome these problems, the conventional absorption cycle can be equipped with a mechanical vapor compressor, forming a hybrid absorption/compression chiller. The basic concept has been theoretically described by (Osenbrück, 1895) and (Altenkrich, 1954), but not realized for water lithium bromide absorption chillers

The concept for realization of the hybrid absorption/compression cycle with an electrically driven high speed turbo compressor which is directly integrated in the single-stage absorption cycle is presented in (Helm, et al., 2015). The development of the hybrid chiller aims at $15 \mathrm{~kW}$ chilled water capacity at $6{ }^{\circ} \mathrm{C}$ chilled water temperature applying very low driving heat temperatures below $80{ }^{\circ} \mathrm{C}$ with dry heat rejection under European climate and high load change ability.

By means of a semi-empirical physical model, a preliminary design of the turbo compressor for the refrigerant water has been developed. Starting from this basic geometric layout, a 3D CFD fluid-dynamic and structural modeling of impeller and diffusor has been performed, using the software packages CF turbo and ANSYS-CFX. For the given conditions, the use of the refrigerant water results in high circumferential impeller velocities with vapor Mach numbers near the sonic barrier and rotational speed up to $90.000 \mathrm{rpm}$ (Eckert, et al., 2016) 
These design conditions and boundaries are fulfilled by a recently commercially available innovative turbocompressor for the natural refrigerant water (R718). As core component, its performance has been experimentally investigated by detailed measurements throughout the entire operating envelope, in order to validate the perspectives of the hybrid chiller concept in advance to the implementation of the entire cycle.

Based on the promising results and practicality tests, a demonstrator of the hybrid chiller has been designed, erected and tested under different operating scenarios.

The overall goal of the development aims at reduced direct and indirect emissions of greenhouse gases for refrigeration by utilization of climate-neutral refrigerants and a high share of renewable or waste heat.

\section{Concept of the hybrid absorption/compression chiller}

In conventional sorption cooling or heat pump systems, a definitive interdependence of the three external temperature levels of the cycle, i.e. provision of cooling, heat rejection to ambient, and driving heat of the cycle, exists. This statement is valid, regardless whether a liquid or a solid sorbent is applied. As a consequence limitations arise for the implementation of chillers and heat pumps. The main aspect is the required temperature level of the driving heat source. In case of the liquid sorbent water/Lithium bromide a second constraint is given by the maximum allowed concentration of the sorbent solution, avoiding crystallization of the solution. In order to cope with the resulting limitation of the temperature lift, for standard cooling applications wet cooling towers have to be applied in order to provide sufficiently low cooling water temperatures.

In general, two system concepts for a single stage hybrid absorption \& compression cycle are available (Eckert, et al., 2015). In the so-called EVA configuration the high speed turbo vapor compressor is integrated between Evaporator (E1) and Absorber (A1). In the DECO concept the compressor is arranged between Desorber (D1) and Condenser (C1).

In Figure 1 flow schemes for both cycle options are shown. The main components are qualitatively arranged according to the respective operating conditions. In analogy to the so-called Raoult plot, equilibrium temperature and pressure can be read from abscissa and ordinate, respectively. The representation is similar to the Dühring plot, where equilibrium temperature and dew point of the fluids are represented by abscissa and ordinate. Evaporator and condenser are aligned to the vapor pressure line of the refrigerant water. Between absorber and desorber sorbent solution is circulated in dilute and concentrated state. The two connecting lines follow the inclination of the respective isosteres in the Raoult plot.

In EVA configuration the absorber pressure is increased with reference to the evaporator, whereas in DECO mode the pressure lift of the compressor is found between desorber and condenser. As a consequence, for constant operating temperatures of the four main components, in EVA configuration the solution loop between absorber and desorber operates at lower $\mathrm{LiBr}$ concentration as compared to the DECO concept.
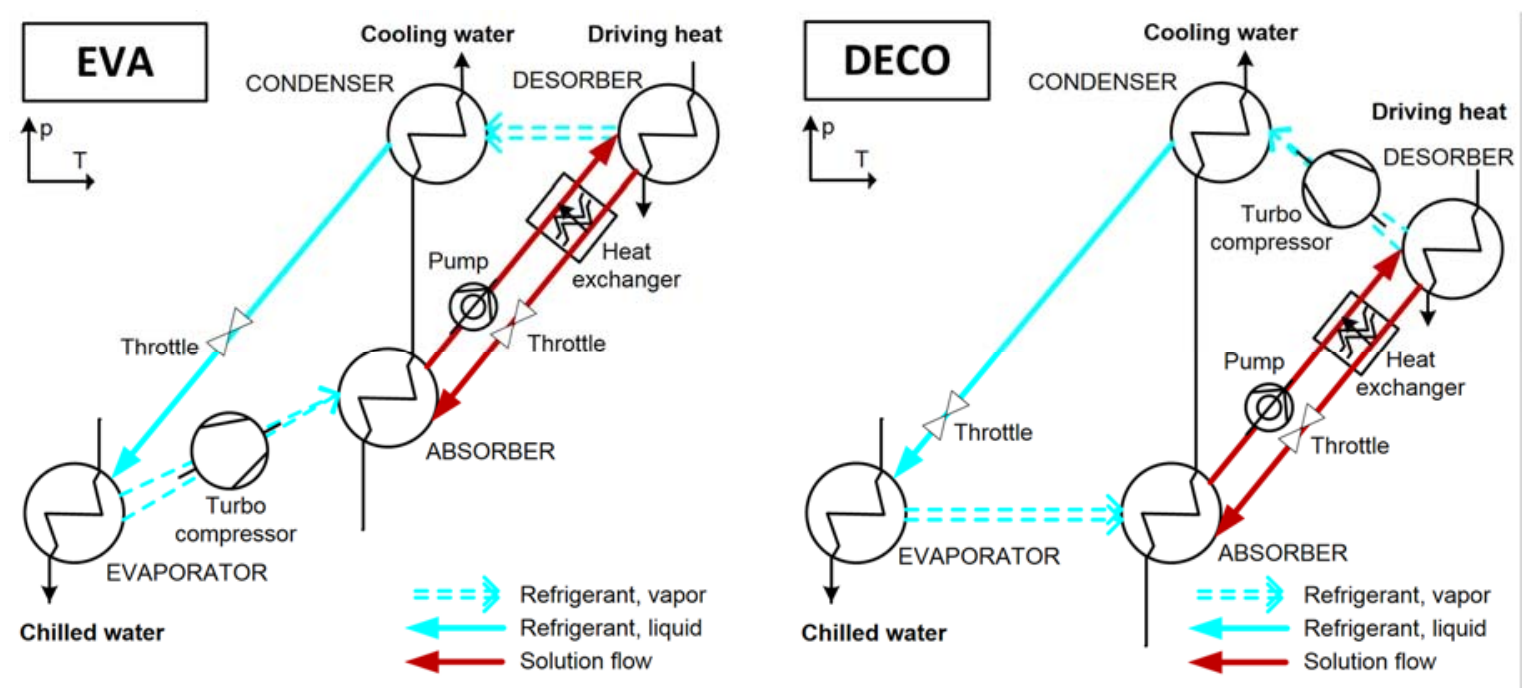

Figure 1: Scheme of the hybrid cycle with integration of the compressor between evaporator and absorber (EVA configuration) or desorber and condenser (DECO configuration). 
The hybrid configuration of the absorption/compression cycle can be applied for different objectives, as shown in Figure 2, again based on the Raoult plot. As a reference, the single stage sorption cycle (Sorption) is shown represented by a rhomb formed by the two pressure levels of the evaporator/absorber pair and the condenser/desorber pair and the vapor pressure lines of the refrigerant water and the sorbent solution. Blue arrows indicate the driving temperature difference between the internal process and the external heat sources at desorber and evaporator and the heat sink at absorber and condenser.

For a given situation of chilled water and cooling water, the mechanical compressor serves for a reduction $\left(\Delta \mathrm{t}_{2}\right)$ of the operating temperature of the desorber. Consequently, driving heat of lower temperature is sufficient for operation of the chiller. This effect is accomplished by both concepts EVA and DECO, without general difference, as shown in Figure 2, left column. Although the temperature level of the driving heat is lowered, the capacity of the chiller remains constant, as expressed by the unchanged driving temperature differences.

The mechanical compressor can also be applied for boosting the capacity during operation with constant external temperatures, as shown in Figure 2, right column, center (Booster). Here the pressure lift of the compressor allows for higher pressure of condensation and lower pressure of evaporation in comparison to the standard sorption cycle. As a result, larger temperature differences for the heat transfer at all main components of the cycle are available, resulting in an increase of the capacity. This effect can be applied for cooling or heat pump applications.

The third major motivation for the integration of the mechanical compressor is the increase of the temperature lift $\left(\Delta \mathrm{t}_{1}\right)$ between the cooling effect provided by the evaporator and the heat rejection from absorber and condenser, as described by Figure 2, right column, bottom (High Lift).

Here "Booster" and "High Lift" are shown in EVA configuration. Of course, both effects can also be accomplished by application of the DECO concept.
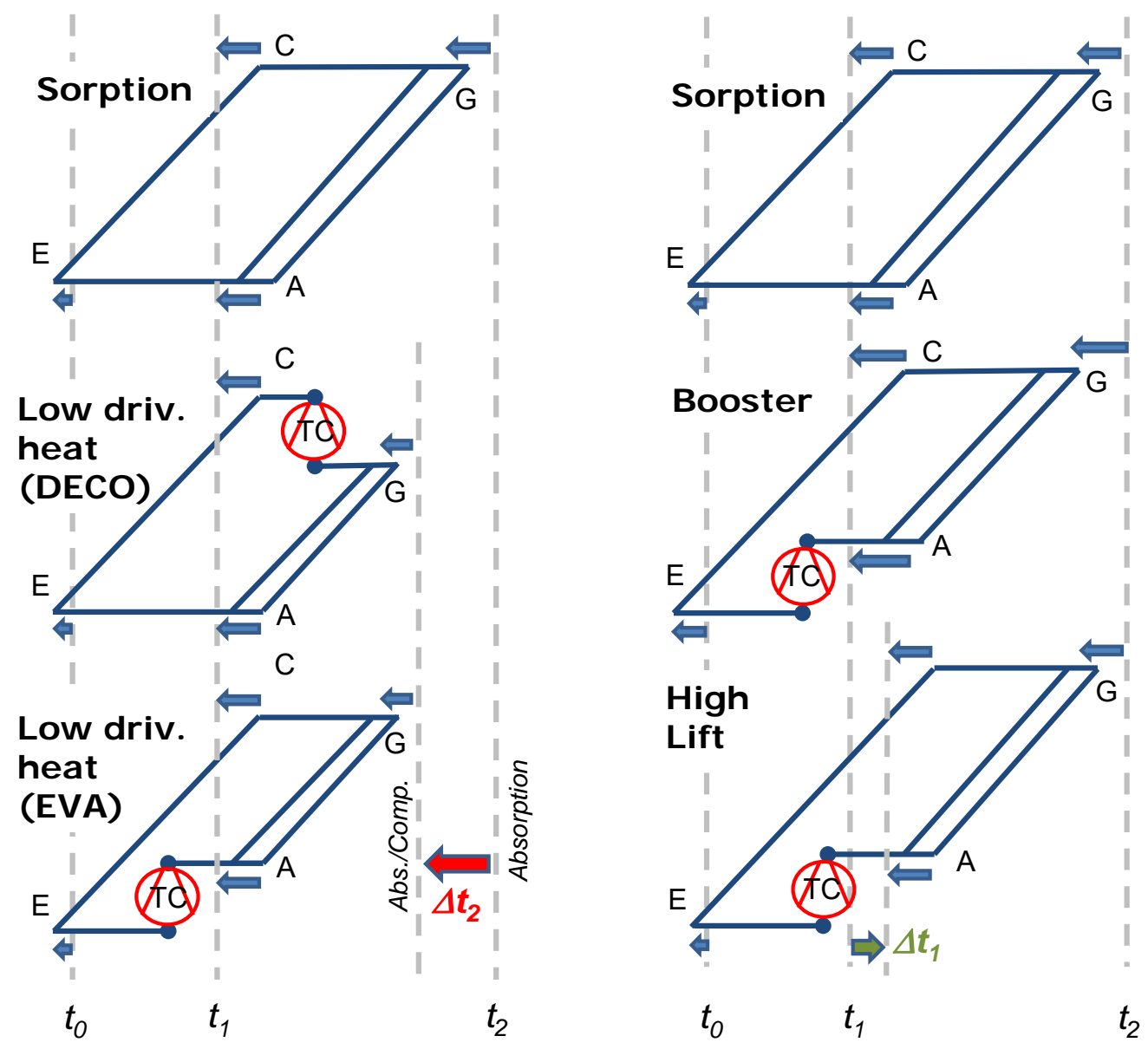

Figure 2: Effect of the mechanical compressor for adaptation of the hybrid sorption/compression cycle to low driving heat (EVA and DECO configuration, left) and for increase of capacity (right, center) or temperature lift (right, bottom) 


\section{Simulation of the hybrid absorption/compression chiller}

A process model of the combined hybrid chiller has been set up by means of equation solver EES Academic Professional V10.268-3D. For the selected design with horizontal falling film tube bundles, preliminary studies showed heat transfer coefficients $\mathrm{u}$ in $\mathrm{kW} \cdot \mathrm{m}^{-2} \cdot \mathrm{K}^{-1}$ of absorption (0.6), condensation (2.5) evaporation (1.2), desorption (0.6) and solution heat exchanger (1.0). In the following, both configurations of a hybrid sorption/compression chiller are simulated for compression ratios $\Pi$ from 1 to 3 with an isentropic efficiency $\eta$ variation of the compressor between 0.6 and 1.0 in order to evaluate process improvements in different operation scenarios. Dependent on the compression ratio $\Pi$ and suction pressure at equilibrium temperature of the refrigerant $\mathrm{T}_{\text {vle_ref, }}$ a certain additional temperature lift $\Delta \mathrm{T}_{\text {lift }}$ is provided to the sorption process. The additional temperature lift serves for improvement of the figures of merit given on the left ordinate of the diagrams shown in the following sections. The specific compressor rating $\mathrm{P}_{\text {spec }}$ represents the consumed electricity with regard to the refrigerating capacity, including flash losses due to the expansion to evaporator equilibrium. The solution flow rate is optimized for each run to obtain maximum efficiency and desired effect.

\subsection{Increased cooling water temperature}

Figure 3 shows the simulation results for increased cooling water inlet temperatures $\mathrm{T}_{\text {cool }}$ for EVA (left) and DECO (right) configuration. Exemplarily, a compression ratio $\Pi$ of 2.5 at equilibrium suction temperature $\mathrm{T}_{\text {vle_ref }}=5.5$ ${ }^{\circ} \mathrm{C}$ (resp. $30{ }^{\circ} \mathrm{C}$ ) adds additional $\Delta \mathrm{T}_{\text {lift }}$ of $14.0 \mathrm{~K}$ (resp. $16.8 \mathrm{~K}$ ) to the sorption process. The difference in $\Delta \mathrm{T}_{\text {lift }}$ is caused by the Clausius-Clapeyron dependency of equilibrium temperature and pressure.

EVA - Configuration

Temperature $\mathrm{T}_{\text {cool }} /{ }^{\circ} \mathrm{C} \quad$ spec. Compressor rating $\mathrm{P}_{\text {spec }} /-$

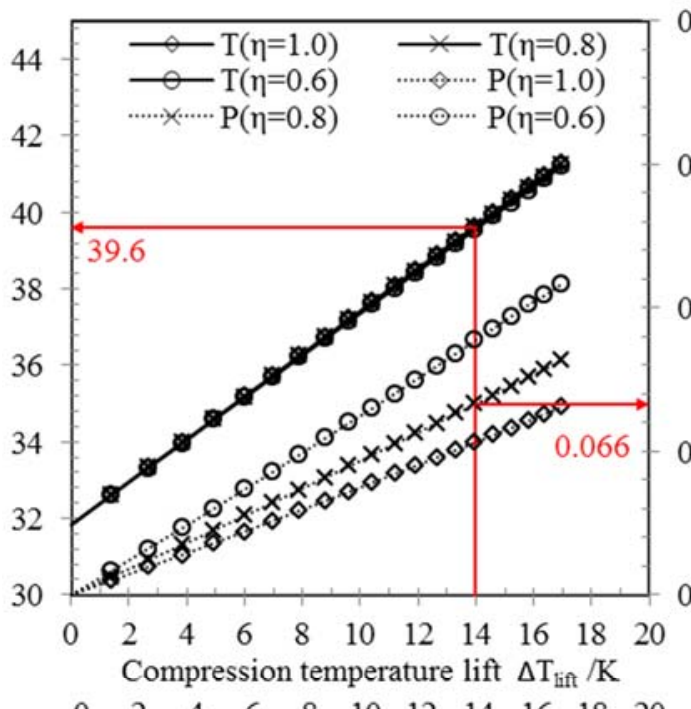

$\begin{array}{lllllllllll}0 & 2 & 4 & 6 & 8 & 10 & 12 & 14 & 16 & 18 & 20\end{array}$

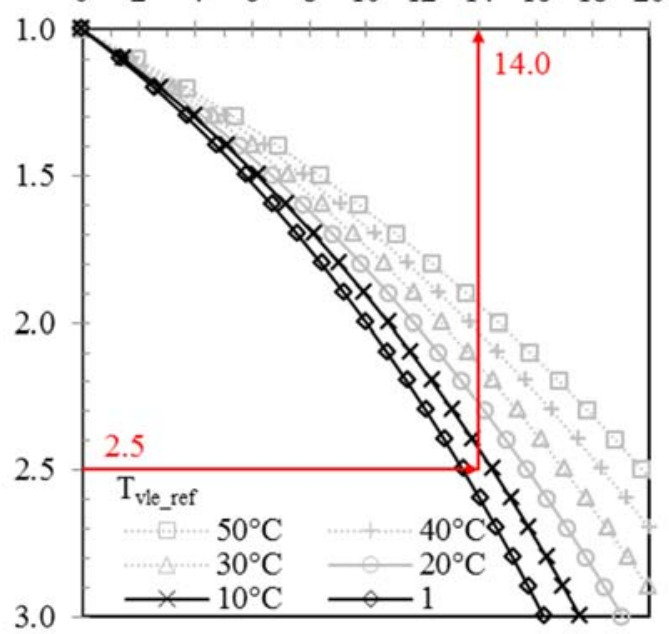

Compression ratio $\Pi /$ -
DECO - Configuration

Temperature $\mathrm{T}_{\text {cool }} /{ }^{\circ} \mathrm{C}$ spec. Compressor rating $\mathrm{P}_{\text {spec }} /-$
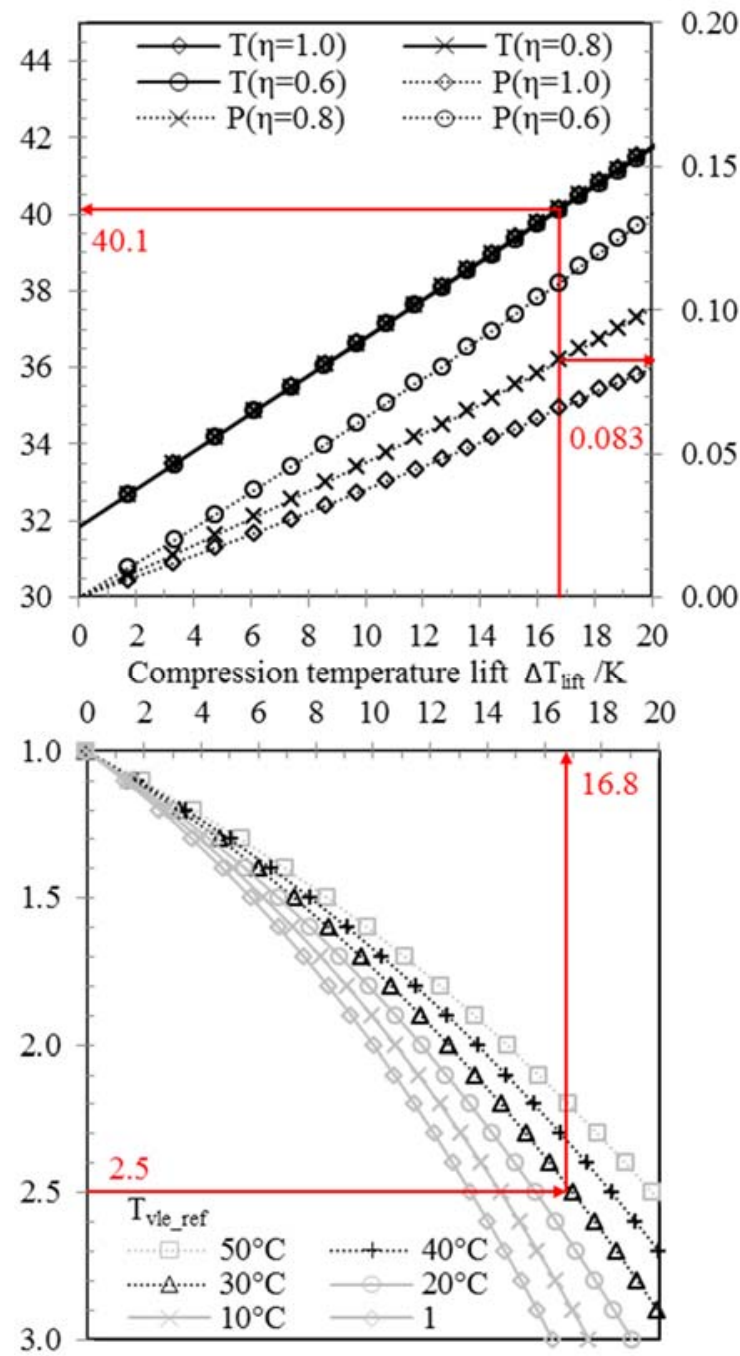

Compression ratio $\Pi$ / -

Figure 3: Process improvement map for increased cooling water temperatures. 
With constant chilled water outlet temperature of $6{ }^{\circ} \mathrm{C}$ and driving heat inlet temperature of $80{ }^{\circ} \mathrm{C}$ the cooling water inlet temperature $\mathrm{T}_{\text {cool }}$ rises from formerly $32{ }^{\circ} \mathrm{C}$ to $39,6^{\circ} \mathrm{C}$ (resp. $40.1^{\circ} \mathrm{C}$ ) at steady refrigerating capacity. This simplifies the dissipation of reject heat to the ambient and even allows the use of dry air coolers. While a decrease in the isentropic efficiency of the compressor $\eta$ has only a minor effect on the attainable temperature level, the related specific auxiliary energy consumption $\mathrm{P}_{\text {spec }}$ increases reciprocally proportional.

\subsection{Reduced driving heat temperature}

When high reject heat temperatures of $40{ }^{\circ} \mathrm{C}$ and more are mandatory, driving heat inlet temperatures $\mathrm{T}_{\text {heat }}$ of almost $100{ }^{\circ} \mathrm{C}$ are required to provide a chilled water temperature of $6{ }^{\circ} \mathrm{C}$. Besides the impendence of crystallisation, this exacts high requirements to system design, reduces efficiency and even prevents the use of absorption technology for some low temperature waste heat applications (e.g. use of heat from CHP-units or solar thermal systems).

Figure 4 depicts the effect on the required driving heat inlet temperature $T_{\text {heat }}$ when a turbo-compressor operates with a compression ratio $\Pi$ of 2.5 at corresponding vapour/liquid refrigerant equilibrium temperature at the compressor inlet $\mathrm{T}_{\text {vle_ref }}=5.5^{\circ} \mathrm{C}$ and $30{ }^{\circ} \mathrm{C}$ in EVA and DECO-configuration respectively. As already observed in the previous operation mode, the isentropic efficiency has again a minor effect on the temperature level. As before, the DECO-configuration shows with $\mathrm{T}_{\text {heat }}=79.7^{\circ} \mathrm{C}$ slightly better results than EVA with $80.9^{\circ} \mathrm{C}$, but converts the additional temperature lift less effectively. The specific auxiliary energy consumption ratio amounts to 0.0036 (EVA) and 0.0042 (DECO) Watts of electricity per Watt refrigerating capacity and Kelvin.

EVA - Configuration

Temperature $\mathrm{T}_{\text {heat }} /{ }^{\circ} \mathrm{C}$ spec. Compressor rating $\mathrm{P}_{\text {spec }} /-$
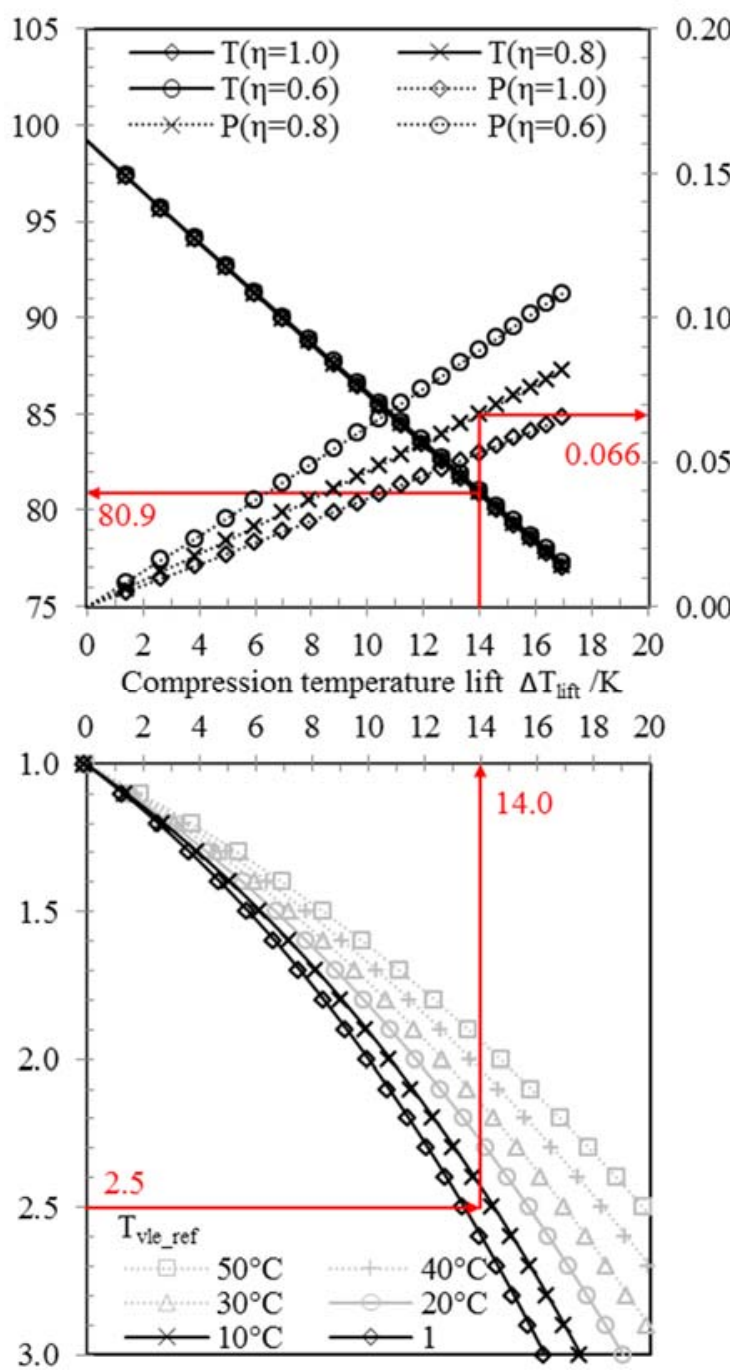

Compression ratio $\Pi /$ -

\section{DECO - Configuration}

Temperature $\mathrm{T}_{\text {heat }} /{ }^{\circ} \mathrm{C} \quad$ spec. Compressor rating $\mathrm{P}_{\text {spec }} /-$
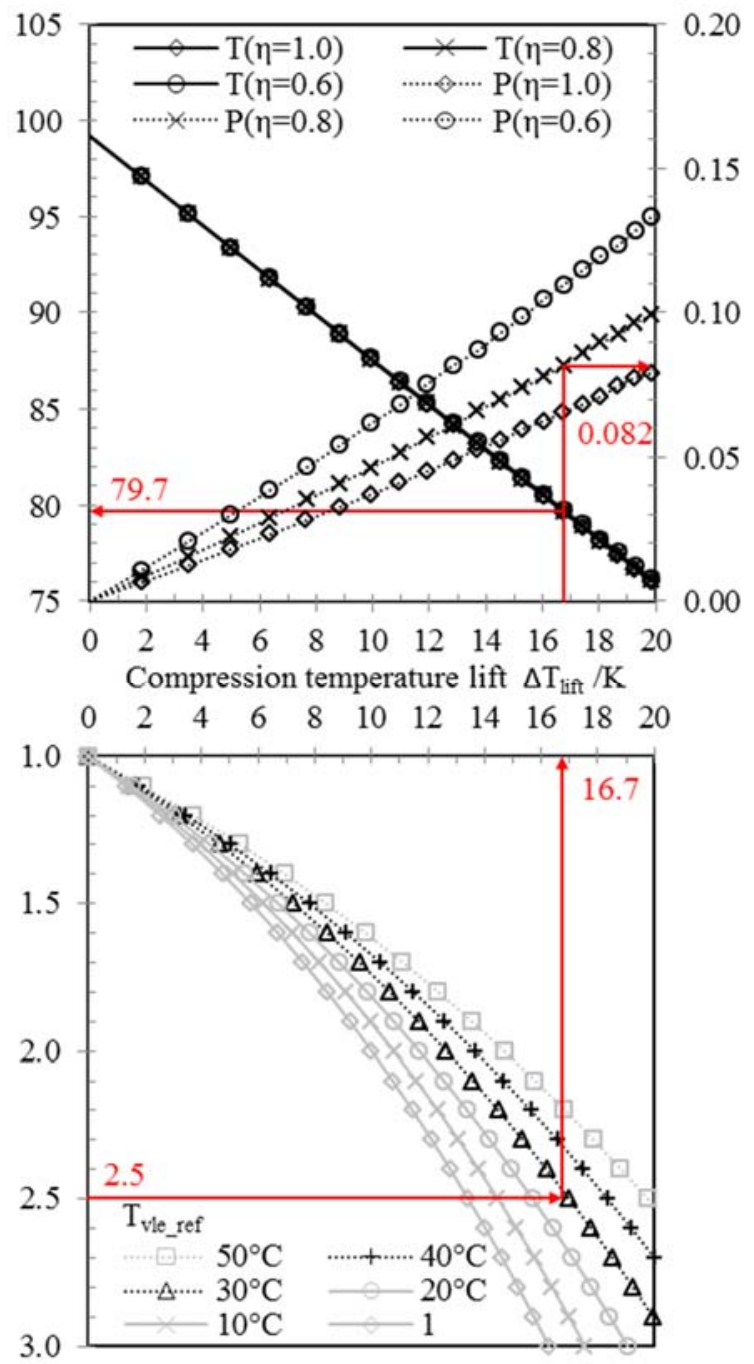

Compression ratio $\Pi$ / -

Figure 4: Process improvement map for reduced driving heat temperature. 
Altogether, the turbo-compressor significantly reduces the required driving heat temperature level at given boundary conditions by up to $20 \mathrm{~K}$ and more at constant chilled water capacity. Consequently, at given inlet temperature the driving heat return temperature can be reduced accordingly, which has been confirmed by additional simulation. Due to size limitations for this publication no explanatory figures are given.

\subsection{Capacity booster}

The overall heat exchanger surface area is the decisive factor for the investment costs of absorption chillers. Usually, the design is made for maximum capacity at unfavourable operating conditions. Thus, the machine is substantially oversized for most of the operating hours. Additionally, the sorption process parameters have to be adjusted according to the fluctuating chilled water capacity to maintain high efficiency over a wide load range. The integrated turbo-compressor offers improvement for both aspects.

Figure 5 shows a significant increase of chilled water capacity related to design capacity Qrel up to $190 \%$ depending on the compression ratio $\Pi$ of the turbo-compressor. Thereby, the additional temperature lift $\Delta \mathrm{T}_{\text {lift }}$ is allocated proportionally to all heat exchanger components of the chiller, resulting in an overall lower evaporating temperature. Thus, the exemplary compression temperature lift in EVA-configuration reaches $13.8 \mathrm{~K}$ only, compared to the previous simulations. Likewise, the isentropic compressor efficiency $\eta$ mainly effects the specific compressor rating, rather than the relative chilled water capacity. Due to the superheated inlet conditions of the refrigerant vapour the DECO-configuration performs worse, again expressed by the higher specific compressor rating $\mathrm{P}_{\text {spec. }}$.

\section{EVA - Configuration}

rel. Capacity $\mathrm{Q}_{\mathrm{rel}} / \% \quad$ spec. Compressor rating $\mathrm{P}_{\text {spec }} /$ -
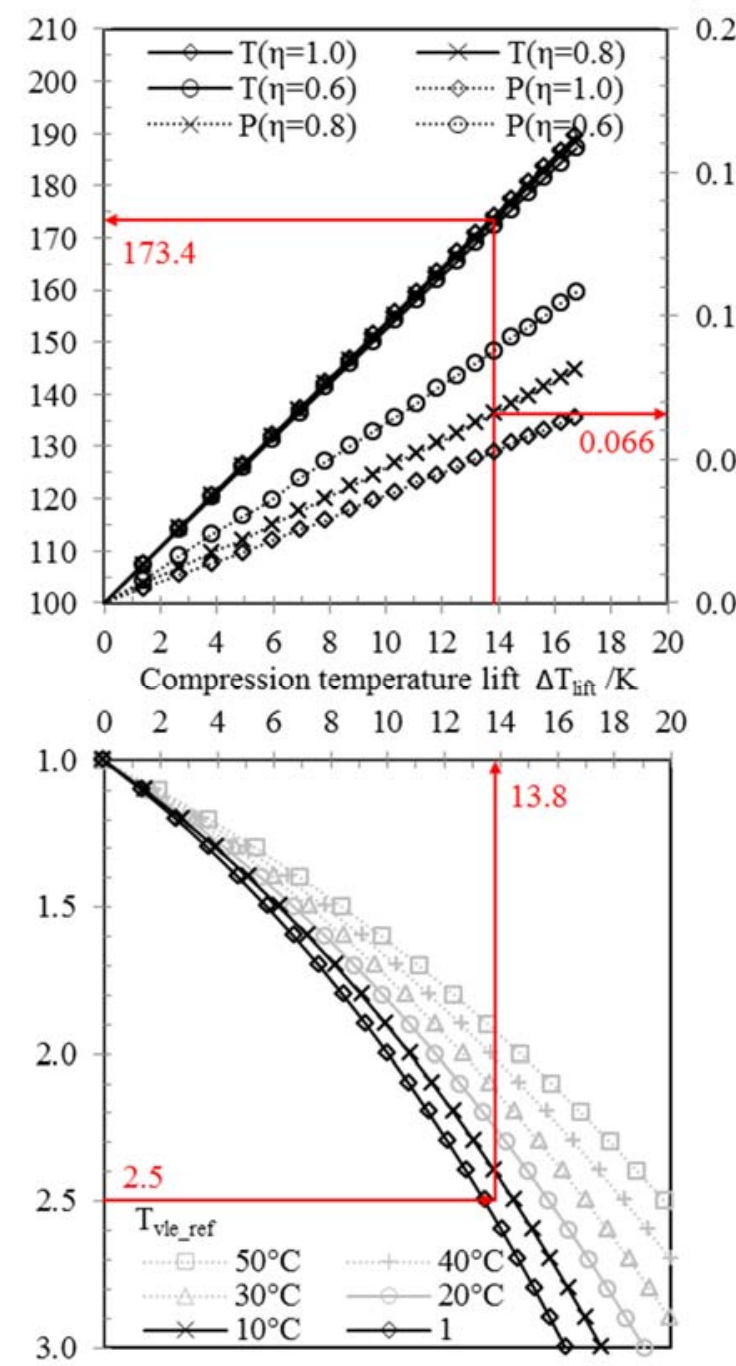

Compression ratio $\Pi /$ -

\section{DECO - Configuration}

rel. Capacity $\mathrm{Q}_{\mathrm{rel}} / \% \quad$ spec. Compressor rating $\mathrm{P}_{\text {spec }} /$ -
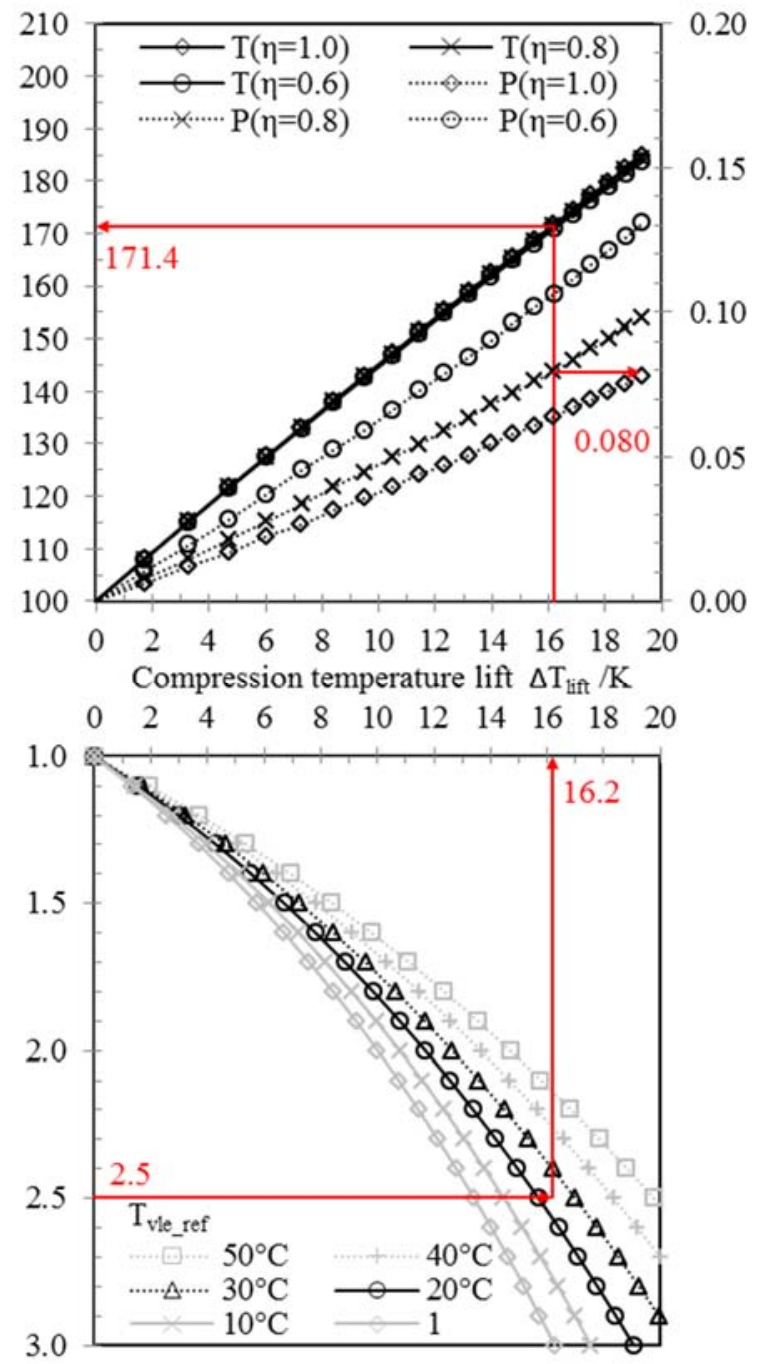

Compression ratio $\Pi /$ -

Figure 5: Process improvement map of capacity booster mode. 


\section{Hybrid chiller design studies and demonstrator setup}

A laboratory test plant of the hybrid absorption/compression chiller has been designed and constructed which can be operated in pure absorption mode and hybrid operation with variable contribution of the mechanical compressor. The centrifugal compressor has been provided by a commercial partner who offers two-stage vapor compression chillers with the refrigerant water (Efficient energy GmbH, 2016) (Meier-Staude \& Kniffler, 2013).

Due to its thermodynamic properties the natural refrigerant Water requires a revised absorption chiller design if a turbo compressor is integrated. In the refrigerant flow pressure losses have to be reduced to a minimum despite extremely high flow conditions near sonic velocity. In addition, entrainment of refrigerant droplets is to be avoided at the compressor inlet.

For the design of the chiller different geometric concepts have been set up and analyzed, as shown in Figure 6 (a) to (f). In all cases a circular or symmetric arrangement has been chosen. For the main components different types of heat exchanger structures are applied. In terms of a preliminary assessment the integration of the cylindrical compressor unit is shown for both pressure vessels, i.e. evaporator/absorber and desorber/condenser unit, respectively
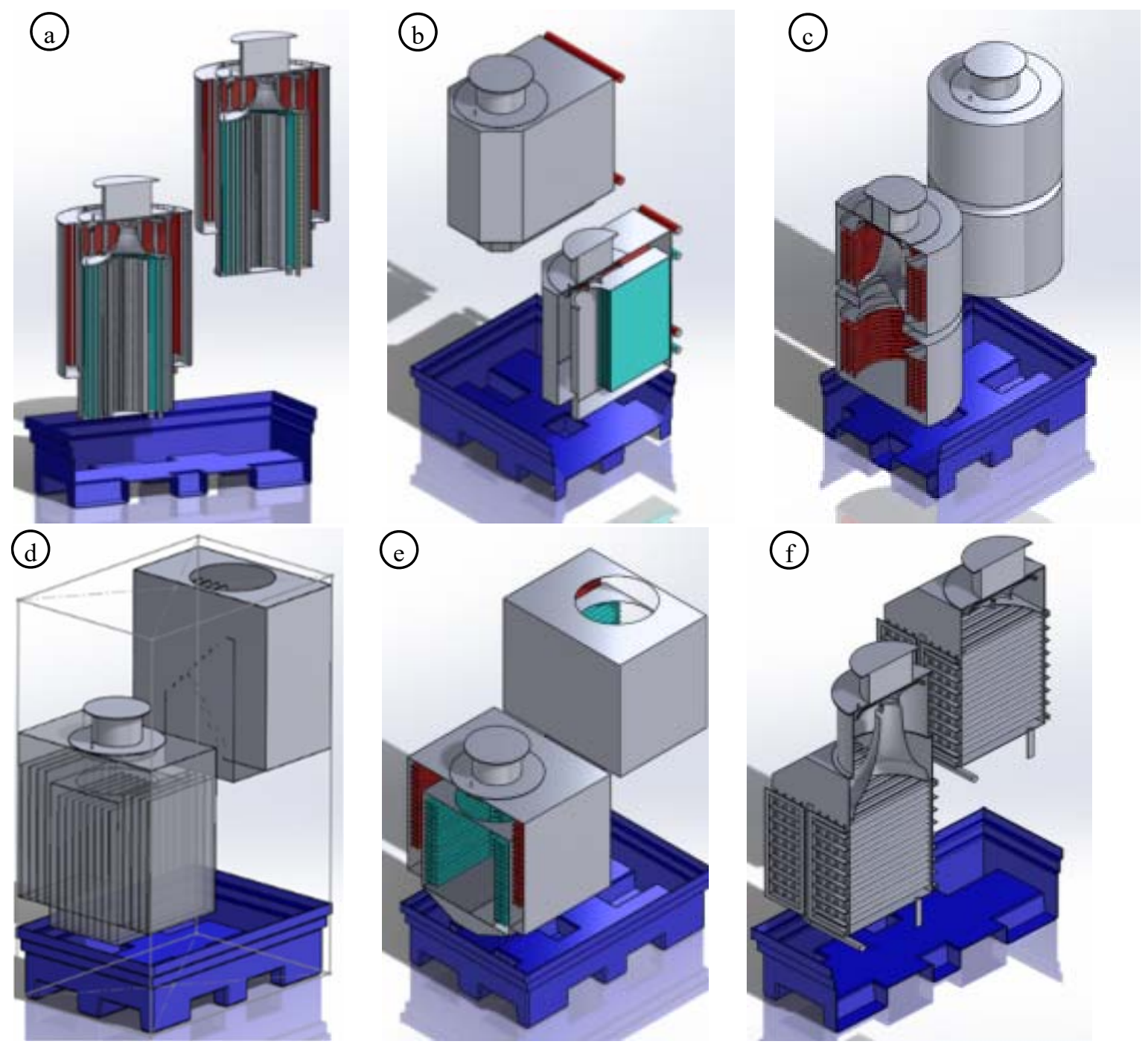

Figure 6: Design concepts for the hybrid chiller test plant; configurations (a) to (f) from top left to bottom right.

In design (a) concentric circular plates form the main component heat exchangers. This concept would offer a perfect match with the circular shape of the turbo compressor. Yet, for the compact dimensions of the commercial compressor circular plate heat exchangers with sufficiently small diameter are not available. In design (b) stacks of parallel thermoplates are used as heat exchangers. In the evaporator/absorber unit the evaporator is positioned in the center. 
The absorber is arranged in two parts and surrounds the evaporator on both sides. A negative aspect is the reduced flow cross-section for the refrigerant vapor at the compressor inlet. Concentric helical tube coils are applied for concept (c). For the internal process this configuration offers similar conditions like a conventional tube bundle. Yet, due to the long tube length high pressure drops occur in the external heat carrier circuits. Design (d) is based on parallel packages of thermoplates. Here again high pressure drops in the refrigerant vapor flow have to be expected within the volume of the heat exchangers.

As a conclusion, resulting from the requirements of the refrigerant vapor flow decision has been taken for a conventional shell and tube design comprising horizontal tube bundles for the main component heat exchangers. In order to match the circular geometry of the compressor first u-shaped tube bundles as shown in design (e) have been taken into consideration. Yet, finally design (f) with classical horizontal tube bundles in parallel arrangement has been chosen in order to avoid complex geometric constructions.

Based on the above design study the test plant of the hybrid chiller has been designed resorting to the conventional falling film design of the main component heat exchangers evaporator, absorber, condenser and desorber. The two components operating at low pressure, and high pressure respectively, are arranged in a symmetric configuration with vapor flow from the central component through the compressor to the outer part of the vessel. In order to reach a symmetric geometry all main components have been split in two parts. In the low pressure part of the chiller the two evaporator sections are positioned in the center, separated by a void volume in which the released refrigerant vapor flow is directed upward to the compressor. The compressed vapor finally reaches the two absorber sections which are positioned in the outer parts of the vessel. Optionally, the compressor can be installed in the high pressure section of the cycle with vapor flow from the desorber to the condenser. Figure 6(f) shows a sectional view of the test plant with identical design of the low and high pressure vessel. The conic suction dome forming the compressor inlet is mounted on top of the lower vessel.

The test plant of the hybrid chiller has been erected and equipped like a conventional sorption chiller with all required auxiliary instrumentation and sensors for scientific measurement as shown in Figure 7. A purge system comprising a liquid/gas ejector and a scroll vacuum pump is applied for conservation of the vacuum. Operation of the internal pumps, concentration of the sorbent solution and anti-freeze control of the evaporator is handled by a compact PLC control unit. In order to assure stable operating conditions for the turbo compressor an antisurge valve has been installed. The valve is equipped with a fast motor drive for opening a return line from the compressor discharge to the suction side of the compressor. By that means the refrigerant flow through the compressor can be maintained above the minimum allowed flow and the occurrence of surge is avoided.

For pure sorption mode of the hybrid chiller without contribution of the compressor bypass-flaps have been forseeen between evaporator and absorber compartment, similar to the design of conventional water/Silicagel adsorption chillers. During standstill of the compressor the refrigerant vapor passes through the self-acting flaps in addition to the flow path across the compressor. Thus, the pressure drop between evaporator and absorber is minimized.

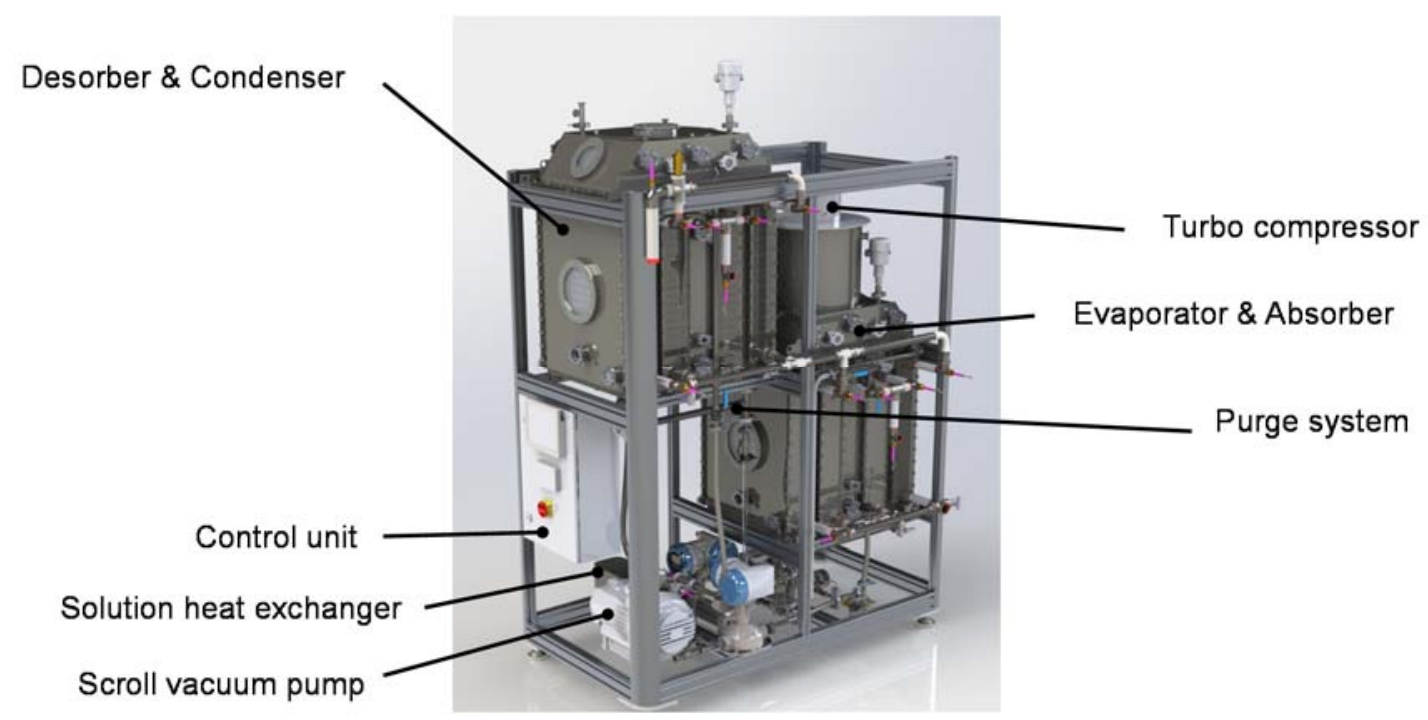

Figure 7:3D-CAD Model of the hybrid chiller demonstrator and main components 


\section{Practical validation of the hybrid chiller concept}

Supported by the additional temperature lift provided by the compressor, the three different effects - increased temperature lift from chilled water supply to heat rejection / reduced temperature level of the driving heat / boostermode with increased chilled water capacity at unchanged operating conditions - have been examined at a test-rig at Munich University of Applied Sciences.

The following tables show the main parameters - such as temperatures $\mathrm{T}$, volume flow rates $\mathrm{V}$ and lithium bromide mass concentration w - in Evaporator (E1), Absorber (A1) and Desorber (D1) as well as the heat ratio $\zeta_{\mathrm{C}}$ of the sorption process. Furthermore, the standard deviation of the sample $\sigma$ during the entire measuring phase of 10 minutes for quasi-stationary evaluation conditions is given. Supportive figures allow a graphical comparison with the EVA simulation results of chapter 3.

Figure 8 depicts measuring results for increased cooling water inlet temperatures $\mathrm{T}_{\text {cool }}$ in relation to the simulation results, depending on the temperature lift $\Delta \mathrm{T}_{\text {lift }}$ provided by the mechanical compressor in EVA-configuration. Additionally, the required specific compressor rating $\mathrm{P}_{\text {spec }}$ is given.

Table 1: Parameters of the absorption-compression process for increased cooling water temperature mode.

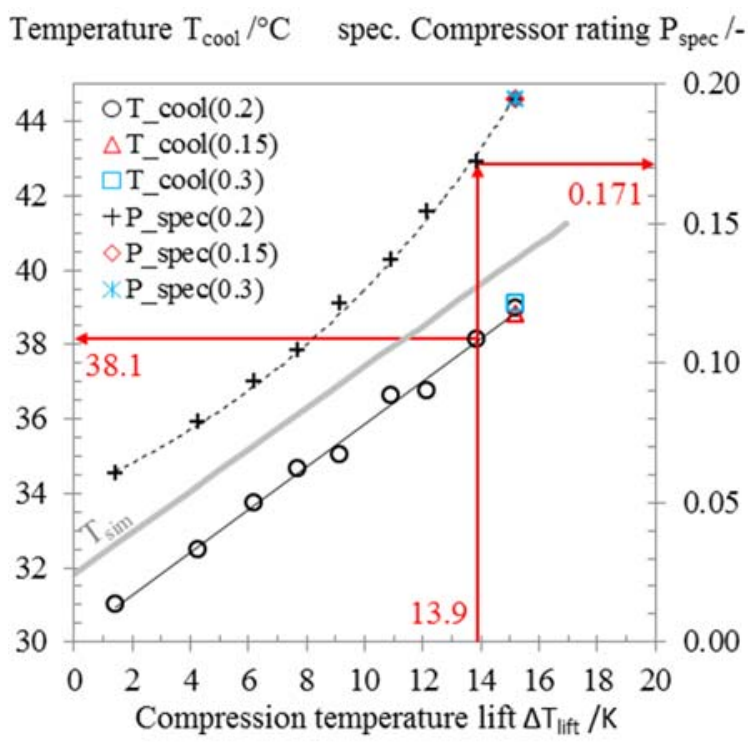

\begin{tabular}{cccc}
\hline Parameter & Unit & Value & $\sigma$ \\
\hline E1\#T_brine_IN & ${ }^{\circ} \mathrm{C}$ & 12.1 & $\pm 3.9 \times 10^{-2}$ \\
E1\#T_brine_OUT & ${ }^{\circ} \mathrm{C}$ & 6.2 & $\pm 2.9 \times 10^{-2}$ \\
A1\#T_cool_IN & ${ }^{\circ} \mathrm{C}$ & 38.1 & $\pm 9.4 \times 10^{-2}$ \\
A1\#V_cool & $\mathrm{m}^{3} \cdot \mathrm{h}^{-1}$ & 3.6 & $\pm 1.3 \times 10^{-2}$ \\
A1\#V_sol_OUT & $\mathrm{m}^{3} \cdot \mathrm{h}^{-1}$ & 0.2 & $\pm 1.0 \times 10^{-2}$ \\
A1\#w_sol_OUT & $\%^{\text {mass }}$ & 50.1 & $\pm 1.7 \times 10^{-2}$ \\
D1\#T_heat_IN & ${ }^{\circ} \mathrm{C}$ & 79.5 & $\pm 1.1 \times 10^{-1}$ \\
D1\#T_heat_OUT & ${ }^{\circ} \mathrm{C}$ & 71.8 & $\pm 8.8 \times 10^{-2}$ \\
D1\#w_sol_OUT & $\%_{\text {mass }}$ & 53.0 & $\pm 1.9 \times 10^{-2}$ \\
Pspec & - & 0.171 & $\pm 8.2 \times 10^{-3}$ \\
$\zeta_{C}$ & - & 0.793 & $\pm 1.3 \times 10^{-2}$
\end{tabular}

Figure 8: Effect of the temperature lift $\Delta T_{\text {lift }}$,provided by the mechanical vapor compressor, on required cooling water inlet temperature $T_{\text {cool }}$ and specific compressor rating $P_{\text {spec }}$ with $\mathrm{H}_{2} \mathrm{O} / \mathrm{LiBr}$-solution flow rates of $0.15,0.2$ and $0.3 \mathrm{~m}^{3} \cdot \mathrm{h}^{-1}$.

A variation of the lithium bromide solution flow rate from 0.15 to $0.3 \mathrm{~m}^{3} \cdot \mathrm{h}^{-1}$ shows no significant effect on the examined parameters. The coefficient of determination $\mathrm{R}^{2}$ reaches $0.9933 \%$ (linear) for T_cool and $0.9989 \%\left(2^{\text {nd }}\right.$ order polynomial) for $\mathrm{P}_{\text {spec }}$. A deviation of about $-1.8 \mathrm{~K}$ between measured and simulated results - represented as bold grey line - is observed and can be mainly attributed to irreversibilities and losses of the test-rig. For an exemplary temperature lift $\Delta \mathrm{T}_{\text {lift }}=13.9 \mathrm{~K}$ the cooling water inlet temperature increases from formerly $30^{\circ} \mathrm{C}$ to $38.1^{\circ} \mathrm{C}$. In that case, the required specific compressor rating amounts to $\mathrm{P}_{\mathrm{spec}}=0.171$ and an overall sorption process heat ratio $\zeta_{\mathrm{C}}$ of 0.793 is achieved. The effect for the operating temperature is in good agreement with the theoretic model as discussed in section 3 . Yet, the electric power demand strongly exceeds the predictions due to the low efficiency of the electric drive of the compressor. Unfortunately, a measurement of the shaft power for more detailed analysis of the fluid mechanic performance has not been available.

As summarized in Table 1, the hybrid chiller provides $6.2^{\circ} \mathrm{C}$ of chilled water (E1\#T_brine_OUT), at a cooling water inlet temperature A1\#T_cool_IN $=38.1^{\circ} \mathrm{C}$ with a driving heat temperature of D1\#T_heat_IN $=79.5^{\circ} \mathrm{C}$ at the desorber inlet. Meanwhile, the maximum lithium bromide concentration remains at a moderate value of D1 $\# \mathrm{w}_{-}$sol_OUT $=53.0 \%$ mass, which has a positive effect on heat and mass transfer coefficients and reduces corrosion potential. Nevertheless, the conversion factor between $\Delta \mathrm{T}_{\text {lift }}$ and the gain in $\mathrm{T}_{\text {cool }}$ is lower than 1 due to the sorption process. This may lead to the conclusion, that an external coupling of sorption and compression cycle might be more effective. Yet, this advantage may be missed if large temperature differences in the external heat transfer circuits occur. 
Figure 9 shows the measured driving heat temperature level $\mathrm{T}_{\text {heat }}$ in comparison to the simulation results, which are represented as bold grey line, in dependency of the mechanical compression temperature lift $\mathrm{T}_{\text {lift. }}$. Additionally, the specific compressor rating $\mathrm{P}_{\text {spec }}$ needed to decrease the driving heat inlet temperature is given. The coefficient of determination $\mathrm{R}^{2}$ reaches $0.925 \%$ (linear) for $\mathrm{T}_{\text {heat }}$ and $0,9975 \%$ ( $2^{\text {nd }}$ polynomial $)$ for $\mathrm{P}_{\text {spec }}$.

Table 2 summarizes the indicative parameters of the hybrid chiller process for an exemplary mechanical temperature lift $\mathrm{T}_{\text {lift }}=13.7$, which causes a specific compressor rating $\mathrm{P}_{\text {spec }}$ of 0.169 , defined as units of electricity per unit cooling (external chilled water capacity plus internal refrigerant expansion losses). As a result, the required driving heat inlet temperature level decreases from formerly almost $100^{\circ}$ to $84.1^{\circ \circ} \mathrm{C}$ for a chilled water outlet temperature E1\#T_brine_OUT of $6.0^{\circ} \mathrm{C}$ and a cooling water inlet temperature to the absorber of A1\#T_cool_IN $=39.9^{\circ} \mathrm{C}$. Meanwhile the cooling water flowrate remains constant at A1\#V_cool $=3.6 \mathrm{~m}^{3} \cdot \mathrm{h}^{-1}$. With a solution flowrate $\mathrm{A} 1 \# \mathrm{~V}$ _sol_OUT $=0.2 \mathrm{~m}^{3} \cdot \mathrm{h}^{-1}$ between Absorber (A1) and Desorber (D1) the lithium bromide concentration $\mathrm{W}$ varies between 51.3 and $54.7 \%$ mass. Without the mechanical compressor at given external temperature levels a much higher driving heat temperature would be required, leading to risky lithium bromide concentrations of $62 \%$ and more, which might result in crystallisation and eventually failure of the chiller. Despite the high temperature difference between chilled and cooling water, the heat ratio of the sorption process $\zeta_{\mathrm{C}}=0.778$ is quite good. Very advantageous is the high conversion factor between $\Delta \mathrm{T}_{\text {lift }}$ and $\mathrm{T}_{\text {heat. }}$ In this case, the mechanical compressor adds $13.7 \mathrm{~K}$ temperature lift to the internal sorption process, which results in a decrease of the driving heat inlet temperature of more than $15 \mathrm{~K}$.

Table 2: Parameters of the absorption-compression process for decreased driving heat temperature mode.

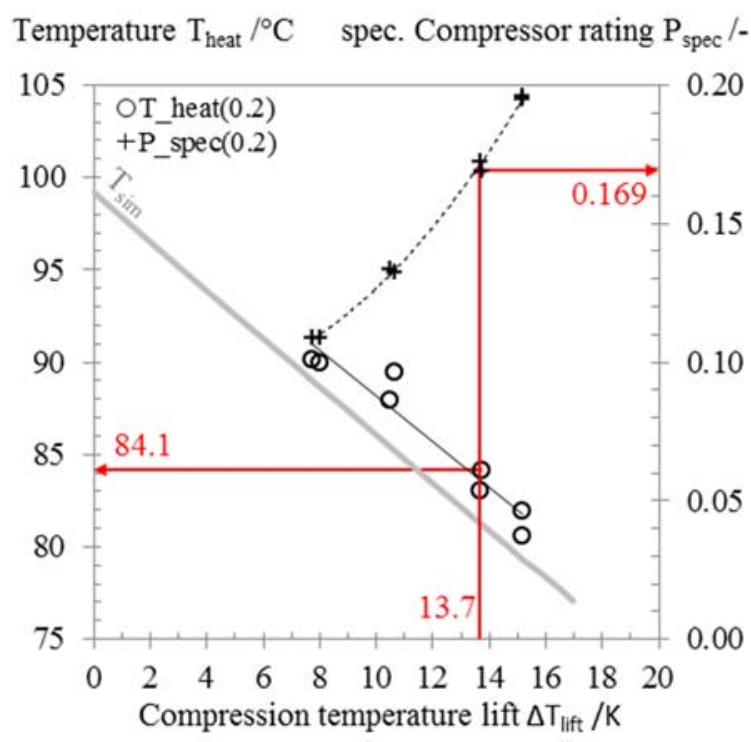

\begin{tabular}{lccc}
\hline Parameter & Unit & Value & $\sigma$ \\
\hline E1\#T_brine_IN & ${ }^{\circ} \mathrm{C}$ & 12.0 & $\pm 3.1 \times 10^{-2}$ \\
E1\#T_brine_OUT & ${ }^{\circ} \mathrm{C}$ & 6.0 & $\pm 2.5 \times 10^{-2}$ \\
A1\#T_cool_IN & ${ }^{\circ} \mathrm{C}$ & 39.9 & $\pm 9.4 \times 10^{-2}$ \\
A1\#V_cool & $\mathrm{m}^{3} \cdot \mathrm{h}^{-1}$ & 3.6 & $\pm 2.2 \times 10^{-2}$ \\
A1\#V_sol_OUT & $\mathrm{m}^{3} \cdot \mathrm{h}^{-1}$ & 0.2 & $\pm 1.0 \times 10^{-2}$ \\
A1\#w_sol_OUT & ${ }^{\circ}{ }_{\text {mass }}$ & 51.3 & $\pm 1.4 \times 10^{-2}$ \\
D1\#T_heat_IN & ${ }^{\circ} \mathrm{C}$ & 84.1 & $\pm 1.1 \times 10^{-1}$ \\
D1\#T_heat_OUT & ${ }^{\circ} \mathrm{C}$ & 76.3 & $\pm 6.3 \times 10^{-2}$ \\
D1\#w_sol_OUT & ${ }^{\circ}{ }_{\text {mass }}$ & 54.7 & $\pm 2.3 \times 10^{-1}$ \\
P & - & 0.169 & $\pm 4.5 \times 10^{-3}$ \\
$\zeta_{\text {spec }}$ & - & 0.778 & $\pm 1.1 \times 10^{-2}$
\end{tabular}

Figure 9: Effect of the temperature lift $\Delta \mathrm{T}_{\text {lift, }}$ by means of mechanical vapour compression, on the required driving heat temperature $T_{\text {heat }}$ and therefore spent specific compressor rating $P_{\text {spec }}$ at aqueous lithium bromide solution flow rate of $0.2 \mathrm{~m}^{3} \cdot \mathrm{h}^{-1}$.

Figure 10 presents the additional chilled water capacity $\mathrm{Q}_{\text {add }}$ when a mechanical vapor compressor provides a certain temperature lift $\Delta \mathrm{T}_{\text {lift }}$ between Evaporator and Absorber. Furthermore, the corresponding compressor rating $\mathrm{P}_{\text {spec }}$ is shown. The tests have been carried out with cooling water inlet temperatures of 30,35 and $40{ }^{\circ} \mathrm{C}$. In contrast to the simulation figures, the increase in chilled water capacity is depicted in absolute values as the reference cooling capacity for each set of cooling water inlet temperature variation deviates.

The most relevant measuring results are listed in Table 3 for an exemplary hybrid chiller test with A1\#T_cool_IN $=34.9{ }^{\circ} \mathrm{C}$ cooling water inlet temperature at constant flowrate A1\#V_cool $=3.6 \mathrm{~m}^{3} \cdot \mathrm{h}^{-1}$ and compression temperature lift $\Delta \mathrm{T}_{\text {lift }}=12.9 \mathrm{~K}$. By means of a specific compressor rating of $\overline{\mathrm{P}}_{\mathrm{spec}}=0.154$ the chilled water capacity increases about $+6.7 \mathrm{~kW}$. The coefficient of determination $\mathrm{R}^{2}$ at cooling water inlet temperatures 30,35 resp. $40{ }^{\circ} \mathrm{C}$ reaches $0.997,0.992$ resp. $0.9863 \%$ (linear) for the additional capacity $Q_{\text {add }}$ and $0.997,0.9989$ resp. $0.9071 \%$ ( $2^{\text {nd }}$ order polynomial) for the specific compressor rating $\mathrm{P}_{\text {spec. }}$. While the compressor rating at $35{ }^{\circ} \mathrm{C}$ cooling water is in good accordance with the simulation results the other two test runs show contradictory curve shape. This can be explained by the characteristic operation map of the turbo-compressor which has been modelled with constant efficiency. 
Under given boundary conditions the refrigerant flow rate through the compressor is quite high and therefore close to the choke limit with reduced compression efficiency. Furthermore, flow losses gain increasing importance. Both effects result in an increase of $\mathrm{P}_{\text {spec }}$ at rising $\Delta \mathrm{T}_{\text {lift. }}$. In contrast to this, a higher cooling water temperature of $40^{\circ}$ shifts the operation point of the turbo-compressor towards its surge limit, again at reduced efficiency. In addition, chilled water capacity is quite low, resulting in an unfavourable operational state of the compressor due to its poor base load performance. Again, both aspects induce an increase of $\mathrm{P}_{\text {spec }}$ at reduced $\Delta \mathrm{T}_{\text {lift. }}$.

Table 3: Parameters of the absorption-compression process for improved chilled water capacity mode.

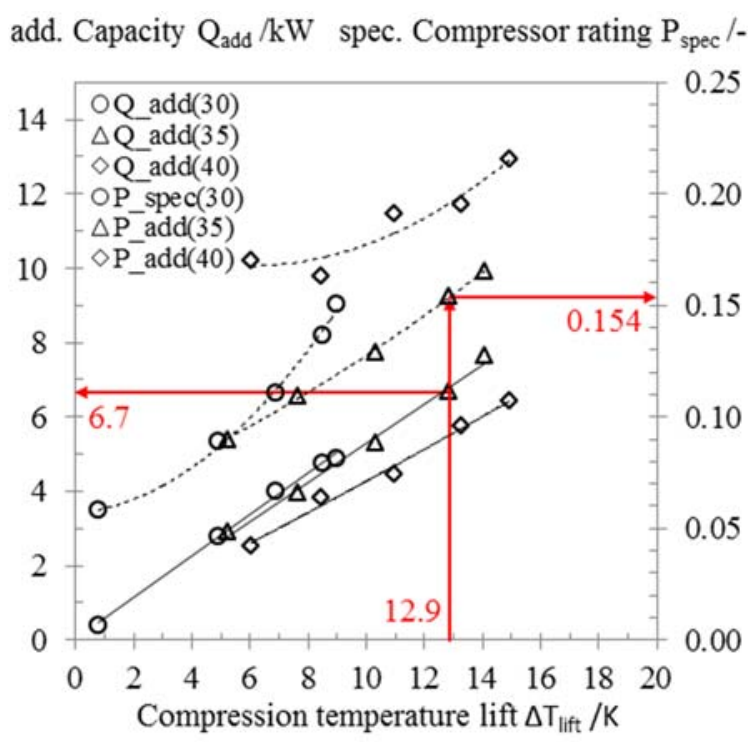

\begin{tabular}{lccc}
\hline Parameter & Unit & Value & $\sigma$ \\
\hline E1\#T_brine_IN & ${ }^{\circ} \mathrm{C}$ & 12.1 & $\pm 2.1 \times 10^{-1}$ \\
E1\#T_brine_OUT & ${ }^{\circ} \mathrm{C}$ & 6.1 & $\pm 1.0 \times 10^{-1}$ \\
A1\#T_cool_IN & ${ }^{\circ} \mathrm{C}$ & 34.9 & $\pm 1.8 \times 10^{-1}$ \\
A1\#V_cool & $\mathrm{m}^{3} \cdot \mathrm{h}^{-1}$ & 3.6 & $\pm 2.1 \times 10^{-2}$ \\
A1\#V_sol_OUT & $\mathrm{m}^{3} \cdot \mathrm{h}^{-1}$ & 0.2 & $\pm 1.0 \times 10^{-2}$ \\
A1\#w_sol_OUT & ${ }^{\circ}{ }_{\text {mass }}$ & 50.1 & $\pm 2.6 \times 10^{-2}$ \\
D1\#T_heat_IN & ${ }^{\circ} \mathrm{C}$ & 80.1 & $\pm 1.7 \times 10^{-1}$ \\
D1\#T_heat_OUT & ${ }^{\circ} \mathrm{C}$ & 70.6 & $\pm 9.4 \times 10^{-2}$ \\
D1\#w_sol_OUT & ${ }^{\circ}{ }_{\text {mass }}$ & 54.1 & $\pm 2.8 \times 10^{-1}$ \\
P & - & 0.154 & $\pm 4.8 \times 10^{-3}$ \\
$\zeta_{\text {c }}$ & - & 0.803 & $\pm 3.4 \times 10^{-2}$
\end{tabular}

Figure 10: Additional chilled water capacity $Q_{\text {add }}$ depending on additional temperature lift $\Delta T_{\text {lift }}$ from the mechanical vapour compression and therefore spent specific compressor rating $P_{\text {spec }}$ at cooling water inlet temperatures 30,35 and $40{ }^{\circ} \mathrm{C}$.

\section{Summary and Outlook}

A hybrid chiller concept based on the natural refrigerant water R718 and consisting of an adapted lithium bromide absorption machine with directly integrated mechanical vapor turbo compressor with variable compression ratio $\Pi$ between 1 and 3 is introduced. Considering conventional design parameters, two constructive combinations are possible in general. The EVA-configuration contains the turbo compressor between Evaporator and Absorber of the sorption process, while in the DECO-configuration it's arranged between Desorber and Condenser.

A steady-state simulation of both hybrid absorption/compression process configurations shows several positive effects on the system behavior under varying boundary conditions for solar cooling applications. For instance, with increasing additional compressor input higher cooling water inlet temperatures up to $+10 \mathrm{~K}$ are possible or the required driving heat temperature level decreases by up to $20 \mathrm{~K}$. In another case, if all external temperature levels remain constant, the compressor input directly boosts the chilled water capacity to almost $190 \%$ of the design value. Based on the promising results, a hybrid chiller demonstrator with conventional horizontal tube falling film heat exchangers and $15 \mathrm{~kW}$ chilled water capacity has been designed, built and tested at Munich University of Applied Sciences laboratories. The thermal results are in good accordance with the simulation for all evaluated operation modes. Yet, rather poor values have been obtained for the effective auxiliary energy consumption, as the power train of the mechanical compressor is not optimized for the given conditions. Thus, due to the lack of a shaft power measurement the energetic effect of the hybrid cycle concept could not be fully evaluated.

Further investigations focus on an effective implementation of the examined operational modes in order to optimize the seasonal performance and investment costs of the hybrid chiller for promising applications such as solar cooling, tri-generation systems and district heating networks.

\section{Acknowledgement}

This project is funded by the German ministry of Education and Research under grant number 13FH023I3 


\section{References}

Altenkrich, E., 1954. Absorptionskältemaschinen. Berlin: Verl. Technik.

Eckert, T., Helm, M., Schweigler, C., 2015. Lithium bromide / R718 Hybrid Soprtion \& Compression Cycle, Yokohama, Japan: 24th IIR International Congress of Refrigeration (ICR2015), Congress Proceedings. doi: 10.18462/iir.icr.2015.0560.

Eckert, T., Helm, M. \& Schweigler, C., 2016. Design of a centrifugal Turbo Compressor with the working fluid water for the operation in a hybrid sorption/compression heat pump cycle. Seoul, Korea, ASME Turbo Expo. doi:10.1115/GT2016-58177.

Efficient energy GmbH, 2016. Technical data eChiller 2-35, Feldkirchen, Germany.

Helm, M., Eckert, T. \& Schweigler, C., 2015. Hybrid Water/LiBr Absorption chiller boosted by high-speed turbo compressor, Rome, Italy: 6th International Conference Solar Air-Conditioning.

Meier-Staude, R. \& Kniffler, O., 2013. Entwicklung und Herstellung von Prototypen der Verdampfer und Verflüssiger für die ct-turbo Wärmepumpe, Feldkirchen: Efficient Energy GmbH.

Osenbrück, A., 1895. Verfahren zur Kälteerzeugung bei Absorptionsmaschinen. Germany: in Kaiserliches Patentamt. 


\title{
Modified Solar-Assisted Ejector Cooling System
}

\author{
Bin-Juine Huang, Hua-Wei Ko, Wei-Zhe Ton, Chen-Chun Wu, \\ Hsien-Shun Chang, Hang-Yuen Hsu, Jen-Hao Liu, Jia-Hung Wu, Rue-Her Yen \\ Department of Mechanical Engineering, National Taiwan University, Taipei, Taiwan
}

\begin{abstract}
Solar-assisted cooling technology (SACH) was developed using a solar heat-driven ejector cooling system (ECS) to cool the condenser and reduce the power consumption of an inverter-type air conditioner (IAC). IAC provides cooling capacity for cooling load of a room, while ECS acts as a means of energy saving for IAC. A perfect system matching design of SACH is difficult since incident solar radiation is unpredictable and unstable. At high solar radiation, the cooling capacity provided by ECS can be larger than the condensing heat of the IAC. A modified SACH (named "SACH-y") is proposed in the present study, which adds another evaporator of the ECS to supply additional cooling capacity to the room. The measured net electrical $\mathrm{COP}_{\mathrm{e}}$ of SACH-y (using an IAC with COP 3.25) reaches 5.54. If the modern advanced IAC with COP 5.7 was used, the total net $\mathrm{COP}_{\mathrm{e}}$ will exceed 10.
\end{abstract}

Keywords: solar cooling, ejector cooling, solar ejector cooling

\section{Introduction}

Many solar cooling researches focus on the heat-driven cooling technology such as absorption/adsorption cooling which needs a backup heater to supply heat to run the cooling system when solar radiation is not available. This is complicated and expensive.

NTU (National Taiwan University) developed solar-assisted cooling technology (SACH) using ejector cooling system (ECS) which is driven by solar thermal collector. The ECS is used to cool the condenser of the inverter-type air conditioner (IAC) to improve its COP (coefficient of performance) and reduce the power input to the IAC. In SACH, IAC provides cooling capacity for cooling load, while ECS acts as a means of energy saving for IAC. No backup heater is required. Several types of SACH have been developed. SACH-k2 (Fig 1) was designed in package for commercialization, in which ECS is in series connection with IAC (Huang et al, 2014).

This research is focused on the reduction of power consumption by peripherals including cooling tower fans, refrigerant pump, water pumping of solar heating system in order to obtain an overall system COP lower than that of conventional IAC to achieve energy saving (Huang et al, 2014). An evaporator temperature control technology was also developed for optimal performance under variable solar radiation (Huang et al, 2010). A tracking control system (maximum-power-point tracking, MPPT) was developed for optimal pumping power consumption in solar heating system which reduces the pumping power by $73 \%$ without decreasing the solar energy collection (Huang et $\mathrm{al}, 2012$ ). The test results show that the overall COP of SACH-k2 reaches 4.5. However, it was found that at high solar radiation, the cooling capacity provided by ECS can be larger than that required to remove the condensing heat of the IAC. This causes cooling capacity loss of ECS. Hence, a modified SACH (named "SACH-y") is proposed. An additional evaporator of the ECS was added to supply additional cooling capacity to the room. 


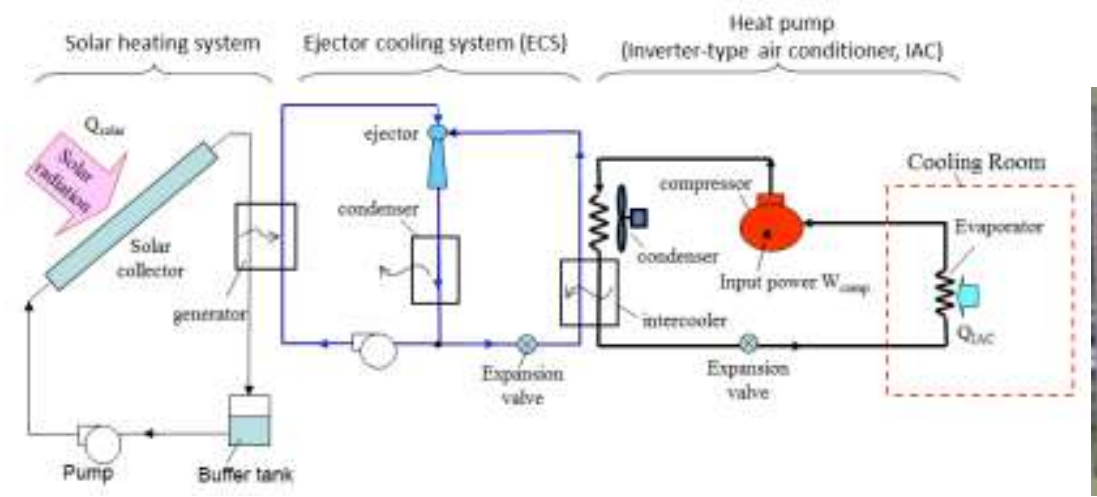

Fig. 1: SACH-k2 (package type) (Huang et al, 2014)

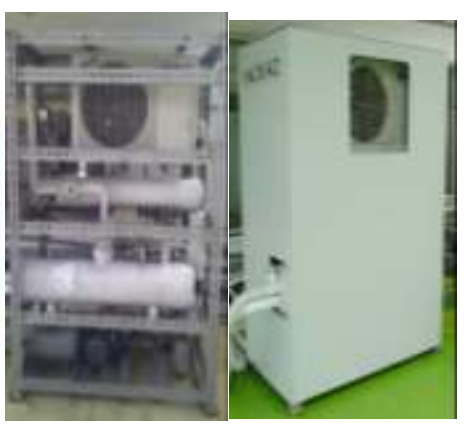

\section{Design of a modified SACH (SACH-y)}

SACH-y is a modified system from SACH-k2. SACH-k2 consists of 3 major parts: solar heating system, ejector cooling system (ECS) with water-cooled condenser, and inverter-type air conditioner (IAC). The schematic diagram is shown in Fig 1. ECS is coupled with IAC at the intercooler, which is the evaporator of ECS or the sub-cooler of IAC. The cooling load of the cooling room is $3.5 \mathrm{~kW}$ (1RT) which matches the rated cooling capacity of the IAC used. The cooling capacity of the ECS is $5.6 \mathrm{~kW}$ which is able to cool the condenser of the IAC at a lower condnsing temperature to increase the COP of IAC. The system design specification of SCH-k2 is shown in Tab 1. R245fa is used as the working fluid of ECS. Tab 2 shows the design specification of ECS. Tab 3 shows the specification of IAC used. Tab 4 shows the design of shell-tube intercooler.

The solar heating system used in SACH-k2 is the same as that used in the study of MPPT (maximum-power-point tracking) control of circulation pump (Huang et al., 2012). The solar heating system (Fig.2) consists of 24 flowthrough vacuum-tube collectors (Model EZL100-6) with $26 \mathrm{~m}^{2}$ total absorber area. Eight collectors are connected in series and three in parallel. Glycol solution is pumped from the buffer tank through the solar collector and absorbs solar energy to heat the generator of ECS. An inverter for rotational speed control of the circulation pump was installed to control flowrate and a PC-based control system was developed for the MPPT control of the circulation pump.

The solar heating system can supply hot water at temperature $70-130^{\circ} \mathrm{C}$ to drive the ejector cooling system. A buffer tank (200L) is used as a storage for stablizing flowrate. The test of solar collector shows that the thermal efficiency of the solar heating system is 0.6 at inlet water temperature $100^{\circ} \mathrm{C}$ (Huang et al, 2010).

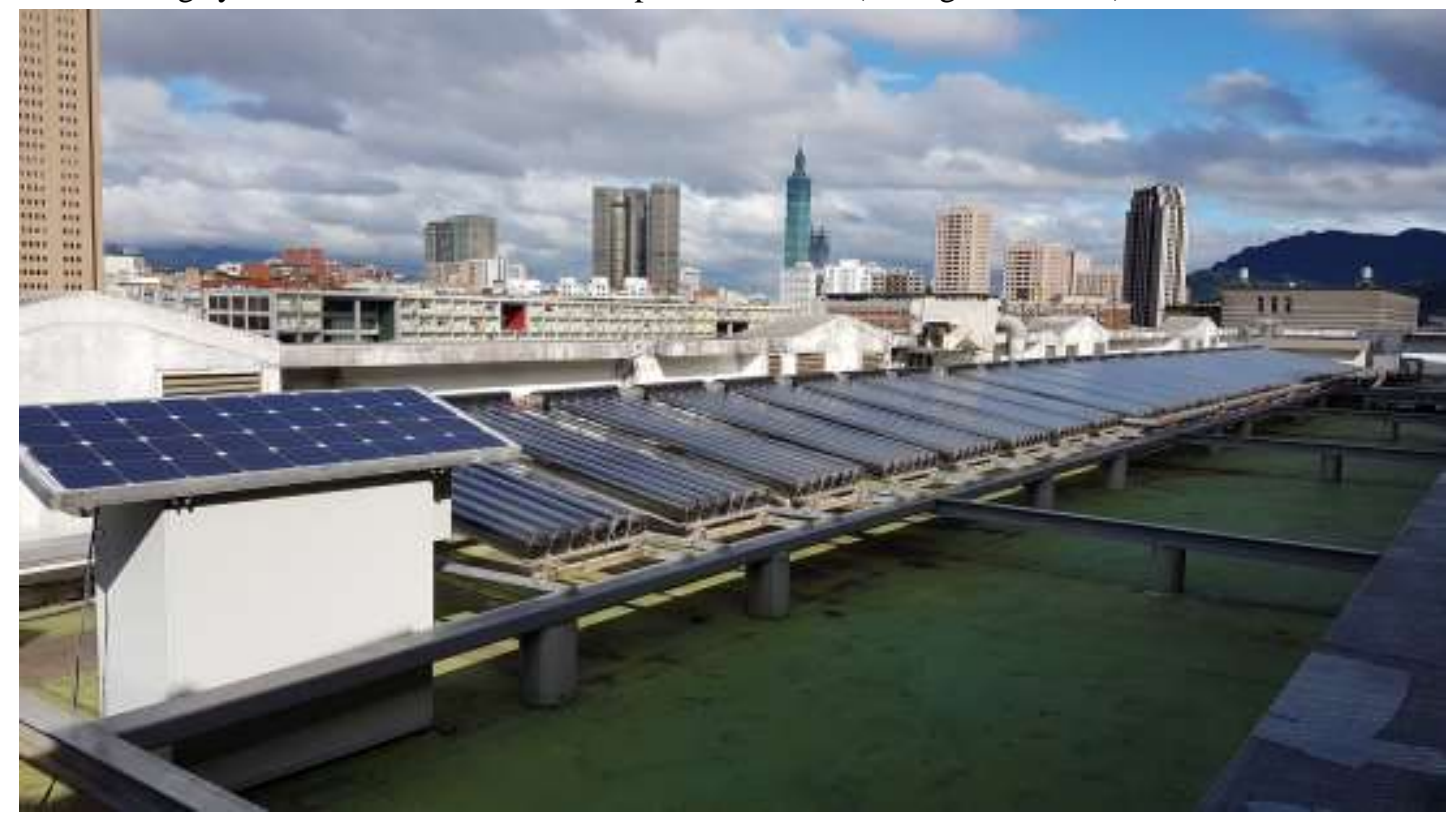

Fig. 2: Vacuum-tube solar collector of SACH (Huang et al., 2012). 
Tab. 1: System design specification of SACH-k2.

\begin{tabular}{lc}
\hline \multicolumn{2}{c}{ Design Specification of IAC } \\
\hline IAC model: & MA732BVY8 \\
Refrigerant: & $\mathrm{R} 22$ \\
Condenser temperature, ${ }^{\circ} \mathrm{C}$ : & 54 \\
Evaporator temperature, ${ }^{\circ} \mathrm{C}:$ & 8 \\
Condenser heat rejection, $\mathrm{kW}:$ & 8 \\
Cooling capacity, $\mathrm{kW}:$ & $1.2 \sim 4.5$ \\
Compressor input, $\mathrm{kW}:$ & $0.4 \sim 1.125$ \\
COPIAC: & 3.25 \\
\hline \multicolumn{1}{c}{ Design Specification of ECS } \\
\hline Refrigerant & $\mathrm{R} 245 \mathrm{fa}$ \\
Generator temperature, ${ }^{\circ} \mathrm{C}$ & 100 \\
Condensing temperature, ${ }^{\circ} \mathrm{C}$ & 40 \\
Evaporator temperature, ${ }^{\circ} \mathrm{C}$ & 20 \\
Generator heat input, $\mathrm{kW}$ & 8.9 \\
Condenser capacity, $\mathrm{kW}$ & 14.6 \\
Evaporator capacity, $\mathrm{kW}$ & 5.6 \\
COPECS & 0.63 \\
\hline
\end{tabular}

Tab. 2: Design specification of ECS

\begin{tabular}{lc}
\hline Refrigerant & R245fa \\
Cooling capacity $(\mathrm{kW})$ & 5.6 \\
Operating temperature: & 100 \\
$\quad$ Generator temperature $\left({ }^{\circ} \mathrm{C}\right)$ & 20 \\
Evaporator temperature $\left({ }^{\circ} \mathrm{C}\right)$ & 40 \\
Condenser temperature $\left({ }^{\circ} \mathrm{C}\right)$ & \\
Flowrate: & 0.030 \\
Primary flowrate $(\mathrm{kg} / \mathrm{s})$ & 0.022 \\
Entrained flowrate $(\mathrm{kg} / \mathrm{s})$ & 2.04 \\
Compression ratio & 0.73 \\
Entrainment ratio & \\
Heat transfer rate: & 8.9 \\
Generator $(\mathrm{kW})$ & 5.6 \\
Evaporator $(\mathrm{kW})$ & 14.5 \\
Condenser $(\mathrm{kW})$ & 0.63 \\
COP & \\
\hline
\end{tabular}

Tab.3: Specification of IAC.

\begin{tabular}{lc}
\hline IAC model: & MA732BVY8 \\
Refrigerant: & $\mathrm{R} 22$ \\
Condensing temperature, ${ }^{\circ} \mathrm{C}:$ & 54 \\
Evaporating temperature, & ${ }^{\circ} \mathrm{C}:$ \\
Condenser heat rejection, $\mathrm{kW}:$ & 8 \\
Cooling capacity, $\mathrm{kW}:$ & 5.6 \\
Compressor input, $\mathrm{kW}:$ & $0.4 \sim 1.125$ \\
$\mathrm{COP}_{\text {IAC: }}$ & 3.25 \\
\hline
\end{tabular}

Tab. 4: Design of intercooler.

\begin{tabular}{ccc|cc}
\hline \multicolumn{5}{c}{ Tab. 4: Design of intercooler. } \\
\hline inlet & outlet & inlet & outlet \\
\hline temperature $\left({ }^{\circ} \mathrm{C}\right)$ & 25 & 35 & 78 & 40 \\
pressure $(\mathrm{MPa})$ & 0.1013 & 0.1013 & 0.143 & 0.121 \\
flowrate $(\mathrm{kg} / \mathrm{s})$ & 0.26 & 0.26 & 0.052 & 0.052 \\
enthalpy $(\mathrm{kJ} / \mathrm{kg})$ & 104.83 & 146.63 & 462.43 & 252.57 \\
\hline Max heat rate $(\mathrm{kW})$ & \multicolumn{5}{c}{10.9} \\
\hline
\end{tabular}


B. Huang et. al. / EuroSun 2018 / ISES Conference Proceedings (2018)

Tab. 5: Overall system performance of SACH-k2 (Huang et al, 2014).

\begin{tabular}{|c|c|c|c|c|c|c|c|c|}
\hline date & \multicolumn{2}{|c|}{$05 / 09$} & \multicolumn{2}{|c|}{$05 / 18$} & \multicolumn{2}{|c|}{$05 / 26$} & \multicolumn{2}{|c|}{$05 / 29$} \\
\hline Test condition & IAC & SACH-k2 & IAC & ACH-k2 & IAC & SACH-k2 & IAC & SACH-k2 \\
\hline Ambient temperature, ${ }^{\circ} \mathrm{C}$ & \multicolumn{2}{|r|}{34} & \multicolumn{2}{|c|}{29.4} & \multicolumn{2}{|c|}{28} & \multicolumn{2}{|r|}{25} \\
\hline $\begin{array}{l}\text { IAC subcooling, }{ }^{\circ} \mathrm{C} \\
\text { IAC power, } \mathrm{kW}\end{array}$ & $\begin{array}{c}- \\
1.09\end{array}$ & $\begin{array}{l}15 \\
0.6\end{array}$ & - & $\begin{array}{l}15.2 \\
0.51\end{array}$ & $\overline{-}$ & $\begin{array}{l}14.8 \\
0.63\end{array}$ & $-\overline{9}$ & $\begin{array}{l}15.2 \\
0.48\end{array}$ \\
\hline Total peripheral power, $\mathrm{kW}$ & - & 0.32 & - & 0.29 & - & 0.27 & - & 0.34 \\
\hline Cooling capacity, kW & 3.2 & 3.7 & 3.2 & 3.6 & 3.1 & 3.8 & 3.0 & 3.6 \\
\hline$C O P_{o}$ & 2.94 & 4.06 & 3.3 & 4.50 & 2.96 & 4.22 & 3.24 & 4.32 \\
\hline
\end{tabular}

The test results (Tab 5) show that the overall COP of SACH-k2 reaches 4.5. It was also found that it is difficult to obtain a perfect system matching design of SACh-k2 since solar radiation variation is unpredictable and unstable. ECS is used to cool the condenser of IAC for sub-cooling to increase the COP of IAC. At high solar radiation, the cooling capacity provided by ECS can be larger than the condensing heat of the IAC. That is, excess cooling capacity of ECS is available in good weather.

To improve the cooling efficiency, we modified SACH-k2 by adding another evaporator (fan-coil unit) of the ECS to supply additional cooling capacity $\left(Q_{E C S}\right)$ to the room (Fig. 3), named "SACH-y". SACH-y combines the design of SACH-2 (parallel configuration) (Huang et al, 2010) and SACH-k2 (series configuration) (Huang et al, 2014).

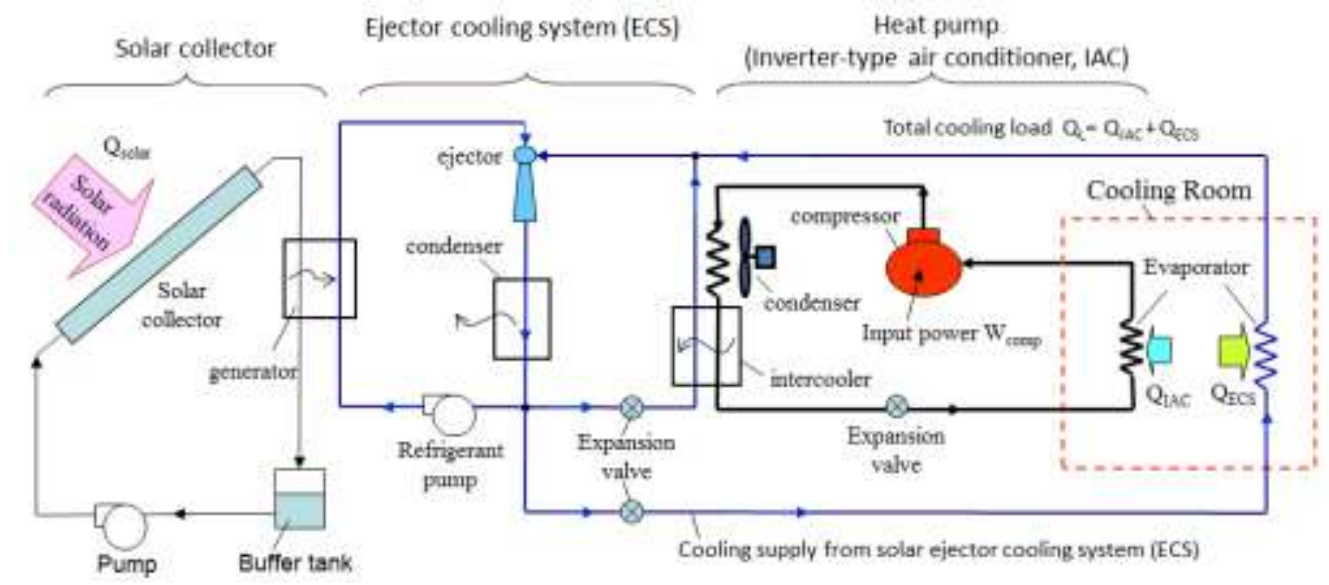

Fig. 3: Schematic of modified SACH (SACH-y).

\section{Test results}

The measured total electrical $\mathrm{COP}_{\mathrm{e}}$ of SACH-y reaches 5.54 (Tab. 5) using an IAC with measured maximum COP 2.63. The technology of SACH-k2 and SACH-y has been developed quite well after a series of researches on ejector design, selection of working fluid, optimal control for stable and optimal performance under variable solar radiation, and optimal control for minimum energy consumption of all peripherals. The present result has shown a better performance than solar cooling systems using absorption/adsorption technology and falls in the target area identified by Wiemken (2010) (Fig.4). If the modern IAC with COP 5.7 was used in SACH-y, the total net COP will exceed 10 (Fig. 4).

Tab. 6: Test results of SACH-y.

\begin{tabular}{|c|c|c|c|c|c|c|c|c|c|c|c|}
\hline \multirow[t]{2}{*}{$\begin{array}{l}\text { Operating } \\
\text { Mode }\end{array}$} & \multirow[t]{2}{*}{$\begin{array}{l}\text { Date } \\
\text { (ambient } \\
\text { temp) }\end{array}$} & \multirow[t]{2}{*}{$\begin{array}{l}\frac{\mathrm{I}_{7} \text { of }}{\mathrm{ECS}} \\
\left({ }^{\circ} \mathrm{C}\right)\end{array}$} & \multirow[t]{2}{*}{$\begin{array}{l}\mathrm{T}_{e} \text { of } \\
\mathrm{ECS} \\
\left({ }^{\circ} \mathrm{C}\right)\end{array}$} & \multirow[t]{2}{*}{$\begin{array}{c}\text { LAC } \\
\text { condensing } \\
\text { temperature } \\
\left({ }^{\circ} \mathrm{C}\right)\end{array}$} & \multicolumn{2}{|c|}{$\begin{array}{c}\text { LAC } \\
\text { intercooler } \\
\text { temperature } \\
\left({ }^{\circ} \mathrm{C}\right)\end{array}$} & \multirow[t]{2}{*}{$\begin{array}{c}\text { Power } \\
\text { consumption } \\
\text { of LAC } \\
\text { (W) }\end{array}$} & \multirow[t]{2}{*}{$\begin{array}{c}\text { Total power } \\
\text { consumption } \\
\text { (W) }\end{array}$} & \multirow[t]{2}{*}{$\begin{array}{l}\text { Cooling } \\
\text { capacity by } \\
\text { IAC } \\
\text { (W) }\end{array}$} & \multirow[t]{2}{*}{$\begin{array}{l}\text { Cooling } \\
\text { capacity by } \\
\text { ECS } \\
\text { (W) }\end{array}$} & \multirow[t]{2}{*}{$\mathrm{COP}_{\mathrm{e}}$} \\
\hline & & & & & inlet & outlet & & & & & \\
\hline LAC alone & $2012 / 5 / 22$ & $\because$ & - & 459 & 33.4 & 31.8 & 998 & & 2629 & - & 2.63 \\
\hline SACH-y & $\left(27^{\circ} \mathrm{C}\right)$ & 93 & 16.7 & 31.4 & 29,0 & 18.6 & 417 & & 2274 & 2002 & 5.54 \\
\hline IAC alone & $2012 / 5 / 23$ & - & - & 49.1 & 35.6 & 35.0 & 1061 & 1061 & 2603 & - & 2.45 \\
\hline SACH-y & $\left(29.4^{\circ} \mathrm{C}\right)$ & 97.1 & 19.6 & 35.1 & 32.6 & 21.3 & 506 & 906 & 2443 & 1629 & 4.55 \\
\hline LAC alone & $2012 / 5 / 23$ & - & - & 49.1 & 35.6 & 35.0 & 1061 & 1061 & 2603 & - & 2.45 \\
\hline $\mathrm{SACH}-\mathrm{y}$ & $\left(29.2^{\circ} \mathrm{C}\right)$ & 98.3 & 18.9 & 34.1 & 31.7 & 20.8 & 441 & 855 & 2378 & 1833 & 4.93 \\
\hline LAC alone & $2012 / 5 / 26$ & 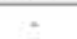 & - & 51.9 & 34.9 & 36.0 & 1083 & 1083 & 2370 . & 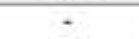 & 2.17 \\
\hline SACH-y & $\left(30^{\circ} \mathrm{C}\right)$ & 91.7 & 20.6 & 37.3 & 34.6 & 26.2 & 525 & 936 & 2310 & 1838 & 4.46 \\
\hline LAC alone & $2012 / 5 / 26$ & $\cdot$ &. & 51.9 & 34.9 & 36.0 & 1083 & 1083 & 2370 & 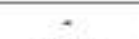 & 2.17 \\
\hline SACH-y & $\left(30^{\circ} \mathrm{C}\right)$ & 92.8 & 21.4 & 35.7 & 33.4 & 23.8 & 455 & 871 & 2318 & 1839 & 4.77 \\
\hline
\end{tabular}




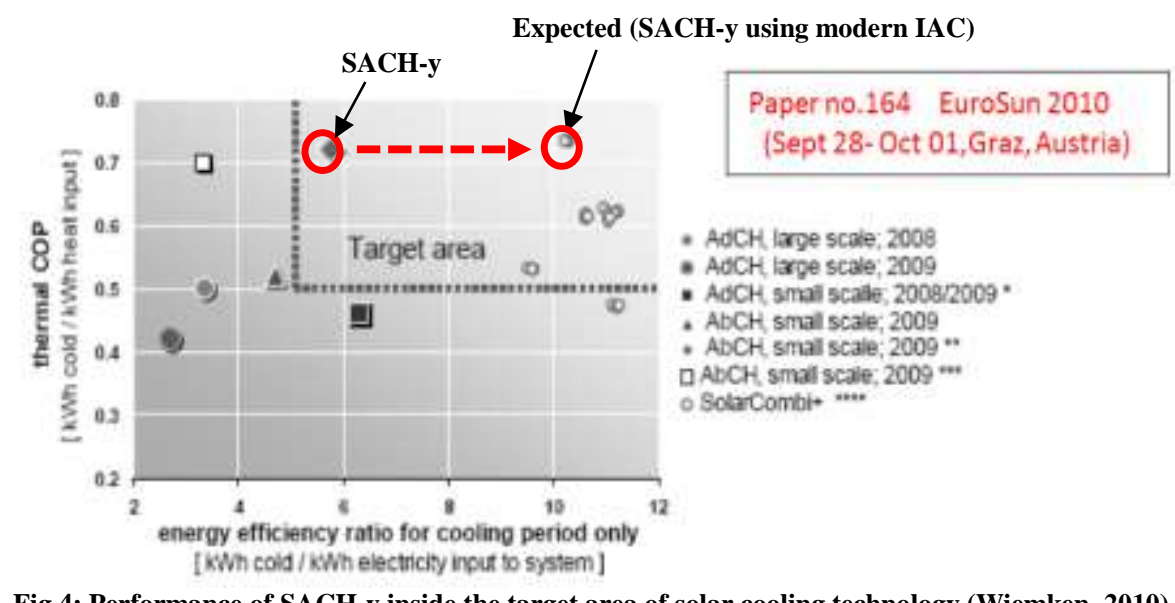

Fig.4: Performance of SACH-y inside the target area of solar cooling technology (Wiemken, 2010).

\section{Conclusion}

In the present study, a solar-assisted cooling technology (SACH) was developed using ejector cooling system (ECS) which is driven by solar thermal energy. SACH-k2 consists of solar heating system, ejector cooling system (ECS) with water-cooled condenser, and inverter-type air conditioner (IAC). ECS is coupled with IAC at the intercooler, which is the evaporator of ECS or the sub-cooler of IAC. Solar heat-driven ECS is used to cool the condenser and reduce the condensing temperature and power consumption of IAC. But, a perfect system matching design of SACh$\mathrm{k} 2$ is difficult since solar radiation variation is unpredictable and unstable. At high solar radiation, the cooling capacity provided by ECS can be larger than the condensing heat of the IAC. This causes cooling capacity loss of ECS. Hence, a modified SACH (named "SACH-y") is proposed in the present study. It was modified from SACH$\mathrm{k} 2$ by adding another evaporator of the ECS to supply additional cooling capacity to the room. The measured total electrical $\mathrm{COP}_{\mathrm{e}}$ of SACH-y reaches 5.54 using an IAC with COP 2.63. If a modern IAC with COP 5.7 was used in $\mathrm{SACH}-\mathrm{y}$, the total net $\mathrm{COP}_{\mathrm{e}}$ will exceed 10.

\section{References}

Huang B.J., Yen C.W., Wu J.H., Liu J.H., Hsu H.Y., Petrenko V.O., Chang J.M., Lu C.W. 2010. Optimal control and performance test of solar-assisted cooling system. Applied Thermal Engineering 30, 2243-2252 http://doi:10.1016/j.applthermaleng.2010.06.004

Huang Bin-Juine, Ton Wei-Zhe, Wu Chen-Chun, Ko Hua-Wei, Chang Hsien-Shun, Yen Rue-Her, Wang Jiunn Cherng. 2012. Maximum-power-point tracking control of solar heating system. Solar Energy 86, 3278-3287 http://dx.doi.org/10.1016/j.solener.2012.08.019

Huang, Bin-Juine, Ton, Wei-Zhe, Wu, Chen-Chun, Ko, Hua-Wei, Chang, Hsien-Shun, Hsu, Hang-Yuen, Liu, JenHao, Wu Jia-Hung, Yen Rue-Her. 2014. Performance Test of Solar-Assisted Ejector Cooling System. Int J Refrigeration 39, 172-185 http://dx.doi.org/10.1016/j.ijrefrig.2013.06.009

Wiemken, E. Performance and perspectives of solar cooling. EuroSun 2010, Sept. 28-Oct.1, 2010. Graz, Austria.

\section{Acknowledgment}

This publication is based on the work supported by Award No.KUK-C1-014-12, made by King Abdullah University of Science and Technology (KAUST), Saudi Arabia. 


\title{
Levelised Cost of Thermal Energy Storage and Battery Storage to Store Solar PV Energy for Cooling Purpose
}

\author{
Christoph Luerssen ${ }^{1,2}$, Oktoviano Gandhi', Thomas Reindl', David Cheong ${ }^{2}$ and Chandra \\ Sekhar $^{2}$ \\ 1 Solar Energy Research Institute of Singapore (SERIS), National University of Singapore (NUS), \\ Singapore (Singapore) \\ 2 Department of Building, National University of Singapore (NUS), Singapore (Singapore)
}

\begin{abstract}
In this paper, we define scenarios for cooling applications that are coupled with photovoltaic (PV) systems and highlight the role of energy storage. Subsequently, we advance the method of Levelised Cost of Storage (LCOS), which has been developed for electricity storage in the literature, to compare thermal energy storage and battery storage for cooling application coupled with PV systems. Lastly, we apply the method to a real scenario and determine the LCOS of chilled water storage and battery storage configurations. The existing 11,000 $\mathrm{m}^{2}$ officecum-retail in the tropics of Singapore utilizes a $1055 \mathrm{~kW}_{\text {th }}$ chiller to supply its air-conditioning needs. Moreover, the rooftop is capable to accommodate a $247.5 \mathrm{~kW}_{\mathrm{p}} \mathrm{PV}$ system. A parametric simulation study was considered by varying the usable energy storage capacity from $100 \mathrm{kWh}$ to $5000 \mathrm{kWh}$. It was found that for battery storage 300 $\mathrm{kWh}$ capacity offers the lowest LCOS of $0.10 \mathrm{USD} / \mathrm{kWh}$ for this particular application. However, the LCOS of the chilled water storage is at 0.06 to $0.08 \mathrm{USD} / \mathrm{kWh}$ for various storage sizes. Nevertheless, the battery storage is able to increase the self-consumption of PV energy more than the thermal energy storage option, as the chiller plant control proved to be crucial for the integration of thermal energy storage.
\end{abstract}

Keywords: Battery, demand side management, energy storage, LCOS, levelised cost of storage, PV powered cooling, solar air-conditioning, thermal energy storage

\section{Introduction}

Solar photovoltaic (PV) systems added to buildings can contribute a certain portion of the building electricity demand. In sunny areas, the electricity demand is often dominated by the cooling power consumption. Cooling applications such as air-conditioning and food conservation can be coupled with solar PV systems. However, the solar irradiance profile, shown as a graph in Figure 1 (top), does not always match the cooling demand of different applications. Figure 1 (bottom) shows the cooling load requirements of different building types over the course of one typical day. Hence, energy storage is essential for many situations in which cooling applications are coupled with solar PV systems. Energy storage is a necessity in off-grid systems and has been gaining importance in ongrid systems to increase the self-consumption of solar PV energy and provide services to the electricity grid (Luthander et al., 2015). Utilising electrical energy generated by a PV system to run a chiller for a cooling application enables both battery storage (Teleke et al., 2010) and thermal energy storage (Arteconi et al., 2017). The implementation of energy storages in combination with PV systems and cooling systems depends not only on the performance of the energy storage solution, but especially on its economic viability.

The literature discusses such configurations mostly in the form of case studies. For example, Arteconi et al. (2017) analysed a case for an industrial building that has a PV system and uses a chilled water tank. They applied the existing chilled water tank in combination with the PV system for demand side management for an industrial building in Italy, which only requires cooling during daytime on weekdays. Hence, the authors used the chilled water tank to shift the electrical load to the weekend, running the chillers to utilise electrical energy generated by the PV system. Based on a calibrated dynamic simulation model, energy performance and economics were investigated. As expected, the cooling system's energy demand rises when the thermal energy storage is used. 
However, the energy costs decrease, as the cheaper PV energy is utilised, which makes the use of the thermal energy storage profitable. Nevertheless, the study assumed that the systems were already in place and did not take into account the cost of initial investment. Adding the thermal energy storage to the existing PV and cooling system might have resulted in a long payback period.

Meanwhile, utilising batteries for cooling applications has not been sufficiently explored in the literature. Many sources focused on the general electricity demand profile and the PV power generation profile to increase the selfconsumption of PV energy. For example, Merei et al. (2016) conducted a sensitivity analysis for a supermarket with PV and battery system in Germany. Energy intensive commercial buildings with large rooftop space can be a compelling case for PV systems coupled with energy storage. According to the economic situation in Germany and the supermarket power consumption profile, the PV system is viable; however, the battery storage becomes only viable when its cost falls below $200 € / \mathrm{kWh}$. The authors mentioned that for different commercial load profiles, battery storage might be feasible.

Previous studies have analysed the economics of case study systems with PV and energy storage for cooling applications, but there is little research comparing the economics of thermal energy storage with that of battery storage. Thus, the objective of this study is to assess energy storage costs for chilled water storage and battery storage to store energy for cooling purpose. A specific office-cum-retail building in Singapore is analysed, as a major portion of building energy consumption accounts for cooling in cities in the tropics. Therefore, energy simulation models are developed and run with varying storage sizes in order to determine the suitable storage size for the specific application. Moreover, a financial method for the assessment of the costs of energy storage is proposed in this work, as there is no suitable method for comparison of thermal energy storage and battery storage yet.

The subsequent sections of this paper are structured as follows: Section 2 explains the variety of PV powered cooling applications, followed by the scenario description in Section 3. The methodology Sections 4 and 5 describe the energy simulation and financial method, respectively. Subsequently, Section 6 presents the results. Finally, the work is concluded in Section 7.
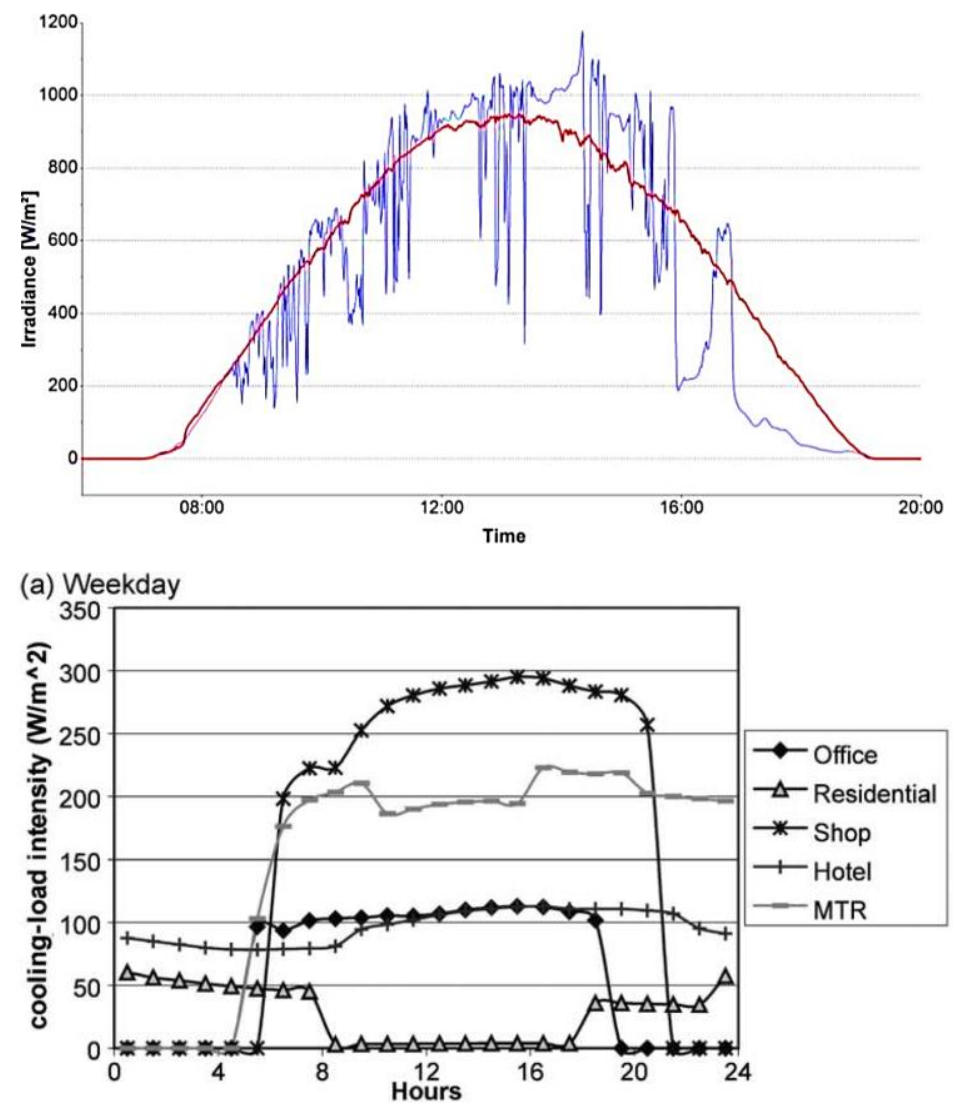

Fig. 1: Measured solar irradiance of a typical clear-sky day (red) and a typical cloudy day (blue) in Singapore (SERIS, 2011) at the top and simulated cooling load for different building types in the subtropical Hong Kong (Chow et al., 2004) at the bottom. 


\section{Energy storage for cooling applications coupled with PV systems}

PV systems to supply energy for cooling applications may be located in areas with access to the public electricity grid (on-grid), or in areas that are not connected to the public electricity grid (off-grid). When PV systems are coupled with cooling system, different configurations can be realised. As shown in Figure 2, the system configuration depends on the availability of a grid connection, which means on-grid (a) or off-grid (b), and the integration of energy storage solutions $(1-5)$.

In an on-grid scenario (e.g. air-conditioned building with a rooftop PV system in a city) energy storage is not a necessity (1a). The total electrical load does not only consist of the chiller plant, but also of other appliances in the building. The PV system offsets a certain portion of the building power consumption that varies with the solar irradiance. If a low-rise building is assumed, the PV power might exceed the building power consumption at times. Then, the surplus power is fed into the public grid. When the building power consumption is higher than the PV power, the remaining power is supplied by the public grid.

However, in an off-grid system there is no public grid to buffer the volatility of power demand and supply. In a scenario without energy storage (1b), that would mean the cooling system can only be powered when the solar irradiance is sufficient. This kind of system would not be able to supply continuous cooling; hence it is not applicable in practice. In order to supply a cooling load sufficiently in an off-grid situation, an energy storage technology such as a battery has to be used (2b).

A well-sized battery absorbs the surplus PV energy and releases electrical power when the solar irradiance is not sufficient to power the cooling system. Battery storages are common in PV off-grid systems such as solar home systems and rural microgrids (Aghamohammadi and Abdolahinia, 2014; Chaurey and Kandpal, 2010; Mohamed and Koivo, 2007). While energy storage is a necessity in off-grid systems, the effective utilization of an energy storage in grid-connected systems depends on the economic viability, which may be achieved by increasing the self-consumption of solar energy instead of selling it to the grid for a lower price (Arteconi et al., 2017).

Due to high shares of renewable energy and their volatile nature, research on features for grid stabilisation via energy storage is prompted (Philipps and Warmuth, 2017). Typically, on-grid battery storage (2a) is considered to provide such services to the grid (Teleke et al., 2010). However, cooling is a thermal load that allows for thermal energy storage (3) to shift the cooling demand. There are different thermal energy storage solutions for cooling applications.

Sensible energy storage is most commonly realised in the form of chilled water (Arteconi et al., 2017). On district cooling scale or in large-scale office buildings, latent heat storage in the form of ice is also common (Chan et al., 2006; Sehar et al., 2012). Other phase change materials have been commercialised and are investigated for application in thermal energy storage systems (Souayfane et al., 2016). Using thermal energy storage implies operating the chillers according to the availability of solar irradiance. Surplus cold is stored in the thermal energy storage to be used when solar energy is not available. This is applicable for on-grid (3a) and off-grid (3b) situations.

A combination of battery storage and thermal energy storage is also possible in on-grid (4a) and off-grid (4b) environments. In urban environments, district cooling (Gang et al., 2016) and urban microgrids (Jones et al., 2013) have become popular topics. Thermal energy storage and battery storage can be realised on a district level to serve the urban microgrid (5a).

Rural microgrids (5b) that are not connected to a public grid have also gained attention. They serve basic electricity needs such as lighting for rural communities. If agriculture or fishing is a source of income for a community, a cold storage could have the potential to improve the economic situation of the community. The food conservation requires continuous cooling, which would result into an enormous battery storage. A thermal energy storage could serve to account for a major part of the required energy storage capacity.

All the cases presented in Figure 2 show the need for energy storage on the one hand, and the diversity of ways of coupling cooling systems with PV systems on the other hand. 


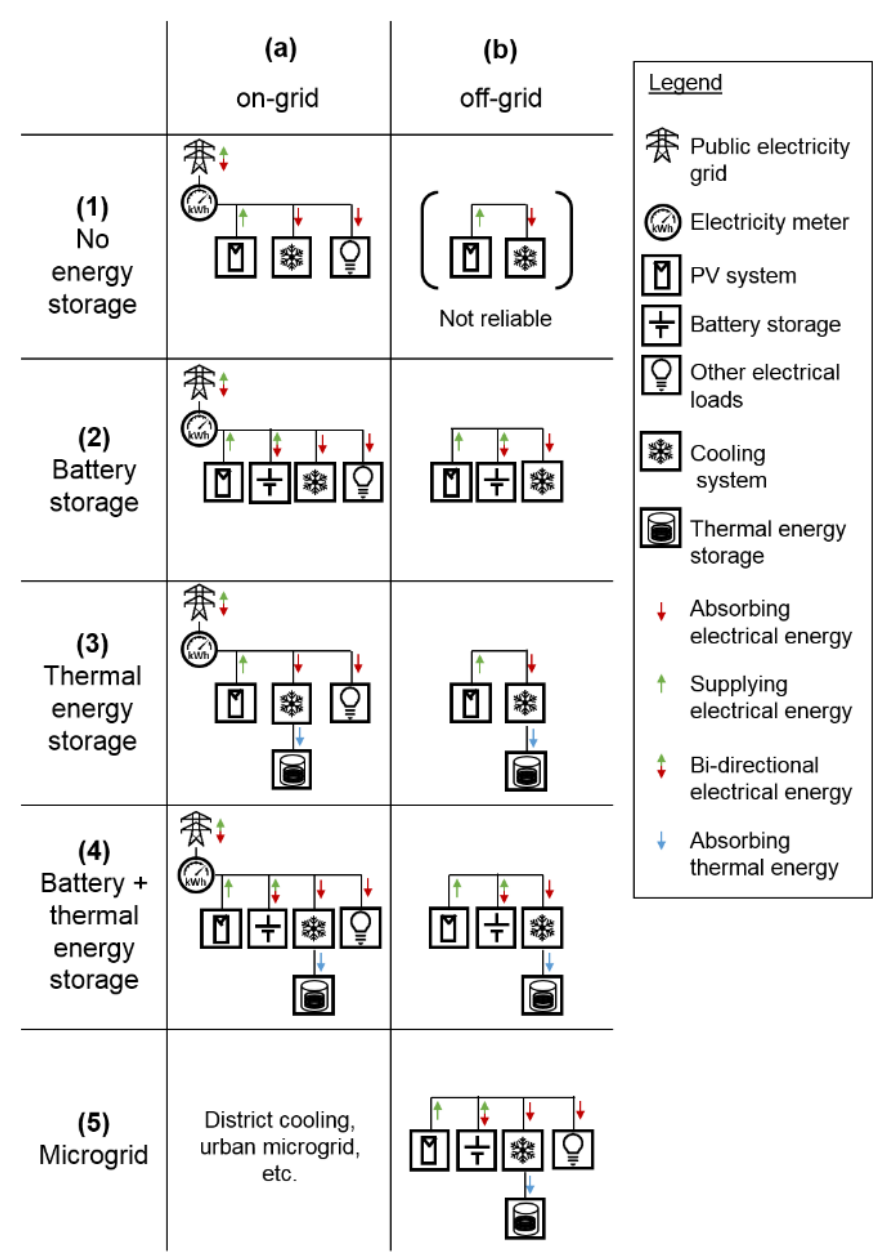

Fig. 2: On-grid and off-grid configurations of PV systems coupled with cooling systems.

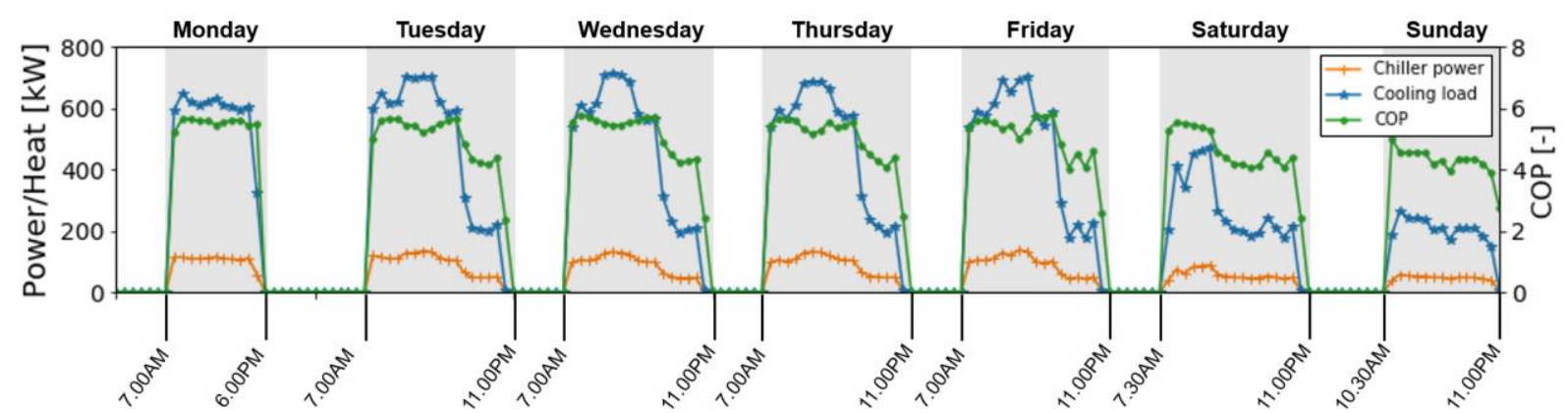

Fig. 3: One week of minutely measured cooling load, chiller plant power and COP profile of an office-cum-retail building in Singapore, which was resampled to hourly data. The weekdays and operating hour are indicated.

\section{Scenario description}

In this study, an on-grid scenario in the urban setting (case (1a), (2a), and (3a) of Figure 2) of Singapore is analysed with regards to the integration of energy storage. The anonymised office-cum-retail building with a restaurant as well as food and beverage outlets on the ground floor was constructed in the mid-1990s. It has eight stories above ground and a basement carpark. The gross floor area is roughly $11,000 \mathrm{~m}^{2}$ of which around 10,000 $\mathrm{m}^{2}$ are airconditioned. Therefore, it belongs to the category of small office buildings under $15,000 \mathrm{~m}^{2}$ according to the local Building and Construction Authority (BCA) Green Mark scheme (BCA_GM, 2018). The air-conditioning needs are supplied by a $1055 \mathrm{~kW}_{\text {th }}$ (300 RT) water-cooled variable speed drive centrifugal chiller for 96 hours per week. The operating hours, cooling load, chiller power consumption and chiller performance are visualised in Figure 3, which shows one week of measured data for the described building. The data were obtained during an energy audit using calibrated equipment and one-minute data logging by a certified Energy Service Company (ESCO). 
During office hours on weekdays, the cooling load is usually within the range of $560 \mathrm{~kW}_{\mathrm{th}}(159 \mathrm{RT})$ and $740 \mathrm{~kW}_{\mathrm{th}}$ (210 RT). The peak load occurs from 10.00am to $3.00 \mathrm{pm}$ on weekdays, when most of the occupants are in the offices. Some tenants operate for half day on Saturdays, which results into a cooling load of $350 \mathrm{~kW}_{\text {th }}(100 \mathrm{RT})$ to $420 \mathrm{~kW}_{\text {th }}(119 \mathrm{RT})$ in the morning. However, the cooling load drops to $265 \mathrm{~kW}_{\text {th }}(75 \mathrm{RT})-280 \mathrm{~kW}_{\text {th }}(80 \mathrm{RT})$ on Saturday afternoon, Sunday and on weekdays at night time. During these times, only the restaurant is supplied by the chiller.

The overall chiller plant system COP is approximately $6.0-5.5(0.59-0.64 \mathrm{~kW} / \mathrm{RT})$ during office hours on weekdays. Whereas at low cooling demand, when only the restaurant operates, the system operates at an inefficient condition where the COP is only $4.7-4.4(0.75-0.8 \mathrm{~kW} / \mathrm{RT})$. Under BCA Green Mark for existing nonresidential buildings (version 3.0) (BCA_GM, 2012), the building was awarded under the highest category ("platinum") because the chiller plant efficiency is better than a COP of $5.0(0.7 \mathrm{~kW} / \mathrm{RT})$ with less than $1758 \mathrm{~kW}_{\text {th }}$ (500 RT) cooling load. The COP of the chiller plant found in the audit was $5.5(0.64 \mathrm{~kW} / \mathrm{RT})$ during office hours; however, the chiller itself operates at a COP of $7.0(0.50 \mathrm{~kW} / \mathrm{RT})$ at office hours when power consumption of the cooling towers, chilled water pumps and condenser water pumps are not considered.

As the building is located in the tropics of Singapore, which are characterized by year-round high temperature and humidity, the exemplary week (Figure 3) can be assumed to be representative for the whole year. Hence, it was duplicated to assemble an annual cooling load and chiller power consumption profile. For this study, it is assumed that a major part of the roof is covered by $300 \mathrm{~W}_{\mathrm{p}} 60$-cell PV modules, which sum up to a total capacity of 247.5 $\mathrm{kW}_{\mathrm{p}}$. The $825 \mathrm{PV}$ modules cover approximately $1400 \mathrm{~m}^{2}$ of roof area. The annual cooling load profile, the chiller power consumption profile, and the annual solar irradiance from the Typical Meteorological Year (TMY) for the location of Singapore, as well as the PV system size, serve as inputs for simulation models that integrate thermal energy storage and battery storage into the described scenario.

\section{Simulation models}

Simulation models for the PV powered cooling system of the office-cum-retail building were developed using TRNSYS 17.1 (TRNSYS, 2018), which is a transient energy simulation tool. Figure 4 shows schematics of the different simulation models. Model (a) contains the PV array and a grid connected inverter that can not only supply the chiller plant, but also feed energy into the grid. In case of insufficient solar power availability, the remaining power consumption is supplied by the electricity grid. In model (b), a Li-Ion battery storage is added. It stores excess solar power until it is fully charged at $90 \%$ State of Charge (SoC) instead of feeding all excess power into the grid and supplies the load until it is fully discharged at $10 \%$ SoC. The grid kicks in only when the battery is fully discharged. This increases the self-consumption of PV power.

As a chilled water storage is integrated into model (c), the chiller plant, including chilled water circuit to supply the cooling load, have to be simulated. Therefore, the chiller was calibrated using the measured cooling load profile and comparing the simulated power consumption profile to the measured chiller plant power consumption profile. The external performance files of the TRNSYS component were adjusted to reflect the real performance at all part load ratios. The full load chiller plant COP was decreased from 5.2 to 4.2, because the chilled water supply temperature is only $4^{\circ} \mathrm{C}$ as compared to the usual $7^{\circ} \mathrm{C}$ to operate the chilled water tank (PG\&E, 1997).

In order to operate the chiller in synergy with the availability of PV power, a control strategy was implemented. In this study, the chiller turns on as soon as the solar power is larger than $1 \mathrm{~kW}$, and turns off when the solar power is smaller than $1 \mathrm{~kW}$. Additionally, it turns on when the average tank temperature rises above $10^{\circ} \mathrm{C}$. And even if solar power is available, the chiller turns off when the average tank temperature decreases to $4.5^{\circ} \mathrm{C}$, which means that the tank is fully charged. As a high switching frequency harms the chiller, a minimum runtime and minimum rest time of one hour were implemented as well.

In order to determine the impact of the energy storage capacity on the self-consumption of PV power and the energy storage costs, the simulation models (b) and (c) are run as a parametric study with different usable energy storage capacities of $100 \mathrm{kWh}$ to $5000 \mathrm{kWh}$ (in $100 \mathrm{kWh}$ steps). A time step of 1 minute was chosen to enable minutely control decisions. The discharged energy over the energy storage lifetime serves as input for financial method development in Section 5. 


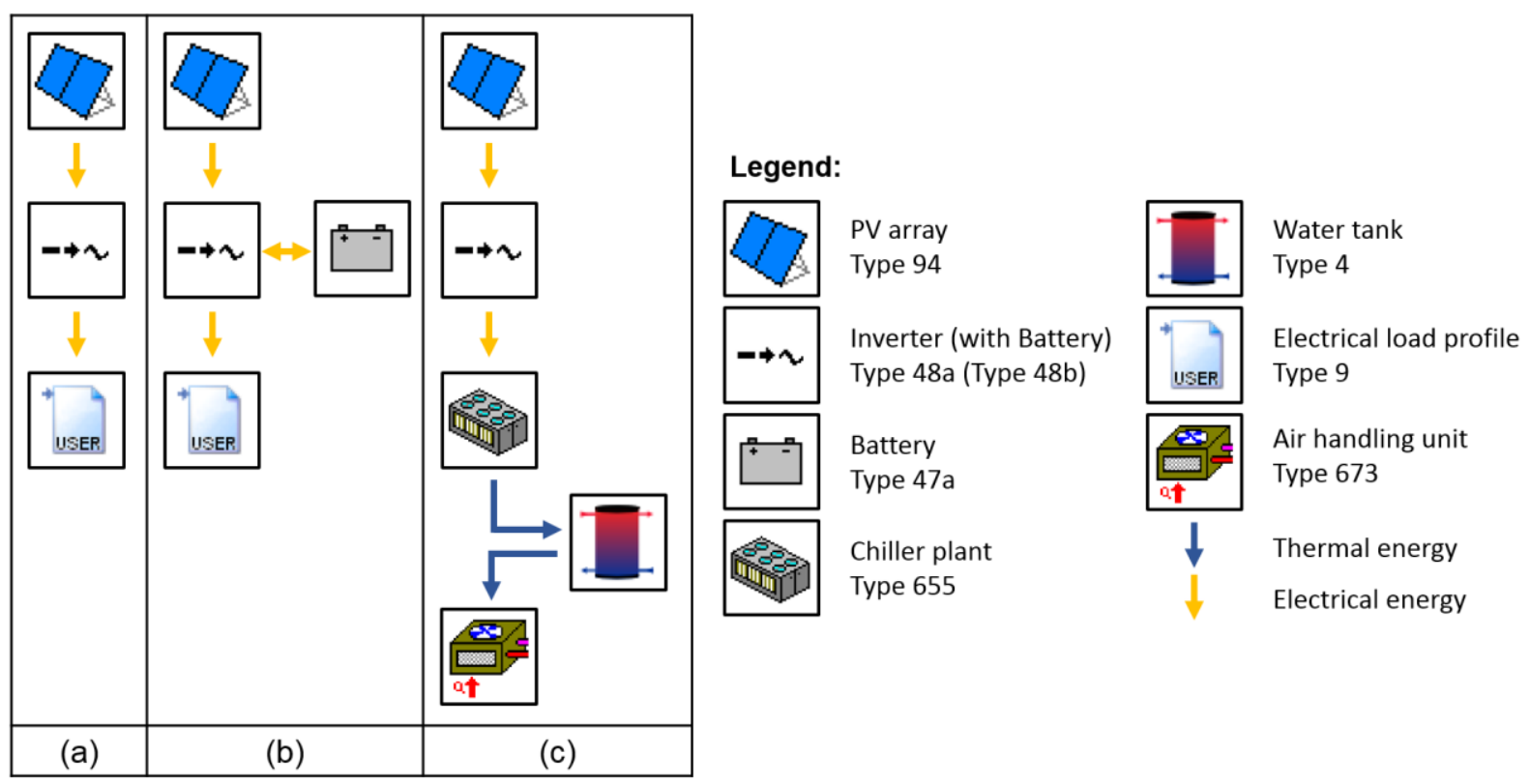

Fig. 4: Schematic of TRNSYS simulation of the PV powered cooling systems without energy storage (a), with battery storage (b), and with chilled water storage (c).

\section{Levelised cost of storage}

In order to compare the different energy storage solutions for a given scenario, a metric that considers the initial investment $(C A P E X)$, the operational costs including the charging costs $\left(\sum_{1}^{t} O P E X\right)$, and the usable energy over the system lifetime $\left(\sum_{1}^{t} E\right)$ is required. Moreover, the residual value ( $\left.V_{\text {residual }}\right)$ may be considered. Independent researchers (Belderbos et al., 2016; Pawel, 2014) and consultancy firms (Apricum, 2016; Lazard, 2017) established the metric of LCOS in slightly different ways. Essentially, all apply the following principle in different levels of detail:

$$
L C O S=\frac{C A P E X+\sum_{1}^{t} O P E X+V_{\text {residual }}}{\sum_{1}^{t} E}
$$

Usually the LCOS method is applied to energy storages that have electrical energy as input and output. In the context of thermal energy storage and battery storage that are coupled with a PV system and a cooling application, this formulation does not allow a meaningful comparison, because usable energy is not electrical energy, but thermal energy for cooling applications. That means a conversion of the battery discharge power to thermal equivalent power using the COP is required.

In the case of the battery storage, the charging energy only comes from the PV system, because of the inverter operation strategy explained in Section 4. The configuration with thermal energy storage requires the chiller to charge the storage. In order to identify the charging costs, the thermal charging power needs to be converted to electrical power using the chiller plant COP. However, this charging power is only partly supplied by the PV system, while the rest is supplied by the electricity grid, as the control strategy explained in Section 4 cannot fully avoid the use of electricity from the grid to charge the thermal energy storage.

The specific Operation and Maintenance (O\&M) costs, specific investment costs, PV LCOE, and electricity price are inputs for the LCOS formula, and are listed in Table 1 . Moreover, the $V_{\text {residual }}$ is assumed to be zero for both energy storage systems and the system lifetime is 10 years, which implies that no battery replacement is required. 
Tab. 1: Specific costs of NCM Li-Ion battery, water tank and electricity. A $100 \mathrm{~kW}$ battery inverter is assumed for all battery storage capacities.

\begin{tabular}{|c|c|c|}
\hline & Specific costs & Reference \\
\hline Battery CAPEX & $387.5 \mathrm{USD} / \mathrm{kWh}$ and 675 USD/kW & DNV_GL (2017) \\
\hline Battery O\&M & $8.5 \mathrm{USD} / \mathrm{kW}$ *a & DNV_GL (2017) \\
\hline Water tank CAPEX & $31 \mathrm{USD} / \mathrm{kWh}$ & Comodi et al. (2017) \\
\hline Water tank O\&M & $5 \%$ of CAPEX & Zhu et al. (2018) \\
\hline Electricity price & $0.173 \mathrm{USD} / \mathrm{kWh}$ & SP_Group (2018) \\
\hline PV LCOE & $0.075 \mathrm{USD} / \mathrm{kWh}$ & NSR (2018) \\
\hline
\end{tabular}

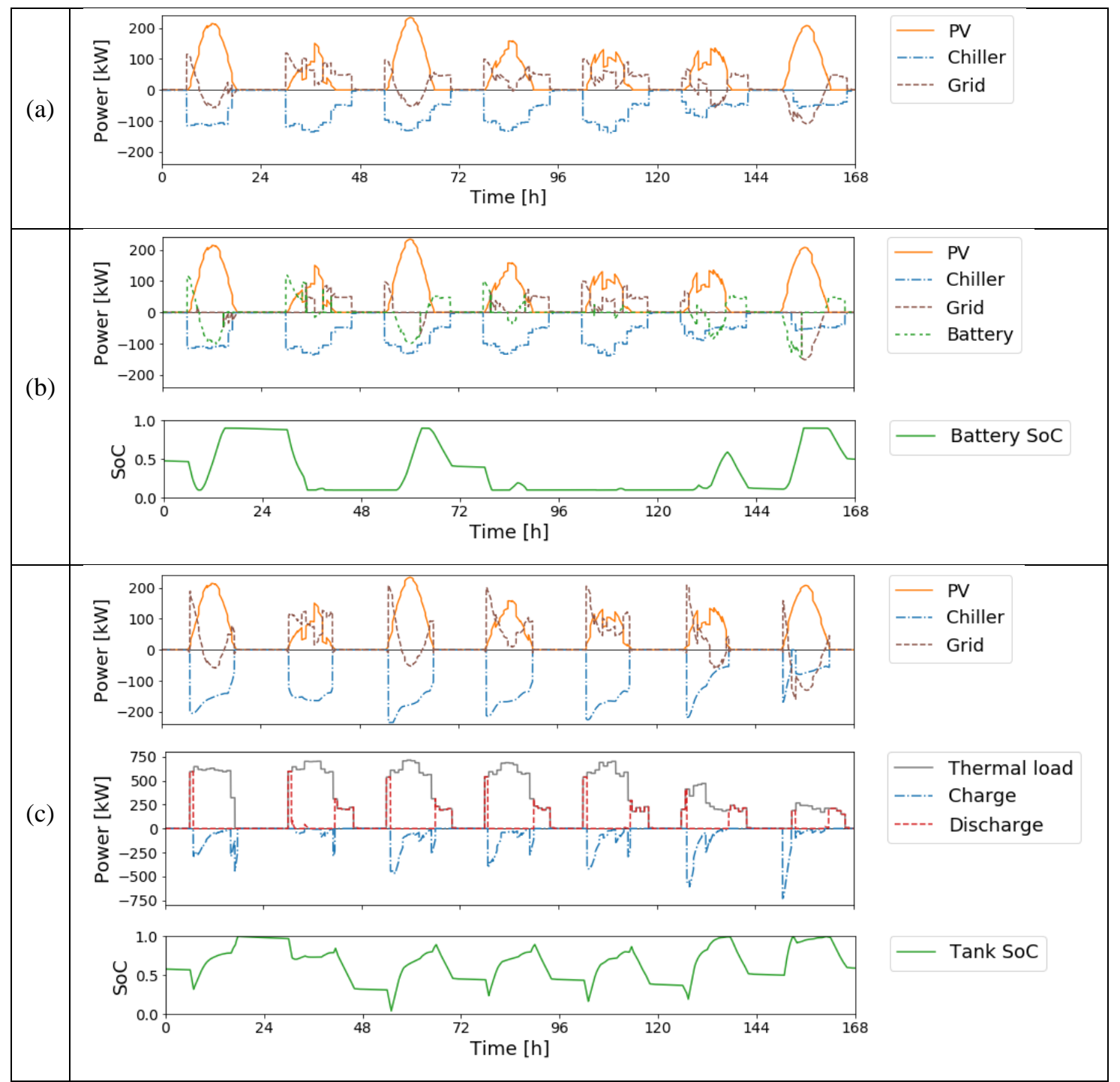

Fig. 6: Dynamic simulation output data of an exemplary week for the simulation model without storage (a), with $500 \mathrm{kWh}$ battery storage (b) and $2000 \mathrm{kWh}$ chilled water storage (c). 

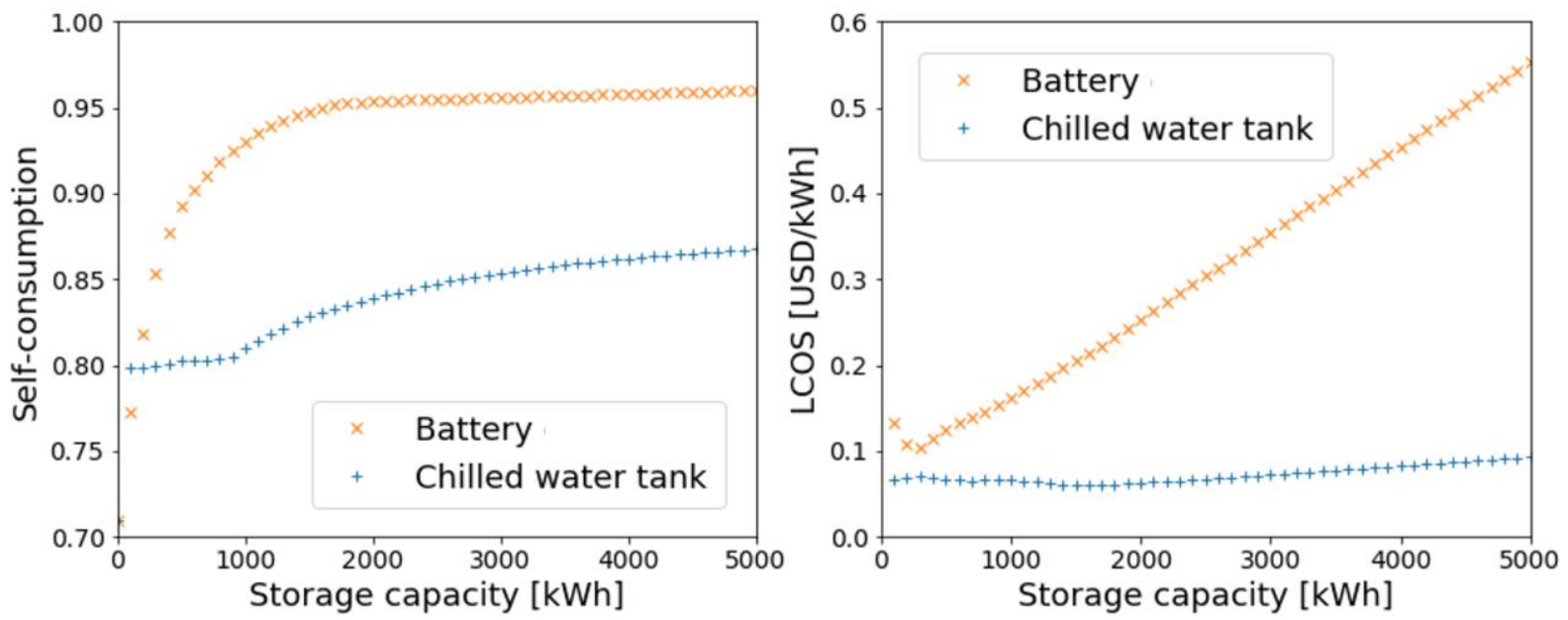

Fig. 7: Energy and economic results for chilled water storage and battery storage: Self-consumption vs. storage capacity (left), LCOS vs. storage capacity (right).

\section{Results}

The results of this study consist of three parts. Firstly, an exemplary week of dynamic simulation output data is shown to discuss the operation of the three different models - without energy storage, with battery storage, and with chilled water tank. Secondly, different storage capacities are compared in terms of self-consumption of PV energy. Thirdly, the LCOS of the chilled water and battery storage are analysed.

Figure 6 shows the simulated data for relevant parameters of the model without storage (a), with $500 \mathrm{kWh}$ battery storage (b) and with $2000 \mathrm{kWh}$ chilled water storage (c). In the system without energy storage, PV power that cannot be consumed instantly is exported to the grid. And if the PV power is insufficient to fulfill the electrical load, the rest is imported from the grid. The case with battery storage (b) reduces the export and import of power by charging and discharging the battery, respectively. The respective SoC graph shows that close to four equivalent full battery cycles are completed within the that particular week with $500 \mathrm{kWh}$ battery storage. The thermal energy storage that is used in (c) decouples chiller operation from the cooling demand, which theoretically allows the chiller to run only when the solar power is available. As can be seen at the top of Figure 6 (c), the solar power is not sufficient to power the chiller entirely in the mornings and evenings. Large amounts of power still need to be imported from the grid.

The SoC of the thermal energy storage (Figure 6 (c)) is zero when the average tank temperature reaches $10^{\circ} \mathrm{C}$ and is one when the tank temperature is $4.5^{\circ} \mathrm{C}$. The tank is mainly discharged before and after office hours when the chiller is not operating. The charging occurs once the chiller turns on and peaks in the morning when the temperature difference between the tank and chilled water supply is largest.

The $247.5 \mathrm{~kW}_{\mathrm{p}} \mathrm{PV}$ system on the building's roof generates $383 \mathrm{MWh} / \mathrm{a}$, while the energy consumption of the chiller plant is higher at $460 \mathrm{MWh} / \mathrm{a}$ for the cases without energy storage and with battery storage. Due to the lower COP, the annual chiller plant consumption is approximately $100 \mathrm{MWh}$ higher for the case with thermal energy storage, that means approximately $560 \mathrm{MWh} / \mathrm{a}$ at a similar cooling load of $2379 \mathrm{MWh} / \mathrm{a}$.

Figure 7 (left) shows the self-consumption of PV energy for various battery and chilled water tank capacities. Without energy storage, $71 \%$ of the PV energy are consumed directly by the chiller plant. With the use of battery storage, the amount of exported energy can be reduced to less than $0.18 \mathrm{MWh} / \mathrm{a}$ at a battery capacity of 2200 $\mathrm{kWh}$. That results into a self-consumption of PV energy of $96 \%$. However, an import of $94 \mathrm{MWh} / \mathrm{a}$ remains as the PV energy cannot fully supply the load. Beyond the usable capacity of $2200 \mathrm{kWh}$, the self-consumption ratio does not increase significantly.

When a chilled water tank is utilized, the self-consumption ratio remains $80 \%$ until a storage size of $1000 \mathrm{kWh}$. Beyond $1000 \mathrm{kWh}$ storage capacity, the self-consumption increases; however, not as fast as for the battery storage, reaching only $87 \%$ at $5000 \mathrm{kWh}$. An improvement could be achieved by optimising the chiller operation and its power consumption to fit the solar power generation better. 
The LCOS for battery and chilled water storage, at various storage capacities is shown in Figure 7 (right). It can be seen that the LCOS for the chilled water storage is lower than that of battery storage for all the storage sizes. It ranges only from 0.06 to $0.08 \mathrm{USD} / \mathrm{kWh}$, most of which is from OPEX. However, the high CAPEX of battery storage causes the LCOS for battery storage to rise linearly for larger storage sizes. Hence, the lowest LCOS is $0.10 \mathrm{USD} / \mathrm{kWh}$ at $300 \mathrm{kWh}$ storage capacity.

Eventually, the selection of the energy storage solution might not only depend on the LCOS, but also on the required space. The chilled water tank can only store $6.4 \mathrm{kWh} / \mathrm{m}^{3}$ compared to the Li-Ion battery storage, which can store $142.5 \mathrm{kWh} / \mathrm{m}^{3}$ (DNV_GL, 2017).

\section{Conclusion and outlook}

In this paper, we proposed an advanced Levelised Cost of Storage (LCOS) method for Photovoltaic (PV) powered cooling application and applied it to an office-cum-retail building in tropical climate to compare chilled water storage and battery storage. The results show that the increase in self-consumption of PV energy is higher using battery storage. This is because the chilled water storage is also partly charged from the grid as the chiller power consumption does not always fit the PV power generation. If more PV energy is used to charge the thermal energy storage, this would not only lead to a higher self-consumption, but also to an even lower LCOS. However, the volume of the chilled water tank is 22 times higher than the volume of the Li-Ion battery, which may not be applicable, especially in urban areas. Therefore, latent heat storage using ice or other phase change materials as media might be an interesting alternative. These solutions could offer a higher energy density at potentially relatively low LCOS.

\section{References}

Aghamohammadi, M. R., Abdolahinia, H., 2014. A new approach for optimal sizing of battery energy storage system for primary frequency control of islanded microgrid. International Journal of Electrical Power \& Energy Systems, 54, 325-333. https://doi.org/10.1016/j.ijepes.2013.07.005

Apricum, 2016. How to determine meaningful, comparable costs of energy storage. Retrieved from: www.apricum-group.com on August 1, 2018.

Arteconi, A., Ciarrocchi, E., Pan, Q., Carducci, F., Comodi, G., Polonara, F., Wang, R., 2017. Thermal energy storage coupled with PV panels for demand side management of industrial building cooling loads. Applied Energy. 185, 1984-1993. https://doi.org/10.1016/j.apenergy.2016.01.025

BCA_GM, 2012. BCA Green Mark for Existing Non-Residential Buildings (Version 3). Retrieved from https://www.bca.gov.sg/GreenMark/others/GM_NREB_V3.pdf on August 1, 2018.

BCA_GM, 2018. $\quad$ BCA Green $\quad$ Mark. Retrieved from https://www.bca.gov.sg/greenmark/green_mark_buildings.html on August 1, 2018.

Belderbos, A., Delarue, E., \& D'haeseleer, W., 2016. Calculating the Levelized Cost of Electricity Storage. Energy: Expectations and Uncertainty, 39th IAEE International Conference, Jun 19-22, 2016. International Association for Energy Economics.

Chan, A. L., Chow, T.-T., Fong, S. K., Lin, J. Z., 2006. Performance evaluation of district cooling plant with ice storage. Energy, 31(14), 2750-2762. https://doi.org/10.1016/j.energy.2005.11.022

Chaurey, A., Kandpal, T., 2010. A techno-economic comparison of rural electrification based on solar home systems and PV microgrids. Energy policy, 38(6), 3118-3129. https://doi.org/10.1016/j.enpol.2010.01.052

Chow, T., Chan, A. L., Song, C., 2004. Building-mix optimization in district cooling system implementation. Applied Energy, 77(1), 1-13. https://doi.org/10.1016/s0306-2619(03)00102-8

Comodi, G., Carducci, F., Sze, J. Y., Balamurugan, N., Romagnoli, A., 2017. Storing energy for cooling demand management in tropical climates: A techno-economic comparison between different energy storage technologies. Energy, 121, 676-694. https://doi.org/10.1016/j.energy.2017.01.038 
DNV_GL, 2017. Battery Energy Storage Study for the 2017 IRP. Retrieved from http://www.pacificorp.com/content/dam/pacificorp/doc/Energy_Sources/Integrated_Resource_Plan/2017_IRP/1 0018304_R-01-D_PacifiCorp_Battery_Energy Storage_Study.pdf on August 1, 2018.

Jones, K. B., Bartell, S. J., Nugent, D., Hart, J., Shrestha, A., 2013. The urban microgrid: Smart legal and regulatory policies to support electric grid resiliency and climate mitigation. Fordham Urb. LJ, 41, 1695.

Lazard, 2017. Lazard's Levelized Cost of Storage Analysis - Version 3.0. Retrieved from: www.lazard.com on August 1, 2018.

Luthander, R., Widén, J., Nilsson, D., Palm, J., 2015. Photovoltaic self-consumption in buildings: A review. Applied Energy, 142, 80-94. https://doi.org/10.1016/j.apenergy.2014.12.028

Merei, G., Moshövel, J., Magnor, D., Sauer, D. U., 2016. Optimization of self-consumption and techno-economic analysis of PV-battery systems in commercial applications. Applied Energy, 168, 171-178. https://doi.org/10.1016/j.apenergy.2016.01.083

Mohamed, F. A., Koivo, H. N., 2007. Online management of microgrid with battery storage using multiobjective optimization. Paper presented at the Power Engineering, Energy and Electrical Drives. POWERENG 2007. https://doi.org/10.1109/powereng.2007.4380118

NSR, 2018. National Solar Repository of Singapore. Retrieved from http://www.solar-repository.sg/ on August $1,2018$.

Pawel, I., 2014. The cost of storage-how to calculate the levelized cost of stored energy (LCOE) and applications to renewable energy generation. Energy Procedia. 46, 68-77. https://doi.org/10.1016/j.egypro.2014.01.159

PG\&E, 1997. Thermal Energy Storage Strategies for Commercial HVAC Systems. https://www.pge.com/includes/docs/pdfs/about/edusafety/training/pec/inforesource/thrmstor.pdf on August 1, 2018 .

Philipps, S., \& Warmuth, W., 2017. Photovoltaics report. Retrieved from Fraunhofer Institute for Solar Energy Systems, ISE: https://www.ise.fraunhofer.de/content/dam/ise/de/documents/publications/studies/PhotovoltaicsReport.pdf on August 1, 2018.

Sehar, F., Rahman, S., Pipattanasomporn, M., 2012. Impacts of ice storage on electrical energy consumptions in office buildings. Energy and Buildings, 51, 255-262. https://doi.org/10.1016/j.enbuild.2012.05.002

SERIS, 2011. SERIS Meteorological Station - Annual Report 2011.

Souayfane, F., Fardoun, F., Biwole, P.-H., 2016. Phase change materials (PCM) for cooling applications in buildings: A review. Energy and Buildings, 129, 396-431. https://doi.org/10.1016/j.enbuild.2016.04.006

SP_Group, 2018. Singapore Power Group. Retrieved from https://www.spgroup.com.sg/what-we-do/billing on August 1, 2018.

Teleke, S., Baran, M. E., Bhattacharya, S., Huang, A. Q., 2010. Rule-based control of battery energy storage for dispatching intermittent renewable sources. IEEE Transactions on Sustainable Energy. 1(3), 117-124. https://doi.org/10.1109/tste.2010.2061880

TRNSYS, 2018. Transient System Simulation Tool. Retrieved from http://www.trnsys.com/ on August 1, 2018.

Zhu, K., Li, X., Campana, P. E., Li, H., Yan, J., 2018. Techno-economic feasibility of integrating energy storage systems in refrigerated warehouses. Applied Energy, 216, 348-357. https://doi.org/10.1016/j.apenergy.2018.01.079 


\title{
Comparison of Modelled and Measured Heat and Mass Transfer in a Liquid Desiccant Air-Conditioning System
}

\author{
Wael Mandow', Martin Mützel', Daniel Fleig', Andrew Lowenstein ${ }^{2}$ and Ulrike Jordan' \\ 1 Institute of Thermal Engineering, Kassel University, Kurt-Wolters-Str.3, 34125-Kassel, Germany \\ ${ }^{2}$ AIL Research Company, 57 Hamilton Ave, Hopewell, NJ 08525, USA
}

\begin{abstract}
In the presented research study, experimental and numerical investigations on the heat and mass transfer of the absorber and regenerator in a liquid desiccant air conditioning system (LDAC-system) were carried out. The absorber and regenerator are designed as a tube bundle heat and mass exchanger with corrugated media as wicking fins. An aqueous solution of lithium chloride $\left(\mathrm{LiCl}-\mathrm{H}_{2} \mathrm{O}\right)$ is used as desiccant. In the experiments all relevant in and outlet parameters of the air, desiccant solution, as well as cooling and heating water are measured for different inlet air humidity ratios in the absorber and for different heating water temperatures in the regenerator. Moreover, three different numerical models are applied to predict the heat and mass transfer in the absorber and regenerator, i.e. a physical model, a simplified single-node effectiveness model, and a multi-node effectiveness model. The impact of the inlet humidity ratio of the process air and the regeneration temperature on the moisture removal rate and the change of fluid temperatures were evaluated. In general, the results showed good agreements between measurements and numerical values.
\end{abstract}

Keywords: Liquid desiccant, Absorber, Dehumidifier, Air conditioning

\section{Introduction}

Desiccant dehumidification is used for air conditioning applications as well as product drying as an alternative to dehumidification with a vapor compression refrigeration cycle. It is possible to improve the performance of the process for a low set humidity and low set temperatures and to replace electrical by thermal energy demand (Yamaguchi et al. 2011; Qi et al. 2014; Mucke et al. 2016). An additional advantage of a desiccant air conditioning system compared to conventional systems are the pollution and bacterial control in the indoor air (Chung et al. 1995; Liu et al. 2015; Park et al.2017). Liquid desiccant air conditioning (LDAC) systems can be driven by lower regeneration temperatures compared to desiccant wheels, i.e. by temperatures lower than $80^{\circ} \mathrm{C}$, to utilize solar energy or waste heat. Originally, liquid-desiccant absorbers and regenerators are designed as adiabatic packed beds with high flow rates of the liquid desiccant with an air to liquid mass flow ratio of about 1 . The main disadvantage of packed-bed configurations are the risk of carryover of liquid droplets into the process air and a high pressure drop of the air Lowenstein et al. (2006).

As an alternative, the absorber and regenerator can be constructed as plate and tube-bundle heat and mass exchangers with a much higher air to liquid mass flow ratio in the range of $\mathrm{MR} \approx 10$ to 50 . The absorption and regeneration process can be internally cooled and heated, respectively. These low flow systems can reach a higher dehumidification performance of the air and a larger spread of the $\mathrm{LiCl}$ mass fraction in the liquid compared to high flow and solid desiccant systems Lowenstein et al. (2006). Experimental investigations of the absorption process were carried out, for example by (Kessling et al. 1998; Lowenstein et al. 2006; Röben 1997; Jaradat, 2016). LDAC systems were used also for humidity control in post harvests, tea, hay drying and low-temperature crop drying in short time with less cost and without heat damage to seeds comparing with hot-air-drying (Sulardjaka et al. 2018; Addy et al. 2014; Khouzam, 2009). Furthermore, using liquid desiccant to dry gelcast parts reduced the drying time significantly without defects that occurred during conventional drying Barati et al. (2003).

In the following section the investigated liquid desiccant air conditioning system is described, followed by a brief description of three numerical models in section 3. In section 4, the evaluated variables are defined. Finally, in section 5, a series of experiments with a focus on the absorption and on the regeneration process are presented. Experimental results of the water vapor mass flow rate and the temperature rise and drop during the processes are presented and compared with results from the three numerical models. 


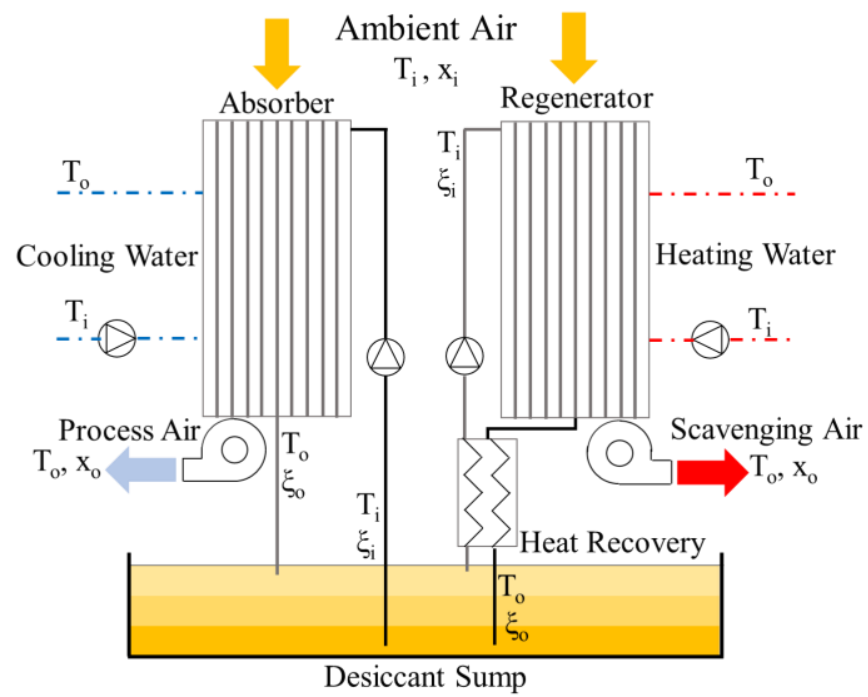

Fig. 1:Liquid desiccant air conditioning system (according to Andrusiak and Harrison, 2009), own drawing)

\section{Investigated Liquid Desiccant System}

A general scheme of a LDAC system is shown in Fig. 1. In the internally cooled absorber, air passes along a liquid desiccant film in cross-flow configuration. Water vapor is absorbed by the concentrated aqueous LiCl-solution due to its lower water vapor pressure above the solution compared to that in the air. Enthalpy of sorption (evaporation and dilution) is released during the process and transferred to the air and liquid desiccant as well as to the cooling water inside the absorber. The diluted desiccant is regenerated afterwards in an internally heated heat and mass exchanger, the regenerator. The absorber and regenerator are made of corrugated fiber glass sheets as wicking fins attached to cupronickel tube bundles, Fig. 3.

The LDAC system developed by AIL Research is shown in Fig. 2. It consists of an absorber with a volume of 105 litres and set-flow rates of $2000 \mathrm{~m}^{3} / \mathrm{h}$ (air) and $320 \mathrm{l} / \mathrm{h}$ (liquid desiccant). The volume of the regenerator is about 40 litres, the flow rates of the air and the desiccant are about $600 \mathrm{~m}^{3} / \mathrm{h}$ and $230 \mathrm{l} / \mathrm{h}$, respectively. The system consists of a 50 litres desiccant sump, a heat recovery unit for the liquid desiccant, as well as pumps and fans with $1.27 \mathrm{~kW}_{\mathrm{el}}$ nominal electrical power.

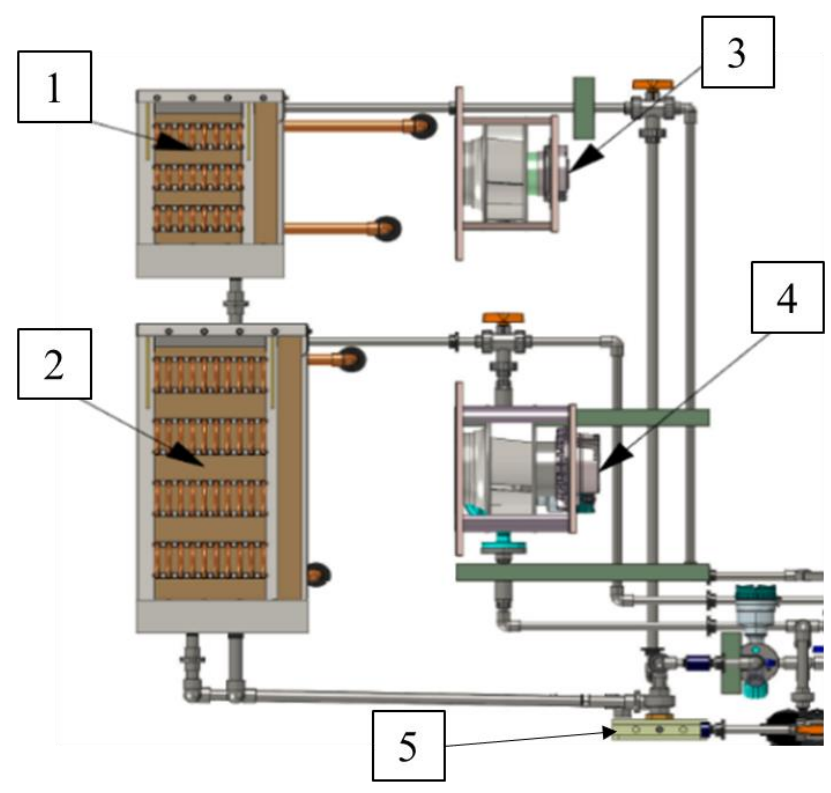

Fig. 2: LDAC-System, schematic diagram

\begin{tabular}{|c|c|}
\hline 1 & Regenerator \\
\hline 2 & Absorber \\
\hline 3 & Outlet air ventilator \\
\hline 4 & Inlet air ventilator \\
\hline 5 & Heat recovery \\
\hline
\end{tabular}

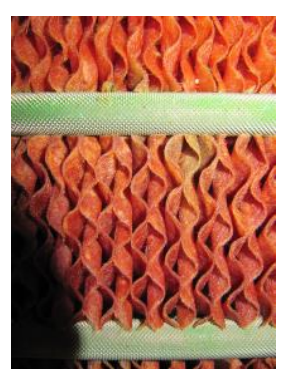

Fig. 3: Heat and mass exchanger design with corrugated wicking material 
All relevant in- and outlet parameters of the air, desiccant solution, and cooling or heating water are measured. Tab. 1 shows measured parameters with uncertainties based on the manufacture's data.

Tab. 1: Estimated measurement uncertainty (based on instrument manufacture's data)

\begin{tabular}{lc}
\hline Instruments & Accuracy \\
\hline Process-air & \\
Inlet and outlet temperature & $\pm 0.3 \mathrm{~K}$ \\
Inlet and outlet relative humidity & $\pm 1 \% \mathrm{RH}$ \\
Volume flow meter & $\pm 1.5 \%$ of reading \\
Liquid desiccant & $\pm 0.5 \mathrm{~K}$ \\
Inlet and outlet temperature & $0.005 \mathrm{~g} / \mathrm{cm}^{3}$ \\
Inlet and outlet density & $\pm 0.15 \%$ of reading \\
Mass flow meter & $\pm 0.5 \mathrm{~K}$ \\
Cooling/ heating water & $\pm 0.5 \%$ of reading \\
Inlet and outlet temperature & \\
Mass flow rate & \\
\hline
\end{tabular}

\section{Numerical Models}

Three numerical models are used to describe the heat and mass transfer and to compare the experimental with numerical results. All models assume steady-state operation, laminar-flow of all fluids, a uniform distribution of the air and of the desiccant solution on the plate surface and they assume that heat transfer to the surroundings is negligible.

\section{a) Physical Model (FDM)}

A three-dimensional physical model was developed to describe the heat and mass transfer of internally heated and cooled absorbers and regenerators. The model is based on the work by Mesquita et al. (2006).

The air and liquid desiccant are assumed to flow in cross-flow configuration. The algorithms are solved with a finite-difference method (FDM). In comparison to semi-empirical approaches ( $\varepsilon$-NTU- model), the model applies solely physical fluid properties. In the presented study, 200 nodes in the two directions of the fluid flow and 50 nodes perpendicular to the flow directions were applied. Moreover, the film thickness of liquid desiccant is considered as constant, heat and mass transfer through convection perpendicular to flow-direction is neglected, and heat and mass transfer through conduction in flow-direction is neglected. The vapor pressure of the desiccant in dependency of fluid temperature and concentration is described by correlation from literature Conde, (2004).

The wicking fins are considered as flat plates with a distance of about $3 \mathrm{~mm}$ between the plates. The heat and mass transfer areas between air and desiccant as well as between liquid desiccant and cooling/heating water is assumed to be equal to the entire plate area.

Solely the heat transfer from the plate to the heating and cooling water is described with a semi-empirical parameter. A thermal conductivity of the plate of $0.21 \mathrm{~W} / \mathrm{mK}$ and an equivalent plate thickness of $0.5 \mathrm{~mm}$ was assumed.

\section{b) Single-node $\varepsilon$-NTU- model (EFFM)}

A second model approach is simplified compared to the physical model. It is based on efficiency correlations with only one node for each fluid to describe the temperature and mass fraction at the phase boundary.

Stevens et al. (1989) already used an NTU- $\varepsilon$ semi-empirical model derived from a model for a cooling tower. The model describes the heat and mass transfer within adiabatic packed bed absorber in a counterflow configuration. In the model the change of the liquid desiccant mass flow rate is assumed to be negligible, the variation of the saturation enthalpy is linear with the temperature, the Lewis number is assumed to be unity, and an ideal surface wetting is assumed.

In the presented study the model was further developed. Other than in the model by Stevens et al. (1989), the temperature and mass fraction is calculated at the phase boundary. The change of mass fraction of the liquid 
desiccant is taken into account and the heat of dilution and vapor pressure are implemented as nonlinear correlations of temperature and mass fraction according to Conde, (2004). The Lewis number is defined from air properties (eq. 1), the mass transfer coefficient is calculated from the Lewis-number and the heat transfer coefficient according to (eq. 2), and $\mathrm{NTU}_{\beta}$ is given by (eq. 3). If the $c_{i}$ is less or equal to unity in (eq. 7) then the $\mathrm{LiCl}$-flow rate is used to calculate $\mathrm{NTU}_{\beta}$., and if it is larger than unity, the air flow rate is applied.

$$
\begin{gathered}
L e=\frac{a_{a}}{D_{a}} \\
\beta=\frac{\alpha \cdot D_{a} \cdot L e^{\frac{1}{3}}}{\lambda_{a}} \\
N T U_{\beta}=\frac{\beta \cdot A}{\dot{m}_{d a}}
\end{gathered}
$$

Different areas can be considered in the model for the heat and mass transfer. Furthermore, the effect of nonuniform wetting can be considered by a wetting-factor. Different wetting factors can be applied for the heat and mass transfer area. Further, the temperature at the phase boundary is assumed to be equal to the liquid desiccant outlet temperature, and as characteristic length of the film, the inlet film thickness is considered.

As for the physical model, the wicking fins are considered as flat plates with a distance of about $3 \mathrm{~mm}$ between the plates. The heat and mass transfer area between air and desiccant is equal to the plate area. However, the heat transfer area between desiccant and cooling/heating water is assumed to be equal to the tube bundle area.

The effectiveness of heat transfer between interface and air as cooling or heating water depends on the dimensionless heat transfer coefficients $\mathrm{NTU}_{\mathrm{a}}$ and $\mathrm{NTU}_{\mathrm{w}}$ as given in eq. 4 and eq. 5:

$$
\begin{aligned}
& \epsilon_{\alpha, a-s o l}=1-\exp \left(-\mathrm{NTU}_{a}\right)=1-\exp \left(-\frac{\alpha A}{c_{P a} \dot{m}_{a}}\right) \\
& \epsilon_{U A, w-S o l}=1-\exp \left(-\mathrm{NTU}_{W}\right)=1-\exp \left(-\frac{U A}{c_{w} \dot{m}_{w}}\right) \quad \text { eq. } 5
\end{aligned}
$$

The effectiveness of the mass transfer process for cross-flow configuration is calculated with eq. 6 and eq. 7 :

$$
\begin{gathered}
\epsilon_{\beta, a-s o l}=\frac{1}{c_{i} \cdot N T U_{\beta i}} \cdot \sum_{m=0}^{\infty}\left\{\left[1-\exp \left(-N T U_{\beta i}\right) \cdot \sum_{j=0}^{m} \frac{1}{j !} N T U_{\beta i}^{j}\right] \cdot[1\right. \\
\left.\left.-\exp \left(-c_{i} N T U_{\beta i}\right) \cdot \sum_{j=0}^{m} \frac{1}{j !}\left(c_{i} \cdot N T U_{\beta i}\right)^{j}\right]\right\} \\
c_{i}=\frac{\dot{\mathrm{m}}_{\text {salt }} \cdot\left(X_{e q}-X_{i}\right)}{\dot{\mathrm{m}}_{d a \cdot} \cdot\left(x_{a, i}-x_{a, e q}\right)}
\end{gathered}
$$

\section{c) Multi-Node $\varepsilon$-NTU- model (AILM)}

The multi-node $\varepsilon$-NTU- model is a physical model based on the work by Kozubal et al. (2014). The plate is divided into eight elements in each direction and the mass and energy conservation equations are solved in each element. A Newton solver is used.

The model assumes negligible heat transfer resistance in the desiccant, and conduction and diffusion perpendicular to the plates only. It contains laminar developing flow transfer coefficients for both, heat and mass transfer from the bulk air to the air-liquid desiccant interface. The model is only applied for the absorber. It is described in Kozubal et al. (2014). 


\section{Evaluated Variables}

The moisture removal rate $\dot{\mathrm{m}}_{\mathrm{v}}$ calculated from both, air and liquid desiccant, are calculated with eq. 8 and eq. 9 :

$$
\begin{array}{cc}
\dot{\mathrm{m}}_{v, \text { air side }}=\dot{\mathrm{m}}_{d a} \cdot\left(x_{i}-x_{o}\right) & \text { eq. } 8 \\
\dot{\mathrm{m}}_{v, \text { sol.side }}=\dot{\mathrm{m}}_{\text {salt }} \cdot\left(X_{o}-X_{i}\right) \text { whereas } \quad X=\frac{1-\xi}{\xi} & \text { eq. } 9
\end{array}
$$

To evaluate the quality of the measurements, the mass balance and energy balance factors $\kappa_{\mathrm{m}}$ and. $\kappa_{\mathrm{e}}$ are defined according to eq. 10 and eq. 11, respectively. The deviation of the evaluated values from 1 is a quality measure of the experiments. $\dot{\mathrm{H}}_{\text {sorp }}$ is the sum of evaporation and dilution enthalpy flow.

$$
\begin{array}{cc}
\kappa_{m}=\frac{\dot{\mathrm{m}}_{v, \text { air side }}}{\dot{\mathrm{m}}_{v, \text { sol.side }}} & \text { eq. } 10 \\
\kappa_{e}=\frac{\dot{\mathrm{H}}_{\text {sorp. }}}{\dot{Q}_{a, \text { sen. }}+\dot{Q}_{\text {sol }}+\dot{Q}_{w}} & \text { eq. } 11
\end{array}
$$

The regeneration specific heat input, RSHI, is defined as the heat demand for the liquid desiccant regeneration to remove one $\mathrm{kg}$ of moisture from the air, eq. 12

$$
R S H I=\frac{\dot{Q}_{\text {heat }}}{\dot{\mathrm{m}}_{v, \text { sol.side }}}
$$

\section{Results and Discussion}

Two test sequences were carried out to study the influence of the inlet air humidity ratio on the absorption process and the influence of the heating temperature on the regeneration process. The duration of each experiment was several hours however the presented time-averaged measurement date refers to sampling times of about 40 minutes, after the inlet desiccant density at the absorber and regenerator reached a constant value.

\section{a) Absorption Process}

Five experiments were performed to study the internally cooled absorption process with inlet air humidity ratios between $9.5 \mathrm{~g}_{\mathrm{w}} / \mathrm{kg}_{\mathrm{da}}$ and $18.6 \mathrm{~g}_{\mathrm{w}} / \mathrm{kg}_{\mathrm{da}}$. The following inlet parameters were maintained constant for the five

\begin{tabular}{|c|c|c|c|c|c|}
\hline$\dot{\mathrm{m}}_{\text {sol }}$ in $\mathrm{kg} / \mathrm{h}$ & 351 & 337 & 320 & 308 & 307 \\
\hline$\xi$ in $\mathrm{kg}_{\text {salt }} / \mathrm{kg}_{\text {sol }}$ & 0.30 & 0.30 & 0.32 & 0.36 & 0.39 \\
\hline $\mathbf{T}_{\text {sol }}$ in ${ }^{\circ} \mathbf{C}$ & 32.8 & 32.3 & 32.4 & 31.7 & 31.7 \\
\hline $\mathbf{T}_{\mathbf{a}}$ in ${ }^{\circ} \mathbf{C}$ & 26.3 & 24.9 & 25.8 & 24.7 & 25.3 \\
\hline$x_{a}$ in $\mathrm{kg}_{\mathrm{w}} / \mathrm{kg}_{\mathrm{da}}$ & 0.0186 & 0.0173 & 0.0153 & 0.0119 & 0.0095 \\
\hline$\dot{\mathbf{m}}_{\mathrm{w}}$ in $\mathrm{kg} / \mathrm{h}$ & 1201 & 1201 & 1201 & 1200 & 1200 \\
\hline $\mathbf{T}_{\mathbf{w}}{ }^{\circ} \mathbf{C}$ & 25.2 & 25.3 & 25.3 & 25.3 & 25.3 \\
\hline$\kappa \mathbf{m}$ & 0.95 & 0.91 & 0.89 & 0.84 & 0.85 \\
\hline$\kappa_{\mathbf{e}}$ & 0.97 & 0.97 & 0.98 & 0.96 & 0.93 \\
\hline RSHI in $\mathrm{kJ} / \mathrm{kg}$ & 3698 & 3884 & 3999 & 4327 & 4818 \\
\hline
\end{tabular}
experiments: The air mass flow rate at about $2270 \mathrm{~kg} / \mathrm{h}$, the cooling water mass flow rate at about $1200 \mathrm{~kg} / \mathrm{h}$ and the cooling water temperature at about $25.3{ }^{\circ} \mathrm{C}$. The inlet temperature of the heating water into the regenerator was about $75^{\circ} \mathrm{C}$ and the hot water mass flow rate was about $1171 \mathrm{~kg} / \mathrm{h}$. Additional values are given in Tab. 2.

Tab. 2: Inlet conditions for different inlet humidity ratios, with a constant inlet air mass flow rate of $(2270 \pm 15) \mathrm{kg} / \mathrm{h}$

The moisture removal rate increases with increasing inlet air humidity ratio nearly linear, as shown in Fig. 4, due 
to the increasing water vapor pressure difference between the air and the liquid desiccant. The dehumidification of the air rises from $\Delta \mathrm{x}_{\mathrm{a}}=3.6 \mathrm{~g}_{\mathrm{w}} / \mathrm{kg}_{\mathrm{da}}$ to $6.1 \mathrm{~g}_{\mathrm{w}} / \mathrm{kg}_{\mathrm{da}}$. The maximal moisture removal rate measured on sorption side is above $14 \mathrm{~kg} / \mathrm{h}$ for an inlet air humidity ratio of $18.6 \mathrm{~g}_{\mathrm{w}} / \mathrm{kg}_{\mathrm{da}}$.

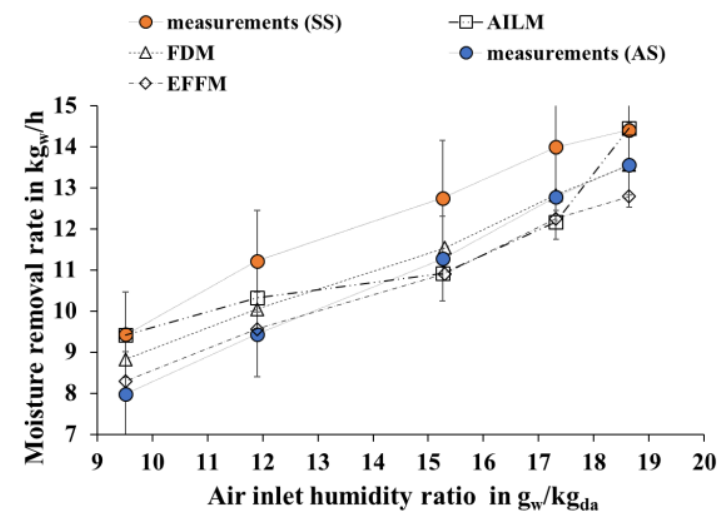

Fig. 4: Absorption process: Experimental and simulation results of the moisture removal rate over the inlet air humidity ratio.

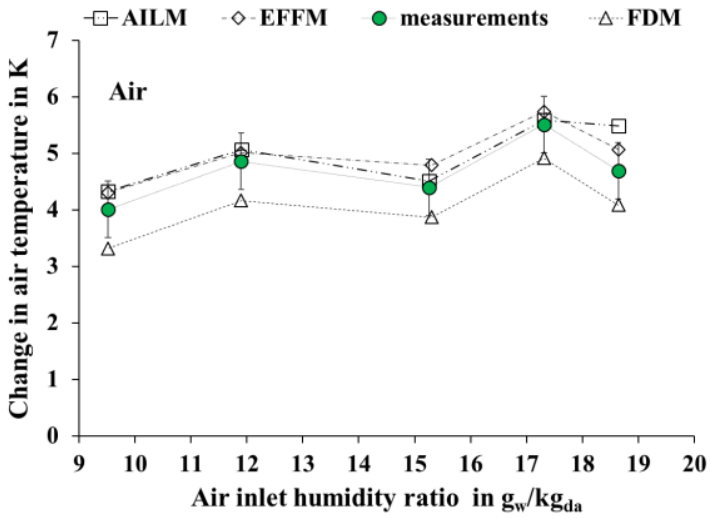

Fig. 5: Experimental and simulation results of the air temperature rise during the absorption process over the inlet air humidity ratio.

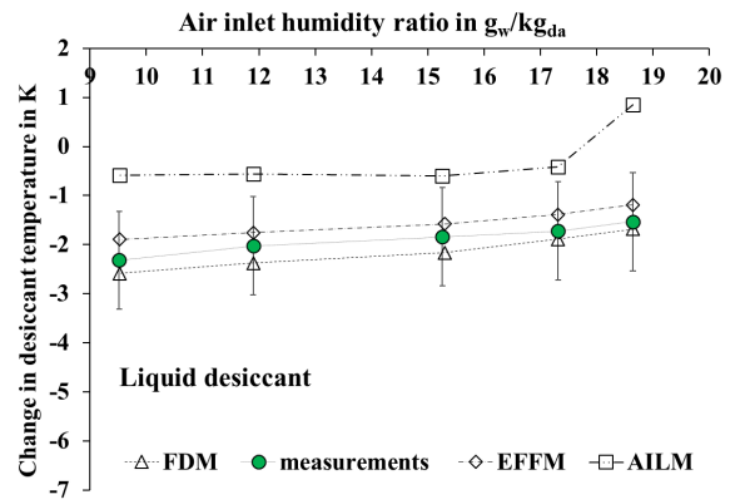

Fig. 6: Experimental and simulation results of the liquid desiccant temperature drop during the absorption process over the inlet air humidity ratio.

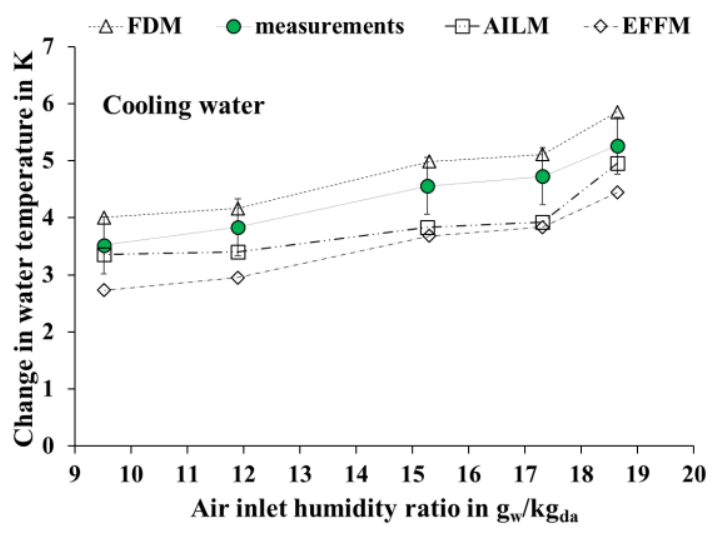

Fig. 7: Experimental and simulation results of the cooling water temperature rise during the absorption process over the inlet air humidity ratio.

The moisture removal rate $\dot{\mathrm{m}}_{\mathrm{v}}$ was calculated from measured data for both, air and liquid desiccant, with eq. 8 and eq. 9 , respectively. The maximal deviation between the values is about $16 \%$. This is mainly due to the uncertainty of the density and of the liquid desiccant outlet temperature. The change of the liquid desiccant mass fraction during the absorption process is relatively small, with a value of about $0.012 \mathrm{~kg}_{\text {salt }} / \mathrm{kg}_{\text {sol }}$.

If the calculated moisture removal rate is too high due to the density uncertainty, the simulated absorption enthalpy flow is too high, as well. This causes deviations between measured and simulated values not only of the moisture removal rate, but also of the change of the fluid temperatures.

The high uncertainty of the liquid desiccant outlet temperature is probably caused by the sensor position in the collecting pipe. The velocity of the liquid desiccant is very slow, the liquid accumulates at the lowest point, and cools down before it enters the collecting pipe.

A comparison between the measured values and the results of the three different numerical models described above, is shown in Fig. 4 to Fig. 7. In general, the experimental and numerical values of the moisture removal rate $\dot{\mathrm{m}}_{\mathrm{v}}$ show a good agreement. The numerical values are within the experimental uncertainty range. The trend of the FDM and EFFM results agrees very well with the trend of the measured data. The maximal deviation between numerical and measured values of the air side moisture removal rate $\dot{\mathrm{m}}_{\mathrm{v}, \mathrm{AS}}$, are $11 \%, 6 \%$ and $18 \%$, for the FDM, EFFM, and AILM, respectively. 
The air and the cooling water are heated during the absorption process due to the absorption heat released, whereas the liquid desiccant is cooled due to its high inlet temperature compared to the air and cooling water inlet temperatures. The measured and simulated change in the air temperature is shown in Fig. 5. The FDM underestimates the measured increase of the air temperature, $\Delta \mathrm{T}_{\mathrm{a}}$, with a maximal deviation of $\Delta \mathrm{T}_{\mathrm{a}}=$ $\frac{\Delta \mathrm{T}_{\mathrm{a}, \mathrm{sim}}-\Delta \mathrm{T}_{\mathrm{a}, \text { meas }}}{\Delta \mathrm{T}_{\mathrm{a} \text {,meas }}}=17 \%$, whereas the EFFM and AILM agree very well with experiments. The decrease of the liquid desiccant temperature for both, the FDM and EFFM, agrees well with experiments, with a maximal deviation of $17 \%$ and $22 \%$, respectively, as shown in Fig. 6 . The measured and simulated temperature rise of the cooling water, $\Delta \mathrm{T}_{\mathrm{w}}$, agrees with the measured values for all models with a maximal deviation of $23 \%$, as shown in Fig. 7.

The EFFM considered an overall heat transfer coefficient between the liquid desiccant and the cooling water in the range of $1152 \mathrm{~W} / \mathrm{K}$ to $1462 \mathrm{~W} / \mathrm{K}$. The heat transfer coefficient between liquid desiccant and tube bundles is in the range of $825 \mathrm{~W} / \mathrm{m}^{2} \mathrm{~K}$ to $1160 \mathrm{~W} / \mathrm{m}^{2} \mathrm{~K}$. With these values, the change of water temperature is calculated too low.

The FDM considered a higher overall heat transfer between liquid desiccant and water, with an equivalent heat transfer coefficient of about $2520 \mathrm{~W} / \mathrm{K}$. This causes an overestimation of the cooling water temperature rise and an underestimation of liquid desiccant as well as air temperature change. The regeneration specific heat input, defined as the regeneration heat to dehumidify the process air by $1 \mathrm{~kg}$ of water vapor, is in the range between about 3700 and $4800 \mathrm{~kJ} / \mathrm{kg}$ for the experiments, with a heating water inlet temperature of about $75{ }^{\circ} \mathrm{C}$ and a hot water mass flow rate of about $1171 \mathrm{~kg} / \mathrm{h}$.

According to the measured values, about $70 \%$ of the heat flow (enthalpy of absorption and heat flow of desiccant) is transferred to the cooling water and about $30 \%$ to the air.

\section{b) Regeneration Process}

Four additional experiments were performed to study the internally heated regenerator process with inlet heating water temperatures between $50^{\circ} \mathrm{C}$ and $80^{\circ} \mathrm{C}$, as shown in Tab. 3. The following inlet parameters were maintained constant for the experiments: The air mass flow rate at about $353 \mathrm{~kg} / \mathrm{h}$, the inlet air humidity ratio at about $12 \mathrm{~g}_{\mathrm{w}} / \mathrm{kg}_{\mathrm{da}}$ and the heating water mass flow rate at about $980 \mathrm{~kg} / \mathrm{h}$. The moisture removal rate from the desiccant to the air and the change in fluids temperature as well as in liquid desiccant mass fraction were studied as a function of the heating water inlet temperature.

Tab. 3: Inlet conditions for different heating water temperatures, with a constant inlet air mass flow rate of $(353 \pm 2.8) \mathrm{kg} / \mathrm{h}$

\begin{tabular}{|c|c|c|c|c|}
\hline$\dot{\mathrm{m}}_{\mathrm{sol}}$ in $\mathrm{kg} / \mathrm{h}$ & 228 & 228.3 & 232 & 234 \\
\hline$\xi_{\text {sol }}$ in $\mathrm{kg}_{\text {salt }} / \mathbf{k g}_{\text {sol }}$ & 0.28 & 0.30 & 0.33 & 0.37 \\
\hline $\mathbf{T}_{\text {sol }}$ in ${ }^{\circ} \mathbf{C}$ & 27.1 & 27.9 & 29.8 & 31.0 \\
\hline $\mathbf{T}_{\mathbf{a}}$ in ${ }^{\circ} \mathbf{C}$ & 24.5 & 24.5 & 24.9 & 24.8 \\
\hline$x_{a}$ in $\mathbf{k g}_{w} / \mathbf{k g}_{d a}$ & 0.0124 & 0.012 & 0.0128 & 0.0123 \\
\hline$\dot{\mathbf{m}}_{w}$ in $\mathrm{kg} / \mathrm{h}$ & 985 & 985 & 976 & 970 \\
\hline $\mathbf{T}_{\mathbf{w}}$ in ${ }^{\circ} \mathbf{C}$ & 50.1 & 60 & 70.2 & 80 \\
\hline$\kappa_{\mathbf{m}}$ & 1.06 & 1.11 & 1.06 & 1.06 \\
\hline$\kappa \mathbf{e}$ & 1.14 & 1.01 & 1.01 & 1.05 \\
\hline$\dot{\mathbf{m}}_{\mathrm{v}, \text { sol,side, abs }}$ in $\mathrm{kg} / \mathrm{h}$ & 5.4 & 7.2 & 8.4 & 10 \\
\hline $\mathrm{RSHI}$ in $\mathrm{kJ} / \mathrm{kg}$ & 3583 & 3862 & 4074 & 4160 \\
\hline
\end{tabular}

The moisture removal rate increases with increasing inlet heating water temperature, as shown in Fig. 8, due to the increasing water vapor pressure difference between the air and the liquid desiccant. The change in the liquid desiccant mass fraction increases from $\Delta \xi=0.004 \mathrm{~kg}_{\text {salt }} / \mathrm{kg}_{\text {sol }}$ to $0.012 \mathrm{~kg}_{\text {salt }} / \mathrm{kg}_{\text {sol }}$. The maximal moisture removal rate is $7.3 \mathrm{~kg} / \mathrm{h}$ (solution side) combined with a $3.3 \%$ point increase of the $\mathrm{LiCl}$ inlet mass fraction for an inlet heating water temperature of $80^{\circ} \mathrm{C}$. 
The maximal deviation of the moisture removal rate calculated from air side and the one calculated from the liquid desiccant is $11 \%$. The main reason for the high deviations is the high uncertainty of the relative humidity measurements at high temperatures. Another reason for the uncertainties in the regeneration process are the high outlet temperatures of the liquid desiccant which cause higher heat losses to the surroundings compared to the values during the absorption process.

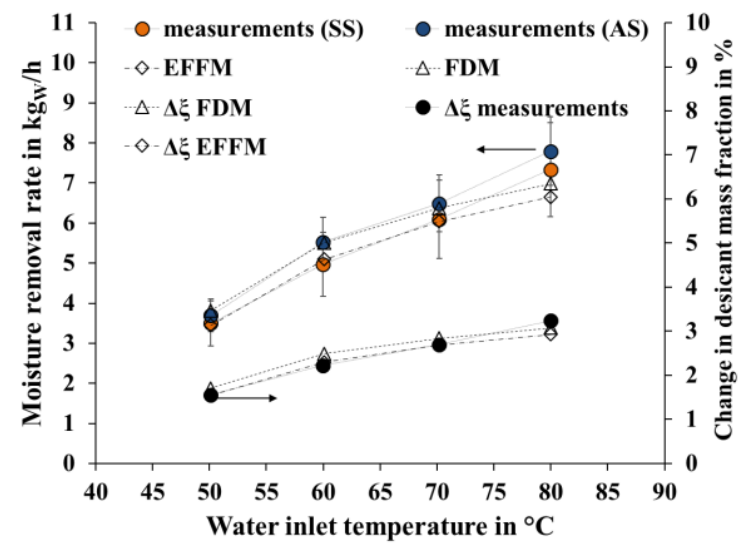

Fig. 8: Regeneration process: Moisture removal rate and increase of the $\mathrm{LiCl}$ mass fraction over the inlet heating water temperature

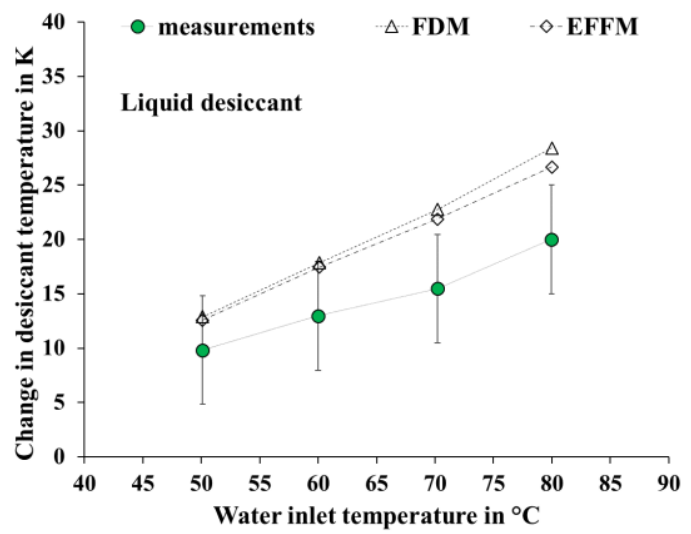

Fig. 10: Experimental and simulation results of the temperature increase of the desiccant during regeneration over the inlet heating water temperature

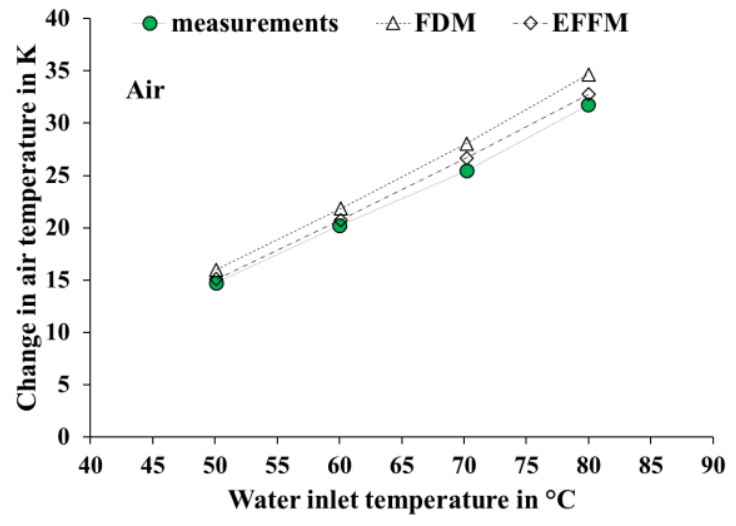

Fig. 9: Experimental and simulation results of the temperature increase of the air during regeneration over the inlet heating water temperature

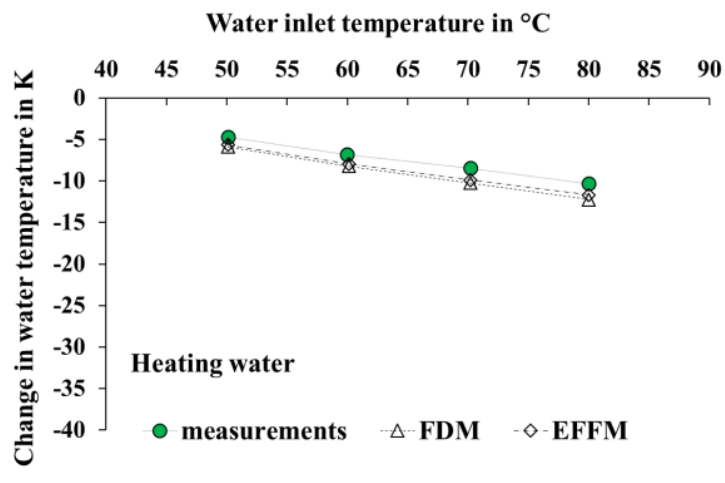

Fig. 11: Experimental and simulation results of the temperature decrease of the heating water during regeneration over the inlet heating water temperature

Fig. 8 shows in addition the comparison between the measured values with the results of the FDM and EFFM. As for the absorption process, the experimental and numerical values for the moisture removal rate show a good agreement and the simulated values are within the experimental uncertainty range. Also, the trend of the FDM and EFFM results agree well with the trend of the measured data. The maximal deviation between numerical and measured values of the air side moisture removal rate $\dot{\mathrm{m}}_{\mathrm{v}, \mathrm{AS}}$, are $10 \%$ and $15 \%$ for the FDM and EFFM, respectively.

The air and liquid desiccant are heated during the regeneration process, whereas the heating water is cooled. The measured and simulated temperature increase of the air during regeneration is shown in Fig. 9. The models overestimate the measured increase of the air temperature, $\Delta \mathrm{T}_{\mathrm{a}}$, with a maximal deviation of $\Delta \mathrm{T}_{\mathrm{a}}=$ $\frac{\Delta \mathrm{T}_{\mathrm{a}, \mathrm{sim}}-\Delta \mathrm{T}_{\mathrm{a}, \text { meas }}}{\Delta \mathrm{T}_{\mathrm{a} \text {,meas }}}$ by $5 \%(\mathrm{EFFM})$ and $10 \%(\mathrm{FDM})$. The models overestimate the liquid desiccant temperature rise with a maximal deviation of more than $40 \%$ compared to the measured results, Fig. 10. The latter can be partly explained by the unfavorable temperature sensor position, as described above. The measured temperature drop of the heating water, $\Delta \mathrm{T}_{\mathrm{w}}$, agrees with the measured values for two models with a maximal deviation of $20 \%$ and $24 \%$, respectively, Fig. 11. 
According to the measured values, about $47 \%$ of the energy supplied by the heating water is used for the regeneration of the liquid desiccant, whereas $26 \%$ of the energy heats the liquid desiccant and about $27 \%$ heats the air.

\section{Conclusions and Outlook}

A liquid desiccant air conditioning system was investigated. The absorber and regenerator are constructed as tube bundle heat and mass exchangers with corrugated media as wicking fins. The mass transfer performance of the absorber and regenerator is evaluated in terms of the moisture removal rate $\dot{\mathrm{m}}_{\mathrm{v}}$ calculated from both, the air and the liquid desiccant side.

During the absorption process the moisture removal rate rises nearly linear with the air inlet humidity ratio, as expected for the investigated operating conditions. The maximum value reached is $\dot{\mathrm{m}}_{\mathrm{v}}=14.4 \mathrm{~kg} / \mathrm{h}$ with a change of the air humidity ratio of $\Delta \mathrm{x}=6.1 \mathrm{~g}_{\mathrm{w}} / \mathrm{kg}_{\mathrm{da}}$ for an inlet humidity ratio of $18.6 \mathrm{~g}_{\mathrm{w}} / \mathrm{kg}_{\mathrm{da}}$ and the given reference conditions. About $70 \%$ of the released energy is transferred to the cooling water.

In a second step, the influence of the heating water temperature on the regeneration process was investigated. For a temperature of $80^{\circ} \mathrm{C}$, the moisture removal rate evaluated from measurements is $\dot{\mathrm{m}}_{\mathrm{v}}=7.3 \mathrm{~kg} / \mathrm{h}$ with a change in the liquid desiccant mass fraction of $\Delta \xi=0.012 \mathrm{~kg}_{\text {salt }} / \mathrm{kg}_{\text {sol }}$ for the given reference conditions. Nearly half of the heat is used for the regeneration of the liquid desiccant, the remaining energy heats up the liquid desiccant and the air with nearly the same heat flow.

High deviations between the moisture removal rates calculated from the air side and from the solution side of up to $16 \%$ arise supposedly mainly from measurement uncertainties of the humidity ratio and liquid desiccant density.

The moisture removal rate and the change in the fluids temperature evaluated from measured data were compared with the results from three different numerical models. The results show good agreement for absorption as well as regeneration. The maximal deviation of the moisture removal rate between the models is $12 \%$ for the absorption process.

It was found that the effective areas for the heat and mass transfer play a significant role for a precise prediction of the three outlet temperatures. Whereas in a physical model both, the heat and mass transfer area are set equal to the plate area, in the single-node effectiveness model only the tube-bundle area was applied as heat transfer area. This leads to a higher heat transfer to the cooling water during the absorption process and a more effective heat transfer in the regeneration process for the physical model compared to the efficiency model.

Further investigations on the uncertainty of the measurements are required.

The single-node effectiveness model to describe the absorption and regeneration process will be used for a system model of the tested liquid desiccant air conditioning system.

\section{Acknowledgements}

The research project was financed by the German Federal Environmental Foundation (DBU) with a PhD scholarship and by the German Federal Ministry of Education and Research (BMBF) in the framework of the research project (OpenSorp, subsidy initiative storage research, code 03SF 0444). The authors would like to express their sincere thanks for the support. We express our gratitude to Mr. Janis Matthes and Mr. Simon Rabener for the operation of the liquid desiccant test unit and the recording of the measurement data 


\section{References}

Addy, J.,Jaradat, M., Fleig, D., Vajen, V., Jordan, U., 2014. Experimentelle Untersuchung an einer offenen Absorptionsanlage zur Heutrocknung. DKV-Tagung 2014.

Andrusiak, M., Harrison, S., 2009. The modeling of a solar thermally-driven liquid-desiccant air conditioning system.

Barati, A., Kokabi, M., Famili, M. H.N., 2003. Drying of gelcast ceramic parts via the liquid desiccant method. Journal of the European Ceramic Society 23 (13), 2265-2272.

Chung, T.-W., Ghosh, T. K., Hines, A. L., Novosel, D., 1995. Dehumidification of Moist Air with Simultaneous Removal of Selected Indoor Pollutants by Triethylene Glycol Solutions in a Packed-Bed Absorber. Separation Science and Technology 30 (7-9), 1807-1832.

Conde, M., 2004. Properties of aqueous solutions of lithium and calcium chlorides: formulations for use in air conditioning equipment design. International Journal of Thermal Sciences 43 (4), 367-382.

Jaradat, M., 2016. Construction and Analysis of Heat-and Mass Exchangers for Liquid Desiccant Systems. Dissertation, Kassel university.

Kessling, W., Laevemann, E., Peltzer, M., 1998. Energy storage in open cycle liquid desiccant cooling systems. International Journal of Refrigeration 21 (2), 150-156.

Khouzam, K., 2009. Developing a Solar Drying Machine for Agricultural Products 2009. RIRDC Publication No 09/026.

Kozubal, E., Herrmann, L., Deru, M., Clark, J., Lowenstein, A., 2014. Low-Flow Liquid Desiccant AirConditioning: Demonstrated Performance and Cost Implications. Technical Report. 104 pp.

Liu, X., Guan, B., 2015. Experimental Study on the Filtration Efficiency of Structured Packing Air Handling Processors. Procedia Engineering 121, 2037-2043.

Lowenstein, A., Slayzak, S., Kozubal, E., 2006. A Zero Carryover Liquid-Desiccant Air Conditioner for Solar Applications, in: Solar Energy. ASME, pp. 397-407.

Mesquita, L.C.S., Harrison, S. J., Thomey, D., 2006. Modeling of heat and mass transfer in parallel plate liquiddesiccant dehumidifiers. Solar Energy 80 (11), 1475-1482.

Mucke, L., Fleig, D., Vajen, K., Jordan, U., 2016. Hybrid liquid desiccant air-conditioning systems: A conceptual study with respect to energy saving potentials. International Journal of Refrigeration 69, 64-73.

Park, J.-Y., Yoon, D.-S., Li, S., Park, J., Bang, J.-I., Sung, M., Jeong, J.-W., 2017. Empirical analysis of indoor air quality enhancement potential in a liquid-desiccant assisted air conditioning system. Building and Environment $121,11-25$.

Qi, R., Lu, L., Huang, Y., 2014. Energy performance of solar-assisted liquid desiccant air-conditioning system for commercial building in main climate zones. Energy Conversion and Management 88, 749-757.

Röben, J., 1997. Sorptionsgestützte Entfeuchtung mit verschiedenen wäßrigen Salzlösungen.

Stevens, D. I., Braun, J. E., Klein, S. A., 1989. An effectiveness model of liquid-desiccant system heat/mass exchangers. Solar Energy 42 (6), 449-455.

Sulardjaka, Nugroho, S., Suyanto, Fitriana, D. F., 2018. Investigation of Mechanical Properties of Al7Si/ $\mathrm{SiC}$ and Al7SiMg/SiC Composites Produced by Semi Solid Stir Casting Technique. MATEC Web of Conferences 159, 2025 .

Yamaguchi, S., Jeong, J., Saito, K., Miyauchi, H., Harada, M., 2011. Hybrid liquid desiccant air-conditioning system: Experiments and simulations. Applied Thermal Engineering 31 (17-18), 3741-3747. 
W. Mandow et. al. / EuroSun 2018 / ISES Conference Proceedings (2018)

\section{Nomenclature and Symbols}

Symbol

NTU

$\mathrm{X}$

$\mathrm{X}$

$\xi$

Le

$\mathrm{V}$

$\dot{m}$

$\mathrm{c}_{\mathrm{p}}$

A

D

a

$\mathrm{U}$
Quantity

Number of transfer unit

Humidity ratio

water content in salt

Mass fraction

Lewis number

volume

Mass flow rate

Specific heat capacity

Transfer area

Diffusion coefficient

Thermal diffusivity

Overall heat transfer coefficient

subscripts

a

da

sol

w

i

o

Eq.

$\mathrm{v}$

sat

eff

sen

abs
Air

Dry air

Liquid desiccant

Cooling or heating water

inlet

outlet

equilibrium

Water vapour

saturated

effective

sensible

absorption
Unit

$\dot{\mathrm{H}}_{\text {sorp. }} \quad$ Sorption enthalpy flow

W

Mass flow rate air/Mass flow rate solution

$\mathrm{kg}_{\mathrm{w}} / \mathrm{kg}_{\mathrm{LiCl}}$

RSHI

Regeneration specific heat

$\mathrm{kJ} / \mathrm{kg}_{\mathrm{V}}$

$\mathrm{m}^{3}$

$\mathrm{kg} / \mathrm{h}$

$\mathrm{kJ} / \mathrm{kg} . \mathrm{K}$

$\mathrm{m}^{2}$

$\mathrm{m}^{2} / \mathrm{s}$

$\mathrm{m}^{2} / \mathrm{s}$

$\mathrm{W} / \mathrm{m}^{2} \mathrm{~K}$ effectiveness

Greek symbols

$\varepsilon$

Mass transfer coefficient

$\mathrm{kg} / \mathrm{m}^{2} \mathrm{~s}$

Heat transfer coefficient

Energy balance factor

Mass balance factor 


\title{
Development of Solar Assisted Sorption Unit for Extraction of Water from Ambient Air in the Desert Climate
}

\author{
Tomas Matuska ${ }^{1}$, Vladimir Zmrhal ${ }^{2}$ and Borivoj Sourek ${ }^{1}$ \\ 1 UCEEB, Czech Technical University in Prague (Czech Republic) \\ 2 Faculty of Mechanical Engineering, Czech Technical University in Prague (Czech Republic)
}

\begin{abstract}
Climate conditions of desert at Arabian Peninsula exhibit high ambient temperatures and very low humidity ratio values during the year. Development of sorption technology for water extraction from ambient air with use of solar energy only is presented.
\end{abstract}

Keywords: sorption wheel, PV system, PVT collector

\section{Introduction}

Lack of potable water resources in the desert regions has led to searching the technologies capable to harvest the water from the ambient air. Number of different technologies has been already developed, tested and applied. However, extreme climate conditions of the desert at Arabian Peninsula restrict the use of the most of them. Autonomous water harvesting unit fully powered only from solar energy resources is an ambitious challenge and subject of development at Czech Technical University in Prague.

\section{Climate conditions}

Characteristic climate conditions of the selected desert locations at Arabian Peninsula are presented in Tab. 1. Table shows severity of the climate in the aspect of air humidity ratio $x_{\mathrm{e}}$ and temperature $t_{\mathrm{e}}$ and also available solar irradiation $H$ on horizontal plane. Fig. 1 shows also cumulative frequency histograms for humidity ratio and ambient temperature. City of Rijad (Saudi Arabia) exhibits the most extreme conditions (temperature, humidity ratio) compared to other environments (Al Dhaid, Al Faqa, Al-Ain or Burajmi) in United Arab Emirates and therefore its climate data have been selected for the design and evaluation of solar water extraction unit with minimum average daily production 100 litres of water. Climate of coastal city Dubai has been added for comparison.
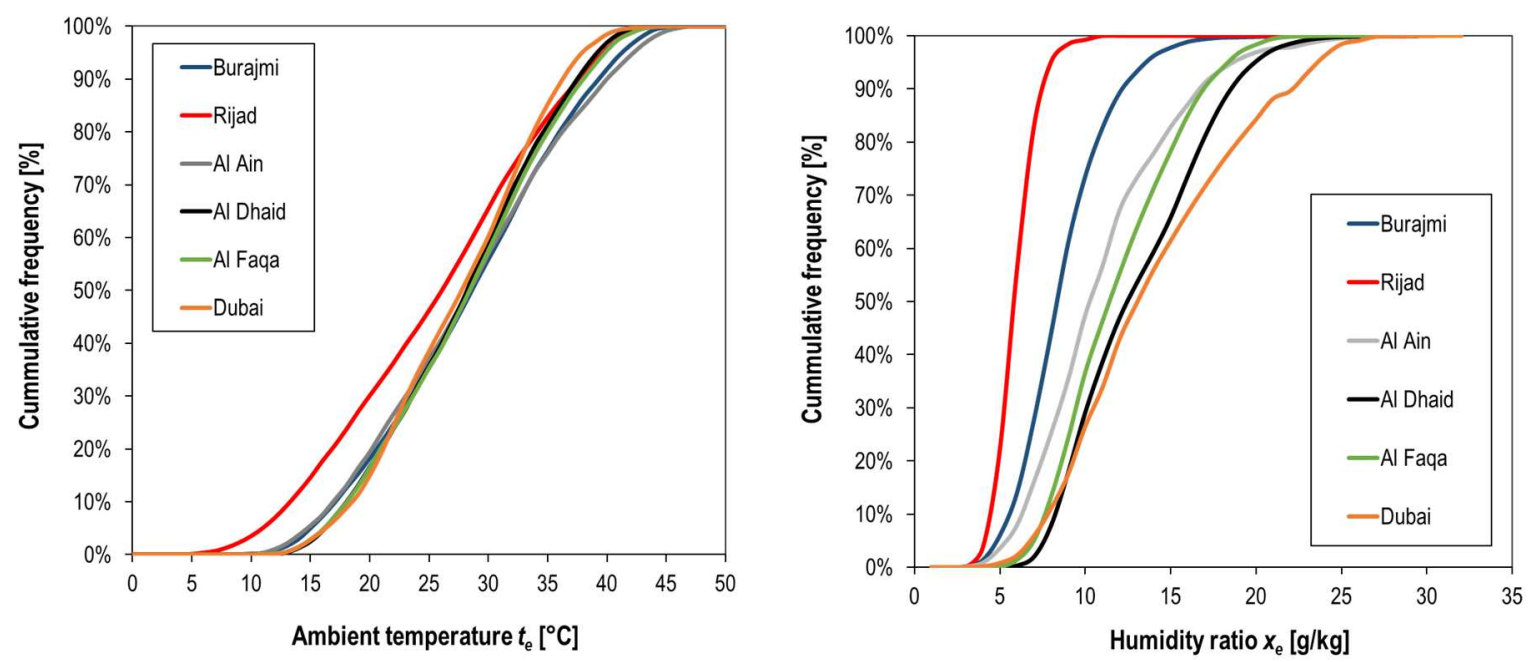

Fig. 1: Ambient temperature and humidity ratio in selected climates at Arabic Peninsula 
Tab. 1: Characteristic parameters for selected climates at Arabic Peninsula

\begin{tabular}{|c|c|c|c|c|c|}
\hline Location & $\begin{array}{c}\boldsymbol{t}_{\mathbf{e}, \mathbf{a v}} \\
{\left[{ }^{\circ} \mathbf{C}\right]}\end{array}$ & $\begin{array}{c}\boldsymbol{x}_{\mathbf{e}, \mathbf{a v}} \\
{[\mathbf{g} / \mathbf{k g}]}\end{array}$ & $\begin{array}{c}\boldsymbol{x}_{\mathrm{e}, \mathbf{m i n}} \\
{[\mathbf{g} / \mathbf{k g}]}\end{array}$ & $\begin{array}{c}\boldsymbol{x}_{\mathrm{e}, \mathbf{m a x}} \\
{[\mathbf{g} / \mathbf{k g}]}\end{array}$ & $\begin{array}{c}\boldsymbol{H} \\
{\left[\mathbf{k W h} / \mathbf{m}^{2} \mathbf{. a}\right]}\end{array}$ \\
\hline Rijad (SA) & 25.6 & 5.9 & 3.0 & 11.0 & 2217 \\
\hline Burajmi (UAE) & 28.4 & 8.7 & 2.7 & 21.7 & 1977 \\
\hline Al Ain (UAE) & 28.7 & 11.0 & 2.2 & 28.2 & 2274 \\
\hline Al Faqa (UAE) & 28.2 & 11.9 & 4.7 & 24.4 & 1997 \\
\hline Al Dhaid (UAE) & 27.9 & 13.1 & 5.3 & 30.4 & 1977 \\
\hline Dubai (UAE) & 27.8 & 14.0 & 2.5 & 28.3 & 2128 \\
\hline
\end{tabular}

Tab. 1 shows that different desert locations have very similar temperatures during the year, but differ significantly in humidity ratio. While location of Rijad represents extremely dry climate conditions, desert locations in UAE seem to be more humid thanks to position between two sea coasts (see Fig. 1, right).

\section{Extraction of water from ambient air}

There are many commercially available units for harvesting the water from air (El-Ghonemy, 2012), which operate on the principle of direct condensation of water vapour from the air on the cooler, more or less effectively performing. Such units can be used in regions with year-round or seasonally high humidity ratio. However, condensation units cannot harvest significant amount of water in case of extremely dry deserts, as analysed further. Therefore, the water harvesting unit under development is based on the sorption system.

\subsection{Condensation unit}

To show the functionality of simple condensation unit with low temperature of cooler surface about $5{ }^{\circ} \mathrm{C}$ (see Fig. 2) the simulations have been performed with use of hourly climate data for Rijad (inland) and Dubai (sea coast). The unit works with total flowrate of ambient air $3500 \mathrm{~m}^{3} / \mathrm{h}$. Annual daily average water production of condensation unit in Rijad is about 30 litres per day. If the condensation unit would be operated in Dubai, the average daily water production will reach 200 litres per day thanks to significantly more humid climate (see Tab. 2).

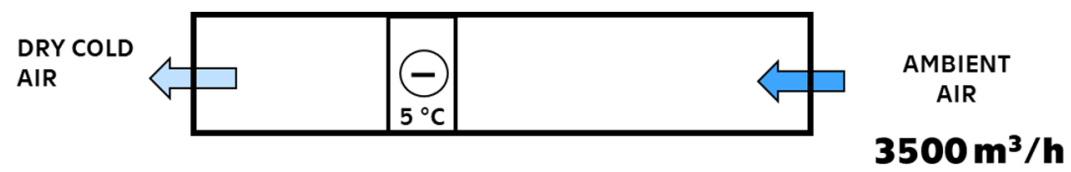

Fig. 2: Condensation unit for extraction of water from air

\subsection{Adsorption unit}

Proposed unit works with adsorption of water molecules on the surface of solid desiccant in the rotary enthalpy heat exchanger (see Fig. 3). Desiccant material (silicagel) adsorbs the water molecules from flowing ambient air to its surface and dehumidified air slightly heated flows back to ambient environment. Ambient air with significantly low flowrate (one third) is used for regeneration of desiccant. Before entering rotary heat exchanger, the air flow is heated to high temperature up to $80^{\circ} \mathrm{C}$. Water molecules are released from the surface into regeneration air flow. Thus regeneration air is humidified to higher humidity ratio and cooled down (evaporation). Humid air than enter the cooler with low surface temperature $\left(5^{\circ} \mathrm{C}\right)$ and water vapour easily condenses as liquid water. To compare the performance of water production with simple condensation, the unit with identical total flowrate of ambient air $3500 \mathrm{~m}^{3} / \mathrm{h}$ has been modelled $\left(2700 / 800 \mathrm{~m}^{3} / \mathrm{h}\right)$. Annual daily average water production of adsorption unit in Rijad is about 170 litres per day. If the adsorption unit would be operated in Dubai, the average daily water production will reach 400 litres per day (see Tab. 2). The model of adsorption unit is based on psychrometric calculations. 


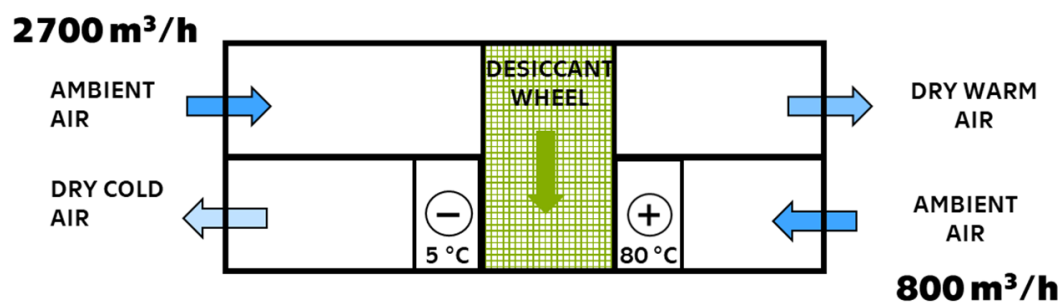

Fig. 3: Adsorption unit for extraction of water from air

The results shown in Tab. 2 has been evaluated for same total flowrates and maximum cooling power of the units for given climates. The advantage of adsorption principle is evident from the figures of water production and energy performance. In case of Rijad climate, the adsorption unit has almost 20 times lower energy demand for litre of produced water. In case of Dubai climate, the differences in results between principles are lower. Fig. 4 shows the water production balance during the year for Rijad climate for both technologies.

Tab. 2: Characteristic parameters for selected climates at Arabic Peninsula

\begin{tabular}{|c|c|c|c|c|}
\hline \multirow{2}{*}{ Parameter } & \multicolumn{2}{|c|}{ Condensation unit } & \multicolumn{2}{c|}{ Adsorption unit } \\
\cline { 2 - 5 } & Rijad & Dubai & Rijad & Dubai \\
\hline Max. cooling power $[\mathrm{kW}]$ & 21 & 29 & 21 & 29 \\
\hline Electricity demand $[\mathrm{MWh} / \mathrm{a}]$ & 30 & 70 & 12 & 13 \\
\hline Water production $\left[\mathrm{m}^{3} / \mathrm{a}\right]$ & 14 & 143 & 96 & 175 \\
\hline Average water production $[1 / \mathrm{day}]$ & 37 & 391 & 262 & 480 \\
\hline Performance factor $[\mathrm{kWh} / \mathrm{l}]$ & 2.2 & 0.49 & 0.12 & 0.07 \\
\hline
\end{tabular}

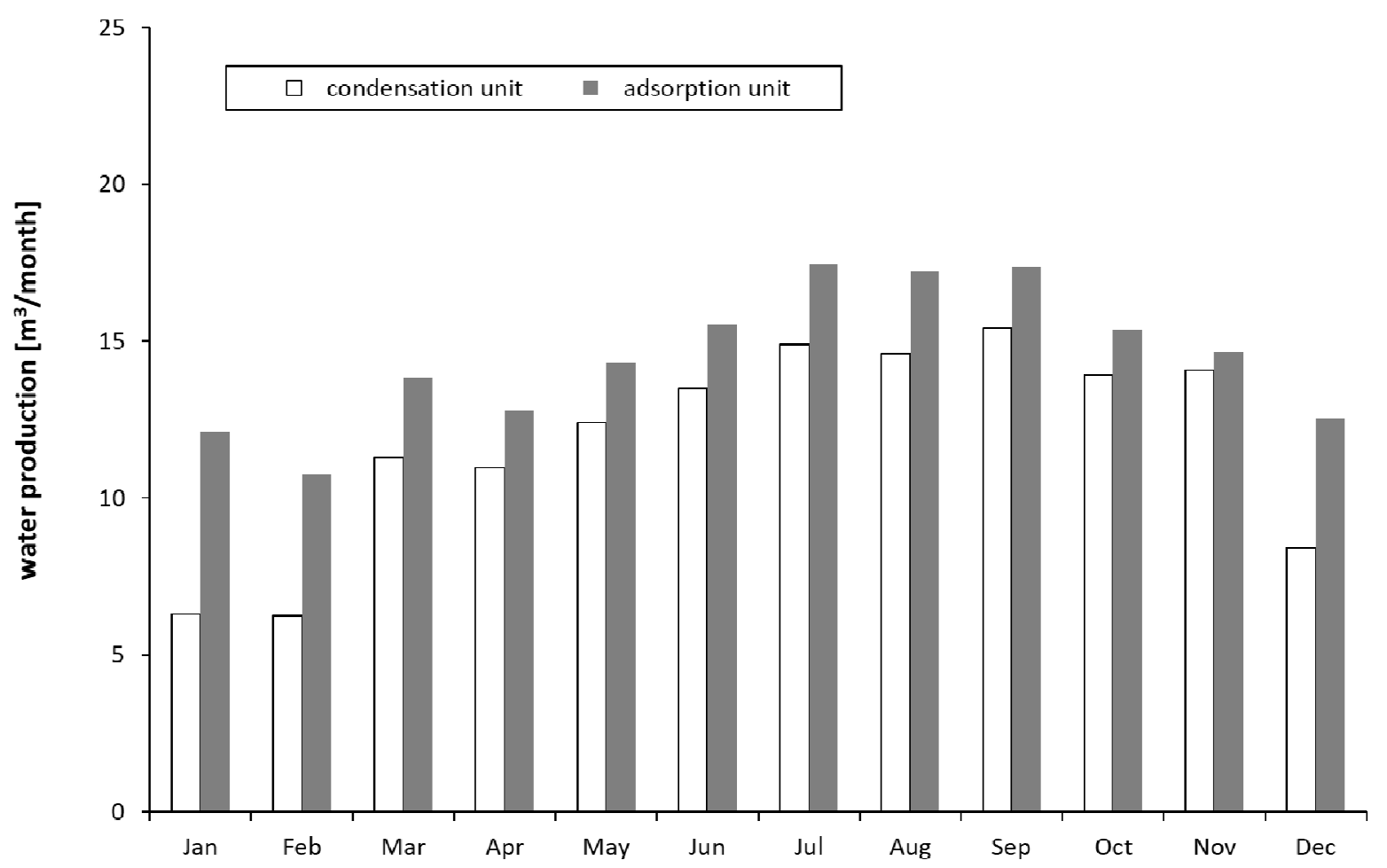

Fig. 4: Comparison of technologies for Rijad climate 


\section{Prototype of adsorption unit and testing}

Air handling unit equipped with a rotary desiccant wheel, integrated refrigerant cycle and additional liquid cooler and heater has been designed and built for testing purposes and further development of theoretical model. The design range of air flowrates is up to $4000 / 1500 \mathrm{~m}^{3} / \mathrm{h}$ (process air / regeneration air). Internal cooling cycle is based on the refrigerant R134a in order to achieve high temperatures up to $80^{\circ} \mathrm{C}$ for regeneration at condenser. The heat from cooling at evaporator is recovered for preheating of the regeneration air on condenser side. Second serial condenser is placed to output of process air channel to transfer the residual heat power from cooling to outflowing process air. Variable speed compressor allows a control of the unit at variable conditions and to reduce power input of the unit when possible. If needed, heating exchanger is used to increase the temperature of regeneration air leaving the condenser by additional heat source, e.g. solar thermal collectors. Heat exchanger placed prior to the evaporator allows to precool the regeneration air leaving the sorption wheel and thus reduces the required cooling power and electric power input of refrigerant loop. The cross section of the unit is presented in Fig. 4 together with photo of the prototype installed in test chamber.
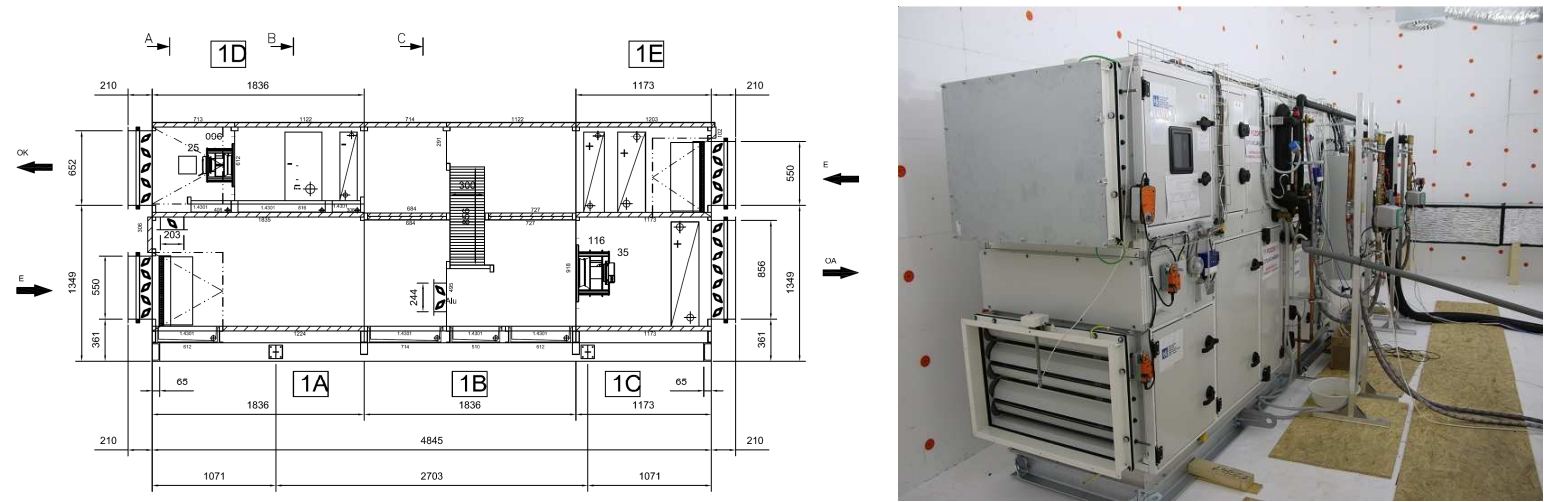

Fig. 4: Prototype of the adsorption unit (cross section, installed in testing chamber)

Tab. 3: Testing conditions in the test chamber

\begin{tabular}{|c|c|c|}
\hline State of air & $\begin{array}{c}\boldsymbol{t}_{\mathbf{e}} \\
{\left[{ }^{\circ} \mathbf{C}\right]}\end{array}$ & $\begin{array}{c}\boldsymbol{x}_{\mathbf{e}} \\
{[\mathbf{g} / \mathbf{k g}]}\end{array}$ \\
\hline 1 & 20 & 6.0 \\
\hline 2 & 20 & 10.0 \\
\hline 3 & 30 & 2.5 \\
\hline 4 & 30 & 5.0 \\
\hline 5 & 30 & 7.5 \\
\hline 6 & 30 & 13.0 \\
\hline 7 & 40 & 10.0 \\
\hline 8 & 40 & 16.0 \\
\hline 9 & 40 & 20.0 \\
\hline 10 & 35 & 24.0 \\
\hline
\end{tabular}

The unit has been tested to further develop the theoretical model of sorption wheel, water production and to investigate its energy performance. External air loop of the test chamber provides the range of climate conditions from cold dry air to humid hot air. Testing conditions (states of air) are summarized in Tab. 3. The model of sorption wheel had to be corrected based on the results from measurements. The air flow rates during the experiment were $2100 / 700 \mathrm{~m}^{3} / \mathrm{h}$. Principle correction was non-adiabatic release of water vapour from the 
desiccant surface of the sorption wheel, which finally results in lower cooling power required at the evaporator of the cooling cycle (less energy needs). Comparison of developed model with measurement is shown in Fig. 5.

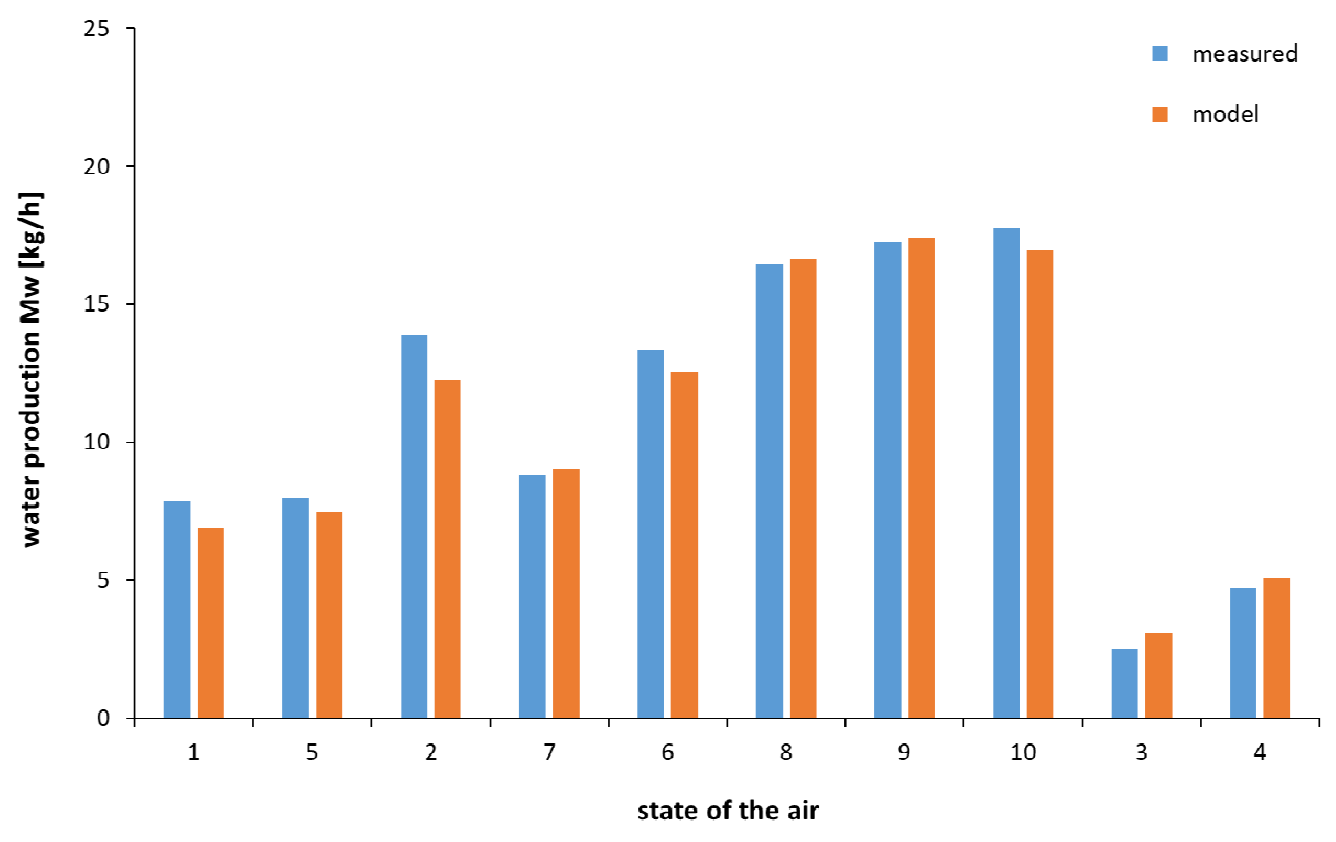

Fig. 5: Comparison of corrected model and measurements

\section{System layout and modelling}

Core of the system for harvesting the water from desert air is the adsorption unit. To operate the unit autonomously in the desert environment, only renewable energy sources available in the desert could be used. Cooling cycle based on speed controlled compressor will be driven by electricity from the photovoltaic modules coupled with battery storage. Heating of process air in case of insufficient temperature of regeneration air at output of condenser will be provided by solar thermal collectors (alternatively with glazed PVT collectors) coupled with thermal water storage tank. Heat removal from precooling heat exchanger will be realized by night radiant cooling (to clear sky, low ambient temperatures) by unglazed PVT collectors in combination of the storage of night cold. The scheme of the system is outlined in Fig. 6.

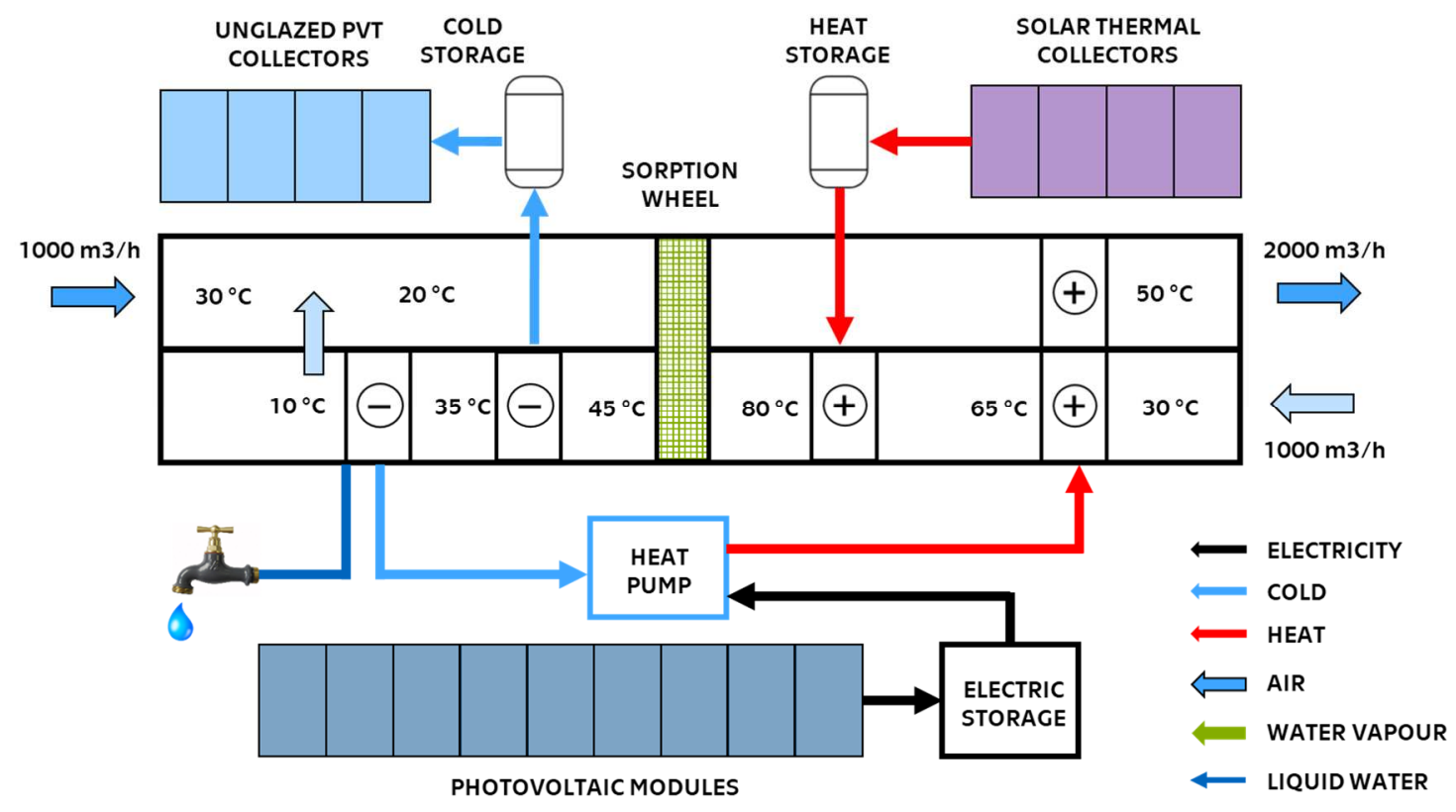

Fig. 6: Principle scheme of solar assisted adsorption system for extraction of water from ambient air in the desert climate 
The whole system has been modelled with use of hourly simulation model. The detailed optimization analysis has led to several improvements of the initial idea, especially concerning the recirculation flap (see Fig. 6). First design of components for the demonstration system has been done: $70 \mathrm{~m}^{2}$ of unglazed PVT collectors as a source of cold and electricity, coupled with $30 \mathrm{~m}^{2}$ of PV modules and $20 \mathrm{~m}^{2}$ of solar thermal collectors as a source of heat. Results of average daily production of water in Rijad for the case of grid connected system and in the case of autonomous operation with use of local renewables only is shown in Fig. 7. For this purpose, volume of water storage for cooling has been considered $2 \mathrm{~m}^{3}$, for heating $1 \mathrm{~m}^{3}$. Battery storage $25 \mathrm{kWh}$ was needed. The results reveal the dependency of the production on available solar radiation. There is underproduction of generated water during the winter and therefore water storage has to be applied as a part of the system. Daily average water production 100 litres calculated from annual figures shows the potential to meet the target, but further optimization (volume of storage tanks, capacity of battery storage) is needed by more detailed parametric simulations, especially with use of advanced control of the system operation (shifting the production to hours with higher humidity, increase of flowrate, balancing the use of electricity and cold). The realistic operation of the energy sources (night cooling, PV system in extreme conditions) will be proved in demonstration installation in the desert located in UAE during 2019.

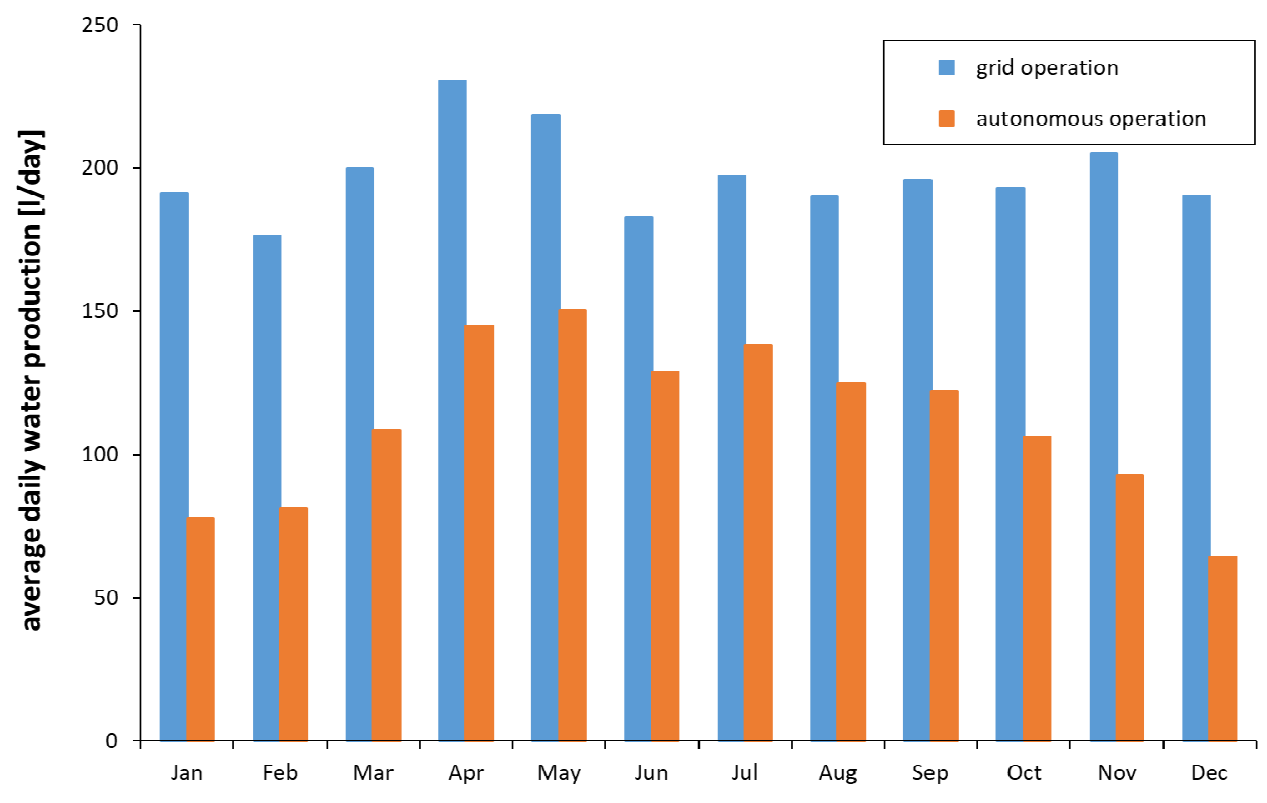

Fig. 7: Water production of the system for Rijad climate

\section{Conclusion}

The development of the adsorption unit for extraction of water from ambient desert air fully powered from solar energy has been presented. The unit has been built and tested in laboratory and existing theoretical model describing the behaviour has been further developed. The system concept of the autonomous unit has been developed with use of renewable energy sources available in the desert climate. First calculations of potential production of the autonomous solar water from air extraction system based on adsorption unit has been performed. The initial target for production 100 litres of water per day can be achieved even in Rijad climate.

\section{References}

El-Ghonemy, A.M.K., 2012. Fresh water production from / by atmospheric air for arid regions using solar energy: Review. Renewable and Sustainable Energy Reviews, 16 (2012), pp. 6384-6422, https://doi.org/10.1016/ j.rser.2012.06.029

This work has been supported by the Ministry of Education, Youth and Sports within National Sustainability Programme I, project No. LO1605. 


\title{
Using the Heat of Sun to Cool: A Case Study of 100 TR (350kWth) Solar Air-Conditioning System

\author{
Kedar Mehta' ${ }^{1}$ Deepak Gadhia ${ }^{2}$
} \\ ${ }^{1}$ Student, Renewable Energy System (M.Sc.), Technische Hochschule Ingolstadt, Germany \\ 2 MSA Renewtech Foundation, Muni Seva Ashram, Kailas Cancer Hospital, Goraj, Vadodara, India
}

\begin{abstract}
This case study presents the solar assisted cooling technology of 100 TR developed by using double effect $\mathrm{Li}-\mathrm{Br}$ absorption chiller and running since last 10 years at Kailash Cancer Hospital and Research Center (KCHRC) run by an NGO Muni Seva Ashram near Vadodara, Gujarat, India. The cooling load of the cancer hospital is 600 TR and provided by the biomass-fired boiler. The key object of opting for solar air conditioning was to reduce the biomass consumption. After the implementation of the system, out of $600 \mathrm{TR}$, 100TR is generated with the solar thermal cooling system. This technology designed and established with double effect evaporator runs with steam which is generated by Scheffler dishes (solar concentrator). Solar generated steam is sent to double effect vapor absorption $\mathrm{Li}-\mathrm{Br}$ chiller which chills the water to $6^{\circ} \mathrm{C}$. This water is piped to the cancer hospital (cooling area) and is sent to Air Handling Units (AHU) which chills the air and ducts to the central air-conditioning system in the cancer hospital. Being sustainable, the institution was looking for replacing and saving wood and thus use of solar concentrator was a perfect and economical solution for cooling. The success of this system, along with the economic benefits, will lead to many new solar thermal cooling systems in developing countries and hopefully, will spread to other countries all over the globe.
\end{abstract}

Keywords: Solar cooling, Scheffler dish, vapor absorption Li-Br, Air-Handling Unit

\section{Introduction}

The requirement of space cooling is rising over the globe due to the adverse effect of the global warming. Basically, air conditioning is defined as the simultaneous operation of temperature, humidity, purification and distribution of airflow to space (Daut et al. 2013). It is important to provide safe and clean cooled air in the hospital as well. Conventionally, the air conditioning is driven by electricity. It leads to an increase in peak electricity demand in developing countries. In addition to that, the growing cooling demand in summertime lead to the overload of the national electric grid and it will turn to blackout or the fluctuations in electric supply (Kalkan 2012). Higher usage of vapor compression cooling machines also leads to increased GHG (Greenhouse gases) emission by leakage of refrigerant as well as the usage of fossil fuel to generate the electricity. Total $\mathrm{CO}_{2}$ emissions from the cooling sectors amount to approximately $4 \mathrm{GT}$ of $\mathrm{CO}_{2}$ emissions in 2018 (equivalent to $11.8 \%$ of the world's direct $\mathrm{CO}_{2}$ emissions) (Birmingham Energy Institute 2018).

The Kailash Cancer Hospital and Research Center (KCHRC) is situated in a small village called Goraj which is 30 $\mathrm{km}$ away from the city Vadodara. The hospital is operated by Non-Governmental Organization named "Muni Seva Ashram". The Kailash cancer hospital serves the people with all modern and hi-tech equipment and amenities which require an air-conditioned environment. Electricity for grid was not able to provide continuous and constant cooling due to fluctuations in voltage. So, the authorities decided to shift from the electric air conditioning to the sustainable cooling. Previously the air conditioning was done by steam generated with a wood fired boiler. The total cooling load is $600 \mathrm{TR}$ of the hospital.

\section{Solar cooling technologies}

Transformation in global temperature and climate will increase external and interior heat loads and might be injurious to health and harm work productivity of millions of people (Schulte and Chun 2009; Ford and Ford 2011). Cooling is having a major contribution to the climate change (Aprea et al. 2012). In such a scenario, solar cooling can be considered viable as well as a sustainable alternative. Moreover, in most cases, the availability of solar radiation and demand for the cooling match. In this section, available technologies for solar cooling are explained. Solar assisted 
cooling structures are either solar electricity driven or solar thermally driven. Figure 1 illustrates the various cooling technologies.

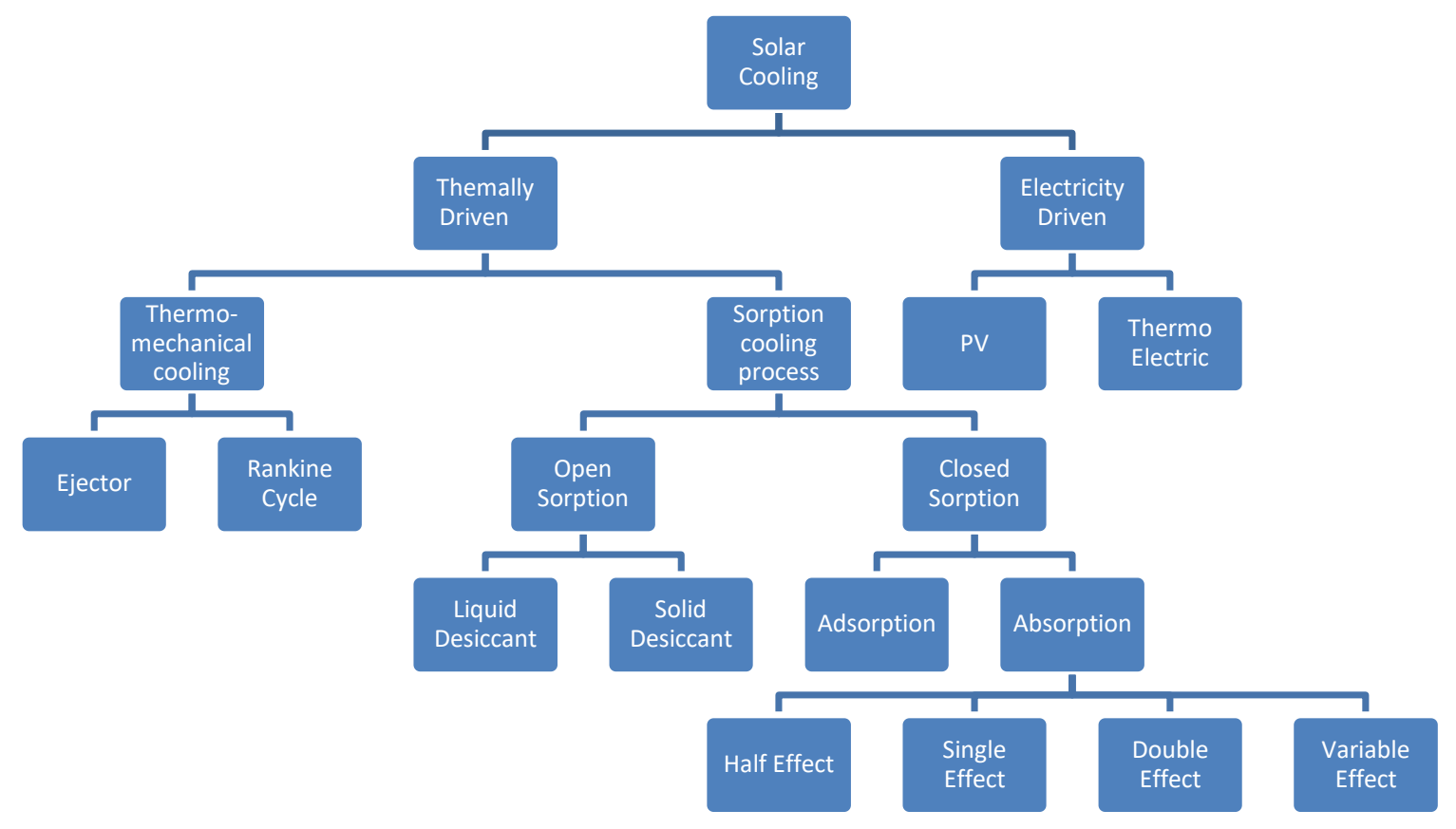

Figure 1 Classification of solar cooling technologies

Solar PV cooling is a simple technology with the low maintenance cost. However, the storage system (batteries) is very expensive. It is the viable option to use solar PV cooling method during sunshine hours to meet the electricity demand. In the solar thermal cooling system, the heat from solar can be used to run the prime movers to compress the refrigerant. The basic principle of thermal driven cooling and electricity driven cooling is represented in Figure 2 .

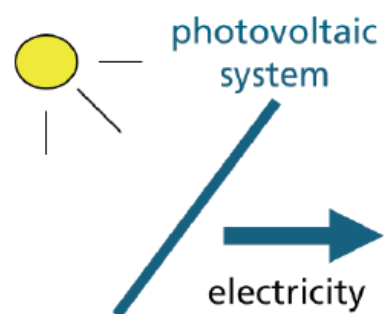

electricity
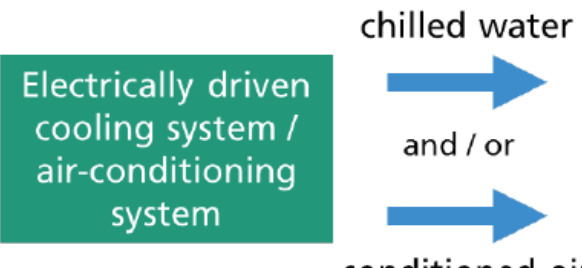

conditioned air

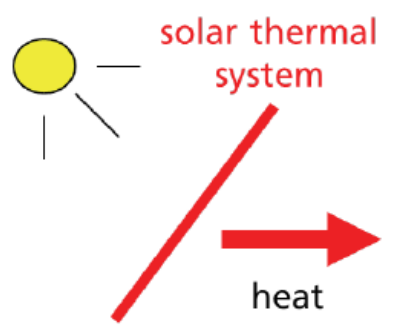

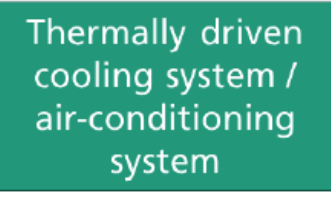

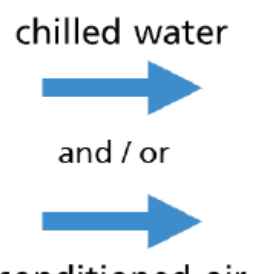

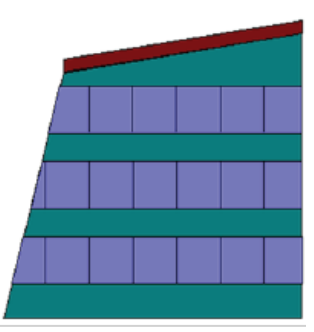

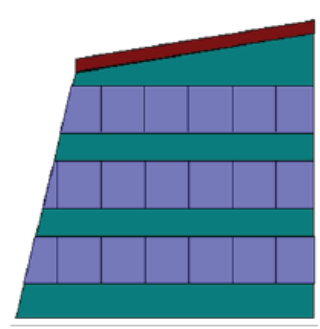

Figure 2 Principles for solar driven cooling systems (Mugnier 2015)

The comparison of COP with respect to hot water inlet is shown in Figure 3. It can be pointed out from the figure that the double effect absorption system is having a higher COP. Hence, the presented technology discussed in this paper is designed on double-effect absorption. 


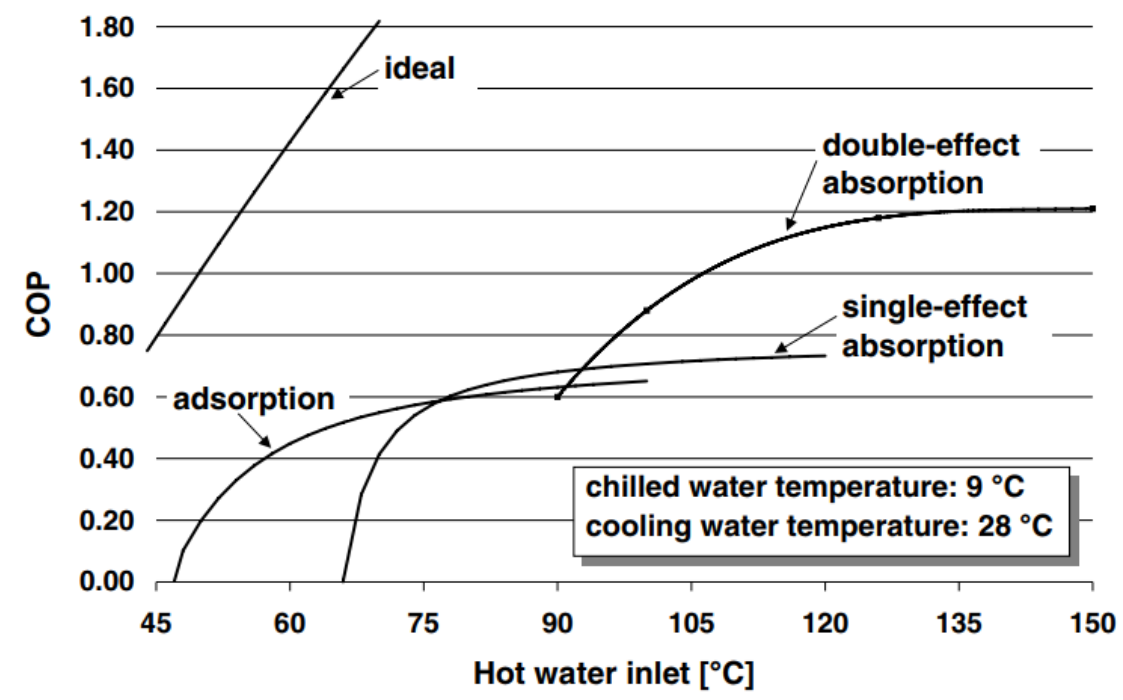

Figure 3 COP comparison of various cooling technologies (Henning 2007)

\subsection{Absorption cooling}

Among the described technologies, the absorption cooling in the most commonly used method under solar cooling. The system has a vapor compression machine that provides cooling by expansion of refrigerant. Figure 4 describes the absorption cooling cycle. The double effect absorption system utilizes two generators. The superheated refrigerant from the first generator is input for the second generator. The second generator will produce the additional refrigerant effect. And this is the reason why the COP is higher for the double effect absorption system.

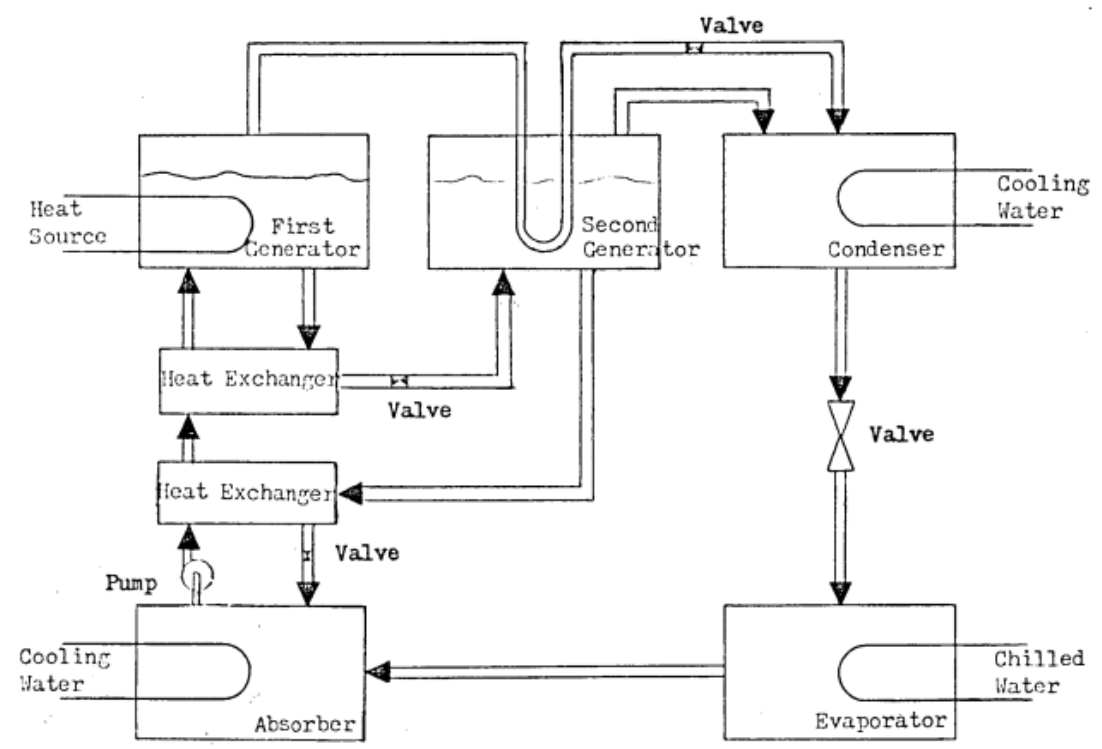

Figure 4 Double-effect absorption system (Vliet et al. 1980)

As compared to the single effect system, the water cooling load is lower per ton of cooling. On the other hand, this system requires the higher temperature, two generator (primary and secondary) and two exchangers, making the system more complex and expensive. However, the higher COP of the system makes the double-effect system relatively viable.

For the absorption cooling system, a combination of two refrigerants is used i.e. Lithium bromide with water, and ammonia with water. Three refrigerant pairs are used for VARS are commercially available in the market: LithiumBromide ( $\mathrm{LiBr}$ )-Water solution, Water-Ammonia and Lithium Chloride ( $\mathrm{LiCl}$ )-Water system. Currently, absorption chillers using $\mathrm{LiBr}$-Water as the working pair are the most commercially developed (Baniyounes et al. 2013; Henning 2007). While naming these, first of the pair is the sorption agent and the second the refrigerant. 


\section{System description}

In 2008, after a pre-feasibility study, it was found that a site had rich solar radiation of $5.29 \mathrm{kWh} / \mathrm{m}^{2} / \mathrm{day}$ (RETScreen 2018). The system was installed in 2008 and is running in good condition. This portion provides the information about solar supported cooling system. As it mentioned before, the solar cooling system is installed at the hospital for space cooling in the hospital. The total cooling load of the hospital is $600 \mathrm{TR}$ out of that $100 \mathrm{TR}$ cooling is done with solar thermal assisted cooling. The hospital has installed the Scheffler dishes as a solar concentrator. It generates steam to drive the components of absorption cooling cycle. Figure 5 represents the aerial view of the site with the installed system.

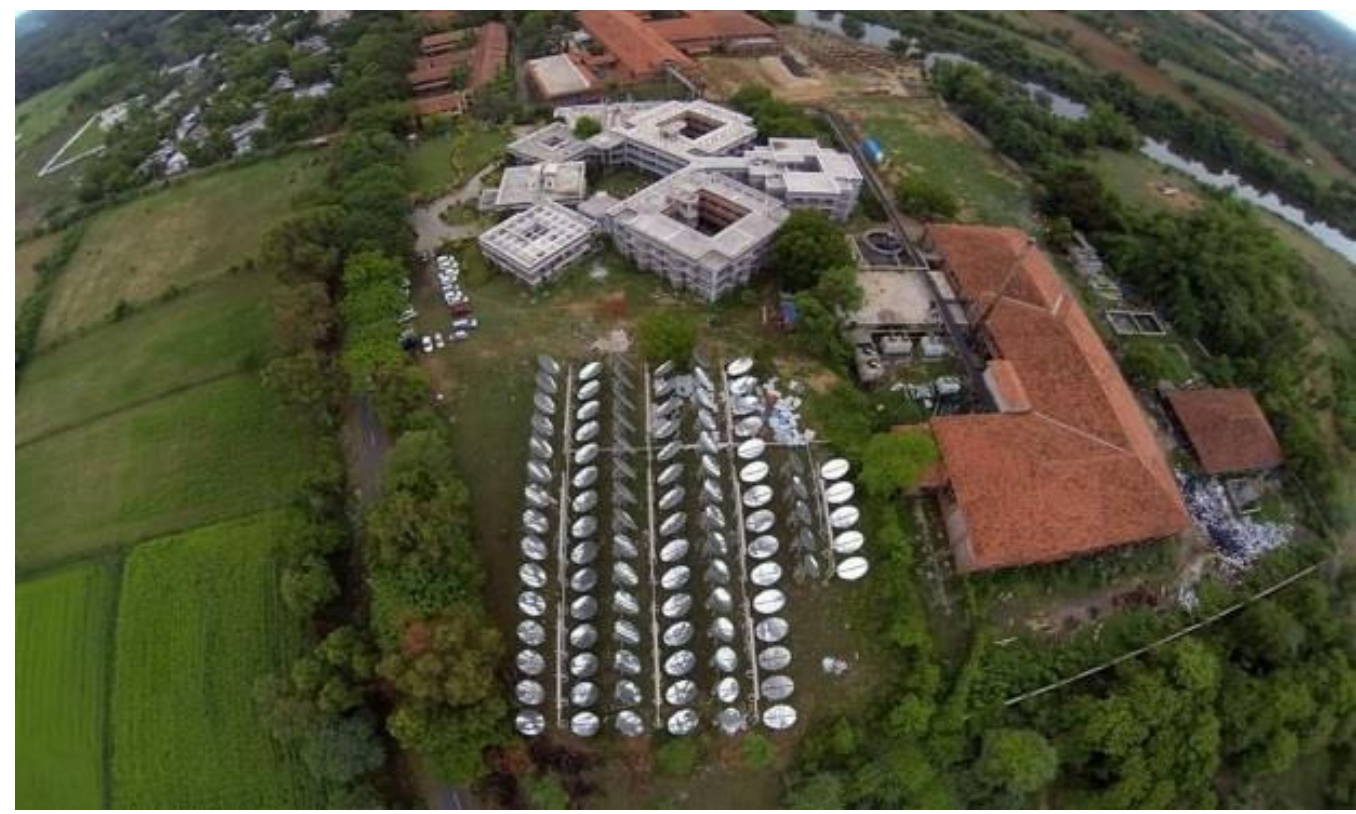

Figure 5 Aerial view of the cancer hospital with solar assisted cooling system

The system has 100 concentrators with $12.5 \mathrm{~m}^{2}$ capacity each. The solar concentrator system consists of 3 rows with 15 pairs each and fourth row with 5 pairs of Scheffler dishes (it can be observed from the Figure 5). The total collector area being $1,250 \mathrm{~m}^{2}$. To completely utilize the solar energy, the system has an automatic East-West tracking. NorthSouth tracking is done manually by every two days. The system arrangement is done in such a way that, the Scheffler dishes placed in a pair with the help of standing dish reflecting the sun rays on the one side of the receiver placed in its focus and the sleeping dish deflecting the sun rays on to the other side of the receiver. Figure 6 illustrates the arrangement of Scheffler dishes and the receiver.

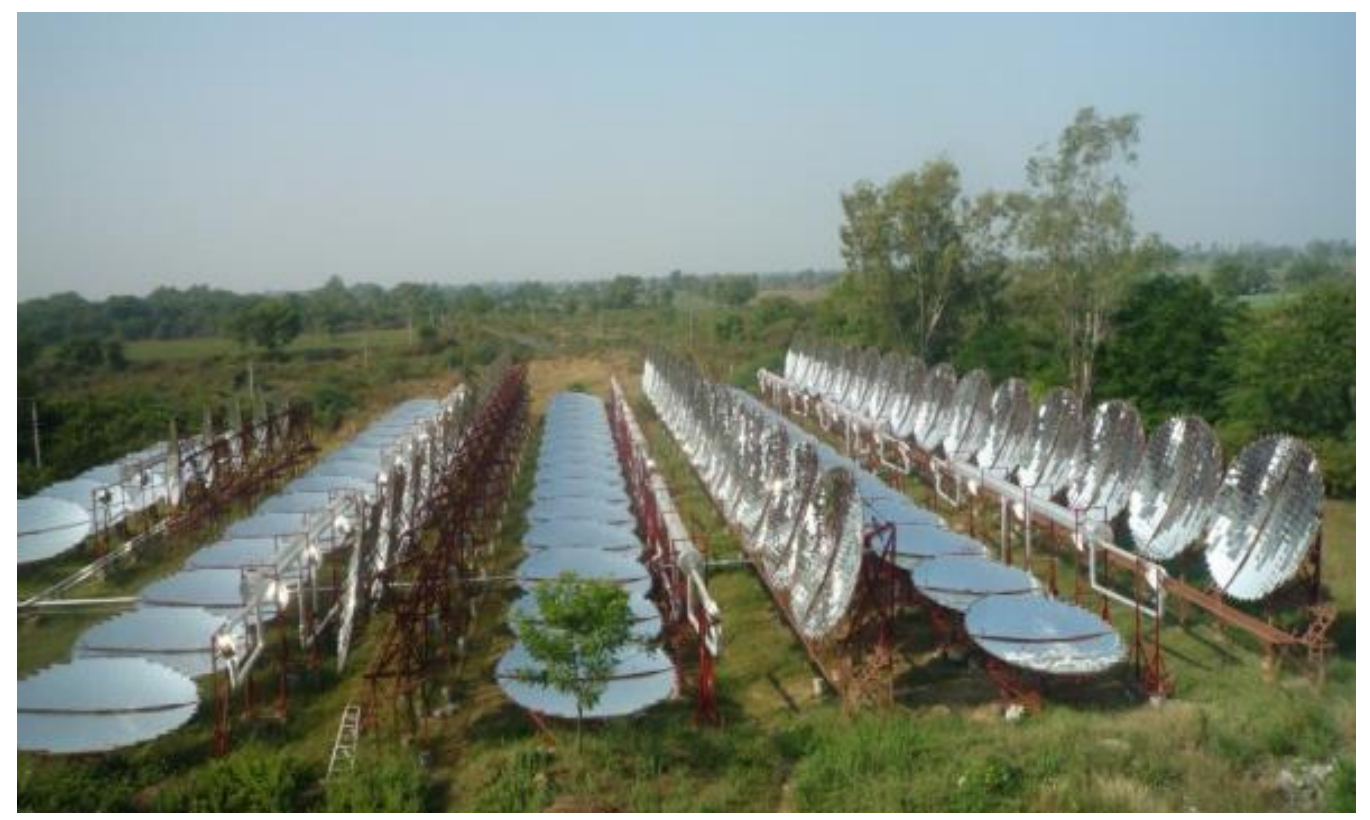

Figure 6 System arrangement 
Steam header pipes are positioned overhead the receiver and the header pipe is filled till half. The water flows into the receiver due to gravity. Due to the high concentration of sunlight on the receiver, water passing through from it receives excessive heat which is returned to the header pipe via thermo siphon effect. This circulation continues until the water reaches to its boiling point. Water with an initial temperature of around $55^{\circ} \mathrm{C}$, gets and converted into a steam of pressure $7.5 \mathrm{bar}$ and the temperature of the steam is $167^{\circ} \mathrm{C}$. From the header, the steam is drawn and supplied to Vapor Absorption Chiller (VAC). Figure 7 represents the block diagram of the system.

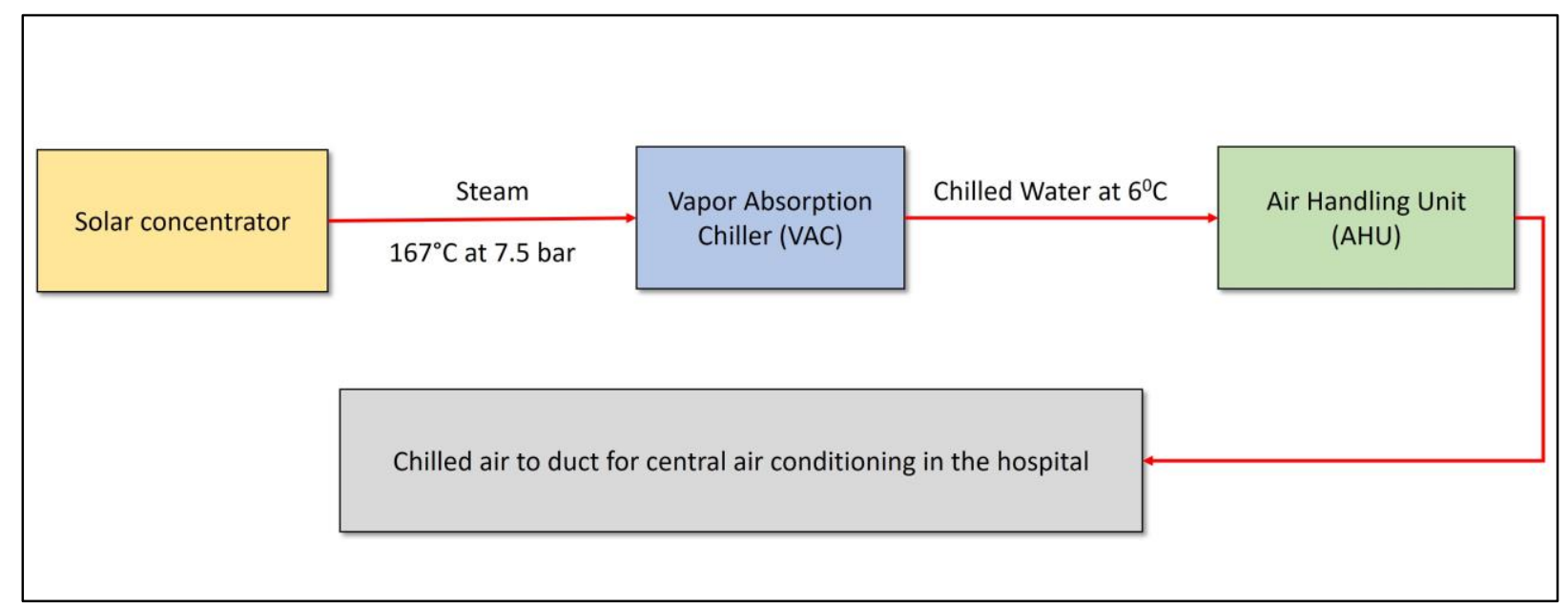

Figure 7 Block diagram of the system

To ensure that the steam maintains the required temperature and pressure, the steam is first sent through back-up biomass boiler, which supplies additional heat if needed, ensuring that Vapor Absorption Chiller (VAC) always gets the steam at desired temperature and pressure. If desirable, the boiler can also run the air-conditioning system at night times and also during bad weather days (during monsoon and cloudy days). Figure 8 presents the picture of a Vapor Absorption Chiller machine. The COP of the double effect evaporator based VAC is 1.12-1.14.

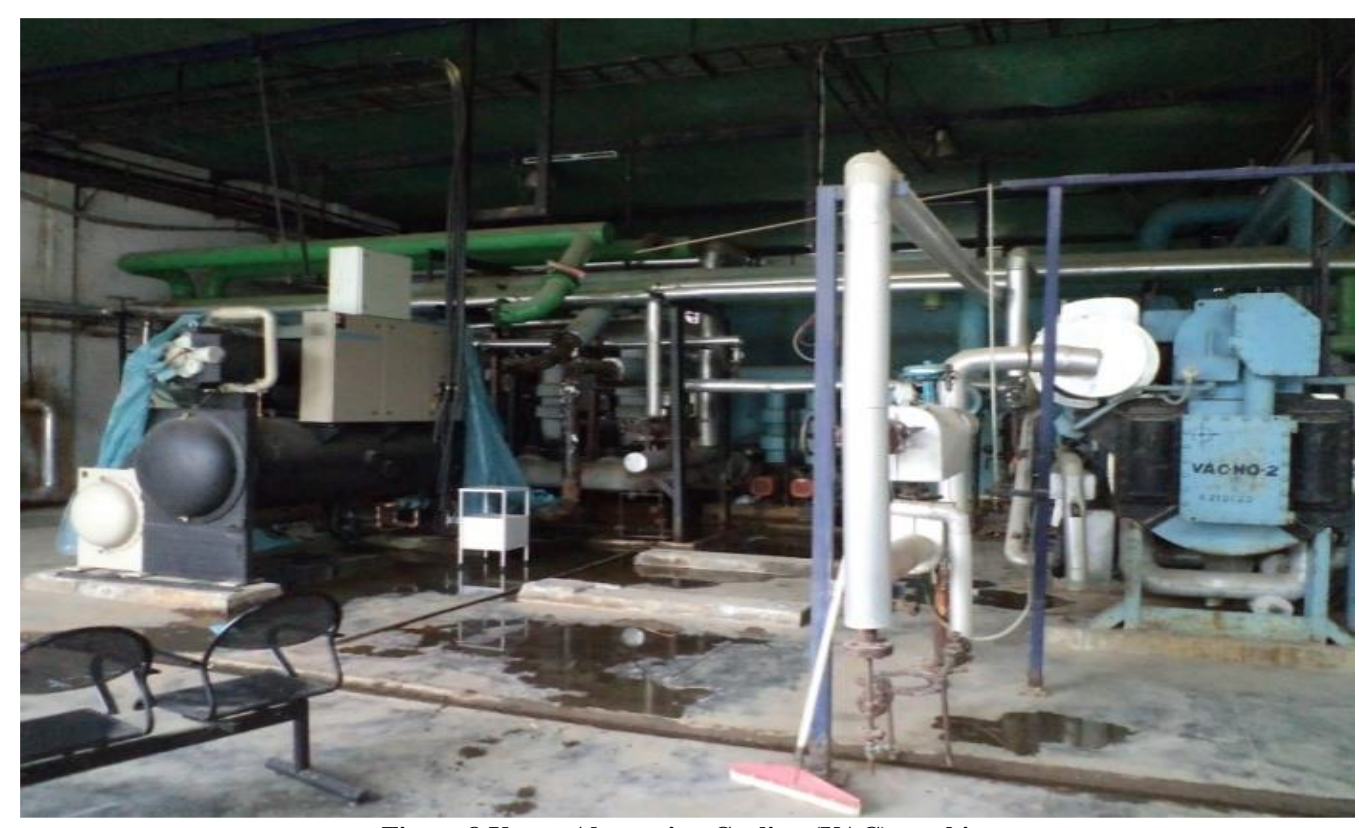

Figure 8 Vapor Absorption Cooling (VAC) machine

\section{Solar - Biomass Hybrid cooling system}

This system is directly driven by solar energy. There is no such provision for storage. So as the cooling system is operated by solar energy, there is a fluctuation in the steam production due to weather effects. Hence, it is required to provide backup/support system. To provide a constant supply of steam, a biomass-fired boiler is installed that work as a support system. It is capable of fulfilling the shortage of steam due to weather effects. The boiler is equipped with an automatic controller which can detect the variation in the steam parameters like temperature and pressure, and accordingly feeds the boiler to produce more steam acceptable for the VAC. Figure 9 represents the biomass-fired boiler from the site. 


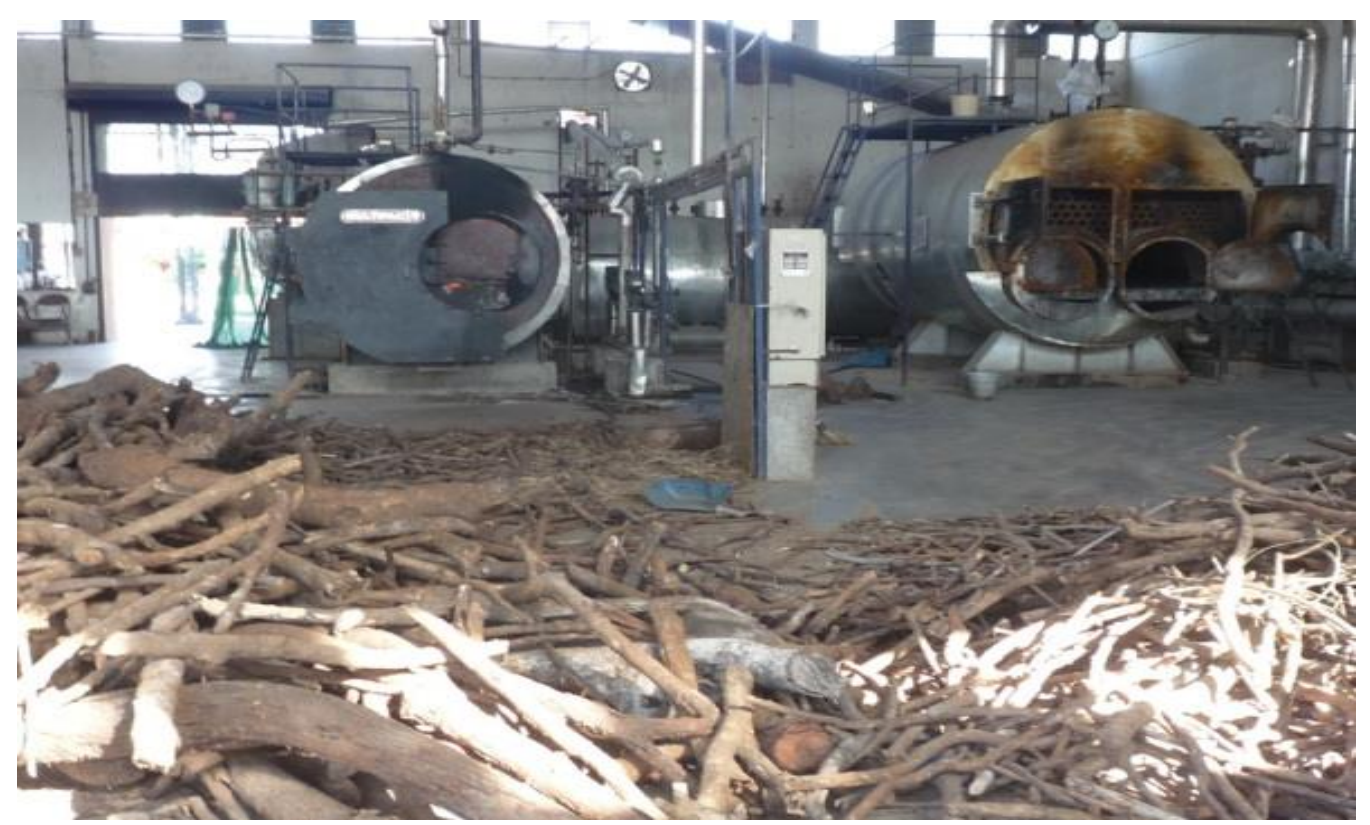

Figure 9 Biomass fired boiler from the site

The steam is condensed while heating a $\mathrm{Li}-\mathrm{Br}$ solution of the VAC system and is pumped back to the solar concentrator to be heated and produce steam again. The return temperature of the hot water is $161^{\circ} \mathrm{C}$ from the $\mathrm{VAC}$ to the solar concentrators. In this way, the steam carries heat from solar collectors to the VAC system in a closed loop. Figure 10 represents the block diagram of the solar -biomass hybrid cooling system.

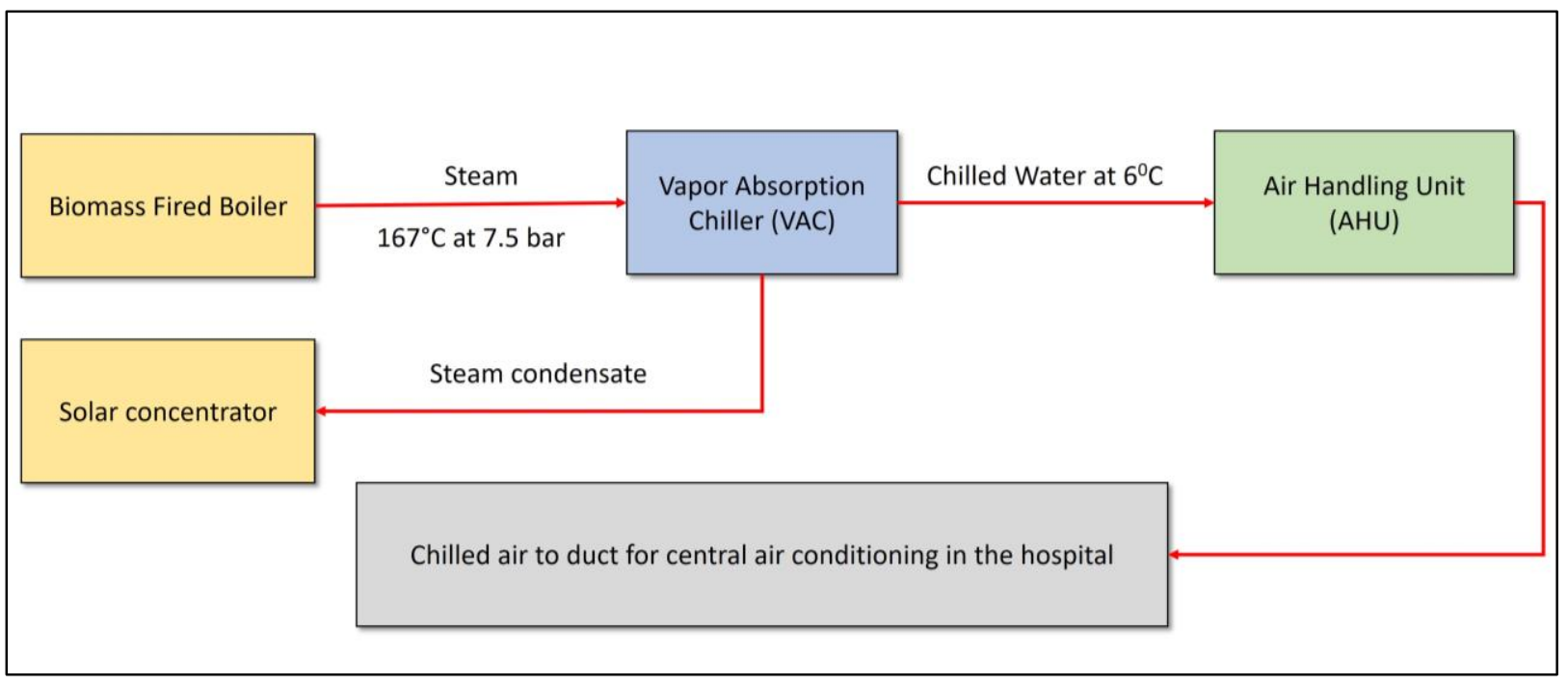

Figure 10 Block diagram of solar-biomass hybrid cooling system

As it is already mentioned that chilled water from the VAC at $6^{\circ} \mathrm{C}$ is fed into Air Handling Unit (AHU). Here, the fin coil exchanger in $\mathrm{AHU}$ chills the air which is pumped in the cancer hospital for space cooling. The chilled water becomes heated to $12^{\circ} \mathrm{C}$ from $6^{\circ} \mathrm{C}$ due to it giving away its chillness to air and is again pumped to VAC for rechilling and thus building additional closed loop. Figure 11 shows the design schematics of a complete solar cooling system.

The cooling load supplied by the system is $100 \mathrm{TR}$ (equivalent to $350 \mathrm{~kW}$ thermal power). The system works from 10:30 AM to 4:30 PM. Steam at $167^{\circ} \mathrm{C}$ at 7.5 bar pressure is generated by harnessing solar thermal energy. The system runs approximately 300 days in a year. 


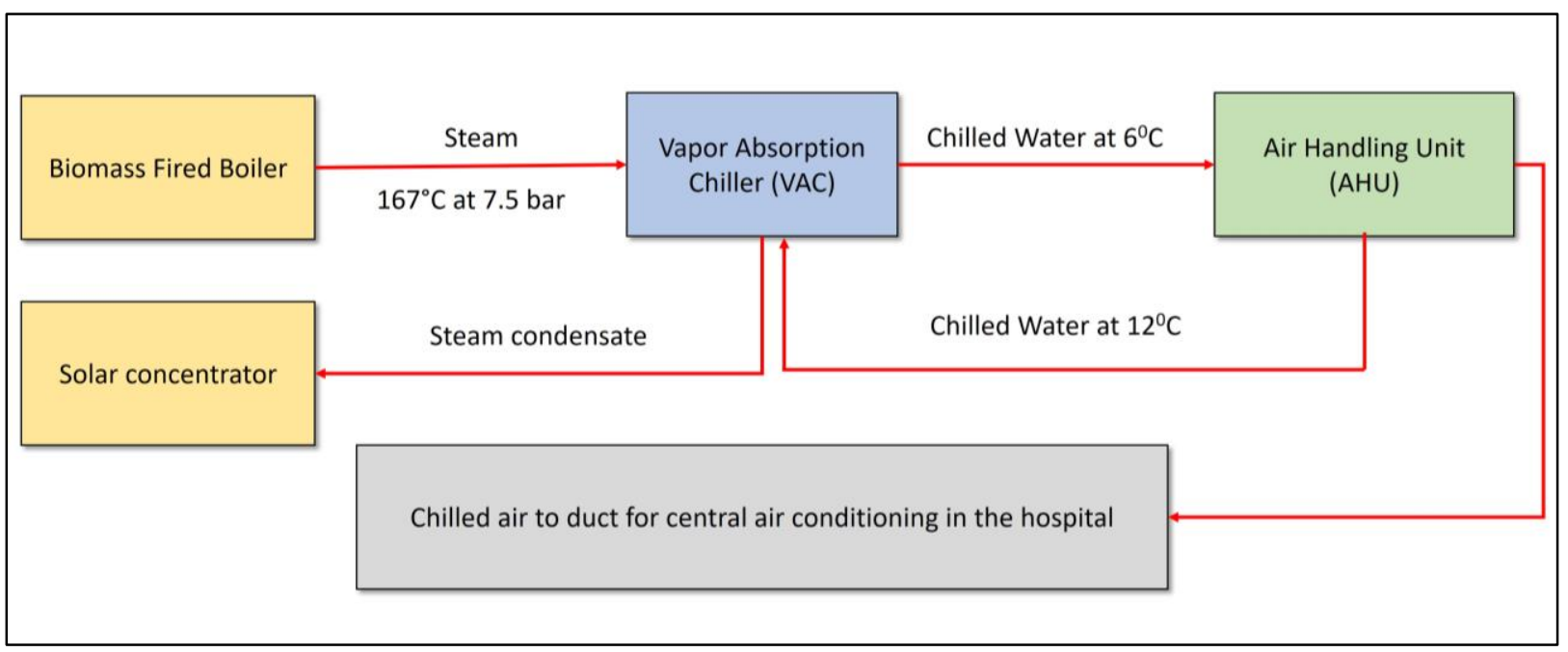

Figure 11 Design schematics of solar cooling system

\section{Operation and Maintenance}

The total cost of 100 TR solar assisted solar cooling was ₹ 12.5 million INR* (Indian Rupees). This is India’s first largest cooling system. At the time of the installation, MNRE supported this iconic project by providing the subsidy of ₹ 5 million INR. MNRE is abbreviated as Ministry of New and Renewable Energy, which is the nodal ministry for the renewable energy. The Ministry is mainly responsible for research and development, intellectual property protection, and international cooperation, promotion, and coordination in renewable energy sources such as wind power, small hydro, biogas, and solar power. Other than the subsidiary price, the remaining amount was borne by the Ashram. This is the only cost for the solar assisted cooling system, it does not include the cost of the backup boiler and VAC system. The Ashram installed this 100 TR Vapor Absorption Chiller, made by Thermax, a Pune (India) based company. By considering the subsidy IRR and payback of the system are $26.63 \%$ and 3.5 years respectively. While without the subsidy, the IRR and payback of the solar thermal cooling system are $12.92 \%$ and 6.4 years respectively.

By installing the $100 \mathrm{TR}$ solar cooling system, around $1000 \mathrm{~kg} /$ day of wood biomass is saved. Earlier the air conditioning was done by steam generated with boiler fed from biomass. At that time, the cost of wood was ₹ $2 / \mathrm{kg}$ but due to the shortage of wood, the price hiked and currently costs $₹ 6 / \mathrm{kg}$. The system requires 3 people for the operation. Every day, the workers fill the steam header with make-up-water which evaporates and thus needs be continually supplied with fresh water. Also, they are responsible for the manual tracking of a solar concentrating system. After 5 years of successful operation of the system, in the year 2013, the mirrors were changed under the UNDP-MNRE repair and renovation project. To reduce the reliance on imported mirrors, the organization has worked with local glass experts of Messer's ARS Gastec. They have developed specific side coatings for solar grade mirrors and also developed methods of sealing edges which gives them a longer life.

\section{Conclusion}

The growing earth temperature leads towards to the growing cooling demand over the globe. Conventional cooling methods are highly responsible for the emission of greenhouse gases, which is asking for sustainable cooling technologies. Solar assisted cooling could be the perfect solution. The presented validated case study introduces 100 TR solar thermal assisted cooling system, which is responsible for the space cooling of the cancer hospital in a rural area of Vadodara, India. This case study includes the design criteria, manufacturing practices, installation, operational $\&$ maintenance experience of these India's first largest solar supported cooling system. The system installed in 2008 and running in good condition. This case study is a significant example of a sustainable renewable cooling application. Because previously the space cooling of the hospital was done by a biomass-fired boiler. By implementing this system, approximately $1000 \mathrm{~kg}$ of wood mass is saved daily. The success of this system, clean environment approach, as well as the economic benefits, will lead to new similar systems for empowerment in developing countries. 


\section{References}

Aprea C., Greco A., and Maiorino A. 2012. The Impact on Global Warming of the Substitution of Refrigerant Fluids in Vapour Compression Plants: An Experimental Study. Singh (Ed.) 2012 - Global Warming. DOI: 10.5772/48349.

Baniyounes AM., Ghadi YY., Rasul MG., and Khan MMK. 2013. An overview of solar assisted air conditioning in Queensland's subtropical regions, Australia. Renewable Sustainable Energy Rev 2013; 26:781-804. http://dx.doi.org/ 10.1016/j.rser.2013.05.053.

Birmingham Energy Institute (2018). A COOL WORLD DEFINING THE ENERGY CONUNDRUM OF COOLING FOR ALL. University of Birmingham. United Kingdom.

Daut I., Adzrie M., Irwanto M., Ibrahim P., and Fitra M. 2013. Solar Powered Air Conditioning System. Energy Procedia TerraGreen 2013 International Conference on Advancements in Renewable Energy and Clean EnvironmentAt: Beirut; Lebanon. Volume 36, 2013, Pages 444-453. DOI: 10.1016/j.egypro.2013.07.050

Ford J. and Ford LB. 2011. Eds. Climate Change Adaptation in Developed Nations: From Theory to Practice; Springer: Dordrecht, The Netherlands, 2011; p. 490. DOI: 10.1007/978-94-007-0567-8.

Henning HM. 2007. Solar assisted air conditioning of buildings_an overview. Appl Therm Eng 2007; 27:1734-49. http://dx.doi.org/10.1016/j.applthermaleng.2006.07.021.

Kalkan N., Young EA., and Celiktas A. 2012. Solar thermal air conditioning technology reducing the footprint of solar thermal air conditioning, Renew. Sustain. Energy Rev. 16 (2012) $6352 \mathrm{e} 6383$.

Mugnier D. 2015. Solar Cooling Position Paper. Operating Agent of Task 48: Quality Assurance and Support Measures for Solar Cooling of the IEA Solar Heating \& Cooling Programme.

RETScreen (2018). RETScreen. Government of Canada [Online]. Available at: http://www.nrcan.gc.ca/energy/software-tools/7465. [Accessed on 25/08/218].

Schulte PA. and Chun H. 2009. Climate change and occupational safety and health: Establishing a preliminary framework. J. Occup. Environ. Hyg. 2009, 6, 542-554.

Vliet GC., Lawson MB., and Lithgow RA. 1980. Water-lithium bromide double-effect absorption cooling analysis. Center for Energy Studies. The University of Texas at Austin. 


\title{
Technical and Economic Performance of Best Practice SHC Plants - A Compilation of IEA SHC Task 53 Results
}

\author{
Daniel Neyer ${ }^{1,2}$, Rebekka Köll ${ }^{3}$ and Daniel Mugnier ${ }^{4}$ \\ ${ }^{1}$ daniel neyer brainworks, Bludenz (Austria) \\ 2 University of Innsbruck, Innsbruck (Austria) \\ 3 AEE INTEC, Gleisdorf (Austria) \\ 4 TECSOL, Perpignan (France)
}

\begin{abstract}
Assessing the performance of solar heating and cooling (SHC) systems in a common comparable format is complicated by the numerous alternative energy sources and design possibilities. A generalized technical and economic assessment methodology was developed and tested in the course of IEA SHC Task 53 and is implemented into an excel tool called T53E4 Tool.
\end{abstract}

Finally, IEA SHC Task 53 is ending and twenty-eight best practice plants are analyzed and compared in a comprehensive format. The systems represent a wide mixture of technologies, applications and locations. All plants are analyzed and assessed regarding their technical and economic performance and a sensitivity analysis to identify the importance of the main boundary conditions is performed.

The results are showing interesting trends, (i) under certain conditions SHC can be cost competitive and show levelized costs of energy below those of pre-defined reference systems, (ii) from technical and environmental point of view, most of the plants can reach non-renewable primary energy savings greater $50 \%$ and up to $95 \%$, depending on their solar fraction (thermal or electrical).

Keywords: Solar heating and cooling, technical and economic assessment, benchmarking, solar thermal, photovoltaic,

\section{Introduction}

On global level the energy demand for space cooling is rising rapidly. Actual 2'000 TWh electricity are used to drive air-conditioner or fans. This demand could rise up to three times till 2050 if energy efficiency is not increased strongly. Even with this increased efficiency the demand will still increase by a factor of roughly 1.5. Main reason for that rising demand are the economic and population growth and thus rising living standards (OECD/IEA 2018). In the last decade this trend was indicated by the increase of sales of air-conditioners already (JRAIA 2017).

The number of solar cooling and heating (SHC) systems is increasing permanently (Mugnier and Jakob 2015) new technologies and different solutions are available on research level but also on the market (Mugnier, 2015). These systems are characterized by a high diversity of design possibilities including not only different cooling and heating technologies, but also a great variety of different renewable and non-renewable energy sources. Main obstacles for a wider and faster spread of solar cooling and heating are based on (i) lack of knowledge. (ii) technical issues but mainly on (iii) economics.

Merging the quintessence of these IEA Task 48 activities led to the verbalization of 10 key principles. These qualitative principles are the core of a compendium including three build, monitored and optimized systems in a Guide called "The Solar Cooling Design Guide: Case Studies of Successful Solar Air Conditioning Design" (Mugnier et al., 2017). The design guide is intended as a companion to the IEA Solar Cooling Handbook (Henning et al., 2013). Three selected examples are used to explained step by step the design in different ranges of scale and technology. Nevertheless, it should be noted that there are many other attractive solar cooling technology solutions. More details on the scientific background and links to past and latest research results are published by Neyer et al. (2018). 
To encourage a strong and sustainable market for solar, photovoltaic and new innovative thermal cooling systems the IEA SHC Task 53 (T53) was initiated. It is building up on earlier IEA SHC work (e.g. Task 38 \& Task 48) to support solutions to make solar driven heating and cooling systems cost competitive. A special focus of the SHC Task 53 is on tested and demonstrated systems (Subtask C). The aim is to analyze the performance of tested and demonstrated new generation solar cooling and heating systems. Therefore, examples of solar cooling systems which are successfully demonstrated, operated or simulated in detail are listed and information about the designs is gathered (Neyer et al., in print). Representative solar cooling systems are selected which will be analyzed within (Köll and Neyer in print) and summarized in this paper. The systems are analyzed on technical and economical basis with the developed T53E4-Tool (Neyer et al., 2016).

Assessing the performance of solar heating and cooling (SHC) systems is challenging because of the wide range of applications and possible technical solutions. It is important to elaborate common standards for a fair and holistic assessment but also for benchmarking against other renewable (solar, etc.) or conventional technologies. A set of technical and economic key performance indicators and the therefore needed data base including conversion factors, efficiencies and investment as well as operational cost are fully discussed and defined in the IEA SHC Task 48 and 53.

A generalized methodology enables the assessment of renewable heating and cooling for a wide range of market available systems. An existing Excel spreadsheet was enhanced to calculate the key figures to evaluate and benchmark the systems; it also contains technical and economic background data. The extended assessment and evaluation tool was tested with best practice examples of both types: (i) solar thermal and (ii) solar electrical driven systems.

\section{Technical and economic assessment}

The T53E4-Tool is an enhanced Version of earlier developments in IEA SHC Task 48 and enables the comparison of different system designs. It considers several renewable and non-renewable energy sources as primary heat source or backups, as well as different types of heating and cooling technologies in combination with hot or cold storages. A more detailed analysis is separating the results by their applications (e.g. space heating, domestic hot water or cooling). This ensures that the analysis distinguishes further optimization potentials, but the analysis also highlights good performing subsystems. An overview of considered energy flows and division of the subsystems is shown in Fig. 1.

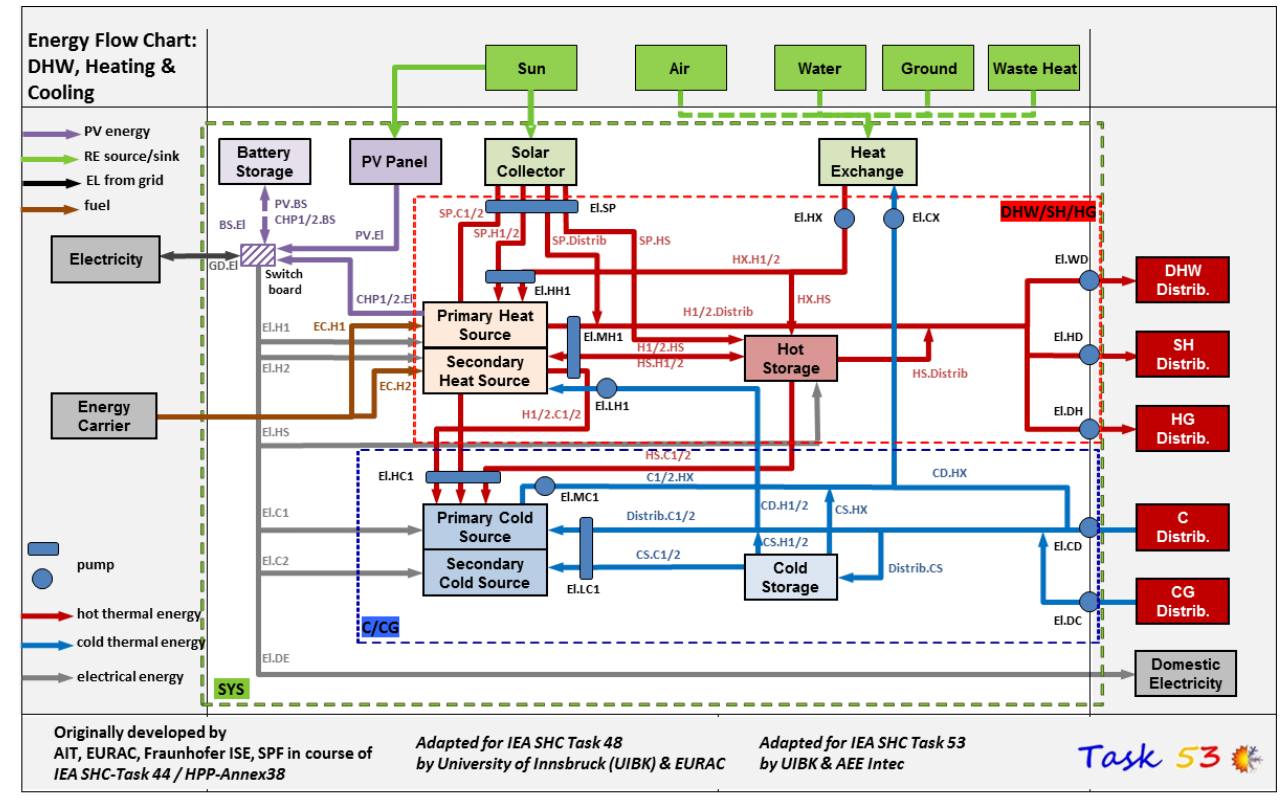

Fig. 1. Energy-flow-chart of all system components that can be taken into account for the assessment by consideration of the different subsystems in T53E4-Tool (Neyer et al. 2016)

The defined KPI's are compared to a reference system defined in Neyer et al. (2016). The reference system uses a natural gas boiler for heating and an air-cooled vapor compression chiller (VCC) for cooling. The efficiency of 
the reference system is depending on the size (technology), energy delivered (full load) and other parameters. The reference system is used to compare the technical and economic performance of the entire SHC system and to calculate the primary energy savings and cost competitiveness.

\section{Technical Assessment}

The key performance indicators (KPI) that are calculated are the non-renewable Primary Energy Ratio (PER $\mathrm{NRE}_{\text {), }}$ the non-renewable primary energy savings $\left(f_{\mathrm{sav}, \mathrm{NRE}}\right)$ and the electrical equivalent Seasonal Performance Factor $\left(\mathrm{SPF}_{\text {equ}}\right)$. They are considered as appropriate indicators for the comparison of the high diversity of SHC systems analyzed with the T53E 4 -Tool. The KPI's are calculated by the tool for the overall system, as well as the subsystems.

\section{- $\quad$ Non-Renewable Primary Energy Ratio}

The non-renewable primary energy ratio $\left(\mathrm{PER}_{\mathrm{NRE}}\right)$ is calculated over a longer period of time (annual or monthly). It is defined as the ratio of useful energy, supplied to satisfy the needs of the application (DHW, SH, Cooling), to non-renewable primary energy input from any energy source (electric or thermal) used within the defined system boundaries.

$$
P E R_{N R E}=\frac{\sum Q_{\text {out }}}{\sum\left(\frac{Q_{e l, i n}}{\varepsilon_{e l}}+\frac{Q_{\text {in }}}{\varepsilon_{\text {in }}}\right)}
$$

The higher the $\mathrm{PER}_{\mathrm{NRE}}$ (in a magnitude of 1 to 2.5 ) the less non-renewable energy is used by the SHC system to cover the heat and cold demand.

The reference System PER $\mathrm{NRE}_{\text {, ref }}$ is also calculated for the equal heat and cooling demand. The reference system calculation follows Napolitano et al. (2010) and has a natural gas boiler for covering the heat demand and an aircooled VCC system for cooling. It includes a small hot water storage for domestic hot water (DHW) purposes and a cold storage volume for a smooth operation of the air cooled VCC. The T53E 4 -Tool also provides the possibility to define a specific reference case for individual assessment, but here the defined standard reference system is used.

$$
\text { PER }_{\text {NRE.ref }}=\frac{\sum \mathrm{Q}_{\text {out }}}{\sum\left(\frac{\mathrm{Q}_{\text {out.heat }}+\mathrm{Q}_{\text {loss.ref }}}{\varepsilon_{\text {in }}{ }^{\eta} \eta_{\text {HB.ref }}}+\frac{Q_{\text {out.cold }}}{\text { SPF }_{\text {C.ref }}{ }^{*} \text { el }}+\frac{Q_{\text {el,ref }}}{\varepsilon_{\text {el }}}\right)}
$$

- $\quad$ Non-renewable primary energy savings $\left(\mathrm{f}_{\text {sav.NRE}}\right)$

The $\mathrm{f}_{\text {sav.NRE }}$ compares the PER NRE.sys $_{\text {of the entire }}$ SHC system to the PER NRE.ref. .

$\mathrm{f}_{\text {sav.NRE }}=\frac{\text { PER }_{\text {NRE.sys }}-\text { PER }_{\text {NRE.ref }}}{\text { PER }_{\text {NRE.sys }}}=1-\frac{\text { PER }_{\text {NRE.ref }}}{\text { PER }_{\text {NRE.sys }}}$

The result for $\mathrm{f}_{\text {sav.NRE }}$ is always below 1 and shows the non-renewable primary energy savings of the SHC system compared to the reference system. A high value indicates also a high solar fraction and low energy input from fossil derived fuels. A negative value points out that the SHC system has a higher non-renewable primary energy consumption than the reference system and no savings could be achieved with the SHC system.

- $\quad$ Electrical equivalent Seasonal Performance Factor (SPFequ)

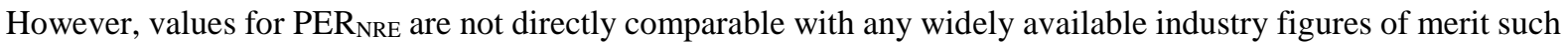
as the EER or SEER of a vapor compression chiller. Therefore, the electrical equivalent Seasonal Performance Factor was introduced and enables a comparison with the SEER of VCC systems or the SPF of electric driven heat pump systems. All energy flows are converted into electrical equivalent units by dividing the PER $\mathrm{NRE}_{\text {with }}$ the primary energy factor of electricity $\left(\varepsilon_{e l}\right)$

$\mathrm{SPF}_{\mathrm{equ}}=\frac{\mathrm{PER}_{\mathrm{NRE}}}{\varepsilon_{\mathrm{el}}}=\frac{\sum \mathrm{Q}_{\mathrm{out}}}{\sum\left(\mathrm{Q}_{\mathrm{el}, \mathrm{in}}+\frac{\mathrm{Q}_{\text {in }}}{\varepsilon_{\mathrm{in}}} * \varepsilon_{\mathrm{el}}\right)}$ 


\section{Economic assessment}

The bases for the economic assessment are the total annual costs of the system. This is the sum of the annual costs for investment, replacement, residual value, maintenance, energy and water costs and is calculated by the T53 $\mathrm{E}^{4}$ Tool by inserting information of the type and size of system components. If the real costs are known the tool enables the possibility to enter the specific values. The annualized costs for the entire system are calculated by using the annuity method. The calculation for investment costs are considering economy of scale prices, which means that the capacity of the components is taken into account when calculating the specific costs. The maintenance, energy and water costs are based on the consumption and are defined under the consideration of VDI 2067. All the costs (investment, replacement, residual value, maintenance, energy and water costs) are expressed in annualized costs $C_{a n}$ and summed up to the total annualized costs $C_{a n . t o t}$ of the SHC system. The Levelized Costs of Energy is the ratio of annualized costs and the overall annual useful energy provided to the application.

$\mathrm{LCOE}=\frac{\mathrm{C}_{\text {an.tot }}}{\mathrm{Q}_{\text {CD.sys }}+\mathrm{Q}_{\text {DC.sys }}+Q_{\text {HD.sys }}+Q_{\mathrm{WD} . \text { sys }}+Q_{\text {DH.sys }}+Q_{\text {el.DE }}}$

Since the uncertainties in cost calculation are varying, the comparison of absolute costs of different SHC systems is resigned and the economic assessment concentrates on the cost ratio by comparing the total levelized energy costs of the SHC system $\mathrm{C}_{\text {an.tot-SHC }}$ to the total levelized energy costs of the reference system $\mathrm{C}_{\text {an.tot-REF} \text {. }}$

$\mathrm{CR}=\frac{\mathrm{LCOE}_{\mathrm{SHC}}}{\mathrm{LCOE}_{\mathrm{REF}}}=\frac{\mathrm{C}_{\mathrm{an} \cdot \mathrm{tot}-\mathrm{SHC}}}{\mathrm{C}_{\mathrm{an} \cdot \mathrm{tot}-\mathrm{REF}}}$

\section{Overview of analyzed plants}

The analysed SHC systems present a great variety of different system designs and applications. The technologies are clustered according to the main component (i) PV: electrical driven and photovoltaic supported systems, (ii) ST: heat driven and solar thermal supported systems, (ii) ST+HP: electrical driven and solar thermal supported systems and (iv) ST+PV: systems supported by photovoltaic and solar thermal. The applications are clustered according to the energy demands of space heating ( $\mathrm{SH}$ ), cooling (C) and domestic hot water (DHW) and different combinations. Fig 2 gives an overview on the distribution of the 28 analysed systems.
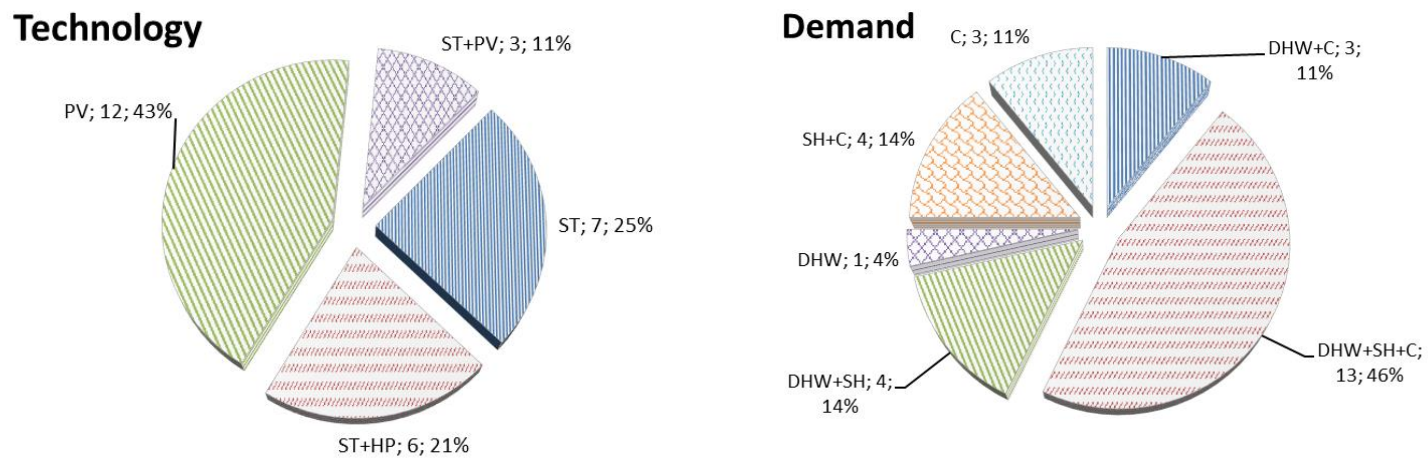

Fig. 2: Overview of chosen SHC systems for the assessment summarized by the used technology (left) and the application / energy demand (right) (Köll and Neyer in print)

The analyzed systems are dominated by small scale systems with a total heating/cooling capacity of below $10 \mathrm{~kW}$ (c.f. Fig 3) and hence also deliver rather small amount of energy over the year. The smaller systems in the assessment are mainly PV systems, whereas most of the solar thermal systems have an energy production of more than $100 \mathrm{MWh}$. The medium sized systems are dominated by systems using heat pump in combination with solar thermal collectors and PV systems.

An overview of the most important characteristic of all plants is displayed in Table 1, further detailed descriptions of each configuration is presented in the appendix of Köll and Neyer (in print). 

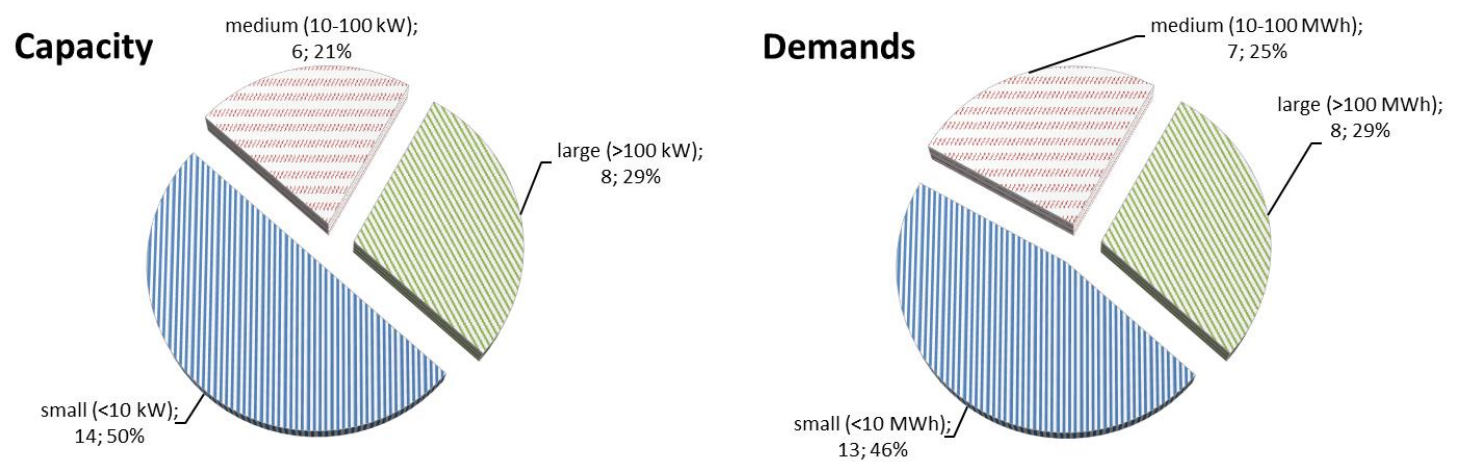

Fig. 3: Plant distribution categorized by the system heating and cooling capacity (left) and by the total yearly energy consumption (right) (Köll and Neyer in print)

Tab. 1: Characteristics of the $28 \mathrm{SHC}$ system considered for the analysis

\begin{tabular}{|c|c|c|c|c|c|c|c|c|c|c|}
\hline \multirow[b]{2}{*}{ 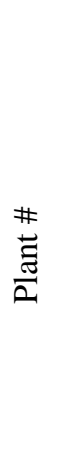 } & Status & \multicolumn{2}{|c|}{ Demand } & \multicolumn{3}{|c|}{ Solar } & \multicolumn{2}{|c|}{ Boiler } & \multicolumn{2}{|c|}{ Chiller } \\
\hline & 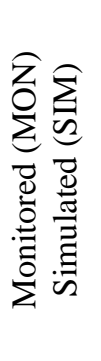 & 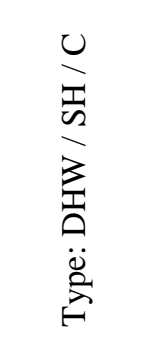 & 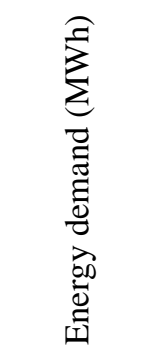 & 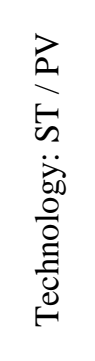 & 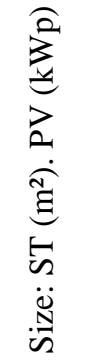 & 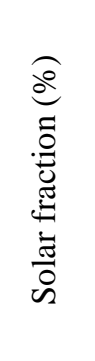 & $\underset{1}{\stackrel{2}{0}}$ & 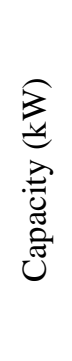 & 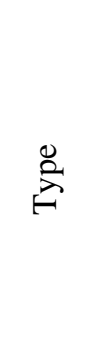 & 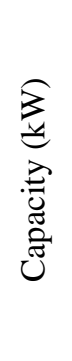 \\
\hline $1 \mathrm{a}$ & MON & \multirow{2}{*}{$\begin{array}{c}\text { DHW } \\
\text { C }\end{array}$} & $133 / 9$ & ST & \multirow{2}{*}{240} & 79 & \multirow{2}{*}{ natural gas } & \multirow[b]{2}{*}{70} & $\mathrm{ACM}$ & 35 \\
\hline $1 b$ & SIM & & $133 / 47$ & ST & & 64 & & & $\begin{array}{l}\text { ACM } \\
\text { VCC }\end{array}$ & $\begin{array}{c}35 \\
250\end{array}$ \\
\hline $2 \mathrm{a}$ & \multirow{6}{*}{ SIM } & \multirow{6}{*}{$\begin{array}{c}\text { DHW } \\
\text { SH } \\
\text { C }\end{array}$} & \multirow{2}{*}{$\begin{array}{c}11 / 28 / \\
21\end{array}$} & PV & 4.8 & 21 & \multirow{6}{*}{$\begin{array}{c}\text { Reversible } \\
\text { AWHP }\end{array}$} & \multirow{4}{*}{34} & \multirow{6}{*}{$\begin{array}{c}\text { Rev. } \\
\text { AWH } \\
\text { P }\end{array}$} & \multirow{4}{*}{34} \\
\hline $2 b$ & & & & ST & 27.6 & 34 & & & & \\
\hline $2 c$ & & & & PV & 4.8 & 17 & & & & \\
\hline $2 d$ & & & ס & ST & 27.6 & 30 & & & & \\
\hline $2 \mathrm{e}$ & & & $2 / 5 / 3$ & \multirow{2}{*}{$\begin{array}{c}\text { PV } \\
\& \mathrm{ST}\end{array}$} & \multirow{2}{*}{$\begin{array}{c}9.2 \\
\& 2.4\end{array}$} & $\begin{array}{l}\text { th: } 49 \\
\text { el: } 30\end{array}$ & & \multirow{2}{*}{8} & & \multirow{2}{*}{8} \\
\hline $2 f$ & & & $2 / 5 / 1$ & & & $\begin{array}{l}\text { th: } 34 \\
\text { el: } 18\end{array}$ & & & & \\
\hline 3 & MON & $\mathrm{SH} / \mathrm{C}$ & $17.2 / 1.8$ & ST & 36 & 34 & $\begin{array}{c}\text { reversible } \\
\text { AHP }\end{array}$ & 24 & $\begin{array}{l}\text { Rev. } \\
\text { AHP }\end{array}$ & 15 \\
\hline 4 & MON & DHW & $3 / 3.5$ & PV & 0.47 & 71 & AWHP & 1.5 & - & - \\
\hline 5 & MON & $\mathrm{SH} / \mathrm{C}$ & 2.2 & PV & 0.705 & 54 & split & 3.81 & split & 3.52 \\
\hline 6 & SIM & SH/DHW & $14.3 / 3$ & PV & 5.7 & 33 & air HP & 5 & - & - \\
\hline
\end{tabular}




\begin{tabular}{|c|c|c|c|c|c|c|c|c|c|c|}
\hline 7 & MON & $\begin{array}{c}\mathrm{SH} / \mathrm{DHW} / \\
\text { process } \\
\text { heat/C }\end{array}$ & $\begin{array}{c}62 / 30 / \\
4.5\end{array}$ & ST & 100 & 23 & $\begin{array}{l}\text { wood chip } \\
\text { boiler }\end{array}$ & 100 & $\mathrm{ACM}$ & 19 \\
\hline $8 a$ & \multirow{2}{*}{ SIM } & \multirow{2}{*}{ DHW / SH } & \multirow{2}{*}{$2 / 7$} & \multirow{2}{*}{ ST } & \multirow{2}{*}{20} & 63 & \multirow{2}{*}{ Brine HP } & \multirow{2}{*}{10} & \multirow{2}{*}{ - } & \multirow{2}{*}{ - } \\
\hline $8 b$ & & & & & & 59 & & & & \\
\hline $9 a$ & \multirow{4}{*}{ SIM } & \multirow{4}{*}{$\begin{array}{c}\text { DHW / SH } \\
\text { / C }\end{array}$} & \multirow{2}{*}{$\begin{array}{c}562 / 545 / \\
82\end{array}$} & ST & 720 & 35 & \multirow{4}{*}{ Natural gas } & \multirow{4}{*}{500} & $\begin{array}{l}\text { ACM } \\
\text { VCC }\end{array}$ & $\begin{array}{l}19 \\
70\end{array}$ \\
\hline $9 b$ & & & & PV & 84.5 & 22 & & & VCC & 80 \\
\hline $9 \mathrm{c}$ & & & \multirow{2}{*}{$\begin{array}{c}541 / 534 / \\
299\end{array}$} & ST & 720 & 81 & & & $\begin{array}{l}\mathrm{ACM} \\
\mathrm{VCC}\end{array}$ & $\begin{array}{c}19 \\
100\end{array}$ \\
\hline $9 \mathrm{~d}$ & & & & PV & 84.5 & 35 & & & VCC & 110 \\
\hline 10 & SIM & $\mathrm{SH} / \mathrm{C}$ & $9 / 32$ & ST & 111 & 99 & $\begin{array}{c}\text { Reversible } \\
\text { air HP }\end{array}$ & 61 & $\begin{array}{c}\mathrm{ACM} \\
\text { air } \\
\mathrm{HP}\end{array}$ & $\begin{array}{l}35 \\
51\end{array}$ \\
\hline $11 \mathrm{a}$ & \multirow{2}{*}{ SIM } & \multirow{2}{*}{$\mathrm{C}$} & \multirow{2}{*}{1} & \multirow{2}{*}{ PV } & \multirow{2}{*}{3.68} & 41 & \multirow{2}{*}{ - } & \multirow{2}{*}{ - } & \multirow{2}{*}{ split } & \multirow{2}{*}{2.5} \\
\hline $11 b$ & & & & & & 42 & & & & \\
\hline 12 & SIM & DHW / SH & $7 / 2$ & PV & 2.5 & 50 & Brine HP & 10 & - & - \\
\hline 13 & MON & $\mathrm{C}$ & 2 & PV & 5 & 38 & - & - & HP & 10.76 \\
\hline 14 & MON & DHW/C & $2 / 0.5$ & PV & 11.1 & 50 & HP & 10.6 & $\begin{array}{l}\text { free } \\
\text { coolin } \\
\mathrm{g}\end{array}$ & 10 \\
\hline 15 & MON & $\mathrm{SH} / \mathrm{C}$ & $6 / 1$ & ST & 8 & 100 & DEC & 4 & DEC & 6.2 \\
\hline 16 & MON & $\mathrm{SH} / \mathrm{C}$ & $0.5 / 0.1$ & $\begin{array}{l}\text { PV } \\
\& \text { ST }\end{array}$ & 2.4 & $\begin{array}{c}\text { el: } 80 \\
\text { th: } \\
100\end{array}$ & DEC & 2.5 & DEC & 1.5 \\
\hline 17 & MON & $\mathrm{C}$ & 284 & ST & 406 & 15 & - & - & $\mathrm{ACM}$ & 500 \\
\hline
\end{tabular}

\section{Results}

The systems are also compared on basis of the total annualized costs including fuel, electricity costs based on the energy production, maintenance, water and replacement costs over the whole life time of 25 years. In Figure 4 the cost distribution based on annualized costs is shown for the solar-thermal and PV-driven systems. If the data available is less than one year (for 4 plants: \#13-14,\#16-17) the cost distribution is not shown as it would distort the analysis. The systems are sorted according to their amount of supplied energy (demands), the more energy supplied the further right they are arranged. In general, the share of investment, replacement and maintenance (as both are calculated depended on investment) is gets less the higher the energy supplied by the system.

The main cost driver of the investigated SHC systems are the investment and energy costs. For the solar-thermal systems the fuel costs for the backup (energy carrier for heating, electricity for cooling) can get larger shares, whereas for systems combined with a heat pump (ST+HP, PV) the electricity costs are dominating. 


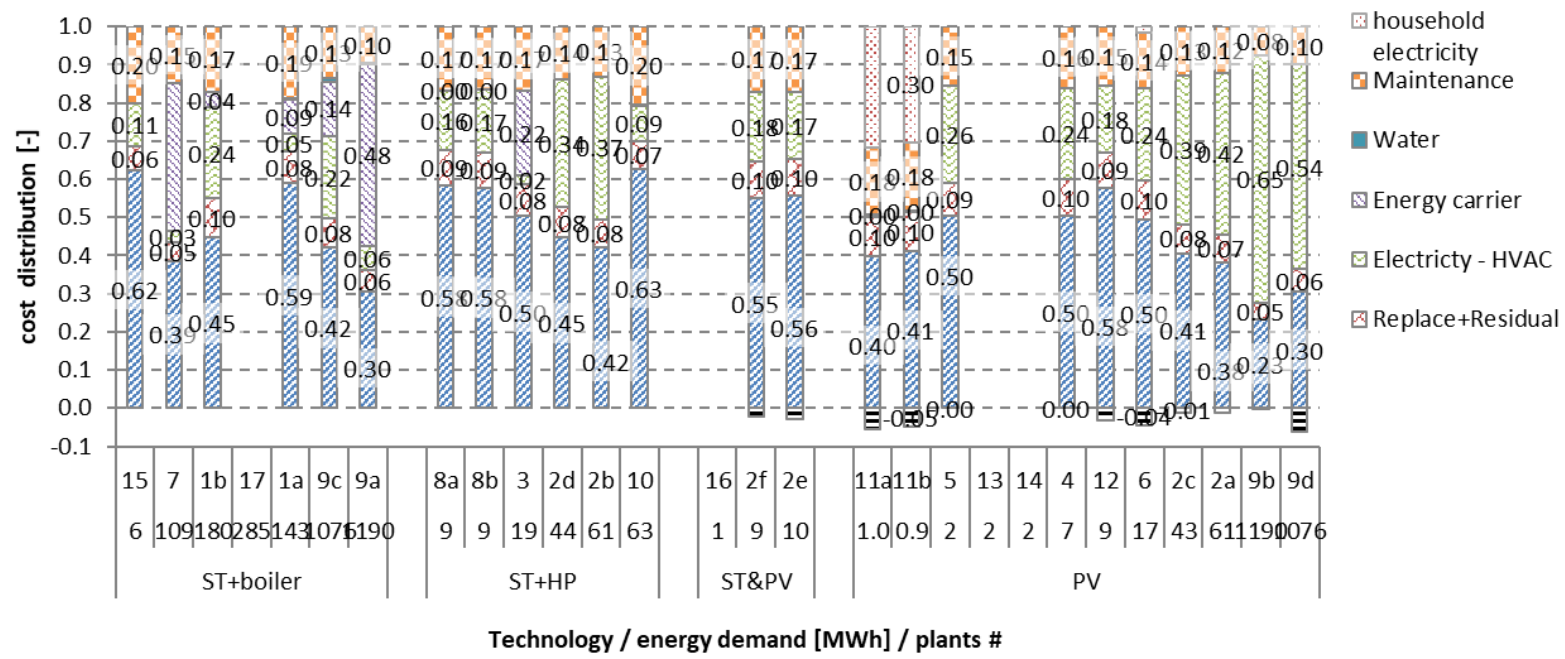

Fig. 4: distribution of total annualized cost of solar thermal supported SHC systems (Köll and Neyer in print)

The overall assessment of the technical and economic performance of the SHC systems is shown as coherence of the non-renewable energy savings $\left(\mathrm{f}_{\text {sav.NRE}}\right.$ ) and of the CostRatio $(\mathrm{CR})$. The chart is showing the Cost Ratio in reversed order, thus the more beneficial a system the more it will appear at the top of the chart. The Cost Ratio shows the ratio between the total annualized costs of the SHC system compared to the total annualized costs of the reference system. A CR greater one indicates higher annualized costs for the SHC system and a CR lower one annualized cost savings for the SHC system. The non-renewable primary energy savings are arranged in normal order, thus the more savings a system can achieve the more it will appear at the right-hand side. The reference system is present at cero savings and a CR of one.

The comparison of the economic and technical performance of the systems shows in general that higher primary energy savings result in higher cost ratio. There are also examples showing that with a well-designed system it is possible to achieve both, high primary energy savings as well as a cost competitive system. The trend analysis of all plants shows that both, solar thermal as well as PV driven SHC systems are cost competitive at lower solar fraction and lower primary energy savings respectively. The cost ratio increases with the increase of primary energy savings. Nevertheless, it can be seen that the variation in this area is much higher and there are several examples showing also cost savings at high solar fraction.

fsav.NRE [-]

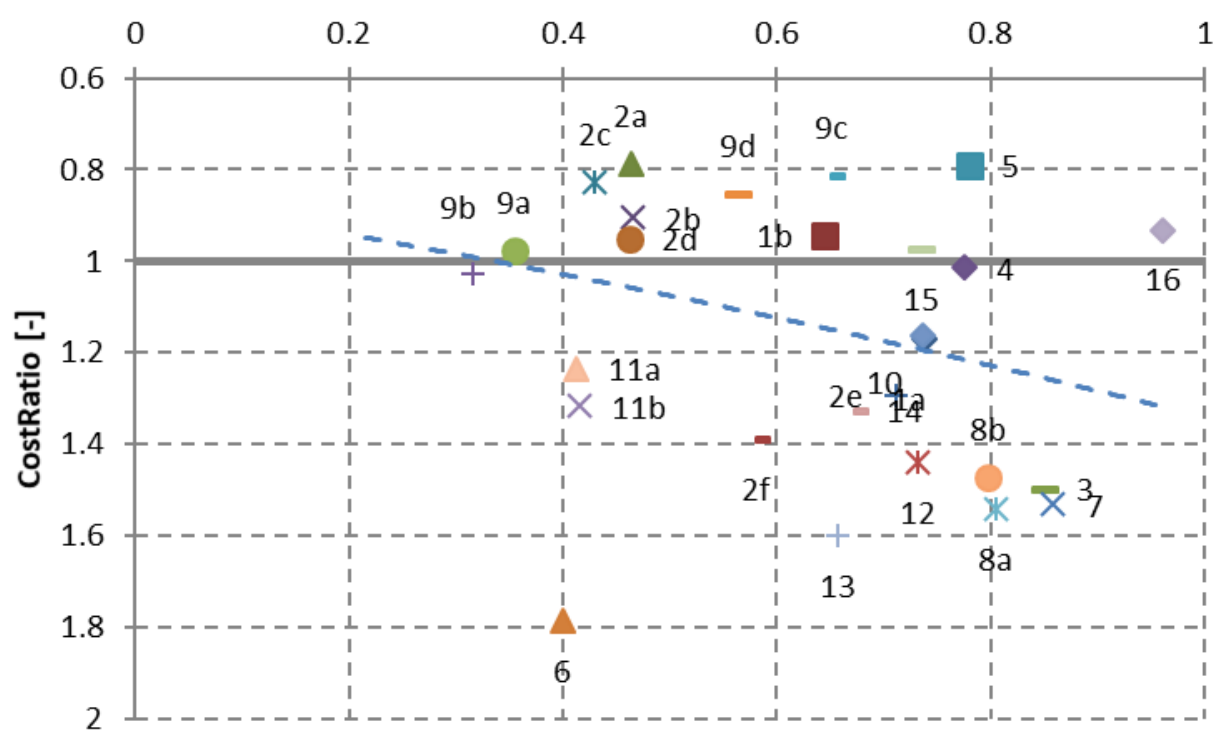

Fig 5. Cost Ratio vs. non-renewable primary energy savings of all 28 systems and the overall trend of the analyzed SHC systems (Köll and Neyer in print) 
Since it is difficult to draw the right conclusion of a high number of individual systems, they are clustered by different characteristics like technology, location, application and load and compared trend wise according to their technical and economic performance. However, all presented results are based upon some predefined technical and economic boundary conditions. If one of these boundaries is changing the results might change more or less significantly. Thus, the crucial boundary conditions are evaluated with a sensitivity analysis. Accordingly, six boundaries are changed in a wide range and the results are summarized for the overall trend, and the trends for northern and southern location separated according to the underlying technology (PV or ST).

The six parameters and their range of variation are shown in Table 2. Each parameter is varied seven times in a selected range to represent a reasonable and market relevant series. The variation is given in $\%$ compared to the base case $(100 \%)$. The results of each single sensitivity analysis are discussed below accordingly.

Tab. 2: Sensitivity parameter and range of variation

\begin{tabular}{|c|c|c|c|c|c|c|c|c|}
\hline \multirow{2}{*}{ Parameter } & Unit / Value & \multicolumn{7}{|c|}{ Variation [\%] } \\
\cline { 3 - 8 } & & $\mathbf{1}$ & $\mathbf{2}$ & $\mathbf{3}$ & $\mathbf{4}$ & $\mathbf{5}$ & $\mathbf{6}$ & $\mathbf{7}$ \\
\hline Investment Cost & $(€ / \mathrm{kW})$ & 40 & 55 & 70 & 85 & 100 & 115 & 130 \\
\hline Electricity price & $(10 \mathrm{ct} / \mathrm{kWh})$ & 50 & 100 & 150 & 200 & 250 & 300 & 350 \\
\hline Natural gas price & $(5 \mathrm{ct} / \mathrm{kWh})$ & 50 & 75 & 100 & 125 & 150 & 175 & 200 \\
\hline Auxiliary demand & $(\mathrm{kWhel})$ & 50 & 60 & 70 & 80 & 90 & 100 & 110 \\
\hline Energy output & $(\mathrm{kWhuse})$ & 80 & 90 & 100 & 110 & 120 & 130 & 140 \\
\hline Conversion factor & $(0.4 \mathrm{kWh} / \mathrm{kWh}$ & 80 & 90 & 100 & 115 & 130 & 145 & 160 \\
\hline
\end{tabular}

In the following only one example is shown, more results of the comprehensive trend and sensitivity analyses is presented in Köll and Neyer (in print). The trendlines are combining a lot of different boundaries e.g. for location or for technology, thus the following figure is combing the two categories accordingly.

The trend in Figure 6 for PV and ST are almost equal in that arrangement. For the southern location the PV trend is showing slightly lower CR, for the northern locations is reversed and ST is showing the lower CRs. The general trend for southern compared to the northern locations is very clear; showing that for southern location the CR are below one for almost all plants, whereas for the northern location only system with low savings can reach cost equity and additional cost of $>40 \%$ occur when savings of $80 \%$ should be reached.
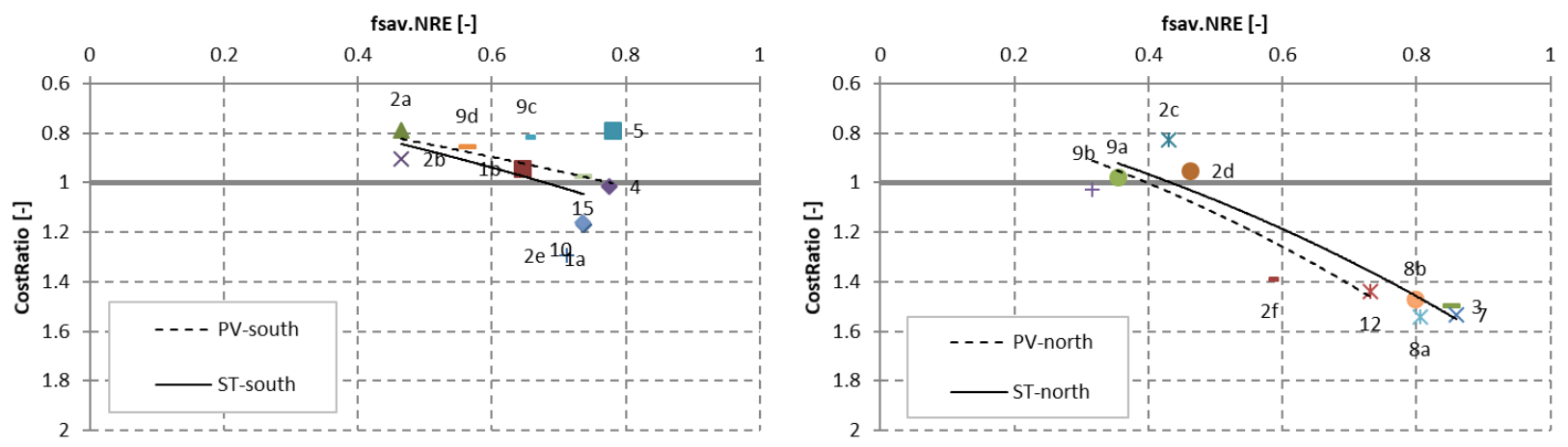

Fig. 6: Trend of the combined technology / location for southern located (left) and northern located (right) systems

A rrepresentative results of the sensitivity analysis is the variation of investment cost shown in Fig. 7. The effect of changing investment costs is larger in northern located SHC systems as they are more investment dominant compared to the southern location, were the (cooling) demand and thus the fuel costs are more important. The blue $100 \%$ lines indicate the initial state (boundary condition).

The southern origin trend (left) starts at a CR of roughly 0.8 and reaches 1.1 for ST supported and 1.05 for PV supported systems. If the investment costs can be decreased this small advantage of PV is equalized. The trends for ST and PV equals at $-15 \%$, ST shows a small advantage at $-30 \%$. This change is pointing on the fact that ST is slightly more investment dominated compared to PV driven systems at the same level of savings. 
The northern trend is representing a much stronger gradient compared to the southern locations. Its original trend starts at a CR of roughly 0.9 with savings of $30 \%$ but is ending at higher savings at a CR of 1.6. In the northern locations the PV is showing slightly higher Cost Ratio's. If the costs are reduced accordingly, the CR drops and a large part of the trendline is ending at CRs smaller than 1. The change in trendlines shows that for northern location the PV supported systems are much more investment dominated than the ST supported ones. This is especially driven by the demands (heating and cooling) and its coincidence of solar irradiation but also due to the design of the systems
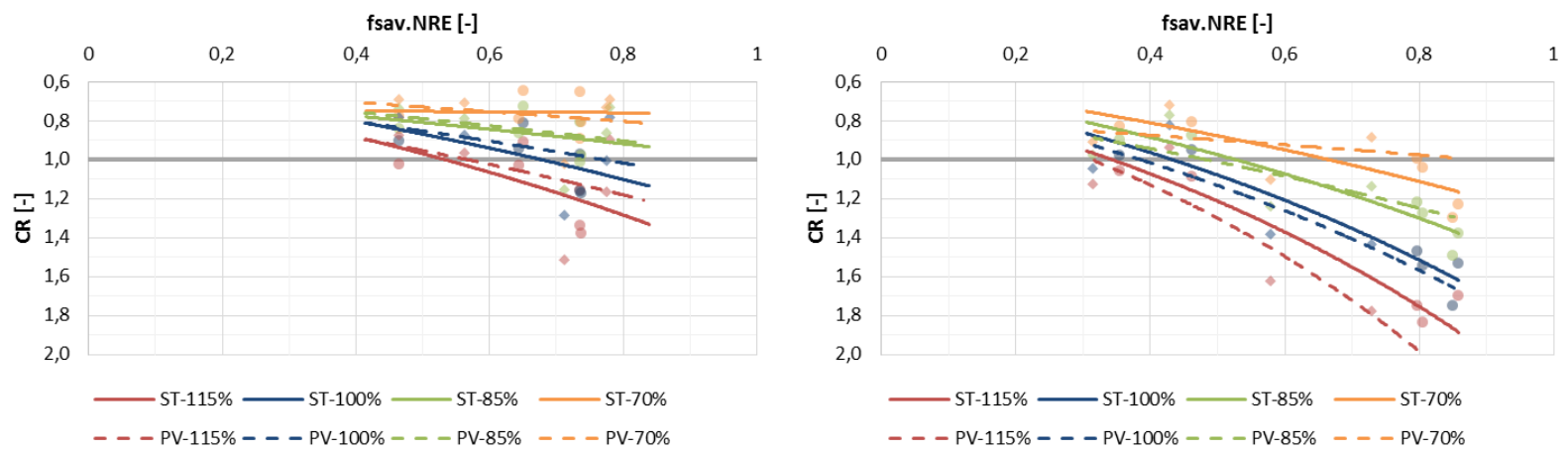

Fig. 6: Sensitivity analysis on investment cost for the southern (left) and northern (right) location separated for PV and ST (Köll and Neyer in print)

The most significant influence on economics (other sensitivity results are not shown here) is driven by the investment costs. With standard investment costs parity of levelized costs of energy $(C R=1)$ is reached by systems designed for less than 30\% non-renewable primary energy savings. With an investment cost reduction of $15 \%$ already systems achieving $65 \%$ savings can reach parity. If a cost reduction of $30 \%$ (not unrealistic, c.f. ROCOCO (Preisler et al. 2008) can be reached the trend line considerably undermatches a Cost Ratio of 1. Thus, the SHC systems can provide an economic benefit over its life time and can possibly assure more than high non-renewable primary energy savings.

Furthermore, a significant influence is occurring due to changes of natural gas costs used for the references systems but also in some SHC plants for backup heater. The standard price is defined to be $5 € \mathrm{ct} / \mathrm{kWh}$, future changes in the prices depend a lot on political, economic and exploration boundary conditions and are hardly possible to be foreseen. Thus, the price is only varied in a range that is already possible due to the change from commercial to private consumers. When the natural gas costs are increased by $50 \%$ to $7.5 € \mathrm{ft} / \mathrm{kWh}$ the parity can be achieved by systems with up to $60 \%$ savings instead of $30 \%$.

\section{Conclusion \& Summary}

New generation SHC systems can be very complex, since they are combining different technologies which interact and influence each other, therefore the evaluation of the complete system as well as subsystems is challenging. Within the SHC Task 53 an assessment tool (T53E4-Tool) was developed for standardized technical and economic analysis and comparison of SHC systems. The technical analysis is based on yearly or monthly energy balance, whereas for the economic analysis standardized costs and efficiencies are considered. A limited number of solar cooling installations are available that are providing monitored data and these projects often need to be considered as demos or pilot plants rather than purely commercial systems. Therefore, the economic aspects of these projects must be considered with significant care. Thus, the cost analysis of all SHC systems and of the reference system performed and presented here are based on the same assumptions.

Among the analyzed systems, the cooling capacity is in a range to be considered as small $(50 \%<10 \mathrm{~kW})$ to medium $(21 \%<100 \mathrm{~kW})$ therefore economy of scale effect was not really achieved. However, the main matters are the entire decrease of specific component costs but also the cost distribution. The ratio between component investment and labor cost / piping / monitoring etc. is changing for small compared to large scale plants. Thus, a focus for small scale systems needs to be on easy to install and maintain systems. Air-cooled systems, either PV or ST supported, might be one option. Especially for small scale absorption chillers/absorption heat pumps the investment costs need to be decreased significantly. The implementation of the entire external piping to the chiller shows high saving potentials (installation costs). Most of the small-scale systems analyzed are PV supported 
systems. The main advantage using Photovoltaic panels for small scale systems is that they can be connected to heat pumps at low investment costs. A standard solar thermal supported system on the other hand requires rather large investments like a cooling tower which can only be designed in a cost-effective way when used for large systems.

The convenience of PV or ST is strictly related to the loads to be covered: if the system does not foresee a sorption device, the application of ST has the higher savings when applied to the DHW production and space heating (if the control strategies allow this mode). On the contrary, PV applications can reduce the electricity demand for cooling and, in the same way, heating and DHW preparation. PV driven systems strongly suffer from lack of long term monitoring feedback compared to ST ones, the experiences gain in the last decade in the field of solar thermal cooling (e.g. IEA SHC Task 38 and IEA SHC Task 48) are an important knowledge base.

However, solar thermal as well as PV-driven system can be cost competitive or even save costs compared to the reference system. The right choice depends on the system configuration and the effort in optimization towards the integration of the solar energy. The sensitivity analysis shows that from a summarized point of view (trend lines and sensitivity analyses for southern and northern location) both technologies are very close in technical and economic performance.

The presented technical and economic assessment of 28 plants and configurations shows that 9 plants were able to reach cost parity or CR even lower than 1 under the present boundary conditions. If boundaries are changing according to the sensitivity analysis already up to 16 plants would reach CR lower than one. Under these conditions best cases come up with CR of roughly 0.7 , presenting $30 \%$ lower levelized cost of energy for the entire systems compared to the reference system!

In general, economics of SHC systems are mainly investment cost driven whereas the reference systems are dominated by the fuel costs. Therefore, SHC systems can be considered as cost efficient if they are integrated for covering baseload and in combination with conventional system for covering peak demands. Although from environmental point of view solar autonomous systems should be from highest interest, they come up with higher costs but also with higher primary energy savings.

Thus, future R\&D priority should focus on investment cost reduction (materials, mass production, simplification, etc.). Minor priority, but only from an economic point of view, is required on efficiency measures. However, efficiency and respective auxiliary demand reduction can get more significant if the first priority was successful and investment costs are getting lower.

\section{References}

Henning, H.-M.; Mugnier, D.; Motta, M. (Eds.) (2013): Solar Cooling Handbook. A Guide to Solar Assisted Cooling and Dehumidification Processes. Basel/Berlin/Boston: Ambra. Available online at http://dx.doi.org/10.1515/9783990434390, checked on 04/2014.

JRAIA (2017): World Air Conditioner Demand by Region. Edited by The Japan Refrigeration and Air Conditiong Industry Association. Available online at https://www.jraia.or.jp/english/World_AC_Demand.pdf, checked on $5 / 8 / 2018$.

Köll, R.; Neyer, D. (in print): Monitoring data analysis on technical issues \& on performances. Deliverable C3, IEA SHC Task 53. Edited by International Energy Agency.

Mugnier, D.; Neyer, D.; White, S. D. (Eds.) (2017): The Solar Cooling Design Guide - Case Studies of Successful Solar Air Conditioning Design. Berlin, Germany: Wilhelm Ernst \& Sohn.

Mugnier, Daniel (2015): Solar cooling position paper. Edited by SHC Solar Heating \& Cooling Programme.

Mugnier, Daniel; Jakob, Uli (2015): Status of solar cooling in the World. Markets and available products. In WIREs Energy Environ 4 (3), pp. 229-234. DOI: 10.1002/wene.132.

Napolitano, A.; Sparber, W.; Thür, A.; Finocchiaro, P.; Nocke, B. (2010): Monitoring Procedure for Solar Cooling Systems, A joint technical report of subtask A and B. International Energy Agency, Solar Heating and Cooling Program, IEA SHC Task 38. 
Neyer, D.; Köll, R.; Vincente, P. G. (in print): Deliverable D-C2: Catalogue of selected systems. Edited by International Energy Agency.

Neyer, Daniel; Neyer, Jacqueline; Stadler, Katharina; Thür, Alexander (2016): Energy-Economy-EcologyEvaluation Tool, T53E4-Tool, Tool Description and introductory Manual. Deliverable C3-1, IEA SHC Task 53. International Energy Agency.

Neyer, Daniel; Ostheimer, Manuel; Mugnier, Daniel; White, Stephen (2018): 10 key principles for successful solar air conditioning design - A compendium of IEA SHC Task 48 experiences. In Solar Energy. DOI: 10.1016/j.solener.2018.03.086.

OECD/IEA (2018): The Future of Cooling. Opportunities for energy efficient air conditioning. Edited by IEA Publications, International Energy Agency.

Preisler, A.; Selke, T.; Siso, L.; LeDenn, A.; Ungerbock, R. (2008): Case Study ROCOCO - Reduction of costs of Solar Cooling systems. In : 1st International Conference on Solar Heating, Cooling and Buildings. (EUROSUN 2008) : Lisbon, Portugal, 7-10 October 2008. Red Hook, NY: Curran Associates.

\section{ACKNOWLEDGE}

The funding of Austrian participation at the IEA SHC Task53 through the Federal Ministry for Transport, Innovation and Technology (BMVIT) is gratefully acknowledged.

The funding of French participation at the IEA SHC Task 53 through the French Agency of Environment and Energy management (ADEME) is gratefully acknowledged. 


\title{
Experimentally validated dynamic model for a hybrid cascade system for solar heating and cooling applications
}

\author{
Valeria Palomba', Andrea Frazzica', Steffen Kühnert ${ }^{2}$, André Große ${ }^{2}$ \\ ${ }^{1}$ Istituto di Tecnologie Avanzate per l'Energia CNR-ITAE, Messina (Italy) \\ 2 Fahrenheit GmbH, Halle (Germany)
}

\begin{abstract}
This paper presents the dynamic modelling of a hybrid cascade chiller for solar cooling in industrial applications driven by Fresnel solar thermal collectors. The chiller comprises an adsorption module, which is directly connected to the bottoming vapor compression chiller. This cascade configuration allows enhancing the overall electric COP, since the adsorption module is operated to dissipate the heat rejected by the vapor compression chiller, thus reducing the condensation temperature quite below the ambient temperature. The model was implemented in Dymola/Modelica, allowing describing heat and mass transfer phenomena inside each component. The complete model was then validated against experimental data obtained on a cascade chiller prototype at the CNR ITAE lab. Finally, a reference daily simulation was performed to evaluate the ability of the developed chiller in providing cooling energy to a typical industrial application.
\end{abstract}

Keywords: Dymola/Modelica, cascade chiller, industrial solar cooling

\section{Introduction}

The cooling demand is continuously growing worldwide in different sectors (Werner, 2016). Particularly, energy consumption and related emissions due to cooling processes in industrial sector are becoming a major issue. For this reason, the integration of renewable thermal energy sources inside industrial sites, for both heating and cooling applications is gaining a lot of attention (Farjana et al., 2018). Usually, it is accomplished with the use of thermally driven sorption machine, driven by thermal energy produced by non-concentrating solar thermal collectors (e.g. flat plate, evacuated tubes) (Murray et al., 2016). Nevertheless, this approach suffers of some weaknesses: first, when renewable source (i.e. solar energy) is not available, a backup system is needed to either operate the sorption chiller (e.g. gas boiler) or to directly produce cooling by means of standard technology (e.g. vapour compression chiller). Secondly, the use of non-concentrating solar thermal collectors technologies often is not sufficient to properly drive the sorption machine, thus making it work under off-design conditions for several hours. Furthermore, these solar thermal collectors cannot be integrated as heating source in most of the industrial sites, since the achievable temperature level is usually not sufficient drive any process.

In such a background, the EU co-funded project HyCool (HyCool, 2018) aims at increasing the use of solar heat in industrial processes, integrating a concentrating Fresnel solar thermal collector technology, with a hybrid cascade chiller, to increase the share of renewable sources for heating and cooling applications in industries.

The present paper deals with the development of a numerical model, implemented in Dymola/Modelica, for the simulation of the innovative cascade chiller. The model describe heat and mass transfer phenomena in each component of the chiller, in order to accurately simulate its operation. Furthermore, it has been validated by means of experimental data measured at the CNR ITAE lab and it will be further used to evaluate optimal operating conditions and management strategies under typical working boundaries of an industrial plant.

\section{The Hybrid cascade chiller}

The hybrid heat pump is made up of two units, working in cascade mode: a thermal unit and an electric unit. The thermal unit is an adsorption chiller, based on the system already commercialised by Fahrenheit, which will be driven by the heat produced by a field of Fresnel solar thermal collectors, for the production of chilled water in the range of $16-22^{\circ} \mathrm{C}$. This unit is hydraulically connected to the condenser of an electric vapour compression unit (i.e. cascading mode), which will provide chilled water to the user. In such a way, the adsorption unit is primarily meant for dissipating the condensation heat of the vapour compression unit. This operation allows increasing the overall electric COP, by reducing the temperature lift between evaporator and condenser of the vapour compression unit, 
thus limiting the compressor work.

Furthermore, the utilization of the cascading operation of the two units allows exploiting the benefits of the two types of systems, i.e. the low primary energy consumption of the thermal unit, which will be fed by renewable solar energy, and the fast response and good temperature control under different conditions of the electric unit (Vasta et al., 2018). A schematic of the hybrid heat pump operation and components as well as the different temperature levels is reported in Figure 1.

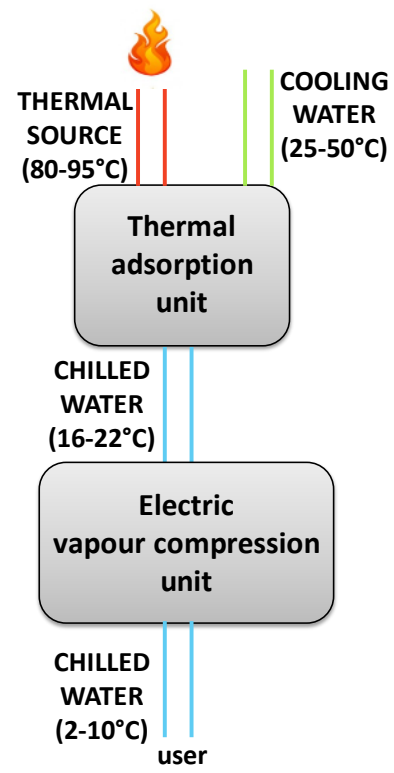

Figure 1: schematic layout of the hybrid heat pump.

\section{Dynamic modeling and validation}

As shown in Figure 1, the hybrid heat pump is realized by hydraulically connecting the thermal and electric units. Consequently, the models for the two units were implemented and tested separately and then the overall model for the system was assembled and calibrated.

\subsection{Model of the adsorption unit}

The thermal adsorption unit implemented in Dymola is composed of four main vacuum vessels: two adsorbers, a condenser and an evaporator, as represented in Figure 2. Furthermore, the hydraulics and valves are included to properly operate the system.

The structure of each modelled components (i.e. adsorber, evaporator and condenser) is similar. Indeed, each of them is composed of two sub-models: one describing the heat transfer on the heat transfer fluid (HTF) side, and the other one representing an equilibrium model, describing heat and mass transfer for the refrigerant (Lanzerath et al., 2015).

The following assumptions were made:

- all components are lumped models with uniform properties;

- the HTF inside the heat exchangers is incompressible;

- pressure drops inside the heat exchangers and the hydraulic circuit are constant;

- gravity is neglected;

- the thermal masses of vacuum vessels is neglected;

- there are no heat losses to the environment;

- there is no direct heat exchange due to conduction between the components;

- there are no inert gases inside the system.

The heat transfer model is based on a mono-dimensional fluid flow from Thermocycle library (Quoilin et al., 2014). It implements mass and energy balance on the HTF fluid side, in which all the thermodynamic properties of the HTF 
are calculated on the basis of its state variables, taken from the Modelica Fluid library.

The heat transfer on the fluid side is calculated as:

$$
\dot{Q}_{\text {wall }}=\alpha S\left(T_{\text {fluid }}-T_{\text {wall }}\right)
$$

Where the heat transfer coefficient $\alpha\left[\mathrm{W} \mathrm{m}^{-2} \mathrm{~K}^{-1}\right]$ takes into account both the convection inside the tubes of the heat exchanger and the thermal conduction through the wall.

The model for adsorption results from the energy conservation inside the adsorber and mass exchange with the condenser/evaporator. Energy conservation is expressed as:

$$
\left(m_{\text {sorb }} c_{p_{\text {sorb }}}+w \cdot m_{\text {sorb }} c_{p_{\text {ref }}}\right) \frac{d T_{\text {sorb }}}{d t}=\dot{Q}+\dot{m}_{\text {ref }} h_{\text {ads }}-m_{\text {sorb }} c_{p_{\text {sorb }}} T_{\text {sorb }} \frac{d w}{d t}
$$

Where, the left-hand side represents the heat stored in the adsorbent, whereas the right-hand side represents the heat transferred through conduction and the mass exchange. The heat of adsorption was considered constant and equal to $2600 \mathrm{~J} \mathrm{~kg}^{-1}$, which is a reliable approximation for the microporous silica gel (i.e. Oker Chemie Siogel ${ }^{\circledR}$ ) used in the tested chiller, as reported in (Bales et al., 2005). The equilibrium data of the adsorbent material are evaluated according to the Dubinin-Astakhov approach (Dubinin and Astakhov, 1971), reporting the uptake as a function of the adsorption potential $\mathrm{A}\left[\mathrm{J} \mathrm{kg}^{-1}\right]$, as reported below:

$$
w=w_{0} \exp (-b A)
$$

Where, $\mathrm{w}\left[\mathrm{kg} \mathrm{kg}^{-1}\right]$ is the adsorption uptake, $\mathrm{w}_{0}\left[\mathrm{~kg} \mathrm{~kg}^{-1}\right]$ is the maximum adsorption uptake at water vapour saturation condition, and $\mathrm{b}\left[\mathrm{kg} \mathrm{J}^{-1}\right]$ is a fitting parameter. The data reported in (Sapienza et al., 2017) were used for characterizing the adsorbent material.

The adsorption kinetic was implemented using the Linear Driving Force (LDF) approach (El-Sharkawy, 2011), where the rate of adsorption/desorption is directly related to the difference between equilibrium and actual adsorption uptake as reported below, as well as to the silica gel grain size and to the diffusion coefficient $\mathrm{D}\left[\mathrm{m}^{2} \mathrm{~s}^{-1}\right]$ (Lanzerath et al., 2015):

$$
\frac{d w}{d t}=\frac{15 m_{\text {sorb }}}{r_{\text {sorb }}^{2}} D\left(w_{\text {eq }}-w\right)
$$

The refrigerant equilibrium model, for evaporator and condenser, consists of mass and energy balance equations, where the properties in liquid and vapour state, as well as in saturation conditions, are calculated from the Modelica Fluid library.

Finally, the vacuum valves are assumed to be two-way valves, characterized by a constant pressure-drop. The valves can be operated either according to the pressure difference between adsorbe and evaporator/condenser or on a time basis, considering the phase of the cycle.

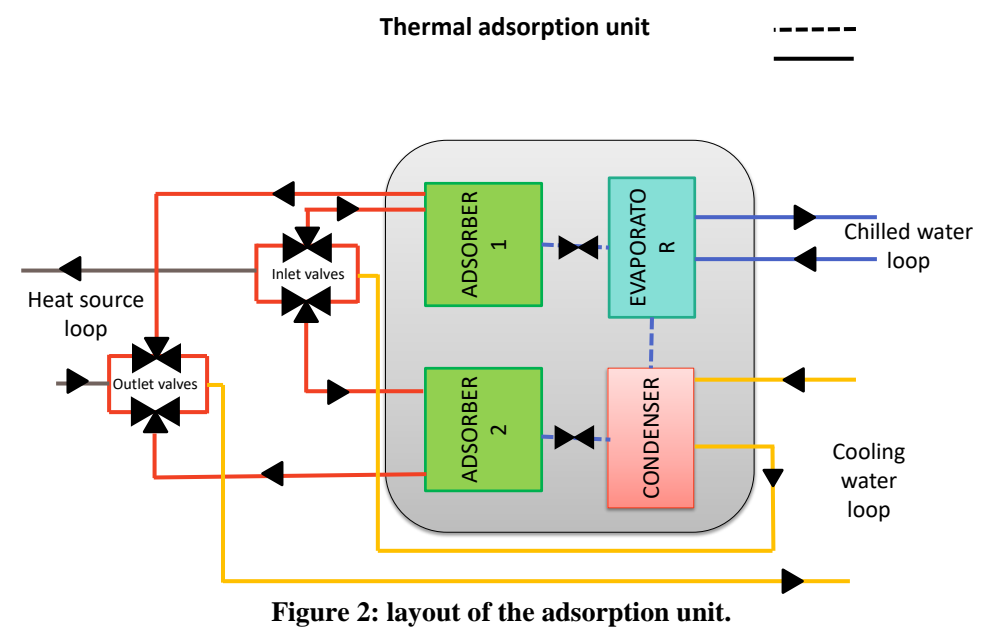

The overall adsorption module, comprising each component as well as the hydraulics, is represented in Figure 3 . 


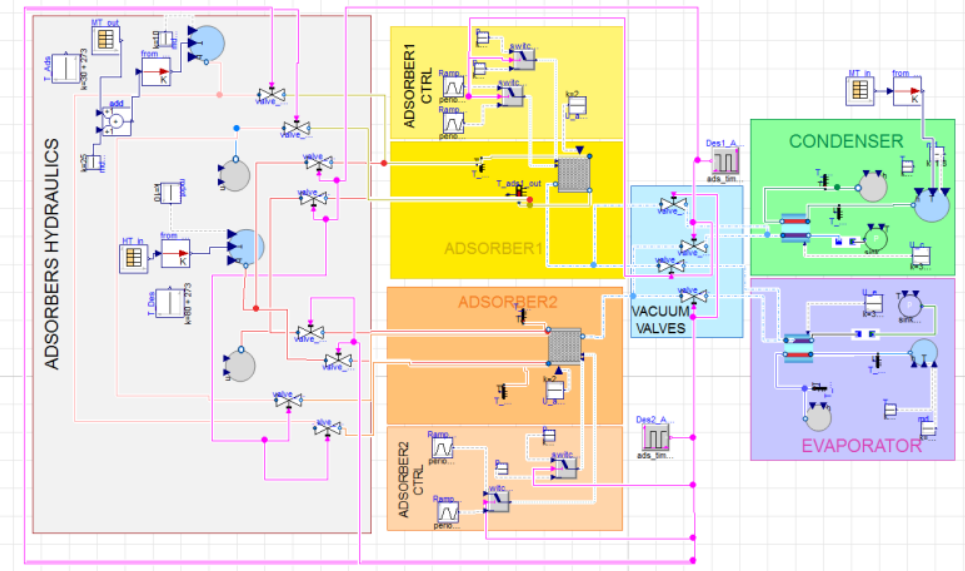

Figure 3: adsorption model implemented in Dymola.

\subsection{Model of the electric vapour compression chiller}

The dynamic model of the vapour compression unit is based on an existing heat pump model of the Thermocycle library. It consists, as shown in Figure 4, of four main elements: the compressor, the condenser, the evaporator and the expansion valve. The chosen refrigerant is R290, which is a natural refrigerant already established as an alternative to traditional refrigerant such as R410a and R407c (Sánchez et al., 2017).

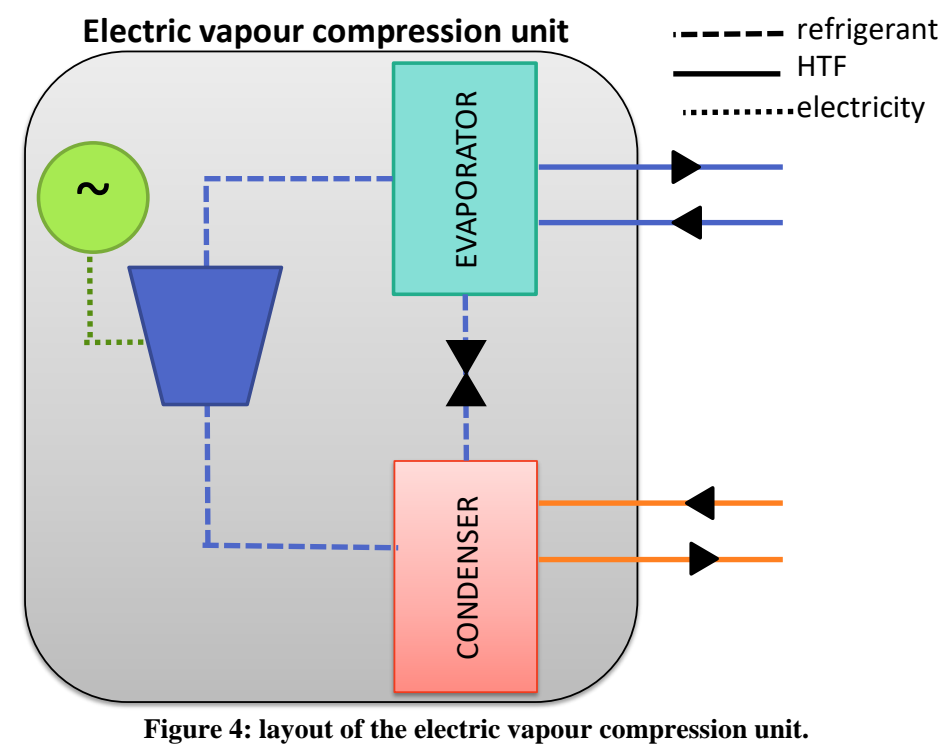

The model for the condenser and evaporator is, similarly for the evaporator and condenser of the adsorption unit, made up of two sub-models, for the heat exchange of the HTF and the equilibrium model for the phase change of the refrigerant. The heat transfer model on the HTF side is equal to the one implemented for the adsorption module.

The model for the heat transfer on the refrigerant side takes into account that it is a compressible medium. Hence, the energy and mass balance are expressed as:

$$
\begin{gathered}
\frac{d m}{d t}=\dot{m}_{\text {in }}-\dot{m}_{\text {out }}=V\left(\frac{\partial \rho}{\partial h} \frac{d h}{d t}+\frac{\partial \rho}{\partial p} \frac{d p}{d t}\right) \\
V \rho \frac{d h}{d t}-V \frac{d p}{d t}=\dot{m}_{\text {in }}\left(h_{\text {in }}-h\right)-\dot{m}_{\text {out }}\left(h_{\text {out }}-h\right)+\dot{Q}
\end{gathered}
$$

The model for the compressor is a generic model for a volumetric compressor where isentropic and volumetric efficiencies are passed as an external parameter, in order to use either a constant value or a correlation based on performance data from the producer. Thermodynamic states at the inlet and outlet of the compressor are calculated using the correlations for the refrigerant implemented in CoolProp library (Bell et al., 2014). The inlet state is defined by means of the outlet temperature of the refrigerant from the evaporator and the assumption that it is in saturated vapour conditions. The outlet conditions are calculated considering a real expansion: 


$$
h_{\text {out }}=h_{\text {in }}+\frac{h_{\text {out }, i s}-h_{\text {in }}}{\eta_{\text {is }}}
$$

The mass balance across the compressor is also implemented. Furthermore, the mass flow rate of refrigerant is a function of the rotational speed of the compressor:

$$
\dot{m}_{\text {in }}=V_{\text {swept }} \frac{r p m}{60} \eta_{v o l} \rho_{\text {in }}
$$

While the power consumption is expressed as:

$$
\dot{W}_{\text {comp }}=\frac{\dot{m}_{\text {in }}\left(h_{\text {out }}-h_{\text {in }}\right)}{\eta_{\text {vol }}}
$$

The model for the expansion valve is implemented considering that the flow rate increases linearly with the opening of the valve and that the pressure drops depend on the flow rate with a quadratic relationship.

\section{Model validation}

The developed models were integrated and the results of the simulations were compared with the experimental results of a silica gel/water unit produced by Fahrenheit and tested at CNR ITAE lab. The comparison of simulated and experimental data is presented in Figure 5. All the inlet temperatures (HT_in, MT_in and LT_in) were passed to the model of the chiller as external text files and the output temperatures (ADS1_out, ADS2_out, MT_out and LT_out) were evaluated. It is possible to notice that the simulated data closely matches the measured ones, thus demonstrating the reliability of the model and its usefulness as a sizing tool. Particularly, the fitting for the adsorbers outlet temperature was only performed during the desorption phases. The deviation between the experimental and simulated outlet temperatures of the adsorber are due to the variable cycle time of Fahrenheit unit, that is adjusted at every cycle, while a constant value was used in the simulations. Nonetheless, the model proved to be a robust and accurate method for the description of the chiller

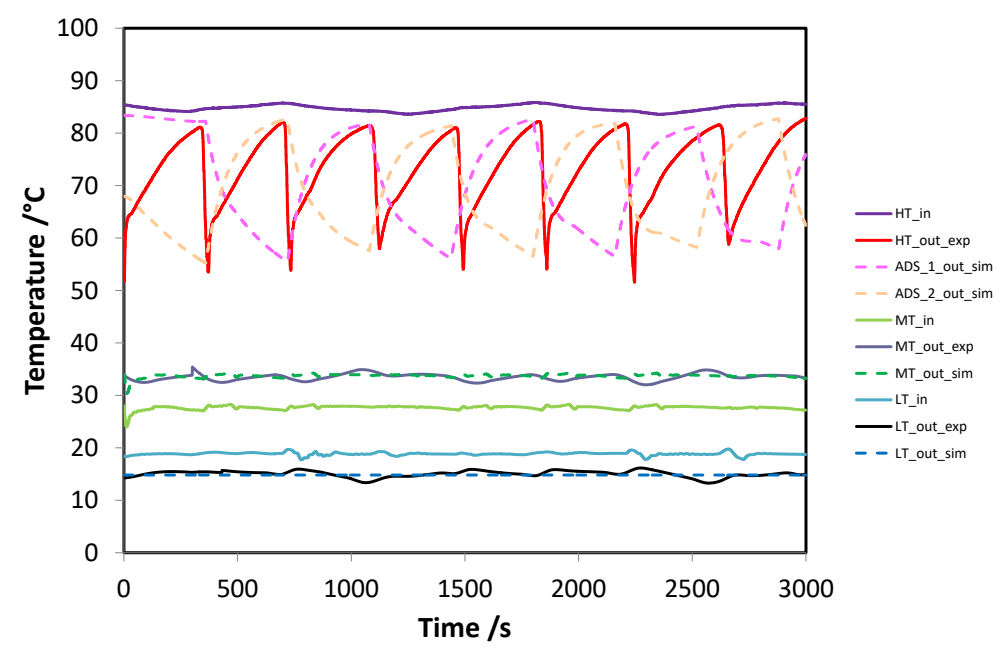

Figure 5: validation of the model by means of experimental data measured at the CNR ITAE lab.

\section{Simulation results}

Preliminary simulations were performed considering typical application for industrial sites in Barcelona, Spain, during summer operation. A daily cooling load reference profile was derived from literature data, while the ambient temperature was taken from Meteonorm library. Since a dry cooler is implemented on the condenser/adsorber side, the medium inlet temperature (MT), after the dry cooler, was considered $5 \mathrm{~K}$ higher than the ambient temperature, as represented in Figure 6.

The temperature profile of the heating source, represented by the Fresnel collector, was generated taking into account that it can be usually described, with good accuracy, by a $2^{\text {nd }}$ order polynomial evolution (Papadimitratos et al., 2016). The extreme temperatures considered for the temperature profiles are $65^{\circ} \mathrm{C}$ and $95^{\circ} \mathrm{C}$. The obtained reference profile is reported in Figure 7 


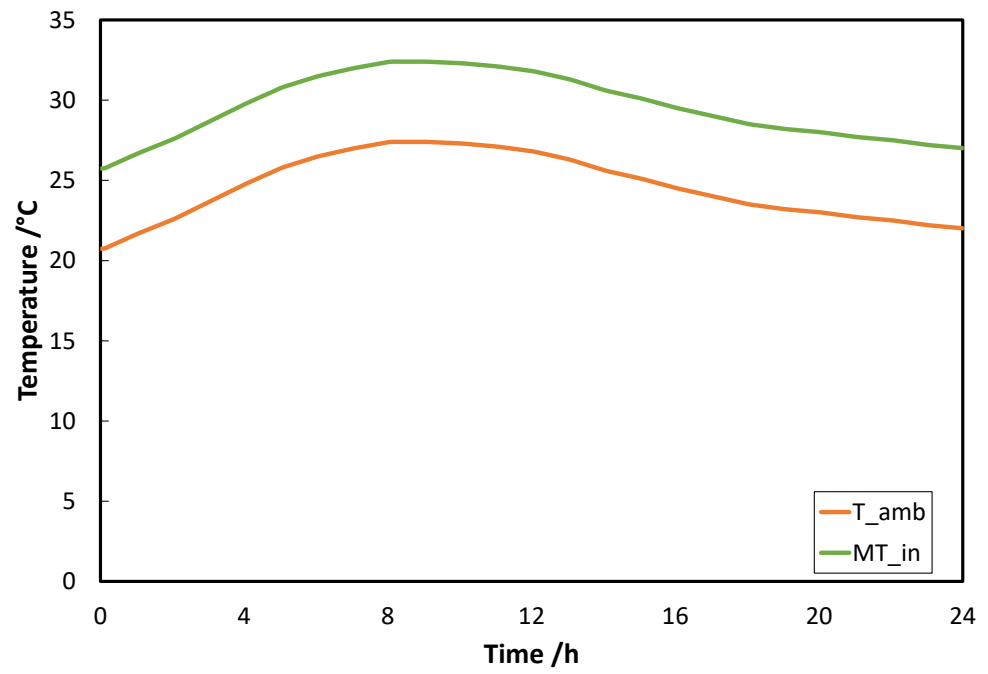

Figure 6: ambient temperature and inlet condenser temperature for Barcelona.

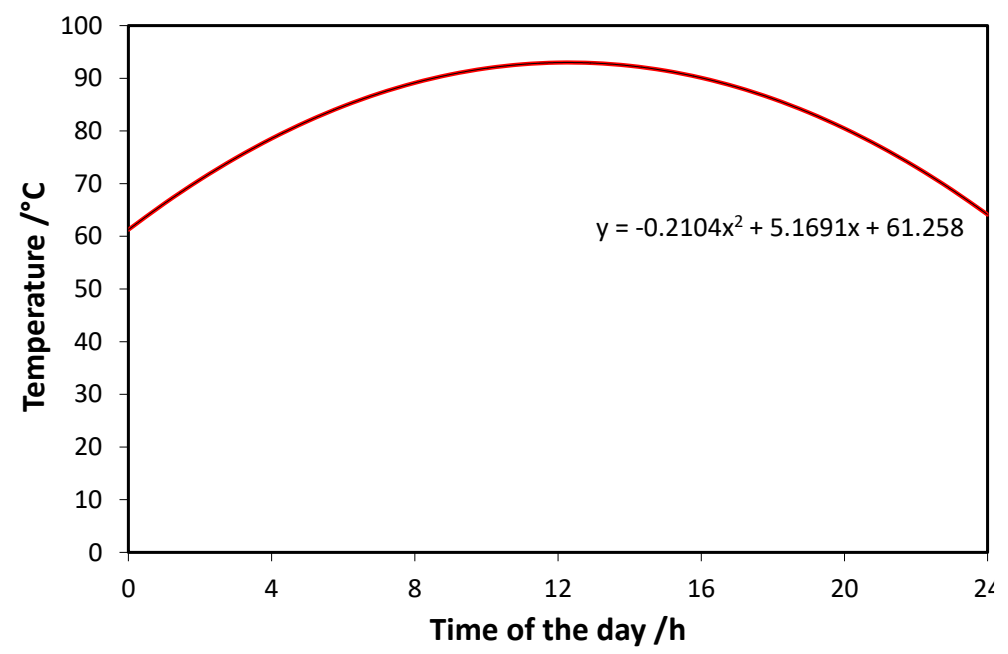

Figure 7: reference daily temperature profile provided by the Fresnel solar thermal collectors.

Starting from the boundary conditions above reported, a parametric analysis was performed to optimize the size of the adsorption unit, in order to properly operate the system, matching both the size of the solar thermal field as well as the cooling demand of the industrial site.

After this optimization phase, a complete daily simulation was performed, in order to verify the ability of the hybrid chiller in providing the needed temperature, satisfying the cooling demand. The results are presented in Figure 8 and Figure 9 that show the evolution of temperatures for the entire day, for the different hydraulic circuits entering and exiting the hybrid heat pump. It is possible to notice that the operation of the electric unit is stable and allows keeping the desired temperatures of chilled water at the evaporator. Similarly, for the optimized sizing of the adsorption chiller, the system is able to efficiently cool down the condenser of the vapour compression unit, thus confirming the reliability of the system to be realised. 


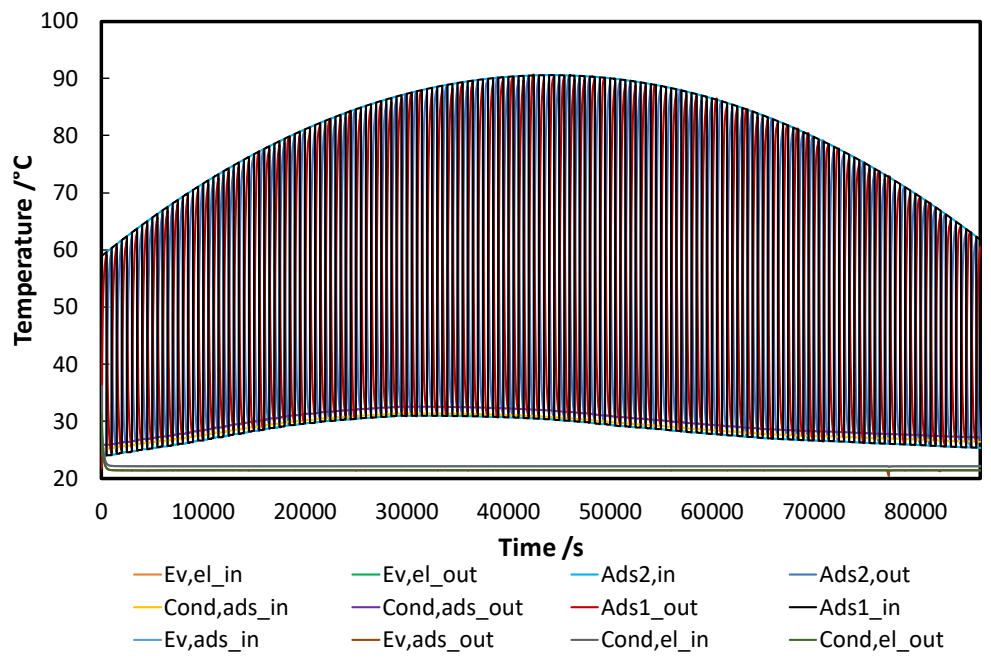

Figure 8: results of a typical daily simulation.

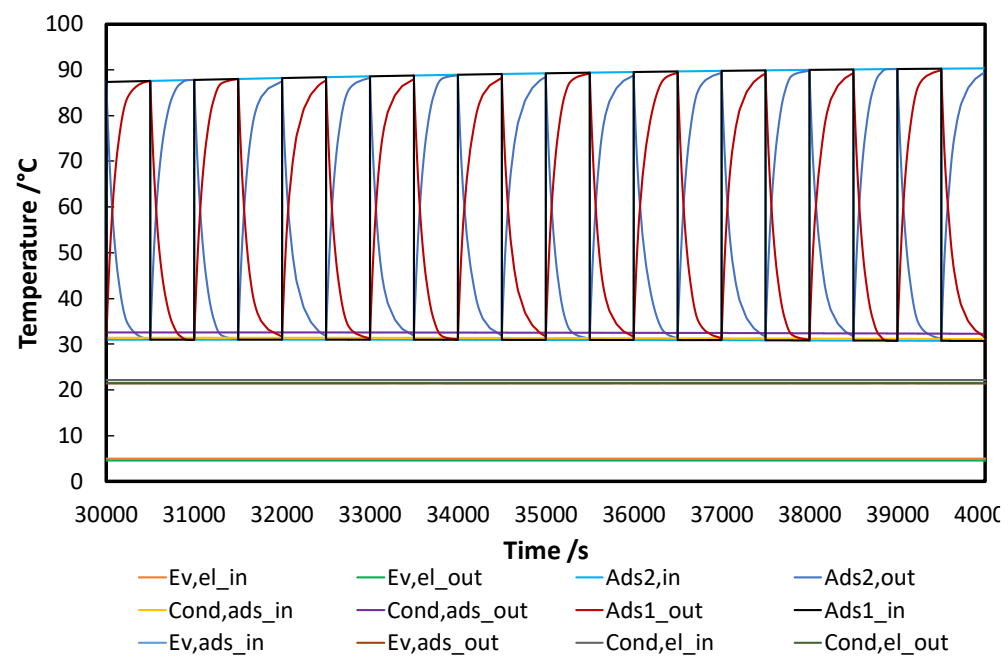

Figure 9: details of the temperature evolutions during a short time period of operation.

\section{Conclusions and future activity}

The Dymola/Modelica modeling of a cascade hybrid adsorption/vapour compression chiller driven by concentrating solar thermal collectors for industrial applications was presented. The two main sub-systems, namely, the adsorption module and the vapour compression chiller, were modelled considering heat and mass transfer propertied for each component, both on the HTF and on the refrigerant side. The implemented system was validated by means of experimental data obtained on a small-scale cascade chiller developed by Fahrenheit and tested at the CNR ITAE lab. Finally, the validated model was used to verify the ability of the cascade chiller to operate under a typical daily cooling profile in an industrial site in Spain. Starting from the developed and validated model, future activities will be oriented towards the operation optimization of the chiller, in terms of matching between thermal and electrical energy provision as well as minimization of the operation under part load conditions.

\section{Acknowledgments}

This project has received funding from the European Union's Horizon 2020 research and innovation programme under grant agreement No 792073 (HYCOOL).

\section{Nomenclature}

\begin{tabular}{|cl|cc|}
\hline A & Adsorption potential, $\mathrm{J} \mathrm{kg}^{-1}$ & $\dot{\mathrm{W}}$ & $\begin{array}{c}\text { Compressor work, } \mathrm{kW} \\
\text { Greek letters }\end{array}$ \\
$\mathrm{b}$ & Equilibrium constant, $\mathrm{kg} \mathrm{J}^{-1}$ & & Heat transfer coefficient, $\mathrm{W} \mathrm{m}^{-2} \mathrm{~K}^{-1}$ \\
$\mathrm{c}_{\mathrm{p}}$ & Specific heat, $\mathrm{J} \mathrm{kg}^{-1} \mathrm{~K}^{-1}$ & $\alpha$ & Efficiency \\
$\mathrm{D}$ & Diffusion coefficient, $\mathrm{m}^{2} \mathrm{~s}^{-1}$ & $\eta$ &
\end{tabular}




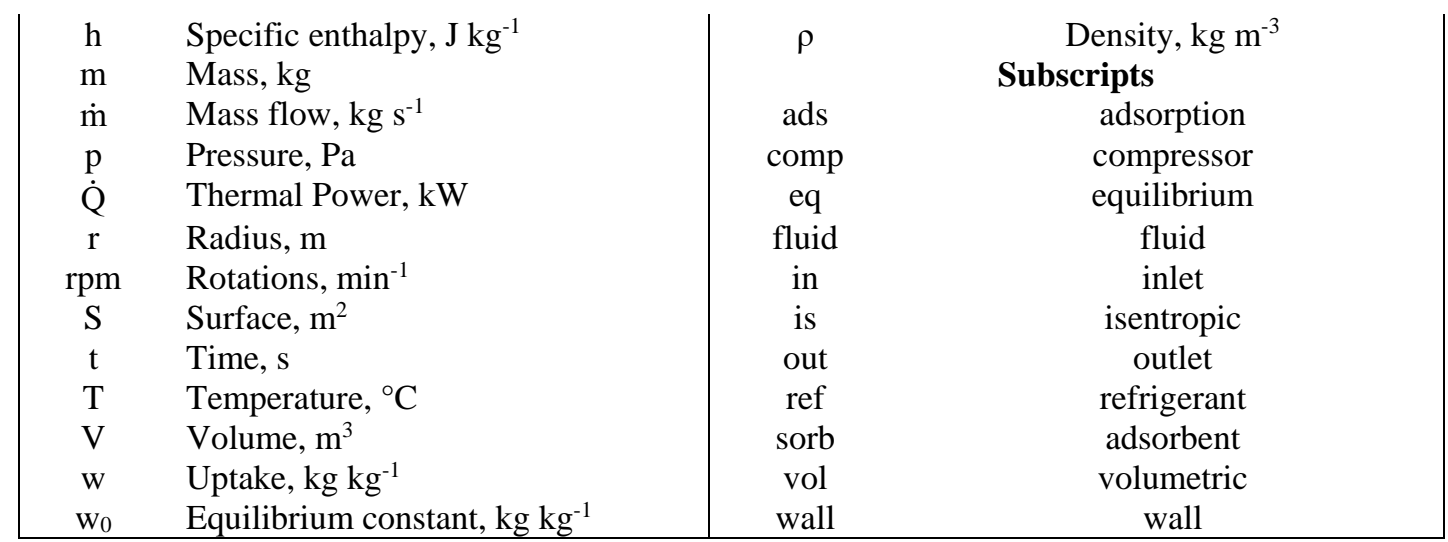

\section{References}

Bales, C., Gantenbein, P., Hauer, A., Henning, H.-M., Jaenig, D., Kerskes, H., ..., 2005. Thermal properties of materials for thermo-chemical storage of solar heat.

Bell, I.H., Wronski, J., Quoilin, S., Lemort, V., 2014. Pure and Pseudo-pure Fluid Thermophysical Property Evaluation and the Open-Source Thermophysical Property Library CoolProp. Ind. Eng. Chem. Res. 53, 2498-2508. https://doi.org/10.1021/ie4033999

Dubinin, M.M., Astakhov, V.A., 1971. Development of the concepts of volume filling of micropores in the adsorption of gases and vapors by microporous adsorbents - Communication 2. General bases of the theory of adsorption of gases and vapors on zeolites. Bull. Acad. Sci. USSR Div. Chem. Sci. 20, 8-12. https://doi.org/10.1007/BF00849308

El-Sharkawy, I.I., 2011. On the linear driving force approximation for adsorption cooling applications. Int. J. Refrig. 34, 667-673. https://doi.org/10.1016/J.IJREFRIG.2010.12.006

Farjana, S.H., Huda, N., Mahmud, M.A.P., Saidur, R., 2018. Solar process heat in industrial systems - A global review. Renew. Sustain. Energy Rev. 82, 2270-2286. https://doi.org/10.1016/J.RSER.2017.08.065

HyCool, 2018. HyCool [WWW Document].

Lanzerath, F., Bau, U., Seiler, J., Bardow, A., Bardow, E., 2015. Optimal design of adsorption chillers based on a validated dynamic object-oriented model. Sci. Technol. Built Environ. 21, 248-257. https://doi.org/10.1080/10789669.2014.990337

Murray, C., Quiñones, G., Cortés, F., Escobar, R., Cardemil, J.M., 2016. Solar Assisted Absorption Machine for the Fermentation Cooling and Maceration Heating Processes in the Winemaking Industry. Energy Procedia 91, 805-814. https://doi.org/10.1016/J.EGYPRO.2016.06.247

Papadimitratos, A., Sobhansarbandi, S., Pozdin, V., Zakhidov, A., Hassanipour, F., 2016. Evacuated tube solar collectors integrated with phase change materials. Sol. Energy 129, 10-19. https://doi.org/10.1016/J.SOLENER.2015.12.040

Quoilin, S., Desideri, A., Wronski, J., Bell, I., Lemort, V., 2014. ThermoCycle: A Modelica library for the simulation of thermodynamic systems, in: Proceedings of the 10th International Modelica Conference. Lund,Sweden. https://doi.org/10.3384/ECP14096683

Sánchez, D., Cabello, R., Llopis, R., Arauzo, I., Catalán-Gil, J., Torrella, E., 2017. Energy performance evaluation of R1234yf, R1234ze(E), R600a, R290 and R152a as low-GWP R134a alternatives. Int. J. Refrig. 74, 269282. https://doi.org/10.1016/J.IJREFRIG.2016.09.020

Sapienza, A., Velte, A., Girnik, I., Frazzica, A., Füldner, G., Schnabel, L., Aristov, Y., 2017. "Water - Silica Siogel" working pair for adsorption chillers: Adsorption equilibrium and dynamics. Renew. Energy 110, 4046. https://doi.org/10.1016/J.RENENE.2016.09.065

Vasta, S., Palomba, V., La Rosa, D., Mittelbach, W., 2018. Adsorption-compression cascade cycles: An experimental study. Energy Convers. Manag. 156, 365-375. https://doi.org/10.1016/j.enconman.2017.11.061

Werner, S., 2016. European space cooling demands. Energy 110, 148-156. https://doi.org/10.1016/J.ENERGY.2015.11.028 


\title{
Performance analysis of a small scale solar cooling plant based on experimental measurements
}

\author{
Augusto Bianchini ${ }^{1}$, Alessandro Guzzini ${ }^{2}$, Marco Pellegrini ${ }^{1}$ and Cesare Saccani ${ }^{2}$ \\ 1 Department of Industrial Engineering, University of Bologna, Forlì (Italy) \\ 2 Department of Industrial Engineering, University of Bologna, Bologna (Italy)
}

\begin{abstract}
The main scope of the paper is analyzing the experimental data and evaluating the techno-economic feasibility of a solar cooling plant with solar thermal concentrators for residential application in Central Italy. An extensive monitoring of a solar cooling system was carried out in Forli (Italy) in the summer of 2014 and 2015. The solar cooling plant was remotely monitored and data on environmental conditions, fluids flowrate and temperatures and both heating and cooling power production were continuously acquired and stored. The results showed that the combination of solar thermal concentrator and absorption chiller can simultaneously satisfy the demand for domestic hot water production and space cooling. Nevertheless, the solar thermal concentrator proved limited efficacy due to suboptimal environmental framework conditions and to low reliability. A preliminary economic analysis has been carried out for a residential application through the Net Present Value method. The Net Present Value has been computed for different effectiveness of the solar cooling plant in meeting the demand for domestic hot water production and space cooling. The results show that i) an investment reduction in comparison to the costs of the experimental plant and ii) incentives are fundamental to make the solar cooling plant profitable.
\end{abstract}

Keywords: Solar cooling, parabolic dish concentrator, experimental measurements, performance analysis.

\section{Introduction}

Cooling applications like air-conditioning and refrigeration become as basics of everyday life. The conventional cooling systems use refrigerants with high ozone depletion potential (ODP) and greenhouse gas (GHG) impact and as a consequence the prohibition of hydrochlorofluorocarbons (HCFCs) has been programmed starting by 2015 (Benhadid-Dib and Benzaoui, 2012). Therefore, innovative solutions for renewable energies development and exploitation are needed to meet human needs while saving the environment. Furthermore, the reduction of electric energy consumption for buildings cooling can contribute in the limitation of electric peak demand in summertime.

Exploring the so-called "solar cooling" concept seems a fascinating idea since cooling needs coincide most of the time with the solar radiation availability. The main alternative routes (Montagnino, 2017; Lazzarin and Noro, 2018) from solar energy into cooling (and heating) are solar "thermal" or "electric" (photovoltaic). One of the most promising plant configuration is the one that combines solar thermal devices with absorption refrigeration chillers (Eicker and Pietruschka, 2009). In fact, the use of solar thermal energy in summertime for different purposes from domestic hot water (DHW) can increase the efficiency and efficacy of the solar thermal plant (Mugnier et al., 2017). In fact, solar cooling could be an effective way to increase the annual solar fraction of DHW production and prevent the solar system from overheating. Indeed, solar thermal plant is usually sized to meet all the hot water requirements in summer to reduce waste heat, thus doing without relevant solar heat contributions in the rest of the year. The integration with a solar cooling plant allows to oversize the solar thermal plant, which would increase the solar fraction throughout the year, and to use the surplus to power an absorption chiller for space cooling in summer.

Thermally driven cooling equipment based on the integration between solar thermal collectors and absorption chillers was commercially available since 70 's. Nevertheless, such equipment still does not penetrate the market, due to both economic and performance issues. Several experimental plants have been realized, usually in insulated regions and with flat plate or evacuated tube solar thermal collectors (Toure at al., 2012; Hang et al., 2014; Lecuona et al., 2015; Aliane et al., 2016), including also the development of simulation tools (Puglisi et al., 2015; Delac et al., 2018).

The main objective of this paper is to measure and to assess the performance of a solar cooling plant in Central Italy 
(or, more in general, Central-South Europe). The solar cooling plant is hosted in the applied research centre on renewable energy called "HEnergia" (HE), located in Forlì (Italy), and which was designed to host different kinds of renewable energy plants (Bianchini et al., 2016, Bianchini et al., 2017). The originality of the paper lies in the fact that i) solar energy is produced by a concentrating solar dish device and ii) the solar cooling plant is located in a tempered zone. Starting from the experimental data analysis, a preliminary economic analysis has been carried out for a residential application in central Italy. Similar studies can be found in literature, but limited to sunny areas, in particular southern Mediterranean areas (Bouhal et al., 2018; Mugnier and Seleme, 2015).

\section{Material and Methods}

\subsection{The solar cooling plant and monitoring system}

In the spring of 2013 eight different photovoltaic (PV) systems, one hybrid photovoltaic/thermal (PV/T) solar system and one solar cooling plant were installed at HE. The solar cooling plant consists of one concentrating solar dish device (the Solar Beam, manufactured by Solartron-Ghibli, $11.5 \mathrm{~kW}$ th peak), one absorption chiller (WFC-SC5 manufactured by Yazaki, $17.5 \mathrm{~kW}$ fr in nominal conditions), two storage tanks ( 8001 volume for hot water produced by the solar dish, 5001 volume for the cooled water produced by the absorption chiller), one cooling tower and all the necessary components for water feeding and control (pumps, valves, instruments). Since the solar cooling plant fed the fan-coils circuit of HE laboratories with chilled water, the plant was integrated with a compression chiller to ensure supply continuity. The Piping and Instrumentation Diagram (P\&ID) of the solar cooling plant is shown in Figure 1, while in Figure 2 a picture of the solar parabolic dish concentrator is shown. Table 1 and Table 2 summarize the main characteristics of the solar parabolic dish and of the absorption chiller, respectively.

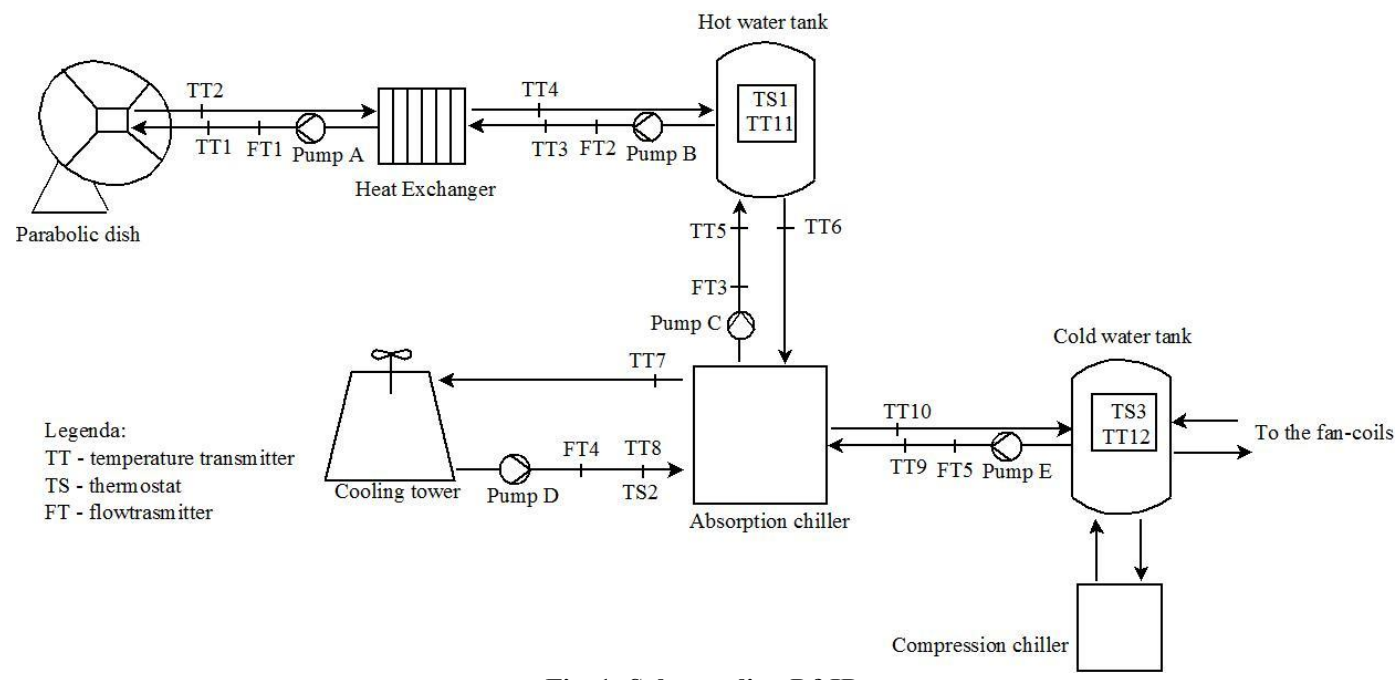

Fig. 1: Solar cooling P\&ID.

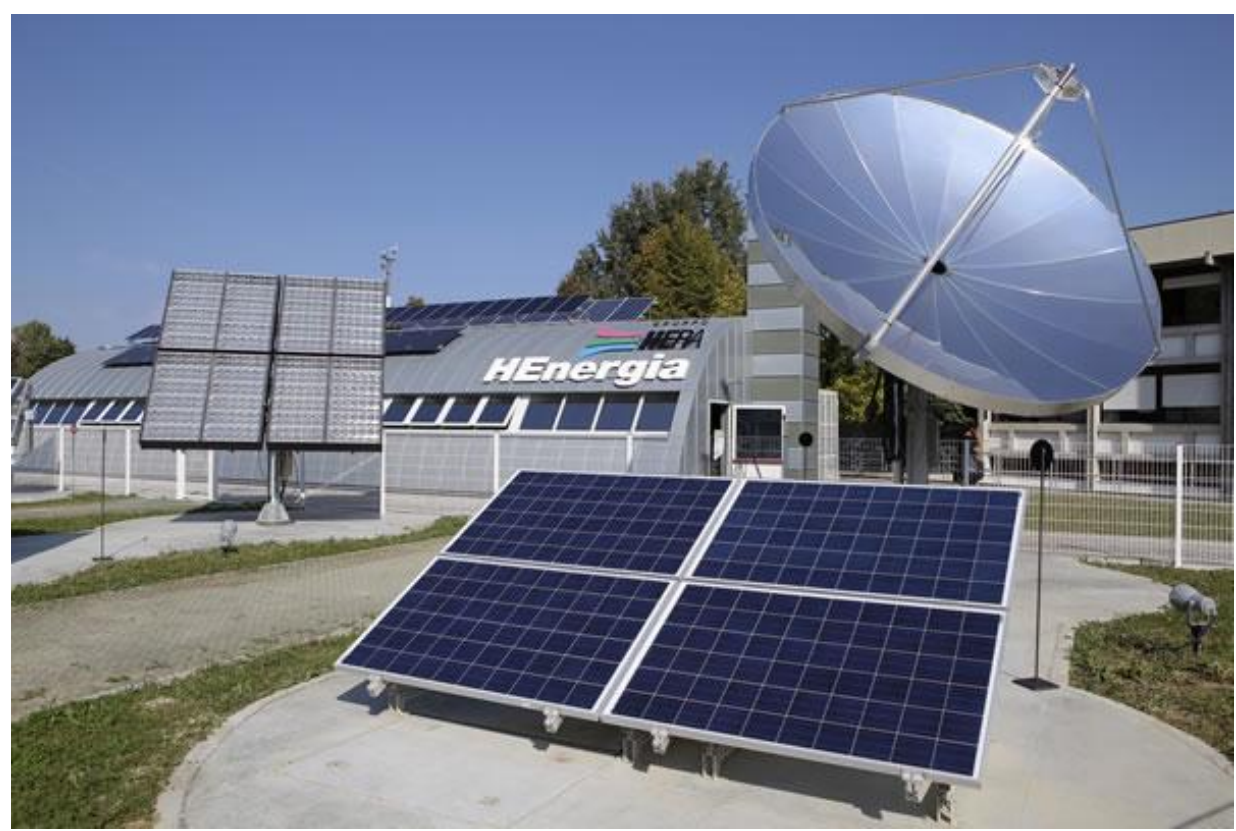

Fig. 2: Picture oft he solar parabolic dish concentrator (on the right). 
Tab. 1: Main characteristics of the solar parabolic dish.

\begin{tabular}{|c|c|c|}
\hline Item & Specification & Unit \\
\hline Peak power production & 11.5 & $\mathrm{~kW}$ \\
\hline Optic efficiency & 0.86 & $\%$ \\
\hline Peak beam thermal efficiency & 0.73 & $\%$ \\
\hline Collector diameter & 4.5 & $\mathrm{~m}$ \\
\hline Gross collector area & 15.9 & $\mathrm{~m}^{2}$ \\
\hline Gross absorber area & 0.065 & $\mathrm{~m}^{2}$ \\
\hline Focal point distance & 2.2 & $\mathrm{~m}$ \\
\hline Mounting post height & 2.4 & $\mathrm{~m}$ \\
\hline Concentration ratio & $1: 245$ & - \\
\hline Weight & 463 & $\mathrm{~kg}$ \\
\hline
\end{tabular}

Tab. 2: Main characteristics of the absorption chiller.

\begin{tabular}{|c|c|c|}
\hline Item & Specification & Unit \\
\hline Cooling capacity at nominal condition & 17.5 & $\mathrm{~kW}$ \\
\hline Heating consumption at nominal condition & 25.1 & $\mathrm{~kW}$ \\
\hline Coefficient of Performance (COP) & 0.7 & - \\
\hline Nominal inlet temperature of heating fluid & 88 & ${ }^{\circ} \mathrm{C}$ \\
\hline Nominal outlet temperature of heating fluid & 83 & ${ }^{\circ} \mathrm{C}$ \\
\hline Nominal flowrate of heating fluid & 1.2 & $1 / \mathrm{s}$ \\
\hline Nominal inlet temperature of cooled water & 12 & ${ }^{\circ} \mathrm{C}$ \\
\hline Nominal outlet temperature of cooled water & 7 & ${ }^{\circ} \mathrm{C}$ \\
\hline Nominal flowrate of cooled water & 0.77 & $1 / \mathrm{s}$ \\
\hline Nominal inlet temperature of cooling water & 31 & ${ }^{\circ} \mathrm{C}$ \\
\hline Nominal outlet temperature of cooling water & 35 & ${ }^{\circ} \mathrm{C}$ \\
\hline Nominal flowrate of cooling water & 2.55 & $1 / \mathrm{s}$ \\
\hline Size & $594 \times 744 \times 1,786$ & $\mathrm{~mm}$ \\
\hline Weight (in operation) & 420 & $\mathrm{~kg}$ \\
\hline Noise level & 46 & $\mathrm{~dB}(\mathrm{~A})$ at 1 meter \\
\hline
\end{tabular}

All the circuits are filled with water, with the exception of the primary circuit of the solar concentrator, which works with a $30 \%$ vol. mixture of water and propylenic glycol. All the pumps connected to the absorption chiller work at constant volume flow rate and have been set accordingly to nominal values (see Table 2). Table 3 summarizes the whole nominal installed electric power of the solar cooling plant. 
Tab. 3: Total installed electric power in the solar cooling plant. Pump items refer to Figure 1.

\begin{tabular}{|c|c|}
\hline Item & Installed power [W] \\
\hline Absorption chiller & 48 \\
\hline Cooling tower fan & 550 \\
\hline Pump A & 130 \\
\hline Pump B & 410 \\
\hline Pump C & 1,100 \\
\hline Pump D & 1,100 \\
\hline Pump E & 410 \\
\hline Total & 3,748 \\
\hline
\end{tabular}

The solar cooling plant is automatically driven and all the water flows (FT in Figure 1) and temperatures (TT in Figure 1) are measured to characterize each component performance. Furthermore, environmental conditions such as solar global radiation, ambient temperature and humidity, wind speed and direction are measured through a local meteorological station, installed on the HE roof. All the installed instruments have a maximum measuring error of $0.5 \%$. The automatic operation logic of the solar cooling plant can be summarized as follows:

- Solar concentrator: the pump of the primary circuit (pump A in Figure 1) turns on when a solar radiation over $300 \mathrm{~W} / \mathrm{m}^{2}$ is measured, while the pump of the secondary circuit (pump B in Figure 1) is turned on if the temperature TT11 in the hot water storage tank is lower than the outlet temperature TT2 of the solar concentrator cooling fluid.

- Absorption chiller: the pump of the hot water circuit (pump $\mathrm{C}$ in Figure 1) turns on or off depending on the temperature measured by thermostat TS1. The temperatures levels at which the pump turns on and off can be remotely set.

- Cooling tower fan: turning on and off of the cooling tower fan is driven by the thermostat TS2, that measures the temperature of the cooling fluid at the absorption chiller inlet. TS2 is an internal instrument of the absorption chiller controller unit and was set with factory values.

- Compression chiller: the compression chiller works as a back-up or integration unit, depending on the end-user cooling demand and on the performance of the solar cooling plant. The compression chiller is turned on by the thermostat TS3 when the temperature in the cold water storage tank is too high, and it is turned off when a satisfactory temperature level is restored. Both temperature levels of thermostats can be remotely set.

The solar cooling plant has been realized for experimental purposes, and that's why some design aspects are not optimized as for a real case application. First of all, the matching between the solar concentrator and the absorption chiller is not optimal, since the peak production of the solar concentrator is lower than the nominal heating demand of the absorption chiller. Due to budget limitations, it was not possible to install one or two additional solar concentrators or other solar thermal devices.

\subsection{Solar cooling plant performance indexes}

The performance of the solar cooling plant is a combination of the efficiency of both solar device and absorption chiller, and it is strongly affected by the effectiveness of storage design and control strategy. The ISO 9806:2017 covers performance, durability and reliability testing of almost all solar thermal collector types available in the market, including concentrating solar thermal collectors. The ANSI/ARI Standard 560:2000 defines test and rating requirements of water-cooled single effect steam and hot water operated water chilling units, water-cooled doubleeffect steam and hot water operated water chilling units, and double-effect Direct-Fired water chilling/heating units.

The ISO 9806:2017 quasi-dynamic test method is normally applied to evaluate concentrating solar thermal collector performance, i.e. the heating power $\mathrm{P}_{\text {th }}$. The quasi-dynamic method is basically the same as the steady-state model, but with some extra correction terms (including, among others, the impact of wind speed, dependence on direct and diffuse radiation, thermal capacitance) that make the mathematical formulation of $\mathrm{P}_{\text {th }}$ complex and consequently complicate the evaluation of the impacts of the single parameter on the performance of the solar device. Nevertheless, $\mathrm{P}_{\mathrm{th}}[\mathrm{kW}]$ produced by concentrating solar thermal collectors can be computed by Eq. 1, once mass flowrate $\mathrm{m}_{\mathrm{F}}[\mathrm{kg} / \mathrm{s}]$ and heat capacity $\mathrm{c}_{\mathrm{F}}[\mathrm{kJ} / \mathrm{kgK}]$ of the cooling fluid are known, and the solar thermal collector inlet $\mathrm{T}_{\text {in }}$ and outlet $\mathrm{T}_{\text {out }}$ temperatures of the cooling fluid $[\mathrm{K}]$ are measured. 


$$
P_{\text {th }}=m_{F} \cdot c_{F} \cdot\left(T_{\text {out }}-T_{\text {in }}\right)
$$

Furthermore, the Reference Yield $Y_{R}$ has been identified as a relevant parameter to describe the environmental working condition. $Y_{R}$ is measured in $\mathrm{Wh} / \mathrm{W}$ and it is defined as the ratio between the global solar radiation energy per surface unit I evaluated in the considered time interval (expressed in $\mathrm{Wh} / \mathrm{m}^{2}$ ) and $\mathrm{G}_{\mathrm{STC}}$, that is the Standard Test Condition (STC) global solar radiation $\left(1,000 \mathrm{~W} / \mathrm{m}^{2}\right.$, as in standard IEC 61724). This parameter is usually related to photovoltaic performance assessment, but it can be effectively adopted also in the field of solar thermal collector to indicate the number of peak sun-hours in a certain period (i.e. day, month, year).

The ANSI/ARI Standard 560:2000 defines the Coefficient of Performance (COP) as the ratio of cooling capacity $[\mathrm{W}]$ the power input values [W] at any given set of rating conditions. So, the COP of the absorption chiller can be computed once inlet and outlet temperatures and fluid flowrate in the generator and in the evaporator have been measured. The COP can be also referred to a certain period (i.e. day, month, year) and can be a useful instrument to measure the efficiency of the absorption chiller over the time.

\subsection{Economics considerations}

The evaluation of the economics of a solar cooling plant is not simple since the system can produce both hot and cold water over the year, and it is usually compared with electric fed devices. So, it is difficult to make a comparison based on the energy production costs (i.e. levelized cost of energy as for electric energy production). The economic analysis of the solar cooling plant studied was carried out through the application of the Net Present Value (NPV) methods in comparison with a reference system. The chosen reference system is a reversible heat pump for seasonal cooling and domestic hot water (DHW) production all over the year. The formula of NPV can be expressed as in Eq. 2:

$$
\mathrm{NPV}=-F_{0}+\sum_{t=1}^{n} \frac{R-C}{(1+i)^{t}}
$$

where $\mathrm{t}$ (years) is time, $\mathrm{n}$ (number of years) is the time period considered for the investment evaluation (which will be assumed equal to both depreciation and technical life time of plants for treatment simplicity purpose), $i(\%)$ is the discount rate (differentiated in household and industry investment), $R$ is the annual revenue $[€], C$ the annual cost $[€]$. The net cash flow $F_{0}$ at $t=0$ corresponds to the starting investment $[€]$ : the simplifying hypotheses of full investment payment and plant operation start in the same year $(\mathrm{t}=0)$ are also assumed. The net cash flow $\mathrm{F}=(\mathrm{R}-\mathrm{C})$ for period $t>0$ was computed taking into account the main costs and revenues components.

The investment has been initially computed similar to the one present in HE on the basis of real HE costs and on market quotations (Table 4): the result is an investment of about 70,000€. Nevertheless, it should be noted that at least two further solar concentrators should be installed to satisfy the demand of the absorption chiller, meaning that the real cost of an effective installation would be considerably higher, i.e. 120,000-130,000€. The result is an estimated investment cost of about 7,000-7,500 €/kWfr, that is quite high if compared with literature data (Eicker and Pietrusckha, 2009; Eicker et al., 2014). This fact can be justified i) by the small size of the plant, ii) by the experimental nature of the installation, and iii) by the high cost of the solar devices.

A yearly cost to be considered is the operating and maintenance cost, which is evaluated on the basis of the experimental campaign findings. In particular, maintenance cost has been computed to be around $1,000 €$ per year, and includes actions like cooling tower seasonal cleaning, parabolic dish cleaning, sun-tracking system maintenance, yearly check of pumps, valves and instruments. The yearly measured maintenance cost is consistent with literature data (Jakob, 2015) The decreasing cost of maintenance activities on the reference plant is not considered, since the reference plant can be considered as a back-up and integration system, and so no relevant cost decreasing can be expected. The yearly operation cost is substantially produced by electric consumption for pumping and for the feeding of the cooling tower fan. The total installed electric power is equal to about $3.8 \mathrm{~kW}$ (see Table 3). Nevertheless, the solar cooling plant is supposed to have a lower mean electric consumption, since the pumps consumption is not equal to the nominal installed power, while the cooling tower fan is not always working. The NPV will be computed by considering $1 \mathrm{~kW}$ of mean electric energy consumption, which has been estimated by considering the nominal pressure losses and a non-continuous operation of the cooling tower fan.

Yearly revenues are produced by the lower electric energy consumption of the reference system, and they are strongly affected by the effectiveness of the solar cooling plant, i.e. the capacity of satisfying the energy demand of the enduser for space cooling and DHW production. The NPV has been computed by assuming an increasing effectiveness $(25 \%, 50 \%, 75 \%$ and $100 \%)$ of the solar cooling plant for both space cooling and DHW production. Electricity price varies considerably, depending also upon the country of installation, and so it can have a huge effect on the NPV 
computation. In this paper, since the solar cooling plant was realized in Italy, averaged figures are used, being representative for the Italian residential energy market. No feed-in tariff or tax deduction have been considered. Table 4 summarizes the main assumptions about economic assessment.

Tab. 4: Assumptions about the economic assessment.

\begin{tabular}{|l|l|l|}
\hline Item & Symbol & Value \\
\hline Evaluation period & $\mathrm{n}$ & 20 years \\
\hline Discount rate & $i$ & $4.0 \%$ \\
\hline Maintenance cost of the solar cooling plant & - & $1,000 € /$ year \\
\hline Electricity price (Italy) & - & $0.229 € / \mathrm{kWh}$ \\
\hline Absorption chiller & $\mathrm{F}_{0}$ & $18,620 €$ \\
\hline Cooling tower & $\mathrm{F}_{0}$ & $3,100 €$ \\
\hline Parabolic dish solar concentrator & $\mathrm{F}_{0}$ & $25,452 €$ \\
\hline $\begin{array}{l}\text { Other solar cooling components (including tanks, piping, valves, fittings, instruments, } \\
\text { pumps) and installation }\end{array}$ & $\mathrm{F}_{0}$ & $10,000 €$ \\
\hline PLC and control software & $\mathrm{F}_{0}$ & $6,000 €$ \\
\hline Solar cooling plant design & $\mathrm{F}_{0}$ & $6,500 €$ \\
\hline
\end{tabular}

\section{Results and discussion}

\subsection{Solar cooling plant performance}

Figure 3 and Figure 4 represent an example of a daily data plotting; the reference day is $18^{\text {th }}$ August 2014, that has been selected as a representative of clear sky and sunny day. Figure 3 shows solar global radiation G, ambient temperature $\mathrm{T}_{\mathrm{a}}$ and wind velocity variation throughout the day.

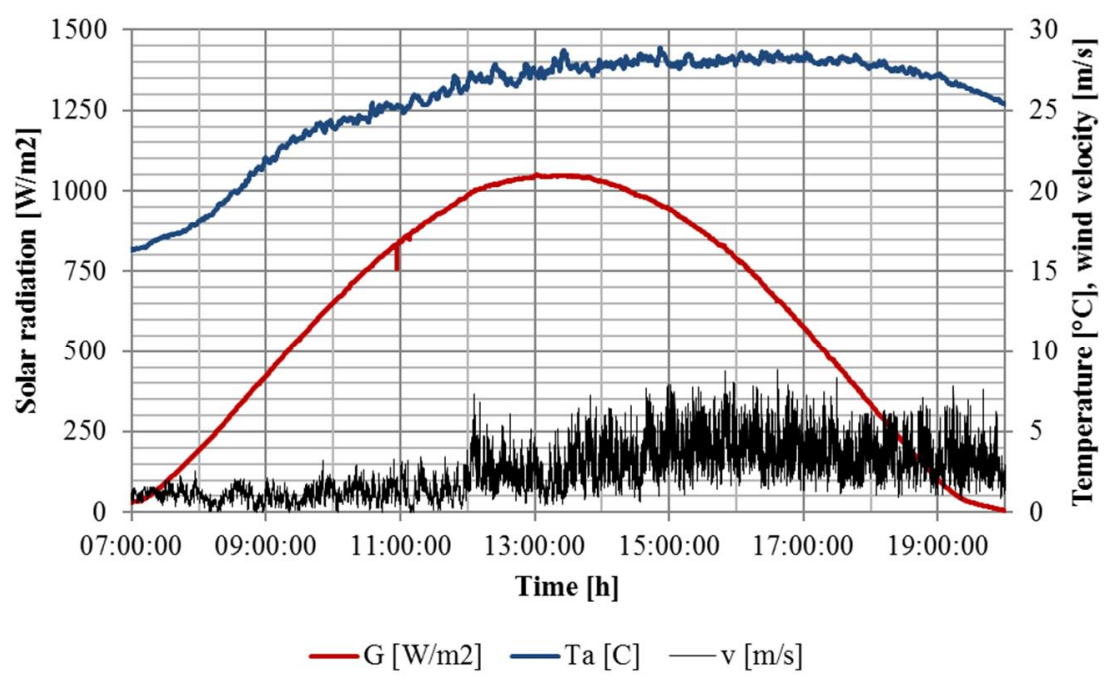

Fig. 3: Example of daily available dataset regarding environmental conditions (global solar radiation, ambient temperature and wind velocity) - reference day $18^{\text {th }}$ August 2014.

Figure 4 and Figure 5 show an example of the daily performance of solar concentrator and absorption chiller: in fact, the measured thermal power $\mathrm{P}_{\text {th }}$ and the outlet temperature $\mathrm{T}_{\text {out conc }}$ produced by the solar concentrator, plus the measured cooling power $\mathrm{P}_{\text {fr }}$, the heat consumed by the absorption chiller $\mathrm{P}_{\text {gen }}$, the inlet hot water temperature (from the hot water tank), inlet cooling water temperature (from the cooling tower) and the outlet cooled water temperature are represented. 


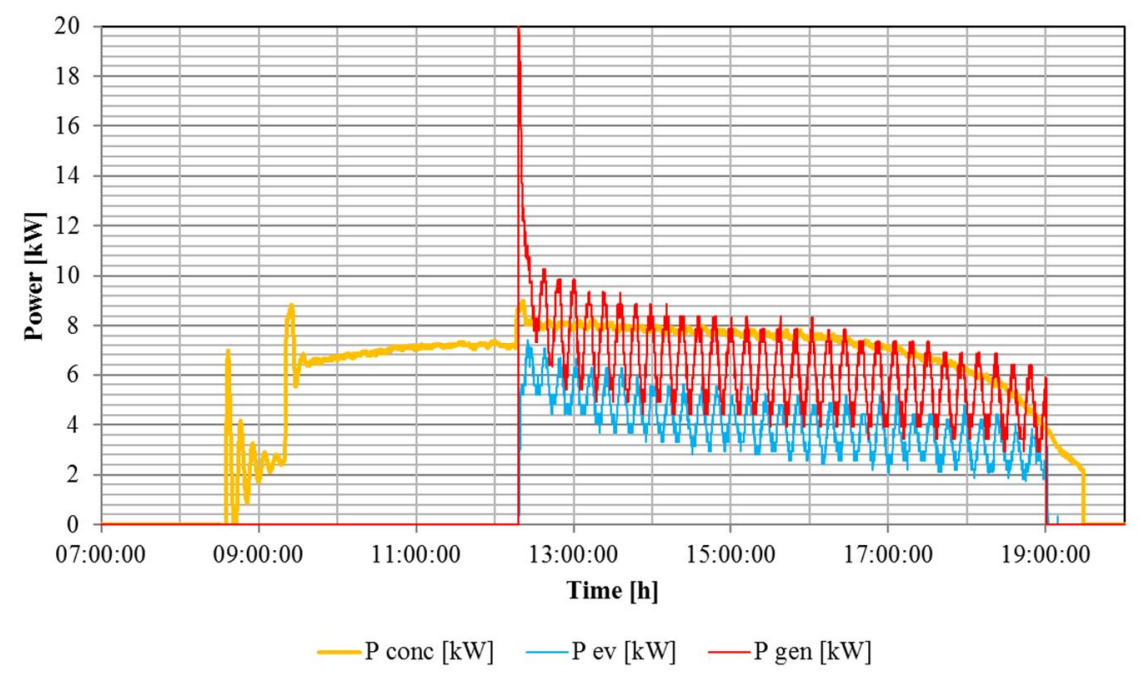

Fig. 4: Example of daily available dataset regarding thermal energy flows produced by the solar cooling plant: heat produced by the solar concentrator ( $P$ conc), cooling power produced by the absorption chiller evaporator $(P$ ev), heat consumed by the absorption chiller generator (P gen) - reference day $18^{\text {th }}$ August 2014.

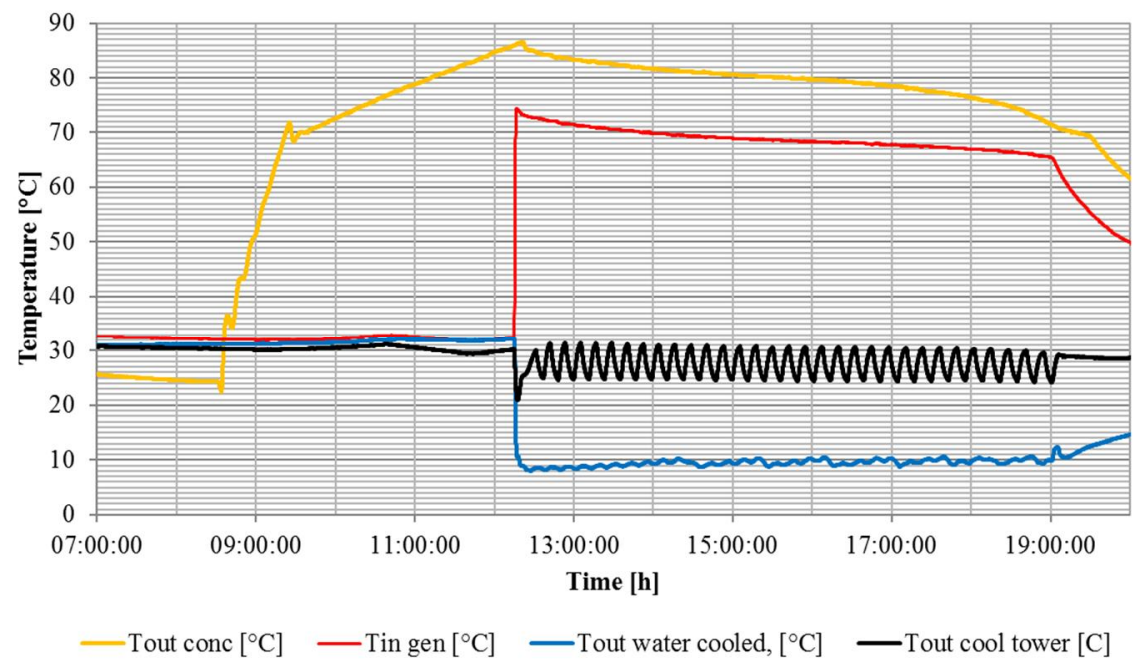

Fig. 5: Example of daily available dataset regarding fluid temperatures of the solar cooling plant - reference day $18^{\text {th }}$ August 2014.

Figure 4 shows an interesting operation behavior of the absorption chiller, i.e. the oscillating production of cooled water and consumption of hot water. The same behavior was observed in all the monitored days. It is also relevant to note that both solar concentrator and absorption chiller are characterized by a full operation delay due to transient time: in the case of the solar concentrator the transient time is about one hour long, while the absorption chiller takes about 15 minutes to start operating. The cooling power expressed by the absorption chiller in Figure 4 is considerably lower than the one expected in nominal condition: nevertheless, the absorption chiller was still far from working at nominal condition, since the inlet temperature of the hot water in the generator (see Figure 5) is about $70^{\circ} \mathrm{C}\left(\right.$ i.e. $18^{\circ} \mathrm{C}$ less than the nominal value). It should be underlined that the solar cooling plant, and the absorption chiller in particular, was tested with different inlet temperature of the hot water feeding the generator. Such an option was made possible due to the presence of the thermostat TS1 (see Figure 1), which allows the hot water to circulate in the generator only if a set temperature was reached. The experimental test carried out on $18^{\text {th }}$ August 2014 was set at $75^{\circ} \mathrm{C}$ to turns on the circulating pump and $65^{\circ} \mathrm{C}$ to turns it off. Different set up were tested, and it was found that, due to the undersize of the solar concentrator device, an upper limit of about $80^{\circ} \mathrm{C}$ should be defined, since if the set of thermostat TS1 would set at higher temperature, the system would not be able to reach that temperature in the hot tank.

Another important comment is about the $8-10^{\circ} \mathrm{C}$ temperature difference measured between the solar concentrator outlet and at the generator inlet. The temperature difference is due to i) the presence of a heat exchanger between the solar concentrator and the hot water tank and ii) the volume of the hot water tank. The installation of the heat exchanger was justified by the experimental nature of the installation, that requires the highest versatility. 
Nevertheless, the heat exchange penalizes the solar section efficacy, since the temperature that can be transferred to the hot water tank is lower than in the case of direct connection between the solar concentrator and the tank. Secondly, also the volume of the tank can negatively influence the solar section efficacy, since if the volume is oversized it may be difficult to satisfy the nominal temperature value at the generator inlet. So, the size of the tank is a key aspect in the design of the solar cooling plant. A possible solution to optimize the system is to foresee the opportunity to by-pass the hot water tank when the performance of the solar devices allows to reach high temperatures, or to develop sophisticated control strategies including variable-volume storage systems (Buonomano et al., 2014).

The oscillating operation of the absorption chiller (see Figure 4) can be explained if Figure 5 is analyzed, since the temperature at the cooling tower outlet shows the same behavior. The oscillating temperature at the cooling tower outlet is produced by the control strategy of the absorption chiller: when the temperature of the fluid coming from the cooling tower enters the absorption chiller at the temperature higher than $31^{\circ} \mathrm{C}$, the absorption chiller control unit directly turns on the fan of the cooling tower through the thermostat TS2 (see Figure 1). The cooling tower is switched off once the temperature goes down at $25^{\circ} \mathrm{C}$. The absorption chiller control unit can be accessed only through an external panel that was not included in the furniture. So, that control strategy cannot be modified. The result of this on/off control of the cooling tower fan is a wide variation of the cooling water temperature (between $25^{\circ} \mathrm{C}$ and $31^{\circ} \mathrm{C}$ ) that highly influence the absorption chiller yield, especially at low inlet generator temperatures. In fact, a variation of about 6-7 $\mathrm{kW}_{\mathrm{fr}}$ can be observed in each oscillating period. Moreover, such a control strategy is the responsible of a high number of start/stop cycles of the cooling tower fan, which may have negative impact on the reliability of the system on the long term. Further analysis is needed to verify the relation (if any) between waves' frequency and amplitude of cooling tower outlet and of absorption chiller yield, and how this relation can affect the control system efficacy.

Different possible actions were identified to improve the control strategy: i) changing the controller strategy by adding an external thermostat, preferably very close to the cooling tower outlet to reduce the response time of the system, thus by-passing the absorption chiller internal control; ii) implementing the control strategy by adding an inverter to control the cooling tower fan rounds per minute; iii) adding a 3-ways thermostatic valve by-pass from the cooling tower inlet to the cooling tower outlet, controlled by the mixed temperature inlet to the absorption chiller, to minimize the temperature inlet to the absorption chiller. In the latter configuration, the cooling tower fan is always running. Further analysis is needed to verify the effectiveness and efficiency of such control strategies and will be included in a following paper.

The first phase of data analysis was carried out by focusing on the performance of the solar parabolic dish. The performance analysis of the solar device shows a high dependence of thermal yield on solar radiation and temperature difference between the cooling fluid and the ambient temperature (Bianchini et al., 2019). Figure 6 shows the monthly thermal yield production (i.e. the whole heat produced in one month per square meter of solar collector), including the monthly average outlet and mean temperature of the cooling fluid and the monthly average reference yield. Data about May and September 2015 are not taken into consideration due to limited number of days of thermal energy production caused by solar parabolic dish malfunctioning. Data about June and July 2015 are missing since a PV/T was tested instead of the solar thermal concentrator (Bianchini et al., 2017).

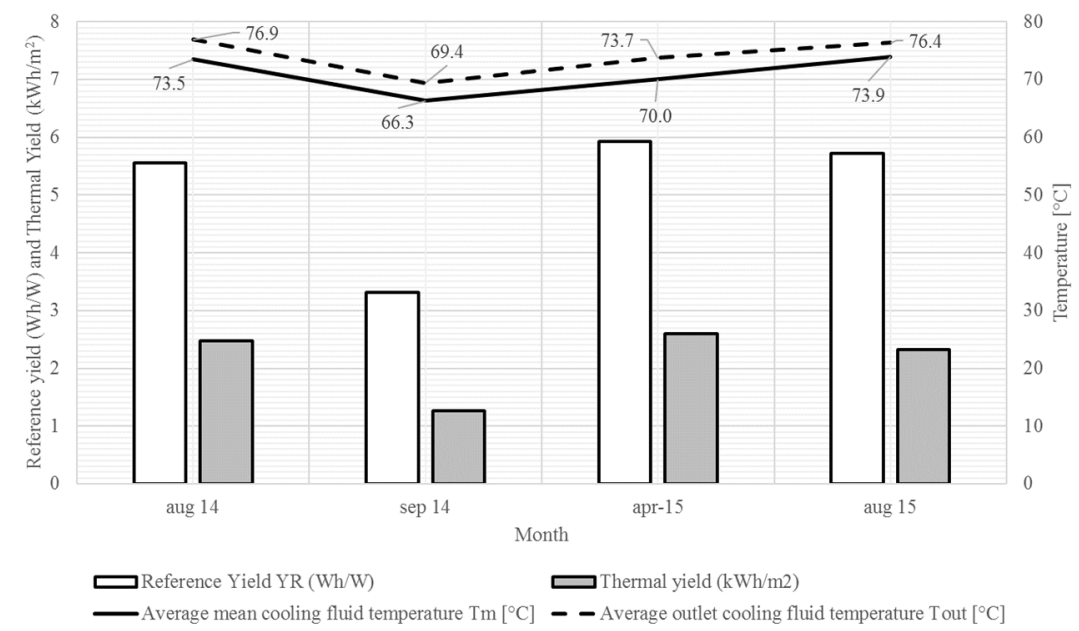

Fig. 6: Average daily thermal yield per square meter for each month of the solar concentratot; also monthly average values of daily reference yield and outlet and mean temperature of the cooling fluid are included (adapted from Bianchini et al., 2019). 
Another important factor in the analysis of parabolic dish concentrator is the mean temperature $T_{m}$ of the cooling fluid [K]. In Figure $7 \mathrm{~T}_{\mathrm{m}}$ and $\mathrm{T}_{\mathrm{a}}$ are analyzed together taking into account global solar radiation: the values are averaged over 30 minutes. When ambient temperature $\mathrm{T}_{\mathrm{a}}$ rises up to $15^{\circ} \mathrm{C}$ an increasing trend can be identified, after which a constant temperature $\mathrm{T}_{\mathrm{m}}$ seems to be achieved, independently from $\mathrm{T}_{\mathrm{a}}$. Therefore, the solar concentrator can produce hot water for the absorption chiller feeding in summertime, as well as hot water for DHW production in wintertime.

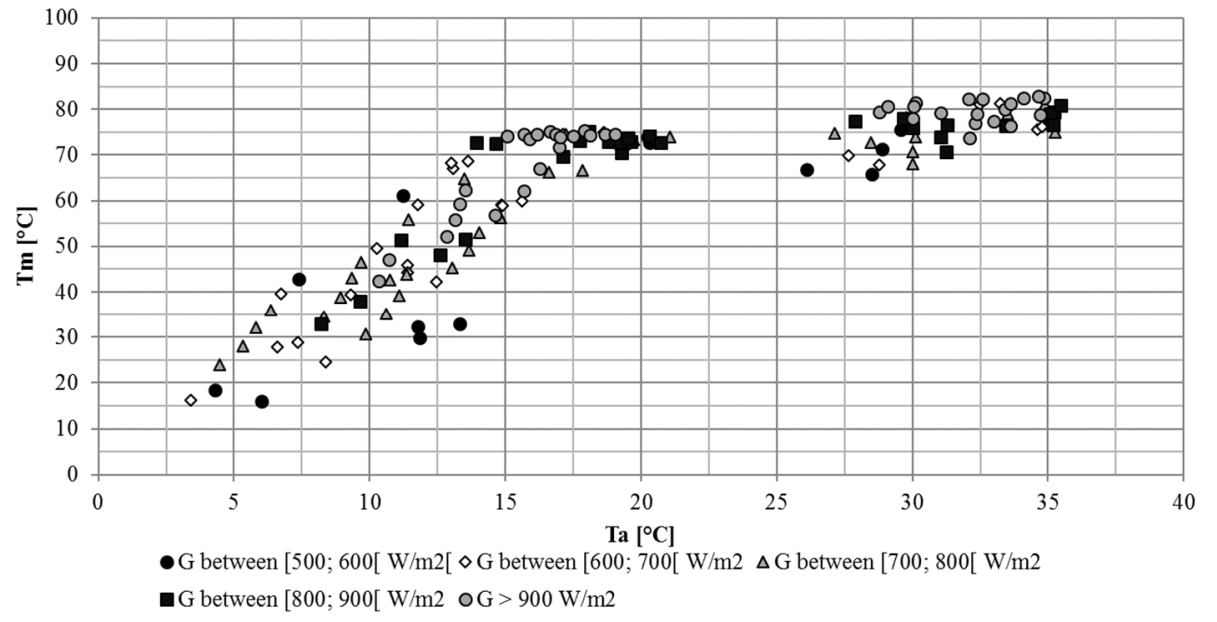

Fig. 7: Correlation between mean temperature $T_{m}$ of the solar device cooling fluid and ambient temperature $T_{a}$ and solar global radiation G.

The recorded working days of the parabolic dish is equal to 279 days: since the potential working days is equal to 301 , it means that the parabolic dish didn't work for 22 days, which mean $7.3 \%$ of potential working days lost due to the reliability concerns (Bianchini et al., 2019). The main problems observed were: mechanical failure on the solar tracker (solved in the first months) and not stopped alarms that require manual cancellation, thus leaving the optical concentrator in the rest position until an operator manually restarts the plant on-site. These potential failures should be considered when comparing a solar thermal concentrator with a fixed solar thermal collector.

The recorded working days of the absorption chiller is equal to 46 days. The instantaneous performance of the absorption chiller is not easy to compute due to the oscillating operation of the system (see Figure 4). Data has been averaged over a period of 10 minutes. Figure 8 shows the instantaneous COP of the absorption chiller computed for different temperatures at the generator inlet. The presence of low COP values (i.e. under 0.6) can be justified by the fact that absorption chiller starts up are included in the analysis. It is interesting how over $70^{\circ} \mathrm{C}$ of inlet generator temperature the COP seems to stabilize around a mean value of 0.7 , thus suggesting that the efficiency of the absorption chiller is not affected by inlet generator temperature variation up to about $20^{\circ} \mathrm{C}$ from nominal conditions. Once again, it seems appropriate to favor the most direct connection between the solar thermal source and the absorption chiller, since even significant variations in the inlet generator temperature do not penalize the efficiency of the system, but only the yield.

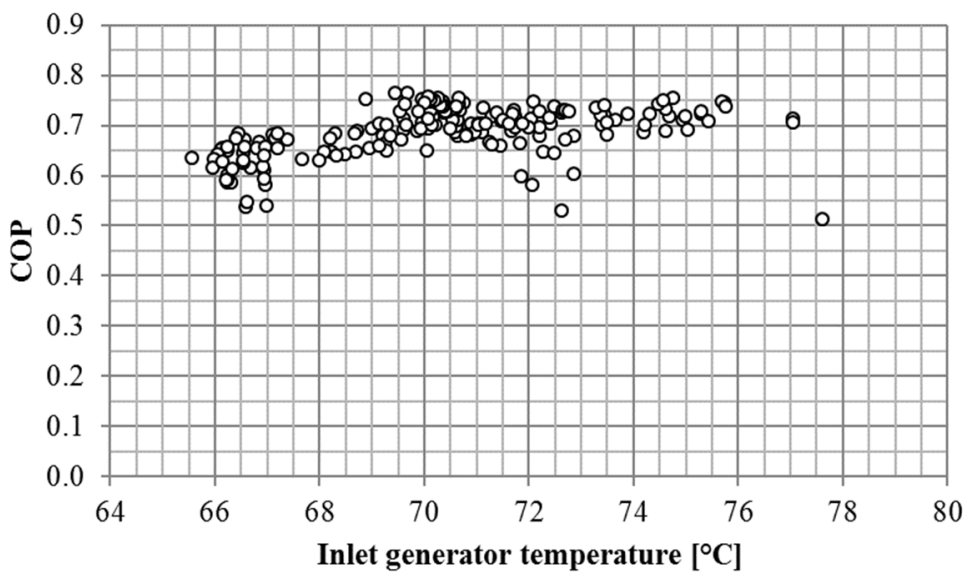

Fig. 8: Correlation between absorption chiller COP and temperatures at the generator inlet. 


\subsection{Economic assessment}

Due to the experimental nature of the installation, it was not possible to directly assess the techno-economic suitability of the solar cooling plant based only on the measurement carried out in HE. The paper aims to evaluate the sustainability of the investment in a solar cooling plant through a comparison with a reversible liquid-air heat pump - considered as the reference technology - for space cooling and DHW production. To do that, an end-user should be defined. A complex of 5 apartments of about $60 \mathrm{~m}^{2}$ each of conditioned area can be considered as suitable for a $17 \mathrm{~kW}_{\mathrm{fr}}$ cooling plant, resulting in a yearly energy demand for space cooling of approximately $22,500 \mathrm{kWh}$ (i.e. 1,500 cooling hours per year). In the hypothesis of about 15 people living in that residential complex, more or less $45 \mathrm{kWh}$ /day of energy should be used for DHW production. The reversible heat pump seasonal efficiencies are estimated in a mean COP of 3.0 in heating mode and a mean energy efficiency ratio (EER) of about 3.0 in cooling mode.

Figure 9 shows the result of the economic analysis carried out by considering different effectiveness of the same plant in reaching the demand for DHW and cooling: the NPV has been computed by considering different level of savings produced by higher meeting demand for DHW and cooling. Based on the assumptions about the residential user characteristics, it is interesting to note that the solar cooling plant should be designed to reach as much as possible the space cooling demand, being the capacity of meeting DHW demand less impacting. Nevertheless, a solar cooling plant can hardly satisfy a percentage higher than $75 \%$ of space cooling demand in residential application, since cooling demand may be present also on late afternoon or night. So, the capacity to satisfy DHW production all over the year becomes essential, i.e. solar panels characteristics regarding hot water production in wintertime. The result is that a solar cooling plant can be feasible only if mutual benefits occur between energy production for DHW and space cooling.

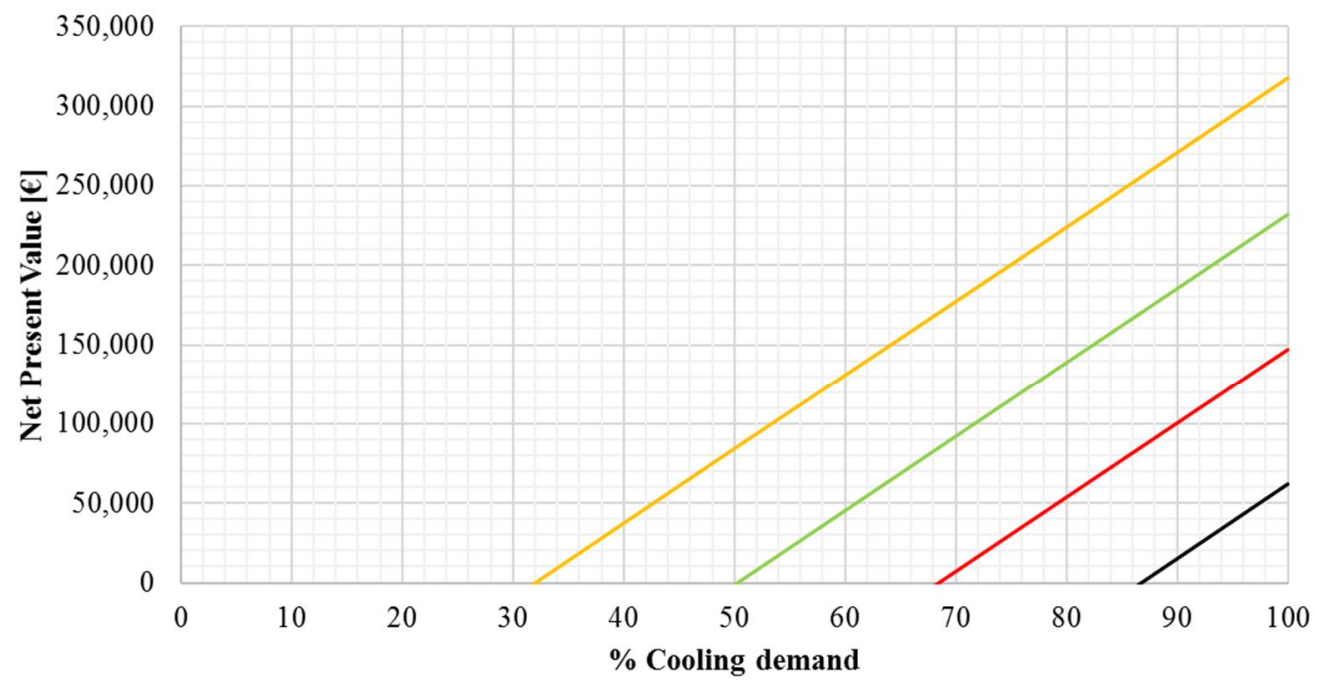

$-25 \%$ DHW demand — $50 \%$ DHW demand — $-75 \%$ DHW demand — $100 \%$ DHW demand

Fig. 9: Net Present Value variation as a function of the effectiveness of the solar cooling plant in meeting the demand for DHW and space cooling.

In an optimistic case of being able to satisfy $50 \%$ of space cooling and $75 \%$ of DHW demands, the NPV would be zero at 20 years. A way to increase the NPV is to reduce the initial investment and/or to increase annual revenues. The first objective can be reached by considering lower cost and/or higher performance solar thermal collectors. Other solar cooling plant costs seem to be not diminishing. A 35\% reduction of solar collectors' costs would reduce the investment to about $5,900 € / \mathrm{kW}$ fr. In this condition, the NPV in the case $50 \%$ cooling and $75 \%$ DHW demands would increase up to $23.830 €$, with a pay-back time of 15 years. Revenues increasing can be achieved only through incentives and tax benefits. In Italy, the "Conto Termico" program pays for two years a variable amount of 0.39-0.43 $\mathrm{c} €$ per kWh of thermal energy produced by solar thermal collectors with an area lower than $50 \mathrm{~m}^{2}$ and that are coupled with an absorption chiller. The subsidies value is considerably lower if the solar thermal collector area is higher than $50 \mathrm{~m}^{2}$. In our application, this means an annual revenue of about $10.000 €$ for two years. The combination of lower investment (35\% reduction of solar thermal collectors) and of incentives reduces the pay-back time of the investment 
to 12 years (NPV near $44.000 €)$.

\section{Conclusion}

The residential application of combined parabolic dish and absorption chiller to produce DHW and guarantee space cooling in central Italy can be effective if: i) $50 \%$ of space cooling and $75 \%$ DHW production demand are covered by the solar cooling plant, ii) a substantial reduction (up to 35\%) in the cost of parabolic dish can be reached and iii) incentives are taken into consideration in the economic assessment.

So, the solar cooling plant can be more attractive from both technical and economic point of views if evacuated tube solar thermal collectors should be coupled with the absorption chiller, since it is fundamental to guarantee system reliability and to produce heat at relatively high temperature (over $70^{\circ} \mathrm{C}$ ) also in cloudy and relatively cold days. Moreover, an effective design of the plant (i.e. storage tank size) and of the control strategy (with a particular focus on the cooling tower operation) are fundamental to gain the highest energy production from the sun. Nevertheless, solar cooling plant application in non-residential frameworks (i.e. office heating and cooling) can be more attractive, since heat and cold demand is usually contextual to sun presence. A further investigation is needed to verify the opportunity to use solar cooling plant for offices heating and cooling, including a system simulation and a sensitive analysis of the techno-economic assessment.

\section{References}

Aliane, A., Abboudi, S., Seladji, C., Guendouz, B., 2016. An illustrated review on solar absorption cooling experimental studies. Renew. Sust. Energ. Rev. 65, 443-458. 10.1016/j.rser.2016.07.012

Benhadid-Dib, S., Benzaoui, A., 2012. Refrigerants and their Environmental Impact Substitution of Hydro Chlorofluorocarbon HCFC and HFC Hydro Fluorocarbon. Search for an Adequate Refrigerant. Energy Procedia. 18, 807-816. 0.1016/j.egypro.2012.05.096

Bianchini, A., Gambuti, M., Pellegrini, M., Saccani, C., Performance analysis and economic assessment of different photovoltaic technologies based on experimental measurements. Renew. Energ. 85, 1-11. 10.1016/j.renene.2015.06.017

Bianchini, A., Guzzini, A., Pellegrini, M., Saccani, C., 2017. Photovoltaic/thermal (PV/T) solar system: Experimental measurements, performance analysis and economic assessment. Renew. Energ. 111, 543-555. 10.1016/j.renene.2017.04.051

Bianchini, A., Guzzini, A., Pellegrini, M., Saccani, C., 2019. Performance assessment of a solar parabolic dish for domestic use based on experimental measurements. Renew. Energ. 133, 382-392. 10.1016/j.renene.2018.10.046

Bouhal, T., Saif ed-Din Fertahi, Agrouaz, Y., El Rhafiki, T., Kousksou, T., Zeraouli, Y. Jamil, A., 2018. Technical assessment, economic viability and investment risk analysis of solar heating/cooling systems in residential buildings in Morocco. Sol. Energy. 170, 1043-1062. 10.1016/j.solener.2018.06.032

Buonomano, A., Calise, F., Ferruzzi, G., Vanoli, L., 2014. Variable-volume storage systems for solar heating and cooling system: a case study for different Italian climates. Energy Procedia. 48, 290-299. 10.1016/j.egypro.2014.02.034

Delac, B., Pavkovic, B., Lenic, K., 2018. Design, monitoring and dynamic model development of a solar heating and cooling system. Appl. Therm. Eng. 142, 489-50110.1016/j.applthermaleng.2018.07.052

Eicker, U., Pietruschka, D., 2009. Design and performance of solar powered absorption cooling systems in office buildings. Energ. Buildings. 41, 81-91. 10.1016/j.enbuild.2008.07.015

Eicker, U., Pietruschka, D., Haag, M., Schmitt, A., 2014. Energy and economic performance of solar cooling systems world wide. Energy Procedia 57, 2581-2589. 10.1016/j.egypro.2014.10.269

Hang, Y., Qu, M., Winston, R., Jiang, L., Widyolar, B., Poity, H., 2014. Experimental based energy performance analysis and life cycle assessment for solar absorption cooling system at University of Californian, Merced. Energ. Buildings. 82, 746-757. 10.1016/j.enbuild.2014.07.078

Jackob, U., 2015. IEA SHC Task 48 - Final Deliverable - Best practice brochure.

Lazzarin, R.M., Noro, M., 2018. Past, present, future of solar cooling: Technical and economical considerations. Sol. 
Energ. 172, 2-13. 10.1016/j.solener.2017.12.055

Lecuona, A., Ventas, R., Vereda, C., Lopez, R., 2015. Absorption solar cooling systems using optimal driving temperatures. Appl. Therm. Eng. 79, 140-148. 10.1016/j.applthermaleng.2014.10.097

Montagnino, F.M., 2017. Solar cooling technologies. Design, application and performance of existing projects. Sol. Energy. 154, 144-157. 10.1016/j.solener.2017.01.033

Mugnier, D., Seleme, L.R., 2015. Practical successful results regarding electrical overall efficiency for a solar water heating and cooling system in South of France. Energy Procedia. 70, 474-479. 10.1016/j.egypro.2015.02.150

Mugnier, D., Neyer, D., White, S.D., 2017. The Solar Cooling Design Guide - Case Studies of Successful Solar Air Conditioning Design: Case Studies of Successful Solar Air Conditioning Design, Ernst\&Sohn GmbH\&Co KG. ISBN: 978-3-433-03125-4

Puglisi, G., Morosinotto, G., Emmi, G., 2015. Development of an advanced simulation model for solar cooling plants. Energy Procedia 70, 495-50310.1016/j.egypro.2015.02.153

Toure, S., Faggianelli, A., Muselli, M., Cristofari, C., 2012. Air Conditioning Using Thermal Solar Collectors Coupled with an Absorption Chiller in Corsica. Proceedings of Power and Energy Engineering Conference (APPEEC), Shanghai, China, 27-29 March. 10.1109/APPEEC.2012.6306949

\section{Acknowledgements}

The authors acknowledge the Innovation and Development Department of HERA S.p.A, which financed the research activities. 


\title{
New Water Adsorbent for Adsorption Driven Chillers
}

\author{
Alenka Ristić ${ }^{1}$, Andraž Krajnc ${ }^{1}$ and Nataša Zabukovec Logar ${ }^{1}$ \\ ${ }^{1}$ National Institute of Chemistry Slovenia, Ljubljana, Slovenia
}

\begin{abstract}
A new water adsorbent for thermally driven adsorption chillers was developed. A stable microporous aluminophosphate with ordered microporous 3-dimensional channel structure and high surface area $\left(784 \mathrm{~m}^{2} \mathrm{~g}^{-1}\right)$ was prepared. The material adsorbs water in a very narrow relative-pressure range and can be charged at $65{ }^{\circ} \mathrm{C}$. The material shows a very good thermal stability up to $850^{\circ} \mathrm{C}$, hydrothermal stability and a water adsorption capacity up to $0.42 \mathrm{gg}^{-1}$. The cooling enthalpy of $730 \mathrm{kJkg}^{-1}$ and COP 0.7 is determined for the boundary conditions: evaporator temperature of $5{ }^{\circ} \mathrm{C}$, cooling temperature of $30{ }^{\circ} \mathrm{C}$ and desorption temperature of $65{ }^{\circ} \mathrm{C}$. As such, it exhibits exceptional properties for applications in cooling devices.
\end{abstract}

Keywords: adsorption chiller, water, APO-LTA, microporous aluminophosphate

\section{Introduction}

Heat transformation systems can reduce the carbon footprint of the building sector. Thermally stable porous adsorbents can be used in adsorption heat transformation (AHT) processes such as heat pumps, thermally driven adsorption chillers or dehumidification, where the main principle is based on the sequential adsorption and desorption processes. The efficiency and cost-effectiveness of such processes are critically governed by the performance of the applied adsorbents. Recently, it has been shown that the adsorbents which adsorption equilibrium with working fluid is characterized by S-shaped adsorption isotherms are advantageous for the adsorption heat transformation (Aristov, 2014). For most applications, the steep increase in the adsorption should take place in a relative pressure range of 0.05-0.3 (Henninger et al., 2017). Recent research activities are focused on the development of materials with high sorption capacity and low charging temperature for efficient utilization of low-temperature solar energy for heating and cooling applications. Adsorbents, which are currently considered for this sorption technology, are activated carbons, silica gels, zeolites, aluminophosphates, MOFs and composites, while as adsorbates water, ethanol, methanol and ammonia are usually used (Freni et al., 2016). A major trend in this field of research is the evaluation of MOFs (Lenzen et al., 2018) and aluminophosphates (Brancato and Frazzica, 2018) in adsorption driven chillers.

Among commercially available aluminophosphates mainly two adsorbents have been investigated, AQSOA ${ }^{\circledR}$ (FAMZ02 and FAM-Z01), SAPO-34 and APO-5, respectively. Both materials present S-shaped isotherms, can adsorb amount of water up to $0.30 \mathrm{gg}^{-1}$ and $0.20 \mathrm{gg}^{-1}$ respectively, within narrow humidity ranges and can be charged at $90^{\circ} \mathrm{C}$ (Kakiuchi et al., 2005a, 2005b).

In this study we present a new aluminophosphate with much higher water uptake $\left(0.42 \mathrm{gg}^{-1}\right)$ and low desorption temperature $\left(65^{\circ} \mathrm{C}\right)$. Cooling enthalpy for the air conditioning working conditions of APO-LTA, SAPO-34 and APO-5, APO-18 and FAPO-34 adsorbents are compared, showing higher cooling enthalpy for the APO-LTA.

\section{Experimental}

APO-LTA was hydrothermally synthesized from a fluoride medium using Kriptofix 222 (K222) as a structuredirecting agent (Krajnc, 2017). The as-synthesized sample was calcined in air at $8500^{\circ} \mathrm{C}$ over night. The crystallinity of the APO-LTA was examined by High-temperature X-ray powder diffraction (HT-XRD) using PANalytical $\mathrm{X}^{\prime}$ Pert PRO high-resolution diffractometer in the $2 \theta$ range from $5^{\circ}$ to $60^{\circ}$ using a step of $0.026^{\circ}$ per $100 \mathrm{~s}$. XRPD patterns were collected at constant temperatures between room temperature and $550{ }^{\circ} \mathrm{C}$. Between the scans, the 


\section{Ristić}

sample was heated at a rate of $10{ }^{\circ} \mathrm{C} \mathrm{min}{ }^{-1}$ in air. To confirm the phase purity, the powder patterns were compared with literature data. The morphology of the material was examined using a scanning electron microscope Zeiss Supra 35VP. Thermogravimetric investigation of the as-synthesised sample was performed with a Q5000IR (TA Instruments). The sample was heated in a stream of argon with a heating rate of $10 \mathrm{~K} \mathrm{~min}^{-1}$. The specific surface area was evaluated by analysis of nitrogen adsorption isotherms measured on a Micromeritics ASAP 2020 instrument. The isotherm was recorded at $77 \mathrm{~K}$. The sample was outgassed at $473 \mathrm{~K}$ for $2 \mathrm{~h}$ in the port of the adsorption analyzer. The BET specific surface area was calculated from adsorption data in the relative pressure range from 0.05 to 0.25 . In addition, water sorption analysis was performed by an IGA-100 gravimetric analyzer (Hiden Isochema Ltd.). Water sorption isotherms were performed at different temperatures at 25 to $40{ }^{\circ} \mathrm{C}$ in the relative pressure range from 0 to 0.9 in order to elucidate sorption enthalpies. Prior to measurements, the samples were degassed at $150{ }^{\circ} \mathrm{C}$ to a constant weight overnight. Hydration/dehydration cycling performance was carried out with the sequential procedure of isothermal measurements at $25{ }^{\circ} \mathrm{C}$ and relative humidity of 0.3 until equilibrium, followed by drying at $150{ }^{\circ} \mathrm{C}$ for $2 \mathrm{~h}$ in vacuum. The sequence was repeated 40 times. The Coefficient of Performance for cooling is defined as:

$\mathrm{COP}=\frac{Q e v}{\text { Qreg }}$, (eq.1)

where $Q_{e v}$ is the heat transferred from the evaporator and $Q_{r e g}$ is the heat needed for regeneration of the adsorbent, i.e. the heat consumed in the desorption part of the cycle. $Q_{r e g}$ includes the heat consumed or released during sorption itself and the sensible heat required to cool the adsorbent. To calculate the cooling enthalpy $\left(Q_{e v}\right.$ per mass of the adsorbent) and the COP, one needs to know the loading function $W(p, T)$ and the differential heat of adsorption of the material $\Delta_{\text {ads }} H(W)$. For APO-LTA, the latter was calculated from the isotherms measured at 25 ${ }^{\circ} \mathrm{C}$ and $40{ }^{\circ} \mathrm{C}$ using a finite difference approximation to the isosteric formula,

$\Delta_{\text {ads }} H(W)=R\left(\frac{\partial \ln (p)}{\partial\left(\frac{1}{T}\right)}\right)_{W} \cdot \quad$ (eq.2)

Because we were unable to measure isotherms at high temperatures, two approximations were made: (i) the enthalpy of adsorption was assumed to be temperature-independent in a temperature range between $25{ }^{\circ} \mathrm{C}$ and $65{ }^{\circ} \mathrm{C}$, (ii) $W(p, T)$ was determined by reformulating water sorption isotherm measured at $40{ }^{\circ} \mathrm{C}$ as a function of adsorption potential,

$A=R T \ln \left(\frac{p_{0}(T)}{p}\right)$, (eq. 3)

where $p_{0}$ is saturation vapour pressure of water. $W(A)$ is assumed to be temperature-independent and thus the loading can be calculated for any given temperature.

\section{Results}

The structure (Fig. 1.) of the new water adsorbent APO-LTA is built of double-four ring, sodalite and LTA cages, which form pore openings of $0.41 \mathrm{~nm}$. The accessible pore volume is $21 \%$ according to the database of zeolite structure types. The BET specific surface area was determined to be $784 \mathrm{~m}^{2} \mathrm{~g}^{-1}$. 
Ristić

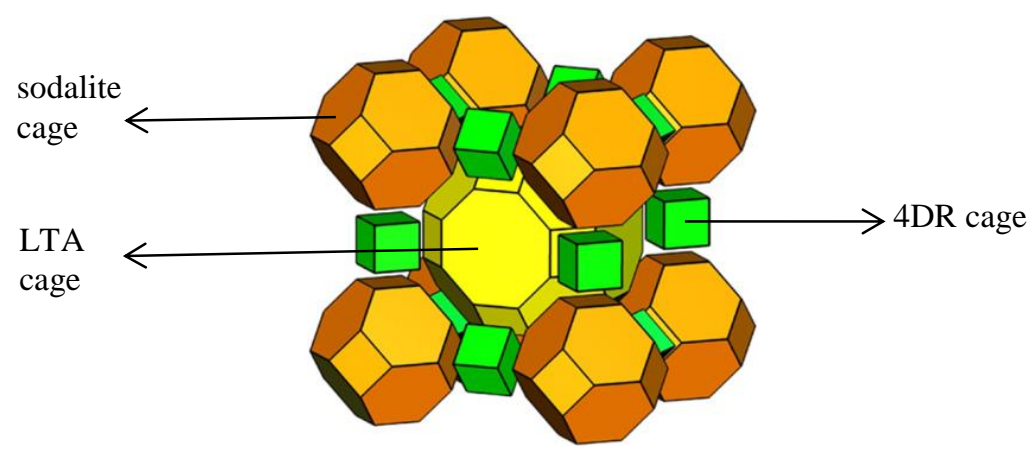

Fig. 1: Scheme of the water adsorbent APO-LTA structure

SEM picture in Fig. 2 shows pure crystalline as-synthesised product composed of cubes with the size from 5 to 20 $\mu \mathrm{m}$.

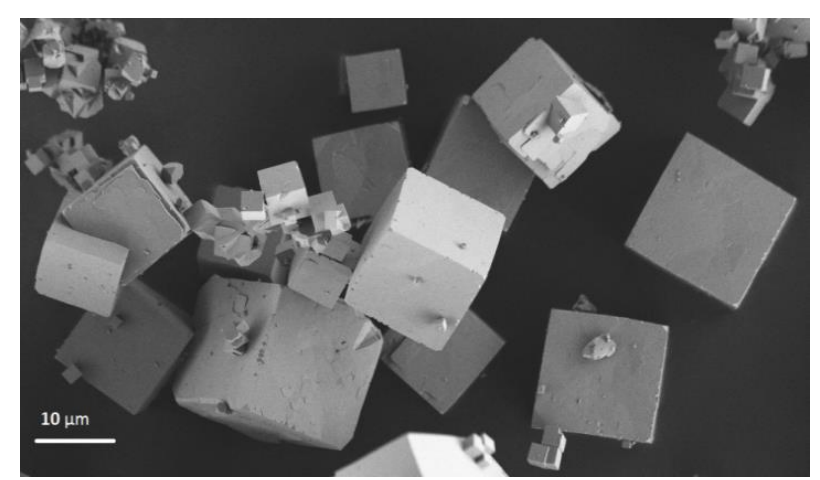

Fig. 2: SEM picture of the as-synthesised APO-LTA

The structure directing agent was removed by calcination in air. The calcined sample was thermally stable up to 850 ${ }^{\circ} \mathrm{C}$. XRD pattern (Fig. 3) of the sample at $550{ }^{\circ} \mathrm{C}$ still shows full crystalline porous material. The structure does not change after cooling to room temperature and exposing to the humidity.

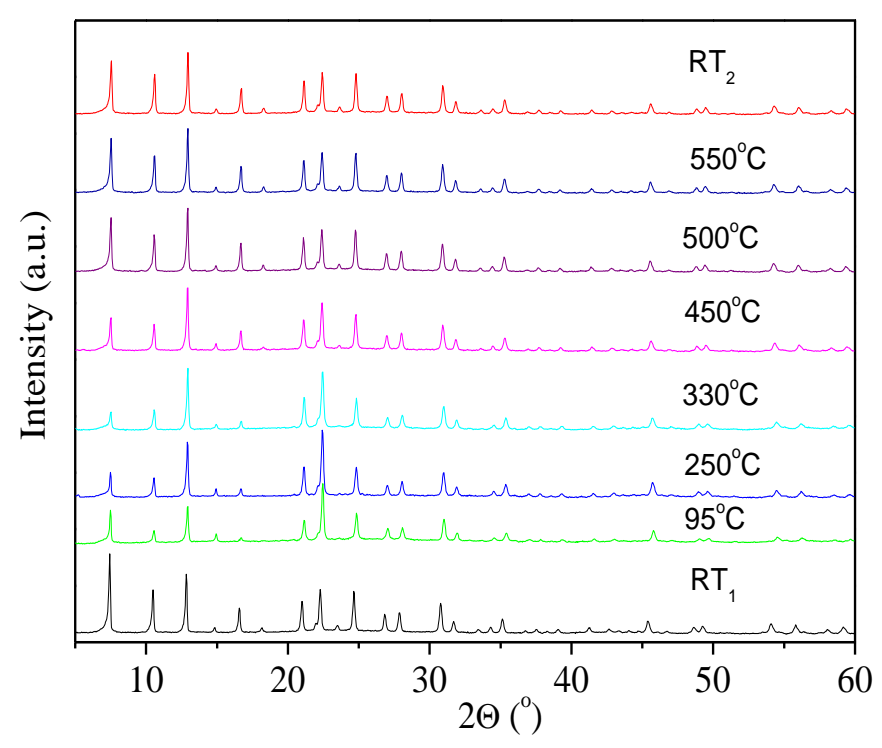

Fig. 3: High temperature XRD patterns of the APO-LTA 


\section{Ristić}

Figure 4 shows water adsorption isotherm gravimetrically determined at $25{ }^{\circ} \mathrm{C}$. The water adsorption capacity of this materials is the highest $\left(0.42 \mathrm{gg}^{-1}\right)$ among aluminophosphate adsorbents due to the structure and high specific surface area $\left(784 \mathrm{~m}^{2} \mathrm{~g}^{-1}\right)$.

The hydrothermal stability was tested by 40 hydration/dehydration cycles between 25 and $150{ }^{\circ} \mathrm{C}$. The minor reduction $(\sim 1 \%)$ of the water adsorption capacity was observed. The characteristic curve of APO-LTA is shown in Fig. 5.

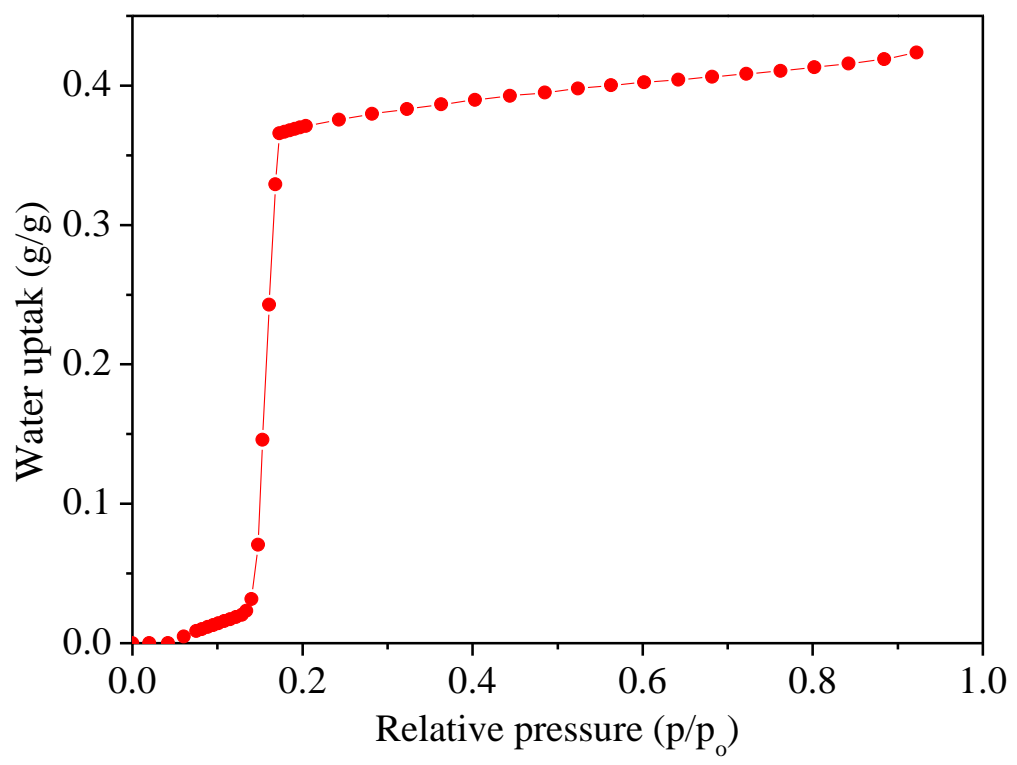

Fig. 4: Water adsorption isotherm of aluminophosphate at $25^{\circ} \mathrm{C}$.

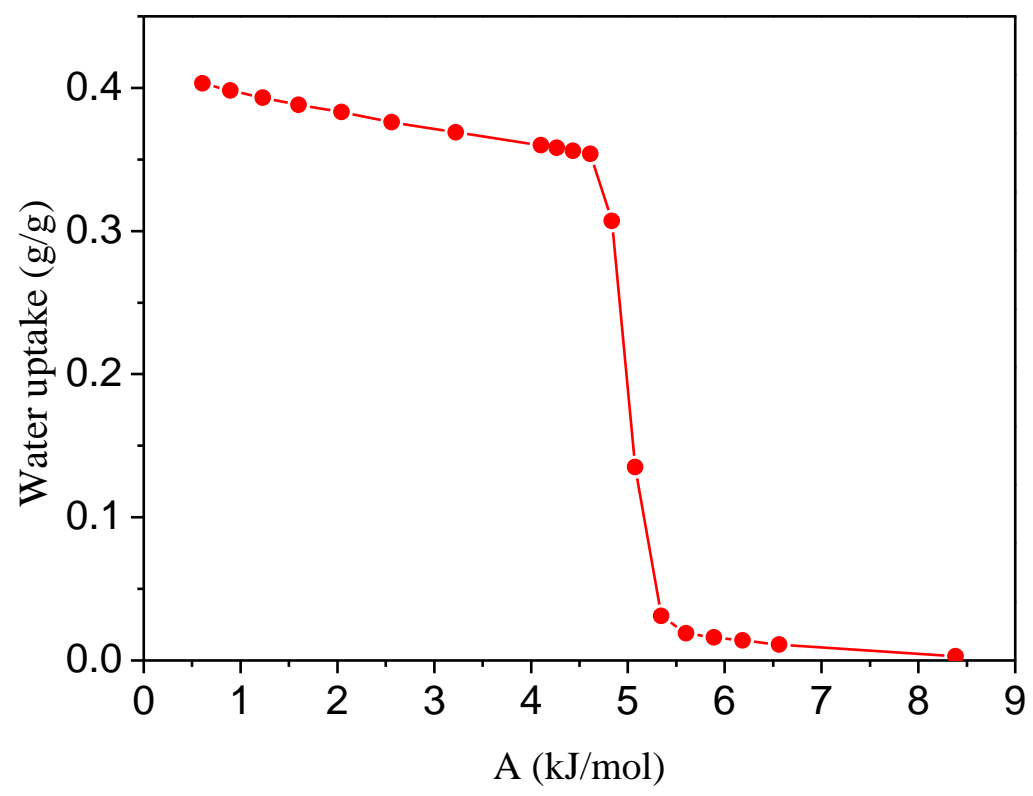

Fig. 5: The characteristic curve of APO-LTA. 


\section{Ristić}

Cooling COP and cooling enthalpy of APO-LTA for air conditioning with desorption (regeneration) temperature of $65{ }^{\circ} \mathrm{C}\left(\mathrm{T}_{\mathrm{ev}}=5{ }^{\circ} \mathrm{C}, \mathrm{T}_{\mathrm{con}}=30{ }^{\circ} \mathrm{C}\right)$ were compared to cooling COP and cooling enthalpy of APO-5 and SAPO-34 (Freni et al., 2016). APO-5 and SAPO-34 are known as AQSOA ${ }^{\circledR} \mathrm{Z} 01$ and Z02 adsorbents, respectively. Adsorption characteristics of these aluminophosphate adsorbents have been investigated by several research groups (Kayal et al., 2016). Among these water adsorbents considered, APO-LTA appeared to be the best candidate for application in air conditioning cycles due to the highest cooling enthalpy, which can be directly translated to higher power density (Freni et al., 2016). APO-5 and APO-LTA achieve similar COPs, but the latter yields much higher cooling enthalpy than APO-5 and SAPO-34 (Fig. 6).

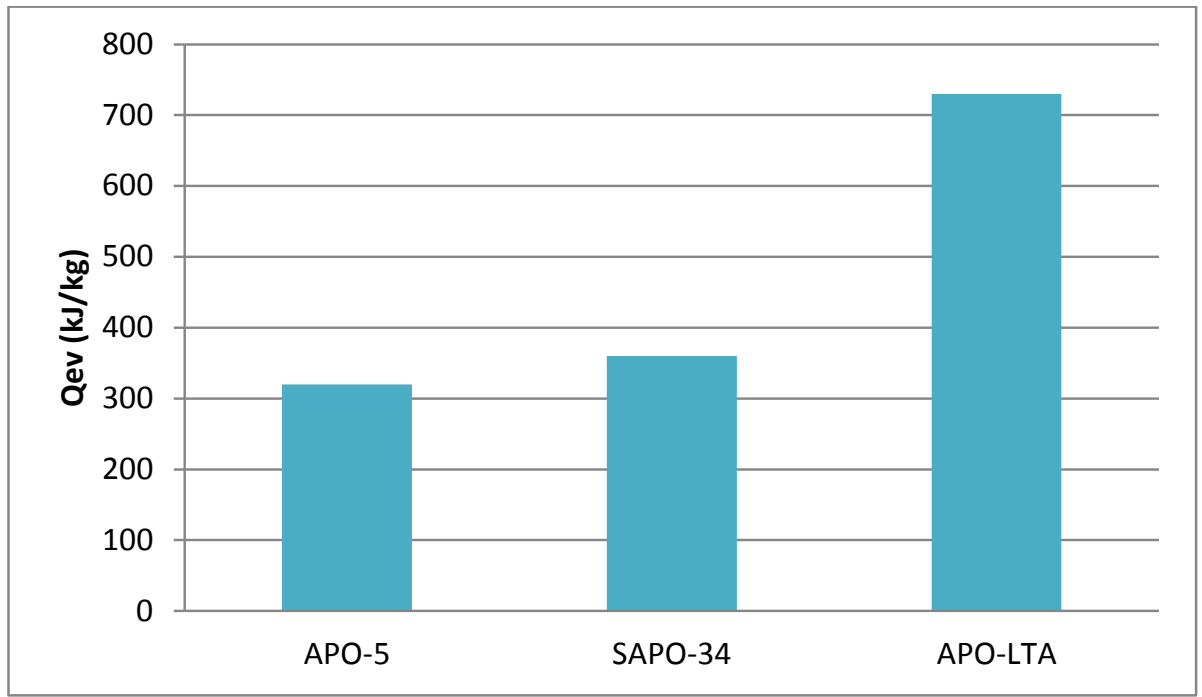

Fig. 6: Comparison of the cooling enthalpy $Q_{\mathrm{ev}}$ for APO-5, SAPO-34 and APO-LTA for boundary conditions $\left(\mathrm{T}_{\text {ev }}=5^{\circ} \mathrm{C}, \mathrm{T}_{\text {con }}=30^{\circ} \mathrm{C}, \mathrm{T}_{\mathrm{des}}=65^{\circ} \mathrm{C}\right)$

Recently, APO-18, SAPO-34 and FAPO-34 were evaluated under boundary conditions $\mathrm{T}_{\mathrm{ev}}=7{ }^{\circ} \mathrm{C}, \mathrm{T}_{\mathrm{con}}=30{ }^{\circ} \mathrm{C}, \mathrm{T}_{\mathrm{des}}=80$ ${ }^{\circ} \mathrm{C}$, showing the highest cooling enthalpy for APO-18 (Brancato and Frazzica, 2018). APO-18 can achieve the cooling enthalpy of $430 \mathrm{kJkg}^{-1}$. Under the same boundary conditions the cooling enthalpy of APO-LTA is determined to be two times higher (Fig. 7).

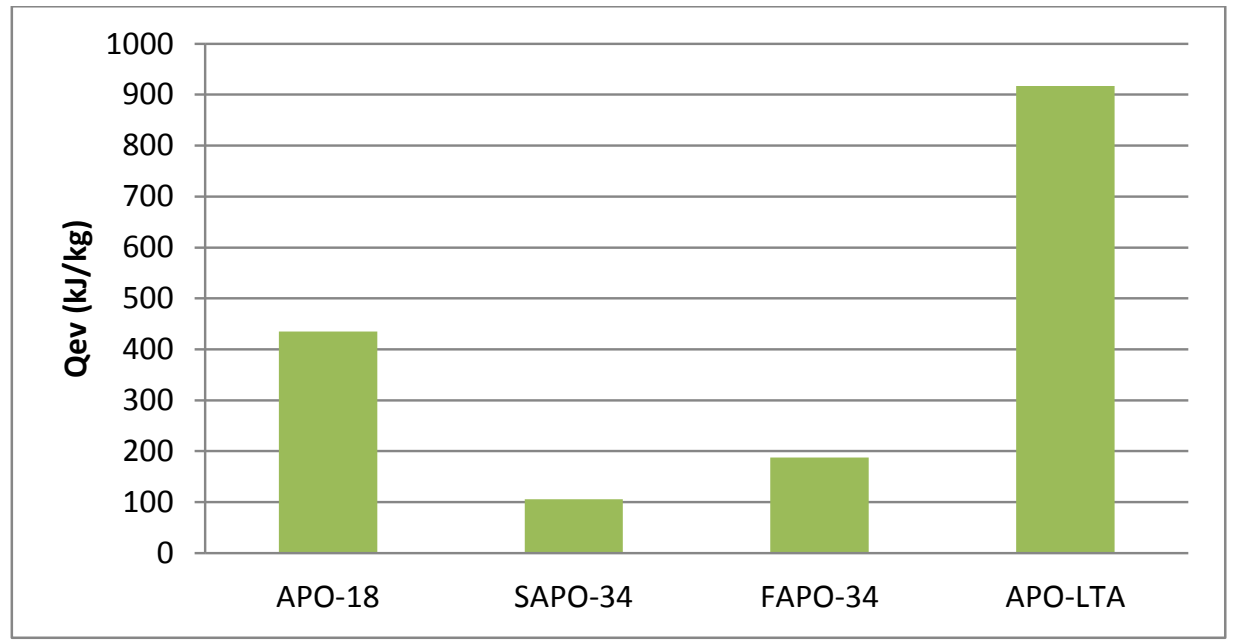

Fig. 7: Comparison of the cooling enthalpy $Q_{\mathrm{ev}}$ for APO-18, SAPO-34, FAPO-34 and APO-LTA for boundary conditions $\left(\mathrm{T}_{\mathrm{ev}}=7^{\circ} \mathrm{C}, \mathrm{T}_{\mathrm{con}}=30^{\circ} \mathrm{C}, \mathrm{T}_{\mathrm{des}}=80^{\circ} \mathrm{C}\right)$ 
Ristić

\section{Conclusions}

New aluminophosphate adsorbent full fills requirements for the ideal performance in the low-temperature (solar energy) heat transformation applications because it performs in the proper relative pressure range with S-shaped water adsorption isotherm. The charging or regeneration temperature is $65{ }^{\circ} \mathrm{C}$. COP and cooling enthalpy for cooling application at boundary conditions: evaporator temperature $\mathrm{T}_{\mathrm{ev}}=5^{\circ} \mathrm{C}$, cooling temperature $\mathrm{T}_{\text {con }}=30{ }^{\circ} \mathrm{C}$ and desorption temperature $\mathrm{T}_{\text {des }}=65^{\circ} \mathrm{C}$ is determined to be 0.70 and $730 \mathrm{kJkg}^{-1}$, respectively.

\section{Acknowledgement}

This work was supported by the Slovenian Research Agency through research program P1-0021-0104. We want to thank prof. Gregor Mali, dr. Matjaž Mazaj and dr. Jure Varlec (National Institute of Chemistry Slovenia) for their contribution to the study of APO-LTA.

\section{References}

Aristov, Y., Concept of adsorbent optimal for adsorptive cooling/heating, 2014, Appl. Therm. Eng., 72, 166-175, doi:10.1016/j.applthermaleng.2014.04.077.

Brancato, V., Frazzica, A., Characterisation and comparative analysis of zeotype water adsorbents for heat transformation applications, 2018, Sol. Energy Mat. Sol. Cells, 180, 91-102, doi.org/10.1016/j.solmat.2018.02.035.

Freni, A., Maggio, G., Sapienza, A., Frazzica, A., Restuccia, G., Vasta, S., Comparative analysis of promising adsorbent/adsorbate pairs for adsorptive heat pumping, air conditioning and refrigeration, 2016, Appl. Therm. Eng., 104, 85-95, doi:10.1016/j.applthermaleng.2016.05.036.

Henninger, S.K., Ernst S.J., Gordeeva, L., Bendix, P., Frohlich, D., Grekova, A.D., Bonaccorsi, L., Aristov, Y., Jänchen, J., New materials for adsorption heat transformation and storage, 2017, Renew. Energy, 110, 59-68, doi: 10.1016/j.renene.2016.08.041.

Kakiuchi, H.; Shimooka, S.; Iwade, M.; Oshima, K.; Yamazaki, M.; Terada, S.; Watanabe, H.; Takewaki, T. Novel water vapor adsorbent FAM-Z01 and its applicability to an adsorption heat pump, 2005a, Kagaku Kogaku Ronbunshu 31, 361-364, doi: 10.1252/kakoronbunshu.31.361.

Kakiuchi, H.; Shimooka, S.; Iwade, M.; Oshima, K.; Yamazaki, M.; Terada, S.; Watanabe, H.; Takewaki, T. Water vapor adsorbent FAM-Z02 and its applicability to adsorption heat pump, 2005b, Kagaku Kogaku Ronbunshu 31, 273-277, doi: 10.1252/kakoronbunshu.31.273.

Kayal, S., Baichuan, S., Saha, B.B., Adsorption characteristics of AQSOA zeolites and water for adsorption chillers, 2016, Int. J. Heat Mass Transfer, 92, 1120-1127, doi:10.1016/j.ijheatmasstransfer.2015.09.060.

Krajnc, A., Varlec J., Mazaj, M., Ristić, A., Logar, N.Z., Mali, G., Superior Performance of Microporous Aluminophosphate with LTA topology in solar-energy storage and heat reallocation 2017, Adv. Ener. Mat., 7, 201601815-1, doi: 10.1002/aenm.201601815.

Lenzen, D., Bendix, P., Reinsch, H., Fröhlich, D., Kummer, H., Möllers, M., Hügenell, P.P.C., Gläser, R., Henninger, S., Stock, N. Scalable Green Synthesis and Full-Scale Test of the Metal-Organic Framework CAU-10-H for Use in Adsorption-Driven Chillers, 2018, Adv. Mat., 30, art. no. 1705869, doi: 10.1002/adma.201705869. 


\title{
Efficient Solar Driven Air Conditioning System for Hot Climate: Case Study of Doha
}

\author{
Z. Tamainot-Telto(1) \\ School of Engineering, University of Warwick, Coventry CV4 7AL, UK
}

\begin{abstract}
An advanced thermal solar driven air conditioning system for hot climate is described and a steady state thermodynamic model is used to predict its performance by using weather data for Doha (Qatar). The proposed system combined both Organic Rankine Cycle (ORC) and conventional mechanical Vapour Compression Cycle (VCC) whereby the expander (Turbine) is coupled to the compressor. Both cycles operate with ammonia refrigerant. For the same collector surface area $\left(20 \mathrm{~m}^{2}\right)$, the corresponding average daily cooling production is high with Evacuated Tube Solar Collector (ETSC) compared to Flat Plate Solar Collector (FPSC): ranging from $3.4 \mathrm{~kW}$ (in July) to around $7.6 \mathrm{~kW}$ (in April) for FPSC and from $4.5 \mathrm{~kW}$ (July) to around $10.2 \mathrm{~kW}$ (in April) for ETSC. The maximum values of COPs obtained ( 0.50 to 1.60 with an optimum driving temperature of about $118^{\circ} \mathrm{C}$ ) are overall above those of standard heat driven systems such as absorption or adsorption refrigeration systems (typical maximum values range: 0.4 to 0.8 ).
\end{abstract}

Keywords: Solar Energy, Air Conditioning, Organic Rankine Cycle, Vapour Compression Cycle.

\section{Introduction}

The hot climate regions (typical ambient temperature above $30^{\circ} \mathrm{C}$ ) often require air conditioning in buildings for better comfort (typical environment temperature above $22^{\circ} \mathrm{C}$ and $50 \%$ relative humidity). So far the air conditioning in buildings are mainly electrically driven leading to the increase of fuel consumption therefore the increase of carbon footprint when power stations burn fossil fuel. Equally, the hot climate regions do have higher solar thermal energy radiation that could be converted into useful cooling for air conditioning. This paper explores the potential use of an advanced thermal solar driven air conditioning system for hot climate that is similar to Qatar with a ground-measured annual average solar radiation of $2113 \mathrm{kWh} / \mathrm{m}^{2} /$ year [1] and the highest annual carbon footprint estimated to 44.4 metric tons of $\mathrm{CO}_{2} /$ person/year [2]. For illustration of performance of the proposed system, the city of Doha is chosen for case study.

\section{System description}

The conceptual proposed system combines both Organic Rankine Cycle (ORC) and conventional mechanical Vapour Compression Cycle (VCC) for refrigeration [3]. There are two distinctive and separated loops operating both with Ammonia refrigerant (R717): the ORC loop and the VCC loop (Fig. 1). The ORC loop consists of a boiler embedded within a thermal solar energy collector, an expander or turbine, a condenser and a liquid pump. The solar collector could either be flat plate type (FPSC) or evacuated tube type (ETSC). The VCC loop has the conventional layout with a condenser, an expansion valve, an evaporator and a mechanical compressor. The turbine is coupled to the mechanical compressor: it is therefore driven by direct expansion of high pressure and high temperature of saturated refrigerant gas coming out of the boiler operating with solar thermal energy gained. The condensers of both ORC and VCC loops are tubular-finned type of heat exchangers that are laid out in parallel in order to operate with a single fan. As optional consideration, each loop (ORC and VCC) could also include an Ammonia liquid receiver located outlet of each condenser.

(1) Corresponding author: E-mail z.tamainot-telto@ warwick.ac.uk - Tel. +44 2476522108 - Fax +44 2476418922 


\section{Thermodynamic model}

A thermodynamic model of the proposed system, operating with Ammonia refrigerant (R717), is used to predict key performance indicators like COPs and cooling power output when the Ammonia steam driving temperature is ranging between $30^{\circ} \mathrm{C}$ to $130^{\circ} \mathrm{C}$ (corresponding to about the critical temperature of Ammonia refrigerant). As example, both ORC and VCC are illustrated on a Pressure-Specific Enthalpy or P-h diagram shown in Fig. 2. Both expander (Turbine) and compressor are assumed to have an isentropic efficiency of $80 \%$ each with transmission coupling efficiency of $80 \%$. Furthermore, both sub-cooling and superheat are $4^{\circ} \mathrm{C}$ and $7^{\circ} \mathrm{C}$ respectively on the mechanical vapour compression machine. Flat plate and evacuated tube types of solar thermal collector (FPSC and ETSC respectively) are used with typical average thermal efficiency of 55\% and $75 \%$ respectively. The reference surface area taken for each collector is $20 \mathrm{~m}^{2}$.

\section{Simulation Results and Discussions}

The simulations were carried out using Doha weather data [4] with an evaporating temperature of $15^{\circ} \mathrm{C}$ and a condensing temperature that is about $5^{\circ} \mathrm{C}$ above the ambient temperature. Fig. 3 and Fig. 4 show monthly mean ambient temperature and monthly global solar radiation respectively. The energy balance on the solar thermal collector/boiler was achieved within about $\pm 2 \%$ throughout the full range of the operating boiling temperature. For that purpose, the final input value of refrigerant mass flow rate on the Organic Rankine Cycle (ORC) will vary not only with the type of collector but also with the operating month as shown in Tab. 1. We have also assumed that the ammonia liquid flowing across the pump (located between the Condenser and the Collector/Boiler) is uncompressible. Simulations are focused between April and November where the cooling demand is most crucial in buildings (as the ambient temperature is above $22^{\circ} \mathrm{C}$ corresponding to normal comfort temperature with 50\% Relative Humidity). Furthermore the monthly solar heat rate gained to operate the system will also take into account the effective sunshine duration as illustrated in Fig. 5.

Fig. 6 and Fig. 7 show the predicted performance indicators with Flat Plate Solar Collector (FPSC) and Evacuated Tube Solar Collector (ETSC) respectively: the best performance are in April when the ambient temperature is relatively low (about $26.4^{\circ} \mathrm{C}$ ) while low performance are in June, July and August when the ambient temperature is relatively high (typically $35^{\circ} \mathrm{C}$ ). Regardless the type of solar collector, the COPs are unchanged (ranging from 0.15 to 1.2 ) since they correspond more to the intrinsic characteristics of conventional mechanical Vapour Compression Cycle (VCC). There is an optimum driving temperature at around $118^{\circ} \mathrm{C}$ that is specific to the refrigerant used and the nature of Organic Rankine Cycle itself. As expected for the same collector surface area, the corresponding average daily cooling production is high with ETSC compared to FPSC: ranging from $3.4 \mathrm{~kW}$ (in July) to around $7.6 \mathrm{~kW}$ (in April) for FPSC and from $4.5 \mathrm{~kW}$ (July) to around $10.2 \mathrm{~kW}$ (in April) for ETSC. For the same optimum driving temperature, the average daily COP is ranging from about 0.53 (July) to 1.2 (November).

\section{Conclusion}

The maximum values of COPs obtained ( 0.50 to 1.60 with an optimum driving temperature of about $\left.118^{\circ} \mathrm{C}\right)$ are overall above those of standard heat driven systems such as absorption or adsorption refrigeration systems (typical maximum values range: 0.4 to 0.8 ). However the optimum driving temperature leading to better performance indicators will require the collector/boiler to withstand high pressure as 88 bar which could impact on the proposed system design specifications and cost. This means that there is trade-off between performance indicators and the high pressure on the Organic Rankine cycle loop in particular. Overall the proposed conceptual design has good potential not only for solar driven air conditioning system in building but also for combined heat and cooling production in Small and Medium-sized Enterprises (SMEs).

\section{Further work}

The current work will be refined by using solar collector/boiler with variable efficiency function of both incident solar radiation and temperature difference between the collector/boiler and the surrounding ambient air. Further work such as the mitigation of intermittent solar energy daily availability (about 8 to 12 hours), the development 
of hermetic turbo-compressors (combined Turbine and Compressor), and detailed cost and CO2 emission saving analysis of the overall system are still needed. Furthermore there are still some scopes of exploring different refrigerants on both ORC and VCC loops.

\section{References}

[1] D. Bachour and D. Perez-Astudillo, Ground measurements of Global Horizontal Irradiation in Doha Qatar, Renewable Energy, 71, pp. 32-36, 2014.

[2] Yousef Alhorr, Eiman Eliskandarani, Esam Elsarrag, Approaches to reducing carbon dioxide emissions in the built environment: Low carbon cities, International Journal of Sustainable Built Environment, 3, pp. 167$178,2014$.

[3] Z. Tamainot-Telto, Advanced heat driven hybrid refrigeration and heat pump systems, Proc. 12th IEA Heat Pump Conference (HPC 2017), Rotterdam (The Netherlands), 15-18 May 2017.

[4] http://qweather.gov.qa/ClimateInfo.aspx (Access date 10/10/2017).

Tab. 1: Doha weather data [4] and estimated value of Ammonia refrigerant mass flow rate on the Organic Rankine Cycle (ORC)

\begin{tabular}{|c|c|c|c|c|c|c|c|c|}
\hline Month & April & May & June & July & August & Sept & Oct & Nov \\
\hline $\mathrm{T}_{\text {average }}\left({ }^{\circ} \mathrm{C}\right)$ & 26.4 & 31.8 & 34.5 & 35.3 & 34.8 & 32.8 & 29.5 & 24.6 \\
\hline $\mathrm{Q}_{\mathrm{r}}\left(\mathrm{kWh} \mathrm{m}{ }^{-2}\right)$ & 5.7 & 6.2 & 6.5 & 6.1 & 5.8 & 5.5 & 4.8 & 4.1 \\
\hline Sunshine $(\mathrm{h})$ & 9 & 10.6 & 11.5 & 10.6 & 10.6 & 10.2 & 9.9 & 9 \\
\hline $\mathrm{m}_{\mathrm{fFPSC}}\left(\mathrm{kg} \mathrm{h}^{-1}\right)$ & 21.96 & 20.88 & 20.16 & 20.88 & 19.8 & 19.08 & 16.92 & 15.84 \\
\hline $\mathrm{m}_{\mathrm{fETSC}}\left(\mathrm{kg} \mathrm{h}^{-1}\right)$ & 29.88 & 26.28 & 27.72 & 28.44 & 27.00 & 25.92 & 23.40 & 21.60 \\
\hline
\end{tabular}

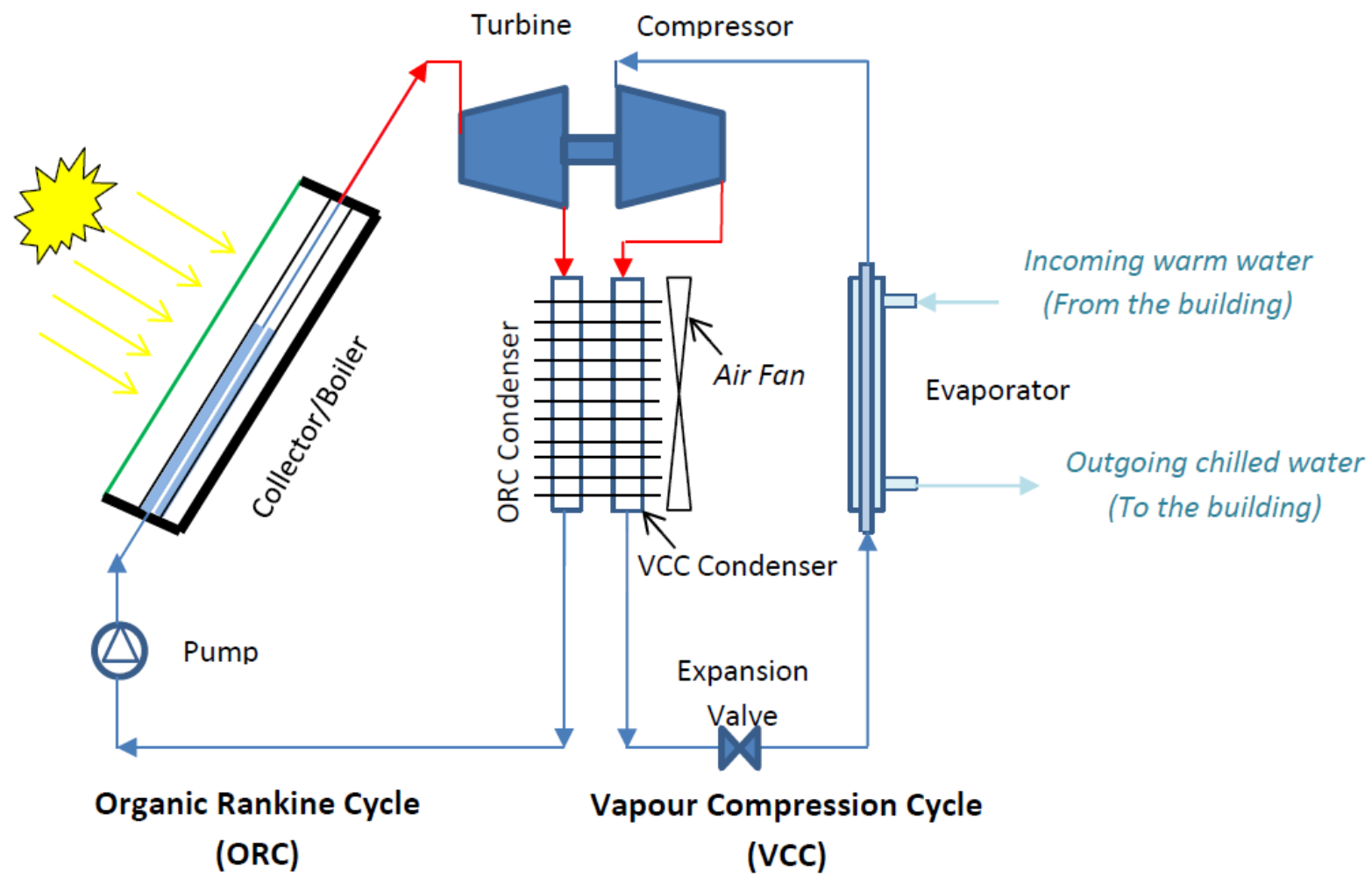

Fig. 1: Illustration of system combining Organic Rankine Cycle (ORC) and conventional Vapour Compression Cycle (VCC) 


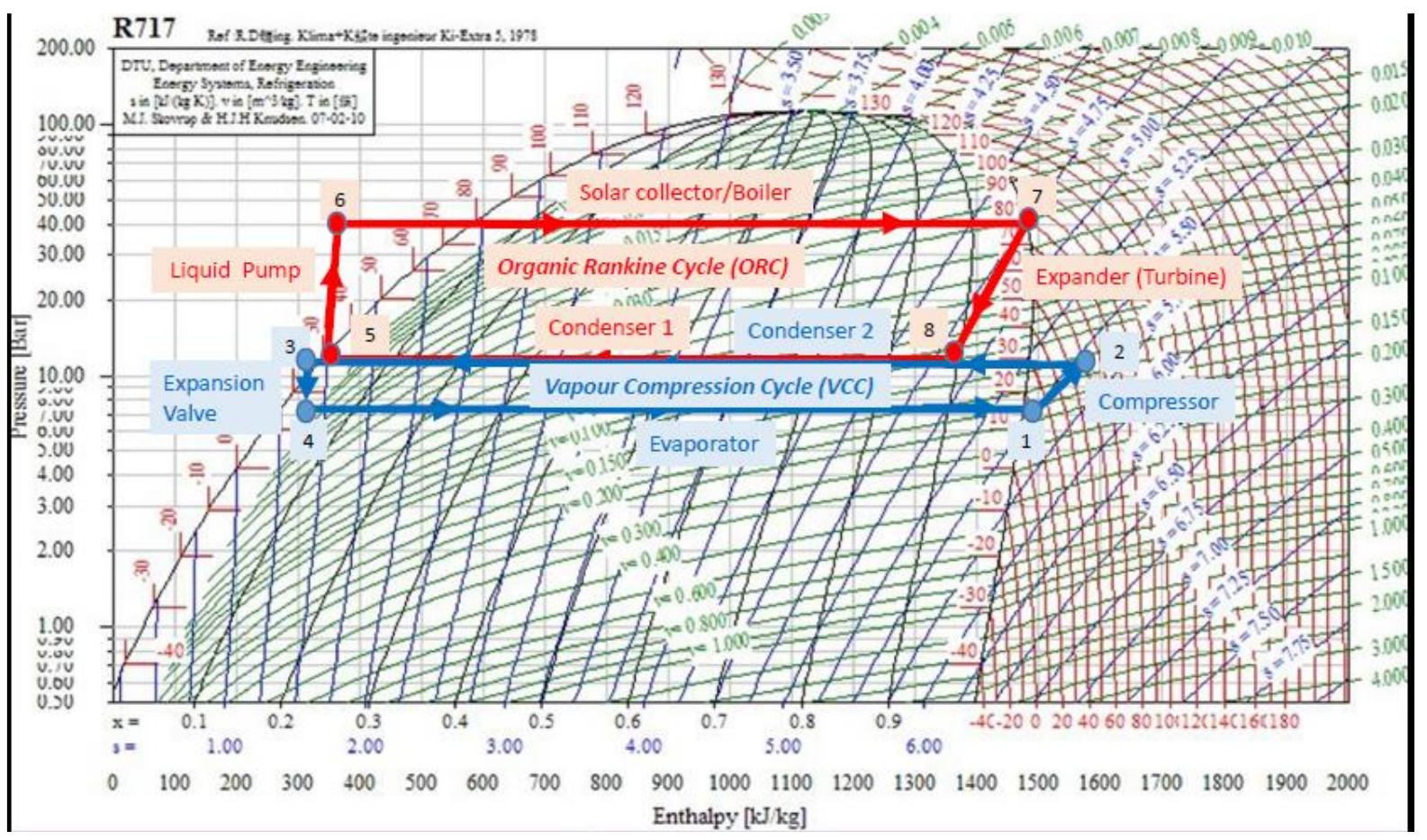

Fig. 2: Illustration example of both Organic Rankine Cycle (ORC) and Vapor Compression Cycle (VCC) with $\mathrm{T}_{\text {Evaporator }}=\mathbf{1 5}^{\circ} \mathrm{C}$, $\mathrm{T}_{\text {Condenser }}=30^{\circ} \mathrm{C}$ and $\mathrm{T}_{\text {Boiler }}=\mathbf{8 0}^{\circ} \mathrm{C}$

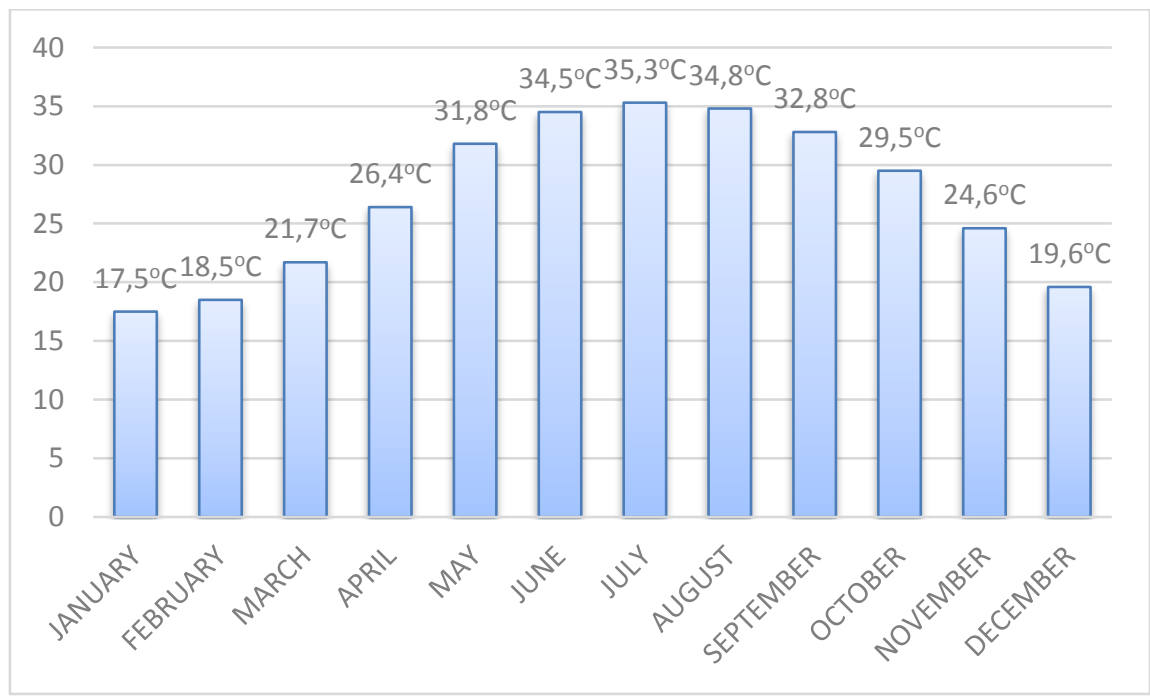

Fig. 3: Daily mean temperature for Doha, Qatar [4] 


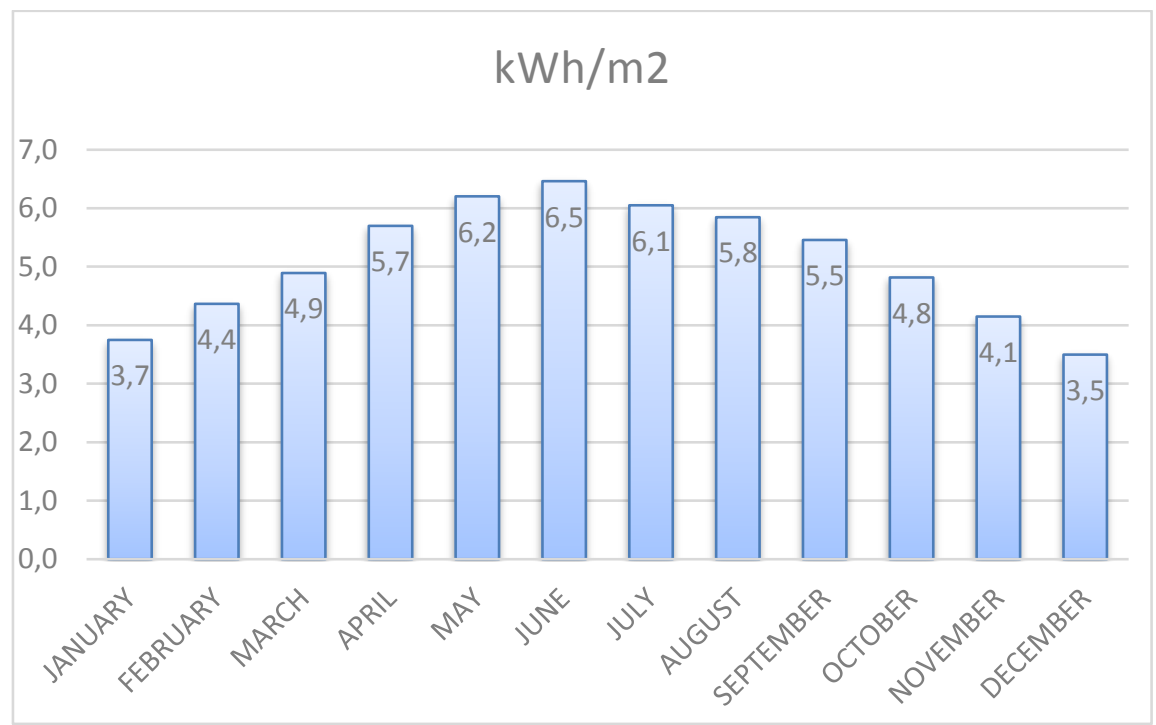

Fig. 4: Daily mean solar radiation for Doha, Qatar [2]

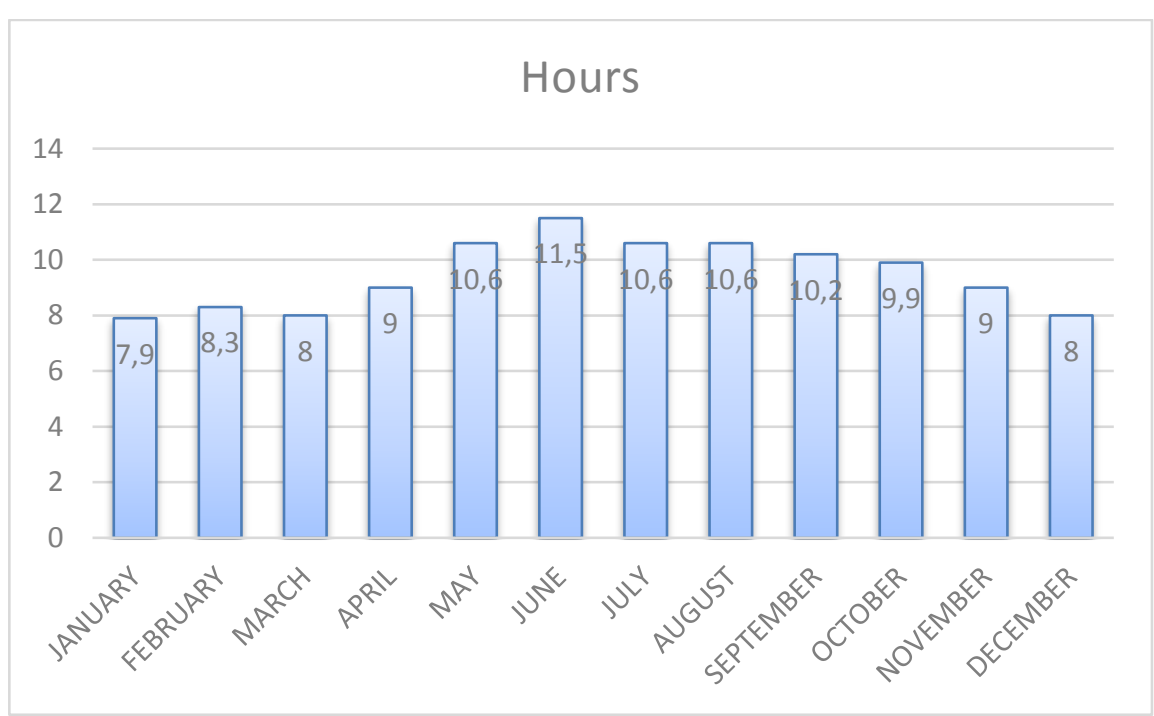

Fig. 5: Daily mean sunshine duration for Doha, Qatar [2]
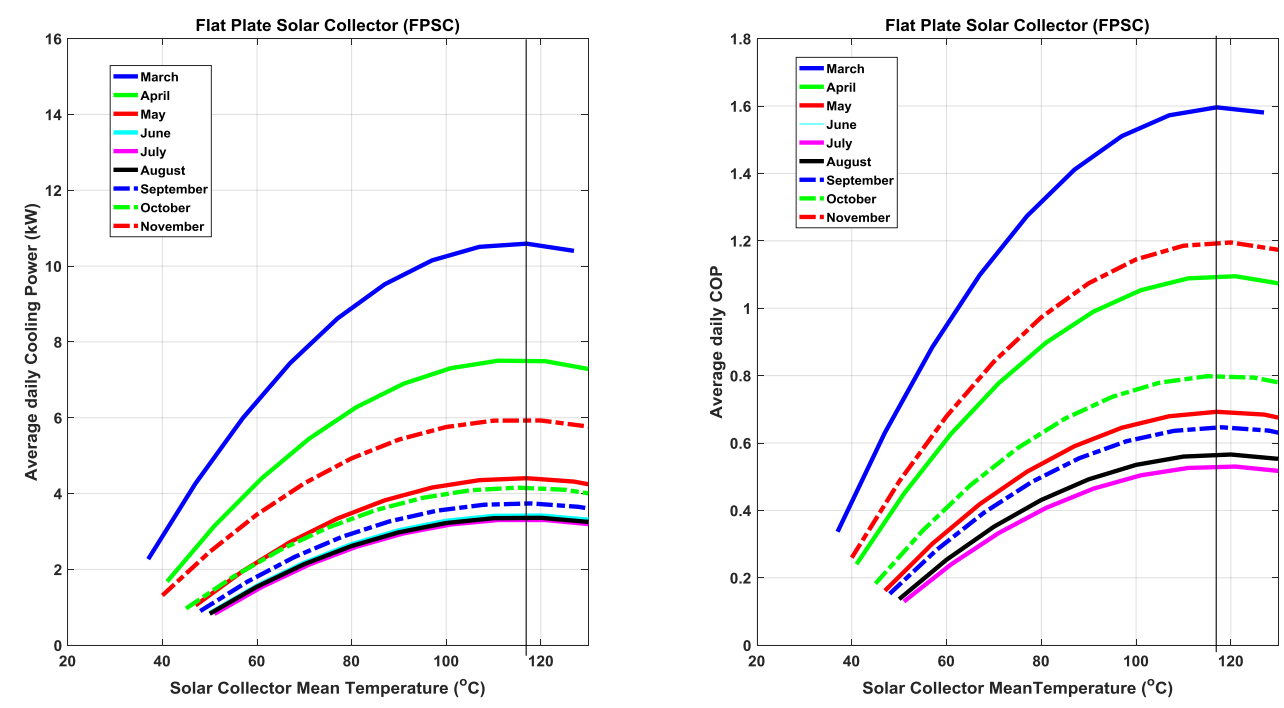

Fig. 6: Key performance indicators with Flat Plate Solar Collector (FPSC) 

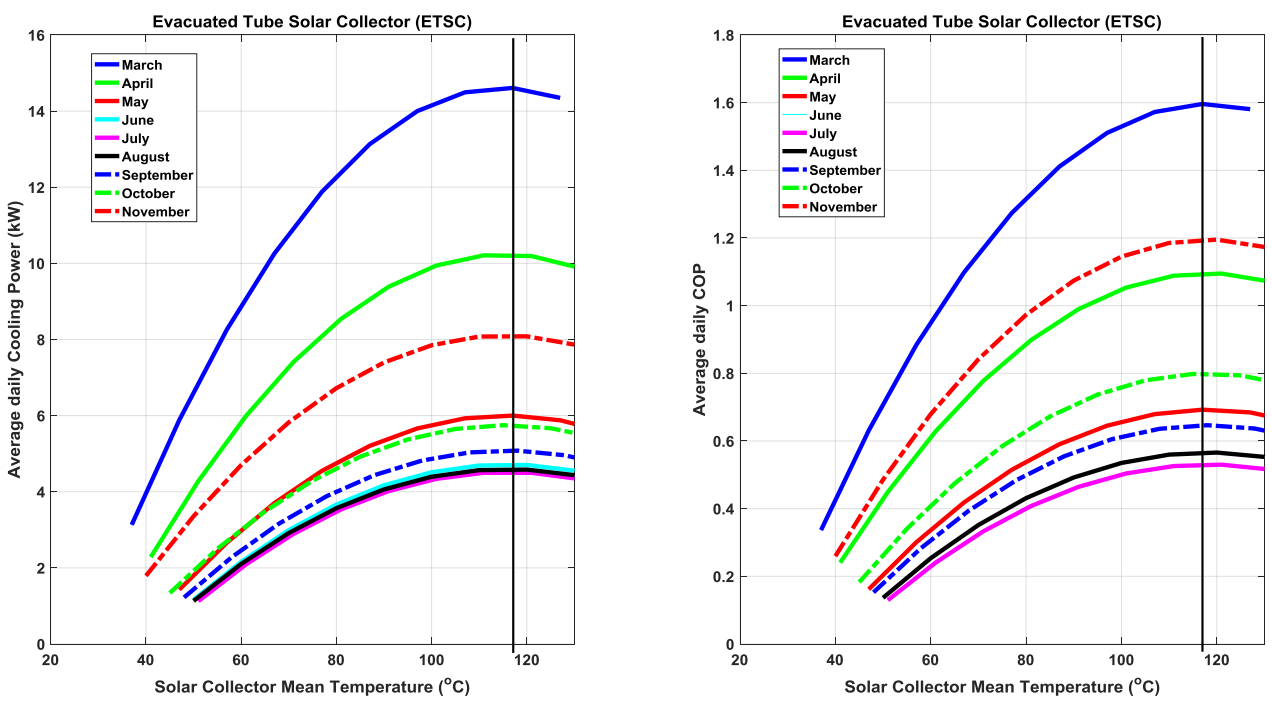

Fig. 7: Key performance indicators with Evacuated Tube Solar Collector (ETSC) 


\title{
Performance Investigation of Liquid Desiccant Dehumidification System Integrated with Solar Thermal Energy and Shallow Geothermal Energy
}

\author{
Ching YI Tseng ${ }^{1}$, Li Hao Yang ${ }^{1}$, Jyun De Liang ${ }^{1}$ and Sih-Li Chen ${ }^{1}$ \\ ${ }^{1}$ National Taiwan University, Taipei (Taiwan, ROC)
}

\begin{abstract}
This paper combines solar thermal energy and shallow geothermal energy with liquid desiccant dehumidification system in the Make-up Air Unit (MAU). The system uses Calcium chloride solution as its absorption solution and utilizes solar thermal energy as a regeneration heat source of the system, regenerating $\mathrm{CaCl}_{2}$ solution. The study improves the dehumidification ability of the MAU with the energy efficient manner. Compared with the traditional dehumidification system, solar energy and shallow geothermal energy can reduce energy consumption. Increasing the air entrance mass rate, absorption solution entrance mass rate, air entrance absolute humidity and absorption entrance concentration improves water removal rate. Decreasing the air entrance mass rate and increasing absorption solution entrance mass rate can improve efficiency. According to the results, the study develops the MAU with an energy-efficient dehumidification manner.
\end{abstract}

Keywords: Solar Thermal Energy, Shallow Geothermal Energy, Liquid Desiccant Dehumidification.

\section{Introduction}

The study mainly combines solar thermal energy liquid desiccant dehumidification system with shallow geothermal energy liquid desiccant dehumidification system. Traditional air conditioners mainly produce cool water with chiller. Cooling and dehumidifying the air by coil tubes, then heating the cool air to a particular temperature lead to high electricity expense. In order to reduce the box energy consumption, the study improves the traditional dehumidification system, dehumidifying and regenerating by solar thermal energy preheat and shallow geothermal energy precool Calcium chloride solution which makes the air reach the moderate temperature and humidity. Calcium chloride solution dehumidification air conditioner is different from the traditional chiller (Bassuoni, 2011). Calcium chloride solution air conditioner has a higher dehumidification effect and is more environmentally-friendly and scalable in the system. Recently, the issue is extensively studied over the world (Zhang et al., 2017). The study simulates the operation of solar thermal energy liquid desiccant dehumidification system and shallow geothermal energy liquid desiccant dehumidification system with heat pump which has the cool side and hot side property, applied to the regeneration side and precool side of dehumidification, utilizing the results to lower the energy consumption of the box as well as improving the dehumidification effect.

\section{Experimental processes and theoretical analysis}

The study uses Calcium chloride solution as its absorption solution, simulating solar thermal energy and shallow geothermal energy with the cool side and the hot side of the heat pump, absorbing and regenerating in the dehumidification process. Removing the water in the air, which turns Calcium chloride solution to dilute concentration solution with pressure difference, and then recovering to thick concentration solution by regeneration. The method can recycle, which save more energy than the traditional air conditioner.

Figure 1 is the illustration of experiment system structure divided to air side and solution side. In the air side, the wet air enters the dehumidification part from point 1 . The air then turns into the dry air after touching dehumidification solution, entering the indoor space from point 2 . The dry air then enters the regeneration part from point 3 , turning to the high temperature and high humidity air, emitting the air at point 4 . In the solution side, low-temperature high concentration absorption solution enters dehumidification part from point a, lowering the concentration after touching the wet air, leaving the dehumidification part from point $b$, entering the regeneration part from point $\mathrm{c}$ through absorption solution preheat heat exchanger. Increasing temperature with solar thermal 
coil pipe, transmitting the solution water part to the air side, reaching the original concentration, leaving the regeneration part from point $\mathrm{d}$. After the Calcium chloride solution is cool down by two-phase through absorption precool heat exchanger and absorption solution cool heat exchanger, entering the next stage cycle from point a.

The experiment contains three parameters at the air side, three parameters on the solution side. Parameters at the air entrance side include air mass rate, air dry ball temperature, air humidity; Parameters at the solution entrance side include solution mass rate, solution temperature, and solution concentration.

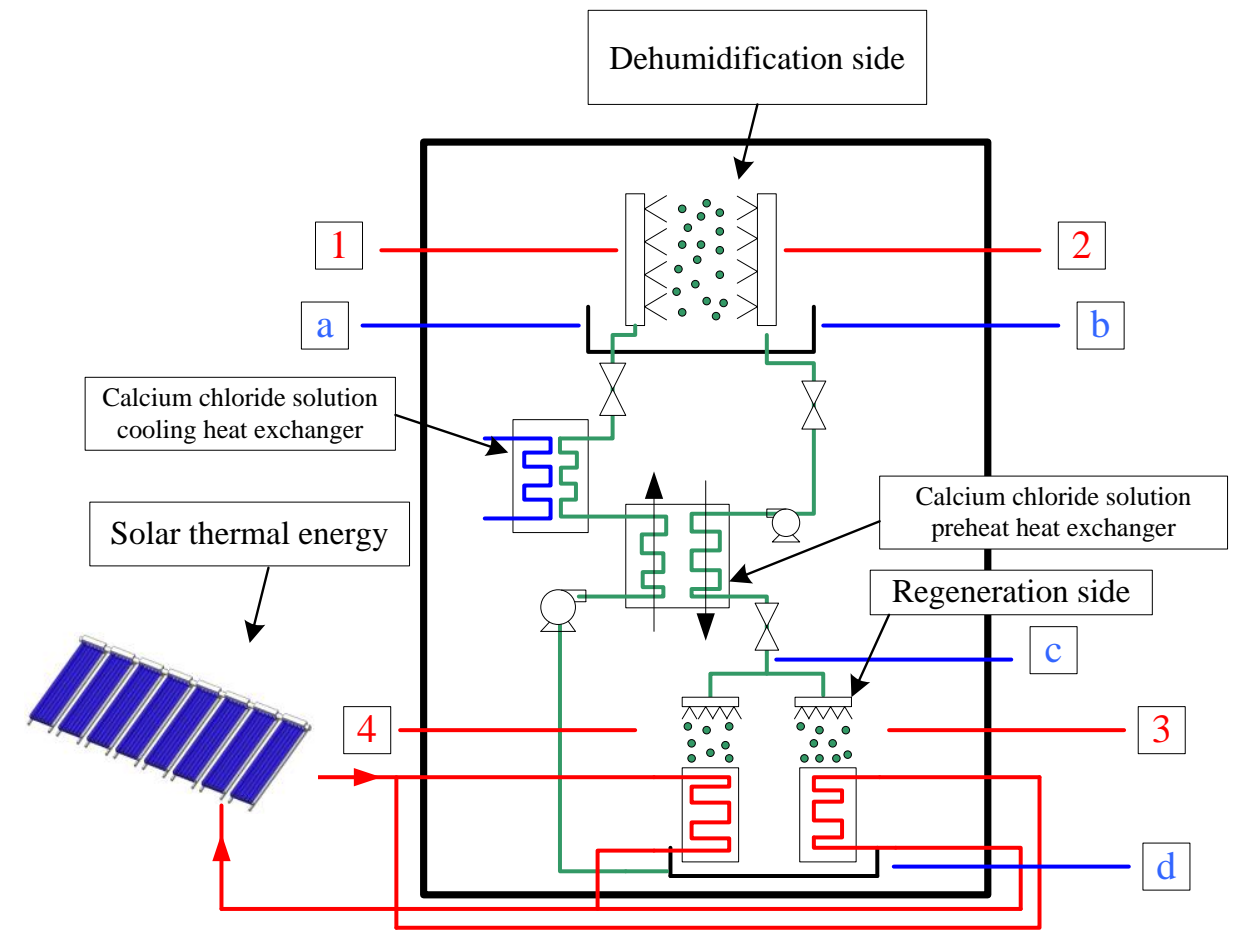

Fig 1. The experimental setup of the dehumidification system.

\section{Mathematical models}

The wet air is a mixture of dry air and water vapor. The humidity content in the wet air reaches saturation from zero, which is completely determined by the temperature and pressure of the environment at that time. The saturated state means a state in which a balance between the wet air and the condensed water phase is maintained.

The temperature and pressure of the air will change with the weather and altitude. The standard atmosphere is a standard that provides a reference for estimating the nature of air at various altitudes. On the horizon, the standard temperature is $15^{\circ} \mathrm{C}$; the standard atmospheric pressure is $101.325 \mathrm{kPa}$. The temperature is assumed to decrease linearly as the height of the troposphere increases, and is constant in the lower range of the stratosphere. The lower atmosphere is assumed to consist of dry air equivalent to the ideal gas. The gravity is also a standard fixed value $-9.806 \mathrm{~m} / \mathrm{s}^{2}$. The following equations (1) and (2) are for pressure and temperature with altitude, and are accurate from $5,000 \mathrm{~m}$ to $11,000 \mathrm{~m}$.

$$
\begin{aligned}
& P=101.325\left(1-2.5577 \times 10^{-5} H\right)^{5.2559} \\
& T=15-0.0065 \times H
\end{aligned}
$$

The dehumidification method of this experiment is chemical dehumidification, and the experiment will be carried out by selecting the reverse flow with the best dehumidification effect. The model of the mathematical theory is shown in Figure 2. The total length of gas-liquid contact in the dehumidification process is cut by the grid. After entering the inlet state, the export data and the status of various parameters of air and solution can be 
calculated in an iterative manner. In the heat and mass transfer process of gas-liquid contact in Figure 2, the air and solution ends must conform to energy conservation and mass conservation.

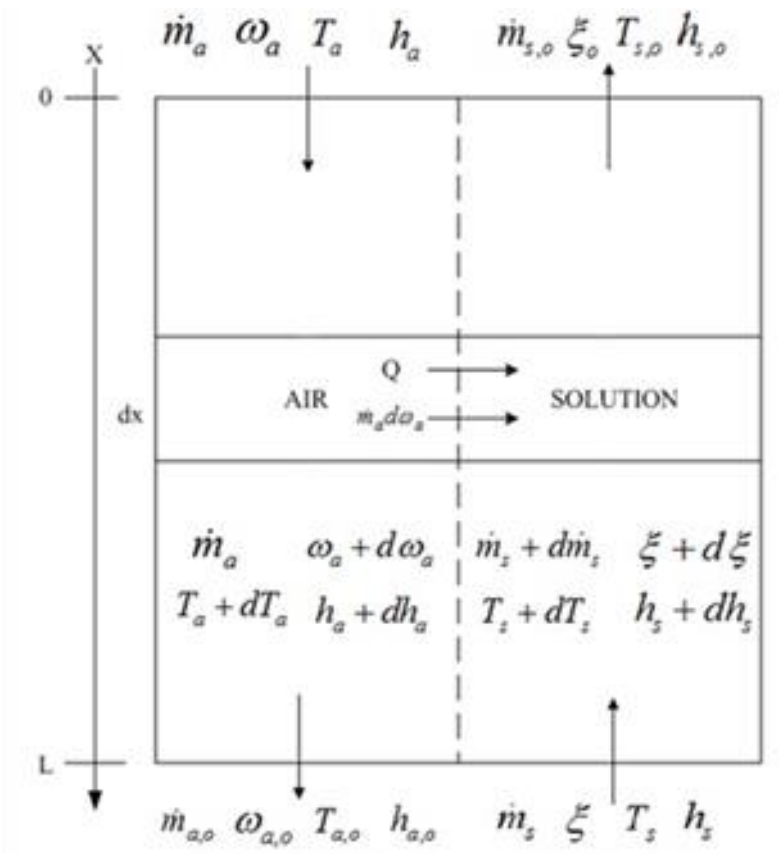

Fig 2. The absorption solution mathematical model architecture diagram.

The governing equations of the dehumidification process will be written into the calculation form of the grid to obtain the export results of the air end and the solution end. In equations (3), (4), (5), (6), and (7), the subscript $i$ is the state of a particular grid, and $i+1$ is the state of the next grid. The calculation is performed for each grid, and the grid is solved in an iterative method.

$$
\begin{aligned}
& \dot{m}_{a}\left(h_{a, i}-h_{a, i+1}\right)=\left(\dot{m}_{s, i+1} h_{s, i+1}-\dot{m}_{s, i} h_{s, i}\right) \\
& \dot{m}_{a}\left(\omega_{a, i}-\omega_{a, i+1}\right)=\left(\dot{m}_{s, i+1}-\dot{m}_{s, i}\right) \\
& \dot{m}_{s, i} \xi_{i}=\dot{m}_{s, i+1} \xi_{i+1} \\
& h_{a, i+1}-h_{a, i}=\frac{N T U}{N}\left(h_{e, i}-h_{a, i}\right) \\
& \omega_{a, i+1}-\omega_{a, i}=\frac{N T U}{N}\left(\omega_{e, i}-\omega_{a, i}\right)
\end{aligned}
$$

From equation (3), the mesh inlet humidity ratio $\left(\omega_{a, i}\right)$ is known, and the air and solution phase equilibrium humidity ratio $\left(\omega_{e, i}\right)$, The obtained method is the temperature and weight concentration of the known solution at this time, and the humidity ratio $\left(\omega_{e, i}\right)$ at the time is obtained, and the humidity ratio $\left(\omega_{a, i+1}\right)$ of the mesh outlet can be calculated. Calculate the enthalpy value of the outlet of the grid solution according to the eq. (3), calculate the mass flow rate of the outlet of the grid solution by using eq. (4), and calculate the concentration of the outlet of the grid solution by the eq. (5).

The process of numerical solution is to discretize these equations and solve them separately in each grid. The inlet state of air and solution is generally known in the calculation, and the absorption liquid is partially formed into a grid form. According to the above solution step, the outlet state of the grid N1 air and the solution can be obtained, and for the next grid N2, the N1 exit state can be regarded as the inlet state. So through the above solution step, the exit state of N2 can be obtained. By repeating the same method, you can find the state of each grid and know the exit status of the system. 


\section{Results and discussion}

This article respectively focuses on the following three experiments to measure and examine the effect of dehumidification with calcium chloride solution and inlet temperature under various situations. The results of experiment and calculation will be discussed in this chapter, mainly as:

1. The influence on dehumidification system with varying mass flow rate and temperature of air inlet.

2. The influence on dehumidification system with varying humidity of air inlet.

3. The influence on dehumidification system with the solution inlet.

\subsection{Testing the properties of calcium chloride}

Before examining calcium chloride's capability of dehumidification, it is essential to make sure that the properties of calcium chloride used are congruent with the ones on Calcium Chloride Handbook, or there will exist deviations that affect the accuracy of this experiment.

Three different brands will be used in this testing. By contacting air with absorbent under long periods of time, moisture will then transfer from air with higher partial pressure to the solution with lower partial pressure. The solution will eventually be diluted, while the air will be dried. The testing will be comparing the dehumidification capability of the three calcium chloride solution brands under different weight percentages and using the best one to compare with the standard chart in Calcium Chloride Handbook.

This experiment is shown in Figure 4-1. The solution is placed in an iron bowl and placed in an airtight box to ensure that the wet air inside and outside the airtight box does not cause exchange effects to affect the experimental results, and then the instrument is inserted into the airtight box to start the experiment.

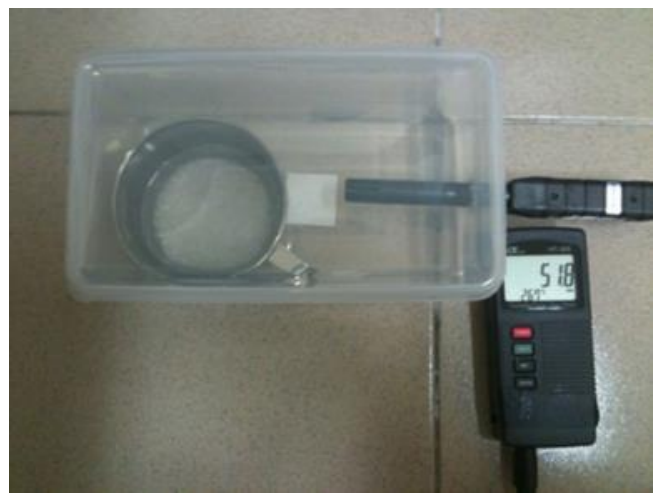

Fig 3. Calcium chloride performance test

The calcium chloride of the three manufacturers was tested at a constant temperature of $10 \%$ to $45 \%$ by weight at $30{ }^{\circ} \mathrm{C}$, and allowed to stand for a long time until the temperature and humidity were no longer changed, and the relative humidity was recorded, as shown in Table 1.

After the various concentrations of the three manufacturers were tested, they were drawn into Figure 4. After comparison, it was found that the relative humidity of the calcium chloride of the manufacturer A was the lowest at each concentration, and the dehumidification effect of the calcium chloride solution representing the manufacturer A was the most, so choose manufacturer A for this experiment.

Tab. 1: Absorption performance of different manufacturers of calcium chloride solution at different weight percentages

\begin{tabular}{llll}
\hline $\begin{array}{l}\text { weight percentage } \\
\text { concentration } \\
(\%)\end{array}$ & $\begin{array}{l}\text { (A)dew-point } \\
\text { temperature after } \\
\text { dehumidification } \\
\left({ }^{\circ} \mathbf{C}\right)\end{array}$ & $\begin{array}{l}\text { (B)dew-point } \\
\text { temperature } \\
\text { after } \\
\text { dehumidification } \\
\left({ }^{\mathbf{O}} \mathbf{C}\right)\end{array}$ & $\begin{array}{l}\text { (C)dew-point } \\
\text { temperature } \\
\text { after } \\
\text { dehumidification } \\
\left({ }^{\circ} \mathbf{C}\right)\end{array}$ \\
\hline 10 & 28.4 & 28.5 & 28.7 \\
20 & 27.2 & 27.5 & 27.8 \\
30 & 22.4 & 22.6 & 22.7 \\
35 & 19.5 & 19.7 & 20.1 \\
40 & 16.4 & 16.7 & 17.0 \\
45 & 10.9 & 11.5 & 11.8 \\
\hline
\end{tabular}




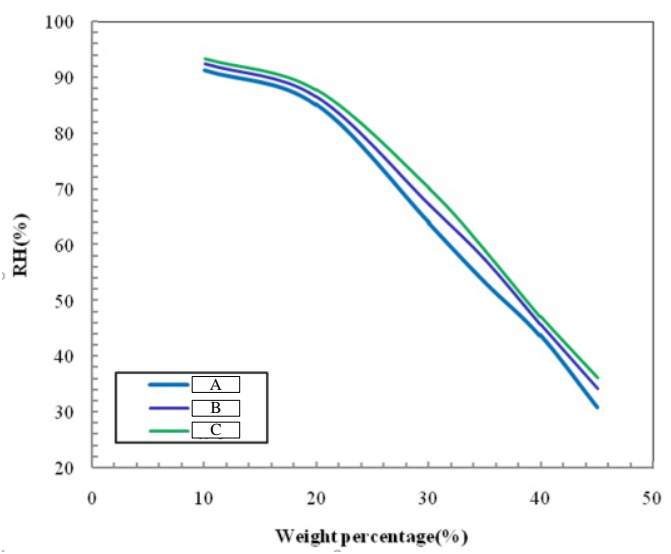

Fig 4. Comparison of dehumidification of calcium chloride solution at different weight percentages

\subsection{Mass flow rate change of air inlet and temperature change affect dehumidification system}

There are three parameters on the air side of the experiment, and three parameters on the solution side, for a total of six parameters. Air inlet side parameters include: air mass flow rate, air dry bulb temperature, air humidity; solution inlet side parameters include: solution mass flow rate, solution temperature, solution concentration. This section changes the inlet mass flow rate of air. The mass flow rate varies from $0.25 \mathrm{~kg} / \mathrm{s}$ to $1.2 \mathrm{~kg} / \mathrm{s}$. Other parameters are controlled as much as possible to reduce the experimental error. The air side inlet dry bulb temperature range is $33.0{ }^{\circ} \mathrm{C} \sim 34.3{ }^{\circ} \mathrm{C}$, the humidity ratio range is $17.2 \mathrm{~g} / \mathrm{kg} \sim 17.7 \mathrm{~g} / \mathrm{kg}$; the solution side inlet mass flow rate is $0.69 \mathrm{~kg} / \mathrm{s}$, the temperature range is $25.0^{\circ} \mathrm{C} \sim 25.2^{\circ} \mathrm{C}$, and the weight percentage is 38.5 . \% .

Humidity ratio is defined as the weight of water content per kilogram of air. Figure 5 shows relation between humidity ratio at air outlet and mass flow rate at air inlet. From the result, humidity ratio at air outlet increases gradually with the increasing mass flow rate at air inlet. At $0.25 \mathrm{~kg} / \mathrm{s}$ inlet flow rate, minimum humidity ratio at outlet is $12.8 \mathrm{~g} / \mathrm{kg}$. Figure 6 shows the relation between humidity ratio difference and mass flow rate of the air. It can be found that as the air inlet mass flow rate increases, the humidity ratio difference will gradually decrease, and the maximum humidity ratio difference is $4.9 \mathrm{~g} / \mathrm{kg}$ when the air inlet mass flow rate is $0.25 \mathrm{~kg} / \mathrm{s}$. The reasonable explanation of the phenomena in Figure 5 and Figure 6 is that when the air inlet mass flow rate is small, the contact time per unit volume of air and solution is more, and the water quality transfer ability is better. Therefore, the outlet humidity ratio is lower and the humidity ratio difference is higher. On the contrary, when the air inlet mass flow rate is large, the contact time per unit volume of air and the solution is small, and the water quality transfer ability is poor, so the outlet humidity ratio is high and the humidity ratio difference is low.

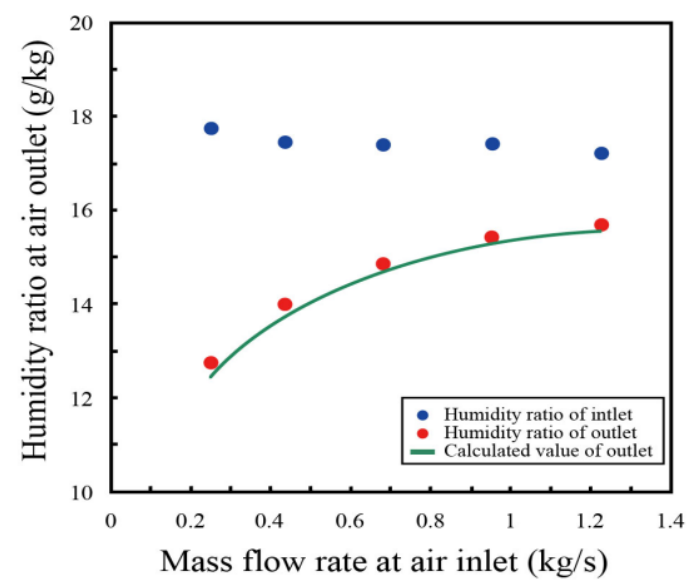

Fig. 5 Relation between humidity ratio at air outlet and mass flow rate at air inlet. 


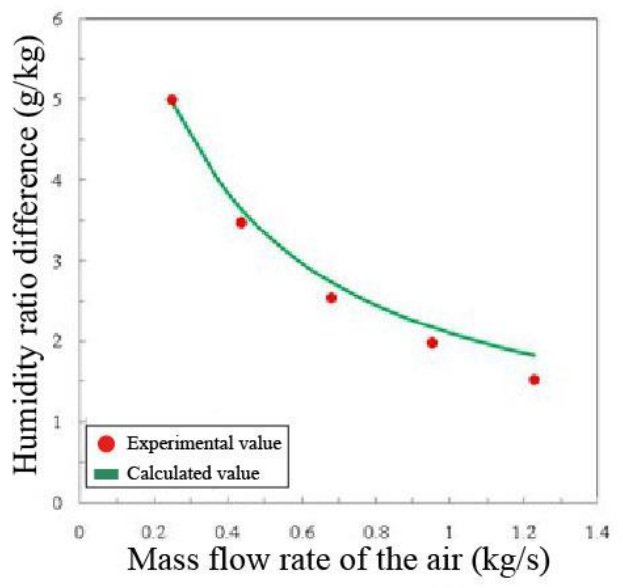

Fig. 6 Relation between humidity ratio difference and mass flow rate of the air.

The humidity removal rate is the product of the difference between the air mass flow rate and the inlet and outlet humidity ratio, which is the weight of water that the system can take away per second. As shown in Figure 7 , as the mass flow rate of the air inlet increases, although the contact time per unit volume of air and the solution is less, However, due to the increase in air mass flow rate, the relationship between the pressure difference between gas and liquid increases. The humidity removal rate of the system shows an increasing trend.

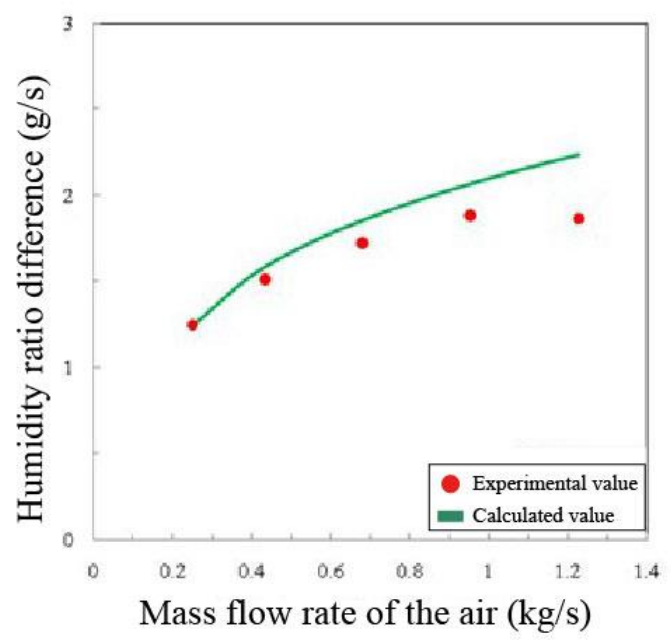

Fig. 7 Relation between humidity removal rate and mass flow rate of the air.

As shown in Figure 8, the air inlet dry bulb temperature condition is controlled between $33{ }^{\circ} \mathrm{C}$ and $34{ }^{\circ} \mathrm{C}$, the solution inlet temperature condition is controlled at about $25^{\circ} \mathrm{C}$, and air inlet dry bulb temperature is higher than the solution inlet temperature. The dry bulb temperature of air outlet gradually increases as the mass flow rate of air inlet increases. The main reason is that as air mass flow rate increases, the contact time between the unit air and the solution decreases. The solution outlet temperature gradually increases as the air inlet mass flow rate changes. The main reason is that as the air mass flow rate increases, the humidity removal rate of the system increases and the heat of melting of calcium chloride increases. The temperature difference between the outlet of the air and the solution gradually increases as the mass flow rate of the air inlet increases, and it is precisely because the contact time of the unit air and the solution decreases as the air mass flow rate increases. 


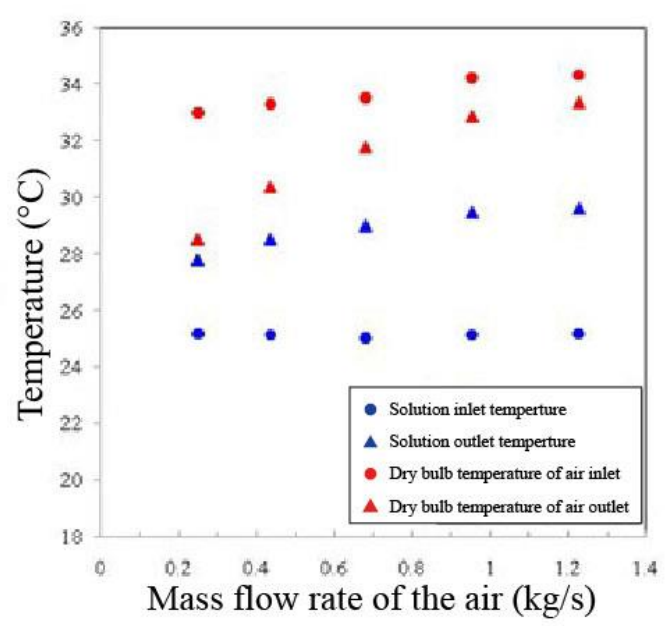

Fig. 8 Relation between temperature and mass flow rate of the air.

The dehumidification efficiency is defined as the experimental value of the difference between the air inlet and outlet humidity ratio and the ratio of the air inlet to the gas-liquid equilibrium humidity content difference. Figure 9 shows the dehumidification efficiency as a function of the air inlet mass flow rate. It can be seen that the dehumidification efficiency decreases as the air inlet mass flow rate increases. Because when the air mass flow rate increases, the moisture exchange time between gas and liquid is shortened, and the water that can be removed per unit volume of air is reduced, resulting in a decrease in dehumidification efficiency. As the air inlet mass flow rate increases from $0.25 \mathrm{~kg} / \mathrm{s}$ to $1.23 \mathrm{~kg} / \mathrm{s}$, the dehumidification efficiency will decrease from $68 \%$ to $55 \%$.

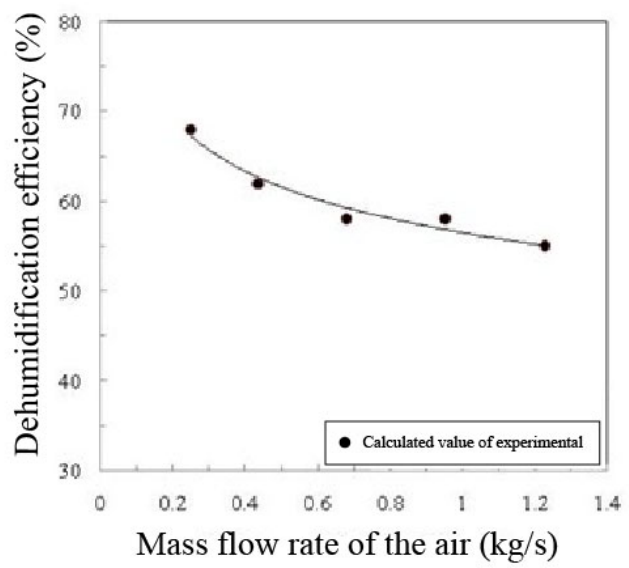

Fig. 9 Relation between dehumidification efficiency and mass flow rate of the air

\subsection{Air inlet humidity changes affect the absorption system}

Figure 10 shows the humidity of the air inlet increases; the humidity ratio of the air outlet will gradually increase. When the air inlet humidity is $12.3 \mathrm{~g} / \mathrm{kg}$, the lowest outlet humidity ratio is $11.5 \mathrm{~g} / \mathrm{kg}$. Figure 11 shows the change in the humidity ratio of the outlet with the humidity of the air inlet. It can be found that as the humidity of the air inlet increases, the humidity ratio will gradually increase. When the air inlet humidity is $18.8 \mathrm{~kg} / \mathrm{s}$, the maximum humidity ratio difference of $3.0 \mathrm{~g} / \mathrm{kg}$ will be obtained. It is reasonably explained by the phenomena in Figures 10 and 11 that when the air inlet humidity is small, the vapor pressure difference between the air end and the solution end is low. The ability to transfer humidity from the air end to the solution end is weak, so the humidity ratio difference is low. Conversely, when the humidity of the air inlet is relatively large, the difference in vapor pressure between the air end and the solution end is large, so that the air transfer capacity of the air end to the solution end is strong, so the humidity ratio difference is high. 


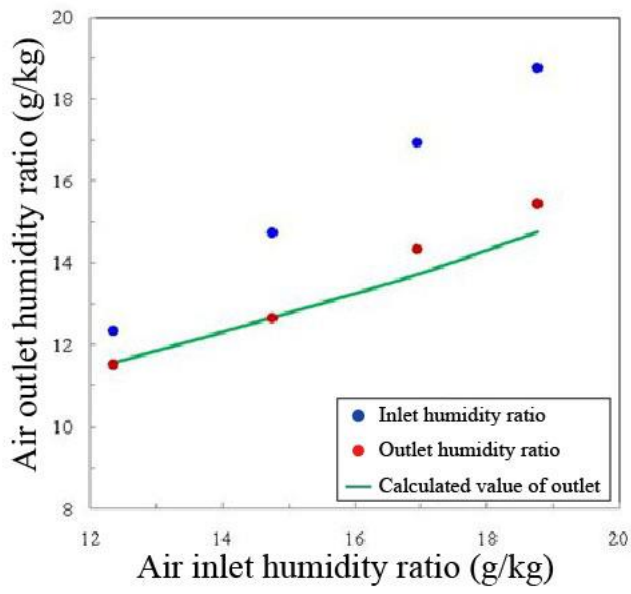

Fig. 10 Relation between Air outlet humidity ratio and air inlet humidity ratio.

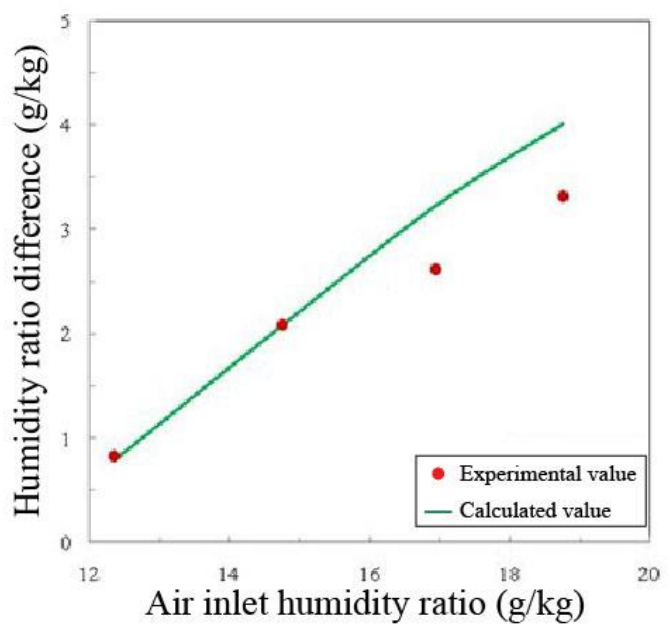

Fig. 11 Relation between humidity ratio difference and air inlet humidity ratio.

Figure 12 shows the relation between system humidity removal rate and air inlet humidity ratio. It can be seen from the figure that as the humidity of the air inlet increases, the vapor pressure of the air increases, so the pressure difference between the air end and the solution end is increased, so that the mass transfer capability of the water is increased. Therefore, the humidity removal rate of the system is increasing.

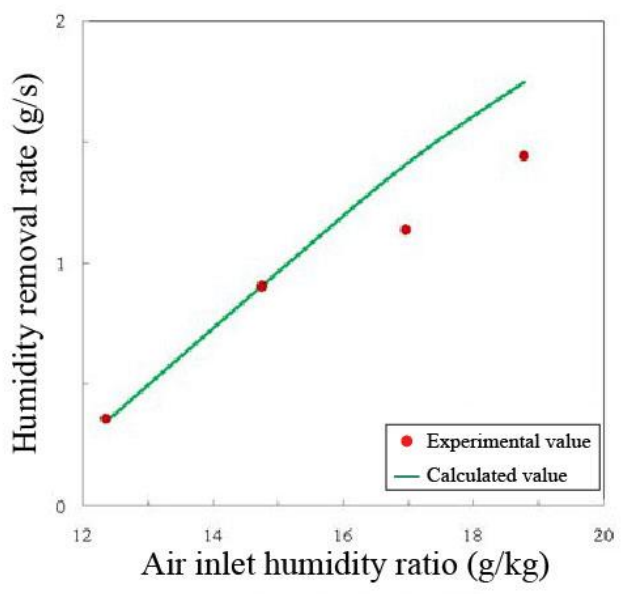

Fig. 12 Relation between humidity removal rate and air inlet humidity ratio. 
Figure 13 shows the change in air side, solution side inlet and outlet temperatures with air inlet humidity. Figure 13 shows that air inlet dry bulb temperature condition is controlled at about $34^{\circ} \mathrm{C}$, the solution inlet temperature condition is controlled at about $25^{\circ} \mathrm{C}$, and air inlet dry bulb temperature is higher than the solution inlet temperature. The outlet temperature of air and solution gradually increases as the humidity of air inlet becomes larger. The main reason is that as the humidity of air inlet increases, the increase in air humidity transfer is accompanied by more heat of dissolution of calcium chloride solution.

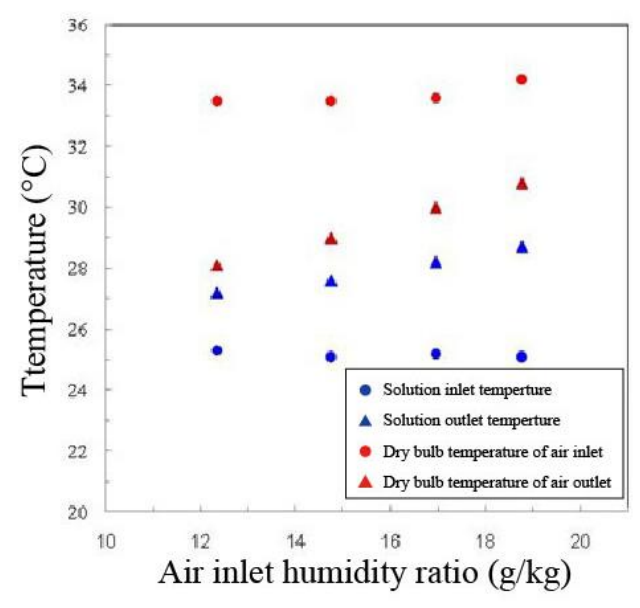

Fig. 13 Relation between change in air side, solution side inlet and outlet temperatures and air inlet humidity ratio.

Figure 14 shows the change in dehumidification efficiency and air inlet humidity. As the air inlet humidity rises from $12.3 \mathrm{~g} / \mathrm{kg}$ to $18.8 \mathrm{~g} / \mathrm{kg}$, the dehumidification efficiency hardly changes with the air inlet humidity.

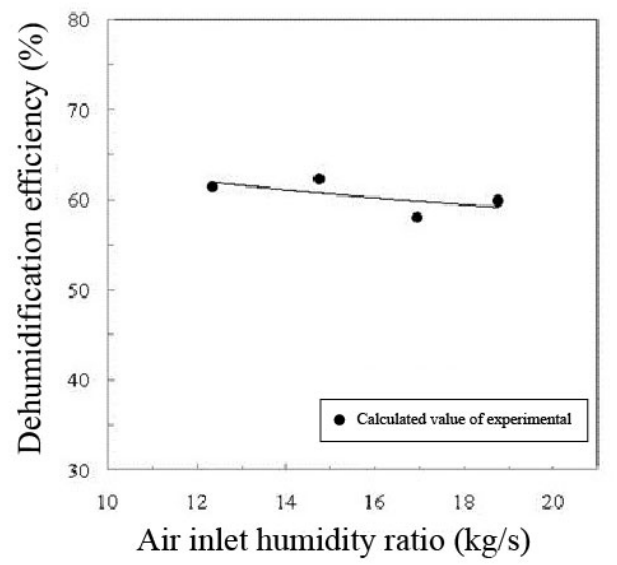

Fig. 14 Relation between dehumidification efficiency and air inlet humidity ratio.

\subsection{Effect of solution inlet on absorption system}

From figure 15, as the mass flow rate of the solution inlet increases, the humidity ratio of the air outlet will gradually decrease. When the mass flow rate of the inlet of the solution is $0.69 \mathrm{~kg} / \mathrm{s}$, the lowest outlet humidity ratio is $14.3 \mathrm{~g} / \mathrm{kg}$. Figure 16 shows the difference between the inlet and outlet humidity ratios as the mass flow rate of the inlet of the solution changes. As the mass flow rate of the solution inlet increases, the humidity ratio difference will increase. The effect of figure 15 and 16 can be reasonably explained as when the mass flow rate at the inlet is low, the contact surface area of air per volume and the solution is small, weakening its capability to transfer mass, which results in higher humidity at the outlet with lower humidity ratio difference. On the contrary, when the mass flow rate at the inlet is high, the contact surface area of air per volume and the solution is big, improving its mass transfer capability, which results in lower outlet humidity with higher humidity ratio difference. 


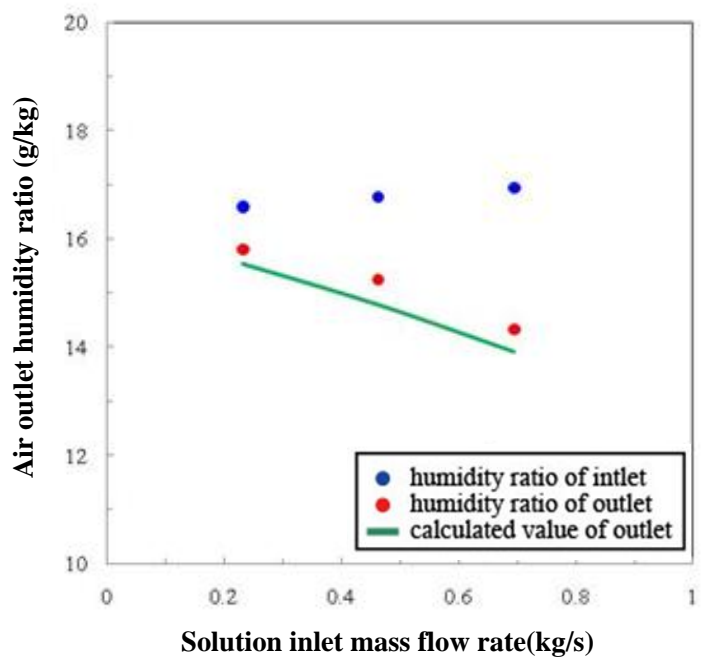

Fig. 15 Relation between air outlet humidity ratio and solution inlet mass flow rate.

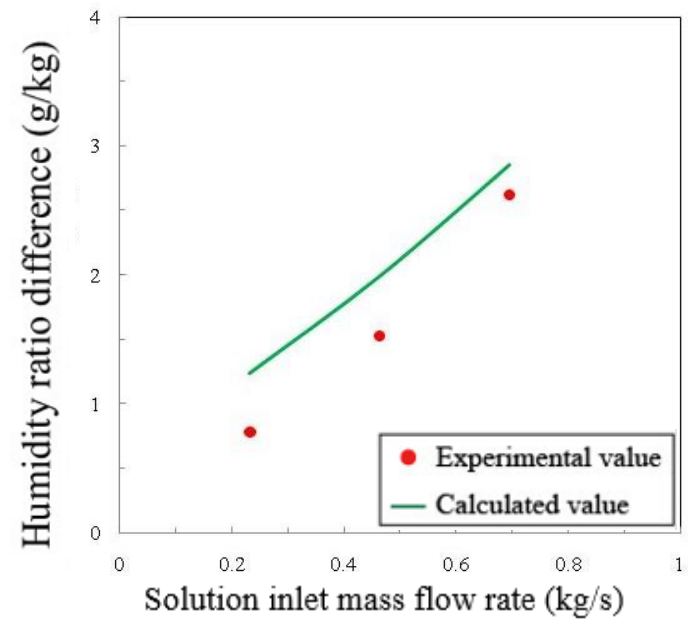

Fig. 16 Relation between humidity ratio and solution inlet mass flow rate.

Figure 17 shows the change in humidity removal rate and solution inlet mass flow rate. As shown in Figure 17, as the mass flow rate of the solution inlet increases, the contact surface area of the unit volume of air and the solution increases, improving its mass transfer capability for more moisture to be removed from the solution, making the system's humidity removal rates a tendency to increase. 


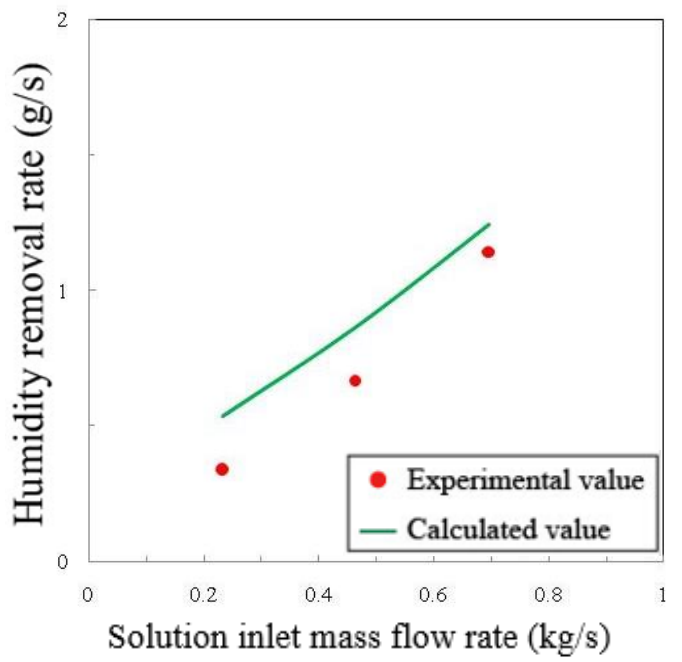

Fig. 17 Relation between humidity removal rate and solution inlet mass flow rate.

Figure 18 shows the change in the inlet and outlet temperatures of the air side and the solution side with the mass flow rate of the solution inlet. As shown in Figure 18, the air inlet dry bulb temperature condition is controlled at about $34{ }^{\circ} \mathrm{C}$, the solution inlet temperature condition is controlled at about $25{ }^{\circ} \mathrm{C}$, and the air inlet dry bulb temperature is higher than the solution inlet temperature. The dry bulb temperature at the air outlet gradually decreases as the mass flow rate of the solution inlet increases, mainly because the contact surface area per unit volume of air and solution increases as the mass flow rate of the solution increases. While the air outlet dry bulb temperature and the solution outlet temperature gradually decrease as the solution inlet mass flow rate increases, which is also due to the increasing contact surface area of air per volume and the solution as solution mass flow rate increases.

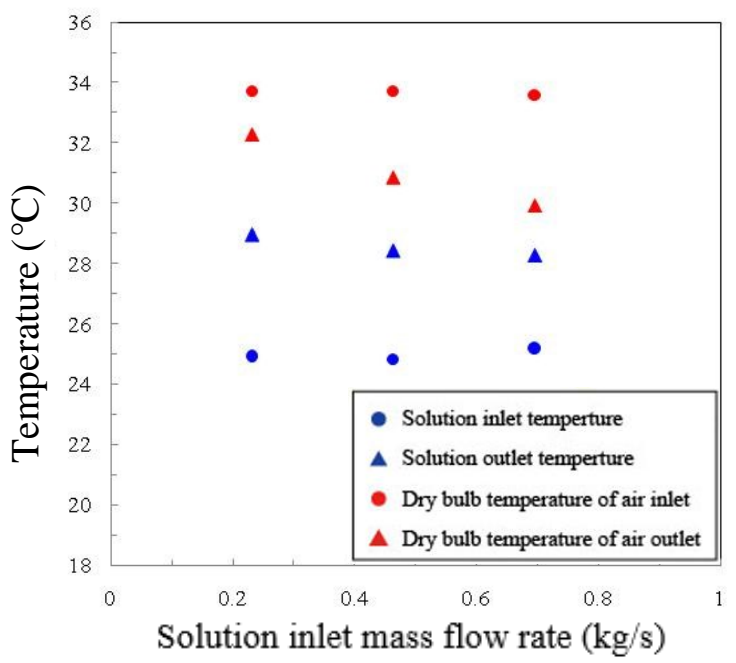

Fig. 18 Relation between change in air side, solution side inlet and outlet temperatures and inlet mass flow rate.

Figure 19 shows the dehumidification efficiency with varying solution inlet mass flow rate. It can be found that dehumidification efficiency increases as solution inlet mass flow rate increases, which is because when solution mass flow rate increases, the rising temperature after solution dehumidification is diminished, which results in greater pressure difference between gas and liquid while improving its mass transfer capability, the dehumidification efficiency is then promoted. As solution inlet mass flow rate rises from $0.23 \mathrm{~kg} / \mathrm{s}$ to $0.69 \mathrm{~kg} / \mathrm{s}$, dehumidification efficiency will rise from $38 \%$ to $61 \%$. 


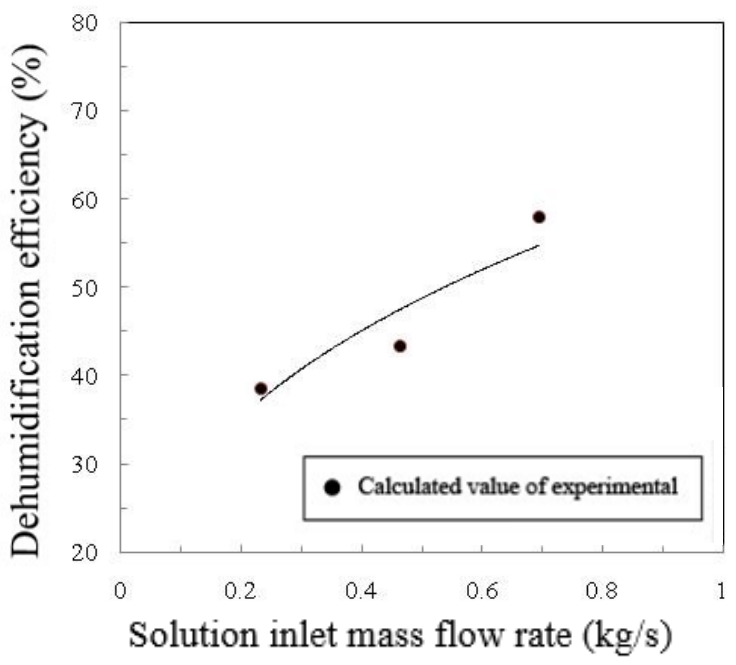

Fig. 19 Relation between dehumidification efficiency and solution inlet mass flow rate.

\section{Conclusions}

The dehumidification system of this paper uses Calcium chloride solution as its absorption solution. This paper discusses the influence inflicted by dehumidification toward air side and solution side.

(1) Utilizing the technique of solar thermal energy and shallow geothermal energy can not only reduce the energy consumption of the compressor but also assist the usage of heat pump, achieving the aim of energysaving.

(2) The air mass rate has the best dehumidification efficiency of $68 \%$ at $0.25 \mathrm{~kg} / \mathrm{s}$. Dehumidification efficiency remains around $60 \%$ for the parameters of air temperature and air humidity.

(3) The solution mass rate has the best dehumidification efficiency of $61 \%$ at $0.69 \mathrm{~kg} / \mathrm{s}$. Dehumidification efficiency of remains around $60 \%$ for the parameters of air temperature and air humidity.

(4) According to the results of the experiment, the best dehumidification efficiency of $68 \%$ happens when air mass rate is $0.25 \mathrm{~kg} / \mathrm{s}$, air dry bulb temperature is $33.0^{\circ} \mathrm{C}$, air humidity ratio is $17.7 \mathrm{~g} / \mathrm{kg}$, solution mass rate is $0.69 \mathrm{~kg} / \mathrm{s}$, solution temperature is $25^{\circ} \mathrm{C}$, solution weight percentage of $38.5 \%$, system atmosphere ratio is $17.7 \mathrm{~g} / \mathrm{kg}$, relative humidity is $60 \%$, which is the most comfortable humidity for human body.

\section{References}

1. M.M. Bassuoni, 2011. An experimental study of structured packing dehumidifier/regenerator operating with liquid desiccant. Energy. 36, 2628-2638.

2. Lun Zhang, Xiaohua Liu, Hongyang Wei, Xiasong Zhang, 2018. Experimental study and analysis of heat and mass transfer ability of counter-flow packing tower and liquid desiccant dehumidification system. Energy and Buildings. 158, 150-161. 


\title{
Application of PCM in Building's Envelope of Lightweight Prefabricated Houses as an addition to a PV driven renovation cooling system by EU project HEART
}

\author{
Eva Zavrl' ${ }^{1}$, Gašper Zupanc ${ }^{2}$, Uroš Stritih ${ }^{1}$ and Mateja Dovjak ${ }^{2}$ \\ 1 University of Ljubljana, Faculty of Mechanical Engineering, Ljubljana (Slovenia) \\ 2 University of Ljubljana, Faculty of Civil and Geodetic Engineering, Ljubljana (Slovenia)
}

\begin{abstract}
Countries with moderate climate have heat gains during the year smaller compared to the heat losses. Therefore, most of the attention on lightweight prefabricated houses is given for thermal insulation (nZEB). Thermal capacity of such envelopes is very low, which can result in overheating of the indoor spaces over the summer months. As a result, the energy needed for mechanical air-conditioning can even exceed the needs for heating. The envelope coupled with PCM layer is introduced. Different types of envelopes applied on residential building are simulated with Energy plus and compared. The results showed that the performance of several variations of PCM are comparable to the heavyweight structure. Also, the mechanical ventilation driven on photovoltaics can efficiently cover the remaining amounts of energy needed for additional cooling. It shows that when the PCM strategy, melting point and capacity are chosen correctly, the produced electrical energy in total can be used for other purposes. This means that a large variety of the products must be available for the building's installation. To satisfy the low energy consumption and thermal comfort (by decreasing inner operative temperatures), the holistic approach (the combination of the active and passive system) is the best solution.
\end{abstract}

Keywords: Overheating, heavyweight, lightweight structure, PCM, PV mechanical cooling

\section{Introduction}

The heat gains during the year in countries with moderate climate are smaller compared to the heat losses Therefore, most of the energy consumption in building's sector is used for heating. Lightweight structures improved with low heat transfer insulations enabled the construction with thin wood load-bearing walls (Pajek et al., 2017). However, the lack of thermal mass or heat capacity results in buildings' overheating (Adekunle and Nikolopoulou, 2016). The consequences are low thermal stability and decreased thermal comfort in summer. As a result, the yearly energy consumption for the mechanical air-conditioning (active cooling) can even exceed the energy needed for heating. To improve the heat capacity of the structures' envelope, the phase change materials (PCM) are introduced. PCMs can store or release the energy by changing the phase of the material. By adding the PCM in the lightweight structure where the environmental temperature fluctuations occur, the thermal stability of the building is improved. The standards and requirements on the topic of overheating are limited. Some of the standards focus on the acceptable temperature ranges based on the health aspects and thermal comfort requirements (ANSI/ASHRAE 55-2013 and CEN CR 1571:1998). The other aspect is the annual energy required for cooling building, calculated per unit of cooled area of the building and it shouldn't exceed $50 \mathrm{kWh} / \mathrm{m}^{2}$ (Directive 2010/31/EU, 2010). Another alternative to the envelope enriched with PCM is mechanical ventilation for cooling powered by the Photovoltaics (PV), as the amount of sun radiation during the overheating periods is usually high. Similar solutions coupled with heating and cooling systems are currently investigated in Horizon2020 project HEART (HEART, 2017). The aim and the scientific contribution of this investigation is: to test the effect of overheating among two different types of envelopes calculated with ID DesignBuilderTM (DesignBuilder Software Ltd., 2017); to study the holistic approach for overheating reduction including active (air-conditioning coupled with PV) and passive systems (envelope enriched with PCM); to assess the overheating based on energy needed for cooling and thermal comfort (including operative temperatures). The passive systems were installed in the lightweight wooden structure with two different strategies. Further on various capacities and melting points were investigated. In order to have more accurate evaluation of the results, additional melting point variations were established. Afterwards, the evaluation based on the thermal comfort in the building with the amount of cooling demand for each method investigated. 


\section{Method}

Figure 1 shows the concept of the renovation approach. The figure shows the solar assisted active cooling system (active) and the passive heat accumulation system (passive) cooling strategy. The active strategy consumes electrical solar/energy for its operation. The active approach system is currently investigated within Horizon 2020 project HEART (HEART, 2017). It can be used for single or multiple family houses. The system has the photovoltaics (PV or BIPV) installed on the optimum location of the building's envelope, which powers the heat pump (HP). The air to water HP is used for both, heating and cooling, so it runs also through the heat and cold storage tank. The water from the heat storage continuous to the smart fan-coil. The smart fan-coil blows the cool air into the space. The connotation 'smart' is added, because the unit includes a local heat pump in it, which can enable a fine regulation of the inlet air temperature for every smart fan-coil in the apartment (normally, one per room).

In order, to reduce the energy consumption, the active system is coupled with the passive one. The passive system accumulates the excess heat. In this way, the remaining energy needed to decrease the room air temperatures generated by the PV can be used for other purposes.

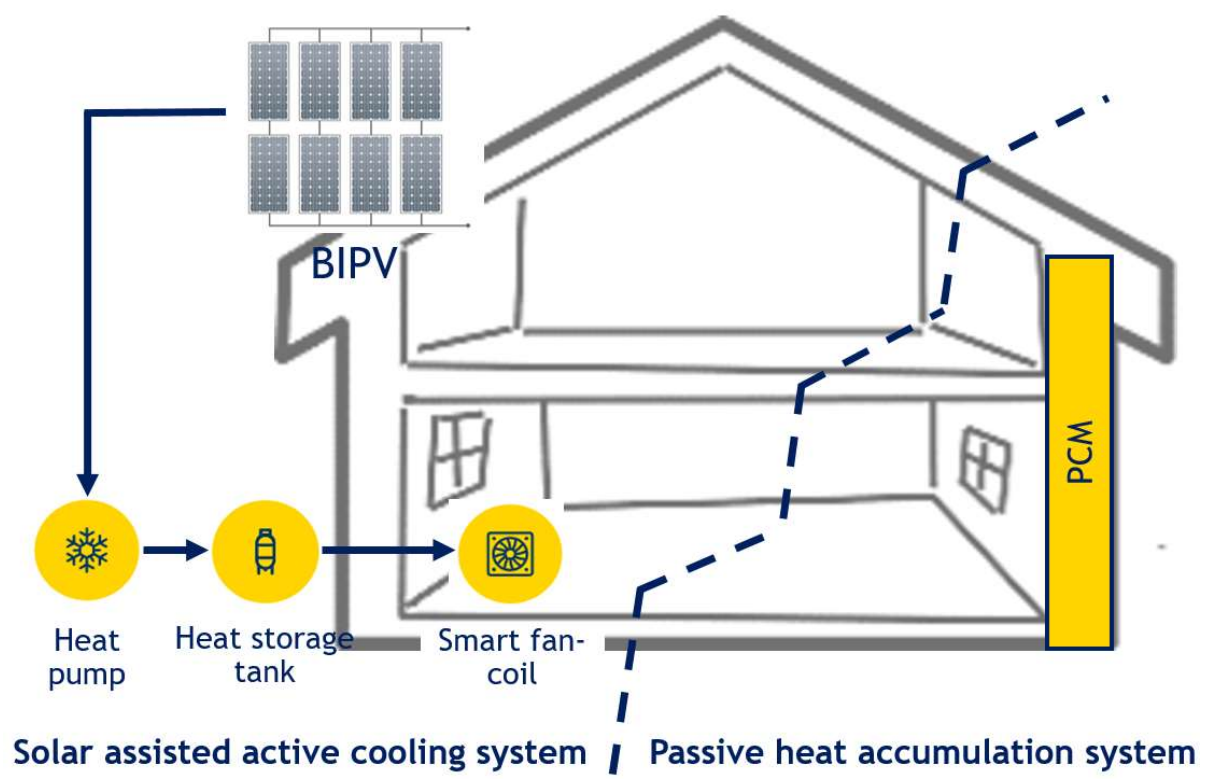

Fig. 1: The holistic cooling approach (active and passive system)

The passive system consists of the lightweight timber envelope which has additional layer of the phase change material (PCM) installed in its walls. When the building's interior is warmed up and the air temperature exceeds the comfortable level the temperature has to be reduced. It can be reduced by adding cool air to the space or by accumulating the excess heat by changing the phase of the material installed in the walls (PCM). PCMs start to melt at certain temperature called melting point. The PCM type should be determined based on its purpose (temperature ranges). So, for the reduction of overheating the melting point should be somewhere within the last acceptable range.

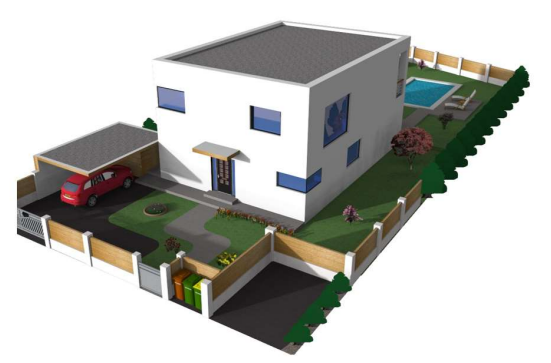

Fig. 2a: Front of the building

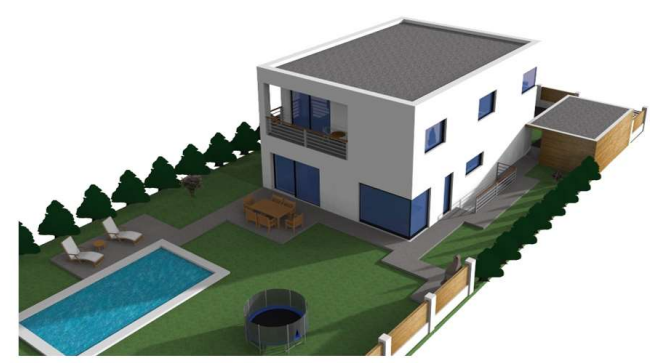

Fig. 2b: Back of the building 
The purpose of this research was to evaluate the energy saving potential of this passive system, based on the operative temperatures obtained over the first week of August (the hottest week) and through the entire test reference year in Ljubljana (Slovenia). Also, the hours during which the space is overheated and the weekly and yearly amount of electrical energy needed for cooling are calculated.

DesignBuilderTM (Design Builder software Ltd, 2017) is a calculation tool used by designers and researchers for calculation of energy consumption (for HVAC, lighting and operation) and use of water in buildings (Energy Plus, 2017). The geometry was inserted following the layout of the building with area of $167 \mathrm{~m}^{2}$ shown in Figures $2 \mathrm{a}$ and $2 \mathrm{~b}$.

The heavyweight (HW) and lightweight wooden frame (LW.WF) structures were investigated The PCM was applied only to the external walls of the LW.WF structure. The passive PCM system was investigated by variation of the strategy (added layer of BioPCM ${ }^{\mathrm{TM}}$ or microencapsulated PCM in gypsum boards), melting points and the PCM thicknesses. The list of investigated cases:

- $\mathrm{HW}$;

- LW.WF (the reference case of the building that needs to renovated in order to reduce the operative temperatures in its interior);

- PCM23.a: M182/Q23;

- PCM25.a: M182/Q25, M91/Q25, M51/Q25 and M27/Q25;

- PCM24.a: M182/Q24, M91/Q24, M51/Q24 and M27/Q24;

- PCM26.a: M182/Q26;

- PCM23.in: two thicknesses of $1.25 \mathrm{~cm}$ and $2.50 \mathrm{~cm}$ and

- PCM25.in: thickness of $1.25 \mathrm{~cm}$.

The graphical investigation approach is explained in Figure 3.

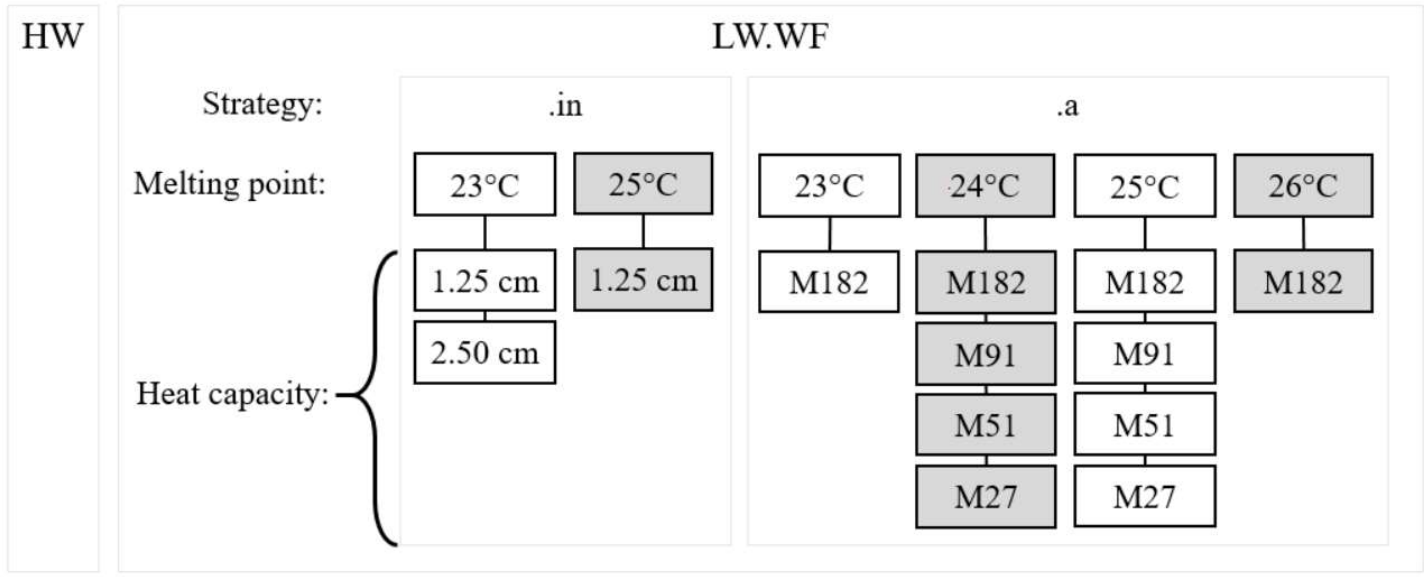

Figure 3: The systematic scheme of the passive system variations investigated

HW structure is chosen for the comparison to the traditional building type with high heat capacity of the building envelope. It has a brick wall with heat transfer $(\mathrm{U})$ of $0.201 \mathrm{~W} /\left(\mathrm{m}^{2} \mathrm{~K}\right)$. In this case, also the roof and floor are massive, where the U-value of the roof is $0.182 \mathrm{~W} /\left(\mathrm{m}^{2} \mathrm{~K}\right)$ and floor $0.260 \mathrm{~W} /\left(\mathrm{m}^{2} \mathrm{~K}\right)$. LW.WF building without the PCM is chosen as a reference case of the building that gets overheated during the summer. The timber envelope with mineral wool panels has the $U$-value of the external of $0.139 \mathrm{~W} /\left(\mathrm{m}^{2} \mathrm{~K}\right)$, of the roof $0.111 \mathrm{~W} /\left(\mathrm{m}^{2} \mathrm{~K}\right)$ and of the $0.260 \mathrm{~W} /\left(\mathrm{m}^{2} \mathrm{~K}\right)$ floor.

The PCM23. $\mathrm{a}$ is the PCM in the building's envelope. Symbol 'a' designates the strategy type, which is a layer of BioPCM ${ }^{\mathrm{TM}}$ added to the buildings envelope. It's has melting point of $23^{\circ} \mathrm{C}$ and thickness of $7.4 \mathrm{~cm}$, which corresponds with it capacity (M182/25Q). Its latent heat storage is $85 \mathrm{Wh} / \mathrm{m}^{2}$ (BioPCM ${ }^{\mathrm{TM}}$, 2017). The PCM25.a 
has melting point of $25^{\circ} \mathrm{C}$ and thickness of $7.4 \mathrm{~cm}$ (M182/25Q) with latent heat storage of $574 \mathrm{Wh} / \mathrm{m}^{2}$ (BioPCM TM, 2017).The PCM24.a is not an existing product, which means that is not commercially available under this brand's name. It was manually designed by knowing the characteristics of the BioPCM ${ }^{\mathrm{TM}}$ with melting point at $23^{\circ} \mathrm{C}(\mathrm{M} 182 / 23 \mathrm{Q})$ in order to find the optimum melting point. Also, the PCM26.a is not an existing product, since it was designed on the basis of characteristics from BioPCM M182/Q27 (BioPCM ${ }^{\mathrm{TM}}$, 2017). The PCM23.in has a different type of the envelope's strategy. The product's name is COMFORTBOARD TM (Knauf, 2016). The PCM capsules are integrated in the gypsum boards, so they are adjusted to the inner side of the envelope. They melt $23^{\circ} \mathrm{C}$ and have a thickness of $1.25 \mathrm{~cm}$. It's thermal conductivity is $0.23 \mathrm{~W} /(\mathrm{mK})$, density: $880 \mathrm{~kg} / \mathrm{m}^{3}$, weight: $11 \mathrm{~kg} / \mathrm{m}^{2}$ where PCM weights $2 \mathrm{~kg} / \mathrm{m}^{2}, \mathrm{c}_{\mathrm{p}}: 12.76$ and $1.17 \mathrm{~kJ} /(\mathrm{kgK})$. It is sensible to add only 1 or 2 layers of gypsum boards due to its mechanical adjustment possibilities.

Operative temperature is determined based on (ISO 7726:1998(E)):

To $=(h c *$ Tai + hr $* \overline{T r}) /(h c+h r)$

where Tai - inner air temperature, $\overline{\mathrm{Tr}}$ - (mean radiant temperature), hc - heat-transfer coefficient by convection and $\mathrm{hr}$ - heat-transfer coefficient by radiation.

The operative temperatures in this article were used to indicate the thermal comfort following the EN 15251:2007 (EN 15251:2007, 2007). The third (the least tolerable) category was used in order to show the worst-case scenario, where $22^{\circ} \mathrm{C}$ is the lower and $27^{\circ} \mathrm{C}$ the higher limit of the operative temperature in the residential buildings in summer.

Thermal capacity of the building materials is used for determining the heat accumulation capability of the building. Thermal capacity $\mathrm{C}\left[\mathrm{J} /\left(\mathrm{m}^{3} \mathrm{~K}\right)\right]$ :

$\mathrm{C}=\rho \cdot \mathrm{c}$

$\rho$ - density $\left[\mathrm{kg} / \mathrm{m}^{3}\right], \mathrm{c}$ - specific heat of the material $[\mathrm{J} /(\mathrm{kgK})]$

The phase delay is calculated based on the number of hours after the outdoor air temperature peak occurred in the building.

\section{Results and discussion}

The figures below present the results of this study.

Figure 4 presents the daily outdoor air temperatures and the operative temperatures obtained in the space with heavyweight structure (HW) and lightweight wooden frame structure (LW.WF). The dark pink dash line designates the upper limit of the operative temperature $\left(27^{\circ} \mathrm{C}\right)$ and the light pink dash line the lower limit of $22^{\circ} \mathrm{C}$.

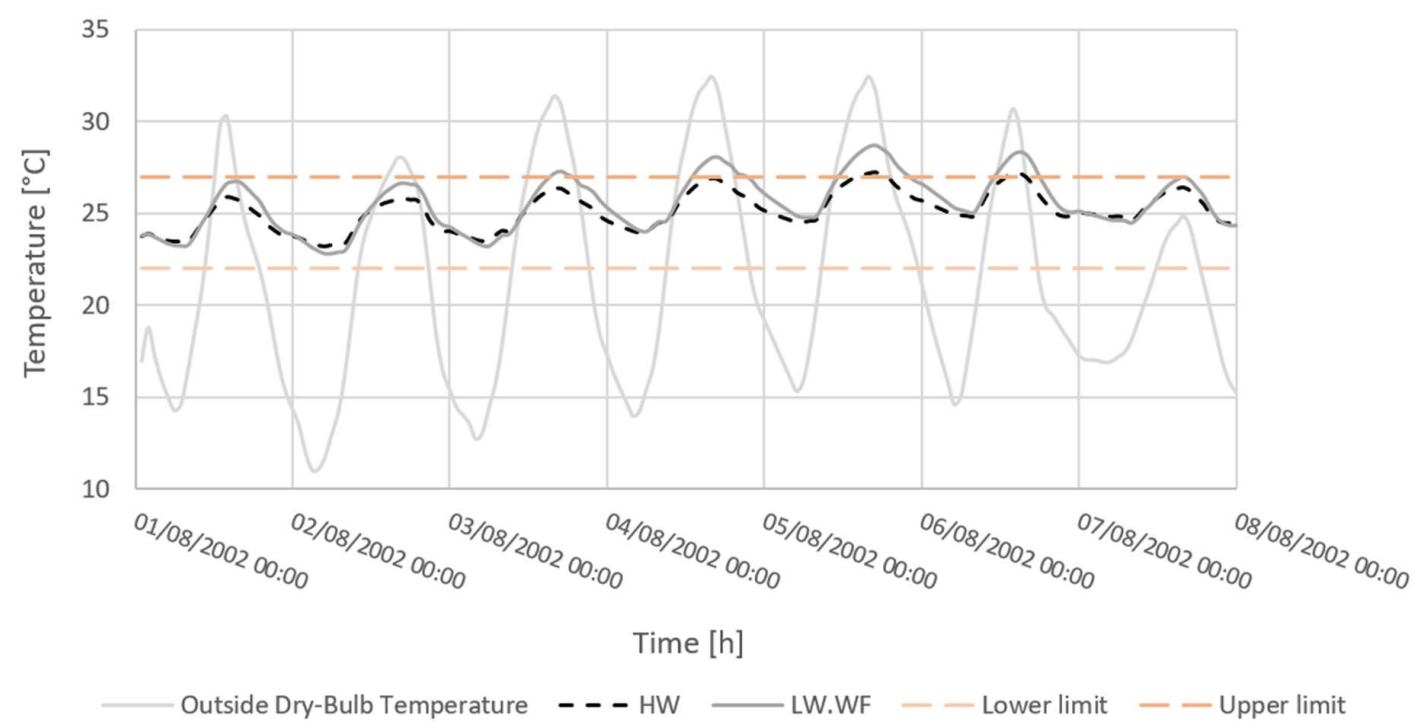


Figure 4: The temperatures obtained with HW and LW.WF structure during the $1^{\text {st }}$ week of Aug

In Figure 4, the light grey line designates the outdoor air temperature fluctuations. The results show that the operative temperatures (hereinafter temperatures) of the $\mathrm{HW}$ structure only in minor (max. $+0.2^{\circ} \mathrm{C}$ ) exceeds the upper limit of $27^{\circ} \mathrm{C}$ on $5^{\text {th }}$ of Aug $(14: 00-18: 00 \mathrm{~h})$ and $6^{\text {th }}$ of Aug (13:00 - 16:00 h), respectively. The LW.WF structure reaches the maximum temperatures of $28.7^{\circ} \mathrm{C}$ on the $5^{\text {th }}$ of Aug at 17:00, although the temperatures are cross the upper limit from 12:00 - 22:00.

The first series of solutions are shown in Figure 5. The strategy chosen is the microencapsulated PCM (.in) with melting points at $23^{\circ} \mathrm{C}(1.25 \mathrm{~cm}$ and $2.50 \mathrm{~cm})$ and $25^{\circ} \mathrm{C}(1.25 \mathrm{~cm})$.

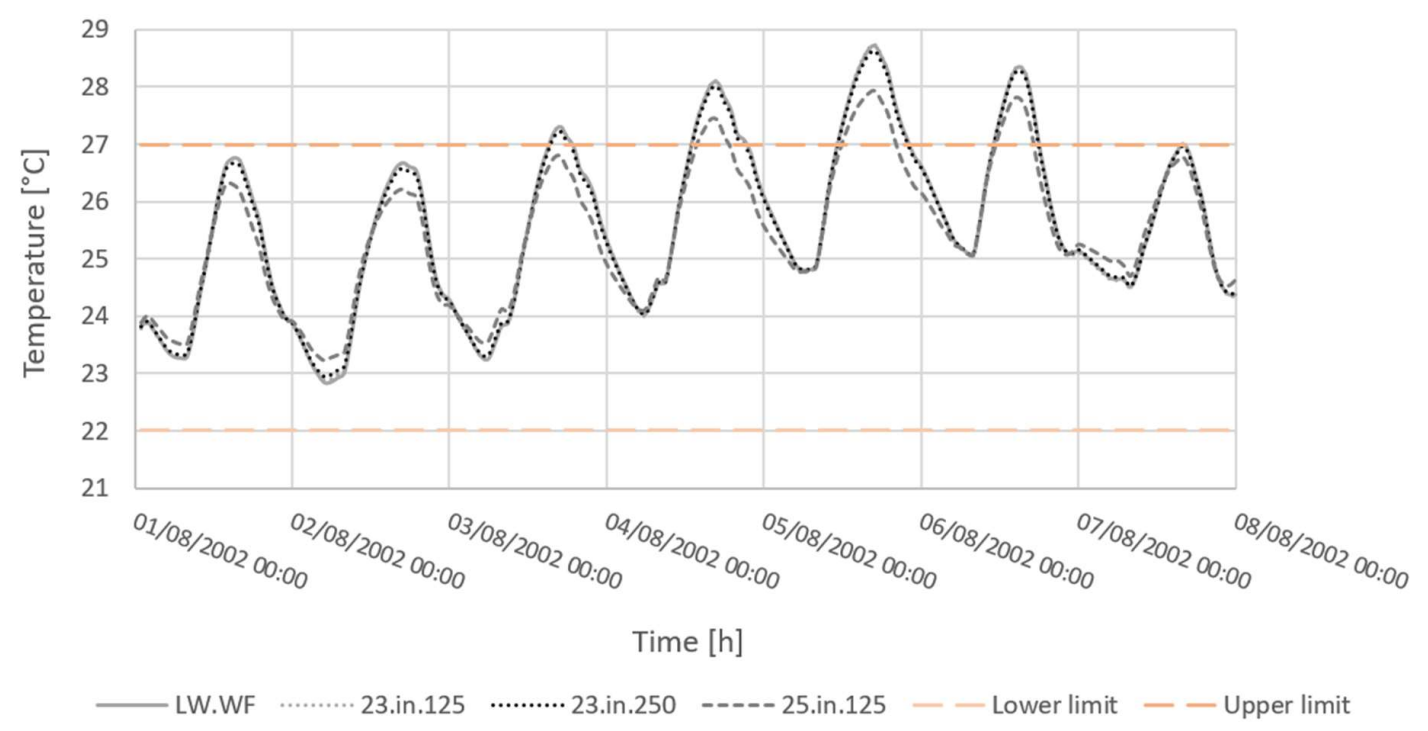

Figure 5: The temperatures obtained with microencapsulated (.in) strategy during the $1^{\text {st }}$ week of Aug

In comparison to LW.WF the microencapsulated PCM with melting point of $23^{\circ} \mathrm{C}$ and thickness of $1.25 \mathrm{~cm}$ (PCM23.in.125) doesn't change the temperature fluctuations. The peak temperature is $28.8^{\circ} \mathrm{C}$ at $17: 00\left(5^{\text {th }}\right.$ of Aug). Similarly, PCM23.in.250 neglectingly softens the main temperature peak to $28.6^{\circ} \mathrm{C}$. When using PCM25.in. 125 the fluctuations slightly dropped compared to LW.WF. The main peak from $5^{\text {th }}$ of Aug was reduced for $0.8^{\circ} \mathrm{C}$ (to $27.9^{\circ} \mathrm{C}$ ). None of the scenarios showed any phase delay.

Figure 6 shows the results obtained using the BioPCM adding strategy (.a) with melting points of $23^{\circ} \mathrm{C}(\mathrm{M} 182)$, $24^{\circ} \mathrm{C}\left(\mathrm{M} 182, \mathrm{M} 91, \mathrm{M} 51\right.$ and M27), $25^{\circ} \mathrm{C}\left(\mathrm{M} 182, \mathrm{M} 91, \mathrm{M} 51\right.$ and M27) and $26^{\circ} \mathrm{C}(\mathrm{M} 182)$. 


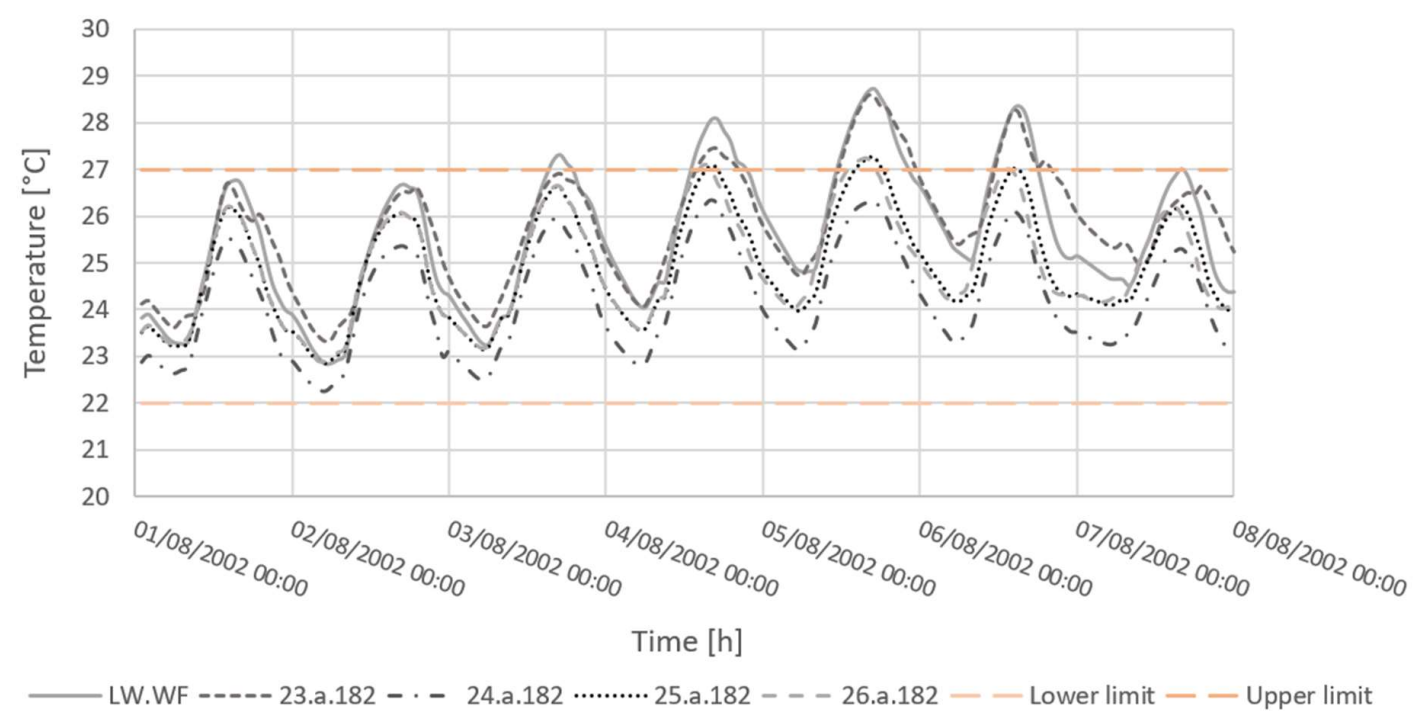

Figure 6: The temperatures obtained with $\operatorname{BioPCM}^{\text {TM }}$ (.a) strategy during the $1^{\text {st }}$ week of Aug

Comparison to LW.WF the BioPCM strategy with melting point of $23^{\circ} \mathrm{C}$ and capacity label of $\mathrm{M} 182$ (PCM23.a.182) reduced the temperatures during the first peak ( $4^{\text {th }}$ of Aug at 17:00). The temperature was reduced for $0.6^{\circ} \mathrm{C}$ (from $28.1^{\circ} \mathrm{C}$ to $27.5^{\circ} \mathrm{C}$ ). However, the PCM23.a. 182 didn't affect the second and the third peak $\left(5^{\text {th }}\right.$ of $\operatorname{Aug}(17: 00 \mathrm{~h})$ and $6^{\text {th }}$ of Aug $\left.(15: 00 \mathrm{~h})\right)$.

The comparison between three strategies within the melting point of $23^{\circ} \mathrm{C}$ is shown in Figure 7. The PCM23.a.182 has the highest capacity among all, however due to its accumulation capabilities it softens only the highest peak but not the latest two $\left(5^{\text {th }}\right.$ and $6^{\text {th }}$ of Aug). From this it could be concluded that, the mis-determination of the melting point cannot be corrected by the addition of the thermal capacity (PCM mass).

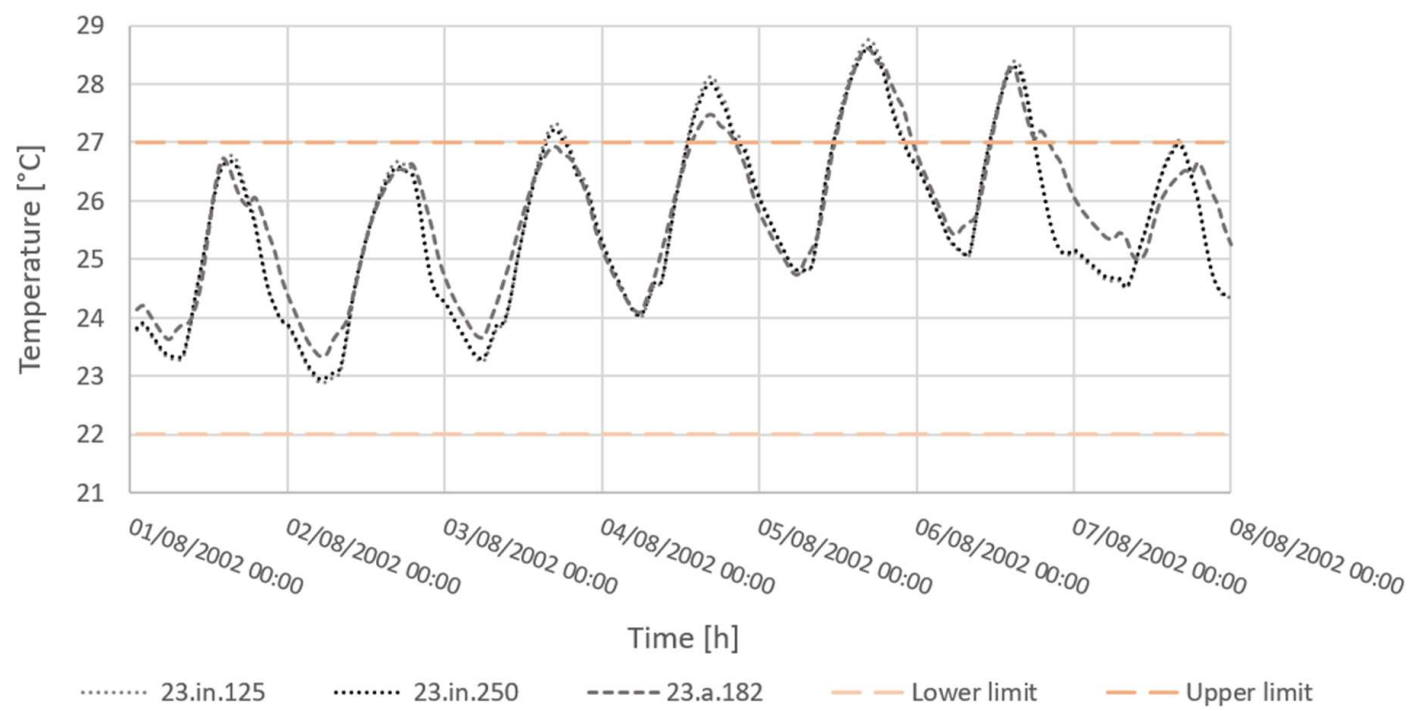

Figure 7: The temperatures obtained with both PCM strategies with melting point of $23^{\circ} \mathrm{C}$ during the $1^{\text {st }}$ week of Aug

In Figure 6 the PCM25.a.182 and PCM26.a.182 showed similar behavior of the fluctuation. Although it is visible that the PCM26.a.182 moves its peaks before peak of LW.WF and PCM25.a.182. The maximum temperature obtained was close to the upper limit. In both cases was on $5^{\text {th }}$ of $\operatorname{Aug}(17: 00 \mathrm{~h})$, is size of $27.3^{\circ} \mathrm{C}\left(-1.5^{\circ} \mathrm{C}\right)$ and 27.0 ${ }^{\circ} \mathrm{C}\left(-1.8^{\circ} \mathrm{C}\right)$ for PCM25.a.182 and PCM26.a.182, respectively. 


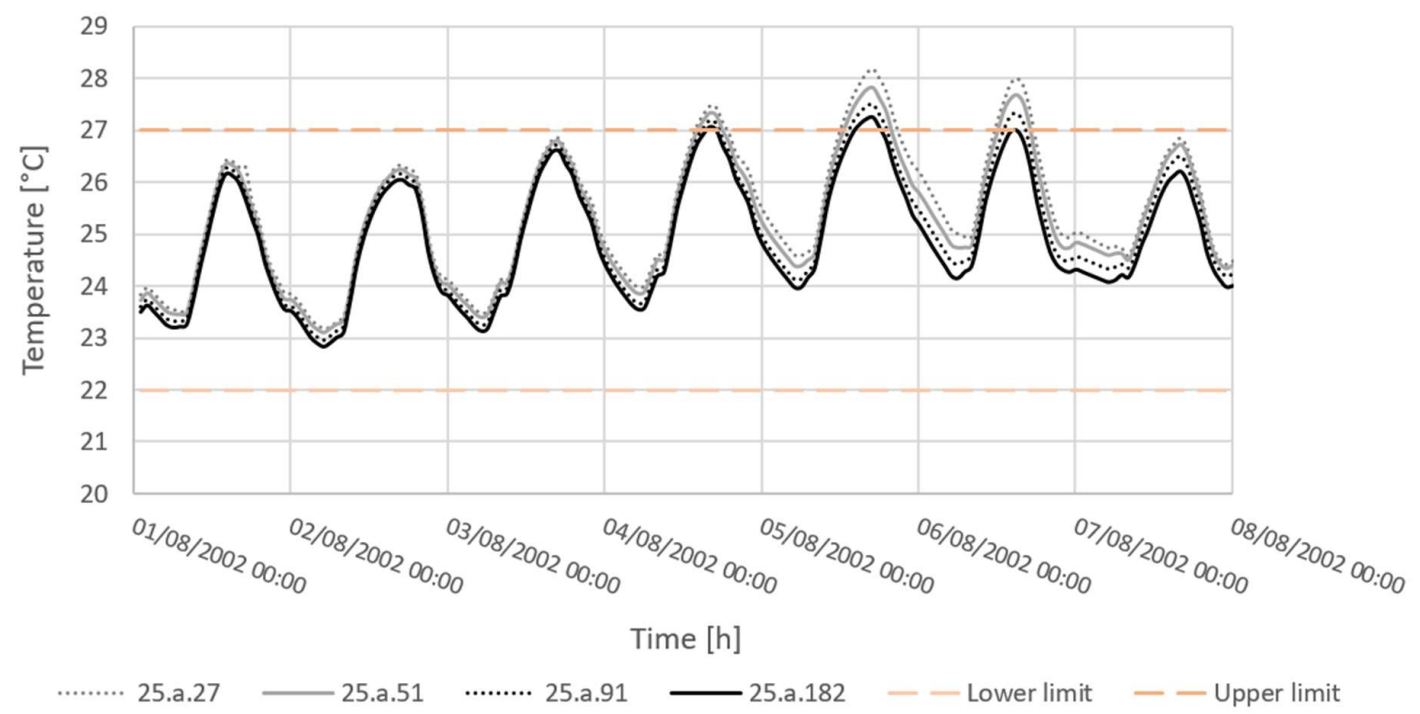

Figure 8: The temperatures obtained with PCM25.a and various heat capacities during the $1^{\text {st }}$ week of Aug

Since the PCM25.a.182 is an existing product, other capacity cases were investigated (M91, M51 and M27) (Fig. 8). It is visible that lower capacity abilities would affect the performance of such case. All of the peaks from $4^{\text {th }}$ to $7^{\text {th }}$ of Aug would increase. Mainly, the highest peak from $5^{\text {th }}$ of August would increase from $27.3^{\circ} \mathrm{C}$ to $27.5^{\circ} \mathrm{C}$, $27.8^{\circ} \mathrm{C}$ and $28.2^{\circ} \mathrm{C}$ for M91, M51 and M27, respectively. The performance of the PCM25.a.91 is similar to the thermal performance of $\mathrm{HW}$.

In Figure 6, the PCM24.a.182 was the most keen on reducing the temperatures, which makes is it the most appropriate choice for this study case. It kept the temperatures below the upper limit during the entire week. On $5^{\text {th }}$ of Aug $(17: 00 \mathrm{~h})$ it reduced the maximum peak of LW.WF for $2.4^{\circ} \mathrm{C}$ (from $28.7^{\circ} \mathrm{C}$ to $26.3^{\circ} \mathrm{C}$ ).

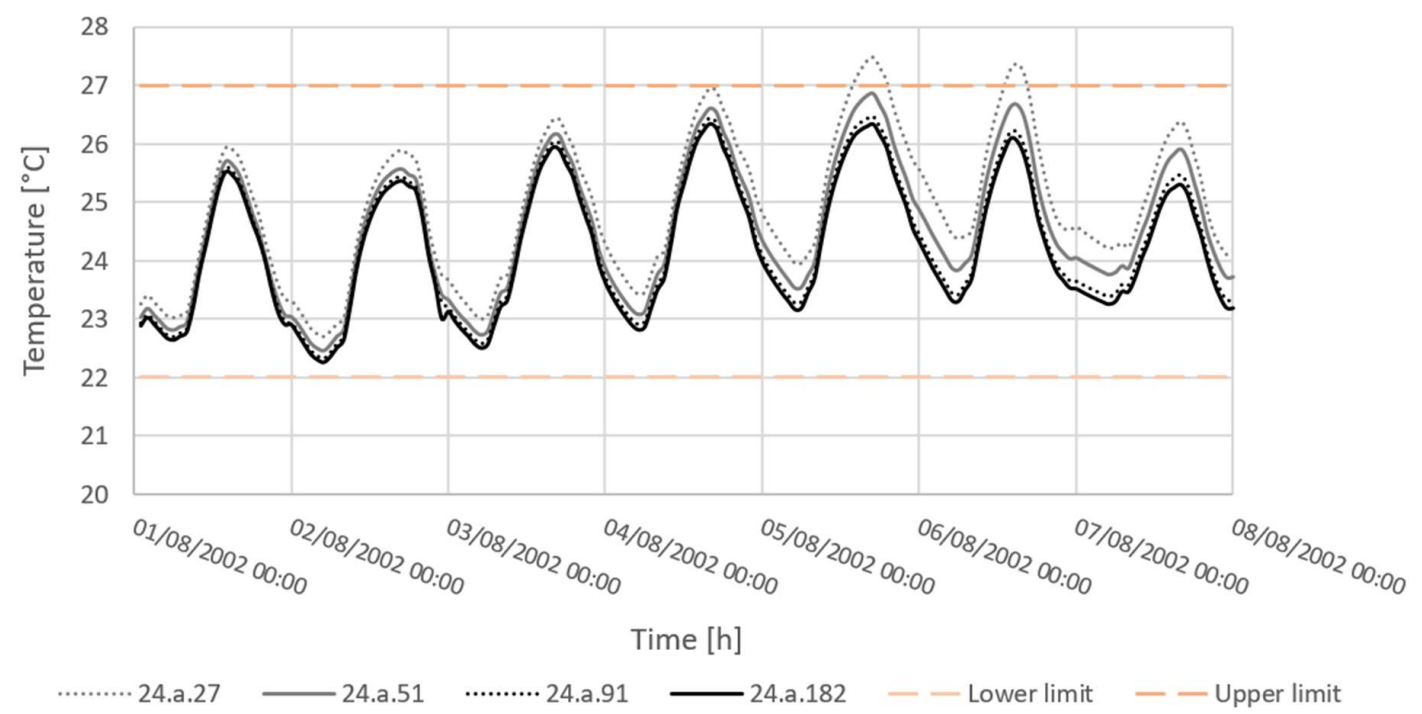

Figure 9: The temperatures obtained with PCM24.a and various heat capacities during the $1^{\text {st }}$ week of Aug

Figure 9 shows, that in comparison to PCM25.a, PCM24.a can keep the temperature peaks below the upper limit in all studied cases but the case with the lowest capacity (M27). This is an indicator of the well chosen melting temperature. In this way, also the costs of the material could be reduced. When using the PCM24.a.M91, the temperature fluctuations remain almost the same, as in case of $\mathrm{M} 182$. Its maximum temperature is $26.5^{\circ} \mathrm{C}$, which is only $0.2^{\circ} \mathrm{C}$ higher compared to M182. With PCM24.a.M51, the temperatures remain below the upper limit, but 
the maximum increases to $26.9^{\circ} \mathrm{C}$. The capacity of PCM24.a.M27 wouldn't be high enough to hold the temperature below the limit and thus the maximum exceeds up to 28.2. In both cases (MP 25 and $24^{\circ} \mathrm{C}$ ), all of the fluctuations are very similar without the phase delays.

On $4^{\text {th }}$ of Aug, the temperatures jumped above the upper limit in most of the cases. Fig. 7, 8 and 9 show the performance of the cases within the same melting point. From the figures, it is possible to observe that on that day the maximum temperatures among cases differ the most. This is probably due to the heat accumulation in the entire building's envelope. As a consequence, the PCM have the time to solidify during the night time. Comparing this case to the following three cases - in their peaks on $5^{\text {th }}, 6^{\text {th }}$ and $7^{\text {th }}$ of Aug, it is possible to observe that the deviations between the maximum temperatures in the peaks are higher. This shows that the material was not completely solidified over the night.

In all of the cases, the phase delay was observed in one hour after the outer temperature changed, with exception of PCM26.a.182. The temperature change occurred instantly with the outer temperature change. It might be, that when the temperature reached $26^{\circ} \mathrm{C}$ the PCM started the accumulation. Before the PCM could started receiving a high amounts of sensible heat, the temperature already started dropping.

In general, the solutions PCM26.a.182, PCM25.a.182 and PCM24.a.182, 91 and 51 performed well enough to be implemented as a support to the earlier presented active system.

In Table 1, the hours above which the upper air and operative temperatures limit was crossed.

Tab. 1: The number of hours of overheating $\mathrm{OH}[\mathrm{h}]$ based on Tai in To (1st week of August)

\begin{tabular}{|c|c|c|c|c|}
\hline Type & HW & LW.WF & PCM25.a182 & PCM23.in.125 \\
\hline Tai, $26^{\circ} \mathrm{C}$ & 51 & 66 & 48 & 66 \\
\hline To, $27^{\circ} \mathrm{C}$ & 6 & 30 & 6 & 30 \\
\hline
\end{tabular}

In the table also the air temperature is given, because the limit within this study is chosen for the $3^{\text {rd }}$ Category. In some residential buildings inhabitants (elderly) might have non-standard or more demanding threshold (upper limit). Thus, the evaluation of the performance should be treated with higher demand (category) or individually. As visible from the table, the overheating occurred in many of the cases (but PCM24.a.182, 91 and 51) and as a consequence the building's interior was overheated. At this point it is important to stress out, that the PCM24.a.182, 91 and 51 are only theoretical and do not represent existing products. To reduce this numbers, it is the additional cooling with active system is required.

The amount of electrical energy needed to cool the rest of the existing products (PCM23.in.125 and PCM25.a.182) is shown in Table 2 .

Tab. 2: The amount of energy needed for cooling $\left[\mathrm{kWh} / \mathrm{m}^{2}\right]$

\begin{tabular}{|c|c|c|c|c|}
\hline Type & HW & LW.WF & PCM25.a182 & PCM23.in.125 \\
\hline Q1st.A & 1.4 & 1.5 & 1.3 & 1.5 \\
\hline Qy & 7.4 & 9.7 & 8.4 & 9.6 \\
\hline Q1st.A-Qy & $19 \%$ & $16 \%$ & $15 \%$ & $16 \%$ \\
\hline
\end{tabular}

The table shows the energy needed for the $1^{\text {st }}$ week of Aug (Q1st.A) and for the entire year (Qy) calculated for the $\mathrm{m}^{2}$ of the building. The table also shows the percentage of the amount of energy needed to cool the building during the $1^{\text {st }}$ week of August, which represents up to $19 \%$ of the cooling demand in comparison to the entire year. The correct choice of the passive system (PCM24.a.182, 91 and 51) could reduce this amount for at least 16 $\%$, which is the hottest week in August. In this way, lightweight buildings can be renovated and both the overheating and energy consumption can be reduced. To find a perfect synergy between the passive and the active system, a detailed investigation of the active systems will be a subject of the future research. 


\section{Conclusions}

Based on the research it can be concluded that the passive system is a good alternative to the active solar cooling system, as it can reduce the cooling demand. Thus, the produced power can be used for other heat reduction purposes in the building, such as an electrical control of the window shutters. The best passive system is chosen based on the outer conditions, such as outdoor air temperature. It is also very important to know what are the characteristics of the building and the ventilation system installed. Lightweight buildings with very little accumulation can be renovated with such systems. In this way, the energy consumption for cooling could be reduced. Thus, when the hours of high solar radiation occur, the energy can be used for other purposes.

It is important that the market offers a wide variety of the products with fine deviations in characteristics, such as melting points. Their availability is crucial for the efficient performance of the passive solution. They might even reduce the amount/capacity of the PCM needed, which can drastically reduce the renovation/installation costs. To guarantee and obtain their full potential, the PCM has to be completely solidified over the night time. The night time solidification has to be a subject of the further investigation. If not passively, the preferred active system for solidification purpose is the studied one. However, the energy consumed has to be minimal.

Another promising investigation is coupling the PCM layers in different combinations. The materials with different melting points combined on the same wall could benefit to the thermal performance of the PCM over the entire year (during the night time in summer and even during the heating season). Moreover, a detailed study of the active/passive system combinations has to be performed in order to find the algorithm for the optimum application of both systems.

\section{References}

Adekunle, T.O., Nikolopoulou, M., 2016. Thermal comfort, summertime temperatures and overheating in prefabricated timber housing. Build Environment, 103, 21-35. DOI: 10.1016/j.buildenv.2016.04.001

Approved American National Standard and American Society of Heating and Air-Conditioning Engineers, 2013. ANSI/ASHRAE Standard 55-2013. Thermal Environmental Conditions for Human Occupancy. Atlanta: ANSI/ASHRAE.

British Standards, 2007. BS EN 15251:2007. Indoor environmental input parameters for design and assessment of energy performance of buildings addressing indoor air quality, thermal environment, lighting and acoustics. London: BSI.

DesignBuilder Software Ltd., 2017. Official webpage. [Online]. [Accessed 10 July 2017]. Available from: https://www.designbuilder.co.uk/

European Committee for Standardization, 1998. CEN CR 1752:1998. Ventilation for buildings - Design criteria for the indoor environment. Brussels: CEN.

European Parliament and Council, 2010. Directive 2010/31/EU of the EU Parliament and of the Council of 19 May 2010 on the energy performance of buildings. Official Journal of the European Union. Available from: https://eur-lex.europa.eu/eli/dir/2010/31/oj

HEART Horizon2020, 2017. [Online]. [Accessed 17 January 2018]. Available from: http://cordis.europa.eu/project/ren/211645 en.html

Knauf Gips KG, 2018. Product Data Sheet Knauf Comfortboard 23: [Online]. [Accessed 10 July 2017]. Available from: http://micronal-pcm-app.de/files/2016-04-16__generic_heat_storage_capacity_comfortboard_23.pdf

Pajek L., Hudobivnik B, Kunič R., Košir M., 2017. Improving thermal response of lightweight timber building envelopes during cooling season in three European locations. Journal of Cleaner Production. 156, 939-952. DOI: 10.1016/j.jclepro.2017.04.098

Phase change Energy Solutions Inc., 2016. BioPCM. [Online]. [Accessed 10 July 2016]. Available from: www.phasechange.com/

Stropnik, R., Stritih, U., 2016. Increasing the efficiency of PV panel with the use of PCM. Renewable Energy 97 , 671-679. DOI: 10.1016/j.renene.2016.06.011 
PV and PVT Systems for Buildings and Industry 


\title{
Field test results of an innovative PV/T collector for an outdoor swimming pool
}

\author{
Laetitia Brottier ${ }^{1,2}$ and Rachid Bennacer ${ }^{2}$ \\ 1 DualSun, Marseille (France) \\ 2 LMT /ENS-Cachan/CNRS/Université Paris Saclay, Cachan (France)
}

\begin{abstract}
Hybrid solar PV/T has the potential to become a major player in the renewable energy sector, but one of the most important barriers is the lack of a proven track record in terms of reliability and performance. In order to address this issue, a study was conducted to monitor field energy performances of an outdoor swimming pool installation near Geneva (Switzerland) equipped with an innovative unglazed PV/T collector $\left(1.64 \mathrm{~m}^{2}, 250 \mathrm{Wp}, 912 \mathrm{Wth}\right)$.

For a $3000 \mathrm{~m}^{3}$ outdoor swimming pool and $8000 \mathrm{~L} /$ day of hot water needs, the installation of $300 \mathrm{~m}^{2}$ of PV/T collectors generated 55MWh of thermal production from mid-May to mid-September and 52MWh annual photovoltaic production. Performances were higher than expected from the TRNSYS study.
\end{abstract}

Keywords: Photovoltaic thermal (PV/T) collector; Field test; Energy performance,

\section{Introduction}

$\mathrm{PV} / \mathrm{T}$ is not a new technology, as Kern and Russell published a report for the MIT already in 1978. Hybrid collectors have been optimized over the years, and even in 2003 Zondag et al. gave a large review of possible designs for collectors. Since the 2000s commercial collectors have been launched, some manufacturers had underestimated the technological difficulties but in the 2010s, the commercial products have become more reliable and at the end of 2013, the norm ISO 9806 proposed a procedure to test the hybrid collector reliability and performances. More recent reviews of PV/T technologies has been done by Zhang et al. (2012), Good et al. (2015), Wu et al. (2016) or Das et al. (2018).

The photovoltaics dropped its price, the competitiveness of the hybrid solution has become more and more obvious. But Dupeyrat et al. noted in 2014 that only a few study with a global system approach with data from the field confirming a competitive application for the technology. This study wants to contribute with data for PV/T collectors heating an outdoor swimming pool.

\section{PV/T characteristics}

The PV/T module in the study is based on the unglazed flat-plate liquid design described in the reviews. It is $1677 \times 990 \times 40 \mathrm{~mm}^{3}$ and has 60 monocrystalline cells for a nominal power of $250 \mathrm{Wp}$ (power loss $-0.44 \% /{ }^{\circ} \mathrm{C}$ ). The thermal characteristics $\left(\eta_{0}=57.8 \% ; \mathrm{b}_{\mathrm{U}}=0.028 \mathrm{~s} / \mathrm{m} ; \mathrm{b}_{1}=12.08 \mathrm{~W} / \mathrm{K} / \mathrm{m}^{2} ; \mathrm{b}_{2}=1.842 \mathrm{~W} . \mathrm{s} / \mathrm{K} / \mathrm{m}^{3}\right)$ were determined by tests conducted at the TÜV Rheinland laboratory following the Solar Keymark certification rules (ISO 9806 : 2013).

Table 1. Electrical and thermal characteristics

\begin{tabular}{|c|c|}
\hline Dimensions & $1677 \times 990 \times 40 \mathrm{~mm}^{3}$ \\
\hline Number of cells & 60 \\
\hline Type of cells & Monocrystalline $(6$ inches) \\
\hline Nominal power $\left(\mathbf{P}_{\mathbf{m p p}}\right)$ & $250 \mathrm{Wp}$ \\
\hline $\mathbf{P V}$ module efficiency $(\boldsymbol{\eta} \mathbf{P v})$ & $15,40 \%($ Tolerance $:-3 \% / 3 \%)$ \\
\hline${\text { Power loss } /{ }^{\circ} \mathbf{C}\left(\boldsymbol{\beta}_{\mathbf{p}}\right)}$ & $-0,44 \% /{ }^{\circ} \mathrm{C}$ \\
\hline
\end{tabular}




\begin{tabular}{|c|c|}
\hline Heat transfer fluid (HTF) & Water/glycol mix \\
\hline Absorber surface area & $1,58 \mathrm{~m}^{\mathbf{2}}$ \\
\hline Conversion factor $\left(\boldsymbol{\eta}_{\mathbf{0}}\right)$ & $57,8 \%$ \\
\hline Heat loss coefficient $\left(\mathbf{b}_{\mathbf{1}}\right)$ & $12,08 \mathrm{~W} / \mathrm{K} / \mathrm{m}^{2}$ \\
\hline Wind dependency of collector efficiency $\left(\mathbf{b}_{\mathbf{U}}\right)$ & $0,028 \mathrm{~s} / \mathrm{m}$ \\
\hline Wind dependency of heat loss coefficient $\left.\mathbf{( b}_{\mathbf{2}}\right)$ & $1,842 \mathrm{~W} . \mathrm{s} / \mathrm{K} / \mathrm{m}^{3}$ \\
\hline Stagnation temperature $\left(\mathbf{T}_{\text {stagn }}\right)$ & $74,7^{\circ} \mathbf{C}$ \\
\hline
\end{tabular}

\section{Presentation of the field test}

Indoor swimming pool systems coupled with PV/T collectors have already been studied by simulation by Buonomano et al. (2015), but few experimental works have confirmed the expected performances with real installations, as has been done in this study.

In order to verify the in-situ reliability and performance for outdoor swimming pools of the innovative hybrid solar PV/T module, an installation was monitored near Geneva in the South of Switerland (Lat/ Long 46.2 / 6.1) with 187 PV/T modules (picture Fig.2) from July 2017 to June 2018. The PV/T modules are connected to heat exchangers and are used to preheat the water for the showers and to heat the pools (Fig.2). In order to monitor the system, Aquametro CALEC calorimeter is placed just before the solar heat exchangers (average data every 4 days).

Key parameters of the solar installation are provided in Table 2.

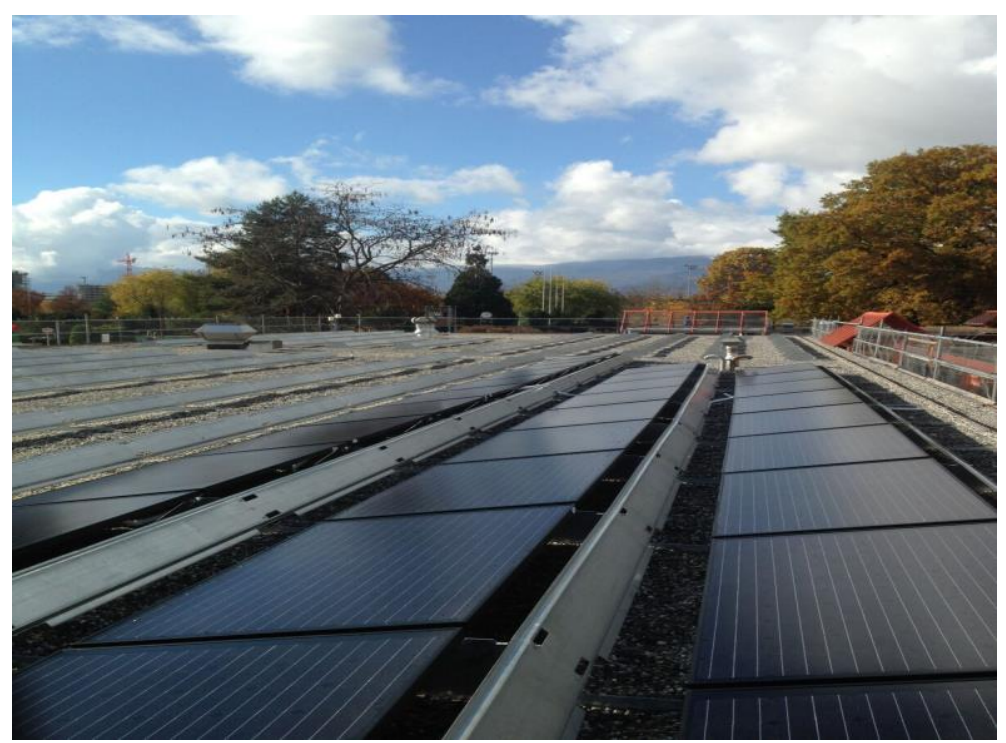

Fig. 2: picture of the installation

Tab. 2: picture and parameters of the installation

\begin{tabular}{|c|c|}
\hline Number of unglazed PV/T & $187\left(\sim 300 \mathrm{~m}^{2}\right)$ \\
\hline Integration type & Superimposed \\
\hline Orientation $\left(\mathbf{0}^{\circ}=\right.$ South $)$ & South $\left(0^{\circ}\right)$ \\
\hline Slope & $11.6^{\circ}$ \\
\hline Shower needs & $\sim 8000 \mathrm{~L} /$ day \\
\hline Swimming pools dimensions & $1960 \mathrm{~m}^{2}$ for $3000 \mathrm{~m}^{3}$ \\
\hline Pool temperature setup & $29^{\circ} \mathrm{C}$ \\
\hline
\end{tabular}

The solar energy goes to hot water preheating if the temperature of the panels is $5^{\circ} \mathrm{C}$ higher than the bottom of the sanitary tank or to the pool if it is higher than $30^{\circ} \mathrm{C}$.

\section{TRNSYS study and field test results}

Simplified hydraulic installed system is given in Figure 3. A TRNSYS model has been performed, and the used 
diagram is given in Figure 4.

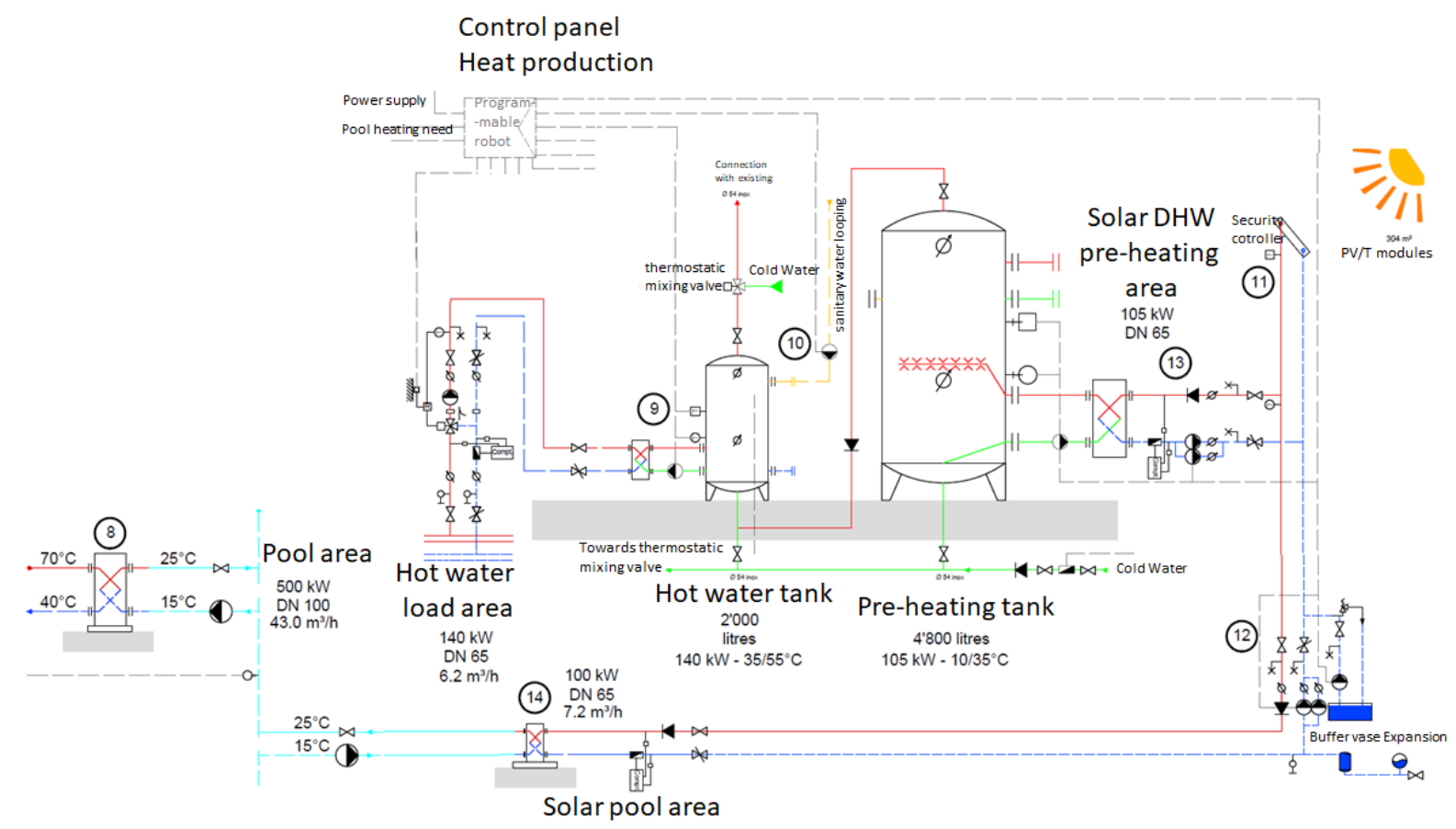

Fig. 3: Simplified hydraulic installed system

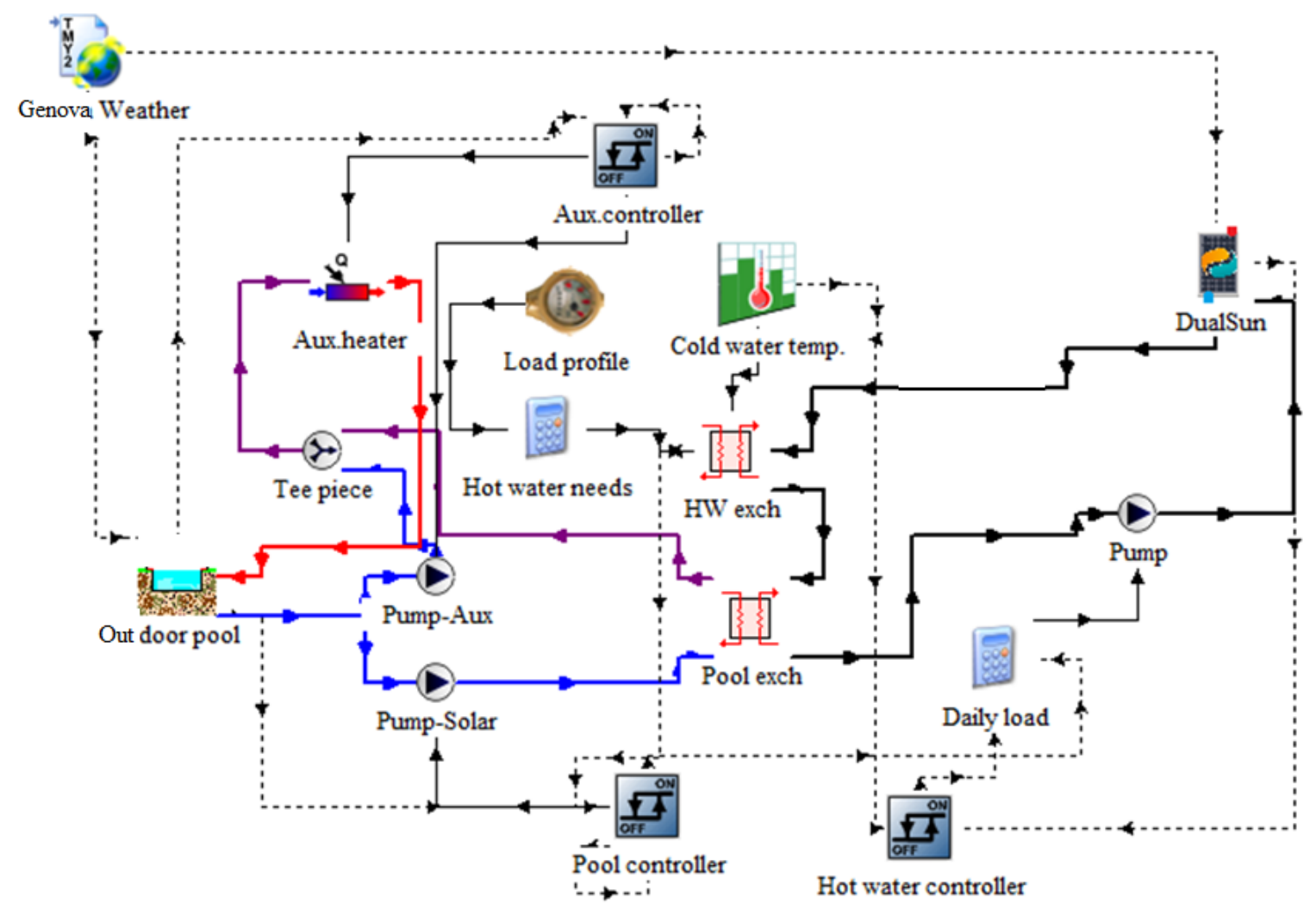

Fig. 4: The TRNSYS diagram of the installation

Photovoltaic and Solar heat for hot water needs are really near to predictions over the opening season (mid-May to mid-September) with respectively a real production of $102 \%$ and $106 \%$ of the simulation result. The monitoring of the solar heat for pools was not yet functionnal but will be in a near future. 


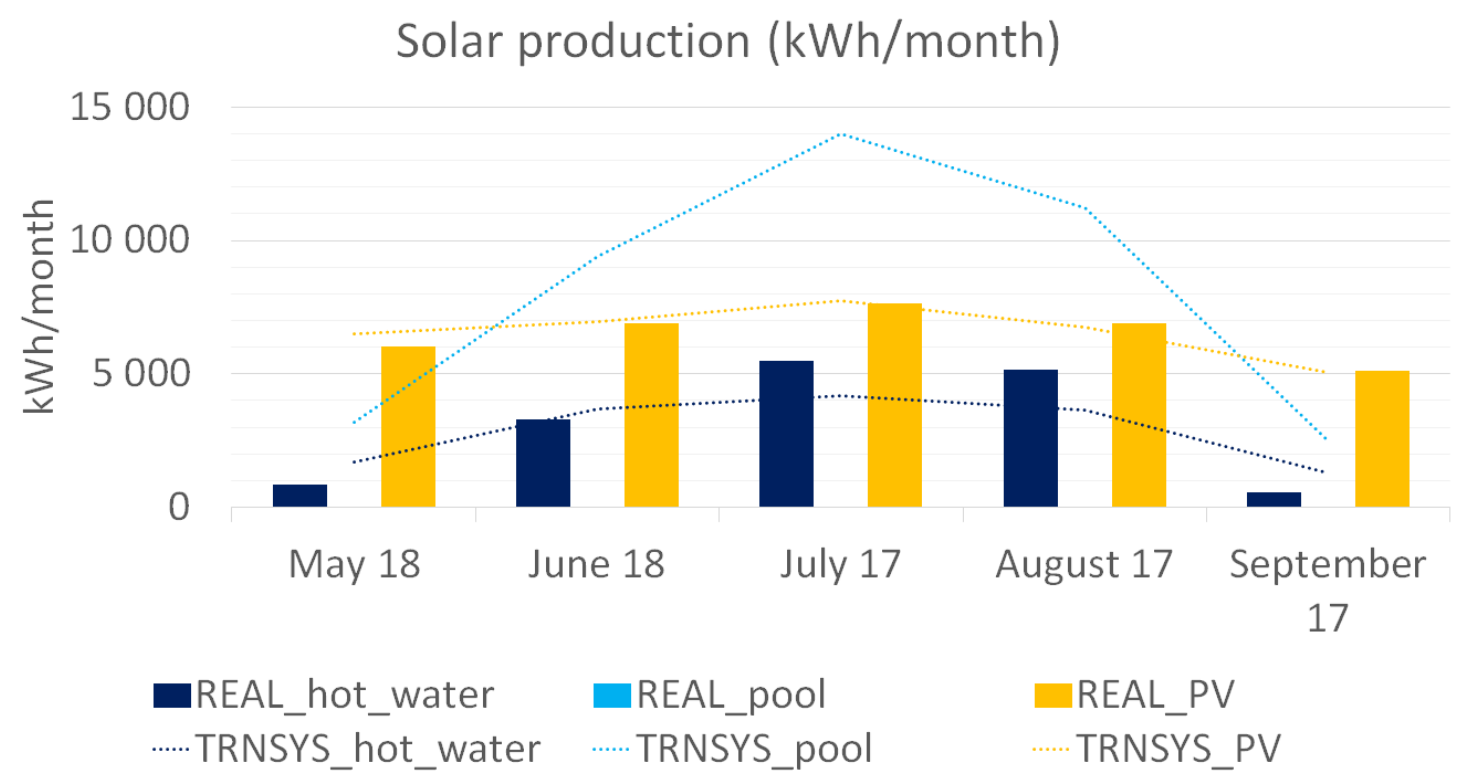

Fig. 5 : Comparison with monitored results (July 2017 to June 2018)

The cost of the installation was approximately $205.000 €$ for $52 \mathrm{MWh}$ of electricity and $55 \mathrm{MWh}$ of solar heat generated per year, not including the subsidies. This leads to a cost of energy of $9,6 \mathrm{c} € / \mathrm{kWh}$ if we assume a stable production over 20 years, neglecting inflation and maintenance costs.

\section{Conclusion}

The $300 \mathrm{~m}^{2} \mathrm{PV} / \mathrm{T}$ panels provide $30 \%$ of the energy for the $8000 \mathrm{~L} /$ day for shower needs and $30 \%$ of the heating needs for the $3000 \mathrm{~m}^{3}$ outdoor swimming pool during 4 months of the year (Mid May - Mid September) and $52 \mathrm{MWh} / \mathrm{yr}$ of photovoltaic electricity. The measured results of the PV/T panels for the photovoltaic and the heat for the showers are very close - and even slightly higher (respectively $+2 \%$ and $+6 \%$ ) from what predicted with the TRNSYS model for the first opening season, the monitoring of the heat for the pool was not yet available but would be soon.

The cost of the energy with this hybrid solution for outdoor swimming pool is already around $10 \mathrm{c} € / \mathrm{kWh}$ and will continue to decrease and may be competitive without subsidies in a few years.

\section{References}

Buonomano, A., De Luca, G., Figaj, R.D., Vanoli, L., 2015. Dynamic simulation and thermo-economic analysis of a PhotoVoltaic/Thermal collector heating system for an indoor-outdoor swimming pool. Energy Conversion and Management. 99, 176-192. https://doi.org/10.1016/j.enconman.2015.04.022.

Dupeyrat, P., Menezo, C., Fortuin, S., 2014. Study of the thermal and electrical performances of PVT solar hot water system. Energy and Buildings. 68, 751-755. http://dx.doi.org/10.1016/j.enbuild.2012.09.032.

Das, D., Kalita, P., Roy, O., 2018, Flat plate hybrid photovoltaic- thermal (PV/T) system: A review on design and development. Renewable and Sustainable Energy Reviews. 84, 111-130. http://dx.doi.org/10.1016/j.rser.2018.01.002.

Good, C., Chen, J., Dai, Y., Grete Hestnes, A, 2015. Hybrid photovoltaic-thermal systems in buildings - a review. Energy Procedia. 70, 683 - 690. http://dx.doi.org/10.1016/j.egypro.2015.02.176.

ISO 9806:2013 Solar energy - Solar thermal collectors - Test methods.

Kern EC, Russell MC, 1978, Combined photovoltaic and thermal hybrid collector systems. In: 13th IEEE, Washington.

Wu, J., Zhang, X., Shen, J., Wu, Y., Connelly, K., Yang, T. Tang, L., Xiao, L., Wei, L., Jiang, K., Chen, C., Xue, P., Wang, H., 2017, A review of thermal absorbers and their integration methods for the combined solar photovoltaic/thermal (PV/T) modules. Renewable and Sustainable Energy Reviews. 75, 839-854. http://dx.doi.org/10.1016/j.rser.2016.11.063. 
Zhang X., Zhao X., Smith S. , Xu J, Yu X. Review of R\&D progress and practical application of the solar photovoltaic/thermal (PV/T) technologies. Renewable and Sustainable Energy Reviews; Vol 16, Issue 1, 2012, p. 599-617. http://dx.doi.org/10.1016/j.rser.2011.08.026.

Zondag, H.A., de Vries, D.W, van Helden, W.G.J, van Zolingen, R.J.C., van Steenhoven, A.A., 2003, The yield of different combined PV-thermal collector designs. Solar Energy. 74, 253-269. http://dx.doi.org/10.1016/S0038$\underline{092 X(03) 00121-X}$. 


\title{
Performance Assessment of a Photovoltaic-Thermal Roof with Modular Heat Exchanger
}

\author{
Steffen Brötje $^{1}$, Maik Kirchner ${ }^{1}$, Thomas Schabbach ${ }^{2}$ and Federico Giovannetti ${ }^{1}$ \\ ${ }^{1}$ Institute for Solar Energy Research GmbH Hamelin (ISFH), Am Ohrberg 1, 31860 Emmerthal \\ Tel.: +495151/999-501; E-Mail: giovannetti@isfh.de \\ ${ }^{2}$ Hochschule Nordhausen, Institut für Regenerative Energietechnik, Weinberghof 4, 99734 Nordhausen
}

\begin{abstract}
This paper presents the thermal performance of a novel photovoltaic-thermal (PV/T) system conceived for roof integration. The methods of prototype design are described briefly. Main feature of the system is the modular assembly of the metallic heat exchanger, which also serves as self-supporting mounting device for the photovoltaic modules and assumes a static function. The design of the heat exchanger has been optimized by using numerical FEM simulations with regard to both energetic and economic requirements. We investigate the performance of the system by means of long-term measurements on a large-sized PV/T roof prototype equipped with thin film CdTe photovoltaic modules under real weather conditions and at different operation conditions. The evaluation is carried out according to the Standard ISO 9806, focusing on the quasi-dynamic test method. The experimental results $\left(\eta_{0, \text { MPP }}=0.66 ; a_{1}=11.56 \mathrm{~W} / \mathrm{m}^{2} \mathrm{~K} ; \mathrm{a}_{2}=0.09 \mathrm{~W} / \mathrm{m}^{2} \mathrm{~K}^{2} ; \mathrm{a}_{3}=1.26 \mathrm{~J} /\left(\mathrm{m}^{3} \mathrm{~K}\right), \mathrm{a}_{6}=0.03 \mathrm{~s} / \mathrm{m}\right)$ prove the efficient heat transfer from the absorber to the fluid and are in good agreement with the simulations.
\end{abstract}

Keywords: photovoltaic-thermal collector, building integration, quasi-dynamic test method

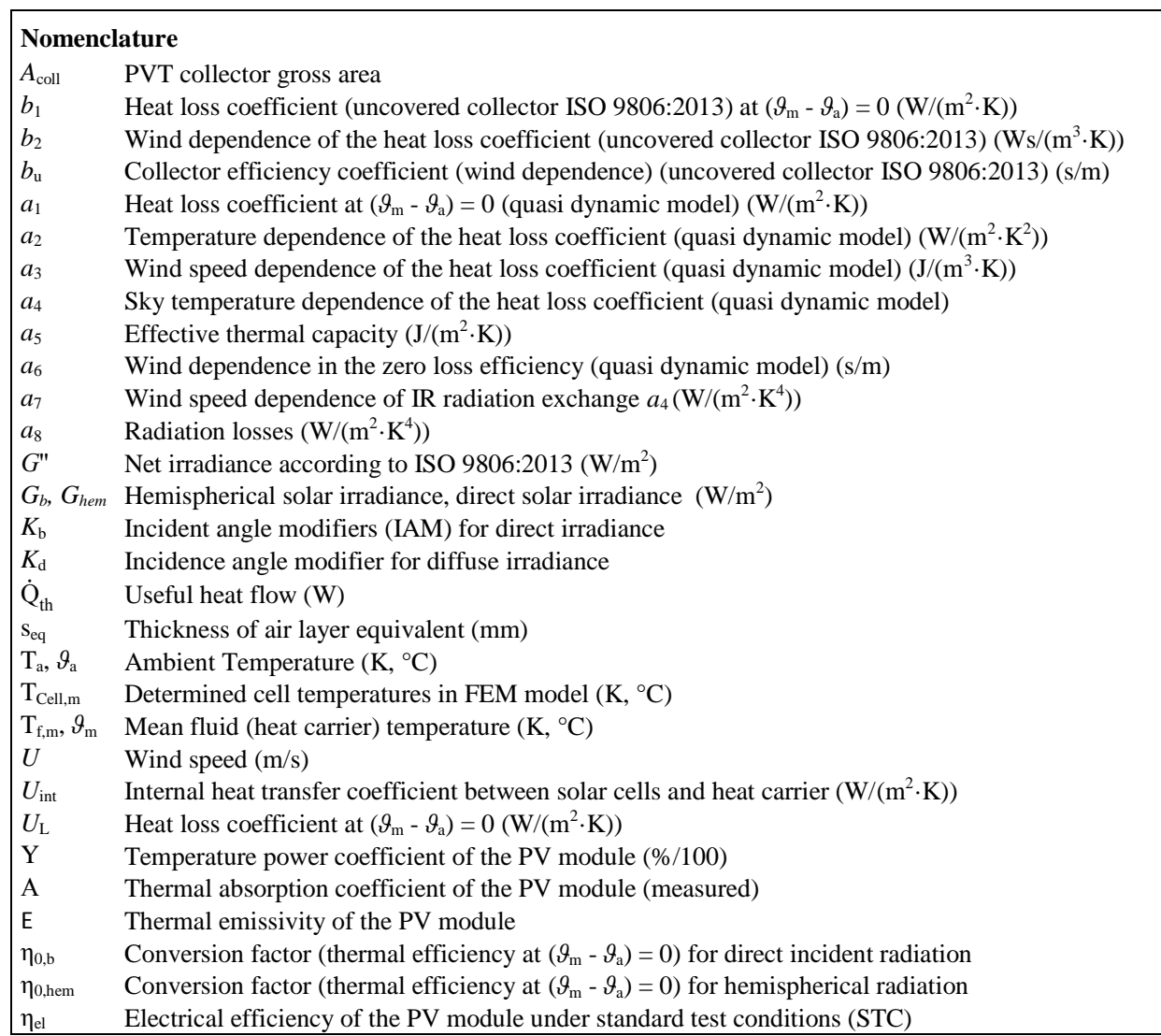

\section{Introduction}

Photovoltaic-thermal (PV/T) devices convert solar radiation into both useful heat and electricity. This paper shows the design optimization and analyses the thermal and electrical performance of a specific uncovered system for roof-integration comprising a particularly slender and uniform architectural appearance. Other solutions exist on the market, most of them intended for on-roof installation (Brötje et al., 2018). For solar heat production, a heat exchanger has been assembled to the rear side of the modules. The geometry of the heat exchanger was improved, which led to the prototypic solution shown in Figure 1: Planar aluminium profiles with 
integrated fluid channels which serve both as mounting system for the PV modules and for the heat carrier transport. Design targets of this device were efficient heat transfer and easy on-roof assembly likewise. The PV modules are clamped onto the aluminium profiles without use of adhesive layers. The design approach improves the architectural appearance of the overall system, as the profiles can be integrated into the roof construction. The design is modular to allow tight adaption to many standard roof dimensions and geometries. This also reduces convective heat losses; apart from tight roof integration, the heat exchanger is not further insulated against the ambience. Hence, the system is designed for low-temperature heat production that generally require heat pump applications to supply space heating or domestic hot water systems.

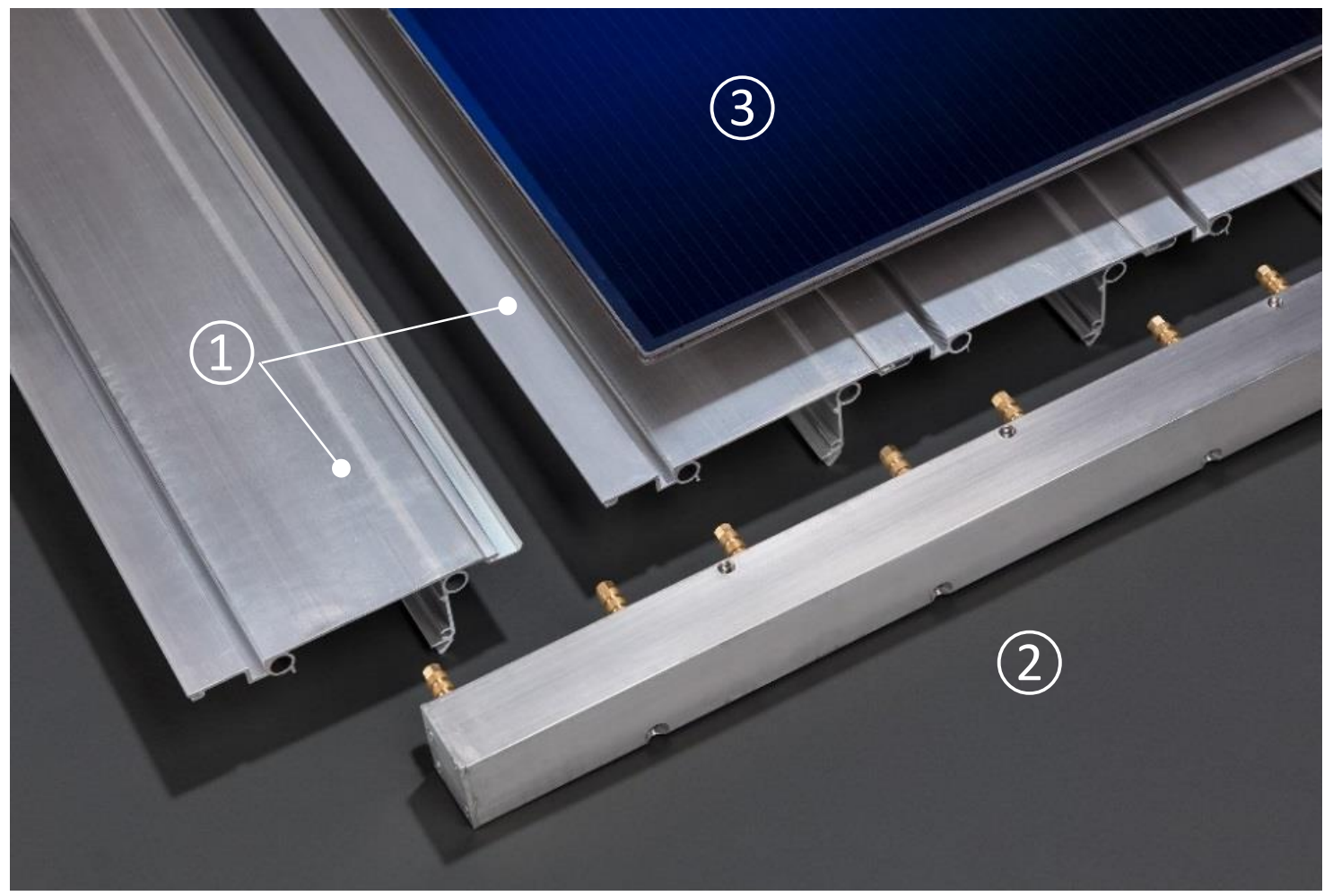

Figure 1: (Unassembled) main components of the PV/T system: Extruded profiles (1), manifold (2) and PV module (3).

During the design process that led to the prototype shown in Figure 1, the overall heat transfer was analysed and optimized by means of finite-element-method (FEM) modelling of the heat transfer and hydraulic resistance modelling. The methods used for evaluating the heat transfer and the energy efficiency are mainly based on previous research works, measurements and numerical calculations referring to the potential of PV/T collectors with glue-free and detachable connections of PV module and heat exchanger, as described in Brötje et al. (2018). We proceed to refer the final design stage of this process in section 2 and report experimental tests obtained with the established prototype in section 3. The prototype was tested at the outdoor test facility of the Institute of Solar Energy Research (ISFH).

\section{Prototype design}

\subsection{Preliminary developments}

Before developing the PV/T system presented here, the manufacturers of the new system developed a predecessor PV/T system. That system built upon an existing roof-integrated cadmium-telluride based PV system by the same manufacturer. Using the same outdoor test environment as in the following investigations, the previous PV/T system showed a thermal zero-loss efficiency of $\eta_{0, \text { hem }}=44 \%$ in open-circuit (OC) operation of the PV generator. Due to the construction, which included loose connections of heat exchanger and fluid pipes as well as profiled, partly curved surfaces, critical heat resistances were detected during testing. These were identified and quantified by a combined simulation/measurements approach. This enabled us to draw conclusions for the new system by means of efficiency and costs. Comparative performance tests on several other PV/T prototypes developed at ISFH have proven a high performance level of the new system, even with clamped and glue-free compound and glass-glass modules. It turned out that the most important design requirement is a flat surface of the extruded aluminium profile (Brötje et al., 2018). 


\subsection{Heat transfer modelling and optimisation}

The heat transfer properties of the PV/T prototype were optimized by means of finite element method (FEM) modelling \& simulation using the software suite Comsol Multiphysics 4.4. The simulation studies concerned variations of the design geometry, material selections, and also variations of manufacturing tolerances (irregularities, macroscopic unevenness and surface roughness of the heat exchanger) that may lead to misconnections between heat exchanger and PV module. Inherent side conditions of the thermal optimization routine were mechanical stability of the device as well as minimal manufacturing effort of the assembly parts (components and hydraulic connections). The following aspects have been considered during the modelling:

- Distance between fluid channels of the heat exchanger profile / number of channels per profile

- Material strengths of heat exchanger profile, PV glass and possible connecting materials

- Special geometries related to the roof integration, such as the distance between heat exchanger upper surface and fluid channels

- Heat resistances between PV module and heat exchanger surface, expressed as equivalent air gap $s_{\text {eq }}$

- Optical properties of heat exchanger coating (e.g. anti-corrosive)

- Type and concentration of heat carriers, such as water and mixtures of water and ethylene glycol or propylene glycol

- Mass flow rate of the heat carrier, correlating with number of fluid channels and channel diameter.

We employ the overall internal heat transfer coefficient $U_{\text {int }}$ as appropriate target quantity for the thermal optimization procedure. It is defined by

$$
U_{\text {int }}=\frac{\dot{Q}_{\mathrm{th}}}{A_{\text {coll }}\left(T_{\text {Cell, } \mathrm{m}}-T_{\mathrm{f}, \mathrm{m}}\right)},
$$

where $\dot{Q}_{\text {th }}$ denotes the useful heat flow, $A_{\text {coll }}$ the PVT collector gross area, $T_{\text {Cell,m }}$ the simulated mean PV module temperatures and $T_{\mathrm{f}, \mathrm{m}}$ the mean temperature of the heat carrier fluid, respectively.

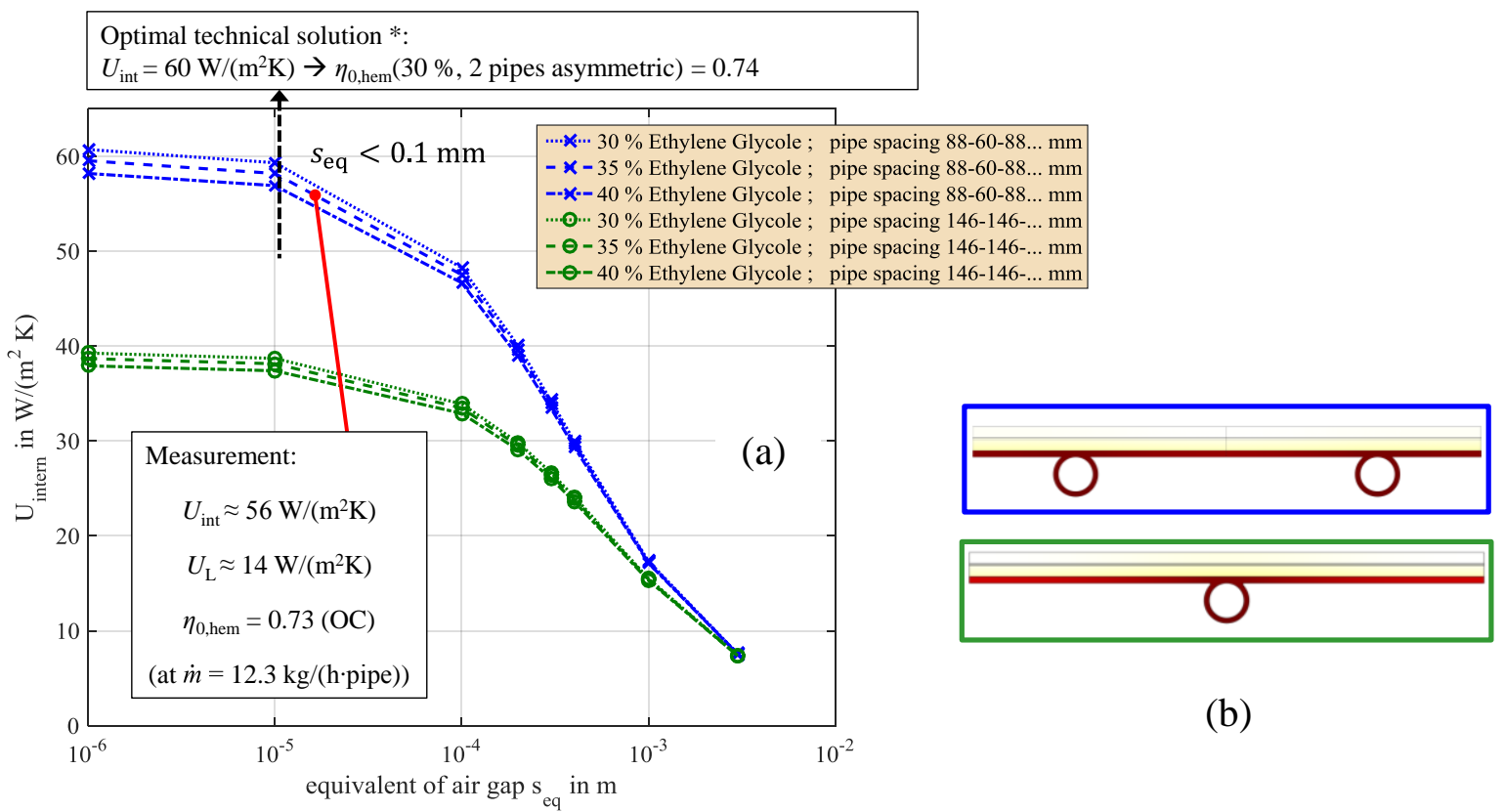

Figure 2: (a) Simulations of the internal heat transfer coefficient $U_{\text {int }}$ compared to the value resulted from the measurement of the PV/T prototype test field. *: 2 sheets Al-Al at 1 bar, according to: (Incropera et al., 2002). (b) Cross-sectional sketches of the final design solutions (pipe separations 88-60-88 mm and 146-146 mm per fin. The asymmetric spacing of the channels of the former results from structural conditions of the mounting system.

Manufacturing irregularities, macroscopic unevenness and surface roughness of the heat exchanger can impair the thermal contact between heat exchanger and PV module. Such misconnections are represented by a homogeneous air gap with variable width $s_{\text {eq }}$ across the collector area in the FEM model. Hence, the modelled heat resistance becomes a function of the width variable $s_{\text {eq }}$, which in turn can be fitted to the measured data of the prototype. Smaller values of $s_{\mathrm{eq}}$ correspond to reduced assembly part misconnections and improve the internal heat transfer coefficient. Reduced misconnections can be achieved through higher manufacturing 
quality, however at the expense of increased manufacturing costs. Since $U_{\text {int }}$ is also dependent of other design options like the distance of the fluid channels or the material choice, a remnant small value of $s_{\text {eq }}$ may be tolerated. (Brötje et al., 2018). Figure 2(a) shows the relation of the internal heat transfer coefficients $U_{\text {int }}$ and the equivalent air gap $s_{\text {eq }}$ for two different designs (88-60-88 $\mathrm{mm}$ and 146-146 mm pipe distance, respectively, see (b)) and different glycole concentrations of the heat carrier fluid. The fluid channels are modelled as parallel pipes for the sake of simplicity, which are part of the mounting plate fins at the given separations. Other pipe configurations have been regarded; it has turned out, however, that denser pipe separations did not lead to relevant increase of the thermal efficiency. The solutions $88-60-88 \mathrm{~mm}$ and $146-146 \mathrm{~mm}$ per fin thus were regarded as optimal designs under economic and constructive boundary conditions, prototyped and subsequently tested at ISFH; the related test method is explained in Section 3. The respective measurements are indicated by the red point in Figure 2(a). Referring to the case of $88-60-88 \mathrm{~mm}$ pipe separation, the data $U_{\text {int }}=56 \mathrm{~W} /\left(\mathrm{m}^{2} \mathrm{~K}\right)$ measured with the prototype falls in the interval between the simulated data nodes $U_{\text {int }}\left(s_{\text {eq }}=0,1 \mathrm{~mm}\right)=48$ $\mathrm{W} /\left(\mathrm{m}^{2} \mathrm{~K}\right)$, and $U_{\text {int }}\left(s_{\text {eq }}=0,01 \mathrm{~mm}\right)=60 \mathrm{~W} /\left(\mathrm{m}^{2} \mathrm{~K}\right)$. By linear extrapolation of the inverse function $s_{\text {eq }}\left(U_{\text {int }}\right)$ we can identify a corresponding air gap width

$$
s_{\text {eq }}\left(56 \mathrm{~W} /\left(\mathrm{m}^{2} \mathrm{~K}\right)\right) \approx 0,025 \mathrm{~mm}
$$

for the tested prototype. We see from the curvature of the simulated data in Figure 2(a), that further reduction of the gap widths $s_{\text {eq }}$ has limited effect on the heat transfer coefficient $U_{\text {int }}$ at this level. Therefore, cost-intensive measures to increase the manufacturing quality are not quite justified.

\section{$2.2 \quad$ Hydraulic field modelling}

The PV/T prototype design also regards hydraulic field simulations. Design target is an optimal (uniform) flow distribution of the fluid through the heat exchanger channels of the profile due to balanced hydraulic pressure resistances. The hydraulic pressure losses of the collector fields was evaluated by means of finite element methods for various flow settings and field geometries. Figure 3 shows the result - overall pressure loss and related thermal power - as function of the area-specific mass flow for a selected parallel hydraulic layout. Due to the hydraulic design of the collector components and the harp construction of the parallel heat exchangers, the collector field exhibits laminar and very uniformly distributed flow conditions within the heat exchanger profiles. Accordingly, the main hydraulic resistance is expected for the main connecting pipes, where turbulent flow states are observed even at very low mas flow rates. The simulations confirm this sensitivity, compare the blue lines in Figure 3 regarding two pipe diameters of $26 \mathrm{~mm}$ (solid line) and $32 \mathrm{~mm}$ (dashed line), respectively.

(a)

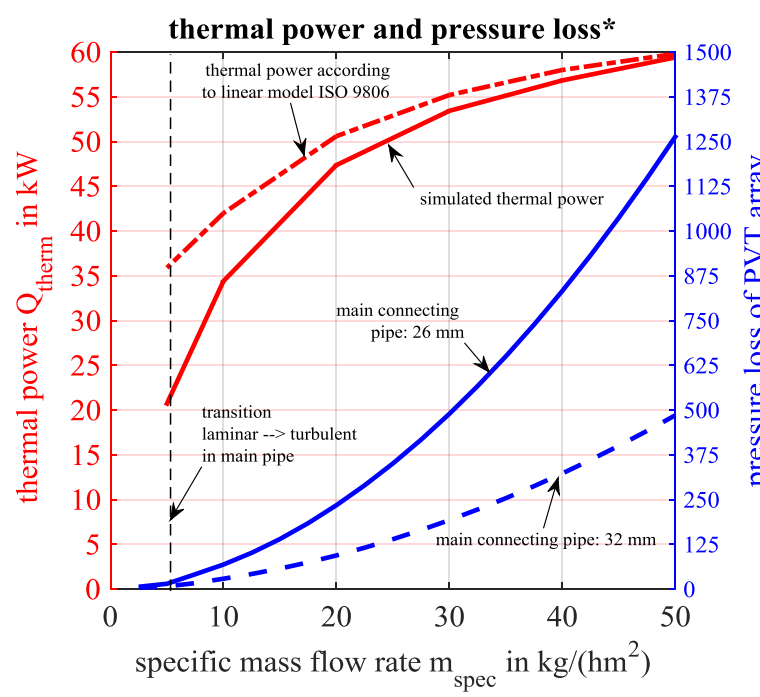

(b)

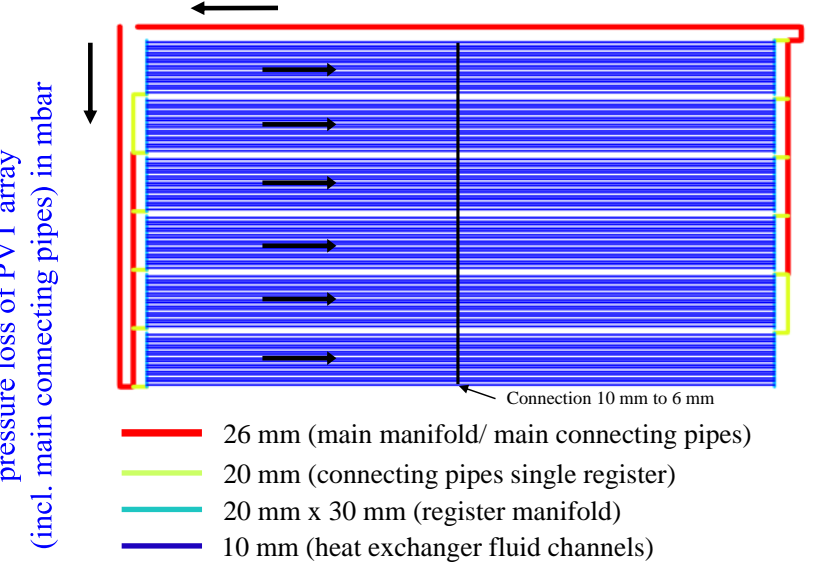

*conditions: $\mathrm{T}_{\mathrm{a}}=15^{\circ} \mathrm{C} ; \mathrm{T}_{\text {in }}=5{ }^{\circ} \mathrm{C}$; wind $1.3 \mathrm{~m} / \mathrm{s} ; \mathrm{G}{ }^{\prime \prime}=900 \mathrm{~W} / \mathrm{m}^{2} ; s_{\text {eq }}=0,01 \mathrm{~mm}$; tilt angle $38^{\circ} ; 35 \%$ ethylene glycol; Calyxo Module with $91 \%$ absorption rate; Collector coefficients based on simulations in 2015 and operation in MPP

Figure 3: (a) Pressure drop simulation and related thermal power of a $14 \times 7.2 \mathrm{~m}^{2} \mathrm{PV} / \mathrm{T}$ field array shown in (b) with selected design pipe dimensions.

Figure 3 indicates that low specific mass flows well reduce the overall pressure losses at the expense of the 
thermal performance (red lines). This is mainly due to an increase of the collector temperature and related heat losses as well as the nonlinear increase of temperature between inlet and outlet. Solid and dashed red lines refer to the FEM model and a linear model according to ISO 9806, respectively. The latter is included for comparison purposes. We see that the linear ISO 9806 model over-estimates the thermal power of the collector device for small flow rates in comparison to the FEM model. The following aspects are responsible for a significant decrease of the thermal power compared to the characteristics at reference value of $50 \mathrm{~kg} /\left(\mathrm{hm}^{2}\right)$ :

- ISO 9806 only regards the heat losses: lower mass flow rates lead to higher average collector temperatures

- ISO 9806 disregards flow-related changes of the internal convective heat transfer coefficient.

- ISO 9806 relays on linear temperature progressions between fluid in- and outlet; that assumption is only valid for higher mass flow rates.

The experimental tests and simulations have been carried out at $50 \mathrm{~kg} /\left(\mathrm{hm}^{2}\right)$. At $10 \mathrm{~kg} /\left(\mathrm{hm}^{2}\right)$, the thermal power is approximately $42 \%$ lower than at the nominal design power, mostly due to the non-linear temperature increase and the higher collector temperature. Only 3 to $4 \%$ of the thermal losses are due to less efficient convective heat transfer. Hence, The collector coefficients identified in standard thermal power tests lose their validity. The expected thermal power is $18 \%$ lower than the calculating value according to ISO 9806. This aspect has a considerable practical relevance, because the mass flow rate of real systems is commonly adapted to the user's demand and to the specific heat supply system, whereas the collector area is dimensioned to fulfil the minimum heat requirement in winter or just to fit the roof size.

\section{Experimental performance assessment}

\subsection{Prototype test array}

To assess the thermal efficiency of the system we installed a $20 \mathrm{~m}^{2}$ prototype test field, as shown in Figure 4, and carried out long-term measurements. To reproduce realistic installation conditions, a wooden substructure was established which the PV/T array is mounted on. The test array consists of 24 thin-film CdTe modules of type Calyxo CX $375 \mathrm{~W}$, of which three horizontal registers á 6 modules per string are used for the PV/T system. The $\mathrm{PV} / \mathrm{T}$ system has a gross area of $14 \mathrm{~m}^{2}$. To evaluate the mounting system and the architectural quality of the installation, a string of the left 6 modules is not thermally activated. Between PV generator and PV/T system, we placed dummy plates of black powder coated aluminium.

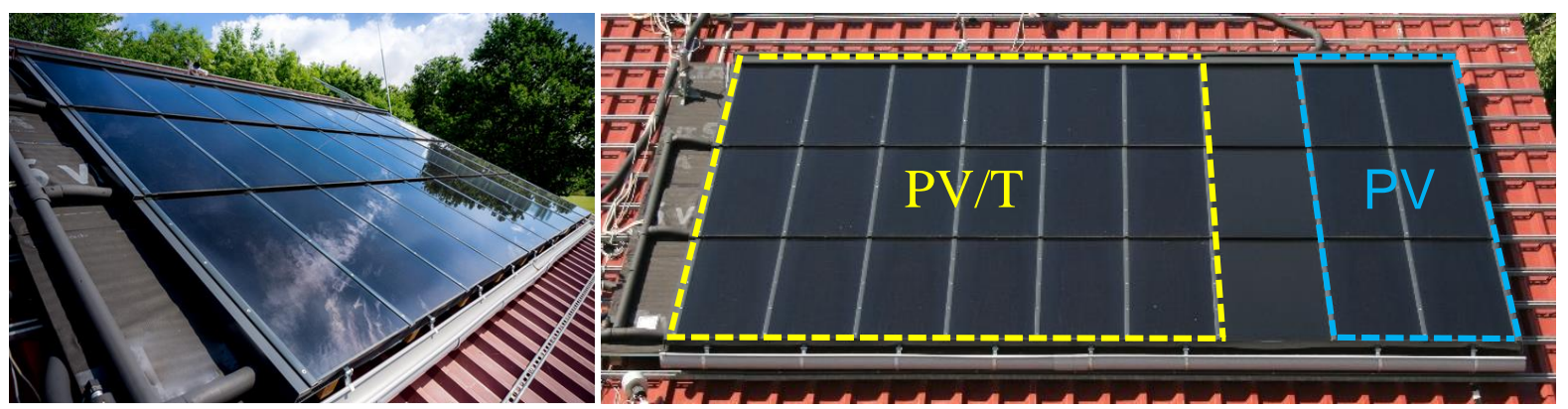

Figure 4: Roof-integrated PV/T prototype test field

The PV/T array is connected to a heat pump system and is operated with a $30 \%$ ethylene glycol mixture over a wide range of inlet temperatures from $-10{ }^{\circ} \mathrm{C}$ to $60^{\circ} \mathrm{C}$. The system is equipped with an extensive system to evaluate the thermal performance according to the Standard ISO 9806, analyse the thermal behaviour of the components and record the electrical voltages and currents of the PV strings. The test facility enables to control inlet temperatures and fluid mass flows. The Maximum Power Point of the PV generator (the largest product of current and voltage) is achieved by using a conventional $2 \mathrm{~kW}$ inverter.

\subsection{Quasi-dynamic performance tests}

For the determination of the thermal collector coefficients according to ISO 9806: 2017 (ISO, 2017), we applied the quasi-dynamic method (QDT, quasi-dynamic testing). The QDT method is particularly suitable for the characterisation of so-called WISC (wind and infrared sensitive collectors) under fluctuating weather conditions. The standard also allows the determination of the thermal power $\dot{Q}_{\text {th }}$ of PV/T collectors, which for this reason have to be tested during operation in MPP. The most commonly used steady-state method (SST) requires very 
stable weather conditions (i.e. clear sky). It gives no information about the heat capacity of the collector and tolerates low scatter of the measurement values. Furthermore, the angular dependence of the incident radiation (IAM, incident angle modifiers) must be determined by separate measurement, e.g. using a sun-tracking test device. However, the measurable collector area is also limited on tracking devices and small collector surfaces lead to high uncertainties concerning the reference surface and, thereby, the results for thermal efficiency. In the quasi-dynamic method, the influence of the incident angle is an integral part of the collector model and is determined from the same data set used to define all other collector efficiency parameters. This allows a comprehensive characterization of the stationary installed large test array.

The model equation to be used for determining the thermal power according to the QDT method incorporates (up to) 11 coefficients (ISO, 2017)

$$
\begin{aligned}
\dot{Q}_{\mathrm{th}} / A_{\mathrm{G}}=\eta_{0, \mathrm{~b}} & K_{\mathrm{b}}\left(\Theta_{\mathrm{L}}, \Theta_{\mathrm{T}}\right) G_{\mathrm{b}}+\eta_{0, \mathrm{~b}} K_{\mathrm{d}} G_{\mathrm{d}}-a_{1}\left(\vartheta_{\mathrm{m}}-\vartheta_{\mathrm{a}}\right)-a_{2}\left(\vartheta_{\mathrm{m}}-\vartheta_{\mathrm{a}}\right)^{2} \\
& -a_{3} u\left(\vartheta_{\mathrm{m}}-\vartheta_{\mathrm{a}}\right)+a_{4}\left(E_{\mathrm{L}}-\sigma T_{\mathrm{a}}^{4}\right)-a_{5} \mathrm{~d} \vartheta_{\mathrm{m}} / \mathrm{d} t-a_{6} u G_{\mathrm{hem}} \\
& -a_{7} u\left(E_{\mathrm{L}}-\sigma T_{\mathrm{a}}^{4}\right)-a_{8}\left(\vartheta_{\mathrm{m}}-\vartheta_{\mathrm{a}}\right)^{4}
\end{aligned}
$$

Note that the angle dependency $K_{\mathrm{b}}$ may be expressed by several coefficients depending on the model (ISO, 2017). The heat output $\dot{Q}_{\mathrm{th}}$ is referred to the gross area $A_{\mathrm{G}}$ or indicated as total module output. The parameters $\eta_{0, \mathrm{~b}}, K_{\mathrm{b}}, K_{\mathrm{d}}$ and $a_{1} \ldots a_{8}$ are determined by fit to measured power data, $\dot{Q}_{\mathrm{th}, \mathrm{m}}$. The coefficient $a_{8}$ is only relevant for concentrating collectors. The standard requires a replacement of the wind $u$ by $u^{\prime}=u-3 \mathrm{~m} / \mathrm{s}$ for comparability with glazed flat-plate collectors, which is neglected here. The quasi-dynamic method was analysed in detail and the physical plausibility of the results was evaluated. We have optimized the calculation procedure, implemented it in the software Matlab and developed a new tool for parameter identification. The collector coefficients according to ISO 9806 are determined from the measured values by applying a multiple and robust least squares regression that uses the nonlinear mathematical identification method based on the Matlab function "nlinfit". The parameter $a_{4}$ represents the sky temperature dependence of the heat-loss coefficient and has a special meaning, since a standard-compliant parameter identification in many cases causes an (unwanted) neglect or miscalculation of the radiation exchange between sky and collector. This depends on correlations between the regressors of $a_{4}, \eta_{0, \mathrm{~b}}$ and the IAM. For WISC collectors, such correlations lead to a statistically uncertain determination of the collector coefficients. To avoid this problem, we refer to the model for uncovered collectors under stationary conditions of ISO 9806: 2013 (ISO, 2013), the predecessor standard of ISO 9806: 2017 (ISO, 2017):

$$
\frac{\dot{Q}_{\mathrm{th}}}{A_{\mathrm{G}}}=\eta_{0, \mathrm{hem}} \cdot G^{\prime \prime}\left(1-b_{\mathrm{u}} \cdot u\right)-\left(b_{1}+b_{2} \cdot u\right)\left(\vartheta_{\mathrm{m}}-\vartheta_{\mathrm{a}}\right)
$$

$G^{\prime \prime}$ takes into account the solar absorption coefficient $\alpha$ and the IR emission coefficient $\varepsilon$ of the upper glass pane as well as the blackbody temperature of the atmosphere $T_{\text {sky }}$ :

$$
G^{\prime \prime}=G+\frac{\varepsilon}{\alpha} \cdot \sigma \cdot\left(T_{\mathrm{sky}}^{4}-T_{\mathrm{a}}^{4}\right)
$$

The ratio $\varepsilon / \alpha$ is the decisive factor for the calculation of the coefficient $a_{4}$, which is to be determined by regression according to ISO 9806: 2017, but was presupposed as known in ISO 9806: 2013 before starting the parameter identification. For the hemispherical emissivity of PV glass, we assume $\varepsilon=0.84$. For the absorption of the used CdTe modules a value of $\alpha=0.91$ was reported (Brötje et al., 2018). By comparison between Eq. (2) and (3) we obtain the following coefficients (see also ISO 9806: 2017):

$$
\begin{gathered}
a_{1}=b_{1} \\
a_{3}=b_{2} \\
a_{4}=\eta_{0, \mathrm{hem}} \cdot \frac{\varepsilon}{\alpha} \\
a_{6}=\eta_{0, \mathrm{hem}} \cdot b_{\mathrm{u}} \\
a_{7}=\eta_{0, \mathrm{hem}} \cdot b_{\mathrm{u}} \cdot \frac{\varepsilon}{\alpha}
\end{gathered}
$$

The nominal efficiency for hemispheric radiation is defined by the equation

$$
\eta_{0, \text { hem }}=\eta_{0, \mathrm{~b}} \cdot K_{\mathrm{b}}(\Theta) \cdot \frac{G_{\mathrm{b}}}{G}+\eta_{0, \mathrm{~b}} \cdot K_{\mathrm{d}} \cdot \frac{G_{\mathrm{d}}}{G}
$$


Neglecting the non-significant coefficients, the final equation reads

$$
\begin{aligned}
& \frac{\dot{Q}_{\mathrm{th}}}{A_{\mathrm{G}}}=\eta_{0, \mathrm{~b}} \cdot K_{\mathrm{b}}(\Theta) \cdot G_{\mathrm{b}}+\eta_{0, \mathrm{~b}} \cdot K_{\mathrm{d}} \cdot G_{\mathrm{d}}-a_{1} \cdot\left(\vartheta_{\mathrm{m}}-\vartheta_{\mathrm{a}}\right)-a_{2} \cdot\left(\vartheta_{\mathrm{m}}-\vartheta_{\mathrm{a}}\right)^{2} \\
& -a_{3} \cdot u \cdot\left(\vartheta_{\mathrm{m}}-\vartheta_{\mathrm{a}}\right)+\eta_{0, \mathrm{hem}} \cdot \frac{\varepsilon}{\alpha} \sigma \cdot\left(T_{\mathrm{sky}}^{4}-T_{\mathrm{a}}^{4}\right)-a_{5} \cdot \frac{\mathrm{d} \vartheta_{\mathrm{m}}}{\mathrm{d} t}-\eta_{0, \mathrm{hem}} \cdot b_{\mathrm{u}} \cdot u \cdot G_{\mathrm{hem}}
\end{aligned}
$$

For the definition of the coefficient $K_{\mathrm{b}}(\theta)$, we implemented the interpolation point model by Isakson (1995), which is applicable to any solar thermal collector and allows to set any support angles for the interpolation depending on the needs and the actual curve of the angular dependence for the direct radiation. Disadvantages are the increased computational effort and an unstable regression in case of an unsuitable selection of the interpolation points. The approach is described in Eq. (12).

$$
K_{\mathrm{b}}\left(\Theta_{\mathrm{j}}\right)=K_{\mathrm{b}}\left(\Theta_{\mathrm{i}}\right)+\left(\Theta_{\mathrm{j}}-\Theta_{\mathrm{i}}\right) \frac{K_{\mathrm{b}}\left(\Theta_{\mathrm{i}}\right)-K_{\mathrm{b}}\left(\Theta_{\mathrm{i}+1}\right)}{\Theta_{\mathrm{i}}-\Theta_{\mathrm{i}+1}}
$$

\subsection{Measurements and data evaluation}

Figure 5 shows the measured values used to determine the thermal collector coefficients in MPP mode according to the specifications from ISO 9806: 2017. The data was recorded every 10 seconds and averaged over 30 seconds for our evaluation. The specific mass flow of the heat carrier was set to $50 \mathrm{~kg} /\left(\mathrm{hm}^{2}\right)$.
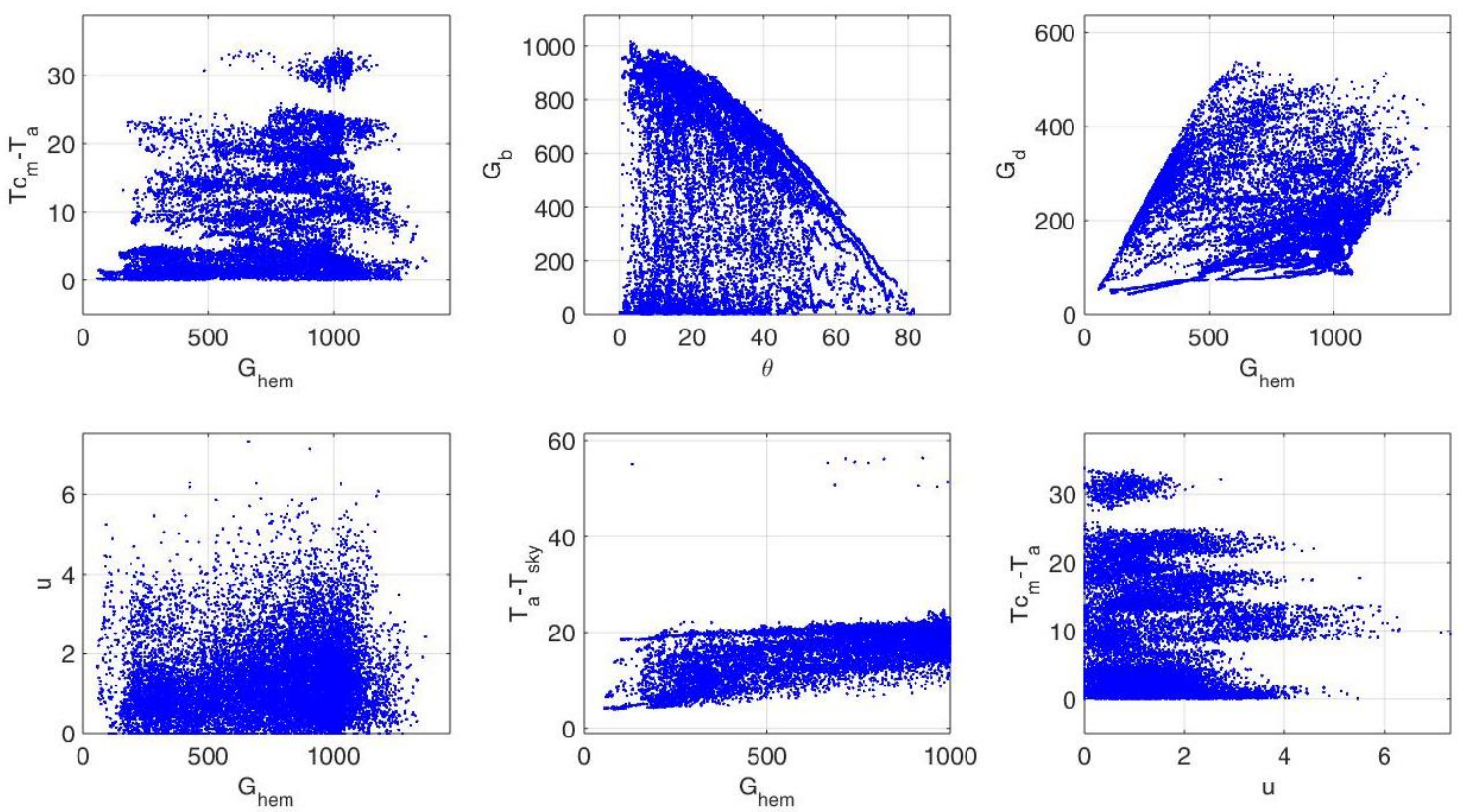

Figure 5: Measurement data filtered according to ISO 9806: 2017 (operated in MPP, march to June 2017)

An iterative procedure was used to determine the parameters of the collector, in order to avoid disturbing influences due to correlations. Each iteration consists of two steps:

1. From the measured values which have already been filtered according to ISO 9806: 2017, only those operating points that fulfil the temperature and incident angle conditions $-1,0 \mathrm{~K}<\vartheta_{\mathrm{m}}-\vartheta_{\mathrm{a}}<+1,0 \mathrm{~K}$ and $-10^{\circ}<\Theta<10^{\circ}$ are considered in the first step. The intervals of $\vartheta_{\mathrm{m}}-\vartheta_{\mathrm{a}}$ and $\Theta$ depend on the available measurement data and on the collector type. They must be carefully selected and, if possible, adjusted to achieve convergence in the regressions. The result is a set of strictly selected data, which is used to identify $\eta_{0, \mathrm{~b}}$ of equation (11). The parameters $K_{\mathrm{b}}(\theta)$ to $a_{6}$ are set as constant start values during this procedure.

2. In a second iteration step, the parameters $K_{\mathrm{b}}(\theta)$ to $a_{6}$ are determined from the complete data set according to the requirements of ISO 9806. During this procedure, the parameter $\eta_{0, \mathrm{~b}}$, is set to the constant value determined in step 1. Using the new set of coefficients, we iterate the procedure until the convergence criteria are matched (such as $\Delta_{\mathrm{i}}(\mathrm{x})<0.01 \%$ for each parameter).

The convergence of the parameter identification procedure is very good for the investigated prototype because of the large amount and variation of test data. Tables 1 to 3 show the characteristics of the installed PV/T collector 
prototype according to the modified power equation model (11). The coefficients were converted according to the equations (5) to (9). The T-ratio is a measure of the statistical certainty of each coefficient and is formed from the numerical value and the standard deviation $\sigma$ of the specific coefficient. A high T-ratio means a safe mathematical regression, but not necessarily a physical correlation as expected in the model. According to ISO 9806, $\mathrm{T}>3$ is required, but $\mathrm{T}>10$ was observed to be a more reliable limit. Absolute uncertainties, if mentioned, refer to the $95 \%$ confidence level.

\subsection{Operation in maximum power point (MPP) of $P V$ generator}

Table 1 features the results of the parameter identification for the prototype test array in MPP mode. A strong convergence with $\Delta_{\mathrm{i}}(\mathrm{x})<0.01 \%$ was achieved after 18 iterations. The support angles selected for the calculation of the IAM were $50^{\circ}, 65^{\circ}$ and $80^{\circ}$.

Table 1: Thermal coefficients of the investigated PV/T test array in MPP mode

\begin{tabular}{|c|c|c|c|c|c|c|c|}
\hline Coefficient & Value & Dimension & $T=x / \sigma$ & Coefficient & Value & Dimension & $T=x / \sigma$ \\
\hline$\eta_{0, \mathrm{~b}}$ & $\begin{array}{c}0.658 \\
\pm 0.018\end{array}$ & - & 329 & $a_{2}$ & 0.09 & $\mathrm{~W} /\left(\mathrm{m}^{2} \mathrm{~K}^{2}\right)$ & 18 \\
\hline$K_{\mathrm{b}}\left(50^{\circ}\right)$ & 0.92 & - & 219 & $a_{3}$ & 1.26 & $\mathrm{~J} /\left(\mathrm{m}^{3} \mathrm{~K}\right)$ & 24 \\
\hline$K_{\mathrm{b}}\left(65^{\circ}\right)$ & 0.90 & - & 51 & $a_{4}(\varepsilon / \alpha)$ & $0.61(0.92)$ & - & (fixed) \\
\hline$K_{\mathrm{b}}\left(80^{\circ}\right)$ & 0.85 & - & 7 & $a_{5}$ & 47.00 & $\mathrm{~kJ} /\left(\mathrm{m}^{2} \mathrm{~K}\right)$ & 179 \\
\hline$K_{\mathrm{d}}$ & 0.99 & - & 198 & $a_{6}$ & 0.03 & $\mathrm{~s} / \mathrm{m}$ & 44 \\
\hline$a_{1}$ & 11.56 & $\mathrm{~W} /\left(\mathrm{m}^{2} \mathrm{~K}\right)$ & 69 & & & & \\
\hline
\end{tabular}

\subsection{Converting coefficients from MPP to OC mode}

The electrical efficiency of the CdTe modules under STC conditions is $\eta_{\mathrm{el}}=10.4 \%$ according to the product data sheet. As shown in Figure 6, the electrical efficiency of the DC side of the PV generator at a calculated cell temperature of $25^{\circ} \mathrm{C}$ is approximately $9.9 \%$. The measured efficiency scatter is quite large; therefore, thus inducing a wide uncertainty range of $\eta_{\mathrm{el}}$.

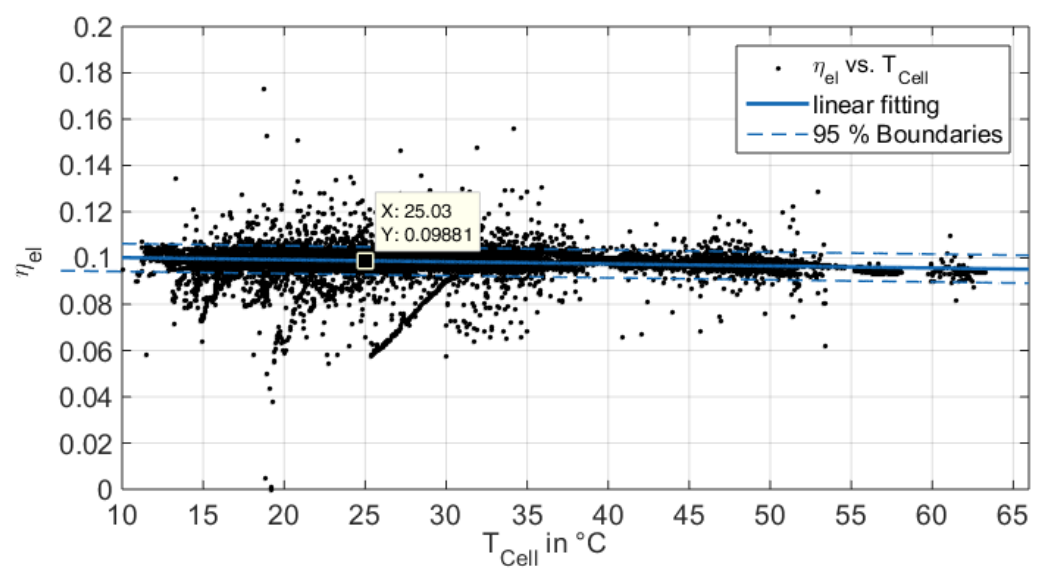

Figure 6: Electrical efficiency of the investigated PV/T test array operating in MPP

By regression of the electrical efficiency data we determined a temperature-power coefficient of $\mathrm{Y}=-0.21 \% / \mathrm{K}$ (data sheet: $-0.25 \% / \mathrm{K}$ ). Some part of the energy is dissipated by radiation and thus it is not available for conversion into sensible heat. Neglecting the low temperature dependence of electrical output of the CdTe modules, we can estimate the thermal zero-loss efficiency in OC mode based on the value measured in MPP mode. Assuming a single node or capacity for the collector, the efficiency in OC mode can be calculated from equation (13).

$$
\eta_{0, \mathrm{OC}} \approx \frac{\eta_{0, \mathrm{MPP}}}{1-\eta_{\mathrm{el}, \mathrm{STC}} / \alpha}
$$

Using $\eta_{\mathrm{el}}=10.4 \%$ and the measured absorption $\alpha=0.91$, we determine a thermal efficiency $\eta_{0, \mathrm{OC}}=0.743$. The collector coefficients in OC operation mode are of interest because collector models used in simulation tools like TRNSYS or Polysun require them (Vela Solaris AG, 2018; Stegmann et al., 2011). The input data must be supplemented by the characteristics of the PV modules. The heat resistance between PV cells and heat carrier is only considered by TRNSYS through the internal heat transfer coefficient $U_{\text {int }}$. 
The electric current $I_{\mathrm{el}}$ and the voltage $U_{\mathrm{el}}$ of the PV modules were additionally recorded during the measurement. Using this information, we can compare the thermal coefficients in MPP and in OC mode more comprehensively. In order to determine the OC characteristics of the PV/T collector by means of multiple regression, we modify the regression model according to Eq. (11). The area-related electrical power results from

$$
p_{\mathrm{el}}=\sum_{\text {String } 1-3}\left(U_{\mathrm{el}} \cdot I_{\mathrm{el}}\right) / 13.6 \mathrm{~m}^{2}
$$

We assume that the conversion of solar radiation into electricity is equivalent to a reduction of the available direct and diffuse radiation and that both radiation components generate the PV power with the same efficiency. The corrected irradiation data are calculated by using equations (15) and (16). We replace $G_{\mathrm{b}}$ and $G_{\mathrm{d}}$ in equation (11) and obtain the collector coefficients shown in table 2. Taking into account the uncertainties of $\eta_{0, \mathrm{~b}}(\mathrm{OC})$ and $\eta_{0, \mathrm{~b}}(\mathrm{MPP})$ of 2 percentage points each in the MPP mode, the result show a good agreement with the value estimated according to equation (13).

$$
\begin{aligned}
& G_{\mathrm{b}}^{\prime}=G_{\mathrm{b}} \cdot\left(1-\frac{p_{\mathrm{el}}}{G \cdot \alpha_{\mathrm{eff}}}\right) \\
& G_{\mathrm{d}}^{\prime}=G_{\mathrm{d}} \cdot\left(1-\frac{p_{\mathrm{el}}}{G \cdot \alpha_{\mathrm{eff}}}\right)
\end{aligned}
$$

\begin{tabular}{|c|c|c|c|c|c|c|c|}
\hline Coefficient & Value & Dimension & $T=x / \sigma$ & Coefficient & Value & Dimension & $T=x / \sigma$ \\
\hline$\eta_{0, \mathrm{~b}}$ & $\begin{array}{c}0.748 \\
\pm 0.019\end{array}$ & - & 323 & $a_{2}$ & 0.13 & $\mathrm{~W} /\left(\mathrm{m}^{2} \mathrm{~K}^{2}\right)$ & 25 \\
\hline$K_{\mathrm{b}}\left(50^{\circ}\right)$ & 0.93 & - & 232 & $a_{3}$ & 1.32 & $\mathrm{~J} /\left(\mathrm{m}^{3} \mathrm{~K}\right)$ & 25 \\
\hline$K_{\mathrm{b}}\left(65^{\circ}\right)$ & 0.91 & - & 52 & $a_{4}(\varepsilon / \alpha)$ & $0.61(0.92)$ & - & (fixed) \\
\hline$K_{\mathrm{b}}\left(80^{\circ}\right)$ & 0.86 & - & 16 & $a_{5}$ & 48.38 & $\mathrm{~kJ} /\left(\mathrm{m}^{2} \mathrm{~K}\right)$ & 187 \\
\hline$K_{\mathrm{d}}$ & 0.97 & - & 204 & $a_{6}$ & 0.03 & $\mathrm{~s} / \mathrm{m}$ & 46 \\
\hline$a_{1}$ & 10.90 & $\mathrm{~W} /\left(\mathrm{m}^{2} \mathrm{~K}\right)$ & 69 & & & & \\
\hline
\end{tabular}

Table 2: Thermal PV/T collector coefficients (OC mode) converted from the characteristics in MPP mode

\subsection{Operation in open circuit (OC) of PV generator}

To determine the thermal characteristics for the actual operation of the PV/T test array without electricity, the PV strings were separated from the inverter. Table 3 reports the collector coefficients determined on the basis of

\begin{tabular}{|c|c|c|c|c|c|c|c|}
\hline Coefficient & Value & Dimension & $T=x / \sigma$ & Coefficient & Value & Dimension & $T=x / \sigma$ \\
\hline$\eta_{0, \mathrm{~b}}$ & $\begin{array}{c}0.743 \\
\pm 0.016\end{array}$ & - & 217 & $a_{2}$ & 0.11 & $\mathrm{~W} /\left(\mathrm{m}^{2} \mathrm{~K}^{2}\right)$ & 9 \\
\hline$K_{\mathrm{b}}\left(50^{\circ}\right)$ & 0.98 & - & 268 & $a_{3}$ & 1.18 & $\mathrm{~J} /\left(\mathrm{m}^{3} \mathrm{~K}\right)$ & 12 \\
\hline$K_{\mathrm{b}}\left(65^{\circ}\right)$ & 0.97 & - & 85 & $a_{4}(\varepsilon / \alpha)$ & $0.61(0.92)$ & - & (fixed) \\
\hline$K_{\mathrm{b}}\left(80^{\circ}\right)$ & 0.45 & - & 7 & $a_{5}$ & 37.03 & $\mathrm{~kJ} /\left(\mathrm{m}^{2} \mathrm{~K}\right)$ & 85 \\
\hline$K_{\mathrm{d}}$ & 0.93 & - & 110 & $a_{6}$ & 0.02 & $\mathrm{~s} / \mathrm{m}$ & 25 \\
\hline$a_{1}$ & 11.24 & $\mathrm{~W} /\left(\mathrm{m}^{2} \mathrm{~K}\right)$ & 43 & & & & \\
\hline
\end{tabular}
measurement data recorded in April 2018.

Table 3: Thermal PV/T collector coefficients as determined from measurements in OC mode

Even in this case, taking into consideration the uncertainties of $\eta_{0, \mathrm{~b}}(\mathrm{OC})$ and $\eta_{0, \mathrm{~b}}(\mathrm{MPP})$, the experimental result is in very good agreement with the value determined according to equation (13). The comparison between tables 2 and 3 shows that the MPP measurements can also be used for a first estimation of the performance of the collector in electrical open circuit (OC). The power curves in OC mode basically result from a parallel shift of the power curves in MPP, as represented in Figure 7 . The heat capacity $a_{5}$ and the incident angle modifiers are the coefficients which most significantly differ in the two operation modes.

The heat capacity $a_{5}$ is an effective, physically simplified quantity and is strongly influenced by the thermal resistance between the PV module and the fluid, the fluid mass flow and the time interval considered in the parameter identification. These influences depend on the use of the single-node model in ISO 9806, which does not take into account transient heat conduction between absorbing material and fluid. The capacity measured in OC mode is supposed to be smaller than in MPP mode because electricity generation is a temporal damper for temperature changes in the collector. The conversion into electrical exergy takes place immediately and significantly faster than the heat transfer processes. 


\subsection{Thermal power curves}

Figure 7 shows the performance characteristics of the PV/T prototype for standard reporting conditions according to ISO 9806: 2017 (see Table 4).

Table 4: Standard reporting conditions (SRC) according to ISO 9806:2017

\begin{tabular}{lrrr}
\hline Weather conditions & Blue sky & Hazy sky & Grey sky \\
\hline Direct radiation $G_{\mathrm{b}}$ & $850 \mathrm{~W} / \mathrm{m}^{2}$ & $440 \mathrm{~W} / \mathrm{m}^{2}$ & $200 \mathrm{~W} / \mathrm{m}^{2}$ \\
\hline Diffuse radiation $G_{\mathrm{d}}$ & $150 \mathrm{~W} / \mathrm{m}^{2}$ & $260 \mathrm{~W} / \mathrm{m}^{2}$ & $200 \mathrm{~W} / \mathrm{m}^{2}$ \\
\hline Ambient temperature $T_{\mathrm{a}}$ & $20^{\circ} \mathrm{C}$ & $20{ }^{\circ} \mathrm{C}$ & $20^{\circ} \mathrm{C}$ \\
\hline Wind speed $u$ in $\mathrm{m} / \mathrm{s}$ & 1,3 & 1,3 & 1,3 \\
\hline Incident angle modifier $K_{\mathrm{b}}$ & 1 & 1 & 1 \\
\hline Thermal radiation $\sigma \cdot\left(T_{\mathrm{sky}}^{4}-T_{\mathrm{a}}^{4}\right)$ & $-100 \mathrm{~W} / \mathrm{m}^{2}$ & $-50 \mathrm{~W} / \mathrm{m}^{2}$ & $0 \mathrm{~W} / \mathrm{m}^{2}$ \\
\hline
\end{tabular}

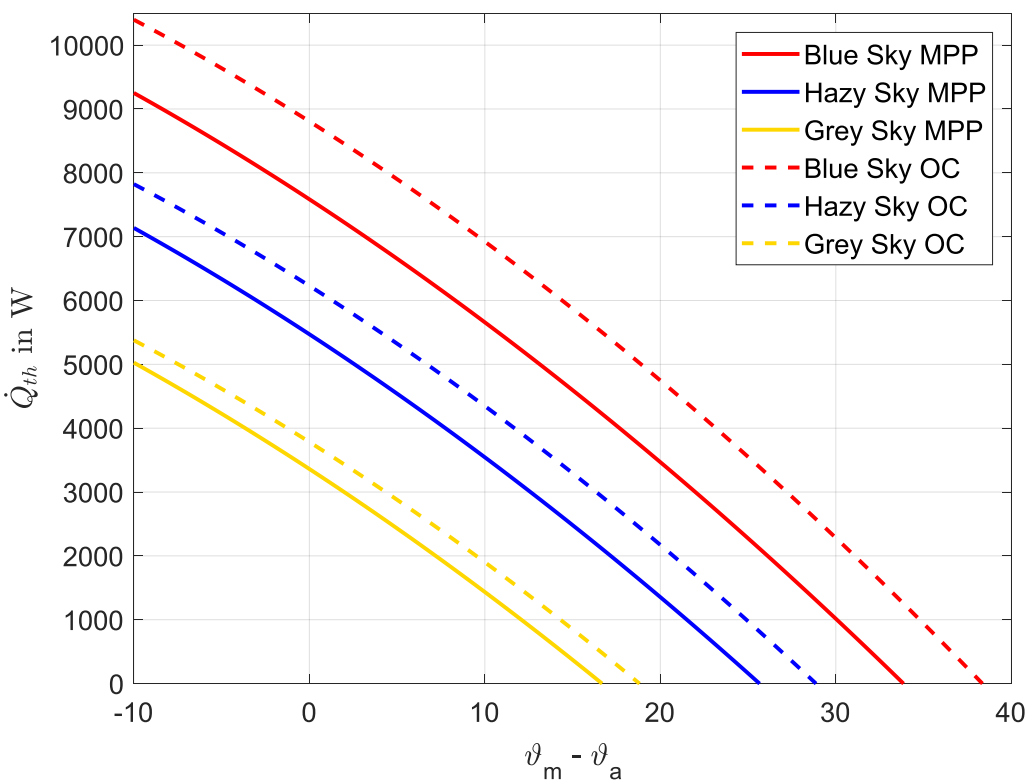

Figure 7: Thermal performance of the developed PV/T at Standard Reporting Conditions based on PV/T gross area $13.6 \mathrm{~m}^{2}$

The curves represent the total thermal power with refer to the thermally activated collector area for MPP and OC operation based on the efficiency parameters from tables 1 and 3. The peak power is calculated according to the Standard for the total area of $13.6 \mathrm{~m}^{2}$ under blue sky conditions, $\vartheta_{\mathrm{m}}-\vartheta_{\mathrm{a}}=0 \mathrm{~K}$ and $\mathrm{u}=1.3 \mathrm{~m} / \mathrm{s}$. $\dot{Q}_{\text {peak }, \mathrm{MPP}}=7586 \pm 232 \mathrm{~W}$ in MPP and $\dot{Q}_{\text {peak }, \mathrm{OC}}=8806 \pm 329 \mathrm{~W}$ in OC. The correspondent area-related thermal output is $\dot{q}_{\text {peak,MPP }}=558 \pm 17 \mathrm{~W} / \mathrm{m}^{2}$ and $\dot{q}_{\text {peak }, \mathrm{OC}}=647 \pm 24 \mathrm{~W} / \mathrm{m}^{2}$. The standard uncertainties for peak power are 3.1 and 3.7 percentage points respectively. The stagnation temperature is defined at $\dot{Q}=0 \mathrm{~W}, \mathrm{u}=0 \mathrm{~m} / \mathrm{s}, 30^{\circ} \mathrm{C}$ ambient temperature and blue sky. It amounts to $69^{\circ} \mathrm{C}$ in MPP and $73^{\circ} \mathrm{C}$ in OC.

\subsection{Internal heat transfer coefficient}

Using eq. (5), (6) and (8) as well as the thermal coefficients from the parameter identification, we can estimate the internal heat transfer coefficient $U_{\text {int }}$ of the new prototype according to Stegmann et al. (2011) by use of equation (17).

$$
U_{\text {int }}=\frac{\alpha_{\text {eff }} \cdot\left(a_{1}+a_{3} \cdot u\right)}{\alpha_{\text {eff }}-\eta_{0, \text { hem }}+a_{6} \cdot u}
$$

The coefficient a2 is not taken into account in this approach because it is referred to ISO 9806:2013. Repeating the parameter identification by neglecting $a_{2}$, we obtain a $95 \%$ confidence interval $U_{\text {int }}=47 \ldots 68 \mathrm{~W} /\left(\mathrm{m}^{2} \mathrm{~K}\right)$ at a wind speed of $1.3 \mathrm{~m} / \mathrm{s}$. Although the collector coefficients are determined with high accuracy, the confidence interval of $U_{\text {int }}$ is quite large. Table 5 sums up the confidence intervals of $U_{\text {int }}$ and of each coefficient, respectively. The results show that the internal heat transfer coefficient is almost unaffected by the wind speed. All results refer to OC operation. 
Table 5: Confidence interval of the internal heat transfer coefficient $U_{\text {int }}$ for different wind speeds and of the collector efficiency parameters

\begin{tabular}{|c|c|c|c|}
\hline Parameter & \multicolumn{2}{|c|}{$95 \%$ confidence interval } & Value \\
\hline & lower limi & upper limit & \\
\hline$\alpha_{\text {eff }}$ & & & 0.91 \\
\hline$\eta_{0, \mathrm{~b}}$ & 0.73 & 0.76 & 0.74 \\
\hline$K_{\mathrm{d}}$ & 0.90 & 0.95 & 0.92 \\
\hline$a_{1}$ & 10.35 & 12.14 & 11.20 \\
\hline$a_{3}$ & 0.85 & 1.51 & 1.18 \\
\hline$a_{6}$ & 0.03 & 0.03 & 0.03 \\
\hline$U_{\text {int }}$ at $0 \mathrm{~m} / \mathrm{s}$ & 48.3 & 70.6 & 57.0 \\
\hline$U_{\text {int }}$ at $1.3 \mathrm{~m} / \mathrm{s}$ & 47.3 & 68.0 & 55.9 \\
\hline$U_{\text {int }}$ at $3 \mathrm{~m} / \mathrm{s}$ & 46.4 & 65.7 & 54.8 \\
\hline
\end{tabular}

The experimentally determined value $U_{\text {int }}=55.9 \mathrm{~W} /\left(\mathrm{m}^{2} \mathrm{~K}\right)$ is marked in Figure 2 to quantitatively evaluate the thermal contact between the PV module and the heat exchanger of the prototype. The comparison with the simulation indicates an equivalent air gap clearly smaller than $0.1 \mathrm{~mm}$. Considering the uncertainties in the determination of $U_{\text {int }}$, the upper limit of the confidence interval of is above technically plausible values. The lower limit of $U_{\text {int }}=47.3 \mathrm{~W} /\left(\mathrm{m}^{2} \mathrm{~K}\right)$ means a still very small average air gap of about $0.1 \mathrm{~mm}$. That result indicates that there is not much potential for performance improvements at this point, since even a perfect connection would improve $\eta_{0, \text { hem }}$ by approximately +0.01 (see Figure 2 ). As already mentioned in Section $2, s_{\text {eq }}$ is an effective value, resulting from both directly contacted areas and areas with air gaps $>0.1 \mathrm{~mm}$.

\section{Simulations of thermal power under non-standard conditions}

In addition to the determination of the characteristic values of the PV/T system under standard conditions, the qualitative behavior under extreme conditions such as negative power (cooling case) and condensation was investigated. Figure 8 displays examples of the measured and calculated area-specific thermal power under different operating and ambient conditions during MPP operation of the PV generator.
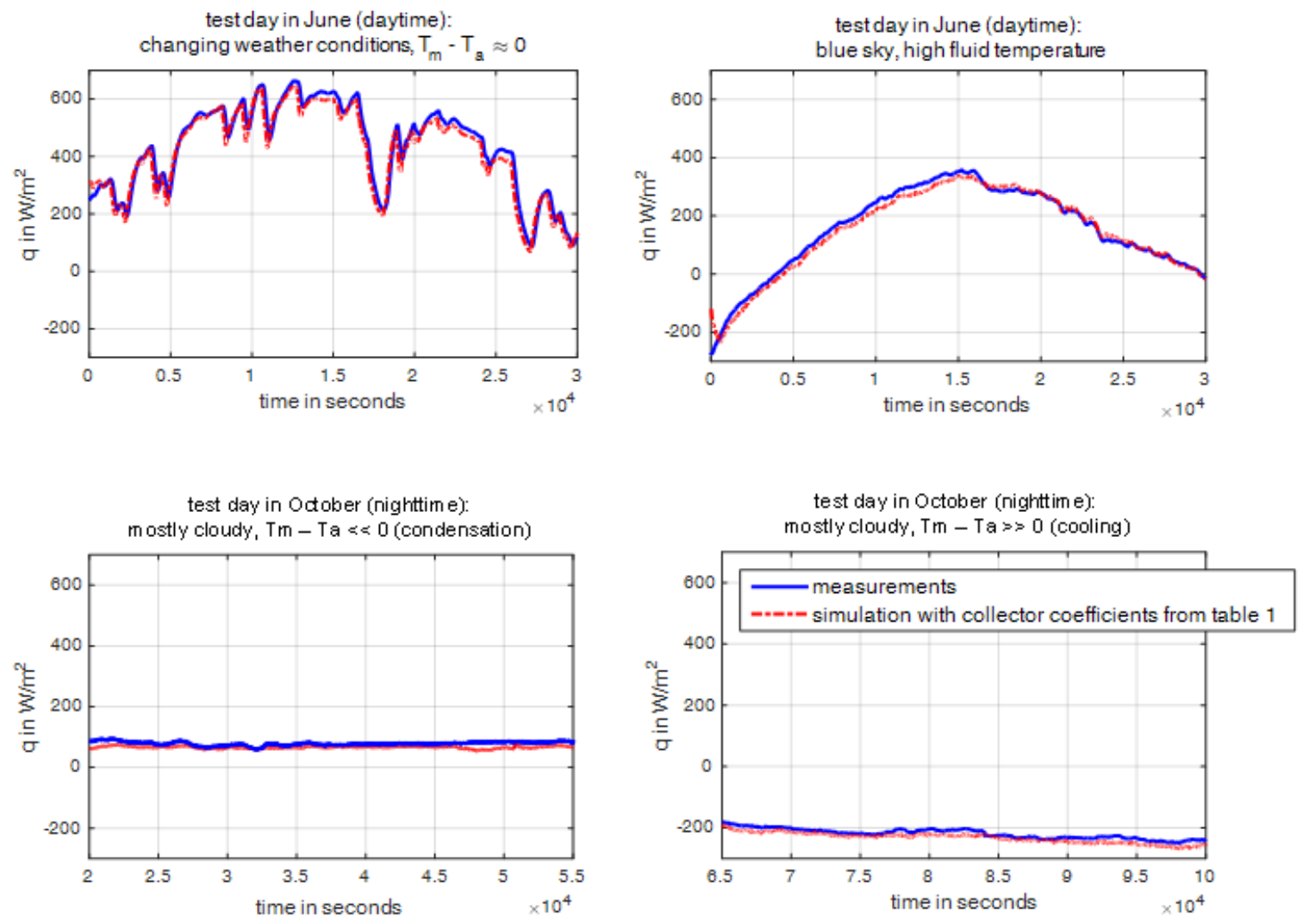

Figure 8: Measured and modeled thermal power output of the investigated prototype PV/T roof (CET: central European time) 
For the calculation of the simulated power, the QDT collector model according to ISO 9806: 2017 was implemented in Matlab Simulink (version R2015a). Thereby, the change of the mean collector temperature is calculated by solving the correspondent differential equation (2), as in the simulation models of e.g. Polysun or TRNSYS. Using the measured temporal change of the mean collector temperature $\mathrm{dTm} / \mathrm{dt}$ would lead to a high level of fluctuation in the simulations, which makes it difficult to evaluate the accuracy of the identified coefficients for the prediction of thermal performance based on weather data.

The comparisons between simulations and measurements show that the determined collector coefficients and the model can reproduce the thermal behavior of the collector with a good accuracy even under conditions that deviate from the measurement conditions used for the parameter identification.

Heat from condensation is predominantly gained at night and can contribute to the thermal yield of uncovered collectors, especially in winter, at low irradiation levels. Operating the collector prototype at low temperatures confirmed the occurrence of condensation. During the investigation period we couldn't collect enough data for a final evaluation of possible heat gains.

\section{Conclusions}

The newly developed PV/T system for roof integration with a glue-free connection between the PV module and the heat exchanger ensures a nearly optimal heat transfer into the fluid due to its robust construction and low manufacturing tolerances, which provide for a very small air gap. Compared to the preliminary system, the zeroloss efficiency could be increased from $44 \%$ to $74 \%$ (OC mode) thanks to the improved design. The efficiency is quite high, also in comparison with other PV/T collectors on market. The modular roof-integrated system features high architectural quality and allows a high flexibility for the application in the building sector. Several public and private pilot projects are about to be implemented.

The quasi-dynamic test method was successfully applied. In order to avoid mathematical correlation problems, the data evaluation was implemented with modified steps. The thermal collector coefficients in OC mode, required for heat transfer evaluation and system simulations, can be calculated from measured data obtained in MPP mode by using simple equations. Therefore, performance tests in OC mode are assessed as non-mandatory for the presented type of collector. This approach has to be tested for different types of PV/T collectors.

\section{Acknowledgements}

This publication is based on the project "ModulTech - Solarhybrid", which is funded by the German Federal Ministry for Economic Affairs and Energy on the basis of a decision of the German Federal Parliament (16KN041920). The authors are grateful for the financial support. The authors thank the project partners, Carsten Grobe Passivhaus and blue energy systems $\mathrm{GmbH}$, for the cooperation. We would like to thank the technicians Ralf Hartmann and Henri Dieckmann for their support and Prof. Dr.-Ing. Oliver Kastner for proofreading. The content of this publication is in the responsibility of the authors.

\section{References}

Incropera, F.P., DeWitt, D.P., 2002. Fundamentals of heat and mass transfer, $5^{\text {th }}$ ed. Wiley, New York.

ISO, 2013. ISO 9806:2013 - Solar energy - Solar thermal collectors - Test methods.

ISO, 2017. ISO 9806:2017 - Solar energy - Solar thermal collectors - Test methods.

Stegmann, M., Bertram, E., Rockendorf, G., 2011. Model of an unglazed photovoltaic thermal collector based on standard test procedures. Proceedings of $30^{\text {th }}$ ISES Solar World Congress, Kassel, Germany 2011. DOI:10.18086/swc.2011.19.30.

Brötje, S., Kirchner, M., Giovannetti, F., 2018. Performance and heat transfer analysis of uncovered photovoltaic-thermal collectors with detachable compound. Solar Energy 170, 406-418. DOI:10.1016/j.solener.2018.05.030.

Vela Solaris AG, 2018. Polysun software. Https://frontstore.velasolaris.com/wordpress/ (last access: 24.11.2018).

Isakson, P., 1995. Solar Collector Model for Testing and Simulation. Final Report for BFR project Nr. 900280-1, Building Services Engineering, Royal Institute of Technology. 


\title{
Electrical and Thermal Performance Evaluation of a District Heating System Composed of Asymmetric low concentration PVT Solar Collector Prototypes
}

\author{
Diogo Cabral ${ }^{1}$, João Costeira ${ }^{2}$, João Gomes ${ }^{1}$ \\ ${ }^{1}$ Department of Building, Energy and Environmental Engineering, University of Gävle, Sweden \\ ${ }^{2}$ Department of Earth Sciences, University of Minho, Portugal
}

\begin{abstract}
Photovoltaic-Thermal (PVT) solar collectors generate electricity and heat from the same gross area. The annual electrical and thermal yields of these systems are dependent on the PVT collector technology, as well as the climate and the type of solar thermal system implemented. This review presents an evaluation of a district heating system composed of 20 asymmetric hybrid low concentrator PVT (C-PVT) solar collector prototypes. The system is installed in a South wall facade in order to maximise the available space (with a tilt of $20^{\circ}$ and an orientation of $5^{\circ} \mathrm{W}$ ). The thermal system is connected to the district heating network, thus heating the University buildings. On the other hand, the electrical system is grid-connected, where it feeds the grid directly. Real measurement data has been collected and compared with a thermal (through ScenoCalc tool) and electrical performance models. The annual thermal and electrical yield achieved $86 \%$ and $89 \%$ of the simulated thermal and electrical yield, respectively.
\end{abstract}

Keywords: C-PVT, System analysis, Electrical and Thermal evaluation

\section{Introduction}

\subsection{State of Art}

Concentrator Photovoltaic-Thermal (C-PVT) solar collectors can be based on Compound Parabolic Collector (CPC) or on parabolic trough collector (Sharaf and Orhan, 2015). C-PVT collectors are hybrid solar collectors that simultaneously generate electrical (through PV cells) and thermal energy (through the solar radiation absorbed by the PV cells that is not converted into electricity).

Concentrating solar collectors re-direct the solar radiation (both beam and diffuse radiation) that passes through an aperture into the receiver over ranges of incidence angles within wide limits (thus defining the acceptance half-angle, $\theta_{c}$ ). For systems of low concentration ratio, part of the diffuse radiation will be reflected into the receiver, with this amount being dependent on the acceptance angle of the concentrator (Duffie and Beckman, 2013).

According to Zondag (2018), this solar collector technology can be classified according to their design (unglazed, glazed, and concentrating), PV cell technology, and their heat transfer medium (water and air). CPVT collectors can also be classified according to their concentration ratio, such as low, medium or high concentration, having the possibility of both stationary and tracked operation (Stine and Harrigan, 1986).

It is acknowledged that each collector technology matches specific temperature stages and corresponding suitable applications, especially if the concentrating technology is applied since higher concentration leads to higher temperatures. Previous studies showed that the efficiency of PV cells is temperature dependent and that for every degree increase in temperature, the cell efficiency decreases around $0.4 \%$, and for that reason, it is necessary to remove and harvest the excess heat by means of an active cooling system.

In order to carry out the excess thermal energy generated by the PV cells, an active cooling fluid is used (generally water with a percentage of glycol to prevent the fluid to freeze), which leads to a decrease in temperature on the solar cells, increasing their overall efficiency. This way, the waste heat harvested by the cooling fluid can be used as a cogenerated product and for heating applications (Kramer and Helmers, 2013).

\subsection{Maximum Reflector Concentration geometry concept}

Several studies on asymmetric concentrating collectors have been reported by Rabl (1976), Mills and Giutronich (1978), Welford and Winston (1989), Tripanagnostopoulos et al. (1999, 2000), Adsten et al. (2005) and Bernardo et al. (2013). These studies led to a novel truncated geometry called Maximum Reflector 
Concentration (MaReCo) collector, due to the asymmetric solar radiation over the year at high latitudes, more specifically in Sweden (Adsten et al., 2005).

The MaReCo suits high latitudes due to the low solar altitude and the large cloud coverage during winter time. The generally form of the MaReCo reflector trough (Fig. 1) consists of two parabolic reflectors with their individual optical axis tilted $20^{\circ}$ and $65^{\circ}$ from the bottom side of the receiver (point 1), collecting all the upcoming irradiation between a solar altitude of $20^{\circ}$ and $65^{\circ}$ i.e. the tilt of the back and front reflector (Fig. 1) (Nilsson, 2005).

The front reflector (section A) reflects most of the irradiation during summer months, having the highest annual output, between both reflectors. The back reflector (sections B and C) reflects more during the rest of the year. The optical axis from the parabola defines the lower and upper acceptance angles. As shown in Fig. 1 the reflector is divided into three sections A, B and C. Section A consists in a lower side parabola extended between points 1 and 4, with the optical axis along the upper acceptance angle and its focal point on the upper part of the receiver (point 5). The circular section between points 1 and 2 characterizes section $\mathrm{B}$, the section that reflects the light rays into the backside of the reflector.

This section has the particularity to replace a hypothetical absorber between point 2 and the focus (dotted line between point 2 and 5) with the back side of the absorber described as the line that connects the point 1 and 5 . The lower tip of the absorber can be placed anywhere in section B. The last section, corresponding to the section $\mathrm{C}$ is the upper parabolic reflector with the optical axis along the lower acceptance angle and its focus at point 5 , represented between points 2 and 3 .

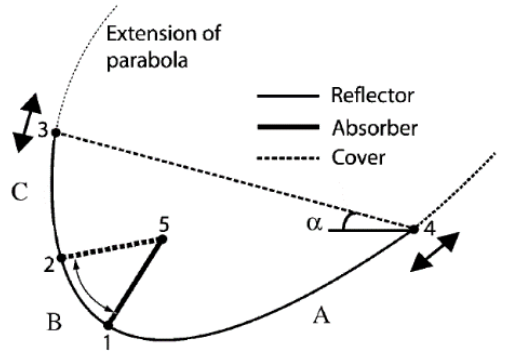

Fig. 1. Sketch of the basic MaReCo design. Part A is the lower parabolic reflector extended from point 1-4; Part B is the connecting circular reflector extended from point 1-2; Part $\mathrm{C}$ is the upper parabolic reflector extended from the point 2-3. The cover glass is found between points 3 and 4 . The position of the cover glass varies along the extended parabola depending on the truncation is the aperture tilt (Adsten et al., 2005).

The position of the cover glass (dotted line between points 3 and 4) can vary along the extensions of the parabola depending on the desired truncation. This position can be obtained by varying the position of the reflector sheet along the extended parabolas, where the maximum annual irradiation is obtained.

The current reflector geometry has a bifacial PVT (with coolant filled tubes) receiver that is parallel to the cover glass, and two sections B and C, as the ones presented in Fig. 1. The collector geometry is described more methodically by Bernardo et al. (2013) and can be seen in the following Fig. 2.

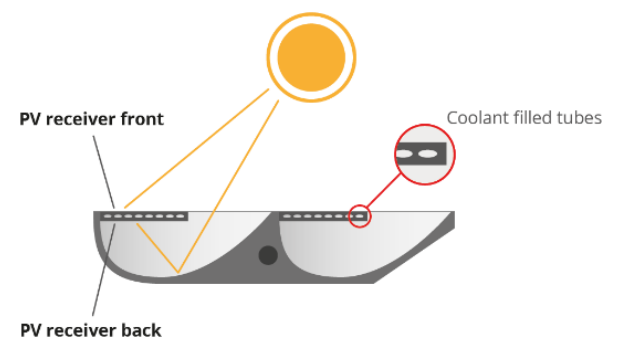

Fig. 2. Profile view of the MaReCo prototype concept, composed of two troughs and two PVT receivers with eight elliptical channels each.

\subsection{Impact of shading in C-PVT solar collectors}

Stationary solar C-PVT collectors use reflectors, which normally cause non-uniform distribution of light on the PV cell string. This non-uniform distribution may also be a consequence of partial shading that can arise from many different effects (clouds, reflector length limitations, shadows and dust or any sort of dirtiness), which in the solar PV modules, may lead to hot spots and cause permanent damage to the cells, as well as lowering the current of the whole string. Partial shading has a stronger impact on the electrical efficiency than 
on the thermal efficiency of PV/PVT systems, since non-uniform radiation in one cell increases the series resistance losses. This effect may induce the developments of hotspots in the solar PV module (Woyte et al., 2003), which may cause permanent damage to the cells that are shaded. The effect is reinforced in a string of series connected cells or arrays and it is always present in compound parabolic concentrators (CPC), as Rabl (1976) presented. In mismatching operating conditions (due to manufacturing tolerances, ageing, different orientation of the solar panels), the energetic efficiency of the PV/PVT systems is strongly compromised.

A C-PVT (non-tracking), to be able to work at its full potential (electrically), needs to ensure that the reflected image of the receiver in the reflector stays as much as possible in the reflector boundaries. At lower solar altitudes (sunrise and sunset) the reflected image in the reflector is not complete, leading to a lower output (as the reflected image is partially out of the reflector boundaries). A way to avoid this effect is to use bypass diodes that allow the current to flow in a different path, shutting down only partially the string (Gomes et al., 2014).

\begin{tabular}{|c|c|c|c|}
\hline \multicolumn{4}{|c|}{ Nomenclature } \\
\hline Symbol & Description [Unit] & Subscripts & \\
\hline$\theta_{c}$ & Acceptance half-angle $\left[{ }^{\circ}\right]$ & $\mathrm{CPC}$ & Compound Parabolic Concentrators \\
\hline$t_{a}$ & Ambient temperature $\left[{ }^{\circ} \mathrm{C}\right]$ & C-PVT & Concentrating Photovoltaic-Thermal \\
\hline$G_{b}$ & Beam irradiance $\left[\mathrm{W} / \mathrm{m}^{2}\right]$ & IAM & Incidence Angle Modifier \\
\hline $\mathrm{C}_{i}$ & Concentration factor $[-]$ & MaReCo & Maximum Reflector Concentration \\
\hline $\mathrm{b}_{0}$ & Constant for incident angle modifier & PVT & Photovoltaic-Thermal \\
\hline$G_{d}$ & Diffuse irradiance $\left[\mathrm{W} / \mathrm{m}^{2}\right]$ & ScenoCalc & $\begin{array}{l}\text { Solar Collector Energy Output } \\
\text { Calculator }\end{array}$ \\
\hline$c_{5}$ & Effective thermal capacity $\left[\mathrm{J} / \mathrm{m}^{2} . \mathrm{K}\right]$ & $\mathrm{T}$ & Thermal \\
\hline$\eta_{e l, S T C}$ & Electrical efficiency at standard testing conditions $[-]$ & & \\
\hline$c_{1}$ & Heat loss coefficient at $\left(t_{m}-t_{a}\right)=0\left[\mathrm{~W} / \mathrm{m}^{2} . \mathrm{K}\right]$ & & \\
\hline$\theta$ & Incidence angle $\left[{ }^{\circ}\right]$ & & \\
\hline$K_{\theta b}\left(\theta_{L}, \theta_{T}\right)$ & Incidence angle modifier for beam radiation $[-]$ & & \\
\hline$K_{\theta d}$ & Incidence angle modifier for diffuse radiation[-] & & \\
\hline$E_{l}$ & Long wave irradiance $(\lambda>3 \mu \mathrm{m})\left[\mathrm{W} / \mathrm{m}^{2}\right]$ & & \\
\hline$t_{m}$ & Mean fluid temperature $\left[{ }^{\circ} \mathrm{C}\right]$ & & \\
\hline$\eta 0, b$ & Peak collector efficiency at $\Delta \mathrm{T}=0 \mathrm{~K}[-]$ & & \\
\hline$c_{8}$ & Radiation losses $\left[\mathrm{W} / \mathrm{m}^{2} . \mathrm{K}^{4}\right]$ & & \\
\hline$\rho$ & Reflectivity $[\%]$ & & \\
\hline$c_{4}$ & Sky temperature dependence of heat loss coefficient [-] & & \\
\hline$P_{e l}$ & Specific electrical power output $\left[\mathrm{W} / \mathrm{m}^{2}\right]$ & & \\
\hline$Q_{t h}$ & Specific thermal power output $\left[\mathrm{W} / \mathrm{m}^{2}\right]$ & & \\
\hline$u$ & Surrounding air speed $[\mathrm{m} / \mathrm{s}]$ & & \\
\hline$\beta$ & Temperature coefficient of electrical power $[\% / \mathrm{K}]$ & & \\
\hline$c 2$ & $\begin{array}{l}\text { Temperature dependence of heat loss coefficient } \\
{\left[\mathrm{W} / \mathrm{m}^{2} \cdot \mathrm{K}^{2}\right]}\end{array}$ & & \\
\hline$c_{6}$ & Wind dependence of the zero loss efficiency $[\mathrm{s} / \mathrm{m}]$ & & \\
\hline$c_{3}$ & $\begin{array}{l}\text { Wind speed dependence of heat loss coefficient } \\
{\left[\mathrm{J} / \mathrm{m}^{3} \cdot \mathrm{K}\right]}\end{array}$ & & \\
\hline
\end{tabular}

\section{Methodology}

\subsection{Prototype concept description}

The asymmetric C-PVT solar collector prototype has a solar glazing protection, being supported by a plastic and metal structure. This glass cover is made of low iron glass with a solar transmittance of $95 \%$ according to the international standard ISO 9050 for solar thermal technologies. The end gables are composed of acrylic materials with a transmittance of around $90 \%$. Solar cells are laminated with a highly transparent and electrically insulated silicone (transparency of $96 \%$ for PV and $93 \%$ for solar thermal) on both sides of the thermal absorber, where a heat transfer medium runs through the channels in order to extract the excess heat released by the PV cells. The upper receiver side works as a standard PV module since it does not have concentration, while the lower receiver (receiver side that faces the reflector) side receives the concentrated reflected sunlight by the reflector. The prototype concept has an overall concentration factor of 1.5. The 
reflector material is made of anodized aluminium with a total solar reflectance of $95 \%$ for solar thermal (measured according to norm ASTM891-87) and a total light reflectance of 98\% for PV. The electrical part of the collector consists of eight cell strings connected in parallel, four on the top side and four on the bottom side. It is composed by two troughs, thus each of them has four cell strings, two at the top side and two at the bottom side. Each receiver side has 2 cell strings, with a layout of 19-19 cells (corresponding to a 1/6 full size monocrystalline solar cell) connected in series, thus a total of 152 cells per trough and 304 cells per collector. The prototype concept has an optical and electrical efficiency of $44 \%$ and $8 \%$, respectively, and a temperature dependence of $0.43 \% /{ }^{\circ} \mathrm{C}$. The collector description has been further discussed by Bernardo et al. (2013) and Fig. 3 presents a profile view of the prototype and how the reflector works (i.e. the focal line stays within the receiver boundaries until the sun passes the $0^{\circ}$ in transversal direction).

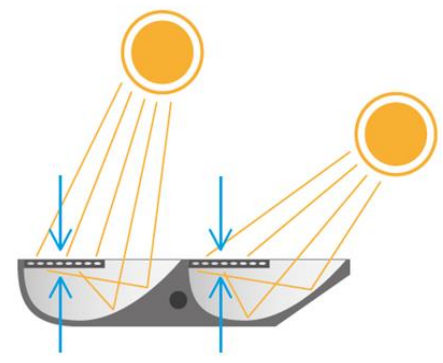

Fig. 3. Profile view of the MaReCo prototype concept, composed of two troughs.

A PVT system configuration and their annual yields were discussed in various publications have been described. Therefore, this paper aims at providing a consistent comparison of the electrical and thermal yield from an electrical and thermal performance model with real data collection, for 20 asymmetric C-PVT prototypes (with hand soldering cell strings) connected to the district heating network. The reflector geometry was developed for thermal collectors for high latitudes, at low working inlet and outlet temperatures (Adsten et al., 2005). Both the simulation and real data collection are for the same installation which is located in Gävle, at the University of Gävle (Sweden). This comparative assessment approach allows an efficient comparison between real data and simulated data for PVT collector technologies (in this study case, an asymmetric geometry), type of solar PVT system, and location.

The focus of the assessment is explicitly placed on the specific electrical and thermal yields of the collector within the context of the given system with its dynamic interaction of collector, system, and weather. The electrical and thermal yields are discussed, where the system yield is evaluated, and general conclusions on the energetic performance of the low concentration PVT collector prototype technology were drawn.

The evaluation of the thermal yield is made by means of a stationary mean working fluid temperature simulation tool called Solar Collector Energy Output Calculator (ScenoCalc), based on a thermal performance model used for test methods for solar thermal collectors described in ISO 9806:2013. The estimation of the electrical yield is based on an electrical performance model presented by Lämmle et al. (2017).

\subsection{System description}

The annual average distribution temperatures in District Heating grids has been $86^{\circ} \mathrm{C}$ for the supply pipes and $47^{\circ} \mathrm{C}$ for the return pipes (Werner, 2017). The systems' inlet and outlet temperature have been selected by the average inlet and outlet temperature values registered for the given year, where the working temperatures varied between $43^{\circ} \mathrm{C}$ and $62^{\circ} \mathrm{C}$. Note that the temperature values were taken for the whole year, thus having an error associated when comparing them to the instant values registered every hour at the system. Low concentrating PVT collectors perform significantly better at low working inlet and outlet temperatures, thus selecting high working temperatures will lead the system to underperform significantly. For that, several sensors have been installed in the system in order to monitor the data throughout the year.

The system is placed at the wall facade of a laboratory building at Gävle University (Sweden), is divided into three rows with 8, 4 and 8 collector prototypes, as can be seen in Fig. 4. 


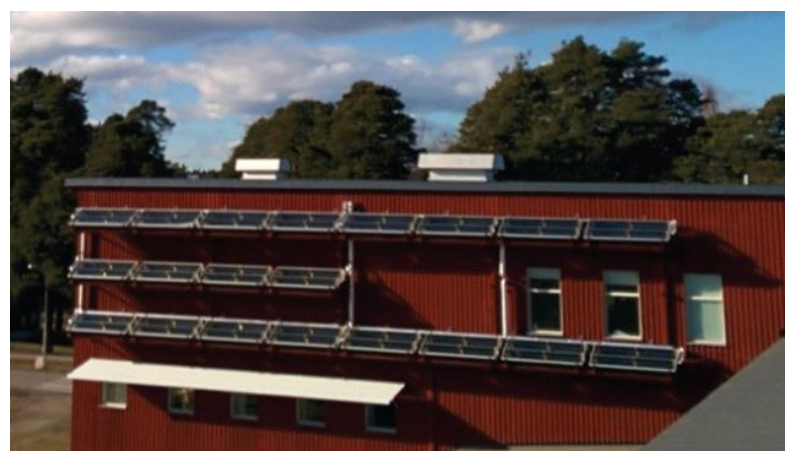

Fig. 4. Wall facade installation of asymmetric C-PVT solar collector prototypes at Gävle University, Sweden.

The thermal system (Fig. 5) is composed of five simple parallel loops with four collectors per loop, where each loop has one sensor installed (Fig. 5, from sensor 1 to 5). The system is connected to a heat exchanger, which is connected to the district heating network, providing heat to the University buildings.

The following Fig. 5 shows the layout of the thermal system with the respective components.

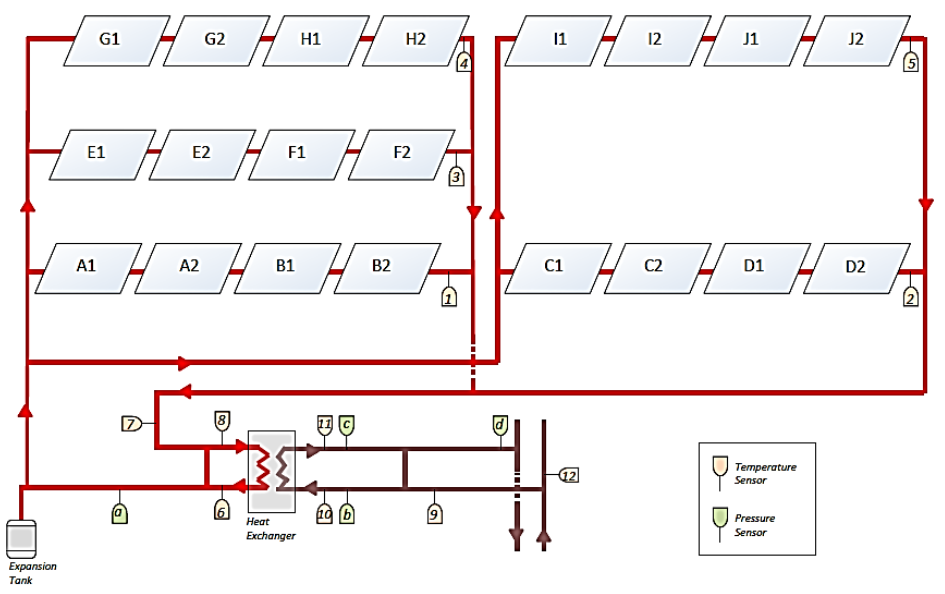

Fig. 5. System thermal layout, connected to the district heating network.

On the other hand, the electrical system presented in Fig. 6, is composed of two systems connected directly to the grid. System 1 is composed by four groups of two collectors (for a total peak power of $1.8 \mathrm{~kW}_{\mathrm{p}}$ ) and system 2 by six groups of two units (for a total peak power of $3 \mathrm{~kW}_{\mathrm{p}}$ ). Each system has an inverter and per two collectors a power optimizer is used. The electrical layout of the system can be seen in the following Fig. 6.

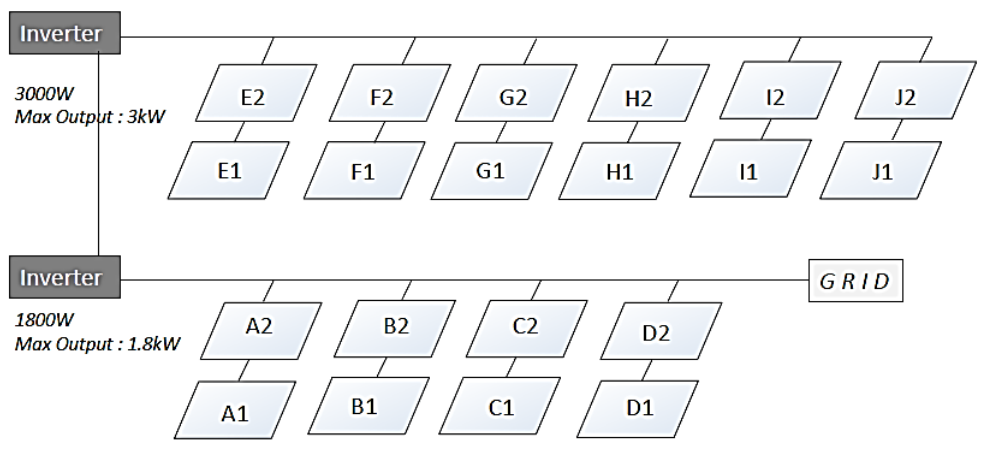

Fig. 6. Electrical system layout, divided into two systems. System 1 with $1.8 \mathrm{~kW}$ and system 2 with $3 \mathrm{~kW}$.

\subsection{Performance models}

In order to accurately calculate both thermal and electrical yield of the different geometries, the collector parameters have been taken into account and normalized to the gross area of the C-PVT, according to the international standard for solar thermal collectors ISO 9806:2013. The thermal and electrical parameters were obtained at the Solar Energy Laboratory (LES), in Lisbon. The testing is based on test methods for solar thermal 
collectors described in ISO 9806:2013.

\subsubsection{Thermal performance model}

The thermal collector parameters for the system, such as the IAM factor for diffused radiation $\left(K_{\theta d}\right.$, that it is given by the inverse of the concentration factor), heat loss coefficient $\left(c_{l}=3.5 \mathrm{~W} / \mathrm{m}^{2} . \mathrm{K}\right)$, temperature dependent heat loss coefficient $\left(c_{2}=0.013 \mathrm{~W} / \mathrm{m}^{2} . \mathrm{K}^{2}\right)$, and the collector optical efficiency for beam radiation $\left(\eta_{0, b}=0.44\right)$ have been employed into Eq. (1).

The prototype concept is characterized by an asymmetric transversal IAM due to the asymmetric MaReCo geometry presented by Adsten et al. (2005), and it is presented below in Fig. 7.

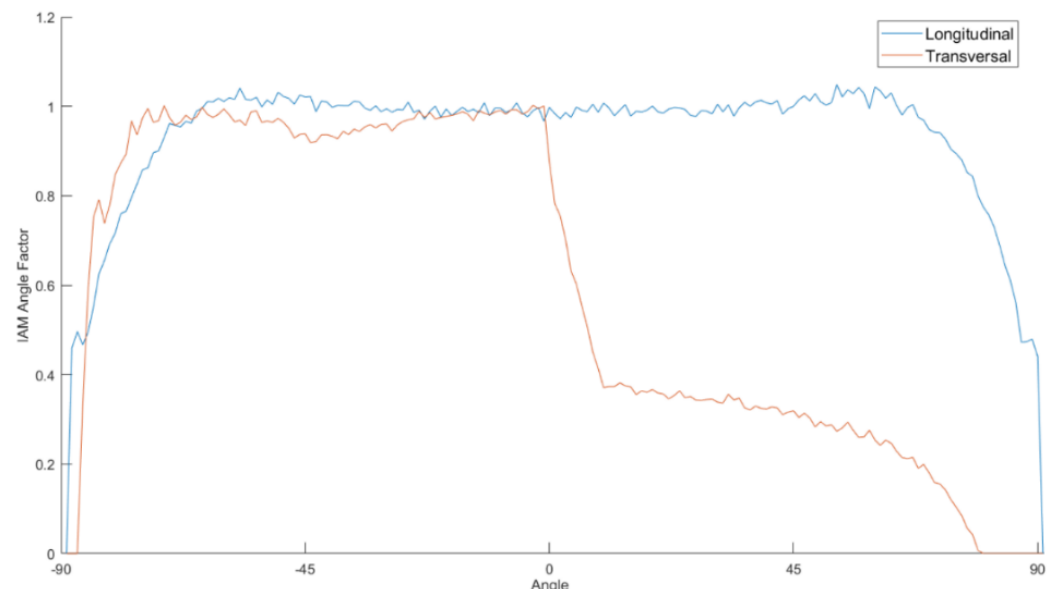

Fig. 7. Transversal (asymmetric red line) and longitudinal (symmetric blue line) IAM for the asymmetric prototype with a MaReCo geometry.

Both transversal and longitudinal IAMs have been normalized for normal incidence as suggested in ISO 9806:2013 for heating solar collectors.

Due to its geometry, the receivers behave differently from each other. The top receiver (receiver facing the sky) acts as a standard PV module, having a symmetrical transversal maximum efficiency curve. On the other hand, the bottom receiver (receiver facing the reflector) is highly dependent on the suns' position. When the sun goes over the $0^{\circ}$ transversal, the MaReCo geometry has no ability to redirect the sun rays towards the receiver, thus the steep decrease seen in Fig. 7.

A simplified quasi-dynamic model for thermal collector performance model has been employed, taking into account the dependence on direct and diffuse radiation, mean fluid temperature and incidence angle modifiers. Eq. (1) shows the energy balance equation of a thermal collector, described in ISO 9806:2013 and used in ScenoCalc.

$Q_{t h}=\eta_{0, b} \cdot\left(K_{\theta b}\left(\theta_{L}, \theta_{T}\right) \cdot G_{b}+K_{\theta d} \cdot G_{d}\right)-c_{1} \cdot\left(t_{m}-t_{a}\right)-c_{2} \cdot\left(t_{m}-t_{a}\right)^{2}-c_{3} \cdot u \cdot\left(t_{m}-t_{a}\right)+c_{4} \cdot\left(E_{L}-\sigma \cdot t_{a}^{4}\right)-c_{5} \cdot \frac{d t_{m}}{d t}$

Where $\eta_{0, b}$ stands for optical efficiency, $K_{\theta b}\left(\theta_{L}, \theta_{T}\right)$ and $K_{\theta d}$ for the IAM coefficients factors for direct and diffuse solar radiation, respectively. The heat losses are given by the coefficients $c_{1}$ and $c_{2}$ in respect to the difference between mean fluid temperature $t_{m}$ and the ambient temperature $t_{a}$. The coefficient $c_{5}$ is the effective thermal capacity, which describes the dependency to the derivate in time of the mean fluid temperature $\frac{d t_{m}}{d t}$. This parameter has been removed due to the fact that the temperature is static with a system of no thermal mass. Both coefficients $c_{3}$ and $c_{4}$ for the given glazed collector prototype are close to zero, due to neglectable wind speed dependence. Eq. (2) shows the final equation used to estimate the thermal yield.

$Q_{t h}=\eta_{0, b} \cdot\left(K_{\theta b}\left(\theta_{L}, \theta_{T}\right) \cdot G_{b}+K_{\theta d} \cdot G_{d}\right)-c_{1} \cdot\left(t_{m}-t_{a}\right)-c_{2} \cdot\left(t_{m}-t_{a}\right)^{2}$ 


\subsubsection{Electrical performance model}

A simplified electrical performance model was based in the a PVT electrical performance model suggested by Lämmle et al. (2017), which takes into account different parameters, such as direction of beam and diffuse radiation, the instantaneous performance ratio (PR) due to incidence angle losses $\left(P R_{I A M}==1-b_{0} \cdot\left(\frac{1}{\cos \theta}-1\right)\right.$; Duffie and Beckman, 2013), the temperature dependence of the electrical efficiency $\left(P R_{T}=1-\beta \cdot\left(t_{c e l l, P V T}-\right.\right.$ $t_{a}$ ); Skoplaki and Palyvos, 2009), and standard panel efficiency $\eta_{e l, S T C}$. The cell temperature in PVT collectors $t_{\text {cell,PVT }}$ presented by Lämmle et al. (2016) was simplified as the fluid mean temperature $t_{m}$ due to lack of sensors in this particular area. Due to the concentration factor of the PVT in the analysis, the low irradiance behaviour $P R_{G}$ presented by Heydenreich et al. (2008) was not considered, thus the instantaneous specific electrical power output $P_{e l}$ is given by the following Eq. (3).

$P_{e l}=\eta_{e l, S T C} \cdot P R_{I A M} \cdot P R_{T} \cdot G$

Where the temperature coefficient of electrical power $\beta$ and the standard panel electrical efficiency $\eta_{e l, S T C}$ are $0.43 \% / \mathrm{K}$ and $8 \%$, respectively.

\section{Results}

In the following section, the electrical and thermal energy yield assessment are presented and discussed. The estimation of the electrical and thermal yields have been determined by using meteorological data records measured at the installation site, with hourly time steps. The system is located in Gävle, Sweden (Lat. $60.67^{\circ} \mathrm{N}$; Long. $17.17^{\circ} \mathrm{E}$ ) and the year is characterised by an average global irradiation in the horizontal plane of 996 $\mathrm{kWh} / \mathrm{m}^{2} /$ year. It is important to state that the collectors in the analysis are prototypes with handmade cell string soldering, leading to some default collectors, and thus lowering the overall performance of the system.

\subsection{System analysis}

In order to perform the simulations a comparison with the irradiation data, the Copernicus Atmosphere Monitoring Service (CAMS) radiation service has been made. This service provides measurements based on satellite data with a time step from 1 min to 1 month. The Global, Direct and Diffuse Radiation can be queried for both the actual weather conditions and for clear sky conditions. On a cloudless day, this data is very accurate, but the exact time resolution on a partially cloudy day is somewhat lost due to the geographic resolution of the satellite data being coarse. Still, it results in a very accurate value on average, with a variation of around $2 \%$.

This review focus on an asymmetric low concentrator PVT solar collector technology, thus the electrical system losses regarding soiling and shading (up to 5\%) presented by Dobos (2014) are not implemented. Dobos (2014) also quantified the different electrical system losses (up to 16\%) for systems composed of flat PV panels, such as mismatch, connections, shading, soiling, amongst others.

Due to lack of literature reviews on this matter for this specific collector technology the electrical system losses implemented in this study were set at $11 \%$, for the reasons mentioned previously. The thermal losses were accounted for $10 \%$ (ESTIF, 2007). It is expected that due to the specific reflector geometry the impact of these parameters to be higher than the ones presented previously, leading to a deviation from the real measurement and simulated data.

For the given system, an electrical yield of $42 \mathrm{kWh} / \mathrm{m}^{2} /$ year was measured, being $11 \%$ rel lower than the simulated data (corresponding to a performance ratio of 0.89 ). The variation of the simulated and measured specific electrical yield for the system is given by Fig. 8 . 


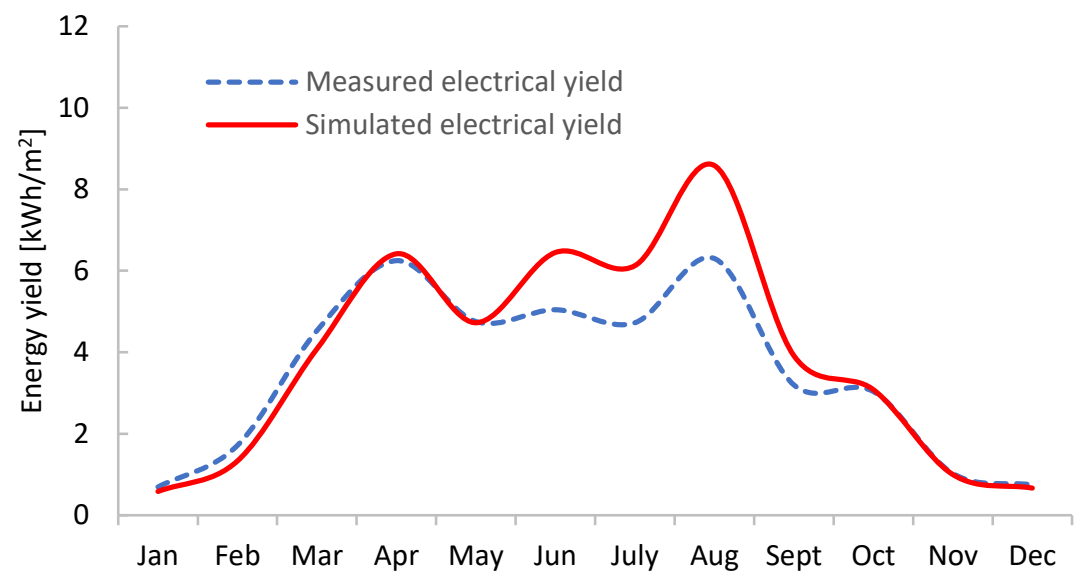

Fig. 8. Comparison between the simulated and measured electrical data for the given system.

As can be seen in Fig. 8, the relevant difference between the simulated and measured electrical data goes from May until October. This discrepancy can be explained due to the fact that the sun in summer times has a higher solar latitude, thus creating shadowing in the prototypes mounted below, as well as at some times of the day the sun passes over the $0^{\circ}$ in the transversal direction, lowering the electrical output of the bottom receiver. As mentioned previously, the prototypes have two strings layout per receiver side and that makes them even more sensitive to shadowing than if a higher string cell layout would be employed. This phenomenon can be applied as well to the PV cell size. Since the heating load during the summer is lower than the winter, the collector provides maximum thermal power during the winter season at high latitudes, due to their asymmetric design that has the ability to concentrate the low solar altitude rays into the absorber, as can be seen in Fig. 6 (from October until May).

On the other hand, a thermal yield of $72 \mathrm{kWh} / \mathrm{m}^{2} /$ year was measured, or $14 \%$ rel lower than the simulated thermal data. This leads to a performance ratio of 0.86 . The variation of the simulated and measured specific thermal yield for the system is given by Fig. 9 .

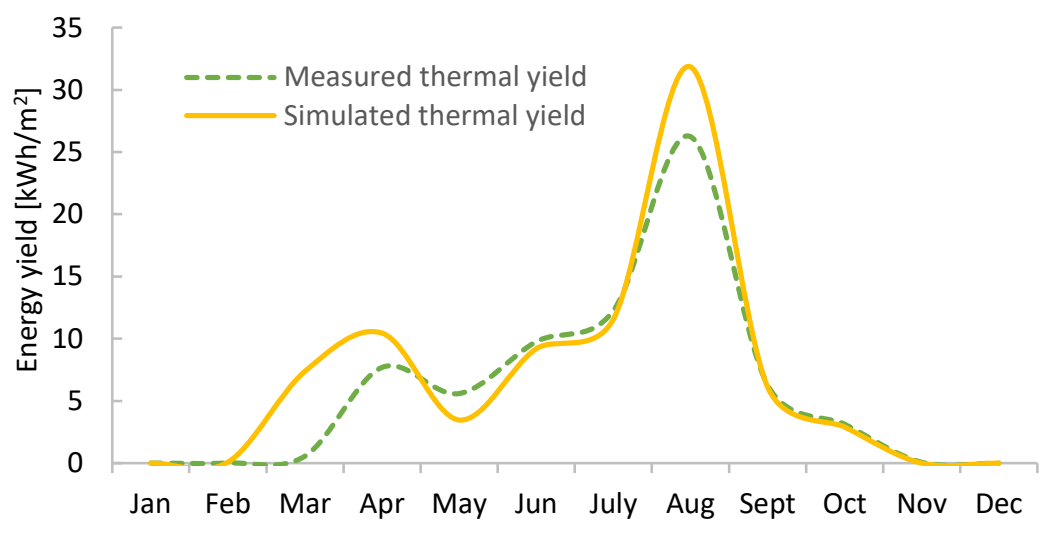

Fig. 9. Comparison between the simulated and measured thermal data for the given system.

The shadowing effect on the thermal system has less impact than in the electrical system, nevertheless, it leads to a lower energy yield. Note that the given simulated mean temperature is constant throughout the year, which can lead to differences as the ones observed in Fig. 9. The measured thermal yield of the system takes into account the variations of the temperature inside the prototype concept, which again can lead to lower energy yields.

\section{Discussion}

The study showed that this collector technology is very sensitive to the different inlet and outlet temperatures, which leads to a thermal performance system of $72 \mathrm{kWh} / \mathrm{m}^{2} /$ year or $14 \%$ lower than the simulated data. The higher inlet temperatures lead to a higher PV cell temperature, thus lowering the electrical yield of the system to $42 \mathrm{kWh} / \mathrm{m}^{2} /$ year or $89 \%$ of the simulated electrical yield. However, on the electrical side, the manual 
production of the cell strings has an influence that is visible in the differences between the outputs of the individual collectors. The shading created by the prototypes placed above, was not taken into account in the simulations and it is estimated to cause an underperformance higher than the $2 \%$ for soiling and $3 \%$ for shading, due to the fact that a concentrating solar collector is more sensitive to shadowing than a flat PV module.

\section{References}

Adsten, M., Helgesson, A., Karlsson, B., 2005. Evaluation of CPC-collector designs for stand-alone, roof- or wall installation. Sol. Energy 79, 638-647.

Bernardo, R., Davidsson, H., Gentile, N., Gomes, J., Gruffman, C., Chea, L., Mumba, C., Karlsson, B., 2013. Measurements of the Electrical Incidence Angle Modifiers of an Asymmetrical Photovoltaic/Thermal Compound Parabolic Concentrating-Collector. Engineering 5, 37-43.

Copernicus Atmosphere Monitoring Service, 2018. http://www.soda-pro.com/web-services/radiation/camsradiation-service

Dobos, A., 2014. PVWatts Version 5 Manual. NREL/TP-6A20-62641.

Duffie, J.A., Beckman, W.A., 2013. Solar Engineering of Thermal Processes. John Wiley \& Sons, New York. Gomes, J., Diwan, L., Bernardo, R., Karlsson, B., 2014. Minimizing the Impact of Shading at Oblique Solar Angles in a Fully Enclosed Asymmetric Concentrating PVT Collector. Energy Procedia 57, 2176-2185.

European Solar Thermal Industry Federation, 2007. Objective methodology for simple calculation of the energy delivery of (small) Solar Thermal systems.

Heydenreich, W., Müller, B., Reise, C., 2008. Describing the world with three parameters: a new approach to PV module power modelling. In: Proceedings of the 23rd European Photovoltaic Solar Energy Conference and Exhibition, September 1-5, 2008, Valencia, Spain.

ISO 9806, 2013. ISO 9806:2013 Solar energy - Solar thermal collectors - Test methods.

Kramer, K., Helmers, H., 2013. The interaction of standards and innovation: Hybrid photovoltaic-thermal collectors. Sol. Energy 98 (Part C), 434-439.

Lämmle, M., Kroyer, T., Fortuin, S., Wiese, M., Hermann, M., 2016. Development and modelling of highlyefficient PVT collectors with low-emissivity coatings. Sol. Energy 130, 161-173.

Lämmle, M., Oliva, A., Hermann, M., Kramer, K., Kramer, W., 2017. PVT collector technologies in solar thermal systems: A systematic assessment of electrical and thermal yields with the novel characteristic temperature approach. Sol. Energy 155, 867-879.

Mills, D.R., Giutronich, J.E., 1978. Asymmetrical non-imaging cylindrical solar concentrators. Sol. Energy 20 (1), 45-55.

Nilsson, J., 2005. Optical Design and Characterization of Solar Concentrators for Photovoltaics. Lund University.

Rabl, A., 1976. Comparison of solar collectors. Sol. Energy 18 (2), 93-111.

Serrats, E. M., Kovacs, P., Kramer, K., Nielsen, J. E., 2012. IEA-SHC Task 43: Research and standardization on solar collector testing and towards a global certification scheme. Energy Procedia 30, 162-171.

Sharaf, O. Z., Orhan, M. F., 2015. Concentrated photovoltaic thermal (CPVT) solar collector systems: Part I Fundamentals, design considerations and current technologies. Renew. Sustain. Energy Rev. 50, 1500-1565.

Skoplaki, E., Palyvos, J., 2009. On the temperature dependence of photovoltaic module electrical performance: A review of efficiency/power correlations. Sol. Energy 83 (5), 614-624.

Stine, W. B., Harrigan, R.W., 1986. Solar Energy Systems Design, John Wiley and Sons, New York.

Tripanagnostopoulos, Y., Yianoulis, P., Papaefthimiou, S., Zafeiratos, S., 2000. CPC solar collectors with flat bifacial absorbers. Sol. Energy 69 (3), 191-203.

Welford, W. T., Winston, R., 1989. Chapter 4 - Non-imaging concentrators: The compound parabolic concentrator in High Collection Nonimaging Optics, Eds. Academic Press, 53-76.

Werner, S., 2017. District heating and cooling in Sweden. Energy 126, 419-429.

Woyte, A., Nijs, J., Balmans, R., 2003. Partial shadowing of photovoltaic arrays with different system configurations: literature review and field test results. Solar Energy 74, 217-233.

Zondag, H.A., 2008. Flat-plate PV-Thermal collectors and systems: A review. Renew. Sustain. Energy Rev. $12(4), 891-959$. 


\title{
Potential of covering electricity needs of a flat of a MFH with decentral compact heat pumps with PV - Simulation study for different DHW profiles and PV field sizes
}

\author{
Toni Calabrese ${ }^{1}$, Fabian Ochs ${ }^{1}$, Dietmar Siegele ${ }^{1}$ and Georgios Dermentzis ${ }^{1}$ \\ 1 Unit for Energy Efficient Building/University of Innsbruck, Innsbruck (Austria)
}

\begin{abstract}
Heat pumps in combination with PV are discussed as one of the key technologies in a future sustainable energy system. A simulation study of a flat in a multi-familiy-house (MFH) with decentral compact heat pumps and with a photovoltaic (PV) field was performed in the CARNOT/Simulink simulation environment in order to evaluate the potential to reduce the purchased grid electricity. PV electricity is self-consumed covering electric power requests for heating, ventilation, appliances and Domestic Hot Water (DHW) preparation. Three different electric power profiles for DHW preparation and two PV fields (roof, roof and façade) were analyzed.

The results of the simulations show that just a small percentage (below 26\%) of electricity demand can be covered from PV field energy. The installation of a PV field also on the façade of the flat does not reduce significantly the purchased electricity ( $-11 \%$ in best of cases), while the use of daily electric storage could be evaluated to decrease further the purchased electricity (maximum reduction of $-27 \%$ ). The use of annual primary energy factor instead of monthly values overestimates the reduction of primary energy demand in all cases compared to the case without photovoltaic system.
\end{abstract}

Keywords: $M F H$, compact heat pumps, deep renovation, $P V$ self-consumption, DHW profiles

\section{Motivation}

One of the promising technologies investigated within IEA SHC task 56 for a future sustainable energy system is represented by the heat pumps in combination with PV systems. Heat pumps systems represent one of the most versatile technology and can be used for heating, cooling and Domestic Hot Water (DHW) preparation. Electricity produced by the photovoltaic (PV) system can cover the electric demand for appliances and can be further used for the heat pump. Such a system can significantly reduce the purchased electricity (i.e. the non-renewable primary energy demand) of a building and the potential of this reduction is influenced, for example, by the PV sizes and the total electric demand of the building.

A simulation study is useful to show the influence of relevant parameters of such a system (e.g. PV sizes, profile of electric demand) on the purchased grid electricity and can give some additional information about possible optimization of the system in order to decrease further the amount of electricity from the grid.

An annual simulation in the CARNOT/Simulink simulation environment for a flat of a typical Multi Family House (MFH) was performed to evaluate the amount of the PV electricity self-consumed in case electric power requests for HVAC system, appliances and DHW preparation are considered. Three different electric power profiles for DHW preparation and two PV fields (roof, roof and façade) were analyzed.

\section{Building model and simulation study}

\subsection{Building and PV field sizes}

Fig. 1 shows the multy-family-house (MFH) with 10 flats considered for the simulation study. Detailed information about the building model are available in [1]. The roof and the façade oriented to South-East were assumed available for the installation of the PV field. Two different PV sizes configurations were simulated: a PV field installed only on the roof and a PV installed on the roof and on the façade (see Tab. 1). For both PV sizes, the total PV electricity production was correspondingly divided by 10 and this electricity was considered available 
for one single flat. The electric power demand of the flat of the first floor oriented to North-East (highlighted in red in Fig. 1) for appliances, ventilation, heating and DHW preparation was considered in this study.

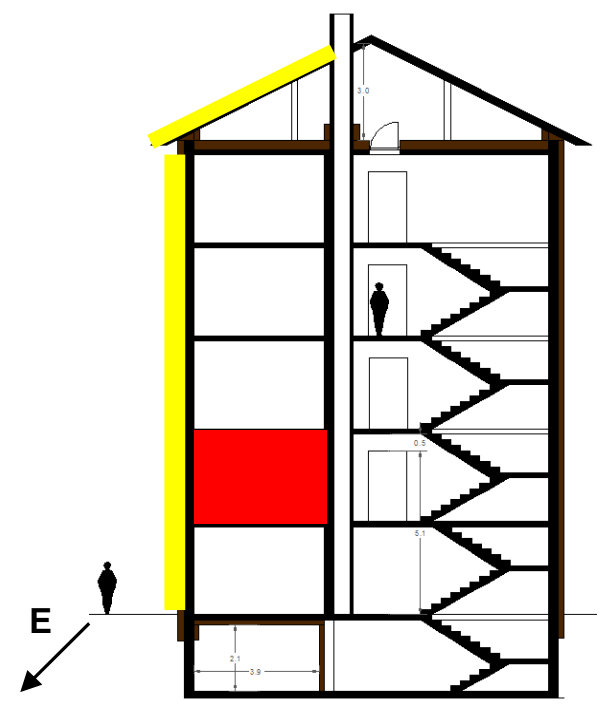

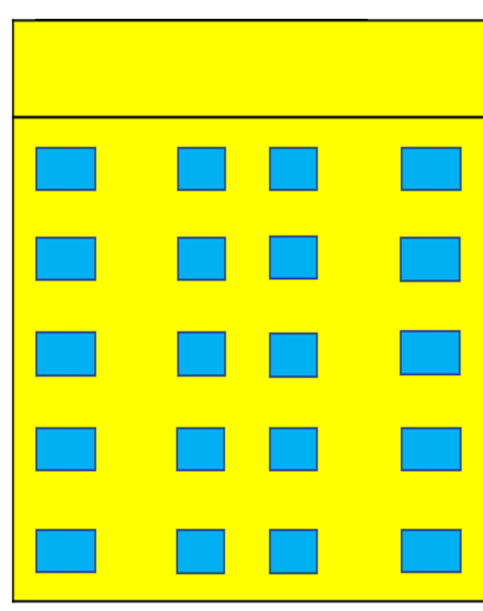

$\mathrm{S}$

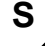

Fig. 1: View of the MFH (10 flats, 2 flats for each floor). The roof and the entire opaque façade area oriented to South-East (highlighted in yellow) were assumed available for installation of the PV field

Tab. 1: Data of PV field sizes considered for one flat

\begin{tabular}{|c|c|c|}
\hline & roof & roof\&façade \\
\hline Slope & $30^{\circ}$ & $30^{\circ}$ (roof) \& $90^{\circ}$ (façade) \\
\hline PV size $\left[\mathrm{m}^{2}\right]$ & 8.2 & 19.8 \\
\hline Peak power $\left[\mathrm{W}_{\mathrm{p}}\right]$ & 1250 & 3000 \\
\hline
\end{tabular}

\subsection{HVAC system and DHW production}

The analyzed flat is heated with a compact supply air - exhaust air heat pump in combination with MVHR (see Fig. 2 and [2] for details). Such a system can be completely integrated into the façade and represents a good solution for deep energy renovation of a flat in a MFH, especially in the case in which centralized renovation solutions are not practicable. The air is extracted from bathroom and kitchen, cooled in the MVHR unit and the remaining enthalpy is used as source for the heat pump. The fresh air is heated by a pre-heater, a Heat Recovery Ventilation (HRV) or Energy Recovery Ventilation (ERV) unit, the condenser of the heat pump and, additionally, a post-heater if the power of heat pump is insufficient, before it is supplied and distributed to the flat. The air distribution system is placed in the corridor and supplies fresh air to the sleeping room, child room and living room. An electric radiator is placed in the bathroom for comfort reasons.

Two different DHW production systems were investigated in this study: electric boiler and ambient air-to-water heat pump.
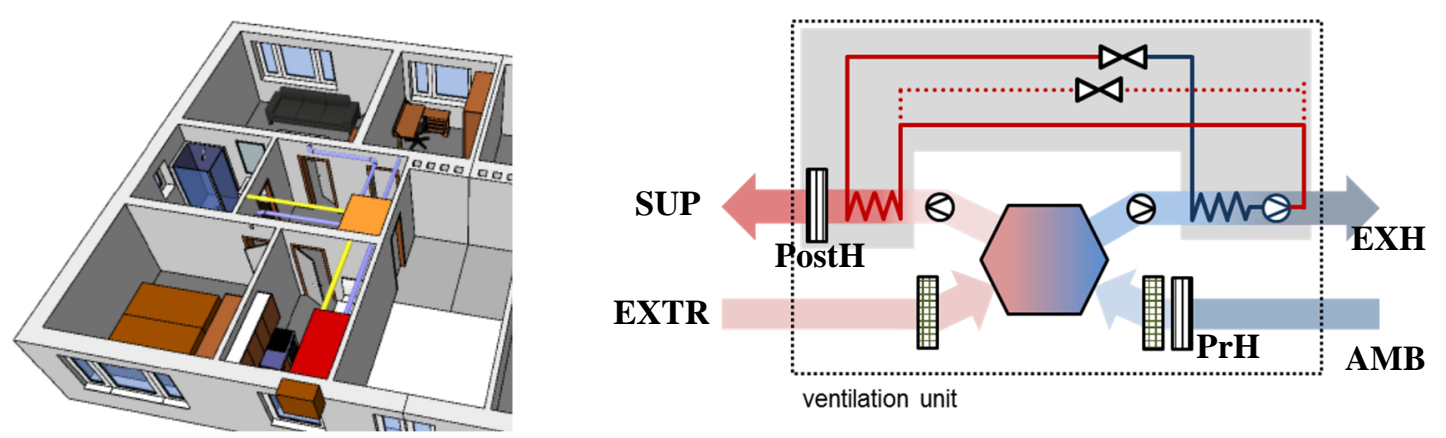

Fig. 2: 3D view of the flat with the supply air heat pump system (left) and scheme of the heat pump in combination with HRV (right). "PostH" and "PrH" represent the post-heater and the pre-heater, respectively [3] 


\subsection{Electricity demand}

Fig. 3 shows the electric power profile of the appliances (see Tab. 5 in appendix for details) corresponding to an electricity demand (Wel) of $2650 \mathrm{kWh} / \mathrm{a}$ distributed to the different rooms of the flat. Six rooms (i.e. six thermal zones) were defined in the flat model: kitchen (KI), sleeping room (SL), corridor (CO), bathroom (BA), child room $(\mathrm{CH})$ and living room $(\mathrm{LI})$. The same profile was assumed for each day of the year. The electric profile is the same for SL and $\mathrm{CH}$, while no appliances were assumed for BA and CO.
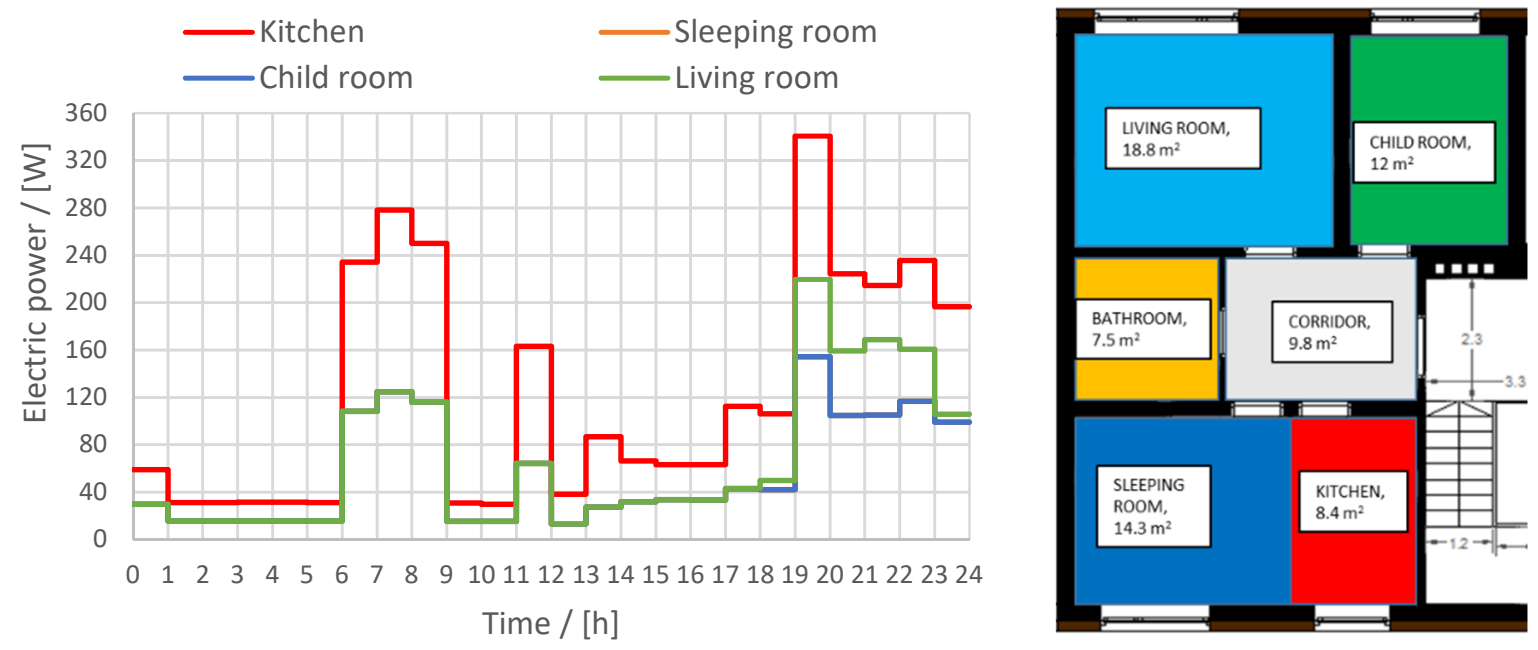

Fig. 3: Electric power profile (left) of the appliances for each room of the flat (Wel $=2650 \mathrm{kWh} / \mathrm{a})$ and floor plan of flat (right).

A balanced ventilation system with a constant airflow rate of $120 \mathrm{~m}^{3} / \mathrm{h}$ was assumed. Specific Fan Power (SFP) of $0.45 \mathrm{Wh} / \mathrm{m}^{3}$ for both fans (i.e. supply and extract airflow rate) was assumed to take into account the electric power supply of the ventilation system (electricity demand of $946 \mathrm{kWh} / \mathrm{a}$ ).

The flat under study with a heating demand (HD) of $33.4 \mathrm{kWh} /\left(\mathrm{m}^{2} \mathrm{a}\right)$ was heated during the winter with a supply air-exhaust air heat pump (with post-heater) and an additional electric radiator placed in the bathroom for comfort reasons (see Fig. 4 and [2] for details). Because of the relative low power of the heat pump (650 W), a relatively high percentage $(26 \%)$ of the HD is covered by direct electric heating.

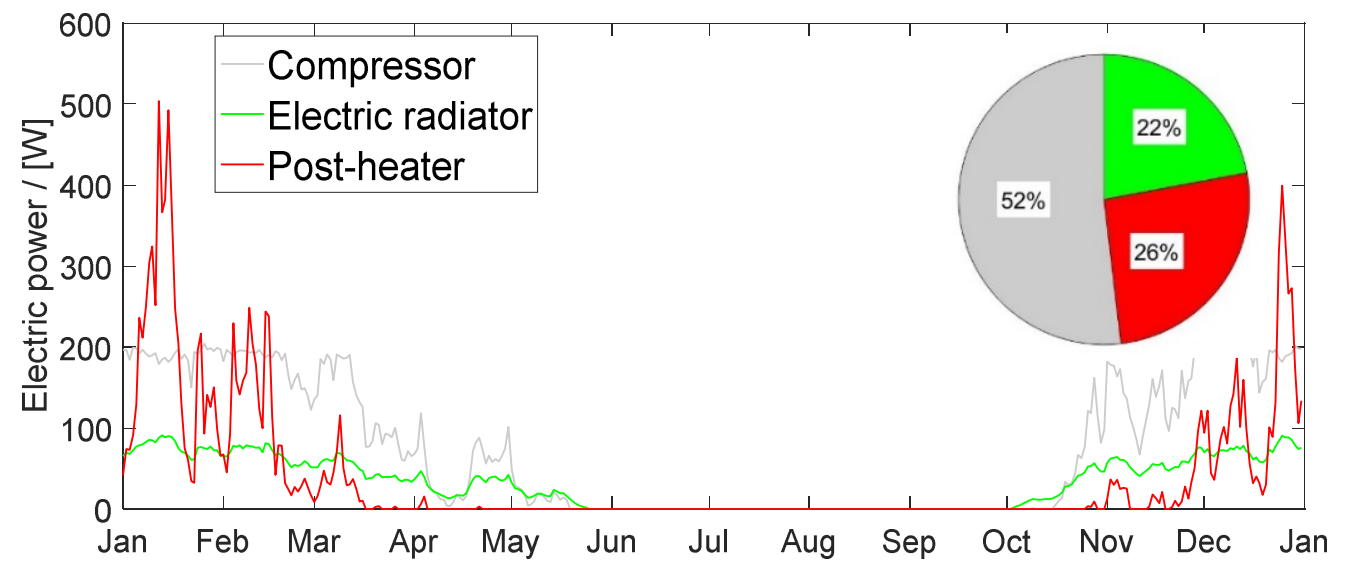

Fig. 4: Daily average values of the electric power request of the heating system $(\mathrm{Wel}=1292 \mathrm{kWh} / \mathrm{a})$

Three different profiles for domestic hot water (DHW) energy demand (see Tab. 2) were considered in this study. DHW(3) is a variation of DHW(2) assuming a preparation with air-to-water heat pump instead of direct electric heating. 
Tab. 2: Details of the three DHW profiles considered in the simulation study

\begin{tabular}{|c|c|c|c|c|}
\hline Case & Preparation & Profile & $\begin{array}{c}\text { Energy } \\
{[\mathbf{k W h} / \mathbf{a}]}\end{array}$ & $\begin{array}{c}\text { Electricity } \\
{[\mathbf{k W h} / \mathbf{a}]}\end{array}$ \\
\hline DHW(1) & Electric & Flat & 2190 & 2190 \\
\hline DHW(2) & Electric & Hourly & 2404 & 2404 \\
\hline DHW(3) & Heat pump & Hourly & 2404 & 906 \\
\hline
\end{tabular}

\subsection{Simulation study}

The assumption in this simulation study is that the electricity of the PV field first covers the appliances electricity demand and only the remaining PV electricity is available to cover the electric power demand of the HVAC system (i.e. ventilation, heating and DHW preparation). The rest of PV electricity is injected to the grid. Fig. 5 shows the simplified scheme of the modelled system. In the model, the balance between the PV production and the electric demand is done each 10 minutes and then the values are integrated to calculate the PV self-consumed and the amount of electricity that is covered by the grid.

Two different PV field configurations (see Tab. 1) and three electric demands for DHW preparation (see DHW(1), DHW(2) and DHW(3) in Tab. 2) were considered in this simulation study. In the following sections "Demand(1)", "Demand(2)" and "Demand(3)" indicate the total electric demand if DHW(1), DHW(2) and DHW(3) are considered, respectively.

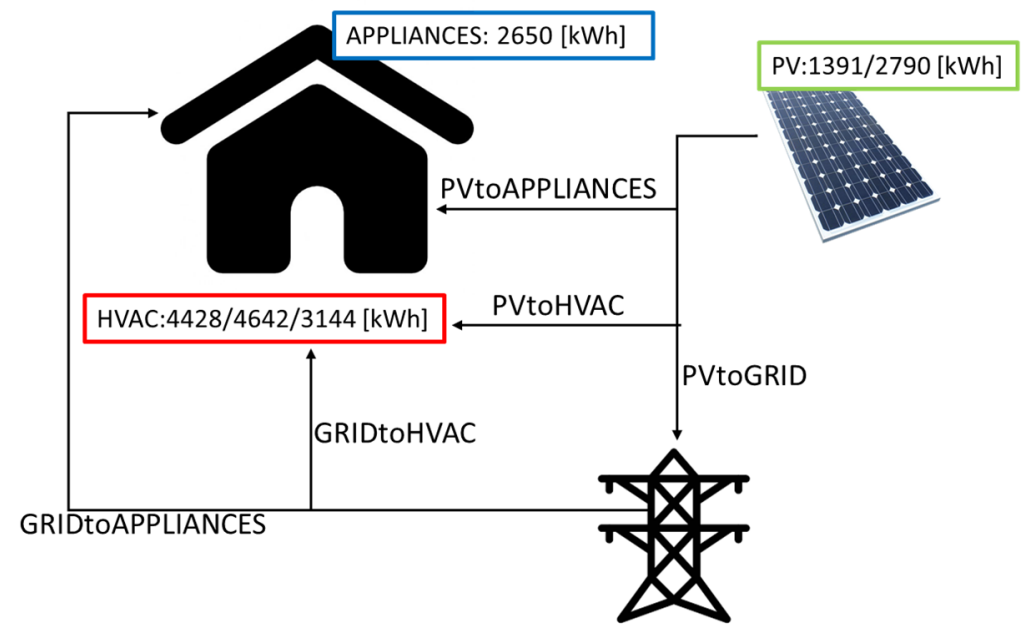

Fig. 5: Simplified scheme of the simulated coupled HVAC - PV system with PV energy production and electricity demand. Two different PV sizes (i.e. PV on the roof $(1391 \mathrm{kWh} / \mathrm{a})$ or also on the façade $(2790 \mathrm{kWh} / \mathrm{a}))$ and three electricity demands depending on the DHW profile (see Tab. 2) were considered. REMARK: "HVAC" indicates the sum of ventilation, heating (with HP) and DHW preparation.

\section{Results and discussion}

The monthly electricity energy flows of the system for all the cases are shown in Fig. 6. During the summer, the electric power request for heating is zero (see Fig. 4) which leads to the lower electricity demand compared to the winter time. In all cases and for each month, the PV production can only partially cover the electricity demand. Even if the best case is considered (i.e. PV(roof \& façade) and Demand(3) in July), electricity from grid is needed to cover the remaining electricity demand. 


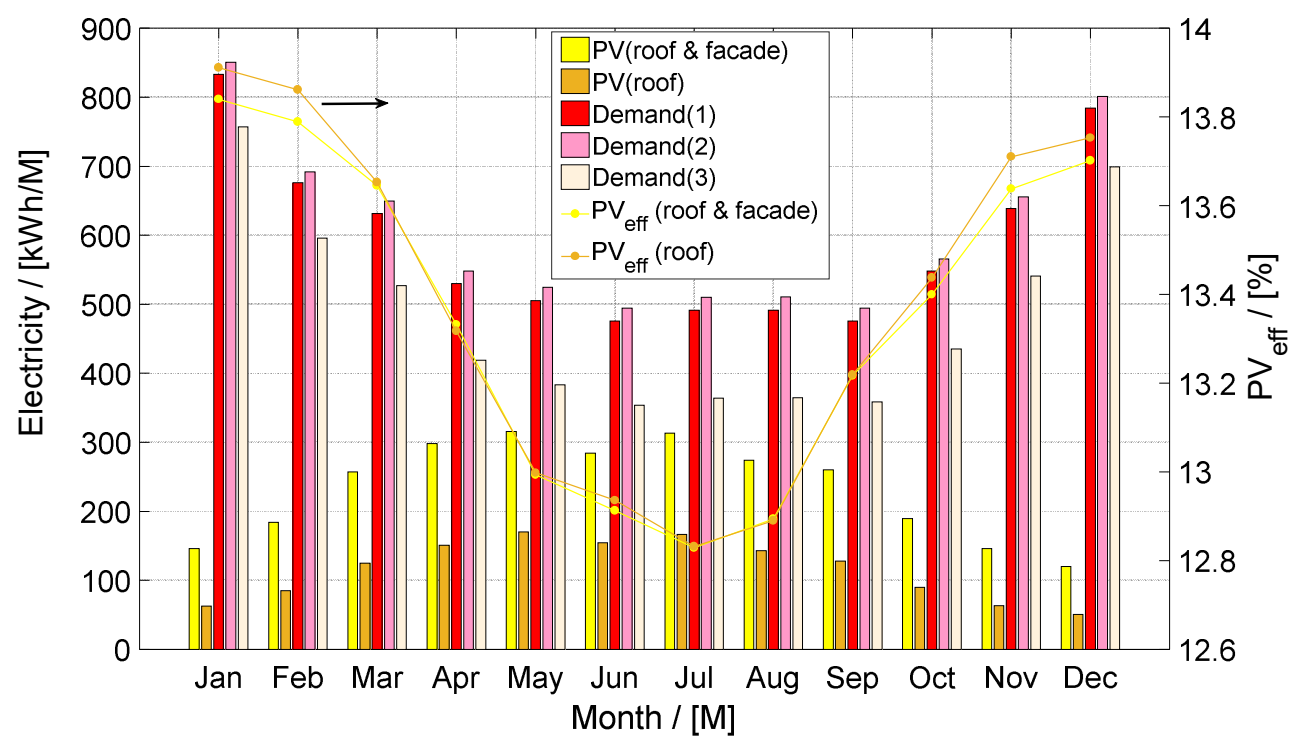

Fig. 6: Monthly electricity balance of the system. The PV production (with PV efficiency on the right axis) of the two investigated PV sizes and the three investigated electricity demands are shown

Fig. 7 shows the electricity balance of the PV system depending on the PV size and electricity demand. For all cases, PV electricity can cover a small percentage of the electricity demand with a maximum value of $18 \%$ and $26 \%$ in case PV is installed on the roof or also on the façade, respectively. For all the three investigated electricity demand profiles, the purchased electricity decreases in case PV is installed also on the façade and this reduction is of $-10 \%$ in case Demand(3) is considered. This reduction is limited by the fact that only the $30 \%$ of the PV produced by the PV on the façade is self-consumed, while the rest $(969 \mathrm{kWh})$ is fed to the grid (see Fig. 8). These results are confirmed by Thür et al. [4] who analyzed the influence of the PV field size on the self-consumed electricity for a Single Family House heated by a heat pump. These results show that only a relative small reduction of the purchased electricity (-7\%) can be obtained in case PV area is doubled $\left(40 \mathrm{~m}^{2}\right.$ instead of $\left.20 \mathrm{~m}^{2}\right)$.

Fig. 8 shows that the $46 \%$ of the PV production is fed to the grid in case PV is installed on the roof and façade. This non self-consumed PV electricity is fed to the grid in the summer period (see Fig. 9) and, to a much less extent, during the winter time. Thus, there is a good potential to reduce further the purchased electricity. More efficient control strategies (e.g. for DHW preparation) or electric storage (i.e. batteries) could be considered to reduce the amount of electricity purchased from the grid, especially if PV is installed also on the façade.

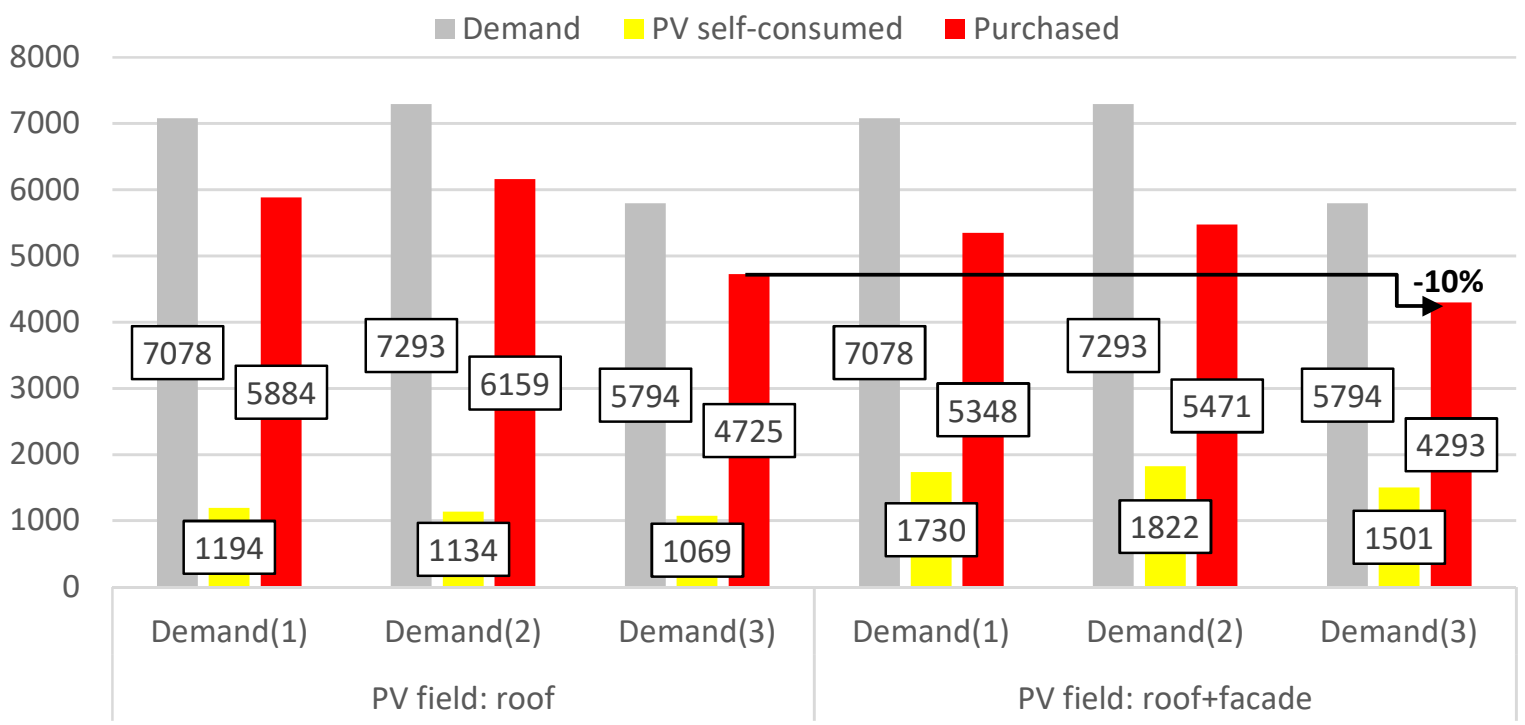

Fig. 7: Annual electricity demand, PV self-consumed and purchased grid electricity depending on the PV size and electricity demand 
T. Calabrese et. al. / EuroSun 2018 / ISES Conference Proceedings (2018)

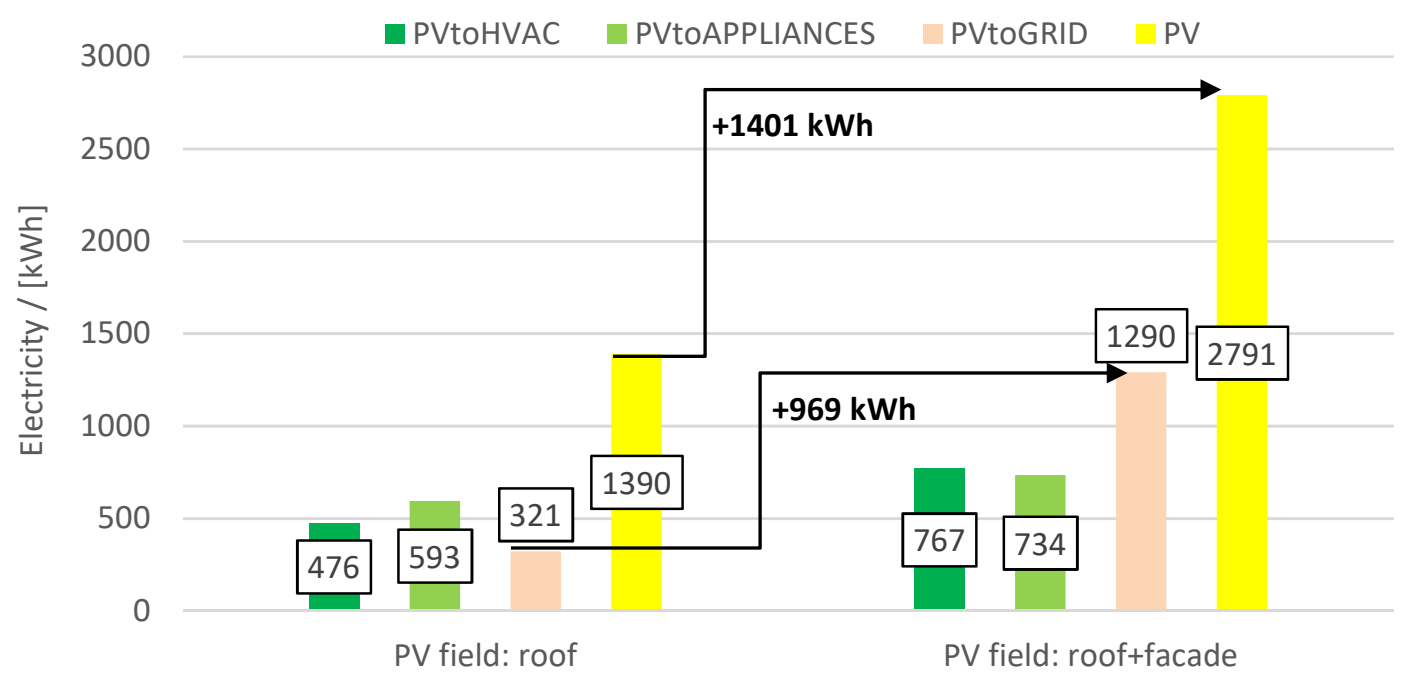

Fig. 8: Use of PV electricity depending on the PV size in case Demand(3) is considered
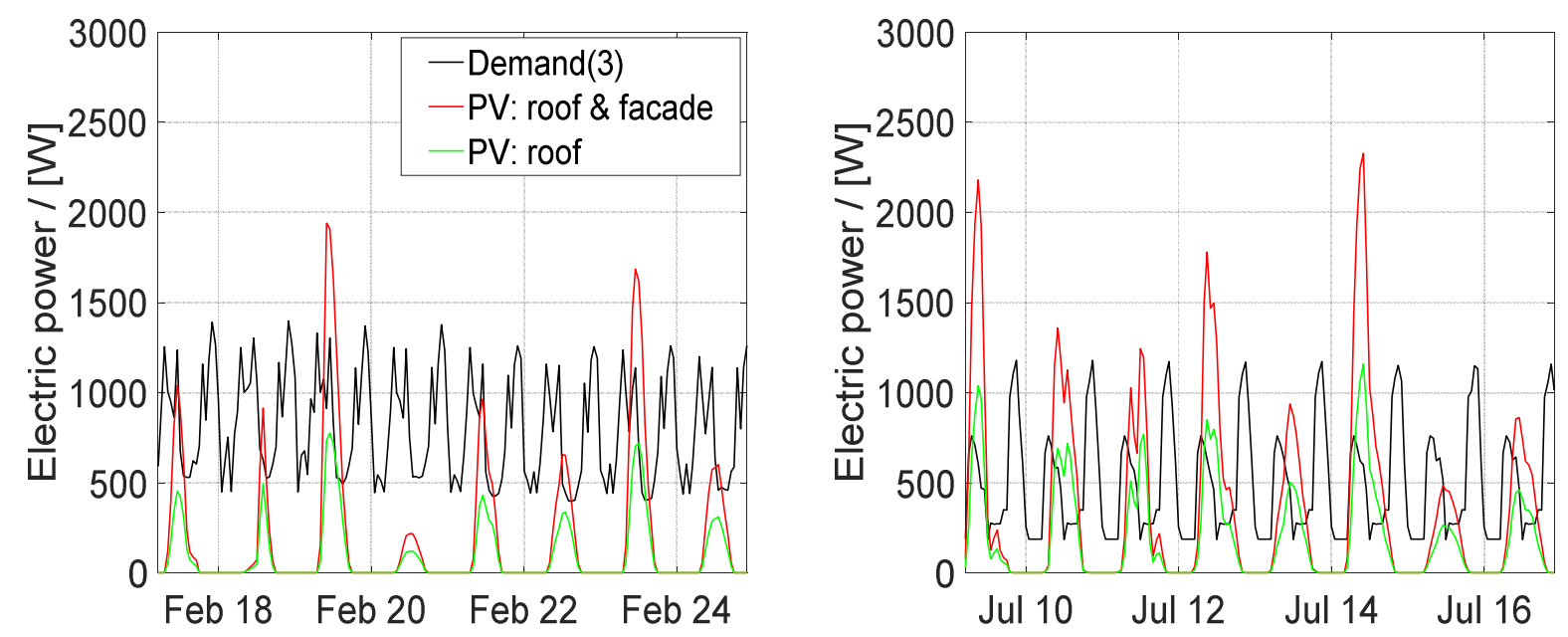

Fig. 9: PV production and electric demand (only Demand(3) is shown) during a winter period (left) and summer time (right)

The use of electric storage has a minor influence on the purchased electricity in case PV is installed just on the roof (see Fig. 9) due to the undersize of PV field compared to the electric demand (reduction of purchased electricity of 7\% in case of Demand(3) if annual electric storage is considered, see Fig. 10). Electric storage can play a more important role in case PV is installed on the façade and on the roof with a reduction of the purchased electricity of $27 \%$ if daily electric storage and Demand(3) are considered. 


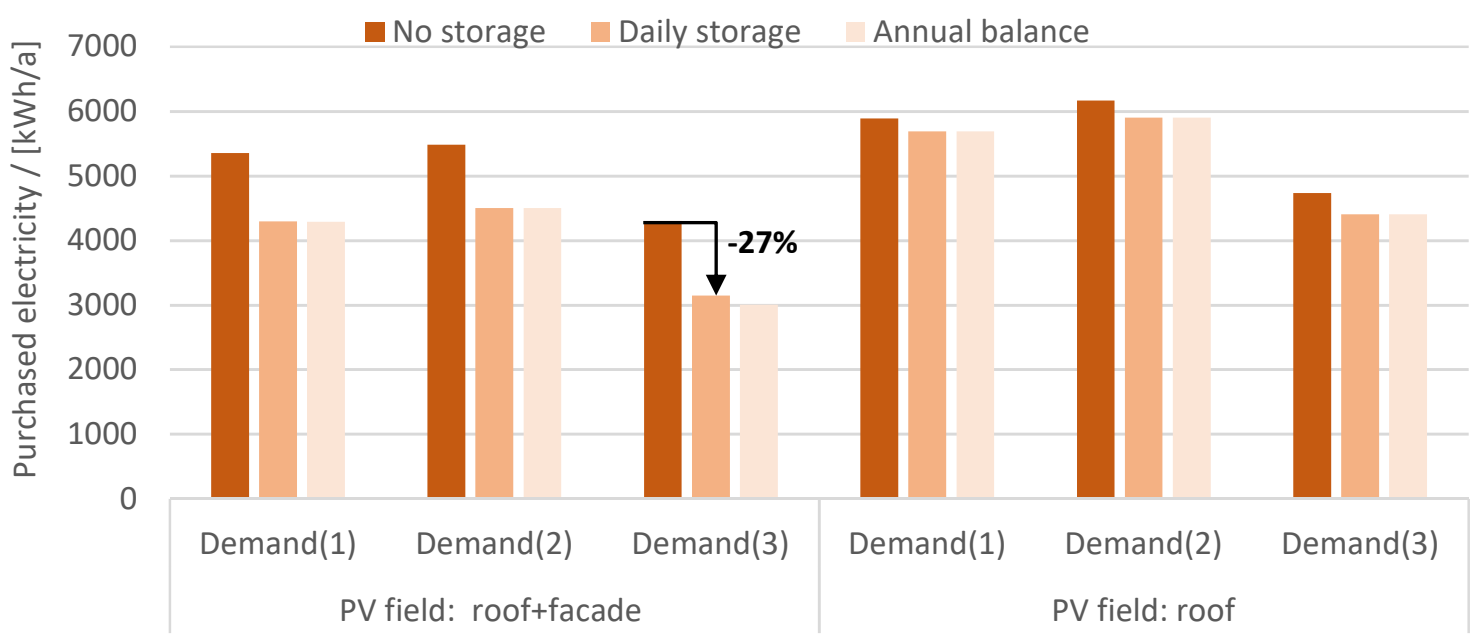

Fig. 10: Annual purchased electricity depending on the capacity of electric storage ("No storage" and "Daily storage") and in case an annual electricity balance is considered ("Annual balance")

As shown previously in Fig. 8, the electricity produced by the PV field installed on the façade of the flat is $1401 \mathrm{kWh}$, which is almost equal to the electricity production of the PV field installed on the roof (i.e. $1390 \mathrm{kWh}$ ). A simulation study of the flat in case of PV installed only on the façade was performed and the results of the comparison with the others PV sizes is reported in Fehler! Verweisquelle konnte nicht gefunden werden.. Even if the PV area is bigger on the façade of the flat $\left(11.6 \mathrm{~m}^{2}\right)$ compared to the PV area on the roof $\left(8.2 \mathrm{~m}^{2}\right)$, the PV production (see Fig. 8) and the purchased electricity are almost the same (with a difference below $2 \%$, see Fig. 12) for the two cases (i.e. "PV on roof" and "PV on façade") for the three electric demand investigated. The same reduction of the purchased electricity (compared to the case without PV) can be obtained through the installation of a PV field on the roof or on the façade, but the economic comparison between the two solutions of energy renovation should consider the higher investment costs in case of PV installed on the façade (due to the bigger PV area for each flat). Furthermore, in reality, a reduced yield for PV on the façade should be expected because of shading in many locations.

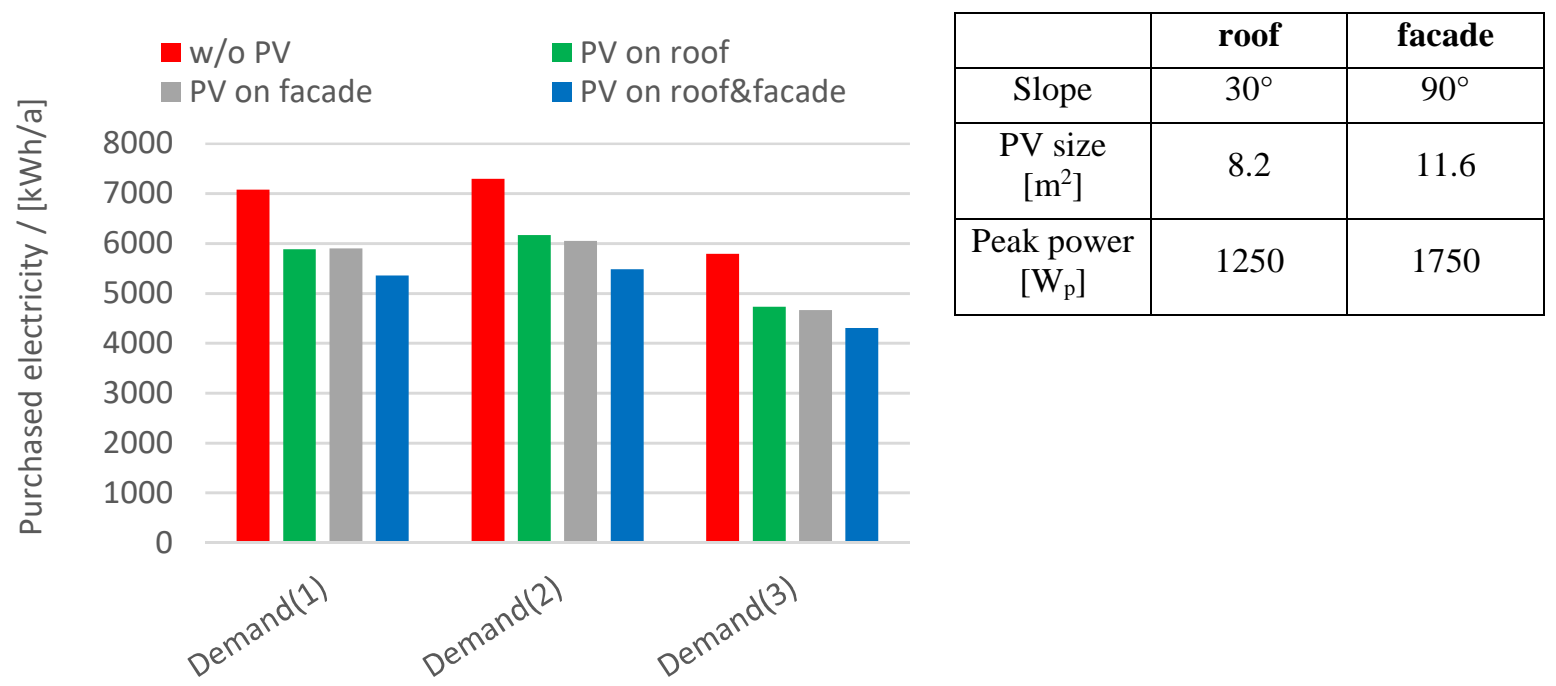

Fig. 11: Annual purchased electricity for the three electric demand investigated (i.e. Demand(1), Demand(2) and Demand(3)) depending on the PV size. "PV on facade" indicates that the PV is installed just on the facade of the flat $\left(A_{P V}=11.6 \mathrm{~m}^{2}\right)$

\subsection{Evaluation of non-renewable primary energy consumption}

The installation of a PV system on the roof (and the façade) of the building can reduce the (non-renewable) primary energy (PE) consumption of the flat. However as previously shown, there is a strong mismatch between high electricity demand in winter and PV excess electricity production in summer. This has influence on the value of electricity with respect of the time of electricity production. 
The seasonal variation of renewable electricity production in the energy mix can be taken into account, by monthly primary energy conversion factors ( $\left.f_{\mathrm{PE}}\right)$. Two scenarios for monthly $f_{\mathrm{PE}}$ are presented in [5] and considered in this study, depending on the different scenarios of the share of renewable energy in the energy mix (10\% hydro, $10 \%$ wind and $10 \% \mathrm{PV}$ for $\mathrm{f}_{\mathrm{PE} 1}$ and $10 \%$ hydro, $30 \%$ wind and $30 \% \mathrm{PV}$ for $\left.\mathrm{f}_{\mathrm{PE} 2}\right)$. $\mathrm{f}_{\mathrm{PE}}$ are higher during the winter season (maximum value of 2) compared to the summer period (see Fig. 12 and Fig. 13). The average annual value is 1.64 and 0.77 for $\mathrm{f}_{\mathrm{PE} 1}$ and $\mathrm{f}_{\mathrm{PE} 2}$, respectively. The electricity mix 10\%-10\%-10\% (i.e. $\mathrm{f}_{\mathrm{PE} 1}$ ) shows similar seasonal variation as the actual electricity mix in Austria (OIB, ENTSO-E, Statistik Austria). The monthly $f_{\mathrm{PE}}$ and the purchased electricity are lower during the summer and this explains the lower PE consumption during the summer for all cases shown. In case $\mathrm{f}_{\mathrm{PE} 2}$ is considered (Fig. 13), monthly PE demand during the summer (May-Aug) is very low (below $31 \mathrm{kWh} / \mathrm{M}$ ) for all the three cases investigated.

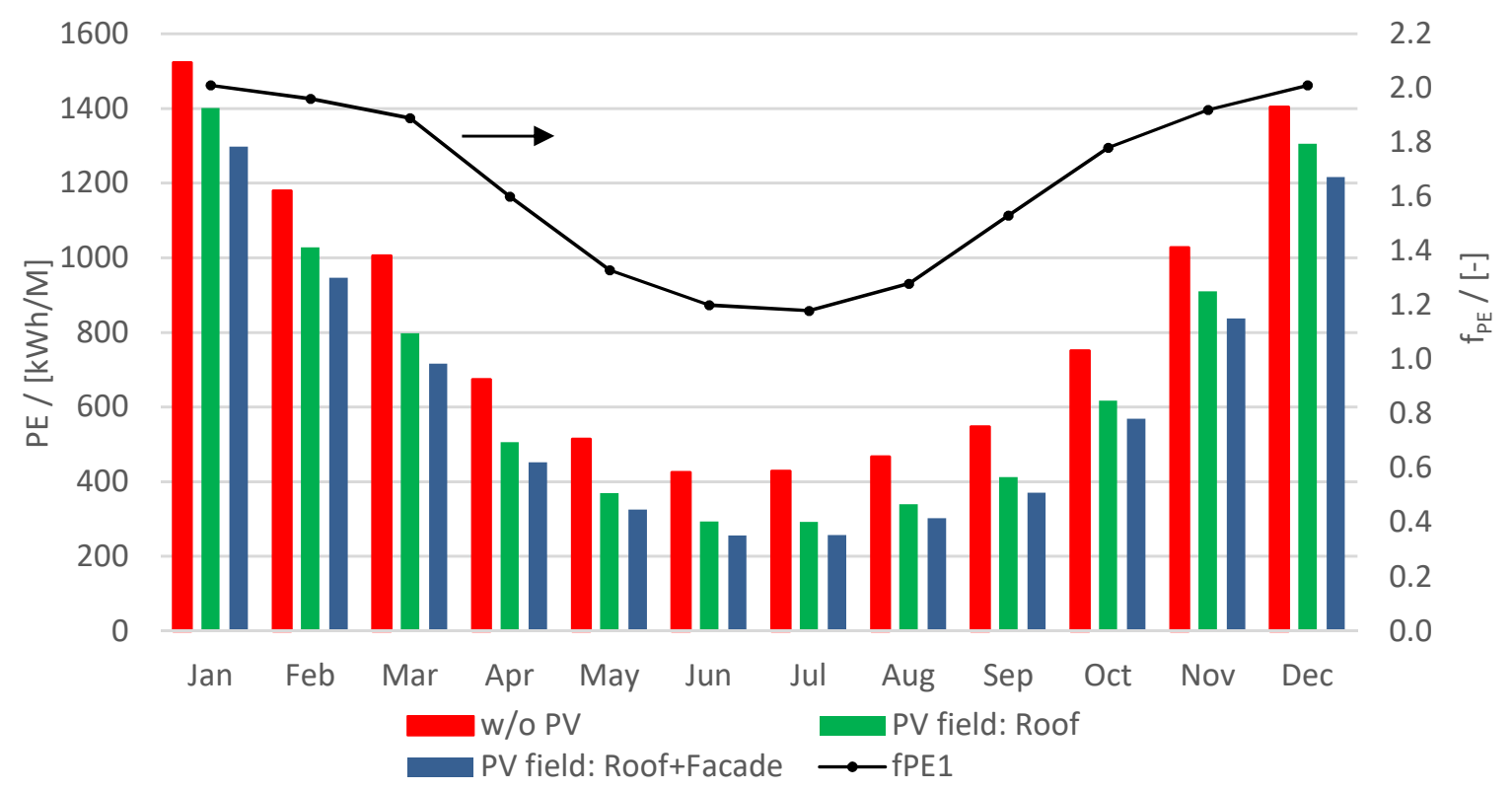

Fig. 12: Monthly Primary Energy (PE) demand with (for the two PV fields considered) and without PV field and monthly PE conversion factors $\left(f_{\mathrm{PE}}\right.$, annual average value of 1.64$)[5]$ in case Demand(3) is considered.

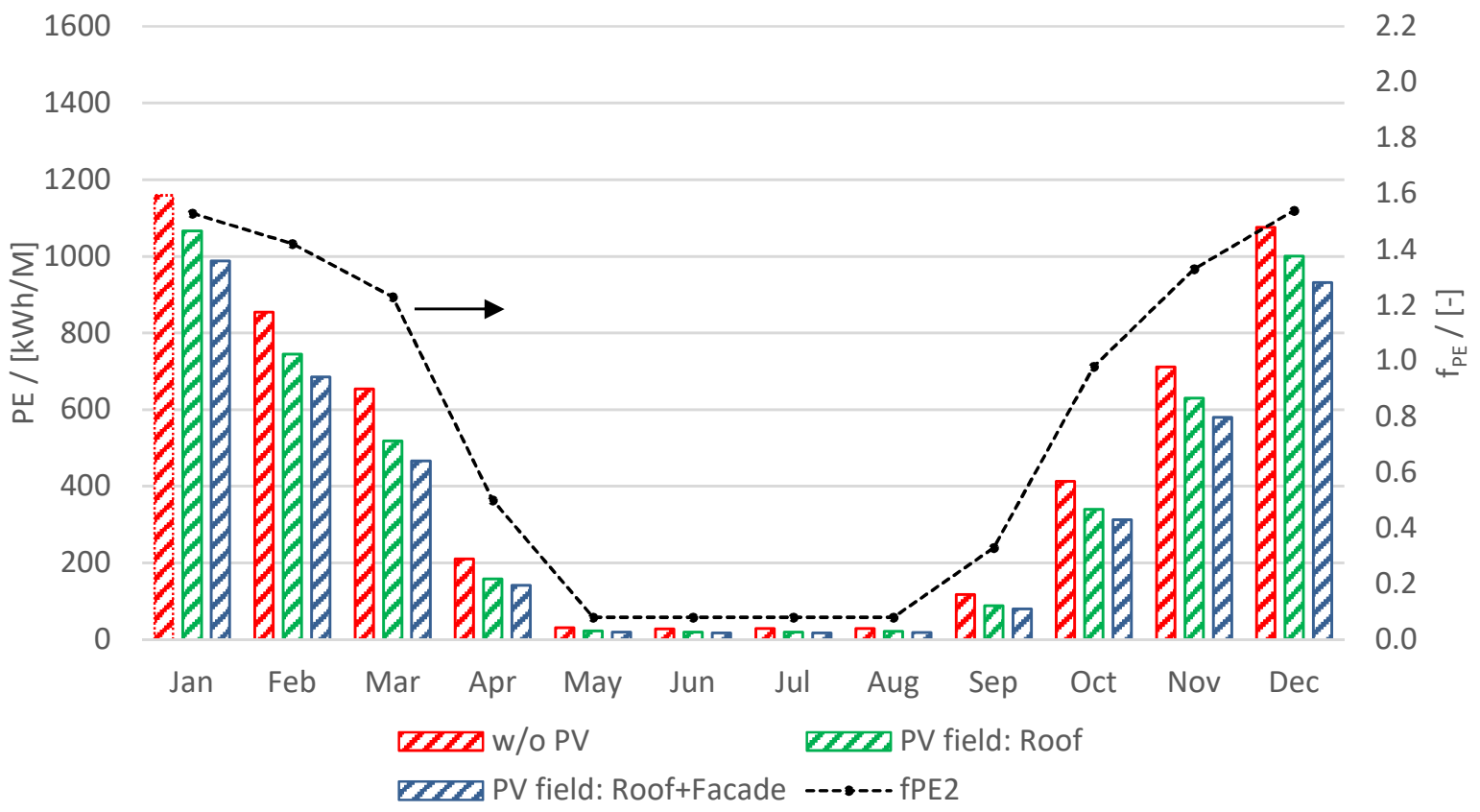

Fig. 13: Monthly Primary Energy (PE) demand with (for the two PV fields considered) and without PV field and monthly PE conversion factors ( $f_{\mathrm{PE} 2}$, annual average value of 0.77$)$ [5] in case Demand(3) is considered.

The influence of the PE conversion factor $\mathrm{f}_{\mathrm{PE}}$ and of the PV size on the annual PE demand is shown in Tab. 3. A reduction of the annual PE demand of $-17 \%$ and $-24 \%$ (for $\mathrm{f}_{\mathrm{PE} 1}$ ) and of $-13 \%$ and $-20 \%$ (for $\mathrm{f}_{\mathrm{PE} 2}$ ) can be obtained 
in case PV is installed on the roof only or also on the façade. If the PV field is installed on the roof and on the façade, a reduction of annual PE demand of $8 \%$ (compared to the case of PV on the roof only) can be obtained. This is because a large percentage (70\%) of the additional PV electricity produced by the PV field of the façade is fed to the grid (especially during the summer season) and cannot be self-consumed. In case PV is installed on the roof and on the façade, the saving of $\mathrm{PE}$ is higher in case of annual $\mathrm{f}_{\mathrm{PE}}$ compared to the case in which monthly $f_{P E}$ values are considered ( $-26 \%$ instead of $-24 \%$ in case of $f_{P E 1}$ and $-26 \%$ instead of $-20 \%$ in case of $\left.f_{P E 2}\right)$. In case an annual primary energy conversion factor is considered, the relative deviation of PE (i.e. $\triangle \mathrm{PE}$ (roof) or $\triangle \mathrm{PE}($ roof\&façade $))$ does not depend on its value.

The relevant influence of the electric storage on the purchased electricity was shown in Fig. 10. Tab. 4 shows the potential of further reduction of PE demand in case an electric storage is considered (i.e. daily storage). The importance of a storage is less relevant in case of PV installed on the roof ( $\triangle \mathrm{PE}$ is increased from $-18 \%$ to $-24 \%$ ) unlike from the case in which PV is installed also on the façade, where the PE demand could be decreased by $46 \%$. It is also interesting to note that a daily electric storage (in case of PV installed on the roof) could lead the $\mathrm{PE}$ to a value of $7226 \mathrm{kWh} / \mathrm{a}$ (in case of $\mathrm{f}_{\mathrm{PE}}=1.64$ ), almost equal to the PE in case of PV installed on the roof and façade without storage $(7059 \mathrm{kWh} / \mathrm{a})$.

Tab. 3: Annual PE demand and relative deviation of PE (respect to the case without PV) depending on the PV field and $f_{P E}$ in case Demand(3) is considered

\begin{tabular}{|c|c|c|c|c|c|}
\hline & \multicolumn{3}{|c|}{ PE [kWh/a] } & \multicolumn{2}{c|}{$\Delta$ PE } \\
\hline & w/o PV & PV on roof & $\begin{array}{c}\text { PV on } \\
\text { roof \&façade }\end{array}$ & $\begin{array}{c}\Delta \text { PE } \\
\text { (roof) }\end{array}$ & $\begin{array}{c}\Delta \text { PE } \\
\text { (roof\&façade) }\end{array}$ \\
\hline Monthly f PE1 $_{\text {Monthly f fE2 }}$ & 9945 & 8266 & 7541 & $-17 \%$ & $-24 \%$ \\
\hline Annual f fE1 $=1.64$ & 5314 & 4628 & 4257 & $-13 \%$ & $-20 \%$ \\
\hline Annual f PE2 $_{1}=0.77$ & 4507 & 7762 & 7059 & $-18 \%$ & $-26 \%$ \\
\hline
\end{tabular}

Tab. 4: Annual PE demand and relative deviation of PE (with respect to the case without PV) depending on the PV field, electric storage and $\mathbf{f}_{\mathrm{PE}}$ in case Demand(3) is considered

\begin{tabular}{|c|c|c|c|c|c|c|c|c|c|}
\hline & \multicolumn{5}{|c|}{ PE [kWh/a] } & \multicolumn{4}{|c|}{$\Delta \mathrm{PE}[\%]$} \\
\hline & \multirow[b]{2}{*}{$\begin{array}{l}\text { w/o } \\
\text { PV }\end{array}$} & \multicolumn{2}{|c|}{ No storage } & \multicolumn{2}{|c|}{ Daily storage } & \multicolumn{2}{|c|}{ No storage } & \multicolumn{2}{|c|}{ Daily storage } \\
\hline & & $\begin{array}{c}\text { PV on } \\
\text { roof }\end{array}$ & $\begin{array}{l}\text { PV on } \\
\text { roof\& } \\
\text { façade }\end{array}$ & $\begin{array}{c}\text { PV on } \\
\text { roof }\end{array}$ & $\begin{array}{l}\text { PV on } \\
\text { roof\& } \\
\text { façade }\end{array}$ & $\begin{array}{c}\Delta \mathbf{P E} \\
\text { (roof) }\end{array}$ & $\begin{array}{c}\Delta \mathrm{PE} \\
\text { (roof\& } \\
\text { façade) }\end{array}$ & $\begin{array}{c}\Delta \mathbf{P E} \\
\text { (roof) }\end{array}$ & $\begin{array}{c}\Delta \mathrm{PE} \\
\text { (roof\& } \\
\text { façade) }\end{array}$ \\
\hline $\begin{array}{c}f_{\mathrm{PE} 1}= \\
1.64\end{array}$ & 9507 & 7762 & 7059 & 7226 & 5162 & $-18 \%$ & $-26 \%$ & $-24 \%$ & $-46 \%$ \\
\hline $\begin{array}{c}f_{\mathrm{PE} 2}= \\
0.77\end{array}$ & 4432 & 3619 & 3291 & 3369 & 2407 & $-18 \%$ & $-26 \%$ & $-24 \%$ & $-46 \%$ \\
\hline
\end{tabular}

\section{Conclusions}

The potential of covering electricity needs (for HVAC system, appliances and DHW preparation) of a flat of a renovated MFH with PV system was investigated for different electric power profiles and PV sizes.

PV electricity can cover a small percentage of the electricity demand with a maximum value of $26 \%$ in case PV is installed on the roof and façade and heat pump is used for DHW preparation (i.e. Demand(3)). The installation of an additional PV field on the façade must be carefully evaluated (the additional investment costs have to be considered) because the saving of purchased electricity is in the range of $9 \%-11 \%$ for all cases compared to the case in which PV is installed just on the roof. The installation of a PV on the roof or on the façade of the flat leads to the same reduction of purchased electricity, even if the PV area available for each flat on the façade is bigger compared to the area available on the roof of the building.

The use of electric storage reduces the purchased electricity, especially if PV is installed on the roof and façade, with a reduction of $27 \%$ in case heat pump is used for DHW preparation and daily electric storage is considered.

A maximum reduction of PE demand of $24 \%$ (compared to the case without PV system) can be obtained in case 
PV is installed on the roof and façade and a monthly primary energy conversion factor with an annual average value of 1.64 is assumed. PE demand can be significantly reduced (-46\% in case of Demand(3) and PV on the roof and the façade) compared to the case without PV in case a daily electric storage is considered. The saving of $\mathrm{PE}$ demand is slightly overestimated (between $1 \%$ and $6 \%$ depending on the case) in case of annual $\mathrm{f}_{\mathrm{PE}}$ compared to the case in which monthly $\mathrm{f}_{\mathrm{PE}}$ values are considered.

\section{References}

[1] System Simulation Models, Residential Buildings - Part B, Ochs F., Siegele D., Calabrese T., Dermentzis G., Venus D., IEA SHC TASK56 - Building Integrated Solar Envelope Systems (unpublished)

[2] Ochs F., Dermentzis G., Siegele D., Façade Integrated MVHR and Heat Pump, in: 12th Conference on Advanced Building Skins 2-3 October 2017, Bern, Switzerland, 2017.

[3] Siegele. Optimization and Appliance of small Air Exhaust Heat Pumps with Focus on Alpine Regions, PhD Thesis, Work in progress (link)

[4] Thür A., Calabrese T., Streicher W., Smart Grid and PV driven Heat Pump as Thermal Battery in Small Buildings for optimized Electricity Consumption, 2018, Solar Energy https://doi.org/10.1016/j.solener.2018.08.087

[5] F. Ochs, G. Dermentzis, Evaluation of Efficiency and Renewable Energy Measures Considering the Future Energy Mix, in: 7th Int. Build. Phys. Conf. IBPC2018, 23-26 Sept., New York, USA, 2018.

\section{Appendix}

Tab. 5: Electric power (W) of the appliances for the different rooms of the flat

\begin{tabular}{|c|c|c|c|c|}
\hline Hour & Kitchen & Bedroom & Childroom & Living room \\
\hline $0-1$ & 59.2 & 29.8 & 29.8 & 29.8 \\
\hline $1-2$ & 31.3 & 15.7 & 15.7 & 15.7 \\
\hline $2-3$ & 31.3 & 15.7 & 15.7 & 15.7 \\
\hline $3-4$ & 31.4 & 15.7 & 15.7 & 15.7 \\
\hline $4-5$ & 31.4 & 15.7 & 15.7 & 15.7 \\
\hline $5-6$ & 31.2 & 15.7 & 15.7 & 15.7 \\
\hline $6-7$ & 234.2 & 108.2 & 108.2 & 108.2 \\
\hline $7-8$ & 278.1 & 124.8 & 124.8 & 124.8 \\
\hline $8-9$ & 250.2 & 116.0 & 116.0 & 116.0 \\
\hline $9-10$ & 30.8 & 15.4 & 15.4 & 15.4 \\
\hline $10-11$ & 29.8 & 15.5 & 15.5 & 15.5 \\
\hline $11-12$ & 163.3 & 64.2 & 64.2 & 64.2 \\
\hline $12-13$ & 38.5 & 13.1 & 13.1 & 13.1 \\
\hline $13-14$ & 86.7 & 27.2 & 27.2 & 27.2 \\
\hline $14-15$ & 66.4 & 32.0 & 32.0 & 32.0 \\
\hline $15-16$ & 63.1 & 33.5 & 33.5 & 33.5 \\
\hline 16-17 & 63.2 & 33.5 & 33.5 & 33.5 \\
\hline 17-18 & 112.4 & 42.8 & 42.8 & 43.3 \\
\hline 18-19 & 106.2 & 42.1 & 42.1 & 49.9 \\
\hline $19-20$ & 340.7 & 154.4 & 154.4 & 219.8 \\
\hline $20-21$ & 224.3 & 104.7 & 104.7 & 159.4 \\
\hline $21-22$ & 214.5 & 105.0 & 105.0 & 168.9 \\
\hline $22-23$ & 235.6 & 116.6 & 116.6 & 160.5 \\
\hline $23-24$ & 196.5 & 99.0 & 99.0 & 105.9 \\
\hline
\end{tabular}




\title{
ASSESSMENT OF THE SUITABILITY OF PHOTOVOLTAIC CELL TECHNOLOGIES FOR PRODUCT DEVELOPMENT OF BUILDING INTEGRATED SOLUTIONS USING THE ANALYTICAL HIERARCHY PROCESS (AHP)
}

\author{
Zoheir Haghighi 1,a), Juan Camilo Ortiz Lizcano 2,a), Andy van den Dobbelsteen ${ }^{1}$, Olindo Isabella ${ }^{2}$ \\ Thaleia Konstantinou ${ }^{1}$, Miro Zeman ${ }^{2}$
}

\author{
${ }^{1}$ Department of Architectural Engineering + Technology, Faculty of Architecture and the Built \\ Environment, Delft University of Technology, Julianalaan 134, 2628 BL, Delft, The Netherlands \\ 2 Photovoltaic Materials and Devices, Faculty of Electrical Engineering, Mathematics and Computer \\ Science Delft University of Technology, Mekelweg 4, 2628 CD Delft, The Netherlands
}

\begin{abstract}
Photovoltaic systems integrated into the built environment can have a significant role in our pursuit to achieve the targets set by regulatory legislation with regards to nearly zero-energy buildings (nZEB). However, the share of Building Integrated Photovoltaic (BIPV) products on the market have seen a slower growth than predicted. One of the main barriers to their diffusion includes the lack of knowledge among different stakeholders. Reducing this knowledge gap between the building industry and the PV industry is of utmost importance. The project presented in this paper aims to use the multi-criteria analysis method of analytical hierarchy process (AHP) as a tool to align the preferences of architects, product developers and engineers for integrated solutions with the most suitable PV technology. This can provide product developers with the necessary information to create PV applications that will better satisfy consumer and designer preferences and reduce the knowledge gap between the different stakeholders.
\end{abstract}

Keywords: AHP, Solar energy, zero-energy buildings, BIPV, MCDM

\section{Introduction}

The energy sector is experiencing a structural transition from fossil energy sources to renewable energy. This is merely driven by environmental concerns to mitigate $\mathrm{CO}_{2}$ emissions and to prevent runaway climate change and aggravated global warming. As a result, there is an urge to promote the development of new products incorporating renewable and clean energy technologies.

From all the renewable energy sources, solar energy is the most abundant, inexhaustible and clean source of energy (Parida et al., 2011). In addition, considering all the technologies for harvesting solar energy, photovoltaics and their applications in the built environment (mainly placed on rooftops or façade-integrated) receive growing attention during recent years (Farkas et al., 2013).

During the past 5 decades, photovoltaics have experienced significant growth in technological development, installed capacity and cost reduction. In terms of PV technology today, almost 20 different PV cell technologies are available (Green et al., 2017). Remarkably, the field of PV technology has the largest share (26\%) in patented innovation compared to other renewable technologies (IRENA 2017). In terms of installed capacity, by the end of 2016, the total amount of solar PV installed across the globe was $320 \mathrm{GW}$; this represents a growth by a factor of 40 in only 10 years (Kurtz et al., 2017). In terms of economy, since 1980, the price of photovoltaics has been reduced by a factor of 50 (Polman et al., 2016). Last year, the world's lowest-ever bid was offered by a consortium led by Abu Dhabi's renewable energy company, for a project in Saudi Arabia, at 1.79 US dollar cent per kilowatt hour (kWh) (Bloomberg, 2018). This significant reduction is due to several reasons, mainly the economies of scale, in addition to technological progress in solar cell efficiencies, standardisation of technologies (conventional PV modules), improved module manufacturing and lower costs of production of feedstock materials (Reinders et al., 2018)

All the above-mentioned facts and figures specify, thanks to efforts of different stakeholders in the PV industry from high-level research organisations working on the multi-junction PV cell technology to the wholesalers of PV modules, PV technology is becoming mainstream in the energy sector (Kurtz et al., 2017). Today, its application varies from residential to utility scale and it is used in agriculture, construction, telecommunication, aerospace,

a) Z. Haghighi and J. C. Oriz Lizcano contributed equally to this work. 
transport, security, military and many other fields. With such a vast array of applications, the demand for photovoltaics is increasing every year (Parida et al., 2011).

Certain features of PV technology make it suitable for application in an urban environment, namely the possibility of integration, scalability and modularity, as well as silent operation (Reinders et al., 2018; Weller, 2010). In addition, physical properties of PV cell technology allow design flexibility for development of different modules in varied form, shape, colour and translucency (Markvart \& Castañer, 2003).

All this growth, innovation and new technologies are allowing development of more and diverse applications or products incorporating PV technology. However, such variety makes the selection of the most suitable technology for a specific application a complex decision (Farkas, Probst, \& Horvat, 2010).

In addition, from literature (Ritzen et al., 2013; Urbanetz et al., 2011) it is evident that there is always a trade-off between the aesthetical value that PV may offer and its functional performance. However, the interrelation between design and technical functionality is not always linear. Therefore, for smart decision making, product developers should be given an opportunity to decide how much energy output he is willing to compromise in return for flexibility in design and shape. Moreover, since the 1970s, when the possibility for the adoption of photovoltaic (PV) technologies in the built environment started to be investigated, the synergy between key stakeholders such as architects/designers and PV engineers was not productive. In time, this created an important gap in knowledge within these communities, which sometimes led to a misunderstanding of the capabilities of PV technologies and failure in product development (Wall, et al., 2012).

On top of what was mentioned about the physical aspects of PV technology and technical performance, in order to address the importance of the transition towards renewable energy and the urge for sustainable development, it is very important to consider environmental impacts of the components of a product or application during its life cycle. Not only there is public pressure for cleaner products, it is becoming mandatory within EU policies to consider environmental issues in the process of new product development (NPD) (Sinha \& Anand, 2018).

Last but not least, economic aspects of each technology is a key criterion in decision making for selecting any component for product development (Kumar et al., 2017; Wang et al., 2009). And product developers are always looking for the best technical performance for the cheapest price or with the shortest payback period. However, in this field, the assumption about the cost of the product can be different when the unit varies. For example, when a product is going to be developed for the built environment, price per square meter mostly is a common unit for comparison, but in the PV sector, the unit is per $\mathrm{W}_{\text {peak }}$ of capacity. So, for any decision making, a uniform unit should be considered.

Multi-criteria analysis is an operational assessment method for decision support that is suitable for addressing complex problems featuring high uncertainty, conflicting objectives, different forms of data and information, multiple interests and perspectives, and the accounting for complex and evolving biophysical and socio-economic systems (Wang et al., 2009). It has been widely applied in social, economic, agricultural, industrial, ecological and biological decision-making process. Especially in many projects related to sustainable development and environmental impact analysis (ibid). And analytical hierarchy process (AHP) is a method for multi-criteria analysis and most preferred for tangible and intangible factors (Ozdemir \& Sahin, 2018).

In this paper, the authors explain the application of the AHP method for the creation of a decision-making tool for new PV product development. In this research, AHP helps to combine user preferences (through a direct and indirect questionnaire) and secondary data from the literature for pairwise comparison of PV cell technology (different alternatives).

\section{Method:}

The AHP method consists of dividing a given problem into different components and established a hierarchy, as shown in

Figure 1. The hierarchy is constructed starting from the main goal of a given decision project. At a second level, the main criteria are selected based on input from stakeholders and quantitative data. Sub-criteria can be introduced to consider further aspects and to make the model more detailed. The structure then is analysed by the selected hierarchy; this means that alternatives are studied according to each sub-criterion and weighted according to the main goal of the project. 


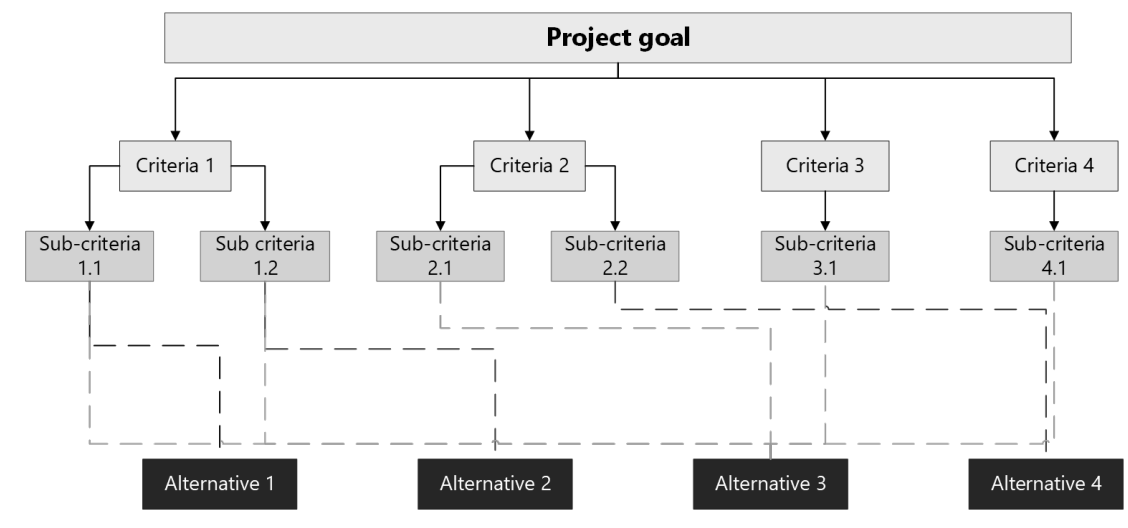

Figure 1 - Multi-level AHP structure

To weight each criterion, a so-called pair-wise comparison is used. Each alternative is compared with another for each sub-criterion, the result of this is a matrix that will be used to calculate ratios and quantify preferences. The comparison may come from a verbal preference or need that is not easily quantifiable. On these cases, the suggestion of Thomas Saaty is used and are summarised in Table

Table 1 - Saaty's fundamental scale of pairwise comparison, extracted from Saaty (1980) and San Cristóbal Mateo (2012) extracted from (Saaty, 1980) and (San Cristóbal Mateo, 2012)

\begin{tabular}{|c|c|l|}
\hline Intensity of importance & Definition & \multicolumn{1}{c|}{ Explanation } \\
\hline 1 & Equal Importance & Element 1 and 2 are equally important \\
\hline 3 & Moderate/weak importance & Experience and judgment slightly favours 1 over 2 \\
\hline 5 & Essential or strong importance & Experience and judgment strongly favours 1 over 2 \\
\hline 7 & Demonstrated importance & 1 is favourite over 2 and has been demonstrated in practice \\
\hline 9 & Absolute importance & The evidence clearly shows that 1 is preferred over 2 \\
\hline $2,4,6,8$ & $\begin{array}{c}\text { An intermediate value between the } \\
\text { judgments presented above }\end{array}$ & Compromise between 2 intensities of importance \\
\hline Reciprocals & \multicolumn{2}{|c|}{ If 1 over 2 has a value of 7, then 2 over one must have a value of 1/7 } \\
\hline
\end{tabular}

The user weights the preference of one criterion to another (e.g. the preference of design to the economy), or the preference of one technology over another, for a specific criterion, as shown in Figure 2.

\section{Efficiency}

\begin{tabular}{|l|l|lllllllll|}
\hline \multirow{2}{*}{ c-Si IBC } & 9 & 7 & 5 & 3 & 1 & 3 & 5 & 7 & 9 & \multirow{2}{*}{ a-Si } \\
\cline { 2 - 6 } & & & & & & & & & &
\end{tabular}

Figure 2 Pairwise comparison example

From this, matrix A is formed:

$$
A=\left(\begin{array}{ccc}
x_{11} & \cdots & x_{1 m} \\
\vdots & \ddots & \vdots \\
x_{l 1} & \cdots & x_{l m}
\end{array}\right)
$$

Where $x_{l m}$ is the evaluation of alternative $l^{t h}$ element with respect to criterion $m^{t h}$. This produces a symmetric matrix on the form of:

$$
\left(\begin{array}{ccc}
1 & x_{12} & x_{13} \\
x_{21} & 1 & x_{23} \\
x_{31} & x_{32} & 1
\end{array}\right)
$$


This means that if:

Then,

$$
x_{12}=\beta
$$

$$
x_{21}=\frac{1}{\beta}
$$

Since the number of alternatives greatly influences the reliability of the method, Once the evaluation matrix is complete, each element of a column is then normalised as follows:

$$
x_{11 n}=\frac{x_{11}}{\sum_{1}^{l} x}
$$

This forms a normalised matrix $A_{n}$ :

$$
A_{n}=\left(\begin{array}{ccc}
x_{11 n} & \cdots & x_{1 m n} \\
\vdots & \ddots & \vdots \\
x_{l 1 n} & \cdots & x_{l m n}
\end{array}\right)
$$

The average of each row of the normalised matrix will yield the weight of each criterion on a vector called $W$.

Finally, the consistency of the method is assessed by performing the following steps (San Cristóbal Mateo, 2012):

1. Compute $A W^{T}, W^{T}$ being the transpose vector $W$.

2. Calculate the value of $\lambda_{\max }$

$$
\lambda_{\max }=\frac{1}{m} \sum \frac{\text { ith value of } A W^{T}}{\text { ith value of } W^{T}}
$$

Consistency is then defined as:

$$
C I=\frac{\lambda_{\max }-m}{m-1}
$$

From the number of alternatives selected, a random index $(R I)$ should be established following (Saaty, 1980):

Table 2- Randomness index (RI) values according to the number of alternatives used

\begin{tabular}{|c|c|c|c|c|c|c|c|c|c|c|c|}
\hline Alternatives & 2 & 3 & 4 & 5 & 6 & 7 & 8 & 9 & 10 & 11 & 12 \\
\hline $\boldsymbol{R I}$ & 0 & 0.58 & 0.9 & 1.12 & 1.21 & 1.32 & 1.41 & 1.45 & 1.49 & 1.51 & 1.48 \\
\hline
\end{tabular}

If $C I / R I<0.01$ the result of the method is reliable as the consistency is considered satisfactory.

Each criterion will produce a vector W, and the values of CI/IR. An alternative matrix is then formed based on each criterion vector and then synthesised with the vector of weighted values that each main criterion has, according to the user's needs.

$$
\left(\begin{array}{c}
C_{1} \\
\vdots \\
C_{m}
\end{array}\right) \times\left(\begin{array}{ccc}
W_{11} & \ldots & W_{n 1} \\
\vdots & \vdots & \vdots \\
W_{1 m} & \ldots & W_{n m}
\end{array}\right)=\left(\begin{array}{c}
A_{1} \\
\vdots \\
A_{m}
\end{array}\right)
$$

The resulting vector gives the final ranking, and the most suitable option is obtained.

\section{Application}

Figure 3 shows different stages of the application of AHP in our research. As is shown, in stage A, the main criteria are to be selected. Then the sub-criteria are chosen as a complementary analysis for each of criterion and to develop the pairwise comparison matrices. All of these criteria are selected based on scientific research. In the other words, experts from the field should have used these criteria as a factor for comparing alternatives. During the next step, 
alternatives for comparison should be selected, i.e. the PV cell technologies. These are known technologies, which are fully developed, and most of them are already available in the market.

In stage $\mathrm{B}$ and $\mathrm{C}$, the weighting process will be conducted. In this process, there are 3 methods for weighting each criterion and sub-criterion. First and second are through a user input (stage B). The tool comprises of the graphical user interface (GUI), where users are directly and indirectly asked to express their preference, according to the type of application for which they want to develop a product. Those values will be used directly in the matrices. Indirect questions are those that will be asked in a way that helps to produce matrix values in connection with other information, which was given earlier. In this questionnaire, the personal and professional information of the users will be documented, which allows further investigation of the preference of a specific group of experts. The other method is the rational weighting method. Here, alternatives are ranked according to their quantitative values. For example, it is obvious and rational to sort the PV cell efficiencies according to the hierarchy of their values. On such a sub-criterion, the users will not be asked whether they want the tool to include the results of the most efficient technology or not. We include them in the weighting process by default. However, if the user gives a low weight on the 'functional performance', for example, which is one of the main criteria, the influence of efficiency on the outcome will be lower.

In stage $\mathrm{D}$, the pair-wise comparison based on sub-criteria and alternatives will be developed and then normalised and averaged, and the criterion vectors will be developed. Later all vectors will be multiplied by the index coming from first user input on main criteria and final ranking will be attained. However, before arriving at final ranking, consistency evaluation should be done to validate the method that leads to final ranking.

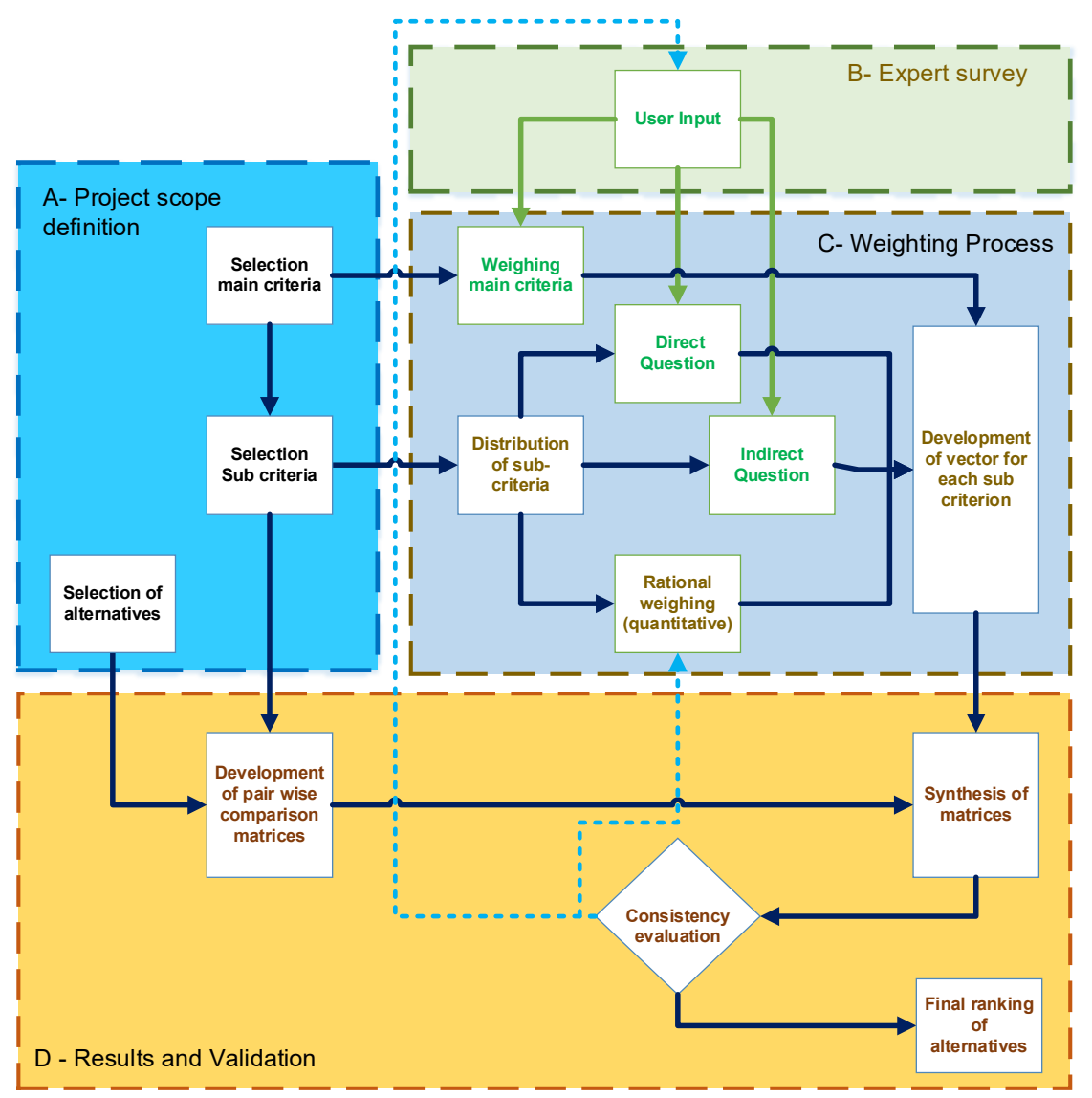

Figure 3: AHP application Process

\section{Example (with sample alternative and Criteria)}

A potential use for this tool, for example, is that of a 'product developer' who wants to design a solar infotainment spot. His device will be placed in different parts of the city, and its aim is to improve the overall experience tourists have when visiting the city. Additionally, it will serve as a means for promoting the use and application of sustainable energy technologies.

The tool for such an example will start by asking the user's (here the product developer) most relevant information, i.e. their professional profile (engineer, architect, designer, developer). In this part, the location, orientation, tilt and other relevant information must be provided by the user to the tool. 
The first step begins via the survey. The developer is asked about the overall goals of the project. For the solar infotainment spot, for example, he might want to select specific characteristics, such as performance, recycling of materials, a long life-span for the device, low price, etc. This defines the main criteria of the project and the second stage in the hierarchical approach.

The second step of the survey will be based on the main criteria. It will help the developer to build a third stage of the hierarchy: the sub-criteria. Regarding performance, for example, the developer will assess the importance of the project of power output per unit of area, by asking about area limitations and desired output, whether the recycling should be performed by specialised labour or be as simple as possible. Other characteristics to be determined are, for instance, transparency, colour and flexibility. The step ends with a hierarchy chart as shown in

Figure 4. The user can then confirm that such a selection of criteria and sub-criteria perfectly describes what is wanted for the project. Subsequently, the software pre-selects the alternative technologies for analysis.

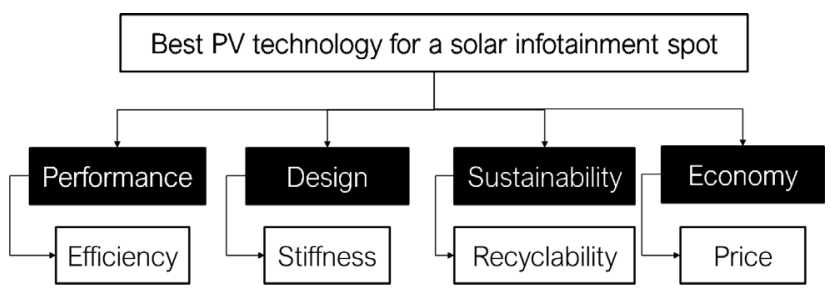

Figure 4 Hierarchy of criteria and sub-criteria developed after the user survey

This pre-selection is done based on those technologies that have the most potential to suit all such criteria. For example, if a long life-span of the project is needed, then technologies that do not fulfil this criterion are ruled out (such as perovskites). If the application is terrestrial, and low price is the main objective, then III-V technologies ${ }^{1}$ are ruled out. All these are currently under development, and with greater expert input (step B) this preselection will be more accurate as the tool progresses.

Afterwards, the professional information of the user input is documented. This allows further improvement of the tool by analysing the preference of specific professions and applications. The user is asked about the type of product or application they are working on. In time, users will be able to choose the type of application to get a specific survey to weight their preferences. Applications such as urban integrated solutions, e-mobility, solar facades, BIPV$\mathrm{T}$, etc. are under development now.

During the last step, the tool combines the methods used in the two previous one with a more quantitative method. Here, the user will weight each criterion with respect to the overall goal of the project. Each criterion will be compared with the others to determine the intensity of importance for the developer. The values assigned will be in accordance to those explained on Table. The developer might feel it is more important for the device to be recyclable than flexibility in design (therefore, sustainability is preferred to aesthetics). If economic and functional aspects are desired more than aesthetic, the latter will be ranked below everything else, as shown in

Figure 5.

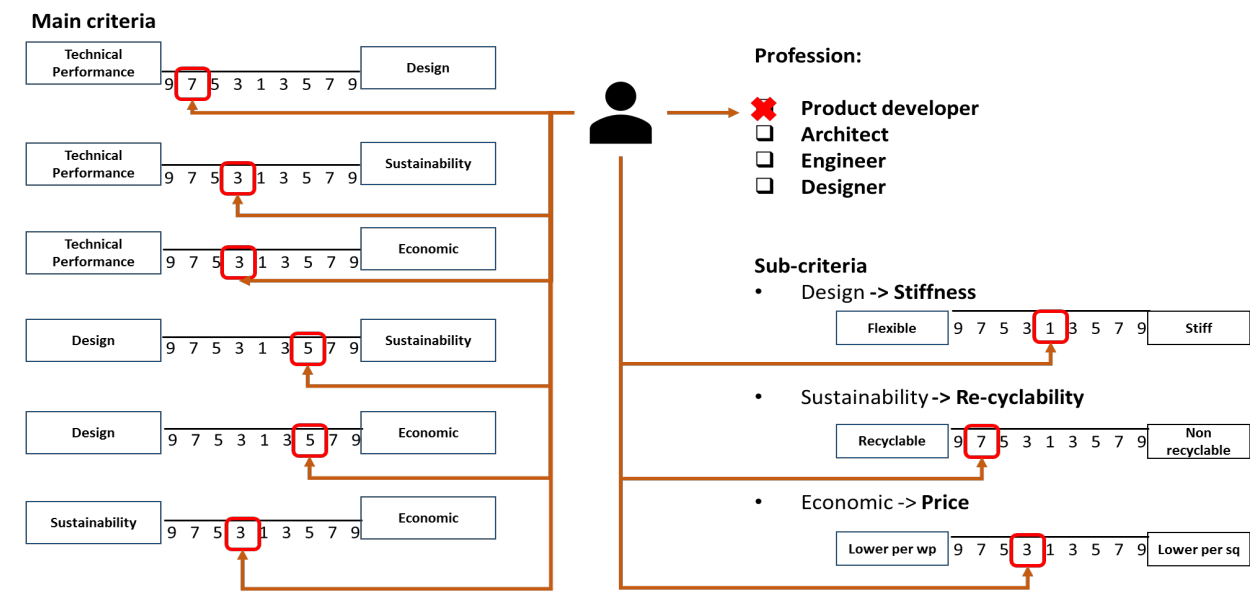

Figure 5 Pair-wise comparison scheme. Based on the answers provided by the developer, the main criteria is weighted with respect to the overall goal of the project.

\footnotetext{
1 "III-V" semiconductor technologies are elements belonging to groups III and V of the periodic table of chemical elements.
} 
Here, as shown in figure 5, the product developer has given his preference thought the survey as follows. In the main criteria, he wants functional performance but also looking at sustainability and economic factors. Both latter aspects have importance with respect to design, but - among them - sustainability is a bit more important. In the sub-criteria, he does not extremely care for the trade-off between stiffness $v$ s flexibility but is interested in relatively low cost (in $€ / \mathrm{Wp}$ ) and rather passionate about recyclability. From this, the pair-wise comparison matrix is then created for each main criterion and sub-criteria.

Pair-wise comparison matrix for the main criteria based on the results of the survey

Performance
Design
Sustainability
Economic $\quad\left(\begin{array}{cccc}1 & 7 & 3 & 3 \\ 1 / 7 & 1 & 1 / 5 & 1 / 5 \\ 1 / 3 & 5 & 1 & 3 \\ 1 / 3 & 5 & 1 / 3 & 1\end{array}\right)$

Then, in accordance with Eq (5), we get the normalised matrix

\begin{tabular}{|c|c|c|c|c|}
\hline \multicolumn{5}{|c|}{ Normalised matrix } \\
\hline & Performance & Design & Sustainability & Economic \\
\hline Performance & 0.55 & 0.39 & 0.66 & 0.42 \\
\hline Design & 0.08 & 0.06 & 0.04 & 0.03 \\
\hline Sustainability & 0.18 & 0.28 & 0.22 & 0.42 \\
\hline Economic & 0.18 & 0.28 & 0.07 & 0.14 \\
\hline
\end{tabular}

By averaging each row, the weighting vector is obtained. This establishes the overall preference of the criteria with respect to the main goal. For this case, Performance and Sustainability account for $78 \%$ of the total weight, meaning that technologies that have a leading edge on these aspects will be most suitable.

$$
\begin{gathered}
\text { Weighting vector } \\
\text { Weighting } \\
\left(\begin{array}{c}
\text { vector } \\
0.51 \\
0.05 \\
0.27 \\
0.17
\end{array}\right)
\end{gathered}
$$

The weighting vector shows the overall preference of each criterion with respect to the main goal. For this case, Performance and Sustainability account for $78 \%$ of the total weight, meaning that technologies that have a leading edge on these aspects will have higher chances of being selected by the tool. The same process is carried out for the main criterion that has more than one sub-criterion. In such a case, the importance or preference of each sub-criterion is weighted with respect to the main criterion. 
Pair-wise comparison of alternatives for the sub-criterion of Efficiency

CdTe $\mathrm{CIGS}$ a-Si $\left(\begin{array}{cccc}1 & 7 & 7 & 9 \\ 1 / 7 & 1 & 1 & 7 \\ 1 / 7 & 1 & 1 & 7 \\ 1 / 9 & 1 / 7 & 1 / 7 & 1\end{array}\right)$

Each alternative is analysed for every sub-criterion (or criterion that do not have sub-criteria). A pair-wise comparison is built based on scientific research, market research and expert insights. In this case, for example, crystalline silicon technologies have a commanding lead compared to other alternatives. It is possible to find solar cells on the market, based on crystalline silicon, which has an efficiency greater than 20\%. Although similar efficiency values are reported on lab-scale devices of CdTe and CIGS, readily available products with such technologies are still around 16\%. Given that this is not an application intended for research, but rather to develop a product ready for sale, the preference for c-Si technologies is very strong. This is even more evident against a-Si cells, that even on lab-scale devices cannot reach an efficiency above 14\% (Polman, et al, 2016).

Complete pair-wise comparison for all the alternatives for each sub-criterion

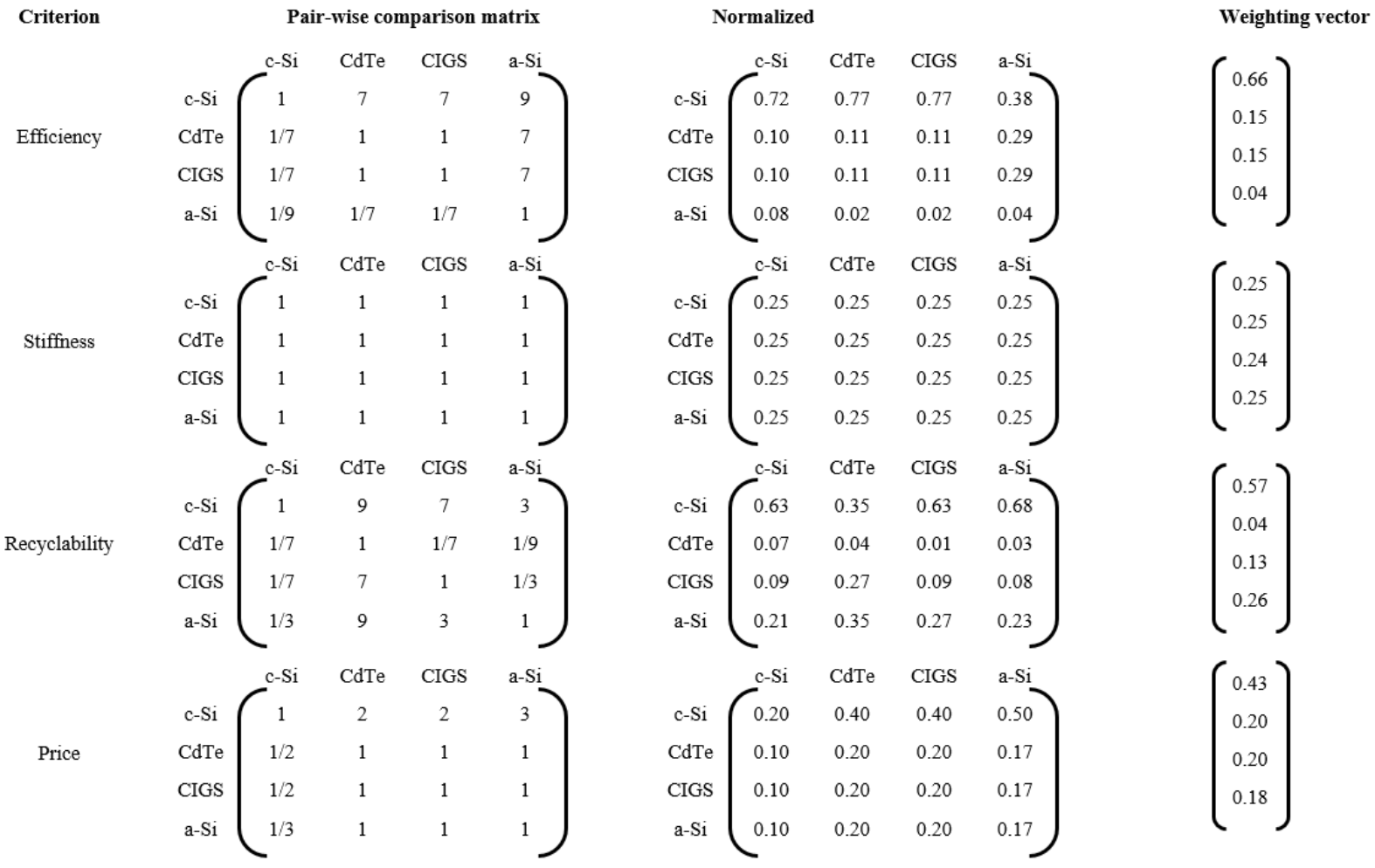

Error! Reference source not found. shows all the pair-wise comparison matrices in which the alternatives are studied for each sub-criterion. The developer prefers a sturdy and durable module for the product. Every technology selected can be built into a rigid module, and such products are easily obtained on the market; therefore, there is no quantifiable preference of one technology over the other. Hence, all the values of the matrix are 1.

Since the product needs to be easily recyclable, c-Si and a-Si have a lead in this aspect compared to CdTe and CIGS. It has been shown that c-Si and a-Si modules can be recycled by relatively simple processes, and furthermore, the cSi cells can be reused (Lee, et al., 2017) (hence, the values of 3 compared to a-Si, and 7 and 9 compared to the remaining technologies). CdTe and CIGS modules require specialized handling, which could increase the costs (Tao $\& \mathrm{Yu}, 2015)$. Furthermore, the toxicity potential of CdTe modules puts the technology at a disadvantage when compared to others on the ease of recycling perspective (Monteiro Lunardi et al 2018). 
Regarding price, the developer stated that a technology with the best value of $€ / \mathrm{Wp}$ should be preferred. Even though a-Si and other thin-film technologies present cheaper products, their lower overall performance puts them at a slight disadvantage compared to c-Si: analysis of large-scale production has demonstrated a small advantage of mc-Si in this area (Horowitz et al 2017).

Once all these pair-wise comparison matrices are normalised and their rows averaged. The weighting vectors for each of them are produced. These vectors indicate the dominance of the technology for that given sub-criterion. In this case, c-Si technologies are by far the better choice, since they dominate on each analysis. The last step, however, is to create a matrix with all the weighting vectors of the alternatives and multiply it with the weighting vector of the criteria, as stated on Eq. (9).

\begin{tabular}{|c|c|c|c|c|c|c|}
\hline & $\mathrm{c}-\mathrm{Si}$ & $\mathrm{CdTe}$ & CIGS & $\mathrm{a}-\mathrm{Si}$ & Criteria & Ranking \\
\hline $\mathrm{c}-\mathrm{Si}$ & 1 & 2 & 2 & 3 & 0.51 & 0.547 \\
\hline $\mathrm{CdTe}$ & $1 / 2$ & 1 & 1 & 1 & 0.05 & 0.134 \\
\hline CIGS & $1 / 2$ & 1 & 1 & 1 & 0.27 & 0.160 \\
\hline $\mathrm{a}-\mathrm{Si}$ & $1 / 3$ & 1 & 1 & 1 & 0.17 & 0.158 \\
\hline
\end{tabular}

The result is the final ranking for the best PV technology to be used on the solar infotainment spot. As stated, c-Si is way above the other alternatives for this application, thanks to its high efficiency, low price, and ease of recycling. This last aspect puts CdTe last, even when, performance wise, has a significant advantage compared to a-Si.

If, for example, the design had been the most important aspect of the product, and flexibility was a must, the ranking could change dramatically, and technologies such as CIGS could be the most appropriate. If transparency was preferred, with energy performance not being an important aspect, then c-Si would possibly be last. The idea of the tool is to guide the user in finding what better suits the need of the project in question, with the aid of a substantial research analysis of the technical aspects of the PV industry.

\section{Conclusion}

AHP allows numerical rating of criteria that might be subjective. Here, an example of how a product developer can use the main stakeholder subjective preferences into objective comparison. As shown in the example, AHP can be a very helpful method for decision making on complex problems. Especially if somehow interrelation between the criteria can be found. In this research, compared to other applications of AHP to answer other questions, we have the intention to present an open outcome based on user preference and not to limit the outcome based on the quantitative survey and preference of a majority in certain professions. There we need to develop a GUI (graphical user interface) for the tool in which the user can freely use the algorithm and ready-made matrices to find the most suitable technology for his application.

In addition, going deep into the application of AHP method and process of product development in the PV sector, we noticed some of the physical aspects of a PV product are not only depended on the suitable PV cell technology and can be later achieved through the selection of different module manufacturing technologies. Therefore, for further development, we should also consider the selection of these technologies to confirm whether one PV technology can be suitable for one application or not. 


\section{References}

Farkas, Klaudia; Frontini, Francesco; Maturi, Laura; Scognamiglio, Alessandra; Munari Probst, Maria Cristina ; Roecker, C. (2013). Designing photovoltaic systems for architectural integration. Criteria and guidelines for product and system developers, 84 .

Farkas, K., Probst, M. C. M., \& Horvat, M. (2010). Barriers and Needs for Building Integration of Solar Thermal and Photovoltaics. Eurosun, (7491).

Kumar, A., Sah, B., Singh, A. R., Deng, Y., He, X., Kumar, P., \& Bansal, R. C. (2017). A review of multi criteria decision making (MCDM) towards sustainable renewable energy development. Renewable and Sustainable Energy Reviews, 69(October 2016), 596-609. https://doi.org/10.1016/j.rser.2016.11.191

Ozdemir, S., \& Sahin, G. (2018). Multi-criteria decision-making in the location selection for a solar PV power plant using AHP. Measurement: Journal of the International Measurement Confederation, 129(July), 218-226. https://doi.org/10.1016/j.measurement.2018.07.020

Ritzen, M., Vroon, Z., \& Geurts, C. (2013). Building Integrated Photovoltaics. In Photovoltaic solar energy : from fundamentals to applications. (Vol. 3, pp. 795-930). Retrieved from http://www.seia.org/policy/solartechnology/photovoltaic-solar-electric

Sinha, A. K., \& Anand, A. (2018). Development of sustainable supplier selection index for new product development using multi criteria decision making. Journal of Cleaner Production, 197, 1587-1596. https://doi.org/10.1016/j.jclepro.2018.06.234

Urbanetz, J., Zomer, C. D., \& Rüther, R. (2011). Compromises between form and function in grid-connected, buildingintegrated photovoltaics (BIPV) at low-latitude sites. Building and Environment, 46(10), 2107-2113. https://doi.org/10.1016/j.buildenv.2011.04.024

Wang, J. J., Jing, Y. Y., Zhang, C. F., \& Zhao, J. H. (2009). Review on multi-criteria decision analysis aid in sustainable energy decision-making. Renewable and Sustainable Energy Reviews, 13(9), 2263-2278. https://doi.org/10.1016/j.rser.2009.06.021 


\title{
Economic Feasibility of Solar PV System for Buildings
}

\author{
Bin-Juine Huang ${ }^{*}$, Po-Chien Hsu', Yi-Hung Wang ${ }^{1}$, \\ Jia-Wei Wang ${ }^{1}$, Wei-Hau Wu' ${ }^{1}$, Ming-Jia Lee ${ }^{1}$, Kang Li' ${ }^{1}$, Kung-Yen Lee ${ }^{2}$ \\ ${ }^{1}$ Department of Mechanical Engineering, \\ 2 Department of Engineering Science and Ocean Engineering, \\ National Taiwan University, Taipei, Taiwan 106
}

\begin{abstract}
A system design optimization and economic feasibility of a solar PV system for self-consumption is studied using long-term system performance simulation. The electric heater is used to replace part of battery storage to reduce the cost. Three parameters, $R_{p L}, R_{h b}, t_{b p}$, are derived to correlate the long-term system performance. It is found that there is an optimal design and the solar PV system is economical if it was used to replace partial demand which is paid at higher grid electricity price. This is the partial grid-parity.
\end{abstract}

Keywords: PV for self-consumption; solar PV system; optimal design of solar PV

\section{Introduction}

Solar PV system for self-consumption with energy storage should be used if solar penetration is high. The installation of conventional grid-tied solar PV systems requires approval from the grid authority. The cost of approval application becomes relatively high for small solar home systems.

Hsu et al (2016) developed a so-called "hybrid solar PV system (HyPV)" which is a distributed energy system for self-consumption. HyPV operates in stand-alone PV mode or grid mode automatically according to the weather and battery conditions, as shown in Fig. 1. HyPV uses switching technique. It operates in either solar or grid mode. No excess solar power is fed into grid. The installation of HyPV dos not requires approval of grid authority. Since no solar PV power is fed into the grid, the system match between the load pattern and the storage capacity needs to be optimized in order to avoid PV generation loss. To reduce the system cost, an electric water heater is installed to replace part of battery storage (Huang et al, 2017). In this paper, a system design optimization is carried out and economic feasibility is studied through long-term system simulation.

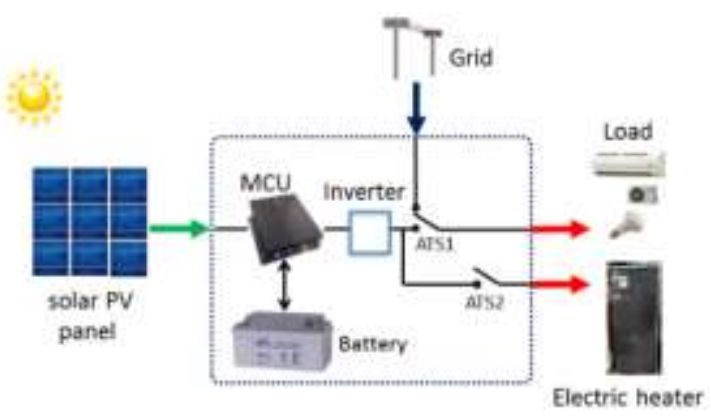

Fig. 1: Hybrid solar PV system (HyPV).

\section{System simulation}

The long-term system simulation is carried out using the performance model of HyPV and meteorological data. The long-term simulation is performed with different system design parameter and load pattern.

The incident solar radiation $\left(I_{T}\right)$ is absorbed and converted into electricity $P_{p v}$ which drives the load $\left(P_{L}\right)$ and charges the battery $\left(P_{b a t}\right)$, as shown in Fig. 2. The energy balance equation, eqn (1), is derived (Hsu et al, 2016).

$$
P_{b a t}=P_{p v}-P_{L}
$$


The battery will be cut off and the PV power generation approximates the load power, if it is fully charged. That is, there are two operating states in PV power generation as described in eqn(2).

$$
\frac{d E_{b a t}(t)}{d t} \approx\left\{\begin{array}{l}
P_{m p}-P_{L}, \text { battery not fully charged } \\
0, \text { battery fully charged }
\end{array}\right.
$$

Where $E_{b a t}$ is the energy storage level (i.e. state of charge SOC).

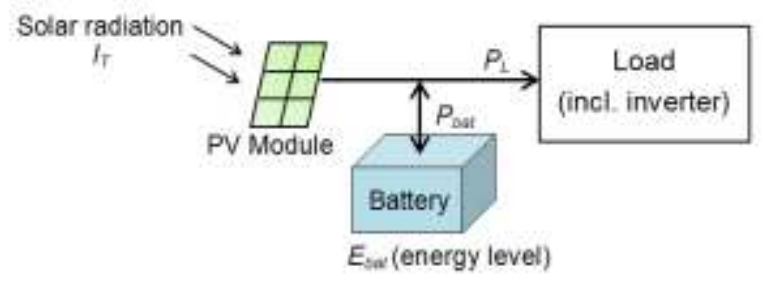

Fig. 2: Schematic of system energy balance of HyPV in PV mode.

\section{System design analysis}

\subsection{System design parameters}

The long-term system simulation for different design parameters is carried out using the local meteorological data. Four load patterns are used in the present study: Load Pattern A (100\% energy used in daytime), Load Pattern B (75\%), Load Pattern C (50\%), and Load Pattern D (25\%). Total PV energy generation over 20 years was calculated. The total investment cost includes initial and maintenance costs (Li battery replacement). Three parameters are defined, eqn(3), to correlate the long-term system performance.

$$
R_{p L}=\frac{P_{m p}}{P_{L \max }} ; R_{h b}=\frac{C_{h s}}{C_{b a t}} ; t_{b p}=\frac{C_{b a t}}{P_{m p}}
$$

$R_{p L}$ is defined as the ratio of maximum PV power generation to maximum load; $R_{h b}$ is the ratio of thermal storage to battery storage; $t_{b p}$ is the charge time for solar PV to fully charge the battery.

\subsection{Performance simulation results}

Fig. 3 is the variation of PV generation cost with $R_{p L}$. It shows that there is an optimal design for PV generation cost. Fig.4 is the variation of PV generation cost with $R_{h b}$. An optimal design for PV generation cost can be found. The optimal ratio of thermal to battery storage capacity $R_{h b}$ is $1 \sim 4$, depending on the battery size

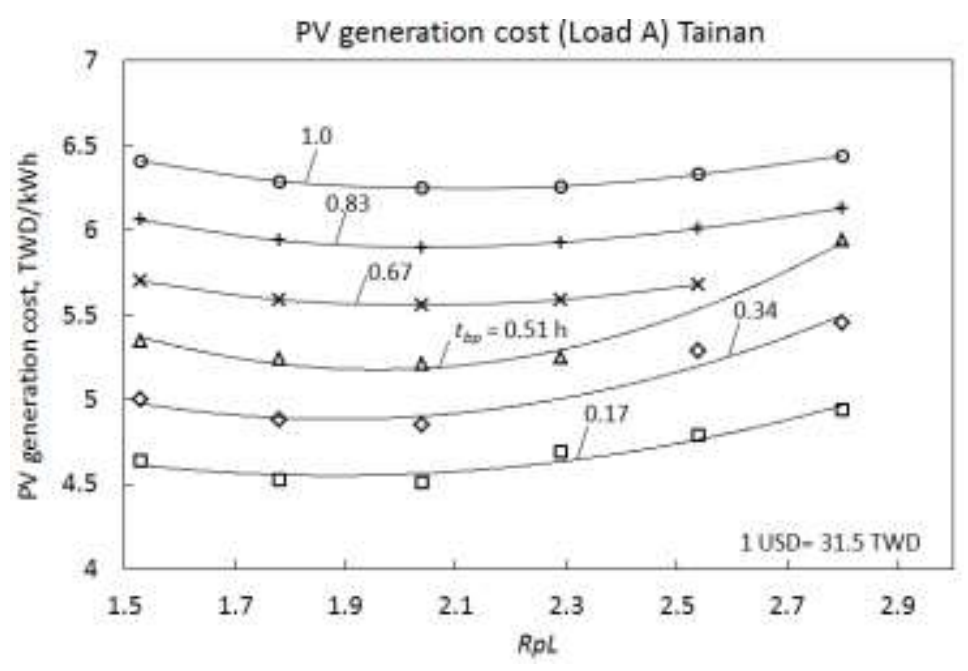

Fig. 3: Variation of PV generation cost with $\boldsymbol{R}_{p L}$. 


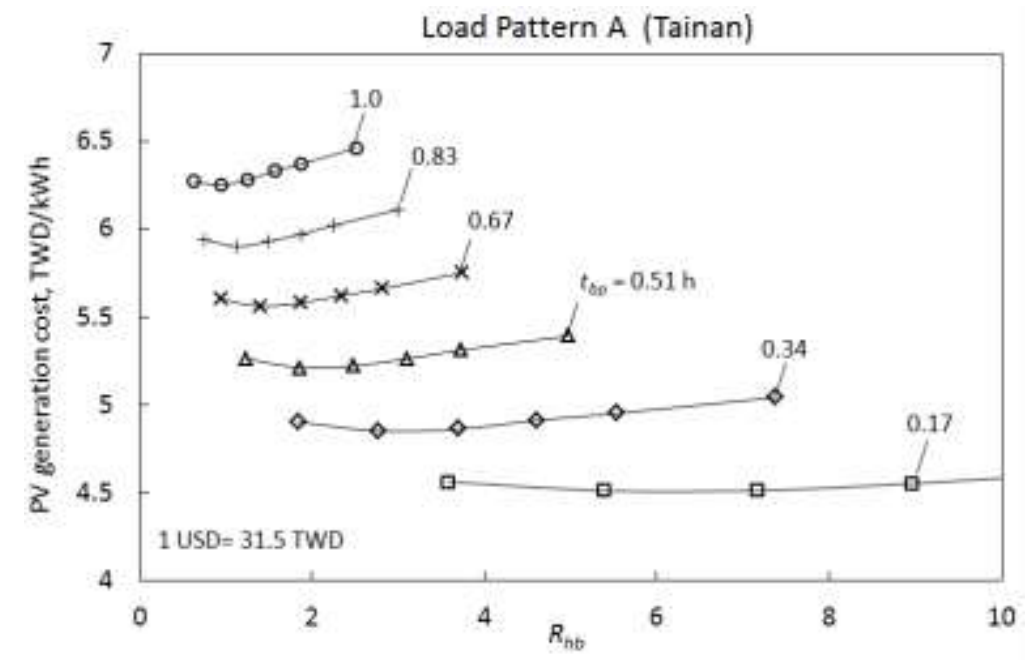

Fig. 4: Variation of PV generation cost with $R_{h b}$

\subsection{PV energy generation cost}

The PV generation cost is compared with the grid electricity price as shown in Fig.5. The categorized grid electricity price in Taiwan is in staircase structure.

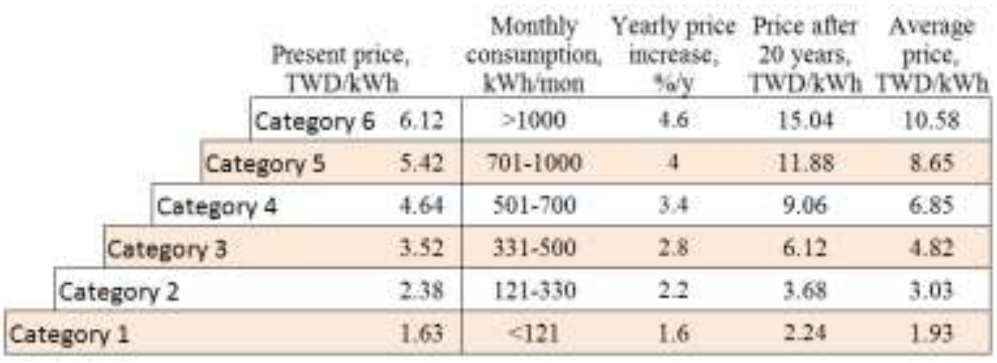

Fig. 5: Categorized grid electricity price. (1 USD=31.5 TWD)

Tab.2 shows the optimal design for four load patterns in three cities of Taiwan. The PV energy production cost is among 4.66-7.24 TWD/kWh (1 USD=31.5TWD). For the electricity bill paid in Category 3 or 4, solar PV replacement is economical. That is, solar PV is economical if it was used to replace partial demand which is paid at higher grid electricity price. This is the partial grid-parity should be arranged to the left, with characters similar to that of the body text and should be numbered.

Tab. 2: Optimal design and economic feasibility.

\begin{tabular}{|c|c|c|c|c|c|c|c|c|c|c|c|c|}
\hline & $R_{h b}$ & $R_{p L}$ & $t_{b p}(\mathrm{~h})$ & $\begin{array}{l}\text { Battery } \\
\text { capacity } \\
\text { (Wh) }\end{array}$ & $\begin{array}{c}\text { Solar PV } \\
\text { panel } \\
\text { (Wp) }\end{array}$ & $\begin{array}{l}20 \text {-year } \\
\text { energy } \\
\text { saving } \\
\text { (TWD) }\end{array}$ & $\begin{array}{c}20 \text {-year } \\
\text { total } \\
\text { investment } \\
\text { (TWD) }\end{array}$ & $\begin{array}{c}\text { PV energy } \\
\text { generation } \\
\text { cost } \\
\text { (TWD } / \mathrm{kWh} \text { ) }\end{array}$ & $\begin{array}{c}\text { Retum on } \\
\text { investment } \\
\text { (\%/year) }\end{array}$ & $\begin{array}{c}\text { PV } \\
\text { generation } \\
\text { loss (\%) }\end{array}$ & $\begin{array}{l}\text { Ratio of } \\
\text { PV energy } \\
\text { supply (\%) }\end{array}$ & $\begin{array}{c}\text { Lowest } \\
\text { electricity price } \\
\text { category for } \\
\text { PV to be } \\
\text { economical }\end{array}$ \\
\hline \multicolumn{13}{|c|}{ Load Patten A } \\
\hline Taipei & 2.77 & 2.04 & 0.34 & 1,360 & 4,000 & 595,627 & 425,322 & 6.65 & 2.00 & 0.67 & 44 & 4 \\
\hline Taichung & 3.69 & 2.04 & 0.34 & 1,360 & 4,000 & 834,713 & 429,172 & 4.65 & 4.72 & 1.66 & 59 & 3 \\
\hline Tainan & 2.77 & 2.04 & 0.34 & 1,360 & 4,000 & 802,813 & 425,322 & 4.85 & 4.44 & 1.79 & 58 & 4 \\
\hline \multicolumn{13}{|c|}{ Load Patten B } \\
\hline Taipei & 3.16 & 2.38 & 0.34 & 1,190 & 3,500 & 517,232 & 371,538 & 6.68 & 1.96 & 1.21 & 36 & 4 \\
\hline Taichung & 3.69 & 2.04 & 0.34 & 1,020 & 3,000 & 629,168 & 326,004 & 4.66 & 4.65 & 0.81 & 44 & 3 \\
\hline Tainan & 3.69 & 2.04 & 0.34 & 1,020 & 3,000 & 606,425 & 326,004 & 4.9 & 4.30 & 0.61 & 44 & 4 \\
\hline \multicolumn{13}{|c|}{ Load Patten C } \\
\hline Taipei & 4.92 & 3.05 & 0.34 & 1,020 & 3,000 & 447,375 & 321,604 & 6.74 & 1.96 & 1.07 & 28 & 4 \\
\hline Taichung & 3.69 & 2.03 & 0.34 & 680 & 2,000 & 416,473 & 222,836 & 4.78 & 4.34 & 0.77 & 30 & 3 \\
\hline Tainan & 3.69 & 2.03 & 0.34 & 680 & 2,000 & 415,211 & 222,836 & 5.03 & 4.32 & 0.58 & 29 & 4 \\
\hline \multicolumn{13}{|c|}{ Load Patten D } \\
\hline Taipei & 5.9 & 5.09 & 0.34 & 850 & 2,500 & 369,075 & 283,120 & 7.24 & 1.52 & 2.84 & 17 & 5 \\
\hline Taichung & 7.38 & 5.09 & 0.34 & 850 & 2,500 & 504,338 & 286,970 & 5.09 & 3.79 & 4.07 & 20 & 4 \\
\hline Tainan & 5.90 & 5.09 & 0.34 & 850 & 2,500 & 493,874 & 283,120 & 5.35 & 3.72 & 5.14 & 20 & 4 \\
\hline
\end{tabular}




\section{Conclusion}

Solar PV system for self-consumption with energy storage should be used if solar penetration is high. The conventional grid-tied solar PV systems is not suitable for small solar home system since it requires high approval cost from the grid authority. The installation of HyPV dos not require approval of grid authority.

A system design optimization and economic feasibility of a solar PV system for self-consumption is studied using long-term system performance simulation. The electric heater is used to replace part of battery storage to reduce the cost. Three parameters, $R_{p L}, R_{h b}, t_{b p}$, are derived to correlate the long-term system performance. It is found that there is an optimal design and the solar PV system is economical if it was used to replace partial demand which is paid at higher grid electricity price. This is the partial grid-parity.

\section{References}

Hsu,P.C., Huang,B.J. , Lin, W.C., Chang,Y.J., Chang, C.J., Li, K, Lee, K.Y. 2016. Effect of switching scheme on the performance of a hybrid solar PV System. Renewable Energy 96, 520-530

Huang,Bin-Juine, Hsu, Po-Chien, Wu,Po-Hsien, Wang, Yi-Hung, Tang,Tzu-Chiao, Wang Jia-Wei, Dong, Xin-Hong, Wu,Wei-Hau, Lee, Ming-Jia, Yeh Jen-Fu. 2017. Hybrid energy storage of solar PV system for self-consumption. International Conference \& Workshop REMOO-2017. Energy for Tomorrow. 10-12 May 2017, Venice / Italy.

\section{Acknowledgment}

This study was supported by National Energy Program II, MOST 103-3113-E-002-006 made by Ministry of Science and Technology, Taiwan. 


\title{
Comparative Economic Analysis of Single- and Dual-fluid Based Photovoltaic Thermal Systems for Building Energy Needs
}

\author{
M. Imtiaz Hussain ${ }^{1}$ and Jun-Tae Kim ${ }^{2}$ \\ ${ }^{1}$ Green Energy Technology Research Center, Kongju National University, Cheonan, Korea \\ ${ }^{2}$ Department of Architectural Engineering, Kongju National University, Cheonan, Korea
}

\begin{abstract}
This study presents a comparative economic analysis of single- and dual-fluid based photovoltaic/thermal (PV/T) systems for energy supply of an apartment with varied demands. Nanofluid (CuO/water) and Conventional heat transfer fluids were operated both separately and simultaneously under the same-sized PV/T system. The performance of single- and dual-fluid PV/T systems for apartment energy needs was investigated for winter from November to February. The apartment heat load and the PV/T system performance were predicted via EnergyPLus ${ }^{\circledR}$ and Matlab ${ }^{\circledR}$ simulation software, respectively. Based on recent inflation rate, interest rate, and utilities unit prices in South Korea, economic viability of both single- and dual-fluid PV/T systems was assessed to supply energy to a top floor apartment of a 4-storey residential building. It is found that dual-fluid PV/T systems powered by nanofluids yield the best life cycle savings and discounted payback period than that of single-fluid PV/T systems. Net savings earned from mitigation of $\mathrm{CO}_{2}$ over the lifetime of dual-fluid PV/T systems are surprisingly higher than the solar collectors associated with single-fluid systems.
\end{abstract}

Keywords: Dual-fluid PV/T system, Transient model, Economic analysis, Building energy needs

\section{Introduction}

Photovoltaic/thermal (PV/T) collector, which integrates photovoltaic (PV) cells and thermal collector into single unit, can reach high yields per unit area (Chow, 2003). The conversion of solar energy into thermal and electrical energy allows the cooling of PV cells and hence exploitation of heat energy from its surface. Myriad of studies have been carried out on performance enhancement of hybrid PV/T systems using different heat transfer fluids such air, water, synthetic oils, and nanofluids (Hussain et al., 2018; Tian and Zhao, 2013). In above-mentioned list of fluids, air is not much effective compared to liquid type coolants because of lower heat capacity. To have high useful energy from PV/T system several techniques such as new coolant materials and optimization of absorber are possible. In this study we are interested in both aforementioned techniques including application of different fluids and modification of absorber design.

Over the years, the utilization of colloidal solutions or nanofluids in solar collecting systems has increased substantially. By adding nanoparticles into conventional fluids can change the thermo-physical properties of the resultant mixture (Hussain and Kim, 2018). The most importantly increasing their thermal conductivity compared to conventional fluids. The heat transfer and electrical efficiency of the PV/T system depends mainly on the thermophysical properties of the coolants (Al-Waeli et al., 2017). Therefore, use of nanofluid as a coolant has proven to be effective at increasing overall efficiency of the PV/T systems.

The simultaneous application of two heat transfer fluids for cooling of PV cells offer a wide range of options, where either fluid can be operated depending on energy demands. In situation where space matters such as high-rise or apartment buildings, dual-fluid PV/T system seems more appealing and an attractive option. Abu Bakar et al., (2014) proposed an improved design of a bi-fluid PV/T system which comprised of copper pipes for carrying water and a single pass air channel. The dual-fluid heat exchanger was designed in such a way that both fluids flow perpendicular to one another and thus creating transverse flow effect. Because of cross flow condition, energy balance equations for each PV/T component were solved using 2D steady state model. Following the 2D 
mathematical model developed by Abu Bakar et al., (2014), Jarimi et al., (2016) added slight modification to this model considering finned air channel configuration. Besides, the developed 2D steady state model was validated using indoor experimental results.

The presented study aims to compare the economic viability of single- and dual-fluid PV/T systems for apartment energy needs, and also address the challenges and opportunities of the nanofluid heat exchanger in comparison to conventional fluids. A mathematical model of a dual-fluid PV/T system is developed and validated using experimental results from published study.

\section{Mathematical Model}

A MATLAB computer program is used to perform the simulation. A thermo-electric model based on interdependent energy balance equations is analyzed using ordinary differential equations (ODE) solver. During simulation real time calculation of heat transfer coefficients has been done and material properties were taken as constant. A generic mathematical model of a PV/T system is developed, which could be applied to both single- and dual-fluid heat exchangers.

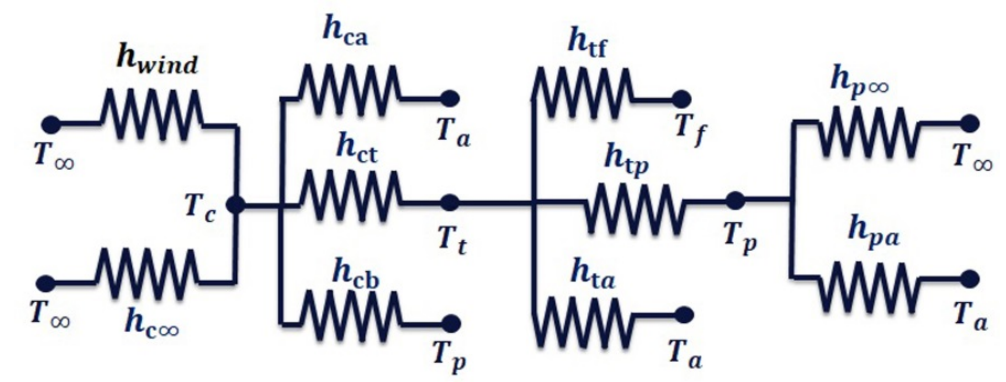

Fig. 1: The dual-fluid PV/T thermal resistance circuit.

In the PV/T system, the temperature change across the interface between layers of different materials is attributed to the thermal resistance, as shown in Fig. 1. Dynamic interdependence temperature responses for different collector components (PV laminate, pipe absorber, nanofluid, inside air, and back panel) were predicted using energy balance equations (Chow, 2003). The energy balance for each collector component is presented as follows:

$\mathrm{M}_{\mathrm{c}} \mathrm{C}_{\mathrm{c}}\left(\mathrm{dT} \mathrm{T}_{\mathrm{c}} / \mathrm{dt}\right)=\mathrm{G} \alpha_{\mathrm{c}}-\mathrm{E}-\mathrm{h}_{\text {wind }} \mathrm{A}_{\mathrm{c} \infty}\left(\mathrm{T}_{\mathrm{c}}-\mathrm{T}_{\infty}\right)-\mathrm{h}_{\mathrm{c} \infty} \mathrm{A}_{\mathrm{c} \infty}\left(\mathrm{T}_{\mathrm{c}}-\mathrm{T}_{\infty}\right)-\mathrm{h}_{\mathrm{ct}} \mathrm{A}_{\mathrm{ct}}\left(\mathrm{T}_{\mathrm{c}}-\mathrm{T}_{\mathrm{t}}\right)-\mathrm{A}_{\mathrm{ca}} \mathrm{h}_{\mathrm{ca}}\left(\mathrm{T}_{\mathrm{c}}-\mathrm{T}_{\mathrm{a}}\right)-$

$\mathrm{h}_{\mathrm{cp}} \mathrm{A}_{\mathrm{cp}}\left(\mathrm{T}_{\mathrm{c}}-\mathrm{T}_{\mathrm{p}}\right)$

$\mathrm{M}_{\mathrm{c}}, \mathrm{C}_{\mathrm{c}}$ and $\mathrm{T}_{\mathrm{c}}$ are the mass, specific heat and temperature of the PV cells, respectively. $\mathrm{G}$ is the solar radiation and $\alpha_{c}$ is the absorptivity of the PV cells. The electrical energy output from the PV module can be calculated using following correlation:

$\mathrm{E}=\mathrm{GP} \mathrm{y}_{\mathrm{e}}$

The electrical efficiency $\left(\mathrm{y}_{\mathrm{e}}\right)$ is estimated as a function of PV cells temperature as recommended by (Florschuetz, 1979) as follows:

$\eta_{\mathrm{e}}=\eta_{\mathrm{r}}\left[1-\beta_{\mathrm{r}}\left(\mathrm{T}_{\mathrm{c}}-\mathrm{T}_{\mathrm{r}}\right)\right]$

$\beta_{\mathrm{r}}$ and $\eta_{\mathrm{r}}$ are the temperature coefficient and electrical efficiency at reference solar cells temperature, respectively. The energy balance equations for the pipe carrying fluid can be written as:

$M_{t} C_{t}\left(d T_{t} / d t\right)=h_{c t} A_{c t}\left(T_{c}-T_{t}\right)-A_{t f} h_{t f}\left(T_{t}-T_{f}\right)-A_{t a} h_{t a}\left(T_{t}-T_{a}\right)-h_{t p} A_{t p}\left(T_{t}-T_{p}\right)$

$h_{t f}=N u_{f} k_{f} / D_{i}$ 
$\mathrm{M}_{\mathrm{t}}, \mathrm{C}_{\mathrm{t}}$ and $\mathrm{T}_{\mathrm{t}}$ are the mass, specific heat and temperature of the pipes, respectively. $N u_{f}$ is the Nusselt number. $k_{f}$ and $D_{i}$ are the thermal conductivity of the circulating fluid and inner diameter of the tube, respectively. In case of nanofluid, the Nusselt number can be calculated using following correlation (Zerradi et al., 2014):

$N u_{n f}=\operatorname{Pr}^{0.1039}\left(1.0257 \phi+1.1397 R e^{0.205}+0.788 \phi R e^{0.205}+1.2069\right)$

$\phi$ is the concentration of nanoparticles in the base fluid. $\mathrm{Pr}$ and $R e$ are the Prandtl and Reynolds numbers, respectively. The heat transfer equation for the temperature node for the fluid flow can be expressed as:

$\mathrm{M}_{\mathrm{f}} \mathrm{C}_{\mathrm{f}}\left(\mathrm{dT} \mathrm{T}_{\mathrm{f}} / \mathrm{dt}\right)=\dot{\mathrm{m}}_{\mathrm{f}} \mathrm{C}_{\mathrm{f}}\left(\mathrm{T}_{\mathrm{f}, \mathrm{o}}-\mathrm{T}_{\mathrm{f}, \mathrm{in}}\right)+\mathrm{A}_{\mathrm{tf}} \mathrm{h}_{\mathrm{tf}}\left(\mathrm{T}_{\mathrm{t}}-\mathrm{T}_{\mathrm{f}}\right)$

$\dot{\mathrm{m}}_{\mathrm{f}}$ and $\mathrm{C}_{\mathrm{f}}$ are the mass flow rate and specific heat of the circulating fluid, respectively. $\mathrm{T}_{\mathrm{f}, \mathrm{in}}$ and $\mathrm{T}_{\mathrm{f}, \mathrm{o}}$ are the fluid inlet and outlet temperatures, respectively. The heat transfer equation for the air node is then written as:

$\mathrm{M}_{\mathrm{a}} \mathrm{C}_{\mathrm{a}}(\mathrm{dT} \mathrm{T} / \mathrm{dt})=\dot{\mathrm{m}}_{\mathrm{a}} \mathrm{C}_{\mathrm{a}}\left(\mathrm{T}_{\mathrm{a}, \mathrm{o}}-\mathrm{T}_{\mathrm{a}, \mathrm{i}}\right)+\mathrm{A}_{\mathrm{pa}} \mathrm{h}_{\mathrm{pa}}\left(\mathrm{T}_{\mathrm{p}}-\mathrm{T}_{\mathrm{a}}\right)+\mathrm{A}_{\mathrm{ta}} \mathrm{h}_{\mathrm{ta}}\left(\mathrm{T}_{\mathrm{t}}-\mathrm{T}_{\mathrm{a}}\right)+\mathrm{A}_{\mathrm{ca}} \mathrm{h}_{\mathrm{ca}}\left(\mathrm{T}_{\mathrm{c}}-\mathrm{T}_{\mathrm{a}}\right)$

$\mathrm{M}_{\mathrm{a}}, \mathrm{C}_{\mathrm{a}}$ and $\dot{\mathrm{m}}_{\mathrm{a}}$ are the mass, specific heat and mass flow rate of the circulating fluid, respectively. Finally, the energy balance for the back panel can be obtained as:

$\mathrm{M}_{\mathrm{p}} \mathrm{C}_{\mathrm{p}}\left(\mathrm{dT} \mathrm{T}_{\mathrm{p}} / \mathrm{dt}\right)=\mathrm{h}_{\mathrm{tp}} \mathrm{A}_{\mathrm{tp}}\left(\mathrm{T}_{\mathrm{t}}-\mathrm{T}_{\mathrm{p}}\right)+\mathrm{h}_{\mathrm{cp}} \mathrm{A}_{\mathrm{cp}}\left(\mathrm{T}_{\mathrm{c}}-\mathrm{T}_{\mathrm{p}}\right)+\mathrm{h}_{\mathrm{ap}} \mathrm{A}_{\mathrm{ap}}\left(\mathrm{T}_{\mathrm{a}}-\mathrm{T}_{\mathrm{p}}\right)-\mathrm{h}_{\mathrm{p} \infty} \mathrm{A}_{\mathrm{p} \infty}\left(\mathrm{T}_{\mathrm{p}}-\mathrm{T}_{\infty}\right)$

$\mathrm{M}_{\mathrm{p}}, \mathrm{C}_{\mathrm{p}}$ and $\mathrm{T}_{\mathrm{p}}$ are the mass, specific heat and temperature of the back panel, respectively. The total useful energy produced and thermal efficiency of the solar collector is given by summation of outcomes from air and liquid fluids heating components as follows:

$\mathrm{Q}_{\mathrm{th}}=\dot{\mathrm{m}}_{\mathrm{f}} \mathrm{C}_{\mathrm{f}}\left(\mathrm{T}_{\mathrm{f}, \mathrm{o}}-\mathrm{T}_{\mathrm{f}, \mathrm{in}}\right)+\dot{\mathrm{m}}_{\mathrm{a}} \mathrm{C}_{\mathrm{a}}\left(\mathrm{T}_{\mathrm{a}, \mathrm{o}}-\mathrm{T}_{\mathrm{a}, \mathrm{in}}\right)$

$\eta_{\text {th }}=\frac{\dot{m}_{f} C_{f}\left(T_{f, o}-T_{f, i n}\right)+\dot{m}_{a} C_{a}\left(T_{a, o}-T_{a, i n}\right)}{A_{c l} G}$

$\mathrm{Q}_{\text {th }}$ and $\eta_{\text {th }}$ are the total useful energy and thermal efficiency of the dual-fluid PV/T system. Net $\mathrm{CO}_{2}$ mitigation and carbon credit earned over the collector life can be calculated as (Barnwal and Tiwari, 2008):

Net $\mathrm{CO}_{2}$ mitigation $=\left(\mathrm{Q}_{\mathrm{th}} *\right.$ lifetime - embodied energy $) * 0.98 * 10^{-3}$

Embodied energy is the amount of energy required during manufacturing of PV module from raw materials to final product use. In this study the value of embodied energy is taken as $1380 \mathrm{kWh} / \mathrm{m}^{2}$ (Tiwari et al., 2007). If the $\mathrm{CO}_{2}$ mitigation is being traded at rate of 20 euro/ton then the earned carbon credit over the collector lifetime can be expressed as:

Net $\mathrm{CO}_{2}$ credit $=$ Net $\mathrm{CO}_{2}$ mitigation $* 20$

\section{Research Design}

To assess the PV/T performance under extreme weather conditions, heating load for a top floor apartment of a 4storey residential building was calculated using EnergyPLus ${ }^{\circledR}$ simulation software. The apartment with facing south-east directions has dimensions of $8 \mathrm{~m}$ x $4 \mathrm{~m}$ x 3.5m. During load calculation, a basic heating, ventilation and air conditioning (HVAC) is used instead of a full HVAC system. A basic HVAC system is also called Ideal Loads Air System.

For PV/T system, a mono-crystalline PV cells with exposed surface area of $1.62 \mathrm{~m}^{2}$ is considered for simulation (Fig.2). The dual-fluid heat exchanger comprised of a parallel tube thermal absorber and a single pass air heater. In order to minimize thermal resistance, the copper tube exchanger is attached directly onto the rear surface of the PV module with help of thermally conductive glue or thermal adhesive. While in conventional finned-tube concept, the absorber sheet is used between tube and PV module. To enhance the turbulence within the air channel, a set of baffles is arranged transverse to air flow. This promotes convection heat transfer to circulating air and hence 
minimizes the thermal resistance between air and channel walls. In order to enhance emissivity, matt black surfaces for copper tube, PV rear and air channel were considered. Copper oxide (CuO) nanoparticles with fixed volume concentration $(0.70 \%)$ in pure water are used for nanofluid preparation.

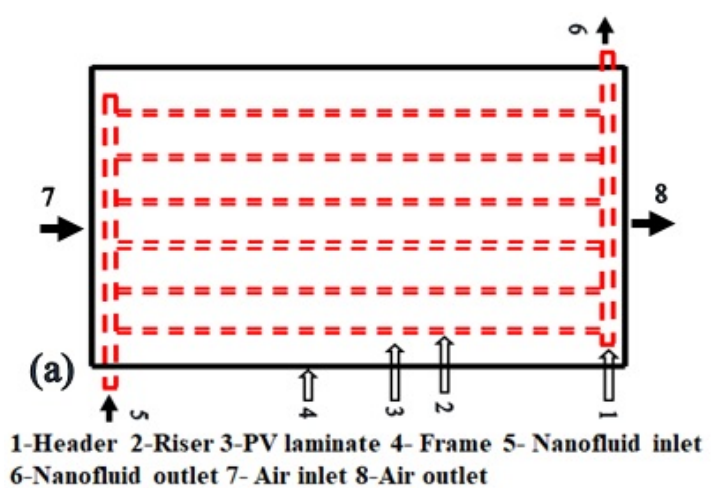

Fig. 2: Dual-fluid PV/T system (a) assembly and flow pattern (b) cross-section view

\section{Results and discussions}

Since we do not have experimental results for the dual-fluid PV/T system, therefore, the validation of the mathematical model was performed using test data from the published article. For this purpose, a simple case of air type PV/T collector published by Joshi et al., (2009) was selected. Using identical geometrical configurations and operating conditions as given in selected published article, the experimental results from the published study were compared with the results from the mathematical model. The root mean square percentage differences for the average PV module and outlet air temperatures between the simulation and test data were no more than $4.4 \%$ and $5.0 \%$, respectively. Therefore, we are now in a position to say that the developed model could be used to predict the $\mathrm{PV} / \mathrm{T}$ performance under a wide range of climatic conditions.

The overall efficiency of the PV/T system mainly depends on the fluid type used for heat removal from the PV module. Considering independent and simultaneous modes of fluid operation, total four modes were taken into consideration such as nanofluid plus air, water plus air, nanofluid and water. The overall efficiency of the PV/T system was plotted against different flow rates of the fluid as presented in Fig. 3. In case of simultaneous modes, nanofluid or water flow rate was varied at fixed air flow rate. Compared to independent fluid modes, the PV/T system associated with simultaneous modes showed greater efficiencies. However, the efficiency of the PV/T system with $\mathrm{CuO}$ nanofluid/air was relatively high compared to other heat transfer fluids. The additional energy produced was due to superior thermo-physical properties of the nanofluid as a coolant which increases total system efficiency per unit area.

The effectiveness of the nanofluids over the conventional heat transfer fluids can be described in terms of heat transfer coefficient. Table 1 shows the variations of convection heat transfer coefficients in function of fluid flow rate, when $\mathrm{CuO}$ nanofluid and water are used as the coolants for the PV/T system. As expected, the convection heat transfer coefficient increases with an increasing concentration of nanoparticles and the mass flow rate. However, compared to water, the nanofluid for all given concentrations has produced higher convection heat transfer coefficients between the absorber surface and the circulating fluid. This may have caused by low specific heat and high thermal conductivity of the nanofluid, which ultimately results in an increase of surface area of the heat exchanger. 


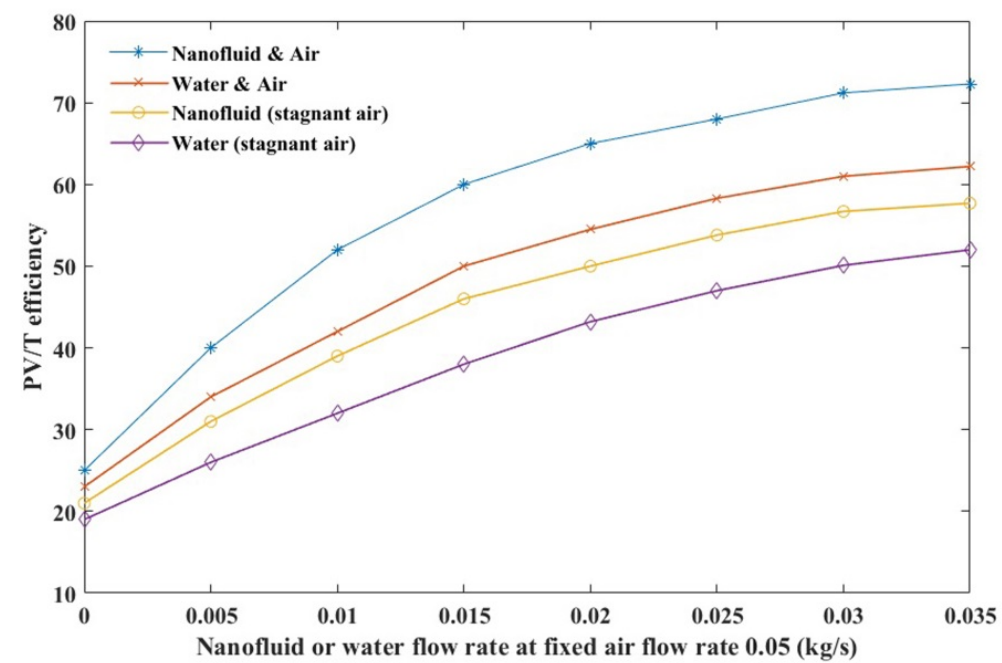

Fig. 3: Variations of PV/T efficiency against variable of nanofluid or water flow at fixed air flow rate

Tab. 1: variations of the convection heat transfer coefficient against flow rate using water and nanofluid

\begin{tabular}{ccccc}
\hline $\begin{array}{c}\text { Mass flow rate } \\
(\mathbf{k g} / \mathbf{s})\end{array}$ & $\boldsymbol{h}_{\boldsymbol{t} \boldsymbol{f}}$ using water & $\begin{array}{c}\boldsymbol{h}_{\boldsymbol{t} \boldsymbol{f}} \text { using } \\
\text { nanofluid (0.3\%) }\end{array}$ & $\begin{array}{c}\boldsymbol{h}_{\boldsymbol{t} \boldsymbol{f}} \text { using } \\
\text { nanofluid (0.5\%) }\end{array}$ & $\begin{array}{c}\boldsymbol{h}_{\boldsymbol{t} \boldsymbol{f}} \text { using } \\
\text { nanofluid (0.7\%) }\end{array}$ \\
\hline 0.005 & 390.21 & 430.07 & 445.99 & 465.30 \\
0.01 & 435.02 & 482.30 & 505.05 & 530.39 \\
0.015 & 470.31 & 520.22 & 548.69 & 575.41 \\
0.02 & 495.44 & 548.93 & 570.76 & 605.02 \\
0.025 & 507.26 & 563.54 & 582.52 & 620.27 \\
0.03 & 506.95 & 574.18 & 593.72 & 635.95 \\
\hline
\end{tabular}

Under similar working conditions, daily PV cells temperature is predicted using different modes of fluid operation (Fig. 4). Hourly solar radiation and ambient temperature data is used to estimate PV module temperature against variable fluid ranges. During simultaneous mode, both nanofluid or water and air were operated at specific sets of fixed flow rates. At a fixed nanofluid or water flow rate of $0.025 \mathrm{~kg} / \mathrm{s}$ and air flow rate of $0.05 \mathrm{~kg} / \mathrm{s}$, the maximum PV module temperature were $48.7^{\circ} \mathrm{C}$ and $43.5{ }^{\circ} \mathrm{C}$ for water/air and nanofluid/air, respectively. Whereas using nanofluid and water individually the PV module temperature is $55.1^{\circ} \mathrm{C}$ and $52.1^{\circ} \mathrm{C}$, respectively. It is observed that utilization of dual-fluid as a coolant removes extra accumulated solar heat from the PV module and hence improves its overall energy production performance. Furthermore, a rise in the temperature for each fluid is calculated as a difference between outlet and inlet fluid temperatures. This is the best way to find the thermal contribution of each fluid when nanofluid or water and air are being operated simultaneously. As shown in Fig. 5, during simultaneous mode both nanofluid and water have the lower temperature rises than that of air. However, due to higher thermal conductivity, the nanofluid in combination with air has the highest thermal output. Lower specific heat causes air to achieve higher temperature in shorter time than that of nanofluid or water. 


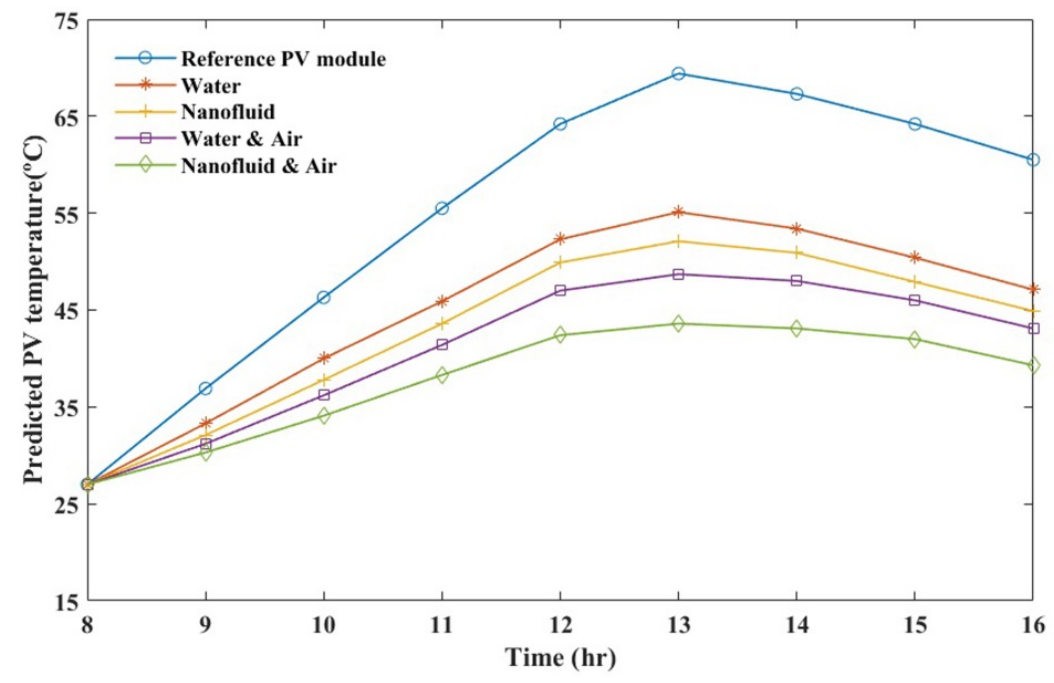

Fig. 4: Variations of PV/T temperature against different modes of fluid operation
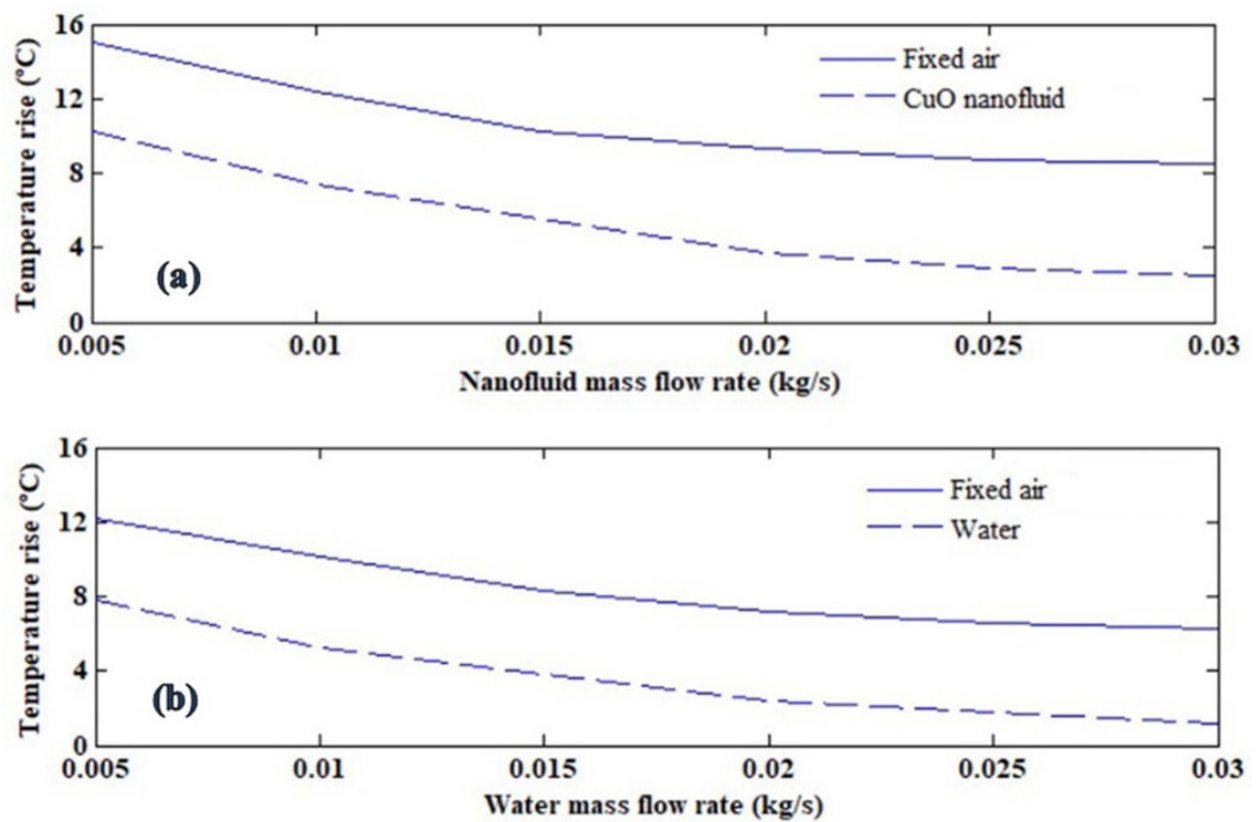

Fig. 5: Temperature rise against variable (a) nanofluid flow rate (b) water flow rate at fixed air flow of $0.05 \mathrm{~kg} / \mathrm{s}$

Economic feasibility and compatibility-prosperity of single- and dual-fluid PV/T systems for apartment energy needs was evaluated as the replacement of commonly used energy sources such as electricity and natural gas. Based on local unit cost of utilities (KEPCO) and load supplied and required by the apartment, the life cycle savings (LCS) and discounted payback period (DPP) of the PV/T systems were estimated (Imtiaz Hussain et al., 2016). When single fluid is used, the LCS based on electricity and natural gas is 1558.7 and 1260.2, and 1418.9 and 1147.2 for $\mathrm{PV} / \mathrm{T}$ with nanofluid and PV/T with water, respectively. For nanofluid based dual-fluid PV/T system, the DPP relative to electricity and natural gas were found to be 8 and 10 years, respectively and LCSs as the replacement of electricity and gas were found to be 1998.6 and 1615.9 USD, respectively (Table 2). The LCS relative to electricity was found to be higher because of high price per unit for electricity compared to natural gas. It is worth to note that LCS based on electricity and natural gas is almost 2 times the present cost of the dual-fluid PV/T with nanofluid, which is promising. 
Tab. 2: Life cycle savings and discounted payback period of the PV/T system based on electricity and natural gas

\begin{tabular}{|c|c|c|c|c|c|}
\hline \multirow[t]{2}{*}{$\begin{array}{l}\text { PV/T System } \\
\text { using }\end{array}$} & \multicolumn{2}{|c|}{$\begin{array}{c}\text { Life Cycle Savings (USD) } \\
\text { Based on }\end{array}$} & \multicolumn{2}{|c|}{ DPP (years) Based on } & \multirow{2}{*}{$\begin{array}{c}\text { Parameters for Economic } \\
\text { Analysis (expected useful } \\
\text { life of } 25 \text { years) }\end{array}$} \\
\hline & Electricity & Natural Gas & Electricity & Natural Gas & \\
\hline Nanofluid plus air & 1998.6 & 1615.9 & 8 & 10 & \multirow{4}{*}{$\begin{array}{c}\text { Present PV/T system cost }= \\
940 \text { USD; Electricity = } 0.094 \\
\text { USD/kWh; Gas = } 0.076 \\
\text { USD/kWh; Inflation rate }= \\
\text { 1.8\%; Interest rate = } 2 \%\end{array}$} \\
\hline Water plus air & 1765.5 & 1432.4 & 10 & 11 & \\
\hline Nanofluid only & 1558.7 & 1260.2 & 13 & 14 & \\
\hline Water only & 1418.9 & 1147.2 & 15 & 16 & \\
\hline
\end{tabular}

Relevant to electricity and natural gas monthly costs, the energy cost for an apartment with PV/T system is presented in Fig. 6. Due to the high energy demands, the monthly cost for January is notably higher than December and February. These higher values can be explained by the fact that freezing ambient temperature condition during that part of the year. It is important to note that the nanofluid based dual-fluid PV/T system totally eliminates the electricity and natural gas consumption for apartment heating for February. Furthermore, in coldest month of the year (January), the dual-fluid PV/T has proved to be the best option which reduces apartment heating cost to 11.91 USD relevant to use of electricity (44.03 USD) and natural gas (36.69 USD). Whereas for February reduce the auxiliary energy consumption to zero, which means that complete energy demand is solely fulfilled by the dual-fluid $\mathrm{PV} / \mathrm{T}$.

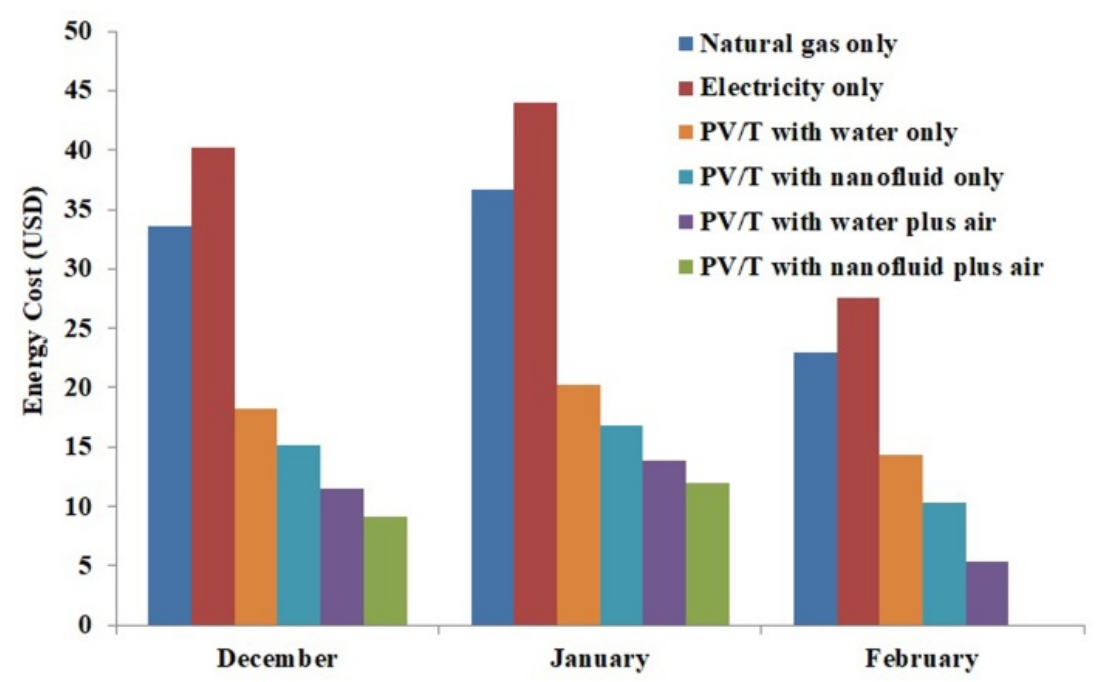

Fig. 6: Energy cost for apartment needs using utilities and PV/T system with different heat exchangers

Based on application of different heat transfer fluids in $\mathrm{PV} / \mathrm{T}$ system the potential $\mathrm{CO}_{2}$ mitigation and carbon credit are presented in Fig. 7. The results show that net savings from emission reduction are higher using dual-fluid powered PV/T systems in comparison with single fluid based systems. However, a combination of nanofluid and air as a dual-fluid provides significant improvement in the PV/T energy efficiency with negligible economic penalty. It was found that using nanofluid plus air, water plus air, nanofluid, and water the $\mathrm{CO}_{2}$ mitigation over the lifetime of PV/T was about 10.2, 8.7, 7.5, and 6.4 tonnes, respectively. It is observed that the value of earned carbon credit (USD) using nanofluid plus air as a dual-fluid is 262 USD which is almost $40 \%$ higher than that of single fluid case. Higher $\mathrm{CO}_{2}$ mitigation and carbon credit with nanofluid powered dual-fluid PV/T can be interpreted as being too 
favorable disposed to superior thermo-physical properties.

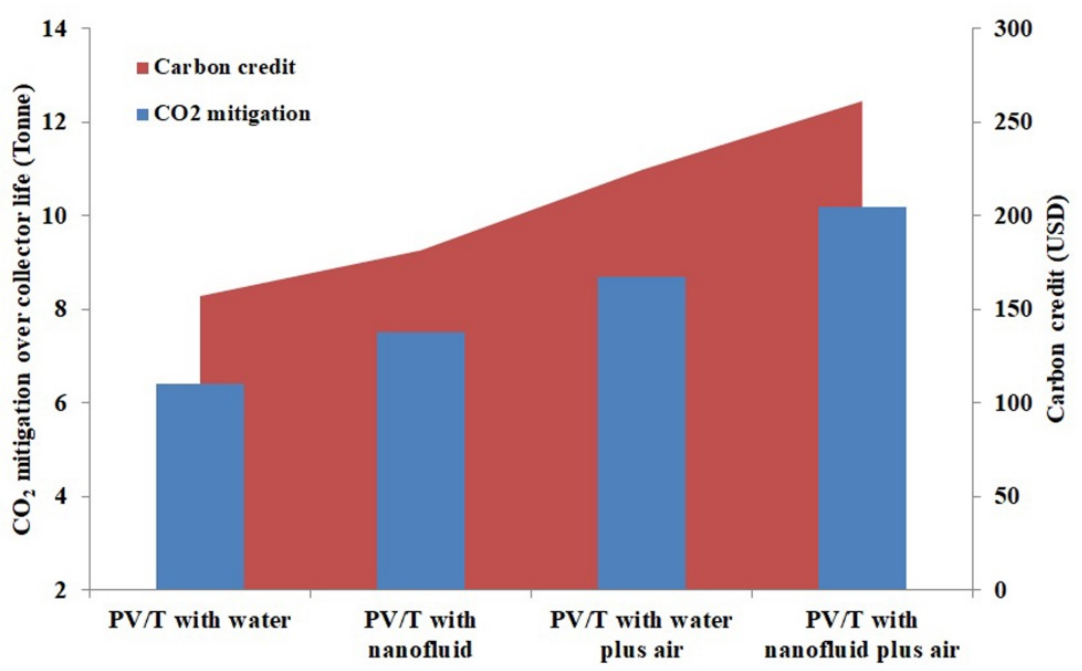

Fig. 7: CO2 mitigation and carbon credit over collector life using different modes of fluid operation

Due to large amounts of thermal losses, top floor apartment of a residential building under normal and severe weather conditions always exhibit high energy needs. To better understand the energy supplied by the PV/T system, a Top floor apartment is considered for performance assessment. Table 3 depicts the monthly variations (November to February) of energy demand load for apartment and total load supplied by the PV/T based on different heat transfer fluids. It was observed that the utilization of nanofluid based PV/T system eliminates the dependency on auxiliary energy for daily energy requirements for a building. According to results, in context of energy supplying the nanofluid based PV/T system dominates over the air and water based systems for above-mentioned five months. Furthermore, application of dual-fluid as a coolant has significant impact on the PV/T performance which results in elimination of auxiliary energy needs for some months e.g. November and February.

Tab. 3: Energy demand load for apartment and total load supplied by the PV/T

\begin{tabular}{|c|c|c|c|c|c|}
\hline \multirow{2}{*}{ Months } & \multirow{2}{*}{$\begin{array}{c}\text { Apartment heating } \\
\text { load (kWh) }\end{array}$} & \multicolumn{4}{|c|}{ Load supplied by PV/T system using (kWh) } \\
\cline { 3 - 6 } & & Water & Nanofluid & Water plus air & Nanofluid plus air \\
\hline November & 115.4 & 92.3 & 110.1 & 131.3 & 152.5 \\
\hline December & 352.1 & 83.9 & 101.3 & 120.8 & 133.4 \\
\hline January & 358.3 & 75.5 & 93.2 & 114.9 & 129.1 \\
\hline February & 180.9 & 97.9 & 123.1 & 153.9 & 185.4 \\
\hline
\end{tabular}

\section{Conclusion}

Economic and energy analyses of single- and dual-fluid type PV/T systems were performed for apartment energy needs. It has been shown that the thermal and electrical energy per unit area yield by dual-fluid PV/T system is almost 30\% higher than that of single-fluid PV/T system. It was found that application of dual-fluid PV/T system eliminates the dependency on auxiliary energy for building heating even in cold winter of Korea. Relevant to electricity and natural gas energy costs, using nano-engineered dual-fluid PV/T system the average heating cost for the January, as the coldest month of the year, was reduced by 68 - 73\%. Furthermore, nanofluid based single- and dual-fluid PV/T systems have shown the best life cycle savings as the replacement of auxiliary energy and also shorter payback periods compared to conventional fluids based PV/T systems. 


\section{Acknowledgements}

This work was supported by the Korea Research Fellowship Program through the National Research Foundation of Korea (NRF) funded by the Ministry of Science and ICT (2016H1D3A1938222); Korea Institute of Energy Technology Evaluation and Planning (KETEP) and the Ministry of Trade, Industry \& Energy (MOTIE) of the Republic of Korea (No. 20173010013420).

\section{References}

Abu Bakar, M.N., Othman, M., Hj Din, M., Manaf, N.A., Jarimi, H., 2014. Design concept and mathematical model of a bi-fluid photovoltaic/thermal (PV/T) solar collector. Renewable Energy 67, 153-164.

Al-Waeli, A.H., Chaichan, M.T., Kazem, H.A., Sopian, K., 2017. Comparative study to use nano-(Al2O3, CuO, and $\mathrm{SiC}$ ) with water to enhance photovoltaic thermal PV/T collectors. Energy Conversion and Management 148, 963973.

Barnwal, P., Tiwari, G., 2008. Life cycle energy metrics and CO2 credit analysis of a hybrid photovoltaic/thermal greenhouse dryer. International Journal of Low-Carbon Technologies 3(3), 203-220.

Chow, T., 2003. Performance analysis of photovoltaic-thermal collector by explicit dynamic model. Solar Energy 75(2), 143-152.

Florschuetz, L., 1979. Extension of the Hottel-Whillier model to the analysis of combined photovoltaic/thermal flat plate collectors. Solar Energy 22(4), 361-366.

Hussain, M.I., Kim, J.-T., 2018. Performance Optimization of Unglazed Nanofluid Photovoltaic/Thermal System: Energy and Exergy Analyses. International Journal of Photoenergy 2018.

Hussain, M.I., Ménézo, C., Kim, J.-T., 2018. Advances in solar thermal harvesting technology based on surface solar absorption collectors: A review. Solar Energy Materials and Solar Cells 187, 123-139.

Imtiaz Hussain, M., Ali, A., Lee, G.H., 2016. Multi-module concentrated photovoltaic thermal system feasibility for greenhouse heating: Model validation and techno-economic analysis. Solar Energy 135, 719-730.

Jarimi, H., Bakar, M.N.A., Othman, M., Din, M.H., 2016. Bi-fluid photovoltaic/thermal (PV/T) solar collector: Experimental validation of a 2-D theoretical model. Renewable Energy 85, 1052-1067.

Joshi, A., Tiwari, A., Tiwari, G., Dincer, I., Reddy, B., 2009. Performance evaluation of a hybrid photovoltaic thermal (PV/T)(glass-to-glass) system. International Journal of Thermal Sciences 48(1), 154-164.

KEPCO, KEPCO. https://home.kepco.co.kr/kepco/EN/F/htmlView/ENFBHP00103.do?menuCd=EN060201. (Accessed March, 20 2017).

Tian, Y., Zhao, C.Y., 2013. A review of solar collectors and thermal energy storage in solar thermal applications. Applied Energy 104, 538-553.

Tiwari, A., Raman, V., Tiwari, G., 2007. Embodied energy analysis of hybrid photovoltaic thermal (PV/T) water collector. International Journal of Ambient Energy 28(4), 181-188.

Zerradi, H.; Ouaskit, S.; Dezairi, A.; Loulijat, H.; Mizani, S., 2014. New Nusselt number correlations to predict the thermal conductivity of nanofluids. Adv. Powder Technol 25 (3), 1124-1131.

\section{Nomenclature and Symbols}

$\begin{array}{ll}M & \text { mass }(\mathrm{kg}) \\ C & \text { specific heat }\left(\mathrm{J} / \mathrm{kg}{ }^{\circ} \mathrm{C}\right) \\ T & \text { temperature }\left({ }^{\circ} \mathrm{C}\right) \\ A & \text { surface area }\left(\mathrm{m}^{2}\right)\end{array}$


$h_{\text {wind }}$

$h_{c \infty}$

$h_{c t}$

$h_{c a}$

$h_{c p}$

$h_{t f}$

$h_{t a}$

$h_{t p}$

$h_{p a}$

$h_{p \infty}$

E

$P$

$G$

Greek

$\alpha$

$\eta$

$\beta_{r}$

Subscripts

c

$t$

f

$a$

$p$

$\infty$

$e$

$r$

$f, o \& f$, in $a, o \& a$, in th

cl

convection heat transfer coefficient due to wind $\left(\mathrm{W} / \mathrm{m}^{2}{ }^{\circ} \mathrm{C}\right)$ radiation heat transfer coefficient between PV \& ambient $\left(\mathrm{W} / \mathrm{m}^{2}{ }^{\circ} \mathrm{C}\right)$ conduction heat transfer coefficient between PV \& tube $\left(\mathrm{W} / \mathrm{m}^{2}{ }^{\circ} \mathrm{C}\right)$ convection heat transfer coefficient between PV \& inside air $\left(\mathrm{W} / \mathrm{m}^{2}{ }^{\circ} \mathrm{C}\right)$ radiation heat transfer coefficient between PV \& back panel $\left(\mathrm{W} / \mathrm{m}^{2}{ }^{\circ} \mathrm{C}\right)$ convection heat transfer coefficient between tube \& fluid $\left(\mathrm{W} / \mathrm{m}^{2}{ }^{\circ} \mathrm{C}\right)$ convection heat transfer coefficient between tube \& inside air $\left(\mathrm{W} / \mathrm{m}^{2}{ }^{\circ} \mathrm{C}\right)$ radiation heat transfer coefficient between tube \& back panel $\left(\mathrm{W} / \mathrm{m}^{2}{ }^{\circ} \mathrm{C}\right)$ convection heat transfer coefficient between back panel \& inside air $\left(\mathrm{W} / \mathrm{m}^{2}{ }^{\circ} \mathrm{C}\right)$ convection heat transfer coefficient between PV \& ambient $\left(\mathrm{W} / \mathrm{m}^{2}{ }^{\circ} \mathrm{C}\right)$ electrical energy (W) packing factor solar radiation $\left(\mathrm{W} / \mathrm{m}^{2}\right)$

absorptivity

efficiency

solar cell temperature coefficient $(\mathrm{l} / \mathrm{K})$

PV plate

absorber tube

nanofluid

inside air

back panel

ambient air

electrical

reference

fluid outlet \& inlet air outlet \& inlet

thermal

collector 


\title{
Implementation and Experimental Validation of a Photovoltaic-Thermal (PVT) Collector Model in TRNSYS

\author{
Danny Jonas ${ }^{1}$, Danjana Theis ${ }^{2}$ and Georg Frey ${ }^{1}$ \\ 1 Saarland University, Chair of Automation and Energy Systems, Saarbrücken (Germany) \\ $2 \mathrm{htw}$ saar, University of Applied Sciences, Saarbrücken (Germany)
}

\begin{abstract}
Photovoltaic-thermal (PVT) collectors are hybrid solutions for solar collectors converting solar energy in electrical and thermal energy. To figure out best solutions and new possibilities for the application of PVT collectors, system simulations are often used as first step before proving in real applications. At this, the development of well-validated PVT collector models is an important task. This contribution presents the implementation of a performance model for the electrical part of PVT collectors in TRNSYS, which can be coupled to existing models of solar thermal collectors for the simulation of hybrid PVT collectors, and first results of the model validation with experimental measurements of three different PVT collectors. Furthermore, a parameter identification process with TRNSYS and GenOpt for a coupled PVT collector model is introduced and described in detail. In addition, a comparison of the electrical model with a four-parameter (single diode) PV model is presented to figure out if its implementation will improve the accuracy of the simulation results. The presented results pointed out that the PVT model in combination with the proposed parameter identification process achieves a good agreement of simulated and measured thermal and electrical power output for the analyzed PVT collector types and operating conditions.
\end{abstract}

Keywords: modeling, simulation, photovoltaic-thermal collectors, experimental validation, TRNSYS

\section{Introduction}

Photovoltaic-thermal (PVT) collectors are hybrid solutions for solar collectors converting solar energy in electrical and thermal energy. The main objective of these hybrid system combinations is to use the large part of unused solar energy in conventional photovoltaic (PV) modules for thermal applications. The thermal coupling of solar thermal absorbers to the solar PV cells results in a thermal energy harvesting system for PV cells. For fluid temperature conditions below the operating temperature of conventional PV modules, the thermal coupling and heat transfer of the thermal solar energy to a heat carrier leads additionally to a cooling of the PV modules and thus to a reduction of the PV cell temperature. As the electrical efficiency of PV modules also depends on the module temperature and increases with decreasing cell temperature, the coupling leads to higher PV performance in combined thermal and electrical operation of the PVT collectors. Especially for applications in buildings, the available roof and wall area is often a limiting factor for the use of PV and solar thermal energy and both systems compete with each other for this area. Depending on the PVT collector type and application, e.g. for the use in heat pump heating systems, the use of PVT collectors counteracts this competition and can lead to a better utilization of the available area and a maximized overall solar yield.

The availability of many different types of PVT collectors on the market necessitates a classification of PVT collector types based on the used technological approaches. In general, PVT collectors can be classified into liquid-based PVT, air-based PVT or others, like PCM-based PVT, depending on the used heat transfer carrier medium. Regarding the design of the collector, PVT collectors are often classified in WISC (wind and/or infrared sensitive collectors, often referred to as 'uncovered'), covered or concentrating collectors. One possibility to further distinguish between special types of WISC or covered PVT collectors is the classification into collectors with backside thermal insulation or without backside thermal insulation (and in case of WISC also retrofit PVT collectors).

To figure out best solutions and new possibilities for the application of different types of PVT collectors, system simulations are often used as first step before proving in real applications. At this, the development of well-validated PVT collector models is an important task to analyze different configurations and designs of energy systems with PVT collector integration in system simulations. In 2018, the International Energy Agency Solar Heating and Cooling 


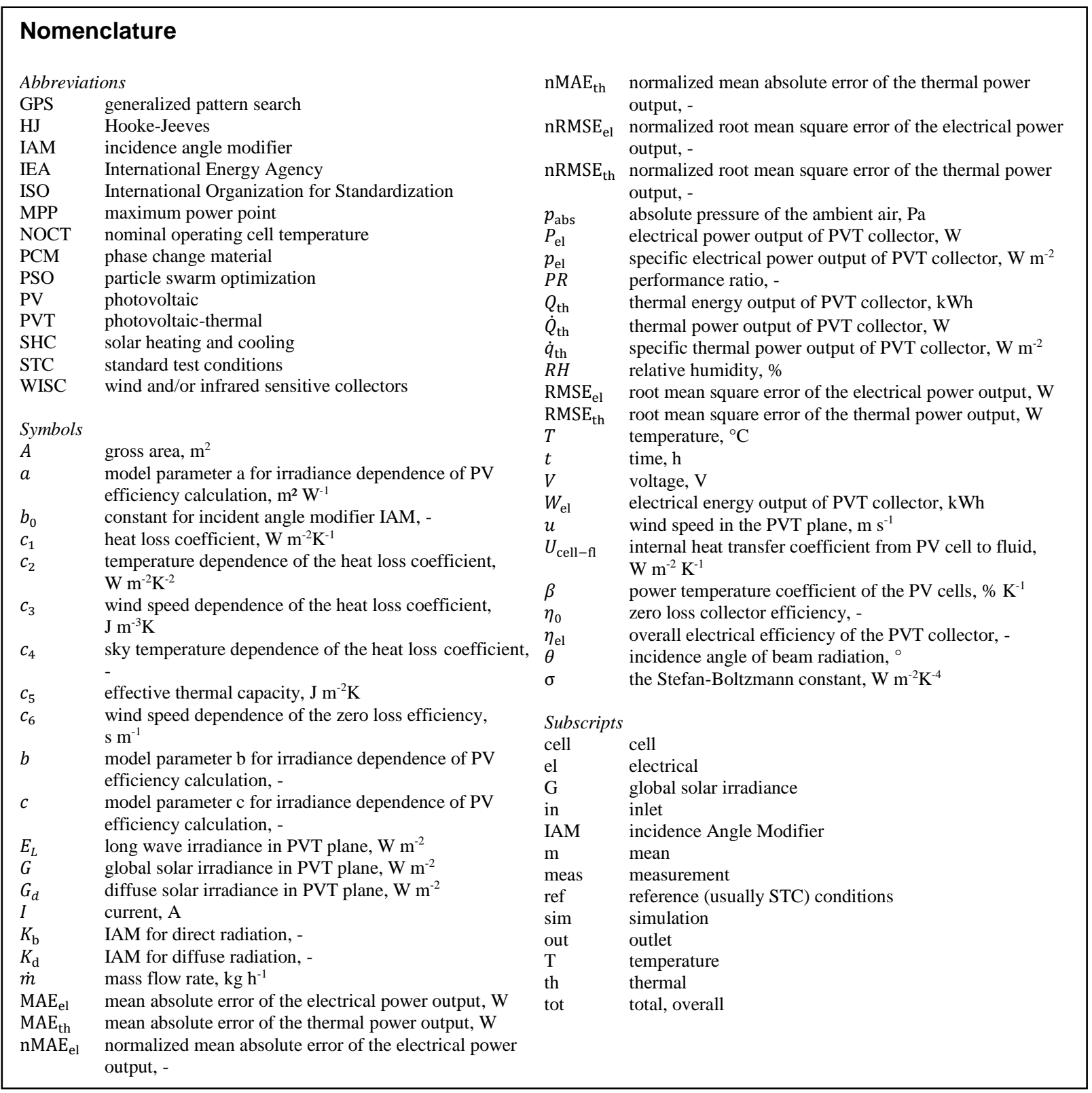

Programme initiated a new task on the application of PVT collectors (IEA SHC Task 60), which focus on the application of PVT collectors with the aim to assess existing solutions and to develop new system solutions with advantages in comparison to classical 'side by side installations' of PV and solar thermal collectors (IEA SHC, 2018). One objective of IEA SHC Task 60 is also to improve the performance characterization and modeling of PVT collectors and systems, which pointed out the need for the development of well-validated PVT simulation models.

Within the research project SolWP-Hybrid, different types of PVT collectors (WISC, covered, with and without backside thermal insulation) will be investigated by simulation and on a test bench for the application in solar thermal and heat pump systems. This contribution presents the implementation of a performance model for the electrical part of PVT collectors in TRNSYS (Type 835: PV model for the coupling with solar thermal absorber and collector models as PVT model), which is based on the work of Lämmle et al. (2017), and first results of the model validation with experimental measurements including the parameter identification procedure. In addition, a comparison of the model results for the electrical part of crystalline modules of the implemented performance model with an adapted standard four-parameter (single diode) PV model in TRNSYS will be presented. The intention of this comparison is to figure out if the implementation of a four-parameter PV model in the developed TRNSYS Type 835 will improve the accuracy of the electrical performance simulation results for crystalline PV modules.

In the following sections, the PVT collector modelling (section 2) and the experimental measurement (section 3) are described. Afterwards, in section 4 the process and results of the parameter identification with TRNSYS and GenOpt are presented. This is followed by the validation of the model with test sequences and the comparison of the electrical results with an adapted four-parameter PV model (section 5). Finally, section 6 provides the main conclusions and an outlook on further work. 


\section{PVT collector modelling in TRNSYS}

\subsection{Overview}

The main idea behind this model, which is based on the work of Lämmle et al. (2017), is to develop a PV performance model in TRNSYS, which can be coupled to existing models of solar thermal collectors or absorbers for the calculation of the electrical power output of WISC and covered PVT collectors (see Fig. 1). It is especially developed for the connection with thermal models which are based on the quasi-dynamic model of ISO 9806:2013 (ISO 9806, 2013) or ISO 9806:2017 (ISO 9806, 2017), e.g. TRNSYS Type 832 (Haller et al., 2013).

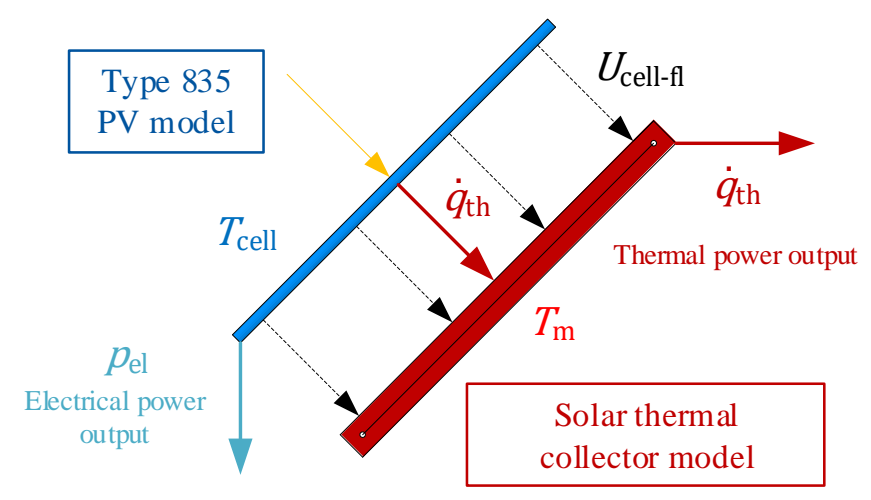

Fig. 1 Coupled PVT model

As addition, the model includes a PV mode to simulate PV modules based on the same performance model, e.g. for a comparison of the electrical yield of a PV module and PVT collectors using identical PV cells. The major difference between the calculation of PV modules and PVT collectors in this approach results from the cell temperatures, which are determined by the fluid temperature in PVT collectors and by a steady-state module temperature in PV modules.

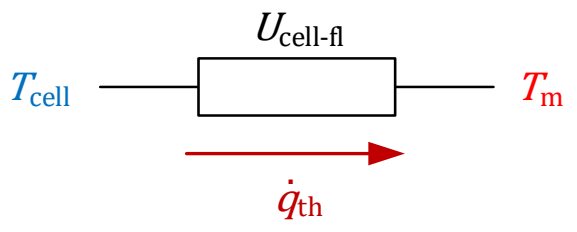

Fig. 2 Thermal network

In case of PVT collectors, the PVT cell temperature $T_{\text {cell }}$ is calculated via an equivalent thermal network with an internal heat transfer coefficient $U_{\text {cell-fl }}$, which connects the PVT cell temperature with the mean fluid temperature $T_{\mathrm{m}}$ of the PVT collector (see Fig. 2), according to the electrical performance model of Lämmle et al. (2017). In case of PV modules, the PV cell temperature is calculated by the Faiman model (Faiman, 2008) or from NOCT conditions. As this contribution focus on PVT collectors, the PV modes of Type 835 are not described in detail.

\subsection{Electrical model}

\section{Overall electrical efficiency and electrical power output}

The overall (or total) electrical efficiency $\eta_{\mathrm{el}}$ of the PVT collector is calculated with:

$$
\eta_{\mathrm{el}}=\eta_{\mathrm{el}, \mathrm{ref}} \cdot P R_{\mathrm{tot}}
$$

The electrical power output of the PVT collector $P_{\mathrm{el}}$ is given by:

$$
P_{\mathrm{el}}=\eta_{\mathrm{el}, \mathrm{ref}} \cdot P R_{\mathrm{tot}} \cdot G \cdot A_{\mathrm{PVT}}
$$

and as specific electrical power output by (Lämmle et al., 2017):

$$
p_{\mathrm{el}}=\eta_{\mathrm{el}, \mathrm{ref}} \cdot P R_{\mathrm{tot}} \cdot G
$$

where $\eta_{\mathrm{el}, \mathrm{ref}}$ is the electrical efficiency at reference conditions (usually STC conditions), $P R_{\text {tot }}$ is the overall instantaneous performance ratio, $G$ the global radiation on PVT plane and $A_{\mathrm{PVT}}$ the PVT collector area.

The overall instantaneous performance ratio is calculated with (Lämmle et al., 2017):

$$
P R_{\text {tot }}=P R_{\mathrm{IAM}} \cdot P R_{\mathrm{T}} \cdot P R_{\mathrm{G}}
$$


The electrical performance model takes into account the following loss effects (performance ratios $P R$ ):

- loss effects of incidence angle $P R_{\mathrm{IAM}}$

- loss effects of irradiance $P R_{\mathrm{G}}$ and

- $\quad P V$ cell temperature dependence of electrical efficiency $P R_{\mathrm{T}}$.

\section{Loss effects of incidence angle}

The instantaneous performance ratio due to incidence angle losses $P R_{\mathrm{IAM}}$ is calculated with (Duffie and Beckman, 2013):

$$
P R_{\mathrm{IAM}}=1-b_{0, \mathrm{el}} \cdot[1 / \cos (\theta)-1]
$$

where $b_{0, \mathrm{el}}$ is the constant for electrical IAM and $\theta$ the incidence angle of beam radiation.

\section{Loss effects of irradiance}

The instantaneous performance ratio due to irradiance losses $P R_{\mathrm{G}}$ is calculated with (Heydenreich et al., 2008):

$$
P R_{\mathrm{G}}=a \cdot G+b \cdot \ln (G+1)+c \cdot\left[(\ln (G+\mathrm{e}))^{2} /(G+1)-1\right]
$$

with the model parameters $a$ in $\mathrm{m}^{2} \mathrm{~W}^{-1}, b$ and $c$ dimensionless, the global irradiance $G$ in $\mathrm{W} \mathrm{m}^{-2}$ and the Euler's number e.

\section{PV cell temperature dependence of the electrical efficiency}

The PV cell temperature dependence of the electrical efficiency is calculated with (Skoplaki and Palyvos, 2009):

$$
P R_{\mathrm{T}}=1-\beta \cdot\left(T_{\text {cell }}-T_{\text {ref }}\right)
$$

where $\beta$ is the power temperature coefficient of the PV cells, $T_{\text {cell }}$ the temperature of the PV cells and $T_{\text {ref }}$ the PV cell temperature at reference conditions (usually STC conditions).

\section{PVT cell temperature}

The PVT cell temperature is calculated with a simple equivalent thermal network with an internal heat transfer coefficient $U_{\text {cell-fl }}$, which connects the PVT cell temperature $T_{\text {cell }}$ with the mean fluid temperature $T_{\mathrm{m}}$ of the PVT collector. The mean fluid temperature is calculated as mean temperature between the thermal model input and output temperature (in this contribution Type 832). The PVT cell temperature is then given by (Lämmle et al., 2016, 2017):

$$
T_{\text {cell }}=T_{\mathrm{m}}+\dot{q}_{\mathrm{th}} / U_{\text {cell-fl }}
$$

where $\dot{q}_{\text {th }}$ is the specific thermal power output of the PVT collector.

\subsection{Thermal model}

The thermal performance of PVT collectors can be described with the following quasi-dynamic collector model, which is implemented in TRNSYS Type 832 and is also described in ISO 9806:2013 (and with two additional terms in ISO 9806:2017):

$$
\begin{aligned}
\dot{q}_{\mathrm{th}}= & \eta_{0} \cdot\left(K_{\mathrm{b}} \cdot G_{\mathrm{b}}+K_{\mathrm{d}} \cdot G_{\mathrm{d}}\right)-c_{1} \cdot\left(T_{\mathrm{m}}-T_{\mathrm{a}}\right)-c_{2} \cdot\left(T_{\mathrm{m}}-T_{\mathrm{a}}\right)^{2}-c_{3} \cdot u \cdot\left(T_{\mathrm{m}}-T_{\mathrm{a}}\right) \\
& +c_{4} \cdot\left(E_{\mathrm{L}}-\sigma \cdot T_{\mathrm{a}}{ }^{4}\right)-c_{5} \cdot \mathrm{d} T_{\mathrm{m}} / \mathrm{d} t-c_{6} \cdot u \cdot G
\end{aligned}
$$

with

$$
K_{\mathrm{b}}=1-b_{0, \mathrm{th}} \cdot[1 / \cos (\theta)-1]
$$

where $\dot{q}_{\mathrm{th}}$ is the specific thermal power output of the PVT collector, $\eta_{\mathrm{o}}$ the zero loss collector efficiency, $K_{\mathrm{b}}$ the IAM for direct radiation, $K_{\mathrm{d}}$ the IAM for diffuse radiation, $c_{1}$ the heat loss coefficient, $c_{2}$ the temperature dependence of the heat loss coefficient, $c_{3}$ the wind speed dependence of the heat loss coefficient, $u$ the wind speed in the PVT plane, $c_{4}$ the sky temperature dependence of the heat loss coefficient, $E_{\mathrm{L}}$ the long-wave irradiance, $\sigma$ the StefanBoltzmann constant, $c_{5}$ the effective thermal capacity, $c_{6}$ the wind speed dependence of the zero loss efficiency, $b_{0, \text { th }}$ the constant for thermal IAM and $\theta$ the incidence angle of beam radiation. As the electrical mode of operation has a significant impact on the thermal efficiency, the thermal performance coefficients for the thermal power output calculation of the PVT collector should be determined in MPP mode (Lämmle et al., 2017). 


\section{Experimental measurements}

The experimental measurements of the PVT collectors were realized in July and August 2018 on an outdoor test bed in Saarbrücken (Germany) at the Laboratory for Solar Energy Systems of the University of Applied Sciences htw saar. Three different types of PVT collectors:

- PVT A - WISC

- $\quad$ PVT B - covered, with backside thermal insulation

- $\quad$ PVT C - covered, without backside thermal insulation

are installed on a test roof and are monitored under dynamic outdoor conditions during MPP operation. Beside of the standard measurements of the thermal performance according to ISO 9806:2017, the relevant electrical values are measured continuously. A systematic scheme of the measurement including the main measured values which are used for the performance characterization of the PVT collectors is shown in Fig. 3. Due to measurement problems, the long-wave irradiation is recalculated for the parameter identification and model validation by the use of a calculated view temperature between ambient and sky temperature (calculated with the ambient air temperature, ambient air pressure and the relative humidity). According to ISO 9806:2017, the following typical days should be included in the quasi dynamic test of the collector performance:

- $\quad$ Day Type 1: $\eta_{0}$-conditions, mostly clear sky conditions

- $\quad$ Day Type 2: elevated operating temperature or $\eta_{0}$-conditions, partly cloudy conditions including broken cloud and clear sky conditions

- $\quad$ Day Type 3: mean operating temperature conditions including clear sky conditions

- Day Type 4: high operating temperature conditions including clear sky conditions.

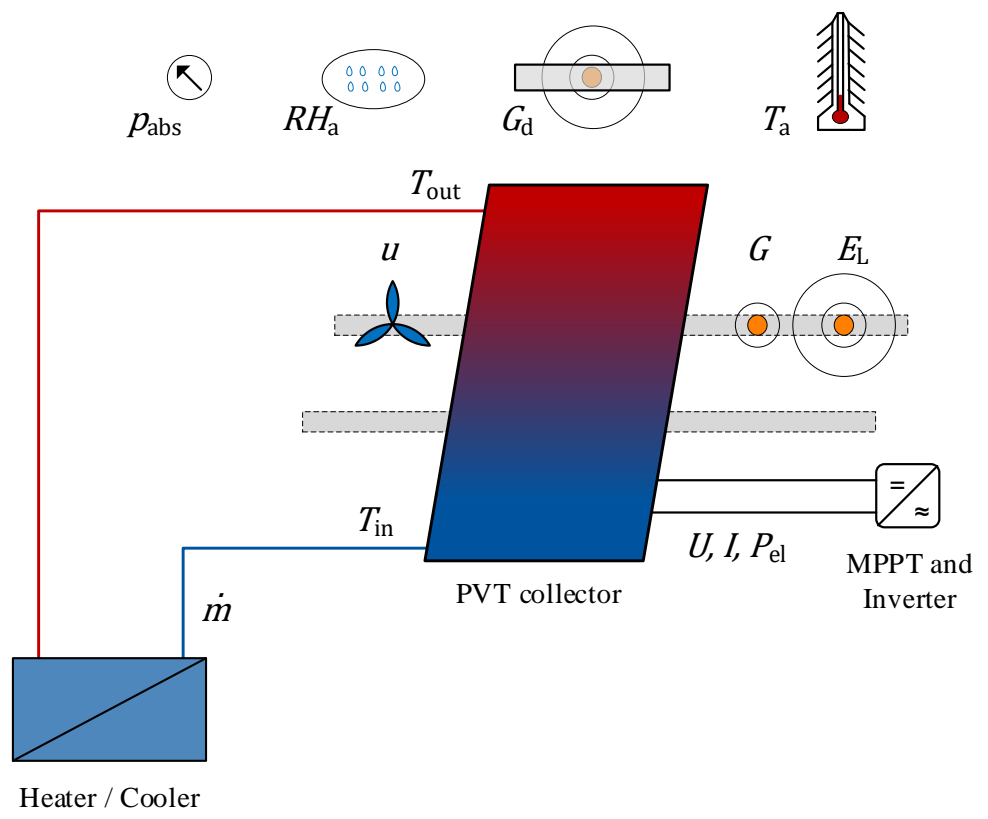

Fig. 3: Measurement scheme of the outdoor test

For the identification of the PVT collector model parameters, the measured test data was evaluated and usable test sequences were chosen for combined test sequences with all four day types. Within the combined test sequences, a Boolean value is defined as indicator if the time step should be taken into account for the parameter identification or not. The objective of this process is the filtering of start-up sequences between the different sequences and bad data, e.g. if something was changed in the test bed or measured values are outside a reliable or usable range.

\section{Parameter identification with GenOpt}

Identification or determination of model parameters by comparing and adjusting simulated results to measured data is a well-known procedure for different applications, especially in the field of solar thermal systems. In general, a 
cost function is defined to assess the agreement of the model results with the measured data. The model parameters are then adjusted to better fit the measurement by minimization of the cost function. In the field of solar thermal collectors and systems, the most common methods for the minimization process are multiple linear regression (MLR), which has been introduced as extended version by Perers (1997), and dynamic parameter identification with the fit program DF (Spirkl, 1997) which use the Levenberg-Marquardt algorithm (Fischer et al., 2012). Furthermore, newer approaches like Budig et al. (2009) or Almeida (2014) use GenOpt (Wetter, 2016) in combination with TRNSYS for the parameter identification process. GenOpt is a generic optimization program to minimize a cost function that is evaluated by an external simulation program like TRNSYS and includes a library with local and global one-dimensional and multi-dimensional optimization algorithms, like Particle Swarm Optimization (PSO, meta-heuristic population-based algorithm, stochastic) or Hooke-Jeeves algorithm (GPS-HJ, generalized pattern search method, deterministic).

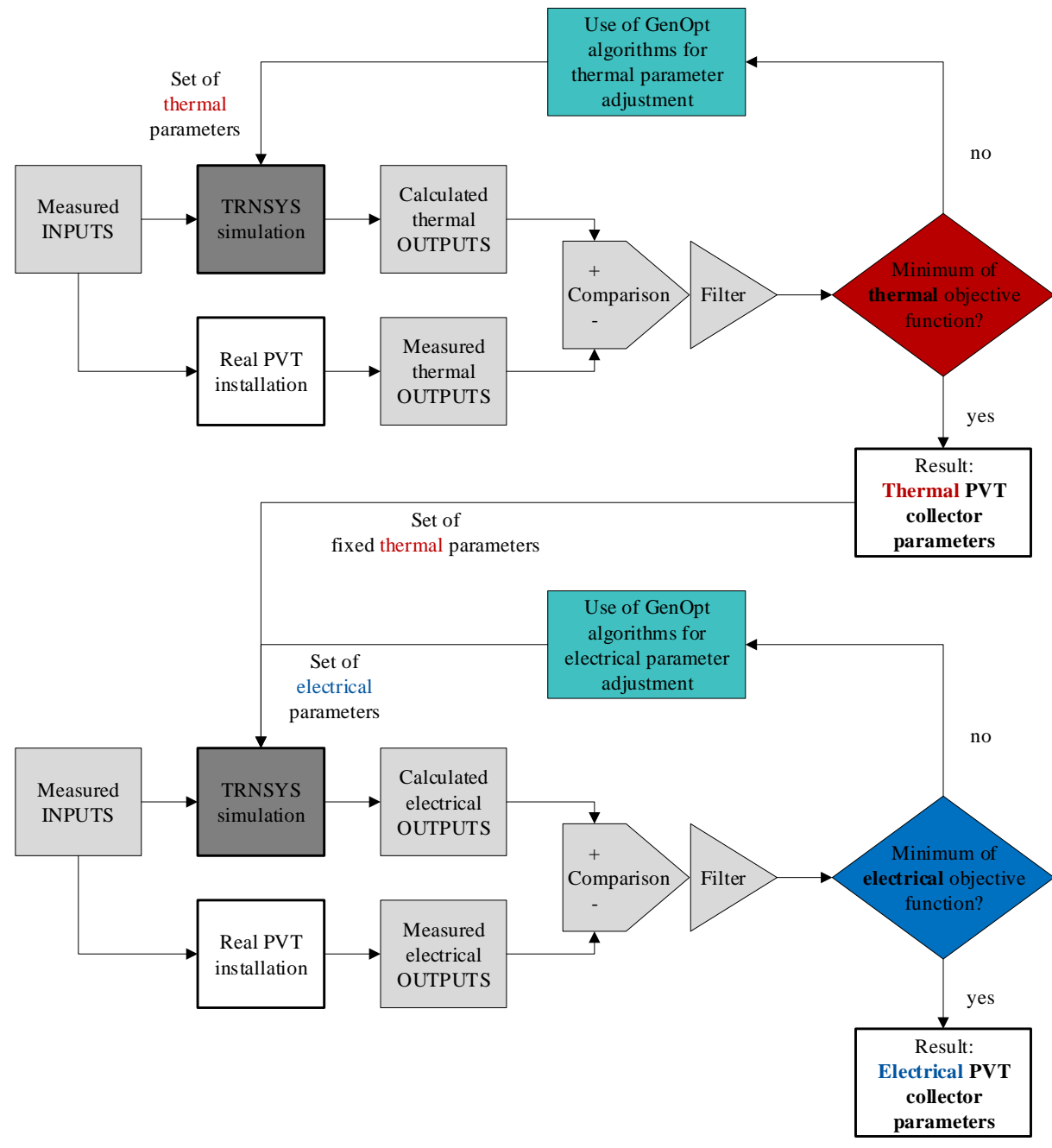

Fig. 4: Model parameter identification process

The proposed parameter identification process with TRNSYS and GenOpt for the PVT collector model is shown in Fig. 4. A set of measured values is used as time dependent input for the TRNSYS simulation via a data reader. The measured inputs $\left(E_{\mathrm{L}}, G, G_{\mathrm{d}}, \theta, T_{\mathrm{a}}, R H_{\mathrm{a}}, p_{\mathrm{abs}}, u, \dot{m}, T_{\mathrm{in}}\right)$ are then used to calculate the thermal and electrical outputs of the TRNSYS model, especially the thermal $\dot{Q}_{\mathrm{th}, \text { sim }}$ and the electrical $P_{\mathrm{el}, \mathrm{sim}}$ power output of the PVT collector. Subsequently, the calculated thermal outputs are compared via the absolute error and filtered with the Boolean function described in chapter 3. This is followed by the calculation of the thermal cost function which has to be minimized. At this, GenOpt is used to adjust the thermal collector parameters $\left(\eta_{0}, K_{\mathrm{d}}, b_{0, \mathrm{th}}, c_{1}-c_{6}\right)$ until the minimum of the thermal cost function is reached. The identified thermal parameters are then used as fixed parameters and the process is repeated for the electrical parameter identification of $U_{\text {cell-fl }}$ and $b_{0, \mathrm{el}}$.

In this work, the mean absolute error (MAE) of the thermal power output is used as cost function for the thermal parameter identification:

$$
\mathrm{MAE}_{\mathrm{th}}=\frac{1}{n \cdot \Delta t} \sum_{i=1}^{n}\left(\left|\dot{Q}_{\mathrm{th}, \mathrm{sim}}-\dot{Q}_{\mathrm{th}, \text { meas }}\right| \cdot \Delta t\right)
$$


and the MAE of the electrical power output for the electrical parameter identification:

$$
\mathrm{MAE}_{\mathrm{el}}=\frac{1}{n \cdot \Delta t} \sum_{i=1}^{n}\left(\left|P_{\mathrm{el}, \mathrm{sim}}-P_{\mathrm{el}, \mathrm{meas}}\right| \cdot \Delta t\right)
$$

The results of the parameter identification of the three different PVT collectors by the use of TRNSYS 17 (TRNSYS, 2015), GenOpt 3.1 (Wetter, 2016), GPS-HJ and MAE as cost function are summarized in Tab. 1. At this, the MAE th is between $13.18 \mathrm{~W}$ and $16.79 \mathrm{~W}$ and the $\mathrm{MAE}_{\mathrm{el}}$ between $2.93 \mathrm{~W}$ and $5.58 \mathrm{~W}$.

Tab. 1: Results of the parameter identification with GPS-HJ algorithm and MAE as cost function

\begin{tabular}{|c|c|c|c|c|}
\hline Parameter & Unit & PVT A - WISC & $\begin{array}{l}\text { PVT B - covered } \\
\text { w/o insulation }\end{array}$ & $\begin{array}{l}\text { PVT C - covered } \\
\text { w/ insulation }\end{array}$ \\
\hline & & \multicolumn{3}{|c|}{ Manufacturer and calculated data } \\
\hline$A_{\mathrm{PVT}}$ & $\mathrm{m}^{2}$ & 1.66 & 1.79 & 1.79 \\
\hline$\eta_{\text {el,ref }}$ & - & 0.1688 & 0.1406 & 0.1390 \\
\hline$\beta$ & $\% / \mathrm{K}$ & 0.467 & 0.370 & 0.370 \\
\hline & & \multicolumn{3}{|c|}{ Identified PVT parameter } \\
\hline$\eta_{0, \text { th }}$ & - & 0.436 & 0.596 & 0.573 \\
\hline$K_{\mathrm{d}}$ & - & 0.91 & 0.93 & 0.94 \\
\hline$b_{0, \text { th }}$ & - & 0.114 & 0.122 & 0.120 \\
\hline$c_{1}$ & $\mathrm{~W} / \mathrm{m}^{2} \mathrm{~K}$ & 7.750 & 6.583 & 5.008 \\
\hline$c_{2}$ & $\mathrm{~W} / \mathrm{m}^{2} \mathrm{~K}^{2}$ & 0.026 & 0.021 & 0.059 \\
\hline$c_{3}$ & $\mathrm{Ws} / \mathrm{m}^{3} \mathrm{~K}$ & 1.640 & 0.000 & 0.011 \\
\hline$c_{4}$ & - & 0.000 & 0.066 & 0.039 \\
\hline$c_{5}$ & $\mathrm{~J} / \mathrm{m}^{2} \mathrm{~K}$ & 35800 & 16075 & 16631 \\
\hline$c_{6}$ & $\mathrm{~s} / \mathrm{m}$ & 0.008 & 0.009 & 0.003 \\
\hline$U_{\text {cell-fl }}$ & $\mathrm{W} / \mathrm{m}^{2} \mathrm{~K}$ & 13.63 & 15.74 & 14.07 \\
\hline$b_{0, \mathrm{el}}$ & - & 0.167 & 0.182 & 0.170 \\
\hline & & \multicolumn{3}{|c|}{ Results of cost functions } \\
\hline $\mathrm{MAE}_{\mathrm{th}}$ & $\mathrm{W}$ & 16.79 & 13.18 & 13.22 \\
\hline $\mathrm{MAE}_{\mathrm{el}}$ & W & 5.58 & 3.04 & 2.93 \\
\hline
\end{tabular}

\section{Model validation and comparison with four-parameter PV model}

For the further validation of the TRNSYS model, the PVT collectors are simulated for two sequences (mostly clear sky and partly cloudy) and the model results are compared with the measured values. The dynamic behavior of the thermal and electrical power output of the PVT collector as well as the main solar irradiance data are shown in Fig. 5 for sequence 1 (mostly clear sky, day type 1) and in Fig. 6 for sequence 2 (partly cloudy, day type 2). A summary of the results including the ratio of the difference between the simulated and measured thermal $\left(\Delta Q_{\mathrm{th}}\right)$ or electrical $\left(\Delta W_{\mathrm{el}}\right)$ energy productions related to the measured thermal $\left(Q_{\mathrm{th}, \mathrm{meas}}\right)$ or electrical $\left(W_{\mathrm{el}, \mathrm{meas}}\right)$ energy is given in Tab. 2. For further analysis of the results, the normalized mean absolute errors (nMAEs), the root mean square errors (RMSEs) and the normalized root mean square errors (nRMSEs) are defined as:

$$
\begin{aligned}
& \mathrm{nMAE}_{\text {th }}=\operatorname{MAE}_{\text {th }} /\left[\frac{1}{n \cdot \Delta t} \sum_{i=1}^{n}\left(\dot{Q}_{\text {th,meas }} \cdot \Delta t\right)\right] \\
& \mathrm{nMAE}_{\mathrm{el}}=\mathrm{MAE}_{\mathrm{el}} /\left[\frac{1}{n \cdot \Delta t} \sum_{i=1}^{n}\left(P_{\mathrm{el}, \mathrm{meas}} \cdot \Delta t\right)\right] \\
& \mathrm{RMSE}_{\mathrm{th}}=\sqrt{\frac{\sum_{i=1}^{n}\left[\left(\dot{Q}_{\mathrm{th}, \mathrm{sim}}-\dot{Q}_{\mathrm{th}, \mathrm{meas}}\right)^{2} \cdot \Delta t\right]}{n \cdot \Delta t}} \\
& \operatorname{RMSE}_{\mathrm{el}}=\sqrt{\frac{\sum_{i=1}^{n}\left[\left(P_{\mathrm{el}, \mathrm{sim}}-P_{\mathrm{el}, \mathrm{meas}}\right)^{2} \cdot \Delta t\right]}{n \cdot \Delta t}} \\
& \mathrm{nRMSE}_{\mathrm{th}}=\mathrm{RMSE}_{\mathrm{th}} /\left[\frac{1}{n \cdot \Delta t} \sum_{i=1}^{n}\left(\dot{Q}_{\mathrm{th}, \text { meas }} \cdot \Delta t\right)\right] \\
& \mathrm{nRMSE}_{\mathrm{el}}=\mathrm{RMSE}_{\mathrm{el}} /\left[\frac{1}{n \cdot \Delta t} \sum_{i=1}^{n}\left(P_{\mathrm{el}, \mathrm{meas}} \cdot \Delta t\right)\right]
\end{aligned}
$$


D. Jonas et. al. / EuroSun 2018 / ISES Conference Proceedings (2018)

Tab. 2: Results of the validation (Day Type 1: 11h15-16h15, Day Type 2: 10h00-14h00)

\begin{tabular}{|c|c|c|c|c|c|c|c|}
\hline \multirow{2}{*}{ Parameter } & \multirow{2}{*}{ Unit } & \multicolumn{2}{|c|}{ PVT A - WISC } & \multicolumn{2}{c|}{$\begin{array}{c}\text { PVT B - covered } \\
\text { w/o insulation }\end{array}$} & \multicolumn{2}{c|}{$\begin{array}{c}\text { PVT C - covered } \\
\text { w/ insulation }\end{array}$} \\
\hline & & Day Type 1 & Day Type 2 & Day Type 1 & Day Type 2 & Day Type 1 & Day Type 2 \\
\hline $\mathrm{MAE}_{\mathrm{th}}$ & $\mathrm{W}$ & 10.68 & 21.32 & 6.50 & 21.34 & 4.59 & 21.16 \\
\hline $\mathrm{nMAE}_{\mathrm{th}}$ & - & $1.79 \%$ & $4.39 \%$ & $0.73 \%$ & $2.89 \%$ & $0.51 \%$ & $2.83 \%$ \\
\hline $\mathrm{RMSE}_{\mathrm{th}}$ & $\mathrm{W}$ & 13.24 & 28.61 & 9.39 & 33.25 & 5.96 & 32.75 \\
\hline $\mathrm{nRMSE}_{\mathrm{th}}$ & - & $2.22 \%$ & $5.89 \%$ & $1.06 \%$ & $4.50 \%$ & $0.67 \%$ & $4.38 \%$ \\
\hline$Q_{\mathrm{th}, \mathrm{sim}}$ & $\mathrm{kWh}$ & 3.034 & 2.005 & 4.447 & 2.971 & 4.472 & 2.994 \\
\hline$Q_{\mathrm{th}, \text { meas }}$ & $\mathrm{kWh}$ & 2.987 & 1.954 & 4.430 & 2.967 & 4.473 & 3.005 \\
\hline$\Delta Q_{\mathrm{th}} / Q_{\mathrm{th}, \text { meas }}$ & - & $+1.58 \%$ & $+2.59 \%$ & $+0.38 \%$ & $+0.15 \%$ & $-0.03 \%$ & $-0.38 \%$ \\
\hline $\mathrm{MAE}_{\mathrm{el}}$ & $\mathrm{W}$ & 2.34 & 3.94 & 2.11 & 4.31 & 1.86 & 4.04 \\
\hline $\mathrm{nMAE}$ & - & $1.12 \%$ & $2.17 \%$ & $1.10 \%$ & $2.54 \%$ & $0.98 \%$ & $2.46 \%$ \\
\hline $\mathrm{RMSE}_{\mathrm{el}}$ & $\mathrm{W}$ & 3.71 & 6.31 & 9.73 & 5.64 & 2.62 & 5.36 \\
\hline $\mathrm{nRMSE}$ & - & $1.77 \%$ & $3.48 \%$ & $5.07 \%$ & $3.32 \%$ & $1.39 \%$ & $3.27 \%$ \\
\hline$W_{\mathrm{el}, \text { sim }}$ & $\mathrm{kWh}$ & 1.037 & 0.735 & 0.970 & 0.681 & 0.938 & 0.656 \\
\hline$W_{\mathrm{el}, \text { meas }}$ & $\mathrm{kWh}$ & 1.046 & 0.729 & 0.961 & 0.682 & 0.945 & 0.660 \\
\hline$\Delta W_{\mathrm{el}} / W_{\mathrm{el}, \text { meas }}$ & - & $-0.82 \%$ & $+0.96 \%$ & $+0.98 \%$ & $-0.27 \%$ & $-0.75 \%$ & $-0.56 \%$ \\
\hline
\end{tabular}

In case of day type 1, the dynamic behavior shows a good agreement to the measured values of the thermal and electrical power output of the PVT collectors, which is also expressed in a small $\mathrm{nRMSE}_{\text {th }}$ between $0.67 \%$ and $2.22 \%$ and a nRMSE el between $1.39 \%$ and $5.07 \%$. The higher $\mathrm{nRMSE}_{\mathrm{el}}$ of $5.07 \%$ in case of covered PVT B can be explained by a short cut-off of the measured PV power at around 14h45 (possibly a short malfunction of the MPP tracker), which results in higher simulation values during this period. The modeled energy production over the period is also in a good accuracy with a $\Delta Q_{\mathrm{th}} / Q_{\mathrm{th} \text {,meas }}$-ratio between $-0.03 \%$ and $1.58 \%$ and a $\Delta W_{\mathrm{el}} / W_{\text {el,meas }}$-ratio between $-0.75 \%$ and $+0.98 \%$.
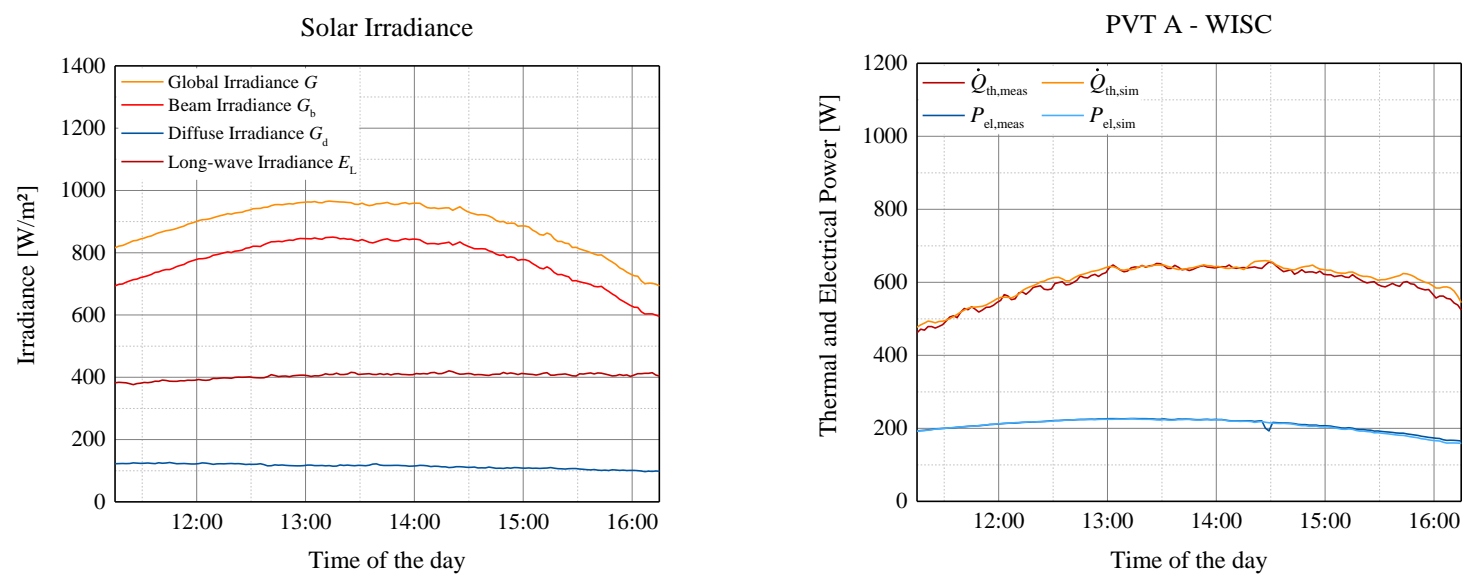

PVT B - covered, w/o insulation
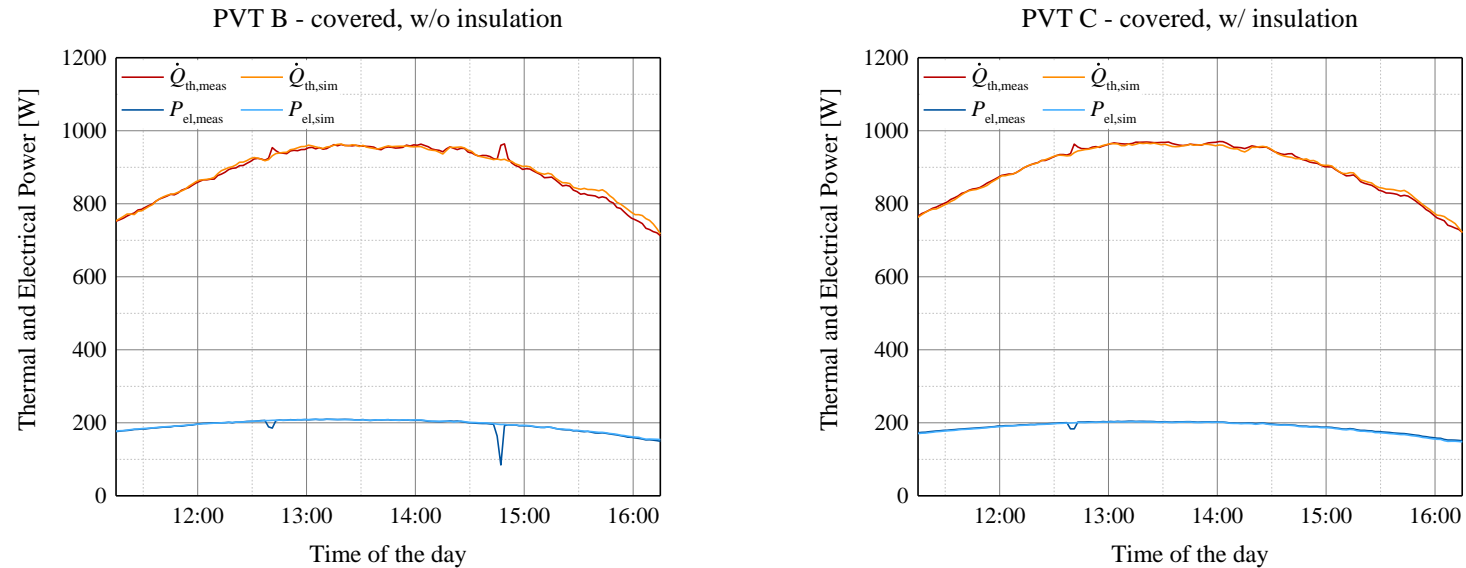

Fig. 5: Model validation - Mostly clear sky (Day Type 1)

For day type 2 with more dynamic behavior of the solar radiation, the differences between the measured and modelled 
results are slightly higher with a nRMSE ${ }_{\text {th }}$ between $4.38 \%$ and $5.89 \%$ and a $\mathrm{nRMSE}_{\text {el }}$ between $3.27 \%$ and $3.48 \%$. However, the modeled energy production over the period is also in a good accuracy with a $\Delta Q_{\text {th }} / Q_{\text {th,meas }}$-ratio between $-0.38 \%$ and $2.59 \%$ and a $\Delta W_{\mathrm{el}} / W_{\mathrm{el}, \text { meas }}$-ratio between $-0.56 \%$ and $+0.96 \%$.
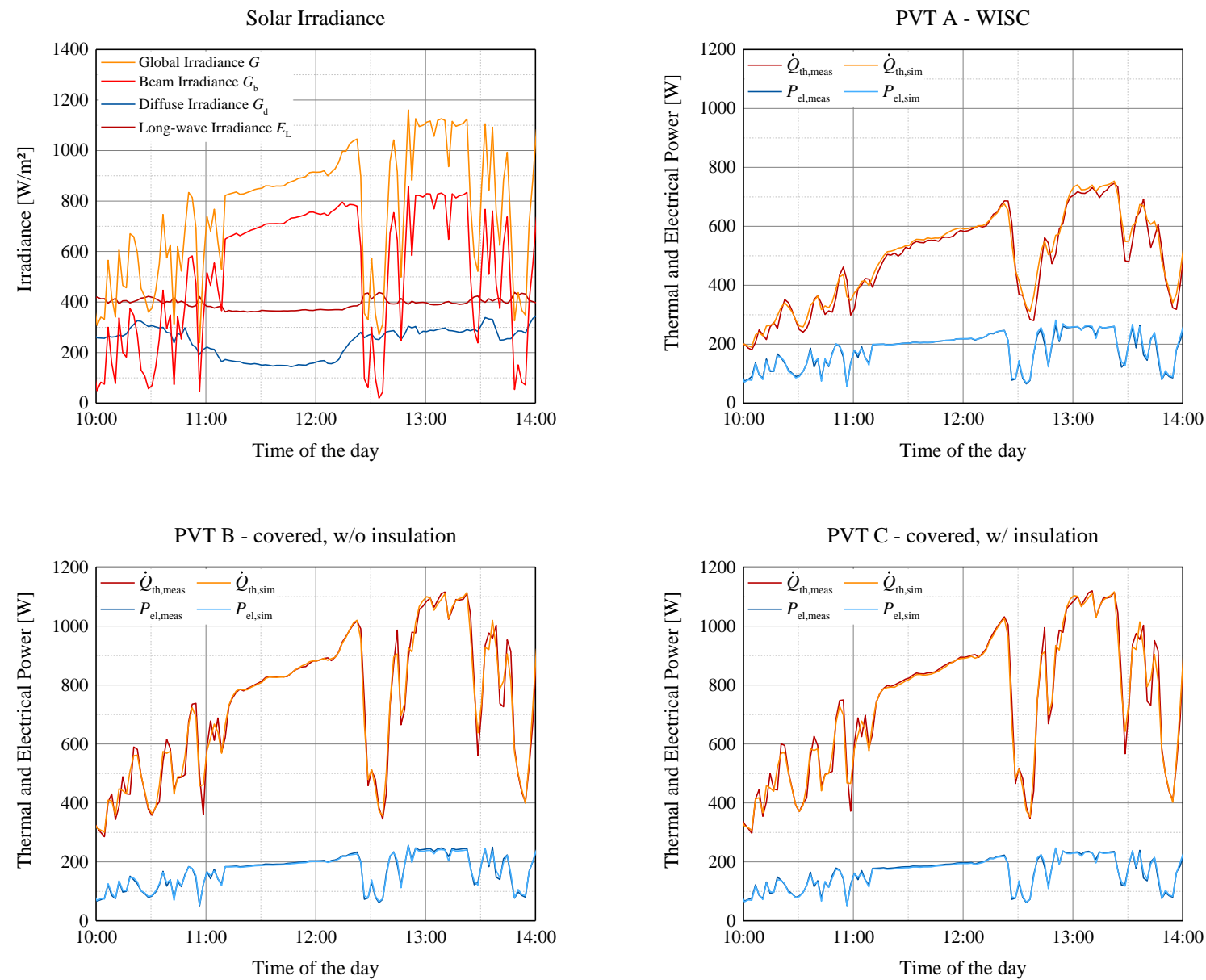

Fig. 6: Model validation - Partly cloudy (Day Type 2)

In general, the electrical results show a better fit of the dynamic behavior then the thermal results, which is expressed

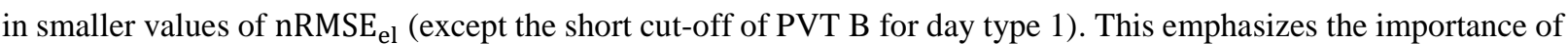
an accurate fit of the thermal capacity of the PVT collectors. Beside of the thermal capacity effects on the transient behavior, the recalculated long-wave radiation and its inaccuracy could lead to higher values of $\mathrm{nRMSE}_{\mathrm{th}}$ as it has an impact on the thermal behavior. This is also expressed in a zero $c_{4}$-coefficient for the WISC PVT, which usually have higher $c_{4}$-coefficents then covered PVT collectors. In further works, it is important to identify the coefficients with a measured long-wave irradiance. As summary, the whole procedure for the PVT model parameter identification with TRNSYS and GenOpt and the model validation is summarized in Fig. 7.

In the following, a comparison of the electrical part of the PVT model with an adapted standard four-parameter (single diode) PV model is presented to figure out if the implementation of a four-parameter PV model in the developed TRNSYS Type 835 will improve the accuracy of the electrical performance results for crystalline PV modules. For the comparison, the standard PV model Type 103 of TRNSYS 18 (TRNSYS, 2018) is recompiled for TRNSYS 17 with extension of the model with the possibility to set the PV cell temperature as input value during the simulation. This allows the usage of the simple equivalent thermal network from section 2 to calculate the PV cell temperature with the internal heat transfer coefficient $U_{\text {cell-fl }}$. The parameter identification process is then repeated for the electrical part in combination with the adapted Type 103. For PVT A the result is an internal heat transfer coefficient $U_{\text {cell }}$ fl of $7.88 \mathrm{~W} / \mathrm{m}^{2} \mathrm{~K}$. Afterwards, the PVT collector PVT A is simulated for the two validation sequences (mostly clear sky and partly cloudy) with the different models for the electrical part and the electrical model results are compared with the measured values. 
1. Preparing test data for parameter identification

Evaluate test data; Select usable test sequences; Build a combined test sequence with all four day types; Indicate which time steps should be used for the analysis (calculation of cost functions), e.g. for filtering start-up sequences

\section{Preparing TRNSYS for parameter identification}

Assign measured data files; Set general simulation parameters (e.g. simulation time); Choose special functions like calculating long-wave radiation via effective sky / view temperature if needed

3. Preparing thermal parameter identification

Select cost function (MAE, RMSE) for thermal parameter identification and save TRNSYS input file

4. Thermal parameter identification

Start TRNOPT interface; Select TRNSYS input file; Select and specify thermal parameter variables (start, max, min, step value); Select thermal cost function and optimization method

5. Run thermal parameter identification with Genopt

6. Select thermal parameter set with minimized cost function

7. Preparing electrical parameter identification

Set identified thermal parameters as fixed parameters in TRNSYS; Select cost function (MAE, RMSE) for electrical parameter identification and save TRNSYS input file

\section{Electrical parameter identification}

Start TRNOPT interface; Select TRNSYS input file; select and specify electrical parameter variables; Select electrical cost function and optimization method

\section{Run electrical parameter identification with Genopt}

10. Select electrical parameter set with minimized cost function

11. Evaluate results with identified PVT parameters by simulation of validation sequences

Fig. 7: Procedure for PVT model parameter identification with TRNSYS and GenOpt

Fig. 8 shows a comparison of the measured electrical power output $\left(P_{\text {el,meas }}\right)$ with the model output of Type 835 $\left(P_{\mathrm{el}, 835}\right)$ and the model output of the adapted four-parameter PV model with $\left(P_{\mathrm{el}, 4 \mathrm{p}, \mathrm{Ucorr}}\right)$ and without $\left(P_{\mathrm{el}, 4 \mathrm{p}}\right)$ correction of $U_{\text {cell-fl. }}$. In this case without correction means that the $U_{\text {cell-fl-value from the parameter identification }}$ of Type 835 is used instead of the identified value for the adapted four-parameter PV model. A summary of the simulation results is given in Tab. 3 .

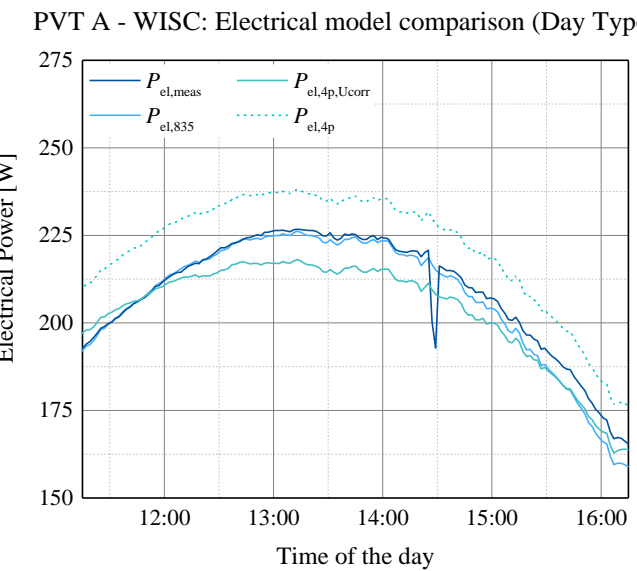

PVT A - WISC: Electrical model comparison (Day Type 2)

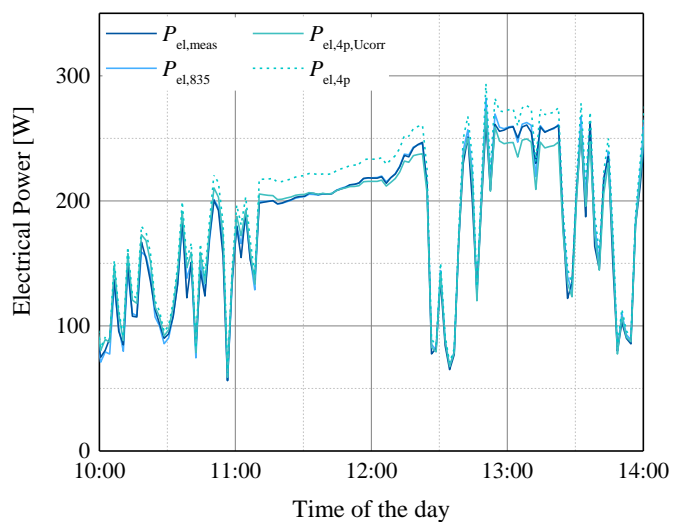

Fig. 8: Electrical model comparison

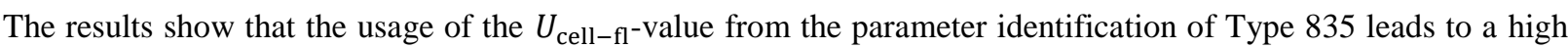
inaccuracy, expressed in $\Delta W_{\mathrm{el}} / W_{\mathrm{el}, \text { meas }}$-values between $+5.92 \%$ and $+7.93 \%, \mathrm{nMAE}_{\mathrm{el}}$ up to $7.97 \%$ and $\mathrm{nRMSE}_{\mathrm{el}}$ up to $8.70 \%$. Hence, a new parameter identification is needed if the electrical model is changed. At this, it should be mentioned that the four-parameter PV model is not equipped with a parameter like $b_{0, \text { el }}$ to adjust the incidence angle dependence of the electrical power output to the individual behavior of different PV modules (or PVT collectors). This could also influence the differences in the results.

In case of day type 1, the adapted four-parameter model with $U_{\text {cell-fl- }}$-correction underestimates the electrical power 
output with a higher $\Delta W_{\mathrm{el}} / W_{\mathrm{el}, \text { meas }}$-value of $-2.60 \%$ compared to $-0.82 \%$ of Type 835 . For day type 2 , the $\Delta W_{\mathrm{el}} / W_{\mathrm{el}, \text { meas }}$-value of $+0.49 \%$ is slightly better for the adapted four-parameter model with $U_{\text {cell-fl-correction }}$ than PVT Type $835(+0.96 \%)$. Nevertheless, in general the PVT Type 835 shows a better overall agreement of the dynamic electrical behavior than the adapted four-parameter model with $U_{\text {cell-fl }}$ correction, expressed in the smallest values of $\mathrm{nRMSE}_{\mathrm{el}}$ for day type $1(1.77 \%)$ and for day type $2(3.48 \%)$ compared to the other models.

Tab. 3: Results of the electrical model comparison

\begin{tabular}{|c|c|c|c|c|c|c|c|}
\hline \multirow[t]{2}{*}{ Parameter } & \multirow[t]{2}{*}{ Unit } & \multicolumn{2}{|c|}{$\begin{array}{c}\text { PVT A - WISC } \\
\text { Type } 835\end{array}$} & \multicolumn{2}{|c|}{$\begin{array}{c}\text { PVT A - WISC } \\
\text { four-parameter model, } \\
\text { w/ } U_{\text {cell-fl-correction }}\end{array}$} & \multicolumn{2}{|c|}{$\begin{array}{c}\text { PVT A - WISC } \\
\text { four-parameter model, } \\
\text { w/o } U_{\text {cell-fl-correction }}\end{array}$} \\
\hline & & Day Type 1 & Day Type 2 & Day Type 1 & Day Type 2 & Day Type 1 & Day Type 1 \\
\hline $\mathrm{MAE}_{\mathrm{el}}$ & $\mathrm{W}$ & 2.34 & 3.94 & 6.23 & 6.38 & 12.41 & 14.44 \\
\hline $\mathrm{nMAE}_{\mathrm{el}}$ & - & $1.12 \%$ & $2.17 \%$ & $2.98 \%$ & $3.52 \%$ & $5.94 \%$ & $7.97 \%$ \\
\hline RMSE $_{\mathrm{el}}$ & W & 3.71 & 6.31 & 6.88 & 8.18 & 12.79 & 15.78 \\
\hline $\mathrm{nRMSE}_{\mathrm{el}}$ & - & $1.77 \%$ & $3.48 \%$ & $3.29 \%$ & $4.51 \%$ & $6.12 \%$ & $8.70 \%$ \\
\hline$W_{\mathrm{el}, \mathrm{sim}}$ & $\mathrm{kWh}$ & 1.037 & 0.735 & 1.019 & 0.732 & 1.108 & 0.786 \\
\hline$W_{\mathrm{el}, \mathrm{meas}}$ & $\mathrm{kWh}$ & 1.046 & 0.729 & 1.046 & 0.729 & 1.046 & 0.729 \\
\hline$\Delta W_{\mathrm{el}} / W_{\mathrm{el}, \mathrm{meas}}$ & - & $-0.82 \%$ & $+0.96 \%$ & $-2.60 \%$ & $+0.49 \%$ & $+5.92 \%$ & $+7.93 \%$ \\
\hline
\end{tabular}

\section{Conclusions and outlook}

This contribution presented the implementation and validation of an electrical PV performance model in combination with a coupled solar thermal collector model for the simulation of PVT collectors in TRNSYS for three different PVT collectors. Using the identified PVT collector model parameters of the proposed parameter identification process with TRNSYS and GenOpt, the normalized root mean square errors of the model for the thermal part nRMSE $_{\text {th }}$ are between $0.67 \%$ and $5.89 \%$ and for the electrical part nRMSE $_{\text {el }}$ between $1.39 \%$ and $5.07 \%$, depending on the day type and PVT collector type. Furthermore, the comparison of the generated energy production shows a good agreement with differences between $-0.38 \%$ and $+2.59 \%$ for the thermal and $-0.82 \%$ and $+0.98 \%$ for the electrical simulated and measured energy related to the measured values. As a result, the presented study pointed out that the implemented PVT model Type 835 in combination with a solar thermal collector model (e.g. Type 832) as well as the proposed parameter identification procedure are suitable for the modeling of PVT collectors in TRNSYS. In addition, the comparison of the electrical model with a four-parameter (single diode) PV model figured out that the implementation of a four-parameter PV model has no noticeable advantages for the simulation of the electrical power output in case of the analyzed PVT collector types and operating conditions in comparison with the existing performance model. In future work, it is important to further analyze and improve the parameter identification process by the use of different optimization algorithms and cost functions. Furthermore, additional thermal models such as the 2-node-model integrated in Type 832, which calculates the absorber temperature of the PVT collector that is often set as cell temperature, has to be compared to the presented modeling approach. For further model validation it is also important to use a measured long-wave irradiance as model input instead of the described calculation from ambient conditions.

\section{Acknowledgements}

This work was part of the research project SolWP-Hybrid. The project was funded by the federal state of Saarland and the European Regional Development Fund (ERDF 2014-2020). The authors are grateful for this support and thank the project partners, Viessmann Heizsysteme GmbH, Sonnenkraft GmbH and DualSun, for their support and cooperation.

\section{References}

Almeida, P., Carvalho, M.J., Amorim, R., Mendes, J.F., Lopes, V., 2014. Dynamic testing of systems - Use of TRNSYS as an approach for parameter identification. Solar Energy 104, 60-70. doi:10.1016/j.egypro.2012.11.142

Budig, C., Orozaliev, J., de Keizer, A.C., Kusyy, O., Vajen, K., 2009. Collector parameter identification methods and their uncertainties. In: Proceedings of the ISES Solar World Congress 2009, Johannesburg, South Africa.

Duffie, J.A., Beckman, W.A., 2013. Solar Engineering of Thermal Processes. Fourth edition, John Wiley \& Sons, New Jersey, United States of America. 
Faiman, D., 2008. Assessing the outdoor operating temperature of photovoltaic modules. Progress in Photovoltaics: Research and Applications 16, 307-315. doi:10.1002/pip.813

Fischer, S., Frey, P., Drück, H., 2012. A comparison between state-of-the-art and neural network modelling of solar collectors. Solar Energy 86, 3268-3277. doi:10.1016/j.solener.2012.09.002

Haller, M., Perers, B., Bales, C., Paavilainen, J., Dalibard, A., Fischer, S., Bertram, E., 2013. TRNSYS Type 832 v5.01, Dynamic Collector Model by Bengt Perers. Updated Input-Output Reference.

Heydenreich, W., Müller, B., Reise, C., 2008. Describing the world with three parameters: a new approach to PV module power modelling. In: Proceedings of the 23rd European Photovoltaic Solar Energy Conference and Exhibition, 2008, Valencia, Spain. doi:10.4229/23rdEUPVSEC2008-4DO.9.4

IEA SHC, 2018. IEA SHC Task 60. PVT Systems: Application of PVT Collectors and New Solutions in HVAC Systems. <http://task60.iea-shc.org/> [Last accessed: 21.08.2018]

ISO 9806, 2013. ISO 9806:2013 Solar energy - Solar thermal collectors - Test methods.

ISO 9806, 2017. ISO 9806:2017 Solar energy - Solar thermal collectors - Test methods. Second edition.

Lämmle, M., Kroyer, T., Fortuin, S., Wiese, M., Hermann, M., 2016. Development and modelling of highly-efficient PVT collectors with low-emissivity coatings. Solar Energy 130, 161-173. doi:10.1016/j.solener.2016.02.007

Lämmle, M., Oliva, A., Hermann, M., Kramer, K., Kramer, W., 2017. PVT collector technologies in solar thermal systems: A systematic assessment of electrical and thermal yields with the novel characteristic temperature approach. Solar Energy 155, 867-879. doi:10.1016/j.solener.2017.07.015

Perers, B., 1997. An improved dynamic solar collector test method for determination of non-linear optical and thermal characteristics with multiple regression. Solar Energy 59, 163-178. doi:10.1016/S0038-092X(97)00147-3

Skoplaki, E., Palyvos, J., 2009. On the temperature dependence of photovoltaic module electrical performance: A review of efficiency/power correlations. Solar Energy 83, 614-624. doi:10.1016/j.solener.2008.10.008

Spirkl, W., 1997. Dynamic System Testing Program Manual. Version 2.7, InSitu Scientific Software.

TRNSYS, 2015. TRNSYS - a Transient System Simulation Program, version 17.02.0005. Solar Energy Laboratory, University of Wisconsin, Madison, Wisconsin, United States of America.

TRNSYS, 2018. TRNSYS - a Transient System Simulation Program, version 18.00.0019. Solar Energy Laboratory, University of Wisconsin, Madison, Wisconsin, United States of America.

Wetter, 2016. GenOpt®. Generic Optimization Program. User Manual. Version 3.1.1, Lawrence Berkeley National Laboratory, University of California, Berkeley, California, United States of America. 


\title{
Numerical Simulation of the Thermal Performance of Four Concentrating Collectors with Bifacial PV Cells
}

\author{
Miguel Lança ${ }^{1}$, João Gomes ${ }^{2}$ and Abolfazl Hayati ${ }^{2}$ \\ ${ }^{1}$ Instituto Superior Técnico, Lisbon University, Portugal \\ ${ }^{2}$ University of Gävle, Sweden
}

\begin{abstract}
Bifacial photovoltaic cells can produce electricity from the incoming solar radiation on both sides. Used in combination with concentrating solar technology, bifacial photovoltaic cells can see its electrical output further augmented, thus decreasing the cost per $\mathrm{kWh}$. It is known, however, that the efficiency reduction when these cells are exposed to increased temperatures is a relevant factor. This can happen, for example, when they are mounted on a glassed collector or receiver. In this study, a thermal analysis is carried out on four prototypes of concentrating collectors with bifacial PV cells. Results show that, as expected, when glass and gables are removed from the collector, much better heat dissipation is achieved, thus resulting in favorable cell operation conditions.
\end{abstract}

Keywords: PV cells, concentrators, reflector geometry, CFD, glass receiver

\section{Introduction}

Concentrators are a route to achieve high photovoltaic cell efficiencies as well as cost reduction. This reduces land utilization as well as area related costs (Mehrdad et al, 2014). In Photovoltaic-Thermal (PVT) technology, for systems with and without concentration, the use of glass cover on the flat-plate hybrid solar collector is common. This enhances the thermal output but not the electric. While a solar thermal panel must be able to retain heat in order to reach high operating efficiencies, a photovoltaic panel behavior is the opposite; the efficiency is reduced with the temperatures increase. Several means for temperature control of the PV cell collector have been studied (Alizadeh et al, 2018; Du, 2017; Kasaeian et al., 2017; Wu et al., 2018).

This paper conducts thermal analysis based on Computational fluid dynamics (CFD) simulations to four prototype Parabolic Concentrators collectors with bifacial PV cells encapsulated in a glass receiver.

Thermal analysis of PVT systems is frequently encountered in literature. Sun and Shi (2009) studied the thermal performance of a C-PVT collector. The results have shown that the solar radiation intensity can be higher than $1200 \mathrm{~W} / \mathrm{m}^{2}$ in most area of the cell surface. The temperature of the air and cell surface was reported to rise along the length of the system. The authors have concluded that the receiver temperature is related to both air mass flow and length, as well as solar radiation and outdoor temperature. Li et al. (2016) studied the influence of the incidence angle on the temperature of the cover and back glass and also on the cell silicone temperature. They performed experiments and CFD calculations for $0^{\circ}, 10^{\circ}, 20^{\circ}, 30^{\circ}$ and $40^{\circ}$ incidences. Crossed Parabolic was the type of concentrator analyzed. Gomes et al. (2012) carried out tests on three prototypes of CPC collectors with bifacial PV cells. Results showed a cell temperature of $88^{\circ} \mathrm{C}$ on a glass-covered outdoor installed CPC collector on a sunny day with $28^{\circ} \mathrm{C}$ of outside temperature. The dependence of electrical efficiency on temperature was reported to be $-0.51 \% / \mathrm{K}$.

\section{The collector prototypes}

The study compares four concentrating bifacial PV collectors designs described in table 1. 
Tab. 1 - A cross-section view (plane $z x$ ) of the four cases studied and each one's composition (not to scale).

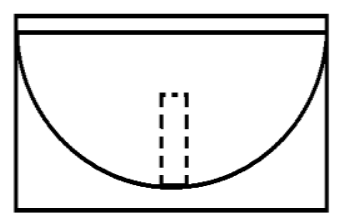

Case 1: Totally covered

- Includes the box structure, side gables, glass cover, glass receiver (dotted line) and reflector.

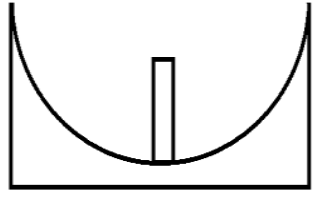

Case 2: Totally uncovered - Includes the box structure, glass receiver and reflector but no glass cover, nor side gables

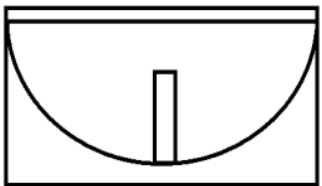

Case 3: Partially

covered - Includes the box structure, glass cover, glass receiver and reflector but not the side gable.

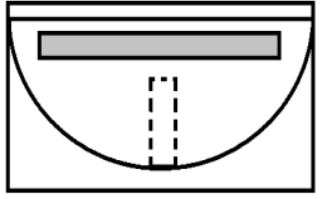

Case 4: Partially uncovered with a ventilation slot -

Includes the box structure, side gables with ventilation slot (in gray in the figure), glass cover, glass receiver (dotted line) and reflector.

All above cases have different heat performance, meaning that the solar cells will operate at different temperatures. Therefore all cases were compared on air velocity, air and collector temperature and heat fluxes. Figure 1 shows an overall picture of the complete solar collector.

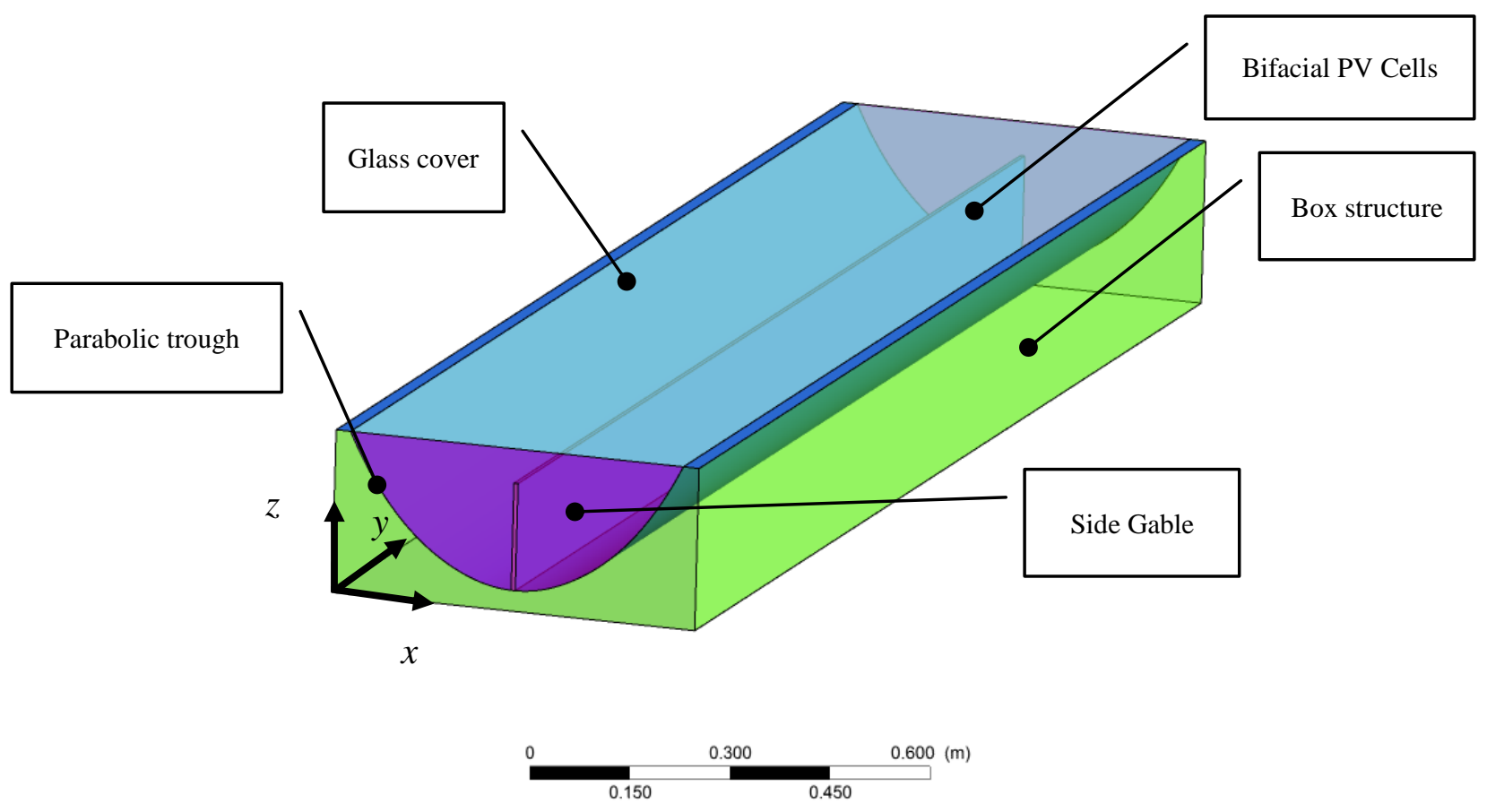

Fig. 1: Model of the glass covered concentrating collector studied.

The collector dimensions are $600 \mathrm{~mm} \times 2250 \mathrm{~mm} \times 250 \mathrm{~mm}(x, y, z)$. The glass over the collector and of the receiver is a $4 \mathrm{~mm}$ glass with a weighted solar light transmittance of $95 \%$ at $600 \mathrm{~nm}$ wavelength. The parabolic trough is made of $2 \mathrm{~mm}$ aluminum with a weighted solar light reflectivity of $93 \%$. The receiver comprises a set of 4 layers: a $0.5 \mathrm{~mm}$ cell between 2 coatings of $0.5 \mathrm{~mm}$ silicone, and a $4 \mathrm{~mm}$ glass attached to one of the sides. A numerical study is carried out using a commercial CFD tool, ANSYS FLUENT. The simulations take in to account the physics when the collector is operating. Energy, continuity, momentum, radiation, turbulence models and boundary conditions are set in order to give the simulation the correct approximation to the lab and field operation. Each mathematical model is explained in detail in section 3. Figure 2 is a heat flow network 
used to describe the thermal analysis used here.

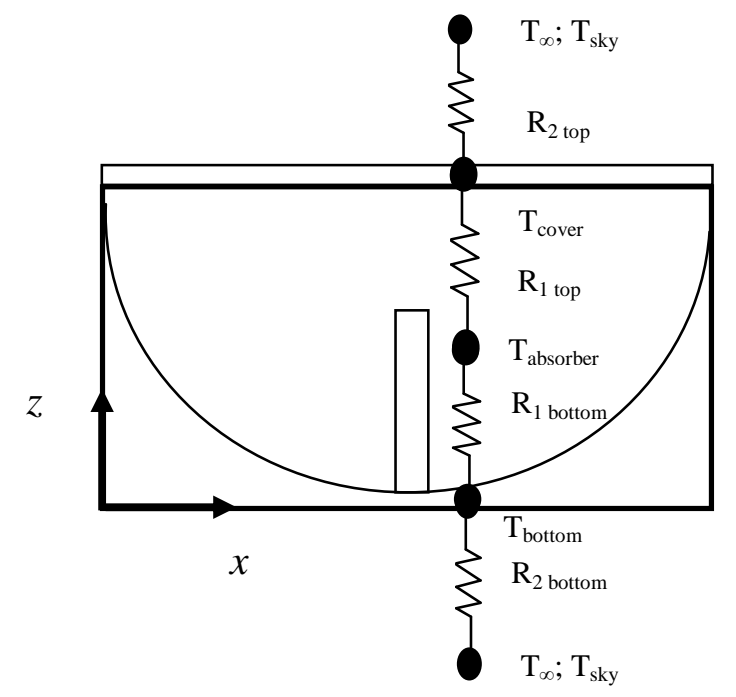

Fig. 2: Equivalent heat flow network for the covered collector.

The overall energy balance for the transient state is given by Eq. 1:

$G_{\text {collector }} A_{\text {absorber }} \tau_{\text {cover }} \alpha_{\text {absorber }}=q_{\text {loss }}+\frac{d e_{\text {collector }}}{d t}$ (eq. 1)

Where $G_{\text {collector }}$ is the solar irradiation striking the collector, $\mathrm{A}_{\text {abossber }}$ is the area of the collector, $\tau_{\text {cover }}$ is the glass transmittance and $\alpha_{\text {absorber }}$ the receiver absorptance. $q_{\text {loss }}$ represent the heat loss due to conduction, convection and radiation and the last term of the second member of the equation denote the transient term. Assuming steady-state and one-dimensional heat analysis, q $\mathrm{q}_{\text {loss }}$ can be calculated as:

$q_{\text {loss }}=\frac{T_{\text {absorber }}-T_{\infty}}{R_{\text {total }}} \quad$ (eq. 2$)$

And each of the convection/radiation combined resistance components as:

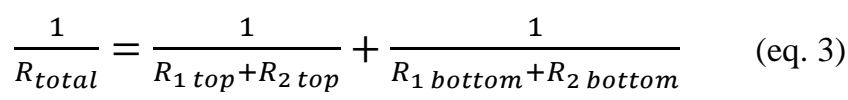

Where $R_{\text {Itop }}$ is a parallel resistance electric analog circuit, consisting of the convection and radiating components taking place between the receiver and the cavity, and $R_{2 t o p}$ representing the combination between the two resistances that form the radiating and convective heat transfer that is being processed between the glass and the exterior medium. The same principle is applied to the bottom, where $R_{1 \text { bottom }}$ and $R_{2 b o t t o m}$ designate the resistances that form the collector bottom surface - convection and radiation, respectively, between the receiver, the cavity and the outer case with the environment.

This study compares collectors with or without glass cover as well as with or without side different types of side gable. The expressions treated above are intended to represent the first case. When the receiver is uncovered, a different thermal approach needs to be taken. There is no need to consider the transmittance of the glass and the radiative and convective components between the receiver and the cavity. $R_{1 \text { top }}$ and $R_{2 \text { top }}$ are in this case, transformed in a single thermal resistance, say $\mathrm{R}_{\text {top. }}$ 


\section{Numerical methods}

Exact or approximate analytical solutions for the temperature and velocity vectors can only be obtained for simple problems and particular boundary conditions.

Since the 1960s, computational fluid dynamics (CFD) has seen an increase in popularity in the aerospace, thermal and biomedical sciences sectors, to name a few. Nowadays, with the mass use of powerful processing computers, it is possible to obtain very good levels of mesh refinement on three dimensions models. These technological improvements coupled with the evolution of knowledge about the theory of turbulence, the simulations today produce results of extraordinary accuracy $(\mathrm{Li}, 2007)$.

In CFD modeling, several equations are solved, i.e. momentum, energy, turbulence, radiation, and concentration, in order to find out how are the boundary conditions transported to the interior of the domain according to the mechanisms of diffusion, convection, and chemical reactions.

In this study, the objective of the CFD simulations is the prediction for the thermal variables when a concentrating PV collector is exposed to peak solar conditions. The simulations resulted from the resolution of the equations referred to a steady and incompressible regime, using the three dimensions in space. Turbulence models were employed according to the RANS - Reynolds Average Navier Stokes method. The effects of radiation, as well as buoyancy, were taken into account.

Errors and uncertainties are part of computational simulations. For this reason, it is essential to develop methods to quantify the confidence level of the results, (Versteeg and Malalasekera, 2007). A set of techniques allows one to solve the equations correctly and, at the same time, also that the right equations are being solved. Residual error, rounding errors or those inherent to the discretization process are some examples. Rounding errors can be quantified by running, for example, two simulations, each with a different selected precision level, and comparing the results. Fluent software classifies these two levels as single precision and double precision. Residual errors, in turn, can be evaluated by comparing the evolution of residuals of one or more variables intrinsic to the study, such as heat flux or temperature. The greater or lesser oscillation of these quantities residuals throughout the iterative process indicates how far away is the actual solution from the final solution. The error inherent on the discretization of equations will depend on the accuracy of the approximation of the differential equations to the arithmetic ones, namely to the truncated terms of higher order in the development of the Taylor series. Since the equations in the differential form are valid at any point in the domain, while the discrete solution is valid only at the points or nodes where the model was divided, it follows that this type of error is usually affected by the time step used in transient simulations and by the quality of the mesh. In this case, this error can be quantified by running simulations in which, for example, the mesh size is varied from case to case.

While errors in CFD simulations are known to the user that can to some extent control them, the magnitude and origin of the uncertainties involved in such calculations are unknown, e.g. geometry, properties of materials used, boundary conditions, turbulence or radiation models.

\subsection{CFD Set-up \\ 3.1.1. Turbulence}

Studies have pointed out that the accuracy in the prediction of turbulent flow behavior is a consequence of the accuracy of the turbulence models used in this same forecast (Spentzos, 2005).

Turbulence is a complex problem. It affects mainly the numerical analysis, although it might also introduce uncertainties in the experimental analysis as well. While the movement of the fluid is continuous, in reality, the motion of the particles is not ordered. When this occurs velocity vectors are affected and these fluctuations influence also the transport of the energy, momentum, and concentration-related variables. Turbulence modeling implies that the Navier-Stokes equations will include the product of the floating components - the so-called Reynolds stress. Closing strategies emerged as a way of solving the new system of equations then generated. Turbulence models may have one or more equations. For the selection of the model to be used, the degree of turbulence evolved needs to be known in order that an acceptable numerical approximation can be obtained. 


\subsubsection{The $k-\varepsilon$ model}

Widely used in studies of fluid mechanics and heat transfer this model combines relative robustness of results and accuracy without being computally expensive. It is a semi-empirical model of two equations in which the turbulent transport variables are the turbulent kinetic energy $(k)$ and the dissipation rate $(\varepsilon)$. The first is defined based on an exact solution whereas the second on empirical solutions which result from the observation of physical phenomena. In this study the standard $k-\varepsilon$ model was used and the following constants were adopted:

Tab. 2: constants used in the $k$ - $\varepsilon$ turbulence model

\begin{tabular}{|c|c|}
\hline Constant & Value \\
\hline $\mathrm{C}_{\mu}$ & 0,09 \\
\hline $\mathrm{C}_{1 \varepsilon}$ & 1,44 \\
\hline $\mathrm{C}_{2 \varepsilon}$ & 1,92 \\
\hline
\end{tabular}

Standard wall functions were also used when the characterization of the flow near the wall.

\subsection{Buoyancy}

In the presence of heat transfer to the air, a variation of its density will occur as a consequence of its heating. The gravitational force will act under different intensities, promoting the movement of the particles. Natural convection is possible to be modeled numerically by Fluent software. In those circumstances, the Boussinesq approach is normally adopted. This approximation treats density as constant in all but in the momentum equation where the density property will be expressed as a function of temperature:

$\left(\rho-\rho_{0}\right) g \approx-\rho_{0} \beta\left(T-T_{0}\right) g \quad($ eq. 4$)$

Where $\rho_{0}$ designates the reference air density and $T_{0}$ is the temperature under study, $\beta$ the air expansion coefficient and $g$ the gravitational acceleration. This approach presents results with acceptable deviations as long as the variations in the air temperature are reduced, that is when $\beta\left(T-\mathrm{T}_{0}\right)<<1$. For the buoyancy modeling to be implemented the gravitational acceleration also has to be introduced, which in this case will act in the direction of the $\mathrm{z}$-axis with a value of $-9.81 \mathrm{~m} / \mathrm{s}^{2}$.

\subsection{Boundary conditions}

The definition of boundary conditions constitutes an important part of the formulation of any problem to be solved by a CFD code, (Versteeg and Malalasekera, 2007).

The boundary conditions were defined in order to describe appropriately the physical conditions. In this work, 3 types of boundary conditions were chosen: wall, pressure-inlet and pressure-outlet whether the collector is covered or uncovered with the glass. Each collector boundary condition is defined in table 3 .

Tab. 3: List of boundary conditions assigned to each surface of the prototypes calculated. LW stands for Law of the Wall.

\begin{tabular}{|c|c|}
\cline { 2 - 2 } \multicolumn{1}{c|}{} & $\begin{array}{c}\text { Type of boundary condition } \\
\text { Case 1/ Case 2/ Case 3/ Case 4 }\end{array}$ \\
\hline Glass (plane $\mathrm{z}=250 \mathrm{~mm})$ & LW/pressure outlet/ LW/ LW \\
\hline East gable $($ plane $\mathrm{y}=0 \mathrm{~mm})$ & $\mathrm{LW} /$ pressure inlet/pressure inlet/pressure inlet+LW \\
\hline West gable $($ plane $\mathrm{y}=2250 \mathrm{~mm})$ & $\mathrm{LW} / \mathrm{pressure} \mathrm{inlet/pressure} \mathrm{outlet/pressure} \mathrm{outlet+LW}$ \\
\hline Box structure & law of the wall \\
\hline
\end{tabular}

The "pressure outlet" was chosen (with gauge pressure taken equal to zero) to define the static pressure at the flow outlets. In this case, backflow total temperature is taken equal to outdoor temperature.

The "wall" boundary condition is used to define the fluid-solid interface. In this option, for viscous flows, the no-slip boundary condition is enforced at the wall and defined as stationary. The remaining external walls were defined considering losses by convection and radiation, according to the properties and thickness of a virtual 
wall. In more than one surface the boundary conditions are classified as convection type which implies the definition of a medium temperature and an external convection coefficient. The latter was calculated analytically considering the air properties at an exterior temperature of $25^{\circ} \mathrm{C}$. The calculated convective coefficient also accounts for the effects of radiation on heat exchanges between the model and the surrounding surfaces or the sky and can, therefore, be referred to as the combined convection coefficient.

The heat conduction is also calculated by Fluent software on solid domains. For this purpose, a mesh was created in those regions. In this study, for reasons of speed of calculation, it was decided to be applied only on the receiver. In the case of glass walls and gable, a mesh was not generated for a resource-saving reason, but rather defined a thickness and specified a material.

\subsection{Radiation}

In the presence of heat transfer by natural convection the radiation component may represent a significant fraction of the heat transferred (Çengel, 2002). Therefore, the radiation emitted by the bodies will be absorbed by the surrounding surfaces conditioning the final balance of energy.

\subsubsection{The surface to surface (S2S) model.}

The surface-to-surface radiation model is typically used to model radiative heat transfer in non-participating mediums. Thus, it is assumed that the heat exchanges by radiation only occur between surfaces. This depends on their area, the distance that separates them and orientation, as well as their optical properties. The interaction between surfaces is given by the calculation of the view factor carried out automatically by the software. The S2S model assumes that all surfaces are diffuse and gray. In this study, the surfaces were also considered opaque except for the top glass. The biggest advantage of this model is its simplicity and the reduction of resources required for not taking into account any absorption, emission, or scattering of radiation by the filling medium, thus, it is appropriate for this problem.

The radiosity of a given surface $J_{s}$ is the sum of the radiation energy $E_{s}$ emitted by the surface $s$ plus the total energy reflected by the same surface:

$J_{s}=E_{s}+\rho_{s} \sum_{r=1}^{N} F_{s r} J_{r}$

Where $\rho_{s}$ is the reflectance of the surface, $F_{s r}$ is the view factor between the $r$ surrounding surfaces and the one considered. As compared to other radiation models, the S2S model is solved by a fast direct method, although the view factor calculation itself is CPU-intensive. The storage and memory requirements increase very rapidly as the number of surface faces increases. To save calculation time, some of the surfaces can be merged into a unique group. In this study, the view factor was calculated considering every surface individually since the calculation time took about 10 minutes.

\subsubsection{The solar model}

The CFD code used enables the calculation of a heat source coming from the sun to predict the effects on the domain. This is accomplished by defining a beam that is modeled using the sun position vector and illumination parameters. The resulting heat flux is coupled to the calculation via a source term in the energy equation. A twoband spectral model is used for direct solar illumination and accounts for separate material properties in the visible and infrared bands. A single-band hemispherical-averaged spectral model is used for diffuse radiation. Opaque materials like the gable are characterized in terms of two-band absorptance. A semi-transparent material as the covering-glass requires specification of absorptance and transmittance.

Two options are available for the model: solar ray tracing and Discrete Ordinates irradiation. The simulations were carried out using the solar ray tracing method. Inputs of $1000 \mathrm{~W} / \mathrm{m}^{2}$ of direct radiation, as well as 100 $\mathrm{W} / \mathrm{m}^{2}$ of diffuse radiation, were considered. The sun direction vector was taken as pointing along z-axis only. Therefore the model assumes the incident solar radiation is striking the collector perpendicularly. 


\subsection{Grid generation}

The mesh used comprises nearly 2000000 elements. The zones where higher velocity gradients are expected have been refined. At the same time, the mesh generation topology avoids sudden transition between elements of different sizes. An overall look of the mesh is represented in fig 3. The effect of mesh size reduction on the results obtained was investigated. Thus, several simulations were made maintaining the same geometry of the model but varying the number of mesh elements. It has been reported that for different mesh sizes, the calculated values of heat fluxes in the gable and air temperature at the receiver also varied considerably. On the other hand, it was found that the solution found difficulties converging or did not converge at all, below a minimum number of elements - around 200 000. On the contrary, when the number of elements was increased, the asymptotic evolution of the results took place. This sensitivity analysis served to optimize the mesh when trying to reach a compromise between the results accuracy and the calculation time. The mesh generation software used also provides quantitative geometric parameters of the mesh such as orthogonal quality and asymmetry. The overall mesh quality was checked and compared with the range of values indicative of a good overall quality - near 1 for orthogonal quality and 0 for asymmetry.

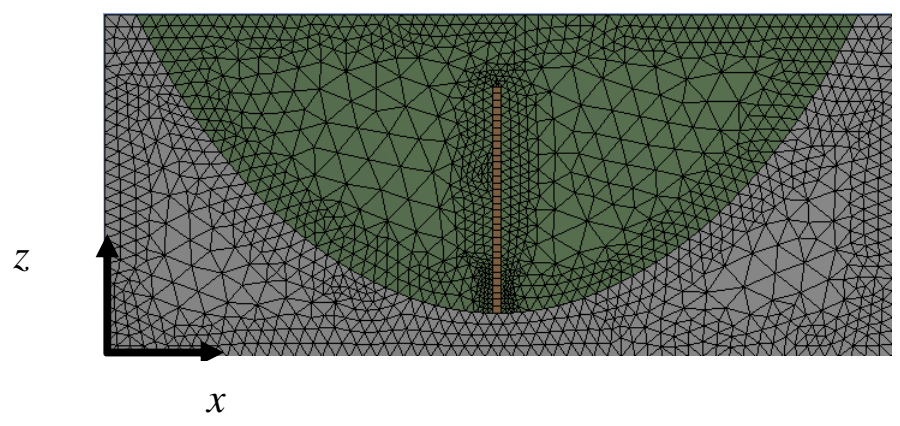

Fig. 3 - Mesh used in the calculations taken at the plane $y=1000 \mathrm{~mm}$.

\subsection{Solver settings}

The 3-D model was incorporated on Fluent software release 14.0. Momentum, energy, radiation and turbulence equations were calculated. The solver general settings were defined as an incompressible steady regime. The pressure-velocity coupling was determined by the algorithm PISO - Pressure Implicit with Splitting of Operators. The discretization of the momentum, energy and turbulence equations was processed using secondorder upwind type numerical schemes.

\section{Results and discussion}

\subsection{Case 1 - Totally Covered}

The temperature and heat flux contours, as well as the velocity vectors for the covered collector case, are shown in Fig. 4. The highest air temperature is reported in the cavity between the glass and the receiver, which ranges between 100 and $130{ }^{\circ} \mathrm{C}$, at the same time that the receiver reaches $150^{\circ} \mathrm{C}$. Of all the cases studied, this is the one that presents the highest temperatures in both the receiver and the surrounding zone, as expected, because of the greenhouse effect created by the presence of the glass. The cavity delimited by the box structure has lower temperatures than the upper zone - between 61 and $140{ }^{\circ} \mathrm{C}$. The air in the base surface of the collector as well as near the walls is colder than the rest of the collector due to the losses that occur by convection and radiation between the collector walls and the environment. Also in the glass vicinity, it can be verified that there is a zone of transition between the highest temperatures of the air and the colder glass surface that form the thermal boundary layer. This collector presents the most severe operating conditions for the PV cells.

The velocity vector field shows the formation of two vortexes one on each side of the receiver. This is due to the temperature differences between this component and the rest of the surrounding air as it has been observed in temperature analysis. Highest velocity gradients happen near the walls (glass, receiver and reflector) especially at the top of the receiver and in the upper part of the reflector. Values between 0.02 and $0.17 \mathrm{~m} / \mathrm{s}$ are encountered. Total heat fluxes (convective and radiative) contours reach $720 \mathrm{~W} / \mathrm{m}^{2}$ maximum and indicate that 
higher losses occur in the glass. This can be explained due to the high air temperatures at these points that lead to greater heat exchanges with the environment.

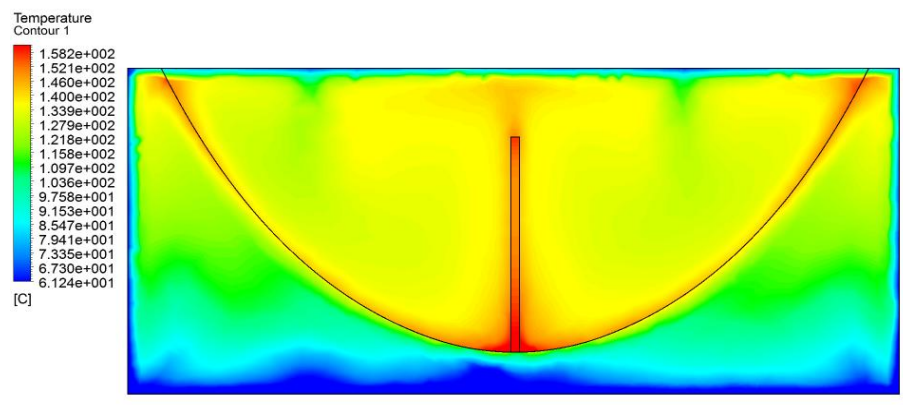

a)

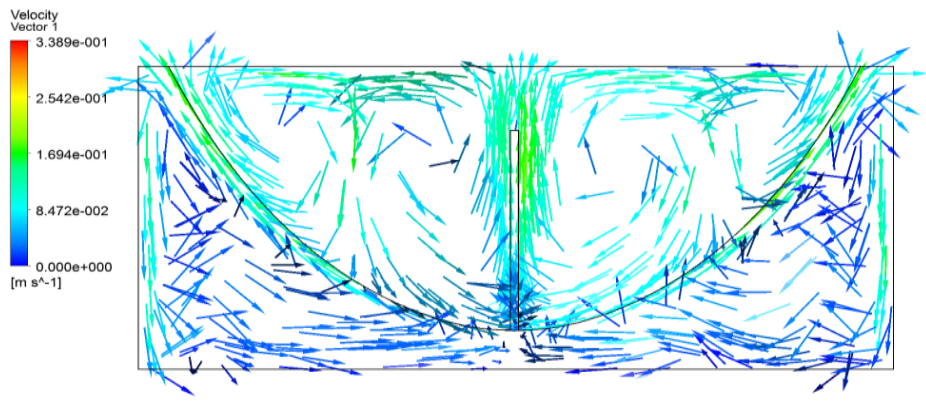

b)

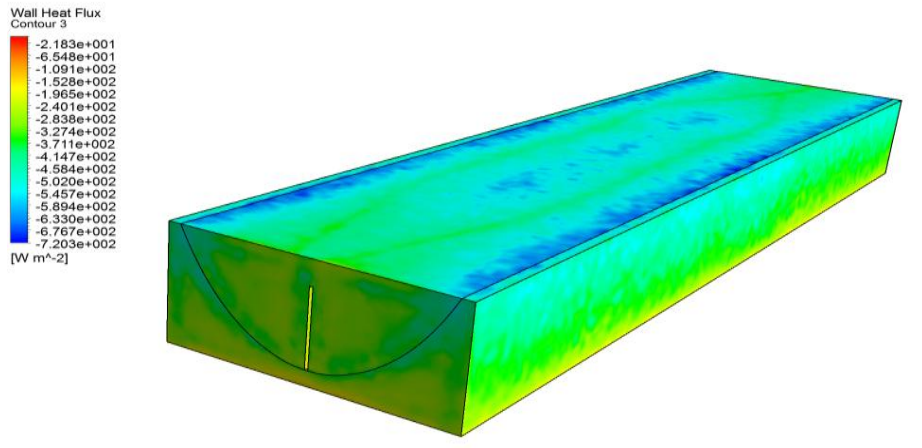

c)

Fig. 4 - Calculated temperature contours (a) and velocity vectors (b) at the plane $\mathbf{y}=\mathbf{1 0 0 0} \mathrm{mm}$ and heat flux (c) contours for case 2.

\subsection{Case 2 - Totally uncovered (no side gables nor top glass)}

Presented data suggest a clear reduction on air and receiver temperatures compared to the covered collector case. Values close to ambient temperature are encountered around the receiver and this is working at $79^{\circ} \mathrm{C}$ at most, with the majority of its interior below $61^{\circ} \mathrm{C}$. The absence of the glass cover makes the cooling of the receiver more efficient, thus decreasing the overall temperatures. There is a $5 \mathrm{~K}$ temperature difference between the bottom of the collector and the outside air, which indicates a less intense heat transfer rate in this region compared to the covered case. The overall receiver and air temperatures were the lowest of all 4 cases calculated. Since the fact that there is no glass, mass transfer is allowed which contributes to the cell temperature regulation.

The calculated velocity vectors indicate a clear direction of the flow from the exterior to the interior of the cavity. Here the exhaust of hotter air takes place along the receiver vertically. Within the zone comprised between the reflector and the gable, the velocity vectors present a direction and magnitude pattern very similar to the case of the covered collector, with particles moving downwards along the side walls of the gable and ascending along the lower surface of the reflector, which is expected since this is the hotter surface of this domain. 
The heat fluxes on the uncovered collector case present lower absolute overall ratios the previous case. The reflector is the component with the highest transfer rates per unit surface i.e. $-296 \mathrm{~W} / \mathrm{m}^{2}$. This value stays considerably below the $720 \mathrm{~W} / \mathrm{m}^{2}$ reported in the previous case. Results are represented in figure 5 .

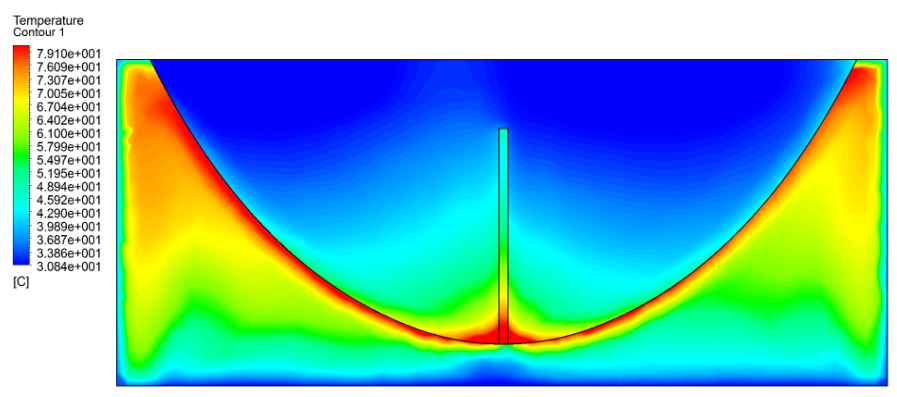

a)

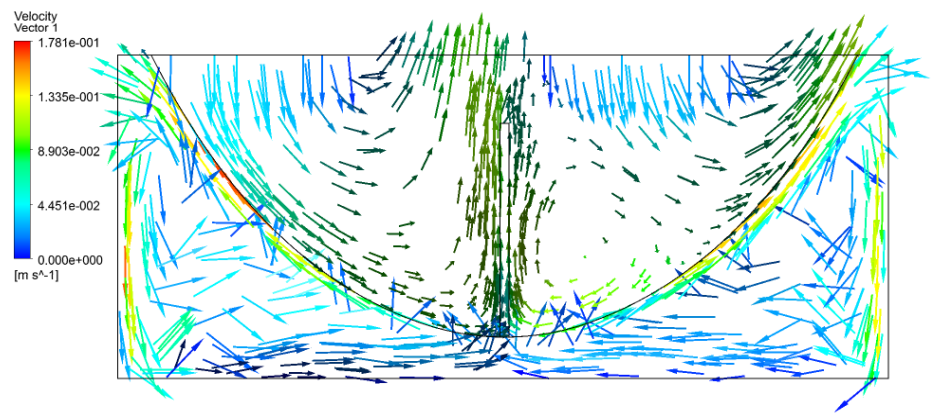

b)
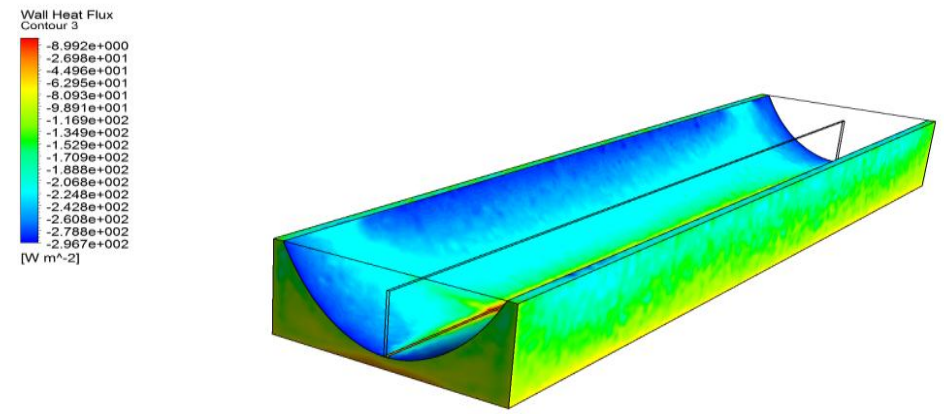

c)

Fig. 5 - Calculated temperature contours (a) and velocity vectors (b) at the plane $y=1000 \mathrm{~mm}$ and heat flux (c) contours for case 2.

\subsection{Case 3 - Partially covered (no side gables)}

As mentioned early, a hybrid solution between the covered and the uncovered collector was simulated in order to investigate a presumably more efficient cooling mechanism of the PV cells than the former. Concerning the temperature contours, this particular configuration show vales of around $65{ }^{\circ} \mathrm{C}$ in the zone between the reflector and the glass. The removal of side covers allows the introduction of outside air and its exhaust resulting in the lowering of the cell temperature from $150{ }^{\circ} \mathrm{C}$ in the case of the covered collector to $90{ }^{\circ} \mathrm{C}$ in this solution figure 6 . This indicates that the cells are being cooled efficiently. In this arrangement, the calculated velocity vectors, show a direction opposite to that found in the case of the covered along the lower surface of the glass. This may be due to the fact that the air intake passing through the area where the side covers were located can cause additional disturbances to the flow in this region. In the case of the cavity below the reflector, no changes are noticed concerning the intensity and the direction of the velocity vectors comparing the two cases. 


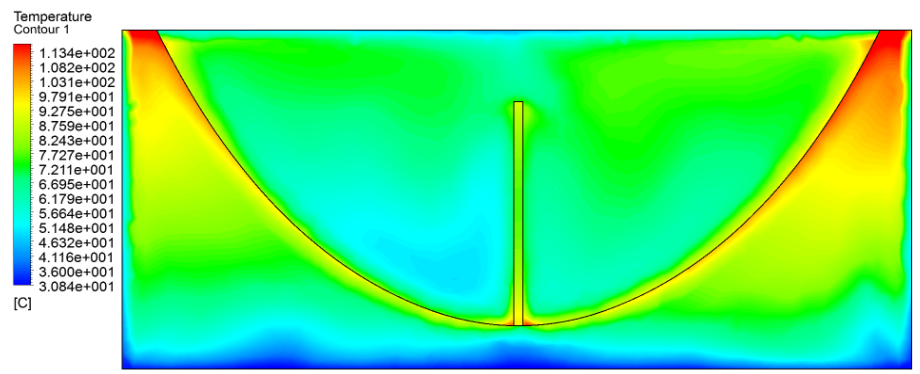

a)

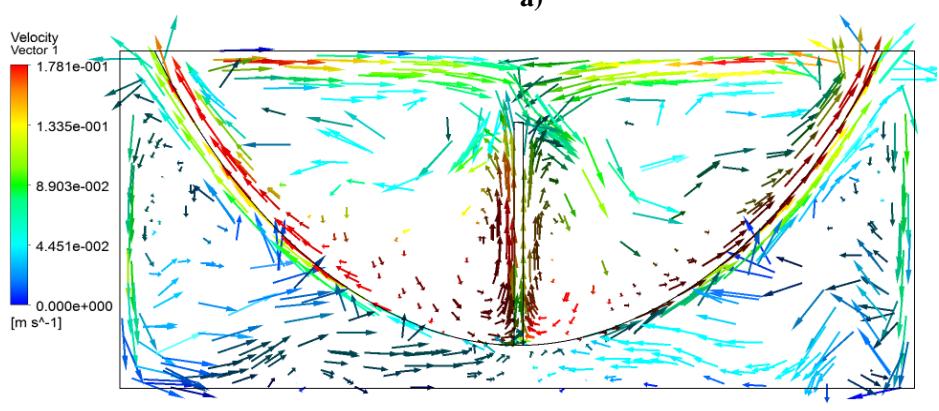

b)
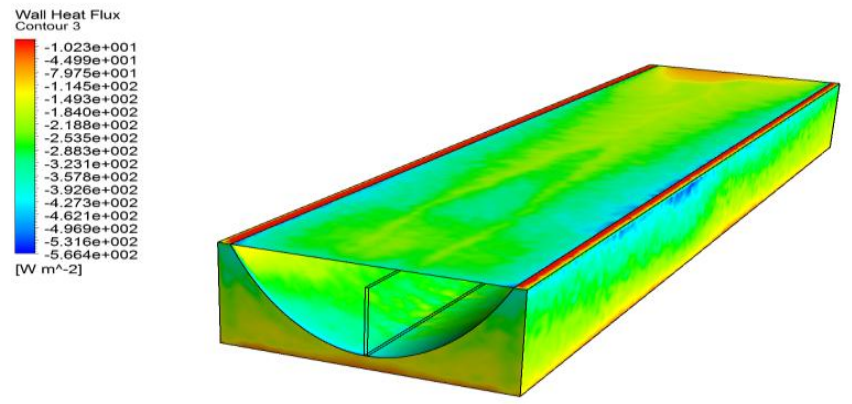

c)

Fig. 6 - Calculated temperature contours (a) and velocity vectors (b) at the plane $y=1000 \mathrm{~mm}$ and heat flux (c) contours for case 3 .

\subsection{Case 4-Partially uncovered (open slot in the side gable)}

Simulations were made in a model with openings in the gables and results shown in figure 7. Those are rectangular shaped and induce some air to enter in the collector while keeping the overall equipment structure installed. The slot has a surface equal to $20 \%$ of the total of each gable area. The results indicate that the cells reach temperatures between 86 and $106^{\circ} \mathrm{C}$. This value is about $35 \%$ lower than that found for case 1, which shows that ventilation promoted by just opening slots of this dimension allows for lowering cells temperature. Both the part of the receiver close to the base and the reflector have a temperature of $110^{\circ} \mathrm{C}$ - the highest to be reported in the collector. This has to do with the location of the slot in the top of the gable producing a jet of cold air that is more likely to cool the air in the upper of the cavity, just below the glass than the rest of the collector. Regarding the calculated velocity field it needs to be pointed out that below the reflector, residual values are encountered, which helps to explain why higher temperatures are expected to take place in that region, as it was mentioned. This is because heat dissipated by convection, dependent on the flow velocity, is this way decreased. Heat fluxes contours figure shows about $600 \mathrm{~W} / \mathrm{m}^{2}$ of heat loss next to the inlet zone, on the left side of the picture. Meanwhile on the other end, next to the exhaust, values of $36 \mathrm{~W} / \mathrm{m}^{2}$ were reported. This is due to the fact that here the air has been heated to a temperature close to the collector surface which indicates an efficient PV cell cooling mechanism. 


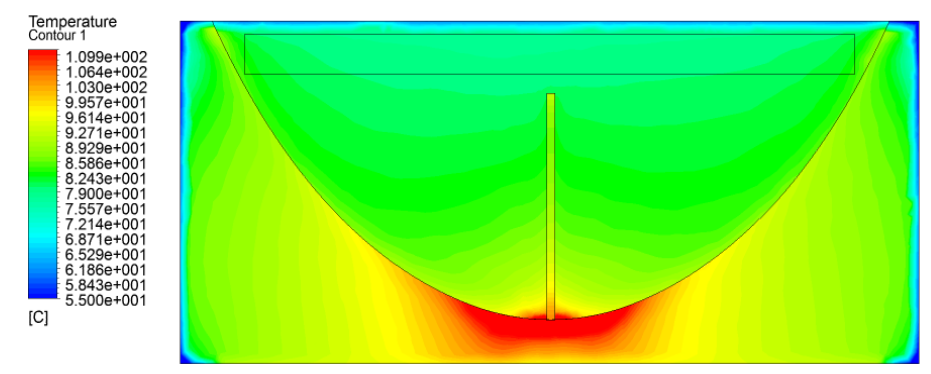

a)

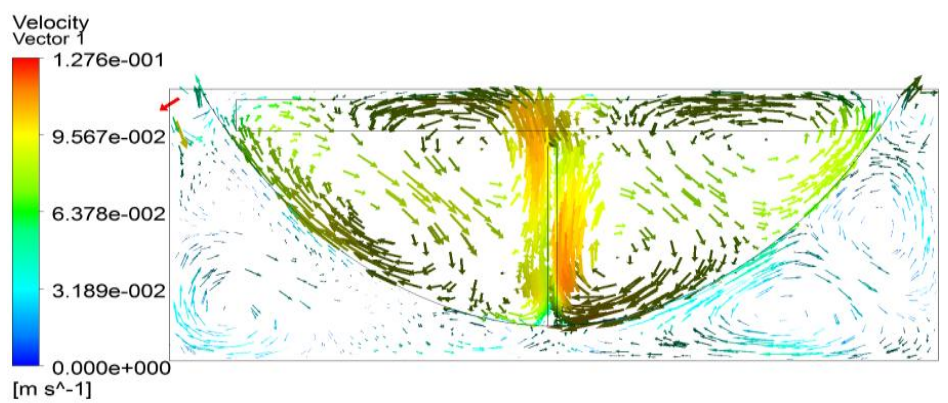

b)

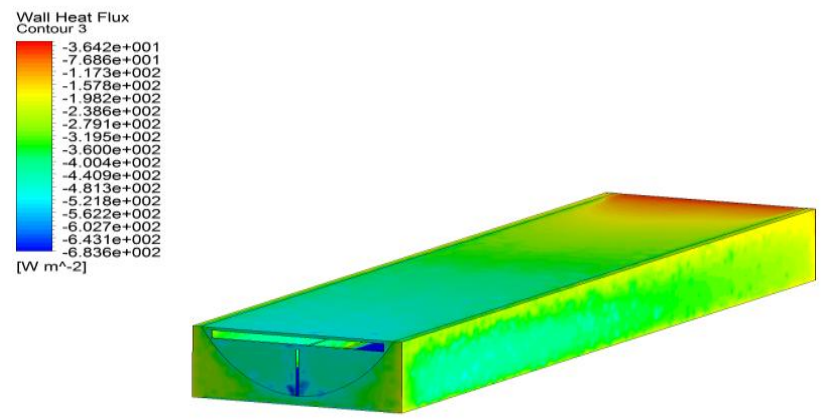

c)

Fig. 7 - Calculated temperature contours (a) and velocity vectors (b) at the plane $y=1000 \mathrm{~mm}$ and heat flux (c) contours for case 4.

\section{Conclusion}

The electric output of PV cells is sensitive to their working temperature. Simulations were carried out on four prototypes of concentrating using bifacial collector. Some conclusions can be drawn about the thermal performance of each configuration studied.

The temperature of the cells decreases as the protections are removed from the collector. In the case of a completely airtight collector, equipped with glass and side covers, the cell's working temperature reaches 150 ${ }^{\circ} \mathrm{C}$. Concerning cell operating conditions, the optimal solution corresponds to the configuration in which both 
the glass and the side protections are eliminated. In this case, the maximum temperature reaches $79^{\circ} \mathrm{C}$, which corresponds to a $47 \%$ reduction from a collector with a completely closed collector.

The case where a slot is opened in one of the gables is a solution that enables better cooling of the cells compared to the case where fully closed collector was studied while still protecting the receiver and reflector from the weather. Different opening geometries and locations in the gable need to be investigated, though, in order to optimize the cooling of the collector.

There is, therefore, a direct relationship between the portion of the collector that is not covered and the decrease in the operating temperature of the cells.

Although the glass and gables act like a mass transfer barrier restricting the desired cells heat dissipation, concerns about the protection against mechanical and chemical agents (dirt, rain or wind) arise because of the potential collector damage and, as a result, decreases efficiency. However, a substantial reduction in the collector overall temperature was achieved just by removing minor areas of this components. A heat sink is a possibility to further dissipate heat.

\section{References}

Alizadeh H., Ghasempour R., Shafii M., Ahmadi M., Yan W., Nazari M., 2018. Numerical simulation of PV cooling by using single turn pulsating heat pipe. International Journal of Heat and Mass Transfer, 127, $203-208$.

Çengel, Y. A., 2002. Heat Transfer: A Practical Approach, $2^{\mathrm{a}}$ Edition, McGraw-Hill.

$\mathrm{Du}, \mathrm{Y} .$, 2017. Advanced thermal management of a solar cell by a nano-coated heat pipe plate: A thermal assessment. Energy Conversion and Management, 134, 70-76.

Gomes, J., Davidsson H., Christian, G., Stefan, M., Karlsson, B., 2012. Testing bifacial PV cells in symmetric and asymmetric concentrating CPC collectors. Engineering. doi:10.4236/eng.2012

Kasaeian, A., Khanjari, Y., Golzari, S., Mahian, O., Wongwises S., 2017. Effects of forced convection on the performance of a photovoltaic thermal system: An experimental study. Experimental Thermal Fluid Science, $85,13-21$.

Li, W., Paul, M. C., Sellami, N., Mallick, T. K., Knox, A. R., 2016. Experimental and numerical investigation of thermal performance of a crossed compound parabolic concentrator with PV cell. $12^{\text {th }}$ International Conference on Heat Transfer, Fluid Mechanics and Thermodynamics.

Li, Z., 2007. Characteristics of Buoyancy-Driven Natural Ventilation through Horizontal Openings. Ph.D. Thesis. Aalborg University.

Mehrdad, K., Salati, H., Egelioglu, F., Faghiri, A., Tarabishi, J., Babadi, S., 2014. A Review of Solar Photovoltaic Concentrators. International Journal of Photoenergy. Article ID 958521, 17 pages, doi:10.1155/2014/958521.

Spentzos, A., 2005. CFD Analysis of 3D Dynamic Stall. Ph.D. Thesis. Glasgow University.

Sun, J., Shi, M., 2009. China Ser. E-Technol. Sci. 52, 3514. https://doi.org/10.1007/s11431-009-0242-x

Versteeg, H. K., Malasasekera, W., 2007. An Introduction to Computational Fluid Dynamics - The Finite Volume Method. Second edition. Parson Education Limited.

Wu, S., Chen, C., Xiao, L., 2018. Heat transfer characteristics and performance evaluation of water-cooled PV/T system with cooling channel above PV panel. Renewable Energy 125, 936-946. 


\title{
Organic PVT - a Novel Hybrid Collector Combining Organic Photovoltaics and Polymer Absorbers
}

\author{
Manuel Lämmle ${ }^{1}$, Hugo Hernandez Gonzalez ${ }^{1}$, Chunghuan Li' ${ }^{1}$, Luciana Pitta Bauermann ${ }^{1}$, \\ Andreas Piekarczyk ${ }^{1}$, Michaela Meir $^{2}$, John Rekstad ${ }^{2}$ \\ 1 Fraunhofer Institute for Solar Energy Systems ISE, 79110 Freiburg (Germany) \\ 2 Aventa AS, Trondheimsveien 436 a, N-0962 Oslo (Norway)
}

\begin{abstract}
A novel hybrid PVT collector concept is presented which combines organic photovoltaics (OPV) with a polymer absorber plate. This combination achieves synergies in terms of temperature requirements and matching of materials. The low-cost, low-weight OPVT collector mainly employs polymeric materials with a small ecological footprint and low material costs.
\end{abstract}

This paper details the characterization of electrical and optical parameters of OPV modules, the development of an OPVT absorber with a suitable bonding process, and test results of a first unglazed OPVT collector, demonstrating the general functionality of the OPVT concept.

Challenges for the technical realization of the OPVT concepts concern degradation and ageing of OPV modules and adhesives at elevated temperatures. Moreover, high reflection losses impose a challenge for the thermal efficiency. Nonetheless, the first experimental results of the unglazed OPVT collector are promising.

Keywords: Hybrid photovoltaic/thermal PV/T collector; solar energy in buildings, solar heat; solar electricity, OPV

\section{Introduction}

Conventional photovoltaic-thermal (PVT) collectors typically employ crystalline silicone PV cells and a metallic absorber (Zondag 2008). However, this combination causes either the electrical or the thermal operation to underperform, due to the diverging temperature requirements.

The novel organic photovoltaic thermal (OPVT) collector combines organic photovoltaic (OPV) modules with a polymeric absorber to simultaneously convert solar energy into electricity and heat in a single component.

Sandnes and Rekstad (2002) developed a PVT collector with a polymer absorber plate but found a high difference of the thermal expansion coefficient of silicone PV cells and the polymer absorber. On the contrary, OPV modules consist of thin, active layers of light absorbing dyes, which are encapsulated in flexible polymeric films. Given their relatively high thermal expansion coefficient, OPV modules seem ideal for the combination with polymer absorbers. An adhesive between the OPV module and the polymer absorber is used for the thermal and mechanical coupling to achieve a good heat transfer and bonding forces between the OPV modules and the absorber.

Silicone PV cells operate most efficiently at low cell temperatures due to their negative temperature coefficient, while the solar thermal application requires a certain fluid temperature level (Lämmle et al. 2017). OPV modules have a constant or even positive temperature coefficient (Brabec 2004). This means that the electrical power is independent of the cell temperature, or even increases slightly with higher cell temperatures. Thus, the application of OPV modules in PVT collectors offers more synergies regarding suitable operating temperatures.

Theoretically, the OPVT collector can be carried out in an unglazed or glazed design variant, with air or water as heat transfer fluid. Fig. 3 shows a schematic cross section of a water-type, unglazed OPVT collector with an extruded polymer absorber from either PP or PPS. For instance, this low-cost, low-weight OPVT collector concept is applicable for stand-alone thermosiphon systems or façade collectors that generate both electricity and heat in a single component.

Several constructive challenges have to be met concerning the technical realization of the OPVT collector 
concept, which are described in the following. Firstly, a suitable OPV module is selected and qualified regarding the electrical performance, optical parameters and degradation at elevated temperatures. Secondly, a suitable bonding technique is developed to couple the OPV module and the polymer absorber mechanically and thermally. Thirdly, an unglazed OPVT collector is designed, built, and tested to demonstrate the functionality of the OPVT concept.

\section{Characterization of electrical and optical properties of the OPV module}

A commercial OPV module was selected and qualified regarding its electrical performance, optical characteristics and degradation at elevated temperatures (Fig. 1).

An electrical efficiency of $\eta_{\mathrm{el}, \mathrm{STC}}=5.7 \%$ was measured in the flasher at the CalLab PV Modules of Fraunhofer ISE. The mentioned efficiency relates to the active OPV module area AOPV, i.e. the non-active area of the cell connectors and the white module border is disregarded.

In contrast to silicone PV technologies, the module temperature has only a small effect on the electrical power. The measurement of the power temperature coefficient yielded $\gamma_{\mathrm{OPV}}=-0.035 \% / \mathrm{K}$. Thus, the drop of electrical power due to temperature increase is smaller by a factor of 10 , than for crystalline silicone PV modules, with a typical temperature coefficient of $\gamma_{\mathrm{c}-\mathrm{Si}}=-0.42 \% / \mathrm{K}$.
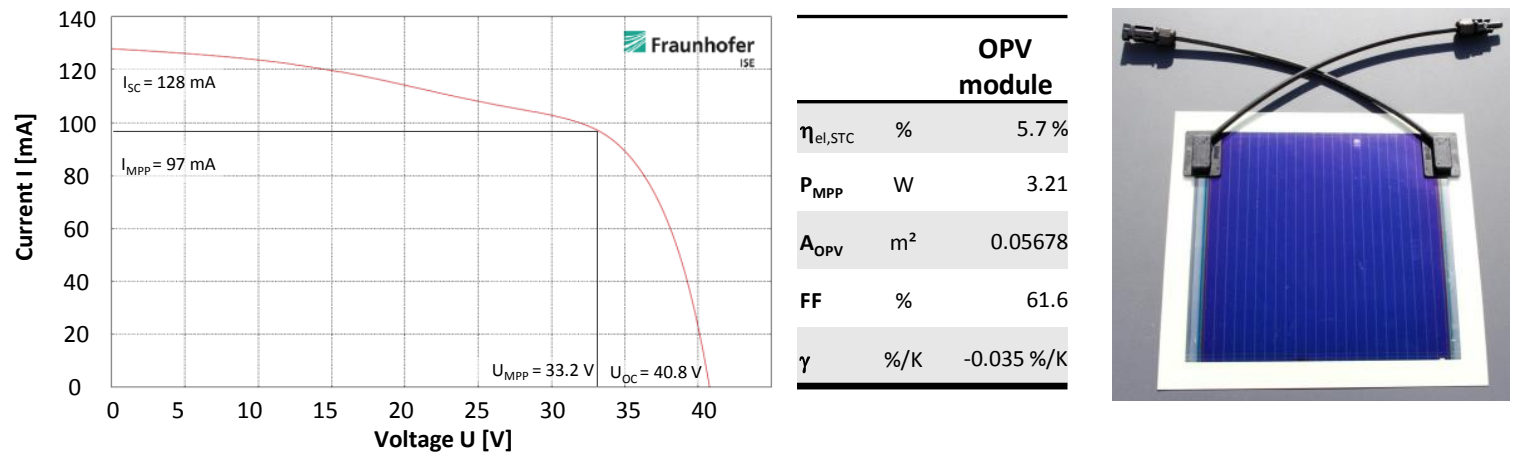

Fig. 1: Electrical characterization of an organic photovoltaic module

The relatively low electrical efficiency of organic PV modules at its current commercial stage is expected to increase in the future. Currently, the production stage of the OPV modules is still in the pilot phase. In the following years, the production lines will be scaled up with an expected drop of production costs and an increase of electrical efficiency.

A sufficiently high optical absorptance of the OPV module is important with regards to the thermal operation. The optical characteristics of the OPV module were measured in a Fourier spectrometer. A relatively low absorptance of $\alpha_{\mathrm{AM} 1.5}=0.65$ and a high reflectance of $\rho_{\mathrm{AM} 1.5}=0.35$ was registered in the AM1.5 spectrum (Fig. 2). The TCO front electrode and the metal back electrode are most likely responsible for the high reflection losses. The high reflectance above $\lambda=0.8 \mu \mathrm{m}$ is considered a challenge for the thermal operation, resulting in a low effective transmittance-absorptance product $(\tau \alpha)_{\text {eff }}$ and a low thermal conversion factor $\eta_{\mathrm{th}, 0}$.

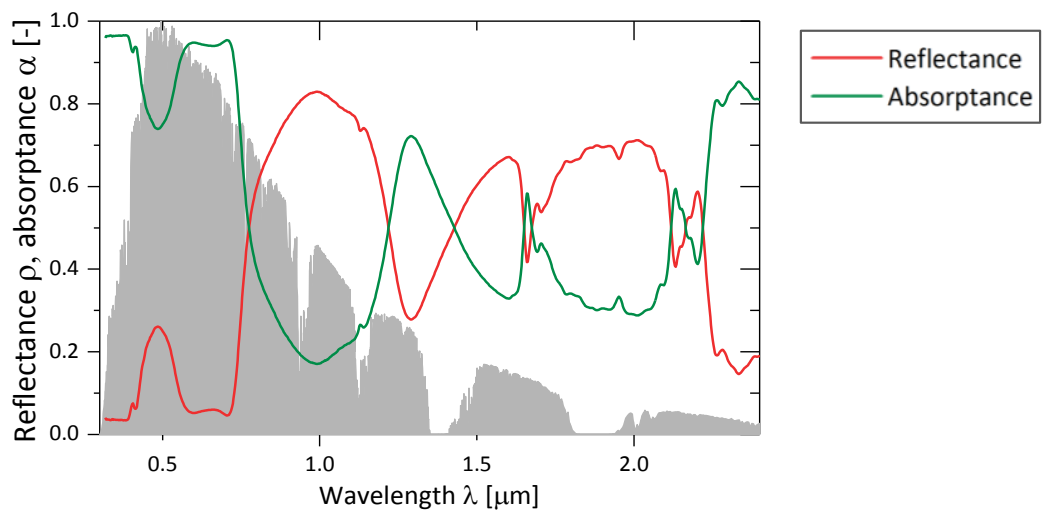


Fig. 2: Characterization of optical properties of organic photovoltaic modules for the application in OPVT collectors

\section{Development of OPVT absorber and bonding process}

The OPVT absorber consists of the OPV module and the polymer absorber, which are bonded by a suitable adhesive (Fig. 3). The selected OPV module uses a backsheet foil of either polyethylene terephthalate (PET) or polyvinyl fluoride (PVF). A polymer absorber in a twin-wall design from either polypropylen (PP) or high-performance polyphenylene sulfide (PPS) is employed.

The glued OPVT compound couples different materials with different thermal expansion coefficients. This requires a balanced choice of components and materials to reduce thermo-mechanic stress and enhance heat transfer.

A multitude of samples with varying type of adhesive, layer thickness, surface pretreatment and method of application were designed. Prior and after ageing, their mechanical properties were characterized. Accelerated ageing tests based on IEC VDI 61215 (2016) included high temperature exposure, thermal cycling, humidity freeze, damp heat, and combined thermal and mechanical loads.

A butyl rubber-based adhesive was selected for the application in the OVPT absorber. The selected adhesive combines good mechanical properties, temperature stability, processability and good heat transfer characteristics.
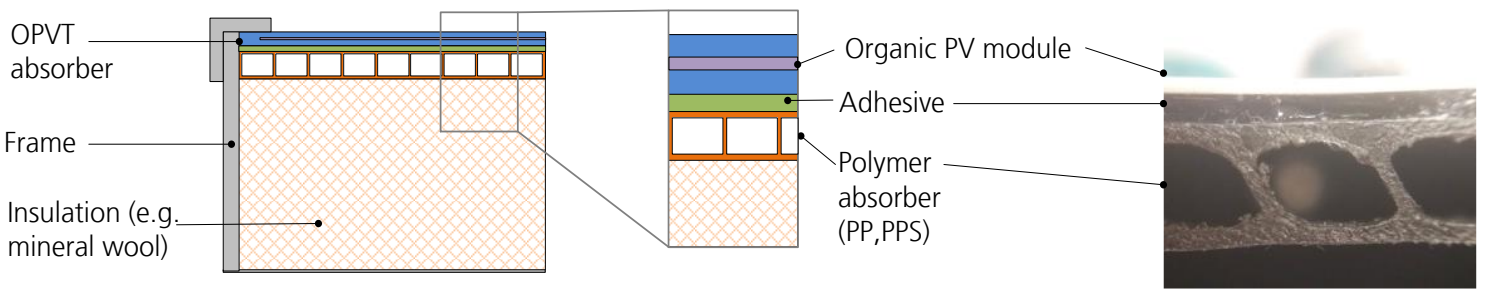

Fig. 3: OPVT collector concept: schematic cross section of an unglazed collector and a glued OPVT absorber compound

\section{Test results of OPVT demonstrators}

Different collector concepts were assessed numerically with a validated numerical PVT collector model (Lämmle et al. 2016). Fig. 4 shows the resulting simulation results of an unglazed and glazed OPVT collector at wind speeds of $u_{\text {wind }}=3 \mathrm{~m} / \mathrm{s}$.

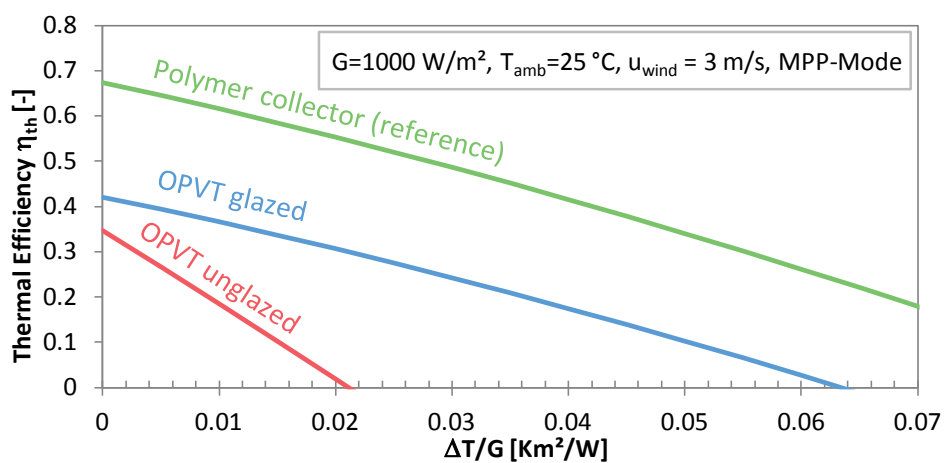

\begin{tabular}{lccc}
\hline & & $\begin{array}{c}\text { OPVT } \\
\text { glazed }\end{array}$ & $\begin{array}{c}\text { OPVT } \\
\text { unglazed }\end{array}$ \\
\hline$\eta_{\mathrm{th}, 0}$ & & 0.421 & 0.347 \\
$\mathbf{c}_{1}$ & $\mathrm{~W} / \mathrm{m}^{2} \mathrm{~K}$ & 5.316 & 15.971 \\
$\mathbf{C}_{2}$ & $\mathrm{~W} / \mathrm{m}^{2} \mathrm{~K}^{2}$ & 0.021 & 0.021 \\
$\mathbf{T}_{\text {stag }}$ & ${ }^{\circ} \mathrm{C}$ & 113.5 & 71.1 \\
\hline
\end{tabular}

Fig. 4: Simulation results of thermal efficiency of an unglazed and glazed OPVT collector

Due to the high reflection losses, the conversion factor $\eta_{\text {th, }, 0}$ is significantly below that of the Aventa reference polymer collector. The thermal losses of the unglazed PVT collector are high due to the absence of a front cover. At the same time, the stagnation temperatures are uncritical and remain below $\mathrm{T}_{\text {stag }}=72{ }^{\circ} \mathrm{C}$.

An optimized collector design for the OPVT collectors was derived from the numerical simulations (Fig. 5). By adjusting the level of thermal insulation, these designs take into account the maximum stagnation temperatures, which the materials (OPV module, adhesive) should not exceed. 

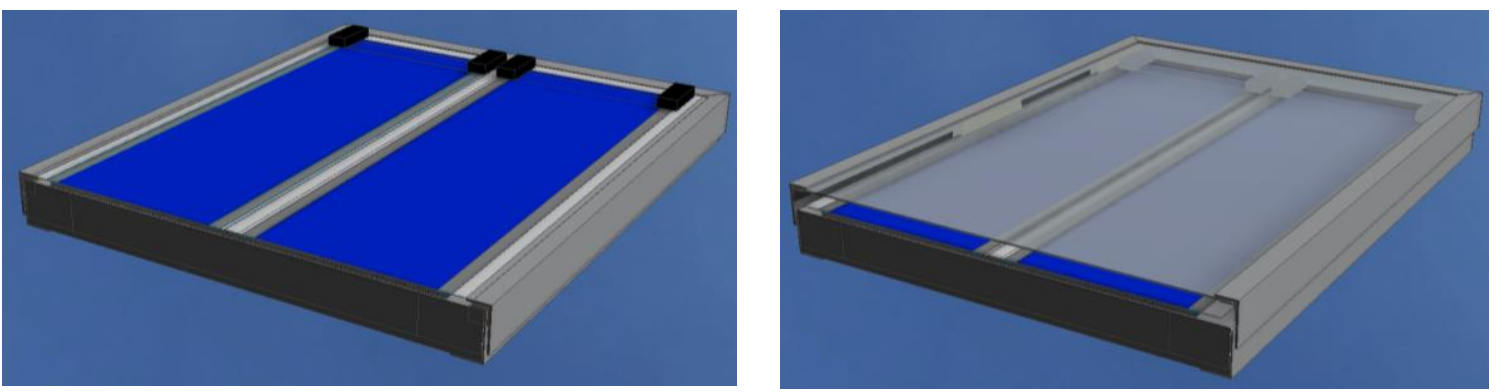

Fig. 5: CAD drawings of the unglazed and glazed OPVT collector designs

As first demonstrator, the unglazed OPVT collector was built. The unglazed OPVT collector features two strips of OPV film glued to a twin-wall PP absorber with the mentioned butyl rubber adhesive. The aperture dimensions amount to $2.0 \mathrm{~m} \times 0.6 \mathrm{~m}$, or $1.21 \mathrm{~m}^{2}$, while the active OPV area amounts to $0.92 \mathrm{~m}^{2}$. Thus, the collector achieves an electrical packing factor of $\mathrm{PF}=0.76$.
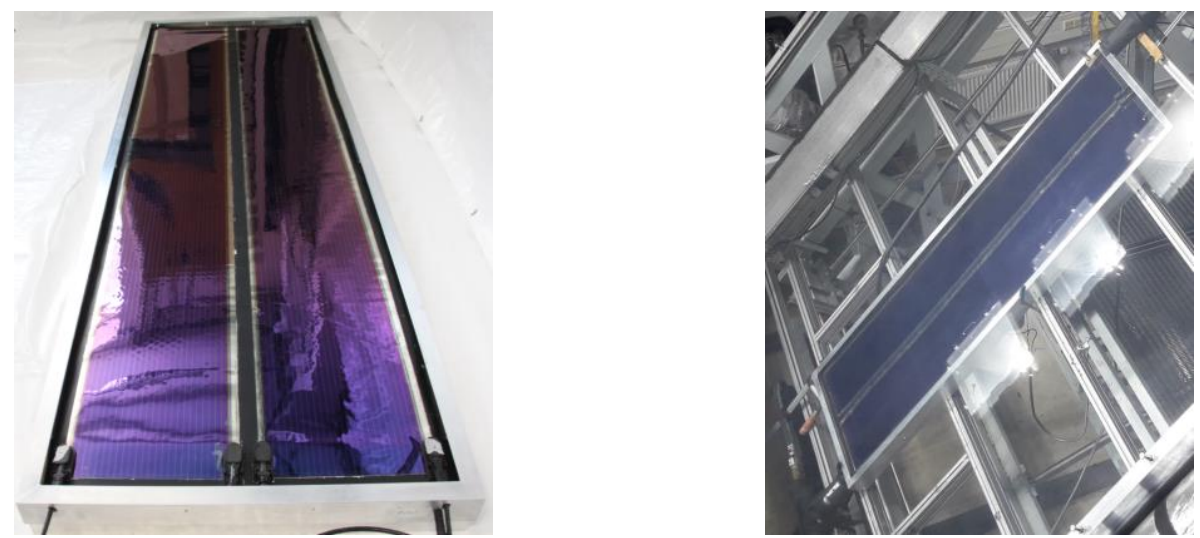

Fig. 6: Unglazed OPVT collector in the solar simulator

The performance of the unglazed OPVT collector was characterized with the steady-state approach in the solar simulator of the TestLab Solar Thermal Systems of Fraunhofer ISE (Fig. 6). The tests of the wind and infrared sensitive collector (WISC) take into account three levels of wind speed in the collector plane $\left(\mathrm{u}_{\mathrm{wind}}=0 \mathrm{~m} / \mathrm{s}, 1.5 \mathrm{~m} / \mathrm{s}, 2.6 \mathrm{~m} / \mathrm{s}\right)$.

Fig. 7 shows the electrical and thermal performance curves for the different wind speeds. The infrared sensitivity, denoted by the collector parameter $c_{5}$, was excluded from the analysis. Hence, the collector parameters $\eta_{\mathrm{th}, 0}, \mathrm{c}_{1}, \mathrm{c}_{3}$ and $\mathrm{c}_{6}$ are evaluated to describe the thermal power output, based on ISO 9806 (2017):

$$
\eta_{t h}=\frac{\dot{Q}}{A_{a p} \cdot G}=\eta_{t h, 0}-c_{1} \frac{\left(T_{m}-T_{a m b}\right)}{G}-c_{3} \frac{u_{w i n d}\left(T_{m}-T_{a m b}\right)}{G}-c_{6} u_{w i n d}
$$

The performance parameters indicated in Fig. 7 are obtained by the application of multiple linear regression. In contrast to ISO $9806(2017)$, the efficiency relates to the aperture area $\left(A_{a p}=1.21 \mathrm{~m}^{2}\right)$ instead of the gross collector area $\left(\mathrm{A}_{\mathrm{g}}=1.38 \mathrm{~m}^{2}\right)$. 


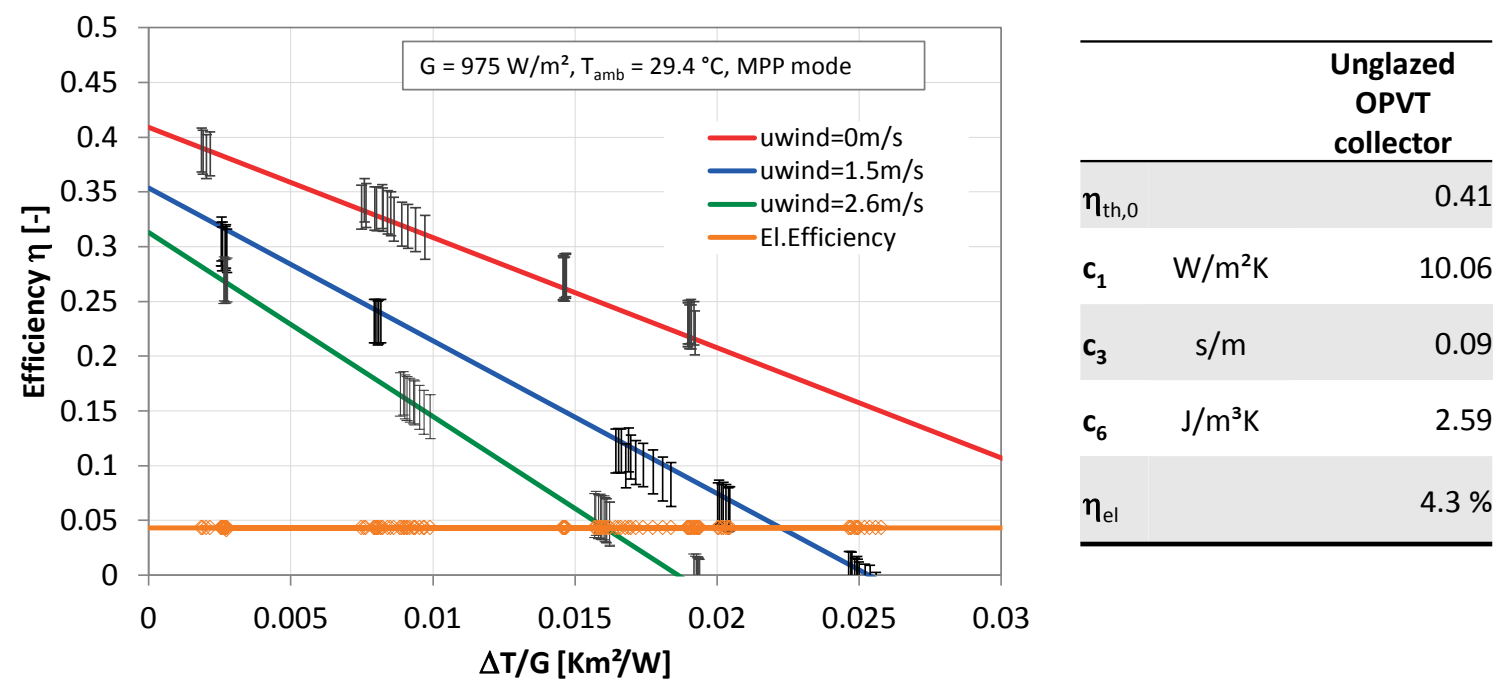

Fig. 7: Characterization of electrical and thermal performance of the unglazed OPVT collector in the solar simulator of the TestLab Solar Thermal Systems. Efficiency related to aperture area $A_{\text {ap }}=\mathbf{1 . 2 1} \mathbf{~ m}^{2}$.

All tests were carried out applying an electrical load in the form of a MPP tracker. The electrical power is basically constant and amounts to $\mathrm{E}_{\mathrm{OPV}}=50.5 \mathrm{~W} \pm 0.3 \mathrm{~W}$ for all steady-state test points. Neither the wind velocity nor the mean fluid temperature have an observable effect on the power output. This is a particularly interesting effect, as for conventional PVT collectors, the electrical and thermal operation are closely interlinked.

The measured electrical efficiency amounts to $\eta_{\mathrm{el}}=4.3 \%$. This corresponds to the rated electrical efficiency of the employed OPV module of $\eta_{\mathrm{el}, \mathrm{STC}}=5.7 \%$ and the packing factor of $\mathrm{PF}=0.76$.

\section{Conclusion and outlook}

This paper presented a novel hybrid PVT collector combining organic PV modules and polymer absorbers. This combination promises synergies regarding materials, manufacturing process, and operating temperatures. The low-cost, low-weight OPVT collector aims at existing markets (stand-alone thermosiphon systems, façade integrated collectors) and novel applications (car washing station, bus station, car parking building).

The major development challenges concern the evaluation of ageing effects of the OPV module and adhesives, the development of a suitable bonding process for the OPVT absorber, and the high optical reflection losses of the OPV module.

A first unglazed OPVT collector was designed, built, and tested. The thermal performance is in the range of crystalline silicone PVT products that are commercially available $\left(\eta_{\mathrm{th}, 0}=41 \%\right)$. Nonetheless, an optimization of the absorptance of the OPV module is the key for an enhanced thermal performance. At the current early commercial stage of organic photovoltaics, the electrical efficiency is still comparably low $\left(\eta_{\mathrm{el}}=4.3 \%\right)$ but a significant increase is expected for OPV modules from future production lines.

Test results of a glazed OPVT collector are pending and will be published subsequently.

\section{Acknowledgements}

This work was funded by BMWi (Germany Ministry of Economic Affairs), grant number 0325873. The authors are grateful for this support and thank the project partners for the fruitful cooperation. The results also contribute to the work and discussion of IEA SHC Task 60 - PVT systems. 


\section{Publication bibliography}

Brabec, Christoph J. (2004): Organic photovoltaics. Technology and market. Solar Energy Materials and Solar Cells 83 (2-3), pp. 273-292. DOI: 10.1016/j.solmat.2004.02.030.

ISO 9806 (2017): ISO 9806:2017 Solar energy - Solar thermal collectors - Test methods.

Lämmle, Manuel; Kroyer, Thomas; Fortuin, Stefan; Wiese, Martin; Hermann, Michael (2016): Development and modelling of highly-efficient PVT collectors with low-emissivity coatings. Solar Energy (130), pp. 161173. DOI: 10.1016/j.solener.2016.02.007.

Lämmle, Manuel; Oliva, Axel; Hermann, Michael; Kramer, Korbinian (2017): PVT collector technologies in solar thermal systems: a systematic assessment of electrical and thermal yields with the novel characteristic temperature approach. Solar Energy (155), pp. 867-879. DOI: 10.1016/j.solener.2017.07.015.

Sandnes, BjØrnar; Rekstad, John (2002): A photovoltaic/thermal (PV/T) collector with a polymer absorber plate. Experimental study and analytical model. Solar Energy 72 (1), pp. 63-73. DOI: 10.1016/S0038092X(01)00091-3.

61215, 2016: Terrestrial Photovoltaic (PV) Modules - Design qualification and type approval - Edition 1.0.

Zondag, H.A. (2008): Flat-plate PV-Thermal collectors and systems: A review. Renewable and Sustainable Energy Reviews 12 (4), pp. 891-959. 


\title{
Degradation of photovoltaic systems based on long-term measurements and laboratory tests
}

\author{
Thomas Schott, Franziska Kuonen, Urs Muntwyler, Eva Schüpbach
}

Bern University of Applied Sciences BFH, Engineering and Information Technology, Photovoltaic

Laboratory, Burgdorf, Switzerland

\begin{abstract}
Results of the analysis of long series of measurements of photovoltaic (PV) plants in Switzerland are presented. The tree PV systems, Jungfraujoch, 3'450 m a.s.l (Alps), Mont-Soleil, 1'270 m a.s.l. (Jura) and Tiergarten, 530 asl. (Swiss Basin) are part of the long-term measurement program of the Photovoltaic Laboratory (PV LAB) at the Bern University of Applied Sciences BFH in Burgdorf (Switzerland). The focus of the long-term measurement program is the question of the effective degradation of photovoltaic plants that have been in operation for more than 20 years, representing different climatic zones in Switzerland. The findings provide essential information about aging-related power losses of PV systems.
\end{abstract}

Keywords: Photovoltaic systems, long-term measurement, degradation, power losses, Jungfraujoch, Mont-Soleil

\section{Introduction}

In the 1990s, in the Swiss Alps (Jungfraujoch, 3'450 m a.s.l., Birg-Schilthorn, 2'677 m a.s.1.), in the Swiss Jura (Mont-Soleil, 1'270 m a.s.l.) and in the Swiss Midland (roof of the Bern University of Applied Sciences BFH in Burgdorf, $540 \mathrm{~m}$ a.s.1..) installed PV systems (Siemens modules) and measured since then (Mont-Soleil only since July 1st, 2001) by the Photovoltaic Laboratory (PV LAB) of the BFH (see e.g. Häberlin, 2010, Muntwyler et al., 2014, Schüpbach et al., 2014 and www.pvtest.ch). This long-term monitoring makes it possible to compare the solar technology used in four different climate zones in Switzerland. The processing of the measurement series is also done by BFH Bachelor students (see for example Breitinger and Moser, 2017).

This article presents the results of the evaluations for the photovoltaic systems Mont-Soleil (Figure 3), Jungfraujoch (Figure 4) and PV plant Tiergarten on the roff of the BFH in Burgdorf, which represent the climate zones Jura (Mont-Soleil), Alps (Jungfraujoch) and Swiss Midland (Tiergarten, Burgdorf).

\section{Calculation of annual degradation}

For the calculation and comparison of the PV systems, the normalized yields YA of the PV modules and the normalized reference yield YR of the pyranometer mounted next to the modules are used (Figure 1).

\begin{tabular}{|l|}
\hline Symbol / Term \\
$\begin{array}{l}\text { Y } \\
\text { = theoretical yield } \\
\text { measured by the } \\
\text { pyranometer }\end{array}$ \\
$\begin{array}{l}Y_{A}=\text { Array Yield } \\
=\text { Generator (DC-) } \\
\text { performance }\end{array}$ \\
\hline
\end{tabular}

\begin{tabular}{|c|c|}
\hline Meaning / Definition & Unit \\
\hline $\begin{array}{l}Y_{R} \text { is equal to the time } \\
\text { that the sun has to shine } \\
\text { with } G_{0}=1 \mathrm{~kW} / \mathrm{m}^{2} \text { to } \\
\text { irradiate the energy } \mathrm{HG}_{\mathrm{G}} \\
\text { onto the solar generator }\end{array}$ & {$\left[\frac{k W h / m^{2}}{d \cdot 1 k W / m^{2}}\right]=\left[\frac{h}{d}\right]$} \\
\hline $\begin{array}{l}Y_{A} \text { is equal to the time } \\
\text { that the } P \vee \text { plant has to } \\
\text { operate with its nominal } \\
\text { power } P_{0} \text { to generate } \\
\text { array (DC-) energy } E_{A}\end{array}$ & {$\left[\frac{k W h}{d \cdot 1 k W}\right]=\left[\frac{h}{d}\right]$} \\
\hline
\end{tabular}

Figure 1: Normalised representation (Häberlin, 2010). 
Since YR represents the actual trapped energy yield and YA represents generator yield converted by the plant, YA can be set in relation to YR and the quotient can be formed. This gives us an indicator for the degradation of a PV system (Figure 2).

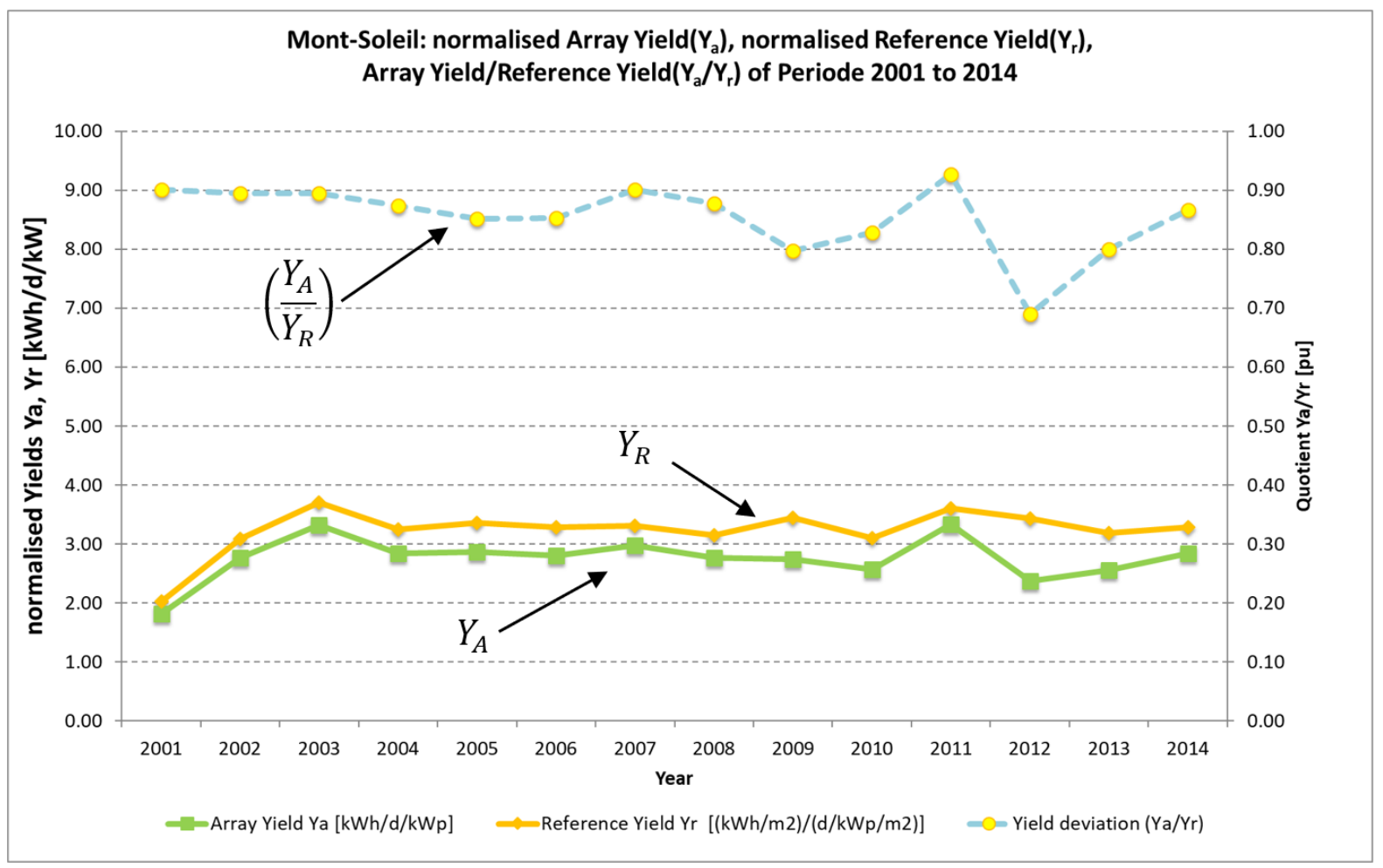

Figure 2: Use of the normalized representation for the determination of the degradation.

When applying a linear curve fit to the graph, the factor a in the function $\mathbf{y}=\mathbf{a x}+\mathbf{b}$ gives the gradient representing the average degradation of the PV modules per year. For the photovoltaic plant on Mont-Soleil, from which the period from 1 July 2001 to 31 December 2014 is available, this results in a degradation of $0.72 \%$ per year (Figure 5).

Snow that remains lying on the PV modules (Figure 3) and shutdowns of the inverter lead to an age-related reduction in DC yield YA. These failures cause a greater degradation of the plant in the calculation than it is effectively the case. Therefore, more attention is being paid to the Jungfraujoch PV plant, where a good data series from 1995 to 2014 is available. This is also because the system is mounted on the façade of the research building and barely covered by snow (Figure 4).

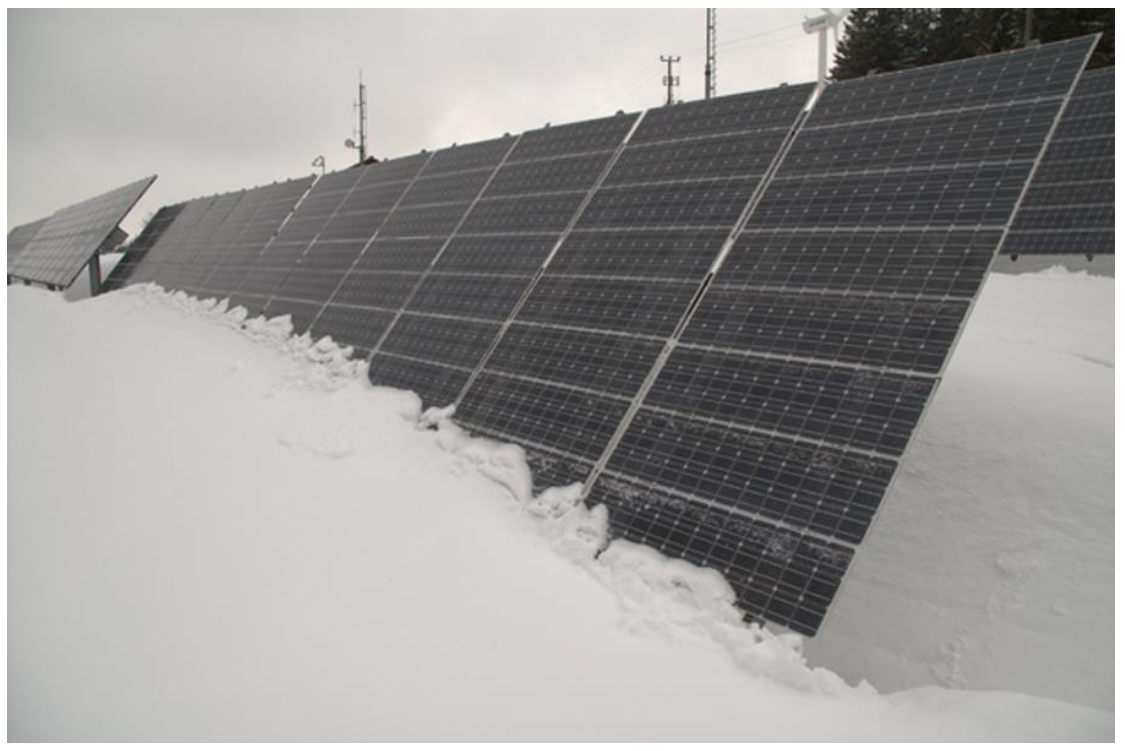

Figure 3: PV system Mont-Soleil with snow-covered modules in winter 2009. 


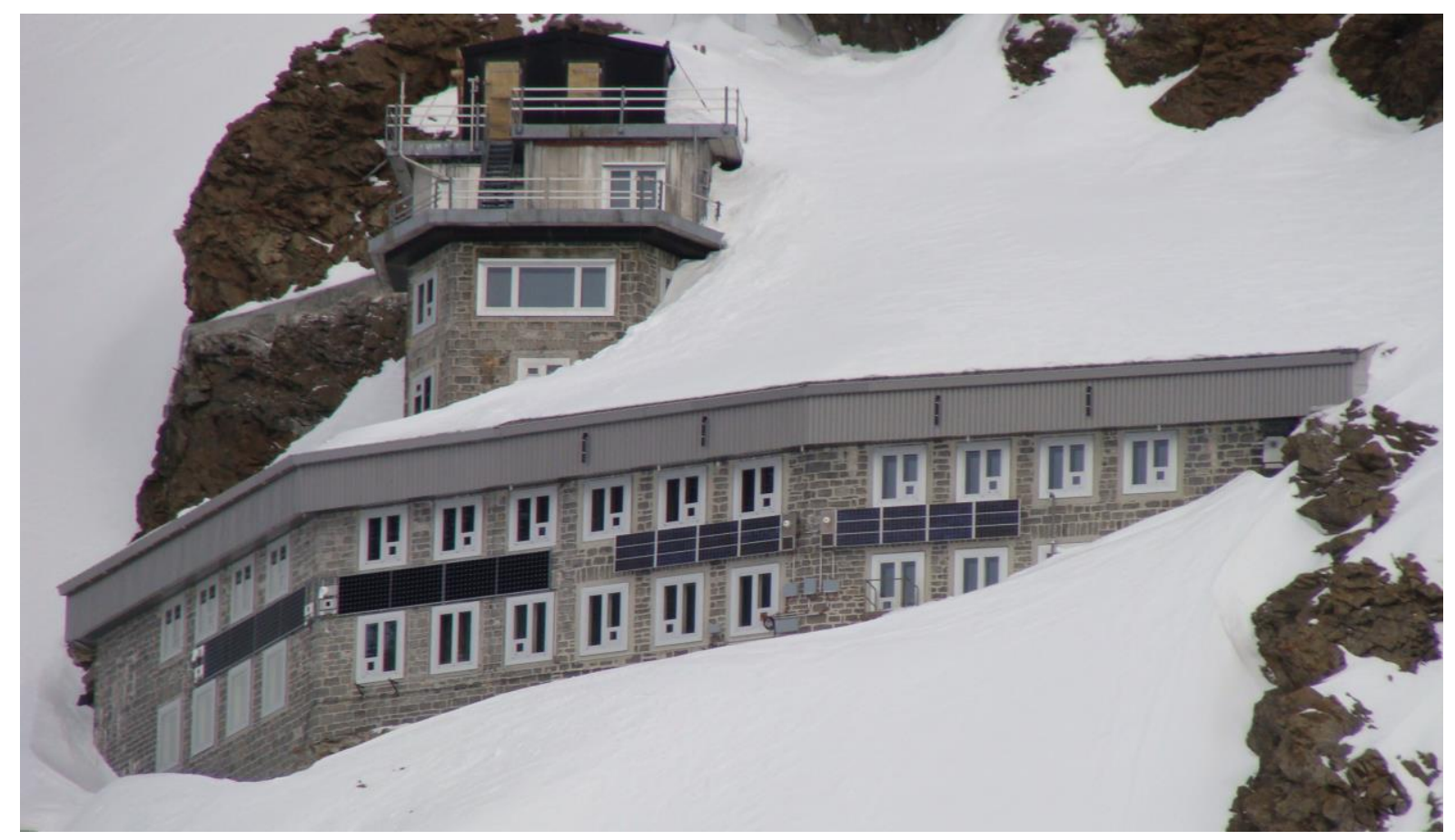

Figure 4: General view of the Jungfraujoch PV system.

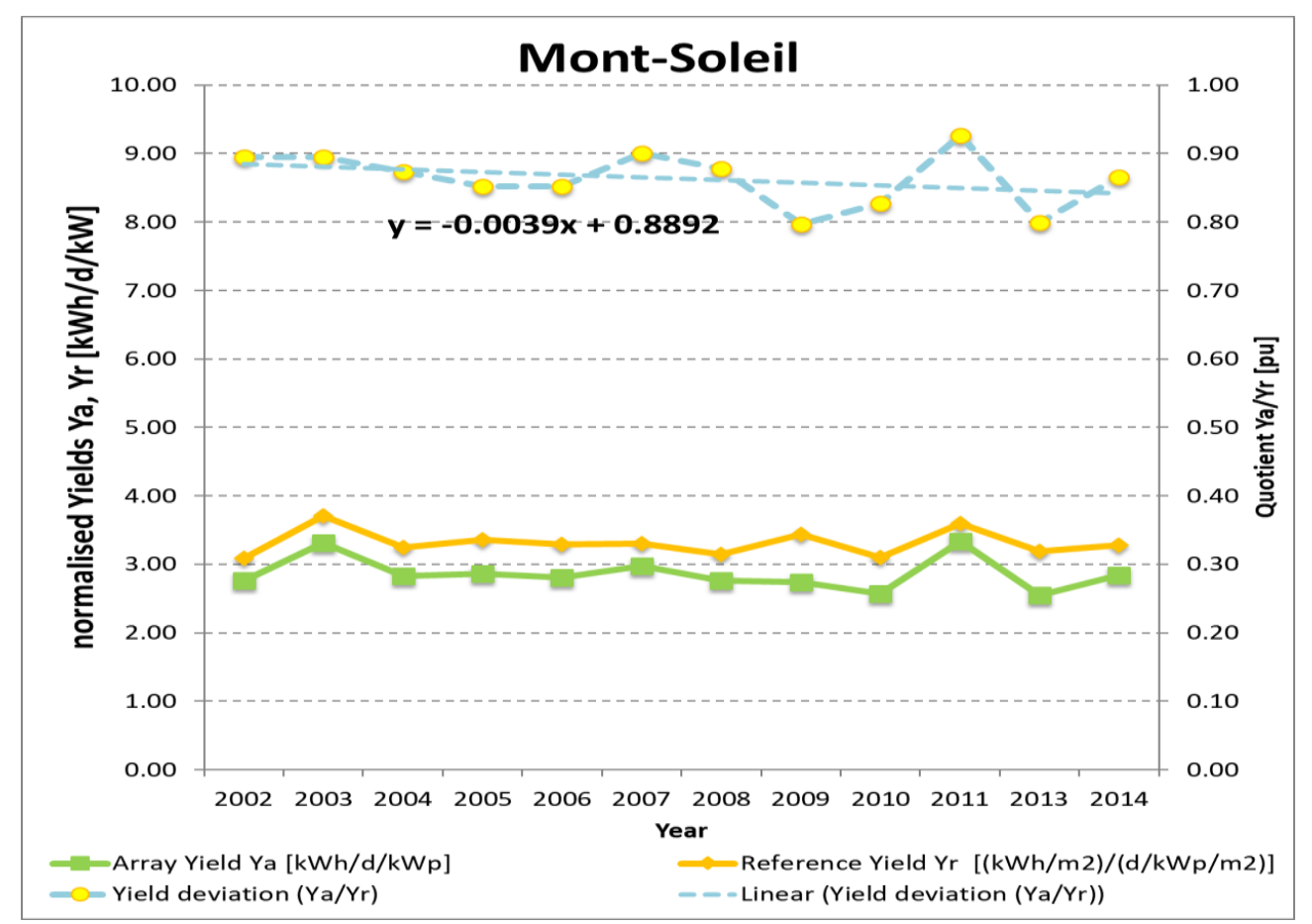

Figure 5: Degradation of 0.39\% per year of the Mont-Soleil PV plant (July 2001 - December 2014). The relatively low value in 2012 (yield deviation) is due to failures due to snow and inverter failures and is excluded in the calculation.

$$
\begin{aligned}
& \frac{\text { Degradation }}{\text { year }}=y^{\prime}=-0.0039 \\
& \frac{\text { Degradation }}{\text { year }}[\%]=-0.0039 \cdot 100=0.39[\%]
\end{aligned}
$$

As Figure 6 shows, the photovoltaic system on the Jungfraujoch from the data series from 1995 to 2014 results in a reduction of the effective yield (degradation) of only $0.11 \%$ per year. 
$\frac{\text { Degradation }}{\text { year }}=y^{\prime}=-0.0011$

$\frac{\text { Degradation }}{\text { year }}[\%]=-0.0011 \cdot 100=0.11[\%]$

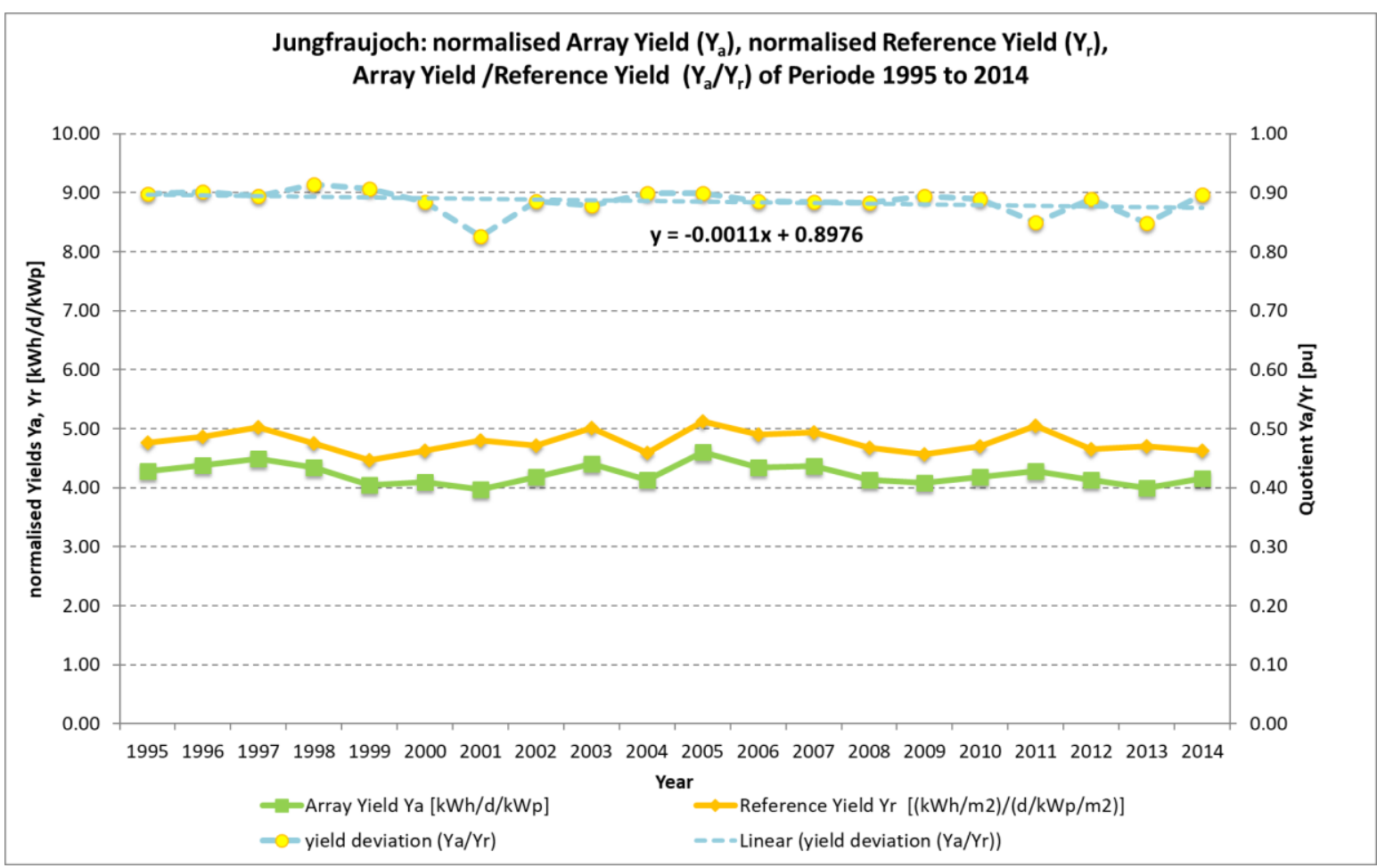

Figure 6: Degradation of 0.11\% per year of the Jungfraujoch PV plant (January 1995 - December 2014).

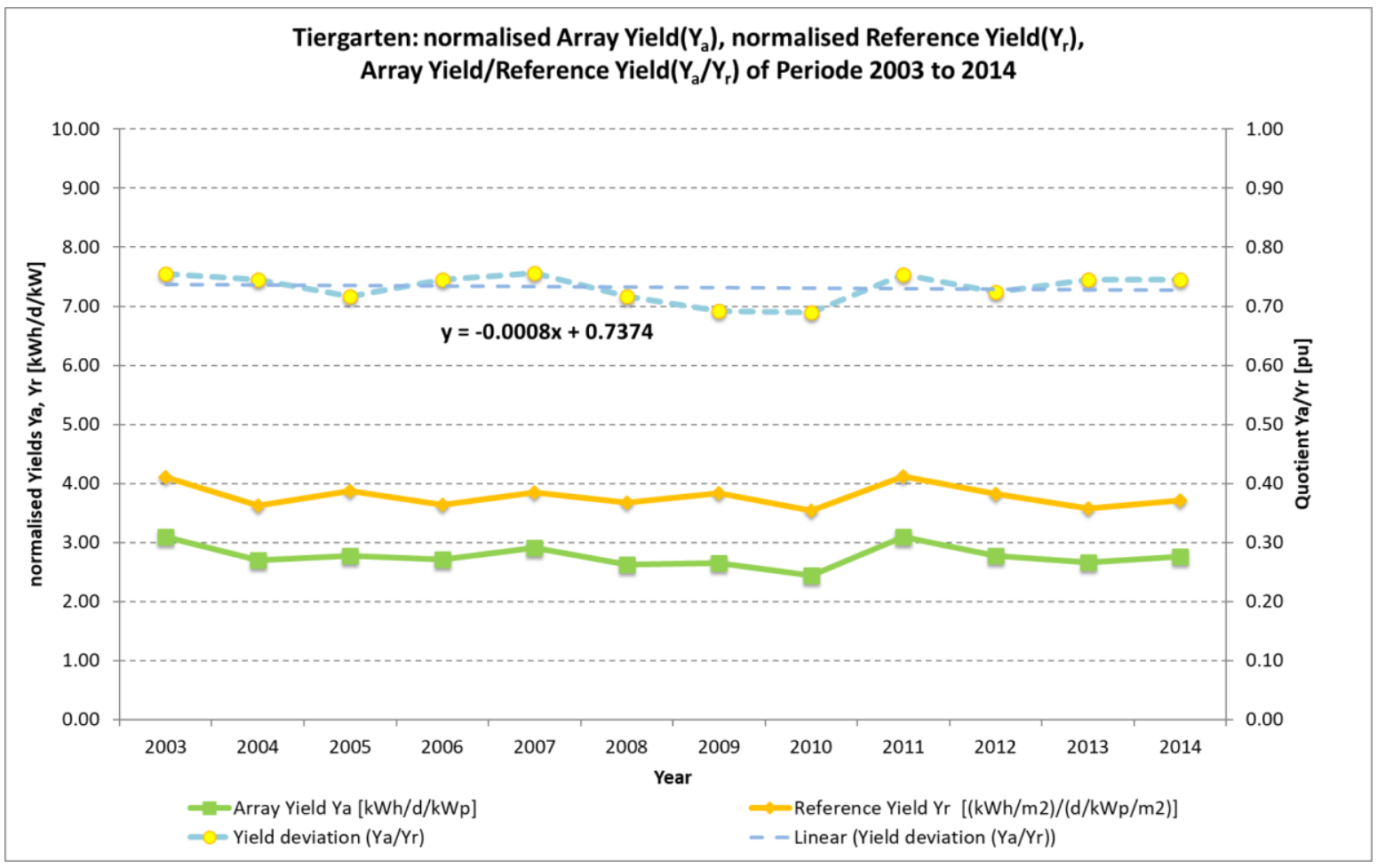

Figure 7: Degradation of 0.08\% per year on the roof of the BFH in Burgdorf (January 2003 - December 2014).

$\frac{\text { Degradation }}{\text { year }}[\%]=-0.0008 \cdot 100=0.08[\%]$ 


\section{Plausibility test by measuring Jungfraujoch PV modules in the Laboratory}

\subsection{Proceeding}

In a next step, the plausibility of the annual degradation of the Jungfraujoch PV system calculated based on the long-term measurements was evaluated. Since the PV modules, installed on the Jungfraujoch in 1993 (Siemens modules M75) with a power of $48 \mathrm{Wp}$, were not measured before installation, there is thus no reference value for the time of commencement of the measurement. However, since we know the bandwidth in which the photovoltaic modules installed on Jungfraujoch had been delivered, we can use the calculated degradation values to find the initial value at the beginning of the measurement and determine whether this is within the known bandwidth. Thus, although we have no exact reference, but a good guide to the plausibility estimate.

According to the data sheet, the production tolerance is $\pm 10 \%$. This results in a power bandwidth of a maximum of $52.8 \mathrm{Wp}$ to a minimum of $43.2 \mathrm{Wp}$. From discussions between the founder of the PV LAB (Prof. Dr. Heinrich Häberlin) and the then module supplier, we know that the effective performance of the 1990s supplied modules for the PV system Jungfraujoch was below the nominal $48 \mathrm{Wp}$. The effective power of the individual modules must therefore have been between the minimum $(43.2 \mathrm{Wp})$ and the nominal $(48 \mathrm{Wp})$ value in the 1990s (i.e., when new).

\subsection{Laboratory measurements}

In June 2017, two Siemens Modules M75 (48 Wp) were removed from the PV plant on the Jungfraujoch, which had been in operation since 1993, and taken to the PV LAB of the BFH in Burgdorf for measurement. In the PV LAB of the BFH in Burgdorf, Breitinger and Moser (2017) analysed the performance of the modules with the flasher and recorded the state of the individual cells by means of electroluminescence. It was shown (Table 1) that one of the photovoltaic modules of the Jungfraujoch plant measured in the PV LAB was slightly below 43.2 Wp and the other PV module slightly above this value. On average, both flashed PV modules are just above the minimum of the production tolerance specified in 3.1.

Table. 1: Results of the flasher measurements of the two PV modules of the Jungfraujoch plant (Breitinger and Moser, 2017)

\begin{tabular}{|c|c|c|c|c|}
\hline Modul & SN 670898 & SN 670897 & Median & Mean value \\
\hline SN 670897 & $41.565 \mathrm{Wp}$ & $41.635 \mathrm{Wp}$ & $41.600 \mathrm{Wp}$ & $41.600 \mathrm{Wp}$ \\
\hline SN 670898 & $44.800 \mathrm{Wp}$ & $44.827 \mathrm{Wp}$ & $44.814 \mathrm{Wp}$ & $44.814 \mathrm{Wp}$ \\
\hline \multicolumn{3}{|c|}{ Median / Mittelwert } & $43.218 \mathrm{Wp}$ & $43.207 \mathrm{Wp}$ \\
\hline
\end{tabular}

Figure 8 shows the current-voltage curve of the PV module SN 670898 removed from the Jungfraujoch plant and examined in the PV LAB of the BFH (see section 3.2).
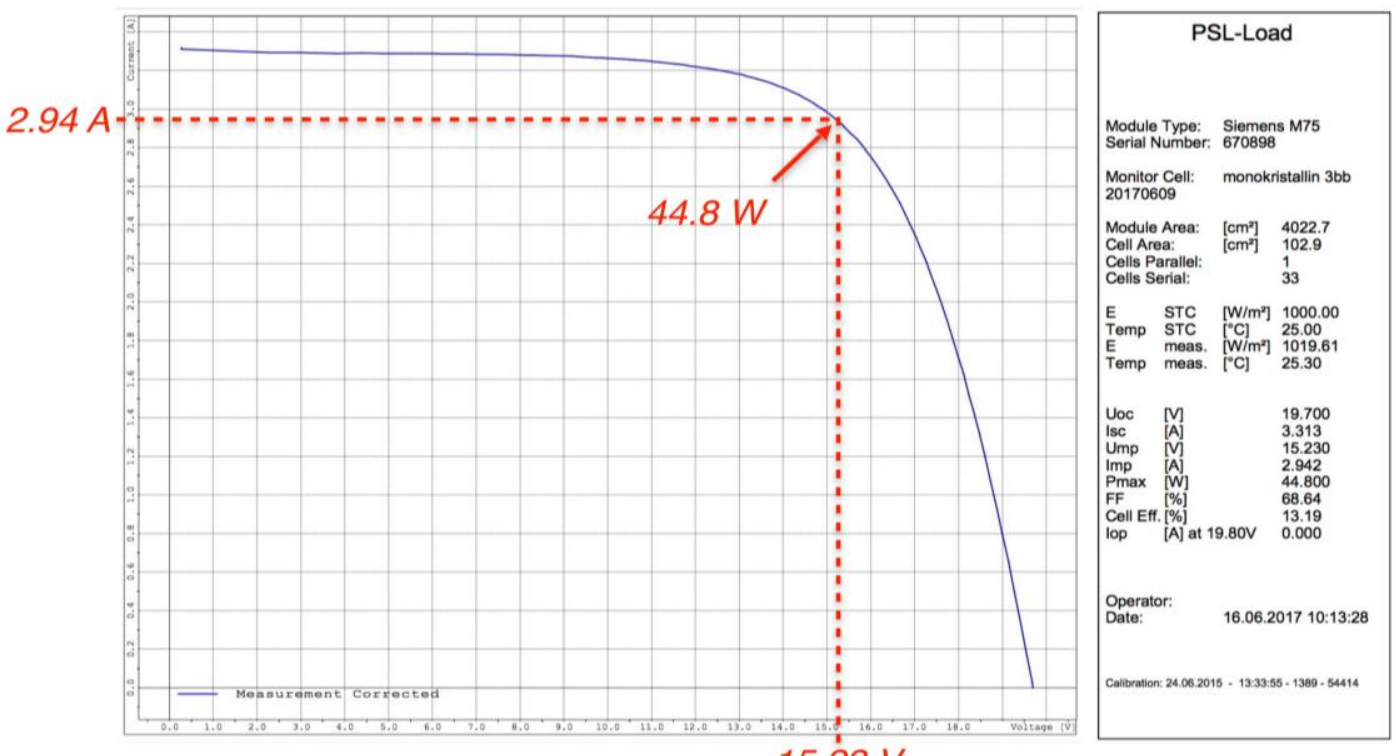

$15.23 \mathrm{~V}$

Figure 8 Flasher power of the SN 670898 module of the Jungfraujoch PV system. 
It can be seen that the performance of the (in the 1990s new) PV modules is pretty much in the middle of the restricted tolerance band between $\mathrm{P}_{\min }=43.2 \mathrm{Wp}$ and $\mathrm{P}_{\text {nominal }}=48 \mathrm{Wp}(48 \mathrm{Wp}+0 \% /-10 \%)$.

\section{Recalculation to new condition}

For the recalculation to the new condition, the period for the calculation of the annual degradation of the Jungfraujoch PV modules - using the methodology in item (2) - back to the beginning of the measurement (1995) was used (see Figure 6).

The recalculated initial value is $45.8 \mathrm{Wp}$ at an annual degradation of $0.11 \%$ on the Jungfraujoch (Figure 9). This confirms that our degradation of $0.11 \%$ per year calculated based on long-term measurements at the Jungfraujoch PV plant is plausible.

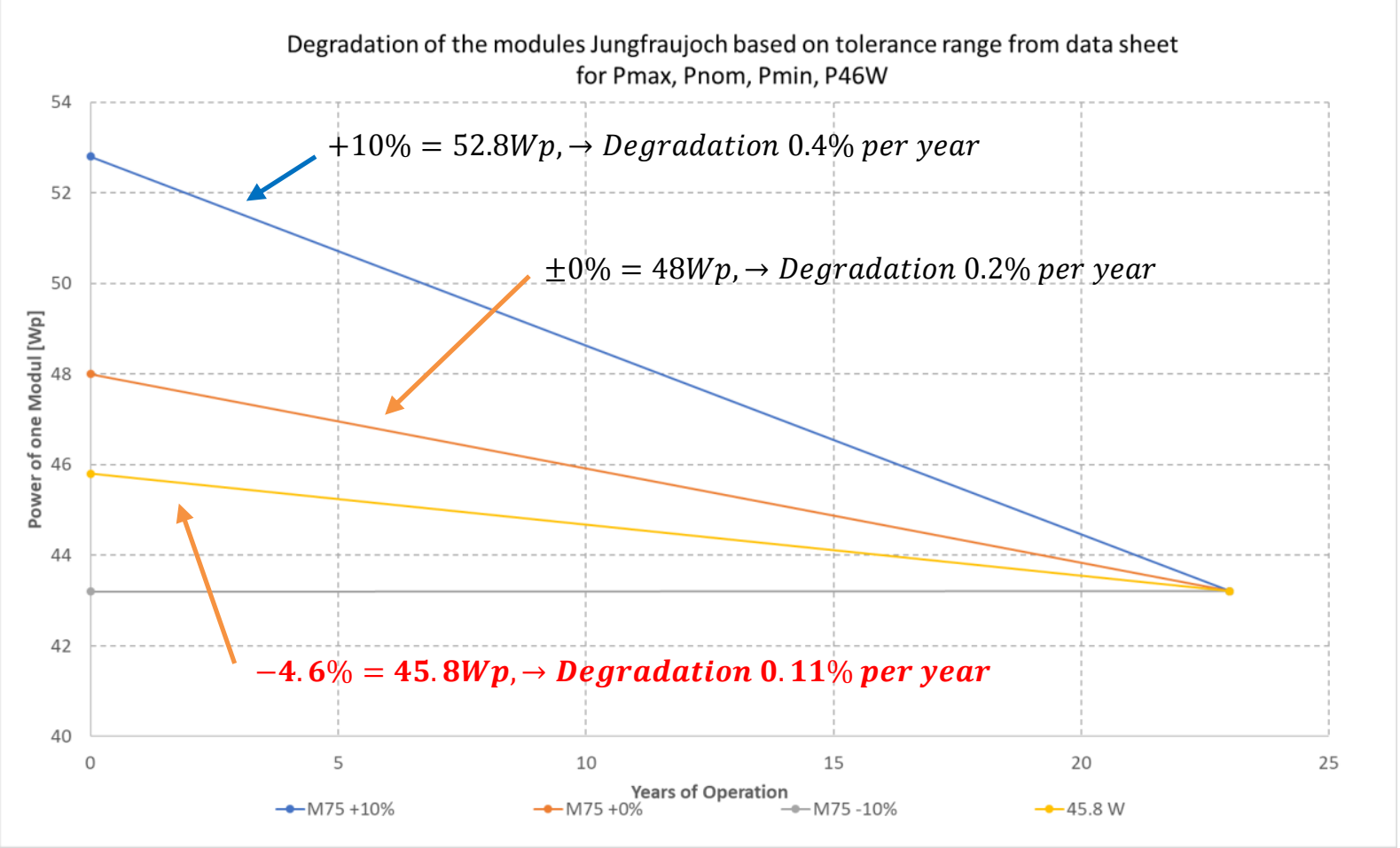

Figure 9: calculation of the average module output of the Jungfraujoch PV plant at $0.11 \%$ annual degradation back to the beginning (Figure 6).

\section{Conclusions}

The PV LAB of the BFH in Burgdorf (Switzerland) has been measuring numerous PV systems since the 1990s. Based on these long-term measurements, the power losses of the Mont-Soleil, Jungfraujoch PV plants and the plant on the roof of the BFH in Burgdorf were analyzed. For the period 2001-2014, the calculated annual degradation was $0.39 \%$ for the Mont-Soleil PV plant (1'270 m a s 1 . in the Jura). Further investigations must be made on this system i to exclude influences such as snow and inverter shutdowns, which disturb the calculation of the degradation. The degradation of the plant on the roof of the BFH in Burgdorf was $0.08 \%$.

With the relatively long data series from 1995 to 2014 of the PV plant Jungfraujoch (3'450 m a.s.l. in the Alps) an annual degradation of $0.11 \%$ could be found. This value was confirmed with a plausibility test based on flasher measurements and electroluminescence in the laboratory. 
From our analyses we conclude:

- That the modules used by the BFH from the 1990s aged much less than the modules from a study of the HTW Berlin in 1999 (Quaschning et al., 1999), and that the mechanical structure of PV modules is therefore not insignificant.

- It seems that the solar radiation has a very small influence on the aging of the PV cells, because with only $0.11 \%$ power loss per year on the Jungfraujoch, where the solar radiation is 1.45 times higher than on the Mont-Soleil, the power loss would have to be greater be.

- That other influences than the intensity of solar radiation are important for the aging of the PV modules, such as the

- Operating temperature

- $\quad$ Moisture (if the PV cells get moist -> "Packaging" of the cells)

- Material properties of the modules (glass, plastics, adhesives, etc.).

- Looking at the degradation of the three plants (25 years of operation), it is noticeable that they are below the $0.8 \%$ reported in the literature for all three plants (ca. factor 8 smaller). This means that these plants produce more than specified after the 25 years. For the Mont-Soleil plant, the year 2012 was omitted due to inverter failure from the evaluation. Nevertheless, the highest degradation can be found here. This comes from snow damage. The modules were mounted without frame and therefore are no longer in the warranty conditions.

\section{Outlook}

In a next step, the PV system Birg-Schilthorn (2'677 mü.M.) is examined. The aim is to compare the long-term degradation of PV systems in four different climate zones in Switzerland.

\section{References}

Breitinger D. und J. Moser, 2017, Auswertung 25 Jahre PV-Anlage Mont-Soleil, (unveröffentlichte) Bachelor Thesis, Berner Fachhochschule BFH Burgdorf (Schweiz).

Häberlin, H., 2010, Photovoltaik, Strom aus der Sonne für Verbundnetz und Inselanlagen, Verlag electrosuisse.

Muntwyler, U., T. Schott und E. Schüpbach, 2014, Long-term study on the efficiency of photovoltaics at alpine sites, HFSJG Activity Report, 138-142.

Quaschning, V., A. Grochowski und R. Hanitsch, 1999, Alterserscheinungen bei Photovoltaikmodulen, Langzeiterfahrung einer PV-Testanlage an der TU-Berlin, 14. Symposium Photovoltaische Solarenerige, Staffelstein.

Schuepbach, E., U. Muntwyler, M. Jost, T. Schott, 2014: Long-term Performance of Swiss Photovoltaic (PV) Installations. Proceed. 29th European Photovoltaic Solar Energy Conference and Exhibition, 22-26 September 2014, Amsterdam, The Netherlands, 2689-2691. 


\title{
Development and Field Testing of a Novel Hybrid PV-Thermal Solar Collector
}

\author{
A. J. Murrell ${ }^{1}$, S. Povall ${ }^{1}$, C. Williams ${ }^{1}$, A. Mellor ${ }^{1,2}$, D. Alonso Alvarez ${ }^{2}$, \\ N. J. Ekins-Daukes ${ }^{3}$ \\ ${ }^{1}$ Naked Energy Ltd, Unit 72, Basepoint Business Centre, Crawley, RH11 7XX, UK \\ ${ }^{2}$ Department of Physics, Imperial College London, London SW7 2AZ, UK \\ ${ }^{3}$ The University of New South Wales, School of Photovoltaic and Renewable Energy Engineering, \\ Sydney NSW 2052, Australia
}

\begin{abstract}
This paper presents laboratory and field data of the new Virtu hybrid PV-thermal solar collector developed by Naked Energy Ltd. By mounting PV cells on a novel phase-change thermosyphon heat plate contained within an evacuated tube, Virtu can deliver hot water in the temperature range that is required for domestic hot water and space heating, whilst providing simultaneous electrical power. Laboratory tests show excellent performance at high output temperatures, and field data collected in Malta show that $40-60^{\circ} \mathrm{C}$ hot water can be delivered all year round. A transmissive low-emissivity coating has been developed and tested leading to further enhancement of the thermal performance.
\end{abstract}

Keywords: hybrid PV-T, solar thermal, emissivity, heating

\section{Introduction}

One effective approach to increase total solar conversion efficiency is to combine photovoltaic and solar thermal into a hydrid PV-T module(Zondag, 2008). By mounting the PV cells on a water cooled substrate, both heat and electrical power can extracted from the same area, increasing the overall power density and maximizing the energy that can be produced from a limited mounting area(Good et al., 2015). Active control of the module temperature can also offer advantages in PV output and long-term reliability. However, combining two technologies into a single module creates some technical challenges, especially as the largest solar thermal application markets require efficient operation in the temperature range $40-80^{\circ} \mathrm{C}$ (Fox et al., 2011; Ramos et al., 2017) (Figure 1), necessitating specific measures to avoid thermal losses to the environment (Mellor et al., 2018).

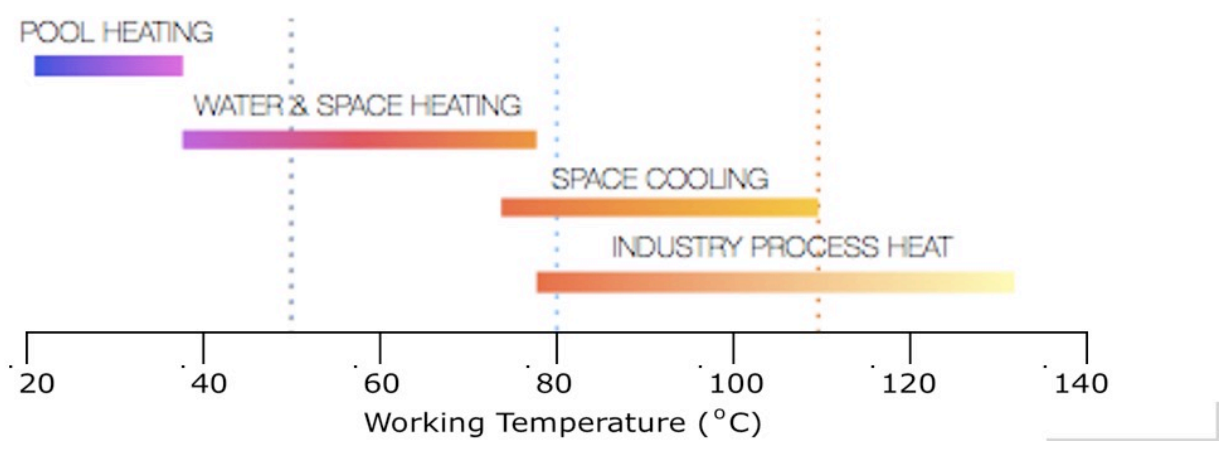

Figure 1. Typical working temperatures of different heat demands 


\section{Technology Elements}

This paper describes a new hybrid PV-T collector called Virtu, in which the PV cells are mounted in a vacuum tube and operated at temperatures up to $90^{\circ} \mathrm{C}$. A novel heat exchanger has been developed that contains a phase change thermo-syphon and delivers highly uniform temperature $\left(+/-2^{\circ} \mathrm{C}\right)$ across the front absorber surface. Mono-crystalline silicon PERC cells have been bonded to the heat exchange plate, but this bond has required careful materials selection to achieve the required vacuum performance and avoid thermal stresses. Vacuum levels within the tube have been optimized as a trade-off between thermal performance and manufacturing cost. A photo of a Virtu tube is shown in Figure 2 (a). Novel low emissivity coatings have also been deposited on to the PV cells, to control radiative losses at the higher operating temperatures. The collector is mounted with the tube horizontal (parallel to the eastwest axis) and the absorber tilted, making roof installation easier than conventional rack mounted panels and also achieving a very low profile on flat roofs (Figure 2 (c)). Self-shading between tubes is accommodated by an optimized spacing, with a linear reflector between each tube maximizing annual sun hour capture. This reflector delivers a peak $30 \%$ boost in both PV and thermal performance at very low incremental cost.

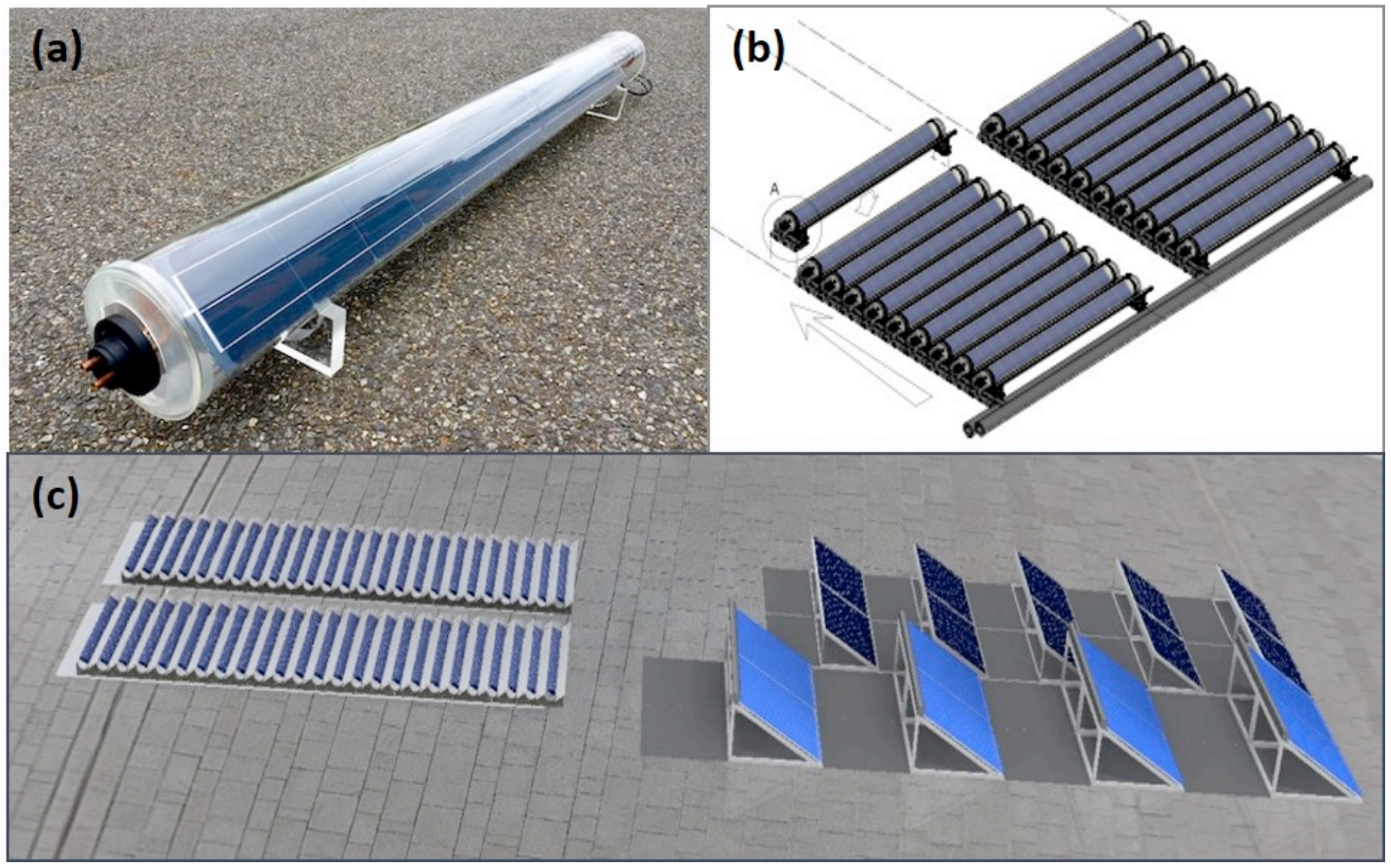

Figure 2. (a) Photo of a Virtu collector tube. (b) Schematic of Virtu's modular assembly. (c) Low profile and compactness of flat-roofmounted Virtu tube array compared to that of flat-plate collectors.

\section{Indoor Performance}

Lab testing and optimization of the collector design was carried out in-house using a bespoke designed 2.3 x $0.8 \mathrm{~m}$ solar simulator (Figure 3 (a)). The irradiance of the simulator is monitored using both a silicon reference cell and a pyrometer, and is close to $1000 \mathrm{Wm}-2$ during measurements. Both the thermal and electrical power output were measured simultaneously under a steady flow rate. The total absorber efficiency plotted in Figure 3 (b) is the sum of the electrical and thermal outputs relative to the radiant power incident on the absorber area. The collector is designed to be operated under vacuum, but we show also results for the same collector filled with air and with Argon for comparison.

The vacuum clearly has a marked effect on the collector performance at higher water 
temperatures, close-to doubling the total efficiency when delivering hot water at $60^{\circ} \mathrm{C}$ above ambient, as compared to the air- and Argon-filled configurations. The total efficiency of the evacuated Virtu collector is on a par with the higher-end of evacuated-tube solar-thermal collectors, and well above that of commercially available PV-T collectors. This demonstrates the efficacy of Virtu's thermal management and heat-plate performance.

(a)

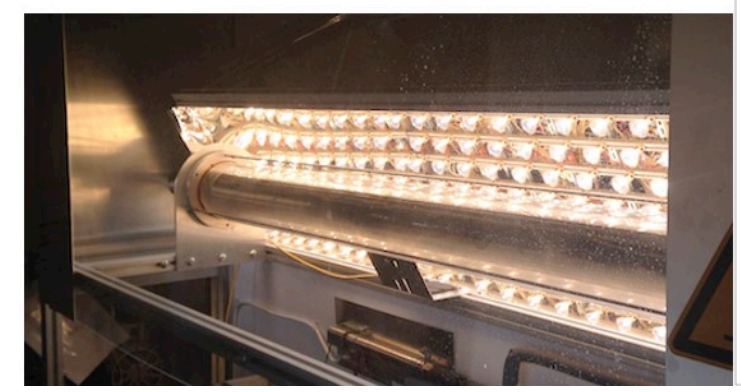

(b)

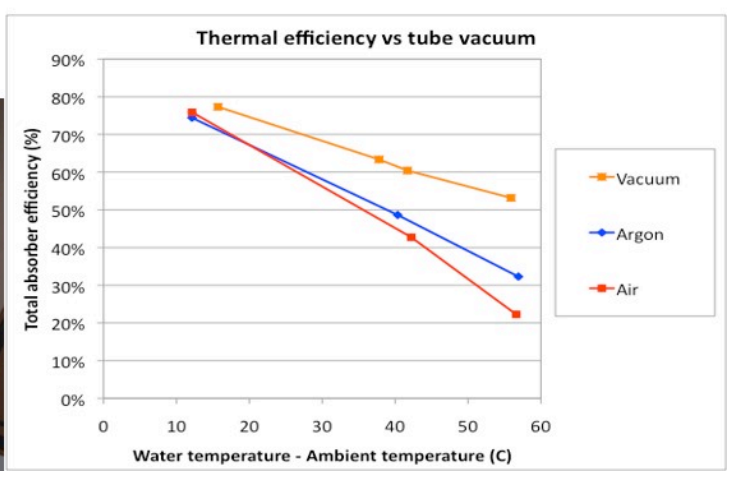

Figure 3 (a) A Virtu tube mounted in the solar simulator used for lab testing. (b) Thermal performance of an evacuated Virtu tube. Also shown is the performance of Virtu tubes when un-evacuated and containing air and Argon.

\section{Field Performance}

Outdoor testing of a manifold of 8 Virtu tubes was performed on the roof of the Dolmen Resort Hotel on the island of Malta over the course of a year. A photo of the array is shown in Fig 4 (a). Fig 4 (b) shows the maximum daily temperature averaged over each month, showing that the array is capable of delivering domestic hot water throughout the year. The daily average thermal and electrical energy output per collector tube is shown for each month in Fig 4 (c) and (d) respectively. The thermal-to-PV ratio reaches 3.8 at the height of summer, but falls to 2.5 in winter due to increased thermal losses when the ambient temperature is low. The thermal output in winter can be improved using transmissive low-emissivity coatings as described in the following section. 
(a)

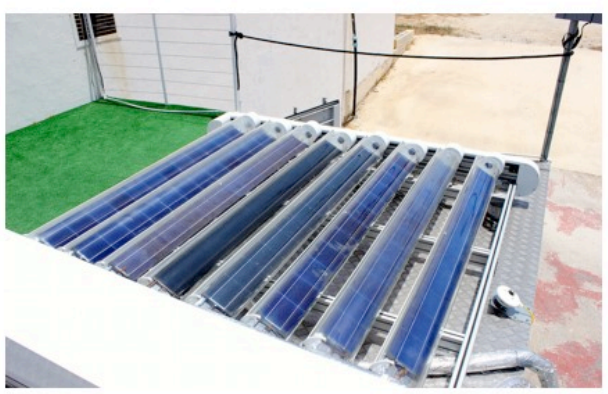

(c)

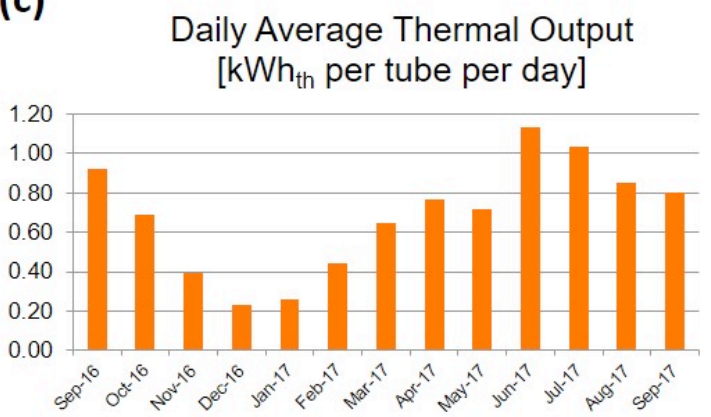

(b)

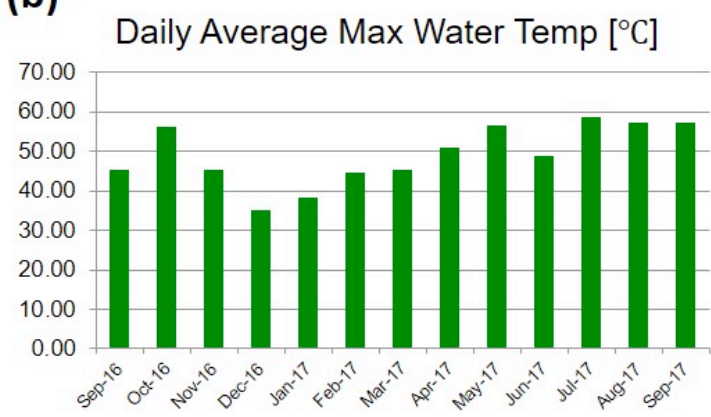

(d)

Daily Average PV Output $\left[\mathrm{kWh}_{\mathrm{el}}\right.$ per tube per day]

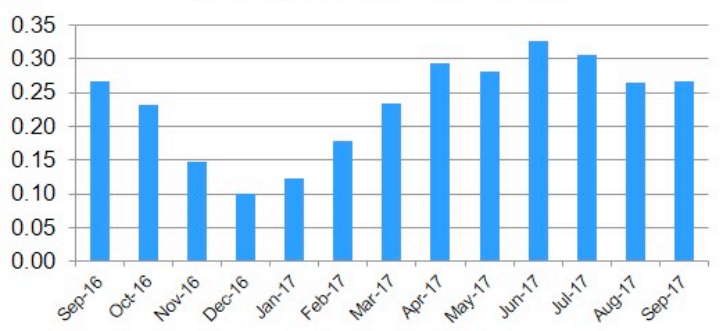

Figure 4. (a) Photo of the tube array used for outdoor testing in Malta. (b) Averaged maximum daily temperature each month over the course of the year. (c) Averaged daily thermal output each month over the course of the year. (d) Averaged daily electrical (PV) output each month over the course of the year.

\section{Future Directions - Low Emissivity Coatings}

To further control thermal losses, ITO-based low emissivity coatings have been developed in collaboration with Imperial College London (Alonso-Álvarez et al., 2017). The coatings are transmissive at solar wavelengths, allowing sunlight to reach the underlying PV cells, but are reflective in the near-infrared, reducing the thermal emissivity. The concept is shown schematically in Figure 5 (a) and a scanning-electron-microscopy (SEM) image of the ITO coating on a silicon PV cell is shown in Figure 5 (b).

The spectral absorptivity of ITO-coated and uncoated silicon PV cells was measured in the $300 \mathrm{~nm}$ to $16 \mu \mathrm{m}$ range by taking hemispherical reflectance and transmission measurements using an FTIR spectrometer with and integrating sphere, and is shown in Figure 5 (c). The spectral absorptivity and spectral emissivity are equal close to thermal equilibrium, and so the curves in Figure 5 (c) also represent the spectral emissivity of the coated and uncoated cells. Also shown for reference are the AM1.5G solar spectrum and a thermal blackbody spectrum at $60{ }^{\circ} \mathrm{C}$. The ITO coating reduces the emissivity from $80 \%$ to $50 \%$ at the peak wavelength of radiative thermal emission, but have only a small effect on the absorptivity at solar wavelengths. Figure 5 (d) shows light-IV curves of ITO-coated and uncoated PV cells. The presence of the ITO film leads to a small reduction in open circuit voltage, due to reduced light transmission into the cell, but the ITO deposition process does not reduce the open circuit or fill factor of the underlying solar cell.

Indoor tests were performed on two equivalent Virtu collector tubes using ITO-coated and uncoated PV cells. The electrical and thermal efficiencies are shown in Figure 5 (e) and (f) respectively. The ITO coatings cause a slight decrease in electrical efficiency, which is consistent with the aforementioned short-circuit-current drop (Figure 5 (d)). However, the benefit of the ITO coatings can be seen in Figure 5 (f), where 10-percentage-point improvement 
in thermal efficiency is observed at a reduced temperature of $0.06 \mathrm{Km}^{2} \mathrm{~W}^{-1}$.

(a)

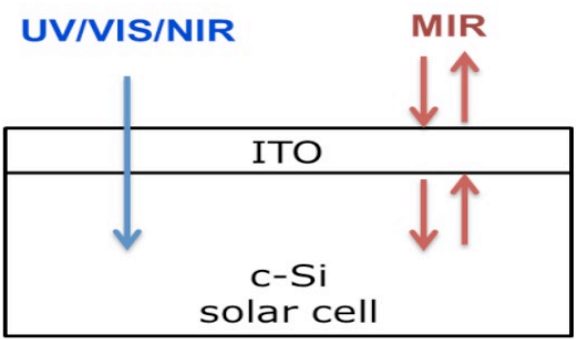

(c)
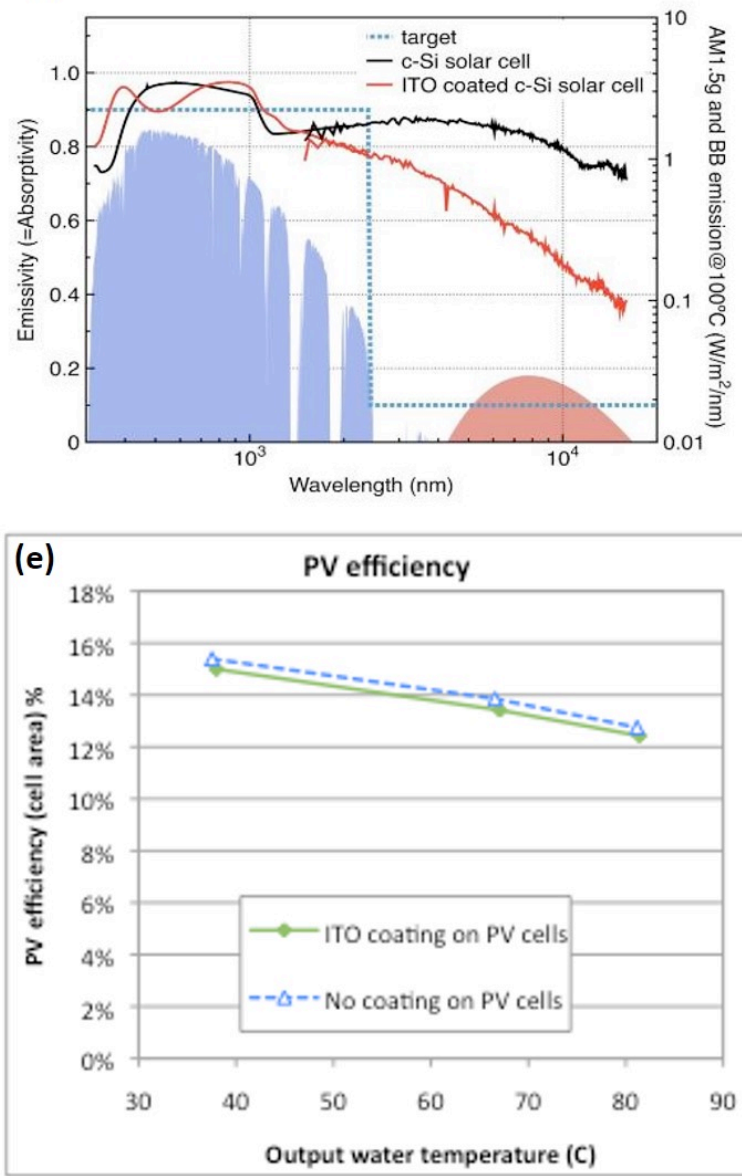

(b)

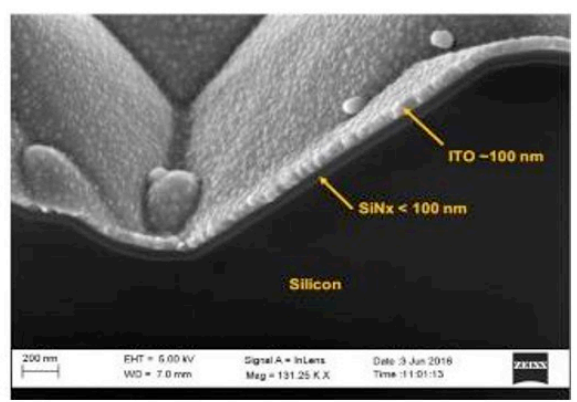

(d)
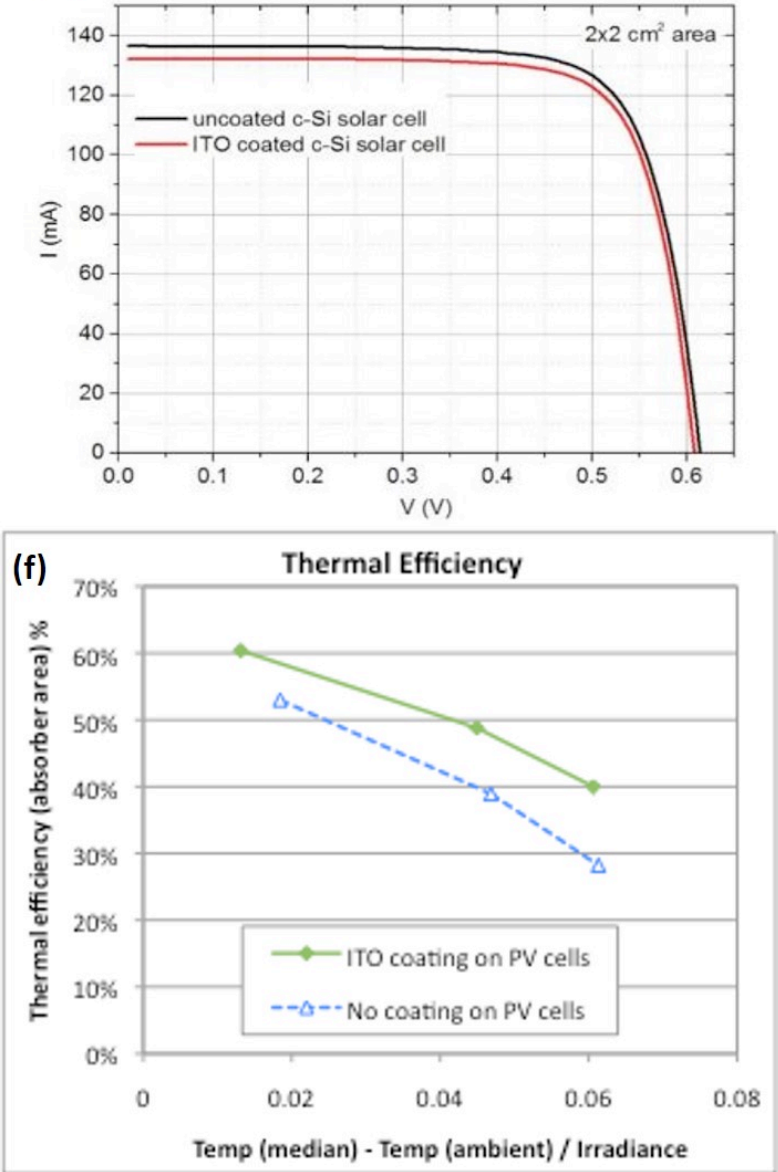

Figure 5. (a) Schematic of transmissive low-emissivity coating concept. (b) SEM image of ITO coating on Silicon PV cell. (c) Spectral emissivity (= absorptivity) of ITO-coated (red curve) and uncoated (black curve) silicon PV cells over the UV, visible and near infrared ranges. Also shown are the AM1.5 solar spectrum (blue shaded area - right axis), and a $60{ }^{\circ} \mathrm{C}$ thermal black-body spectrum (red shaded area - right axis). (d) light IV curves of ITO coated and uncoated silicon PV cells. (e) PV efficiency of Virtu collector tubes containing uncoated and ITO-coated cells. (f) Thermal efficiency of Virtu collector tubes containing uncoated and ITO-coated cells.

\section{Conclusions}

Virtu is a new hybrid PV-T collector in which the PV cells are mounted in a vacuum tube on phase-change thermo-syphon heat plate, and operated at temperatures up to $90^{\circ} \mathrm{C}$. Lab testing under a solar simulator has shown that the total efficiency of the Virtu collector is similar to that of high-performing solar thermal collectors, and well above that of other commercially available PVT collectors, particularly when delivering water in the $40-80^{\circ} \mathrm{C}$ temperature range required for domestic hot water and space heating. Field tests in Malta have shown that the tubes can deliver the temperatures required for domestic hot water all year round. Finally, a transmissive low-emissivity coating has been developed and tested leading to enhanced thermal efficiency with minimal electrical efficiency loss. Further improvements can be expected by 
continued optimization of the coating.

\section{References}

Alonso-Álvarez, D., Ferre Llin, L., Mellor, A., Paul, D.J., Ekins-Daukes, N.J., 2017. ITO and AZO films for low emissivity coatings in hybrid photovoltaic-thermal applications. Solar Energy 155, 82-92. DOI:10.1016/j.solener.2017.06.033

Fox, D.B., Sutter, D., Tester, J.W., 2011. The thermal spectrum of low-temperature energy use in the United States. Energy \& Environmental Science 4(10), 3731-3740. DOI: 10.1039/C1EE01722E

Good, C., Chen, J., Dai, Y., Hestnes, A.G., 2015. Hybrid Photovoltaic-thermal Systems in Buildings - A Review. Energy Procedia 70, 683-690. DOI: 10.1016/j.egypro. 2015.02.176

Mellor, A., Alvarez, D.A., Guarracino, I., Ramos, A., Lacasta, A.R., Llin, L.F., Murrell, A.J., Paul, D.J., Chemisana, D., Markides, C.N., Ekins-Daukes, N.J., 2018. Roadmap for the NextGeneration of Hybrid Photovoltaic-Thermal Solar Energy Collectors. Solar Energy(In Press).

Ramos, A., Chatzopoulou, M.A., Guarracino, I., Freeman, J., Markides, C.N., 2017. Hybrid photovoltaic-thermal solar systems for combined heating, cooling and power provision in the urban environment. Energy Conversion and Management 150, 838-850. DOI: 10.1016/j.enconman.2017.03.024

Zondag, H.A., 2008. Flat-plate PV-Thermal collectors and systems: A review. Renewable and Sustainable Energy Reviews 12(4), 891-959. DOI: 10.1016/j.rser.2005.12.012 


\title{
Study on Distributed MPPT System in Solar EV \\ Yuki Nemoto ${ }^{1}$ and Toru Fujisawa ${ }^{1}$ \\ ${ }^{1}$ Kanagawa Institute of Technology, Atsugi (Japan)
}

\begin{abstract}
In this study, we investigated a photovoltaic (PV) system for a solar powered Electric Vehicle (converted from a Honda Gyro Canopy). PV modules were installed on four surfaces of a rear-delivery-box (top, rear, right, and left). Each PV module had a maximum power point tracker (MPPT). To maximize total output power, two types of distributed MPPT systems using series-parallel connections were examined, and the output power was measured in outdoor experiments. The results clearly indicate that differences in the currents lead to a reduction of output power of the top and rear surfaces in a series-parallel system in which the left and right surfaces are in parallel.
\end{abstract}

Keywords: PV system, Solar EV, Converted EV, Distributed MPPT System, Through-mode

\section{Introduction}

One solution for environmental problems is the development of vehicles that utilizes renewable energy. The prevalence of vehicles that directly utilize solar energy is limited, particularly solar racing vehicles. Every year, emissions from automobiles are becoming increasingly regulated all over the world, especially in European countries. Since 2015, the Euro 6 standards (EU, 2012) have been adopted by products across the market, and vehicle emissions must be zero by 2040 (BBC, 2017; D. Muoio, 2017). We intend to develop a solar electric vehicle (EV) utilizing a park-and-solar-charge system for future commercial use in such vehicles as the Sion (Sono Motors, 2017) and the ehome (Dethleffs, 2018). In this study, the output power and conversion efficiency of a distributed photovoltaic (PV) system in a solar EV for personal mobility are discussed.

\section{PV System}

Fig. 1(a) shows the solar powered EV, which is converted from a Honda Gyro Canopy. Fig. 1(b) shows a delivery box installed on the rear of the solar EV. The power unit of the solar EV is a surface permanent magnet-type synchronous motor. Four PV modules and four pyranometers are installed on four surfaces (top, rear, left, and right) of the delivery box of the solar powered EV. The top surface contains 32 crystalline Si cells in its module and the other vertical surfaces contain 24 crystalline cells in each module. The total area of the four PV modules is $0.975 \mathrm{~m}^{2}$.

Fig. 2 illustrates block diagram of the PV system. Each PV module has a maximum power point tracker (MPPT) set on each individual surface. The power-generating system with the distributed MPPT charges a valve-regulated 27 Ah lead-acid battery. The MPPT is a KW-MPPT Rev 3.0 (Takanori, 2014), which is able to boost the output voltage to a range of $7.5 \mathrm{~V}$ (minimum) to $37 \mathrm{~V}$ (maximum). Its DC-DC efficiency is $99 \%$ with a voltage boost ratio of 1.1. The KW-MPPT has a through-mode function, which is activated when the input drops below $7.5 \mathrm{~V}$ or the boost ratio drops below 1.1. In through mode, the MPPT does not operate at the peak power point or boost the voltage, but photovoltaic current still flows.

In the distributed PV system, series, parallel, and series-parallel connections can be utilized to charge the battery (Toru, 2016). An ammeter and a voltmeter are connected to each input/output of the MPPT to measure its operating performance. ML-02 pyranometers (EKO, Tokyo) are set on the surface near each PV module for a total of four surfaces of irradiance being measured and compared at the same experimental conditions. 


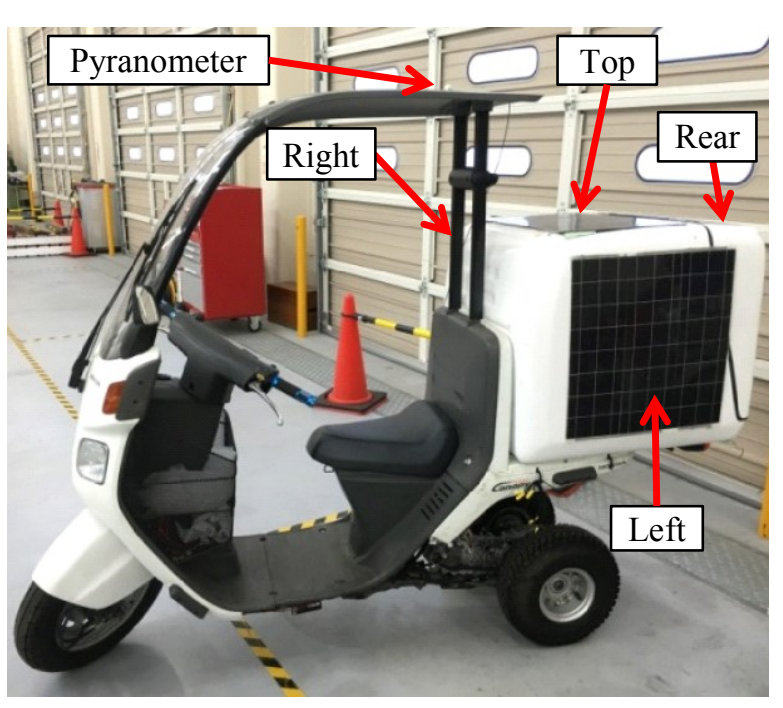

(a) Converted solar EV

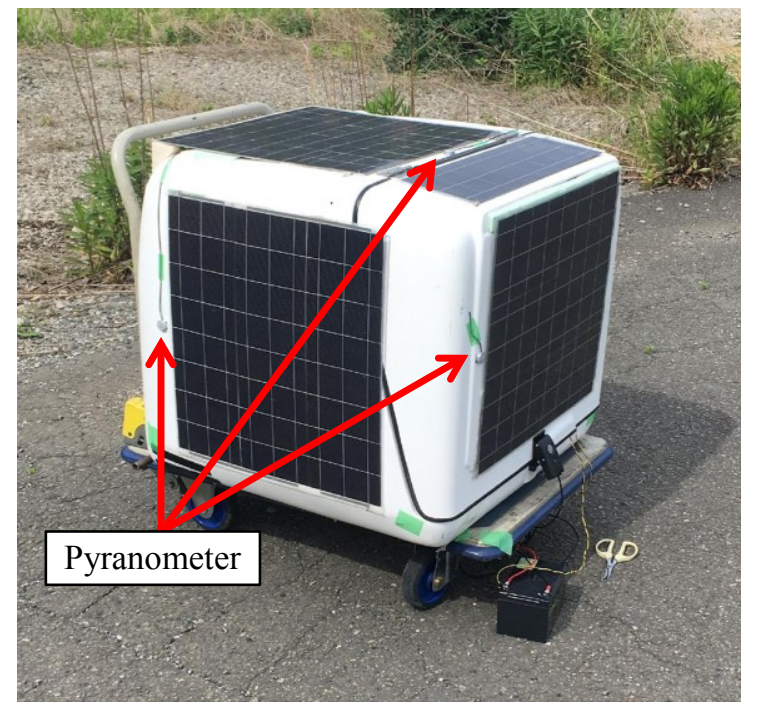

(b) Delivery box with PV modules on four surfaces

Fig. 1: Honda Gyro Canopy and delivery box

The photovoltaic conversion efficiency is measured with PV modules placed on the delivery box, as shown in Fig. 1(b). An I-V curve tracer from Oyo Electric (Kyoto) and the aforementioned pyranometers are used to evaluate the I-V characteristic curve and peak power point. In this experiment, the rear surface is oriented to the south. The I-V curve was measured every hour for each module on each surface on 26-Aug. 2018 from 9:25 to $15: 40$.

Tab. 1 shows the experimental results of irradiance and the maximum output power of the PV modules for each surface (top, rear, right, and left).

Tab. 1: Conversion efficiencies of photovoltaic modules

\begin{tabular}{|c|c|c|c|c|}
\hline Time & Top Surface & Rear Surface & Right Surface & Left Surface \\
\hline $9: 30$ & 11.14 & 6.213 & 11.09 & 6.141 \\
\hline $10: 30$ & 11.01 & 10.91 & 10.01 & 11.97 \\
\hline $11: 30$ & 10.90 & 10.07 & 10.27 & 10.89 \\
\hline $12: 30$ & 10.41 & 10.30 & 10.54 & 10.33 \\
\hline $13: 30$ & 10.72 & 9.388 & 9.960 & 11.53 \\
\hline $14: 30$ & 11.59 & 8.462 & 9.819 & 12.01 \\
\hline $15: 30$ & 12.15 & 8.255 & 9.081 & \\
\hline
\end{tabular}

\section{Experiments}

To evaluate the distributed MPPT system, outdoor experiments were conducted. We discuss two series-parallel systems. One system consists of two parallel PV modules on the left surface and the right surface of the delivery box. The other system consists of three parallel PV modules on the left, rear, and right surfaces of the delivery box. Fig. 2 shows the block diagrams of these systems. The load is provided by a valve-regulated $48 \mathrm{~V} / 27 \mathrm{Ah}$ lead-acid battery. Two Graphtec midi LOGGER GL200 units are used for data logging to measure the input/output current and voltage. A GL220 data logger is used to measure the irradiances. Resistors of $0.005 \Omega$ and $0.05 \Omega$ are respectively applied to measure the input and output currents for the MPPT. 


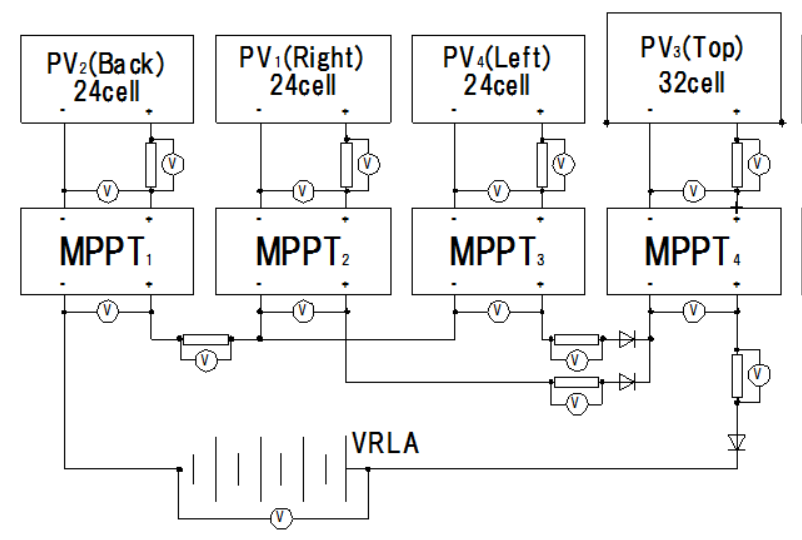

(a) Right and left panels in parallel

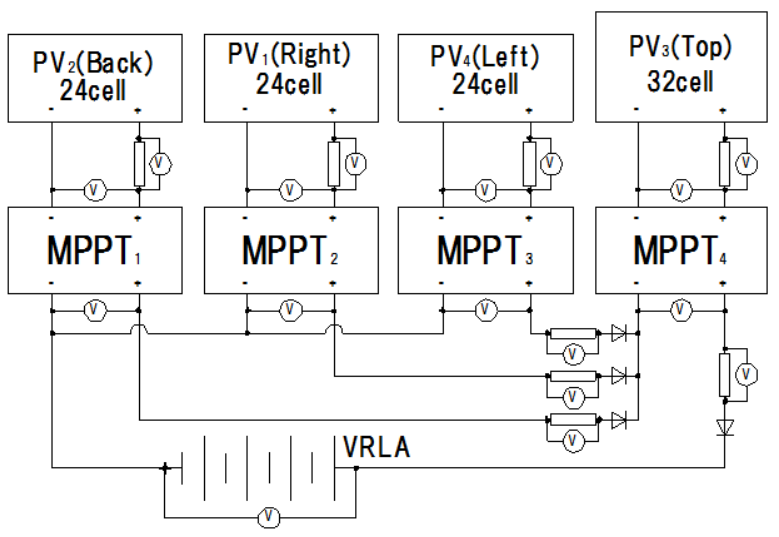

(b) Right, left, and rear panels are in parallel Fig. 2: Block diagrams of distributed MPPT system with series-parallel connections

\subsection{Series-Parallel (Right and Left) Connection}

An experiment was conducted outdoors to evaluate the series-parallel connection. In Fig. 2(a), it can be seen that the right and left surfaces are connected in parallel, since the I-V characteristic curve shows less output current for those surface - thus, they are intended to complement each output. The experiment was conducted on 1-May 2018 from 9:00 to 15:00 with the rear surface is oriented to the south. Fig. 3 shows the irradiance on each surface. Fig. 4 shows the output power for each surface. A peak irradiance of $1,121 \mathrm{~W} / \mathrm{m}^{2}$ (horizontal irradiance) was obtained on the top surface. Simultaneously, the incident irradiance of the other surface were $37.8 \%$, $21.9 \%$, and $30.7 \%$ for the rear, right, and left surfaces, respectively, normalized by the irradiance of the top surface. Since the delivery box is cube-shaped, the difference in irradiance is significant.

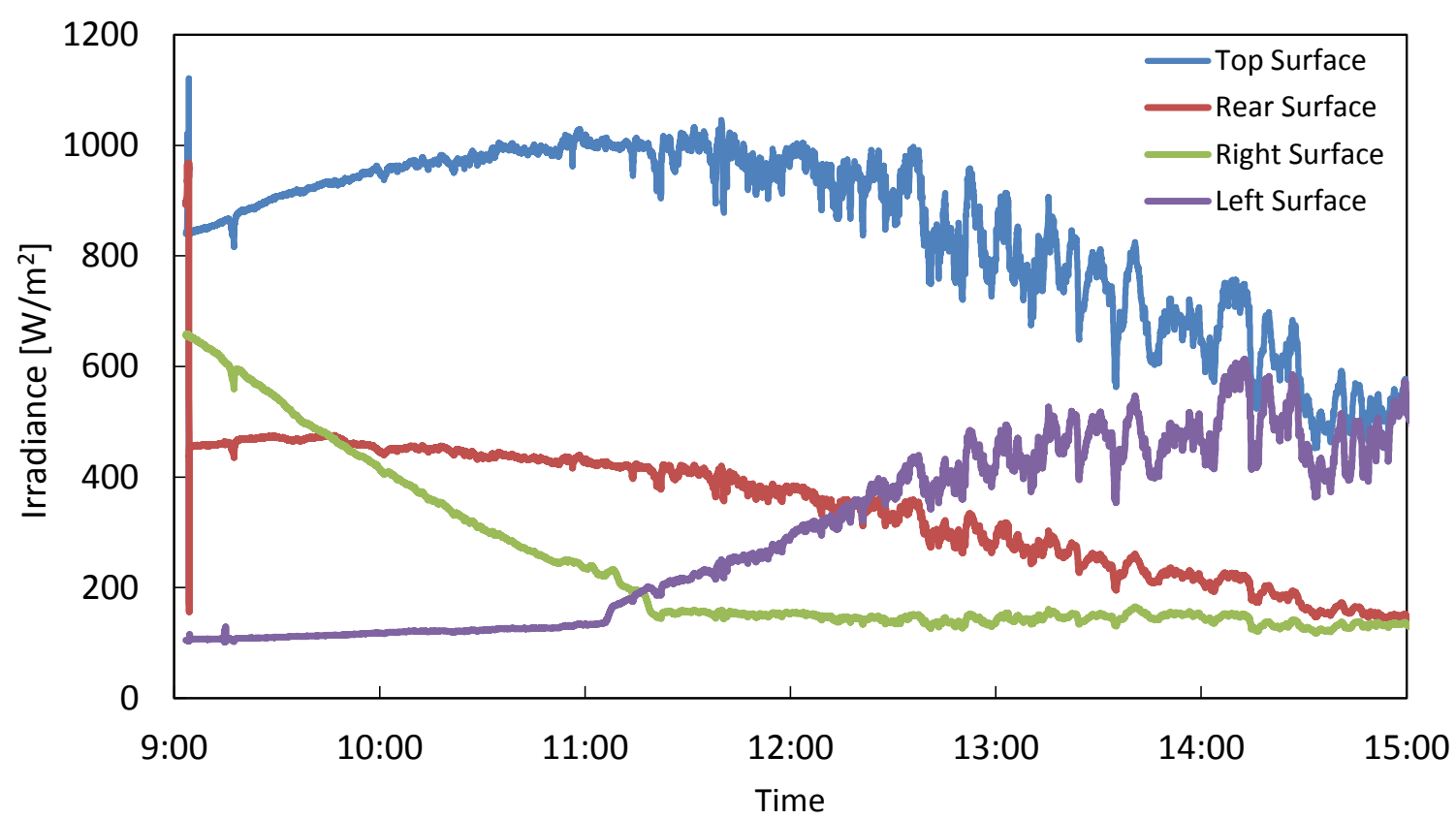

Fig. 3: Plot of the irradiance on 1-May 2018 for 4 surfaces 


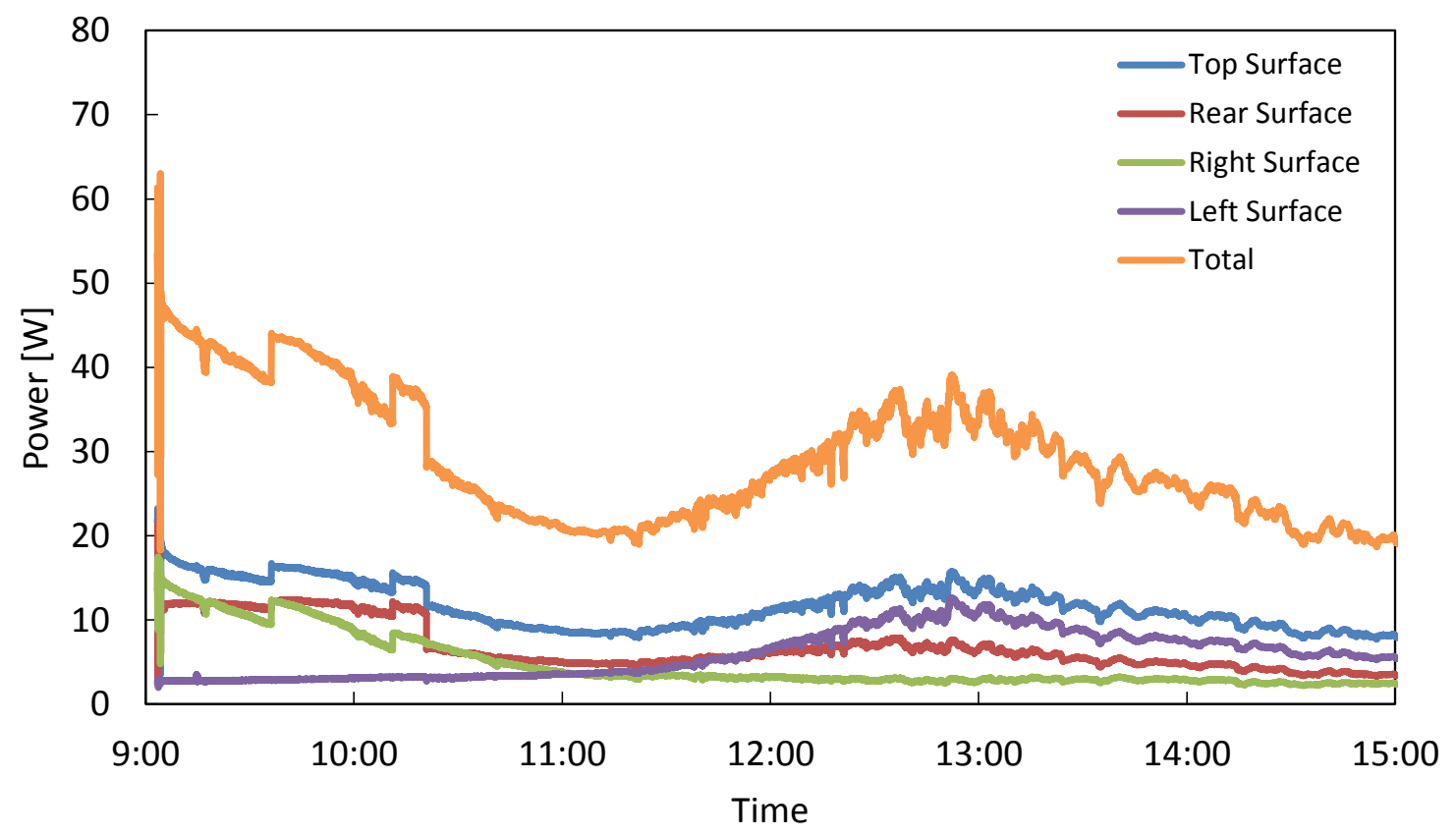

Fig. 4: Plot of the output power on 1-May 2018 for MPPT in four directions

Due to the shadow of the delivery box, the irradiance was less than $200 \mathrm{~W} / \mathrm{m}^{2}$ in the morning for the left surface and in the afternoon for the right surface. From the results, it is observed that the MPPT output currents in the morning (left surface) and afternoon (right surface) were insufficient, as expected. Therefore, Fig. 4, which shows the output power, demonstrates that direct sunlight yields $10 \mathrm{~W}$ or more but indirect sunlight yields $5 \mathrm{~W}$ or less. Generally, the generated output power of a PV module is directly proportional to irradiance, but the irradiance during 10:20-12:40 does not produce high output power on the top surface or rear surface. In other words, the output power of the right and left surfaces decreased proportionally with the irradiance, causing the current to decrease as well, which ultimately means that the MPPT current of the top and rear surfaces was restricted by the lower current. To reduce current restriction, the MPPTs on the left and right surfaces are placed in parallel. However, if the output current of both sides were insufficient, then the MPPT output current of the top and rear surfaces would be significantly restricted by the lack of current in a series circuit.

In a 4-hour outdoor experiment that took place from 11:00 to 15:00, the total charging energy was $105.6 \mathrm{Wh}$ and the average value was $26.4 \mathrm{Wh}$ per hour. Fig. 5 shows the ideal power calculated from the measured photovoltaic conversion efficiency and irradiance, as in Fig. 3. In the Fig. 5, the accumulated total output power was $187 \mathrm{Wh}$ with an average value of $46.8 \mathrm{Wh}$ per hour. An ideal output of $76 \%$ greater than the measured output is obtained. From calculations of the ideal case, the output capability is estimated to be $187 \mathrm{Wh}$ at the same conditions of irradiance. 


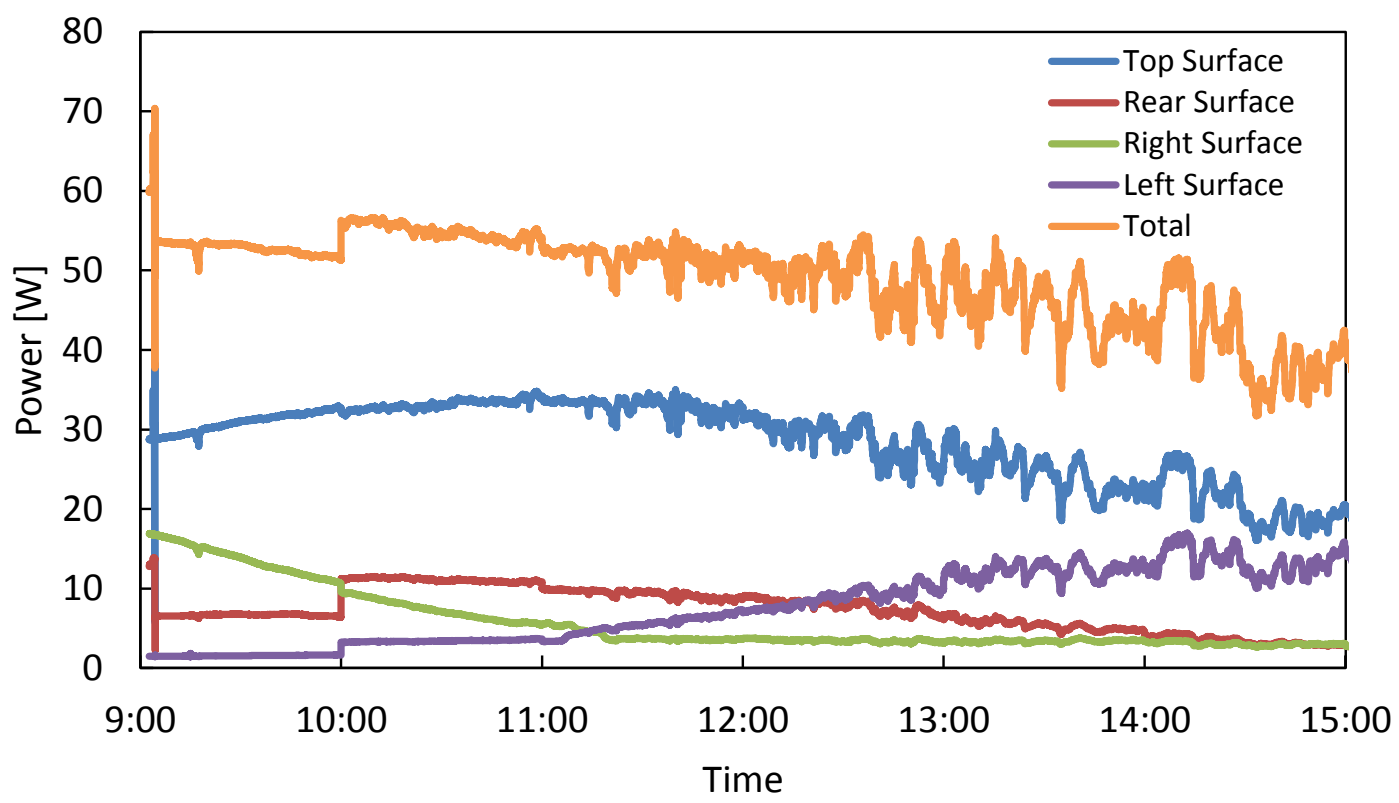

Fig. 5: Ideal power calculated by measured photovoltaic conversion efficiency and irradiance

Tab. 2: Accumulated horizontal irradiance and output power

\begin{tabular}{|c|c|c|}
\hline Period & $\begin{array}{c}\text { Horizontal Irradiance } \\
{\left[\mathbf{W h} / \mathbf{m}^{2}\right]}\end{array}$ & Output energy [Wh] \\
\hline $11: 00-15: 00$ (4.0 hours) & 3,215 & 105.6 \\
\hline
\end{tabular}

\subsection{Series-Parallel (Right, Left, and Rear) Connection}

The connections of the three vertical surfaces of the MPPTs were changed such that the right, left, and rear were placed in parallel, after which an outdoor experiment was conducted. Fig. 2(b) illustrates the block diagram of the distributed series-parallel MPPT system.

A battery-charging experiment was conducted on 25-May 2018 from 11:00 to 15:00 with the rear surface oriented to the south. Because the current produced by connecting a pair of the opposite-vertical-surfaces (the left and right) in parallel was relatively low, based on the results of the previous experiment, the rear MPPT current was added to complement that of the left and right. Fig. 6 shows the irradiance of each surface, and Fig. 7 shows the output power of each PV module.

Irradiance characteristics are affected by clouds. Thus, the output power from the MPPTs varies widely. At noon, a horizontal irradiance over $1000 \mathrm{~W} / \mathrm{m}^{2}$ was obtained, though the output power of the top surface was not proportional to the irradiance. On the other hand, the output power measurements from the left, right, and rear surfaces were not restricted by the top surface at noon and around 14:00 compared to the left and right surfaces of the parallel system, as shown in Fig. 4. The output of the left surface was proportional to the irradiance of the left surface. The output energy from the series-parallel MPPT system over the four hours (11:00 to 15:00) was $167 \mathrm{Wh}$, or an average of $41.8 \mathrm{Wh}$ per hour, as listed in Tab. 2. Fig. 8 represents the ideal output power of each surface based on the conversion efficiency from the I-V curves, listed in Tab. 1. The accumulated output energy was assumed to be $176 \mathrm{Wh}$ over the four hours, or $44.0 \mathrm{Wh}$ per hour. 


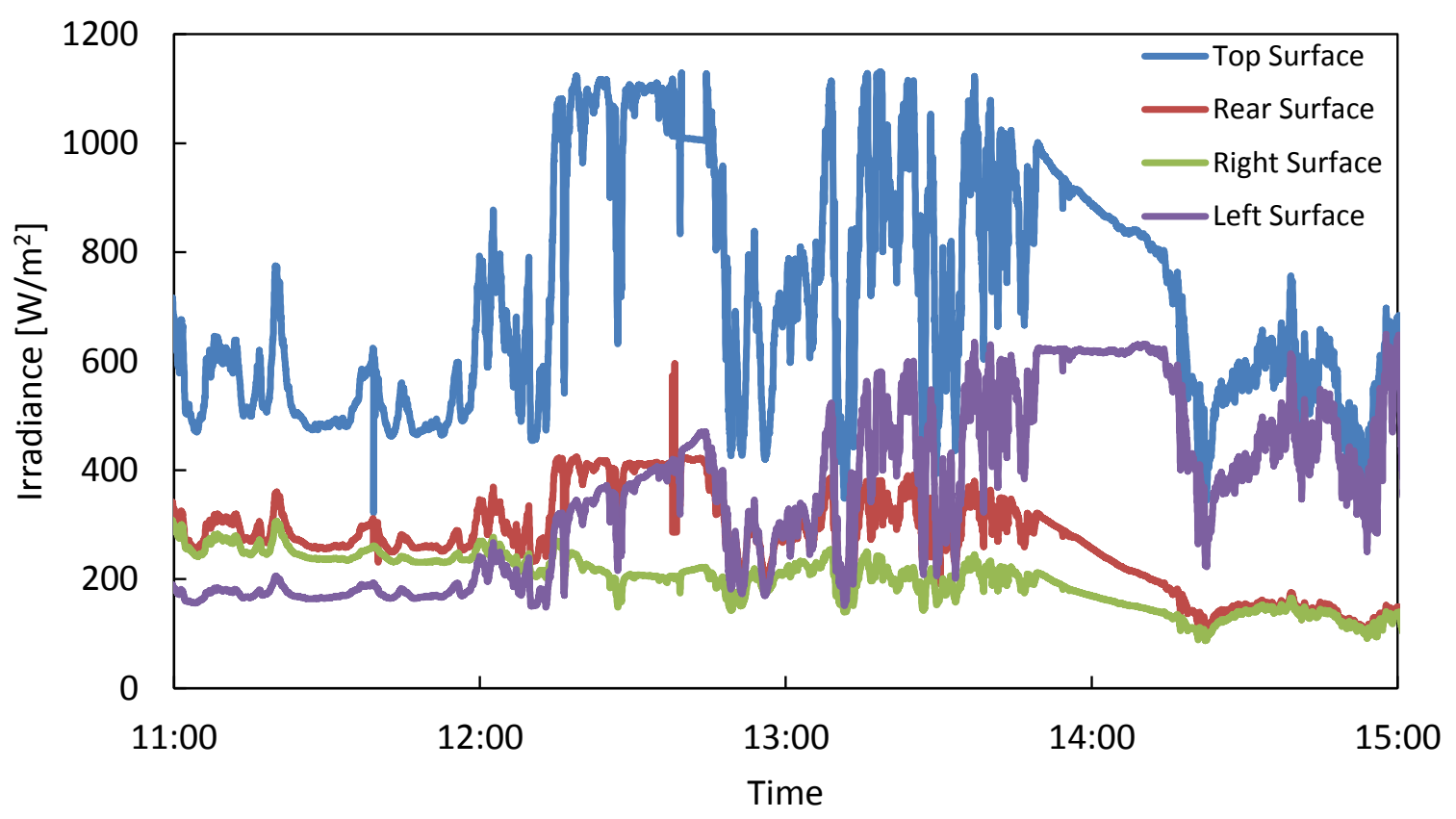

Fig. 6: Plot of the irradiance of the four surfaces on 25-May 2018

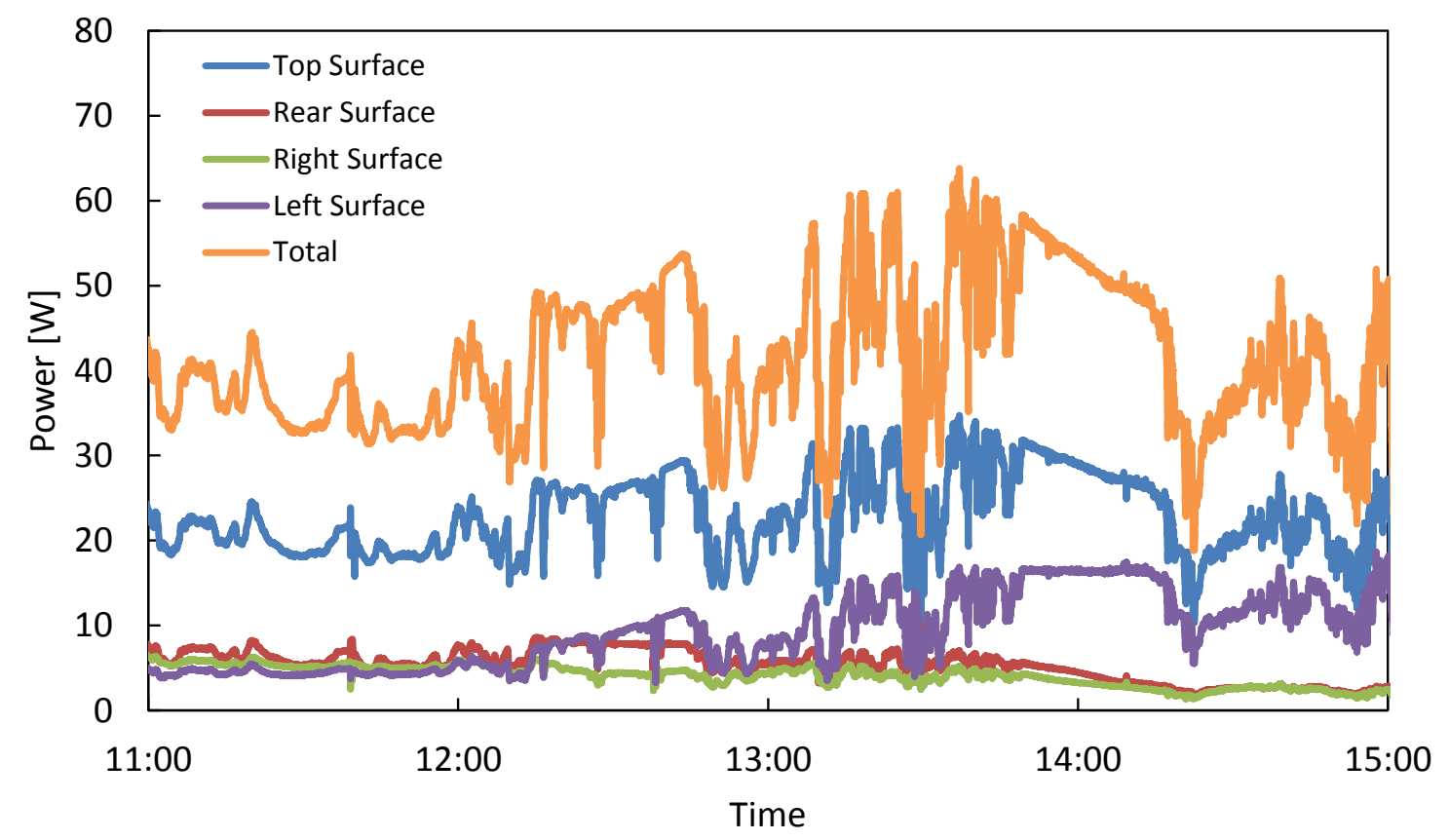

Fig. 7: Plot of the output power on 25-May 2018 for the four MPPTs 


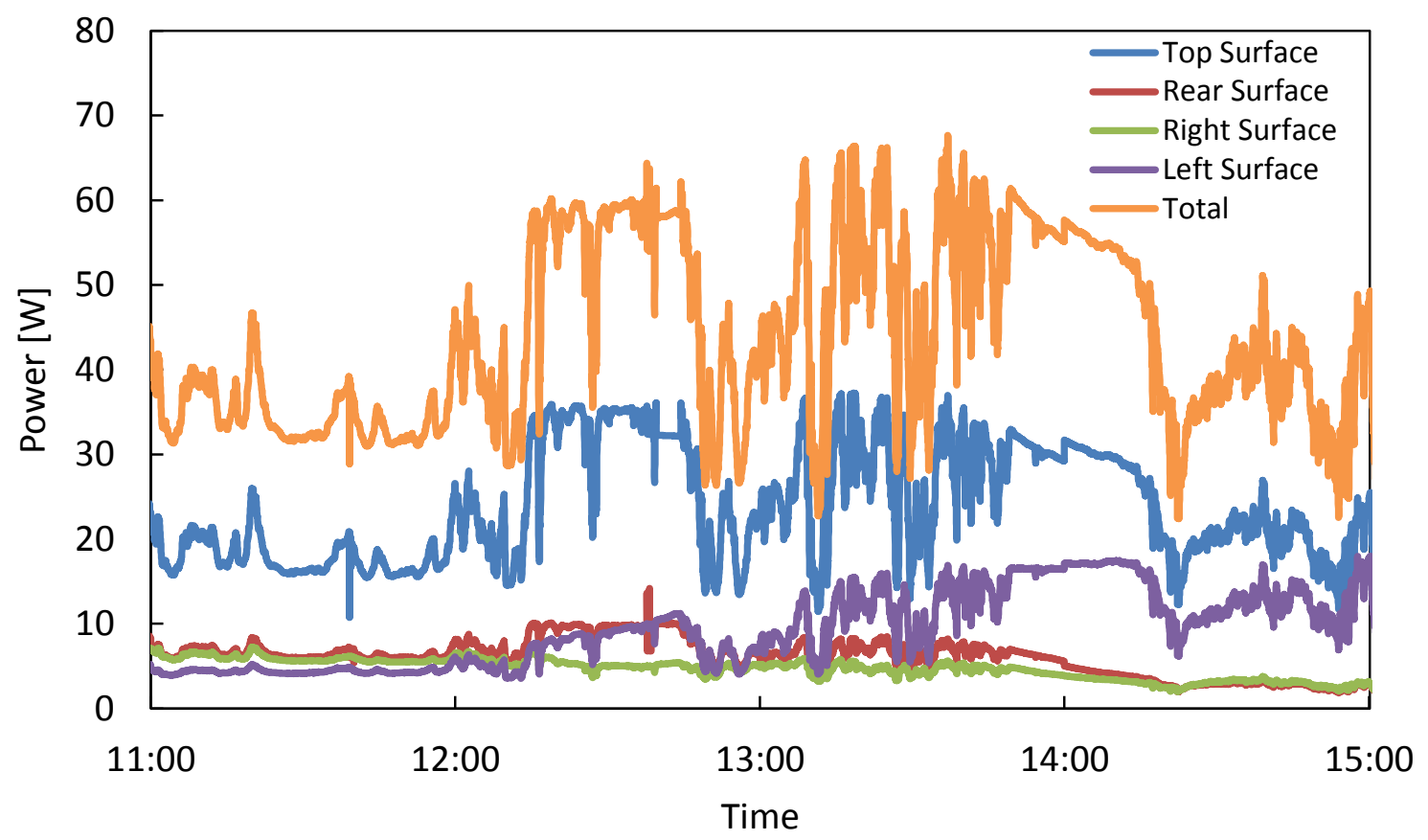

Fig. 8: Ideal output power on 25-May 2018 of the four MPPTs from the irradiance, I-V characteristic curves, and conversion efficiency.

Tab. 3: Accumulated horizontal irradiance and output power

\begin{tabular}{|c|c|c|}
\hline Period & $\begin{array}{c}\text { Horizontal Irradiance } \\
{\left[\mathbf{W h} / \mathbf{m}^{2}\right]}\end{array}$ & Output energy [Wh] \\
\hline $11: 00-15: 00$ (4.0 hours) & 2,763 & 167.2 \\
\hline
\end{tabular}

\subsection{Power Generation Efficiency}

We now discuss the power-generating efficiency of the distributed MPPT system. If the MPPT is operated at the peak power point the entire time, the power-generating efficiency can be described by the irradiance, photovoltaic efficiency of the PV module, and DC-DC boost efficiency. Thus, the power-generating efficiency of the distributed MPPT system is defined by eq. 1 .

$$
\eta=\frac{P_{\text {mppt_out }}}{A E}
$$

where $\eta$ is the power-generating efficiency, $P_{\text {mppt_out }}$ is the output power of the MPPT, $A$ is the surface area of the PV module, and $E$ is the irradiance on the surface of the delivery box. Fig. 9 shows the power-generating efficiency on 1-May 2018. Fig. 10 shows the power-generating efficiency on 25-May 2018.

In Fig. 9, there are points at which the power-generating efficiency changes rapidly. These rapid changes appeared when the voltage changed, which means that the operating voltage of the MPPT and DC-DC converter changes due to current limitations in the series circuit. On the top, rear, and right surfaces, the power-generating efficiency also decreases. The power reduction on the top surface is especially significant while irradiance is strong, and which the power-generating efficiency is lower than 5\%. From this, a power-weighted average value does not exceed $10 \%$. The low power-generating efficiency of the series-parallel MPPT system is assumed to be the result of power limitations of the top and rear surfaces.

In Fig. 10, large changes in power-generating efficiency occur less frequently, and no rapid breakdowns occur. The power generation efficiency is not lower than $5 \%$ on the top surface and the power-weighted average is stable around $10 \%$. However, decreases in the power-generating efficiency arose in the top surface around 12:30. This is because the parallel connection of the MPPT for the right, left, and rear surfaces causes current summation, but this effect was insufficient due to the MPPT output current of the top surface. A decrease in the 
power-generating efficiency was partially avoided by adding current from the MPPT to the entirety of the vertical surfaces. Therefore, reducing the current difference in a series MPPT is required to increase the output power of a series-parallel distributed MPPT system. This can be achieved effectively by adding a parallel MPPT connection. Moreover, for a low-irradiance surface and a low-power-generating MPPT, it is possible to decrease the upper voltage limit of the boost ratio in a DC-DC converter to avoid decreased current in a series circuit. Another method by which to obtain commensurate output current from the MPPTs for each series connection is to equalize the solar energy and current such that the series MPPT system behaves like a voltage adder.

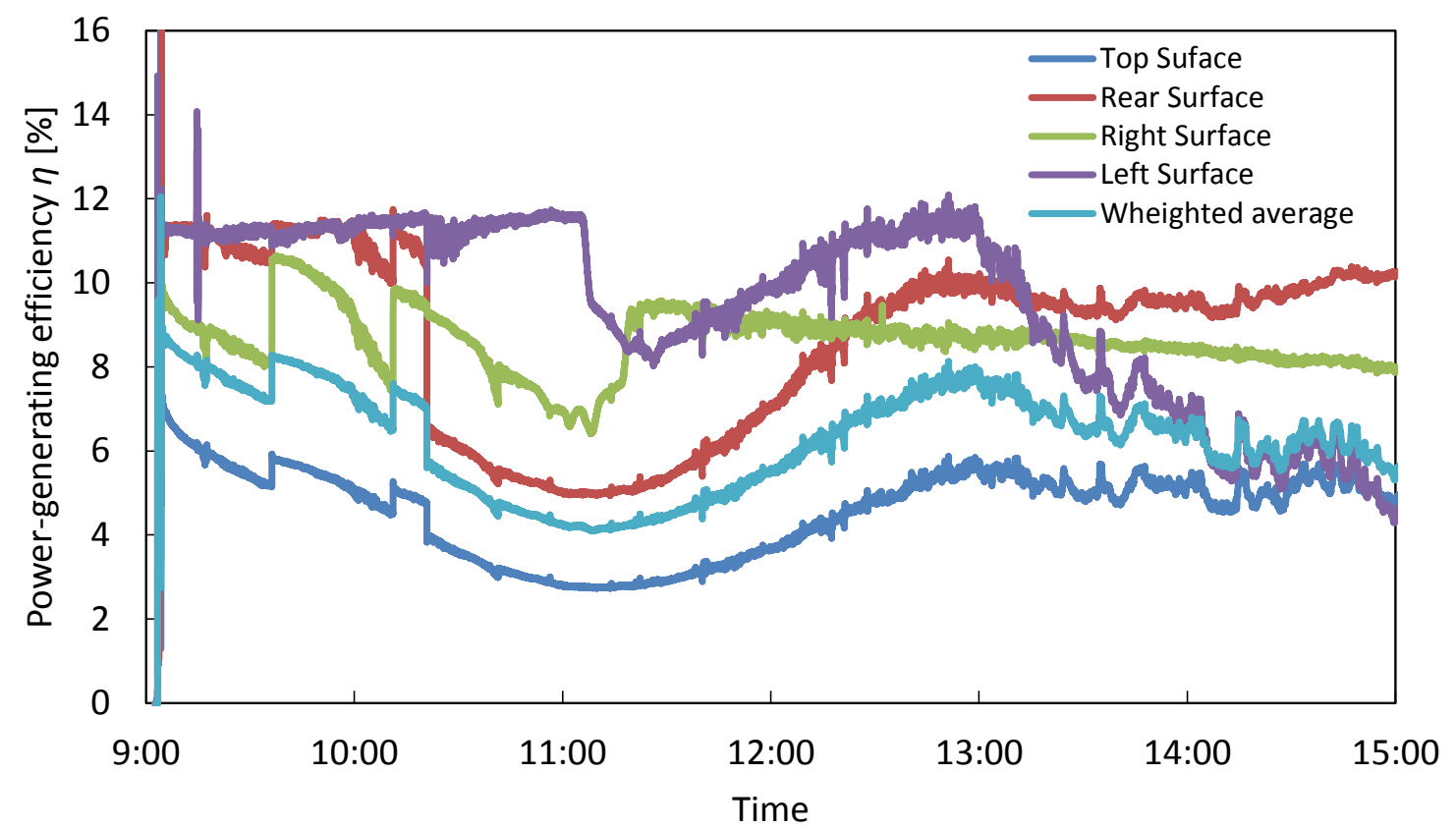

Fig. 9: Power-generating efficiency of the distributed MPPT system (left and right surfaces in parallel) on 1-May 2018

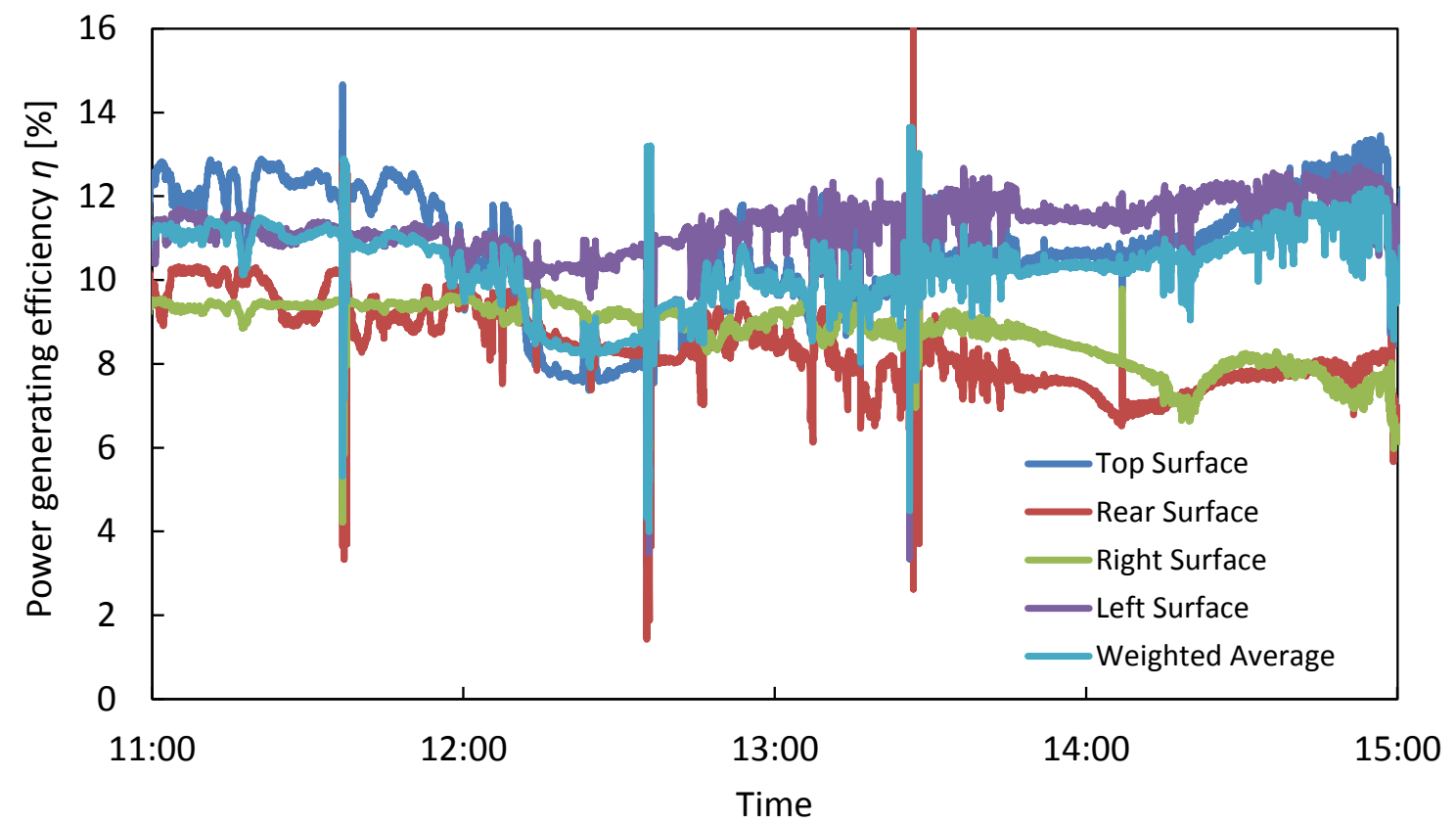

Fig. 10: Power-generating efficiency of the distributed MPPT system (left, right, and rear surfaces in parallel) on 25-May 2018 


\section{Conclusions}

In this study, we discussed a distributed MPPT system for four surfaces on a cube-shaped delivery box of a solar EV. The results clearly indicate that differences in the currents lead to a reduction of output power of the top and rear surfaces in a series-parallel system in which the left and right surfaces are in parallel. As a result, solution methods for the problem can be proposed as follows,

- Adding photovoltaic current to equalize the output current for a series circuit.

- Optimizing the output voltage settings to level the output currents for a series circuit.

- In order to obtain more generated power, increase or decrease the area of photovoltaic module on each surface for adjusting input powers and output currents of the MPPT.

- Considering the change in transmittance and reflectivity of the PV modules with greater incident angle of the irradiance (Akihiko, 2015).

- Using by-pass diode against the partial shadow or uneven irradiance on the PV module.

\section{References}

Akihiko ITAGAKI, 2015. Revised Edition New Solar Energy Utilization Handbook, JSES, 3-39.

Takanori MATSUYAMA, et al., 2014. Experimental Introduction of Distributed Maximum Power Point Tracking Systems for PV Systems and Effect Applied to Solar Car, J. JSES., vol.40, 51-60.

Toru FUJISAWA, Takashi KAWAGUCHI, 2016. Performance Evaluation and Trial Making of Compact Solar EV, EuroSun 2016, Palma de Mallorca. DOI: 10.18086/eurosun.2016.08.05

BBC News, 6-July-2017, https://www.bbc.com/news/world-europe-40518293. Accessed 3-Sept.-2018.

Daniell Muoio, "These countries are banning gas-powered vehicles by 2040", BUSINESS INSIDER, Oct. 23, 2017. https://www.businessinsider.com/countries-banning-gas-cars-2017-10/\#norway-will-only-sell-electricand-hybrid-vehicles-starting-in-2030-1. Accessed 3-Sept.-2018.

Dethleffs, 2018. e.home, https://www.dethleffs.de/pressebereich/bilder-reisemobile-2018/ehome/. Accessed 3Sept.-2018.

EU, 2012. "Commission Regulation (EU) No 459/2012 of 29 May 2012 amending Regulation (EC) No $715 / 2007$ of the European Parliament and of the Council and Commission Regulation (EC) No 692/2008 as regards emissions from light passenger and commercial vehicles (Euro 6)". Eur-lex.europa.eu. Retrieved 201206-01.

SONO MOTORS, 2017. Sion, https://sonomotors.com/sion.html/. Accessed 3-Sept.-2018. 


\title{
Glazed PVT collector integrated into façade module
}

\author{
Nikola Pokorny ${ }^{1}$, Tomas Matuska ${ }^{1}$, Borivoj Sourek ${ }^{1}$, Vladimir Jirka ${ }^{1}$ \\ 1 UCEEB, CTU in Prague, Bustehrad (Czech Republic)
}

\begin{abstract}
The paper presents the results of the outdoor measurement of glazed photovoltaic-thermal (PVT) collectors integrated into façade modules. Outdoor measurement of two different façade modules has been carried out under real climatic conditions. The paper analyses thermal and electrical performance of glazed PVT collector with and without highly transparent spectrally selective coating. Test cell for long-term tests of energy-active façade has been built and used for the test of integrated PVT collectors.
\end{abstract}

Keywords: solar energy, glazed PVT collector, building integration, energy-active façade, solar heat

\section{Introduction}

Solar energy utilization on the south oriented façades is rational way and step further to solar energy active buildings. Area on the roof of residential buildings is usually limited by other HVAC facilities. Therefore significant potential in innovative solar devices for building envelopes exist (dual collectors, daylighting, heat and electricity production). Combination of solar thermal and photovoltaic (PV) technology is very promising. Research and development in the PVT collector area have increased last years. More investigated PVT technology is based on systems using liquid as heat transfer fluid instead of air. Thermal energy from air PVT collectors is difficult to utilize during summer time. Different design construction of liquid PVT collectors exist which is possible divide into unglazed, glazed, and concentrating collectors. Unglazed PVT collectors are now available on the market but the usage is only for applications where low temperatures are needed (preheat for heat pump primary circuit or preheat of cold water). Unglazed PVT collectors can achieve slightly higher electrical efficiency for low operational temperatures due to cooling of PV part. On the other hand glazed PVT collectors are represented on the market only by two manufactures. Glazed PVT collectors have stagnation temperature from $150{ }^{\circ} \mathrm{C}$ to $200{ }^{\circ} \mathrm{C}$ but maximum operation temperature of ethylene-vinyl-acetate (EVA) lamination is $85{ }^{\circ} \mathrm{C}$ (Zondag et al., 2002). Lack of available manufactures of glazed PVT collectors on the market is caused by the restriction with the degradation of EVA lamination during high temperatures which has not been solved yet. The research in glazed PVT area is now separated into overheating protection way (Harrison \& Cruickshank, 2012; Lammle , 2016) and usage of thermal resistance material instead of EVA laminate (Matuska, 2015). Main advantage of glazed PVT collectors is the big potential in the most common application in Europe which is preparation of domestic hot water. Glazed PVT collectors have comparable thermal efficiency with conventional thermal collectors. It is necessary to apply low emissivity (low-e) coating on the glazing at the top of PVT absorber so that heat output could be similar to conventional solar thermal collector. Some studies exist which investigated potential of application of spectral selective low-e coating in solar thermal area (Giovannetti, 2014).

Glazed PVT collector presented in this paper has PV cells encapsulated by means of polysiloxane gel instead of EVA lamination. This paper presents developed and tested integrated PVT collector into building envelope. Façade modules have been tested under steady state and real dynamic climatic conditions. Two different PVT collector designs were compared to confirm better thermal performance thanks to spectral selective coating on the PVT absorber. One integrated PVT collector was with standard solar glass (transmittance 0.91, emissivity 0.85) on the top of the PVT absorber and second collector has spectrally selective low-e coating on the top of the absorber. Due to the low-e coating on the absorber heat radiative losses are decreased. Today low-e coatings have high transparency for visible range but unfortunately significantly reduced transmittance for near infrared region of solar radiation spectrum where is not negligible amount of energy. The presented glazed selective PVT collector has been made with low-e coating with optimized of the emissivity (0.3) and transmittance (0.85). Thermal performance should be significantly higher due to low-e coating and at the same time electrical power should be 
slightly lower according to reduced transmittance. One of the purpose of this paper is to present measurement results of the comparison of two different PVT collector design related to thermal and electrical performance.

\section{Integrated glazed liquid PVT collector}

Developed glazed PVT collector is based on sandwich structure (see Fig. 1). PV cells are encapsulated between a double glazing and the copper heat exchanger by means of polysiloxane gel. Polysiloxane gel as PV encapsulant offers a large range of operation temperatures (from -60 to $+250{ }^{\circ} \mathrm{C}$ ), high transparency for solar radiation and allows the compensation of thermal dilatation stresses thanks to low modulus of elasticity (Poulek, 2012). The absorber is copper sheet with soldered pipe register (common technology). Sheet and tube absorber consist of 18 riser pipes with distance $50 \mathrm{~mm}$. Double-glazing consists of low-iron solar glazing $6 \mathrm{~mm}$ thick with a gap $16 \mathrm{~mm}$ filled with argon. Two prototypes of façade modules were constructed. One prototype has commercial available glazing from Euroglas attached to absorber with low emissivity coating (30\%) with transparency for solar radiation $85 \%$. Second prototype has low-iron solar glazing attached on the absorber with emissivity $85 \%$ and transparency for solar radiation $91 \%$. The front glazing is solar glass with transparency $94 \%$ for both prototypes. The PV part of the collector has 60 cells at size $125 \times 125 \mathrm{~mm}$ in three parallel strings. Nominal efficiency of PV cell is $16.3 \%$ under standard test conditions. Area of PV part is $60 \%$ of gross area. Gross area of PVT collector part in the façade element is $1.56 \mathrm{~m}^{2}$, aperture area is $1.4 \mathrm{~m}^{2}$. On the back side is $14 \mathrm{~cm}$ insulation.
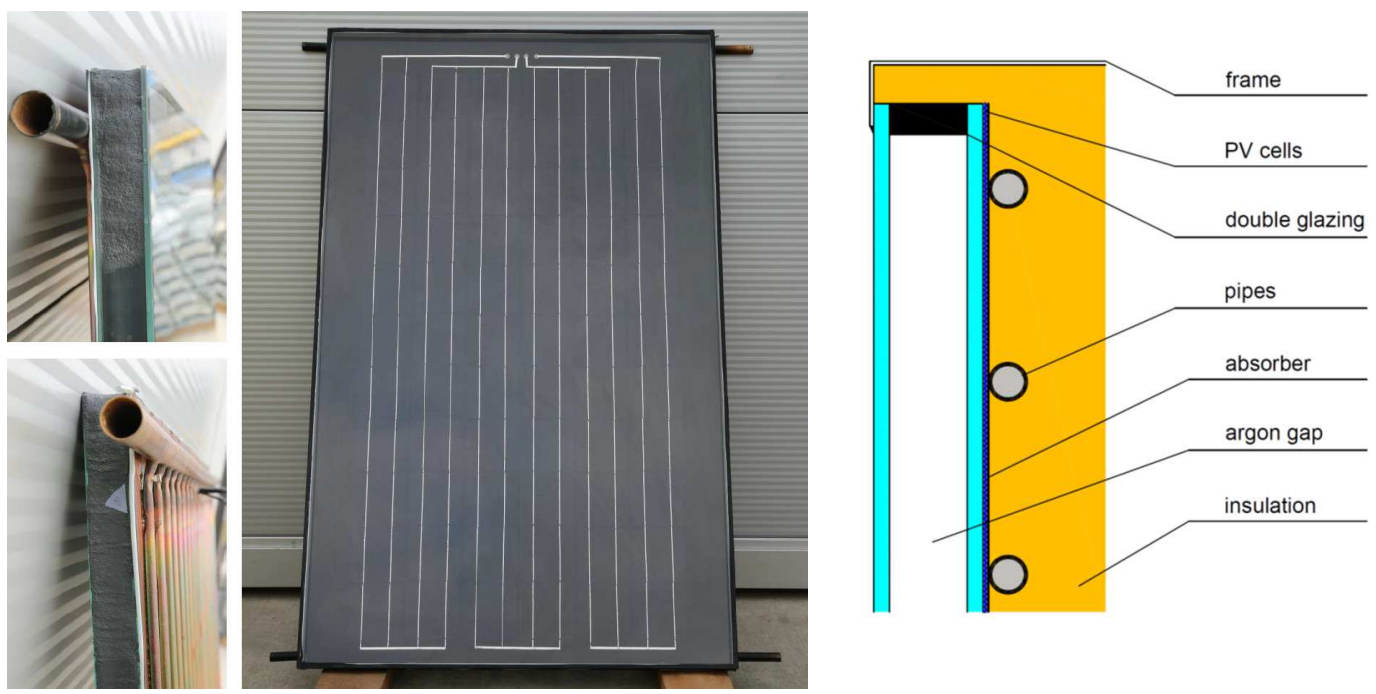

Fig. 1: Glazed PVT collector component prepared for building envelope integration

Integrated PVT collector for the administration building was constructed (see Fig. 2). The façade module consist of glazed PVT collector, window with triple glazing, and glass rasters. Thanks to glass rasters is possible to decrase heat gains during summer and to increase during winter. Glass rasters reflects beam radiation during summer months a during winter months rasters allow radiation entry to the indoor environment (Jirka, 2017). Glass rasters are not subject of this paper further. The whole façade module size is $1,501 \times 2,175 \mathrm{~m}$. Glass raster size is $1,463 \times 1 \mathrm{~m}$. The weight of the module is $120 \mathrm{~kg}$. 

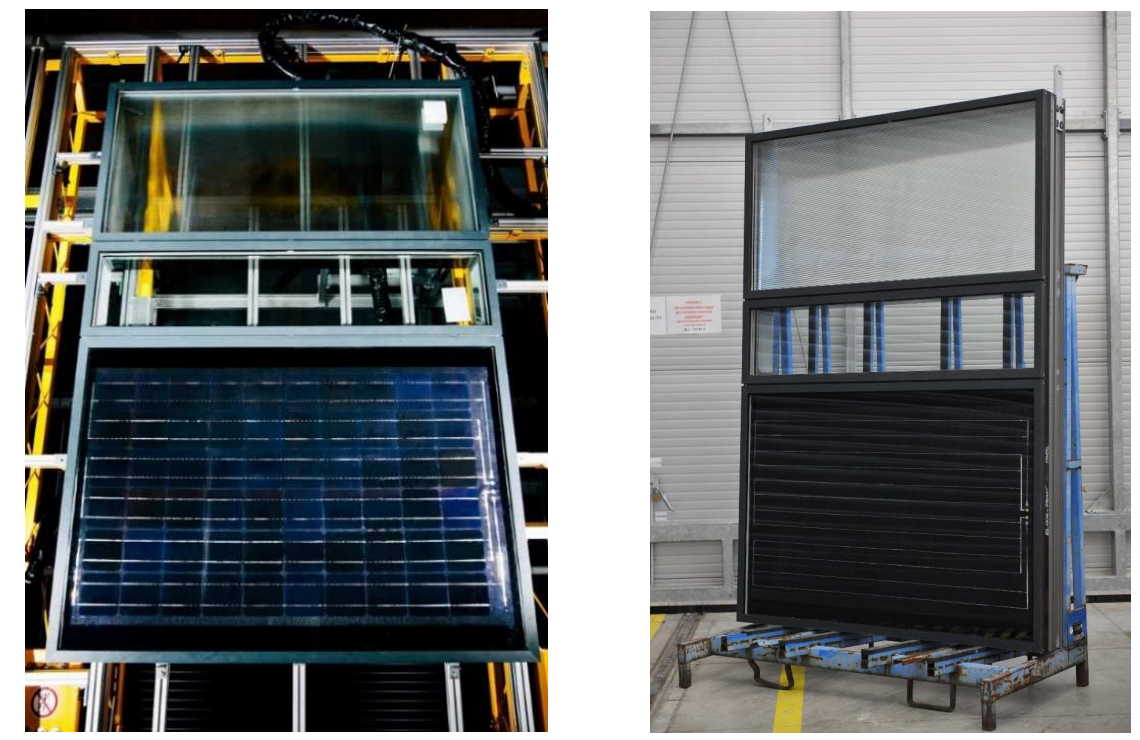

Fig. 2: Tested facade module with PVT collector

Integrated PVT collector only without selective coating was tested under steady state conditions according to EN ISO 9806. The collector was tested at Solar laboratory (UCEEB CTU) with use of indoor solar simulator. Required accuracy of measurement according to EN ISO 9806 was respected. Characteristic of thermal efficiency has been tested in two modes (see Fig. 3). On the axis y there is thermal and electrical efficiency which is determined as a ratio of the heat and electrical power divided by incident irradiance on the gross area. On the axis $\mathrm{x}$ there is reduced temperature difference which includes influence of ambient temperature $T_{a}\left[{ }^{\circ} \mathrm{C}\right]$, mean fluid temperature $T_{m}\left[{ }^{\circ} \mathrm{C}\right]$, and incident irradiance $G\left[\mathrm{~W} / \mathrm{m}^{2}\right]$. In the hybrid mode, the PV part was connected to MPP tracker with measured load. In open circuit mode, the PVT collector thermal performance was tested without electric load. Thermal and electric characteristics have been related to gross area of the PVT collector which is $1.56 \mathrm{~m}^{2}$.

Open circuit test conditions were following: the global irradiance was kept at the average value $924 \mathrm{~W} \cdot \mathrm{m}^{-2}$ during the test. The collector tilt angle was set up to $45^{\circ}$. Ambient temperature was fixed at $16.4^{\circ} \mathrm{C}$. Collector zero loss thermal efficiency was evaluated $68 \%$ (related to gross area). Stagnation temperature was determined $161{ }^{\circ} \mathrm{C}$.

Hybrid mode conditions were following: the global irradiance was kept at the average value $988 \mathrm{~W} \cdot \mathrm{m}^{-2}$ during the test. The collector tilt angle was set up to $45^{\circ}$. Ambient temperature was fixed at $18.2^{\circ} \mathrm{C}$. Collector zero loss thermal efficiency was evaluated $60 \%$ and the electrical efficiency $8.4 \%$ (both related to gross area). Stagnation temperature was determined $156^{\circ} \mathrm{C}$. 


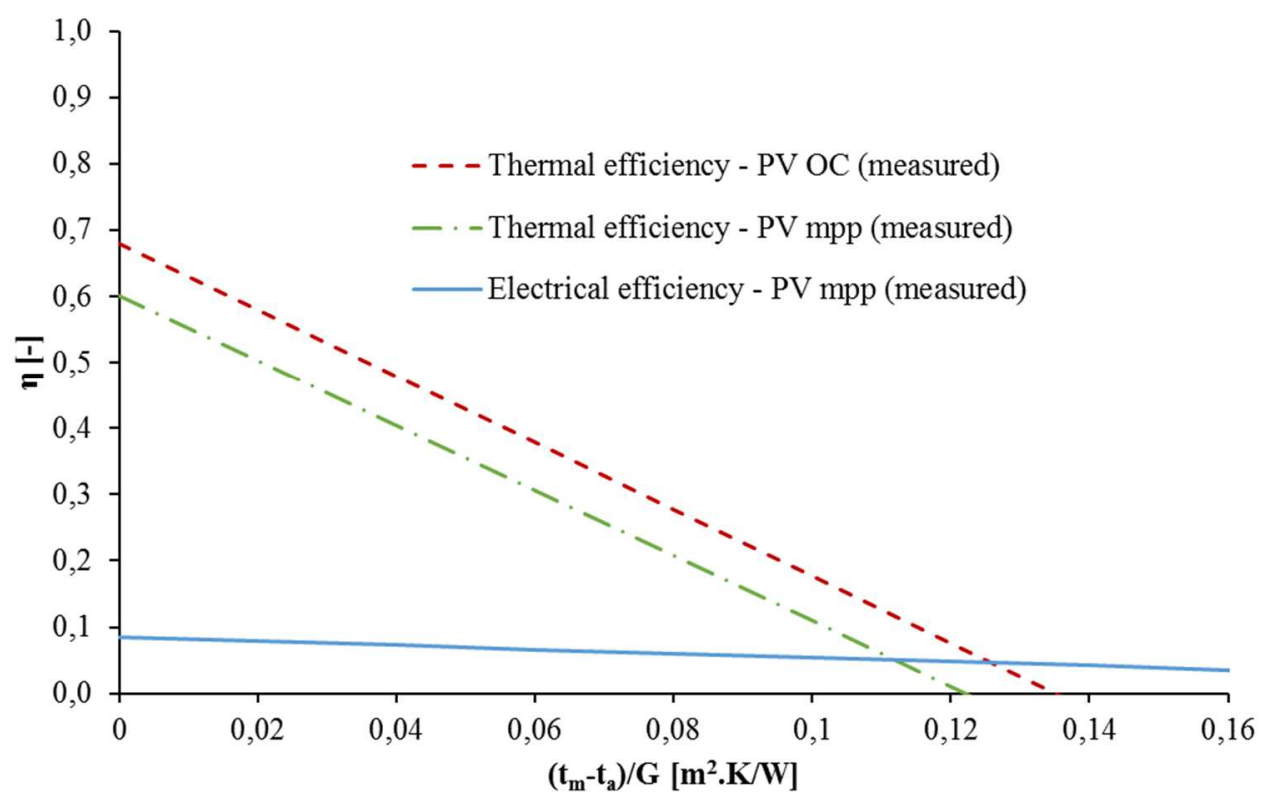

Fig. 3: Measured thermal and electrical characteristics for integrated PVT collector (related to gross area)

\section{Test cell for energy-active facades}

Test cell for long-term testing of energy-active façade modules was built (see in Fig. 4) on the experimental area of the UCEEB CTU in Bustehrad. Two different facade modules were installed on the south wall (azimuth $-15^{\circ}$ ) of the test cell. Test cell is divided into two parts. First part is for necessary HVAC facilities, second part is testing room with controlled indoor temperature. Thermal energy from PVT collectors is stored in 1601 solar tank. Electrical energy from PVT collectors is stored in battery and subsequently discharged.

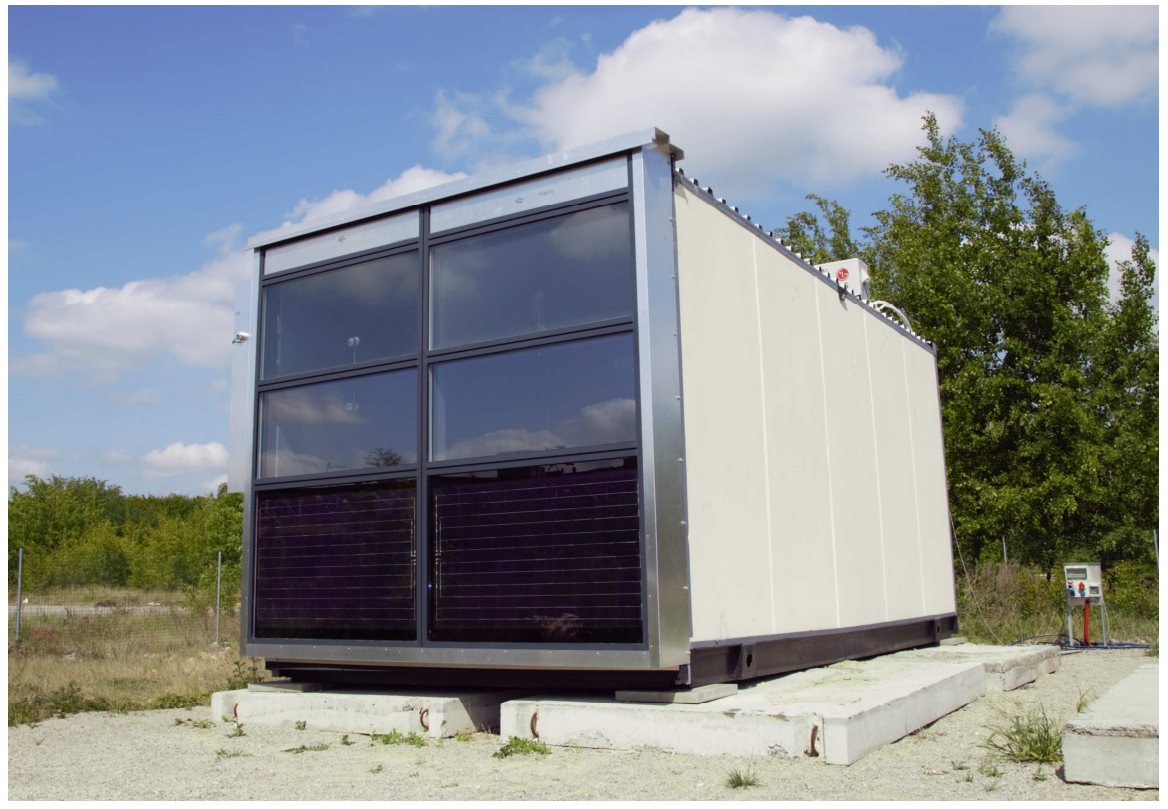

Fig. 4: Experimental test cell for energy-active façades

\subsection{Electrical part}

Measurement of the electrical performance was done separately for both PVT collectors according to the scheme in Fig. 5. It was not possible to connect PVT collectors directly with inverter and then waste the electrical energy in the grid. Therefore the connection with charging by collectors and discharging battery by resistance was chosen. Control of the discharging battery is based on maintaining voltage in range from $11,8 \mathrm{~V}$ to $13,8 \mathrm{~V}$ ( BATT - $12 \mathrm{~V}$ 
$\mathrm{x} 140 \mathrm{Ah}=1680 \mathrm{Wh}$ ) to avoid full charged battery and reduction of useful PV electricity generation. Then it is certainty that the PVT collectors are working in the MPP mode. Voltage and current on the collector is measured separately according to scheme.

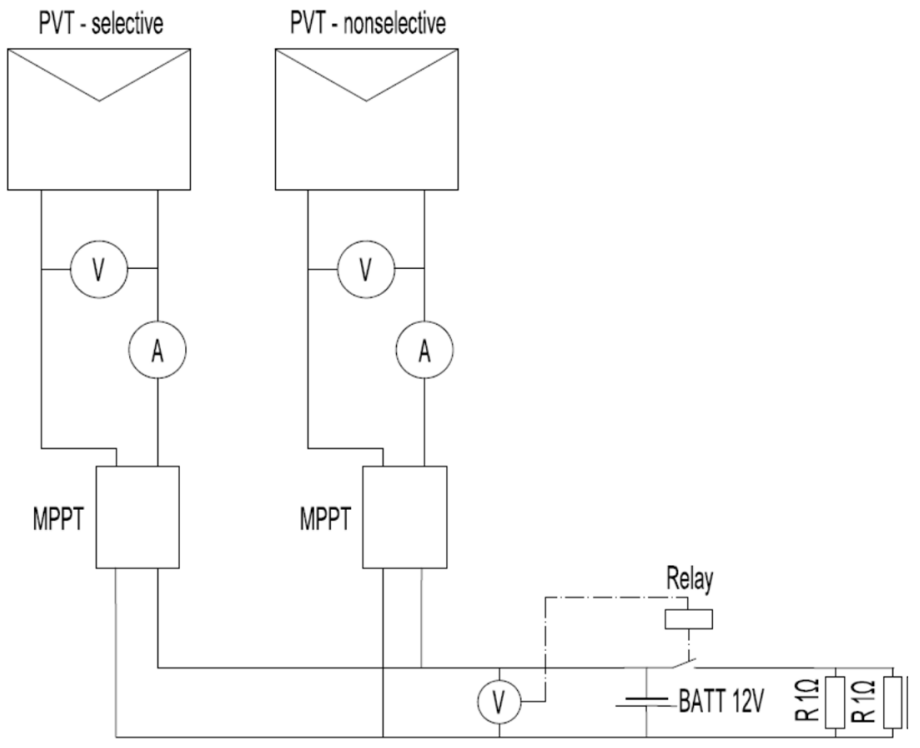

Fig. 5: Electrical scheme

\subsection{Thermal part}

Solar PVT system is dedicated to the preparation of domestic hot water in 1601 tank. Conventional controller has been installed with the monitoring of the temperature difference and switching on and off the circulation pump of the system. Mass flow in the collector loop was set to $901 . \mathrm{h}^{-1}$. Hot water load has been emulated by pump between solar tank and cold water tank. Every night was the solar tank discharged till the temperature in the top of the tank was $20{ }^{\circ} \mathrm{C}$. In near future it will be desirable to create simple hot water load profile consisted from at least 4 loads. Cooling unit above the roof is for cooling of 2001 cold water tank. This cooled water is used for cooling in the testing room and for controlled cooling of the solar tank. Second part of the test cell is isolated testing room where ambient temperature is controlled by the electric heater and air cooler. Both cooling power and heating power are measured. For measurement 4 x pyranometer (type CMP 3) has been used for solar irradiance. For measurement of electric consumption $2 \mathrm{x}$ wattmeter has been used. For measurement of thermal output in testing loops $3 \mathrm{x}$ magnetic flowmeters and temperature sensors Pt100 has been used. $2 \mathrm{x}$ voltmeter and $2 \mathrm{x}$ ammeter has been used for measurement of PV power.

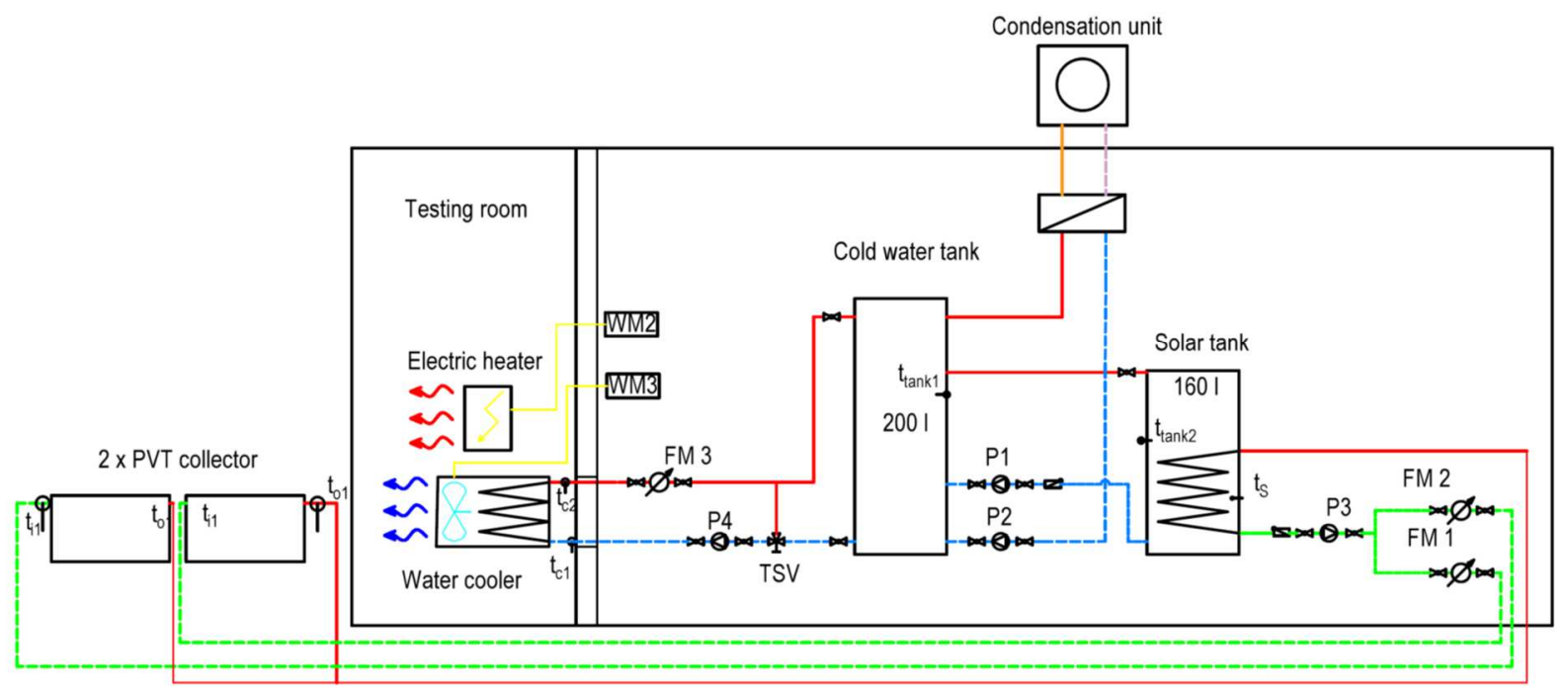

Fig. 6: Scheme of the thermal part of the system 


\section{Measurement results}

Measurement started at the beginning of the year 2018. Many changes of the measurement have been done during the year. Therefore for the comparison only some periods were chosen. In Tab.1 there is a comparison of thermal and electrical gain for both type of PVT collectors. Eleven days in February were chosen for OC mode because it was a period without any electric load. July was chosen for hybrid mode because there were not any changes in electrical measurement.

Tab. 1: Comparison of the thermal and electrical gain for are $1.56 \mathrm{~m}^{2}$

\begin{tabular}{|c|c|c|c|c|c|}
\hline Time range & $\begin{array}{c}\text { Incident } \\
\text { solar } \\
\text { irradiation }\end{array}$ & $\begin{array}{c}\text { Measured } \\
\text { heat gain } \\
\text { (selective) }\end{array}$ & $\begin{array}{c}\text { Measured } \\
\text { electrical } \\
\text { gain } \\
\text { (selective) }\end{array}$ & $\begin{array}{c}\text { Measured } \\
\text { heat gain } \\
\text { (nonselective) }\end{array}$ & $\begin{array}{c}\text { Measured } \\
\text { electrical gain } \\
\text { (nonselective) }\end{array}$ \\
\cline { 2 - 6 } & $\mathbf{k W h}$ & $\mathbf{k W h}$ & $\mathbf{k W h}$ & $\mathbf{k W h}$ & $\mathbf{k W h}$ \\
\hline $\begin{array}{c}\text { February 2018-from } \\
\text { 10.2. to 21.2. (OC mode) }\end{array}$ & $\mathbf{4 3 , 4}$ & $\mathbf{2 3 , 0}$ & - & $\mathbf{2 0 , 2}$ & - \\
\hline July 2018 (MPP mode) & $\mathbf{1 6 3 , 4}$ & $\mathbf{9 0 , 4}$ & $\mathbf{9 , 8}$ & $\mathbf{8 1 , 9}$ & $\mathbf{1 1 , 8}$ \\
\hline $\begin{array}{c}\text { Sunny day 3.7.2018 } \\
\text { (MPP mode) }\end{array}$ & $\mathbf{6 , 4 2}$ & $\mathbf{3 , 2 6}$ & $\mathbf{0 , 3 7}$ & $\mathbf{2 , 9 4}$ & $\mathbf{0 , 4 5}$ \\
\hline $\begin{array}{c}\text { Cloudy day -1.7.2018 } \\
\text { (MPP mode) }\end{array}$ & $\mathbf{5 , 8 3}$ & $\mathbf{2 , 8 2}$ & $\mathbf{0 , 3 4}$ & $\mathbf{2 , 4 6}$ & $\mathbf{0 , 4 1}$ \\
\hline
\end{tabular}

In Fig. 7 and 8 there is a comparison of thermal and electrical performance for cloudy and sunny day. Comparison of thermal performance for OC mode is shown in Fig. 9.

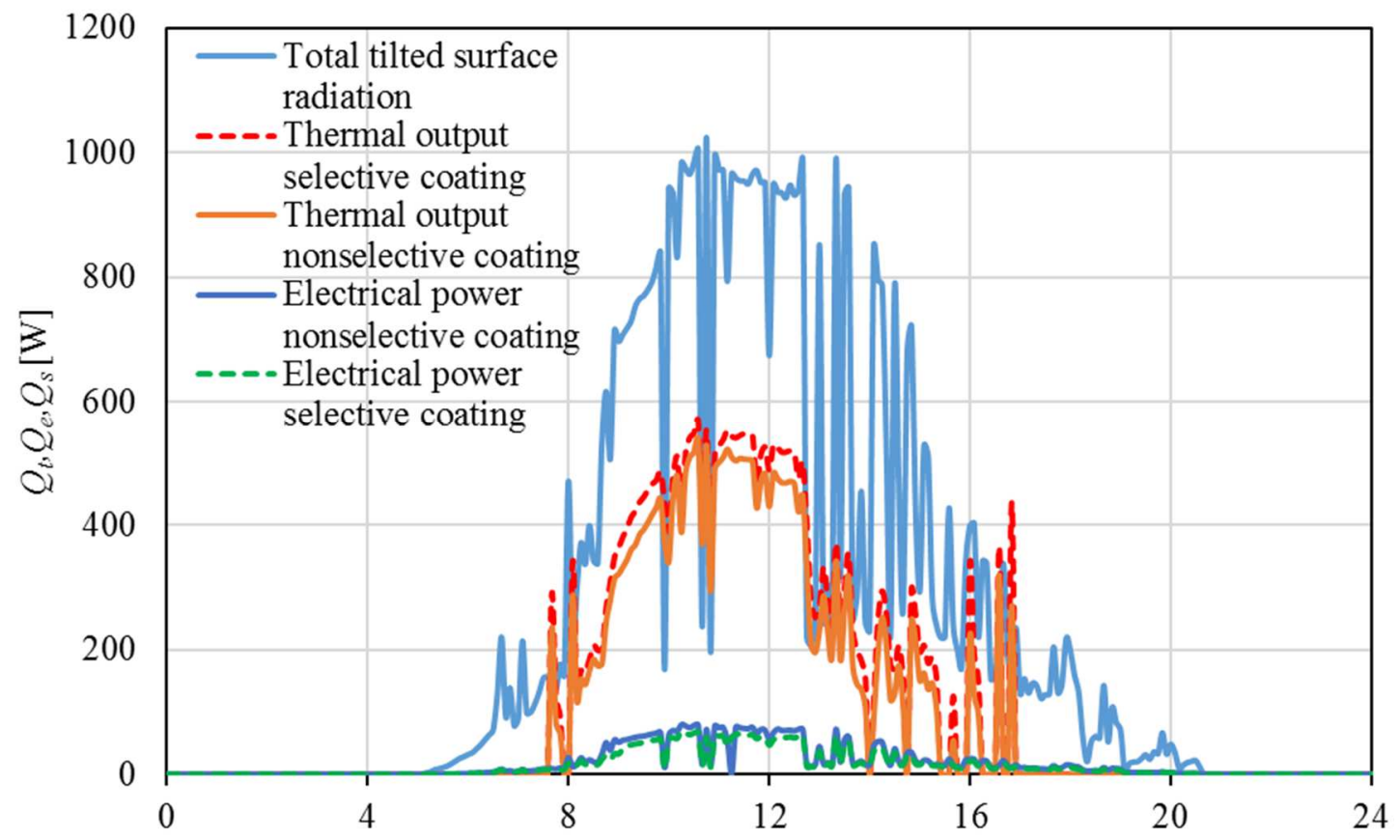

Fig. 7: Comparison of the thermal and electrical performance for cloudy day 


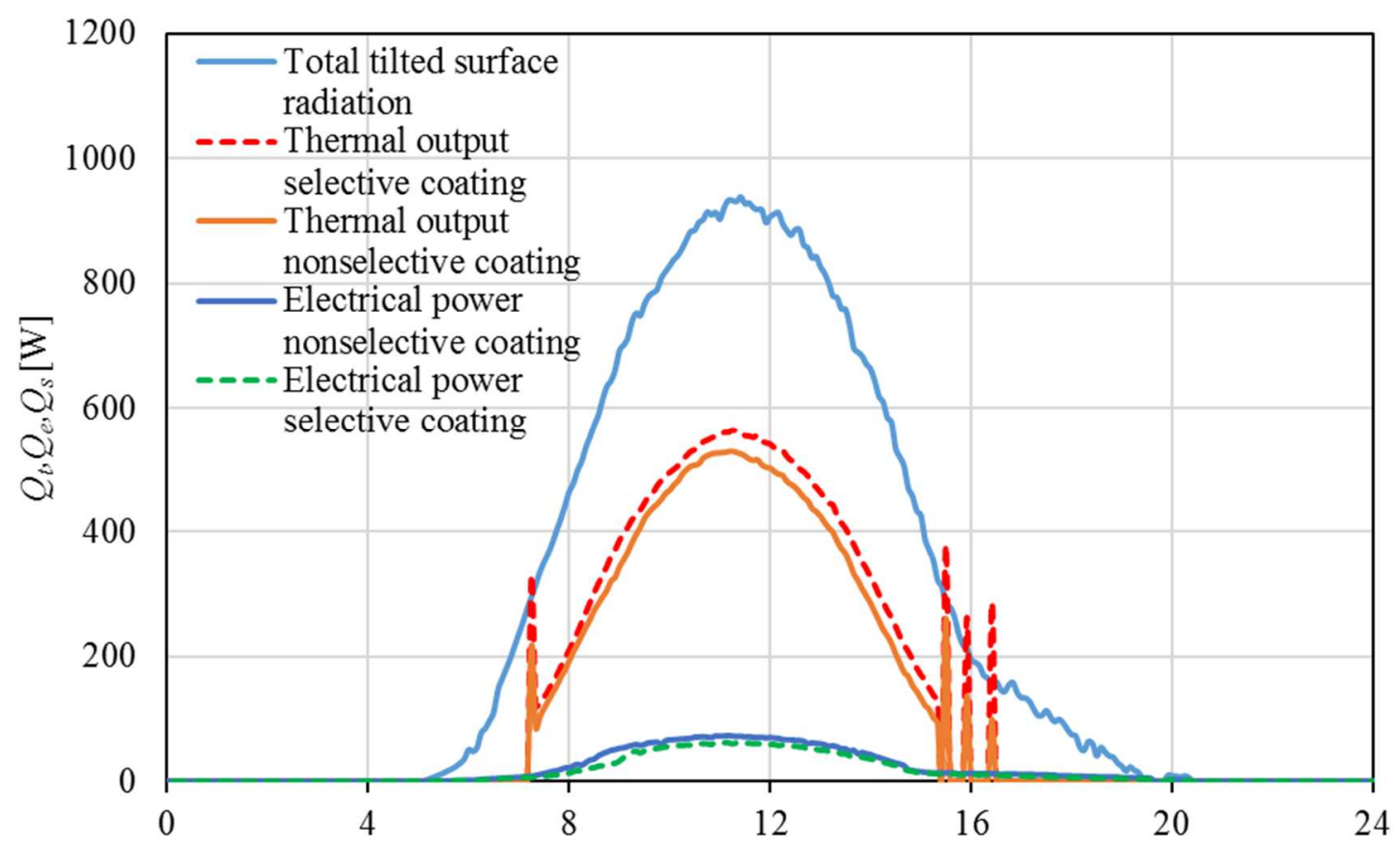

Fig. 8: Comparison of the thermal and electrical performance for sunny day

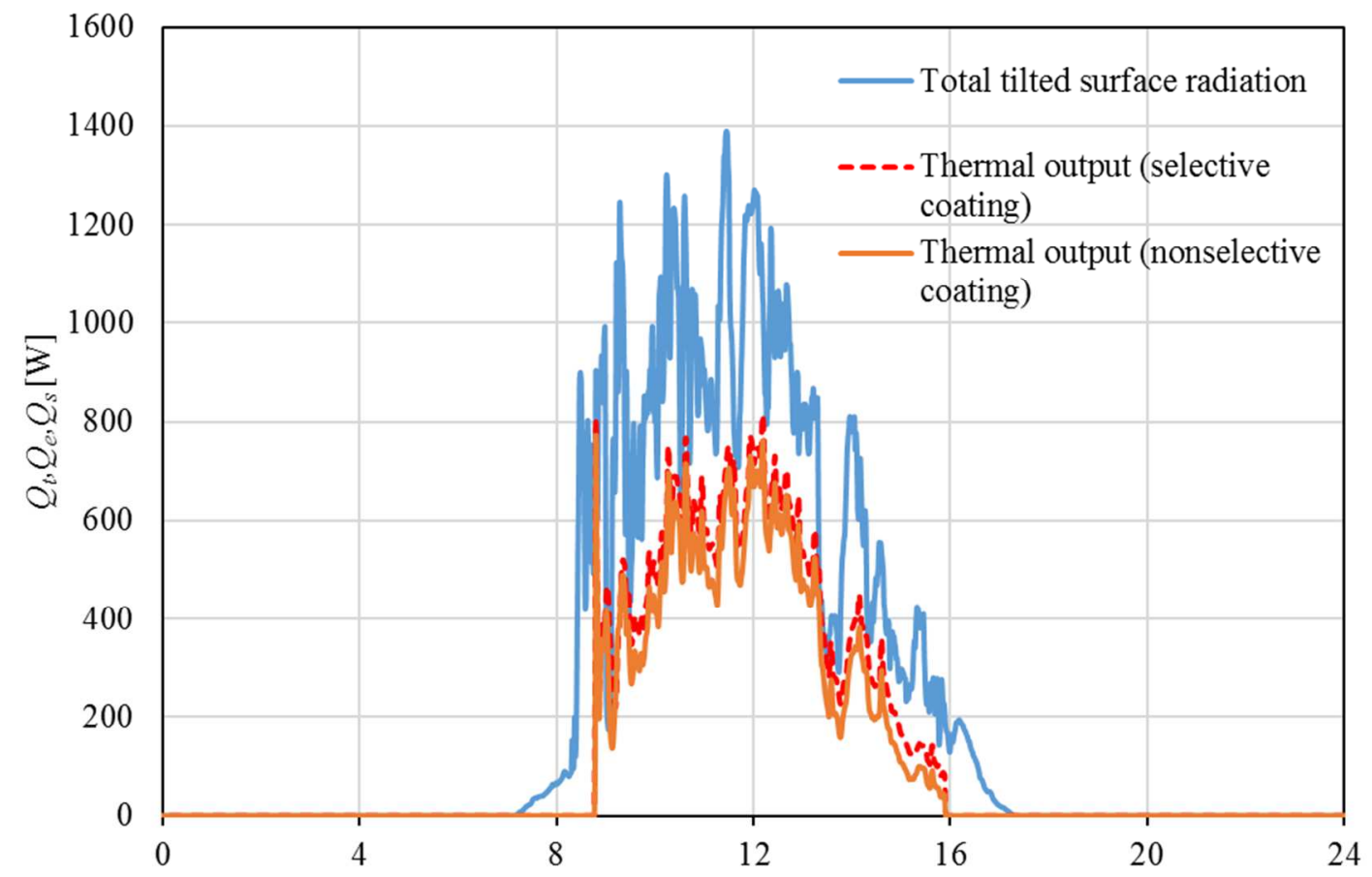

Fig. 9: Comparison of the thermal performance during OC mode

Moreover $U-I$ characteristics were measured under outdoor conditions (see in Fig. 10). Total tilted surface radiation was $675 \mathrm{~W} . \mathrm{m}^{-2}$, ambient temperature $25^{\circ} \mathrm{C}$, mean fluid temperature $35^{\circ} \mathrm{C}$, angle of incidence was $54^{\circ}$. These conditions are not standard but sufficient to show the difference in short circuit current between selective and nonselective absorber. The selective coating has $17 \%$ lower short circuit current for mentioned outdoor conditions. 


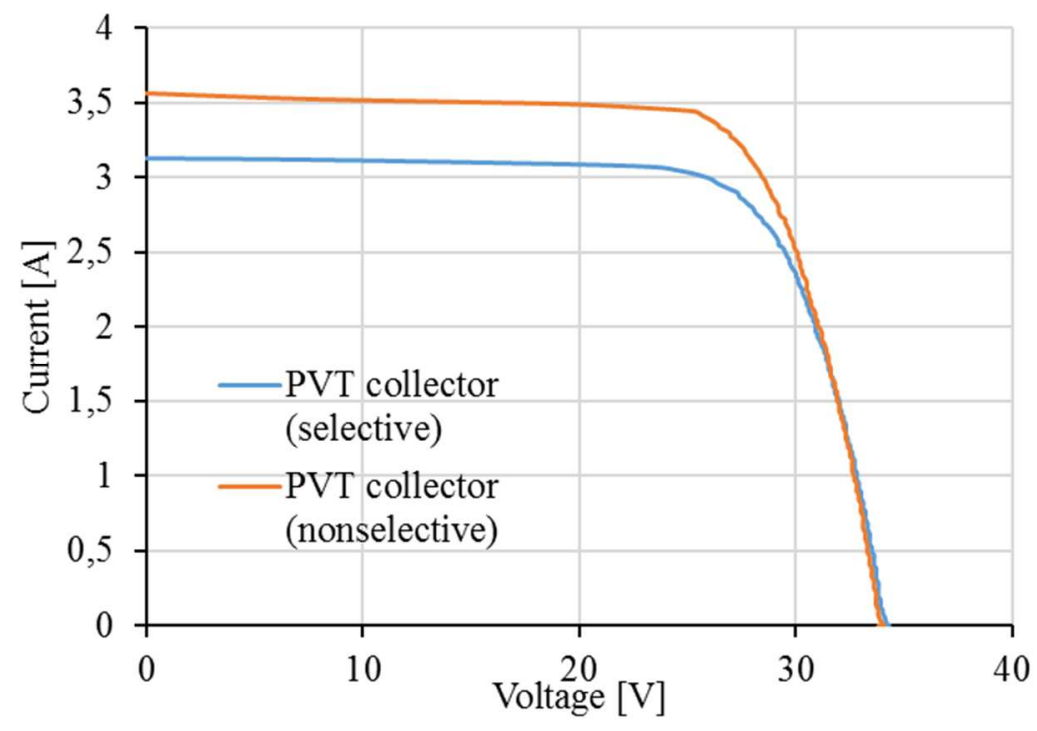

Fig. 10: $U-I$ characteristic for both collectors $\left(G=675 \mathrm{~W} / \mathrm{m}^{2}, t_{m}=35^{\circ} \mathrm{C}\right)$

In Fig. 11 infrared image of the front side of the façade module is shown. On the left hand side there is nonselective PVT collector which has higher temperature. On the right hand side there is selective PVT collector. Double glazing does not allow to measure temperature distribution on the PVT absorber unfortunately. Therefore it is not possible to identify eventually defects in PV part.

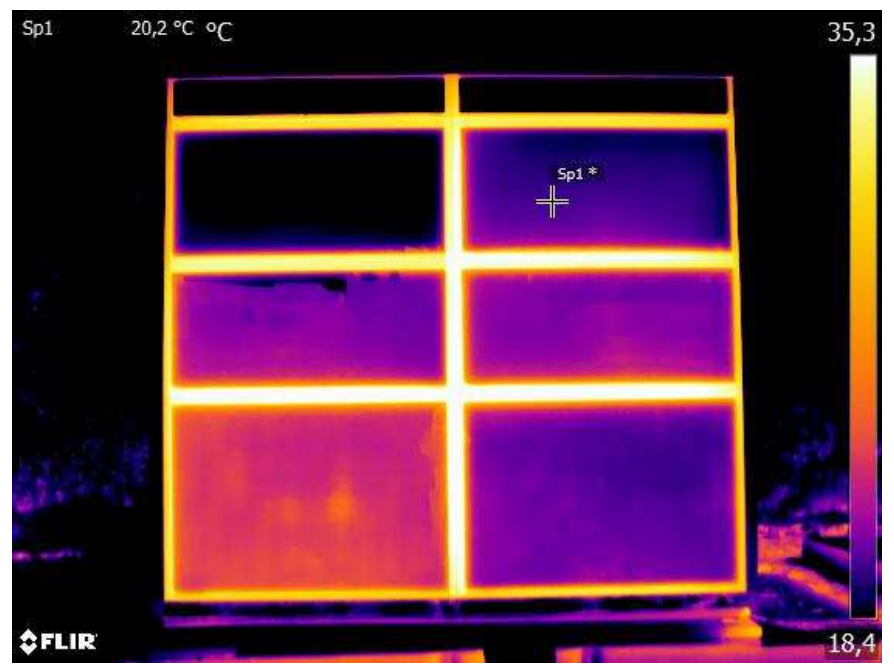

Fig. 11: Infrared image of the front side of the façade modules

\section{Conclusion}

New prototype of integrated PVT collector into façade module was developed and tested. Application of low-e coating enhanced thermal output and decrease electric power. Comparison of nonselective and selective PVT collector has been carried out under real climatic conditions. Advantage of low-e coating is disputable in this case. The increase of thermal production is approximately $10 \%$ which was anticipated. The increase of thermal energy production is even higher (14\%) in OC mode. However decrease in electrical production was measured around $17 \%$. Decrease of electrical production was expected around $2 \%$. Therefore expected overall positive influence of energy output by application of low-e coating on the absorber was not achieved. One possible reason of such a decrease of electrical energy production are micro cracks of PV cells. Electroluminescence analysis should be done in the near future to ensure that there are not micro cracks on the PV cells. Moreover the spectral optical properties of glazing with low-e coating for real climatic conditions will be necessary to measure separately. 


\section{Acknowledgement}

This work has been supported by the Ministry of Education, Youth and Sports within National Sustainability Programme I, project No. LO1605.

\section{References}

Giovannetti, F., Föste, S., Ehrmann, N., \& Rockendorf, G. (2014). High transmittance, low emissivity glass covers for flat plate collectors: Applications and performance. Solar Energy. https://doi.org/10.1016/j.solener.2013.10.006

Harrison, S., \& Cruickshank, C. A. (2012). A review of strategies for the control of high temperature stagnation in solar collectors and systems. In Energy Procedia. https://doi.org/10.1016/j.egypro.2012.11.090

Jirka, V., Shemelin, V., Šourek, B., \& Matuška, T. (2017). Simulation of office room with lightweight building envelope with optical rasters. Vytapeni, Vetrani, Instalace.

Lammle, M., Thoma, C., \& Hermann, M. (2016). A PVT Collector Concept with Variable Film Insulation and Low-emissivity Coating. In Energy Procedia (Vol. 91, pp. 72-77). https://doi.org/10.1016/j.egypro.2016.06.174

Matuska, T., Sourek, B., Jirka, V., \& Pokorny, N. (2015). Glazed PVT Collector with Polysiloxane Encapsulation of PV Cells: Performance and Economic Analysis. International Journal of Photoenergy, 2015. https://doi.org/10.1155/2015/718316

Poulek, V., Strebkov, D. S., Persic, I. S., \& Libra, M. (2012). Towards 50 years lifetime of PV panels laminated with silicone gel technology. Solar Energy, 86(10), 3103-3108. https://doi.org/10.1016/j.solener.2012.07.013 


\title{
Design and Performance Assessment of a Prefabricated BIPV/T Roof System Coupled with a Heat Pump
}

\author{
E. D. Rounis', Z. loannidis', R. Dumoulin', O. Kruglov', A. Athienitis', T. Stathopoulos' \\ ${ }^{1}$ Centre for Zero Energy Building Studies, Department of Building, Civil and Environmental \\ Engineering, Concordia University, Montreal, Canada
}

\begin{abstract}
This paper describes the design, development and simulated performance of a building integrated photovoltaic/thermal (BIPV/T) roof system, coupled with a water-to-water heat pump. This system is installed on a prefabricated low-energy house, designed for the Solar Decathlon China 2018 contest. The open-loop, air-based $\mathrm{BIPV} / \mathrm{T}$ roof system is fully integrated and is based on the design of a curtain wall BIPV/T prototype. The preheated air collected by the system is driven through a custom manifold to an air-to-water heat recovery ventilator (HRV) unit which is in turn linked to the cold storage tank of the heat pump. The objective of this paper is to provide insight on the design and performance of fully integrated BIPV/T roof systems and introduce concepts of modular prefabrication of such systems. The performance of the coupled BIPV/T-heat pump system was modelled in TRNSYS.
\end{abstract}

Keywords: Building-integrated photovoltaic/thermal, prefabricated net-zero house, modelling, TRNSYS.

\section{Introduction}

Integration of photovoltaic/thermal (PV/T) systems with the building envelope is a crucial part of the net-zero energy building concept. An active envelope system becomes the energy generating part of the building, while the integration itself entails such benefits as superior aesthetics and increased cost effectiveness due to the replacement of common envelope materials (Yang and Athienitis, 2016). Open-loop, air-based BIPV/T systems have an air channel behind the photovoltaic (PV) modules which serves both as a means of cooling the PV modules and of collecting preheated fresh air. Although there are several studies on BIPV/T systems (Chen et al, 2010; Athienitis et al 2010; Zogou and Stapountzis, 2011) and stand-alone PV/T systems (Wolf, 1976; Florschuetz, 1979; Hegazy, 2000; Hussain et al, 2015, Tonui and Tripanagnostopoulos, 2007), such systems currently hold the smallest share of PV applications. This can be attributed to two main factors, namely, the lack of a BIPV/T design and performance standard and the adherence of the engineering community to known building practices.

This study introduces a novel BIPV/T roof system (Fig. 1) coupled with a two-tank, water-to-water heat pump, installed on a prefabricated low-energy/net-zero residential building. The building, also known as the "Deep Performance Dwelling" or "DPD", is of a row house typology with a floor area of $200 \mathrm{~m}^{2}$ and was designed for the Solar Decathlon China 2018 competition, in Dezhou, China. This system is based upon a BIPV/T curtain wall prototype (Rounis et al, 2017; Kruglov et al, 2017). Several aspects of the design are presented, such as the structural and architectural integration, building envelope considerations, as well as the coupling with an HRV unit via a custom manifold. Concepts of modularity and prefabrication are also discussed.

The coupled system's performance was modelled using TRNSYS and simulated for the local climate of Dezhou, China. The results focus on the electrical and thermal output of the system, both in terms of heat recovery at the air collector's end and heat delivered at the mechanical system. The main goals of this investigation are to provide insight on the design and performance of BIPV/T roof systems intended for full integration, as well as analyze thermal utilization strategies through numerical investigation of the coupled BIPV/T-heat pump system.

\section{Overall building and mechanical system description}

The Deep Performance Dwelling (DPD) (Figure 1) is a two-story building of the row house typology, with a foot print of $116 \mathrm{~m}^{2}$ and a total heated space of $200 \mathrm{~m}^{2}$. It was designed by Team Montreal for the 2018 Solar Decathlon 
Competition, held in Dezhou, China. The building was designed to represent one unit of attached row houses, a residential building typology very common in dense urban settings. The design of the house included three main components, namely, passive design with a highly insulated, air-tight envelope to minimize the energy demand for conditioning, on-site energy generation with integrated systems and electrical and thermal storage for optimal use of that energy.
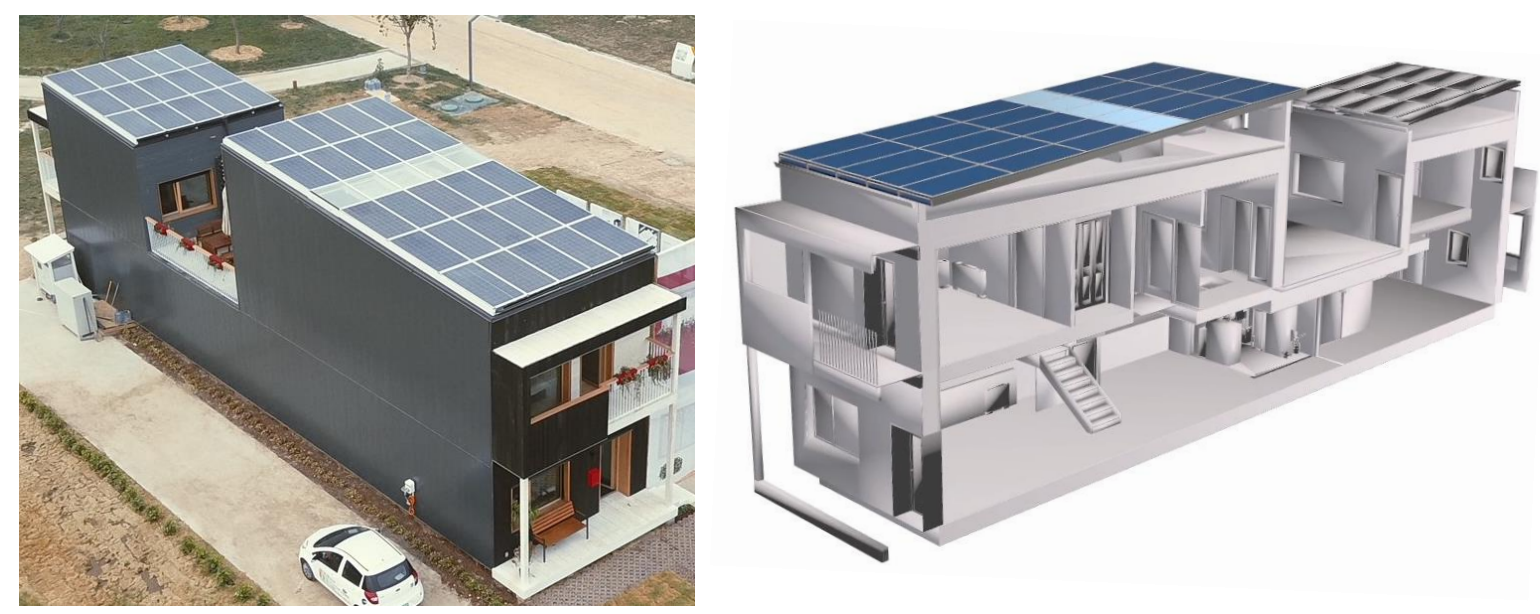

Fig. 1: The Deep Performance Dwelling (DPD). Installed on the back roof is a building integrated photovoltaic system (BIPV) and on the front roof a building integrated photovoltaic /thermal (BIPV/T) system with an integrated skylight.

\subsection{Passive design and HVAC}

The passive design reduces the heating energy demand of the house by $80 \%$ on average versus poorly insulated housing. This is achieved by the highly insulated walls (RSI 10.4) and roof (RSI 15.3), as well as the highperformance triple-glazed windows (RSI 1) and skylight system.

An important aspect of the design process was the concept of prefabrication and modularity. The building envelope (walls, roof) was prefabricated in modules which were assembled on site with the use of a crane. This was partly used for the BIPV and BIPV/T roofs of the building, the construction of which combined pre-assembled parts of the frame with on-site assembly.

Heating and cooling is provided by four local, two-pipe fan-coil units, one for each primary thermal zone of the house, which can operate in independent modes. These units are supplied with water by two 450-litre thermal storage tanks, one hot and one cold, depending on the demand of each zone. The two tanks temperature is maintained at desired setpoints (below $7^{\circ} \mathrm{C}$ for the cold tank and $35^{\circ} \mathrm{C}$ for the hot tank in summer mode and over $0^{\circ} \mathrm{C}$ for the cold tank and $45^{\circ} \mathrm{C}$ for the hot tank in winter mode) via a 2-ton water to water heat pump. Domestic hot water is supplied by a 190-litre hybrid HP water heater, which utilizes the heat produced by the equipment in the mechanical room by storing it in the tank via an air to water heat pump, also controlling the temperature of the room itself. A high-efficiency Energy Recovery Ventilation unit is used for heat and moisture recovery during the winter and dehumidification during the summer.

\subsection{Energy generation and storage}

An air-based, open-loop Building Integrated Photovoltaic/Thermal (BIPV/T) system is installed on the front roof of the house and a Building Integrated Photovoltaic (BIPV) system is installed on the back roof, as demonstrated in Figure 1. During winter, the thermal energy harvested from the BIPV/T system is stored on the cold tank of the two tank-heat pump system via an air-to-water heat exchanger unit. The same unit is used during the summer to remove heat from the hot tank and release it to the ambient environment. This results in reduction of the temperature difference of the two tanks in both cooling and heating mode and thus increasing the water-to-water heat pump's coefficient of performance (COP).

Furthermore, a 10-kWh lithium-ion battery serves as electrical storage, which can both provide back-up in case of power outages, as well as assist the grid in the peak power demand periods. Figure 2 demonstrates a simplified schematic of the mechanical system. 


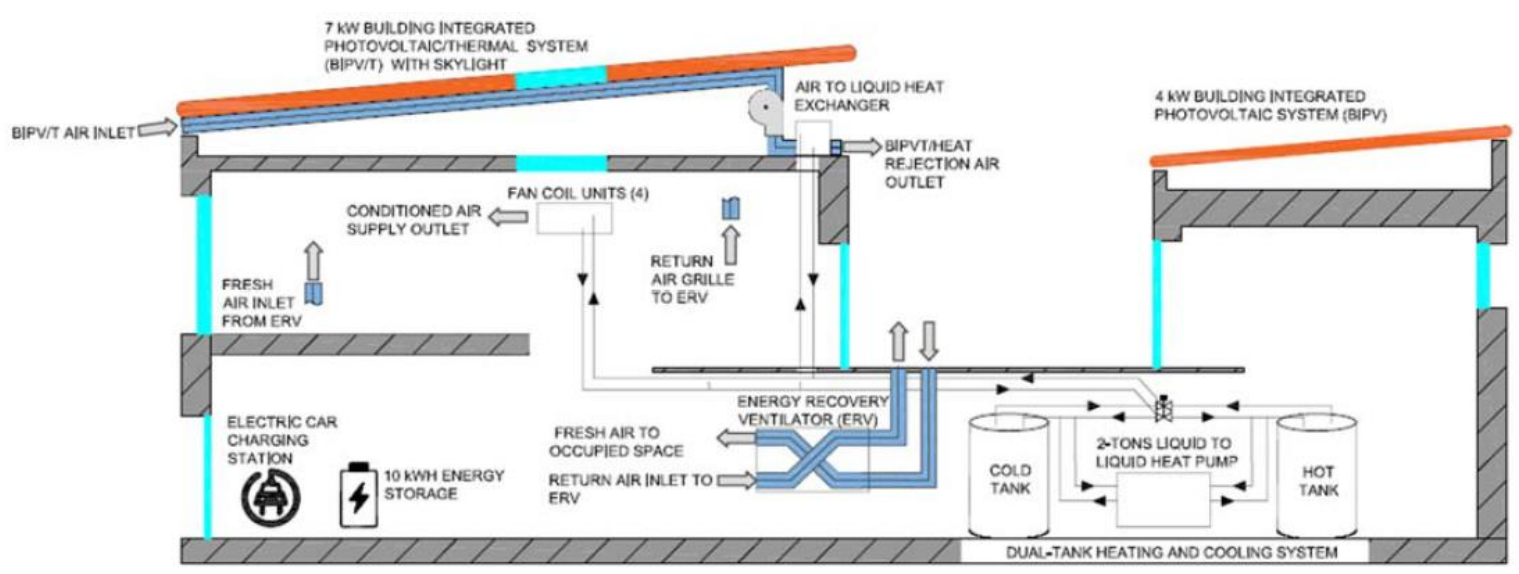

Fig. 2: Simplified schematic of the mechanical system of the DPD

\section{BIPV/T and BIPV systems}

\subsection{BIPV/T Curtain Wall prototype}

A BIPV/T curtain wall prototype designed, developed and tested at Concordia University in Montreal, served as the basis for the design of the BIPV/T system implemented in the DPD. The development of the prototype was done within the scope of implementing common building techniques in the design of BIPV/T systems, which could lead to the standardization of such systems and wider application in the market.

For the development of the prototype, the curtain wall concept was adopted and modified in order to accommodate the air flow of the system. The design and development of the prototype is documented in detail in Rounis et al (2017) and Kruglov et al (2017). The prototype (Figure 3) consists of an aluminum curtain wall frame with commercial mullion extrusions, frameless PVs fixed on the frame with Pressure plates as well as point supports (brackets) and rigid insulation supported by a typical aluminum back pan. The experimental prototype also features an extra air intake (inlet) as a method of enhancing heat extraction from the PV by disrupting the thermal boundary layer formed on the inner PV surface.

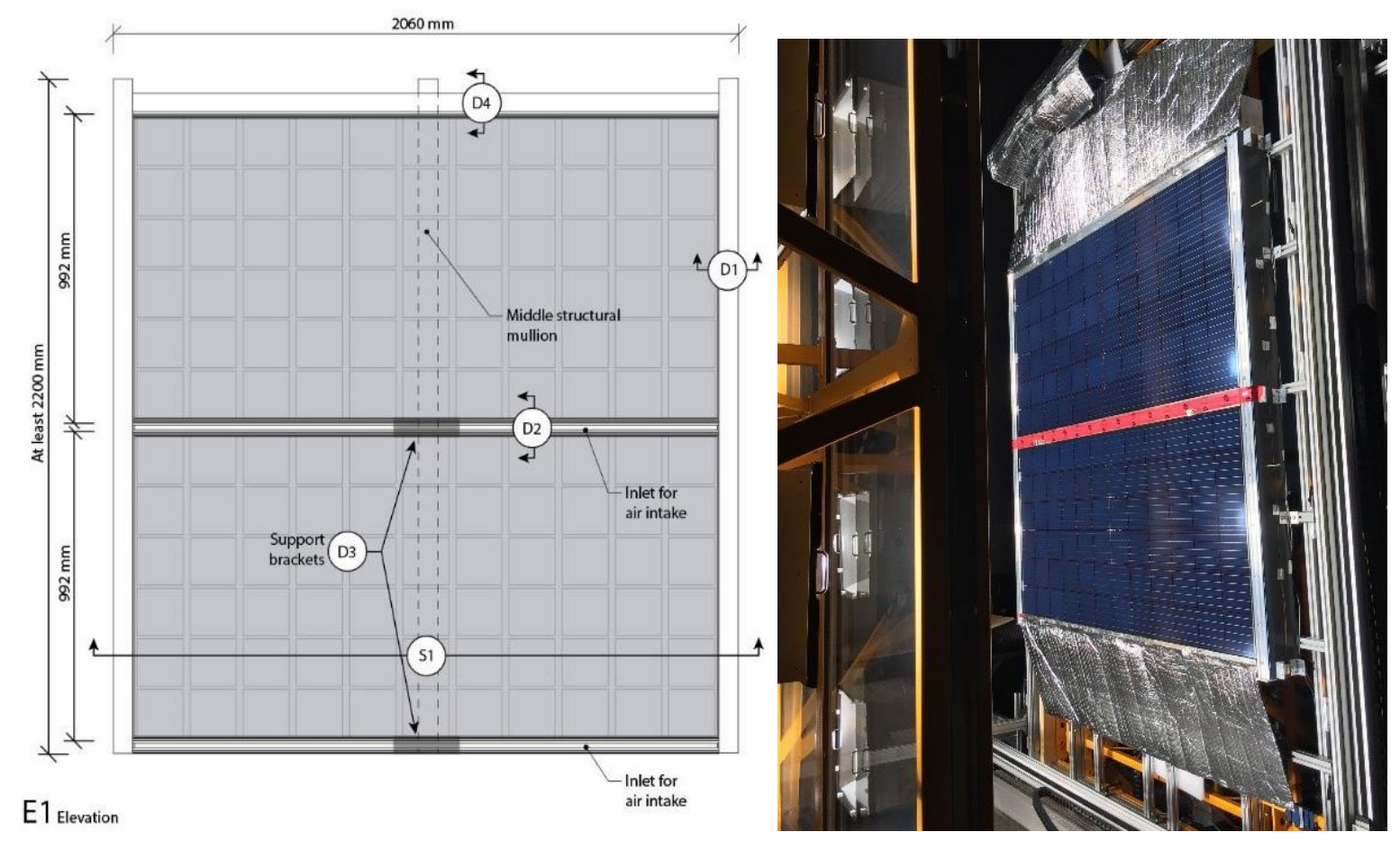

Fig. 3: Experimental BIPV/T curtain wall prototype design (left) and testing (right)

The prototype's construction features the curtain wall stick built method of assembly. The potential of designing a unitized system with a modular approach is currently under investigation. Modularization of BIPV/T can further 
encompass the system's standardization, as well as extend its range of application for both new buildings and retrofits.

\subsection{BIPV/T and BIPV roof systems of the DPD}

The curtain wall concept was adopted for the integrated roof systems of the DPD. The front and back roof of the DPD employ a BIPV/T and a BIPV system respectively. Both systems incorporate a curtain wall aluminum framing system. The following section focuses on the features of the open-loop BIPV/T system of the front roof.

The BIPV/T consists of 25 CS6X-310W PV modules, forming a $7.75 \mathrm{~kW}$ peak power system, with an integrated skylight system supported by a curtain wall frame. The frame consists of vertical and horizontal structural elements (mullions), of which the horizontal has a shallow height in order to allow the air flow for the air channels formed between the vertical. Semi-rigid insulation is set at a distance of $10 \mathrm{~cm}$ from the PV surface and supported by aluminum back pans at the rear side of the frame. Five air channels are thus formed (5 PV modules and a glazing unit for each channel) as shown on the structural breakdown of the BIPV/T system in Figure 4.

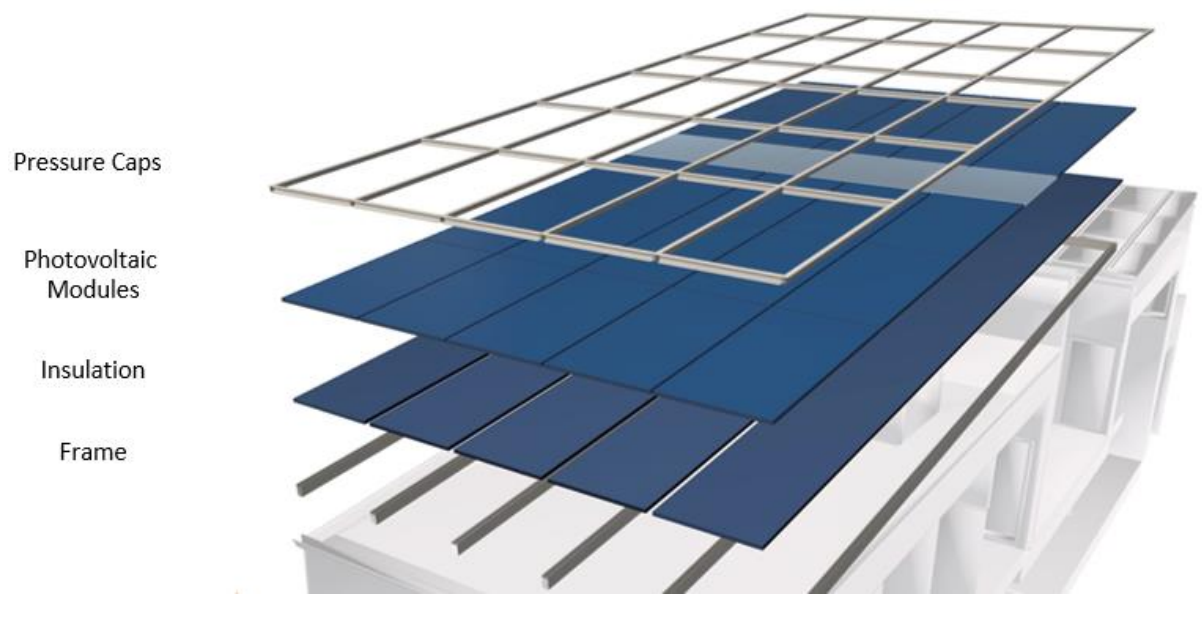

Fig. 4: BIPV/T roof breakdown

The curtain wall technique allowed for an easy incorporation of a skylight system that allows natural daylight in the living space bellow. The latter is a challenge for row houses, especially when incorporating a PV roof. The skylight consists of a double-glazing unit on top and a single glazing on the bottom, allowing for a continuous air channel. Figure 5 showcases the seamless architectural integration of the PV and the skylight.

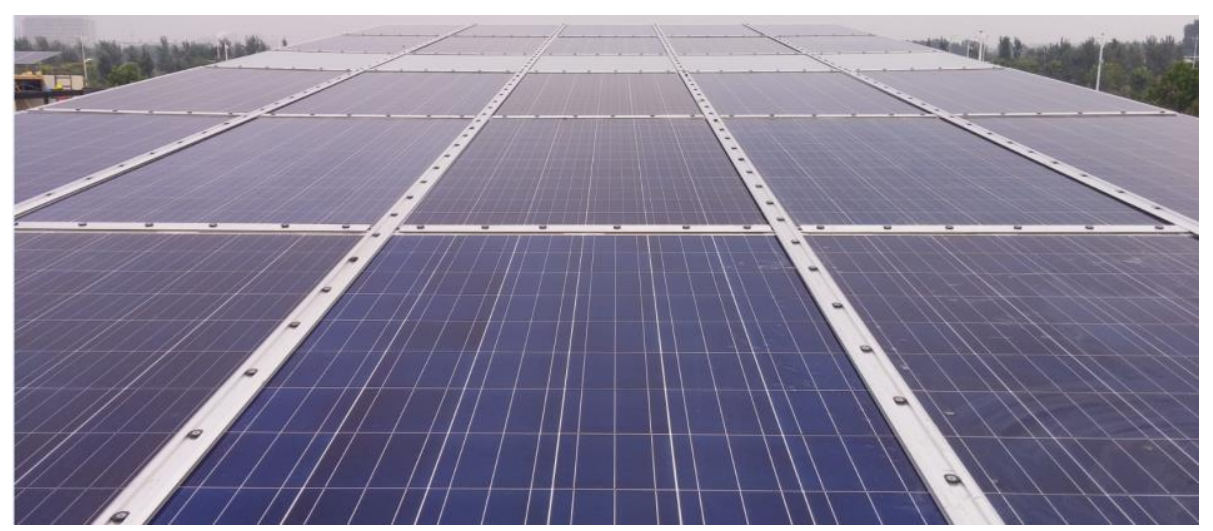

Fig. 5: Finished BIPV/T roof with integrated skylight

The BIPV system of the back roof consists of 15 CS6X-310W PV modules (4.65 kW peak power), also employing a curtain wall frame. Its design is simpler since it is comprised only of the PV modules supported by the frame, without the air channel.

Both roof systems have a $5^{\circ}$ tilt which to meet the competition's maximum height requirements, although the optimal tilt would closer to $40^{\circ}$ in order to maximize incident solar irradiation annually and avoid snow accumulation. The effect of an optimal and a non-optimal system tilt is discussed in section 4.2. 


\subsection{Thermal operation}

At the top of the BIPV/T system a custom manifold was connected via two take-offs per channel to ensure flow uniformity for all channels. The manifold (Figure 6) was previously balanced at Concordia University via manually operated dampers installed at each take off.

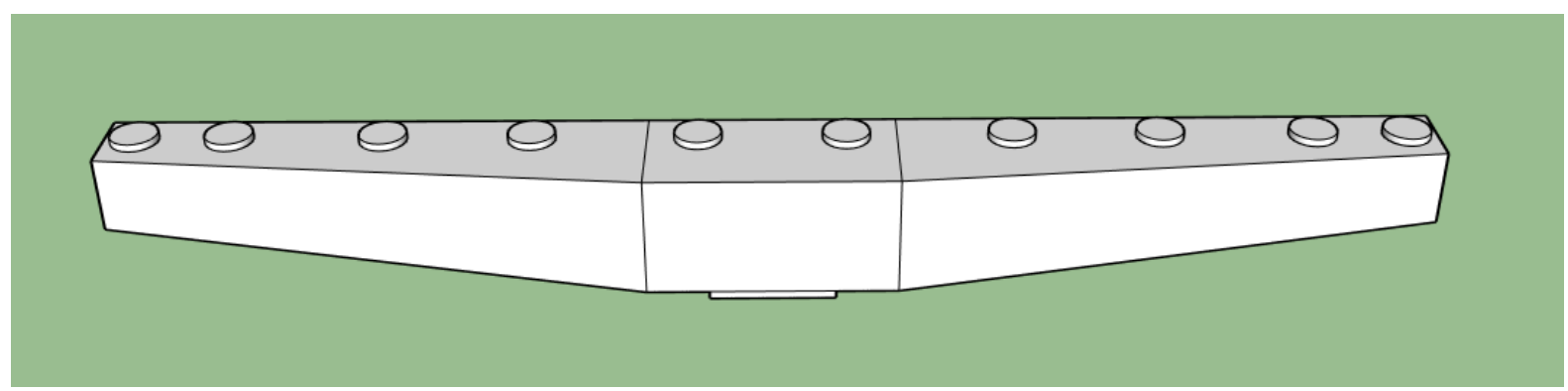

Fig. 6: The BIPV/T manifold (two take-offs per channel)

The main duct of the manifold is connected to an air-to-water heat exchanger. The water loop of the heat exchanger is connected to the two-tank heat pump system. In winter mode, the heat transferred by the pre-heated air from the BIPV/T system to the water loop, is then stored in the cold tank to increase its temperature. During summer mode, the BIPV/T system is naturally ventilated via dumpers, while the heat exchange unit is now used to cool the hot tank of the system. Figure 7 demonstrates a schematic of the connection between the BIPV/T and the mechanical system of the building.

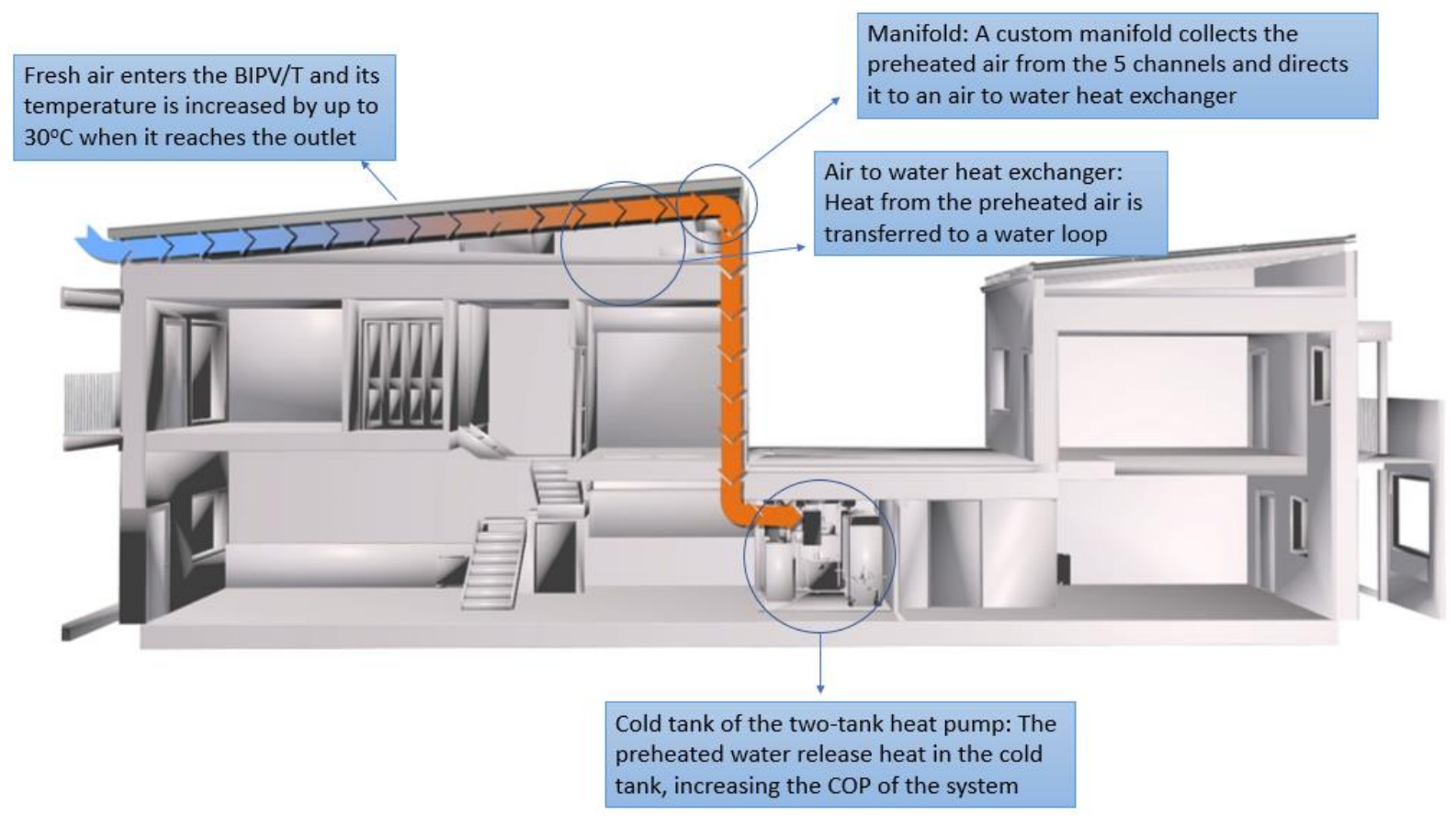

Fig. 7: Integrattion of the BIPV/T and the mechanical system

\section{Modelling and simulations}

The performance of the BIPV/T system in conjunction with the mechanical system was evaluated using the software TRNSYS. The following section summarizes the modelling assumptions and methodology, as well as results on the thermal performance of the system during winter for various flow rates of the air channel and of the water loop.

\subsection{BIPV/T modelling}

The BIPV/T modelling was done in TRNSYS using a modified version of Type 567 from the Thermal Energy Systems Specialists (TESS) libraries (TESSLibs 17), interfacing with Type 56 for multi-zone buildings. A semiconditioned zone was defined between the building and the BIPV/T system, with the latter set as a boundary of 
that zone.

The BIPV/T energy balance has been well documented in literature (Candanedo et al, 2011; Chen et al, 2010; Yang and Athienitis, 2014) and the resulting governing equations are solved in an iterative manner in TRNSYS, using initial guesses for the PV and back surface temperatures. A typical energy balance for a photovoltaic thermal system is presented in Figure 8 in the form of a thermal network.

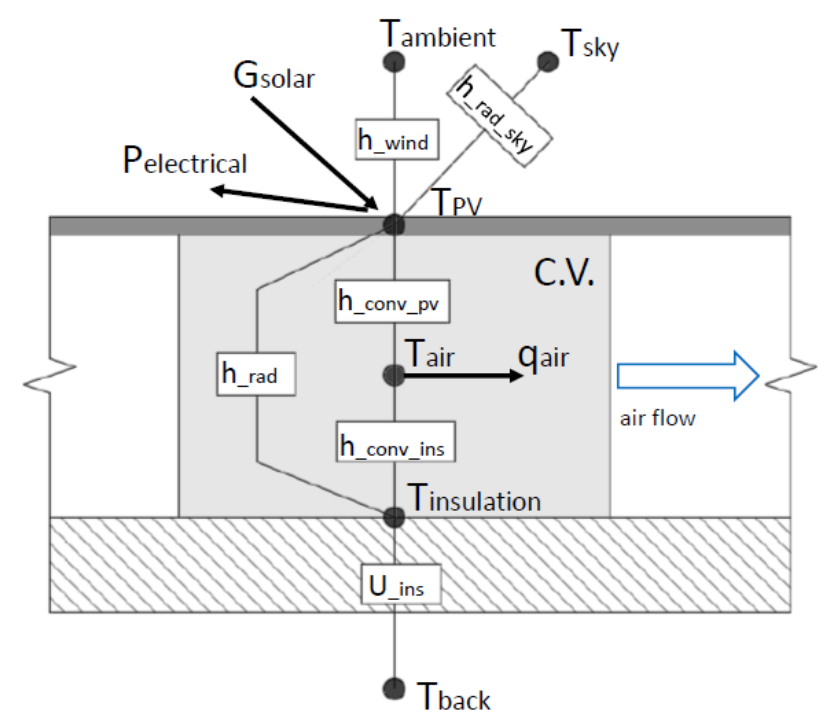

Fig. 8: Finished BIPV/T roof with integrated skylight

Where $\mathrm{T}_{\text {ambient }}, \mathrm{T}_{\text {sky }}, \mathrm{T}_{\mathrm{PV}}, \mathrm{T}_{\text {air }}, \mathrm{T}_{\text {insulation }}$ and $\mathrm{T}_{\text {back }}\left({ }^{\circ} \mathrm{C}\right)$ are the temperatures of the ambient, sky, $\mathrm{PV}$, cavity air, insulation surface and back room respectively; $\mathrm{h}_{-}$rad_sky, $\mathrm{h}_{-}$rad $\left(\mathrm{W} / \mathrm{m}^{2} \mathrm{~K}\right)$ are the coefficients for radiative heat exchange between the PV and the sky and PV and the insulation respectively, $\mathrm{h}_{-}$conv_PV, $\mathrm{h}_{\text {_conv_ins }}\left(\mathrm{W} / \mathrm{m}^{2} \mathrm{~K}\right)$ are the convective heat transfer coefficients inside the air cavity, $\mathrm{U}_{\text {ins }}\left(\mathrm{W} / \mathrm{m}^{2} \mathrm{~K}\right)$ is the insulation $\mathrm{u}$-value, $\mathrm{G}_{\text {solar }}\left(\mathrm{W} / \mathrm{m}^{2}\right)$ is the insident solar irradiation, $\mathrm{P}_{\text {electrical }}\left(\mathrm{W} / \mathrm{m}^{2}\right)$ is the electrical power generated by the $\mathrm{PV}$ and $\mathrm{q}_{\mathrm{air}}\left(\mathrm{W} / \mathrm{m}^{2}\right)$ is the rate of heat transfer in the cavity air stream.

Type 567 (and generally BIPV/T types in TRNSYS) assumes a single convective heat transfer coefficient (CHTC or $\mathrm{h}_{\text {conv }}$ ) for top (PV) and bottom (insulation) surfaces of the air channel, evaluated using the Nusselt number, which in turn is calculated depending the flow regime. The CHTC $\left(\mathrm{h}_{\text {conv }}\right)$ is then calculated as follows:

$h_{\text {conv }}=\frac{N u \cdot k}{L}$

Where $\mathrm{k}(\mathrm{W} / \mathrm{m} \mathrm{K})$ is the thermal conductivity of the fluid and $\mathrm{L}(\mathrm{m})$ the characteristic length, which in the case of non-circular pipes is the hydraulic diameter of the air channel, $D_{h}=4 \cdot A_{c} / p$, where $\mathrm{A}_{\mathrm{c}}\left(\mathrm{m}^{2}\right)$ is the channel crosssectional area and $\mathrm{p}(\mathrm{m})$ its perimeter.

For the case of forced, turbulent flow, the Nusselt number $(\mathrm{Nu})$ is calculated according to the Dittus-Boelter equation (eq. 2).

$\overline{N u}=0.023 \operatorname{Re}^{0.8} \operatorname{Pr}^{n}$

Where Re is the Reynolds number, which indicates the flow regime, Pr is the Prandtl number of air and $n$ is an exponent equal to $n=0.3$ when heat is transferred from the fluid to the duct wall and $n=4$ when heat is transferred from the surface to the fluid.

The Dittus-Boelter equation has been developed for smooth duct with developed turbulent flow (Candanedo et al, 2011). It may, therefore, underestimate convective heat transfer in the air channel of a BIPV/T, since the channel is not smooth due to frame protrusions and the surface roughness and it may also neglect the entrance effects, where heat exchange is highest at the entrance region of the flow. This correlation was modified within the TRNSYS type and channel convection was evaluated by the empirical correlations developed and validated by Chen et al (2010) for a fool scale roof BIPV/T system (eq. 3). 
$h_{\text {conv }}=\left\{\begin{array}{lr}10.2 & \text { if } 0.4 \leq v_{\text {fluid }} \leq 0.6 \mathrm{~m} / \mathrm{s} \\ 12 \cdot v_{\text {fluid }}+3 & \text { if } v_{\text {fluid }}>0.6 \mathrm{~m} / \mathrm{s}\end{array}\right.$

Where $v_{\text {fluid }}(\mathrm{m} / \mathrm{s})$ is the average air speed within the BIPV/T channel. Equation (3) also assumes a single value for the top and bottom convective heat transfer coefficients of the channel, as well as an average value for the whole channel length. The heat collected by the system on the air side is calculated as follows:

$q_{\text {thermal }}=\dot{m} \cdot C_{p} \cdot \Delta T$

Where $\mathrm{q}_{\text {thermal }}(\mathrm{W})$ is the heat recovered from the BIPV/T system, $\mathrm{C}_{\mathrm{p}}$ is the specific heat capacity of air and $\Delta \mathrm{T}$ is the air temperature difference between the inlet and outlet of the BIPV/T air channel.

The thermal efficiency $\left(\eta_{\text {thermal }}\right.$ ) on the air side (outlet of the BIPV/T system) is defined as the ratio of the heat recovered $\left(\mathrm{q}_{\text {thermal }}\right)$ over the total incident solar irradiation. The rest of the equipment, namely, the heat exchanger, the water loop and the two-tank heat pump system have been modelled as black boxes in TRNSYS. The thermal efficiency at the water side (heat delivered to the cold tank), is defined as the ratio of the heat delivered to the cold tank over the total incident irradiation on the BIPV/T surface. Heat is delivered to the cold tank only when the temperature of water in the water loop is higher than that of the water in the cold tank.

Regarding the electrical output of the system, this is calculated as a function of the PV temperature (Kaiser et al, 2014; Tonui and Tripanagnostopoulos, 2006; Anderson et al, 2008; Skoplaki and Palyvos, 2009). The electrical efficiency, $\eta_{\text {elec}}$, is calculated as follows:

$\eta_{\text {elec }}=\eta_{o} \cdot\left[1-\beta \cdot\left(T_{P V}-T_{S T C}\right)\right]$

Where $\eta_{\text {ref }}$ is the reference efficiency of the PV module at standard testing conditions (STC), $\beta$ is the temperature coefficient of the $\mathrm{PV}, \mathrm{T}_{\mathrm{PV}}$ is the average $\mathrm{PV}$ module temperature and $\mathrm{T}_{\mathrm{STC}}$ is a reference $\mathrm{PV}$ temperature of $25^{\circ} \mathrm{C}$ (STC).

\subsection{Simulations and results}

A numerical investigation was carried out in TRNSYS regarding the thermal performance of the combined BIPV/T-heat pump system, for a cold sunny day in Dezhou, China. For the selected day, simulations were run to investigate the thermal output for the air side (heat collected by the air in the air channel of the BIPV/T) and the water side (the end heat delivered by the water loop to the cold tank). Two roof tilts were considered, namely the $5^{\circ}$ tilt the house was designed with for the competition and a $45^{\circ}$ slope which would be near optimal for maximum annual incident solar irradiation over the PV surface. Finally, four total mass flow rates were considered, corresponding to four average velocities in the air channel, namely, $0.25 \mathrm{~m} / \mathrm{s}, 0.5 \mathrm{~m} / \mathrm{s}, 0.75 \mathrm{~m} / \mathrm{s}$ and $1 \mathrm{~m} / \mathrm{s}$.

Figures $9 \mathrm{a}$ and $9 \mathrm{~b}$ demonstrate the heat recovery at the air and water side against average air velocity in the air channel, for the actual roof slope of $5^{\circ}$ and the near optimal roof slope of $40^{\circ}$ respectively. Figures $10 \mathrm{a}$ and $10 \mathrm{~b}$ show the corresponding thermal efficiency for the two roof slopes.

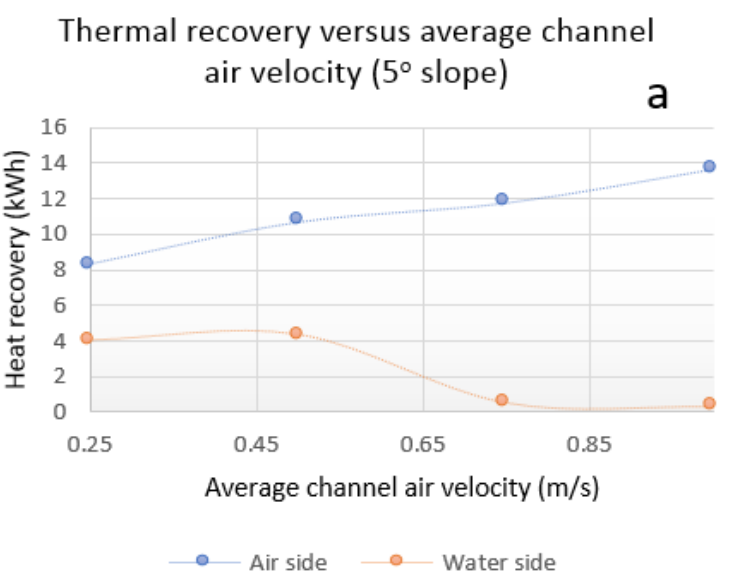

\section{Thermal recovery versus average channel air velocity $\left(40^{\circ}\right.$ slope $)$}

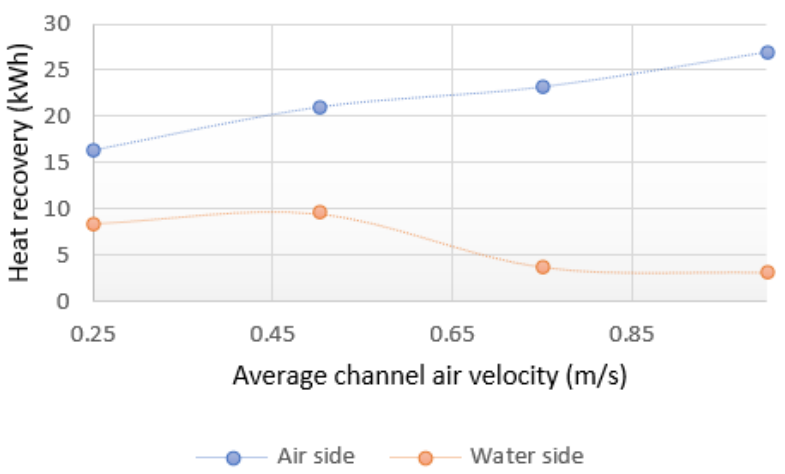

Fig. 9: Thermal recovery versus average air velocity inside the cavity for the air side (air outlet of the BIPV/T) and the water side (delivered to the cold tank) for a. $5^{\circ}$ roof slope and $\mathrm{b} .40^{\circ}$ roof slope 
Thermal efficiency versus average channel air velocity $\left(5^{\circ}\right.$ slope $)$

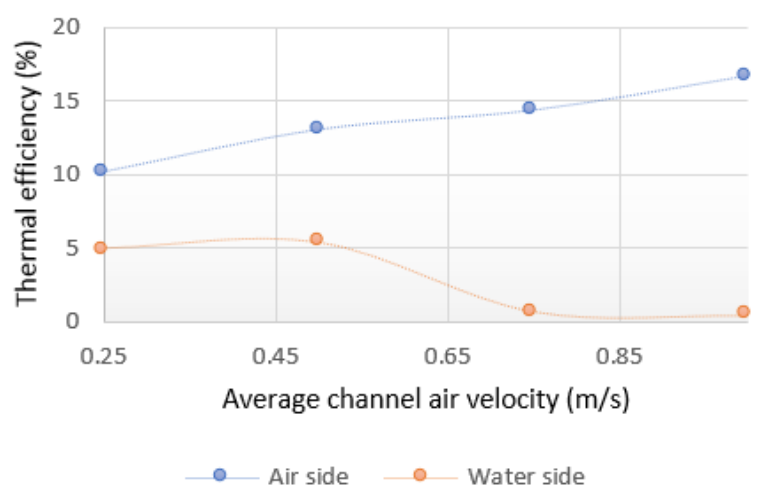

Thermal efticiency versus average channel air velocity $\left(40^{\circ}\right.$ slope $)$

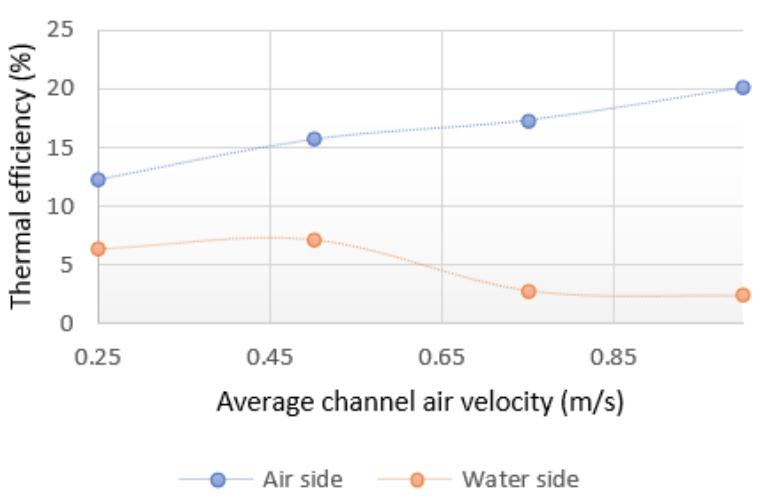

Fig. 10: Thermal efficiency versus average air velocity inside the cavity for the air side (air outlet of the BIPV/T) and the water side (delivered to the cold tank) for a. $5^{\circ}$ roof slope and b. $40^{\circ}$ roof slope

From the results it can be concluded that increasing the average channel air velocity increases the heat recovered from the BIPV/T, in accordance with previous studies (Bambrook and Sproul, 2012; Yang and Athienitis, 2014; Hegazy, 2000). The thermal efficiency of the BIPV/T can be over $20 \%$, for optimal tilt and for an average air cavity velocity of $1 \mathrm{~m} / \mathrm{s}$. However, in terms of overall heat recovery and end use, which in this case is heat delivered to the cold tank of the two-tank system, maximum airflow is not the optimal. An algorithm could be used to optimize flow rate at any given time, however, the simulations showed that a fixed velocity of $0.5 \mathrm{~m} / \mathrm{s}$ yields the best results for the heating season, simplifying the controls of the system.

A lower heat transfer rate in the cavity produces more favorable results for this system configuration, since the delivery of useful heat depends on the temperature differential between the cavity air and the fluid in the heat exchanger on the air side and the temperature difference between the fluid and the water in the cold tank on the water side. The useful heat delivered to the cold tank has been calculated to be up to $4 \mathrm{MWh}$ annually.

Finally, the results showcase the importance of the roof slope. Optimizing the roof slope resulted in more than double the amount of useful heat delivered to the system as opposed to the actual building slope. This is also evident in the average monthly electrical and thermal output of the system for the two roof slopes, as demonstrated in Figure 11.
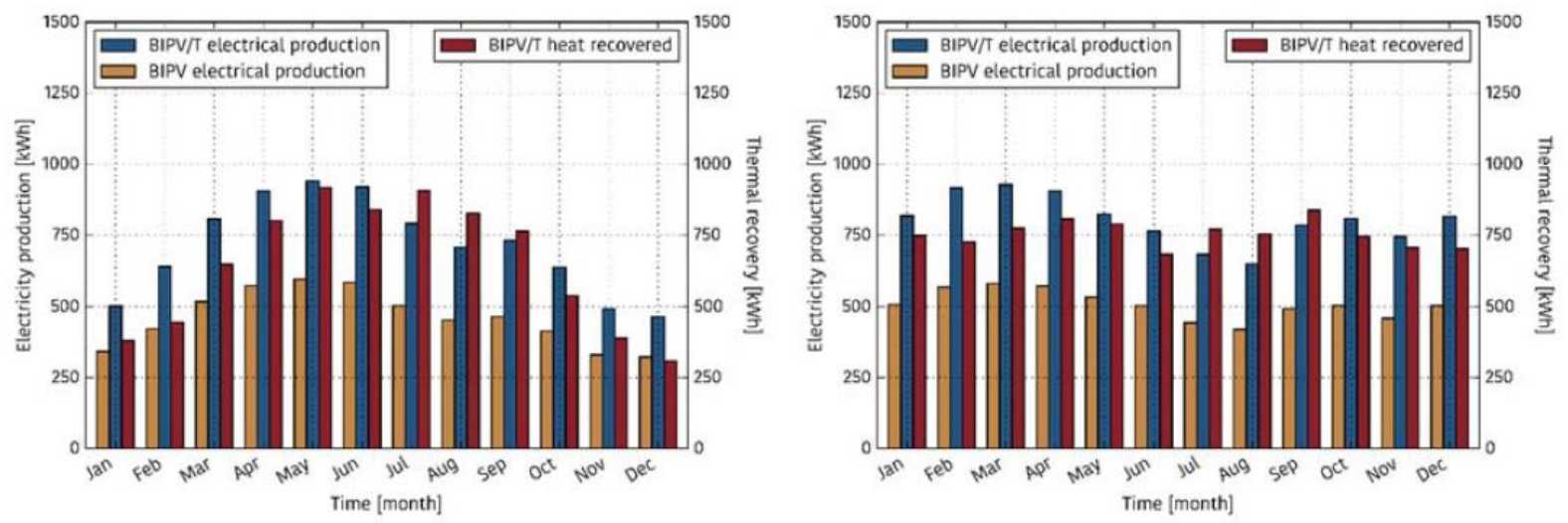

Fig. 11: Monthly electrical and thermal output of the BIPV/T system for a $5^{\circ}$ roof slope (left) and a $45^{\circ}$ roof slope (right).

It must be noted that the specific way that heat from the BIPV/T was utilized is only one of many potential options and was dictated by construction restrictions and requirements for system compactness. Other options could include preheating of domestic hot water (DHW), as well as a solar heating driven cooling system, such as desiccant cooling, in which cases heat from the BIPV/T could be further exploited even during the cooling season.

\section{Summary and Conclusions}

In this paper the design, development and simulated performance of a roof BIPV/T system coupled with a water to water heat pump is described. The curtain wall building technique has been adopted as a novel way to implement 
BIPV/T systems, which could lead to the standardization of such systems and has the potential for prefabrication and modularization.

The performance of the coupled BIPV/T-heat pump system was modelled in TRNSYS. From the simulated system's performance the following can be concluded:

- The tilt of the BIPV/T system, determined by the building's slope, has a critical effect on its annual electrical and thermal performance.

- Increasing the flow rate in the air cavity produces higher thermal output at the end of the BIPV/T collector, but this can be at the cost of the required temperature for the mechanical system linked to the BIPV/T. The flow rate in the BIPV/T system's cavity must be optimized according to the end use

- Although the thermal efficiency is a common reference for the characterization and comparison of photovoltaic/thermal systems, it is the heat delivered to the actual thermal application that should dictate the design and performance optimization of the system at the collector level.

\section{References}

Anderson, T.N., Duke, M., Morrison, G.L., Carson, J.K., 2009. Performance of a building integrated photovoltaic/thermal (BIPVT) solar collector. Sol. Energy 83, 445-455. doi:10.1016/j.solener.2008.08.013

Bambara, J., Athienitis, A.K., O’Neill, B., 2011. Design and performance of a photovoltaic/thermal system integrated with transpired collector. ASHRAE Trans. 117, 403-410. doi:10.1016/j.solener.2010.10.008

Bambrook, S.M., Sproul, A.B., 2012. Maximising the energy output of a PVT air system. Sol. Energy 86, 18571871. doi:10.1016/j.solener.2012.02.038

Candanedo, L.M., Athienitis, A., Park, K.-W., 2011. Convective Heat Transfer Coefficients in a BuildingIntegrated Photovoltaic/Thermal System. J. Sol. Energy Eng. 133, 21002. doi:10.1115/1.4003145

Chen, Y., Athienitis, A.K., Galal, K., 2010. Modeling, design and thermal performance of a BIPV/T system thermally coupled with a ventilated concrete slab in a low energy solar house: Part 1, BIPV/T system and house energy concept. Sol. Energy 84, 1892-1907. doi:10.1016/j.solener.2010.06.013

Florschuetz, L.W., 1979. Extension of the Hottel-Whillier model to the analysis of combined photovoltaic/thermal flat plate collectors. Sol. Energy 22, 361-366. doi:10.1016/0038-092X(79)90190-7

Hegazy, A.A., 2000. Comparative study of the performances of four photovoltaic / thermal solar air collectors. Energy Convers. Manag. 41.

Hussain, F., Othman, M.Y.H., Yatim, B., Ruslan, H., Sopian, K., Anuar, Z., Khairuddin, S., 2015. An improved design of photovoltaic/thermal solar collector. Sol. Energy 122, 885-891. doi:10.1016/j.solener.2015.10.008

Kaiser, A.S., Zamora, B., Mazon, R., Garcia, J.R., Vera, F., 2014. Experimental study of cooling BIPV modules by forced convection in the air channel. Appl. Energy 135, 88-97. doi:10.1016/j.apenergy.2014.08.079

Kruglov O., Rounis, E.D., Athienitis, A.K., Ge, H., 2017. Experimental investigation and implementation of a multiple-inlet BIPV/T system in a curtain wall. Proceedings of the $15^{\text {th }}$ Canadian Conference on Building Science and Technology (CCBST), Vancouver, 2017.

Rounis, E.D., Kruglov, O., Ioannidis, Z., Athienitis, A.K., Stathopoulos, T., 2017. Experimental investigation of BIPV/T envelope system with thermal enhancements for roof and curtain wall applications. Proceedings of the $34^{\text {th }}$ European PV Solar Energy Conference (EU PVSEC), Amsterdam, 2017.

Skoplaki, E., Palyvos, J.A., 2009. On the temperature dependence of photovoltaic module electrical performance: A review of efficiency/power correlations. Sol. Energy 83, 614-624. doi:10.1016/j.solener.2008.10.008

Tonui, J.K., Tripanagnostopoulos, Y., 2006. Improved PV/T solar collectors with heat extraction by forced or natural air circulation. Int. J. Hydrogen Energy 31, 2137-2146. doi:10.1016/j.ijhydene.2006.02.009

Tonui, J.K., Tripanagnostopoulos, Y., 2007. Air-cooled PV/T solar collectors with low cost performance improvements. Sol. Energy 81, 498-511. doi:10.1016/j.solener.2006.08.002 
TESSLibs 17, Component libraries for the TRNSYS simulation environment. Vol. 3, Electrical library mathematical reference.

Wolf, M., 1976. Performance analyses of combined heating and photovoltaic power systems for residences. Energy Convers. 16, 79-90. doi:10.1016/0013-7480(76)90018-8

Yang, T., Athienitis, A.K., 2016. A review of research and developments of building-integrated photovoltaic/thermal (BIPV/T) systems. Renew. Sustain. Energy Rev. 66, 886-912. doi:10.1016/j.rser.2016.07.011

Yang, T., Athienitis, A.K., 2014. A study of design options for a building integrated photovoltaic/thermal (BIPV/T) system with glazed air collector and multiple inlets. Sol. Energy 104, 82-92. doi:10.1016/j.solener.2014.01.049

Zogou, O., Stapountzis, H., 2011. Energy analysis of an improved concept of integrated PV panels in an office building in central Greece. Appl. Energy 88, 853-866. doi:10.1016/j.apenergy.2010.08.023 


\title{
Solar hybrid PVT coupled heat pump systems towards cost-competitive NZEB
}

\author{
Asier Sanz ${ }^{1}$, Raquel Fuente ${ }^{2}$ and Antonio J. Martín ${ }^{3}$ \\ 1 TECNALIA Research \& Innovation, Derio (Spain) \\ 2 University of the Basque Country UPV/EHU, Bilbao (Spain) \\ ${ }^{3}$ Energy Panel, Lucena (Spain)
}

\begin{abstract}
The high energy consuming building sector needs to meet both electricity and heat demands. In a nearly zero energy building scenario most of the consumed energy would be generated locally by means of renewable solutions that nowadays seem not to provide an attractive cost-competitiveness. Solar based technologies tend to be the most promising ones, but for high densely populated and restricted areas the usual photovoltaic or thermal single approaches may not be efficient enough. The current work is focused on the analysis of dual use of solar resource by means of hybrid collectors and their smart combination with heat pumps through predictive control strategies towards entire-lifetime feasible solutions. A techno-economic analysis of the proposed system, market standard solutions and different solar coupled heat pumps has been carried out for multiple domestic hot water application case studies. The results show the cost-competitiveness of the solution in different European climates.
\end{abstract}

Keywords: PVT, heat pump, hybrid, NZEB

\section{Introduction}

According to the International Energy Outlook of 2017 the global energy consumption continues rising. The reference for 2015 was 575 quadrillion British thermal units with a $28 \%$ estimated increase by 2040 . The European Commission states that buildings are responsible for $40 \%$ of the energy consumption and $36 \% \mathrm{CoO}_{2}$ emissions, and pretends to reduce their impact through measures. The vast majority of those buildings need to meet both electricity and heat demands, for domestic hot water (DHW) and space heating/cooling (H\&C). In the close nearly zero energy building (NZEB) scenario most of the consumed energy would be generated locally by means of renewable resources. Unfortunately, current renewable solutions could not provide an overall, simultaneous, integral and local solution to this need ensuring cost-competitiveness.

However, solar energy is available all over the surface of the earth. Thus, buildings should try to take more value form every beam of light reaching their envelopes. Photovoltaics (PV) are becoming today, and solar thermal (ST) applications in the past, widely used for built environment on-site generation. Nevertheless, for high densely populated and shadow-restricted areas this kind of single approaches are not enough to satisfy building energy needs. Detailed analysis of solar resource in built environments shows that not only roofs but also façades should be considered with higher efficiency solar conversion devices such as PVT (Sotehi et al, 2016).

Harnessing solar energy should be a must for new and refurbished buildings, but when the Sun is not shining and energy stores are empty solar based solutions always require back-up systems that reduce their competitiveness. The electrical grid makes things easier for some loads, but thermal needs are still highly fossil fuel dependent in great part of Europe. However, heat pumps (HP) seem to be a promising technology towards a reduction of $\mathrm{CO}_{2}$ emission related to buildings thermal comfort and enable the use of the electrical infrastructure to use them as back-up source. Therefore, if solar and HP are individually suitable for electricity and heat generation, merging them in a unique hybrid system will enable obtaining even higher benefits. Anyway, it is usually hard to intercompare technologies and quantify those real benefits to simply conclude which one shows overall greater performance. Thus, within the current work a dual techno-economic approach is proposed in order to shed some light among solar merged HP based solutions for different case studies. 


\section{Addressed technologies}

The hybrid systems coupling solar collection and HPs could lead to multiple solutions. In the current work, seven different technological solutions have been analysed, focused just on their DHW application version. Every system has been selected according to its cost-competitiveness potential and/or current market share. These solutions could be classified into the following three different categories.

- Well-known non-renewable technologies.

- Commercially available HP based systems and their combination.

- One additional PVT smart coupled HP solution.

\subsection{Non-renewable}

Although this kind of solutions will gradually loose relevance and probably will not be part of the future energy ecosystem, still represent nowadays a huge market share in most of the countries (BSRIA, 2014). The most common non-renewable solutions for satisfying locally building heat demands are electric and gas boilers. Their simplicity, end-user acceptance and centralized energy grid infrastructures make these solutions hard to be beaten despite their high operation cost and service uncertainties. Thus, within the current analysis both boiler solutions have been considered.

\subsection{Conventional HP base}

The HP solutions market sector is experiencing a significant growth. The household appliance sales for all heating and cooling (H\&C) market technologies increased by $20 \%$ in 2015 and show a great potential for near future (EurObservER HPs barometer, 2016). The emerging trend over the last years is that: 1) air-source units are clearly gaining market share to the detriment of the ground-source market, 2) the use of air as the energy vector is taking advantage of record temperatures that has boosted the cooling market, 3) the energy independence and the growth of the self-consumption markets are driving another trend that can turn as a further advantage, 4) the units must reduce the greenhouse emissions with low global-warming potential (GWP) refrigerant selection, load reductions and efficiency improvements, and 5) a greater performance enhancement should come by combining with solar based systems. According to these trends, the air-water source HPs (awHP) and their combination with an additional uncoupled parallelly installed PV system has been included in the study in order to analyse also the performance of the a solar electrically driven solution.

Furthermore, solar thermally assisted HPs have also been considered. The approach of direct/indirect driven HP solution by means of solar thermal collectors makes scientific sense in order to improve efficiency and renewable share. Economically it may still be interesting for high power systems, but for single building scale application the solution seems to be far from being cost-competitively attractive in the near future if no disruptive innovation appears. Thus, the thermally driven HP has been studied trough the direct expansion solar assisted heat pump (DX-saHP) concept, first studied by Sporn and Ambrose (1955) and more recently widely worked out by Li et al (2007a, 2007b). In DX-saHP systems the conventional air or water evaporator exchangers are replaced by bare flat-plate collectors where the refrigerant evaporates after expansion. This kind of collectors absorb the heat transferred by convection with the ambient and solar radiation. In the same way as for the awHP concept, the solar assisted HP (saHP) solution has also been analysed with a non-merged and parallelly installed PV system to quantify the extra solar electrical potential.

\subsection{The proposed solution}

The proposed solar hybrid PVT coupled HP solution is a fully-integrated system comprising an unglazed hybrid solar collector, a DX-saHP and an overall system control (Fig 1). The base of the technology has been widely studied before by different research groups for comparative analysis (Pei et al, 2008) and experimental studies (Ji et al, 2008; Fu et al, 2012). The union of PV and solar thermodynamic technologies in one collector enables the simultaneous electricity and heat generation and in a kind of symbiosis both technologies work optimally without 
mismatching the performance of the other (Jie Ji et al, 2009) like occurs in conventional PVT where a trade-off between thermal and electric performance of the collector output is needed. Thus, the dually assisted HP increases significantly the total annual use of the solar resource while the primary energy consumption is reduced.

The proposed solution innovations are focused on two critical elements impacting the solution cost and performance, the solar hybrid collector and the overall system control. On the one hand, the proposed lightweight collector is almost a conventional PV module with a thermal recovery unit as backsheet, with no isolation or additional components. On the other hand, the day-ahead prediction service enables achieving higher solar fractions and self-consumption ratios, optimizing the overall system performance without affecting end-user comfort or grid impact.
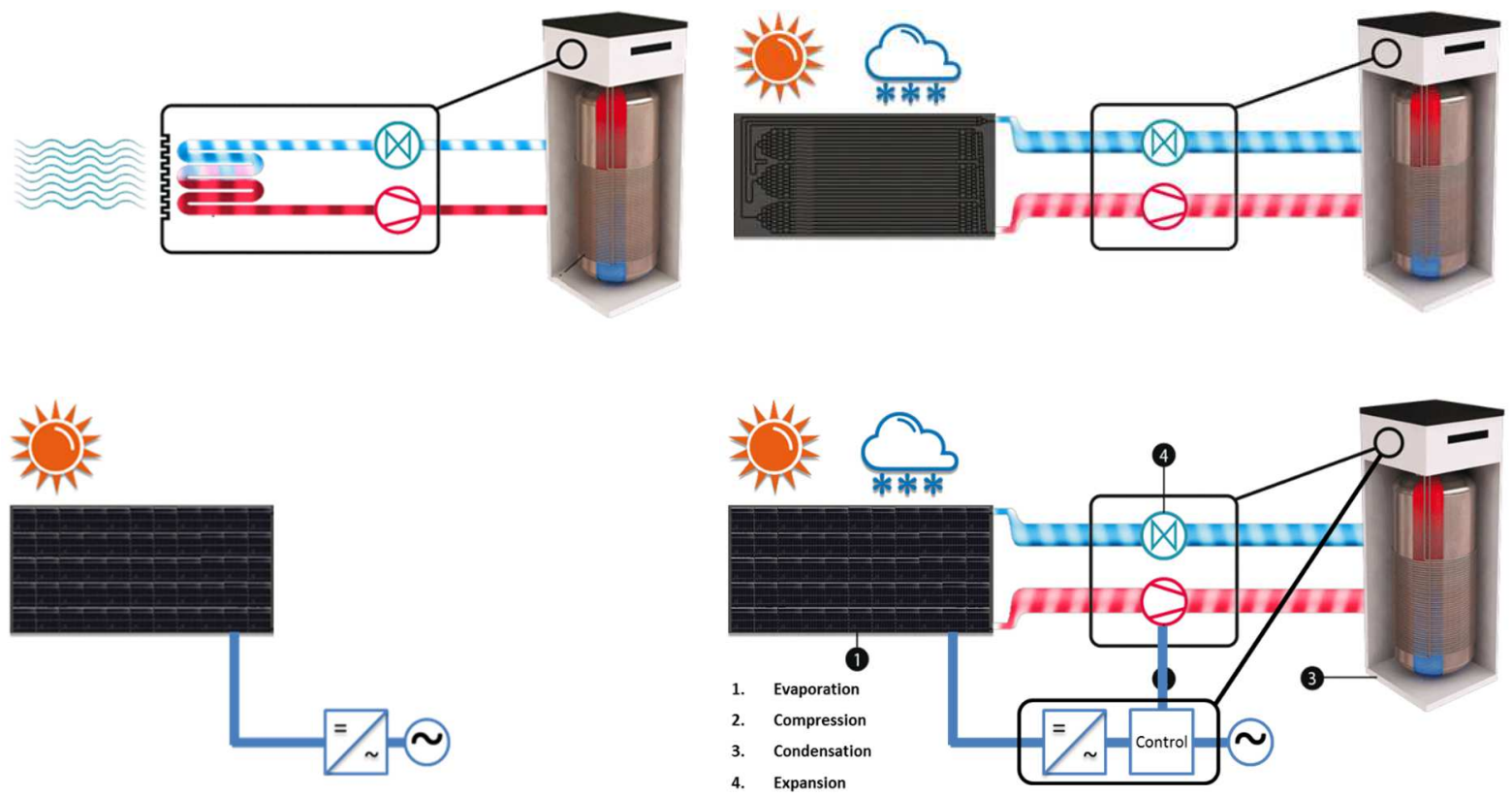

Fig. 1: Scheme of the different HP solutions analysed in the study, awHP (up left corner), saHP (up right), additional PV system (left low corner) to be added to saHP to generate the hybrid versions PV+saHP or PV+awHO, and finnaly the PVTaHP (low right)

\section{Methodology}

The assessment of new disruptive technologies or incremental innovations is commonly addressed just from cost or performance side, but real market success and massive deployment tends to come from a delicate balance of both. In the field of NZEB, the energy solutions will come from a technically feasible but economically marketcompetitive technology and/or systems combinations. Thus, as a previous step of the proposed PVT dually coupled saHP technology development, the potentially more-competitive different solutions comparative technoeconomic analysis is needed.

The holistic techno-economic analysis carried out pretends to address the energy performance and economics as a whole, trying to clarify the traditional gap between the great efficiency results of new research results and real market standard solutions lower cost. In this sense, the implemented methodology is based on a simple quantitative multiple-approach of solutions entire lifetime costs and system performance, in order to conclude with the following key performance indicators (KPI).

- Financials: investment, operation \& maintenance costs, return on investment and internal rate of return.

- Energy: building annual primary energy consumption, seasonal performance factor and self-sufficiency.

- $\quad$ Mixed: levelized cost of energy (LCOE). 


\subsection{Economics}

The economic assessment of each addressed technology is based on traditional capital expenditures (CAPEX) and operating expenditures (OPEX). The CAPEX is essentially composed of system cost and turnkey installation. The OPEX is obtained as sum of system grid energy consumption, periodic maintenance labours and plausible lifetime component replacement. The market-dependent CAPEX and OPEX systems figures are usually high-sensitive, so retail prices, maintenance services and energy costs used in the analysis are a consequence of a deep market study. In the same way, in order to minimise the uncertainty of non-technology related phenomena, no financial costs are assumed but conservative energy costs updates are included.

\subsection{Performance}

The performance of the analysed solutions is based on annual operation simulation, for same load profiles and operating conditions (irradiation, ambient and tap water temperature). The tool determines the annual performance based on hourly-profiles of one representative day of each month in one year. The models used for each technology are listed by category below. One representative day of each of the

Non-renewable

The non-intermittent source for these grid dependent technologies makes easier their black-box basic performance modelling. Thus, the models implemented for electric (eq. 1) and gas (eq. 2) boilers are just characterized by constant conversion efficiencies (for each month and hour of day), where no start-stop energy losses or lifespan degradation is considered. The demand is satisfied by instant operation of units with no thermal store. According to conventional market available electric and natural gas boilers, the following efficiencies have been used $\eta_{\text {Eboiler }}=\eta_{N G \text { boiler }}=0.9$.

$$
\begin{aligned}
& E_{\text {Load }}=\eta_{\text {Eboiler }} \cdot E_{\text {Egrid }} \\
& E_{\text {Load }}=\eta_{N \text { Gboiler }} \cdot E_{\text {NGgrid }}
\end{aligned}
$$

\section{Conventional HP based}

Four out of the seven analysed technologies of the study are based on market available conventional HP solutions. The cost and performance of these systems are often highly dependent. The scope of the study is focused on the assessment of different technological solution more than on specific products. Thus, in order to minimise the impact of comparing high performance (high cost) solutions versus cheaper (poorer performance) options, the core of all HP variations has been maintained the same. This approach enables the possibility of using the same compressor model and parameterization for both HP versions, the awHP and DX-saHP.

This way the model for the determination of the performance of the awHP is obtained through the following equations. The evaporation temperature is defined for $10 \mathrm{~K}$ below the ambient (eq. 3), but limited to a maximum of $15{ }^{\circ} \mathrm{C}$. Then, the awHP evaporator capacity could be obtained, with an error below $3 \%$, as function of the evaporation temperature (eq. 4$)$ and the polynomic coefficients $\left(q_{0}=1182.6 ; q_{1}=49.25 ; q_{2}=0.6213\right)$ for a cycle-representative condensation temperature of $40{ }^{\circ} \mathrm{C}$, as well as the compressor electric consumption (eq. 5) for the following parameterization $\left(p_{0}=396.14 ; p_{1}=2.7365 ; p_{2}=-0.0734 ; p_{3}=-0.0037\right)$, fan electric consumption $P_{\text {fan }}$ and annual equivalent day average defrost energy losses $P_{\text {defrost }}$. Then, the awHP coefficient of performance (COP) could be calculated (eq. 6) and the tank energy balance is obtained (eq. 7) for whole day state integration, where no thermal losses are considered. Finally, the electric grid consumption (eq. 8).

$$
\begin{aligned}
& T_{\text {eva }}=T_{a}-\Delta T \\
& Q_{a w H P}=q_{0}+q_{1} \cdot T_{\text {eva }}+q_{2} \cdot T_{\text {eva }}{ }^{2} \\
& P_{\text {awHP }}=p_{0}+p_{1} \cdot T_{\text {eva }}+p_{2} \cdot T_{\text {eva }}{ }^{2}+p_{3} \cdot T_{\text {eva }}{ }^{3}+P_{\text {fan }}+P_{\text {defrost }} \\
& C O P_{a w H P}=\left(Q_{a w H P}+P_{\text {awHP }}\right) / P_{\text {awHP }} \\
& Q_{\text {tank }}=\sum_{h=0}^{23}\left(Q_{\text {awHP }}-E_{\text {Load }}\right) \\
& E_{\text {Egrid }}=E_{\text {Load }} /{ }_{C O P_{\text {awHP }}}
\end{aligned}
$$


Using the same approach, the DX-saHP performance is described through the equations below (eq. 9-14). The modifications are applied just to two expressions. On one the hand, the evaporation temperature (eq. 9), where the solar gain needs to be considered. The collector-based evaporation was modelled and validated (MorenoRodriguez A. et al, 2012), where in absence of irradiation the evaporation temperature is decreased $\left(T_{G_{0}}=8 \mathrm{~K}\right)$ but for standard test conditions (STC) the evaporation temperature could be increased $15 \mathrm{~K}$ above the ambient $\left(k_{G}=23.1\right)$. On the other hand, for the DX-saHP electric consumption (eq. 11) the evaporator fan and defrosting consumptions are removed.

$$
\begin{aligned}
& T_{\text {eva }}=T_{a}-\Delta T-T_{G_{0}}+k_{G} \frac{G}{G_{S T C}} \\
& Q_{D X-s a H P}=q_{0}+q_{1} \cdot T_{\text {eva }}+q_{2} \cdot T_{\text {eva }}{ }^{2} \\
& P_{D X-s a H P}=p_{0}+p_{1} \cdot T_{\text {eva }}+p_{2} \cdot T_{\text {eva }}{ }^{2}+p_{3} \cdot T_{\text {eva }}{ }^{3} \\
& C O P_{D X-s a H P}=\left(Q_{D X-s a H P}+P_{D X-s a H P}\right) / P_{D X-s a H P} \\
& Q_{\text {tank }}=\sum_{h=0}^{23}\left(Q_{D X-s a H P}-E_{\text {Load }}\right) \\
& E_{\text {Egrid }}=E_{\text {Load }} / C O P_{D X-s a H P}
\end{aligned}
$$

For the additional parallelly installed PV systems, the electric performance is obtained from satellite-based data and PVGIS models. Then, for the PV plus awHP or DX-saHP solutions the grid net consumption equations (eq. 8 and 14, respectively) need to be rewritten (as eq. 15 and 16). The PV and HP systems are just electric grid connected, so depending on the operational mode (self-consumption, net balance, net billing or off-grid) the PV generation should be computed in a different way (totally, partially or not useful). .

$$
\begin{aligned}
& E_{\text {Egrid }}=E_{\text {Load }} / C_{C O P_{a w}}-E_{P V}(O M) \\
& E_{\text {Egrid }}=E_{\text {Load }} /_{C O P_{D X-s a H P}}-E_{P V}(O M)
\end{aligned}
$$

The proposed solution

In the case of the PVT coupled saHP, the expressions used above are slightly modified to consider the singularities of both, the hybrid collection of sunlight and the full-integration of the electric performance. The first variation is made on the evaporation temperature equation, where the saHP version (eq. 9) is evolved (eq. 17) to include the PVT collector PV layer irradiation attenuation. This peculiarity is introduced as a function of the electrical STC conversion efficiency $\left(\eta_{P V}\right)$, neglecting higher operation temperature conversion losses, and considering it is only applied to the PVT collector where active PV cells are placed, by means of the packing factor ( $p f$ ). The second modification is a result of the fully merged operation of both systems, the PV side of the PVT field and the HP compressor. The active management of the PV generation for driving variable speed compressor enables instant self-consumption, minimising the HP grid electrical consumption and boosting the overall COP (eq. 19).

$$
\begin{aligned}
& T_{\text {eva }}=T_{a}-\Delta T-T_{G_{0}}+k_{G} \frac{G \cdot\left(1-\eta_{P V} \cdot p f\right)}{G_{S T C}} \\
& Q_{P V T a H P}=q_{0}+q_{1} \cdot T_{\text {eva }}+q_{2} \cdot T_{\text {eva }}{ }^{2} \\
& P_{P V T a H P}=p_{0}+p_{1} \cdot T_{\text {eva }}+p_{2} \cdot T_{\text {eva }}{ }^{2}+p_{3} \cdot T_{\text {eva }}{ }^{3}-E_{P V}(O M) \\
& Q_{\text {tank }}=\sum_{h=0}^{23}\left(Q_{P V T a H P}-E_{L o a d}\right) \\
& C O P_{P V T a H P}=\left(Q_{P V T a H P}+P_{P V T a H P}\right) /_{P V T a H P} \\
& E_{\text {Egrid }}=E_{\text {Load }} /_{C O P_{P V T a H P}}
\end{aligned}
$$




\section{Results}

Multiple case studies have been carried out to determine the potential of the analysed technologies under different operating conditions. In order to provide a better comprehension of the results, the case studies shown in the current work have been focused just on a DHW application for a typical 4-member family. The consumption profiles used for thermal loads quantifications are the ones established in the Ecodesign Directive (European Union, 2013) for the XL profile, resulting on $6961 \mathrm{kWh} /$ year heat demand.

\section{Baseline}

The following case study is the one that has been used as the baseline along the current work. The study is located at Barcelona and the additional parameters for full characterization of the analysis are described below.

The main economic parameters for each technological solution are listed on Tab. 1. The energy cost is hourly variable for electricity $(9.91-13.52 \mathrm{c} € / \mathrm{kWh})$ and constant for natural gas $(0.095 \mathrm{c} € / \mathrm{kWh})$. Average annual grid energy cost increments have been considered for electricity (3\%/year) and natural gas ( $2 \% / y e a r)$.

Tab. 1: Economic parameters for the baseline case study of Barcelona

\begin{tabular}{|c|c|c|c|c|c|c|c|}
\hline $\begin{array}{c}\text { CAPEX } \\
\& \\
\text { OPEX (just maintenance) }\end{array}$ & 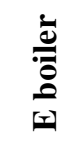 & 乙 & $\hat{\bar{T}}$ & $z+\frac{\hat{z}}{\tilde{F}_{n}}$ & 产 & $\vec{z}+\frac{\hat{z}}{\vec{z}}$ & 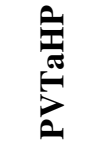 \\
\hline $\begin{array}{l}\text { Retail price } \\
+ \text { turnkey installation }(€)\end{array}$ & 600 & 1100 & 2964 & 4314 & 3155 & 4505 & 4151 \\
\hline $\begin{array}{l}\text { Annual (revision + repair) } \\
\text { maintenance (€/year) }\end{array}$ & 0 & 50 & 20 & 47 & 20 & 47 & 35 \\
\hline
\end{tabular}

Furthermore, the following technical parameters have been used for performance modelling and simulation.

- For the operating conditions, PVGIS irradiance and ambient temperature have been used. Monthly variable tap water temperature $\left(8-16^{\circ} \mathrm{C}\right)$ has been considered.

- $\quad$ For HP based systems a 2501 volume tank has been used, with a hot water set point of $50{ }^{\circ} \mathrm{C}$.

- For awHP solution outdoor evaporator operation has been assumed, with a $65 \mathrm{~W}$ fan power and an equivalent defrost cycle consumption of $0.266 \mathrm{kWh} /$ day.

- $\quad$ For PV added solutions, PV+saHP and PV+awHP, a $540 \mathrm{Wp}$ optimum tilt $\left(37^{\circ}\right)$ south orientation grid tie installation has been considered. The operation mode of the PV installation is self-consumption, limited to a $70 \%$ in order to avoid transient not entire balance situations. Additional energy losses have been considered, due to temperature and low irradiance (9.7\% using local ambient temperature), due to angular reflectance effects $(2.5 \%)$, other balance of system losses (14\%), resulting on combined PV system losses of $24.3 \%$.

- For PVTaHP collector characterization, a $19 \%$ electrical conversion efficiency, $85 \%$ packing factor, normal cell operation temperature (NOCT) of $47^{\circ} \mathrm{C}$ and $-0.4 \% / \mathrm{K}$ temperature coefficient has been used. The collector PV layer performance is identical to the PV system added to the PV+saHP and PV+awHP solutions, except the cooling effect. A total of 2 collector $(540 \mathrm{Wp})$ are used in same parallel connexion.

- For PVTaHP system smart control characterization, the early morning thermal store initial charge state $60 \%$ has been considered. 
With these parameters the obtained KPI results are summarised in Tab. 2.

Tab. 2: Barcelona (baseline) case study summary KPIs by technology

\begin{tabular}{|c|c|c|c|c|c|c|c|}
\hline $\begin{array}{c}\text { Barcelona (Baseline) } \\
\text { KPIs }\end{array}$ & $\frac{\overline{0}}{\frac{\overline{0}}{\Delta}}$ & Z & $\hat{\underline{T}}$ & $\vec{z}+\frac{\hat{\pi}}{\mathbb{F}_{n}}$ & $\hat{E}$ & $\vec{z}+\frac{\hat{\bar{z}}}{\overline{\mathrm{E}}}$ & 言 \\
\hline CAPEX (€) & 600 & 1100 & 2964 & 4314 & 3155 & 4505 & 4151 \\
\hline OPEX (€/year) & 1184 & 906 & 270 & 153 & 290 & 173 & 126 \\
\hline ROI $_{\text {Tech.Rel. }}$ (years) & 4.19 & 4.46 & 10.47 & - & 7.69 & - & \\
\hline $\operatorname{IRR}_{10}(\%)$ & $12.4 \%$ & $8.0 \%$ & - & - & $-17.9 \%$ & - & \\
\hline $\operatorname{IRR}_{15}(\%)$ & $22.6 \%$ & $19.2 \%$ & $-6.0 \%$ & - & $4.3 \%$ & - & \\
\hline $\operatorname{IRR}_{20}(\%)$ & $25.4 \%$ & $22.4 \%$ & $4.1 \%$ & - & $10.9 \%$ & - & \\
\hline $\mathrm{LCOE}_{10}(\mathrm{c} € / \mathrm{kWht})$ & 16.6 & 14.0 & 7.9 & 8.3 & 8.4 & 8.8 & 7.7 \\
\hline $\mathrm{LCOE}_{15}(\mathrm{c} € / \mathrm{kWht})$ & 17.6 & 14.1 & 6.7 & 6.3 & 7.2 & 6.8 & 5.8 \\
\hline $\operatorname{LCOE}_{20}(\mathbf{c} € /$ kWht $)$ & 18.9 & 14.5 & 6.3 & 5.5 & 6.8 & 5.9 & 4.9 \\
\hline $\begin{array}{l}\text { Primary energy } \\
\text { consumption }(k W h)\end{array}$ & 7734 & 7734 & 1616 & 797 & 1742 & 923 & 569 \\
\hline SPF (pu) & 0.90 & 0.90 & 4.31 & 8.73 & 4.00 & 7.54 & 12.23 \\
\hline Self-sufficiency (\%) & $-11 \%$ & $-11 \%$ & $77 \%$ & $89 \%$ & $75 \%$ & $87 \%$ & $92 \%$ \\
\hline
\end{tabular}

According to them, the following observations could be highlighted:

- A quick CAPEX analysis shows that the proposed solution is far from the current market standard solution (electric boilers are around 7 times cheaper), still more expensive than conventional HP versions (around $+40 \%$ ) but could be cheaper than installing a combined solution of 2 different systems (around $-4 \%$ for PV+saHP and $-8 \%$ for PV+saHP).

- The OPEX analysis, performance driven operational costs plus maintenance labours, show that the proposed PVT dually assisted HP offers the lowest O\&M numbers (126 €/year). The closest lower O\&M costs are the ones of the PV+saHP solution, $22 \%$ above (Fig. 2 right).

- The technology related additional investment shows that each monetary unit dedicated to the PVTaHP is always returned in less than 11 years, where the most critical ROI comparison is against the saHP solution. The lifespan of the solution is above 20 years, but for shorter horizons the extra investment on the PVTaHP might be critically returned.

- The IRR analysis evidence that the extra cost of the PVTsHP solution compared to saHP and awHP needs more time to be attractive, although even for the expected 20 years operation period, figures could still not be financially acceptable for some end-users/regions with no favourable PV regulation.

- The energy performance KPIs show great figures for HP based solutions, that could significantly be improved with PV generation. The PVTaHP primary energy reduction compared to non-renewable ones is important (only the $7.35 \%$ of current market standard consumption).

- The SPF analysis evidences the huge electrical gain due to PV energy, boosting by 2 the initial figures for saHP (from 4.31 to 8.73 ) and 1.88 times for awHP (from 4 to 7.54). However, the PVTaHP figures are again the greatest, mainly due to the smart control (77\% of the gain compared to PV+saHP) and the PV extra generation $(6.23 \%)$ due to the PV cooling effect of the thermal recovery backsheet $(23 \%$, the rest of the gain compared to $\mathrm{PV}+\mathrm{saHP})$.

- In the same way as for other energy KPIs, the self-sufficiency figures of PVTaHP are above all competitors and close to full autarky, enabled by the maximization of the self-consumption and higher PV yields while maintaining low HP gross grid consumption.

- For mix KPI as LCOE (Fig. 2 left), the good energy results are merged with tighter economic figures. Even in this field the proposed PVTaHP offers more attractive cost than the cheapest renewable solution for a 10-year period (-2.5\% below saHP) and conceptually closest PV assisted HPs at 15 and 20 years. 
Graphically the results are shown below.
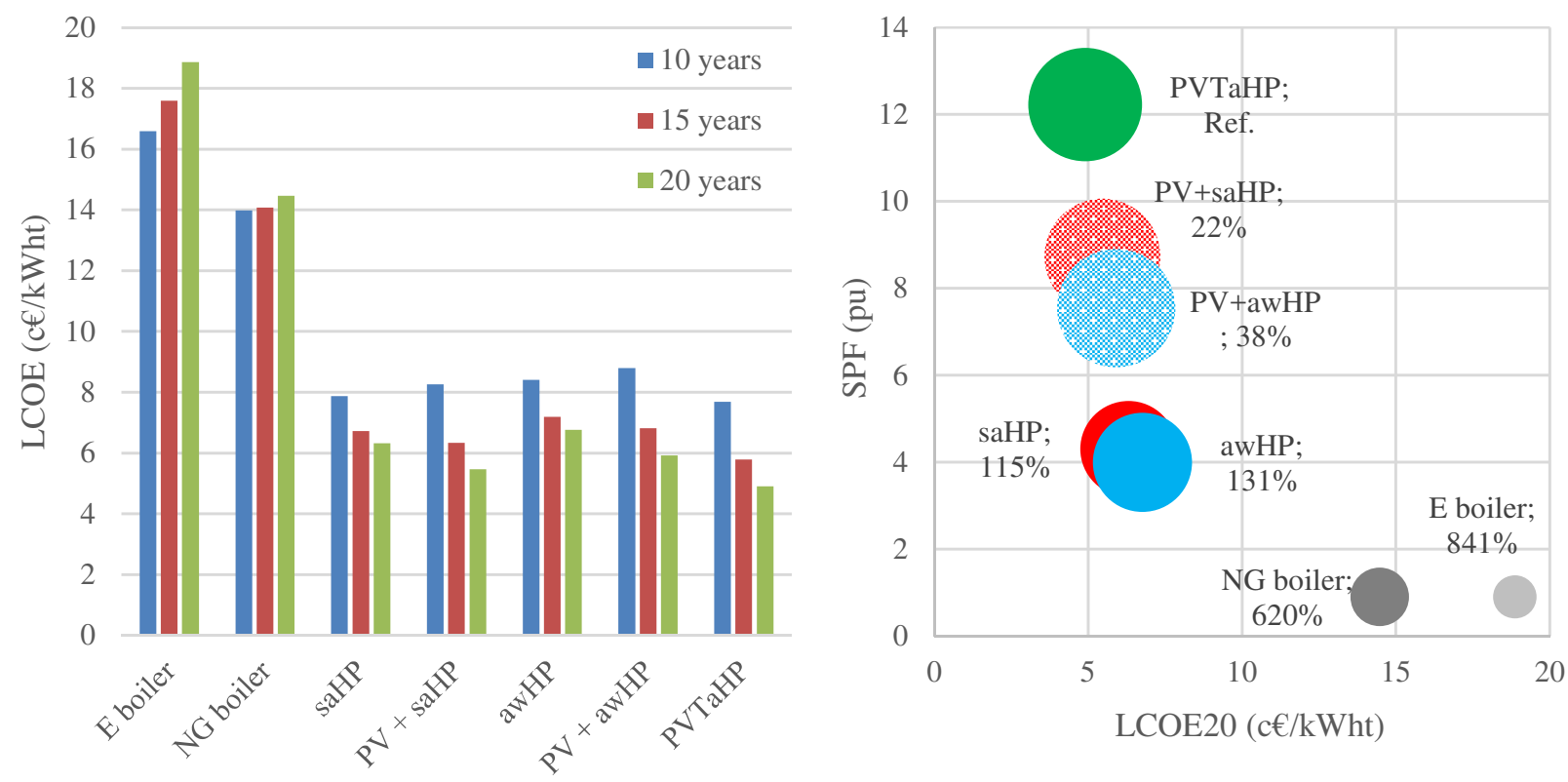

Fig. 2: LCOE for the analysed technologies and years of calculation (left) and SPF (right) versus system 20-year LCOE and CAPEX (bubble area), with PVTaHP relative OPEX comparison (labels).

The energy performance of each technological solution is a key factor for understanding the previously discussed underlaying results. Thus, the grid net energy consumption per month and technology is represented below (Fig. 3) and energy generation origin for the PVTaHP solution in Fig. 4.

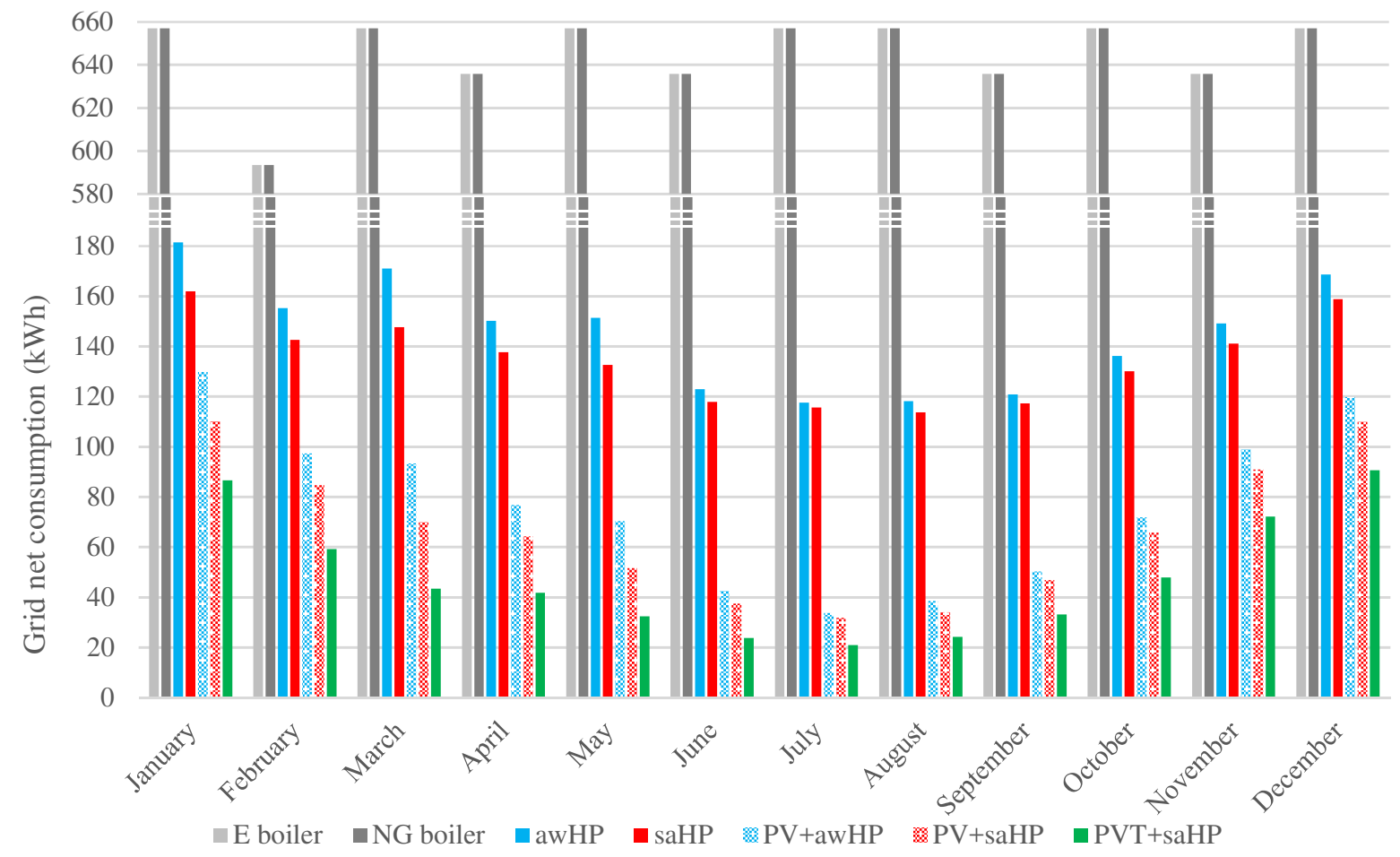

Fig. 3: Grid net energy consumption per month and technology 


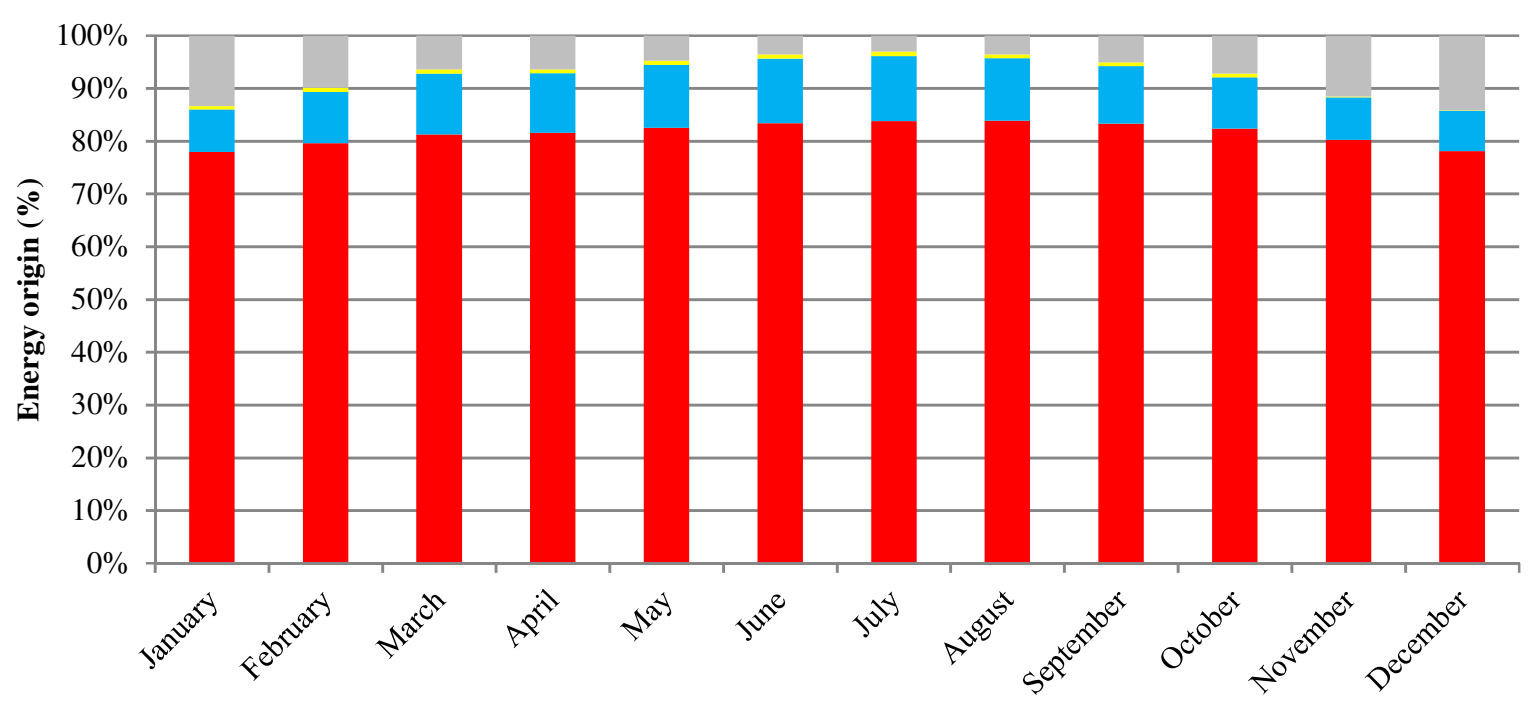

- TH generation (\%) $\quad$ PV generation (\%) $\quad$ PV extra generation (\%) $\square$ HP grid net consumption (\%)

Fig. 4: Energy generation origin for the PVTaHP

\section{Location}

The location of the case study is usually one of the most sensitive parameters when comparative analysis conclusions are extrapolated. Thus, within the following Tab. 3 and 4 the same Barcelona baseline scenario has been obtained for London and Rome, respectively. The most important parameters on location modification are meteorological features (irradiance, ambient and tap water temperature) and energy costs (same CAPEX has been considered). For London the annual irradiation is $1300 \mathrm{kWh} / \mathrm{m}^{2}$, average mean ambient and tap water temperatures are 10.9 and $5.1{ }^{\circ} \mathrm{C}$, annual mean electricity and natural gas costs of 20.1 and $0.065 \mathrm{c} € / \mathrm{kWh}$. For Rome the annual irradiation is $1930 \mathrm{kWh} / \mathrm{m}^{2}$, average mean ambient and water temperatures are 16.61 and $8.46{ }^{\circ} \mathrm{C}$, annual mean electricity and gas costs of 23.4 and $0.95 \mathrm{c} € / \mathrm{kWh}$. While for Barcelona the annual irradiation is $2010 \mathrm{kWh} / \mathrm{m}^{2}$, average mean ambient and water temperatures are 17.05 and $12.64{ }^{\circ} \mathrm{C}$, annual mean electricity and natural gas costs of 11.5 and $0.96 \mathrm{c} € / \mathrm{kWh}$. For all locations same CAPEX figures have been considered.

Tab. 3: London case study summary KPIs by technology

\begin{tabular}{|c|c|c|c|c|c|c|c|}
\hline $\begin{array}{l}\text { London } \\
\text { KPIs }\end{array}$ & $\frac{\overline{0}}{\overline{0}}$ & 乙 & $\hat{\mathbb{T}}$ & 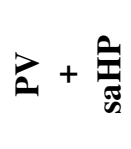 & 产 & $\vec{\theta}+\frac{\hat{\theta}}{\vec{z}}$ & $\frac{\hat{\sigma}}{2}$ \\
\hline OPEX (€/year) & 1927 & 630 & 516 & 381 & 539 & 404 & 338 \\
\hline ROITech.Rel. (years) & 2.78 & 11.15 & 8.43 & - & 6.25 & - & \\
\hline $\operatorname{IRR}_{10}(\%)$ & $31.4 \%$ & - & - & - & $-6.1 \%$ & - & \\
\hline $\operatorname{IRR}_{15}(\%)$ & $37.3 \%$ & $-14.8 \%$ & $1.3 \%$ & - & $10.4 \%$ & - & \\
\hline $\operatorname{IRR}_{20}(\%)$ & $38.6 \%$ & $-1.4 \%$ & $8.9 \%$ & - & $15.5 \%$ & - & \\
\hline $\operatorname{LCOE}_{10}(\mathrm{c} € / \mathrm{kWht})$ & 26.5 & 10.2 & 11.1 & 11.3 & 11.7 & 11.9 & 10.5 \\
\hline $\mathrm{LCOE}_{15}(\mathrm{c} € / \mathrm{kWht})$ & 28.3 & 10.1 & 10.3 & 9.6 & 10.8 & 10.1 & 8.8 \\
\hline $\mathrm{LCOE}_{20}(\mathrm{c} € / \mathrm{kWht})$ & 30.4 & 10.3 & 10.1 & 9.0 & 10.6 & 9.5 & 8.2 \\
\hline $\begin{array}{l}\text { Primary energy } \\
\text { consumption }(\mathbf{k W h})\end{array}$ & 7734 & 7734 & 1921 & 1379 & 2024 & 1483 & 1181 \\
\hline SPF (pu) & 0.90 & 0.90 & 3.62 & 5.05 & 3.44 & 4.69 & 5.90 \\
\hline Self-sufficiency (\%) & $-11 \%$ & $-11 \%$ & $72 \%$ & $80 \%$ & $71 \%$ & $79 \%$ & $83 \%$ \\
\hline
\end{tabular}


The comparative analysis between Barcelona, London and Rome offers interesting results. The Mediterranean cities present similar climatology but different electricity costs, while London and Rome present closer electricity costs but different operating conditions. Regarding London, the results show that the UK cheap gas price make the boiler the hardest competitor with the lowest LCOE below 10 years and stable for longer periods, what enables a PVTaHP solution recovery. On the other hand, ROI figures show a fast return $(<3$ years $)$ of the additional investment against the electric boiler. However, the energy performance indicators show that great annual efficiency and self-sufficiency values could also be obtained in such low irradiance cold climate. In Rome the conclusion is clear for both non-renewable boilers, where double electricity cost compared to Barcelona show that the PV gain becomes even more interesting.

Tab. 4: Rome case study summary KPIs by technology

\begin{tabular}{|c|c|c|c|c|c|c|c|}
\hline $\begin{array}{l}\text { Rome } \\
\text { KPIs }\end{array}$ & $\frac{\dot{0}}{\stackrel{0}{0}}$ & 乙 & 宸 & 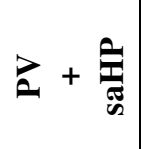 & 宣 & $\vec{z}+\frac{\hat{\theta}}{\vec{z}}$ & $\underbrace{0}_{\substack{\pi \\
0}}$ \\
\hline OPEX (€/year) & 2244 & 897 & 556 & 329 & 581 & 354 & 246 \\
\hline ROI Tech.Rel. (years) & 2.21 & 5.27 & 4.81 & - & 3.74 & - & \\
\hline $\operatorname{IRR}_{10}(\%)$ & $43.4 \%$ & $-0.1 \%$ & $6.3 \%$ & - & $17.7 \%$ & - & \\
\hline $\operatorname{IRR}_{15}(\%)$ & $47.4 \%$ & $13.7 \%$ & $18.3 \%$ & - & $26.5 \%$ & - & \\
\hline $\operatorname{IRR}_{20}(\%)$ & $48.1 \%$ & $17.9 \%$ & $21.8 \%$ & - & $28.8 \%$ & - & \\
\hline $\mathrm{LCOE}_{10}(\mathrm{c} € / \mathrm{kWht})$ & 30.7 & 13.9 & 11.7 & 10.6 & 12.3 & 11.2 & 9.3 \\
\hline $\mathrm{LCOE}_{15}(\mathrm{c} € / \mathrm{kWht})$ & 32.8 & 13.9 & 10.8 & 8.9 & 11.4 & 9.4 & 7.5 \\
\hline LCOE20 $_{2}(\mathbf{€} / \mathbf{k W h t})$ & 35.4 & 14.3 & 10.8 & 8.2 & 11.3 & 8.7 & 6.8 \\
\hline $\begin{array}{l}\text { Primary energy } \\
\text { consumption }(\mathrm{kWh})\end{array}$ & 7734 & 7734 & 1714 & 933 & 1811 & 1029 & 660 \\
\hline SPF (pu) & 0.90 & 0.90 & 4.06 & 7.46 & 3.84 & 6.76 & 10.55 \\
\hline Self-sufficiency $(\%)$ & $-11 \%$ & $-11 \%$ & $75 \%$ & $87 \%$ & $74 \%$ & $85 \%$ & $91 \%$ \\
\hline
\end{tabular}

\section{Collector field}

The solar gain offers greater performance figures but not always the extra investment is returned. In order to determine the impact of the solar collector field on the techno-economic figures the baseline scenario has been modified increasing by $50 \%$ the collector area. For the PV+saHP combo just the PV field has been increased but for the PVTaHP one more collector has been considered (a total of 3 collectors).

Tab. 5: Barcelona (baseline $+50 \%$ collector field) case study summary KPIs by technology

\begin{tabular}{|c|c|c|c|c|c|c|c|}
\hline $\begin{array}{c}\text { Barcelona } \\
(+\mathbf{5 0} \% \text { collector field }) \\
\text { KPIs }\end{array}$ & 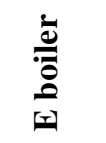 & Z & 롤 & $\vec{z}+\underline{\underline{\varepsilon}}$ & êt & $\vec{z}+\frac{\hat{z}}{\xi}$ & $\underset{2}{e}$ \\
\hline CAPEX (€) & 600 & 1100 & 2964 & 4989 & 3155 & 5180 & 5636 \\
\hline OPEX (€/year) & 1184 & 906 & 282 & 106 & 301 & 126 & 80 \\
\hline ROITech.Rel. (years) & 5.71 & 6.31 & 16.97 & 40.29 & 14.33 & 14.38 & \\
\hline $\operatorname{IRR}_{10}(\%)$ & $-1.8 \%$ & $-8.9 \%$ & - & - & - & - & \\
\hline $\operatorname{IRR}_{15}(\%)$ & $13.0 \%$ & $8.5 \%$ & - & - & - & $-15.8 \%$ & \\
\hline $\operatorname{IRR}_{20}(\%)$ & $17.5 \%$ & $13.8 \%$ & $-8.6 \%$ & - & $-3.5 \%$ & $-0.8 \%$ & \\
\hline $\mathrm{LCOE}_{10}(\mathrm{c} € / \mathrm{kWht})$ & 16.6 & 14.0 & 8.0 & 8.6 & 8.6 & 9.1 & 9.2 \\
\hline $\mathrm{LCOE}_{15}$ (c€/kWht) & 17.6 & 14.1 & 6.9 & 6.3 & 7.3 & 6.8 & 6.6 \\
\hline $\mathrm{LCOE}_{20}(\mathrm{c} € / \mathrm{kWht})$ & 18.9 & 14.5 & 6.5 & 5.2 & 6.9 & 5.7 & 5.2 \\
\hline $\begin{array}{l}\text { Primary energy } \\
\text { consumption }(\mathrm{kWh})\end{array}$ & 7734 & 7734 & 1616 & 387 & 1742 & 513 & 131 \\
\hline SPF (pu) & 0.90 & 0.90 & 4.31 & 17.97 & 3.99 & 13.56 & 53.17 \\
\hline Self-sufficiency (\%) & $-11 \%$ & $-11 \%$ & $77 \%$ & $94 \%$ & $75 \%$ & $93 \%$ & $98 \%$ \\
\hline
\end{tabular}


As expected, the obtained results show that lower OPEX (63.5\%) and higher energy performance could be achieved. The SPF is exponentially increased with low grid consumption scenarios (by 4.34 the baseline) and the self-sufficiency is boosted (6 points more) till achieving almost full sufficiency. The LCOE figures for PVTaHP are still the most competitive ones compared to other technologies but slightly higher than the baseline scenario for a 20-year period (from 4.9 to $5.2 \mathrm{c€} / \mathrm{kWh}$ ). The PV summer production covers completely the HP demand and for July around $19 \%$ of the electric generation is injected into the grid for free. Modifying the operational mode to net-metering would reduce the LCOE figures even more $(4.8 \mathrm{c} € / \mathrm{kWh})$. However, from an economic point of view the extra cost of $50 \%$ higher collection field is not traduced on a lower ROI.

\section{Cost and performance sensitivity}

Innovations cost and performance are rarely as initially expected. Incrementation on solution cost and reduction on performance features are common from lab prototypes to market products. Thus, a sensitivity analysis of both has been considered on the following case studies. The Tab. 6 shows the figures obtained for the baseline $+20 \%$ in the CAPEX (retail price + turnkey installation) and Tab. 7 a baseline $+40 \%$ in performance (non-maintenance) expenditures caused due to worst collector layers thermal behaviour and/or control algorithm failure.

Tab. 6: Barcelona (baseline $+20 \%$ CAPEX) case study summary KPIs by technology

\begin{tabular}{|c|c|c|c|c|c|c|c|}
\hline $\begin{array}{c}\text { Barcelona } \\
(+20 \text { CAPEX }) \\
\text { KPIs }\end{array}$ & $\frac{\grave{0}}{\stackrel{0}{0}}$ & 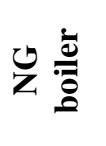 & है & $\vec{z}+\overrightarrow{\underline{z}}$ & 를 & $\vec{z}+\frac{\hat{\theta}}{\vec{z}}$ & $\underset{2}{\stackrel{0}{*}}$ \\
\hline CAPEX (€) & 600 & 1100 & 2964 & 4314 & 3155 & 4505 & 4981 \\
\hline ROITech.Rel. (years) & 5.17 & 5.67 & 17.79 & 34.88 & 14.09 & 13.49 & \\
\hline $\operatorname{IRR}_{10}(\%)$ & $2.9 \%$ & $-3.5 \%$ & - & - & - & - & \\
\hline $\operatorname{IRR}_{15}(\%)$ & $16.0 \%$ & $11.6 \%$ & - & - & - & $-15.2 \%$ & \\
\hline $\operatorname{IRR}_{20}(\%)$ & $19.9 \%$ & $16.3 \%$ & $-10.5 \%$ & - & $-3.2 \%$ & $-0.7 \%$ & \\
\hline $\mathrm{LCOE}_{10}$ (c€/kWht) & 16.6 & 14.0 & 7.9 & 8.3 & 8.4 & 8.8 & 8.9 \\
\hline $\mathrm{LCOE}_{15}$ (c€/kWht) & 17.6 & 14.1 & 6.7 & 6.3 & 7.2 & 6.8 & 6.6 \\
\hline $\mathrm{LCOE}_{20}(\mathrm{c} € / \mathbf{k W h t})$ & 18.9 & 14.5 & 6.3 & 5.5 & 6.8 & 5.9 & 5.5 \\
\hline
\end{tabular}

Tab. 7: Barcelona (baseline $+40 \%$ in performance) case study summary KPIs by technology

\begin{tabular}{|c|c|c|c|c|c|c|c|}
\hline $\begin{array}{c}\text { Barcelona } \\
(+40 \% \text { in performance }) \\
\text { KPIs }\end{array}$ & $\frac{\dot{0}}{\stackrel{0}{8}}$ & Z & $\underset{乛}{\not}$ & $\vec{E}+\underset{\tilde{E}}{\vec{E}}$ & 른 & $z+\frac{\hat{z}}{\hat{z}}$ & $\underset{n}{*}$ \\
\hline OPEX (€/year) & 1184 & 906 & 270 & 153 & 290 & 173 & 162 \\
\hline ROITech.Rel. (years) & 4.34 & 4.66 & 14.11 & 16.03 & 9.93 & - & \\
\hline $\operatorname{IRR}_{10}(\%)$ & $10.9 \%$ & $5.9 \%$ & - & - & - & - & \\
\hline $\operatorname{IRR}_{15}(\%)$ & $21.4 \%$ & $17.7 \%$ & $-20.1 \%$ & - & $-4.0 \%$ & - & \\
\hline $\operatorname{IRR}_{20}(\%)$ & $24.5 \%$ & $21.2 \%$ & $-3.0 \%$ & - & $5.4 \%$ & - & \\
\hline $\mathrm{LCOE}_{10}(\mathrm{c} € / \mathrm{kWht})$ & 16.6 & 14.0 & 7.9 & 8.3 & 8.4 & 8.8 & 8.2 \\
\hline $\mathrm{LCOE}_{15}$ (c€/kWht) & 17.6 & 14.1 & 6.7 & 6.3 & 7.2 & 6.8 & 6.3 \\
\hline $\mathrm{LCOE}_{20}(\mathrm{c} € / \mathrm{kWht})$ & 18.9 & 14.5 & 6.3 & 5.5 & 6.8 & 5.9 & 5.5 \\
\hline $\begin{array}{l}\text { Primary energy } \\
\text { consumption }(\mathbf{k W h})\end{array}$ & 7734 & 7734 & 1616 & 797 & 1742 & 923 & 797 \\
\hline SPF (pu) & 0.90 & 0.90 & 4.31 & 8.73 & 4.00 & 7.54 & 8.73 \\
\hline Self-sufficiency (\%) & $-11 \%$ & $-11 \%$ & $77 \%$ & $89 \%$ & $75 \%$ & $87 \%$ & $89 \%$ \\
\hline
\end{tabular}

The last case studies versus baseline results comparative analysis show that such deviations make the solution less attractive in economic terms, as the ROI compared to the HP base solution is increased significantly, where the $\mathrm{PV}+$ saHP technology remains as the most critical competitor. However, even in the current over-cost scenario competitive LCOE figures are obtained. Furthermore, in a close LCOE competitive scenario, the better solar resource and available building surface harnessing of PVT technology could still be the key factor. 


\section{Conclusions}

The techno-economic analysis carried out shows that the proposed solution of merging PVT dual collection with a saHP based unit by means of smart control strategies in one unique system is a current cost-competitive solution for highly populated and restricted NZEB areas.

More in detail, the initial investment is very far from the market standard non-renewable solution, slightly above conventional awHP or saHP equipment, but below combo systems where a PV installation is added to a HP based solution. From an OPEX perspective the proposed PVTaHP clearly offers lower costs among the rest of competitors, where the closest in terms of annual O\&M expenses is the PV+saHP, even it requires double collection field surface.

The financial figures show that the PVT based solution extra investment is easily returned during its lifetime, although short payback-time demanding end-users and/or applications should take into consideration more than just economics, instead may not find them attractive enough. NZEB will imply to go one step further than the current non-sustainable lifestyle and economics, so future assessments will need to take it into consideration.

The performance of the proposed solution for the different case studies (location, collector field size, cost and performance sensitivity analysis) is great in comparison with the rest of the analysed technologies in terms of primary energy reduction, overall efficiency and self-sufficiency. When merging performance with economics under LCOE perspective, the PVTaHP shows the most competitive costs for 10, 15 and 20 years periods.

\section{Acknowledgments}

The work carried out is comprised under the HANDLE innovation project between Tecnalia Research \& Innovation, Energy Panel S.L, Termoidraulica Brotto, Termosol and InnoEnergy, with the collaboration of the University of the Basque Country.

\section{References}

EurObservER HPs barometer, 2016. https://www.eurobserv-er.org/heat-pumps-barometer-2016/

European Commission building needs, 2018. https://ec.europa.eu/energy/en/topics/energy-efficiency/buildings

EU law, 2009. https://eur-lex.europa.eu/legal-content/EN/TXT/HTML/?uri=CELEX:32009L0125\&from=ES

Fu et al, 2012. Experimental study of a photovoltaic solar-assisted heat-pump/heat-pipe system, DOI: 10.1016/j.applthermaleng.2012.02.036

G. Pei, J. Ji, T.T. Chow, H. He, K. Liu, 2008. Performance of the photovoltaic solar-assisted heat pump system with and without glass cover in winter: a comparative analysis, DOI: $10.1243 / 09576509 J P E 431$

International Energy Outlook of 2017, 2018. https://www.eia.gov/outlooks/ieo/

J. Ji, G. Pei, T.T. Chow, K.L. Liu, H.F. He, J.P. Lu, C.W. Han, 2008. Experimental study of photovoltaic solar assisted heat pump system. Sol. Energy, 82, DOI: 10.1016/j.solener.2007.04.006

Jie Ji et al, 2009. Distributed dynamic modeling \& experimental study of PV evaporator in a PV/T SAHP, DOI: 10.1016/j.ijheatmasstransfer.2008.08.017

Latest trends in the World Traditional \& Renewable Heating Markets, BSRIA, 2014.

https://www.iea.org/media/workshops/buildingwebinars/webinar4/4BSRIAKrystynaPresentationforIEA.pdf

Moreno-Rodriguez A. et al, 2012. Theoretical model and experimental validation of a direct-expansion solar assisted heat pump for domestic hot water applications, DOI: $\underline{10.1016 / \text { j.energy.2012.07.021 }}$

Sotehi, 2016. PV/T Hybrid Solar Water Collector for nZEB in Algeria, DOI: 10.1016/j.desal.2016.01.034

Sporn P, Ambrose ER, 1955. The heat pump and solar energy. Proceedings of the world symposium on applied solar energy, Phoenix, Arizona, DOI: $\underline{\text { 10.1063/1.3060075 }}$

Y.W. Li, R.Z. Wang, J.Y. Wu, Y.X. Xu, 2007. Experimental performance analysis and optimization of a direct expansion solar-assisted heat pump water heater. Energy, DOI: 10.1016/j.desal.2016.01.034

Y.W. Li, R.Z. Wang, J.Y. Wu, Y.X. Xu, 2007. Experimental performance analysis on a direct expansion solarassisted heat pump water heater. Applied Thermal Engineering, DOI: $\underline{10.1002 / \mathrm{er} .893}$ 


\title{
EXPERIMENTAL PERFORMANCE EVALUATION OF PV/T PANELS AT NEGATIVE REDUCED TEMPERATURES
}

\author{
Riccardo Simonetti, Luca Molinaroli and Giampaolo Manzolini \\ Department of Energy, Politecnico di Milano, Via Lambruschini 4, 20156 Milano, (Italy)
}

\begin{abstract}
This work summarizes the performance of photovoltaic thermal panels integrated with a heat pump in a Solar Assisted Heat Pump (SAHP) system working with a negative reduced temperature. This concept brings about a higher electric production, due to the lower temperature of the panels, and that the heat produced by PV/T panels can be used also during winter period. A detailed experimental campaign was conducted in an outdoor laboratory in real ambient conditions to evaluate the performance of PV/T panels in this configuration. The results show a very high thermal efficiency, which go beyond the value of $200 \%$ due to the contribution of the convective heat transfer with the ambient, which has a higher temperature than the working fluid flowing inside the PV/T panels.
\end{abstract}

Keywords: Photovoltaic Thermal modules, Solar Assisted Heat Pumps.

\section{Introduction}

Photovoltaic thermal (PV/T) modules combine thermal and electricity production. (Chow, 2010) and (Kim \& Kim, 2012) have analyzed and demonstrated the potentiality of this technology, but the main drawback is the low thermal efficiency and stagnation temperature because of the high thermal losses (Zondag, et al., 2003) (Aste, et al., 2014). Insulation systems like vacuum chamber or the adoption of concentrators can be considered but require the installation of auxiliary rejection systems to control the PV cell temperature when the heat demand is absent (Kumar, et al., 2015). An option to exploit their potentiality keeping a simple module structure is the PV/T integration with a heat pump, leading to the so-called Solar-Assisted Heat Pump (SAHP) concept, where the heat recovered by the PV/T modules supplies the low temperature energy to the evaporator of the heat pump (Ji, et al., 2008). Different works described the advantages of this system with models and experimentation ( $\mathrm{Li}$, et al., 2014) (Calise, et al., 2016). In this configuration, the low stagnation temperature of the PV/T modules is not an issue due to the low operating temperatures of the working fluid and, moreover, the PV power output is higher than corresponding conventional PV module thanks to low cell temperature (Migliorini, et al., 2017). (Simonetti, et al., 2017) analyzed with a numerical model the behavior of a SAHP with roll-bond PV/T typology, confirming the energetic feasibility of the system and pointing out the working conditions of the panels, which could have a mean temperature of the cooling fluid under the ambient one. Experimental campaigns with temperatures below the ambient are not available in literature as the analysis is usually focus on the entire system (heat produced, energy consumption) and not on the PV/T subsection.

In this work, an experimental campaign was conducted at the laboratory SolarTech ${ }^{\mathrm{LAB}}$, Politecnico di Milano, to evaluate the behavior and the performance of $\mathrm{PV} / \mathrm{T}$ panels coupled with a heat pump in different real ambient conditions, with particular focus on working conditions in which the mean temperature of the working fluid was below the ambient one.

The paper is structured as follow. Section 2 describes the experimental set-up, the PV/T modules, the measurement apparatus and the experimental conditions. Section 3 discusses the methodology adopted to collect and filter the data acquired. Section 4 presents the uncertainty analysis. In Section 5 results are presented and discussed. Finally, in Section 6 conclusions are drawn. 


\section{Experimental Facility}

The experimental set-up used in the present work is an outdoor laboratory whose layout is shown in Fig. 1. The experimental facility consists of: (i) a cold water loop (blue line), (ii) a water-to-water heat pump and (iii) a hot water loop (red line).

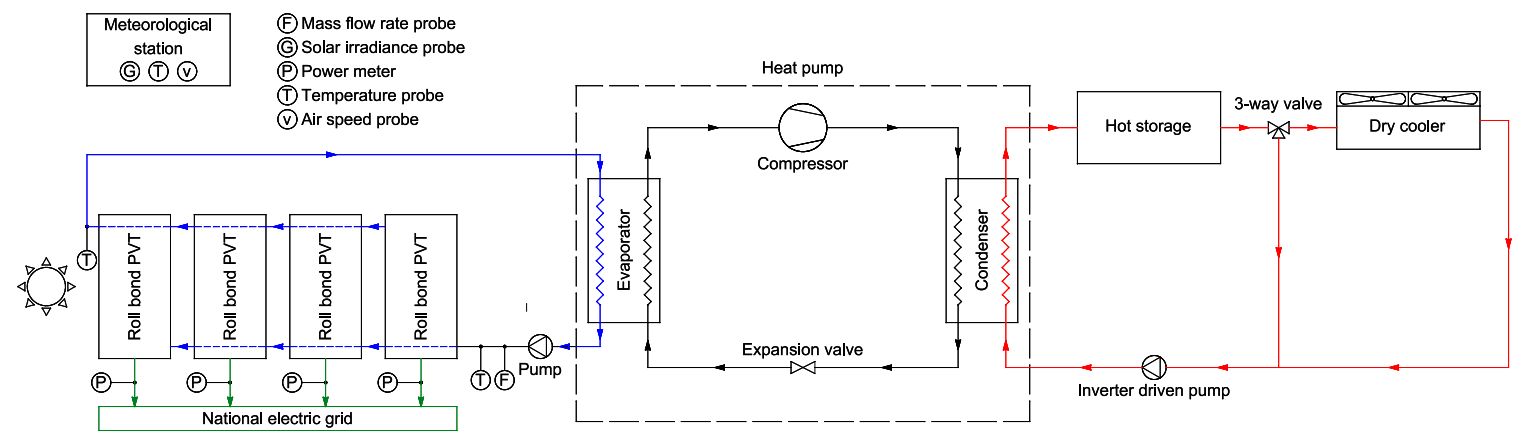

Fig. 1 - Schematic of the SAHP concept

In the cold water loop, the water at the outlet of four roll-bond PV/T collectors (SoLink, 2017) is used to feed the evaporator of the heat pump where it is cooled and sent back to the PV/T modules; the heat provided by the PV/T field acts as the low temperature heat source of the heat pump and the temperature achieved in the cold water loop may be lower than the ambient one which, in turn, increases both the electric and the thermal efficiency of the PV/T system.

In the hot water loop, the water is heated inside the condenser of the heat pump and sent to a hot storage tank. After that, thanks to a 3-ways valve, the fluid could directly return to the inlet of the condenser or pass through an air dry cooler. The fans of this component are automatically regulated to maintain the inlet temperature of the condenser of the HP stable and equal to a fixed value during experimentation.

\subsection{PV/T Modules}

As stated before, the PV/T modules adopts a roll-bond heat exchanger attached to the back of the module which recovers the excess heat, heating up a stream of water-glycol mixture. The roll-bond configuration allows an easy manufacturing as it is independent from the PV module which is a standard one. The solar cell is a polysilicon technology and the four panels have a heat exchanger circulation that allows to have a parallel configuration with simple tubes connection, as shown by the scheme in Fig. 2.
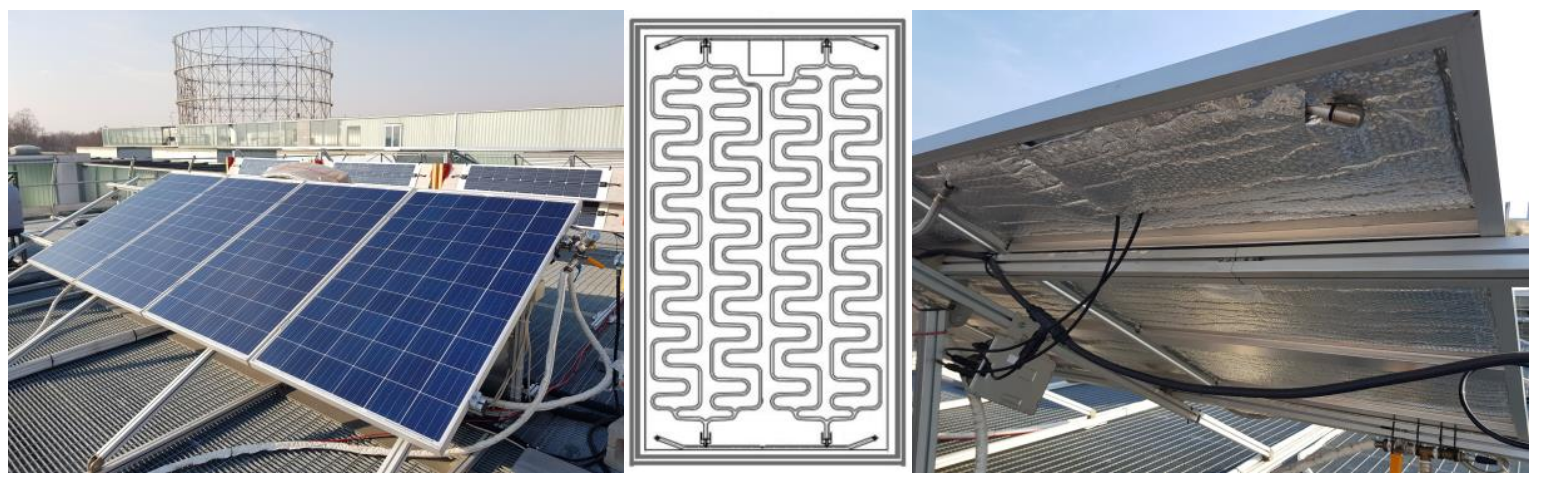

Fig. 2 - Front, circuitation and back of PV/T modules

The back of the modules is covered with an insulating layer (see Fig. 2), and each module is connected with its own inverter, in order to separately measure the electric performance of each.

Table 1 shows technical characteristics of the PV/T modules reported in the module datasheet. 
Table 1 - Technical characteristic of PV/T modules

\begin{tabular}{lr}
\hline Electrical Power Output & $250 \mathrm{~W}$ \\
Electrical Efficiency & $15.3 \%$ \\
Thermal Power Output & $850 \mathrm{~W}$ \\
Optical Efficiency & $52.3 \%$ \\
Thermal Losses Coefficient & $-13.8 \mathrm{~W} /\left(\mathrm{m}^{2} \mathrm{~K}\right)$ \\
Absorber Area & $1.63 \mathrm{~m}^{2}$
\end{tabular}

The PV/T modules are connected to a commercially available heat pump with a thermal power equal to $3.40 \mathrm{~kW}$ (a) $45^{\circ} \mathrm{C}$ and a COP equal to 4.09 .

\subsection{Measurement Apparatus}

The objective of the experimentation is to evaluate the thermal efficiency of the PV/T modules at different ambient conditions. The thermal efficiency is calculated as reported in the following equation:

$\eta_{\text {th }}=\frac{\dot{Q}_{\text {th }}}{\dot{Q}_{\text {in }}}=\frac{\dot{\boldsymbol{V}} \cdot \rho \cdot c \cdot\left(\boldsymbol{T}_{\text {out }}-\boldsymbol{T}_{\text {in }}\right)}{\boldsymbol{G}_{\boldsymbol{T}} \cdot A_{\text {panel }} N_{\text {panels }}}$

in bold, the measured variables, which are the inlet and outlet temperatures of the PV/T panels, the water flow rate and the solar irradiance, are reported. $\mathrm{G}_{\mathrm{T}}$ is the solar irradiance on the panels aperture area. Also the ambient temperature measurement is required to evaluate the reduced temperature, according to eq. 2 :

$T_{R}=\frac{\left(\boldsymbol{T}_{\text {out }}+\boldsymbol{T}_{\text {in }}\right) / 2-\boldsymbol{T}_{\boldsymbol{a m b}}}{\boldsymbol{G}_{\boldsymbol{T}}}$

Temperature measurements are performed with thermoresistances Pt100 inserted in the hydraulic circuit. Volumetric flow rate measurements are performed with a flow meter whose operating principle is based on Von Karman's vortices: the flow rate is related to the frequency of this phenomenon. Furthermore, each PV/T module is connected with a micro-inverter that communicates with a computer to measure and maximize the power produced by each module. Finally, the laboratory is equipped with a weather station to monitor and collect experimental ambient data. Fig. 3 shows the configuration and the different weather measurement devices.

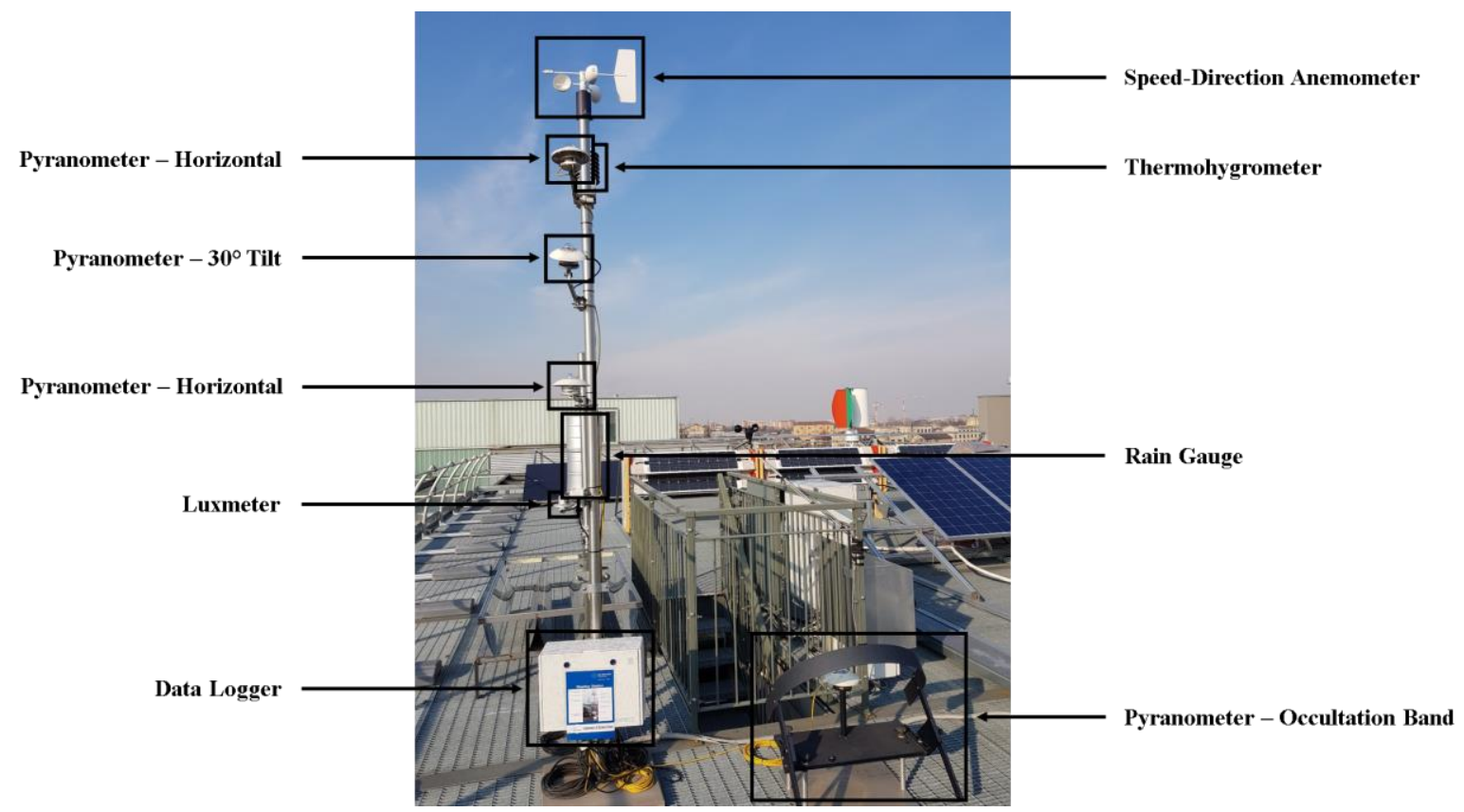

Fig. 3 - Weather station 
The station is equipped with the following measurement instruments:

- a thermohygrometer, measuring the air temperature and the atmospheric humidity

- two pyranometers, which determine the global solar irradiance on the horizontal plane (one first standard and one secondary standard)

- a secondary standard pyranometer that measures the global solar irradiance on a surface inclined at $30^{\circ}$

- a pyranometer with an occultation band, which detects the diffusive radiation

- a wind gauge to detect wind speed and direction

- a pluviometer to measure the amount of rain

$\mathrm{G}_{\mathrm{T}}$ can be calculated from the measurements of the global solar irradiance on the horizontal plane $\mathrm{G}_{\mathrm{G}, \mathrm{H}}$, the diffuse solar irradiance $G_{D, H}$, the position of the sun in the sky $\left(\theta_{z}\right.$ and $\left.\gamma_{s}\right)$, the orientation of the panels respect to the South $\gamma$ and the inclination respect to the Zenith $\beta$ according to the following equations:

$\cos \vartheta=\cos \vartheta_{z} \cdot \cos \beta+\sin \theta_{z} \cdot \sin \beta \cdot \cos \left(\gamma-\gamma_{s}\right)$

$G_{T}=\left(G_{G, H}-G_{D, H}\right) \cdot \frac{\cos \theta}{\cos \theta_{z}}+G_{D, H} \cdot \frac{1+\cos \beta}{2}$

Detailed data of the instruments are reported in Table 2.

Table 2 - Technical information of the measurement instruments

\begin{tabular}{lccc}
\hline \multicolumn{1}{c}{ Instrument } & Model & Range & Uncertainty \\
\hline RTD & Pt 100 & $-50^{\circ} \mathrm{C}-250^{\circ} \mathrm{C}$ & $1 / 10 \mathrm{~B}$ (DIN EN 60751) \\
Flowmeter & Huba-Control -210 & $0.91 / \mathrm{min}-151 / \mathrm{min}$ & $\pm 1 \% \mathrm{FS}$ \\
Power meter (Inverter) & Power One - Aurora Micro & $<250 \mathrm{~W}$ & $\pm 1 \% \mathrm{RV}$ \\
Pyranometer & LSI - DPA 252 & $<2000 \mathrm{~W} / \mathrm{m}^{2}$ & $<2 \% \mathrm{RV}$ \\
Thermohygrometer & LSI - DMA 875 & $-30^{\circ} \mathrm{C}-70^{\circ} \mathrm{C}$ & $1 / 3 \mathrm{~B}$ (DIN EN 60751) \\
\hline
\end{tabular}

A National Instrument ${ }^{\mathrm{TM}}$ cRIO rack is used for data acquisition; data are sent via LAN to a host PC where a $\mathrm{LabVIEW}^{\mathrm{TM}}$ program is used to read, visualize, analyze and store the measurements. Data are read every second and saved in a file for further analysis and elaboration. Fig. 4 shows a screenshot of the developed program.

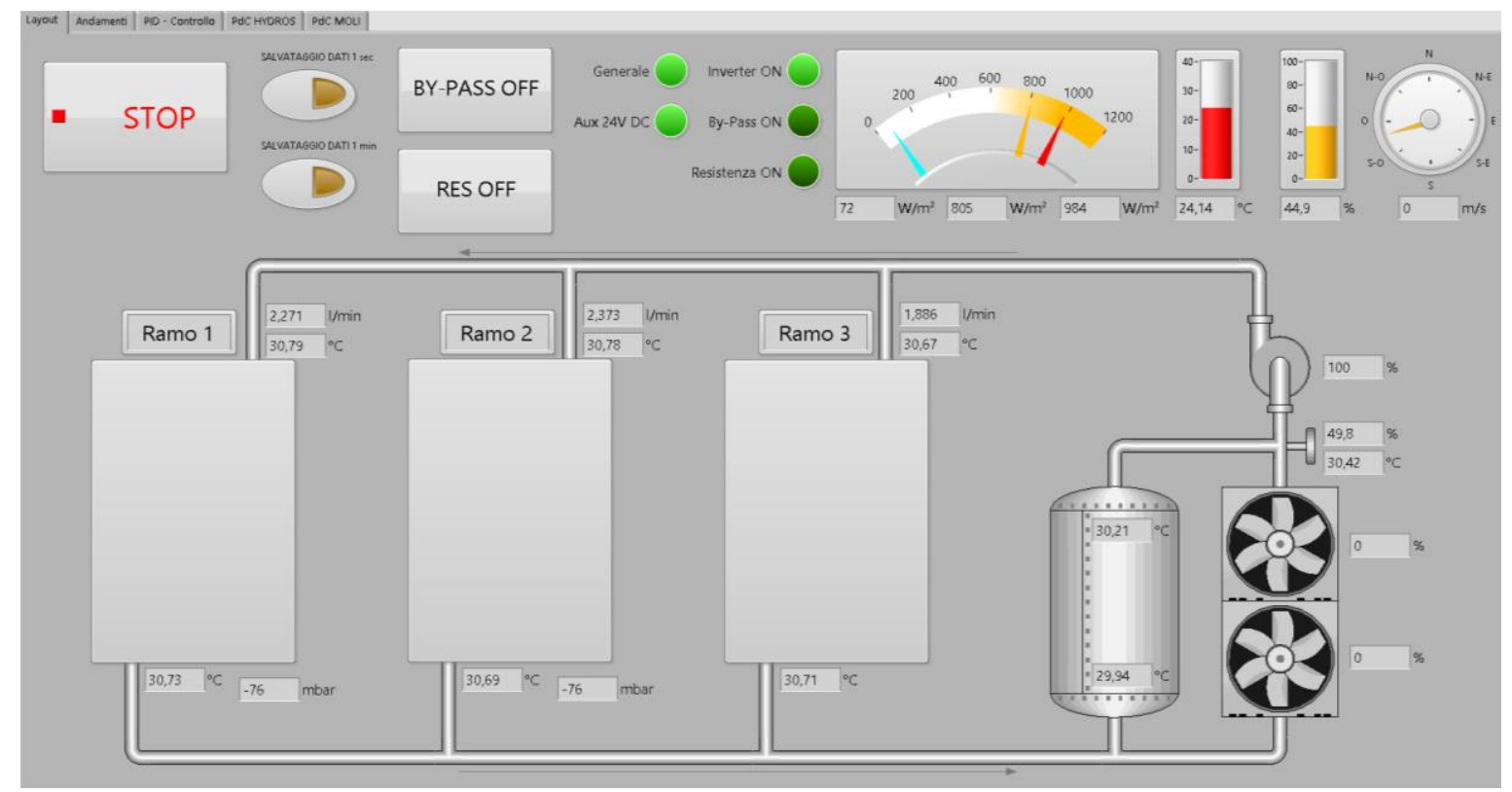

Fig. 4 - Screeshot of the control program 


\subsection{Experimental Conditions}

The experimental setup is located in the North of Italy, at SolarTech laboratory on the roof of the Department of Energy of Politecnico di Milano; whose geographical coordinates are latitude 45 $30^{\prime} 10.588^{\prime \prime} \mathrm{N}$ and longitude $9^{\circ} 9^{\prime} 23.677^{\prime \prime} \mathrm{E}$. PV/T panels are tilted of an angle of $27^{\circ}$ and oriented respect of the South of an angle of $-3^{\circ}$ (positive clockwise). A pump, controlled by the HP, completes the PV/T loop and a mixture of water and glycol is used to avoid freezing problems. Tests were carried out in the period from 13th of March to 26th of April 2018, 20 days of experimentation, with ambient temperature between $6.2^{\circ} \mathrm{C}$ and $29.0^{\circ} \mathrm{C}$ and solar irradiance of horizontal plane between $141.9 \mathrm{~W} / \mathrm{m}^{2}$ and $886.1 \mathrm{~W} / \mathrm{m}^{2}$. Fig. 5 shows example of temperatures trend during a day.

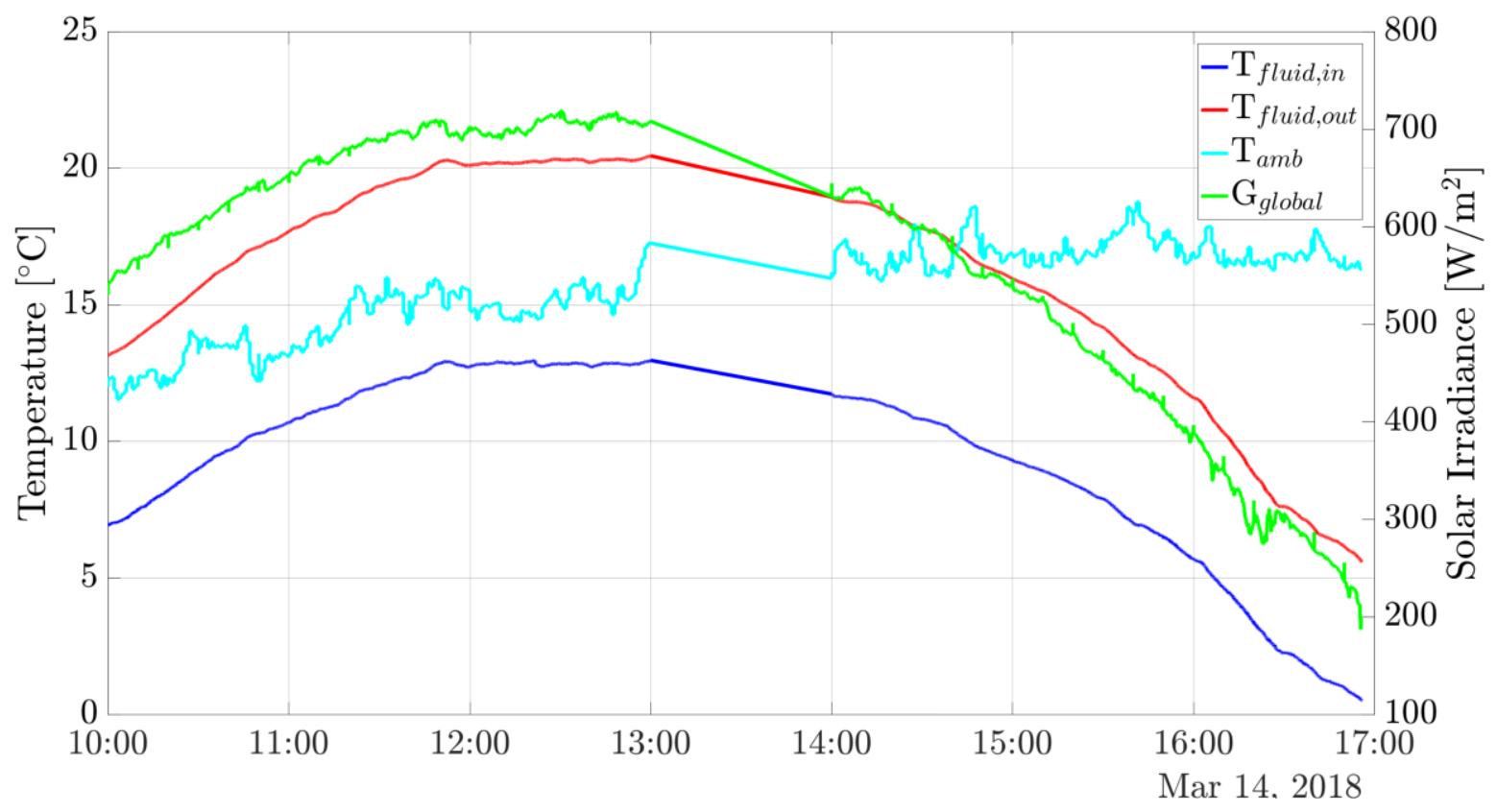

Fig. 5 - Temperatures at the inlet and outlet of the PV/T modules during a sunny day

\section{Methodology}

To improve the feasibility of the methodology to estimate the characteristic curve of PV/T modules, data filtering is required in order to avoid the inclusion of outliers and transient phenomena.

First step consists of selecting days with suitable weather conditions, meaning high and constant solar radiation and negligible wind. All the measured data are imported every second in MATLAB ${ }^{\circledR}$ where one-minute average value is calculated to smooth the variability. Then, steady state conditions of the system are ensured by applying some filtering criterions which all must be verified simultaneously; if only one of the filter fails for a certain minute, the whole data for that minute are neglected.

The set of variables and filters adopted in the process is summarized in Table 3.

Table 3 - Variable used for filtering and thresholds

\begin{tabular}{|c|c|}
\hline Control Bounds & $\dot{V}>0 l / \mathrm{min} \& \dot{Q}_{t h}>0 \mathrm{~W}$ \\
\hline Flow Rate - Standard Deviation & $\sigma(\dot{V})<0.035 \mathrm{l} / \mathrm{min}$ \\
\hline $\mathrm{T}_{\text {in }} / \mathrm{T}_{\text {out }}-$ Variation between two minutes & $\Delta T<0.2^{\circ} \mathrm{C}$ \\
\hline $\mathrm{T}_{\text {in }} / \mathrm{T}_{\text {out }}-$ Standard Deviation & $\sigma(T)<0.05^{\circ} \mathrm{C}$ \\
\hline Solar Irradiance - Mean Value & $G>100 \mathrm{~W} / \mathrm{m}^{2}$ \\
\hline Solar Irradiance - Standard Deviation & $\sigma(G)_{\%}<1 \%$ \\
\hline
\end{tabular}


In Fig. 6 shows the application of the filter to the solar irradiance.

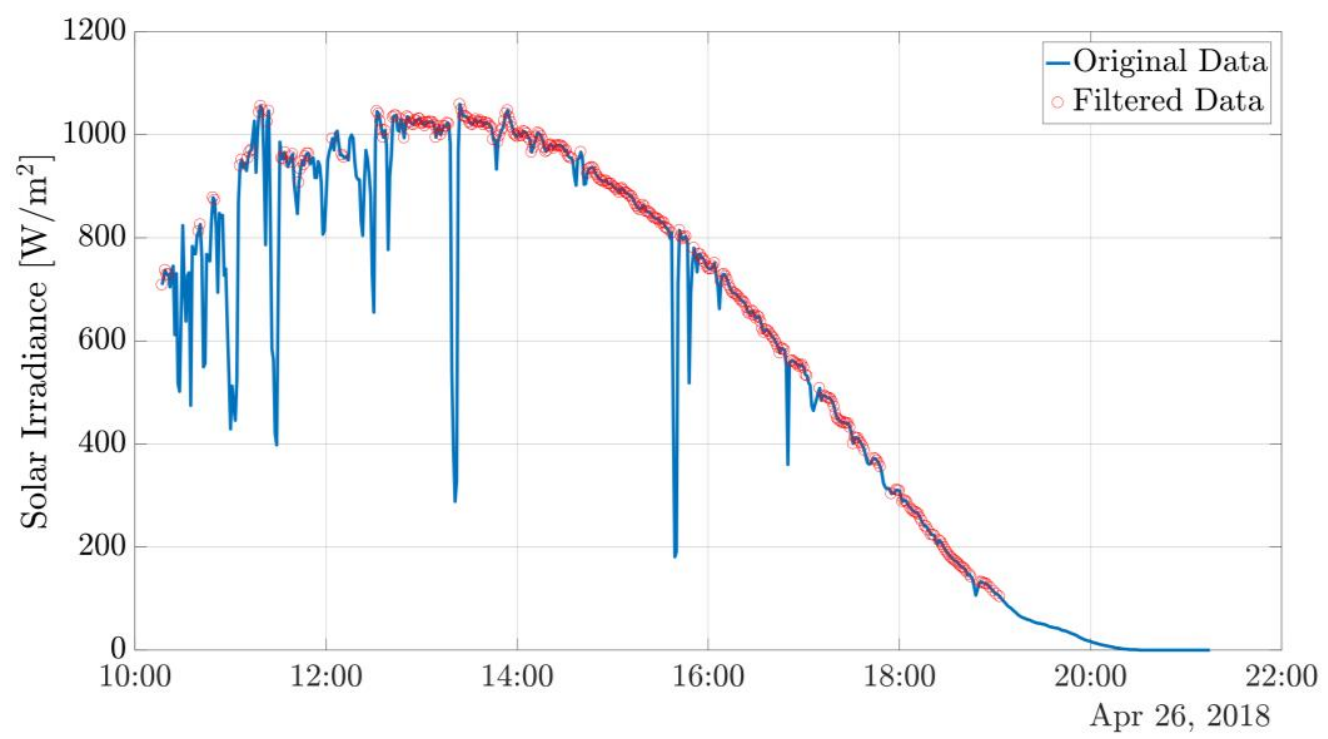

Fig. 6 - Example of data filtering

\section{Uncertainty Analysis}

Any experimental measurements have an error component, which could be small, but it always must be considered. In this way, the measured value is affected by uncertainty, so it is necessary to estimate quantitatively the quality of each single measurement. The evaluation of the uncertainty is related to the following equation:

$U\left(x_{i}\right)=\sqrt{U_{A}^{2}\left(x_{i}\right)+U_{B}^{2}\left(x_{i}\right)}$

The values measured every second are averaged in a window of one minute, hence an uncertainty of type $A$ is present. The sample is not large enough $(\mathrm{N}=60)$, thus it is necessary to adopt the $\mathrm{t}$-student distribution to predict the confidence interval of the measured data.

To evaluate the t-value, the degree of freedom (number of sample - 1) and the confidence level are required. For 59 degree of freedom and a $97.5 \%$ of confidence level, the t-value corresponds to 2.00 and uncertainty of type A can be calculated as follow:

$U_{A}\left(x_{i}\right)=t_{0.025} \cdot \frac{\sigma\left(x_{i}\right)}{\sqrt{N}}$

The uncertainties of quantities measured (uncertainty of type B) directly are evaluated referring to technical datasheets, whose main features are summarized in Table 2.

In order to estimate the uncertainty of indirect quantities, the propagation theory is applied: considering $\mathrm{y}$ as a generic quantity depending on the $\mathrm{M}$ samples of the direct quantities, calculated as $\mathrm{y}=\mathrm{y}\left(\mathrm{x}_{1}, \mathrm{x}_{2}, \ldots, \mathrm{x}_{\mathrm{j}}, \mathrm{x}_{\mathrm{M}}\right)$, its absolute uncertainty is computed with the equation:

$U(y)=\sqrt{\sum_{j=1}^{M}\left(\frac{\partial f}{\partial x}\right)^{2} \cdot U\left(x_{j}\right)^{2}}$

With this equation it is possible to calculate $U\left(\dot{Q}_{t h, i}\right)$ and $U\left(\eta_{t h, i}\right)$ by using the following expressions:

$$
\begin{aligned}
& U_{\%}\left(\dot{Q}_{t h, i}\right)=\sqrt{U_{\%}\left(\dot{V}_{i}\right)^{2}+\frac{1}{\left(T_{\text {out }, i}-T_{\text {in }, i}\right)^{2}} \cdot\left(U\left(T_{\text {out }, i}\right)^{2}+U\left(T_{\text {in }, i}\right)^{2}\right)} \\
& U_{\%}\left(\eta_{t h, i}\right)=\sqrt{U_{\%}\left(\dot{V}_{i}\right)^{2}+\frac{1}{\left(T_{\text {out }, i}-T_{\text {in }, i}\right)^{2}} \cdot\left(U\left(T_{\text {out }, i}\right)^{2}+U\left(T_{\text {in }, i}\right)^{2}\right)+U_{\%}\left(G_{T, i}\right)^{2}}
\end{aligned}
$$




\section{Results}

The aim of the experimental campaign is to determine the thermal efficiency curve for the PV/T modules as a function of the reduced temperature, according to eq. 10.

$\eta_{t h}=\eta_{o p t}+a_{1} \cdot \frac{\left(T_{o u t}+T_{\text {in }}\right) / 2-T_{a m b}}{G_{T}}$

In Fig. 7 it is reported the thermal efficiency vs. reduced temperature plot after the data filtering process explained in section 3, to remove all the measurements not in steady state condition. The regression line calculated according to eq. 10 is reported too.

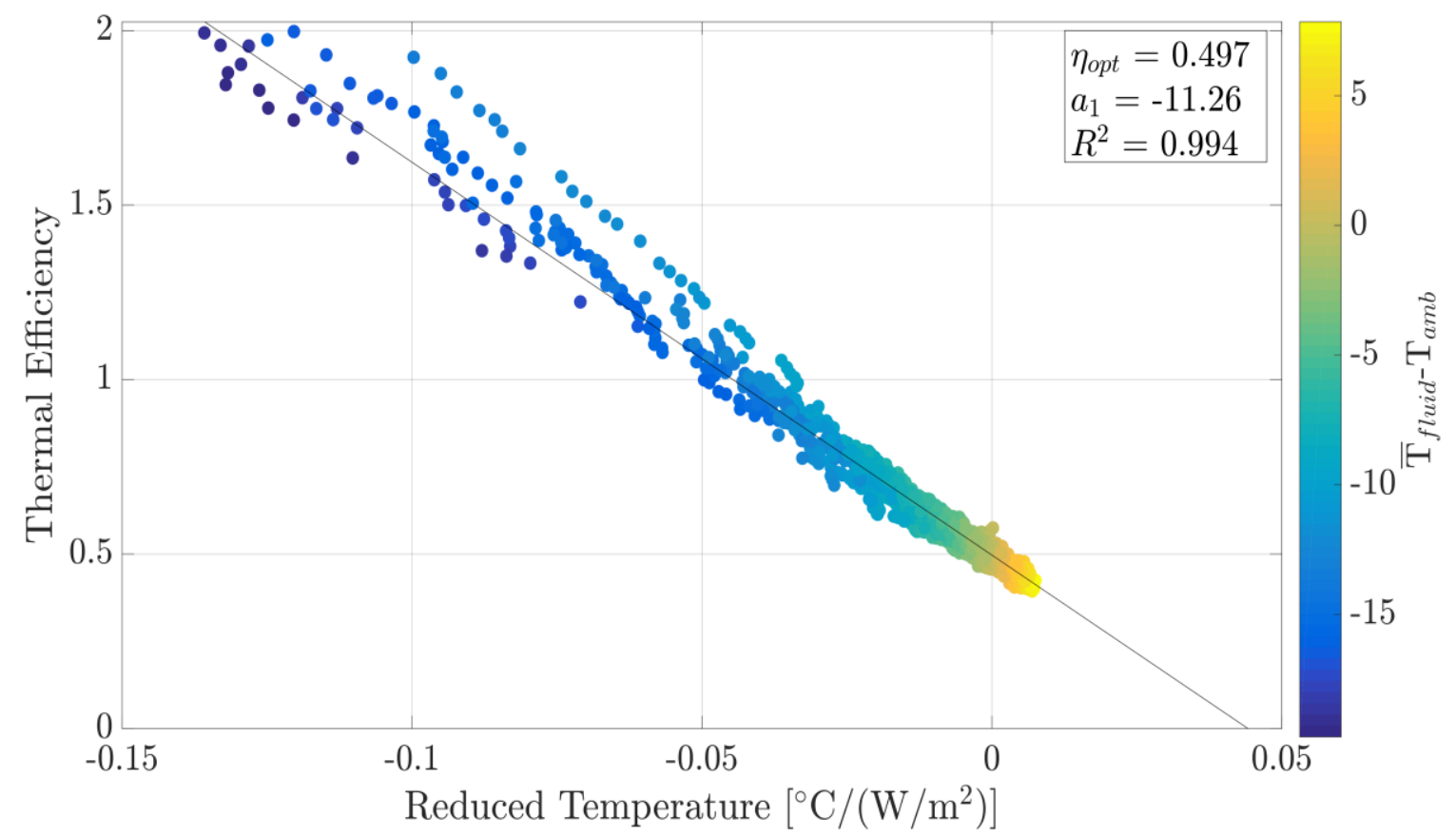

Fig. 7 - Thermal efficiency vs reduced temperature plot for all the PV/T measurements

Firstly, it is possible to see that all the measurements follow a linear trend, as expected by the theory. This is also confirmed by the parameter $\mathrm{R}^{2}$, which is higher than 0.99 , pointing out the goodness of the filtering process of the data and the possibility to evaluate the performance of PV/T panels also in real environmental conditions. The fluid mean temperature can reach values lower than $15 \mathrm{~K}$ with respect to the ambient temperature. Analyzing the results of the linear regression, we notice that both the optical efficiency $\eta_{\text {opt }}$ and the loss coefficient $\mathrm{a}_{1}$, equal to $49.7 \%$ and $-11.26 \mathrm{~W} /\left(\mathrm{m}^{2} \mathrm{~K}\right)$ respectively, are lower respect of the values present in the datasheet. This depends by the different laboratory typology (outdoor laboratory in this work and indoor one for datasheet) where the two characterization took place.

Therefore, thermal efficiency overcomes the optical efficiency in several cases, reaching also values near 2 for reduced temperatures around $-0.13^{\circ} \mathrm{C} /\left(\mathrm{W} / \mathrm{m}^{2}\right)$. Obviously, a condition with a very negative reduced temperature has not a real application: the aim of the experimentation is to confirm the linear trend of thermal efficiency also with the mean temperature of $\mathrm{PV} / \mathrm{T}$ panels significantly lower than the ambient one, removing the limit of some certificated PV/T curve characterization that need a high solar irradiance (higher than $\left.600 \mathrm{~W} / \mathrm{m}^{2}\right)$.

Results also confirm the advantages of the SAHP concept respect of a standard PV/T system: instead of producing directly the heat required by the house with a low thermal efficiency (especially during early spring and the last part of autumn), the heat is used to feed the HP, with a considerable higher thermal efficiency. A fraction of or all the electrical production of PV/T modules can also be used to supply the electrical consumption of the HP, reducing the exchanges with the national grid. 


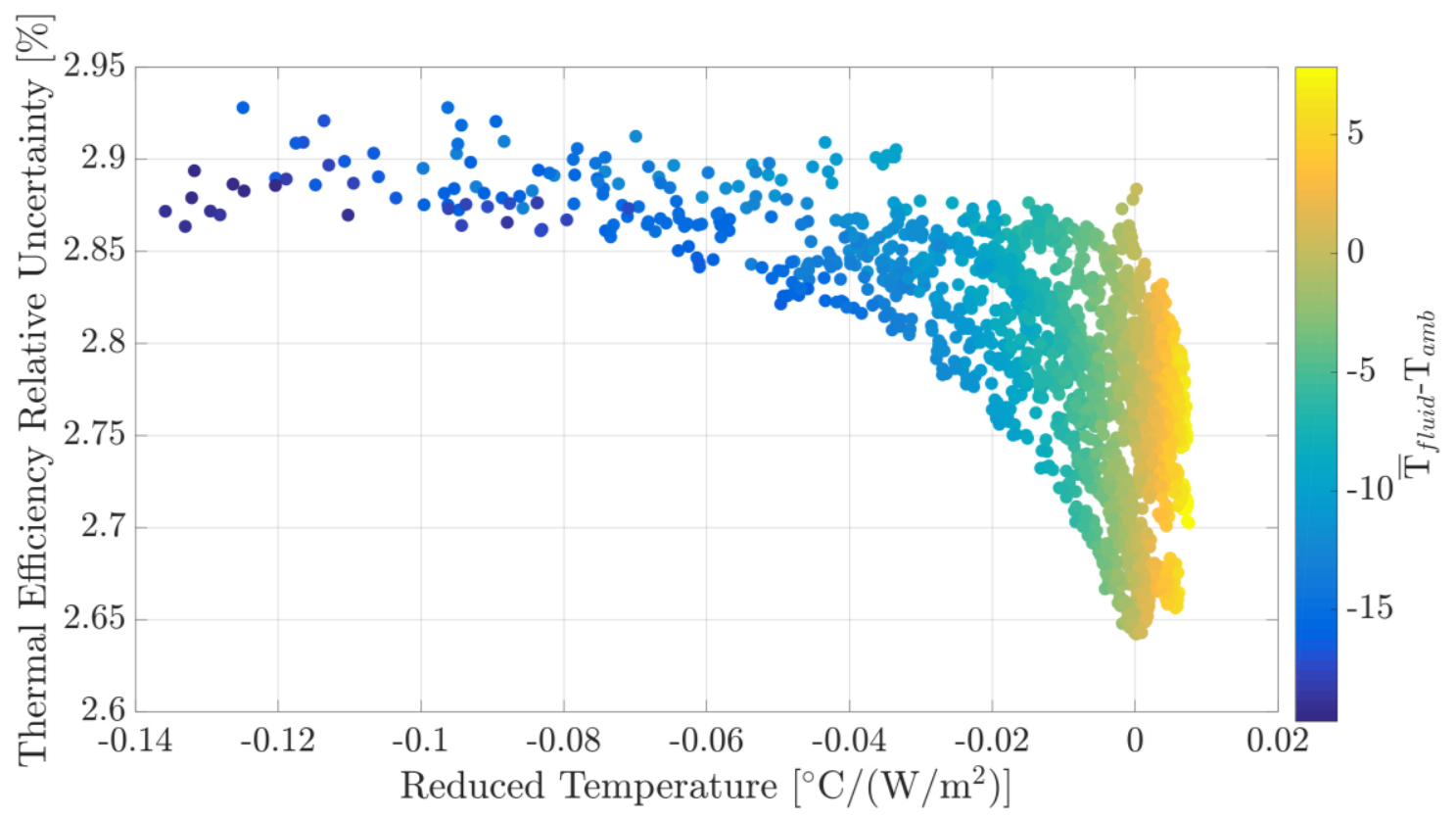

Fig. 8 - Thermal efficiency relative uncertainty vs. reduced temperature plot for all the PV/T measurements

Fig. 8 shows the relative uncertainty of thermal efficiency; it is possible to see that the fluctuation is inside a narrow band, varying between $2.65 \%$ and $2.95 \%$. This value is small and acceptable to consider reliable the data collected during the experimental campaign. Uncertainty increases with the decreasing of the reduced temperature, related to the reduction of the solar irradiance and the temperature difference between inlet and outlet of the panels. As can be deduced from Table 2, the highest contribute to the uncertainty value of thermal efficiency is given by the flowmeter instrument; to improve the quality of the measurement process, a substitution of this instrument can be done with another with lower uncertainty or lower full-scale (near the range of the flow rate user for testing).

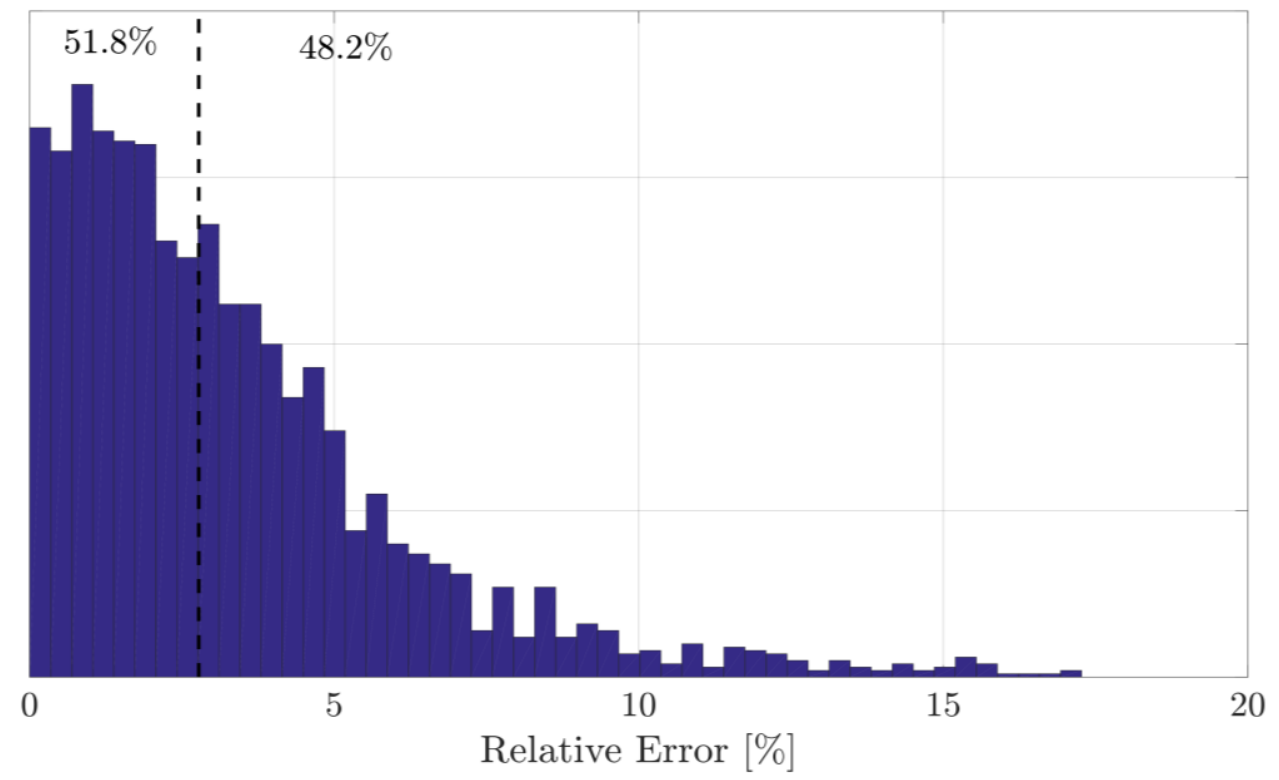

Fig. 9 - Relative error of the thermal efficiency (histogram) compared with the mean value of the uncertainty of the thermal efficiency (dashed line)

Fig. 9 explains the comparison between the relative error of thermal efficiency, calculated as the relative difference between the measured data and the estimated data using the linear regression, and the mean of the relative uncertainty calculated from the experimental data. It is possible to see that almost a half of the measured points have an error respect of the modeled curve that is lower than the uncertainty, which means the model in that cases predict correctly the thermal efficiency. 


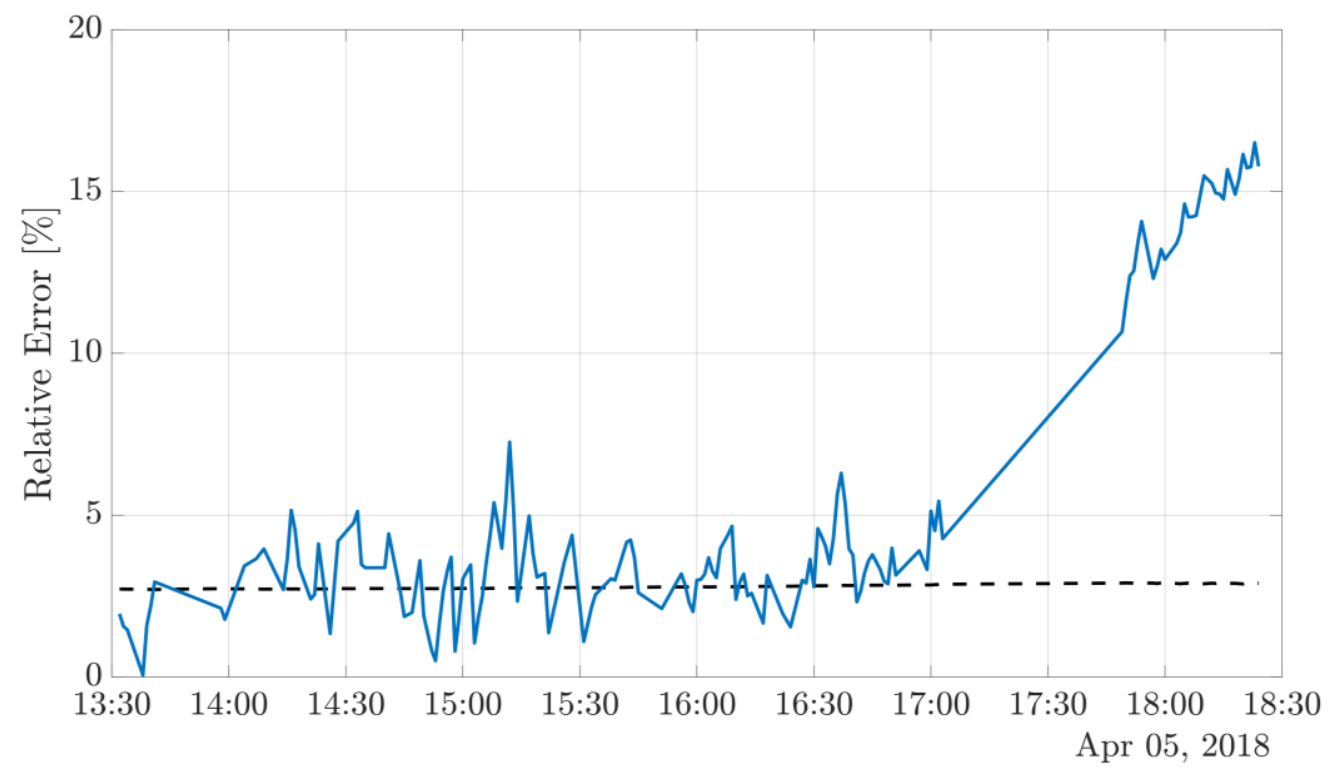

Fig. 10 - Relative error of thermal efficiency of a representative day (blue line) compared to uncertainty of thermal efficiency (dashed line)

This fraction is not prevalent (only $51.8 \%$ ) because the relative error is significantly higher than the uncertainty in the last part of the day (Fig. 10). This is caused by the reduction of solar irradiance and consequently the temperature difference between inlet and outlet of the solar panels, which penalizes the thermal power produced by PV/T modules and the power input from the Sun. To avoid this problem and measure correctly thermal efficiency also with very low reduced temperature, a solution can be the replacement of the HP with a greater one (in order to increase the cold heat required and consequently reduce the mean temperature of the $\mathrm{PV} / \mathrm{T}$ modules) or reduce the number of panels used to feed the HP.

\section{Conclusions}

In this paper, an experimental campaign was conducted at the laboratory SolarTech ${ }^{\mathrm{LAB}}$, Politecnico di Milano, for 20 days between March and April of 2018, to evaluate the behavior and the performance of four PV/T panels connected in parallel used as the cold source of a heat pump in different real ambient conditions, with particular focus on working conditions in which the mean temperature of the working fluid was below the ambient one. The experimental apparatus was built up with instruments that allow to measure inlet and outlet temperature of the modules, the volumetric flow rate, the electric production of each panel and the ambient conditions (solar irradiance and ambient temperature). A program developed with the software LabVIEW ${ }^{\mathrm{TM}}$ was used to control the laboratory, monitor the tests, collect the data and save them with a time step of one second. Furthermore, a filtering process was also worked out to remove all the measurements not in steady state conditions. Finally, uncertainty analysis was done to evaluate the goodness of the instruments and the measurement method.

Results shows that the behavior of PV/T modules follows the linear trend as the theory expose, also when the reduced temperature is very low. Thermal efficiency is higher than the optical one in several cases, reaching values of $200 \%$. Linear regression from the data has a very high $\mathrm{R}^{2}$ (up to 0.99 ) and the values of $\eta_{\text {opt }}$ and $\mathrm{a}_{1}$ are $49.7 \%$ and $-11.26 \mathrm{~W} /\left(\mathrm{m}^{2} \mathrm{~K}\right)$ respectively. Uncertainty analysis explains that the experimental apparatus is well build: in fact, the mean value of the uncertainty of thermal efficiency is $2.8 \%$. A possibility to reduce this value is findable changing the flow meter. Comparing the relative error between the measured value and the calculated from the regressed curve and the uncertainty, the work has shown that only half the points considered have a relative error lower than the uncertainty. Most of the other half points is concentrated in periods when the Sun is rising: in these conditions the difference between inlet and outlet temperature of PV/T panels is very limited and the error on the evaluation of the behavior of the system is reasonable greater.

The works finally evinces the scientific relevance to combine the PV/T technology with a HP, increasing the thermal efficiency due to the lower mean temperature of the working fluid and consequently increasing the electrical production, extending the utilization of PV/T panels also in the cold period. 


\section{References}

Aste, N., Del Pero, C. \& Leonforte, F., 2014. Water flat plate PV-thermal collectors. A review. Solar Energy, Volume 102, pp. 98-115, DOI: http://dx.doi.org/10.1016/j.solener.2014.01.025.

Calise, F., Dentice d'Accadia, M., Figaj, R. \& Vanoli, L., 2016. A novel solar-assisted heat pump driven by photovoltaic/thermal collectors: Dynamic simulation and thermoeconomic optimization. Energy, Volume 95, pp. 346-366, DOI: https://doi.org/10.1016/j.energy.2015.11.071.

Chow, T. T., 2010. A review on photovoltaic/thermal hybrid solar technology. Applied Energy, 87(2), pp. 365379, DOI: http://dx.doi.org/10.1016/j.apenergy.2009.06.037.

Ji, J. et al., 2008. Experimental study of photovoltaic solar assisted heat pump system. Solar Energy, Volume 82, pp. 43-52, DOI: https://doi.org/10.1016/j.solener.2007.04.006.

Kim, J. \& Kim, J., 2012. The experimental performance of an unglazed PV-thermal collector with a fully wetted absorber. Energy Procedia, Volume 30, pp. 144-151, DOI: http://dx.doi.org/10.1016/j.egypro.2012.11.018.

Kumar, A., Baredar, P. \& Qureshi, U., 2015. Historical and recent development of photovoltaic thermal (PVT) technologies. Renewable and Sustainable Energy Reviews, Volume 42, pp. 1428-1436, DOI: http://dx.doi.org/10.1016/j.rser.2014.11.044.

Li, H., Sun, L. \& Zhang, Y., 2014. Performance investigation of a combined solar thermal heat pump heating system. Applied Thermal Engineering, 71(1), pp. 460-468, DOI: https://doi.org/10.1016/j.applthermaleng.2014.07.012.

Migliorini, L., Molinaroli, L., Simonetti, R. \& Manzolini, G., 2017. Development and experimental validation of a comprehensive thermoelectric dynamic model of photovoltaic modules. Solar Energy, Volume 144, pp. 489-501, DOI: https://doi.org/10.1016/j.solener.2017.01.045.

Simonetti, R., Manzolini, G. \& Molinaroli, L., 2017. Modeling of Solar Assisted Heat Pumps Combined with Photovoltaic Thermal Modules. Proceedings of SWC2017/SHC2017, pp. 1-12, DOI: https://doi.org/10.18086/swc.2017.33.08.

SoLink, 2017. SoLink PVT. [Online] Available at: http://www.solink.it [Accessed 5 September 2018].

Zondag, H., De Vries, D., Van Helden, W. \& Van Zolingen, R., 2003. The yield of different combined PVthermal collector designs. Solar Energy, Volume 74, pp. 253-269, DOI: https://doi.org/10.1016/S0038092X(03)00121- X. 


\title{
Experimental Investigation of PV/T Collectors with Phase Change Material
}

\author{
Raquel Simón-Allué, Isabel Guedea, Raúl Villén and Gonzalo Brun \\ EndeF Engineering SL, Zaragoza (Spain)
}

\begin{abstract}
In the current work we evaluate the experimental operation of two different types of photovoltaic-thermal collectors (PV/T) and their performance after adding a layer of phase change material (PCM) within the panel. Each PV/T collector selected has a heat absorber unit different in material and geometry and was tested under four different configurations: unglazed, unglazed with PCM, glazed and glazed with PCM. Results show a slightly variation in the electrical generation but a great difference in the thermal performance between glazed and unglazed configuration. The addition of PCM results in a better distribution of the heat production, generating up to $30 \%$ of maximum thermal values after removing sun exposure. No significant differences are found between heat absorber units for similar configurations.
\end{abstract}

Keywords: Solar energy, Photovoltaic-thermal (PV/T); Phase change material; Experimental study.

\section{Introduction}

The increase on the world energy consumption observed during last decades has forced society to investigate new technologies and energy resources. Traditional energy technologies imply the use of fossil fuels and other precious resources whose future availability is limited and entail the generation of pollution in terms of air, water, soil and climate. This fact, together with the hardening of the European Union's policies relative to gas emissions and energy efficiency ${ }^{1}$, have encourage the development and use of renewable energies, as a clean, cheap and reliable alternative. However, in order to reach the level of maturity required to face fossil fuels, new technologies need further research. In this frame, solar technologies emerges as one of the most promising alternatives due to the abundant, inexhaustible and clean nature of the sun (Parida, Iniyan, and Goic 2011). Regarding the flat plate collector, solar technology is traditionally subdivided into two main groups: solar thermal (ST) and photovoltaics (PV).

Solar thermal collector was the first panel type investigated and their typical efficiency rounds $80 \%$ (Colangelo et al. 2016; Hossain et al. 2011). However, its use has been gradually cushioned due to the high installation costs and common hydraulic problems. Photovoltaic panels, on the contrary, present efficiency values ranged between 5-20\% depending on the PV cell technology (Islam et al. 2016), but the PV market has undergone a great development in last decade which helped to reduce both production and installation costs while improving the technology. These efficiency values, however, can be penalized due to the temperature increment of the panel (M. J. Huang, Eames, and Norton 2006; Radziemska 2003), and is estimated to drop at rate of $0.45 \% /{ }^{\circ} \mathrm{C}$ in case of crystalline silicon cells (Du, Darkwa, and Kokogiannakis 2013). To limit the PV cell temperature during operation, several solutions have been proposed including the use of a heat absorber piece to remove surplus heat (usually named PV/T collectors) or the incorporation of phase change material (PCM).

First PV/T (photovoltaic-thermal) panels were suggested in mid1970 (Hendrie 1979; Kern and Russell 1978; Martin Wolf 1976) with the only objective of removing heat from the PV laminate. The technology was afterwards developed to make use of the heat removed but it was not until 1990s that the hybrid technology became a viable commercial solution (Bergene and Løvvik 1995; Garg and Adhikari 1999). Common PVT collectors are based on heat absorber unit adhered to a PV laminate so they can generate both electricity and low-grade thermal energy

\footnotetext{
${ }^{1}$ European Commission, 2017. Energy Strategy 2020: https://ec.europa.eu/energy/en/topics/energy-strategy-and-energy-union/2020-energystrategy
} 
during the daytime (Chow 2010; Michael, Iniyan, and Goic 2015). The combination of both systems on the same module lowers the thermal performance with respect to a thermal collector, but incorporates the electrical production with enhanced performance with respect to the individual PV due to the cooling effect provoked by the stream fluid. As a result, the PV/T system produces more energy per unit area compared to a PV module and a thermal collector adjacent to each other (Tripanagnostopoulos et al. 2005; Zondag et al. 2002). Each energy rate can vary depending on the PV/T features: existence of frontal cover, absorber geometry and material, PV cell type or fluid stream for example. Although this technology has been widely studied during last decade (Beaudin and Zareipour 2015; Besheer et al. 2016; Good 2016; Palaskar and Deshmukh 2012), the high upfront investment cost and the low efficiency rates compared to fossil fuel systems restrain their use. According to experts, the great breakthrough is yet to come, but highlight the necessity of further research to increase efficiencies and reduce costs.

The use of phase change materials (PCM) as a way to regulate the temperature of the PV cells was introduced in 1978 (Stultz 1978) and since then, many works have focused on the benefits of this technology, from experimental (Ahmad Hasan et al. 2014; Klugmann-radziemska and Wcisło-kucharek 2017; Mahamudul et al. 2016) to numerical (M. J. Huang, Eames, and Norton 2007; Sarwar et al. 2011) point of view. This material is able to store thermal energy when it changes the phase during the warming, and releases it gets cold again and recover the initial state. This way, the use of this material can limit the maximum temperature reached on the PV cells if they exceed the PCM melting range. According to literature, the appropriate selection of PCM is essential for the success of the application. Factors like the PCM nature (organic, inorganic), melting point or total thickness directly condition the potential impact on PV performance. Its effect has been experimentally studied in controlled testing plants (A Hasan et al. 2010) or applied to buildings integration (BIPV) (Aelenei et al. 2014; Yin et al. 2013), and included in the International Energy Agency throughout the Annex 17 (International Energy Agency 2005) and the Task 42 of the Solar Heating \& Cooling Programme (Rommel, Hauer, and Van Helden 2015).

The application of PCM to PV/T modules is less common than its use to PV of ST separated. Most of previous works tackle the combination with the PCM located in an external thermal energy storage (TES) (Lin et al. 2014; Ren et al. 2017; Yin et al. 2013). A few studies referred to cases with PCM directly inserted on the panel from the numerical approach (Malvi, Dixon-Hardy, and Crook 2011; Su et al. 2017) and experimental assessment (Besheer et al. 2016; Good 2016; Yang et al. 2018). All of them focused on sheet-and-tube copper heat absorbers, but no additional materials or configurations were explored.

With this work we aim to fill this gap and analyzed the effect of the same PCM on two types of PV/T modules: traditional sheet-and-tube copper and a roll-bond sheet aluminum heat absorber. Both models were experimentally addressed to evaluate the thermal and electrical performance with and without PCM. In the case of PV/T rollbond aluminum absorber, glazed and unglazed configurations were considered in order to assess the influence of the cover into the PV/T performance.

\section{Material \& methods}

\subsection{Description of the prototype design and manufacturing}

Two PV/T models were considering for the testing based in different heat absorber types: sheet-and-tube copper pipes and a roll-bond aluminium absorber. In the case of the aluminium, two configurations were explores, glazed and unglazed. Moreover, each model was investigated with and without PCM. Thus, a total of 6 PV/T panel models are analysed in this work.

Table 1: List of PV/T cases considered for the testing.

\section{Case name}

Al PVT-1

Al PVT-1 + PCM

Al PVT-2

Al PVT-2 + PCM

EC PVT-2

EC PVT-2 + PCM

\section{Absorber type}

Roll-bond, aluminium

Roll-bond, aluminium

Roll-bond, aluminium

Roll-bond, aluminium

Sheet-and-tube, copper

Sheet-and-tube, copper
Frontal cover

NO

NO

YES

YES

YES

YES
PCM NO YES

NO

YES

NO

YES


Sheet-and-tube copper absorber corresponds to the traditional model commonly employed in literature. For this case, the commercial ECOMESH panel was employed ${ }^{2}$. This hybrid panel contains a copper absorber, formed by a flat sheet and longitudinal tubes where the fluid flows. Second model was made based on a roll-bond absorber, developed by CGA technologies. The roll-bond sheet has two faces: one is flat to be in contact with the PV laminate and maximize the contact between surfaces, the other presents a wavy pattern with the fluid channels. In both models absorber pieces are located between the PV laminate, consisting on 60 polycrystalline cells with nominal power set at $270 \mathrm{~W}$, and the insulating layer, conformed by a $2.5-\mathrm{mm}$ rock wool layer. Rest of absorber specifications are listed in Table 2.

To obtain the glazed configuration, an additional glass layer was placed over the frontal side of the panel. The cover consisted on a 3.2-mm glass layer located and glued to the PV module, with a 12-mm air camera left between them. PCM was inserted between the absorber unit and the insulation layer with the help of several metallic bars placed across the PVT panel to ensure the PCM position during the experimental testing and the contact with the absorber.

Table 2: Specifications of absorbers of the PV/T models tested.

\begin{tabular}{lccc|} 
Magnitude & Units & EC model & Al model \\
\hline Dimensions of collector & $\mathrm{mm}$ & $1590 \times 960$ & $1420 \times 940$ \\
\hline Area & $\mathrm{m}^{2}$ & 1.53 & 1.46 \\
\hline Absorber Material & - & Copper & Aluminum \\
Maximum operating temp. & ${ }^{\circ} \mathrm{C}$ & 150 & 85 \\
Operating pressure & $\mathrm{bar}$ & 2 & 4 \\
Maximum pressure & $\mathrm{bar}$ & 10 & 6 \\
Pressure drop & $\mathrm{bar}$ & 0.04 & 0.15 \\
Nominal flow rate & $1 / \mathrm{h}$ & 120 & 100 \\
Weight & $\mathrm{kg}$ & 7 & 6 \\
Water content & 1 & 1.2 & 0.88
\end{tabular}

\section{PCM selection and insertion}

PCMs are components able to store thermal energy during the process of phase change. At ambient temperature the PCM remains in solid state, but when the temperature increases up to a particular value it changes into solid state, absorbing energy from the surrounded area. When applied to solar applications, PCM comply with particular requirements such us: ability to work for many cycles, chemical stability between $0-100^{\circ} \mathrm{C}$ or small volume changes among others. Besides the general requirements, the suitability of a PCM is directly conditioned by the melting point selected. Attending to the fluid temperature inside PV/T panels, which may reach maximum values of $60-70^{\circ} \mathrm{C}$ in extreme environmental conditions, we have established the phase change range suitable for this application between $45-50^{\circ} \mathrm{C}$.

Our objective with this PCM melting point selection is to store only the surplus heat generation over $45^{\circ} \mathrm{C}$ and to prevent PV laminate from reaching excessive high temperatures. On this basis, we have selected the salt hydrate (inorganic PCM) C48, ClimSEL ${ }^{\mathrm{TM}}$ line of Climator Sweden, with a phase change temperature established at $48^{\circ} \mathrm{C}$ (see Figure 1).
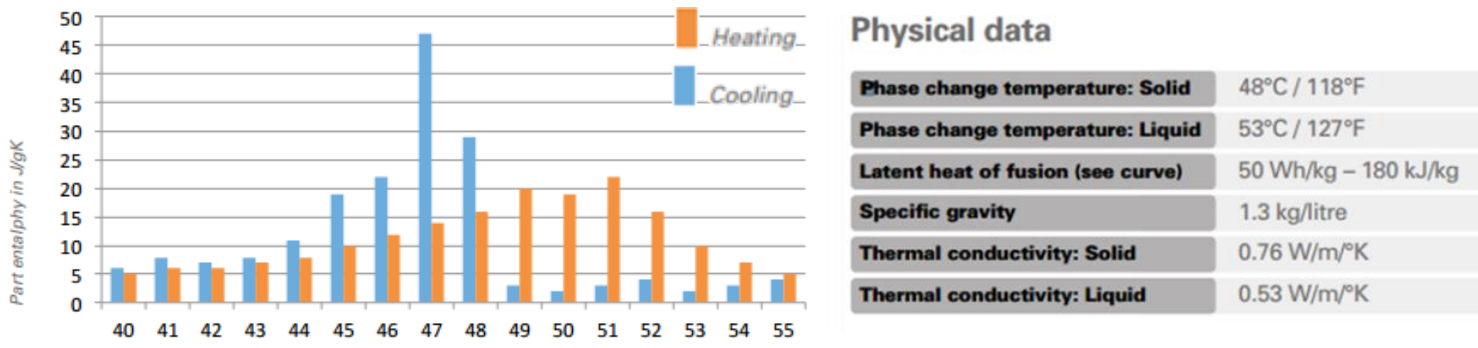

Figure 1: Inorganic C48 PCM technical sheet.

\footnotetext{
${ }^{2}$ Solar hybrid panel ECOMESH, EndeF Engineering SL. https://endef.com/en/products/
} 
In order to prevent hybrid collector units from possible PCM leaks during the liquid state, PCM was added to the panel covered by an external enclosure. The material employed for the enclosure was aluminium foil pouches to favour the heat transmittance from the absorber to the PCM. A total of $16 \mathrm{~kg}$ was inserted in each panel, distributed in 32 pouches of $0.5 \mathrm{~kg}$ and $10 \mathrm{~mm}$ of thickness.

\subsection{Description of the testing procedure}

All PV/T units were tested in EndeF facilities, located in Zaragoza, Spain. Experiments were carried out in a testing bench with capacity for two solar panels. Hydraulic connection was set so that the heat exchange fluid flows in a close loop, crossing both panels on its way. Other components of the testing rig were: pump, hydraulic valves, an expansion vessel, heat dissipator and an electric board. Electrical production of the PVT prototype was generated in DC power and turned into AC power through the micro inverter located on the rear side of the panel, corresponding to the SMI-D480W-60-UL model, by Enecsys.

During the testing, data was continuously monitored in a PLC Modicon 241 and computationally registered for the postprocessing. The description of the main measurement instruments is included Table 3.

Table 3: List of sensors set on the testing bench.

\begin{tabular}{lcccc} 
Magnitude & Sensor model & Amount & Range & Accuracy \\
\hline Temperature & Pt100, several brands & 7 & $-50-400{ }^{\circ} \mathrm{C}$ & $\pm 0.05^{\circ} \mathrm{C}$ \\
\hline Flow & Analogic DRG-L343, Kobold & 1 & $1-301 / \mathrm{min}$ & $\pm 3 \% \mathrm{~F} . \mathrm{S}$. \\
Pressure & UNIK 5000, GE & 1 & $0.7-700 \mathrm{bar}$ & $\pm 0.04 \%$ \\
\hline Irradiance & Pyranometer, LP PYRA 03 AC & 1 & $0-2000 \mathrm{~W} / \mathrm{m} 2$ & $0.025 \mathrm{~W} / \mathrm{m} 2$ \\
\hline Current & HT-RS-0, Herten SL & 2 & $0-10 \mathrm{~V}$ & $\pm 0.5 \%$
\end{tabular}

Experiments were carried out with natural irradiance during the summer season in Zaragoza (Spain). In order to obtain constant values of irradiance, the rig was manually oriented along the light hours with respect to the solar rays' angle. The measurement period lasted from $11 \mathrm{am}$ to $5 \mathrm{pm}$, reaching at two stable working points: first from $11 \mathrm{am}$ to $3 \mathrm{pm}$ and second from $3 \mathrm{pm}$ to $5 \mathrm{pm}$. The working temperature of the PV/T unit was higher in the second stable point. Internal temperatures were monitored during the rest of the day to evaluate the effect of the PCM.

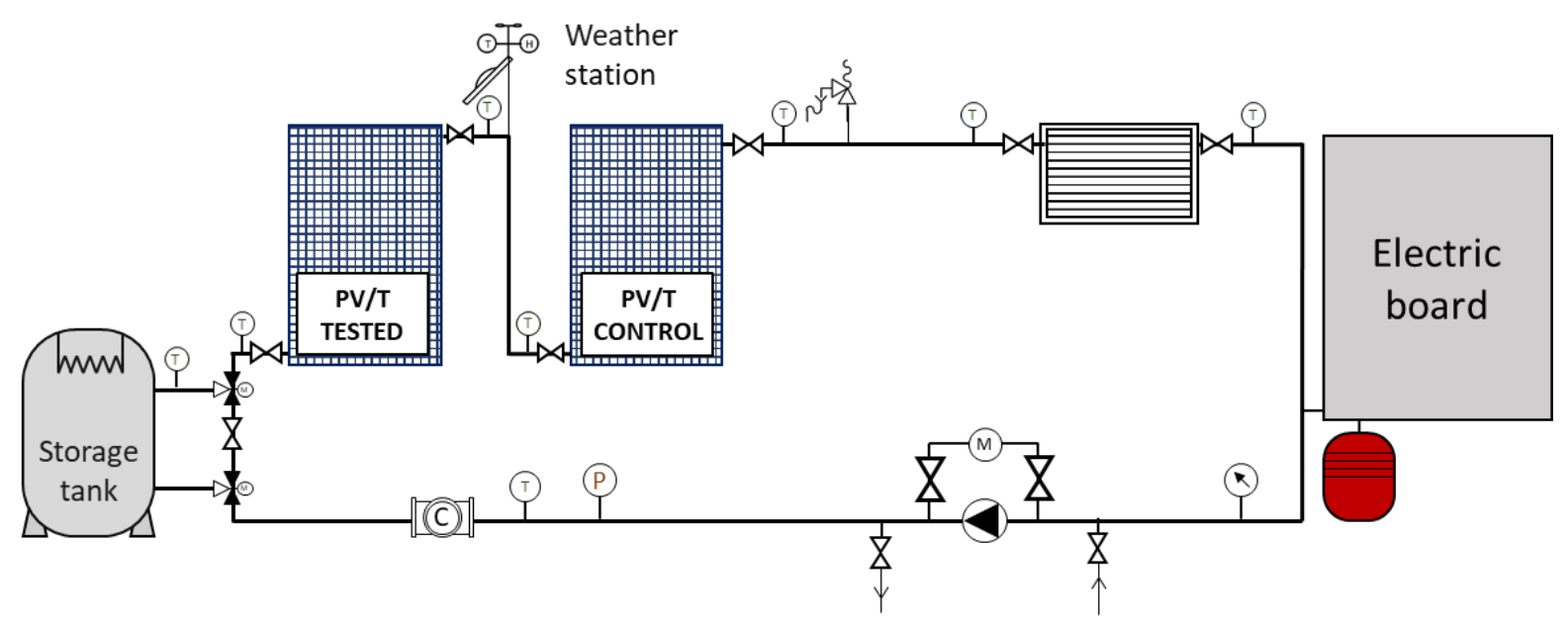

Figure 2: Hydraulic scheme of the testing bench.

\subsection{Analytical considerations}

Based on the information acquired by the different sensors and measuring equipment installed in the testing rig, the evaluation of several performance parameters was addressed.

The instantaneous heat power generated by each prototype was calculated form the flow rate of the fluid, $\dot{m}$, the specific heat of water, $c_{f}$, and the thermal leap of the fluid in its path across the panel $\Delta T$, as given en Eq. (1). Based on this heat power, we define the instant thermal efficiency of the PV/T panel as indicated in Eq. (2). With $A_{G}$ as the gross area of the photovoltaic laminate, sized in $1.56 \mathrm{~m}^{2}$, and $\mathrm{G}$ the amount of solar irradiation measured by the pyranometer in $\mathrm{W} / \mathrm{m}^{2}$ attached on the rig. 


$$
\begin{aligned}
& \dot{\boldsymbol{Q}}=\dot{\boldsymbol{m}} \cdot \boldsymbol{c}_{\boldsymbol{f}} \cdot \Delta \boldsymbol{T} \\
& \boldsymbol{\eta}_{t h}=\dot{\boldsymbol{Q}} /\left(\boldsymbol{A}_{G} \cdot G\right)
\end{aligned}
$$

Attending to the electrical part, electrical output $\left(W_{p}\right)$ was directly measured during the experiments through the use of a current isolator. From this data, cell efficiency was calculated as defined in Eq. (3), considering the irradiance capture by the PV laminate (Irradiance x PV area).

$$
\eta_{P V}=\frac{W_{p}}{(I \cdot A)}
$$

In order to directly compare all PV/T models, a general PV/T efficiency was defined transforming the energy quantities into primary-energy. To that end, we employ the conversion coefficient $\eta_{\text {power }}$ previously used in literature to transform electrical energy into thermal equivalent value and usually established in $38 \%$ (B. J. Huang et al. 2001; Ji et al. 2007; Kamthania and Tiwari 2014). The overall PV/T performances is therefore define as indicated in Eq. (4).

$$
\boldsymbol{\eta}_{\text {tot }}=\boldsymbol{\eta}_{\text {th }}+\boldsymbol{\eta}_{P V} / \boldsymbol{\eta}_{\text {power }}
$$

\section{Results \& Discussion}

Environmental conditions corresponding to the testing days of each prototype are shown in Figure 3.Solar radiation was ranged between $800-1000 \mathrm{~W} / \mathrm{m}^{2}$ during the testing period and environmental temperature did not differ from each other more than $10^{\mathrm{a}} \mathrm{C}$.

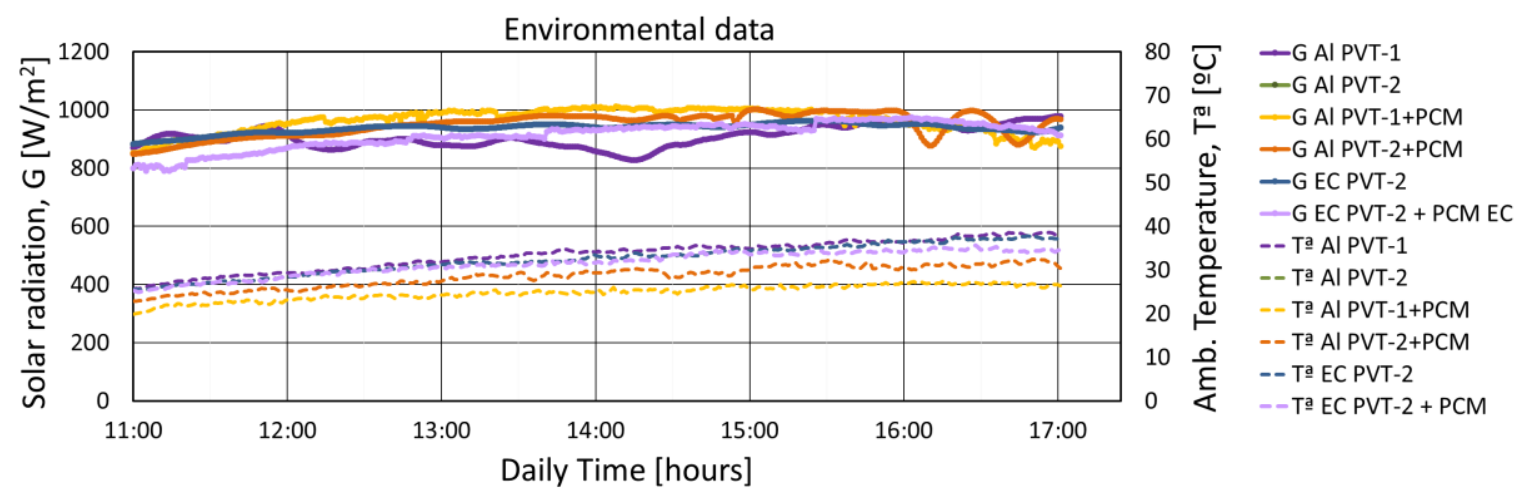

Figure 3: Environmental conditions on testing days.

Instantaneous heat power generated in each PV/T case throughout the testing day is shown in Figure 4. Based on this data, no significant differences are found with regard to the absorber type, with indicates similar thermal behavior for the two absorbers here considered.

In the case of the aluminum absorber, there is a noticeable difference between glazed and unglazed configurations. As expected, higher thermal power was generated in those cases with glass cover on the front side, reaching up to exceed in a $60 \%$ the generation of unglazed units. This difference becomes bigger when the working temperature of the panel increases at the secondary stable point, due to rise on thermal losses given on the unglazed units. At this point, the glazed cases reach to exceed the unglazed production in a $140 \%$.

The incorporation of the PCM did not lead to a significant improvement on the thermal performance, but provoked some alterations on the heat power generation. First, the addition of $32 \mathrm{~kg}$ of PCM lead to increment the thermal inertia of the whole, which slowed down the temperature changes given on the panel, both in the beginning and the changing between stable points. Second, during the period between $12 \mathrm{am}$ to $3 \mathrm{pm}$, cases without PCM reached to a stable point with quasi-constant heat power generation. However, cases with PCM showed a slow increment though time, reaching in some cases to higher values than the same model without PCM. Finally, the most relevant effect of the PCM is found at the end of the testing when the radiation is cut. At this moment, cases without PCM quickly recovered the initial state of null generation while cases with PCM exhibit a period of heat production, as 
a result of the energy releases in the PCM phase change. The amount of thermal energy releases is greater in the glazed configurations rather than the unglazed one, probably because the higher working temperature reached on the glazed cases allowed PCM to store more energy.

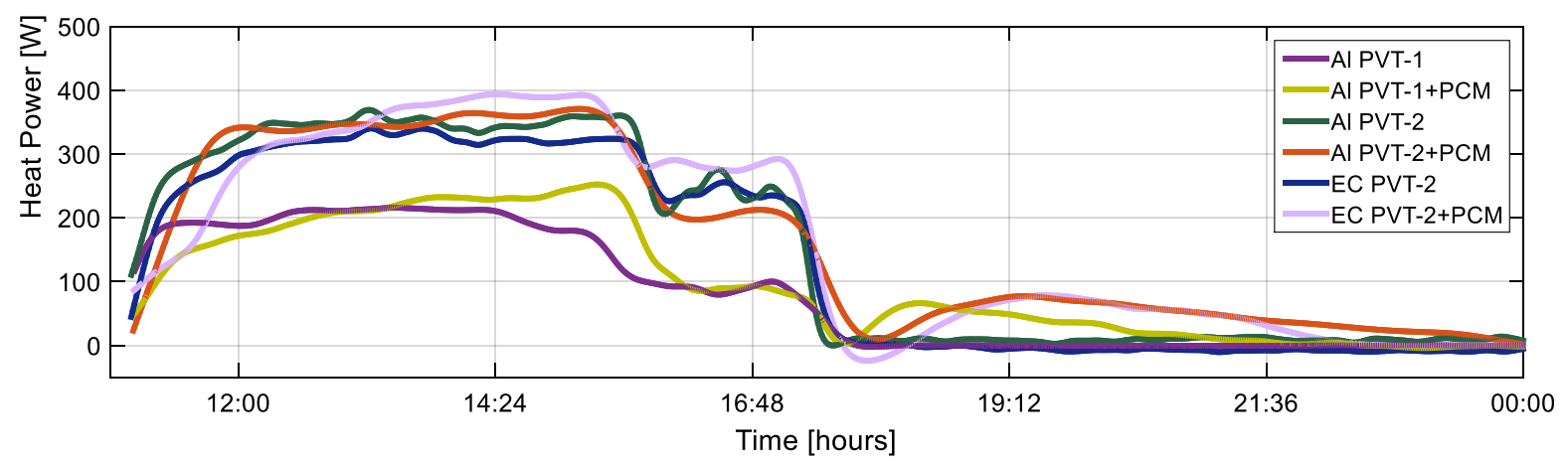

Figure 4: Daily distribution of heat power generation.

The melting point of the PCM varied from one case to other, because of its dependency on the operation temperature of the panel. Most of them however, reached the phase change temperature $\left(48^{\circ} \mathrm{C}\right)$ when changing from the first stable point to the second. PV/T working temperature during the second stable point surpassed $60^{\circ} \mathrm{C}$ for all cases, which ensure the melting of the PCM attached to the absorber.

Total thermal energy generated for each case during the period of testing is shown in Figure 5. In this graph, values in bold refer to the total generation in $\mathrm{Wh}$, including the period with sun radiation (from $11 \mathrm{am}$ to $5 \mathrm{pm}$ ) and the period without it (from 5pm on). The deviation between glazed and unglazed configurations on the thermal production is easily visible here, as well as the PCM contribution to the total generation. No great differences are found between glazed models, even considering the disparity of absorber types.

The heat production resulting from the PCM was accounted for $135 \mathrm{Wh}$ for the Al PVT-1 case, $263 \mathrm{Wh}$ for the Al PVT-2 and 198 Wh for the EC PVT-2. PCM inclusion allowed to generate up to $30 \%$ of maximum thermal power values obtained during sun exposure in the unglazed case, and up to $25 \%$ in the glazed case.

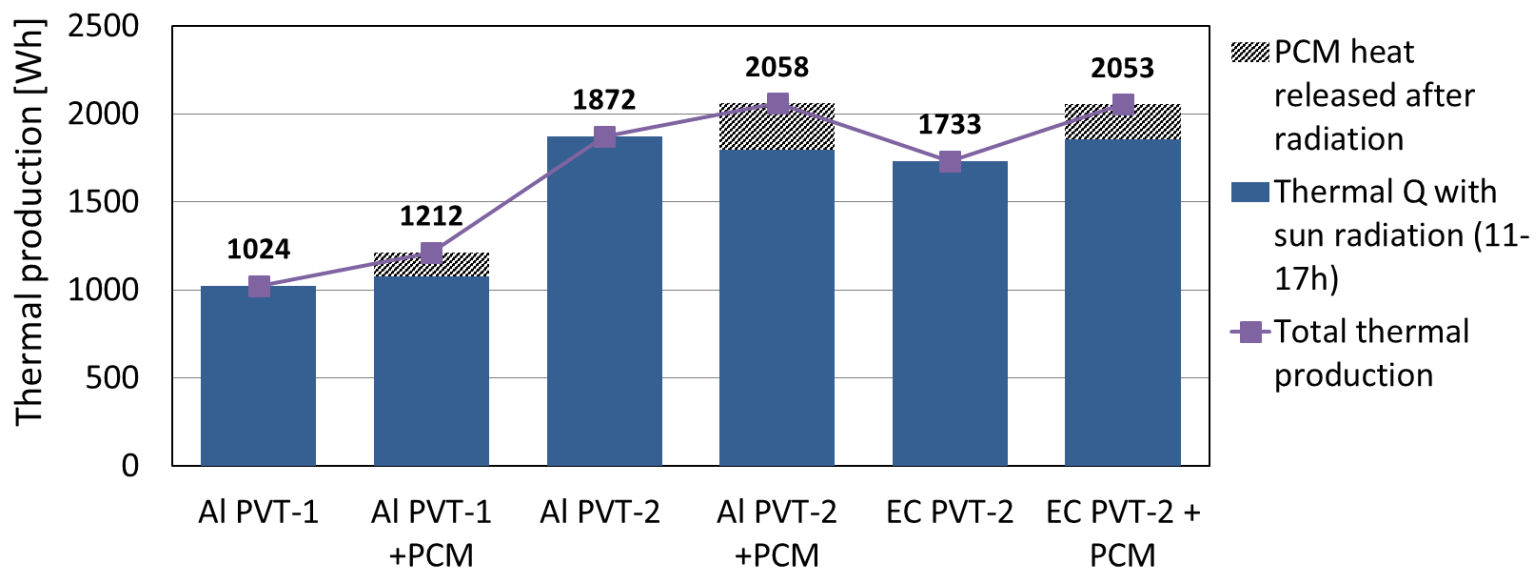

Figure 5: Total heat generated during the measurement period (11am- 5pm)

Besides the daily generation, we also have also evaluated the instantaneous electrical and thermal power generated in each case. To that end, we have calculated the average output during the stable period from $12 \mathrm{am}$ to $3 \mathrm{pm}$ and the respective efficiencies calculated from Eqs. (2) and (3). Graphical results are shown in Figure 6.

Electrical output was similar for all PV/T cases and it was ranged between 200 and $220 \mathrm{~W}$. Electrical efficiencies, however, showed small differences and presented higher values for the unglazed configurations. This result is in concordance with previous studies found on PV/T (Besheer et al. 2016; Daghigh, Ruslan, and Sopian 2015) which underline the improvement on the electrical generation for the coverless panels. Efficiency values ranged 13-15\%, which is in line with the typical efficiency given to the commercial p-Si cells in photovoltaic solar panels (Han et al. 2017; Hermann 1998; Islam et al. 2016). 
Thermal output presented more differences between PV/T cases than the electrical part. As previously indicated, maximum values were found for the glazed configurations, which reached to work with a thermal efficiency much greater than the unglazed cases. This difference of the efficiencies is enlarged for higher working temperatures, where the capacity of the glass cover to reduce thermal losses is highlighted. In all cases, thermal efficiency values were lower than expected for typical PV/T panels (Al-Waeli et al. 2017; Zondag 2008), which suggest some thermal limitations on the test bench. Results are valid for establishing a comparison between models but further experiments are needed to fully characterize the thermal response.
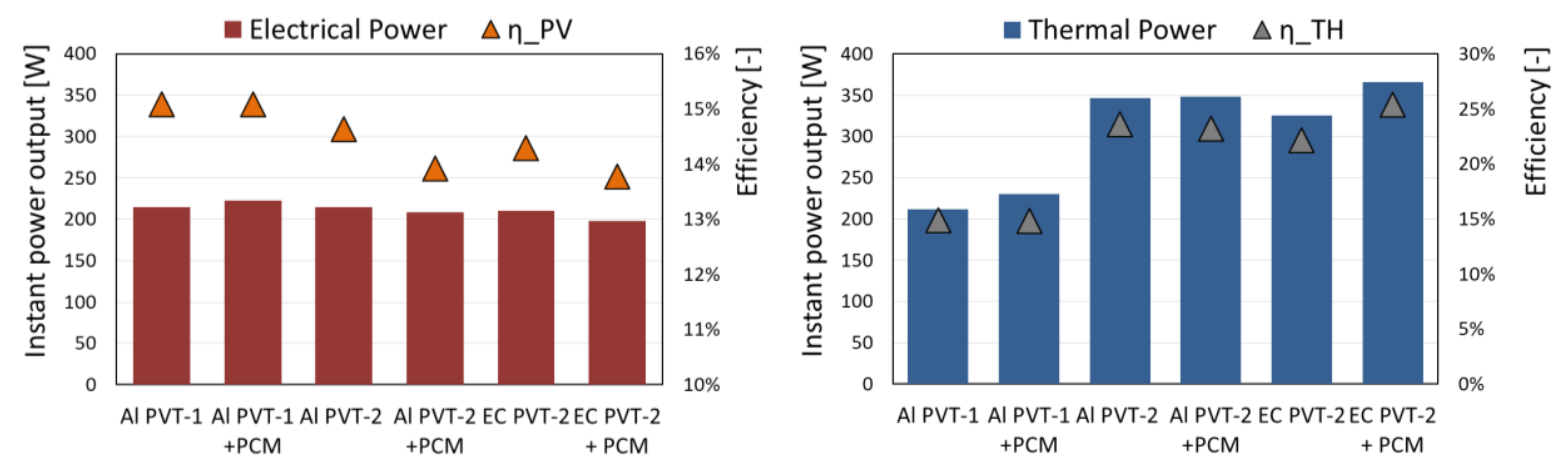

Figure 6: Electrical (left) and thermal (right) power and efficiencies during first stable period.

With the aim to compare the general performance of different PV/T cases, overall efficiency was estimated following the definition exposed in Eq (4). Values are shown in Figure 7. It should be noted that these performance values do not consider the heat generated by the PCM after the sun radiation, but only the efficiency ratios measured during the first stable period.

According to the overall efficiency, glazed configurations presented the best energy performance of the PV/T tested, despite the electrical benefits found in the unglazed aluminum cases. No relevant differences were found between cases with different absorber and the inclusion of the PCM did not seem to provoke changes on the overall efficiency. This assumption is based on the idea that deviations of $2 \%$ in the overall performance are not considered significant to assess differences.

Although the inclusion of the PCM did not directly affect to electrical and thermal efficiencies, it did allowed to redistribute the heat from the sun peak hours to the end of the day. As a result, a significant amount of heat it generated without any income of sun radiation. Moreover, the redistribution of the heat entails some benefits that are not directly reflected on the thermal or electrical performance. First, the PCM works as a storage element that can allow to reduce the thermal storage tank present in all PV/T installation, decreasing the initial investment of the end user. Besides that, it contributed to cushion the maximum working temperatures found in the PVT panel during sun exposure. This effect may be very beneficial in warm locations, since it prevents PV modules from overheating and contributes to extend the lifespan of PV/T panels.

In the authors' view, further studies focussig on the long-term PCM effect are needed to completely assess the benefits of this technique. With this in mind, an PV/T installation with PCM inserted is projected to take place in the south of Spain by next months to analized in depth the effect of this type of material on PV/T solar panels.

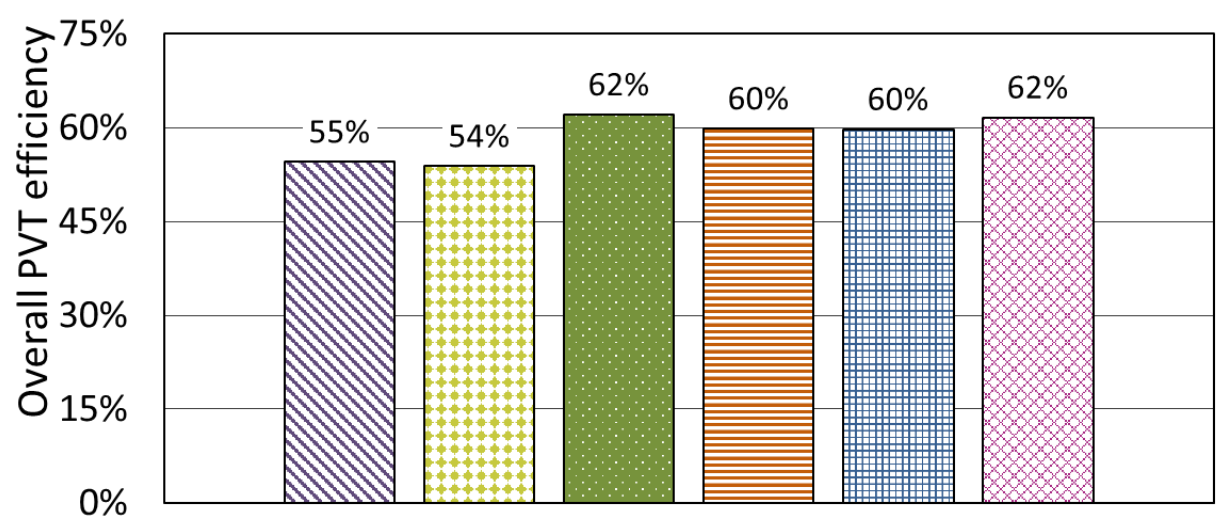

\& Al PVT-1

$\square$ Al PVT-1 +PCM

$\square$ Al PVT-2

$\square$ Al PVT-2 +PCM

䧃 EC PVT-2

圆EC PVT-2 + PCM

Figure 7: Overall performance measured during stable period. 


\section{Conclusions}

In this work we evaluate the experimental performance of six PV/T panels. Two cases were carried out based on traditional sheet-and-tube copper heat absorber, glazed model with and without PCM, and the other four on rollbond aluminum absorbers, glazed and unglazed, with and without PCM.

Result indicated similar energy production for the glazed configurations, independently of the absorber type. Greater differences were found between the glazed and unglazed configurations, where the coverless presented slightly better electrical efficiencies but meaningful lower thermal performance. This differences become greater with the increase on the working temperature, which mostly penalizes the unglazed PV/T models.

The addition of PCM did not lead to a direct improvement on the PV/T efficiency, but provoked a reallocation of the heat generation from the peak sun hours to the end of the day. This characteristic entails other benefits for the $\mathrm{PV} / \mathrm{T}$ installation, such as reduction of the required storage volume or protection of prevention of the PV laminate from overheating. The long term effect of this protection would be the lifespan enlargement of the photovoltaic module and the whole PV/T installation, although further studies are needed to ensure that benefit.

\section{Acknowledgment}

Part of the work here presented takes part of the LowUp project (LOW valued energy sources UPgrading for buildings and industry uses) which has received funding from the European Union's Horizon 2020 Research and Innovation Program under Grant Agreement n²723930.

\section{References}

Aelenei, L., Pereira, R., Gonçalves, H., Athienitis, A. 2014. Thermal Performance of a Hybrid BIPV-PCM: Modeling, Design and Experimental Investigation. Energy Procedia 48: 474-83. doi:10.1016/j.egypro.2014.02.056.

Al-Waeli, A.H.A., Sopian, K., Kazem, H.A., Chaichan, M.T. 2017. Photovoltaic/Thermal (PV/T) Systems: Status and Future Prospects. Renew. Sustain. Energy Rev. 77: 109-30. doi:10.1016/j.rser.2017.03.126.

Beaudin, M., Zareipour, H. 2015. Home Energy Management Systems: A Review of Modelling and Complexity. Renew. Sustain. Energy Rev. doi:10.1016/j.rser.2015.01.046.

Bergene, T., Løvvik, O.M. 1995. Model Calculations on a Flat-Plate Solar Heat Collector with Integrated Solar Cells. Sol. Energy 55: 453-62. doi:10.1016/0038-092X(95)00072-Y.

Besheer, A.H. et al. 2016. Review on Recent Approaches for Hybrid PV/T Solar Technology. Int. J. Energy Res. 40: 2038-53. doi:10.1002/er.3567.

Chow, T.T. 2010. A Review on Photovoltaic/Thermal Hybrid Solar Technology. Appl. Energy 87: $365-79$. doi:10.1016/j.apenergy.2009.06.037.

Colangelo, G., Favale, E., Miglietta, P., De Risi, A. 2016. Innovation in Flat Solar Thermal Collectors: A Review of the Last Ten Years Experimental Results. Renew. Sustain. Energy Rev. 57: 1141-59. doi:10.1016/j.rser.2015.12.142.

Daghigh, R., Ruslan, M.H., Sopian, K. 2015. Parametric Studies of an Active Solar Water Heating System with Various Types of PVT Collectors. Sadhan 40: 2177-96.

Du, D., Darkwa, J., Kokogiannakis, G. 2013. Thermal Management Systems for Photovoltaics (PV) Installations : A Critical Review. Sol. Energy 97: 238-54. doi:10.1016/j.solener.2013.08.018.

Garg, H.P., Adhikari, R.S. 1999. System Performance Studies on a Photovoltaic/Thermal (PV/T) Air Heating Collector. Renew. Energy 16: 725-30. doi:10.1016/S0960-1481(98)00263-8.

Good, C. 2016. Environmental Impact Assessments of Hybrid Photovoltaic-Thermal (PV/T) Systems - A Review. Renew. Sustain. Energy Rev. 55: 234-39. doi:10.1016/j.rser.2015.10.156.

Han, G. et al. 2017. Towards High Efficiency Thin Film Solar Cells. Prog. Mater. Sci. 87: $246-91$. doi:10.1016/j.pmatsci.2017.02.003.

Hasan, A., Mccormack, S.J., Huang, M.J., Norton, B. 2010. Evaluation of Phase Change Materials for Thermal Regulation Enhancement of Building Integrated Photovoltaics. Sol. Energy 84: 1601-12. doi:10.1016/j.solener.2010.06.010. 
Hasan, A., McCormack, S.J., Huang, M.J., Norton, B. 2014. Energy and Cost Saving of a Photovoltaic-Phase Change Materials (PV-PCM) System through Temperature Regulation and Performance Enhancement of Photovoltaics. Energies 7: 1318-31. doi:10.3390/en7031318.

Hendrie, S.D. 1979. Evaluation of Combined Photovoltaic/Thermal Collectors. In Proceedings of the ISES International Congress, Atlanta, USA, 1865-69.

Hermann, A.M. 1998. Polycrystalline Thin-Film Solar Cells - A Review. Sol. Energy Mater. Sol. Cells 55: 7581. doi:10.1016/S0927-0248(98)00048-8.

Hossain, M.S. et al. 2011. Review on Solar Water Heater Collector and Thermal Energy Performance of Circulating Pipe. Renew. Sustain. Energy Rev. 15: 3801-12. doi:10.1016/j.rser.2011.06.008.

Huang, B.J., Lin, T.H., Hung, W.C., Sun, F.S. 2001. Performance Evaluation of Solar Photovoltaic / Thermal Systems. Sol. Energy 70: 443-48. doi:10.1016/S0038-092X(00)00153-5.

Huang, M.J., Eames, P.C., Norton, B. 2006. Phase Change Materials for Limiting Temperature Rise in Building Integrated Photovoltaics. Sol. Energy 80: 1121-30. doi:10.1016/j.solener.2005.10.006.

Huang, M.J., Eames, P.C., Norton, B. 2007. Comparison of Predictions Made Using a New 3D Phase Change Material Thermal Control Model with Experimental Measurements and Predictions Made Using a Validated 2D Model. Heat Transf. Eng. 28: 31-37. doi:10.1080/01457630600985634.

International Energy Agency. 2005. Implementing Agreement on Energy Conservation through Energy Storage Annex 17.

Islam, M.M., Pandey, A.K., Hasanuzzaman, M., Rahim, N.A. 2016. Recent Progresses and Achievements in Photovoltaic-Phase Change Material Technology: A Review with Special Treatment on Photovoltaic ThermalPhase Change Material Systems. Energy Convers. Manag. 126: 177-204. doi:10.1016/j.enconman.2016.07.075.

Ji, J. et al. 2007. A Sensitivity Study of a Hybrid Photovoltaic/Thermal Water-Heating System with Natural Circulation. Appl. Energy 84: 222-37. doi:10.1016/j.apenergy.2006.04.009.

Kamthania, D., Tiwari, G.N. 2014. Energy Metrics Analysis of Semi-Transparent Hybrid PVT Double Pass Facade Considering Various Silicon and Non-Silicon Based PV Module Hyphen Is Accepted. Sol. Energy 100: 124-40. doi:10.1016/j.solener.2013.11.015.

Kern, J., Russell, M. 1978. Combined Photovoltaic and Thermal Hybrid Collector Systems. In 13th IEEE Photovoltaic Specialists., Washington, DC. USA, 1153-57.

Klugmann-radziemska, E., Wcisło-kucharek, P. 2017. Photovoltaic Module Temperature Stabilization with the Use of Phase Change Materials. Sol. Energy 150: 538-45. doi:10.1016/j.solener.2017.05.016.

Lin, W., Ma, Z., Sohel, M.I., Cooper, P. 2014. Development and Evaluation of a Ceiling Ventilation System Enhanced by Solar Photovoltaic Thermal Collectors and Phase Change Materials. Energy Convers. Manag. 88: 218-30. doi:10.1016/j.enconman.2014.08.019.

Mahamudul, H. et al. 2016. Temperature Regulation of Photovoltaic Module Using Phase Change Material : A Numerical Analysis and Experimental Investigation. Int. J. Photoenergy: 1-8.

Malvi, C.S., Dixon-Hardy, D.W., Crook, R. 2011. Energy Balance Model of Combined Photovoltaic SolarThermal System Incorporating Phase Change Material. Sol. Energy 85: 1440-46. doi:10.1016/j.solener.2011.03.027.

Martin Wolf. 1976. Performance Analyses of Combined Heating and Photovoltaic Power Systems for Residences. Energy Convers. 16: 70-90. doi:10.1016/0013-7480(76)90018-8.

Michael, J.J., Iniyan, S., Goic, R. 2015. Flat Plate Solar Photovoltaic-Thermal (PV/T) Systems: A Reference Guide. Renew. Sustain. Energy Rev. 51: 62-88. doi:10.1016/j.rser.2015.06.022.

Palaskar, V.N., Deshmukh, S.P. 2012. Design Configurations of Hybrid Photovoltaic/Thermal Solar System Technology. Proc. Indian Natl. Sci. Acad. 78: 725-34.

Parida, B., Iniyan, S., Goic, R. 2011. A Review of Solar Photovoltaic Technologies. Renew. Sustain. Energy Rev. 15: 1625-36. doi:10.1016/j.rser.2010.11.032.

Radziemska, E. 2003. The Effect of Temperature on the Power Drop in Crystalline Silicon Solar Cells. Renew. Energy 28: 1-12. doi:10.1016/S0960-1481(02)00015-0.

Ren, H., Lin, W., Ma, Z., Fan, W. 2017. Thermal Performance Evaluation of an Integrated Photovoltaic ThermalPhase Change Material System Using Taguchi Method. Energy Procedia 121: 118-25. doi:10.1016/j.egypro.2017.08.008. 
Rommel, M., Hauer, A., Van Helden, W. 2015. 42 IEA Solar Heating and Cooling Programme Task 42 - Compact Thermal Energy Storage.

Sarwar, J. et al. 2011. Experimental Validation of CFD Modelling for Thermal Regulation of Photovoltaic Panels Using Phase Change Material. In International Conference for Sustainable Energy Storage, Belfast, Ireland, 2124.

Stultz, J.W. 1978. Jet Propulsion Laboratory. Thermal and Other Tests of Photovoltaic Modules Performed in Natural Sunlight. Pasadena, California.

Su, D., Jia, Y., Lin, Y., Fang, G. 2017. Maximizing the Energy Output of a Photovoltaic-thermal Solar Collector Incorporating Phase Change Materials. Energy Build. 153: 382-91. doi:10.1016/j.enbuild.2017.08.027.

Tripanagnostopoulos, Y., Souliotis, M., Battisti, R., Corrado, A. 2005. Energy, Cost and LCA Results of PV and Hybrid PV/T Solar Systems. Prog. Photovoltaics Res. Appl. 13: 235-50. doi:10.1002/pip.590.

Yang, X. et al. 2018. Experimental Investigation on Performance Comparison of PV/T-PCM System and PV/T System. Renew. Energy 119: 152-59. doi:10.1016/j.renene.2017.11.094.

Yin, H.M., Yang, D.J., Kelly, G., Garant, J. 2013. Design and Performance of a Novel Building Integrated PV / Thermal System for Energy Efficiency of Buildings. Sol. Energy 87: 184-95. doi:10.1016/j.solener.2012.10.022.

Zondag, H.A. et al. 2002. The Thermal and Electrical Yield of a PV-Thermal Collector. Sol. Energy 72: 113-28. doi:10.1016/S0038-092X(01)00094-9.

Zondag, H.A. 2008. Flat-Plate PV-Thermal Collectors and Systems: A Review. Renew. Sustain. Energy Rev. 12: 891-959. doi:10.1016/j.rser.2005.12.012. 


\title{
A Techno-Economic Comparison between PV and PVT Integrated Ground Source Heat Pumps for Multi-Family Houses
}

\author{
Nelson Sommerfeldt and Hatef Madani \\ KTH Royal Institute of Technology, Stockholm, Sweden
}

\begin{abstract}
As the demand for sustainable energy technologies grows, solar photovoltaics (PV) and heat pumps are increasingly being used in buildings. Hybrid PV-thermal (PVT) collectors have been researched for decades, but have not yet had success in the market. This study combines PVT and ground source heat pumps (GSHP) in a series connection for a multi-family house, and compares the technical and economic performance to GSHP and PV+GSHP systems. A complete systems model in TRNSYS is used for the solar heat pump system, and climate and economic boundary conditions come from the Swedish market. The results show that reducing the borehole length and/or spacing with no or a limited loss of efficiency is the greatest benefit of adding PVT, however a fully sized borehole field with PV is found to be the lowest cost design option. In systems with poor efficiency and high auxiliary boiler use, the addition of PVT can be the lowest cost option but is not preferable to the PV+GSHP when space is not a limitation. The reduction in borehole field area for a given heat pump efficiency is notable since many multi-family homes cannot install GSHP due to a lack of drilling space. PVT+GSHP systems could offer a new, low-carbon heating alternative for buildings previously outside of the heat pump market.
\end{abstract}

Keywords: Solar heat pump, solar hybrid, systems analysis, green buildings, energy efficiency, TRNSYS

\section{Introduction}

Integrating solar collectors into heat pump systems presents an opportunity for increased renewable energy fractions in buildings. There are two main strategies: solar thermal (ST) and photovoltaic (PV). With ST, the collectors are a secondary heat source that can either supply hot water directly, relieving the heat pump, or act as a supplemental heat source. With PV, renewable electricity directly powers the compressor for a portion of its operation. Most research has focused on the many forms of ST based systems however, the popularity of PV in Europe has led to a growth in interest in PV and PV-thermal (PVT) hybrid assisted heat pumps.

In northern Europe, a barrier to high solar fractions is the strong negative correlation between solar supply and space heating demand. Boreholes provide one option for seasonal thermal storage and large buildings with ground source heat pumps (GSHP) often have a borehole field that is more suitable than the single borehole often found in single family houses. The most common borehole storage applications use ST collectors (Rad and Fung, 2016) and can be combined with or without heat pumps depending on the mean store temperature, borehole geometry, and solar collector design (Chapuis and Bernier, 2009).

There are an increasing number of PVT+GSHP systems being constructed with borehole regeneration in Europe, but there are relatively few published simulation studies as compared to solar thermal systems. To help build this knowledge base, a PVT+GSHP system is analyzed in a Swedish climate, where the PVT collectors are connected in series between the boreholes and heat pump. This design has the benefit of keeping average collector temperatures low, simplifies system integration, and gives the collectors a direct connection to the borehole storage (Sommerfeldt and Madani, 2016).

Within emerging technologies, publically published economic results are particularly difficult to find. Series connected systems have been shown to reduce electricity demand, but may not be enough to justify the cost of the PVT array (Haller and Frank, 2011). The PVT can also reduce the necessary borehole length resulting in drilling cost savings (Bertram et al., 2012; Kjellsson et al., 2010; Reda, 2015), but how this compares with the marginal cost of PVT is less understood. This paper presents a techno-economic comparison of a solar GSHP system combined with $\mathrm{PV}$ and series connected PVT with the goal of identifying the net marginal gain of adding a thermal connection between the solar and heat pump systems. 


\section{Methodology}

The focus of this study is a multi-family house located in Stockholm, Sweden with 30 apartments, average energy consumption, and a high potential for solar energy (i.e. south facing roof with no shading). A baseline GSHP system is designed and tested with PV and series connected PVT arrays using TRNSYS17 (Klein et al., 2009). A parametric analysis is made considering reduced borehole field sizes to capture savings in drilling cost, and reduced solar array area to represent buildings with less ideal conditions for solar energy. The key performance indicators (KPI) used for comparison are seasonal performance factor (SPF) and total lifecycle cost (TLCC). Due to a lack of available empirical data of an equivalent system, this study is limited as a theoretical exploration. However, the heat pump system model has been checked against like systems and the PVT model is confirmed in a separate study.

\subsection{System and Model Descriptions}

A conceptual diagram of the series connected PVT+GSHP system is given in Fig. 1, which includes the notation for energy flows that are described in Tab. 1. The PV+GSHP system simply removes the thermal connection between the solar array and borehole circuit. A simplified version of the TRNSYS model is given in Fig. 2 where most of the outputs and controls are removed for clarity. Simulations are run with a three-minute time step for 20 years.

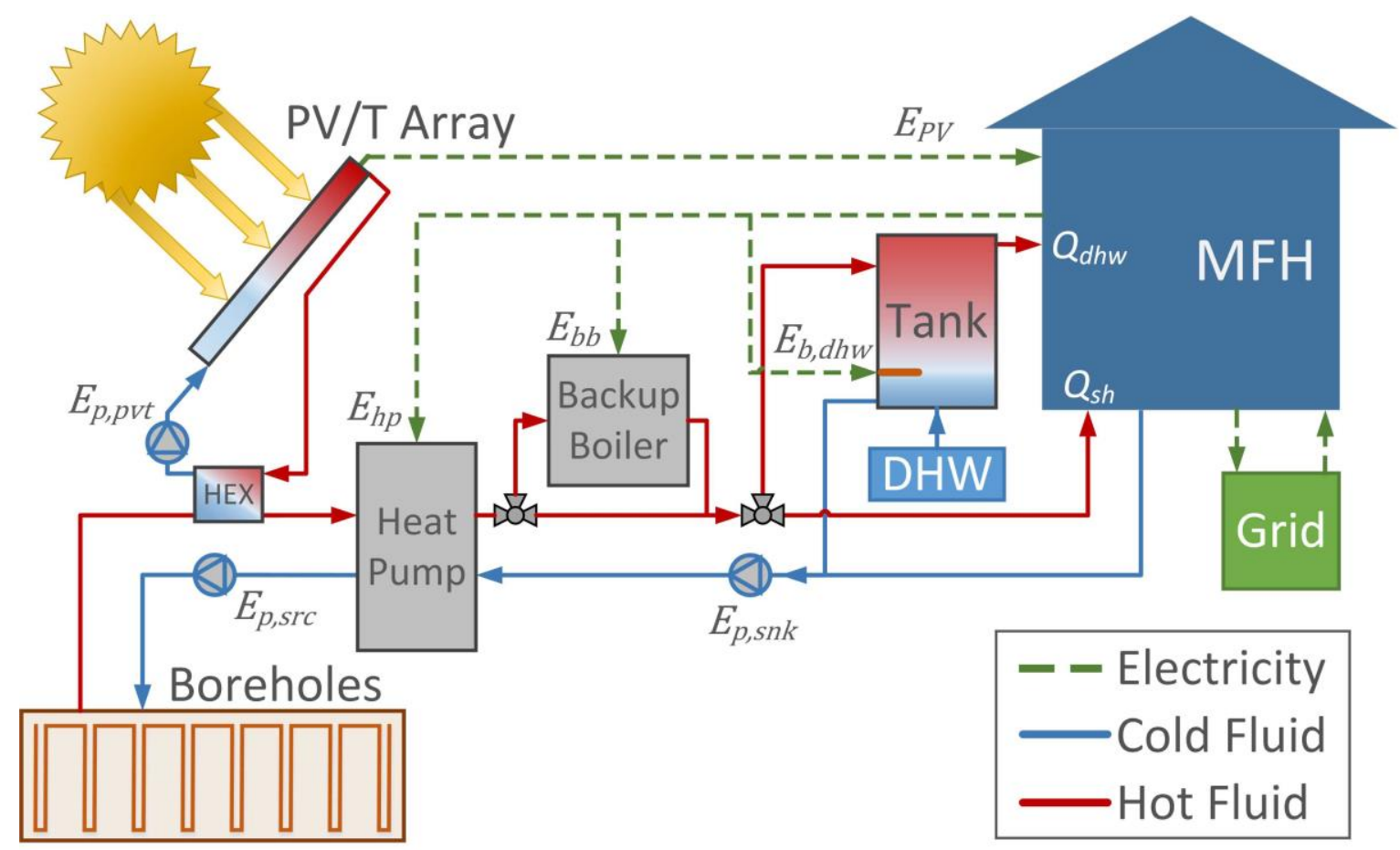

Fig. 1: Conceptual diagram of the PVT+GSHP system

Tab. 1: Technical nomenclature

\begin{tabular}{cc}
\hline Symbol & Quantity \\
\hline$Q_{s h}$ & Delivered thermal energy to space heating \\
$Q_{d h w}$ & Delivered thermal energy to domestic hot water \\
$E_{h p}$ & Electric energy to heat pump compressor \\
$E_{p, s r c}$ & Electric energy to borehole circuit (source) pump \\
$E_{p, s n k}$ & Electric energy to heat delivery (sink) pump \\
$E_{b b}$ & Electric energy to backup boiler \\
$E_{b, d h w}$ & Electric energy to backup elements in DHW tanks \\
$E_{p, p v t}$ & Electric energy to PVT circuit pump \\
$E_{P V}$ & Electric generation from PV array \\
$E_{a p t}$ & Electric plug loads in the apartments \\
$E_{H P}$ & Electric demand for entire HVAC system \\
$E_{p c, s c}$ & PV generation used by the heat pump (self-consumed) \\
$E_{p v, o p}$ & PV generation sold to the grid \\
\hline
\end{tabular}




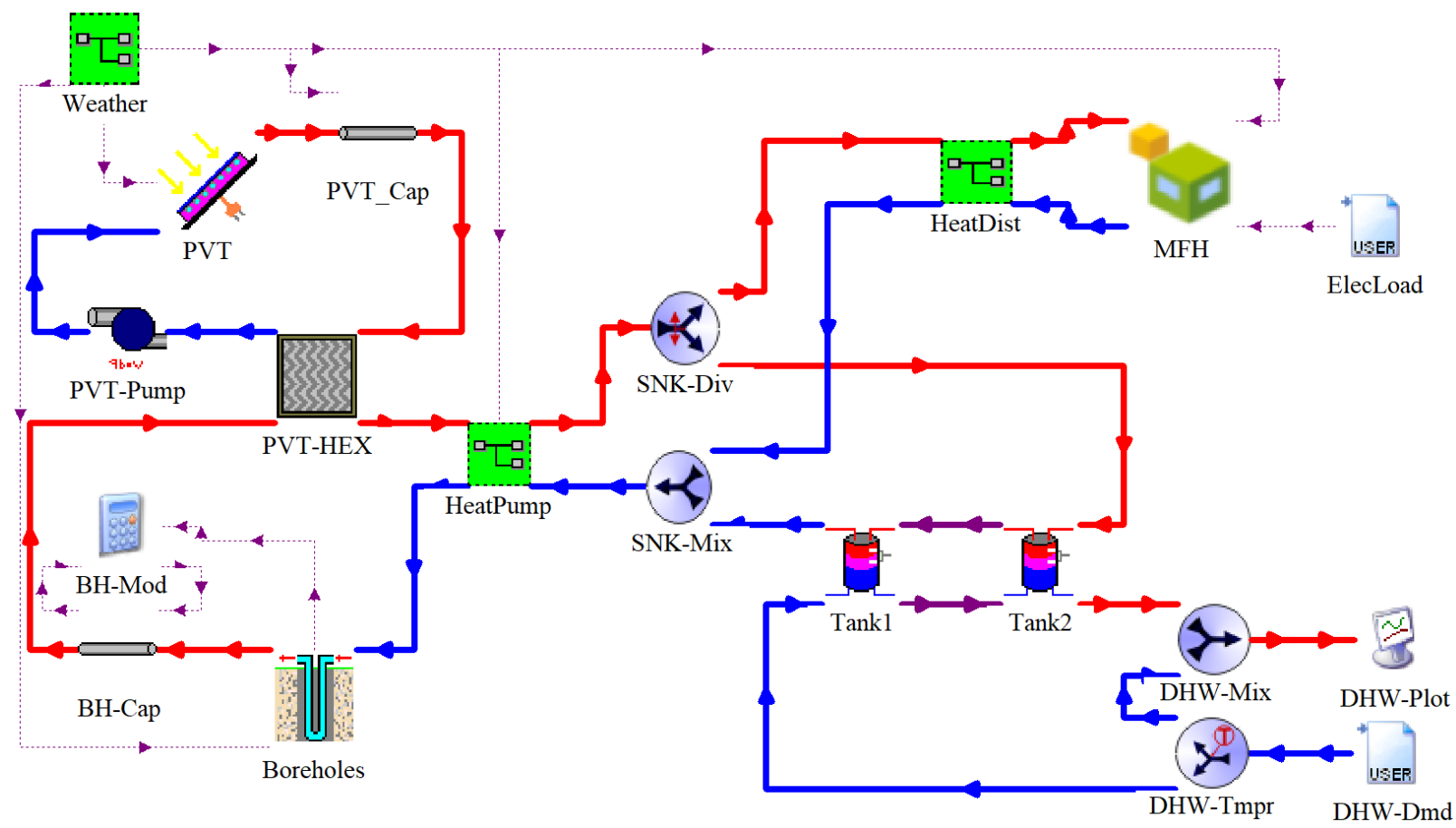

Fig. 2: TRNSYS model representing the PVT+GSHP system

The climate data is based on a typical metrological year for Stockholm and generated using Meteonorm 7.2 (Remund and Kunz, 2018). The solar irradiation is based on the same dataset but has one-minute time steps synthetically generated using the Hofmann model (Hofmann et al., 2014) and averaged across the three-minute time step.

The building characteristics are from a typical Swedish multi-family house constructed between 1985 and 2005 (Spets, 2012), modeled using Type 56. Total conditioned area is $2000 \mathrm{~m}^{2}$ split across four floors and modeled with eight zones, where heating is delivered by wall mounted radiators (Type 1231). Domestic hot water is stored in two 1000 liter fully mixed tanks (Type 60 ) at $55^{\circ} \mathrm{C}$ and delivered at $50^{\circ} \mathrm{C}$. DHW and apartment electricity usage is stochastically generated in one-minute time steps and averaged across the three-minute time step (Widén et al., 2009; Widén and Wäckelgård, 2010). Space heating demand is $125 \mathrm{kWh} / \mathrm{m}^{2}-\mathrm{yr}$, DHW demand is $38 \mathrm{kWh} / \mathrm{m}^{2}$-yr, and each apartment uses $2000 \mathrm{kWh}$ per year of electricity equivalent to $30 \mathrm{kWh} / \mathrm{m}^{2}$-yr. The roof has a gross area of $266 \mathrm{~m}^{2}$, faces directly south with a $20^{\circ}$ tilt, and is absent of shading or objects. Considering setbacks and collector geometry, the maximum array size is 144 collectors totaling $236 \mathrm{~m}^{2}$ and $40.3 \mathrm{~kW}_{\mathrm{p}}$.

The heat pump has a variable speed compressor with a nominal heating capacity of $52 \mathrm{~kW}$ (B0/W35) at $3600 \mathrm{RPM}$ and a power range of 21 to $88 \mathrm{~kW}$ corresponding to $1500-6000 \mathrm{RPM}$. The nominal coefficient of performance is 5.30. Compressor demand $\left(\mathrm{E}_{\mathrm{hp}}\right)$ and thermal output $\left(\mathrm{Q}_{1}\right)$ is modeled with a black box approach based on threedimensional interpolation of the source temperature, supply temperature, and compressor speed from a standard performance map (Madani et al., 2011). Heat extraction at the evaporator $\left(\mathrm{Q}_{2}\right)$ is calculated from $\mathrm{Q}_{1}-\mathrm{E}_{\mathrm{hp}}=\mathrm{Q}_{2}$. Compressor speed is managed with a PID controller (Type 23) based on a heating curve and the supply temperature. There is a $100 \mathrm{~kW}$ direct electric backup boiler for supporting the heat pump during peak loads and replacing it during faults. A fault happens when the inlet temperature from the boreholes falls below $-10{ }^{\circ} \mathrm{C}$. Additionally, each DHW tank has $18 \mathrm{~kW}$ backup heaters.

The baseline borehole field is sized using a modified ASHRAE method (Rolando et al., 2015) and has 12 x $300 \mathrm{~m}$ deep boreholes spaced $20 \mathrm{~m}$ apart with single U-tubes. Type 557a is used to model the field with boundary conditions based on typical Swedish granite absent water flow. The PVT collectors are based on a prototype design using a 280 W Perlight glass-glass PV module with an aluminum and copper heat exchanger fixed to the rear side. Modeling is done using Type 560 with validated boundary conditions (Sommerfeldt and Ollas, 2017). PV-only systems use the same model but without the PVT circulation pump activated. The PVT pump uses a dead-band controller between the outlet temperatures of the PVT collector and the boreholes (i.e. temperature difference at the heat exchanger). 


\section{$2.2 \mathrm{KPls}$ and System Boundaries}

The numerous components and approaches to solar heat pump system design makes uniform definitions for system performance difficult (Hadorn, 2015; Poppi et al., 2018). The primary perspective of this study is from the building owner, meaning the focus is on total heating system or building performance. SPF is defined using $\mathrm{SPF}_{4} \mathrm{from}$ Nordman et al. (2012) and modified to include the circulation pump for PVT, referred to here as SPF $4+$ and given in eq. 1 . In systems without PVT, the term $E_{p, p v t}$ is simply zero. No consideration for PV electricity supplying the heat pump is considered in the SPF definition. TLCC is described by eq. 2 and includes three major components: initial investment $(I)$, operations and maintenance $(O M)$, and residual value $(R V)$.

$$
\begin{aligned}
& S P F_{4+}=\frac{Q_{s h}+Q_{d h w}}{E_{h p}+E_{p, s r c}+E_{p, s n k}+E_{b b}+E_{b, d h w}+E_{p, p v t}} \\
& T L C C=I_{H P}+I_{B H}+I_{P V(T)}+O M_{S Y S}-R V_{P V(T)}-R V_{B H}
\end{aligned}
$$

The economic lifetime of the system is assumed 20 years to correspond with typical heat pump expectations. The OM costs are represented by eq. 3, which includes the purchase of electricity and maintenance of the solar and heat pump systems. A negative cost (i.e. revenue) is earned from the sale of PV overproduction to the grid. The PV and PVT systems are assumed to last 30 years and the boreholes 60 years, and therefore have a residual value that reduces the TLCC. The solar is represented by equation eq. 4 and is equivalent to the value of PV generation between years 21 to 30, and the residual borehole value uses the equivalent annual cost method shown in eq. 5 .

$$
\begin{aligned}
& O M_{S Y S}=\sum_{y=1}^{20} \frac{\left(E_{H P} \cdot\left[P_{e l, r} \cdot\left(1+r_{e l, r}\right)^{y}\right]\right)-\left(E_{p v, o p}+P_{e l, s}\right)+M_{H P}+M_{P V(T)}}{(1+d)^{y}} \\
& R V_{P V(T)}=\sum_{y=21}^{30} \frac{\left(E_{p v, s c}+\left[P_{e l, r} \cdot\left(1+r_{e l, r}\right)^{y}\right]\right)+\left(E_{p v, o p}+P_{e l, s}\right)-M_{P V(T)}}{(1+d)^{y}} \\
& R V_{B H}=\sum_{y=21}^{60} \frac{I_{B H}}{1-(1+d)^{60} / d} * \frac{1}{(1+d)^{y}}
\end{aligned}
$$

A table of critical economic values are given in Tab. 2. All prices are shown without VAT, however a $25 \%$ VAT is included in the results as it is an expected cost to the target building owner group. A government supplied $30 \%$ investment rebate is also applied to the PV and PVT systems. Costs and prices are originally in Swedish Kronor and converted to Euros using a 10:1 exchange rate. Retail electricity prices $\left(P_{e l, r}\right)$ are assumed to grow at $1 \%$ over the lifetime while wholesale $\left(P_{e l, s}\right)$ remains fixed, and all prices and discounting are in real terms.

Tab. 2: Economic boundary conditions and assumptions

\begin{tabular}{cccc}
\hline Symbol & Quantity & Value & Units \\
\hline$I_{H P}$ & Heat pump investment cost & 30,000 & $€$ \\
$I_{B H}$ & Borehole investment cost (Fixed) & 10,000 & $€$ \\
$I_{B H}$ & Borehole investment cost (Variable) & 29 & $€ / \mathrm{m}$ \\
$I_{P V}$ & PV investment cost & 1.2 & $€ / \mathrm{W}_{\mathrm{p}}$ \\
$I_{P V T}$ & PVT investment cost (Fixed) & 13,000 & $€$ \\
$I_{P V T}$ & PVT investment cost (Variable) & 800 & $€ /$ coll. \\
$P_{e l, r}$ & Retail electricity price & 0.12 & $€ / \mathrm{kWh}$ \\
$r_{e l, r}$ & Retail electricity price growth rate & 1 & $\% / \mathrm{year}$ \\
$P_{e l, s}$ & Wholesale (selling) electricity price & 0.03 & $€ / \mathrm{kWh}$ \\
$M_{H P}$ & Annual maintenance cost for HP & 600 & $€$ \\
$M_{P V}$ & Annual maintenance cost for PV & $1 \% \times I_{P V}$ & $€$ \\
$M_{P V T}$ & Annual maintenance cost for PVT & $2 \% \times I_{P V T}$ & $€$ \\
$d$ & Real discount rate & 3 & $\%$
\end{tabular}




\section{Results}

Results are presented in several stages that build on each other: first, there is a parametric analysis of the boreholes considering total length, spacing, and a combination of the two. Next, the minimum temperature in the borehole circuit is increased and one set of borehole patterns are rerun. Finally, one set of boreholes with the increased temperature limit are presented with reduced solar array sizes.

\subsection{Parametric Analysis for Boreholes}

The baseline borehole field has 12 holes at $300 \mathrm{~m}$ deep and $20 \mathrm{~m}$ apart. The length is reduced by removing two holes at each step and leaving the depth at $300 \mathrm{~m}$. Fig. 3 shows boreholes with as much as a $50 \%$ total length reduction with and without PVT over 20 years (note the y-axis starts at 2.4). In the baseline $3600 \mathrm{~m}$ case, the PVT has a negligible effect, lifting $\mathrm{SPF}_{4+}$ from 3.22 to 3.34 in year 20, a 3.7\% improvement. With a 50\% reduced length (1800 $\mathrm{m})$, the PVT improved $\mathrm{SPF}_{4+}$ from 2.79 to 3.00 in year 20 , a $7.5 \%$ improvement.

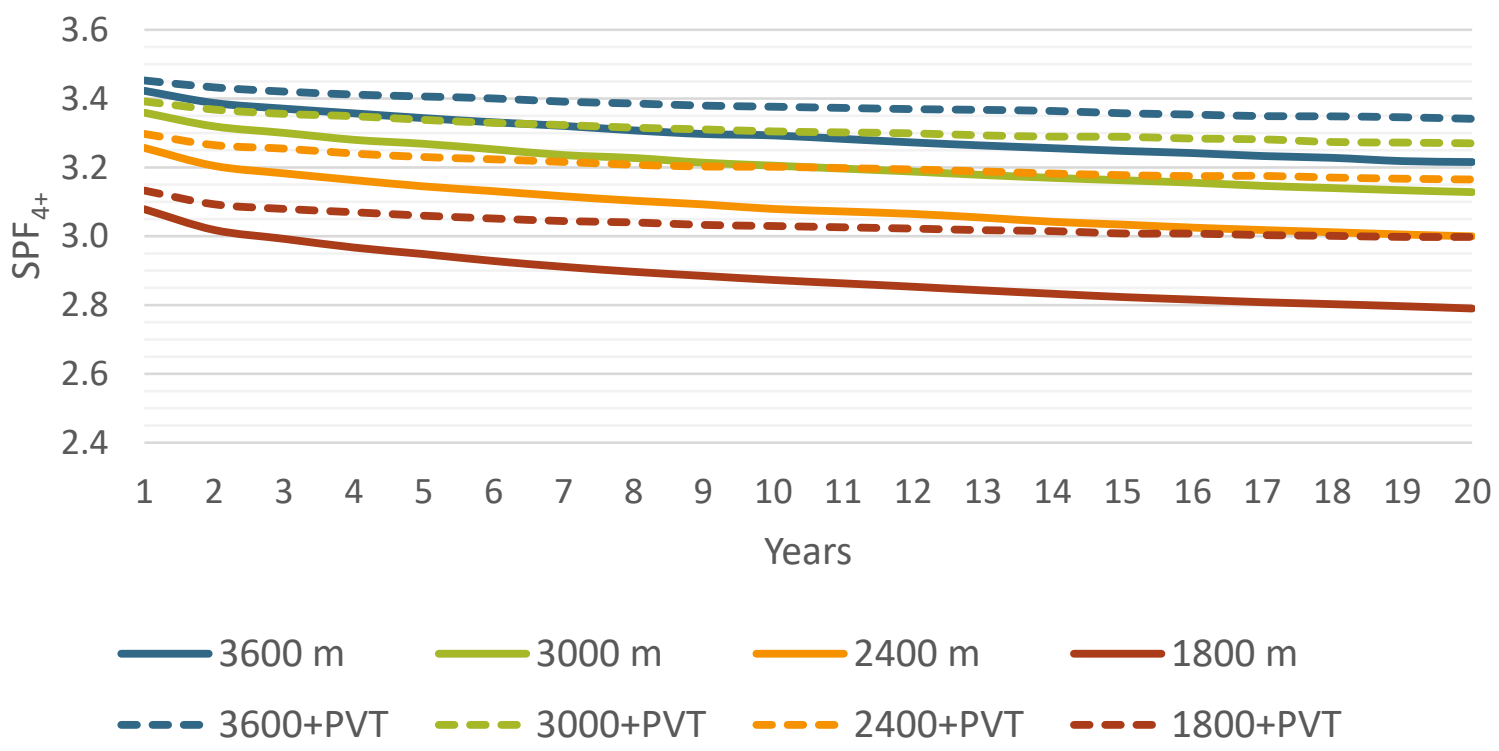

Fig. 3: $\mathrm{SPF}_{4+}$ over 20 years considering a reduced borehole length

When the borehole spacing is reduced, Fig. 4 shows that the impact of the PVT array is more pronounced. In the extreme $5 \mathrm{~m}$ case, PVT improves $\mathrm{SPF}_{4+}$ from 2.85 to 3.21 in year 20, which is a $13 \%$ improvement and the same performance as the $20 \mathrm{~m}$ baseline case. While the drilling costs would be similar due to the consistent length, the addition of PVT could significantly reduce the land area needed for a large GSHP system.

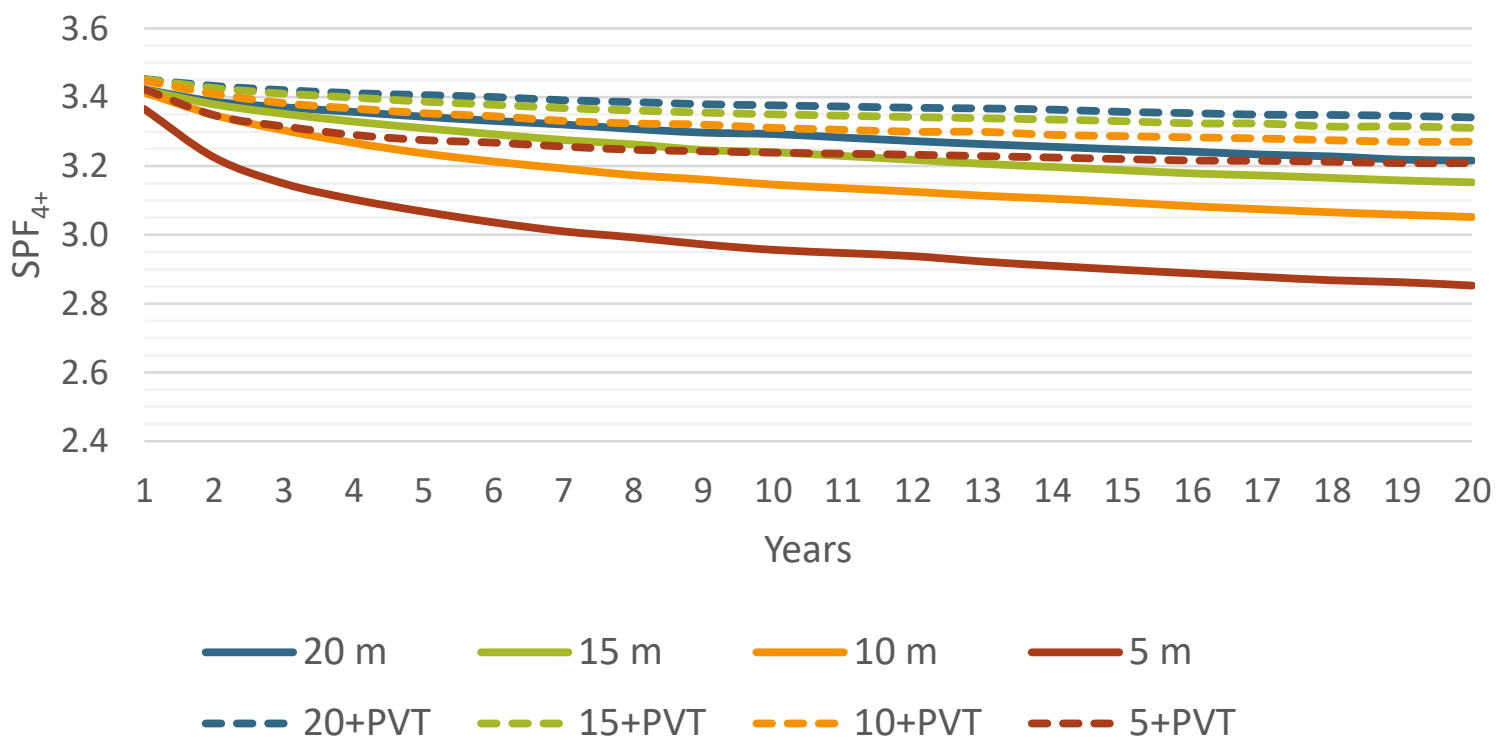

Fig. 4: $\mathrm{SPF}_{4+}$ over 20 years considering reduced borehole spacing 
To find a more extreme case, the borehole count and spacing are reduced together in combination cases. The legend in Fig. 5 shows the combinations without PVT in the top row, with total length as the first number and spacing as the second. The results with PVT are marked with code names for brevity. In comparison with the previous parametric results, $\mathrm{SPF}_{4+}$ is reduced by about $10-15 \%$. In the $1800 \times 5$ case, in year $20 \mathrm{SPF} 4+$ is 2.50 and becomes 2.91 when PVT is added, a $16 \%$ improvement.

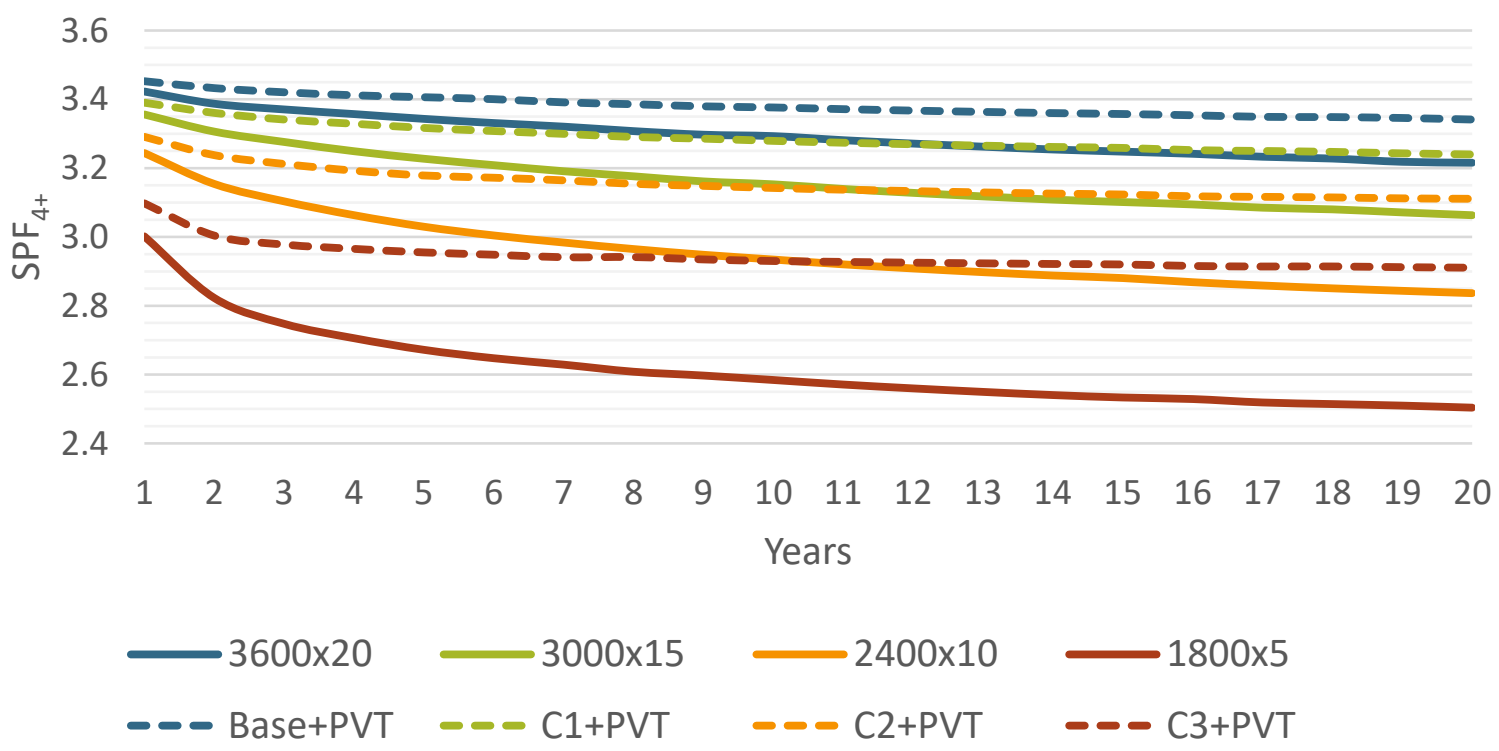

Fig. 5: $\mathrm{SPF}_{4+}$ over 20 years considering reduced borehole length and spacing

The performance of the undersized and compacted borehole fields, while low for a modern GSHP, are still surprisingly high. This is reflected in the TLCC, given in Fig. 6, where the lifecycle cost of GSHP are shown to be similar in all cases. The $1800 \times 5$ case is the highest due to the higher electricity consumption, but the cost savings of the boreholes makes up for most of it. In all cases, the PV array reduces energy costs, which is expected given the profitability of PV in Sweden (Sommerfeldt and Madani, 2017). However, PVT systems are 10-20\% more expensive than both PV and GSHP only systems, demonstrating that the electricity savings are not enough to justify a PVT investment.

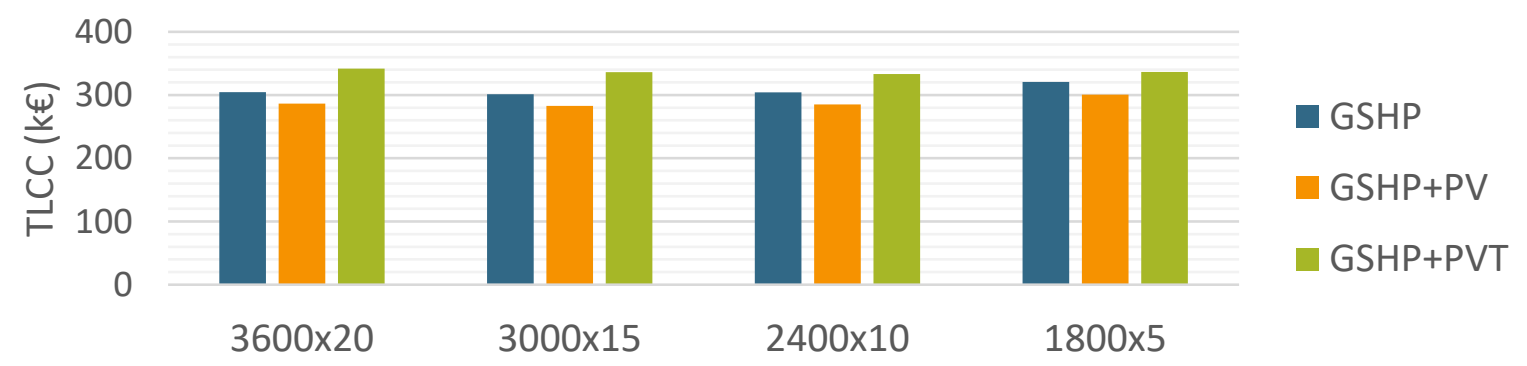

Fig. 6: TLCC for the combination borehole reduction cases

The results suggest an undersized borehole field and PV is the least cost option, however this is largely due to the operating range of the heat pump. Fig. 7 shows the monthly outlet fluid temperature from ground in the extreme 1800x $5 \mathrm{~m}$ case in Fig. 5. The solid lines represent the maximum and minimum while the dashed line is the average. Even without PVT, the minimum inlet temperature to the evaporator, $-10^{\circ} \mathrm{C}$, is never reached and thus the backup boiler is rarely used. However, the borehole temperature remains below freezing for the entire year, which could potentially damage the polyethylene pipes if liquid water inside the borehole froze and expanded. 


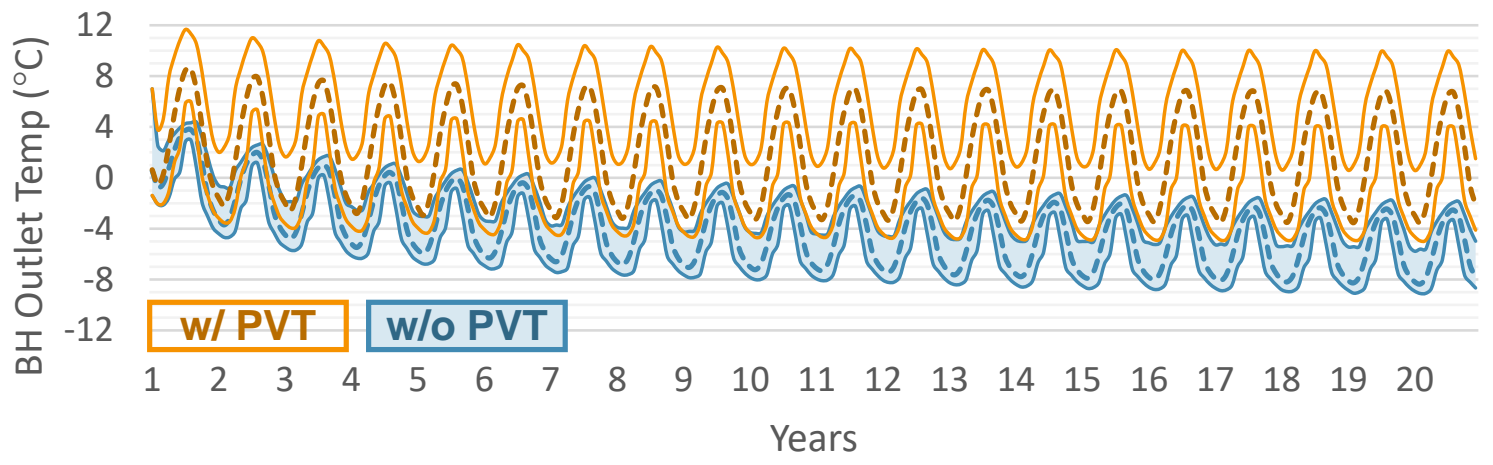

Fig. 7: Monthly minimum, maximum, and average borehole fluid outlet temperatures in the 1800x5 case with and without PVT

\subsection{Increased Minimum Borehole Temperature}

To test the impact borehole temperature limits have on performance, the combination borehole patterns in Fig. 5 are simulated with a $-4{ }^{\circ} \mathrm{C}$ minimum inlet temperature to the evaporator, which are given in Fig. 8 (note the change in scale on the y-axis). The results show a reduction in $\mathrm{SPF}_{4+}$ in the $2400 \times 10$ and $1800 \times 5$ cases, 1.70 and 2.53 in year 20 , respectively, due to frequent faults in the winter and increased direct electric boiler use. In the 1800x5 case, the backup boiler is still needed even with the PVT array, but its electricity use is reduced by $80 \%$. The $\mathrm{SPF}_{4+}$ values for the $1800 \times 5$ case in year 20 with and without PVT are 1.70 and 2.70 , respectively, a $60 \%$ improvement.

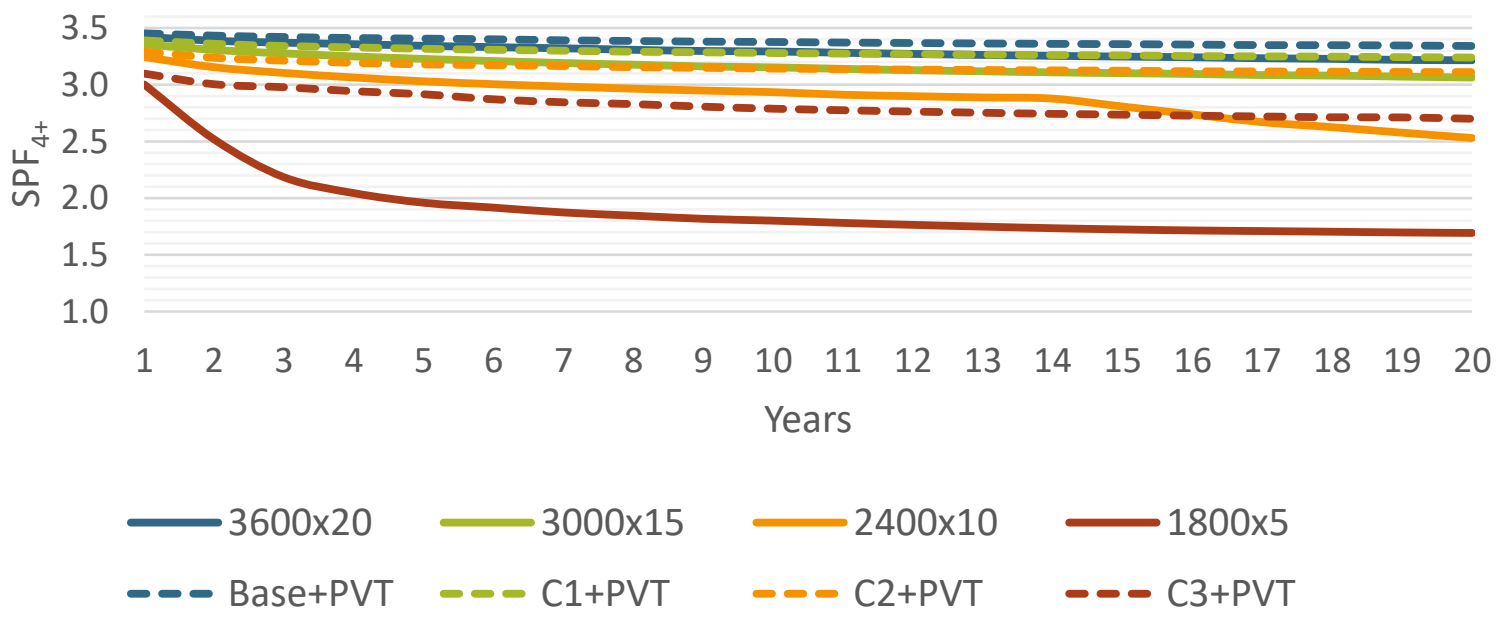

Fig. 8: $\mathrm{SPF}_{4+}$ of the combined borehole reductions with a $-4{ }^{\circ} \mathrm{C}$ minimum evaporator inlet temperature

A review of the borehole outlet temperatures with the $-4{ }^{\circ} \mathrm{C}$ limit, given in Fig. 9, shows how shutting down the heat pump keeps the borehole temperature higher. However even with this limit, without PVT the fluid temperature is below freezing most of the year, meaning the risk for damage is not entirely removed. With PVT, the fluid temperatures remain within an acceptable operating range, even in year 20 when they are showing signs of reaching steady state.

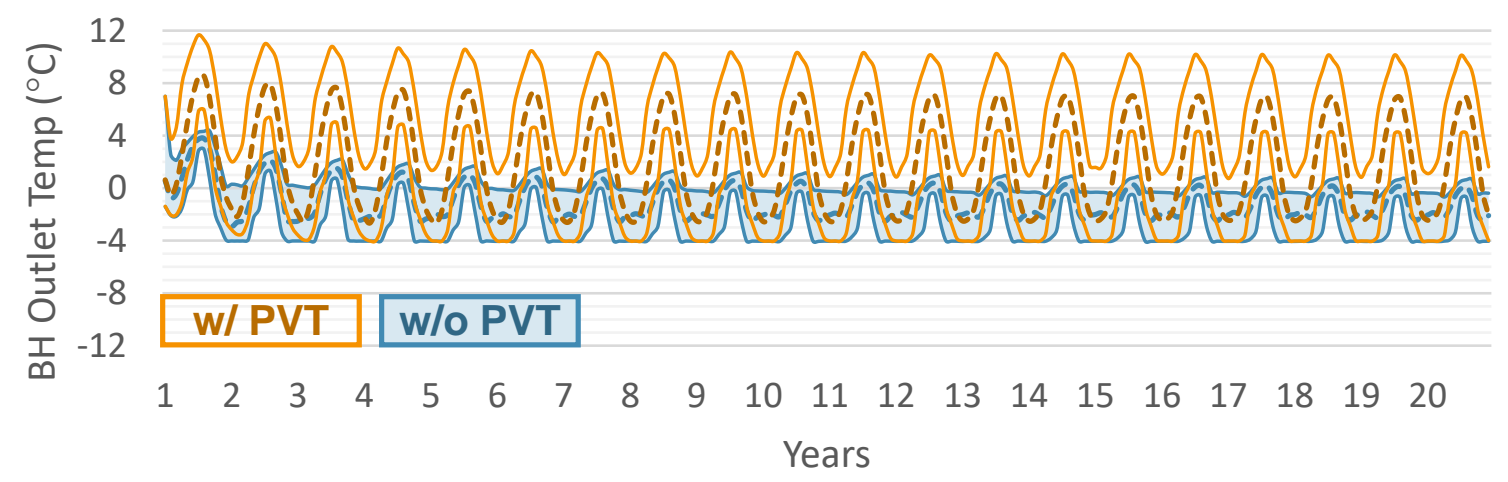

Fig. 9: Borehole fluid outlet temperatures of the $1800 \times 5$ case with a $-4{ }^{\circ} \mathrm{C}$ minimum evaporator inlet temperature 
The increased use of the backup boiler has a notable impact on $\mathrm{SPF}_{4+}$, which translates into a change in the economics. Fig. 10 shows the TLCC with the revised temperature limit, where it can be seen that there is now a case where PVT becomes the most economical option. In the 1800x5 case, PVT results in a savings of $70 \mathrm{k} €$, or $17 \%$. This is still a higher cost than any other borehole option in the study, suggesting that PVT is economically advantageous only in cases with high direct electric boiler usage with poor efficiency and a risk for borehole damage.

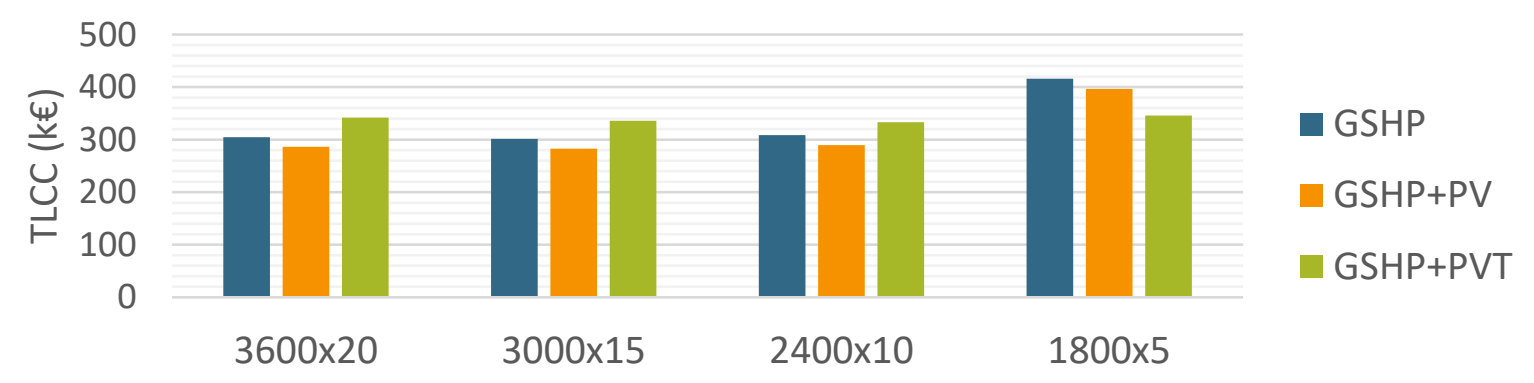

Fig. 10: TLCC for the combined borehole cases with a $-4^{\circ} \mathrm{C}$ minimum evaporator inlet temperature

\subsection{Parametric Analysis for Solar Arrays}

The building geometry and open roof space assumed in this study is atypical of many multi-family houses. Therefore, a reduction in solar collector area will indicate the potential for PVT+GSHP in a larger range of building types. The results shown in Fig. 11 are generated with the 1800x 5 borehole pattern and $-4{ }^{\circ} \mathrm{C}$ evaporator limit with PVT arrays from 144 down to 48 collectors $\left(79 \mathrm{~m}^{2}\right.$ and $13.4 \mathrm{~kW}_{\mathrm{p}}$ ). The addition of 48 collectors results in an $\mathrm{SPF}_{4+}$ improvement in year 20 from 1.70 to 2.09 , or $23 \%$. The improvement from additional collectors has diminishing returns but are can still be significant savings due to the low SPF values in consideration.

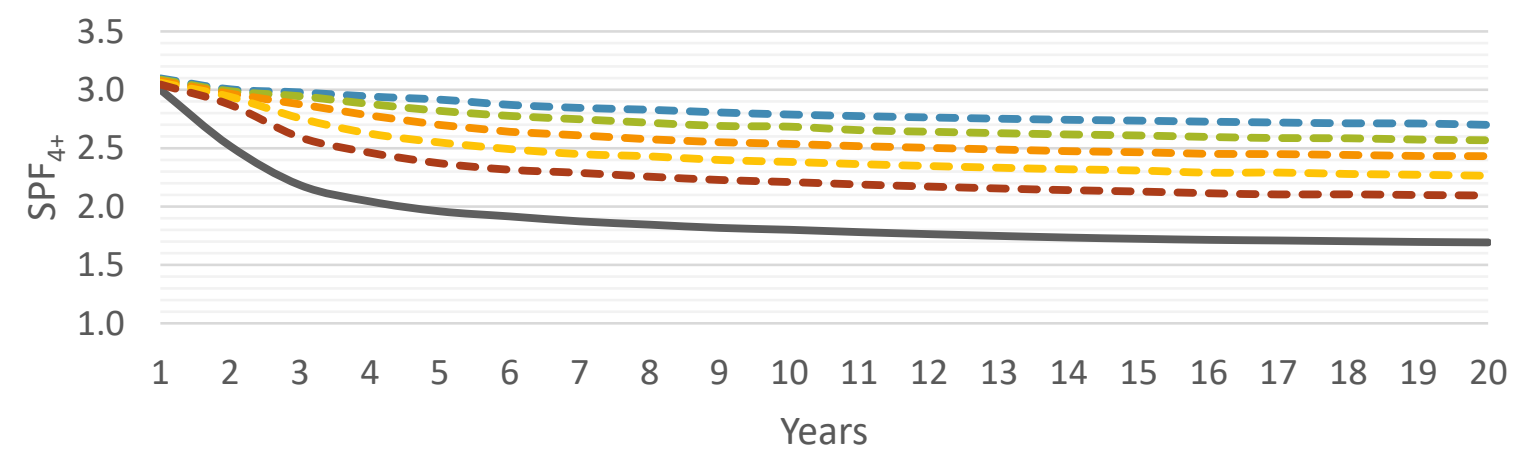

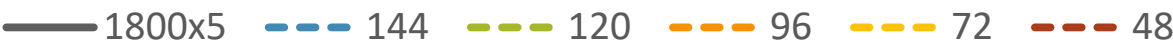

Fig. 11: $\mathrm{SPF}_{4+}$ for the $1800 \times 5$ / $-4^{\circ} \mathrm{C}$ case without and with PVT in several array sizes

In Fig. 12, the economic results show a similar pattern, where the addition of collectors has diminishing returns, however the full roof of 144 collectors has the lowest TLCC. This is due to the continued need for the auxiliary boiler even with the 144 collectors. In cases where the PVT can eliminate faults due to low-temperatures, the marginal costsavings will rapidly reduce and an optimal sizing point is likely to be found. This explanation comes by combining the results Fig. 12 and Fig. 6, and future study cases will be sought that can demonstrate this optimum directly.

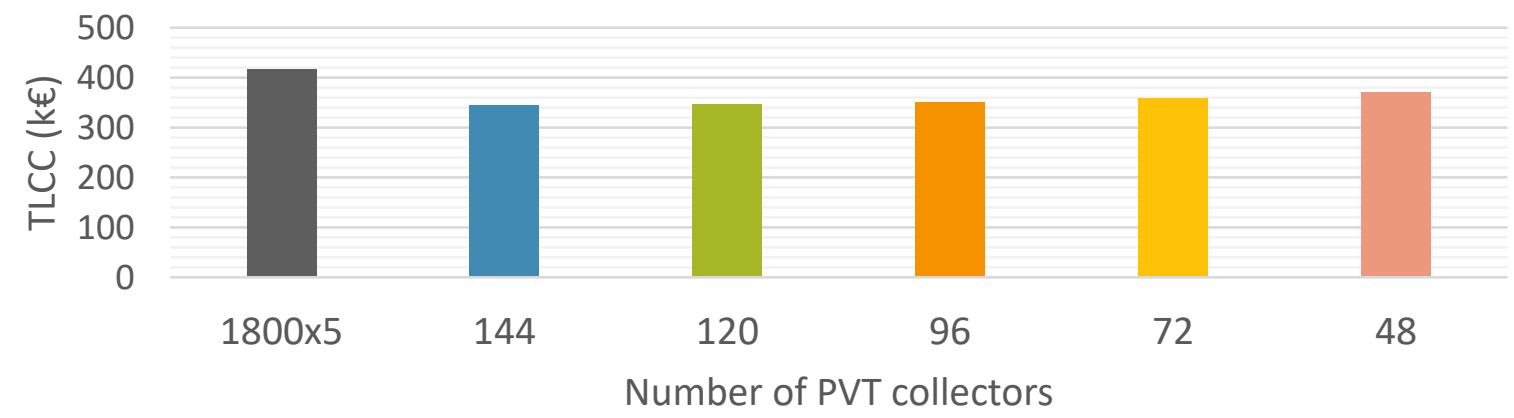

Fig. 12: TLCC of the reduced solar array cases using the $1800 \times 5$ boreholes and $-4{ }^{\circ} \mathrm{C}$ evaporator limit 


\section{Discussion and Conclusions}

The cost reductions in PV has led to an increased interest in PVT technologies, particularly in combination with heat pumps. This study provides new information regarding the cost-effectiveness of a series connected PVT heat pump in multi-family buildings. The results show that the least cost and highest efficiency option is to install a full-sized borehole field with PV. PVT does enable a notable reduction in the land area required for a borehole field, which is often a challenge for multi-family houses in densely populated areas. For example, the area required in this study was reduced from $2400 \mathrm{~m}^{2}$ (3x4 pattern with $20 \mathrm{~m}$ spacing) to just $50 \mathrm{~m}^{2}$ ( $2 \times 3$ pattern with $5 \mathrm{~m}$ spacing) with a $13 \%$ increase in TLCC (ignoring the cost savings of land). In these cases, where the borehole length and/or spacing is restricted, PVT can be a cost-effective method to reduce auxiliary boiler usage and maintain higher ground temperatures, potentially opening new markets to GSHP.

Undersized boreholes can also occur in retrofit cases where a new, more efficient heat pump is installed to borehole(s) that have been cooled for two decades and are now expected to supply more heat. This is a growing problem in more mature heat pump markets, such as Sweden, where heat pumps have been used for many years. In cases with a potential for high boiler use, PVT could be a successful secondary heat source and will be explored in future work.

There are a considerable number of design options and variables in solar heat pump systems, both in configuration and control. This study presented a limited range of design choices that may be difficult to extend to other cases. A continuation of this work will include a broader parametric analysis with the goal of providing normalized results that are more widely applicable. Likewise, the economic results are limited to the Swedish market, where electricity and drilling prices are relatively low as compared to Europe. In markets with higher costs for drilling and/or electricity, then PVT+GSHP systems could become favorable. A decrease in PV and/or PVT costs could also change the results. A sensitivity analysis on these factors will also be included in future work.

The primary insight from this study is that series connect PVT+GSHP systems offer the most benefit to cases with undersized or constrained borehole fields. In markets where fossil fuels and/or district heating are the only options, PVT+GSHP offers a potential solution for reducing carbon emissions in large residential buildings in cold climates. It also has potential in retrofit markets for small or large applications and should be studied further to better describe the system behavior and benefits of the concept. Test site data is also needed for confirmation of the model results, and should be prioritized in future work.

\section{Acknowledgements}

This work is funded by the Swedish Energy Agency's Effsys Expand program (project number 40936-1) for which the authors are grateful.

\section{References}

Bertram, E., Glembin, J., Rockendorf, G., 2012. Unglazed PVT collectors as additional heat source in heat pump systems with borehole heat exchanger. Energy Procedia 30, 414-423. doi:10.1016/j.egypro.2012.11.049

Chapuis, S., Bernier, M., 2009. Seasonal storage of solar energy in borehole heat exchangers, in: Eleventh International IBPSA Conference. Glasgow, pp. 599-606.

Hadorn, J.-C. (Editor), 2015. Solar and Heat Pump Systems for Residential Buildings, First. ed. Ernst \& Sohn GmbH \& Co., Berlin.

Haller, M.Y., Frank, E., 2011. On the potential of using heat from solar thermal collectors for heat pump evaporators, in: ISES Solar World Congress. Kassel, Germany, pp. 1-10.

Hofmann, M., Riechelmann, S., Crisosto, C., Mubarak, R., Seckmeyer, G., 2014. Improved synthesis of global irradiance with one-minute resolution for PV system simulations. Int. J. Photoenergy 2014. doi:10.1155/2014/808509

Kjellsson, E., Hellström, G., Perers, B., 2010. Optimization of systems with the combination of ground-source heat pump and solar collectors in dwellings. Energy 35, 2667-2673. doi:10.1016/j.energy.2009.04.011

Klein, S., Beckman, W.A., Mitchell, J., Duffie, J.A., Freeman, T., 2009. TRNSYS 17, A Transient System Simulation Program.

Madani, H., Claesson, J., Lundqvist, P., 2011. Capacity control in ground source heat pump systems: Part I: Modeling and simulation. Int. J. Refrig. 34, 1338-1347. doi:10.1016/j.ijrefrig.2011.05.007

Nordman, R., Kleefkens, O., Riviere, P., Nowak, T., Zottl, A., Arzano-Daurelle, C., Lehmann, A., Polyzou, O., 
Karytsas, K., Riederer, P., Miara, M., Lindahl, M., Andersson, K., Olsson, M., 2012. SEasonal PErformance factor and MOnitoring for heat pump systems in the building sector SEPEMO-Build: FINAL REPORT.

Poppi, S., Sommerfeldt, N., Bales, C., Madani, H., Lundqvist, P., 2018. Techno-economic review of solar heat pump systems for residential heating applications. Renew. Sustain. Energy Rev. 81. doi:10.1016/j.rser.2017.07.041

Rad, F.M., Fung, A.S., 2016. Solar community heating and cooling system with borehole thermal energy storage Review of systems. Renew. Sustain. Energy Rev. 60, 1550-1561. doi:10.1016/j.rser.2016.03.025

Reda, F., 2015. Long term performance of different SAGSHP solutions for residential energy supply in Finland. Appl. Energy 144, 31-50. doi:10.1016/j.apenergy.2015.01.059

Remund, J., Kunz, S., 2018. Meteonorm 7.2.

Rolando, D., Acuna, J., Fossa, M., 2015. A Web Application for Geothermal Borefield Design. World Geotherm. Congr. 2015 19-25.

Sommerfeldt, N., Madani, H., 2017. Revisiting the techno-economic analysis process for building-mounted, gridconnected solar photovoltaic systems: Part two - Application. Renew. Sustain. Energy Rev. 74, 1394-1404. doi:10.1016/j.rser.2017.03.010

Sommerfeldt, N., Madani, H., 2016. Review of Solar PV/Thermal Plus Ground Source Heat Pump Systems for European Multi-Family Houses, in: 11th ISES Eurosun Conference. Palma de Mallorca, Spain.

Sommerfeldt, N., Ollas, P., 2017. Reverse Engineering Prototype Solar PV / Thermal Collector Properties from Empirical Data for Use in TRNSYS Type 560, in: Proc. of the ISES Solar World Congress 2017. ISES, Abu Dahbi.

Spets, K., 2012. TABULA Webtool [WWW Document]. URL http://webtool.building-typology.eu (accessed 5.31.15).

Widén, J., Lundh, M., Vassileva, I., Dahlquist, E., Ellegård, K., Wäckelgård, E., 2009. Constructing load profiles for household electricity and hot water from time-use data-Modelling approach and validation. Energy Build. 41, 753-768. doi:10.1016/j.enbuild.2009.02.013

Widén, J., Wäckelgård, E., 2010. A high-resolution stochastic model of domestic activity patterns and electricity demand. Appl. Energy 87, 1880-1892. doi:10.1016/j.apenergy.2009.11.006 


\title{
MULTI-OBJECTIVE OPTIMIZATION OF A SOLAR HEAT PUMP SYSTEM USING PVT AND ICE-BASED LATENT STORAGE
}

\author{
Justin Tamasauskas ${ }^{1}$, Michel Poirier ${ }^{1}$ and Radu Zmeureanu ${ }^{2}$ \\ ${ }^{1}$ CanmetENERGY/Natural Resources Canada, Varennes, Canada \\ 2 Dept. of Building, Civil, and Environmental Engineering, Concordia University, Montreal, Canada
}

\begin{abstract}
This paper examines the optimization of a novel solar heat pump concept according to the competing objective functions of lifecycle energy and cost. First, the system concept is presented, combining photovoltaic/thermal collectors with ice storage and a heat pump to provide space and hot water heating. Next, the optimization methodology is discussed, including selected decision variables and optimization algorithm. Results for a high performance home in Montreal, QC, Canada, show a clear tradeoff between reduced lifecycle energy and increased costs, with the addition of PVT panels shown to be the main driver between solutions in the Pareto set. An additional case study explores the optimal balance between photovoltaic and photovoltaic/thermal collectors, and demonstrates the advantages of a properly sized system in comparison to a conventional heat pump using only photovoltaics.
\end{abstract}

Keywords: Heat Pump, PVT, Thermal Storage, Multi-Objective Optimization

\section{Introduction}

Heat pumps are widely recognized as key components of high performance buildings (IEA HPC, 2012), efficiently addressing thermal loads while facilitating the integration of renewable energy into the building. However, conventional air-source heat pumps experience a significant degradation of performance at colder ambient temperatures, presenting a major challenge in cold climates such as Canada. As such, alternative thermal sources must be considered in order to maximize heat pump performance during the coldest winter months.

Combining solar thermal and heat pump technologies has demonstrated strong potential to reduce building energy use and improve renewable energy fractions. However, a major challenge associated with these types of systems is the strong temporal discrepancy between solar availability and thermal demands. Several authors have proposed the use of ice-based thermal storage to address this issue (Trinkl et al., 2009; Tamasauskas et al., 2012; Dott \& Afjei, 2014; Carbonell et al., 2016), with potential benefits including smaller storage volumes and improved solar collector efficiencies. These advantages are especially interesting when coupled with photovoltaic/thermal panels (PVT), where low temperature fluid from the ice tank can simultaneously cool photovoltaic modules to improve electrical efficiencies while also recovering low-grade thermal energy for use by the heat pump. In order for these types of systems to achieve a significant market share, it is vital that designers carefully balance energy and economic performance throughout the planned lifecycle.

Multi-objective optimization techniques are an important tool for exploring the design space and identifying tradeoffs in competing objectives. More commonly applied to building form and envelope selection, the use of these techniques for sizing solar thermal and PVT systems is still relatively limited in the literature. For solar combisystems, Bornatico et al. (2012) used a weighted sum approach to optimize three competing objective functions, while Ng Cheng Hin and Zmeureanu (2014) compared optimization results using three different objective functions. Rey and Zmeureanu (2016) later built upon this work by applying a multi-objective particle swarm approach to simultaneously optimize lifecycle cost and energy. However, to date, there has been limited systems level optimization of PVT-assisted heat pumps, especially for cold climates such as Canada.

This paper applies a multi-objective optimization algorithm to the sizing of a solar heat pump system using ice storage and PVT panels. First, the proposed concept is introduced, along with key modes of operation. Next, the optimization problem is formulated, followed by a presentation of the simulation methodology employed. Finally, results are provided for a high performance home in Montreal, Canada, with several solutions from the Pareto front examined to better understand the performance of the selected algorithm. 


\section{System Concept and Operations}

The proposed system is shown in Figure 1, based on the work of Tamasauskas et al. (2016). The system operates year round to serve heating and DHW loads in the building.

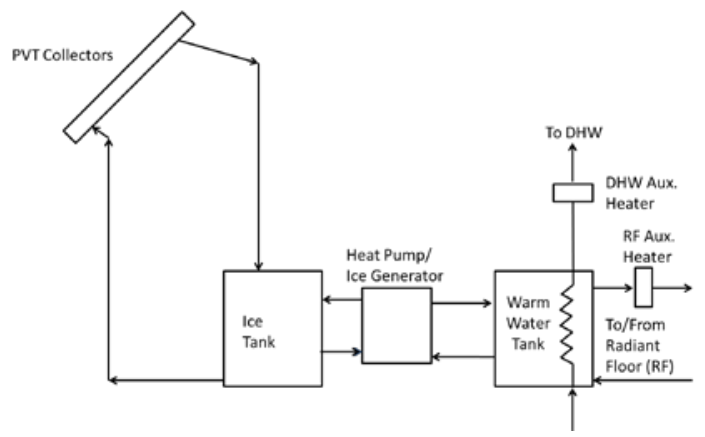

Figure 1: Proposed system concept

\subsection{System Description}

The system concept integrates liquid-based PVT with ice storage and heat pump technologies. Combining these technologies offers three key advantages:

I. Improved Thermal and Electrical PVT Efficiencies. Using ice storage allows a colder temperature fluid to be circulated to the PVT collectors. This minimizes thermal losses from the collector array, and provides effective cooling of the PV cells in order to maximize electrical efficiencies.

II. Increased Energy Storage Densities. The latent heat available during the ice/water phase change (333 $\mathrm{kJ} / \mathrm{kg}$ ) increases energy storage densities vs. sensible-only storage, minimizing tank volumes.

III. Stable Heat Pump Operations. Ice storage places a lower limit on the source temperature for the heat pump. This allows for more efficient heat pump operations, especially in comparison to conventional air-source heat pumps in cold climates such as Canada, where outdoor temperatures can often fall to $-30^{\circ} \mathrm{C}$ during the winter months.

A PVT array (liquid based, using either glazed or unglazed collectors) on the south facing roof of the building acts as the primary source of thermal energy. Low-grade thermal energy obtained from the PVT collectors is then stored in ice tank. Ice storage is based on the use of ice slurry (a mixture of small diameter ice particles and water), with the ice tank operated in a non-agitated configuration to allow ice and water to separate via buoyancy into two distinct layers (Tamasauskas et al., 2012). Energy stored in the ice tank is upgraded by a water-water heat pump/ice generator for use in radiant flooring and domestic hot water (DHW) loops. Auxiliary electric heaters in the radiant floor and DHW loops supplement system operations as needed. All systems are electrically based to facilitate the use of electricity generated by the PVT panels, with no additional connections for natural gas or other fuel sources.

\subsection{System Control}

Control of the system is best understood in terms of three main loops:

Solar Loop Control: The solar loop is responsible for circulating fluid between the PVT collectors and ice tank. Loop operations are based on the following variables:

i. $\quad$ Useful Solar Gains. A predicted fluid temperature rise $\left(\Delta T_{C o l, I}\right)$ exceeding $3^{\circ} \mathrm{C}$ is required to start the solar loop pump. This ensures that the loop only operates when suitable solar gains into the system are available. Loop operations continue as long as the actual temperature rise (under flow conditions) remains above $1^{\circ} \mathrm{C}$.

ii. $\quad$ Ice Tank Fluid Temperature. A maximum average fluid temperature of $26^{\circ} \mathrm{C}$ is defined for the ice tank ( $T_{\text {Fluid,IT }}$ ), based on available heat pump information (ClimateMaster, 2010).

Heat Pump Loop Control: Heat pump control is based on the following variables:

i. $\quad$ Ice Mass in Ice Tank. The heat pump is allowed to operate if the ice mass in the ice tank is below a defined maximum $\left(M_{\text {Ice,Max }}\right)$. This maximum has been set at $60 \%$ of the tank fluid mass, based on the maximum fraction obtained during experiments on a test bench system (Tamasauskas et al., 2016).

ii. $\quad$ Fluid Temperature in Warm Tank. The heat pump maintains a $45^{\circ} \mathrm{C}$ temperature at the top of the warm water tank $\left(T_{\text {Fluid,WT }}\right)$. 
A summary of the control parameters required to operate both the solar and heat pump loops is provided below in Table 1.

Table 1: Summary of Solar and Heat Pump Control Loops

\begin{tabular}{lll}
\hline & & Control Parameters \\
\hline Solar Loop & Heat Season & $\Delta T_{\text {Col, },}>3^{\circ} \mathrm{C}, T_{\text {Fluid, } I T}<26^{\circ} \mathrm{C}$ \\
Heat Pump & Heat Season & $M_{\text {Ice }}<M_{\text {Ice,Max },} T_{\text {Fluid, } W T}<45^{\circ} \mathrm{C}$ \\
\hline
\end{tabular}

Radiant Floor Loop Control: The radiant flooring loop meets the space heating loads of each level of the building. Space air temperatures are maintained at $21^{\circ} \mathrm{C}$ for the two above ground floors, and $18^{\circ} \mathrm{C}$ for the basement. Fluid supply temperatures are varied with an outdoor air reset, ranging from $40^{\circ} \mathrm{C}$ at design conditions to $25^{\circ} \mathrm{C}$ at an ambient temperature of $18^{\circ} \mathrm{C}$.

\section{Optimization Formulation}

A multi-objective optimization has been performed to determine tradeoffs in system sizing over a lifecycle of 40 years (Leckner, 2008). This section formulates the multi-objective optimization problem, including a presentation of the selected decision variables, objective functions and algorithm.

\subsection{Decision Variables}

Decision variables used in the optimization focus on the thermal supply and storage capabilities of the system, and are summarized in Table 2. Maximum values for the storage tank volumes and number of solar collectors are based on available space within the building, with the maximum number of solar collectors varying by type due to the slightly smaller size of the unglazed collectors vs. the glazed ones. The range of specific flow rates used for the PVT collectors is selected based on information provided by the panel manufacturer (Solimpeks, 2014). Product lifecycles are used to identify when and how many times a piece of equipment must be replaced during the 40 -year system lifecycle.

Table 2: Summary of optimization decision variables

\begin{tabular}{llccc}
\hline Variables & Type & Min & Max & Product Lifecycle (Years) \\
\hline \# PVT Collectors, Glazed $\left(\mathrm{N}_{\mathrm{PVT}},-\right)$ & Discrete & 1 & 29 & 25 \\
\# PVT Collectors, Unglazed $\left(\mathrm{N}_{\mathrm{PVT}},-\right)$ & Discrete & 1 & 31 & 25 \\
Volume Ice Tank $\left(\mathrm{V}_{\mathrm{IT}}, \mathrm{m}^{3}\right)$ & Continuous & 0.3 & 5 & 15 \\
Volume Warm Tank $\left(\mathrm{V}_{\mathrm{wT}}, \mathrm{m}^{3}\right)$ & Continuous & 0.3 & 5 & 15 \\
Collector Spec Flow $\left(\dot{m}_{\mathrm{col}}, \mathrm{kg} / \mathrm{s} \cdot \mathrm{m}^{2}\right)$ & Continuous & 0.007 & 0.035 & 10 (Circ. Pumps) \\
\hline
\end{tabular}

\subsection{Objective Functions}

The optimization problem is based on the minimization of both lifecycle energy (LCE) and lifecycle cost (LCC). Details regarding each objective function is provided below.

Lifecycle Cost (LCC). The lifecycle cost analysis focused on three main elements:

I. Initial purchase and installation of equipment associated with each decision variable

II. Purchase and installation of replacement equipment at end of equipment lifecycle, and

III. Utility costs associated with system operations over the defined lifecycle.

Mathematically, total lifecycle costs can be written as:

$$
\left.L C C=P W_{I n}+P W_{R e p}+P W_{\text {ops }} \quad \text { (eq. } 1\right)
$$

Where $\mathrm{PW}_{\mathrm{In}}, \mathrm{PW}_{\mathrm{Rep}}$, and $\mathrm{PW}$ Ops are the initial, replacement, and operating costs, respectively, discounted to the start of the analysis period in \$CAD. Future cash flows were discounted to present worth using an inflation rate of $1.45 \%$ and a nominal discount rate to $2.88 \%$, based on the current Canadian financial market. 
The costs associated with each decision variable are summarized in Table 3.

Table 3: Summary of equipment costs associated with decision variables

\begin{tabular}{|c|c|c|}
\hline Component & Cost (Equipment + Install, \$ CAD) & Source \\
\hline PVT Collector (Glazed) & $1028 *$ NPVT & $\begin{array}{l}\text { Equipment: Haus Und Solar, } 2016 \\
\text { Installation: RS Means, } 2013\end{array}$ \\
\hline PVT Collector (Unglazed) & $0.95 * 1028 *$ NpvT & $\begin{array}{l}\text { Equipment: Haus Und Solar, } 2016 \\
\text { Renewable Energy Hub, } 2018 \\
\text { Installation: RS Means, } 2013\end{array}$ \\
\hline PV Panel & $584 * \mathrm{NPV}$ & Equip./Install: EnergyHub.org, 2018 \\
\hline Warm Tank & $2870 * V_{W T}+995$ & Equip./Install: Ng Cheng Hin, 2013 \\
\hline Ice Tank & $2870 * V_{\text {ITT }}+995$ & Equip./Install: Ng Cheng Hin, 2013 \\
\hline Solar Circulation Pump & $\begin{array}{l}\text { 8.27* } \mathrm{P}_{\text {Rated }}+168.68 \text {, if } \mathrm{P}_{\text {Rated }}<93 \mathrm{~W} \\
0.56 * \mathrm{P}_{\text {Rated }}+901.61 \text {, if } \mathrm{P}_{\text {Rated }} \geq 93 \mathrm{~W}\end{array}$ & Equip./Install: RS Means, 2013 \\
\hline
\end{tabular}

Utility costs are summarized in Table 4, based on current rates and structures for the Montreal region (Hydro Quebec, 2017). Fixed daily costs are neglected, as these remain the same for all systems. Only electrical utilities are presented, as all systems are electrically based. Escalation rates are derived from the five-year average for Montreal.

Table 4: Utility rates for Montreal region

\begin{tabular}{lll}
\hline Variable & Tier & Value \\
\hline Electricity Rate & First 30 kWh/day & $5.71 \mathrm{C} / \mathrm{kWh}$ \\
& Above 30 kWh/day & $8.68 \mathrm{C} / \mathrm{kWh}$ \\
Escalation Rate & - & $1.80 \%$ \\
\hline
\end{tabular}

Lifecycle Energy. Lifecycle energy examines both:

I. The embodied energy of each component associated with a decision variable, and

II. The energy use of the system over its complete lifecycle.

Mathematically, this can be written as:

$$
L C E=E_{E m b, I}+E_{E m b, R}+E_{O p s} \quad \text { (eq. 2) }
$$

Where $E_{E m b, I}$ is the embodied energy of the initial components $(\mathrm{kWh}), \mathrm{E}_{\mathrm{Emb}, \mathrm{R}}$ is the embodied energy of any replacement components $(\mathrm{kWh})$, and $\mathrm{E}_{\mathrm{Ops}}$ is the energy use of the system over the 40 year lifecycle $(\mathrm{kWh})$.

Table 5 summarizes the embodied energy of each system component involved in the optimization. For the PVT collectors, little information was available regarding embodied energy. As such, an expression was derived using information from Ng Cheng Him (2013) for a glazed solar thermal collector, and Leckner (2008) for a monocrystalline PV panel, as used in the selected PVT collectors. For the unglazed case, the embodied energy associated with the glass panel is subtracted from the glazed expression. Pump embodied energy is based on the use of a cast iron as the main component material.

Table 5: Embodied energy associated with decision variables

\begin{tabular}{lll}
\hline Component & Lifecycle Energy (kWh) & Source \\
\hline PVT Coll. & Gl: $2012 * A_{\mathrm{PVT}} \mathrm{N}_{\mathrm{PVT}}+63.5 * \mathrm{~N}_{\mathrm{PVT}}+675$ & Solar Thermal: Ng Cheng Him (2013) \\
& UG: $1951 * \mathrm{~A}_{\mathrm{PVT}} \mathrm{N}_{\mathrm{PVT}}+63.5 * \mathrm{~N}_{\mathrm{PVT}}-675$ & Glazing: Chow \& Ji, 2012 \\
PV & $1496 * \mathrm{~A}_{\mathrm{PV}} * \mathrm{~N}_{\mathrm{PV}}$ & Leckner (2008) \\
Warm Tank & $1960 * \mathrm{~V}_{\mathrm{WT}}{ }^{0.6}$ & Ng Cheng Hin (2013) \\
Ice Tank & $1960 * \mathrm{~V}_{\mathrm{IT}}{ }^{0.6}$ & Ng Cheng Hin (2013) \\
Solar Pump & $\mathrm{M}_{\mathrm{pump}} *(32.8 * 0.28)$ & Derived via Spence \& Kultermann (2017) \\
\hline & Where $\mathrm{A}_{\mathrm{PV}}$ is the area of a PV panel, $\mathrm{N}_{\mathrm{PV}}$ is the number of PV panels, and $\mathrm{M}_{\mathrm{Pump}}$ is the mass of the pump (kg)
\end{tabular}


Operational energy is defined as the total energy use of the home, and can be written as:

$$
E_{\text {Ops }}=N_{\text {Lifecycle }}\left(E_{H P}+E_{\text {Aux }}+E_{\text {FansPumps }}+E_{\text {LightRecp }}-E_{P V}\right) \text { (eq. 3) }
$$

Where $\mathrm{N}_{\text {Lifecycle }}$ is the total lifecycle of the system (years), $\mathrm{E}_{\mathrm{HP}}$ is the annual energy use of the heat pump (kWh), $\mathrm{E}_{\text {Aux }}$ is the annual energy use for auxiliary heating in the heating and DHW loops (kWh), EFansPumps is the annual energy use for pumps and fans (kWh), ELightRecp is the annual energy use for lights and receptacles (kWh), and $E_{P V}$ is the annual electricity generated from the PV array, PVT array, or both (kWh).

\subsection{Optimization Algorithm}

The non-dominated sorting genetic algorithm (NSGA-II) was selected to develop the Pareto front (Deb et al., 2002) due to its widespread use in building simulation and HVAC system sizing problems, and its availability in several common optimization packages such as MOBO (Palolen et al., 2013) and Matlab (Mathworks, 2018). A summary of key optimization parameters is provided in Table 6, based mainly on those recommended by Palolen et al. (2013).

Table 6: Optimization algorithm parameters

\begin{tabular}{lc}
\hline Parameter & Value \\
\hline Population Size & 16 \\
No. of Generations & 40 \\
Mutation Probability & 0.034 \\
Crossover Probability & 0.9 \\
\hline
\end{tabular}

\section{Simulation Methodology}

TRNSYS v.17 (Klein et al., 2010) and the multi-objective optimization program MOBO (Palonen et al., 2013) were linked to perform the study. The two programs shared information as shown in Figure 2. At each generation, MOBO created a series of TRNSYS input files (one for each member of the population) using the set of decision variable values associated with each candidate in the population. TRNSYS then performed annual simulations for each population member, and reported the corresponding lifecycle cost and energy use back to MOBO. Finally, MOBO used this data to support the NSGA-II algorithm in its selection process in order to develop the next generation of candidate points.

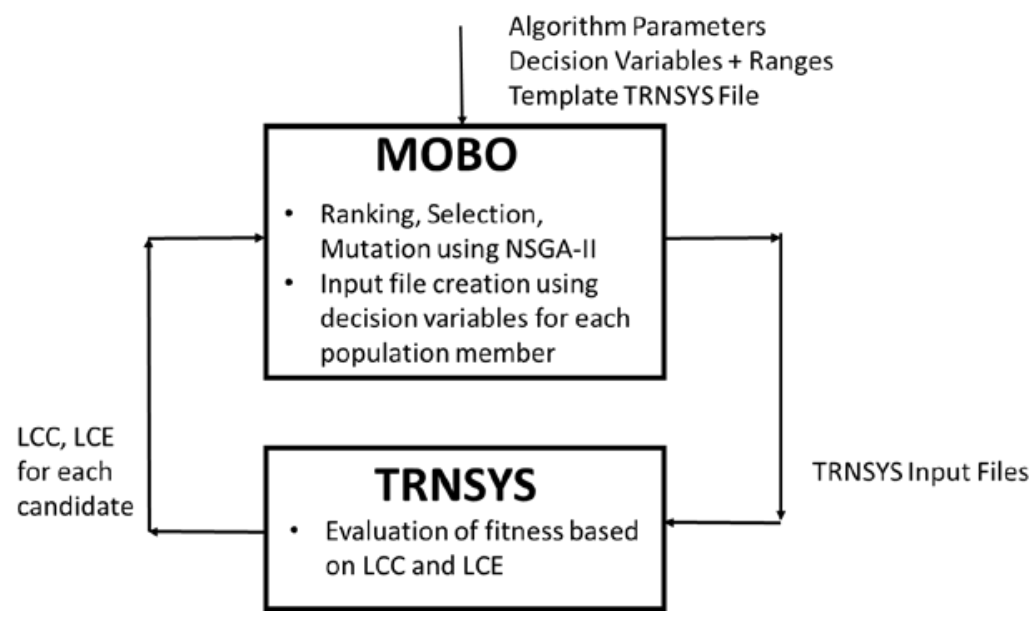

Figure 2: Simulation architecture using MOBO and TRNSYS

The remainder of this section examines the components used in TRNSYS. 


\subsection{TRNSYS System Simulations}

TRNSYS was selected for all system simulations because of its ability to simulate the complex and unique HVAC system proposed in this work. All models were simulated at a time step of 3.75 minutes, with this small time step required to appropriately model system control decisions and promote solution convergence in TRNSYS. The choice of 3.75 minutes has also been specifically chosen because this time step is of the form $1 / 2 n$ hours (where $n$ is a userselected integer), which ensures that there are no issues with TRNSYS components writing data to external files (Bradley, 2016). Table 7 summarizes key TRNSYS components used in the system model.

Table 7: Summary of key TRNSYS components

\begin{tabular}{lll}
\hline Component & TRNSYS Type & Notes \\
\hline Building & Type 56 & Single family home in Montreal, Canada \\
Heat Pump & Type 927 & 4 ton, COP Rated $=4.28^{1}$ \\
Ice Generator & Equation Type & Derived from Guilpart \& Fournaison (2005) \\
Ice Tank & Type 217 (Custom Model) & Custom model, non-agitated ice slurry, Tamasauskas et al. (2012) \\
Warm Tank & Type 534 & Stratified storage, 4 nodes \\
PVT Array (Glazed) & Type 50 & Liquid PVT, APanel $=1.43 \mathrm{~m}^{2} /$ panel \\
PVT Array (Unglazed) & Type 50 & Liquid PVT, Apanel $=1.33 \mathrm{~m}^{2} /$ panel \\
Heating Control & Type 23 & Separate PID control for each RF Loop \\
Radiant Flooring & Type 56 Active Layer & Separate Loops for all three levels \\
\hline
\end{tabular}

Building Model. The system was integrated into a single family home in Montreal, QC, Canada. The geometry for the home was based on the Canadian Centre for Housing Technology (CCHT) test home (Swinton et al., 2005), and consists of two above ground floors and a finished basement with a heated floor area of $284 \mathrm{~m}^{2}$. This home is considered representative of typical single family homes in Canada. The envelope of the home was then modified to meet an EnerGuide rating of ERS-86 (OEE, 2005). Details on the housing model and its development can be found in Kegel et al. (2012). Key envelope performance is summarized in Table 8.

Table 8: House envelope properties

\begin{tabular}{ll}
\hline Envelope Property & Value \\
\hline Roof RSI & $8.93 \mathrm{~m}^{2} \cdot{ }^{\circ} \mathrm{C} / \mathrm{W}$ \\
Wall RSI & $5.65 \mathrm{~m}^{2} \cdot{ }^{\circ} \mathrm{C} / \mathrm{W}$ \\
Basement Wall RSI & $4.95 \mathrm{~m}^{2} \cdot{ }^{\circ} \mathrm{C} / \mathrm{W}$ \\
Basement Slab RSI & $2.58 \mathrm{~m}^{2} \cdot{ }^{\circ} \mathrm{C} / \mathrm{W}$ \\
Window U-Value & $1.01 \mathrm{~W} / \mathrm{m}^{2} \cdot{ }^{\circ} \mathrm{C}$ \\
Infiltration & $0.75 \mathrm{ACH}_{50}$ \\
\hline
\end{tabular}

To assess solar system performance it was also important to define two base case mechanical systems representing conventional and more efficient heating technologies. Table 9 summarizes key details for each system. In all cases, DHW draws are set to 233 L/day. Tank volumes for Base Case 2 are larger as this tank serves both DHW and radiant flooring loops. Heat pump performance was based on manufacturer data (Daikin, 2018).

Table 9. Base case mechanical systems

\begin{tabular}{lll}
\hline & Base Case \#1 & Base Case \#2 \\
\hline Heating System & Electric Baseboard & Air-Water Heat Pump (COP 3.29 ${ }^{\dagger}$ ), Radiant Flooring \\
Ventilation & HRV, 0.84 effectiveness & HRV, 0.84 effectiveness \\
DHW & Electric Conventional Tank & Air-Water Heat Pump + Tankless Electric (if needed) \\
& Tank Volume 0.23 $\mathrm{m}^{3}$ & Tank Volume 0.50 $\mathrm{m}^{3}$ (Serves RF and DHW loops) \\
\hline
\end{tabular}

Each base case is also equipped with a PV system sized for the full south-facing roof of the home $\left(\sim 41 \mathrm{~m}^{2}\right)$. 
PVT System. PVT properties and parameters are provided in Table 10. It is assumed that all PV/PVT systems are grid tied, and can feed into the electricity grid when generation exceeds building demand. Provided information is derived from Solimpeks (2014), Notton et al. (2005), and Boubekri et al. (2009).

Table 10: Parameters for PVT system

\begin{tabular}{ll}
\hline Parameter & Type/Value \\
\hline PV Type & Mono-Crystalline \\
PV Efficiency & $14.88 \%$ \\
PV Efficiency Modifier & -0.0044 \\
Slope/Orientation & $40 \%$ Due South \\
Panel Area & $1.43 \mathrm{~m}^{2}$ (Glazed PVT \& PV) \\
& $1.33 \mathrm{~m}^{2}$ (Unglazed PVT) \\
\hline
\end{tabular}

\section{Results}

Optimizations have been completed for several cases using an Intel Core i7-3840QM CPU @ 2.80 GHz. Results are presented first for an optimization of the PVT-only system, followed by an exploration of the optimal balance between PV and PVT collectors.

\subsection{Overall Optimization Results: PVT Only Case}

Figure 3 compares the Pareto fronts for glazed and unglazed collectors. In nearly all cases, the glazed collector offers both superior lifecycle energy and cost performance, dominating candidate solutions using unglazed PVT. This result can primarily be attributed to the superior thermal performance of the glazed collector in Montreal, and the relatively small price and embodied energy increments between the two collector types. The only exception to this is at the far right of the graph, at the extreme minimum of lifecycle energy. In this situation, the primary thermal demands of the system are well matched using both the glazed and unglazed collector. As such, the extra electricity offered by the unglazed collector offers a slight improvement in lifecycle energy performance. While not included in this study, it is important to keep in mind that many regions include a feed-in tariff for onsite renewable generation. This would increase the attractiveness of PVT systems, especially for unglazed collectors, which prioritize electricity generation.

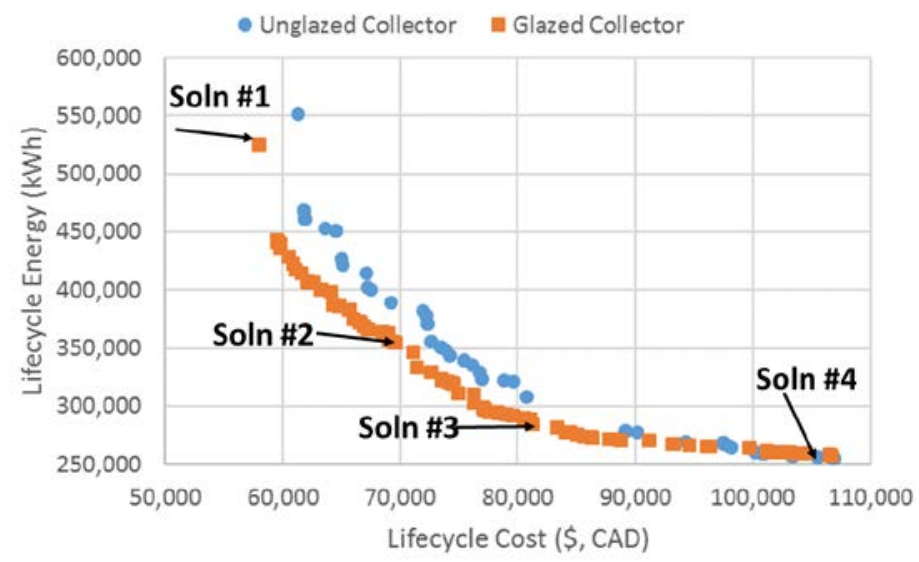

Figure 3: Pareto fronts for glazed and unglazed PVT cases

Table 11 summarizes optimized decision variables and objective functions for the four candidate solutions in Figure 3. Solutions with greater energy savings are associated with higher lifecycle costs. However, the relationship between increased costs and greater energy savings differs greatly over the Pareto front. Starting with a relatively small PVT array and storage capacity (Solution \#1), it is possible to achieve a $32 \%$ reduction in lifecycle energy with only a $19 \%$ increase in lifecycle costs (Solution \#2). The impact of additional investments becomes attenuated beyond this point, as moving from Solution \#2 to Solution \#3 yields a 19\% reduction in lifecycle energy for a $17 \%$ increase in lifecycle costs. Finally, along the extreme right of the Pareto front, additional investments in equipment have little effect on lifecycle energy savings, with a 33\% increase in lifecycle costs resulting in only a $12 \%$ reduction in lifecycle energy (Solution \#3 to Solution \#4). Increased collector area and tank storage volumes appears to be the main drivers towards reduced lifecycle energy (and increased lifecycle costs). 
Table 11: Candidate solutions from the combined Pareto front

\begin{tabular}{|c|c|c|c|c|}
\hline & \multicolumn{4}{|c|}{ Solution } \\
\hline & 1 & 2 & 3 & 4 \\
\hline PVT Type & Glazed & Glazed & Glazed & Unglazed \\
\hline $\mathbf{N}_{\text {collectors }}$ & 6 & 24 & 29 & 31 \\
\hline$V_{\text {Ice }}\left(\mathbf{m}^{3}\right)$ & 0.50 & 0.60 & 1.20 & 4.30 \\
\hline VWwST (m³) & 0.33 & 0.33 & 0.97 & 1.66 \\
\hline $\mathbf{m}_{\text {col }}\left(\mathrm{kg} / \mathrm{s} \cdot \mathrm{m}^{2}\right)$ & 0.0071 & 0.0071 & 0.0156 & 0.0321 \\
\hline LCC (\$, CAD) & 58,000 & 69,000 & 80,500 & 106,900 \\
\hline LCE( kWh) & 524,800 & 356,900 & 289,800 & 255,400 \\
\hline
\end{tabular}

Table 12 presents the distribution of lifecycle energy by system element. It is immediately evident that the distribution of energy by component, and between the equipment and operations phases, changes significantly between the four solutions presented. As solutions move towards lower lifecycle energy, a greater portion of this total is associated with the embodied energy of the system components, especially the PVT collectors. Also evident is the lower embodied energy of the storage tanks, which never exceed $9 \%$ of total system lifecycle energy. Embodied energy for the pumps remains constant, as there is little variation in the mass between the pump sizes used in this case study.

Table 12: Division of lifecycle energy by component for candidate solutions

\begin{tabular}{lcccccccc}
\hline \multicolumn{7}{c}{ Lifecycle Energy (kWh) } \\
\hline \multicolumn{1}{c}{$\mathbf{1}$} & \multicolumn{2}{c}{$\mathbf{2}$} & $\mathbf{3}$ & $\mathbf{4}$ \\
\hline Total System & 524,800 & \multicolumn{2}{c}{356,900} & 289,800 & 255,400 \\
PVT & 35,810 & $7 \%$ & 141,210 & $40 \%$ & 170,490 & $59 \%$ & 164,560 & $64 \%$ \\
Ice Tank & 3,800 & $1 \%$ & 4,140 & $1 \%$ & 6,410 & $2 \%$ & 14,120 & $6 \%$ \\
Warm Tank & 3,010 & $1 \%$ & 3,010 & $1 \%$ & 5,760 & $2 \%$ & 7,960 & $3 \%$ \\
Pumps & 110 & $<1 \%$ & 110 & $<1 \%$ & 110 & $<1 \%$ & 110 & $<1 \%$ \\
Operations & 482,070 & $92 \%$ & 208,430 & $58 \%$ & 107,030 & $37 \%$ & 68,650 & $27 \%$ \\
\hline
\end{tabular}

Table 13 presents similar information for lifecycle cost. From the economic perspective, there is also a shift from (i) low initial investment and high operating costs, to (ii) a far greater initial expenditure on the system, but with lower costs during operations. In contrast to lifecycle energy results, a far more significant proportion of costs is also associated with larger storage tanks, especially for Solutions \#3 and \#4. This breakdown of lifecycle costs can be particularly useful for designers and building owners: A long-term owner/operator may prefer to have a higher initial expenditure while saving on operating costs and hedging against future utility price fluctuations, especially when subsidies for efficient equipment are available.

Table 13: Division of lifecycle cost by component for candidate solutions

\begin{tabular}{lcccccccc}
\hline \multicolumn{7}{c}{ Lifecycle Cost (\$, CAD) } \\
\hline \multirow{2}{*}{ Total System } & \multicolumn{2}{c}{$\mathbf{1}$} & \multicolumn{2}{c}{$\mathbf{2}$} & $\mathbf{3}$ & \multicolumn{2}{c}{$\mathbf{4}$} \\
PVT & $\$ 10,510$ & $18 \%$ & $\$ 42,050$ & $61 \%$ & $\$ 50,820$ & $63 \%$ & $\$ 51,600$ & $48 \%$ \\
Ice Tank & $\$ 5,880$ & $10 \%$ & $\$ 6,400$ & $9 \%$ & $\$ 10,620$ & $13 \%$ & $\$ 32,920$ & $31 \%$ \\
Warm Tank & $\$ 4,770$ & $8 \%$ & $\$ 4,770$ & $7 \%$ & $\$ 9,290$ & $12 \%$ & $\$ 14,170$ & $13 \%$ \\
Pumps & $\$ 1,130$ & $2 \%$ & $\$ 1,280$ & $2 \%$ & $\$ 2,490$ & $3 \%$ & $\$ 3,220$ & $3 \%$ \\
Operations & $\$ 35,710$ & $62 \%$ & $\$ 14,500$ & $21 \%$ & $\$ 7,280$ & $9 \%$ & $\$ 4,990$ & $5 \%$ \\
\hline
\end{tabular}


Table 14 compares the annual energy performance by end use for each candidate solution, and the two base cases defined in Table 9. While all candidate solutions offer reductions over the first base case (electric resistance elements for heating and DHW), it is interesting to note that only Solutions \#3 and \#4 provide net annual energy use reductions versus the air-water heat pump case (Base \#2). Each of these two solutions takes a different approach to achieving lower lifecycle energy. In Solution \#3, the glazed PVT area is maximized in order to increase thermal energy supply and reduce energy use for heating and DHW. Solution \#4 uses unglazed collectors with a larger ice tank volume, sacrificing performance in heating and DHW modes in order to increase electricity production. It is also important to note the impact of cooling the PV panels: In Solution \#4, annual PV production is boosted by approximately 60 $\mathrm{kWh}$, although this increase is mitigated somewhat by limited solar loop operations during the warmer months when there is reduced demand for heating and DHW in the building.

Table 14: Annual energy use for candidate solutions

\begin{tabular}{lcc|cccc}
\hline & Base \#1 & Base \#2 & Soln \#1 & Soln \#2 & Soln\#3 & Soln \#4 \\
\hline Heating+DHW (kWh) & 13,780 & 6,970 & 8,260 & 5,750 & 4,410 & 4,580 \\
Fans+Pumps (kWh) & N/A & 990 & 930 & 960 & 980 & 1,000 \\
Lighting+Receptacles (kWh) & 4,480 & 4,480 & 4,480 & 4,480 & 4,480 & 4,480 \\
\hline Total Electricity Use (kWh) & 18,260 & 12,440 & 13,670 & 11,190 & 9,870 & 10,060 \\
Total PV Generation (kWh) & 8,280 & 8,280 & 1,610 & 5,970 & 7,190 & 8,340 \\
Net Electricity Use (kWh) & 9,980 & 4,160 & 12,060 & 5,220 & 2,680 & 1,720 \\
\hline
\end{tabular}

\subsection{Overall Optimization Results: PVT \& PV Case}

In addition to the PVT-only optimization, a second optimization was performed to determine the best balance between PV and glazed PVT collectors. This optimization was run using the same objective functions and optimization parameters as the previous case. However, instead of leaving unused roof space if the PVT array area was less than its maximum, the remaining available roof space was instead covered with PV panels. Each PV panel was assumed to have an identical area to the glazed PVT panel $\left(1.43 \mathrm{~m}^{2}\right)$, with the total number of PV panels then:

$$
N_{P V}=29-N_{P V T} \text { (eq. 4) }
$$

Where $\mathrm{N}_{\mathrm{PV}}$ is the number of PV panels, and 29 represents the maximum number of solar collectors (PV or PVT) that can be integrated onto the south facing roof. The embodied energy and cost of the PV panels were then included in the optimization to appropriately assess the impact of their integration.

Figure 4 shows the Pareto front for this new optimization case. It is immediately evident this front is far shallower than for the glazed PVT-only case. The addition of PV, via its electrical generation capacity, greatly reduces the lifecycle energy use of the lowest-cost solutions. For solutions at the low end of lifecycle costs, adding PV results in only a small net cost increase in comparison to the PVT-only case, primarily because utility bills are reduced. As lifecycle cost increases, solutions tend to closely approach the PVT-only case, as higher-cost candidates are associated with near-maximum PVT areas.

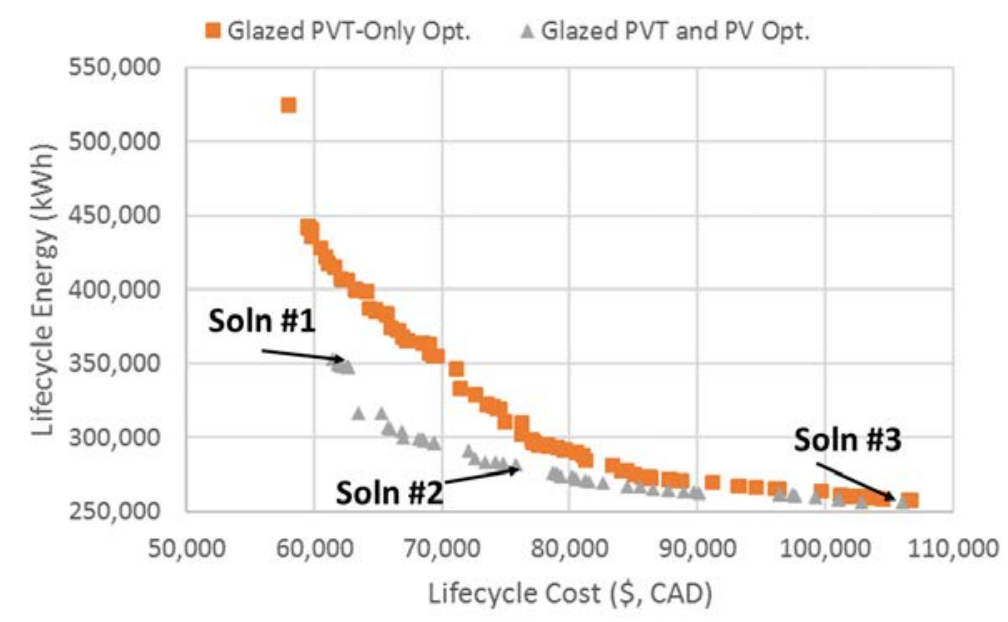

Figure 4: Pareto front for PVT \& PV case 
Table 15 summarizes the decision variables and objective function values for each of the three solutions identified in Figure 4. As with the PVT-only case, solutions are driven towards lower lifecycle energy by the addition of PVT collectors and increased storage tank volumes. However, the integration of glazed PVT appears to have both a lower and an upper limit. If less than 7 PVT collectors are used, increased system energy use for heating and DHW outweighs the additional electricity that could be obtained from a greater number of PV panels. At the upper limit, the system is able to achieve suitable thermal supply with 24 PVT collectors, when combined with sufficiently large storage tanks. Integrating additional PVT panels beyond this point results in a net increase in lifecycle energy, primarily because the reductions in electricity generation outweigh additional savings for heating and DHW.

Table 15: Candidate solutions for PVT \& PV optimization

\begin{tabular}{|c|c|c|c|}
\hline \multicolumn{4}{|c|}{ Solution } \\
\hline & 1 & 2 & 3 \\
\hline $\mathbf{N}_{\text {collectors }}$ & 7 & 18 & 24 \\
\hline$V_{\text {Ice }}\left(\mathbf{m}^{3}\right)$ & 0.40 & 1.10 & 4.60 \\
\hline Vwwst $\left(\mathrm{m}^{3}\right)$ & 0.41 & 1.53 & 2.12 \\
\hline$m_{\text {col }}\left(\mathrm{kg} / \mathrm{s} \cdot \mathrm{m}^{2}\right)$ & 0.0153 & 0.0108 & 0.0143 \\
\hline $\operatorname{LCC}(\$, C A D)$ & 62,000 & 75,800 & 106,100 \\
\hline LCE( kWh) & 349,500 & 281,500 & 256,200 \\
\hline
\end{tabular}

Table 16 compares the annual energy performance of each system, along with the corresponding electricity generation and net electricity use. Similar to the PVT-only case, all systems offer net energy use reductions in comparison to the electrical resistance base case (Base \#1), while only the final two solutions present savings vs. the more efficient heat pump system (Base \#2). However, these reductions are now more drastic given that the complete roof has some form of PVT or PV, with net energy use savings ranging from $31 \%$ with Solution \#2 to $58 \%$ with Solution \#3. It is also interesting to note the strong energy performance in heating/DHW for Solution \#3. Although the number of PVT collectors is less than a similar solution in the PVT-only case (Solution \#3, PVT-only), increased storage tank volumes are able to achieve an additional $15 \%$ energy use reduction for heating and DHW (46\% vs. the air-water base case (Base \#2)).

Table 16: Annual energy performance of candidate solutions for PVT\&PV optimization

\begin{tabular}{lcc|ccc}
\hline & Base \#1 & Base \#2 & Soln \#1 & Soln \#2 & Soln \#3 \\
\hline Heating+DHW (kWh) & 13,780 & 6,970 & 7,900 & 5,140 & 3,770 \\
Fans+Pumps (kWh) & N/A & 990 & 940 & 970 & 980 \\
Lighting+Receptacles (kWh) & 4,480 & 4,480 & 4,480 & 4,480 & 4,480 \\
\hline Total Electricity Use (kWh) & 18,260 & 12,440 & 13,320 & 10,590 & 9,230 \\
Total PV Generation (kWh) & 8,280 & 8,280 & 8,150 & 7,700 & 7,500 \\
Net Electricity Use (kWh) & 9,980 & 4,160 & 5,170 & 2,890 & 1,730 \\
\hline
\end{tabular}

Table 17 compares the lifecycle performance of the three solutions with the air-water heat pump base case. Both Solutions \#2 and \#3 are able to offer important lifecycle energy savings, driven by improved performance in heating and DHW modes. These reductions however, are less dramatic than those for annual energy use, primarily because of the higher embodied energy associated with the PVT panels and storage tanks.

It is also interesting to note the substantially lower lifecycle cost offered by the air-water heat pump (assuming that heat pumps would cost an identical amount for all cases), with this system dominating a number of solutions along the Pareto front. This result also highlights the importance of a properly sized system: Solar-assisted heat pumps with insufficient thermal supply or storage will likely result in increased lifecycle energy use and cost vs. a conventional $\mathrm{HP}+\mathrm{PV}$, as shown when comparing the base case with Solution \#1.

Table 17: Comparison life lifecycle performance for base case and candidate solutions

\begin{tabular}{lcccc}
\hline & Base \#2 & Soln \#1 & Soln \#2 & Soln \#3 \\
\hline LCC (\$, CAD) & $\$ 46,900$ & $\$ 62,000$ & $\$ 75,800$ & $\$ 106,100$ \\
LCE(kWh) & 293,800 & 349,500 & 281,500 & 256,200 \\
\hline
\end{tabular}




\section{Conclusions}

This paper presents the multi-objective optimization of a novel solar heat pump system according to the competing objectives of lifecycle energy and cost. The optimization methodology was first applied to determine optimal system sizing, assuming that the system only used PVT panels. Results showed a clear trade-off between increased investment for PVT panels and storage tank volumes, and reduced lifecycle energy use of the system. However, this relationship was shown to follow a trend of diminishing returns, with limited additional energy savings beyond certain collector areas and tank volumes. In general, glazed PVT collectors were found to dominate the Pareto front, except for solutions at the extreme minimum of lifecycle energy use, where unglazed collectors were preferred due to their lower cost and increased electricity-generating potential.

A second optimization explored the balance between PV and glazed PVT collectors. Solutions in the Pareto front were found to weigh (i) thermal energy supply from the PVT panels with (ii) increased electricity generating potential from the PV panels. System comparisons demonstrated the potential of the proposed solar heat pump, when sized appropriately, to offer substantial lifecycle energy savings in comparison to a base case using an air-water heat pump with PV. However, the base case heat pump and PV combination was found to offer attractive lifecycle economics, while still providing superior energy performance vs. solar heat pump systems with more limited thermal supply and storage capacity.

These results represent an initial examination of system performance for a single building type (single family home) and city (Montreal, QC). It is likely that system deployment in larger buildings will offer greater potential energy use and cost reductions, due to the ability to more easily integrate significant collector areas and storage volumes, and reduce capital investment via economies of scale. Regions with higher electricity rates will also result in the PVT systems offering a more economically viable alternative to conventional heat pumps, as the monetary impacts of energy savings will hold greater significance.

\section{References}

Bornatico, R., Pfeiffer, M., Andreas W., Guzzella L., 2012. Optimal sizing of a solar thermal building installation using particle swarm optimization. Energy 41, 221-228. https://doi.org/10.1016/j.energy.2011.05.026

Boubekri, M., Chaker, A., Cheknane A., 2009. Numerical approach for performance study of hybrid PV/Thermal collector. Revue des Energies Renouvelables 12, 355-368. Available at: https://www.cder.dz/spip.php?article370

Bradley, D., 2016. How to set simulation start and timestep to avoid error. Available at: http://onebuilding.org/ [Accessed Jun. 2016]

Carbonell, D., Phillippen, D., Haller, M.Y., Brunold, S., 2016. Modeling of an ice storage buried in the ground for solar heating applications: Validations with one year of monitored data from a pilot plant. Solar Energy 125, 398414. https://doi.org/10.1016/j.solener.2015.12.009

Chow, T., Ji, J., 2012. Environmental Life-Cycle Analysis of Hybrid Solar Photovoltaic/Thermal Systems for Use in Hong Kong. International Journal of Photoenergy 2012, 101968. http://dx.doi.org/10.1155/2012/101968

ClimateMaster, 2010. TMW Water-To-Water Series. Available at: http://www.climatemaster.com [Accessed Jan. 2012]

Daikin, 2018. ERLQ-CV3. Available at: https://www.daikin.co.uk/en_gb/products/ERLQ-CV3.html [Accessed Spt. 2018]

Deb K., Pratap A., Agarwal S., Mayarivan T., 2002. A Fast and Elitist Multiobjective Genetic Algorithm: NSGA-II. IEEE Transactions on Evolutionary Computation 6, 182-197. https://doi.org/10.1109/4235.996017

Dott, R., Afjei, T., 2014. Evaluation of Solar \& Heat Pump System Combinations. In Proceedings of IEA HPC 2014, IEA HP.

EnergyHub.org, 2018. Average Cost of Solar Panels in Canada 2018. Available at: https://solarpanelpower.ca/costsolar-panels-canada/ [Accessed August 2018]

Guilpart, J., Fournaison, L., 2005. The Control of Ice Slurry Systems. In Kauffeld, M., Kawaji, M., Egolf, P. (Eds.), Handbook on Ice Slurries. International Institute of Refrigeration, Paris, pp. 281-285.

Haus \& Solar, 2017. Volther PowerTherm PV-T Hybrid Collector. Available at: http://www.hausundsolar.de/Volther-PowerTherm-PV-T-Hybrid-Collector-185W [Accessed February 2017]

Hydro Quebec, 2017. Rates for residential customers (domestic rates). Available at: http://www.hydroquebec.com/residential/ [Accessed January 2017]

IEA Heat Pump Centre (IEA HPC), 2012. The role of heat pumps in net zero energy buildings. IEA Heat Pump Centre Newsletter 30, 3. Available at: https://heatpumpingtechnologies.org/publications/52485/ 
Kegel, M., Sunye, R., Tamasauskas, J., 2012. Lifecycle Cost Comparison and Optimisation of Different Heat Pump Systems in the Canadian Climate. In Proceedings of eSim 2012 Halifax, IBPSA Canada, 492-505.

Klein S. A., et al., 2010. TRNSYS 17 - A TRaNsient SYstem Simulation program user manual. University of Wisconsin-Madison Solar Energy Laboratory, Madison, WI, USA.

Leckner, M., 2008. Life cycle energy and cost analysis of a net zero energy house using solar combisystem. Master Thesis, Concordia University, Montreal, Canada.

MathWorks, 2018. MATLAB - The Language of Technical Computing Available at: http://www.mathworks.com/products/matlab/ [Accessed Sept. 2018]

Ng Cheng Hin, J., 2013. Life Cycle Optimization of a Residential Solar Combisystem for Minimum Cost, Energy Use, and Exergy Destroyed. Master Thesis, Concordia University, Montreal, Canada.

Ng Cheng Hin J., Zmeureanu R., 2014. Optimization of a residential solar combisystem for minimum life cycle cost, energy use, and exergy destroyed. Solar Energy 100, 102-113. https://doi.org/10.1016/j.solener.2013.12.001

Notton, G., Cristofari, C., Mattei, M., Poggi, P., 2005. Modelling of a double-glass photovoltaic module using finite differences. Applied Thermal Engineering 25, 2854-2877. https://doi.org/10.1016/j.applthermaleng.2005.02.008

Office of Energy Efficiency (OEE), 2005. EnerGuide for New Houses: Administrative and Technical Procedures. Natural Resources Canada, Ottawa, Canada. Available at: http://www3.cec.org/islandoragb/en/islandora/object/greenbuilding\%3A43

Palonen, M., Hamdy, M., Hasan, A., 2013. MOBO A new software for multi-objective building performance optimization. Proceedings of BS 2013, IBPSA, Chambery, France. Available at: http://www.ibpsa.org/proceedings/bs2013/p_1489.pdf

Renewable Hub, 2018. PowerVolt. Available at: https://www.renewableenergyhub.co.uk/product/powervolt.html [Accessed August 2018]

Rey A., Zmeureanu R., 2016. Multi-objective optimization of a residential solar thermal combisystem. Solar Energy 139, 622-632. https://doi.org/10.1016/j.solener.2016.10.008

RS Means, 2013. RS Means Mechanical Cost Data 2013. Reed Construction Data, Norwell, USA.

Solimpeks, 2014. Installation, Operation, and Maintenance: Solar Panels. Available at: http://www.solimpeks.com, [Accessed Mar. 2016]

Spence, W., Kultermann, E., 2017. Construction Materials, Methods, and Techniques, fourth ed. Cengage Learning, Boston.

Swinton, M.C., Entchev, E., Szadkowski, F., Marchand, R., 2003. Benchmarking twin houses and assessment of the energy performance of two gas combo heating systems. Canadian Centre for Housing Tech, Ottawa, Canada. Available at: http://www.ccht-cctr.gc.ca/eng/projects/gas_combo.html

Tamasauskas, J., Poirier, M., Zmeureanu, R., Sunye, R., 2012. Modeling and optimization of a solar assisted heat pump using ice slurry as a latent storage material. Solar Energy 86, 3316-3325. https://doi.org/10.1016/j.solener.2012.08.021

Tamasauskas, J., Poirier, M., Zmeureanu, R., Kegel, M., Sunye, R., McDonald, E., 2016. The Potential of Liquidbased BIPVT and Ice Storage for High Performance Housing in Canada. In Proceedings of 4th International High Performance Buildings Conference, Purdue University, West Lafayette, IN, USA. Available at: https://docs.lib.purdue.edu/ihpbc/208/

Trinkl, C., Zorner, W., Hanby, V., 2009. Simulation study on a Domestic Solar/Heat Pump Heating System Incorporating Latent and Stratified Thermal Storage. J. Sol. Energ.-T. ASME 131, 041008-1 to 041008-8. http://dx.doi.org/10.1115/1.3197845 


\title{
PV Power Production Estimation by Using radiometric and Meteorological Data
}

\author{
Trigo-González M. ${ }^{1}$, Marzo A. ${ }^{1-4}$, Alonso-Montesinos J. ${ }^{2-3}$, Cortes M. ${ }^{1-4}$, Portillo C. ${ }^{1-4}$, Batlles F.J. ${ }^{2}$ \\ ${ }^{1}$ Centro de Desarrollo Energético de Antofagasta (CDEA). Universidad de Antofagasta, 02800, \\ Antofagasta, Chile) \\ 2Departamento de Química y Física, Universidad de Almería, España. \\ ${ }^{3}$ CIESOL, Joint Centre of the Universidad de Almería-CIEMAT, España. \\ ${ }^{4}$ Solar Energy Research Center (SERC-Chile), Chile.
}

\begin{abstract}
World total installed photovoltaic (PV) capacity reached $320 \mathrm{GWp}$ by the end of 2017. New market shave shown a rapid development in the implementation of large PV plants connected to the grid, but it is needed to face new challenges to overcome barriers for the massive deployment. The incorporation of renewable energy sources, such as solar, can affect the stability of the electrical grid. Predicting the energy production of PV plants is crucial for the massive integration of PV technologies in the grid. The aim of this research is to estimate the energy production within an infrahour period using minimal knowledge about weather conditions. In order to achieve this goal, a mathematical model is proposed which directly computes the energy as a function of module temperature and the available solar resource. The results of the model validation test show a root mean square error value of $6.42 \%$ and an mean bias error value of $1.51 \%$ and a good performance regardless the sky condition.
\end{abstract}

Keywords: estimation, production, photovoltaic, multiple linear regression, solar energy.

\section{Introduction}

Total installed capacity in photovoltaic (PV) plants worldwide reached $320 \mathrm{GW}$ at the end of 2016 (Ise, 2018). The main contributors in this capacity are China with $26 \%$, Europe with 33\%, North America with 15\%, Japan with 13\%, and the rest of the countries of the world with $13 \%$. New markets such as Asians, Africans and South Americans have shown a rapid development in the implementation of large photovoltaic plants connected to the grid, however, they face great challenges to overcome the different barriers that a massive production of photovoltaic electricity implies (Haas et al., 2018). Among these challenges, it is worth highlighting the variability of the solar resource. At present, there is a great business interest in photovoltaic technology, both in the issue of energy self-consumption, and in large photovoltaic plants, connected to the electricity grid. This fact is mainly due to the decrease in the prices of photovoltaic panels. At the end of 2016, the average sale price of the photovoltaic panel, worldwide, was of the order of 0.37 USD / Wp (Metz et al., 2017). The variability of solar radiation and climatic conditions have a direct impact on the production of a photovoltaic plant. To massively integrate photovoltaic technology, it is essential to accurately estimate the electrical production of the plant.

The methods used to predict the production of PV plants can be classified as indirect and direct. The indirect ones require first, to predict the solar irradiance (Moretón et al., 2017), and later determine the production of power through a parametrized model of the plant. On the other hand, direct methods directly determine the power produced by statistical techniques and artificial intelligence. Additionally, there are hybrid methods, which are a mixture of both methods. The largest effort in research has been made in direct methods, which correspond to $72 \%$ of published works, while $11 \%$ and $17 \%$ correspond to indirect and hybrid methods (Antonanzas et al., 2016). Statistical models do not need information on the internal model of the plant. These are fed with past data from which relationships are extracted that allow predicting the behavior in real time and future of the plant. The quality of historical data is essential for a good quality estimate. This technique is superior to indirect methods; however, it requires a large amount of historical data (meteorological, and power measurements, among others) recorded with the plant operating. This method has the advantage that it allows to correct systematic errors that originate in the measurements of the input variables.

The main statistical techniques used are regressive, autoregressive and artificial intelligence models, among which the Artificial Neural Network (RNA) stands out. The regressive techniques determine the correlation between a 
dependent variable, in our case the electrical energy produced by the plant and the independent variables, such as radiometric, meteorological variables, as well as those of the photovoltaic panels. As an example, in (Zamo et al., 2014) different regression methods were implemented to study the relationship between energy produced and meteorological variables. The results obtained show that the RMSE for individual plants is between $9 \%$ and $10 \%$, while the prediction of the total production of the plants presents an error between $10 \%$ and $12 \%$.

Different regressive methods have been proposed by the international literature. Notable among these is Osterwald's (Fuentes et al., 2007) which expresses the maximum power of the cell according to the maximum power under standardized test conditions (STC), and the temperature coefficient of the maximum power of the cell. Another model is the one proposed by Araujo-Green (Araujo et al., 1982) which expresses the power produced as a function of the irradiance, the electrical variables and the parameters of the modules. Investigations carried out (Almonacid et al., 2011) show that the relative error of the Osterwald model is in the range of $15 \%-21 \%$, and $14 \%-18 \%$ for the Araujo-Green method. More recent models consider nonlinear relationships between the power produced and variables such as the irradiance of the inclined plane, ambient temperature, and wind speed (Dias et al., 2017, Myers, 2009).

From the reviews made in the previous paragraphs it is concluded that the main effort has been oriented to the development of short-term to long-term prediction models of solar radiation and energy production of photovoltaic plants. However, few works are reported in relation to estimation of real-time power production of photovoltaic plants. Considering this aspect, the objective of this work is to develop a model that allows to estimate the production of a photovoltaic plant from minimum radiometric and meteorological data. To do this, a linear regression model is designed to estimate PV production with the minimum environmental parameters.

\section{Materials and methods}

\subsection{Climatological description of the place under study}

The Antofagasta Region is one of the four Chilean Regions located in the Atacama Desert in the north of the country. This Region is characterized by having a well-defined morphology and four climatological zones as defined by the Chilean Meteorological Directorate in (Cruz Silva and Calderón Suenzen, 2008), see Fig. 1

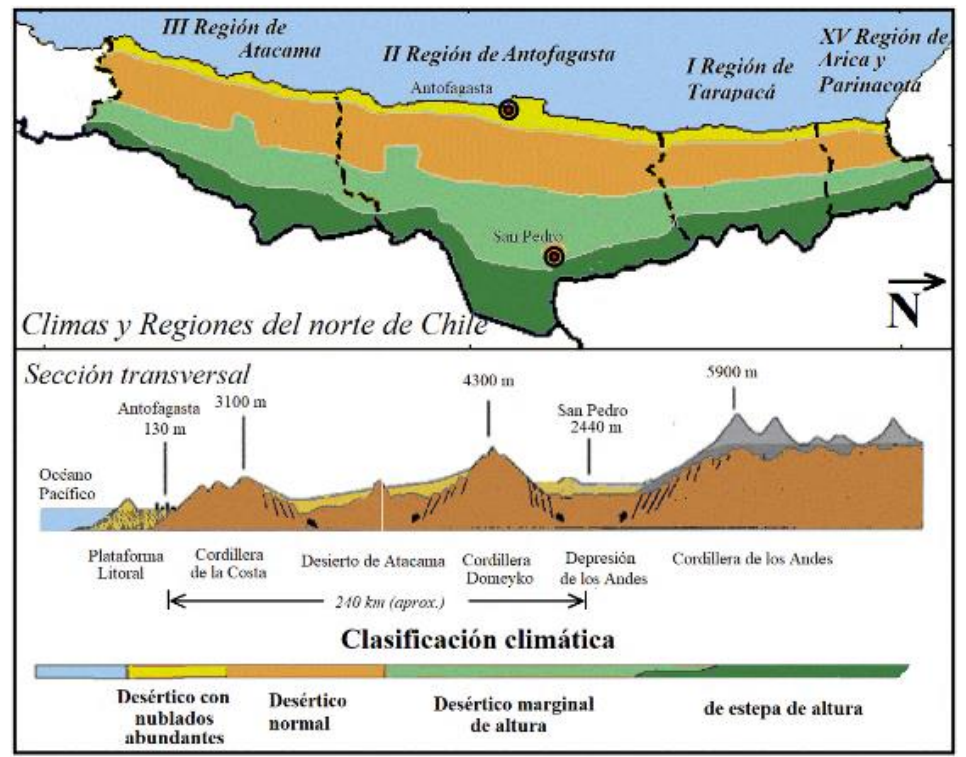

Fig. 1 - Above: climatic zones of the Northern Regions of Chile: XV-Arica and Parinacota, I-Tarapacá, II-Antofagasta and IIIAtacama. Below: cross section of the Antofagasta Region, its different geological formations and elevations, and climatic classification.

The study area is located in the town of San Pedro de Atacama, is located in the interior of the desert, at 2440 meters above sea level, 22.55 degrees south and 68.12 degrees west. A high thermal amplitude of $20{ }^{\circ} \mathrm{C}$ is registered throughout the year and its annual precipitation is $68.2 \mathrm{~mm}$, concentrating most during the summer season, with 19.6 $\mathrm{mm}$. The maximum registered temperature is $28.6^{\circ} \mathrm{C}$ during the summer and $19.1^{\circ} \mathrm{C}$ in winter, reaching minimum values of $0^{\circ} \mathrm{C}$ at this time of year. The location of this town, where the desert climate predominates, makes it possible to observe a high number of clear days throughout the year. 


\subsection{Description of the PV plant used in the study}

The Energy Development Center of Antofagasta (CDEA) of the University of Antofagasta, since 2010 has a pilot photovoltaic plant consisting of cadmium telluride modules (CdTe) located in the basic school E-26 of San Pedro de Atacama. This plant consists of $40 \mathrm{CdTe}$ modules with an inclination angle of $10^{\circ}$ facing north. Its nominal power is $3.00 \mathrm{kWp}$ with an area of $28.8 \mathrm{~m} 2$. The modules are divided into two groups, each consisting of 8 strings in parallel that are connected to an SMA SB3000TL-20 inverter.

\subsection{Instrumentation and database}

The parameters measured in the plant previously mentioned for the realization of the present study were: the environmental temperature (Tamb), the temperature of the module (Tmod), the irradiation in the generation plane (G), the wind speed (WS) and the energy injected into the network (Eac).

All these variables were recorded in a Weblog PRO (ADQ) datalogger. Table 2 shows the technical data of the monitoring system of the photovoltaic plant.

Tab. 1: Instrumentation used to record data in the PV plant

\begin{tabular}{|c|c|c|c|}
\hline Nomenclature & Instrument & Model & Measurement range \\
\hline $\mathrm{G}$ & Calibrated photocell & Si-12Tc & 0 a $1500 \mathrm{~W} \mathrm{~m}^{-2}$ \\
\hline Tamb & Thermocouple & PT100 & $-20,+100^{\circ} \mathrm{C}$ \\
\hline Tmod & Thermocouple & PT100 & $-20,+100{ }^{\circ} \mathrm{C}$ \\
\hline WS & Anemometer & Cup & $0.8,40 \mathrm{~m} / \mathrm{s}$ \\
\hline ADQ & Data acquisition system & Meteocontrol & $16 \mathrm{bits}$ \\
\hline
\end{tabular}

From the San Pedro plant, 3767 registered samples were used with a sampling frequency of 5 minutes during the years 2010 and 2014.

\section{Description of the methodology}

The objective of this work is to estimate the production of PV plants in Wh terms by means of the multiple linear regression method (MLR). Figure 2 describes the steps of the proposed methodology.

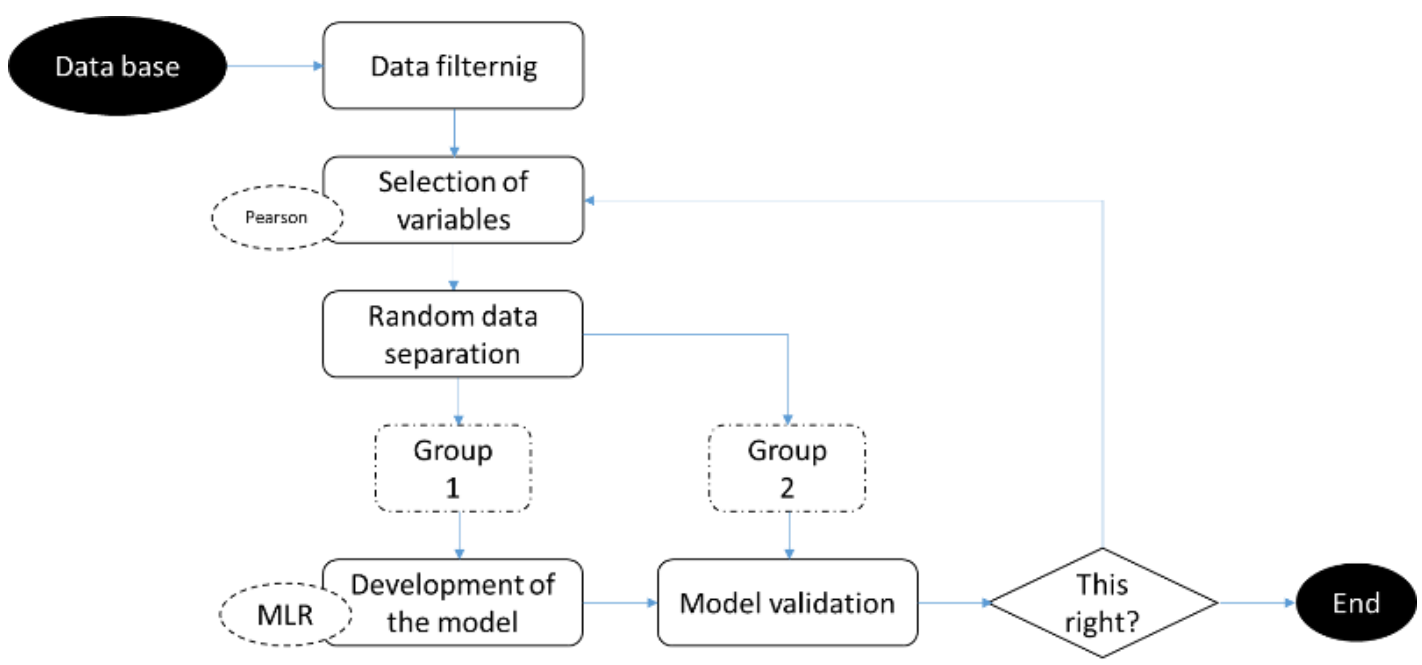

Fig. 2 - Scheme of the proposed methodology for the development of the production estimation model in PV plants. 
- From the available database, the elimination of atypical data that interfere in the adjustment of the model is done. And at the same time the hour values of the variables were calculated, with the aim of developing a model that estimates the hourly photovoltaic production.

- Subsequently, a statistical study was carried out to measure the degree of correlation between the different variables by calculating the Pearson coefficient and, in this way, selecting the parameters to be taken into account.

- The database was randomly divided into two groups: the first group of $2 / 3$ of the database was used for the development of the model, the second group consisted of one third of the data and served for the validation of the generated model.

- $\quad$ The model was adjusted using the statistical technique of multiple linear regressions (MLR).

- The models were validated using the group of validation data, different from the one used to adjust the model, to corroborate the effectiveness of the extrapolation to other geographical locations.

\section{Results and discussion}

\subsection{Selection of variables}

For the selection of the variables to be used in the model, the Pearson coefficient between them was calculated. This allowed to identify the degree of direct correlation of the variables with the production of the PV plants. This coefficient varies in the interval $[-1,1]$ : when the absolute value of the coefficient approaches one, it indicates a linear correlation; while moving away from this value, approaching zero, shows that the correlation between variables is not linear (Hall, 2000). This criterion allowed discarding variables that did not contribute to the adjustment of the model.

Figure 3 shows a set of graphs that represent the correlation between the variables measured in both PV plants, and the result of the Pearson coefficient of each variable is also shown.

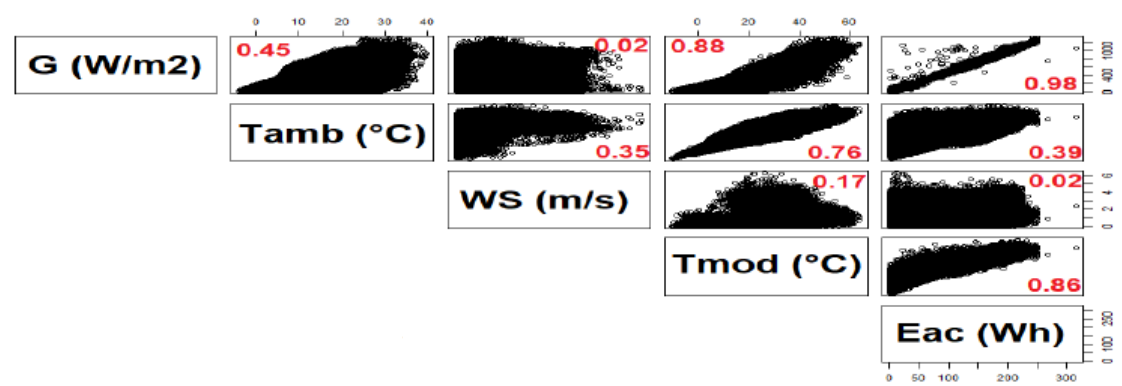

Fig. 3 - Pearson coefficients of the set of variables measured in the PV plants of Cd-Te technology.

If we look at the graphs in the last column, these represent the relation of the Photovoltaic Energy (EAC) vs the meteorological variables that are G, Tamb, WS and Tmod, the results of the Pearson coefficient were $0.98,0.39,0.02,0.86$, respectively. Which leads to selecting the variables $\mathrm{G}$ and Tmod for the adjustment of the model, because it has a very high linear correlation with photovoltaic energy.

\subsection{Development of the estimation model of PV plant production with RLM}

As mentioned above, the present work focused on the calculation of a model for estimating the production of PV plants based on CdTe technology. For this purpose, two groups of data were randomly separated: one was used for the development of the models, while the remaining quantity was reserved for the validation of the same models.

The expression proposed in equation 1, relates the statistical adjustment of the energy production of the plant (PPV) in Wh with the hour average of the module temperature under insolation conditions $(\Delta T \bmod )$ in ${ }^{\circ} \mathrm{C}$, the hourly solar irradiation $(\mathrm{G})$ in $\mathrm{Wh} \mathrm{m}^{-2}$.

$$
P_{p v}=4.08+0.21 \cdot G-0.03 \cdot T_{\bmod }
$$

A method to quantify the effectiveness of the estimation is by means of two statistical indicators, namely: the root means square error (RMSE) method, given by the equation. 2, and the average bias error (MBE), given by Eq. 3 . 
M. Trigo et. al. / EuroSun 2018 / ISES Conference Proceedings (2018)

$$
\begin{aligned}
& \operatorname{RMSE}(\%)=\frac{100}{E a c_{\text {media }}}\left[\sqrt{\frac{1}{N} \sum_{j=1}^{N}\left(E a c_{\text {est. }}-E a c_{\text {med }}\right)^{2}}\right] \\
& \operatorname{MBE}(\%)=\frac{100}{\text { Eac }_{\text {media }}}\left[\frac{1}{N} \sum_{j=1}^{N}\left(E a c_{\text {est. }}-E a c_{\text {med. }}\right)\right]
\end{aligned}
$$

The result of the validation was an RMSE of $6.42 \%$ with an MBE of $1.51 \%$.

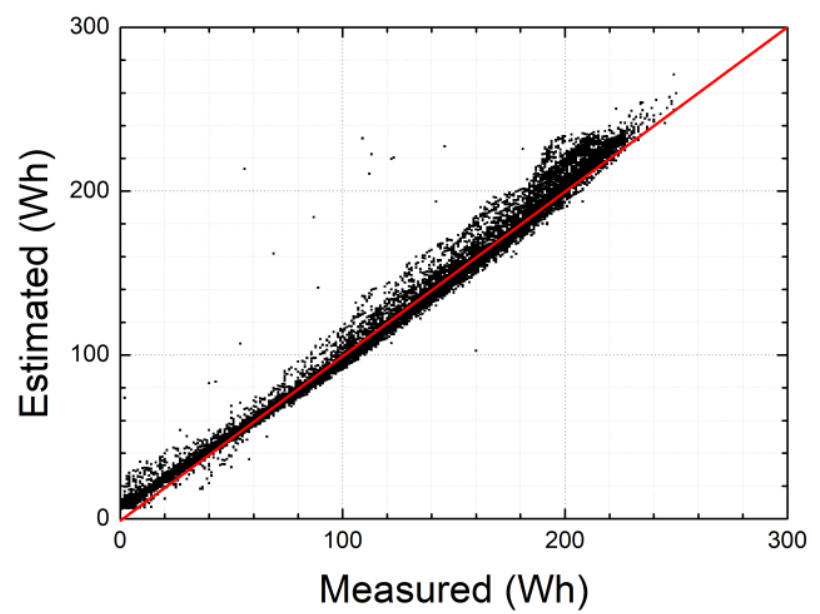

Fig. 4 - Estimation of the PV production of a CdTe plant at San Pedro de Atacama, Chile, by using the model base don multiple linear regression method.

\subsection{Test}

A test was carried out with days cleared, partially cloudy and totally cloudy, using the data registered in the town of San Pedro de Atacama. The objective is to study the effectiveness of the model in different sky type conditions, with the possibilities of extrapolating the results of the estimates in other places. The results are shown in the following table.

Tab. 2: Results of the errors of the statistical indicators for different types of sky.

\begin{tabular}{|c|c|c|c|}
\hline Type of sky & MBE\% & RMSE\% & $\mathbf{R}^{\mathbf{2}}$ \\
\hline Clear sky & 2.12 & 5.40 & 0.92 \\
\hline Party cloudy sky & -1.75 & 5.35 & 0.95 \\
\hline Cloudy sky & 10.29 & 17.24 & 0.85 \\
\hline
\end{tabular}

The results of the table indicate that, for a clear and partially cloudy type of sky, the results are approximately equal, with an RMSE of $5.4 \%$ and $5.35 \%$, respectively. It is observed that for the partially cloudy day the MBE has to underestimate, with respect to the others.

In the case of the cloudy sky type, the error is higher, and this is mainly due to the fact that the adjustment of the model was made under conditions of a climate that most of the year is with clear days.

Figure 5 shows the actual measurement of the energy generated by the photovoltaic plant (black color) and the model estimates (red color), for the three conditions of the sky. 

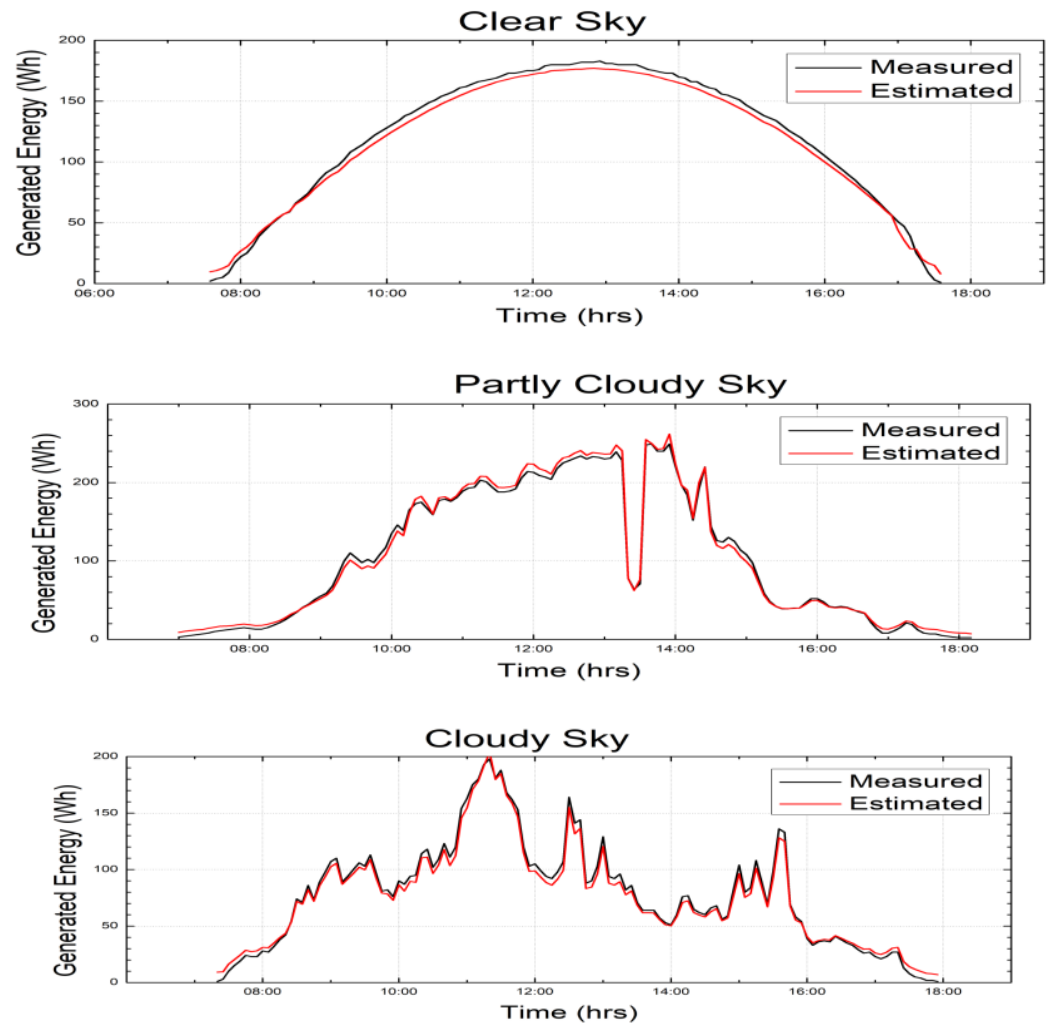

Fig. 5 - Results of the test for different sky conditions, with a model adjusted by the MRL technique

The results highlight the good fit of the model for any condition of the sky, observing in the previous graphs that the model has a good response to follow the trend of the radiation curve for the 3 types of sky conditions.

\section{Conclusions}

- In this work we propose a model to estimate the electrical production of a CdTe technology photovoltaic plant by using multiple linear regression method.

- The Pearson coefficient was used to select the variables of the model. Irradiance and module temperature showed the highest linear correlation with photovoltaic energy production.

- The results of the model validation show a root mean square error value of $6.42 \%$ and an mean bias error value of $1.51 \%$

- The model continues to show good performance according to the generation of energy regardless the sky condition.

\section{References}

Almonacid, F., Rus, C., Pérez-Higueras, P., Hontoria, L., 2011. Calculation of the energy provided by a PV generator. Comparative study: Conventional methods vs. artificial neural networks. Energy 36, 375-384. doi:10.1016/J.ENERGY.2010.10.028

Antonanzas, J., Osorio, N., Escobar, R., Urraca, R., Martinez-de-Pison, F.J., Antonanzas-Torres, F., 2016. Review of photovoltaic power forecasting. Sol. Energy 136, 78-111. doi:10.1016/J.SOLENER.2016.06.069

Araujo, G.L., Sánchez, E., Martí, M., 1982. Determination of the two-exponential solar cell equation parameters from empirical data. Sol. Cells 5, 199-204. doi:10.1016/0379-6787(82)90027-8

Cruz Silva, C., Calderón Suenzen, J., 2008. Guía Climática Práctica. Dirección Meteorológica de Chile, Santiago de Chile, Chile.

Dias, C.L. de A., Castelo Branco, D.A., Arouca, M.C., Loureiro Legey, L.F., 2017. Performance estimation of photovoltaic technologies in Brazil. Renew. Energy 114, 367-375. doi:10.1016/J.RENENE.2017.07.033

Fuentes, M., Nofuentes, G., Aguilera, J., Talavera, D.L., Castro, M., 2007. Application and validation of algebraic methods to predict the behaviour of crystalline silicon PV modules in Mediterranean climates. Sol. Energy 81, 1396-1408. doi:10.1016/j.solener.2006.12.008

Haas, J., Palma-Behnke, R., Valencia, F., Araya, P., Díaz-Ferrán, G., Telsnig, T., Eltrop, L., Díaz, M., Püschel, S., Grandel, M., 
Román, R., Jiménez-Estévez, G., 2018. Sunset or sunrise? Understanding the barriers and options for the massive deployment of solar technologies in Chile. Energy Policy 112, 399-414. doi:10.1016/J.ENPOL.2017.10.001

Hall, M.A., 2000. Correlation-based feature selection of discrete and numeric class machine learning, Computer Science Working Papers, Computer Science Working Papers. University of Waikato, Department of Computer Science.

Ise, F., 2018. Photovoltaics Report.

Korachagaon, I., Mudgal, D.N., Kottur, R.M., Patil, S.K., Bapat, V.N., 2015. Global solar radiation estimation model with two parameters and its ANN validation, in: 2015 IEEE 9th International Conference on Intelligent Systems and Control (ISCO). IEEE, pp. 1-3. doi:10.1109/ISCO.2015.7282286

Marzo, A., Trigo-Gonzalez, M., Alonso-Montesinos, J., Martínez-Durbán, M., López, G., Ferrada, P., Fuentealba, E., Cortés, M., Batlles, F.J., 2017. Daily global solar radiation estimation in desert areas using daily extreme temperatures and extraterrestrial radiation. Renew. Energy 113, 303-311. doi:10.1016/j.renene.2017.01.061

Mellit, A., Sağlam, S., Kalogirou, S.A., 2013. Artificial neural network-based model for estimating the produced power of a photovoltaic module. Renew. Energy 60, 71-78. doi:10.1016/J.RENENE.2013.04.011

Metz, A., Fischer, M., Trube, J., 2017. International Technology Roadmap for Photovoltaics (ITRPV) 8 th edition: Crystalline Silicon Technology-Current Status and Outlook.

Monteiro, R.V.A., Guimarães, G.C., Moura, F.A.M., Albertini, M.R.M.C., Albertini, M.K., 2017. Estimating photovoltaic power generation: Performance analysis of artificial neural networks, Support Vector Machine and Kalman filter. Electr. Power Syst. Res. 143, 643-656. doi:10.1016/j.epsr.2016.10.050

Moretón, R., Lorenzo, E., Pinto, A., Muñoz, J., Narvarte, L., 2017. From broadband horizontal to effective in-plane irradiation: A review of modelling and derived uncertainty for PV yield prediction. Renew. Sustain. Energy Rev. 78, 886-903. doi:10.1016/j.rser.2017.05.020

Myers, D., 2009. Evaluation of the Performance of the PVUSA Rating Methodology Applied to Dual Junction PV Technology: Preprint (Revised).

Quesada-Ruiz, S., Linares-Rodríguez, A., Ruiz-Arias, J.A., Pozo-Vázquez, D., Tovar-Pescador, J., 2015. An advanced ANNbased method to estimate hourly solar radiation from multi-spectral MSG imagery. Sol. Energy 115, 494-504. doi:10.1016/J.SOLENER.2015.03.014

Zamo, M., Mestre, O., Arbogast, P., Pannekoucke, O., 2014. A benchmark of statistical regression methods for short-term forecasting of photovoltaic electricity production, part I: Deterministic forecast of hourly production. Sol. Energy 105, 792-803. doi:10.1016/J.SOLENER.2013.12.006 


\title{
Improvents on the Efficiency of the Photovoltaic Panel by Integrating a Spray Cooling System with Shallow Geothermal Energy Heat Exchanger \\ Li-Hao Yang ${ }^{1}$, Jyun-De Liang ${ }^{1}$, Ching-Yi Tseng ${ }^{1}$ and Sih-Li Chen ${ }^{1 *}$ \\ ${ }^{1}$ Department of Mechanical Engineering, National Taiwan University, Taipei (Taiwan, ROC)
}

\begin{abstract}
A spray cooling system with shallow geothermal energy is experimentally investigated to mitigate the photovoltaic (PV) panel efficiency decline problem, which is due to high temperatures. This cooling system is utilized to cool PV panels by spraying water on the back of the panel, and a tank is used to reclaim the cooling water. To enhance the cooling capacity, the recycled water is poured into U-shaped borehole heat exchanger (UBHE), which is installed in existing well, and the water exchanges heat with the shallow geothermal energy. Finally, the recycled cooling water is sprayed again to cool the panel. The experiments contain three parts: The first is the PV panel operation without any cooling system. The second is the panel operation with the cooling system but without the UBHE. The third is the cooling system operation with the UBHE. The results of experiments show that this cooling system can improve the efficiency of PV panels about 8.2\%.
\end{abstract}

Keywords: PV Panel Cooling, Spray Cooling, Shallow Geothermal Energy, Borehole Heat Exchanger.

\section{Introduction}

Solar energy is the major factor in renewable energy development, but the energy conversion efficiency of photovoltaic (PV) panels is too low. Most of the solar energy is transferred into waste heat. This waste heat can cause the panel temperature to increase, and high temperature reduces the efficiency of the panel, with the efficiency dropping by about $0.5 \%$ for every $1{ }^{\circ} \mathrm{C}$ increase in temperature (Kane et al., 2017). Thus, PV panels require an effective cooling system to maintain a suitable working temperature.

The commonly used cooling methods are divided into air and water cooling methods. Air cooling requires lesser energy than water cooling, but its cooling ability is also mediocre. Conversely, water cooling has better cooling capability than air cooling, and its equipment costs are usually higher than air cooling. Kaiser et al. (2014) set a large air fan under the PV panel for cooling and discussed the influence of the air-channel size and the flow velocity on the efficiency of the PV panel. The results showed that the power output of a PV panel can be improved with air cooling. Water cooling methods include sprinkling water on the panel top or the use of channels for a working fluid to cool the panel (Bigorajski, 2018; Abdolzadeh, 2009; Chandrasekar, 2015). Moharram et al. (2013) found that the cooling system should be turned on when the panel temperature reaches $45^{\circ} \mathrm{C}$ or more and the PV panel has the optimum power output. Nižetić, et al. (2016) indicated that a water spray cooling technique is more efficient than other already analyzed cooling techniques except for the water submersion method (when the PV panel is completely flooded with water). Zhu and Si (2012) has found that the amount of solar energy accepted by the panel is decreased when using water spray cooling on front of the panel, and the amount of cooling water is also decreased quickly. Thus, it is preferable to spray water on the back of the PV panel when the panel temperature achieves $45^{\circ} \mathrm{C}$ and to reuse the cooling water. However, the cooling water temperature will increase as the water is reused, and its cooling capacity decreases as the water temperature increases. Thus, the cooling water requires an extra cooling source to maintain its low-temperature state.

Shallow geothermal energy is a stable low-temperature geothermal resource that is distributed on the earth's surface $(3-50 \mathrm{~m})$ soil, and it has some advantages, including renewability, ease of use, stable temperature, and wide distribution; it is a clean energy (Chen et al., 2015; Soni, 2015). In this study, a full year period of soil temperatures in Taiwan had been measured, and the results are shown in Fig. 1. According to these results, the temperatures of the soil $5 \mathrm{~m}$ below the earth's surface at Taiwan were about 24 to $27^{\circ} \mathrm{C}$ for a full year, which are lower than the PV panel temperature. Moreover, this temperature of the soil is not constrained by weather and region; i.e., it is relatively steady (Soni, et al., 2015; Luo, et al., 2018). Thus, this characteristic could be employed through heat exchange methods for cooling the PV panel. Jakhar et al. (2017) placed the water channels at the 
rear of the panel and used cooling water to cool the PV panel, then utilized an earth water heat exchanger (EWHE), which is a horizontal-type borehole heat exchanger, to cool the water. The results showed that this system can improve the PV panel efficiency. Horizontal-type borehole heat exchangers were used in early periods, but such systems were influenced by atmospheric temperature (Chen et al., 2015) and need large spaces for installation. By comparison, a U-shaped borehole heat exchanger (UBHE) is only minimally influenced by ambient temperature (Chen et al., 2015); moreover, the UBHE requires little space for installation (Schiel, et al., 2016), and it can thus save most initial costs (Gemelli, et al., 2011). The cooling water of UBHE is first used to cool the equipment, and then, the waste heat from the water is transferred to the soil. Finally, the cooled water is used for cooling the equipment again, and the cycle is completed.

As a result of all the above reasons, in this study, spray water was used to cool the back of a PV panel. The waste heat was discharged into the well with the cooling water that continually flowed through the UBHE, and continuous recycling was used to improve the capacity of the cooling system. The PV panel cannot function at night, but the soil can discharge heat during that time. Then, the soil could cool the cooling water during the daytime, and hence, the cooling system could be combined with UBHE. Thus, the system can maintain a suitable working temperature for the panel and improve its efficiency.

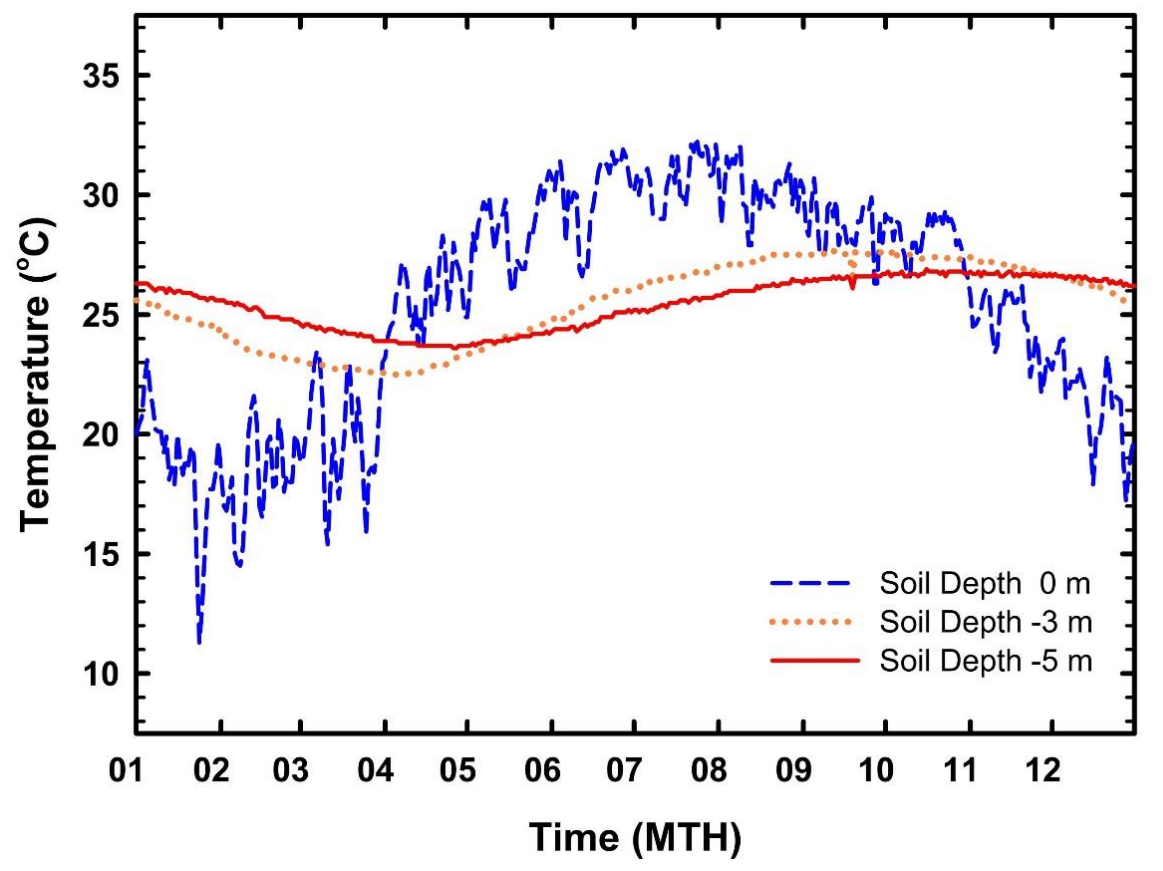

Fig. 1: Soil temperature in Taichung, Taiwan over a one-year period

\section{Experimental Investigation}

\subsection{Experimental processes and configuration}

The schematic diagram of the system, equipment setup, and photographic view are shown in Fig.2 and Fig. 3. A 60-W PV panel (MSX-60) manufactured by SOLAREX was used in the experiments, and the spray cooling system was combined with the UBHE. The water in this cooling system first cools the PV panel, and then the shallow geothermal energy through the UBHE is used to cool the cooling water and to maintain the cooling capacity of this cooling system. Temperature variation of this system would be observed during the experimental process. This experimental investigation includes three experiments, as explained below: First, the differences between the PV panels with and without the cooling system are investigated; second, the influence of shallow geothermal energy on the cooling system is determined by changing the experimental control method. Because the solar intensity is relatively stronger during summer (July) midday and relatively weaker during the afternoon, every experiment is carried out from 11:40 to 14:45. In the experimental process, the power output and the temperature variations of this system are measured.

In the first experiment, the system without the cooling system is constructed as the base model for all 
experiments, and its power output and temperature variation are observed during the process. In the second experiment, a common cooling system is used, in which pipes are used to link the pump to propel the fluid flow and recycling. The cooling water for cooling the PV panels is sprayed through nozzles. The initial temperature of the cooling water is $31.5^{\circ} \mathrm{C}$. The cooling system is switched on once the panel temperature reaches $45^{\circ} \mathrm{C}$. Because the cooling capacity decreases after the cooling water cools the panel, the working time according to the experiment control was set as $240 \mathrm{~s}$. The panel temperature increases again after the cooling system is switched off until it reaches $45^{\circ} \mathrm{C}$, after which the cooling system is switched on again and the entire process is repeated. In the third experiment, the cooling system combined with the UBHE is used. The cooling water cools the PV panel, and then, the UBHE cools the cooling water using ground water and soil. Because the cooling water is cooled through the UBHE, its cooling capacity can be maintained, and thus, the experimental control differs from that in the previous experiment. The pump is switched on once the panel temperature reaches $45^{\circ} \mathrm{C}$ and is switched off once the panel temperature is cooled to $35^{\circ} \mathrm{C}$. The panel temperature increases again after the cooling system is switched off until the temperature reaches $45^{\circ} \mathrm{C}$, after which the cooling system is switched on again and the entire process is repeated.

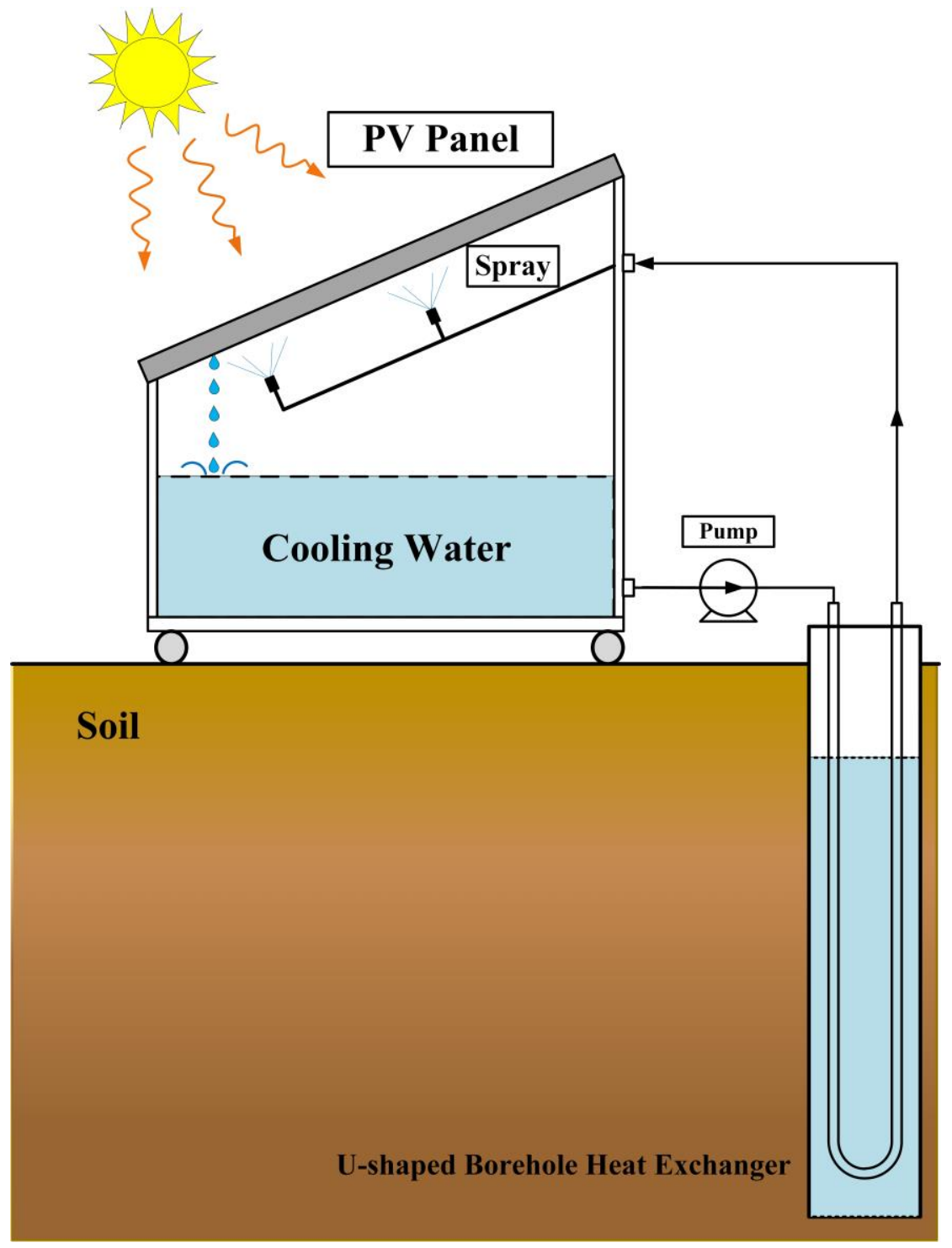

Fig. 2: System scheme 


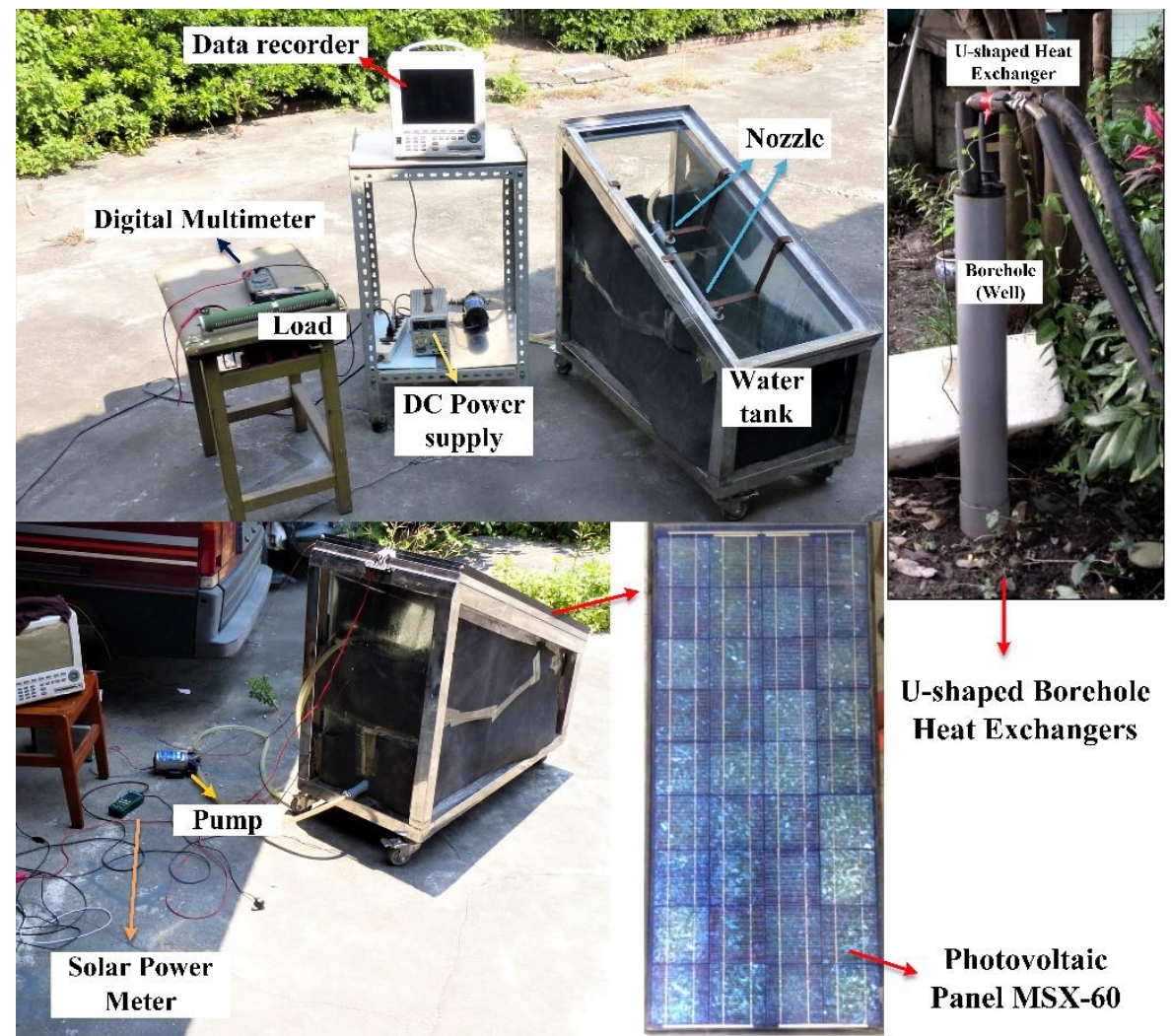

Fig. 3: Photographic view of the experimental equipment

\subsection{Experimental equipment}

The specifications of the PV panel are listed in Tab. 1; the maximum output power under the standard test condition is $60 \mathrm{~W}$, the maximum conversion efficiency is $10.9 \%$, the size is $1.1 \mathrm{~m} \times 0.5 \mathrm{~m} \times 0.05 \mathrm{~m}$, and the weight is $7.8 \mathrm{~kg}$. The Solar Power Meter (Datalogging TES-132) used for measuring the solar radiation has an operating range from 200 to $2000 \mathrm{~W} / \mathrm{m}^{2}$, and the accuracy is $\pm 10 \mathrm{~W} / \mathrm{m}^{2}$. The walls of the cooling water tank are made of glass, and two nozzles installed in the tank are linked with the outside pump (DC Diaphragm pump HF8367) through pipes. The total weight of cooling water in the tank is $60 \mathrm{~kg}$. The caliber of nozzles is $0.8 \mathrm{~mm}$; the total flow rate is 0.57 LPM; the distance of the nozzles from the panel is approximately $0.22 \mathrm{~m}$, and the spray angle is $68.5^{\circ}$. The UBHE system includes pipes and a borehole wall. Groundwater is placed between the pipe and the borehole wall, and the groundwater level distance from the earth's surface is about $2 \mathrm{~m}$. The external and internal diameter of the well are $0.135 \mathrm{~m}$ and $0.125 \mathrm{~m}$, respectively. The pipe is made from stainless steel. It is located at a depth of $5 \mathrm{~m}$, its length, external diameter, and internal diameter are $10.3 \mathrm{~m}, 0.018 \mathrm{~m}, 0.016 \mathrm{~m}$. The working fluid is water. The rated voltage of the pump is DC $24 \mathrm{~V}$, the working current is $0.21-0.85 \mathrm{~A}$, and the maximum volume flow rate is 1.2 LPM. This study applies a DC power supplier to adjust the pump flow rate and power consumption by controlling the supplied voltage. The total flow rate is $0.57 \mathrm{LPM}$, corresponding to $5 \mathrm{~W}$. A T-type thermocouple is used to measure temperature. The error range of T-type thermocouples is $\pm 0.5^{\circ} \mathrm{C}$ for a temperature range of $" 0^{\circ} \mathrm{C} \leq \mathrm{T} \leq 200^{\circ} \mathrm{C}$ ", and the accuracy is $\pm 0.2^{\circ} \mathrm{C}$ after correction.

\subsection{Efficiency evaluation}

Because the experiments could not be carried out under the same solar strength every time, the average energy conversion efficiency was applied to assess the performance of the system in order to avoid errors caused by different solar strengths. Moreover, the average conversion efficiency $\left(\eta_{\text {ori }}\right)$ before cooling could be calculated as follows:

$$
\eta_{\text {ori }}=\frac{\int_{0}^{t_{t}} P_{p v} d t}{A \varphi t_{t}}
$$

where $\mathrm{P}_{\mathrm{pv}}$ is the output power of the $\mathrm{PV}$ panel, $\mathrm{A}$ is the panel area, $\varphi$ is solar radiation intensity, and $\mathrm{t}_{\mathrm{t}}$ is the total 
operating time.

The average conversion efficiency $\left(\eta_{s p}\right)$ after cooling and inclusion of the energy consumption of the pump could be expressed as follows:

$$
\eta_{s p}=\frac{\int_{0}^{t_{t}} P_{p v} d t-P_{p p} t_{o t}}{A \varphi t_{t}}
$$

The enhanced effect of the average conversion efficiency could be expressed as:

$$
\delta=\frac{\eta_{s p}-\eta_{o r i}}{\eta_{\text {ori }}}
$$

Tab. 1: Experimental specifications of PV Panel (MSX-60)

\begin{tabular}{|c|c|c|c|c|}
\hline Area $\mathbf{( m}^{\mathbf{2}}$ ) & 0.556 & Pmax Voltage (Volt) & 17.7 \\
\hline Length (m) & 1.108 & Pmax Current (Ampere) & 3.5 \\
\hline Absorption, $\boldsymbol{\alpha}^{\prime}$ & 0.7 & Open-circuit voltage (Volt) & 21.1 \\
\hline Emissivity, $\boldsymbol{\varepsilon}$ & 0.9 & $\begin{array}{c}\text { Short-circuit current } \\
\text { (Ampere) }\end{array}$ & 3.8 \\
\hline slope angle, $\boldsymbol{\theta}\left({ }^{\circ}\right)$ & 23.5 & $\begin{array}{c}\text { Temperature coefficient of } \\
\text { power }\left(\% /{ }^{\circ} \mathbf{C}\right)\end{array}$ & $-(0.5 \pm 0.05)$ \\
\hline $\begin{array}{c}\text { Maximum Power } \\
(\mathbf{W})\end{array}$ & 60 & $\begin{array}{c}\text { Nominal Operating Cell } \\
\text { Temperature, NOCT }\left({ }^{\circ} \mathbf{C}\right)\end{array}$ & $47 \pm 2$ \\
\hline
\end{tabular}

\section{Results and discussion}

\subsection{The system without any cooling system}

The purpose of the first experiment is to investigate the working characteristics of the PV panel and to build a base model for comparison in all analyses. Following is a discussion of the high PV panel temperature effect on the PV efficiency. During the experimental period, the PV panel worked from 11:40 to 14:45. As $t=20-170 \mathrm{~min}$, the period for the experiment is about 12:00-14:30. During this period, the solar intensity is the strongest and relatively steady. Fig. 4 shows the PV panel temperatures. The initial temperature of the PV panel is $52{ }^{\circ} \mathrm{C}$, and the highest temperature in experimental results is above $65^{\circ} \mathrm{C}$. Fig. 5 shows the relationship between the solar intensity and the power output. According to Fig. 4 and Fig. 5, the factors that affect the power output are solar intensity as well as panel temperature. According to Fig. 5, the solar intensity at $t=0$ min is approximately the same as that at $\mathrm{t}=180 \mathrm{~min}$, i.e., about $850 \mathrm{~W} / \mathrm{m}^{2}$, but the temperatures of the panels are different. Because the temperature of the panel at $\mathrm{t}=180 \mathrm{~min}$ is higher than that at $\mathrm{t}=0 \mathrm{~min}$, the power output is lower at $\mathrm{t}=180 \mathrm{~min}$. The results show that the power decreases as the temperature increases, and that the output power of the PV panel without the cooling system decreases as the temperature increases. This experiment measured the relationship between the power output and the temperature of the panel, and the energy conversion efficiency $\eta_{\text {ori }}$ of the PV panel without the cooling system calculated from eq. 1 is about $6.56 \%$. The experimental results are presented in Tab. 2. 

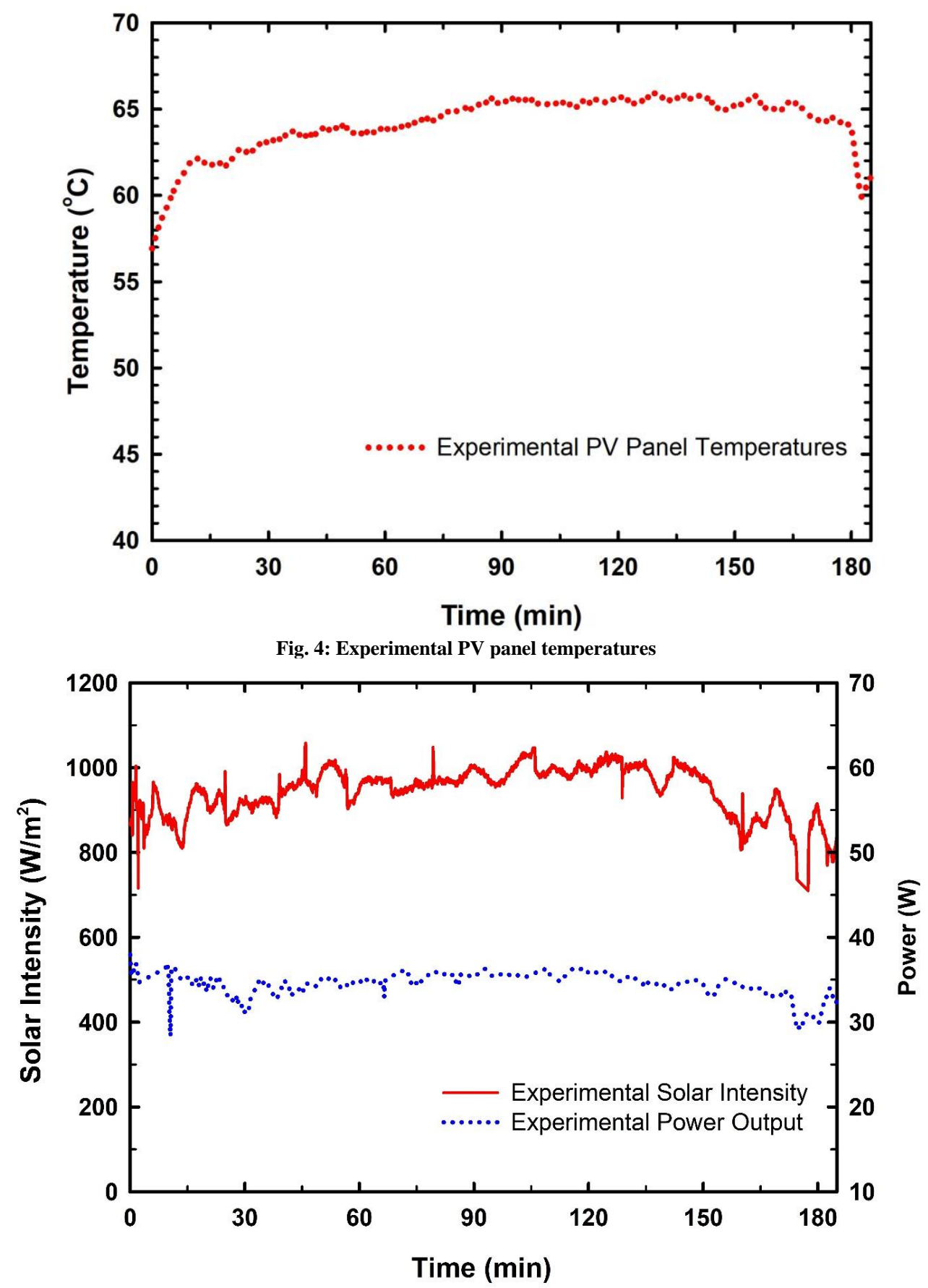

Fig. 5: Relationship between solar intensity and power output

\subsection{The system with the cooling system without UBHE}

In the second experiment, the PV panel was cooled using a cooling system without the UBHE. The output and the average conversion efficiency of this system were observed during the working period. The cooling water was sprayed onto the PV panel through two nozzles, and the total flow rate of the nozzles was 0.57 LPM; and the temperatures of the nozzles and the tank were equal. In this experiment, the cooling system was switched on for $240 \mathrm{~s}$ when the panel temperature reached $45^{\circ} \mathrm{C}$, and then, it was switched off until the temperature reached 45 ${ }^{\circ} \mathrm{C}$ again. The above steps were repeated for a total operational time of 3 hours 5 minutes.

The experimental results are shown in Fig. 6 and Tab. 2. After the cooling system was switched off, the panel temperature increased, and each cooling cycle caused the cooling water's temperature to increase from 31.3 to $40.2{ }^{\circ} \mathrm{C}$, which represents an increase of about $8.9^{\circ} \mathrm{C}$, and as a result, the cooling effect of the cooling system deteriorated. In the first cooling cycle, the cooling water could cool the PV panel temperature to $35^{\circ} \mathrm{C}$, but in the 
final cooling cycle, the PV panel temperature was only cooled to $43^{\circ} \mathrm{C}$. The cooling capacity decreased because of the increase in the temperature of the cooling water temperature. Further, as shown in Fig. 6 and Fig. 7, after a working time of $\mathrm{t}=150 \mathrm{~min}$, the solar intensity decreased gradually, and hence, the temperature increase of the cooling water was not obvious. To compare Fig. 7 with Fig. 4, Fig. 5 and Fig. 6, when the solar intensity was approximately $900 \mathrm{~W} / \mathrm{m}^{2}$, the power output of the panel with cooling system was enhanced by $4 \mathrm{~W}$. This indicates that the temperature increase considerably affects the output efficiency, and thus, the cooling system can improve the efficiency of the panel, but the pump also needs additional energy. The average conversion efficiency after cooling could be obtained through eq. 2 , and the average conversion efficiency is calculated to be about $6.64 \%$ after the pump energy consumption is included. For improving the cooling capacity and reducing the energy consumption. Moreover, the results in Fig. 9 show that as the cooling system operates for a longer period, the cooling capacity decreases as the water temperature of the tank rises. Thus, the cooling water needs to be cooled to maintain its capability, and UBHE is used to cool the cooling water in the next experiment.

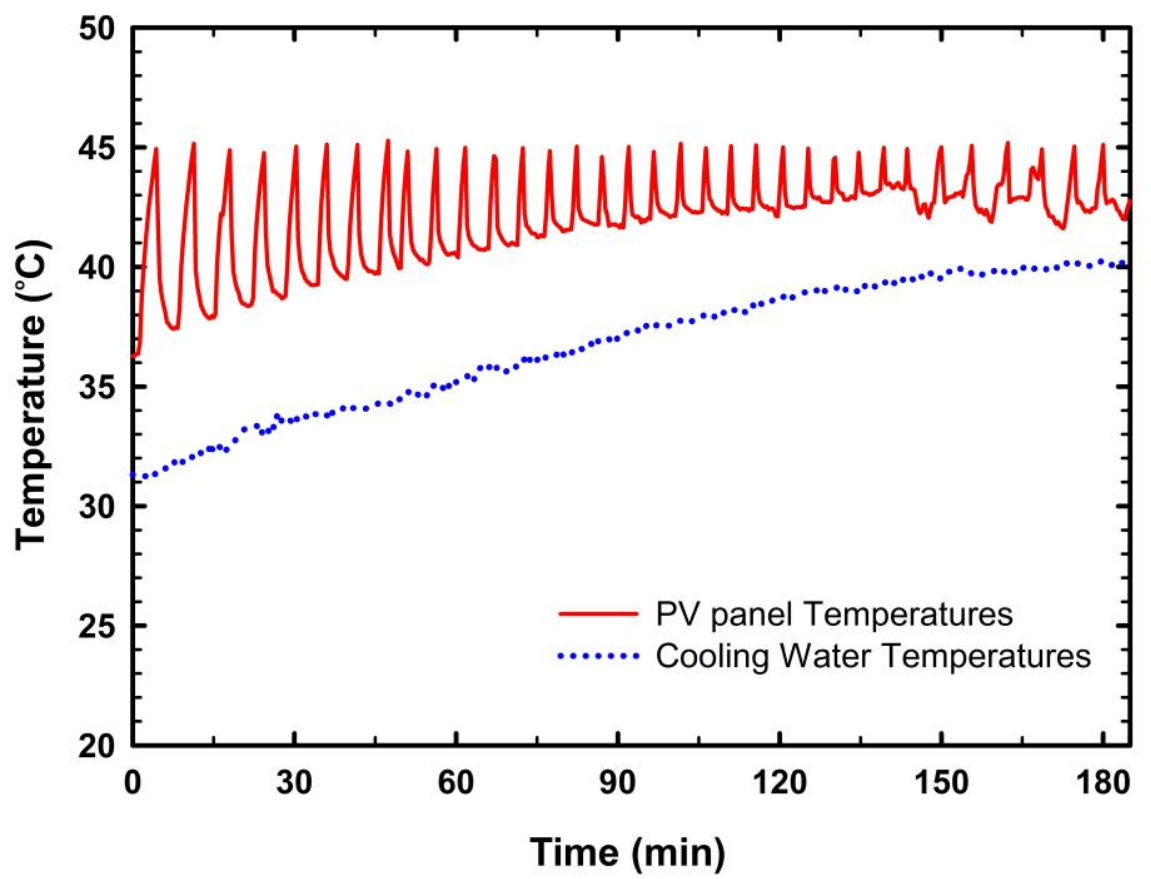

Fig. 6: Relationship between the PV panel temperatures and the cooling water temperatures in the experimental results

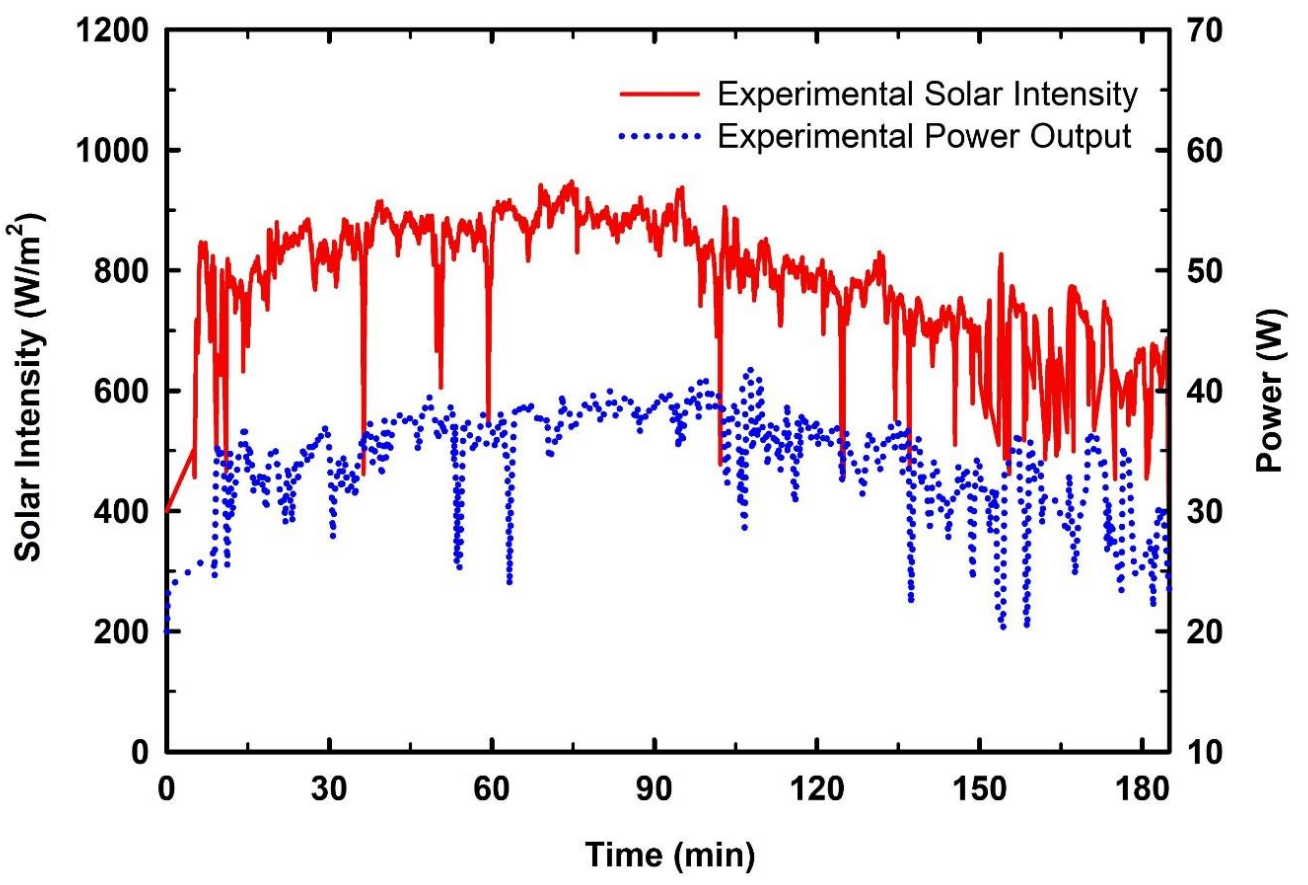

Fig. 7: Relationship between solar intensity and power output 


\subsection{The system with the UBHE cooling system}

According to the above experimental results, the cooling capacity of the cooling system decreased as the temperature increased, and thus, this experiment combined the UBHE with the cooling system to enhance its cooling capacity and efficiency.

The cooling water total flow rate of this experiment was 0.57 LPM, the nozzle temperature was equal to the UBHE outlet temperature, and the cooling system was switched on to cool the PV panel once the temperature reached $45^{\circ} \mathrm{C}$. Through a test conducted before this experiment, it was found that the cooling system combined with the UBHE can maintain its cooling capacity for cooling the PV panel to $35{ }^{\circ} \mathrm{C}$ over time, and thus, the experimental control method differs from that in the previous experiment on the system without the UBHE. In this experiment, once the PV panel was cooled to $35^{\circ} \mathrm{C}$, the cooling system was switched off, and it was switched on once the panel temperature reached $45{ }^{\circ} \mathrm{C}$ again. Then, this operational cycle was repeated throughout the working period of 3 hours 5 minutes. The experimental results are shown in Fig. 8 and Tab. 2. The cooling water temperature increase from the initial temperature in the experiment was about $3.5^{\circ} \mathrm{C}$.

A comparison of the experimental results between the cases with and without the UBHE shows that the increase in the cooling water temperature is clearly moderated in the case with the UBHE. Because the cooling water temperature could be maintained at about 27 to $29^{\circ} \mathrm{C}$ effectively, the cooling capacity of this system is considerably improved. Thus, the cooling capacity of every cooling cycle in this experiment was equivalent to that in the first cooling cycle. Fig. 9 shows the relationship between solar intensity and power output. During midday, the solar intensity is the highest in a day, and the solar intensity decreases in the afternoon. At $t=170$ min, because the solar intensity is lower, the output of the PV panel is also lower. The cooling water temperature increased during the working period; the temperature increased from 27 to $29{ }^{\circ} \mathrm{C}$ because of the increase in the groundwater temperature. The final temperature difference between the outlet and the inlet of the borehole was about $7{ }^{\circ} \mathrm{C}$, and this result displayed that the UBHE had enough cooling capacity until the end of the experiment. The experimental results shown in Fig. 10 indicate the relationship among the groundwater temperature, tank water temperature, cooling water temperature, and soil temperature. Because the water in the borehole exchanges its heat with the U-shaped heat exchangers, the water temperature increases as the working time increases, but the variation in the soil temperature is small. During the working period, the soil temperature maintained at about 28 ${ }^{\circ} \mathrm{C}$. The results show that the soil temperature variation is small in the heat exchange period, so the soil could be used to cool the UBHE. The average conversion efficiency after cooling could be obtained through eq. 2 , and the average conversion efficiency is calculated to be about $7.1 \%$ after the pump energy consumption is included.

According to the previous experiment, because the temperature of the tank increases continually, the cooling capacity decreases continually, and the pump working time also increases as the cooling capacity decreases, so more energy is consumed. The results of the third experiment indicate that the cooling system combined with the UBHE can provide lower temperature cooling water for the system. Until the experiment completed, the nozzle temperature only increased to $29^{\circ} \mathrm{C}$, whereas that in the second experiment increased to $40.4{ }^{\circ} \mathrm{C}$. This shows an obvious improvement in the final experiment, and thus, the cooling capacity in the last experiment is better than that in the second experiment. Further, the pump working time in the third experiment is also decreased owing to the improvement of the cooling capacity, and thus, the energy consumption is decreased. After the PV panel is combined with the UBHE, its efficiency could be improved. 


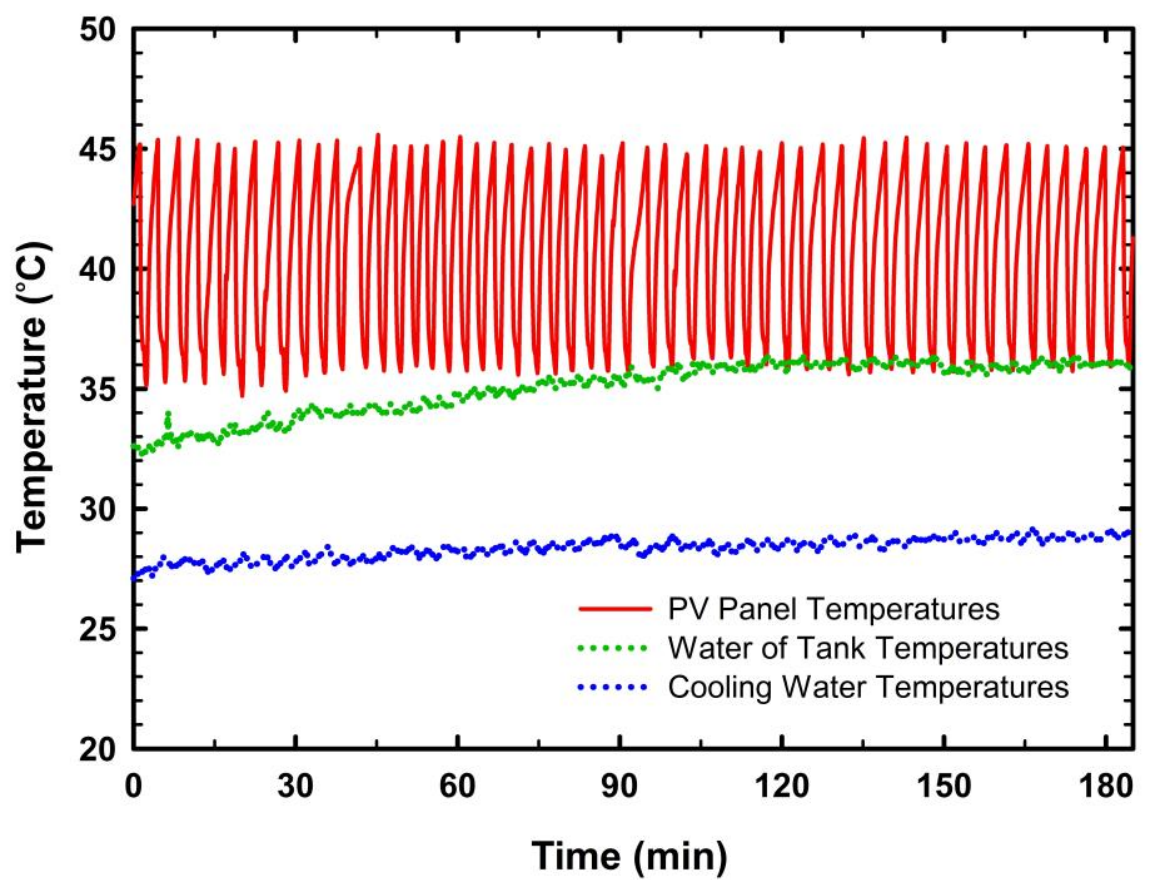

Fig. 8: Relationship between the PV panel temperatures and the cooling water temperatures in the experimental results

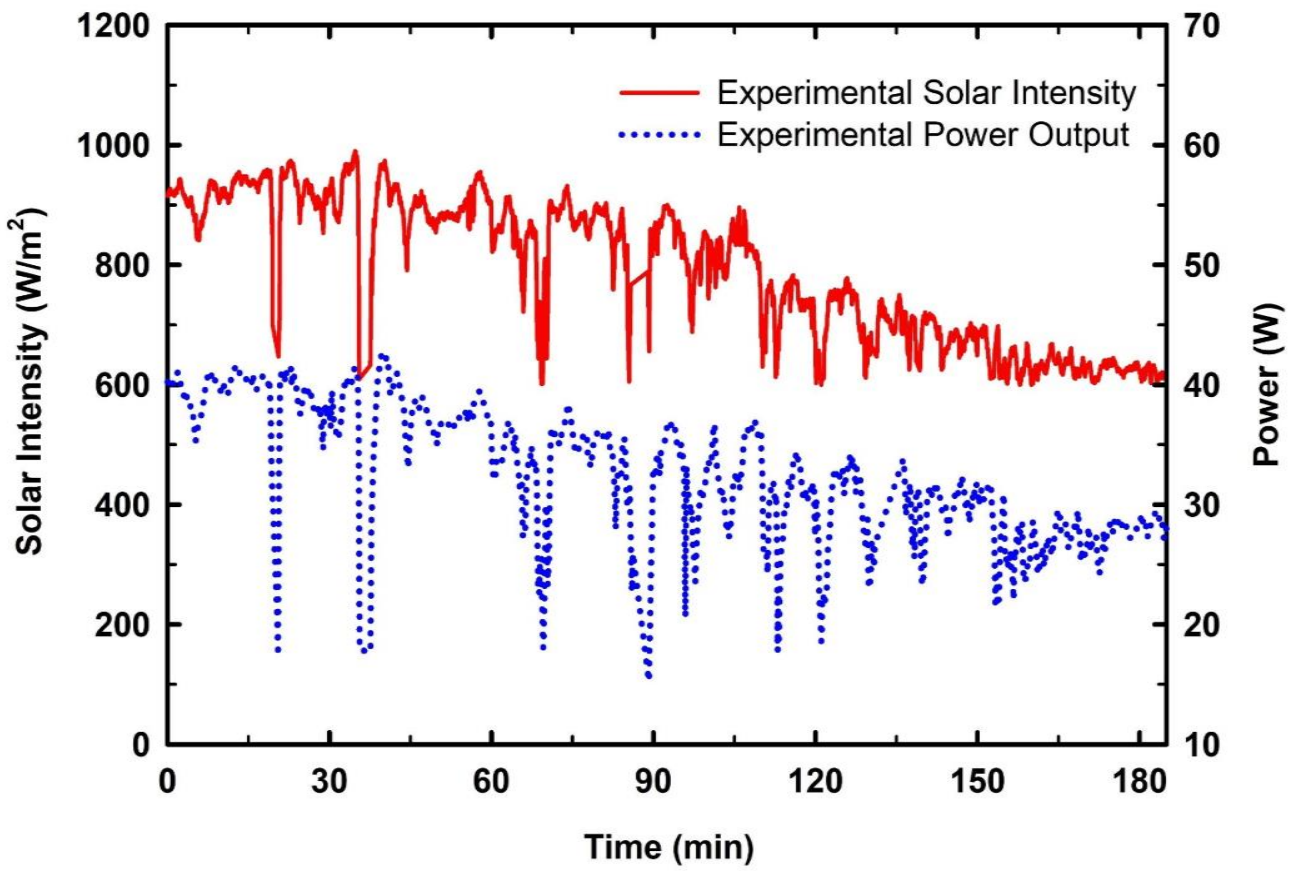

Fig. 9: Relationship between solar intensity and power output 


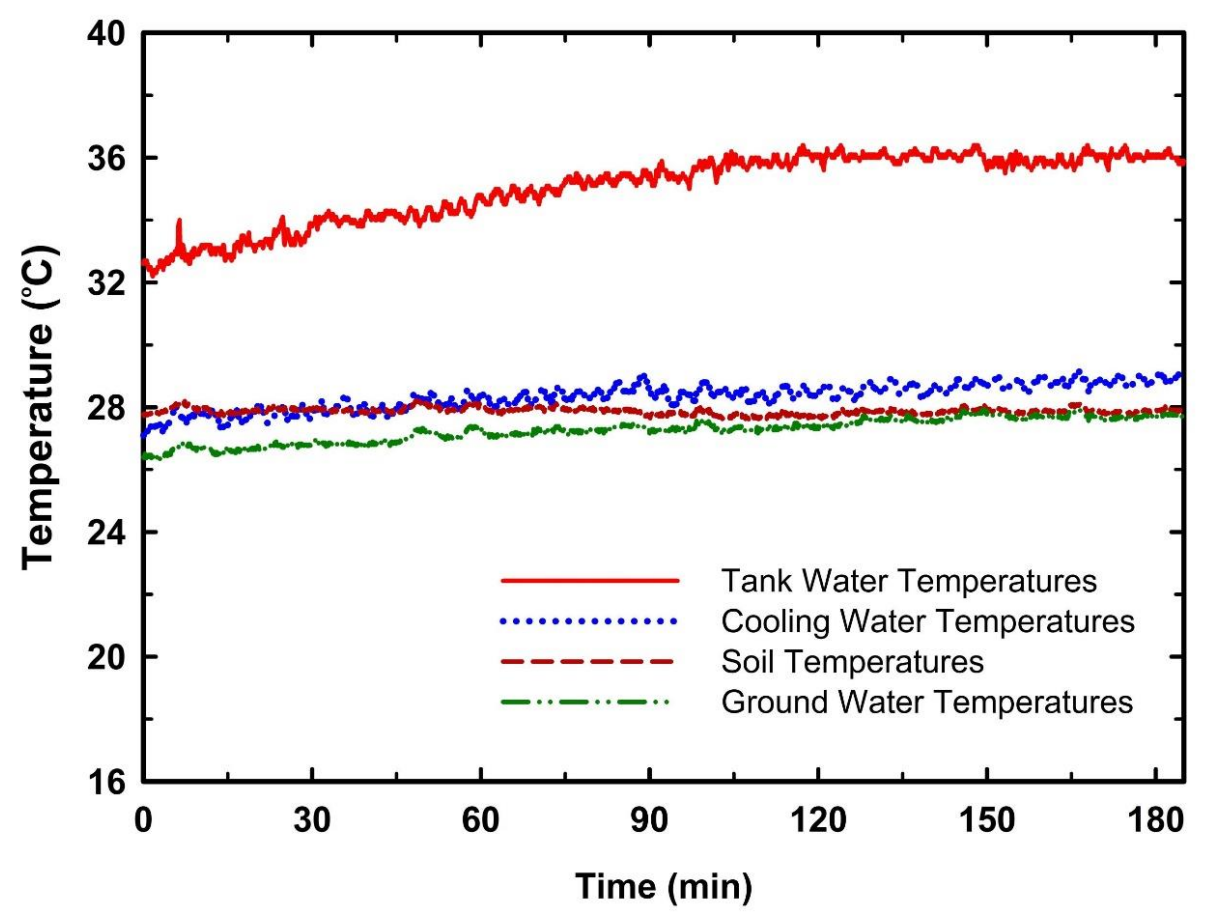

Fig. 10: Relationship among tank water temperatures, cooling water temperatures, soil temperatures, and groundwater temperatures

Tab. 2: Results of experiment; Case1: Without cooling system, Case 2: Cooling system without UBHE, and Case 3: Cooling system with UBHE

\begin{tabular}{|l|c|c|c|c|c|c|}
\hline Case & $\begin{array}{c}\text { Average } \\
\text { solar } \\
\text { intensity } \\
\left(\mathbf{W} / \mathbf{m}^{\mathbf{2}}\right)\end{array}$ & $\begin{array}{c}\text { Maximal } \\
\text { solar } \\
\text { intensity } \\
\mathbf{( W / m 2 )}\end{array}$ & $\begin{array}{c}\text { Pump } \\
\text { working } \\
\text { time (s) }\end{array}$ & $\begin{array}{c}\text { Average } \\
\text { power } \\
\text { output }(\mathbf{W})\end{array}$ & $\begin{array}{c}\text { Average net } \\
\text { power output } \\
\text { (W) }\end{array}$ & $\begin{array}{c}\text { Conversion } \\
\text { efficiency } \\
\mathbf{( \% )}\end{array}$ \\
\hline Case 1 & 946.5 & 1,058 & - & 34.5 & 34.5 & 6.56 \\
\hline Case 2 & 729.3 & 948 & 8,400 & 30.7 & 27.0 & 6.64 \\
\hline Case 3 & 777.1 & 990 & 3,605 & 32.3 & 30.7 & 7.10 \\
\hline
\end{tabular}

\section{Conclusions}

According to the experimental results, the factors mainly affecting PV panel power output are solar intensity and panel temperature. However, solar intensity cannot be easily controlled, and a method that improves efficiency by reducing the PV panel working temperature is more feasible. This paper presents such a method to mitigate the PV panel efficiency decline problem, which is due to high temperatures. Cooling capacity of the cooling system is further improved through combination with a UBHE. To compare with the cooling system without UBHE, the UBHE system also reduces the energy consumption of the cooling system. The following conclusions can be obtained:

(1) The water temperature of the nozzle outlet could be maintained at $27-29^{\circ} \mathrm{C}$ after the cooling water passes through the UBHE, and the cooling water temperature increased to $29^{\circ} \mathrm{C}$ until the experiment ended. However, for the cooling system without UBHE, its cooling water temperature would increase to $40.4^{\circ} \mathrm{C}$; thus, the system with UBHE can cool the PV panel more effectively than the system without UBHE.

(2) The UBHE system can reduce the pump operating time; thus, the pump energy consumption can decrease. The result indicates that the cooling capacity of the cooling system with the UBHE is better than that of the system without the UBHE, and this cooling system can improve the efficiency of PV panels about $8.2 \%$; moreover, as the temperatures and the number of panels increase, the benefit is more obvious. 


\section{References}

Aari Kane, Vishal Verma, Bhim Singh, 2017. Optimization of thermoelectric cooling technology for an active cooling of photovoltaic panel. Renewable and Sustainable Energy Reviews. 75, 1295-1305.

Alberto. Gemelli, Adriano Mancini, Sauro Longhi, 2011. GIS-based energy-economic model of low temperature geothermal resources: A case study in the Italian Marche region. Renewable Energy. 36, 24742483.

A.S. Kaiser, B. Zamora, R. Mazón, J.R. García, F. Vera, 2014. Experimental study of cooling BIPV modules by forced convection in the air channel. Applied Energy. 135, 88-97.

J. Bigorajski, D. Chwieduk, 2018. Analysis of a micro photovoltaic/thermal - PV/T system operation in moderate climate. Renewable Energy.

Jinhua Chen, Lei Xia, Baizhan Li, Daniel Mmereki, 2015. Simulation and experimental analysis of optimal buried depth of the vertical U-tube ground heat exchanger for a ground-coupled heat pump system. Renewable Energy. 73, 46-54.

Jin Luo, Zequan Luo, Jihai Xie, Dongsheng Xia, Wei Huang, Haibin Shao, Wei Xiang, Joachim Rohn, 2018. Investigation of shallow geothermal potentials for different types of ground source heat pump systems (GSHP) of Wuhan city in China. Renewable Energy. 118, 230-244.

K.A. Moharram, M.S. Abd-Elhady, H.A. Kandil, H. El-Sherif, 2013. Enhancing the performance of photovoltaic panels by water cooling. Ain Shams Engineering Journal. 4, 869-877.

Kerry Schiel, Olivier Baume, Geoffrey Caruso, Ulrich Leopold, 2016. GIS-based modelling of shallow geothermal energy potential for CO2 emission mitigation in urban areas. Renewable Energy. 86, 1023-1036.

M. Abdolzadeh, M. Ameri, 2009. Improving the effectiveness of a photovoltaic water pumping system by spraying water over the front of photovoltaic cells. Renewable Energy. 34, 91-96.

M. Chandrasekar, S. Rajkumar, D. Valavan, 2015. A review on the thermal regulation techniques for non integrated flat PV modules mounted on building top. Energy and Buildings. 86, 692-697.

Qunzhi Zhu, Leilei Si, 2012. Electrical Outputs and Thermal Outputs of Water/Air Cooled AmorphousSilicon Photovoltaic Modules. International Conference on Environmental Engineering and Technology Advances in Biomedical Engineering. 8, 83-88.

Sanjeev Jakhar, Manoj S. Soni, Nikhil Gakkhar, 2017. An integrated photovoltaic thermal solar (IPVTS) system with earth water heat exchanger cooling: Energy and exergy analysis. Solar Energy. 157, 81-93.

S. Nižetić, D. C`oko, A. Yadav, F. Grubišić-C`abo, 2016. Water spray cooling technique applied on a photovoltaic panel: The performance response. Energy Conversion and Management. 108, 287-296.

Suresh Kumar Soni, Mukesh Pandey, Vishvendra Nath Bartaria, 2015. Ground coupled heat exchangers: A review and applications. Renewable and Sustainable Energy Reviews. 47, 83-92. 


\title{
Extended Hottel-Whillier Models for uncovered PVT collectors
}

\author{
Mattia Battaglia, Daniel Zenhäusern and Stefan Brunold \\ SPF Institute for Solar Technology, HSR Rapperswil (Switzerland)
}

\begin{abstract}
Photovoltaic thermal (PVT) collectors are getting more and more attention for their simultaneous production of electricity and low temperature heat. Established mathematical models for the thermal efficiency of thermal collectors as well as the electrical efficiency of PV modules don't include the interactions between the thermal and electrical energy balance. In order to predict efficiencies, we extend the standard Hottel-Whillier collector model to collectors with an additional PV-layer and distinguishable temperature levels for the front side and the back side of the collector. The model is then included in a discrete model of a collector field mounted with a ventilated back side. Based on the field model, we analyze the effect of different sizes of the air gap.
\end{abstract}

Keywords: Type your keywords here, separated by commas,

\section{Introduction}

Photovoltaic thermal (PVT) collectors enable the conversion of solar radiation into electrical energy and usable heat (for a review see e.g. [1]). Since they utilize heat, which, in the case of pure PV modules would dissipate, PVT collectors achieve a particularly high level of area-specific energy yield. At the same time, the lower PV cell temperatures lead to higher electrical efficiencies compared to conventional PV modules.

The characterization of PV or thermal components is described in IEC 61215 and EN 12975 / ISO 9806, respectively. In a PVT collector, the thermal and electrical components interact. The maximum amount of solar energy available for heat generation depends on how much of the solar radiation is converted into electrical energy. Photovoltaic efficiency on the other hand depends on the cell temperature, which in turn depends significantly on the fluid temperature. Models for efficiency of pure PV or thermal components do not take these interactions into account and therefore do not describe PVT collectors sufficiently.

A parameterization, which is used for the characterization of products, must find the best possible compromise between simplicity and detail. Several simple models for PVT collectors have been proposed. The model of Florschuetz [2] is based on the assumption that the heat transfer between PV cells and absorber is very good and therefore the cell temperature can be set equal to the absorber temperature. With the model of Stegmann et al. [3] it is assumed that the difference in temperature between PV cells and heat transfer fluid is proportional to the useful heat flow. Another approach, which is used e.g. by the software Polysun [4], is based in equating the cell temperature with the fluid temperature. All these approaches allow a relatively good mapping of the thermal performance of PVT collectors. The quality of the assumptions made to determine the cell temperature depends strongly on the design of the collector. For the quantitative mapping of the additional electrical yield, which results from the cooling of the PV cells, these models are therefore only sufficiently accurate with appropriate restrictions.

We present a simple extension of the Hottel-Whillier model, familiar for pure thermal solar collectors, which can be applied to uncovered PVT collectors. The model allows the identification of new PVT-specific parameters, which allow a good mapping of the PV cell temperature. The parameters can be measured without great additional effort by measuring the cell temperature (via measurement of the open-circuit voltage) during the thermal performance test. For the validation of the model and the determination of the corresponding parameters, indoor and outdoor measurement were carried out. 


\section{Extensions of the Hottel-Whillier Model}

The presented modelling approach is based on the general approach of the Hottel-Whillier-Model [5]. The presented extension has already been published for the special case in which the ambient temperature in the front and the back of the collector can be assumed to be equal [6]. The general geometry of the investigated collector is shown in Figure 1. The collector consists of a front glass, a cell layer, and an absorber structure at the back. The conjunction between the cell layer and the absorber can thereby contain several distinguishable components like protection foils or sheet for stability and heat conduction.

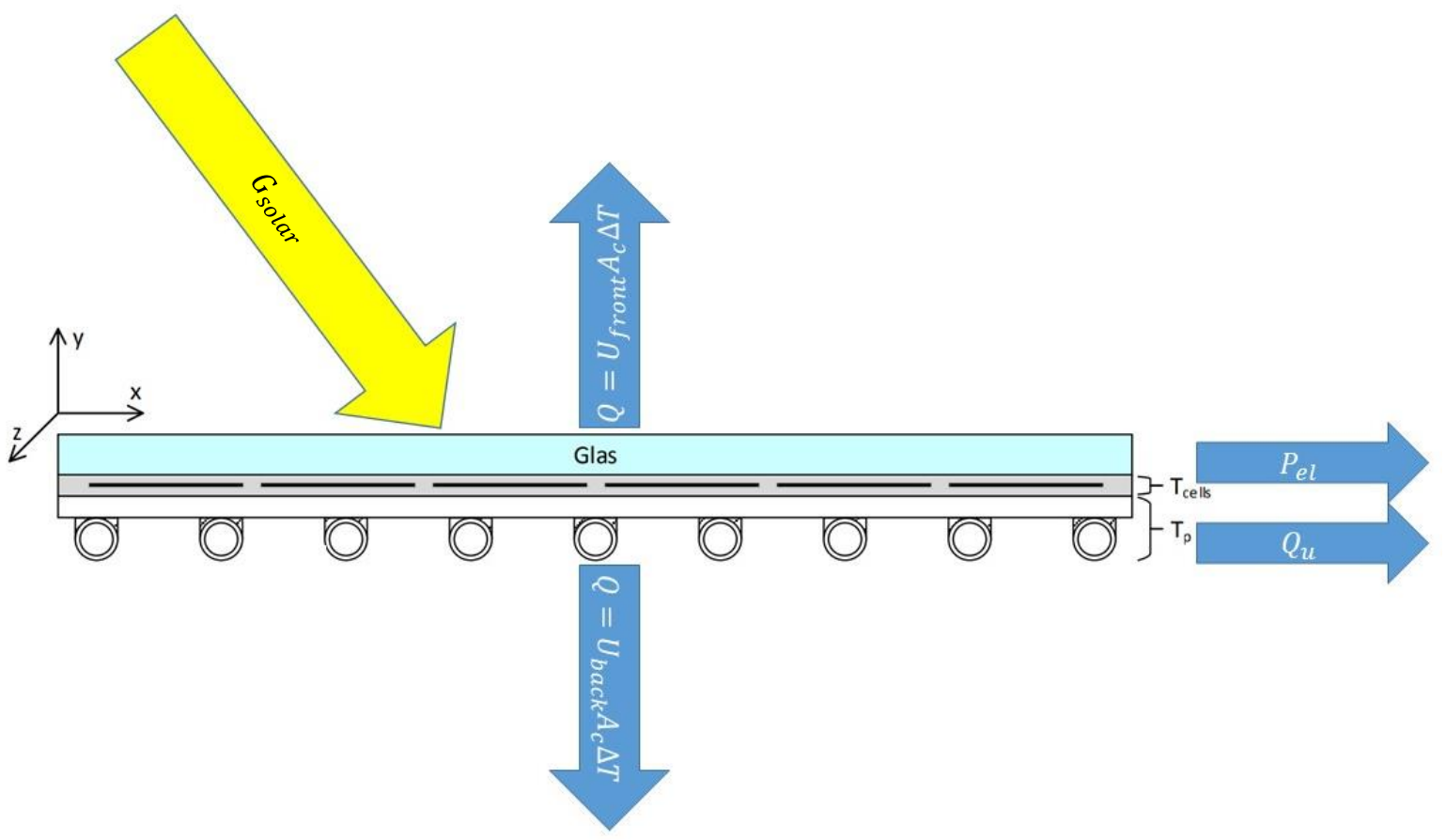

Figure 1 Scheme of the modelled PVT collector.

In the modelling approach of Hottel-Whillier, it is assumed that there is no temperature gradient inside a single layer. Furthermore, the heat conduction in $\mathrm{x}$ - and $\mathrm{z}$-direction are treated as independent. In addition, it is assumed that all solar irradiation is absorbed in the cell layer and that the heat conduction in this layer is negligible. Under these assumptions, the energy balance of the cell layer can be represented as

$$
\begin{gathered}
G_{\text {eff }}=U_{\text {front }, \text { conv }}\left(T_{\text {cells }}(x)-T_{\text {front }, a m b}\right)+U_{\text {front }, \text { rad }}\left(T_{\text {cells }}(x)-T_{\text {front }, l w}\right) \\
+h_{\text {ca }}\left(T_{\text {cells }}(x)-T_{p}(x)\right),
\end{gathered}
$$

where the thermal part of the solar gain is defined as the total solar irradiation transmitted through the front glass subtracted by the area specific electrical gain as

$$
G_{e f f}=\alpha G_{\text {solar }}-P_{e l} / A_{c}
$$

The local energy balance in the sheet layer of the absorber can be described by

$$
\begin{aligned}
\mathrm{k}_{\mathrm{p}} \delta_{p} \frac{d T_{p}(x)}{d x}= & U_{\text {back,conv }}\left(T_{p}(x)-T_{\text {back,amb }}\right)-U_{\text {back,rad }}\left(T_{p}(x)-T_{\text {front }, l w}\right) \\
& -h_{c a}\left(T_{\text {cells }}(x)-T_{p}(x)\right),
\end{aligned}
$$

where $\mathrm{k}_{\mathrm{p}}$ and $\delta_{p}$ are the heat conductivity and the thickness of the absorber layer respectively. By inserting $T_{\text {cells }}(x)$ from Equation (1) into Equation (3) the problem can be rewritten as a second order differential equation in $T_{p}(x)$ 


$$
\begin{gathered}
\frac{d T_{p}(x)}{d x}=\frac{U_{L}}{\mu_{\text {top }} k_{p} \delta_{p}}\left(T_{p}(x)-\frac{U_{\text {back }, \text { conv }} \mu_{\text {top }}}{U_{L}} T_{\text {back }, \text { amb }}-\frac{U_{\text {back }, \text { rad }} \mu_{\text {top }}}{U_{L}} T_{\text {back }, l w}\right. \\
\left.-\frac{U_{\text {front }, \text { conv }}}{U_{L}} T_{\text {front }, \text { amb }}-\frac{U_{\text {front }, \text { rad }}}{U_{L}} T_{\text {front }, l w}-\frac{1}{U_{L}} \tilde{I}\right),
\end{gathered}
$$

where $U_{L}$ is defined as

$$
U_{L}=U_{\text {front }, \text { conv }}+U_{\text {front }, \text { rad }}+\mu_{\text {top }}\left(U_{\text {back,conv }}+U_{\text {back }, \text { rad }}\right),
$$

and $\mu_{\text {top }}$ is defined as

$$
\mu_{\text {top }}=\frac{h_{c a}+U_{\text {front }, \text { conv }}+U_{\text {front }, \text { rad }}}{h_{c a}} .
$$

This differential equation can then be solved by making use of the constraints as shown in [5]. The procedure leads to a final form for the usable energy $Q_{u}$ in dependency of the fluid temperature $T_{m}$

$$
\begin{aligned}
Q_{u}=A_{c} F^{\prime}\left(G_{\text {eff }}\right. & -U_{\text {front }, \text { conv }}\left(T_{m}-T_{\text {front }, a m b}\right)-U_{\text {front }, \text { rad }}\left(T_{m}-T_{\text {front }, l w}\right) \\
& \left.-\mu_{\text {top }} U_{\text {back }, c o n v}\left(T_{m}-T_{\text {back }, a m b}\right)-\mu_{\text {top }} U_{\text {back }, \text { rad }}\left(T_{m}-T_{\text {back }, l w}\right)\right),
\end{aligned}
$$

where the correction factor $F^{\prime}$ can be considered to be a fin efficiency of the harp-like piping of the absorber. Its mathematical definition is a result of the solution of the differential equation.

$$
\begin{aligned}
F & =\frac{\tanh \left(\frac{\widetilde{m}(W-D)}{2}\right)}{\frac{\widetilde{m}(\mathrm{~W}-D)}{2}} \\
F^{\prime} & =\frac{1}{U_{L} \mathrm{~W}\left(\frac{\mu_{t o p}}{U_{L}(D+(W-D) F)}+\frac{1}{C_{b}}+\frac{1}{\pi D h_{f i}}\right)}
\end{aligned}
$$

The additional variables are the distance between two pipes $W$ and the diameter of a single pipe $D$, the bond conductivity of the junction between absorber sheet and absorber piping $C_{b}$, the internal heat transfer coefficient of the fluid flow in the pipe $h_{f i}$, and $\widetilde{m}$ is defined as

$$
\widetilde{m}=\sqrt{\frac{U_{L}}{\mu_{t o p} k_{p} \delta_{p}}} .
$$

\section{Parametrization of the thermal efficiency}

For uncovered collectors, it is a common practice to include long wave losses in a corrected irradiance value $G^{\prime \prime}$ [7]. The corrected value $G^{\prime \prime}$ represents the absorbed solar irradiance subtracted by the energy lost by long wave radiation exchange (for the case in which the module is at ambient temperature) depending on the emissivity of the module $\epsilon$ and its hemispherical absorption coefficient $\alpha$ for the solar spectrum.

$$
G^{\prime \prime}=G_{\text {solar }}+\frac{\epsilon}{\alpha}\left(E_{L}-\sigma T_{a}^{4}\right)
$$

Under this approach, the long wave temperature of equation (7) can be replaced by the general ambient temperature. The thermally useful part of $\mathrm{G}^{\prime \prime}$ can be determined by subtracting the electrical power.

$$
G^{\prime \prime}{ }_{e f f}=G^{\prime \prime}-\frac{P_{e l}}{\alpha A_{c}}
$$


In the following, the thermal efficiency of the PVT collector can be defined as

$$
\begin{aligned}
\eta_{\mathrm{th}}=\frac{\mathrm{Q}_{\mathrm{u}}}{A_{c} G^{\prime \prime}{ }_{\text {eff }}}= & \alpha F^{\prime}-\frac{F^{\prime}\left(\left(U_{\text {front }, \text { conv }}+U_{\text {front }, \text { rad }}\right)\left(T_{m}-T_{\text {front }, a m b}\right)\right)}{G^{\prime \prime}{ }_{\text {eff }}} \\
& -\frac{F^{\prime} \mu_{\text {top }}\left(U_{\text {back,conv }}+U_{\text {back,rad }}\right)\left(T_{m}-T_{\text {back }, a m b}\right)}{G^{\prime \prime}{ }_{\text {eff }}} .
\end{aligned}
$$

For the special case in which $T_{\text {front }, a m b}=T_{b a c k, a m b}=T_{a m b}$, this simplifies to

$$
\eta_{\mathrm{th}}=\frac{\mathrm{Q}_{\mathrm{u}}}{A_{c} G^{\prime \prime}{ }_{\text {eff }}}=\alpha F^{\prime}-\frac{F^{\prime} U_{L}\left(T_{f}-T_{a m b}\right)}{G^{\prime \prime}{ }_{\text {eff }}}
$$

which is of the same form as the parametrization according to ISO 9806

$$
\eta_{\mathrm{th}}=\eta_{0}\left(1-b_{u} u\right)-\left(b_{1}+b_{2} u\right) \frac{T_{m}-T_{a}}{G^{\prime \prime}{ }_{\text {eff }}} .
$$

Therefore, in the case of no electrical energy production and $G^{\prime \prime}{ }_{\text {eff }}=G^{\prime \prime}$, it is possible to link the theoretically determined values of the model directly to the parameters usually measured in collector certifications. If the parameters are only available for measurements with concurrent production of electrical energy, the collector efficiency can be expressed as

$$
\eta_{\mathrm{th}}=\frac{\mathrm{Q}_{\mathrm{u}}}{A_{c} G^{\prime \prime}}=\frac{\alpha F^{\prime} G_{e f f}^{\prime \prime}}{G^{\prime \prime}}-\frac{F^{\prime} U_{L}\left(T_{f}-T_{a m b}\right)}{G^{\prime \prime}}=\alpha F^{\prime}\left(1-\eta_{e l}\right)-\frac{F^{\prime} U_{L}\left(T_{f}-T_{a m b}\right)}{G^{\prime \prime}} .
$$

\section{Modelling of PVT-Collectors with ventilated back side}

The explicit distinction between front and back side ambient temperature and heat transfer values makes it possible to apply the model to a large scale model of a PVT field, whose back side is not insulated but in contact with an air gap. The presence as well as the width of this air gap is dependent on the used mounting system and can also be favorable for the system performance, when the PVT collector should also be used to extract ambient heat as a source for a heat pump. In air gaps of thermal components, natural convection can occur due to temperature differences and change the heat transfer values of the system significantly [8]. Therefore, in such a system the air flow on the back of the PVT-field has to be modelled independently.

A simple approach to model the temperature gradients along the air flow direction is to discretize the PVT collector temperature, the air gap temperature and the roof temperature in z-direction and to use the model of equation (7) for each control volume separately. The discretization of the mounted collector and the air gap is shown in Figure 2. The back side ambient temperatures $T_{b a c k, a m b, i}$ can be assumed to be the temperature of the air gap node and the roof temperature can be used as the back side temperatures for the long wave part $T_{b a c k, l w, i}$. For the front side an overall ambient temperature can be used for all control volumes when no temperature differences in z-direction are expected. For the collector fluid with flow rate $\dot{m}_{f}$ the energy balance between the different control volumes can be formulated as

$$
Q_{u, i}=\dot{m}_{f} c_{p, f}\left(T_{m, i+1}-T_{m, i}\right)
$$

The energy balance of the air gap control volume can be represented as

$$
\begin{aligned}
m_{\text {alr }} c_{p, a i r}\left(T_{a i r, i+1}\right. & \left.-T_{\text {air }, i}\right) \\
= & \frac{U_{\text {back }, c o n v, i} A_{c}}{N}\left(\overline{T_{p}}-T_{\text {air }, i}\right)+\frac{U_{\text {back }, \text { rad }, i} A_{c}}{N}\left(T_{\text {back }, l w / w a l l, i}-T_{\text {air }, i}\right),
\end{aligned}
$$

where $\mathrm{N}$ is the number of control volumes, $A_{c}$ the total collector area and $\overline{T_{p}}$ the average absorber temperature. 


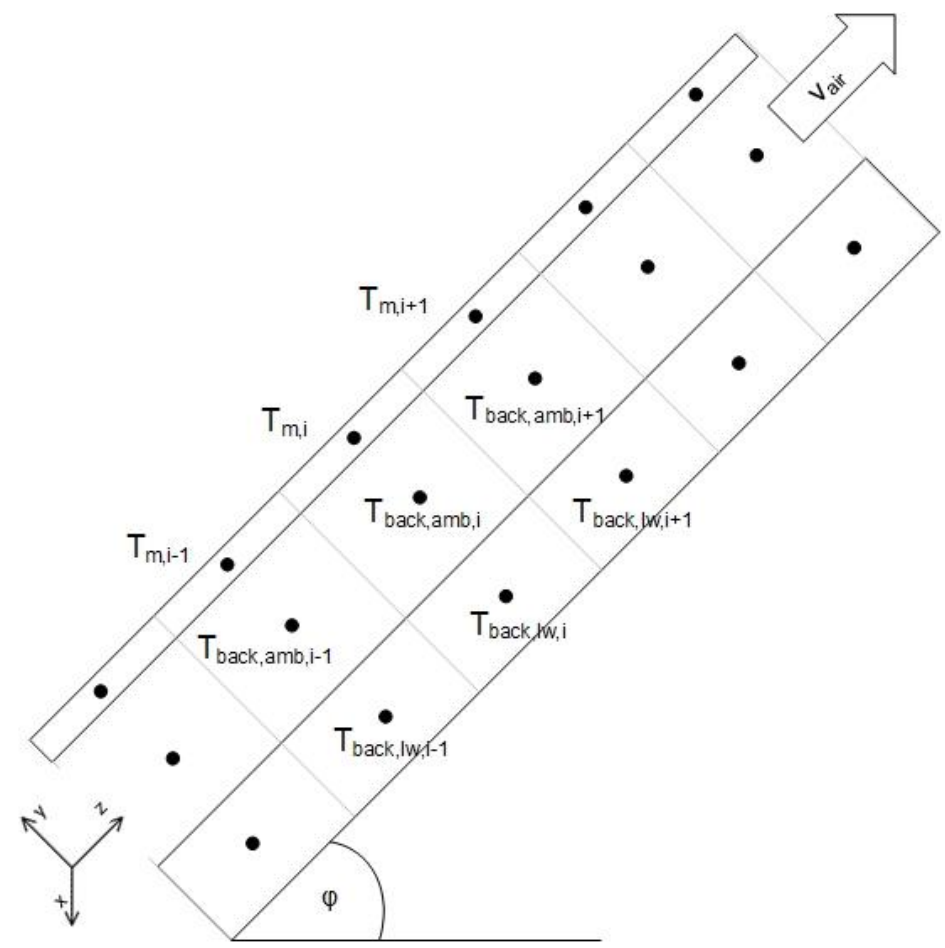

Figure 2 Discretization of the PVT collector field.

For the heat transfer coefficients in the air gap $U_{b a c k, c o n v, i}$ empirical correlations for internal flows can be used [9].

$$
N u_{D}=\frac{\left(\frac{f}{8}\right)\left(R e_{D}-1000\right) P r}{1+12.7\left(\frac{f}{8}\right)^{\frac{1}{2}}\left(\operatorname{Pr}^{2}-1\right)}
$$

The developing natural convection in the air gap can be determined by computing the pressure difference induced by temperature differences between the ambient and the air in the channel. The pressure difference due to buoyancy and friction in one control volume can thus be described by

$$
P_{i}-P_{i+1}=g \Delta z \rho(T) \cos (\phi) \pm \frac{f \rho(T) v^{2}}{2 D_{h}}
$$

where $g$ is the gravitational acceleration, $\Delta z$ is the length of a control volume in $z$ direction, $f$ the friction factor, $v$ the air stream velocity and $D_{h}$ the hydraulic diameter of the air duct. The friction factor can be derived from empirical correlations for the Reynolds number $R e_{D}$ e.g. [10]:

$$
f=\left(0.790 \ln R e_{D}-1.64\right)^{-2} .
$$

The pressure difference between the upper and the lower end of the air gap can then be compared with the difference associated by an equivalent air column with uniform temperature. The resulting pressure difference will be equalized by mass flow according to the dynamic pressure formula

$$
\Delta P_{\text {out }}= \pm \frac{1}{2} \rho v_{\text {air }}^{2}
$$

\section{Influence of the ventilated back side}

With the resulting model, the effect of different depths of the air gap can be analyzed. An example system with a total height (channel length) of $6 \mathrm{~m}$ and an inclination of $60^{\circ}$ was investigated. The values used in the model equations are shown in Table 1 . The absorption coefficient $\alpha$ was chosen such that the model results for $T_{m}^{*}=0$ are equal to Solar Keymark measurement values of a commercially available PVT collector [11]. 
Table 1 Model parameters

\begin{tabular}{|c|c|c|c|}
\hline Variable & Description & Value & Unit \\
\hline$U_{\text {front,conv }}$ & $\begin{array}{c}\text { Front side convective heat } \\
\text { transfer rate }\end{array}$ & 2.8 & {$\left[\mathrm{~W} /\left(\mathrm{m}^{2} \mathrm{~K}\right)\right]$} \\
\hline$h_{c a}$ & $\begin{array}{c}\text { Heat transfer coefficient } \\
\text { between absorber sheet and } \\
\text { PV layer }\end{array}$ & $\left.297 /\left(\mathrm{m}^{2} \mathrm{~K}\right)\right]$ \\
\hline$k$ & $\begin{array}{c}\text { Heat conductivity of the } \\
\text { absorber sheet }\end{array}$ & $5 * 10^{-4}$ & {$[\mathrm{~W} /(\mathrm{mK})]$} \\
\hline$\delta_{p}$ & Thickness of absorber sheet & 0.08 & {$[\mathrm{~m}]$} \\
\hline$W$ & Separation absorber pipes & 0.01 & {$[\mathrm{~m}]$} \\
\hline$D$ & Diameter absorber pipe & 100 & {$[\mathrm{~W} /(\mathrm{mK})]$} \\
\hline$C_{b}$ & $\begin{array}{c}\text { Bond conductance absorber } \\
\text { sheet/pipe }\end{array}$ & 300 & {$\left[\mathrm{~W} /\left(\mathrm{m}^{2} \mathrm{~K}\right)\right]$} \\
\hline$h_{f i}$ & $\begin{array}{c}\text { Internal heat transfer } \\
\text { coefficient absorber pipe }\end{array}$ & $5.67^{*} 10^{-8}$ & {$\left[\mathrm{~W} /\left(\mathrm{m}^{2} \mathrm{~K}^{4}\right)\right]$} \\
\hline$\sigma$ & Boltzmann constant & 0.85 & {$[-]$} \\
\hline$\alpha$ & Absorption coefficient PV \\
\hline$\epsilon$ & layer & 0.9 & {$[-]$} \\
\hline
\end{tabular}

The results of the model calculation are shown in Figure 3. The collector efficiency values are compared with the values computed from the Solar Keymark Test of the mentioned PVT collector. It can be seen that the computed overall performance of the collector field is similar to the measurement. The model results show that for $T_{m}^{*}<0.02$ all efficiency curves slightly exceed the measured reference. This indicates that at the corresponding temperature levels, the very low level of buoyancy driven flow inside the channel leads to less heat loss on the back side than the free convection present on the experimental test bench. For higher values of $T_{m}^{*}$ the calculated efficiency of the PVT collectors mounted on a backside air channel drops below the reference measurement for all depths of the air channel. This can be explained by the increasing air flow due to natural convection that is caused by the larger temperature difference between ambient air and the collector.

On the right hand side of Figure 3 the corresponding average values for the convective heat transfer coefficient between the collector and the air inside the channel is shown. It can be seen that increased temperature differences lead to increased flow and thereby to increased heat transfer rates. In addition, according to the model, the convective heat transfer inside the air channel is increasing for smaller air gap depths.
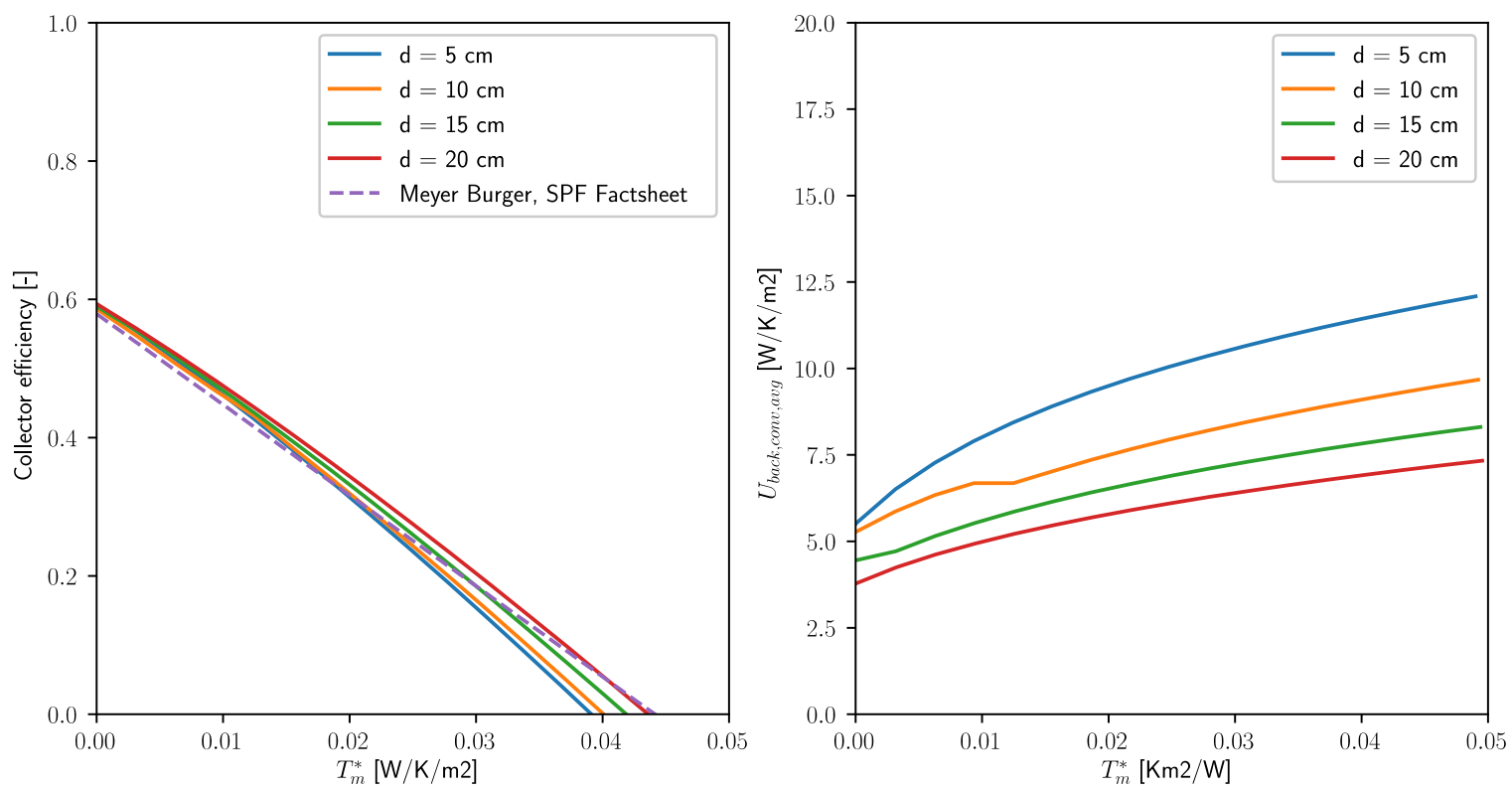

Figure 3 Model results for the inclined PVT field with ventilated back side. 


\section{Conclusion}

We extended the standard Hottel-Whillier-Model to uncovered photovoltaic-thermal collectors. In addition to previous publications we formulated the model equations such that different temperature levels for the front side and the back side of the collector can be used. Based on this extended model for the PVT collector, we modelled a PVT installation with ventilated back side. For the PVT field model we used a simple discretization in the flow direction for both the PVT collector field and the flow in the back side air channel.

The model of the PVT installation with ventilated back side was used to investigate the effect of free convection in an air channel at the back side of a PVT field. The calculations showed that the presence of a ventilated air gap at the back side of the PVT field leads to an increased heat transfer rate especially in the case of high temperature differences between the ambient air and the collector. The effect was found to be increasing for smaller air gaps down to a depth of $5 \mathrm{~cm}$. For systems in which the PVT collectors are used to collect ambient heat, such an installation can be used to enhance the system performance.

\section{References}

[1] H.A. Zondag, Flat-plate PV-Thermal collectors and systems: A review, Renewable and Sustainable Energy Reviews. 12 (2008) 891-959. doi:10.1016/j.rser.2005.12.012.

[2] L.W. Florschuetz, Extension of the Hottel-Whillier model to the analysis of combined photovoltaic/thermal flat plate collectors, Solar Energy. 22 (1979) 361-366. doi:10.1016/0038092X(79)90190-7.

[3] M. Stegmann, E. Bertram, G. Rockendorf, S. Janßen, Model of an Unglazed Photovoltaic Thermal Collector Based on Standard Test Procedures, in: Solar World Congress 2011 Proceedings, Kassel, Germany, 2011. https://www.researchgate.net/publication/314383446_Model_of_an_Unglazed_Photovoltaic_Thermal_Co llector_Based_on_Standard_Test_Procedures (accessed August 21, 2018).

[4] Software zur Planung von PV-, Solarthermie-, Geothermie- und kombinierte Anlagen - Produktübersicht Produkt - Vela Solaris AG | Polysun Simulation Software, http://www.velasolaris.com/produkt/produktuebersicht.html (accessed August 21, 2018).

[5] J.A. Duffie, W.A. Beckman, Solar Engineering of Thermal Processes, 4th Edition, Wiley, 2013.

[6] D. Zenhäusern, A. Bohren, M. Rommel, S. Dittmann, T. Friesen, F. Frontini, Thermische und elektrische Charakterisierung von unabgedeckten PVT-Kollektoren, in: 25. OTTI Symposium Thermische Solarenergie, OTTI e.V., Regensburg, Kloster Banz, Bad Staffelstein, Germany, 2015. P:ISPFPublikationen\2015\150506_OTTI TSE_Bad Staffelstein\Zenhäusern_PVTKollektor\Paper|Zenhaeusern_PVT.pdf.

[7] G.L. Morrison, D. Gilliaert, Unglazed Solar Collector Performance Characteristics, Journal of Solar Energy Engineering. 114 (1992) 194-200. doi:10.1115/1.2930005.

[8] D. Faggembauu, M. Costa, M. Soria, A. Oliva, Numerical analysis of the thermal behaviour of ventilated glazed facades in Mediterranean climates. Part I: development and validation of a numerical model, Solar Energy. 75 (2003) 217-228. doi:10.1016/j.solener.2003.07.013.

[9] V. GNIELINSKI, New equations for heat and mass transfer in turbulent pipe and channel flow, Int. Chem. Eng. 16 (1976) 359-368. https://ci.nii.ac.jp/naid/10024972801/ (accessed September 6, 2018).

[10] B.S. Petukhov, Heat Transfer and Friction in Turbulent Pipe Flow with Variable Physical Properties, in: J.P. Hartnett, T.F. Irvine (Eds.), Advances in Heat Transfer, Elsevier, 1970: pp. 503-564. doi:10.1016/S0065-2717(08)70153-9.

[11] Solar Collector Factsheet Meyer Burger Hybrid 280/900 Sky, http://www.spf.ch/fileadmin/daten/reportInterface/kollektoren/factsheets/scf1649de.pdf (accessed September 6, 2018). 
D. Zenhäusern et. al. / EuroSun 2018 / ISES Conference Proceedings (2018) 


\title{
An Overview of PVT modules on the European Market and the Barriers and Opportunities for the Dutch Market
}

\author{
Corry de Keizer ${ }^{1}$, Jeffrey Bottse ${ }^{1}$, Minne de Jong ${ }^{1}$ and Wiep Folkerts ${ }^{1}$ \\ 1 SEAC / TNO, Eindhoven (Netherlands)
}

\begin{abstract}
The market for Photovoltaic-Thermal (PVT) systems and the number of PVT module suppliers is growing. We will present a summary of our recently published market survey of PVT modules. In our market investigation we found 54 different PVT module types that are currently being sold. The largest share of these, roughly three out of four, are uncovered flat plate PVT collectors. Furthermore, a list of barriers and opportunities will be presented as perceived by a wide range of stakeholders in the Netherlands. The main opportunities that were identified are a higher combined thermal and electrical yield per square meter. Furthermore, a combination with heat pumps and the possibility to achieve a (near) zero energy building and aesthetic integration was seen as an opportunity. Several barriers were identified. The largest is the complexity of the system design, the optimization of the system and installation. Furthermore, the high upfront costs and the lack of standardization were mentioned as barriers.
\end{abstract}

Keywords: PVT collector, PVT market study

\section{Introduction}

The market for Photovoltaic-Thermal (PVT) systems and the number of PVT module suppliers is growing. This paper presents a market survey of PVT modules and a classification of PVT heat pump systems. Furthermore, a list of barriers and opportunities will be presented as perceived by a wide range of stakeholders in the Netherlands.

In the built environment, the main energy use consists of electricity and heat. Regular PV systems convert approximately $15-20 \%$ of the incoming radiation to electricity, while ca. $75 \%$ is converted into waste heat. In hybrid Photovoltaic-Thermal (PVT) systems, a part of this energy is transferred to a liquid or air, and harvested as (useful) heat. This way, multi-functional PVT roofs can play an important role in the supply of local renewable energy, both in the form of electricity and heat. A promising option to reach near zero energy residential buildings is the combination of PVT collectors with a heat pump.

This benchmark report takes a look at the PVT market in Europe with a special focus on the Netherlands. We will answer the following research questions:

- Which PVT collector producers are active on the market?

- What type of PVT collector are produced?

- What are the current market prices for PVT collectors?

- What are the opportunities and barriers for PVT products in the Netherlands

\section{PVT Market Survey}

\subsection{Module classification}

Several previous market surveys have been published and include a classification of modules (Zondag, et al., 2006; Adam, et al., 2014; Zenhäusern, et al., 2017; Department for Business, Energy and Industrial Strategy, 2017). The attention for PVT systems and the number of suppliers is steadily growing. There are a lot of parameters that can vary and characterize a PVT module. These include e.g.: 
- Type of PV laminate: crystalline silicon, CIGS, CdTe, III-V etc.

- Type of collector: flat plate liquid, flat plate air, concentrator, vacuum tube

- Type of heat transfer medium: air, water or water-glycol mixture

- Type of absorber: sheet and tube, a free-flow and a dual channel, roll bond.

- Type of insulation: covered, uncovered with or without thermal insulation

- Building integrated or not building integrated

- Method for attaching the PV module to the absorber

In this benchmark we use the classification as defined in the PVT Norm Project (Adam, et al., 2014), see also figure 1.

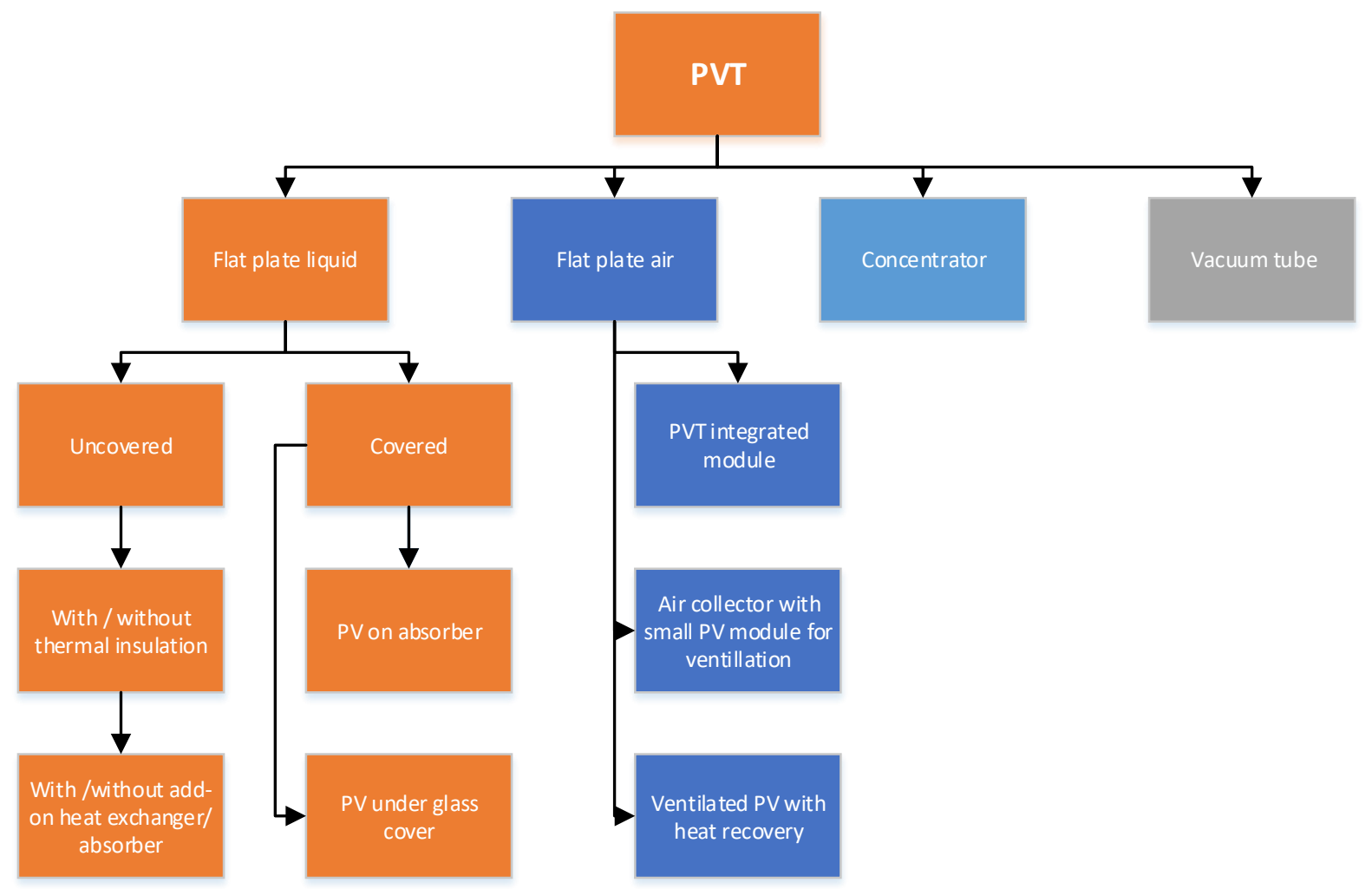

Fig. 1: PVT Module Classification (adapted from (Adam, et al., 2014))

\subsection{Market analysis}

A market analysis on available PVT products was carried out in 2017. The modules have been categorized into different categories. Out of the 92 different PVT modules found, 54 modules are currently sold, out of which 11 originate from the Netherlands. Furthermore, 6 products are in development and 32 have been taken out of production. A full list is provided in the PVT benchmark report (de Keizer, et al., 2018).

The PVT market is very dynamic, with new companies entering the market, as well as PVT products being taken off the market. The last decade has seen a growing number of companies offering PVT modules. This is thought to have originated from a decline in prices of photovoltaic modules as well as a stronger focus on reducing fossil energy use in the built environment. 


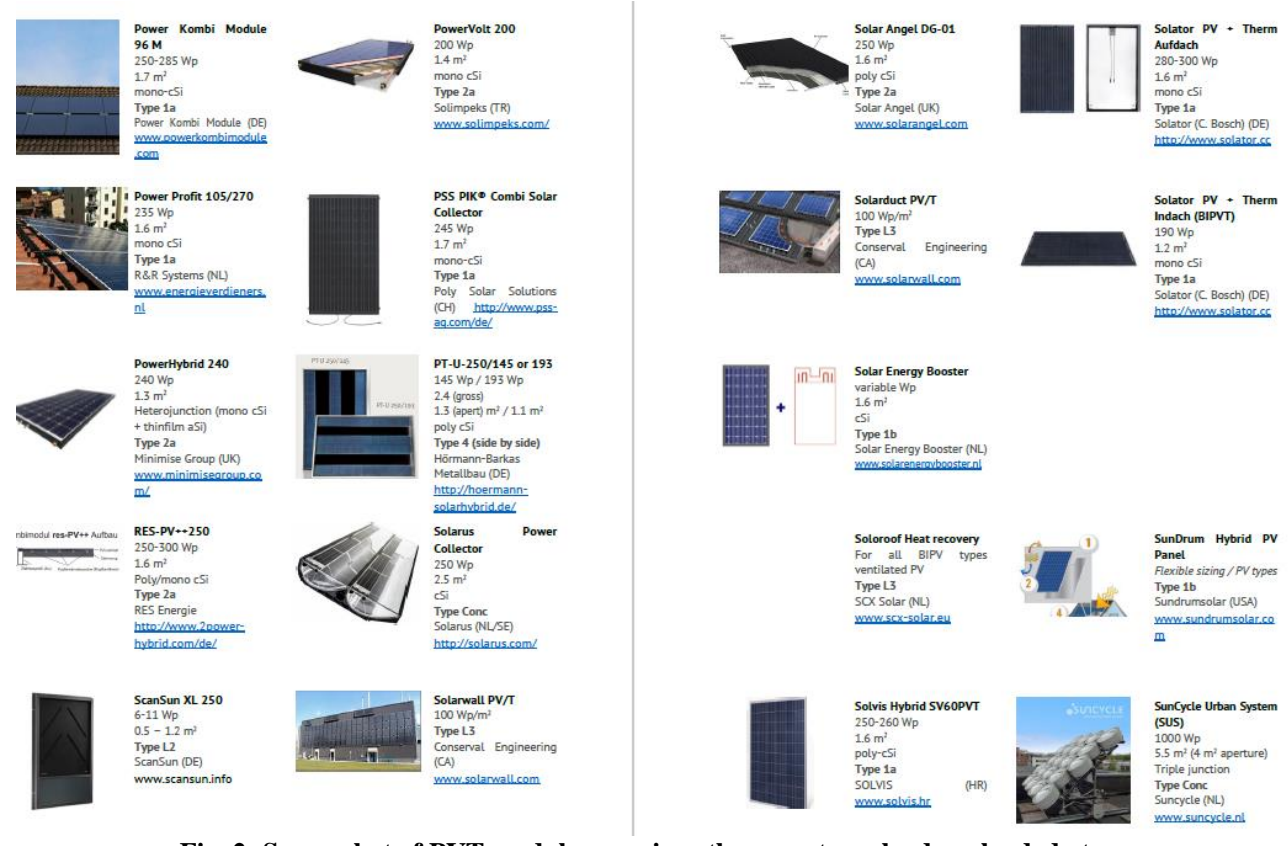

Fig. 2: Screenshot of PVT module overview, the report can be downloaded at www.seac.cc

The classification in Figure 2 shows a large share of uncovered flat plate liquid collectors. These account for $72 \%$ of the total PVT module availability. In the Netherlands, the uncovered flat plate liquid modules even represent $82 \%$ of all modules. Uncovered flat plate collectors perform well for applications that require a low temperature, like regeneration of a ground-source heat pump or in general with heat pumps. Furthermore, for covered PVT products there is a large tradeoff between the desired higher temperature for thermal applications and the desired low temperature for PV cells. Furthermore, stagnation can lead to very high PV temperatures.

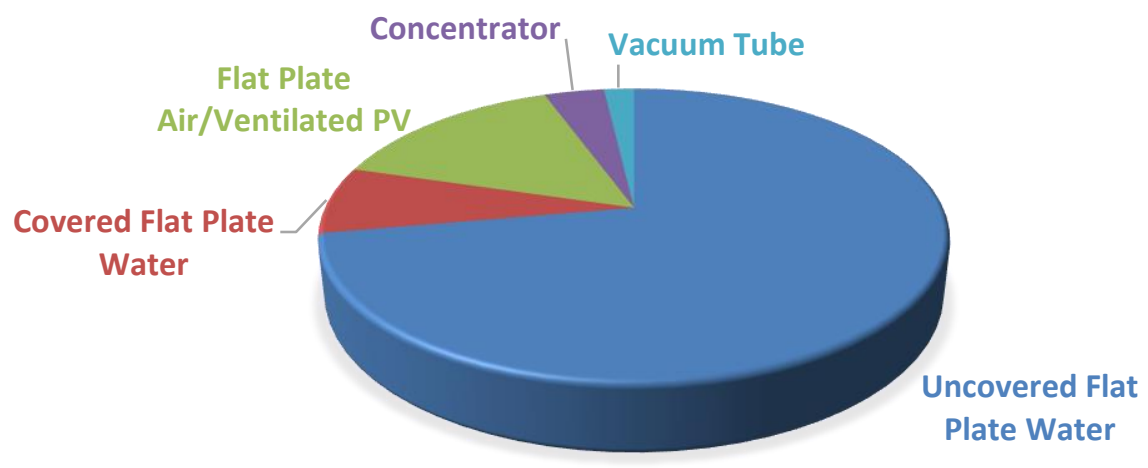

Fig. 3: Types of PVT modules on the market

A price survey for uncovered flat plate liquid PVT modules was conducted. The results are shown in Figure 3. The left graph shows a box plot of the module price, the middle shows the normalized module price in $€ / \mathrm{m} 2$ and the right graph shows the price per $\mathrm{Wp}$. It can be seen that there is a large range in pricing. The average price of PVT modules is $323 € / \mathrm{m} 2$ with a standard deviation of $98 €$. The PVT price is about half of that in 2005 , however, this decline is mainly caused by declining PV prices. Since PVT is still a technological niche, there are expectations that prices can decline further in the future. 

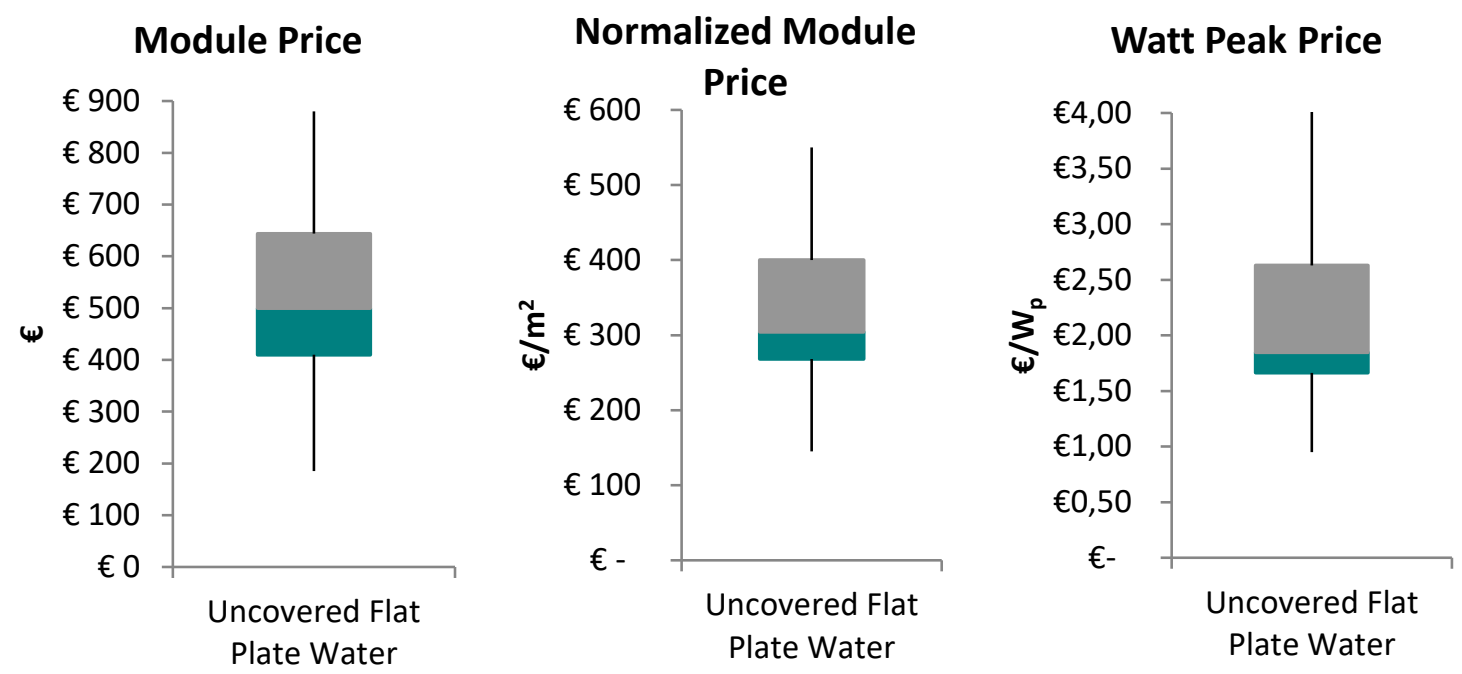

Fig. 4: PVT Module Price, Normalized Module Price and Watt-peak Price

\section{Barriers and opportunities}

PVT is a promising technology, as the exergy output of the module can be higher than that of solar thermal collectors or photovoltaic modules per square meter. However, this alone is not a guarantee for becoming a dominant technology or conquering a large share of the market. In this section, we present the current barriers and opportunities for PVT in the Netherlands as perceived by different stakeholders. 28 interviews of different stakeholders in the Netherlands were carried out, among the interviewees were PVT, PV, solar thermal and heat pump producers, government parties, experts, installers and project developers. Furthermore, a literature study was carried out that included 15 research papers that were published between 2000 and 2016.

Many opportunities are identified in the literature and interviews, while also many barriers are mentioned. The literature seems more optimistic than the interviewees. Table 1 shows an overview of the most frequently mentioned barriers and opportunities.

According to literature, the advantages of PVT heavily outweigh the disadvantages. About half of the papers analysed, mention economic aspects for PVT as an opportunity as well as a high energy efficiency and yields. However, from the interviews it was concluded that the economic profitability is still low, while initial investment costs are high and that can be a hurdle. Some synergy effects in literature that would lead to lower pricing, like use of one installer and less material costs than both a separate PV and solar thermal system were not confirmed in the interviews. However, this does not mean it cannot grow into an opportunity in the future.

The main strength of PVT is based on the compactness: PVT is convenient or maybe necessary for those with limited roof area, as well as for consumers demanding the most energy per unit of area. In practice, many solutions do not require the full roof area, unless a transition to a zero-energy home is made. The main barriers for PVT are either in the technical or economic domain; technical improvements often directly improve the economics. 
Tab.1: Overview of opportunities and barriers found from literature (L) and interviews (I)

\begin{tabular}{|c|c|c|c|c|c|}
\hline Strength \& Opportunities & $\begin{array}{l}\mathbf{L}^{*} \\
15\end{array}$ & $\begin{array}{l}* \\
26\end{array}$ & Weaknesses \& Barriers & $\begin{array}{l}\mathrm{L} \\
15\end{array}$ & $\begin{array}{c}\text { I } \\
26\end{array}$ \\
\hline Compactness and yields & 12 & 18 & $\begin{array}{c}\text { Complexity of system design and } \\
\text { installation, difficulties in optimisation }\end{array}$ & 9 & 20 \\
\hline Combination of PVT with heat pump & 12 & 25 & Reliability & 8 & 6 \\
\hline BIPVT (Building integrated PVT) & 8 & 2 & $\begin{array}{l}\text { Low economic profitability and high } \\
\text { investment costs }\end{array}$ & 8 & 21 \\
\hline $\begin{array}{l}\text { Third-party owned business models } \\
\text { (financing schemes) }\end{array}$ & & 3 & $\begin{array}{l}\text { Competition with PV and solar thermal } \\
\text { collectors }\end{array}$ & 5 & 8 \\
\hline $\begin{array}{c}\text { Energy performance regulations for } \\
\text { dwelling (EPC/BENG) and renewable } \\
\text { energy targets }\end{array}$ & 3 & 11 & $\begin{array}{l}\text { Lack of testing, standards and } \\
\text { certification, EPC calculations unclear }\end{array}$ & 4 & 9 \\
\hline \multirow[t]{4}{*}{ Aesthetics (homogenous roof) } & 10 & 5 & $\begin{array}{l}\text { Conflict of interests real estate } \\
\text { developer and resident }\end{array}$ & & 10 \\
\hline & & & Subsidy Landscape unclear & 3 & 3 \\
\hline & & & Thermal yield hard to monitor & & 6 \\
\hline & & & Lack of awareness & 8 & 12 \\
\hline
\end{tabular}

* L - Literature, I - interview. In the literature also financial attractiveness and reduced cost because of combining installations are mentioned. However, this is currently not the case. Two different installers might make it more complicated. In the interviews also an improved PV performance is mentioned, because of lower temperatures.

Table 1 shows that many barriers are faced by PVT technology. A PVT system is more complex than a PV system for both planning and installation. There are less rules of thumb and easy planning tools available. Demand for hot water and space heating lead to a higher complexity of dimensioning and optimization of the system configuration and component sizes. The thermal performance for a badly designed system as well as reliability can be low. Furthermore, there has been a lack of continuation of PVT producing companies, this can lead to distrust and lack of warranties. The complexity of the installations, mentioned many times by the interviewees was not foreseen by the literature. In fact, the literature opted for lower installation costs due to a combined installation, but in practice, this is far from happening. The main advantage of PVT is seen as the compactness of the modules and the ability to generate high yields. The combination with a heat pump showed to be the preferred system configuration and the aesthetic integration of PVT can be the first major improvement for PVT. Many interviewees argue that uncovered PVT cannot become financially attractive without a heat pump. Many interviewees expect a longer lifetime and higher electrical efficiency in PVT due to cooling, however this is insufficiently proven in practice yet.

The high investment costs are also a barrier, this could partially be overcome by introducing innovative, thirdparty owned business models, exploiting the system and omitting the threshold of the initial investment. Having low economic profitability is a common factor for innovations. Having no clear regulations, standards and certifications is a common barrier for niche technologies. Furthermore, the possible conflict of interest between real estate developers and residents retains the diffusion of renewable energy technologies. Despite the lack of a clear overview of calculations, it is expected that installing PVT could contribute greatly to the 2020 and future goals of the government. The social factors show that the aesthetics of a PVT system fits between a BIPV and a side-by-side system, and can be improved if the BIPVT development accelerates. The awareness for PVT is still low for both potential consumers as well as the installers, which should be the largest sales channel.

The conclusion can be drawn that PVT is still a technological niche. The early adopters and especially the innovators consider environmental benefits and being precursors by showing new innovations as requisites for adoption. The uncovered PVT module combined with a heat pump is currently the most promising system configuration according to most interviewees. The barriers of high investments costs and low economic profitability are less relevant for the innovators, while they attach value to the transition towards renewables and aesthetics of their building. Such a system would generate domestic hot water as well as space heating and can be 
a retrofit, renovation of part of a newly-built dwelling. Such a system with a heat pump is easiest installed in a new dwelling, reducing costs and complexity of the installation. The interviewees consider both the construction and renovation as possible markets for PVT. Furthermore, technological innovation and a growing market could help to overcome certain barriers.

\section{Conclusion}

The market for Photovoltaic-Thermal (PVT) systems and the number of PVT module suppliers is growing. In our market investigation we found 54 different PVT module types that are currently being sold. 11 of these originate from the Netherlands. The largest share of these, roughly three out of four, are uncovered flat plate PVT collectors.

Opportunities and barriers were identified by interviews and a literature review. The main opportunities that were identified are a higher combined thermal and electrical yield per area. The largest barrier that was identified is the complexity of the system design, the optimization of the system and installation. Furthermore, the high upfront costs and the lack of standardization were mentioned. To become a successful market product, these barriers should be addressed.

\section{References}

Adam, M., Wirth, H. P. \& Radosavljevic, R., 2014. Verbundprojekt: Standardisierung und Normung von multifunktionalen PVT Solarkollektoren (PVT-Norm), s.l.: Fachhochschule Düsseldorf. https://zies.hsduesseldorf.de/forschung-und-entwicklung/erneuerbare-energien/Projekte_e2/Documents/PVT_Norm_FHD.pdf

de Keizer, C., Bottse, J., de Jong, M. \& Folkerts, W., 2018. PVT Benchmark; An overview of PVT modules on the European market and the barriers and opportunities for the Dutch Market, Eindhoven: SEAC. https://www.seac.cc/wp-content/uploads/2018/04/PVTinSHaPeBenchmark_final_update19_3_2018.pdf

Department for Business, Energy and Industrial Strategy, 2017. Evidence Gathering - Low Carbon Heating Technologies - Hybrid Solar Photovoltaic Thermal Panels, London, UK: s.n. https://www.gov.uk/government/uploads/system/uploads/attachment_data/file/545246/Solar_PVT_FINAL_1_. pdf

Zenhäusern, D., Bamberger, E. \& Baggenstos, A., 2017. PVT Wrap-Up; Energiesysteme mit PhotovoltaischThermischen Solarkollektoren, Rapperswil: Institut für Solartechnik SPF. www.spf.ch/fileadmin/user_upload/Forschung/Projekte/PVT_WrapUp_Final_mit_FR_Zfsg.PDF

Zondag, H., Bakker, M. \& van Helden, W., 2006. PVT Roadmap; A European guide for the development and market introduction of PV-Thermal technology, Petten: ECN. https://www.ecn.nl/docs/library/report/2005/rx05170.pdf

\section{Acknowledgements}

This work was supported by the 'Netherlands Enterprise Agency' (Rijksdienst voor Ondernemend Nederland, RVO) and the Dutch Topteam Energy via the project: 'PVT inSHaPe: PVT integrated Solar Heat Pump systems' with grant number TEUE116189. 


\section{Solar Thermal Collectors and Solar Loop Components}




\title{
Annual efficiency- Easy understanding of collector performance
}

\author{
Stefan Abrecht
}

Solar-Experience GmbH, Keltern (Germany)

\begin{abstract}
The Solar Keymark certification with the now mandatory data sheet 2 shows an annual collector output for reference locations and reference conditions. This enables the determination of a new parameter called annual efficiency $\eta_{a}\left(\vartheta_{m}\right)$ for collectors, which is typical for the respective climate zone and the belonging temperature level or applications with this temperature requirement. A study of the range of collectors available on the market from the simplest non-selective to the high vacuum collector at various locations worldwide shows an almost linear dependence of the annual efficiency on climatic conditions. This confirms that annual efficiency is a technical parameter that determines the performance of collectors. It can be used as a simple and single parameter for comparisons in a first selection process without the need for complex simulations. Moreover, a comparison to the efficiency of PV is possible too.
\end{abstract}

Keywords: Solar Keymark, annual collector output, annual efficiency

\section{Introduction}

For many years, there has been no agreed rating and performance system for solar thermal collectors. While for PV the module efficiency and peak power are undisputed parameters, which allow for a simple calculation of the energy yield, the huge and complicated set of performance parameters for solar thermal collectors, e.g. peak collector efficiency, heat loss and incident angle modifier facilitates various interpretations. Unlike PV, where the output in form of electricity is barely influenced by ambient temperature and not by the application, for solar thermal collectors the ambient and supply temperature play a significant role in combination with the irradiation and rule their performance. The assessment of the different parameters regarding the energy output for a selected temperature level is difficult for experts, for consumers such figures are useless.

\section{Initial situation and task description}

Solar heat suffers from the fact that, in the competition for renewable energies, it is usually not possible to make a first quick statement about how much energy collectors can supply. The experts' answer is usually: „It depends on the application, we have to simulate it". So customers prefer photovoltaics, which likes to make simple and concrete statements immediately about performance and costs. This has led to the fact that solar thermal energy is usually no longer in demand and PV is on everyone's lips. The advantage that solar collectors can harvest 3-4 times more energy per square meter than PV is little known but very important when it comes to making optimal use of limited available space for solar heat and power supply. Instead, valuable solar power is also used for direct heating of water. The task is therefore easily defined: The competitiveness of solar heat is to be represented physically and technically correct with the help of one single parameter. This is not only technically necessary but also politically required. Due to the lack of a suitable parameter, the EU Commission has determined a so-called collector efficiency $\eta_{c o l}$. It is defined in CDR (EU) No $811 / 2013^{1}$ as collector efficiency of the solar collector at a temperature difference between the solar collector and the surrounding air of $40 \mathrm{~K}$ and a global solar irradiance of $1000 \mathrm{~W} / \mathrm{m}^{2}$. In the EU regulation and its labelling for heating systems $\eta_{c o l}$ is used as the sole parameter to describe the contribution of the solar thermal system to space heating and so represents an efficiency criteria. Up to now this unrealistic and improper value is not actively questioned by solar industry and experts but has found access to European standards according to the stipulations. To protect solar thermal from further harm this situation must be changed and an appropriate parameter found to easily show the potential performance of solar collectors. 


\section{Basis and methodology}

The Solar Keymark database ${ }^{2}$ provides the necessary basic information especially data sheet 2 which has been introduced 2011 and is today an obligatory part of the certification scheme. While the known collector performance parameters are listed in data sheet 1 , data sheet 2 shows the annual collector output $A C O_{\text {module }}$ of the collector modules for 3 medium collector temperatures $\vartheta_{m}\left(25^{\circ} \mathrm{C}, 50{ }^{\circ} \mathrm{C}\right.$ and $\left.75{ }^{\circ} \mathrm{C}\right)$ at 4 reference locations. The latest certificates also show the specific ACO per $\mathrm{m}^{2}$ of gross collector area $A C O_{\text {spec }}$. This annual output is generated by a free and publicly accessible Excel program called ScenoCalc ${ }^{3}$. Test institutes have validated this software and it is acknowledged in Europe. Thus, the specific annual collector output is a physical correct value, which is determined by simulation. It is obvious to generalize this parameter. This can be done by dividing the $A C O_{\text {spec }}$ with the sum of the belonging hemispherical irradiation $H$ which is also given on the datasheet 2. This leads to the new parameter annual efficiency $\eta_{a}\left(\vartheta_{m}\right)$.

$$
\eta_{a}\left(\vartheta_{m}\right)=\frac{A C O_{s p e c}\left(\vartheta_{m}\right)}{H}
$$

\section{Worldwide evaluation and results}

The examination was conducted for a whole series of typical collectors. They cover the entire range of nonconcentrating available collectors. From simple non-selective flat plate, collectors to high-end vacuum flat plate collectors and various versions of vacuum tube collectors were examined (see Tab. 1).

Note: ETC were calculated with their belonging bi-axial incidence angle modifier not presented in the table.

Tab. 1: Overview of the collectors examined

\begin{tabular}{|c|c|c|c|c|c|}
\hline \multicolumn{2}{|r|}{ Collector } & \multicolumn{4}{|c|}{ Performance parameters/gross area } \\
\hline Type & Model & $\eta_{0}$ & $a_{1}$ & $a_{2}$ & $K_{\text {hem }}\left(50^{\circ}\right)$ \\
\hline \multirow{9}{*}{$\begin{array}{l}\text { Flat plate } \\
\text { collectors }\end{array}$} & (7) Vacuum-FPC & 0,675 & 0,630 & 0,005 & 0,92 \\
\hline & (6) double glazing & 0,729 & 2,250 & 0,005 & 0,92 \\
\hline & $(5 b)=(4)+$ better insulation $=$ Premium FPC & 0,729 & 3,150 & 0,014 & 0,92 \\
\hline & $(5 a)=(4)+$ better $F^{\prime}$ or $A R$ & 0,756 & 3,600 & 0,014 & 0,92 \\
\hline & $(4)=(3)+$ better absorber coating & 0,729 & 3,600 & 0,014 & 0,92 \\
\hline & $(3)=(2)+$ better glazing & 0,711 & 3,600 & 0,014 & 0,92 \\
\hline & (2) simple selective FPC & 0,693 & 3,600 & 0,014 & 0,88 \\
\hline & (1) min. FPC for grants & 0,693 & 4,050 & 0,014 & 0,88 \\
\hline & (0) non selective FPC & 0,675 & 5,400 & 0,027 & 0,85 \\
\hline \multirow{8}{*}{$\begin{array}{c}\text { Evacuated } \\
\text { tubular } \\
\text { collectors (ETC) } \\
\text { with single } \\
\text { glazing (SG) } \\
\text { or } \\
\text { double glazing } \\
\text { (DG) }\end{array}$} & (7) ETC-DG/direct flow + CPC reflector & 0,606 & 0,540 & 0,003 & 0,96 \\
\hline & (6) ETC-SG/direct flow + reflector 6 tubes & 0,528 & 1,338 & 0,002 & 1,18 \\
\hline & (5) ETC-SG/Heat pipe + reflector 6 tubes & 0,486 & 1,360 & 0,000 & 1,25 \\
\hline & (4) ETC-SG/direct flow 7 tubes & 0,570 & 1,422 & 0,004 & 1,00 \\
\hline & (3) ETC-SG/direct flow 6 tubes & 0,488 & 1,219 & 0,004 & 1,00 \\
\hline & (2) ETC-SG/Heat pipe 7 tubes & 0,510 & 1,614 & 0,004 & 1,03 \\
\hline & (1) ETC-SG/Heat pipe 6 tubes & 0,437 & 1,383 & 0,003 & 1,03 \\
\hline & (0) ETC-DG/Heat pipe & 0,387 & 1,382 & 0,000 & 1,34 \\
\hline
\end{tabular}

In addition to the European locations implemented in the standard version of ScenoCalc, more locations in North America, Asia and Oceania were selected from the Database of Meteonorm $7^{4}$ which are typical for their climatic zones (see Tab. 2) and are used as reference locations or interesting because they have special climatic conditions. Together they cover the world's most important climate regions. For every collector model at every location the annual collector output for $25{ }^{\circ} \mathrm{C}, 50{ }^{\circ} \mathrm{C}$ and $75{ }^{\circ} \mathrm{C}$ was determined at a fixed collector tilt $\beta$ facing the equator according the stipulations of the Solar Keymark data sheet 2. Moreover the annual efficiency was calculated.

$$
\beta=\max \left[\left(|\Phi|-15^{\circ}\right) \text { rounded to the nearest } 5^{\circ} ; 25^{\circ}\right]
$$


Tab. 2: Overview of the locations examined

\begin{tabular}{|c|c|c|c|c|c|c|}
\hline Continent & $\begin{array}{l}\text { Location/ } \\
\text { Latitude } \Phi\end{array}$ & $\begin{array}{l}\text { Reference for } \\
\text { colder, average, } \\
\text { or warmer } \\
\text { climate of the } \\
\text { continent }\end{array}$ & $\begin{array}{c}\text { Annual } \\
\text { irradiation } \\
\text { on collector } \\
\text { plane } H \\
{\left[\mathrm{kWh} / \mathrm{m}^{2}\right]}\end{array}$ & $\begin{array}{c}\text { Mean } \\
\text { annual } \\
\text { ambient air } \\
\text { temperature } \\
\bar{v}_{a} \\
{\left[{ }^{\circ} \mathrm{C}\right]}\end{array}$ & $\begin{array}{c}\text { Collector } \\
\text { orientation, } \\
\text { tilt } \beta\end{array}$ & Reference \\
\hline \multirow{5}{*}{ Europe } & Athens $/ 38,0^{\circ}$ & warmer & 1765 & 18,5 & South, $25^{\circ}$ & \multirow{4}{*}{$\begin{array}{c}\text { ScenoCalc } \\
5.1\end{array}$} \\
\hline & Davos $/ 46,8^{\circ}$ & - & 1630 & 3,2 & South, $30^{\circ}$ & \\
\hline & Würzburg/49,8 $8^{\circ}$ & average & 1244 & 9 & South, $35^{\circ}$ & \\
\hline & Stockholm/59, $3^{\circ}$ & colder & 1166 & 7,5 & South, $45^{\circ}$ & \\
\hline & Moskva/55, $8^{\circ}$ & - & 1166 & 6,3 & South, $40^{\circ}$ & \multirow{15}{*}{$\begin{array}{c}\text { Meteonorm } \\
7\end{array}$} \\
\hline \multirow{5}{*}{ Asia } & Xigaze $/ 29,3^{\circ}$ & - & 2337 & 7,6 & South, $25^{\circ}$ & \\
\hline & Abu Dhabi $/ 24,4^{\circ}$ & warmer & 2130 & 28,2 & South, $25^{\circ}$ & \\
\hline & Mumbai/19,1º & average & 1936 & 27,4 & South, $25^{\circ}$ & \\
\hline & Beijing $/ 40,0^{\circ} \mathrm{N}$ & colder & 1540 & 12,9 & South, $25^{\circ}$ & \\
\hline & Novosibirsk $/ 55,1^{\circ}$ & - & 1516 & 2,2 & South, $40^{\circ}$ & \\
\hline \multirow{5}{*}{$\begin{array}{l}\text { North } \\
\text { America }\end{array}$} & Los Angeles $/ 33,9^{\circ}$ & warmer & 2017 & 16,7 & South, $25^{\circ}$ & \\
\hline & Denver $/ 39,8^{\circ}$ & - & 1918 & 10,3 & South, $25^{\circ}$ & \\
\hline & Orlando $/ 28,4^{\circ}$ & - & 1739 & 22 & South, $25^{\circ}$ & \\
\hline & New York $/ 40,7^{\circ}$ & average & 1605 & 12,2 & South, $25^{\circ}$ & \\
\hline & Winnipeg MB $/ 49,9^{\circ}$ & colder & 1724 & 3,4 & South, $35^{\circ}$ & \\
\hline \multirow{4}{*}{$\begin{array}{c}\text { Australia/ } \\
\text { New } \\
\text { Zealand }\end{array}$} & Alice Springs/-23, $8^{\circ}$ & - & 2405 & 21,6 & North, $25^{\circ}$ & \\
\hline & Rockhampton/-23,3 & warmer & 2139 & 22,4 & North, $25^{\circ}$ & \\
\hline & Sydney/-33,9 & average & 1851 & 18,1 & North, $25^{\circ}$ & \\
\hline & Auckland/-37,0 & colder & 1709 & 15,2 & North, $25^{\circ}$ & \\
\hline
\end{tabular}

Temperature specific analysis

The annual efficiency of a collector can be plotted in a diagram above the ratio of annual irradiation sum $H$ and the temperature difference $\Delta T$ between the mean collector $\vartheta_{m}$ and mean annual ambient temperature $\bar{\vartheta}_{a}$.

$$
\Delta T=\vartheta_{m}-\overline{\vartheta_{a}}
$$

Thus only one digram is necessary to display the results for one temperature level. On the linear axis, the different locations worldwide are listed according to their ratio H/DT. From cold Swedish capital Stockholm with low irradiation to hot reference location Abu Dhabi with high irradiation. Fig. 1 shows a selection of 3 different flat plate and 3 evacuated tube collectors at $50{ }^{\circ} \mathrm{C}$ for all reference locations. It is obviously that the annual efficiency of a collector at a medium collector temperature of $50{ }^{\circ} \mathrm{C}$ is in very good approximation a linear function of the ratio of annual irradiation sum per temperature difference $H / \Delta T$ in $[\mathrm{kWh} / \mathrm{K}]$. The same fact can be extracted from Fig. 2 where the annual efficiency is presented at $75^{\circ} \mathrm{C}$. 


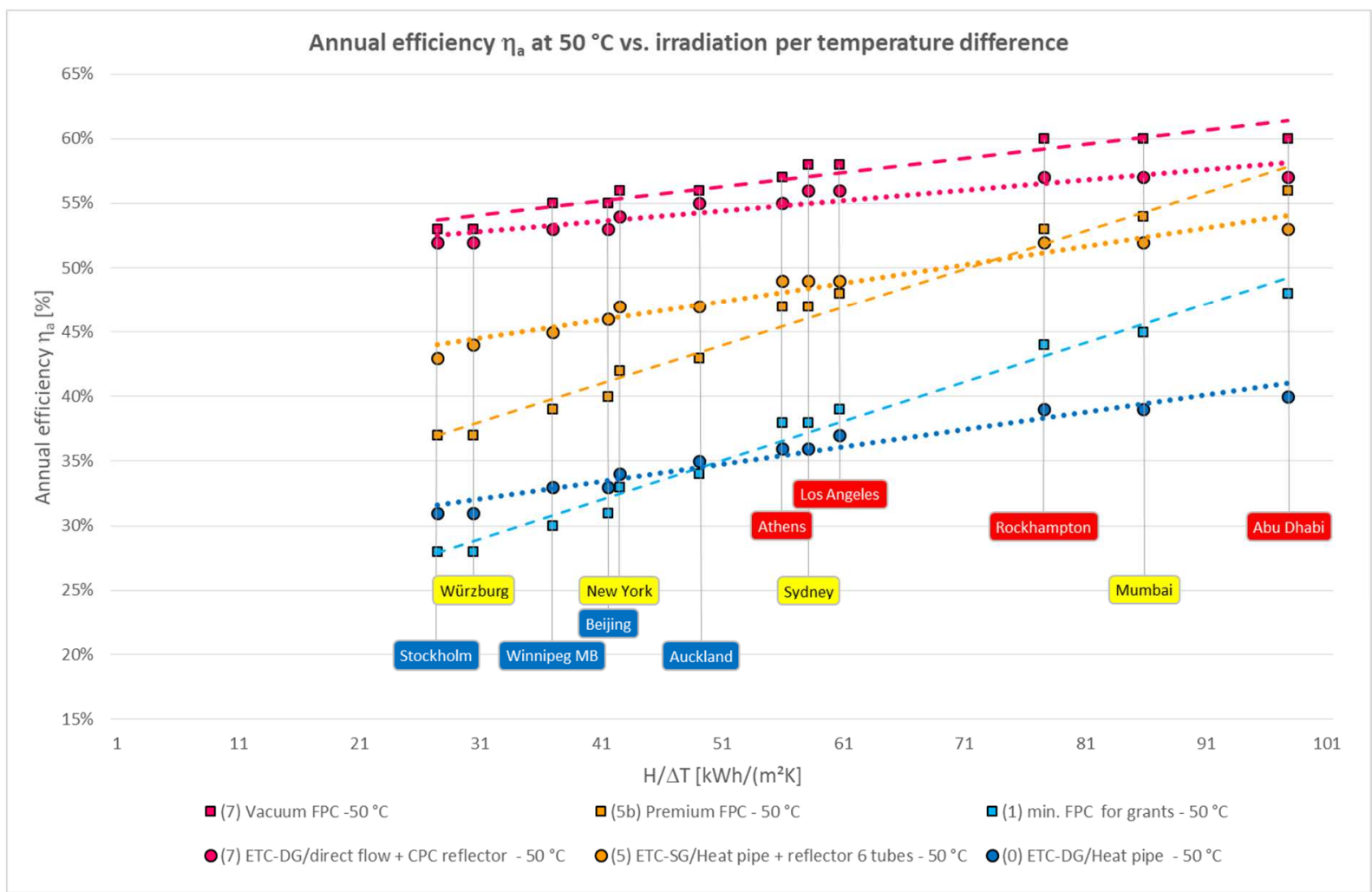

Fig. 1: Annual efficiency at $50{ }^{\circ} \mathrm{C}$ medium collector temperature

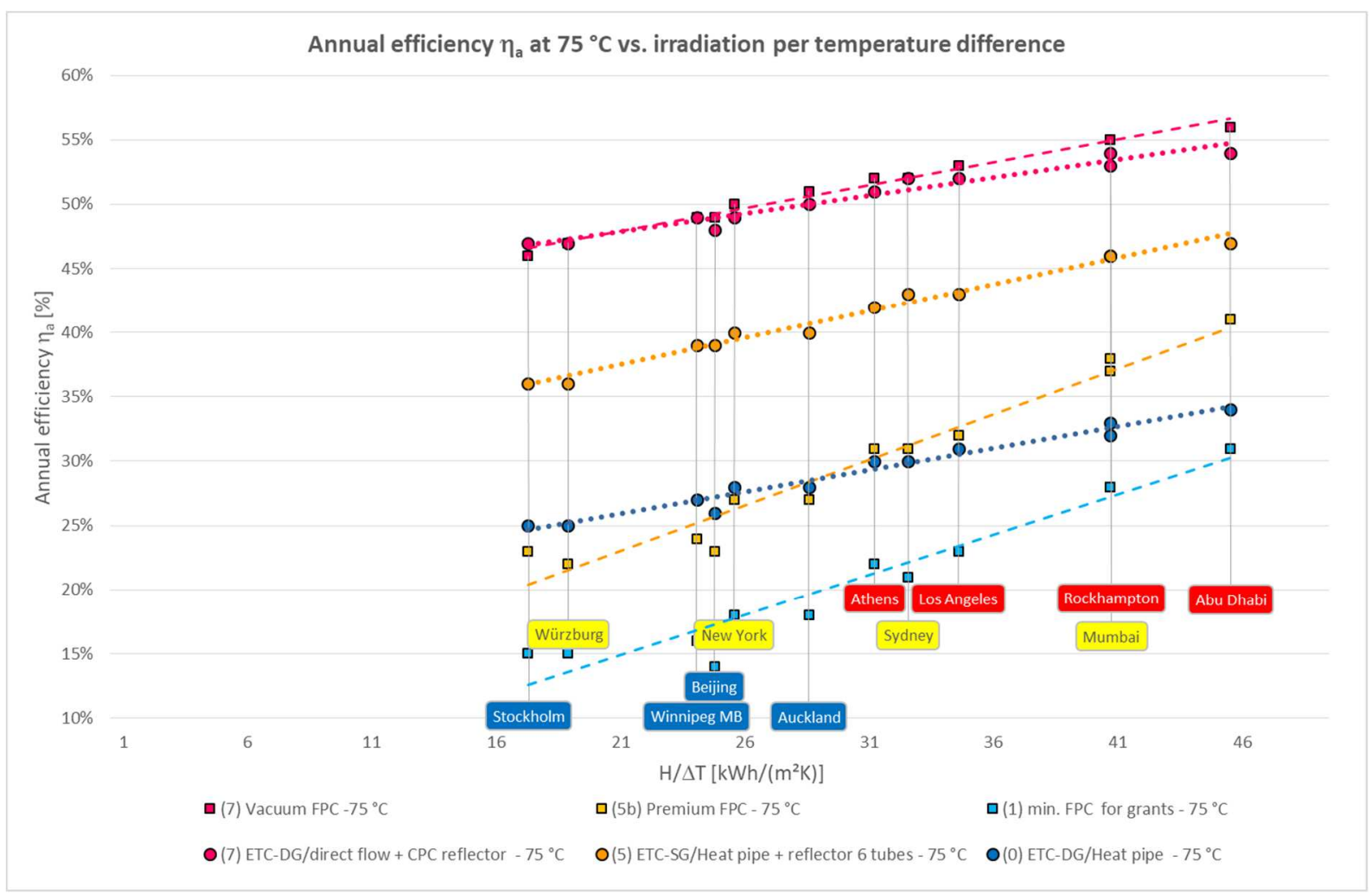

Fig. 2: Annual efficiency at $75^{\circ} \mathrm{C}$ medium collector temperature

The accuracy of the linear fit curves is quite high. Even considering the extreme climates, which are not shown in the diagram, the coefficient of determination $\mathrm{R}^{2}$ is typically $>0.9$ and for most reasonable application $>0.95$. Another finding: The lower the heat losses of the collector models are, the more accurate the linear fit. Using the annual efficiency of Würzburg and Rockhampton for a linear curve provides already very good results so there is no need for extensive calculations. 


\section{General analysis}

A further investigation was to combine the results of the annual efficiency for $25^{\circ} \mathrm{C}, 50^{\circ} \mathrm{C}$ and $75^{\circ} \mathrm{C}$ in one diagram. For this purpose as similar approach as for the instantaneous efficiency of collectors has been chosen. The annual efficiency was plotted over the ratio of the temperature difference per irradiation sum $\Delta T / H$ in $\left[\mathrm{m}^{2} \mathrm{~K} / \mathrm{kWh}\right]$.

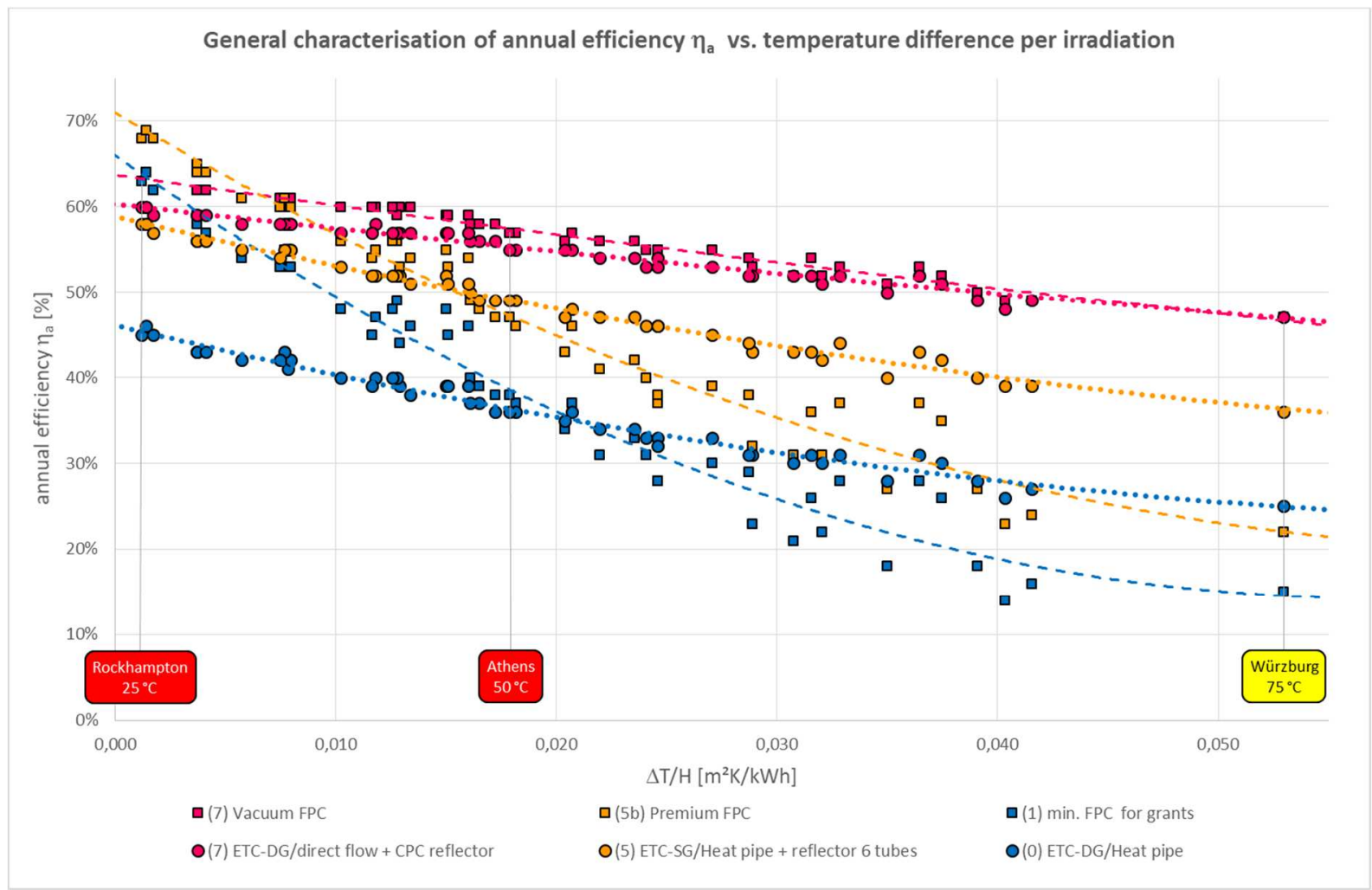

Fig. 3: General characterization of annual efficiency using all annual efficiencies of all reference locations

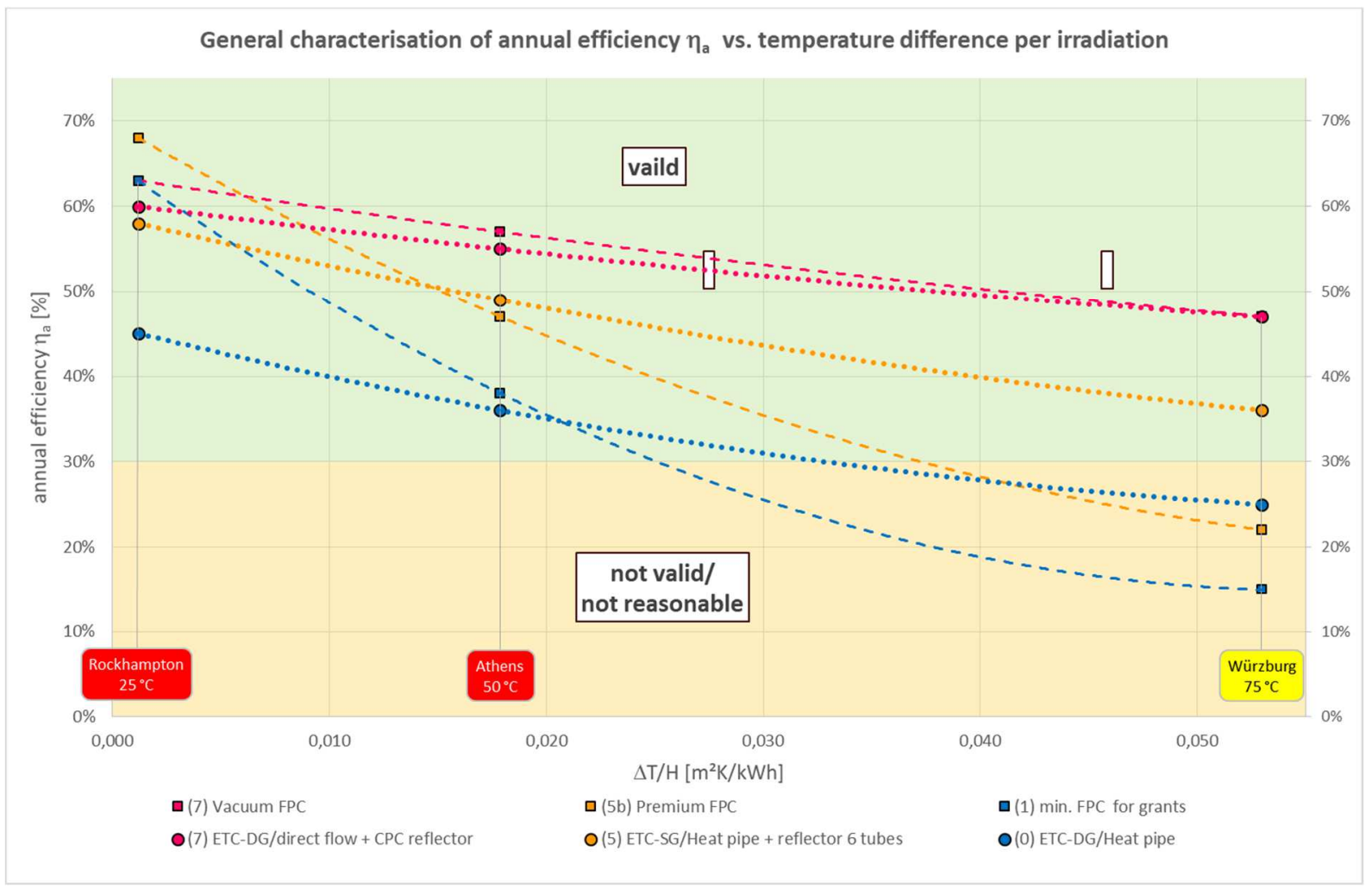

Fig. 4: General characterization of annual efficiency using only 3 annual efficiencies of 3 reference locations 
In Fig. 3 this general characterization is highlighted for the same selection of collector models like for the specific analysis. The single points for each collector can be approximated by a second order polynomial curve. While the shape for vacuum collectors is almost linear, collectors with higher heat losses have a concave characteristic. This means that they lose disproportionally more efficiency with higher temperature differences and/or lower irradiation sums at low $\Delta T / H$ values while the decline is reduced for higher $\Delta T / H$ values. With 3 efficiencies of Rockhampton at $25^{\circ} \mathrm{C}$, Athens at $50{ }^{\circ} \mathrm{C}$ and Würzburg at $75{ }^{\circ} \mathrm{C}$ the polynoms can be determined with a similar accuracy as with the entire data set. Anyway the scope of validity should be limited to $\eta_{a}>30 \%$, as the accuracy of the modelling decreases with low efficiencies and practically it does not make sense to use products for applications with such low values while PV is already approaching the $20 \%$ mark.

\section{Conclusion:}

The parameter $\eta_{a}$ allows a simplified but nevertheless technically correct representation of the annual efficiency of solar collectors worldwide. The determination of the annual energy yield for 3 locations is sufficient. Two of them are already available in the Solar Keymark data sheet 2 (Würzburg and Athens). In addition, the calculation must only be performed for the reference site Rockhampton in Australia which is included in the registration process for the SOLERGY label Oceania. With the help of the corresponding annual efficiencies, curves and diagrams as described above can be determined. They can be used to estimate $\eta_{a}\left(\vartheta_{m}\right)$ worldwide either for concrete temperature levels with very good accuracy or even in general in good approximation. To determine results for any location, only the annual sum of the irradiation on the tilted collector plane $H$ and the ambient air temperature averaged over the year $\bar{\vartheta}_{a}$ is required. This simplification is made possible by the fact that the annual collector yield already processes all important relevant collector parameters through the simulation with ScenoCalc. The evaluation shows that the data of the locations, such as latitude, global radiation sum, ambient air temperature, which are very different worldwide, do not have such a significant influence that a good approximation is impossible. For collectors with low heat losses, the error in determining the yield is in the order of magnitude of the fault tolerance of collector tests. The validity of the study refers to the optimal inclination and orientation of the location as specified by Solar Keymark and is limited to positive temperature differences $\Delta T$. Although variations of inclination and azimuth were not investigated, it can be expected that smaller deviations of collector tilt and orientation are represented as well when the belonging irradiation sum is used.

\section{Application}

The method of annual efficiency provides a simple but technically correct understanding of different collector technologies and their potential performance on a global scale. The annual efficiency is useful to select appropriate collectors for different temperatures levels resp. applications and thus gives transparent information for costumers. It can be used to bridge the gap between solar thermal experts and nonprofessionals like consumers, users and politicians. The annual efficiency also enables fair competition with other renewable energies such as PV and biomass. The first implementation of the annual efficiency was carried out by DIN CERTCO as part of the voluntary registration scheme Collector Output Label ${ }^{3}$ and can be found in the collector output sheet of registered companies see Fig. 5. The values have been classified in accordance with the EU efficiency label in order to give the end customer a better understanding. They are displayed graphically in labels and are available for Europe and Oceania see Fig. 6. Labels for North America and Asia are in preparation.

A further necessity is to replace the meaningless $\eta_{c o l}$ of the EU in the regulation. The annual efficiency $\eta_{a}$ cannot only provide a reasonable substitute but has the potential to be used in calculations for the package label as well. Proposals have already been made for the revision. Implementation in the collector standard ISO 9806 makes sense in order to strengthen the position of solar thermal as important basis for the energy transition in the heating sector.

The general characterization of a collector enables the easy assessment of deviations concerning the irradiation and temperature level and their influence on the collector yield. This tool can be used e.g. in contracts about output guarantee to determine the annual efficiency/yield in case of larger deviations from the agreed boundary conditions. 


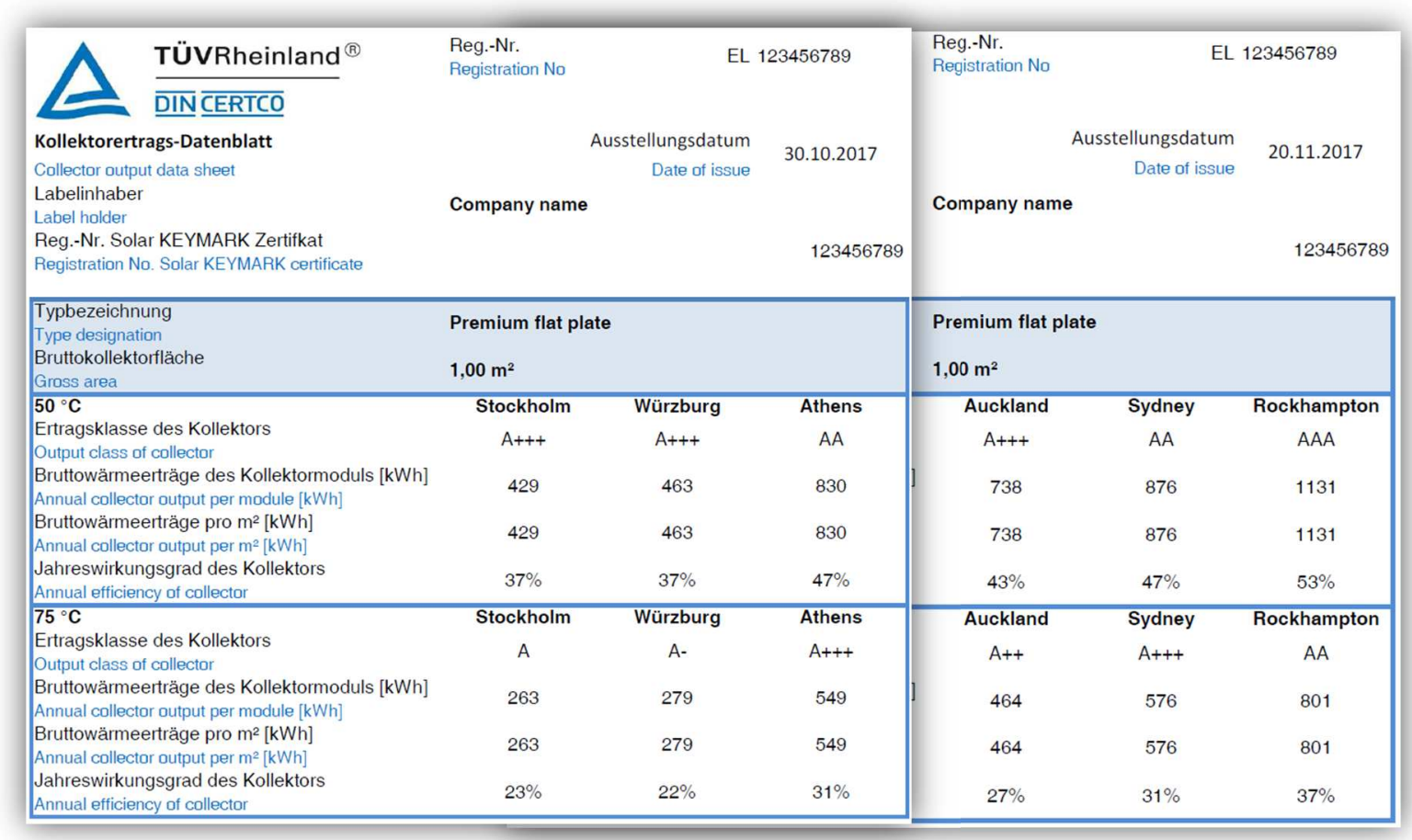

Fig. 5: Collector output data sheet Europe and Oceania
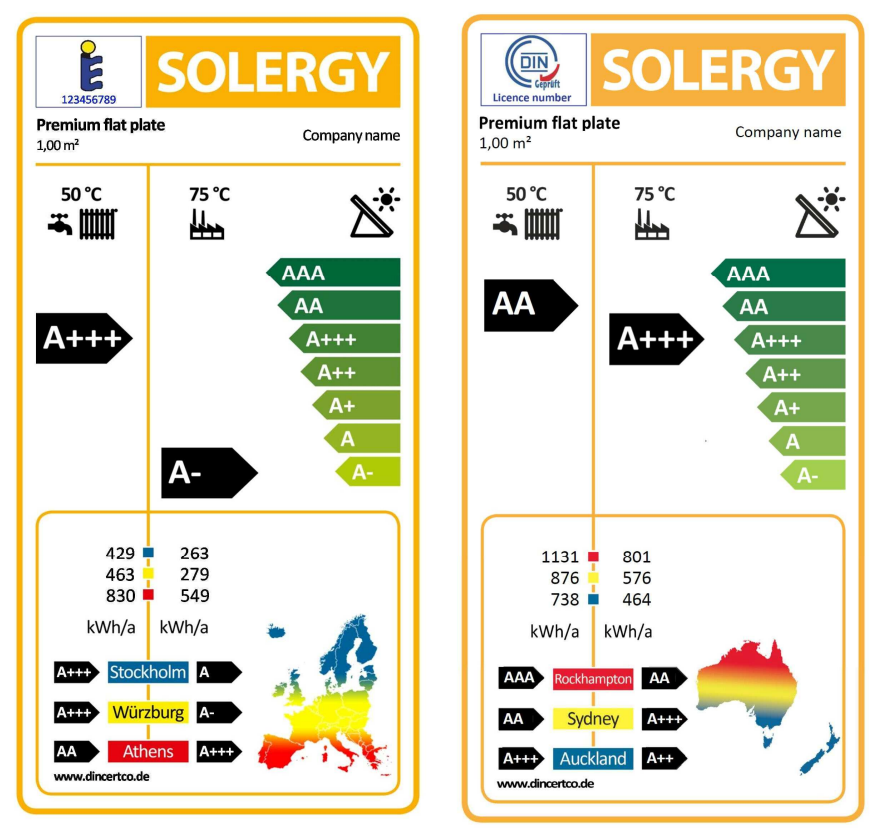

Fig. 6: Collector output Label Europe and Oceania

\section{References}

${ }^{1}$ https://eur-lex.europa.eu/legal-content/EN/TXT/PDF/?uri=CELEX:32013R0811\&from=DE

${ }^{2}$ http://www.solarkeymark.dk/CollectorCertificates

${ }^{3}$ http://www.sp.se/en/index/services/solar/ScenoCalc/Sidor/default.aspx

${ }^{4}$ https://www.meteonorm.com/

${ }^{5}$ http://www.dincertco.de/en/dincertco/produkte_leistungen/zertifizierung_produkte/umwelt_1/

kollektorertragslabel/kollektorertragslabel.html 


\section{Appendix: Units and Symbols}

\begin{tabular}{lll}
\hline Quantity & Symbol & Unit \\
\hline Latitude & $\Phi$ & 0 to $\pm 90^{\circ}$; North is +ive \\
Collector tilt & $\beta$ & $\circ$ \\
Irradiation sum on tilted plane & $H$ & $\mathrm{kWh} \mathrm{m}^{-2}$ \\
Mean annual ambient temperature & $\vartheta_{a}$ & ${ }^{\circ} \mathrm{C}$ \\
Medium collector temperature & $\vartheta_{m}$ & ${ }^{\circ} \mathrm{C}$ \\
Peak collector efficiency collector & $\eta_{0}$ & - \\
Heat loss coefficient & $a_{1}$ & $\mathrm{Wm}^{-2} \mathrm{~K}^{-1}$ \\
Temperature dependence of the heat loss coefficient & $a_{2}$ & $\mathrm{Wm}^{-2} \mathrm{~K}^{-2}$ \\
Incidence angle modifier for hemispherical solar radiation & $K_{\text {hem }}$ & - \\
Annual Collector Output of collector module & $A C O_{m o d u l e}$ & $\mathrm{kWh}^{-2}$ \\
Specific Annual Collector Output & $A C O_{\text {spec }}$ & $\mathrm{kWh} \mathrm{m}^{-2}$ \\
Annual efficiency depending on the mean collector temperature & $\eta_{a}\left(\vartheta_{m}\right)$ & ${ }_{0}$ \\
Collector efficiency (EU-Definition) & $\eta_{\text {col }}$ & ${ }_{0}$ \\
\hline
\end{tabular}




\title{
Assessment of Durability of Solar Absorbers - Performance Criterion Soraia Páscoa ${ }^{1}$, Maria João Carvalho ${ }^{1}$ and Teresa Cunha Diamantino ${ }^{1}$ \\ ${ }^{1}$ Laboratório Nacional de Energia e Geologia, I.P., Lisbon (Portugal)
}

\begin{abstract}
Solar fraction, $F_{\mathrm{s}}$, defined as the ratio between the delivered energy from a solar domestic hot water (DHW) system and the load (thermal energy necessary to satisfy domestic water heating needs), is widely accepted as performance indicator for this type of systems. Considering solar absorptance $\alpha_{s}$ and thermal emittance $\varepsilon_{t}$ as the most relevant characteristics of solar absorbers, the relation between the depreciation of these optical properties and depreciation of $F_{\mathrm{s}}$ was used by Hollands et al (1992) to define a performance criterion (PC) for assessment of long-term behavior and service life of selective solar absorbers. The PC was established mainly for solar DHW systems working with solar fractions lower than 50\%. In this work, systems working with solar fractions higher than $50 \%$, in climates of south of Europe, are considered and the suitability of solar fraction as performance indicator to develop an adequate PC is studied. As a first step simulations of thermal performance of systems using an in-house software were performed for a reduction of 5\% and $10 \%$ of $F_{\mathrm{s}}$. In ISO 22975-3, solar fraction $F_{\mathrm{s}}$ degradation must be lower than $5 \%$ to guarantee 25 years of service life for DHW system. The results showed that the parameters obtained to define the PC were incoherent considering solar fractions higher than $50 \%$. In a second step, supplied energy was considered as performance indicator and using similar methodology as Hollands et al (1992), but using as performance indicator energy supplied by the solar system, the PC for systems working with solar fractions higher than $50 \%$, in climates of south of Europe, was establish. The results showed that this is not significantly different from the PC considered in ISO 22975-3.
\end{abstract}

Keywords: Durability, Solar Absorbers, Performance Criterion

\section{Introduction}

Assessment of long-term behavior and service life of selective solar absorbers used in solar thermal collectors for domestic hot water (DHW) systems can be performed according to ISO 22975-3. The Performance Criterion used in the standard was establish considering that for a service life of 25 years, reduction in solar fraction $F_{S}$ should not be higher than 5\%. In the frame of Task X of the IEA Solar Heating and Cooling Programme (Carlsson, B. et al, 1994) and according to Hollands et al (1992) it was possible to establish a performance criterion given by the change in optical properties of solar absorbers, namely, solar absorptance, $\alpha_{s}$, and thermal emittance, $\varepsilon_{t}$ :

$$
P C=-\Delta \alpha_{s}+0.25 \Delta \varepsilon_{t} \leq 0,05
$$

where $\Delta \alpha_{s}=\alpha_{s}-\alpha_{s 0}$ and $\Delta \varepsilon_{t}=\varepsilon_{t}-\varepsilon_{t 0}$, according to ISO 22975-3 (2014).

The selection of this expression was established assuming that this equation is representative of the degradation of solar absorber surfaces used in DHW systems with solar fractions lower than $50 \%$ and corresponds to a reduction of $5 \%$ of the solar fraction.

Latter, changes introduced by Köhl, M. et al (2004) conduct to the expression presently used in the standard:

$$
P C=-\Delta \alpha_{s}+0.50 \Delta \varepsilon_{t} \leq 0,05
$$

and considered valid for collectors working at higher temperatures.

In this work the procedure for establishment of the performance criterion is revisited considering DHW systems working with higher solar fractions, in climates of the south of Europe. In section 2, the methodology proposed by Hollands et al (1992) was applied considering as performance indicator the Solar Fraction. In section 3, a different performance indicator, supplied energy, is used and deduced. In section 4. conclusions are presented. 


\section{Solar Fraction as performance indicator}

\subsection{Methodology}

Considering different combinations of optical properties, through analytical expressions according to (D.E. Roberts and A. Forbes, 2012) it was possible to obtain the thermal performance coefficients $\eta_{0}(-), a_{l}\left(\mathrm{Wm}^{-2} \mathrm{~K}^{-1}\right)$ and $a_{2}$ $\left(\mathrm{Wm}^{-2} \mathrm{~K}^{-2}\right)$ for a flat plate collector whose constructive characteristics are known (see Tab. 1). Computer simulations of thermal performance of systems were performed, using an in house software (SolTerm, V5.3, 2017), in order to analyze the solar fraction $\left(F_{s}\right)$ of DHW systems, with a collector area of $4.3 \mathrm{~m}^{2}$ and storage volumes of $200 \mathrm{~L}$ (a), $250 \mathrm{~L}$ (b) and $300 \mathrm{~L}$ (c), located in Lisbon. These systems have different ratios between store volume and collector area, $46.5 \mathrm{~L} / \mathrm{m}^{2}$ (a), $58.1 \mathrm{~L} / \mathrm{m}^{2}$ (b) and $69.8 \mathrm{~L} / \mathrm{m}^{2}$ (c) respectively. In Tab. 1 are presented the assumed values of input parameters used in the analytical expressions and computer simulations. Symbols in Tab. 1 follow the nomenclature of D.E. Roberts and A. Forbes (2012) and the input parameters signaled with $(*)$ are according with this reference.

Tab. 1: Assumed values of input parameters for computer simulation of thermal performance of system (a). (*) Input parameters according with (D.E. Roberts and A. Forbes, 2012)

\begin{tabular}{|c|c|c|c|}
\hline \multicolumn{2}{|r|}{ Input parameter } & Assumed value & Unit \\
\hline$G$ & Incident solar power & $800(*)$ & {$\left[\mathrm{Wm}^{-2}\right]$} \\
\hline$A_{c}$ & Collector area & 4.3 & {$\left[\mathrm{~m}^{2}\right]$} \\
\hline & Collector tilt angle & $33^{\circ}$ & \\
\hline & Collector orientation & South-facing $(*)$ & \\
\hline & Tank volume & 200 & {$[\mathrm{~L}]$} \\
\hline$T_{s p}$ & Set point temperature & $50(*)$ & {$\left[{ }^{\circ} \mathrm{C}\right]$} \\
\hline & Heat exchanger effectiveness & 0.55 & \\
\hline$\delta$ & Collector absorber plate thickness & 0.0003 & {$[\mathrm{~m}]$} \\
\hline$D$ & Diameter of tube & 0.008 & {$[\mathrm{~m}]$} \\
\hline$W$ & Distance between fins & 0.125 & {$[\mathrm{~m}]$} \\
\hline$\tau$ & Cover plate transmission & 0.885 & \\
\hline$T_{a}$ & Ambient temperature & 293.15 & {$[\mathrm{~K}]$} \\
\hline$T_{\text {in }}$ & Inlet water temperature & 288.15 & {$[\mathrm{~K}]$} \\
\hline$h_{b}$ & Conduction heat loss coefficient through base & 1.167 & {$\left[\mathrm{Wm}^{-2} \mathrm{~K}^{-1}\right]$} \\
\hline$L_{b}$ & Thickness of base insulation & 0.030 & {$[\mathrm{~m}]$} \\
\hline$k_{b}$ & Conductivity of insulation & 0.035 & {$\left[\mathrm{Wm}^{-1} \mathrm{~K}^{-1}\right]$} \\
\hline$m$ & Total mass flow rate of fluid & $0.02(*)$ & {$\left[\mathrm{Kgs}^{-1}\right]$} \\
\hline$C_{b}$ & Conductance of fin to plate bond & $100(*)$ & {$\left[\mathrm{Wm}^{-1} \mathrm{~K}^{-1}\right]$} \\
\hline$\sigma$ & Stefan-Boltzman constant & $5.6704 \times 10^{-8}$ & {$\left[\mathrm{Wm}^{-2} \mathrm{~K}^{-4}\right]$} \\
\hline$h_{f i}$ & Heat transfer coefficient fin to fluid & $250(*)$ & {$\left[\mathrm{Wm}^{-2} \mathrm{~K}^{-1}\right]$} \\
\hline$h_{0}$ & $\begin{array}{l}\text { Temperature independent convection heat loss coefficient, } \\
\text { absorber to cover plate }\end{array}$ & $3.07(*)$ & {$\left[\mathrm{Wm}^{-2} \mathrm{~K}^{-1}\right]$} \\
\hline$h_{l}$ & $\begin{array}{l}\text { Temperature dependent convection heat loss coefficient, absorber } \\
\text { to cover plate }\end{array}$ & $0.0096(*)$ & {$\left[\mathrm{Wm}^{-2} \mathrm{~K}^{-2}\right]$} \\
\hline$h_{2}$ & $\begin{array}{l}\text { Wind speed independent convection heat loss coefficient, cover } \\
\text { plate to ambient }\end{array}$ & $6.9(*)$ & {$\left[\mathrm{Wm}^{-2} \mathrm{~K}^{-1}\right]$} \\
\hline$h_{3}$ & $\begin{array}{l}\text { Wind speed dependent convection heat loss coefficient, cover } \\
\text { plate to ambient }\end{array}$ & $3.87(*)$ & {$\left[\mathrm{Wm}^{-3} \mathrm{sK}^{-1}\right]$} \\
\hline$V$ & Wind speed & 2 & {$\left[\mathrm{~ms}^{-1}\right]$} \\
\hline$k_{c}$ & Thermal conductivity of collector & $385(*)$ & \\
\hline$C_{p}$ & Specific heat of water & $4190(*)$ & {$\left[\mathrm{JKg}^{-1} \mathrm{~K}^{-1}\right]$} \\
\hline$\alpha_{s 0}$ & Initial solar absorptance & 0.96 & \\
\hline$\varepsilon_{0}$ & Initial thermal emittance & 0.11 & \\
\hline
\end{tabular}


The methodology proposed by Hollands et al (1992) was also used. Fig. 1 illustrates the solar fraction $F_{s}$ as a function of solar absorptance $\alpha_{s}$ and each curve corresponds to a fixed value of thermal emittance $\varepsilon_{t}$ for situation (a). In this figure it is also possible to visualize which combinations of $\alpha_{s}$ and $\varepsilon_{t}$ will produce a 5 and $10 \%$ loss in solar fraction, $F_{s}$. In this analysis the initial optical properties considered are $\alpha_{s 0}=0.96$ and $\varepsilon_{0}=0.1$, which characterized the initial status of the flat plate collector considered. The simulations considered combinations of 0.025 increments in solar absorptance $\alpha_{s}$, from 0.1 to 0.96 , and 0.1 increments in thermal emittance $\varepsilon_{t}$, from 0.11 to 1 .

Two possible states of failure are considered when compared with the initial solar fraction $F_{s 0}$, i.e., when $F_{s}=0.90 F_{s 0}$ and $F_{s}=0.95 F_{s 0}$, respectively. $F_{s 0}$ represents the solar fraction when the solar DHW system operates with $\alpha_{s}=\alpha_{s 0}$ and $\varepsilon_{t}=\varepsilon_{t}$. The combination values of $\alpha_{s}$ and $\varepsilon_{t}$ that correspond to a reduction of $5 \%$ or $10 \%$ in the system solar fraction were determined from Fig. 1. The intersection between the horizontal lines and the curves of fixed $\varepsilon_{t}$ for $F_{s}$ versus $\alpha_{s}$ gives the combination of $\alpha_{s}$ and $\varepsilon_{t}$ that will produce a 5 and $10 \%$ loss in solar fraction $F_{s}$. In Fig. 2, $-\Delta \alpha_{s}$ is represented as a function of $\Delta \varepsilon_{t}$ for the three systems considered, (a), (b) and (c).

From Hollands et al (1992), these results are highly influenced by geographical location. However, it is possible to see that they are not dependent on the variation of system configuration, i.e, the results are very similar when considering storage volumes of $200 \mathrm{~L}$ (a), $250 \mathrm{~L}$ (b) and $300 \mathrm{~L}$ (c) as can be seen in Fig. 2.

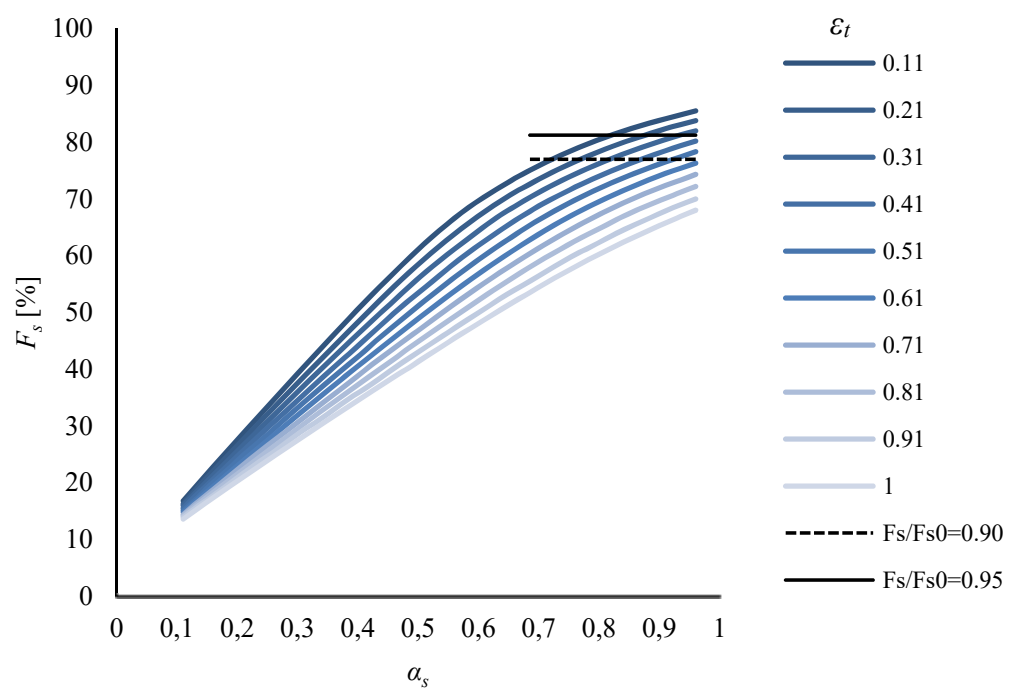

Fig. 1: Solar fraction as a function of $\alpha_{s}$ and $\varepsilon_{t}$ for system (a) for a system located in Lisbon (latitude $=37.8^{\circ}$ )

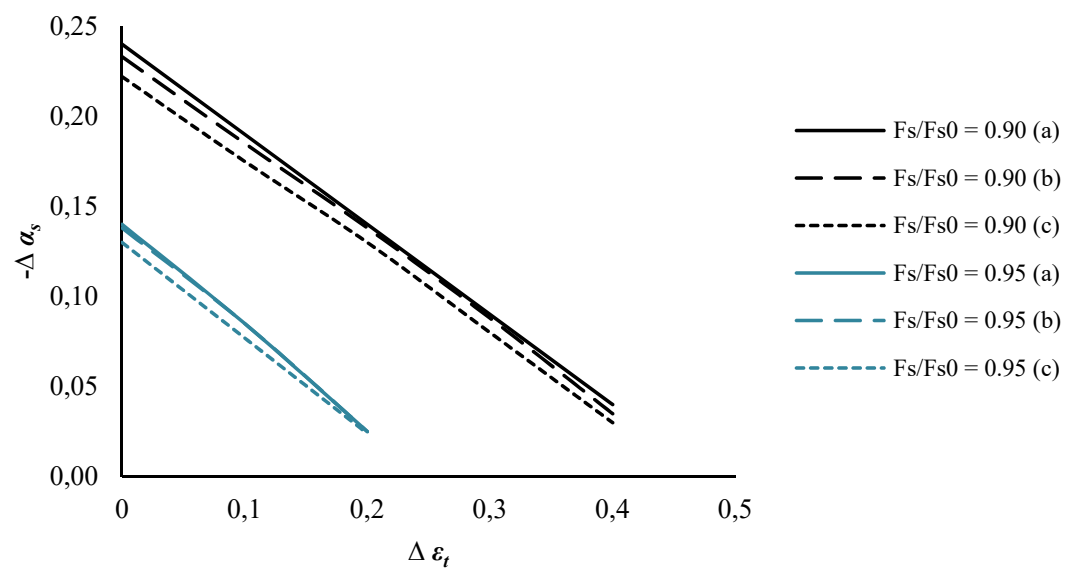

Fig. 2: $\Delta \alpha_{S}$ versus $\Delta \varepsilon_{t}$ for the three systems ( $a, b$ and c) considered for a system located in Lisbon (latitude $=37.8^{\circ}$ )

The relationship between $\Delta \alpha_{s}$ and $\Delta \varepsilon_{t}$ is very close to linear, as already presented in Hollands et al (1992), which makes easier further interpretation of these graphs to determine which will be the adequate expression for PC considering solar fractions higher than $50 \%$ in climates of South of Europe.

Following the methodology proposed by Hollands et al (1992), $\Delta \alpha_{s}$ versus $\Delta \varepsilon_{t}$ can be expressed as:

$$
-\Delta \alpha_{s}=a-\frac{a}{b} \Delta \varepsilon_{t}
$$


When $\Delta \varepsilon_{t}$ is equal to zero, the parameter $a$ is obtained (vertical intercept). When $\Delta \alpha_{s}$ is equal to zero, the parameter $b$ is obtained (horizontal intercept).

The Eq. 3 can be transformed into

$$
-\Delta \alpha_{s}+k_{1} \Delta \varepsilon_{t}=k_{2}
$$

Where

$$
\begin{aligned}
& k_{1}=\frac{a}{b} \\
& k_{2}=a
\end{aligned}
$$

Which gives a general form of the expression of PC presently used in the standard ISO 22975 (2014),

$$
P C=-\Delta \alpha_{s}+k_{1} \Delta \varepsilon_{t} \leq k_{2}
$$

\subsection{Results}

Considering the situation (a) in Fig. 2 , when and $F_{s}=0.95 F_{s 0}$ we find $a=0.14$ and $b=0.24$ and, when $F_{s}=0.90 F_{s}$ we find $a=0.24$ and $b=0.48$. The parameter $b$ was calculated by determining the linear function that best fits each case, since it is not possible to directly obtain the horizontal intercept from Fig.2 $\left(\Delta \alpha_{s}=0\right)$.

According to Hollands et al (1992), if all solar radiation absorbed by the collector is converted in useful energy, i.e., is transferred to the load, a reduction of the solar fraction $F_{s}$ will be proportional to a reduction on $\alpha_{s}$, if all other parameters are unchanged, i.e., $\Delta \varepsilon_{t}=0$. This meaning that, in Fig. 2, the vertical intercept (denoted by $a$ ) corresponding to $\Delta \varepsilon_{t}=0$ would be $0.96 \times 0.05=0.048$ (for $5 \%$ reduction in solar fraction) or $0.96 \times 0.10=0.096$ (for $5 \%$ reduction in solar fraction) since $\alpha_{s 0}=0.96$.

The difference in $a$ value determined based on the simulations and giving the linear representation of Fig. 2 and equations 3 to 6 , can only be explained due to the fact that for higher solar fractions not all energy is transferred to load. There is dumped energy and the proportionality between a decrease in $\alpha_{s}$ and $F_{s}$ can no longer be considered.

For higher solar fractions we have:

$$
a=\left.\Delta \alpha_{s 0}\right|_{\Delta \varepsilon_{t}=0}>\alpha_{s 0} \times \frac{\Delta F_{S}}{F_{s 0}}
$$

or:

$$
\text { ratio }=\frac{\frac{\mathrm{a}}{\alpha_{S 0}}}{\frac{\Delta F_{S}}{F_{S 0}}}>1
$$

Following Hollands et al (1992), the ratio (Eq. 9) versus $F_{s}$ was analyzed taking into account all the simulations performed considering different ratios $\Delta F_{S} / F_{s 0}$ for the DHW system studied in this work.

Tab. 2: Effect of the (arbitrarily-chosen) ratio $F_{s} / F_{s 0}$ on the vertical intercept $a$ and ratio $\left(a / \alpha_{s}\right) /\left(\Delta F_{s} / F_{s}\right)$

\begin{tabular}{|c|c|c|c|c|}
\hline $\boldsymbol{F}_{\boldsymbol{s}} / \boldsymbol{F}_{\boldsymbol{s} \boldsymbol{0}}$ & $\Delta \boldsymbol{F}_{\boldsymbol{s}} / \boldsymbol{F}_{\boldsymbol{s} \boldsymbol{0}}$ & $\boldsymbol{F}_{\boldsymbol{s}}$ & $\boldsymbol{a}$ & $\left(\boldsymbol{a} / \boldsymbol{\alpha}_{\boldsymbol{s} 0}\right) /\left(\Delta \boldsymbol{F}_{\boldsymbol{s}} / \boldsymbol{F}_{\boldsymbol{s} 0}\right)$ \\
\hline 0.95 & 0.05 & 0.812 & 0.14 & 2.92 \\
\hline 0.90 & 0.10 & 0.770 & 0.24 & 2.50 \\
\hline 0.80 & 0.20 & 0.684 & 0.38 & 1.98 \\
\hline 0.70 & 0.30 & 0.599 & 0.48 & 1.65 \\
\hline 0.60 & 0.40 & 0.513 & 0.56 & 1.45 \\
\hline 0.50 & 0.50 & 0.428 & 0.63 & 1.31 \\
\hline 0.40 & 0.60 & 0.342 & 0.71 & 1.22 \\
\hline 0.30 & 0.70 & 0.257 & 0.78 & 1.15 \\
\hline 0.20 & 0.80 & 0.171 & 0.85 & 1.11 \\
\hline
\end{tabular}




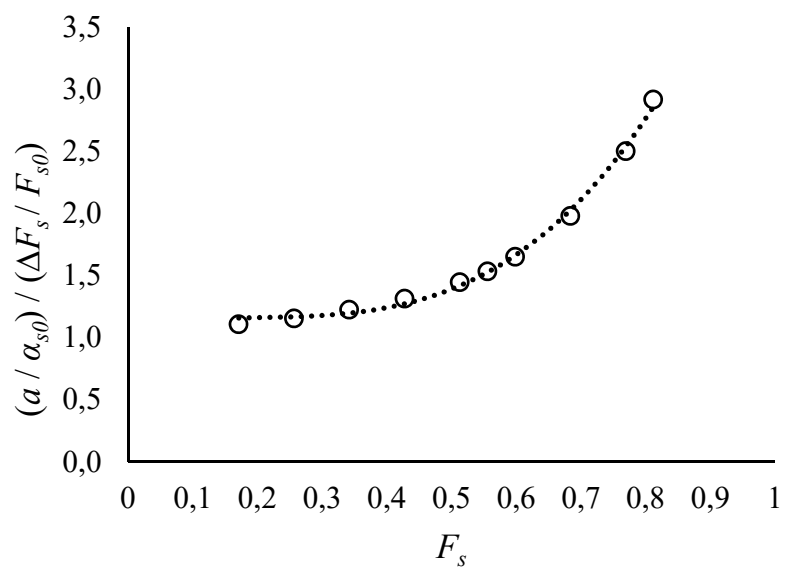

Fig. 3: Dependence of the ratio $\left(a / \alpha_{s 0}\right) /\left(\Delta F_{s} / F_{s 0}\right)$ on $F_{s}$.

According to the results presented in Tab. 2, the proportionality between $\Delta \alpha_{s}$ and $\Delta F_{s}$ is clear at low solar fraction $\left(F_{s}<0.5\right)$ since the ratio $\left(a / \alpha_{s 0}\right) /\left(\Delta F_{s} / F_{s 0}\right)$ shows a tendency to become constant and close to 1.1. Fig. 3 gives the dependence of the ratio $\left(a / \alpha_{s}\right) /\left(\Delta F_{s} / F_{s 0}\right)$ on $F_{s}$ and shows the same tendency for low solar fraction given by Hollands et al (1992).

According to Hollands et al (1992) and the above results, Eq. 10 shows the relationship between $k_{2}$ and $a$, given Eq. 6.

$$
k_{2}=a \approx \alpha_{s 0} \times \frac{\Delta F_{s}}{F_{s 0}} \times \text { ratio }
$$

The performance criterion was determined for three different situations in order to meet the main objective of this study, i.e, the adequate expression for performance criterion considering solar fractions higher than $50 \%$ in climates of South of Europe. The results are presented in Tab. 3, 4 and 5. The parameter $k_{l}$ was calculated considering $a$ and $b$, according to Eq. 5 . The parameter $k_{2}$ was calculated considering $\alpha_{s 0}=0.96$, the $\Delta F_{s} / F_{s 0}$ and the respective ratio, according to Eq. 10 .

Firstly, the performance criterion was determined for low solar fraction considering an average value for all the solar fractions up to $50 \%$, i.e. the average solar fraction between $20 \%$ and $50 \%$, and then, compared with the performance criterion given by Hollands et al (1992). Secondly, the performance criterion was determined for solar fractions lower than $80 \%$, considering an average value of all solar fractions from $20 \%$ up to $80 \%$. Thirdly and last, the performance criterion was determined for a solar fraction equal to $80 \%$, considering the ratio $\left(a / \alpha_{s}\right) /\left(\Delta F_{s} / F_{s 0}\right)$ specific for that solar fraction.

For the first situation, shown in Tab. 3, for $F_{s} / F_{s 0}=0.95, a=0.14$ and $b=0.24$ are obtained and taking into account $\alpha_{s 0}=0.96$ and ratio $=1.1$ (low solar fraction), this leads to $k_{1}=0.58$ and $k_{2}=0.05$. The approximation $k 2 \approx a$ was not found in this case. This also applies for $F_{s} / F_{s 0}=0.90$, where it is obtained $a=0.24$ and $b=0.48$, for the same $\alpha_{s 0}$ and ratio, leading to $k_{1}=0.50$ and $k_{2}=0.11$, where $k_{2}$ is clearly different from $a$.

Tab. 3: Performance criterion for low solar fraction $F_{s}<0.5$, considering an average value of all solar fractions up to $50 \%$

\begin{tabular}{|c|c|c|c|c|c|c|}
\hline $\boldsymbol{F}_{\boldsymbol{s}} / \boldsymbol{F}_{\boldsymbol{s} \boldsymbol{0}}$ & $\boldsymbol{a}$ & $\boldsymbol{b}$ & $\boldsymbol{k}_{\boldsymbol{1}}$ & $\boldsymbol{r a t i o}\left(\boldsymbol{a} / \boldsymbol{\alpha}_{\mathbf{s} 0}\right) /\left(\Delta \boldsymbol{F}_{\boldsymbol{s}} / \boldsymbol{F}_{\boldsymbol{s} \boldsymbol{0}}\right)$ & $\boldsymbol{k}_{\boldsymbol{2}}$ & $\mathbf{P C}$ \\
\hline 0.95 & 0.14 & 0.24 & 0.58 & $\approx 1.1$ & 0.05 & $P C=-\Delta \alpha_{s}+0.58 \Delta \varepsilon \leq 0.05$ \\
\hline 0.90 & 0.24 & 0.48 & 0.50 & $\approx 1.1$ & 0.11 & $P C=-\Delta \alpha_{s}+0.50 \Delta \varepsilon \leq 0.11$ \\
\hline
\end{tabular}

For the second situation, presented in Tab. 4, for $F_{s} / F_{s 0}=0.95, a=0.14$ and $b=0.24$ are also obtained and considering $\alpha_{s 0}=0.96$ and ratio $=1.68$ (solar fraction $F_{s}<0.8$ ), this leads to $k_{1}=0.58$ and $k_{2}=0.08$. The approximation $k_{2} \approx a$ was also not found in this case. This also applies for $F_{s} / F_{s}=0.90$, where it is obtained $a=0.24$ and $b=0.48$, for the same $\alpha_{s 0}$ and ratio, leading to $k_{1}=0.50$ and $k_{2}=0.16$, where $k_{2}$ is different from $a$. 
Tab. 4: Performance criterion for solar fraction $F_{s}<0.8$, considering an average value of all solar fractions until $80 \%$

\begin{tabular}{|c|c|c|c|c|c|c|}
\hline $\boldsymbol{F}_{\boldsymbol{s}} / \boldsymbol{F}_{\boldsymbol{s} \boldsymbol{0}}$ & $\boldsymbol{a}$ & $\boldsymbol{b}$ & $\boldsymbol{k}_{\boldsymbol{1}}$ & $\boldsymbol{r a t i o}\left(\boldsymbol{a} / \boldsymbol{\alpha}_{\boldsymbol{s}}\right) /\left(\Delta \boldsymbol{F}_{\boldsymbol{s}} / \boldsymbol{F}_{\boldsymbol{s} \boldsymbol{0}}\right)$ & $\boldsymbol{k}_{\mathbf{2}}$ & PC \\
\hline 0.95 & 0.14 & 0.24 & 0.58 & $\approx 1.68$ & 0.08 & $P C=-\Delta \alpha_{s}+0.58 \Delta \varepsilon \leq 0.08$ \\
\hline 0.90 & 0.24 & 0.48 & 0.50 & $\approx 1.68$ & 0.16 & $P C=-\Delta \alpha_{s}+0.50 \Delta \varepsilon \leq 0.16$ \\
\hline
\end{tabular}

At last, for the third situation given by Tab. 5, for $F_{s} / F_{s 0}=0.95, a=0.14$ and $b=0.24$ are also obtained and considering $\alpha_{s 0}=0.96$ and ratio $=2.76$ (solar fraction $F_{s}=0.8$ ), this leads to $k_{1}=0.58$ and $k_{2}=0.13$. The approximation $k_{2} \approx a$ was found for this situation. For $F_{s} / F_{s}=0.90$, where it is obtained $a=0.24$ and $b=0.48$, for the same $\alpha_{s 0}$ and ratio, leading to $k_{1}=0.50$ and $k_{2}=0.26$, where $k_{2}$ is quite close to $a$. This result is as expected, since the ratio used is obtained for higher solar fraction values.

Tab. 5: Performance criterion for solar fraction $F_{s}=0.8$, considering the ratio corresponding to a solar fraction of $80 \%$

\begin{tabular}{|c|c|c|c|c|c|c|}
\hline $\boldsymbol{F}_{\boldsymbol{s}} / \boldsymbol{F}_{\boldsymbol{s} \boldsymbol{0}}$ & $\boldsymbol{a}$ & $\boldsymbol{b}$ & $\boldsymbol{k}_{\boldsymbol{1}}$ & $\boldsymbol{r a t i o}\left(\boldsymbol{a} / \boldsymbol{\alpha}_{\mathbf{s}}\right) /\left(\Delta \boldsymbol{F}_{\boldsymbol{s}} / \boldsymbol{F}_{\boldsymbol{s} \boldsymbol{0}}\right)$ & $\boldsymbol{k}_{\boldsymbol{2}}$ & $\mathbf{P C}$ \\
\hline 0.95 & 0.14 & 0.24 & 0.58 & 2.76 & 0.13 & $P C=-\Delta \alpha_{s}+0.58 \Delta \varepsilon \leq 0.13$ \\
\hline 0.90 & 0.24 & 0.48 & 0.50 & 2.76 & 0.26 & $P C=-\Delta \alpha_{s}+0.50 \Delta \varepsilon \leq 0.26$ \\
\hline
\end{tabular}

Although for higher solar fractions, values of $k_{2}$ and $a$ are similar (Tab. 5), the PC obtained would correspond to a less demanding requirement, i.e., higher depreciation of $\alpha_{s}$ could be considered. Since collectors used in systems working at higher solar fractions are expected to work at higher temperatures, this less demanding requirement is not adequate, i.e., this methodology is unclear regarding to the suitability of the expression for performance criterion considering solar fractions higher than $50 \%$.

\section{Supplied energy as performance indicator}

\subsection{Methodology}

It was decided to adopt another methodology in order to obtain more enlightening results. The methodology proposed by Hollands et al (1992) was also used but considering, as performance indicator, the supplied energy $E$ of DHW system instead of solar fraction $F_{s}$. The initial supplied energy $E_{0}$ corresponds to the DHW initial state when $\Delta \alpha_{s}=0$ and $\Delta \varepsilon_{t}=0$.

When replacing the solar fraction $F_{S}$ for supplied energy $E$, it was considered that supplied energy higher to Load was still useful energy. In this situation the depreciation in supplied energy is proportional do the depreciation in $\alpha_{s}$ which means a reduction of 5 or $10 \%$ in $\alpha_{s}$ that will cause a reduction of the supplied energy $E$.

Still following Hollands et al (1992) methodology, the ratio presented in Eq. 9 is transformed into Eq. 12, where the ratio versus $E_{0}$ was analyzed taking into account all the simulations performed considering different ratio $E / E_{0}$ for the DHW system studied in this work. Eq. 13 shows the relationship between $k_{2}$ and $a$, given Eq. 6 .

$$
\begin{aligned}
& \text { ratio }=\left(\frac{a}{\alpha_{s 0}} / \frac{\Delta \mathrm{E}}{E_{0}}\right) \\
& k_{2}=a \propto \alpha_{s 0} \times \frac{\Delta E}{E_{0}} \times \text { ratio }
\end{aligned}
$$

Similar to previous analysis, Fig. 4 illustrates the supplied energy $E$ as a function of solar absorptance $\alpha_{s}$ and each curve corresponds to a fixed value of thermal emittance $\varepsilon_{t}$ for situation (a). From this figure, combinations of $\alpha_{s}$ and $\varepsilon_{t}$ that will produce a 5 and $10 \%$ loss in supplied energy are obtained. Two possible states of failure are represented when compared with the initial solar supplied energy $E_{0}$, i.e., when $E=0.90 E_{0}$ and $E=0.95 E_{0}$, respectively. $E_{0}$ represents the supplied energy when the DHW system operates with $\alpha_{s}=\alpha_{s 0}$ and $\varepsilon_{t}=\varepsilon_{t 0}$. In Fig. $5,-\Delta \alpha_{s}$ is represented as a function of $\Delta \varepsilon_{t}$.

According to Eq. 12 and the results presented in Tab. 6, the proportionality between $a$ and $E_{0}$ is evident for all supplied energies $E$ and not only for a few situations has it happened (see Tab. 2 and Fig. 3) when solar fractions were used in the studied equations. The ratio $\left(a / \alpha_{s}\right) /\left(\Delta E_{s} / E_{0}\right)$ shows a tendency to become constant, particularly close to 1.1, for all supplied energies. Fig. 6 shows this dependence of the ratio on supplied energy $E$. 


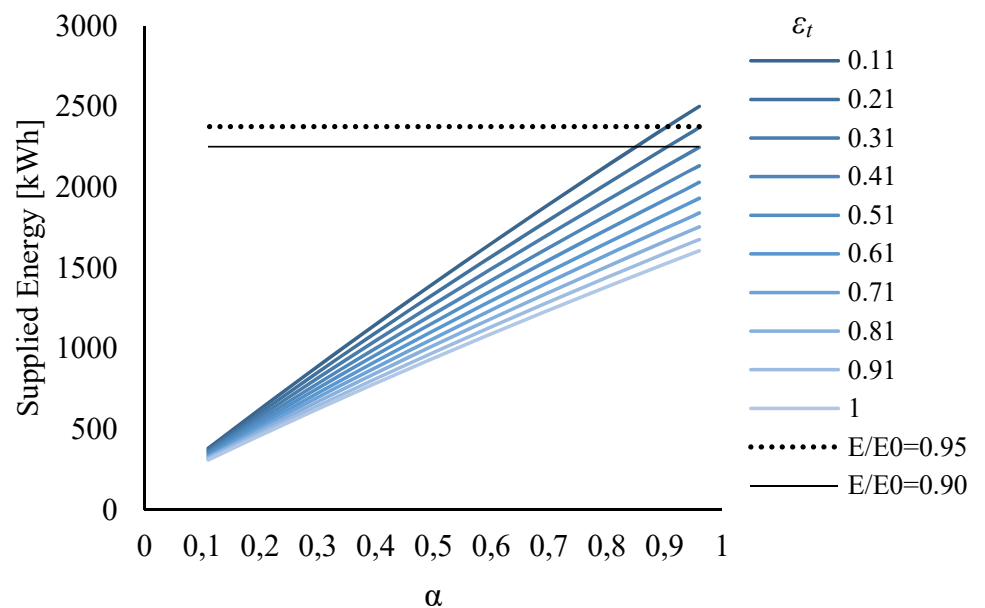

Fig. 4: Supplied energy as a function of $\alpha_{s}$ and $\varepsilon_{t}$ and combinations of $\alpha_{s}$ and $\varepsilon_{t}$ that will produce a $5 \%$ and $10 \%$ loss in the supplied energy of DHW system (a) located in Lisbon (latitude $=37.8^{\circ}$ )

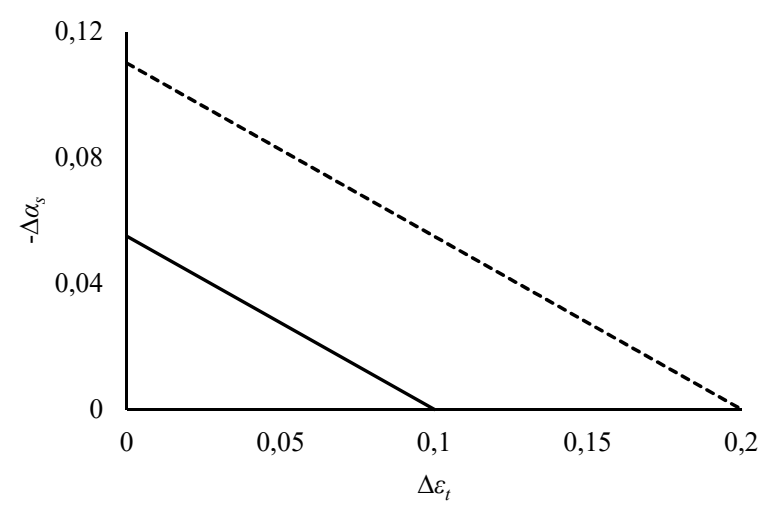

$\mathrm{E} / \mathrm{E} 0=0.95$

$\mathrm{E} / \mathrm{E} 0=0.90$

Fig. 5: Combinations of $\alpha_{s}$ and $\varepsilon_{t}$ that will produce a $5 \%$ and $10 \%$ loss in the supplied energy of DHW system (a) located in Lisbon (latitude $=37.8^{\circ}$ )

Tab. 6: Effect of the (arbitrarily-chosen) ratio $E / E_{0}$ on the vertical intercept a and ratio $\left(a / \alpha_{s}\right) /\left(\Delta E / E_{0}\right)$

\begin{tabular}{|c|c|c|c|c|}
\hline $\boldsymbol{E} / \boldsymbol{E}_{\boldsymbol{o}}$ & $\Delta \boldsymbol{E} / \boldsymbol{E}_{\boldsymbol{0}}$ & $\boldsymbol{E}$ & $\boldsymbol{a}$ & $\left(\boldsymbol{a} / \boldsymbol{\alpha}_{\mathbf{s} 0}\right) /\left(\Delta \boldsymbol{E} / \boldsymbol{E}_{\boldsymbol{\theta}}\right)$ \\
\hline 0.95 & 0.05 & 2378 & 0.14 & 1.15 \\
\hline 0.90 & 0.10 & 2253 & 0.24 & 1.15 \\
\hline 0.80 & 0.20 & 2002 & 0.38 & 1.12 \\
\hline 0.70 & 0.30 & 1752 & 0.48 & 1.11 \\
\hline 0.60 & 0.40 & 1502 & 0.56 & 1.10 \\
\hline 0.50 & 0.50 & 1252 & 0.63 & 1.08 \\
\hline 0.40 & 0.60 & 1001 & 0.71 & 1.07 \\
\hline 0.30 & 0.70 & 751 & 0.78 & 1.06 \\
\hline 0.20 & 0.80 & 501 & 0.85 & 1.05 \\
\hline
\end{tabular}




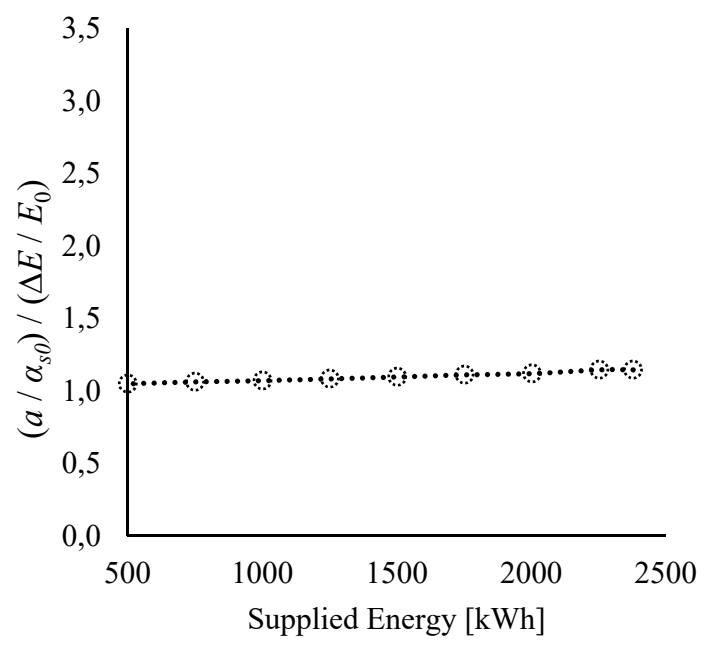

Fig. 6: Dependence of the ratio $\left(a / \alpha_{s 0}\right) /\left(\Delta E / E_{0}\right)$ on $E$.

\subsection{Results}

According to Tab. 6, for $E / E_{0}=0.95, a=0.055$ and $b=0.1$ were obtained and, considering $\alpha_{s 0}=0.96$ and ratio $=1.1$, this leads to $k_{1}=0.55$ and $k_{2}=0.055$. The approximation $k_{2}=a$ is clearly found in this situation. For $E / E_{0}=0.90, a=0.11$ and $b=0.2$ where obtained and, for the same $\alpha_{s 0}$ and ratio, this leads to $k_{1}=0.55$ and $k_{2}=0.11$, where $k_{2}$ is equal to $a$.

Since the ratio $\left(a / \alpha_{s}\right) /\left(\Delta E_{s} / E_{0}\right)$ shows to be constant for all supplied energies, there is not a distinction between low or high supplied energy has it happens for solar fraction $F_{s}$. Then, the performance criterion given in Tab. 7 can be accept as a general equation. These results are consistent with the performance criterion given by ISO 22975-3:2014.

Tab. 7: Parameter $k_{1}, k_{2}$, ratio and performance criterion (PC)

\begin{tabular}{|c|c|c|c|c|c|c|}
\hline $\boldsymbol{E} / \boldsymbol{E}_{\boldsymbol{0}}$ & $\boldsymbol{a}$ & $\boldsymbol{b}$ & $\boldsymbol{k}_{\boldsymbol{1}}$ & ratio $\left(\boldsymbol{a} / \boldsymbol{a}_{\mathbf{s}}\right) /\left(\Delta \boldsymbol{E} / \boldsymbol{E}_{\boldsymbol{0}}\right)$ & $\boldsymbol{k}_{\boldsymbol{2}}$ & PC \\
\hline 0.95 & 0.055 & 0.100 & 0.550 & $\approx 1.1$ & 0.055 & $P C=-\Delta \alpha_{s}+0.550 \Delta \varepsilon \leq 0.055$ \\
\hline 0.90 & 0.110 & 0.200 & 0.550 & $\approx 1.1$ & 0.110 & $P C=-\Delta \alpha_{s}+0.550 \Delta \varepsilon \leq 0.110$ \\
\hline
\end{tabular}

\section{Conclusions}

In this work, solar DHW systems working with solar fractions higher than $50 \%$, in climates of south of Europe, were considered. The suitability of solar fraction as performance indicator to develop an adequate PC was studied.

As a first step, simulations of thermal performance of systems using SolTerm software were performed for a reduction of $5 \%$ and $10 \%$ of $F_{s}$. According to Hollands et al (1992), if all solar radiation absorbed by the collector is converted in useful energy, i.e., is transferred to the load, a reduction of the solar fraction $F_{s}$ will be proportional to a reduction on $\alpha_{s}$, if all other parameters are unchanged, i.e., $\Delta \varepsilon_{t}=0$. It was verified that this is only applicable for solar fraction lower than $50 \%$ and the results showed that the parameters obtained to define the PC were incoherent. For higher solar fractions, the PC obtained would correspond to a less demanding requirement, i.e., higher depreciation of $\alpha_{s}$ could be considered. Since collectors used in systems working at higher solar fractions are expected to work at higher temperatures, this less demanding requirement is not adequate, i.e., this methodology is unclear regarding to the suitability of the expression for performance criterion considering solar fractions higher than $50 \%$.

In a second step, supplied energy was considered as performance indicator and using similar methodology as Hollands et al (1992), the PC for systems working with solar fractions higher than 50\%, in climates of south of Europe, was establish.

When replacing the solar fraction $F_{s}$ by supplied energy $E$, it was considered that supplied energy higher to load was still useful energy. In this situation the depreciation in supplied energy is proportional to the depreciation in $\alpha_{s}$ which means a reduction of 5 or $10 \%$ in $\alpha_{s}$ that will cause a reduction of the supplied energy $E$. 
The results showed that the parameters used to define the PC are now not significantly different from the PC considered in ISO 22975-3.

The expression for performance criterion given by ISO 22975-3:2014 is adequate for solar fractions higher than 50\% in climate of South of Europe.

\section{Acknowledgments}

The authors would like to thank to Doctor Nobumitsu Shohoji for valuable suggestions on the presentation of results of this work.

This work is a result of the project FCOMP-01-0124-FEDER-027507 (Ref ${ }^{\mathrm{a}}$ FCT RECI/EMS-ENE/0170/2012) supported by Operational Competitiveness Programme (COMPETE) through the European Regional Development Fund (ERDF) and supported by FCT- Fundação para a Ciência e a Tecnologia, I.P. through National Funds and the project POCI-01-0145-FEDER-016709 (Ref ${ }^{a}$ FCT PTDC/EMS-ENE/0578/2014) supported by COMPETE 2020 and LISBOA 2020 under the PORTUGAL 2020 Partnership Agreement through the European Regional Development Fund (ERDF) and supported by FCT through National Funds.

\section{References}

K. G. T. Hollands, A. Karagiozis, A. P. Brunger, Effect of Selective surface degradation on the performance of solar water heating systems, Sol. Energy Mater. Sol. Cells 25 (1992) 125-141, https://doi.org/10.1016/0927$\underline{0248(92) 90022-\mathrm{H}}$

B. Carlsson, U. Frei, M. Köhl, K. Möller, Accelerated life testing of solar energy materials. Case study of some selective solar absorber coating materials for DHW-systems; A report of IEA Task X; Solar materials Research and development; $\quad$ SP $\quad$ Report 94:13; ISBN 91-7848-472-3 (http://ri.divaportal.org/smash/record.jsf?pid=diva2\%3A961896\&dswid=-5275)

D. E. Roberts, A. Forbes, An analytical expression for the instantaneous efficiency of a flat plate solar water heater and the influence of absorber plate absorptance and emittance, Sol. Energy 86 (2012) 1416-1427, https://doi.org/10.1016/j.solener.2012.01.032

ISO 22975-3:2014, Solar Energy-collector components and materials - Part 3: Absorber surface durability, ISO 2014 ASTM G173 - 03, Standard Tables for Reference Solar Spectral Irradiances: Direct Normal and Hemispherical on $37^{\circ}$ Tilted Surface, 2012

SolTerm, LNEG, Version 5.3 - September 2017 (http://www.lneg.pt/iedt/projectos/370/) 


\title{
Accelerated Aging Tests for Solar Absorber Coatings
}

\author{
T. C. Diamantino', R. Gonçalves ${ }^{1}$, S. Páscoa ${ }^{1}$, II Nascimento $^{1}$, T. Chambino ${ }^{1}$, C. Ferreira ${ }^{1}$ and \\ M J. Carvalho' \\ 1 LNEG - Laboratório Nacional de Energia e Geologia. Estrada do Paço do Lumiar, 1649-038 \\ Lisboa, Portugal
}

\begin{abstract}
The need of a higher role of solar energy within the energy mix in the coming decades obliges the systems to increase their performance and reliability. It is demanded that the solar absorbers, as the key component of solar thermal systems, should be low cost with high efficiency for extended lifetimes under different kinds of environments. Commercially, there are two different types of solutions as selective solar absorbers coatings: coatings obtained by physical vapor deposition (PVD) and by paint coatings (PC). These coatings present different physical and chemical characteristics. Therefore, it is important to know how these coatings degrade over time in different environments. Results obtained with two different PVD coatings and three PC, under different accelerated aging tests, are presented. The aging tests performed included different environmental stress corrosion conditions: temperature, humidity, chlorides, sulphur dioxide and nitrogen oxides. Cyclic variation of corrosion promoting gases (sulfur dioxide and nitrogen dioxide), higher humidity, salt spraying and drying seem to be an aging test that reflects the different environments where the solar thermal collectors are exposed. In addition to the contaminants, drying / wetting cycles also play an important role in degradation mechanisms of absorber coatings.
\end{abstract}

Keywords: Aging Tests, Solar Absorbers Coatings

\section{Introduction}

In order to study the durability of selective solar absorber coatings, two alternatives must be considered. One is to study its durability on different natural exposure test sites (Slamova et al. 2016) and, the other, is to develop accelerated aging test procedures in which the stress levels of one or more degradation factors are kept higher relative to in-use conditions (Carlsson et al. 2004 and ISO/TR 16335:2013). The study of the durability of different selective solar absorber coatings in natural exposure was already performed and published by the authors (Diamantino et al. 2017) and is an important knowledge for the optimization of accelerated aging tests to be applied for qualification in terms of durability of the different solar absorber coatings.

Long-term behaviour of selective solar absorbers, used in solar thermal collectors for domestic hot water (DHW) systems, can be performed according to the standard ISO 22975-3:2014. This standard considers three aging tests to guarantee a 25-year service life of selective solar absorbers, which are: 1) assessing thermal stability, 2) determining the resistance to condensed water and 3 ) resistance to high humidity air containing sulphur dioxide. Evaluation of absorber coatings according to the standard ISO 22975-3:2014 is based on a performance criterion $(P c)$ dependent directly on the optical properties of the collector. In order to an absorber coating to be qualified, the value of $P c$ shall be lower or equal to 0.05 . The qualification of an absorber coating according to the standard ISO 22975-3:2014 takes a minimum of 600 hours for each test and it is very demanding in laboratory equipment to perform all the test sequences. Besides it does not include all major contaminants to which these selective coatings are subjected (Carvalho et al. 2017, Diamantino et al. 2016 and 2017).

In this work, based on results obtained from natural exposure and from the climatic conditions inside collectors, a screening of accelerated aging tests with two PVD coatings and three PC was performed considering different environmental stress corrosion conditions. The objectives are to know the optical behaviour (solar absorptance, thermal emittance, performance criterion function and figure of merit) and the corrosion protection of the different coatings and to propose alternative aging tests for qualification in terms of durability of the different solar absorber coatings. 


\section{Methodology}

\subsection{Selective solar absorber coatings}

In this study, five selective absorber coatings applied on aluminum were considered, two coatings obtained by PVD are commercially available and were acquired from STC manufacturers (PVD 1 - commercial name mirotherm $\mathbb{R}$ and PVD 2 - commercial name eta plus ${ }^{\circledR}$ ); three selective paint coatings (two PCs thickness sensitive spectrally selective (TSSS) with silicone binders (PC1 and PC2) which commercial names are SUNCOLOR TS S Black and SOLKOTE HI/SORB-II ${ }^{\text {TM}}$, respectively. PC3 is a thickness insensitive spectrally selective (TISS) type paint coating (commercial name: SUNCOLOR PUR Black). Details of the surface preparation and paints application were already described (Diamantino et al. 2017). The evaluated samples have a dimension of $65 \times 65$ $\mathrm{mm}$ and $65 \times 140 \mathrm{~mm}$. Sample dimension selection depends on the test chambers dimensions.

\subsection{Optical properties}

All the selective solar absorber samples used specifically in this study were optically characterized by measurement of solar absorption $\left(\alpha_{s}\right)$ and thermal emittance $\left(\varepsilon_{t}\right)$. The solar absorption $\left(\alpha_{s}\right)$ was determined based on the reference solar spectral irradiance (incident on a $37^{\circ}$ tilted plane, equator-facing) and the reflectance measurements performed on Perkin Elmer's Spectrophotometer Lambda 950 UV/VIS/NIR with a $150 \mathrm{~mm}$ integrating sphere. The thermal emittance $\left(\varepsilon_{t}\right)$ was determined using a Spectrophotometer Frontier IR/NIR of Perkin Elmer with integrating sphere. A diffuse gold coating reference, calibrated by Avian Technologies LLC, was used for the spectral reflectance measurement between 2.5 and $20 \mu \mathrm{m}$.

Two parameters were used to evaluate the optical behaviour of the materials: 1) performance criterion $(P c)$ (according to ISO 22975-3:2014) and 2) figure of merit (FM) (Roberts, D. E. 2013).

1) $P c=-\Delta \alpha_{s}+0.5 \Delta \varepsilon_{t}$

Where $\Delta \alpha_{s}$ is the change of solar absorptance during an aging test and $\Delta \varepsilon_{t}$ the change in thermal emittance in the same test. According to ISO 22975-3 absorber coating is qualified if the value of $P c$ is lower or equal to 0.05 .

2) $F M=\alpha_{s}-0.44 \varepsilon_{t}$

Roberts, D. E. (2013) introduces a figure of merit $(F M)$ based on these optical properties with the purpose of evaluating the performance of solar absorber coatings, the larger the value of $F M$ the better the performance.

\subsection{Accelerated aging tests}

Table 1 resumes the parameters of all the accelerated aging tests. The aging test according to the standard ISO 21207:2015 with the code NSS + SO2 + NO2 + DW was performed with three different preconditions (samples without thermal preconditioning, $5 \mathrm{~h}$ and $18 \mathrm{~h}$ of thermal conditioning) to evaluate the influence of temperature $\left(193^{\circ} \mathrm{C}\right)$ in the behaviour of solar absorber coatings to this corrosive environment. NSS+DW and SO2+NO2+DW aging tests were performed with 5 hours of pre thermal conditioning.

The thermal conditioning of the different solar absorber coatings was performed at $193^{\circ} \mathrm{C}$, because it was the higher absorber temperature obtained according to the standard ISO 22975-3:2014 for the coatings considered. The equipment used for thermal conditioning was Heratherm Oven OMH100. The codes assigned to these aging tests are: $\mathrm{NSS}+\mathrm{SO} 2+\mathrm{NO} 2+\mathrm{DW}, 5 \mathrm{~h} \mathrm{NSS}+\mathrm{SO} 2+\mathrm{NO} 2+\mathrm{DW}$ and $18 \mathrm{~h} \mathrm{NSS}+\mathrm{SO} 2+\mathrm{NO} 2+\mathrm{DW}$ (Table 1).

The NSS and SO2 are aging tests with continuous exposure of contaminants and the remaining tests involve cyclical conditions with different combination of corrosion promoting gases ( $\mathrm{SO} 2$ and $\mathrm{NO} 2$ ), relative humidity, neutral salt spray and drying, with and without previous thermal conditioning of samples.

\subsection{Corrosivity of accelerated aging tests performed according to ISO standards}

The corrosivity of the accelerated aging tests performed according to ISO standards were obtained based on corrosion rate measurement of standard specimens (carbon steel, zinc, copper and aluminum). The standard 
specimens were acquired, cut, prepared and exposed according to the standard ISO 9226:2012. After exposure to aging tests (NSS, $\mathrm{SO}_{2}, \mathrm{NSS}+\mathrm{TDW}, \mathrm{NSS}+\mathrm{SO}_{2}+\mathrm{NO}_{2}+\mathrm{DW}$ ) during 7 days, corrosion products of each metal were removed in accordance with the standard ISO 8407:2009.

Tab. 1: Details of the accelerated aging tests

\begin{tabular}{|c|c|c|c|c|}
\hline $\begin{array}{l}\text { Test type } \\
\text { (code) }\end{array}$ & $\begin{array}{c}\text { Standard } \\
\text { (if applicable) }\end{array}$ & $\begin{array}{l}\text { Testing } \\
\text { time } \\
\text { (h/cycles) }\end{array}$ & Testing conditions & $\begin{array}{c}\text { Test } \\
\text { chambers }\end{array}$ \\
\hline $\begin{array}{c}\text { Continuous neutral salt spray } \\
\text { (NSS) }\end{array}$ & $\begin{array}{c}\text { ISO } \\
9227: 2017\end{array}$ & $120 \mathrm{~h}$ & $\begin{array}{l}{[\mathrm{NaCl}]=50 \pm 5 \mathrm{~g} / \mathrm{L} ;} \\
\mathrm{T}=35 \pm 2{ }^{\circ} \mathrm{C} ; \mathrm{RH}=100 \% ; \\
\mathrm{pH}=6.5-7.2\end{array}$ & $\begin{array}{l}\text { Erichsen } \\
\text { Model } \\
606 / 400 \mathrm{~L} \\
\end{array}$ \\
\hline $\begin{array}{l}\text { Continuous saturated } \\
\text { atmosphere with sulphur } \\
\text { dioxide } \\
\left(\mathbf{S O}_{2}\right)\end{array}$ & $\begin{array}{c}\text { ISO } \\
3231: 1993\end{array}$ & $120 \mathrm{~h}$ & $\begin{array}{l}\text { Each } 24 \mathrm{~h}: 8 \mathrm{~h} 40{ }^{\circ} \mathrm{C} \pm 3{ }^{\circ} \mathrm{C} \\
\text { and } 100 \% \text { of } \mathrm{RH}\left(\mathrm{SO}_{2}-\right. \\
0.2 \mathrm{~L}) \text { and } 16 \mathrm{~h} \text { at } 18-28{ }^{\circ} \mathrm{C} \\
\text { and } \mathrm{RH} \max 75 \% \text { (test } \\
\text { chamber vented)) }\end{array}$ & $\begin{array}{l}\text { VLM Model } \\
\text { CCT 400-Air } \\
\text { CTD-A }\end{array}$ \\
\hline $\begin{array}{l}\text { Cyclic exposure to dry and wet } \\
\text { (TDW) }\end{array}$ & NA & $240 \mathrm{~h}$ & $\begin{array}{l}\text { Cycles with } 2 \mathrm{~h} \\
\mathrm{~T}=35 \pm 2{ }^{\circ} \mathrm{C}(\mathrm{RH}>95 \%) \\
+4 \mathrm{~h} \mathrm{~T}=60 \pm 2{ }^{\circ} \mathrm{C} \\
(\mathrm{RH}<30 \%)+2 \mathrm{~h} \\
\mathrm{~T}=50 \pm 2{ }^{\circ} \mathrm{C}(\mathrm{RH}>95 \%)\end{array}$ & $\begin{array}{l}\text { Q-Panel Q- } \\
\text { FOG/CCT600 }\end{array}$ \\
\hline $\begin{array}{c}\text { Cyclic exposure to salt mist, dry } \\
\text { and wet } \\
\text { (NSS + TDW) }\end{array}$ & $\begin{array}{c}\text { ISO } \\
\text { 14993:2001 }\end{array}$ & $240 \mathrm{~h}$ & $\begin{array}{l}\text { Cycles with } 2 \mathrm{~h} \text { neutral salt } \\
\text { spray (NSS) (ISO } \\
9227: 2017) \\
+4 \mathrm{~h} \mathrm{~T}=60 \pm 2{ }^{\circ} \mathrm{C} \\
(\mathrm{RH}<30 \%)+2 \mathrm{~h} \\
\mathrm{~T}=50 \pm 2{ }^{\circ} \mathrm{C}(\mathrm{RH}>95 \%)\end{array}$ & $\begin{array}{l}\text { Q-Panel Q- } \\
\text { FOG/CCT600 }\end{array}$ \\
\hline $\begin{array}{c}\text { Cyclic variation of corrosion } \\
\text { promoting gases }\left(\mathrm{SO}_{2}+\mathrm{NO}_{2}\right), \\
\text { high humidity, neutral salt spray } \\
\text { and dry } \\
\left(\mathrm{NSS}+\mathbf{S O}_{2}+\mathbf{N O}_{2}+\mathbf{D W}\right) \\
\left(\mathbf{5 h} \mathrm{NSS}+\mathbf{S O}_{2}+\mathbf{N O}_{2}+\mathbf{D W}\right) \\
\left(\mathbf{1 8 h} \mathbf{N S S}+\mathbf{S O}_{2}+\mathbf{N O}_{2}+\mathbf{D W}\right)\end{array}$ & $\begin{array}{c}\text { ISO } \\
21207: 2015\end{array}$ & $\begin{array}{c}672 \mathrm{~h} \\
(4 \text { cycles })\end{array}$ & $\begin{array}{l}\text { Each cycle }(1 \text { week }): 2 \mathrm{~h} \\
\text { neutral salt spray }(\mathrm{NSS}) \\
(\text { ISO } 9227: 2017)+22 \mathrm{~h} \\
\text { standard climate }\left(23^{\circ} \mathrm{C} \text { and }\right. \\
50 \% \mathrm{RH})+120 \mathrm{~h} \text { with } \\
\text { corrosive atmosphere } \\
\left(\mathrm{NO}_{2}=1.5 \times 10^{-6}+\right. \\
\left.\mathrm{SO}_{2}=0.5 \times 10^{-6}\right)\left(25^{\circ} \mathrm{C} \text { and }\right. \\
95 \% \mathrm{RH})+24 \mathrm{~h} \text { standard } \\
\text { climate }\left(23{ }^{\circ} \mathrm{C} \text { and } 50 \% \mathrm{RH}\right)\end{array}$ & $\begin{array}{l}\text { Erichsen } \\
\text { Model } \\
606 / 400 \text { L }+ \\
\text { WEISS WK3- } \\
\text { 340/0-BSB }\end{array}$ \\
\hline $\begin{array}{l}\text { Cyclic variation of high } \\
\text { humidity (without gases), } \\
\text { neutral salt spray and dry } \\
\text { (NSS+ DW) }\end{array}$ & NA & $\begin{array}{c}672 \mathrm{~h} \\
(4 \text { cycles })\end{array}$ & $\begin{array}{l}\text { Each cycle }(1 \text { week }): 2 \mathrm{~h} \\
\text { neutral salt spray (NSS) } \\
\text { (ISO } 9227: 2017)+22 \mathrm{~h} \\
\text { standard climate }\left(23{ }^{\circ} \mathrm{C} \text { and }\right. \\
50 \% \mathrm{RH}) 120 \mathrm{~h} \text { at } 25^{\circ} \mathrm{C} \\
\text { and } 95 \% \mathrm{RH} \\
+24 \mathrm{~h} \text { standard climate } \\
\left(23^{\circ} \mathrm{C} \text { and } 50 \% \mathrm{RH}\right)\end{array}$ & $\begin{array}{l}\text { Erichsen } \\
\text { Model } \\
606 / 400 \mathrm{~L}+ \\
\text { Fitoclima } \\
\text { S600 }\end{array}$ \\
\hline $\begin{array}{l}\text { Cyclic variation of corrosion } \\
\text { promoting gases }\left(\mathrm{SO}_{2}+\mathrm{NO}_{2}\right), \\
\text { high humidity and dry } \\
\left(\mathbf{S O 2}+\mathbf{N O}_{2}+\mathbf{D W}\right)\end{array}$ & NA & $\begin{array}{c}672 \mathrm{~h} \\
(4 \text { cycles })\end{array}$ & $\begin{array}{l}\text { Each cycle }(1 \text { week }): 24 \mathrm{~h} \\
\text { standard climate }\left(23^{\circ} \mathrm{C} \text { and }\right. \\
50 \% \mathrm{RH})+120 \mathrm{~h} \text { with } \\
\text { corrosive atmosphere } \\
\left(\mathrm{NO}_{2}=1.5 \times 10^{-6}+\right. \\
\left.\mathrm{SO}_{2}=0.5 \times 10^{-6}\right)\left(25^{\circ} \mathrm{C} \text { and }\right. \\
95 \% \mathrm{RH})+24 \mathrm{~h} \text { standard } \\
\text { climate }\left(23^{\circ} \mathrm{C} \text { and }\right. \\
50 \% \mathrm{RH})\end{array}$ & $\begin{array}{l}\text { WEISS WK3- } \\
340 / 0-B S B\end{array}$ \\
\hline
\end{tabular}




\section{Results and Discussion}

\subsection{Accelerated aging tests}

Photographic records of the samples submitted to neutral salt spray (NSS), continuous saturated atmosphere with sulfur dioxide $\left(\mathrm{SO}_{2}\right)$ and cyclic exposure to temperature, dry and wet without (TDW) and with salt spray $(\mathrm{NSS}+\mathrm{TDW})$ are shown in Table 2. Figure 1 shows the results of optical performance $(P c$ and $F M)$ of these samples during the exposure to the same accelerated aging tests. The red line, that can be seen in the graphs of $P C$, represents the value 0.05 considered by the standard ISO 22975-3:2014 as the higher limit acceptable after aging tests for an absorber coating to be qualified.

When comparing Table 2 with Figure 1, it is clear the direct relationship between corrosion and change in optical performance $(P c)$.

Tab. 2: Photographic records of PVDs (PVD1 and PVD2) and PCs (PC1, PC2 and PC3) after NSS, $\mathrm{SO}_{2}$, TDW and NSS + TDW aging tests

\begin{tabular}{|c|c|c|c|c|}
\hline \multirow{2}{*}{$\begin{array}{l}\text { Absorber } \\
\text { Coating }\end{array}$} & \multicolumn{4}{|c|}{ Aging test (test time) } \\
\hline & NSS (120h) & $\mathrm{SO}_{2}(120 \mathrm{~h})$ & TDW (240 h) & $\begin{array}{c}\text { NSS + TDW } \\
\quad(240 \mathrm{~h})\end{array}$ \\
\hline PVD1 & & & & \\
\hline PVD2 & & & & \\
\hline $\mathrm{PC} 1$ & & & & \\
\hline PC2 & & & & \\
\hline PC3 & & & & \\
\hline
\end{tabular}


Neutral salt spray led to a higher degradation in PVDs than in PCs. Considering only PVDs, PVD2 showed higher degradation than PVD1. For PCs, PC3 showed the best behaviour in terms of anticorrosive protection and optical properties (lower $P c$ and higher $F M$ ). For the sulfur dioxide resistance test, opposite results were observed, i.e., the PCs showed higher degradation than PVDs. No significant changes were observed between the two PVDs and the three PCs.

The TDW and NSS tests showed that the PVD2 coating exhibits higher susceptibility than PVD1 to cycles with temperature $(P C$ and $F M)$. This fact was also observed, but with less intensity, during the thermal test for coatings qualification according to the standard ISO 22975-3:2014 (Diamantino et al. 2016). Thermal tests according to the standard ISO 22975-3:2014 are performed at higher temperature but without cycles of dry and wet. The opposite occurs with paint coatings (PC1, PC2 and PC3) that maintains or improves $F M$ after TDW testing. In the NSS + TDW test the high susceptibility of PVD coatings in chloride environments is evident again, although this test has lower corrosivity than NSS for aluminum (Figure 4).

In order to better understand the influence of different environmental contaminations, thermal conditioning and drying/wetting on the degradation of these surfaces, five additional accelerated aging tests were carried out $\left(\mathrm{NSS}+\mathrm{SO}_{2}+\mathrm{NO}_{2}+\mathrm{DW}, \quad 5 \mathrm{~h} \quad \mathrm{NSS}+\mathrm{SO}_{2}+\mathrm{NO}_{2}+\mathrm{DW}, \quad 18 \mathrm{~h} \quad \mathrm{NSS}+\mathrm{SO}_{2}+\mathrm{NO}_{2}+\mathrm{DW}, \quad \mathrm{NSS}+\mathrm{DW}\right.$ and $\left.\mathrm{SO}_{2}+\mathrm{NO}_{2}+\mathrm{DW}\right)$.

Before these accelerated aging tests, the influence of thermal conditioning on optical properties of absorber coatings (Figure 2) was also studied. By these results, within PVD coatings only PVD1 shows a slight decrease of $F M$ after thermal conditioning. The paint coatings show a little increase in the $F M$ after $18 \mathrm{~h}$ of thermal conditioning. This tendency also occurred in the TDW test, as well as in the thermal test according to the standard ISO 22975-3:2014 (Diamantino et al. 2016).

Table 3 and Figure 3 show, respectively, the results of the optical properties and visual degradation of the different selective solar absorber surfaces after the exposure to these five accelerated aging tests.

From Figure 3 and table 3, it is also evident the strong effect of chloride on degradation of PVDs and PCs, higher on PVDs. The thermal conditioning does not seem to have a significant effect on the corrosion behaviour and in $P c$ and $F M$. Only PVD2 presented a higher $P c$ and a lower $F M$ with $18 \mathrm{~h}$ of thermal conditioning, confirming its thermal susceptibility.

The results obtained with the methodology described in the standard ISO 21207:2015 (NSS $+\mathrm{SO}_{2}+\mathrm{NO}_{2}+\mathrm{DW}$ test), considering an accelerated aging test with cyclic variation of corrosion promoting gases $\left(\mathrm{SO}_{2}\right.$ and $\left.\mathrm{NO}_{2}\right)$, higher humidity, salt spraying and drying, are similar to those presented by Diamantino et al. 2017, with the same solar absorber coatings exposed to outdoor exposure testing sites with different corrosivity (urban test site with marine influence - medium corrosivity and an industrial/marine test site with very high /extreme corrosivity) in terms of the ranking of $P c, F M$ and anticorrosive protection.

Another important result was obtained from the data of $P c$ and $F M$ during NSS + DW test, comparatively to $\mathrm{NSS}+\mathrm{SO}_{2}+\mathrm{NO}_{2}+\mathrm{DW}$ test. A worse behaviour of PVDs was observed in NSS + DW than in $\mathrm{NSS}+\mathrm{SO}_{2}+\mathrm{NO}_{2}+\mathrm{DW}$. The only difference between these two aging tests is the presence or absence of corrosive gases (NSS $+\mathrm{SO}_{2}+\mathrm{NO}_{2}+\mathrm{DW}$ with gases and $\mathrm{NSS}+\mathrm{DW}$ without gases). It would be expected that the absence of these two corrosive gases would reduce the corrosion, as occurred with paint coatings, and not the reverse as o with PVDs, especially with PVD2. The corrosive gases seems to have some stabilization effect on PVDs degradation. This phenomenon is being investigated. 
T. Diamantino et. al. / EuroSun 2018 / ISES Conference Proceedings (2018)

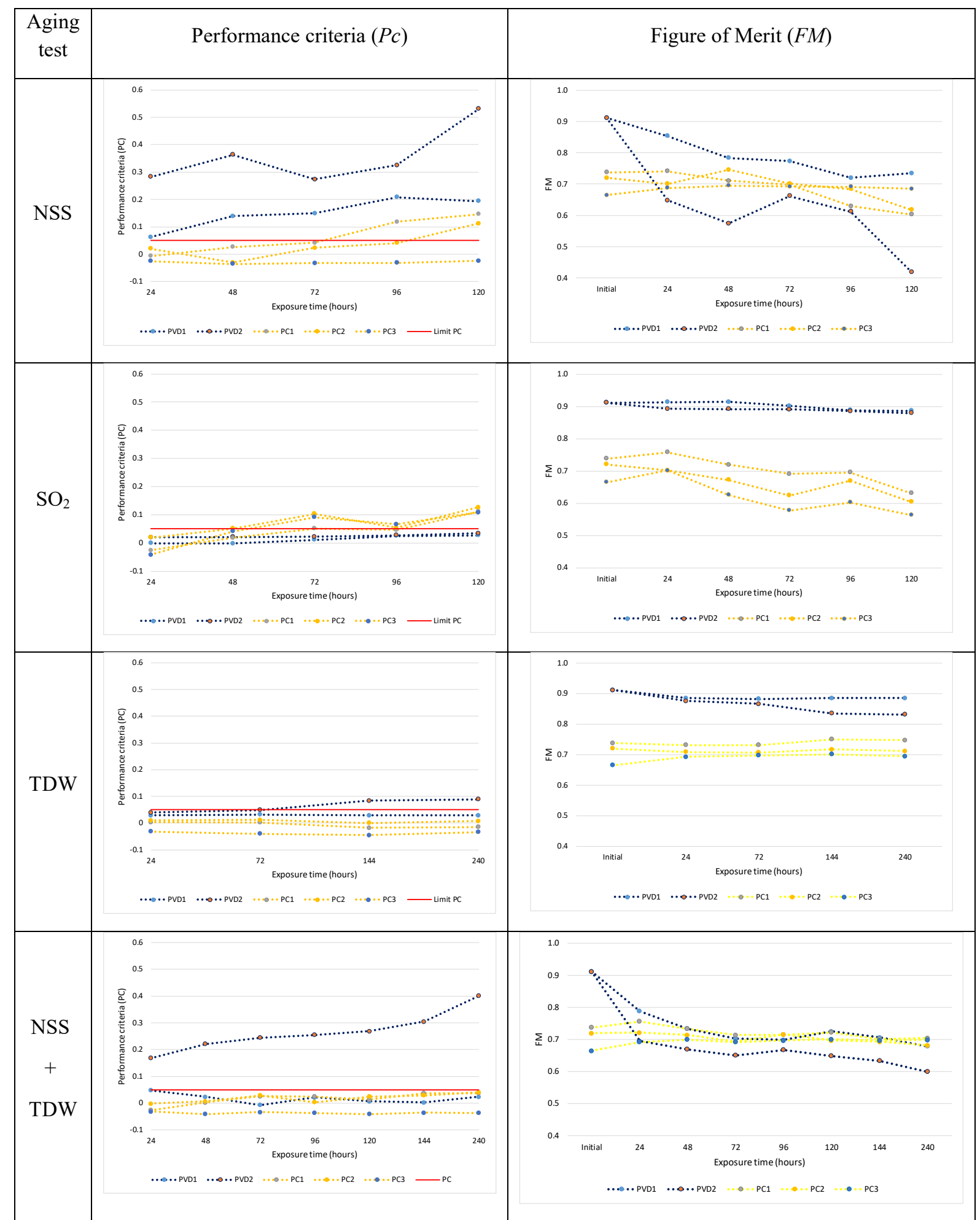

Fig. 1: Evolution of optical properties in terms of Performance Criteria $(P c)$ and Figure of Merit $(F M)$ of selective solar absorber coatings after $\mathrm{NSS}, \mathrm{SO}_{2}$, TDW and NSS + TDW aging tests 


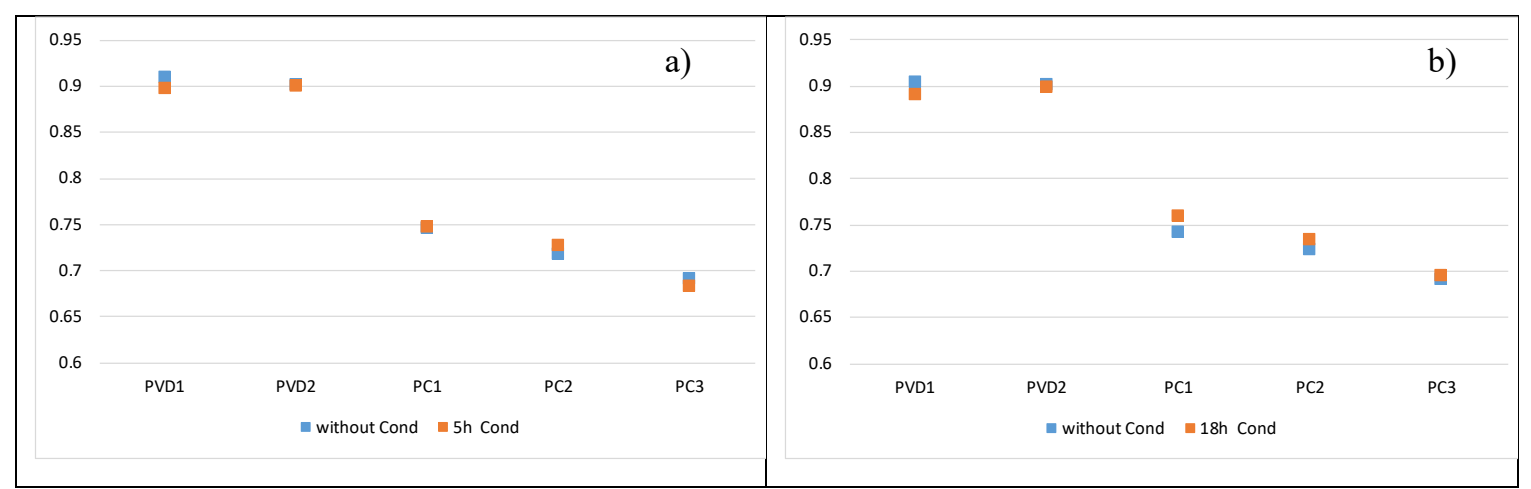

Fig. 2: Figure of Merit (FM) of absorber coatings before and after thermal conditioning during $5 \mathrm{~h}(\mathrm{a}))$ and $18 \mathrm{hours}(\mathrm{b}))$ at $192{ }^{\circ} \mathrm{C}$

Tab. 3: Photographic records of PVDs (PVD1 and PVD2) and PCs (PC1, PC2 and PC3) after $\mathrm{NSS}+\mathrm{SO}_{2}+\mathrm{NO}_{2}+\mathrm{DW}, 5 \mathrm{~h}$ $\mathrm{NSS}+\mathrm{SO}_{2}+\mathrm{NO}_{2}+\mathrm{DW}, 18 \mathrm{~h} \mathrm{NSS}+\mathrm{SO}_{2}+\mathrm{NO}_{2}+\mathrm{DW}, \mathrm{NSS}+\mathrm{DW}$ and $\mathrm{SO}_{2}+\mathrm{NO}_{2}+\mathrm{DW}$

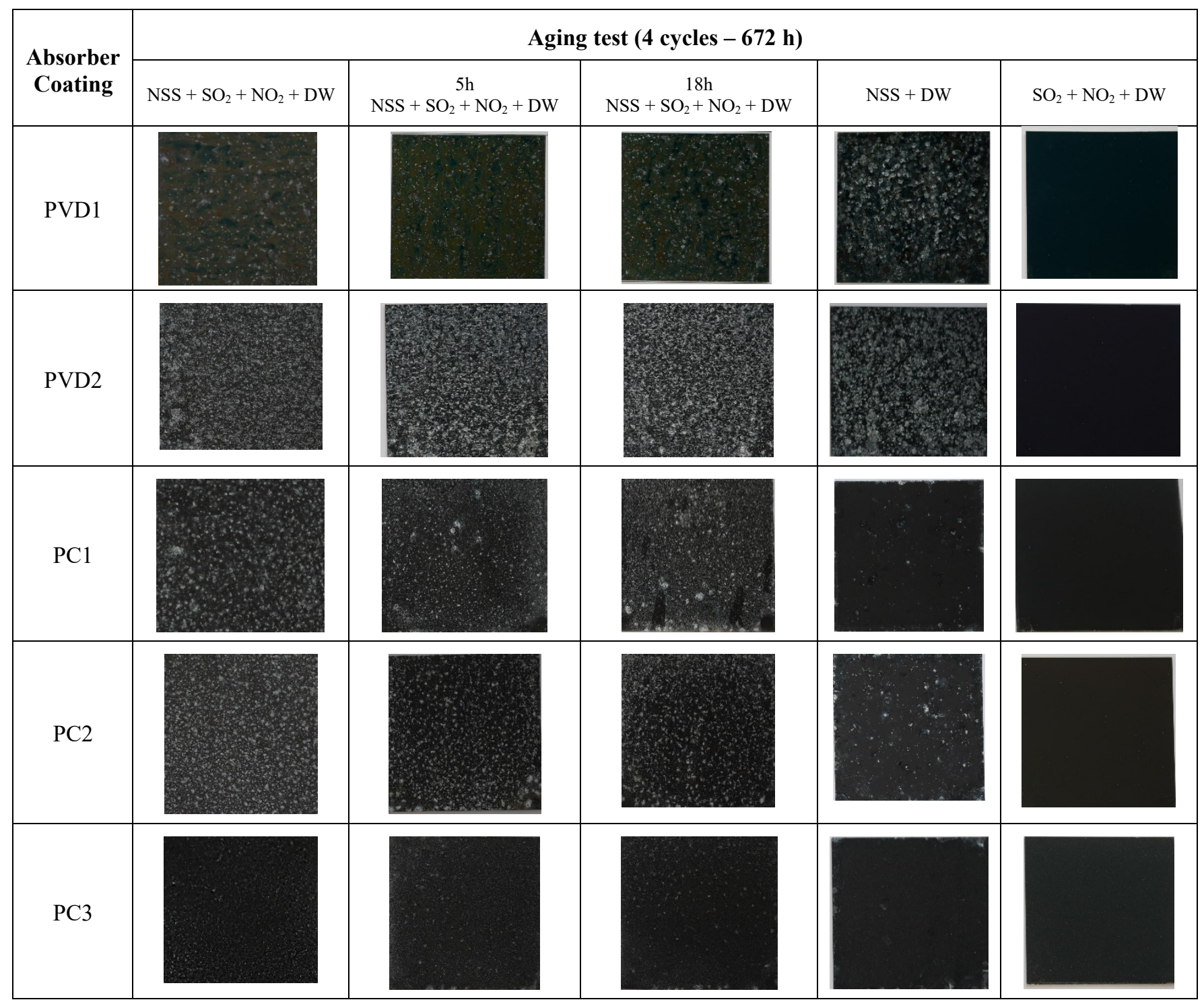


T. Diamantino et. al. / EuroSun 2018 / ISES Conference Proceedings (2018)

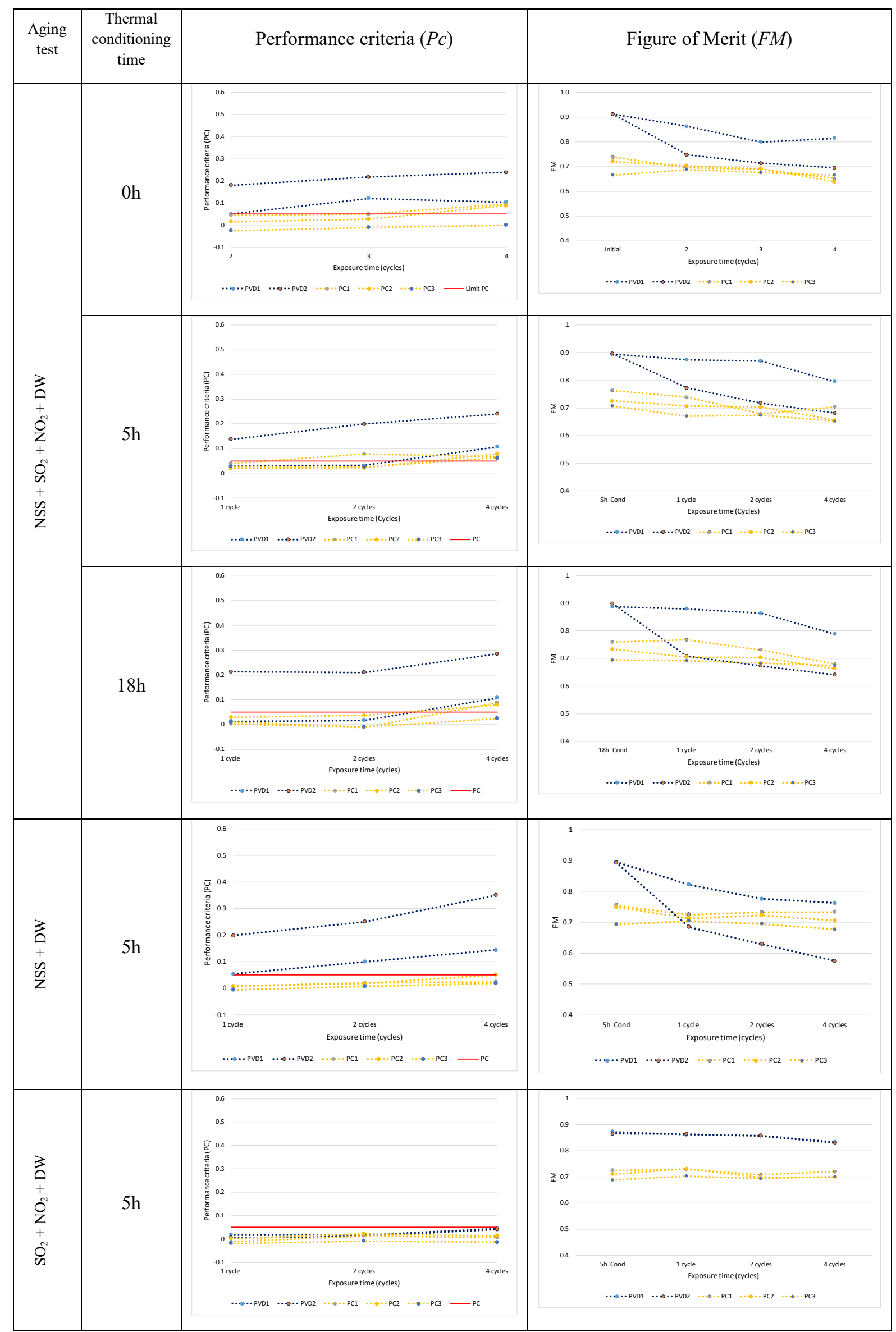

Fig. 3: Evolution of optical properties in terms of Performance Criteria $(P c)$ and Figure of Merit $(F M)$ of selective solar absorber coatings after $\mathrm{NSS}+\mathrm{SO}_{2}+\mathrm{NO}_{2}+\mathrm{DW}, 5 \mathrm{~h} \mathrm{NSS}+\mathrm{SO}_{2}+\mathrm{NO}_{2}+\mathrm{DW}, 18 \mathrm{~h} \mathrm{NSS}+\mathrm{SO}_{2}+\mathrm{NO}_{2}+\mathrm{DW}$ and $\mathrm{NSS}+\mathrm{DW}, \mathrm{SO}_{2}+\mathrm{NO}_{2}+\mathrm{DW}$ aging tests 


\subsection{Corrosivity of accelerated aging tests performed according to ISO standards}

Figure 4 presents the results of the mass loss obtained with four reference materials (steel, aluminum, zinc and copper) after $168 \mathrm{~h}$ of exposure (1 cycle/1 week). As can be seen the different materials had different corrosion behaviour depending on the environment. The comparison between the corrosivity of standard aging tests shows that it depends of the material type. For example, aging test performed according with the standard ISO 14993:2001 is a very aggressive test for steel and zinc but not for aluminum and copper. The evaluation of corrosion rate of different aging tests with different reference materials, the same materials and methodologies used during the evaluation of atmosphere corrosivity, gives an important information to understand and correlate the corrosion mechanisms observed in natural outdoor exposure.

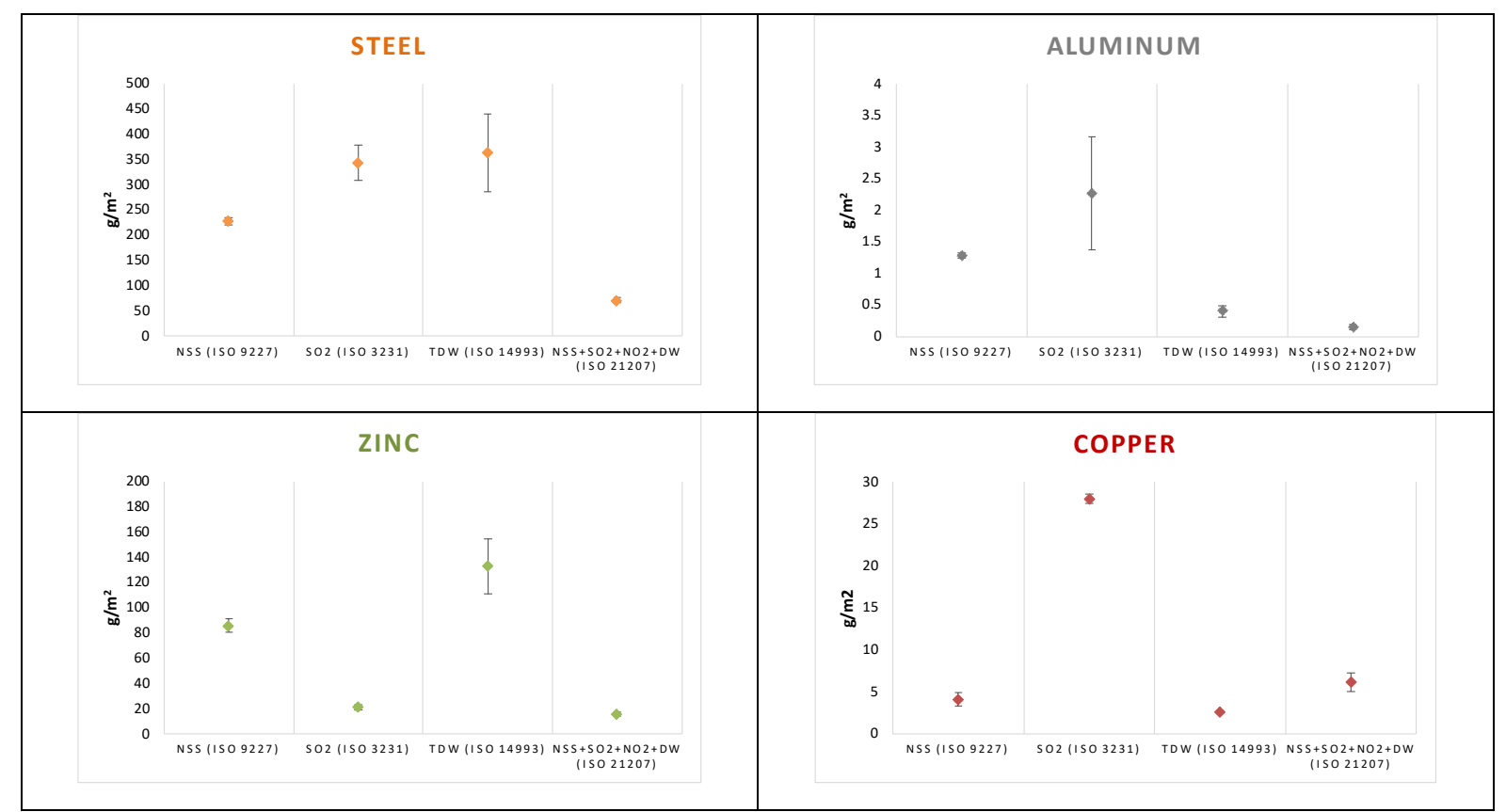

Fig. 4: Mass loss $\left(\mathrm{g} / \mathrm{m}^{2}\right)$ of reference materials (steel, zinc, copper and aluminum) after $168 \mathrm{~h}$ of exposure to standard aging tests

\section{Conclusions}

The main conclusions are:

- Different accelerated aging tests show that PVDs coatings are more susceptible to degradation induced by chlorides (NSS) rather than corrosive gases $\left(\mathrm{SO}_{2}\right)$ and, in some conditions, the presence of corrosive gases $\left(\mathrm{SO}_{2}+\mathrm{NO}_{2}\right)$ seem to provoke a delay in degradation process. In opposite, paint coatings (PC) suffer further degradation with $\mathrm{SO}_{2}$ than with NSS.

- Cyclic variation of corrosion promoting gases $\left(\mathrm{SO}_{2}+\mathrm{NO}_{2}\right)$, higher humidity, salt spraying and drying (NSS $+\mathrm{SO}_{2}+\mathrm{NO}_{2}+\mathrm{DW}$ ) seems to be an aging test that reflects the different environments to which the solar thermal collectors are exposed. In addition to the contaminants ( $\mathrm{NSS}+\mathrm{SO}_{2}+\mathrm{NO}_{2}$ ), drying/wetting cycles (TDW) also play an important role in degradation mechanisms of absorber coatings. Pre-thermal conditioning is also important to be included.

- To define an alternative aging test that guarantee a 25 -year service life, additional research is in progress in order to define the influence of the sulfur dioxide and nitrogen oxides in the degradation of absorber coatings.

- It is important to have methodologies to qualify selective absorber coatings as proposed in the standard ISO 22975-3:2014. However, the tests proposed require many hours and do not fully reflect the environments where the collectors are exposed, nor the only test with a corrosive agent $\left(\mathrm{SO}_{2}\right)$ indicated in this standard seems to be suitable. 


\section{Acknowledgments}

The authors would like to thank to the colleagues Ana Soares Vieira and Frederico Ferreira for technical support in the experimental work.

This work is a result of the project FCOMP-01-0124-FEDER-027507 ( Ref $^{a}$ FCT RECI/EMS-ENE/0170/2012) supported by Operational Competitiveness Programme (COMPETE) through the European Regional Development Fund (ERDF) and supported by FCT- Fundação para a Ciência e a Tecnologia, I.P. through National Funds and the project POCI-01-0145-FEDER-016709 (Ref ${ }^{a}$ FCT PTDC/EMS-ENE/0578/2014) supported by COMPETE 2020 and LISBOA 2020 under the PORTUGAL 2020 Partnership Agreement through the European Regional Development Fund (ERDF) and supported by FCT through National Funds.

\section{References}

Carlsson B., Möller K., Köhl M., Heck M., Brunold S., Frei U., Marechal J.-C., Jorgensen G.. The applicability of accelerated life testing for assessment of service life of solar thermal components, Sol. Energ. Mat. Sol. C. 84 (2004) 255-274 http://dx.doi.org/10.1016/j.solmat.2004.01.046

Carvalho M.J., Páscoa S., Mexa N., Gonçalves R., Correia J., Gano A., Diamantino T.. Solar thermal collector's degradation - Influence of corrosivity inside and outside the collectors. SHC Conference. Abu Dhabi, $20^{\text {th }}$ October- 2nd November, 2017

Diamantino, T. C., Gonçalves R., Nunes A., Páscoa S., Carvalho M. J.. Durability of different selective solar absorber coatings in environments with different corrosivity. Sol. Energ. Mat. Sol. C., (2017) 166, 27-38 https://doi.org/10.1016/j.solmat.2017.03.004

Diamantino T. C., Nunes A., Gonçalves R., Páscoa S., Chambino T. and Carvalho M. J.. Selective Absorber Coatings Qualification - ISO 22975-3:2014 Full Application EuroSun 2016 / ISES Conference Proceedings (2016), Palma, 11-14 October, 2016

D.E. Roberts, A figure of merit for selective absorbers in flat plate solar water heaters, Solar Energy 98 (2013) 503-510 http://dx.doi.org/10.1016/j.solener.2013.10.012

Slamova K., Duerr I., Kaltenbach T., Koehl M.. Degradation effects of maritime atmosphere on metallic components of solar collectors, Sol. Energ. Mat. Sol. C. 147 (2016) 246-254 http://dx.doi.org/10.1016/j.solmat.2015.12.011 


\title{
Influence of Using Different $\mathrm{SiO}_{2}$ Antireflective Coatings and Sintering Conditions on the Durability and Optical Performance of the Selective Solar Absorber
}

\author{
Meryem Farchado ${ }^{1}$, Gema S. Vicente ${ }^{1}$, Nuria Germán ${ }^{1}$ and Ángel Morales ${ }^{1}$ \\ ${ }^{1}$ CIEMAT-Plataforma Solar de Almería, Madrid (Spain)
}

\begin{abstract}
A multilayered absorber for low temperature thermal applications on aluminum substrate (Al$\mathrm{CuMnO}_{x} / \mathrm{FeMnCuO}_{x} / \mathrm{SiO}_{2}$ ) has been reported in the previous work. It is based on a single layer of $\mathrm{CuMnO}_{\mathrm{x}}$ as absorber material and two antireflective (AR) coatings deposited by the dip-coating method. Given the appealing values of solar absorptance $(0.957)$ and thermal emittance at $100^{\circ} \mathrm{C}(0.038)$ reached for this three layers configuration, an additional research was carried out for completing the feasibility study of the proposed absorber. As this selective absorber is intended to use in low-temperature solar collectors which operate in outdoor conditions, it has to accomplish the crucial requirement to withstand some ambient conditions such as high humidity and high temperatures, among others. Therefore, with a view to achieve the best durability performance of the selective absorber, a comparative study focused on using two different $\mathrm{SiO}_{2}$ antireflective solutions as third layer and different sintering conditions of this specific layer was carried out. The influence of this layer on the optical parameters as well as the long term durability of the final selective absorber has been studied.
\end{abstract}

Keywords: Selective absorber, spinel, antireflective coating, dip-coating, optical properties, durability tests.

\section{Introduction}

Nowadays, renewable clean energy plays an important role in the attempt of minimizing the environmental pollution and ecological destruction as consequence of the large amount of fossil energy consumption in the world. One of the preventive measures already taken is based on promoting the use of the pollution-free solar energy. Taking advantage of the solar radiation, several applications can be covered such as space heating, domestic hot water, industrial process heating, desalinated seawater or generation of solar electricity.

Many efforts have been put in the development of different technologies for solar thermal collectors (STC); acquiring special interest the durability studies of the selective absorber coatings during the last two decades (Colangelo et al., 2016; Diamantino et al., 2016, 2017). As it is well known, the absorber is the key component of the thermal system, playing his performance an important role in solar-thermal conversion efficiency (Yang et al., 2016). Concretely, high conversion efficiencies are obtained by using solar selective absorbers whose surface implies a minimum reflection in the solar spectrum region and the maximum reflectance in the infrared wavelength region (Joly et al., 2014). Besides, to be categorized as commercially competitive, these selective absorbers should absorb at least $95 \%$ of the incoming radiation and should have a thermal emittance lower than 0.05 (Amri et al., 2014). However, manifold outdoor conditions can significantly deteriorate the material's performance. Therefore, in order to ensure a successful solar selective absorber, selective coatings have to possess long-term performance stability apart from achieving good spectral selectivity.

Some papers have found the degradation processes that can undergo the solar absorbers as consequence of high temperature, high humidity, water condensation, and airborne pollutants (Kotilainen et al., 2015; Brunold et al., 2000). In the specific case of selective absorbers, the degradation reactions and layers modifications are mainly caused by high temperatures, high humidity and condensed water (Dudita et al., 2015). Concretely, high temperatures can speed up oxidation processes and high levels of humidity may create hydrolytic reactions i.e. 
electrochemical corrosion (Boström et al., 2005; Chen and Boström, 2016). All these processes can lead to variations in the optical properties. Taking into account these devastating consequences, the aim of this work is to determine the best stable antireflective material $\left(\mathrm{SiO}_{2}\right.$ antireflective coating) for the proposed $\mathrm{Al}$ $\mathrm{CuMnO}_{\mathrm{x}} / \mathrm{FeMnCuO}_{\mathrm{x}} / \mathrm{SiO}_{2}$ absorber, focusing mainly on its ability to withstand successfully the accelerated ageing tests.

\section{Experimental}

Prior to the dip-coating deposition of the constituent absorber films, a chemical etching treatment ( 10 seconds in a $5 \% \mathrm{HF}$ solution ) of the aluminum substrate was performed in order to guarantee homogeneous layers. Afterwards, the layers deposition was carried out at the optimized withdrawal rates of $42 \mathrm{~cm} / \mathrm{min}$ for the $\mathrm{CuMnO}_{\mathrm{x}}$ film, $18 \mathrm{~cm} / \mathrm{min}$ for the first $\mathrm{FeMnCuO}_{\mathrm{x}}$ antireflective coating and $12 \mathrm{~cm} / \mathrm{min}$ for the $\mathrm{SiO}_{2}$ antireflective coating (Farchado et al., 2018).

The $\mathrm{CuMnO}_{\mathrm{x}}$ and $\mathrm{FeMnCuO}_{\mathrm{x}}$ solutions were prepared from the metallic precursors of $\mathrm{Cu}\left(\mathrm{NO}_{3}\right)_{2}(\mathrm{Sigma}$ Aldrich, 98-103\%), $\mathrm{Mn}\left(\mathrm{NO}_{3}\right)_{2}$ (Panreac, 97\%) and $\mathrm{Fe}\left(\mathrm{NO}_{3}\right)_{3}$ (PRS Panreac, 98\%) at molar ratios of 1:1 for $\mathrm{CuMnO}_{\mathrm{x}}$ and 1:1:2 for $\mathrm{FeMnCuO}_{\mathrm{x}}$ and the absolute ethanol as solvent. A complexing agent and a wetting additive were also added to stabilize the solution and improve the film adherence (Morales, 2002). In relation to the $\mathrm{SiO}_{2}$ antireflective layer, two kinds of silica were tested: A1 based on the high-density silica prepared using a two-step methodology under reflux conditions at $60^{\circ} \mathrm{C}$ (Morales and Durán, 1997) and A2 referred to the silica solution prepared without any reflux system and at room temperature. Both $\mathrm{SiO}_{2}$ solutions were prepared maintaining unchanged their composition but varying their preparation methodology. Both solutions were obtained by dissolving the Tetraethyl ortosilicate (TEOS) precursor in a solution based on a mixture of distilled water, absolute ethanol and hydrochloric acid as catalyst. The corresponding TEOS:ethanol:water molar ratio was 1:18:5. Additionally to the different $\mathrm{SiO}_{2}$ antireflective coatings studied, different sintering processes of this third constituent absorber layer at $500^{\circ} \mathrm{C}$ (blower or oven, 5-30 minutes) were analysed.

Regarding the durability tests, the condensation ageing experiment was performed in a Q.U.V. weathering chamber where the samples were exposed to constant condensation at $40^{\circ} \mathrm{C}$ during 150,300 and 600 hours meanwhile the thermal stability test was carried out in a conventional circulating air furnace where the samples were first heated at $250^{\circ} \mathrm{C}$ for 200 hours and then at $300^{\circ} \mathrm{C}$ for $200,400,600$ and finally 800 hours. Both ageing experiments were fulfilled following the procedure developed by the international standard ISO 22975-3 (2014).

In order to evaluate the possible degradation of the samples, optical measurements were performed before and after different testing time intervals to calculate the following parameters:

$>$ Solar absorptance $\left(\alpha_{\mathrm{s}}\right)$, which was calculated as specified in the standard procedure (UNE 206009:2013) by using the direct AM1.5 solar spectrum from ASTM G173-03 in the 0.3-2.5 $\mu \mathrm{m}$ range and the hemispherical reflectance spectra of the samples recorded from 0.3 to $2.5 \mu \mathrm{m}$. The equipment used for the hemispherical reflectance measurements was a UV-VIS-NIR Perkin-Elmer LAMBDA 950 double beam spectrophotometer equipped with a $150 \mathrm{~mm}$ Spectralon ${ }^{\circledR}$ coated integrating sphere. The associated measurement uncertainty was $1 \%$.

$>$ Thermal emittance $\left(\varepsilon_{\mathrm{T}}, 100^{\circ} \mathrm{C}\right)$, which was calculated by using the hemispherical IR-reflectance spectra recorded from 2.5 to $17 \mu \mathrm{m}$ at room temperature and the black body spectrum at $100{ }^{\circ} \mathrm{C}$. A Perkin Elmer Frontier FTIR spectrophotometer equipped with a diffuse gold-coated integrating sphere was used. The accuracy of the reflectance data was estimated to be $2 \%$ for the FTIR-spectrophotometer.

$>$ Performance criterion function (PC), which shows the changes in performance of an absorber surface in terms of solar absorptance and thermal emittance (Eq.1)

$$
\left.\mathrm{PC}=-\Delta \alpha_{\mathrm{s}}+0.50 \Delta \varepsilon \leq 0.05 \quad \text { (eq. } 1\right)
$$

where: $\Delta \alpha_{\mathrm{s}}$ is the change in the solar absorptance: $\Delta \alpha_{\mathrm{s}}=\alpha_{\mathrm{s}, \mathrm{t}}-\alpha_{\mathrm{s}, \mathrm{i}},\left(\alpha_{\mathrm{s}, \mathrm{t}}\right.$ is the value of the solar absorptance at the actual testing time and $\alpha_{\mathrm{s}, \mathrm{i}}$ is the initial value of solar absorptance) and $\Delta \varepsilon_{\mathrm{T}, 100}$ is the change in the thermal emittance: $\Delta \varepsilon_{\mathrm{T}, 100}=\varepsilon_{\mathrm{t}}-\varepsilon_{\mathrm{i}}\left(\varepsilon_{\mathrm{t}}\right.$ is the value of the thermal emittance at the actual testing time and $\varepsilon_{\mathrm{i}}$ is the initial value of thermal emittance). This parameter establishes that an absorber can be considered qualified or suitable only if after the test PC $\leq$ 0.05, according to standard ISO 22975-3 (2014). 
An optical microscope Leica DM4 M was used to study layers degradation.

\section{Results and discussion}

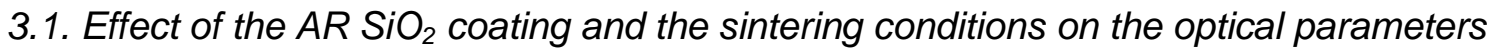

The preparation process for the $\mathrm{SiO}_{2}$ solutions determines the structure of the films of the coatings. Reflux and high temperature conditions allow obtaining high coating densities by controlling the degree of hydrolysis and the condensation rate. Both kinds of AR silica coatings as third layer (high-density silica A1 or silica prepared without reflux system A2) and different sintering conditions can alter the hemispherical reflectance spectra of the samples and therefore the optical properties of the selective absorber.

Figure 1 shows the variations observed in the reflectance curve shape of the samples (a) $\mathrm{CuMnO}_{\mathrm{x}} / \mathrm{FeMnCuO}_{\mathrm{x}} / \mathrm{A} 1$ and (b) $\mathrm{CuMnO}_{\mathrm{x}} / \mathrm{FeMnCuO}_{\mathrm{x}} / \mathrm{A} 2$ by using different sintering conditions of the silica layer. In Figure 1a), it can be observed that the samples whose third layer (high-density A1) was sintered in the oven for both 15 and 30 minutes reached higher values of reflectance in the second maximum (from $700 \mathrm{~nm}$ to the absorption edge) than the samples whose silica layer was sintered in the blower. Also, a shift of the absorption edge to higher wavelengths and a reflectance decrease in the NIR range were observed for these absorbers whose $\mathrm{SiO}_{2}$ layer was sintered in the oven. Specifically, as far as the absorption edge position is concerned, it is observed that this absorption edge is positioned around $1600 \mathrm{~nm}$ for both samples whose dense silica layer was sintered in the oven while for the samples whose $\mathrm{SiO}_{2}$ layer was sintered in the blower, the absorption edge is registered at $1450 \mathrm{~nm}$. Additionally, focusing on both sintering times studied in the oven, it was noted that as the sintering time increases the second maximum reached slightly higher values of reflectance; being also accompanied by a reflectance decrease in the NIR range.

In counterpart, fewer variations were observed for the absorbers whose A2 antireflective coating was used as third layer. In fact, no differences were appreciated between sintering the silica layer in the blower or oven for 15 minutes. Figure 1b) corroborates that both samples remained identical and maintained the same curve shape. Nevertheless, clear variations were identified for the samples whose A2 layer was sintered in the oven for 30 minutes. Concretely, based on the hemispherical reflectance spectra displayed in Figure 1b), it can be seen that a longer sintering time in the oven implies an increase of the second maximum (going from 5.3 to $7.3 \%$ in reflectance at $1120 \mathrm{~nm}$ ), a displacement of the absorption edge towards higher wavelengths and a decrease in the NIR range.

a) $\mathrm{CuMnO} / \mathrm{FeMnCuO} / \mathrm{A1}$

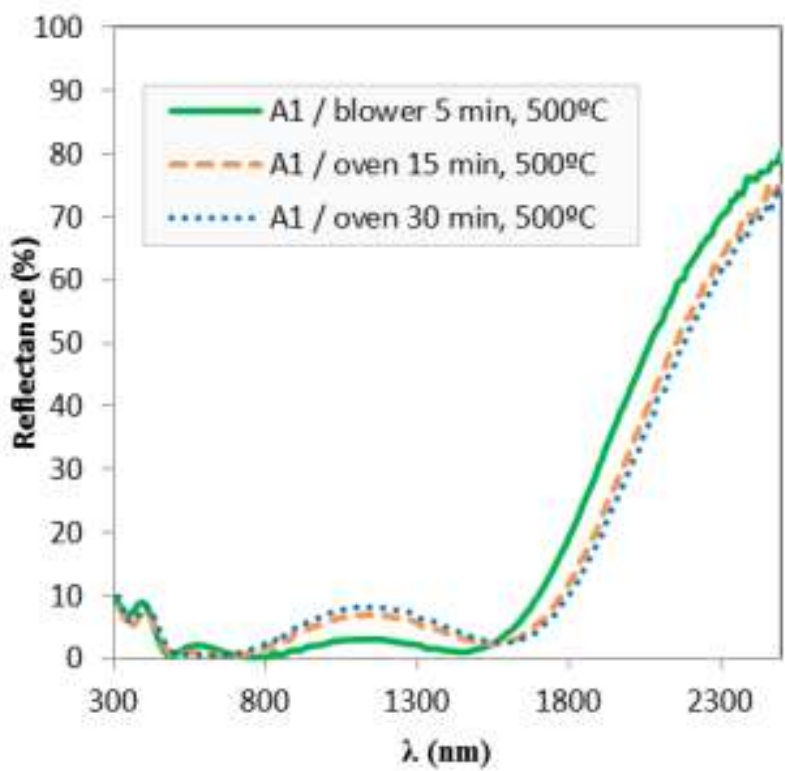

b) $\mathrm{CuMnO}_{\mathrm{x}} / \mathrm{FeMnCuO}_{\mathrm{x}} / \mathrm{A2}$

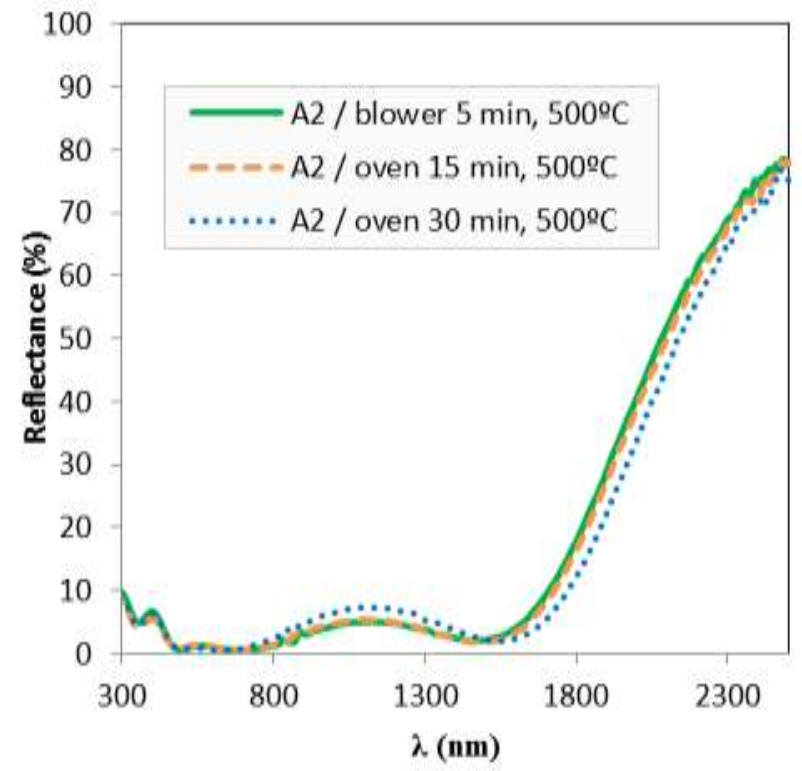

Fig. 1: Variation in the hemispherical reflectance spectra depending on the kinds of $\mathrm{SiO}_{2}$ antireflective coatings and sintering processes used. Samples whose $\mathrm{SiO}_{2}$ antireflective coating was the $\mathrm{A1}$ (a) and $\mathrm{A2}$ (b). 
The changes observed in the reflectance curve of the samples in the solar range as consequence of the use of different AR coatings and sintering processes of the third constituent absorber layer are closely bound up with the differences in the optical parameters. Table 1 shows the solar absorptance and thermal emittance values obtained for each studied sample. As it can be seen, greater variations in solar absorptance values are perceived than thermal emittance values since the relevant changes in the curve shapes occurred in the solar range, being almost identical the curves in the mid/far IR region. Specifically, in the case of $\mathrm{CuMnO}_{\mathrm{x}} / \mathrm{FeMnCuO}_{\mathrm{x}} / \mathrm{A} 1$ samples, a loss of the absorptance value is perceived by sintering the dense silica layer in the oven (0.950-0.953) instead of using the blower (0.957). Regarding the opposite side related to $\mathrm{CuMnO}_{\mathrm{x}} / \mathrm{FeMnCuO}_{\mathrm{x}} / \mathrm{A} 2$ samples, a small variation in the solar absorptance value can be remarked. In fact, only a loss of $0.1 \%$ of the absorptance value is identified by sintering the A2 layer in the oven for 30 minutes (0.954) instead of using the blower or oven for less time (0.955).

Tab. 1: Variation in the optical parameters of samples with different kinds of silica layer and sintering processes.

\begin{tabular}{c|c|c|c|c}
\hline \multirow{2}{*}{$\begin{array}{c}\text { Sintering process of } \mathrm{SiO}_{\mathbf{2}} \\
\text { antireflective coating }\end{array}$} & \begin{tabular}{c} 
A1 \\
Solar \\
\cline { 2 - 5 }
\end{tabular} & $\begin{array}{c}\text { Thermal } \\
\text { emittance }\left(\boldsymbol{\varepsilon}_{\mathbf{T}}\right)\end{array}$ & $\begin{array}{c}\text { Solar } \\
\text { absorptance }\left(\boldsymbol{\alpha}_{\mathbf{s}}\right)\end{array}$ & $\begin{array}{c}\text { Thermal } \\
\text { emittance }\left(\boldsymbol{\varepsilon}_{\mathbf{T}}\right)\end{array}$ \\
\hline Blower & 0.957 & 0.038 & 0.955 & 0.039 \\
Oven, $15 \mathrm{~min} 500^{\circ} \mathrm{C}$ & 0.953 & 0.036 & 0.955 & 0.037 \\
Oven, $30 \mathrm{~min} 500^{\circ} \mathrm{C}$ & 0.950 & 0.039 & 0.954 & 0.037 \\
\hline
\end{tabular}

Definitely, by analysing the obtained results it can be concluded that the absorbers whose A1 antireflective coating was used as the third layer were subjected to greater variations with the sintering conditions than the absorbers whose $\mathrm{SiO}_{2}$ layer corresponded to the $\mathrm{A} 2$ antireflective coating.

\subsection{Durability study}

Apart from studying the consequences resulting from varying the $\mathrm{SiO}_{2}$ antireflective coating used as third layer and its sintering process in the optical properties of the absorber, thermal stability and condensation tests were carried out separately in order to determine the influence of ageing time at high temperatures and hydrolysis conditions on the durability performance of the absorber. These durability tests were performed in accordance with the international standard ISO 22975-3 (2014).

Regarding the thermal stability test, the accelerated ageing study at high temperatures was performed in a circulating air furnace. Six replicas of each sample whose third layer A1 or A2 was sintered in the blower or oven for 15 minutes were firstly exposed at $250^{\circ} \mathrm{C}$ for $200 \mathrm{~h}$ and afterward at $300^{\circ} \mathrm{C}$ for $200 \mathrm{~h}, 400 \mathrm{~h}, 600 \mathrm{~h}$ and $800 \mathrm{~h}$; being therefore the total duration of the thermal stability test 1000 hours. After each exposure period, the degradation of the samples was analyzed in order to evaluate the performance of both kinds of silica at the sintering processes tested. This degradation study was determined by the optical measurements (solar absorptance and thermal emittance) and the performance criterion parameter (PC). Once concluded the 1000 hours of testing, it was observed that apart from conserving all the samples studied their initial appearance, the absorbers' optical performance was still very good being concretely reduced in all cases less than 5\% of its original value. Table 2 shows the average results achieved for the six replicas of each sample analysed after each degradation time interval constituting the thermal stability test. Based on these results, it can be affirmed that all the studied absorber surfaces $\left(\mathrm{Al} / \mathrm{CuMnO}_{\mathrm{x}} / \mathrm{FeMnCuO} \mathrm{x}_{\mathrm{x}} / \mathrm{A} 1\right.$ and $\left.\mathrm{Al} / \mathrm{CuMnO}_{\mathrm{x}} / \mathrm{FeMnCuO}_{\mathrm{x}} / \mathrm{A} 2\right)$ are qualified with respect to their thermal stability regardless of both $\mathrm{SiO}_{2}$ solutions used and sintering processes of this third constituent absorber layer. 
Tab. 2: Average solar absorptance, thermal emittance and $P C$ values calculated before and after each degradation interval for the samples during the thermal stability test.

\begin{tabular}{|c|c|c|c|}
\hline Samples / $\mathrm{SiO}_{2}$ sintering process & $\begin{array}{c}\text { Solar absorptance } \\
\left(\alpha_{s}\right)\end{array}$ & $\begin{array}{c}\text { Thermal emittance } \\
\left(\varepsilon_{\mathrm{T}}\right)\end{array}$ & $\mathbf{P C}$ \\
\hline \multicolumn{4}{|l|}{$\mathrm{CuMnO}_{\mathrm{x}} / \mathrm{FeMnCuO}_{\mathrm{x}} / \mathrm{A1}$ (blower) } \\
\hline Initial & 0.957 & 0.038 & \\
\hline $200 \mathrm{~h} / 250^{\circ} \mathrm{C}$ & 0.957 & 0.038 & 0 \\
\hline $200 \mathrm{~h} / 250^{\circ} \mathrm{C}+200 / 300^{\circ} \mathrm{C}$ & 0.956 & 0.038 & 0.0012 \\
\hline $200 \mathrm{~h} / 250^{\circ} \mathrm{C}+400 \mathrm{~h} / 300^{\circ} \mathrm{C}$ & 0.956 & 0.038 & 0.0014 \\
\hline $200 \mathrm{~h} / 250^{\circ} \mathrm{C}+600 \mathrm{~h} / 300^{\circ} \mathrm{C}$ & 0.956 & 0.038 & 0.0014 \\
\hline $200 \mathrm{~h} / 250^{\circ} \mathrm{C}+800 \mathrm{~h} / 300^{\circ} \mathrm{C}$ & 0.956 & 0.038 & 0.0014 \\
\hline \multicolumn{4}{|l|}{ 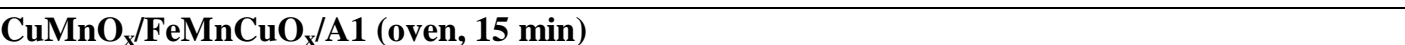 } \\
\hline Initial & 0.956 & 0.038 & \\
\hline $200 \mathrm{~h} / 250^{\circ} \mathrm{C}$ & 0.956 & 0.033 & 0 \\
\hline $200 \mathrm{~h} / 250^{\circ} \mathrm{C}+200 / 300^{\circ} \mathrm{C}$ & 0.953 & 0.035 & 0.0014 \\
\hline $200 \mathrm{~h} / 250^{\circ} \mathrm{C}+400 \mathrm{~h} / 300^{\circ} \mathrm{C}$ & 0.954 & 0.034 & 0.0001 \\
\hline $200 \mathrm{~h} / 250^{\circ} \mathrm{C}+600 \mathrm{~h} / 300^{\circ} \mathrm{C}$ & 0.954 & 0.034 & 0.0001 \\
\hline $200 \mathrm{~h} / 250^{\circ} \mathrm{C}+800 \mathrm{~h} / 300^{\circ} \mathrm{C}$ & 0.954 & 0.034 & 0.0001 \\
\hline \multicolumn{4}{|l|}{$\mathrm{CuMnO}_{\mathrm{x}} \mathrm{FeMnCuO}_{\mathrm{x}} / \mathrm{A2}$ (blower) } \\
\hline Initial & 0.955 & 0.039 & \\
\hline $200 \mathrm{~h} / 250^{\circ} \mathrm{C}$ & 0.955 & 0.040 & 0.0007 \\
\hline $200 \mathrm{~h} / 250^{\circ} \mathrm{C}+200 / 300^{\circ} \mathrm{C}$ & 0.951 & 0.038 & 0.0027 \\
\hline $200 \mathrm{~h} / 250^{\circ} \mathrm{C}+400 \mathrm{~h} / 300^{\circ} \mathrm{C}$ & 0.952 & 0.037 & 0.0020 \\
\hline $200 \mathrm{~h} / 250^{\circ} \mathrm{C}+600 \mathrm{~h} / 300^{\circ} \mathrm{C}$ & 0.951 & 0.037 & 0.0025 \\
\hline $200 \mathrm{~h} / 250^{\circ} \mathrm{C}+800 \mathrm{~h} / 300^{\circ} \mathrm{C}$ & 0.950 & 0.037 & 0.0035 \\
\hline \multicolumn{4}{|l|}{$\mathrm{CuMnO}_{\mathrm{x}} / \mathrm{FeMnCuO}_{\mathrm{x}} / \mathrm{A2}$ (oven, $\left.15 \mathrm{~min}\right)$} \\
\hline Initial & 0.952 & 0.036 & \\
\hline $200 \mathrm{~h} / 250^{\circ} \mathrm{C}$ & 0.951 & 0.038 & 0.0018 \\
\hline $200 \mathrm{~h} / 250^{\circ} \mathrm{C}+200 / 300^{\circ} \mathrm{C}$ & 0.948 & 0.035 & 0.0028 \\
\hline $200 \mathrm{~h} / 250^{\circ} \mathrm{C}+400 \mathrm{~h} / 300^{\circ} \mathrm{C}$ & 0.950 & 0.035 & 0.0018 \\
\hline $200 \mathrm{~h} / 250^{\circ} \mathrm{C}+600 \mathrm{~h} / 300^{\circ} \mathrm{C}$ & 0.949 & 0.035 & 0.0028 \\
\hline $200 \mathrm{~h} / 250^{\circ} \mathrm{C}+800 \mathrm{~h} / 300^{\circ} \mathrm{C}$ & 0.949 & 0.035 & 0.0028 \\
\hline
\end{tabular}

Conversely to the successful results obtained from the thermal stability test, not favorable results were achieved for all the studied samples at the condensation test which implied to keep six replicas of each studied sample at $40^{\circ} \mathrm{C}$ under constant condensation conditions in the weathering chamber. The extent of degradation of each examined sample was determined after $150 \mathrm{~h}, 300 \mathrm{~h}$ and $600 \mathrm{~h}$ of testing by evaluating the aspect of the samples as well as their relative optical measurements. As it can be seen in Table 3, the best data were recorded by the samples whose third layer coincided with the A1 antireflective coating regardless of the sintering process used for this layer. The worst outcomes were obtained for the absorbers whose A2 antireflective layer was applied as third layer. This different behaviour and tendency presented by both types of silica at different sintering processes were expected since the use of different types of silica involves different resulting film structures and the employment of different sintering processes comprises a different burning process of the organic matter in the layer (Khatiri et al., 2014).

As regards the results of resistance to condensed water study of $\mathrm{Al} / \mathrm{CuMnO}{ }_{\mathrm{x}} / \mathrm{FeMnCuO}_{\mathrm{x}} / \mathrm{A} 1$ samples, it should be pointed out the different layer degradation that the samples undergone depending on the sintering process used for the A1 layer. In the case of samples whose A1 layer was sintered in the blower, the degradation of the sample surface began to be noticeable only after 600 hours of testing meanwhile the absorbers whose dense silica layer was sintered in the oven (15 and 30 minutes), the corrosion and colour degradation phenomena were perceived since the first $150 \mathrm{~h}-300 \mathrm{~h}$ of testing; being clearly accented after 600 hours of testing. These visible alterations in the surface of the samples were also reflected on the optical behaviour. Table 3 summarizes the optical parameters as well as the PC values registered for each sample before and after each exposure period. As it can be seen, the three types of $\mathrm{Al} / \mathrm{CuMnO}_{\mathrm{x}} / \mathrm{FeMnCuO}_{\mathrm{x}} / \mathrm{A} 1$ absorbers studied presented a slight decrease of the average solar absorptance value and an increase of the average thermal emittance value with the exposure, except for exposure times between 150 and 300 hours in which the values of solar absorptance, thermal 
emittance and PC remained unaltered. Otherwise, following with this analysis, it is concluded that the best outcomes are obtained for the samples whose high-density silica is sintered in the blower.

Tab. 3: Average solar absorptance, thermal emittance and PC values calculated before and after each degradation interval for the samples during the condensation test.

\begin{tabular}{|c|c|c|c|}
\hline Samples / $\mathrm{SiO}_{2}$ sintering process & $\begin{array}{c}\text { Solar absorptance } \\
\left(\alpha_{s}\right)\end{array}$ & $\begin{array}{c}\text { Thermal emittance } \\
\left(\varepsilon_{\mathrm{T}}\right)\end{array}$ & $\mathbf{P C}$ \\
\hline \multicolumn{4}{|l|}{$\mathrm{CuMnO}_{\mathrm{x}} / \mathrm{FeMnCuO} / \mathrm{A} 1$ (blower) } \\
\hline Initial & 0.957 & 0.038 & \\
\hline $150 \mathrm{~h} / 40^{\circ} \mathrm{C}$ & 0.955 & 0.036 & 0.0010 \\
\hline $300 \mathrm{~h} / 40^{\circ} \mathrm{C}$ & 0.955 & 0.036 & 0.0010 \\
\hline $600 \mathrm{~h} / 40^{\circ} \mathrm{C}$ & 0.954 & 0.038 & 0.0030 \\
\hline \multicolumn{4}{|l|}{$\mathrm{CuMnO}_{\mathrm{x}} / \mathrm{FeMnCuO} \mathrm{X}_{\mathrm{x}} / \mathrm{A} 1$ (oven, $\left.15 \mathrm{~min}\right)$} \\
\hline Initial & 0.953 & 0.035 & \\
\hline $150 \mathrm{~h} / 40^{\circ} \mathrm{C}$ & 0.950 & 0.039 & 0.0055 \\
\hline $300 \mathrm{~h} / 40^{\circ} \mathrm{C}$ & 0.950 & 0.039 & 0.0055 \\
\hline $600 \mathrm{~h} / 40^{\circ} \mathrm{C}$ & 0.945 & 0.042 & 0.0113 \\
\hline \multicolumn{4}{|l|}{$\mathrm{CuMnO}_{\mathrm{x}} / \mathrm{FeMnCuO} \mathrm{X}_{\mathrm{x}} / \mathrm{A} 1$ (oven, $\left.30 \mathrm{~min}\right)$} \\
\hline Initial & 0.950 & 0.039 & \\
\hline $150 \mathrm{~h} / 40^{\circ} \mathrm{C}$ & 0.945 & 0.039 & 0.0051 \\
\hline $300 \mathrm{~h} / 40^{\circ} \mathrm{C}$ & 0.945 & 0.039 & 0.0051 \\
\hline $600 \mathrm{~h} / 40^{\circ} \mathrm{C}$ & 0.935 & 0.040 & 0.0145 \\
\hline \multicolumn{4}{|l|}{$\mathrm{CuMnO}_{\mathrm{x}} / \mathrm{FeMnCuO}_{\mathrm{x}} / \mathrm{A2}$ (blower) } \\
\hline Initial & 0.955 & 0.039 & \\
\hline $150 \mathrm{~h} / 40^{\circ} \mathrm{C}$ & 0.952 & 0.041 & 0.0036 \\
\hline $300 \mathrm{~h} / 40^{\circ} \mathrm{C}$ & 0.952 & 0.041 & 0.0036 \\
\hline $600 \mathrm{~h} / 40^{\circ} \mathrm{C}$ & 0.942 & 0.049 & 0.0181 \\
\hline
\end{tabular}

Despite the variations observed in the optical properties and aspect of the $\mathrm{Al} / \mathrm{CuMnO}_{\mathrm{x}} / \mathrm{FeMnCuO}_{\mathrm{x}} / \mathrm{A} 1$ absorbers, all these samples maintained the typical selective absorber curve shape at the end of the ageing test and reached a well below $\mathrm{PC}$ value of $\mathrm{PC} \leq 0.015$. Therefore, based on these results, it can be concluded that all the $\mathrm{Al} / \mathrm{CuMnO}_{\mathrm{x}} / \mathrm{FeMnCuO}_{\mathrm{x}} / \mathrm{A} 1$ absorbers studied, regardless of the sintering process of the A1 layer, are qualified according to the standard ISO 22975-3 (2014) with respect to their resistance to condensed water.

Regarding the condensation accelerated ageing study of samples whose third constituent absorber layer was A2, it should be highlighted the influence of the sintering process of the A2 layer on the durability performance of the absorber. Not all the sintering processes tested for the A2 layer achieved acceptable results. In fact, good results were obtained for samples whose A2 layer was sintered in the blower meanwhile disappointing conclusions were reached for samples whose A2 layer was sintered in the oven.

In relation to the $\mathrm{Al} / \mathrm{CuMnO}_{\mathrm{x}} / \mathrm{FeMnCuO} \mathrm{X}_{\mathrm{x}} / \mathrm{A} 2$ samples whose silica layer was sintered in the blower, a degradation associated to corrosion and washing away of the silica layer began to be noticed after the first 300 hours of testing. These degradation phenomena reached pronounced effects at the end of the accelerated ageing test, i.e. after 600 hours of testing. Figure 2 shows photographs of the process of degradation undergone by the sample under study as the condensed test proceeds. 


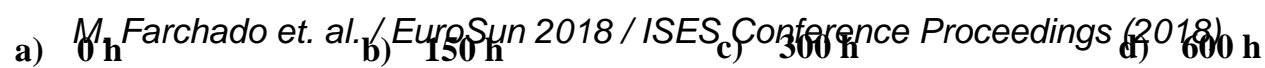
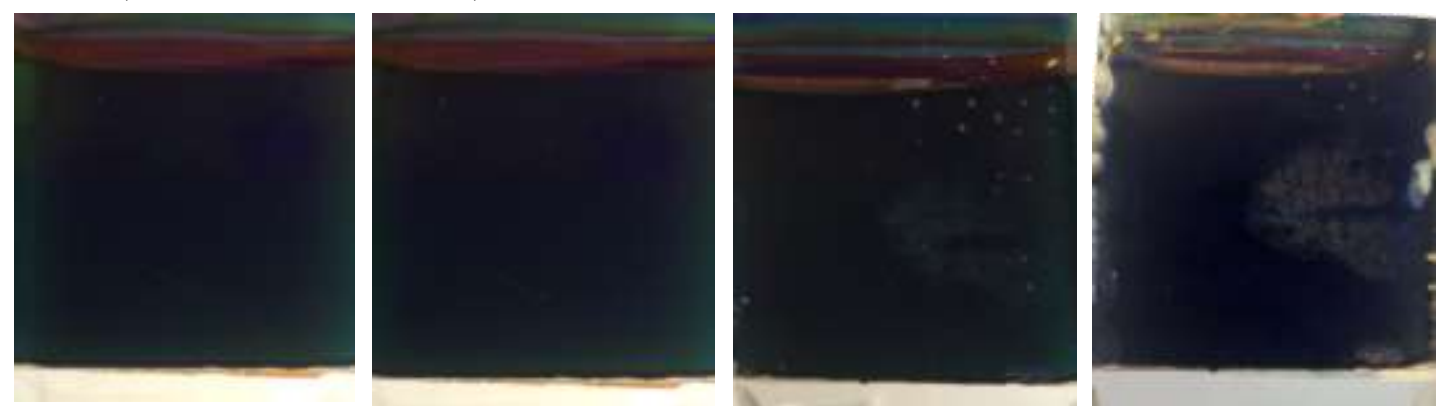

Fig. 2: Photographs of the $\mathrm{Al} / \mathrm{CuMnO}_{\mathrm{x}} / \mathrm{FeMnCuO}_{\mathrm{x}} / \mathrm{A2}$ (blower) selective absorber before (a) and after exposure to condensation at $40^{\circ} \mathrm{C}$ after 150 hours of testing (b), 300 hours (c) and 600 hours (d).

Each degradation in the aspect of these samples was accompanied by an alteration of the final reflectance spectra of the samples (keeping at all time the typical selective absorber curve shape) and in turn the optical properties. Figure 3 represents the variations observed in the hemispherical reflectance spectra of $\mathrm{Al} / \mathrm{CuMnO}_{\mathrm{x}} / \mathrm{FeMnCuO}_{\mathrm{x}} / \mathrm{A} 2$ (blower) samples before and after each studied ageing step in the weathering chamber. By analysing the reflectance spectra, it is seen that the highest variations were registered for the samples which were subjected to a longer time in the weathering chamber (600 hours), remaining almost identical the curve shape of the samples before and after 300 hours of testing. Focusing on the trend followed by the reflectance spectra recorded in the solar wavelength range along the condensed test, it can be established that as the ageing test proceeds, a slight reflectance decrease in the UV-VIS wavelength range is achieved with a slight displacement of this first maximum (400-430 nm) towards longer wavelengths. This variation related to the first maximum is also accompanied by an increase of the second maximum (700 nm until the absorption edge) and a displacement of the absorption edge towards longer wavelengths and higher values of reflectance. A significantly decrease in the NIR range is also produced being clearly confirmed this occurrence in the reflectance spectra recorded from 0.3 to $17 \mu \mathrm{m}$ wavelengths. These variations lead to important differences in thermal emittance values (Table 3).

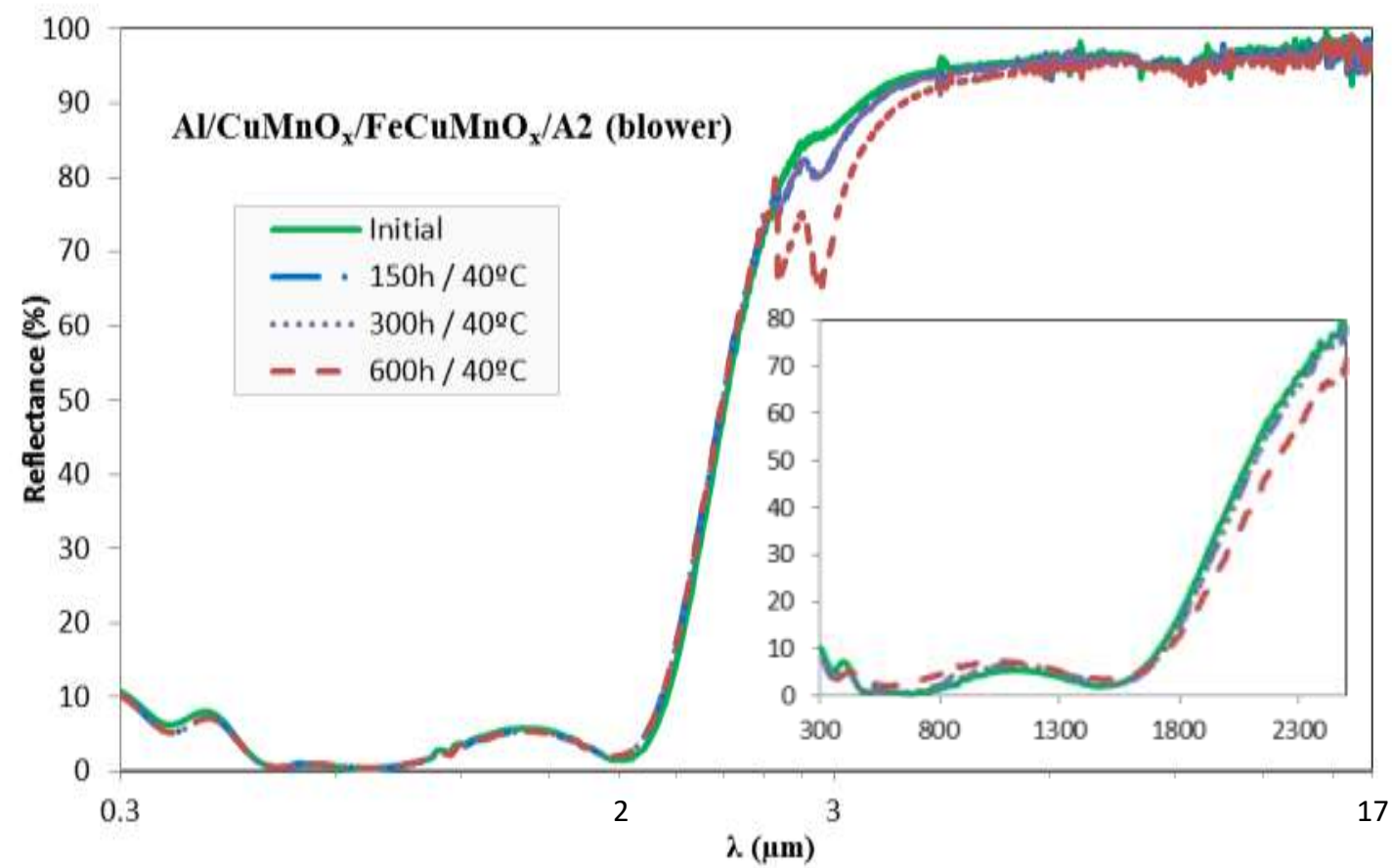

Fig. 3: Variation of the hemispherical reflectance spectra for wavelengths from 0.3 to $17 \mu \mathrm{m} \mathrm{of} \mathrm{Al} / \mathrm{CuMnO}_{\mathrm{x}} / \mathrm{FeMnCuO}_{\mathrm{x}} / \mathrm{SiO}_{2}$ (blower) samples before and after each ageing step in the weathering chamber and a zone amplification of the solar range (inset).

Based on the results shown in Table 3, it can be seen that the average solar absorptance value of the $\mathrm{Al} / \mathrm{CuMnO}_{\mathrm{x}} / \mathrm{FeMnCuO}_{\mathrm{x}} / \mathrm{A} 2$ (blower) sample decreases from 0.955 (un-aged) to 0.942 (after 600 hours at $40^{\circ} \mathrm{C}$ ) as the time of exposure proceeds and the average thermal emittance value increases from 0.039 (un-aged) to 0.049 (after 600 hours at $40^{\circ} \mathrm{C}$ ). Nevertheless, even though the relevant alterations observed for the samples 
after 600 hours of testing, it should be highlighted that these samples presented a well below PC value, PC $\leq$ 0.018 , and conserved the typical selective absorber curve shape at the end of the ageing test. Therefore, based on these results, it can be concluded that the absorbers whose A2 layer was sintered in the blower are qualified according to the standard ISO 22975-3 (2014) with respect to their resistance to condensed water.

However, different results were obtained for samples whose A2 silica layer was sintered in the oven for 15 and 30 minutes. These samples underwent a strong degradation since the first 150 hours of testing; resulting covered by many white spots due to the oxidation of the aluminum substrate and losing the typical absorber colour given the degradation of the silica layer. The worst results were registered for the $\mathrm{Al} / \mathrm{CuMnO}_{\mathrm{x}} / \mathrm{FeMnCuO}_{\mathrm{x}} / \mathrm{A} 2$ samples whose silica layer was sintered in the oven for 30 minutes. In this way, a detailed study focused on these samples is shown.

Figure 4a) and Figure 4b) show photographs of the degradation phenomenon of the $\mathrm{Al} / \mathrm{CuMnO} \mathrm{x}_{\mathrm{x}} / \mathrm{FeMCuO}_{\mathrm{x}} / \mathrm{A} 2$ (oven, 30 minutes) sample before (a) and after (b) the first 150 hours of testing at $40^{\circ} \mathrm{C}$. By comparing both images, it can be deduced that the initial coating appearance of the sample with an excellent uniformity and a minimum number of defects (Figure 4a) disappears after the first 150 hours of testing (Figure 3b) given its degradation.

\section{a) Before condensation}

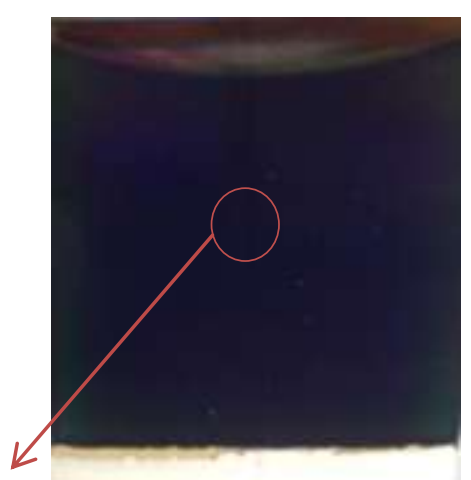

\section{b) After $150 \mathrm{~h}$ at $40^{\circ} \mathrm{C}$}

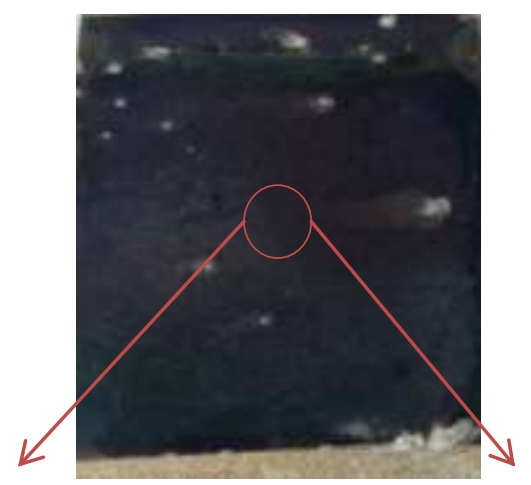

b.1

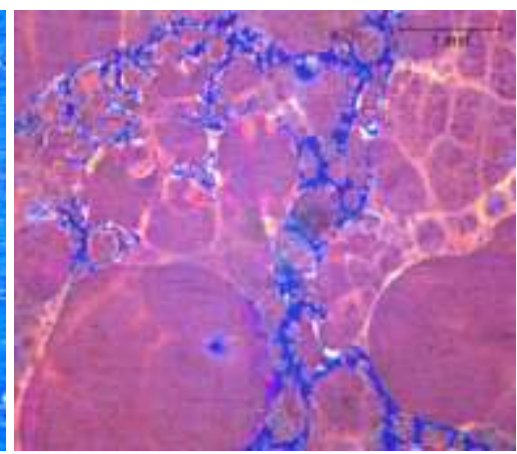

b.2

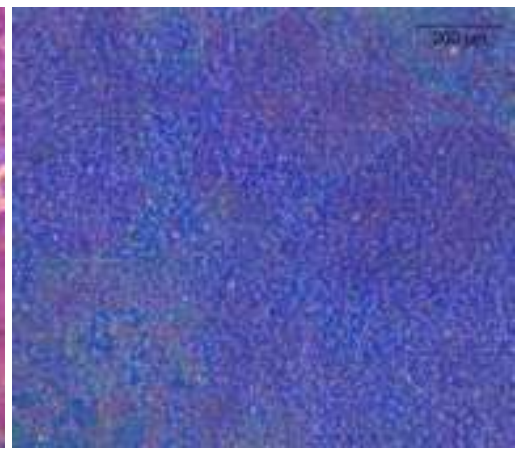

Fig. 4: Photographs of $\mathrm{Al} / \mathrm{CuMnO}_{\mathrm{x}} / \mathrm{FeMnCuO}_{\mathrm{x}} / \mathrm{A} 2$ samples whose silica layer was sintered in the oven before (a) and after the first 150 hours (b) of exposure to condensation at $40^{\circ} \mathrm{C}$. Images a.1 (x100), b.1 (x25) and b.2 (x100) correspond to the analysis carried out with the optical microscope.

Additionally, in order to understand the degree of degradation to which the $\mathrm{A} / / \mathrm{CuMnO}_{\mathrm{x}} / \mathrm{FeMnCuO}_{\mathrm{x}} / \mathrm{A} 2$ (oven) samples are subjected during the condensation test, images of the samples were obtained with the optical microscope. The surface uniformity of the un-aged absorber observed in Figure 4a) was confirmed by analyzing Figure 4a.1), which clearly shows a uniform colour with some lines that come from the machining process for obtaining the aluminum substrate. However, as it can be seen in Figure 4 b.1, the initial coating uniformity disappears after 150 hours of condensation testing being identified two different areas; associating the blue colour to the area of the sample where the A2 layer has not been strongly affected by constant condensation conditions and the red-pink colour to the area of the sample where the A2 layer has been devoid and therefore degraded. Besides, a supplementary reasoning was reached by analysing the sample at a greater magnification 
(x100) in the optical microscope. Concretely, focusing on Figure 4b.2 it is leaded the conclusion that even the area of the sample which had apparently conserved to a larger extent the integrity of the silica layer in Figure 4b.1) was really degraded after 150 hours of testing since the coating surface was full of white spots, presenting a non-uniform aspect.

The evident alterations observed in the aspect of $\mathrm{Al} / \mathrm{CuMnO}_{\mathrm{x}} / \mathrm{FeMnCuO}_{\mathrm{x}} / \mathrm{A} 2$ samples whose $\mathrm{A} 2$ layer was sintered in the oven were also accompanied by the loss of the typical selective absorber curve shape and the drop of the solar absorptance value. These results demonstrated that the optical degradation was correlated with the visual changes observed. Figure 5 shows the variations registered in the hemispherical reflectance spectra of the absorbers whose A2 layer was sintered in the oven for 15 minutes (a) and 30 minutes (b) since the first 150 hours of testing in the weathering chamber.

a) $\mathrm{Al} / \mathrm{CuMnO} / \mathrm{FeCuMnO} / \mathrm{A} 2$ (15 min, oven)

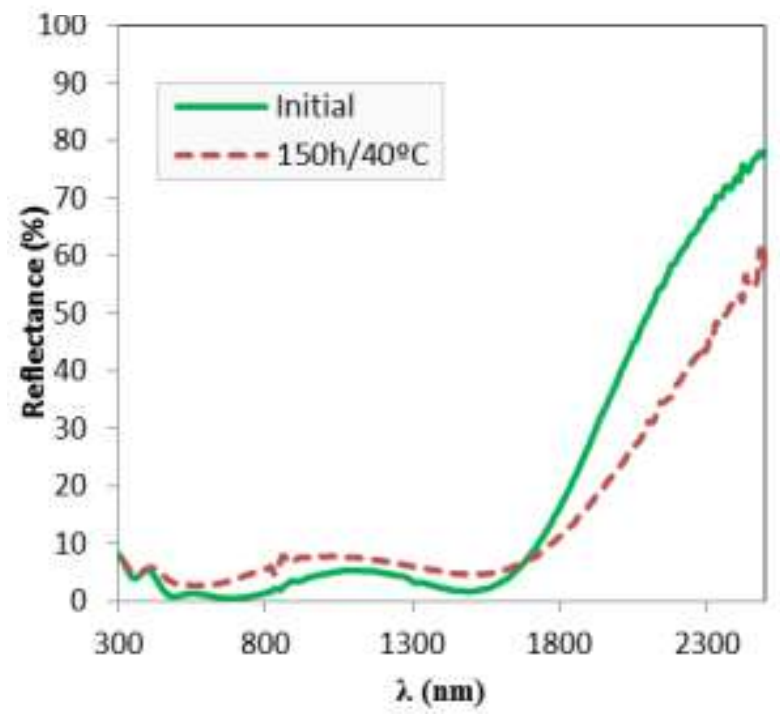

b) $\mathrm{Al} / \mathrm{CuMnO} / \mathrm{FeCuMnO}_{\mathrm{x}} / \mathrm{A2}(30 \mathrm{~min}$, oven $)$

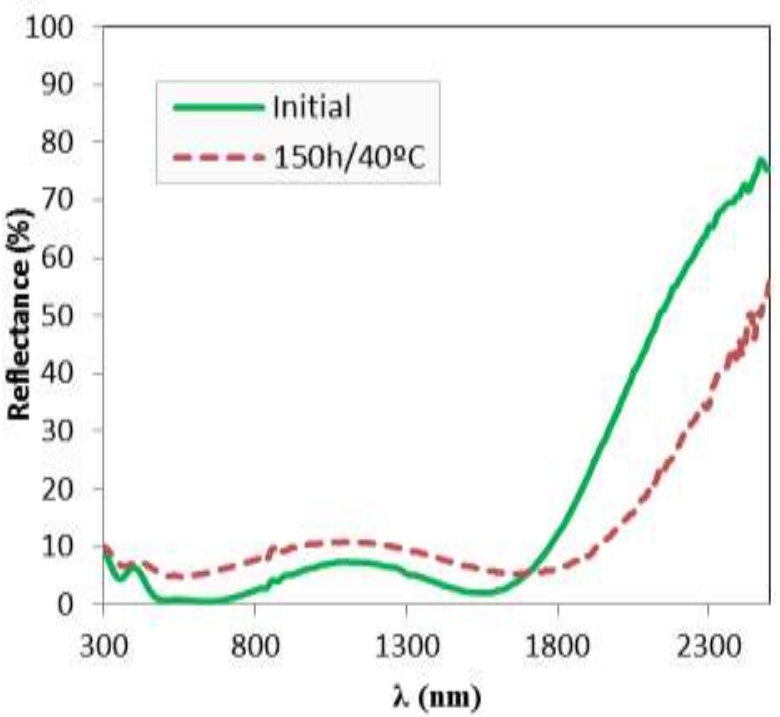

Fig. 5: Variations in the curve shape of the absorbers whose A2 layer was sintered in the oven for 15 minutes (a) and 30 minutes (b) after 150 hours of testing under constant condensation at $40^{\circ} \mathrm{C}$ in the weathering chamber.

A drop in the solar absorptance value to 0.94 was registered for the absorbers whose A2 layer was sintered in the oven for 15 minutes and 0.90 for the absorbers whose A2 was sintered in the oven for 30 minutes. Both samples presented a PC $\leq 0.05$ after the first 150 hours of condensation testing. However, the totally loss of the typical selective absorber curve shape of the samples whose layer was sintered in the oven during both tested times forced to stop the condensation test for these samples. Therefore, based on the results reached, it is established that the $\mathrm{CuMnO}_{\mathrm{x}} / \mathrm{FeMnCuO}_{\mathrm{x}} / \mathrm{A} 2$ absorbers whose $\mathrm{A} 2$ layer was sintered in the oven, regardless of the time of sintering, are not qualified for the condensation test.

Definitely, excluding the $\mathrm{CuMnO}_{\mathrm{x}} / \mathrm{FeMnCuO}_{\mathrm{x}} / \mathrm{A} 1$ absorbers in their entirety and the $\mathrm{CuMnO}_{\mathrm{x}} / \mathrm{FeMnCuO}_{\mathrm{x}} / \mathrm{A} 2$ absorbers whose A2 layer was sintered in the blower which were qualified with respect to the condensation test with a PC $\leq 0.02$ after $600 \mathrm{~h}$ of testing, the rest of the absorbers whose A2 antireflective layer was sintered in the oven, failed the condensation ageing test since they have undergone a strong degradation after the first 150 hours of testing at $40^{\circ} \mathrm{C}$. In this way, based on the global results obtained, it can be clearly pointed out that the dense structural silica coating degraded significantly slower and less aggressively than the non-dense silica coating.

\section{Conclusions}

The performance of the $\mathrm{SiO}_{2} \mathrm{AR}$ coatings was evaluated as it can limit the lifetime performance of the absorber. Concretely, the effect of using two kinds of $\mathrm{SiO}_{2}$ antireflective coatings and different sintering processes of this third constituent absorber layer on the optical properties and the $\mathrm{SiO}_{2}$ ability to protect the integrity of the absorber after long term durability tests were studied. 
Different conclusions were achieved by comparing the results obtained from both components of the durability test confirming the general trend which considers much more aggressive the condensation tests than the thermal stability tests. The results indicated that the typical testing conditions of the thermal stability test have not enough influence on the optical properties of the samples studied being in this way all of them qualified regardless of the $\mathrm{SiO}_{2}$ antireflective coating used as well as the sintering process of this layer. However, in the case of the condensed accelerated ageing test, not all tested samples withstood the condensation conditions. The results obtained revealed that these testing conditions affected differently the samples studied. Concretely, two absorber types whose A2 antireflective layer was sintered in the oven (15 and 30 minutes) failed the ageing test after the first 150 hours of testing. Although these samples presented an accepted $\mathrm{PC}$ criterion $(\mathrm{PC} \leq 0.05)$ once concluded the first 150 hours of testing, they cannot be qualified according to the international standard ISO 22975-3 since they underwent such a strong degradation that they lost the typical selective absorber curve shape. The other absorbers, which correspond to $\mathrm{CuMnO}_{\mathrm{x}} / \mathrm{FeMnCuO}_{\mathrm{x}} / \mathrm{A} 1$ in its entirety and $\mathrm{CuMnO}_{\mathrm{x}} / \mathrm{FeMnCuO}_{\mathrm{x}} / \mathrm{A} 2$ whose A2 layer was sintered in the blower, passed successfully the PC criteria and were qualified according to ISO 22975-3 with respect to the condensation test.

Based on all the results obtained along this work, it can be confirmed that the methodology used for the preparation of the $\mathrm{SiO}_{2}$ antireflective coating as well as its sintering process are determinant regarding the ability of the silica layer to withstand, in greater or lesser way, the outdoor conditions. The best results obtained by the $\mathrm{CuMnO}_{\mathrm{x}} / \mathrm{FeMnCuO}_{\mathrm{x}} / \mathrm{A} 1$ absorbers corroborated that the high-density silica layer acquires a better film structure than the silica layer prepared without a reflux system. Concretely, these successful results can be attributed to the sol-gel chemistry process with which the dense silica layer has been prepared; due to the greater layer compaction obtained for the A1 antireflective coating taking into account the larger polymeric chains which are typically obtained by the sol-gel process.

\section{References}

Amri, A., Jiang, Z.T., Pryor, T., Yin, C., Djordjevic, S., 2014. Developments in the synthesis of flat plate solar selective absorber materials via sol-gel methods: A review. Renew. Sustain. Energy Rev. 36, 316-328. DOI: 10.1016/j.rser.2014.04.062

Brunold, S., Frei, U., Carlsson, B., Möller, K., Köhl, M., 2000. Accelerated life testing of solar absorber coatings: testing procedure and results. Sol. Energy 68, 313-323. DOI: 10.1016/S0038-092X(00)00034-7

Boström, T.K., Wäckelgard, E., Westin, G., 2005. Durability tests of solution-chemically derived spectrally selective absorbers. Sol. Energy Mater. Sol. Cells 89, 197-207. DOI: 10.1016/j.solmat.2005.01.014

Chen. Z., Boström, T., 2016. Accelerated ageing tests of carbon nanotube spectrally selective solar absorbers. Sol. Energy Mater. Sol. Cells 157, 777-782. DOI: 10.1016/j.solmat.2016.07.017

Colangelo, G., Favale, E., Miglietta, P., Risi, A., 2016. Innovation in flat solar thermal collector: A review of the last ten years experimental results. Renew. Sustain. Energy Rev. 57, 1141-1159. DOI: 10.1016/j.rser.2015.12.142

Dudita, M., Brunold, S., Ruesch, F., Omlim, L., Gantenbein, P., Marot, L., Kaufmann, A., 2015. Durability of solar selective absorbers under condensation test. OTTI Symposium Thermische Solarenergie.

Diamantino, T.C., Nunes, A., Gonçalves, R., Páscoa, S., Chambino, T., Carvalho, M.J., 2016. Selective absorber coatings qualification - ISO 22975-3:2014 full application. ISES Conference Proceedings, EuroSun 2016.

Diamantino, T. C., Gonçalves, R., Nunes, A., Páscoa, S., Carvalho, M.J., 2017. Durability of different selective solar absorber coatings in environments with different corrosivity. Sol. Energy Mater. Sol. Cells 166, 27-38. DOI: 10.1016/j.solmat.2017.03.004 
Farchado, M., Rodríguez, J.M., San Vicente, G., Germán, N., Morales, A., 2018. Optical parameters of a novel competitive selective absorber for low temperature solar thermal applications. Sol. Energy Mater. Sol. Cells 178, 234-239. DOI: 10.1016/j.solmat.2018.01.031

Joly, M., Antonetti, Y., Python, M., Lazo, M.A.G., Gascou, T., Hessler-Wyser, A., Scartezzini, J.L., Schüler, A., 2014. Selective solar absorber coatings on receiver tubes for CSP - Energy-efficient production process by solgel dip-coating and subsequent induction heating. Energy Procedia 57, 487-496. DOI: 10.1016/j.egypro.2014.10.202

Khatiri, M., Razzaghi, H., Panahpour, A., Baradaran, M., Barbaran, J.H., 2014. The effect of different heating methods on properties of a nano-porous silica thin film. Opt. Quant. Electron. 47, 1071-1081. DOI: $10.1007 / \mathrm{s} 11082-014-9963-6$

Kotilainen, M., Mizohata, K., Honkanen, M., Hyvärinen, L., Vuoristo, P., 2015. Temperature-induced ageing of solar absorbers on plain and anodized aluminuim substrates. Sol. Energy Mater. Sol. Cells 134, 244-251. DOI: 10.1016/j.solmat.2014.12.006

Morales, A., Durán, A., 1997. Sol-gel protection of front surface silver and aluminum mirrors. J. Sol-Gel Sci. Technol. 8, 451-457. DOI: 10.1007/BF02436881

Morales, A., Process to deposit metal and metal oxide coatings. European Patent: EP1321539 (A3).

Solar thermal electric plants. Terminology. UNE 206009: 2013.

Solar Energy - Collector components and materials - Part 3: Absorber surface durability. International Standard ISO 22975-3 (2014).

Standard Tables for Reference Solar Spectral Irradiances: Direct Normal and Hemispherical on $37^{\circ}$ Tilted Surface. Designation: G 173 - 03.

Yang, R., Liu, J., Lin, L., Qu, Y., Zheng, W., Lai, F., 2016. Optical properties and thermal stability of colored solar selective absorbing coatings with double-layer antireflection coatings. Sol. Energy 125, 453-459. DOI: 10.1016/j.solener.2015.12.022 


\title{
Testing and modeling of Direct Seam Generating Parabolic Trough Collectors
}

\author{
Souha Ferchichi' ${ }^{1}$, Hamdi Kessentini ${ }^{1}$, Sergio Morales ${ }^{2}$, Lisa Willwerth ${ }^{4}$, João Soares ${ }^{3}$, Jesús \\ Castro $^{2}$, Chiheb Bouden', Armando Oliveira ${ }^{3}$, Ridha Ben Cheikh1 \\ ${ }^{1}$ Université Tunis el Manar, École Nationale d'Ingénieurs de Tunis,Tunis,(Tunisia). \\ 2 Technical University of Catalonia, Heat and Mass Transfer Technological center,Terrassa \\ Barcelone (Spain) \\ ${ }^{3}$ University of Porto- Faculty of Engineering,Porto (Portugal). \\ ${ }^{4}$ German Aerospace Center (DLR), Institute of Solar Research Cologne,Germany.
}

\begin{abstract}
The present work is elaborated in the framework of the REELCOOP research project. A mini hybrid (solar/biomass) power plant was installed and is under testing at ENIT (Ecole Nationale d'Ingénieurs de Tunis), Tunisia. The power plant relies on Parabolic Trough Collectors (PTC) operating with Direct Steam Generation (DSG), an Organic Rankine Cycle (ORC) for power generation, and a boiler as a backup system.

A general numerical model is developed to predict the thermal behavior of the two-phase flow in the PTC collector. The model is validated against experimental results carried out in DISS test facility and good agreement is found between the numerical and experimental results. The model is then used to investigate the performances of a PTC using hot water under Tunisian climatic conditions.

Preliminary tests of the REELCOOP installation were performed for solar only mode on August 2017 and the DSG was successfully demonstrated. The test results showed that the plant is able to produce steam up to $176^{\circ} \mathrm{C}$.
\end{abstract}

Keywords: Parabolic Trough Collector, Direct Steam Generation, Performance analysis.

\section{Introduction}

Concentrating Solar Power (CSP) is one of the most promising electricity generation technologies especially in areas with abundant solar radiation and high electricity demand, such as North Africa (Salazar, 2008).CSP plants concentrate the solar radiation through their mirrors and reflect it on to a receiver using a thermal fluid as a Heat Transfer Fluid (HTF), exchanging heat with heat exchangers to generate steam and run a power cycle. Another perspective is to directly generate steam in the collectors, eliminating the need for heat transfer fluid in the solar field. This approach avoids the harmful effects of oils, improves the overall efficiency of the system by avoiding heat exchangers and therefore reduces the cost per kWh produced.(Birnbaum et al., 2011). One of the challenges DSG presents is the dynamic behavior, under the effect of the variation of the solar radiation, of the absorber tube in which the direct production of steam occurs. This issue is addressed in the framework of a European research project (REELCOOP), funded under the FP7 program, which aims at the demonstration, at ENIT university, of a small scale CSP plant with a capacity of $60 \mathrm{~kW}$ using a Rankine organic cycle turbine and PTCs $\left(1000 \mathrm{~m}^{2}\right)$ for direct steam production. This plant is equipped with a backup system using biomass (Oliveira and Coelho, 2013).

Different research studies including, modeling, simulation, and optimization of DSG in PTCs, have been carried out with the aim to predict the behavior of a direct steam generating PTC. The approaches included CFD models (Lobón et al., 2014b), steady state and transient models (Biencinto et al.,2016; Hachicha et al.,2018; Lobón and Valenzuela,2013; Odeh et al.,1998 and Odeh et al., 2000)and simulation tools 
(Aurousseau et al., 2015 ; Kurup et al., 2017 and Serrano-Aguilera and Valenzuela, 2016). The current developed model is based on solving the governing equations for the fluid flow, and applying the energy balance for the solid parts (receiver and glass envelope). The implementation of this approach is straightforward and it has a short simulation time. Besides, it predicts the flow behavior along the receiver tube with a good accuracy.

The main objectives of this work are: first to develop a thermal model taking into consideration the phase change as well as the transition between the different phases inside the PTC absorber tube; secondly, to simulate the performance of the PTC using hot water as HTF; thirdly, to present the DSG preliminary tests of REELCOOP facility. The developed model will serve as a future and fast practical tool to simulate the REELCOOP prototype solar field.

\section{Numerical Model Description}

The developed model is based on solving the governing equations (mass, momentum and energy) for the fluid flow inside the absorber tube, and applying the energy balance for the solid parts (absorber and glass envelope). The model applied for single phases was solved using the energy balance for the fluid flow and tube walls also. The heat transfer in a cross section of the Heat Collector Element (HCE) is shown in Fig.1.

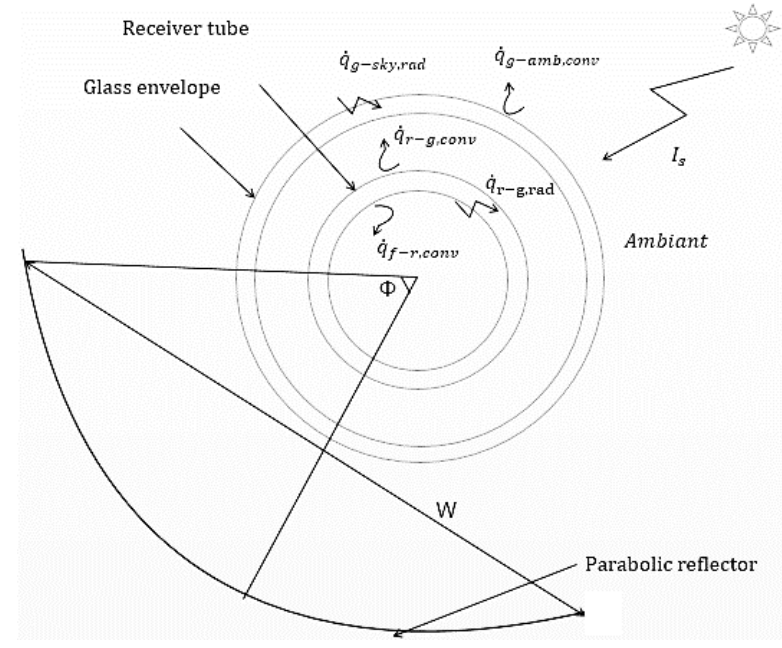

Fig. 1: Heat transfer in a cross section of a HCE

Most of the incoming solar radiation is absorbed by the receiver tube thanks to the high absorptance provided by its coating. A part of the absorbed energy is gained by the HTF inside the receiver tube, and the remaining is transmitted to the glass envelope by natural and forced convection. The heat losses from the glass envelope are in the form of convection to the ambient, and radiation to the sky (Forristall, 2003).

The energy balance equations are discretized between the HTF and the ambient by applying the Finite Volume Method (FVM) on the solar collector, and the set of the non-linear algebraic equations are solved using a step by step method.

The HCE is discretized in the axial direction, and the steady state energy balance for the receiver is expressed by:

$$
C \times \dot{q}_{r, \text { SolAbs }}=\dot{q}_{r-g, \text { conv }}+\dot{q}_{f-r, \text { conv }}+\dot{q}_{r-g, r a d}
$$

Where $\mathrm{C}$ presents the geometrical concentration factor and is expressed as follows:

$$
C=\frac{W-D_{r, e}}{\pi D_{r, e}}
$$

Similarly, the energy balance for the glass envelope is given by:

$$
\dot{q}_{r-g, \text { conv }}+\dot{q}_{f-r, \text { conv }}+\dot{q}_{g, \text { SolAbs }}=\dot{q}_{g-a, \text { conv }}+\dot{q}_{g-s k y, r a d}
$$


The heat transfer coefficients corresponding to the losses by convection and radiation are evaluated using empirical correlations.

The governing equations are discretized in the fluid flow axial direction as shown in Fig.2, while considering the flow to be steady state and separated. In fact, the liquid and vapor phase are considered to flow separately at different velocities.

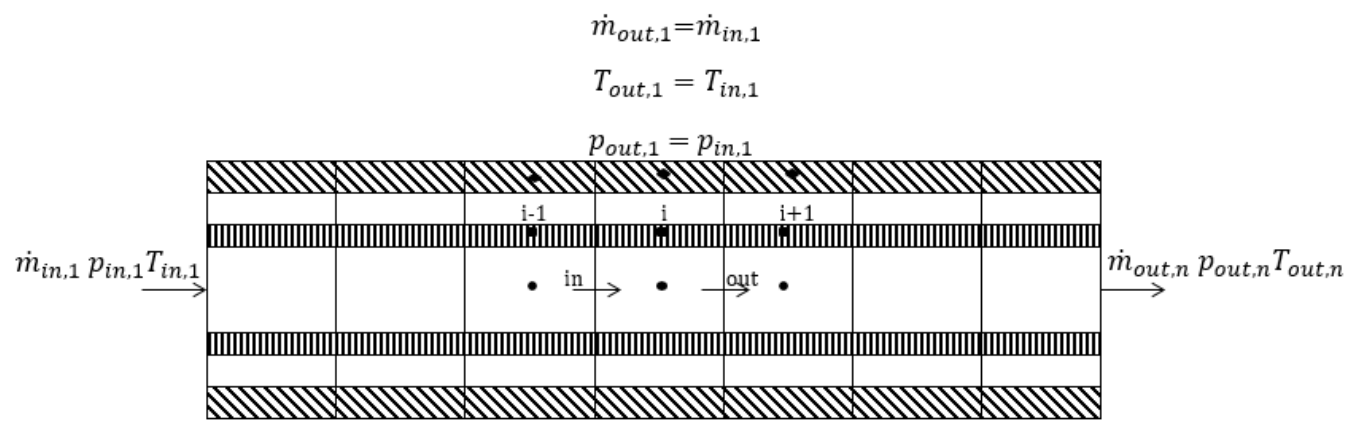

- Nodes for the fluid

- Nodes for the receiver

-Nodes for the glass envelope

Fig. 2: Discretization scheme of the calculation domain

The discretized continuity equation results in the outlet mass flow rate

$\dot{m}_{\text {in }}=\dot{m}_{\text {out }}=\dot{m}$

The discretized momentum equation is solved for the outlet pressure

$$
p_{\text {out }}=p_{\text {in }}-\frac{\Delta z}{A_{f}}\left(\left(\Phi \bar{f} \pi D_{r, i} \frac{\bar{m}^{2}}{8 A_{f}^{2} \bar{\rho}_{t p}}+\frac{\left[\dot{m}\left(x_{g} v_{g}+\left(1-x_{g}\right) v_{l}\right)\right]_{\text {in }}^{\text {out }}}{\Delta z}\right)\right)
$$

The two-phase density is expressed as: $\rho_{t p}=\rho_{g} \varepsilon_{g}+\left(1-\varepsilon_{g}\right) \rho_{l}$

The liquid and vapor velocities are given by: $v_{g, \text { out }}=\left[\frac{\dot{m} x}{\rho_{v} \varepsilon_{g} A_{f}}\right]_{\text {out }} ; v_{l, \text { out }}=\left[\frac{\dot{m}(1-x)}{\rho_{l}\left(1-\varepsilon_{g}\right) A_{f}}\right]_{\text {out }}$

The discretized energy equation is solved for the outlet enthalpy

$$
H_{\text {out }}=\frac{2 \dot{q}_{\text {wall }} \pi D_{\text {rint }} \Delta x-\dot{m}_{\text {out }} a 1+\dot{m}_{\text {in }} a 2}{\dot{m}_{\text {out }}+\dot{m}_{\text {in }}}
$$

$a 1=\left(x v_{g}+(1-x) v_{l}\right)_{\text {out }}^{2}-H_{\text {in }}$

$a 2=\left(x v_{g}+(1-x) v_{l}\right)_{i n}^{2}+H_{i n}$

Where: $\dot{q}_{\text {wall }}=h\left(T_{r}-T_{f}\right)$

The thermodynamic properties of the fluid are introduced in the form of equations, and the fluid temperatures as well as equilibrium quality are calculated using the NIST database for water, as a function of pressure and enthalpy.

The equilibrium quality is given by (Kandlikar, 1991):

$$
x=\frac{H-H_{l}}{H_{g}-H_{l}}
$$




\subsection{Single phase flow empirical correlations}

The heat transfer coefficient in the single phase flow is evaluated using the correlation of Gnielinski and Petukhov (Gnielinski, 1975; Kandlikar, 1991; Petukhov and Popov, 1963). The choice of the correlation is based on the flow regime (laminar or turbulent). Besides Churchill correlation is adopted for the calculation of the friction factor (Churchill, 1977).

\subsection{Two-phase flow correlations}

Kandlikar (Kandlikar, 1990) correlation is used to evaluate the two phase heat transfer coefficient. The method presents two expressions taking into consideration convective and nucleate boiling, and the heat transfer coefficient is calculated according to the dominant heat transfer process.

The void fraction is calculated using Zivi (Zivi, 1964) correlation, for separated flow models, the friction factor is evaluated using the same correlation as in the single phase region, and the two phase multiplier $\Phi$ which is evaluated by means of the Friedel (Friedel, 1979) .

\section{Numerical algorithm}

The model relies on dividing the absorber tube into a finite number of elements and evaluating the fluid outlet temperature, pressure, enthalpy, quality, heat loss, thermal efficiency, heat gain and the useful energy. The solution process is programmed in c++ language. Initially, the geometrical and optical parameters of the PTC, the meteorological data, the fluid inlet conditions (temperature, pressure, mass flow etc), are introduced as input data to the algorithm in one hand, and the temperature and pressure distribution for the components of the HCE are initialized in the other hand.

As a following step, the thermodynamic and transport properties of the HTF and the annulus gas are computed to evaluate heat transfer coefficients and the heat fluxes defined in the previous section (section 2).

For each element, the governing equations and the energy balance equations are solved, and the outlet variables values are set equal to the inlet variables of the next element.

\section{Validation results}

The validation of the developed numerical model was validated for single-phase flow using Syltherm oil, water and superheated steam, and for two-phase flow predicting the DSG inside the receiver tubes.

Firstly, the model was validated for the case of PTC with Syltherm oil and hot water using experimental results carried out at Sandia National Laboratories (SNL) (Dudley et al., 1994) for a SEGS LS2 collector.

The numerical and experimental results, of Syltherm oil as HTF, are presented in Fig.3. The thermal efficiency and the heat losses from the HCE are illustrated as a function of the temperature above ambient defined as: $\Delta T-T_{a}$, where $\Delta T=T_{o}-T_{i}$.

The validation was carried out for two types of receiver coatings (cermet and black chrome), and for vacuum and air in the gap between the receiver and the glass envelope.

The fluid outlet temperature and thermal efficiency in case of water as HTF are presented in Tab.1. The numerical results show good agreement with the experimental measurements. The mean relative errors obtained for the thermal efficiency are $1.5 \%$ in the case of vacuum in the annular space and $1.35 \%$ in the case of air. As for the heat losses, the mean relative errors obtained are $13.8 \%$ and $3.2 \%$ for vacuum and air in the annular space respectively. 

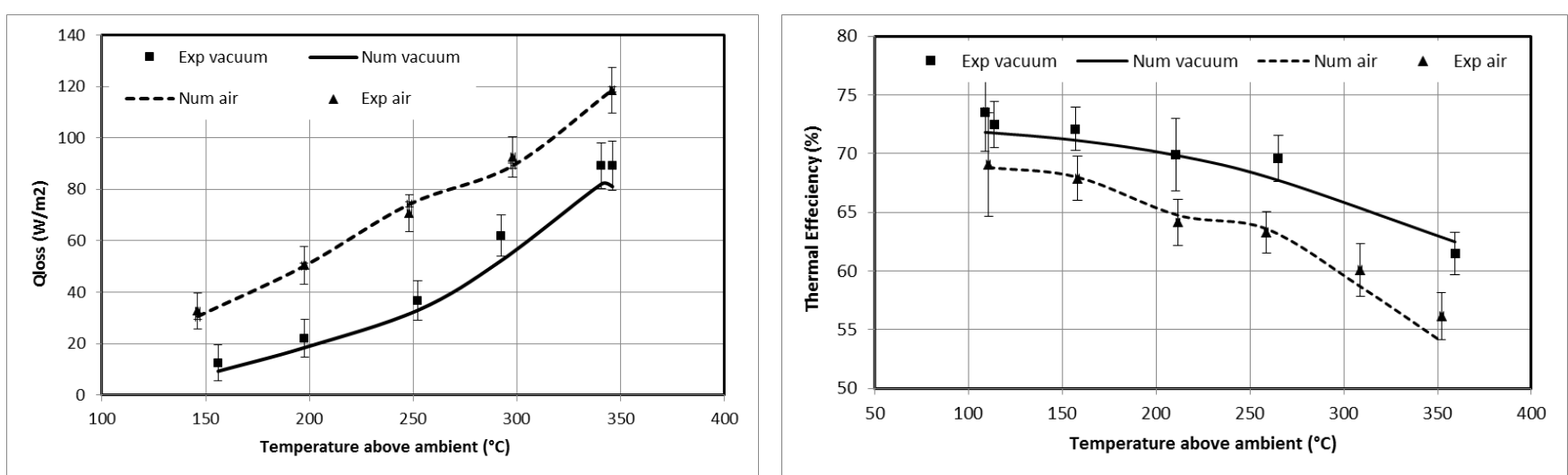

Fig. 3: Numerical (Num) and experimental (Exp) results of thermal efficiency and heat losses using synthetic oil

Tab. 1: Validation table for hot water (Dudley et al., 1994)

\begin{tabular}{|c|c|c|c|c|c|c|c|c|c|c|c|}
\hline $\begin{array}{c}\text { DNI } \\
\left(\mathbf{W ~ m ~}^{-2}\right)\end{array}$ & $\begin{array}{c}\text { Pressure } \\
(\mathbf{M P a})\end{array}$ & $\begin{array}{c}\text { Ambient } \\
\mathbf{T} \\
(\mathbf{K})\end{array}$ & $\begin{array}{c}\text { Wind } \\
\text { velocity } \\
\left(\mathbf{m ~ s ~ s}^{-1}\right)\end{array}$ & $\begin{array}{c}\text { Mass } \\
\mathbf{f l o w} \\
\left(\mathbf{k g ~ s}^{-1}\right)\end{array}$ & $\boldsymbol{T}_{\boldsymbol{i}}(\mathbf{K})$ & $\eta_{\text {th }}$ & $\eta_{\text {th,exp }}$ & $\begin{array}{c}\eta_{t h} \mathbf{E r r} \\
\mathbf{\%}\end{array}$ & $\boldsymbol{T}_{\boldsymbol{o}}(\mathbf{K})$ & $\begin{array}{c}\boldsymbol{T}_{\boldsymbol{o}, \text { exp }} \\
(\mathbf{K})\end{array}$ & $\begin{array}{c}\boldsymbol{T}_{\boldsymbol{o}} \mathbf{E r r} \\
\mathbf{\%}\end{array}$ \\
\hline 807.5 & 0.1 & 288.95 & 1 & 0.306 & 291.45 & 0.68 & 0.73 & 6.48 & 308.65 & 309.25 & 0.19 \\
\hline
\end{tabular}

The superheated steam numerical results were validated against experimental results carried out in DISS test facility for an LS3 collector with a 4.06 m tube length (Serrano-Aguilera et al., 2014).

Tab.2: Validation table for superheated steam (Serrano-Aguilera et al., 2014)

\begin{tabular}{|c|c|c|c|c|c|c|c|c|c|c|c|}
\hline $\begin{array}{c}\text { DNI } \\
\left(\begin{array}{c}\text { W m } \\
\left.{ }^{-}\right)\end{array}\right.\end{array}$ & $\begin{array}{c}\text { Pressure } \\
\text { (MPa) }\end{array}$ & $\begin{array}{c}\text { Ambient } \\
\mathbf{T} \\
(\mathbf{K})\end{array}$ & $\begin{array}{c}\text { Wind } \\
\text { velocity } \\
\left(\mathrm{m} \mathrm{s}^{-1}\right)\end{array}$ & $\begin{array}{c}\text { Mass } \\
\text { flow } \\
\left(\mathrm{kg} \mathrm{s}^{-1}\right)\end{array}$ & $\boldsymbol{T}_{\boldsymbol{i}}(\mathbf{K})$ & $\eta_{t h}$ & $\eta_{t h, \text { exp }}$ & $\begin{array}{c}\eta_{t h} \operatorname{Err} \\
\%\end{array}$ & $\begin{array}{l}\boldsymbol{T}_{o} \\
(\mathbf{K})\end{array}$ & $\begin{array}{c}T_{o, \text { exp }} \\
(\mathbf{K})\end{array}$ & $\begin{array}{c}T_{o} \operatorname{Err} \\
\%\end{array}$ \\
\hline 921 & 6.188 & 303.3 & 0.5 & 0.64 & 560 & 0.58 & 0.64 & 10.11 & 564.17 & 565.00 & 0.15 \\
\hline 804 & 6.125 & 307.2 & 0.5 & 0.53 & 551.6 & 0.57 & 0.65 & 11.61 & 555.83 & 556.50 & 0.12 \\
\hline 771 & 3.237 & 309.6 & 0.5 & 0.52 & 532.8 & 0.58 & 0.62 & 6.81 & 538.61 & 539.90 & 0.24 \\
\hline 790 & 3.223 & 307.9 & 0.5 & 0.5 & 527.8 & 0.58 & 0.64 & 9.53 & 533.95 & 535.10 & 0.22 \\
\hline 853 & 10.085 & 307 & 0.5 & 0.58 & 616.5 & 0.56 & 0.52 & 7.38 & 619.92 & 620.40 & 0.08 \\
\hline 823 & 6.113 & 305.6 & 0.5 & 0.53 & 585.5 & 0.57 & 0.62 & 8.67 & 590.39 & 592.10 & 0.29 \\
\hline 910 & 5.854 & 299 & 0.5 & 0.64 & 576 & 0.57 & 0.58 & 1.46 & 580.52 & 581.40 & 0.15 \\
\hline 804 & 3.161 & 301.8 & 0.5 & 0.53 & 551.7 & 0.57 & 0.6 & 4.31 & 557.88 & 559.20 & 0.24 \\
\hline
\end{tabular}

At the outlet of the PTC tube, the calculated temperature and thermal efficiency $\left(\eta_{t h}\right)$ are evaluated and compared to the DISS experimental data. A mean relative error of $7.5 \%$ is obtained for the thermal efficiency, and $0.18 \%$ for the outlet temperature.

Finally, the DSG numerical model, predicting the phase change and the heat transfer in the PTC, was validated against experimental measurements from DISS facility (Lobón et al., 2014a), and the outlet pressure and temperature are displayed as a function of the receiver length in Fig 4, for the inlet conditions reported in Tab 3. 
Tab. 3 Inlet conditions for a DISS test case (Lobón et al., 2014a)

\begin{tabular}{|c|c|c|c|}
\hline $\mathbf{P}_{\text {in }}(\mathbf{M P a})$ & $\mathbf{T}_{\text {in }}\left({ }^{\circ} \mathbf{C}\right)$ & $\dot{\mathbf{m}}_{\text {in }}(\mathbf{k g} / \mathbf{s})$ & DNI $\left(\mathbf{W} / \mathbf{m}^{\mathbf{2}}\right)$ \\
\hline 3.38 & 196 & 0.47 & 807 \\
\hline
\end{tabular}

As can be seen in Fig.4, the obtained numerical results are in good agreement with the experimental ones, and the mean relative errors for the outlet pressure and temperature are $0.55 \%$ and $5.42 \%$ respectively. The highest discrepancies are noticed in the superheating section, where the model tends to over predict the outlet temperature. These discrepancies may due the heat transfer coefficients correlations used in the superheating section.
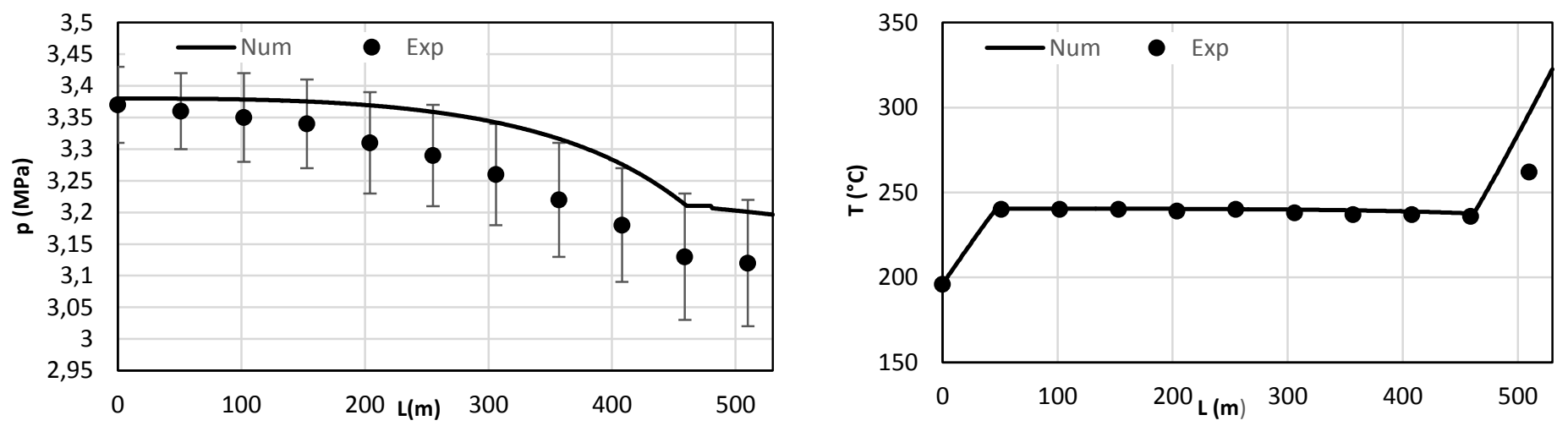

Fig. 4: Numerical vs experimental results of the DSG model, for the outlet pressure (left) and temperature (right)

The DSG model developed is general and includes all three phases, as well as the dryout regime, which can occur at the end of the saturated two-phase region. The model will be applied on the PTC of REELCOOP installation to evaluate its performance. Only saturated steam is generated in the installation. and so the liquid, and saturated phases only will be needed for the simulations. Besides, the REELCOOP prototype relies on recirculation mode to prevent any dryout that may occur in the receiver tube. Thus, the dryout part will be excluded as well.

\section{Performance analysis with Hot water}

The developed model for single phase flow is used to simulate a PTC generating hot water. Two typical days in summer and winter were chosen for the simulations. The heat gain by the HTF is evaluated in both cases and illustrated in Fig.5 along with the DNI, ambient temperature and wind speed.

We conclude from the graphs that the PTC can be operational for an average of 10 hours during the summer with a maximum heat gain of $626 \mathrm{~W} / \mathrm{m}^{2}$, and 7 hours during winter, with $318 \mathrm{~W} / \mathrm{m}^{2}$ as maximum heat gain. 

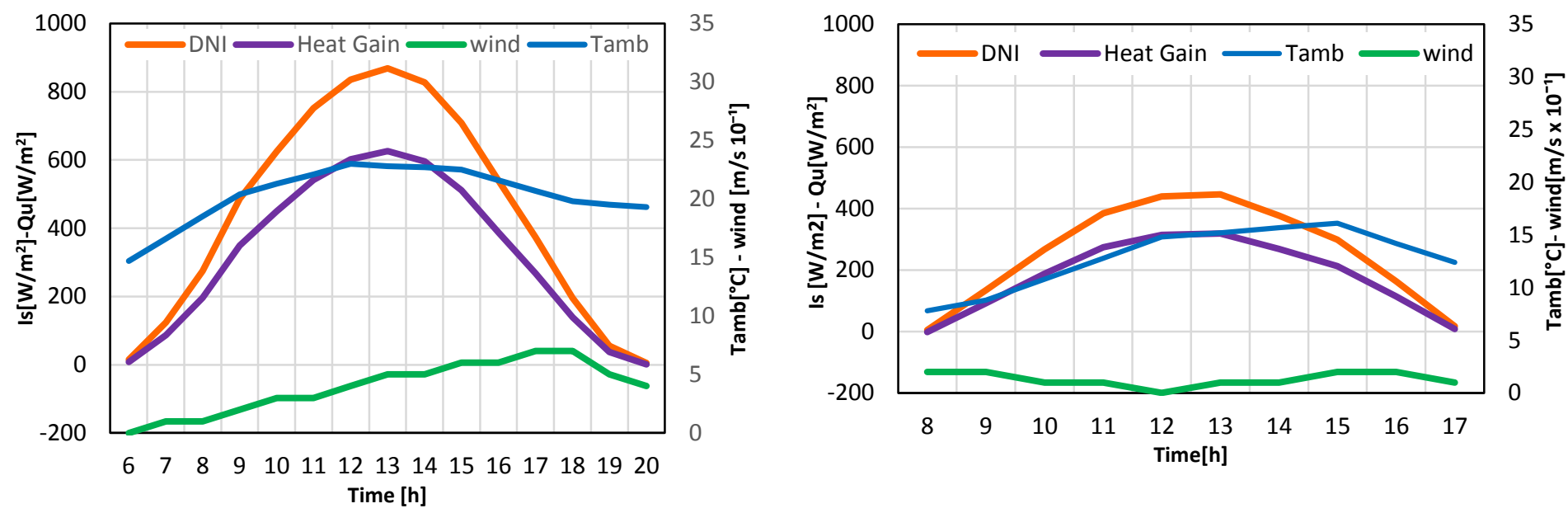

Fig.5: Hourly useful heat per unit of aperture area of the PTC in June (left), and December (right)

\section{Commissioning and testing of REELCOOP facility}

The prototype implemented in Tunisia relies on parabolic trough collectors and an organic Rankine cycle (ORC) enhanced by a biogas boiler. It is currently under installation at the École Nationale d'Ingénieurs de Tunis (ENIT) in Tunisia. This installation will then be used for demonstration, and for training students on the involved renewable technologies.

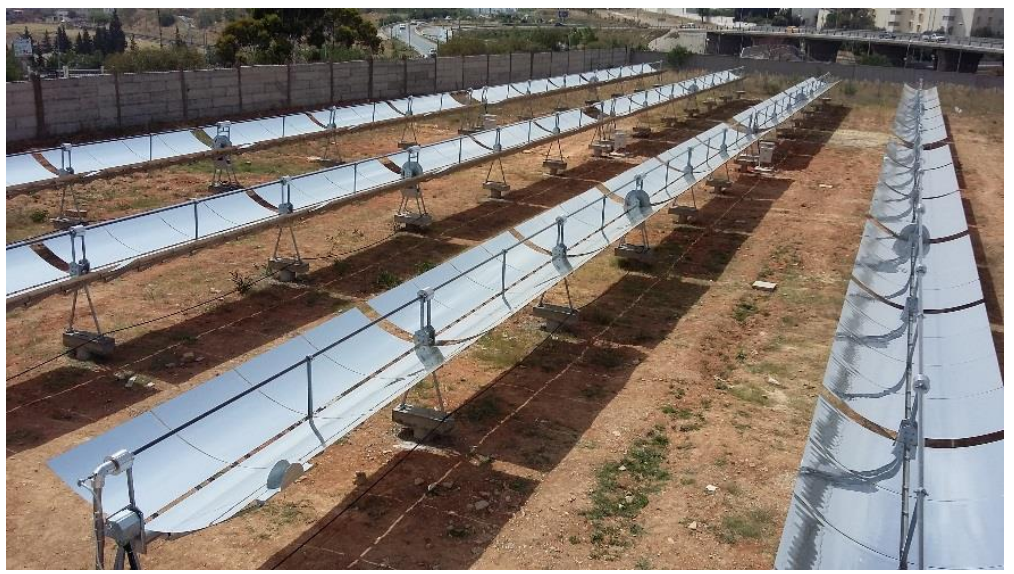

Fig.6: Solar field of REELCOOP plant

\subsection{REELCOOP mini power plant technical description}

The plant uses a completely innovative approach which is the hybridization of renewable resources: solar and biomass. It consists of three parallel rows of parabolic troughs with a net collecting surface of $1000 \mathrm{~m}^{2}$ (Fig.6) operating in direct steam generation (DSG) concept, and generating saturated steam at $175{ }^{\circ} \mathrm{C} / 8.9$ bar. The Organic Rankine Cycle (ORC) turbine with a newly developed generator design generates up to $65 \mathrm{~kW}$ electrical from low temperature steam produced by the solar field, with a nominal gross efficiency reaching 14\%. Biomass anaerobic digestion and phase change storage are demonstrated as well (Krüger et al., 2017). Fig.7 illustrates the P\&ID of the DSG closed loop in REELCOOP plant. 


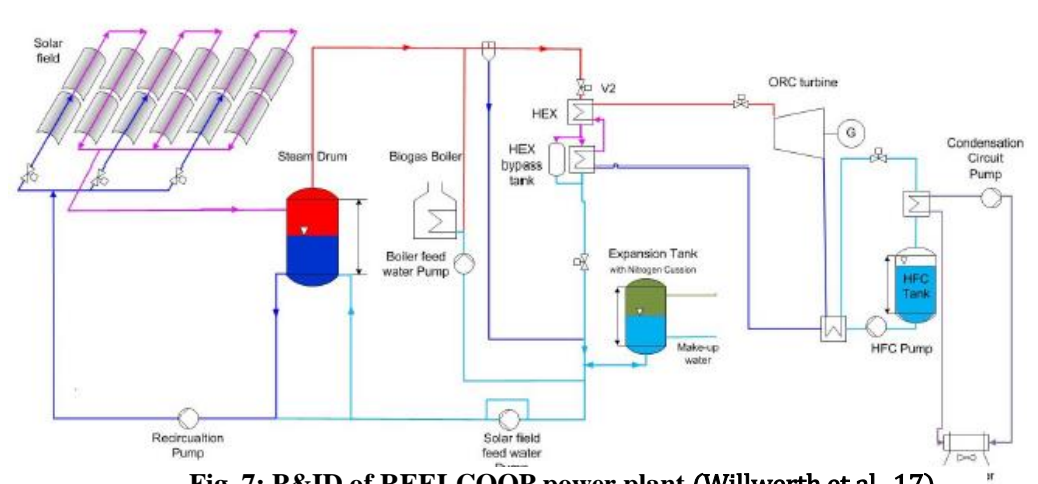

Fig. 7: P\&ID of REELCOOP power plant (Willwerth et al., 17)

The solar collectors are oriented in a North-South direction and they track the sun throughout the day from East to West. The curved shapes send most of the heat collected from the sun to a receiver placed on the focal line and generate the steam directly. Subcooled water at a temperature of $148^{\circ} \mathrm{C}$ is pumped to the solar field. In the first collector of each loop the whole water flow is heated up by the radiation of the sun. The water is partially evaporated in the remaining segment of the collector loop. Downstream the evaporation section, a steam drum is placed to separate steam from water. The steam is sent off to the turbine to spin a generator, after it is condensed and sub-cooled in the ORC heat exchangers to $80^{\circ} \mathrm{C}$ and finally pumped back by the feed water pump.

Before leaving the steam drum. the water coming from the solar field at $175{ }^{\circ} \mathrm{C}$ mixes with subcooled water at $80^{\circ} \mathrm{C}$ and is then recirculated back to the solar field by a recirculation pump.

\subsection{Preliminary test results}

The commissioning and testing of the plant took place at ENIT for solar only mode, started the $21^{\text {st }}$ of August, 2017 and lasted five days. The solar field was firstly tested with low temperatures, and then was operated in part load for steam generation. The PTCs produced steam at approximately $177^{\circ} \mathrm{C} / 8.3$ bars. All the data of the solar field and the whole plant are sent to a control and data acquisition system for a good monitoring of the facility.

One of the main purposes of the tests was to detect the steam generation in the solar field. Two view-glass were implemented in the installation including one between the solar field and the steam drum. Different flow regimes are depicted in Fig.8.

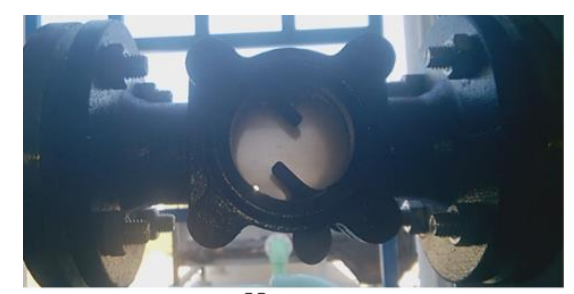

Hot water

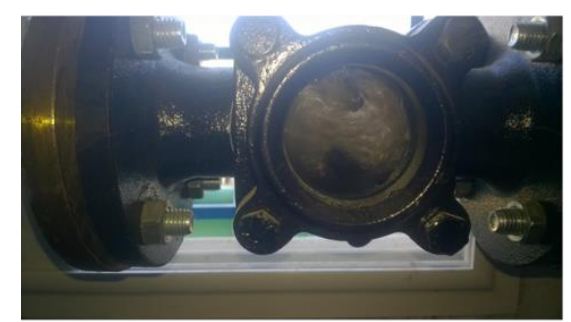

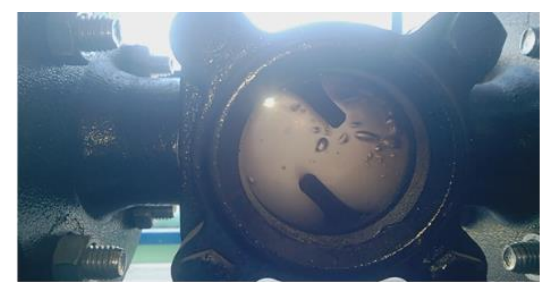

Bubble formation

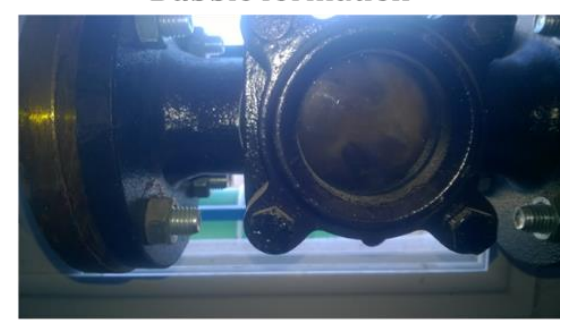

Liquid + vapor mixture

Fig 8: flow regimes at the outlet of the solar field 
Three sets of results for three different days were obtained (e.g.: August 21. 22 and 23. 2017). The data set includes the inlet and outlet temperature pressure and mass flow at the plant's different components. In this paper, we will present the solar field results obtained.

The solar only mode test results on August 21.2017 are presented in Fig.9. On the right part of the figure, the inlet and outlet temperature and pressure are displayed, and on the left part, the acquisition system with the corresponding sensors implemented in the solar field.

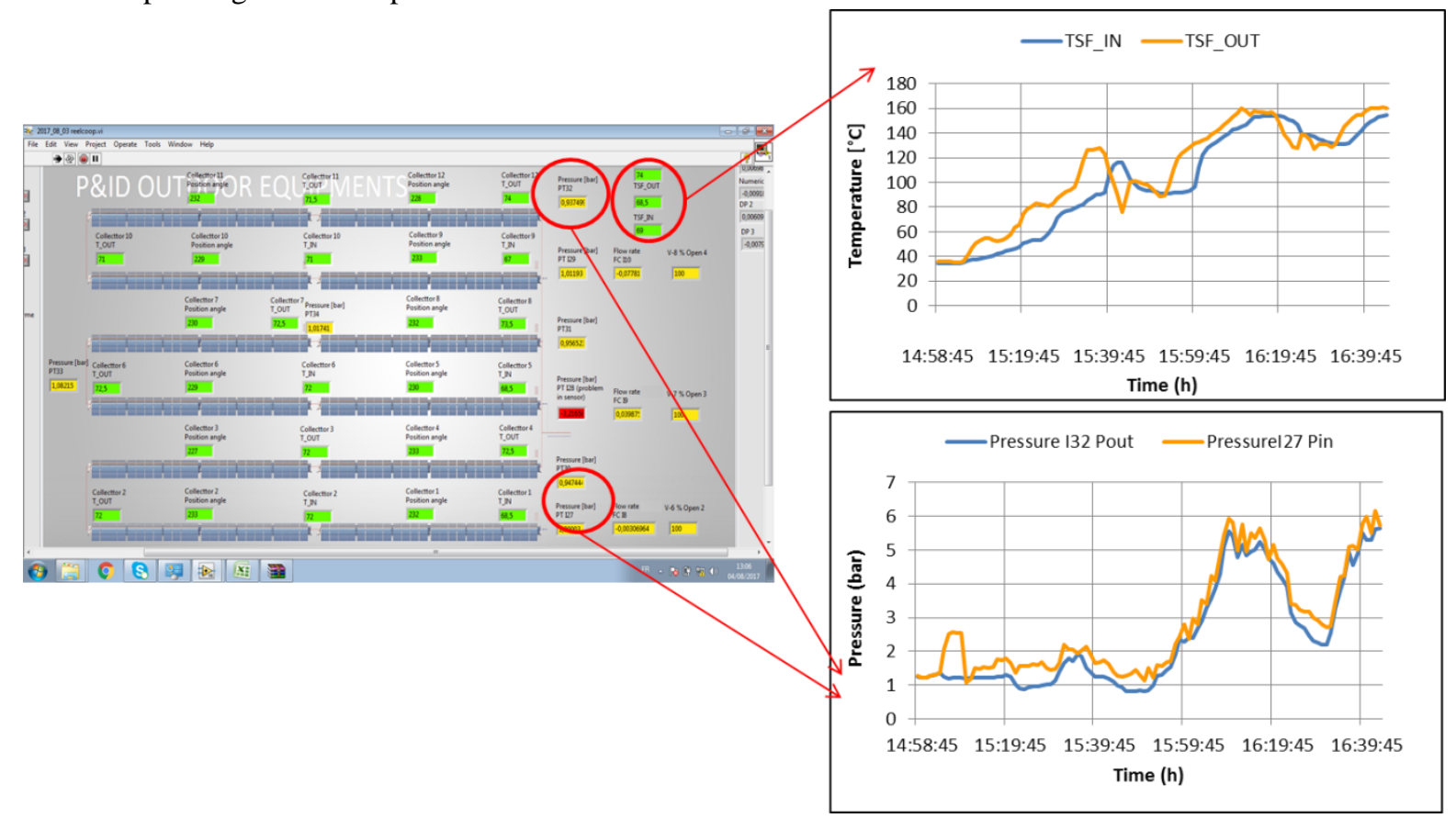

Fig. 9: August 21 ${ }^{\text {st }}, 2017$ solar field test results

The data shown was registered between $11 \mathrm{am}$ and $5 \mathrm{pm}$ (Fig.10) on the second day of the tests. The chart of DNI shows the DNI on the collector. When the collector is defocused, the DNI graph falls to zero. As noticed, both temperature (TSF_OUT) and pressure (Pout) keep increasing with time as soon as the collector is focused. The sudden decrease in temperature and pressure is explained by a defocus of the collectors. Since it was the first time operating the plant, the collectors were defocused several times during the tests in order to control the overheating, and also in order to follow the behavior of the phase change closely. As can be noted from the graph, once the solar field is focused, the temperature of the fluid rises quickly to reach $177^{\circ} \mathrm{C}$ at around 4:20 PM.

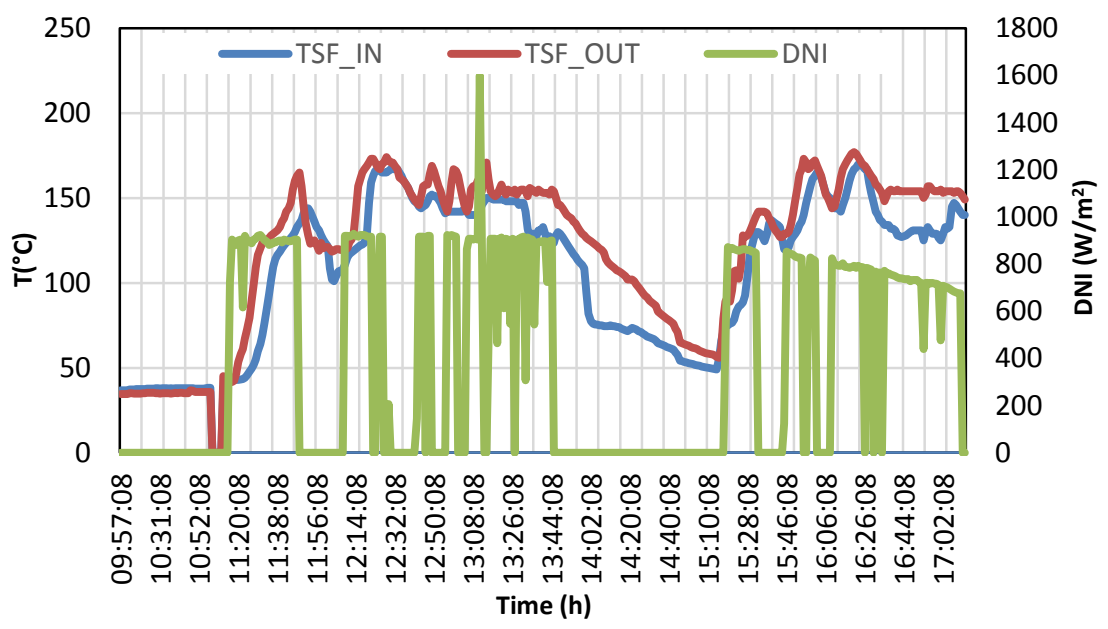

Fig 10 August 22 ${ }^{\text {nd }}, 2017$ solar field test results 


\section{Conclusion}

The current work presents a DSG model to predict the phase change and the heat transfer in a PTC. The model is based on solving the governing equations for the fluid flow and the energy balance for the tube walls. The validation was carried out for single phase flow using Syltherm oil, water and superheated steam as a first step. The model was then validated for single phase (water and steam) and two-phase fluid against DISS test facility measurements. The numerical results proved that the model is capable of predicting the experimental performance with good accuracy. As a second part of the work, the preliminary tests of a mini power plant PTC installed at ENIT, Tunisia were presented. Overall, three test day results were obtained. Even though the plant was operated in part load, the steam was successfully generated and the temperature at the solar field outlet reached $177{ }^{\circ} \mathrm{C}$ and higher. The developed numerical model will be used to simulate the REELCOOP PTC, while considering only the liquid and saturated phases. Performance analysis will be carried out under Tunisian climatic conditions, in order to prove the feasibility of implementing PTC relying on DSG in Tunisia, and in the Mediterranean region.

\section{Acknowledgment}

This work has been financed by REELCOOP project which receives funding from the European Union Seventh Framework Programme (FP7/2007-2013), under grant agreement no. 608466. S.Ferchichi also wishes to thank ERASMUS+KA107 programme for its support in the form of a doctoral scholarship.

\section{References}

Aurousseau, A., Vuillerme, V., Bezian, J.-J., 2015. Modeling of Linear Concentrating Solar Power using Direct Steam Generation with Parabolic Trough, Proceedings of the 11th International Modelica Conference, Versailles, France, September 21-23, 2015. Linköping University Electronic Press, pp. 595-603. http://www.ep.liu.se/ecp/118/064/ecp15118595.pdf

Biencinto, M., González, L., Valenzuela, L., 2016. A quasi-dynamic simulation model for direct steam generation in parabolic troughs using TRNSYS. Appl. Energy 161, 133-142. doi: 10.1016/j.apenergy.2015.10.001

Birnbaum, J., Feldhoff, J.F., Fichtner, M., Hirsch, T., Jöcker, M., Pitz-Paal, R., Zimmermann, G., 2011. Steam temperature stability in a direct steam generation solar power plant. Sol. Energy 85, 660-668. Churchill, S.W., 1977. Friction-factor equation spans all fluid-flow regimes. Chem. Eng. 84, 91-92. doi:10.1016/j.solener.2010.10.005

Dudley, V., Kolb, G., Sloan, M., Kearney, D., 1994. SEGS LS2 solar collector-test results. Rep. Sandia Natl. Lab. Rep. No SANDIA94-1884.

http://large.stanford.edu/publications/coal/references/troughnet/solarfield/docs/segs_ls2_solar_collector.pdf

Forristall, R., 2003. Heat transfer analysis and modeling of a parabolic trough solar receiver implemented in engineering equation solver. National Renewable Energy Lab., Golden, CO. (US). doi: 10.2172/15004820

Friedel, L. (1979). Improved Friction Pressure Drop Correlations for Horizontal and Vertical Two-Phase Pipe Flow. ROHRE - ROHRELEITUNGSBAU - ROHRELEITUNGSTRANSPORT. 18. 485-491. https://ci.nii.ac.jp/naid/80000503954/

Gnielinski, V., 1975. Neue Gleichungen für den Wärme- und den Stoffübergang in turbulent durchströmten Rohren und Kanälen. Forsch. Im Ingenieurwesen A 41, 8-16. doi: 10.1007/BF02559682

Hachicha, A.A., Rodríguez, I., Ghenai, C., 2018. Thermo-hydraulic analysis and numerical simulation of a parabolic trough solar collector for direct steam generation. Appl. Energy 214, 152-165.

doi: 10.1016/j.apenergy.2018.01.054 
Kandlikar, S.G., 1990b. A general correlation for saturated two-phase flow boiling heat transfer inside horizontal and vertical tubes. ASME J Heat Transf. 112, 219-228. doi:10.1115/1.2910348

Kandlikar, S.G., 1991. Development of a flow boiling map for subcooled and saturated flow boiling of different fluids inside circular tubes. J. Heat Transf. 113, 190-200. doi:10.1115/1.2910524

Krüger, D., Willwerth, L., Dathe, S., 2017. Research Cooperation in Renewable Energy Technologies for Electricity Generation REELCOOP Report on commissioning and testing. German Aerospace Center DLR.

Kurup, P., Parikh, A., Möllenkamp, J., Beikircher, T., Samoli, A., Turchi, C., n.d. SAM process heat model development and validation : liquid-HTF trough and Direct Steam Generation linear focus systems. Int. Conf. Sol. Heat. Cool. Build. Ind. 29 OCT-02-NOv 2017 Abu Dhabi UAE. doi: 10.18086/swc.2017.26.06

Lobón, D.H., Baglietto, E., Valenzuela, L., Zarza, E., 2014a. Modeling direct steam generation in solar collectors with multiphase CFD. Appl. Energy 113, 1338-1348. doi: /10.1016/j.apenergy.2013.08.046

Lobón, D.H., Valenzuela, L., 2013. Impact of pressure losses in small-sized parabolic-trough collectors for direct steam generation. Energy 61, 502-512. doi: /10.1016/j.energy.2013.08.049

Lobón, D.H., Valenzuela, L., Baglietto, E., 2014b. Modeling the dynamics of the multiphase fluid in the parabolic-trough solar steam generating systems. Energy Convers. Manag. 78, 393-404.

doi: 10.1016/j.enconman.2013.10.072

Odeh, S.D., Behnia, M., Morrison, G.L., 2000. Hydrodynamic analysis of direct steam generation solar collectors. J. Sol. Energy Eng. 122, 14-22. doi:10.1115/1.556273

Odeh, S.D., Morrison, G.L., Behnia, M., 1998. Modelling of parabolic trough direct steam generation solar collectors. Sol. Energy 62, 395-406. doi: 10.1016/S0038-092X(98)00031-0

Oliveira, A.C., Coelho, B., 2013. REELCOOP project: developing renewable energy technologies for electricity generation, in: 12th International Conference on Sustainable Energy Technologies (SET2013). Hong Kong. http://www.reelcoop.com/admin/content/news/paper_set2013_reelcoop_en_1385484468.pdf

Petukhov, B.S., Popov, V.N., 1963. Theoretical calculation of heat exchange and frictional resistance in turbulent flow in tubes of an incompressible fluid with variable physical properties(Heat exchange and frictional resistance in turbulent flow of liquids with variable physical properties through tubes). High Temp. 1, 69-83.https://ci.nii.ac.jp/naid/10011325838/

Salazar, C.M., 2008. An overview of csp in europe, north africa and the middle east. CSP Today. http://www.csptoday.com/reports/CSPinEU\&MENA.pdf

Serrano-Aguilera, J.J., Valenzuela, L., 2016. Transient validation of RELAP5 model with the DISS facility in once through operation mode, in: AIP Conference Proceedings. AIP Publishing, p. 040006. doi : $10.1063 / 1.4949097$

Serrano-Aguilera, J.J., Valenzuela, L., Parras, L., 2014. Thermal 3D model for direct solar steam generation under superheated conditions. Appl. Energy 132, 370-382. doi: 10.1016/j.apenergy.2014.07.035

Zivi, S.M., 1964. Estimation of steady-state steam void-fraction by means of the principle of minimum entropy production. J. Heat Transf. 86, 247-251. doi:10.1115/1.3687113 


\section{Units and Symbols}

\begin{tabular}{lll}
\hline Quantity & Symbol & Unit \\
\hline Cross section area & $\mathrm{A}$ & $\mathrm{m}^{2}$ \\
Concentration factor & $\mathrm{C}$ & - \\
Diameter & $\mathrm{D}$ & $\mathrm{m}$ \\
Density & $\rho$ & $\mathrm{kg} \mathrm{m}^{-3}$ \\
Enthalpy & $\mathrm{H}$ & $\mathrm{J} \mathrm{kg}^{-1}$ \\
Equilibrium quality & $\mathrm{x}$ & - \\
Efficiency & & $\mathrm{\eta}$ \\
Friction factor & $\mathrm{f}$ & - \\
Heat flux & $\dot{\mathrm{q}}$ & $\mathrm{W} \mathrm{m} \mathrm{m}^{-2}$ \\
Mass flow & $\dot{\mathrm{m}}$ & $\mathrm{kg} \mathrm{s}^{-1}$ \\
Pressure & $\mathrm{p}$ & $\mathrm{MPa}^{-1}$ \\
Temperature & $\mathrm{K}$ & $\mathrm{T}$ \\
velocity & $\mathrm{v}$ & $\mathrm{m} \mathrm{s}$ \\
Void fraction & $\varepsilon$ & - \\
Width & $\mathrm{W}$ & $\mathrm{m}$ \\
\hline
\end{tabular}

\begin{tabular}{ll}
\hline Subscript & Symbol \\
\hline Ambient & $\mathrm{a}$ \\
Convection & conv \\
Experimental & exp \\
Fluid & $\mathrm{f}$ \\
Glass envelope/vapor & $\mathrm{g}$ \\
Inlet & in \\
Inner & $\mathrm{i}$ \\
Outer & $\mathrm{e}$ \\
Liquid & $\mathrm{l}$ \\
Outlet & out \\
Receiver & $\mathrm{r}$ \\
Radiation & rad \\
Absorbed solar radiation & SolAbs \\
Thermal & th \\
\hline
\end{tabular}




\title{
Basic Study on Flow Stabilization of Top-heat-type Thermosiphon
}

\author{
Toru Fujisawa ${ }^{1}$, Takashi Kawaguchi ${ }^{1}$ and Takeshi Kawashima ${ }^{1}$ \\ ${ }^{1}$ Kanagawa Institute of Technology, Atsugi (Kanagawa, Japan)
}

\begin{abstract}
A top-heat-type thermosiphon utilizing vapor bubble pumping, which can realize heat transfer without any external electric power, has been extensively studied. However, its application has some problems, one of which is the unstable heat transfer, that is, intermittent circulation flow rate of the working fluid. This occurs under the conditions of less solar radiation during the morning and evening, and has been investigated by conducting a field experiment using a model house. To overcome this problem, a thermosiphon control system has been proposed to realize stable heat transfer, that is, almost constant flow rate of the working fluid. In this study, a method for reducing the buffer chamber pressure is adopted to stabilize the flow rate. The control system comprises a buffer chamber, a solenoid valve, a pressure transducer, a vacuum pump with tank, and an embedded computer. The pressure of the buffer chamber is ratcheted down to avoid violent boiling. In addition, the effectiveness of the system is demonstrated using the indoor experimental apparatus.
\end{abstract}

Keywords: Renewable energy, Solar thermal, Solar thermosiphon, Top heat type, Low-temperature heat, Control.

\section{Introduction}

The emission reduction effort of greenhouse effect gases, which cause global warming, is an essential problem for humankind. An effective use of renewable energy is a key challenge for sustainable development. Renewable energy is low-density energy, with a wide distribution globally. Therefore, it is important to find a new way to use the energy. Power generation systems using renewable energy, for example, solar energy, hydraulic power, wind power, geothermal power, and biomass energy, are being intensively studied. In addition, the utilization of photovoltaic energy continues to increase. However, the generated power fluctuates according to the cloud conditions. In addition, a certain amount of thermal energy converted from electric power is utilized in modern society. Thus, we focus on utilizing solar thermal energy, which is affected less by the weather than photovoltaic energy, and a top-heat-type thermosiphon, which enables heat transfer from solar energy collectors on the roof to an accumulator on the ground, which is a heat storage unit, without any external electric power source.

To date, several measures have been adopted to use solar energy for heating water, including using a thermosiphon (Morrison, 2001; Jamar et al., 2016; Jafari et al., 2016). The thermosiphon, which can transfer heat without any external electric power source, is being intensively studied. In this study, we focus on the top-heat-type thermosiphon, which can transfer heat form the top of the system to the bottom. Various top-heat-type thermosiphons have been proposed to date, such as the wick heat pipe type, osmotic heat pipe type, vapor pressure type, and vapor bubble pumping type (Imura and Koito, 2005 (in Japanese)). The wick heat pipe-type thermosiphon requires capillary tubes, while the osmotic pipe type requires semipermeable membranes. Thus, these two types have difficulty increasing the flow rate. Meanwhile, the vapor pressure type requires a complex valve operation (Koito et al., 2006 (in Japanese)). Therefore, the present study focuses on the vapor bubble pumping-type thermosiphon because of the simplicity of its configuration and scalability. This system has been proposed and studied since the 1970s (Hirashima et al., 1993 (in Japanese); Ippohshi et al., 2003). Ito et al. (2007) proposed separating the condenser and reservoir for closer to practical use. Thereafter, the circulation of a working fluid of height $4 \mathrm{~m}$ was realized by conducting a field test using a model house (Hagino and Yoshida, 2011; Imada et al., 2013 (in Japanese)). Furthermore, the hydraulic power generation using the flow of a working fluid was studied (Yoshida, et al., 2014), and the drive performance of the working fluid was analyzed (Hagino, et al., 2016 (in Japanese)). 
However, the practical use of the thermosiphon still has some problems. One of the problems is unstable heat transfer, that is, intermittent circulation flow rate of the working fluid. This happens under the condition of less solar radiation during morning and evening, and was investigated by conducting a field experiment using a model house (Hagino and Yoshida, 2011). To solve this problem, we propose a control system for the thermosiphon system to realize a stable heat transfer, namely almost constant flow rate of the working fluid, and generate the operation power for the controller from renewable energy such as photovoltaic energy. However, the control of the thermosiphon has been rarely studied (Bratsun et al., 2008). In this study, a method for reducing the buffer chamber pressure is adopted to stabilize the flow rate. The control system comprises a buffer chamber, a solenoid valve, a pressure transducer, a vacuum pump with tank, and an embedded computer, and the pressure of the buffer chamber is ratcheted down to avoid violent boiling. In addition, the effectiveness of the system is demonstrated using indoor experimental apparatus.

\section{Experimental apparatus of thermosiphon and the operating principle}

A photograph of the thermosiphon experimental apparatus is shown in Fig. 1(a), and the sematic illustration is shown in Fig. 1(b). This apparatus includes a buffer chamber, a recuperator, a condenser, a heater, a heat exchanger, and translucent pipes made of translucent perfluoroalkoxy alkane. Boiled water is used as the working fluid to reduce the amount of gas dissolved in the working fluid. The flow rate of the working fluid; the pressure of the buffer chamber; and the inlet and outlet temperatures of the heater, condenser, recuperator, and heat exchanger are measured and recorded in a multi-channel data logger. One feature of this apparatus is that it observes the boiling of the working fluid in the heater, two-phase flow in the flexible pipe from the heater to the condenser, and disappearance of vapor bubble in the condenser. To achieve this feature, one surface of the heater, condenser, and recuperator is made of a clear acrylic plate, and the translucent flexible heat-resistant pipes between the heater and the condenser.

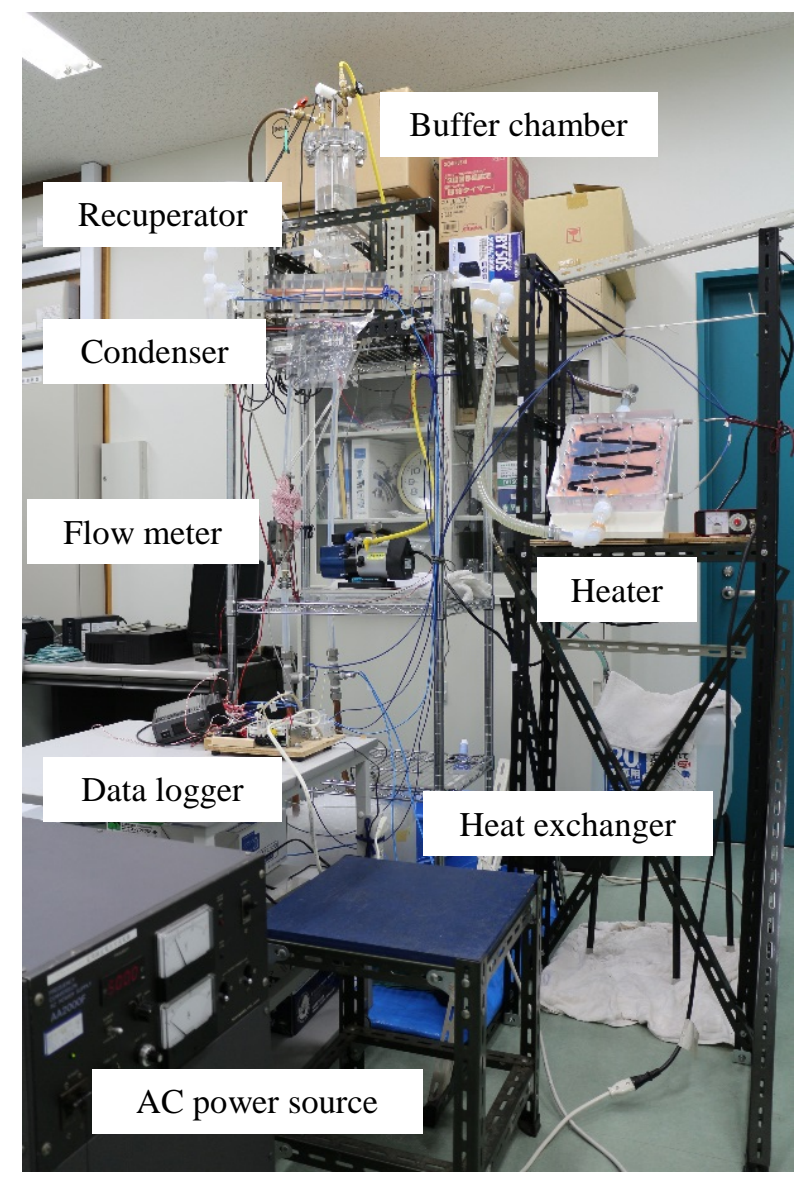

(a) Photograph

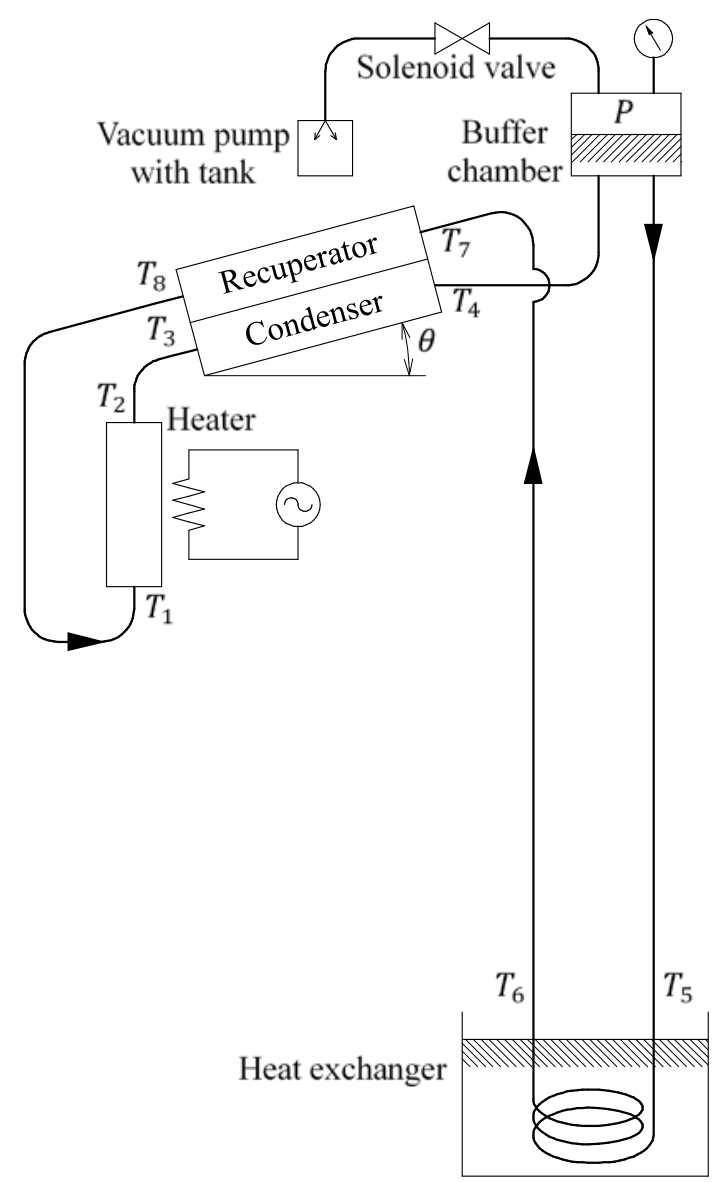

(b) Schematic illustration

Fig. 1: Experimental apparatus for thermosiphon utilizing vapor bubble pumping 
Next, the operating principle of the experimental thermosiphon apparatus is explained. The pressure of the buffer chamber is first decreased using the vacuum pump for decreasing the boiling point of the working fluid. The working fluid is heated by the heater, which is modeled as a solar collector. The two-phase flow of the boiling working fluid moves upward in the pipe to the condenser and drives the entire working fluid. The vapor bubble of the two-phase flow disappears in the condenser by cooled water flowing through the recuperator, in contact with the condenser, and the working fluid flowing through the recuperator is preheated. The heated working fluid flows to the heat exchanger through the buffer chamber. The sensible heat of the working fluid transfers to a water cooled by the ice in the heat exchanger. Then, the cooled working fluid is preheated in the recuperator, and returned to the heater. In this system, the working fluid is circulated and the absorbed heat in the working fluid at the upper side of the system is transferred to the lower side.

\section{Intermittent working flow under the condition of insufficient thermal energy input}

The intermittent working flow under the condition of insufficient thermal energy input is examined here. Representative results obtained using the experimental apparatus mentioned above are shown in Figs. 2 and 3.

Figure 2 shows the result in the case where the input power of the heater is the simulated amount of solar radiation at the equinoctial point. The maximum input power of the heater is $200 \mathrm{~W}$. The pressure of the buffer chamber in the beginning is about $30 \mathrm{kPa}$. The change in the input power of the heater is shown in Fig. 2(a), the changes in the temperatures of the heater inlet $T_{1}$ (thin line), outlet $T_{2}$ (bold line), and the calculated boiling point (broken line) are shown in Fig. 2(b). The changes in the temperatures of the condenser inlet $T_{3}$ (thin line) and outlet $T_{4}$ (bold line) are shown in Fig. 2(c), the changes in the temperatures of the heat exchanger inlet $T_{5}$ (thin line) and outlet $T_{6}$ (bold line) are shown in Fig. 2(d), and the changes in the temperatures of the recuperator inlet $T_{7}$ (thin line) and outlet $T_{8}$ (bold line) are shown in Fig. 2(e). The change in the pressure of the buffer chamber is shown in Fig. 2(f), and the change in the flow rate of the working fluid is shown in Fig. 2(g). The water in the heater starts boiling at about $225 \mathrm{~min}$ as the input power increases to about $62 \%$ of the maximum power. Next, the working fluid flows intermittently from about $225 \mathrm{~min}$ to $255 \mathrm{~min}$, and $T_{1}$ fluctuates significantly. Then, the working fluid becomes stable because the temperature distribution of the fluid becomes stable.

Figure 3 shows the result in the case where the input power of the heater is the simulated amount of solar radiation at the equinoctial point and saturated at $64 \%$ of the maximum power simulating the cloudy weather. The maximum input power of the heater is $200 \mathrm{~W}$. The pressure of the buffer chamber in the beginning is about $30 \mathrm{kPa}$. The water in the heater starts boiling at about $220 \mathrm{~min}$ as the input power increases to about $62 \%$ of the maximum power, and then, the working fluid continues to flow intermittently under the insufficient input power condition. Moreover, the temperatures fluctuate except for the heat exchanger input, because it is made stable by the fluid flowing through the buffer chamber.

For comparison, the result in the case where the maximum input power of the heater is $800 \mathrm{~W}$ is shown in Fig. 4. The input power of the heater is the simulated amount of solar radiation at the equinoctial point. The pressure of the buffer chamber in the beginning is about $30 \mathrm{kPa}$. The scales of vertical axes of Figs. 4(a), (f), and (g) are modified. The water in the heater starts boiling at about $120 \mathrm{~min}$, as the input power increases to about $25 \%$ of the maximum power. The working fluid begins and continues to flow stably under the sufficient input power condition. Moreover, the temperatures become stable.

Therefore, in the next chapter, the control system is proposed to stabilize the intermittent flow of the working fluid under the condition of insufficient thermal energy input. 


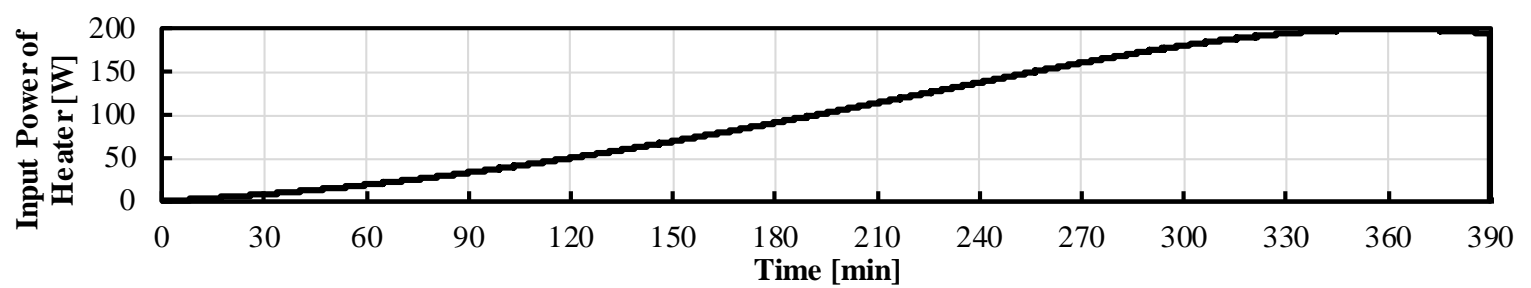

(a): Input power of heater

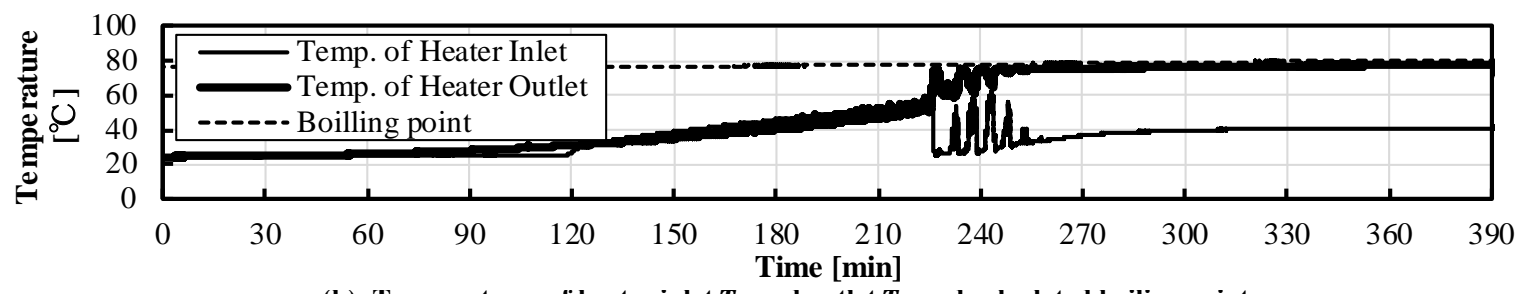

(b): Temperatures of heater inlet $T_{1}$ and outlet $T_{2}$ and calculated boiling point

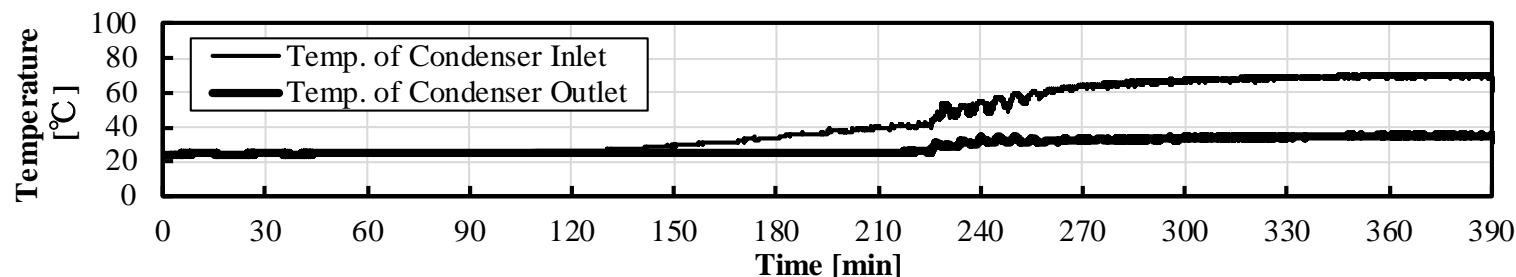

(c): Temperatures of condenser inlet $T_{3}$ and outlet $T_{4}$

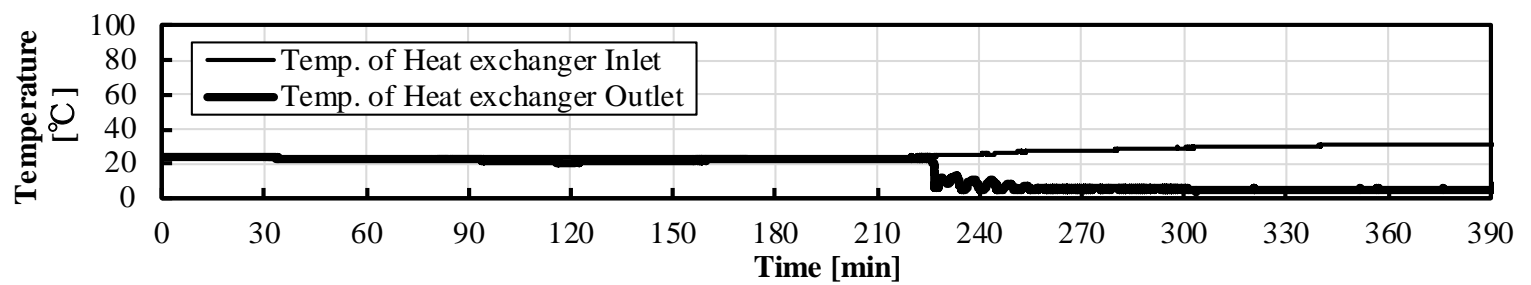

(d): Temperatures of heat exchanger inlet $T_{5}$ and outlet $T_{6}$

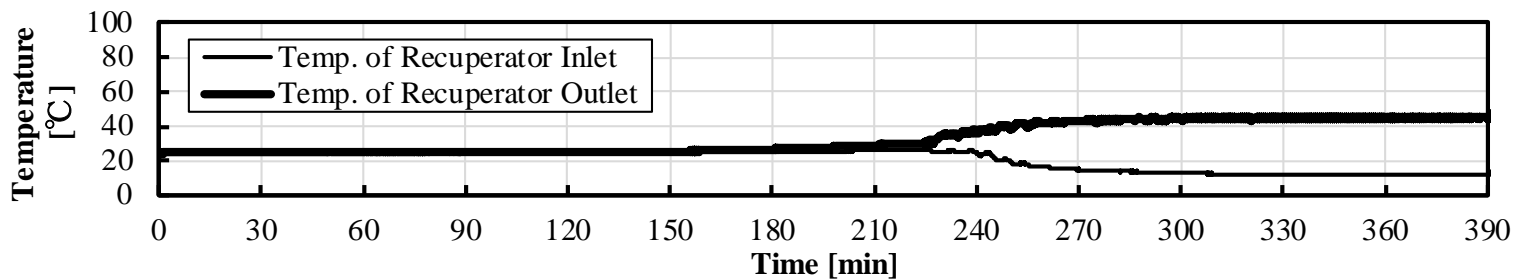

(e): Temperatures of recuperator inlet $T_{7}$ and outlet $T_{8}$

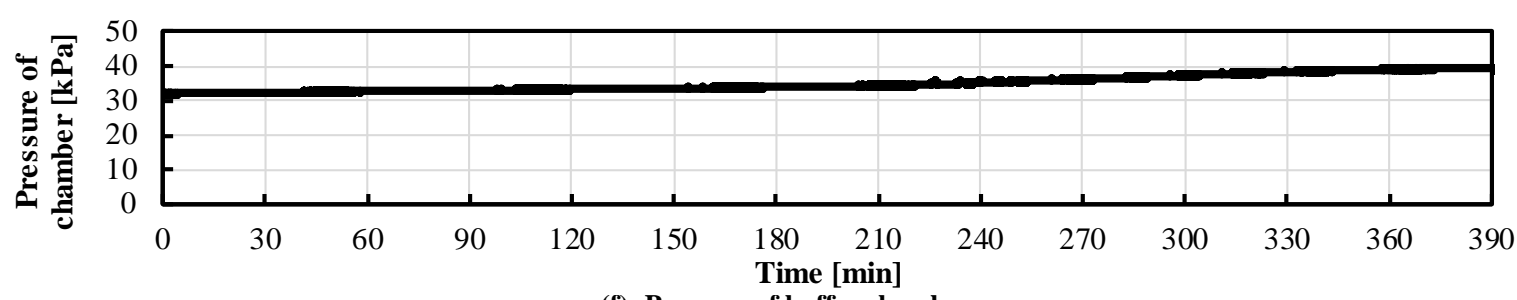

(f): Pressure of buffer chamber

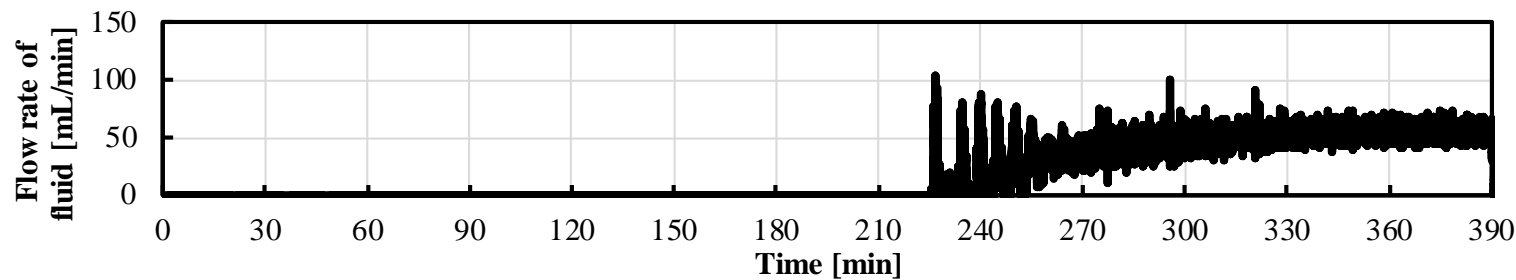

(g): Flow rate of working fluid

Fig. 2: Experimental result under the condition of insufficient thermal energy input (the input power is the simulated amount of solar radiation at the equinoctial point. The maximum input power is $200 \mathrm{~W}$.) 


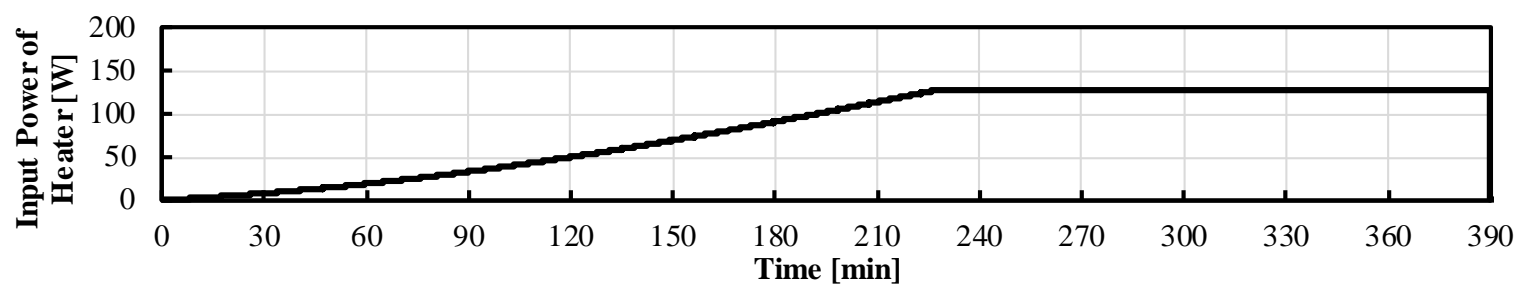

(a): Input power of heater

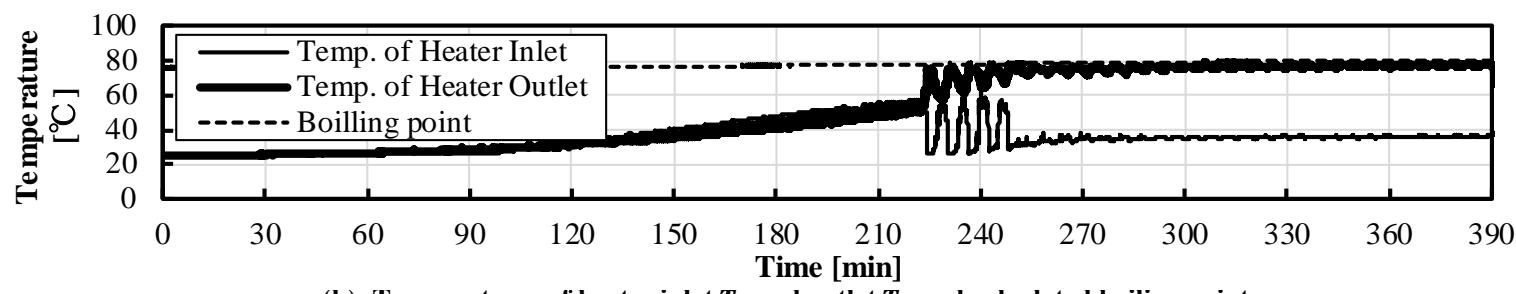

(b): Temperatures of heater inlet $T_{1}$ and outlet $T_{2}$ and calculated boiling point

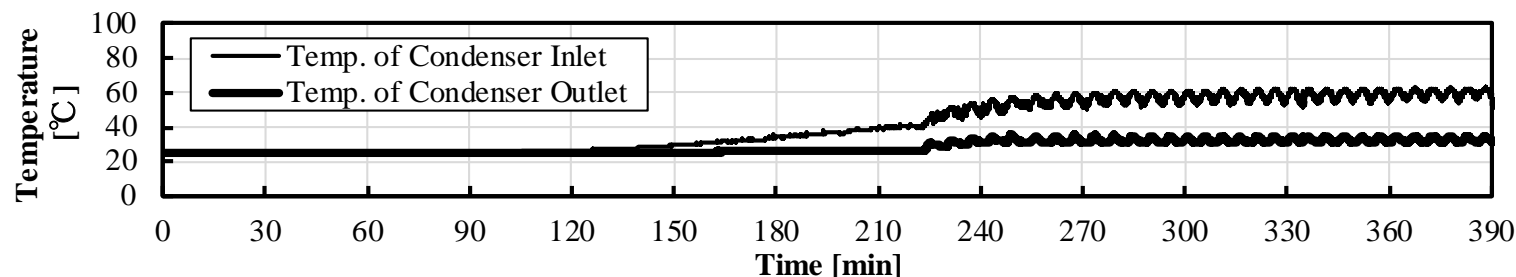

(c): Temperatures of condenser inlet $T_{3}$ and outlet $T_{4}$

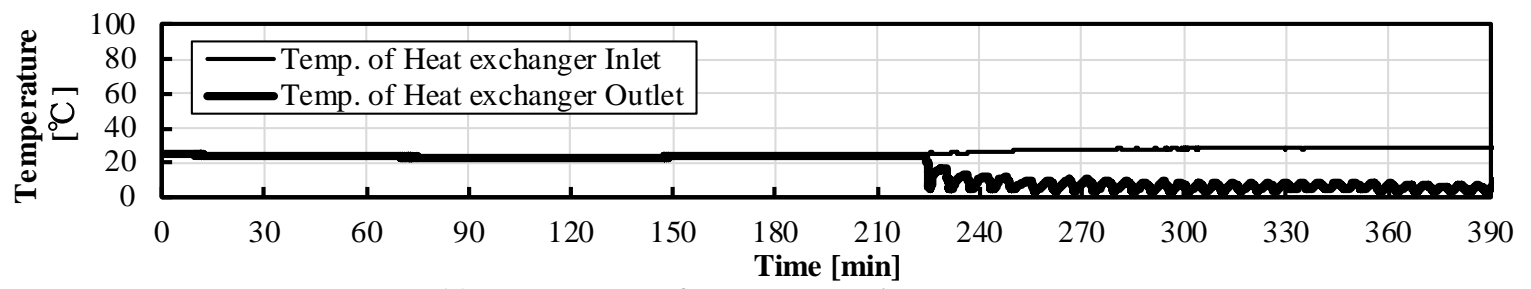

(d): Temperatures of heat exchanger inlet $T_{5}$ and outlet $T_{6}$

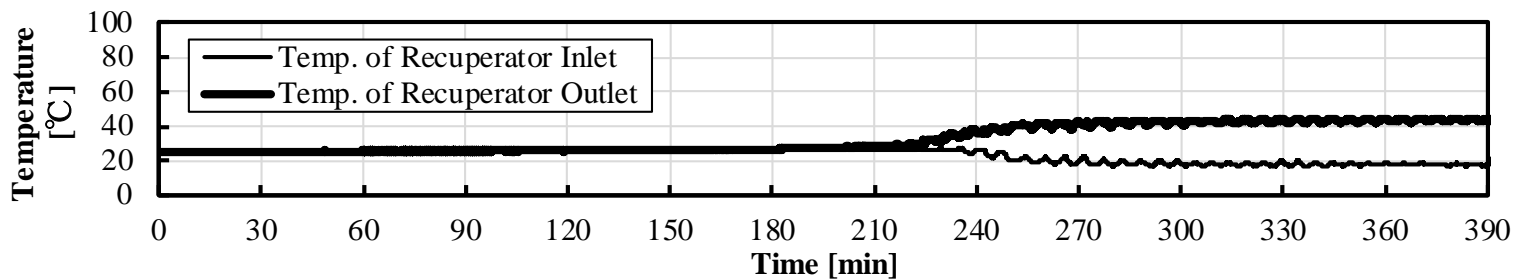

(e): Temperatures of recuperator inlet $T_{7}$ and outlet $T_{8}$

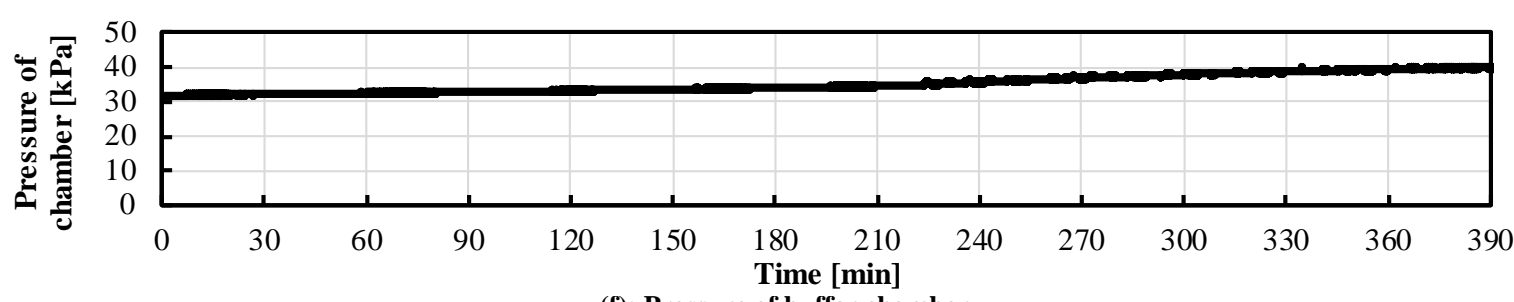

(f): Pressure of buffer chamber

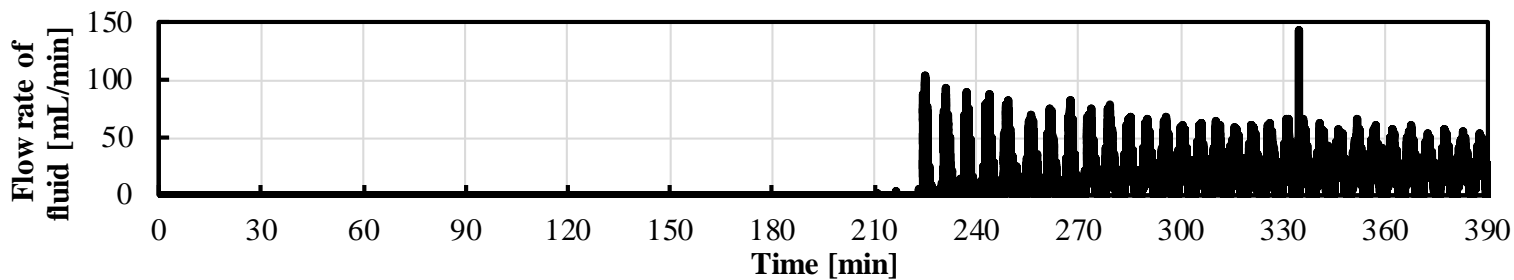

(g): Flow rate of working fluid

Fig. 3: Experimental result under the condition of insufficient thermal energy input (the input power is the simulated amount of solar radiation at the equinoctial point and saturated at $64 \%$ of the maximum power simulating the cloudy weather. The maximum input power is $200 \mathrm{~W}$.) 


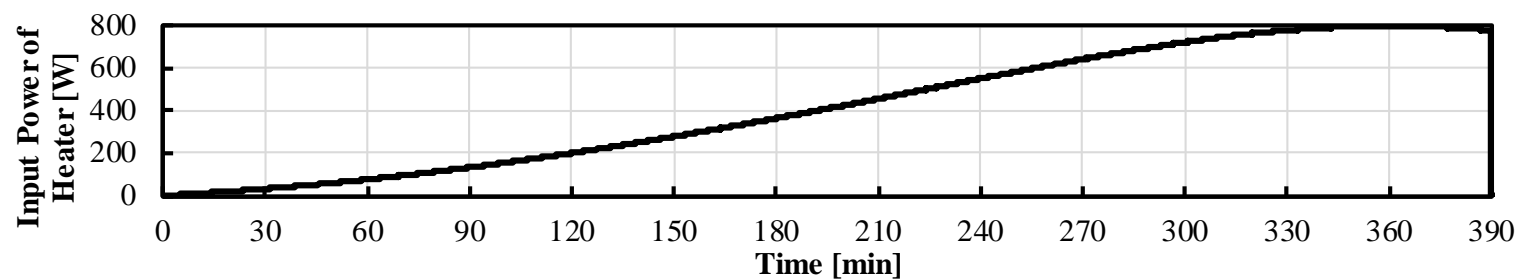

(a): Input power of heater

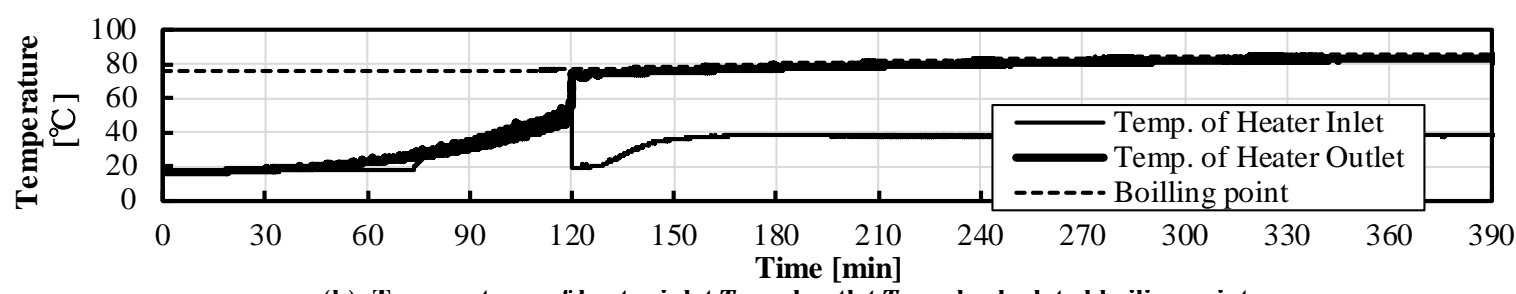

(b): Temperatures of heater inlet $T_{1}$ and outlet $T_{2}$ and calculated boiling point

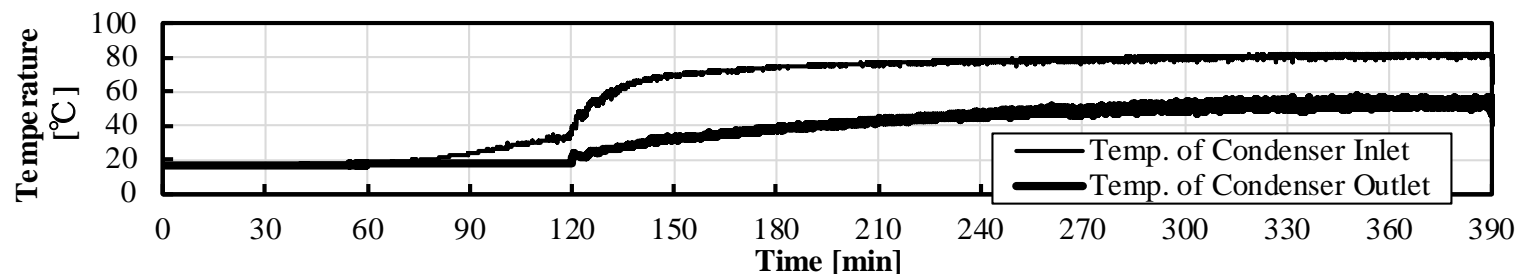

(c): Temperatures of condenser inlet $T_{3}$ and outlet $T_{4}$

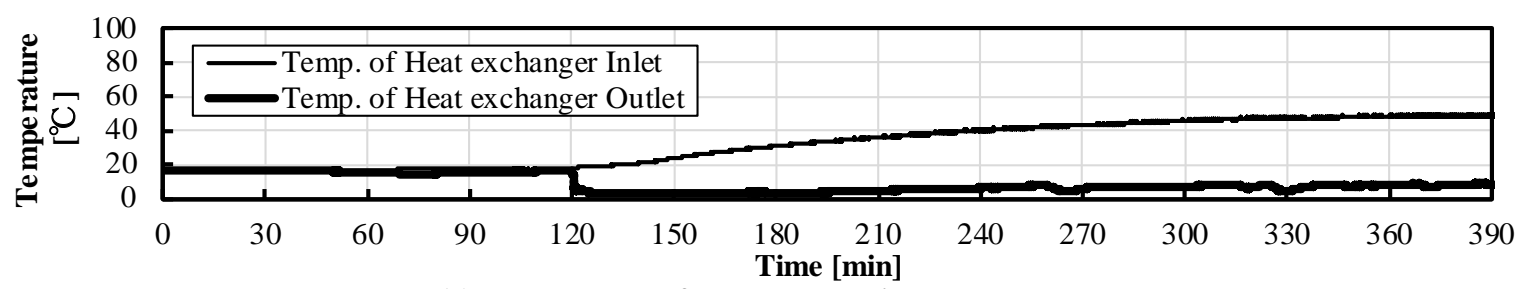

(d): Temperatures of heat exchanger inlet $T_{5}$ and outlet $T_{6}$

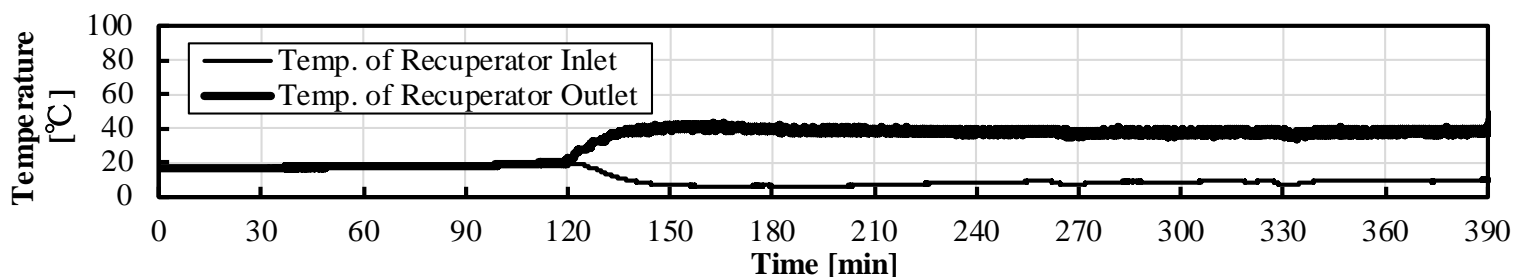

(e): 'Temperatures of recuperator inlet $T_{7}$ and outlet $T_{8}$

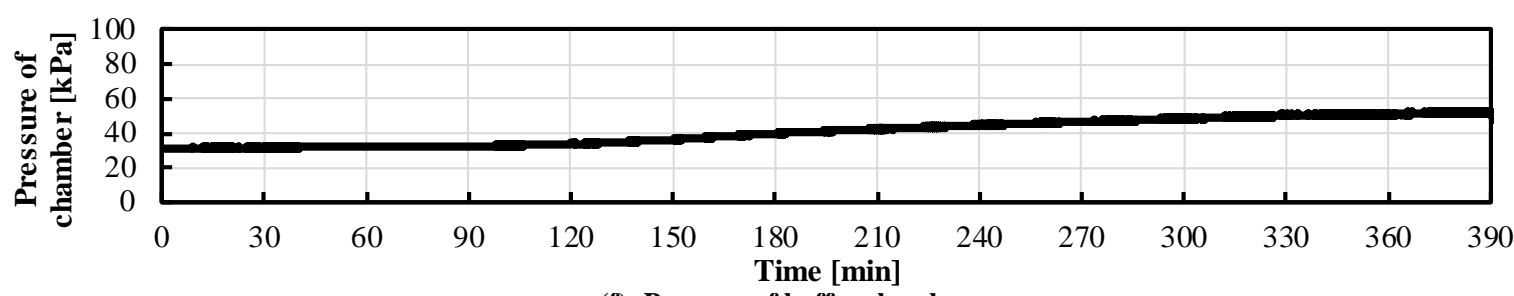

(f): Pressure of buffer chamber

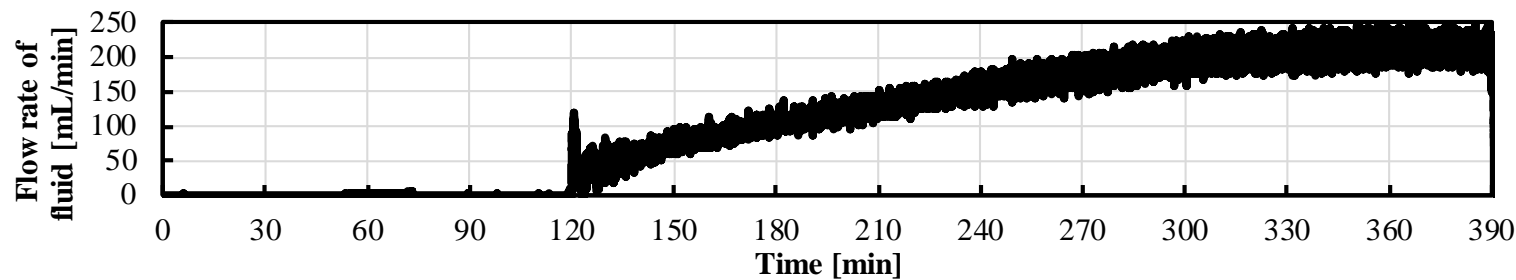

(g): Flow rate of working fluid

Fig. 4: Experimental result under the condition of sufficient thermal energy input (the input power is the simulated amount of solar radiation at the equinoctial point. The maximum input power is $800 \mathrm{~W}$.) 


\section{Thermosiphon control system}

There are a few control methods available for stabilizing the intermittent circulation flow rate of the working fluid (Bratsun et al., 2008). We focuses on the control method used to adjust the pressure of the buffer chamber. The block diagram of the pressure control system for the thermosiphon is shown in Fig. 5. The control system comprises a solenoid valve, a pressure transducer, a vacuum pump with tank, and an embedded computer. The pressure of the buffer chamber and the flow rate of the working fluid are measured using a pressure gauge and a Coriolis flow meter, respectively. The pressure is ratcheted down slowly to avoid violent boiling.

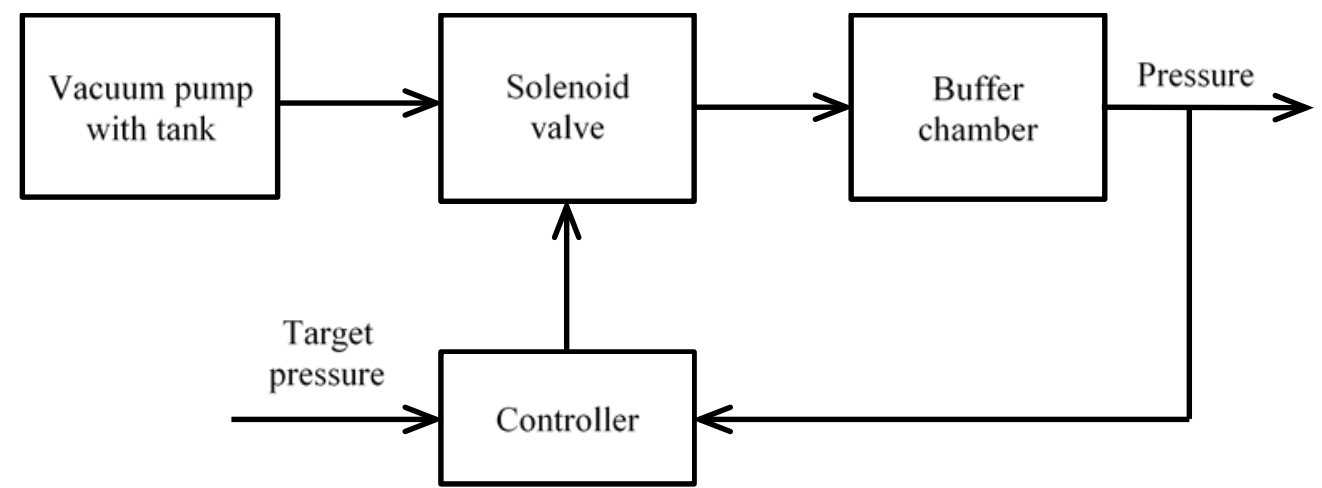

Fig. 5: Block diagram of the pressure control system for thermosiphon utilizing vapor bubble pumping

The working fluid in the heater begins to boil as the fluid is heated. However, the rest of the working fluid is still cold. The boiling fluid flows upward and toward the condenser with the vapor bubbles, and the cold fluid flows into the heater. Under the conditions of small thermal energy input from the heater, the flow of the working fluid stops, although it continues under the condition where enough thermal energy is supplied for boiling the fluid. Therefore, a stable flow rate of the working fluid can be achieved by decreasing the pressure of the buffer chamber to decrease the boiling point of the fluid.

Under this consideration based on the experimental results, we propose the following algorithm.

1. The control algorithm starts from the static condition of the thermosiphon, that is, no flow rate of the working fluid with no thermal energy supply.

2. The flow rate of the working fluid in the first boil is detected.

3. If the flow stops, the solenoid valve is opened for one second every $30 \mathrm{~s}$ until the pressure of the buffer chamber gradually decreases to the setting value.

\section{Results of control experiment}

The effectiveness of the proposed control system is verified by conducting control experiments using the thermosiphon experimental apparatus. Representative results obtained using the experimental apparatus mentioned above are shown in Figs. 6 and 7.

Figure 6 shows the result in the case where the input power of the heater is the simulated amount of solar radiation at the equinoctial point. The maximum input power of the heater is $200 \mathrm{~W}$. The pressure of the buffer chamber in the beginning is about $30 \mathrm{kPa}$. The pressure of the vacuum tank is adjusted from $15 \mathrm{kPa}$ to $23 \mathrm{kPa}$ by the vacuum pump. The target pressure of the buffer chamber is set to $20 \mathrm{kPa}$. The water in the heater starts boiling at about $220 \mathrm{~min}$ as the input power increases to about $62 \%$ of the maximum power. Then, the pressure control system starts opening the solenoid valve for one second every $30 \mathrm{~s}$ until the pressure of the buffer chamber gradually decreases to the setting value. The pressure of the buffer chamber reaches the target pressure by opening the solenoid valve 10 times. The intermittent flow of the working fluid decreases in comparison with the result without 
control shown in Fig. 2. Therefore, the hard boiling of the heater, which degrades the heater, can also be avoided.

Figure 7 shows the result in the case where the input power of the heater is the simulated amount of solar radiation at the equinoctial point and saturated at $64 \%$ of the maximum power simulated the cloudy weather. The maximum input power of the heater is $200 \mathrm{~W}$. The pressure of the vacuum tank is adjusted from $15 \mathrm{kPa}$ to $23 \mathrm{kPa}$ by the vacuum pump. The pressure of the buffer chamber in the beginning is about $30 \mathrm{kPa}$. The water in the heater starts boiling at about $225 \mathrm{~min}$ as the input power increases to about $62 \%$ of the maximum power. Then, the pressure control system starts opening the solenoid valve for one second every $30 \mathrm{~s}$ until the pressure of the buffer chamber gradually decreases to the setting value. The pressure of the buffer chamber reaches the target pressure by opening the solenoid valve six times. The intermittent flow of the working fluid is also decreased in comparison with the result without control shown in Fig. 3.

As a result, the intermittent flow under the condition of a small thermal energy input from the heater can be controlled by decreasing the pressure of the buffer chamber. Then, the effectiveness of the proposed control system can be confirmed using a model experiment.

If the pressure of the buffer chamber is further lowered, more stable circulation of the working fluid can be achieved. However, this requires more energy of the vacuum pump.

Subsequently, the photovoltaic capacity required for the proposed control system is estimated to operate the control system without any external electric power source.

Assumptions:

1. In the pressure control, a vacuum pump of $200 \mathrm{~W}$ rated power is operated for about $60 \mathrm{~s}$ per day, with an efficiency of $80 \%$. Furthermore, the operation power of the embedded microcomputer and sensors is $5 \mathrm{~W}$ in total. Then, on average, an electric energy of $163 \mathrm{MJ}$ is required per year.

2. A photovoltaic cell of $1 \mathrm{~kW}$ rated capacity generates electric energy of 1,100 kWh per year, on average, that is, 3.96 GJ per year.

3. The area of a photovoltaic cell of $1 \mathrm{~kW}$ rated capacity is $5.19 \mathrm{~m}^{2}$.

As a result, a photovoltaic cell of $41.2 \mathrm{~W}$ rated capacity is required, with an area of $0.214 \mathrm{~m}^{2}$. Since the capacity and area of the photovoltaic cell are small enough, the feasibility of the proposed control system for the top-heattype thermosiphon can be confirmed.

\section{Conclusions}

This paper focuses on the top-heat-type thermosiphon, which can facilitate heat transfer from solar energy collectors on the roof to an accumulator on the ground, which is the heat storage unit, without any external electric power source for using solar thermal energy. However, this has some problems, one of which is unstable heat transfer, that is, intermittent circulation flow rate of the working fluid. This happens under the condition of less solar radiation during morning and evening. To resolve this problem, a method for reducing the buffer chamber pressure is proposed to stabilize the flow rate of the working fluid. The effectiveness of this system is demonstrated using the indoor experimental apparatus.

The development of the energy harvesting system for the power of the control system and the field test are future challenges. 


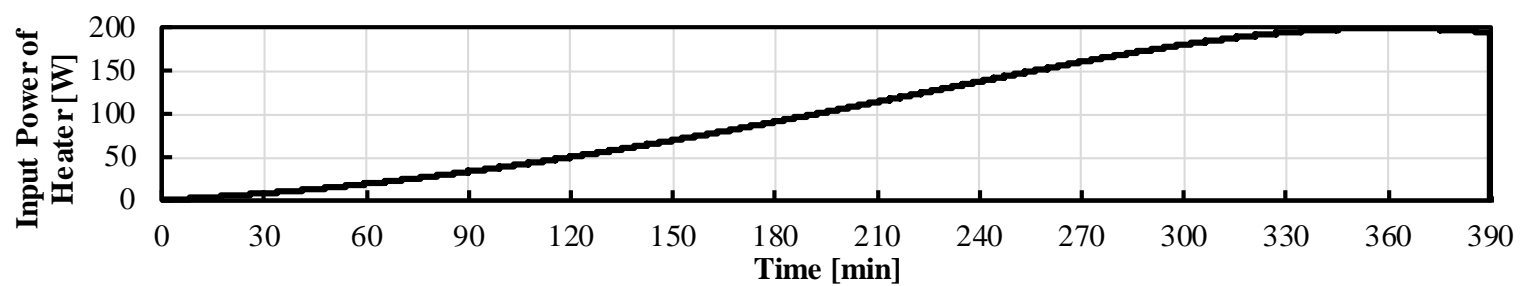

(a): Input power of heater

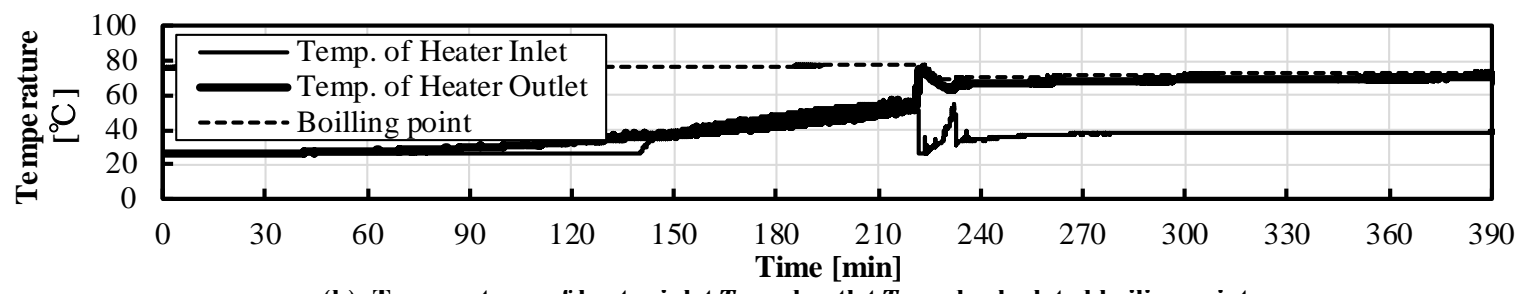

(b): Temperatures of heater inlet $T_{1}$ and outlet $T_{2}$ and calculated boiling point

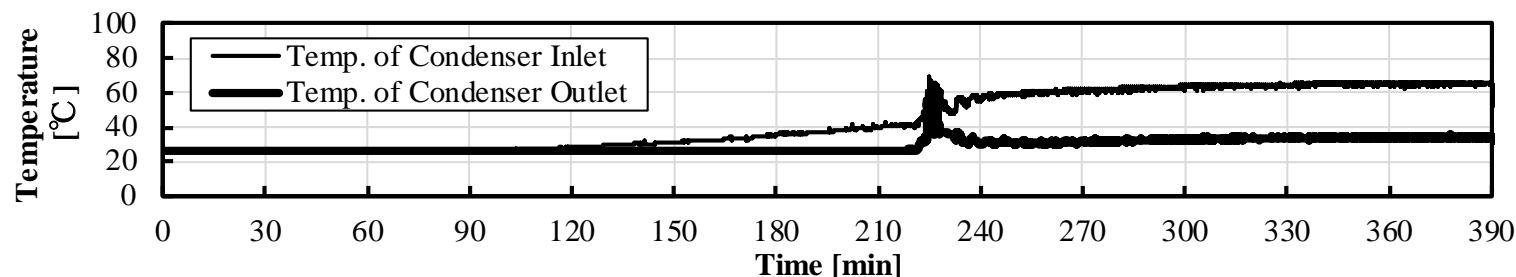

(c): Temperatures of condenser inlet $T_{3}$ and outlet $T_{4}$

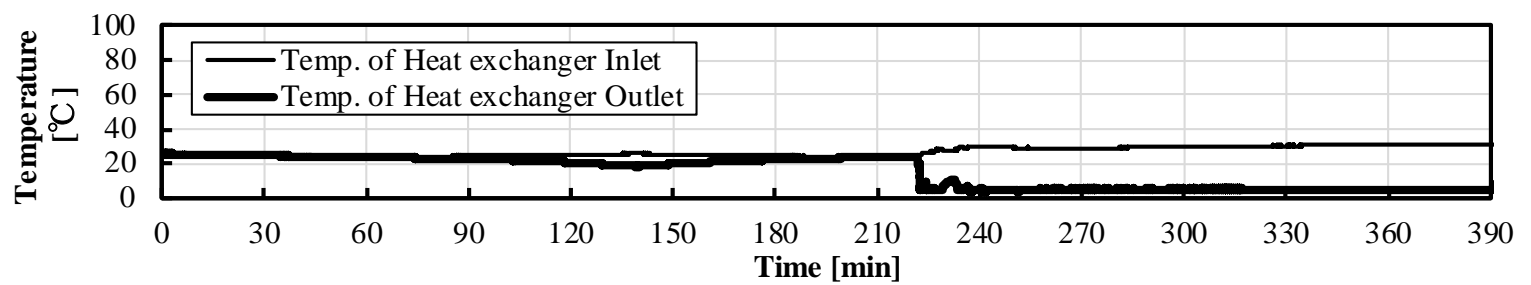

(d): Temperatures of heat exchanger inlet $T_{5}$ and outlet $T_{6}$

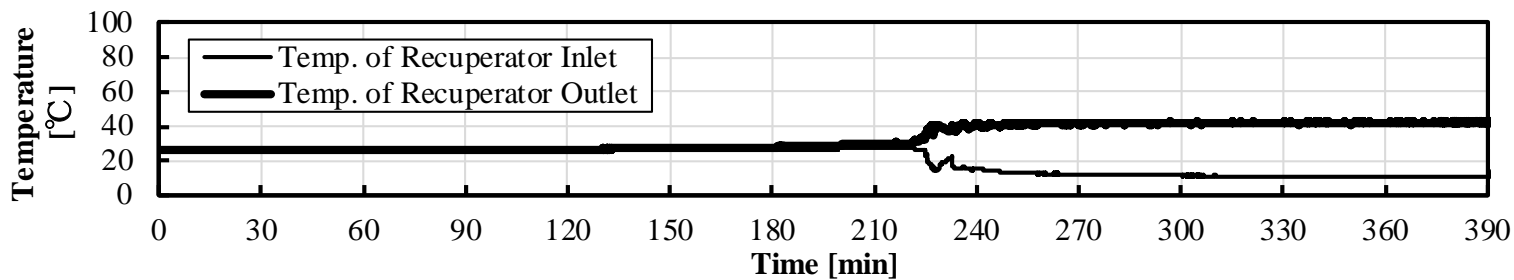

e): Temperatures of recuperator inlet $T_{7}$ and outlet $T_{8}$

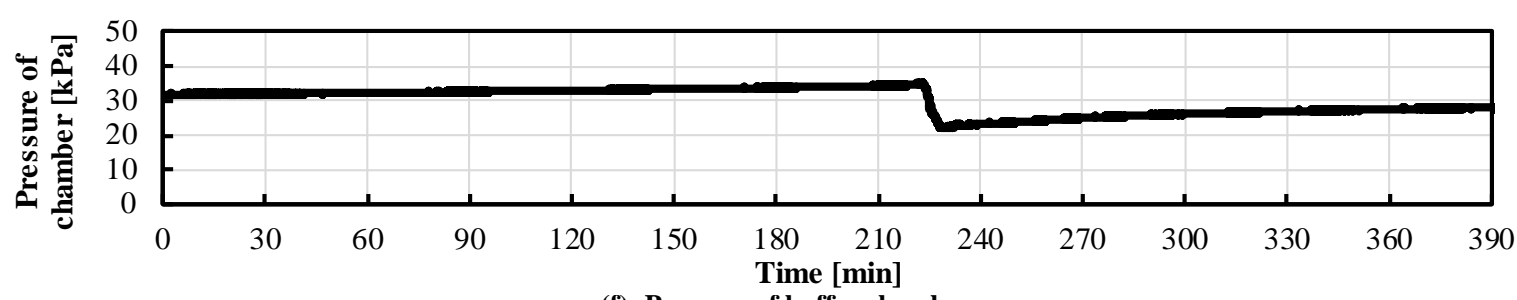

(f): Pressure of buffer chamber

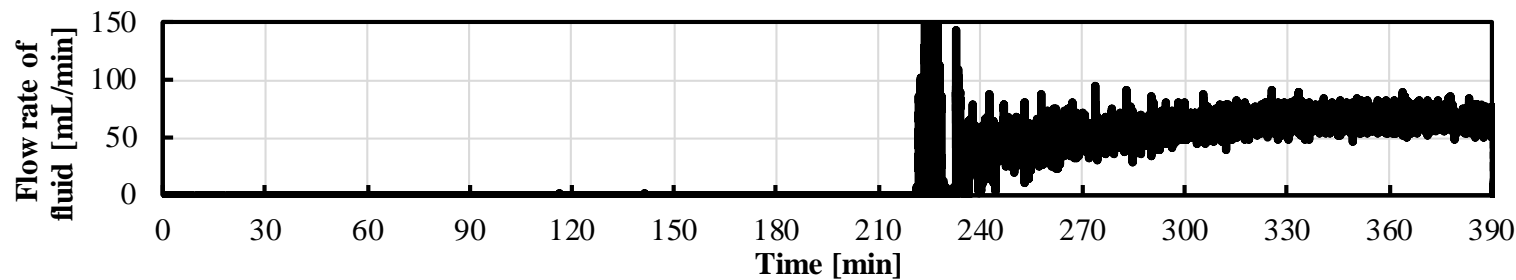

(g): Flow rate of working fluid

Fig. 6: Result of control experiment under the condition of insufficient thermal energy input (the input power is the simulated amount of solar radiation at the equinoctial point. The maximum input power is $200 \mathrm{~W}$.) 


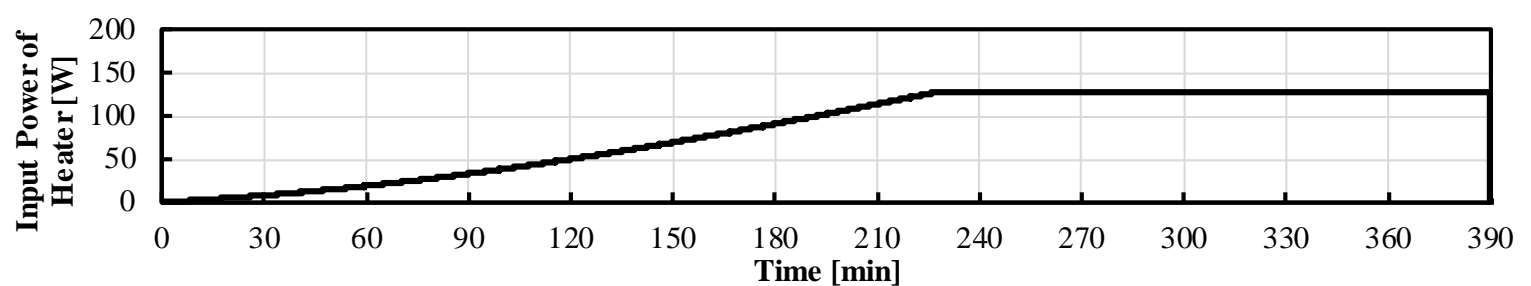

(a): Input power ot heater

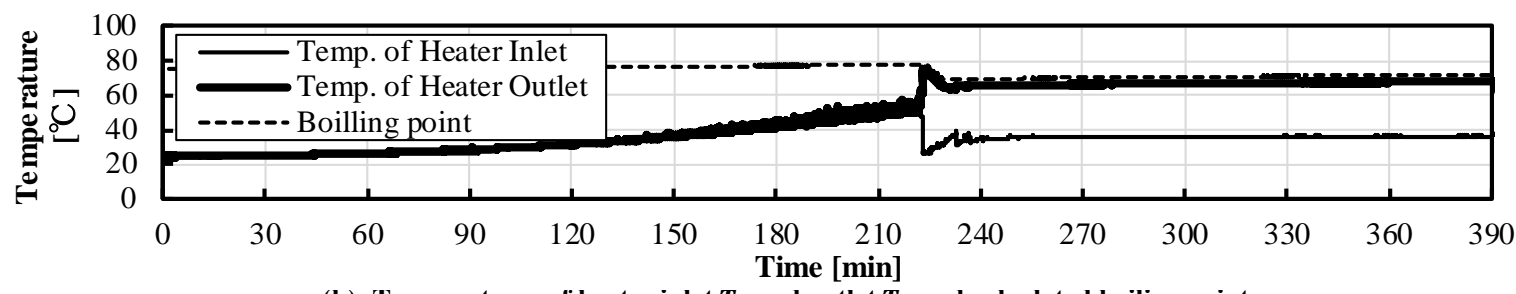

(b): Temperatures of heater inlet $T_{1}$ and outlet $T_{2}$ and calculated boiling point

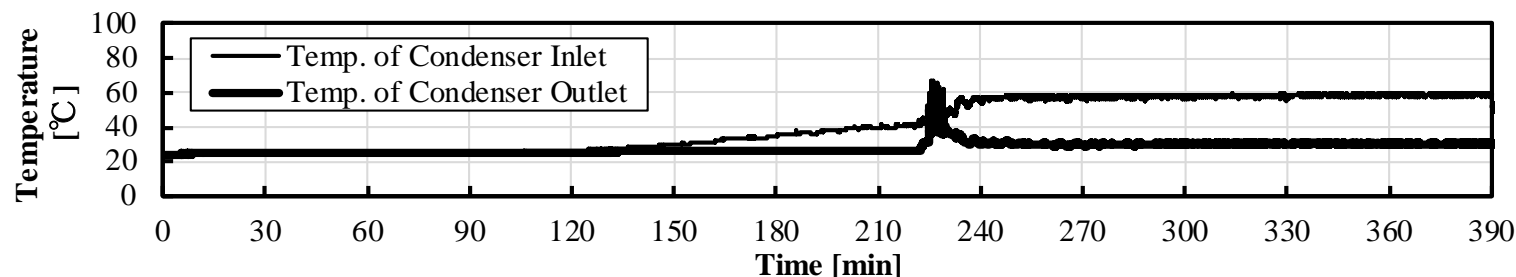

(c): Temperatures of condenser inlet $T_{3}$ and outlet $T_{4}$

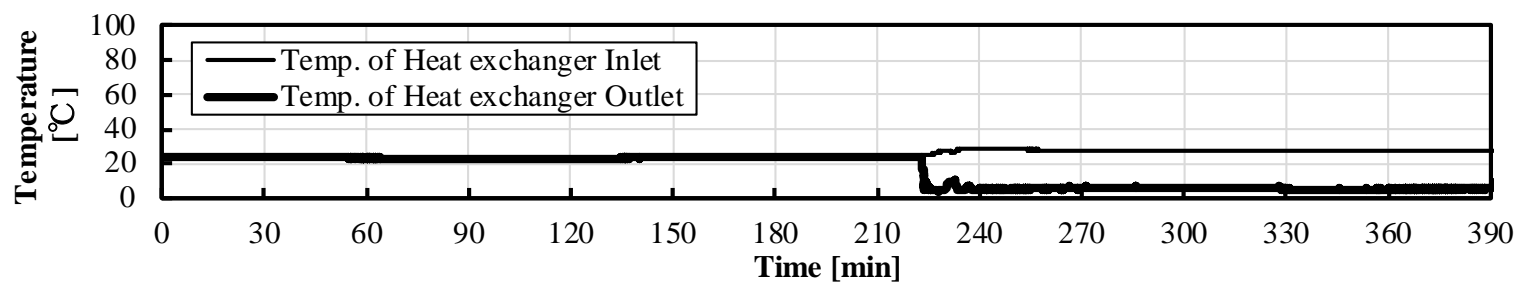

(d): Temperatures of heat exchanger inlet $T_{5}$ and outlet $T_{6}$

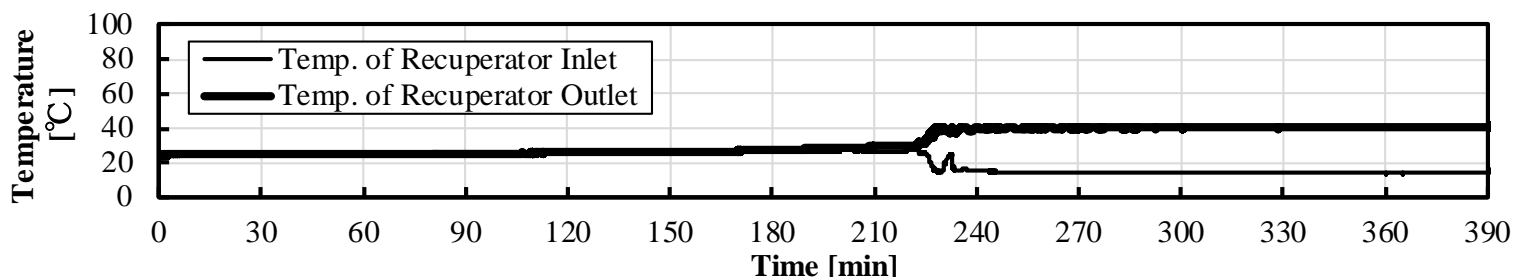

(e): Temperatures of recuperator inlet $T_{7}$ and outlet $T_{8}$

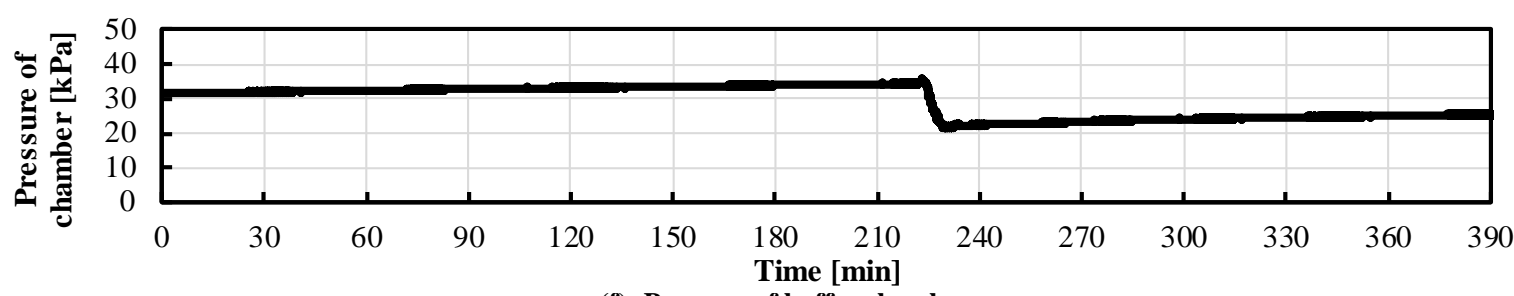

(f): Pressure of buffer chamber

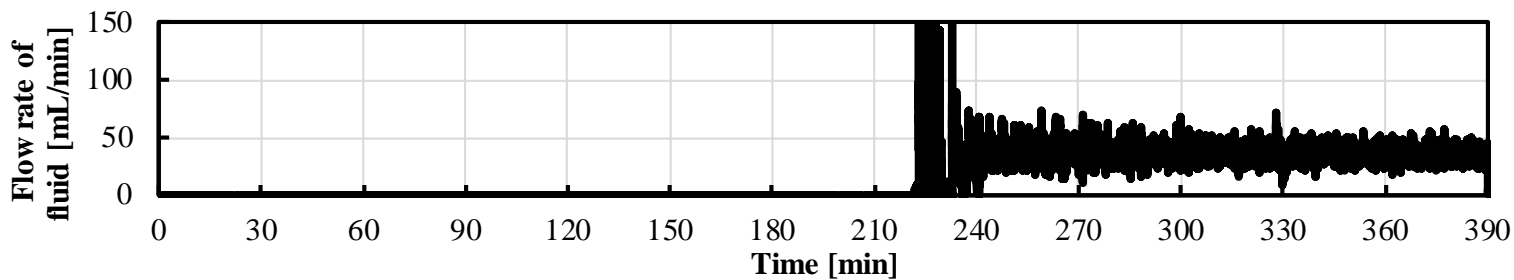

(g): Flow rate of working fluid

Fig. 7: Result of control experiment under the condition of insufficient thermal energy input (the input power is the simulated amount of solar radiation at the equinoctial point and saturated at $64 \%$ of the maximum power simulating the cloudy weather.

The maximum input power is $200 \mathrm{~W}$.) 


\section{References}

Bratsun, D.A., Zyuzgin, A.V., Polovinkin, K.V., Putin, G.F., 2008. Active Control of Fluid Equilibrium in a Thermosyphon. Tech. Phys. Lett. 34(8), 650-652.

Hagino, N., Yoshida, H., 2011. PERFORMANCE OF A SELF-CIRCULATING THERMOSYPHON. ASME Power Conference, July 12-14, Denver, Colorado, USA. POWER2011-55358.

Hagino, N., Yoshida, H., Imada, H., 2016. A study of self-circulating thermosiphon (Basic performance). Trans. Japan Soc. Mech. Eng. 82(837), DOI: 10.1299/transjsme.15-00596. (In Japanese)

Hirashima, M., Kimura, K., Utsumi, Y., Kimura, K., Negishi, K, 1993. Experimental Study of Top Heat Mode Thermosyphon (On the Lifting Mechanism of Working Fluid Effects on the Extension of Stable Working Range). Trans. Japan Soc. Refrig. Air Condition. Eng. 10(2), 83-92. (In Japanese)

Imada, H., Hagino, N., Yoshida, H., 2013. Field Experiment of Solar Thermosyphon. Trans. Japan Soc. Mech. Eng. Ser. B. 79(801), 809-813. (In Japanese)

Imura, H., Koito, Y., 2005. Heat Transport Using Top-heat-type Thermosyphons. Trans. Japan Soc. Refrig. Air Condition. Eng. 22(1), 1-12. (In Japanese)

Ippohshi, S., Tabara, S., Motomatu, K., Mutoh, A., Imura, H., 2003. DEVELOPMENT OF A TOP-HEATMODEL LOOP THERMOSYPHON. The $6^{\text {th }}$ ASME-JSME Thermal Engineering Joint Conference, March 1620, Hawaii. TED-AJ03-578.

Ito, S., Tateishi, K., Miura, N, 2007. STUDIES OF A THERMOSYPHON SYSTEM WITH A HEAT SOURCE NEAR THE TOP AND HEAT SINK AT THE BOTTOM. ISES Solar World Congress 2007, September 18-21, Beijing, China. 930-934.

Jafari, D., Franco, A., Filippeschi, S., Marco, P.D., 2016. Two-phase closed thermosyphons: A review of studies and solar applications. Renew. Sust. Energy Rev. 53, 575-593. DOI: 10.1016/j.rser.2015.09.002.

Jamar, A., Majid, Z.A.A., Azmi, W.H., Norhafana, M., Razak, A.A., 2016. A review of water heating system for solar energy applications. Int. Comm. Heat Mass Transfer. 76, 178-187. DOI: 10.1016/j.icheatmasstansfer.2016.05.028.

Koito, Y., Horiuchi, Y., Yamaguchi, T., Imura, H., Torii, S., 2006. Development of a Top-heat-type Heat Transport Loop Utilizing Vapor Pressure. Trans. Japan Soc. Mech. Eng. Ser. B. 72(718), 1574-1581. (In Japanese)

Morrison, G.L., 2001. Solar water heating, in: Gordon, J. (Ed.), Solar energy: the state of the art: ISES position papers, James \& James, London, pp. 223-289.

Yoshida, H., Imada, H., Hagino, N, Yada, N., 2014. Hydropower Geberation by Solar Thermosyphon. International Conference on Solar Energy and Buildings (EuroSun 2014), September 16-19, Aix-les-Bains, France. 506-511. DOI: 10.18086/eurosun.2014.16.24. 


\title{
Ray Tracing Method for the Evaluation of Yearly Performance of a Solar Thermal Concentrator
}

\author{
Olga R. Delgado1, Héctor D. García-Lara1, Alejandro Gutiérrez² and Carlos A. Ramírez² \\ 1 Universidad Autónoma de Nuevo León, Ave. Universidad s/n, Ciudad Universitaria, 66455, San \\ Nicolás de los Garza, Nuevo León (México) \\ 2 Universidad de Monterrey, Ave. Ignacio Morones Prieto 4500 Pte., 66238, San Pedro Garza García, \\ Nuevo León (México)
}

\begin{abstract}
A method for evaluating the yearly performance of a solar concentrator is presented. The simulation is achieved using the commercial forward ray-tracing tool Tracepro in conjunction with MATLAB. Ray tracing methods are often used to assess the performance of solar concentrators; however, most works on this area simplify the simulation process by considering only a handful of representative scenarios along the year, for example, summer and winter solstices for tracking studies or monthly average days for evaluating the annual average output of the system. The present method is able to achieve a year-long simulation on an hourly basis using MATLAB to setup each simulation within Tracepro via the Dynamic Data Exchange (DDE) protocol; for increased fidelity hourly irradiance data from Meteonorm is also taken into account. The simulation results showed that the proposed method is able to provide valuable data that can be used as input for broader studies, for example, annual dynamic simulations that consider site-specific energy demands.
\end{abstract}

Keywords: Ray-tracing, solar concentrator, Tracepro, annual simulation

\section{Introduction}

The ray tracing method is a novel tool applied for the evaluation of solar concentration systems. The method is based on the simulation of a large amount of sunrays in order to determine their distribution and intensity on optical bodies (Duffie and Beckman, 1980). The results are often used to optimize the geometry and orientation of said bodies in order to reduce optical aberrations caused by misalignments of the solar tracking system or to predict the amount of energy concentrated.

It can be found in the literature several works that applied this tool to evaluate the performance of solar concentrators. For example, in Hu et al. (2018) presented a new tracking method aimed to reduce the cosine loss effect on a central tower concentrator by means of a novel refractive body installed before the receiver. Similarly, this technique has been used to evaluate the performance of linear concentrators. An example is shown by Terrón et al. (2018), who evaluated a compound parabolic concentrator by establishing multiple positions to the Sun. Similar studies carried by Su et al. (2017); and Waghmare and Gulhane (2016) have also applied this technique to develope solar tracking strategies for parabolic trough concentrators. In the study described by Yeh, P. and Yeh, N. (2018), the ray-tracing method was used during computational simulation in order to increase the concentration ratio by optimizing the geometry of a curved Fresnel lens able to refract incident radiation onto a secondary concentrator. The method has also been applied in central tower concentration systems. An example is shown by Eddibi et al. (2017), where a novel heliostat field distribution is proposed in order to reduce geometric losses (blockage and shadows) by simulating the solar position at solstices and equinoxes.

A tool that allows these types of analysis is TracePro, an opto-mechanical simulation software. It has been used for the optical analysis of models used in some of the previously mentioned works (Hu et al., 2018; Su et al., 2017; Yeh And Yeh, 2018). To do this, the software evaluates the intensity associated with each beam that propagates through CAD models imported into the workspace. In addition, it has a Macro functionality, which 
allows the software to be controlled by other applications using the Dynamic Data Exchange (DDE) communication protocol. This latter shares information between softwares through an item able to identify particular commands required by the program that establishes the communication. However, the application of this simulation technique has been limited for the optimization of novel optical systems (González, 2015).

As observed, the ray tracing method can be applied on different types of solar concentrators. However, the studies are limited to evaluate the performance of said systems taking into account specific moments of the day or a few days along the year, leaving unexplored time periods. Therefore, the present investigation evaluates a continuous performance of a solar concentrator by using the ray tracing method considering one-hour intervals along a year. As a case of study, a central receiver system is evaluated.

\section{Method}

The ray tracing evaluation method is depicted in Fig. 1. In the first stage, the concentration system is defined, including the solar tracking strategy, the heliostats CAD models and their relative position to each other. Then, a MATLAB code is developed including the equations to find the altitude and azimuth solar angles $(\alpha, \gamma)$ and the heliostats' position to the Sun and receiver. This information is then translated to TracePro through the DDE protocol in order to establish both, the radiation source and the heliostats' position to begin the simulation process. The obtained results for each cycle are then stored on MATLAB, including the amount and distribution of the concentrated energy on the receiver.

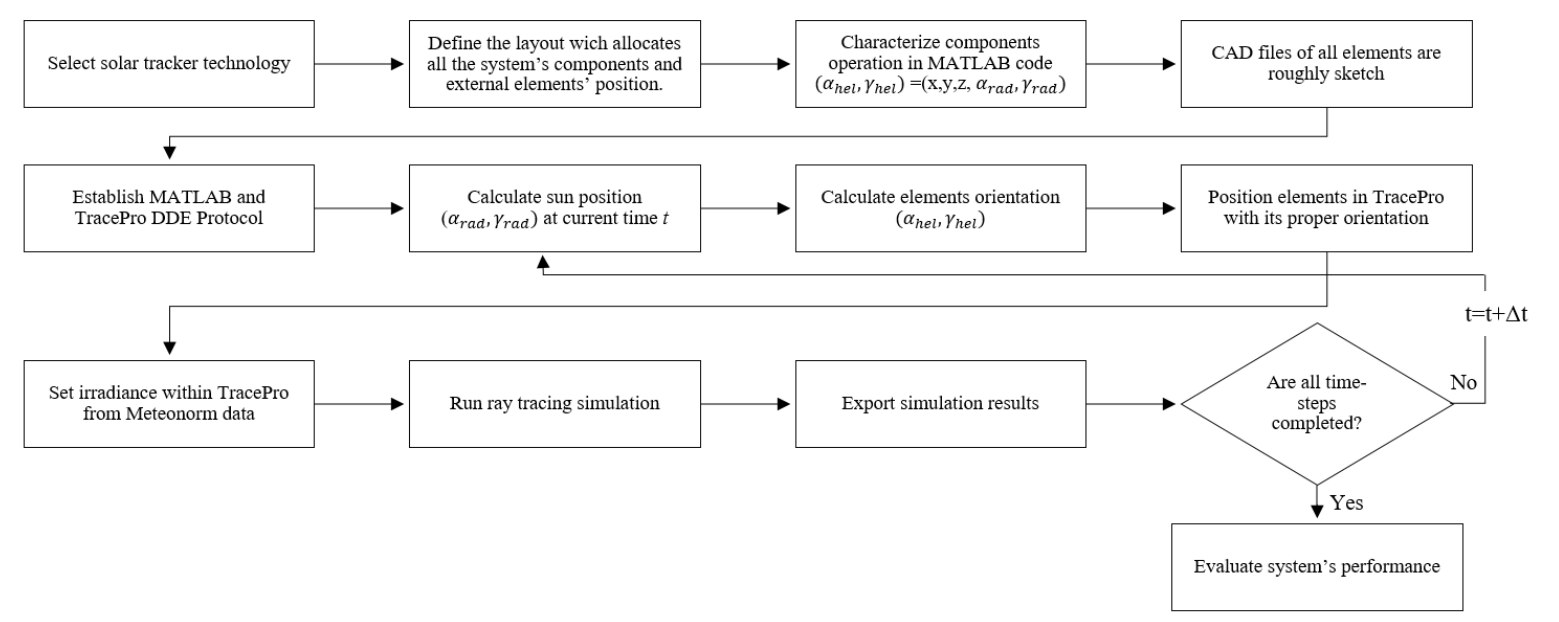

Fig. 1: Proposed ray tracing method

\subsection{Solar tracking strategy}

For each heliostat, a two-axis tracking strategy is defined in order to reflect the incoming radiation from the source to the center of the receiver as shown in Fig. 2. The purpose of the tracking method is to find the altitude and azimuth angles $\left(\alpha_{h e l}, \gamma_{h e l}\right)$, as shown in a general way in Fig. 2(a), for each heliostat according to its relative position to the source and receiver. The difference of the unit vectors representing the position of the receiver and each heliostat $\vec{t}, \vec{h})$ results on the reflected vector $\vec{R}$ of the incoming sunrays. With this vector and the vector representing the incident sunrays $\vec{S}$, a normal vector $\vec{N}$ at the surface of the heliostat is obtained, which is used to calculate the reflection angle to the target.

\subsection{Apparent solar movement}

Another input on the strategy is the solar position at any given time in order to obtain the incident ray vector $\vec{S}$ previously mentioned. The solar altitude and azimuth angles $(\alpha, \gamma)$ are calculated according to the latitude of interest, the day of the year and the hour. These angles are calculated from the equations developed by Duffie et al. (1980). 


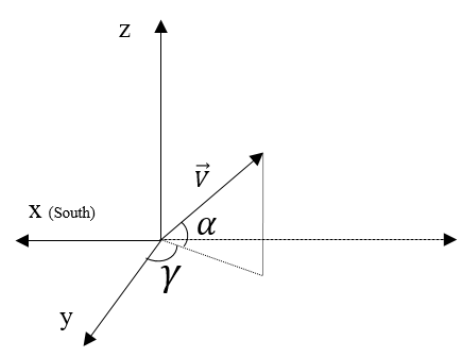

(a)

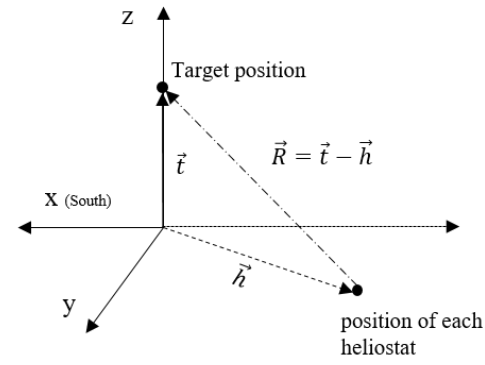

(b)

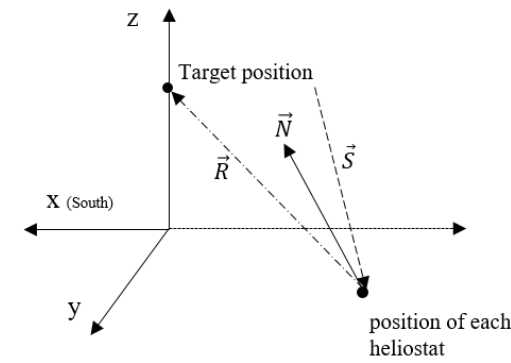

(c)

Fig. 1: Solar tracking strategy

\subsection{Performance evaluation}

The overall performance of a central tower concentrator is affected by cosine losses, refletance, shadows, blockage and spillage. These factors reduces the amount of concentrated energy on the receiver compared to the incoming energy from the source. The different types of losses are described below.

Cosine losses. They are caused by the position of the heliostats to the Sun and receiver. This loss is proportional to the cosine of the angle $\theta$ between the normal vector of the reflecting surface $\vec{N}$ and the vector of the incoming sunrays $\vec{S}$. The cosine loss $\eta_{\cos }$ can be found from eq. 1, that represents the effective area fraction of the $i^{t h}$ heliostat. Since every heliostat is in a different position to the target, the cosine loss on every surface varies. The total effective area of the heliostats field is given by eq. 2 , where $A_{h}$ corresponds to the heliostat area, in this case $1 \mathrm{~m}^{2}$ and $h$ is the total number of heliostats.

$$
\begin{gathered}
\eta_{\cos }=\cos \theta=\vec{S} * \vec{N} \\
A_{e f f}=\sum_{i=1}^{h} A_{h} * \eta_{\cos _{i}}
\end{gathered}
$$

Reflectance. These losses are caused since the reflecting surface absorbs a percentage of the incoming radiation. For each heliostat, a reflectance of $\eta_{\text {ref }}=0.85$ is considered.

Shadows. The proximity of the heliostats causes the interference of the incoming radiation that strikes on them, thus producing a shadow on the reflective area. The shadow loss $\eta_{s h}$ is determined from eq. 3 , where $H F$ is the amount of solar radiation that strikes on each heliostat and DNI is the direct solar radiation.

$$
\eta_{s h}=\frac{\sum_{i=1}^{h} H F_{i}}{D N I * A_{e f f}}
$$

Blockage. Blockage losses refer to the obstruction of the reflected radiation due to heliostats proximity. The blockage loss $\eta_{\text {block }}$ can be obtained from eq. 4 , where $B F$ is the amount of energy that hits the back surface of each heliostat.

$$
\eta_{\text {block }}=1-\frac{B F}{\left(\sum_{i=1}^{h} H F_{i}\right) * \eta_{c o s} * \eta_{s h} * \eta_{\text {ref }}}
$$

Spillage. It is caused by the difference between the receiver and the heliostats' area. Since the position of the latters varies along the day for solar tracking, the projected heliostat area on the receiver varies. In general terms, spillage loss means the rate of reflected radiation and unblocked which cannot reach the receiver surface. Therefore, the amount of energy loss is the difference between the available energy, the energy that reaches the $T F$ receiver and the blocked energy. Spillage $\eta_{s p i}$ can be found form eq. 5 as follows 


$$
\eta_{s p i}=1-\frac{\left[\left(\sum_{i=1}^{h} H F_{i}\right) * \eta_{c o s} * \eta_{s h} * \eta_{r e f}\right]-B F-T F}{\left(\sum_{i=1}^{h} H F_{i}\right) * \eta_{c o s} * \eta_{s h} * \eta_{r e f} * \eta_{\text {block }}}
$$

By calculating the loss factors described above, the solar concentrator's efficiency $\eta$ may be obtained from eq. 6.

$$
\eta=\frac{T F}{D N I * h * A_{h}}=\eta_{\text {cos }} * \eta_{s h} * \eta_{\text {ref }} * \eta_{\text {block }} * \eta_{\text {spi }}
$$

During the application of the present method, is posible obtain the energy fraction lost by shadows or blockage, without do an analisys of area projection of neighbors heliostats. This is the most commonly used technique in different studies for the evaluation of heliostats fields such as FIELD (Collado and Guallar, 2012), DELSOL (Kistler, 1986) and MIRVAL (Learly and Hankins, 1979). However, the computational time for calculations increases with a greater amount of heliostats on the array. This limits the efficiency analysis of the system to a specific moment of the day or year, thus obtaining limited results.

\section{Results}

The proposed method was applied to an array of five heliostats in order to calculate their efficiency taking into account the loss factors. For simulation purposes, radiation data from 1998 to 2016 (omitting leap years) in one hour periods from 07:00 to 21:00 h were used. The data was obtained from Meteonorm, an online database platform that offers accurate irradiation data from any place of the Earth. In this case, irradiation data from Monterrey, Mexico $\left(25^{\circ} \mathrm{N}, 100^{\circ} \mathrm{W}\right)$ was used. The simulations were executed only when the radiation value was greater than zero and the solar altitude angle greater than $15^{\circ}$, this latter considered as the minimum elevation angle for the operation of this type of systems (Collado and Guallar, 2012; Li et al., 2017).

As a preliminary validation, the method was applied to a single $1 \mathrm{~m}^{2}$-heliostat. The target was placed $10 \mathrm{~m}$-height from the ground, tilted $40^{\circ}$ to the vertical and $8.9 \mathrm{~m}$ from the heliostat's center over the horizontal. The simulation was executed for a single year, in this case 2015. The annual solar radiation is shown in Fig. 3. This data is used to calculate the useful fraction of the heliostat reflective area by using the ray tracing method here proposed. The results obtained from the simulation can be seen in Fig. 4. On the one hand, since there is only one reflective surface, blockage losses are neglected. Therefore, the useful fraction is close to 1 most of the year. On the other hand, at the beginning and end of the period, this value decreases around noon since the target shades a percentage of the incoming radiation due to its position between the Sun and the helisotat. A comparison of $H F$ values on winter (from day 3 to 19 of the year) and summer (from day 150 to 165 of the year) are show on Fig. 5(a) and 6, respectively. These plots present HF values calculated theorically and obtained from Ray-Tracing, in winter, due to solar altitude is lower than summer, the target causes shadow over the heliostat, as shown in a detailed plot in Fig. 5(b).

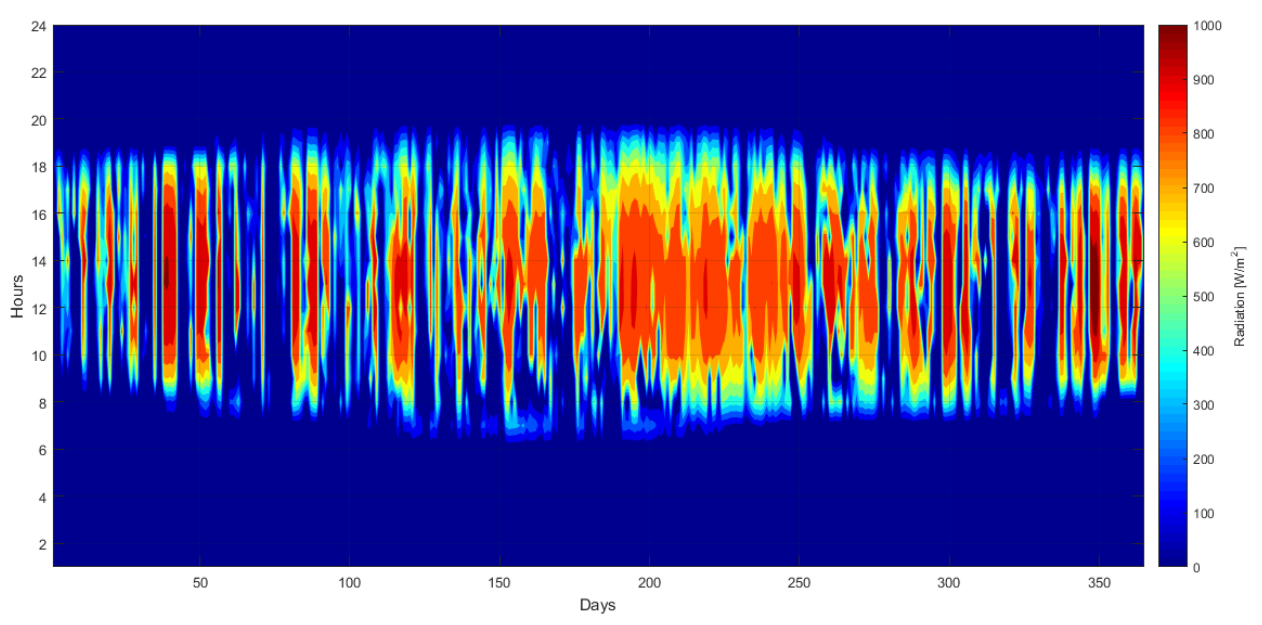

Fig. 3: Annual solar radiation (2015) 


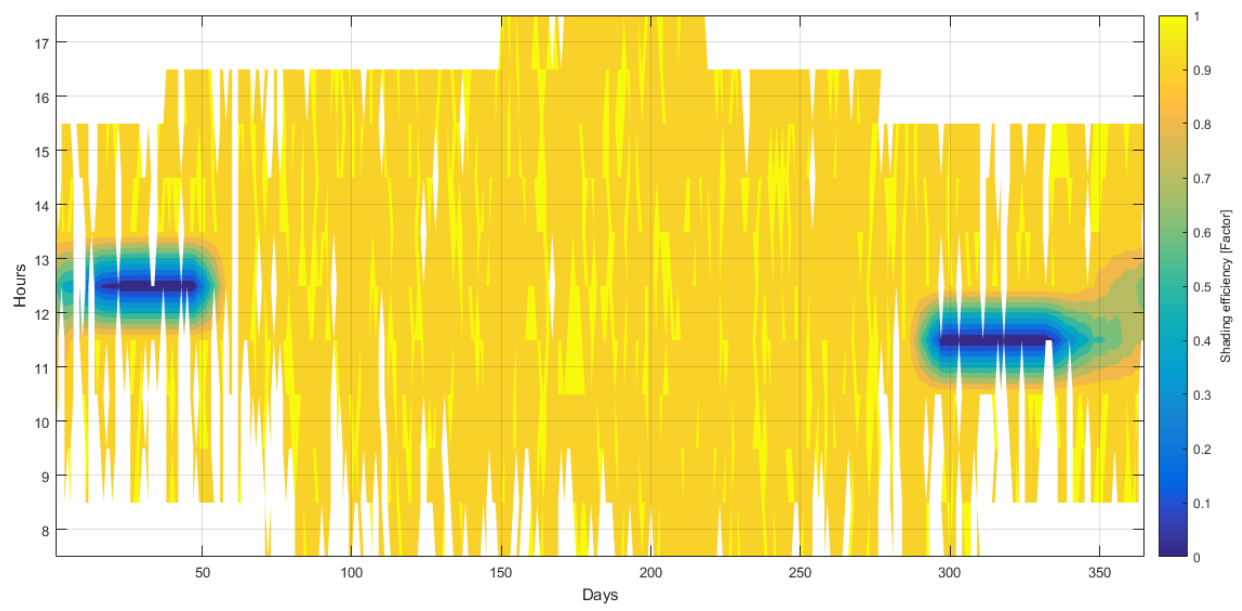

Fig. 4: Annual performance of a single heliostat (2015)

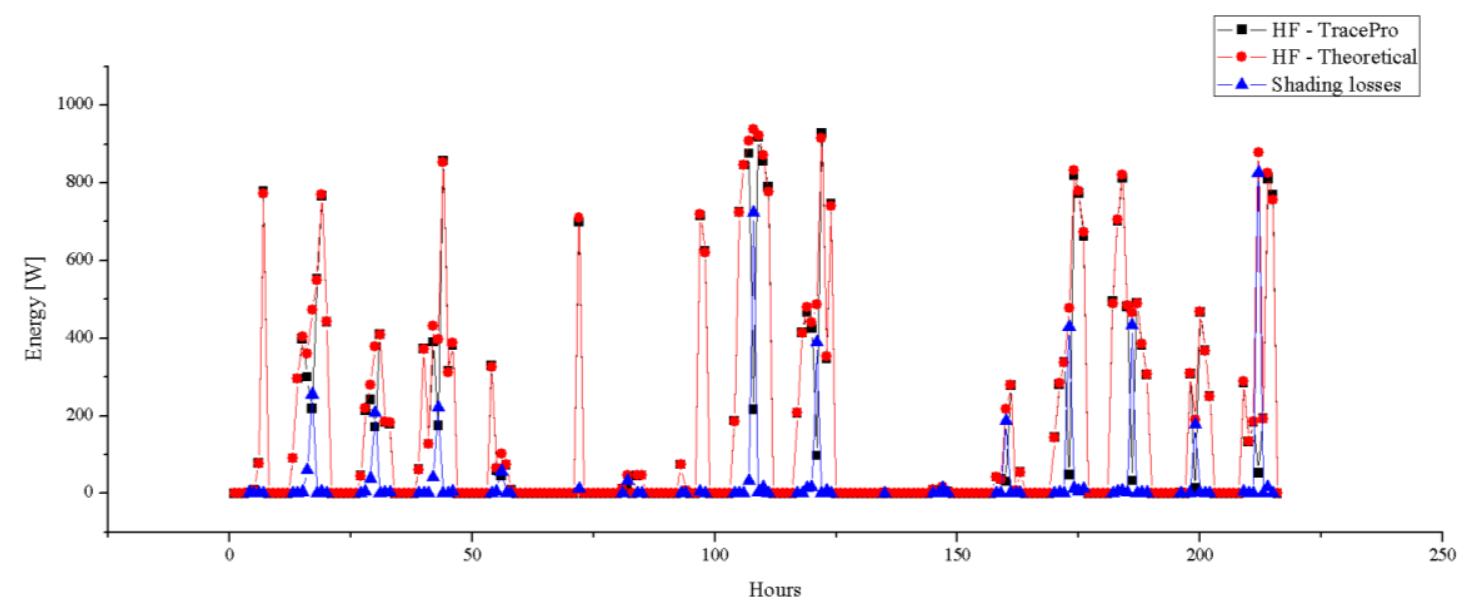

(a)

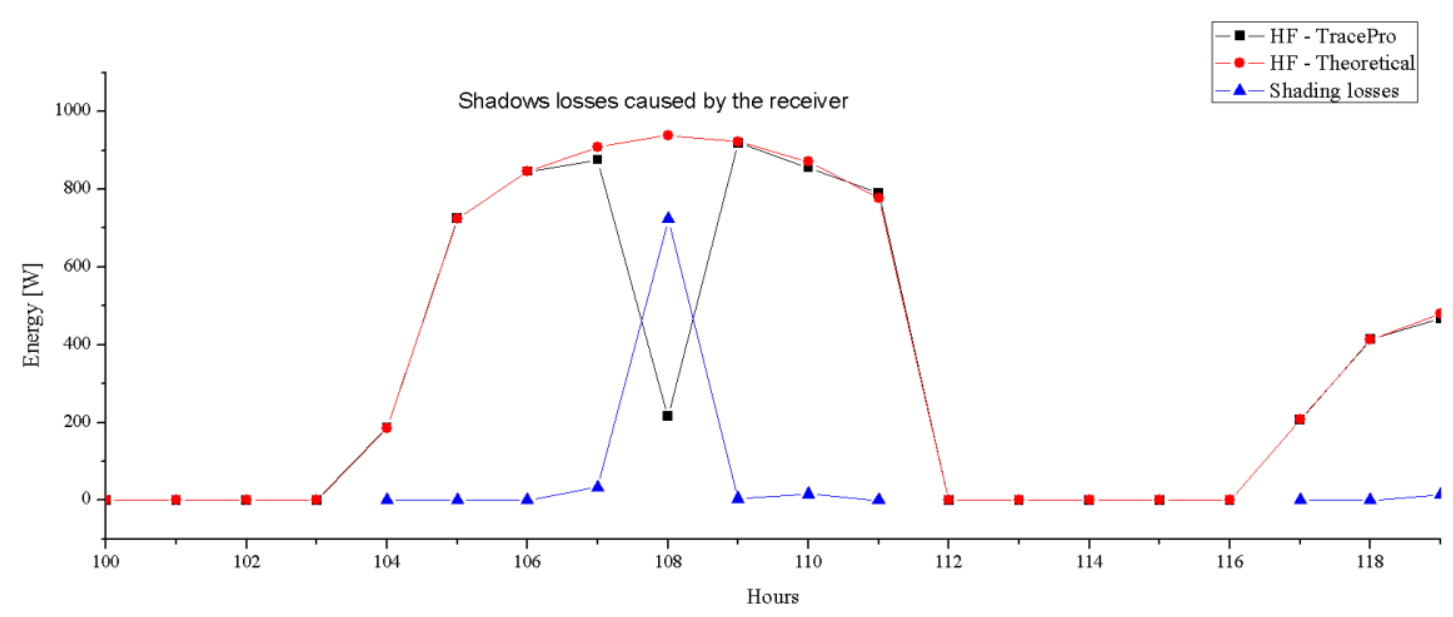

(b)

Fig. 5: Solar radiation hitting on a single heliostat in winter 


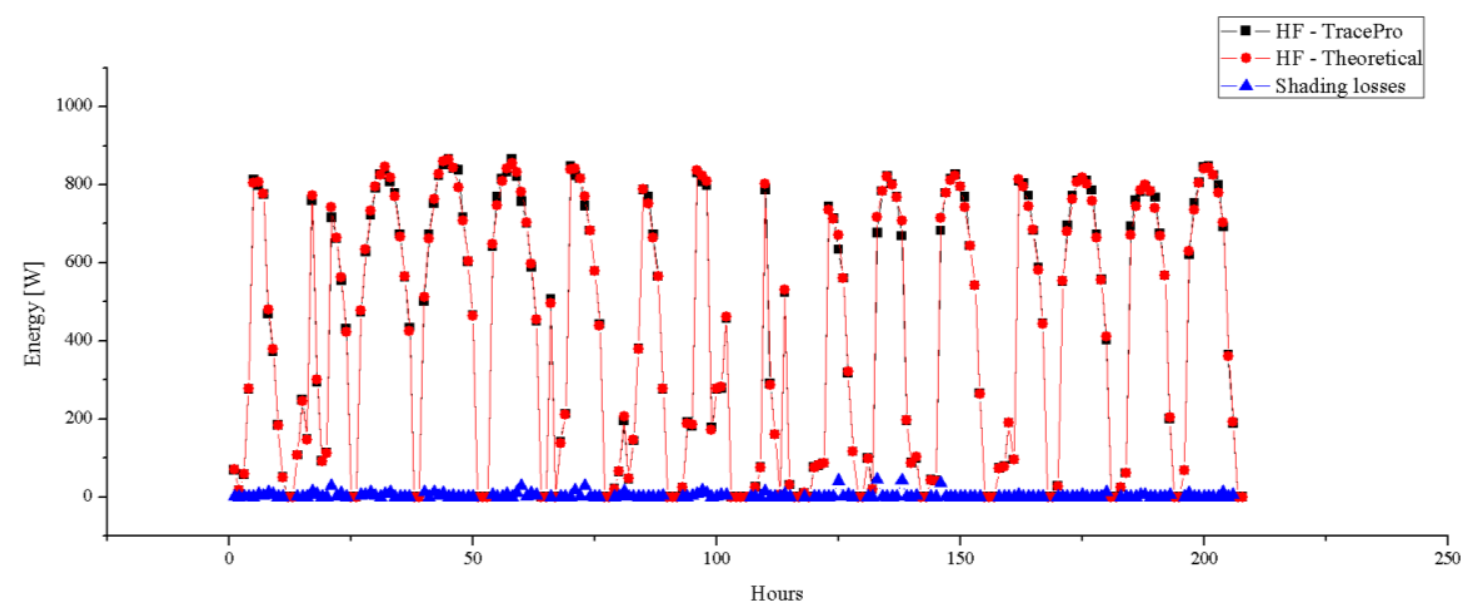

Fig. 6: Solar radiation hitting on a single heliostat in summer

After the simulation of the single heliostat along a year, a set of five heliostats was simulated in order to calculate their optical and geometrical losses. The system distribution is illustrated in Fig. 7. Each heliostat has an area of $1 \mathrm{~m}^{2}$ and its position has been established in such a way that there is a deliberated obstruction of radiation between them. Fig. 8 shows an instant of the Tracepro simulation (day 190, 13:00 h). Each heliostat position allows the reflection of the incoming radiation onto the center of the target.

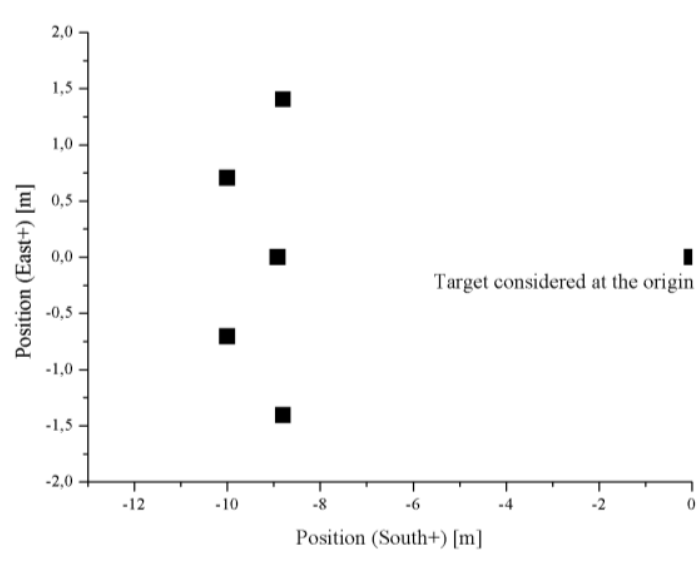

Fig. 7: Distribution of the heliostats array and target

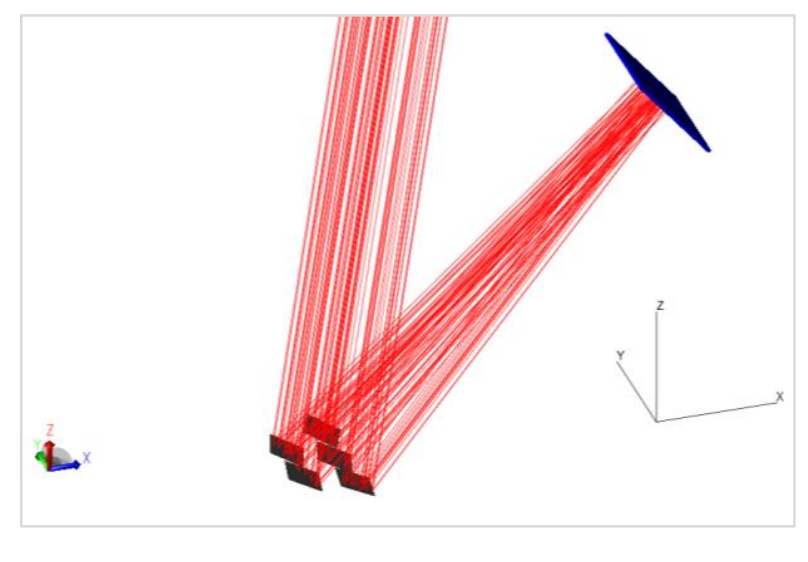

Fig. 8: Tracepro simulation of an instant

Fig. 9 shows the monthly average efficiency for each simulated year, neglecting leap-years. The efficiency of every heliostat is affected by the optical performance losses previously described. In this case, spillage losses were neglected and a reflective value of 0.85 remained constant. As it is observed, the most considerable loss is caused by the radiation blockage between heliostats. However, in real applications blockage is avoided by using algorithms that establish the optimal separation between contiguous heliostats. Similarly, the system's performance is affected by cosine losses, which represents one of the most significant loss of this type of solar concentrators. Finally, shadow losses due to interference between heliostats and/or the projection of the receiver on the reflecting surfaces is the factor that least affects the performance of the system. The concentrator performance was obtained from the simulation taking into account the previously described losses. It can be seen that the efficiency factor varies from 0.35 to 0.5 along the simulated period of time. 


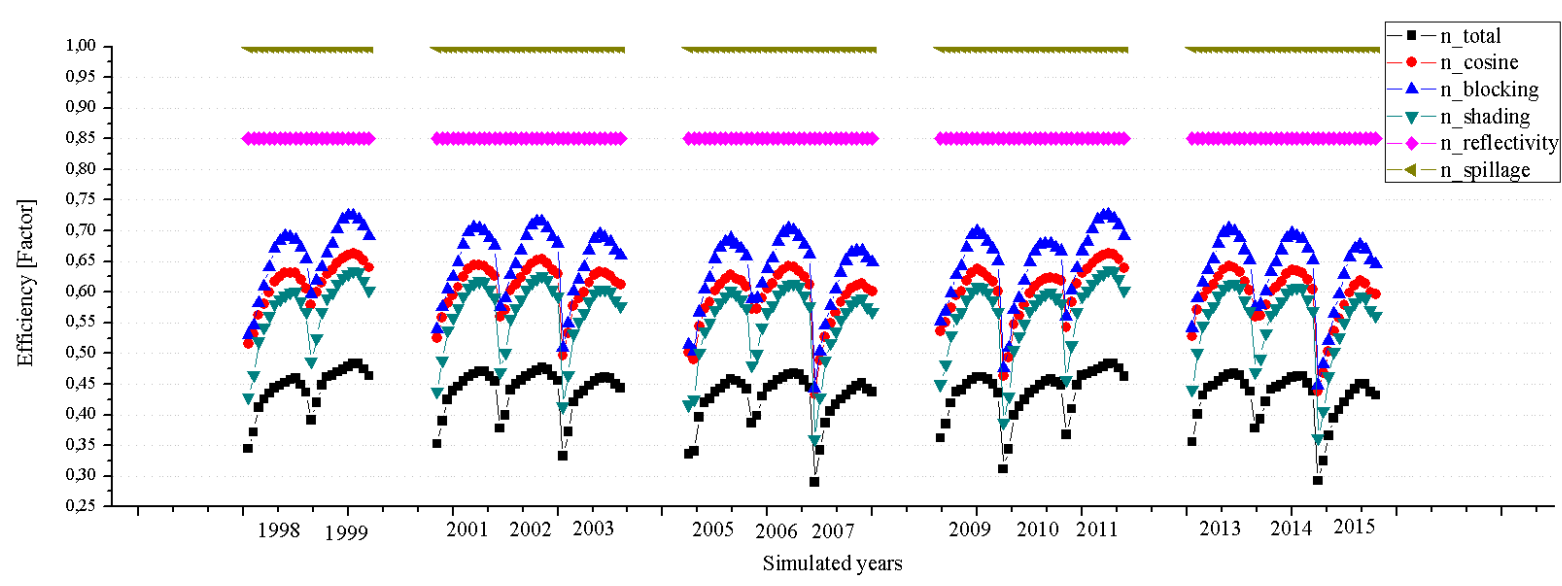

Fig. 9: Monthly average heliostats' performance from 1998 to 2015 (leap-years neglected)

\section{Conclusions}

In the present research, the performance of an array of heliostats was obtained through a ray tracing iterative method. The routine was successfully implemented by simulating a conventional heliostats array widely studied in the literature. The result of annual simulations in one hour intervals can be applied to different distributions of heliostats, a common study in this type of technology. In addition, the obstruction of radiation caused by nearby objects, either between heliostats themselves or other external objects, can be obtained.

Although the present method was evaluated in a simplified set of heliostats, the tool can be applied for the evaluation and optimization of other types of solar concentrators, especially those in which their annual performance has not been validated using experimental data. In addition, the method has the ability to include external elements such as trees, buildings or other objects that may be present in a real environment.

The obtained results through this method can be used in other softwares such as TRNSYS, regularly used to perform annual energy studies in short time intervals. In addition, the method allows the evaluation of solar concentration systems by using continuous data records in order to validate the annual results obtained from conventional simulations.

\section{Acknowledgements}

The authors would like to thank the Roberto Garza Sada Center (CRGS) at the University of Monterrey (UDEM) and the projects No. UIN18557 and UIN18558 for finnancial support; and the Faculty of Mechanical and Electrical Engineering of the UANL and the PRODEP Fund project No. 223045 for the financial support provided during the development of this research.

\section{References}

Collado, F., Guallar, J., 2012. Campo: Generation of regular heliostat fields. Ren. Ener. 46, 49-59. DOI: https://doi.org/10.1016/j.renene.2012.03.011

Duffie, J.A., Beckman, W.A., 1980. Solar Engineering of Thermal Processes, Wiley Interscience, New York. DOI: $10.1119 / 1.14178$

Eddhibi, F., Amara, M. B., Balghouthi, M., Guizani, A., 2017. Design and analysis of a heliostat field layout with reduced shading effect in southern Tunisia. Int. J. Hydrogen Ener. 42(48), 28973-28996. DOI: https://doi.org/10.1016/j.ijhydene.2017.07.217 
González, M., 2015. Procesos de optimización de diseño óptico aplicados a dispositivos de iluminación, balizamiento y concentración de luz. Doctoral Thesis. Complutense Universtity of Madrid. Madrid, 2015.

Hu, Y., Shen, H., Yao, Y., 2018. A novel sun-tracking and target-aiming method to improve the concentration efficiency of solar central receiver systems. J. Ren. Ener. 120, 98-113. DOI: 10.1016/J.RENENE.2017.12.035

Kistler, B. L., 1986. A user's manual for DELSOL3: a computer code for calculating the optical performance and optimal system design for solar thermal central receiver plants, Sandia National Laboratories, Sandia Report No. SAND86-8018, CA. URL: https://prod.sandia.gov/techlib-noauth/access-control.cgi/1986/868018.pdf.

Leary PL, Hankins JD., 1979. A user's guide for MIRVAL: A computer code for comparing designs of heliostat-receiver-optics for central receiver solar power plants, Sandia National Laboratories, SAND77-8280, CA. DOI: $10.2172 / 6371450$

Li, C., Zhai, R., Liu, H., Yang, Y., Wu, H., 2017. Optimization of a heliostat layout using hybrid PSO-GA algorithm. Appl. Therm. Eng. 128, 33-41. DOI: https://doi.org/10.1016/j.applthermaleng.2017.08.164

Su, Z., Gu, S., \& Vafai, K., 2017. Modeling and simulation of ray tracing for compound parabolic thermal solar collector. Int. Comm. Heat Mass Trans. 87, $169-174 . \quad$ DOI: https://doi.org/10.1016/j.icheatmasstransfer.2017.06.021

Terrón, M., Peña, M. I., Carrillo, J. G., Ayala, U., Flores, V., 2018. Solar ray tracing analysis to determine energy availability in a CPC designed for use as a residential water heater. Ener. 11(2), 291. DOI: 10.3390/en11020291.

Waghmare, S. A., \& Gulhane, N. P., 2016. Design and ray tracing of a compound parabolic collector with tubular receiver. So.1 Ener. 137, 165-172. DOI: 10.1016/J.SOLENER.2016.08.009.

Yeh, P., Yeh, N, 2018. Design and analysis of solar-tracking 2D Fresnel lens-based two staged, spectrumsplitting solar concentrators. J. Ren. Ener. 120, 1-13. DOI: 10.1016/J.RENENE.2017.12.032. 


\title{
Tailoring Alumina Matrix Optical Properties for Colored Solar Thermal Absorber Coatings
}

\author{
Luminita Isac, Dana Perniu and Anca Duta \\ Renewable Energy Systems and Recycling Research Center, Transilvania University of Brasov, \\ Brasov, Romania
}

\begin{abstract}
The absorber plate is the key component in a flat plate solar thermal collector. Most of the black and some of the colored absorber coatings are based on cermets, composed of metals or inorganic pigments embedded in a ceramic matrix of metal oxides, such as alumina $\left(\mathrm{Al}_{2} \mathrm{O}_{3}\right)$.

The current work describes the optimization steps of the alumina matrix to get optical properties and morphology suitable for the pigment layers infiltration to develop efficient colored (yellow and green) solar absorber coatings/plates. The alumina matrices were obtained by the depositing the alumina layer on the $\mathrm{Al}$ substrate using two different methods: immersion and robotic spraying of a diluted sol. The optimized alumina matrix, obtained by immersing the $\mathrm{Al}$ substrate in a diluted alumina sol $\left(\mathrm{Al}_{2} \mathrm{O}_{3}\right.$ sol: $\left.\mathrm{H}_{2} \mathrm{O}=1: 9\right)$ for 24 hours, has a porous morphology and promising optical properties: $\alpha=0.16, \varepsilon=0.06$.
\end{abstract}

Keywords: solar thermal collectors, absorber coatings, alumina matrix, robotic spraying deposition, optical properties

\section{Introduction}

The main challenges faced in the research on solar thermal collectors are focused on enhancing the thermal performance, increasing the reliability and the long-term performance stability (Fernandes et al., 2017). Additionally, a solar thermal collector must be economically feasible, thus should have a low cost, that means not only low cost materials, technologies and component parts but also a long service lifetime (Sun et al., 2014). Besides increasing the efficiency and durability, the architectural acceptance of the solar thermal collectors currently represents an important research topic, colored solar thermal collectors being aesthetically preferred to the standard black or dark-blue ones, although their thermal efficiency is expected to be lower. Therefore, new, affordable and efficient solutions are expected, supporting the integration of the solar thermal systems on the building's facades, according to their design specifications, mainly related to architectural acceptance and good conversion efficiency. Recently, Visa et al (2017) reported the development of a trapezoidal solar thermal collector, with $0.67 \mathrm{~m}^{2}$ active area and $69.42 \%$ nominal efficiency, which can be used as a building block in arrays with various surfaces, shapes and colours.

The active component in a solar thermal collector is the absorber plate, usually coated with a black or dark blue layer to absorb as much solar radiation as possible and convert it into thermal energy. This energy is further transferred to the working fluid, thus the absorber plates must possess good thermal and radiative properties (Alami and Aokal, 2018). Solar selective absorber (SSA) coatings are designed using materials with carefully engineered optical properties: high solar absorptance $(\alpha>0.9)$ over the solar spectrum and low thermal emittance $(\varepsilon<0.1)$ in the IR region, at the operating temperature, along with thermal and mechanical resistance. Cost-effective and environmentally friendly production processes represents additional requirements for SSA coatings. In this context, spray pyrolysis (SP) and sol-gel (SG) are relatively simple and industrial up-scalable techniques that are considered suitable for manufacturing SSA coatings (Isac et al., 2018).

The most frequently developed industrial solar selective absorbers are based on metal-dielectric composites also called cermets, mainly consisting of nanoscale metal particles ( $\mathrm{Ni}, \mathrm{Au}, \mathrm{Co}, \mathrm{Mo}, \mathrm{Cr}$ ) or inorganic pigment particles $\left(\mathrm{Fe}_{2} \mathrm{O}_{3}, \mathrm{CuS}, \mathrm{V}_{2} \mathrm{O}_{5}\right)$ embedded in a dielectric, ceramic matrix (Céspedes et al., 2014, Duta et al., 2014, 
Estrella-Gutiérrez et al., 2016, Purghel et al., 2008). Cermet based SSA coatings with good solar selectivity, even at high temperatures, have been already successfully commercialized (Bermel et al., 2012).

Among cermet composite coatings, SSA coatings with alumina $\left(\mathrm{Al}_{2} \mathrm{O}_{3}\right)$ matrix have been widely used as selective solar absorber surfaces with good optical properties (low thermal emittance, $\varepsilon<0.1$ ) and thermal stability, due to the possibility of tailoring the coating's surface aspect to obtain a porous morphology, suitable for further metal/pigment particles infiltration. Alumina is a dielectric material with excellent properties, such as high thermal and chemical stability, high hardness, high refractive index $(n=1.61-1.75)$, low permeability of alkali ions and high radiation resistance (Balakrishnan et al., 2013, Khatibani and Rozati, 2015). Amorphous and/or crystalline alumina thin films with good adhesion on different substrates ( $\mathrm{Al}, \mathrm{Cu}$, stainless steel) are considered promising materials acting as ceramic matrix in solar selective absorber coatings.

This work focuses on the development and optimization of the alumina matrix $\left(\mathrm{Al} / \mathrm{Al}_{2} \mathrm{O}_{3}\right)$ obtained by the deposition of alumina layer on the aluminium substrate using two simple and low-cost techniques: the immersion in diluted alumina sol and robotic spraying, at average temperature $\left(\mathrm{T}=130{ }^{\circ} \mathrm{C}\right)$, of a diluted alumina sol. The optical properties $(\alpha, \varepsilon)$ of the alumina matrix were correlated with the chemical composition (XRD and EDX), crystalline structure (XRD) and morphology (SEM).

\section{Experimental}

In developing the colored absorber coatings, before the infiltration with pigment particles, the Al substrate and alumina matrix are necessary to be optimized, using the spectral selectivity (S) as output property.

The Al substrates ( $3 \mathrm{~cm} \times 3 \mathrm{~cm}$ samples) were chemically pre-treated in three steps:

- Degreasing in ethanol (98\%, ChimReactiv) and conditioning the commercial Al substrates $(99,5 \%$ Beofon, thickness $1 \mathrm{~mm}$ ) in 4\% NaOH solution ( $\mathrm{NaOH} 99 \%$, Scharlau Chemie);

- Immersing the alkali treated aluminium substrates in $\mathrm{HNO}_{3}\left(\mathrm{HNO}_{3} 65 \%\right.$, Chimopar $)$ solution, at different acid concentrations: $0.5 \mathrm{M}, 0.75 \mathrm{M}$ and $1 \mathrm{M}$, for $0.5 \mathrm{~h}, 3 \mathrm{~h}$ and $20 \mathrm{~h}$;

- Neutralizing the residual acid on the aluminum substrates by immersing in $2 \% \mathrm{Na}_{2} \mathrm{CO}_{3}$ solution $\left(\mathrm{Na}_{2} \mathrm{CO}_{3} 99.9 \%\right.$, Scharlau Chemie) for 10 minutes, followed by rinsing with distilled water and drying in compressed air flow.

The alumina matrix represents an additional layer of $\mathrm{Al}_{2} \mathrm{O}_{3}$ deposited on the pre-treated $\mathrm{Al}$ substrate (nominated as $\mathbf{A})$ that was obtained using two different deposition techniques:

- Immersion of the $\mathrm{Al}$ substrates in a diluted alumina sol $\left(\mathrm{Al}_{2} \mathrm{O}_{3}: \mathrm{H}_{2} \mathrm{O}=1: 9\right.$ in volumes) for 24,48 or 72 hours; the samples were nominated as A/AOSG24, A /AOSG48 and A/AOSG72;

- Robotic spraying, at $\mathrm{T}=130{ }^{\circ} \mathrm{C}$, of a diluted sol (1:9) using 5, 10 or 15 spraying sequences; the samples were nominated as A/AOSGs5, A/AOSGs10 and A/AOSGs15.

The alumina sol was prepared using the sol-gel technique, according to Milea et al. (2013): aluminium chloride hexahydrate $\left(\mathrm{AlCl}_{3} \cdot 6 \mathrm{H}_{2} \mathrm{O}, 98 \%\right.$, Scharlau Chemie) was added in a mixture of bi-distilled water and absolute ethanol $(1: 1)$ under continuous stirring, at room temperature $\left(25^{\circ} \mathrm{C}\right)$, to promote the hydrolysis and condensation processes; after 10 minutes, 5.5 millilitres of polyethylene glycol (PEG 400, synthesis grade, Scharlau Chemie) was gradually added ( 0.5 millilitres/minute) under continuing stirring; the resulted sol was left for ageing 5 days. Afterwards, the sol was diluted and used as precursor for the $\mathrm{Al}_{2} \mathrm{O}_{3}$ deposition on the chemically pretreated Al substrate A.

The optical properties of the Al substrates and alumina matrices $(\varepsilon, \alpha)$ were evaluated using Fourier Transform Infrared spectroscopy (FTIR, Bruker Vertex 70, equipped with a integrated sphere coated with gold) and UVVIS-NIR spectrophotometry (UV-VIS-NIR Spectrophotometer Perkin Elmer, double-beam spectrophotometer, equipped with integrating sphere to $150 \mathrm{~mm}$ ).

The thermal emittance, $\varepsilon$, was calculated from the reflectance spectra recorded in the IR domain $(\lambda=2.5-20$ $\mu \mathrm{m})$, as the weighted fraction between the absorbed energy and the Planck blackbody energy $\left(\mathrm{I}_{\mathrm{P}}\right)$ at certain wavelength $(\lambda)$ and temperature (T, ambient temperature in this work), using eq. (1) (Duta et al., 2014): 
$\boldsymbol{\varepsilon}=\frac{\int_{2.5}^{20} \mathrm{I}_{\mathrm{p}}(\lambda)(1-\mathrm{R}(\lambda, \mathrm{T})) \mathrm{d} \lambda}{\int_{2.5}^{20} \mathrm{I}_{\mathrm{p}}(\lambda, \mathrm{T}) \mathrm{d}(\lambda)}$

The solar absorptance $(\alpha)$ was calculate using eq. (2) (Duta et al., 2014) from the reflectance spectra recorded in the UV-VIS-NIR domain $(\lambda=0.28-2.5 \mu \mathrm{m})$ :

$\boldsymbol{\alpha}=\frac{\int_{0.28}^{2.5} \mathrm{I}_{\mathrm{sol}}(\lambda)(1-\mathrm{R}(\lambda)) \mathrm{d} \lambda}{\int_{0.28}^{2.5} \mathrm{I}_{\text {sol }}(\lambda) \mathrm{d}(\lambda)}$

where: $R(\lambda)$ is the material's reflectance and $I_{\text {sol }}$ is the solar irradiance (ISO 9854-1, 1992) with an air mass of 1.5 .

The ratio of the two important optical parameters, solar absorptance $(\alpha)$ and thermal emittance $(\varepsilon)$, gives the spectral selectivity, $\mathrm{S}$, which generally characterizes the optical performance of an absorber material. Spectral selectivity is defined as the ability of a material to ideally behave as a black body, absorbing the maximum of the incoming solar radiation and minimizing energy losses through infrared radiation (Isac et al., 2017).

The overall crystallinity degree (estimated using the device software EVA 1.4) and the composition of the crystalline phases in the samples were evaluated by X-Ray Diffraction (XRD, Bruker D8 Discover Diffractometer with $\mathrm{Cu}_{\mathrm{K} \alpha 1}$ line) using the locked-couple technique in the $2 \theta$ range from $20^{\circ}$ to $70^{\circ}$. The crystalline phase composition (weight \%) was obtained using the integration of the diffraction data (calculating the area, $\mathrm{S}$, under the diffraction peak by mathematical integration) and then eq. (3) was applied (Birkholz, 2005):

$A(\%)=\frac{\sum_{i}^{n} S_{i(A)}}{\sum_{i}^{n} S_{i(A)}+\sum_{j}^{m} S_{j(B)}+\ldots .} \times 100$

where $S_{\mathrm{i}(\mathrm{A})}, \mathrm{S}_{\mathrm{j}(\mathrm{B})}$ are the estimated peaks areas for the individual crystalline phases $\mathrm{A}, \mathrm{B}$.

The surface morphology of the alumina substrate and of the alumina matrix was investigated using Scanning Electron Microscope (SEM 3500N, Hitachi). The surface elemental composition of the samples was identified using an energy dispersive spectrometer (EDS), mounted on the SEM.

\section{Results and discussions}

\subsection{The Al substrate optimization}

The influence of the $\mathrm{HNO}_{3}$ solution concentration and of the immersion duration on the optical properties (thermal emittance, preferably $\varepsilon<0.2$ ) of the aluminium substrates was investigated and the results are presented in Table 1. Based on the experimental values, the aluminium substrates with lowest thermal emittance $(\varepsilon=0.22 \ldots 0.26)$ were further investigated by UV-VIS-NIR spectrometry and the results show that the solar absorptance has similar values: $0.12 \ldots 0.13$.

Tab. 1: The thermal emittance values for chemically pre-treated $\mathrm{Al}$ substrates in $\mathrm{HNO}_{3}$ solution with different concentrations, at different immersion times

\begin{tabular}{|c|c|c|c|c|}
\hline \multicolumn{2}{|c|}{ Optical property } & \multicolumn{3}{|c|}{$\varepsilon$} \\
\hline \multicolumn{2}{|c|}{ HNO $_{\mathbf{3}}$ concentration $[$ moles/L] } & $\mathbf{0 . 5}$ & $\mathbf{0 . 7 5}$ & $\mathbf{1}$ \\
\hline $\begin{array}{c}\text { Immersion time } \\
{[\mathbf{h}]}\end{array}$ & $\mathbf{0 . 5}$ & $0.36 \ldots 0.45$ & $0.35 \ldots 0.42$ & $0.35 \ldots 0.40$ \\
\cline { 2 - 5 } & $\mathbf{3}$ & $0.25 \ldots 0.42$ & $0.24 \ldots 0.36$ & $0.21 \ldots 0.36$ \\
\cline { 2 - 5 } & $\mathbf{2 0}$ & $0.22 \ldots 0.31$ & $0.22 \ldots 0.26$ & $0.17 \ldots 0.32$ \\
\hline
\end{tabular}

The chemically treated substrate with the best spectral selectivity $(\mathrm{S}=0.59)$, having $\alpha=0.13, \varepsilon=0.22$ was obtained by immersion in $0.75 \mathrm{M} \mathrm{HNO}_{3}$ solution for 20 hours and was nominated as $\mathbf{A}$. 
According to the X-Ray diffraction results in Fig. 1 and Table 3, the optimized chemically treated substrate A shows a crystallinity degree of $94.4 \%$ and contains, besides aluminium, crystalline phases of orthorhombic $\mathrm{Al}_{2} \mathrm{O}_{3}$ (PDF 00-052-0803, 45.76\%) and hydrated aluminium oxides (54.24\%): gibbsite $\left(\mathrm{Al}_{2} \mathrm{O}_{3} \cdot 3 \mathrm{H}_{2} \mathrm{O}, \mathrm{PDF} 00\right.$ 002-0192) and gibbsite syn, $\mathrm{Al}(\mathrm{OH})_{3}$ (PDF 00-023-0018), with monoclinic structure. As expected, the presence of aluminium-oxygen based compounds on the chemically treated Al substrate is confirmed by EDS analysis: 96\% $\mathrm{Al}$ and $4 \% \mathrm{O}$ (weight percents). The surface morphology of this optimized substrate A, investigated using Scanning Electron Microscope, shows a porous structure as presented in Fig. 2 a.

\subsection{The alumina matrix optimization}

For a better infiltration of the colored pigment in the substrate's pores, an additional layer of $\mathrm{Al}_{2} \mathrm{O}_{3} \mathrm{was}$ deposited on the optimized substrate A by: a) immersion of Al substrate in a diluted sol of alumina for 24, 48 or 72 hours, and b) robotic spraying of diluted alumina sol, at $\mathrm{T}=130{ }^{\circ} \mathrm{C}$, using 5,10 or 15 spraying sequences.

The influence of the immersion time and number of spraying sequences on the optical properties (thermal emittance, $\varepsilon$ ) of the alumina matrix was investigated and the results are presented in Table 2.

Tab. 2: The thermal emittance of alumina matrices obtained by depositing the $\mathrm{Al}_{2} \mathrm{O}_{3}$ layer on the $\mathrm{Al}$ substrate by immersion in the diluted sol, respectively by spraying the diluted sol at average temperature

\begin{tabular}{|c|r|r|r|r|r|r|}
\hline Sample & A/AOSG24 & A/AOSG48 & A/AOSG72 & A/AOSGs5 & A/AOSGs10 & A/AOSGs15 \\
\hline $\boldsymbol{\varepsilon}$ & $0.06 \ldots 0.19$ & $0.08 \ldots 0.17$ & $0.14 \ldots 0.20$ & $0.24 \ldots 0.35$ & $0.37 \ldots 0.40$ & $0.38 \ldots 0.43$ \\
\hline
\end{tabular}

It was observed that the values of the thermal emittance decrease $(\varepsilon<0.2)$ for the samples obtained by immersion in the diluted sol and significantly increase $(\varepsilon>0.24)$ for the sprayed alumina matrices. Therefore, from each series of alumina matrices there was selected, for further characterization, the sample with the lowest thermal emittance value: A/AOSG24, respectively A/AOSG24s5.

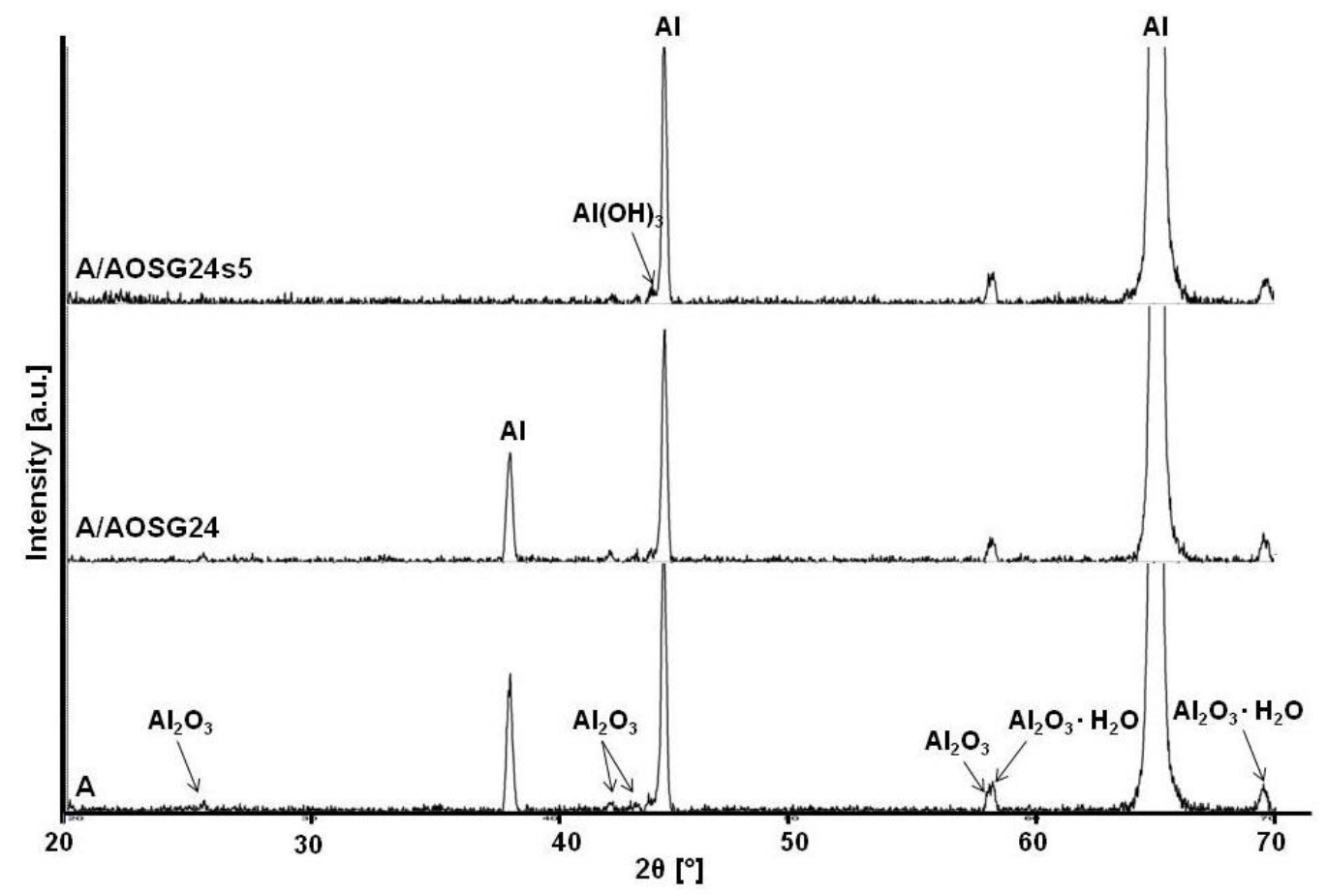

Fig. 1: XRD patterns of substrate $A$ and alumina matrices

The X-Ray diffraction spectra, Fig. 1, show that both alumina matrices have polycristalline structures, with crystalline phases similar to the A substrate, but with quite different compositions (wieght \%). The results in Table 3 show that using two different techniques for the alumina layer deposition on the Al substrate, causes no 
significant changes in the crystallinity degree (92 - 94\%), but significant changes in the crystalline phase compositions can be observed. In the matrix obtained by spraying the diluted sol on the Al substrate, the anhidrous $\mathrm{Al}_{2} \mathrm{O}_{3}$ content significantly decreases, compared to that of $\mathrm{Al}$ substrate, respectively $\mathrm{Al}$ matrix A/AOSG24. It is expected that a lower content of alumina in the matrix leads to less suitable optical properties (higher $\varepsilon$ ), reducing the optical performance of the matrix A/AOSG24s5.

Moreover, the line attributed to the $\mathrm{Al}$ crystalline phase $\left(2 \theta=38.54^{\circ}\right)$ is not detected in XRD pattern of sample A/AOSG24s5, which means that the layer deposited by spraying is thicker than that deposited by immersion. In this case, increasing the thickness of the matrix layer may influence the matrix morphology by covering the pores of the substrate, resulting in denser layers that have a reduced possibility of pigment film/particles infiltration.

Tab. 3: The crystallinity and estimative crystalline phases composition of the optimized Al substrate and alumina matrices

\begin{tabular}{|c|c|c|c|c|}
\hline Sample & $\begin{array}{c}\text { Crystallinity } \\
{[\%]}\end{array}$ & $\begin{array}{c}\mathbf{A l}_{2} \mathbf{O}_{3} \\
{[\%]}\end{array}$ & $\begin{array}{c}\text { Gibbsite, } \mathbf{A l}_{\mathbf{2}} \mathbf{O}_{\mathbf{3}} \cdot \mathbf{3} \mathbf{H}_{\mathbf{2}} \mathbf{O} \\
{[\%]}\end{array}$ & $\begin{array}{c}\text { Gibbsite syn, } \mathbf{A l}(\mathbf{O H})_{3} \\
{[\%]}\end{array}$ \\
\hline $\mathbf{A}$ & 94.4 & 45.76 & 52.12 & 2.12 \\
\hline A/AOSG24 & 93.9 & 59.98 & 32.53 & 7.49 \\
\hline A/AOSG24s5 & 92.1 & 26.35 & 67.30 & 6.35 \\
\hline
\end{tabular}

The elemental composition analyzed by EDS, represented in Fig. 2, gives information about the surface composition and, consequently, about the growth and adhesion among the successive layers, allowing the most accurate design of the alumina and the final absorber layers. It is interesting to note that in the matrix obtained by immersion of the $\mathrm{Al}$ substrate in diluted sol (A/AOSG24), the increase in the oxygen content is not observed, as expected. Instead, the aluminium content in matrices significantly decreases, especially in the A/AOSG24s 5 sample, where the $\mathrm{Al}$ content is three times lower than in the substrate, that can be the result of the thicker and more denser layer. However, for the investigated alumina matrices, the EDS results mostly confirm the differences highlighted in XRD composition. The presence of amorphous carbon/carbon compounds in the alumina matrices is due to the PEG additive used in alumina sol synthesis to control the hydrophilic/hydrophobic balance and support the gelation and phase separation processes (Milea et. al, 2013).

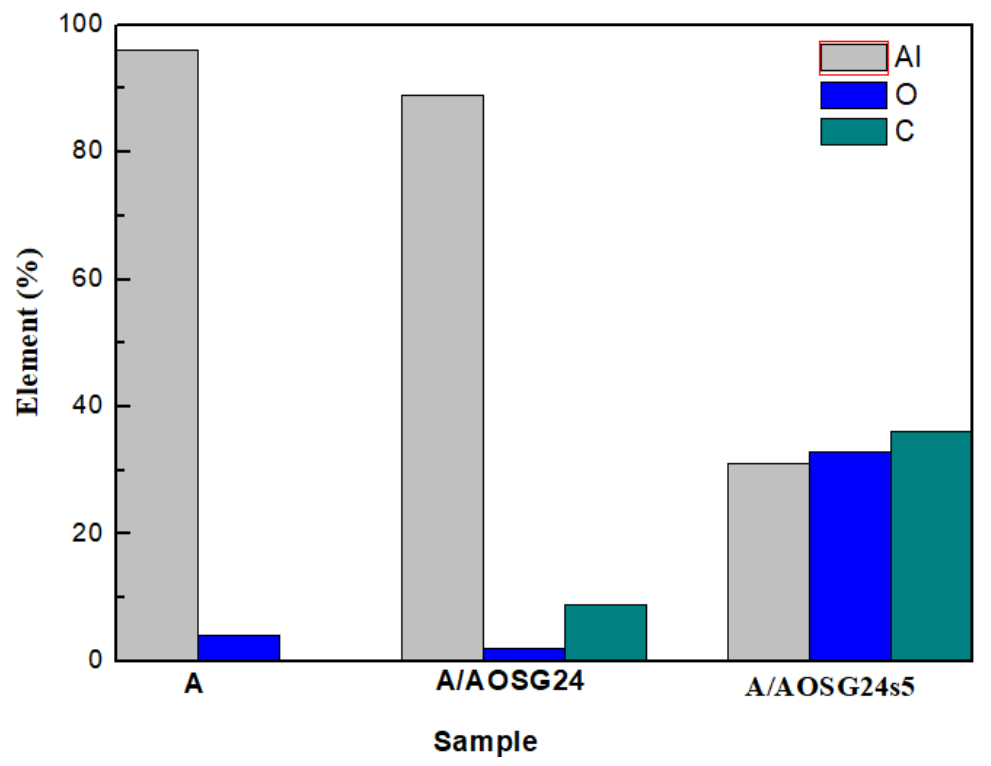

Fig. 2: Elemental composition graphs for Al substrate and alumina matrices

The surface morphology, along with the composition and crystalline structure, is considered an important property with consequences on the optical performances of an absorber material. One of the most efficient and affordable solution to improve the heat transfer and energy efficiency in a solar coating is to used porous materials as components (Rashidi et al., 2017). Both the chemically pre-treated substrate A and the matrix A/AOSG24 show relative porous morphologies with slightly larger pores for the matrix, as is shown in Fig. $3 \mathrm{~b}$. 
The highly porous Al substrate or/and the alumina matrix are expected to represent good hosts for further infiltration with pigment layers to develop efficient solar selective absorber coatings, for coloured solar thermal collectors.

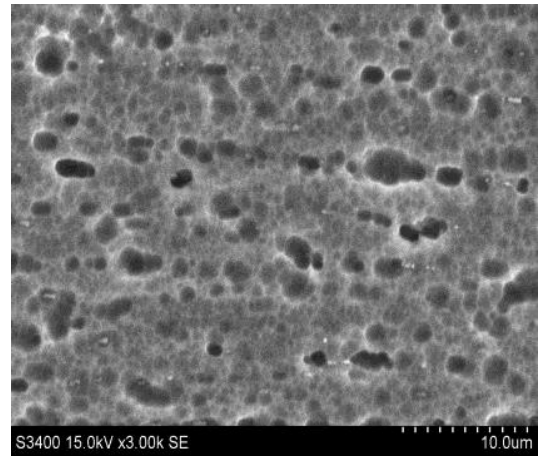

Fig. 3: a) SEM image of optimized substrate A

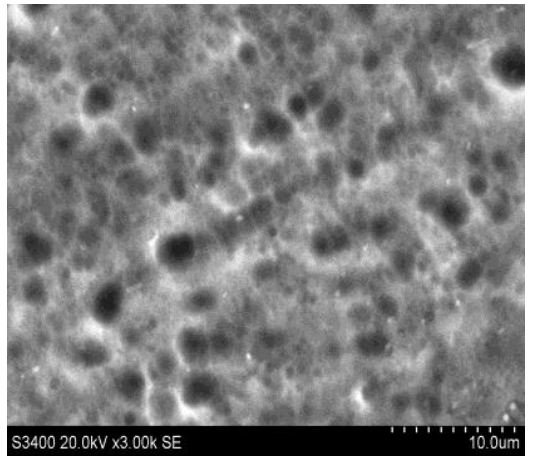

Fig. 3: b) SEM image of alumina matrix A/AOSG24

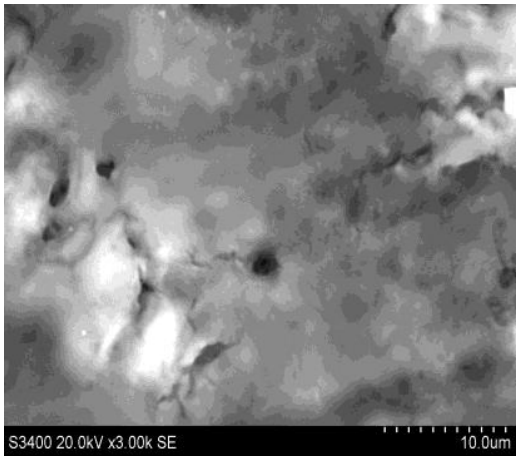

Fig. 3: c) SEM image of alumina matrix A/AOSG24s5

According to the SEM image in Fig. 3c, the morphology of the alumina layer deposited on the optimized Al substrate by spraying, is quite different (with micro-cracks), comparing with morphologies of Al substrate (Fig. 3a) and alumina layer obtained by immersion (Fig. 3b). Moreover, the alumina layer is thicker and covers a large part of the substrate pores, confirming the EDS results. Consequently, the light reflections on this surface are significantly reduced, confirming the increase (almost double) of the thermal emittance value, thus decreasing the optical performances of the alumina matrix A/AOSG24s5.

The solar absorptances $(\alpha)$, calculated from the reflectance spectra of the samples and presented in Table 4, slightly increases for the alumina matrix, while the thermal emittances have different variation: significantly decreases, for matrix obtained by immersion, and are close to that of the substrate, for the matrix obtained by spraying.

Tab. 4: Optical properties for optimized Al substrate and alumina matrices

\begin{tabular}{|c|c|c|c|}
\hline Sample & $\boldsymbol{\alpha}$ & $\boldsymbol{\varepsilon}$ & $\mathbf{S}$ \\
\hline A & 0.13 & 0.22 & 0.59 \\
\hline A/AOSG24 & 0.16 & 0.06 & 2.66 \\
\hline A/AOSG24s5 & 0.19 & 0.24 & 0.79 \\
\hline
\end{tabular}

These results are expected, considering the matrices chemical compositions and surface morphologies and are in good agreement with those obtained from the crystalline phases composition and elemental analysis.

\section{Conclusions}

The first step in designing colored solar selective absorber coatings is the obtaining of an alumina matrix layer with controlled morphology, to be further infiltrated with metal particles or/and inorganic pigment(s).

The paper reports on the development, characterization and optimization (using spectral selectivity $\mathrm{S}$ as output property), of the alumina matrix $\left(\mathrm{Al} / \mathrm{Al}_{2} \mathrm{O}_{3}\right)$ obtained by the deposition of the alumina layer on the optimized, chemically pre-treated aluminum substrate, using two simple and low-cost techniques: immersion and robotic spraying of a diluted alumina sol.

According to the crystalline phases composition and surface morphology, the alumina matrix obtained by immersing the $\mathrm{Al}$ substrate in a diluted alumina sol for 24 hours shows the best optical results: $\alpha=0.16, \varepsilon=0.06$ and $\mathrm{S}=2.66$. This matrix is suitable for further infiltration of yellow (based on $\mathrm{V}_{2} \mathrm{O}_{5}$ ) and green (based on $\mathrm{CuS}$ ) prigment particles to develop colored absorber coatings, for market-acceptable solar thermal collectors with increased architectural acceptance, for facades integration in Nearly Zero Energy Buildings.

\section{References}


Alami, A.H., Aokal, K., 2018. Enhencement of spectral absorption of solar thermal collectors by bulk graphene addition via high-pressure graphite blasting. Energ. Convers. Manage. 156, 757-764. https://doi.org/10.1016/j.enconman.2017.11.040

Balakrishnan, G., Tripura Sundari, S., Ramaseshan, R., Thirumurugesan, R., Mohandas, E., Sastikumar, D., Kuppusami, P., Kim, T.G., Song, J.I., 2013. Effect of substrate temperature on microstructure and optical properties of nanocrystalline alumina thin films. Ceram. Int. 39, 9017-9023. https://doi.org/10.1016/j.ceramint.2015.08.145

Bermel, P., Lee, J., Joannopoulos, J.D., Celanovic, I., Soljačić, M., 2012. Selective solar absorbers - Chapter 7. in: Annual Review of Heat Transfer 15, Begell House Inc., pp. 231-254.

Birkholz, M., 2005. Thin film analysis by X-Ray Scattering. Wiley-VCH Verlag GmbH \& Co.

Céspedes, E., Wirz, M., Sánchez-García, J.A., Alvarez-Fraga L., Escobar-Galindo, R., Prieto, C., 2014. Novel $\mathrm{Mo}-\mathrm{Si}_{3} \mathrm{~N}_{4}$ based selective coating for high temperature concentrating solar power applications. Sol. Energy Mater. Sol. Cells 122, 217-225. https://doi.org/10.1016/j.solmat.2017.08.021

Duta A., Isac L., Milea A., Ienei E., Perniu, D., 2014. Coloured Solar-thermal Absorbers - A Comparative Analysis of Cermet Structures. Energy Procedia 48, 543-553. https://doi.org/10.1016/j.egypro.2014.02.064

Estrella-Gutiérrez, M.A., Lizama-Tzec, F.I., Arés-Muzio, O., Oskam, G., 2016. Influence of a metallic nickel interlayer on the performance of solar absorber coatings based on black nickel electrodeposited onto copper. Electrochim. Acta 213, 460-468. https://doi.org/10.1016/j.electacta.2016.07.125

Fernandes, J.C.S., Nunes, A., Carvalho, M.J., Diamantino, T.C., 2017. Degradation of selective solar absorber surfaces in solar thermal collectors - An EIS study. Sol. Energy Mater. Sol. Cells 160, 149-163. http://dx.doi.org/10.1016/j.solmat.2016.10.015

Isac, L., Nicoara, L., Panait, R., Enesca, A, Perniu, D., Duta, A., 2017. Alumina matrix with controlled morphology for colored spectrally selective coatings. Environ. Eng. Manag. J. 16(3), 715-724.

Isac, L., Panait, R., Enesca, A., Bogatu, C., Perniu, D., Duta, A., 2018. Development of black and red absorber coatings for solar thermal collectors, in: Visa, I., Duta, A. (Eds.), Nearly Zero Energy Communities. Springer Proceedings in Energy. Springer International Publishing AG, pp. 263-282. https://doi.org/10.1007/978-3-31963215-5_20

Khatibani, A.B. and Rozati, S.M., 2015. Optical and morphological investigation of aluminium and nickel oxide composite films deposited by spray pyrolysis method as a basis of solar thermal absorber. Bull. Mater. Sci. 38 (2), 319-326. https://doi.org/10.1007/s12034-015-0880-5

Milea C.A., Ienei E., Bogatu C., Duta A., 2013. Sol-gel $\mathrm{Al}_{2} \mathrm{O}_{3}$ powders-matrix in solar thermal absorbers. J.Sol-Gel Sci. Techn. 67, 112-120. https://doi.org/10.1007/s10971-013-3056-Z

Purghel, E., Voinea, M., Isac, L., Duta, A., 2008. Optical properties of $\mathrm{Ni} / \mathrm{NiO}_{\mathrm{x}}$ as infiltration agent in cermet solar Ir absorber. Rev. Chim-Bucharest 59, 469-471.

Rashidi, S., Esfahani, J.A., Rashidi, A., 2017. A review on the applications of porous materials in solar energy systems. Renew. Sust. Energ. Rev. 73, 1198-1210. https://doi.org/10.1016/j.rser.2017.02.028

Sun, X-Y., Sun, X-D., Li, X-G., Wang Z-Q., He, J., Wang B-S., 2014. Performance and building integration of all-ceramic solar collectors. Energ. Buildings, 75, 176-180. https://doi.org/10.1016/j.enbuild.2014.01.045

Visa, I., Moldovan, M.D., Comsit, M., Neagoe, M., Duta, A., 2017. Facades integrated solar-thermal collectors challenges and solutions, Energy Procedia, 112, 176-185. https://doi.org/10.1016/j.egypro.2017.03.1080

\section{Acknowledgements}

We hereby acknowledge the structural founds project PRO-DD (POS-CCE, O.2.2.1., ID 123, SMIS 2637, No 11/2009) for providing the infrastructure used in this work and the project PNIII-PED SOL_TRI_COL, contract no. 58/2017 financed by UEFISCDI. 


\title{
Experimental Investigations on the Stagnation Behavior of Thermochromic Flat Plate Collectors
}

\author{
Sebastian Müller ${ }^{1}$, Rolf Reineke-Koch ${ }^{1}$, Federico Giovannetti ${ }^{1}$, Bernd Hafner ${ }^{2}$ \\ 1 Institut für Solarenergieforschung Hameln (ISFH), Am Ohrberg 1, D-31860 Emmerthal (Germany), \\ Phone: +49 5151 999-646, E-Mail: mueller@isfh.de \\ 2 Viessmann Werke GmbH \& Co. KG, Viessmannstraße 1, D-35108 Allendorf (Germany)
}

\begin{abstract}
A thermochromic absorber coating in a solar thermal flat plate collector switches its emissivity for thermal radiation depending on the absorber temperature. Thus, the stagnation temperature can be reduced by $30 \mathrm{~K} \mathrm{com-}$ pared to a standard flat plate collector and an overheating of the heat transfer fluid can be prevented. On the basis of 58 selected stagnation events we analyze and compare the stagnation behavior of solar thermal systems with standard and thermochromic collectors. We have carried out well defined stagnation experiments to determine the steam expansion, steam volume and steam producing power for the two solar thermal systems with unfavorable system hydraulics. By the use of thermochromic collectors at a standard system overpressure (1.0 bar) the steam expansion can be halved, the overall steam volume can be lowered by $33 \%$ and the stagnation time can be reduced by $20 \%$. The steam expansion and the vaporization of the heat transfer fluid can be prevented at system overpressures above 3.4 bar and 4.1 bar, respectively. The steam producing power can be limited to $40 \mathrm{~W} \cdot \mathrm{m}^{-2}$.
\end{abstract}

Keywords: thermochromic absorber coating, flat plate collector, stagnation behavior, stagnation load

\section{Introduction}

The stagnation temperature of standard flat plate collectors with a highly selective absorber coating (absorptance $\alpha \geq 95 \%$, emittance $\varepsilon \approx 5 \%$ ) can easily reach up to $200{ }^{\circ} \mathrm{C}$. Especially in summer, with high solar irradiance and low domestic hot water demand, the downtime of the solar pump increases. In case of stagnation, high thermal loads occur both in systems for solar domestic hot water (SDHW) preparation and solar assisted space heating. A stagnation event is usually accompanied with the vaporization of the heat transfer fluid in the collector array. The steam replaces the fluid in the collector and can spread vastly into the solar piping. The temperature stress can damage sensitive solar loop components (e.g. pumps, membrane expansion vessel, insulation material, valves). To protect these components, temperature resistant materials or additional devices have to be installed to withstand the stagnation load. Furthermore, high system temperatures induce a faster degradation of the heat transfer fluid as reported in Scheuren et al. (2006). This results in higher investment, installation and maintenance costs.

The stagnation loads can be reduced significantly by preventing the vaporization of the heat transfer fluid. Scheuren and Kirchner (2008a) investigated the stagnation behavior in detail and characterized different collector types on the basis of their steam producing power. To prevent overheating and handle the stagnation loads, Harrison et al. (2012) and Frank et al. (2015) summarized different protective arrangements and stagnation control strategies. Föste et al. (2016a) and Schiebler et al. (2018a) developed different types of heat pipe collectors which can reduce the thermal stagnation loads by avoiding the vaporization of the heat transfer fluid. Drainback solar thermal systems can prevent the vaporization in the solar loop as well, as reported by Botpaev et al. (2016). To reduce the stagnation loads in flat plate collectors, Brunold et al. (2007) suggested the use of thermochromic layers (based on vanadium oxides) and Föste et al. (2016b) investigated industrially manufactured thermochromic flat plate collectors. First stagnation experiments with these kind of collectors were carried out by Müller et al. (2017). 
Thermochromic absorber coatings have a highly temperature dependent emissivity for thermal radiation. Above a predetermined "switching point" (ca. $68{ }^{\circ} \mathrm{C}$ absorber temperature) its emittance increases from $5 \%$ up to $35 \%$. This process is due to a semiconductor-to-metal transition of the active absorber layer, is fully reversible and increases the thermal heat losses significantly. Thus, the stagnation temperature can be reduced by $30 \mathrm{~K}$ compared to a standard flat plate collector. Despite slightly worse optical properties at the present development stage, the high performance of thermochromic flat plate collectors in a SDHW system was confirmed by Müller et al. (2017) by means of dynamic system testing according to ISO 9459-5.

This paper presents and discusses the experimental results concerning the stagnation behavior of thermochromic flat plate collectors in a SDHW system with a collector area of $10 \mathrm{~m}^{2}$, focusing on the steam expansion, steam volume, steam producing power and the stagnation dynamics.

\section{Process of stagnation}

The downtime of the pump in a solar thermal system despite high solar irradiance is called stagnation. Usually, this operating condition occurs, if the storage tank reaches its cut-off temperature. Stagnation has to be considered as a conventional operating condition during the planning and dimensioning of a SDHW system. However, fatal system errors, like a damaged solar pump, leakages of the piping or a blackout, can effect stagnation too. In this case, the solar irradiance on the collector after solar pump shutdown is still converted into thermal energy, which cannot be transferred to the solar loop. Once the absorber temperature $T_{\mathrm{Abs}}$ exceeds the saturation temperature $T_{\mathrm{S}}$ of the heat transfer fluid at a given system pressure, the fluid starts to vaporize and steam replaces the collector fluid content. The steam spreads into the solar piping and the collector outlet temperatures $T_{\mathrm{FL}}$ and $T_{\mathrm{RL}}$ rise abruptly while the system overpressure $p_{\text {Coll }}$ at the collector outlet reaches a maximum. The remaining liquid vaporizes quickly during the stagnation event and overheated steam can expand into the solar piping. With decreasing irradiance the steam condensates gradually and backs down to the collector. This general stagnation behavior is shown in Fig. 1.

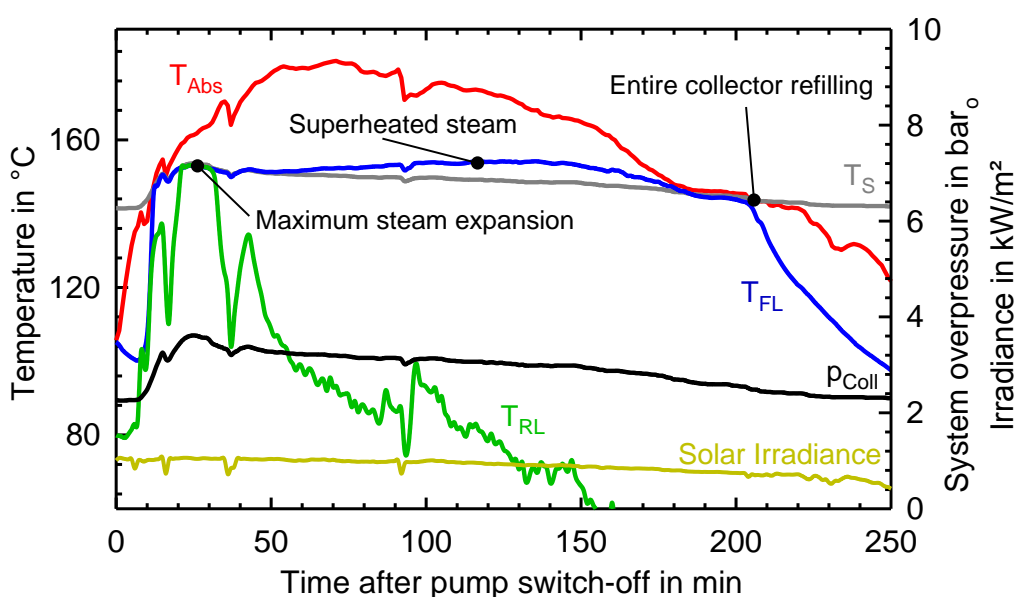

Fig. 1: Typical temporal progression of the system overpressure $\left(p_{\mathrm{Coll}}\right)$, the absorber temperature $\left(T_{\mathrm{Abs}}\right)$ and the temperatures of the collectors' in- and outlet $\left(T_{\mathrm{FL}}, T_{\mathrm{RL}}\right)$ after pump shutdown.

The stagnation process in a solar thermal collector array can be described by characteristic parameters, like the steam expansion into the solar piping, the steam producing power, the system steam volume and the remaining fluid volume within the collector array. These are important indicators for a proper dimensioning of the membrane expansion vessel (MEV) and additional cooling components. They depend on the collector efficiency at stagnation and on the hydraulic design.

\subsection{Steam expansion}

The temporal progression of steam expansion $(S E)$ can be detected by the use of temperature sensors mounted directly onto the stainless steel corrugated solar piping (cf. Fig. 3.b). We identify the steam expansion in the piping by temperature sensors placed at discrete positions $s$. The temperature detected between two nodes $s_{\mathrm{n}}$ and $s_{\mathrm{n}+1}$ is compared to the saturation temperature $T_{\mathrm{S}}$. If the expansion front is located in between these nodes, the distance is averaged accord to eq. 1, both for flow (FL) and return line (RL). The overall steam expansion $S E$ is the sum of the two single steam expansions (cf. eq. 2). 


$$
\begin{aligned}
& S E_{\mathrm{FL} / \mathrm{RL}}=\frac{1}{2} \cdot\left(s_{\mathrm{n}}+s_{\mathrm{n}+1}\right) \\
& S E=S E_{\mathrm{FL}}+S E_{\mathrm{RL}}
\end{aligned}
$$

The uncertainty of this measurement method depends primarily on the distance between two temperature sensors and is equal or lower than $\pm 0.87 \mathrm{~m}$ for $S E$. The saturation temperature $T_{\mathrm{S}}$ of the used heat transfer fluid Tyfocor LS (60 vol\% water, $40 \mathrm{vol} \%$ propylene glycol) depends on the absolute system pressure at the geodetic height of the collector array $p_{\text {Coll, }, \mathrm{a}}$. According to the manufacturers' datasheet, $T_{\mathrm{S}}$ can be calculated approximately as

$$
T_{\mathrm{S}}=100{ }^{\circ} \mathrm{C}+35.1 \mathrm{~K} \cdot \ln \left(p_{\text {Coll,a }}\right) .
$$

\subsection{Steam producing power}

Scheuren et al. (2006) assumed that the thermal losses of the insulated pipe are equal to the steam producing power $(S P P)$ of the collector array at the moment of maximum $S E$, so that $S P P\left[\mathrm{~W} \cdot \mathrm{m}^{-2}\right]$ can be calculated as

$$
S P P=\frac{S E \cdot \dot{q}_{\text {Loss,Pipe }}}{n_{\mathrm{Coll}} \cdot A_{\text {Coll,Ap }}} .
$$

The length-specific thermal losses of the solar piping $\dot{q}_{\text {Loss,Pipe }}$ have been measured in preliminary tests for fluid temperatures up to $105^{\circ} \mathrm{C}$. The results were quadratically fitted in terms of the temperature difference of the fluid temperature $T_{\text {Fluid }}$ and the collector ambient temperature $T_{\text {ca }}$ (cf. eq. 5). In case of a stagnation event, $T_{\text {Fluid }}$ is assumed equal to the saturation temperature $T_{\mathrm{S}}$.

$$
\dot{q}_{\text {Loss,Pipe }}=0.23604 \frac{\mathrm{W}}{\mathrm{m} \cdot \mathrm{K}} \cdot\left(T_{\text {Fluid }}-T_{\text {ca }}\right)+0.00046 \frac{\mathrm{W}}{\mathrm{m} \cdot \mathrm{K}^{2}} \cdot\left(T_{\text {Fluid }}-T_{\text {ca }}\right)^{2}
$$

Based on several stagnation experiments, Scheuren and Kirchner (2008a) developed a model for SPP as a function of the collector efficiency parameters $\left(\eta_{0}, a_{1}\right.$ and $\left.a_{2}\right)$, environmental conditions (effective irradiance $G_{\text {Stag, }}$ ambient temperature $T_{\mathrm{ca}}$ ) and the system pressure (through the saturation temperature $T_{\mathrm{S}}$, cf. eq. 3 ). Their model assumes, that the temperature of the absorber plate and the steam is equal to the saturation temperature $T_{\mathrm{S}}$. At maximum $S E$ a quantity referred to as "theoretical collector performance during stagnation" $P_{\text {Stag }}$ is calculated according to

$$
P_{\mathrm{Stag}}=G_{\mathrm{Stag}} \cdot \eta_{0}-a_{1} \cdot\left(T_{\mathrm{S}}-T_{\mathrm{ca}}\right)-a_{2} \cdot\left(T_{\mathrm{S}}-T_{\mathrm{ca}}\right)^{2} .
$$

From their investigations the authors derived three different collector classes with good (A), moderate (B) and bad (C) draining behavior, which are characterized by increasing SPP.

\subsection{System steam volume}

The overall system steam volume $(S V)$ can be used for both dimensioning the MEV and evaluating the draining behavior of the system. During a stagnation event the replaced collector fluid is received by the MEV and thus, the system pressure increases. The overall system steam volume $S V$ may be referred to the net expansion volume $V_{\exp }$ of the MEV according to

$$
S V=V_{\text {exp, max }}-V_{\text {exp }, 0}
$$

where $V_{\text {exp, } 0}$ and $V_{\text {exp,max }}$ are the volumes at the beginning of the stagnation event and at maximum steam expansion, respectively. This methodology was introduced by Scheuren (2008b). For each MEV the expansion volume as a function of the system overpressure has to be determined in a calibration test bed. The calibration curves for three different pre-set pressures are displayed in Fig. 2. Two MEV specific parameters, the nominal volume $V_{\mathrm{N}}$ and the MEV constant $c_{\mathrm{MEV}}$, are determined during the calibration process as well. The expansion volume $V_{\exp }$ can then be calculated with the measured absolute system pressure $p_{\mathrm{MAG}, \mathrm{a}}$ at the MEV inlet according to eq. 8 .

$$
V_{\text {exp }}=V_{\mathrm{N}}-c_{\mathrm{MAG}} \cdot\left(\frac{T_{\mathrm{MEV}}}{p_{\mathrm{MEV}, \mathrm{a}}}\right)
$$




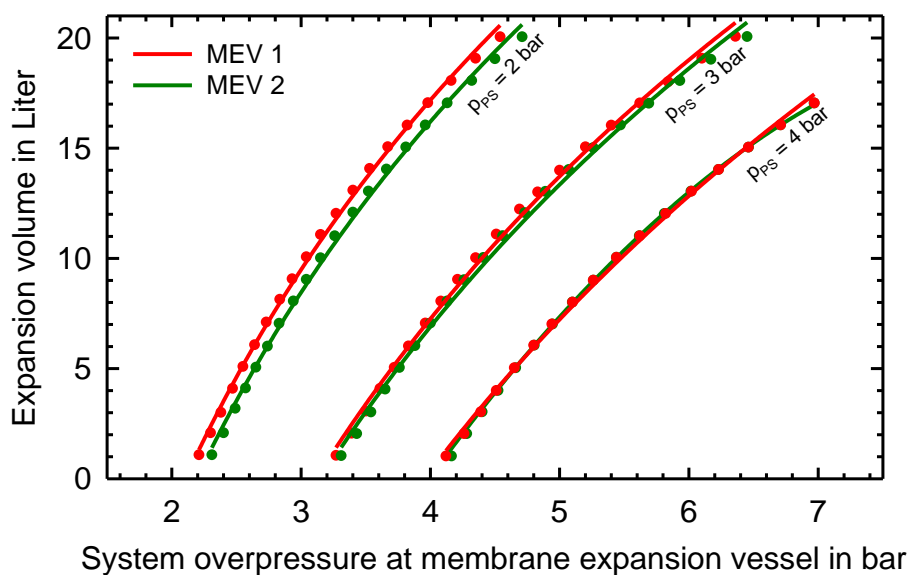

Fig. 2: Expansion volume of both calibrated MEVs with a nominal volume of 50 liters as a function of the system overpressure for three different MEV pre-set pressures.

The nominal volumes of the identically manufactured MEV are $V_{\mathrm{N}, \mathrm{MEV} 1}=46.6$ liters and $V_{\mathrm{N}, \mathrm{MEV} 2}=46.5$ liters. The two MEV constants also depend on the absolute pre-set pressure $p_{\mathrm{ps}, \mathrm{a}}$ and can be calculated as

$$
\begin{aligned}
& c_{\mathrm{MEV} 1}=0.1460 \cdot p_{\mathrm{ps}, \mathrm{a}}-0.067 \text { and } \\
& c_{\mathrm{MEV} 2}=0.1325 \cdot p_{\mathrm{ps}, \mathrm{a}}-0.120 .
\end{aligned}
$$

Following Scheuren (2008b), this calibration method exhibits an uncertainty for the determination of $V_{\operatorname{Exp}}$ for low and high fluid inlet temperatures $T_{\mathrm{MEV}}$ of $5 \%$ and $10 \%$, respectively.

\subsection{Remaining liquid within the collector}

After the collector draining a significant volume of heat transfer fluid can remain in the collector. This remaining fluid volume $(R F V)$ consists of concentrated propylene glycol, which exhibits a higher boiling temperature than water. The amount of $R F V$ depends significantly on the draining behavior of the collector array. $R F V$ is calculated indirectly from the system steam volume $S V$ and the steam expansion $S E$ as

$$
R F V=n_{\text {Coll }} \cdot V_{\text {Coll }}^{\prime}+S E \cdot V_{\text {Pipe }}^{\prime}-S V .
$$

The installed corrugated stainless steel piping has a length-specific fluid volume $V^{\prime}{ }_{\text {Pipe }}=0.27$ liters per meter (DN 16). The collector fluid content $V^{\prime}$ Coll $=1.80$ liters per collector. In both of our systems $n_{\text {Coll }}=4$ collectors are installed. According to Scheuren (2008b), the calculation of the $R F V$ exhibits a large uncertainty of approximately $30 \%$. Especially in the wave troughs of corrugated pipes a not definable amount of fluid can remain. Thus, the real $R F V$ in the collector is always lower than the calculated value according to eq. 10 .

\section{Experimental investigations on the stagnation behavior}

Föste et al. (2016b) predicted by means of simulations, that a thermochromic SDHW system could lower the stagnation time (here: timespan, during which the absorber temperature is above $120{ }^{\circ} \mathrm{C}$ ) by more than $70 \%$. To verify their simulative results, we have carried out extensive stagnation tests on real systems under natural environmental conditions.

\subsection{Experimental setting}

Two identical SDHW systems were installed on an outdoor testing roof at ISFH: A thermochromic system and a reference system with standard flat plate collectors (see Fig. 3.a). Each collector array consists of four flat plate collectors with a gross area of $10 \mathrm{~m}^{2}$. The solar piping of both systems feature identical designs, so as to guarantee the same thermohydraulic behavior. The overall length of the solar piping is $30 \mathrm{~m}$ for each system, installed bottom-up the roof, which can be considered as a worst-case scenario. Hence, the measured steam expansion and steam volume can be considered as maximum values for this hydraulic configuration.

We installed temperature sensors (Pt1000) in the wave trough of the corrugated stainless steel piping, starting from the collector in- and outlet in regular intervals of 1.5 meters, to determine the steam expansion according 
to eq. 1 . The temperature distribution in the collector array is measured at the absorber plate of each collector. In addition, we installed sensors at thermal sensitive components, like the MEV or the solar pump. One pressure sensor was added at the collector array outlet to investigate the stagnation dynamics and possible hydraulic shocks. All sensors and their positions are displayed in the hydraulic schema of Fig. 3.b.

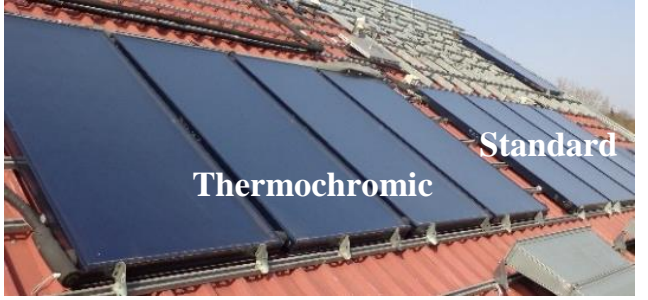

a)

b)

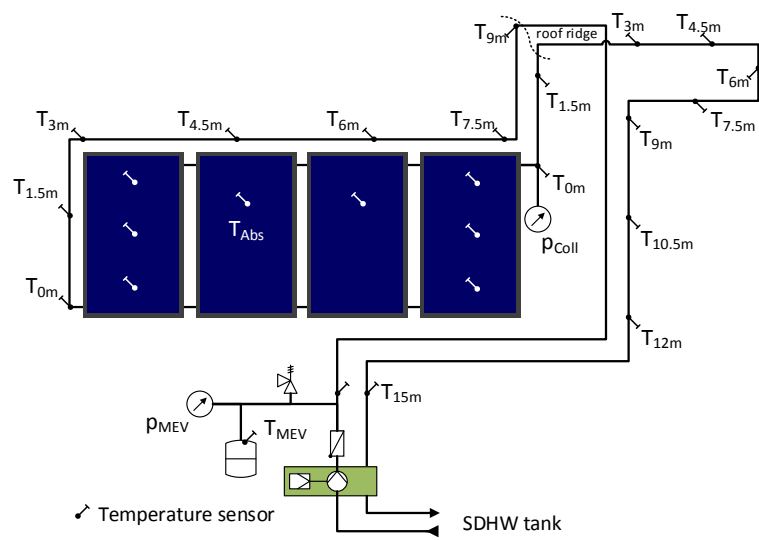

Fig. 3: Standard and thermochromic SDHW systems installed on our outdoor testing roof to evaluate the stagnation loads (a) and positions of the sensors used in our investigations (b).

We performed several stagnation tests by operating the two systems synchronously to directly compare their stagnation behavior. The stagnation events were carried out in the evaluation period from 20.06. - 21.10.2017 and 03.04. - 02.07.2018 (212 days, 4.898 hours of data) under natural environmental weather conditions with a great variability of the ambient temperature $T_{\text {ca }}\left(16.6 \ldots 37.0^{\circ} \mathrm{C}\right)$ and the effective solar irradiance $G_{\text {Stag }}$ $\left(800 \ldots 1150 \mathrm{~W} \cdot \mathrm{m}^{-2}\right)$ at the beginning of a stagnation event. We operated both SDHW systems on four different resting overpressures measured at the geodetic height of the collector outlet (cf. Fig. 3.b) between 1.0 and 4.0 bar. This pressure is referred to as "system overpressure" in the sequel.

\subsection{Methodology of evaluation}

The experiments can be distinguished into two characteristic stagnation types: full-time stagnation and noon stagnation. At a full-time stagnation the solar pump remains deactivated throughout the day, which results in an early stagnation start. Hence, the stagnation time and the maximum thermal loads of the heat transfer fluid can be determined. At a noon stagnation the solar pump is switched off manually at solar noon (circa 12:00...12:30PM). Both stagnation types are presented in Fig. 4. During the considered experimental period we have recorded 58 stagnation events, 34 of them as noon and 24 as full-time stagnation experiments.
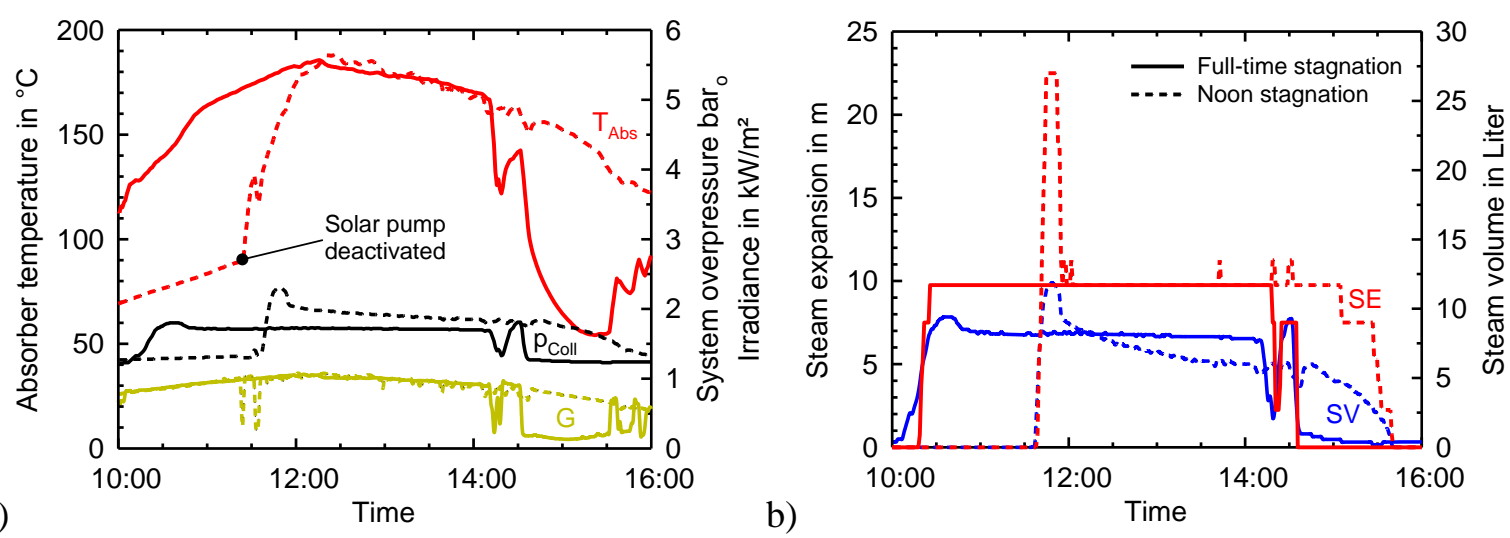

Fig. 4: Absorber temperature $T_{\mathrm{Abs}}$ and overpressure at collector height $p_{\text {Coll }}$ (a) as well as steam expansion $S E$ and steam volume $S V$ (b) of thermochromic and standard system in comparison for different stagnation types. The slashed and the solid curves are related to a noon stagnation and a full-time stagnation, respectively.

The maximum absorber temperature $T_{\mathrm{Abs}}$ is independent from the stagnation type and reaches in both cases $190{ }^{\circ} \mathrm{C}$ for a standard flat plate collector. During a full-time stagnation the vaporization starts typically at approximately $10 \mathrm{AM}$, indicated by the increase of the system overpressure $p_{\text {Coll }}$ from 1.2 bar to 1.8 bar. In contrast, for a noon stagnation experiment we detected overpressures up to 2.3 bar (see Fig. 4.a). The collector 
efficiency at the beginning of the stagnation event is an important indicator for the $S E$. Due to high solar irradiance, the collector efficiency for a noon stagnation is higher than for a full-time stagnation and results in an $S E$ of $23 \mathrm{~m}$. If the vaporization starts early in the morning, the $S E$ does not exceed $11 \mathrm{~m}$ in our experiments (see Fig. 4.b).

\section{Evaluation of stagnation events}

\subsection{Thermal loads}

We define the stagnation time $t_{\text {Stag }}$ as the timespan between beginning vaporization of the heat transfer fluid and full re-condensation of any steam in the system. At a standard system overpressure of $1.0 \mathrm{bar}, t_{\text {stag }}$ can be reduced with thermochromic collectors by $20 \%$ and at 3.0 bar up to $60 \%$. The measured temperature and steam expansion distributions as detected for four system overpressures are displayed in Fig. 5 for noon stagnations.

a)
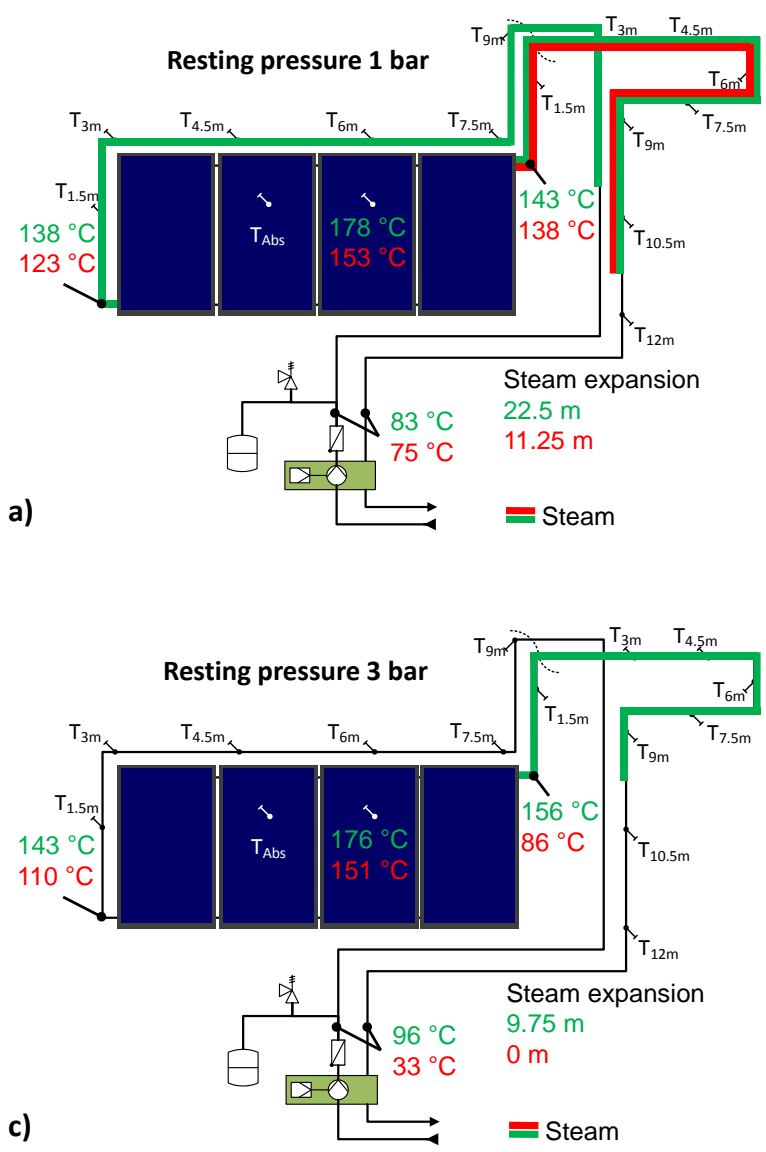
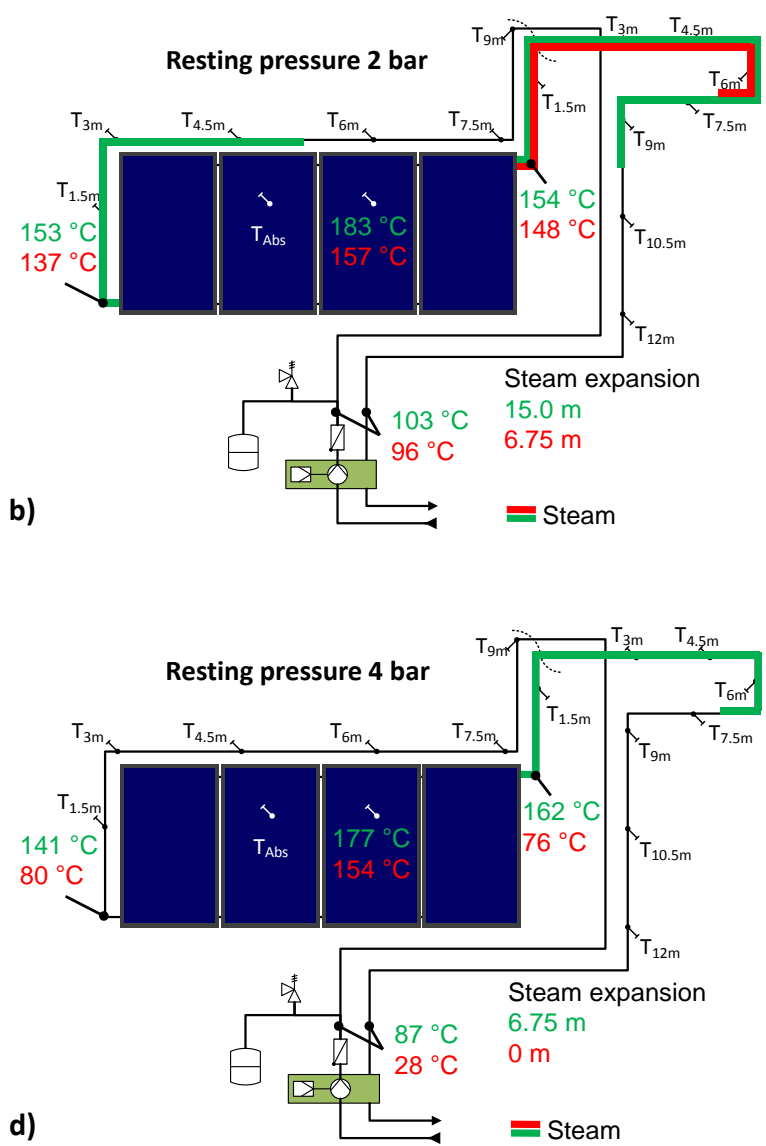

Fig. 5: Temperature distribution and steam expansion in both SDHW systems for four representative noon stagnation events. (green values: standard collector, red values: thermochromic collector)

At a system overpressure of 1.0 bar, the absorber temperature exceeds easily the current saturation temperature (ca. $125^{\circ} \mathrm{C}$ ) and the heat transfer fluid vaporizes. In the reference system with standard collectors and in the system with thermochromic collectors we detect a steam expansion of $22.5 \mathrm{~m}$ and $11.3 \mathrm{~m}$, respectively (see Fig. 5.a). The installed temperature sensors allow a time-resolved analysis of the draining behavior. In both SDHW systems the heat transfer fluid is draining through the return line in case of vaporization and thereupon the steam expands only in the flow line at first. The steam spreads into the upper section of the piping up to the geodetic height of the collector array inlet and not till then into the return line as well. In the thermochromic system we can only detect a steam expansion into the flow line due to a permanently refilling of the collector array over the return line. We can report a reduction of the maximum absorber temperature of thermochromic collectors up to $25 \mathrm{~K}$ compared to standard flat plate collectors. Due to the length of the solar piping the steam never expands to sensitive system components. Nevertheless, hot fluid may reach the solar pump station or the MEV. At a system overpressure of 2.0 bar temperatures of $100{ }^{\circ} \mathrm{C}$ were detected at the solar pump station (see Fig. 5.b). In contrast, for the thermochromic system at elevated system overpressure the temperature does not 
exceed $35{ }^{\circ} \mathrm{C}$. If the steam expansion can be prevented, the maximum collector outlet temperature in the thermochromic system decreases to $86{ }^{\circ} \mathrm{C}$ compared to $156{ }^{\circ} \mathrm{C}$ for standard flat plate collectors (see Fig. 5.c) and the inlet temperatures can be reduced to $110^{\circ} \mathrm{C}$. At a system overpressure of 4.0 bar any vaporization in the thermochromic system can be prevented (see Fig. 5.d). Thus, the collector array in- and outlet temperatures do not exceed $80{ }^{\circ} \mathrm{C}$ compared to $160{ }^{\circ} \mathrm{C}$ in the standard system.

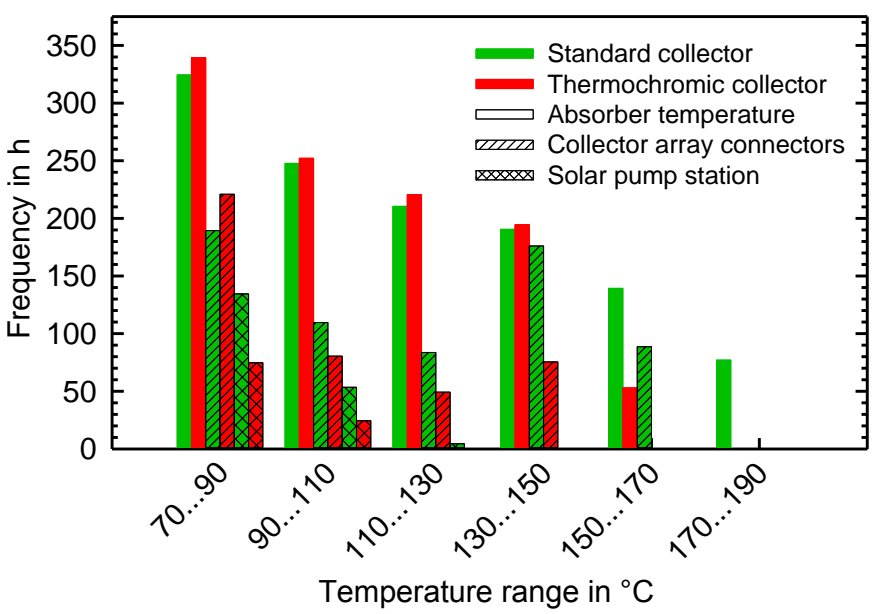

Fig. 6: Frequency distribution of several system temperatures occurred during the evaluation period for the standard (green) and the thermochromic (red) SDHW system.

We provide the frequency distributions of the observed temperatures in Fig. 6. We report maximum absorber temperatures in the thermochromic and standard system up to $164{ }^{\circ} \mathrm{C}$ and $191{ }^{\circ} \mathrm{C}$, respectively. For a total time of 77 hours temperatures above $170{ }^{\circ} \mathrm{C}$ occurred in the standard system, which exceeds the design temperature of the heat transfer fluid. High thermal loads lead to a thermal decomposition of the propylene glycol, which can strongly reduce its lifetime and can impair the reliability of the whole system. The temperature at the collector array connectors (maximum in- and outlet temperature) during stagnation is primarily defined by the saturation temperature $T_{\mathrm{S}}$ due to steam expansion into the solar piping. Maximum temperatures of $150{ }^{\circ} \mathrm{C}$ and $167{ }^{\circ} \mathrm{C}$ can be measured for the thermochromic and the standard SDHW system, respectively. According to the manufacturer, the design temperature of the solar pump station is $110^{\circ} \mathrm{C}$. Maximum temperatures directly in front of the solar pump station higher than $120{ }^{\circ} \mathrm{C}$ temporarily occur in both systems. We measured for a total time of 0.8 hours and 4.8 hours temperatures higher than $110^{\circ} \mathrm{C}$ in the thermochromic and the standard SDHW system, respectively. Especially at low system overpressures of $1 \ldots 2$ bar, a noon stagnation results in a high steam expansion and thus high temperatures at the solar pump station.

\subsection{Steam expansion}

The maximum steam expansion ( $S E$ ) have generally been observed for noon stagnation experiments. The measured $S E$ for both systems is plotted against the system overpressure in Fig. 7. At 1.0 bar a noon stagnation results for the standard and the thermochromic system in a $S E$ of $22.5 \mathrm{~m}$ and $11.3 \mathrm{~m}$ respectively. The steam expansion is halved for thermochromic collectors at this specific system overpressure. Above a system overpressure of 3.4 bar, the steam expansion into the solar piping is suppressed for the thermochromic system. In the standard system we still measure a steam expansion of $10 \mathrm{~m}$. For full-time stagnations, the $S E$ in the thermochromic system is generally $40 \ldots .50 \%$ lower than in the reference system.

The great variability of measured $S E$ for one specific system overpressure results on the one hand on the different environmental weather conditions (cf. Fig. 8.a) and on the other hand on noon-stagnation events, which were temporarily interrupted by clouds while steam expansion. 


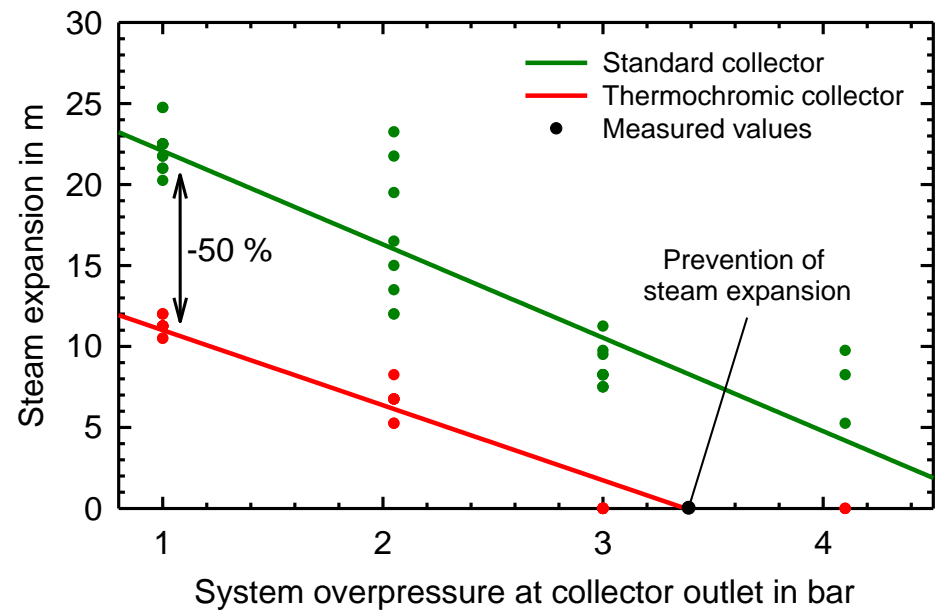

Fig. 7: Steam expansion as a function of the system overpressure at the collector outlet for all measured noon stagnations.

\subsection{Steam producing power}

The resulting SPP are shown in Fig. 8.a as a function of the effective solar irradiance $G_{\text {Stag. }}$. We employ linear regressions to emphasize the trend progression. Inspection shows that for the standard collector under full-time stagnation conditions the SPP is $55 \%$ lower than under noon stagnation conditions. For thermochromic collectors the $S P P$ is limited to approximately $40 \mathrm{~W} \cdot \mathrm{m}^{-2}$. The mean $S P P$ for different system overpressures are represented in Fig. 8.b. We see that at a system overpressure of 1.0 bar the mean $S P P$ is $77 \mathrm{~W} \cdot \mathrm{m}^{-2}$ and $37 \mathrm{~W} \cdot \mathrm{m}^{-2}$ for standard and thermochromic collectors, respectively. Similar results are reported for a system overpressure of 2.0 bar. We conclude that the SPP of the studied systems is reduced by about $50 \%$ with thermochromic compared to standard collectors. Note that for system overpressures above 3 bar no steam expansion occurs in the thermochromic system, due to the high saturation temperature of the heat transfer fluid (cf. Fig. 7). The error bars characterize a variability of the results of up to $\pm 15 \mathrm{~W} \cdot \mathrm{m}^{-2}$.
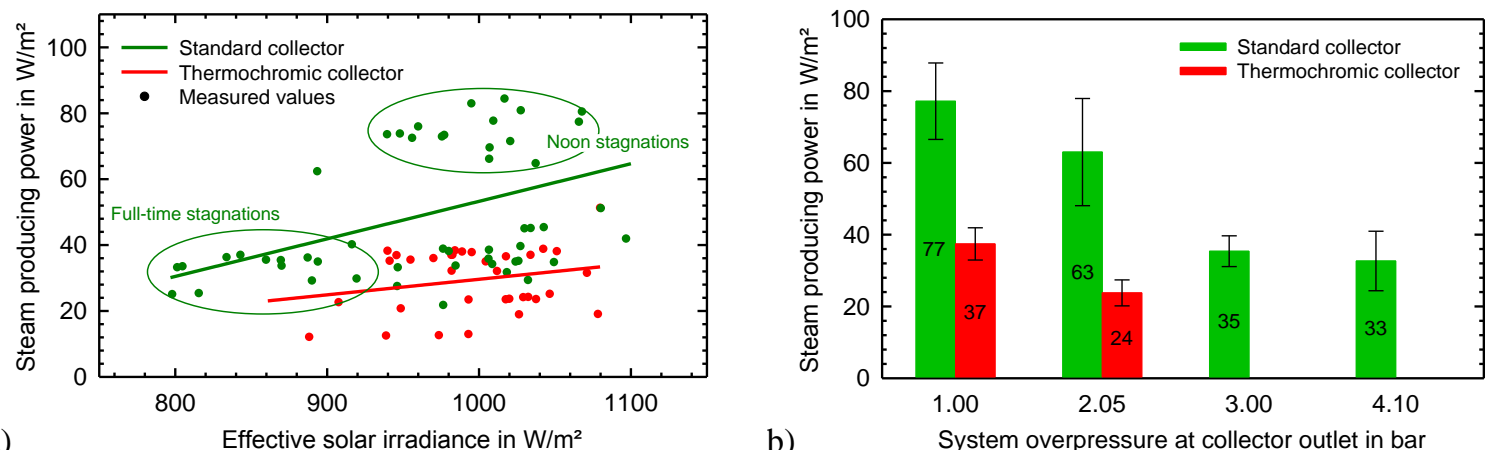

Fig. 8: Steam producing power as a function of the effective solar irradiance for all measured stagnation events (a) and mean $S P P$ plotted against the system overpressure at collector outlet just for noon stagnations (b). The error bars represent the standard deviation of the calculated mean SPP.

The theoretical collector performance of all experiments are evaluated according to the model of Scheuren and Kirchner (2008a) (cf. eq. 6, see Fig. 9). Again, linear regressions are used to visualize trend behavior. The plots confirm that the SPP increases with the theoretical collector performance, as expected. According to their classification the standard system may be categorized as Class B, which corresponds to a system with flat plate collectors and unfavorable draining behavior in the author's original work. The thermochromic system exhibits under identical hydraulic conditions lower $S P P$ and may be classified between Class A and B, according to this scheme. We conclude that an increase of $P_{\text {Stag }}$ in the thermochromic system results in lower SPP compared to the standard system. 


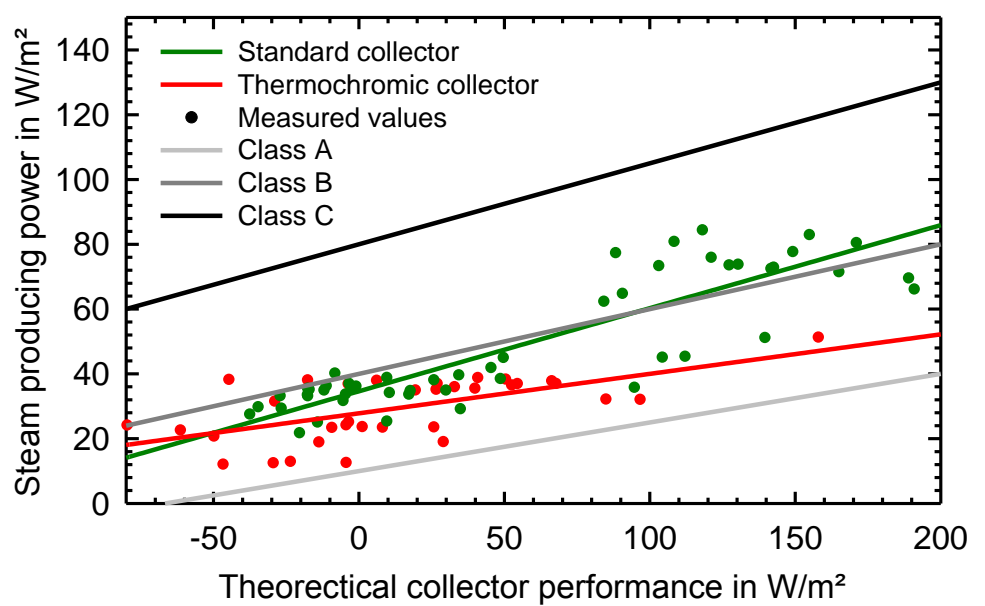

Fig. 9: Steam producing power as a function of the theoretical collector performance for all measured stagnation events.

Note that for negative theoretical collector performances both collector arrays produce a significant amount of steam, which is basically related to the model assumption, that the mean collector (absorber and fluid) temperature is equal to the saturation temperature $T_{\mathrm{S}}$ (cf. eq. 6). For collectors with unfavorable draining behavior this assumption might often not be valid, because a great amount of remaining fluid volume could significantly reduce the average collector temperature.

\subsection{Steam volume and remaining fluid}

The overall system steam volume, which we determine with the calibrated MEVs (cf. eq. 7), is shown as a function of the system overpressure in Fig. 10. For system overpressures of 1.0 bar, $S V$ can be reduced by $33 \%$ with thermochromic collectors. For 2.0 bar, $S V$ can be halved compared to standard collectors. Although we could not measure a $S E$ for a system pressure above 3.0 bar, a certain amount of 2 liters can be detected within the thermochromic system. The steam does not expand into the solar piping and only remains within the collector array. Based on the physical properties of the heat transfer fluid and the occurring temperatures, the vaporization can be prevented above system overpressures of 4.1 bar (stagnation temperature $157^{\circ} \mathrm{C}$ ) for thermochromic collectors, whereas 9.6 bar would be necessary for standard collectors $\left(183^{\circ} \mathrm{C}\right)$. Such a high system overpressure clearly exceeds the components acceptable operating conditions.

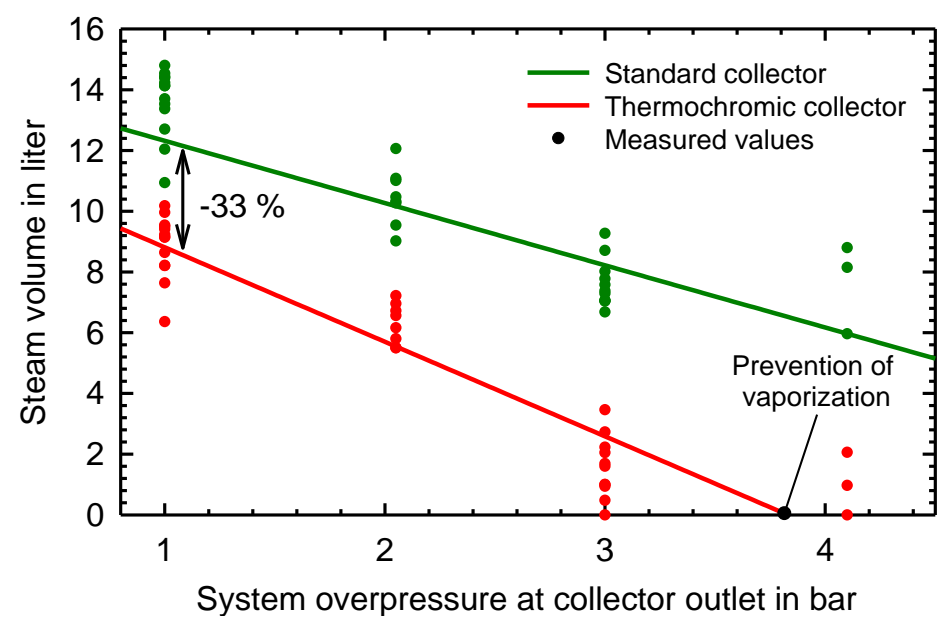

Fig. 10: Steam expansion as a function of the system overpressure at collector outlet for noon stagnations.

The remaining fluid volume $(R F V)$ was calculated for all selected noon stagnations according to eq. 10 and is plotted in Fig. 11. Generally, the $R F V$ depends on the system overpressure. With rising system overpressure the collector efficiency and thus, the steam volume and steam expansion decreases, while the mean $R F V$ increases. We could determine mean $R F V \mathrm{~s}$ at standard system overpressure (1.0 bar) of 0.4 and 1.4 liters for the standard and thermochromic system, respectively. At 2.0 bar the mean $R F V$ s increase to 1.4 and 2.7 liters and at 3.0 bar to 1.8 and 5.5 liters. The measured steam expansion at a specific system overpressure is almost independent from the $R F V$. In our investigation a large number of measured $R F V \mathrm{~s}$ can result in the same steam expansion. In 
the thermochromic system for example at a system overpressure of 1.0 bar we measured $R F V$ s between 0.1 and 4.1 liters, which correspond to measured steam expansions between 10.5 and $12 \mathrm{~m}$.

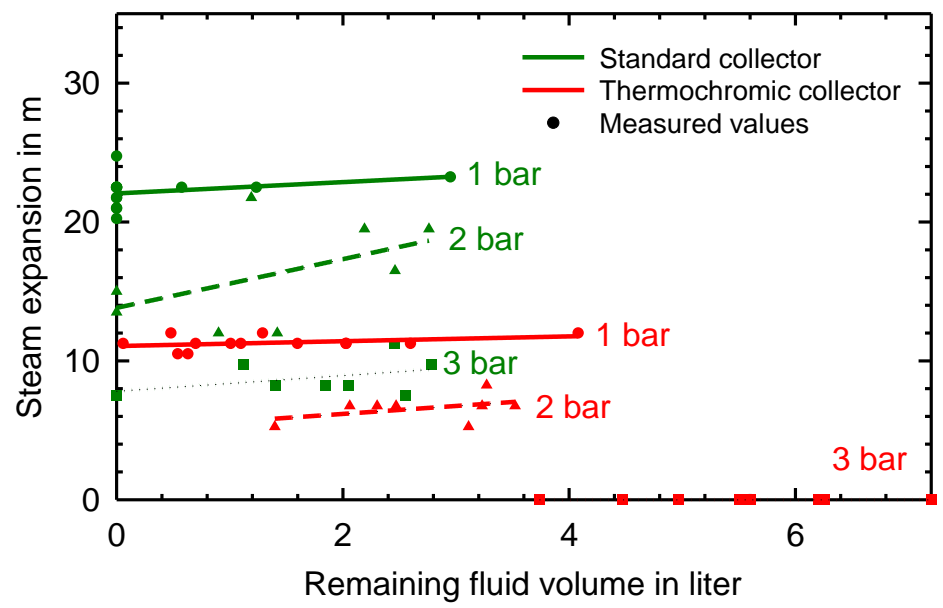

Fig. 11: Steam expansion as a function of the remaining fluid volume at various system overpressures for noon stagnations.

We can determine only a marginal increase of steam expansion for higher values of $R F V$ (linear regressions in Fig. 11). At low $R F V \mathrm{~s}$ the collector piping is extensively filled with steam and the heat transfer between the absorber plate and the heat transfer fluid is inhibited. Hence, the collector efficiency decreases and the steam expansion is accordingly lower. Furthermore, the collector array hydraulics and the connection of the solar piping are significantly responsible for the amount of $R F V$.

\section{Conclusions and outlook}

We experimentally investigated the stagnation behavior of thermochromic flat plate collectors in a solar thermal domestic hot water system by analyzing several stagnation events in detail. For our tests we installed two collector arrays consisting of four standard and four thermochromic collectors respectively, with an overall gross area of $10 \mathrm{~m}^{2}$ each. The two systems were operated synchronously under the same environmental conditions. We identified and evaluated important system parameters, like the steam expansion, the overall system steam volume and the remaining fluid volume in the collector.

On the basis of 58 selected stagnation events at four different system overpressures, we report a significant reduction of the thermal loads in the thermochromic system in case of stagnation compared to the standard system. The maximum absorber temperature can be reduced up to $30 \mathrm{~K}$, which confirms our previous laboratory results (Föste et al., 2016b). At a system overpressure of 1.0 bar the steam expansion into the solar piping can be halved from $22.5 \mathrm{~m}$ to $11.3 \mathrm{~m}$ and the overall system steam volume can be reduced by $33 \%$. At a system overpressure of 2.0 bar the thermal loads are significantly lower: By the use of thermochromic collectors both the stagnation time (here: timespan, in which any steam occurs in the system) and the steam volume can be halved. At a system overpressure of 3.4 bar the steam expansion in the thermochromic system can be prevented. Hence, the temperature at the collector in- and outlet can be limited to $110{ }^{\circ} \mathrm{C}$ and reduced by $70 \mathrm{~K}$. At system overpressures above 4.1 bar the vaporization of the heat transfer fluid can be avoided. For the standard system this state is expected above 9.6 bar, i.e. for pressure conditions which solar components are not designed for.

We conclude, that the use of thermochromic collectors in a commonly dimensioned solar thermal system operating under standard conditions can significantly reduce the temperature occurring in the case of stagnation. By slightly increasing the system pressure, the vaporization can be completely suppressed and thus, the thermal load in the whole system can be reduced. This offers a great potential for a substantial reduction of the specific system costs for investment, installation (e.g. use of plastics for the solar piping or avoidance of additional measures like cooling devices) and maintenance (e.g. longer lifetime of the heat transfer fluid) as reported by Schiebler et al. (2018b). 


\section{Acknowledgement}

This investigations were carried out in the frame of the project "Process technology, quality assessment and system solutions for thermochromic absorbers in solar thermal collectors (ProTASK)", which is funded by the German Federal Ministry of Economic Affairs and Energy based on a decision of the German Federal Parliament (reference numbers 0325858 A and B). The project ProTASK is carried out in cooperation with Viessmann Werke GmbH \& Co. KG.

The authors are grateful for the financial support and responsible for the paper's content.

\section{References}

Botpaev, R., Louvet, Y., Perers, B., Furbo, S., Vajen, K., 2016. Drainback solar thermal systems: A review. Solar Energy 128, pp. 41 - 60. DOI: 10.1016/j.solener.2015.10.050.

Frank, E., Mauthner, F., Fischer, S., 2015. Overheating prevention and stagnation handling in solar process heat applications. IEA SHC Task 49, Technical Report A.1.2.

Föste, S., Schiebler, B., Giovannetti, F., Rockendorf, G., Jack, S., 2016. Butane heat pipes for stagnations temperature reduction of solar thermal collectors. Energy Procedia 91, pp. 35 - 41. DOI:

10.1016/j.egypro.2016.06.168.

Föste, S., Pazidis, A., Reineke-Koch, R., Hafner, B., Mercs, D., Delord, C., 2016. Flat plate collectors with thermochromic absorber coatings to reduce loads during stagnation. Energy Procedia 91, pp. 42 - 48. DOI: 10.1016/j.egypro.2016.06.169.

Harrison, S., Cruickshank, C. A., 2012. A review of strategies for the control of high temperature stagnation in solar collectors and systems. Energy Procedia 30, pp. 793 - 804. DOI: 10.1016/j.egypro.2012.11.090.

ISO 9459-5, 2007. System performance characterization by means of whole-system tests and computer simulation. Beuth Verlag, Berlin.

Müller, S., Reineke-Koch, R., Giovannetti, F., Hafner, B., 2017. Flat Plate Collectors with Thermochromic Absorber Coating Under Dynamic System Tests. Proceedings ISES Solar World Congress 2017, pp. 2062 2070, Abu Dhabi. DOI: 10.18086/swc.2017.31.10.

Scheuren, J., Kirchner, M., Eisenmann, W., 2006. Reduction of Stagnation Load of Large-Scale Collector Arrays. Proceedings EuroSun 2006, International Solar Energy Society (ISES), Freiburg.

Scheuren, J., Kirchner, 2008. Analysis and Prediction of the Steam-Producing Power in Large-Scale Collector Arrays under Stagnation Conditions. Proceedings EuroSun 2008, International Solar Energy Society (ISES), Freiburg.

Scheuren, J., 2008. Untersuchung zum Stagnationsverhalten solarthermischer Kollektorfelder. Kassel University Press.

Schiebler, B., Jack, S., Dieckmann, H., Giovannetti, F., 2018. Experimental and theoretical investigations on temperature limitation in solar thermal collectors with heat pipes: Effect of superheating on the maximum temperature, Solar Energy 171, 271 - 278. DOI: 10.1016/j.solener.2018.06.036.

Schiebler, B., Giovannetti, F., Fischer, S., 2018: Levelized cost of heat of solar domestic hot water systems with overheating prevention, IEA SHC TASK 54, Info Sheet B5. 


\title{
Theoretical Analysis of Combined Solar System Based on Dual Purpose Solar Collector
}

\author{
Viacheslav Shemelin ${ }^{1}$, Nikola Pokorny ${ }^{1}$, Tomas Matuska ${ }^{1}$ and Borivoj Sourek ${ }^{1}$ \\ ${ }^{1}$ University Centre for Energy Efficient Buildings, Czech Technical University in Prague
}

\begin{abstract}
In the present work, the detailed mathematical model of a dual purpose solar collector (DPSC) has been developed and experimentally verified. To demonstrate the application of the DPSC, three buildings with different energy consumption were chosen as case studies and four solar collector systems were compared among one another. The solar yield of the described systems was determined by detailed thermal simulations in TRNSYS using TRNSYS Building environment (TRNBuild) and a detailed theoretical model of DPSC. The results of the modeling indicate that, in the case of combining domestic hot water preparation system and recirculating air heating system based on DPSC, it is possible to achieve a higher solar energy yield compared to a conventional solar domestic hot water preparation system.
\end{abstract}

Keywords: Solar energy, Dual purpose solar collector, Detailed model, Performance analysis

\section{Introduction}

Flat plate solar collectors are probably the most fundamental and most studied technology for solar-power domestic hot water systems. Flat plate collector technology has evolved over 60 years. Products on sale today have been proven to be durable and reliable and therefore collectors are considered as a fairly mature technology. However, even if this device has reached good technological level and position on the market, the scientific, and technological world has shown a constant attention to improve the energy performance of the collector. The ways of increasing the energy performance generally can be divided into two categories: the use of new technology, material, component and the combination of already existing solar utilization technologies in one facility (hybrid collector).

The objective of combining two different solar utilization technologies is to make application field for given collector wider and increase potential energy gain from the area occupied by the collector. Known example of such multipurpose collector is e.g. photovoltaic-thermal solar collector combining PV technology and solar thermal collector. The present study is focused on dual fluid solar collector, combining air and liquid solar collector. The idea to combine both types of technology in dual purpose solar collector (DPSC) is not new. It has emerged from the typical situation for moderate and cold climatic zones, where solar radiation is sufficient for preparation of hot water for households needs $\left(50-60^{\circ} \mathrm{C}\right)$ in summer, whereas the output temperatures from solar collectors in winter generally do not reach values higher than $30^{\circ} \mathrm{C}$, however, it can be sufficient, for example, for pre-heating of fresh air. Such integrated design allows to increase an annual energy yield of the solar system and to maximize the operation time, which makes it more cost-effective than the conventional solar water or air systems.

Number of researchers has studied the thermal performance of solar collectors working with two different types of fluids simultaneously. Assari et al. (2011) presented a mathematical model for dual purpose solar collector by effectiveness method. The model was experimentally verified and subsequently was used for the performance analysis of dual purpose solar collector with three different kinds of air channels, such as: rectangular fin, triangular fin and without fin. The results of the modelling indicated that rectangular have better performance compared with the others. Jafari et al. (2011) provided energy and exergy analysis of dual purpose solar collector with triangle air channels. The study showed that dual purpose solar collector has better energy and exergy efficiency that conventional liquid or air collector. Ma et al.(2011) presented experimental and theoretical analysis of the efficiency of dual purpose solar collector with L-shape fins and confirmed that the air flow rate is a key factor for the thermal efficiency. Later Mohajer et al. (2013) conducted an experimental investigation of dual 
purpose solar collector designed by Assari et al. (2011). The experiments showed that the system based on dual purpose solar collectors could be used as for domestic drying system as well as for providing domestic hot water. Arun and Arun (2013) concentrated their research on the utilization of porous medium in the construction of dual purpose solar collector and indicated that utilization of porous medium lead to the increase in the thermal efficiency of the collector. Nematollahi et al. (2014) presented an experimental comparison of single purpose solar system based on liquid collector and dual purpose solar system based on dual purpose solar collector. The results showed the dual purpose system has higher efficiency than single purpose. Venkatesh and Christraj (2015) provided an experimental investigation of multipurpose solar collector system based on combination of water an air collector and confirmed the higher system efficiency compared with the conventional system. As opposed to the previous studies, Ji et al. (2011) provided an analysis of the separate utilization of air and water parts of dual purpose solar collector. In the proposed system building-integrated dual-function solar collector was used to provide space heating in cold winter and water heating in summer. The results showed a decrease in heating load in winter and well performed hot water preparation system in summer season.

In the present study, the detailed theoretical model of DPSC has been developed and experimentally verified. Subsequently the model had been used for annual performance simulation of four different solar systems. To demonstrate the application of the DPSC, three buildings with different energy consumption were chosen as case studies. The distinctive feature of the presented study is a comparison of the different potential applications of dual purpose solar collectors for the buildings with the different heat energy consumption.

\section{Detailed Theoretical Model of DPSC}

A presented theoretical model of dual purpose solar collector (Type 207) has been developed for TRNSYS simulations based on the previous self-developed models of liquid solar collector (Type 205) and air solar collector (Type 206). More detail information about these models could be found in Shemelin and Matuska, (2017a), Shemelin and Matuska, (2017b) and Shemelin et al. (2017).

\subsection{Description of the Model}

The presented model is a detailed mathematical model developed for thermal performance simulations of two different solar collector designs. The considered designs of DPSC shown in Fig. 1: Design 1 - It is an absorber pipe upper bond configuration with a single air flow between absorber and a bottom plate; Design 2 - It is an absorber pipe upper bond configuration with a single air flow between an absorber and a transparent insulation.

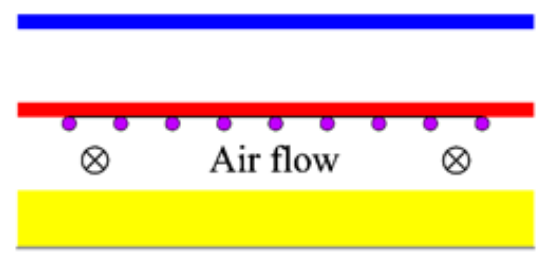

Design 1

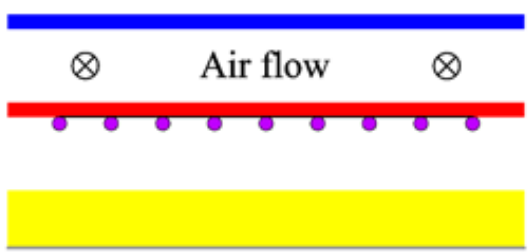

Design 2

Fig. 1: The considered solar DPSC designs

The DPSC can be specified by a variety of detailed parameters, optical properties of the transparent cover, the absorber and thermophysical properties of main components of the solar collector. Moreover, the transparent cover (glazing, plastic or another transparent insulation structure) and the back thermal insulation are defined by temperature dependent thermal conductance.

The implementation of the model in TRNSYS environment as Type 207 offers the parametric analysis for different construction alternatives for annual solar collector performance in the given solar system application. There is also a possibility to change mathematical models describing the fundamental heat transfer phenomena (natural convection, wind convection, forced convection, etc.) and perform sensitivity analysis for selection of the models.

The presented model does not imply simultaneous work of liquid and air part. It means that DPSC model operates either as a liquid collector or as an air collector, depending on the input - Operating Mode. If Operating Mode is equal to 0 , the model operates as a liquid collector; if it is equal to 1 , it operates as an air collector. 


\subsection{Liquid mode (operation of solar liquid collector)}

The core of the liquid mode (operation of solar collector for liquid heating) is a mathematical model for solar flatplate liquid collector solving one-dimensional heat transfer balances. Hottel and Woertz (1942), Hottel and Whillier (1955) and Bliss (1959) developed the simplest assumptions: thermal capacitances are neglected and a single value of collector overall heat loss coefficient is considered. Based on these assumptions and considering that the heat transfer is mainly one-dimensional and predominant in the direction normal to the flow plane, Duffie and Beckman (2013) developed a simplified model (with the electrical analogy) to characterize the solar collector in steady-state conditions. The model solves the energy balance of the solar collector under steady-state conditions according to the principle Hottel-Whillier equation for usable thermal output:

$\dot{Q}_{u}=A_{a b s} F_{R}\left[(\tau \alpha)_{n} G_{t}-U\left(\vartheta_{i n}-\vartheta_{a m b}\right)\right]$

In this equation, $A_{a b s}$ is the absorber area $\left(\mathrm{m}^{2}\right), F_{R}$ is the collector heat removal factor $(-), \tau$ is the solar transmittance of the collector cover (-), $\alpha$ is the solar absorptance of the absorber $(-), G_{t}$ is the total solar irradiance $\left(\mathrm{W} \mathrm{m}^{-2}\right)$, $U$ is the overall heat loss coefficient of collector $\left(\mathrm{W} \mathrm{m}^{-2} \mathrm{~K}^{-1}\right), \vartheta_{\text {in }}$ is the inlet fluid temperature (K), and $\vartheta_{a m b}$ is the ambient temperature $(\mathrm{K})$.

The main planes of the collector are cover exterior surface $\left(f_{2}\right)$, cover interior surface $\left(f_{1}\right)$, absorber $(a b s)$, back insulation interior surface $\left(b_{1}\right)$, back frame exterior surface $\left(b_{2}\right)$, edge insulation interior surface $\left(e_{1}\right)$, and edge frame exterior surface $\left(e_{2}\right)$. A surface temperature is determined for each plane of collector during the calculation procedure. The main collector planes are schematically outlined in Fig. 2.

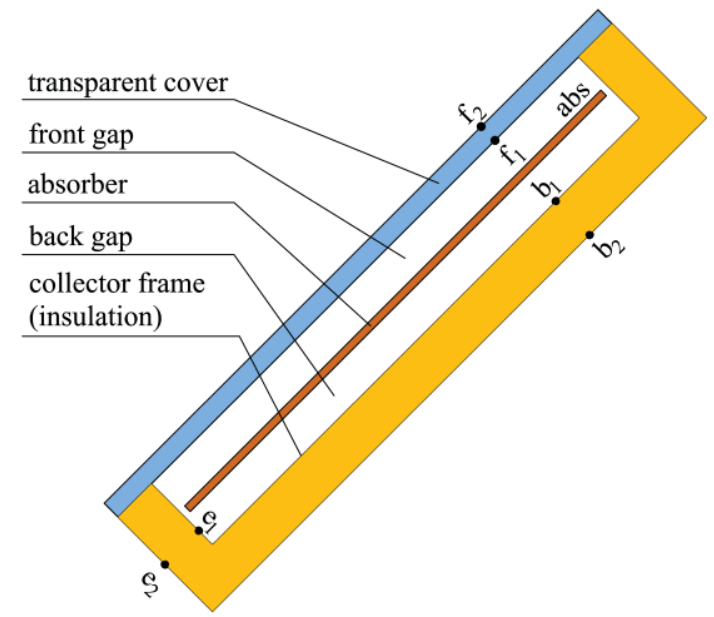

Fig. 2: The main collector planes (surfaces) in the solar collector model

The model in general consists of two parts: external energy balance of absorber (heat transfer from absorber surface to ambient environment) and internal energy balance of absorber (heat transfer from absorber surface into heat transfer fluid). Both external and internal energy balances are mutually dependent. The overall collector heat loss coefficient $U\left(\mathrm{~W} \mathrm{~m}^{-2} \mathrm{~K}^{-1}\right)$ as the main output from external balance is one of the inputs for internal balance. On the other side, mean absorber temperature $\vartheta_{a b s}(\mathrm{~K})$ as one of the outputs from internal balance is used as a necessary input for external balance. Iteration loop has been introduced to transfer the results from external balance to starting internal balance and the results from internal balance are put to external balance. Loop iterates as long as the difference between absorber temperatures calculated in two adjacent iteration steps is higher than the required minimum.

\subsection{Air mode (operation of solar air collector)}

The core of the air mode (operation of solar collector for air heating) is a mathematical model for an air solar collector solving one-dimensional heat transfer balances. This model is a bit more complicated and is described in more details.

To illustrate the procedure for deriving of usable heat gain $Q_{u}(\mathrm{~W})$, efficiency with respect to reference collector area (gross area $A_{G}\left(\mathrm{~m}^{2}\right)$ ) and output heat transfer fluid temperature $\vartheta_{\text {out }}(\mathrm{K})$, we derive equations for the most common design of air collector - Design 1 in Fig. 3. The equations for the second design is derived in a similar manner. 
Design 1

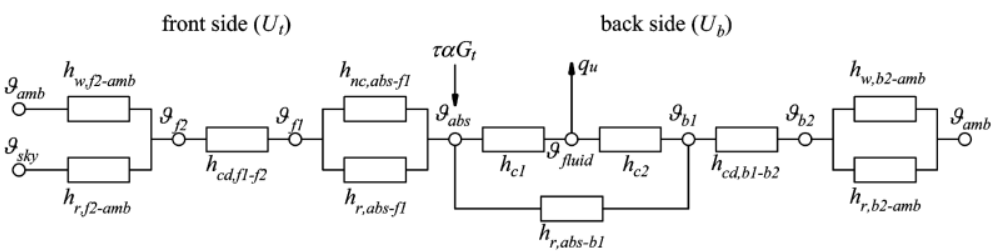

Design 2

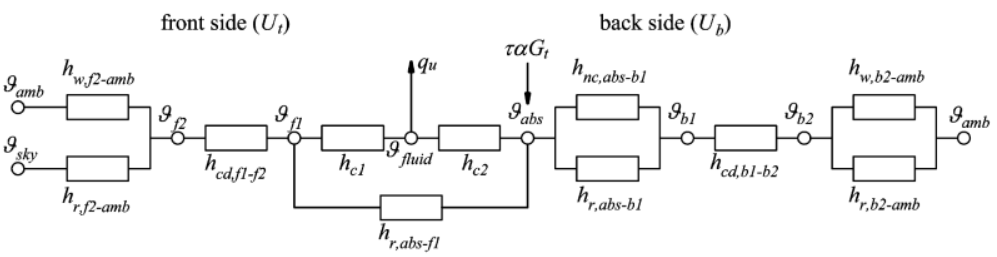

Fig. 3: Thermal network for a solar air collector

Since heat transfer coefficients are temperature dependent, a set of mean temperatures is approximated which allows the heat transfer coefficients to be evaluated as a first guess. Then the surface temperatures are estimated according to a temperature difference between an absorber and an ambient environment uniformly. After that heat transfer coefficients can be calculated and collector heat loss coefficients $U_{t}\left(\mathrm{~W} \mathrm{~m}^{-2} \mathrm{~K}^{-1}\right)$ and $U_{b}\left(\mathrm{~W} \mathrm{~m}^{-2} \mathrm{~K}^{-1}\right)$ can be obtained. Since these coefficients have been calculated for incorrect temperatures, next iteration step follows. From heat transfer coefficients $h\left(\mathrm{~W} \mathrm{~m}^{-2} \mathrm{~K}^{-1}\right)$ and heat flows through the front and back sides of a collector the temperature distribution can be obtained by reverse calculation process. To evaluate the new mean temperatures, two different calculation Modes can be used. Mode 1 is based on the Hottel-Whiller-Bliss (eq. 1) general equation for a solar collector performance. Mode 2 uses the heat balances equations for each temperature level and matrix inversion method. The newly calculated mean temperatures are then compared with the initially-guessed temperatures. The iterative process is repeated until all consecutive results of mean temperatures differ by less than $0.01 \mathrm{~K}$.

\subsubsection{Mode 1}

In steady state, the performance of a solar collector is described by an energy balance that indicates the distribution of incident solar energy into useful energy gain, thermal losses, and optical losses. The solar radiation absorbed by a collector per unit area of absorber $A_{a b s}\left(\mathrm{~m}^{2}\right)$ is equal to the difference between the incident solar radiation and the optical. The thermal energy lost from the collector to the surroundings by conduction, convection, and infrared radiation can be represented as the product of a heat transfer coefficient $U\left(\mathrm{~W} \mathrm{~m}^{-2} \mathrm{~K}^{-1}\right)$, times the difference between the mean fluid temperature $\vartheta_{\text {fluid }}(\mathrm{K})$ and the ambient temperature $\vartheta_{\text {amb }}(\mathrm{K})$ :

$\dot{Q}_{u}=A_{a b s} F^{\prime}\left[(\tau \alpha)_{n} G_{t}-U\left(\vartheta_{\text {fluid }}-\vartheta_{a m b}\right)\right]$

The problem with this equation is that the overall heat loss coefficient $U\left(\mathrm{~W} \mathrm{~m}^{-2} \mathrm{~K}^{-1}\right)$ and the collector efficiency factor $F^{\prime}(-)$ is difficult to calculate. The algebra is somewhat tedious and only results of deriving $F^{\prime}(-)$ and $U\left(\mathrm{~W} \mathrm{~m}^{-2} \mathrm{~K}^{-1}\right)$ are presented.

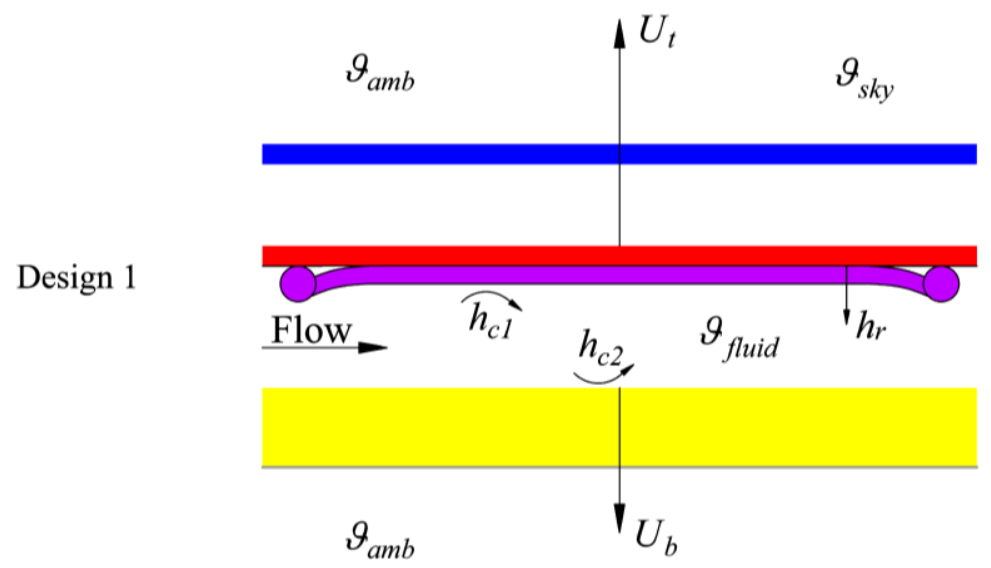

Fig. 4: Schematic view of solar air collector with single air flow between an absorber and a bottom plate 


$$
\begin{aligned}
U & =U_{t}+U_{b} \\
F^{\prime} & =\frac{1}{1+\frac{U}{h_{c 1}+\frac{1}{\frac{1}{h_{c 2}}+\frac{1}{h_{r, a b s}-b 1}}}}
\end{aligned}
$$

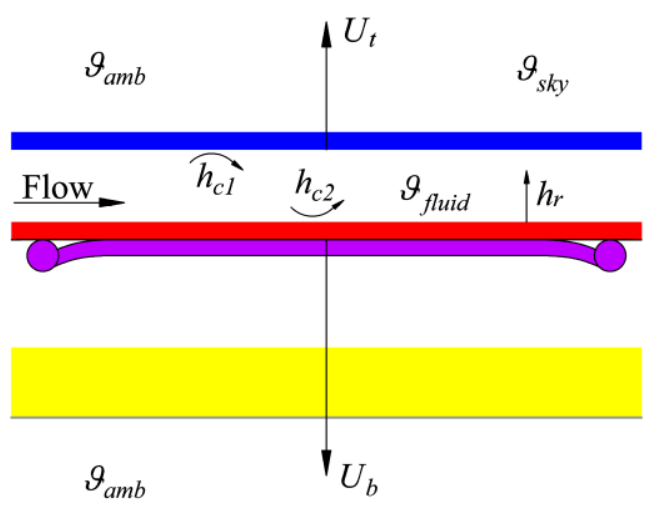

Fig. 5: Schematic view of solar air collector with single air flow between absorber and transparent insulation

$U=\frac{\left(U_{t}+U_{b}\right)\left(h_{c 1} h_{c 2}+h_{r, a b s-f 1} h_{c 1}+h_{r, a b s-f 1} h_{c 2}\right)+U_{b} U_{t}\left(h_{c 1}+h_{c 2}\right)}{h_{c 1} h_{r, a b s-f 1}+h_{c 2} U_{t}+h_{c 2} h_{r, a b s-f 1}+h_{c 1} h_{c 2}}$

$F^{\prime}=\frac{h_{r, a b s-f 1} h_{c 1}+h_{c 2} U_{t}+h_{c 2} h_{r, a b s-f 1}+h_{c 1} h_{c 2}}{\left(U_{t}+h_{r, a b s-f 1}+h_{c 1}\right)\left(U_{b}+h_{c 2}+h_{r, a b s-f 1}\right)-h_{r, a b s-f 1}^{2}}$

(eq. 6)

After that the collector flow factor $F^{\prime \prime}(-)$, the collector heat removal factor $F_{R}(-)$, the useful energy gain, and the outlet temperature can be obtained. Since these values have been calculated for first estimates of temperatures, next iteration step should follow. To calculate heat transfer coefficients at main surfaces of solar collector and to assess the overall collector heat loss coefficient $U\left(\mathrm{~W} \mathrm{~m}^{-2} \mathrm{~K}^{-1}\right)$ in the next iteration step, the absorber temperature, the mean fluid temperature, and the temperature distribution should be derived.

\subsubsection{Mode 2}

Mode 2 operates in a principally different manner. The core of the Mode 2 is a set of heat balance equations obtained from the thermal network at the points:

$$
\begin{aligned}
& \vartheta_{f 1}: h_{r, f 2-a m b}\left(\vartheta_{f 2}-\vartheta_{s k y}\right)+h_{w, f 2-a m b}\left(\vartheta_{f 2}-\vartheta_{a m b}\right)=h_{c d, f 1-f 2}\left(\vartheta_{f 1}-\vartheta_{f 2}\right) \\
& \vartheta_{f 2}: h_{c d, f 1-f 2}\left(\vartheta_{f 1}-\vartheta_{f 2}\right)=h_{r, a b s-f 1}\left(\vartheta_{a b s}-\vartheta_{f 1}\right)+h_{n c}\left(\vartheta_{a b s}-\vartheta_{f 1}\right) \\
& \vartheta_{a b s}: \tau \alpha G=\left(h_{r, a b s-f 1}+h_{n c}\right)\left(\vartheta_{a b s}-\vartheta_{f 1}\right)+h_{r, a b s-b 1}\left(\vartheta_{a b s}-\vartheta_{b 1}\right)+h_{c 1}\left(\vartheta_{a b s}-\vartheta_{f l u i d}\right) \\
& \vartheta_{f l u i d}: h_{c 1}\left(\vartheta_{a b s}-\vartheta_{f l u i d}\right)=h_{c 2}\left(\vartheta_{f l u i d}-\vartheta_{b 2}\right)+\frac{2 m c_{f}}{s}\left(\vartheta_{f l u i d}-\vartheta_{i n}\right) \\
& \vartheta_{b 2}: h_{r, a b s-b 1}\left(\vartheta_{a b s}-\vartheta_{b 1}\right)+h_{c 2}\left(\vartheta_{f l u i d}-\vartheta_{b 1}\right)=h_{c d, b 1-b 2}\left(\vartheta_{b 1}-\vartheta_{b 2}\right) \\
& \vartheta_{b 1}: h_{c d, b 1-b 2}\left(\vartheta_{b 1}-\vartheta_{b 2}\right)=h_{r, b 2-a m b}\left(\vartheta_{b 2}-\vartheta_{a m b}\right)+h_{w, b 2-a m b}\left(\vartheta_{b 2}-\vartheta_{a m b}\right)
\end{aligned}
$$

By rearranging, we obtain a system of linear equations in the matrix form:

$$
\left[\begin{array}{cccc}
h_{r, f 2-a m b}+h_{w, f 2-a m b}+h_{c d, f 1-f 2} & -h_{c d, f 1-f 2} & 0 & 0 \\
-h_{c d, f 1-f 2} & h_{c d, f 1-f 2}+h_{r, a b s-f 1}+h_{n c} & -h_{r, a b s-f 1}-h_{n c} & 0 \\
0 & -h_{r, a b s-f 1}-h_{n c} & h_{r, a b s-f 1}+h_{n c}+h_{r, a b s-b 1}+h_{c 1} & -h_{c 1} \\
0 & 0 & h_{c 1} & -h_{c 1}-h_{c 2}-\frac{2 m c_{f}}{s} \\
0 & 0 & h_{r, a b s-b 1} & h_{c 2} \\
0 & 0 & 0 & 0
\end{array}\right.
$$

$$
\left.\begin{array}{cc}
0 & 0 \\
0 & 0 \\
-h_{r, a b s-b 1} & 0 \\
h_{c 2} & 0 \\
-h_{r, a b s-b 1}-h_{c 2}-h_{c d, b 1-b 2} & h_{c d, b 1-b 2} \\
h_{c d, b 1-b 2} & h_{r, b 2-a m b}+h_{w, b 2-a m b}+h_{c d, b 1-b 2}
\end{array}\right]\left[\begin{array}{c}
\vartheta_{f 2} \\
\vartheta_{f 1} \\
\vartheta_{a b s} \\
\vartheta_{f l u i d} \\
\vartheta_{b 2}
\end{array}\right]=\left[\begin{array}{c}
h_{r, f 2-a m b} \vartheta_{s k y}+h_{w, f 2-a m b} \vartheta_{a m b} \\
0 \\
\tau \alpha G \\
\frac{2 m c_{f}}{S} \vartheta_{i n} \\
0 \\
h_{r, b 2-a m b} \vartheta_{a m b}+h_{w, b 2-a m b} \vartheta_{a m b}
\end{array}\right]
$$


In general, the above matrices may be displayed as

$[A][T]=[B]$

(eq. 14)

The mean temperature vector may be determined by matrix inversion as

$[T]=[A]^{-1}[B]$

Since the mean temperature vector is calculated, the outlet fluid temperature and the useful energy gain can be determined.

\subsection{Model verification}

The model has been experimentally validated on prototype of DPSC (design 1) in the frame of solar collectors testing according to the European standard EN ISO 9806 in the accredited Solar Laboratory of Czech Technical University in Prague. The verification of liquid and air parts has been conducted separately. The prototype of DPSC has been built from the experimental solar water collector by adjusting the interior air gap (Fig. 6). The detailed parameters of the produced prototype are listed in the Tab. 1. If the operation mode is liquid heating, water flows in the copper tubes, and the air channels are closed at inlet and outlet. On the other side, the inlet and outlet of water pipes are closed in air heating mode.
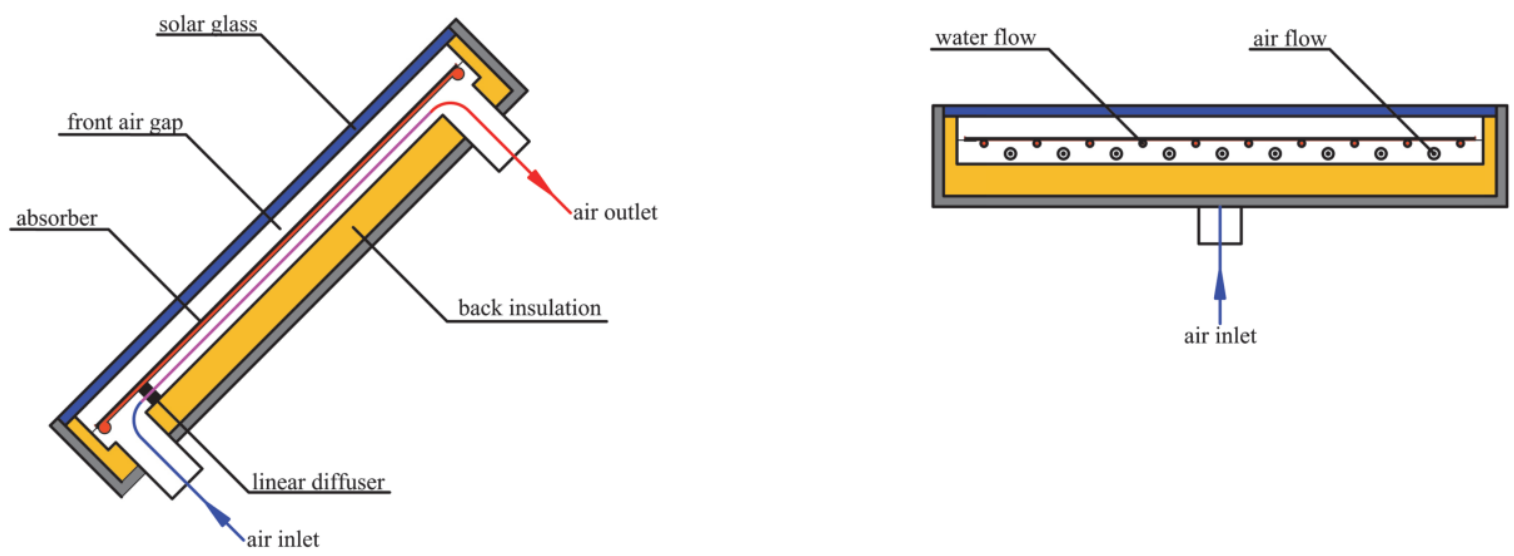

Fig. 6 Design of prototype of DPSC collector

Tab. 1: Design parameters of the DPSC used in the analysis

\begin{tabular}{|c|c|c|c|}
\hline Collector parameter & Value & Collector parameter & Value \\
\hline Dimensions (W/L/H) & $1 \times 1.6 \times 0.087 \mathrm{~m}$ & Absorber emissivity & 0.05 \\
\hline $\begin{array}{c}\text { Area (gross, aperture, } \\
\text { absorber) }\end{array}$ & $1.6 \mathrm{~m}^{2}, 1.52 \mathrm{~m}^{2}, 1.49 \mathrm{~m}^{2}$ & Header pipe & $\mathrm{Cu} 22 \times 1 \mathrm{~mm}$ \\
\hline Cover material & Solar glass $4 \mathrm{~mm}$ & Number of riser tubes & 10 \\
\hline Front air gap thickness & $30 \mathrm{~mm}$ & $\begin{array}{l}\text { Distance between riser } \\
\text { pipes }\end{array}$ & $100 \mathrm{~mm}$ \\
\hline Absorber material & Aluminium $0.4 \mathrm{~mm}$ & Air flow channel & $20 \mathrm{~mm}$ \\
\hline Cover transmittance & 0.92 & Back insulation thickness & $30 \mathrm{~mm}$ \\
\hline Absorber absorptance & 0.95 & Insulation material & Rockwool \\
\hline
\end{tabular}

Fig. 7 and Fig. 8 show experimentally evaluated efficiency points and theoretically modelled efficiency characteristics both in liquid and air operation modes. Experimental data points of solar collector efficiency are coupled with combined standard uncertainty bars in the graphs. The uncertainty analysis has been provided based on methodology published in Mathioulakis et al. (1999) and Müller-Schöll and Frei (2000). The theoretical calculation of efficiency characteristic by the model is subjected to the uncertainty of real collector parameters which are used as inputs for the model. Therefore, the results of theoretical calculation could be presented as two delimiting curves where the collector efficiency values can be found in reality. It is evident from the results that 
simulated efficiency characteristics fit the measurements relatively well, which gives confidence in the developed model. More information about model verification and uncertainty analysis can be found in Shemelin et al. (2017).

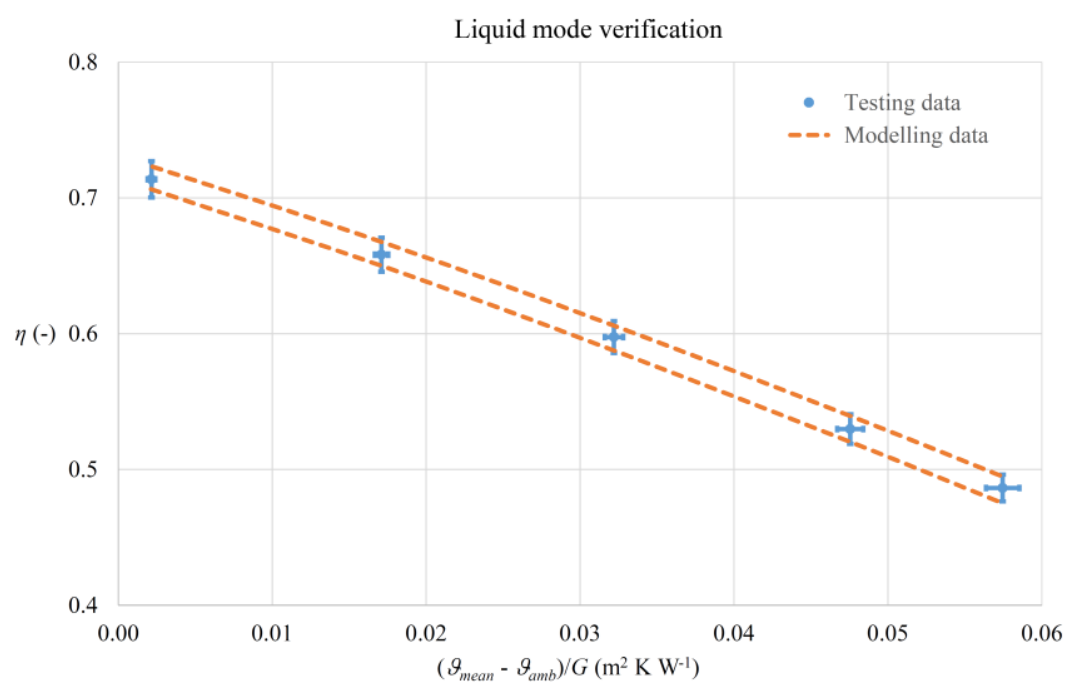

Fig. 7: Mathematical model verification - liquid heating mode

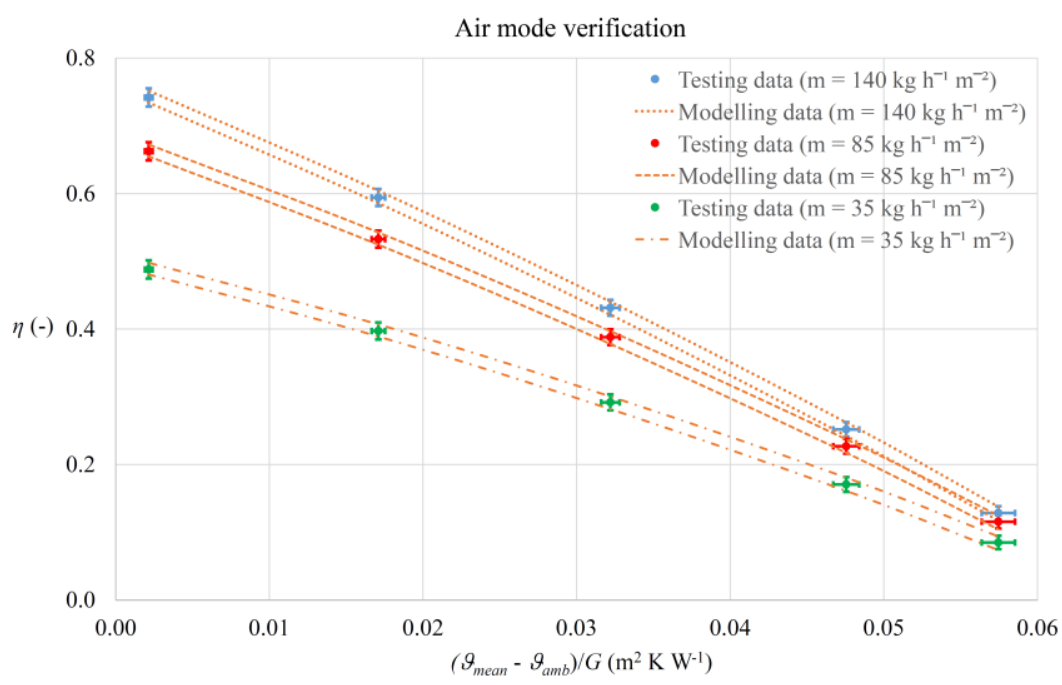

Fig. 8: Mathematical model verification - air heating mode

\section{Hybrid solar energy system}

To evaluate the energy performance of DPSC system, system annual solar yield has been analyzed for a specific site and under the specific conditions. Three single family houses with the same heated floor area of $246 \mathrm{~m}^{2}$ and with different energy consumption were considered as case studies for comparative analysis (Fig. 9). The detailed buildings parameters are listed in the Tab. 2.

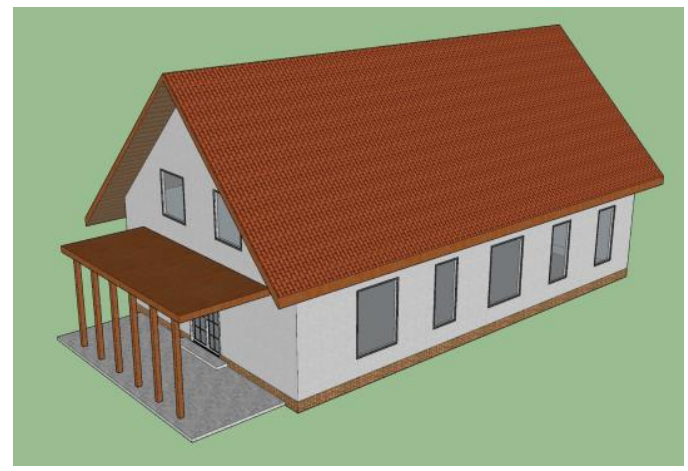

Fig. 9: Three-dimensional geometry of the considered buildings 
Tab. 2: The buildings key values

\begin{tabular}{|c|c|c|c|}
\hline Key Values & Building A & Building B & Building C \\
\hline \multicolumn{4}{|c|}{ General data } \\
\hline Occupancy & \multicolumn{3}{|c|}{4 persons } \\
\hline City location & \multicolumn{3}{|c|}{ Prague } \\
\hline Climate data source & \multicolumn{3}{|c|}{ Meteonorm } \\
\hline Annual total horizontal radiation & \multicolumn{3}{|c|}{$998 \mathrm{kWh} \mathrm{m}^{-2}$} \\
\hline Mean annual temperature & \multicolumn{3}{|c|}{$8.9^{\circ} \mathrm{C}$} \\
\hline Set point temperature (day/night) & \multicolumn{3}{|c|}{$20^{\circ} \mathrm{C} / 20^{\circ} \mathrm{C}$} \\
\hline Ventilation air flow rate & \multicolumn{3}{|c|}{$100 \mathrm{~m}^{3} \mathrm{~h}^{-1}$} \\
\hline Internal gains (occupants + equipments) & \multicolumn{3}{|c|}{$2 \mathrm{~W} \mathrm{~m}^{-2}$} \\
\hline Heating season & \multicolumn{3}{|c|}{234 days } \\
\hline \multicolumn{4}{|c|}{ Building geometry data } \\
\hline Gross Floor Area & \multicolumn{3}{|c|}{$286 \mathrm{~m}^{2}$} \\
\hline Heated Floor Area & \multicolumn{3}{|c|}{$246 \mathrm{~m}^{2}$} \\
\hline Ventilated Volume & \multicolumn{3}{|c|}{$607.1 \mathrm{~m}^{3}$} \\
\hline \multicolumn{4}{|c|}{ Specific Annual Demands } \\
\hline Hot water generation & $12 \mathrm{kWh} \mathrm{m}^{-2}$ & $12 \mathrm{kWh} \mathrm{m}^{-2}$ & $12 \mathrm{kWh} \mathrm{m}^{-2}$ \\
\hline Net heating energy & $38 \mathrm{kWh} \mathrm{m}^{-2}$ & $79 \mathrm{kWh} \mathrm{m}^{-2}$ & $112 \mathrm{kWh} \mathrm{m}^{-2}$ \\
\hline Net cooling energy & $7 \mathrm{kWh} \mathrm{m}^{-2}$ & $2 \mathrm{kWh} \mathrm{m}^{-2}$ & $0 \mathrm{kWh} \mathrm{m}^{-2}$ \\
\hline
\end{tabular}

Four different solar energy systems were compared in the analysis. The reference system (RS) is a standard solar domestic hot water system with a solar fraction $60 \%$ based on conventional flat-plate liquid collectors with the following parameters: optical efficiency 0.81 , linear heat loss coefficient $3.58 \mathrm{~W} \mathrm{~m}^{-2} \mathrm{~K}^{-1}$, quadratic heat loss coefficient $0.0045 \mathrm{~W} \mathrm{~m}^{-2} \mathrm{~K}^{-2}$, incidence angle modifier $\mathrm{IAM}_{50}=0.92$. The detailed parameters of the reference system are listed in the Tab. 3 .

Tab. 3: Solar domestic hot water system parameters and operating conditions (RC, V1, V2 and V3)

\begin{tabular}{|c|c|}
\hline Parameter & Description \\
\hline Collector orientation & South, $45^{\circ}$ \\
\hline Collector area & $4.8 \mathrm{~m}^{2}$ (gross area) \\
\hline Collector mass flow rate & $501 \mathrm{~h}^{-1} \mathrm{~m}^{-2}$ \\
\hline Heat transfer medium & Propylene Glycol \\
\hline Pump control & Pump switching on/off temperature difference collector-storage $8 \mathrm{~K} / 2 \mathrm{~K}$ \\
\hline Piping & $\begin{array}{l}\text { Supply and return pipes are located in the internal and external environments: } \\
10 \mathrm{~m} \text { each, DN } 16 \text { with } 25 \mathrm{~mm} \text { thermal insulation }\left(\lambda=0.04 \mathrm{~W} \mathrm{~m}^{-2} \mathrm{~K}^{-1}\right) \text {. }\end{array}$ \\
\hline Heat exchanger & $\begin{array}{c}\text { Smooth tube heat exchanger with } U A=400 \mathrm{~W} \mathrm{~K}^{-1}( \pm 15 \%) \text { for } 42^{\circ} \mathrm{C} / 40^{\circ} \mathrm{C} \\
\text { (inlet temperature/tank storage temperature) }\end{array}$ \\
\hline Tank storage & Volume: 2001 , heat loss: $1.4 \mathrm{kWh}$ day $^{-1}$, height/diameter ratio: 2.5 \\
\hline Cold water temperature & $10^{\circ} \mathrm{C}$ \\
\hline $\begin{array}{l}\text { Building interior } \\
\text { temperature }\end{array}$ & $20^{\circ} \mathrm{C}$ \\
\hline Hot water consumption & 1601 day $^{-1}(7.00: 651 ; 12.00: 301 ; 19.00: 651)$, hot water te \\
\hline
\end{tabular}

The first alternative system (V1) is based on DPSC which operates from May to September in a liquid mode for hot water preparation (as the reference system) and the rest of the year (winter) for pre-heating of fresh air before 
the heat recovery unit. In the air mode, the fresh air is led through the collector and then optionally heated in the heat recovery unit. In the case of insufficient sunlight (clouded sky or night time), the air bypasses the collector.

The second system (V2) has the same configuration as the first alternative (V1) with the exception that the collector is installed at output of the heat recovery unit. In the air heating mode, the fresh air is firstly preheated in the heat recovery unit and then optionally is led through the collector. The preheated air is led through the collector only in the case if the collector has a potential to heat the air, otherwise the preheated air bypasses the collector.

The third system (V3) differs from the previous two systems - the DPSC operates from May to September in a liquid mode for hot water preparation (as the reference system) and in the rest of the year operates as solar air collector in direct recirculating air heating system. In the air heating mode, the circulating air sucked from the rooms is heated in the collector and is led to the building. The fresh air, after preheating in the heat recovery unit, is mixed with the circulation air and only after is brought into the living rooms. On cloudy days and at night the circulation air does not flow through the collector.

The design parameters of the DPSC collector which were used for simulation of all alternative systems (V1, V2, and V3) are the same as the prototype DPSC and are listed in the Tab. 1. The solar domestic hot water system parameters in the liquid mode is are same as for reference system and are listed in the Tab. 3. The air heating mode system parameters are shown in the Tab. 4.

Tab. 4: Air heating mode (V1, V2, and V3)

\begin{tabular}{|c|c|c|c|}
\hline Parameter & V1 & $\mathbf{V 2}$ & $\mathbf{V 3}$ \\
\hline Collector orientation & \multicolumn{3}{|c|}{ South, $45^{\circ}$} \\
\hline Collector area & \multicolumn{3}{|c|}{$4.8 \mathrm{~m}^{2}$} \\
\hline Reference area & \multicolumn{3}{|c|}{ Gross area } \\
\hline Set point temperature & \multicolumn{3}{|c|}{$22^{\circ} \mathrm{C}$} \\
\hline Function & $\begin{array}{l}\text { Fresh air preheating } \\
\text { (before h.r. u.) }\end{array}$ & $\begin{array}{l}\text { Fresh air preheating } \\
\text { (after h. r. u.) }\end{array}$ & $\begin{array}{l}\text { Direct air heating } \\
\text { (circulating air) }\end{array}$ \\
\hline Air flow rate & $100 \mathrm{~m}^{3} \mathrm{~h}^{-1}$ & $100 \mathrm{~m}^{3} \mathrm{~h}^{-1}$ & $400 \mathrm{~m}^{3} \mathrm{~h}^{-1}$ \\
\hline
\end{tabular}

The overview of the compared solar systems is presented in Fig. 10.

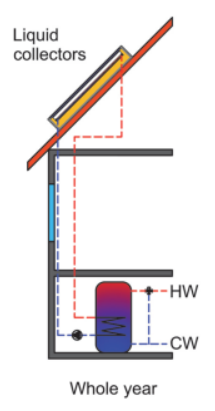

RV

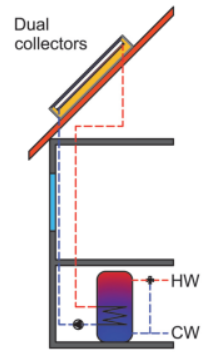

Liquid mode: May-September

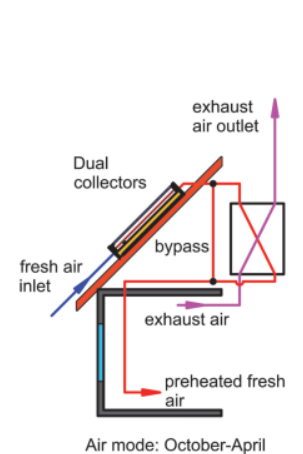

V1

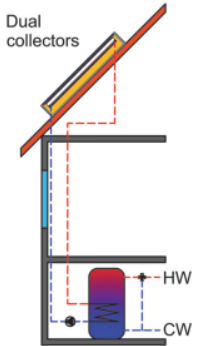

Liquid mode: May-September

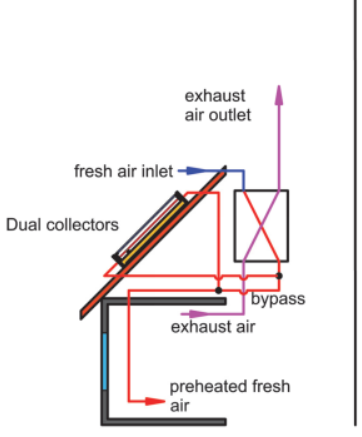

Air mode: October-April

V2

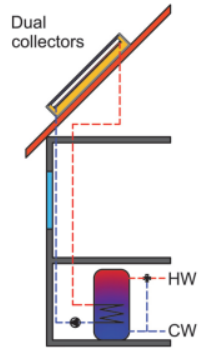

Liquid mode: May-September

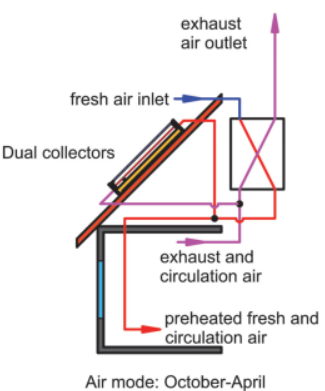

V3

Fig. 10: Considered solar collector system variants 


\section{Results and discussion}

To demonstrate the application of the DPSC, three buildings with the different energy consumption (Building A, $\mathrm{B}$, and $\mathrm{C}$ ) were chosen as case studies and four solar collector systems (RV, V1, V2, and V3) were compared. The solar yield of the described systems was determined by detailed thermal simulations in TRNSYS, using TRNSYS Building environment (TRNBuild) and detailed theoretical model of DPSC.

The results are shown in Fig.11 and in Tab. 5. Firstly, the results of the simulation indicate that DPSC design allows increasing the annual energy yield of the solar system. It can be explained by the fact, that in winter the intensity of solar radiation is not sufficient to heat the heat transfer liquid by $8{ }^{\circ} \mathrm{C}$ (pump switching temperature), but on the other hand, it is sufficient to heat the fresh or circulation air. Besides, it can be seen that the higher building heat energy consumption is respectively correlated to the higher solar energy yield of compared systems. It means that DPSC in air mode not only reduces the ventilation heat loss but also contributes to a reduction of the overall heating demand.
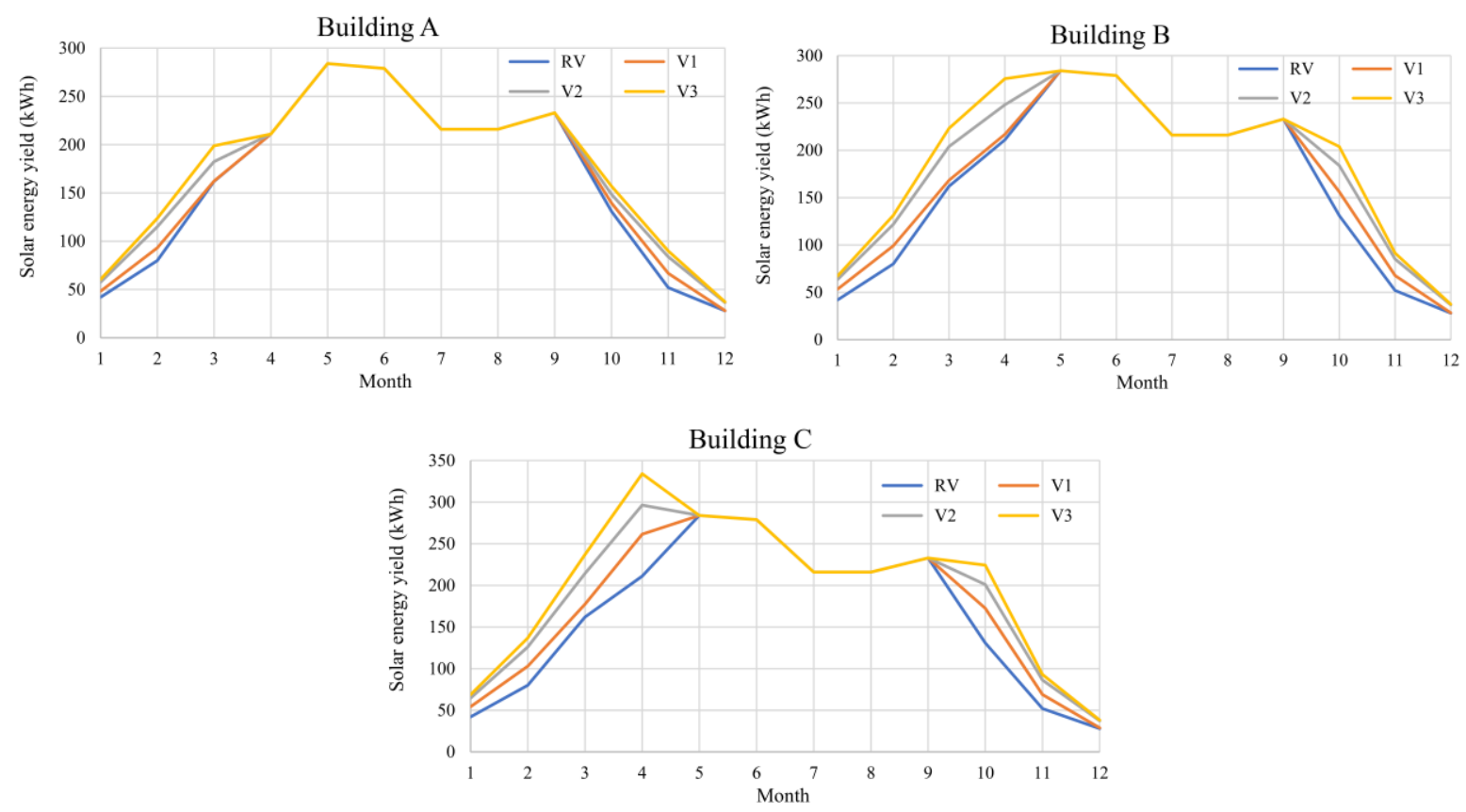

Fig. 11: Annual performance of the compared solar systems

Tab. 5: Annual solar energy yield of solar system alternatives $\left(\mathrm{kWh} \mathrm{m}^{-2}\right)$

\begin{tabular}{|c|c|c|c|c|}
\hline Building & RS & V1 & V2 & V3 \\
\hline $\begin{array}{c}\text { Building A (annual heat } \\
\text { demand 38 } \mathrm{kWh} \mathrm{m}^{-2} \text { ) }\end{array}$ & 403 & 412 & 430 & 470 \\
\hline $\begin{array}{c}\text { Building B (annual heat } \\
\text { demand 79 } \mathrm{kWh} \mathrm{m}^{-2} \text { ) }\end{array}$ & 403 & 420 & 452 & 492 \\
\hline $\begin{array}{c}\text { Building C (annual heat } \\
\text { demand 112 } \mathrm{kWh} \mathrm{m}^{-2} \text { ) }\end{array}$ & 403 & 436 & 470 & 49 \\
\hline
\end{tabular}

Secondly, it can be observed that the third alternative system V3 shows the highest annual solar energy yield among the compared systems. This result is a consequence of higher efficiency of DPSC (air mode) in the system V3. The efficiency of air part of DPSC depends on a number of parameters and the mode dominant of these is collector air flow rate (Fig. 8). Since in the case of the first and of the second alternative systems the collector air flow rate is limited by the ventilation air flow rate $100 \mathrm{~m}^{3} \mathrm{~h}^{-1}$, in the case of the third alternative system can be increased to $400 \mathrm{~m}^{3} \mathrm{~h}^{-1}$.

The combination of DPSC system with heat recovery from the exhaust air reduces the effectively possible heating energy savings by the DPSC collector. The DPSC and heat recovery system compete and the potential savings are limited in total. 
In the case of the first alternative system V1, the performance of the heat recovery unit is limited because the air temperature after DPSC is higher than the outdoor temperature. Moreover, if the fresh air temperature after DPSC is higher than $18^{\circ} \mathrm{C}$, the fresh air bypasses the heat recovery unit and flows directly to the building.

If the collector is placed behind the heat recovery unit to provide additional temperature rises of the room inlet air, the collector system is energetically more favourable (system V2). Nevertheless, the efficiency of DPSC is limited because the air temperature after the heat recovery unit is higher than the outdoor temperature and consequently the solar collector thermal losses are higher compared to system V1.

\section{Conclusion}

Detailed mathematical model of DPSC has been developed and validated by the experiment for the collector in liquid and air mode. Subsequently, the comprehensive analysis of different solar systems based on DPSC for three buildings with the different energy consumption has been provided.

Based on the simulation runs using practical design data, the following can be concluded:

- All compared alternative systems based on DPSC have shown the higher annular solar energy yield than the reference system based on liquid solar collectors.

- The combination of DPSC system with heat recovery from the exhaust air reduces the effectively possible heating energy savings.

- The third alternative system V3 shows the highest annual solar energy yield among the compared systems.

Based on the promising simulation results now it is possible to proceed to parametric analyses and optimization of the design of DPSC towards the higher performance.

\section{Acknowledgment}

This work has been supported by the Ministry of Education, Youth and Sports within National Sustainability Programme I, project No. LO1605.

\section{References}

AK, A.V., Arun, P., 2013. Simulation studies on porous medium integrated dual purpose solar collector. Int. J. Renew. Energy Res. 3, 114-120.

Assari, M.R., Basirat Tabrizi, H., Jafari, I., 2011. Experimental and theoretical investigation of dual purpose solar collector. Sol. Energy 85, 601-608. https://doi.org/10.1016/j.solener.2011.01.006

Bliss Jr., R.W., 1959. The derivations of several "Plate-efficiency factors" useful in the design of flat-plate solar heat collectors. Sol. Energy 3, 55-64. https://doi.org/10.1016/0038-092X(59)90006-4

Duffie, J.A., Beckman, W.A., 2013. Solar engineering of thermal processes. John Wiley \& Sons.

Hottel, H., Whillier, A., 1955. Evaluation of flat-plate solar collector performance. Trans. Conf. Use Sol. Energy; 3, 74-104.

Hottel, H., Woertz, B., 1942. Performance of flat-plate solar-heat collectors. Trans. ASME (Am. Soc. Mech. Eng.); (United States) 64, 91-104.

Jafari, I., Ershadi, A., Najafpour, E., Hedayat, N., 2011. Energy and exergy analysis of dual purpose solar collector. Acad Sci Technol 81, 259-261.

Ji, J., Luo, C., Chow, T.-T., Sun, W., He, W., 2011. Thermal characteristics of a building-integrated dual-function solar collector in water heating mode with natural circulation. Energy 36, 566-574. https://doi.org/10.1016/j.energy.2010.10.004 
Ma, J., Sun, W., Ji, J., Zhang, Y., Zhang, A., Fan, W., 2011. Experimental and theoretical study of the efficiency of a dual-function solar collector. Appl. Therm. Eng. 31, 1751-1756. https://doi.org/10.1016/j.applthermaleng.2011.02.019

Mathioulakis, E., Voropoulos, K., Belessiotis, V., 1999. Assessment of uncertainty in solar collector modeling and testing. Sol. Energy 66, 337-347. https://doi.org/10.1016/S0038-092X(99)00034-1

Mohajer, A., Nematollahi, O., Joybari, M.M., Hashemi, S.A., Assari, M.R., 2013. Experimental investigation of a Hybrid Solar Drier and Water Heater System. Energy Convers. Manag. 76, 935-944. https://doi.org/10.1016/j.enconman.2013.08.047

Müller-Schöll, C., Frei, U., 2000. Uncertainty analyses in solar collector measurement. Tc 1000, 7.

Nematollahi, O., Alamdari, P., Assari, M.R., 2014. Experimental investigation of a dual purpose solar heating system. Energy Convers. Manag. 78, 359-366. https://doi.org/10.1016/j.enconman.2013.10.046

Shemelin, V., Matuska, T., 2017a. TRNSYS type 205-Model of glazed solar liquid collector based on detailed construction parameters and energy balance. Available at: http://users.fs.cvut.cz/tomas.matuska/?page_id=582 [Accessed November 20, 2018].

Shemelin, V., Matuska, T., 2017b. TRNSYS type 206-Model of glazed solar air collector based on detailed construction parameters and energy balance. Available at: http://users.fs.cvut.cz/tomas.matuska/?page_id=951 [Accessed November 20, 2018].

Shemelin, V., Matuska, T., Sourek, B., 2017. TRNSYS type 207 - Model of dual solar air-liquid collector based on detailed construction parameteres and energy balance. Available at: http://users.fs.cvut.cz/tomas.matuska/?page_id=965 [Accessed November 20, 2018]

Venkatesh, R., Christraj, W., 2015. Experimental Investigation of Multipurpose Solar Heating System. J. Energy Eng. 141, 04014009. https://doi.org/10.1061/(ASCE)EY.1943-7897.0000166. 


\title{
Solar flux map distribution of a parabolic-spheric dish based on photographic method
}

\author{
Mattia Roccabruna ${ }^{1}$, Fabio Menna ${ }^{2}$, Fabio Remondino ${ }^{2}$, Luigi Crema ${ }^{1}$ \\ ${ }^{1}$ Fondazione Bruno Kessler (FBK), Applied Research on Energy Systems (ARES) unit, Trento, Italy \\ ${ }^{2}$ Fondazione Bruno Kessler (FBK), 3D Optical Metrology (3DOM) unit, Trento, Italy
}

\begin{abstract}
This paper presents a novel method to derive solar flux map of irradiation near to the focal plane of an innovative concentrating point focusing technology facility. The system has a reflector covered by mirrors focusing sun radiation on a Stirling engine. It has been designed and manufactured from the sketch. It consists of a novel dish of $8.6 \mathrm{~m}$ in diameter, whose reflector is made of glass mirrors and has a focal distance of about $4.5 \mathrm{~m}$. The profile is the innovative part of this facility where the mirrors have been designed in order to reduce manufacturing costs. The inner part of the concentrator consists in a spherical shape profile and the external part represents a parabolic profile. Flux measurements is obtained integrating photogrammetric and photometric procedures. The approach used here is presented in a real case application which provides pixel values of radiation for the receiver plane. The solar flux map achieved for a sunny day is reported and compared with the one obtained by a ray-tracing analysis.
\end{abstract}

Keywords: Solar energy, point focus technologies, dish, flux measurement, spherical reflector.

\section{Introduction}

Point focusing technologies are the candidate for achieving high solar flux and operate at high temperatures, never the less, several problems exist for mechanical components and tracking systems. Achieving high temperature brings concentrated solar power to be a highly promising renewable energy source with great potential. High temperature processes are nowadays present in a lot of fields and they are continuing to grow. Interests are strong in many fields, for example, metallurgical processes, CHP (Combined Heat and Power) systems, chemical industries and fuel production. Solar thermal power can help in this way considering temperature level can be as high as conventional fuels. Characterization of solar high flux irradiance technologies is becoming a main item in the growing variety of research fields in Concentrated Solar Power. Few methods to measure solar flux maps currently exist Roger et al. (2014). Although, most of them have not been tested in commercial plants. These methods are mainly classified as direct or indirect measure systems, the first consists in having the sensors placed in the focus plan directly exposed to the concentrated radiation, the second measure the radiant flux through a correction of the flux reflected or emitted by the target surface. The most common method consists in an indirect solution based on photometry using cameras which are able to recognize the brightness reflected by a target from an image. This characteristic is represented by the "grey-level" of each camera pixel and can be calibrated to a flux density value. The calibration can be done with a direct punctual measurement through a direct measure using for example a Gordon radiometer, knowing the total energy reflected on a certain surface or through a solar image knowing the present direct normal irradiation. The point focusing technology presented here consists in a facility realized within a regional research project in order to demonstrate m-CHP. Similar plants have already been presented, Reinalter et al. (2006). The approach used for the design wants to realize a very precise and low-cost Stirling-dish application. The Stirling engine used is the SOLO-V161, fixed on a manual controlled system movement, that easily permits eventual displacement of the equipment in the focal area. The aim of this facility is to realize a precise point focusing concentrator technology, also useful in other applied research for high temperature topics, such as solar fuel production.

This paper presents the methodology used to produce the flux map from an indirect image of the Lambertian target, coupled with a calibration method of the radiation to the grey-scale value following a solar image procedure on the same target. 


\section{System description}

The system is mainly composed of a support structure fixed to the ground which include two cinematic joints allowing elevation and azimuth movements where the mirrors are hung. The structure parts realized by laser cutting and the mirror joint regulation permit to have a rigid and precise structure. Six metallic beams are connected to the dish perimeter to support the Stirling engine frame. Two single turn encodes are connected in the two slewing bearing as feedback position measurements with 16 bits resolution each. Both axes are moved from a brushless motor with respect $1.57 \mathrm{~kW}$ for the azimuth and $2.89 \mathrm{~kW}$ for the elevation. To equilibrate the structure two counterweights are filled with concrete and fixed opposite the dish (Fig. 1).

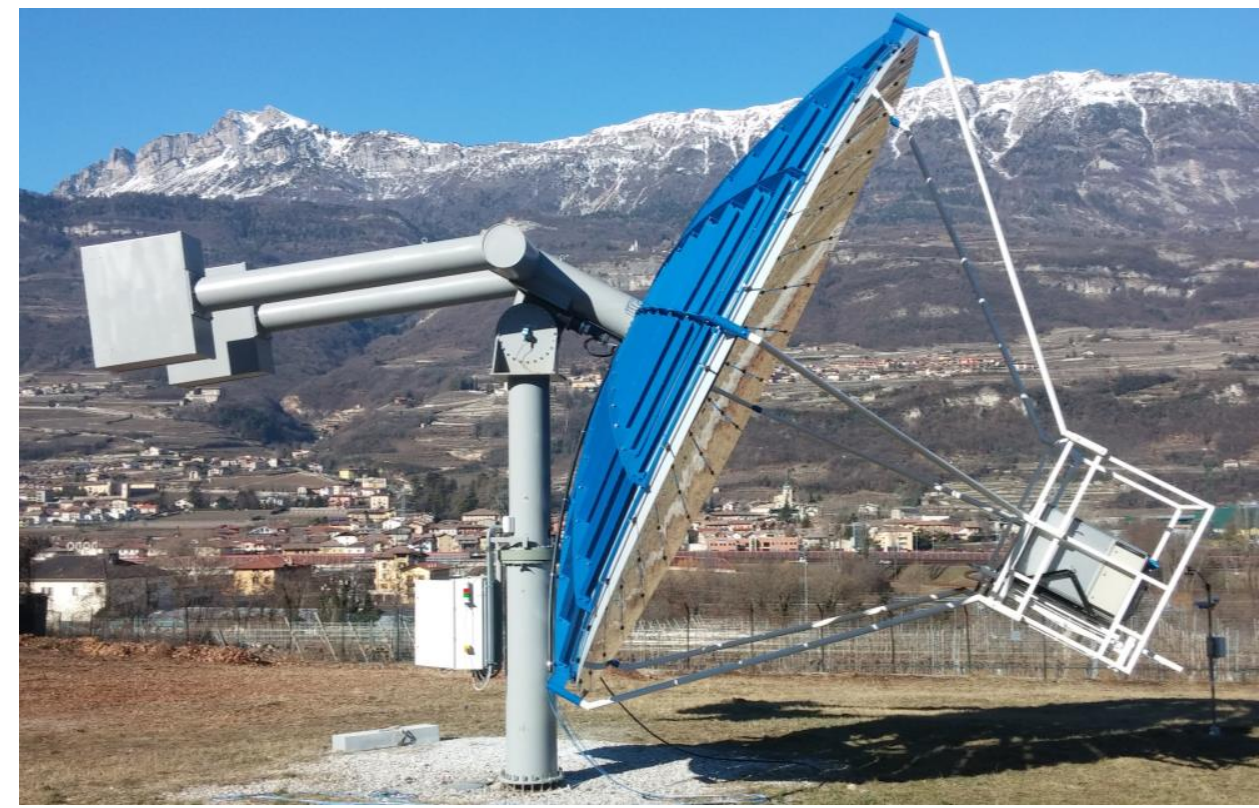

Fig. 1: Lateral view of the realized system.

The design of the geometrical shape of the reflector was created with the aim of cost reduction, especially in the realization of the mirrors, whose major costs are due to the glass molds fabrication. For this reason, a spherical shape was chosen; a viable solution for having mirrors not constrained with respect to a radial direction orientation. This permits to fill empty spaces on the dish surface better, by having only two kinds of mirrors instead of three. The overall dish has a diameter of $8.6 \mathrm{~m}$ and is covered by two differently shaped mirrors, in the central part and in the peripherical ring (Fig. 2). The spherical part, located in the central zone of the dish, is filled with 30 hexagonal mirrors, the best candidate for filling the circular area. The spherical curvature is $9.293 \mathrm{~m}$ and represents the dish profile from 0 to $2.850 \mathrm{~m}$ in radius. The external parabolic reflector is built with 32 mirrors shaped as an annulus sector and covers the rest of the dish from $2.850 \mathrm{~m}$ to $4.305 \mathrm{~m}$ in radius. They are built following a parabolic profile in the radial dish direction and circular shape on the tangential one. The mirrors have a thickness of $0.004 \mathrm{~m}$ and are made by glass tempered on the surface. The production method starts from a plane glass formed as the envelope of the final one, heated up to $800^{\circ} \mathrm{C}$ then shaped by a pressing of two molds and finally quickly cold down by a high air flux on the glass surfaces. They are rigid enough to be self-supporting in all the dish zenith positions. Both the hexagonal and the annulus sector shaped mirrors are supported with six plastic swabs located in the corners for the hexagonal ones and along the radial sides of the others. Each swab locks the mirror and the adjacent one and can move slightly for an eventual needed of position correction. A spherical profile has the advantage that the mirrors are not constrained in having a fix orientation with the radial direction of the dish being the same curvature for all of the mirror tangential vectors. 


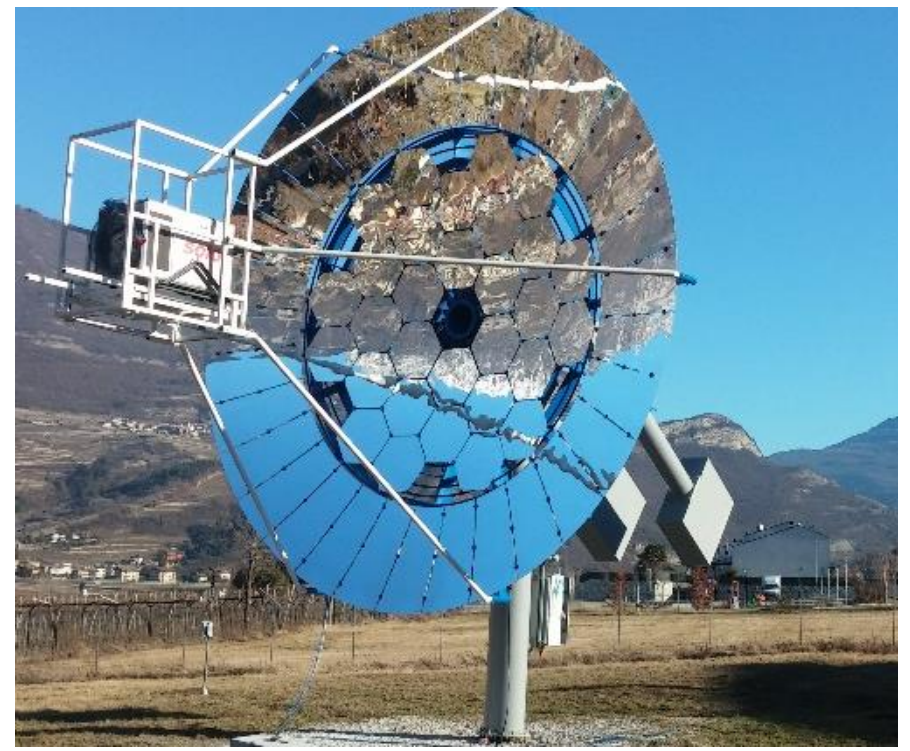

Fig. 2: Front view of the system: the reflector presents spherically shaped hexagonal mirrors in the center and parabolic ones in the external ring.

This permits each spherical mirror to rotate respect its main symmetry axis without changing the dish's profile surface. Thanks to this it is easy to fill the dish better, arranging all the mirrors minimizing the empty space.

This aspect brings the necessity to optimize the filling ratio. The dependent parameters are the mirror shape, mirrors arrangement and the main dimension of the mirror. This combination can fill the dish in different configurations (Fig. 3). Using SolidWorks has optimized the filling of the central part of the dish. The implemented feature "Fill Patterns" fills the defined region with a pattern of features or a predefined cut shape. Three case studies have been considered and the first has been selected (Fig. 3) having a filling ratio of $81.8 \%$. This choice also allows free space for sensors, in fact the locations of the unused space are concentrated in six defined sectors. In one of them a digital industrial sun sensor has been installed for solar tracking - model ISST5 from the company SOLAR-MEMS.
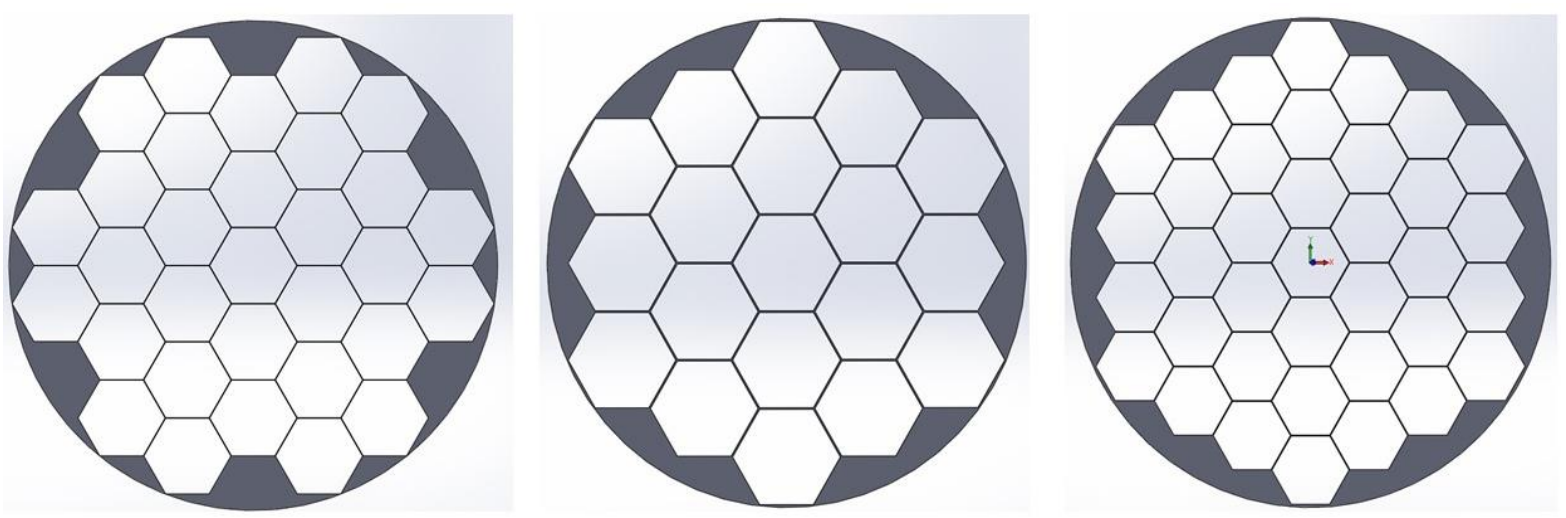

Fig. 3: Optimization results for the filling ratio. CASE 1: 81,8 \% (left), CASE 2: 79,5 \% (center), CASE 3: 79,0\% (right).

The curvature of the reflector has been designed taking into consideration the technical specification of the Stirling Engine SOLO V161. The reflector profile needs to take into account the amount of thermal power used to introduce in the cavity of the Stirling, flux distribution and hot spots. The ideal situation, as reported by Reinalter et al. (2006) would be to introduce $40 \mathrm{kWt}$ through the hole as homogeneous as possible around the receiver. The more non-homogeneous is the flux the more possibilities there is to burn the tubes on the receiver. For Eurodish system, reference values are: for solar flux on the receiver is around $1500 \mathrm{~kW} / \mathrm{m} 2$, power delivered by the dish around $44 \mathrm{kWt}, 38 \mathrm{kWt}$ in the cavity and $32 \mathrm{kWt}$ inside the receiver (gas side). According to SOLO's manual the maximum thermal power input for their receiver is $33 \mathrm{kWt}$.

A single parabolic profile was not suitable, theoretically having a gaussian as flux map distribution. For this reason, a different geometric shape needs to be selected to maintain a homogenous flux distribution. The work began analyzing the dish profile as a combination of two and three concatenate arcs of parabolic profiles until the final parabolic-spheric solution was selected. In order to maintain a good efficiency in the concentration it is important 
to define acceptable tolerances for the geometrical profile and the solar tracking. An analytical function (Li et al. (2013)) to predict the performances of a paraboloidal dish solar concentrator with a cavity, has been applied for the errors estimation. The graphic below shows the results of the intercept factor calculated with our characteristic dimensions of the dish (Fig. 4).

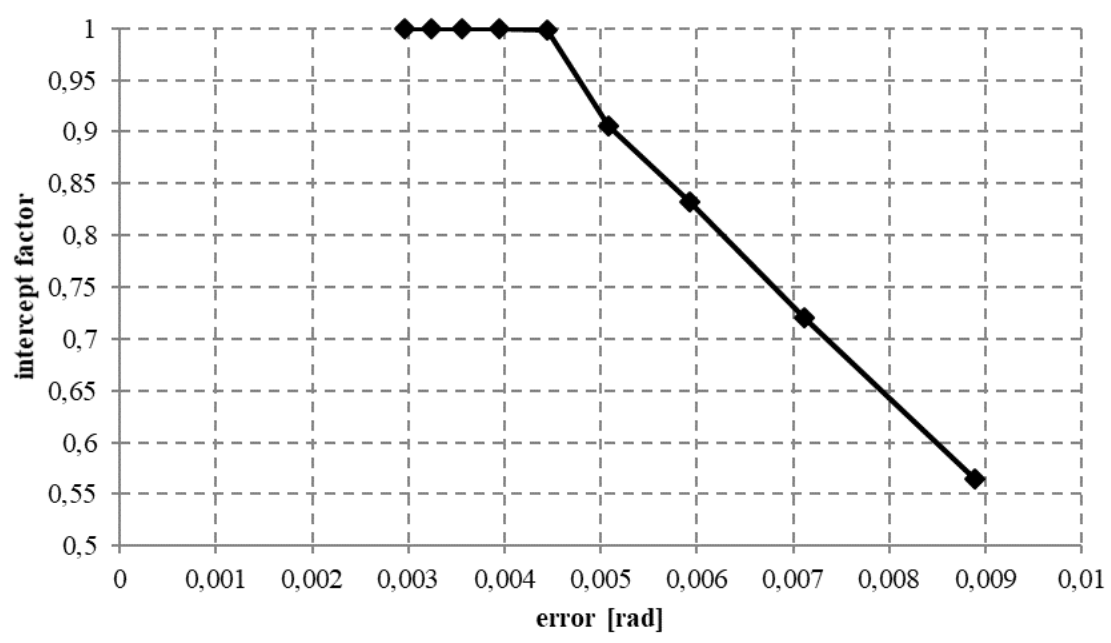

Fig. 4: Intercept factor as a function of total errors.

These results have been validated for our personal application using a ray-tracing software. Errors were simulated whilst modifying the dish profile and introducing an offset for the sun position. Theoretic radiation flux map has been modeled in order to keep peak solar flux on the receiver plane around $1500 \mathrm{~kW} / \mathrm{m} 2$. The design was analytical and then evaluated using ray-tracing methods (Fig.5).
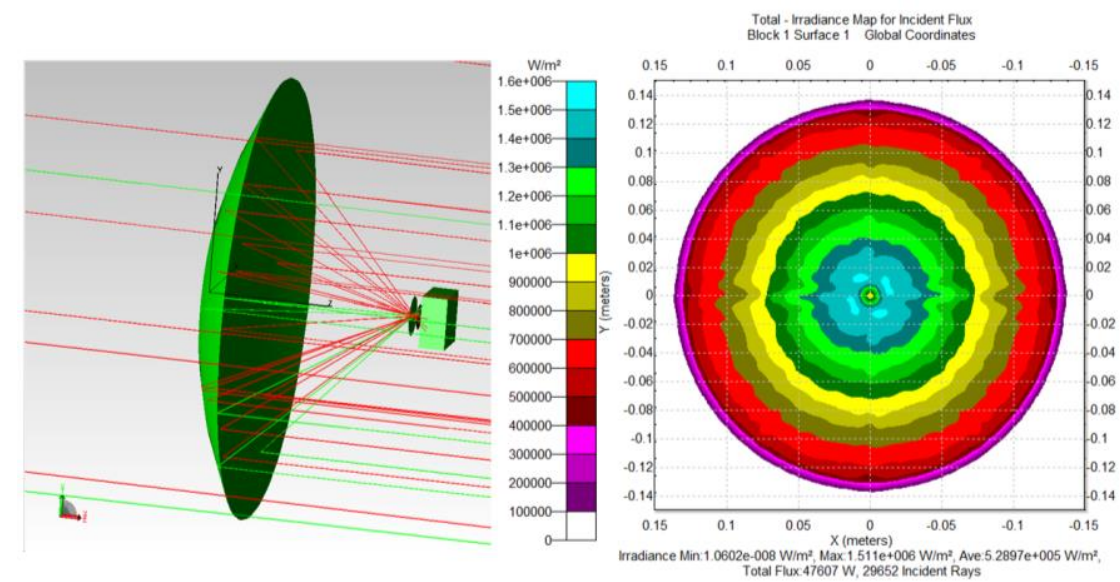

Fig. 5: Ray tracing analysis (left),

example of simulation in with a certain offset from the focal plane (right).

The dish has been fully designed and constructed with off the shelves components, excluding the mirrors. The system allows an easy dismount and alignment due to the Stirling engine being fixed on a 3-axis regulation system. This flexibility allows you to easily replace the equipment in focus for different research purposes. The control logic developed on a PLC from Beckhoff, is uncoupled between the dish and the Stirling engine to permit convenient use of the facility when equipment in the focus changes. Tracking control has been implemented both pointing the astronomic sun position and by using ISST5 sensor as feedback. For the coordinate tracking manner in order to improve the precision an accelerometer has been mounted on the structure and a routine is able to calculate the vertical error of the azimuth cinematic joint.

\section{Experimental setup and methodology}

During the design of the solar facility it has been considered the need to measure the radiant flux map and the fact that a small surface in the center of the dish wouldn't be participating in the concentration, because it would have been shadowed by the equipment on the focus point. For such reasons a free space in the center of the dish was left for the camera, with the advantage to have it parallel to the receiver surface normal, thus minimizing geometrical 
distortion (Fig. 6).

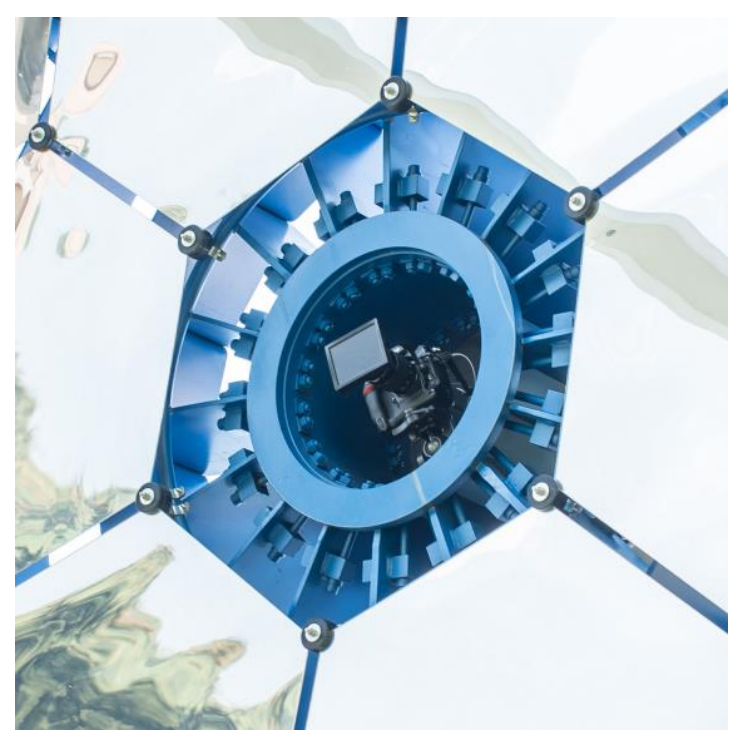

Fig. 6: The camera fixed in the center of the dish.

The support for the camera was realized in order to have the symmetry axis of the parabola collimated with the lens. The target specifically used for this test (a square with $0.45 \mathrm{~m}$ side) is placed near to the focal plane a bit forward respect the theoretical focal point because of a mechanical constrain. It has been manufactured with an aluminum plate $0.008 \mathrm{~m}$ thick, cooled on the back side by water (Fig. 7). The water flows in two channels machined in the plate with a depth of $0.003 \mathrm{~m}$. The cooling system is implemented with a centrifugal pump connected to a hand primer bulb pump at the inlet to fill the suction pipe and the centrifugal pump. The open water circuit utilizes a 30 liter tank which is hung to the focus structure and is instrumented with two thermocouples placed at the inlet and outlet of the target to protect the system in case it over heats as well as estimating the total energy absorbed in the future. The mass flow in the target with the circuit connected is approximately $15 \mathrm{l} / \mathrm{min}$.
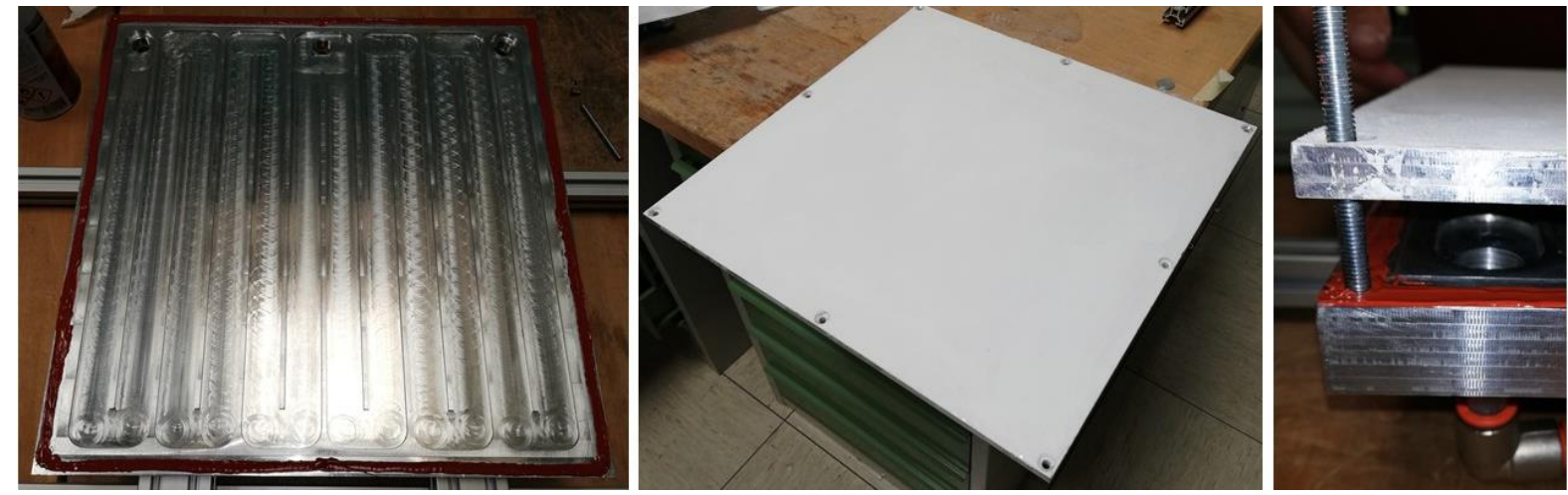

Fig. 7: Back support of the target with the water channel distribution (left), surface target coated with the painting (center), assembled phase (right).

The ideal target for the experiment would be Lambertian in order to be entirely diffusely reflecting. In practice the target available deviates from Lambertian reflectance. Materials and finish exposed are the most important parameters influencing this property. Moreover, in concentrate solar power with high intensity flux we also have critical condition in terms of surface heating and thermal stress. The surface is covered with an alumina based paint mixed with calibrated particles. This choice permits to have a controlled surface finish and a material that from the literature is one of the best candidate for reflectance characteristics (Harner and Menzies, 1989). After a mechanical cleaning of the surface to eliminate aluminum oxide the mixed slurry (powder and liquid in a 3 to 1 ratio by weight) has been applied to the surface with a roller and a brush trying to have a uniform coating. During this process it was difficult to keep the slurry homogeneous because the powder tended to deposit despite the liquid part. After the coating, the surface was not perfectly homogeneous because of different thicknesses and roughness. To improve sandpaper has been used adjusting thickness and roughness. After this the aluminum plate was heated at $93^{\circ} \mathrm{C}$ for 2 hours following the product specification. The target at this point was assembled with some screws to the back side with the water channel using a high temperature silicone sealant for a reliable seal in flanges.

To map the irradiance distribution over the focal plane, a new method inspired by Ho and Khalsa (2012) was used. 
The method consists in estimating a radiometric scale factor for the brightness values (BV) of the image pixels to the irradiance values of the target. A reference image of the sun is taken with neutral density filters to estimate the scale factor, then photographs of the target are taken with same exposure parameters but different neutral density filters. The map of the irradiance distribution is thus obtained using the scale factor from BV to irradiance taking also into consideration the filter factors for the new photograph.

The main innovation here presented is given by the design of the reflector: (i) its moderate size allows a removable target (Fig. 7) to be used and (ii) the camera can be placed with the optical axis orthogonally aligned to the target. This represents a big simplification in the method as the target can be removed from the focal plane of the solar concentrator allowing an image of the target to be acquired while exposing it ane sun and another image while placed over the focal plane of the solar concentrator. The scale factor from brightness values (BV) of the image to irradiance values of the target were here done measuring the DNI with a pyrheliometer Kipp \& Zonen, CHP1. With the aim to validate the method, and to characterize the target reflectivity, also an image of the sun was taken.

Being the images of the target acquired with the same camera (using different exposure times) and by measuring the actual DNI reaching the target, values of the irradiance flux can be estimated regardless of the values of target reflectivity. The exposure factors between the image of the target acquired when exposed at one sun with respect to when exposed over the focal plane of the reflector were considered. Moreover, with respect to the method presented in Ho and Khalsa (2012), accurate geometrical parameters of the camera were estimated through a bundle adjustment with self-calibration (Brown, 1971; Remondino and Fraser, 2006). Using the parameters given by the camera calibration, and measuring the distance between the target and the camera, an accurate value for the ground sample distance - GSD (the pixel size expressed in object space units) was determined. The GSD is then used for calculating the area imaged by each pixel in the object space.

Also, in this paper the working f-number was used instead of the f-number by considering the actual magnification given by focusing the camera not at infinity but at $6 \mathrm{~m}$, distance of the target from the camera.

A Nikon D3X 24 Mpx DSLR camera mounting a $0.105 \mathrm{~m}$ lens was used for the tests. Neutral density filters were used to reduce the exposure values within the acceptable ones for the camera thus avoiding signal saturation. Different gradations were used according to the weather conditions (hazy or clear sky) with optical density typically in the range 2.0-4.0. The images, acquired in RAW format by the camera, were linearized using the software DCRAW, then MATLAB environment was used for successive computation and analyses.

Preliminary tests were performed acquiring the images from the ground, then an ad hoc mount has been built to accommodate the camera in the center of the parabola. This setup allows the image to be acquired almost perpendicularly to the target. A wireless remote controller (Fig. 8) for setting the camera parameters and downloading the images online has also been developed using a microcomputer Raspberry Pi and gphoto2 open source software.

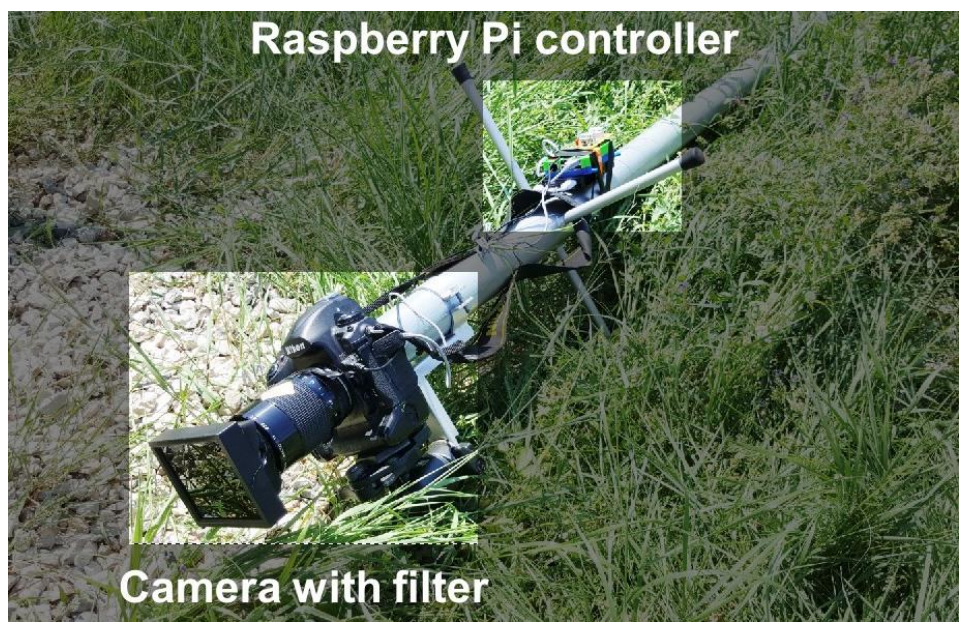

Fig. 8: Equipment used for the image acquisition fixed on the support.

\section{Results}

Tab. 1 summarizes the main parameters and settings of an experimental test carried out on $31^{\text {st }}$ July 2018 . The resolution of the camera in combination with the used lens and the camera-to-target distance allowed for a submillimeter resolution of the radiant flux map. The result of the irradiated target placed near the focal plane, 
shows very precise circular shapes. It means that the dish geometry is very accurate and homogenous. Some other specific measurements of the flux map will be done in the future to validate the profile and the ray tracing model used for the design.

Tab. 1. Main parameters and settings of an experimental test.

\begin{tabular}{|c|c|}
\hline Parameters and settings & Values and characteristics \\
\hline DNI measured by the pyrheliometer & $918 \mathrm{~W} / \mathrm{m}^{2}$ \\
\hline Camera & Nikon D3x 24 Mpx full frame sensor DSLR \\
\hline Sensor characteristics & CMOS $-5.95 \mu \mathrm{m}$ pixel size \\
\hline Calibrated principal distance & $107.29 \mathrm{~mm}$ \\
\hline Camera to target distance & $6 \mathrm{~m}$ \\
\hline $\begin{array}{l}\text { Ground sample distance - GSD (the pixel size expressed in object space } \\
\text { units) }\end{array}$ & $0.34 \mathrm{~mm}$ \\
\hline Irradiance for each $\mathrm{GSD}^{2}$ on the target illuminated by one sun & $108.63 \mu \mathrm{W}$ \\
\hline Working f-number & f/16.3 \\
\hline Area of the entrance pupil & $34.028 \mathrm{~mm}^{2}$ \\
\hline Exposure settings for the camera pointed at sun & $1 / 1000 \mathrm{sec}, \mathrm{f} / 16$, ISO 100 \\
\hline $\begin{array}{l}\text { Exposure settings for the image of the target over the focal plane of the solar } \\
\text { concentrator }\end{array}$ & $1 / 15 \mathrm{sec}, \mathrm{f} / 16$, ISO 100 \\
\hline Exposure settings for the image of the target exposed at 1 sun & $4 \mathrm{sec}, \mathrm{f} / 16$, ISO 400 \\
\hline
\end{tabular}

Figure 9 shows the irradiance map of the target placed on the focal plane of the solar concentrator.

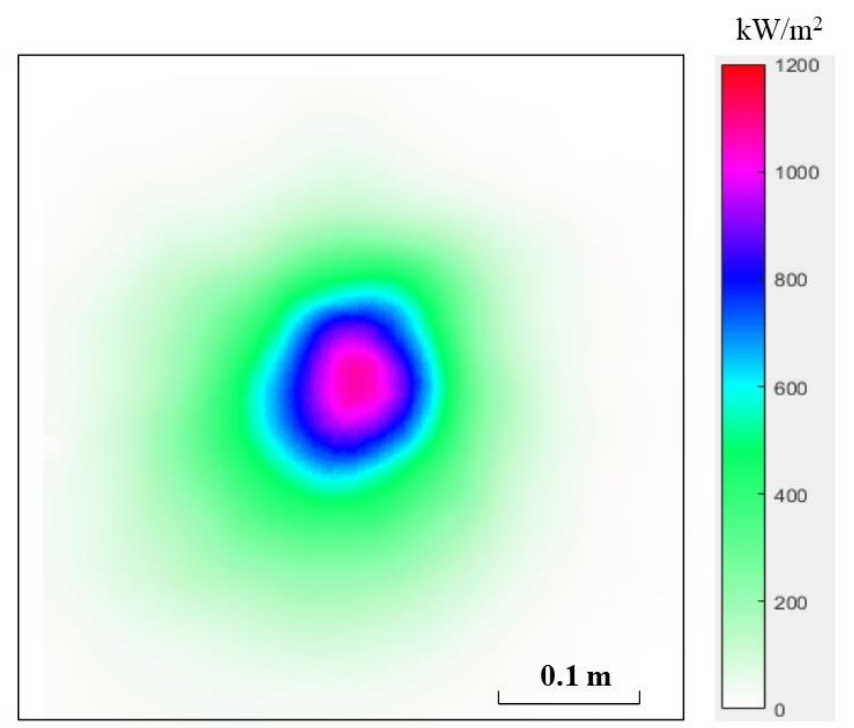

Fig. 9: The obtained irradiance distribution map with the proposed photogrammetric method.

\section{Conclusion}

The presented work proposed a photographic method as an efficient and inexpensive way to estimate the concentration map on focusing technologies. The method has been applied to a real facility installed nearby Trento (Italy) and has demonstrated an easy system for solar flux map characterization. The advantage with respect to other solutions to avoid any additional equipment near to the focal plane for estimating pixel radiation intensity or total amount of energy received has been practically verified. Moreover, a comparison between design data and measurements is done. The design of the facility has been validated both for the spherical and paraboloidal portion of the reflector. The target used treated with alumina-based painting demonstrates to be Lambertian and resistant for the high concentration value obtained. Considering the archived results, the method will be improved analyzing error sources and accuracy. From a comparison between the flux map calculated by ray-tracing and the measured 
one, the conclusion is that the tolerances calculated for the dish geometry, tracking errors and mirrors precision have been respected. . Future activity will be focused on the measurement of the reflectivity of the Lambertian target to validate the method proposed for the analysis.

\section{Acknowledgement}

The research leading to these results has received funding from the European Union's through H2020-LCE-20162017 under agreement no. 731287 - INSHIP project. "Integrating National Research Agendas on Solar Heat for Industrial Processes".

\section{References}

Brown, D.C, 1971. Close-range camera calibration. Photogramm. Eng, 37(8), pp.855-866

DCRAW, www.cybercom.net/ dcoffin/dcraw/ (last access: September 2018)

David A. Haner and Robert T. Menzies, 1989. Reflectance characteristics of reference materials used in lidar hard target calibration. APPLIED OPTICS Vol. 28, No. 5

Ho, C.K. and Khalsa, S.S., 2012. A photographic flux mapping method for concentrating solar collectors and receivers. Journal of Solar Energy Engineering, 134(4), p.041004

Huairui Li, Weidong Huang, Farong Huang, Peng Hu and Zeshao Chen, 2013. Optical analysis and optimization of parabolic dish solar concentrator with a cavity receiver, Solar Energy 92 288-297, http://dx.doi.org/10.1016/j.solener.2013.03.011

M. Röger, P. Herrmann, S. Ulmer, M. Ebert, C. Prahl, F. Göhring. Techniques to Measure Solar Flux Density Distribution on Large-Scale Receivers, Solar Energy AUGUST 2014, Vol. 136, DOI: 10.1115/ 1.4027261

MATLAB, www.mathworks.com (last access: September 2018)

Remondino, F., Fraser, C., 2006: Digital camera calibration methods: considerations and comparisons. International Archives of Photogrammetry, Remote Sensing and Spatial Information Sciences, Vol. XXXVI, part 5, pp. 266-272

SOLAR-MEMS http://www.solar-mems.com/smt_pdf/ISSTX_Technical_Specifications.pdf, (last access: September 2018)

W. Reinalter, S. Ulmer, P. Heller, T. RauchJ, M. Gineste, A. Ferriere and F. Nepveu, Detailed performance analysis of the 10-kw CNRS-PROMES dish/stirling system, SolarPACES2006 A7-S72 


\title{
Abrasion and Cleaning Tests on Antireflective and Antireflective/Anti-soiling Coatings for Solar Glass Glazing
}

\author{
Gema San Vicente ${ }^{1}$, Meryem Farchado ${ }^{1}$, Aránzazu Fernandez-García ${ }^{2}$, Nuria Germán ${ }^{1}$, Lucía \\ Martínez-Arcos ${ }^{2}$, Ángel Morales ${ }^{1}$ \\ ${ }^{1}$ CIEMAT-Plataforma Solar de Almería, Madrid (Spain) \\ ${ }^{2}$ CIEMAT-Plataforma Solar de Almería, Almería (Spain)
}

\begin{abstract}
The application of antireflective (AR) coatings on glass components for solar thermal collectors and PV modules increases the solar efficiency by increasing the sun energy that reaches the active layer. The low refractive index of this material required to satisfy the condition of producing destructive interference in AR/glass interfaces, makes necessary to deposit porous silica layers which are mechanically weaker than dense silica layers. Soiling of AR coated glass glazing not only can reduce the solar transmittance and increase the scattering but also can deteriorate the surface of the AR coating leading to irreversible damage by abrasion and reducing the long-term performance. The use of an anti-soiling (AS) coating on the top of the AR surface could avoid this yield loss due to soiling and increases the durability of the solar device. This paper describes the effect on the soiling and cleaning of an AS treatment on AR coated glass samples. The effect of the sample soiling, the type of sand applied and the brush used has been studied. The AS coating not only affects the sample soiling but also diminishes the surface damage.
\end{abstract}

Keywords: Antireflective, anti-soiling, glass, cleaning, glazing

\section{Introduction}

It is widely known the use of AR coatings on glass covers to increase the efficiency of solar systems (PV and solar thermal technologies). The most common commercial AR coatings for glass consist of a porous silica layer which satisfies the low refractive index requirement. The porous structure is linked to weak mechanical properties which are essential to assure long-term performance. In addition, its surface is more reactive than uncoated glass surfaces, being more susceptible to soiling. The interaction between dust particles and AR coatings on glass has been already studied by Klim et al. (2015). This soiling affects performance and durability of the system and decreases its optical efficiency. Concerning the effect of climatic conditions, it has been found that high precipitation accompanied by high wind velocity create a natural cleaning, but the combination of dust with low precipitation or high humidity produces mud patches that cause an opposite effect and may result in permanent decrease in solar efficiency (Mazumder et al., 2015). Recently, the application of AS treatments on the AR coated glass is generating great interest as the transmittance by soiling is reduced as well as the abrasion produced by sand particles and/or cleaning processes is also diminished (San Vicente et al, 2011; Pendse et al., 2018; Quan and Zhang, 2018; Wiesinger et al., 2018). Additionally, cleaning processes of optical surfaces in solar power plants is a key point as they can degrade the optical surface and as these processes imply important operation and maintenance $(\mathrm{O} \& \mathrm{M})$ costs in manpower. Water availability is also required in locations where it is costly and difficult to obtain it. In fact, European Union Horizon 2020 projects as WASCOP or MinWaterCSP are focused on reducing the water consumption in CSP plants by strategies as using new concepts of cleaning and the application of AS coatings. This work presents the results of applying contact cleaning on artificially soiled glass samples coated with an AR coating and the effect of using a commercial AS treatment on them. The sample resistance to abrasion of cleaning, the effect of the type of brush and the type of sand used for the artificial soiling are studied by transmittance measurements and visual inspection. 


\section{Experimental}

\subsection{Sample preparation}

Borosilicate flat glass samples with a thickness of $3 \mathrm{~mm}$ and a size of $1000 \mathrm{~mm}$ x1000 mm were coated with a silica sol-gel solution by dip-coating. The solution was composed of Tetraethyl orthosilicate (TEOS), Methyltriethoxysilane (MTES), water and ethanol being the molar ratio alkoxide:water:ethanol of 1:5:48 respectively. Hydrochloric acid was used as catalyst and Triton X-100 was added at $30 \mathrm{~g} / \mathrm{l}$ concentration as a pore generator (Morales, 2002). Samples were heated at $500^{\circ} \mathrm{C}$ for 15 minutes to burn the pore generator and other organic matter and to obtain the AR porous silica film. In some of the samples, a commercial solution (ClearShield Eco-System ${ }^{\mathrm{TM}}$ ) was applied on one side for preparing the hydrophobic AS surface. This AS solution was applied with a cotton pad wetted with the solution.

\subsection{Soiled Sample preparation}

Two types of sand taken from highly representative sites of CSP plants were employed. One of them was collected from The Sustainable City at Dubai (UAE) and the other from the Ouarzazate Solar complex in Ouarzazate, Morocco. Both sands present very different properties between them regarding colour, particle size and composition. A detailed characterization of both sands used has been performed by Fernández-García et al. (2018). Before soiling the samples, the sands were sieved with a sieve size of $180 \mu \mathrm{m}$. Some samples were artificially soiled with the described sands, using the next procedure: demineralized water was sprayed on the AR or AS/AR coated glass to wet the surface; then, $1 \mathrm{~g}$ of sand was deposited with the fingers over the entire surface and demineralized water was sprayed again. At least 12 hours were waited before testing.

\subsection{Cleaning test and Characterization}

The equipment used in the cleaning/abrasion test is an Erichsen Washability and Scrubbing Tester model 494, equipped with a microdose pump and a metal holder. The test procedure was performed according to UNE-EN ISO 11998:2006, and consists in moving linearly and horizontally a wetted brush that is mounted on a metal holder on the sample surface. 200 cycles were applied meanwhile demineralized water was added with a feed rate of $4 \mathrm{~mL}$ per minute, being one cycle the brush movement over all the length in two-ways. Two brush types with different properties were used and nominally labelled as "soft" and "hard". The soft brush is manufactured with nylon bristles of $0.1 \mathrm{~mm}$ thickness meanwhile the hard brush is made of pig bristles according to DIN53778. The equipment and both brushes used are shown in Figure 1.
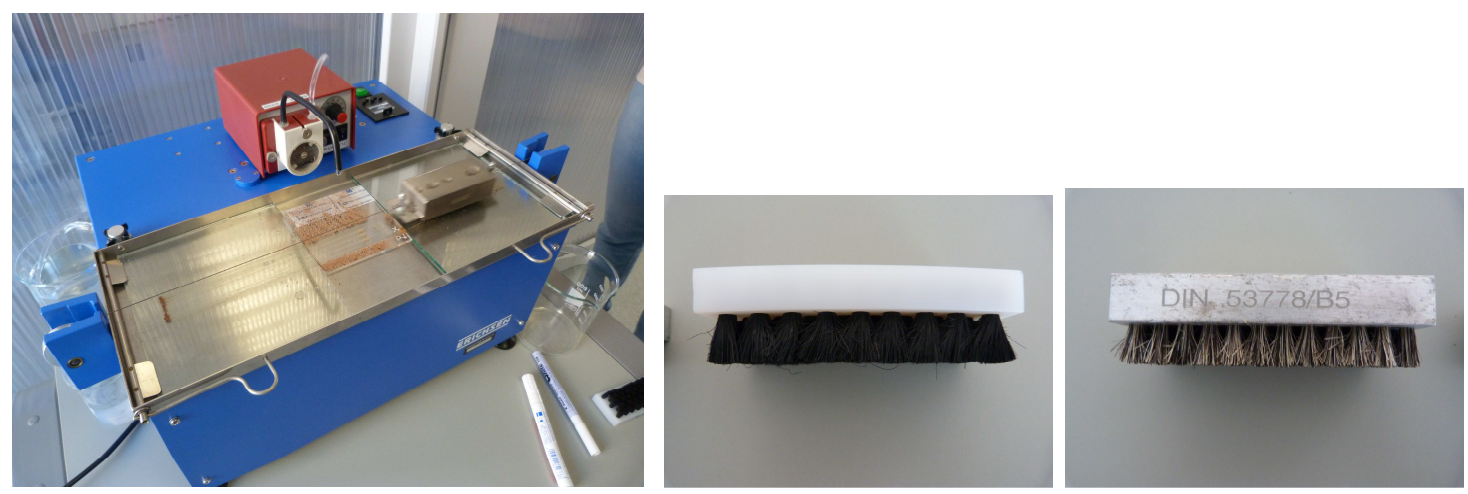

Fig. 1: Photographs of the equipment used during the test (left) and the two types of brushes tested ("soft" on the centre and "hard" on the right).

The effect of soiling and resistance at the cleaning test was evaluated by measuring the hemispherical transmittance spectra of the samples at the wavelength range of 300-2500nm. The equipment used was a UV/VIS/NIR Perkin-Elmer LAMBDA 950 double beam spectrophotometer with a 150-mm diameter Spectralon ${ }^{\circledR}$ coated integrating sphere. The solar transmittance $\left(\tau_{s, h}\right)$ was calculated by averaging the transmittance data over the direct AM1.5 solar spectral irradiance given by the current standard ASTM G-17303, following the IEC62862-1-1 standard as it is expressed in equation 1. 


$$
\tau_{s, h}(300,2500)=\frac{\int_{300}^{2500} \tau_{\lambda, h}(\lambda) G_{b}(\lambda) d \lambda}{\int_{300}^{2500} G_{b}(\lambda) d \lambda}
$$

Where $\tau_{\lambda, h}(\lambda)$ is the spectral hemispherical transmittance and $G_{b}(\lambda)$ is the spectral direct solar irradiance.

An optical microscope Leica DM4 M was used to study the microscopic appearance after the cleaning test. Additionally, water static contact angle (WCA) measurements were performed with a KSV CAM 200 instrument to study the effect of the commercial hydrophobic treatment.

\section{Results and Discussion}

\subsection{Effect of AS treatment on soiling behaviour and solar transmittance}

The effect of applying the commercial AS treatment on the surface of the AR coated glass is clearly shown when water is sprayed on the sand applied on the sample surface, as it can be seen in Figure 2. When the water was sprayed on the sand deposited on the AR coated glass, the sand remained uniformly distributed on the surface. However, when the same procedure was made on the AS/AR surfaces the sand was dragged with the water drops, leaving many places of the surface clean. The WCA measurements show the modification of the AR surface after applying the hydrophobic treatment, being the value increased from around $55^{\circ}$ to $100^{\circ}$. Photographs of the water droplets on the surface before and after the AS treatment are also shown in Figure 2.
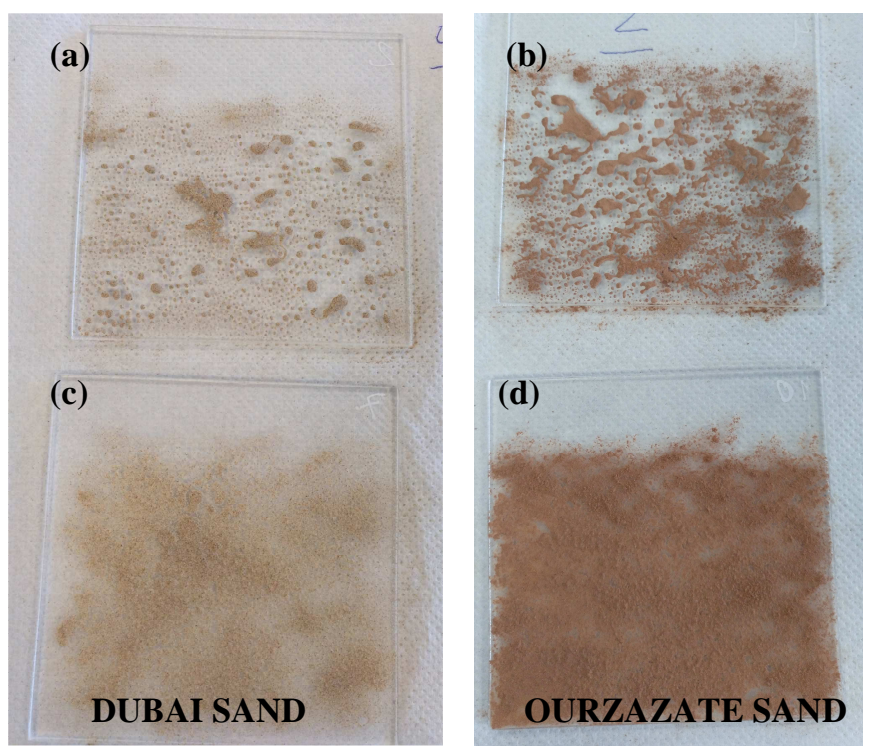
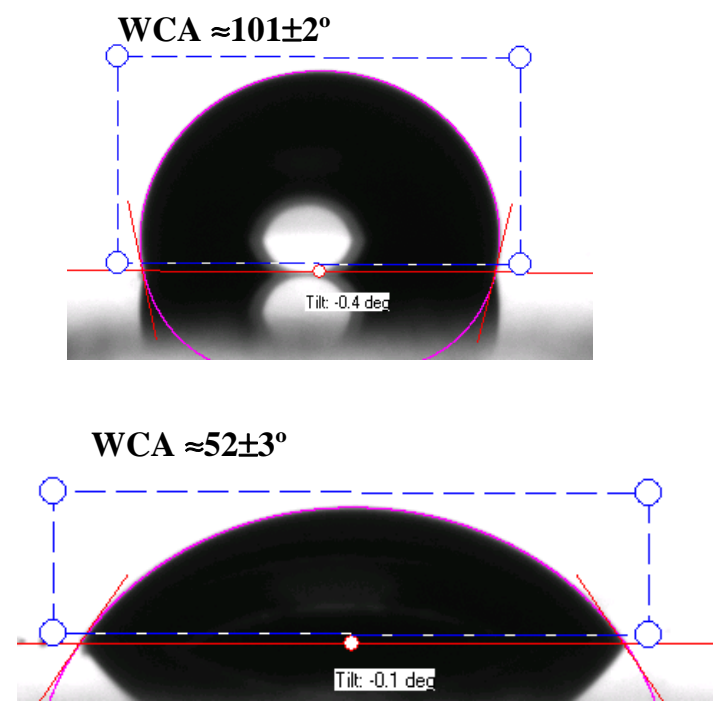

Fig. 2: Picture of AS/AR samples ((a) and (b)) and AS samples ((c) and (d)) after Dubai and Ouarzazate sands application (left and center, respectively). Photographs of the water droplets obtained in the static water contact angle (WCA) measurements in the AS/AR sample surface (top right) and in the AR sample surface (top bottom).

The AS treatment changes slightly the optical properties of the samples, as it can be seen in Tab. 1. The application of the AR coating increases remarkably the solar transmittance of the glass, being this value for the uncoated glass around 0.920 and around 0.975 after depositing the porous silica coating. When the AS treatment is applied, the solar transmittance decreases less than 0.010 points, obtaining values between 0.965 and0.972. The solar transmittance of the samples soiled with both types of sand are also presented in Tab. 1 and it can be seen that an important decrease is obtained. Noticeable differences are observed when the samples with the AS treatment are soiled, being the solar transmittance more than the double of the same samples without the AS. It should be noted that the three transmittance spectra are recorded in different zones of the same sample to minimize mistakes, and that the standard deviation is higher in the samples with AS than without AS, due to the heterogeneities in soiling (pictures in Fig.2). The values shown in Tab. 1 are the mean values of the three measurements. Moreover, an influence of the sand used is also observed, presenting the samples soiled with 
Ouarzazate sand lower solar transmittance values than the samples soiled with Dubai sand. This is attributed to the smaller-size particles of Ouarzazate sand that have more specific surface area and are distributed more uniformly than coarser dust particles, reducing the voids between the particles through which light can pass. The same effect of particle size in soiling has been already observed previously by Klim et al. (2016) and Javed et al. (2016).

As conclusion, it can be remarked that the AS treatment modifies the artificial soiling with natural sand from Ouarzazate and Dubai, being the solar transmittance loss in average of $40 \%$ when the AS treatment is applied and of $78 \%$ without AS treatment. Moreover, the same quantity of Ouarzazate sand produces higher transmittance loss than Dubai sand.

Tab. 1: Solar transmittance values of AR coated glass before and after applying the AS treatment and after being artificially soiled.

\begin{tabular}{|c|c|c|c|c|}
\hline & \multicolumn{4}{|c|}{ Solar transmittance $\left(\boldsymbol{\tau}_{\boldsymbol{s}, \boldsymbol{h}}\right)$} \\
\hline Sample & Initial & After AS & Soiled (Ouarzazate sand) & Soiled (Dubai sand) \\
\hline AR & 0.976 & - & - & 0.244 \\
\hline AS/AR & 0.976 & 0.967 & - & 0.681 \\
\hline AR & 0.975 & - & 0.207 & - \\
\hline AS/AR & 0.976 & 0.972 & 0.524 & - \\
\hline
\end{tabular}

\subsection{Contact cleaning Test}

The effect of the AS treatment, the sand and the brush used during the contact cleaning test is examined in this section.

\section{Effect of sand and AS treatment}

The images obtained by optical microscopy from AR and AS/AR coated glass after the cleaning experiment with the soft brush are presented in Tab. 2, for samples without soiling and artificially soiled with Dubai and Ouarzazate sands. Furthermore, the solar transmittance variation of all the samples tested with respect to the value before testing is presented in Tab. 5. By analysing the images and solar transmittance values, it can be seen that the presence of sand or not strongly affects to the surface abrasion and optical performance. When no sand is present on the surface, very few scratches are made by the brush and even no scratches are visible when the AS treatment is applied. In fact, a -0.003 decrease in solar transmittance was obtained for the AR sample and no decrease for the AS/AR sample. When samples were previously soiled, the damage is more significant and in both cases (AR and AS/AR samples), and greater damage is produced when the sand used was from Ouarzazate. The solar transmittance drop values showed in Tab. 5 perfectly confirm the results obtained by the images. It is important to note that the application of the AS treatment diminished the damage produced by the cleaning in all the cases and in fact no damage is produced without sand. The same trends were obtained for the sample tested by using the hard brush (see next section). 
Tab. 2: Optical microscopy images of AR and AS/AR samples after the cleaning test with soft brush, and without sand, soiled with Dubai sand and soiled with Ouarzazate sand.

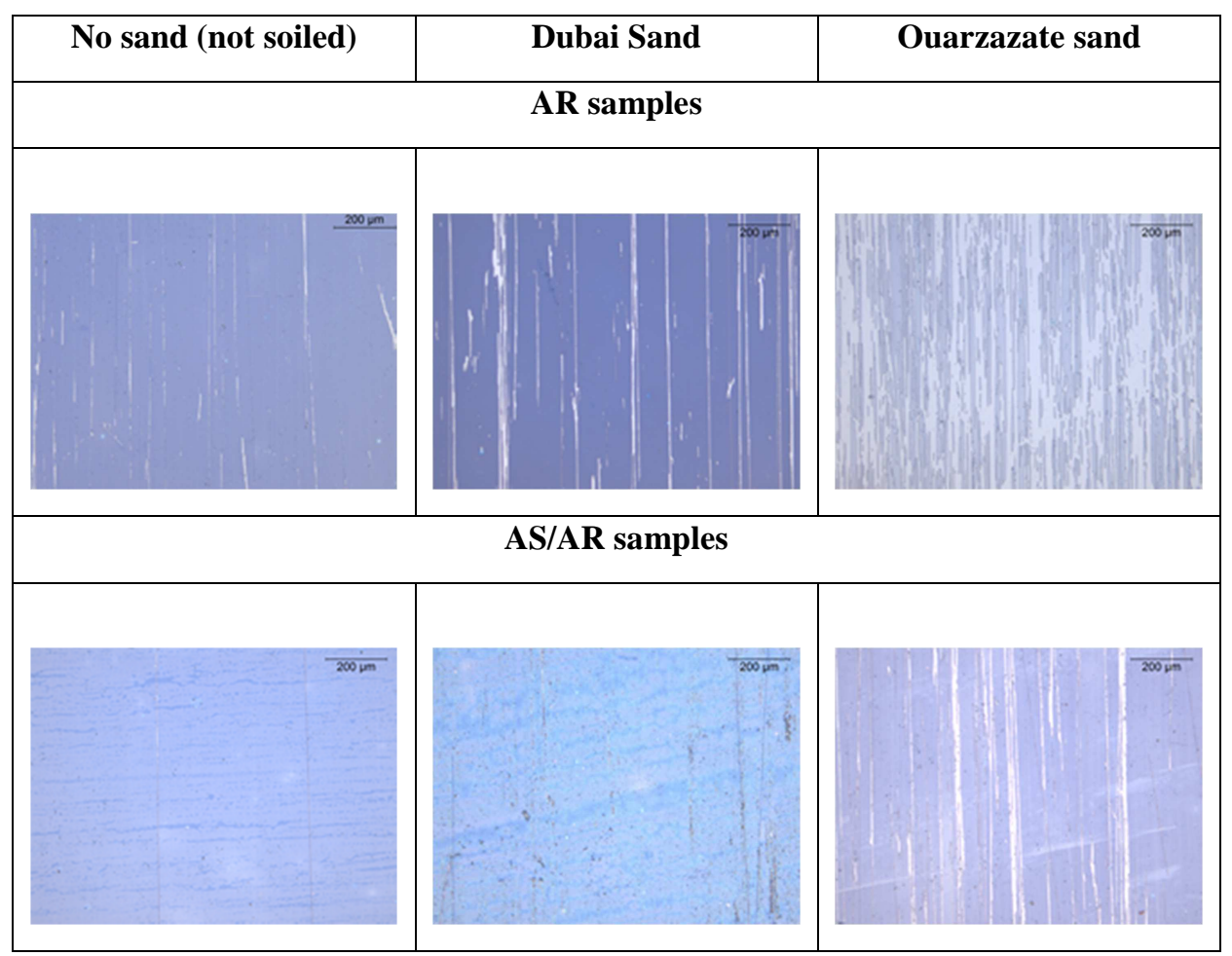

\section{Effect of brush type and AS treatment}

Tab. 3 and Tab. 4 show the images of samples tested comparing the two types of brush, not soiled and soiled for AR and AS/AR coated glasses, respectively. With regards to the AR samples, the images clearly show that the soft brush causes less surface scratches than the hard brush. Thus, soiled samples images show that the AR coating was practically removed in the tested side after the cleaning test with the hard brush. In the case of Ouarzazate sand, it can be also noticed some sand remainder that is not completely removed. The solar transmittance drop values (Tab. 5) show the same tendency, being the highest drop obtained (-0.029) the corresponding to the AR sample tested with the hard brush and the Ouarzazate sand.

Regarding the AS/AR samples, the role played by the brush type is similar to that played in the AR samples. The harder the brush, the more scratched the sample surface. It should be noted that when the samples were not soiled, not damage is produced independently of the brush type used. So, the application of the AS treatment allow to use the hard brush when the samples are not artificially soiled. It is also remarkable in these soiled samples that scratches are produced but less than in the case of the AR samples. The solar transmittance drop is nearly one-half of what they are in the samples without the AS treatment, as it is recorded in Tab. 5. This strongly suggests that the AS treatment not only avoid the adherence of sand particles but also increases the abrasion resistance of the surface. Similar results were obtained previously in samples tested in a sandstorm chamber, where the use of the AS treatment reduced considerably the erosion rate (Wiesinger et al., 2018). 
G. San Vicente et. al. / EuroSun 2018 / ISES Conference Proceedings (2018)

Tab. 3: Comparison of optical microscopy images of AR samples after the cleaning test with the two different brushes.

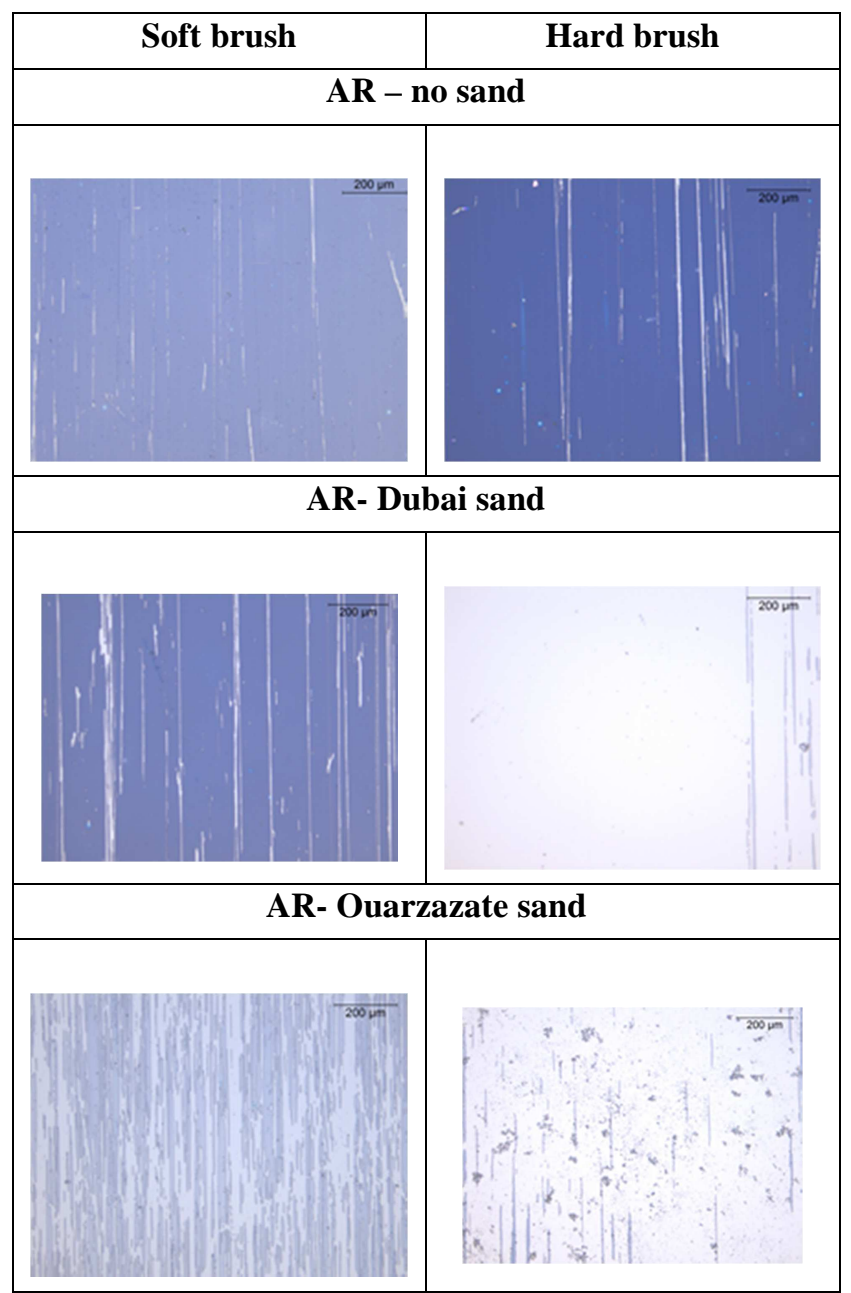


Tab. 4: Comparison of optical microscopy images of AS/AR samples after the cleaning test with the two different brushes.

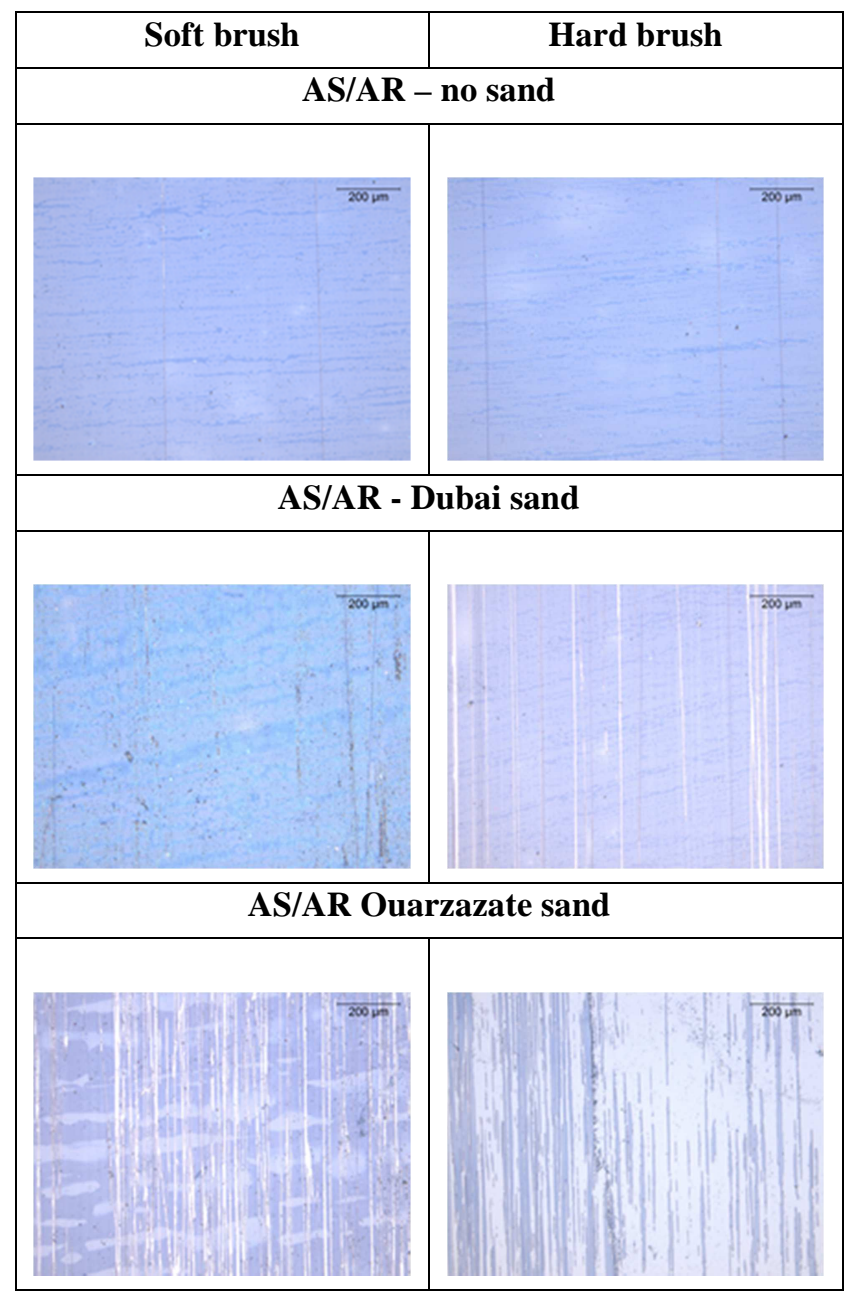

Tab. 5: Results of solar transmittance drop from all the samples after the contact cleaning test.

\begin{tabular}{|c|c|c|c|c|}
\hline & \multicolumn{2}{|c|}{ Soft Brush } & \multicolumn{2}{c|}{ Hard brush } \\
\hline & AR & AS/AR & AR & AS/AR \\
\hline No sand & -0.003 & 0.000 & -0.003 & 0.000 \\
\hline Dubai sand & -0.005 & -0.004 & -0.023 & -0.004 \\
\hline Ouarzazate sand & -0.023 & -0.013 & -0.029 & -0.016 \\
\hline
\end{tabular}

\section{Conclusions}

This work shows the effect in transmittance and soiling behaviour of applying a commercial AS treatment on the AR coated borosilicate glass for solar components. The importance of studying the properties of the sand of each location has been demonstrated and so small-size particles adhered strongly to the surface produce higher surface damage, with the corresponding loss in transmittance. The contact cleaning method can be used on the samples but the erosion produced will be dependent of the soil level and type of samples, as this damage is produced by the joint action of the brush with the sand. Finally, the application of the AS treatment decreases slightly the solar transmittance but makes more difficult the adhesion of sand in presence of humidity and moreover improves the abrasion resistance to cleaning processes. 


\section{References}

ASTM G173-03, 2012. Standard Tables for Reference Solar Spectral Irradiances: Direct Normal and Hemispherical on $37^{\circ}$ Tilted Surface.

DIN-EN ISO 53778-2, 1983. Emulsion paints for interior use; evaluation of cleanability and of wash and scrub resistance of coatings. International Organization for Standardization (ISO): Geneva, Switzerland.

Fernández-García A., Juaidi A., Sutter F., Martínez-Arcos L., Manzano-Agugliaro F. 2018. Solar reflector materials degradation due to the san deposited on the backside protective paints. Energies, 11, 808, 1-20, DOI: 10.3390/en11040808.

IEC-62862-1-1, 2018. Solar thermal electric plants- Part 1-1:Terminology.International Electrotechnical commission.

Javed W., Guo B., Wubulikasimu Y., Figgies B.W., 2016. Photovoltaic performance degradation due to soiling and characterization of the accumulated dust. IEEE International Conference on Power and Renewable Energy (ICPRE), 580-584. DOI: 10.1109/ICPRE.2016.7871142.

Klimm E., Ost L. Köhl M., Weiss K-A. 2016. Microscopic measurement and analysis of the soiling behavior of surfaces with standardized and real dust - a parameter study. Energy Procedia 91, 338-345. DOI: 10.1016/j.egypro.2016.06.239.

Klimm E., Kaltenbach T., Philipp D., Masche M., Weiss K-A., Köhl M., 2015. Soiling and abrasion testing of surfaces for solar energy systems adapted to extreme climatic conditions. Proceedings 31st European PV Solar Energy Conference and Exhibition, 2521-2523.

Mazumder M.K., Horestein M.N., Heiling C., Stark J.W., Sayyah A., Yellowhair J., Raychowdhury A. 2015. Environmental degradation of the optical surface of PV modules and solar mirrors by soiling and high RH and mitigation methos for minimizing energy yield losses. IEEE 42nd Photovoltaic Specialist Conference (PVSC), 1-6. DOI: 10.1109/PVSC.2015.7355973

Morales A., 2002. Sol- gel process for the preparation of porous coatings, using precursor solutions prepared by polymeric reactions. EP Patent 1329433.

Pendse S., Chandra Sekhar Reddy K., Narendra C., Murugan K., Sakthivel S., 2018. Dual-functional broadband antireflective and hydrophobic films for solar and optical applications. Solar Energy 163, 425-433. DOI: 10.1016/j.solener.2018.02.019.

San Vicente G., Bayón R., Germán N. Morales A., 2011. Surface modification of porous antireflective coatings for solar glass covers. Solar Energy 85, 676-680. DOI: 10.1016/j.solener.2010.06.009

Quan Y-Y., Zhang L-Z. 2017. Experimental investigation of the anti-dust effect of transparent hydrophobic coatings applied for solar cell covering glass. Solar Energy Materials \& Solar Cells 160, 382-389. DOI: 10.1016/j.solmat.2016.10.043.

UNE-EN ISO 11998:2006 standard, 2006 Paints and varnishes. Determination of wet-scrub resistance and cleanability of coatings. International Organization for Standardization (ISO): Geneva, Switzerland.

Wiesinger F., San Vicente G., Fernández-García A., Sutter F., Morales A., Pitz-Paal R. 2018. Sandstorm erosion testing of anti-reflective glass coatings for solar energy applications. Solar Energy Materials and Solar Cells 179, 10-16. https://doi.org/10.1016/j.solmat.2018.02.018.

Acknowledgments: This research received funding from the European Union's Horizon 2020 research and innovation program under grant agreement No 654479, project WASCOP. 


\title{
Radiative Collector and Emitter: Experimental Results
}

\author{
Sergi Vall, Albert Castell, Cristian Solé and Marc Medrano \\ Department of Computer Science and Industrial Engineering, University of Lleida, Edifici CREA, Pere \\ de Cabrera s/n, 25001 Lleida, Spain
}

\begin{abstract}
In order to increase the use of renewable energy in buildings, solar collection and radiative cooling can be combined in a single device (Radiative Collector and Emitter (RCE)) to produce both hot and cold water. In this paper, the potential of such a device to produce hot and cold water is evaluated experimentally, determining the capacity of such system to produce hot water during day and cool down water below ambient temperature during night. Experimental results demonstrate the capability of the RCE to produce heat during the day as well as to cool down water during night.
\end{abstract}

Keywords: Radiative cooling, Solar collection, Renewable energy production.

\section{Introduction}

In the roadmap to a new renewable energy model, the building sector is identified as a crucial user of nonrenewable energy. It accounts for $40 \%$ of total energy consumption in the European Union (European Parliament), representing space conditioning (space heating and cooling) $65 \%$ of the building energy budget and $13.8 \%$ for domestic hot water (DHW) (ODYSSEE-MURE project). In order to improve this situation, passive strategies are fostered to reduce energy demands. However, energy consumption is not reduced to zero if thermal comfort conditions are to be preserved (Yang et al., 2014). Therefore, renewable energy sources are required to cover these energy needs.

Domestic Hot Water (DHW) can be achieved by solar thermal collectors. However, for cooling there is still no simple renewable alternative with such potential and development. Two possibilities for cooling are compression heat pumps and absorption heat pumps. However, they are either non-renewable or too complex. Compression heat pumps are the most common cooling devices. Although compression heat pumps are considered as a renewable source under certain circumstances (European Commission, 2013/114/EU; European Parliament. Directive 2009/28/EC), they consume high amounts of electricity. On the other hand, although absorption heat pumps may use solar energy as driving heat (Yin et al., 2000), they present some important disadvantages, such as being not available for residential applications, having low overall efficiencies, requiring high operation temperatures, and needing large cooling towers (Hassan and Mohamad, 2012).

On the other hand, radiative cooling uses the sky as a heat sink taking advantage of its effective temperature lower than ambient. Energy is dissipated to the sky taking advantage of the infrared atmospheric window (7$14 \mu \mathrm{m})$ that allows some infrared radiation pass directly to space without intermediate absorption and reemission (Bell et al., 1960; Berdahl and Fromberg, 1982). A comprehensive review of radiative cooling is presented in (Vall and Castell, 2017).

Research evaluating experimentally this technology is scarce. First attempts used unglazed solar collectors to behave as radiative collectors (Erell and Etzion, 2000; Hosseinzadeh and Taherian, 2012). The capability of such modified solar collectors to produce cold was demonstrated, although the efficiency and power were low. Other authors focused on the development and evaluation of more sophisticated materials (Raman et al., 2014; Chen et al., 2016), allowing lower temperatures by providing radiative cooling even under sunlight conditions. On the other hand, some research has been conducted in the development of numerical models (Ferrer Tevar et al., 2015). However, none of such systems has reached the market due to its low available cooling rates (between 20-80 W/m² (Cavelius et al., 2005), with peak values of $120 \mathrm{~W} / \mathrm{m}^{2}$ (Eicker and Dalibard, 2011)). 
Therefore, significant improvements in the materials or the concept need to be developed for radiative cooling to become feasible.

The combination of solar collection and radiative cooling into a single device could result in a significant improvement of the feasibility of the device. The new device would be capable to produce both heat and cold, thus covering, partially or totally, the Domestic Hot Water and the cooling demands. However, these two technologies are not generally prepared to work together when they are designed to work autonomously (Hu et al., 2015); therefore some adjustments have to be done for this purpose.

Radiative cooling and solar thermal collection use different radiation wavelength (longwave radiation for radiative cooling and shortwave radiation for solar thermal collection), and solar thermal collection takes place during sunlight hours while radiative cooling mainly when there is no sunlight. However, it is possible to couple them as they are not used at the same time, so there is no interference between them.

Moreover, the combination of radiative cooling and solar collection in a single device would be a qualitative leap forward to renewable suitability for meeting different energy demands. The use of both technologies may substantially reduce the non-renewable primary energy consumption for space conditioning and domestic hot water. This new concept that combines solar thermal collection and radiative cooling in a single device is based on radiation heat transfer, since it collects radiation (solar) from the Sun as a heat source, and emits radiation (thermal) to the sky to provide cooling. Therefore, this concept will be mentioned from here on as Radiative Collector and Emitter (RCE). In this paper, first experimental results of an RCE system are presented.

To combine both functionalities, a device with architecture similar to a flat plate solar thermal collector could be used (an absorber/emitter surface and a cover on top of it). To modes of operation would be possible: solar collection mode and radiative cooling mode. The use of a movable cover would allow the RCE system to change functionality. This cover would be composed of two different sections (one for each operation mode) made of different materials. The section of the cover used for the solar collection mode would let solar radiation pass through and block mid and far infrared radiation (glass will be used in this paper). On the contrary, the section used for radiative cooling would let thermal radiation pass through (polyethylene will be used in this paper). A sliding cover system would allow the two different sections to be exchanged to perform each function (solar collection during the day and radiative cooling during the night). This concept has been theoretically presented in (Vall et al., 2018).

The present paper explains the first experimental results of the concept of Radiative Collector and Emitter (RCE), combining both solar collection and radiative cooling production.

\section{Experimental set-up}

The experimental setup consisted of a solar collector, a radiative cooler, 2 water tanks, a pump, 6 temperature sensors, 2 flow meters, a pyrgeometer and the control and data acquisition systems. The solar collector used is model FUJI-P. It is a $2 \mathrm{~m} \times 1 \mathrm{~m} \times 80 \mathrm{~mm}$ aluminum frame collector, with transparent $3 \mathrm{~mm}$ glass and $30 \mathrm{~mm}$ glasswool back insulation. The collector has 8 cooper pipes of $8 \mathrm{~mm}$ diameter and $0.6 \mathrm{~mm}$ thick. On the other hand, the radiative cooler is the same solar collector (FUJI-P) but replacing the glass screen by a $0.6 \mathrm{~mm}$ thick Polyethylene (PE) film and painting the surface of the radiator with black paint in order to adapt it to the required characteristics of radiative cooling mode (Fig. 1).
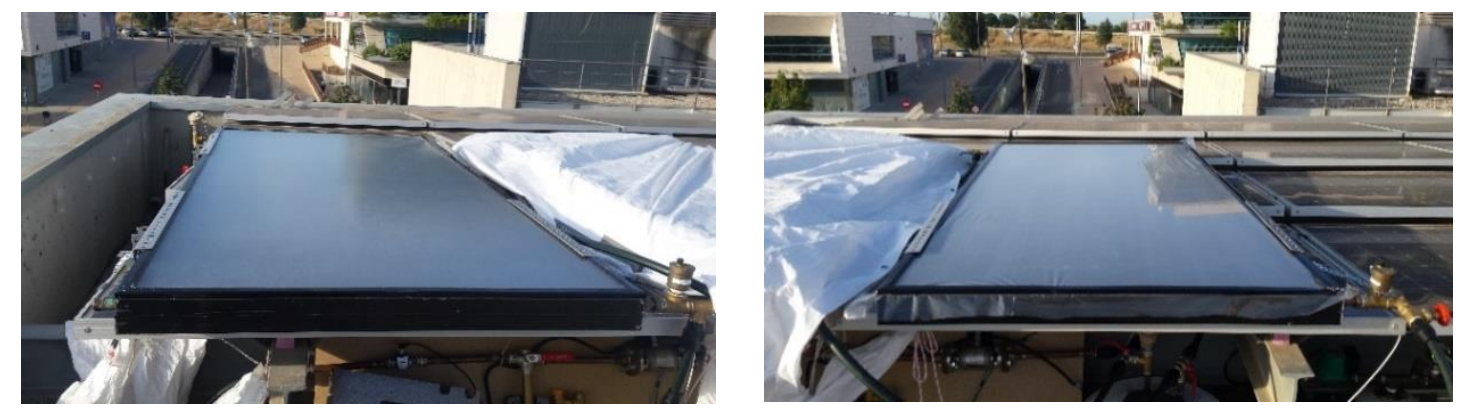

Fig. 1: Solar collector (left), and modified solar collector used as radiative cooling device (right).

For the sake of simplification, two separate devices were used instead of a single RCE device. This was 
sufficient to provide accurate data for model and concept validation, which was the main objective of this research. Four temperature sensors ( $\mathrm{Pt}-100$, with an accuracy of $0.1^{\circ} \mathrm{C}$ ) were used to monitor the inlet and outlet water temperature of the solar collector and the radiative cooling device. Water flow rates were monitored using a flowmeter for the operation under solar collection mode (Badger Meter - Primo Advanced, 0.25\% accuracy), and a flowmeter for the radiative cooling mode (Schmidt Mess - SDNC 503 GA-20, 4\% accuracy). Weather data was extracted from a nearby weather station. However, incoming infrared radiation was measured using a pyrgeometer on-site (LP PIRG 01 - DeltaOhm, 5\% accuracy).

Water was circulated through the solar collector during daylight hours in order to determine the solar collection power. Water was stored in a $150 \mathrm{~L}$ tank were average water temperature was monitored. On the other hand, during night, water was circulated through the radiative cooler to determine the energy dissipation and RCE cooling performance. For this operation mode, water was stored in a $50 \mathrm{~L}$ water tank, were average water temperature was monitored. Experiments were performed for short periods of time (3-4 days) combining solar collection mode ( $8-20 \mathrm{~h})$ and radiative cooling mode (20-8h). In each mode, only one of the collectors and one of the water tanks were used. The experiments were performed during summer period in Lleida (Dry Mediterranean Continental climate), since in this period both domestic hot water and cooling are required.

To evaluate the performance of the device, production rates were calculated for both solar collection and radiative cooling modes (Eq. 1). In order to obtain accurate results, the transition period from one operation mode to the other one was not considered in the evaluation (7-9h and 19-21h).

$$
\dot{\mathrm{q}}=\mathrm{v} \cdot \rho \cdot \mathrm{Cp} \cdot \Delta \mathrm{T} \quad \text { (Eq. } 1)
$$

Where:

$\dot{\mathrm{q}}$ is the power of the device in [W].

$v$ is de volumetric flow rate in $\left[\mathrm{m}^{3} / \mathrm{s}\right]$.

$\rho$ is the density of the fluid $\left[\mathrm{kg} / \mathrm{m}^{3}\right]$.

$\mathrm{Cp}$ is the heat capacity of the fluid $[\mathrm{J} / \mathrm{kg} \cdot \mathrm{K}]$.

$\Delta \mathrm{T}$ is the temperature difference between inlet flow and outlet flow in $[\mathrm{K}]$.

\section{Results and discussion}

Experiments presented in this paper represent two typical weather scenarios: clear day (from July $26^{\text {th }}-28^{\text {th }} 2017$ ) and cloudy day (from July $31^{\text {st }}$ - August $4^{\text {th }} 2017$ ). During both periods, nights had clear skies. For the clear day experiments, the meteorology was stable with all day clear and sunshine, the outdoor temperature oscillated form 19 to $40^{\circ} \mathrm{C}$, with Global Horizontal Irradiance (GHI) peak values up to $960 \mathrm{~W} / \mathrm{m}^{2}$ and Incoming Infrared Radiation average value on $340 \mathrm{~W} / \mathrm{m}^{2}$. For the cloudy day experiments, the meteorology was stable with cloudy days, the outdoor temperature oscillated from 23 to $42^{\circ} \mathrm{C}$, with $\mathrm{GHI}$ peak values up to $935 \mathrm{~W} / \mathrm{m}^{2}$ and Incoming Infrared Radiation average value on $355 \mathrm{~W} / \mathrm{m}^{2}$.

\subsection{Clear day experiments}

Under clear sky condition the RCE was capable to produce heat, reaching maximum outlet temperature values close to $65^{\circ} \mathrm{C}$ (Fig. 2), achieving average heating powers $300-350 \mathrm{~W} / \mathrm{m}^{2}$ (Fig. 3 and Tab. 1), and average temperature differences between the outlet water and the ambient around $17-22^{\circ} \mathrm{C}(\mathrm{Tab} .1)$. On the other hand, the RCE also showed the capability to produce cold water, reaching minimum outlet water temperatures close to $16^{\circ} \mathrm{C}$ (Fig. 2), with average cooling powers between $12-34 \mathrm{~W} / \mathrm{m}^{2}$ (Fig. 3 and Tab. 1), and average temperature differences between the outlet water and ambient around $2-3^{\circ} \mathrm{C}$ (Tab. 1). 


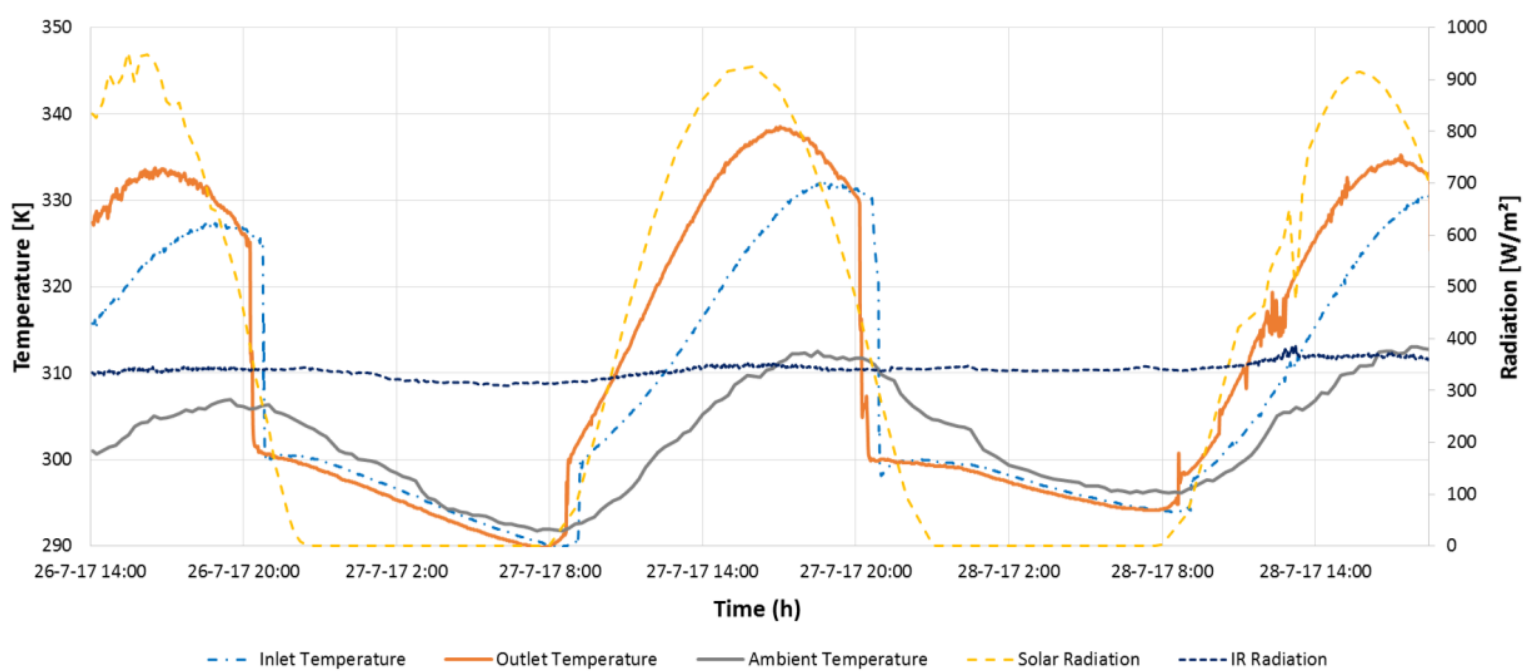

Fig. 2: Experimental results of the RCE concept for clear day experiments.

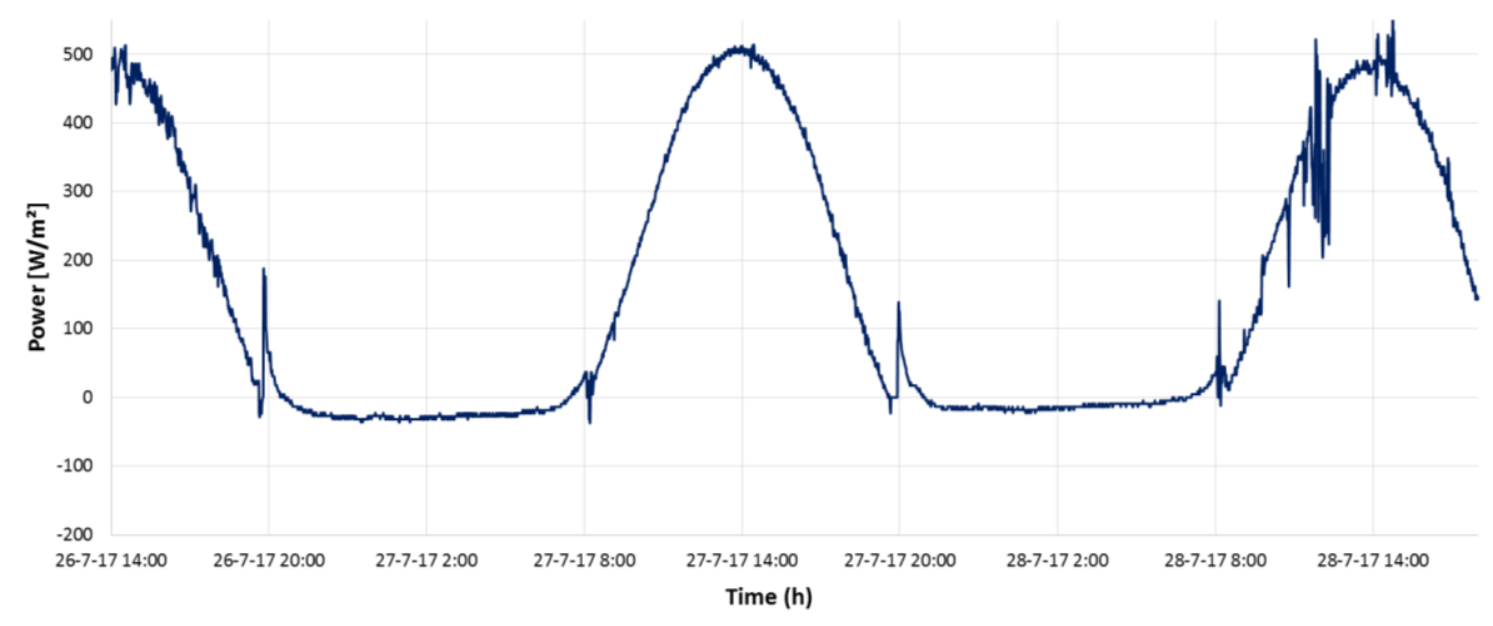

Fig. 3: Available power from the RCE concept for clear day experiments.

\subsection{Cloudy day experiments}

Under cloudy sky condition the RCE was capable to produce heat, reaching maximum outlet temperature values close to $65^{\circ} \mathrm{C}$ (Fig. 4), achieving average heating powers $135-280 \mathrm{~W} / \mathrm{m}^{2}$ (Fig. 5 and Tab. 1), and average temperature differences between the outlet water and the ambient around $8-14^{\circ} \mathrm{C}$ (Tab. 1). No cloudy conditions were observed during the night; therefore, no experimental data is available for cloudy conditions under radiative cooling operation.

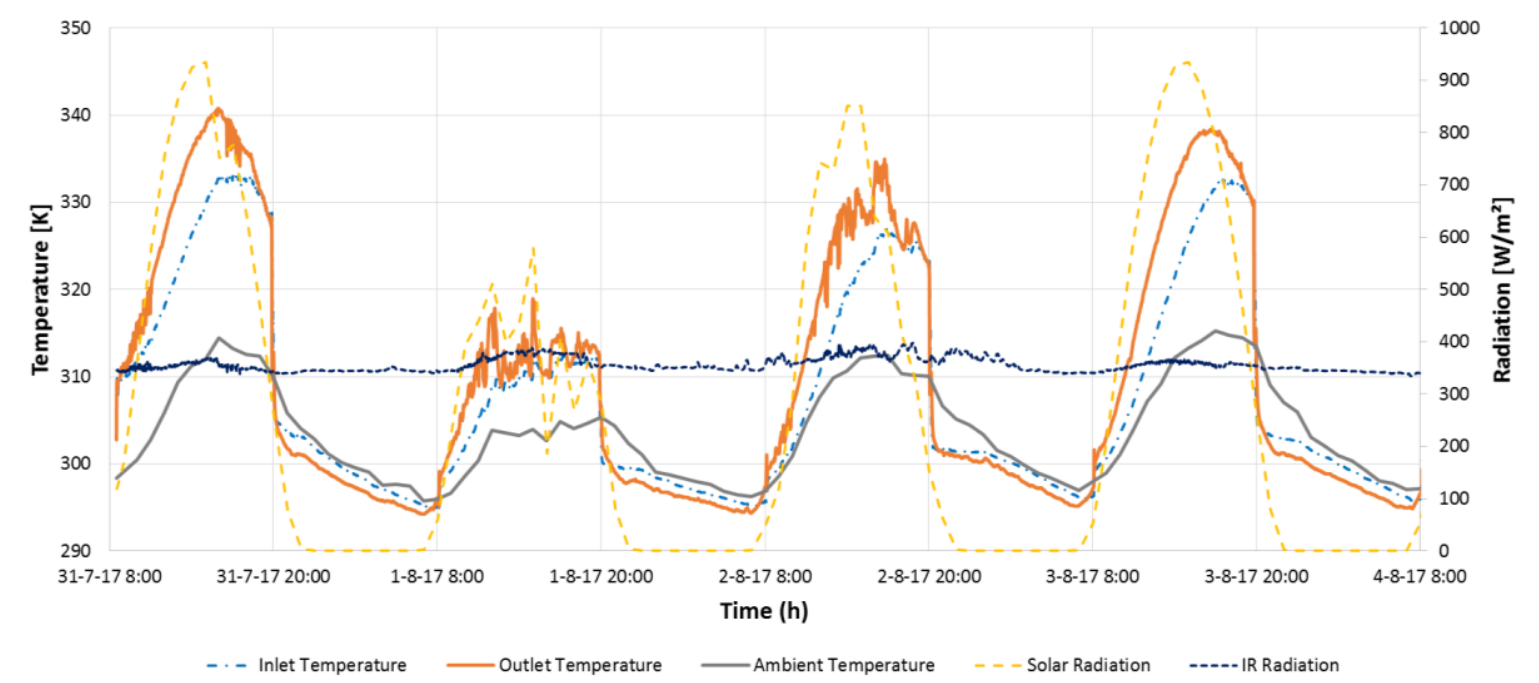


Fig. 4: Experimental results of the RCE concept for cloudy day experiments.

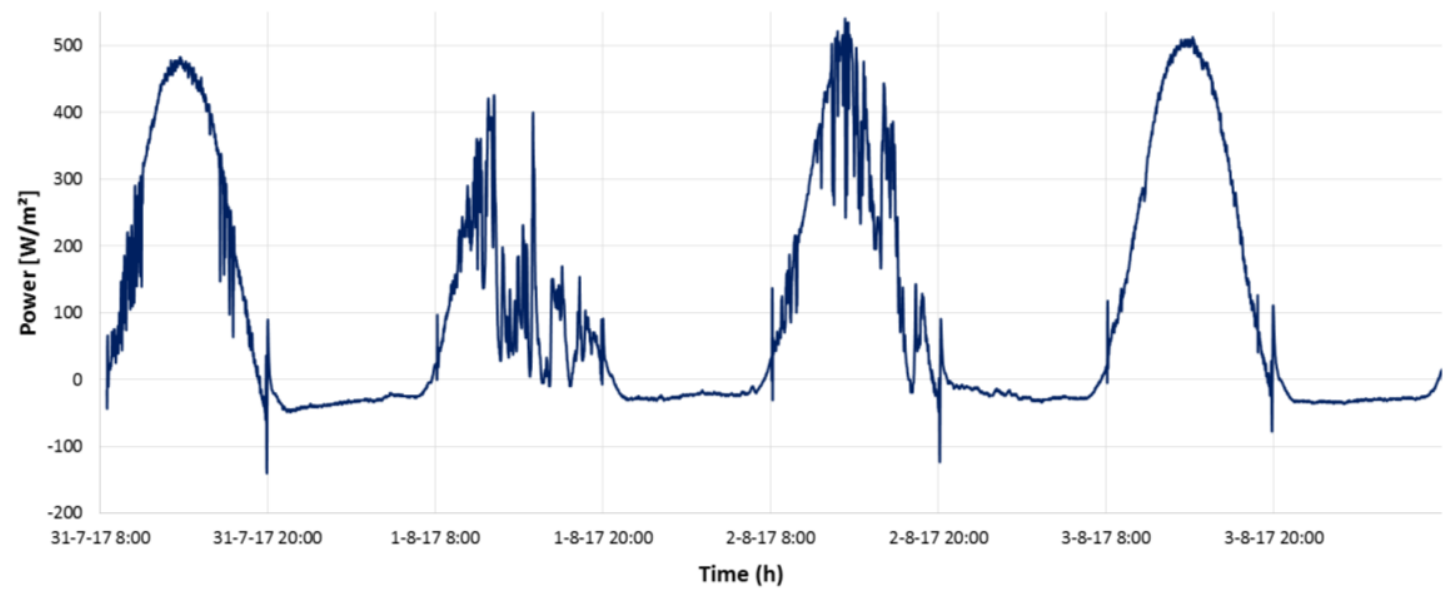

Fig. 5: Available power from the RCE concept for cloudy day experiments.

Tab. 1: Average power produced by the RCE for both heat and cold production.

\begin{tabular}{|c|c|c|c|c|c|}
\cline { 3 - 6 } \multicolumn{2}{c|}{} & \multicolumn{2}{|c|}{ Average power $\left(\mathbf{W} / \mathbf{m}^{2}\right)$} & \multicolumn{2}{c|}{ Average $\mathbf{T}_{\text {out }}-\mathbf{T}_{\text {amb }}(\mathbf{K})$} \\
\cline { 3 - 7 } & & Heating & Cooling & Heating & Cooling \\
\hline \multirow{5}{*}{ Clear sky } & $27 / 07 / 17(9: 00-19: 00)$ & 345.36 & - & 21.31 & - \\
\cline { 2 - 7 } & $26 / 07 / 17(21: 00)-27 / 07 / 17(7: 00)$ & - & 26.06 & - & -2.14 \\
\cline { 2 - 7 } & $27 / 07 / 17(21: 00)-28 / 07 / 17(7: 00)$ & - & 12.65 & - & -2.68 \\
\cline { 2 - 7 } & $31 / 07 / 17(21: 00)-01 / 08 / 17(7: 00)$ & - & 33.35 & - & -2.47 \\
\cline { 2 - 7 } & $01 / 08 / 17(21: 00)-02 / 08 / 17(7: 00)$ & - & 23.85 & - & -2.56 \\
\cline { 2 - 7 } & $02 / 08 / 17(21: 00)-03 / 08 / 17(7: 00)$ & - & 22.70 & - & -2.63 \\
\cline { 2 - 7 } & $03 / 08 / 17(21: 00)-04 / 08 / 17(7: 00)$ & - & 30.65 & - & \\
\cline { 2 - 7 } & & & & & - \\
\hline \multirow{5}{*}{ Cloudy sky } & $31 / 07 / 17(9: 00-19: 00)$ & 305.44 & - & 21.55 & - \\
\cline { 2 - 7 } & $01 / 08 / 17(9: 00-19: 00)$ & 136.25 & - & 8.74 & - \\
\cline { 2 - 7 } & $02 / 08 / 17(9: 00-19: 00)$ & 277.95 & - & 13.83 & - \\
\cline { 2 - 7 } & $03 / 08 / 17(9: 00-19: 00)$ & 342.82 & - & 17.14 & - \\
\hline
\end{tabular}

\section{Conclusions}

Experimental results demonstrate the potential of the RCE concept to heat up water during daylight hours and to cool down water during night. Although improvements are required in order to maximize the cold production and reach useful temperature levels, the concept is probed to cool down water below ambient temperature by the use of sky night radiation, while heating up water during day.

The cold produced during night can be used either as a cooling source or as a heat sink for other cooling technologies (such as heat pumps) in order to improve its efficiency, thus reducing the use of non-renewable energies. However, further improvements are required to take full advantage of this new concept.

\section{Acknowledgments}

The authors would like to thank the Oficina de Desenvolupament i Cooperació de la Universitat de Lleida for its project grant. The authors would like to thank the Catalan Government for the project grant (2017 SGR 659) given to their research group. Sergi Vall would like to thank the Secretaria d'Universitats i Recerca del 
Departament d'Economia i Coneixement de la Generalitat de Catalunya for its research fellowship.

\section{References}

Bell, E., Eisner, L., Young, J., Oetjen, R., 1960. Spectral-Radiance of Sky and Terrain at Wavelengths between 1 and 20 Microns. II. Sky Measurements. J Opt Soc Am 50, 1313-20. doi:10.1364/JOSA.50.001313.

Berdahl, P., Fromberg, R., 1982. The thermal radiance of clear skies. Sol Energy 29, 299-314. doi:10.1016/0038-092X(82)90245-6.

Cavelius, R., Isaksson, C., Perednis, E., Read, G.E.F., 2005. Passive cooling technologies, Austrian Energy Agency.

Chen, Z., Zhu, L., Raman, A., Fan, S., 2016. Radiative cooling to deep sub-freezing temperatures through a 24-h day-night cycle. Nat Commun 7, 1-5. doi:10.1038/ncomms13729.

Eicker, U., Dalibard, A., 2011. Photovoltaic-thermal collectors for night radiative cooling of buildings. Sol Energy 85, 1322-35. doi:10.1016/j.solener.2011.03.015.

Erell, E., Etzion, Y., 2000. Radiative cooling of buildings with flat-plate solar collectors. Build Environ 35, 297-305. doi:10.1016/S0360-1323(99)00019-0.

European Commission. Decision of 1 March 2013 (2013/114/EU) establishing the guidelines for Member States on calculating renewable energy from heat pumps from different heat pump technologies pursuant to Article 5 of Directive 2009/28/EC of the European Parliament. Off J Eur Union 2013;62:27-35.

European Parliament. Directive 2009/28/EC of the European Parliament and of the Council of 23 April 2009 on the promotion of the use of energy from renewable sources and amending and subsequently repealing Directives 2001/77/EC and 2003/30/EC. Off J Eur Union 2009;140:16-62. doi:10.3000/17252555.L_2009.140.eng.

European Parliament. Directive 2010/31/EU of the European Parliament and of the Council of 19 May 2010 on the energy performance of buildings. Off J Eur Union 2010;153:13-35.

Ferrer Tevar, J.A., Castaño, S., Garrido Marijuán, A., Heras, M.R., Pistono, J., 2015. Modelling and experimental analysis of three radioconvective panels for night cooling. Energy Build 107, 37-48. doi:10.1016/j.enbuild.2015.07.027.

Hassan, H.Z., Mohamad, A.A., 2012. A review on solar cold production through absorption technology. Renew Sustain Energy Rev 16, 5331-48. doi:10.1016/j.rser.2012.04.049.

Hosseinzadeh, E., Taherian, H., 2012. An Experimental and Analytical Study of a Radiative Cooling System with Unglazed Flat Plate Collectors. Int J Green Energy 9, 766-79. doi:10.1080/15435075.2011.641189.

Hu, M., Pei, G., Li, L., Zheng, R., Li, J., Ji, J., 2015. Theoretical and Experimental Study of Spectral Selectivity Surface for Both Solar Heating and Radiative Cooling. Int J Photoenergy 2015, 1-9. doi:10.1155/2015/807875.

ODYSSEE-MURE project. ODYSSEE and MURE database 2014. www.odyssee-mure.eu (accessed March 15, 2017).

Raman, A.P., Anoma, M.A., Zhu, L., Rephaeli, E., Fan, S., 2014. Passive radiative cooling below ambient air temperature under direct sunlight. Nature 515, 540-4. doi:10.1038/nature13883.

Vall, S., Castell, A., 2017. Radiative cooling as low-grade energy source : A literature review. Renew Sustain Energy Rev 77, 1-18. doi:10.1016/j.rser.2017.04.010.

Vall, S., Castell, A., Medrano, M., 2018. Energy savings potential of a novel radiative cooling and solar thermal collection concept in buildings for various world climates. Energy Technology 6, 2200-2209. doi: 10.1002/ente.201800164

Yang, L., Yan, H., Lam, J.C., 2014. Thermal comfort and building energy consumption implications - A review. Appl Energy115, 164-73. doi:10.1016/j.apenergy.2013.10.062.

Yin, J., Shi, L., Zhu, M.S., Han, L.Z., 2000. Performance analysis of an absorption heat transformer with different working fluid combinations. Appl Energy 67, 281-92. doi:10.1016/s0306-2619(00)00024-6. 


\title{
Surface Modification of AISI 316L Stainless Steel by Oxynitrocarburizing for Solar Collector Applications
}

\author{
Gregorio Vargas ${ }^{1}$, Lizsandra López ${ }^{1}$ and Aldo. F. Chávez ${ }^{1}$ \\ ${ }^{1}$ Centro de Investigación y de Estudios Avanzados del IPN, Saltillo (México)
}

\begin{abstract}
The surface modification of AISI 316L stainless steel was studied using a mixture of cyanate and sodium carbonate salts. This mixture was placed in paste form on previously polished steel substrates. The oxinitrocarburizing treatment was carried out at $580^{\circ} \mathrm{C}$ for 5 to 20 minutes by the eutectic mixture paste of sodium cyanate (NaCNO) and sodium carbonate $\left(\mathrm{Na}_{2} \mathrm{CO}_{3}\right)$ salts. Characterization of the materials was carried out using XRD, SEM/EDS, UV/Vis, FT-IR spectroscopy techniques. The oxynitrocarburizing time played an important role in the surface modification of the stainless steel, in terms of the nature of the phases formed in the resulting oxidized and nitrided layers, thickness of both layers and surface optical properties of the treated samples. The development of a thick surface oxidized layer was detrimental for the surface optical properties of the samples. In this sense, a 5 min oxynitrocarburizing treatment produced the best results. The best optical properties obtained at the surface of the steel were an absorptance $(\alpha)$ of 0.90 and an emittance $(\varepsilon)$ of 0.1 .
\end{abstract}

Keywords: surface modification, thermochemical treatment, pastes, optical properties.

\section{Introduction}

Spectrally selective surfaces for applications in solar thermal collectors should have high absorptance $(\alpha)$ values in the visible spectrum region and low emittance $(\varepsilon)$ in the infrared region [Tian and Zhao 2013, Thirugnanasambandam et al 2010]. A more specific way to evaluate the spectral selectivity is to calculate the relationship between solar absorptivity and thermal emittance $(\alpha / \varepsilon)$. However, this method is considered inappropriate for evaluating the photothermal conversion efficiency. For example, a solar absorber with a solar absorptivity of 0.60 and a thermal emittance of 0.03 achieves a ratio of 20 but does not have a higher photothermal conversion efficiency than an absorber with a solar absorptance of 0.90 and a thermal emittance of 0.1 that achieves a ratio of only 9 . To classify the spectral selectivity and, therefore, the performance of a solar absorber, the expression $\alpha-0.5 \varepsilon$ is used to reflect the weight factor of the thermal emittance in a more reasonable way according to ISO 22975-3 [Caliari and Timelli 2015].

Currently there is a wide variety of surface modification technologies aimed at improving the functional properties of metal alloys. Many of these technologies have already been tested industrially but their initial investment, the degree of control required, their maintenance and operation expenses and their interaction with the environment prevent their widespread dissemination. There is a continuous effort to improve the existing technologies and to search for novel treatments to improve the performance of the surface functionality. A selection of the optimal technique depends on the capability, the economics and easiness of scaling up of the process, the size characteristics and geometry of the component to be modified or coated, their functionality requirements. The environmental aspect has also become a driver of new technological requirements.

The surface blackening of stainless steels is among the spectrally selective surfaces that meet the main requirements. Electroplating is one of the more suitable coating techniques employed by the solar thermal industry for over 50 years. Chemical conversion, spray pyrolysis, vacuum deposition, and chemical vapor deposition are the other common coating techniques [Wijewardane and Goswami 2012]. Surface modification of steels by thermochemical treatments has been commonly used to improve their wear properties, hardness and corrosion resistance; however, the effect of the oxynitrocarburizing processes on the surface optical properties of stainless steels, have not been reported for their application in solar collectors. Besides the formation of stable nitrides occurring during the salt oxynitrocarburizing of a stainless steel, the formation of a black, dense and thermally stable oxide layer could be 
formed on top of the nitride layer. The characteristics of this two-layered coating configuration could be tailored to obtain the surface optical properties required for applications in solar collectors.

In this sense, the present work was aimed to obtain a spectrally selective surface on AISI 316L Stainless Steel for its application in solar collectors. This innovative method allows homogeneous and uniform modified surfaces in short times using a self-protective diffusion paste. Depending on the ingredients, the paste can diffuse different elements such as nitrogen on the surface of a material to harden and protect the surface against corrosion or modify its optical properties. The main advantages of the self-protecting pastes in thermochemical treatment of metals are:

- No protective atmosphere is required during the heat treatment,

- They are easy to handle and quick to prepare,

- They are suitable for the partial or selective treatment of a surface

- The thermochemical treatments can be done in a wide variety of conventional ovens.

- With respect to molten salts, this method substantially increases the performance of the reagents and radically decreases the disposal of waste or the regeneration of the salts.

- The treatment can be carried out at lower temperatures because the melting state is not required.

In the nitrocarburized materials, a "compound layer", comprised by iron and chromium nitrides and iron carbide, is commonly formed at the outermost zone of the substrate surface, while a "diffusion zone", comprising a solid solution of nitrogen in the base alloy, is formed just underneath the latter layer. In the "oxy-nitrocarburizing" processes, the steel is subjected to an additional post-oxidation stage [Thirugnanasambandam 2010]. The postoxidation is used to create a layer of $\mathrm{Fe}_{3} \mathrm{O}_{4}$ on top of the compound layer [Caliari and Timelli 2015]. The simultaneous oxidation and nitriding of steel in a single treatment is not common [Grabke et al 2003]; oxidation of the workpiece is commonly considered detrimental and thus it is usually avoided during the nitriding process. However, to generate spectrally selective black coatings our process uses a single and relatively short treatment cycle, without the post oxidative treatment.

\section{Experimental method}

The composition of the steel used was analyzed by atomic emission spectroscopy (AES). Its chemical composition is indicated by Table 1 .

Table 1. Chemical Composition of AISI 316L Stainless Steel

\begin{tabular}{|c|c|c|c|c|c|c|c|c|c|c|c|c|c|}
\hline $\mathbf{C}$ & $\mathbf{S i}$ & $\mathbf{M n}$ & $\mathbf{P}$ & $\mathbf{S}$ & $\mathbf{C r}$ & $\mathbf{M o}$ & $\mathbf{N i}$ & $\mathbf{A l}$ & $\mathbf{C u}$ & $\mathbf{N b}$ & $\mathbf{T i}$ & $\mathbf{V}$ & $\mathbf{W}$ \\
\hline 0.013 & 0.234 & 1.63 & 0.06 & 0.022 & 16.69 & 2.06 & 9.7 & 0.0005 & 0.48 & 0.0002 & 0.007 & 0.082 & 0.073 \\
\hline
\end{tabular}

The steel specimens were polished at a mirror level, then subjected to an ultrasonic cleaning procedure. The paste was formed using a mixture of $\mathrm{NaCNO}$ and $\mathrm{Na} 2 \mathrm{CO} 3$ salts with carboxymethyl cellulose as a binder. The oxynitrocarburizing treatment was carried out at $580^{\circ} \mathrm{C}$ for 5 to 20 minutes. The XRD analyses were carried out directly on the treated surface of the samples, without any prior preparation, using for this a Bruker AXS D8 Advance XRD apparatus, with monochromated $\mathrm{CuK} \alpha$ radiation, voltage of $40 \mathrm{KV}$, current density of $30 \mathrm{~mA}$, and a step size of $0.02^{\circ}(2 \theta)$ per second. For the SEM/EDS analyses, the treated samples were cross-sectioned. Then, the samples were hot mounted in resin with the cut surface facing downwards. This surface was then metallographically prepared with a final polish using a colloidal silica suspension with a particle size of $0.04 \mu \mathrm{m}$. Then, the metallographically prepared surfaces of the samples were etched for a minimum of $20 \mathrm{~s}$ using glyceregia etchant at room temperature and observed and analyzed by using a PHILIPS XL30ESEM scanning electron microscope, employing for this an acceleration voltage of $20 \mathrm{keV}$. The optical properties of the treated surfaces were evaluated by UV/Vis and FT-IR spectroscopy techniques, using for this a LAMBDA $350 \mathrm{UV} /$ Vis Spectrophotometer and a Frontier FT-IR spectrometer, respectively, both from PerkinElmer. The UV/Vis Spectrophotometer was fitted with a $150 \mathrm{~mm}$ integrating sphere, which allowed us to obtain the spectral reflectance of the samples in the solar radiation wavelength range. The FT-IR spectrometer was fitted with a diffuse reflectance accessory, which allowed us to obtain the nearinfrared (NIR) spectral reflectance of the samples.

The solar absorptance $(\alpha)$ and the thermal emittance $(\varepsilon)$ of the nitrided materials were determined using the procedure described by [Li 2000], taking the required solar irradiance values from the ASTM G173-03. 


\section{Results and discussion}

Phase Evolution. The XRD (Figure 1) studies, together with the EDS spectra and the microstructure of Figure 2 obtained by SEM, revealed that the compound layer was a double-layered zone. The layer located at the outermost zone of the samples was composed by intermixed crystals of $\mathrm{Fe}_{3} \mathrm{O}_{4}$, and $\varepsilon-\mathrm{Fe}_{3} \mathrm{~N}$, with increasing relative proportions of the first phase and decreasing relative proportions of the second phase with increasing treatment time.

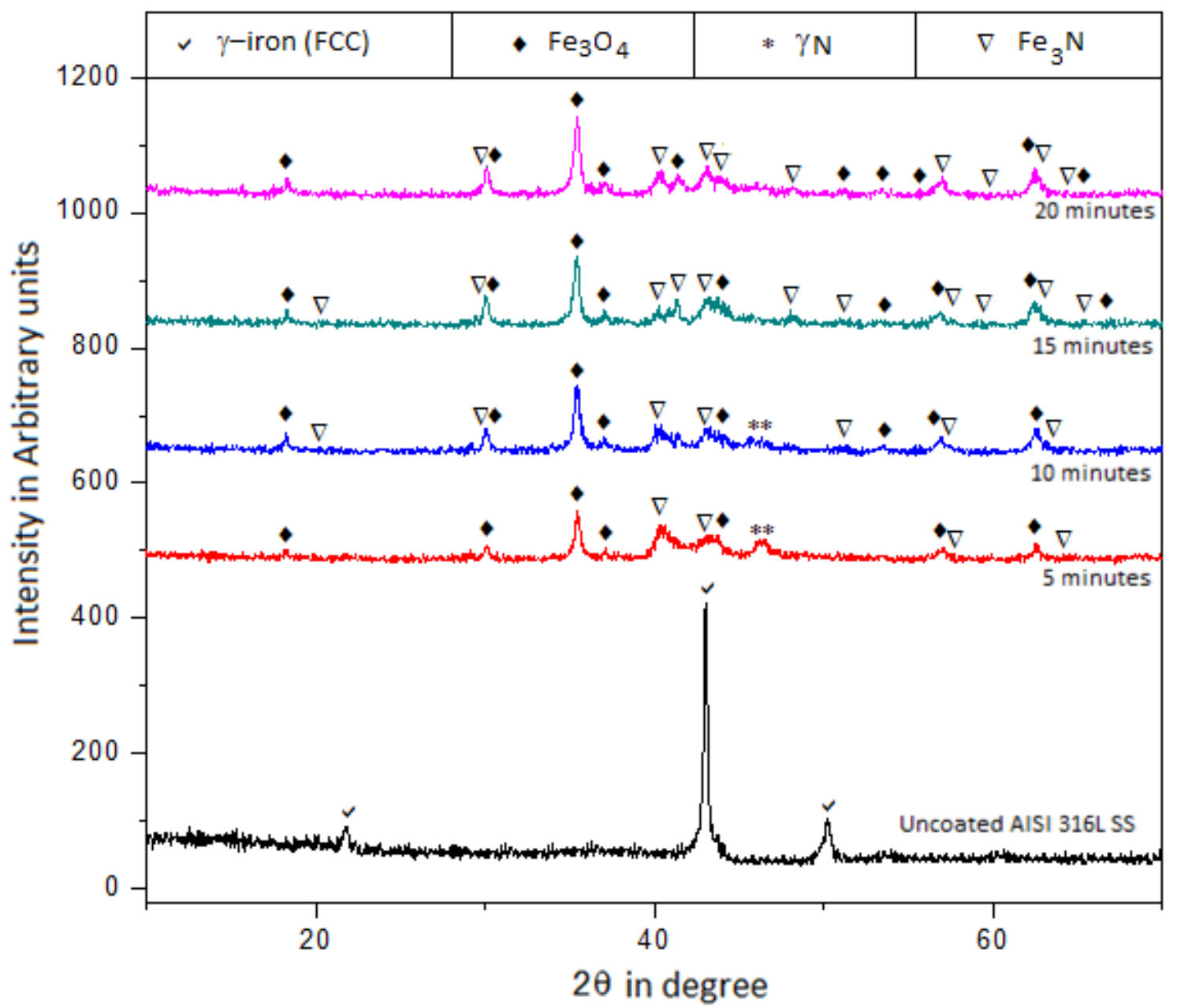

Figure 1 XRD analysis of Stainless Steel 316L before and after thermochemical treatments at $580^{\circ} \mathrm{C}$ during $5,10,15$ y 20 minutes

In the XRD pattern obtained for the sample treated for 20 minutes we can see the presence of a single, relatively short and broad, diffraction peak centered at $\sim 43^{\circ}$. This peak was assigned to the $\mathrm{Fe}_{3} \mathrm{O}_{4}$ and $\varepsilon-\mathrm{Fe}_{3} \mathrm{~N}$ phases. It is well known that the intensity of the XRD peaks can be affected, among other things, by the crystallite size and by the occurrence of "preferred orientation” phenomenon. Smaller crystallite size causes peaks being lower and wider, while preferred orientation may cause the peaks of some planes becoming unusually tall. The broad peaks located at $44^{\circ}$ and $46^{\circ}$ for the samples treated for 5 and 10 minutes were ascribed to expanded austenite $(\gamma \mathrm{N})$.

The thickness of the compound layer, as well as that of the diffusion zone, increased with increasing treatment time. Our results confirm that two different phenomena, oxidation and nitrocarburizing, took place in parallel at the surface of the stainless-steel substrates immersed in the salt bath at $580^{\circ} \mathrm{C}$ for different times.

Formation of the oxidized compound layer. Figure 2 shows the microstructure of an AISI 316L sample after thermochemical treatment of 20 minutes at $580^{\circ} \mathrm{C}$. Shortly after heating at $580^{\circ} \mathrm{C}$, the salt paste contains $\mathrm{Na}^{+}, \mathrm{CO}_{3}{ }^{2-}$, $\mathrm{CN}^{-}, \mathrm{N}, \mathrm{C}, \mathrm{O}^{2-}, \mathrm{CO}$ and $\mathrm{CO}_{2}$ chemical species. Later, highly reactive and oxidizing peroxide ions $\left(\mathrm{O}_{2}{ }^{2-}\right)$ started to be continuously produced by reaction of the salt with $\mathrm{O}_{2}$ from the air atmosphere, which is practically insoluble in the bath at $\sim 600{ }^{\circ} \mathrm{C}$ [Andresen 1979; Frangini and Scaccia 2004, 2014; Appleby and Nicholson 1972]. Then, the $\mathrm{O}^{2-}$ and 
$\mathrm{O}_{2}{ }^{2-}$ ions reacted with the $\mathrm{Cr}_{2} \mathrm{O}_{3}$ surface film of the samples to form $\mathrm{Na}_{2} \mathrm{CrO}_{4}$ [Spiegel et al 1997; Salih et al 2001], which is very soluble in the molten salt [Mehlig 1936; Biedenkopf et al 2000]. This significantly diminished the corrosion resistance of the stainless steel [Pettersson et al 2011a, 2011b]. This oxide is a p-type metal-deficient (with excess oxygen) non-stoichiometric semiconductor [Schmalzred 1986; Danielewski 2003; Bhat 2018], in which the oxygen atoms are practically immobile while the metal atoms can easily move through the cation vacancies (predominant defects) [Craig 1991]. When this kind of oxides are exposed to an oxidation potential gradient, a flux of cation vacancies is established from the side with the highest oxidation potential (substrate/bath interface) toward the side with the lowest oxidation potential (compound layer/diffusion zone interface), with a simultaneous flux of cation ions (Fe) in the opposite direction [Vedula 1987]. On reaching the sample surface, the diffused Fe reacts with the $\mathrm{O}^{2-}$ and $\mathrm{O}_{2}{ }^{2-}$ ions from the salt bath, forming a layer of $\mathrm{Fe}_{3} \mathrm{O}_{4}$ on top of the previous layer. $\mathrm{The} \mathrm{Fe}_{3} \mathrm{O}_{4}$ is chemically compatible with the molten salt, and it is also the most stable phase at the highest oxidation potential conditions found at the substrate / bath interface [Davies and Dinsdale 2005].

Part of the diffused Fe that reaches the sample surface reacts with $\mathrm{C}$ and $\mathrm{N}$ coming from the salt, forming $\varepsilon-\mathrm{Fe}_{3} \mathrm{~N}$ and creating a zone with intermixed crystals of both phases and $\mathrm{Fe}_{3} \mathrm{O}_{4}$ at the outermost region of the compound layer. Since carbon has a very low solubility and diffusivity in $\mathrm{Fe}_{3} \mathrm{O}_{4}$ [Grabke and Wolf 1987; Wolf and Grabke 1988; Bonnet et al 2003], it could not go deeper into the sample surface. In contrast, since $\mathrm{Fe}_{3} \mathrm{O}_{4}$ is permeable to nitrogen [Schaaf and Landry 1998], also shows the same behavior, the continuous diffusion of nitrogen into the steel matrix was not hindered. The formation of $\varepsilon-\mathrm{Fe}_{3} \mathrm{~N}$ was promoted by the presence of carbon and oxygen ion species at that site [Schaaf and Landry 1998; Pye 2003].

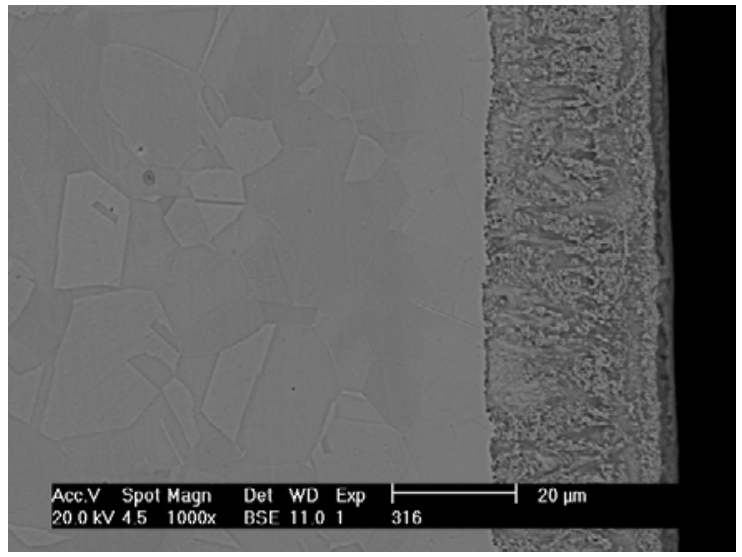

Figure 2 Microstructure of AISI 316L after thermochemical treatment of 20 minutes at $580^{\circ} \mathrm{C}$

Formation of the diffusion zone. The diffusion zone was mainly composed by nitrogen solid solution in austenite, with a small amount of $\mathrm{CrN}$ also present in it for the case of the samples treated for times longer than 5 minutes.

The fact that the diffusion zone showed a considerable growth, even after the compound layer was formed, indicates that the latter layer did not hinder the diffusion of nitrogen into the steel matrix. As already mentioned, $\mathrm{Fe}_{3} \mathrm{O}_{4}$ is permeable to nitrogen [Schaaf and Landry 1998], and since $\mathrm{FeCr}_{2} \mathrm{O}_{4}$ has the same structure, it may also have a similar behavior, although related information was not found in the published literature. It is also known that the formation of $\mathrm{Fe}_{3} \mathrm{O}_{4}$ results in a significant increase in the substrate surface area, and that this promotes the nitrogen uptake; $\varepsilon-\mathrm{Fe}_{3} \mathrm{~N}$ also allows the diffusion of nitrogen, although to a lesser extent with respect to other iron nitrides and $\mathrm{Fe}_{3} \mathrm{O}_{4}$ [Hosseini et al 2010]. $\mathrm{Fe}_{3} \mathrm{C}$ acts as a diffusion barrier for both carbon and nitrogen [Nikolussi et al 2010]. Thus, except for the latter phase, all the other phases that were present in the compound layer allowed a relatively easy diffusion of nitrogen into the steel matrix. However, an additional factor that must be considered is the diffusion of nitrogen through the grain boundaries and extended defects that were present at that site. This explains why the $\mathrm{Fe}_{3} \mathrm{C}$ phase also did not hinder the diffusion of nitrogen into the steel matrix, although it could be expected to do so.

The "expanded austenite" phase, also known as $\gamma \mathrm{N}$ phase, was formed in the samples treated for 5 and 10 minutes, which indicates that this phase was developed initially but it rapidly decomposed into $\mathrm{CrN}$ and austenite [Manova et al 2016; Wang et al 2012; Chistiansen and Somers 2006]. This also agrees with previous literature reports [Fernandes et al 2012; Williamson et al 1991], in which it was mentioned that expanded austenite can be formed after relatively short times at $\sim 450-600^{\circ} \mathrm{C}$. It has been reported [Mändl et al 2003] that this phase is usually formed at $350-400{ }^{\circ} \mathrm{C}$ in nitrided austenitic stainless steels, with a nitrogen content in interstitial solid solution varying from 5 to 30 at. \%, which causes an expansion of up to $13 \%$ of the austenite crystal lattice. The formation of this phase 
has also been reported during the salt bath nitriding of 304 austenitic stainless steel at $570{ }^{\circ} \mathrm{C}$ for $2 \mathrm{~h}$ [Monteiro et al 2017]. This leads to the development of compressive stresses near the sample surface [Tkacz-Smiech et al 2016], with a corresponding increase in its hardness, wear resistance, strength and toughness [Williamson et al 1991; Mändl et al 2003; Monteiro et al 2017; Tkacz-Śmiech et al 2016; Manova et al 2017].

To confirm the diffusion of nitrogen in the steel, a line scan by EDS analysis was carried out for the samples of each treated times (See micrographs of Figure 3).
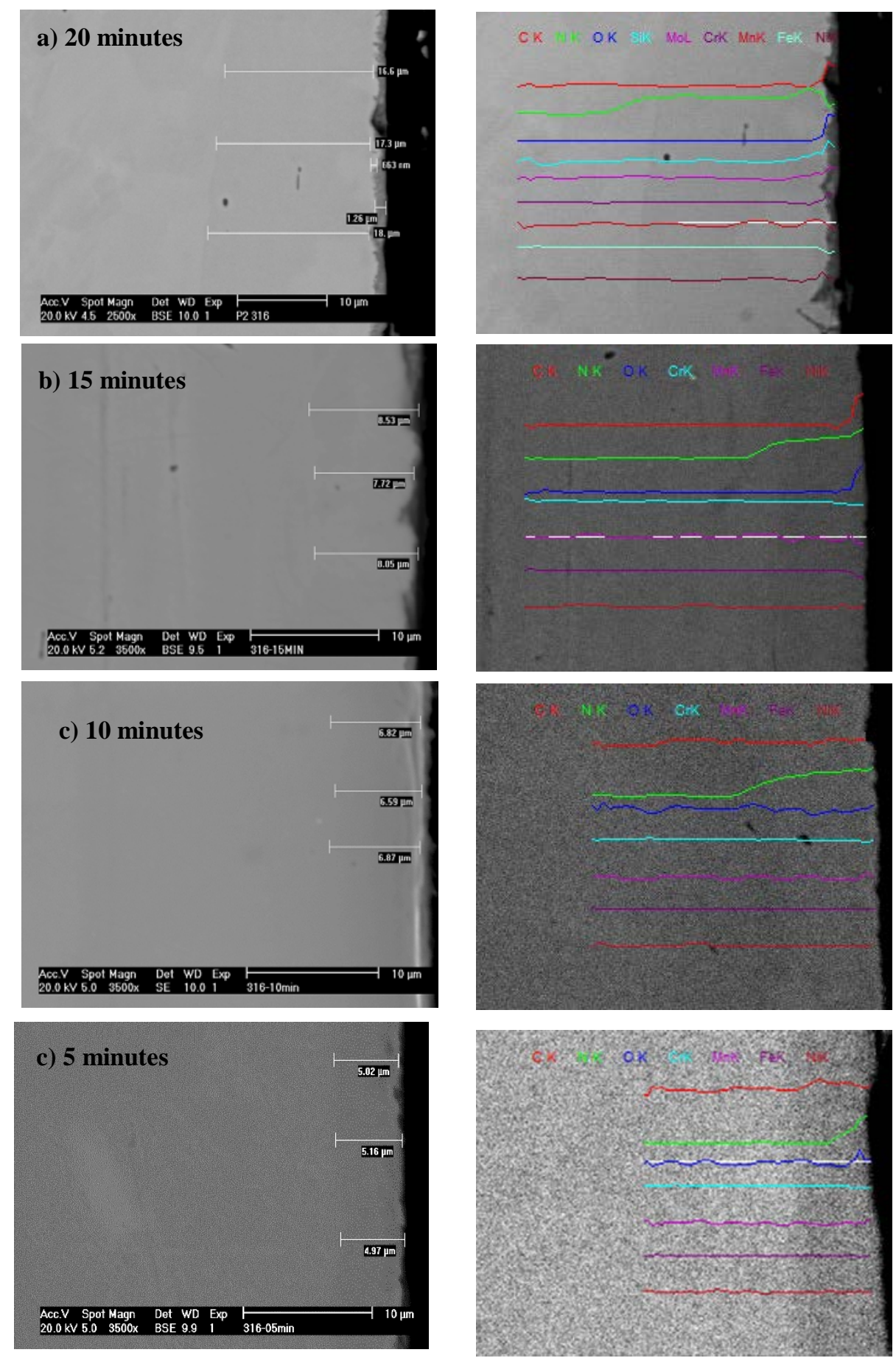

Figure 3. Micrographs and Line scans by EDS of AISI $316 \mathrm{~L}$ steel samples treated at $580{ }^{\circ} \mathrm{C}$ for: a) $20 \mathrm{~min}$, b) $15 \mathrm{~min}$, c) $10 \mathrm{~min}$ and d) $5 \mathrm{~min}$

Surface optical properties of the treated samples. The thermochemical processes like the one employed in this work have not been used with the purpose of modifying the surface optical properties of austenitic stainless steels, they have only been used to improve their wear resistance, hardness and corrosion resistance [Mittemeijer 2013]. The black appearance of the samples obtained by the oxynitrocarburized samples was the reason that motivated us 
to investigate the possibility of using the oxynitrocarburized AISI 316L stainless steel for potential applications in solar collectors.

Table 2 shows the values of $\alpha$ and $\varepsilon$ determined by UV/Vis and FT-IR spectroscopy techniques for the oxynitrocarburized samples. During the first 20 minutes, the value of $\alpha$ tended to increase with increasing treatment time; longer treatment times made no significant difference on the value of this property. On the other hand, the lower value of $\varepsilon$ were obtained with the shorter processing table 2 shows that the material treated for 5 minutes achieved a selectivity ratio of 0.85 , as well as solar absorptance and thermal emittance values of 0.90 and 0.10 , respectively, which were the closest ones to the ideal values. The thermal emittance obtained for this material was close to that reported for black chrome electrodeposited coatings [Hutchins 1983].

We surmised that the combination of $\mathrm{Fe}_{3} \mathrm{O}_{4}, \gamma \mathrm{N}$ and $\mathrm{Fe}_{3} \mathrm{C}$ phases formed at the substrate surface after 5 minutes of treatment, as well as the configuration of the oxidized compound layer achieved under such conditions, mainly regarding the small thickness of the latter, were responsible for the best surface optical properties obtained for this sample. The surface optical properties of the substrates were negatively affected by the larger relative proportions of $\mathrm{Fe}_{3} \mathrm{C}$ and $\mathrm{Fe}_{3} \mathrm{O}_{4}$, formed at the outermost zone of the compound layer with longer treatment times, along with the simultaneous thickening of this layer occurring under such conditions. All these factors led to an unwanted increase in the thermal emittance of the treated samples. This is supported by the similarity shown by the behavior of the optical properties of our treated samples with respect to those of the two-layered coating configuration mentioned in the literature [Hutchins 1983], in which an absorbing layer is combined with a reflecting layer. The absorbing layer might be a dielectric semiconductor, such as the oxides of various metals, while the reflecting layer is usually a metal with high IR reflectivity, which in certain cases can be the substrate itself. The absorbing layer has a typical thickness of $\sim 1 \mu \mathrm{m}$, which is much shorter than the peak wavelength of emission of a black body. Under these conditions, the absorber is transparent to the IR radiation, allowing the reflecting layer to be "seen" by the incoming radiation, minimizing in this way the thermal emittance of the combination. Thus, the coating configuration and thickness have a great influence on the spectrally selective properties of the material surface. In our case, the absorptance gradually increased with increasing thickness of the compound layer, which gradually became mostly formed by semiconductor spinel-type oxides.

With the development of this work we intended to offer an alternative way to modify the surface optical properties of AISI 316L stainless steel for potential applications in solar collectors. Other well-established ways to do this exist, but the procedure used by us could offer some advantages, such as use of simpler and cheaper equipment, easier process to scaling up and operation, and lower overall operational costs.

Table 2: Oxynitrocarburizing Time Effect on Optical Properties of AISI $316 \mathrm{~L}$ SS Surface at $580^{\circ} \mathrm{C}$

\begin{tabular}{|c|c|c|}
\hline Treatment Time (minutes) & Emittance $(\boldsymbol{\varepsilon})$ & Absorptance $(\boldsymbol{\alpha})$ \\
\hline 20 & 0.30 & 0.93 \\
\hline 15 & 0.20 & 0.90 \\
\hline 10 & 0.15 & 0.90 \\
\hline 5 & 0.10 & 0.90 \\
\hline
\end{tabular}

According to table 2, the oxynitrocarburizing time played an important role in the surface modification of the stainless steel in terms of surface optical properties of the treated samples. The development of a thick surface oxidized layer was detrimental for the surface emittance of the samples. In this sense, a 5 min oxynitrocarburizing treatment produced the best results. According to microstructural characterization two different layers were developed at the surface of the treated samples, especially with treatment times longer than 5 minutes. These were an outermost oxidized layer, underneath which a nitrided layer was formed. After 5 minutes of treatment, both layers were very thin and without a clear separation existing between them. The phases formed in this case were a Fe-Cr spinel oxide, $\mathrm{Fe}_{3} \mathrm{O}_{4}, \mathrm{Fe}_{3} \mathrm{C}$, and $\gamma \mathrm{N}$, and probably a solid solution of $\mathrm{N}$ in Fe. With treatment times longer than 5 minutes, both zones became wider and perfectly distinguishable from each other, with a growth rate much faster for the nitrided layer than for the oxidized layer, with diffusion control in the first case and with a likely reaction control in the second. For these treatment times, the oxidized layer became composed by $\mathrm{Fe}_{3} \mathrm{O}_{4}$, and $\mathrm{Fe}_{3} \mathrm{~N}$, while the nitrided zone was composed by a solid solution of $\mathrm{N}$ in Fe and $\gamma \mathrm{N}$. 


\section{Conclusions}

We studied the surface microstructural evolution of AISI 316L stainless steel oxy-nitrocarburized from 5 to 20 minutes at $580{ }^{\circ} \mathrm{C}$ using a salt paste based on the eutectic composition of the system $\mathrm{NaCNO}-\mathrm{Na}_{2} \mathrm{CO}_{3}$. Simultaneous oxidation and nitrocarburizing of the sample surface took place during the thermochemical treatments, with formation of an outermost oxidized compound layer under which a nitrided diffusion zone was developed. Two different sublayers were developed at the compound layer, which was more evident for treatment times longer than 5 minutes. The outermost sublayer was composed by a mixture of $\mathrm{Fe}_{3} \mathrm{O}_{4}$, and $\gamma \mathrm{N}$ phases, with increasing relative proportions of $\mathrm{Fe}_{3} \mathrm{O}_{4}$ and decreasing relative proportions of $\gamma \mathrm{N}$, with increasing treatment time.

The material treated for 5 minutes was found to be better for potential applications in solar collectors. This material showed a solar absorptance of 0.90 , a thermal emittance of 0.10 , and a selectivity factor $(\alpha-0.5 \varepsilon)$ of 0.85 , which were relatively close to those of good spectrally selective solar absorber.

\section{Acknowledgements}

This work was supported by the Mexican Center for Innovation in Solar Energy (CeMIE-Sol), Renewable Energy Institute of the Mexican National University (IER-UNAM) [CONACYT-SENER-Energy Sustainability Sectorial Fund, Strategic Project No. P-18]; APGM gratefully acknowledges a PhD scholarship granted by CONACYT.

\section{References}

Andresen A.E., 1979. Solubility of oxygen and sulfur dioxide in molten sodium sulfate and oxygen and carbon dioxide in molten sodium carbonate, J. Electrochem. Soc. 126, 328-334.

Appleby A.J., 1972. Nicholson S.J., Oxygen reduction in carbonate melts: Significance of the peroxide and superoxide ions, J. Electroanal. Chem. Interfacial Electrochem. 38, 13-18.

ASTM G173-03., 2012. Standard Tables for Reference Solar Spectral Irradiances.

Bhat S., 2018. The desired features of an oxide film on stainless steel tubing, Mater. Perform. 57, 40-43.

Biedenkopf P., M. Bischoff M., Wochner T., 2000. Corrosion phenomena of alloys and electrode materials in Molten Carbonate Fuel Cells, Mater. Corros. 51, 287-302.

Bonnet F., Ropital F., Berthier Y., Marcus P., 2003. Filamentous carbon formation caused by catalytic metal particles from iron oxide, Mater. Corros. 54, 870-880.

Caliari D., Timelli G., 2015. An investigation into the effects of different oxy-nitrocarburizing conditions on hardness profiles and corrosion behaviour of 16MnCr5 Steels, Int. J. Metall. Mater. Eng. 110, 1-9.

Christiansen T., Somers M.A.J., 2006. Decomposition kinetics of expanded austenite with high nitrogen contents, Z. Metallkd. 97, 79-88

Craig B.D., 1991. Fundamental Aspects of Corrosion Films in Corrosion Science, Springer Science \& Business Media, New.

Danielewski M., 2003, Kinetics of Gaseous Corrosion Processes, Corrosion: Fundamentals, Testing, and Protection, in: ASM Handbook, Volume 13A, ASM International, Materials Park, Ohio, pp. 97-105.

Fernández F.A.P, Casteletti L.C., Totten G.E., Gallego J., 2012. Decomposition of expanded austenite in AISI 316L stainless steel nitrided at 723K, Int. Heat Treat. Surf. Eng. 6, 103-106.

Frangini S, Scaccia S. 2014. The role of foreign cations in enhancing the oxygen solubility properties of alkali molten carbonate systems: Brief survey of existing data and new research results, Int. J. Hydrogen Energy 39, 12266-12272.

Frangini S, Scaccia S., 2004. Sensitive determination of oxygen solubility in alkali carbonate melts, J. Electrochem. Soc. $151,1251-1256$.

Grabke H.J., Strauss S., Vogel D., 2003. Nitridation in NH3-H2O-mixtures, Mater. Corros. 54, 895-901. 
Grabke H.J., Wolf I., 2014. Carburization and oxidation, Mater. Sci. Eng. 87, 23-33.

Hosseini S.R., Ashrafizadeh F., Kermanpur A., 2010. Calculation and experimentation of the compound layer thickness in gas and plasma nitriding of iron, Iran. J. Sci. Technol., Trans. B: Eng. 34, 553-566.

Hutchins M.G., 1983. Selective thin film coatings for the conversion of solar radiation, Surf. Technol. 20, 301-320.

Li L., 2000. AC anodization of aluminum, electrodeposition of nickel and optical property examination, Sol. Energy Mater. Sol. Cells 64, 279-289.

Mändl S., Scholze F., Neumann H., Rauschenbach B., 2003. Nitrogen diffusivity in expanded austenite, Surf. Coat. Technol. 174-175, 1191-1195.

Manova D., A. Lotnyk A., Mändl S., Neumann H. and Rauschenbach B., 2016. CrN precipitation and elemental segregation during the decay of expanded austenite, Mater. Res. Express 3, 066502, 1-15.

Manova D., Mändl S., Neumann H., Rauschenbach B., 2017. Formation of metastable diffusion layers in Crcontaining iron, cobalt and nickel alloys after nitrogen insertion, Surf. Coat. Technol. 312, 81-90.

Mehlig J.P., 1936. The determination of chromium in chromite, J. Chem. Educ. 13, 324-325.

Monteiro W.A., Lima S.A., Vatavuk J., 2017. Nitriding process characterization of cold worked AISI 304 and 316L austenitic stainless steels, J. Metall. 2017, 1-7.

Nikolussi M., Leineweber A., 2010. Mittemeijer E.J., Nitrogen diffusion through cementite layers, Philos. Mag. 90, 1105-1122.

Pettersson J, Folkeson N., Johansson L.G., Svensson J.E., 2011. The effects of $\mathrm{KCl}, \mathrm{K}_{2} \mathrm{SO}_{4}$ and $\mathrm{K}_{2} \mathrm{CO}_{3}$ on the high temperature corrosion of a 304-type austenitic stainless steel, Oxid. Met. 76, 93-109.

Pettersson J., Froitzheim J., Pettersson C., Jonsson T., Halvarsson M., Johansson L.G., Svensson J.E., 2011. Effects of alkali salts on the high temperature corrosion of stainless steels, IFRF, Scandinavian-Nordic Section of the Combustion Institute, Pitea, Sweden.

Pye D.,2003. Practical Nitriding and Ferritic Nitrocarburizing, ASM International, Materials Park, Ohio.

Salih S.A., El-Masri A.N., Baraka A.M., 2001. Corrosion behaviour of some stainless steel alloys in molten alkali carbonates (I), J. Mater. Sci. 36, 2547-2555.

Schaaf P., Landry F., 1998. Mössbauer investigation of nitriding processes, gas nitriding and laser nitriding, in: MSMS'98, Senice, Slovakia, 1-14.

Schmalzried H., 1986. Behavior of (semiconducting) oxide crystals in oxygen potential gradients, React. Solids 1, $117-137$

Thirugnanasambandam M., et al. 2010. A review of solar thermal technologies. Renowable and sustainable energy reviews. $14,312-322$.

Tian Y., Zhao C.Y., 2013. A review of solar collectors and thermal energy storage in solar thermal applications. Applied energy 104, 538-553.

Tkacz-Śmiech K., Wierzba B., Bożek B., Danielewski M., 2016. Nitrogen diffusion and stresses during expanded austenite formation in nitriding, Defect Diffus. Forum 371, 49-58.

Vedula K., 1987. Modeling of transient and steady-state demixing of oxide solid solutions in an oxygen chemical potential gradient, Oxid. Met. 28, 99-108.

Wang J., Lin Y., Yan J., Zeng D., Huang R, Hu Z., 2012. Modification of AISI 304 Stainless Steel Surface by the Low Temperature Complex Salt Bath Nitriding at $430^{\circ} \mathrm{C}$, ISIJ Int. 52, 1118-1123

Wijewardane S., Goswami D.Y., 2012. A review on surface control of thermal radiation by paints and coatings for new energy applications. Renewable and Sustainable Energy Reviews. 16, 1863-1873

Williamson D.L., Ozturk O., Glick S., Wei R., Wilbur P.J., 1991. Microstructure of ultrahigh dose nitrogenimplanted iron and stainless steel, Nucl. Instrum. Methods B 59, 737-741. 
G. Vargas et. al. / EuroSun 2018 / ISES Conference Proceedings (2018)

Wolf I., Grabke H.J, Schmidt P., 1988, Carbon transport through oxide scales on Fe-Cr alloys, Oxid. Met. 29, 289306. 


\title{
Electroplating of selective surfaces for concentrating solar collectors
}

\author{
Erik Zäll' ${ }^{1}$ Andreas Nordenström ${ }^{1}$, Jonatan Mossegård² and Thomas Wågberg1 \\ 1 Umeå University, Umeå (Sweden) \\ ${ }^{2}$ Absolicon Solar Collector AB, Härnösand (Sweden)
}

\begin{abstract}
A spectrally selective surface is produced by electrodeposition of a Co-Cr coating on a stainless steel substrate. The plating bath consisted of $\mathrm{CrCl}_{3} \cdot 6 \mathrm{H}_{2} \mathrm{O}$ and $\mathrm{CoCl}_{2} \cdot 6 \mathrm{H}_{2} \mathrm{O}$ dissolved in a deep eutectic solvent (DES) of choline chloride and ethylene glycol. This DES enables the use of trivalent $(\mathrm{Cr}(\mathrm{III}))$ instead of hexavalent chromium $(\mathrm{Cr}(\mathrm{XI}))$ which significantly reduces health risks associated with chromium electroplating. The selective surface exhibits an absorptance $(\alpha)$ of 0.96 and an emittance $(\epsilon)$ of 0.13 at $100^{\circ} \mathrm{C}$ making it well adapted for mid- to lowtemperature concentrating solar collectors. The $1.8 \mu \mathrm{m}$ thick coating exhibits a porous structure on the surface as well as throughout the entire coating. The surface of the coating comprises of Co oxides and hydroxides, while the bulk consists of metallic and oxidized $\mathrm{Co}$ and only small fractions of $\mathrm{Cr}$ compounds. Initial tests of the thermal stability indicate that the coating does not maintain optical properties at an acceptable level over a lifetime of 25 years. At approximately $438^{\circ} \mathrm{C}$ significant parts of the coating is oxidized in an oxygen rich environment.
\end{abstract}

Keywords: spectrally selective coating, Co-Cr coating, electroplating, absorptance, emittance, surface structure

\section{Introduction}

Electroplating is an old and well established technique that has been used to produce selective surfaces for solar collectors since at least 1970 (Selvakumar \& Barshilia, 2012). Several metals, including nickel, cobalt and chromium, have been used to electroplate selective surfaces. Black chromium exhibited the best optical properties and as a result electroplated black chrome became one of the most commonly used selective surfaces (Abbas, 2000). However, conventional electroplating of chromium is being legally restricted because it is based upon solutions containing $\mathrm{Cr}(\mathrm{XI})$ in the form of chromic acid which is carcinogenic and toxic (Zhang, et al., 2015). As a result, the black chrome has largely been replaced by selective coatings produced with different physical vapor deposition (PVD) techniques. These coatings are competitive in terms of both optical performance as well as durability (Selvakumar \& Barshilia, 2012). But the demand for advanced equipment makes the production of these coatings costly. Hence, efforts are being made to amend the health related issues associated with the black chrome coatings by replacing the $\mathrm{Cr}(\mathrm{XI})$ with $\mathrm{Cr}(\mathrm{III})$ in the electroplating bathes.

In this work, a spectrally selective Co-Cr coating is produced. The coating is electroplated using $\mathrm{Cr}(\mathrm{III})$ which is enabled by the DES based electrolyte used, significantly reducing the health related issue.

\section{Theory}

When evaluating the degradation of the optical properties of a selective coating the following performance criteria function (PC) is used

$$
P C=-\left(\alpha_{f}-\alpha_{i}\right)+x\left(\epsilon_{f}-\epsilon_{i}\right),
$$

where indices $f$ and $i$ indicates represents properties after (final) and before (initial) exposure to the degradation test. The parameter $x$ is a weighting factor used to adjust for the fact that absorptance and emittance does not affect the optical performance of the selective surface equally. Both the working temperature, irradiance and the concentrating factor of a collector affects the weighting factor. In this case the selective coating is intended for a parabolic trough collector with glass covering the entire trough, which results in

$$
x=\frac{\mathrm{d} \pi \sigma\left(T_{s}^{4}-T_{a m b}^{4}\right)}{\tau \rho \mathrm{b} I_{d i r}},
$$


where $\mathrm{d}$ is the diameter of the receiver pipe, $\sigma$ is the Stefan-Boltzmann constant, $T_{S}$ is the surface temperature of the receiver pipe, $T_{a m b}$ is the ambient temperature, $\tau$ is the transmittance of the cover glass, $\rho$ is the reflectance of the reflector, $\mathrm{b}$ is the width of the aperture area and $I_{\text {dir }}$ is the direct solar irradiance. While a weighting factor can be used to evaluate a selective surface with regards to a certain collector or conditions, the selectivity $(\mathrm{S})$ is often used to evaluate a selective surface in general. The selectivity is given by

$$
\mathrm{S}=\frac{\alpha}{\epsilon} \text {. }
$$

When constructing an aging test for a selective surface intended for a solar collector, the effective temperature $\left(T_{e f f}\right)$ is necessary to introduce. $T_{e f f}$ is necessary to relate a certain number of years of use at a certain working temperature, to the conditions and time of an accelerated aging test. For more information about the effective temperature of a solar collector see Qualification test procedure for solar absorber surface durability by Carlsson et al. (Carlsson, et al., 2000). In the case with of a solar collector with a controlled working temperature of $160^{\circ} \mathrm{C}$ it is given by

$$
\mathrm{e}^{\frac{-E_{T}}{R T_{e f f}}}=\frac{2800 \mathrm{e}^{\frac{-E_{T}}{R(433 K)}}+\mathrm{e}^{\frac{-E_{T}}{R(333 K)}}}{8760},
$$

where $E_{T}$ is the Arrhenius energy of the surface and $R$ is the ideal gas constant.

\section{Experimental}

The plating process was conducted with a working electrode (WE) of stainless steel (AISI 304) and a titanium mesh, coated with noble metal oxides, as a counter electrode (CE). Prior to deposition the substrate was sonicated in acetone for 15 minutes, electropolished and submerged in a $13 \mathrm{wt} \% \mathrm{HCl}$ solution. The electropolishing process was performed according to the method developed by Lin \& $\mathrm{Hu}$ to ensure an as smooth and clean surface as possible ( $\mathrm{Lin} \& \mathrm{Hu}$, 2008). The electrolyte consisted of $\mathrm{CrCl}_{3} \cdot 6 \mathrm{H}_{2} \mathrm{O}$ and $\mathrm{CoCl}_{2} \cdot 6 \mathrm{H}_{2} \mathrm{O}$ with a molar ratio of 2:1, dissolved in a DES of ethylene glycol and choline chloride with a molar ratio of 16:1.

The parameters used for the electroplating process was determined in a report by Andreas Nordenström using the design of experiment method ${ }^{1}$. The optimization was conducted with the intention of optimizing the coating for applications in Absolicon's T160 model. As a result, a weighting factor calculated with equation 2 for the T160 model at $160^{\circ} \mathrm{C}$ was used $(\mathrm{x}=0.16)$ resulting in the importance of the emittance being much lower than if the more conventional selectivity, see equation 3 , was used.

The electroplating was conducted using chronopotentiometry for 10 minutes with the electrolyte kept at a temperature of $44^{\circ} \mathrm{C}$. The electrolyte was stirred prior but not during the deposition to ensure a homogenous distribution in terms of salt concentration as well as temperature without disrupting the deposition process. The current density (CD) used was $9.2 \mathrm{~mA} / \mathrm{cm}^{2}$ for the coating optimized for the T160 and $8 \mathrm{~mA} / \mathrm{cm}^{2}$ for the coating with the highest selectivity. When necessary samples coated with 9.2 and $8 \mathrm{~mA} / \mathrm{cm}^{2}$ are called S_9.2 and S_8.0 respectively. Whenever this distinction is not made the sample in question is one deposited with a CD of 9.2 $\mathrm{mA} / \mathrm{cm}^{2}$.

To determine the optical properties the reflectance was measured in the region $0.3-23 \mu \mathrm{m}$. A Perkin Elmer 900 spectrophotometer with a $15 \mathrm{~cm}$ diameter integrating sphere for the UV/Vis/NIR region $(0.3-2.5 \mu \mathrm{m})$ and a Bruker fourier transform infrared spectroscope for the IR region $(2.5-23 \mu \mathrm{m})$. The direct $1.5 \mathrm{AM}$ solar spectrum provided by the National renewable energy laboratory (NREL, 2018) was used to calculate the $\alpha$, and $\epsilon$ was calculated at $100^{\circ} \mathrm{C}$ using the blackbody spectrum. The surface and cross section of the coating was investigated using scanning electron microscopy (SEM). The cross section was revealed using a focus ion beam (FIB) to mill a ramp into the surface of the coating. The chemical composition was investigated using X-ray photoelectron spectroscopy (XPS) and Energy-Dispersive X-ray spectroscopy (EDX).

The thermal stability of the selective surface was evaluated with a method that was based upon a standardized test for selective surface in flat plate solar collectors developed in task X (Carlsson, et al., 2000), but slightly adjusted to adopt to selective surfaces in concentrating solar collectors after conversation with Stefan Brunold at the SPF institute for solar technology. The adjustments consisted of altering the test temperature to $320^{\circ} \mathrm{C}$, using an

\footnotetext{
${ }^{1}$ Nordenström, A., 2018. Investigating an electroplating method of Co-Cr alloys - A design of experiment approach to determine the impact of key factors on the electroplating process, Master Thesis, Umeå University
} 
effective temperature derived with equation 4 and using a weighting factor (equation 2) adapted for the relevant parabolic trough collector. The Arrhenius energy was assumed to be $50 \mathrm{~kJ} / \mathrm{mol}$ and the test was conducted by exposing samples to $320^{\circ} \mathrm{C}$ in a muffle furnace and removing them from the furnace successively to investigate the degradation of the optical properties using equation 1 . The weighting factor $(x)$ given by equation 2 was calculated with $T_{S}=100^{\circ} \mathrm{C}$ giving $x=0.06$. Two samples, $\mathrm{S} 1$ and $\mathrm{S} 2$ were investigated after 43 and 136.4 hours in the furnace respectively.

The thermal degradation of the coating was further investigated by us of thermogravimetric analysis (TGA). Two runs of TGA was performed, where the first was conducted at $2{ }^{\circ} \mathrm{C} / \mathrm{min}$ up to $1000^{\circ} \mathrm{C}$ in a nitrogen atmosphere flowing at $40 \mathrm{~cm}^{3} / \mathrm{min}$. The second one was conducted at $10^{\circ} \mathrm{C} / \mathrm{min}$ up to $900^{\circ} \mathrm{C}$ in an oxygen atmosphere flowing at $40 \mathrm{~cm}^{3} / \mathrm{min}$

\section{Result \& Discussion}

The reflectance of the coating presented with the $1.5 \mathrm{AM}$ Direct solar spectrum and the $100^{\circ} \mathrm{C}$ black body spectra can be seen over the interval $0.3-23 \mu \mathrm{m}$ in figure 1. Both samples exhibit strongly selective properties with $\alpha=$ 0.961 and $\epsilon=0.149$ for sample S_9.2 and $\alpha=0.958$ and $\epsilon=0.131$ for sample S_8.0. As mentioned previously, this results in $S_{-} 8.0$ having the highest selectivity with $S=7.31$. The optical properties make it suitable for a lowto mid-temperature concentrating solar collectors where the absorptance is of greater importance than the emittance.

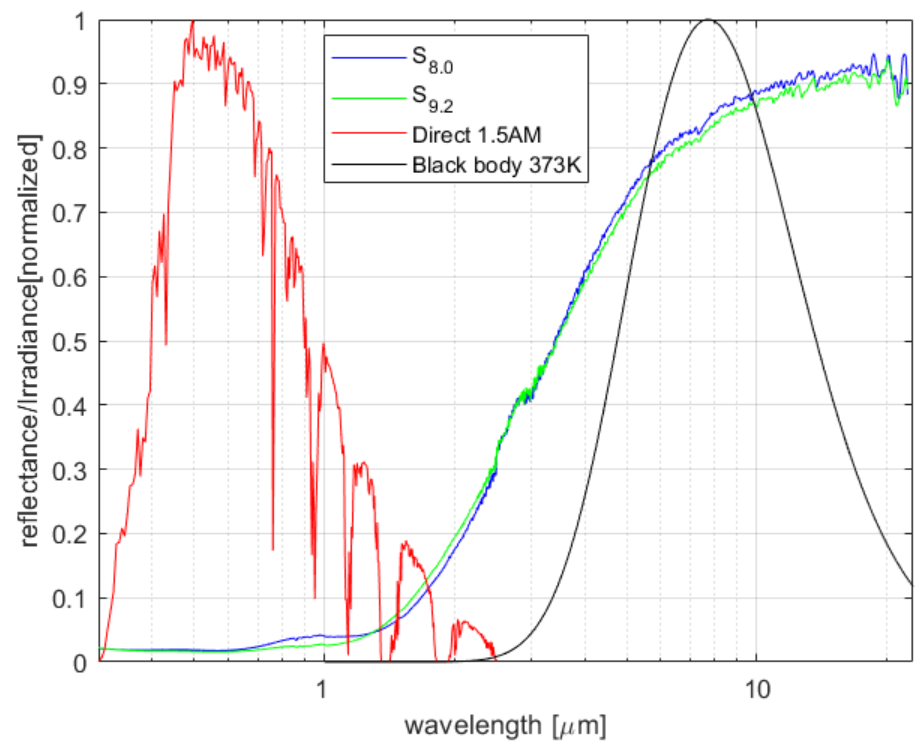

Fig. 1: Reflectance spectra of sample $S \_8.0$ and $S \_9.2$ presented with the direct 1.5 solar spectra and the $100^{\circ} \mathrm{C}$ black body spectra.

The reflectance spectra follow the expected general appearance of a selective surface with very low reflectance (roughly 0.02 ) in the UV range, a transition to highly reflective starting at $1.5 \mu \mathrm{m}$ and a reflectance of above 0.8 from $5 \mu \mathrm{m}$ and upwards. The only things that deviate from this is a local maximum, that is more pronounced for S_8.0 than S_9.2, at roughly $1 \mu \mathrm{m}$ and the fact that the transition between instruments is not perfect. The spectra from the UV/Vis/NIR and the FTIR does not overlap perfectly as the spectra from the aforementioned instrument is a bit higher at the transition at $2.5 \mu \mathrm{m}$. This mismatch is not large and if anything, it would indicate that the optical properties are better than presented here as the UV/Vis/NIR spectra and FTIR spectra would have to be moved down respectively up to correct for it.

The absorptance is competitive compared to many selective surfaces in literature where only the best coatings reach an absorptance above 0.95 (Atkinson, et al., 2015) (Kennedy, 2002). It is however possible to achieve up to $\alpha=0.99$ with a chromium coating produced with similar method (Surviliene, et al., 2014). It is however unclear what the emittance of this exceptionally absorbing coating is, especially considering that optimizing one of the optical properties to the extreme often comes at the expense of the other.

Considering that the substrate is polished stainless steel $(\epsilon=0.093)$ an achieved emittance in the region $0.13-$ 0.15 is in line with best expectations. This is because the low emittance of these kinds of surfaces are generated by having a substrate with low emittance and the coating being close to transparent in the IR region. Hence, the 
emittance can never be lower than the substrate itself and is typically higher because the coating isn't completely transparent. This makes the pretreatment of the surface as well as the thickness of the coating key aspects in achieving a surface with a low emittance.

\subsection{Structure of the coating}

Investigation of the surface with SEM shows a surface with structures resembling sheets with cavities in between, see figure 1 . The length and thickness of the sheet-like surface structures varies, but a rough estimate of an average is $1 \mu \mathrm{m}$ long and $0.1 \mu \mathrm{m}$ thick. No reoccurring pattern can be seen in the orientation of the structures, but the surface is very homogeneous (more visible when less magnified) and does not exhibit any cracks.

Based upon the look of the surface it is plausible to assume that the absorptance of the coating is at least partly generated by the use of surface texture, where a structure generating multiple reflections within the structure to generate a higher absorptance that the intrinsic absorptance of the material itself (Testafamichael, 2000). For this to work the size of the structures determines which wavelengths are absorbed. If the wavelength is much longer than the structures on the surface the light will not reflect multiple times and the absorptance is lower, this is how the surface can maintain a high reflectance in the IR spectra.

It has been observed that the CD strongly affect the size of the surface structures of the finished coating, with the correlation being that a higher CD gives larger surface structures. Hence, a higher CD gives higher absorptance of longer wavelengths. Likely, the local reflectance maxima at $1 \mu \mathrm{m}$ is more pronounced for S_8.0 because it was applied with a lower $\mathrm{CD}$ and hence can be expected to exhibit smaller surface structure.

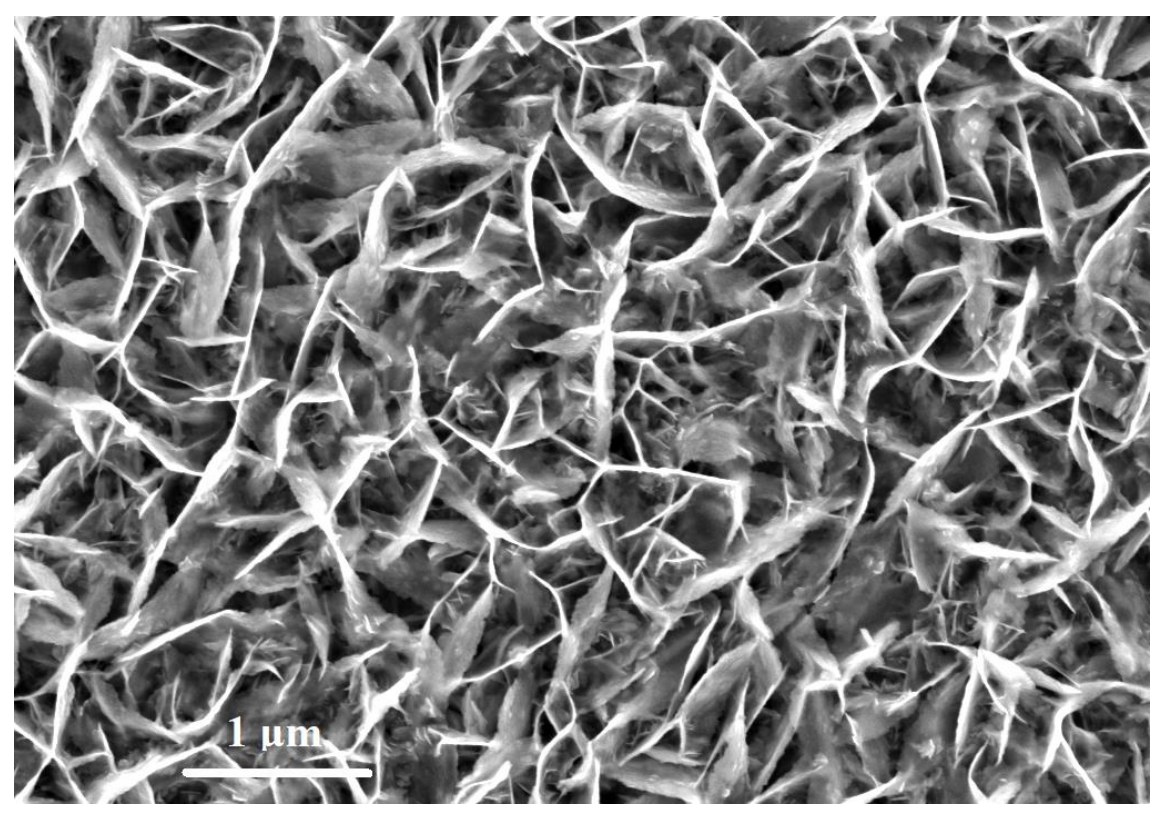

Fig. 2: SEM image of the surface of the Co-Cr coating.

A SEM image of the cross section (CS) of the coating (exposed by use of FIB) can be seen in figure 3. The coating is approximately $1.8 \mu \mathrm{m}$ thick and there are cavities throughout the entire coating. According to literature, the optimal thickness of a coating of this kind is 0.5-2 $\mu \mathrm{m}$ (Eugénio, et al., 2011). While there is no guarantee that this is at all true for this coating, there might be room for improvement by decreasing the thickness and thereby lowering the emittance without reducing the absorptance. 


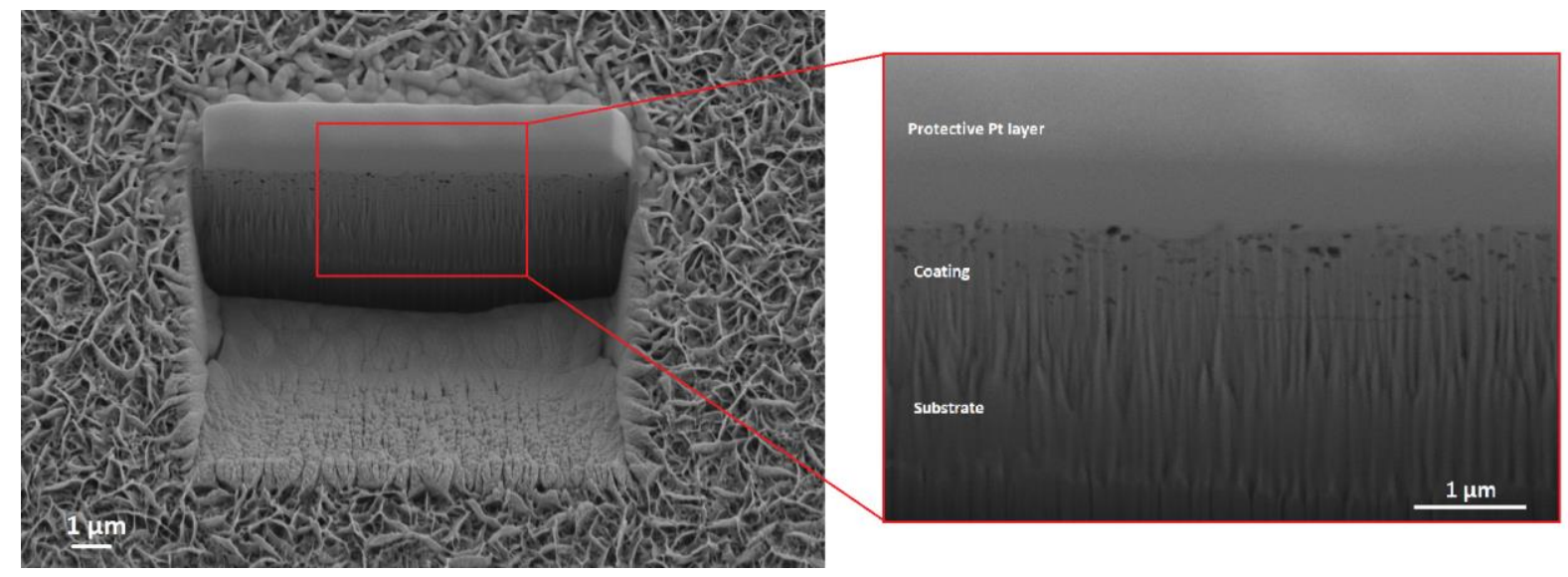

Fig. 3: SEM images of the ramp milled down into the surface of the coating (left) and the exposed cross section of the coating (right).

\subsection{Chemical composition}

The XPS measurements, the result of which can be seen in table 1, shows that the surfaces mostly consist of Co compounds. Almost $70 \%(69.64 \%)$ of the signal is associated with cobalt bonds with $\mathrm{Co}=\mathrm{O}, \mathrm{Co}-\mathrm{OH}$ and $\mathrm{Co}(\mathrm{III})$ compounds constituting $26.36,17.42$ and 25.86 at $\%$ respectively. There is also a small amount of $\mathrm{Cr}(0.26$ at\%) in the form of $\mathrm{Cr}(\mathrm{III})$ compounds, but there are neither $\mathrm{Co}$ or $\mathrm{Cr}$ in the form of metal. At least in the case of Co this is expected as Co exposed to air at room temperature a thin layer of Co hydroxide $(\mathrm{Co}(\mathrm{OH}) 2)$ is formed within seconds (Tompkins \& Augis, 1981). The carbon is mainly contributed to pollution from the atmosphere.

Tab. 1: XPS results on the surface of the selective surface.

\begin{tabular}{|c|c|c|c|c|c|}
\hline \multicolumn{3}{|c|}{ C1s } & \multicolumn{3}{|c|}{ O1s } \\
\hline Bond & $\mathrm{Be}, \mathrm{eV}$ & $\mathrm{AC}$, at $\%$ & Bond & $\mathrm{Be}, \mathrm{eV}$ & $\mathrm{AC}$, at $\%$ \\
\hline $\mathrm{C}-(\mathrm{C}, \mathrm{H})$ & 284.6 & 17.84 & $\mathrm{Co}=\mathrm{O}$ & 529.7 & 26.36 \\
\hline $\mathrm{C}-\mathrm{O}$ & 286,2 & 2.71 & $\mathrm{Co}-\mathrm{OH}$ & 531.1 & 17.42 \\
\hline $\mathrm{COOH}$ & 287.9 & 2.82 & $\mathrm{C}=\mathrm{O}$ & 532.2 & 5.25 \\
\hline $\mathrm{CO}_{3}^{2-}$ & 289.2 & 1.02 & $\mathrm{C}-\mathrm{OH}$ & 533.3 & 1.46 \\
\hline \multicolumn{3}{|c|}{ Co 2p 3/2 } & \multicolumn{3}{|c|}{ Cr 2p 2/3 } \\
\hline Bond & $\mathrm{Be}, \mathrm{eV}$ & $\mathrm{AC}$, at $\%$ & Bond & $\mathrm{Be}, \mathrm{eV}$ & $\mathrm{AC}$, at $\%$ \\
\hline $\mathrm{Co}(\mathrm{III})$ & 779,5 & 25.86 & $\mathrm{Cr}(\mathrm{III})$ & 576.2 & 0.26 \\
\hline
\end{tabular}

The result of the EDX investigation of the surface as well as CS of the coating is presented in table 2. The most abundant element in the coating is Co considering the 62.3 and 63.1 at $\%$ readings from the surface and CS of the coating. The form of the Co is however not as clear. Considering that there should not be any Fe in the coating, the fact that the surface scan has a 1.3 at\% reading of Fe means that the penetration depth is all the way through the coating to the substrate. This means that the oxygen reading can't be entirely from the surface oxides/hydroxides apparent in the XPS results, but that there are some Co oxides and hydroxides in the coating as well. However, considering the low level of oxygen compared to Co there is most likely also metallic Co in the coating. 
Tab. 2: Result of the EDX investigation of the coating presented in at\%.

\begin{tabular}{l|cccccccccc} 
Area $\backslash$ Element & $\mathbf{C}$ & $\mathbf{O}$ & $\mathbf{C l}$ & $\mathbf{C r}$ & $\mathbf{F e}$ & $\mathbf{C o}$ & $\mathbf{M n}$ & $\mathbf{N i}$ & $\mathbf{G a}$ & $\mathbf{P t}$ \\
\hline Surface & 15.4 & 17.7 & 0.7 & 2.3 & 1.3 & 62.3 & & & & \\
CS coating & 8.8 & 0.8 & 0.2 & 6.7 & 16.5 & 63.1 & & 1.2 & 1.8 & 0.9 \\
CS substrate & 3.2 & 0.2 & & 19.1 & 66.9 & 2.3 & 1.3 & 5.9 & 0.9 & 0.3
\end{tabular}

Considering that the substrate (stainless steel AISI 304) contains a large amount of $\mathrm{Cr}$ the reading on the surface and in the coating CS has to be compared to other components of the substrate to determine if there is some $\mathrm{Cr}$ in the coating or if the $\mathrm{Cr}$ readings are all results of the $\mathrm{Cr}$ in the substrate. If we compare the ratio between $\mathrm{Cr}$ and $\mathrm{Fe}(\mathrm{Cr} / \mathrm{Fe})$ for the three readings we get $0.29,0.41$ and 1,77 for the substrate (note that 19.1 and 66.9 at\% is within the concentrations for $\mathrm{Cr}$ and Fe in AISI 304 according to specification), coating and surface respectively. By doing this it becomes clear that the $\mathrm{Cr}$ reading is not a result of the content in the substrate but rather that there are $\mathrm{Cr}$ in the coating. It is however not possible to determine that there are more $\mathrm{Cr}$ towards the surface based upon the results since the $25^{\circ}$ angle used when performing the EDX of the coating CS causes that reading to penetrate deeper into the substrate than the reading on the surface.

The fact that there are $\mathrm{Cr}$ in the coating is supported by the fact that removing the $\mathrm{Cr}$ (III) component in the electrolyte results in a layer of reduced Co on the WE with extremely poor adhesion, it falls of when rinsing after deposition. This indicates that the Cr plays an important role in the initial steps of the deposition process at the very least. This together with the small amount of $\mathrm{Cr}$ at the surface according to the XPS results indicates that the $\mathrm{Cr}$ concentration is rather higher at the substrate and that there is a negative concentration gradient towards the surface of the coating.

The CS was also investigated with EDX mapping, the result of which can be seen in figure 4. In the picture showing the distribution of Co it is clearly visible that it is limited to the coating, where it also is abundant as expected. The $\mathrm{Fe}$ and $\mathrm{Cr}$ on the other hand has the strongest signal from the substrate, but they differ in the way that the $\mathrm{Cr}$ concentration does not decrease as abruptly at the transition to the coating. While still being clearly lower than in the substrate, there is also $\mathrm{Cr}$ in the coating, however at a relatively low concentration. The oxygen does not show as abrupt changes in the concentration, but it shows a distinct positive gradient towards the surface of the coating. 

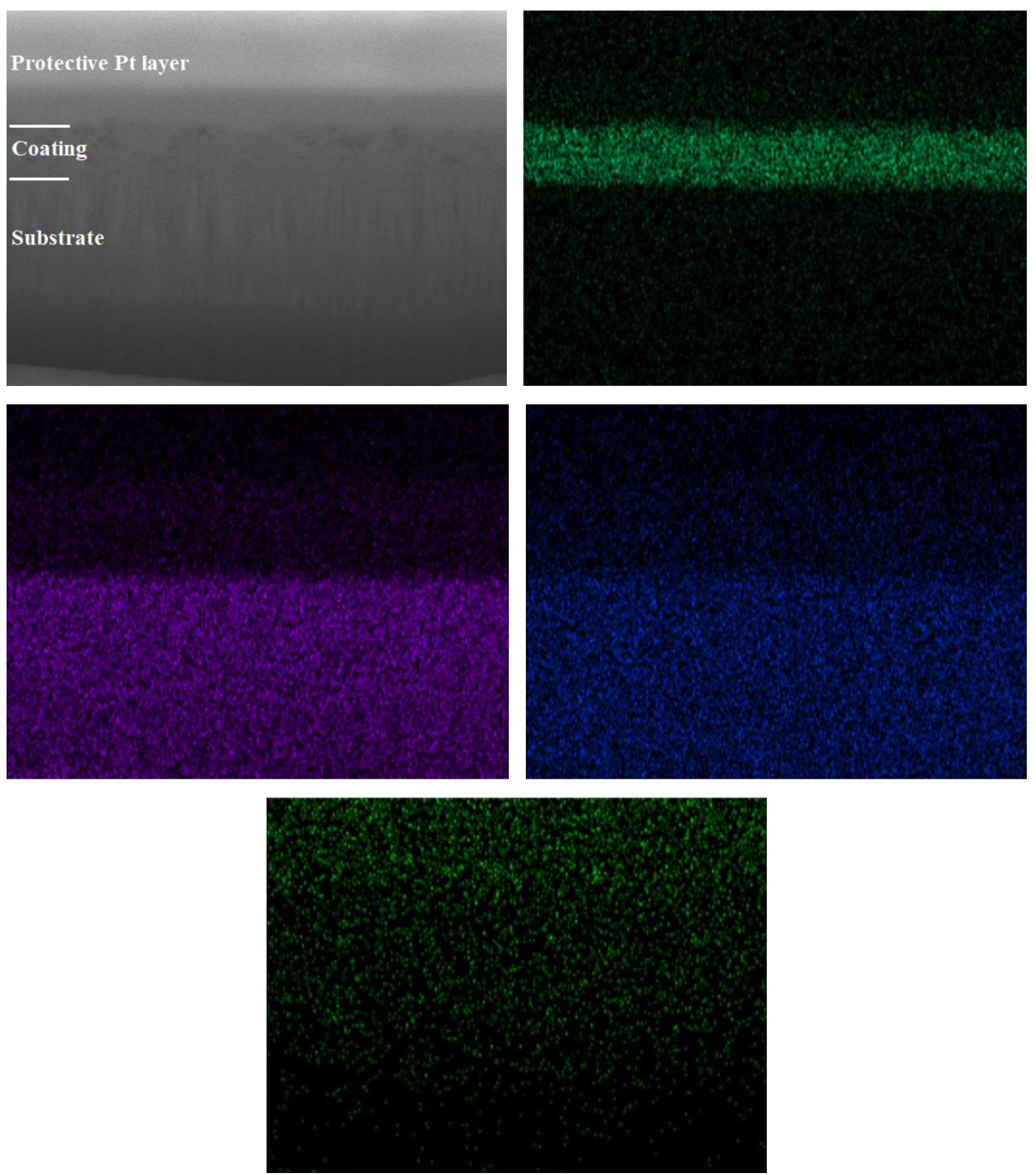

Fig. 4: SEM of the cross section (upper left) and EDX mapping of the cross section divided after the elements Co (upper right), Fe (middle left), $\mathrm{Cr}$ (middle right) and $\mathrm{O}$ (bottom).

\subsection{Thermal stability}

The result of the thermal stability test can be seen in table 3 . The degradation in terms of optical performance after a simulate lifetime of 0.63 and 2 years respectively is $\mathrm{PC}=0.023$ and 0.081 . Using a polynomial fit of only those two data points gives a degradation of 0.05 after a simulated lifetime of 0.95 years. Considering that the $5 \%$ degradation is the limit for what is acceptable over a 25 -year lifetime the coating has clearly failed the test.

Tab. 3: Result of the thermal stability test performed at $320^{\circ} \mathrm{C}$ in a muffle furnace.

\begin{tabular}{l|ccc} 
Sample & Time in furnace $[\mathbf{h}]$ & Simulated Lifetime [years] & PC \\
\hline S1 & 43 & 0.63 & 0.034 \\
S2 & 136.4 & 2 & 0.10
\end{tabular}


The reflectance spectra over the interval $0.28-1.1 \mu \mathrm{m}$ of two samples, S1 and S2, before and after being exposed to a high temperature can be seen in figure 5 . The reflectance of the tow samples after the test is very similar, almost perfectly overlapping, over the interval $0.28-0.8 \mu \mathrm{m}$, but S2 had a lower reflectance initially giving it a greater degradation. It is unclear if the reflectance the two samples exhibit in this region after the test is a stable level from which the degradation does not continue, or if the fact that they align is a coincidence caused by the initial difference in the reflectance. In the region $0.8-1.1 \mu \mathrm{m}$ on the other hand, the two samples exhibit very different reflectance. S1 having ha peak and a trough at roughly 0.87 and $1.01 \mu \mathrm{m}$ respectively, while S2 have a peak at roughly $0.99 \mu \mathrm{m}$ before declining sharply towards the edge of the registered spectra $(1.1 \mu \mathrm{m})$. A possible explanation to the differences in this region is a gradual degradation of the surface structures of the samples, changing how efficiently they capture the light in these wavelengths.

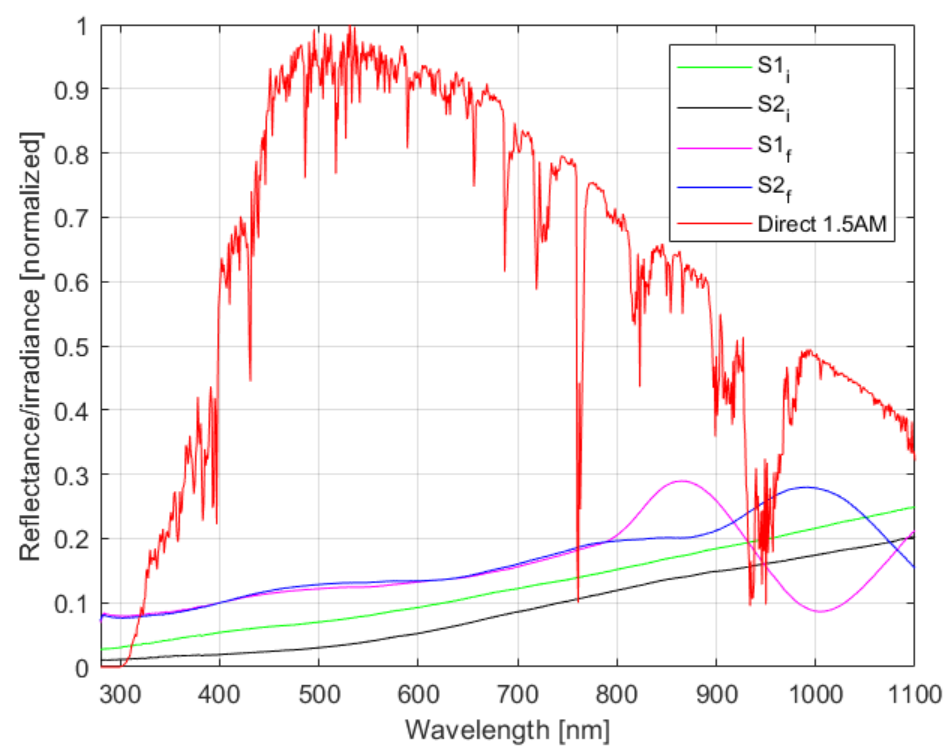

Fig. 5: Reflectance of two samples before (i) and after (f) aging tests presented with the 1.5AM solar spectra.

The result of the TGA performed in a nitrogen and an oxygen atmosphere can be seen in figure 6 and 7 respectively. The nitrogen run reveals a gradually decreasing weight to approximately $400^{\circ} \mathrm{C}$ before it gradually increases for the rest of the test. The absence of transformation peaks at 30,252 and $800^{\circ} \mathrm{C}$ reveals that the samples do not contain $\mathrm{Co}(\mathrm{OH})_{2}, \mathrm{CoOOH}$ or $\mathrm{Co}_{3} \mathrm{O}_{4}$ there would be distinct reactions at 130,252 and $800^{\circ} \mathrm{C}$ respectively (Yang, et al., 2010).

The TGA performed in air reveals a small reaction at $331^{\circ} \mathrm{C}$ that could be contributed to a small amount of cobalt carbonate decomposing to $\mathrm{Co}_{3} \mathrm{O}_{4}$ (Ei, et al., 1996). This is supported by the small reading of carbonate in the XPS results. The largest reaction reaction visible is however an oxidation centered around $438^{\circ} \mathrm{C}$ at which the weight of the sample increases from 95 to $116 \%$ of the original weight, resulting in a $22 \%$ increase in weight. This indicates an oxidation of a big part of the sample. One possibility is that there is large amount of metallic Co available that is oxidized to $\mathrm{Co}_{3} \mathrm{O}_{4}$, and that cobalt (II)oxide is what starts to decomposes to $\mathrm{CoO}$ at $850^{\circ} \mathrm{C}$ (Ei, et al., 1996) causing the drop in weight between 850 and $900^{\circ} \mathrm{C}$. 


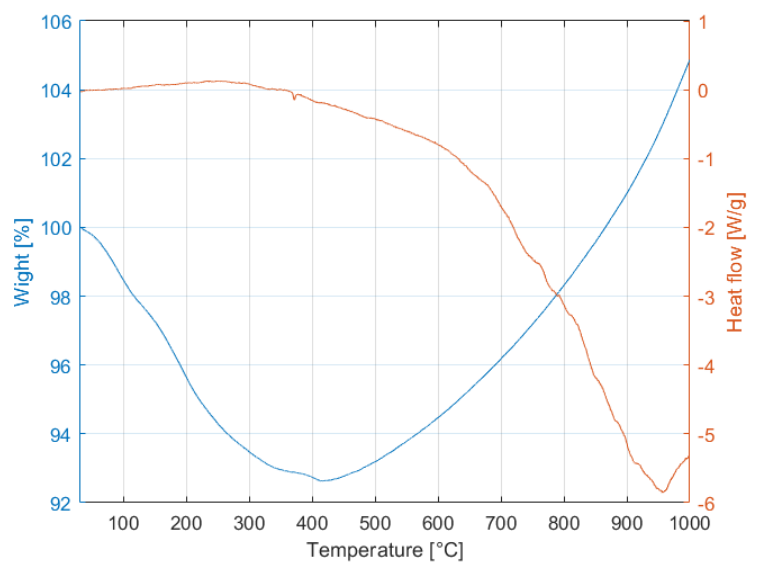

Fig. 6: TGA data for the coating in a nitrogen atmosphere.

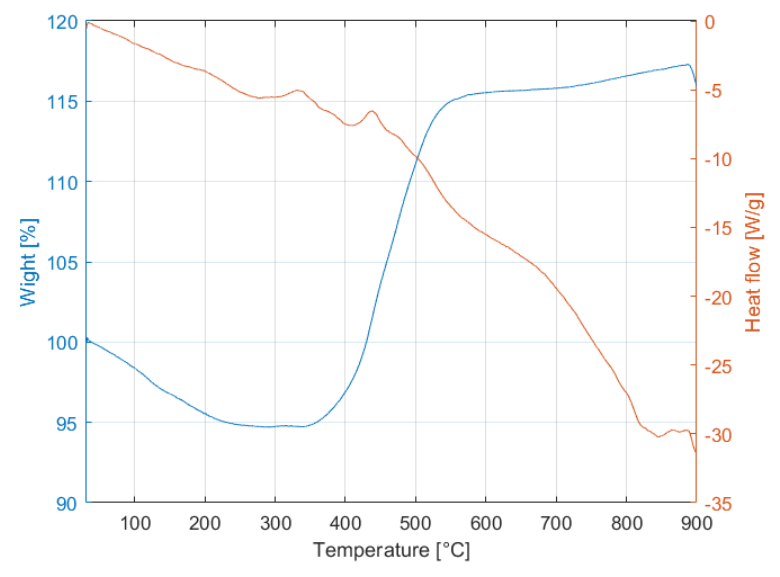

Fig. 7:TGA data for the coting in an air atmosphere.

\subsection{General discussion}

As previously discussed, the $\mathrm{CD}$ is central for important aspects of the coating, like thickness and surface structure. Because of this it must be mentioned that all the depositions in this project has been conducted in an electrochemical cell where both CE and WE are flat electrodes. As a result, only one side of the WE were facing the CE during the deposition. As a result, there is an uncertainty in the actual CD of the side facing the CE because the amount of the side facing away from the Ce that is electroplated varies between samples. As expected, a higher CD results in a larger part of the "back" of the WE that is being electroplated. It should be noted that the amount of the "back" that is plated is small, roughly $10-20 \%$. Since the CD mentioned in this report is calculated using the area of the side of the WE that face the CE it is an overestimation, however it not large.

\section{Conclusions}

The electroplated surface is strongly selective as $\alpha$ and $\epsilon$ are 0.96 and 0.13 respectively, giving a selectivity of $S=$ 7.4. These optical properties make the surface suitable for a low- to mid-temperature concentrating solar collector. The selective Co-Cr coating is $1.8 \mu \mathrm{m}$ thick and exhibits a porous structure throughout the coating and has a surface structure resembling sheets around $1 \mu \mathrm{m}$ long with cavities between. The surface of the coating is covered in Co oxides and hydroxides, while the bulk of the coating consists of Co in the form of both metallic and oxidized Co and only a small fraction of $\mathrm{Cr}$ compounds. Initial tests of the thermal stability indicate that the coating does not maintain optical properties at an acceptable level over a lifetime of 25 years and that a large part of the coating is oxidized at approximately $438^{\circ} \mathrm{C}$ in an oxygen rich environment.

\section{Future works}

Based upon the result of the DoE optimization done there are room for improvement in terms of optimization with regards to the optical properties ${ }^{1}$. However, considering that the optical properties are already at a competitive level, the focus of the work going forward will be the problem with thermal stability. Initially by thoroughly evaluating the degradation process to determine which reactions cause the degradation and under which circumstances. After that efforts to increase the thermal stability can be made.

One way to increase the thermal stability could be to apply a protective layer on top of the selective coating that is also anti reflective increasing the absorptance of the surface. This has been successfully done with a AlOOH coating on a selective surface of carbon nano tubes with (Bera, et al., 2016).

It could also be possible to oxidize the $\mathrm{Co}-\mathrm{Cr}$ in a controlled manner, increasing the stability of it by changing the Co compounds to $\mathrm{Co}_{3} \mathrm{O}_{4}$ while keeping the surface structure of the coating. Either through electrolytical oxidation at room temperature, or by exposing it to a temperature and an atmosphere adapted to oxidize the sample without ruining the optical properties.

\footnotetext{
${ }^{1}$ Nordenström, A., 2018. Investigating an electroplating method of Co-Cr alloys - A design of experiment approach to determine the impact of key factors on the electroplating process, Master Thesis, Umeå University
} 
It is also possible to use a highly reflective undercoating of nickel to prevents diffusion from the substrate to the coating. This also lowers the emittance of the substrate potentially increasing the selectivity of the finished surface.

\section{Acknowledgements}

The partial financing of the research by Absolicon Solar Collector AB is gratefully acknowledged. The Umeå Core Facility for Electron Microscopy (UCEM) is acknowledged for providing the equipment and the help necessary during the SEM, EDX and FIB measurements. Arne Roos at the Ångström laboratory is acknowledged for performing the optical measurement. Andrey Shchukarev at Umeå University is acknowledged for performing the XPS measurements.

\section{References}

Abbas, A., 2000. Solchrome solar selective coatings - an effective way for solar water heates globally. Renewable Energy, Volym 19, pp. 145-154., Avaliable from: doi: 10.1016/S0960-1481(99)00028-2.

Atkinson, C., Sansom, C. L., Almond, H. J. \& Shaw, C. P., 2015. Coatings for concentrating solar systems - A review. Renewable and Sustainable Energy Reviews, Volym 45, pp. 113-122., Avaliable from: doi:

10.1016/j.rser.2015.01.015.

Bera, R. K., Mhaisalkar, S. G., Mandler, D. \& Magdassi, S., 2016. Formation and performance of highly absorbing solar thermal coating based on carbon nanotubes and boehmite. Energy Conversion and Management, Volym 120, pp. 287-293., Avaliable from: doi: 10.1016/j.enconman.2016.04.081.

Carlsson, B., Möller, K., Köhl, M., Frei, U., Brunold, S., 2000. Qualification test procedure for solar absorber surface durability. Solar Energy Materials and Solar Cells, 61(3), pp. 255-275. , Avaliable from: doi: 10.1016/S0927-0248(99)00111-7.

Ei, G. A., Ahmad, A. S., Ai, A. N. \& Ei, H. G., 1996. TI . RMAL DECOMPOSITION OF BASIC COBALT AND COPPER CARBONATES Thermal stability of the produced oxides as influenced by. October, Volym 46, pp. 1801-1808., Avaliable from: doi: 10.1007/BF01980784.

Eugénio, S., Rangel, C. M., Vilar, R. \& Botelho Do Rego, A. M., 2011. Electrodeposition of black chromium spectrally selective coatings from a Cr(III)-ionic liquid solution. Thin Solid Films, 519(6), pp. 1845-1850., Avaliable from: doi: 10.1016/j.tsf.2010.10.029.

Kennedy, C. E., 2002. Review of Mid- to High- Temperature Solar Selective Absorber Materials Review of Midto High- Temperature Solar Selective Absorber Materials, u.o.: u.n.

Lin, C.-C. \& Hu, C.-C., 2008. Electropolishing of 304 stainless steel: Surface roughness control using experimental design strategies and a summarized electropolishing model. Electrochimica Acta, 53(8), pp. 3356-3363., Avaliable from: doi: 10.1016/j.electacta.2007.11.075.

NREL, 2018. nrel.gov., [Online] Available at: https://www.nrel.gov/grid/solar-resource/spectra-am1.5.html, [Accessed 0509 2018].

Selvakumar, N. \& Barshilia, H. C., 2012. Review of physical vapor deposited (PVD) spectrally selective coatings for mid- and high-temperature solar thermal applications. Solar Energy Materials and Solar Cells, Volym 98, pp., Avaliable from: doi: 1-23.10.1016/j.solmat.2011.10.028.

Surviliene, S., Cesuniene, A., Juskenas, R., Selskiene, A., Bucinskiene, D., Kalinauskas, P., Juskevicius, K., Jureviciute, I., 2014. The use of trivalent chromium bath to obtain a solar selective black chromium coating. Applied Surface Science, Volym 305, pp. 492-497., Avaliable from: doi: 10.1016/j.apsusc.2014.03.122.

Testafamichael, T., 2000. Characterization of Selective Solar Absorbers. u.o.:u.n.

Tompkins, H. G. \& Augis, J. A., 1981. The oxidation of cobalt in air from room temperature to $467^{\circ} \mathrm{C}$. Oxidation of Metals, 16(5-6), pp. 355-369., Avaliable from: doi: 10.1007/BF00611349.

Yang, J., Liu, H., Martens, W. N. \& Frost, R. L., 2010. Synthesis and Characterization of Cobalt Hydroxide. Physical Chemistry, 114(7), pp. 1-11.

Zhang, J., Gu, C., Tong, Y., Gou, J., Wang, X., Tu, J., 2015. Microstructure and corrosion behavior of $\mathrm{Cr}$ and $\mathrm{Cr}-\mathrm{P}$ alloy coatings electrodeposited from a $\mathrm{Cr}$ (III) deep eutectic solvent. RSC Adv., 5(87), pp. 71268-71277., Avaliable from: doi:10.1039/C5RA13056E. 
Thermal Storage 


\title{
Stratification in Large Thermal Storage Tanks

\author{
Mattia Battaglia ${ }^{1}$ and Michel Haller ${ }^{1}$
} \\ 1 SPF Institute for Solar Technology, Rapperswil (Switzerland)
}

\begin{abstract}
Thermal storage tanks are important components in both, solar thermal as well as heat pump systems, because they can bridge the time between production and demand of heat. For low exergy energy sources such as solar thermal collectors, heat pumps, and waste heat recovery, the stratification within the tank is of key importance for the efficiency of the system. In this project, existing recommendations for the design of stratified storages are generalized to any storage size. The deflection relation is identified as a relevant variable. If this deflection relation is less than 0.12 for vertical inlet and less than 0.5 for inlet via an upward or downward elbow pipe pointing towards the top or bottom of the tank, the unintended deflection of the entering fluid stream into local vertical flows is low and an existing storage stratification is effectively maintained.
\end{abstract}

Keywords: Thermal Storage Tank, Stratification, Computational Fluid Dynamics, Field Study

\section{Introduction}

Storage stratification has a major influence on the usable storage volume and the efficiency of the connected systems. This is especially the case when storage tanks are combined with so-called low exergy processes like solar thermal systems, heat pumps or heat recovery. The importance of stratification has been demonstrated in particular for solar combi-storage tanks in which sections dedicated to domestic hot and space heating are in contact to each other. It was shown that the stratification efficiency of combi-storage tanks operated in combination with heat pumps has a greater influence on the overall efficiency of the system than the storage heat losses [1].

The temperature stratification in fluids adjusts automatically due to gravity and the temperature-dependent density of water. This natural process can be disturbed or destroyed by various processes [2]:

1. heat conduction in water and in the storage tank internals

2. plume entrainment

3. kinetic energy of direct inlets (inlet jet mixing)

Heat conduction has a significant effect, especially with very long loading and downtimes as well as with low height to horizontal diameter ratios. In short-term storage processes, the kinetic energy and the entraining flow of direct storage tank charging as well as the poor stratification capability of internal heat exchangers are the main causes for destratification.

Plume entrainment occurs when fluid with a certain temperature and density flows into a zone with a different temperature and density. Due to the difference in density, gravitational forces cause the fluid to be deflected or accelerated in a vertical direction. Similar to the steam plume above a chimney, a vertical turbulent flow, driven by the buoyancy force, is created, which, after a more or less pronounced overshoot, stratifies into the temperature layer of equal density. At the border zone of the flow, surrounding fluid is continuously drawn into the motion (see e.g.[3]). In thermal storages, this can be prevented by injecting the fluid at the level at which the temperature is identical to the temperature of the entering fluid. If the vertical position of this layer is not known in advance, an inlet stratifyer unit can be used, which results in a stronger physical separation between ascending or descending fluid and the remaining storage area. 
Loading with high kinetic energy can cause turbulences and flows in the storage tank and thus destroy existing storage stratification. To prevent this, the entry velocity must be kept low. The literature contains a multitude of investigations with mathematical models and experiments, which give threshold values and recommendations for maximum inlet velocities and maximum Reynolds numbers of the entering fluid. A compilation of these results was presented in [4]. In this paper, a work that supplements existing recommendations and develop a standardized criterion that can be applied to different storage sizes is presented. The criterion is validated both with results from fluid dynamics simulations (CFD) and a field data from 7 different storage tanks.

\section{Deflection relation as the defining dimensionless quantity}

In fluid mechanic problems, it is common to use laws of scaling and dimensionless quantities. This is particularly useful because experiments and simulations are often time-consuming. Large systems in particular are usually difficult or impossible to be tested in the laboratory or simulated with sufficient degree of detail with available computing capacity and time. This problem also arises when considering large thermal storages. Measurements of stratification efficiency with laboratory test methods were performed with tank volumes of approx. $1 \mathrm{~m}^{3}$ [1]. A measurement of larger storage tanks would be possible in principle, but test stands for sizes up to $100 \mathrm{~m}^{3}$ are not readily available and testing times and cost would increase substantially. In addition, flow simulations of large storage tanks require a great deal of computing power. A one-hour simulation of a combi-storage with 8001 capacity requires a computing time of $55 \mathrm{~h}$ with $12 \mathrm{CPU}$ cores (see [4]). If the storage volume is increased to $100 \mathrm{~m}^{3}$, simulations can take several weeks, which makes efficient work and the production of results difficult.

For this reason, it is helpful to develop scaling laws that enable the transferability of results from small storage sizes to any size. Starting from the results that were published for an $800 \mathrm{l}$ combi-storage tank (cf [1,4]), scaling effects were examined with the aid of CFD simulations, with the objective to find appropriate scaling laws. Dimensionless quantities have also been used to characterize mixing in thermal storage tanks in [5] where the Fraud number was used in combination with the Reynolds number to define a correlation between inlet velocities and the amount of mixing caused by the jet.

We hypothesize that in the case of a turbulent jet entering the storage horizontally, the relevant dimensionless quantity is the ratio between the characteristic length $l_{s}$ in which the jet is deflected and the free distance to the next obstacle $\mathrm{d}_{\mathrm{f}}$. In the present case of an intended downward stratification, only obstacles that permit an upward deflection need to be taken into account. This dimensionless quantity as a deflection relation $\chi$ is defined as:

$$
\chi=\mathrm{l}_{\mathrm{s}} / \mathrm{d}_{\mathrm{f}}
$$

The length $\mathrm{l}_{\mathrm{s}}$ can be formed as a quotient of inflow pulse flow $M_{0}$ and buoyancy flow $F_{0}$, which in turn is calculated from the volume flow $\dot{V}_{0}$; the inlet velocity $v_{0}$, the gravitational acceleration $g$, the density of the inflowing fluid $\rho$, and the density difference $\Delta \rho$ given by the temperature differences (see:[3]):

$$
l_{s}=\frac{\left(M_{0} / \rho\right)^{\frac{3}{4}}}{\left(F_{0} / \rho\right)^{\frac{1}{2}}}=\frac{\left(\dot{V}_{0} v_{0}\right)^{\frac{3}{4}}}{\left(\frac{\dot{V}_{0} g \Delta \rho}{\rho}\right)^{1 / 2}}
$$

\section{CFD settings}

The CFD simulations created in the project were carried out with ANSYS CFX 18.2. The models and meshing settings experimentally validated in the StorEx project were adopted, so that a new validation of these settings was not necessary. A detailed description of the validation process can be found in [4]. The scale adaptive shear stress transport model was used as the turbulence model. The meshing was also carried out analogously to the earlier work with an element length of $2 \mathrm{~cm}$. However, for tanks smaller than $800 \mathrm{l}$ the net length has been reduced to $1 \mathrm{~cm}$. A vertical plane of symmetry was inserted in the direction of the inlet pipe. The storage wall was assumed to be a completely adiabatic border. 


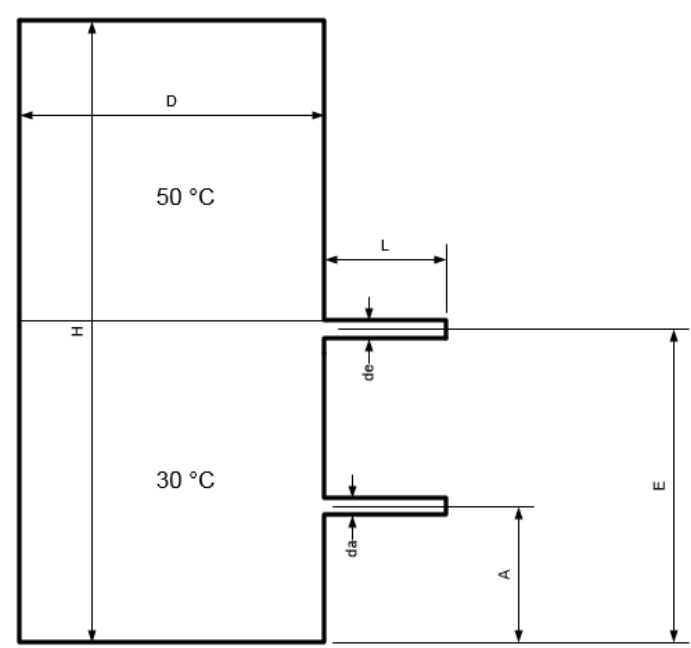

Figure 1 Dimensions of the simulated storage charging.

\section{Results for horizontal inlets}

To investigate scaling effects more closely, the experiment described in Gwerder et al. (2016) was simulated. In this experiment, the loading of the space heating part of a combi-storage tank was investigated. For this application, it is particularly important that the inflowing fluid does not cause strong circulation flows in the storage tank. If the hot water part is affected by the fluid flowing into the space heating part, this leads to entropy production and to a strong decrease in system efficiency, especially when a heat pump is used for charging [1]. The $800 \mathrm{l}$ combi-storage used as the base case has a height of $\mathrm{H}=1.84 \mathrm{~m}$ and a diameter of $\mathrm{D}=0.75 \mathrm{~m}$. The inlet is located in the middle of the storage tank at a height of $\mathrm{E}=0.92 \mathrm{~m}$ from the ground. The outlet is located at a height of $\mathrm{A}=0.387 \mathrm{~m}$. At the beginning of the simulations, the temperature in the lower part of the storage tank was 30 ${ }^{\circ} \mathrm{C}$, while the upper area had a temperature of $50{ }^{\circ} \mathrm{C}$. A scheme of the used storage tank layout is shown in Figure 1.

By the use of the dimensionless deflection relation $\chi$, stratification results of one storage size can be scaled to other storage sizes. The validity of the deflection relation as a dimensionless quantity for characterizing stratification quality was tested with a set of CFD simulations. For the case of a horizontal inlet, simulations were done with a direct inlet and with a baffle plate. The velocity of the fluid entering the storage was in the range of approx. 0.1-0.2 $\mathrm{m} / \mathrm{s}$. When using a baffle plate, a higher mass flow rate is reached with the same velocity at the outlet of the diffuser due to the higher cross-sectional surface of the flow path. The storage tank was scaled by the factors $0.5,1.48$ and 1.93 in each dimension, starting from the basic case of the $800 \mathrm{l}$ storage tank, whereby for the baffle plate variant only the basic size and the scaling by the factor 1.48 were simulated

Exemplary scaling results in relation to the vertical temperature curve of the horizontal inlet experiment with direct entry are shown in Figure 2. All results describe the temperature in the storage tank after $50 \%$ of the storage fluid has been replaced by the inlet and outlet flow. It can be seen that for a given deflection relation, the vertical thermocline shift caused by turbulences and motions created by the incoming fluid is relatively independent from the storage size, with a more pronounced displacement of the thermocline for higher deflection relations (Figure 2).

In addition to the shift of the thermocline, the stratification efficiency was evaluated. The storage tanks were simulated without losses to the ambient, and thus the stratification efficiency can be defined as follows [6,7].

$$
\begin{aligned}
& \Delta \mathrm{S}_{\text {irr,sim }}=-\left(\Delta S_{\text {in } \backslash \text { out }}+\Delta S_{\text {storage }}\right)>0 \\
& \zeta_{\text {str }}=1-\frac{\Delta \mathrm{S}_{\text {irr,sim }}}{\Delta S_{\text {irr,mix }}}
\end{aligned}
$$


In order to evaluate the stratification efficiency of the simulated experiments, it was assumed that the inlet and outlet always take place at a constant temperature level over the simulation period. This condition is almost fulfilled for sufficiently well stratified storage tanks, since in this case the lower storage area is heated only slightly in the defined combi-storage loading experiment. As a result of this simplification, $\Delta S_{\text {in } \backslash \text { out }}=0$ applies and thus $\Delta S_{i r r, \text { sim }}$ can be calculated directly from the temperatures in the storage tank before and after the experiment. As reference value $\Delta S_{\text {irr,mix }}$ the entropy production for a storage tank, which is completely mixed after the simulation period, was calculated.

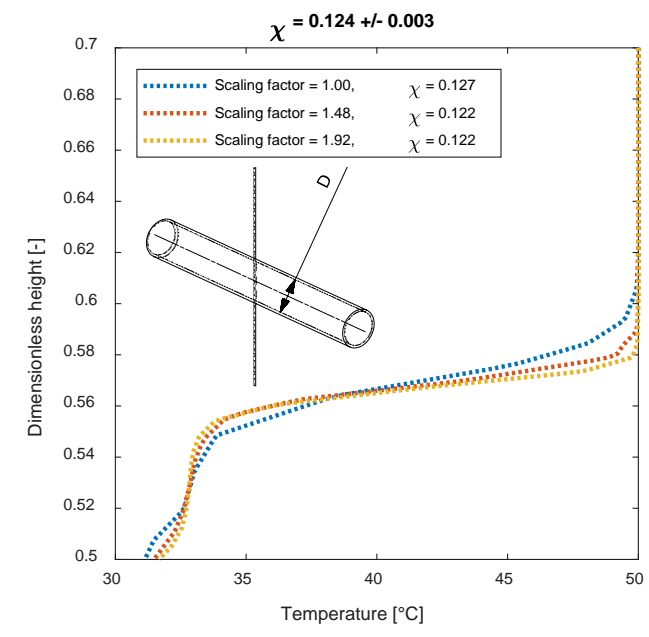

(a)

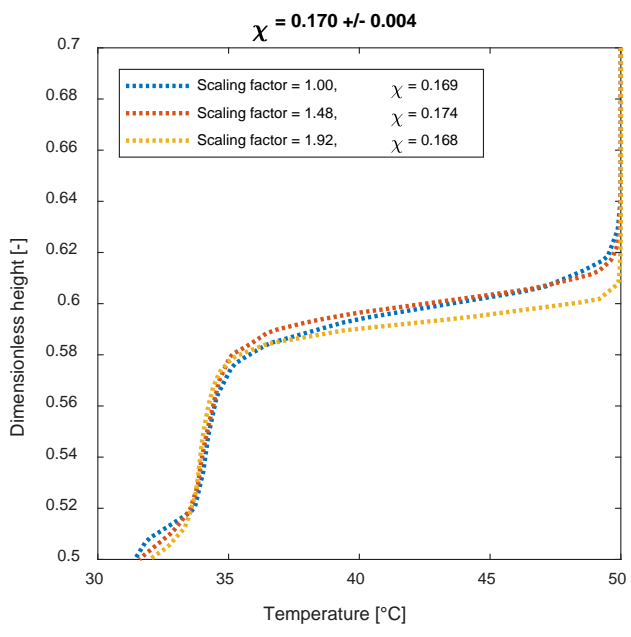

(b)

Figure 2 Vertical temperature line after a replacement of $50 \%$ of the storage volume by incoming fluid at mid-height with constant deflection relations of $0.124+/-0.03$ (a) and $0.170+/-0.04$ (b).

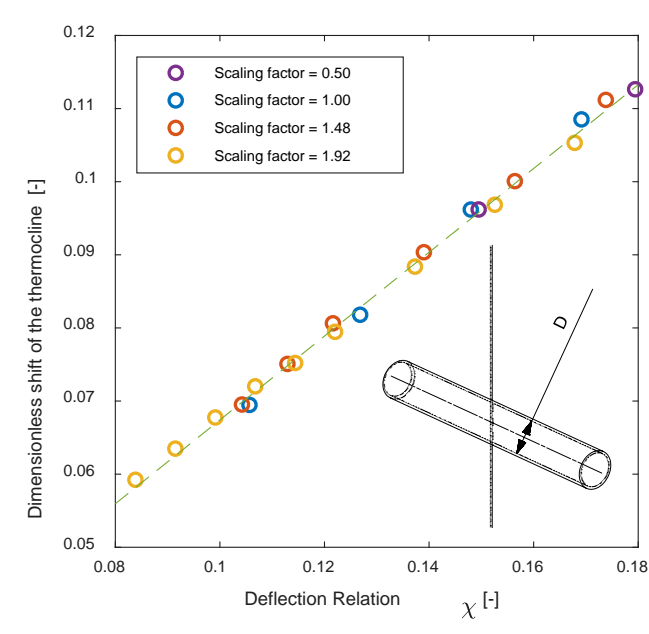

(a)

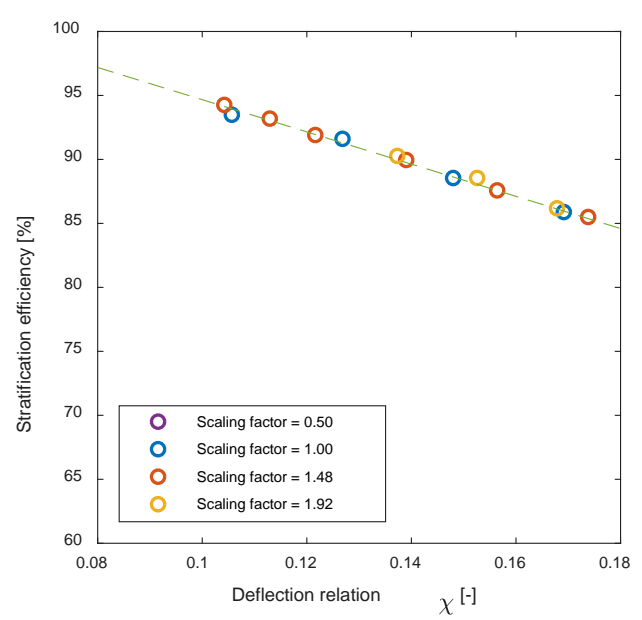

(b)

Figure 3 Correlation of the shift of the thermocline (a) and the stratification efficiency (b) with the deflection relation in case of a direct inlet.

Figure 3 shows the correlation between deflection relation and thermocline shift (left) and between deflection relation and stratification efficiency (right). The results are based on simulations of storage tanks with different dimensions and different volume flow rates of charging. The scaling factors from 0.5 to approximately 2 for each dimension indicate that the largest storage volume evaluated was $4 \times 4 \times 4=64$ larger than the smallest one. The simulation results show that both the relative displacement of the thermocline and the stratification efficiency show a linear dependence on the deflection relation in the investigated area. The $\mathrm{R}^{2}$ value of the linear correlation of the thermocline shift is 0.997 that of the stratification efficiency is 0.994 . In Table 1 , different quantities that 
describe the simulation runs are given for a selected number of performed CFD charging experiments with direct horizontal inlets.

Table 1 Relevant quantities for selected simulation cases with direct horizontal inlet.

\begin{tabular}{|c|c|c|c|c|c|c|c|}
\hline $\begin{array}{c}\text { Volume } \\
\text { (l) }\end{array}$ & $\begin{array}{c}\text { Scaling } \\
\text { factor s } \\
\text { (-) }\end{array}$ & $\begin{array}{c}\text { Pipe } \\
\text { diameter } \\
\text { (inch) }\end{array}$ & $\begin{array}{c}\text { Volume } \\
\text { flow rate } \\
\text { (l/h) }\end{array}$ & $\begin{array}{c}\text { Deflection } \\
\text { relation } \\
\chi(-)\end{array}$ & $\begin{array}{c}\text { Inlet velocity } \\
\text { (m/s) }\end{array}$ & $\begin{array}{c}\text { Reynold } \\
\text { number (-) }\end{array}$ & $\begin{array}{c}\text { Stratification } \\
\text { efficiency (\%) }\end{array}$ \\
\hline 800 & 1 & $2 ”$ & 953 & 0.127 & 0.12 & 7507 & 91.5 \\
\hline 2593 & 1.48 & $3 ”$ & 2434 & 0.122 & 0.14 & 13574 & 91.8 \\
\hline 5751 & 1.93 & $4 ”$ & 4682 & 0.122 & 0.16 & 20165 & 90.2 \\
\hline 800 & 1 & $2 ”$ & 1279 & 0.169 & 0.16 & 15015 & 85.8 \\
\hline 2593 & 1.48 & $3 ”$ & 3477 & 0.174 & 0.20 & 27148 & 85.4 \\
\hline 5751 & 1.93 & $4 ”$ & 6438 & 0.168 & 0.22 & 40330 & 86.1 \\
\hline
\end{tabular}

The same method was used to examine the storage tank inlet via a baffle plate. The shape of the baffle plate is shown in Figure 4. The initial conditions, the height of the inlet and the outlet as well as the simulation time are identical to the case with direct inlet. As a base case, a mass flow rate that only slightly exceeds the recommended inlet velocity of $0.1 \mathrm{~m} / \mathrm{s}$ when leaving the baffle plate was used. To check the limits of the proposed deflection relation the entry velocity was doubled for another simulation. In Table 2 the used inlet velocities for the scaled storage as well as other relevant quantities are shown. The two resulting temperature curves are shown in Figure 4. The thermocline shift and stratification efficiency are shown in Figure 5. It becomes evident that the same inlet velocity leads to a higher impulse flux due to the higher inlet cross section area and consequently to an increased deflection relation compared to the direct inlet with a smaller cross section. While a deflection relation of $\chi=$ 0.166 still leads to a similar temperature distribution in both simulated cases, a larger difference of the two temperature curves is present when the entry velocity is doubled and the corresponding deflection relation increases to $\chi=0.331$. For the simulation experiments with baffles, the correlation values of 0.904 for the thermocline shift and 0.955 for stratification efficiency are significantly lower than in the case of the direct inlet.

Table 2 Relevant quantities for selected simulation cases with baffle plate horizontal inlet.

\begin{tabular}{|c|c|c|c|c|c|c|c|c|}
\hline $\begin{array}{l}\text { Volume } \\
\text { (l) }\end{array}$ & $\begin{array}{l}\text { Scaling } \\
\text { factor S } \\
(-)\end{array}$ & $\begin{array}{c}\text { Baffle } \\
\text { plate area } \\
\qquad \begin{array}{c}a \cdot b \\
\left(\mathrm{~cm}^{2}\right)\end{array}\end{array}$ & $\begin{array}{l}\text { Baffle plate } \\
\text { length L } \\
\text { (one side) } \\
\text { (cm) }\end{array}$ & $\begin{array}{l}\text { Volume } \\
\text { flow } \\
\text { rate } \\
\text { (l/h) }\end{array}$ & $\begin{array}{l}\text { Deflection } \\
\text { relation } \chi \\
(-)\end{array}$ & $\begin{array}{c}\text { Inlet } \\
\text { velocity } \\
(\mathbf{m} / \mathbf{s})\end{array}$ & $\begin{array}{c}\text { Reynold } \\
\text { number } \\
(-)\end{array}$ & $\begin{array}{l}\text { Stratification } \\
\text { efficiency (\%) }\end{array}$ \\
\hline 800 & 1 & 90 & 26.7 & 3104 & 0.167 & 0.10 & 8137 & 86.9 \\
\hline 2593 & 1.48 & 197 & 39.5 & 3104 & 0.164 & 0.13 & 13574 & 89.2 \\
\hline 800 & 1 & 90 & 26.7 & 4682 & 0.333 & 0.2 & 15656 & 73.1 \\
\hline 2593 & 1.48 & 197 & 39.5 & 1279 & 0.329 & 0.26 & 31312 & 76.9 \\
\hline
\end{tabular}




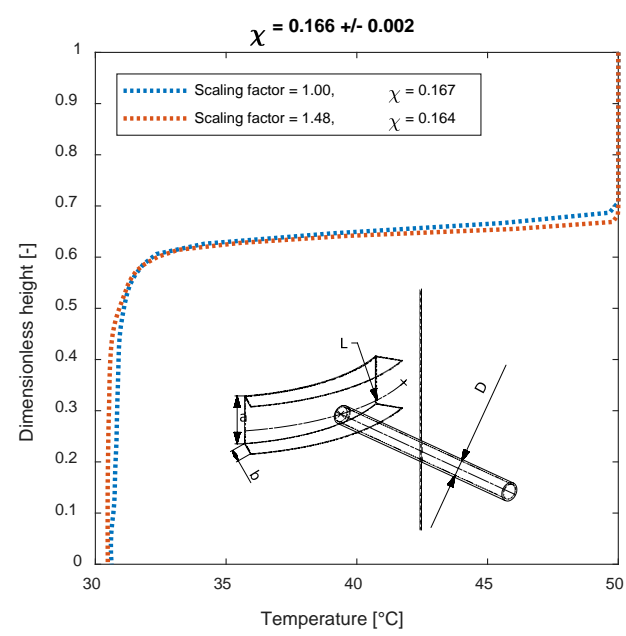

(a)

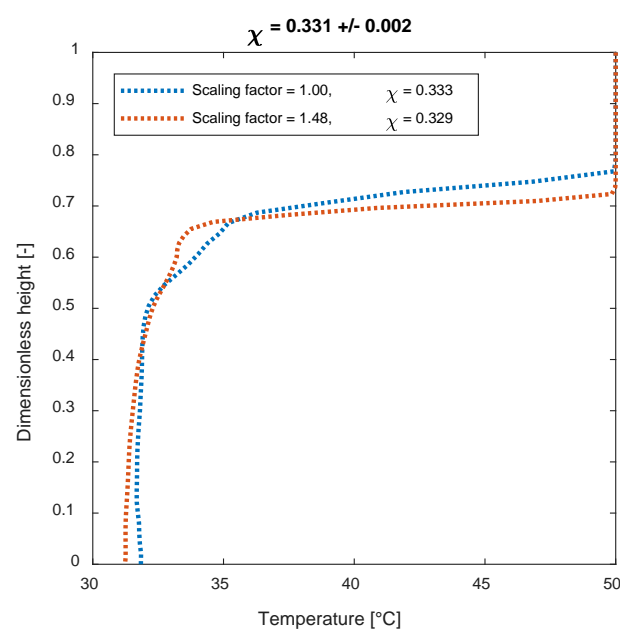

(b)

Figure 4 Vertical temperature profile after a replacement of $50 \%$ of the storage volume with constant deflection relations of 0.166 +/-0.002 (a) and $0.331+/-0.02$ (b) through an inlet with a baffle plate.

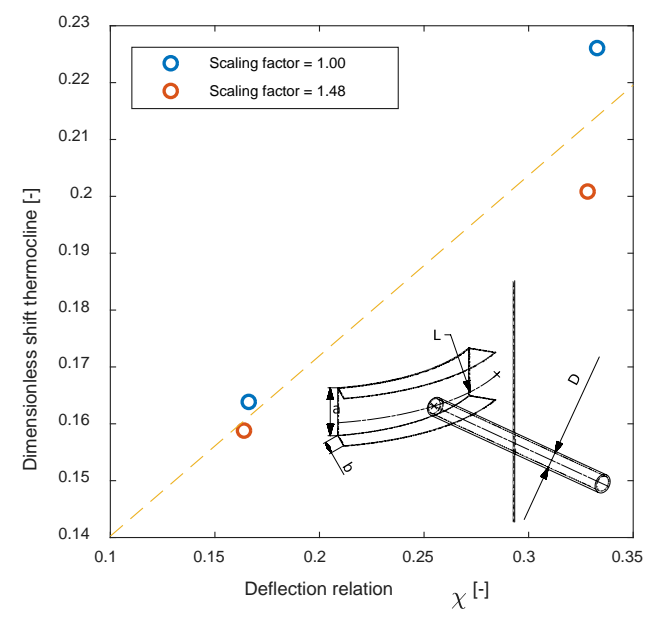

(a)

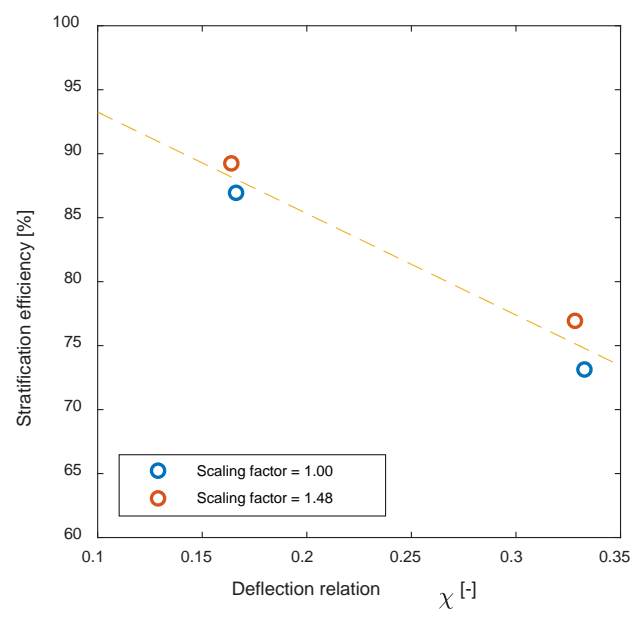

(b)

Figure 5 Correlation of the shift of the thermocline (a) and the stratification efficiency (b) with the deflection relation in case of an inlet with a baffle plate.

\section{Results for inlets bent towards the top or bottom of the tank}

Besides solar combi-storages, also storage tanks used as buffers that even out the mismatch between the production of a single heat source and a single heat sink are common, especially in larger installations. A field study that was carried out within this project showed that a common form of integrating a storage tank with more than $5 \mathrm{~m}^{3}$ volume is to place it as a hydraulic separator between two T-pieces. Frequently, these tanks have an elbow pipe that directs the fluid motion towards the top (hot) or the bottom (cold) of the tank. Consequentially, investigations were carried out on the scaling effects during a charging process with this storage type. An example storage tank configured in ANSYS 18.2 CFX and initialized to $45^{\circ} \mathrm{C}$. In the simulated experiment, fluid is entering the upper inlet until $30 \%$ of the tank volume is replaced. A sketch of the simulated tank as well as the used dimensions for the base case (scaling factor 1) are shown in Table 2 and in Figure 6.

To check the usability of the deflection relation for the charging experiment 2 with curved pipe, the scaling factors 0.5 and 0.25 were tested, starting from the basic storage tank with $6400 \mathrm{l}$ volume. The tested inlet velocity range was $0.12-0.44 \mathrm{~m} / \mathrm{s}$. Two different temperature difference between initial storage temperature and the entering fluid 
are used (5K and $20 \mathrm{~K}$ ). When calculating the deflection relation, the storage diameter was again used as the characteristic length. The choice of the characteristic length is heuristic and other definitions may be used instead by other authors, e.g. the height of the storage. Which size results in more robust correlations under varying proportions between height and width has yet to be clarified in future studies. The storage tank temperature at the start of the simulation was $45^{\circ} \mathrm{C}$, and two different charging temperatures of $65^{\circ} \mathrm{C}$ and $50{ }^{\circ} \mathrm{C}$ were analyzed.

Table 3 Dimensions of the simulated storage with inlets bent towards the top and bottom.

\begin{tabular}{|l|l|}
\hline \multicolumn{1}{|c|}{ Quantity } & \multicolumn{1}{c|}{ Value } \\
\hline Volume (m ${ }^{3}$ ) & 6.4 \\
\hline Diameter (m) & 1.7 \\
\hline Height (m) & 3.15 \\
\hline Inlet diameter (m) & 0.105 \\
\hline $\begin{array}{l}\text { Distance inlet to tank top/bottom } \\
\text { (m) }\end{array}$ & 0.225 \\
\hline
\end{tabular}

The temperature curves in Figure 7 show simulations with a charging temperature of $65{ }^{\circ} \mathrm{C}$. In this case, the displacement of the thermocline is not a suitable indicator for the mixture in the storage, as it results from the plug flow of the fluid in the storage. For this reason, only the stratification efficiency was considered for the evaluation. The results show a clear extension of the boundary layer between warm and cold area, and accordingly also a lower stratification efficiency for higher values of the deflection relation. The quality of the correlation decreases for increasing values of $\chi$. The resulting $\mathrm{R}^{2}$ value of the linear correlation of stratification efficiency with the deflection relation is 0.963 .

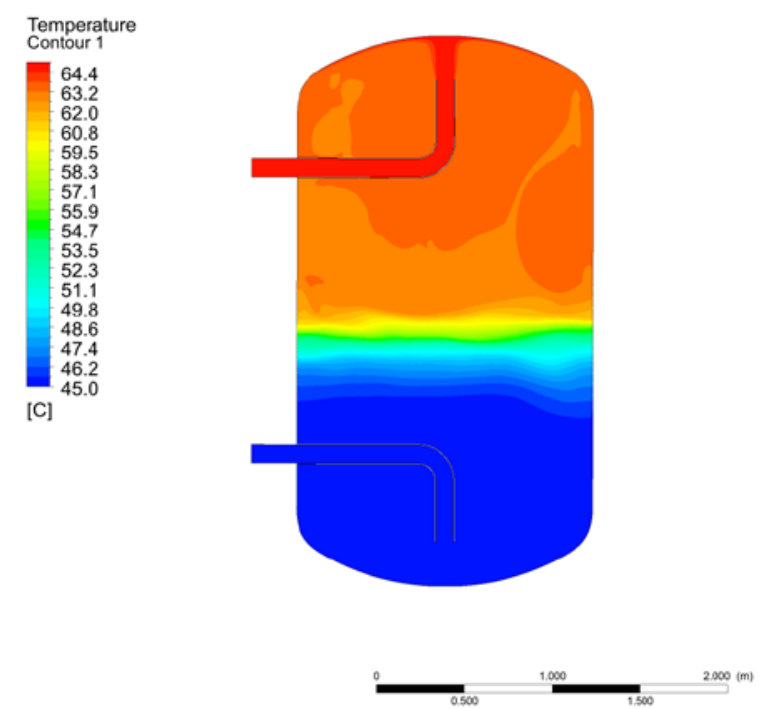

Figure 6 Cross section of the simulated tank with inlet bent towards the top. 


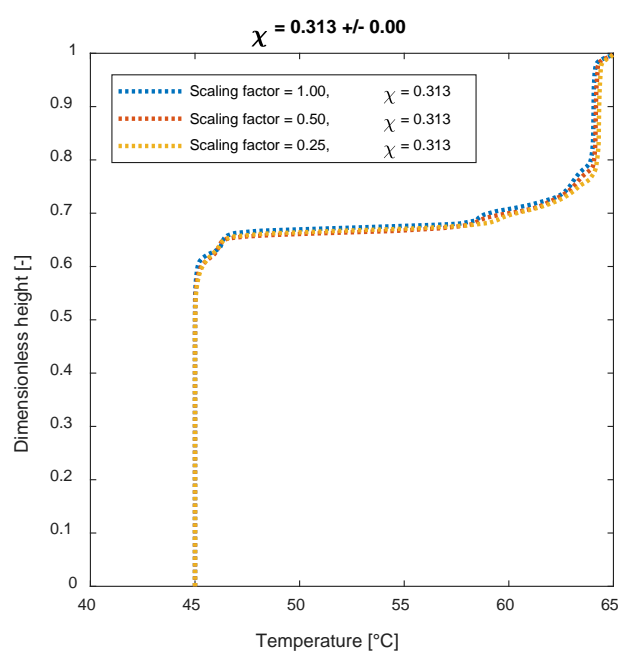

(a)

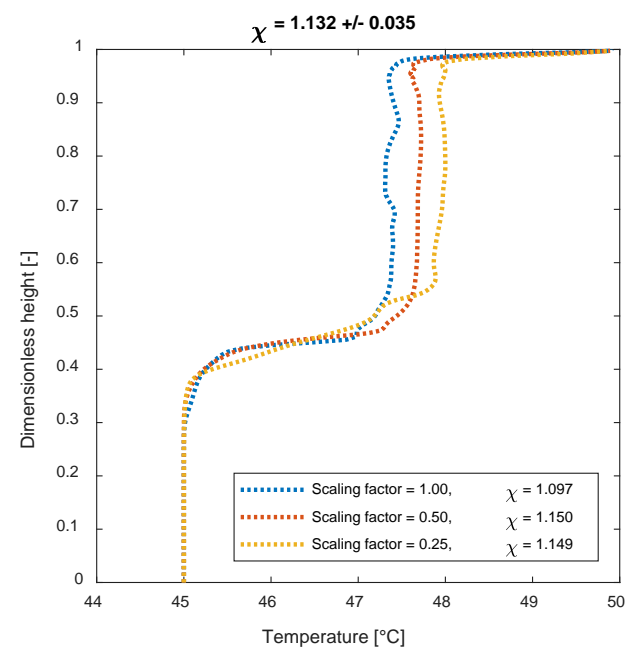

(c)

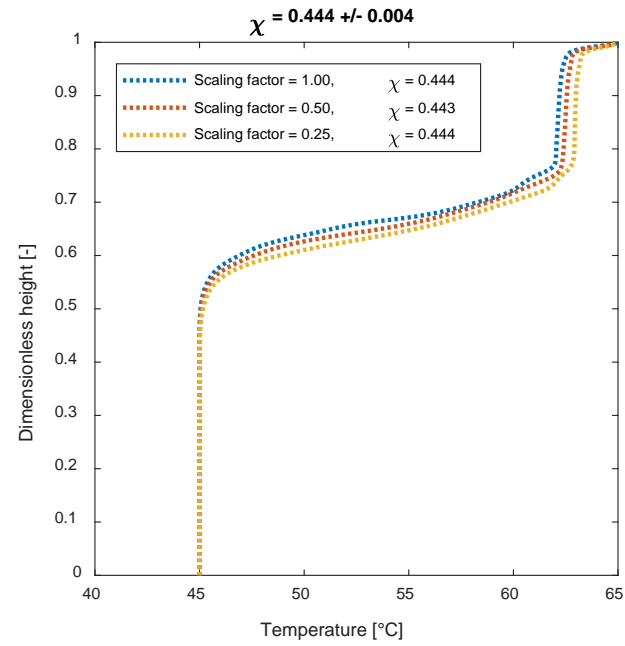

(b)

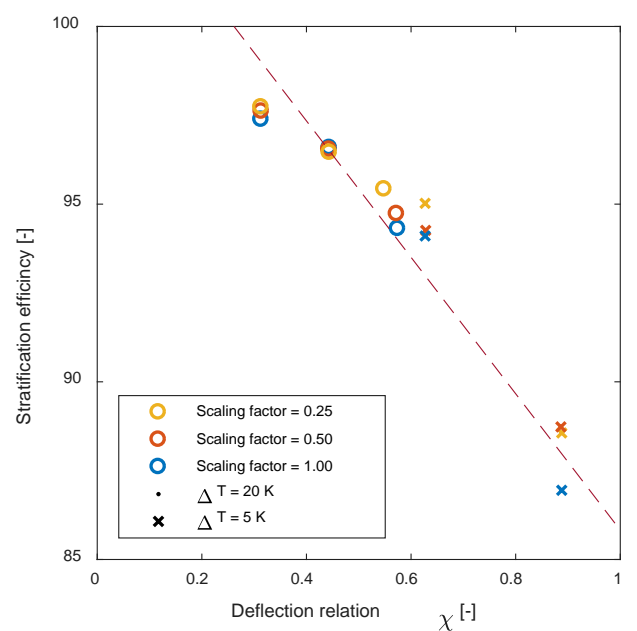

(d)

Figure 7 Vertical temperature profile after $30 \%$ of the tank volume was replaced with fluid from a topward bent inlet and deflections relations $0.313+/-0.00$ (a), $0.444+/-0.004$ (b) and 1.132 +/- 0.035 (c). Correlation of the deflection relation with the stratification efficiency (dt).

The results for the three investigated inlet geometries show that the deflection relation is a suitable dimensionless quantity for characterizing the expected reduction in stratification efficiency that results from the kinetic energy of the inlet jet into the storage and the circulation flows caused thereby. The results in Table 4 show that the Reynolds number of well stratified cases is between 7'500 and 20'500, whereas Reynolds numbers between 15'000 and 41'000 are observed for cases with low stratification efficiency. Inlet velocities for well stratified results are between $0.11-0.16 \mathrm{~m} / \mathrm{s}$ and for less stratified results between $0.16-0.22 \mathrm{~m} / \mathrm{s}$. However, neither Reynolds numbers nor the inlet velocity take into account the presence of an obstacle in the path of the entering fluid. Thus, the deflection relation is a more suitable and stable criteria for the design of a well stratified storage tank than the inlet velocity or the Reynolds number.

According to Gwerder et al. (2016), $0.1 \mathrm{~m} / \mathrm{s}$ is a suitable limit value for the $800 \mathrm{l}$ storage that was considered by the authors. An entry velocity of $0.1 \mathrm{~m} / \mathrm{s}$ leads to a deflection relation of 0.127 in the defined $800 \mathrm{l}$ storage with $2 "$ connection. From this it can be estimated that the deflection relation of $\chi<0.12$ can be regarded as the first reference value for the still permissible relationship between free distance to the next vertical obstacle and the 
kinetic energy of the inflowing fluid. A comparison with the values of the other inlet geometries shows that a deflection relation of $\chi<0.12$ in the horizontal inlet case and a deflection relation of approx. $\chi<0.5$ in the vertical inlet case leads to only a minor impairment of the stratification efficiency. All linear regression curves show a stratification efficiency of more than $90 \%$ for these values. For this reason, it can be concluded that the deflection relation is a good guideline for the design, assessment and dimensioning of storage facilities.

\section{Comparison with monitoring data and conclusion}

Seven field systems with large storage tanks of at least $2 \mathrm{~m}^{3}$ were evaluated in different system variants. It was shown that especially storages positioned as hydraulic separators between the source and sink with large temperature differences between the supply and return are well stratified. It is more difficult to ensure stratification in systems with smaller temperature differences. The two systems with temperature difference of less than $10 \mathrm{~K}$ showed no clear stratification in the evaluation. With the method developed for assessing the expected stratification efficiency for large tanks, field systems can be dimensioned and evaluated without the need for complex and time-consuming CFD simulations. Table 7 lists the relevant variables and the resulting deflection relation for the investigated field systems, together with the quality of stratification that was observed from the temperature curves.

Systems 2, 4 and 5 do not fulfil the condition of $\chi<0.12$ for storage tanks with horizontal inlet and $\chi<0.5$ for storage tanks with top/bottom bent pipe inlets set out in chapter 4 . Conversely, all storages that were judged to be well-stratified meet the condition of the distraction relation. Although this confirms the applicability of the deflection relation, it is desirable to add further field system results in order to broaden the data basis for the validity for a larger range of systems and conditions.

Table 4 Results of field systems

\begin{tabular}{|c|c|c|c|c|c|c|c|}
\hline Number & $\begin{array}{l}\text { Diameter } \\
\text { Inlet (m) }\end{array}$ & $\begin{array}{l}\text { Maximal } \\
\text { volume } \\
\text { flow }\left(\mathbf{m}^{3} / \mathbf{h}\right)\end{array}$ & $\begin{array}{l}\text { Distance } d_{f} \\
\text { (m) }\end{array}$ & Geometry & $\begin{array}{l}\Delta \mathrm{T} \\
\text { storage } \\
(\mathrm{K})\end{array}$ & $\begin{array}{l}\text { Deflection } \\
\text { relation } \chi \\
(-)\end{array}$ & $\begin{array}{l}\text { Stratification } \\
\text { quality (-) }\end{array}$ \\
\hline 1 & 0.114 & 10 & 1.7 & bent & 20 & 0.370 & good \\
\hline 2 & 0.114 & 30 & 1.7 & bent & 20 & 1.109 & average \\
\hline 3 & 0.114 & 10 & 1.5 & bent & 15 & 0.392 & good \\
\hline 4 & 0.273 & 3 & 1.11 & horizontal & 4.3 & 0.434 & mixed \\
\hline 5 & 0.036 & 52 & 3.8 & bent & 30 & 0.484 & good \\
\hline 6 & 0.115 & 72 & 3.5 & bent & 28 & 0.304 & good \\
\hline 7 & 0.114 & 37 & 1.9 & bent & 5 & 1.108 & mixed \\
\hline
\end{tabular}

\section{Acknowledgement}

This project has received funding from the Swiss Federal Office of Energy (SFOE), contract number: SI/50031503

\section{References}

[1] Haller, M.Y., Haberl, R., Persdorf, P. \& Reber, A., 2015. StorEx - Theoretische und experimentelle Untersuchungen zur Schichtungseffizienz von Wärmespeichern. Bundesamt für ENergie BFE.

[2] Hollands, K.G.T. \& Lightstone, M.F., 1989. A Review of Low-Flow, Stratified-Tank Solar Water Heating Systems. Solar Energy, 43(2), p.97-105. 
[3] Lee, J.H. \& Chu, V.H., 2003. Turbulent Jets and Plumes: A Lagrangian Approach. Springer Science \& Business Media.

[4] Gwerder, C., Lötscher, L., et al., 2016. Horizontal Inlets of Water Storage Tanks With Low Disturbance of Stratification. Journal of Solar Energy Engineering, 138(5), p.051008-051008.

[5] Baeten, B., Confrey, T., Pecceu, S., Rogiers, F. \& Helsen, L., 2016. A validated model for mixing and buoyancy in stratified hot water storage tanks for use in building energy simulations. Applied Energy, 172, p.217-229.

[6] Haller, M.Y., Cruickshank, C., Streicher, W., Harrison, S.J., Andersen, E. \& Furbo, S., 2009. Methods to Determine Stratification Efficiency of Thermal Energy Storage Processes - Review and Theoretical Comparison. Solar Energy, 83(10), p.1847-1860.

[7] Haller, M.Y., Yazdanshenas, E., Andersen, E., Bales, C., Streicher, W. \& Furbo, S., 2010. A method to determine stratification efficiency of thermal energy storage processes independently from storage heat losses. Solar Energy, 84(6), p.997-1007. 
M. Battaglia et. al. / EuroSun 2018 / ISES Conference Proceedings (2018) 


\title{
Thermal Collection and Seasonal Storage Potential of a Mixed-Use Neighborhood
}

\begin{abstract}
This paper summarizes the energy performance of a mixed-use community, which combines residential and commercial/institutional buildings, in a northern cold climate. The energy performance criteria include, in addition to thermal and electrical consumption, the balance between energy consumption and solar energy generation. The community is designed according to various existing guidelines of sustainability. Energy efficiency measures are implemented in all building types, while PV panels are assumed to be integrated on all available near south-facing roof surfaces. A solar thermal collector system combined with a borehole thermal energy storage is designed to investigate the impact on the overall performance of the neighbourhood. The design of solar thermal collectors and the sizing of short-term thermal storage is based on the analysis of the thermal loads for heating and domestic hot water in each district of the community. The results indicate that implementing thermal collectors and seasonal storage, in this high energy performance neighbourhood, leads to a net positive energy status.
\end{abstract}

Keywords: Seasonal storage, thermal collectors, solar energy, mixed-use neighborhoods, energy efficiency.

\section{Introduction}

Space and water heating constitute a large portion of energy consumption of the residential sector, especially in cold climate regions. For instance, in Canada around $82 \%$ of energy consumed by the residential sector is allocated to space heating and domestic hot water (NRCan, 2013). While implementation of energy efficiency measures in buildings enables reduction of energy consumption by up to 35\% (ECBCS News, 2012; ASHRAE 2008), it is not sufficient to address an expected increase in future energy demand of the building sector (Cellura et al, 2013). Coupling these measures with increased renewable energy production technologies, enables energy generation amounting to a large portion of a buildings' energy consumption, and in some cases exceeding it, thus reducing dependence on fossil fuel.

Utilizing solar energy in applications such as passive and active space heating, domestic hot water (DHW) and for electricity generation is a large step towards increasing efficiency and reducing GHG emissions by the built environment. This is especially applicable in a cold sunny climate such as the climate of Alberta (Canada), the pilot location of this study. In addition, due to the abundance of solar radiation during the cold period of the year, in this region, thermal storage becomes a promising method to reduce or eliminate the need for space and water heating.

A number of studies have been carried out to determine the potential of solar collection and thermal storage (longterm and short-term) in reducing energy consumption for space heating and domestic hot water. These includes studies on single buildings and on residential small-scale neighbourhoods. Results of some of these studies indicate that solar systems can cover all the heating and domestic hot water needs of a typical house located in cold climate (Montreal, Canada), without using electricity for the storage tank (Hugo et al, 2008). On a neighbourhood level, a demonstration project shows that it is possible to supply around $97 \%$ of the total thermal demand (including DHW of 52 houses using solar thermal collectors and seasonal thermal storage (Drake landing, Calgary, Canada), (McDowell and Thornton, 2008; Sibbit et al., 2005).

Mixed-use communities that combine commercial and residential buildings offer several environmental and economic advantages, however they can also present significant challenges to achieve high-energy performance. Exploring the benefits of solar thermal collection and storage for such communities represents a significant strategy towards reaching energy self-sustained communities (Hachem et al, 2018).

The paper presents a summary of research of the energy performance of a mixed-use solar community combining various types of buildings. The energy performance includes the potential of solar thermal collection and storage, and solar electricity generation of this mixed-use neighbourhood. 


\section{Methodology}

A large-scale mixed-use neighbourhood of land area of 64 hectares is designed, based on various considerations of sustainable design (see section 2.1) (Hachem, 2016). The residential buildings include single-family detached houses, attached houses, and mid-rise apartment buildings ( 3 to 5 stories). The main commercial amenities include office buildings, retail area and grocery store, in addition to a primary school (See Figure 1 below).

The methodology employed in this study comprises a detailed simulation of the buildings energy performance and of the energy systems employed. For the thermal study, the neighbourhood is divided into sub-districts, each equipped with a set of thermal solar collectors, closed in a loop with a thermal storage tank system. A geothermal seasonal storage is assumed to interface with each of these tanks through a hot water system, allowing mutual charging between the two storage systems. The studied parameters include solar collectors' performance, hot water tanks sizes and thermal features, pipelines geometry and thermal properties, and thermal loads.

Thermal energy consumption for heating and domestic hot water are first computed using EnergyPlus software (EnergyPlus. 2016) in conjunction with Openstudio (Legacy OpenStudio Plug-in for SketchUp, 2014), which is used to generate the geometry of the various types of buildings. The thermal load is then employed to explore the potential of solar thermal collection and seasonal storage of the studied neighbourhood. TRNSYS (University of Wisconsin et al., 2014) is employed to determine the thermal collection and seasonal storage potential. The simulation settings include a one-year pre-heating for the geothermal storage and five overall years of simulation.

The major stages of the study are summarized below.

\subsection{Overall design considerations}

The mixed-use neighbourhood is designed employing guidelines of traditional neighbourhood developments (TND) (Traditional Neighbourhood Development (TND)), the Canada Mortgage and Housing Corporation (CMHC) fused grid (CMHC, 2011), and other existing design guidelines. A TND, known as a village-style development, includes a variety of residential building types, a mixed land use, an active centre, a walkable design, and often a transit option within a compact neighbourhood area. TND defines as well approximate land areas for each of the functions.

The CMHC fused grid is designed to allow mixed-use, densification and efficient public transportation, and thus can be a comprehensive basis for the design of a new energy efficient sustainable neighbourhood. As such, the neighbourhood is composed of 16 quadrants (as shown in Figure 1), with some of these quadrants consisting of low-density detached houses, while other quadrants contain both commercial and residential buildings.

A low density is assumed on average in this study to correspond to the prevailing density in the area (outskirt of Calgary), around 15 units per hectare $(\mathrm{u} / \mathrm{h})(6$ units per acre $(\mathrm{u} / \mathrm{a}))$. The central business district, which includes all commercial buildings, is located at the edge of the neighbourhood, while the school is located at the center of the development (See Fig. 1). These design decisions are based on common acceptable practices in the region. 


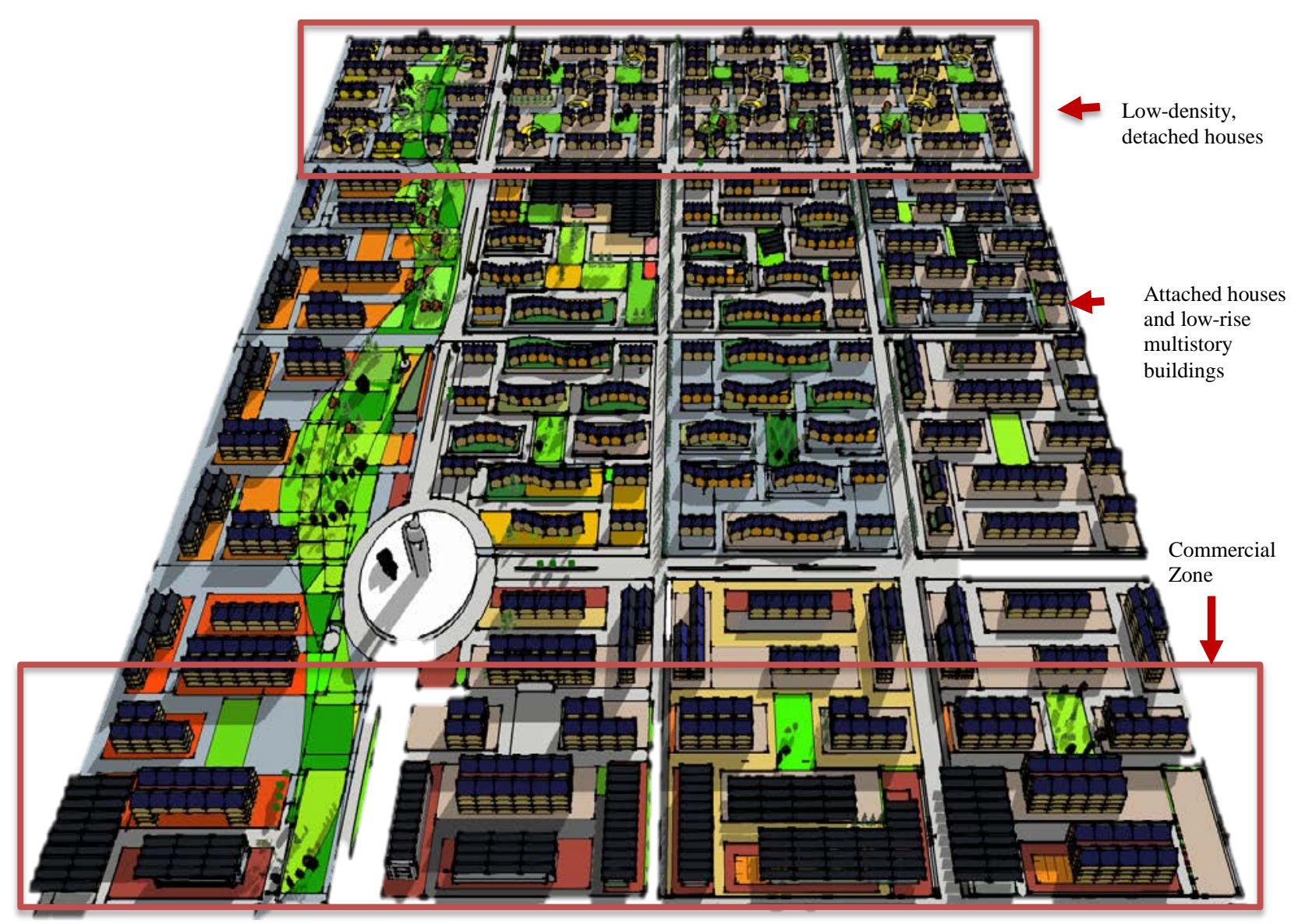

Fig 1: Different views of the overall neighbourhood design

\section{Buildings design assumptions}

\section{Residential Buildings}

Residential buildings consist of single-family houses and apartment buildings. Two types of houses are designed, a detached house of total floor area of $180 \mathrm{~m}^{2}$ and attached houses (townhouses) of floor area of $120 \mathrm{~m}^{2}$ each. The area is based on average areas of houses in the studied location (CHBA Pulse Survey, 2014). Two-storey house design is employed for both attached and detached houses. Low-rise multi-storey buildings (3, 4 and 5- floors) are considered in this base case study. Apartments have a floor area of $110 \mathrm{~m}^{2}$ (average apartment size in Canada (Armestrong et al, 2009)). Design of houses and south facing apartments take into account passive solar design principles, to maximize solar capture and utilization.

An occupancy of 2.5 persons per residential unit is adopted throughout the study, to match the average Canadian occupancy.

\section{Commercial and public buildings}

The commercial/public buildings considered in this mixed-use neighbourhood consist of office buildings, a school and a supermarket/retail building. Below is a summary of the commercial buildings included in the study. These buildings are illustrated in Figure 2.

- Three mid-size 3-storied office buildings of $3200 \mathrm{~m}^{2}$ each are assumed.

- A single storied school building is designed to specifications for a primary school serving a residential population, based on an estimated number of pupils, based on the population of the neighbourhood (Barton et al, 2010).

- Other commercial buildings include a supermarket and a retail building of $1200 \mathrm{~m}^{2}$ each. Since only $20 \%$ of the total land use is dedicated to commercial buildings, this retail area is adopted to fit the concept of TND development, and the available space. 

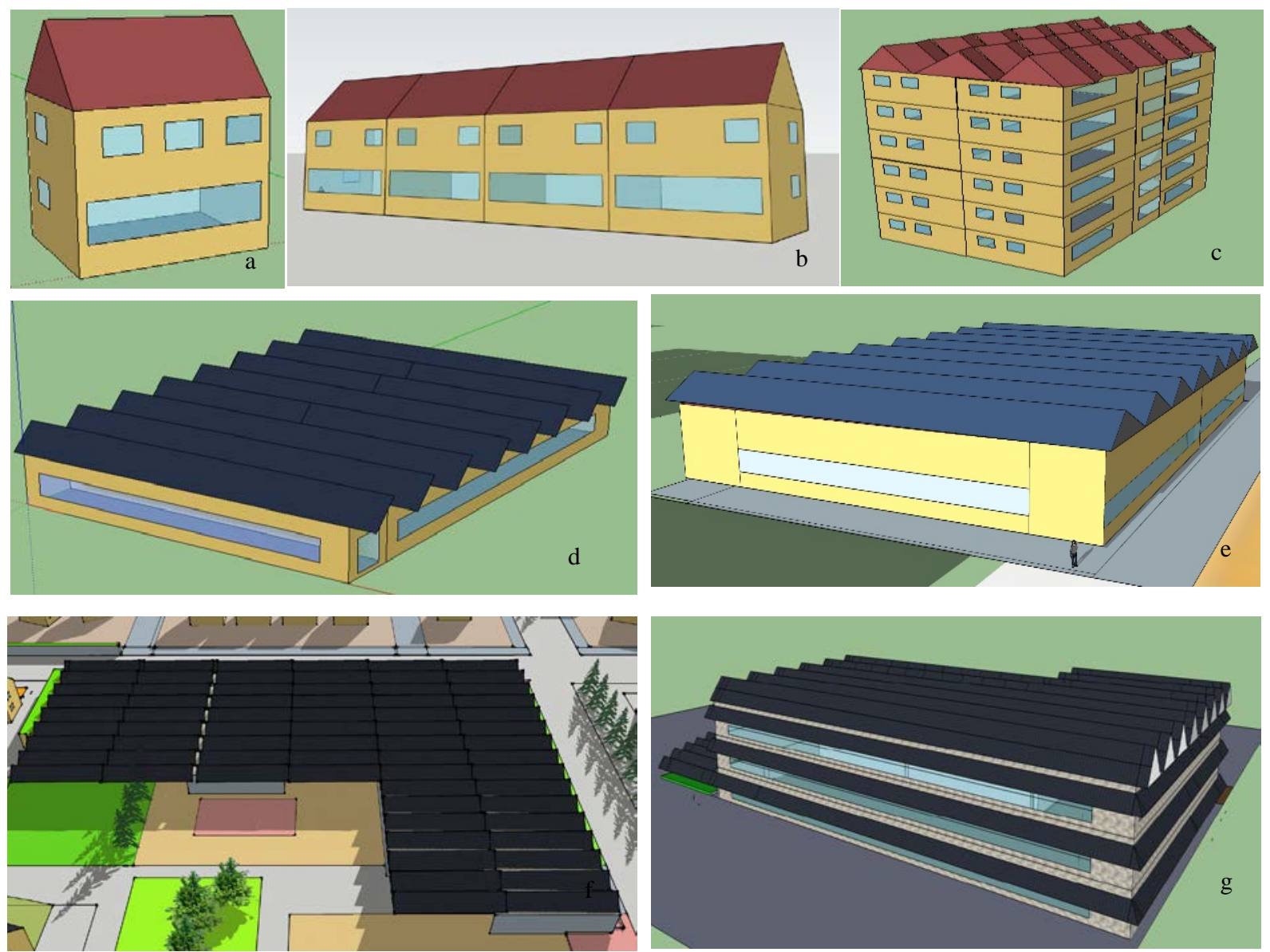

Figure 2. (a) detached house model, (b) attached houses, (c) Apartment building, (d) Supermarket, (e ) Retail , (f) School, (g) Office building

An all-electrical neighbourhood is assumed throughout this study. This assumption is adopted to enable comparison of total energy consumption per building (as electricity) to the potential of energy generation from PV systems, and therefore to assess the potential of these neighbourhoods to achieve an on-site net-zero energy status.

Buildings are designed with the objective of achieving net zero energy status. High performance building envelope is assumed in all types of buildings: wall and roof insulation of $7 \mathrm{~m}^{2} \mathrm{k} / \mathrm{W}$ and $10 \mathrm{~m}^{2} \mathrm{k} / \mathrm{W}$, respectively; triple glaze, low-e argon fill windows, and airtight construction. High performance building envelope can significantly improve the energy efficiency of buildings. In addition, the design of residential units assumes optimal passive solar principles such as longer south façade (with respect to the perpendicular facades) and larger south facing windows (about 35\% of south façade) (Hachem et al, 2013). Commercial buildings assume the same building envelope characteristics as residential, while energy consumption is determined based on lighting and electrical specifications of the National Energy Code of Canada for Buildings.

Building integrated PV (BIPV) system is assumed to cover the complete south facing roof surface of all buildings. For buildings with large plan area, including multi-storey and commercial buildings, the roof is designed as "saw tooth", where PV is integrated on south facing surfaces (See Fig. 2). In the saw-tooth design, the south facing BIPV surface has a $45^{\circ}$ tilt angle and the saw-tooth has a total width 2.5 times the height, to reduce shading.

\subsection{Thermal collectors and seasonal storage}

This study assumes a design of thermal collectors and thermal storage that can cover the total requirement of heating and domestic hot water of the whole community. The neighbourhood spatial arrangement consisting of sixteen equally sized neighbourhoods termed districts (or quadrants) facilitate the spatial design of the thermal network, summarized in the following

The solar thermal systems are first sized to cover the thermal needs of each quadrant. The total solar collectors' area per single district range from $2500 \mathrm{~m}^{2}$ in district 1 to around $750 \mathrm{~m}^{2}$ in districts $13-16$. The solar thermal collectors (STCs) are assumed to be installed on dedicated structures within the area of the each quadrant, which 
serve as public areas (e.g. parking lots, gathering areas, etc.). A south orientation and tilt angle of $50^{\circ}$ are employed in the simulations of the STC system.

Thermal storage is based on two different levels: district solar tanks and seasonal borehole thermal energy storage (BTES). The short-term tanks representing a first level of energy storage are directly connected to the solar thermal collectors and to the building loads. All thermal storage tanks are connected, via an insulated pipework system, the borehole thermal energy storage, which uses the thermal capacity of the ground as seasonal storage, to be used during the cold period. The cylindrical storage tanks volume for each district is directly related to the respective thermal collectors' area and ranges from around $250 \mathrm{~m}^{3}$ in quadrant 1 to around $75 \mathrm{~m}^{3}$ in quadrants 13 to 16 , with an average loss coefficient equal to $5 \mathrm{~kJ} /\left(\mathrm{hr} \mathrm{m}^{2}\right) \mathrm{K}$. This is due to the different thermal load requirement in each quadrant. A distribution system connects the buildings through a district heating network providing both heating and domestic hot water.

Figure 3 presents an overview of the thermal network. Each quadrant uses a short-term thermal storage (pink tank in Fig 3), connected to the solar collector systems. Every short term thermal storage system is then connected through pipelines (the red lines) to the borehole energy storage (BTES), placed in quadrant 10.

$840 \mathrm{~m}$
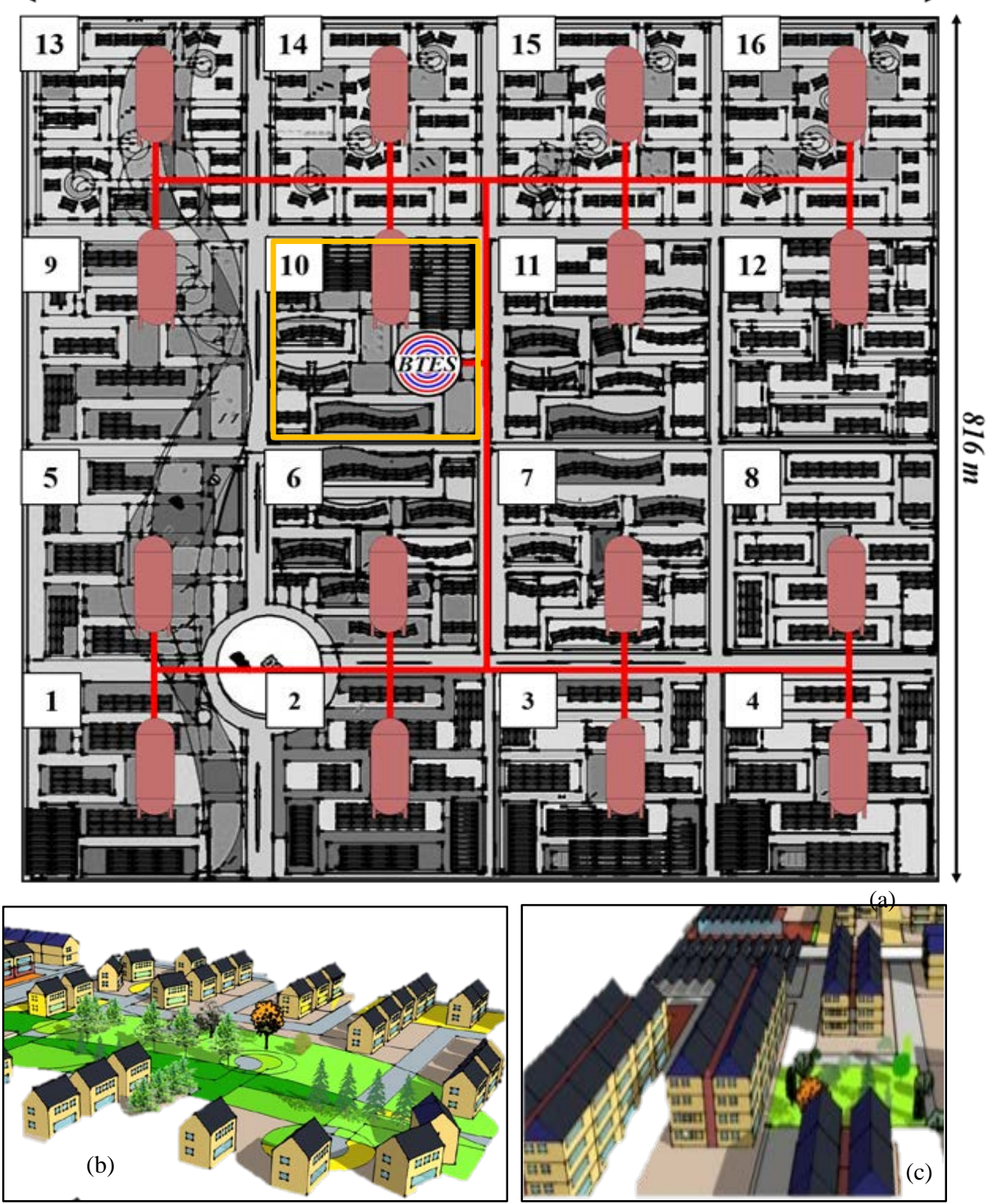

Fig. 3. (a) Concept of the energy management of the system investigated, (b) example of residential low density district (D13), (c) example of a commercial buildings district (D4). 


\subsection{Simulations}

The simulations of annual heating and cooling thermal loads, as well as PV electricity generation, are carried out using EnergyPlus. The weather files of EnergyPlus based on the Canadian Weather for Energy Calculations (CWEC) are used for the simulations (EnergyPlus: Weather files). PV array is selected from the EnergyPlus database to provide approximately 15\% electricity generation efficiency.

TRNSYS is used to perform detailed simulation of the heat pump and chiller, assumed in all scenarios, to supplement the heating and cooling for all buildings. For this purpose, the hourly heating and cooling loads of each building in the neighbourhood, estimated in EnergyPlus, are used as input for the analysis performed in TRNSYS.

Simulation of the solar thermal system employs TRNSYS environment. The simulation settings include a one year pre-heating for the geothermal storage and five overall years of simulation. For each district, a single thermal storage tank is modelled. Thermal stratification is considered through eight isothermal nodes modelled in the storage tanks. The fluid flow temperature is set at $55^{\circ} \mathrm{C}$ to allow heating through fan coils and domestic hot water. Auxiliary space heating is provided through an auxiliary heater in order to meet the set-point.

The geothermal BTES is modelled employing TRNSYS Type 557, a model based on (Mazzarella 1993) and (Pahud et al., 1996). The heat flow from the pipe to the ground is determined by the temperature of the fluid, the heat transfer properties and the temperature in the ground surrounding the pipe. These parameters are considered variable along the pipes. The ground heat exchangers are assumed to be uniformly placed in the storage region.

The most relevant thermal and geometrical features are summarized in Table 1

Table 1: Thermal and geometrical features of the BTES

\begin{tabular}{lll}
\hline Ground & Value & Units \\
Thermal conductivity & 2.11 & $\mathrm{~W} /(\mathrm{m} \mathrm{K})$ \\
Thermal Capacity & 2500 & $\mathrm{~kJ} /\left(\mathrm{m}^{3} \mathrm{~K}\right)$ \\
Top insulation & & \\
Thickness & 20 & $\mathrm{~cm}$ \\
Thermal conductivity & 0.043 & $\mathrm{~W} /(\mathrm{m} \mathrm{K})$ \\
Boreholes & & \\
Height & 40 & $\mathrm{~m}$ \\
Diameter & 15 & $\mathrm{~cm}$ \\
Header depth & 1 & $\mathrm{~m}$ \\
Thermal resistance & 0.223 & $(\mathrm{~m} \mathrm{~K}) / \mathrm{W}$ \\
Number of boreholes & 2500 & \\
Borehole spacing & 1.6 & $\mathrm{~m}$ \\
\hline
\end{tabular}

\section{Results}

The results presented in this section summarize the performance of each building type included in the studied neighbourhood, as well as the overall performance of the neighbourhood. The results are presented first for the high-performance neighbourhood, without the implementation of the STC/BTES system.

\subsection{Energy consumption and PV generation}

Yearly energy consumption of each type of building - total and per unit area - is presented in Figure 4. Due to high-energy efficiency measures, houses as well as apartment units have low energy intensity (around 60kWh/m² and $70 \mathrm{kWh} / \mathrm{m}^{2}$, respectively). Retail and school are energy intensive, while supermarket building is the highest energy intensity building type, consuming about $264 \mathrm{kWh} / \mathrm{m}^{2}$, after implementation of various energy efficiency measures. 


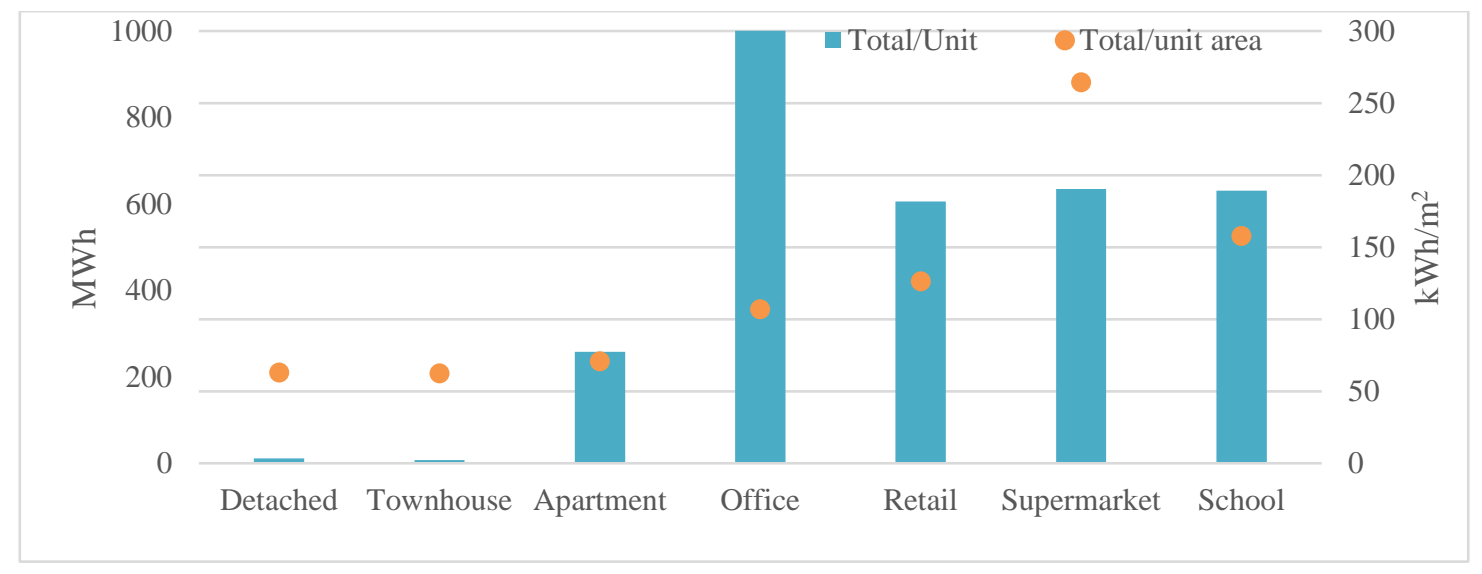

Fig. 4: Yearly energy consumption of each type of building, total and per unit area

Comparing energy consumption to potential energy generation, single-family houses, both detached and attached, can achieve an energy positive status, under the given climatic conditions. All buildings (other than houses) generate a portion of consumption, as detailed.Apartment buildings generate about $67 \%$ of their total energy consumption. The commercial buildings generate a portion of their energy consumption ranging between $45 \%$ for the office buildings and about $54 \%$ for the retail and supermarket. The school, due to its large roof area relative to its surface, generate about $90 \%$ of its energy consumption. Figure 5 presents the total energy consumption of all buildings and their potential electricity generation from BIPV.

On the level of neighbourhood, integrating PV in all available roof areas allows generation of up to $70 \%$ of the total energy consumption of this neighbourhood.

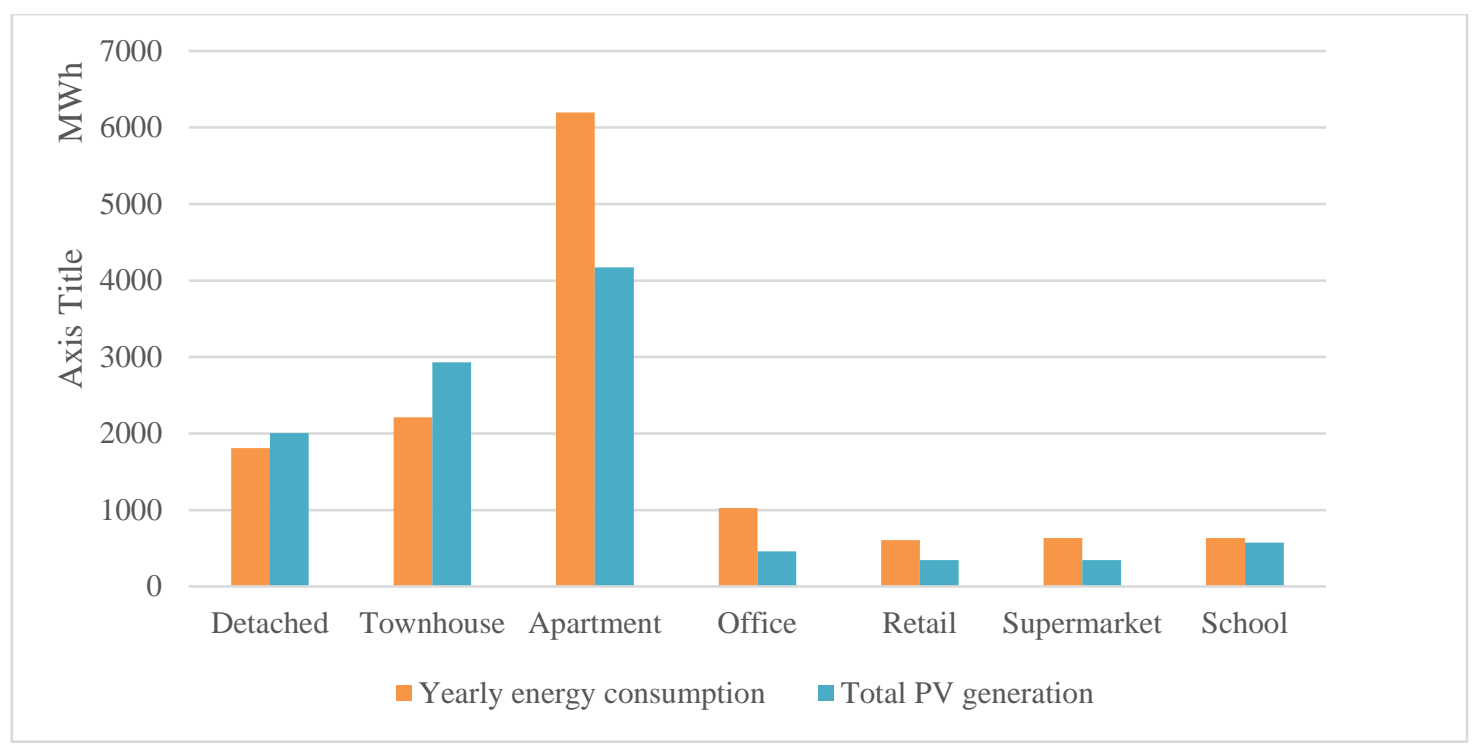

Fig. 5: Yearly energy consumption and potential electricity generation of all buildings, by building type

\subsection{Solar thermal potential}

Table 2 presents the combined energy needs for heating and domestic hot water for each district and their respective peak demand. The table presents as well the area used for thermal collectors, the peak thermal energy generation, and the volume of the thermal energy storage tanks. Some of the quadrants are characterized by similar profiles of energy requirements, depending on the number and types of buildings included in these districts. For instance, D13-D16 (Fig 3) are low-density residential districts with the same amount of housing units, and therefore have identical heating and DHW profiles. 
Table 2: Thermal loads, generation from solar thermal and solar storage tanks

\begin{tabular}{|c|c|c|c|c|c|c|c|}
\hline Districts & & $\mathrm{D} 1,2,4$ & D3 & D5-8 & D9,11,12 & D10 & D13-16 \\
\hline Total energy req. (H+DHW) & MWh & 888.46 & 767.10 & 481.90 & 500.64 & 563.49 & 265.35 \\
\hline Peak thermal power demand & MW & 1.22 & 1.00 & 0.65 & 0.66 & 0.91 & 0.35 \\
\hline $\begin{array}{l}\text { Area solar thermal } \\
\text { Peak generated thermal power }\end{array}$ & $\mathrm{m} 2$ & 2500 & 2159 & 1356 & 1409 & 1586 & 747 \\
\hline $\begin{array}{l}\text { from ST } \\
\text { Volume thermal energy storage }\end{array}$ & MW & 1.50 & 1.30 & 0.81 & 0.85 & 1.15 & 0.45 \\
\hline
\end{tabular}

Table 3 presents the total solar thermal energy generation potential of the neighbourhood, together with the auxiliary heating, and the solar fraction for each of the 5-year simulations period. Solar fraction is defined as the ratio of energy provided by the solar thermal collectors to the total thermal energy required by the neighbourhood. The results show that the solar thermal energy can supply up to $90 \%$ of the total thermal energy use in the last year (i.e. year 5 of the simulation period).

Table 3: Summary of solar fractions for the whole community

\begin{tabular}{llll}
\hline & \multicolumn{2}{l}{ Energy from solar collectors } & \\
& [MWh] & Auxiliary heating [MWh] & Solar Fraction [-] \\
Year 1 & $13,565.81$ & $2,012.80$ & $76.28 \%$ \\
Year 2 & $12,521.39$ & $1,381.45$ & $83.72 \%$ \\
Year 3 & $12,088.67$ & $1,131.81$ & $86.66 \%$ \\
Year 4 & $11,951.01$ & $1,060.33$ & $87.51 \%$ \\
Year 5 & $11,882.50$ & $1,017.68$ & $88.01 \%$ \\
\hline
\end{tabular}

\subsection{Impact of thermal collection}

The implementation of solar thermal collections to supply heating and domestic hot water for the neighbourhood is presented in this section. Both the original neighbourhood, where heat pump is employed to supply heating and cooling, and the updated solar neighbourhood implementing STC and BTES are presented in Figure 6.

The results show that employing STC combined with BTES has a significant potential to reduce the overall energy consumption of the residential sector (by up to 50\%) (See Fig. 6a). Although the impact of this technology is somewhat lower on the commercial sector, energy reduction can reach up to $30 \%$ for some building types (e.g. Retail) (Fig6b).
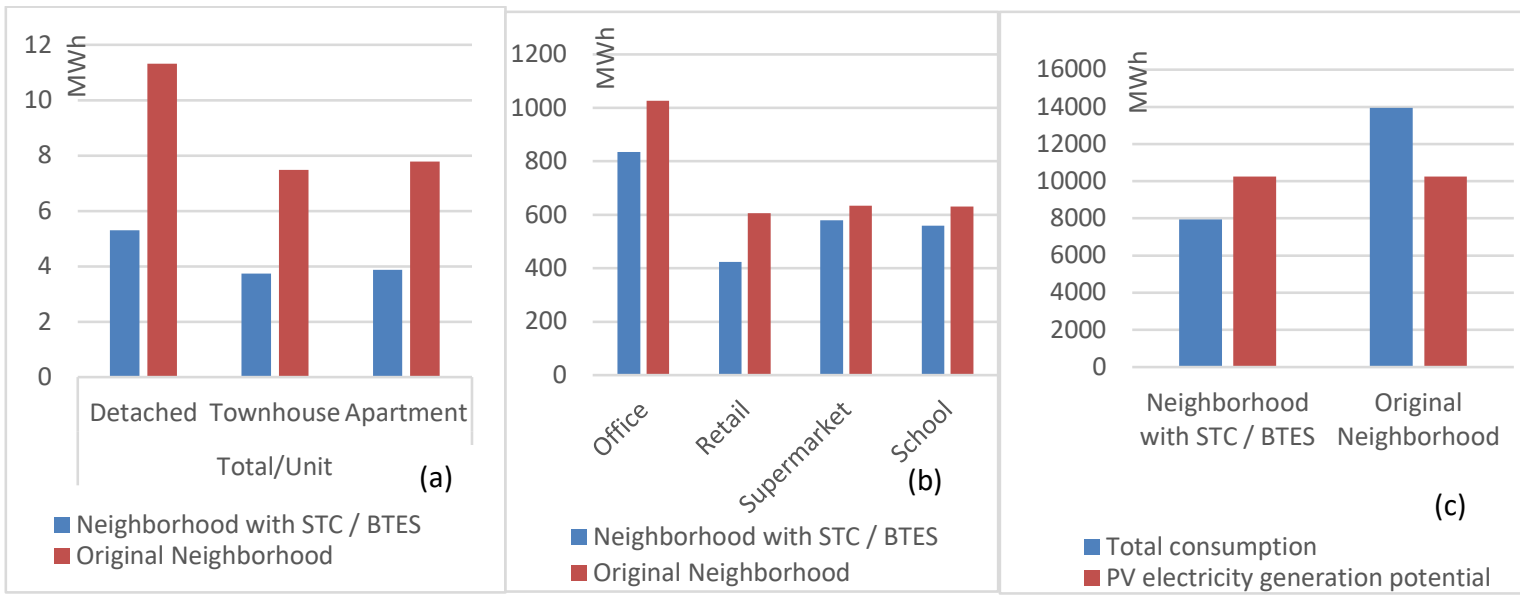

Fig. 6: performance of each type of building and of the neighbourhood, with and without the implementation of the STC/BTES; (a) Energy consumption of residential buildings, (b) Energy consumption of commercial buildings, (c) energy generation and energy consumption of all the neighbourhood

The reduction in energy consumption of the whole neighbourhood as compared to the original neighbourhood 
(high performance but without STC+BTES) is about $40 \%$ (see Fig 6c). This is mostly due to the reduction in energy consumption of residential sector especially the apartment buildings, which contribute to a large part of the energy consumption of the neighbourhood. The neighbourhood as a whole is $20 \%$ energy positive with implementation of STC, BTES (See Fig. 6c).

\section{Conclusion}

This paper presents a mixed-use neighbourhood (residential and commercial) designed in Calgary, AB, Canada, based on available guidelines and on existing standards of community designs. This neighbourhood is developed through a series of studies to achieve a high-energy performance. In addition, a solar thermal collection and storage system is implemented.

The paper summarizes the performance of various types of buildings, the overall energy performance of the neighbourhood, as well as the impact of implementing solar thermal collectors coupled with thermal storage on the performance of this neighbourhood.

The study shows that under the given climatic conditions, and the assumption that PV panels are integrated on all available south facing roof areas, apartment buildings and offices are capable of generating only a portion of their energy consumption while detached and attached houses can achieve an energy positive status.

Combining solar collection (STC) with geothermal storage (BTES) technologies can significantly reduce the overall electrical energy consumption of both residential and commercial/institutional sectors (by up to $50 \%$ and $30 \%$ respectively, for the model neighbourhood). This is particularly relevant to high-density apartment buildings, having energy consumption higher than their potential to generate renewable energy from building integrated PV systems, due to reduced available building surfaces for PV integration. Employing STC and BTES leads to over $40 \%$ overall electrical energy reduction of the whole neighbourhood, as compared to the scenario of high performance but without STC/BTES. Implementing STC coupled with BTES, allows this high-performance neighbourhood to achieve an energy positive status, generating up to $20 \%$ energy in excess of consumption. This represents a significant improvement to the original neighbourhood, which supplies about $70 \%$ of its total energy consumption. The storage system, needs however about 3 to 5 years to reach stable performance, with solar fraction of about $90 \%$.

\section{References}

Armstrong, M., Swintona, M.C., Ribberink, H., Beausoleil-Morrison, I., Millette, J., 2009. Synthetically Derived Profiles for Representing Occupant-Driven Electric Loads in Canadian Housing, Journal of Building Performance Simulation.

Barton, H., Grant, M., Guise, R., 2010. Shaping Neighbourhoods: For Local Health and Global Sustainability, Routledge; 2nd edition.

Cellura, M., Di Gangi, A., Longo, S., Orioli, A. 2013. An Italian input-output model for the assessment of energy and environmental benefits arising from retrofit actions of buildings. Energy and Buildings, 62, 97-106. doi:10.1016/j.enbuild.2013.02.056

Cellura, M., Guarino, F., Longo, S., Mistretta, M., \& Orioli, A. 2013. The role of the building sector for reducing energy consumption and greenhouse gases: An Italian case study. Renewable Energy, 60, 586-597. doi:10.1016/j.renene.2013.06.019

CHBA Pulse Survey, 2014. http://chba.ca/uploads/pulse\%20survey\%20results/Pulse\%20-\%20Alberta\%20\%20Winter\%202014-5.pdf

CMHC, 2011. The Fused Grid. http://www.cmhc.ca/en/inpr/su/sucopl/fugr/index.cfm, visited on Jan. 12, 2014.

De Winter F. Solar collectors, energy storage, and materials. Massachusetts: The MIT press; 1991.

EnergyPlus. 2016 Version 7.2, Lawrence Berkeley National Laboratory, Berkeley, CA

Hachem , C., Guarino, F., and Cellura, M., 2018, Towards Achieving Net-Zero Energy Communities: Investigation of Design Strategies and Seasonal Solar Collection and Storage net-zero, Journal of Solar Energy, 
in press.

Hachem C., Fazio, P., and Athienitis, A., 2013. Solar optimized residential neighbourhoods: Evaluation and design methodology, Journal of Solar Energy, 95, 42-64.

Hachem, C., 2016. Impact of neighbourhood design on energy performance and GHG emissions, Applied Energy, 177, 422-434.

Hugo, A., Zmeureanu, R., and Rivard H., Modelling of a Seasonal Thermal Storage System in a Residential Building, 3rd Canadian Solar Buildings Conference Fredericton, N.B., Aug. 20-22, 2008.

Legacy OpenStudio Plug-in for SketchUp, 2014. https://bigladdersoftware.com/projects/euclid/

McDowell, T.\& Thornton, J. 2008. Simulation and model calibration of a large-scale seasonal storage system. Proceedings of the 3rd National Conference of the International Buildings Performance Simulation Association, USA, Berkeley.

NRCan (2013). Office of Energy Efficiency. Energy Efficiency Trends in Canada 1990 to 2013. https://www.nrcan.gc.ca/sites/www.nrcan.gc.ca/files/energy/pdf/trends2013.pdf

Pahud D., Hellstrom G., MazzarellaL, 1996. Duct Ground Heat Storage Model, Manual for Computer Code, Department of Mathematical Physics, University of Lund, Sweden.

Sibbit, B., McClenahan, D., Djebbar, R., Paget, K. 2015 Groundbreaking Solar, High Performance Buildings Magazine p 1-12, www.hpbmagazine.org.

Thermal Storage Model. Lund-DST. TRNSYS 13.1 Version 1993. ITW, Universität Stuttgart, Germany, Dipartimento di Energetica, Politechnico di Milano, Italy.

Traditional Neighbourhood Development (TND). http://www.sustainablecitiesinstitute.org/topics/land-use-andplanning/traditional-neighbourhood-development-\%28tnd\%29), last accessed on 19/12/2017.

University of Wisconsin et al., 2014, TRNSYS 17 http://sel.me.wisc.edu/trnsys/index.html, last accessed on 19/12/2017. 


\title{
Experimental Study of a 600 W Seasonal Solar Heat Storage Reactor for the Heating of Buildings \\ Samuel HENNAUT ${ }^{1}$, Elisabeth DAVIN ${ }^{1}$, Romain BAIWIR ${ }^{1}$, Laurent COLLARD ${ }^{1}$ and Philippe ANDRE ${ }^{1}$ \\ ${ }^{1}$ BEMS, SPHERES Research Unit, Université de Liège, Arlon (Belgium)
}

\begin{abstract}
A prototype of sorption-based solar heat storage is tested. It integrates a vibrating circular reactor designed for batch operation with around $2 \mathrm{~kg}$ of composite (Silica Gel with $40 \%$ of $\mathrm{CaCl}_{2}$ ). The global performance of the system and of each component is evaluated during adsorption and desorption. The influence of different parameters of the system is measured through a parametric variation: temperatures, flow rates, adsorbent mass and granulometry, air humidity and reactor insulation. The prototype is connected to the experimental building allowing to make semi-virtual experimentations in controlled conditions. In conditions considered as realistic, the reactor average heat flow is around $600 \mathrm{~W}$ of which $250 \mathrm{~W}$ are transferred to the heating loop. The efficiency of a cycle desorption/adsorption is around $13 \%$ for a water uptake between 12 and $40 \%$. Parameters identified as crucial are the adsorbent granulometry, the low temperature heat source temperature and location, the load return temperature and the hot source temperature and flow rate.
\end{abstract}

Keywords: thermal storage, adsorption, silica gel and $\mathrm{CaCl}_{2}$ composite, fluidized bed reactor

\section{Introduction}

Today, energy storage is commonly admitted as a necessary solution to improve the utilization of renewable energy. For heating applications with solar thermal collectors, an efficient seasonal storage would allow reaching high solar fraction. Sorption-based heat storage is generally cited as promising solution for seasonal efficient long term storage, due to the expected energy density and the absence of "chemical losses" during the storage period. However this technology is not yet mature and it needs still a lot of research and development. Sorption systems are also known as complex technologies, because it relies on chemical reactor, which must, most of the time, be connected to some auxiliary components in order to improve the system efficiency.

This paper presents experimental performance evaluation of such a system. The influence of the related components is specifically analyzed. A $600 \mathrm{~W}$ adsorption reactor, for the seasonal storage of solar heat, was tested between June 2016 and January 2018, in conditions corresponding to the space heating of a residential building. This reactor is integrated in a closed air loop including a humidifier, and several heat exchangers: a recovery heat exchanger and others connected to the hot source, to the load and to a low temperature heat source. The prototype is built to allow opening the loop to use fresh air during desorption.

This paper will firstly describe the tested system, then principle and the objectives of the experimental campaign are presented. Finally, main results are analysed with a focus on the performance in standard test conditions.

\section{Description of the system}

The general basic scheme of the system is illustrated on Figure 1 and its integration in the laboratory is shown on Figure 2. Main components are described in this section. 


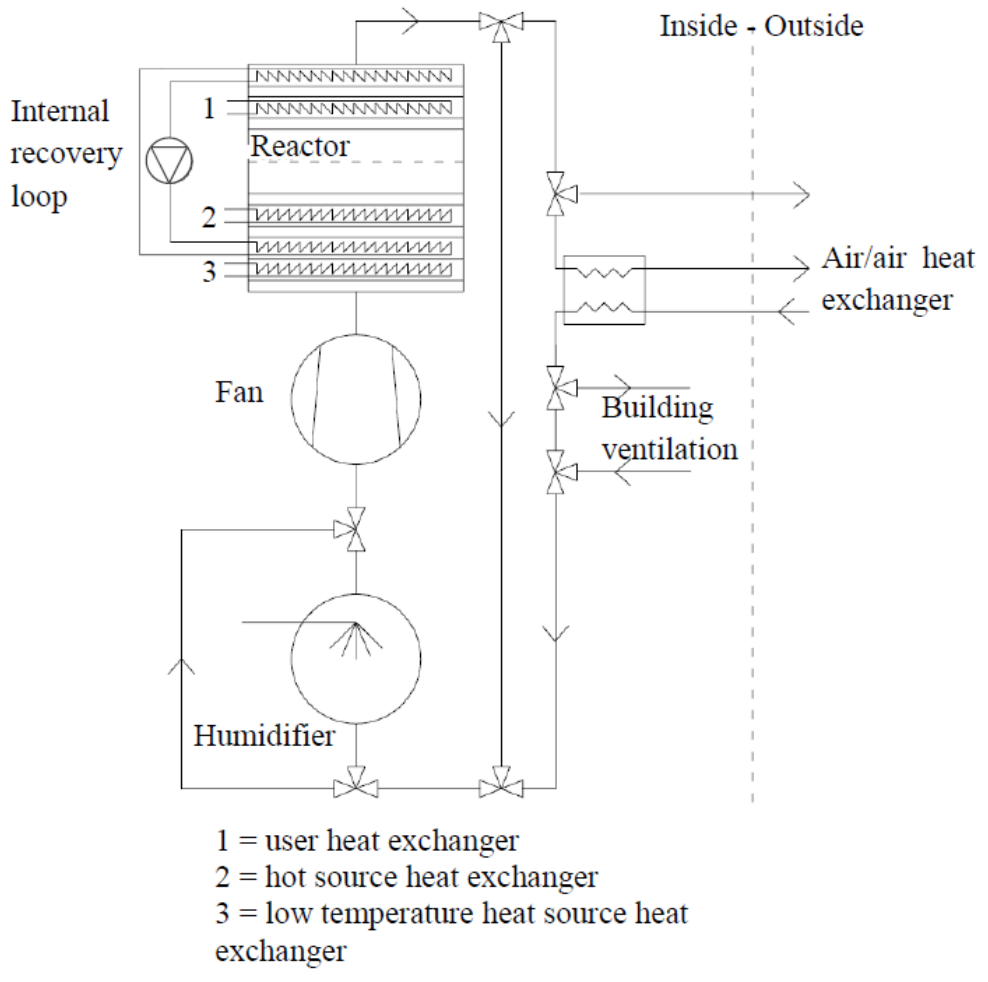

Figure 1 - System general basic scheme

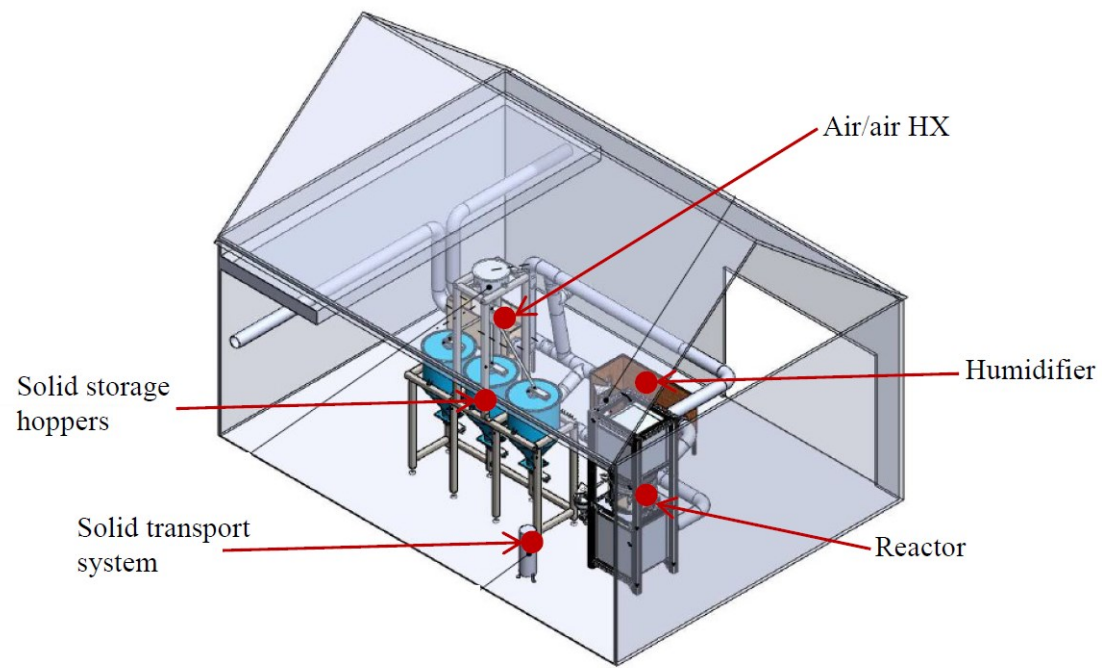

Figure 2 - Implantation of the prototype in the laboratory (3D view)

\subsection{Description of the reactor}

The main component of the tested system is the circular reactor where the sorption reaction takes place. It's a separate reactor (the adsorbent is not stored in the reactor) designed for batch operation with around $2 \mathrm{~kg}$ of dehydrated adsorbent: it is introduced in the reactor where it is hydrated or dehydrated according to its initial state and to the conditions (temperature and humidity) of the air flow crossing the reactor. The adsorbent rests on a sieve that allows air to pass from the bottom to the top of the reactor. The flow rate is adjusted to cause fluidization of the bed (Figure 3). During the reaction, the adsorbent circulates on the sieve along a spiral trajectory from the centre to the edge, thanks to vibrations of the reactor generated by unbalanced motor. Once at the edge, the adsorbent is returned to the centre of the reactor by a ramp. When the desired hydration level of the adsorbent is reached, it is removed from the reactor and stored in hermetic hoppers. Then, a new quantity of solid can be introduced in the reactor for a new reaction. 


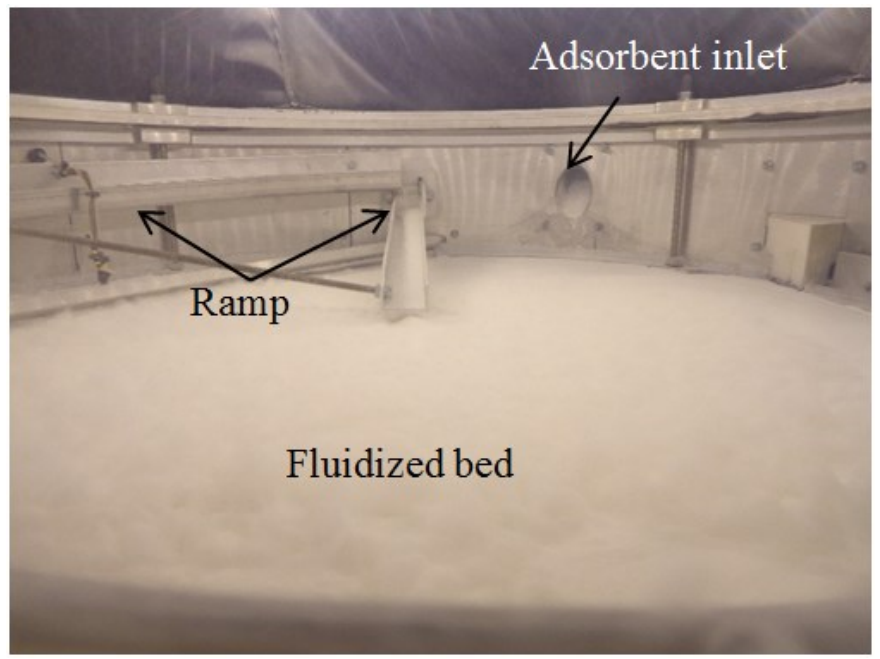

Figure 3 - Inside the reactor during adsorption (D'Hondt, 2016)

\subsection{Reagent couple}

The following results were obtained using a composite adsorbent made of silica gel and $\mathrm{CaCl}_{2}$. It contains slightly more than $40 \%$ of $\mathrm{CaCl}_{2}$. The bulk density of dry adsorbent is almost $700 \mathrm{~kg} / \mathrm{m}^{3}$. The adsorbate is water vapour. Two "versions" of the composite were tested in the reactor. These 2 versions were produced according to the same protocol, but using 2 Silica Gel from different suppliers which differ mainly in the granulometry. In this document, the composite is also equally called, solid, or adsorbent.

\subsection{Air/water heat exchangers}

This reactor is surrounded by 5 air/water heat exchangers (HXs). In fact, each HX is composed of 3 air/water HXs in series. The reactor and the HXs are integrated in the same closed volume without duct in between.

At the top, the first heat exchanger above the reactor is used to transfer the heat from the air flow (coming from the reactor during adsorption) to the water loop from the building heating system (water tank or heat emitter). In the following, it will be called "User HX". Above the User HX, there is the upper HX of the internal heat recovery loop. This internal heat recovery loop is called "Internal HX" below. It consists of two air/water HX connected by a water loop and a pump circulating water between both HX. The upper HX of the Internal HX (called "Upper HX") recover the heat remaining in the air after the user HX and transfer it to the lower HX of the Internal HX, below the reactor, by the water loop.

At the bottom, the first HX below the reactor is used to transfer the heat from the hot source (from the solar loop or from a tank) to the air flow supplied to the reactor during desorption. In the following, it will be called "Hot Source HX". Below the Hot Source HX, there is the lower HX of the Internal HX (called "Lower HX"). It transfers the heat coming from the upper HX to the air flow before the Hot Source HX. The air flow is then preheated, reducing the contribution of the hot spring (in desorption), or increasing temperature at the reactor inlet (in adsorption). Below the Lower HX, there is the last air/water HX connected to a low temperature heat source (LTHS). In the following, it is called "LTHS HX". This HX can be used during adsorption to preheat the air flow between the humidifier and the Internal HX, thanks to the LTHS source.

\subsection{Fan}

The fan is integrated below the LTHS HX and flow the air through the reactor, the HXs and the other components connected to them in the air loop. Different air loops are described below. The air flow supplied by the fan is evenly distributed on the LTHS HX area, thanks to a repartition sieve placed before the HXs. The maximum power of the fan is $81 \mathrm{~W}$.

\subsection{Humidifier}

The humidification is realized thanks to an evaporative cooling media (Figure 4 a) that maximize the evaporation of water thanks to its large surface area of contact between air and water (D'Hondt, 2016). The honeycomb panel, made of impregnated cellulose, is humidified by water pumped to its top (D'Hondt, 2016). The water flowing down the panel is collected in a small tank were it can be pumped again to the top. The evaporative panel and the pump are integrated in an insulated box of wood (Figure $4 \mathrm{~b}$ ). 
The circulation loop existing in the humidifier can also be used to integrate a heat exchanger connected to the LTHS. The objective of this combination of the humidifier and the LTHS is to enhance the efficiency of the LTHS in comparison to its integration by the air/water HX.

The humidifier allows humidifying the air flow before the reactor during adsorption, if the air runs in closed loop. It can also be used with open air loop to increase the humidity before the reactor during adsorption.
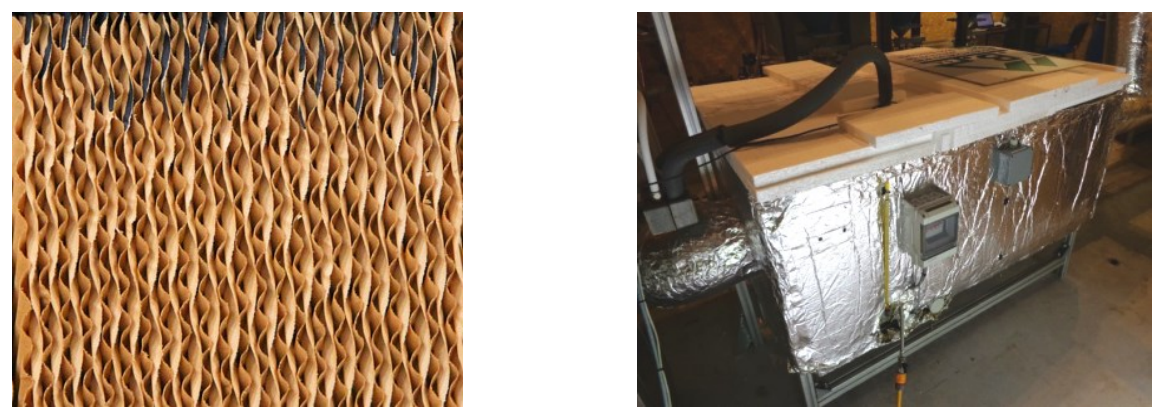

Figure 4 - (a) Evaporative cooling media; (b) Insulated box of wood integrating the evaporative panel. (D'Hondt, 2016).

\subsection{Air loops}

All components described above are connected by insulated air ducts ( $4 \mathrm{~cm}$ of mineral wool). The diameter of ducts is $200 \mathrm{~mm}$. The system was designed to be adjustable and allow the configuration of different air loops. The objective was being able to realize tests in different conditions. Dampers strategically placed in air pipes allow imposing the desired path to the air flow. Both configurations (one for adsorption and the other for desorption) used to produce following results are:

- "Adsorption closed loop" configuration (Figure 5a): the air circulates in a closed circuit. The air must absolutely be humidified to compensate the humidity adsorbed in the reactor. The reaction heat is provided to the load thanks to the User HX and the Internal HX is used. In order to compensate the temperature decrease during humidification, a LTHS can be connected to the LTHS HX or to the humidifier. This configuration has also a duct and specific dampers to by-pass the humidifier, for example when the adsorbent reached the desired hydration level.

- "Desorption open loop" configuration (Figure 5b): the outside air by-bass the humidifier, is preheated by the Internal HX (Lower HX) and then is heated by the Hot Source HX before it's supplied to the reactor for desorption. After the reactor, the air goes through the Upper HX to preheat the inlet air, before it's exhausted.
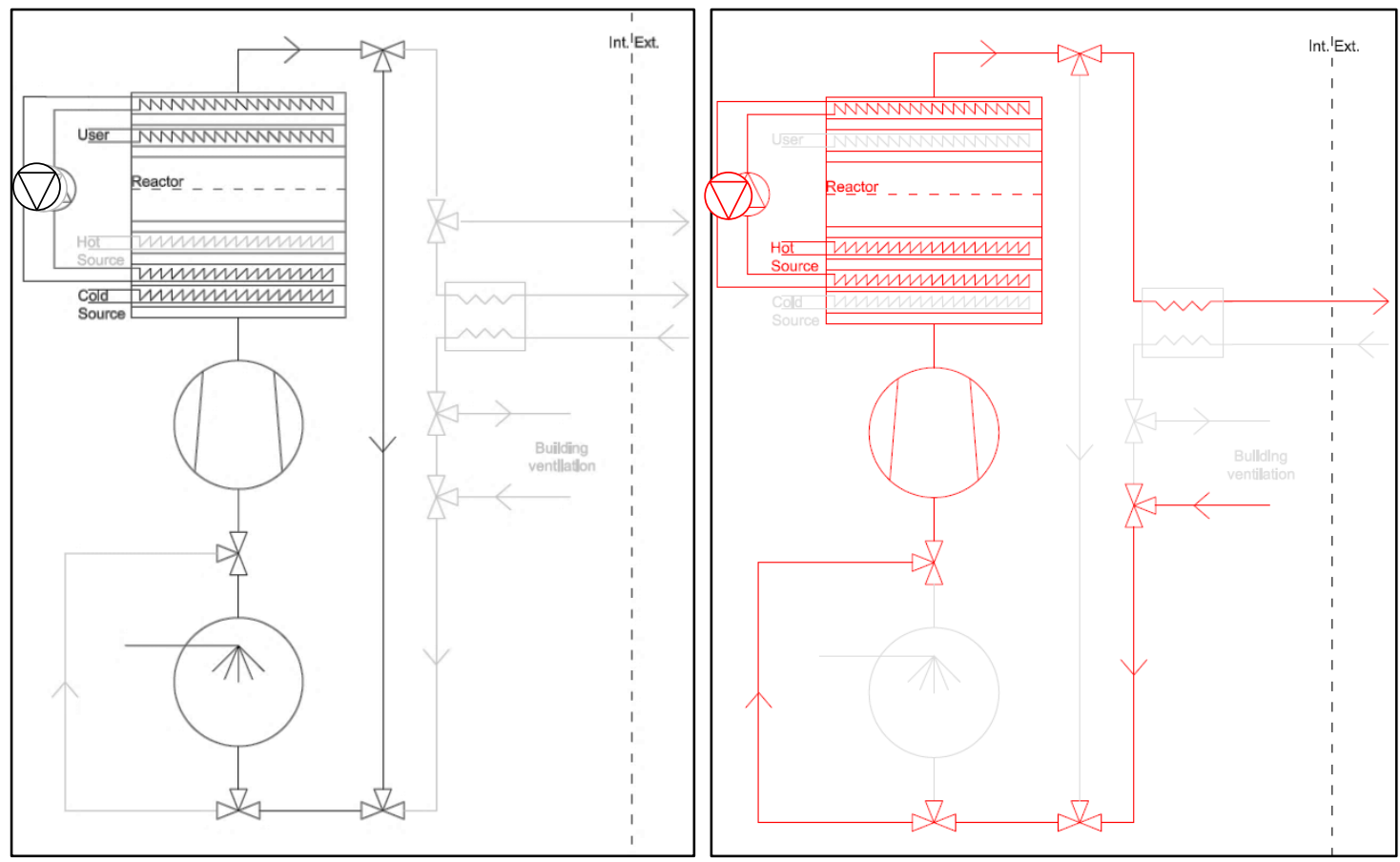

Figure 5 - (a) “Closed air loop" configuration for adsorption; (b) “Open air loop" configuration for desorption 


\section{Experimental campaign}

The experimental campaign was divided in 3 phases corresponding to 3 objectives: The first and major objective was to test the influence of each component of the system through a parametric variation. For this purpose, most tests were realized in controlled conditions, in order to compare more easily the different configurations tested, and obtain reproducible experiments. To determine the influence of each parameter correctly, all parameters should remain as constant as possible during the test. Then, tests were done to analyse the influence of the adsorbent aging on thermal behaviour, by reproducing 15 cycles of adsorption/desorption on the same adsorbent volume. Finally, some tests were realised in realistic conditions or, at least, closer to reality than totally controlled conditions. The results presented below concern only closed-loop adsorptions and open-loop desorption, realised in controlled conditions.

\subsection{Experimental protocol in controlled conditions}

In order to control as much as possible the boundary conditions and the parameters of the system, the principle of emulation (semi-virtual experimentation) is used for the various components connected to prototype: heating storage/distribution and LTHS for adsorption or hot source (solar) and inlet air for desorption. The main objective is to impose a constant temperature at the inlet of the heat exchangers or a constant humidity ratio at the air inlet of the system. A specific attention is also paid to flows control even if this aspect is trickier.

The experimental protocol is mainly divided in 2 parts:

- The preparation of the experiment, which mainly includes stabilization of experimental conditions. The preparation phase is considered finished when the prototype (air loop) and its inlets reach a "nearly steady state". This period is also used to prepare the adsorbent: the composite hydration rate is measured by dehydration at $150^{\circ} \mathrm{C}$ in order to introduce always the same quantity of solid (measure at $150^{\circ} \mathrm{C}$ ) in the reactor.

- The proceedings of the experiment. For adsorption, it is necessary to realize 2 tests in a row, to harmonize initial conditions and produce reproducible results. The stopping criterion is the hydration of the solid computed by the data acquisition program (moisture balance of the reactor). However this computation is not perfect, so in adsorption as 2 tests are realized in a row, the results of the first test is used to adapt the reaction duration of the second test. During desorption, the humidity ratio difference between the inlet and outlet of the reactor is also a good indicator to identify the end of the reaction. The objective is to reach $12 \%$ in desorption and $40 \%$ in adsorption.

After preliminary tests on the system, some conditions were identified as "standard conditions" and used as reference for comparison. Parametric variations were constructed around these standard conditions. For adsorption, the configuration of test number 51 was selected as reference and for desorption the test number 60 was chosen. Standard test conditions are detailed in Table 1. Parameters presented in this table were the main ones studied in the parametric variation, in controlled conditions, in addition to the Silica Gel granulometry.

Table 1 - Standard test conditions \& parameters studied

\begin{tabular}{|c|c|c|}
\hline Parameter & Adsorption (\#51) & Desorption (\#60) \\
\hline Water uptake & $2.15 \mathrm{~kg}$ of anhydrous (at $150^{\circ} \mathrm{C}$ ) SMG1_2 \\
\hline Mass of solid in reactor & \multicolumn{2}{|c|}{$250 \mathrm{~m}^{3} / \mathrm{h}$} \\
\hline Air flow rate & Not insulated & \\
\hline Water flow rates & $25^{\circ} \mathrm{C} / \mathrm{min}$ & $85^{\circ} \mathrm{C}$ \\
\hline Reactor insulation & $/$ & \\
\hline User HX inlet temperature & $8^{\circ} \mathrm{C}$ & \\
\hline Hot source HX inlet temperature & in humidifier & \\
\hline LTHS inlet temperature & $/$ & \\
\hline LTHS location & & \\
\hline Inlet air humidity ratio & & \\
\hline
\end{tabular}




\subsection{Instrumentation of the prototype}

The prototype was monitored continuously during experiments. Temperature sensors are installed before and after each component and at the boundaries of the prototype. The flow rate is measured in each water loop and in the air loop. Humidity sensors are located before and after components influencing the air moisture (reactor, and humidifier) but also at the air inlet and outlet.

\section{Results and discussion}

All graphical representations and computations presented in this section (unless otherwise specified) correspond to measurements realized on the prototype between the solid introduction into the reactor and the opening of the reactor evacuation valve.

For adsorptions, these results are only relative to the second batch realized in row (less than 15 minutes after the first), unless otherwise specified. For desorption, sometimes, experiments were longer than necessary. In fact, it seems that it would sometimes have been possible to stop the test several minutes earlier without excessively influencing the amount of solid adsorbed at the end. All tests are analyzed as is, but for some tests, the treatment of results is also proposed for a shorter version of the test. The criteria used to determine the new end of the test is that the heat flow provided to the reactor decrease below $450 \mathrm{~W}$ for a hot source temperature of $85{ }^{\circ} \mathrm{C}$.

\subsection{Adsorption: standard test conditions}

Figures 6 to 9 concern test number 51, realised with standard conditions for adsorption (only second batch). On Figure 6, main heat flows of prototype are illustrated. The average power supplied by the reactor is about $600 \mathrm{~W}$, of which about $250 \mathrm{~W}$ are supplied to the user loop. The adsorption duration is 47 minutes. On this basis, an energy density of $153 \mathrm{kWh} / \mathrm{m}^{3}$ is computed, considering the reactor production. It drops to $65 \mathrm{kWh} / \mathrm{m}^{3}$ if we consider the energy recovered by the user loop. These densities are computed per $\mathrm{m}^{3}$ of solid, considering a bulk density of 700 $\mathrm{kg} / \mathrm{m}^{3}$. The system efficiency in adsorption, defined as the ratio between the energy provided by the reactor and the energy supplied to the user loop is $42 \%$. The energy removed from the humidifier (P.Wat.Hum), around $100 \mathrm{~W}$, almost balances the gains due to the humidifier circulation pump (around $72 \mathrm{~W}$ ). We can thus consider this test configuration corresponds to a situation without low temperature heat source.

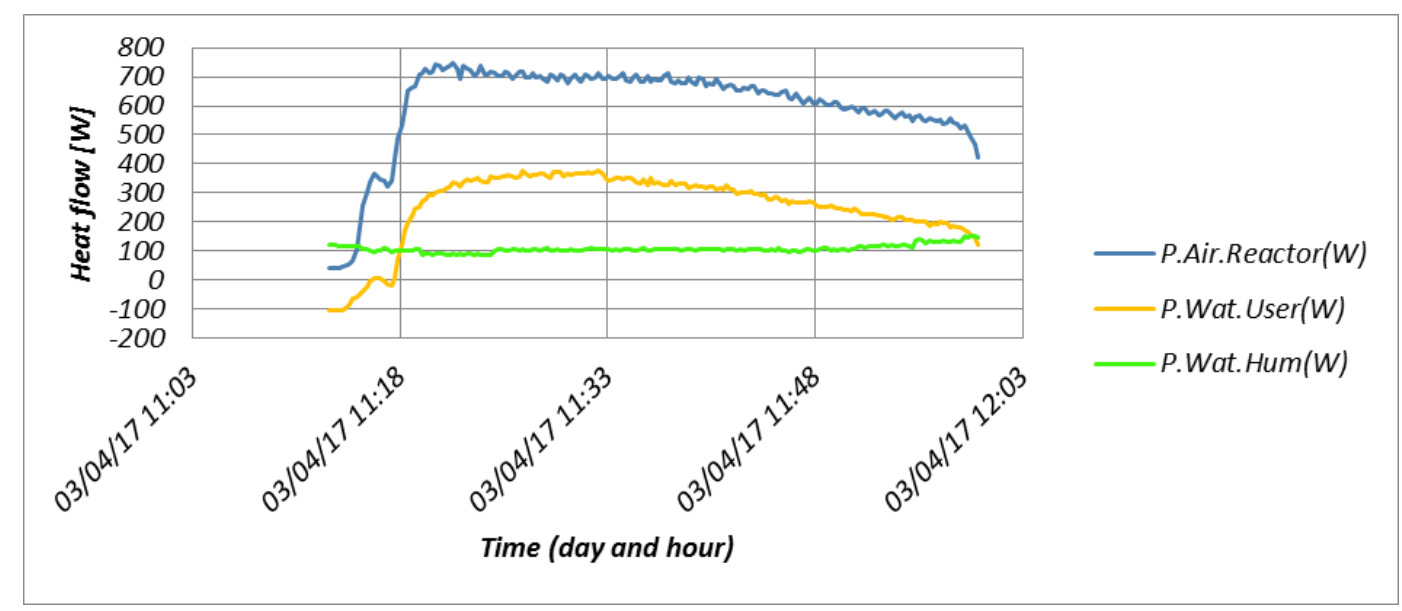

Figure 6 - Test \# 51 - Heat flows in standard adsorption conditions: Heat flow supplied by the reactor (P.Air.Reactor), heat flow supplied to the user water loop (P.Wat.User), Heat flow removed from the humidifier (P.Wat.Hum).

Regarding temperatures (Figure 7), the user HX inlet temperature (T26) is imposed constant at $25^{\circ} \mathrm{C}$. The return temperature (T27) supplied to the user loop has a mean value of $27.8^{\circ} \mathrm{C}$ during the test with a maximum reaching $29^{\circ} \mathrm{C}$. At reactor boundaries, the average temperatures vary from $21.7{ }^{\circ} \mathrm{C}$ at the inlet $\left(\right.$ TavgIn - maximum $22.4{ }^{\circ} \mathrm{C}$ ) to $29^{\circ} \mathrm{C}$ at the outlet (TavgOut - maximum $30.8^{\circ} \mathrm{C}$ ). We also observe that the temperature of the air at the humidifier outlet (T19) never drop below $9.8^{\circ} \mathrm{C}$ (average temp. $10.6{ }^{\circ} \mathrm{C}$ ). This makes the use of a geothermal source for LTHS in the LTHS HX impossible. 


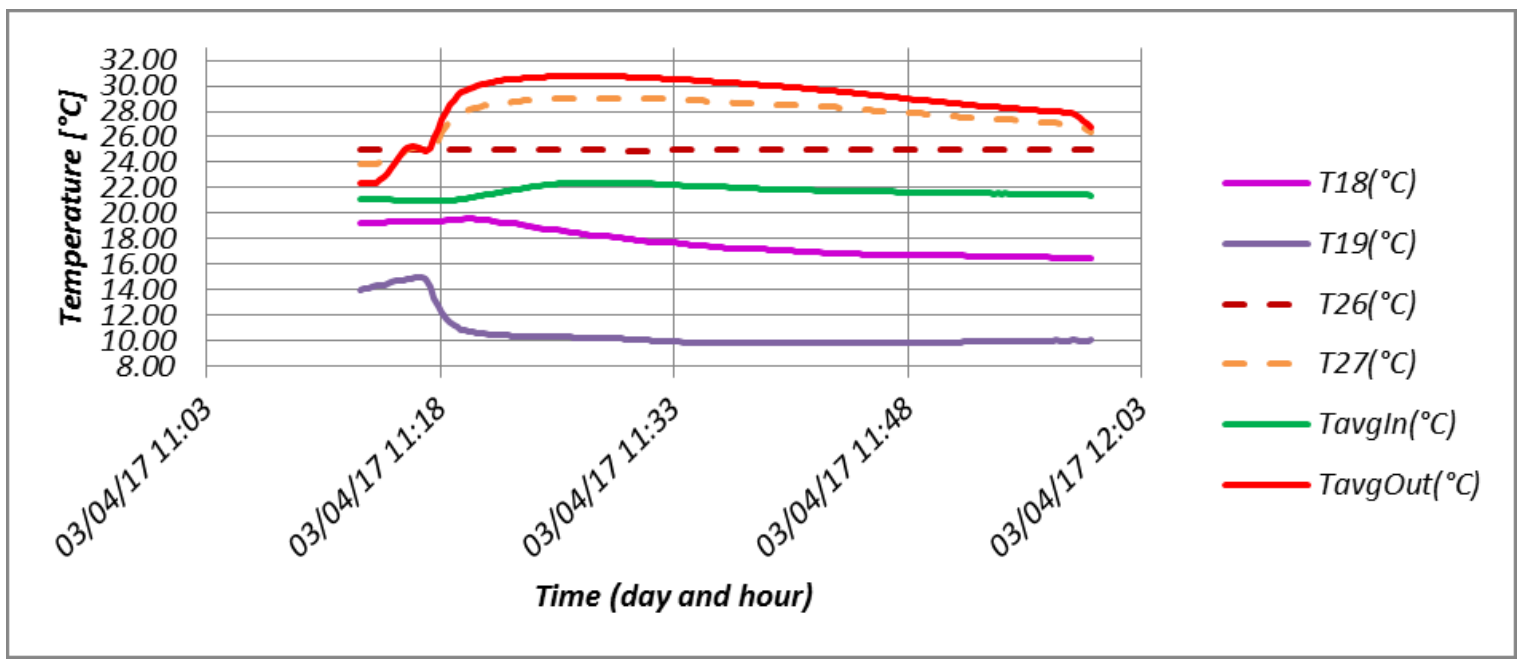

Figure 7 - Test \# 51 - Temperatures in standard adsorption conditions: Average temperatures at the reactor inlet (TavgIn) and outlet (TavgOut), Temperature of water at the user heat exchanger inlet (T26) and outlet (T27), Temperature of air at humidifier inlet (T18) and outlet (T19).

On the humidity ratio side (Figure 8), the reactor inlet humidity (AH2) is around $7 \mathrm{~g} / \mathrm{kg}$, quite fairly constant over time. The reactor outlet humidity (AH1) varies from almost $3.5 \mathrm{~g} / \mathrm{kg}$ at the beginning to $5 \mathrm{~g} / \mathrm{kg}$ at the end. The difference between inlet and outlet decreases during the test and the gap at the end shows the solid is far from the equilibrium when the reaction is stopped. The decrease of solid humidification rate during the test is due the reduction of the deviation from the equilibrium when the water uptake of the solid increases. This also explains that both temperature and heat flows, on the user and reactor side, decrease a bit during the test.

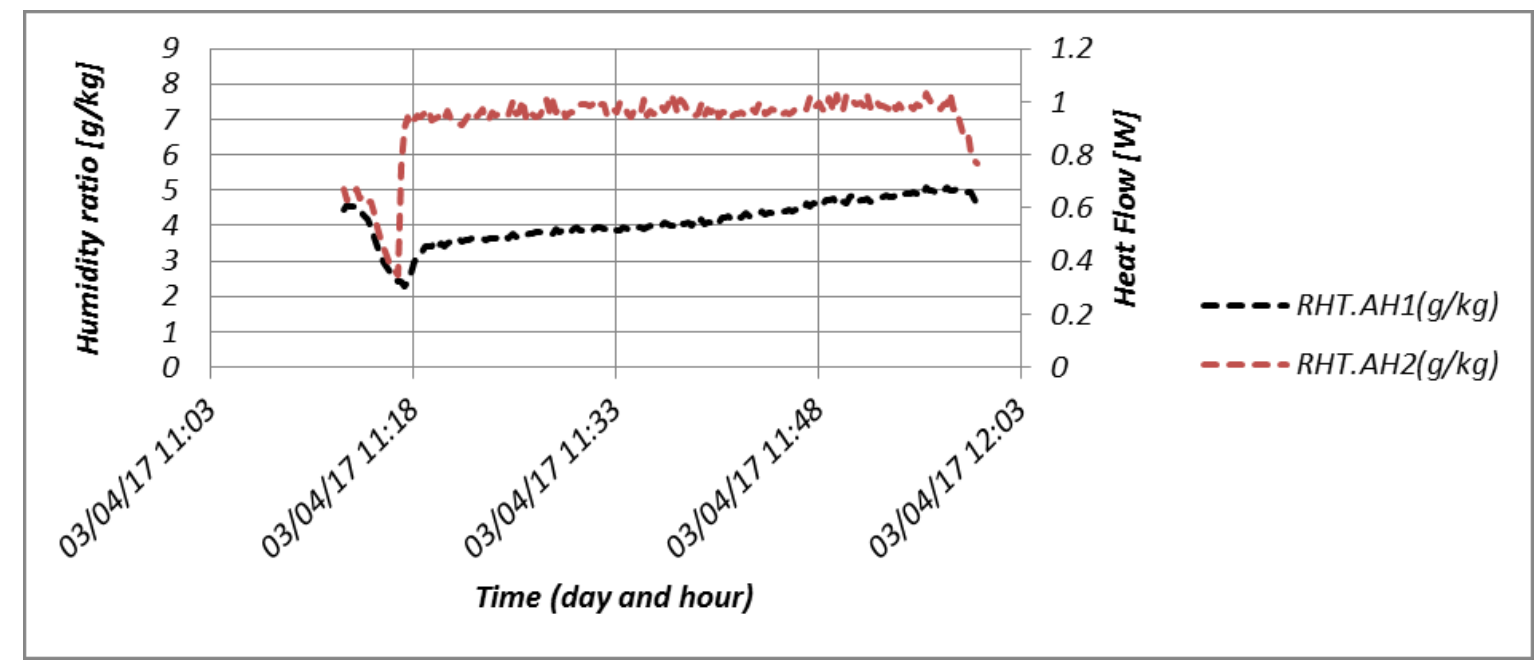

Figure 8 - Test \# 51 - Humidity ratio in standard adsorption conditions at the inlet (RHT.AH2) and outlet (RHT.AH1) of the reactor.

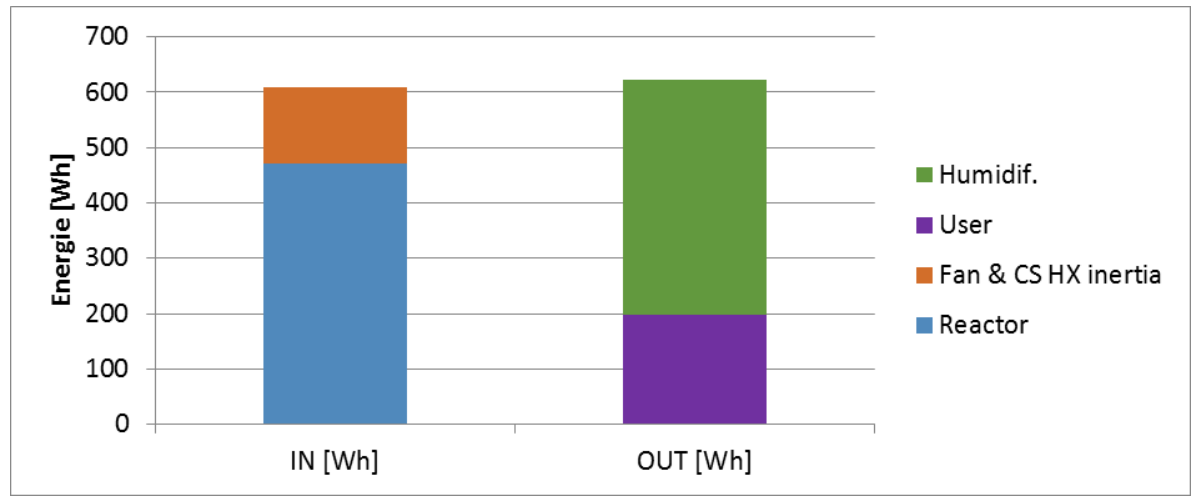

Figure 9 - Test \# 51 - Energy balance of the system in standard adsorption conditions

The energy balance of the system along test number 51 is illustrated on Figure 9. We can observe that the major part of the hydration reaction of the solid is used to compensate the energy necessary for the humidification of the air. On the input side of the energy balance, we observe that other heat sources than the reaction heat represent around $20 \%$ of the energy supplied to the system. Other sources are mainly, the fan, the energy stored in the LTHS 
HX before the beginning of the reaction (due to reactor warm up) before reaction and the energy gained by the air through pipe walls (between the reactor and the humidifier).

\subsection{Adsorption: main results of parametric variations}

In adsorption, the first parameter identified as important, was quite surprising, and not initially integrated in the experimental campaign. Anyway, the granulometry of the silica gel appeared as a crucial parameter to allow a correct behaviour of the solid in the reactor and reaching desired adsorbed mass at the end of the reaction, without crust formation or solid aggregation. Behind the hydration level, there is of course the question of the energy density. With the exception of the aggregation problem, both composites have the same thermal behaviour.

The temperature of the LTHS and, maybe more interesting, the location of this source were identified as very important questions. Firstly, it was shown that a geothermal LTHS was too cold to be valorised in this closed air loop after the humidification. Secondly, it appears that the position of the LTHS in the air loop was crucial when the source temperature increases. Figure 10 shows that the combination of the LTHS and the humidifier (compared to the connection at the LTHS) makes the prototype efficiency rising by $3 \%$ for a LTHS at $10^{\circ} \mathrm{C}$, but the improvement reach $13 \%$ for a LTHS at $20^{\circ} \mathrm{C}$ (the heat flow to the load increase by $80 \%$. $20^{\circ} \mathrm{C}$ is not a conventional temperature for a free LTHS, but this temperature level (up to $30^{\circ} \mathrm{C}$ ) was tested, in order the estimate the potential for the valorisation of industrial heat losses or geothermal solar heat storage at the end of the heating period. However, we see that with a $30^{\circ} \mathrm{C}$ LTHS the average heating supply temperature reach only $35,6^{\circ} \mathrm{C}$, which is for example not enough for DHW production.

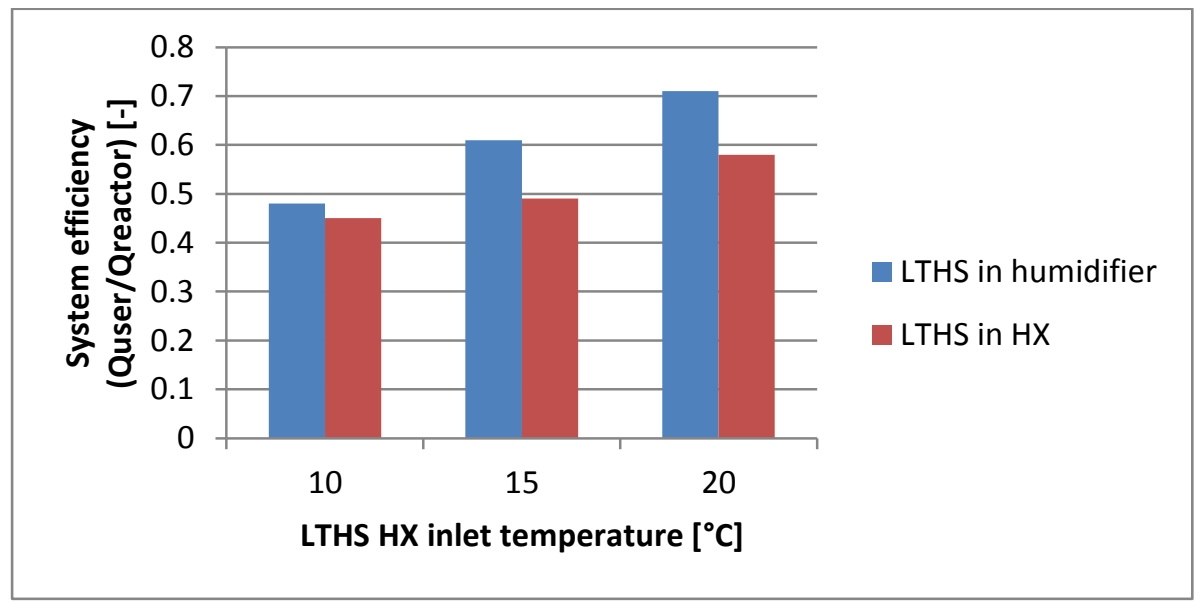

Figure 10 - Influence of the LTHS temperature and location

Another important parameter in adsorption is the load return temperature. So, the efficiency of the heat emitters is very important to allow working at low temperature and to have a good efficiency of the prototype. Figure 11 shows that the efficiency is divided by more than 2 when passing from 25 to $30^{\circ} \mathrm{C}$ at the inlet of the user $\mathrm{HX}$.

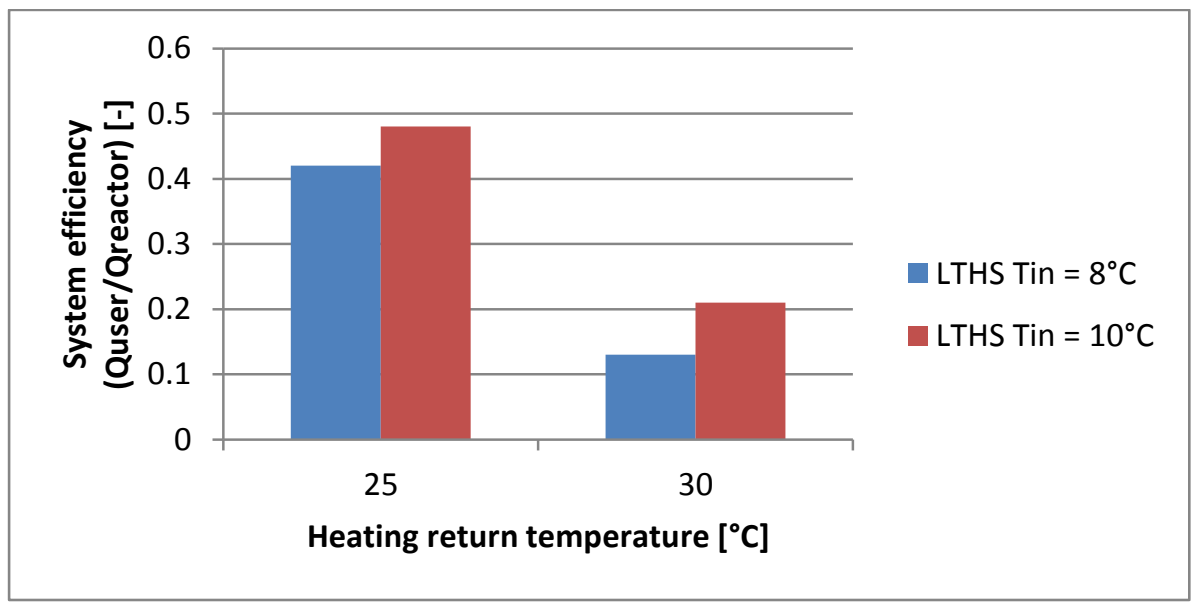

Figure 11 - Influence of the heating return temperature (temperature at the inlet of the user HX) for 2 LTHS.

Concerning air flow rate, we observe that the heat flow supplied by the reactor increase proportionally with the flow rate. It is the same for the user heat flow. The duration of the reaction is reduced if the flow rate becomes grater. However, the difference in terms of efficiency and energy density are not significant. 


\subsection{Desorption: standard test conditions}

Figure 12 to 15 concern test number 60, realised with standard conditions for desorption (only 1 batch).

Figure 12, shows main heat flows in the system. The average heat flow provided by the hot source (P.Wat.Solar) is about $2.39 \mathrm{~kW}$, of which $1.35 \mathrm{~kW}$ are provided to the reactor (P.Air.Reactor). The desorption lasts 37 minutes. According to these measurements, the energy density necessary for desorption corresponds to $277 \mathrm{kWh} / \mathrm{m}^{3}$ (computed at reactor boundary) or $481 \mathrm{kWh} / \mathrm{m}^{3}$ (computed at hot source boundary). This Figure also highlights that the average energy lost in the air leaving the open loop (P.Air.Out) is close to $0.9 \mathrm{~kW}$. The system efficiency in desorption, defined as the ratio between mean powers from the reactor and fromthe hot source is around $56 \%$, which means nearly $45 \%$ of losses. The heat flow measured on the reactor also includes the thermal losses through the reactor walls. A hypothesis is that these losses correspond almost to the heat flow supplied to the reactor at the beginning and at the end of the test (around $450 \mathrm{~W}$ ). We see that the efficiency of desorption (ratio between energy used and energy provided) decreases as the desorption progress. 26 minutes after the beginning of the reaction, the losses become greater than the energy absorbed in the reactor.

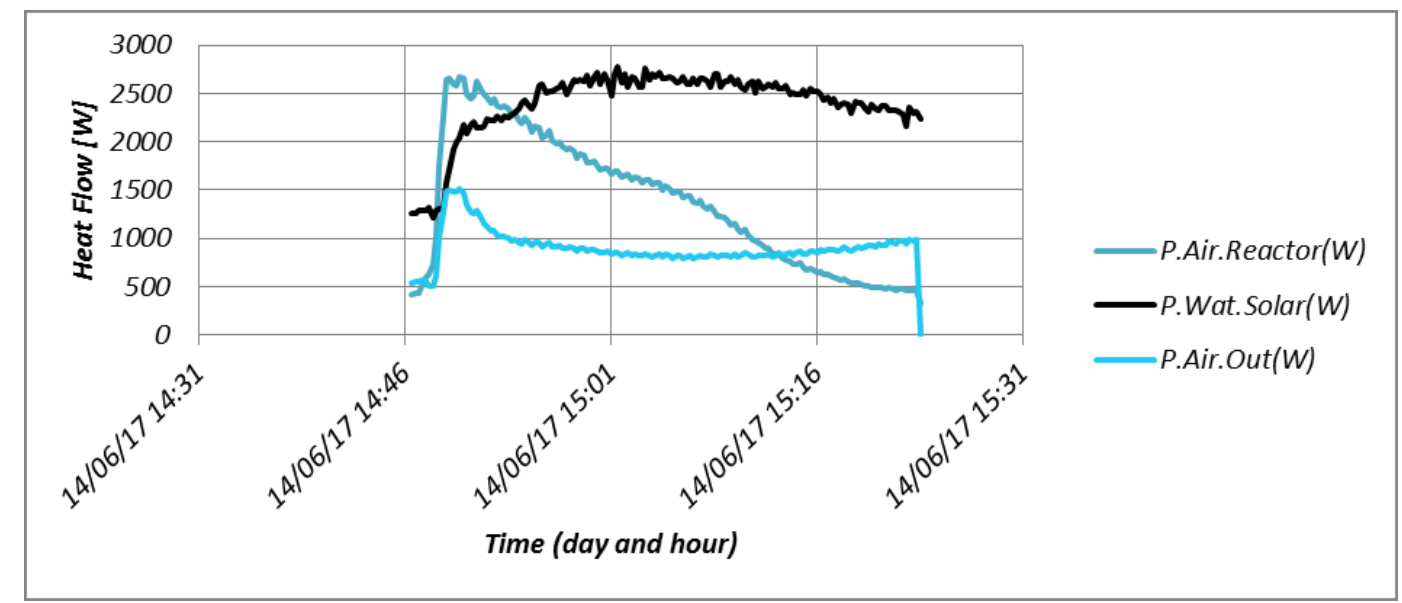

Figure 12 - Test \# 60 - Heat flows in standard desorption conditions: Heat flow supplied by hot source (P.Wat.Solar), heat flow supplied to the reactor (P.Air.reactor), Heat flow lost due to temperature rise of the air between system inlet and outlet (open loop).

Regarding temperatures (Figure 13), the hot source inlet temperature (T24) is imposed constant at $85{ }^{\circ} \mathrm{C}$. The inlet average temperature of the air in the open loop (T18) is $22.4^{\circ} \mathrm{C}$ and the outlet temperature (T16) is always above $30^{\circ} \mathrm{C}$. At reactor boundaries, the average temperatures vary from $79.3{ }^{\circ} \mathrm{C}$ at the inlet $\left(\right.$ TavgIn - maximum $83.3{ }^{\circ} \mathrm{C}$ ) to $62.3^{\circ} \mathrm{C}$ at the outlet (TavgOut - maximum $73.3{ }^{\circ} \mathrm{C}$ ).

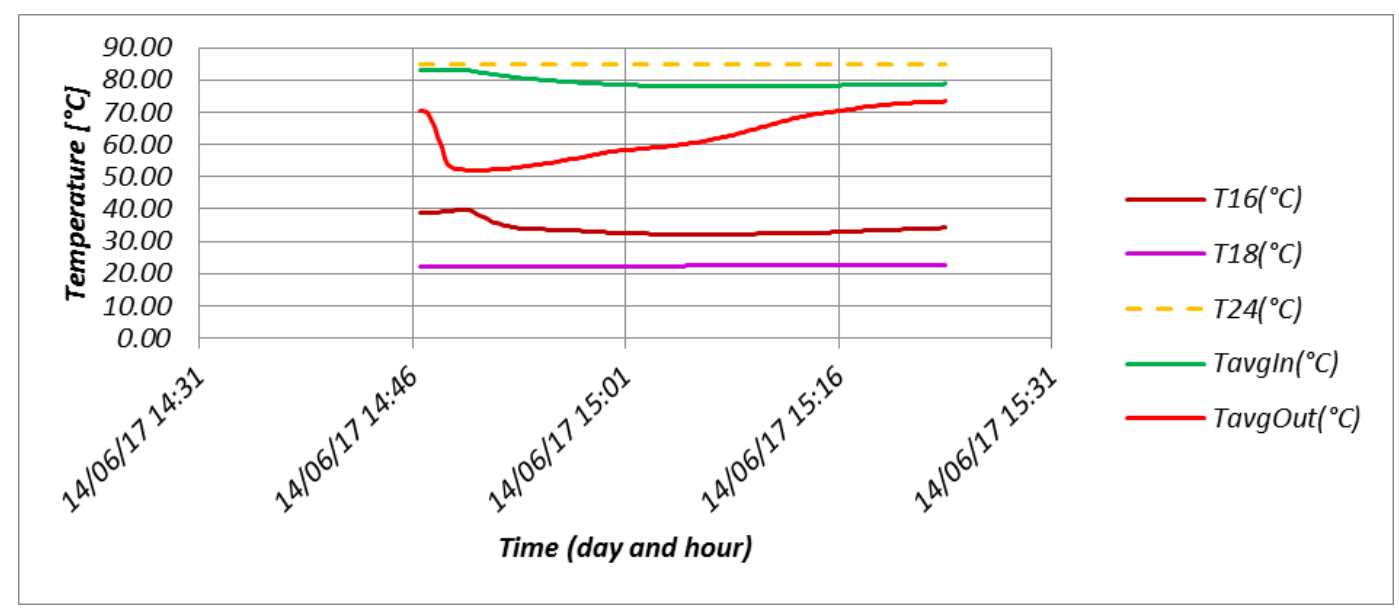

Figure 13 - Test \# 60 - Temperatures in standard desorption conditions: Average temperatures at the reactor inlet (TavgIn) and outlet (TavgOut), Temperature of air at open loop inlet (T18) and outlet (T16), temperature of water supplied by the hot source (T24).

Concerning humidity ratio (Figure 14), $7.7 \mathrm{~g} / \mathrm{kg}$ in average are imposed at the reactor inlet (AH2), even if the control of this input is not perfect, on account of the technology used. The humidity at the outlet varies between 16 $\mathrm{g} / \mathrm{kg}$ a few minutes after the introduction of the solid in the reactor and $8 \mathrm{~g} / \mathrm{kg}$ at the beginning and at the end of the test (average $11.5 \mathrm{~g} / \mathrm{kg}$ ). The fact that the humidity at the outlet of the reactor equals the inlet value means the solid is close to the equilibrium when the reaction is stopped. The outlet curve meets the inlet curve a few minutes before the evacuation of the solid, which means that the reaction duration can maybe be a bit reduced. This is interesting 
on account of the low efficiency of the system at the end of the desorption.

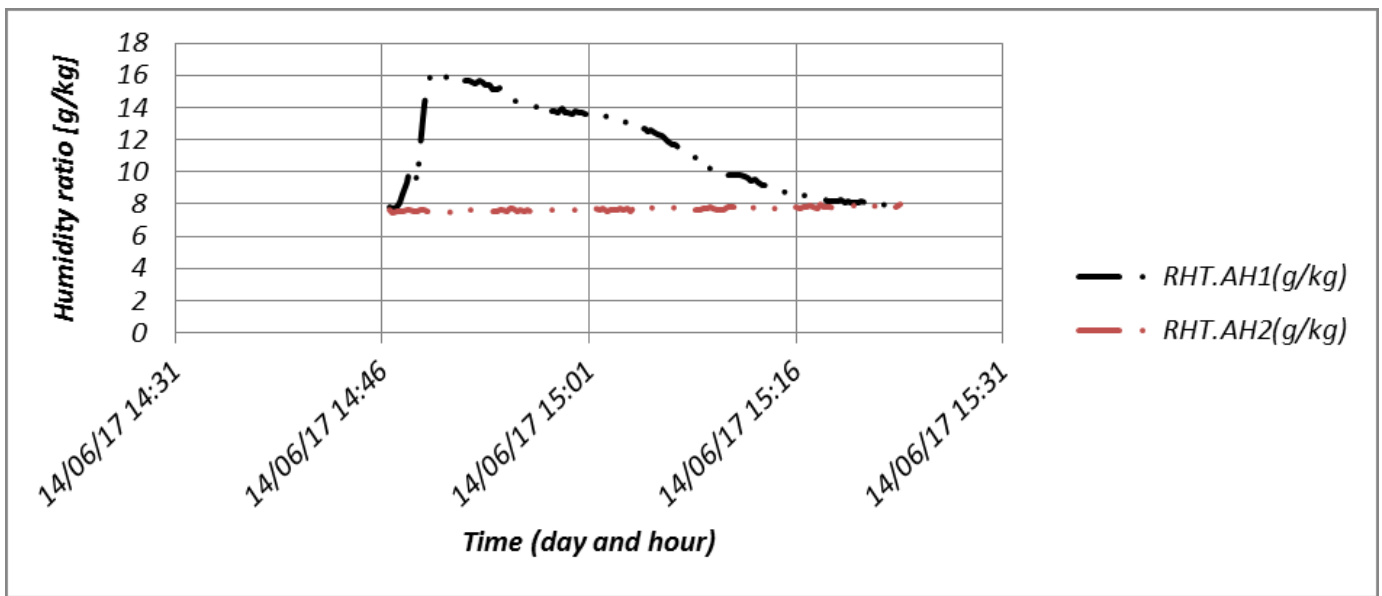

Figure 14 - Test \# 60 - Humidity ratio in standard desorption conditions at the inlet (RHT.AH2) and outlet (RHT.AH1) of the reactor.

The energy balance of the system along test number 60 is illustrated on Figure 15 . We can observe that the major part of the energy provided by the hot source is used for the dehydration of the solid, but around $40 \%$ are lost in the air released at the outlet of the open air loop. Some specific action should probably be done to improve the utilisation of this energy. With a temperature above $30^{\circ} \mathrm{C}$, this temperature can maybe be used to preheat the DHW during summer.

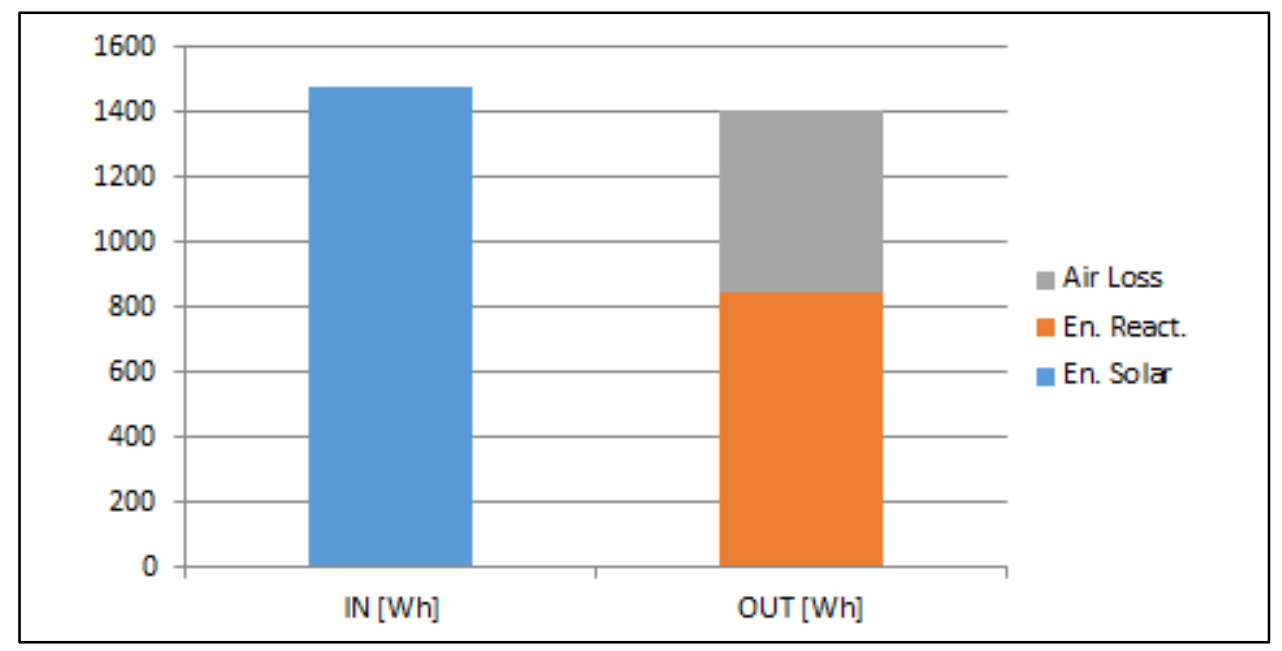

Figure 15 - Test \# 60 - Energy balance of the system in standard desorption conditions

\subsection{Desorption: main results of parametric variations}

Figure 16 shows that increasing the hot source temperature between 65 and $85^{\circ} \mathrm{C}$ allows improving the efficiency of the system in desorption.

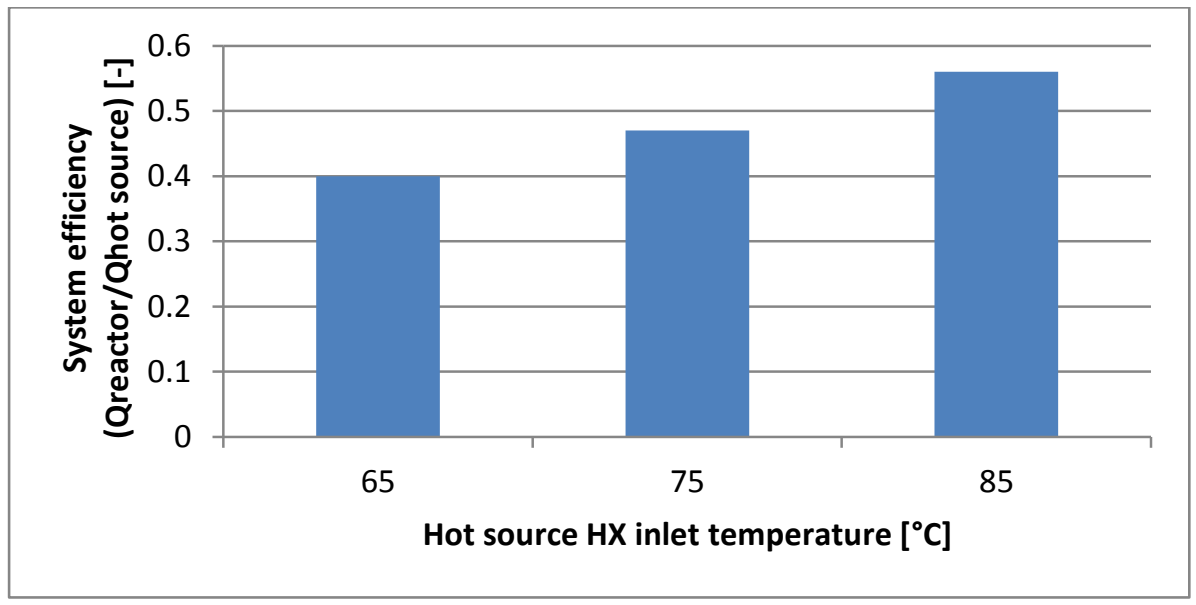

Figure 16 - Influence of the hot source temperature 
The improvement is mainly due to the reduction of the reaction duration. The reaction is more than 2 times longer at $65{ }^{\circ} \mathrm{C}$ compared to $85^{\circ} \mathrm{C}$. The higher temperature at the reactor inlet increases the difference with the thermodynamic equilibrium, which speed up the reaction. The heat flow provided by the solar loop increases with the temperature, as the heat flow lost at the loop outlet or the heat flow provided to the reactor, but the reduction of the duration has a better impact on the efficiency.

The control of water flow rate in the hot source loop to have the same heat capacity on both sides of the air/ water exchanger was also highlighted as an important parameter. Increase the flow rate has nearly the same influence in terms of efficiency and energy density than decrease it. Increase the air flow rate will mainly increase the hot source heat flow, but without clear increasing of the reactor heat flow (so this energy is lost). On the opposite, reduce the flow rate will reduce the reactor heat flow and thus increase the time of the reaction, and the attached losses.

\subsection{Influence of reactor insulation}

There is no significant influence of the insulation of the reactor on the system performance. It can be explained by the poor quality of the insulation, with no consideration of the airtightness. Indeed, 2 major technical constraints make the insulation of the reactor very complicated. Firstly, the insulation can't be glue on the reactor wall without perturbations of the vibrations. Secondly, unbalanced motors need to be out of the insulation because they can't resist to higher temperatures reached in desorption, this create large spaces not insulated around motors. Moreover, the important instrumentation of the prototype creates a lot of paths for hot air in the insulation.

\subsection{Cycle efficiency in standard conditions}

The efficiency of the cycle desorption/adsorption computed with test number 51 and 60 is presented on Figure 17. This cycle varies the water uptake of the solid between 13 and $41 \%$. The efficiency of this cycle for the system in standard conditions is around $13.5 \% .481 \mathrm{kWh}$ are supplied by the hot source for the desorption of the solid and 65 $\mathrm{kWh}$ are recovered by the user loop. If we compute the efficiency of the reactor (ratio between the energy provided to the reactor for desorption and the energy recovered from adsorption at reactor boundary) it reaches $55 \%$.

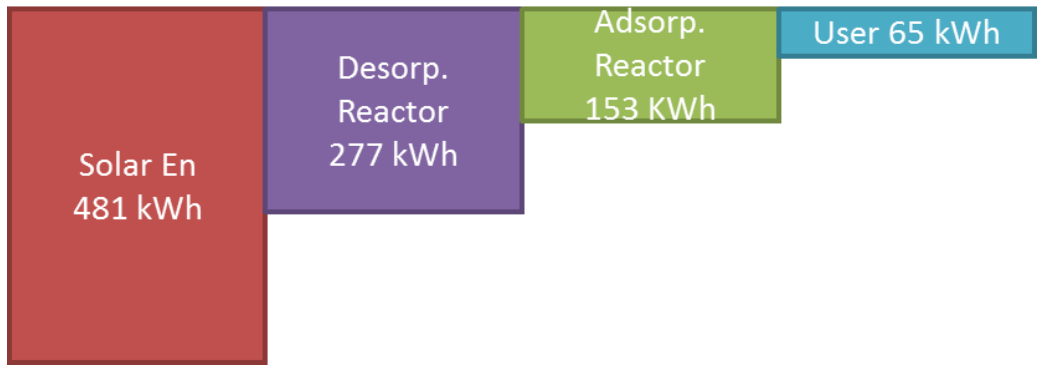

Figure 17 - Energy balance of a complete cycle desorption/adsorption (based on tests \#51 and 60).

\section{Conclusion and outlook}

This experimental campaign allowed testing the system, prove the concept is working and submit it to a wide range of conditions. This kind of "experimental parametric variation" allowed identifying most important parameters of the system, i.e. those to which special attention should be paid in future developments.

The experimental campaign shows the concept is working during a quite large period, but it also highlighted weakness of the prototype and especially robustness and conception problems. Therefore, the robustness of the prototype and the automation must be improved to make it usable without any operator. Regarding the automation, the main challenge is to find a reliable stopping criterion of reaction, in order to maximize the energy density without solid aggregation.

More generally, the inefficiency of the reactor insulation in adsorption and desorption was observed. This is certainly a crucial point to increase the reactor efficiency. The reflexion about the insulation should certainly be integrated in the conception of future prototypes. More generally, the reduction of other losses would to improve the quite low system efficiency constitute a priority in future development. As a consequence, the cycle efficiency is also quite low. Its improvement could also rely on the increasing of the recovery heat exchanger efficiency.

Even if the concept of this reactor is already nearly out of date at the end of the experimental campaign, some future investigations would remain interesting: i.e. study deeply the connection off the prototype to the building ventilation without any additional ventilation. 


\section{Acknowledgements}

This research was conducted in the SOTHERCO project (FP7 - Grant agreement n²95775) with following partners: Be-Sol (Coordinator, Belgium), UMons (Belgium), AIT (Austria), UVSQ (France), CEA/INES (France), ULB (Belgium), ULiège (Belgium), CLIPSOL (France). The prototype was mainly developed, built and installed in the laboratory by Be-Sol (Gilbert Descy, Michel Beeckmans, Alexandre Descy, Léon Chalon, Ludovic Polomé).

\section{References}

D'Hondt, M. (2016). Expérimentation d'un stockage solaire thermochimique. (Master en Sciences et Gestion de l'Environnement Master Thesis), Université de Liège, Arlon. 


\title{
Sensible Thermal Energy Storage in Packed Bed for Industrial Solar Applications
}

\author{
Burcu Koçak ${ }^{1}$, Halime Paksoy² \\ 1 Institute of Natural and Applied Science, Çukurova University, Adana (Turkey) \\ 2 Faculty of Art and Science, Chemistry Department, Çukurova University, Adana (Turkey)
}

\begin{abstract}
This paper presents a study on development of sensible thermal energy storage in a laboratory scale packed bed for industrial solar applications. In the cylindrical storage tank with $0.30 \mathrm{~m}$ diameter and $0.90 \mathrm{~m}$ height, two different types of packing materials from waste materials are used. First one is produced from building demolition wastes, which are molded in different geometries. For the second one, hallow silane crosslinking of polyethylene (PEX-b) pipe, which are leftovers from pipe manufacturers are used. The system design includes cycles that simulates storage and recovery of heat controlled by temperature. In further studies the performance of the system will be tested at different operating conditions and life cycle assessment will be made. Inertiazing such waste materials are expected provide low-cost and sustainable sensible heat storage systems for industrial solar applications.
\end{abstract}

Keywords: Packed-bed, Solar Heat Industrial Applications, Sensible Thermal Energy Storage (STES), Solar Energy,

\section{Introduction}

Total energy consumption in the world is increasing rapidly. According to International Energy Agency (IEA), global energy consumption has increased more than twice over the last forty years. Industries consume $29 \%$ of the world's total delivered energy with energy systems generally using of fossil fuels (IEA, 2017). The use of fossil fuels in industry reduces the competitiveness in global market. In addition, the environmental impacts and increased $\mathrm{CO} 2$ emissions emphasizes the importance of the usage of renewable energy sources in industries. Although solar energy can be potentially used in many industrial processes, variability of sunlight is the main barrier for continuous utilization (EESI, 2011).

The mismatch between supply and demand of solar energy can be covered by thermal energy storage (TES) systems. There are three TES concepts, namely thermo-chemical storage, sensible heat storage and latent heat storage. The thermochemical storage is still being developed and it is not widely used in industrial applications. Sensible heat storage, utilizes temperature changes of storage materials. Latent heat storage using phase change materials (PCM) has higher storage capacity than sensible heat storage materials, but the cost of PCMs, especially at temperatures above $150^{\circ} \mathrm{C}$ is very high (Mawire and McPherson, 2009). Due to the technical difficulties and high price of PCM, latent heat storage is costly for industrial applications. Sensible heat is the most preferable TES concept in industrial applications, due to the availability and low-cost sensible thermal energy storage materials (STESM). Basalt, aluminum, carbon steel, and iron are among the well known sensible heat storage materials. Also, recently, inertized products such as by-products of mining and metallurgical industry, asbestoscontaining wastes, and post-industrial ceramic are being developed for high temperature. The properties of other STESMs in literature are given in Tab. 1. 
Tab. 1: Properties of sensible thermal energy storage materials (STESM) in literature

\begin{tabular}{|c|c|c|c|c|c|}
\hline Materials & $\begin{array}{c}\text { Density, }(\rho \\
) \\
\left(\mathrm{kg} / \mathrm{m}^{3}\right) \\
\end{array}$ & $\begin{array}{c}\text { Thermal } \\
\text { Conductivity,(k } \\
\text { ) } \\
(\mathrm{W} / \mathrm{mC})\end{array}$ & $\begin{array}{c}\text { Specific } \\
\text { Heat, (Cp) } \\
\text { (kJ/kgK) }\end{array}$ & $\begin{array}{c}\text { Heat } \\
\text { Capacity, }(\rho . C \\
\text { p) }\left(\mathbf{k J} / \mathbf{m}^{3} \mathbf{K}\right)\end{array}$ & Ref. \\
\hline Brick & 3200 & 0.1 & 0.80 & 2560 & $\begin{array}{c}\text { Kuravi et } \\
\text { al, } 2013\end{array}$ \\
\hline Silica & 2500 & 0.1 & 0.90 & 2250 & $\begin{array}{l}\text { Bruch et } \\
\text { al, } 2014\end{array}$ \\
\hline Gneiss Rock & 2740 & 3.0 & 0.82 & 2260 & $\begin{array}{l}\text { Jemmal et } \\
\text { al, } 2016\end{array}$ \\
\hline $\begin{array}{l}\text { Alumina balls }\left(\mathrm{Al}_{2} \mathrm{O}_{3} \geq 89.5 \mathrm{wt}\right. \\
\%)\end{array}$ & 3350 & 30 & 0.90 & 3020 & $\begin{array}{l}\text { Cascetta et } \\
\text { al, } 2015\end{array}$ \\
\hline Basalt & 2644 & 2.08 & 0.77 & 2040 & $\begin{array}{l}\text { Tiskatine } \\
\text { et al, } 2017\end{array}$ \\
\hline $\begin{array}{l}\text { Cofalit (asbestos containing } \\
\text { waste) }\end{array}$ & 3120 & 2.1 & 0.80 & 2490 & $\begin{array}{l}\text { Motte et } \\
\text { al, } 2015\end{array}$ \\
\hline $\begin{array}{l}\text { BOF-Slag (By-product } \\
\text { generated in steel industry) }\end{array}$ & 3972 & - & 0.91 & 3460 & $\begin{array}{l}\text { Grosu et } \\
\text { al, } 2018\end{array}$ \\
\hline Municipal waste glass & 2962 & 1.16 & 0.71 & 3430 & $\begin{array}{l}\text { Gutierrez } \\
\text { et al, } 2016\end{array}$ \\
\hline
\end{tabular}

TES systems provide alternative solutions to benefit from renewable energy sources in various sectors in a sustainable way (Paksoy, 2007). In recent years, TES systems have been investigated to reduce energy consumption and effective use of solar energy for industrial applications. The balance between supply and demand of solar energy can be ensured through the use of TES systems (Brunch et al, 2014).

In most of the recent studies, numerical evaluation of packed bed TES for industrial solar applications have been reported, but only a few studies are on experimental demonstrations, especially using liquid heat transfer fluids (Brunch et al, 2014).

In this study, laboratory scale packed bed TES system is designed with the purpose of storing heat at $130-180$ ${ }^{\circ} \mathrm{C}$ that will be suitable for industrial solar applications. Two new packing materials developed from waste materials will be tested in this TES system for a more sustainable operation.

\section{Sensible Thermal Energy Storage Materials (STESM)}

Providing storage material with cheap and high energy density is very crucial for low-cost and high-efficient thermal energy storage systems. For this reason, using waste materials as STESM is a better option in TES systems. Two types of STESM developed from waste materials, which are shown in Fig.1 and Fig.2 will be used in this study. Building demolition wastes from urban development projects are processed and molded into different geometries to obtain STESM. PEX-b pipe leftovers in pipe manufacturers cannot be recycled and re-used in pipe production. PEX-b durable to high temperatures can be utilized as packing material to store high temperature heat. 


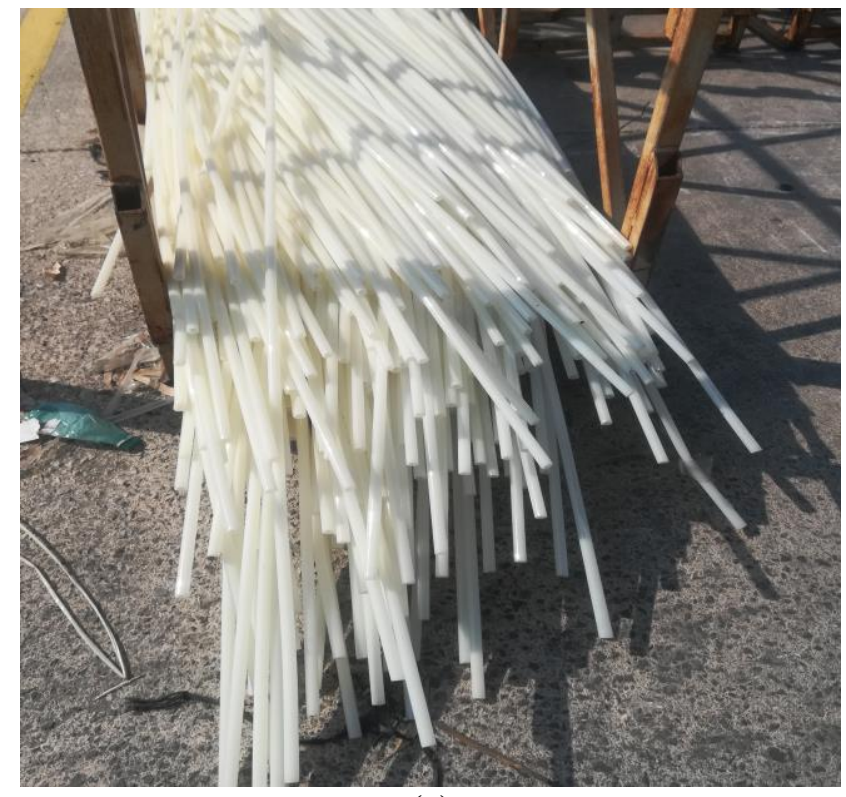

(a)

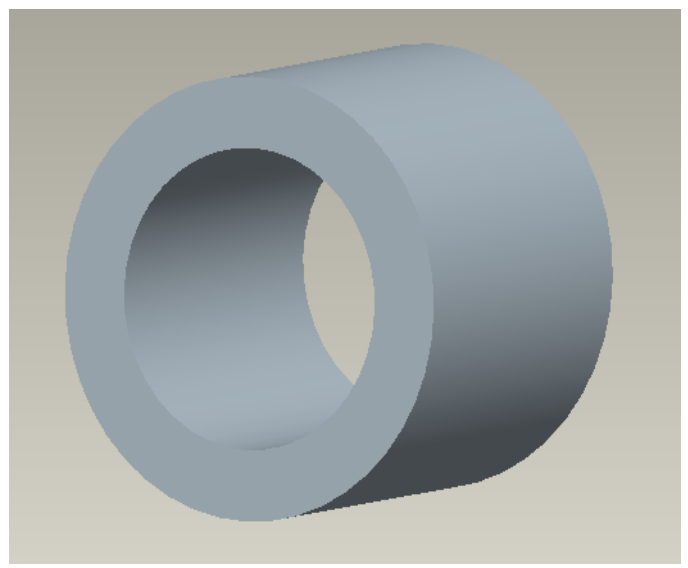

(b)

Fig. 1: PEX-pipe as STESM, a)Scrap of PEX-pipe, b) Section of PEX-pipe

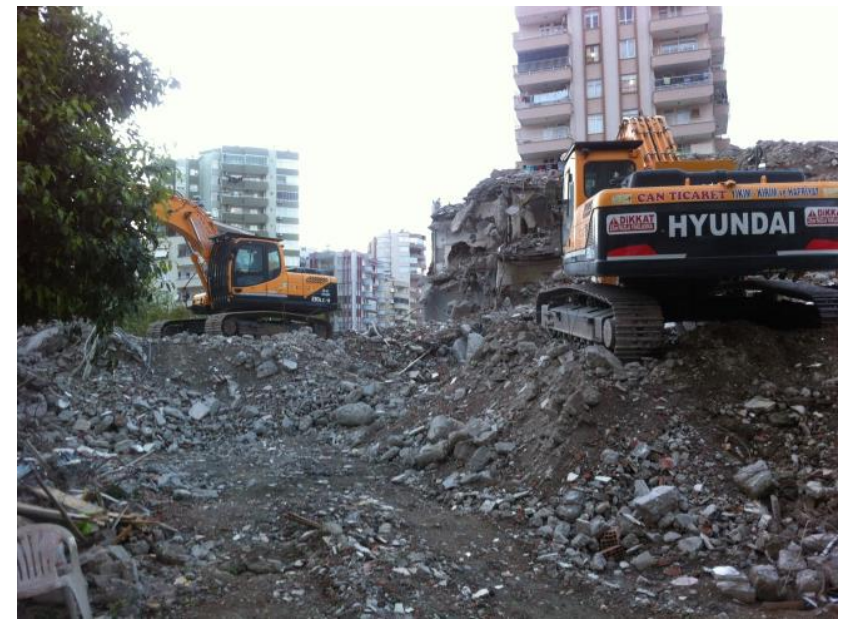

(a)

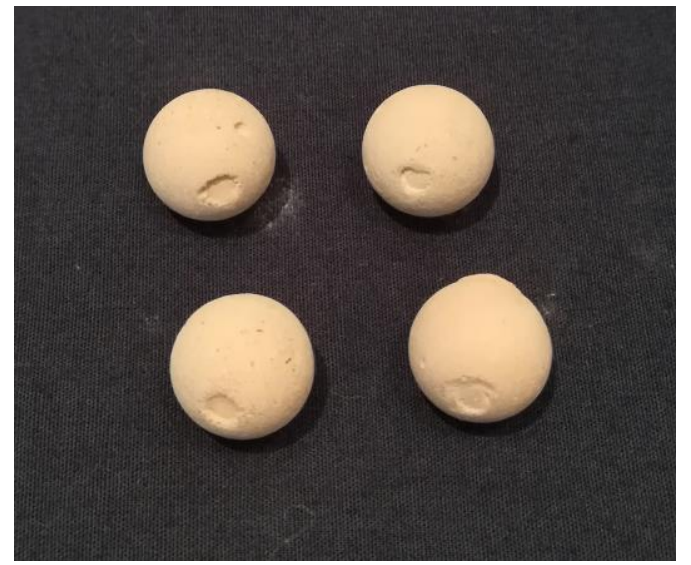

(b)

Fig. 2: Demolition waste as STESM, a) Demolition wastes from urban development projects, b)Demolition waste after processed as STESM

The most important parameters for storage materials are high specific heat capacity and density, capability for operating at suitable temperature range, good thermal conductivity and low cost (Klein et al, 2015). The properties of two types of STESM developed in this study are given in Tab. 2.

Tab. 2: Properties of sensible thermal energy storage materials (STESM) used in this study

\begin{tabular}{lccc}
\hline STESM & $\begin{array}{c}\text { Density, }(\boldsymbol{\rho}) \\
\left(\mathbf{k g} / \mathbf{m}^{\mathbf{3}}\right)\end{array}$ & $\begin{array}{c}\text { Specific Heat, }(\mathbf{C p}) \\
(\mathbf{k J} / \mathbf{k g K})\end{array}$ & $\begin{array}{c}\text { Heat Capacity, (p.Cp) } \\
\left(\mathbf{k J} / \mathbf{m}^{\mathbf{3}} \mathbf{K}\right)\end{array}$ \\
\hline Demolition Waste & 2100 & 1.53 & 3213 \\
Waste of PEX-b pipe & 930 & 2.3 & 2139 \\
\hline
\end{tabular}

Their heat capacities vary from 2100 to $3200 \mathrm{~kJ} / \mathrm{m}^{3} \mathrm{~K}$. The heat capacities of STESM developed in this study from waste materials are comparable to the previous studies with values in the range of 2000 to $3500 \mathrm{~kJ} / \mathrm{m}^{3} \mathrm{~K}$ as given in Tab.1. 


\section{Design of Packed Bed Thermal Energy Storage System}

The laboratory scale packed bed TES system is developed based on the scheme shown in Figure 3 (Bruch et al., 2014). This system consists of charging and discharging cycles for storing and recovering solar heat in packed bed column. In the charging cycle to the left of the packed bed column, a heat transfer fluid (HTF) bath with a heater is used to simulate solar heat. The stored heat is recovered in the discharging cycle through a heat exchanger shown to the right of the packed bed column. The system includes pump, flowmeter, valves and thermocuples to control and collect data from experiments.
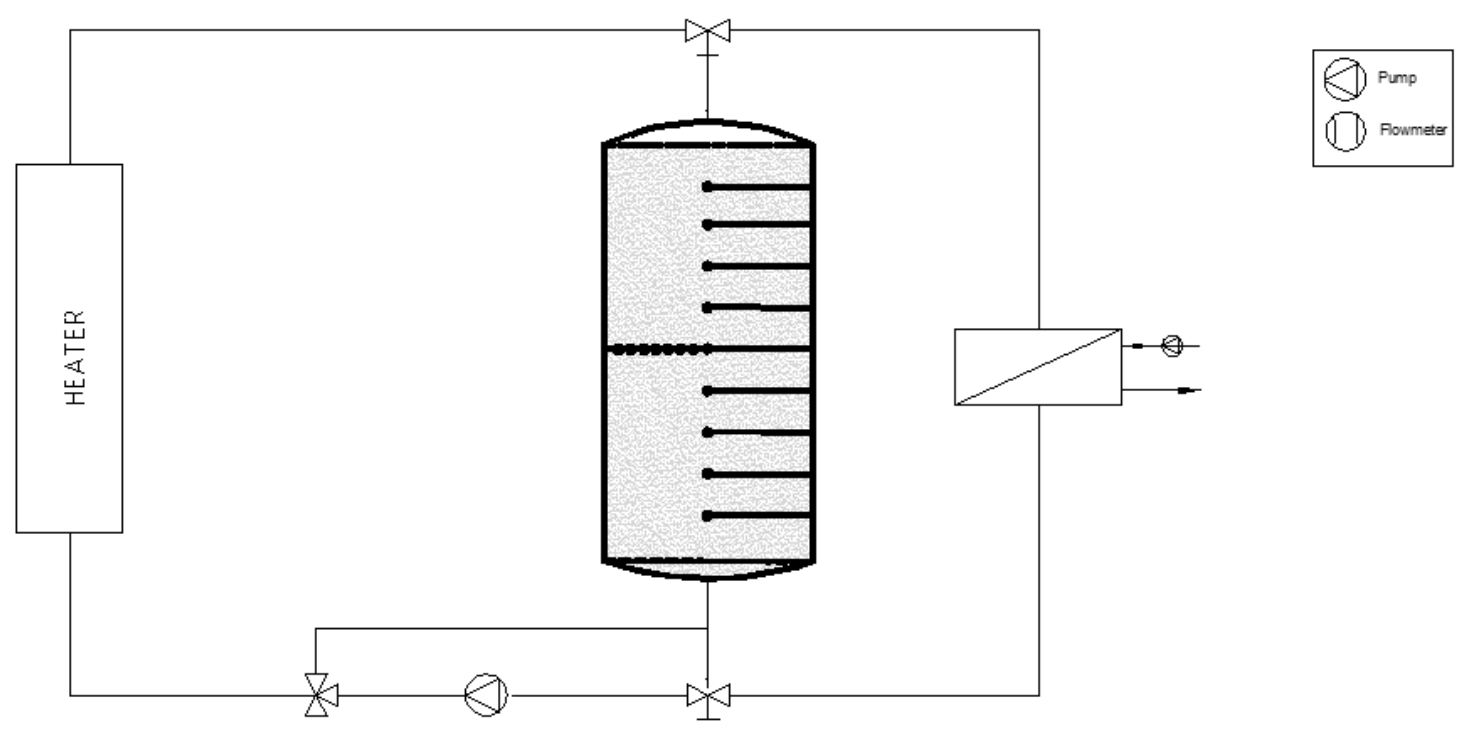

Fig. 3: Scheme of packed bed TES system

The real system constructed based on this scheme is shown in Fig.4. The packed bed column is a cylindrical storage tank of $0.30 \mathrm{~m}$ diameter and $0.90 \mathrm{~m}$ height made of stainless steel with aspect ratio of 3 . The tank is insulated with $0.02 \mathrm{~m}$ glass wool. Demolition wastes developed in different geometries and PEX-b pipe leftovers will be tested for the first time as STESMs. The ratio the diameter of the tank to the characteristic diameter of packing was chosen to be greater than 30 , i.e. $D_{\text {tank }} / D_{s}>30$, to have negligible wall effects (Bruch et al, 2014). Synthetic thermal oil (Therminol 66) is be used as HTF for storing heat between $130-180^{\circ} \mathrm{C}$. For storing heat below $100{ }^{\circ} \mathrm{C}$ water is used as HTF. Twelve thermocouples (PT100 type) with a precision of $\pm 0.5^{\circ} \mathrm{C}$ are used in the system for temperature measurement. Ten of them are placed inside the packed bed column to measure the porous media temperature on vertical and axial lines and two of them are located at the inlet and outlet of the heat exchanger. HTF bath with $50 \mathrm{~L}$ capacity includes a $2 \mathrm{~kW}$ electric heater for simulating solar heat at desired temperature. The Oil pump, a maximum rotation speed of $1500 \mathrm{rpm}$, used for circulating HTF in the system is manufactured by KUPARPUMP. Direction of HTF flow is controlled by 2-way and 3-way ball valves, which are operated based on temperature measurements by data logger. For the discharge cycle a plate type heat exchanger from HTF to water was used for heat recovery. Flow rate of HTF can be controlled by QTLD turbine flow meter. Oro et al (2013) designed a packed bed column with capacity of 4.0 L filled with spherically encapsulated PCM and water as HTF. Their experimental results analyzed with different numerical models showed that constant velocity profile gave better performance than variable one. TES system parameters are summarized in Tab. 3 . Charging and discharging experiments will be carried out with constant fluid velocity up to $12 \mathrm{~mm} / \mathrm{s}$ for laminar flow to allow the Reynolds number (Re) given in eq. 1 to be less than 2300.

$R e=\frac{\rho_{f} V_{0} D_{P}}{\mu_{f}}=\frac{V_{0} D_{P}}{v_{f}}$

The density $\left(\rho_{\mathrm{f}}\right)$, kinematic viscosity $\left(v_{\mathrm{f}}\right)$ and the specific heat capacity $\left(\mathrm{C} \mathrm{p}_{\mathrm{f}}\right)$ of the synthetic thermal oil vary with temperature and are represented with eq. 2 , eq. 3 and eq. 4 , respectively. 
$\rho_{f}\left(\frac{k g}{m^{3}}\right)=-0.614254 * T\left({ }^{\circ} \mathrm{C}\right)-0.000321 * T^{2}\left({ }^{\circ} \mathrm{C}\right)+1020.62$

$v_{f}\left(\frac{m m^{2}}{s}\right)=e^{\left(\frac{586.375}{T\left({ }^{\circ} \mathrm{C}\right)+62.5}\right)-2.2809}$

$C p_{f}\left(\frac{k J}{k g K}\right)=0.003313 * T\left({ }^{\circ} \mathrm{C}\right)+0.0000008970785 * T^{2}\left({ }^{\circ} \mathrm{C}\right)+1.496005$

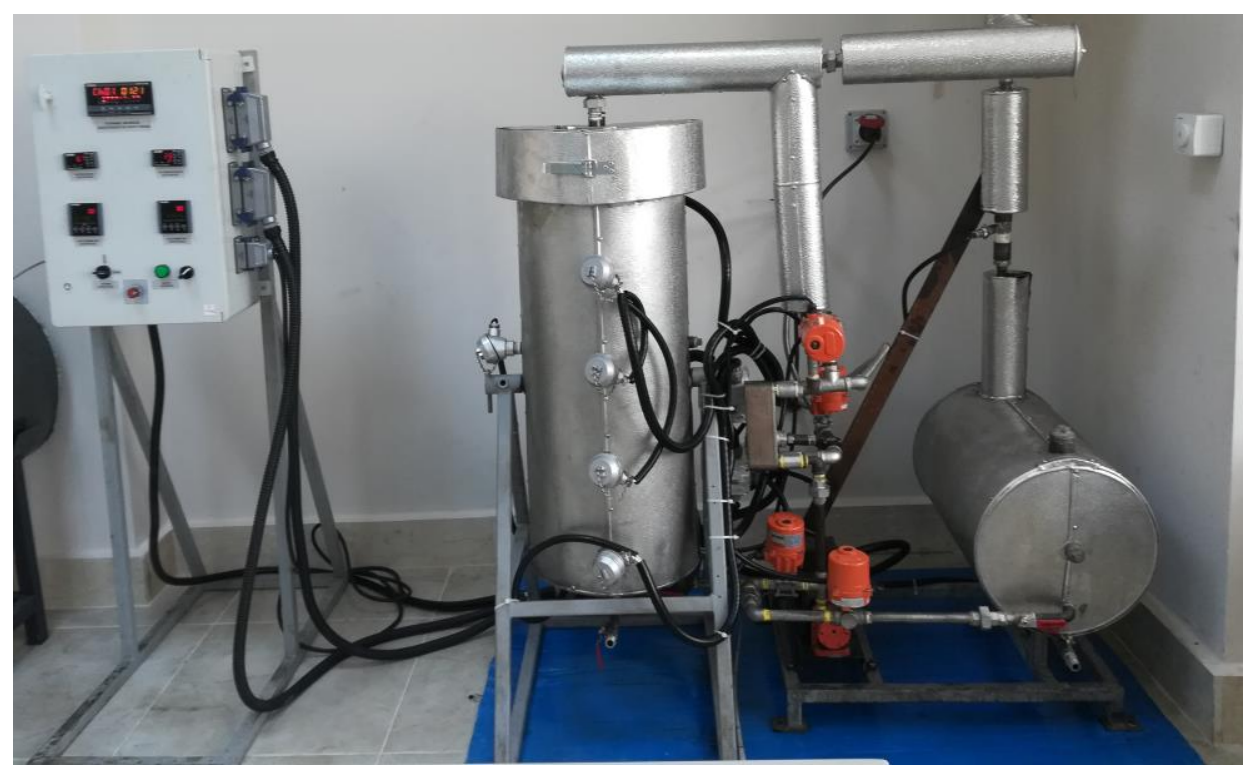

Fig. 4: Laboratory scale packed bed TES system

Tab. 3: TES system parameters

\begin{tabular}{|l|c|}
\hline \multicolumn{1}{|c|}{ Parameter } & Value \\
\hline Height of storage tank; $\mathrm{h}_{\text {tank }}(\mathrm{m})$ & 0.90 \\
\hline Diameter of storage tank; $\mathrm{D}_{\text {tank }}(\mathrm{m})$ & 0.30 \\
\hline Inlet temperature range $\left({ }^{\circ} \mathrm{C}\right)$ for demolition waste & $130-180$ \\
\hline Inlet temperature range $\left({ }^{\circ} \mathrm{C}\right)$ for Pex-b pipe & $50-80$ \\
\hline Diameter of demolition waste as STESM, $\mathrm{D}_{\mathrm{s}}(\mathrm{mm})$ & 10 \\
\hline Diameter of PEX pipe, $\mathrm{D}_{\text {pex }}(\mathrm{mm})$ & 16 \\
\hline Thickness of PEX pipe, $\mathrm{t}_{\mathrm{pex}}(\mathrm{mm})$ & 2.0 \\
\hline Fluid velocity range; $\mathrm{V}_{0}(\mathrm{~mm} / \mathrm{s})$ & $0-12$ \\
\hline Density of Therminol 66 as $\mathrm{HTF}, \rho_{\mathrm{f}}$ & Given by eq. 1 \\
\hline Specific heat of Therminol 66 as $\mathrm{HTF}, \mathrm{Cp} \mathrm{p}_{\mathrm{f}}$ & Given by eq.3 \\
\hline Density of water as $\mathrm{HTF}, \rho_{\mathrm{w}}\left(\mathrm{kg} / \mathrm{m}^{3}\right)$ & 1000 \\
\hline Specific heat of water as $\mathrm{HTF}, \mathrm{Cp} \mathrm{w}_{\mathrm{w}}(\mathrm{kJ} / \mathrm{kgK})$ & 4.187 \\
\hline
\end{tabular}

During the charging process, hot HTF flows into top of the storage tank. STESM absorbs heat from the hot HTF and thus heat is stored in STESM by increasing temperature of storage material. While during the discharging process, cold HTF enters through bottom of the tank and hot STESMs are releasing heat to the cold HTF. STESMs with same diameter are packed in the cylindrical storage tank and HTF flows through the void space of the storage tank. The void fraction of the storage tank filled with STESMs will be calculated according to eq.5.

$\varepsilon=V_{H T F} / V_{\text {tank }}$ 
where $\mathrm{V}_{\mathrm{HTF}}$.is volume of heat transfer fluid in storage tank, and $\mathrm{V}_{\text {tank }}$ is the volume of storage tank. Also, maintaining stratification with regular flow of heat transfer fluid is an important criterion for better performance. Therefore, filters should be used in the system to prevent clogging caused by storage materials and provide homogeneous distribution of HTF in the bed (Oro et al, 2013). In this system, two filters with 0.8 mm diameter openings are placed at the bottom and top of the tank.

The packed bed TES system will be investigated both experimentally and numerically under different operating conditions. The numerical model will be developed based on the packed bed column filled with STESM illustration shown in Fig. 5. In Fig b and $\mathrm{c}$ the enlarged portion of the packed bed for use in numerical modeling are given. Fig $5 \mathrm{c}$ shows the PEX-Pipe pieces packed aligned in the same orientation. Random packing with PEXPipe pieces will also be analyzed.

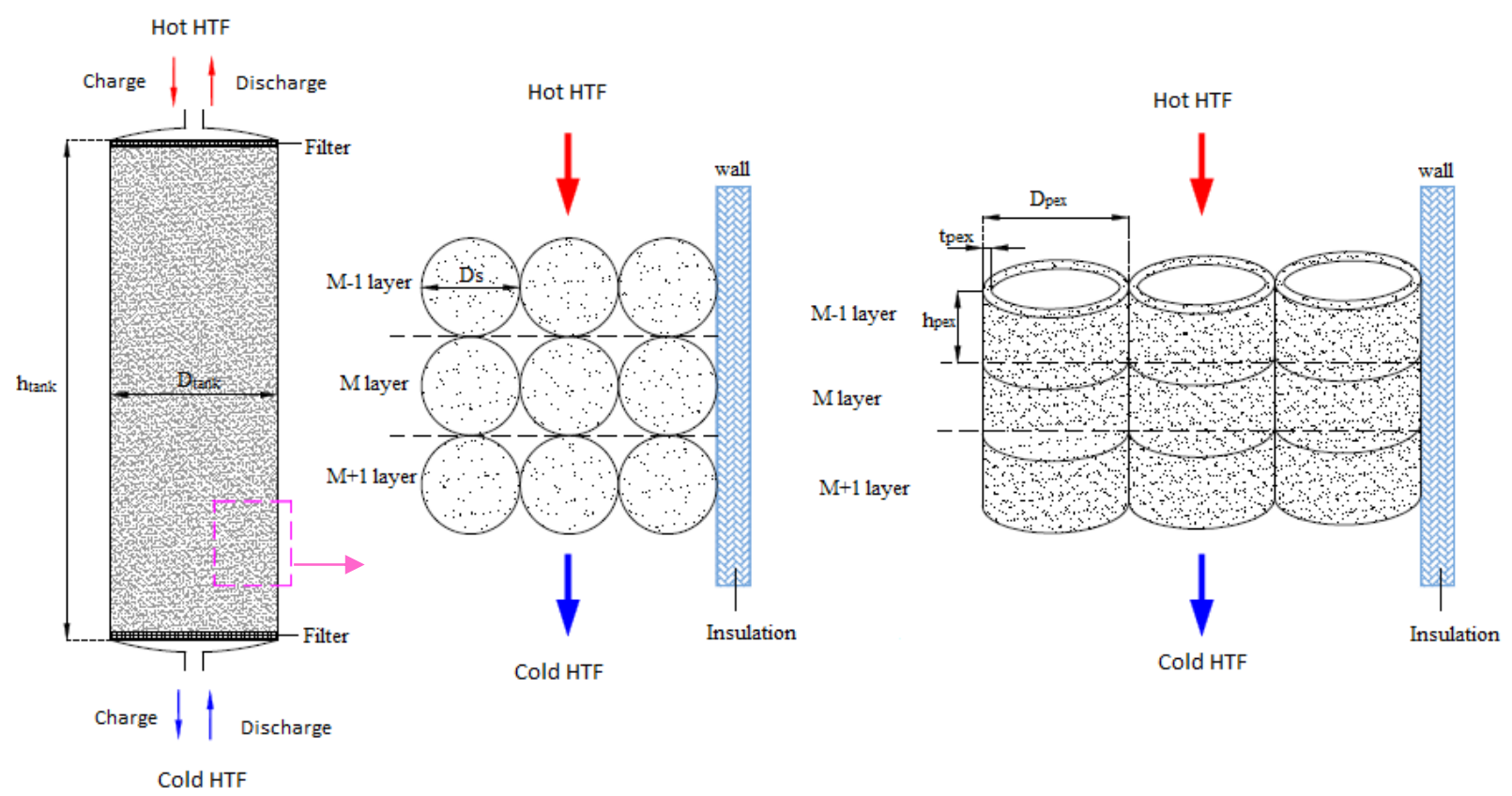
a) Packed-bed
b)Demolition waste as STESM
c)PEX-pipe as STESM

Fig.5: Sketch of a sensible heat storage system in packed-bed

Bruch et al. (2014) developed a one-dimensional model for rock bed used for thermal energy storage with thermal oil. Their results showed this model can be used in different dual media and liquid HTF in a wide range of operating conditions (Bruch et al., 2014). This model will be adapted to determine pressure and temperature changes along the packed bed using the new packing materials developed here. The result from the model will be validated with experimental results.

\section{Conclusions and Outlook}

A laboratory scale TES system with a packed-bed column is designed and built for solar energy storage in industrial applications.. The lab-scale packed bed column TES system will be numerically and experimentally studied. In this system, two types of STESM developed from waste materials demolition waste and PEX-pipe leftovers will be used. Inertiazing such waste materials is expected provide low-cost and sustainable sensible heat storage systems for industrial solar applications. To evaluate thermodynamic behavior of TES system, in further studies, the performance of the system will be tested at different operating conditions and life cycle assessment will be made. 


\section{Acknowledgements}

The authors would like to acknowledge the support provided by the Çukurova University Research Fund under the project No: FDK-2018-9602.

\section{References}

Bruch A., Fourmigue J. F., Couturier R., Molina S., 2014. Experimental and numerical investigation of stability of packed bed thermal energy storage for CSP power plant, Energy Procedia 49,743 - 751

Jemmal Y, Zari N, Maaroufi M., 2016. Thermophysical and chemical analysis of gneiss rock as low cost candidate material for thermal energy storage in concentrated solar power plants. Solar Energy Materials \& Solar Cells, 157, $377-382$.

Cascetta M, Cau G, Puddu P, Serra F., 2015. A study of a packed bed thermal energy storage device: test rig, experimental and numerical results. Energy Procedia, 81, 987-994

EESI, Solar Thermal Energy for Industrial Uses, 2011, http://www.eesi.org/files/solar_thermal_120111.pdf, (Access date: 26.01.2018)

Grosu Y., Fernández I. O., Fernández L. G., Nithiyanantham U., Baba Y., Mers A., Faik A., 2018. Natural and by-product materials for thermocline-based thermal energy storage system at CSP plant: Structural and thermophysical properties, Applied Thermal Engineering, 136, 185-193

Gutierrez A., AntoniGill, Aseguinolaza J., Barreneche C., Calvet N., Py X., Fernández A. I., Grágeda M., Ushak S., Cabeza L. F., 2016. Advances in the valorization of waste and by-product materials as thermal energy storage (TES) materials, Renewable and Sustainable Energy Reviews, 59, 763-783

International Energy Agency (IEA), Key World energy statics, 2017, http://www.iea.org/publications/freepublications/publication/KeyWorld2017.pdf (Access Date:07.01.2018)

Khare S., Amico M. D., Knight C., McGarry S., 2013. Selection of materials for high temperature sensible energy storage, Solar Energy Materials \& Solar Cells, 115, 114-122

Klein P., Roos T.H., Sheer T.J., 2015. Parametric Analysis of a High Temperature Packed Bed Thermal Storage Design for a Solar Gas Turbine, Solar Energy.

Kuravi S, Trahan J, Goswami Y, Jotshi C, Stefanakos E, Goel N., 2013. Investigation of a high temperature packed bed sensible heat thermal energy storage system with large sized elements. Journal of Solar Energy Engineering, 135:041008.

Mawire A., McPherson M., 2009. Experimental and simulated temperature distribution of an oil-pebble bed thermal energy storage system with a variable heat source, Applied Thermal Engineering 29, 1086-1095

Motte F., Falcoz Q., Veron E., Py X., 2015. Compatibility tests between Solar Salt and thermal storage ceramics from inorganic industrial wastes, Applied Energy, 155, 14-22

Oro E., Chiu J., Martin V., Cabeza L. F., 2013. Comparative study of different numerical models of packed bed thermal energy storage systems, Applied Thermal Engineering 50, 384-392

Paksoy H.Ö., 2007. Thermal energy storage for sustainable energy consumption fundamentals, Case Studies and Design, Editor, NATO Science Series, II. Mathematics, Physics and Chemistry - Vol 234, Springer.

Tiskatine R, Aharoune A, Bouirden L, Ihlal A., 2017. Identification of suitable storage materials for solar thermal power plant using selection methodology. Applied Thermal Engineering, 117, 591-608 


\title{
Encapsulation of Inorganic Phase Change Materials by Sol-Gel Method for Thermal Energy Storage
}

\author{
Beatriz Lucio, Manuel Romero, José González-Aguilar \\ IMDEA Energy Institute, Avda. Ramón de la Sagra, 3. 28935 Móstoles, Spain.
}

\begin{abstract}
The macroencapsulation of inorganic phase change materials (PCMs) for eventual application in latent heat thermal energy storage (LHTES) is herewith carried out by a multi-step preparation procedure. These steps are (1) pelletization and sintering (using different granulation techniques); (2) surface treatment (forming an intermediate polymeric layer) and coating via sol-gel method; and (3) final thermal treatment for the densification of the ceramic layer and polymer removal. Effectiveness and reproducibility of each procedure step as well as quality of layers were elucidated by means of Scanning Electron Microscopy (SEM) with Energy-Dispersive Xray spectroscopy (EDX) and mechanical crush tests. Macro-encapsulation procedure was optimized analyzing the thermal performance of capsules by Thermo-Gravimetric Analysis and Differential Scanning Calorimetry (TGA/DSC) and in a conventional oven.
\end{abstract}

Keywords: Inorganic PCMs, Macro-scale encapsulation, Sol-gel coating, Granulation techniques.

\section{Introduction}

Latent heat thermal energy storage (LHTES) is one option currently analyzed for concentrating solar power (CSP) plants. The primary features of LHTES lie to its high energy density and capability to operate in isothermal and low pressure conditions. For high-temperature solar thermal applications, phase change materials (PCMs) based on inorganics materials are promising candidates. However, there are some challenges such as the low thermal conductivity, the volume changes during the phase change and the contact surface area, where the effort must focus on the research (Nithyanandam et al., 2016). PCM encapsulation aims at improving the heat transfer between PCM and heat transfer fluid by increasing contact surface. Additionally it serves for two more purposes: (1) it prevents the phase segregation and sedimentation, and (2) it offers a high ratio of area for heat transfer to volume (Alva et al., 2017). Most common encapsulation methods for core-shell PCMs is the sol-gel method, being the only physical method for inorganic materials. Creating an intermediate polymeric layer between the salt and the shell prevents solid salt dissolution during the sol-gel application. On the other hand, an internal void space could provide the expected volume change of the salt, during the heating and melting (Milián et al., 2017).

This work addresses the development of a procedure of encapsulation of inorganic salts shaped in cylindrical pellets on the millimeter-scale, through sol-gel method using dense shells. In order to achieve the best conditions to obtain good quality coatings, different granulations techniques, surface treatments and several ceramic shells have been analyzed. Sodium nitrate and sodium chloride have been retained as representative PCMs, since their melting points (approx. 300 and $800^{\circ} \mathrm{C}$, respectively) are typical temperature ranges in CSP. Titania and silica coatings have been selected to perform the shells. It should be highlighted the potential cost reduction due to the availability of the materials and simplicity of the methods employed in the manufacturing. Customized analysis and experiments have been used to discriminate and to assess the behavior of the products under the working conditions of the aimed application. The characterization methodology employed in this study, which is based on widespread tools used in material research such as SEM-EDX, Dynamometer and TGA/DSC, could became a protocol that allow for comparing researches in the field of the macroencapsulation of PCMs. 


\section{Experimental}

\subsection{Sample preparation}

The products from the multi-step macroencapsulation procedure are illustrated in Fig. 1, and their preparation was performed as follows:

1. Pelletization and sintering. Two granulation methods were used. The first technique is based on a wet method and produces cylindrical pellets with a diameter of $3 \mathrm{~mm}$ and with $2 \mathrm{~mm}$ of length. In this pelletization, each milled salt was mixed with an additive and water, in a weight ratio of Salt:Additive:Water equal to 10:1:1. As organic binder (OB), oxalic acid (OA) was selected for sodium nitrate and hemicellulose (HC) for sodium chloride. These choices were made taking into account the consistence of the products, being discarded other employed organic compounds. The mixtures were placed in a mold and dried. The second method via dry granulation produces tablets (13 mm of diameter), through which milled salts were compacted under pressure into a mold, using a manual hydraulic press. After pelletization, pellets and tablets were subjected to a first thermal treatment, for the removal of the additive and the sintering of the salt grains. Due to the different physical properties of the salts, the thermal treatment in a conventional oven was specifically designed for each one.

2. Surface treatment and coating. Second step for the encapsulation procedure is the sacrificial layer forming, through the impregnation of the agglomerated salt in a solution of polymer (poly-methyl methacrylate or PMMA in benzene). After that, granules were allowed to dry. For the surface treatment, other methods were explored such as the multi-layer forming and also a process of melting the polymer on the substratum. Subsequently, for dense ceramic shell forming two different sols of silica and titania were employed, and after the dip-coated, a drying treatment was included. The process with the coupled steps of immersiondrying, was repeated 3 times obtaining multiple ceramic layers.

3. Final thermal treatment. A treatment at higher temperature was performed to densify the film over the substratum, and at the same time, to decompose the polymer.

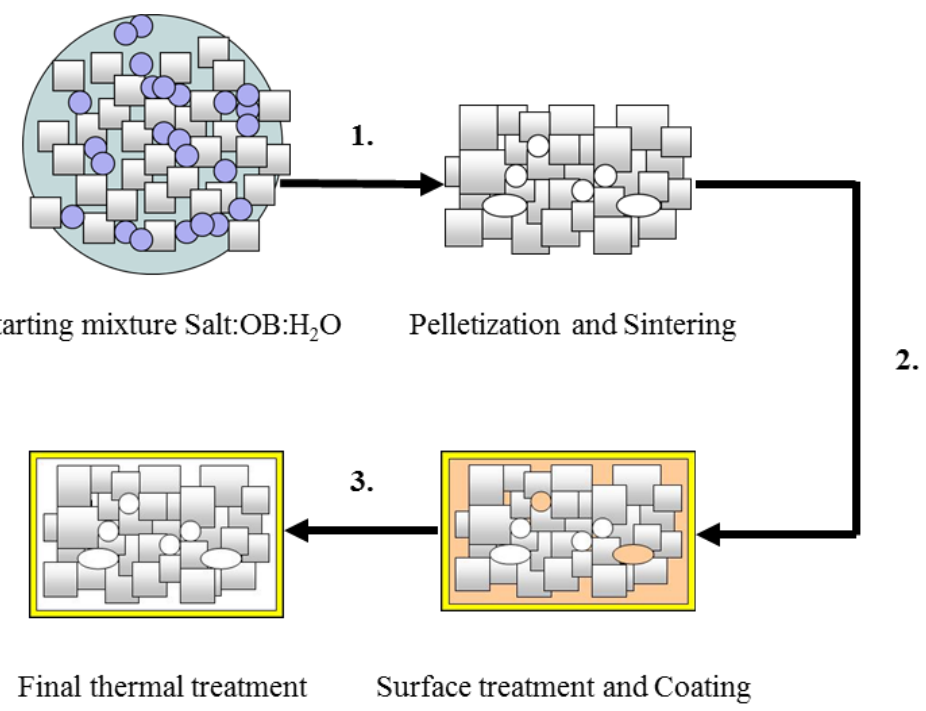

Fig 1. Macroencapsulation procedure.

\subsection{Structural and thermal characterization of EPCM}

Surface morphology and structure were observed using a scanning electron microscope (SEM) with a TM-1000 Hitachi equipment. This instrument had an energy-dispersive X-ray spectroscopy (EDX) unit, which allows determining the local composition. Samples' volume and density were estimated from the average dimensions and weight of three randomly-chosen samples. Mechanical resistance under compression was studied over the pellets using a dynamometer (Chatillon MT Ametek). Here samples were placed between two parallel plates and subjected to a compressive force until failure and the measurements where performed ten times obtaining the mean value. Designed thermal experiments were used to estimate the thermal resistance of the EPCMs. The first 
cyclic test consisted of heating pellets in a conventional oven (Naberthem LHT 02/16 - LHT 08/18 series) in air at $10^{\circ} \mathrm{C} \mathrm{min}^{-1}$, from room temperature up to $50^{\circ} \mathrm{C}$ above the melting point of the salt and the subsequent cooling. This is repeated five times. The phase change properties of coated PCMs were evaluated through a second thermal characterization run in parallel via thermo-gravimetric analysis and differential scanning calorimetry (TGA/DSC). The equipment used was an SDT Q600 by TA Instruments, with a balance sensitivity of $0.1 \mu \mathrm{g}$ and a calorimetric accuracy of $\pm 2 \%$. Measurements were performed using a heating/cooling rate of $10{ }^{\circ} \mathrm{C} \mathrm{min}{ }^{-1}$ and an air flow rate of $100 \mathrm{~mL} \mathrm{~min}^{-1}$.

\section{Results and discussion}

\subsection{Optimization of the steps of the encapsulation procedure over tablets}

The appearance of the sintered granules is shown on the left side of Figure 2 for $\mathrm{NaNO}_{3}$. The wet granulation produces cylindrical pellets $3 \mathrm{~mm}$ in diameter and $2 \mathrm{~mm}$ in length, of which dimensions vary after the sintering step (Figure 2.a). As can be observed in the SEM micrograph on the right side of Figure 2, the pellets present a rough and porous surface due to the additive removal in the sintering treatment. Figure 2.b) shows tablets, which present $13 \mathrm{~mm}$ in diameter, obtained by dry granulation. From micrograph, tablets microstructure seems to be composed of particles of a size smaller than $20 \mu \mathrm{m}$ connected by the grain boundaries. Tablets possess a more compact structure than pellets and their smooth and flat surface was useful to assess the effectiveness of each step on macroencapsulation using SEM micrographs.

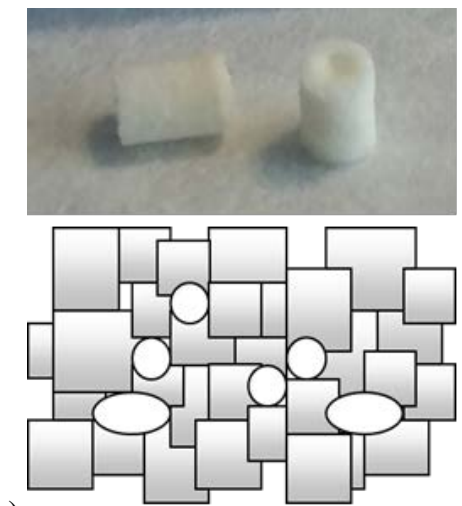

a)
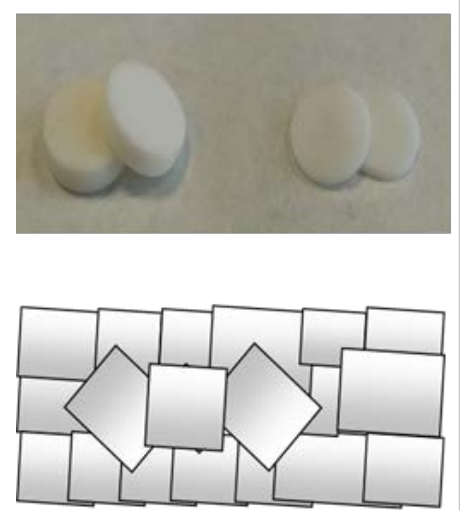

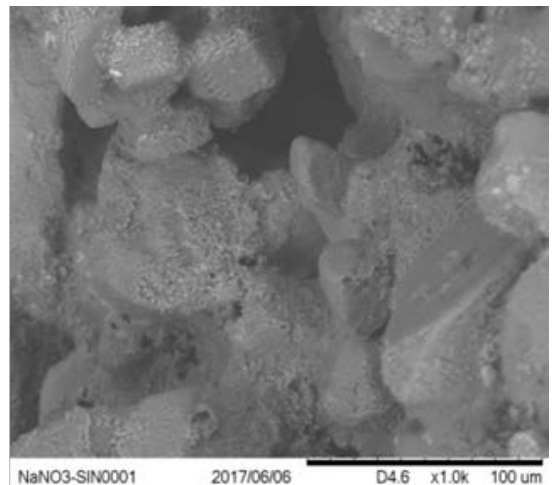

NaNO3.SIN0001 $2017 / 06 / 06$

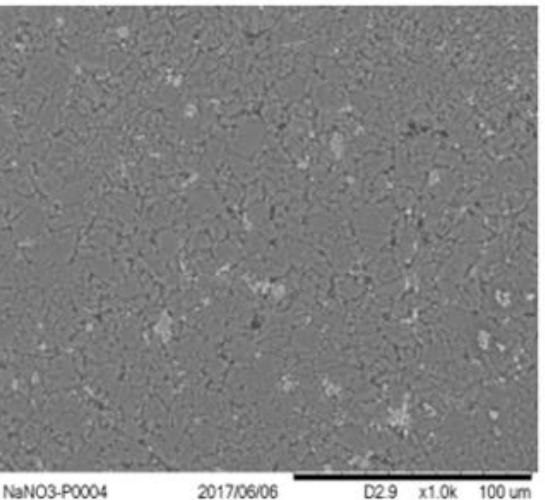

b)

Fig 2. (a) Pellets and (b) tablets made of $\mathrm{NaNO}_{3}$.

Thus, after granulation the next step applied is the sacrificial layer forming, made with PMMA. In this point, different methods were explored, obtaining the best surface treatment by applying three consecutive impregnations of tablets in the solution of polymer.

The last step applied for the macroencapsulation procedure is the ceramic shell made of $\mathrm{SiO}_{2}$ and $\mathrm{TiO}_{2}$. To form the capsules over substratum, the treated tablets were immersed into the corresponding sol using the dip-coating technique and a drying treatment was included for solvent removal, obtaining a xerogel. A final thermal treatment 
at higher temperature was necessary to be applied in order to densify the metal oxide film over the tablets. In this step, the multiple ceramic coverings were also explored. The micrographs of Figure 3 show the extension of the silica coating when a single or triple layer was deposited over tablets of sodium nitrate. In the single-layer sample, there were some sheets of ceramic material embedded in the salt and the area quantification of silicon element was of 52 wt.\%. Although cracked, the metal oxide layer was of a greater coverage when we resorted to the multiple coating, given that Si content achieved $80 \mathrm{wt}$ \% in this zone. Thus, multiple depositions of sols could be considered as the optimized method for the step of the ceramic shell forming. This is a widespread conclusion among all the macroencapsulations performed, regardless of the salt and the sol employed.
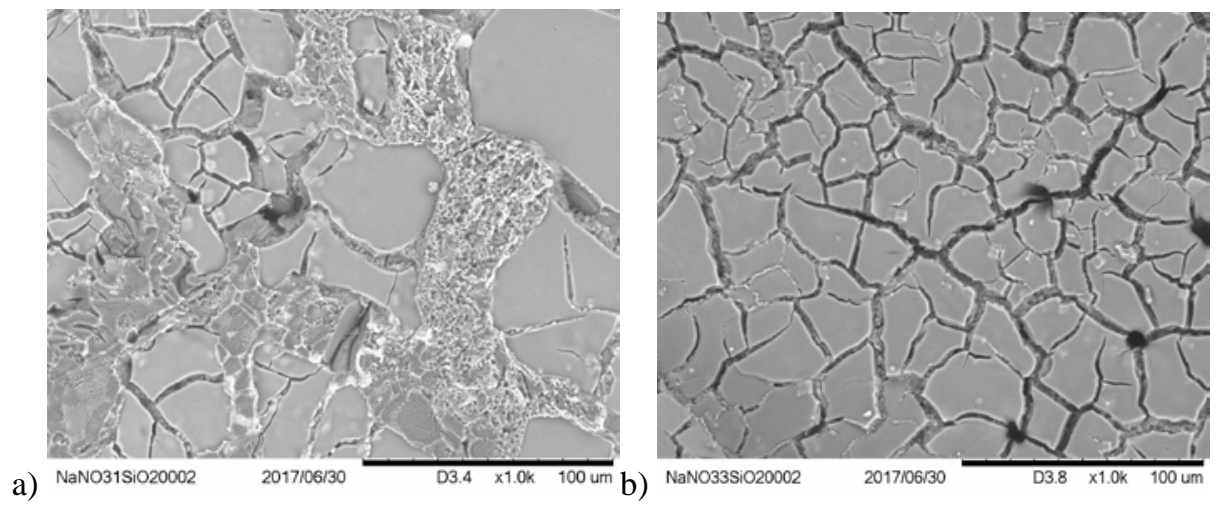

Fig. 3. Tablets of $\mathrm{NaNO}_{3}-\mathrm{PMMA}^{-\mathrm{SiO}_{2}}$ coated with $\mathrm{SiO}_{2}$. (a) Single and (b) multiple coating.

From the structure analysis of the coatings over nitrate tablets, it can be claimed silica provide better results than the $\mathrm{TiO}_{2}$ sol taking into account the extension of the metal oxide layers. Titania seems to cover better $\mathrm{NaCl}$ surfaces. Regarding the interaction between the polymer layer and the ceramic shells, it was observed that $\mathrm{SiO}_{2}$ coated better than $\mathrm{TiO}_{2}$ on surfaces previously covered by PMMA.

Additionally a first assessment on the reproducibility of the procedure showed that careful analysis on synthesis parameters should be performed. Finally, effect of the aging time of sols were also studied and it was confirmed changes on surface morphology using aged sols.

\subsection{Appearance and mechanical properties}

Once determined the best conditions of the macroencapsulation procedure, these were applied over cylindrical pellets. Appearance, size, density and mechanical strength (resistance) were examined after each macroencapsulation stage, from the wet granulation products to the resulting EPCMs. This characterization allowed for identifying and quantifying how the macroencapsulation stages affect each specimen and their main features are summarized in Table 1.

Table 1. Evolution of the parameters for pellets.

\begin{tabular}{llll}
\hline Parameter & \multicolumn{2}{l}{ Salt/OB/Sol-gel: $\mathrm{NaNO}_{3} / \mathrm{OA} / \mathrm{SiO}_{2}$} & \\
& $\begin{array}{l}\text { After } \\
\text { Pelletization }\end{array}$ & $\begin{array}{l}\text { After } \\
\text { Sintering }\end{array}$ & $\begin{array}{l}\text { After } \\
\text { Encapsulation }\end{array}$ \\
\hline Color & White & Light yellow & Brown \\
Structure & Granular & Compact & Wrinkled surface \\
Volume $\left(\mathrm{cm}^{3}\right)$ & 0.023 & 0.022 & 0.033 \\
Density $\left(\mathrm{g} / \mathrm{cm}^{3}\right)$ & 1.557 & 1.329 & 1.370 \\
Resistance $(\mathrm{N})$ & 8 & 19 & 39 \\
\hline Color & Salt/OB/Sol-gel: $\mathrm{NaCl} / \mathrm{HC} / \mathrm{TiO} 2$ & \\
Structure & Light brown & Light grey & Light grey \\
Volume $\left(\mathrm{cm}^{3}\right)$ & Granular & Granular & Granular \\
Density $\left(\mathrm{g} / \mathrm{cm}^{3}\right)$ & 0.018 & 0.015 & 0.014 \\
Resistance $(\mathrm{N})$ & 1.228 & 1.229 & 1.201 \\
\hline
\end{tabular}


The sample of $\mathrm{NaNO}_{3}$ agglomerated with OA, after being taken out from the mold and allowing to dry (Figure 4.a), possesses white and granular homogeneous surface, a well-defined cylindrical shape and mechanical consistency, withstanding a force of $8 \mathrm{~N}$ before crush. After OB removing and salt sintering (Figure 4.b), the appearance changes to a more compact and yellowish structure. Density has decreased, and compression resistance has increased. When the triple coat of $\mathrm{SiO}_{2}$ is densified over pellet (Figure 4.c), volume suffers an expansion (final volume, $33 \mathrm{~mm}^{3}$ ), and mechanical properties has been improved much more (final resistance, $39 \mathrm{~N}$ ), being compared with the initial pellet. A final rough and brown surface suggests color is provided by the components of the gel or the presence of calcination products coming from the organic binder (OA) or from the plastic sacrificial layer.

a)

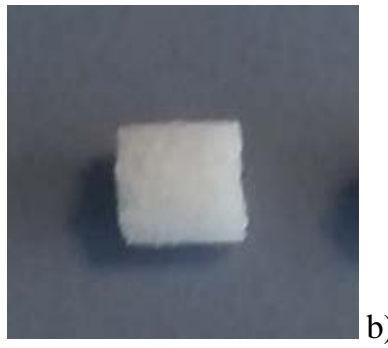

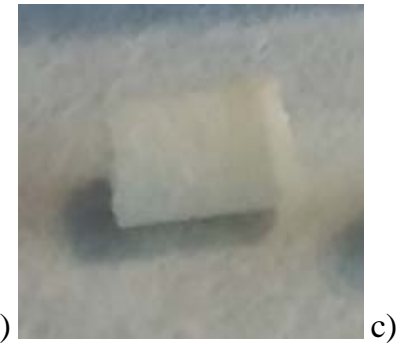

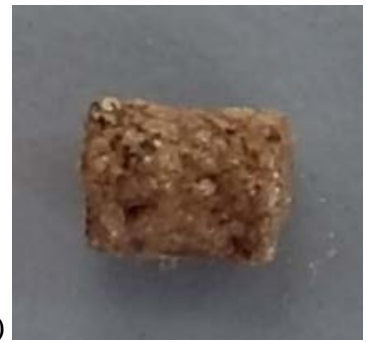

Fig. 4. Evaluation of appearance for the pellets $\mathrm{NaNO}_{3} / \mathrm{OA} / \mathrm{SiO}_{2}$.

As Figure 5 shows, the initial sample of $\mathrm{NaCl}$ with $\mathrm{HC}$ presents a dark color and irregular shape. When the layer of $\mathrm{TiO}_{2}$ is applied, a sample with a light grey granular structure is obtained. This is the smallest (final volume, 14 $\mathrm{mm}^{3}$ ) and least dense pellet, with the highest mechanical properties (final resistance, $69 \mathrm{~N}$ ).

a)

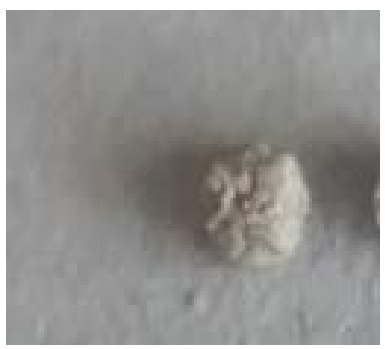

b)

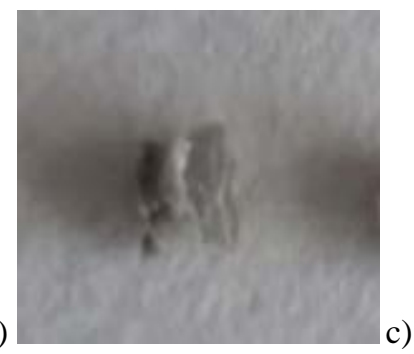

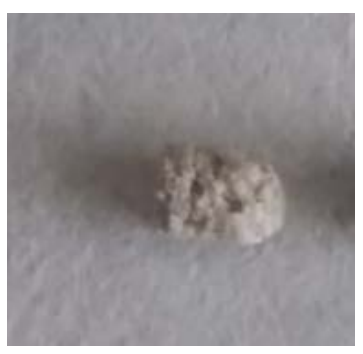

Fig. 5. Evaluation of appearance for the pellets $\mathrm{NaCl} / \mathrm{HC} / \mathrm{TiO}_{2}$.

\subsection{Thermal characterization of the pellets under working conditions}

The thermal characterization procedure was described in section 2.2. Thermal tests provide the response of the products in terms of thermal stability for using in storage systems. For $\mathrm{NaCl}$ pellets, the maximum testing temperature was $850{ }^{\circ} \mathrm{C}$. It was observed that the free volume in these products could not be enough to house all the amount of molten salt. In addition, the formed shell could not be dense or sealed enough to overcome the test. Anyway, relative high vapor partial pressure of this salt at the liquid state $\left(4 \cdot 10^{-4}\right.$ at $\left.801^{\circ} \mathrm{C}\right)$, causes its vaporization during the successive cycles. $\mathrm{NaNO}_{3}$ samples could have higher thermal stability because of a lower vapor pressure at the melting point $\left(1.7 \cdot 10^{-46}\right.$ at $\left.308^{\circ} \mathrm{C}\right)$. This characterization allowed us to discriminate pellets made of $\mathrm{NaCl}$.

Thermal stability and thermal performance in cycling are both important properties to thermal storage materials. So the second characterization for the capsules was carried out via TGA/DSC. This technique enables to link the latent heat and temperature during the phase change. Figure 6 shows thermogravimetric and calorimetric curves of $\mathrm{NaNO}_{3} / \mathrm{OA} / \mathrm{SiO}_{2}$ pellet obtained in $200-350{ }^{\circ} \mathrm{C}$ range and for 5 consecutive cycles. DSC results are collected in Table 2. 


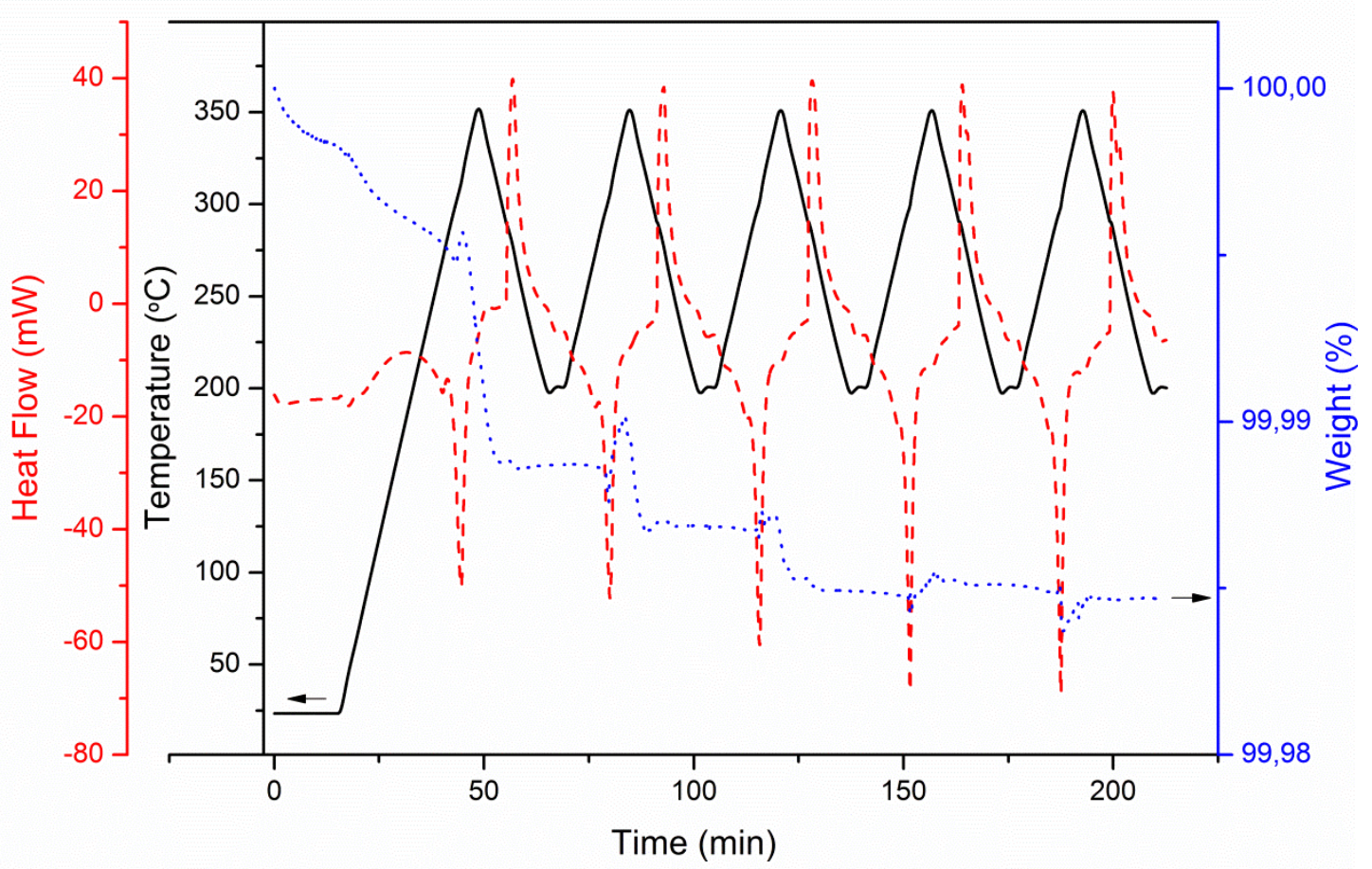

Figure 6. Cyclic TGA/DSC of $\mathrm{NaNO}_{3} / \mathrm{OA} / \mathrm{SiO}_{2}$ pellets under dynamic conditions at $10{ }^{\circ} \mathrm{C} / \mathrm{min}$, from 200 to $350{ }^{\circ} \mathrm{C}$ and air flow of $100 \mathrm{ml} \mathrm{min}^{-1}$.

Tab. 2. Calorimetric results of the characterization for $\mathrm{NaNO}_{3} / \mathrm{OA} / \mathrm{SiO}_{2}$ pellets.

\begin{tabular}{ccccc}
\hline Cycle & $\boldsymbol{T}_{\boldsymbol{m}}\left({ }^{\circ} \mathbf{C}\right)$ & $\boldsymbol{\Delta H}_{\boldsymbol{m}}(\mathbf{J} / \mathbf{g})$ & $\boldsymbol{T}_{\boldsymbol{s}}\left({ }^{\circ} \mathbf{C}\right)$ & $\Delta \boldsymbol{H}_{\boldsymbol{s}}(\mathbf{J} / \mathbf{g})$ \\
\hline 1 & 309 & 113 & 275 & 161 \\
2 & 304 & 93 & 277 & 166 \\
3 & 301 & 95 & 284 & 172 \\
4 & 299 & 99 & 284 & 175 \\
5 & 301 & 97 & 288 & 172 \\
\hline
\end{tabular}

From calorimetric curve (dashed red line in Figure 6), the initial melting peak of $\mathrm{NaNO}_{3} \mathrm{EPCM}$ is located at $309{ }^{\circ} \mathrm{C}\left(T_{m}\right)$. This maximum of rate fluctuates slightly from the second cycle until the end of the run. Thus, mean value of melting point is $303^{\circ} \mathrm{C}$. Regarding the mean value of the latent heat to achieve the liquid state $\left(\Delta H_{m}\right)$, it is $99 \mathrm{~J} \mathrm{~g}^{-1}$. Solidification heat $\left(\Delta H_{s}\right)$ could be considered as $169 \mathrm{~J} \mathrm{~g}^{-1}$, on average. Freezing peak $\left(T_{s}\right)$ is observed at approximately $30{ }^{\circ} \mathrm{C}$ lower than the melting temperature.

On the other hand, TGA/DSC equipment registered simultaneously the changes of the mass while the process was happening. In this case, there is not a considerable loss of mass in each cycle (dotted blue line in Figure 6), where the lost scarce exceeds $1 \%$ of the pellet. Thus loss of mass can be considered negligible and TGA/DSC results indicate that $\mathrm{NaNO}_{3} / \mathrm{OA} / \mathrm{SiO}_{2}$ pellet exhibits promising capabilities to store thermal energy.

\section{Conclusions}

A macroencapsulation multi-step procedure was developed for two inorganic salts and applied to produce cylindrical pellets for thermal energy storage in concentrated solar power plants. Encapsulated phase change materials consisted of an inorganic core composed of sodium chloride or sodium nitrate and two concentric layers made of polymethyl methacrylate and silica or titania by sol-gel process, with subsequent removal of the polymer.

Pellets and tablets were obtained through two different granulation methods. Pellets presented rougher and higher 
porosity than tablets, so the effectiveness of each macroencapsulation step was initially evaluated and optimized over tablets. These steps were the surface treatment, the drying step for the sol-gel method and the multi-layer ceramic coating. Microstructure of the shells, mechanical properties of pellets, thermal stability and thermal behavior, allowed to select the best coating for each substrate.

$\mathrm{NaNO}_{3}$ samples with the optimal surface treatment and optimal coating made of $\mathrm{SiO}_{2}$, presented a better aptitude as phase change material than $\mathrm{NaCl}$ core-shell products, for a thermal energy storage system. Thus, the core melting of $\mathrm{NaNO}_{3}$ EPCMs will allow to work under isothermal conditions and it can help to solve the efficiency problem in solar thermal power plants based on steam/water thermodynamic cycles.

\section{References}

Alva, G., Liu, L., Huang, X., Fang G., 2017. Thermal energy storage materials and systems for solar energy applications. Renew. Sustain. Energy Rev. 68, 693-706.

Milián, Y.E., Gutiérrez, A., Grágeda, M., Ushak, S., 2017. A review on encapsulation techniques for inorganic phase change materials and the influence on their thermophysical properties. Renew. Sustain. Energy Rev. 73, 983-999.

Nithyanandam, K., Stekli, J., Pitchumani, R., 2016. High-temperature latent heat storage for concentrating solar thermal (CST) systems. Elsevier Ltd. 


\title{
Preliminary Results for the First Year of Operation of a Seasonal Storage Solar Combisystem for a Single Detached House
}

\author{
Curtis Meister and lan Beausoleil-Morrison \\ Carleton University, Ottawa (Canada)
}

\begin{abstract}
This work describes the operation of a solar combisystem equipped with a buried water tank for seasonal storage. The combisystem supplies space heating and domestic hot water to a single-detached house in a cold climate. The system was operated over the summer of 2017 through spring of 2018, and achieved solar fractions of $66 \%$ and $60 \%$ for space heating and domestic hot water, respectively. However, a number of issues prevented consistent operation and/or monitoring of the system, and the solar thermal array was found to underperform significantly. Thus, the results of this cycle should not be taken as the definitive performance of such a system. The data collected from the system's first year of operation will be used to develop and validate models of the seasonal storage tank and other system components.
\end{abstract}

Keywords: seasonal storage, solar thermal, solar combisystems, solar heating

\section{Introduction}

Our reliance on fossil fuels in the residential sector could be drastically reduced by replacing conventional space and hot water heating systems with solar combisystems. Solar combisystems provide space heating and hot water to loads through solar-thermally-charged hot water storage tanks. Solar combisystems are typically equipped with short-term heat storage, referred to herein as diurnal thermal energy storage (DTES). The DTES would consist of one or multiple hot water tanks, typically less than 1000 litres in volume. Combisystems with diurnal heat storage have usually been shown to produce solar fractions ranging from 50-60\% (see: Dincer and Rosen (2011), Edwards (2014)), or in optimized cases, upwards of 70\% (Ray and Zmeureanu (2018)). To meet a higher fraction of space heating and domestic hot water loads, solar combisystems will need to take advantage of excess solar heat availability in the summer. Seasonal thermal energy storage (STES) aims to do so. Rather than storing solar heat for a few days, seasonal stores should store heat for several months, such that energy is available when loads peak mid-winter.

Seasonal storage has thus become an active area of research. In the 1980s, Task 7 of the International Energy Agency's (IEA) Solar Heating and Cooling (SHC) program focused on central heating plants with STES. As a result of the program, a large number of district STES systems were installed in Europe (over 20, according to Ochs et al. (2009)). Several types of STES were built, including buried water tanks, rockpits, borehole fields, and underground water caverns (aquifers). These systems typically achieved solar fractions of 50-60\% for space heating and DHW (Bauer et al (2010), Ochs et al. (2009), Schmidt et al (2004)). Nearly all of the systems reported experienced higher than expected storage losses. Ochs et al. (2009) attribute this to moisture diffusion within the storage insulation, and provides a method for calculating an estimated "effective conductivity" of moist insulation.

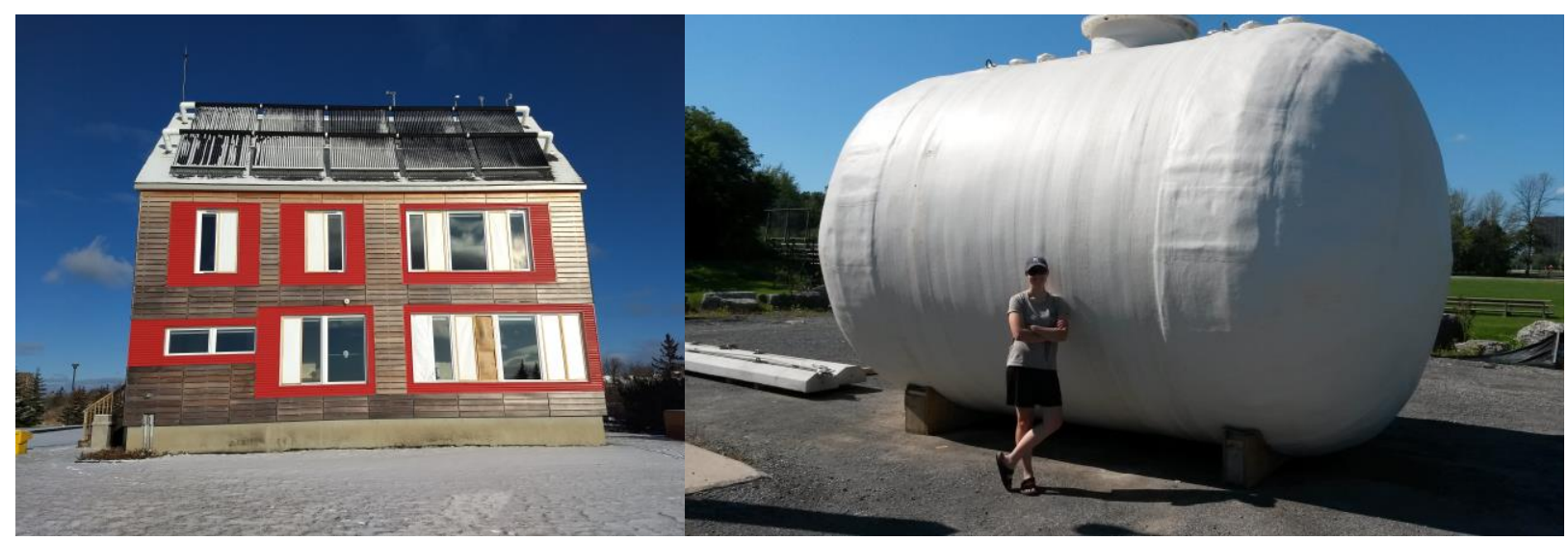

a)

b)

Fig. 1: a) The Urbandale Centre for Home Energy Research and b) Seasonal Storage Tank Installation 
Recent attempts at district STES have achieved a better thermal performance. The Drake Landing Solar Community (DLSC) is detailed in Mesquita et al. (2017) and Sibbitt et al. (2012). The DLSC is a 52-house community with an average heated floor area of $145 \mathrm{~m}^{2}$. It uses $2293 \mathrm{~m}^{2}$ of flat plate solar collectors to charge a large field of 144 boreholes used as seasonal storage. Over the past 5 years, the DLSC has achieved an average annual solar fraction of $96 \%$ for space heating (Mesquita et al. (2017)).

Seasonal storage has received less attention on the smaller single-home scale, especially in terms of experimental systems. Colcough et al. (2011) outlines a STES system that was installed on a passive house in Ireland. The system had a $10.8 \mathrm{~m}^{2}$ evacuated tube solar array, 300 litre DTES tank and a $23 \mathrm{~m}^{3}$ STES tank. The system achieved solar fractions of 56\% and $93 \%$ for space heating and domestic hot water respectively. The researchers found that losses from the STES tank were significant, up to double the design value (Clarke (2014)). While a high solar fraction experimental combisystem was not found in the literature, several authors have presented simulated systems that have achieved high solar fractions. In the precursor to this work, Wills (2013) and Kemery (2017) simulated solar combisystems with STES for a single-detached house in Ottawa, Canada. Wills (2013) found that a flat-plate based combisystem could achieved an $89 \%$ solar fraction utilizing an $80 \mathrm{~m}^{3}$ STES tank. Kemery (2017) simulated a STES system similar to the as-built system described in this work, and found that solar fractions over $93 \%$ were attainable. Hugo and Zmeureanu (2010) found that solar fractions of over 93\% could be attained for a house in Montreal, Canada with tank sizes ranging from $27-39 \mathrm{~m}^{3}$.

Clearly, there exists potential for STES systems to meet the majority of energy demands for single detached homes. However, this potential has not yet been demonstrated via full-scale experiment. This work aims to fill this knowledge gap. To this end, this work describes the performance of a combisystem with STES installed at the Urbandale Centre for Home Energy Research (CHEeR) in Ottawa, Canada. The system (Figure 1) features an evacuated tube solar array of gross area $43 \mathrm{~m}^{2}$ and a buried seasonal storage tank that is approximately $36 \mathrm{~m}^{3}$ in volume. Data on the various energy flows in the system were collected over the first proper heating season under operation. In this paper, we present the results of the heating season and identify a number of areas of underperformance.

\section{Experimental Setup}

\subsection{Solar Combisystem with Seasonal Storage Tank}

Figure 2 shows a schematic of the solar combisystem. The solar array features ten sets of 30-tube evacuated tube collectors, arranged in two parallel lines and tilted at $60^{\circ}$. The array can charge either the STES tank or DTES Tank A. DTES Tank A can subsequently exchange water with Tank B and C. Because a form of glycol is used in the collector loop, all solar charging is indirect, i.e. a heat exchanger and separate pump are used on the tank side of the solar charging loop. The seasonal storage tank is $36 \mathrm{~m}^{3}$ in volume. It is buried behind the house to minimize heat losses, and has $30.5 \mathrm{~cm}$ of spray-on polyurethane insulation. This gives the tank a nominal $\mathrm{U}$-value of $0.075 \mathrm{~W} / \mathrm{mK}$.

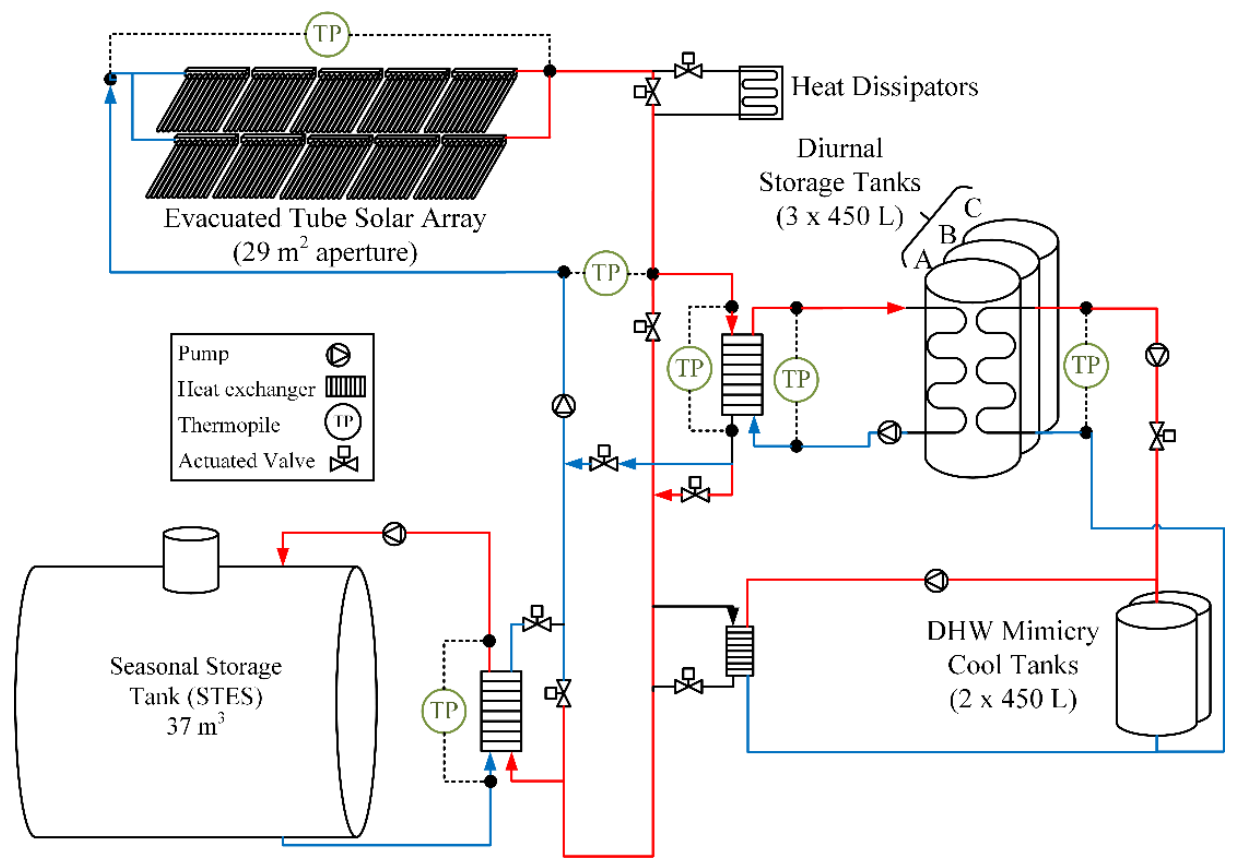

Fig. 2: Simplified schematic of CHEeR's solar thermal system with seasonal storage 
Space heating is performed through a hydronic radiant floor, which can be heated by either the STES tank or through DTES Tank B or C. Thus, space heating via the DTES requires solar heat from Tank A to be transferred to Tank B or C. A small pump can move water from Tank A to either tank B or C to do so. Domestic hot water is supplied exclusively from DTES A. Because the house does not have mains water connection, mains water is mimicked. Hot water from the tank is exchanged with two cool tanks, which are cooled via the solar loop's dissipators overnight. This configuration thus limits the effectiveness of heat exchange in summer months, as the cool tanks do not always reach realistic mains water temperatures. More detail on the research house and the combisystem's instrumentation and design is provided in Meister and Beausoleil-Morrison (2017).

\subsection{Control of the Solar Combisystem}

Meister and Beausoleil-Morrison (2017) give the general control scheme for the combisystem used in this research. The solar pump turns on when a pyranometer senses a collector-plane irradiance of more than $150 \mathrm{~W} / \mathrm{m}^{2}$. The system "preheats" the solar loop until an RTD on the array senses a temperature $3^{\circ} \mathrm{C}$ above any active load. The system then directs flow to charge whichever load was exceeded. A priority and setpoint based system is implemented in the control scheme to help ensure both space heating and domestic hot water loads are met. The priorities for solar charging were as follows:

1. Charge DTES Tank A to $55^{\circ} \mathrm{C}$ to meet domestic hot water loads.

2. (If DTES Tank B/C active for space heating) Charge DTES tanks to $70^{\circ} \mathrm{C}$.

3. Charge STES to $93^{\circ} \mathrm{C}$.

Space heating had a similar priority system. The supply temperature for the radiant floor was $30^{\circ} \mathrm{C}$. If either DTES Tanks B and C or the STES was over $30^{\circ} \mathrm{C}$ at its top, it was eligible for space heating. For space heating, heating via the diurnal storage is prioritized over the STES tank. If neither thermal store exceeded the desired supply temperature, the auxiliary boiler would turn on. For the heating season reported here, only DTES Tank A and B were operated. While Tank A operated throughout the season, Tank B was enabled from January 26-February 27, 2018

\subsection{Virtual DTES Tank}

As many experiments take place at the CHEeR house, it was not possible to access the DTES tanks for the entire testing period. Thus, to emulate the effect of charging the diurnal storage when the real DTES was unavailable, a "virtual tank" was simulated in the control scheme. In reality, charging the virtual tank consisted of dissipating solar heat to the ambient air via the heat dissipators. The virtual tank consisted of a simple lumped-heat capacitance model of the real DTES Tank A. It would gain heat in response to the measured heat dissipation rate, and lost heat via standing losses and domestic hot water demands. When operated, the virtual DTES tank was controlled in the same fashion as the real DTES tank. The virtual tank was used in place of the real DTES from August 15 to October 16, 2017.

\section{Preliminary Results}

This section present preliminary results from operating the STES system through its first heating season. Results are presented starting July 27,2017 , when the data collection system was fully commissioned, through to the end of the heating season in late April. Figure 3 shows the temperature of the seasonal storage tank throughout this period. As reported in Meister and Beausoleil-Morrison (2017), a cooldown test of the seasonal storage tank was conducted from July 17 to August 7, after which charging of the STES continues. The peak temperature reached by the STES tank was approximately $80^{\circ} \mathrm{C}$ in early October. To begin the heating season, the DTES tanks were not yet configured to allow space heating, and thus, all space heating came from the STES tank. From the time space heating began in late October until late December, much of the tank's stored heat was already depleted. Regrettably, a key period of data (Dec 22 - Jan 4th) was lost due to a power failure. This period of data represented the coldest stretch of the year in Ottawa, with average daily temperatures falling below $-25^{\circ} \mathrm{C}$. It is evident from Figure 3 that the STES temperature dropped significantly over this period, falling below $30^{\circ} \mathrm{C}$ when data becomes available on January $5^{\text {th }}$. 


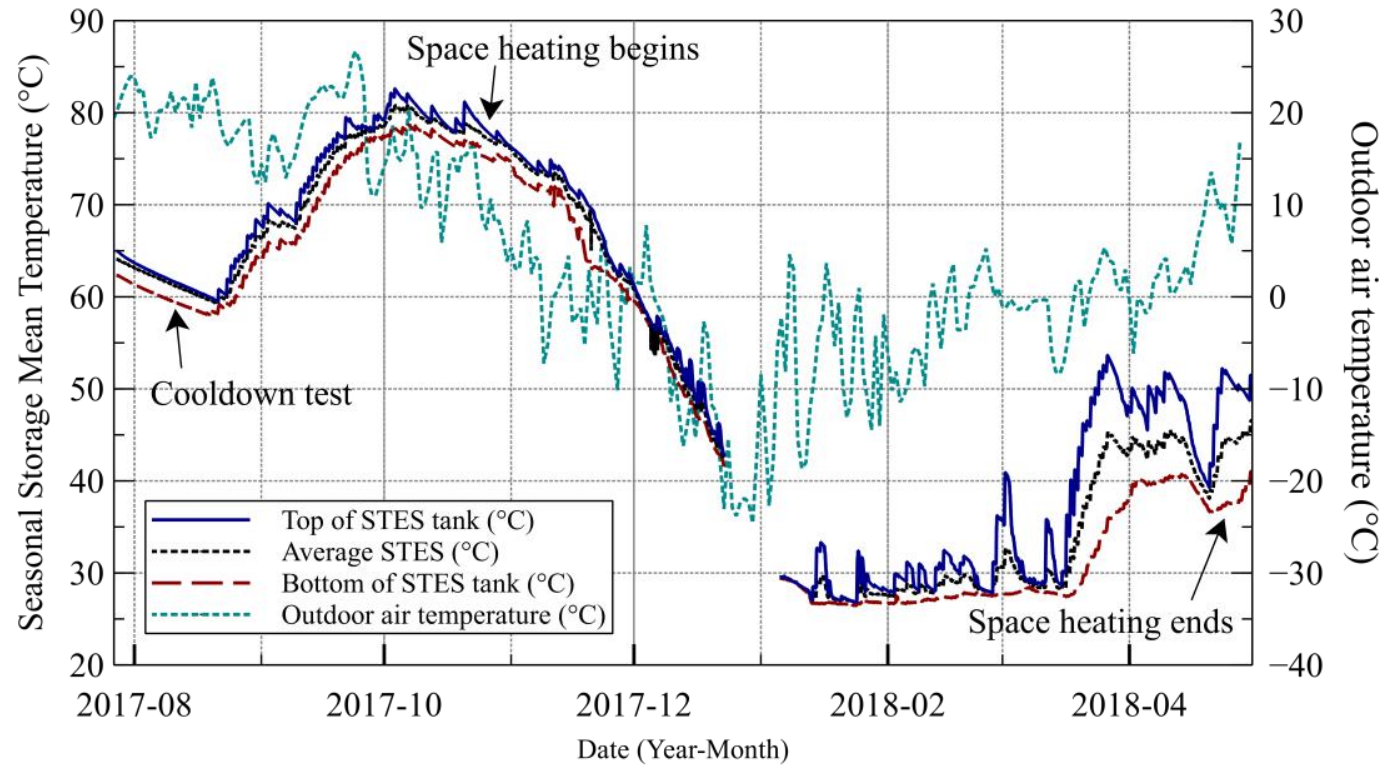

Figure 3: Seasonal storage tank and outdoor air temperatures

The diurnal storage was configured to supply space heating through DTES Tank B on January $26^{\text {th }}$. Once enabled, much of the solar heat was directed to the DTES tanks, thus the STES tank temperature remained relatively constant. DTES Tank B was enabled throughout January and February, after which the STES temperature begins to rise again. The pump speed through the STES tank was lowered from approximately $11 \mathrm{~L} / \mathrm{min}$ to $5.5 \mathrm{~L} / \mathrm{min}$ in February. This change can be seen to significantly increase stratification in the STES tank during charging, however, discharging appears to rapidly destroy the stratification achieved.

\subsection{Solar Collection}

Figure 4 presents an overview of the measured energy supplied to each storage tank throughout the period of analysis. Solar thermal generation was highest in March, when the STES was at a low temperature, and in August and September. Note that results for August only include data for 18 days of the month. Table 1 shows the number of days analyzed in each month.

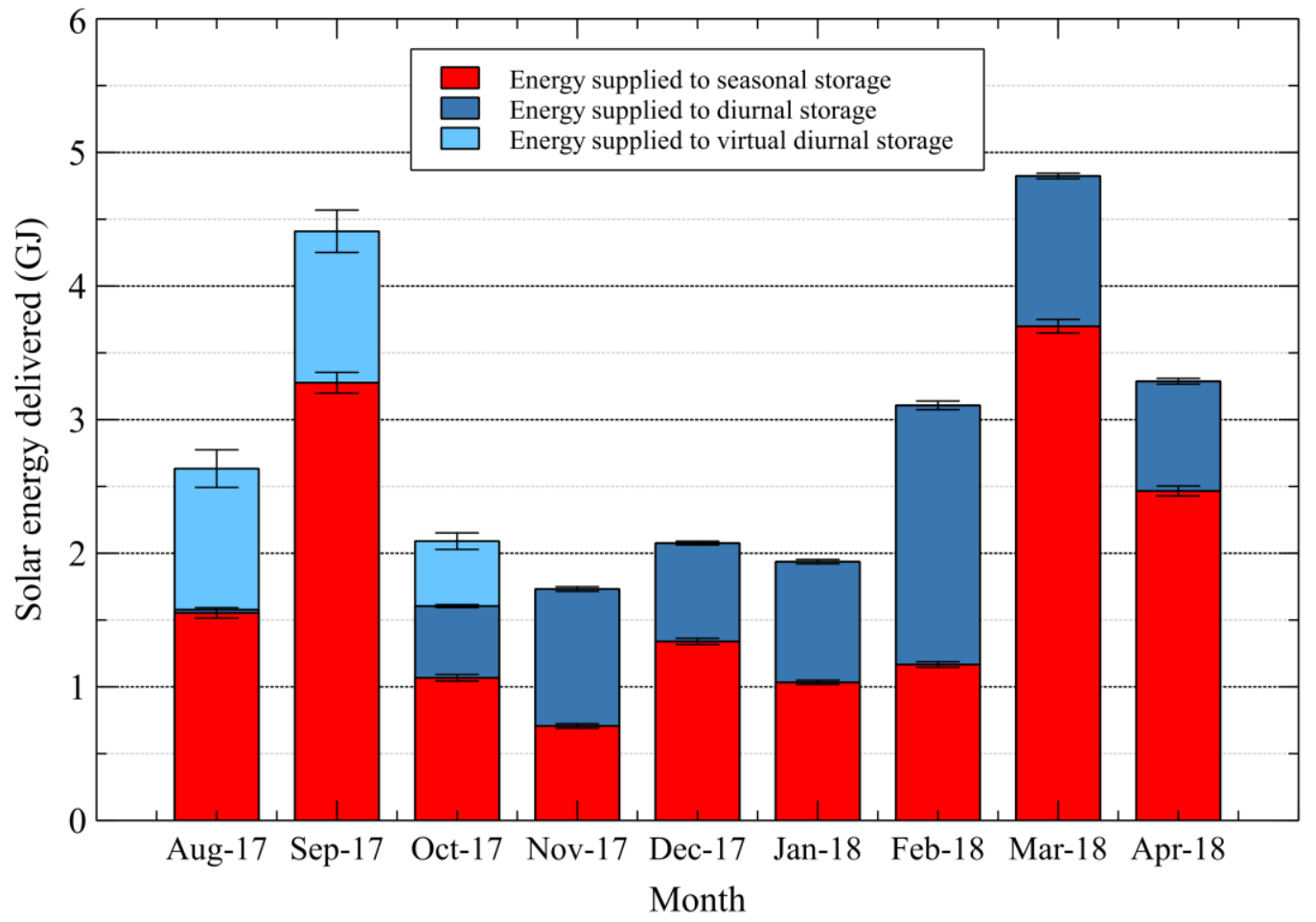

Fig. 4: Solar energy delivered to thermal storage tanks 
Tab. 1: Number of days of data recorded in each month

\begin{tabular}{|c|c|c|c|c|c|c|c|c|}
\hline August & September & October & November & December & January & February & March & April \\
\hline 18 & 30 & 30 & 30 & 22 & 26 & 27 & 31 & 29 \\
\hline
\end{tabular}

\subsection{Space Heating}

Figure 5 shows the distribution of space heating energy over the analysis period. Through December, all space heating was provided by the STES tank. The space heating energy for the missing data period is not shown here, but is estimated to be approximately 2 GJ. When the STES was depleted in January, the auxiliary boiler supplied most of space heating loads until DTES Tank B was enabled on January 26. DTES Tank B remained on for nearly all February, providing $38.6 \%$ of space heating for this period. Contrasting January and February, it is evident that enabling diurnal storage for space heating improves thermal performance. The solar fractions for space heating were $29 \%$ and $52 \%$ in January and February, respectively. Notably, the measured total space heating load for the year was only $10 \mathrm{GJ}$, or approximately $12 \mathrm{GJ}$ with the estimated load during the missing data period. Previous simulation work by Kemery (2017) predicted a space heating load of $20 \mathrm{GJ}$ for the CHEeR house. It is likely that this difference is a function of the various internal gains in the research house, which were not considered in the simulation.

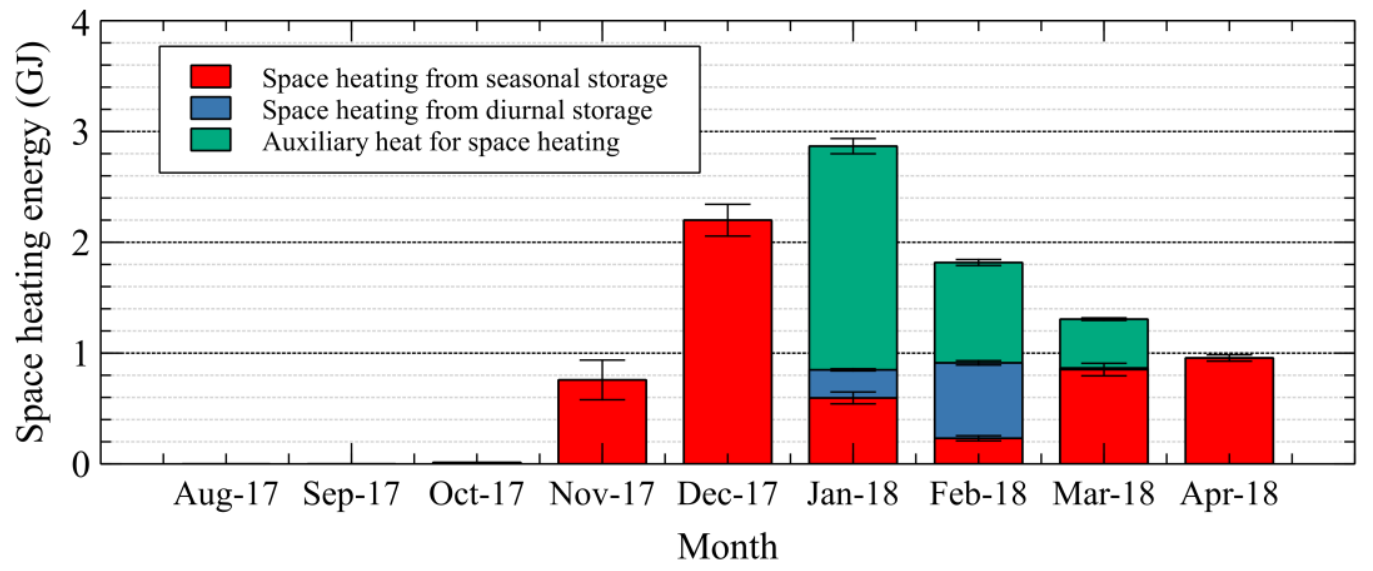

Fig. 5: Space heating energy supplied by each storage

\subsection{Domestic Hot Water}

Figure 6 presents the energy supplied for domestic hot water throughout the analysis period. In August and September, nearly all the DHW energy demand was met by "charging" the virtual tank. In the month of November, no domestic hot water draws were measured. However, it is believed this was due to a faulty flowmeter. Future work will attempt to identify the quantity of heat removed from DTES Tank A during this period.

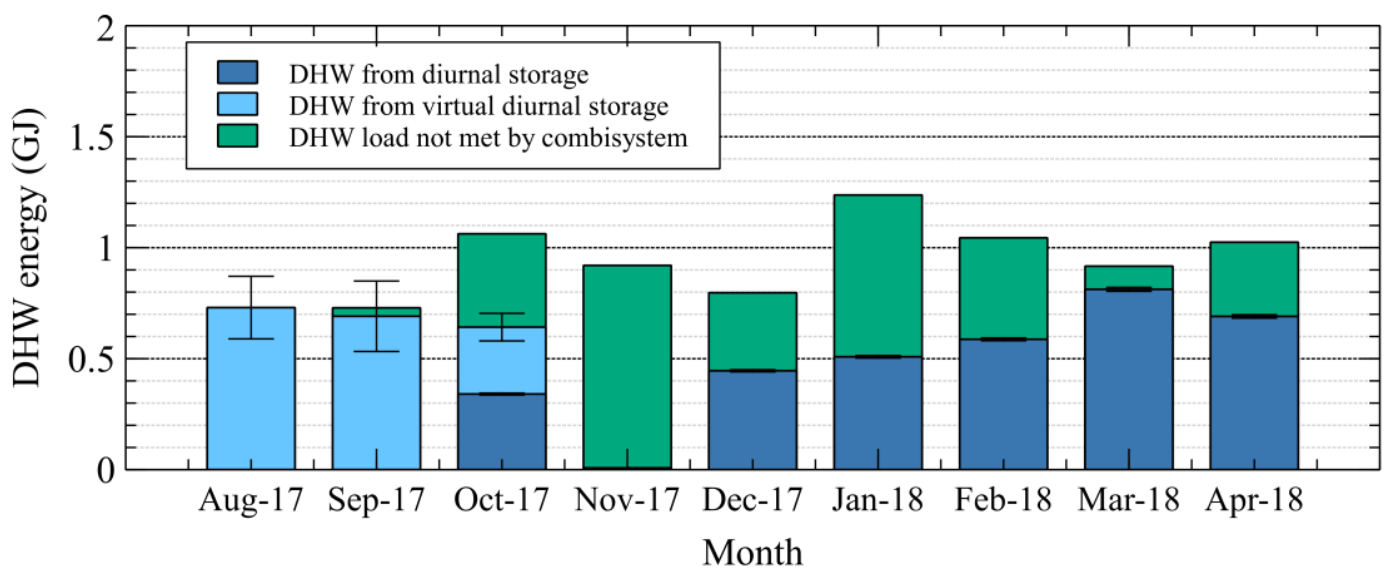

Fig. 6: Domestic hot water supplied by each storage

Further investigation into the performance of the DHW mimicry system is required to determine the relatively poor performance. It was expected that the combisystem would easily meet most DHW loads due to the large evacuated 
tube array. However, certain control decisions may have hampered the system's performance. For instance, the system was constrained to only provide domestic hot water during the 5 minute interval in which a demand was present in the draw profiles. The setpoint of $55^{\circ} \mathrm{C}$ for diurnal storage Tank A may have also led to underperformance, as a higher setpoint may have ensured that early-morning draws were more easily met.

\subsection{Summarized Results}

Table 2 presents the total energy quantities measured over the analysis period. Based on the measured data, the solar fractions for space heating and domestic hot water were $66 \%$ and $60 \%$, respectively. The overall solar fraction for the combisystem was $63 \%$, and the total heat demand (space heating plus domestic hot water) was 18.4 GJ for the year. It must be noted that this does not include the missing data period, in which a large amount of energy was removed from the STES tank.

Tab. 2: Energy flows for the solar thermal system

\begin{tabular}{|c|c|c|c|c|c|c|c|c|c|c|}
\hline \multirow{2}{*}{ Month } & \multicolumn{2}{|c|}{$\begin{array}{l}\text { Solar energy } \\
\text { addition }\end{array}$} & \multicolumn{3}{|c|}{$\begin{array}{c}\text { Space heating demands } \\
\text { met }\end{array}$} & \multicolumn{2}{|c|}{$\begin{array}{l}\text { Domestic hot water } \\
\text { demands met }\end{array}$} & \multirow{2}{*}{$\mathbf{f S H}_{\mathrm{SH}}$} & \multirow{2}{*}{ f } & \multirow{2}{*}{$f_{\text {tot }}$} \\
\hline & $\begin{array}{l}\text { STES } \\
\text { (GJ) }\end{array}$ & $\begin{array}{l}\text { DTES } \\
\text { (GJ) }\end{array}$ & $\begin{array}{l}\text { STES } \\
\text { (GJ) }\end{array}$ & $\begin{array}{l}\text { DTES } \\
\text { (GJ) }\end{array}$ & $\begin{array}{c}\text { Boiler } \\
\text { (GJ) }\end{array}$ & $\begin{array}{c}\text { DTES } \\
\text { (GJ) }\end{array}$ & $\begin{array}{l}\text { Not met } \\
\text { (GJ) }\end{array}$ & & & \\
\hline August & 1.55 & 1.08 & 0 & 0 & 0 & 0.73 & 0 & 1 & 1 & 1.00 \\
\hline September & 3.28 & 1.13 & 0 & 0 & 0 & 0.69 & 0.04 & 1 & 0.95 & 0.95 \\
\hline October & 1.07 & 1.02 & 0.01 & 0 & 0 & 0.64 & 0.42 & 1 & 0.60 & 0.61 \\
\hline November & 0.71 & 1.02 & 0.76 & 0 & 0 & 0.01 & 0.91 & 1 & 0 & 0.46 \\
\hline December & 1.34 & 0.74 & 2.20 & 0 & 0 & 0.45 & 0.35 & 1 & 0.56 & 0.88 \\
\hline January & 1.03 & 0.90 & 0.60 & 0.25 & 2.02 & 0.51 & 0.73 & 0.29 & 0.41 & 0.33 \\
\hline February & 1.17 & 1.94 & 0.23 & 0.68 & 0.91 & 0.59 & 0.46 & 0.49 & 0.56 & 0.51 \\
\hline March & 3.70 & 1.12 & 0.85 & 0.01 & 0.44 & 0.81 & 0.10 & 0.68 & 0.89 & 0.76 \\
\hline April & 2.47 & 0.82 & 0.96 & 0 & 0 & 0.69 & 0.33 & 1 & 0.67 & 0.83 \\
\hline Total & 16.3 & 7.11 & 5.60 & 0.95 & $\mathbf{3 . 3 7}$ & 5.11 & $\mathbf{3 . 3 5}$ & 0.66 & 0.60 & 0.63 \\
\hline
\end{tabular}

Table 3 shows the energy flows in and out of the STES tank, including the heat injection, removal, and losses to the ground. Heat losses are calculated from Equation 1,

$$
\Delta E_{\text {tank }}=Q_{\text {in,solar }}-Q_{\text {out }, \text { SH }}-Q_{\text {loss }}
$$

Where $\Delta \mathrm{E}_{\text {tank }}$ represents the internal energy change in the STES tank,

$$
\Delta E_{\text {tank }}=m_{\text {tank }} c_{w}\left(T_{\text {avg }, 2}-T_{\text {avg }, 1}\right)
$$

Where $\mathrm{m}_{\mathrm{tank}}$ is the mass of water in the tank and $\mathrm{c}_{\mathrm{w}}$ is its specific heat capacity. For this simplified calculation, these are taken as constants equal to $36,300 \mathrm{~kg}$ and $4180 \mathrm{~J} / \mathrm{kgK}$, respectively. The variables $\mathrm{T}_{\text {avg }}$ represent a weightedaverage of 75 thermocouples within the STES tank. Losses are especially significant in November and December, despite the tank's maximum temperatures occurring in October. However, the rate of heat loss from the STES is likely a function of the tank temperature, soil temperatures, and the temperature of the outdoor air (as the tank's hatch is above ground). 
Tab. 3: Energy balance on the seasonal storage tank

\begin{tabular}{|c|c|c|c|c|}
\hline Month & $\begin{array}{c}\text { Solar energy in } \\
(\mathrm{GJ})\end{array}$ & $\begin{array}{c}\text { Space heating out } \\
(\mathrm{GJ})\end{array}$ & $\begin{array}{c}\text { Internal energy change } \\
(\mathrm{GJ})\end{array}$ & Losses \\
& 1.55 & 0 & 0.87 & 0.68 \\
\hline August & 3.28 & 0 & 1.84 & 1.43 \\
\hline September & 1.07 & 0.01 & -0.52 & 1.57 \\
\hline October & 0.71 & 0.76 & -2.3 & 2.27 \\
\hline November & 1.34 & 2.20 & -2.82 & 1.96 \\
\hline December & 1.03 & 0.60 & -0.31 & 0.75 \\
\hline January & 1.17 & 0.23 & 0.46 & 0.48 \\
\hline February & 3.70 & 0.85 & 1.92 & 0.93 \\
\hline March & 2.47 & 0.96 & 0.47 & 1.04 \\
\hline April & $\mathbf{1 6 . 3} \pm \mathbf{0 . 3}$ & $\mathbf{5 . 6 0} \pm \mathbf{0 . 5}$ & $\mathbf{- 0 . 4} \pm \mathbf{0 . 0 0 7}$ & $\mathbf{1 1 . 1} \pm \mathbf{0 . 7}$ \\
\hline Total & & & &
\end{tabular}

\subsection{Cooldown Test}

Two previous cooldown tests were reported on in Meister and Beausoleil-Morrison (2017), but it was identified that a much longer cooldown test was required to obtain a temperature drop with a smaller amount of experimental uncertainty. To further identify heat loss characteristics of the STES tank, a cooldown test was initiated on May 28, 2018. The tank began the cooldown at a temperature of $65^{\circ} \mathrm{C}$, and has remained cooling since. Figure 7 shows the tank's mean temperature over 124 days of cooling. It was previously identified that the tank's nominal UA value of $4.7 \mathrm{~W} / \mathrm{K}$ was unlikely to be realistic. In Figure 7, this is further evidenced; several "expected" rates of cooling are plotted for four possible mean ground temperatures. This shows that if the tank's UA value were equal to its design value, the ground temperature would have to be below $0^{\circ} \mathrm{C}$ and $-20^{\circ} \mathrm{C}$. Clearly, the UA value must be far higher than design.

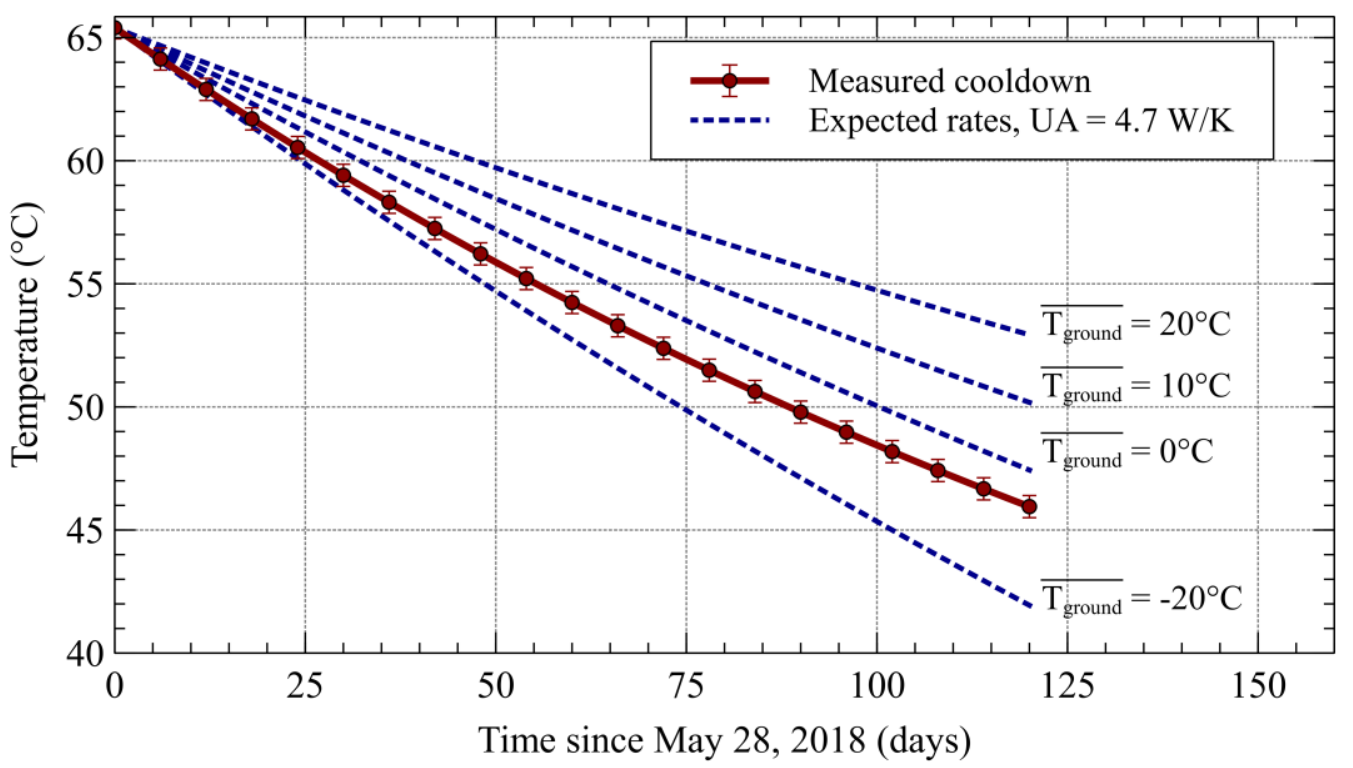

Fig. 7: Measured and predicted temperature decay of the seasonal storage tank

\subsection{Solar Collector Performance}

During the first year of operation of the STES system, it was noticed that the solar collectors routinely did not achieve their predicted efficiency. The collectors' ISO 9806-based efficiency equation (ISO, 2017) was obtained from the Solar Rating and Certification Corporation (SRCC) and is expressed using:

$$
n_{\text {coll }}=0.456+1.35090\left(\frac{\Delta T}{G}\right)-0.00380\left(\frac{\Delta T^{2}}{G}\right)
$$

Figure 8 compares the output of Equation 3 with data from the CHEeR house's solar array. Each data point represents 
a point where solar collector operation was steady (less than $10 \%$ variation in efficiency) for at least 45 minutes prior to measurement. It is clear from the plot that the solar collectors did not reach their rated performance. It is estimated that the collector output was approximately $60 \%$ of the rated output. The manufacturers of the solar array have since provided replacement heat pipes for the array. They suggest that the observed underperformance could be a result of a now-outdated freeze protection process. The new heat pipes will be installed in the Fall of 2018. Based on the predictions of Kemery (2017), the authors remain optimistic that with the expected amount of solar collections, a high solar fraction can be demonstrated.

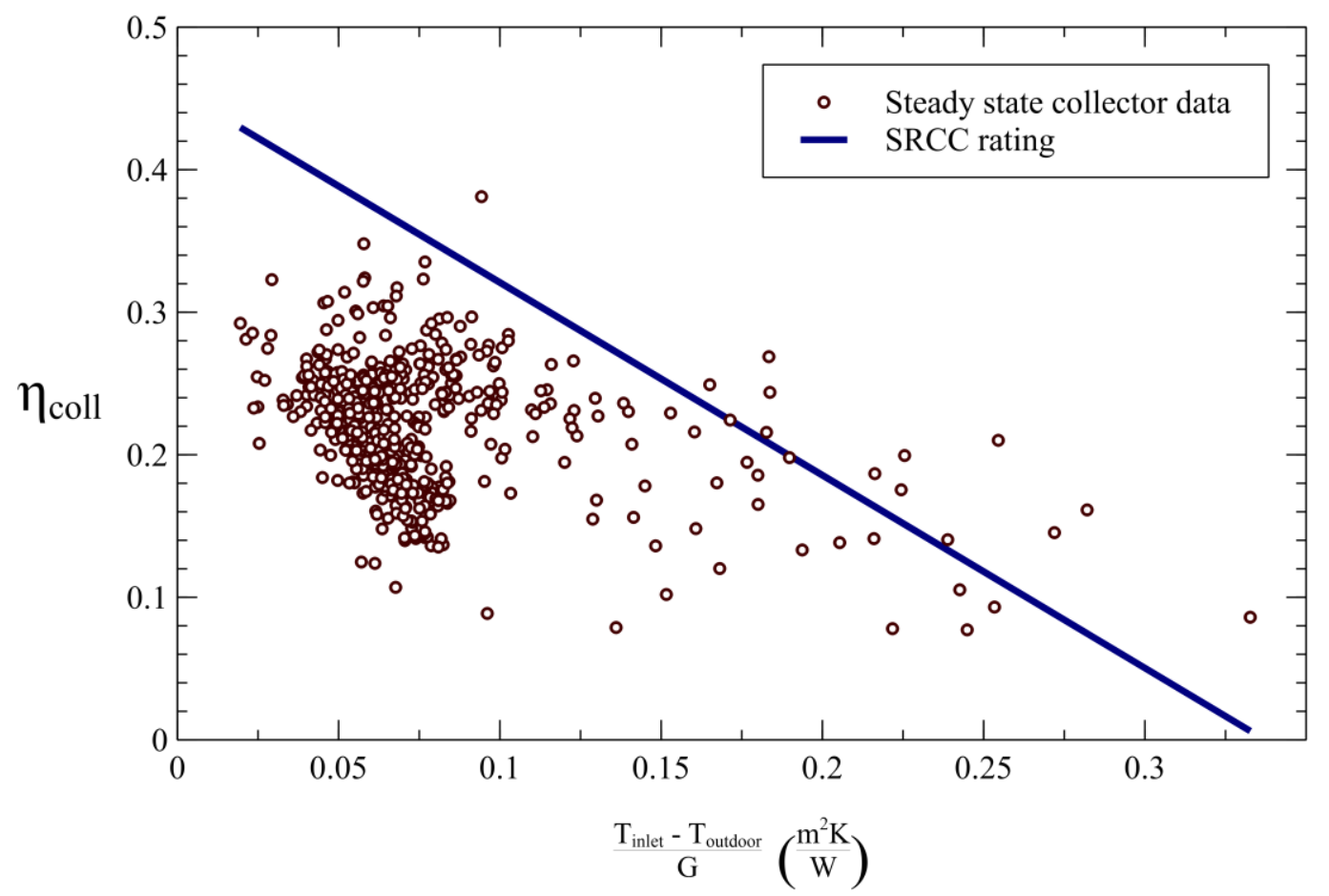

Fig. 8: Rated and measured solar collector efficiencies

\subsection{Missing Data Period}

Not all data was lost during the "missing data period" from December 23 to January $5^{\text {th }}$. Based on available data, the number of hours the house was receiving heat was logged, as was weather data. These are shown here to have somewhat linear effects on the space heating load and solar energy collection. Figure 9 shows the space heating load varies linearly with the number of hours in heating mode, however, the fit is not sufficient to make an accurate predictions. The solar energy collection, however, is shown to be very well predicted by the integrated radiation on the collector plane. Future work will attempt to model the full solar combisystem and CHEeR house, providing better predictions of the performance during this lost period. However, in the mean time, our best estimate of the space heating load for the missing data period is approximately $2 \mathrm{GJ}$, consistent with the internal energy lost from the STES tank over the period. Were this true, the true solar fraction for space heating would be $72 \%$ rather than $66 \%$

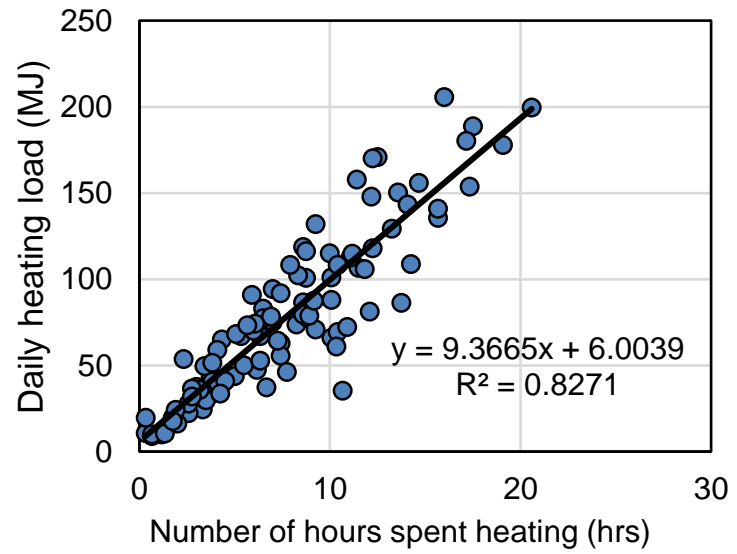

Fig. 9: Space heating load vs. heating time

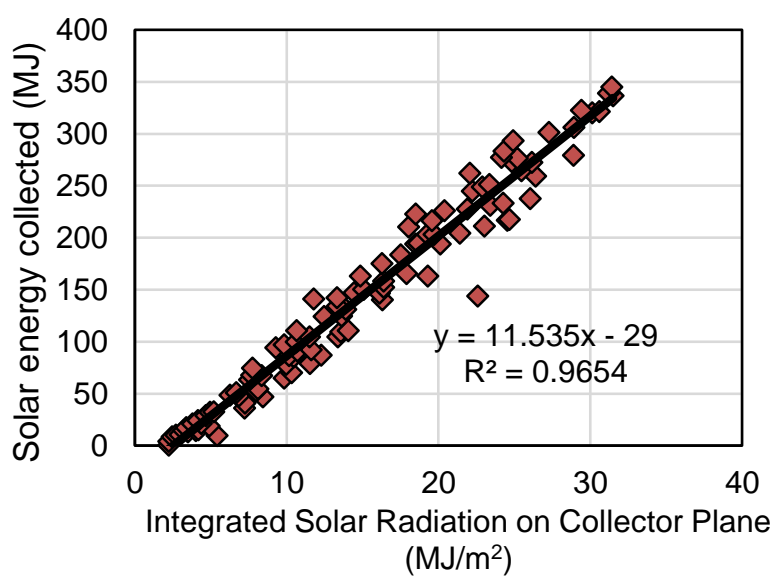

Fig. 10: Solar energy collection vs. irradiation 


\section{Conclusions and Outlook}

The overall solar fraction was measured to be approximately $63 \%$, far lower than the expected solar fraction of over $90 \%$. However, several issues may have played a factor in this results. Most prominently, the solar collectors did not achieve their rated performance, meaning the solar energy input to the system was significantly less than anticipated. The work of Kemery (2016) showed that with the solar array operating at its expected performance, the STES tank would reach its maximum temperature of $93^{\circ} \mathrm{C}$ early into the summer, rather than struggling to reach $80^{\circ} \mathrm{C}$. The effects of low solar collection were compounded by higher than expected losses from the STES tank. For the period of operation shown in this paper, losses from the STES tank were nearly double the heat extracted for space heating. Finally, the DHW system experienced some issues, including unmeasured water draws and a sub-optimal control scheme that may have restricted the energy delivery potential of the system.

As a result of this heating season, a number of methods for performance improvement have been identified. Firstly, the combisystem achieved better thermal performance when DTES Tank B was enabled to allow space heating. Were the diurnal storage allowed to provide space heating early in the heating season, the seasonal storage tank would likely not be depleted in early January, and could better serve its purpose of providing heat in mid-winter. Thus, it is recommended to enable Tank B (and possibly C) for the full heating season. Further, since the combisystem underperformed in terms of DHW loads, a higher setpoint for the diurnal storage should be investigated. Both of these recommendations fall in line with the recommendations of Dincer and Rosen (2011), who state that when storing thermal energy, one should attempt to store energy at the highest temperature possible, or at the highest exergetic state.

The results of this heating season will be used to develop a full-system model of the solar combisytem and STES tank. The model will be used to provide rapid energy predictions for the performance of the system so that a large number of control options can be explored prior to being tested on the experimental system. Based on these simulation studies, a recommended control scheme for the CHEeR STES system will be determined. With an improved control strategy and upgraded solar collectors, the CHEeR STES system may be capable of demonstrating a high solar fraction in future experiments.

\section{References}

Bauer, D., Marx, R., Nußbicker-Lux, J., Ochs, F., Heidemann, W. and Müller-Steinhagen, H., 2010. German central solar heating plants with seasonal heat storage. Solar Energy, 84(4), pp.612-623.

Clarke, J., Colclough, S., Griffiths, P., and McLeskey Jr., J.T., 2014. A Passive House with Seasonal Solar Energy Store: In Situ Data and Numerical Modeling, International Journal of Ambient Energy, 35(1): 37-50.

Colclough, S., Grihs, P., and Hewitt, N.,2011. A year in the life of a passive house with solar energy store. In Energy Storage Conference, (Belfast, Ireland), IC-SES.

Dincer, I. and Rosen,M., 2011 Thermal Energy Storage: Systems and Applications, second ed. John Wiley \& Sons, Hoboken, NJ, USA.

Edwards, S., 2014. Sensitivity Analysis of Two Solar Combisystems Using Newly Developed Hot Water Draw Profiles. M.A.Sc Thesis, Carleton University.

Hugo, A., Zmeureanu, R. and Rivard, H., 2010. Solar combisystem with seasonal thermal storage, Journal of Building Performance Simulation, 3:4, pp.255-268.

ISO 9806. Solar energy - Solar thermal collectors - Test methods. Standard, International Organization for Standardization, 2017.

Kemery, B., 2017. Analysis and design of a solar-combisystem for high solar fraction Canadian housing with diurnal and seasonal water-based thermal stores, M.A.Sc. thesis, Carleton University.

Meister, C. and Beausoleil-Morrison, I., 2017. Experimental Characterization of a Solar Combisystem with Seasonal Storage for a Single Detached House. In Proceedings of the Solar World Congress 2017.

Mesquita, L. McClenahan, D., Thornton, J., Carriere, J. and Wong, B., 2017. Drake Landing Solar Community: 10 Years of Operation. In Proceedings of the Solar World Congress 2017.

Ochs, F., 2009. Modeling large-scale thermal energy stores. Ph.D. thesis, University of Stuttgart.

Rey, A. and Zmeureanu, R., 2018. Multi-objective optimization framework for the selection of configuration and 
equipment sizing of solar thermal combisystems. Energy, 145, pp.182-194.

Schmidt, T., Mangold, D. and Müller-Steinhagen, H., 2004. Central solar heating plants with seasonal storage in Germany. Solar energy, 76(1-3), pp.165-174.

Sibbitt, B., McClenahan, D., Djebbar, R,. Thornton, J., Wong, B., Carriere, J. And Kokko, J., 2012. The performance of a high solar fraction seasonal storage district heating system - five years of operation. Energy Procedia, 30:856865.

Wills, A., 2013. Design and co-simulation of a seasonal solar thermal system for a Canadian single-family detached house. M.A.Sc. thesis, Carleton University. 


\title{
Modeling and Validation of the Ice Growth in an Ice Storage System Stefanie Paulini ${ }^{1}$, Tobias Plessing ${ }^{1}$ and Dieter Brüggemann ${ }^{2}$ \\ 1 Institute for Water and Energy Management at Hof University, Hof (Germany) \\ 2 Department of Engineering Thermodynamics and Transport Processes (LTTT) at University of \\ Bayreuth, Bayreuth (Germany)
}

\begin{abstract}
This work deals with the optimization of the icing process in an ice storage system. It is focused on the improvement of the icing behavior, which is to be achieved by different heat exchanger geometries in the ice storage tank. Therefore, CFD simulations were implemented to acquire and visualize the flow conditions, the temperature behavior and the growth of the ice layer during the cooling process. The results are compared and validated with model experiments on an experimental ice storage. It could be shown that the heat extraction of current technologies can be increased by more than $50 \%$ by using geometries that are more efficient.
\end{abstract}

Keywords: CFD simulation, ice storage, model validation

\section{Introduction}

Ice storage systems enable to supply heat pumps with temperatures above $-10{ }^{\circ} \mathrm{C}$ for a longer time. To increase the annual operating efficiency and the overall efficiency of the heat pump system, the ice storage has to be fully exploited. Therefore, the flow conditions in the ice storage tank have to be analyzed. A homogeneous mixing during the icing process enables a longer sensible heat extraction and temperatures above $0{ }^{\circ} \mathrm{C}$ for a longer time. In addition, the $4{ }^{\circ} \mathrm{C}$ sump could be avoided by homogeneous mixing.

In the presented project, the heat input into a solar ice storage with a helix and a star-shaped heat exchanger is examined. In addition to model experiments, CFD simulation is used for the acquisition and visualization of the flow conditions, the temperature profile and the ice build-up. The aim is to optimize the heat input into the ice storage tank and the icing process upon the heat exchanger plates by adapting the heat exchanger geometry.

\section{Boundary conditions}

The main aim is to enhance the overall icing process in the ice storage tank. The convective flow within in the water tank should be improved in order to achieve a more homogeneous mixing in the ice storage system. The aim of the further investigation is to optimize the ice building process in the ice storage tank along the heat exchanger surface. By keeping the ice built up parallel to the heat exchanger plates as long as possible, the temperature of the return flow of the heat pump decreases slowly and the heat pump can be supplied with temperatures above $-10^{\circ} \mathrm{C}$ for a longer period. This increases the annual operating efficiency and thus the overall efficiency of the heat pump system. An adapted ice growth on the heat exchanger plates increases the proportion of the water volume which could be iced. The influence of the heat exchanger geometry on the flow, the temperature layering and the ice growth is pictured and analyzed by CFD simulations. Therefore, 2D and 3D models of the ice storage and heat exchangers are built with ANSYS Fluent. The simulation models are validated by model experiments on a horizontally divided hemispherical experimental ice storage on a scale of 1:2 to the original ice storage. Numerical simulation of the phase change is tried to be solved by several methods. Some of them are compared in the study of König-Haagen et al. (2017). This study shows that though using small simulation areas, errors between the numerical results and reference solutions could be detected. In the following work, the simulation is done for the whole ice storage tank, so errors between the simulation results and the measurements were predicted and could not be prevented.

\section{Setup and results}




\section{Stefanie Paulini}

Based on former CFD simulations, a model test bench was created for the visualization of the icing process in the ice storage tank. The test bench consists of an $8 \mathrm{~kW}$ heat pump with a refrigerating capacity of $6 \mathrm{~kW}$, a $2.5 \mathrm{~m}^{3}$ horizontally divided hemispherical ice storage tank and a small storage with electrical heating rod as shown in figure 1 .

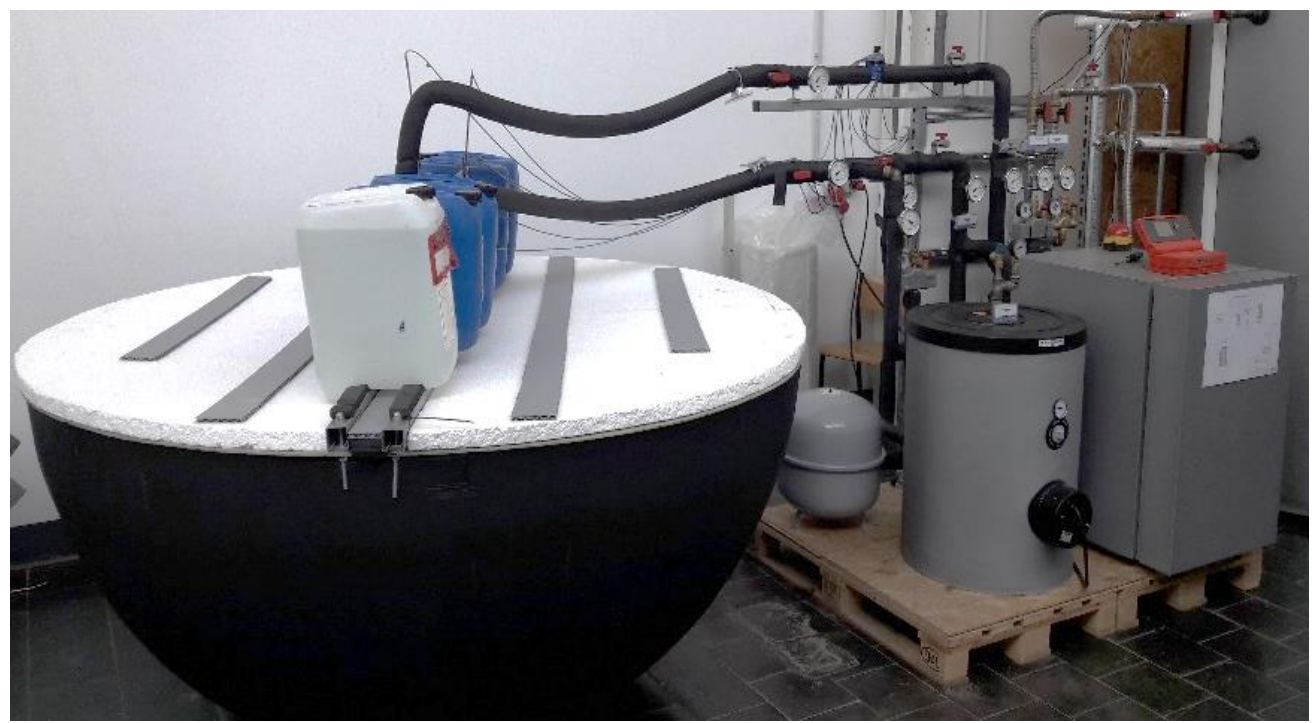

Fig. 1: Test bench with isolated ice storage (left), storage with heating rod (middle) and heat pump (right)

The ice storage tank was insulated to reduce the heat input from the surrounding area. The small storage with the heating rod was installed to reheat the ice storage after the icing experiments. The water-filled tanks on top of the ice storage counteract the rising buoyancy force of the ice during the icing process. As a basis for the first model experiments, a helix heat exchanger was chosen. The ice storage was iced until the return flow temperature of the heat pump reached the switch-off temperature of $-10^{\circ} \mathrm{C}$. Afterwards the heat exchanger was replaced by a starshaped geometry with an arrangement of 24 heat exchanger plates. Thereafter, the number of the heat exchanger plates was halved from 24 to 12 plates to improve the icing process. Six temperature sensors in the ice storage and one temperature sensor in each case in the flow and return flow of the primary circuit of the heat pump documented the icing process.

The simulation of the phase change was realized by the ANSYS Fluent solidification and melting tool. The solver settings were designed according to Al-abidi et al. (2013) and Nayak et al. (2011). To solve the simulation the pressure-based Navier-Stokes solution algorithm with the absolute velocity formulation was used. The time option was set transient to enable a time-dependent solution.

The geometry was transferred to a 1:1 scale CFD model, simulated with boundary conditions of the model experiments and then validated with the data from the model experiments.

The helix heat exchanger was realized with 2D-CFD simulation. The model was simulated in horizontal and vertical cut through the heat exchanger and the ice storage as seen in figure 2 and 3.

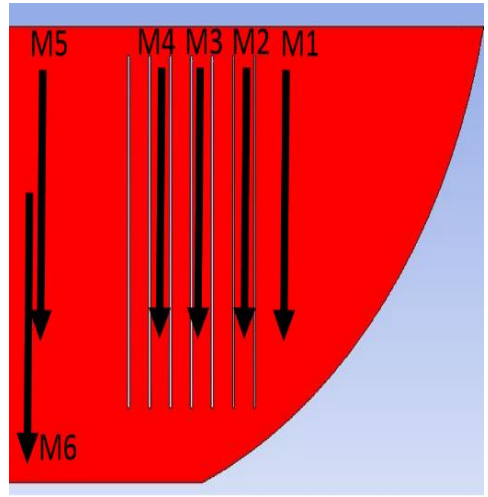

Fig. 2: Horizontal cut through the helix heat exchanger with points of temperature measurement 


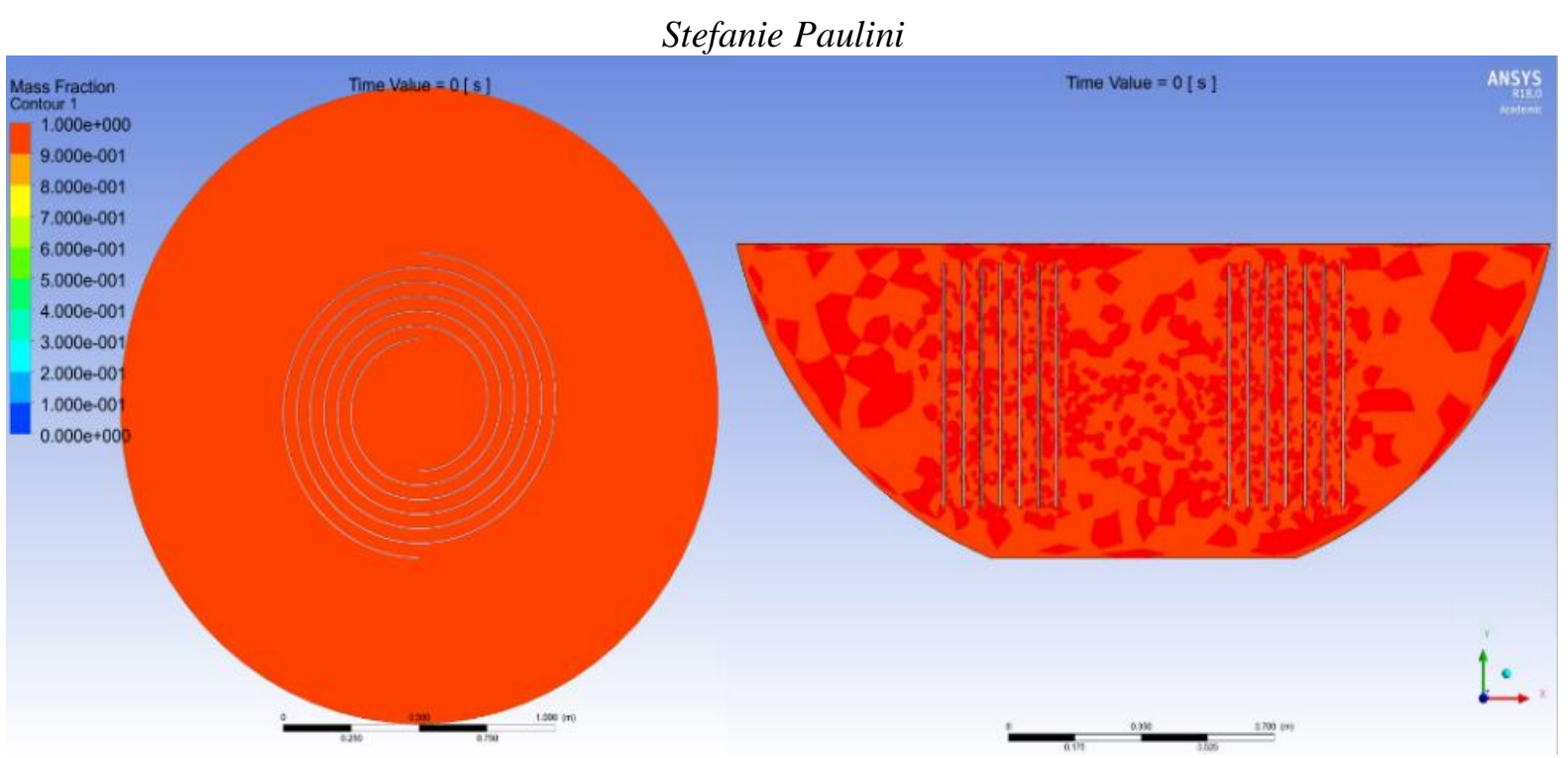

Fig. 3: Horizontal (left) and vertical (right) cut through the helix heat exchanger

The points of temperature measurement were set to the same places as the temperature sensors in the model test bench. Five sensors were set in a horizontal row to picture the temperature behavior through the horizontal cut of the ice storage and one was set to the ground of the ice storage to picture the $4{ }^{\circ} \mathrm{C}$ sink at the bottom of the tank. This sink is due to the anomaly of water.

The heat exchanger temperature from the model experiments was implemented as a boundary condition for the plate temperature for the simulations. The simulation models were validated and adjusted with the measurement results from the model experiments with the helix heat exchanger.

The star shaped heat exchanger was simulated with 3D-CFD simulation. Due to the radial symmetry of the model, only $1 / 12$ of the ice storage was transferred to a simulation model. The modelled geometry with two heat exchanger plates is shown in figure 4.

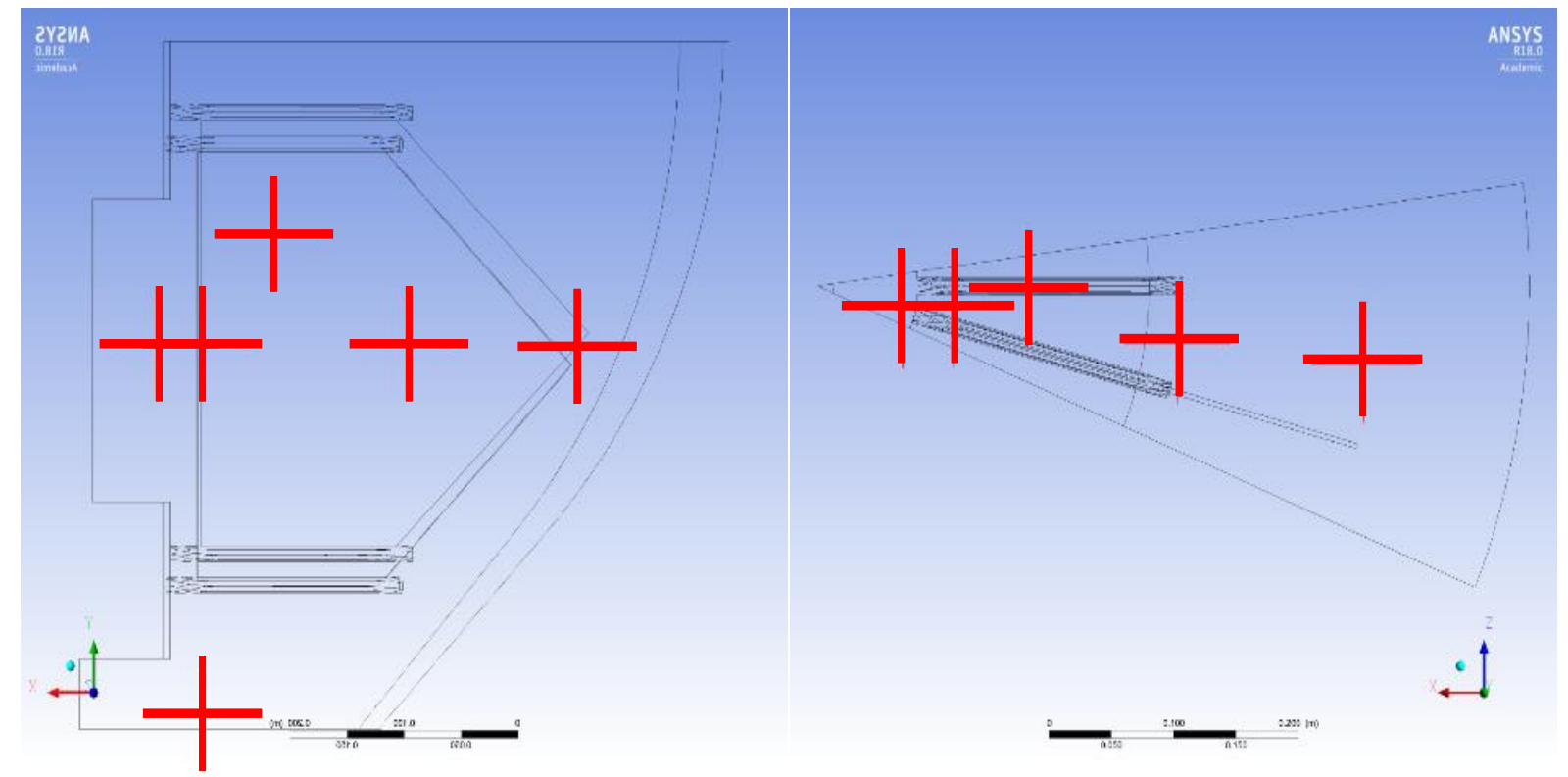

Fig. 4: Arrangement of the temperature sensors in the simulated part with two heat exchanger plates

The red crosses represent the six points at which the temperature is logged during the simulations. They are similar with the six temperature sensors in the ice storage volume at which the temperature is measured during the experiments at the model test bench. Similar to the 2D-CFD simulation the heat exchanger temperature from the model experiments was implemented as a boundary condition for the plate temperature for the simulations. The simulation models were also validated and adjusted with the measurement results from the model experiments with the star-shaped heat exchanger. 


\section{Stefanie Paulini}

The results of the 2D-CFD simulation of the helix heat exchanger and the measurements at the test bench are shown below. The simulation showed good accordance with the results of the model experiments from the test bench. The temperature profile of the temperature sensor 2 until the switch-off point of the heat pump is pictured in figure 5 .

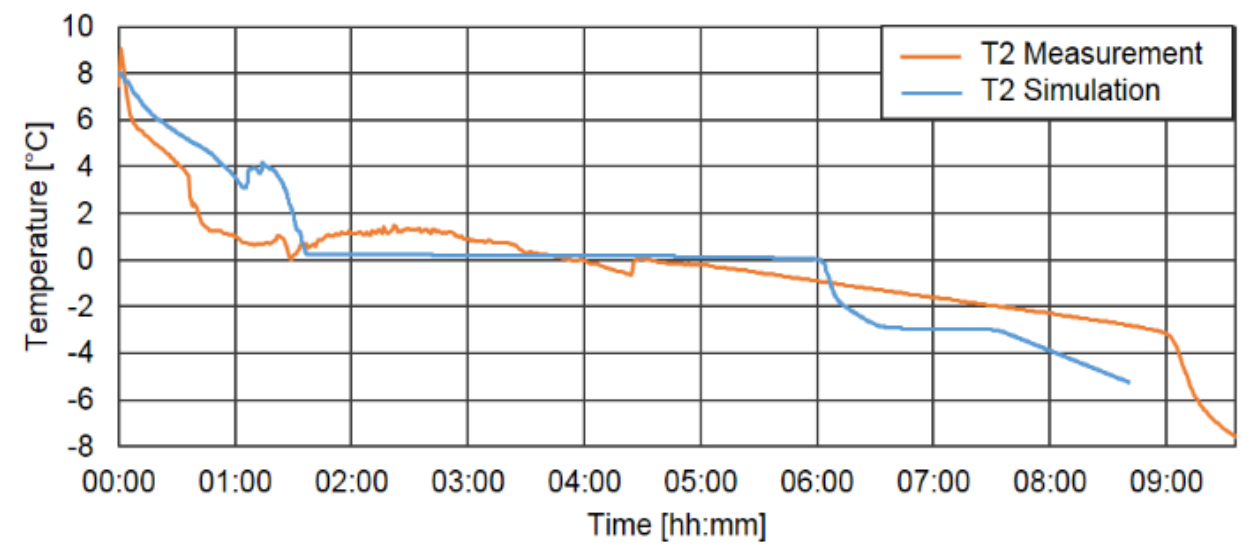

Fig. 5: Temperature profile of the model experiment (orange) and the simulation (blue) during the icing process

The latent heat transfer could be mapped very well in the simulation (blue line) by the long temperature stability during the ice build-up between 1:30 and 6:00 of the simulation time. The measured temperature (orange line) shows, that some effects like supercooling could only be insufficiently described by the simulation. Nevertheless, the overall temperature behavior of the simulations fits with the experimental values. The decreasing temperature line of the model experiment (orange line) pictures the dipping of the temperature sensor into the ice. The temperature drop at the end of the time line describes the point at which the ice walls grow together.

Several model experiments on the helix heat exchanger showed the reproducibility of the individual temperature behavior. Slight divergences could be explained by the different starting temperatures in the ice storage volume. The simulation clearly shows the temperature stratification in the ice storage with the $4{ }^{\circ} \mathrm{C}$ sink at the bottom of the ice storage tank. Although the heat exchanger plates are already freezing, half of the fluid volume is still warmer than $1^{\circ} \mathrm{C}$. These two circumstances lead to the fact that the heat exchanger plates begin to freeze in the upper third and the lower part of the plates are not yet frozen at the end of the simulation. Though the phenomena of starting freezing in the upper third of the heat exchanger plates is also pictured in the model experiments, it is shown in figure 6.

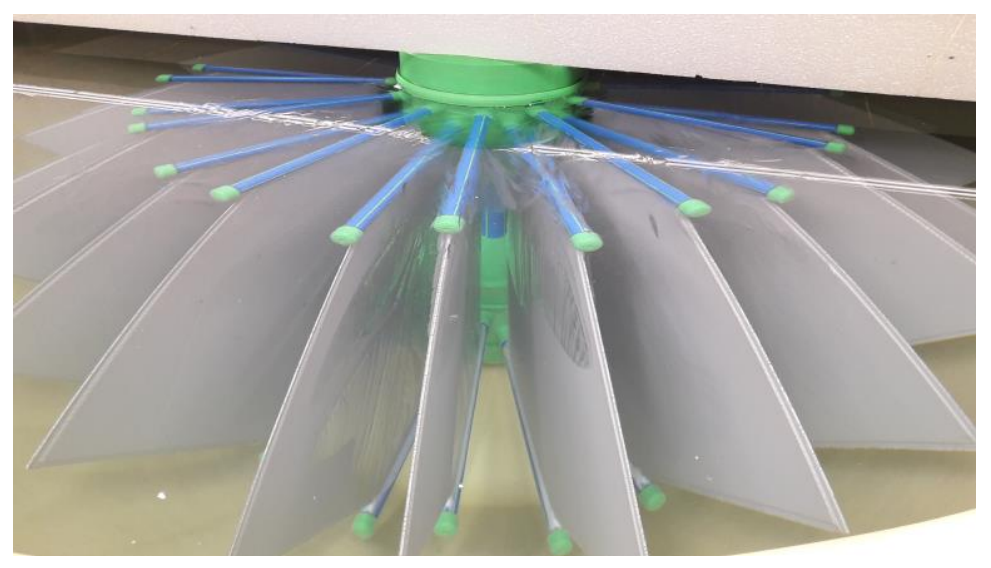

Fig. 6: Beginning of freezing at the star-shaped heat exchanger with 24 plates

This also shows the unfavorable shape of the heat exchanger compared to the surrounding fluid in the simulation. Due to the geometry, only a fraction of the existing fluid can really be iced. This results in a latent heat extraction of $50.59 \mathrm{kWh}$ in $8 \mathrm{~h} 42 \mathrm{~min}$ by a heat exchanger surface of $34 \mathrm{~m}^{2}$. 


\section{Stefanie Paulini}

Based on these basic experiments and simulations, a preferred geometry is to be determined, which represents the basis for a subsequent development. A star shaped heat exchanger with 24 plates was chosen for the further analyses. The geometry was reduced to 12 plates after the first experiments. The number of heat exchanger plates influences the point on which the ice walls on the plates grow together and the temperature in the return flow of the heat pump drops off. The arrangement of the star-shaped heat exchanger with 12 and 24 plates with the temperature sensor 1 (red dot) is shown in figure 7 .
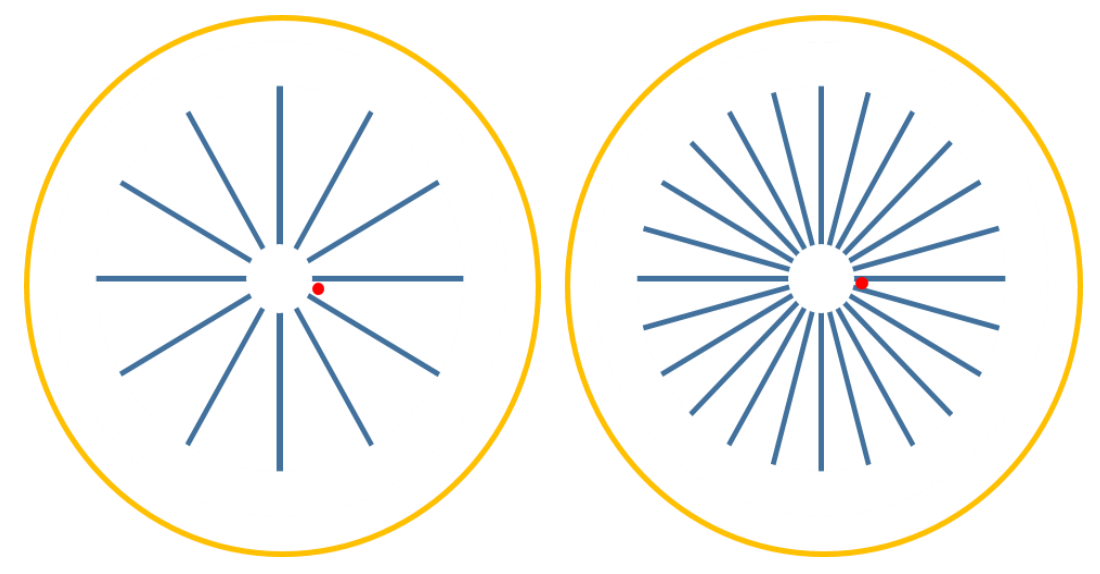

Fig. 7: Arrangement of the heat exchanger plates and temperature sensor 1 in the star-shaped model with 12 plates (left) and 24 plates (right)

The temperature sensor 1 is the point, where the ice grows together first. When the temperature at sensor 1 falls below $0{ }^{\circ} \mathrm{C}$, it is dipping into the ice. Due to the reduction of heat exchanger plates, the specific extraction of heat of each heat exchanger plate is doubled compared to the star-shaped heat exchanger with 24 plates.

The results of the star-shaped heat exchanger are shown below. The star shaped heat exchanger with 24 plates has a theoretical ice thickness of $13.3 \mathrm{~cm}$. During the icing experiments at the ice storage test bench, this value could not be reached. One of the reasons was the small distance between the backs of the plates in the middle of the star geometry. That led to a fast growing together of the ice walls, what reduced the overall ice surface. Therefore, the temperature at the heat pump return flow decreased and the heat pump stopped working. The ice buildup after one icing cycle until the heat pump shut-off at $-10^{\circ} \mathrm{C}$ is pictured in figure 8 .

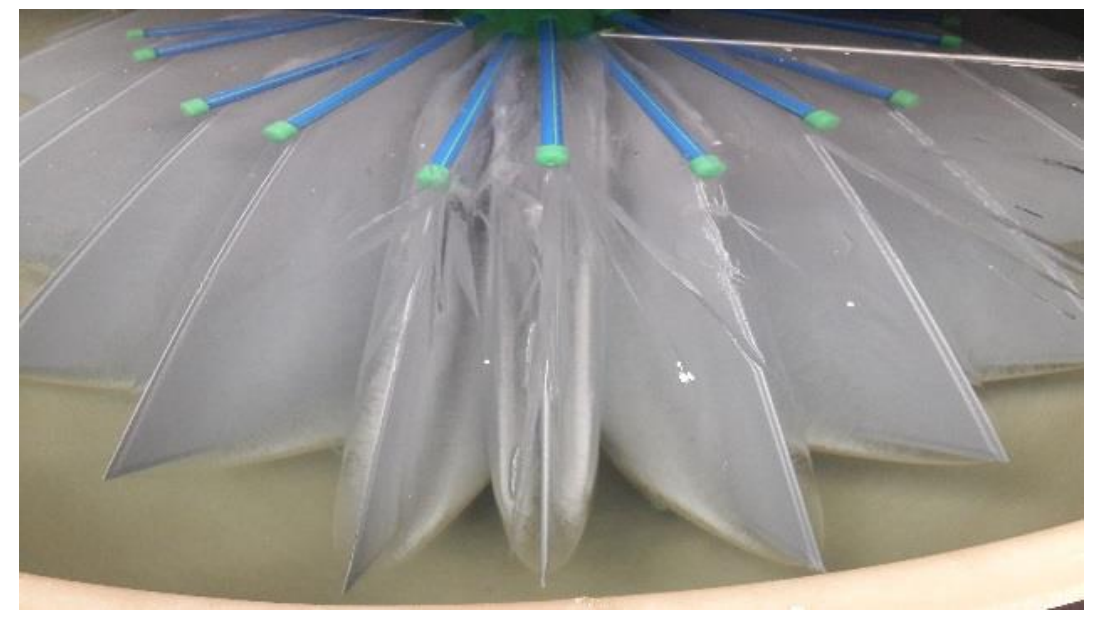

Fig. 8: Ice built-up after one icing cycle of the heat pump at the star shaped heat exchanger with 24 plates

The picture shows the small ice layer of only about $6 \mathrm{~cm}$. The back surfaces of the plates are grown together, what can also be seen in the temperature profile of the temperature sensor 1 and the return flow temperature of the primary circuit of the heat pump. The ice built-up results in a latent heat extraction of $105.14 \mathrm{kWh}$ in $15 \mathrm{~h} 52 \mathrm{~min}$ by a heat exchanger surface of $34 \mathrm{~m}^{2}$, which is twice the value of the helix heat exchanger. The comparison of the return flow temperatures of the primary circuit of the heat pump of the helix heat exchanger and the star shaped 
with 24 plates is illustrated in figure 9.

\section{Stefanie Paulini}

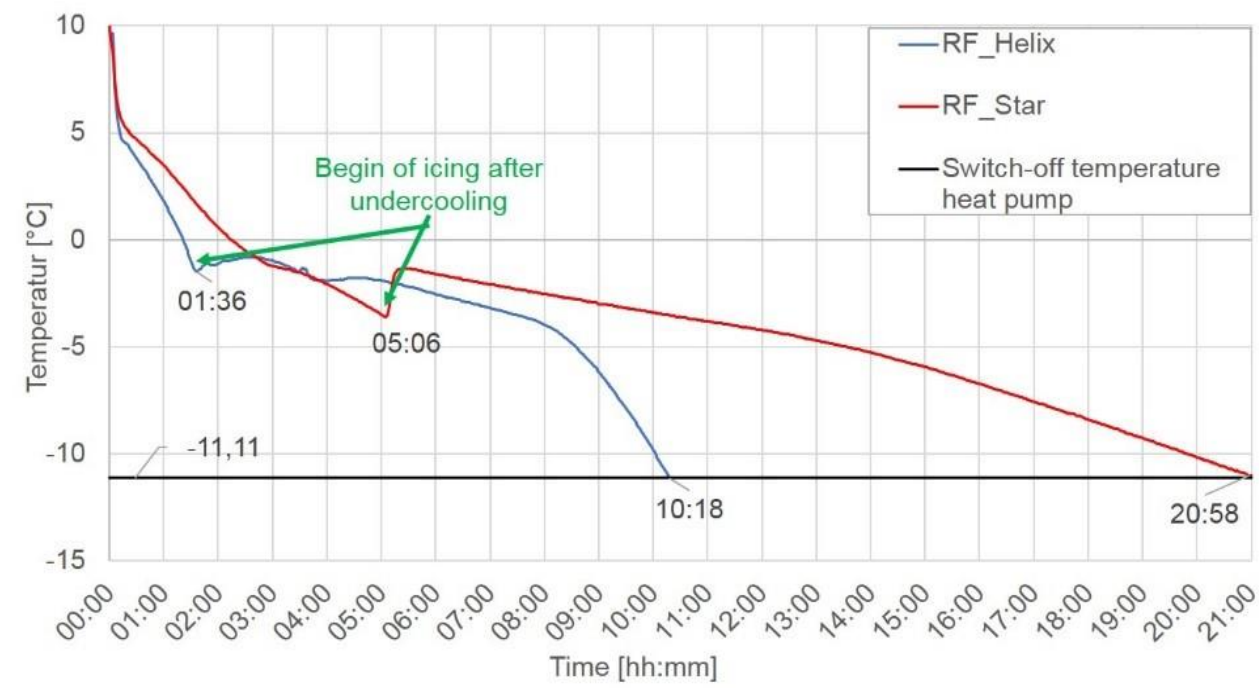

Fig. 9: Difference of the return flow temperatures of the primary circuit of the heat pump with helix (blue) and star-shaped (red) heat exchanger with 24 plates

The improved flow through the ice storage with star-shaped heat exchanger significantly delayed the onset of icing and increased the amount of sensible heat extracted by 50\%. The rapid decreasing in the return flow temperature of the helix structure after 8 hours of experimentation is attributable to the coalescing ice layers between the helical turns and thus to a rapid reduction of the heat transfer surface. In the star-shaped geometry, the heat transfer surface is reduced only slowly, which is reflected in the gradually decreasing temperature curve of the return flow temperature. In both cases, it comes to a significant supercooling of the heat transfer medium before the icing of the heat exchanger surfaces starts. In the helical geometry, the supercooling is $-1.8^{\circ} \mathrm{C}$, in the star-shaped structure even $-3.7^{\circ} \mathrm{C}$. Since the sensitive heat depends on the flow, the amount of water and the start temperature of the water volume in the ice storage tank, it is not considered in this work.

The icing experiments with the star-shaped heat exchanger with 12 plates showed good accordance to the theoretical icing behavior. The theoretical calculated ice thickness of $6.6 \mathrm{~cm}$ per plate surface could be reached during the icing process as pictured in figure 10.

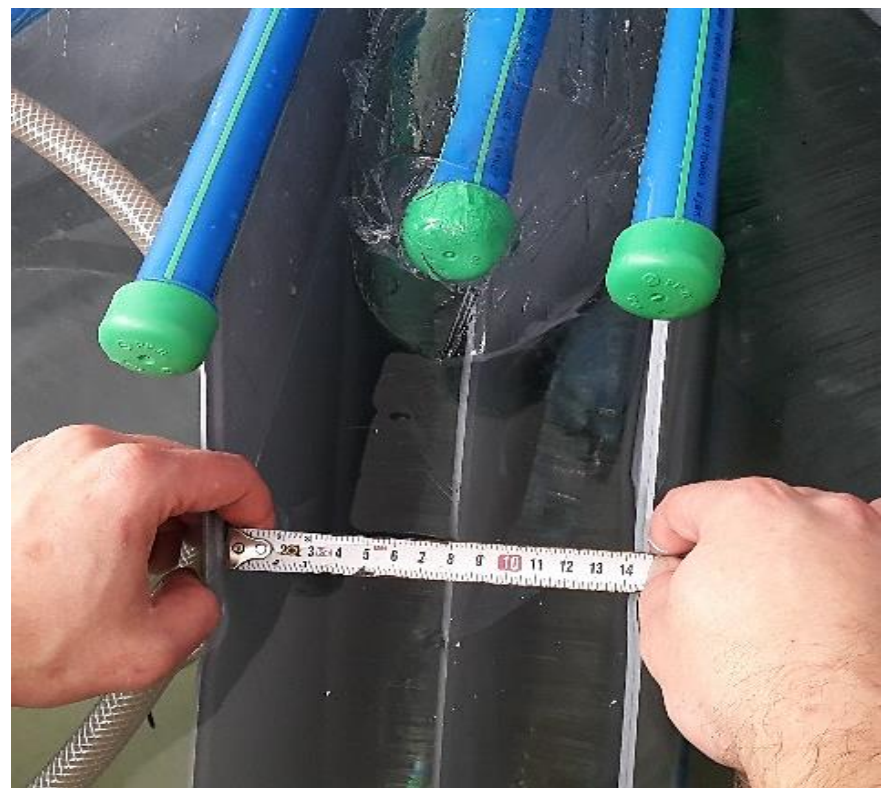

Fig. 10: Thickness of the ice walls of $14 \mathrm{~cm}$ from ice surface to ice surface with plate in the middle after one icing circuit with the star-shaped heat exchanger with 12 plates

Due to the big distance between the individual plates, the ice built-up could proceed parallel during the whole 


\section{Stefanie Paulini}

icing process. This shows that the reducing heat exchanger surface was the limiting factor for the ice built-up with 24 plates and helix heat exchanger in the former experiments. This restriction could also be outlined by the temperature profiles of temperature sensor 1 during the icing experiments with the helix heat exchanger and the star-shaped heat exchanger with 24 and with 12 plates in figure 11.

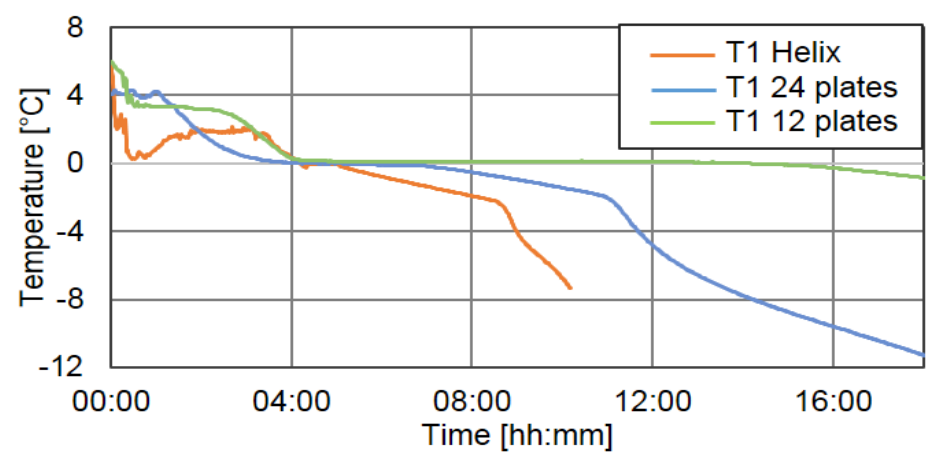

Fig. 11: Difference of the temperature profile of temperature sensor 1 with helical heat exchanger (orange), 24 plates (blue) and 12 plates (green) heat exchanger during the icing process

The drop off in the orange and blue temperature profile of the helical and the 24 plates heat exchanger is owed to the coalescing ice layers and the rapid reduction of the heat transfer surface. The heat exchanger with 12 plates starts icing together at the end of the icing experiments. This shows, that there is a parallel icing during the whole process.

The difference of the icing behavior of the heat exchanger with 24 and with 12 plates is clearly shown in figure 12 below. It illustrates the difference in the return flow temperatures of the primary circuit of the heat pump for 12 and 24 plates of the star-shaped heat exchanger and the temperature sensor 1 in both cases on the model test bench.

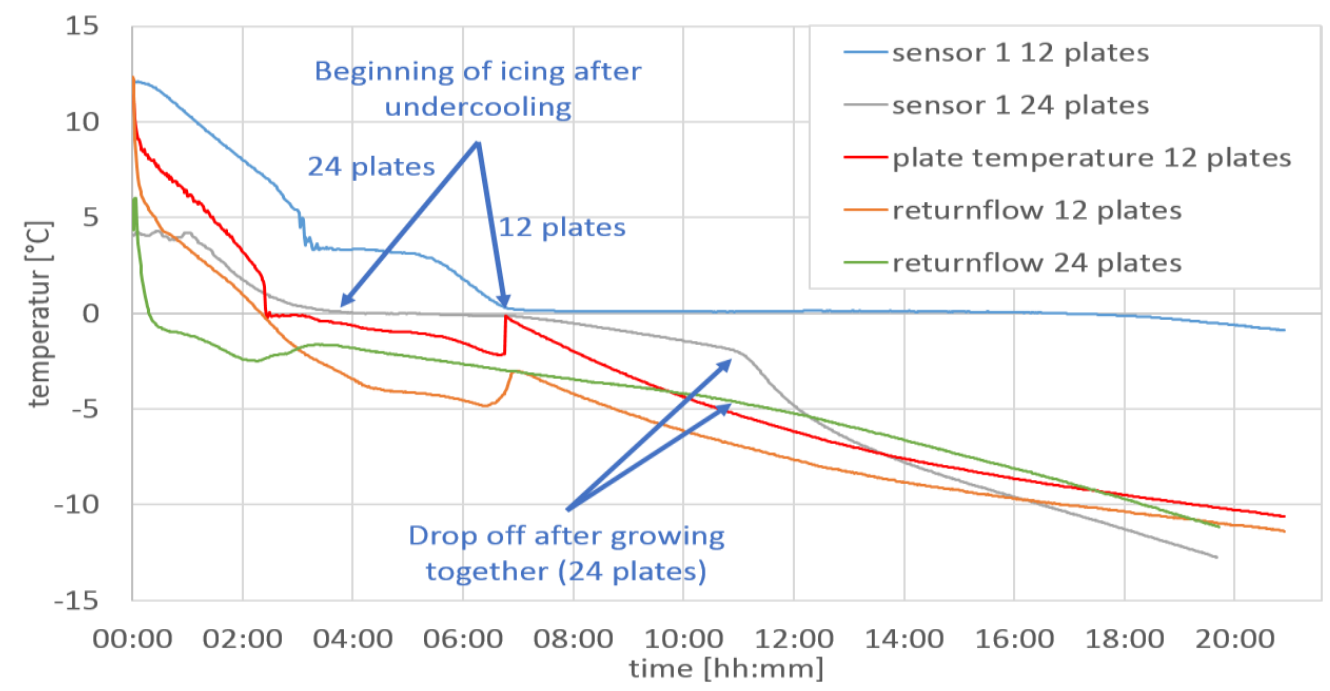

Fig. 12: Difference of the return flow temperatures of the primary circuit of the heat pump with 12 (yellow) and 24 (green) heat exchanger and of the temperatures between the plates (blue and grey)

The plate temperature ( 12 plates) clarifies the beginning of the icing process after the undercooling process.

The time of the parallel icing from the beginning of icing after undercooling until the temperature drop-off is much longer at the heat exchanger with 12 plates than with 24 plates. The undercooling of the return flow temperature with 24 plates is $-2.5^{\circ} \mathrm{C}$, while the undercooling of the return flow temperature with 12 plates reaches $-4.8^{\circ} \mathrm{C}$. One of the reasons for this effect are the improved flow conditions at the geometry with 12 plates.

Though the 3D simulation of the star-shaped heat exchanger with 24 plates took several months to calculate, it is only considered for a qualitative statement. The ice built-up of the 3D simulation and the icing experiment with the star-shaped heat exchanger with 24 plates is shown in figure 13. 


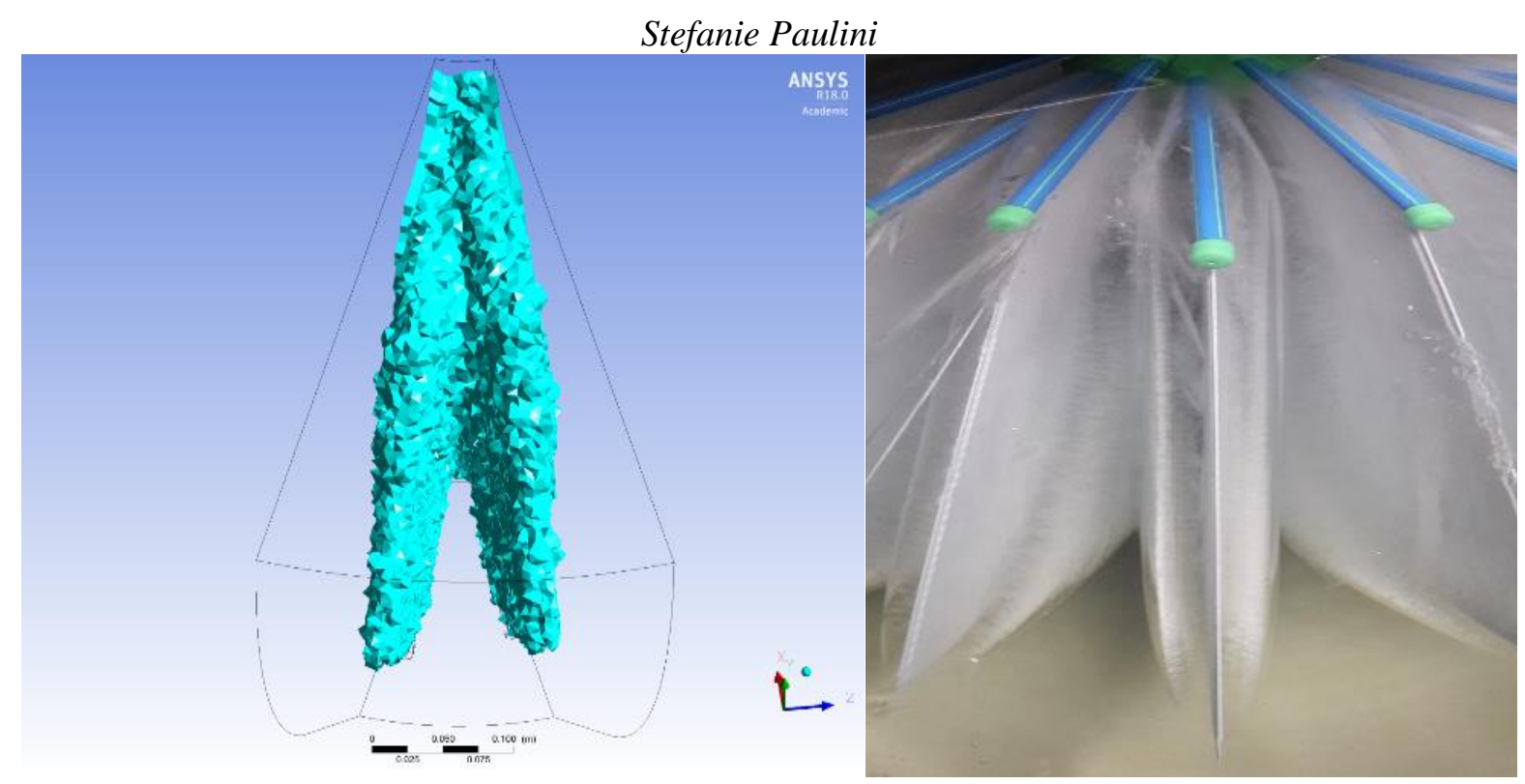

Fig. 13: Ice built-up in the simulation (left) and icing experiment (right) for the star-shaped heat exchanger with 24 plates

Due to the coarse grid, the surface of the simulated ice layer is irregular. The simulation resulted in an ice volume of $0.616 \mathrm{~m}^{3}$ or $576 \mathrm{~kg}$, while the experiment resulted in a calculated ice layer of about $590 \mathrm{~kg}$.

\section{Conclusion and future work}

The modeling of an ice storage system with 2D- and 3D-CFD simulation with ANSYS Fluent and the validation of these simulations with model test bench experiments is shown in this work. The temperature behavior during the cooling and icing process in the ice storage could be mapped very well despite a time gap by 2D-CFD simulations. The ice build-up could be predicted well by the 2D- and 3D-CFD simulations. The simulations and the experiments showed the increasing of the heat extraction by using a star-shaped heat exchanger geometry.

The accuracy of the 2D simulations should be further improved by adapting the parameters and boundary conditions. The 3D simulation should be improved by model reduction.

\section{References}

Al-abidi, A. A., et al., 2013. CFD applications for latent heat thermal energy storage: a review. Renewable and Sustainable Energy Reviews. 20, 353-363.

König-Haagen, A., Franquet, E., Pernot, E. and Brüggemann, D., 2017. A comprehensive benchmark of fixedgrid methods for the modeling of melting. International Journal of Thermal Sciences. 118, 69-103

Nayak, A. O., Ramkumar, G., T.Manoj, T., and Vinod, R. 2011. Comparative Study between Experimental Analysis and CFD Software Analysis of PCM material in Thermal Energy Storage System. International Journal of Chemical Engineering and Applications. Vol. 2, No. 6.

\section{Acknowledgement}

This work has been funded by the Bavarian State Ministry of Education, Science and the Arts within the framework "TechnologieAllianzOberfranken (TAO)" and the Federal Ministry for Economic Affairs and Energy within the framework "Zentrales Innovationsprogramm Mittelstand (ZIM)". The authors gratefully acknowledge this support. 


\author{
Validation of an Ice Storage Model and its Integration into a Solar-Ice System \\ Daniel Philippen ${ }^{1}$, Mattia Battaglia', Daniel Carbonell1, Bernard Thissen², and Lars Kunath ${ }^{3}$ \\ ${ }^{1}$ SPF Institute for Solar Technology, Rapperswil (Switzerland) \\ 2 Energie Solaire SA, Sierre (Switzerland) \\ ${ }^{3}$ Vela Solaris AG, Winterthur (Switzerland)
}

\begin{abstract}
Ice storages allow the storing of solar heat in a compact volume for the later use as source for a heat pump that provides heat for a building. In the paper a novel ice storage with $2 \mathrm{~m}^{3}$ water volume is described which contains heat exchanger plates for extracting the latent heat. Most of the components of the storage are made of stainless steel ensuring a long service life time. We present a detailed numerical model for heat exchanger plates that was implemented into the system simulation software Polysun. The model allows now for the first time to simulate ice storages with heat exchanger plates in Polysun. The accuracy of the modelling approach is evaluated based on lab measurements. The new ice storage model was implemented into a system simulation template in Polysun which was designed according to a field installation. The field installation includes three of the novel ice storages and will be used for the validation of the system template. The system template can be used as a design tool for solar-ice systems.
\end{abstract}

Keywords: Novel ice storage, heat exchanger plates, ice storage model, solar-ice system, validation

\title{
1. Introduction
}

Ice storages have been used for many decades in the cooling industry and for air-conditioning of buildings (Ashrae, 2015). If designed for this kind of application, ice storages are optimized for the provision of high cooling power in industrial processes and for the dispersal of cooling loads for air-conditioning over the day in order to reduce chiller needs at peak times of electricity cost. Different requirements are necessary when ice storage systems are used to provide space heating and domestic hot water in buildings in combination with a heat pump. Especially in this case, it is of high importance that the storage has low investment costs, is easy to install, and needs minimal maintenance.

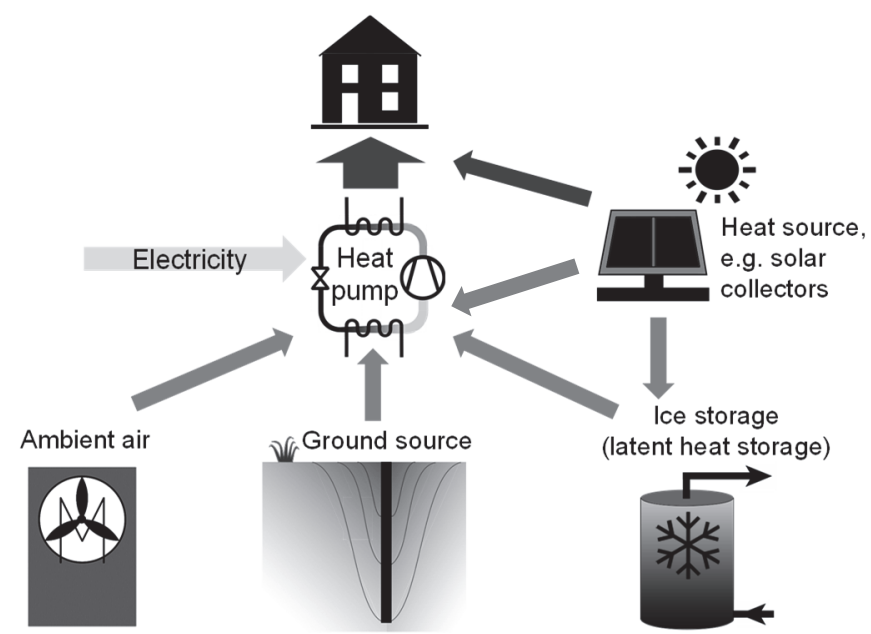

Fig. 1: Principle use of an ice storage as heat source for a heat pump in a solar-ice system. The solar heat stored in the ice storage is used alternatively to ambient air or ground source.

In combination with an ice storage, solar collectors are an alternative heat source that can replace the use of ambient air or of ground source (see Fig. 1). When the sun shines, solar collectors can provide enough heat directly to the building or to the heat pump evaporator. However, at cloudy or night time periods, another heat source is necessary. In this situation, the ice storage act as a temporal heat source, which is regenerated with the solar collectors at a very high efficiency. The heat pump can extract the sensible and latent heat via heat exchangers that are immersed into 
the ice storage water. Through the heat exchangers a heat transfer fluid is pumped which brings the heat to the heat pump. When the surface temperature of the heat exchanger drops below $0{ }^{\circ} \mathrm{C}$, ice is formed on the heat exchanger and latent heat of the storage water is extracted. By freezing the storage water a high amount of heat can be extracted: per kilogram of water $333 \mathrm{~kJ}(0.093 \mathrm{kWh})$ are released during this process. Compared to that, using the sensible heat of water at temperatures above $0{ }^{\circ} \mathrm{C}, 4.19 \mathrm{~kJ} /(\mathrm{kg} \mathrm{K})$ or $0.001 \mathrm{kWh} /(\mathrm{kg} \mathrm{K})$ can be extracted. From these numbers it can be derived that by freezing $1 \mathrm{~kg}$ of water the same amount of heat is released as by cooling $1 \mathrm{~kg}$ of water from approximately $80^{\circ} \mathrm{C}$ to $0{ }^{\circ} \mathrm{C}$.

\subsection{Characteristics of ice storages in heating systems}

In general, the following characteristics of ice storages are of interest for solar thermal and heat pump heating systems (Carbonell et al., 2017a):

- The use of the enthalpy of phase change of water leads to a high volumetric storage capacity, i.e. relatively small-sized ice storages can store a large amount of heat. Ice storages usually gain heat in winter from the surroundings.

- If the ice storage is installed outside the building (especially if buried in the ground) a thermal insulation of the walls of the ice storage may not be necessary. Eliminating the thermal insulation allows to achieve a heat gain in winter from the surrounding ground enabling to reduce the ice storage volume significantly.

- The impact on-site is lower compared to other heat sources for heat pumps like boreholes or air heat exchangers (no potential restrictions or risks like for boreholes and no visual or acoustic impacts like for air-source heat exchangers).

- The regeneration of the ice storage with solar heat at a low temperature level leads to additional solar gains in times during which the solar heat cannot be used directly for space heating or domestic hot water preparation.

- Low temperature heat sources like waste heat of e.g. exhaust air or waste water can deliver heat for melting the ice.

- If the ice formed in winter is stored until summer or if the building has both heating and cooling demands, the storage can be used as a heat sink for free cooling.

- The system design allows flexibility, i.e. lack of roof area can be compensated by larger ice storage volume and vice versa.

\subsection{Heat exchanger types for ice storages}

Several heat exchanger concepts for extracting the latent heat from ice storages can be used (Carbonell et al., 2017a). Each concept has to ensure that the ice layer on the specific heat exchanger reaches a maximum thickness that is appropriate for the concept and does not result in too low source temperatures for the heat pump. In principle, two strategies exist for the design of heat exchangers for ice storages:

(a) Large heat exchanger area homogeneously distributed throughout the whole storage volume. Depending on the extraction power of the heat pump and on the specific characteristics of the heat exchanger, a maximum ice layer thickness ranging from several centimeters to a few decimeters is usually allowed. This maximum ice thickness determines the distribution of the heat exchanger in the storage volume. The following heat exchanger types are commonly used:

- Coils or capillary mats typically made of plastic that are mounted on a supporting structure. These systems are known as "Ice-on-coil" type with suppliers such as e.g. Viessmann/Isocal, Fafco, Consolar, Calmac and Clina.

- Flat heat exchanger plates mounted on a supporting structure. Materials can be plastic or stainless steel with supplier such as e.g. Energie Solaire, MEFA and BITHERM.

- Spheres made of plastic filled with water (ice balls). The ice storage is filled with the spheres and brine is pumped through the gaps between the spheres, with a supplier such as Cristopia.

(b) Small heat exchanger in or outside the storage with prevention of ice formation on the heat exchanger or active removing of ice from the heat exchanger surface: 
- Ice slurry machines that can be mounted outside the storage. On a compact heat exchanger either water is sub-cooled and freezes after being released into the ice storage or ice is directly formed on the heat exchanger, continually scraped away by a mechanic device, and washed into the storage (Abrahamsson, 1981). Suppliers such as e.g. Mycom Mayekawa and Shinryo Corporation.

- Falling water film: the storage water is sprayed over a heat exchanger mounted above an open storage. The storage water freezes on the heat exchanger which is periodically de-iced thermally by a hot gas (Mehling and Cabeza, 2008). This system is known as an ice harvesting system.

- Flat immersed heat exchanger plates made of stainless steel. The plates are mounted vertically at the bottom of the storage and have a low height compared to the water level. The plates are periodically de-iced thermally by low grade heat (Philippen et al., 2012).

From the above mentioned systems only the homogeneously distributed concepts are established in the solar and heat pump heating market. A comparison of the performance of commonly used heat exchangers for ice storages based on lab tests is given in Carbonell et al. (2017a).

\subsection{Aim of developing a new ice storage and a design tool for system sizing}

Most of the market available ice storage tanks have been designed for cooling applications and do not meet the specific needs of solar-ice heating systems. The number of manufacturers of ice storages is small and only a few designs of ice storages are available. Some of the ice storages available for solar-ice applications have to be installed outside the building due to their design and sizes (e.g. Viessmann/Isocal, DE) or are very small (few hundreds of liters) and thus only usable for single family houses (e.g. Consolar, DE). Further, market available ice storages have a guaranteed life time of only 10 years while heating systems should last at least 20 to 25 years, especially the storage tanks.

One goal of the presented work was to develop an ice storage in the range of $2 \mathrm{~m}^{3}$, where mainly stainless steel components are used in order to ensure a long service life time of 25 years. The developed heat exchanger of the $2 \mathrm{~m}^{3}$ storage consists of several heat exchanger plates and is meant for being used also in larger ice storages, meaning, its area can be scaled up for larger storage volumes.

In the design of solar-ice systems, hereafter named "ICESOL", the frequently encountered trade-off between system efficiency and cost is partially caused by the installed heat exchanger area inside the ice storage. While a higher efficiency can be achieved by increasing the area, the number of installed heat exchanger is also a major cost driver in the system installation (Carbonell et al., 2017b).

Due to the dependence from heating demand, climate and the variability of the components, solar-ice systems are not easy to design and to size. There is a need of dynamic system simulations to get reliable results in the planning phase. For this reason, it was decided to implement a model of the new ice storage with its heat exchanger plates into the simulation software Polysun. The ice storage model that had been implemented in Polysun in a previous program version takes only ice-on-coil heat exchangers into account and cannot be used for plate heat exchangers.

In addition to the goal of developing an ice storage, further goals of the project presented were i) to do a transcription of a mathematical model of an ice storage written in Fortran language from a TRNSYS type developed in Carbonell et al. (2017a) into JAVA language and its simplification and implementation into the software Polysun and ii) to validate the new model with measurement data from laboratory tests. Further, a whole solar-ice heating system was implemented in Polysun containing the new ice storage model. The system as well will be validated with measurement data from a field installation of a multi-family building were three units of the new ice storage were installed. Due to delays in installing the field installation, the measurement data is still missing and the validation of the system could not be finished.

\section{Design of the new modular ice storage and set-up of lab measurements}

A cylindrical ice storage was developed (Fig. 2) that can easily be installed in clusters to get larger total ice storage volumes if needed. The main components of the storage, like the cylindrical vessel, heat exchangers, pipes, fixtures and fittings are made of stainless steel which ensures long service life time and prevent diffusing of oxygen into the brine cycle. Tab. 1 gives an overview on most important parameters of the storage.

Four pairs of heat exchanger plates are mounted and hydraulically connected in parallel. Each pair consists of two 
plates that are connected in series. The heat exchanger plates have a distance between each other of $12 \mathrm{~cm}$. Hence, the maximum ice thickness on the heat exchanger surfaces is $6 \mathrm{~cm}$. The heat exchanger is made of stainless steel with a "cushion" geometry (Fig. 3). Each cushion has a size of $60 \mathrm{~mm} \times 60 \mathrm{~mm}$. The square bumps of the front sheet are set off half a pass towards the square bumps of the back sheet in a way to allow full irrigation. Both sheets are spot welded together and combined at the edges by welding. There is already 6 years of experience with the use of this heat exchanger in ice storage tanks which has given confidence in their reliability for this new application.

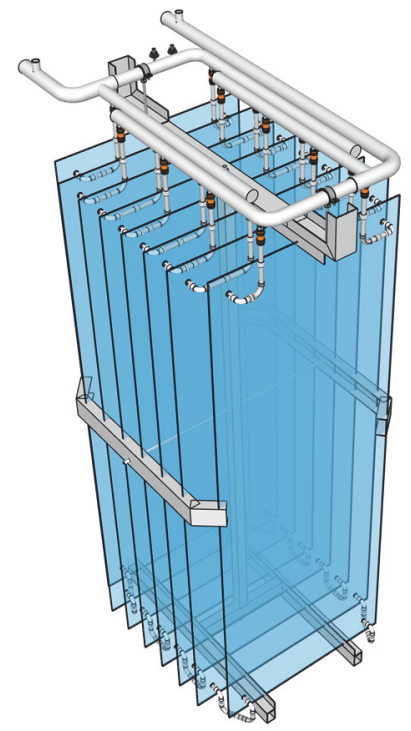

(a)

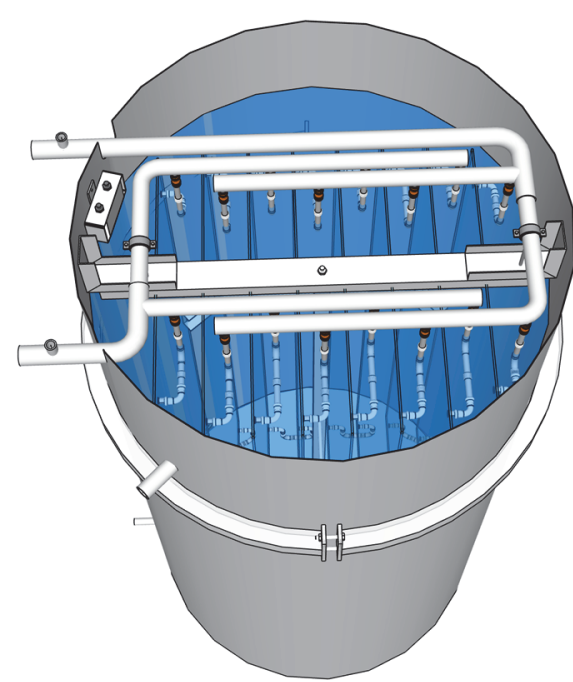

(b)

Fig. 2: Drawing of (a) the ICESOL heat exchanger with eight heat exchanger plates made of stainless steel (transparency in the drawing as artefact) and (b) the ICESOL ice storage with the heat exchanger immersed into the storage water.

To gather data for the model validation and for testing the mechanical stability of the storage, laboratory tests were conducted with a storage like specified in Tab. 1 following the test cycles described in Carbonell et al. (2017a). The test cycles include sensible heating of the ice storage up to $40{ }^{\circ} \mathrm{C}$, sensible cooling, fully icing with decreasing brine temperature down to $-10^{\circ} \mathrm{C}$, cycling (melting \& freezing) at high ice fractions, and melting. Mass flow rates of $1^{\prime} 000 \mathrm{l} / \mathrm{h}$ and $2^{\prime} 000 \mathrm{l} / \mathrm{h}$ were used for the tests.

Tab. 1: Main specifications of the ice storage as tested in the lab.

\begin{tabular}{|l|l|r|}
\hline Diameter of storage & $\mathrm{mm}$ & 1200 \\
\hline Height of storage & $\mathrm{mm}$ & 1950 \\
\hline Water content & $\mathrm{m}^{3}$ & 1.97 \\
\hline Number of parallel pairs of hx-plates & $\#$ & 4 \\
\hline Distance between plates & $\mathrm{mm}$ & 120 \\
\hline Active surface of heat exchangers & $\mathrm{m}^{2}$ & 21.7 \\
\hline Latent heat (max.) & $\mathrm{kWh}$ & 129 \\
\hline Maximum icing fraction & of mass & $70 \%$ \\
\hline
\end{tabular}

During the icing test phase a very high ice fraction was achieved and the ice layers reached the wall of the storage (Fig. 4). At this state of fully icing, the cycling phase of melting and icing started. As a result, mechanical tensions in the ice were dissipated and the ice cracked causing a slight movement of the ice. However, no deformation or damage could be detected neither at the built-in components nor at the wall of the cylindrical storage after melting all ice. As a result, the laboratory tests have shown also for harsh conditions that the ice storage is sufficient stable against the mechanical stress the ice is causing. 


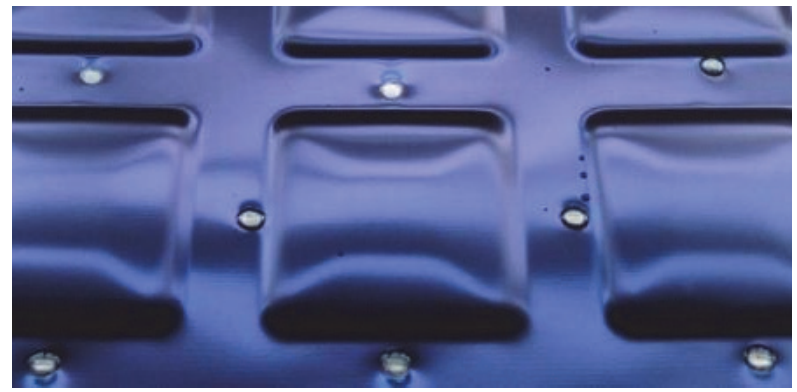

(a)

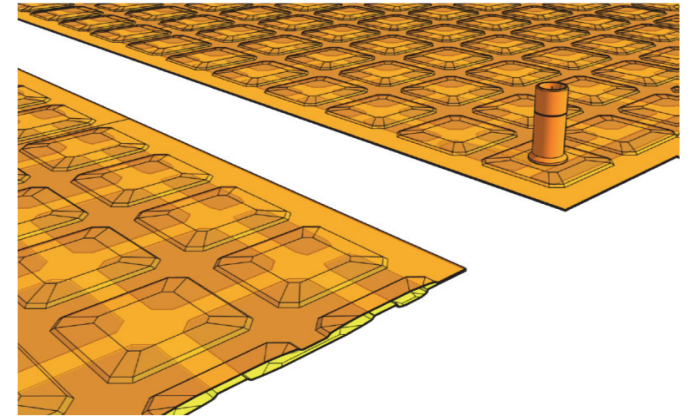

(b)

Fig. 3: (a) Surface of the solar absorber of manufacturer Energie Solaire SA which - without dark coating - can be used as a heat exchanger in ice storage tanks; (b) section of the heat exchanger and 3D view.

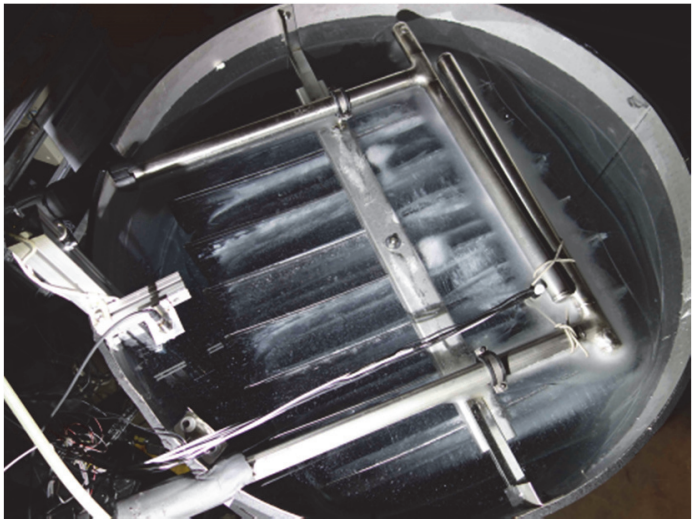

(a)

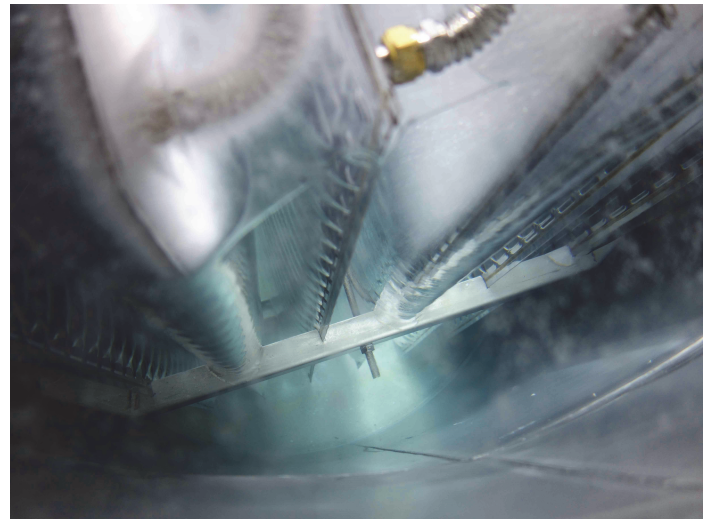

(b)

Fig. 4: Ice storage with iced heat exchangers during measurements in the lab (tank cover removed). (a) The heat exchanger inside the cylindrical ice storage and (b) View into the ice storage with water between storage wall and iced heat exchangers.

\section{Mathematical model of heat exchanger plates}

The mathematical model of the ice storage itself is based on discrete control volumes with the corresponding heat transfer equations. The implemented version is a simplified version of the model described in Carbonell et al. (2017a) which is restricted to heat exchanger plates. In comparison to the original model, the number of control volumes used in the storage is fixed to 1 . The general structure of the model is shown in Fig. 5.

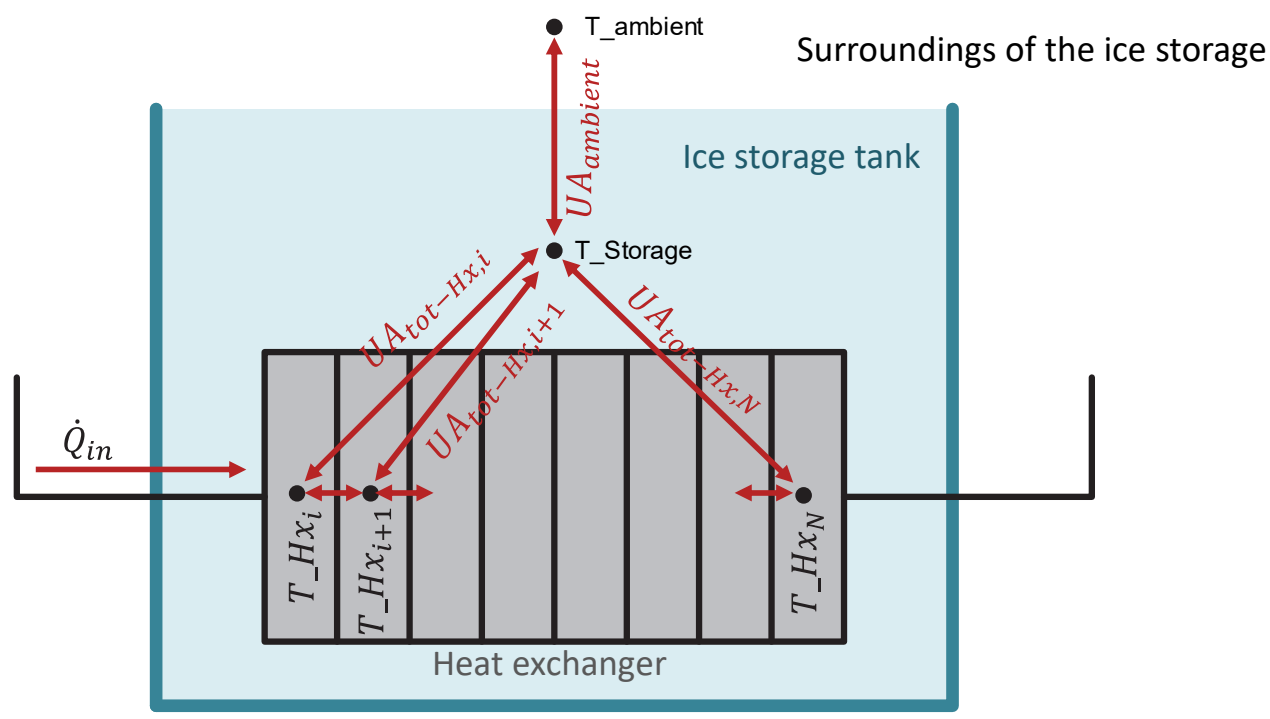

Fig. 5: Temperature nodes and UA-values of the ice storage model. 
In the modelling approach used for the heat exchanger plates, apart from the chosen control volume geometry, the heat transfer coefficients $(\mathrm{U})$ are the most important factors. In the following section, the governing equations for the heat transfer coefficients multiplied by the relevant surface area (UA-values) are presented. The energy transfer due to fluid flow in between the control volumes is computed according to Polysun's standard fluid flow interface.

The core elements of the model are the heat transfer values $\left(U A_{i}\right)$ between the brine inside the heat exchangers and the water inside the storage. The UA-values limit the maximum power that can be extracted from or injected into the storage and thus, have a large influence on the simulation results. Sensible heating, sensible cooling, as well as icing are treated individually as they all inflict different physical dynamics in the fluid on small scales that effect the overall heat balance. In all states, the UA-values are derived from general heat transfer correlations.

In the following section the control volume number index $i$ is omitted for simplicity reasons and all UA-values represent the values associated to one control volume. The heat exchanger has a fixed number of 12 control volumes which was found to be a good compromise between the accuracy on the heat exchanger model and the simulation time needed by the model.

The overall UA-value per control volume $\left(\mathrm{UA}_{\mathrm{tot}}\right)$ is a combination of the heat transfer area product coefficients between heat exchanger fluid and heat exchanger wall $U A_{\text {in }}$, through the wall $U A_{\text {wall }}$, through the ice $U A_{\text {ice }}$ and from the wall or the ice layer to the storage water $U A_{\text {out }}$

$$
\mathrm{UA}_{\mathrm{tot}}=\left(\frac{1}{U A_{\text {in }}}+\frac{1}{U A_{\text {wall }}}+\frac{1}{U A_{\text {ice }}}+\frac{1}{U A_{\text {out }}}\right)^{-1}
$$

\subsection{Heat Exchanger Plates}

The heat transfer area product coefficient between the heat exchanger fluid and the wall $\left(U A_{i n}\right)$ of the heat exchanger plates is calculated as follows.

If the Reynolds number $R e<70$.

$$
N u_{\text {laminar }}=1.68 \operatorname{Re} e^{0.4}\left(\operatorname{Pr} * \frac{d_{h}}{b}\right)^{0.4}
$$

If $R e>150$

$$
N u_{\text {turbulent }}=0.2 \operatorname{Re}^{0.67} \operatorname{Pr}^{0.4}
$$

If $70<R e<150$, a linear interpolation between $N u_{\text {laminar }}$ and $N u_{\text {turbulent }}$ is used.

The diameter $d_{h}$ of the flow cross section in the calculation of the Reynolds number is reduced by a factor of two in the case of corrugated heat exchangers. Based on the Nusselt numbers, the UA value can be computed as:

$$
U A_{\text {in }}=2 A \cdot N u \cdot \lambda_{\text {fluid }} / d_{h}
$$

The factor of two indicates that the heat exchanger plate has both front sides in contact with the water.

Accordingly, $U A_{\text {wall }}$ is calculated as:

$$
U A_{\text {wall }}=2 A \cdot \lambda_{\text {wall }} / x_{\text {wall }}
$$

\subsection{Sensible heating and cooling without ice}

In the case of no ice on the heat exchanger $U A_{\text {ice }}=\infty$ and the equation of $\mathrm{UA}_{\text {tot }}$ reduces to

$$
\mathrm{UA}_{\mathrm{tot}}=\left(\frac{1}{U A_{\text {in }}}+\frac{1}{U A_{\text {wall }}}+\frac{1}{U A_{\text {out }}}\right)^{-1}
$$

In this case $U A_{\text {out }}$ is calculated based on the Rayleigh number $R a$. 


$$
\begin{aligned}
& R a=9.81 \beta \rho^{2}\left(\mathrm{~T}_{\text {storage }}-T_{\text {wall }}\right) l_{c}^{3} c_{p} \mu \lambda_{\text {tank,fluid }} \\
& N u=0.55 \cdot R a^{0.33} \\
& U A_{\text {out }}=2 A \cdot N u \cdot \lambda_{\text {tank,fluid }} / l_{c}
\end{aligned}
$$

\subsection{I cing}

The model assumes that icing starts to build on the heat exchanger as soon as $T_{\text {storage }}$ reaches $0{ }^{\circ} \mathrm{C}$ and the brine temperature is below $0{ }^{\circ} \mathrm{C}$ (no supercooling is taken into account). No simultaneous energy transfer due to latent and sensible heating is modeled. When ice is present in the storage, the model distinguishes between a state where ice grows on the outer surface of the ice layer and a second state where a layer of liquid water is present between the outer surface of the heat exchanger and the ice layer due to partially melting the ice layer at previous time steps. At the maximum one layer of liquid is assumed between the heat exchanger surface and the ice layer. In case this liquid layer is present due to a partial melting phase, during the next icing, this inner water layer is iced first and only the thickness of the inner ice layer $x_{\text {ice,inner }}$ is considered for the calculation of the UA-value until it reaches the priory melted thickness. The following applies:

$$
\mathrm{UA}_{\text {tot }}=\left(\frac{1}{U A_{\text {in }}}+\frac{1}{U A_{\text {wall }}}+\frac{1}{U A_{\text {ice }}}\right)^{-1}
$$

where

$$
U A_{\text {ice }}=2 A \cdot \lambda_{\text {ice }} / x_{\text {ice,inner }}
$$

If there is only a single layer of ice and ice grows at the outer surface, $U A_{i c e}$ is calculated using the full thickness of the ice:

$$
U A_{i c e}=2 A \cdot \lambda_{i c e} / x_{i c e}
$$

The thickness of the ice layer $x_{i c e}$ or $x_{i c e, \text { inner }}$ are updated after each time step by the total energy transferred through the section of the heat exchanger $Q_{h x, i}$.

$$
\Delta x_{i c e, i}=\frac{Q_{h x, i}}{\Delta H \rho_{i c e}} \cdot \frac{1}{2 A}
$$

\subsection{Melting}

During melting, $\mathrm{UA}_{\text {tot }}$ is calculated as

$$
\mathrm{UA}_{\mathrm{tot}}=\left(\frac{1}{U A_{\text {in }}}+\frac{1}{U A_{\text {wall }}}+\frac{1}{U A_{\text {out }}}\right)^{-1}
$$

Melting is modelled with two different phases. At first, when the thickness of the melted layer $x_{\text {melt }}$ is smaller than $0.01 \mathrm{~m}$, the $U A_{\text {out }}$ is assumed to be dominated by conduction

$$
U A_{\text {out }}=2 A \cdot \lambda_{\text {water }} / x_{\text {melt }}
$$

For larger depths of the melted layer $\left(x_{\text {melt }}>0.02 \mathrm{~m}\right)$ convection is assumed to become relevant:

$$
\begin{aligned}
& R a=9.81 \beta \rho^{2}\left(\mathrm{~T}_{\text {storage }}-T_{\text {wall }}\right) l_{c}^{3} c_{p} \mu \lambda_{\text {tank,fluid }} \\
& N u=0.3 \cdot R a^{0.208} \\
& U A_{\text {out }}=2 A \cdot N u \cdot \lambda_{\text {tank,fluid }} / l_{c}
\end{aligned}
$$

In the transition a linear interpolation is used. 


\section{Model validation}

The model implemented was validated using data from the test cycles mentioned in chapter 2 . An example of the icing phase that is crucial for system performance is shown in Fig. 6. The results of the original model implemented in TRNSYS in Carbonell et al. (2017a) are also given. In the bottom right figure, it can be seen, that the UA-value of the Polysun model approximates the measured UA-value equally well than the TRNSYS model when the ice fraction is above $10 \%$. For lower ice fractions, the UA-value of the Polysun model surpasses the TRNSYS model up to a factor of 2 . The source of this behavior was identified to be the different fluid properties used for the brine in Polysun and TRNSYS. Since in the tested configuration the brine was in the transition phase between turbulent and laminar flow, slightly different values in fluid properties lead to large deviations in $U A_{\text {in }}$. The calculations of both models are lying outside the uncertainty of the measurement quite often. However, especially for the aggregated values like energy and ice fraction the simulations are matching the measurement results well.

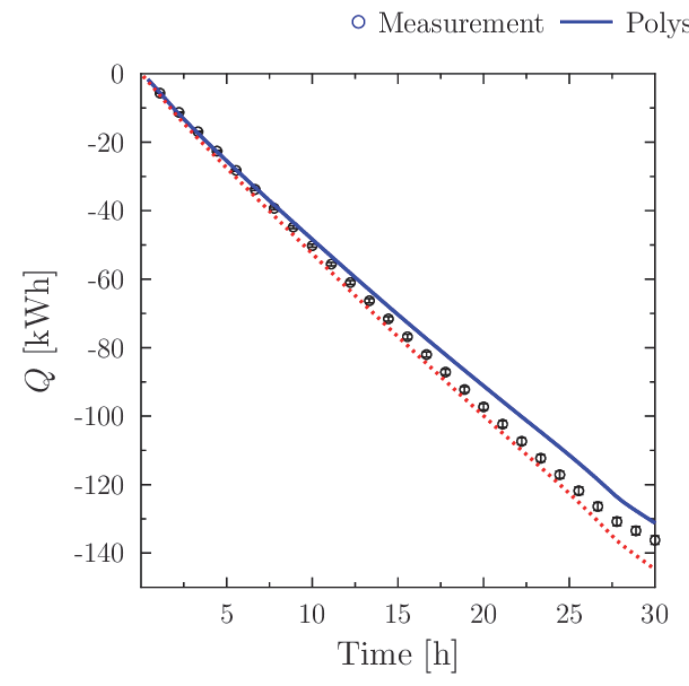

(a)

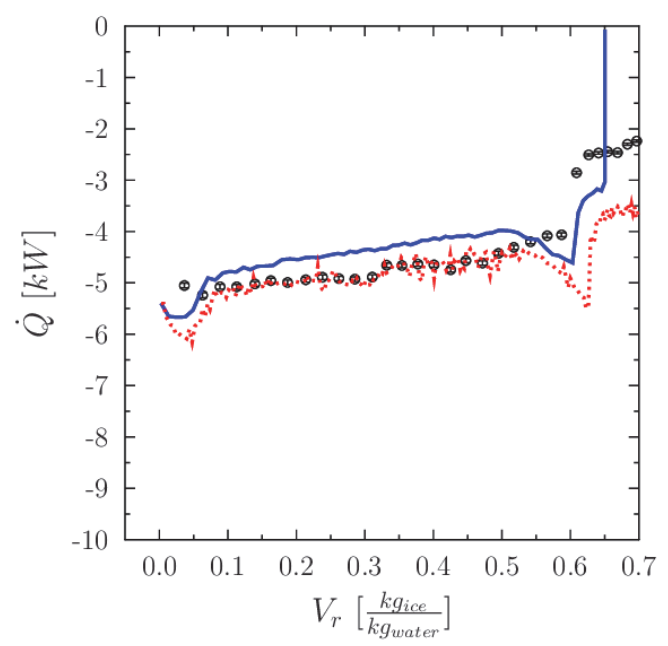

(c)

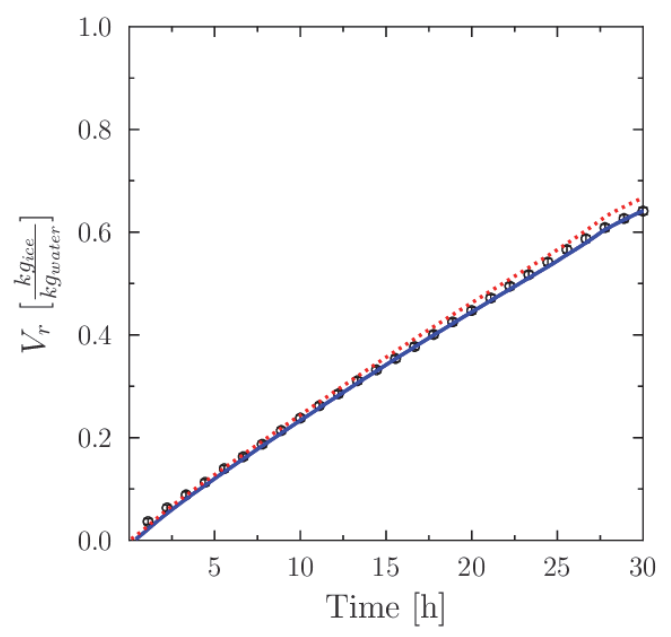

(b)

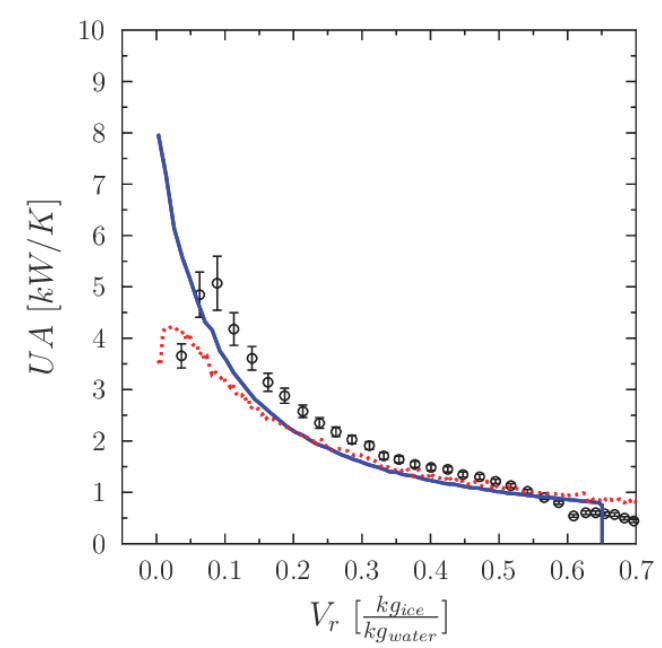

(d)

Fig. 6: Icing of 8 heat exchanger plates in the ice storage. Comparison of the new Polysun ice storage model with lab measurements and with a TRNSYS model. With extracted energy $(Q)$, ice fraction $\left(V_{r}\right)$, extracting power $(\dot{Q})$, and $U A-v a l u e$. At $V_{r}=0.65$ the Polysun model assumes maximum icing fraction (due to the special conditions within the ice storage tank) and the heat extraction drops to Zero.

The power $\dot{Q}$ (lower left figure) is slightly underestimated by the Polysun implementation leading to a slower increase of the cumulative extracted energy $Q$ (top left figure). This behavior is a result of the Polysun storage model simplification where only one control volume is used. During icing, this control volume has a constant temperature of $0{ }^{\circ} \mathrm{C}$ leading to a smaller temperature difference compared to the original TRNSYS model where each control volume of the heat exchangers is linked to a control volume of the storage. As a consequence, during icing, storage temperatures slightly higher than $0^{\circ} \mathrm{C}$ are possible for the TRNSYS model due to the higher spatial resolution. Although the Polysun model shows a slower increase of the cumulative extracted energy over time, the increase of ice fraction is faster. This is due to different definitions of ice fraction used in the model implementation of the two simulation frameworks. While in the TRNSYS implementation the ice fraction represents the mass fraction, in the 
Polysun model it represents the volume fraction.

Sensible heating of the ice storage from approx. room temperature to $40{ }^{\circ} \mathrm{C}$ is shown in Fig. 7. Although lying often not exactly inside the range of uncertainty of the measurement data, the new Polysun model shows a very good correlation with the measurement for the relevant values $\mathrm{Q}, \dot{Q}$, and the outlet temperature of the heat exchanger $\left(\mathrm{T}_{\text {out }, \mathrm{hx}}\right)$. This is the case also where sudden changes in the load power occur due to the regulation of the heater. Some larger deviations can be seen for the UA value (hours 5 to 9) but no relevant deviations for the other values can be seen as implication.

○ Measurement — Polysun Multinode-HEX …… Type 861 (TRNSYS)

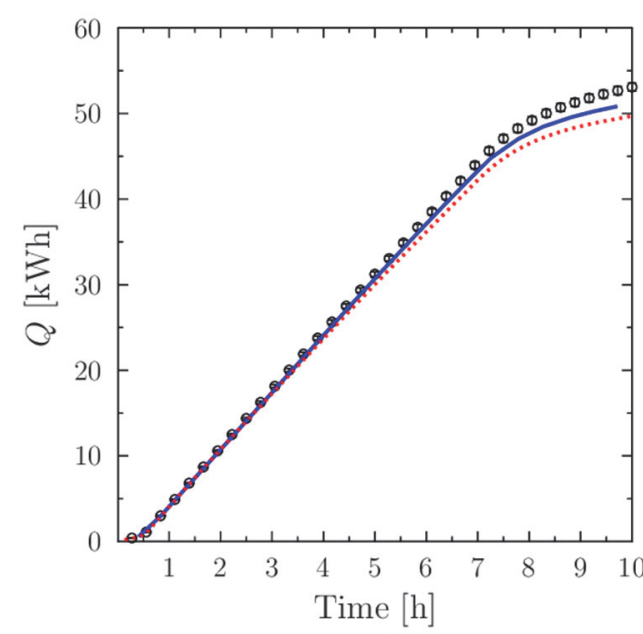

(a)

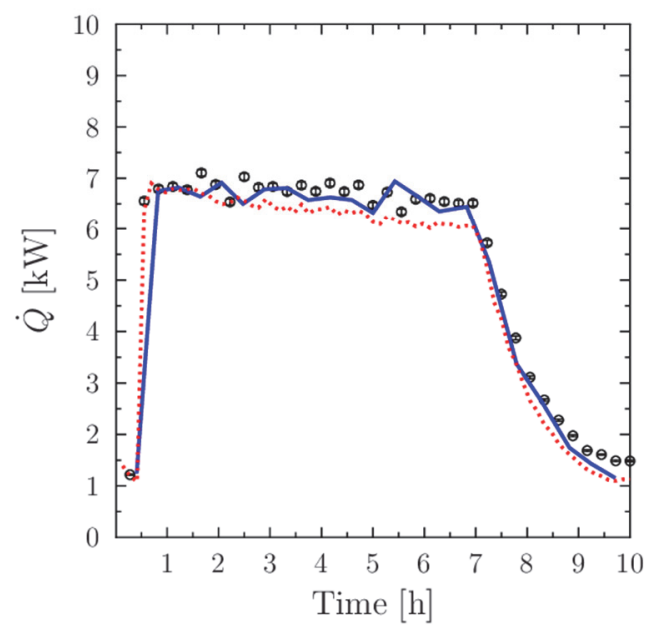

(c)

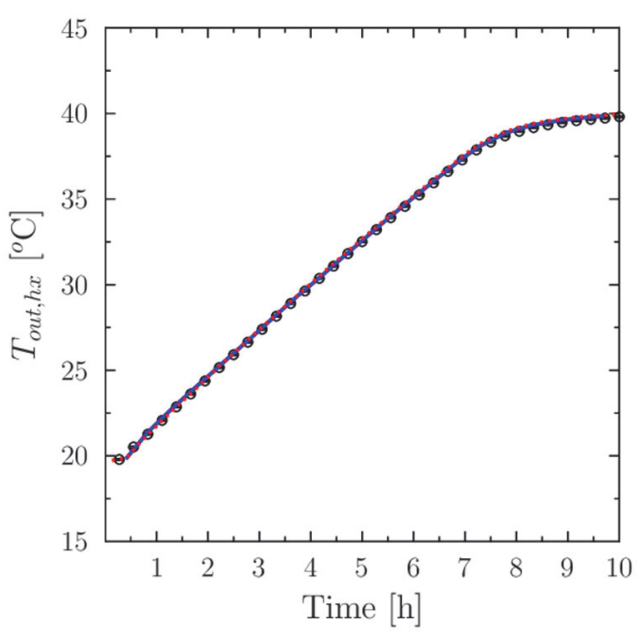

(b)

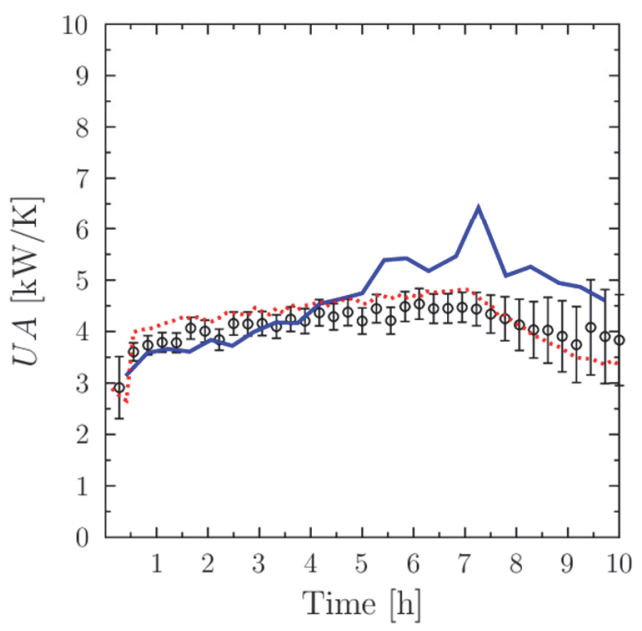

(d)

Fig. 7: Sensible heating with 8 heat exchanger plates in the ice storage up to $40{ }^{\circ} \mathrm{C}$. Comparison of the new Polysun ice storage model with lab measurements and a TRNSYS model. With extracted energy $(Q)$, outlet temperature of the heat exchanger $\left(\mathrm{T}_{\text {out,hx }}\right)$, extracting power $(\dot{Q})$, and $\mathrm{UA}-$ Value.

\section{Field Installation and System Integration into Polysun}

In winter 2017/2018 a solar-ice system with the developed ice storage was installed in a multifamily building that was refurbished and extended in 2017 to $1^{\prime} 800 \mathrm{~m}^{2}$ of heated floor area (Figure 8). The building is located in the south-west of Switzerland near Geneva on a height of $360 \mathrm{~m}$ above sea level. The heating system is monitored and the monitoring data will be used to validate a newly integrated solar-ice heating system in Polysun.

The main components of the solar-ice system in the building are: a heat pump with a nominal thermal power of $30 \mathrm{~kW}$ (B0/W35), a field of unglazed solar collectors of $110 \mathrm{~m}^{2}$, and three of the developed ice storages with a water volume of $2 \mathrm{~m}^{3}$ each. The ice storages are regenerated with solar heat and also with the exhaust air of the ventilation system. As an air-to-air heat recovery system for the ventilation could not be realized due to the local conditions, the 
warm exhaust air is used to load the ice storage which is done with an air-to-water heat exchanger. This steady heat input into the ice storages allows to use a reduced ice storage volume in this heating system.

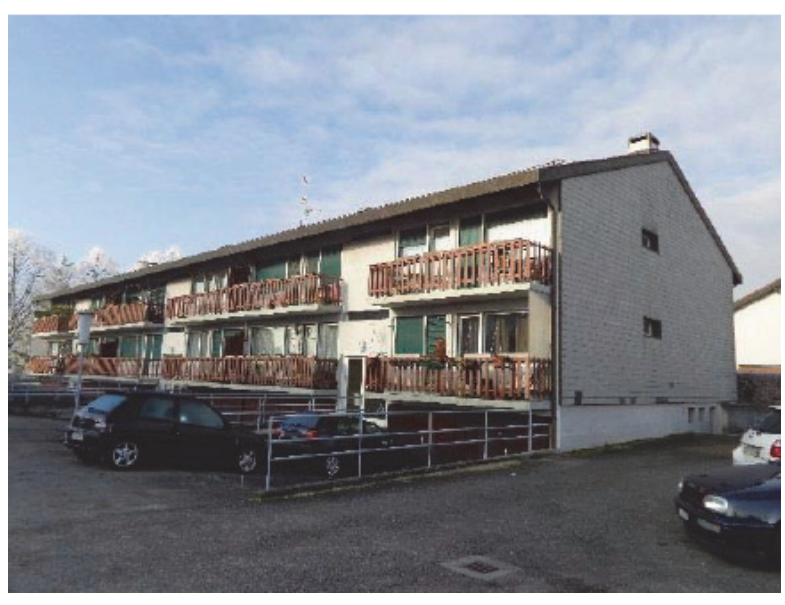

(a)

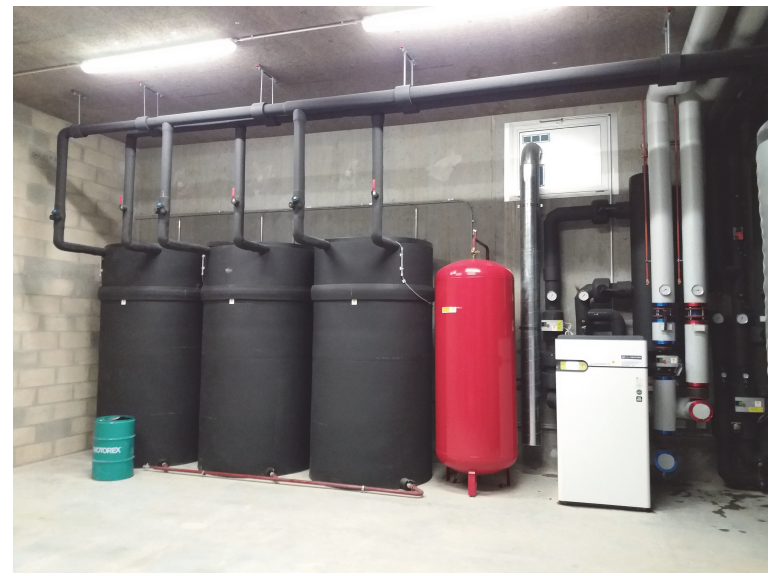

(c)

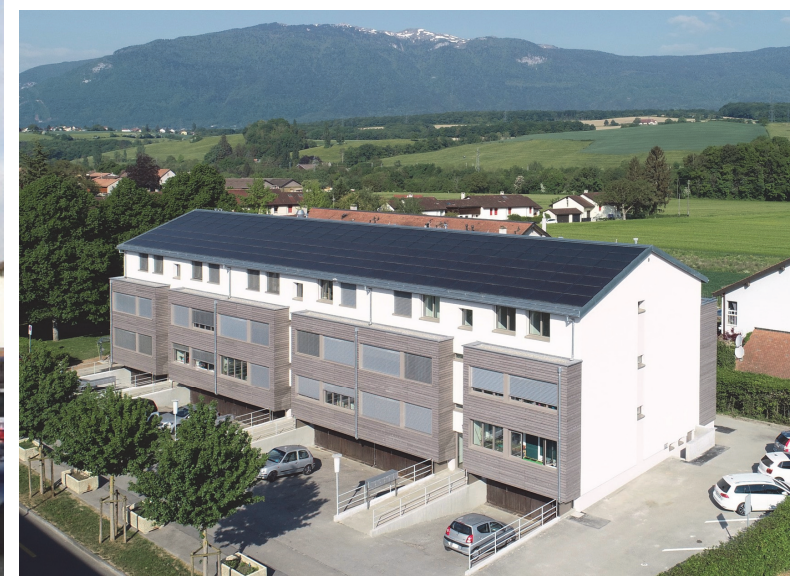

(b)

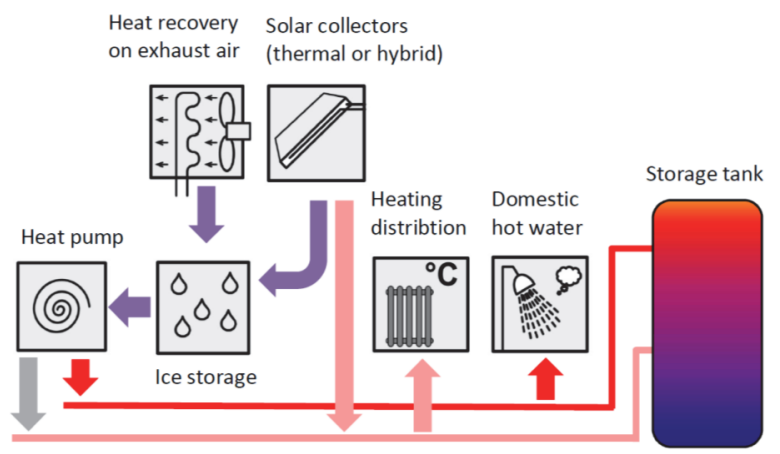

(d)

Fig. 8: Field installation including the developed ice storage, installed in a multi-family building. Building (a) before and (b) after the refurbishment and extension to $1^{\prime} 800 \mathrm{~m}^{2}$ heated floor area. (c) Cellar with three ice storages of $2 \mathrm{~m}^{3}$ volume each and (d) scheme of the energy flows in the heating system.

The ICESOL system including the new ice storage model was implemented according to the specifications of the field installation into Polysun. The system will serve as template for the ICESOL systems of ESSA and will be validated with the monitoring data from the field installation. The template will be available in new Polysun versions and will allow to size heating systems containing an ice storage with flat heat exchanger plates.

The validation of the system template has still to be done as the finalization of the field installation was delayed and no measurement data from the heating system could be gathered during the last winter. After winter 2018/2019 the measured energy flows between the different main components (collector field, ice storage, heat pump, storages, and building) and their changes in temperature will be used for a validation of the system template.

\section{ICESOL solar-ice heating systems}

The ICESOL system installed at La Cigale in Geneva (largest MINERGIE-P refurbishment project in Switzerland www.renov-lacigale.ch) has shown that large ICESOL systems (500 kW heating power) are a valuable alternative to heat pump systems with boreholes, especially when borehole drilling is prohibited or technically not possible. The estimated geothermal potential in Switzerland is limited. In large areas ground source heat pumps are not allowed because of groundwater protection. Additionally, in urban environment drilling boreholes is not always technically feasible. Ice storages together with solar thermal as sources for heat pumps are relatively new and not explicitly considered in official predictions for energy supply. It is difficult to estimate the potential of the ICESOL heating system, since it is quiet young on the market. However, the market potential of his technology is high. The company 
Energie Solaire SA, as example, is involved in several large projects that are planned in Switzerland in the next few years with a heating power of up to $1.5 \mathrm{MW}$ per system, with large ice storage tanks of up to $300 \mathrm{~m}^{3}$.

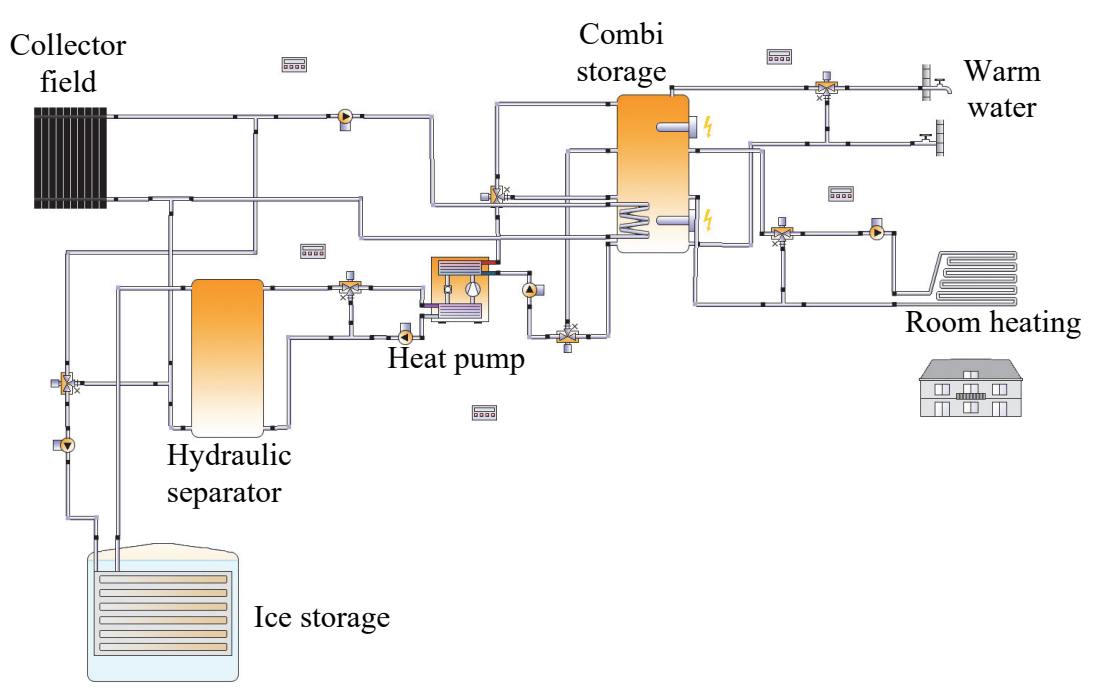

Fig. 9: Template of the solar-ice system with the new ice storage model which was implemented into the Polysun simulation software.

Main advantages of solar-ice-systems are as follows:

- High seasonal performance factors (SPF) are achievable.

- The system is competitive in comparison to geothermal heat pump systems.

- Unlike air-source heat pumps, ICESOL is silent and does not produce noise disturbances.

- Apart from using low temperature solar thermal heat, ICESOL can use low temperature waste heat recovery to de-ice the ice storage.

- Heat-exchangers in ice storages can easily be replaced in case of a default, which is not the case for boreholes.

- Solar collectors, the heat source for ICESOL heat pump systems, can quiet easily be integrated in the building envelope (roof, façade, etc.).

- Since the ice storages are relatively small they can be installed in the building or be part of the building, without using a lot of space.

\section{Conclusion}

A new ice storage with $2 \mathrm{~m}^{3}$ water volume ( $129 \mathrm{kWh}$ latent heat) was designed including heat exchanger plates made of stainless steel. With lab tests it could be shown that the ice storage and its built-in components are mechanically stable against icing and melting of the storage water. The ice storage was energetically characterized with measurements. The heat exchanger in the ice storage consists of four parallel pairs of heat exchanger plates. To get larger ice storage volume, a cluster of several ice storages can be used and connected in parallel. To obtain very large ice storages, the heat exchanger can be implemented in any kind of storage vessel and can be scaled by increasing the number of heat exchanger pairs.

The advanced ice storage model that was developed for Polysun and validated with measurement data extends the capabilities of Polysun to represent different kinds of ice storages. While the already existing model relies on an empirical fitting function fixed to the specific kind of coil heat exchanger geometry, the new model was designed to simulate an ice storage with any number of flat plate heat exchangers. The heat exchanger material and geometry as well as the distance between heat exchangers in the ice storage can be parametrized. In the following, the model can be used to test and simulate new ice storage configurations ad hoc without the need of providing experimental data. In addition, in comparison to the already existing ice storage model in Polysun, the new model accounts for measureable differences in the heat transfer properties between icing and melting making it more precise in reproducing both behaviors. 
A new template for a solar-ice system including the new ice storage model was implemented into Polysun. The template will be validated with measurement data from a field installation in a multifamily building. As the installation of the monitoring equipment was delayed, no measurement data could be obtained until publishing of this paper and the validation of the system template is still pending. We expect to finalize the system validation by summer 2019.

\section{References}

Abrahamsson, T., 1981. Heat from Solar Energy and Air with Storage in Water and Ice. Swedish Council for Building Research.

Ashrae, 2015. 2015 ASHRAE Handbook-HVAC Applications, I-P Edition. ASHRAE.

Carbonell, D., Battaglia, M., Philippen, D., Haller, M., 2017a. IceEx, Exchanger Analyses for Ice Storages in Solar and Heat Pump Applications, Final Report.

Carbonell, D., Battaglia, M., Philippen, D., Haller, M.Y., 2017b. Cost-Energetic Analyses of Ice Storage Heat Exchangers in Solar-Ice Systems. Presented at the ISES Solar World Conference 2017 and the IEA SHC Solar Heating and Cooling Conference for Buildings and Industry 2017.

Mehling, H., Cabeza, L.F., 2008. Heat and cold storage with PCM: An up to date introduction into basics and applications 2008. Berlin: Springer 16, 4.

Philippen, D., Haller, M.Y., Logie, W., Thalmann, M., Brunold, S., Frank, E., 2012. Development of a heat exchanger that can be de-iced for the use in ice stores in solar thermal heat pump systems, in: Proc. of the EuroSun 2012 Conference. Rijeka and Opatija, Croatia. 


\title{
Decentralized DHW Production from Exhaust air in the Bathroom Prewall
}

\author{
Florian Ruesch ${ }^{1}$, Patrick Persdorf ${ }^{1}$, Duglas Hunziker ${ }^{2}$, Elias Büchel ${ }^{3}$ and Michel Haller ${ }^{1}$ \\ 1 SPF Institute for solar technology, HSR, Rapperswil (Switzerland) \\ 2 PV Laboratory, BFH, Burgdorf (Switzerland) \\ ${ }^{3}$ IES institute for energy systems, NTB, Buchs (Switzerland)
}

\begin{abstract}
In urban multifamily houses, decentralized DHW systems using gas or electric boilers are still widely used. Their replacement with renewable energy sources is difficult and generally needs centralized DHW systems with a circulation system that ensures comfort and hygiene at the price of elevated heat losses. A consortium of three academic and one industry partner developed a decentralized DHW system, which uses the residual heat from the exhaust air of a controlled ventilation unit as energy source for a micro heat pump. The entire system, including ventilation unit, heat pump, and storage tank fits into the bathroom prewall and produces hot water for one apartment. This contribution gives an overview of the system and focusses on the development of the flat storage tank that fits into the prewall space of less than $30 \mathrm{~cm}$ width.
\end{abstract}

Keywords: Decentralized DHW, micro heat pump, flat DHW tank

\section{Introduction}

In Switzerland, there are still about half a million decentralized electric domestic hot water (DHW) boilers in operation, of which a large share will be replaced in the next decade. In most of the cases of multifamily buildings a central DHW installation with circulation system has to be installed, which can be complicated and expensive and needs to be coordinated with all inhabitants. Especially for the case of individually owned apartments, a possibility to replace old DHW systems with renewable energy sources is desirable, but difficult to achieve.

DHW circulation systems in multifamily houses are subject to heat losses of 20-65\% (rel. to the consumed energy) when correctly designed and installed (Vetsch et al. 2012) and even higher numbers have been found in field measurements (Citherlet et al. 2011). Large DHW circulation systems also provide an elevated risk of legionella contamination and need to be operated at high temperatures.

Various heat pump boiler systems using the surrounding air as heat source are available on the market. Since the operation of a heat bump boiler cools down the surrounding room, an installation in the apartment is often not possible or causes additional use of space heat energy in winter (Von Euw et al. 2014).

A consortium of three universities and an industry partner developed a decentralized DHW preparation system with a small heat pump that uses exhaust air of a controlled ventilation unit. The developed system provides a possibility to replace decentral DHW systems and include modern ventilation in existing apartments when renovating the bathroom. The flat construction fits behind a bathroom prewall and therefore is invisible for the user and does not use any additional space. It includes (Fig 1):

1. A modern controlled ventilation system with heat and humidity recovery for the entire apartment (max. capacity of $180 \mathrm{~m}^{3} / \mathrm{h}$ ).

2. A small heat pump designed especially for the purpose of using exhaust air of a single apartment ventilation unit. It provides a power of $0.3-0.5 \mathrm{~kW}_{\text {th }}$, depending on the temperature conditions. A direct condenser is included in the storage volume. 
3. A cuboid unpressurized storage tank with a water volume of 831 and vacuum insulation. DHW is prepared with a stainless steel internal heat exchanger.

4. An electric flow through heater as a backup to ensure comfort also for long tappings.

5. A thermostatic tap for automatic compensation of temperature drops caused by the small volume of the storage tank.

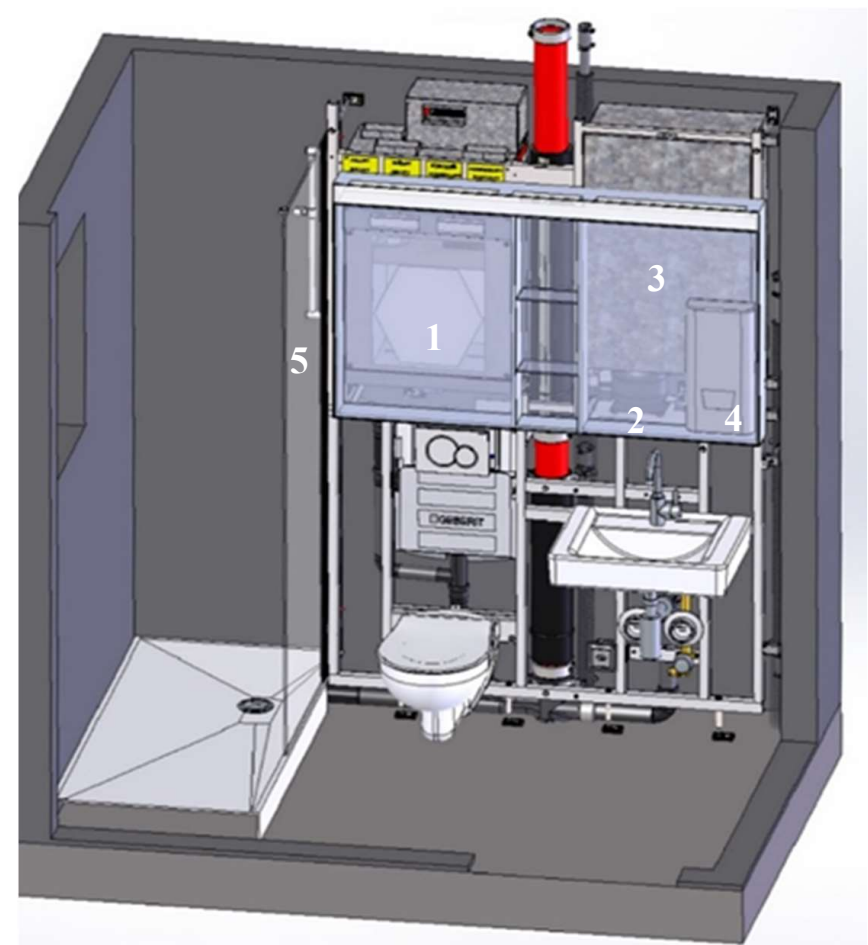

Figure 1: DHW system in the bathroom prewall.

The entire prewall (with the framing, the DHW system, the ventilation unit, all water and air piping and connections) is assembled in the factory and can be brought to the construction site in two parts. Therefore a high standardization and quality of the assembly can be achieved and the installation time is very short.

\section{Storage Tank}

The design of a storage tank that fits into the limited space behind a bathroom prewall with a spacing of only 30 $\mathrm{cm}$, but at the same time exhibits low thermal losses, was challenging. This challenge was tackled with the following approaches:

\subsection{Cuboid polypropylene container}

The cuboid form of the storage tank was given by the limited available space in the bathroom prewall. The DHW pressure would create elevated forces onto the flat walls which cannot be compensated with a construction of reasonable wall thickness. Therefore, an unpressurized but closed construction was chosen in combination with a stainless steel internal heat exchanger. Due to this construction, there are little requirements on the tank vessel and a cost effective solution based on polymers was possible. Out of an analysis of different materials and construction techniques, a roto-molded polypropylene construction was selected to be the most cost effective solution for small to middle sized production series. FEM simulations were carried out to optimize the design for minimal dilatations within a lifetime of 30 years at a temperature of $60^{\circ}$. Even though there is only the static pressure of the tank height $(<1 \mathrm{~m})$, three metal enforcements were needed to avoid dilatations greater than 2.5 $\mathrm{mm}$. Due to the higher coefficient of thermal expansion of polypropylene in comparison to water, a negative pressure is expected when heating the storage tank, which can be compensated with a small volume of air in the upper part of the vessel. This construction allows to close the vessel without inducing pressure changes due to 
temperature variations.

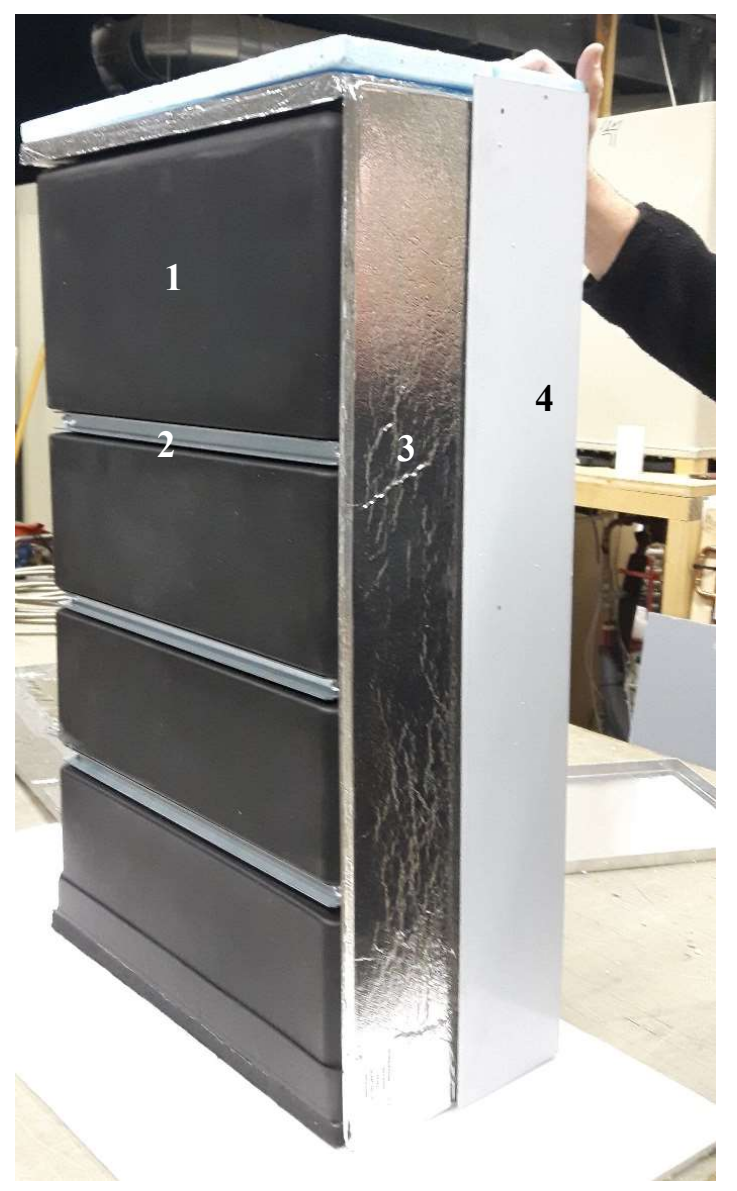

1 Polypropylene vessel manufactured with rotomolding

2 Metal reinforcement

3 Vacuum insulation panel (VIP)

4 Metal cover to protect VIP during transport and installation.

Figure 2: Photo of the storage tank vessel with metal reinforcement and VIP insulation.

\subsection{High performance vacuum insulation}

The flat cuboid form of the vessel is not favorable in terms of heat losses, due to the high ratio of surface to volume. Therefore, a good insulation is of particular importance. Different combinations of vacuum insulation panels (VIP), aerogel insulation and conventional insulation were simulated in 2D FEM. Material properties of the VIP were taken from the manufacturer's data sheet ("va-Q-vip" from the company va-Q-tec AG) and special attention was given to the joints of the VIP. Prototypes of the most promising solutions were constructed and heat losses were measured. As can be seen in Figure 3, the measured values of the overall heat loss coefficient was lower than the simulated ones for all tested configurations. This is due to a conservative value for the thermal conductivity in the data sheet $(<0.005 \mathrm{~W} / \mathrm{mK})$. The measurements show that the actual thermal conductivity, at least in an unaged state, is clearly lower than the declared limit. Furthermore, thermal bridges at the joints of the VIP (at the corners) can be minimized by the cuboid construction and don't lead to additional losses in the real prototype compared to the idealized simulation. 


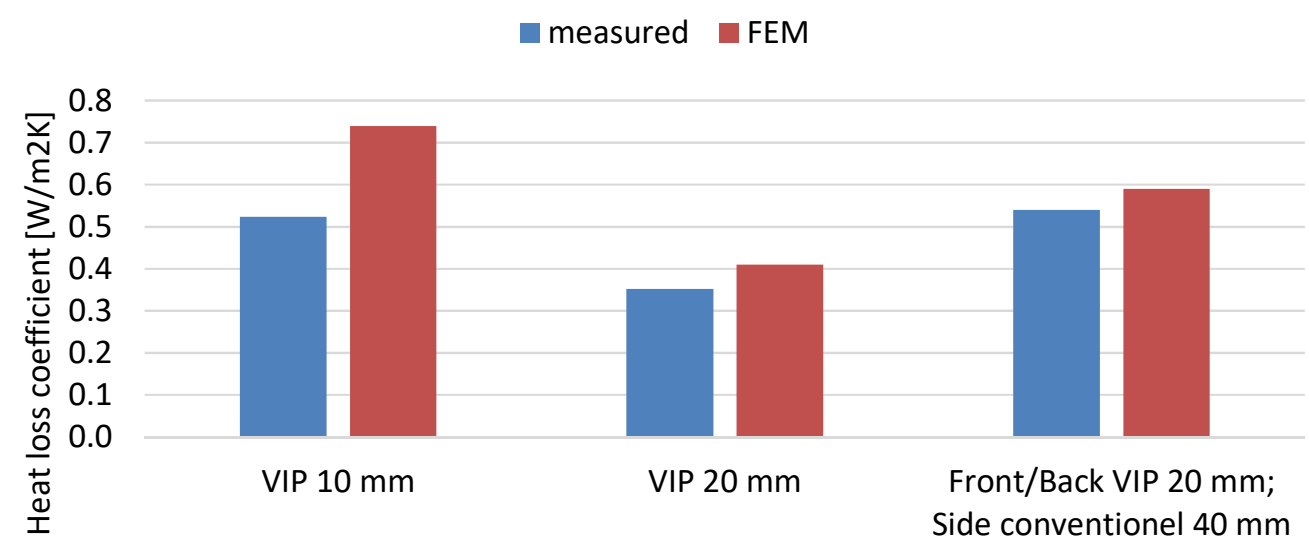

Figure 3: Measured heat loss coefficients vs. the predictions from FEM simulations.

\subsection{Connections only at the bottom}

In order to avoid heat losses and to simplify the construction of the tank all connections are integrated in a metal flange fixed to the bottom of the tank. This includes DHW heat exchanger, heat pump condenser and valves for filling and drain. The heat pump condenser consists of copper piping directly welded to the heat pump cycle. Conventional insulation is used at the bottom, which can be fitted around the connections.

\section{Other components}

More details on the development of the heat pump, including detailed performance measurement in the laboratory, is given by Büchel et al. 2016 and is therefore not explained in detail in this paper. Available standard products were used for the controlled ventilation (Zehnder, ComfoAir 180) unit and the electrical flow through backup heater (CLAGE, CEX ELECTRONIC MPS).

\section{Simulation}

Simulations were carried out with the simulation tool Polysun (Brönner et al. 2011) in order to characterize energy efficiency, the need of the electric backup heater and the possible direct consumption of PV electricity. The simulations were focused on the DHW system and the effect of the controlled ventilation was not considered.

- As there is no heat pump model with internal storage condenser available, an external heat pump was used. This heat pump was parametrized with measured data given by Büchel et al. 2016. A set point of $60^{\circ} \mathrm{C}$ was used for the heat pump control.

- Tapping profiles for 1-5 persons $\left(621 / \mathrm{p} @ 40^{\circ} \mathrm{C}\right)$ were generated with the DHWcalc tool from Jordan \& Vajen, 2003 and applied to different storage configurations. Special profiles with one second time steps during tapping were used to force the program to use small simulation time steps during these periods and to fit simulation parameters to measured data.

- Only cylindrical storage tanks can be implemented in the software. Therefore, insulation parameters were fit in order to match measured heat losses in four heights of the tank.

- Also the parameters of the internal heat exchangers were fit in order to match measured data rather than using the design geometries.

- Air flows and controlled ventilation units cannot be simulated in detail in the software polysun. As the heat pump only uses exhaust air it does not affect the operation of the unit and the simplified model with a constant recovery efficiency coefficient that is included in the building model can be used. On the other hand, the effect of the ventilation unit has to be considered when parametrizing the heat pump. 


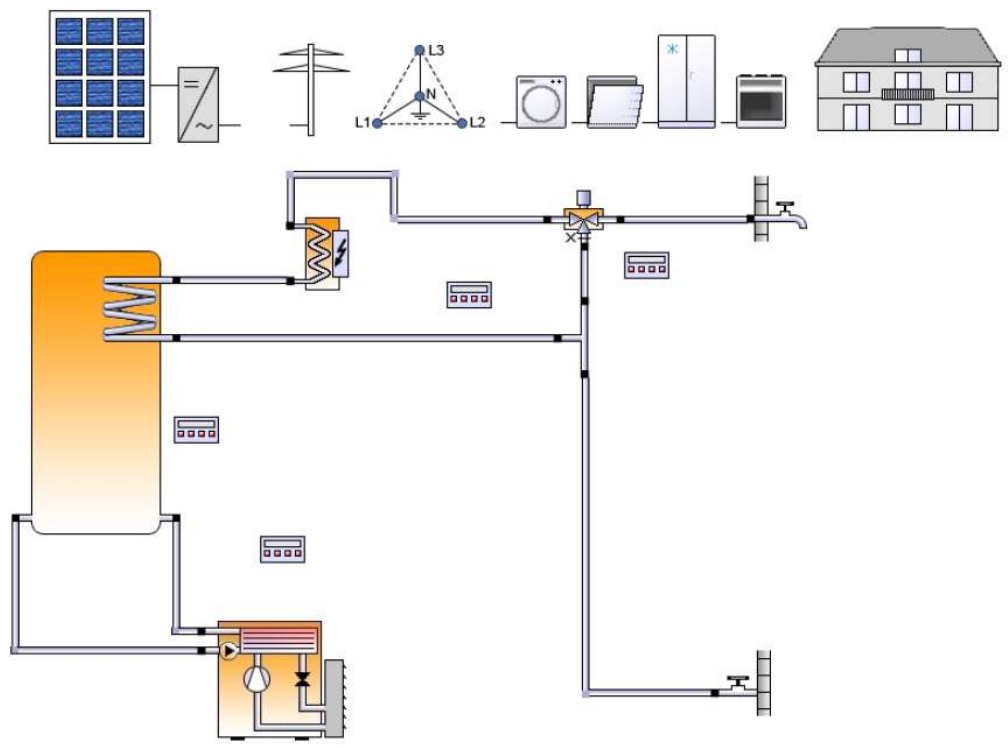

Figure 4: Simulation scheme in the software Polysun.

\section{Results of the simulations}

\subsection{Internal heat exchanger}

The size/surface of the internal storage heat exchanger affects the output temperature especially for longer tapping, which exceed the volume of the DHW stored inside the heat exchanger. High output temperatures are desired in order to keep the consumption of the additional electrical heater connected in series low. However, the consumption of the electrical backup heater also depends on the variable temperature/state of the storage tank and the tapping profile, which cannot be evaluated by a single measurement.

Figure 5 shows the influence of different tested internal heat exchangers on the annual consumption of the electric backup heater during dynamic operation with a stochastic tapping profile for three persons (186 1/day @ $40{ }^{\circ} \mathrm{C}$ ). A duplication of the length of the internal heat

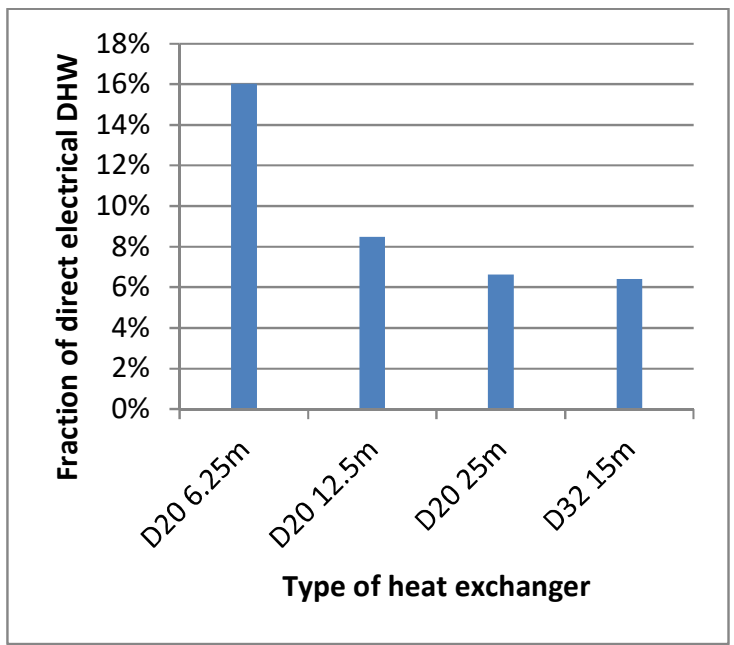

Figure 5: Annual fraction of direct electrical DHW heating with different internal heat exchangers.

exchanger from $6.25 \mathrm{~m}$ to $12.5 \mathrm{~m}$ cuts the use of the direct electricity use to half. The effect of a further duplication to $25 \mathrm{~m}$ is much less pronounced. In terms of a compromise between cost and efficiency a length of $12.5 \mathrm{~m}$ was used for the system prototype.

\subsection{System performance}

The main interest of the simulation was to gain knowledge about the performace of the system in different Situations. The most important parameter, is the amount of DHW consumption. Therefore, stochastic tapping profiles for one to five persons $\left(621 /\right.$ person $\left.@ 40^{\circ} \mathrm{C}\right)$ were used for the simulations. Figure 6 shows the electricity consumption of the heat pump as well as the direct electrical heater and the seasonal performance factor (SPF) of the heat pump and the entire system for different numbers of users. The electrical energy consumed by the heat 
pump increases nearly linearly from one to three persons. For more persons the possible runtime of the heat pump limits its contribution as it runs nearly continuously $(>8000 \mathrm{~h} / \mathrm{a})$ for five persons. This is compensated by a strong increase of the direct electricity consumption for more than three users. An increased DHW consumption leads to lower mean storage temperatures and therefore to less storage losses and increased SPF of the heat pump. A combination of all effects leads to the highest system performance (SPF 1.9) with 3-4 users.

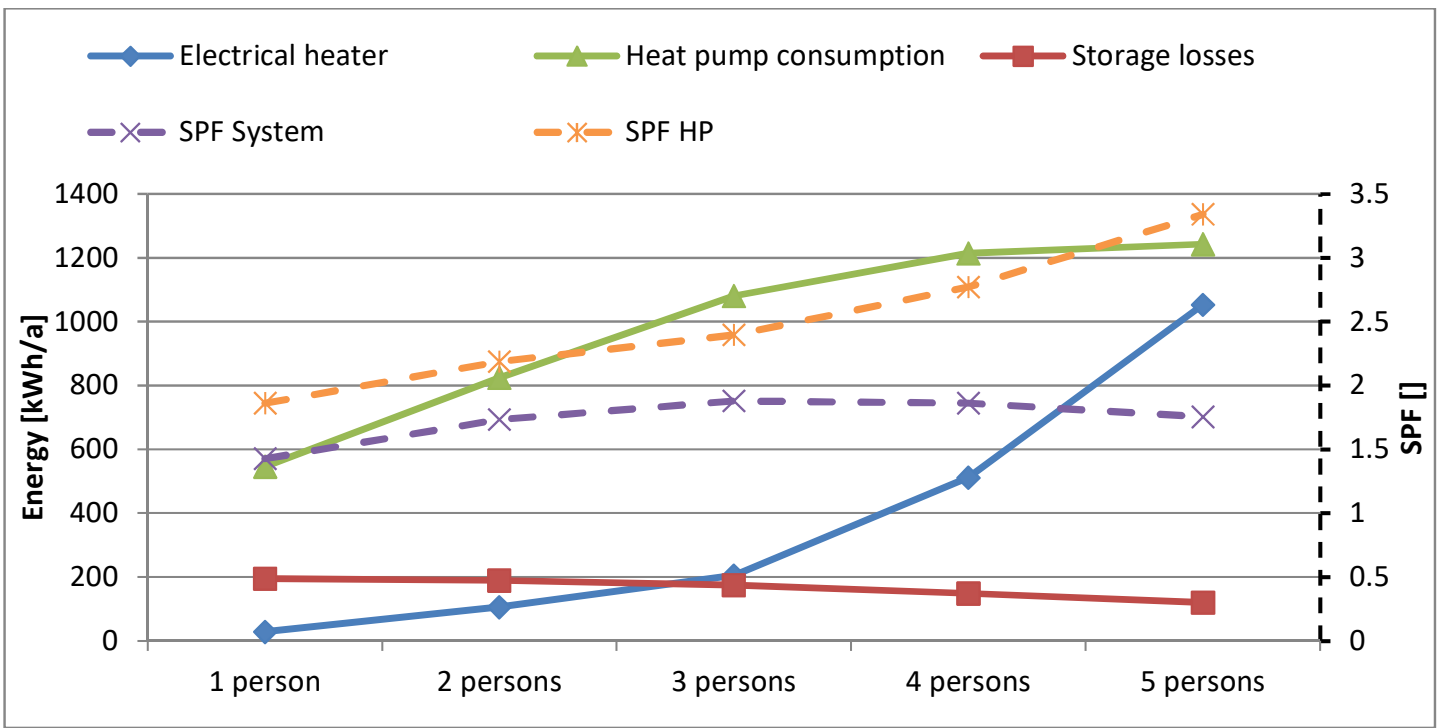

Figure 6: SPF and energy consumption of selected components for varying number of users.

The small size and therefore long runtimes of the heat pump limit the flexibility with respect to control and maximization of PV self-consumption. Simulations with different control strategies were carried out, but didn't result in great differences. However, as the heat pump generally runs during daytime, the system is suitable for the combination with PV-installations.

\section{Prototype testing}

A prototype of the system was constructed and installed in the lab. Different tapping profiles were automatically induced by a timer clock; two or three draw-offs of $100 \mathrm{l} / \mathrm{d}$ and a tapping profile similar to the EU tapping profile M (370 1/d, some small tapping were accumulated because the timer only handled 15 tapping per day). The different tapping profiles were run over various days, but with some interruptions and during different seasons. No systematic test was run was performed for an entire year.

In Figure 7, the temperature evolution in the tank and the tapping rates of the profile (similar to EU M) are given for an exemplary day. The fraction of direct electrical heater and the daily performance factor (DPF) of the heat pump is given in Figure 7 for all day operated with this profile (Sept. - Nov.). A clear dependence of the mean ambient temperature can be identified for the fraction of the direct electrical heater. On the other hand, there is no clear tendency for the DPF. This is due to the fact, that lower ambient temperatures result in lower output power of the heat pump and therefore in lower mean storage temperatures. The efficiency loss from cold ambient temperatures is therefore compensated by the efficiency gain caused by lower storage temperatures. This effect is especially pronounced when a lot of DHW is used (370 1 with this profile).

During the entire testing, which includes various profiles irregularly distributed over more than a year, a heat pump SPF of 2.8 and a system SPF of 2.0 was measured (temperature set point $60^{\circ} \mathrm{C}$ ). 


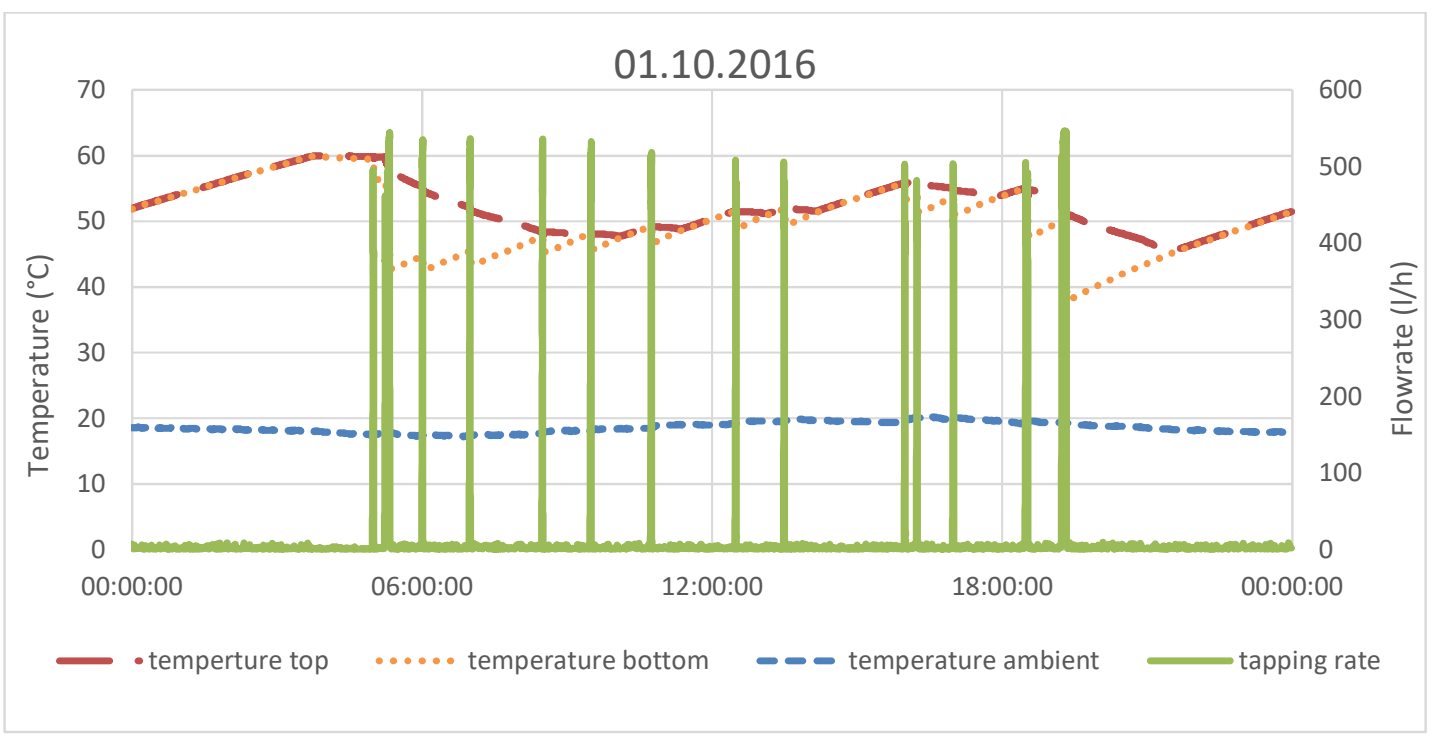

Figure 7: Temperature development at an exemplary day for a tapping profile similar to EU M.

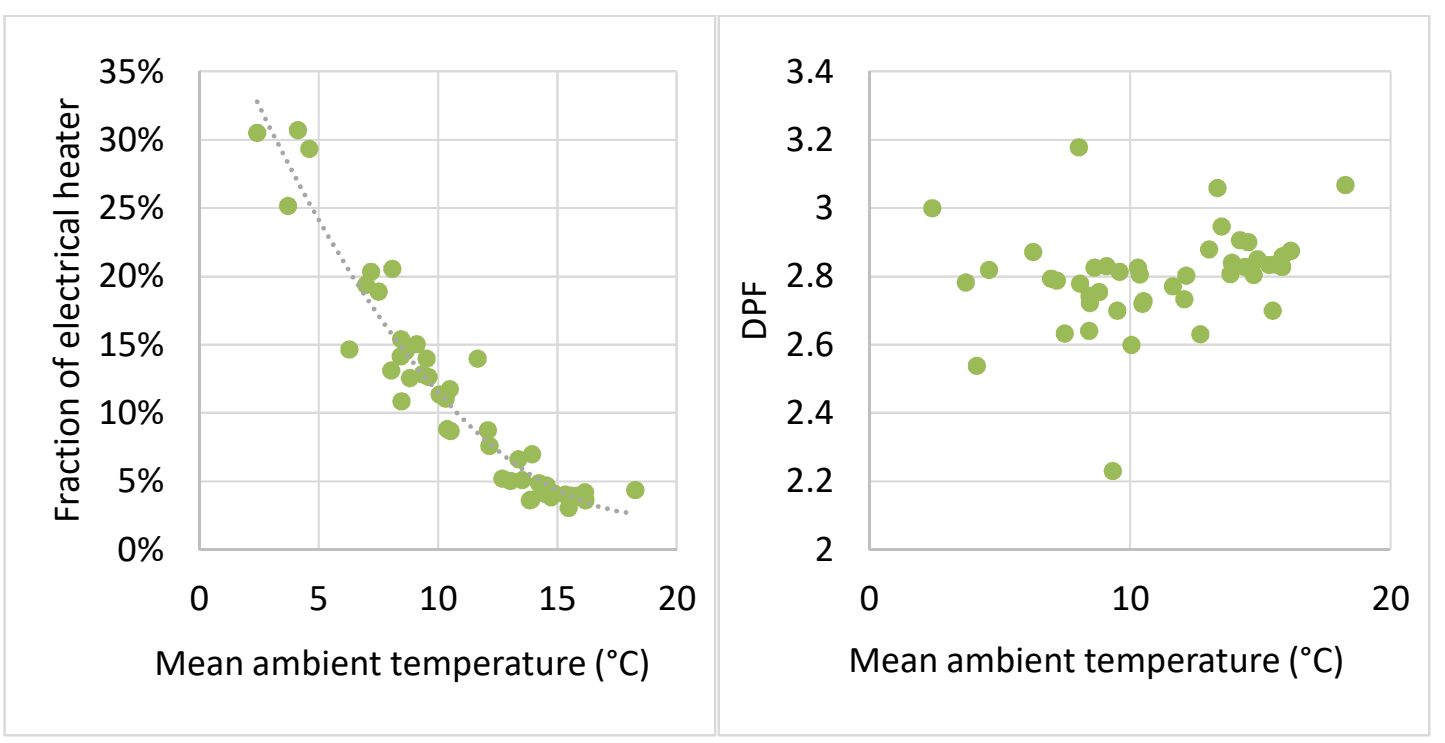

Figure 8: Fraction of the needed heat from the electrical heater (left) and corresponding DPF for all tested days with the profile EU $M$ as a function of the mean ambient temperature.

\section{Discussion and Conclusion}

- High performance VIP is well suited for the insulation of small cuboid storage tanks. In the contrary to initial concerns, the effect of thermal bridges at joints was low and good performance could be achieved despite the unfavorable surface/volume ratio. Manufacturer data on the heat conductivity were undermatched with the actual prototype set up and measured un-aged.

- A final test of the storage tank with an intermediate VIP thickness of $15 \mathrm{~mm}$ according to CDR (EU) No $812 / 2013$ resulted in a heat loss coefficient of $0.78 \mathrm{~W} / \mathrm{K}$ and an energy label "B" just at the limit to "A". The storage tank will be placed in the small space in the bathroom prewall, which will be heated up by thermal losses of the storage and the heat pump. This effect is expected to lower thermal losses in practice.

- The simulated system SPF of 1.9 (three persons) corresponds well to the measured value of 2.0, even though the values are not directly comparable because of interruptions and different tapping profiles in the measurements. 


\title{
Design and evaluation of a compact thermal storage system using river stones for a continuous process of agricultural products in Peru
}

\author{
Ronald Tipula1, Sandra Vergara', Miguel Hadzich'1, Evelyn Lopez², Esteban Herrera ${ }^{3}$ \\ 1 Pontificia Universidad Católica Del Perú, Lima (Perú) \\ 2 Instituto Tecnológico y de Estudios Superiores de Monterrey, Estado de México (México) \\ ${ }^{3}$ Centro de Innovación Tecnológica de Industrias Alimentarias, Lima (Perú)
}

\begin{abstract}
Drying only during the day is a problem for the solar drying process of several products in Peru, for this reason a low-cost thermal storage system that can carry out a continuous drying process has been designed. This system consists of an insulated bed filled with storage material, $400 \mathrm{~kg}$ stones of the river, and a solar air heater with 2.8 $\mathrm{m}^{2}$ of area to extract thermal energy from the sun for the air. The system was tested with two mass flow rate, from $0.0311 \mathrm{~kg} \mathrm{~s}^{-1}$ and $0.0251 \mathrm{~kg} \mathrm{~s}^{-1}$, to determine the optimal speed. The maximum temperature obtained in the stones was $50.3^{\circ} \mathrm{C}, 30$ degrees more than the ambient temperature. In addition, the maximum energy obtained is given at 3:30 p.m. The discharge efficiency was $57.7 \%$ and the collection of $39.4 \%$ taking into account that the heat loss found was $1^{\circ} \mathrm{C}$ per hour. The experimental results were similar to the theoretical results with a maximum difference of $4.1^{\circ} \mathrm{C}$.
\end{abstract}

Keywords: Solar thermal energy, drying, thermal storage, rural sector, productive use.

\section{Introduction}

Currently, in Peru, the most commonly used method that has become traditional is direct drying exposed to the sun. It is an economic method for the conservation of agricultural products for commercialization and/or consumption. However, exposure is to both sunlight and the environment; this generates non-uniform drying, since the variables such as air speed, temperature, and relative humidity are not controlled. Likewise, the product, when exposed to the environment, is affected by animals, insects, rain and debris, and generates significant losses (Kumar et al., 2016).

Although the vast majority of crop production is sun-dried, there are innovations in solar dryers, such as tunneltype dryers, where the quality of the product is preserved, but they are not entirely efficient; drying is discontinuous because it is only done during the day and not during the night. The discontinuous drying brings consequences such as the re-humidification of the product because at night the air is colder and gains moisture. This, in addition to affecting the quality of the product, delays drying for several days.

It is proposed to continue drying during the hours when the sun does not intervene, making solar drying a continuous and efficient process. It is proposed to make use of solar thermal energy in the design of a thermal storage system using river stones and achieve an increase in temperature or maintain constant temperature during the night; improving the quality of the dry agricultural product avoiding its re-humidification at night when using a continuous process. With this form will also reduce the time of the drying process.

This thermal storage system is built with easily accessible materials such as wood, glass, stones, etc. It is also important to optimally select the size of the stones to be around $5 \mathrm{~cm}$ in diameter equivalent to not have too many pressure losses and store the maximum possible energy (Maithani, R. et al., 2003).

This system has been built and installed in Cieneguilla, Lima, Peru (fig 1) with coordinates $12^{\circ} 04^{\prime} 10.0^{\prime \prime} \mathrm{S}$ $76^{\circ} 45^{\prime} 15.5^{\prime \prime} \mathrm{W}$.

This research was done in conjunction with the center of technological innovation in food industries "CITE ALIMENTA" within the framework of the project "Design and development of a portable dehydrator for the 
transformation and conservation of pickled chili in Lambayeque, using renewable energies."

\section{Nomenclature}

\begin{tabular}{lll}
\hline Quantity & Symbol & Unit \\
\hline Area of solar collector & $A_{r}$ & $\mathrm{~m}^{2}$ \\
Cross-sectional area of the bed with stones & $A_{c}$ & $\mathrm{~m}^{2}$ \\
Specific heat of air & $c_{a}$ & $\mathrm{~J} \mathrm{~kg}^{-1} \mathrm{~K}^{-1}$ \\
Specific heat of river stone & $c_{s}$ & $\mathrm{~J} \mathrm{~kg}^{-1} \mathrm{~K}^{-1}$ \\
Period of data taken & $d t$ & $\mathrm{~s}$ \\
Equivalent spherical diameter & $D_{e}$ & $\mathrm{~m}$ \\
Volumetric heat transfer coefficient & $h_{v}$ & $\mathrm{~W} \mathrm{~m} \mathrm{~K}^{-1}$ \\
Global irradiance & $G$ & $\mathrm{~W} \mathrm{~m}$ \\
Mass flow rate & $\dot{m}_{a}$ & $\mathrm{~kg} \mathrm{~s}^{-1}$ \\
Total number of river stone & $N$ & - \\
Heat energy collected in the bed with stones & $\dot{Q}_{c}$ & $\mathrm{~W}$ \\
Heat energy retrieved from the bed with stones & $\dot{Q}_{r c}$ & $\mathrm{~W}$ \\
Time & $t$ & $\mathrm{~S}$ \\
Inlet air flow temperature & $T_{a i}$ & $\mathrm{~K}$ \\
Outlet air flow temperature & $T_{a o}$ & $\mathrm{~K}$ \\
Ambient temperature & $T_{a}$ & $\mathrm{~K}$ \\
Total volume of the river stone & $V_{t}$ & $\mathrm{~m}^{3}$ \\
Temperature gradient of node & $d T / d t$ & $\mathrm{~K} \mathrm{~s}$ \\
Thickness of the nodal elements & $\Delta x$ & $\mathrm{~m}$ \\
Density of air & $\rho_{a}$ & $\mathrm{~kg} \mathrm{~m}^{-3}$ \\
Density of the river stone including voids & $\rho_{s}$ & $\mathrm{~kg} \mathrm{~m}^{-3}$ \\
Void ratio & $\varepsilon$ & $\%$ \\
Packed bed collector efficiency & $e t a_{c}$ & $\%$ \\
Heat retrieval efficiency of the bed & $e t a_{r c}$ & $\%$ \\
\hline
\end{tabular}

\section{Methodology used}

This work is based on the study of energy efficiency of a thermal storage system consisting of a bed with stones proposed by Panna Lal Singh in 2015. To achieve a continuous process in any solar dryer, a storage system with river stones was used to store thermal energy during the day and inject it overnight into a dryer; these operations are illustrated in figure 2.

The isolated bed has a capacity of $0.3 \mathrm{~m}^{3}$; it was full of river stones with diameters of $4.5 \mathrm{~cm}$ and the area of the solar air heater is $2.8 \mathrm{~m}^{2}$.

The tests were carried out following a test protocol consisting of three phases. First, the system was tested in different airflows to obtain the temperature curve of the bed versus the speed, establish the hours at which the stone bed was reached maximum temperature, and obtain the maximum stored energy. Second, with the optimum speed, the isolation time of the bed was obtained after reaching the maximum stored energy. Finally, the heat discharge time and the efficiency of the system were determined. 


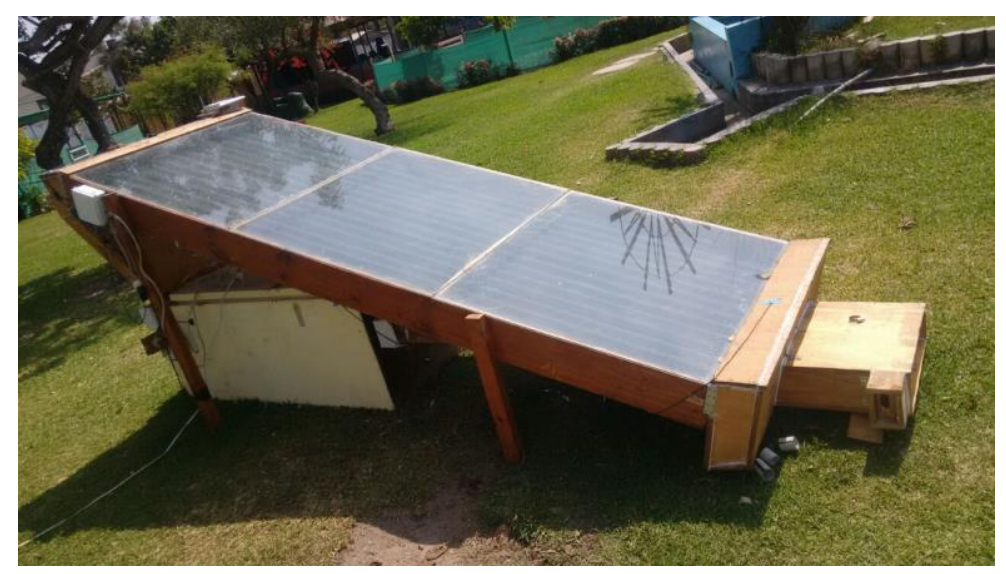

Fig. 1 Installation of the thermal storage system in Cieneguilla, Lima, Peru

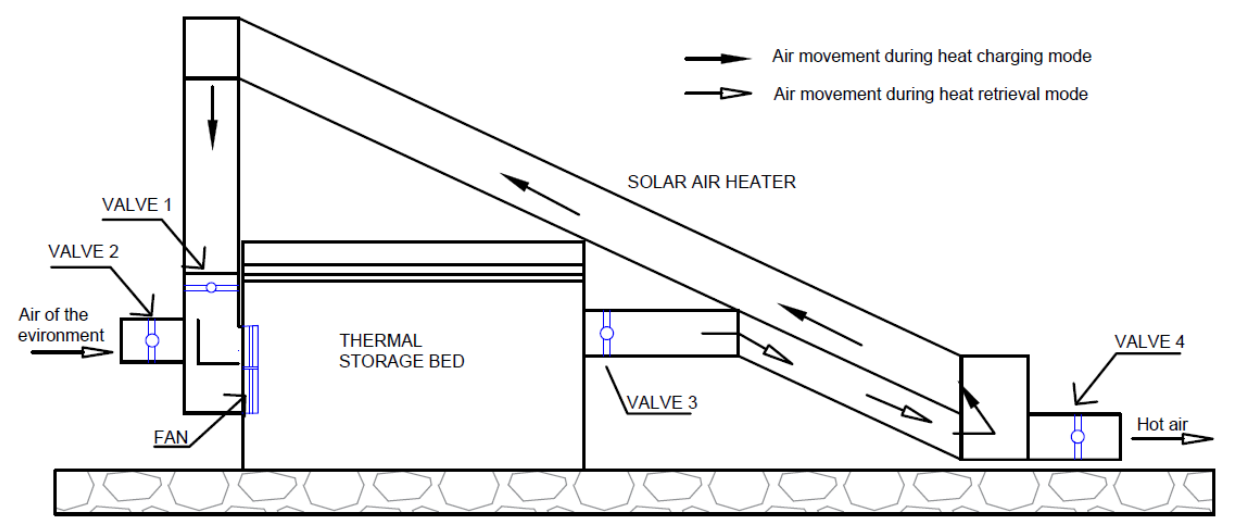

Fig. 2 Diagram of the parts and operation of the thermal storage system

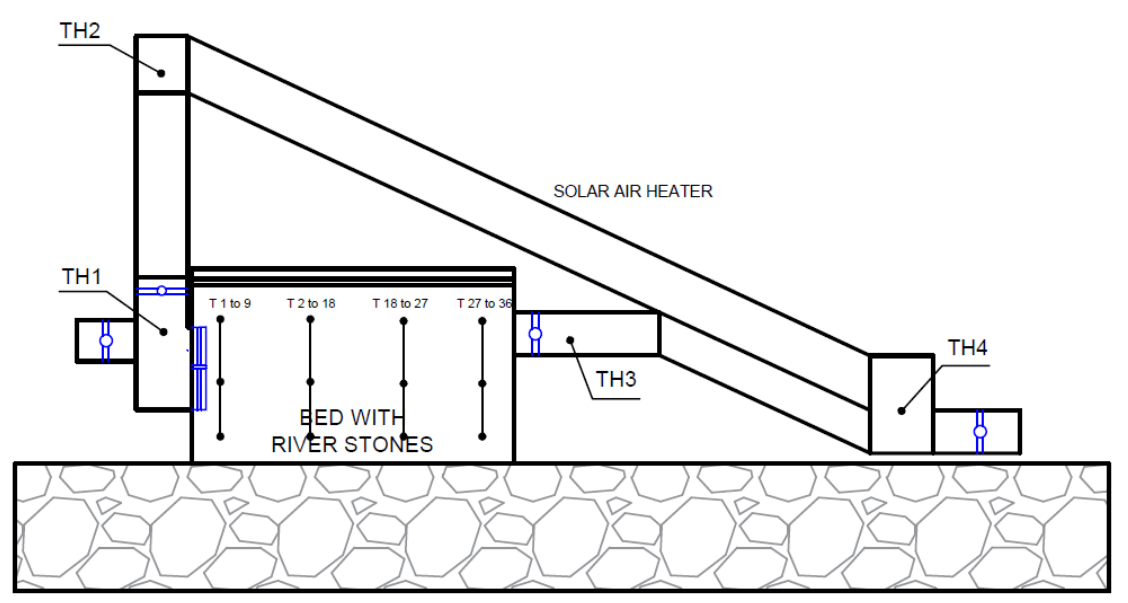

Fig. 3. Diagram of sensors inside the thermal storage system.

\subsection{Measurements}

A measurement system was built with an ATMega 2560 microcontroller where data was recorded every 1 minute. Temperature of the bed, temperature before the bed, temperature after the bed, temperature before the solar air heater, temperature after the solar air heater, the ambient temperature, and the global irradiance were recorded. The temperature in the bed was measured in 36 points located uniformly throughout its volume (figure 3 ) in order to compare the results with the simulation of the bed. 
Tab. 1: Physical properties of the rock pebble packed bed.

\begin{tabular}{|l|l|}
\hline \multicolumn{1}{|c|}{ Parameters } & \multicolumn{1}{c|}{ Values } \\
\hline Specific heat of the river stone & $0.8 \mathrm{~kJ} \mathrm{~kg}^{-1} \mathrm{~K}^{-1}$ (Kürklü, 2003) \\
Porosity of river stones & $42 \%$ (measured) \\
Density of river stones include voids & $1350 \mathrm{~kg} \mathrm{~m}^{-3}$ (measured) \\
Equivalent diameter of rock pebbles & $45 \mathrm{~mm} \mathrm{[} \mathrm{calculated} \mathrm{from} \mathrm{eq.} \mathrm{(1)]}$ \\
Specific heat of air & $1000.5 \mathrm{~kJ} \mathrm{~kg}^{-1} \mathrm{~K}^{-1}$ (Kürklü, 2003) \\
Density of air & $1.1 \mathrm{~kg} \mathrm{~m}^{-3}($ Singh, 2015) \\
Volumetric heat transfer coefficient of bed with stones & $1363 \mathrm{~W} \mathrm{~m}^{-3} \mathrm{~K}^{-1}$ [ calculated from eq. (6)] \\
\hline
\end{tabular}

\subsection{Determination of equivalent rock pebble diameter, porosity, and pebble density}

The porosity was determined by measuring the volume of a container with rock pebbles and the volume of water in the same container. Division of the former to the latter one gave the porosity of rock pebble bed (Kürklü et al., 2003). Equivalent diameter ( $D e$ ) of the rock pebbles was calculated by using the equation given below (Chandra et al., 1981):

$$
D_{e}=\left[\frac{6 V_{p}(1-\epsilon)}{\pi N_{p}}\right]^{1 / 3}
$$

Density of the rock pebbles was determined by net weight of the pebbles in the container divided by volume of the container. Taking the container volume into consideration, the density was then expressed as $\mathrm{kg} \mathrm{m}^{-3}$ (Singh., 2015). The thermo-physical properties of the used rock pebbles bed are given in Table 1.

\subsection{Solar energy collection and heat retrieval efficiencies}

Following equations were used in the calculations of solar energy collected and energy recovered respectively;

$$
\begin{aligned}
& Q_{c}=m_{a} c_{a}\left(T_{a i}-T_{a o}\right) \\
& Q_{r c}=m_{a} c_{a}\left(T_{a o}-T_{a i}\right)
\end{aligned}
$$

Daily solar energy collection and energy recovery efficiencies were determined respectively, as follows;

4)

$$
e t a_{c}=\frac{\int_{t 1}^{t 2} Q_{c} d t}{\int_{t 1}^{t 2} G A_{c} d t}
$$

5)

$$
e t a_{r c}=\frac{\int_{t 1}^{t 2} Q_{r c} d t}{\int_{t 1}^{t 2} Q_{c} d t}
$$

\subsection{Modelling of the bed with river stones}

The energy equations that govern the heat transfer in the thermal storage system are based on the following assumptions. The stone accumulator is uniformly packed and has the same bulk density and uniform apparent thermal capacity throughout. The thermal gradient within the solid particles is negligible. The transfer of heat in the rocks in the radial direction was neglected. The numerical approximation of the infinite difference was applied to model the bed of river stones. The bed of river rocks was divided into segments/nodes of equal thickness in the opposite direction to the air flow. The temperature of the fluid (air) in the center of each segment was calculated using the developed model. The volumetric heat transfer coefficient $(h v)$ was calculated as given below (Löf and Hawley, 1948): 


$$
h_{v}=652\left[\frac{m_{a}}{A_{r} D_{e}}\right]^{0.7}
$$

If the calculated value of the $h v$ is quite high, it can be said that the air temperature and the temperatures of the stones are considered equal at any node. The following rule was used for the stability of numerical equations (Garzoli, 1989):

$$
\frac{h_{v} A_{r} \Delta x}{m_{a} c_{a}}<1
$$
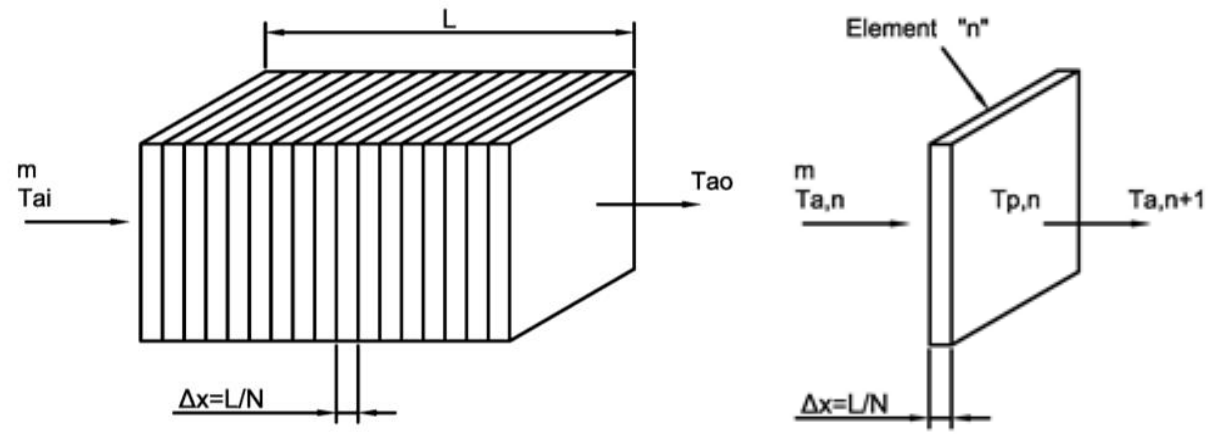

Fig. 4 Diagram of the mathematical model of the bed with river stones

The entire bed was divided into 30 nodes/segments and the thickness of each segment was $0.041 \mathrm{~m}$, an example of the illustrated model is shown in figure 4 . The energy balance of any node was as indicated below:

$$
\rho_{s} c_{s} A_{r} \Delta x\left(\frac{d T_{p, n}}{d t}\right)=m_{a} c_{a}\left(T_{a, n-1}-T_{a, n}\right)
$$

Considering that the temperatures of the air and the stones are equal, $T_{a, n}=T_{p, n}$ the above equation can be rewritten as:

$$
\rho_{s} c_{s} A_{r} \Delta x\left(\frac{d T_{p, \mathrm{n}}}{d t}\right)=m_{a} c_{a}\left(T_{a, n-1}-T_{p, n}\right)
$$

Considering any step ' $\mathrm{P}$ ' and the next step 'P +1 ', the above equation can be expressed as:

$$
\rho_{s} c_{s} A_{r} \Delta x\left(T_{p, n}^{P+1}-T_{p, n}^{P}\right)=h_{v} A_{r} \Delta x\left(T_{a, n-1}^{P+1}-T_{p, n}^{P+1}\right) d t
$$

By maintaining the period interval (dt) for the data in one minute $(60 \mathrm{~s}$, expecting a slow increase / decrease in the temperature of the bed), the value of $T_{p, n+1}^{P}$ can be obtained from the above equation written as:

$$
T_{p, n}^{P+1}=\frac{(60 \mathrm{~s}) m_{a} c_{a} T_{a, n-1}^{P+1}+\rho_{s} c_{s} A_{r} \Delta x T_{p, n}^{P}}{(60 \mathrm{~s}) m_{a} c_{s}+\rho_{s} c_{s} A_{r} \Delta x}
$$

To calculate in the next step, $T_{p, n}^{P}$ was taken equal to $T_{p, n+1}^{P}$ and the calculations continued until the required final 
time.

\section{Results and discussion}

\subsection{Average temperature of the river stones vs time with different mass flow rate}

This part of the experiment was done in order to find the maximum energy stored in the river stones, which depends on the maximum average temperature reached, and the time of day it is reached. In this stage, the thermal storage system was evaluated at different mass flow rate, which were $0.0311 \mathrm{~kg} \mathrm{~s}^{-1}$ as shown in fig. 5 and 0.0251 $\mathrm{kg} \mathrm{s}^{-1}$ as shown in fig. 6 . The prototype was operating in a closed cycle, which implies that valves 1 and 3 are open, and valves 2 and 4 are closed.

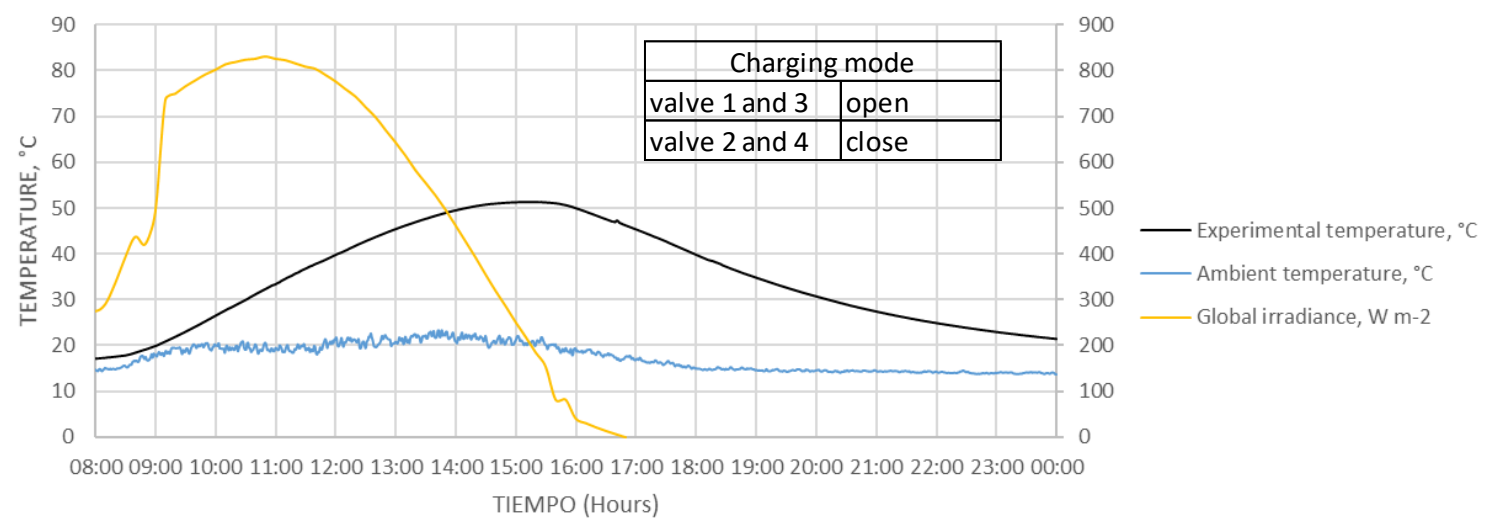

Fig.5: Behavior of the bed temperature, solar radiation and ambient temperature. Mass flow rate $=0.0311 \mathrm{~kg} \mathrm{~s}^{-1}$

In fig. 5 the maximum average temperature in the stones is $50.5^{\circ} \mathrm{C}$ with a difference of $30.5{ }^{\circ} \mathrm{C}$ with respect to the ambient temperature $\left(20^{\circ} \mathrm{C}\right)$. In fig. 6 , the maximum average temperature in the stones is $45.5^{\circ} \mathrm{C}$ with a difference of $25.5^{\circ} \mathrm{C}$ compared to the ambient temperature $\left(20^{\circ} \mathrm{C}\right)$.

In fig. 5 and 6, the maximum temperature obtained in the stones is reached around 3:30 PM.

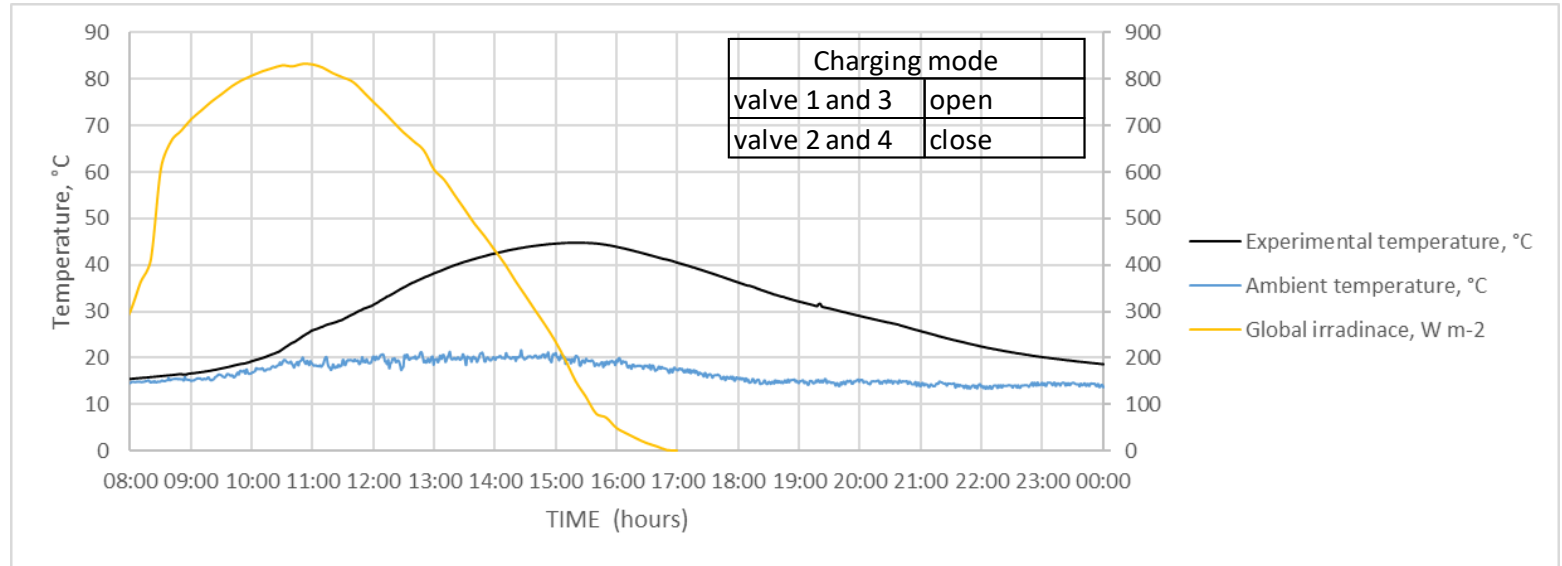

Fig.6: Behavior of the bed temperature, solar radiation and ambient temperature. Mass flow rate $=0.0251 \mathrm{~kg} \mathrm{~s}^{-1}$

\subsection{Rate of heat loss through insulation of the bed with river stones after reaching the maximum temperature}

In this part of the experiment, the objective was to find the time in which the river stones lost the heat gained by the air circulation system. In this stage, the thermal storage system with the mass flow rate of $0.0311 \mathrm{~kg} \mathrm{~s}^{-1} \mathrm{was}$ evaluated as shown in fig. 7 because at that mass flow rate the maximum average temperature of the river stones was obtained. The prototype was operating in a closed cycle, which implies that valves 1 and 3 are open, and valves 2 and 4 are close until 3:30 pm, then all valves closed and the fan turned off. 


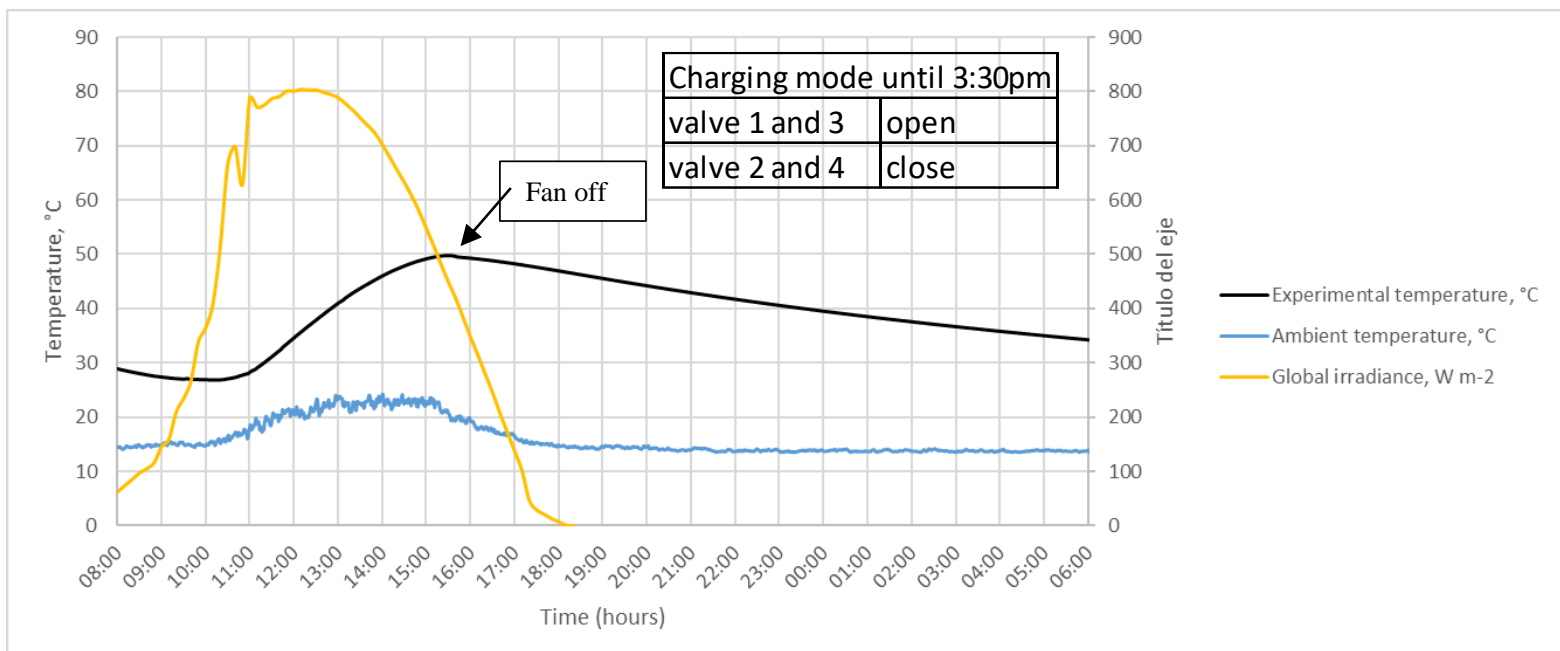

Fig.7: Behavior of the bed temperature, solar radiation and ambient temperature. Mass flow rate of charge $=0.0311 \mathrm{~kg} \mathrm{~s}^{-1}$ and fan off at 3:30 pm.

In fig. 7, the maximum temperature reached was $50{ }^{\circ} \mathrm{C}$ with a difference of $30{ }^{\circ} \mathrm{C}$ with the ambient temperature $\left(20^{\circ} \mathrm{C}\right)$. In addition, the loss of temperature is very similar to a linear function and is lost at a rate of $1{ }^{\circ} \mathrm{C}$ per hour.

\subsection{Efficiency of the energy returned from the bed with river stones and retrieval time}

The objective of this stage was to find the time in which the system was discharged and its efficiency. In addition, the theoretical and experimental components of the average stone temperature were compared.

The prototype operated in load mode (valve 1 and 3 are open and valves 2 and 4 are closed) and with a constant mass flow rate of $0.0311 \mathrm{~kg} \mathrm{~s}^{-1}$ until $3: 30 \mathrm{pm}$ as shown in fig. 8. Immediately after, it operated in discharge mode (valves 1 closed and valves 2, 3 and 4 open) with a mass flow rate of less than $0.0161 \mathrm{~kg} \mathrm{~s}^{-1}$ in order to increase the discharge time. In the discharge mode, the air that enters the bed with river stones is at room temperature.

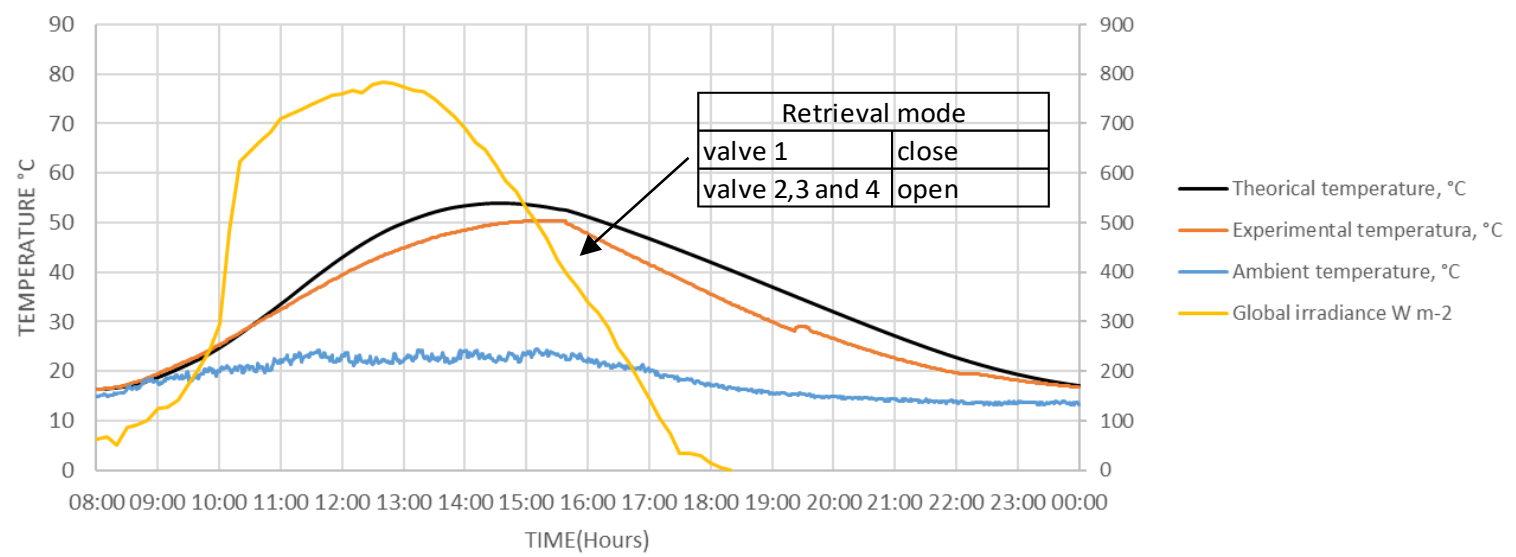

Fig.8: Behavior of the bed temperature, solar radiation and ambient temperature. Mass flow rate of charge $=0.0311 \mathrm{~kg} \mathrm{~s}^{-1}$, discharge $=0.0161 \mathrm{~kg} \mathrm{~s}^{-1}($ at 3:30 $\mathrm{pm})$.

For the realization of the test, 2 days after the initial one, the similarity of radiation levels with the previous test was assured. In fig. 8, the maximum temperature reached is $50{ }^{\circ} \mathrm{C}$ at $3: 30 \mathrm{pm}$ with a difference of $30{ }^{\circ} \mathrm{C}$ with respect to the ambient temperature $\left(20^{\circ} \mathrm{C}\right)$. The energy gained by the system was $12.63 \mathrm{MJ}$ and the energy returned was 7.29 MJ with an efficiency of 57.7\%. Efficiency is low due to heat losses through insulation. In addition, the theoretical and experimental curves are very close with a difference of $4.1{ }^{\circ} \mathrm{C}$. 


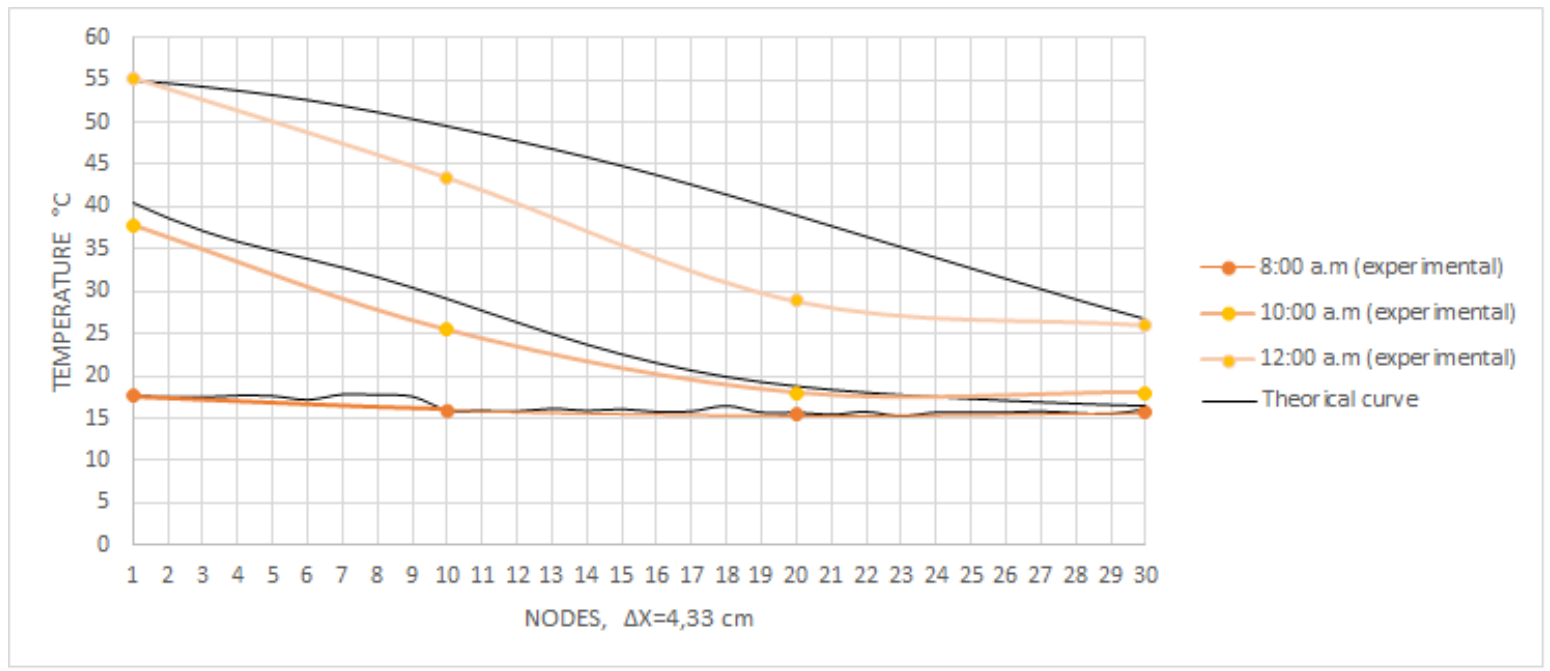

Fig.9 Behavior of the temperature throws the bed during the charge.

In fig, 9 the temperature varies throughout the bed with river stones at the time when the system is charging. In addition, the comparison between the theoretical and experimental curve model. The river stones are heated at the entrance of the hot air, which comes out colder at the exit.

\section{Conclusions}

Temperature of the river stones was raised up to $50.3{ }^{\circ} \mathrm{C}$ from $16{ }^{\circ} \mathrm{C}$ during charging mode.

The temperature values obtained from the mathematical model compared with the experimental data were acceptable.

In addition, using the thermal storage system in charging mode until 3:30 pm allows a discharge efficiency of $57.7 \%$ and the collection efficiency of $39.4 \%$

This system uses materials that are easy to find in rural areas, which makes it economical. On the other hand, hot air can be used in other applications, such as heating schools and homes in very cold rural areas.

\section{References}

Chandra, P., Albright, L.D., Wilson, G.E., 1981. Pressure drop of unidirectional air flow through rock beds. $T$ ASA, pp. 1010-3.

Kumar, M., Sansaniwal, S. K., Khatak, P., 2016. Progress in solar dryers for drying various commodities. Renewable and Sustainable Energy Reviews. 55, 346-360.

Kürklü, A., Bilgin, S., \& Özkan, B. (2003). A study on the solar energy storing rock-bed to heat a polyethylene tunnel type greenhouse. Renewable Energy, 28(5), 683-697.

Löf, G.O.G., Hawley, R.W., 1948. Unsteady-state heat transfer between air and loose solids. Ind Eng Chem. 40(6), 1061-70.

Maithani, R., Patil, A. K., Saini, J. S., 2013. Investigation of effect of stratification on the thermal performance of packed bed solar air heater. International journal of energy science. 3,4 .

Singh, P.L., Deshpandey, S.D., Jena, P.C., 2015. Thermal performance of packed bed heat storage system for solar. Energy for Sustainable Development. 29,112-117 


\title{
Development of A Solar Paddy Drying by Fluidization Technique Using Energy from Solar Pond
}

\author{
Sura Tundee*, Manus Sirijun, Mongkon Laongoen and Kanchit Rongchai \\ Department of Mechanical Engineering, Faculty of Engineering, Rajamangala University of \\ Technology Isan Khon Kaen Campus,Thailand.
}

\begin{abstract}
In this research a new approach for employing heat from solar pond as the main source of energy for paddy drying was introduced. The drying test rig was designed, fabricated and evaluated. The rig consists of paddy dryer and solar pond. The area of solar pond was $50 \mathrm{~m}^{2}$ and a depth of $2.5 \mathrm{~m}$ was built at Khon Kaen in North-Eastern Thailand. Air mass flow rate was measured by an orifice plate, the temperatures were monitored by $\mathrm{K}$ type thermocouples, the solar insolation was recorded by a pyranometer. One of the objectives in this research was to evaluate the effect of mass flow rate and interval time of paddy discharging on the rate of paddy drying by the dryer and was conducted at temperatures of 40, 50, and 60 degrees Celsius at the flow rates of hot water of $0.56,0.75$, and 1.67 liters per minute respectively. The wind speed to be applied was $5 \mathrm{~m} / \mathrm{s}$. Heat in the experiment was obtained from the solar pond. The experiment was conducted at the flow rates of water of 2, 2.5, and 3 liters per minute respectively and was continuously run for 24 hours. In addition, the experiment took 3 days for each of the flow rates and data were recorded every 1 minute. The results showed that the flow rate of 2.5 liters per minute could take heat into application better than the flow rates of 2 and 3 liters per minute. At such the flow rate, moisture dropped from $23.4 \%$ to $15 \%$ for the first time of drying and for the second and third times, the moistures dropped to $13 \%$ and $11 \%$ respectively. Reduction in moisture content of the paddy met the criteria set which was $1 \%$ to $5 \%$ per round of drying.
\end{abstract}

Keywords: Solar Energy, Solar Pond, Paddy Dryer.

\section{Introduction}

Energy is one of the factors necessary for everyone. We use energy in various forms over the year, which causes a number of significant power sources in the World to decline by the amount of time spent. As a result, many countries start to realize and have already began to look for alternative renewable energy to replace those that are vanishing. There are many types of renewable energy such as wind power, hydro power, and biomass. There is also another type of renewable energy that is always available, inexhaustible, and not adversely affecting the environment. It is solar energy. To use such energy; however, there must be a device that can store heat energy from the sun so that the stored energy can be utilized later for various usages. Rice is one of Thailand's major commodities and the nation is the largest rice exporter in the world The rice generates the highest income in Thailand in 2015, exporting 9,795,763 million tons equivalent to 4,613 million US dollars. As opposed to using traditional manual harvest methods, more rice paddy is harvested using machinery resulting in high moisture content due to lack of drying. It is important that the grains are dried before storage. Drying methods can be done in many ways such as solar drying, hot wind drying or using a fluidised bed method. Each method has advantages and disadvantages. The fluidised bed method is appealing because relatively shorter drying time is required compared to other methods. Energy sources for fluidised-bed drying are important and concern.

Solar pond is another option that can be used to collect heat from the sun due to its lower cost per square meter than other types of solar energy equipment. This research has therefore used the solar pond as a storing source of thermal energy from the sun and uses the fluidized bed for paddy dryer.

Solar pond is a device to collect and store energy. It can operate continuously all year long. Solar ponds collect energy from solar radiation. The radiant heat is collected at the bottom side of the pond and this amount of heat would be used later.

The first recorded solar pond to a natural solar lake was that of Kalecsinsky who decribed the Lake Madoc (Medie Lagoon), located at $\left(42^{\circ} 44^{\prime} N, 28^{\circ} 45^{\prime} E\right)$ in Transylvania This lake showed temperatures increasing up to $70{ }^{\circ} \mathrm{C}$. at a depth of $1.32 \mathrm{~m}$ at the end of the summer. The minimal temperatures were $26^{\circ} \mathrm{C}$.during early 
spring. Of which compare ambient temperature with higher than the others. The idea of solar energy collection was conduct by creating artificial solar pond hinted by Kalecsinsky.(Kalecsinsky, 1902)

The structure of solar pond is shown in Fig. 1. It is noted that the size of pond depends on the aim of energy use such as water heating, crop drying, desalination, and electrical power generation.

There is an amount of saline inside the pond. Generally, the saline solution is Sodium Chloride or Magnesium Chloride solution. The pond can be divided into three regions namely the upper convective zone (UCZ),the middle non-convective zone (NCZ), and the lower convective (LCZ).(Abhijit,et al. 2013.)

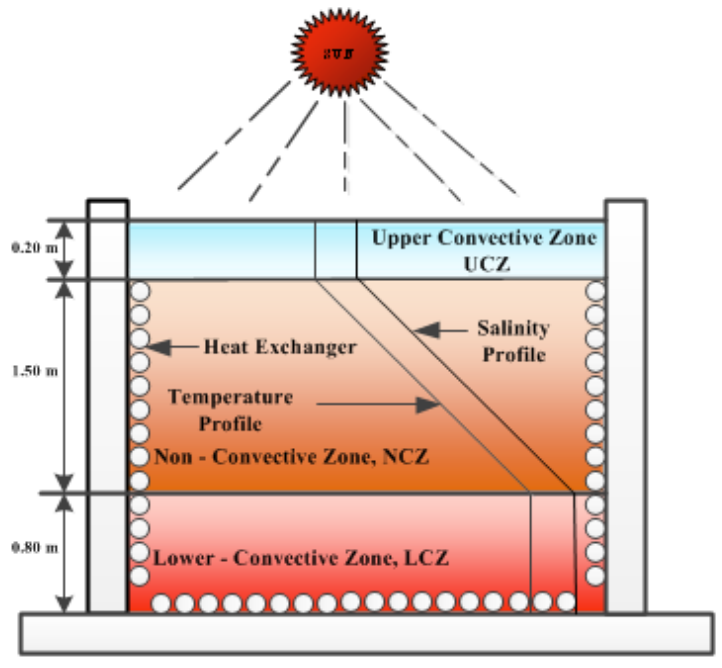

Fig.1: Schematic of the solar pond

The upper convective zone is located at the top of the pond. The temperature of this zone is nearly closed to the ambient temperature. The salt concentration is also near the clean water. Due to the contact between the top layer of this zone and the ambient, there is energy loss from convection and evaporation.

The next zone, non-convection zone, is below the upper convection zone. In this zone, the salt concentration is changed with the depth measured from the interface of the upper convective zone and nonconvection zone. The increasing of depth from this interface results in the increasing of salt concentration. The function of this zone is to protect the heat convection from the optimum thickness of this zone yielding the high efficiency of energy storing inside the pond.( Andrew and Akbarzadeh 2005; Ha, 1984; Tabor and Doron,1986)

The last zone, lower convection zone, is the most salt-concentrated zone. The concentration in this zone is uniform. When the pond receives heat from solar radiation, the heat penetrates through the upper and nonconvection zone to be stored at the bottom side.

Investigations on heat extraction systems have been conducted by a number of researchers generally performed by means of single-phase heat transfer using sensible heat gain by the liquid working fluid which is mostly water. The current method of heat extraction suffers from two main limitations. Firstly, the active circulation of the working fluid inside the in-pond heat exchanger requires pumping power which is unsuitable in the remote areas where solar ponds are most viable. Secondly, single phase heat exchangers are bulky in size and are required to handle large mass flow rates of heat transfer fluid in order to transfer kilowatt range heat provided by the solar ponds.

A crucial aspect of solar pond technology is the heat extraction from the LCZ (Sherman, 1989; John and Walton, 2001; Kumar and Kishore, 1999). Presently it is carried out in one of the following two ways: by using a submerged heat exchanger located on the bottom of the pond, or by pumping brine from the lower convective zone to an external heat exchanger and then returning it to the pond. The first method implies high costs for the maintenance of the heat exchanger, as it is fully submerged in the hot brine, which is a highly corrosive medium. The second method generates local temperature differences of which final effect is to destabilise the salinity gradient layer, because this brine extraction injection process is performed at a specific point of the solar pond, generally close to the centre of a circular solar pond.

Aboul-Enein et al.,(2004) investigated the thermal performance of a shallow solar-pond under the batch mode of heat extraction. They proved that the pond could provide $361 \mathrm{~K}$ of hot water at a maximum temperature of $60{ }^{\circ} \mathrm{C}$. at sunset. Also the pond can retain hot water until 7.00AM next day at a temperature of $47^{\circ} \mathrm{C}$. 
(Ramadan et al., 2004) studied the thermal performance of solar pond under continuous mode of heat extraction. They proved that the continuous mode of heat extraction is more efficient than the batch mode of heat extraction. (Jaefarzadeh, 2006) studied the heat extraction from the solar pond with an area of $4 \mathrm{~m}^{2}$ and a depth of $1.1 \mathrm{~m}$ by using in-pond heat exchangers with water as the working fluid. In this investigation, a system of internal and external heat exchangers was used. The internal heat exchanger was installed in the LCZ that helps to extract heat from the bottom of the pond by using circulating fresh water and transfer it to the water to air heat exchanger placed externally to the pond. It was concluded that the solar pond can deliver heat either continuously with low efficiency or intermittently with relatively high thermal efficiency (Chyng, Lee, and Huang, 2003; Wang, Akbarzadeh, 1982; Andrews and Akbarzadeh, 2005; Leblanc et al., 2011; Tundee et al., 2010; Valderrama et al., 2011).

Bansal, Hrishikesan, and Garg 1984) studied the effect of the heat extraction on the performance of solar pond at the flow rate of $0.1-0.2 \mathrm{~kg} / \mathrm{s}$. The solar pond efficiency was found to be $60 \%$ when calculated from the calorific value from the radiation of the sun at the surface of the pond. (Sabetta, Pacetti and Principi, 1985) built a heat exchanger which is made from poly ethylene tube, installed inside the solar pond at the lower convective zone. Throughout the experiment, the heat exchanger showed no corrosion in the brine. (Prakash,Garg, and Hrishikesan, 1989; Taga, Fujimoto, and Ochi, 1996) designed and tested a solar pond with a cover made from a transparent double film (González, Pérez, and Benítez, 1992) studied theoretically and experimentally the effect of water depth on the pond performance throughout daytime hours in order to find the optimal water depth. (Ali, 1987; Ali, Akhlaghi, 1987) developed a theoretical model, which was validated experimentally, to predict the performance of a solar pond. Transient analysis of the SSP water heaters integrated with baffle plates has been presented by (Dutt1, Rai1 and Tiwari, 1987; Madhuri and Tiwari,1986). It is concluded that better performance of the solar pond can be achieved with the use of baffle plates. ( Parkash, Garg and Hrishikesan, 1989) have investigated the effect of using a movable insulation cover on the performance of a collector-cum-storage water-heating system. (Abhijit et al. 2013) studied heat extraction from non-convective and lower convective zone of the solar pond. it is found that temperature of the LCZ and the average annual solar pond efficiency is very sensitive to the mass flux of the heat transfer fluid that flows through the in-pond heat exchangers.(Sharma and Tiwari, 2010) proposed system modifications to enhance the performance of shallow solar pond. It is found that use of glass glazing along with the P.V.C., the final temperature rises to $79^{\circ} \mathrm{C}$. (Wang et al., 2015) studied experimentally the effectiveness of using the thermal and porosity properties of cleaned and screened coal cinders to achieve higher temperature in the lower convective zone (LCZ) of a salt-gradient solar pond. It is concluded that adding porous medium in lower convective zone may cause the increase of the temperature of this layer, and it can be deduced that the effect of porous medium on salt diffusion will be also influenced with the increase of the temperature. Zomorodian et al.(2007) Introduced a new approach for employing solar radiation as the main source of energy for paddy drying. The drying test rig was designed, fabricated and evaluated. The rough rice solar dryer was a cross-flow and an active mixed mode type with a new and an efficient timer assisted semi continuous discharging system. The maximum overall efficiency of drying system was $21.24 \%$ (with average drying air temperature of $55{ }^{\circ} \mathrm{C}$ ) and the fraction of energy consumed by the auxiliary heating channel during the drying process compared with solar energy was only 6-8\%. The maximum capacity of the dryer was about $132 \mathrm{~kg}$ of rough rice with initially $27 \%$ d.b. down to $13 \%$ d.b. final moisture content in $3 \mathrm{~h}$ of drying period Sutherland and Ghaly (1982) were probably the first research group who investigated feasibility of using fluidization technique for paddy drying. They were reported showed that head yield was 58-61\% when paddy was dried from 28.2 to $20.5 \%$ but was $15-24 \%$ when the final moisture content was 19\%. Tumambing and Driscol (1991) found that drying temperature and bed thickness affected on the drying rate of paddy. Drying conditions were as follows: drying air temperature of $40-100{ }^{\circ} \mathrm{C}$, bed thickness of 5-20 cm and air velocity of $1.5-2.5 \mathrm{~m} / \mathrm{s}$ in their experiments. Soponronnarit, Yapha, and Prachayawarakorn (1995) designed and tested a prototype of 0.82 ton/h capacity fluidized bed paddy dryer for high moisture paddy. Results showed that the unit operated efficiently and yielded high product quality in terms of head yield and whiteness. The moisture content was reduced from $45 \%$ to $24 \%$ d.b. by using air temperature of $100-120^{\circ} \mathrm{C}$, fraction of air recycled of 0.66 , specific air flow rate of $0.05 \mathrm{~kg} / \mathrm{s} \mathrm{kg}$ dry matter, superficial air velocity of $3.2 \mathrm{~m} / \mathrm{s}$, bed depth of $0.1 \mathrm{~m}$. Reid and Siebenmorgen (1998) explored the relationships between rough rice surface temperature, amount of moisture removed and harvest moisture content and head rice yield reduction (HRYR) and developed a model describing HRYR as a function of these variables Queiroz, Couto, and Haghighi (2000) developed a model to simulate the moisture diffusion during the drying process of rough rice by using finite element analysis. The simulated model could predict the temperature of the air and grain and 
the moisture movement inside the rough rice kernel. Soponronnarit, Wetchacama, Trutassanawin, and Jariyatontivait (2001) designed, constructed and tested a prototype of vibro-fluidized bed paddy dryer with a capacity of 2.5-5.0 ton/h and developed a mathematical model that determines optimum operating parameters. Comparison between the experimental and simulated results showed that the mathematical model could predict fairly well. From the survey of previous works, there have been no reports of an investigation into paddy drying using a fluidised bed that incorporates an alternative energy source from a solar pond.

\subsection{Energy balance on solar pond}

\section{Theory}

The system being considered is the one dimensional heat transfer problem through a parallel piped whose base is a unit surface area of the pond, and its height is the depth of the pond. To obtain better results from the model developed, it is more convenient to address each zone in respect to the boundary conditions. For this purpose, the pond is considered to have three zone, as in Fig 2. The UCZ and LCZ are considered as single grid points which have a thickness of $\mathrm{Z}_{0}$ and $\mathrm{Z}_{\mathrm{A}}$, respectively. The total depth of the pond is $\mathrm{Z}$. Conservation of energy is then applied on each zone. For NCZ, the energy equation can be written as follow;

$$
\rho C \frac{\partial T}{\partial t}=\frac{\partial}{\partial z}\left(k \frac{\partial T}{\partial z}\right)+q-q_{l o s s}
$$

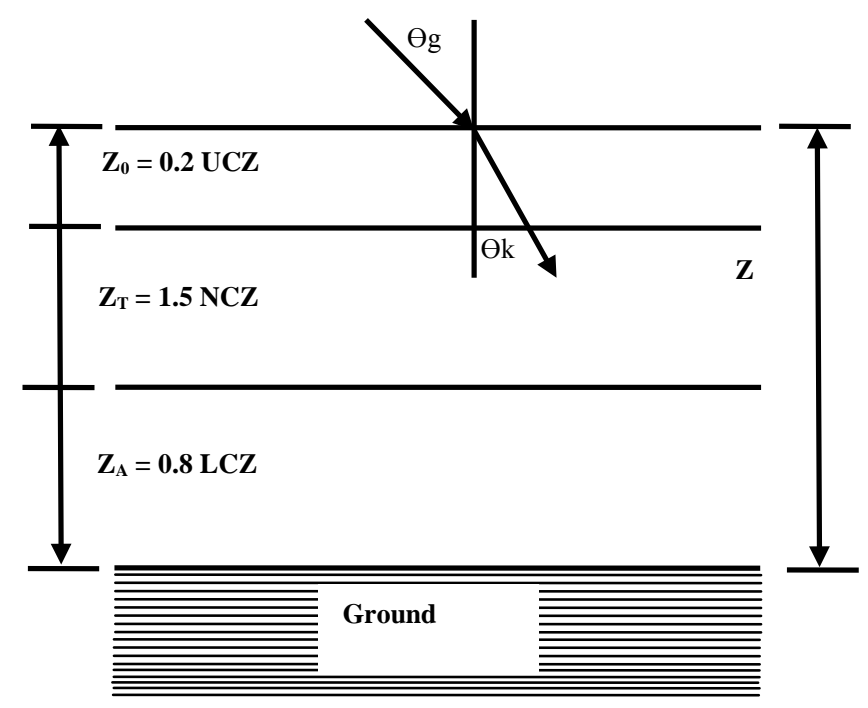

Fig. 2: The physical structure of the coordinate system of the solar pond model

For LCZ, the energy equation is also written as follow;

$$
\rho c_{p} A D_{L} \frac{\partial T_{L}}{\partial t}=Q_{R}-Q_{u p}-Q_{s}-Q_{G}-Q_{L}
$$

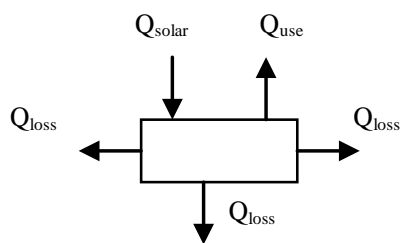

Fig. 3: Diagram of control volume

By assuming that the pond is well insulted, heat loss around the pond is small comparative with amount of heat extraction. The equation (2), thus, can be written as follow; 


$$
Q_{\text {solar }}=Q_{s}+m c_{p} \frac{\Delta T}{\Delta t}
$$

From the fact that extracted heat from the solar pond is equal to the heat extracted by thermosyphon. Substitute (3) into (2), we got;

\subsection{Fluidization}

Fluidization is a process in which solids are caused to behave like a fluid by blowing gas or liquid upwards through the solid-filled reactor. Fluidization is widely used in commercial operations; the applications can be roughly divided into two categories.

- physical operations, such as transportation, heating, absorption, mixing of fine powder, etc. and

- chemical operations, such as reactions of gases on solid catalysts and reactions of solids with gases.

When the solid particles are fluidized, the fluidized bed behaves differently as velocity, gas and solid properties are varied. It has become evident that there are number of regimes of fluidization, as shown in Figure 4. When the flow of a gas passed through a bed of particles is increased continually, a few vibrate, but still within the same height as the bed at rest. This is called a fixed bed (Figure 4.A). With increasing gas velocity, a point is reached where the drag force imparted by the upward moving gas equals the weight of the particles, and the voidage of the bed increases slightly: this is the onset of fluidization and is called minimum fluidization (Figure 4.B) with a corresponding minimum fluidization velocity, $\mathrm{U}_{\mathrm{mf}}$. Increasing the gas flow further, the formation of fluidization bubbles sets in. At this point, a bubbling fluidized bed occurs as shown in Figure 4C. As the velocity is increased further still, the bubbles in a bubbling fluidized bed will coalesce and grow as they rise. If the ratio of the height to the diameter of the bed is high enough, the size of bubbles may become almost the same as diameter of the bed. This is called slugging (Figure 4D). If the particles are fluidized at a high enough gas flow rate, the velocity exceeds the terminal velocity of the particles. The upper surface of the bed disappears and, instead of bubbles, one observes a turbulent motion of solid clusters and voids of gas of various sizes and shapes. Beds under these conditions are called turbulent beds as shown in Figure 4E. With further increases of gas velocity, eventually the fluidized bed becomes an entrained bed in which we have disperse, dilute or lean phase fluidized bed, which amounts to pneumatic transport of solids

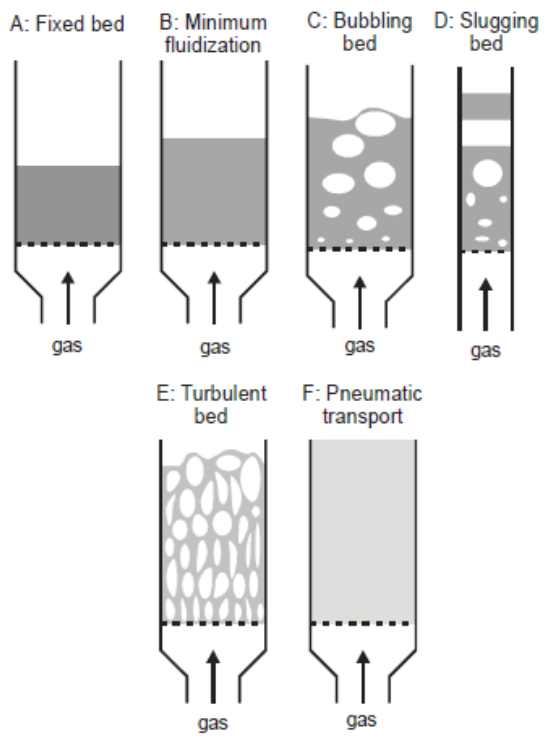

Fig.4: Schematic representation of fluidized beds in different regime (kunii and Levenspiel,1991)

Under a fluidised condition, solid particles are suspended freely in a fluid. The particles are in equilibrium between two forces: the weight of the particle and the resultant force exerted by the fluid including frictional forces. The relationship can be written as equations (4) and (5).

$$
\begin{aligned}
& \triangle P A=W=\left(A L_{m f}\right)\left(1-\varepsilon_{m f}\right) \frac{g}{g_{c}}\left(\rho_{p}-\rho_{g}\right) \\
& \frac{P}{L_{m f}}=\left(1-\varepsilon_{m f}\right) \frac{g}{g_{c}}\left(\rho_{p}-\rho_{g}\right)
\end{aligned}
$$


When

$\Delta \mathrm{P}=$ The pressure drop across the bed, $\left(\mathrm{N} / \mathrm{m}^{2}\right)$

$L_{m f}=$ The length of the bed (m)

$A=$ Cross section area of $\operatorname{bed}\left(\mathrm{m}^{2}\right)$

$W=$ Weight of bed $(\mathrm{Kg})$

$g=$ Gravitational acceleration $\left(\mathrm{m} / \mathrm{s}^{2}\right)$

$\rho_{p} \quad=$ The density of fluid $\left(\mathrm{kg} / \mathrm{m}^{3}\right)$

$\rho_{p} \quad=$ The density of solid $\mathrm{kg} / \mathrm{m}^{3}$ )

$\varepsilon_{m f}=$ Void fraction

$g_{c}=$ Gravitational constant

Ergun's equation (6) shows the pressure drop caused by the fluid passing through the bed at the beginning of the fluidized bed.

$$
\frac{\Delta P g_{c}}{L_{m f}}=\frac{150\left(1-\varepsilon_{m f}\right) \mu U_{m f}}{\varepsilon_{m f}^{3}\left(\emptyset_{s} d_{p}\right)^{2}}+\frac{1.75\left(1-\varepsilon_{m f}\right)}{\varepsilon_{m f}^{3} \emptyset_{s} d_{p}}
$$

Equation (5) and (6)

$$
\frac{1.75}{\emptyset_{S}}\left[\frac{d_{p} U_{m f} \rho_{g}}{\mu}\right]^{2}+\left[\frac{150-\left(1-\varepsilon_{m f}\right)}{\emptyset_{S}^{2} \varepsilon_{m f}^{3}}\right]\left[\frac{d_{p} U_{m f} \rho_{g}}{\mu}\right]=\frac{d_{p}^{3} \rho_{g\left(\rho_{p-\rho_{g}}\right) g_{c}}}{\mu^{2}}
$$

When

$U_{m f}=$ Lowest speed of Fluidized bed, $(\mathrm{m} / \mathrm{s})$

$\mu \quad=$ The dynamic viscosity of the fluid, $(\mathrm{kg} / \mathrm{m} . \mathrm{s})$

$d_{p} \quad=$ Diameter of particle, $(\mathrm{m})$

$\emptyset_{s}=$ Particle size, (Surface area of the sphere Surface area of particles) $(\mathrm{m} / \mathrm{s})$

\subsection{Solar pond}

\section{Experimental setup and data processing}

In the present experimental work, solar pond with an area of $50 \mathrm{~m}^{2}$ and a depth of $2.5 \mathrm{~m}$ was built at Rajamangala University of Technology in north east of Thailand (16.479312N102.958760E). The built solar pond was used to characterize the daily temperature variations and possible heat extraction rate from the salinity-gradient solar ponds. Fig. 5 illustrates various zones in the solar pond and their thicknesses. In this case, the pond was built above ground with concrete walls $25 \mathrm{~cm}$ thick. The temperature measurements were taken at different locations along the inner concrete wall of the pond, as indicated in the Fig. 6, by using K-type thermocouples with an accuracy of $\pm 0.5^{\circ} \mathrm{C}$. These thermocouples were equally spaced at $0.05 \mathrm{~m}$ interval with the starting point at $0.05 \mathrm{~m}$ and end point at $2.45 \mathrm{~m}$ from the bottom surface of the pond.

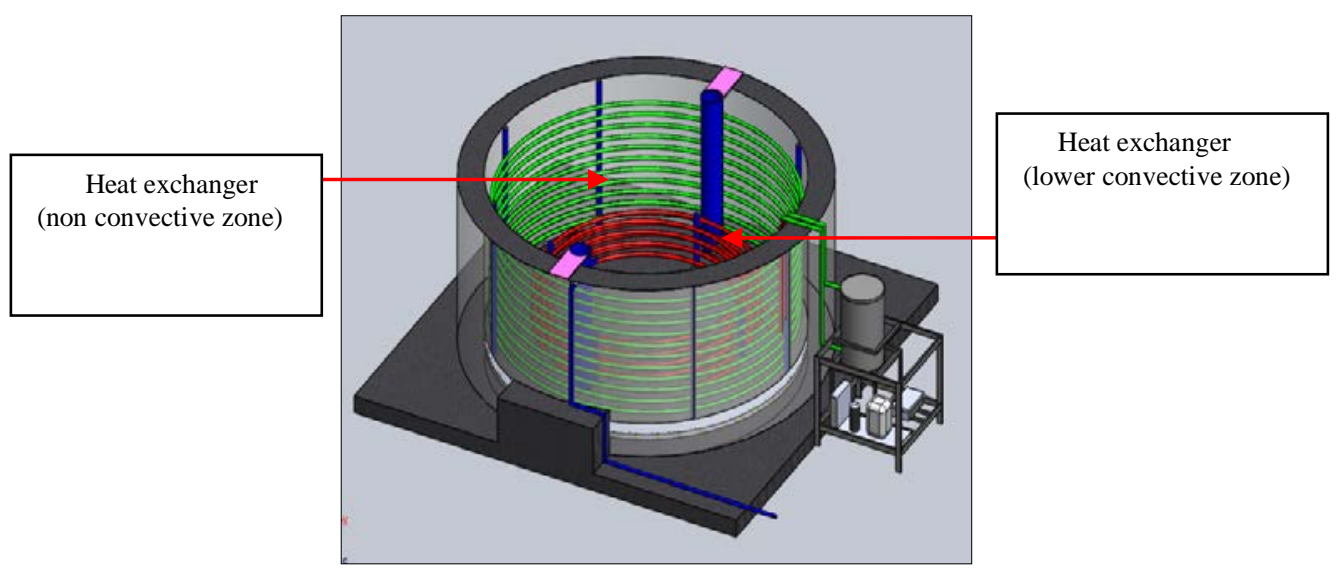

Fig.5: Schematic view of the solar pond and the system of heat extraction.

The temperature distributions at these regions were recorded at $5 \mathrm{~min}$ time interval by using the data acquisition system connected to these thermocouples. For monitoring and processing the output data, the data acquisition unit was connected to a computer system. The solar radiation intensity (in $\mathrm{W} / \mathrm{m}^{2}$ ) incident on the 
horizontal surface was measured at an interval of 10 min by using a 105HP type pyranometer with an uncertainty of $\pm 5 \%$ of the output reading. In order to record the density profile for the solar pond, samples of the saline water was extracted from different depths of the pond using simple gravity assisted siphoning technique. Density was measured using DMA 35N Density meter from Anton Paar which has an accuracy of \pm 1 $\mathrm{kg} / \mathrm{m}^{3}$. Within the solar pond, it installed the heat exchanger for 2 sets. Set 1 installed within lower convective zone, there is the heat exchange area of 7.85 square meters and set 2 installed at the inner wall of the solar pond $50 \mathrm{~mm}$ away from the wall and there is the heat exchange area of 7.85 square meters.

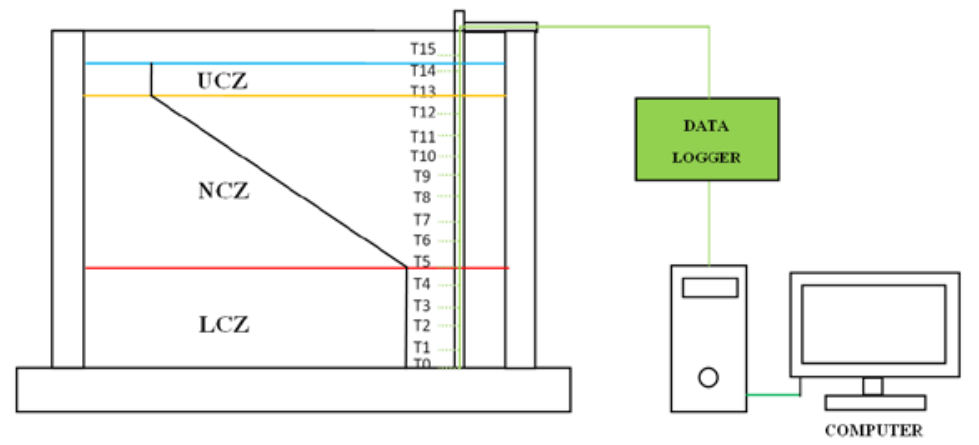

Fig.6: Experimental setup, pond heat extraction system and associated data acquisition facilities

The water is used as the receiver of the heat in the heat extraction from the lower convective zone and the non convective zone to control the incoming water temperature at $25-30{ }^{\circ} \mathrm{C}$. It is installed the Thermocouple; $T_{0}$ is in the bottom next to the pond ground, $T_{1}$ is $5 \mathrm{~cm}$ away from the pond ground, and $T_{1}$ to $\mathrm{T}_{14}$ are away from each in $10 \mathrm{~cm}$, and $\mathrm{T}_{15}$ took the atmospheric temperature, the Data Logger were used to collect the data in every 1 minute. When observing the heat extraction experiment, they will additional install the Thermocouple for 4 points which is to take the inlet water temperature for 2 points and the outlet water temperature for 2 points and collected the data in every 1 minute.

\subsection{Fluidized bed dryer}

1.Heat exchanger

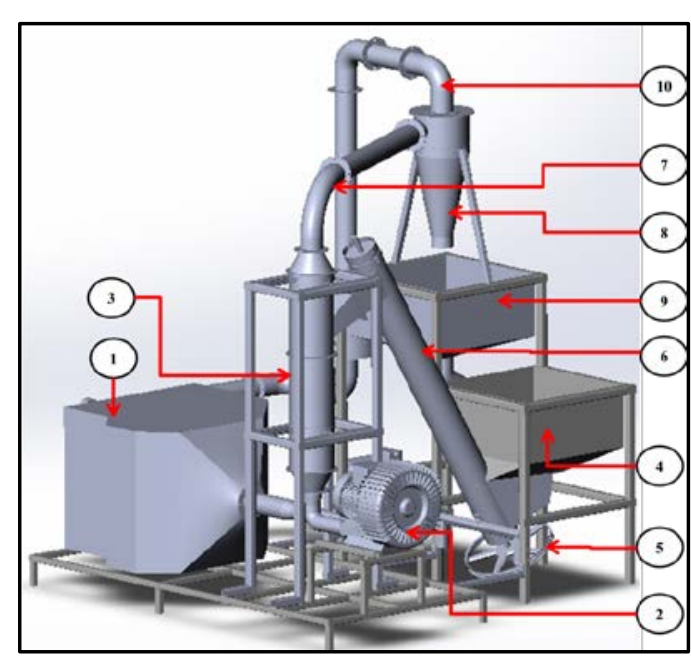

2.Blower

3.Drying chamber

4.Paddy inlet container

5.Feeder pulley

6.Rotary Feeder inlet

7.Paddy outlet

8.Cyclone

9.Paddy outlet container

10.Air recycled

Fig. 7 : Schematic view fluidized bed paddy dryer

The main components of the fluidised-bed paddy dryer with a solar pond are shown in Fig 9. The system consists of a counter-flow heat exchanger (1) which receives heat from the solar pond via 3 heat radiators. Heat in the water is transferred to the air which is blown over the radiators by a blower (2). Hot air is then channelled to the drying chamber (3). The paddy which is stored in the paddy inlet container (4) is transferred by a rotary feeder inlet (6). The volume of rice intake to the drying chamber is controlled by a feeder pulley (5). When hot air has entered the paddy drying chamber, the fluidised-bed drying operation will begin. Starting from hot air travelling at a speed which causes fluidisation travels through the air diffuser to the bed where paddy is stored. The paddy grains are lifted and become suspended in hot air. Heat from the hot air 
transfers to the grains. Dry grains exit through the paddy outlet (7) into the cyclonic chamber (8) to remove impurities from the grains. The clean paddy grains will be stored in the paddy outlet container (9). Some of the hot air will be recirculated into the heat exchanger through the air recirculation duct (10) to receive heat in (1) and re-enter the cycle.

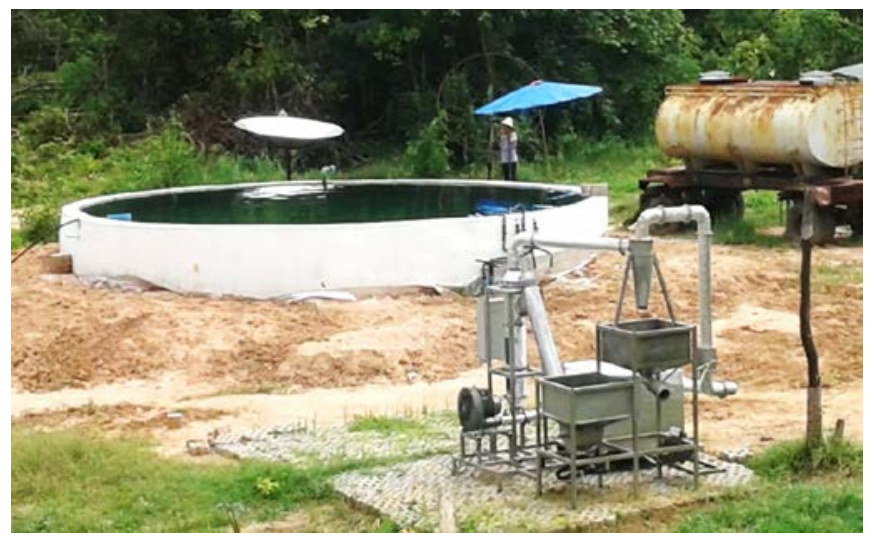

Fig. 8: Photos experiment fluidized - bed paddy dryer and solar pond

Fig 8 illustrates the solar pond and the fluidised-bed paddy dryer. The solar pond receives and store solar energy. It acts as a heat source to the system. The stored heat is the extracted to the dryer. The renewable source of energy does not have negative impacts on the environment.

\section{Results and discussions}

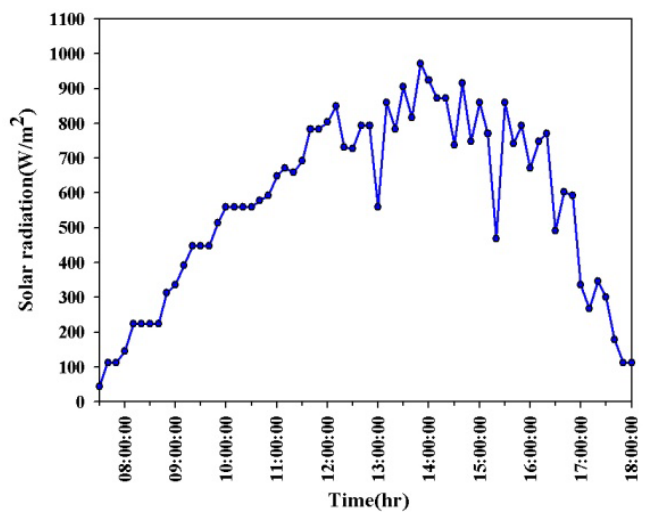

Fig. 9: Change of the solar radiation with time

The experiments were performed in July 1017, in Khon Kaen Province, Thailand. Fig. 9 shows the solar radiation rate compared to the time. It can be seen that in the morning, it will be low due to the low impinging amount of solar light intensity and it will be increased according to the intensity of the radiation from the sun. The highest solar rate is found in the duration around 12:30 to $13: 30 \mathrm{pm}$ and when the intensity of radiation is high, the solar radiation rate also increased with the time as well. When the solar radiation rate begins to decline until it cannot be measured in the evening at approximately18:30 am. The change starts from low to high and highest and then began to decline. Because the characteristic of increasing, decreasing and then going up again, because the trial will be experimenting with solar, the experimental sets will be installed outdoors, according to the weather conditions of the experiment day, such as sun, rain, heat, humidity, and so on. Because it is during the rainy season, it results in an increase and decrease of the rate change according to environmental conditions as shown in Fig 9. 


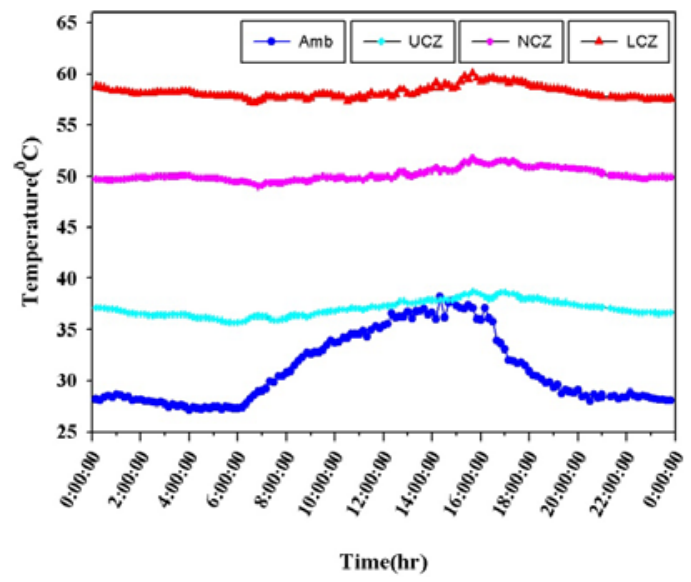

Fig. 10: Average temperature in the solar pond at the UCZ, NCZ LCZ and Ambient

Fig. 10 shows average temperature in the solar pond at the UCZ, NCZ LCZ and Ambient. Thermocouples were installed in the solar pond with a distance of $5 \mathrm{~cm}$ from the bottom of the solar pond up to the upper layer. The average values were calculated from five measure points in the 20-cm-thick UCZ. . The temperature in the UCZ was similar to the ambient value. It can be seen that during daytime, when the temperature of the atmosphere was high, the three average temperatures increased accordingly. At night, when the atmospheric temperature dropped, the temperature in the UCZ dropped as a result. By contrast, the average temperature of the NCZ exhibited small reduction or increase during the night and daytime respectively.

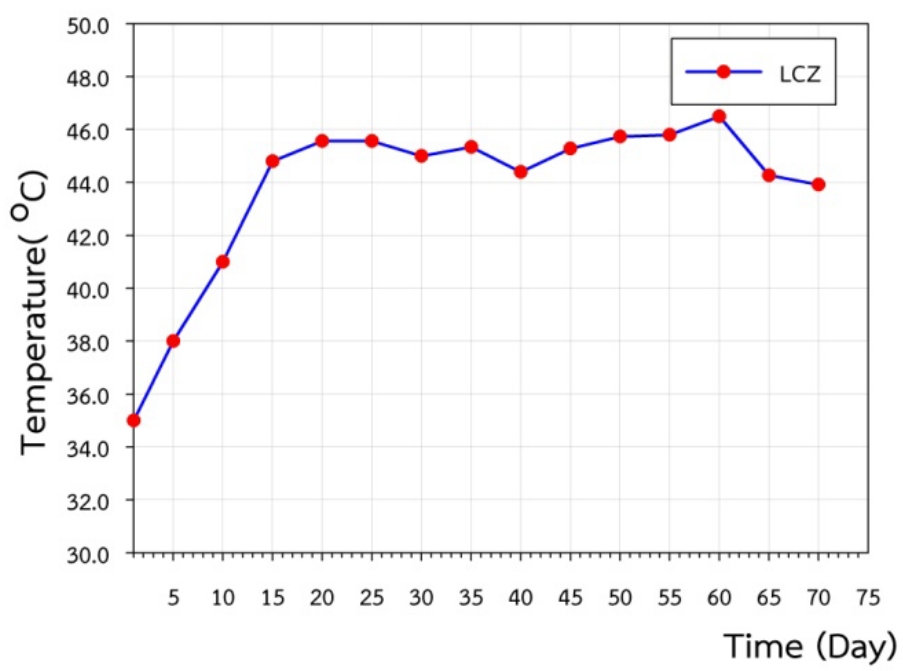

Fig. 11: shows the average temperature of the lower convection zone (LCZ)

Fig 11 shows the average temperature of the lower convection zone (LCZ) of the solar pond over the course of 70 days of experiment. It can be seen that during the first 15 days of the test, the temperature rose relatively rapidly because the pond could receive and store a high amount of heat due its low initial temperature. When the amount of heat received by the solar pond is similar to the amount of heat dissipated to the atmosphere, the rise in temperature of the solar pond became slower and depends on daily solar irradiation. The temperature increased on a sunny day and decreased on a cloudy day. It was observed that the highest temperature that the solar pond could store was $47^{\circ} \mathrm{C}$ after the pond had 60 days. 


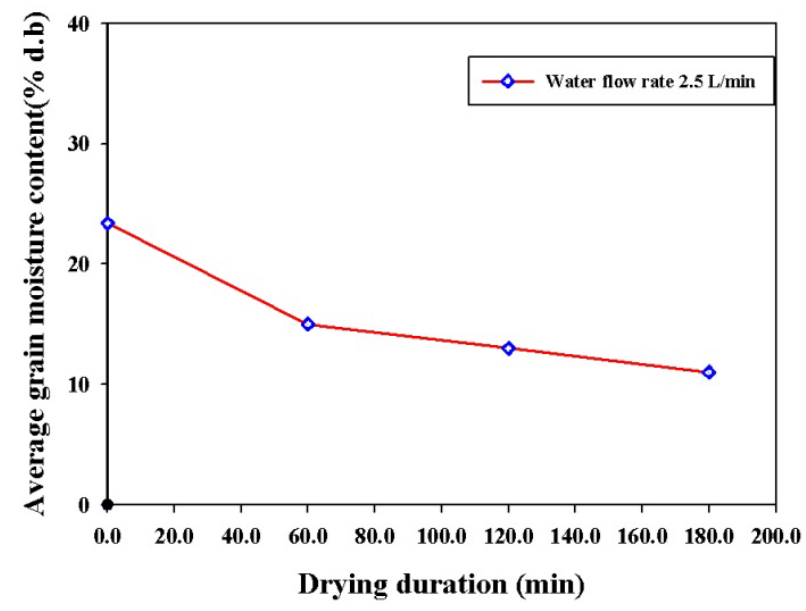

Fig .12: Evolution of moisture content

Drying curves of paddy are presented in Fig. 12. It is apparent that moisture ratio decreases continuously with drying time. As indicated in these curves, there was no constant rate period in drying of paddy. All the drying process occurred in the falling rate period, starting from the initial moisture content ( $23 \pm 0.5 \%$, wet basis) to final moisture content ( $11 \pm 0.5 \%$, wet basis).

\section{Conclusions}

In order to shine some light on the subject, our research aims to study the application of this novel renewable and environmentally-friendly technique to rice paddy drying that could benefit many farmers and the economy not just nationally but globally. The results showed that the flow rate of 2.5 liters per minute could take heat into application better than the flow rates of 2 and 3 liters per minute. At such the flow rate, moisture dropped from $23.4 \%$ to $15 \%$ for the first time of drying and for the second and third times, the moistures dropped to $13 \%$ and $11 \%$ respectively. Reduction in moisture content of the paddy met the criteria set which was $1 \%$ to $5 \%$ per round of drying.

\section{Acknowledgments}

The authors would like to express Their appreciation to the Rajamangala University of Technology Isan and Research\& Development Institute, Faculty of engineering Rajamangala Rajamangala University of Technology Isan Khon Kaen Campus for providing financial support for attending International Conference on Solar Heating and Cooling for Building and industry (ISES, 2018)

\section{References}

Abhijit, D.,Yusli, Y., Ashwin, D., Shankar, K., Akbarzadeh, A., 2013. Heat extraction from non-convective and lower convective zones of the solar pond: A transient study. Solar Energy 97, 517-528.

Aboul-Enein, S., El-Sebaii, A.A., Ramadan, M.R., Khallaf, A.M., 2004. Parametric study of a shallow solar pond under the batch mode of heat extraction. Applied Energy 78 (2), 159 -177.

Andrew, j., Akbarzadeh, A., 2005. Enhancing the thermal efficiency of solar ponds by extracting heat from the gradient layer. Solar Energy 78, 704-716.

Ali, H. M., 1987. Study on shallow solar pond applications at Tehran. Energy Conversion and Management 27(1), 33 - 38.

Ali, H.M., Akhlaghi, M., 1987. Experimental study in a shallow solar pond. Solar \& Wind Technology 4 (4), $425-430$. 
Bansal, P. K., Hrishikesan, D.S.,Garg, H.P., 1984. Effect of heat exchange on the performance of a shallow solar pond water heater. Energy Conversion and Management 24 (4), 259 - 63.

Chyng, J. P., Lee, C.P., Huang,B.J., 2003. Performance analysis of a solar-assisted heat pump water heater. Solar Energy 74 (1), 33 - 44.

Dutt, D.K., Rai, S.N., Tiwari, G. N., 1987. Transient analysis of a shallow solar pond water heater integrated with a baffle plate. Energy Conversion and Management 27 (3), 303 - 307.

Ergun, S., 1952. Fluid flow through packed columns. Chemical Engineering Progress 48(2), 89 - 94.

González, J., Pérez, L.R., Benítez, J., 1992. Modeling the thermal process in a shallow solar pond water heater. Solar Energy 48 (4), 261 - 265.

Ha, B., 1984. Ormat Turbines, Arava Solar Pond Inaugurated, Sunworld.8(1) 18.

Jaefarzadeh, M. R., 2006. Heat extraction from a salinity-gradient solar pond using in pond heat exchanger. Applied Thermal Engineering 26 (16),1858 - 1865.

John, H. L.,Walton, C., 2001. Desalination coupled to salinity gradient solar ponds. Desalination 136,13-23.

Kalecsinsky, A. V., 1902. Ueber die ngarischen natuerlich waermeaccumulatoren. Annalen der Physik IV 7,408 - 416.

Kumar, A., Kishore,V.V.N., 1999. Constuction and operational experience of A $6000 \mathrm{~m}^{2}$ solar pond at Kutch,India. Solar Energy 65(4), 237 - 249.

Leblanc, J., Aliakbar, A., Andrews, J., Lu, H., Golding,P., 2011. Heat extraction methods from salinity-gradient solar ponds and introduction of a novel system of heat extraction for improved efficiency. Solar Energy 85(12), 3103 - 3142.

Madhuri.,Tiwari,G.N., 1986. The effect of a baffle plate on the transient performance of a shallow solar pond water heater. Energy Conversion and Management 26(7), 217 - 220.

Prakash, J., Garg., H.P., Hrishikesan, D., Ranjana ,J., 1989. Performance studies of an integrated solar collector-cum-storage water heating system with transparent insulation cover. Solar \& Wind Technology 6 (2), $171-176$

Queiroz, D. M., Couto, S. M., \& Haghighi, K.,2000. Parametric finite element analysis of rice drying. Presented at the 2000-ASAEAnnual- International-Meeting, Milwaukee, WI, USA, 9 - 12.

Ramadan, M. R. I., El-Sebaii, A.A., Aboul-Enein, S., Khallaf,A.M., 2004. Experimental testing of a shallow solar pond with continuous heat extraction. Energy and Buildings 36 (9), 955-964.

Reid, J. D., \& Siebenmorgen, T. J., 1998. Using surface temperature and moisture content to describe head rice yield reduction during thin-layer drying of rough rice. ASAE-Annual- International-Meeting,

Sabetta, F., Pacetti, M., Principi, P., 1985. Aninternal heat extraction system for solar. 34 (4), 297 - 302.

Sharma, S. C. and Ashesh Tiwari. 2010. Performance Enhancement of Shallow Solar Pond by System Modification. International Journal on Emerging Techonologies 1(1), 92 - 96.

Sherman, B. S., 1989. Modelling and Control of a Solar Pond. The University of Westen Australia. 
Soponronnarit, S., Wetchacama, S., Trutassanawin, S., \& Jariyatontivait,W.,2001. Design,testing, and optimization of vibro-fluidized bed paddy dryer. Drying Technology, 19(8), 1891 -1908.

Soponronnarit, S., Yapha, M., \& Prachayawarakorn, S.,1995. Crossflow fluidized bed paddy dryer: prototype and commercialization. Drying Technology, 13(8 \& 9), 2207 - 2216.

Sutherland,J.W.and Ghaly,T.F., 1982.Heated - Air Drying of Oilseeds.Stored products Research.18(2), 43-54.

Tabor, H., and Doron, B., 1986. Solar Ponds- Lessons learned from the $150 \mathrm{~kW}$ power plant at Ein Boqek, Proc. of the ASME Solar Energy Div., Anaheim, California.

Taga, M., K. Fujimoto, and T. Ochi., 1996. Field Testing on Non -Salt Solar Ponds. Solar Energy 56(3), 267 277.

Tumambing, J. A., \& Driscol, R. H., 1991. Modeling the performance of continuous fluidized bed dryer for pre-drying of paddy. In Presented at the Proceedings of the $14^{\text {th }}$ ASEAN seminar on grain postharvest technology, Philippines.

Tundee, Sura, Pradit Terdtoon, Phrut Sakulchangsatjatai, Randeep Singh, and Aliakbar Akbarzadeh. 2010. Heat Extraction from Salinity-Gradient Solar Ponds Using Heat Pipe Heat Exchangers. Solar Energy 84(9),1706 - 16.

Valderrama, Cesar et al., 2011. Solar Energy Storage by Salinity Gradient Solar Pond: Pilot Plant Construction and Gradient Control. Desalination 279(1-3),445 - 450.

Wang, Hua, Xiaolei Yu, Feiling Shen, and Liugang Zhang. 2015. A Laboratory Experimental Study on Effect of Porous Medium on Salt Diffusion of Salt Gradient Solar Pond. Solar Energy

Wang Y.F, Akbarzadeh, A. 1982. A Study on the Transient Behavior of Solar Ponds. Solar Energy 7(12),1005 1017.

Zomorodian A, Zare D, Ghasemkhani H., 2007. Optimization and evaluation of a semicontinuous solar dryer for cereals (Rice, etc.). Desalination,209,129 - 135. 


\title{
High Temperature Seasonal Borehole Thermal Energy Storage for Effective Load Shifting and $\mathrm{CO}_{2}$ Emission Reduction
}

\author{
Robert Weber, Luca Baldini \\ Urban Energy Systems / Empa, 8600 Dubendorf (Switzerland)
}

\begin{abstract}
A borehole thermal energy storage (BTES) shall be built on the Empa campus. It will be charged with waste heat in summer and discharged with a heat pump in winter. Instead of the currently planned low temperature BTES, a high temperature BTES with a radial temperature gradient shall be investigated with charging from the center and discharging from the outer ring. The aim is to realize an effective seasonal load shifting and a reduction of the yearly $\mathrm{CO}_{2}$ emission through optimizing for high coefficients of performance (COP) of the heat pump operation in winter. With the help of TRNSYS, different cases with variation of the operational temperature as well as geometrical and hydraulic parameters were simulated. The electrical consumption assigned to the operation of the BTES was converted into $\mathrm{CO}_{2}$ emissions with the help of dynamic $\mathrm{CO} 2$ emission data available for Switzerland. The results show that with the physical limitations given on the Empa campus and the simplified sampling of the $\mathrm{CO}_{2}$ data used performance expectations could not be confirmed and a consequent implementation of a high temperature BTES on Empa campus will not be realized.
\end{abstract}

Keywords: BTES, power to heat, seasonal storage, load shifting, $\mathrm{CO}_{2}$ emission reduction

\section{Introduction}

Today, the energy system of the Empa campus relies mainly on fossil fuels and it is the goal to transform the system such that $\mathrm{CO}_{2}$ emissions can be significantly reduced. Heat and cold production as well as the existing heat distribution network will be re-engineered and transformed in the following years. In future, operational waste heat shall be re-used as far as possible. In addition, renewable energy supply shall be increased with a planned PV capacity of $600 \mathrm{kWp}$. The new campus' energy system is based on the following four pillars: 1) electrical chillers and heat pumps, 2) seasonal borehole thermal energy storage (BTES), 3) heat distribution network with combined mid-temperature line for heat rejection and space heating, 4) bio-gas boilers for covering peak heat demand and a combined heat and power plant.

In the initial planning, a regular BTES is foreseen as found in many other sites in Switzerland (e.g. ETH Zürich Campus Hoenggerberg, Suurstoffi Rotkreuz, Familienheimgenossenschaft Zürich, etc.) with mean storage temperatures close to the natural soil temperatures. Those BTES are typically coupled with a low temperature heating and cooling network.

From a research perspective more interesting is a BTES with higher mean storage temperatures. We hypothesize that storage temperatures in the range of $40-50^{\circ} \mathrm{C}$ allow for a more significant load shifting from winter to summer in a power to heat application and eventually for direct heating or at least for operation of the heat pumps with higher COP's. Variable seasonal $\mathrm{CO}_{2}$ loads of grid electricity (higher in winter and lower in summer) as found in Switzerland and many other countries would consequently lead to lower over-all $\mathrm{CO}_{2}$ emission for heat and cold use.

In this paper the design of a BTES system with elevated temperatures, tailored to the Empa case, is presented and its performance is compared to a standard BTES system as foreseen in the initial planning. 


\section{Case description}

\section{Robert Weber}

Measurements of the campus' heating and cooling loads in 2012 (hourly data) show maximum values of around 4000 and $1500 \mathrm{~kW}$ respectively (see Fig. 1). Heating loads are typically high in winter due to the large space heating demand. Cooling loads are naturally more expressed during summer but there is a minimum cooling load of about $300 \mathrm{~kW}$ throughout the year for cold supply needed for research purpose. The thermal energy demand of the year 2012 for heating and cooling is 5660 and 2645 MWh respectively.

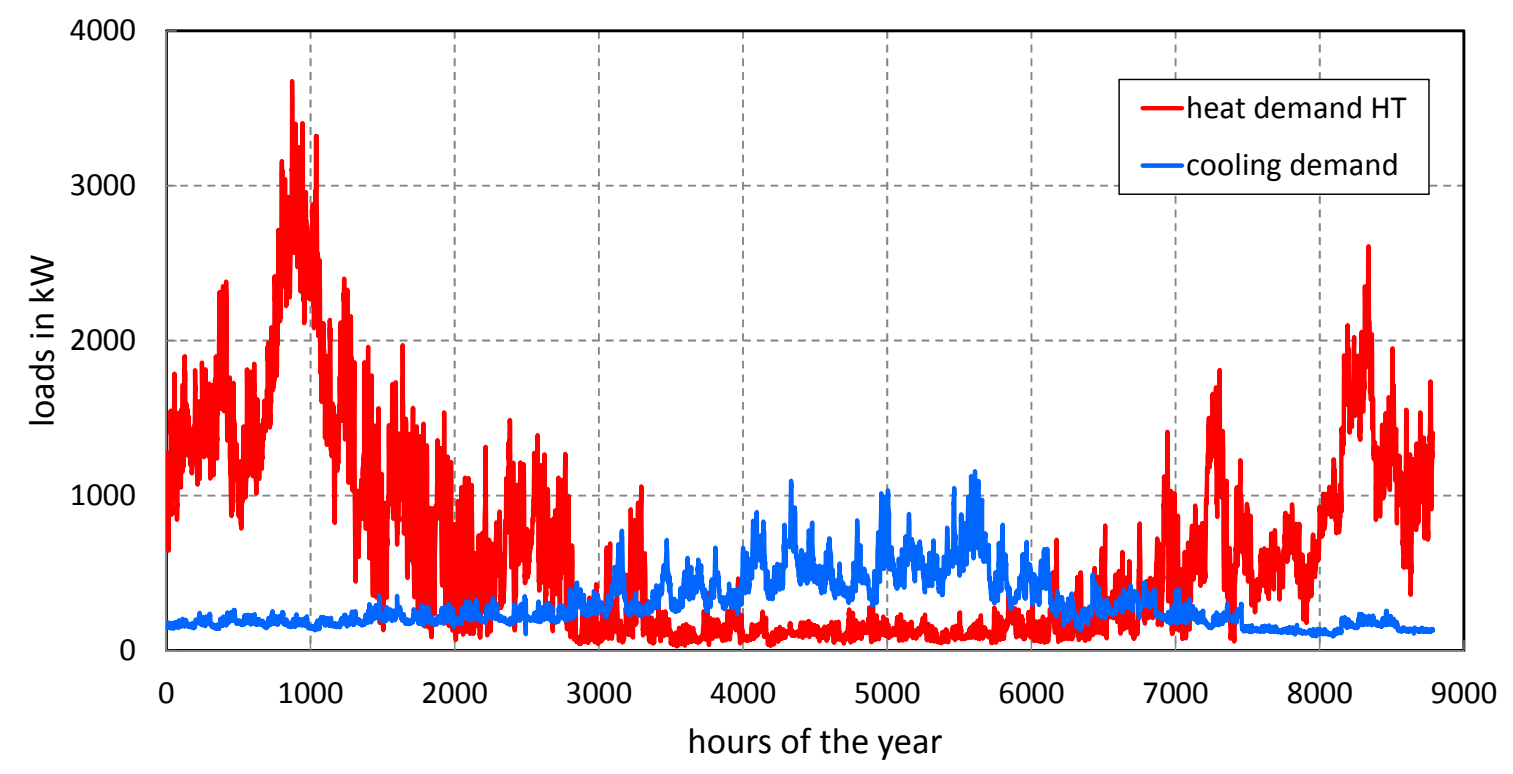

Fig. 1: Hourly heat and cold demand of Empa campus in 2012

The current thermal energy distribution system is based on three networks of different temperatures (see left side of Fig. 2). The heating network uses $65-70 / 45{ }^{\circ} \mathrm{C}$ on the hot/cold side. The former heat rejection network operated at $20 / 28{ }^{\circ} \mathrm{C}$ is in transformation towards an undirected and combined heating and heat rejection network with temperatures of $38 / 28^{\circ} \mathrm{C}$. The cooling network uses temperatures of $6 / 12^{\circ} \mathrm{C}$. The different networks with distinct temperature levels available facilitate the integration of a BTES with temperatures well above the natural soil temperatures.

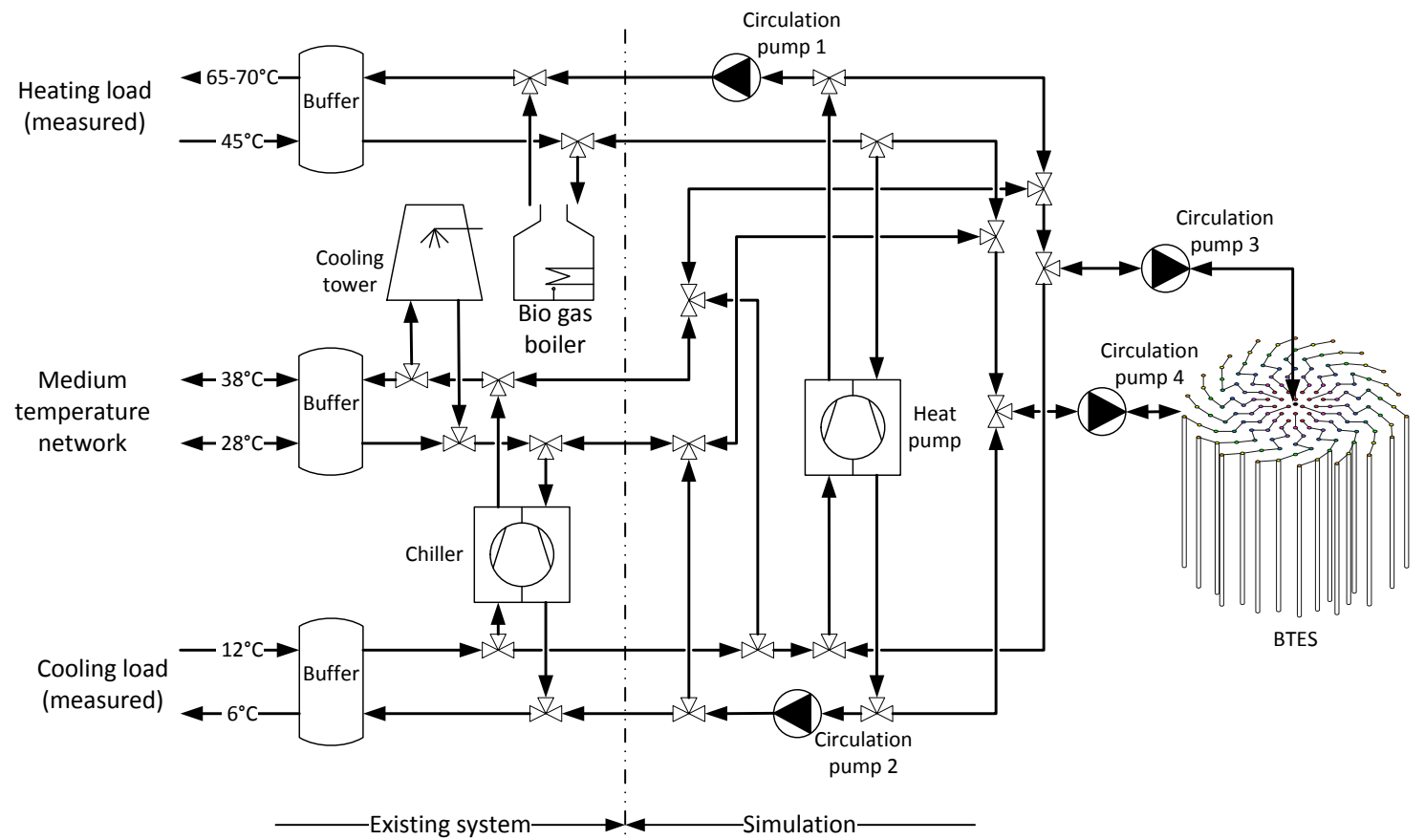




\section{Robert Weber}

Fig. 2: Schematic of the simulated system

The BTES shown on the right side of the hydraulic schematic depicted in Fig. 2 shall be added to the existing energy system and is the subject investigated. As the base energy system of the Empa campus is already built, there are some physical limitations that have to be considered as boundary conditions in the planning phase. The main duct between the central thermal power station and the designated place where the BTES shall be installed already exists. Unfortunately, this duct has limited space and therefore, only two tubes can be placed instead of four as ideally required. This restriction has severe consequences for the performance and hence feasibility of the high temperature gradient storage as will be discussed later.

The heat stored to or used from the BTES is the difference between the hourly heat and cold demand. As Fig. 1 shows, there is also heat demand in summer as well as a cold demand in winter. This simultaneous heating/cooling demand is covered directly by the heat pump, delivering cold and heat to the according buffer tanks. This means that from the yearly $2645 \mathrm{MWh}$ cooling demand, $1270 \mathrm{MWh}$ can be delivered directly and the waste heat produced thereby does not need to be stored in the BTES.

The maximum power with which heat can be stored in the BTES is limited by the cumulated length of the ground heat exchanger (GHX) and the temperature difference of the brine inlet temperature and the ground temperature. To guarantee the operation of Empa's cooling infrastructure during peak hours, beside the BTES, a cooling tower is installed. In winter the heat load beyond the one covered by heat pumps, is covered by a gas boiler.

For the BTES, three different fields where investigated (Fig. 3). All BTES fields where equipped with 144 GHX, with 40mm double U tubing, 102 meter deep and thermally insulated on the top two metres.

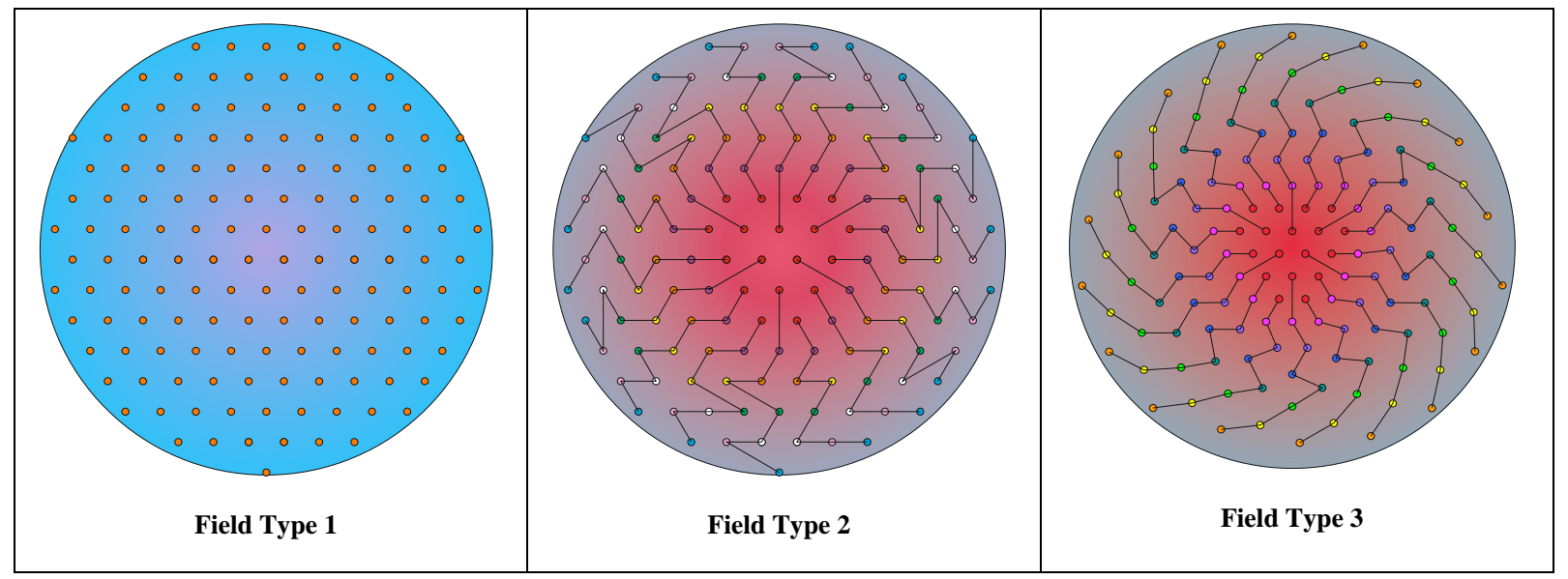

Fig. 3: Three different Types of BTES fields were investigated

Field type 1 is a conventional type of a BTES with parallel feed $(144 \mathrm{x} 1)$ of the brine. This field is equipped with PE-100 tubes; therefore the maximum inlet temperature allowed is $40^{\circ} \mathrm{C}$. The minimal outlet temperature in winter is limited to $-6^{\circ} \mathrm{C}$, in order to have a high temperature range between summer and winter. This requires frost protection and ethylene glycol is added to the brine. This field type is simulated as there is a similar field proposed to Empa and serves as a reference case. Two versions of the field are simulated with two different borehole distances: $4 \mathrm{~m}$ and $4.5 \mathrm{~m}$ respectively.

Field type 2 is a BTES where the GHXs are arranged in 18 parallel strings with 8 GHXs in series (18x8). The field is equipped with PEX tubes, therefore input temperatures up to $90^{\circ} \mathrm{C}$ are allowed. Hot water is feed in the center and cold water on the periphery. The distance between the boreholes is always $4 \mathrm{~m}$, but there are different combinations of maximum inlet temperatures and minimal outlet temperatures simulated. Pure water is recirculated as minimum temperatures will always be above the freezing point of water.

Field type 3 is a BTES where the GHXs are again arranged in 18 parallel strings with 8 GHX in series. Also this 


\section{Robert Weber}

field is equipped with PEX tubes. The difference to field type 2 is the varying distances between the boreholes. In the center, the borehole distance is $3 \mathrm{~m}$, on the periphery, the distance increases to $4.5 \mathrm{~m}$. Also this field is simulated with different combinations of maximum inlet temperatures and minimal outlet temperatures and pure water without anti-freeze.

Tab. 1: Cases simulated

\begin{tabular}{|c|c|c|c|c|c|c|}
\hline Simulation cases & $\begin{array}{c}\text { BTES } \\
\text { field } \\
\text { type }\end{array}$ & $\begin{array}{c}\text { BTES } \\
\text { field } \\
\text { diameter } \\
\text { [m] }\end{array}$ & $\begin{array}{c}\text { Distance } \\
\text { between } \\
\text { GHX } \\
\text { [m] }\end{array}$ & Hydraulic & $\begin{array}{c}\text { Inlet } \\
\text { temperature } \\
\text { charging } \\
\text { ['C] }\end{array}$ & $\begin{array}{c}\text { Min. ground } \\
\text { temperature } \\
\text { discharging } \\
\text { ['C] }\end{array}$ \\
\hline Par_4m & 1 & 48 & 4 & $144 \times 1$ & 38 & 6 \\
\hline Par_45m & 1 & 54 & 4.5 & $144 \times 1$ & 38 & 6 \\
\hline Ser_4m_55_15 & 2 & 48 & 4 & $18 \times 8$ & 55 & 15 \\
\hline Ser_4m_55_20 & 2 & 48 & 4 & $18 \times 8$ & 55 & 20 \\
\hline Ser_4m_60_20 & 2 & 48 & 4 & $18 \times 8$ & 60 & 20 \\
\hline Ser_4m_65_15 & 2 & 48 & 4 & $18 \times 8$ & 65 & 15 \\
\hline Ser_4m_65_20 & 2 & 48 & 4 & $18 \times 8$ & 65 & 20 \\
\hline Ser_4m_65_25 & 2 & 48 & 4 & $18 \times 8$ & 65 & 25 \\
\hline Ser_4m_65_30 & 2 & 48 & 4 & $18 \times 8$ & 65 & 30 \\
\hline Ser_4m_70_20 & 2 & 48 & 4 & $18 \times 8$ & 70 & 20 \\
\hline Grad_345m_55_15 & 3 & 47 & $3-4.5$ & $18 \times 8$ & 55 & 15 \\
\hline Grad_345m_55_20 & 3 & 47 & $3-4.5$ & $18 \times 8$ & 55 & 20 \\
\hline Grad_345m_60_20 & 3 & 47 & $3-4.5$ & $18 \times 8$ & 60 & 20 \\
\hline Grad_345m_65_15 & 3 & 47 & $3-4.5$ & $18 \times 8$ & 65 & 15 \\
\hline Grad_345m_65_20 & 3 & 47 & $3-4.5$ & $18 \times 8$ & 65 & 20 \\
\hline Grad_345m_65_25 & 3 & 47 & $3-4.5$ & $18 \times 8$ & 65 & 25 \\
\hline Grad_345m_65_30 & 3 & 47 & $3-4.5$ & $18 \times 8$ & 65 & 30 \\
\hline Grad_345m_70_20 & 3 & 47 & $3-4.5$ & $18 \times 8$ & 70 & 20 \\
\hline
\end{tabular}

\section{Methods}

Simulations performed to study the storage behavior and over-all system performance is done with TRNSYS 17.1 (2016). The BTES is simulated with an unreleased TRNSYS TYPE based on the TRNSBM (Pahud et al., 1996). This TYPE allows for almost any combination of hydraulic connections between the boreholes and offers the flexibility needed for performance optimization. The theoretical foundation of the simulation model used is the g-function method introduced by (Eskilson, 1986).

For the heat pump, a compressor driven system with the refrigerant R717 (ammonia) was assumed. For the simulation a constant electrical power of $150 \mathrm{kWe}$ was chosen and for partial load on/off operation was used to meet the actual heating/cooling demand. The COP of the heat pump was calculated with a regression according to the diagram in (Sigrist, 2010):

$$
\text { COP }=0.6 \cdot \frac{T_{h o t}+3.0}{T_{h o t}+3.0-T_{l o w}-2.0}
$$

Different BTES inlet temperatures in summer (charging) were assumed (see Tab. 1). To reach high inlet temperatures in the BTES fields $2 \& 3$, the according mass flow had to be reduced, as the heat pump has limited power. This leads to the desired temperature gradient over GHXs which are configured in series. It was checked that the mass flow always allowed for turbulent flow and adequate heat transfer. 


\section{Robert Weber}

The inlet temperature in winter (discharging) was calculated as:

$$
T_{\text {in,BTES }}=\operatorname{Max}\left(T_{\text {Min, cold }}, T_{\text {out }, \text { BTES }}-T_{\text {cold,diff }}\right)
$$

with a minimum temperature $T_{\text {Min,cold }}=4^{\circ} \mathrm{C}$ for the serial cases and $-9^{\circ} \mathrm{C}$ for the parallel cases and temperature differences $T_{\text {cold,diff }}$ of $15 \mathrm{~K}$ for the serial cases and $3 \mathrm{~K}$ for the parallel cases. The mass flow was adapted accordingly. Discharging is stopped when the BTES outlet temperature $T_{\text {out BTES }}$ of the preceding hour fell below the min. ground temperature (see Tab. 1).

Either of the circulation pumps $1 \& 2$ (see Fig. 2) is considered to have a nominal electric load of $3 \mathrm{~kW}$, when the heat pump was on and cold or heat was delivered to a buffer tank. The actual electrical consumption of the circulation pumps 3 or 4 was calculated according to eq. 2 with $\eta=0.65$ :

$$
P=\dot{m} \cdot(0.790 \cdot \ln (R e)-1.64)^{-2} \cdot \frac{\rho_{\text {brine }}}{2 \cdot d} \cdot L_{\text {tube }} \cdot \eta
$$

The initial idea of the study was to reduce the yearly $\mathrm{CO}_{2}$ emission of Empa's energy supply. Fig. 4 shows, that the $\mathrm{CO}_{2}$ emission of the Swiss electric grid in summer is highly reduced in comparison to winter. (http://www.electricitymap.org). As the measured energy demand of Empa and the $\mathrm{CO}_{2}$ Intensity are not from the same year, in the simulation, a regression is used to calculate the hourly $\mathrm{CO}_{2}$ demand (Fig. 4).

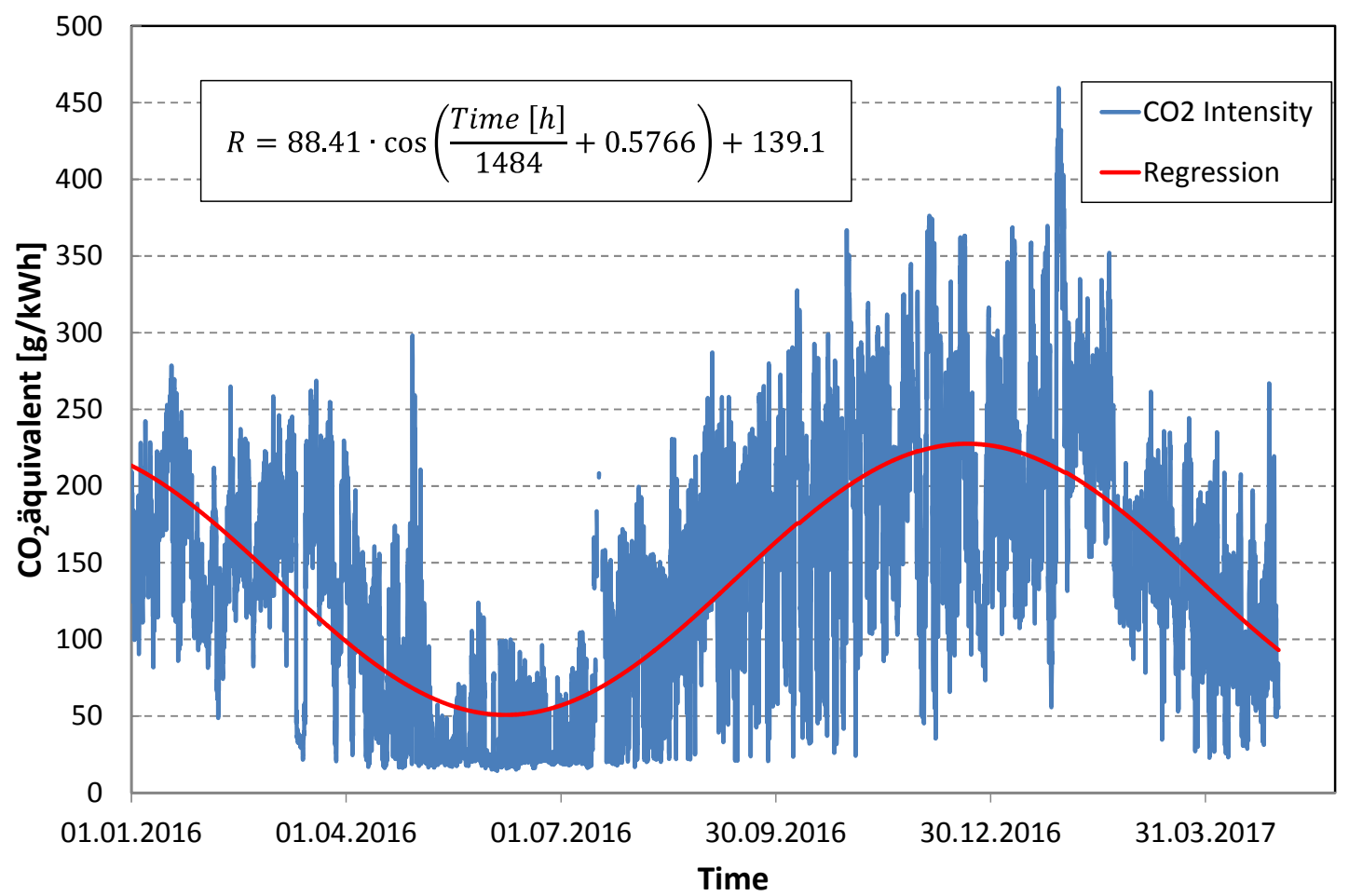

Fig. 4: A regression for dynamic $\mathrm{CO}_{2}$ emissions (embodied energy included) was calculated using data from (http://www.electricitymap.org)

The operating strategy for the simulation in summer (cooling demand higher than heating demand) is divided into three steps:

1. Cooling demand is covered by the heat pump as far as possible whereby waste heat produced is being rejected to the high temperature heating network to directly cover heating demand.

2. For additional cooling demand chillers are being operated, rejecting their heat to the medium temperature network in the parallel BTES cases. In the serial BTES cases heat from heat pump operation between cooling and high temperature network is used to charge the storage.

3. Surplus waste heat, which can't be delivered to the BTES is cooled away with a cooling tower (typically necessary in case of peak cooling demand). 


\section{Robert Weber}

In winter, the operating strategy for heating (heating demand higher than cooling demand) is also divided into three steps:

1. The central heat pump is operated to satisfy the cooling demand taking heat from the cooling network and rejecting to the high temperature heating network.

2. Additional heat is delivered to the high temperature heating network by the heat pump while discharging the BTES.

3. Peak heat demand, which cannot be covered by the BTES and the heat pump is covered by a gas boiler.

\section{Results and Discussion}

The analysis of simulation results showed that after 10 years of operation ground temperatures were almost steady with reference to former years and hence close to final operating temperatures. Therefore, all results presented are representing year ten of operation.

The following graphs compare the different cases in terms of:

1. absolute waste heat stored in summer (charging the storage)

2. absolute heat delivered in winter to the heat pump to provide heat at $65^{\circ} \mathrm{C}$

3. yearly produced $\mathrm{CO}_{2}$ (excluding contribution from gas boiler)

As already mentioned earlier, the aim of this study is to find a BTES in the frame of Empa's restrictions (no possibility of multiple connections to the BTES) which delivers a high fraction of heat in winter with a very small fraction of $\mathrm{CO}_{2}$ emitted.

The amount of heat stored in the BTES depends on many factors: on the ground temperature, the GHX length, the distance between the individual GHXs, the inlet temperature during charging, the power of the heat pump, the specific heat and heat transfer coefficient of the ground. The last two factors can't be changed, but they have an influence on the heat loss over a year. In Fig. 6. it can be seen, that for all cases the cooling capacities are higher than the heating capacities. This effect is a consequence of the average storage temperatures being

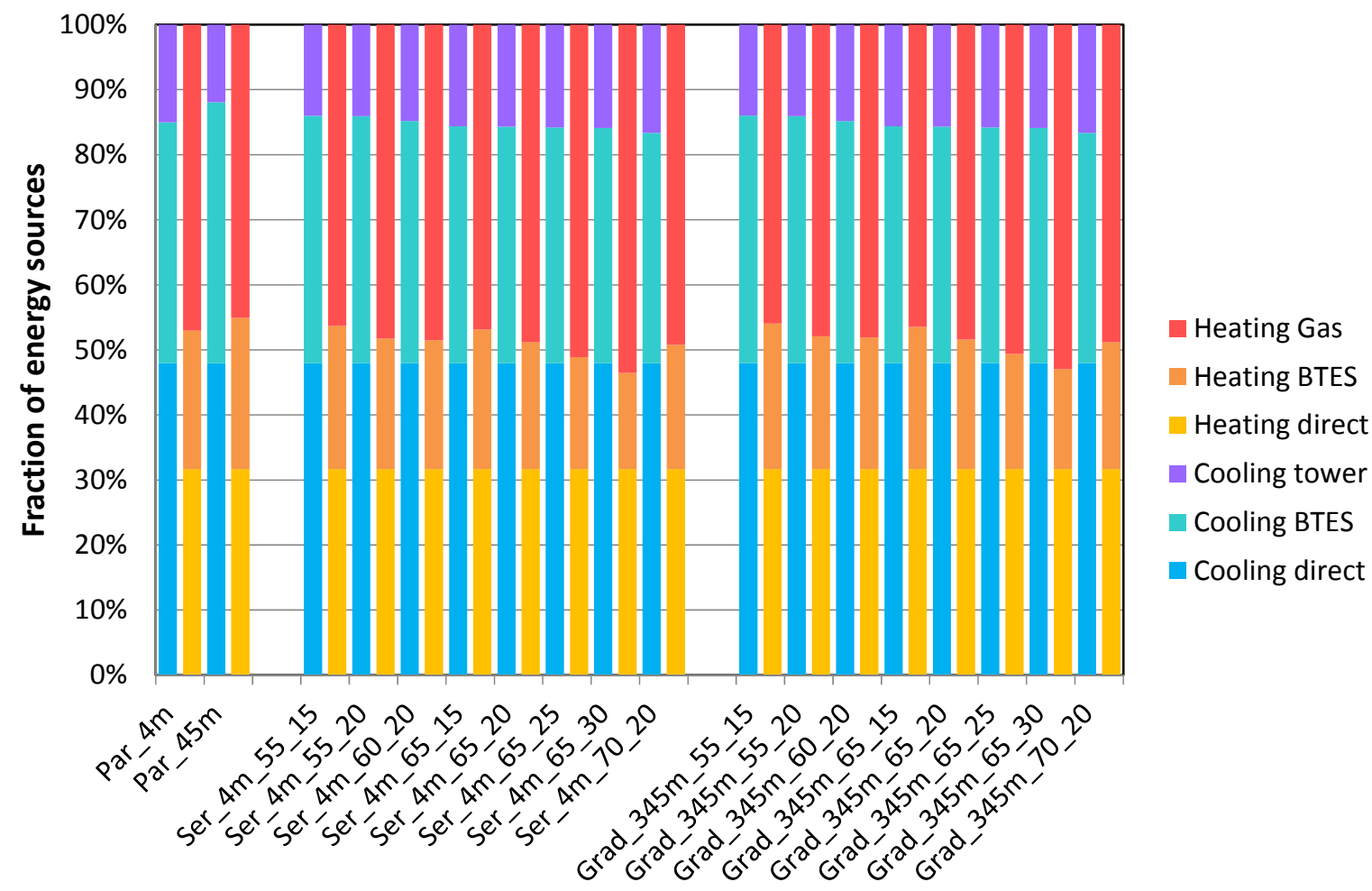

Fig. 5: Sources used to cover cooling and heating demand 


\section{Robert Weber}

higher than the undisturbed surrounding ground temperature. This leads to a permanent heat loss to the ground and to the atmosphere and hence to a depletion of the storage

Interestingly, the simulation showed that among all cases the fractions of different energy sources used to satisfy the demand are quite similar (Fig. 5). In "heating direct" and "heating BTES" the electrical consumption from the heat pump is included. What one does not see in this representation is the fraction of source energy used by the heat pump to provide the heat, i.e. the COP.

The fraction of direct cooling and heating is constant for all cases, as this is the first step in the above mentioned operating strategy applied within the simulation.

The results from figures 5.-7. show, that differences between field 2 and 3 are very small. However, it can be noticed in figure 6 that field 3, even with just a little lower field diameter shows a slightly higher heating capacity. As this is the only notable difference to field 2, only results of field 2 are further discussed.

Figure 6. shows that the storage capacity of case "Par_45m" for both, cooling and heating are superior to all other cases. One reason for this result is the bigger ground volume involved $(+20 \%)$. The other reason is the different hydraulic link to the power plant. There is a power limitation for the heat stored in the BTES for all serial cases, as only heat from the heat pump is used. For the parallel cases, waste heat from the chillers is directly used (without involving the heat pump). There, no mass flow limitation exists but the temperature is limited to $38^{\circ} \mathrm{C}$. Especially in the early summer, peak cooling loads can be better stored in the parallel flow BTES, whereas peak loads in late summer can be better stored by the serial approach because of higher inlet temperatures available.

The cases with $\mathrm{T}_{\text {min, ground }}=20^{\circ} \mathrm{C}$, seem to show a strange behavior (Fig. 6). The higher the inlet temperature $\left(55^{\circ} \mathrm{C}\right.$ up to $\left.70^{\circ} \mathrm{C}\right)$, the lower the heat stored in the BTES. The reason of that behavior is a constant operation time of the heat pump in summer (for all serial cases) to meet the cooling demand. The heat stored is then dominated by the decreasing COP for higher inlet temperatures, resulting in less heat rejected to the storage.

The influence of the increasing $\mathrm{T}_{\min , \text { ground }}$ can easily be seen in the cases "Ser_4m_65_15" to "Ser_4m_65_30". The idea of a higher ground temperature was to have a higher COP in winter. Unfortunately, the effect of the heat losses predominates (Fig. 6) finally resulting in higher specific $\mathrm{CO}_{2}$ emissions (Fig. 7).

The cases "Ser_4m_55_15" and "Ser_4m_65_15" show an unexpected high specific $\mathrm{CO}_{2}$ emission for the heating case. The reason is the increased mass flow of the brine compared to the other serial cases when the ground temperature comes close to the minimal achievable temperature. As mentioned earlier, the typical temperature difference between BTES inlet and outlet is in the range of $15 \mathrm{~K}$. As pure water is being used as heat transfer fluid, the inlet temperature is not allowed to be lower than $4^{\circ} \mathrm{C}$. This limitation leads to a significantly higher mass flow which is again resulting in a higher electrical consumption of the circulation pump.

Figure 7. shows the total $\mathrm{CO}_{2}$ emission per $\mathrm{kWh}$ heat or cold delivered per year. The results depend on the $\mathrm{CO}_{2}$ regression (Fig. 4), the total operation time of the heat pump per year, and the storage capacity of the BTES case. The $\mathrm{CO} 2$ emissions of the cooling tower operation and the gas boiler are not included.

As a tendency it can be stated: A high BTES inlet temperature causes a high $\mathrm{CO}_{2}$ emission in the heating case opposing the initial hypothesis. It is clearly visible, that the cases with the parallel flow (field 1) are best relative to the heat they provide. The parallel cases do not need to operate the heat pump in summer to charge the storage (more efficient chiller operation instead) but they have a higher electrical consumption for heat pump operation in winter (low COP). However compared with all cases, they still have the lowest $\mathrm{CO}_{2}$ emission for the heating operation.

With surprisingly low emissions comes the cooling case "Ser_4m_65_30". The reason is the low storage capacity of the field (see Fig. 6). This reduces the total operating hours of the heat pump in winter and with that, the emissivity over the whole year becomes small. As the charging energy still is in the range of the other cooling cases, the relative emissivity also becomes small. 
Robert Weber

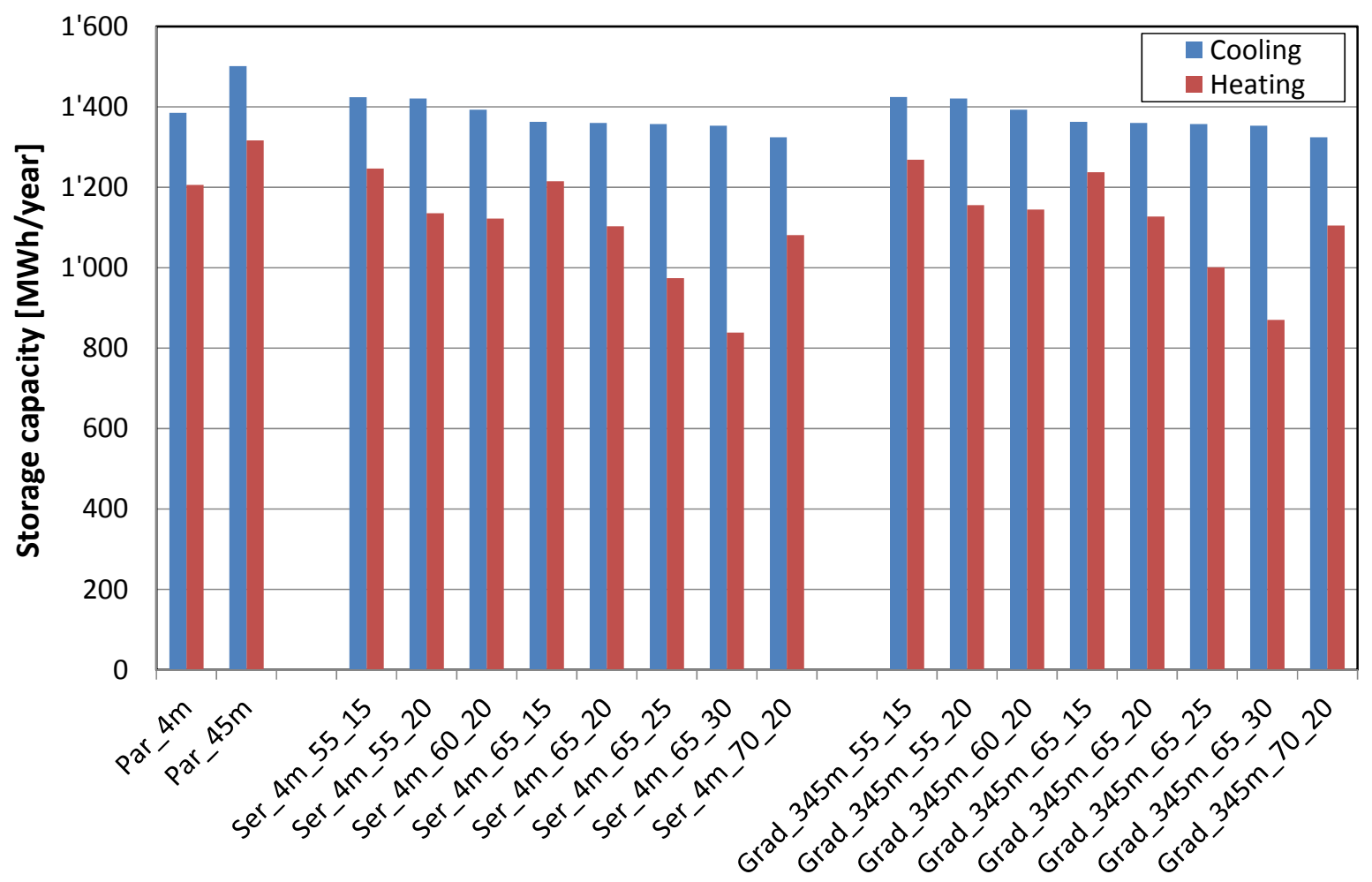

Fig. 6: Total yearly storage capacity under the condition defined

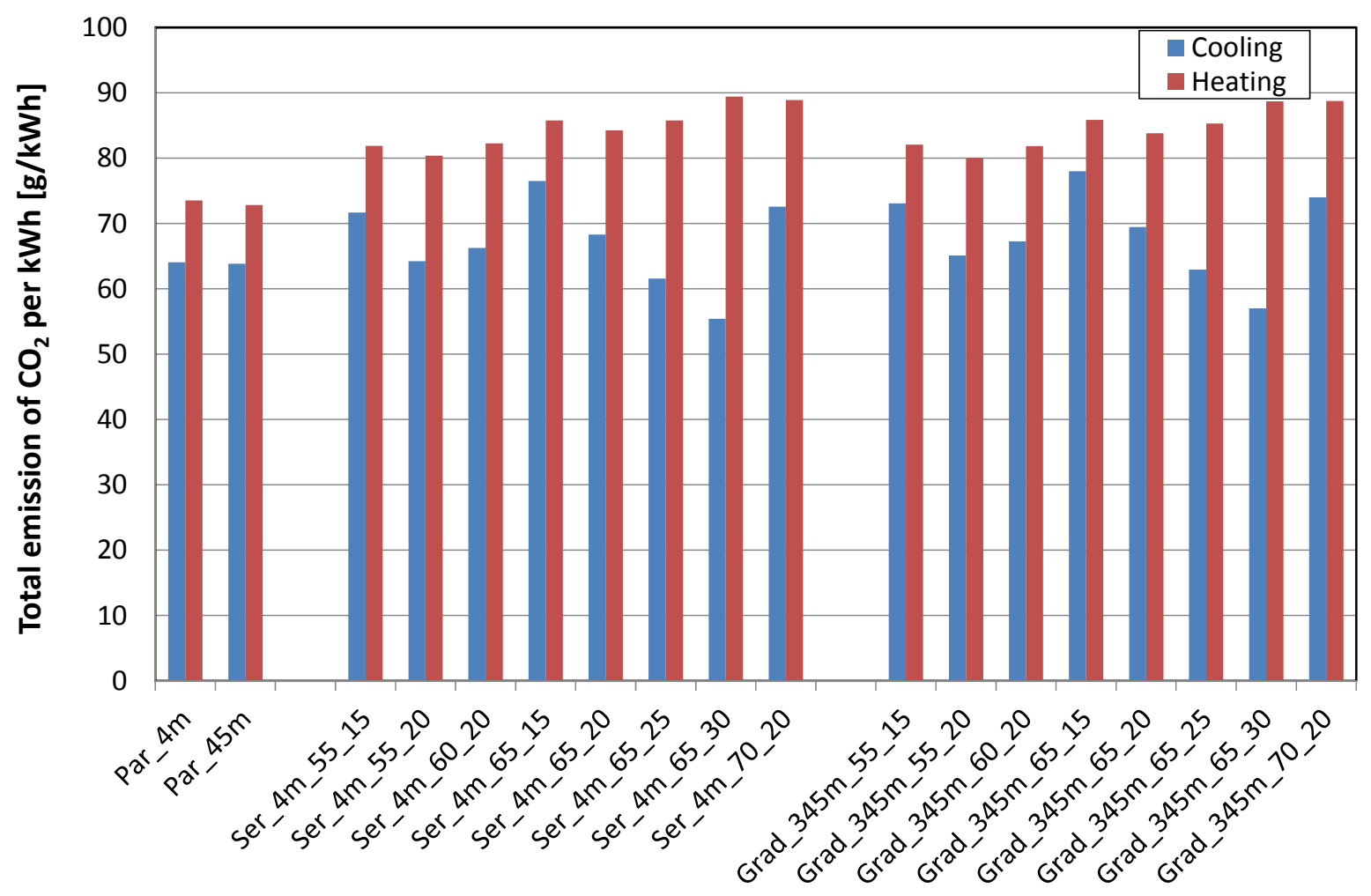

Fig. 7: Total $\mathrm{CO}_{2}$ emission per $\mathrm{kWh}$ heat or cold delivered per year

The initially expected effect on having a BTES system with which excess electricity with low $\mathrm{CO}_{2}$ loads in summer can be shifted to winter could not be proven with the cases considered. As this is a preliminary study only, not all influencing parameters could be considered properly. 
For instance:

\section{Robert Weber}

- The regression of the $\mathrm{CO}_{2}$ emissions per $\mathrm{kWh}$ is a very rough assumption. Typically, high cooling demand comes along with a high local PV production. This leads to a significant lower emission per $\mathrm{kWh}$ electricity than the regression implies. This low value would be beneficial for all cases with high inlet temperatures.

- The original idea for a high temperature BTES was to work with a field with multiple thermal zones. To charge the field, the outer zones would be fed with water from the medium temperature network and the inner zones only with heat of the high temperature network supplied from the heat pump. With that, much lower electricity demand would result for brine circulation and a significantly higher fraction of waste heat could be stored in the field. Unfortunately, this approach needs four tubes to connect the central thermal power station and the BTES, which is not possible at Empa because of spatial limitations in the existing duct.

- To use the thermal energy from the BTES in winter directly in the medium temperature network, the temperature of the BTES was too low. By increasing the temperature, the heat losses to the surrounding ground increase as well. This idea could hence only be implemented in even bigger fields or in fields, where an insulated wall is installed.

As some of the heat and cooling capacities of the simulated serial cases are in the same range as the parallel cases and as there is a possibility that the $\mathrm{CO}_{2}$ loads of the electricity supplied change considerably, it can be concluded, that there is a chance to find a high temperature BTES solution which clearly shows an electrical grid friendly behavior. Consequently, there is still a chance, that the overall $\mathrm{CO}_{2}$ emissions as a consequence of above mentioned changes might be reduced compared to a conventional parallel BTES field.

\section{Outlook}

The simulation study presented revealed a lack of advantage of installing a high temperature BTES at Empa Campus. Physical limitations encountered in this very case though are not considered relevant for the general approach of a high temperature BTES. For this reason, work will be continued and a foreseen approach with borehole fields of larger size and with multiple thermal zones will be further investigated in future.

\section{References}

1. SEL, University of Wisconsin, Transsolar Stuttgart. TRNSYS 17.1, 2016.

2. Pahud et al., 1996, The superposition borehole model for TRNSYS (TRNSBM), User Manual, Lausanne

3. Eskilson P., 1986, Superposition borehole model, Manual for Computer Code, University of Lund

4. Sigrist T., 2010, GWP mit Kältemittel R717 (Ammoniak NH3), HK-Gebäudetechnik 10-05, 2-5 (German)

5. $\mathrm{CO}_{2}$ emissions of electricity consumption: http://www.electricitymap.org 


\title{
Semi continuous thermochemical reactor for thermal storage
}

\author{
Joël Wyttenbach ${ }^{1}$, Gilbert Descy ${ }^{2}$ and Alexandre Descy ${ }^{2}$ \\ 1 Univ. Grenoble Alpes, F-38000 Grenoble, France. CEA, LITEN, F-38054 Grenoble, France \\ 2 BESOL, rue de la Griotte, 2a, 5580 Rochefort, Belgium
}

\begin{abstract}
A new semi-continuous thermochemical reactor prototype for seasonal heat storage was designed, manufactured and tested. Its cross flow vertical moving bed design improves a combination of performance factors, including energy density, heat power, temperature level, reversibility, thermal losses and auxiliary consumption. Tests were conducted on a dynamically controlled air flow equipment where a calibrated instrumentation allowed measuring thermal power with temperature and humidity methods, in addition to mass gradients.

After an initialization phase, the reactor works semi-continuously and heat power shows only small variations. It was measured at $415 \mathrm{~W}$ in both modes, and is almost proportional to air flow rate, while coefficient of performance is excellent (19 to 45). Those results were confirmed by two distinct measurement methods, based alternately on temperature and humidity. Charging phase could be performed at only $60.3^{\circ} \mathrm{C}$, which is a major result because it leads to increasing system efficiency of solar thermal storage systems. Besides, it was highlighted that a better reaction real time monitoring would ease the control and increase performance, especially regarding energy density. Temperature maps were installed on both sides of the reacting bed. Results suggest that beyond the qualitative results, they could be used to calculate a real time distribution of composite hydration level.
\end{abstract}

Keywords: Thermochemical reactor, Semi-continuous, Performance test, Seasonal storage, Space heating

\section{Introduction}

On a yearly basis, a limited solar collector surface is able to produce enough energy to meet heating needs of a building in a temperate climate. However, solar resource is mostly not available during winter season, which is why a long term storage is required to fully take advantage of the annual solar irradiation (Letz, 2002). In this context, thermochemical technology offers very interesting energy density and almost no long term thermal losses compared to sensible and even phase change storage methods (Marias, 2015). Indeed, energy is stored as a chemical potential within a solid material that is alternately hydrated and dehydrated through respectively exoor endothermic reactions.

Setting up an appropriate reversible reactor is of a major importance in order to optimize heat storage and generation. Indeed, the challenge is to increase the mass transfer rate between water vapor and solid hydrate, while controlling outlet heat power and minimizing electrical consumption.

This article describes a new reactor type that was designed to answer the needs of thermochemical seasonal heat storage. Its tested performances are discussed in this context.

\section{Prototype presentation}

As pure water is not available in gaseous phase at atmospheric pressure and space heating temperature, thermochemical reactors usually work either at low pressure or with moist air water content (Michel et al., 2012). In the first case, water has to be either stored in an expansive low pressure vessel or dynamically generated with consistent energy consumption. Although several low pressure reactor types were designed and tested by various research teams (Van Helden et al., 2014) (Mauran et al., 2008), their technical complexity is usually quite high in the context of building industry.

In the second reactor concept, moist air moves water and heat to and from solid hydrate, which allows to work at atmospheric pressure. Water storage is therefore optional since it is possible to work with outside air, as long as water content fluctuation can be dealt with. In addition, this configuration allows to separate solid hydrate storage and reactor location since it is easier to design a conveying device working at atmospheric pressure. With this separation concept, both reactant flows can be controlled in order to optimize reaction process. Given this degree 
of freedom, the goal is to find the best compromise between power, energy and exergy performance factors. A first step is to describe what influences these factors.

- Heat power increases with

- Better reaction kinetics

- Higher transfer rates in the heat carrier exchangers.

- Larger cross section on air flow

- Counterflow or crossflow configuration

- Continuous solid flow

- Thermal energy stored or restituted increases when hydration level difference increases between dehydrated and hydrated phases of solid material. Electrical energy consumption decreases when reactants' flows are facilitated.

- Exergy performance reaches its target when heat carrier temperature is high enough to ensure sufficient heat transfer to the building.

Solid/gas thermochemical reactors also have to adapt to the very high volume difference between reactants, especially when they work with moist air, as the gaseous reactant is diluted in the heat carrier. Thermodynamically, this dilution also lowers maximum outlet temperature, which requires to reduce exergy losses.

These specific requirements lead to design a crossflow vertical moving bed reactor operating with semi continuous solid flow and atmospheric moist air.

This reactor is made of a narrow $8 \mathrm{~mm}$ wide cavity limited by two vertical metallic sieves and a bottom valve. The moist air flow runs through the solid material located in the cavity, its movement is facilitated by a generous $0.36 \mathrm{~m}^{2}$ cross section and a limited depth. Solid material flows downwards thanks to gravity and the bottom valve controls its speed so that only a fraction of the load is replaced at each open/close cycle, which defines a semicontinuous working principle. With a $520 \mathrm{~mm}$ height, solid material path is 65 times longer than gaseous one. This helps reducing the reactants' volume difference impact, leading to a better energy performance. The upper opening of the reactor communicates with a small reservoir filled with solid reactant that makes the vessel practically airtight. The solid material used is made of a silica gel matrix impregnated with around $43 \mathrm{wt} \%$ of Calcium Chloride $\left(\mathrm{CaCl}_{2}\right)$. The synthesis method and the characterization tests were described by Courbon et al (Courbon et al., 2017) for different patented composites (Courbon et al., 2015)

When air flows through the reactor, it carries water vapor molecules either to or from the solid material. This happens respectively when an exothermic water adsorption reaction or an endothermic desorption reaction takes place (Mette et al., 2014). Air acts as heat carrier in both cases, which is why the reactor is well insulated and airtight.

Since solid material needs to move slowly, the reactor control works with open/close cycles that allow to drain approximately one sixth of the full load at each opening, which defines a reaction step. New solid material enters the reactor through the upper opening thanks to gravity.

The reactor illustrated on Figure 1 relies on efficient convective mass- and heat transfers that increase its generated power. As an example of technical compromise, the air pressure drop through the solid bed is high enough to create an even velocity distribution across the section plane, leading to a better exergy performance, while it is low enough to limit auxiliary power consumption, leading to a better energy performance.

While taking into account the above mentioned criteria, the reactor's type and shape remain quite similar to thermochemical systems found in the literature, as described for example by Kerskes et al (Kerskes et al., 2012), Bonk et al. (Bonk et al., 2017) and Nonnen et al. (Nonnen et al., 2016). However, the reactor bed's thickness is particularly thin compared to references mentioned above, which is a major asset to lower air pressure drop and the auxiliary electrical consumption. In addition, some design decisions were taken to keep technical realization simple, for example regarding crossflow rather than counterflow configuration. Therefore, it was decided to test the reactor in order to assess its actual performances and to identify practical use issues. 

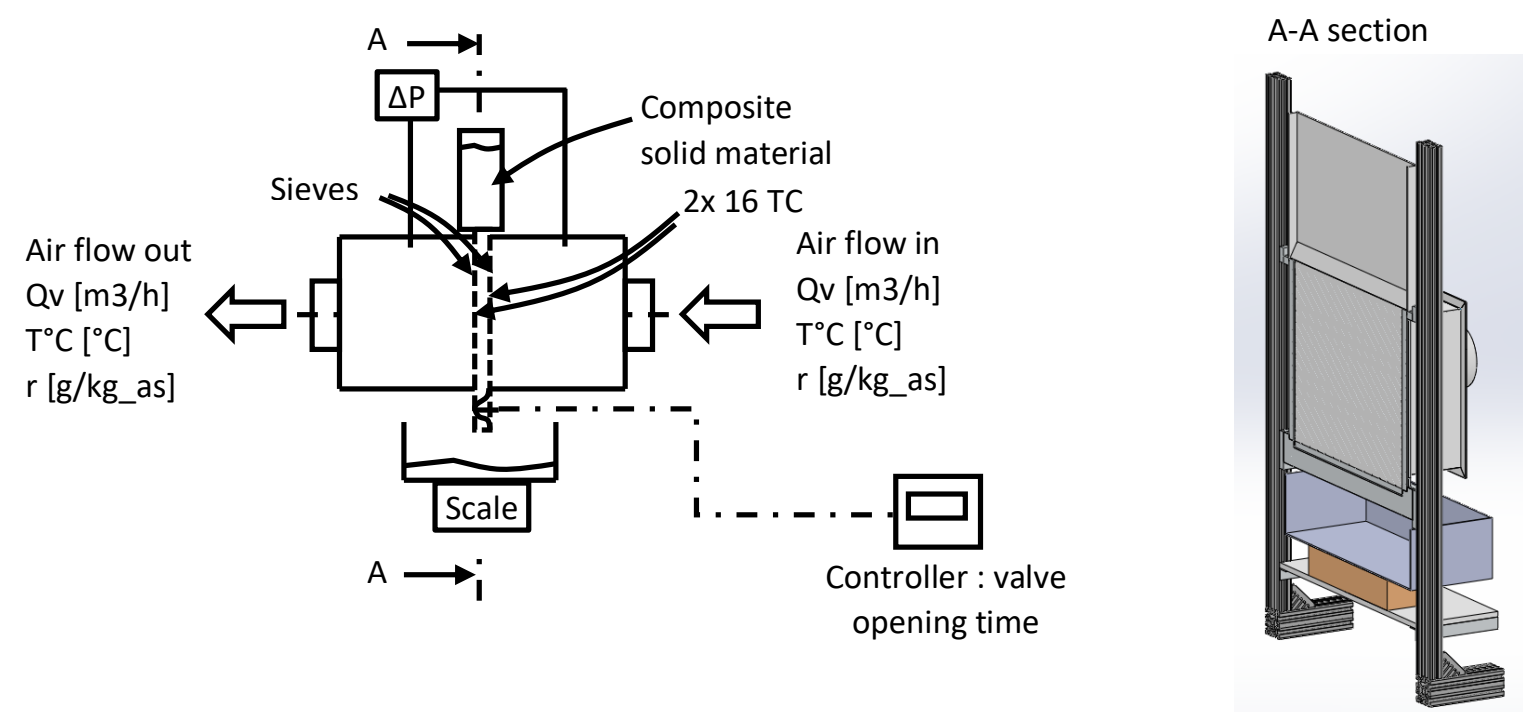

Figure 1 - Semi continuous cross flow reactor

Prior to testing the reactor, solid flow control issues need to be discussed. Indeed, reactor's first load is entirely made of "new" composite: for a hydration reaction, the initial solid material load is entirely dehydrated. This is not the case anymore in continuous operation mode: the horizontal layers are increasingly hydrated on the way down, for a hydration reaction. This means that reaction starts with an initialization period during which time heating or cooling power is greater. Then, power stabilizes after a certain amount of partial draining, and when outlet temperature and humidity remain constant for two consecutive steps, we consider that the semi continuous phase starts.

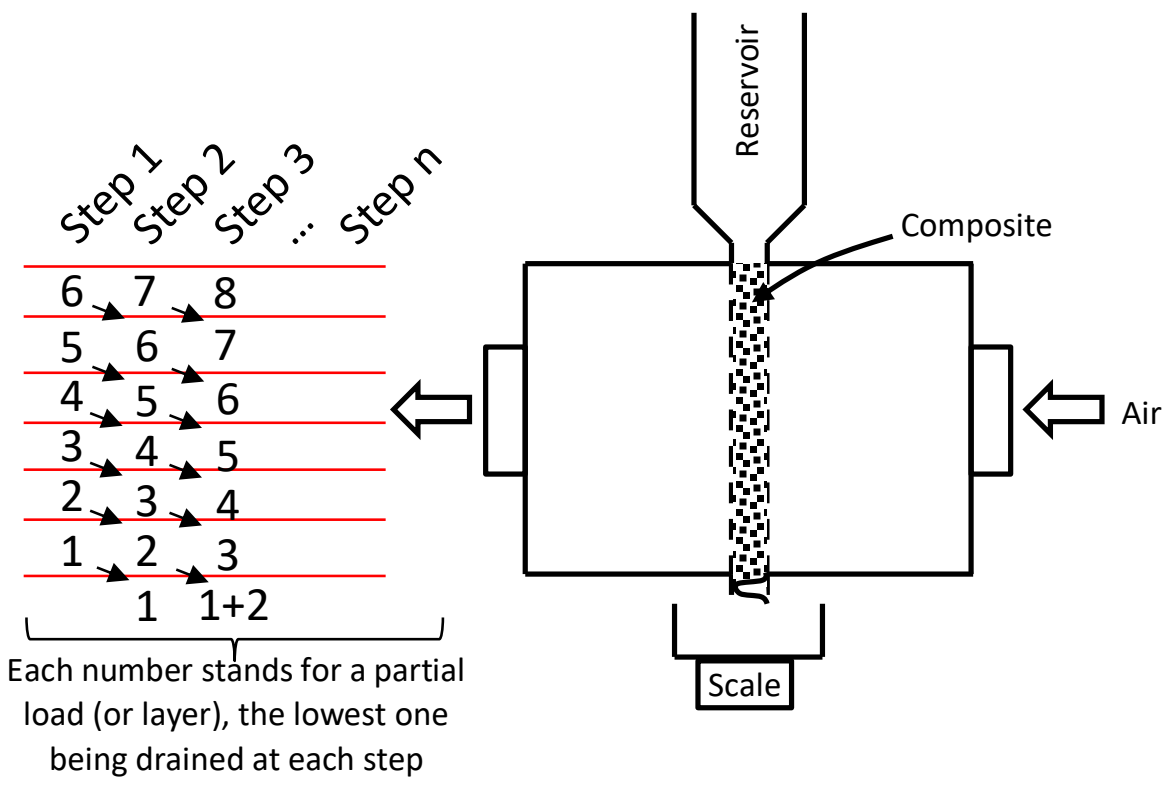

Figure 2-Control of a semi continuous reactor

This cross flow vertical reactor is a volumetric machine, which induces that each step should be defined as a fraction of total reactive volume, as it is suggested on Figure 2. For technical reasons, a time based valve is rather installed, and exiting solid mass is measured with a weighing scale. Not having the volume information requires additional calculations: a real time water vapor mass counter is setup using specific humidity measurements (Equation 1). Then, a target mass uptake is calculated (Equation 2) so that the solid material reaches the forecasted final hydration level. Water vapor mass counter is initialized after each draining. When it reaches the value described by Equation 3, a new partial draining takes place. The solid mass $M_{\text {drained }}[\mathrm{kg}]$ to be drained at one step is given by Equation 4 . 


$$
\begin{aligned}
& \Delta M_{\text {water }}(t)=\int_{t=0}^{t} \dot{m}_{d r y \text { air }} \cdot\left(w_{i}-w_{o}\right) \cdot d t \\
& \text { Equation } 1 \\
& \Delta M_{\text {water_expected }}=M_{\text {solid }_{\text {anhydrous }}}\left(\mathrm{X}_{\text {final }} \text { expected }_{\text {enitial }}\right) \\
& \text { Equation } 2 \\
& \Delta M_{\text {water }}\left(t_{d}\right)=\frac{\Delta M_{\text {water_expected }}}{\text { Number of steps }} \\
& \text { Equation } 3 \\
& M_{\text {drained }}=\frac{M_{\text {solid }_{\text {anhydrous }}} *\left(1+\mathrm{X}_{\text {final }_{\text {expected }}}\right)}{\text { Number of steps }} \\
& \text { Equation } 4
\end{aligned}
$$

Where $\Delta \mathrm{M}_{\text {water }}(\mathrm{t})[\mathrm{kg}]$ is water mass uptake, $m_{\text {dry air }}[\mathrm{kg} / \mathrm{s}]$ is dry air mass flow, $\mathrm{w}_{\mathrm{i}}$ and $\mathrm{wo}_{\mathrm{o}}[\mathrm{kg} / \mathrm{kg}$ da $]$ are reactor inlet and outlet air specific humidity, $\Delta \mathrm{M}_{\text {water_expected }}[\mathrm{kg}]$ is expected water mass uptake, $\mathrm{M}_{\text {solid_anhydrous }}[\mathrm{kg}]$ is the mass of the solid in its anhydrous state, $X_{\text {final_expected }}[\mathrm{kg} / \mathrm{kg}]$ is expected solid composite final hydration level, $t_{d}[\mathrm{~s}]$ is the time when partial draining occurs and Number of steps [-] is the amount of steps needed to fully drain the reactor.

However, this control scheme is global rather than a layer per layer approach. To compare real time counter results to a reference, exiting solid material hydration level is characterized with a moisture analyzer. This comparison helps increasing the team's know-how regarding reactor control, but test conditions are still not perfectly replicable, which is why results have to be analyzed carefully.

The solid flow management issue highlights that mass measurement is less appropriate than volume to control such reactor type. Furthermore, individual layer hydration level is difficult to calculate accurately, especially in a realistic environment with variable air inlet conditions. This highlights the need of an advanced instrumentation able to provide a reactor load hydration level map in real time. We also note that the reactor behaves quite differently during initialization phase, which is why initialization's occurrence has to be minimized.

\section{Test method}

\section{Test setup}

The objective of the tests is to measure reactor's power and energy during at least one period of semi-continuous operation. It is also important to measure temperature elevation in order to define potential application of the technology. To do this, the reactor is connected to the MATher test equipment that prepares the air flow at the expected temperature and humidity ratio. Reactor performances are measured with following instrumentation setup:

- Inlet and outlet humidity ratio and air flow rate are measured with high accuracy sensors, as part of permanent and periodically controlled MATher test equipment. Air flow relies on vortex speed sensors and humidity on best-in-class capacitive sensors.

- Reactor inlet and outlet temperatures are measured with 6 calibrated thermocouples

- Solid bed inlet and outlet temperatures are measured with 32 calibrated thermocouples spread over inlet and outlet sieves.

- Solid composite exiting reactor is monitored in real time with a weighing scale for flow control issues. Entering and exiting solid composite mass is measured by a second weighing scale with a finer resolution for better metrological results.

- A differential pressure sensor measures the reactor pressure drop in order to calculate a realistic coefficient of performance. 

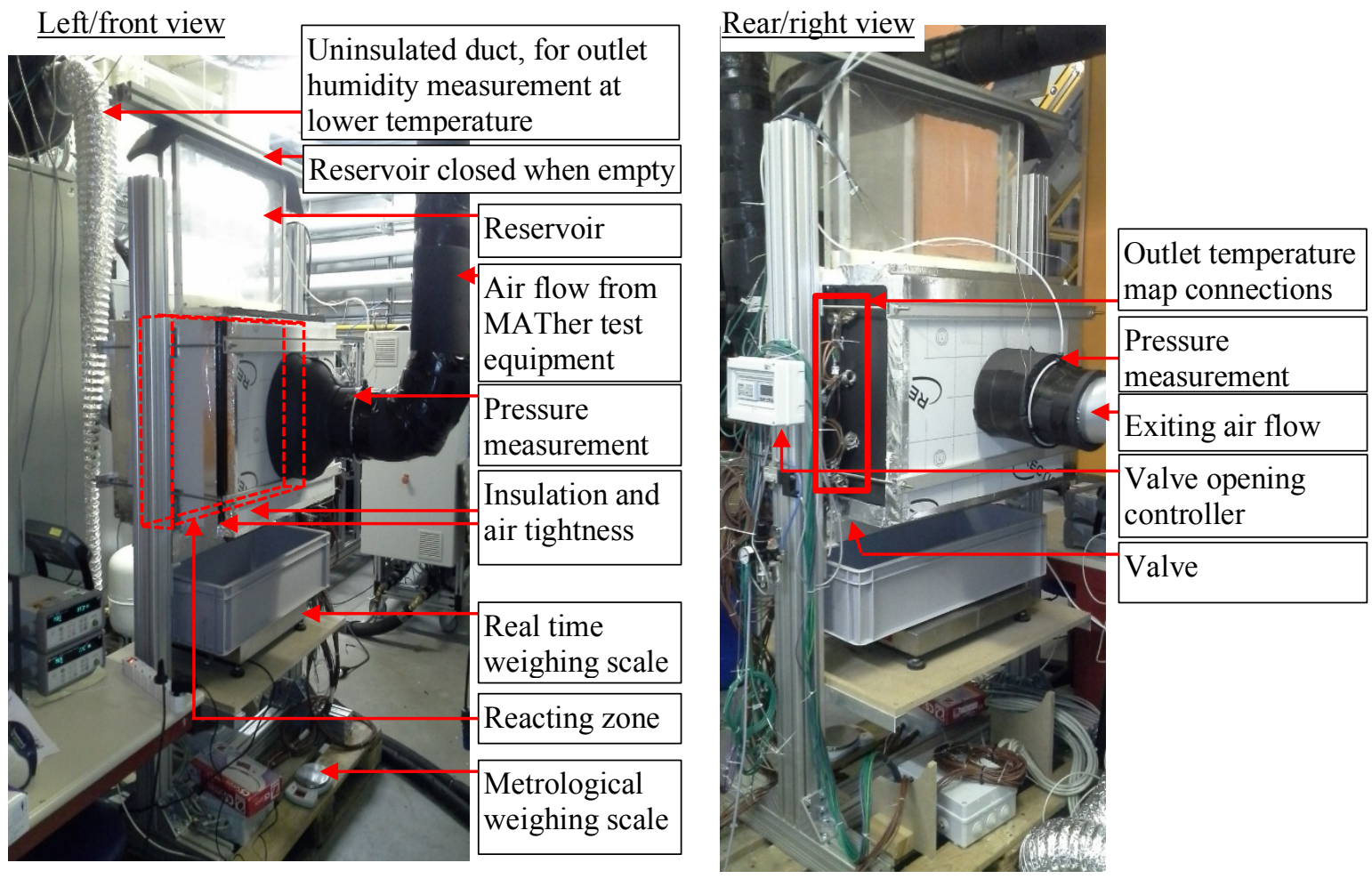

Figure 3 - Reactor connected to the test equipment, with specific instrumentation

Moving solid may induce uneven reactor behavior within the air flow cross section. Therefore, 16 temperature sensors are installed on each side of the solid material vertical bed in order to check locally if the reactor behaves as expected. Indeed, a temperature map is greatly influenced by air flow rate, hydration level or thermal losses disorders. Moreover, temperature maps allow to check experimentally if expected behavior can be actually observed, which is a vertical gradient and constant values along horizontal lines.

Higher dehydration temperatures (up to $90.9^{\circ} \mathrm{C}$ ) raise a problem about humidity measurement, as commonly used capacitive or dew point sensor technologies are better suited to temperatures below $40^{\circ} \mathrm{C}$. For this reason, two specific measuring configurations are setup:

- Inlet humidity is measured further up on the air flow line of MATher test equipment, where air temperature never exceeds $40^{\circ} \mathrm{C}$. Downstream, a final heating stage allows to increase temperature to the expected level with no effect on humidity content.

- Outlet humidity measurement needs to be performed after an air flow cooling stage, which is not implemented on the well-insulated outlet lines. Therefore, a long uninsulated duct is added between reactor outlet and permanent outlet lines in order to cool the air flow by yielding heat to the ambience. Dimensioning is performed experimentally to reach enough cooling without any condensation risk.

\section{Test conditions}

Testing conditions and the statistical approach to select them are reported on Table 1. Calculations are performed with following parameters:

- Brussels climate with extreme and mid-season cases

- A $16 \mathrm{~m}^{2}$ area of flat solar thermal panel, for dehydration temperature calculation

- Constant air flow rate for first performance tests, as it is a function of reactor cross section.

- Variable air flow rate in hydration mode for sensitivity analysis

- Constant temperature in hydration mode: we suppose that the house is provided with an air recovery heat exchanger. The reactor is located downstream on the fresh air flow line.

Dehydration temperature comes from dynamic thermal simulation 
Table 1 -Inlet temperature and humidity test conditions

\begin{tabular}{|c|c|c|c|c|c|}
\hline Mode & $\mathrm{T}_{\text {in }}\left[{ }^{\circ} \mathrm{C}\right]$ & $r_{\text {in }}\left[\mathrm{g} / \mathrm{kg}_{\mathrm{da}}\right]$ & $\mathrm{Q}_{\mathrm{v}}\left[\mathrm{kg} / \mathrm{m}^{3}\right]$ & Reference & Statistical approach \\
\hline Hydration & 20.2 & 4 & 120 & Winter & $\begin{array}{l}\text { Most frequent humidity when } \mathrm{T}_{\text {outside }} \text { is } \\
\text { between }-1 \text { and }+1^{\circ} \mathrm{C}\end{array}$ \\
\hline Hydration & 20.2 & 9 & 120 & Mid season & $\begin{array}{l}\text { Most frequent humidity when } \mathrm{T}_{\text {outside }} \text { is } \\
\text { between } 14 \text { and } 16^{\circ} \mathrm{C}\end{array}$ \\
\hline Dehydration & 60.3 & 4 & 120 & Early spring & Most frequent day humidity in March \\
\hline Dehydration & 76.5 & 6 & 120 & Mid season & $\begin{array}{l}\text { Most frequent day humidity over March to } \\
\text { May plus September period }\end{array}$ \\
\hline Dehydration & 90.5 & 11.5 & 120 & Summer & Most frequent day humidity in August \\
\hline Hydration & 20.2 & 4 & 75 & Winter & \multirow{3}{*}{$\begin{array}{l}\text { Most frequent humidity when } \mathrm{T}_{\text {outside }} \text { is } \\
\text { between }-1 \text { and }+1^{\circ} \mathrm{C}\end{array}$} \\
\hline Hydration & 20.2 & 4 & 102 & Winter & \\
\hline Hydration & 20.2 & 4 & 152 & Winter & \\
\hline
\end{tabular}

Where $T_{\text {in }}\left[{ }^{\circ} \mathrm{C}\right]$ is inlet air temperature, $r_{\text {in }}\left[\mathrm{g} / \mathrm{kg}_{\mathrm{da}}\right]$ is inlet air specific humidity and $\mathrm{Q}_{\mathrm{v}}\left[\mathrm{kg} / \mathrm{m}^{3}\right]$ is air volume flow rate.

\section{Experimental results}

\section{Hydration}

The hydration test with air inlet conditions at $20.2^{\circ} \mathrm{C}, 3.9 \mathrm{~g} / \mathrm{kg}_{\mathrm{da}}$ and $122 \mathrm{~kg} / \mathrm{h}$ is shown on Figure 4 with its initialization phase. We see that heat power is higher at the beginning of the test, when the whole reactor is filled with dry composite. Then, the solid load moves downwards at each partial draining step, which finally creates a hydration level vertical gradient. Consequently, heat power decreases and stabilizes. The second highlighted period can be therefore considered as semi-continuous operation.

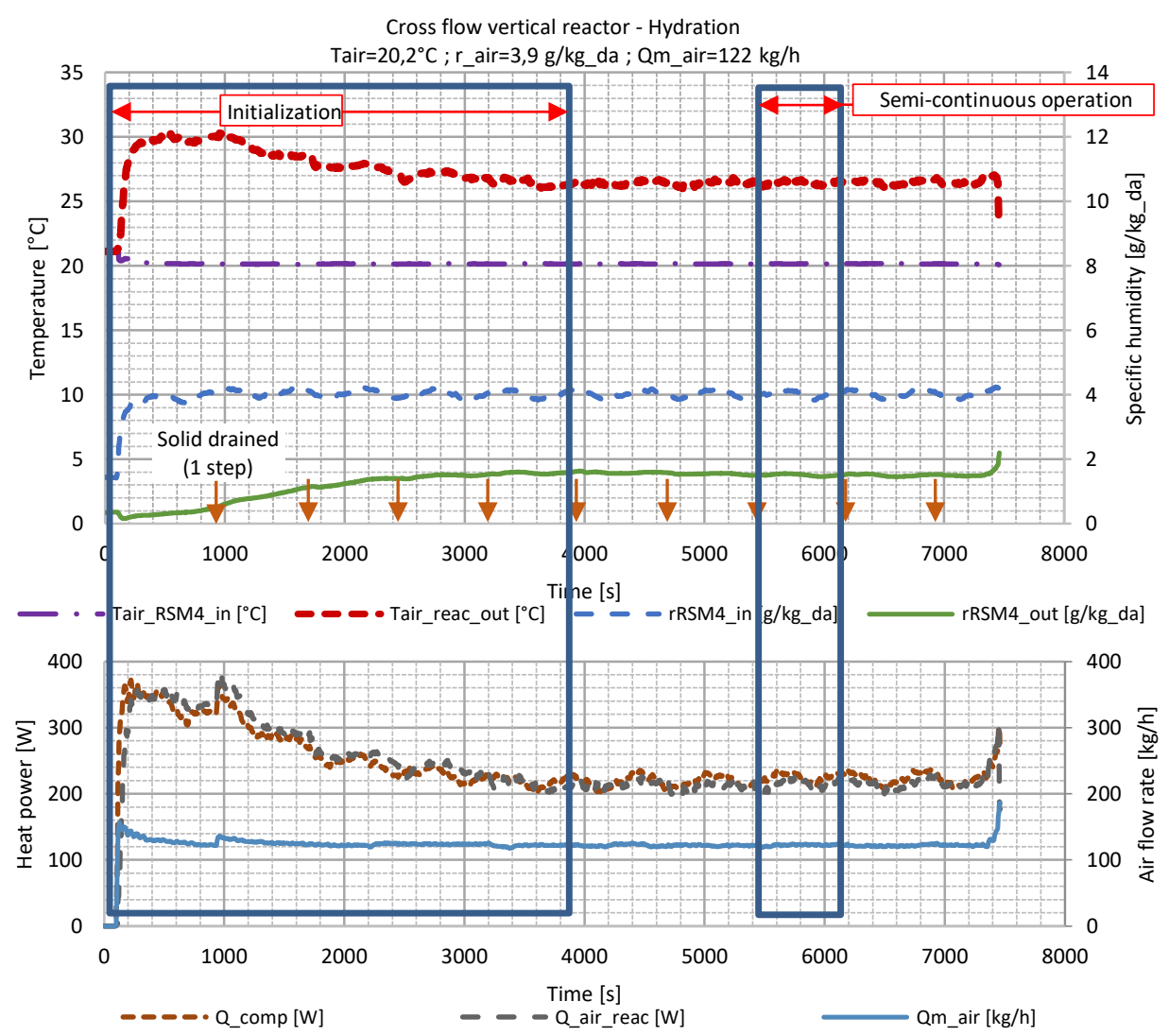

Figure 4 - Full hydration test, with initialization phase

Where Tair_RSM4_in $\left[{ }^{\circ} \mathrm{C}\right]$ is air temperature at reactor inlet, Tair_reac_out $\left[{ }^{\circ} \mathrm{C}\right]$ is air temperature at reactor outlet, Qm_air $[\mathrm{kg} / \mathrm{h}]$ is air mass flow rate, rRSM4_in $\left[\mathrm{g} / \mathrm{kg}_{\mathrm{da}}\right]$ is air specific humidity at reactor inlet, rRSM4_out $\left[\mathrm{g} / \mathrm{kg}_{\mathrm{da}}\right]$ is air specific humidity at reactor outlet, Q_comp [W] is heating/cooling power measured on the 
composite, and Q_air_reac [W] is heating/cooling power measured on the air.

Hydration heat power is quite stable during the one step period of semi-continuous operation highlighted on Figure 4. Besides, the two calculation methods (temperature and humidity) provide very close results, although heat power is slightly lower with temperature method, probably because thermal losses are taken into account. This confirms that the measurement method is adapted to calculate reactor's heat power.

In order to further analyze performances, indicators presented on Table 2 and reported on Table 3 are averaged over the duration of one step period, between two draining.

Table 2 - Performance indicators description

\begin{tabular}{|c|c|c|}
\hline Indicator & Unit & Parameter description \\
\hline$\Delta$ Tair & {$[\mathrm{K}]$} & Average* air temperature variation through reactor \\
\hline$\Delta \mathrm{r}$ & {$\left[\mathrm{g} / \mathrm{kg}_{\mathrm{da}}\right]$} & Average $^{*}$ air humidity ratio variation through reactor \\
\hline$\Delta \mathrm{P}$ & {$[\mathrm{Pa}]$} & Average $^{*}$ reactor air pressure drop \\
\hline Xinit & {$[-]$} & $\begin{array}{l}\text { Initial composite hydration level, measured with moisture } \\
\text { analyzer }\end{array}$ \\
\hline Xfinal_ $150^{\circ} \mathrm{C}$ & {$[-]$} & $\begin{array}{c}\text { Final composite hydration level, measured with moisture } \\
\text { analyzer }\end{array}$ \\
\hline$\Delta \mathrm{m}_{\text {vapor }}$ & [g] & Water vapor mass transferred, measured on air humidity \\
\hline E_Density & {$[\mathrm{Wh} / \mathrm{kg}]$} & Energy density measured on air temperature \\
\hline Q_air & [W] & Heating power, measured on air temperature \\
\hline COP & {$[\mathrm{W} / \mathrm{W}]$} & Ratio Q_air/Q_elec, with Q_elec $=\mathrm{f}\left(\Delta \mathrm{P} ; \mathrm{Qm} \_\right.$air $)$ \\
\hline
\end{tabular}

Table 3 - Hydration performance indicators

\begin{tabular}{|c|c|c|c|c|c|}
\hline Test ID & $\begin{array}{c}\text { Hydration } \\
20.2^{\circ} \mathrm{C}, \\
3.9 \mathrm{~g} / \mathrm{kg}_{\mathrm{da}}, \\
122 \mathrm{~kg} / \mathrm{h}\end{array}$ & $\begin{array}{c}\text { Hydration } \\
20.2^{\circ} \mathrm{C} \\
9 \mathrm{~g} / \mathrm{kg}_{\mathrm{da}} \\
118 \mathrm{~kg} / \mathrm{h}\end{array}$ & $\begin{array}{c}\text { Hydration } \\
20.2^{\circ} \mathrm{C}, \\
4.1 \mathrm{~g} / \mathrm{kg} \text { da, } \\
90 \mathrm{~kg} / \mathrm{h}\end{array}$ & $\begin{array}{c}\text { Hydration } \\
20.2^{\circ} \mathrm{C}, \\
4.2 \mathrm{~g} / \mathrm{kg} \text { da, } \\
122 \mathrm{~kg} / \mathrm{h}\end{array}$ & $\begin{array}{c}\text { Hydration } \\
20.1^{\circ} \mathrm{C}, \\
4.1 \mathrm{~g} / \mathrm{kg}_{\mathrm{da}}, \\
182 \mathrm{~kg} / \mathrm{h}\end{array}$ \\
\hline$\Delta$ Tair $[\mathrm{K}]$ & 6,08 & 12,61 & 4,93 & 5,78 & 5,3 \\
\hline$\Delta \mathrm{r}\left[\mathrm{g} / \mathrm{kg}_{\mathrm{da}}\right]$ & $-2,5$ & $-5,03$ & $-1,92$ & $-2,64$ & $-2,12$ \\
\hline$\Delta \mathrm{P}[\mathrm{Pa}]$ & 112,9 & 98,4 & 89,7 & 115,2 & 187,6 \\
\hline Xinit & $9,3 \%$ & $9,5 \%$ & $10,2 \%$ & $10,2 \%$ & $10,2 \%$ \\
\hline Xfinal_ $150^{\circ} \mathrm{C}$ & $34,4 \%$ & $31.55 \% *$ & $41,0 \%$ & $36,7 \%$ & $41,7 \%$ \\
\hline$\Delta \mathrm{m}_{\text {vapor }}[\mathrm{g}]$ & 64,1 & 57,6 & 56,4 & 87,5 & 118,1 \\
\hline $\begin{array}{c}\text { E_Density } \\
{[\mathrm{Wh} / \mathrm{kg}]}\end{array}$ & 161,7 & 139,2 & 146,6 & 221,8 & 260,5 \\
\hline Q_air [W] & 214,9 & 415,1 & 128,9 & 195,8 & 275,7 \\
\hline $\mathrm{COP}[\mathrm{W} / \mathrm{W}]$ & 19,48 & 45,1 & 19,35 & 17,56 & 10,17 \\
\hline
\end{tabular}

*Uncertain measurement

Hydration heat power is almost twice when air inlet humidity increases from 3,9 to $9 \mathrm{~g} / \mathrm{kg}_{\text {da. }}$. However, it is important to note that the $9 \mathrm{~g} / \mathrm{kg}_{\text {da }}$ test was stopped too early, which explains why final hydration ratio is not high enough. With a longer test, final hydration levels would be similar and it is likely that the heating power difference would be slightly less pronounced.

Hydration coefficient of performance (COP) is very high (up to 45), which means that reactor design decisions really lead to minimizing auxiliary electrical power.

The energy density is not an accurate measurement as it is measured on the full reactor load and given on Table 3 for only a partial load. Therefore, it is more relevant to consider final hydration ratio for energy density purposes. Each time solid material exits reactor with a water content below $40 \%$, energy density is less than expected. This is the case for the $3.9 \mathrm{~g} / \mathrm{kg}_{\mathrm{da}}$ test as this partial load was drained too early. Indeed, with limited real time monitoring means, the reactor control was not optimized yet. A longer reaction would bring energy density back to its expected value, while this would slightly reduce averaged heating power.

Air flow variations impact is shown on the 3 right columns of Table 3 . Heat power tends to be a linear function of air flow rate: twice the air flow means approximately twice the heat power, but also approximately half the 
COP (coefficient of performance). This means that reactor power modulation is possible through air flow control, with the limitation of electrical consumption. However, it is important to note that comparing those latter tests can be misleading because the hydration level distribution within the reactor is not well known. Indeed, it is likely that the three tests show different distributions, which affects heat power even if all other parameters are constant.

Energy density indicator is extrapolated considering a perfect semi-continuous operation with constant inlet conditions. However, air flow rate variations effects are measured during a single test without initialization between measurement steps. As a consequence, energy density results cannot be interpreted.

Although hydration global results are very interesting for space heating application, there is a need to better monitor the solid hydration level distribution within a reactor load, for control and performance optimization. Looking at the inlet and outlet temperature maps provide interesting information about how the reactor works. Table 4 shows outlet temperature map averaged over one step duration between two solid draining in semicontinuous phase, for adsorption test at $20.2^{\circ} \mathrm{C}, 3.9 \mathrm{~g} / \mathrm{kg}_{\mathrm{da}}$ and $122 \mathrm{~kg} / \mathrm{h}$. Sensor locations are illustrated on Figure 5.

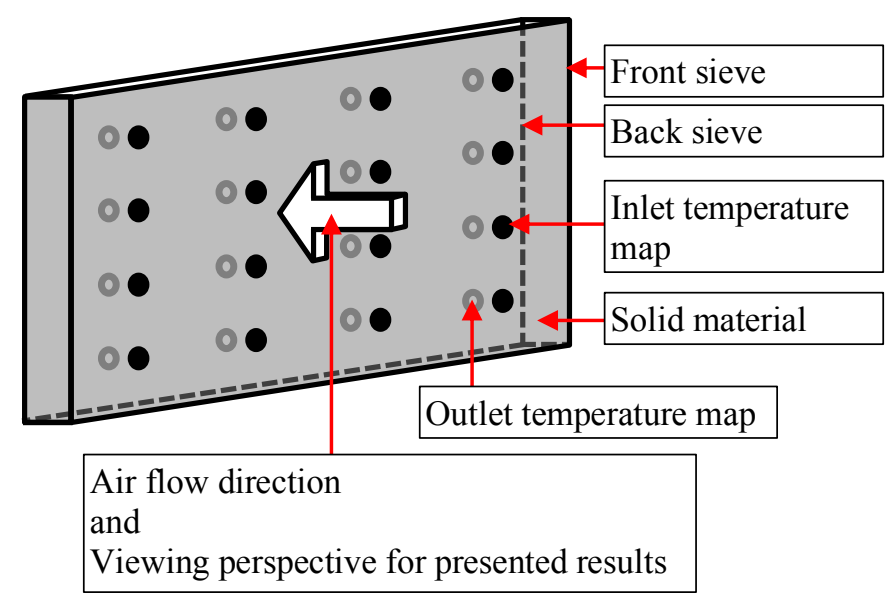

Figure 5 - Sensor spatial distribution in the temperature maps

Table 4 - Reactor outlet temperature map during hydration at $20.2^{\circ} \mathrm{C}, 3.9 \mathrm{~g} / \mathrm{kg}_{\text {da }}$ and $122 \mathrm{~kg} / \mathrm{h}$

Reactor outlet time averaged temperature map $\left[{ }^{\circ} \mathrm{C}\right]$

\begin{tabular}{|l|l|l|l|}
\hline 29,7 & 29,2 & 29,1 & 30,2 \\
\hline 26,1 & 29,4 & 27,4 & 28,0 \\
\hline 25,5 & 26,4 & 25,8 & 26,2 \\
\hline 23,4 & 25,5 & 25,4 & 25,7 \\
\hline
\end{tabular}

Standard deviation over time of reactor outlet temperatures [K]

\begin{tabular}{|c|c|c|c|}
\hline 0,6 & 0,5 & 0,6 & 0,8 \\
\hline 0,1 & 0,2 & 0,2 & 0,2 \\
\hline 0,1 & 0,1 & 0,2 & 0,1 \\
\hline 0,1 & 0,2 & 0,1 & 0,2 \\
\hline
\end{tabular}

Adsorption outlet temperature is higher on the upper part of the reactor. Indeed, upper layer solid material is less hydrated than lower layer one, since it stayed in the reactor for a shorter time, its reaction kinetic is therefore higher for a given entering absolute humidity. We also note that temperatures are comparable on horizontal lines. These two expected results are now measured, which means that reactor's qualitative behavior matches with theoretical approach.

The standard deviation over time highlights that the lower temperatures are stable while upper layer shows more variation. Again, upper layer reacts faster, which slightly modifies solid material hydration level during one 
reaction step. Therefore, upper outlet temperature shows a slight decrease during the selected time step.

Beyond the qualitative information given by the temperature map, we can note that each outlet temperature is a function of inlet air conditions and solid material hydration level. All other parameters being measured, it is possible to solve a thermodynamic equation system in order to compute the local hydration level of solid material facing each temperature measurement. As stated earlier, the availability of a real time hydration level map would be a great improvement, as solid flow would be controlled with a much better precision. Draining would occur only when a layer reaches its target hydration level, just below clogging limit, which is a key for a better energy density, a better storage management and less dysfunction.

\section{Dehydration}

The entire dehydration test with air at $60.3^{\circ} \mathrm{C}, 4 \mathrm{~g} / \mathrm{kg}_{\mathrm{da}}$ and $124 \mathrm{~kg} / \mathrm{h}$ is presented on Figure 6 . First, we see that the semi-continuous phase may have never been reached during the test, solid composite material quantity being limited.

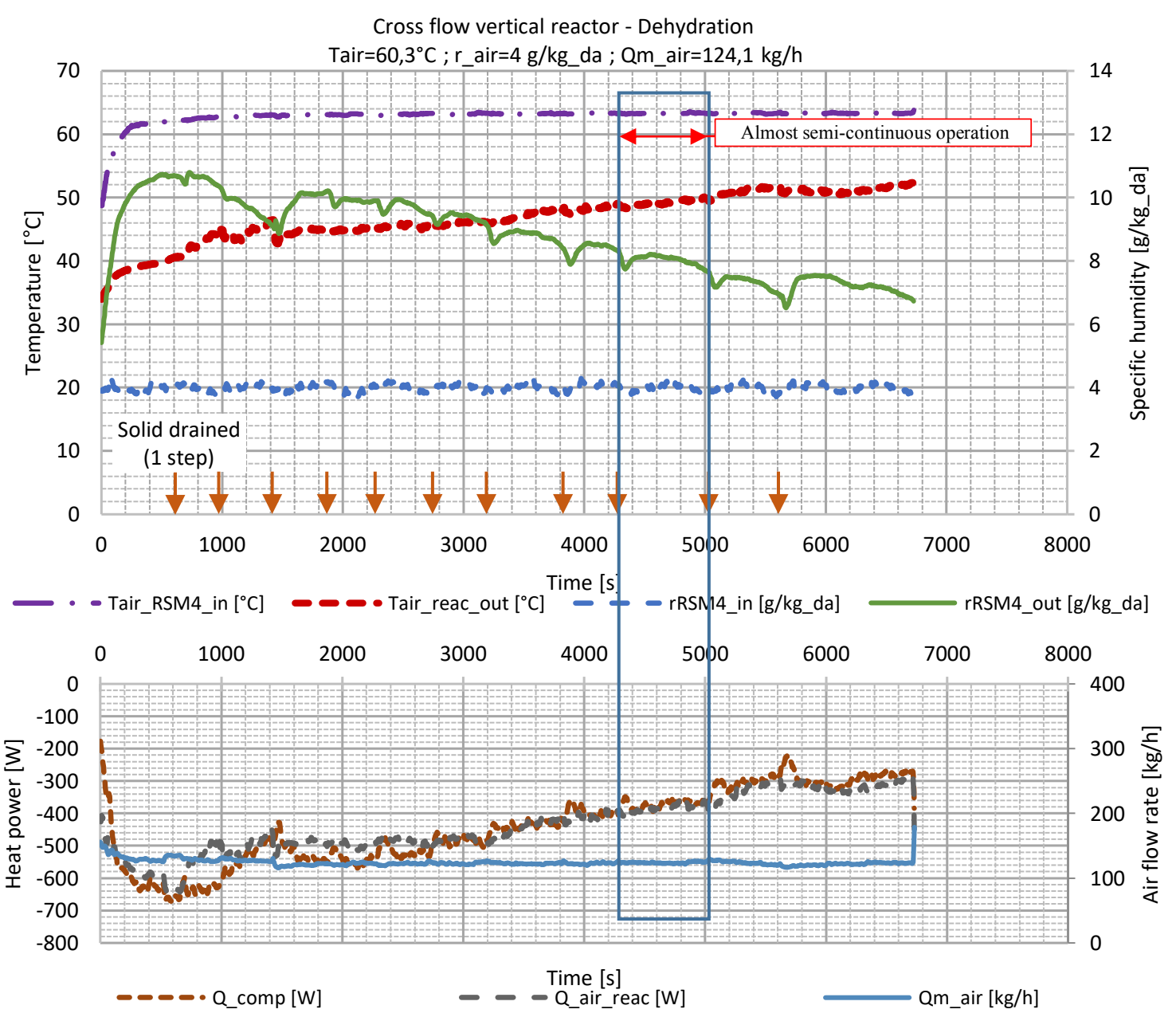

Figure 6-Full dehydration test, with initialization phase

The stabilization time is indeed much longer than expected $(\geq 1 \mathrm{~h} 45)$, based on what was measured in hydration mode $(\approx 1 \mathrm{~h})$. As a consequence, the detailed one step analysis was performed before full stabilization, which means that following results have to be understood as almost but not exactly semi-continuous operation.

New solid material entering the reactor is much colder than the rest of the reacting load. Therefore, average temperature decreases at each partial drain/load, which explains that the reaction efficiency is lowered at the beginning of the highlighted step (Figure 6 ) for approximately 2 minutes. Then, heat power increases and stabilizes for more than 3 minutes before decreasing again due to slower reaction of dehydrated composite.

Cooling power calculated using temperature or humidity methods are very close, which confirms that the measurement setup is adapted to high temperature air flow. Thermal losses induce a slightly higher power for the temperature based calculation. 
Table 5 presents the average performance indicators for three different dehydration tests. Cooling power is highly influenced by inlet conditions, and globally in the range of hydration heat power. Dehydration cooling power tends to increase with higher inlet temperature, but it also tends to decrease with higher inlet humidity ratio, at a given air flow rate and composite hydration level. Although this result was expected from thermodynamic equilibrium, it was not easy to highlight it on former prototypes. The $385 \mathrm{~W}$ cooling power at $60.3^{\circ} \mathrm{C}$ and $4 \mathrm{~g} / \mathrm{kg}_{\mathrm{da}}$ is also an interesting result as it shows that consistent dehydration process is possible even at a modest temperature in the context of solar thermal flat panel heat.

Table 5 - Dehydration performance indicators

\begin{tabular}{|c|c|c|c|}
\hline Test ID & $\begin{array}{c}\text { Dehydration } \\
60.3^{\circ} \mathrm{C} \\
4 \mathrm{~g} / \mathrm{kg}_{\mathrm{da}} \\
124 \mathrm{~kg} / \mathrm{h} \\
\end{array}$ & $\begin{array}{c}\text { Dehydration } \\
76.4^{\circ} \mathrm{C} \\
6 \mathrm{~g} / \mathrm{kg}_{\mathrm{da}} \\
122 \mathrm{~kg} / \mathrm{h} \\
\end{array}$ & $\begin{array}{c}\text { Dehydration } \\
90.9^{\circ} \mathrm{C} \\
11 \mathrm{~g} / \mathrm{kg}_{\mathrm{da}} \\
122 \mathrm{~kg} / \mathrm{h} \\
\end{array}$ \\
\hline$\Delta$ Tair $[\mathrm{K}]$ & $-14,61$ & $-11,8$ & $-16,38$ \\
\hline$\Delta \mathrm{r}\left[\mathrm{g} / \mathrm{kg}_{\mathrm{da}}\right]$ & 4,08 & 2,63 & 4,21 \\
\hline$\Delta \mathrm{P}[\mathrm{Pa}]$ & 163,6 & 172 & 146,2 \\
\hline Xinit & $40,3 \%$ & $39,3 \%$ & $40,0 \%$ \\
\hline Xfinal_ $150^{\circ} \mathrm{C}$ & $17,6 \%$ & $18,4 \%$ & $16,1 \%$ \\
\hline$\Delta$ mvapor $[\mathrm{g}]$ & $-107,6$ & $-86,7$ & $-101,3$ \\
\hline E_Density [Wh $/ \mathrm{kg}]$ & 247,9 & 208,7 & 250,9 \\
\hline Q_air [W] & $-384,5$ & $-289,2$ & $-415,3$ \\
\hline $\mathrm{COP}[\mathrm{W} / \mathrm{W}]$ & 21,51 & 15 & 24,46 \\
\hline
\end{tabular}

Again, the lack of solid material hydration level information disturbs reaction control. Therefore, expected final hydration level of $10 \%$ is not reached on exiting solid material because reaction is stopped too early.

In addition, the exiting solid does not always flow evenly, which means that some clogging occurs in the reactor, inducing different vertical solid speeds. Since clogging issues were reported especially for the $76,4^{\circ} \mathrm{C}$ dehydration test, its outlet temperature map is presented on Table 6 .

Table 6 - Reactor outlet temperature map during dehydration at $76.4^{\circ} \mathrm{C}, 6 \mathrm{~g} / \mathrm{kg}$ da and $122 \mathrm{~kg} / \mathrm{h}$

\begin{tabular}{|c|c|c|c|}
\hline \multicolumn{4}{|c|}{ Reactor outlet average temperature map $\left[{ }^{\circ} \mathrm{C}\right]$} \\
\hline 71,0 & 70,8 & 69,4 & 66,4 \\
\hline 73,7 & 68,4 & 60,0 & 65,8 \\
\hline 74,4 & 70,1 & 72,0 & 69,4 \\
\hline 74,0 & 64,6 & 65,2 & 63,9 \\
\hline
\end{tabular}

Standard deviation of reactor outlet temperatures [K]

\begin{tabular}{|l|l|l|l|}
\hline 0,2 & 0,2 & 0,3 & 0,3 \\
\hline 0,2 & 0,4 & 0,7 & 1,5 \\
\hline 0,2 & 0,6 & 1,1 & 2,8 \\
\hline 0,1 & 1,0 & 0,5 & 0,4 \\
\hline
\end{tabular}

The left temperature column is $6 \mathrm{~K}$ warmer than the rest of the reactor. As it is shown in the literature (Michel et al., 2016) (Marias, 2015), fixed bed reactors' cooling power decreases with time, therefore outlet temperature increases. Since this left column acts as if it was a fixed bed, it means that solid does not move anymore, probably because it is clogged.

Despite higher temperatures, inlet spatial standard deviation is under $1.3 \mathrm{~K}$ for all three dehydration tests. This shows that thermal insulation performance is good enough, otherwise cold walls would increase temperature differences. However, outlet standard deviations along some horizontal lines are well above $5 \mathrm{~K}$. Left column is 
even $10 \mathrm{~K}$ warmer than the rest for the $90.9^{\circ} \mathrm{C}$ dehydration test. This obvious clogging is not fully investigated yet, but there are at least two hypothesis:

- Solid material enters the reactor at ambient temperature. Because of its inertia, its cooling effect on the air is much more important at the beginning of the test. Consequently, air temperature might drop under the limit where hydration occurs. Solid material being already hydrated at about $40 \%$, it is possible that a solution appears, clogging the reactor.

- As it is mentioned in the literature about fixed bed thermochemical reactors (Marias, 2015), reaction front is quite steep, meaning in our case that air reacts first with the first solid column it crosses. This reaction cools the air while increasing its specific humidity, which brings it closer to the thermodynamic hydration/dehydration limit. If for any reason the downstream solid material columns are more hydrated or colder, hydration can occur, and liquid solution appears, clogging the reactor

\section{Conclusion}

Based on previous work regarding integrated and separated moist air thermochemical systems (Pardo et al., 2014) (Wyttenbach et al., 2014), a new reactor concept was designed, manufactured and tested in order to improve not only one but a combination of three main performance factors that are energy, heat power, and exergy in both heating and storage modes. The new prototype works with moist air and is a cross flow vertical moving bed separate reactor operating semi continuously. The solid material load doesn't move during a reaction period, then only the lowest fraction is drained while the rest of the load moves one step downward and new materials enters the reactor from the top. Outlet temperature shows limited periodic variations and the solid flow control actuator remains simple compared to a fully continuous technology.

Tests were conducted on a dynamically controlled air flow equipment, where a calibrated instrumentation allowed to measure thermal power with temperature and humidity methods, in addition to mass gradients. Comprehensive measurements with consistent results showed that the reactor was well designed with low thermal losses and good air tightness. In addition, this validated the measurement methods and the understanding of the thermochemical concepts. The reactor was tested in both heating and storage modes for Brussels climate under 5 different operating conditions representing winter, mid-season, summer and intermediate cases, with $16 \mathrm{~m}^{2}$ of flat panel solar thermal collectors. Three additional heating cases were measured in order to evaluate air flow influence.

A first algorithm was developed for controlling the semi continuous solid flow, which allowed to run the tests. However, it was highlighted that monitoring solid hydration level in real time would definitely help managing the reaction, and that a volumetric valve would be more appropriate than a time based valve. It was also shown that the reactor requires an initialization period, during which its behavior is quite different from continuous operation. The energy density being lower, initialization occurrence has to be minimized.

The reactor heating (or hydration) power is highly influenced by inlet humidity ratio: it reaches $215 \mathrm{~W}$ at 3.9 $\mathrm{g} / \mathrm{kg}_{\mathrm{da}}$ and $415 \mathrm{~W}$ at $9 \mathrm{~g} / \mathrm{kg}_{\mathrm{da}}$, according to stabilized measurements with both temperature and humidity methods. The coefficient of performance is very high (19 to 45$)$, which confirms that auxiliary power is quite low. In addition, it was measured that doubling the air flow rate multiplies heating power by 2.1 and divides coefficient of performance by 1.9. As a consequence, reaction power can be easily adjusted by controlling fan speed, with the limit of electrical consumption. A 16-points temperature map located at reactor outlet's sieve showed a downward decreasing gradient, which confirmed the theoretical approach, where dryer upper composite reacts faster. This enlarges the potential functionalities of the temperature map, as we see that solving a heat equation system would allow to estimate solid material hydration level in several reactor locations. Without real time hydration level, energy density was rather estimated and may be inaccurate. Nevertheless, it seems to be lower than expected because of reaction control issues that shortened the tests. Conversely, an optimal test duration would likely lead to slightly lower averaged heat power.

The reactor heat storing (or dehydration) power reaches $385 \mathrm{~W}$ at $60.3^{\circ} \mathrm{C}$ and $415 \mathrm{~W}$ at $90.9^{\circ} \mathrm{C}$. Because of a higher temperature, stabilization time is much longer than for heating mode. Due to a limited quantity of prepared solid composite, dehydration analysis had to be performed before full continuous operation occurs, which means with less accuracy. As for heating mode, tests were shortened because of reaction control issues. Thermal power increases with temperature and decreases with specific humidity, it remains high and stable even at solar heat favorable temperature, which is a major result for energy efficient storage systems. Some reactor clogging occurred and was confirmed by a warmer left column on the outlet temperature map, meaning a lower composite 
flow in this section. As for heating mode, there was an excellent heat power correlation between temperature and humidity methods, which means that the specific humidity measurement setup compensates the lack of accuracy at higher temperature. This lead to an appropriate measurement of the physical phenomenon involved in a prototype that minimizes air leaks and thermal losses.

\section{Acknowledgment}

This research was performed within the SoTherCo project, which has received funding from the European Union's Seventh Framework Programme for research, technological development and demonstration under grant agreement $n^{\circ} 295775$.

\section{References}

Bonk, S., Kerskes, H., Drück, H., 2017. Development and testing of a thermo-chemical energy store - Results of a five year research project. Presented at the ISES Solar World Congress 2017 - IEA SHC International Conference on Solar Heating and Cooling for Buildings and Industry 2017, Proceedings, pp. 695-704. https://doi.org/10.18086/swc.2017.13.01

Courbon, E., D’Ans, P., Permyakova, A., Skrylnyk, O., Steunou, N., Degrez, M., Frère, M., 2017. A new composite sorbent based on $\mathrm{SrBr} 2$ and silica gel for solar energy storage application with high energy storage density and stability. Appl. Energy 190, 1184-1194. https://doi.org/10.1016/j.apenergy.2017.01.041

Courbon, E., Frère, M., Heymans, N., D’Ans, P., 2015. Hygroscopic composite material. WO 2015197788 A1.

Kerskes, H., Mette, B., Bertsch, F., Asenbeck, S., Drück, H., 2012. Chemical energy storage using reversible solid/gas-reactions (CWS) - results of the research project. Energy Procedia, 1st International Conference on Solar Heating and Coolingfor Buildings and Industry (SHC 2012) 30, 294-304. https://doi.org/10.1016/j.egypro.2012.11.035

Letz, T., 2002. Validation and Background Information on the FSC Procedure (IEA Task 26 - Reports of Subtask A).

Marias, F., 2015. Seasonal storage of solar energy by thermochemical reactions at atmospheric pressure for household applications. PhD Thesis, Université de Grenoble.

Mauran, S., Lahmidi, H., Goetz, V., 2008. Solar heating and cooling by a thermochemical process. First experiments of a prototype storing $60 \mathrm{kWh}$ by a solid/gas reaction. Sol. Energy 82, 623-636. https://doi.org/10.1016/j.solener.2008.01.002

Mette, B., Kerskes, H., Drück, H., 2014. Experimental and numerical investigations of different reactor concepts for thermochemical energy storage. Presented at the Energy Procedia, pp. 2380-2389. https://doi.org/10.1016/j.egypro.2014.10.246

Michel, B., Mazet, N., Mauran, S., Stitou, D., Xu, J., 2012. Thermochemical process for seasonal storage of solar energy: Characterization and modeling of a high density reactive bed. Energy, Asia-Pacific Forum on Renewable Energy 2011 47, 553-563. https://doi.org/10.1016/j.energy.2012.09.029

Michel, B., Mazet, N., Neveu, P., 2016. Experimental investigation of an open thermochemical process operating with a hydrate salt for thermal storage of solar energy: Local reactive bed evolution. Appl. Energy 180, 234-244. https://doi.org/10.1016/j.apenergy.2016.07.108

Nonnen, T., Beckert, S., Gleichmann, K., Brandt, A., Unger, B., Kerskes, H., Mette, B., Bonk, S., Badenhop, T., Salg, F., Gläser, R., 2016. A Thermochemical Long-Term Heat Storage System Based on a Salt/Zeolite Composite. Chem. Eng. Technol. 39, 2427-2434. https://doi.org/10.1002/ceat.201600301

Van Helden, W., Wagner, W., Schubert, V., Krampe-Zadler, C., Kerskes, H., Mette, B., Jänchen, J., 2014. First tests on a solid sorption prototype for seasonal solar thermal storage. Presented at the Thermische Solarenergie, Staffelstein, Germany. 
Testing \& Certification 


\title{
Optical Properties of Solar Absorbers - Results on Round Robin and Guidelines
}

\author{
M.João Carvalho', Soraia Páscoa', Fabienne Sallaberry², Helen Rose Wilson ${ }^{3}$, Stephan \\ Fischer $^{4}$, Anders Loren ${ }^{5}$, Andreas Bohren ${ }^{6}$ and Jan Erik Nielsen ${ }^{7}$ \\ ${ }^{1}$ LNEG - Laboratório Nacional de Energia e Geologia, Lisboa (Portugal) \\ ${ }^{2}$ CENER - Centro Nacional de Energías Renovables, Sarriguren (Spain) \\ ${ }^{3}$ Fraunhofer Institute for Solar Energy Systems ISE, Freiburg (Germany) \\ 4 ITW, Stuttgart (Germany) \\ ${ }^{5}$ RISE - Research Institutes of Sweden, Borås (Sweden) \\ ${ }^{6}$ SPF - Institut für Solartechnik, Hochschule für Technik, Rapperswil (Switzerland) \\ 7 Solarkey, Hvalsoe (Denmark)
}

\begin{abstract}
The scope of the standard ISO 22975-3:2014 is the determination of the long term behavior and service life of selective solar absorbers for use in vented flat plate collectors used in typical solar domestic hot water systems or combisystems. With this scope, this standard can be the basis for the certification of solar absorbers in the framework of Solar Keymark European Certification Scheme. Measurements of optical properties are fundamental to support this certification. Six test laboratories participated in a Round Robin test for the measurement of solar absorptance and thermal emittance of different absorber coatings. The samples used were one PVD coating and two selective paint coatings all on aluminum substrates.

The results were submitted anonymously and were analyzed according to standard ISO 13528:2015. The results obtained showed good agreement among the measurements made by the participants and allowed the preparation of guidelines to guarantee quality of the measurements of optical properties of solar absorbers.
\end{abstract}

A proposal to include absorber coatings in the Solar Keymark certification scheme was prepared.

Keywords: Absorber Coatings, Optical Properties, Round Robin

\section{Introduction}

In the framework of the international standardization committee ISO TC 180, standards for collector components and materials are being developed. The first standard published is ISO 22975-3:2014. The scope of this standard covers the determination of the long-term behavior and service life of selective solar absorbers for use in vented flat plate collectors used in typical solar domestic hot water systems or combisystems. This standard can be the basis for the certification of solar absorber coatings in the framework of the Solar Keymark Certification Scheme.

ISO 22975-3:2014 uses a failure criterion based on the optical properties for the evaluation of the durability of the absorbers. The measurement of the optical properties, namely solar absorptance and thermal emittance, is to be performed according to Annex A of ISO 22975-3:2014. In order to evaluate the quality of the measurements performed according to this standard, six laboratories cooperated to perform a Round RobinRound Robin for the measurement of these parameters. 


\section{Methodology}

\subsection{Round Robin Procedure}

The main purpose of this Round Robin was to compare the solar absorptance and thermal emittance measurements of absorber coatings for flat plate collectors. The Round RobinRound Robin procedure was agreed among the six test laboratories and based on Annex A of ISO 22975-3:2014. Six samples of three different selective coatings (one PVD and two paint coatings) were distributed to the participating laboratories and two measurement rounds were performed. Each laboratory measured three samples during the first round, then sent those three samples to the next laboratory and finally measured the next three samples that it had received from another laboratory during the second round.

Results were submitted anonymously to the evaluator. The standard ISO 13528:2015 was used to analyze the results of the Round Robin.

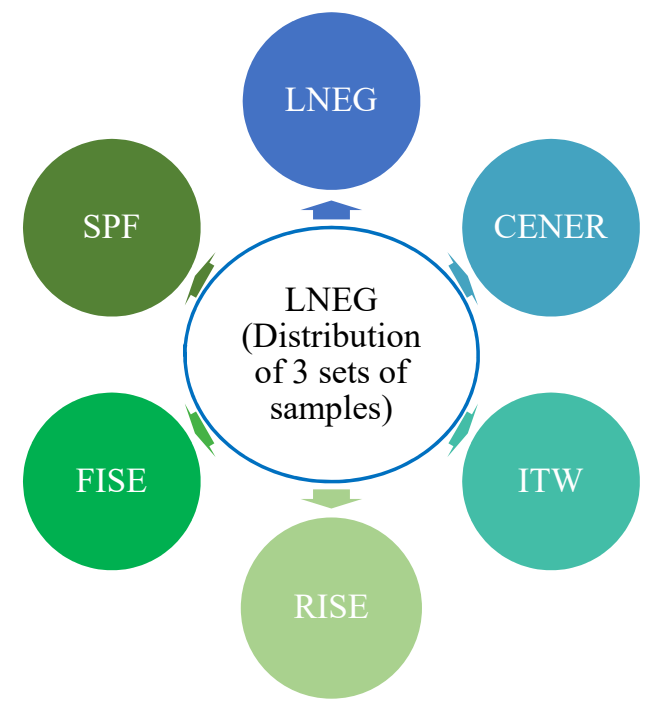

\begin{tabular}{|c|c|c|c|c|c|}
\hline Set 1 & Set 2 & Set 3 & Set 4 & Set 5 & Set 6 \\
\hline LNEG & CENER & ITW & RISE & FISE & SPF \\
\hline CENER & FISE & SPF & ITW & LNEG & RISE \\
\hline
\end{tabular}

Fig. 1 - Samples distribution and its exchange between laboratories.

\subsection{Evaluation of spectral absorptance values and spectral emittance values}

According to Annex A of ISO 22975-3:2014, the evaluation of the solar absorptance $(\alpha)$ is based on the measurement of spectral near-normal/hemispherical reflectance of the sample, $R_{s}(\lambda)$ and measurement of spectral near-normal/hemispherical reflectance of the reference, $\mathrm{R}_{\mathrm{r}}(\lambda)$. The spectral range for this measurement is from $0.30 \mu \mathrm{m}$ to $2.50 \mu \mathrm{m}$, with at least 40 wavelengths measured. The calculation of near-normal/hemispherical spectral absorptance $\alpha(\lambda)$ is given by:

$$
\alpha(\lambda)=1-\rho(\lambda)=1-\frac{R_{s}(\lambda)}{R_{r}(\lambda)} \rho_{r}(\lambda)
$$

where: $\rho_{r}(\lambda)$ is the near-normal/ hemispherical reflectance of the reference.

According to Annex A from ISO 22975-3 (2014), the evaluation of the thermal emittance $\varepsilon(T)$ is also based on the measurement of spectral near-normal/hemispherical reflectance of the sample, $R_{s}(\lambda)$ and measurement of spectral near-normal/hemispherical reflectance of the reference, $\mathrm{R}_{\mathrm{r}}(\lambda)$.

The spectral range for this measurement is from $2.0 \mu \mathrm{m}$ to $50.0 \mu \mathrm{m}$. If only a narrower wavelength range is available for measurements (e.g. up to $25 \mu \mathrm{m}$ ), the last measured value can be considered as constant up to $50 \mu \mathrm{m}$ 
for the following calculations.

The calculation of near-normal/hemispherical spectral emittance $\varepsilon(T)$ is given by:

$$
\varepsilon(\lambda)=1-\rho(\lambda)=1-\frac{R_{s}(\lambda)}{R_{r}(\lambda)} \rho_{r}(\lambda)
$$

where: $\rho_{r}(\lambda)$ is the near-normal/ hemispherical reflectance of the reference.

\subsection{Determination of solar absorptance and thermal emittance of absorber surfaces}

According to Annex A from ISO 22975-3:2014, the solar absorptance $\alpha_{s}$ is calculated from the following expression:

$$
\boldsymbol{\alpha}_{s}=\frac{\sum_{i=1}^{n}\left[\alpha\left(\lambda_{\mathrm{i}}\right) \times S_{\left.\lambda_{\mathrm{i}} \times \Delta \lambda_{\mathrm{i}}\right]}\right.}{\sum_{i=1}^{n}\left[\boldsymbol{S}_{\lambda_{\mathrm{i}}} \times \Delta \lambda_{\mathrm{i}}\right]}
$$

where

$\alpha(\lambda)$ is the near-normal/hemispherical spectral absorptance as defined in Equation 1

$S_{\lambda_{\mathrm{i}}}$ is the reference solar spectral irradiance (ISO 9050:2003)

$\lambda_{\mathrm{i}}$ is the selected measuring wavelength

$\Delta \lambda_{\mathrm{i}}$ is the respective wavelength interval

The thermal emittance $\varepsilon(T)$ is calculated from the following expression:

$$
\varepsilon(T)=\frac{\sum_{i}^{n} \varepsilon\left(\lambda_{\mathrm{i}}\right) \times \boldsymbol{P}_{\lambda_{\mathrm{i}}}(T) \times \Delta \lambda_{\mathrm{i}}}{\sum_{i}^{n} \boldsymbol{P}_{\lambda_{\mathrm{i}}}(T) \times \Delta \lambda_{\mathrm{i}}}
$$

where

$P_{\lambda_{\mathrm{i}}}(T)$ is the value of the Planck function for black body radiation at the selected wavelengths and temperature

$\varepsilon(\lambda)$ is the near-normal/hemispherical spectral emittance as defined in Equation 2

$\lambda_{\mathrm{i}}$ is the selected measuring wavelengh

$\Delta \lambda_{\mathrm{i}}$ is the respective wavelength interval

The Planck function is defined by the following expression:

$$
E(\lambda, T)=\frac{c_{1}}{\lambda^{5}\left[\exp \left(\frac{C_{2}}{\lambda T}\right)-1\right]}
$$

where

$C_{1}=8 \pi h c\left[\mathrm{Wm}^{2}\right]=3.74 \times 10^{-16}\left[\mathrm{Wm}^{2}\right]$

$C_{2}=\frac{h c}{k}[\mathrm{mK}]=1.44 \times 10^{-2}[\mathrm{mK}]$

and

$E$ is the spectral radiance $\left(\mathrm{Js}^{-1} \cdot \mathrm{m}^{-2} \cdot \mathrm{sr}^{-1} \cdot \mathrm{Hz}^{-1}\right)$

$T$ is the temperature of the black body $(\mathrm{K})$

$h$ is Planck's constant (Js)

$c$ is the velocity of light $\left(\mathrm{ms}^{-1}\right)$

$e$ is Euler's number (dimensionless) 


\subsection{Analyses of Round Robin results}

The analyses of the Round Robin results was performed according to standard ISO 13528: 2015.

For the calculation of the standard deviation for proficiency assessment (Round RobinRound Robin), $\sigma_{\mathrm{p} t}$, the normalized interquartile range was considered, as seen in Eq. 6. This is considered as a robust estimator of the standard deviation of the participant results.

$$
\sigma_{p t}=n I Q R(x)=0.7413\left[Q_{3}(x)-Q_{1}(x)\right]
$$

where:

$\mathrm{Q}_{1}(\mathrm{x})$ is the 25 th percentile of $\mathrm{xi}(\mathrm{i}=1, \ldots, 6)$

$\mathrm{Q}_{3}(\mathrm{x})$ is the 75 th percentile of $\mathrm{xi}(\mathrm{i}=1, \ldots, 6)$

A correction for non-homogeneity of the distributed samples was introduced by considering the estimator of standard deviation given by Eq. 7:

$$
\sigma_{p t}^{\prime}=\sqrt{\sigma_{p t}^{2}+s_{s}^{2}}
$$

where $\mathrm{s}_{\mathrm{s}}$ is the "between samples" standard deviation as defined in ISO 13528:2015. The comparison of the results was made using the z-score value defined by:

$$
z_{i}=\frac{\left(x_{i}-x_{p t}\right)}{\sigma^{\prime} p t}
$$

where:

$\mathrm{x}_{\mathrm{pt}}$ is the assigned value and $\mathrm{x}_{\mathrm{i}}$ the measured value.

The assigned value of the proficiency test (Round Robin) is the median of the values measured by each participant. The interpretation of z-scores according to ISO 13528:2015 is:

- A result that gives $|z| \leq 2.0$ is considered to be satisfactory;

- A result that gives $2.0 \leq|z| \leq 3.0$ is considered to be questionable;

- A result that gives $|z| \geq 3.0$ is considered unsatisfactory.

\section{Results and discussion}

To check the homogeneity of the test items (samples distributed), a measurement of the optical properties of all samples was made by LNEG before the distribution of samples.

According to ISO 22975-2 the test samples to be used in the durability tests shall have standard deviation in the determined values of solar absorptance of less than 0.01 and for the determined values of thermal emittance of less than 0.04 .

The sets of three samples, each with six specimens, distributed and initially measured by LNEG showed the following standard deviations (table 1), which satisfy the criteria of ISO 22975-2.

Tab. 1: Values of standard deviation of samples, as determined by a single laboratory

\begin{tabular}{|c|c|c|}
\hline Sample Type & Solar Absorptance & Thermal Emittance \\
\hline Sample A & 0.001 & 0.001 \\
\hline Sample B & 0.001 & 0.008 \\
\hline Sample C & 0.008 & 0.023 \\
\hline
\end{tabular}

As a criterion for homogeneity, the standard ISO 13528:2015 indicates that the "between specimens" standard 
deviation, $s_{s}$, and the standard deviation for proficiency assessment, $\sigma_{\mathrm{pt}}$, shall satisfy Eq. 9:

$$
s_{s} \leq 0,3 \sigma_{p t}
$$

The calculation of the "between sample" standard deviation was performed according to section B3, of Annex B of the standard and used, for each sample type, three repeated measurements for each of six samples. The number of specimens recommended by ISO 13528:2015 for the homogeneity check is 10 but the Round Robin only has six partners; for this reason, only six specimens of each sample are considered.

For each sample type and for each parameter measured (solar absorptance and thermal emittance), the values of $\mathrm{s}_{\mathrm{s}}$ and $\sigma_{\mathrm{pt}}$ are listed in Table 2. For calculation of $\sigma_{\mathrm{pt}}$, all measurements were considered (first and second round measurement).

Table 2 - Values of $s_{s}$ and $\sigma_{\mathrm{pt}}$ as determined in the Round Robin with six participating laboratories

\begin{tabular}{|l|c|c|c|l|c|c|c|c|}
\hline & \multicolumn{3}{|c|}{ Solar Absorptance } & \multicolumn{4}{c|}{ Thermal Emittance } \\
\hline & $\mathrm{s}_{\mathrm{s}}$ & $\sigma_{\mathrm{pt}}$ & $0.3 \sigma_{\mathrm{pt}}$ & & $\mathrm{s}_{\mathrm{s}}$ & $\sigma_{\mathrm{pt}}$ & $0.3 \sigma_{\mathrm{pt}}$ & \\
\hline Sample A & 0.0337 & 0.0028 & 0.0008 & NHom & $0{ }^{1}$ & 0.0371 & 0.0111 & Hom \\
\hline Sample B & 0.0337 & 0.0038 & 0.0011 & NHom & 0.0067 & 0.0200 & 0.0060 & NHom \\
\hline Sample C & 0.0923 & 0.0096 & 0.0029 & NHom & 0.0248 & 0.0474 & 0.0142 & NHom \\
\hline
\end{tabular}

From Table 2 we can conclude that for the parameter solar sbsorptance, all sample types have to be considered non-homogeneous (Nhom) and for thermal emittance only sample type A can be considered homogeneous (Hom).

In Table 3, the median values $\mathrm{x}_{\mathrm{pt}}$ of each parameter and sample type are presented as well as the corresponding standard deviation $\sigma_{\mathrm{pt}}$ of the proficiency test and the values corresponding to the z-score limits. Table 4 shows the same values considering the homogeneity correction.

Tab. 3: Compilation of values of median $\mathrm{x}_{\mathrm{pt}}$ and standard deviation $\sigma_{\mathrm{pt}}$ of proficiency test, $\sigma_{\mathrm{pt}}$, without homogeneity correction.

\begin{tabular}{|c|c|c|c|c|c|c|}
\hline Parameter / Sample type & $\mathbf{x}_{\mathbf{p t}}$ & $\sigma_{\mathbf{p t}}$ & $\mathbf{Z = - 3}$ & $\mathbf{Z}=\mathbf{- 2}$ & $\mathbf{Z = 2}$ & $\mathbf{Z}=\mathbf{3}$ \\
\hline$\alpha_{\mathrm{s}}$ / Sample A & 0.948 & 0.0009 & 0.945 & 0.946 & 0.950 & 0.951 \\
\hline$\alpha_{\mathrm{s}}$ / Sample B & 0.928 & 0.0023 & 0.921 & 0.923 & 0.933 & 0.935 \\
\hline$\alpha_{\mathrm{s}}$ / Sample C & 0.913 & 0.0069 & 0.892 & 0.899 & 0.926 & 0.933 \\
\hline$\varepsilon(\mathrm{T})$ / Sample A & 0.059 & 0.0371 & $-0.052^{2}$ & $-0.015^{2}$ & 0.133 & 0.170 \\
\hline$\varepsilon(\mathrm{T})$ / Sample B & 0.489 & 0.0200 & 0.429 & 0.449 & 0.529 & 0.549 \\
\hline$\varepsilon(\mathrm{T})$ / Sample C & 0.511 & 0.0474 & 0.369 & 0.416 & 0.606 & 0.653 \\
\hline
\end{tabular}

Tab. 4: Compilation of values of median $\mathrm{x}_{\mathrm{pt}}$ and standard deviation $\sigma_{\mathrm{pt}}$ of proficiency test, $\sigma_{\mathrm{pt}}$, with homogeneity correction.

\begin{tabular}{|c|c|c|c|c|c|c|}
\hline Parameter / Sample type & $\mathbf{x p t}$ & $\sigma_{\mathbf{p t}}$ & $\mathbf{Z = - 3}$ & $\mathbf{Z}=\mathbf{- 2}$ & $\mathbf{Z = 2}$ & $\mathbf{Z}=\mathbf{3}$ \\
\hline$\alpha_{\mathrm{s}}$ / Sample A & 0.948 & 0.0015 & 0.944 & 0.945 & 0.951 & 0.952 \\
\hline$\alpha_{\mathrm{s}}$ / Sample B & 0.928 & 0.0025 & 0.920 & 0.923 & 0.933 & 0.936 \\
\hline$\alpha_{\mathrm{s}}$ / Sample C & 0.913 & 0.0109 & 0.880 & 0.891 & 0.934 & 0.945 \\
\hline$\varepsilon(\mathrm{T})$ / Sample A & 0.059 & 0.0371 & $-0.052^{2}$ & $-0.015^{2}$ & 0.133 & 0.170 \\
\hline$\varepsilon(\mathrm{T})$ / Sample B & 0.489 & 0.0211 & 0.426 & 0.447 & 0.531 & 0.552 \\
\hline$\varepsilon(\mathrm{T})$ / Sample C & 0.511 & 0.0536 & 0.350 & 0.404 & 0.618 & 0.672 \\
\hline
\end{tabular}

\footnotetext{
${ }^{1}$ The value obtained is $-4 \mathrm{E}-06$, and for negative values $\mathrm{s}_{\mathrm{s}}$ is considered to be equal to 0 (ISO 13528:2015).

2 This limit is not in agreement with physical considerations since the lower limit value is 0 .
} 
In Figs. 1 to 6 the Z-scores for each sample and parameter are presented considering the homogeneity correction.

Considering the correction for non-homogeneity, the parameter solar absorptance shows one questionable result for sample $\mathrm{A}$, one questionable result for sample $\mathrm{B}$ and for sample $\mathrm{C}$ all results are satisfactory. The results with non-homogeneity correction for the parameter thermal emittance show a questionable result for sample A and for Sample B two unsatisfactory results. For sample C all results are satisfactory. According to the standard ISO 13528:2015, participants should check their measurement procedures in case of questionable or unsatisfactory results.

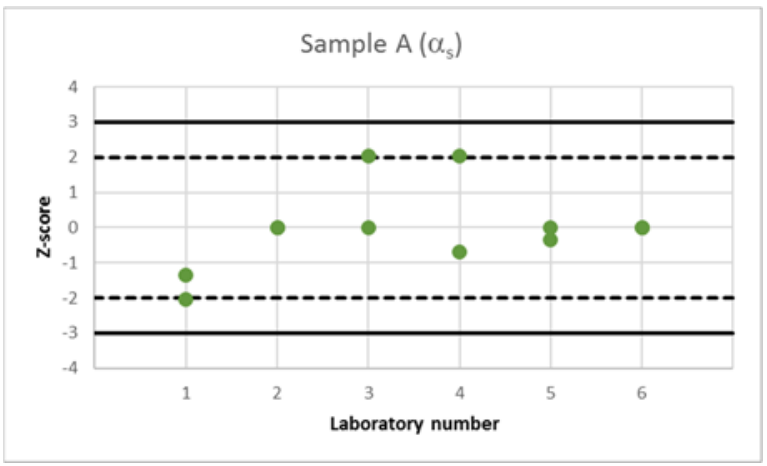

Fig. 1: z-score of parameter $\alpha_{\text {s }}$ for sample type A, with correction for sample inhomogeneity

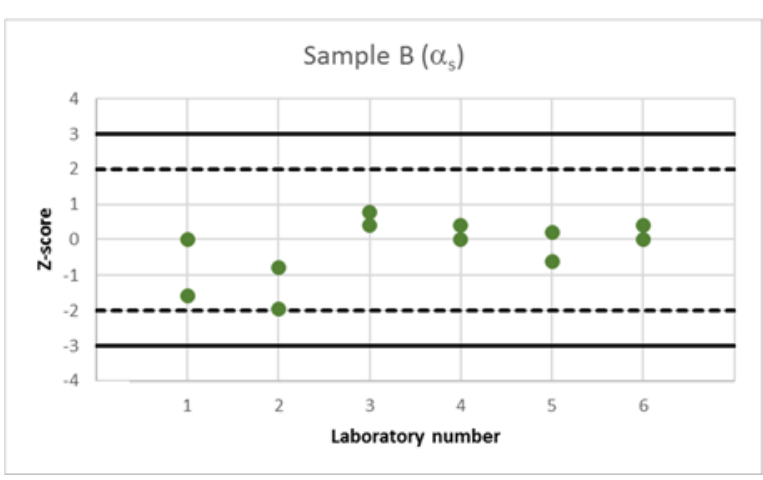

Fig. 3: z-score of parameter $\alpha$ for sample type $B$, with correction for sample inhomogeneity

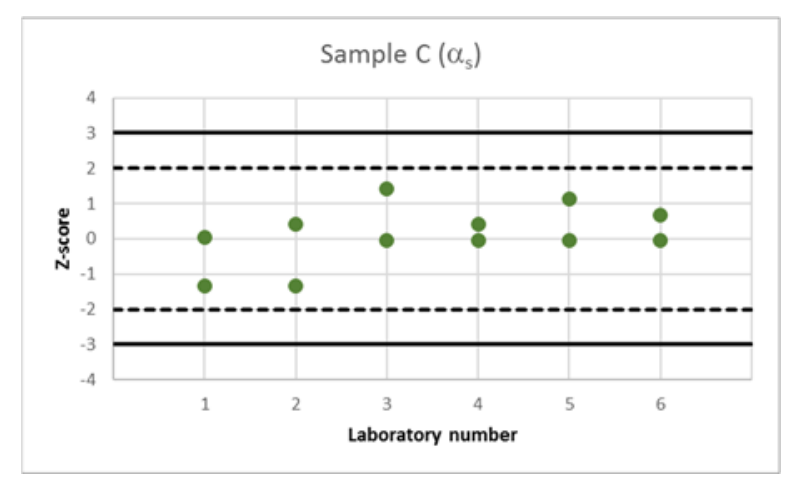

Fig. 5: z-score of parameter $\alpha$ sor sample type $C$, with correction for sample inhomogeneity

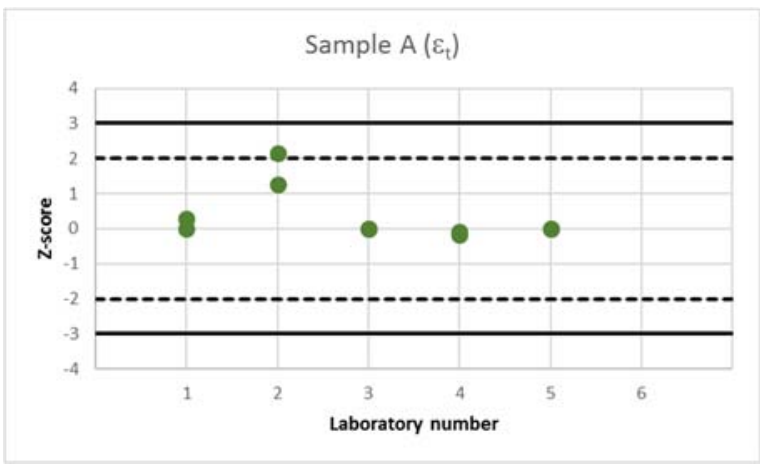

Fig. 2: z-score of parameter $\varepsilon_{t}$ for sample type A, with correction for sample inhomogeneity

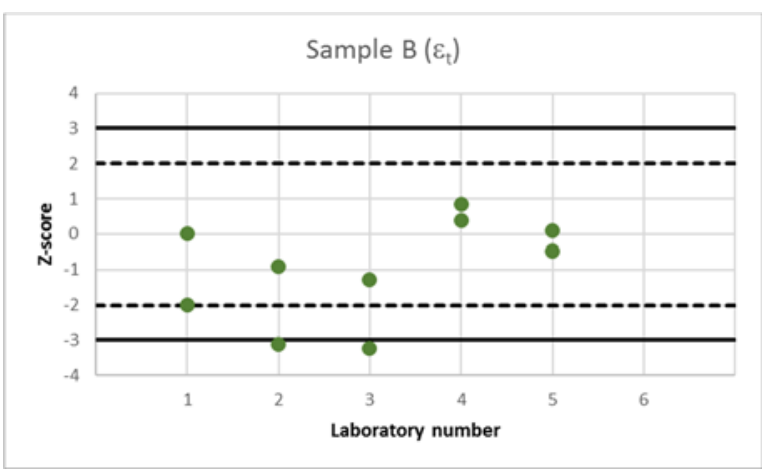

Fig. 4: z-score of parameter $\varepsilon t$ for sample type $B$, with correction for sample inhomogeneity

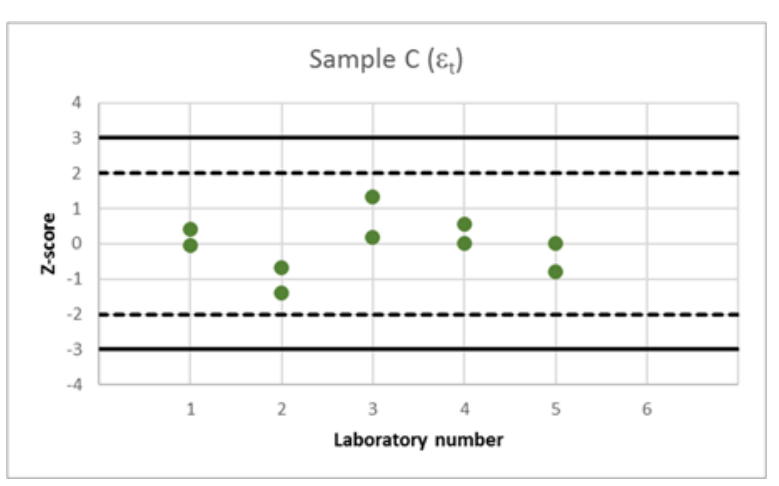

Fig. 6: z-score of parameter $\varepsilon_{t}$ for sample type $C$, with correction for sample inhomogeneity.

\section{Guidelines}

Based on the results of the Round Robin, guidelines were prepared for the determination of the parameters, solar absorptance and thermal emittance,. The guidelines present the necessary equations for calculation of the parameters, which are as indicated in section 2. of this article. 
Additional aspects to be considered in the measurement are:

a. Samples with a linear structure (typical of rolled metal) should be mounted for be measured according to the schematic representation of Fig. 7. This is to increase the probability of determining an accurate near-normal/hemispherical reflectance value for the spatially inhomogeneous reflection ("streak") in widespread commercial integrating spheres. To evaluate whether this is necessary, photographs with high resolution e.g. using SEM - scanning electron microscope, may be needed, but often the structures are visible to the naked eye.

b. Adequate sampling for representativeness of production line variation but the fulfilling requirements of ISO 22975-3:2014;

c. Correct maintenance of measuring equipment - annual maintenance is a good practice;

d. Traceability of the calibration spectra of reference materials R_r $(\lambda)$ used in equations 1 and 2.

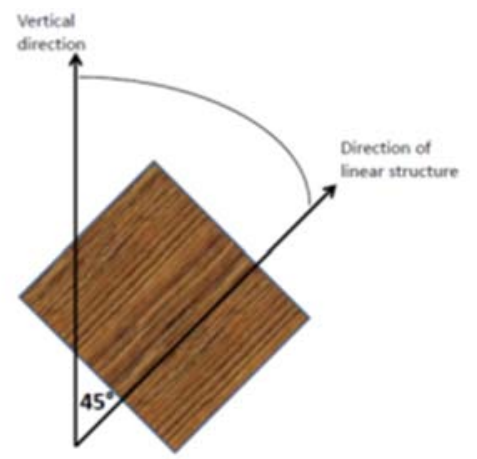

Fig. 7: Visualization of the recommended mounting position, assuming that the optical plane of the spectrophotometer is horizontal

\section{Proposal for Solar Keymark Scheme Rules}

In the framework of the Solar Certification Fund project that supported this work, a proposal for revision of Solar Keymark Scheme rules was prepared to allow the possibility to certify absorber coatings according to ISO 229753:2014.

It is considered that the selection of samples for the absorber coating certification shall be done such that it is representative of the whole production (e.g. samples from the left side of the coil, from the middle and from the right side). The test report shall include photos of the samples used in the tests (before and after each test) and the test laboratory shall store samples in good conditions for any necessary future measurements or tests. For instance, the standard conditions for sample conditioning can be considered as $23 \pm 2{ }^{\circ} \mathrm{C}$ and $50 \pm 5 \%$ relative humidity, according to the standard ISO 3270:1984.

\section{Conclusions}

It is possible to conclude that the measurement of solar absorptance and thermal emittance can be done with a majority of satisfactory results by the different test laboratories. Guidelines were prepared that can support other laboratories to perform good quality measurements. For future such interlaboratory comparisons intended to demonstrate measurement proficiency, it is strongly recommended that the homogeneity of specimens for a single sample type is ensured before distribution, so that the effects of sample inhomogeneity do not have to be compensated by additional statistical analysis.

based on the results of the Round Robin a document with guidelines for the measurement of the optical properties was prepared. A proposal for a change in the Solar Keymark Scheme rules was considered to allow the certification of absorber coatings for flat plate collectors according to ISO 22975-3:2014. 


\section{Acknowledgement}

This work was possible due to the support of the Solar Certification Fund to the project 8C02.1 SK-Abs_LNEG Solar Keymark Scheme rules for absorber coatings - guidelines for comparable optical properties measurements.

This work was also supported in the framework of the project POCI-01-0145-FEDER-016709 (Ref ${ }^{a}$ FCT PTDC/EMS-ENE/0578/2014) supported by COMPETE 2020 and LISBOA 2020 under the PORTUGAL 2020 Partnership Agreement through the European Regional Development Fund (ERDF) and supported by FCT through National Funds.

\section{References}

ISO 22975-3: 2014 Solar energy - collector components and materials - part 3: Absorber surface durability

ISO 13528: 2015 Statistical methods for use in proficiency testing by interlaboratory comparison.

ISO 9050: 2003, Glass in building - Determination of light transmittance, solar direct transmittance, total solar energy transmittance, ultraviolet transmittance and related glazing factors.

ISO 3270: 1984, Paints and varnishes and their raw materials - Temperatures and humidities for conditioning and testing.

Specific CEN Keymark Scheme Rules for Solar Thermal Products (DRFAT incl. absorber coatings), Version 30 - April 2017

Deliverable D4 - Guidelines - SCF 8th Call - Project: SCF8-SK-Abs - Solar Keymark Scheme rules for absorber coatings - guidelines for comparable optical properties measurements. May 2018 


\title{
In Situ Characterization of Thermal Collectors in Field Installations
}

\author{
Sven Fahr, Urs Gumbel, Dr. Annie Zirkel-Hofer, Dr. Korbinian Kramer \\ Fraunhofer Institute for Solar Energy Systems ISE, Freiburg, Germany
}

\begin{abstract}
Reliable and significant determination of the collector performance in field installations is necessary for a number of reasons, such as commissioning tests or product certification. The standard measurement methods from ISO 9806 are subject to numerous restrictions and only partially applicable to solar field installations. In a current project, different solar thermal plants are being monitored in order to examine the adaptability of standard procedures and measurement equipment to the requirements of in situ testing in comparison with a non-standard dynamic testing approach. Within the scope of the examinations is the comparability of field and laboratory results with respect to different evaluation methods, measurement equipment, system boundaries and process conditions. A new software tool to handle and visualize large data volumes was implemented as well as an advanced analysis procedure of parameter quality via alternative confidence interval computation. This is crucial to evaluate the uncertainties associated with larger field testing.
\end{abstract}

Keywords: field measurement, collector performance, quasi-dynamic method, parameter quality, bootstrapping method

\section{Introduction}

From design optimization to commissioning tests, from process monitoring to yield assessments and product certification of special collector technologies, which are not suitable for laboratory testing: the number of technical issues is large that require reliable methodologies to evaluate the energy output of thermal collectors in field installations. While the choice of proper measurement instrumentation and data acquisition as well as the choice of a suitable evaluation methodology depend on the very target of the examination, other challenges have to be met in any case:

- Reliable data transfer and data integrity have to be ensured

- Large data volumes have to be managed and processed

- Data shall be visualized and accessible quickly and easily

- Significant results shall be achieved without compromising regular plant operation

- Results should be of general validity and transferable to other plants of similar design

The project "ZeKon in-situ" deals with both technical issues related to the metrological recording of ambient conditions and collector performance, and issues related to secure data transmission and automated data processing and visualization. The measurement data is transferred via LTE using cryptographic procedures. Using a new tool for time series management and data visualization designed to handle big data volumes, the collectors are characterized with different evaluation methods. The focus of the project is on the applicability of the quasi-dynamic test method (QDT) known from EN ISO 9806 to measurement data recorded in the solar field under normal operating conditions and the derivation of necessary adjustments. In comparison, the data is evaluated using an alternative dynamic test method (DT), which has already been successfully validated and extensively used in the past to measure and evaluate concentrating collectors (Hofer et al. 2015; Zirkel-Hofer, 2018). The project objective is to enable collector parametrization during regular plant operation, applicable for the broadest possible range of technologies and designed to customer request in terms of cost and accuracy.

In this paper, the first results of a collector measurement in the field, including necessary adjustments of the methodology, are compared with the results of the characterization of an identically constructed collector in 
the laboratory according to the normative specifications.

\section{Methodological approach}

\subsection{Experimental setup}

When measuring the collector in the laboratory as a reference, all normative regulations regarding measurement technology, collector design and permissible operating conditions according to EN ISO 9806:2017 were satisfied (EN ISO 9806:2017). The evaluation with the QDT method was also carried out in accordance with the normative specifications regarding the determination of the collector parameters as well as the required measurement sequences and data basis.

In the field measurement, the identically constructed collector was measured as part of a collector field. The first and the last collector of a row were equipped with measuring technology in order to be able to balance both, the individual collectors and the row as a whole. For the measurement of global and diffuse irradiation, an SPN1 irradiation sensor from Delta-T Devices was used instead of the class 1 pyranometer according to ISO 9060 (Figure 1). This sensor allows the determination of global and diffuse irradiance without tracking or the adjustment of a shading device and is therefore suitable for field measurements without regular access to the system. However, compared to standard measurement technology, the sensor has a higher measurement uncertainty, the influence of which will be investigated in the further project, but has not yet been taken into account in this comparison. All other sensors used in the field meet the normative requirements.

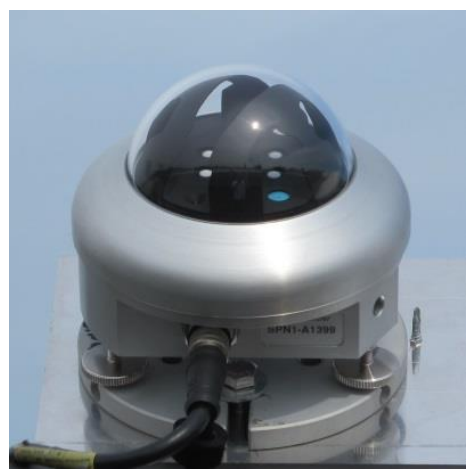

Figure 1: SPN1 sensor for the determination of diffuse and global irradiance

\subsection{Measurement methods}

It is the objective of "ZeKon in-situ" to investigate prerequisites and methods for reliable and meaningful characterization of collectors in the field. The quasi-dynamic test method of EN ISO 9806 presents the focus of interest in this examination. Because the normative restrictions of QDT to the permissible process conditions are too strict for meaningful application in the field, the possibilities to expand these restrictions are explored in the project.

As an alternative, the DT method, which has successfully been applied in evaluations of concentrating collectors, is being adapted to an application for flat plate and vacuum tube collectors. It is based on a dynamic plug-flow simulation model and using an optimization algorithm to identify performance parameters based on thermal measurement data of the collector output (Hofer et al., 2015). Its major advantage compared with the QDT from ISO 9806:2017 is the absence of any limit to the variations in mass flow and inlet temperature. It uses the very same collector equation in a dynamic simulation and produces the identical set of parameters.

\subsection{Evaluation of parameter quality}

In order to assess the quality of performance measurements, a solid knowledge of the uncertainty and interdependence of different parameters is required. This applies to laboratory measurements, but above all to measurements in the field, which are often accompanied by greater uncertainties. Since statistical standard methods often do not consider the complexity of data series from the QDT method, the so-called bootstrapping method (BS) is used here, which allows a more realistic analysis of the parameter quality. On 
the basis of the residuals between the metrologically determined and calculated collector power determined during the first parameterization, a large number of new data sets are created by resampling. For this purpose, randomly selected data blocks of residuals from the original data are used. This creates a newly sampled noise on the measurement data derived from the original residuals between measurement and calculation. By parameterizing these newly created measurement data multiple times, a large number of parameter sets are produced for the same collector, the scattering and co-variances of which can then be analyzed. The confidence intervals determined with BS are not based on as many and often simplifying assumptions as standard statistical methods, and are therefore more suitable for the use on time series data in particular. Like the DT method, the BS method has already been verified and used with great success in the measurement of concentrating collectors (Zirkel-Hofer et al., 2018).

\section{Results}

\subsection{Laboratory measurements}

For the comparative evaluation of the laboratory measurement with QDT and DT, the identical data basis was used.

For the QDT evaluation, a conditioning interval of 15 minutes and an averaging interval of 5 minutes were used, as well as a permissible fluctuation of the inlet temperature of $1 \mathrm{~K}$ and the mass flow of $1 \%$. Although an average time of 5 minutes has not been required in the standard since 2013, comparative evaluations with a shorter interval of 30 seconds in the laboratory and the sensitivity analysis in the field described below suggest that shorter intervals can have a significant influence on the parameters and are not advisable, especially for field measurements.

For the DT evaluation, no restrictions were specified with regard to the permissible fluctuations and the measurement data were evaluated in their 5 s resolution.

Both evaluations lead to almost identical parameters except for a slight deviation in the incidence angle modifier (IAM). Figure 2 and Figure 3 show the efficiency curve and the IAM curve for both evaluations in comparison. Because absolute values cannot be disclosed, Table 1 shows the deviations of the parameters of the DT evaluation in comparison to the QDT. The comparison shows that the DT method is very well suited to also evaluate non-concentrating collectors and leads to almost identical results with respect to the QDT method.

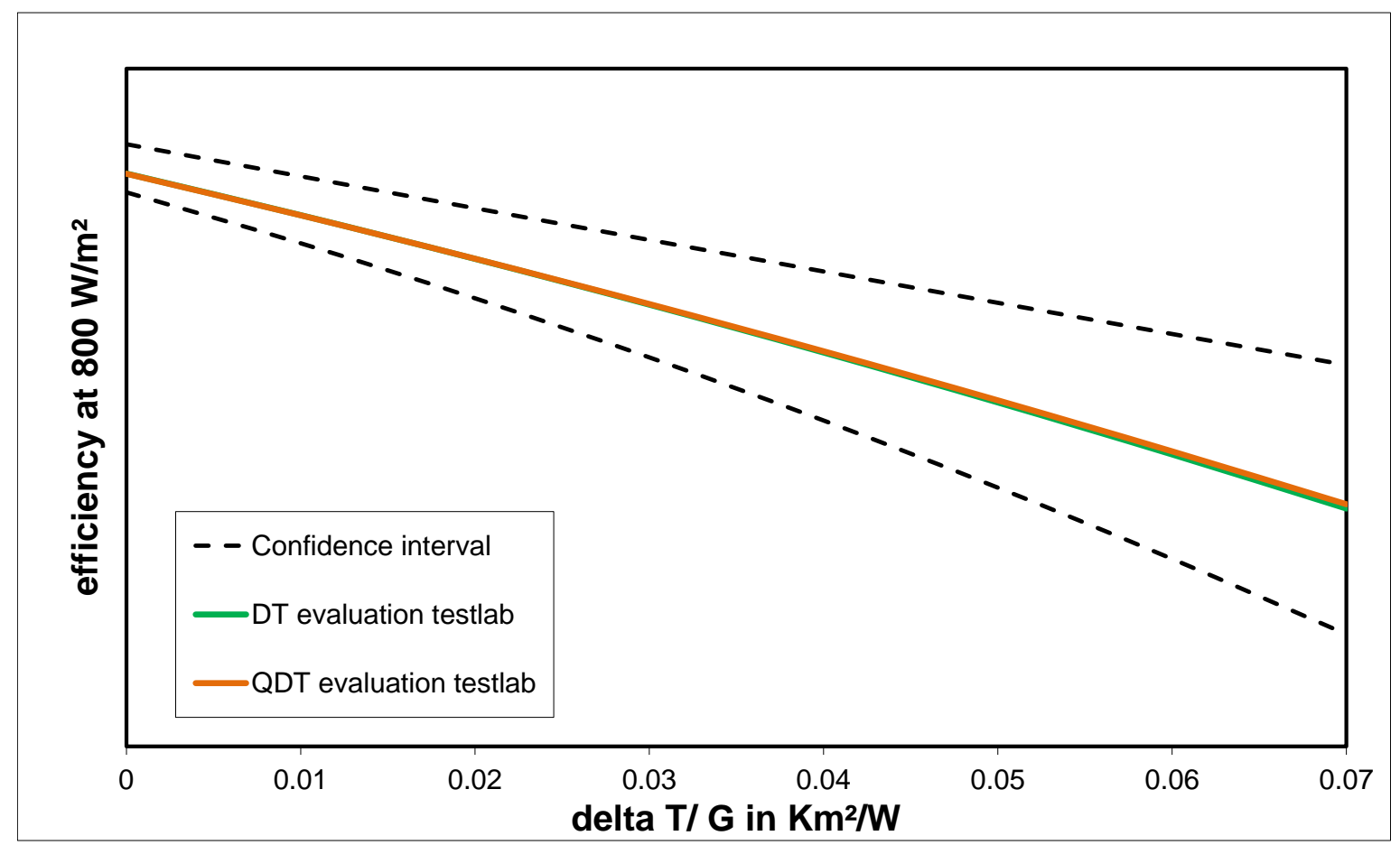

Figure 2: Efficiency curves with QDT and DT from the laboratory 
Table 1: Deviations of the evaluation with DT compared to QDT in the laboratory

\begin{tabular}{|c|c|c|c|c|}
\hline $\begin{array}{c}\eta_{\mathbf{0}, \mathbf{b}} \\
{[-]}\end{array}$ & $\begin{array}{c}\mathbf{a}_{\mathbf{1}} \\
{\left[\mathbf{W} / \mathbf{m}^{2} \mathbf{K}\right]}\end{array}$ & $\begin{array}{c}\mathbf{a}_{\mathbf{2}} \\
{\left[\mathbf{W} / \mathbf{m}^{2} \mathbf{K}^{2}\right]}\end{array}$ & $\begin{array}{c}\mathbf{K}_{\mathbf{b}(\mathbf{5 0})} \\
{[-]}\end{array}$ & $\begin{array}{c}\mathbf{K}_{\mathbf{d}} \\
{[-]}\end{array}$ \\
\hline 0.001 & 0.00 & 0.001 & 0.013 & 0.00 \\
\hline
\end{tabular}

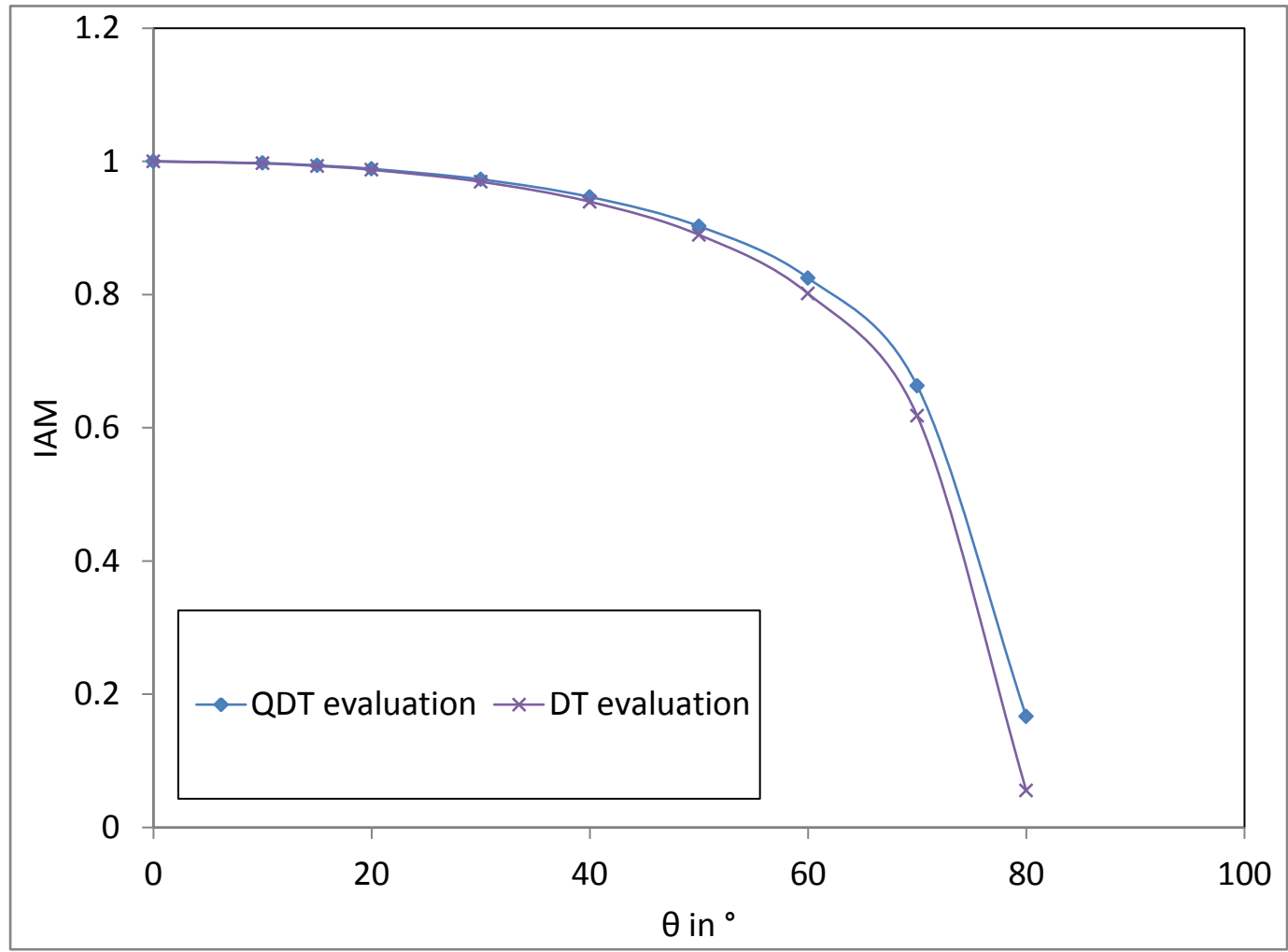

Figure 3: IAM curves determined with QDT and DT in the laboratory

In order to analyze the quality of the parameter sets in detail and to determine their confidence intervals, the bootstrapping procedure described above was used. For the parameters from the QDT method 500 runs were performed, creating the same number of parameter sets. The scattering of the parameters and the covariances among each other were evaluated and graphically illustrated. Figure 4 shows the scattering for $\eta_{0, b}$ of the laboratory measurement according to QDT. The orange line represents the average of all BS values. The blue lines mark the lowest and the highest $2.5 \%$ of the results and enclose the $95 \%$ confidence interval. This may results in asymmetric confidence intervals if the scattering is not normally distributed. The confidence intervals on the basis of the BS results for the efficiency curve as a whole are shown in Figure 2.

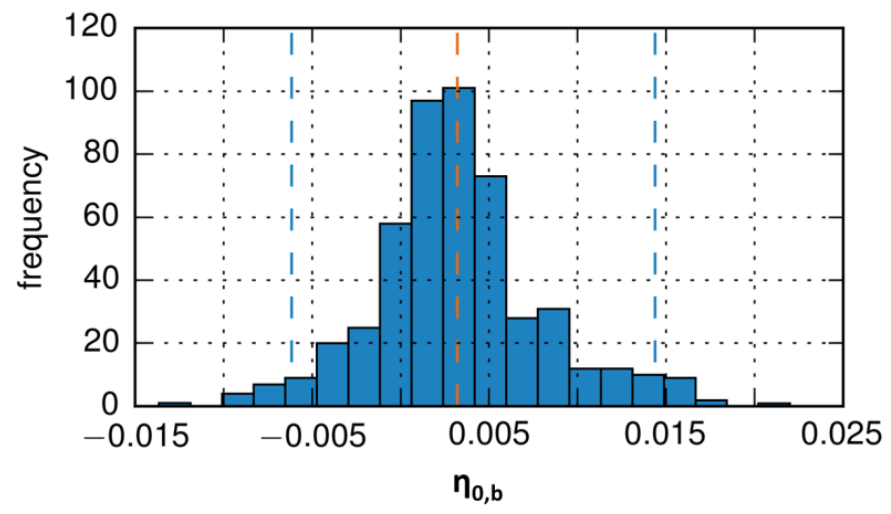


Figure 4: Histogram for the scattering of $\eta_{0, b}$ of the laboratory measurement according to QDT (normalized)

When analyzing the parameters, particular attention was paid to the IAM, as this shows the greatest difference in the comparison of QDT and DT results. It was found that the bootstrapping for the QDT results shows a much greater co-variance of the IAM parameter with the value for $\eta_{0, b}$ than is the case for the DT results. While for the QDT higher IAM values clearly correlate with lower values for $\eta_{0, \mathrm{~b}}$ (Figure 5, left), no obvious interdependence can be detected for the DT results (Figure 5, right).
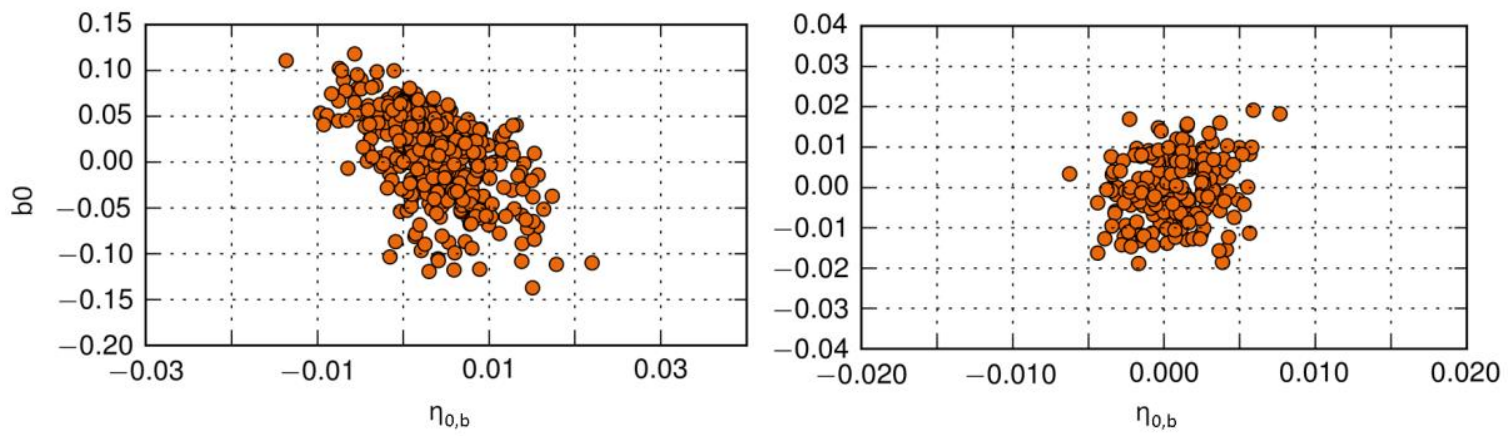

Figure 5: Co-Variance between IAM and $\eta_{0, b}$ for evaluation with QDT (left) and DT (right), both normalized

The further analysis of the existing measurement points and residuals showed that the DT method included significantly more measurement points at large angles of incidence than the QDT for the same data basis, due to the lack of limits in the permissible boundary conditions. Due to this small (and very limited) number of measuring points with large angles of incidence, the angular influence on the collector power in the QDT was apparently underestimated.

The histogram for the IAM parameter from the BS analysis of the QDT could have been an indication of this undervaluation even without direct comparison to the DT method. The scatter in Figure 6 does not show a normal distribution but a clear tendency towards higher IAM values.

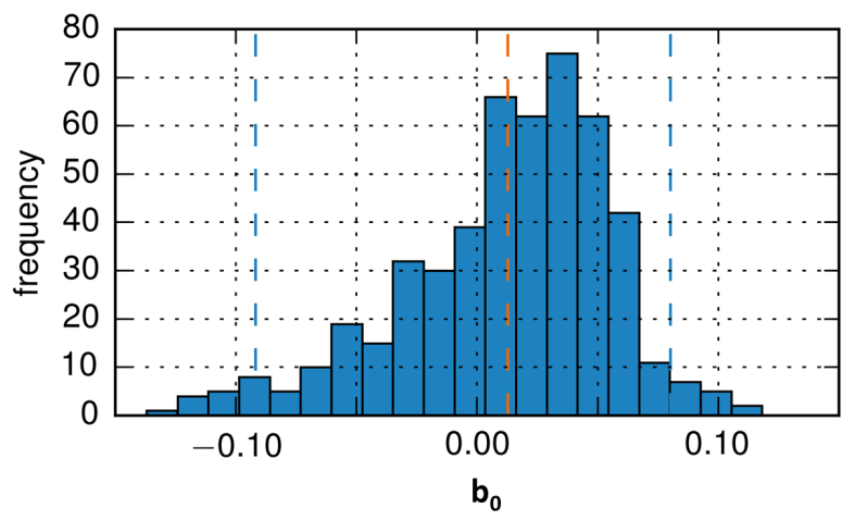

Figure 6: Scattering of the IAM parameter of the QDT evaluation (normalized)

The bootstrapping method has therefore proved to be extremely helpful in determining confidence intervals and analyzing the interrelationship between the parameters. Strictly normative measurements are always more or less error-prone and BS allows an in-depth analysis that helps to identify deficits.

Due to the detailed parameter analysis and the validation with almost identical results by the two evaluation methods, the results of the laboratory measurement can be used as a solid reference for the evaluation of the field measurements.

\subsection{In situ measurements}

The declared aim of the project is to test the suitability of the QDT for the evaluation of field measurement data which are recorded under regular operating conditions, that is, without specific operating states being brought about. This implies that the relative strict stability limits of the standard, especially with regard to inlet temperature and mass flow, cannot generally be complied with. Therefore, the core of the present study 
consisted in a sensitivity analysis to check the influence of different boundary conditions on the measurement results. For this purpose, the underlying measurement data, which cover a period of approximately three months, were parameterized multiple times under systematic variation of the permissible boundary conditions. At the same time, the first and last collector of the row as well as the combination of both individual collectors and the entire row were used to examine different energy balance areas. Fehler! Verweisquelle konnte nicht gefunden werden. lists the variants for all boundary conditions considered in the sensitivity analysis.

Table 2: Variations of the boundary conditions during sensitivity analysis

\begin{tabular}{|c|c|}
\hline Criterion & Variants \\
\hline Balance area & $\begin{array}{c}\text { First collector, last collector, combination of both } \\
\text { individual collectors, complete row }\end{array}$ \\
\hline Conditioning interval & $3 \mathrm{~min}, 5 \mathrm{~min}, 10 \mathrm{~min}, 15 \mathrm{~min}, 20 \mathrm{~min}$ \\
\hline Averaging interval & $15 \mathrm{~s}, 30 \mathrm{~s}, 5 \mathrm{~min}, 10 \mathrm{~min}, 15 \mathrm{~min}$ \\
\hline Min. temperature lift & $0.01 \mathrm{~K}, 0.1 \mathrm{~K}, 0.25 \mathrm{~K}, 0.5 \mathrm{~K}, 1 \mathrm{~K}$ \\
\hline Max. variation input temperature & $1 \mathrm{~K}, 2 \mathrm{~K}, 3.5 \mathrm{~K}$ \\
\hline Max. fluctuation mass flow & $1 \%, 2 \%, 3 \%, 5 \%, 15 \%, 40 \%$ \\
\hline
\end{tabular}

A total of approx. 1500 different evaluations of the same data basis were carried out from which then those parameter sets were filtered from which all values lie within the confidence interval of the laboratory measurement. By analyzing the conditions under which the remaining 34 parameter sets were identified, clear tendencies can be determined:

- All but one of the parameter sets originate from the first collector in the series

- All except one parameter set are based on a minimum temperature lift of $0.5 \mathrm{~K}$

- All are based on an average interval of $5 \mathrm{~min}$

- The conditioning intervals of $3 \mathrm{~min}, 5 \mathrm{~min}$, and $15 \mathrm{~min}$ occur in approximately equal parts

- The 3 different filter limits for the input temperature occur in equal parts

- With the filter limit for the mass flow there is a clear tendency to the higher values, about $2 / 3$ of the parameter sets are based in equal parts on $15 \%$ and $40 \%$ fluctuation limit, the remaining third is distributed among the other 3 variations

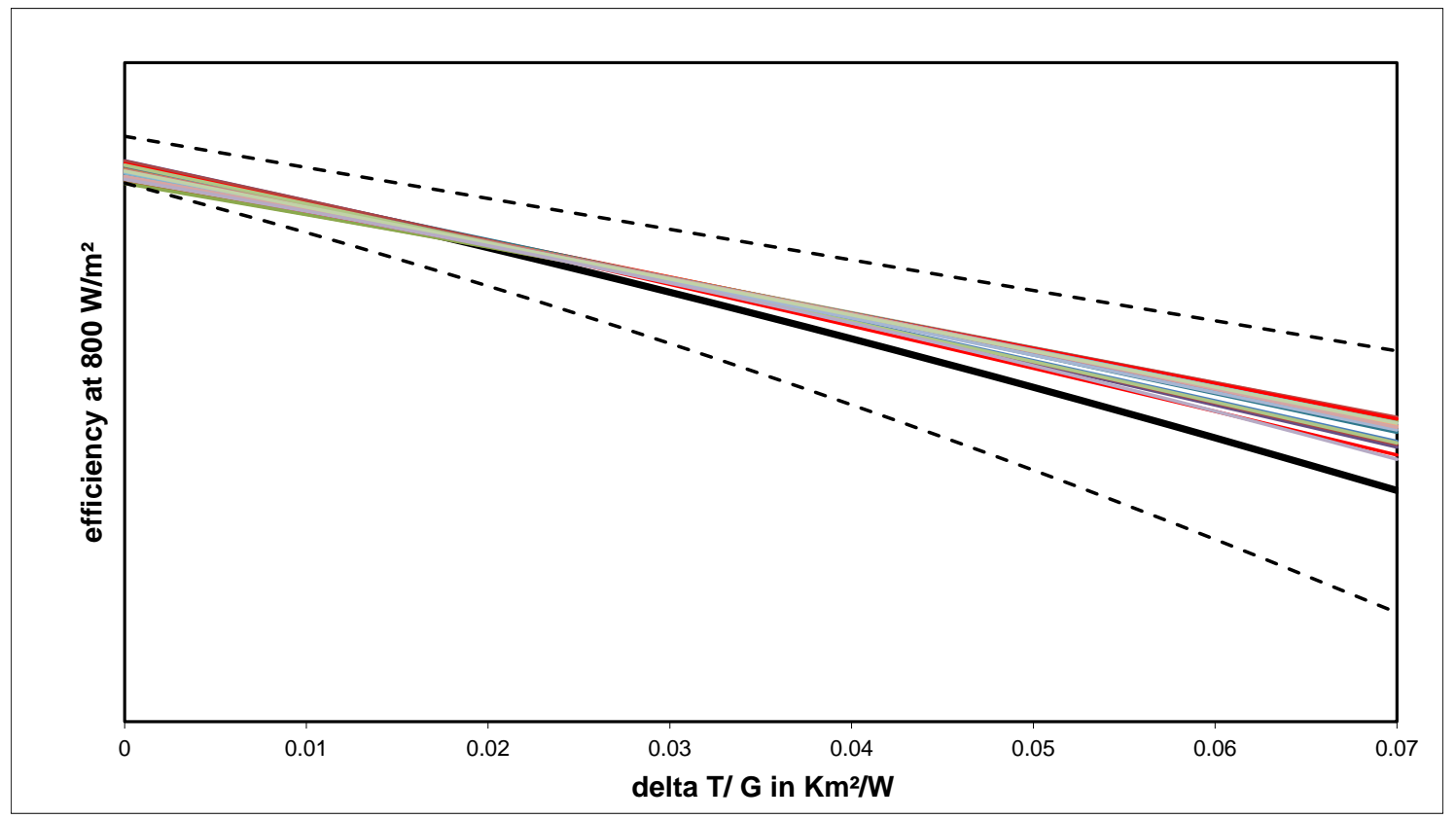

Figure 7: Selected efficiency curves from the field in the confidence interval (Intermediate results at time of publication)

Figure 7 depicts the efficiency curves for all the mentioned 34 cases and shows that all filtered parameter sets have similar characteristics. Compared to the reference measurement (black line) they show a very good 
agreement regarding $\eta_{0, b}$, but all imply slightly lower heat losses. Why the heat losses in those cases are consistently lower, is the subject of ongoing investigations; a first explanatory approach is the dominance of measured values at a lower temperature level at the first collector in the series. The definite integral in the measuring range (up to $\mathrm{T}_{\text {mean }}-\mathrm{T}_{\mathrm{amb}} / \mathrm{G}=0.07 \mathrm{Km}^{2} / \mathrm{W}$ ) is used as a criterion to select the data set which is closest to the reference measurement. This is used for the subsequent comparisons with the DT method and is shown again in Figure 9 in comparison with the reference and the DT result.

If the same filter criteria as above are used, but only the results based on a combination of the first and last collectors in the series are considered, the result gives a completely different picture (see Figure 8). Here, measuring points of higher temperature levels are significantly more dominant and lead to a tilting of the efficiency curves in comparison to the reference measurement: The values for $\eta_{0, b}$ tend to be significantly higher than in the reference measurement (black line), but the heat loss coefficients are also higher. However, most of these parameter sets are outside the confidence interval of the reference measurement.

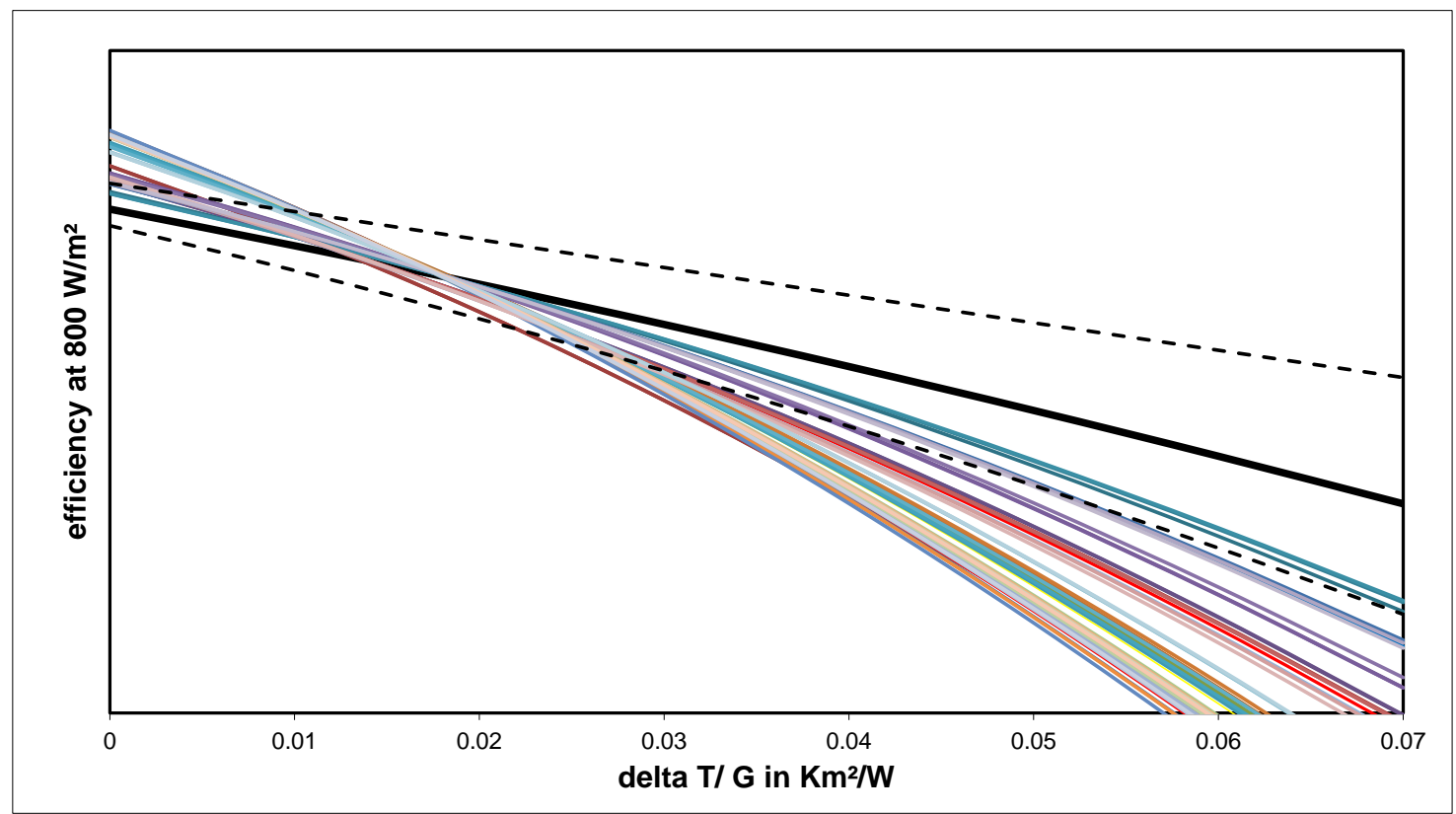

Figure 8: Efficiency characteristics for the combined evaluation of the first and last collector of the series (Intermediate results at time of publication)

If only parameter sets are considered which are based only on measured values of the last collector of the series, where low temperature levels hardly occur, results are completely and far above the confidence interval of the reference measurement. As they are not plausible they are not presented here.

In connection with the results of the sensitivity analysis listed above, the following keys are drawn:

- $\quad$ The QDT reaches its limits in very dynamic processes, a sufficiently long averaging interval should therefore be used. In this case, 5 minutes turned out to be the optimal interval.

- If sufficient conditioning and averaging intervals are given, the normative limits for the maximum permissible fluctuation of input temperature and mass flow are almost superfluous. They could be exceeded many times over without significantly changing the characteristic curve.

- In principle, the importance of the widest possible variance of all relevant boundary conditions cannot be overestimated for QDT. With regard to the operating temperatures covered, reaching temperatures close to the ambient temperature seems to be even more important than covering the uppermost temperature range.

- The QDT has the potential to be used in the field without active intervention in plant operation even under more varying process conditions, provided there is sufficient variance of all relevant boundary conditions.

The DT method is particularly suitable for the use in field measurements because it does not impose any limitations on the permissible boundary conditions. The collector was therefore also evaluated with this method, again using both, the individual collectors and the entire collector series as a balance room. The only 
restrictions made here were a minimum of three minutes preceding pump activity and minimum temperature lift of $0.1 \mathrm{~K}$. It should be noted at this point that the evaluation with DT does not refer to the exact same period as the QDT evaluations, but rather to a somewhat more extensive data set due to its subsequent use.

The results of the DT method also differ from the reference measurement depending on the balance area under consideration. Strikingly, the largest deviations result for the first collector in the series and are far outside the confidence interval (Figure 9, brown line), while this produced the best results for the QDT. The reasons for this are the subject of ongoing investigations.

Looking at the last collector in the series and the series as a whole, however, Figure 9 shows good agreement with the reference measurement with regard to optical efficiency.

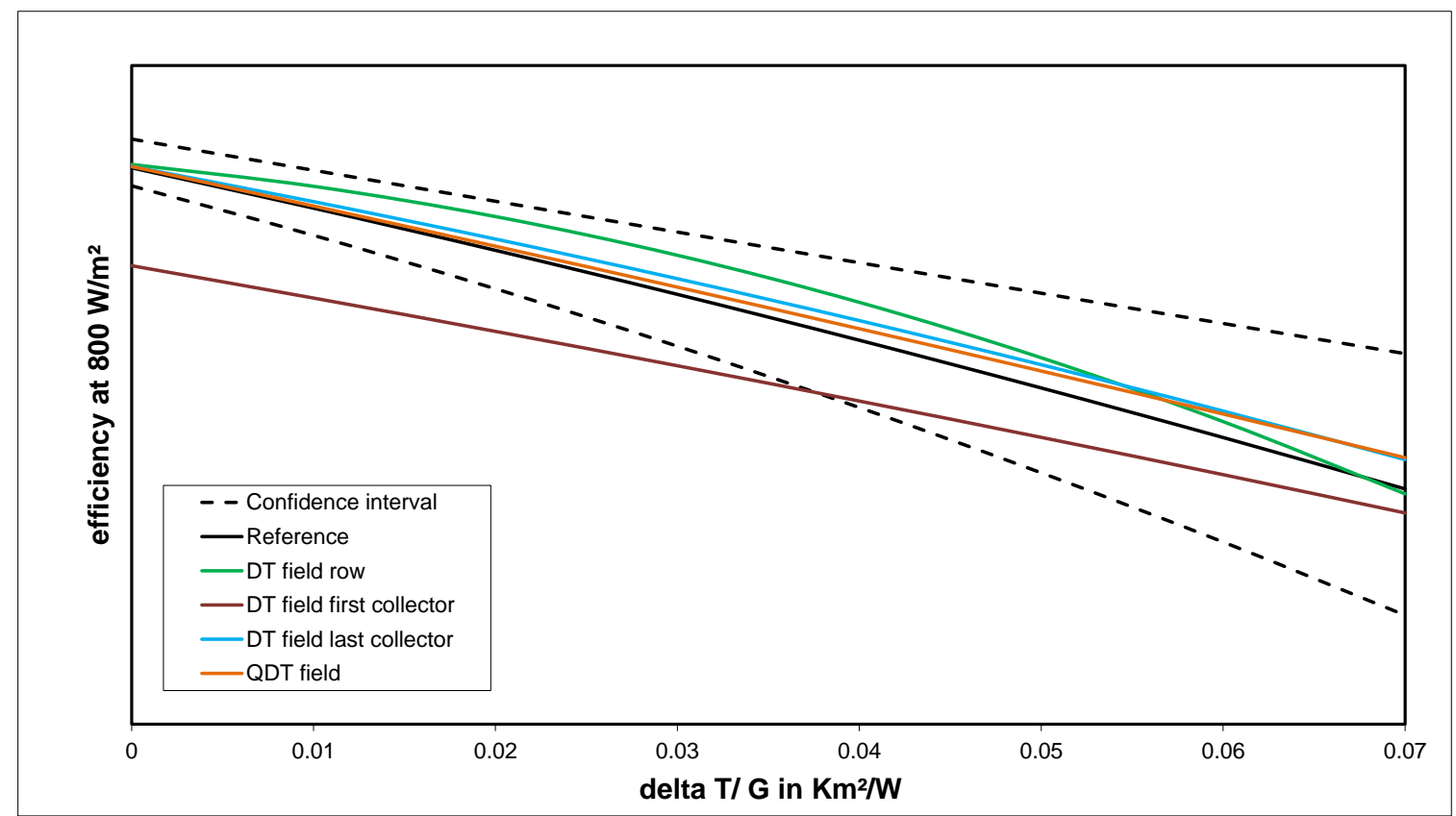

Figure 9: Efficiency lines from the field for DT (different balance areas) and QDT (selected data set) in comparison to laboratory measurement (Intermediate results at time of publication)

As with QDT, the thermal losses are slightly lower than in laboratory measurements. For the last single collector of the series, however, this cannot be explained by a lack of representation of measuring points at a high temperature level. The significantly greater curvature of the efficiency curve when evaluating the entire series may be attributed to the lack of correction of heat losses at the collector connections. It is obvious that these are less influential in the first part of the collector row at a low temperature level than at the high temperatures at the end of the row. In a next step, these connectors will be supplemented in the simulation model to verify this hypothesis. As already shown above, the angular dependence in the reference measurement has apparently been underestimated. This may also explain the somewhat larger differences between the IAM values from field and laboratory. Fehler! Verweisquelle konnte nicht gefunden werden. summarizes the deviations between the reference measurement and different evaluations in the field.

Table 3: Deviations of the selected field measurements from the reference measurement

\begin{tabular}{|c|c|c|c|c|c|}
\hline & $\begin{array}{c}\eta_{\mathbf{0 , b}} \\
{[-]}\end{array}$ & $\begin{array}{c}\mathbf{a}_{\mathbf{1}} \\
{\left[\mathbf{W} / \mathbf{m}^{2} \mathbf{K}\right]}\end{array}$ & $\begin{array}{c}\mathbf{a}_{\mathbf{2}} \\
{\left[\mathbf{W} / \mathbf{m}^{2} \mathbf{K}^{2}\right]}\end{array}$ & $\begin{array}{c}\mathbf{K}_{\mathbf{b}(\mathbf{5 0})} \\
{[-]}\end{array}$ & $\begin{array}{c}\mathbf{K}_{\mathbf{d}} \\
{[-]}\end{array}$ \\
\hline $\begin{array}{c}\text { QDT (selected } \\
\text { parameter set) }\end{array}$ & 0,000 & $-0,17$ & $-0,004$ & $-0,035$ & $-0,046$ \\
\hline $\begin{array}{c}\text { DT Last } \\
\text { collector }\end{array}$ & 0,001 & $-0,365$ & 0,002 & 0,005 & 0,031 \\
\hline $\begin{array}{c}\text { DT complete } \\
\text { row }\end{array}$ & 0,002 & $-1,484$ & 0,023 & $-0,020$ & $-0,001$ \\
\hline
\end{tabular}


Looking at the BS results for the selected QDT measurement in the field, it can be seen that the confidence intervals of the parameters are in the same order of magnitude as in the laboratory and even tend to be smaller. This can be attributed to the far greater number of measurement points collected during the threemonth field measurement than was the case during the laboratory measurement, which lasted only a few days. Also, the confidence intervals in the field are rather normally distributed. Figure 10 shows an example of the distribution for $\eta_{0, b}$. Compared to the representation for the laboratory measurement in Figure 4 , it can be seen that the variance is slightly lower and more even around the mean value here as well.

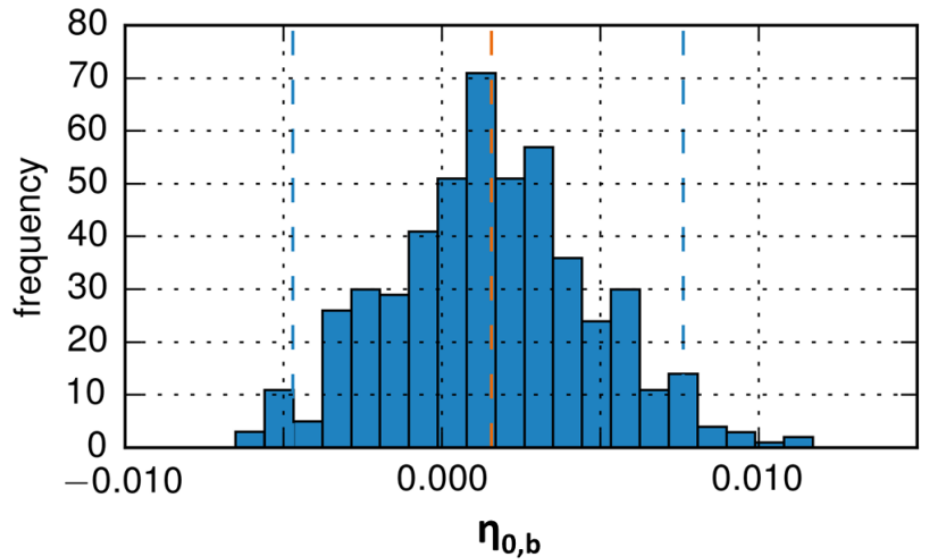

Figure 10: Histogram for the scattering of $\eta_{0, b}$ for the selected field parameter set from QDT (normalized)

Fehler! Verweisquelle konnte nicht gefunden werden. shows the confidence intervals of all parameters of the selected field measurement and the laboratory measurement relative to their parameter values.

Table 4: Upper and lower limits of the confidence intervals relative to the parameter value

\begin{tabular}{|c|c|c|c|c|}
\hline & \multicolumn{2}{|c|}{ QDT laboratory measurement } & \multicolumn{2}{c|}{ QDT select field measurement } \\
\hline & Lower limit & Upper limit & Lower limit & Upper limit \\
\hline$\eta_{\mathbf{0}, \mathbf{b}}[-]$ & $-0,009$ & 0,011 & $-0,006$ & 0,006 \\
\hline $\mathbf{b}_{\mathbf{0}}[-]$ & $-0,105$ & 0,068 & $-0,017$ & 0,016 \\
\hline $\mathbf{K}_{\mathbf{d}}[-]$ & $-0,055$ & 0,043 & $-0,025$ & 0,027 \\
\hline $\mathbf{a}_{\mathbf{1}}\left[\mathbf{W} / \mathbf{m}^{\mathbf{2}} \mathbf{K}\right]$ & $-0,541$ & 0,571 & $-0,457$ & 0,436 \\
\hline $\mathbf{a}_{\mathbf{2}}\left[\mathbf{W} / \mathbf{m}^{2} \mathbf{K}^{2}\right]$ & $-0,008$ & 0,006 & $-0,007$ & 0,007 \\
\hline
\end{tabular}

The covariances between the optical parameters are also lower for the field measurement, which is also attributed to a better variance of the underlying data. Covariances between the optical parameters are still present in the field, but also smaller than in laboratory measurements. As an example, Figure 11 shows the dependence between $\eta_{0, b}$ and the IAM parameter $b_{0}$ in the laboratory (left) and in the field (right).
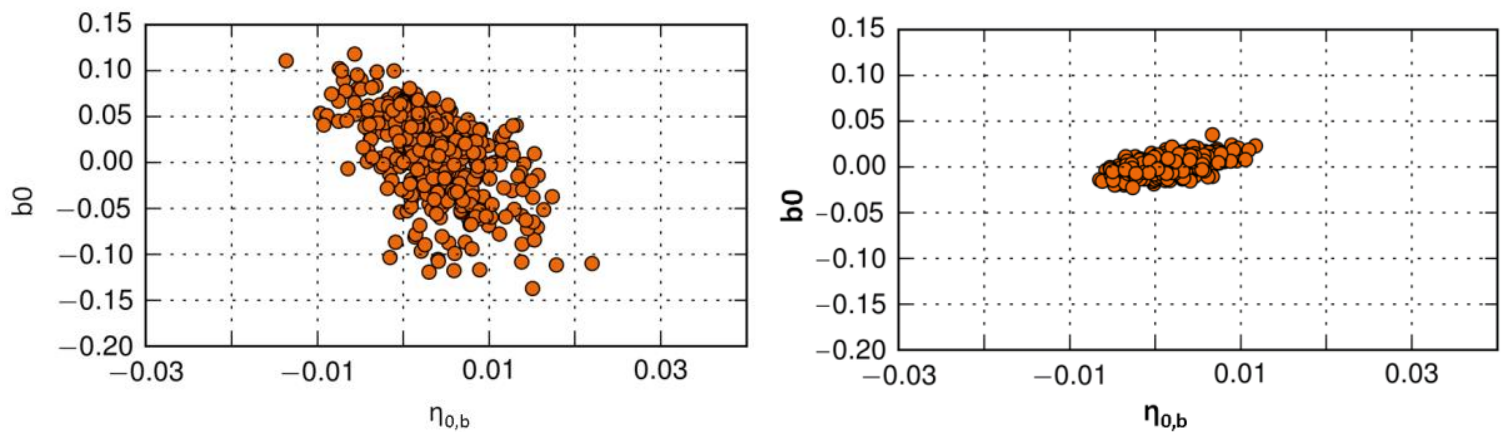

Figure 11: Co-Variance between $b_{0}$ and $\eta_{0, b}$ for evaluation with QDT in the laboratory (left) and in the field (right), both normalized 


\section{Summary}

Based on the comparative evaluation of the same data basis from a laboratory measurement, it was shown, that the DT method is absolutely suitable for flat plate collectors and delivers almost identical results as the QDT method from the testing standard. It was additionally proven that the BS method can provide very useful additional information in order to assess the quality and independence of parameters. It can thus help to detect deficits in parameter sets that can occur even in strictly normative measurements.

On the basis of a sensitivity analysis, the influence of different filter criteria on the results of a QDT measurement was investigated in order to test their suitability for the evaluation of field measurement data. It turned out that the QDT reached its limits with very dynamic data and only worked well with longer averaging and conditioning times. If these averaging times were given, however, larger than the normative fluctuations of the input temperature and the mass flow could also be permitted in order to measure collectors in the field without interference with their regular operating conditions. A broad coverage of all relevant boundary conditions proved once more to be essential, in particular the sufficient consideration and weighting of input temperatures close to the ambient temperature. Under these premises, the QDT was able to generate results in the field within the confidence interval of the laboratory measurement. The remaining differences, especially in the heat losses, will continue to be investigated.

Results were also achieved with the DT method, which are largely within this confidence interval, but differ depending on the balance area considered. Although some deviations still exist which cannot yet be explained correctly, the method was able to demonstrate its general function and its great potential for application in the field testing. The consideration of losses at collector connections promises still improvement possibilities.

The project "ZeKon in-situ" is supported by the Federal Ministry for Economic Affairs and Energy on the basis of a decision of the German Bundestag.

\section{References}

EN ISO 9806:2017, Solar energy - Solar thermal collectors - Test methods (ISO 9806:2017-09), URL https://www.beuth.de/de/ norm/din-en-iso-9806/280715291

Hofer A., Buchner D., Heimsath A., Fahr S., Kramer K., Platzer W., Scholl S., 2015. Comparison of Two Different (Quasi-) Dynamic Testing Methods for the Performance Evaluation of a Linear Fresnel Process Heat Collector, Energy Procedia (69) 84-95, ISSN 18766102, URL http://www.elsevier.com/ locate/procedia.

Zirkel-Hofer, A.: Enhanced dynamic performance testing method for line-concentrating solar thermal collectors. Dissertation, Cuvillier Verlag, 2018, ISBN: 978-3-73699-786-8

Zirkel-Hofer, A. et al: Confidence interval computation method for dynamic performance evaluations of solar thermal collectors. Solar Energy 162 (2018), 585-596 


\title{
Modelling the Relative Humidity Inside Flat Plate Collectors
}

\author{
Stephan Fischer, Fabian Marquez \\ University of Stuttgart, Institute for Building Energetics, Thermotechnology and Energy Storage \\ (IGTE) ${ }^{1}$, Pfaffenwaldring 6, 70550 Stuttgart, Germany
}

\begin{abstract}
A mathematical model based on physical phenomena is introduced to model the relative humidity within flat plate collectors. Using the model, the water vapor which enters and leaves the collector as well as the water which is ad- and desorbed by the thermal insulation material during operation can be calculated. The paper describes the model and shows its application on three different collectors exposed Kochi, India. The water masses which enter and leave the collector during one month of operation as well as the water masses which are adsorbed and desorbed by the thermal insulation material for the three flat plate collectors are presented. This knowledge can be used for the design of an accelerated aging test procedure for flat plate collectors. The results are discussed and an outlook for future work is given.
\end{abstract}

Keywords: relative humidity in flat plate collectors, adsorption isotherm, water vapor adsorption, thermal insulation material, air volume flow through collectors, accelerated aging test, lifetime prediction

\section{Introduction}

During their lifetime solar thermal collectors are exposed to a variety of partially overlapping aging effects. These are introduced on the one hand from the system type and the mode of operation resulting in different inlet temperatures of the heat transfer fluid. On the other hand site-specific climatic conditions have an important impact on the aging process as shown by B. Traub et al. (2012) and P. Kofler et al. (2013).

To assess and judge the durability and reliability of solar thermal collectors for different system types and different locations a test procedure which takes into account these different ageing processes is needed which goes far beyond the existing durability and reliability test sequences which are documented in the ISO 9806 (2013) testing standard. Within the German project SpeedColl "Development of Accelerated Ageing Tests for Solar Thermal Collectors and their Components" a test procedure was developed taking into account ageing processes a solar thermal related to UV radiation, salty environment, humidity temperature cycles and high temperatures. The test procedure is described by S. Fischer (2017).

Within the follow-up project SpeedColl2 "Estimation of the service life of solar collectors and its components" the developed test procedures will be reviewed and further developed. This paper will introduce a model of the relative humidity within flat plate collectors as a basis for the review of the humidity test developed in the SpeedColl project. To model the relative humidity within the collector 3 different mass transfer phenomena were taking into account:

1. Air exchange between the ambient and the inner of the collector

2. Diffusion of water vapor through the leaks of the collector

3. Adsorption and desorption of water vapor by the thermal insulation material

\section{Collectors investigated}

For the modelling of the relative humidity 3 different collectors were investigated. Within the Tab. 1 the main characteristics of the 3 collectors are summarised.

\footnotetext{
${ }^{1}$ On July 1, 2018 the Institute for Building Energetics (IGE), the Institute of Thermodynamics and Thermal Engineering (ITW) with its Research and Testing Centre for Thermal Solar Systems (TZS) as well as the Institute of Energy Storage (IES) have been merged to the Institute for Building Energetics, Thermotechnology and Energy Storage (IGTE)
} 
Tab. 1: Characteristics of the collectors investigated

\begin{tabular}{|c|c|c|c|}
\hline Characteristic & Collector 1 & Collector 2 & Collector 3 \\
\hline Thermal insulation & Mineral wool & Mineral wool & Melamine foam \\
\hline Collector ventilation & $\begin{array}{c}\text { In and out in the air gap } \\
\text { between absorber and } \\
\text { transparent cover }\end{array}$ & $\begin{array}{c}\text { In and out in the air gap } \\
\text { between absorber and } \\
\text { transparent cover }\end{array}$ & $\begin{array}{c}\text { Through the thermal } \\
\text { insulation in and out in } \\
\text { the air gap between } \\
\text { absorber and } \\
\text { transparent cover }\end{array}$ \\
\hline Absorber coating & selective & selective & selective \\
\hline Transparent cover & Solar glass uncoated & Solar glass uncoated & Solar glass with AR \\
coating
\end{tabular}

\section{Measurements}

To develop a model for the relative humidity within a flat plate collector the temperature as well as the relative humidity within the collector must be known in addition to the ambient temperature and the relative humidity of the ambient air. All 6 SpeedColl test sites (Stuttgart (Germany), Freiburg (Germany), Zugspitze (Germany), Gran Canaria (Spain), Sede Boker (Israel) and Cochi (India)) are equipped with extensive measuring sensors to measure the ambient conditions. At the exposure sites in Stuttgart (Germany) and Kochi (India) additional sensors were installed to measure the temperature and relative humidity within the air gap between absorber and transparent cover of the three collectors listed in Tab. 1.

Fig. 1 shows the sensors installed in the air gap and outside the collector. In Fig. 2 two of the collectors with installed combined temperature and humidity sensors are shown together with the cooling unit installed in Kochi, India. The sensors are visible as bright dots in the middle of the two collectors shown.
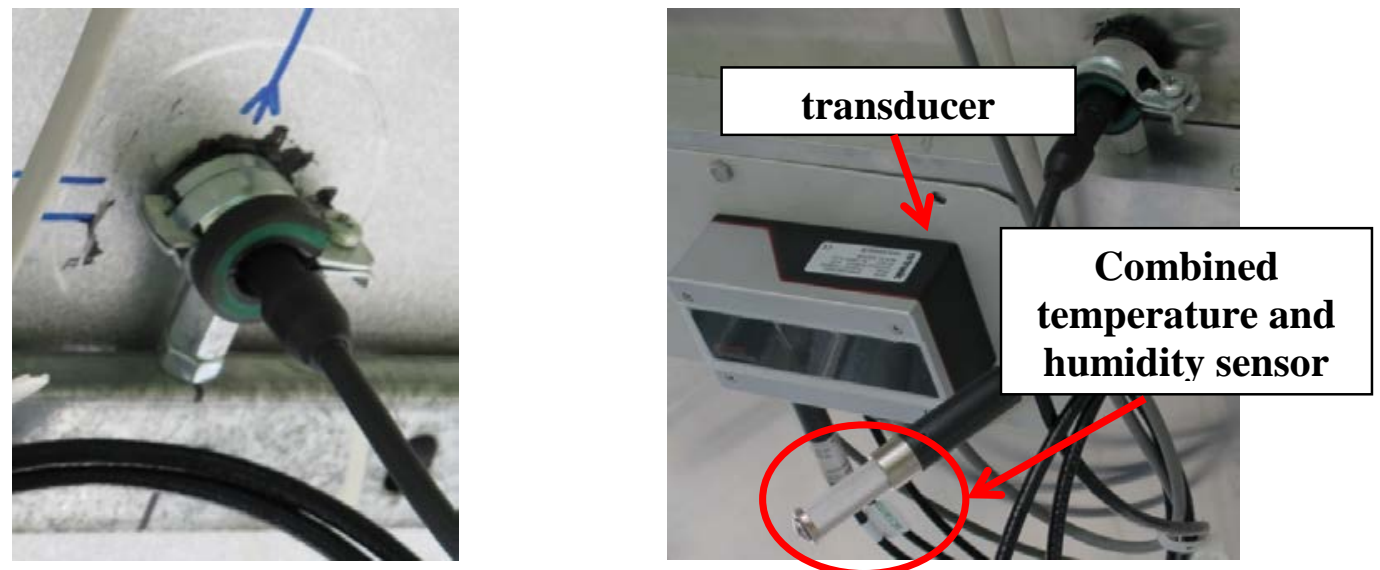

Fig. 1. Back side of one collector with immerged combined temperature and humidity sensor (left) and a second sensor for the measurement of the ambient temperature and relative humidity (right)

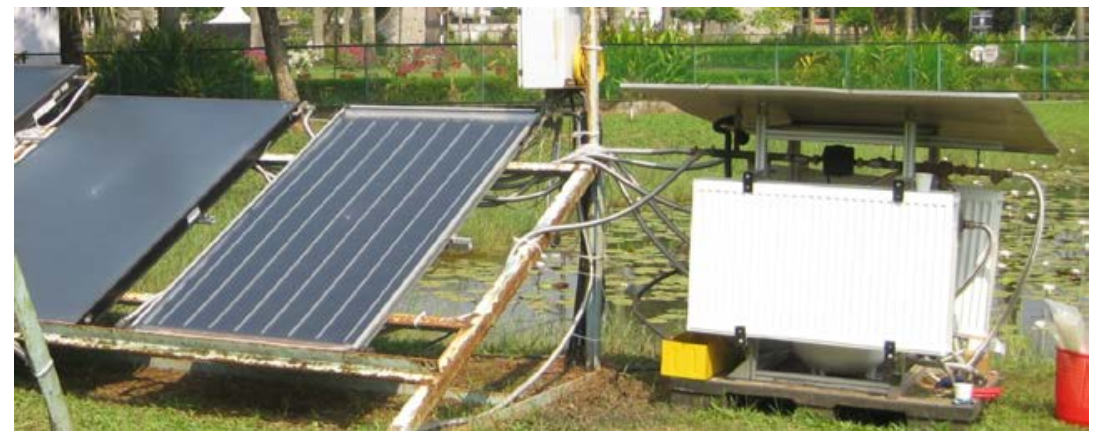

Fig. 2. Cooling unit (right) and collector 1 and collector 2 with combined temperature and humidity sensor (left) at the exposure site Kochi, India

In Fig. 3 measured data for three consecutive days (16.-12. - 18.12.2014) of the hemispherical irradiance, ambient 
temperature and the resulting temperature in the air gap between absorber and transparent cover of all three collectors are displayed. The maximum absorber temperature is kept by approx. $80^{\circ} \mathrm{C}$ with the cooling unit. The difference in the air gap temperature of the three collectors is due to the different thermal performance. The corresponding relative humidity ( $\mathrm{rH})$ of the ambient and in the air gap of the three collectors can be seen in Fig. 4 .

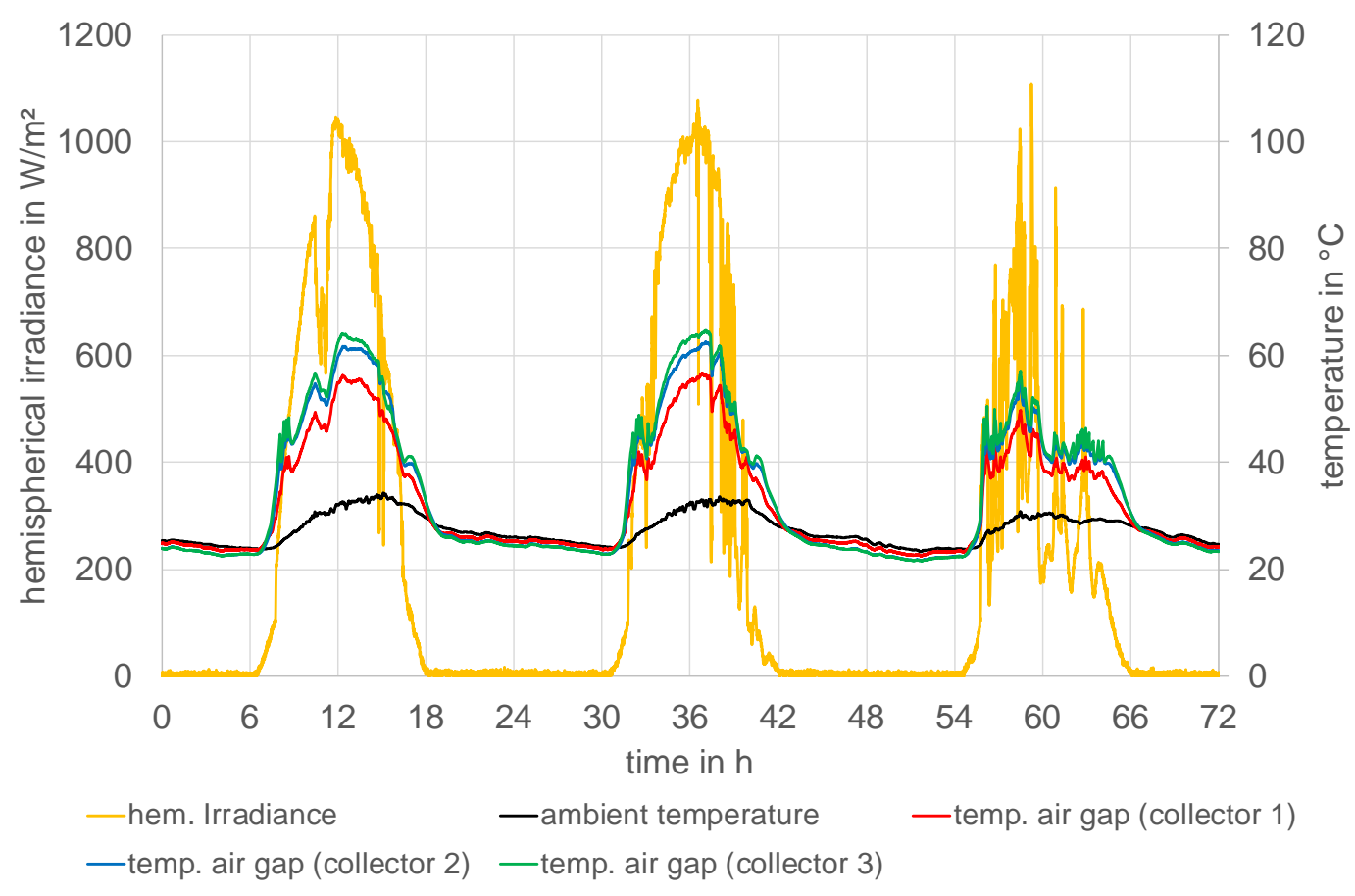

Fig. 3. Measurement for three consecutive days of the hemispherical irradiance, ambient temperature and the resulting temperature in the air gap between absorber and transparent cover of all three collectors at the exposure site Kochi, India

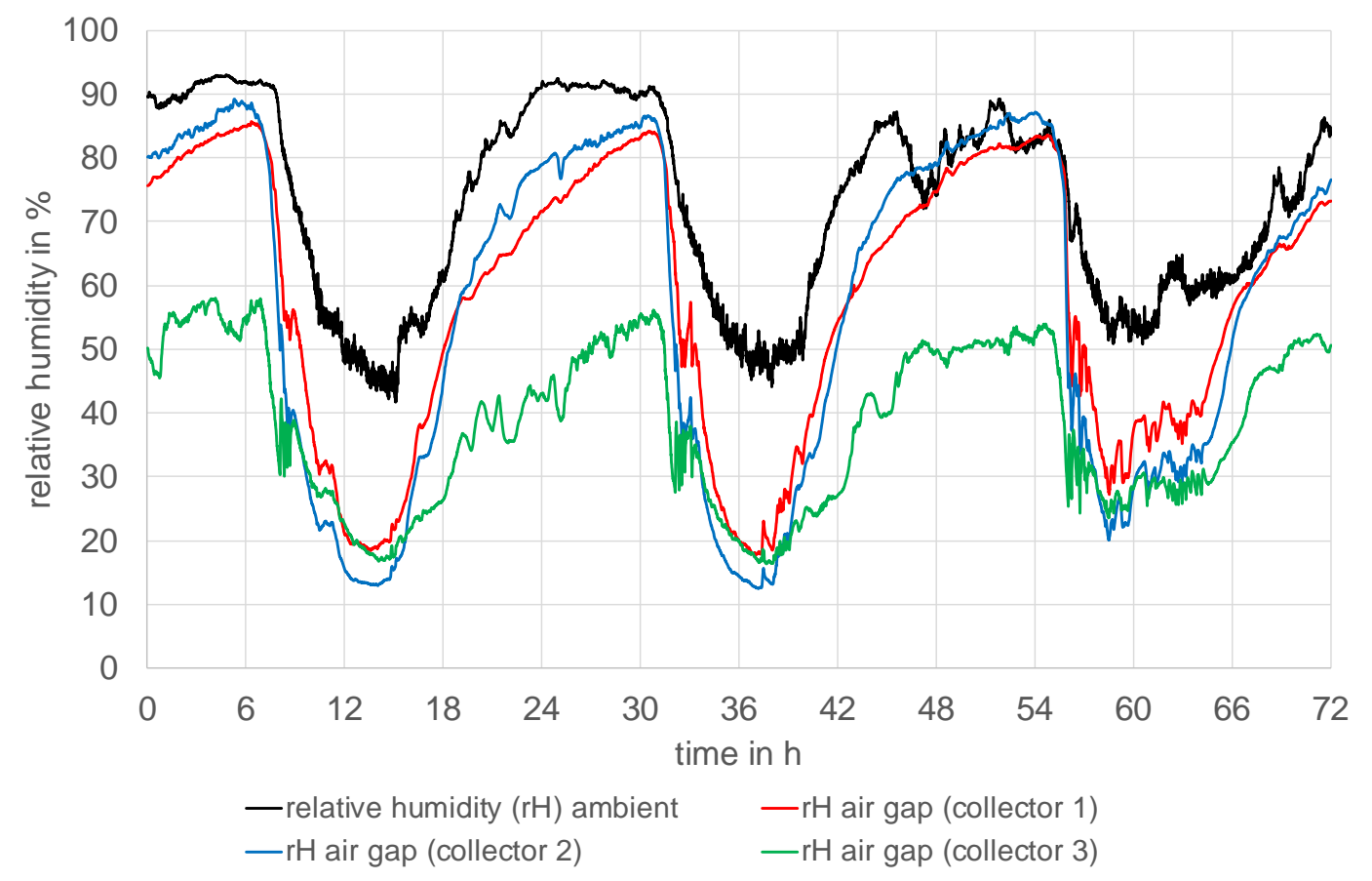

Fig. 4. Measurement for three consecutive days of the relative humidity of the ambient and in the air gap between absorber and transparent cover of all three collectors at the exposure site Kochi, India

The relative humidity of the ambient shows the expected development: high during night time (no irradiance, low ambient temperature) and low during daytime (irradiance, high ambient temperatures). The relative humidity within the air gap between absorber and transparent cover follows in principle the development of the relative humidity of the ambient. However, it is for all three collectors always lower and at times with high temperatures 
within the collector (high irradiance) significant lower. The relative humidity within collector 1 and 2 are very similar due to the use of the same collector ventilation strategy and similar thermal insulation material (mineral wool). Collector 3 shows a different behaviour due to the use of melamine foam and the ventilation though the side insulation.

The goal of the mathematical model described in the next section is to derive parameters which allow for the simulation of the relative humidity in the air gap between the absorber under any ambient conditions.

\section{Mathematical model for the relative humidity}

The model consists on a differential equation, which was derived from a mass balance of water vapor into the air gap between the absorber and the glass cover. For this, the ad- and desorption of water vapor by the insulation material, the diffusion of water vapor through the leaks of the collector and the transport of humidity caused by the air flowing through the ventilation openings of the collector were taken into account. The corresponding water mass flows were expressed as function of adjustment factors, which include all the unknown parameters for their direct calculation. The value of these were determined by using the least squared method based on measuring data recorded for three collectors in December 2014 in Kochi/India for a period of one month.

The adsorption behaviour is given by the so called adsorption isotherm curves. It represents the dependence of the mass fraction of water into the insulating material on the relative humidity of the surrounding air by a constant temperature. The IUPAC (International Union of Pure and Applied Chemistry) classifies the adsorption isotherms into six types depending on the shape of these curves (Sing et. al. (1985)). The type I describes the asymptotical saturation of the solid with condensed gas molecules. The types II and III are typical for materials which does not reach a saturation state during the adsorption process through unlimited multilayer condensation. The types IV and $\mathrm{V}$ describes the materials which reach a saturation state during a capillary condensation of gas molecules into the micropores ( $2 \mathrm{~nm}<\emptyset_{P}<50 \mathrm{~nm}$ ) after a multilayer condensation into the macropores $\left(\emptyset_{P}>50 \mathrm{~nm}\right)$, where the mass fraction of condensed gas into the material increased strongly with the relative humidity of the surrounding gas. The type VI is characteristic for materials which can undergo several capillary condensations before reaching the saturated state. The different behaviours are shown in Fig. 5

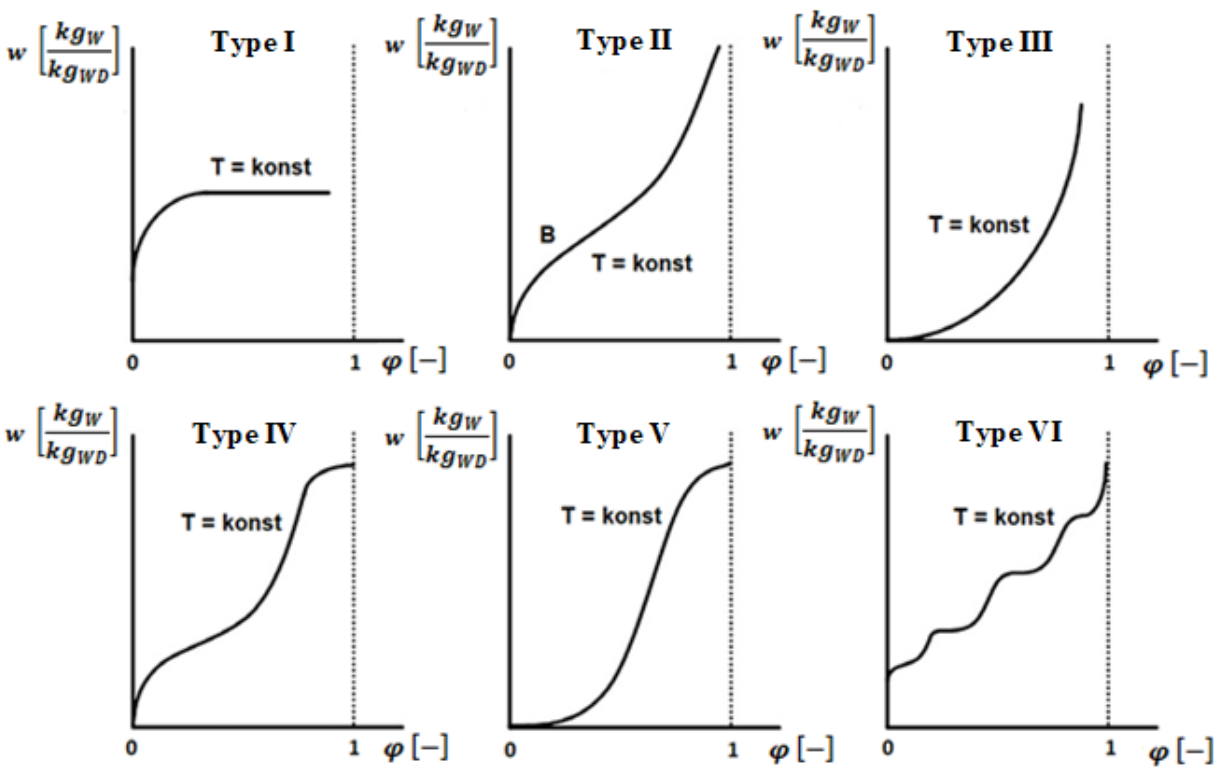

Fig. 5. IUPAC classification of adsorption isotherms

A linear behaviour of the adsorption isotherms was not included into this classification. It is described by the Henry's law Feng (2001). The temperature depending proportionality constant is given by the condensation enthalpy of adsorbed gas into the solid.

$$
\mathrm{w}_{\mathrm{H}}(\mathrm{t})=\mathrm{k}_{\mathrm{H}}(\mathrm{T}(\mathrm{t})) \cdot \varphi(\mathrm{t})
$$




$$
\begin{aligned}
& \mathrm{k}_{\mathrm{H}}(\mathrm{T}(\mathrm{t}))=\mathrm{k}_{\mathrm{H}, \mathrm{o}} \cdot \exp \left(\frac{\mathrm{k}_{\mathrm{H}, \mathrm{T}}}{\mathrm{T}(\mathrm{t})}\right) \\
& \mathrm{k}_{\mathrm{H}, \mathrm{T}}=\frac{\Delta \mathrm{H}_{\mathrm{H}}}{\mathrm{R}_{\mathrm{W}}}
\end{aligned}
$$

As insulating materials in the collectors, mineral wool and melamine foam were used. Their adsorption behaviour can be well described with an adsorption isotherm of type IV and with the Henry's Law. Collet et al. (2011) proposed the GAB model (Guggenheim, Anderson and De Boer) for the adsorption isotherms of type IV as function of the adsorption enthalpy of the monolayer and the multilayer condensation, which was also used for the model development.

$$
\begin{aligned}
& \mathrm{w}_{\mathrm{GAB}}(\mathrm{t})= \mathrm{w}_{\mathrm{mG}} \cdot \mathrm{C}_{\mathrm{G}}(\mathrm{t}) \cdot \mathrm{k}(\mathrm{t}) \cdot \varphi(\mathrm{t}) \\
& \cdot {\left[(1-\mathrm{k}(\mathrm{t}) \cdot \varphi(\mathrm{t})) \cdot\left(1-\mathrm{k}(\mathrm{t}) \cdot \varphi(\mathrm{t})+\mathrm{C}_{\mathrm{G}}(\mathrm{t}) \cdot \mathrm{k}(\mathrm{t}) \cdot \varphi(\mathrm{t})\right)\right]^{-1} } \\
& \mathrm{C}_{\mathrm{G}}(\mathrm{t})=\exp \left(\frac{\mathrm{E}_{\mathrm{a}}-\mathrm{E}_{\mathrm{m}}}{\mathrm{R}_{\mathrm{W}} \cdot \mathrm{T}(\mathrm{t})}\right) \\
& \mathrm{k}(\mathrm{t})=\exp \left(\frac{\mathrm{E}_{\mathrm{L}}-\mathrm{E}_{\mathrm{m}}}{\mathrm{R}_{\mathrm{W}} \cdot \mathrm{T}(\mathrm{t})}\right)
\end{aligned}
$$

Since the adsorption enthalpies of water vapour into the insulating materials are unknown, they were expressed as function of adjustment factors, which are to be determined with the least squared method.

$$
\begin{aligned}
& \mathrm{k}_{1}=\frac{\mathrm{E}_{\mathrm{a}}-\mathrm{E}_{\mathrm{m}}}{\mathrm{R}_{\mathrm{W}}} \\
& \mathrm{k}_{2}=\frac{\mathrm{E}_{\mathrm{L}}-\mathrm{E}_{\mathrm{m}}}{\mathrm{R}_{\mathrm{W}}}
\end{aligned}
$$

The mass flow of water vapour out or into the insulating material is given by the time derivate of the used equation for the adsorption isotherm curve.

$$
\dot{\mathrm{m}}_{\mathrm{ads}}=\mathrm{m}_{\mathrm{IM}} \cdot \frac{\mathrm{d}}{\mathrm{dt}}(\mathrm{w}(\mathrm{t}))
$$

The diffusion mass flux through the leaks of the collector is proportional to the partial pressure difference of water vapour between the ambient air and the air in the air gap between absorber and transparent cover. The proportionality constant is given by the diffusion coefficient of water vapour into air, the gas constant for water, the average temperature between the ambient air and the mentioned space, the diffusion resistance factor and the flow distance of the vapour through the leaks.

$$
\begin{aligned}
& \dot{\mathrm{m}}_{\mathrm{D}}{ }^{\prime \prime}(\mathrm{t})=-\frac{\mathrm{D}(\mathrm{t})}{\mathrm{R}_{\mathrm{W}} \cdot \mathrm{T}_{\mathrm{m}}(\mathrm{t}) \cdot \mu \cdot \delta} \cdot\left(\mathrm{p}_{\mathrm{d}, \mathrm{c}}(\mathrm{t})-\mathrm{p}_{\mathrm{d}, \mathrm{a}}(\mathrm{t})\right) \\
& \mathrm{D}(\mathrm{t})=0.231 \cdot 10^{-4} \cdot \frac{98100 \mathrm{~Pa}}{\mathrm{p}} \cdot\left(\frac{\mathrm{T}_{\mathrm{m}}(\mathrm{t})}{273 \mathrm{~K}}\right)^{1,81} \\
& \dot{\mathrm{m}}_{\mathrm{D}}(\mathrm{t})=\mathrm{k}_{\mathrm{D}} \cdot \frac{\mathrm{D}}{\mathrm{R}_{\mathrm{W}} \cdot \mathrm{T}_{\mathrm{m}}(\mathrm{t})} \cdot\left(\mathrm{p}_{\mathrm{d}, \mathrm{c}}(\mathrm{t})-\mathrm{p}_{\mathrm{d}, \mathrm{a}}(\mathrm{t})\right) \\
& \mathrm{k}_{\mathrm{D}}=\frac{\mathrm{A}_{\mathrm{D}}}{\delta \cdot \mu}
\end{aligned}
$$

The area of the leaks, through which water diffusion can occur, the diffusion resistance factor and the flow distance of the vapour through the leaks are brought together into the constant $k_{\text {Diff }}$.

The volume flow of air through the ventilation openings is modelled with a power law as function of the driving pressure difference for the air buoyancy due to a temperature difference between the ambient air and the space between the glass cover and the absorber. The corresponding mass flow of air is then calculated with the specific volume and the water content of the humid air at the ambient conditions for each measurement.

$$
\begin{aligned}
& \dot{\mathrm{V}}_{\mathrm{B}}(\mathrm{t})=\mathrm{k}_{\mathrm{p}} \cdot \Delta \mathrm{p}_{\mathrm{T}}(\mathrm{t})^{\mathrm{n}} \\
& \Delta \mathrm{p}_{\mathrm{T}}(\mathrm{t})=\rho_{\mathrm{N}} \cdot \mathrm{T}_{\mathrm{N}} \cdot \mathrm{g} \cdot \mathrm{h}_{\mathrm{c}} \cdot\left(\frac{1}{\mathrm{~T}_{\mathrm{a}}(\mathrm{t})}-\frac{1}{\mathrm{~T}_{\mathrm{c}}(\mathrm{t})}\right) \\
& \mathrm{v}_{\mathrm{a}}(\mathrm{t})=\frac{\left(1+1,61 \cdot \mathrm{x}_{\mathrm{a}}(\mathrm{t})\right)}{\left(1+\mathrm{x}_{\mathrm{a}}(\mathrm{t})\right)} \cdot \frac{\mathrm{T}_{\mathrm{a}}(\mathrm{t}) \cdot \mathrm{R}_{\mathrm{a}}}{\mathrm{p}} \\
& \dot{\mathrm{m}}_{\mathrm{B}}(\mathrm{t})=\dot{\mathrm{V}}_{\mathrm{B}}(\mathrm{t}) \cdot \frac{1}{\mathrm{v}_{\mathrm{a}}(\mathrm{t}) \cdot\left(1+\mathrm{x}_{\mathrm{a}}(\mathrm{t})\right)}
\end{aligned}
$$

The exponent $\mathrm{n}$ is assumed to be one. In consideration of the water vapour mass flow due to these mechanisms, the mass balance of humidity in the space between absorber and glass cover can be written as follows:

$$
\frac{\mathrm{d}}{\mathrm{dt}}\left(\mathrm{m}_{\mathrm{W}, \mathrm{c}}(\mathrm{t})\right)=-\dot{\mathrm{m}}_{\mathrm{ads}}(\mathrm{t})-\dot{\mathrm{m}}_{\mathrm{D}}(\mathrm{t})-\dot{\mathrm{m}}_{\mathrm{B}}(\mathrm{t}) \cdot\left(\mathrm{x}_{\mathrm{c}}(\mathrm{t})-\mathrm{x}_{\mathrm{a}}(\mathrm{t})\right)
$$


From this mass balance, a differential equation for the water mass fraction of the air in the space between absorber and glass cover was derived depending on the used adsorption model and the unknown variables for each mass flow.

Henry's Law:

$$
\begin{aligned}
& \frac{\mathrm{d}}{\mathrm{dt}}\left(\mathrm{x}_{\mathrm{c}}(\mathrm{t})\right)=-\mathrm{c}_{1, \mathrm{H}} \cdot \frac{\mathrm{d}}{\mathrm{dt}}\left(\mathrm{w}_{\mathrm{H}}(\mathrm{t})\right)-\mathrm{c}_{2} \cdot \dot{\mathrm{m}}_{\mathrm{B}}{ }^{*}(\mathrm{t}) \cdot\left(\mathrm{x}_{\mathrm{c}}(\mathrm{t})-\mathrm{x}_{\mathrm{a}}(\mathrm{t})\right)-\mathrm{c}_{3} \cdot \dot{\mathrm{m}}_{\mathrm{D}}{ }^{*}(\mathrm{t}) \\
& \mathrm{c}_{1, \mathrm{H}}=\frac{\mathrm{m}_{\mathrm{IM}} \cdot \mathrm{k}_{\mathrm{H}, \mathrm{o}}}{\mathrm{m}_{\mathrm{a}, \mathrm{c}}} \\
& \mathrm{c}_{2}=\frac{\mathrm{k}_{\mathrm{p}} \cdot \mathrm{h}_{\mathrm{c}}}{\mathrm{m}_{\mathrm{a}, \mathrm{c}}} \\
& \mathrm{c}_{3}=\frac{\mathrm{k}_{\mathrm{D}}}{\mathrm{m}_{\mathrm{a}, \mathrm{c}}} \\
& \dot{\mathrm{m}}_{\mathrm{B}}^{*}(\mathrm{t})=\rho_{\mathrm{N}} \cdot \mathrm{T}_{\mathrm{N}} \cdot \mathrm{g} \cdot \mathrm{h}_{\mathrm{c}} \cdot\left(\frac{1}{\mathrm{~T}_{\mathrm{a}}(\mathrm{t})}-\frac{1}{\mathrm{~T}_{\mathrm{c}}(\mathrm{t})}\right) \cdot\left[\mathrm{v}_{\mathrm{a}}(\mathrm{t}) \cdot\left(1+\mathrm{x}_{\mathrm{a}}(\mathrm{t})\right)\right]^{-1} \\
& \dot{\mathrm{m}}_{\mathrm{D}}^{*}(\mathrm{t})=\frac{\mathrm{D}}{\mathrm{R}_{\mathrm{W}} \cdot \mathrm{T}_{\mathrm{m}}(\mathrm{t})} \cdot\left(\mathrm{p}_{\mathrm{d}, \mathrm{c}}(\mathrm{t})-\mathrm{p}_{\mathrm{d}, \mathrm{a}}(\mathrm{t})\right)
\end{aligned}
$$

GAB-Model:

$$
\begin{aligned}
& \frac{\mathrm{d}}{\mathrm{dt}}\left(\mathrm{x}_{\mathrm{c}}(\mathrm{t})\right)=-\mathrm{c}_{1, \mathrm{GAB}} \cdot \frac{\mathrm{d}}{\mathrm{dt}}\left(\mathrm{w}_{\mathrm{GAB}}(\mathrm{t})\right)-\mathrm{c}_{2} \cdot \dot{\mathrm{m}}_{\mathrm{B}}{ }^{*}(\mathrm{t}) \cdot\left(\mathrm{x}_{\mathrm{c}}(\mathrm{t})-\mathrm{x}_{\mathrm{a}}(\mathrm{t})\right)-\mathrm{c}_{3} \cdot \dot{\mathrm{m}}_{\mathrm{D}}{ }^{*}(\mathrm{t}) \\
& \mathrm{c}_{1, \mathrm{GAB}}=\frac{\mathrm{m}_{\mathrm{IM}}}{\mathrm{m}_{\mathrm{a}, \mathrm{c}}}
\end{aligned}
$$

The parameters related with the mass balance $\left(c_{1, H}, c_{1, G A B}, c_{2}, c_{3}\right)$ and the parameters related with the adsorption models $\left(\mathrm{k}_{1}, \mathrm{k}_{2}, k_{H, T}\right)$ are set as adjustment variables and the water content of the air into the air gap between the absorber and transparent cover, which is calculated from the available measurement data, is set as target variable for the least squared method. For the calculation of the optimal set of parameters the Matlab ${ }^{\circledR}$ function "Isqcurvefit" was used. The relative humidity of this space is then derived from the corresponding value of temperature and the derived value for the water content for the air space. The time behavior of each mass flow is finally calculated with the optimal parameters from the least squared method and the mass of dry air to get the daily exchanged water quantities in the air space. For this, time integration for a time period of one day with the Matlab ${ }^{\circledR}$ function "trapz" is used.

$$
\begin{array}{ll}
\mathrm{m}_{\mathrm{ads}}(\mathrm{t})=\mathrm{m}_{\mathrm{a}, \mathrm{c}} \cdot \int_{0}^{\mathrm{t}} \dot{\mathrm{m}}_{\mathrm{ads}}(\mathrm{t}) \mathrm{dt} & \text { If } \dot{\mathrm{m}}_{\mathrm{Ads}}>0 \\
\mathrm{~m}_{\mathrm{des}}(\mathrm{t})=\mathrm{m}_{\mathrm{a}, \mathrm{c}} \cdot \int_{0}^{\mathrm{t}}\left|\dot{\mathrm{m}}_{\mathrm{ads}}(\mathrm{t})\right| \mathrm{dt} & \text { If } \dot{\mathrm{m}}_{\mathrm{Ads}}<0 \\
\mathrm{~m}_{\mathrm{in}}(\mathrm{t})=\mathrm{m}_{\mathrm{a}, \mathrm{c}} \cdot \int_{0}^{\mathrm{t}}\left|\dot{\mathrm{m}}_{\text {trans }}(\mathrm{t})\right| \mathrm{dt} & \text { If } \dot{\mathrm{m}}_{\mathrm{tr}}(\mathrm{t})<0 \\
\mathrm{~m}_{\mathrm{out}}(\mathrm{t})=\mathrm{m}_{\mathrm{a}, \mathrm{c}} \cdot \int_{0}^{\mathrm{t}} \dot{\mathrm{m}}_{\text {trans }}(\mathrm{t}) \mathrm{dt} & \text { If } \dot{\mathrm{m}}_{\mathrm{tr}}(\mathrm{t})>0 \\
\dot{\mathrm{m}}_{\mathrm{tr}}(\mathrm{t})=\dot{\mathrm{m}}_{\mathrm{D}}(\mathrm{t})+\dot{\mathrm{m}}_{\mathrm{B}}(\mathrm{t}) \cdot\left(\mathrm{x}_{\mathrm{c}}(\mathrm{t})-\mathrm{x}_{\mathrm{a}}(\mathrm{t})\right)
\end{array}
$$

\section{Results}

\subsection{Comparison of measured and modelled relative humidity}

Fig. 6, Fig. 7 and Fig. 8 show the comparison of the measured and modelled relative humidity in the air gap between absorber and transparent cover. For collector 1 and collector 2 the agreement between modelled (GAB Model) and measured values are very good. For collector 3 the agreement is not as good like for collector 1 and 2 , however, the development of the relative humidity is still quite well modelled. The reason for the larger deviation is the fact that a significant portion of the humidity in the air entering the collector is absorbed locally in the insulation material which is passed by the entering air. This is not the case for collector 1 and collector 2 where the ambient air is entering directly the air gap between absorber and transparent cover without passing through the insulation material. 
S. Fischer et. al. / EuroSun 2018 / ISES Conference Proceedings (2018)

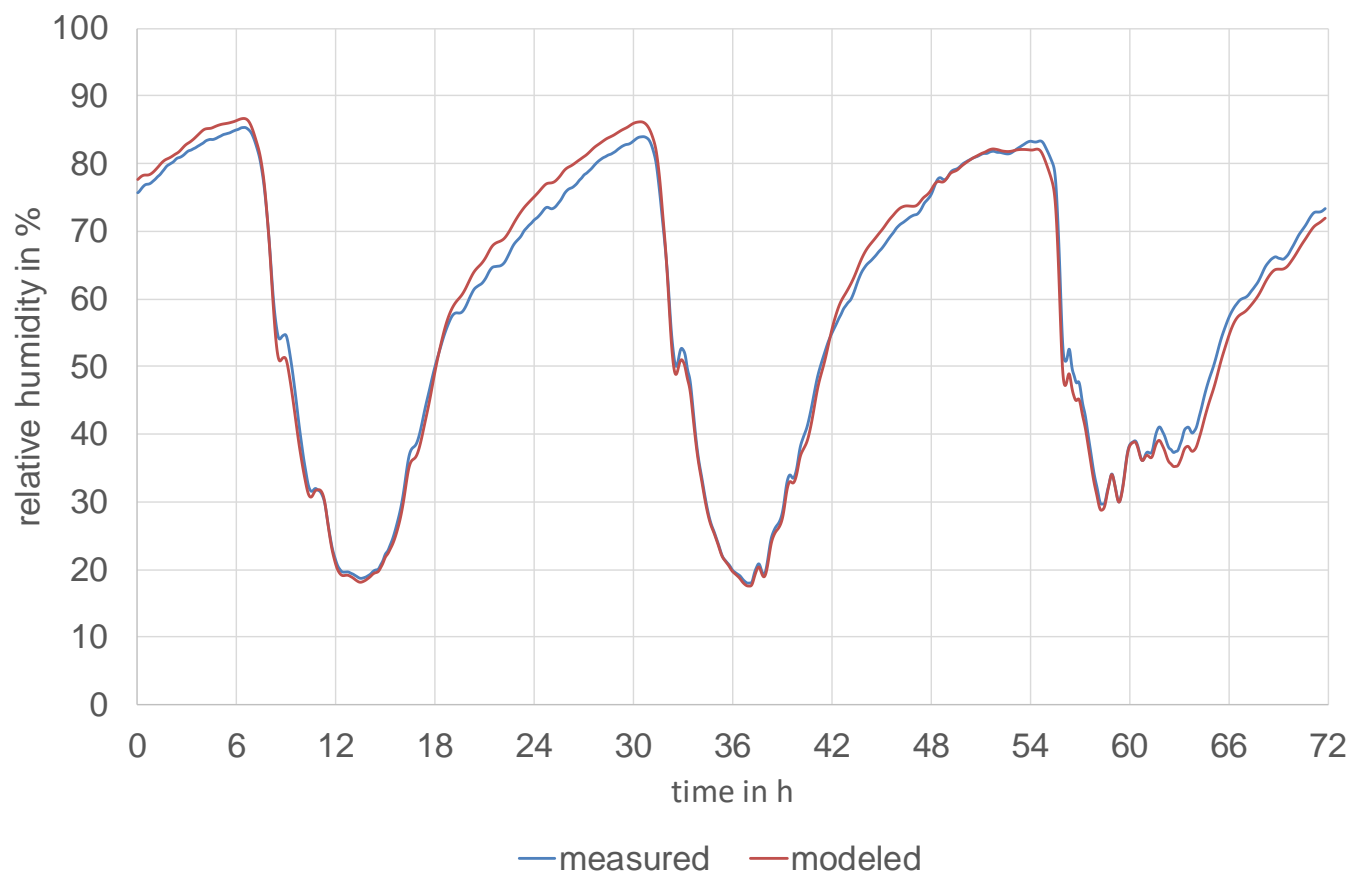

Fig. 6. Comparison measured and modelled relative humidity in the air gap between absorber and transparent cover of collector 1 at three consecutive days at at the exposure site Kochi, India

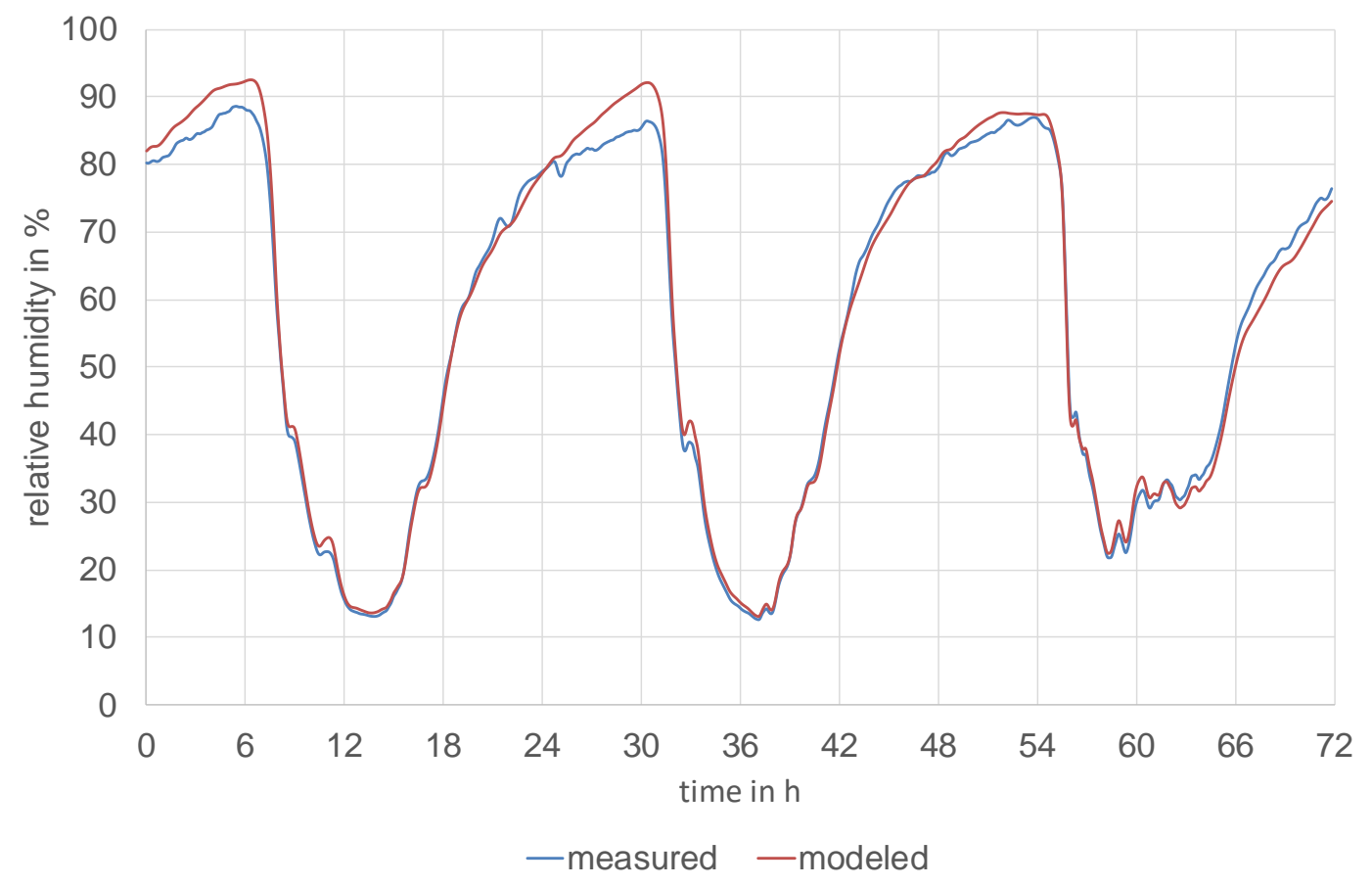

Fig. 7. Comparison measured and modelled relative humidity in the air gap between absorber and transparent cover of collector 2 at three consecutive days at at the exposure site Kochi, India 


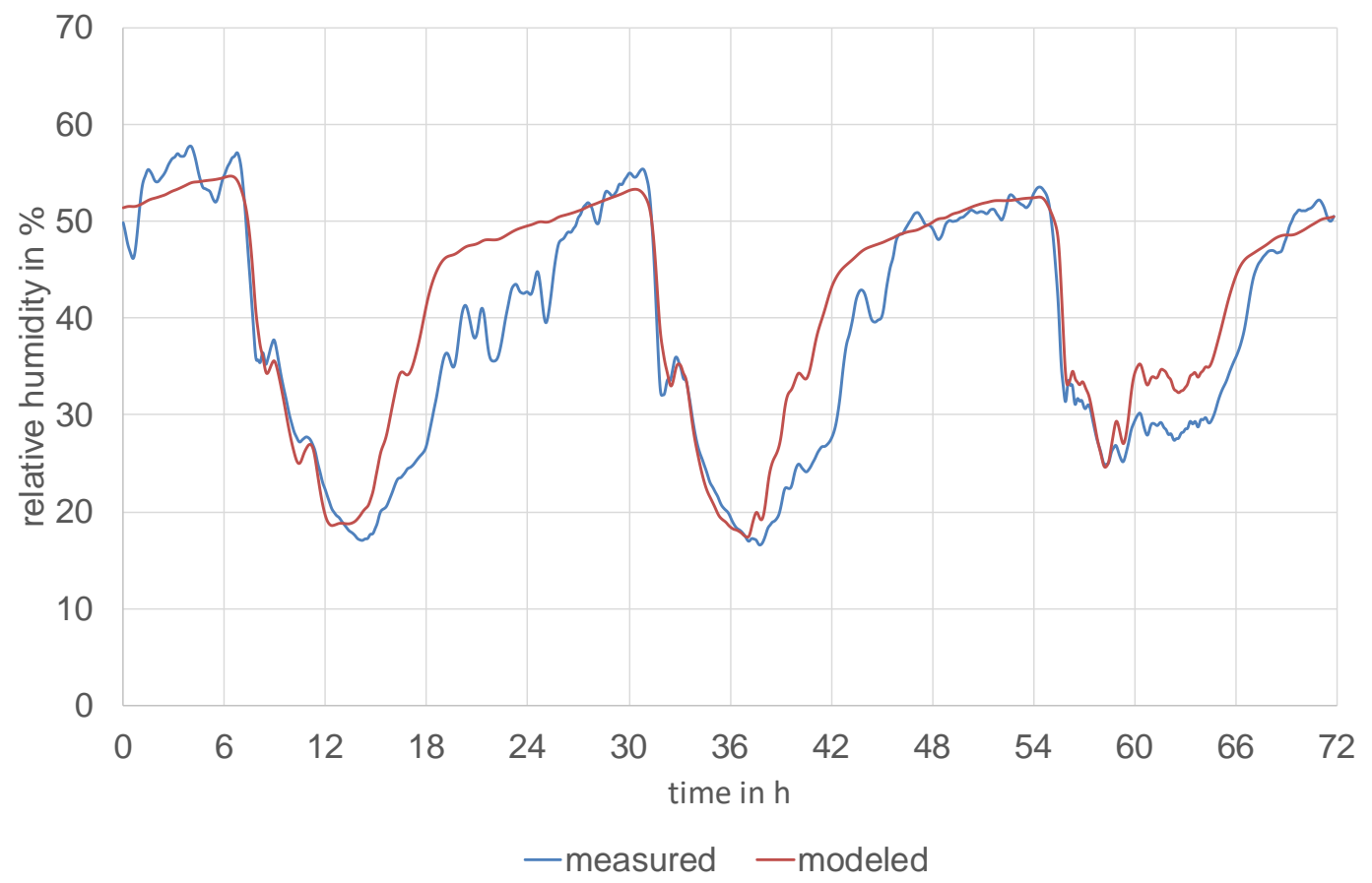

Fig. 8. Comparison measured and modelled relative humidity in the air gap between absorber and transparent cover of collector 3 at three consecutive days at at the exposure site Kochi, India

\subsection{Water exchange between the inside of the collector and ambient}

Using the equations shown in section 4 the water vapor adsorbed and desorbed from the insulation material can be calculated as well as the water vapor entering and leaving the air gap between the absorber and the transparent cover. Fig. 9 and Fig. 10 show the adsorbed (blue dots) and desorbed (red dots) water as well as the entering (green dots) and leaving (black dots) water for collector 2 and collector 3 for January 2015 at the exposure site Kochi, India. The solid lines represent the mean values for the month.

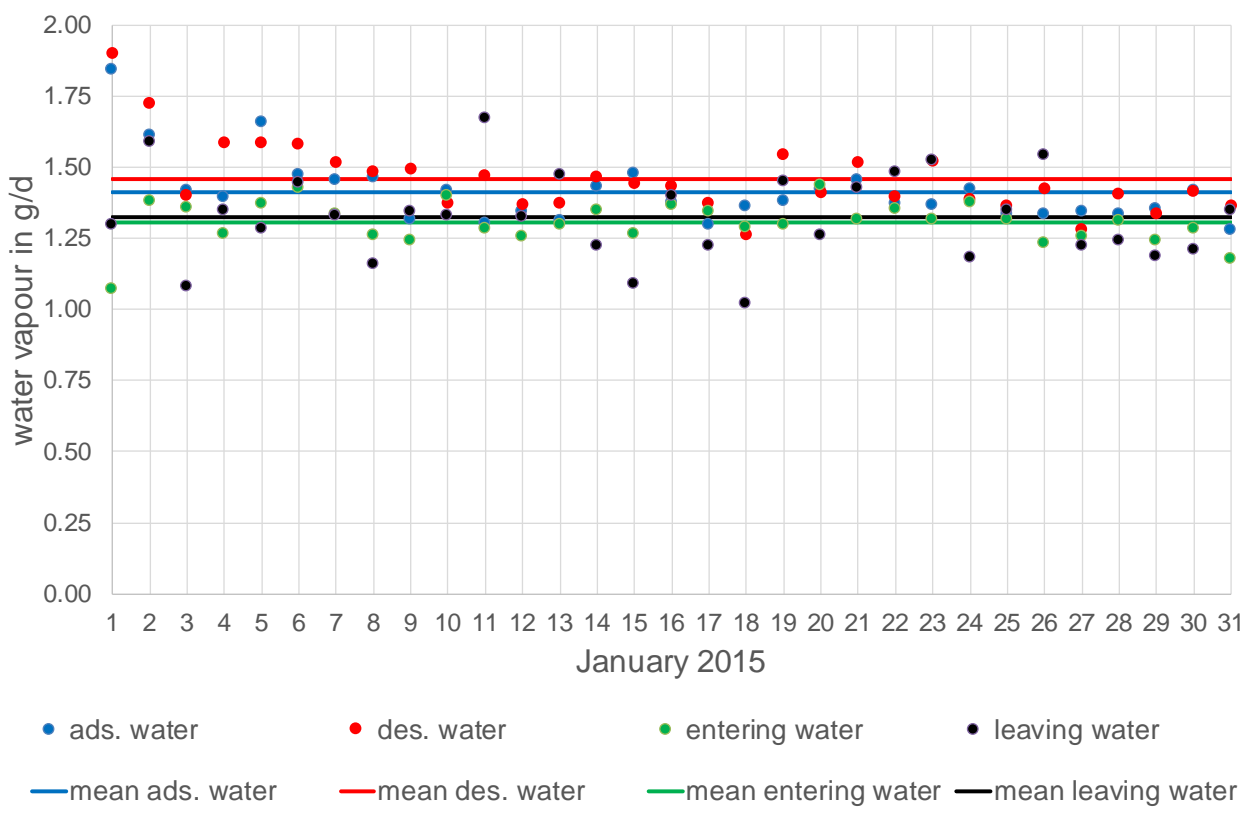

Fig. 9. Water vapour adsorbed (blue) and desorbed (red) by the insulation material and water vapour entering (green) and leaving (black) the air gap between the absorber and transparent cover for collector 2 at the exposure site Kochi, India 


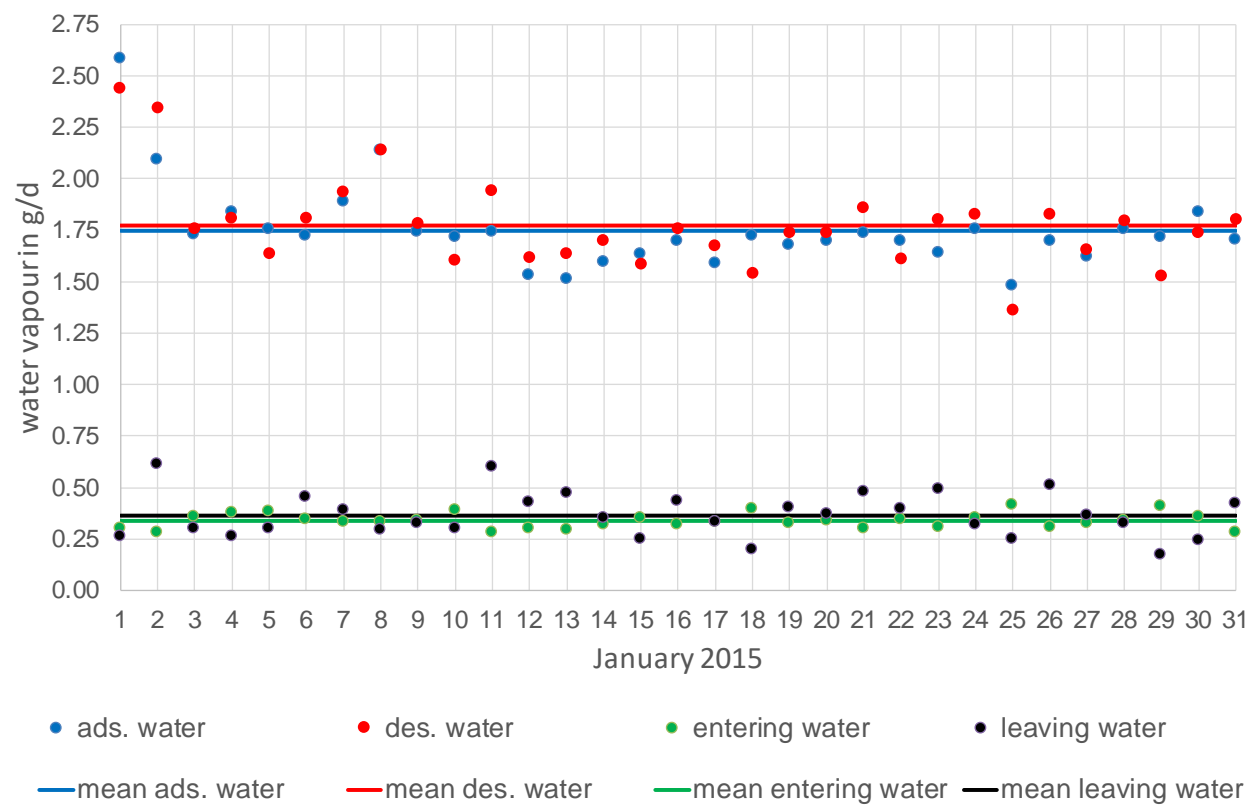

Fig. 10. Water vapour adsorbed (blue) and desorbed (red) by the insulation material and water vapour entering (green) and leaving (black) the air gap between the absorber and transparent cover for collector 3 at the exposure site Kochi, India

The amount of water adsorbed and desorbed as well as the water entering and leaving the air gap between absorber and transparent cover can be quite different from day to day depending on the weather conditions, however, the mean values show that in the long run the quantities (adsorbed/desorbed and entering/leaving) are the same.

A big difference in the amount of water entering and leaving the air gap between the absorber and the transparent cover can be observed for collector 2 and 3. This is due to the different ventilation strategies of the collectors. Collector 2 allows the ambient air to enter the air gap directly whereas the ambient air needs to pass through insulation material at collector 3 before entering the air gap and vice versa which results in ad- and desorption of water in the insulation material and a smaller air volume flow through the air gap, see Fig. 11 and thus to a smaller amount of water vapor entering and leaving the air gap between absorber and transparent cover, see Fig. 12.

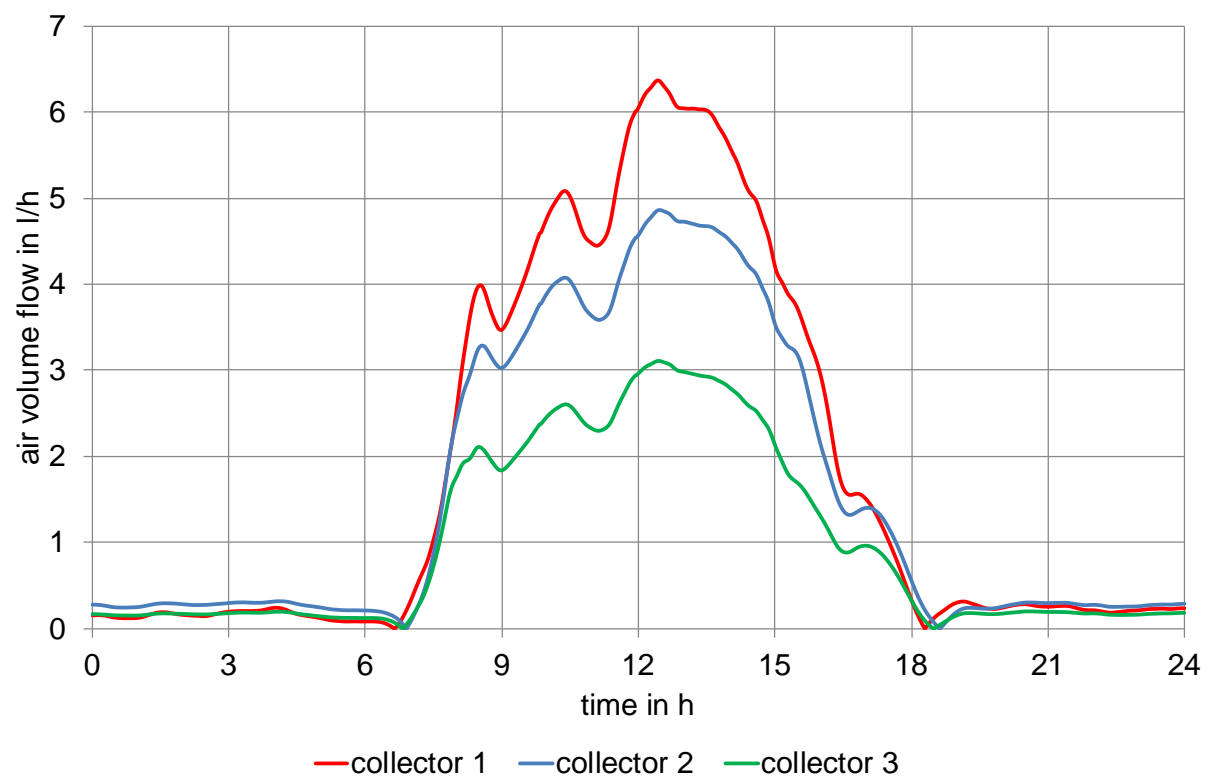

Fig. 11. Air volume flow through air gap between absorber and transparent cover on 16.12 .2014 at the exposure site Kochi, India 


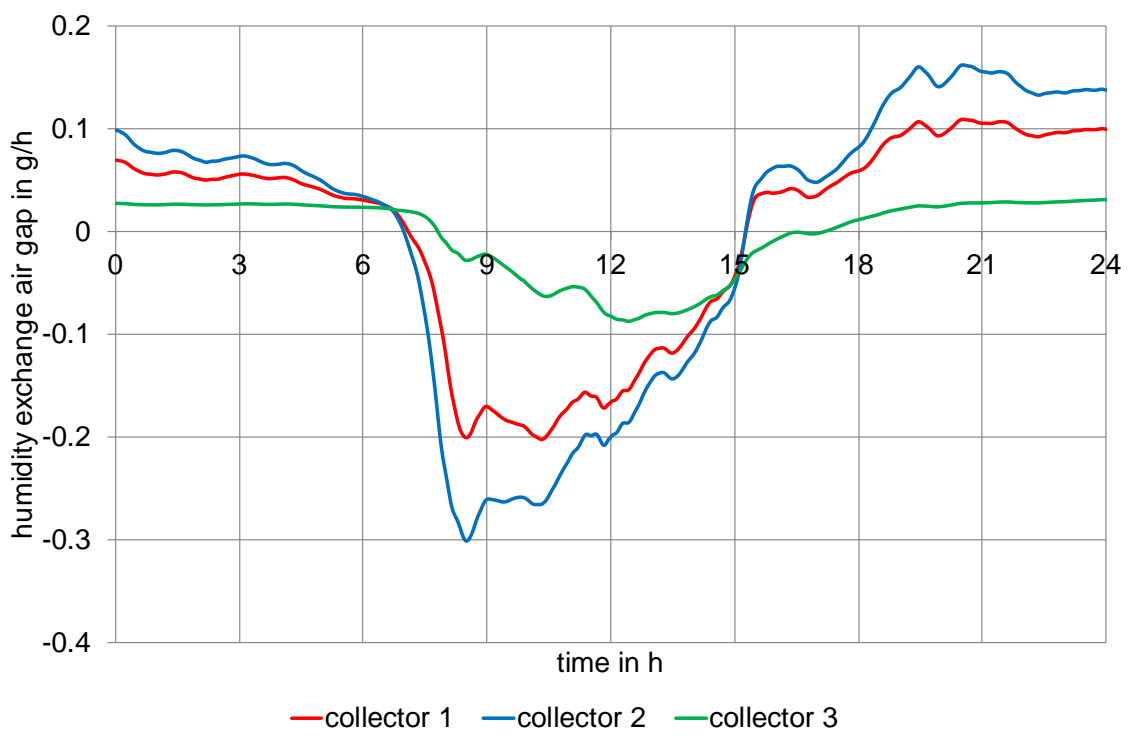

Fig. 12. Humidity exchange between ambient and air gap between absorber and transparent cover on 16.12 .2014 at the exposure site Kochi, India

\subsection{Interpretation of the results}

Although the model is able to calculate the relative humidity in the air gap between the absorber and the transparent cover very well (see Fig. 6, Fig. 7 and Fig. 8) the values for the water vapor ad- and desorbed as well as the water vapor entering have to be questioned and discussed respectively.

In case of collector 1 and 2 which use mineral wool as thermal insulation material the amount of water vapor adsorbed and desorbed are in a realistic range when compared to indoor measurements of adsorption isotherms and mass increase when the material is charged with water vapor. However, for collector 3 using melamine foam as thermal insulation material there is a discrepancy between the calculated values and the theoretical values based on adsorption isotherms. Here the amount of adsorbed water vapor should be higher. The reason for this is the fact that on the one side most of the water vapor properly will locally adsorbed at the areas were the ambient air enters the collector through the insulation material and the air from the air gap leaves the collector through the insulation material. Whereas on the other hand only one sensor to measure the relative humidity is placed in the middle of the collector.

The volume flow of air entering and leaving the air gap between absorber and transparent cover is underestimated for all three collectors by the model. Realistic values should be 10 to 20 times higher. The reason for this is the overestimation of the diffusion of water vapor though leaks in the casing without air exchange and the placement of the temperature and humidity sensor at a location where the volume flow of air in the air is rather small compared to other locations. Nevertheless, the model is able to give a qualitative statement about the humidity balance within the solar collectors and their ventilation strategies.

\section{Summary and outlook}

A mathematical model based on physical phenomena is introduced to model the relative humidity within flat plate collectors. Using the model, the water vapor which enters and leaves the collector as well as the water which is ad- and desorbed by the thermal insulation material during operation can be estimated and conclusion can be drawn about the humidity balance in the investigated flat plate collectors and their ventilation system.

Based on this knowledge special indoor humidity test can be developed as part of an overall accelerated aging test procedure for flat plate collectors.

For further understanding and modelling of the humidity balance of flat plate collectors more detailed experiments using humidity and air flow sensors will be carried out within the SpeedColl2 project. These measurements are also used to validate CFD models which are also developed with in the project. 


\section{Nomenclature and Symbols}

Tab. 2: List of symbols

\begin{tabular}{|c|c|c|}
\hline Quantity & Symbol & Unit \\
\hline Area & A & $\mathrm{m}^{2}$ \\
\hline Diffusion coefficient of water in air & $\mathrm{D}$ & $\mathrm{m}^{2} \mathrm{~s}^{-1}$ \\
\hline Constants of mass balance & $c_{1}, c_{2}, c_{3}$ & - \\
\hline Adsorption enthalpy of water (monolayer condensation) & $\mathrm{E}_{\mathrm{a}}$ & $\mathrm{J} \mathrm{kg}^{-1}$ \\
\hline Mean adsorption enthalpy of water & $E_{m}$ & $\mathrm{~J} \mathrm{~kg}^{-1}$ \\
\hline Adsorption enthalpy of water (multilayer condensation) & $\mathrm{E}_{\mathrm{L}}$ & $\mathrm{J} \mathrm{kg}^{-1}$ \\
\hline Constants of GAB model & $\mathrm{k}_{1}, \mathrm{k}_{2}$ & $\mathrm{~K}$ \\
\hline Constant for diffusion mass flux & $\mathrm{k}_{\mathrm{D}}$ & $\mathrm{m}$ \\
\hline Proportionality constant Henry’s law & $\mathrm{k}_{\mathrm{H}}$ & $\mathrm{kg} \mathrm{kg}^{-1}$ \\
\hline Constant for temperature dependence of Henry’s law & $\mathrm{k}_{\mathrm{H}, \mathrm{o}}$ & $\mathrm{kg} \mathrm{kg}^{-1}$ \\
\hline Constant for temperature dependence of Henry’s law & $\mathrm{k}_{\mathrm{H}, \mathrm{T}}$ & $\mathrm{K}$ \\
\hline Flow coefficient of the ventilation openings & $\mathrm{k}_{\mathrm{p}}$ & $\mathrm{m}^{3} \mathrm{pa}^{-1} \mathrm{~s}^{-1}$ \\
\hline Vertical distance between ventilation openings & $\mathrm{h}_{\mathrm{c}}$ & $\mathrm{m}$ \\
\hline Mass & $\mathrm{m}$ & $\mathrm{kg}$ \\
\hline Mass flow & $\dot{\mathrm{m}}$ & $\mathrm{kg} \mathrm{s}^{-1}$ \\
\hline Mass flux & $\dot{\mathrm{m}}^{\prime \prime}$ & $\mathrm{kg} \mathrm{m}^{-2} \mathrm{~s}^{-1}$ \\
\hline Total pressure & $\mathrm{p}$ & $\mathrm{Pa}$ \\
\hline Partial pressure of water & $\mathrm{p}_{\mathrm{d}}$ & $\mathrm{Pa}$ \\
\hline Gas constant & $\mathrm{R}_{\mathrm{L}}$ & $\mathrm{J} \mathrm{kg}^{-1} \mathrm{~K}^{-1}$ \\
\hline Time & $t^{L}$ & S \\
\hline Temperature & $\mathrm{T}$ & $\mathrm{K}$ \\
\hline Normed temperature & $\mathrm{T}_{\mathrm{N}}$ & $\mathrm{K}$ \\
\hline Mean temperature between collector and ambient & $\mathrm{T}_{\mathrm{m}}$ & $\mathrm{K}$ \\
\hline Specific volume of air & $\mathrm{v}$ & $\mathrm{m}^{3} \mathrm{~kg}^{-1}$ \\
\hline Volume flow & $\dot{\mathrm{V}}$ & $\mathrm{m}^{3} \mathrm{~s}^{-1}$ \\
\hline Water content of insulating material & w & $\mathrm{kg} \mathrm{kg}^{-1}$ \\
\hline $\begin{array}{l}\text { Water content of insulating material after monolayer } \\
\text { condensation }\end{array}$ & $\mathrm{w}_{\mathrm{mG}}$ & $\mathrm{kg} \mathrm{kg}^{-1}$ \\
\hline Water content of air & $\mathrm{x}$ & $\mathrm{kg} \mathrm{kg}^{-1}$ \\
\hline
\end{tabular}

Tab. 3: List of Greek symbols

\begin{tabular}{lll}
\hline Quantity & Symbol & Unit \\
\hline Relative humidity & $\varphi$ & - \\
Diffusion resistance factor & $\mu$ & $\mathrm{m}$ \\
Flow distance of the vapour through the leaks & $\delta$ & $\mathrm{kg} \mathrm{m}^{-3}$ \\
Normed density & $\rho_{\mathrm{N}}$ & $\mathrm{J} \mathrm{kg}$ \\
Adsorption enthalpy of water & $\Delta \mathrm{H}_{\mathrm{H}}$ & $\mathrm{Pa}$ \\
Pressure difference for air buoyance & $\Delta \mathrm{p}_{\mathrm{T}}$ & \\
\hline
\end{tabular}

Tab. 4: Subscripts

\begin{tabular}{ll}
\hline Quantity & Symbol \\
\hline Air & a \\
Water adsorption & ads \\
Air buoyance & B \\
Space between glass cover and absorber & $\mathrm{c}$ \\
Water diffusion & $\mathrm{D}$ \\
Desorption & des \\
GAB model & GAB \\
Henry’s law & $\mathrm{H}$ \\
Inlet & in \\
Insulating material & $\mathrm{IM}$ \\
Outlet & out \\
Transported & tr \\
Water & w \\
\hline
\end{tabular}




\section{References}

Collet F., Achchaq F., Djellab K., Marmoret L., Beji H. 2011, „Water vapor properties of two hemp wools manufactured with different treatments, "Construction and Building Materials, pp. 1079-1085, 15 July 2011.

Feng J. 2001, "Interaction and permeability of water with liquid crystalline thermoset," University of Florida, Florida, 2001

Fischer, S. 2017. Test Procedure for Accelerating Aging of Solar Thermal Collectors, ISES Solar World Congress \& SHC Conference, Abu Dhabi, 29.10. - 02.11.2017, ISES conference Proceedings (2017)

Kofler, P., Traub, B., Fischer, S., Drück, H., 2013. Alterungseinflüsse auf Sonnenkollektoren in gemäßigten und tropischen Klimazonen, Tagungsband zum 23. Symposium Thermische Solaranlagen, Seiten 138-139 (Kurzfassung), Kloster Banz, Bad Staffelstein, 24. - 26.04.13, ISBN 978-3-943891-10-2

Sing K. S. W., Everett D. H., Haul R. A. W., Moscou L., Pierotti R. A., Rouquérol J., Siemieniewska T., "Reporting physisorption data for gas/solid systems with special reference to the determination of surface area and porosity, ”Pure and Applied Chemistry, Vol. 57. No. 4, pp.603-219, 1985.

Traub, B., Kofler, P., Fischer, S., Drück, H., 2012. Beanspruchung von Sonnenkollektoren unter Berücksichtigung unterschiedlicher Klimazonen und Anwendungen, Tagungsband zum 22. Symposium Thermische Solaranlagen, Seiten 154-155 (Kurzfassung), Kloster Banz, Bad Staffelstein, 09.05. - 11.05.12, ISBN 978-3-941785-89-2

\section{Acknowledgements}

The research projects "Development of Accelerated Ageing Tests for Solar Thermal Collectors and their Components", acronym "SpeedColl", and "Estimation of the service life of solar collectors and its components", acronym "SpeedColl2", are funded by the German Federal Ministry for Economic Affairs and Energy by resolution of the German Parliament and managed by Project Management Jülich (PTJ) under grant numbers 0325969B and 0325865B. The author gratefully acknowledges this support and take the responsibility for the contents of this publication. 


\title{
Comparative Analysis of Life-Cycle Assessment Tools (LCA) Using the Example of Different Energy Supply Variants of a Purpose-Built Building
}

\author{
Ronny Kastner ${ }^{1}$, Michaela Reim ${ }^{1}$, Yue $\mathbf{Y u}^{1}$ and Stephan Weismann ${ }^{1}$ \\ ${ }^{1}$ Bavarian Center for Applied Energy Research (ZAE Bayern), Magdalene-Schoch-Str. 3, 97074 \\ Würzburg (Germany)
}

\begin{abstract}
Using a newly planned building as example, the results of three life cycle assessment (LCA) tools, which use different databases, were in this paper compared.

The first research question in this paper was which energy concept can be used to achieve the lowest environmental impact depending of the used LCA tool within the lifecycle of the building.

The second research question of the paper is which tool is most practical for the life cycle assessment of new office and administrative buildings. The evaluated LCA tools were eLCA, SBS, LEGEP and LEGEP precheck, which are using different databases (OEKOBAUDAT 2011, 2013, 2015 and 2016). Corresponding to the same assessment basis, the resulting degree of fulfilment values using Ökobaudat 2015 or 2016 are significantly higher than those using Ökobaudat 2011 or 2013 . Both the emission related environmental impact and the energy demand are significantly higher for the final results than for the preliminary results obtained in the pre-planning phase.
\end{abstract}

Keywords: LCA, eLCA, SBS, LEGEP, LEGEP precheck, life cycle assessment tools, Environmental station, LCA, recycled concrete, eco-concrete, ice storage, daylight utilization

\section{Introduction}

Life-cycle assessment (LCA) is a technique to assess environmental impacts associated with all the stages of a product's life from raw material extraction through materials processing, manufacture, distribution, use, repair and maintenance, and disposal or recycling. For building assessments in Germany and Europe, a uniform evaluation method is defined by the standard DIN EN 15978:2011. For the certification of sustainable buildings according to BNB ("Bewertungssystem Nachhaltiges Bauen") or DGNB ("Deutsche Gesellschaft Nachhaltiges Bauen") a life cycle assessment according to this standard is required.

Using the example of the new 'Environmental Station' in Würzburg, located in the south of Germany, three life cycle assessment tools - eLCA (eLCA 2018), SBS (SBS 2018) and LEGEP (LEGEP 2018) - are tested and compared. The Environmental Station is an information and education point for the citizens of the City of Würzburg and was planned as an office and administration building. The floor area is approximately $700 \mathrm{~m} 2$. It was constructed mostly in reinforced concrete and recycling concrete.

The Environmental Station should serve as a model in terms of environmental impact and energy consumption. Therefore, one main research object was to find an energy supply concept which shows the lowest environmental impact within the lifecycle of the building. In this context, different LCA tools were used to investigate a bunch of possible options for the energy concept.

A life cycle analysis could be a time consuming task. Especially during the planning phase, quick decision about possible design variants must be made and this should be done on a well-defined knowledge basis. There is a need for LCA tools which can be easy handled in the daily use with little time expenditure. Therefore, a second research question of the paper was which LCA tool is most practical for the life cycle assessment buildings during the planning and construction phase. 


\section{LC analysis of the Environmental Station}

The Environmental Station design was derived by an architecture competition. Part of the concept is to adapt the building to the existing natural environment and to create a connection between architecture and nature (see Figure 1). The entrance floor welcomes the visitor with its generously proportioned entrance foyer. There is plenty of space for temporary exhibitions and terrariums that provide information about the local flora and fauna. An extensive library as well as two media workstations are available to young and old visitors as a source of information. Adjacent to the foyer are the reception office and an office for two further employees. In addition, the ground floor houses the archive and storage rooms as well as the necessary technical rooms. On the upper floor there are two seminar rooms in which lectures and courses for adults and children take place. In addition, there are sufficient offices where interested citizens can obtain advice on topics such as waste, the environment and energy.

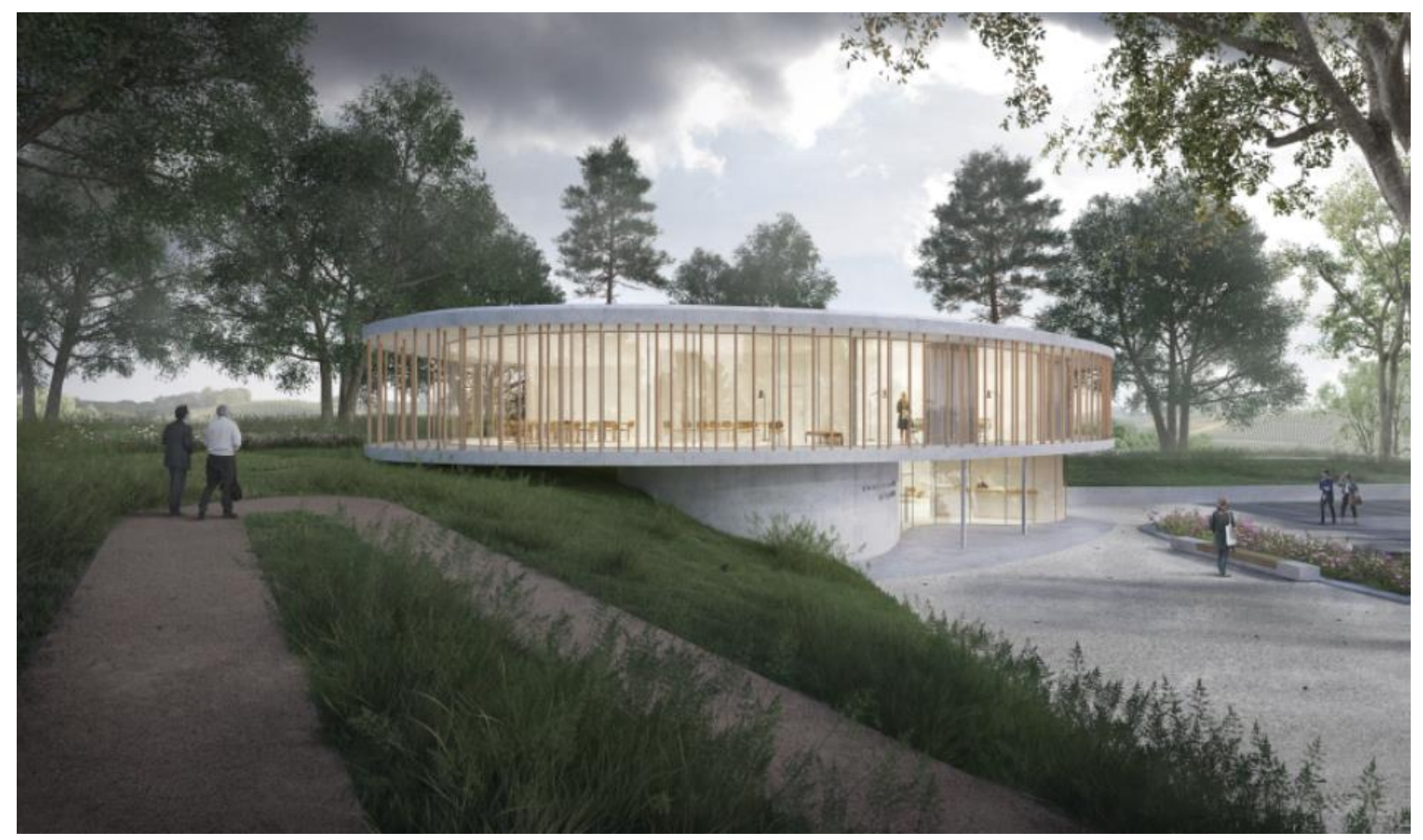

Fig. 1: Visualization of the winning design of the planned Environmental Station $\odot$ balda architekten.

The LCA tools used here are $e L C A, S B S, L E G E P$ and LEGEP Precheck.

$\boldsymbol{e L C A}$ is an open source online tool for building-based life cycle assessment. eLCA was introduced at the end of 2015 and addressed to "planners, architects and builders" (BBSR 2015). The development was developed by the German „Bundesinstitut für Bau-, Stadt- und Raumforschung (BBSR)“, supported by the „Bundesministerium für Umwelt, Naturschutz, Bau und Reaktorsicherheit (BMUB)““.

SBS Building Sustainability is a building-related online tool. Constructions with individual layer structures can be created based on Ökobau.dat and other databases (Fraunhofer IBP and PE International 2013). The evaluations show both the LCA values and evaluation points for a DGNB certification.

LEGEP (abbreviation for "Lebenszyklus-Gebäude-Planung" (Pelzeter 2006) is a commercial calculation tool for "integral planning of sustainable buildings". It is the oldest tool among the three solutions and was originally developed in 2000 by a research project of the University of Karlsruhe (Pelzeter 2006). The tool is maintained by LEGEP Software GmbH (LEGEP 2018). LEGEP consists of different modules. Based on a proprietary method, which provides a step-by-step detailed presentation, lifecycle costs, production costs and energy requirements can be calculated in addition to life cycle assessment (Pelzeter 2006). The ecological and economic parameters can be used for the assessment according to the BNB or DGNB certification system (ZAE 2016). A special feature of this program is that product declarations EPD that are not yet included in the eco-budget can be included in the program. 
LEGEP Precheck is a simplified tool used for preliminary estimations according to DGNB. It is based on typical benchmark values for the construction and final energy demand of the building (ZAE 2016).

The LCA-tools base on records contained in the associated LCA-database (latest version is Ökobaudat 2018). Older versions Ökobaudat 2011, 2013, 2015 and 2016 were obtained from different LCA software tools - eLCA, SBS and LEGEP. Furthermore a comparing analysis of the combination of the variants of the insulation standard with the various building techniques was performed. Subsequently, the variants of the energy standard of the building envelope were combined with the various technical building systems resulting in 24 variations generated from four LCA-Tools. The emissions-related environmental impacts global warming potential (GWP), acidification potentials (AP), ozone depletion potential (ODP), photochemical ozone creation potential (POCP) and the eutrophication potential (EP) and furthermore the non-renewable primary energy demand and the total primary energy demand were calculated. Additionally, a plausibility analysis was carried out to determine incorrectly entered data.

For comparison of the variations the evaluation system of the DGNB NBV15 (DGNB, 2015) was applied. Finally, a degree of fulfillment according to DGNB was determined. This degree of fulfilment is a measure of the ecological quality of the building. It is based on two parts, the emission-related environmental impact and the primary energy demand of the building. From these values a dimensionless property in the range from zero to 111.7 is calculated, a higher value means a better ecological quality of the building. For a new office and administration building a degree of fulfillment above about 80 is an excellent value.

Further boundary conditions were:

- In the preliminary planning / design planning, it was still unclear which heating technology was to be used. Therefore, an ecological calculation was carried out with different heat supply variants: pellet heating, an air-water heat pump or a water-water heat pump with ice storage.

- A planned large PV system was not taken into account when calculating the LCA according to DGNB. Calculations with PV (estimated output $28.000 \mathrm{kWh}$ per year) showed that an extremely good result in the LCA of the DGNB near the maximum score could be achieved. In this case the properties of the building structure itself has no more significant influence on the results of the LCA.

Three different variants for the energy concept were investigated. All variations are for the energy PLUS house insulation standard (even better than passive house standard).

\section{Results}

\subsection{Comparison of SBS, eLCA and LEGEP}

Table 1, table 2 and table 3 show the comparison of the degree of fulfillment for different variations of the building analyzed with different LCA-tools The first variation in table 1 is for pellet heating (pellet), table 2 is for heat pump (HP) and table 3 is for heat pump with ice-storage (HP + icestorage) as heat supply system. The results are (whereby a degree of fulfillment of 80 is considered very well according to the DGNB classification system):

- Using the tool eLCA, the fulfillment levels are between 73.8 and 85.4, which is relatively high. The best building variant is the "Plus building envelope with pellet heating" variant.

- Using the tool SBS the fulfillment levels are between 75.7 and 89.3, which is relatively high, too. The best variant is again the "Plus building envelope with pellet heating".

- With LEGEP, compliance levels are between 86.4 and 106.8, close to the full score, which is significantly higher than using the eLCA and SBS tools. In contrast to the other tools, however, the best variant is the "Plus building envelope with heat pump (WP) and ice storage". During this project, LEGEP was used with three different databases: Ökobaudat 2011, Ökobaudat 2015 and Ökobaudat 2016.

- LEGEP Precheck is a simplified procedure in LEGEP, which shows the complete building construction with average values according to the LCA of the DGNB. It should help the user to get an initial, easy and quick ecological estimate for the building. Required for the entry is only the energy consumption of 
the planned building and the corresponding reference building calculated according to EnEV (EnEV 2018). Consequently, the user can save a lot of time using Precheck. The fulfillment degrees calculated with LEGEP Precheck are between 97.9 and 103.1 points, which are also similar than the results obtained with LEGEP, but much better results than the results obtained with eLCA and SBS tools for the best variant. On the other hand, the big advantage of LEGEP Precheck is that the data input takes only a couple of minutes.

However, further plausibility analysis yielded that the reason for the good results of the variants with heat pump (WP) calculated with LEGEP and Precheck was that the auxiliary energy for heat pump was not considered (software bug in LEGEP).

In summary, the results from eLCA and SBS are relatively consistent, and LEGEP and LEGEP Precheck are relatively consistent as well but at a higher degree of fulfillment.

Tab. 1: Comparison of all tools for the Energy PLUS-house standard with pellet heating as energy supply according to the DGNB (German Sustainable Building Council) degree of fulfillment. Implausible results are marked with red digits.

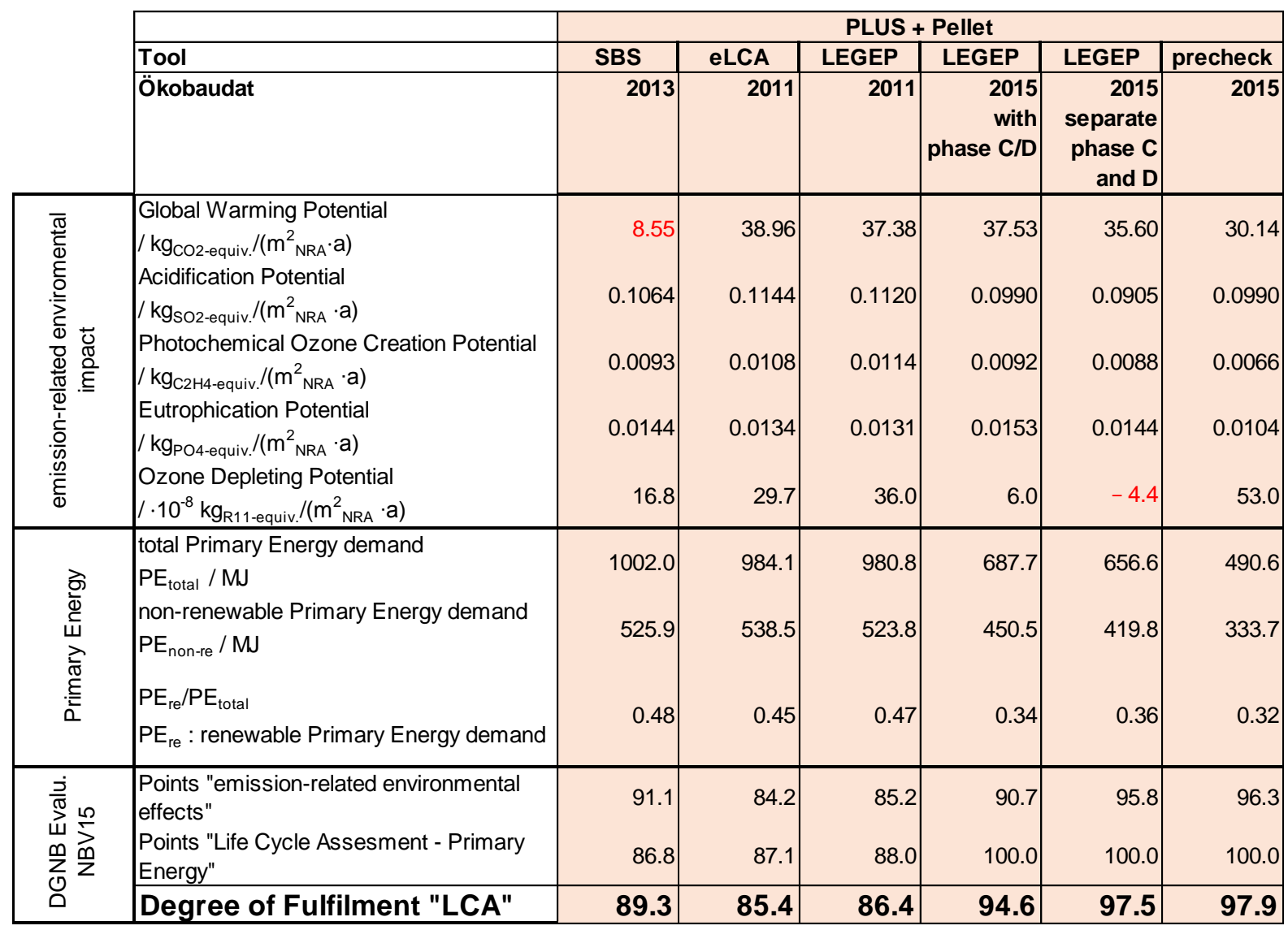

Table 1 shows a very good agreement with regard to the individual values and the overall result "degree of fulfillment LCA" between LEGEP and eLCA with the Ökobaudat 2011. The results with SBS and the Ökobaudat 2013 were slightly higher in the degree of fulfillment than the evaluations with SBS and LEGEP 2011.

The evaluations with the Ökobaudat 2015 in LEGEP showed a clear improvement. Taking into account the separate phases C (dismantling) and D (recycling) according to DIN EN 15804 using LEGEP 2015, the result improves significantly. Detailed evaluations have shown that LEGEP 2015 with common phase C / D completely disregarded the recycling credits in phase D. Consequently, the result of LEGEP 2015 with separate phase C and D is more accurate than the evaluation LEGEP 2015 with joint phase C / D. 
A detailed evaluation of the use phase of the building within 50 years shows that the global warming potential calculated with SBS and the Ökobaudat 2013 results in implausible values. Within the project it was not possible to determine the reason for that.

In a new program version of LEGEP (published during this project), it was possible to investigate the separation of phases C and D according to DIN EN 15804. LEGEP and the according Ökobaudat 2015 with separate phase $\mathrm{C}$ and $\mathrm{D}$ show an even better result with 97.5 points. The earlier program version of LEGEP has ignored recycling (phase D). If, as in the new LEGEP versions, phase C (dismantling) and phase D are considered separately, the result in almost all ecological values changed once again for the better. This is caused by the credits in the recycling phase. Detailed evaluations confirmed that previously LEGEP did not consider phase D.

However, the result of the ozone depletion potential (marked in red in table 1) as a negative value is implausible. Further research found that this was due to unrealistically high Phase D credits. Considering phase D, significantly better ecological results are expected in the future. Thus, ecological calculations from different software versions are definitely not comparable.

Tab. 2: Comparison of all LCA tools for the Energy PLUS insulation standard with heat pump (HP) according to the DGNB degree of fulfillment. Implausible values are again marked red.

\begin{tabular}{|c|c|c|c|c|c|c|c|}
\hline & & \multicolumn{6}{|c|}{ PLUS + HP } \\
\hline & \multirow{2}{*}{\begin{tabular}{|l|} 
Tool \\
Ökobaudat
\end{tabular}} & SBS & eLCA & LEGEP & LEGEP & LEGEP & precheck \\
\hline & & 2013 & 2011 & 2011 & \begin{tabular}{|r|}
2015 \\
with \\
phase $\mathrm{C} / \mathrm{D}$
\end{tabular} & $\begin{array}{r}2015 \\
\text { separate } \\
\text { phase C } \\
\text { and D }\end{array}$ & 2015 \\
\hline \multirow{5}{*}{ 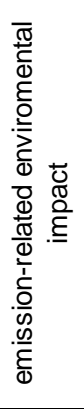 } & $\begin{array}{l}\text { Global Warming Potential } \\
/ \mathrm{kg}_{\mathrm{CO} \text {-equiv }} /\left(\mathrm{m}^{2}{ }_{\mathrm{NRA}} \cdot \mathrm{a}\right)\end{array}$ & 48.17 & 43.65 & 30.84 & 33.11 & 37.72 & 27.49 \\
\hline & $\begin{array}{l}\text { Acidification Potential } \\
/ \mathrm{kg}_{\text {so2-equiv. }} /\left(\mathrm{m}^{2}{ }_{\mathrm{NRA}} \cdot \mathrm{a}\right)\end{array}$ & 0.0907 & 0.0943 & 0.0700 & 0.067 & 0.0711 & 0.0650 \\
\hline & $\begin{array}{l}\text { Photochemical Ozone Creation Potential } \\
/ \mathrm{kg}_{\mathrm{C} 2 \mathrm{H} 4 \text {-equiv. }} /\left(\mathrm{m}^{2}{ }_{\text {NRA }} \cdot \mathrm{a}\right)\end{array}$ & 0.0079 & 0.0095 & 0.0076 & 0.0065 & 0.0067 & 0.0063 \\
\hline & $\begin{array}{l}\text { Eutrophication Potential } \\
/ \mathrm{kg}_{\mathrm{PO} \text {-equiv. }} /\left(\mathrm{m}_{\mathrm{NRA}}^{2} \cdot \mathrm{a}\right)\end{array}$ & 0.0102 & 0.0097 & 0.0073 & 0.0088 & 0.0100 & 0.0092 \\
\hline & $\begin{array}{l}\text { Ozone Depleting Potential } \\
/ \cdot 10^{-8} \mathrm{~kg}_{\mathrm{R} 11 \text {-equiv. }} /\left(\mathrm{m}^{2}{ }_{\mathrm{NRA}} \cdot \mathrm{a}\right)\end{array}$ & 30.8 & 46.1 & 34.0 & 6.0 & -3.5 & 53.0 \\
\hline \multirow{4}{*}{ 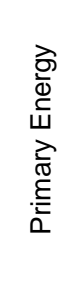 } & $\begin{array}{l}\text { total Primary Energy demand } \\
\mathrm{PE}_{\text {total }} / \mathrm{MJ}\end{array}$ & 1016.7 & 809.3 & 528.2 & 555.9 & 707.8 & 525.7 \\
\hline & $\begin{array}{l}\text { non-renewable Primary Energy demand } \\
P E_{\text {non-re }} / M J\end{array}$ & 669.4 & 710.8 & 445.5 & 394.0 & 477.9 & 366.1 \\
\hline & $\mathrm{PE}_{\mathrm{re}} / \mathrm{PE}_{\text {total }}$ & 034 & 012 & 016 & 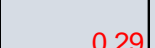 & 032 & 0.30 \\
\hline & $P E_{r e}$ : renewable Primary Energy demand & & & & & & \\
\hline \multirow{3}{*}{ 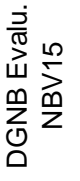 } & $\begin{array}{l}\text { Points "emission-related environmental } \\
\text { effects" }\end{array}$ & 80.1 & 77.2 & 109.0 & 108.3 & 99.4 & 102.4 \\
\hline & $\begin{array}{l}\text { Points "Life Cycle Assesment - Primary } \\
\text { Energy" }\end{array}$ & 69.4 & 69.1 & 100.0 & 100.0 & 97.6 & 100.0 \\
\hline & Degree of Fulfilment "LCA" & 75.7 & 73.8 & 105.3 & 104.8 & 98.6 & 101.4 \\
\hline
\end{tabular}

Table 2 shows, that the difference between the variants is sometimes very large, especially using Ökobaudat 2015. However, this was also the case for the building variant with pellet heating (see Table 1 and Table 3 ).

In a detailed analysis we were able to determine that some results in LEGEP resulted in erroneous results due to a program error according to the heat pump (values marked red in Tab. 2). In the program version "LEGEP 2015 separate Phase C and D" (penultimate column), an implausible negative value in the ozone depleting potential is highlighted in red. However, this influences the degree of fulfillment only slightly. The software error causing this was localized in a detailed study in phase D. 
Tab. 3: Comparison of all LCA tools for the Energy PLUS insulation standard with heat pump (HP) and icestorage system. Values are according to the DGNB (German Sustainable Building Council) degree of fulfillment.

\begin{tabular}{|c|c|c|c|c|c|c|c|c|}
\hline & \multirow[b]{2}{*}{ Tool } & \multicolumn{7}{|c|}{ PLUS + HP + Ice storage } \\
\hline & & \multicolumn{3}{|r|}{ LEGEP } & LEGEP & LEGEP & LEGEP & precheck \\
\hline & Ökobaudat & 2013 & 2011 & 2011 & $\begin{array}{r}2015 \\
\text { with } \\
\text { phase } \mathrm{C} / \mathrm{D}\end{array}$ & $\begin{array}{r}2015 \\
\text { separate } \\
\text { phase C } \\
\text { and D }\end{array}$ & $\begin{array}{r}2016 \\
\text { separate } \\
\text { phase } \mathrm{C} \\
\text { and D }\end{array}$ & 2015 \\
\hline \multirow{5}{*}{ 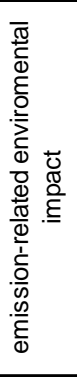 } & $\begin{array}{l}\text { Global Warming Potential } \\
\left./ \mathrm{kg}_{\mathrm{CO} 2 \text {-equiv. }} / \mathrm{m}_{\mathrm{NRA}}^{2} \cdot \mathrm{a}\right)\end{array}$ & 45,94 & 41,53 & 28,69 & 31,32 & 35,93 & 39,57 & 25,24 \\
\hline & $\begin{array}{l}\text { Acidification Potential } \\
/ \mathrm{kg}_{\text {sO2-equiv. }} /\left(\mathrm{m}^{2}{ }_{\mathrm{NRA}} \cdot \mathrm{a}\right)\end{array}$ & 0,0871 & 0,0901 & 0,0660 & 0,064 & 0,0685 & 0,0780 & 0,0610 \\
\hline & $\begin{array}{l}\text { Photochemical Ozone Creation Potential } \\
/ \mathrm{kg}_{\mathrm{c} 2 \mathrm{H} 4 \text {-equiv. }} /\left(\mathrm{m}_{\mathrm{NRA}}^{2} \cdot \mathrm{a}\right)\end{array}$ & 0,0076 & 0,0092 & 0,0073 & 0,0063 & 0,0065 & 0,0072 & 0,0060 \\
\hline & $\begin{array}{l}\text { Eutrophication Potential } \\
/ \mathrm{kg}_{\mathrm{PO} 4 \text {-equiv. }} /\left(\mathrm{m}^{2}{ }_{\mathrm{NRA}} \cdot \mathrm{a}\right)\end{array}$ & 0,0099 & 0,0093 & 0,0070 & 0,0083 & 0,0095 & 0,0081 & 0,0086 \\
\hline & $\begin{array}{l}\text { Ozone Depleting Potential } \\
/ \cdot 10^{-8} \mathrm{~kg}_{\mathrm{R} 11 \text {-equiv. }} /\left(\mathrm{m}^{2}{ }_{\text {NRA }} \cdot \mathrm{a}\right)\end{array}$ & 29,6 & 45,7 & 33,0 & 6,0 & $-3,5$ & 20,5 & 53,0 \\
\hline \multirow{3}{*}{ 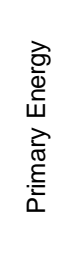 } & $\begin{array}{l}\text { total Primary Energy demand } \\
\mathrm{PE}_{\text {total }} / \mathrm{MJ}\end{array}$ & 976,9 & 765,0 & 483,2 & 512,6 & 625,1 & 592,2 & 479,2 \\
\hline & $\begin{array}{l}\text { non-renewable Primary Energy demand } \\
\mathrm{PE}_{\text {non-re }} / \mathrm{MJ}\end{array}$ & 635,6 & 673,3 & 407,2 & 366,7 & 424,9 & 493,8 & 335,9 \\
\hline & $\begin{array}{l}P E_{r e} / P E_{\text {total }} \\
P E_{r e}: \text { renewable Primary Energy demand }\end{array}$ & 0,35 & 0,12 & 0,16 & 0,28 & 0,32 & 0,17 & 0,30 \\
\hline \multirow{3}{*}{ 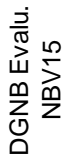 } & $\begin{array}{l}\text { Points "emission-related environmental } \\
\text { effects" }\end{array}$ & 84,4 & 82,4 & 111,7 & 111,5 & 103,2 & 99,3 & 105,3 \\
\hline & $\begin{array}{l}\text { Points "Life Cycle Assesment - Primary } \\
\text { Energy" }\end{array}$ & 74,3 & 75,8 & 100,0 & 100,0 & 100,0 & 100,0 & 100,0 \\
\hline & Degree of Fulfilment "LCA" & 80,2 & 79,6 & 106,8 & 106,7 & 101,9 & 99,6 & 103,1 \\
\hline
\end{tabular}

In Table 3 are implausible values again marked in red digits. The reason for the wrong values are the same as explained at table 2. In addition, the results of a newer version of the program are shown in the penultimate column "LEGEP 2016 separate phase C and D". This gives a flawless result with a degree of fulfillment "LCA" of 99.6. The reason for this was again a software error: the heat demand calculated according to EnEV was used instead of heat for the heat pump.

\subsection{Comparison of all degrees of fulfilment}

Table 4 shows the degree of fulfilment using different software tools and databases for all three variants of the energy supply system. Results from the software tool LEGEP for variants including a heat pump are wrong or implausible (marked red) because of an error in the software version used here.

Tab. 4: Comparison of all tools and variants according to the DGNB degree of fulfillment. Implausible or wrong values are marked red.

\begin{tabular}{|c|c|c|c|c|}
\hline & Ökobaudat & Pellet & HP & HP + Icestorage \\
\hline SBS & 2013 & 89.3 & 75.7 & 80.2 \\
\hline eLCA & 2011 & 85.4 & 73.8 & 79.6 \\
\hline LEGEP & 2011 & 86.4 & 105.3 & 106.8 \\
\hline LEGEP - with phase C/D & 2015 & 93.9 & 104.8 & 106.7 \\
\hline $\begin{array}{l}\text { LEGEP - separate phase C and D } \\
-1 \text {. Correction }\end{array}$ & 2015 & 97.5 & 98.6 & 101.9 \\
\hline $\begin{array}{l}\text { LEGEP - separate phase C and D } \\
\text { - 2. Correction }\end{array}$ & 2016 & - & - & 99.6 \\
\hline precheck & 2015 & 97.9 & 101.4 & 103.1 \\
\hline
\end{tabular}


Fig. 2 shows the values from Tab. 4 as a bar chart. In each case, the results are grouped by the used software. The results show that with the same assessment basis, the resulting degree of fulfilment values using Ökobaudat 2015 or 2016 are significantly higher than those using Ökobaudat 2011 or 2013.

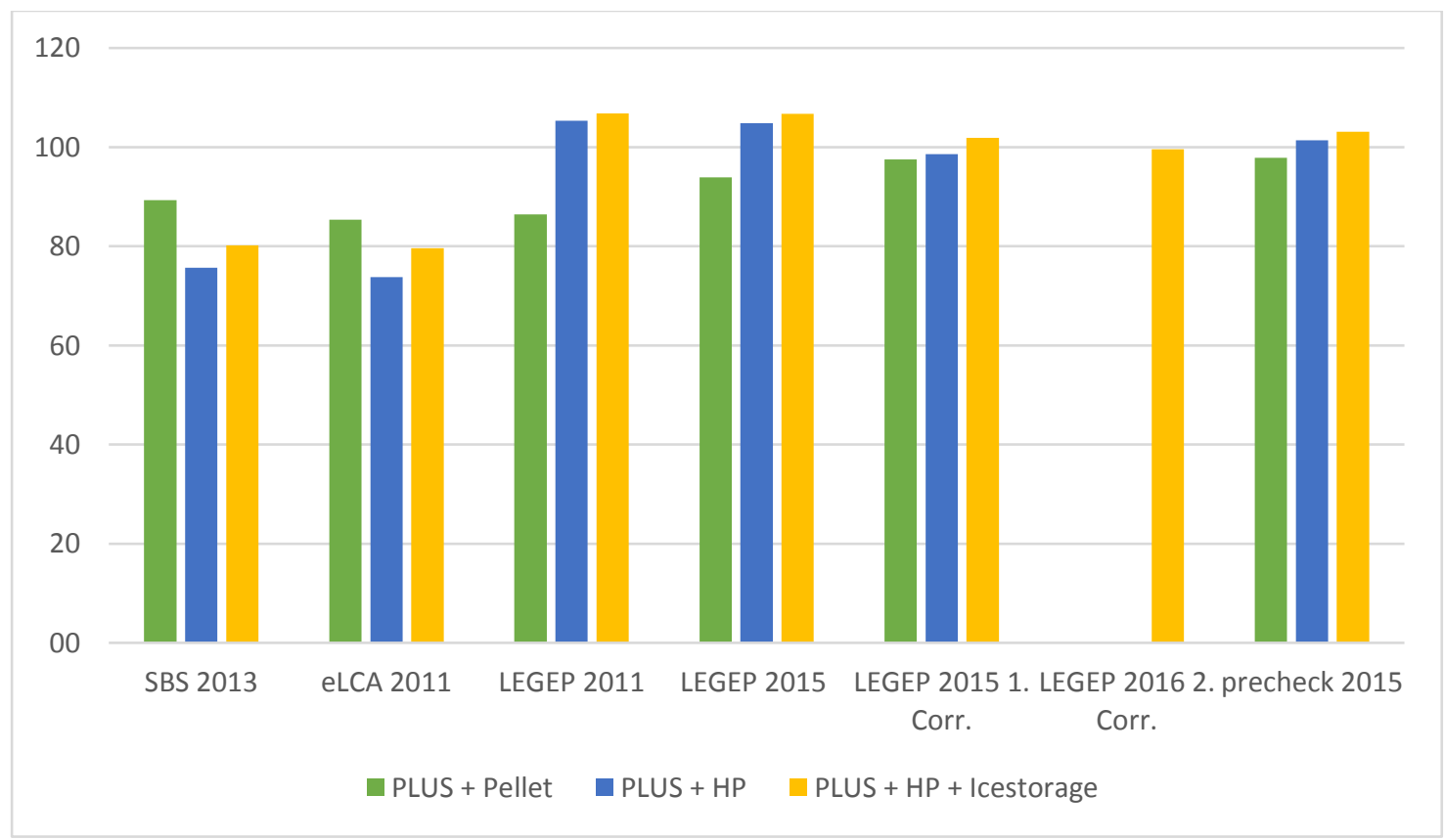

Fig. 2: Comparison of the degree of fulfilment of all LCA-Tools for the three different heat supplies, SBS 2013 takes ökobaudat from 2013 into account, eLCA 2011 the ökobaudat 2011, LEGEP 2015 and precheck 2015 the ökobaudat from 2015.

\subsection{Comparison of Preliminary Planning and Detailed Design}

In the detailed analysis of the building after the end of the bidding phase, the over 2400 bill of lading positions to be built were examined, of which about 630 positions were taken over in LEGEP. The large difference between the bidding phase positions and the actual inserted positions in LEGEP is mainly due to many small parts without any ecological material data in the database.

Table 5 takes only the phases A1 to A3 into account, corresponding to the current construction progress of the environmental station. Phase B would be identical for both program versions, phase C and D would depend on the future maintenance of the building within 50 years. Maintenance is currently also not reproducible in LEGEP. 
Tab. 5: Comparison of LEGEP 2015 (Ökobaudat 2015) for the preliminary planning and LEGEP 2016 (Ökobaudat 2016) for the detailed design (Energy PLUS insulation standard) with heat pump and ice storage according to the DGNB degree of fulfillment; the calculation in the preliminary planning was done with elements and for the detailed design with performance positions. The last column shows the ratio of the preliminary results (LEGEP 2015) to the final results (LEGEP 2016).

\begin{tabular}{|c|c|c|c|c|}
\hline & \multirow[b]{2}{*}{ Construction phase $\mathbf{A} 1-\mathbf{A} 3$} & \multicolumn{3}{|c|}{ PLUS + HP + Icestorage } \\
\hline & & $\begin{array}{c}\text { preliminary planning } \\
\text { LEGEP } 2015 \\
\text { without PV moduls } \\
\end{array}$ & $\begin{array}{c}\text { detailed design } \\
\text { LEGEP } 2016 \\
\text { without PV moduls } \\
\end{array}$ & $\begin{array}{c}\text { quotient } \\
\text { preliminary/detailed } \\
\text { in } \% \\
\end{array}$ \\
\hline \multirow{5}{*}{ 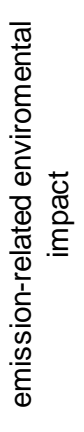 } & $\begin{array}{l}\text { Global Warming Potential } \\
/ \mathrm{kg}_{\mathrm{CO} 2 \text {-equiv. }} /\left(\mathrm{m}_{\mathrm{NRA}}^{2} \cdot \mathrm{a}\right)\end{array}$ & 11.70 & 13.10 & $89 \%$ \\
\hline & $\begin{array}{l}\text { Acidification Potential } \\
/ \mathrm{kg}_{\text {so2-equiv. }} /\left(\mathrm{m}^{2}{ }_{\text {NRA }} \cdot \mathrm{a}\right)\end{array}$ & 0.0330 & 0.0392 & $84 \%$ \\
\hline & $\begin{array}{l}\text { Photochemical Ozone Creation } \\
\text { Potential } / \mathrm{kg}_{\mathrm{C} 2 \mathrm{H} 4 \text {-equiv. }} /\left(\mathrm{m}^{2}{ }_{\text {NRA }} \cdot \mathrm{a}\right)\end{array}$ & 0.0029 & 0.0046 & $62 \%$ \\
\hline & $\begin{array}{l}\text { Eutrophication Potential } \\
/ \mathrm{kg}_{\mathrm{PO} 4 \text {-equiv. }} /\left(\mathrm{m}_{\mathrm{NRA}}^{2} \cdot \mathrm{a}\right)\end{array}$ & 0.0037 & 0.0040 & $91 \%$ \\
\hline & $\begin{array}{l}\text { Ozone Depleting Potential } \\
/ \cdot 10^{-8} \mathrm{~kg}_{\mathrm{R} 11 \text {-equiv. }} /\left(\mathrm{m}^{2}{ }_{\text {NRA }} \cdot \mathrm{a}\right)\end{array}$ & 5.1 & 52.3 & $10 \%$ \\
\hline \multirow{4}{*}{ 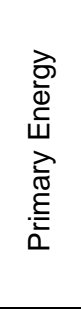 } & $\begin{array}{l}\text { total Primary Energy demand } \\
\mathrm{PE}_{\text {total }} / \mathrm{MJ}\end{array}$ & 161.3 & 184.9 & $87 \%$ \\
\hline & $\begin{array}{l}\text { non-renewable Primary Energy } \\
\text { demand } \mathrm{PE}_{\text {non-re }} / \mathrm{MJ}\end{array}$ & 125.6 & 147.4 & $85 \%$ \\
\hline & $\mathrm{PE}_{\mathrm{re}} / \mathrm{PE}_{\text {total }}$ & & & \\
\hline & $\begin{array}{l}\mathrm{PE}_{\mathrm{re}} \text { : renewable Primary Energy } \\
\text { demand }\end{array}$ & 0.22 & 0.20 & $109 \%$ \\
\hline
\end{tabular}

The ratio of preliminary results to final results from Tab 5 are shown in Figure 3, normalized to 100\%. Both the emission related environmental impact and the energy demand is higher for the final results than for the preliminary results obtained in the pre-planning phase.

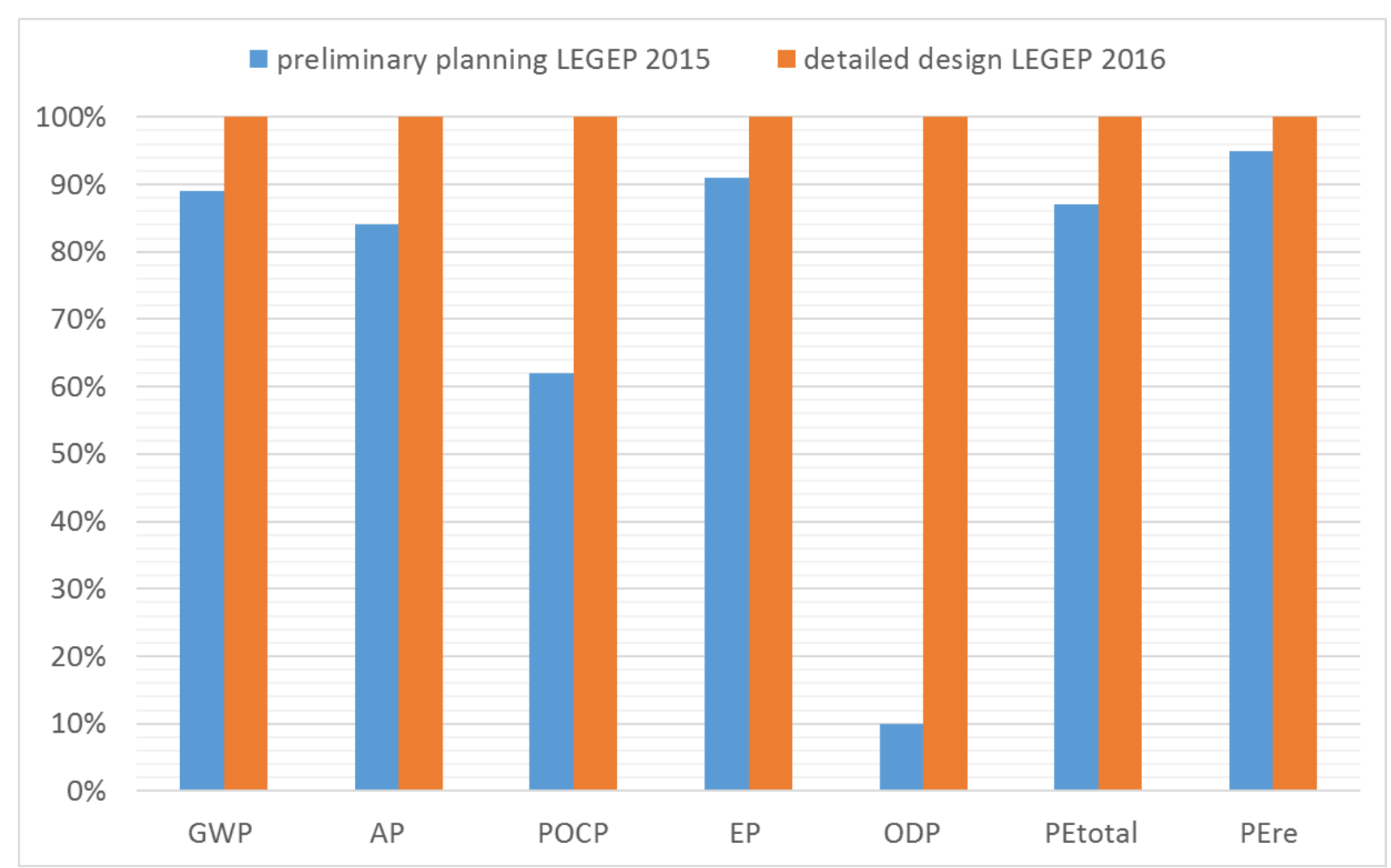

Fig. 3: Comparison of the preliminary planning and the detailed design for the construction phase A1-A3 


\section{Conclusion}

The evaluation methodology of the DGNB can be used to answer the question of which energy concept achieves a certain degree of fulfillment over the life cycle of the building.

The detailed analysis using the environmental station in Würzburg as an example shows that the values calculated during the pre-planning phase lead to an excessive degree of fulfillment of the life cycle assessment because the individual ecological indicators result in values that are too low.

The accurate and detailed comparison of the results using different LCA tools in this project brought out a lot of software bugs causing implausible values. Most of these bugs were removed during this project by the makers of the software packages.

Therefore, there is still a considerable need for research in order to better forecast the LCA in the preliminary planning phase. Additionally, there is further need for research to harmonize the results using different LCA tools with different databases. Actually, the results from different tools are in some points not comparable.

\section{References}

1. eLCA, 2018. https://www.bauteileditor.de/, last seen 28.2.2018

2. SBS, 2018. https://www.sbs-onlinetool.com/, last seen 09.08.2018

3. LEGEP, 2018. https://legep.de/, last seen 09.08.2018

4. Ökobaudat, 2018. http://www.oekobaudat.de/, last seen 28.2.2018

5. DGNB, 2015. http://www.dgnb-system.de/de/system/Systemversion2015.php, last seen 28.2.2018

6. EnEV, 2018. https://www.gesetze-im-internet.de/enev_2007/index.html, last seen 14.8.2018

7. InUmWue, 2018. https://www.dbu.de/projekt_33520/01_db_2409.html, last seen 14.8.2018

8. BMUB (Bundesministerium für Umwelt, Naturschutz, Bau und Reaktorsicherheit), 2015. Ökobilanzdaten http://www.bmub.bund.de/themen/bauen/bundesbauten/nachhaltiges-bauen/bewertungssystem/oekobilanzdaten/ (Rev. 10.10.2016)

9. Fraunhofer IBP (Fraunhofer Institut für Bauphysik), PE International, 2013. SBS Building Sustainability (SBS) Nutzer-Handbuch.

10. Pelzeter, A. 2006. Lebenszykluskosten von Immobilien. European Business School

11. ZAE Bayern 2016. Abschlussberichts des Projektes „Erarbeitung eines innovativen Energie-, Ökologie- und Informationskonzepts für die Umweltstation der Stadt Würzburg“" (InnUmWü).

\section{Acknowledgments}

The results in this paper are a part of the research project InUmWue (InUmWue 2018), which was funded by the Deutsche Bundesstiftung Umwelt. 


\title{
Quasi-Dynamic Testing of a Novel Concentrating Photovoltaic Solar Collector According to ISO 9806:2013
}

\author{
Ali Kurdia ${ }^{1}$, João Gomes ${ }^{2}$, George Pius ${ }^{2}$, Patrik Ollas ${ }^{3}$ and Olle Olsson ${ }^{4}$ and \\ ${ }^{1}$ Högskolan Dalarna, Borlänge (Sweden) \\ 2 Högskolan i Gävle, Gävle (Sweden) \\ ${ }^{3}$ RISE Research Institutes of Sweden, Borås (Sweden) \\ ${ }^{4}$ Absolicon, Gävle (Sweden)
}

\begin{abstract}
Testing and certification of solar thermal collectors has been widely researched and improved over the years, however, many of the developments in the test standards has been focused primarily on generic flat plate collectors. In this study, the focus was on depicting the applicability of the current standard in characterizing the performance of a novel concentrating solar collector of design.

The applicability of the Quasi-Dynamic Testing (QDT) method for collector certification, by the ISO 9806:2013, is studied to be used in characterizing the novel concentrating PVT collector, and to point out the weaknesses observed, and essential additions required.
\end{abstract}

Keywords: Concentrating Photovoltaic Thermal Collector, C-PVT, Quasi-Dynamic Testing, QDT

\section{Introduction}

Testing and characterizing performance is an essential task when developing any new technology. Regarding solar collectors, their thermal performance must be tested and characterized. To achieve this, the two methods listed by ISO 9806:2013 are Steady State testing and Quasi-Dynamic Testing (QDT). Though testing under steady state conditions can yield useful results, testing under dynamic conditions using the Quasi-Dynamic methodology offers some advantages:

- It allows for the characterization of a wider range of collectors

- $\quad$ Testing can be conducted under a wider range of operating and ambient conditions

- It yields a more complete and complex characterization

The process to achieve the goals of this study is as follows: identifying the key parameters in the QDT equation, setting up the test sequence according to the QDT methodology, verifying the usability of the test system for conducting QDT by testing a generic flat plat collector, testing and characterizing a novel concentrating PVT collector, and finally comparing and analyzing the results to draw conclusions.

Looking at the thermal collector model under the QDT procedure, the Quasi-Dynamic thermal collector model equation as adapted by the ISO 9806:2013 can be identified as:

$$
\begin{aligned}
\frac{\dot{Q}}{A}= & F^{\prime}(\tau \alpha) K_{\theta b}\left(\theta_{L}, \theta_{T}\right) G_{b}+F^{\prime}(\tau \alpha) K_{\theta d} G_{d}-c_{1}\left(t_{m}-t_{a}\right)-c_{2}\left(t_{m}-t_{a}\right)^{2} \\
& -c_{3} u\left(t_{m}-t_{a}\right)+c_{4}\left(E_{L}-\sigma T_{a}^{4}\right)-c_{5} \frac{d t_{m}}{d t}-c_{6} u G
\end{aligned}
$$

Running the parametric characterization for this equation typically yields an accurate representation of the expected operational performance of a solar thermal collector. However, this does not fully cover PVT collectors or collectors with a unique geometry due to three main reasons:

- Obtaining enough data points for the transversal Incident Angle Modifier (IAM) for a non-symmetrical collector geometry can be difficult. 
- In practice, the averaging period used to obtain a single data entry point for the QDT is maximally 10 minutes, which might not necessarily be enough for a collector with a special geometry.

- The standard permits neglecting the long wave radiation if the collector to be tested is glazed, which is not always negligible for concentrating collectors operating at elevated temperatures under different sky conditions.

\section{Methodology}

The Quasi-Dynamic Testing (QDT) method for thermal solar collectors was implemented to characterize the thermal performance of a generic flat plate collector (FPC). This was done so that the test rig utilized could be validated. Subsequently, the QDT methodology was implemented to characterize the Solarus PowerCollector ${ }^{\mathrm{TM}}$ (PC).

\subsection{Solarus PowerCollector ${ }^{\mathrm{TM}}$}

Figure 1 illustrates an exploded view of the the Solarus PowerCollector ${ }^{\mathrm{TM}}$ (PC). It is a concentrating, hybrid solar photovoltaic and solar thermal panel (C-PVT). Concentrating (C) means that it has a curved mirror to collect and reflect more sunlight throughout the day. Hybrid means that it combines solar photovoltaic (PV) generation of electricity with solar thermal $(\mathrm{T})$ generation heat.

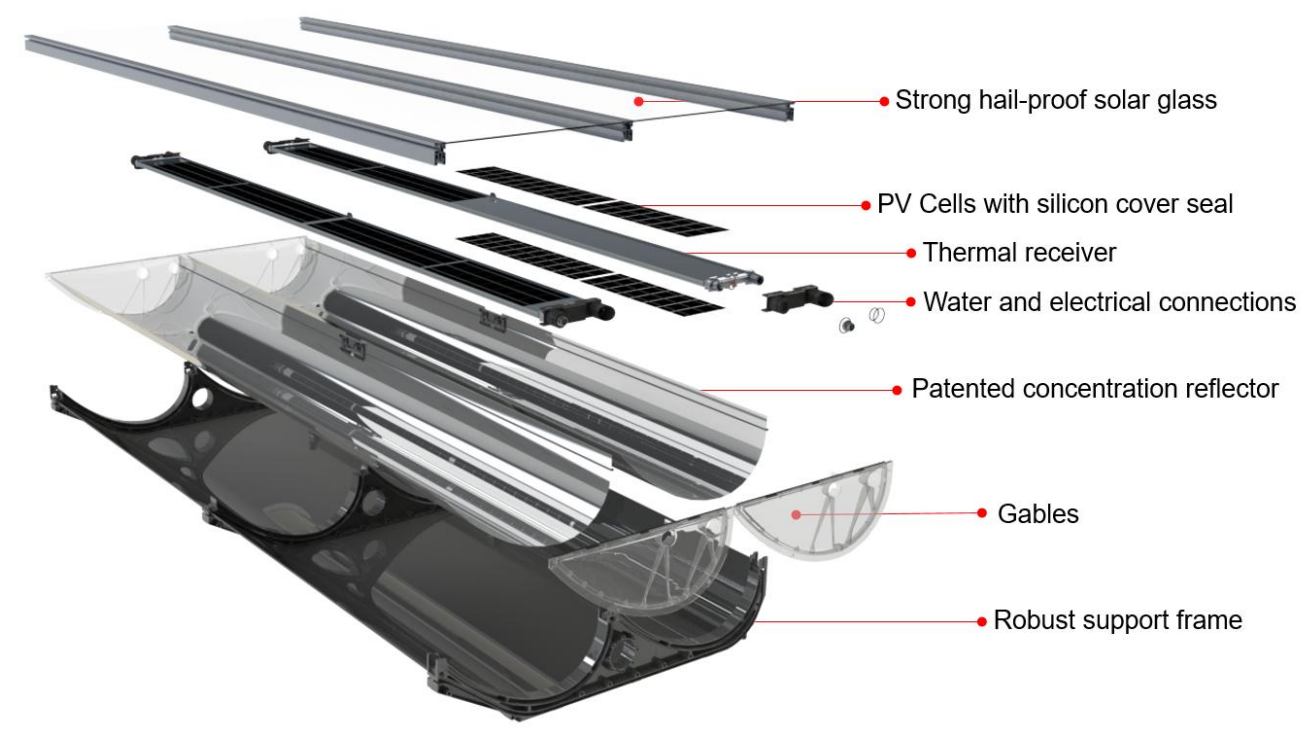

Fig. 1: Solarus PowerCollector ${ }^{\mathrm{TM}}$ (PC).

The PC consists of two major components: the collector box and the receiver core.

The collector box can be sub divided into 4 components:

- A black plastic solid frame that provides structural support to the reflector.

- A gable with a reported transparency of $90 \%$ and that is made from Polymethylmethacrylate (PPMA) that seals the collector sides.

- A $4 \mathrm{~mm}$ tempered solar glass with anti-reflective treatment (on both sides) to reach an absorptance of 1.5 $\%$ and a reflectance of $2 \%$ per side.

- A $0.4 \mathrm{~mm}$ aluminium reflector with a concentration factor of 1.7 and a reflectance of $92 \%$ reflectance at an air mass of 1.5 , according to the standard.

The receiver core is the heart of the Solarus C-PVT. It is $2321 \mathrm{~mm}$ long, $165 \mathrm{~mm}$ wide and $14.5 \mathrm{~mm}$ thick. As shown in Figure 2, there are solar cells on both sides of the aluminum receiver. These solar cells are encapsulated by highly transparent silicone with a reported transparency of $97 \%$. 


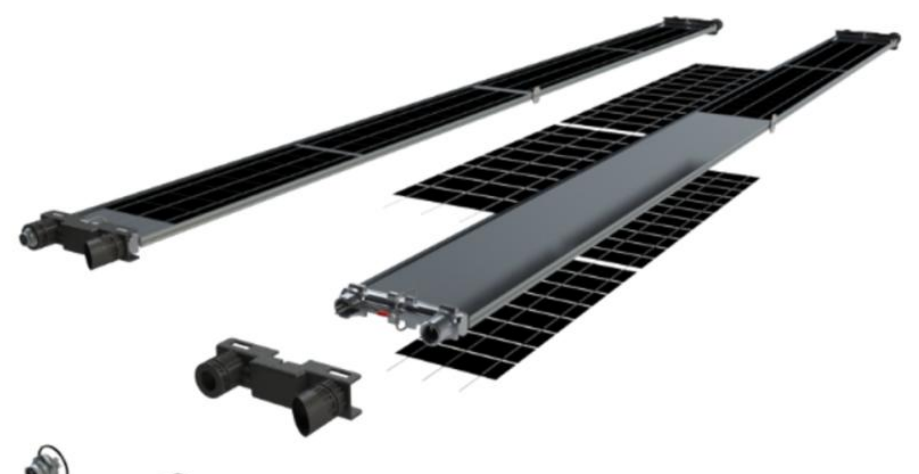

.

Figure 2: Receiver core.

The receiver consists on an aluminum receiver with 8 elliptical channels as shown Figure 3. The cooling fluid flows through the 8 channels in order to extract heat from the collector. The core is made of extruded aluminum.

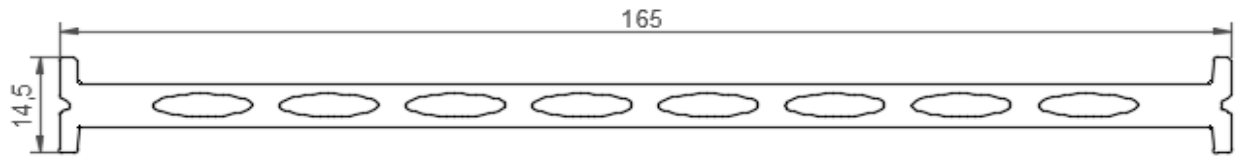

Figure 3: Elliptical channels in receiver

The collector uses standard monocrystalline solar silicon cells with an efficiency of $19.7 \%$. The cell string layout consists in 4 cells strings in the bottom and 4 in the top side of the receiver. This is shown in Figure 4:

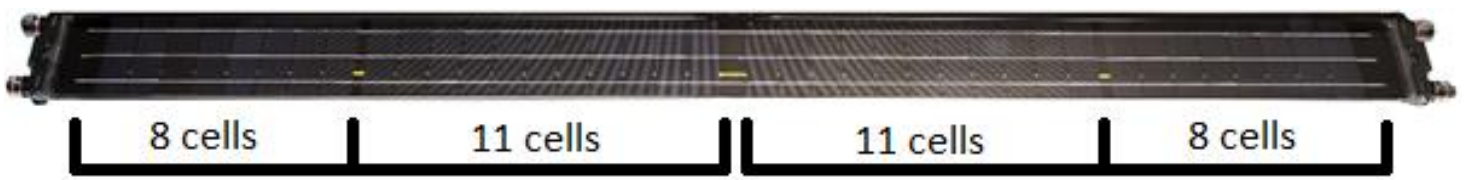

Figure 4: Receiver, showing 4 cell strings and its distribution in the receiver.

\subsection{Test Rig}

A solar thermal collector test rig was set up on a rooftop according to the European standard EN 12975-2:2006, the predecessor to the current ISO standard, to run tests according to the SST method. Furthermore, on the roof, a rotatable mounting platform is available for mounting and testing of thermal collectors as shown in Figure 5.

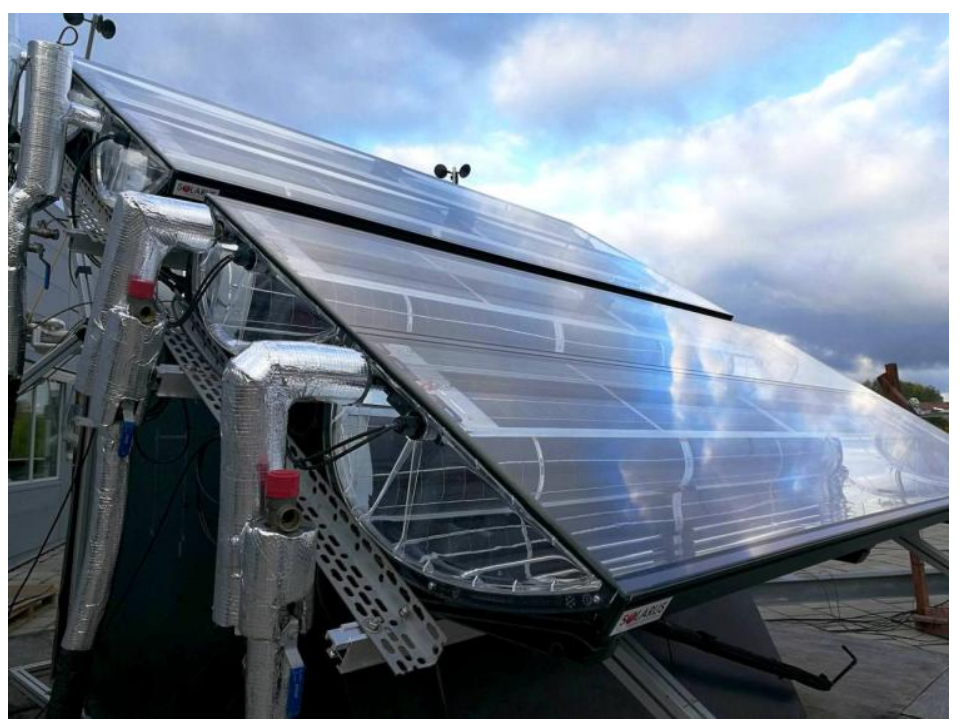

Figure 5: Rooftop collector mounting stand.

The test rig possesses an advanced hydraulic circuit that is capable of sustaining testing conditions for two separate collectors and is schematically compatible with the recommended circuit layout as provided by the ISO 9806:2013 standard. 
All test measurements are obtained using a data acquisition device, and this data acquisition device is connected to a computer that logs the measurements every 10 seconds. Figure 6 shows a schematic of the data measurement and logging system.

(3)

(1)

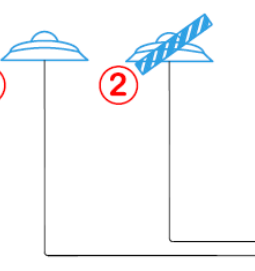

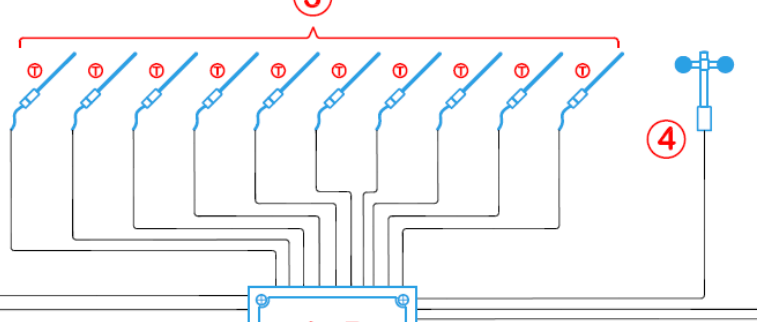

J. B.
(5)

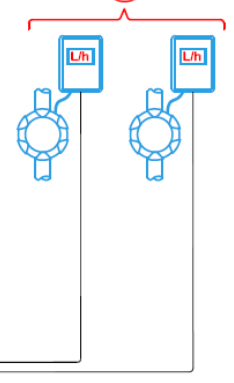

(6)

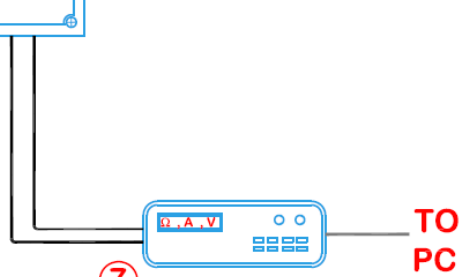

(7) PC

Figure 6: Data measurement and logging system.

Table 1 lists the details of the temperature and flow regulation system:

Table 1: Details of temperature and flow regulation system.

\begin{tabular}{|c|c|c|c|c|}
\hline $\begin{array}{c}\text { Item } \\
\text { No. }\end{array}$ & Description & Manufacturer & Model & Relevant Info \\
\hline 1 & Pyranometer & Kipp \& Zonen & CM11 & \multirow{2}{*}{$\begin{array}{l}\text { Industry standard for monitoring and logging } \\
\text { solar irradiance. } \\
\text { Sensitivity } 7 \mu \mathrm{V} \cdot \mathrm{W}^{-1} \cdot \mathrm{m}^{-2}-14 \mu \mathrm{V} \cdot \mathrm{W}^{-1} \cdot \mathrm{m}^{-2} \\
\text { Non-linearity }<0.2 \% \text {. }\end{array}$} \\
\hline 2 & $\begin{array}{l}\text { Pyranometer } \\
\text { with shading } \\
\text { ring }\end{array}$ & Kipp \& Zonen & CM11 & \\
\hline 3 & $\begin{array}{l}\text { Temperature } \\
\text { sensors }\end{array}$ & Unknown & PT100 & 4 wire RTD sensor, individually calibrated \\
\hline 4 & $\begin{array}{l}\text { Wind Speed } \\
\text { sensor }\end{array}$ & Thies Clima & N/A & $\begin{array}{l}\text { Accuracy } \pm 0.5 \mathrm{~m} \cdot \mathrm{s}^{-1} \\
\text { Resolution }<0.1 \mathrm{~m} \cdot \mathrm{s}^{-1} \\
\text { Range } 0.5 \mathrm{~m} \cdot \mathrm{s}^{-1}-50 \mathrm{~m} \cdot \mathrm{s}^{-1}\end{array}$ \\
\hline 5 & Flow Sensors & Krohne & IFC 300 & $\begin{array}{l}\text { Electromagnetic flow sensor Accuracy } \pm 0.3 \% \\
\text { of mean value }\end{array}$ \\
\hline 6 & Junction Box & -- & -- & -- \\
\hline 7 & $\begin{array}{l}\text { Data logging } \\
\text { device }\end{array}$ & $\begin{array}{c}\text { Agilent } \\
\text { Technologies }\end{array}$ & $34972 \mathrm{~A}$ & $\begin{array}{l}\text { Highly sophisticated programmable data } \\
\text { measurement and export device capable of } \\
\text { high-resolution voltage, current, and resistance } \\
\text { measurements simultaneously with PC } \\
\text { interface for logging }\end{array}$ \\
\hline
\end{tabular}

A dedicated temperature and flow regulation control panel is used to regulate the operational set-values as shown in Figure 7. It offers the possibility to control the pump speed, and the heating and cooling elements, in order to achieve the required test boundaries dictated by the standard. 


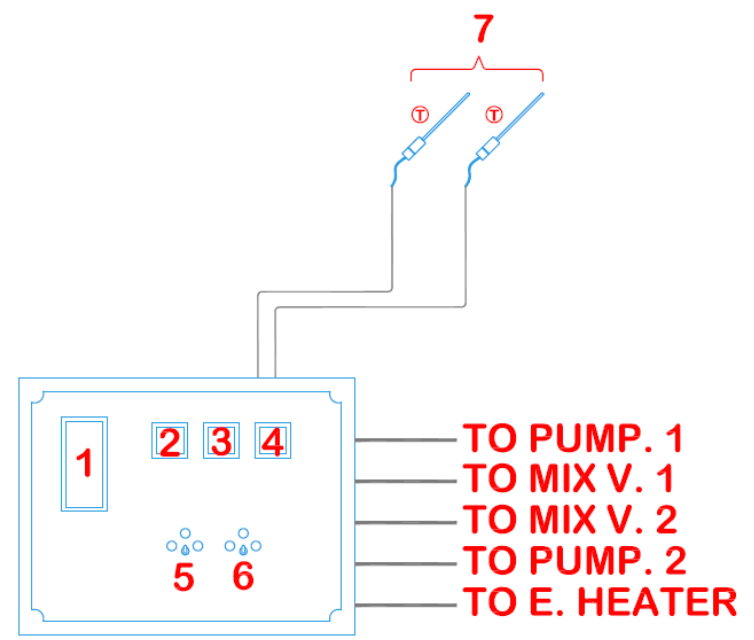

Figure 7: Temperature and flow regulation system.

Table 2 lists the details of the temperature and flow regulation system:

Table 2: Details of temperature and flow regulation system.

\begin{tabular}{|c|c|c|c|c|}
\hline Item No. & Description & Manufacturer & Model & Relevant Info \\
\hline 1 & Pump control panel & Danfoss & $2216 \mathrm{e}$ & $\begin{array}{l}\text { Frequency drive pump controller } \\
\text { regulating the primary pump (Pump. 1) } \\
\text { flow rate }\end{array}$ \\
\hline 2 & Heater control unit & Eurotherm & $2216 \mathrm{e}$ & $\begin{array}{l}\text { PID controller regulating operation of the } \\
\text { system's electrical heating elements } \\
\text { based on a temperature set point, } \\
\text { temperature signal is taken from an RTD } \\
\text { sensor located in line after the heating } \\
\text { element. }\end{array}$ \\
\hline 3 & $\begin{array}{l}\text { Control unit - } \\
\text { cooling circuit } 1\end{array}$ & Eurotherm & $2216 \mathrm{e}$ & $\begin{array}{l}\text { PID controller regulating operation of the } \\
\text { system's borehole cooling pump (Pump. } \\
\text { 2) and mixing valve (Mix V. 1) based on } \\
\text { a temperature set point, temperature } \\
\text { signal is taken from an RTD sensor } \\
\text { located in line after the cooling circuit } \\
\text { heat exchanger. }\end{array}$ \\
\hline 4 & $\begin{array}{l}\text { Control unit - } \\
\text { cooling circuit } 2\end{array}$ & Eurotherm & $2216 \mathrm{e}$ & $\begin{array}{l}\text { Unused heat pump cooling circuit } \\
\text { controller }\end{array}$ \\
\hline 5 & $\begin{array}{l}\text { Mixing valve - } \\
\text { cooling circuit } 1\end{array}$ & -- & -- & $\begin{array}{l}\text { Electrically actuated mixing valve } \\
\text { controlled by the borehole cooling } \\
\text { control unit to regulate the coolant fluid } \\
\text { flow from the borehole. }\end{array}$ \\
\hline 6 & $\begin{array}{l}\text { Mixing valve - } \\
\text { cooling circuit } 2\end{array}$ & -- & -- & Unused heat pump cooling circuit mixer \\
\hline 7 & Temperature sensors & Unknown & PT100 & $\begin{array}{l}2 \text { RTD sensor, one after the heating } \\
\text { element, and one after cooling circuit } 1\end{array}$ \\
\hline
\end{tabular}

\subsection{Testing Procedure}

The testing procedure for the FPC and the PC are almost identical and consisted of the following steps:

- Full day tests including all day type sequences were conducted. This lasted 7 days for the FPC and 17 days for the PC. Data was logged at 100 second intervals.

- The raw data was filtered so that unusable data points could be removed. Input values were averaged over 
a period of 10 minutes to characterize the thermal capacitance.

- The data was validated via visual inspection to check for compliance with the required criteria for QDT. Four visual inspections of data are conducted. First, the reduced temperature vs total irradiance is plotted. It is checked to make sure that all the inlet temperatures tested can be identified. Second, diffuse irradiance vs total irradiance is plotted. From this it is ensured that the diffuse irradiance fraction is within acceptable limits. Third, wind speed vs total irradiance is plotted. From this it is ensured the wind distribution is diverse over a range of irradiance as required by the standard. Finally, incidence angle vs beam and diffuse irradiance is plotted. It is ensured that a diverse distribution of beam and diffuse irradiance is achieved for the full range of incidence angles.

- Multiple Linear Regression (MLS) is used to determine the required coefficients.

\section{Results}

\subsection{Test results for the flat plat collector under QDT conditions}

An outdoor test was conducted under QDT conditions to characterize the FPC.

Latitude: $60.48^{\circ}$

Longitude: $15.44^{\circ}$

Collector azimuth: $0^{\circ}$

Collector tilt: $35^{\circ}$

Orientation of absorber tubes during testing: Horizontal

Peak Power, $Q_{p}\left(G=1000 \mathrm{~W} / \mathrm{m}^{2}\right)$ per collector unit: $1490 \mathrm{~W}$

Table 3 shows the power output for the FPC:

Table 3: Power output in W/m $\mathbf{m}^{2}$ (FPC).

\begin{tabular}{|c|c|c|c|}
\hline \multicolumn{4}{|c|}{ Irradiance } \\
\hline tm-ta [K] & $\begin{array}{c}400 \mathrm{~W} \cdot \mathrm{m}^{-2} \\
\left(\mathbf{G b}=200 \mathrm{~W} \cdot \mathrm{m}^{-2},\right. \\
\left.\mathbf{G d}=200 \mathrm{~W} \cdot \mathrm{m}^{-2}\right)\end{array}$ & $\begin{array}{c}700 \mathrm{~W} \cdot \mathrm{m}^{-2} \\
\left(\mathbf{G b}=440 \mathrm{~W} \cdot \mathrm{m}^{-2},\right. \\
\left.\mathbf{G d}=260 \mathrm{~W} \cdot \mathrm{m}^{-2}\right)\end{array}$ & $\begin{array}{c}1000 \mathrm{~W} \cdot \mathbf{m}^{-2} \\
\left(\mathbf{G b}=850 \mathrm{~W} \cdot \mathbf{m}^{-2},\right. \\
\left.\mathbf{G d}=150 \mathrm{~W} \cdot \mathbf{m}^{-2}\right)\end{array}$ \\
\hline 0 & 570 & 1,020 & 1,490 \\
\hline 10 & 470 & 910 & 1,380 \\
\hline 30 & 260 & 710 & 1,180 \\
\hline 50 & 50 & 500 & 970 \\
\hline 70 & 0 & 290 & 760 \\
\hline 89 & 0 & 100 & 570 \\
\hline
\end{tabular}


A. Kurdia et. al. / EuroSun 2018 / ISES Conference Proceedings (2018)

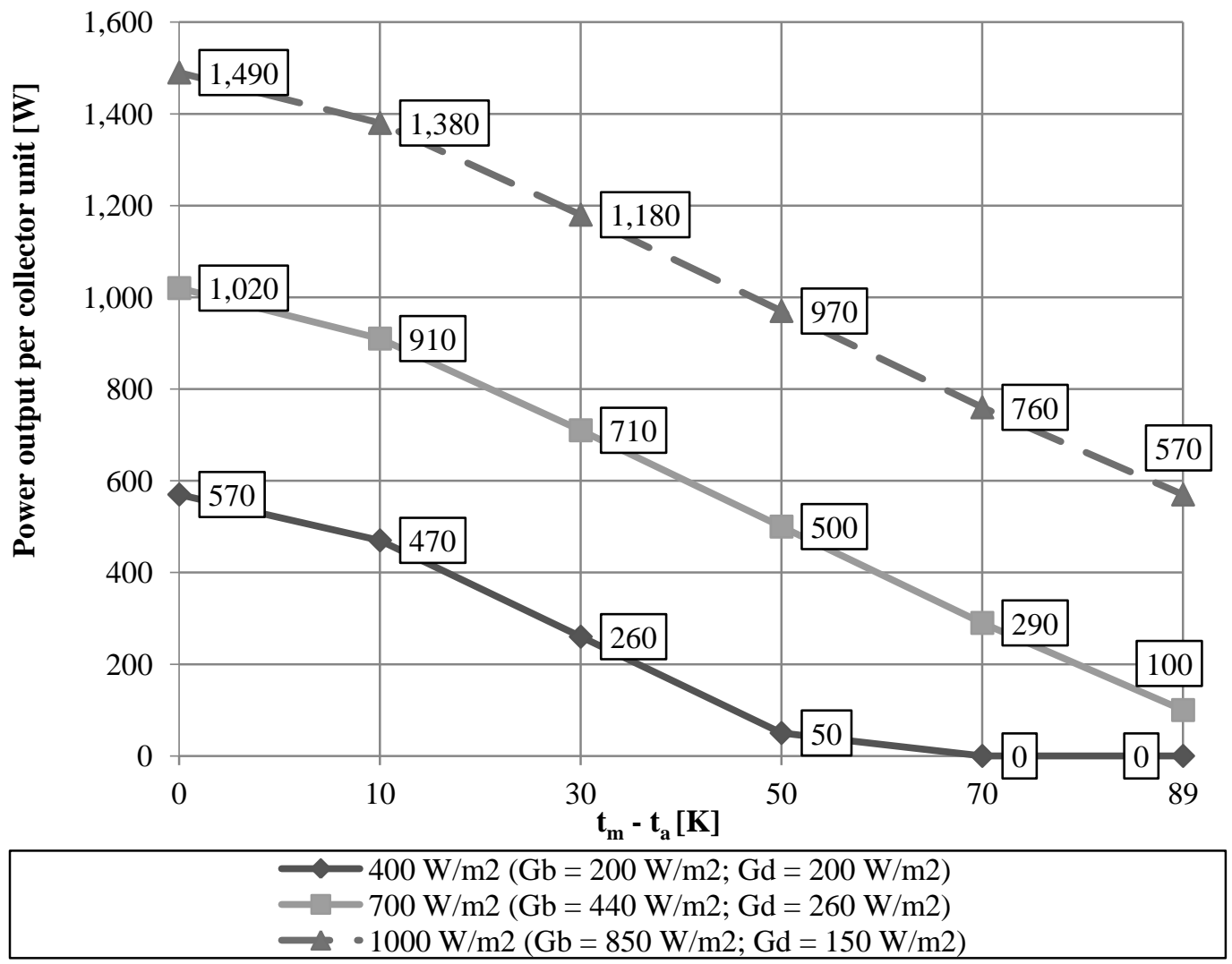

Figure 8: Power output per collector unit (FPC).

Thermal performance based on gross area and mean temperature of heat transfer fluid.

Gross area used for curve: $2.00 \mathrm{~m}^{2}$

Fluid flow rate used for the test: $0.04 \mathrm{~kg} / \mathrm{s}$

Table 4 lists the thermal performance formula (equation 1) coefficients for the FPC:

Table 4: Thermal performance formula coefficients

\begin{tabular}{|c|c|c|}
\hline \multicolumn{3}{|c|}{ Gross Area: $\mathbf{2 . 0 0} \mathbf{~ m}^{\mathbf{2}}$} \\
\hline Coefficient & Value & $\begin{array}{c}\text { Standard } \\
\text { deviation }\end{array}$ \\
\hline $\boldsymbol{\eta}_{\mathbf{0}, \boldsymbol{b}}$ & $75.5 \%$ & $2 \%$ \\
\hline $\boldsymbol{K}_{\boldsymbol{\theta} \boldsymbol{d}}$ & 0.90 & $1 \%$ \\
\hline $\mathbf{b}_{\mathbf{0}}$ & 0.136 & $2 \%$ \\
\hline $\mathbf{C}_{\mathbf{1}}$ & 4.352 & $-2 \%$ \\
\hline $\mathbf{C}_{\mathbf{2}}$ & 0 & - \\
\hline $\mathbf{C}_{\mathbf{3}}$ & 0.28 & $-22 \%$ \\
\hline $\mathbf{C}_{\mathbf{4}}$ & 0 & - \\
\hline $\mathbf{C}_{\mathbf{5}}$ & $-6,779$ & $11 \%$ \\
\hline $\mathbf{C}_{\mathbf{6}}$ & 0 & - \\
\hline
\end{tabular}


Table 5 lists the incidence angle modifier for the Solarus PC:

Table 5: Incidence angle modifier

\begin{tabular}{|c|c|c|c|c|c|c|c|c|}
\hline $\boldsymbol{\theta}$ & $\mathbf{1 0}$ & $\mathbf{2 0}$ & $\mathbf{3 0}$ & $\mathbf{4 0}$ & $\mathbf{5 0}$ & $\mathbf{6 0}$ & $\mathbf{7 0}$ & $\mathbf{8 0}$ \\
\hline $\boldsymbol{K}_{\boldsymbol{\theta} \boldsymbol{b}}$ & 0.98 & 0.98 & 0.97 & 0.95 & 0.92 & 0.90 & 0.80 & 0.72 \\
\hline
\end{tabular}

\subsection{Test results for Solarus PowerCollector ${ }^{\mathrm{TM}}$ under QDT conditions}

An outdoor test was conducted under QDT conditions to characterize the Solarus PC.

Outdoor test.

Latitude: $60.48^{\circ}$

Longitude: $15.44^{\circ}$

Collector azimuth: $0^{\circ}$

Collector tilt: $35^{\circ}$

Orientation of absorber tubes during testing: Horizontal

Table 6 shows the power output for the FPC:

Table 6: Power Output (PC)

\begin{tabular}{|c|c|c|c|}
\hline \multicolumn{4}{|c|}{ Irradiance } \\
\hline $\mathbf{t}_{\mathbf{m}-\mathbf{t}_{\mathbf{a}}[\mathbf{K}]}$ & $\begin{array}{c}\mathbf{4 0 0} \mathbf{W} / \mathbf{m}^{\mathbf{2}} \\
\left(\mathbf{G}_{\mathbf{b}}=\mathbf{2 0 0} \mathbf{W} / \mathbf{m}^{2},\right. \\
\left.\mathbf{G}_{\mathbf{d}}=\mathbf{2 0 0} \mathbf{W} / \mathbf{m}^{2}\right)\end{array}$ & $\begin{array}{c}\mathbf{7 0 0} \mathbf{W} / \mathbf{m}^{\mathbf{2}} \\
\left(\mathbf{G}_{\mathbf{b}}=\mathbf{4 4 0} \mathbf{W} / \mathbf{m}^{2},\right. \\
\left.\mathbf{G}_{\mathbf{d}}=\mathbf{2 6 0} \mathbf{W} / \mathbf{m}^{2}\right)\end{array}$ & $\begin{array}{c}\mathbf{1 0 0 0} \mathbf{W} / \mathbf{m}^{\mathbf{2}} \\
\left(\mathbf{G}_{\mathbf{b}}=\mathbf{8 5 0} \mathbf{W} / \mathbf{m}^{2},\right. \\
\left.\mathbf{G}_{\mathbf{d}}=\mathbf{1 5 0} \mathbf{W} / \mathbf{m}^{2}\right)\end{array}$ \\
\hline $\mathbf{0}$ & 350 & 680 & 1,140 \\
\hline $\mathbf{1 0}$ & 290 & 620 & 1,090 \\
\hline $\mathbf{3 0}$ & 150 & 480 & 940 \\
\hline $\mathbf{5 0}$ & 0 & 290 & 750 \\
\hline $\mathbf{7 0}$ & 0 & 50 & 510 \\
\hline $\mathbf{1 0 5}$ & 0 & 0 & 0 \\
\hline
\end{tabular}




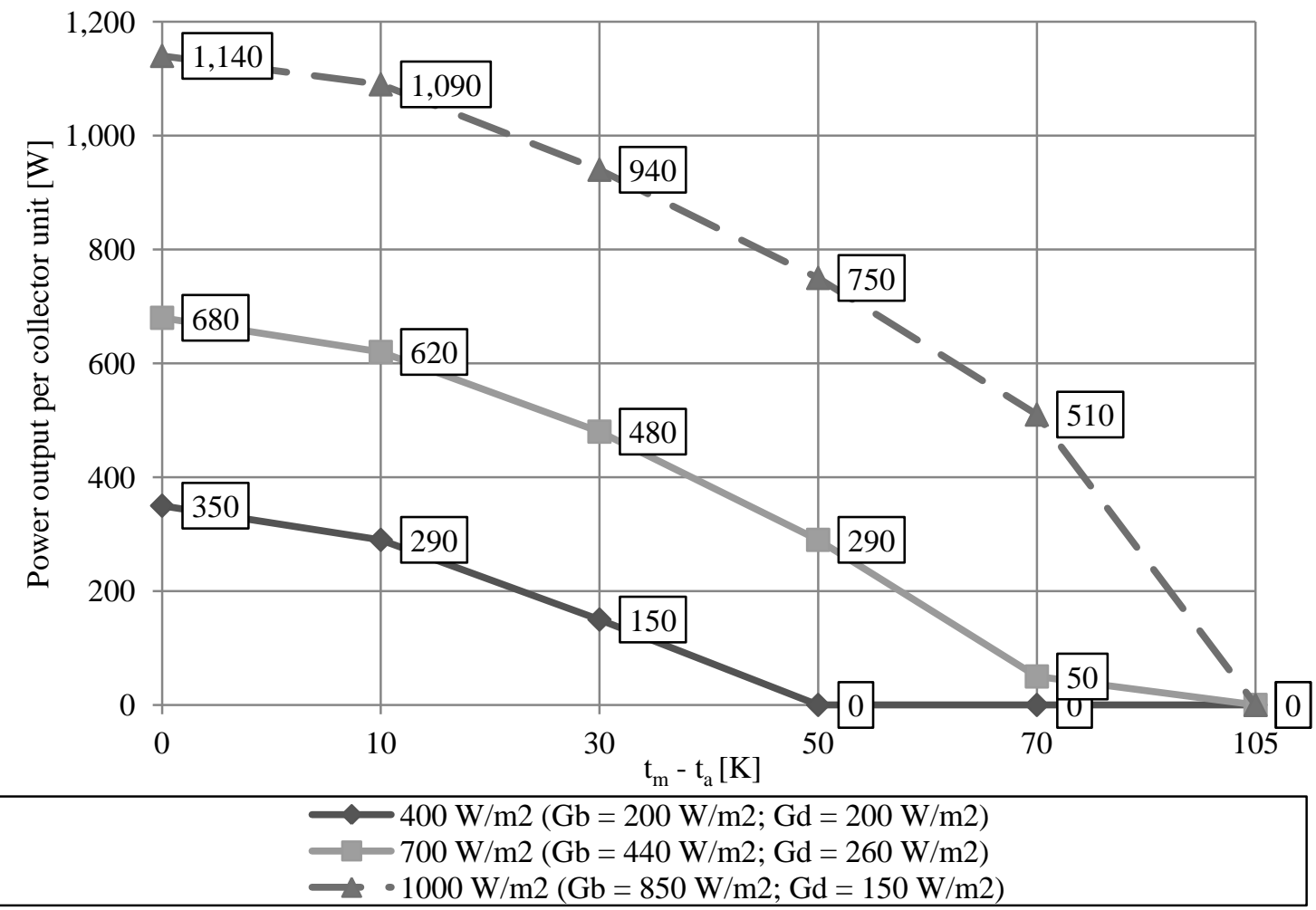

Figure 9: Power output per collector unit (FPC).

Thermal performance Based on gross area and mean temperature of heat transfer fluid.

Gross area used for curve: $2.57 \mathrm{~m}^{2}$

Fluid flow rate used for the test: $0.04 \mathrm{~kg} / \mathrm{s}$

Table 7 lists the thermal performance formula (equation 1) coefficients for the Solarus PC:

Table 7: Thermal performance formula coefficients (PC)

\begin{tabular}{|c|c|c|}
\hline \multicolumn{3}{|c|}{ Gross Area: $\mathbf{2 . 5 7} \mathbf{~ m}^{\mathbf{2}}$} \\
\hline Coefficient & Value & $\begin{array}{c}\text { Standard } \\
\text { deviation }\end{array}$ \\
\hline $\boldsymbol{\eta}_{\mathbf{0}, \boldsymbol{b}}$ & $48.9 \%$ & $3 \%$ \\
\hline $\boldsymbol{K}_{\boldsymbol{\theta} \boldsymbol{d}}$ & 0.38 & $9 \%$ \\
\hline $\mathbf{b}_{\mathbf{0}}$ & 0.192 & $3 \%$ \\
\hline $\mathbf{C}_{\mathbf{1}}$ & 1.294 & $-20 \%$ \\
\hline $\mathbf{C}_{\mathbf{2}}$ & 0.023 & $-14 \%$ \\
\hline $\mathbf{C}_{\mathbf{3}}$ & 0.2 & $-74 \%$ \\
\hline $\mathbf{C}_{\mathbf{4}}$ & 0 & - \\
\hline $\mathbf{C}_{\mathbf{5}}$ & -5929 & $38 \%$ \\
\hline $\mathbf{C}_{\mathbf{6}}$ & 0 & - \\
\hline
\end{tabular}

Table 8 lists the incidence angle modifier for the Solarus PC:

Table 8: Incidence angle modifier (PC)

\begin{tabular}{|c|c|c|c|c|c|c|c|c|}
\hline $\boldsymbol{\theta}$ & $\mathbf{1 0}$ & $\mathbf{2 0}$ & $\mathbf{3 0}$ & $\mathbf{4 0}$ & $\mathbf{5 0}$ & $\mathbf{6 0}$ & $\mathbf{7 0}$ & $\mathbf{8 0}$ \\
\hline $\boldsymbol{K}_{\boldsymbol{\theta} \boldsymbol{b}}$ & 0.96 & 0.94 & 0.96 & 0.95 & 0.89 & 0.78 & 0.71 & 0.46 \\
\hline
\end{tabular}




\section{Discussion and Conclusions}

\subsection{Flat Plate Collector}

To test the parameter characterization of the FPC, actual power generated is plotted against the power calculated from the formulated model. The results of both are in harmony indicating the success in the parameter characterization. These results were as expected and also validate the test rig. This was confirmed and illustrated in Figure 10.

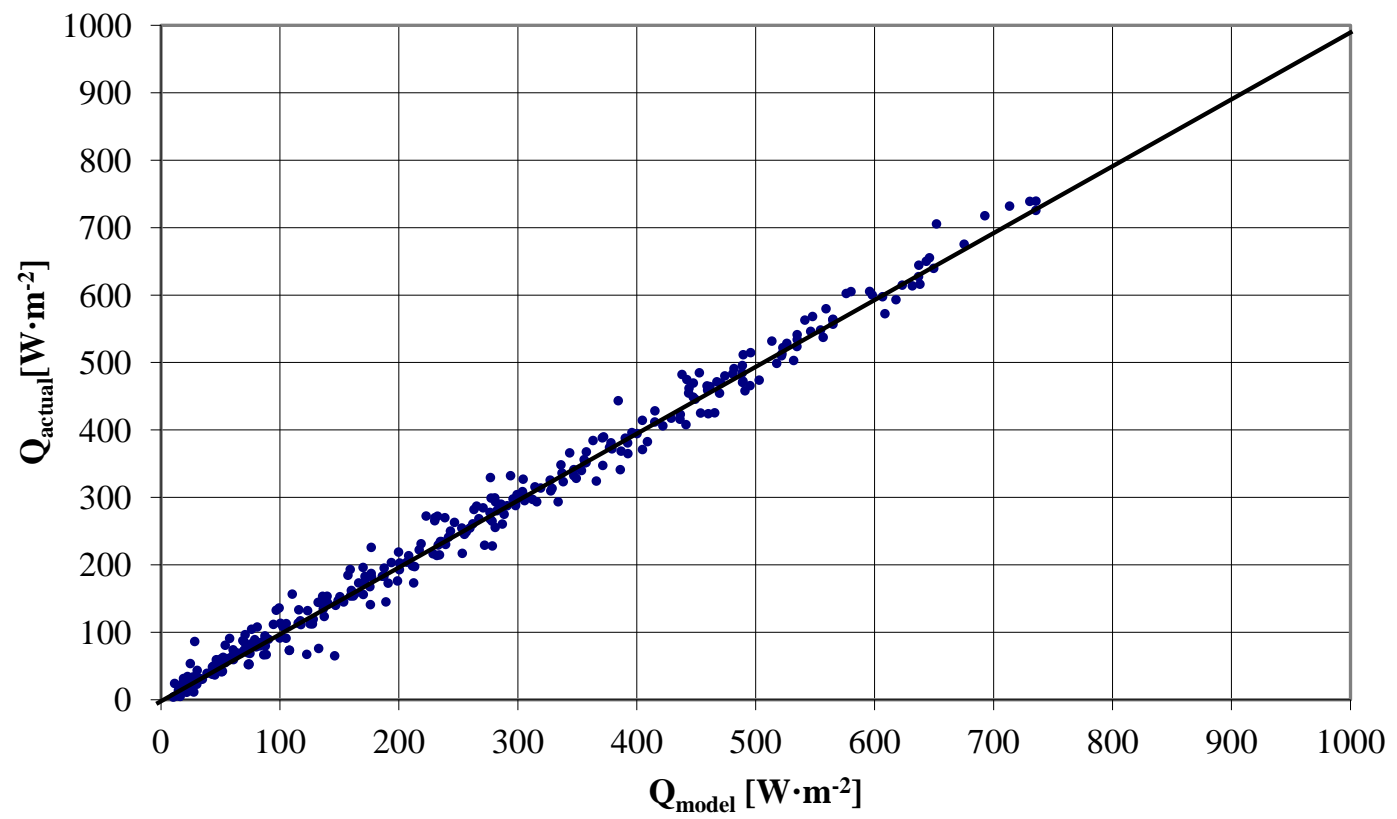

Figure 10: Actual measured production to model predicted production (FPC).

Coefficients $\mathrm{C}_{4}$ and $\mathrm{C}_{6}$, where omitted as per the recommendation of the standard or glazed collectors. On the other hand, coefficient $\mathrm{C}_{2}$ (the temperature dependence of heat losses) is usually essential in the model unless it comes out as statistically insignificant even with enough data points at elevated testing temperature, in that case the standard permits omitting it and the MLR is repeated without including its data.

However, coefficient $\mathrm{C}_{3}$ could have been omitted initially, but it was attempted to include its data points, and they proved to be statistically significant to be include in the model even though it possesses a relatively high standard deviation.

\subsection{Solarus PowerCollector ${ }^{\mathrm{TM}}$}

Although with a higher standard deviation, the power output from both the formulated model and measured the values were congruent. Hence, it can be concluded that the parameter characterization was successful. This was confirmed and illustrated in Figure 11. 


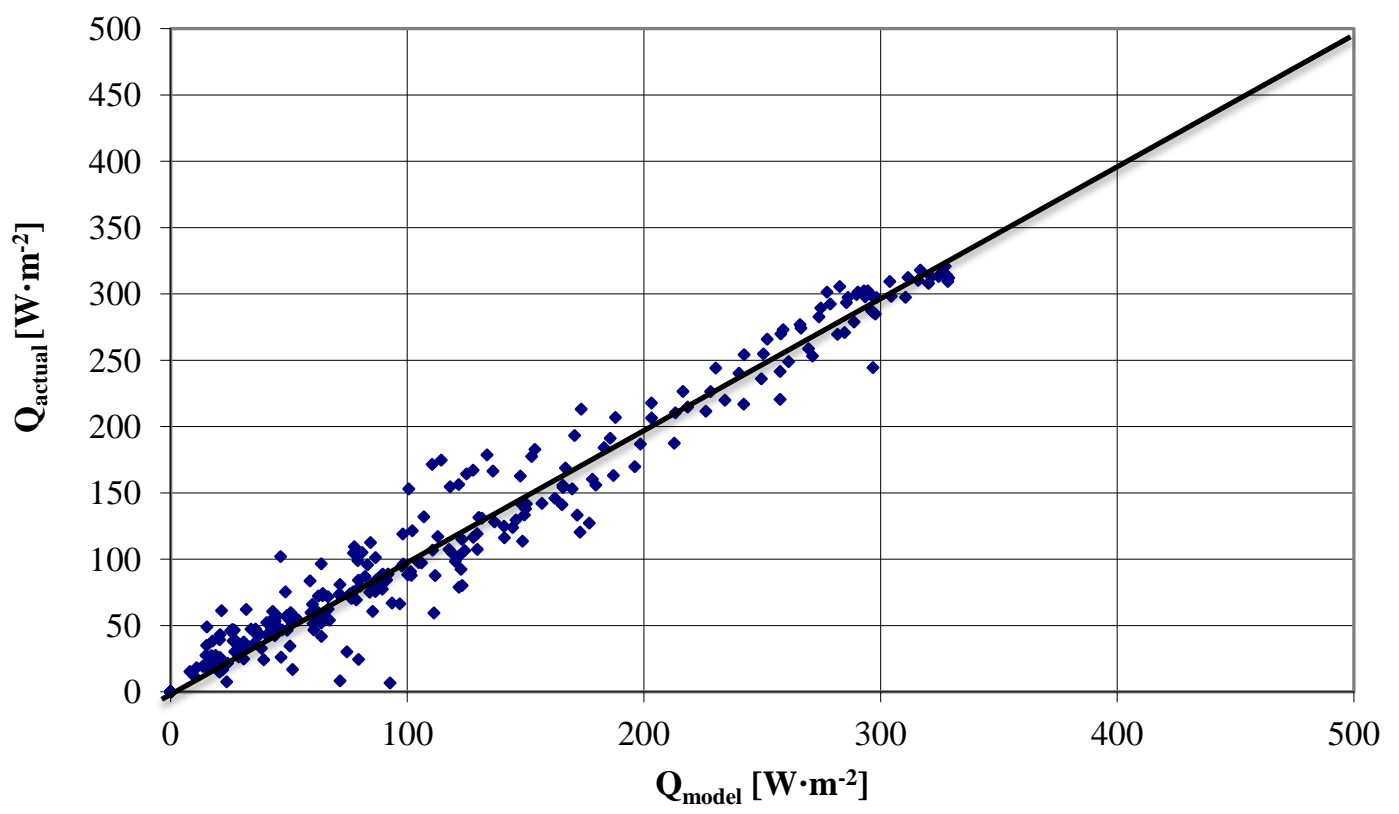

Figure 11: Actual measured production to model predicted production (PC).

Furthermore, the power production using the obtained parameters of QDT and the parameters obtained from the AEL test lab $\left(\eta=0.496, a_{1}=3.155 \mathrm{~W} / \mathrm{m}^{2} \mathrm{~K}, \mathrm{a}_{2}=0.022 \mathrm{~W} / \mathrm{m}^{2} \mathrm{~K}^{2}\right)$ is shown in Figure 12. Comparison conditions assumed at $1000 \mathrm{~W} / \mathrm{m}^{2}$ hemispherical irradiance, no diffuse, $3 \mathrm{~m} / \mathrm{s}$ wind speed, and normal incidence angle. The results in this comparison are also in congruence.

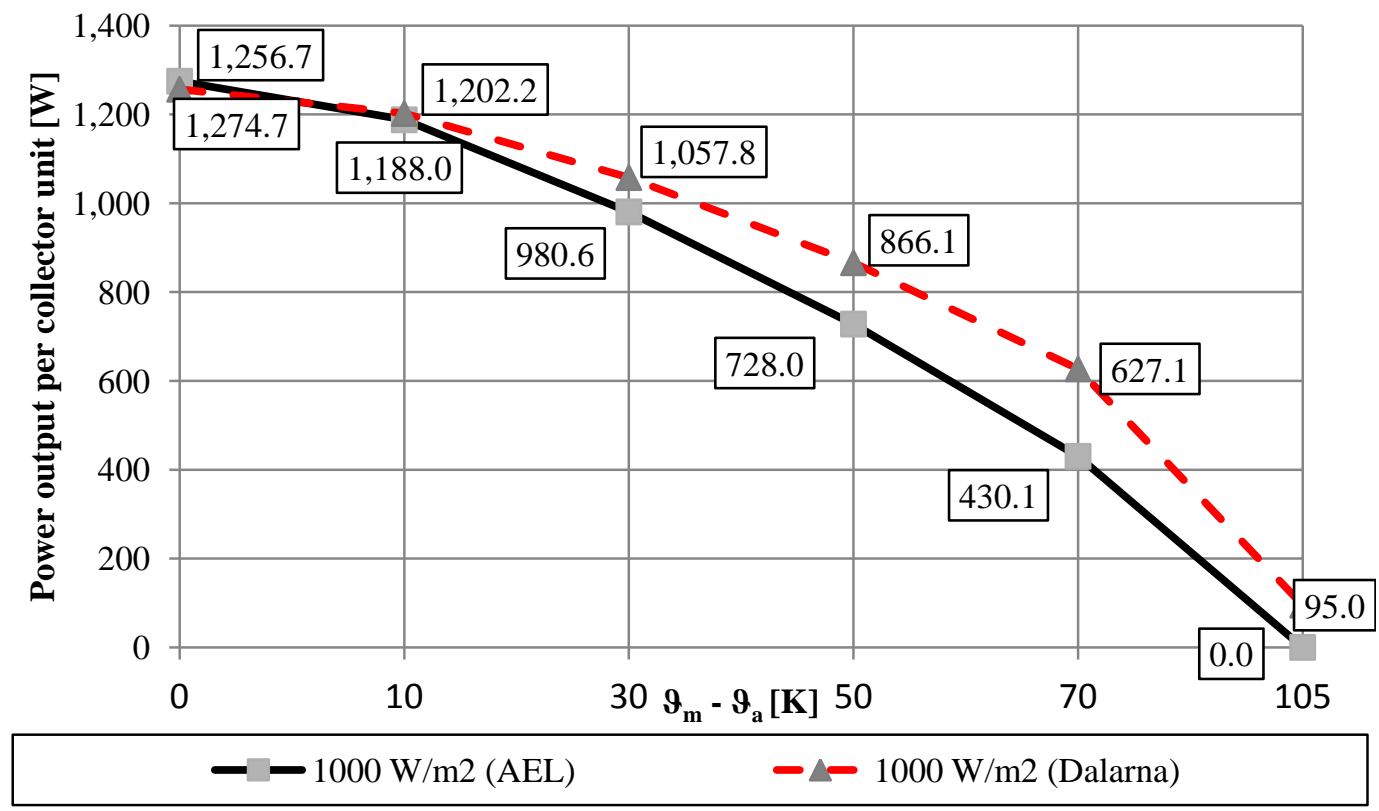

Figure 12: Actual measured production to model predicted production (PC). 


\section{References}

Fischer, S., Heidemanna, W., Müller-Steinhagena, H., Perersb, B., Bergquistc, P., Hellströmd, B., Collector test method under quasi-dynamic conditions according to the European Standard EN 12975-2, Solar Energy, Vol. 76, Issues 1-3, 117-123.

International Organization for Standards, 2013, ISO/FDIS 9806: Solar energy — Solar thermal collectors — Test methods.

Osório, T., Carvalho, M.J., Testing of solar thermal collectors under transient conditions, Solar Energy, Vol. 104, $71-81$

Seené, G., Ollas, P., Optimization of the Quasi Dynamic Method for Solar Collector Testing. 


\title{
Comparison of Two Whole System Test Methods: CCT and PLPE \\ Diego Menegon ${ }^{1}$, Robert Haberl ${ }^{2}$ and Michel Haller ${ }^{2}$ \\ ${ }^{1}$ Eurac Research, Institute for Renewable Energy, Bolzano (Italy) \\ 2 SPF Institute for Solar Technology, HSR University of Applied Sciences, Rapperswil (Switzerland)
}

\begin{abstract}
To perform a reliable performance evaluation under realistic boundary conditions, in the last twenty years, different research institutes have developed and applied whole system test methods. The methodologies are based on a common approach but the literature presents several differences on the steps that compose the test methods. This leads to different advantages and drawbacks.

The paper compares two methodologies in order to investigate on the different results that could be obtained in the same conditions applying two different methodologies. In this paper, we analyze the difference between the CCT method and the PLPE method in terms of boundary conditions (test sequences and load) and present a common application case.

Despite the different procedures in the definition of test sequence and emulations, the two methods bring to similar results in the characterization of the seasonal performance of a solar and heat pump system. The CCT method estimates a SPF of 4.09 while the PLPE 4.13.
\end{abstract}

Keywords: dynamic test, whole system testing, solar assisted heat pump, CCT method, PLPE method.

\section{Introduction}

A reliable performance prediction is one of the key factors to increase the efficiency and the contribution of renewable energy sources of heating and cooling systems. If one (or more) renewable energy source is integrated in a heating system, the reliable performance evaluation is not a trivial task. In this case, there are several effects interacting with each other such as the control strategy, the operation of each component, the availability of renewable energy source, the dynamics of load and so on. The consequence is that the system works under dynamic working conditions. Therefore, it is very important to study the performance considering realistic and dynamic working conditions as well as interaction between components.

In the last years, different whole system test procedures have been developed (Haller et al., 2013) namely CCT (Haberl et al., 2009), PLPE (Menegon et al., 2017b), Combitest (Bales, 2004), SCSPT (Albaric et al., 2008), DST and so on. The common approach of these methods is the test of the whole system considering a short sequence (of 6 or 12 days) and the emulation of the boundary conditions. As general approach, the system is installed as a whole in the laboratory; a short sequence reproduces the boundary conditions that represents the entire year, the load and the components that are not installed are emulated in real time. The data recorded during the test is used to analyze the system performance. However, the different methods present several differences on:

- 1) the selection of the test sequence;

- 2) the definition of load;

- 3) the emulation of the components that cannot be installed in the lab;

- 4) the extrapolation of the seasonal performance from the test sequence;

- 5) the extrapolation of the seasonal performance to other climates;

- 6) the applicability of methodologies (climates, system typologies, loads). 
From the literature, a simple comparison between the test methods could be done, considering all steps that compose the test methods. Table 1 shows a brief comparison of the different methodologies.

Tab. 1: Comparison of main test methods presented in literature.

\begin{tabular}{|c|c|c|c|c|}
\hline Method & $\begin{array}{c}\text { Test sequence - } \\
\text { Climate }\end{array}$ & Emulation & Extrapolations & Application \\
\hline PLPE & $\begin{array}{c}\text { 6 day- clustering } \\
\text { applicable for } \\
\text { any climate }\end{array}$ & $\begin{array}{c}\text { with simplified } \\
\text { emulations, load } \\
\text { files }\end{array}$ & Direct & $\begin{array}{c}\text { Solar thermal system + heat } \\
\text { pumps } \\
\text { Solar cooling }\end{array}$ \\
\hline CCT & 6 day-Zurich & with TRNSYS & Direct & $\begin{array}{c}\text { Solar thermal system + biomass } \\
\text { Solar thermal system + heat } \\
\text { pumps }\end{array}$ \\
\hline Combitest & 6 day - Zurich & with TRNSYS, & Direct & $\begin{array}{c}\text { Solar thermal system + biomass } \\
\text { load files }\end{array}$ \\
\hline SCSPT & 6 day-3 climates & with TRNSYS & ANN & $\begin{array}{c}\text { Solar thermal system + biomass } \\
\text { Solar thermal system + heat } \\
\text { pumps }\end{array}$ \\
\hline DST & In situ & On field test & Simulation & Solar heating - DHW systems \\
\hline
\end{tabular}

The table has been compiled comparing different literature sources. (Chèze et al., 2015, Haberl et al., 2015b, Haller et al., 2013, Lazrak et al., 2015, Menegon et al., 2017b, Schicktanz et al., 2014).

From this table, it is not easy to understand which are the differences on the final results when different test methods are applied on the same system. As an example, the user can understand which method is the simplest one to be applied in his own laboratory, but there is a lack of any kind of quantitative comparison. To cover this gap, in this paper, we have compared the CCT method (Haberl et al. 2015) with the PLPE method (Menegon et al. 2017b).

The analysis performed in this paper compares the two test methods in terms of the different steps composing the methods (e.g. boundary conditions, load, emulations and results). To quantify these differences, a solar assisted heat pump system has been simulated comparing the short sequences of PLPE and CCT with the annual performance.

\section{Method of comparison of CCT and PLPE}

The CCT and the PLPE present several differences in the steps that compose the procedures. The main differences can be identified in the definition of test sequence, in the definition of load and in the emulation of not-installed components. These aspects are compared in the paper in the following sections:

- $\quad 2.1$ Boundary conditions: definition test sequences for the climate of Zurich

- 2.2 Load: definition of load for the test sequence.

- $\quad 2.3$ Emulation: definition of emulation performed during the test.

- 2.4 Simulation of the two test methods on one case study.

\subsection{Boundary conditions}

The first comparison is made on the methodology used to define the short test sequence and a comparison of the two boundary conditions that are used during the test.

The choice of the CCT method is to define the test sequence for the climate of Zurich. The CCT does not foresee 
any other climate in order to perform a benchmark test for the different systems that are tested. Differently, the PLPE applies a clustering methodology to define the short boundary condition for a climate that the user can choose (Menegon et al., 2017a). With this method, the user can also choose to variate the length of the test sequence. The motivation of this choice is to allow the redefinition of test boundary conditions for specific applications required by the manufacturer of the system.

Since the CCT has a fixed six-day sequence, in order to compare the two methods, a six-day sequence for the Zurich climate has been defined with the PLPE. The results of this comparison are presented in section 3.1,

The CCT sequence has reduced the original sequence of twelve days to six days (Chèze et al., 2016). This was developed with an iterative simulation that has minimized the deviation between a direct extrapolation of results and the annual performance and that have satisfied the requirements of the CCT method.

\subsection{Load}

The two test methods define two different approaches for the definition of the load.

The CCT method considers a load file coupled with the building emulation performed with the type 5897. the sixdays sequence is simulated in order to get a load file. Then, during the test, the load file is limiting the heat input into the building within certain boundaries during the day, and to a fixed value at the end of the test-day. Thus, an equal amount of heating by all systems is guaranteed for the same day of the profile alhough the building is simulated in parallel and the correct return temperature from the building is supplied during the test.

The PLPE method considers a fixed load file that is coupled with the distribution system emulation. In the second case, an annual load file is calculated with the simulation of a reference building and the test sequence load profile is defined considering the load that occurs during the days selected with the clustering. In that case, the load is the same that occurs during the year as if during the test the annual days between two sequence days are simulated to precondition the building.

In other words we can say that the CCT adopts a "six-day simulated load" while the PLPE adopts a "load file from annual".

The two test methods allow to extrapolate the corresponding annual load from the test sequences even if they present a different distribution of the load in the sequence. The load considered by the CCT and PLPE is different since they adopt a different reference building: the CCT considers a building with $140 \mathrm{~m}^{2}$ and specific load of $60 \mathrm{kWh} / \mathrm{m}^{2}$ while the PLPE considers a building with $180 \mathrm{~m}^{2}$ and specific load of $70 \mathrm{kWh} / \mathrm{m}^{2}$. The values of load are calculated for the climate of Zurich. The PLPE method considers also the cooling load when the climate conditions requires it.

Concerning the DHW consumption, the PLPE defines one daily profile of $7 \mathrm{kWh}$ that is repeated each day of test (42 kWh for the whole sequence) while the CCT present a profile different for each day with a total sequence load of $50 \mathrm{kWh}$. To be able to compare the two methods, in this study the CCT profile has been scaled to reach the same energy extraction of the PLPE DHW profile.

\subsection{Emulations}

In the installation of the whole system, it is not possible to install all the component in the laboratory. That means that the laboratory should emulate the behavior of the components not installed.

Table 2 compares the emulations of the PLPE and the CCT test methods. In general, the PLPE performs emulation based on simplified emulation that can be implemented in the control system of the laboratory while the CCT couples the control of the lab with the TRNSYS types described in the table. 
Tab. 2: Emulation of components.

\begin{tabular}{|c|c|c|}
\hline Emulation & PLPE & CCT \\
\hline Load & $\begin{array}{l}\text { Load file defined with Type } 56 \text { and } \\
\text { simplified emulation of distribution system }\end{array}$ & $\begin{array}{c}\text { Non-Standard Type } 5897 \text { coupled with the } \\
\text { load file }\end{array}$ \\
\hline DHW & DHW load file & DHW load file \\
\hline $\begin{array}{c}\text { Solar } \\
\text { collector }\end{array}$ & Equation based on the EN 12975-2. & Non-Standard Type 832 \\
\hline Air source & $\begin{array}{l}\text { Linear regression based on the test of air unit } \\
\text { Applicable in case of not availability of a } \\
\text { climatic chamber }\end{array}$ & Not applicable. \\
\hline $\begin{array}{c}\text { Ground } \\
\text { probes }\end{array}$ & Under development & Non-Standard Type 451 \\
\hline
\end{tabular}

Sources: Type 5897: (Leconte et al., 2014). Type 832: (Haller et al., 2012); Type 451: (Wetter and Huber, 1997). Emulations of PLPE: (Menegon et al., 2017b).

\subsection{Comparison on an application case}

The differences presented in the section 2.1 and 2.2 have consequence on the variation of the boundary conditions. To understand how these factors influence the performance evaluation, the two test methods were compared considering the simulation of a solar assisted heat pump system.

Figure 1 shows the layout of the system that was considered in this study. The system model was developed in TRNSYS 17 (Klein and et al., 2012) and was validated with experimental data. This comparison allows to compare the two methods in terms of deviation on the direct extrapolation of the seasonal performance figures (load and energy sources, performance factors and so on).

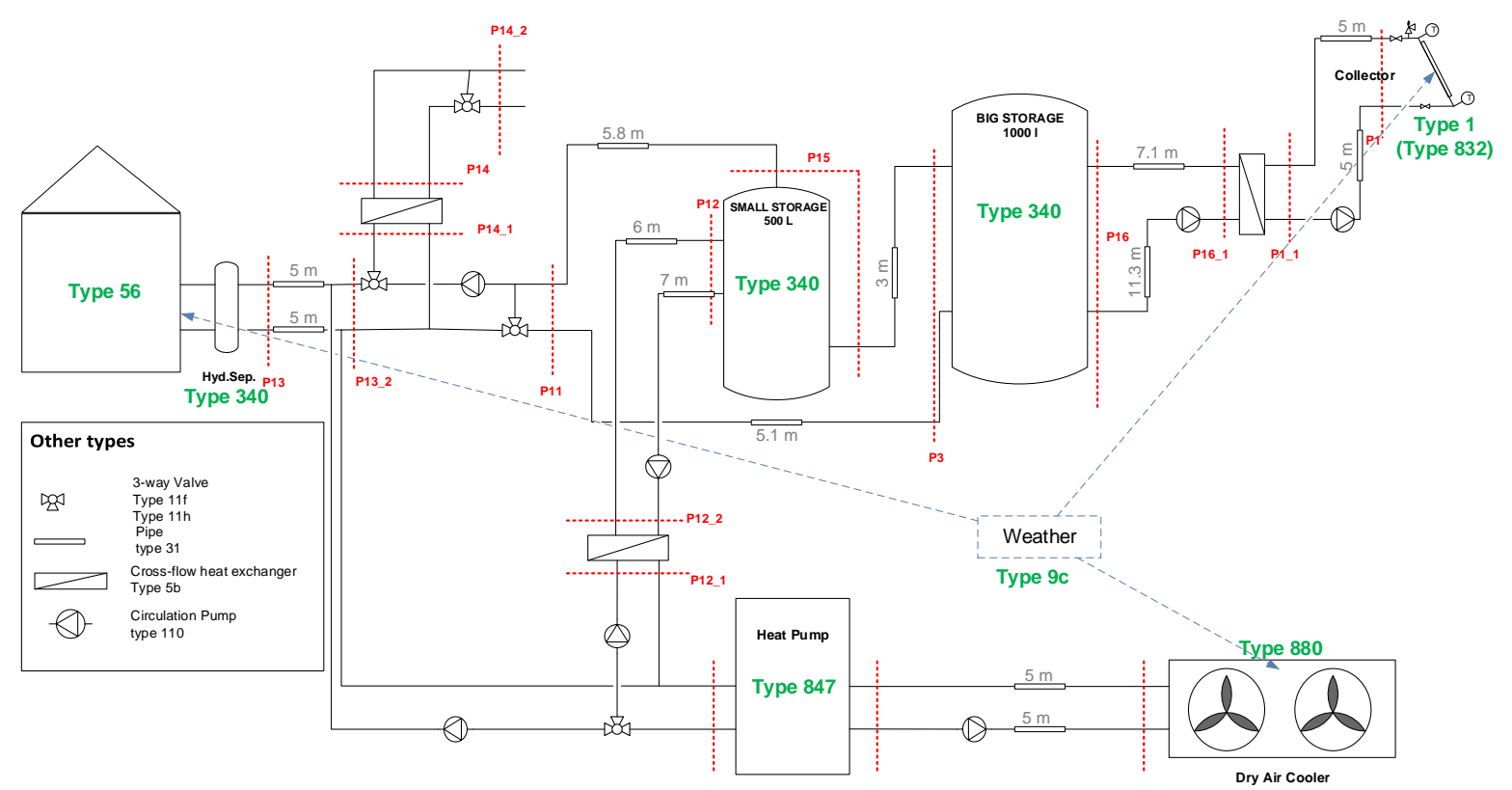

Fig. 1: Layout of the system considered for the comparison of PLPE and the CCT method.

From the short sequence, the annual energies are calculated with a direct extrapolation. The CCT scales the energies calculated with the test sequence with a direct proportion between the number of days of the sequence and the year (eq. 1) while the PLPE weights the daily energies with the cluster size of each day $\left(\mathrm{N}_{\mathrm{i}}\right)$. In addition, the results obtained with the CCT sequence are adjusted according to the correction factors defined in the CCT method (Menegon, 2016). 


$$
\begin{aligned}
& Q_{a, C C T}=Q_{s e q, C C T} \cdot \frac{365}{6} \cdot F C \\
& Q_{a, P L P E}=\sum_{i=1}^{6} Q_{i, P L P E} \cdot N_{i}
\end{aligned}
$$

Where Q represents the energies of load (space heating, DHW, total), the energy of sources (e.g. solar collector) and the consumptions (e.g. electric, gas or biomass). The subscript "a" indicates the annual value, "seq" the sequence, " $i$ " the number of the day.

The values calculated with the eq. 1 and eq. 2 has been compared with the annual simulation calculating the deviation in the following way:

$$
\delta=\frac{Q_{a, s e q}-Q_{a}}{Q_{a}}
$$

Where the deviation $\delta$ is calculated for the space heating, DHW, total load, the collector yield, the electric consumption and the SPF. The subscript "seq" is valid for the CCT and PLPE values.

\section{Results of comparison of CCT and PLPE}

\subsection{Boundary conditions}

Figure 2 compares the temperature and irradiance profiles of the CCT and PLPE sequences. The CCT sequence spaces between the minimum temperature point of $-8.9^{\circ} \mathrm{C}$ and the maximum temperature point of $20.3^{\circ} \mathrm{C}$. The temperature profile of PLPE variates between $-4.59^{\circ} \mathrm{C}$ and $25.7^{\circ} \mathrm{C}$. Therefore, the CCT sequence reaches the minimum temperature while the PLPE reaches the maximum temperature. In both sequence, the coldest day present the lowest irradiation while the hottest day present the highest irradiation.
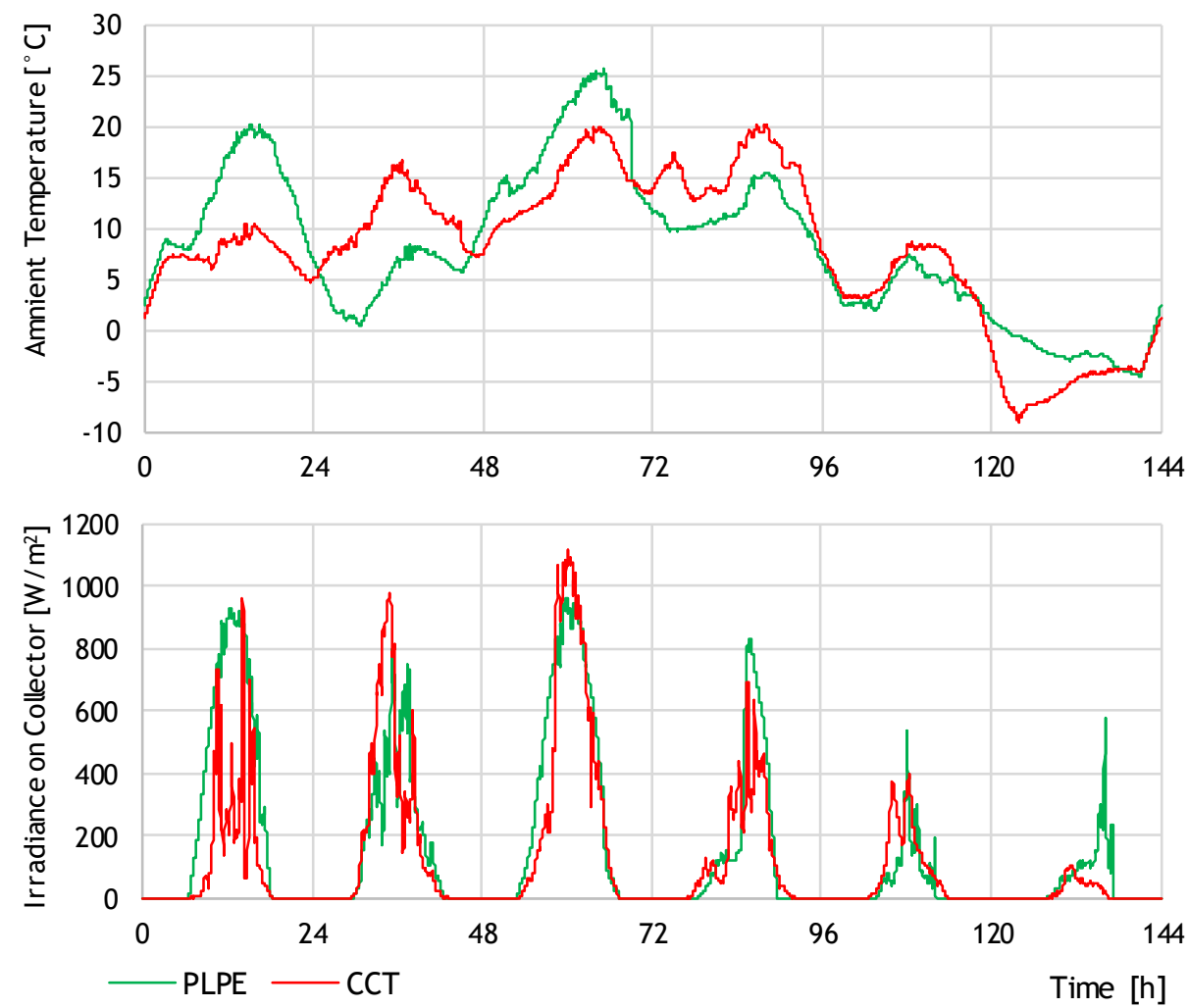

Fig. 2: Comparison of PLPE and CCT profiles of the ambient temperature and irradiation on the collector surface during the short test sequence. 
To understand how the profiles are positioned and distributed in the test reference year, Figure 3 presents the position of the six-day sequences in the 365 days of the year. The left-hand figure presents the daily irradiation on horizontal as a function of the daily average temperature, while the right-hand figure presents the daily load as a function of daily average temperature distinguished into heating load (red points) and cooling load (blue points). The annual temperature spaces between $-8.3^{\circ} \mathrm{C}$ and $26.04^{\circ} \mathrm{C}$, the irradiation between $123 \mathrm{Wh} / \mathrm{m}^{2}$ and $8245 \mathrm{Wh} / \mathrm{m}^{2}$, the maximum heating load is $125 \mathrm{kWh}$.

From the figure, it can be noticed that the cooling load is not relevant if compared with the heating load. Both the sequence do not present any day with cooling load.

The points of the PLPE sequence are well-distributed in the graphs and that is a direct consequence of the clustering methodology. The PLPE sequence is closer to the border of the area identified with the days of the year.
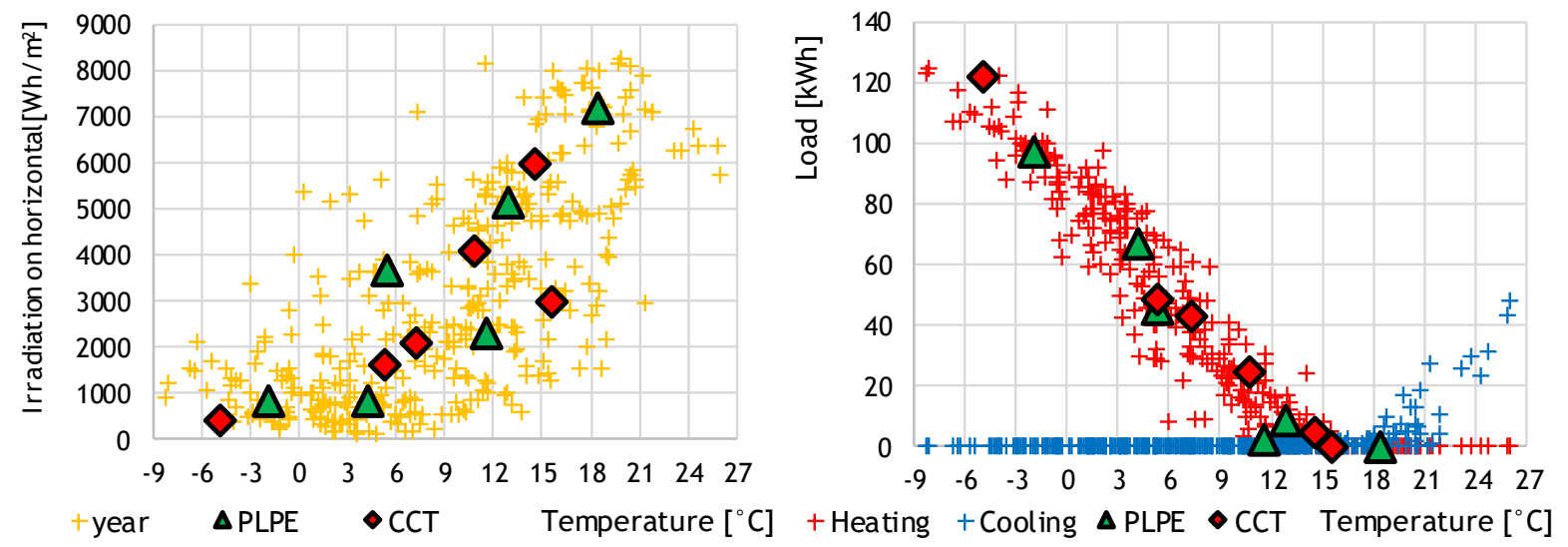

Fig. 3: Identification of six-days sequences of PLPE and CCT. Zurich Climate.

Figure 4 compares the two sequences in terms of daily average temperature, irradiation on horizontal and load. The figures present the average of the six-day profiles and of the annual average profile. Since the PLPE method uses a weight based on the size of clusters for the calculation of seasonal performance, also the average of temperature, irradiation and load has been calculated with a weighted average.

The comparison of the sequence average temperature and annual average temperature shows that the PLPE is closer to the annual average temperature. That is a direct consequence of the selection methodology. Indeed the difference between PLPE average temperature with the annual value is $0.2^{\circ} \mathrm{C}$ while the $\mathrm{CCT}$ is $0.9^{\circ} \mathrm{C}$. The $\mathrm{CCT}$ sequence presents the coldest day closer to the minimum annual value. This day presents $3.4^{\circ} \mathrm{C}$ more than the annual coldest day, while the PLPE coldest day presents an average temperature $6.4^{\circ} \mathrm{C}$ higher than the coldest annual day. At opposite, the hottest day of PLPE sequence has an average temperature $7.7^{\circ} \mathrm{C}$ lower than the annual hottest day, while the CCT is further (10.4 lower). The motivation of this higher distance compared to the coldest day is that the colder conditions are more frequent than the warmer days. Therefore, these higher distances of the highest temperature days are not relevant for the system characterization with the two test methods.

The same trend is verified for the irradiation where the PLPE sequence presents an average irradiation higher than the annual average about $54 \mathrm{Wh} / \mathrm{m}^{2}$ while the CCT presents an average irradiation $175 \mathrm{Wh} / \mathrm{m}^{2}$ lower than the annual average value. The PLPE sequence represents better the annual average conditions for the motivation previously explained. Again, the day with the lowest irradiation of the CCT sequence presents an irradiation $289 \mathrm{Wh} / \mathrm{m}^{2}$ higher than the annual minimum point while the PLPE $701 \mathrm{Wh} / \mathrm{m}^{2}$. At opposite the day with the highest irradiation of CCT sequence is quite far from the day of the year with maximum irradiation $\left(2235 \mathrm{Wh} / \mathrm{m}^{2}\right)$ while the PLPE is closer to the annual maximum $\left(1040 \mathrm{Wh} / \mathrm{m}^{2}\right)$.

In the PLPE, the hottest day presents also the highest irradiation while in the CCT the two maximum points (temperature and irradiation) are distinguished into two different days.

As final comparison, the days selected in the two test sequence present different loads. In this graph, the load is the one that occurs during the year (note: it is not the load considered in the CCT method. The CCT considers the load coming from the sequence simulation). As for temperature and irradiation, also the heating load of PLPE sequence is close to the annual average value. The difference between the average load of the CCT days with the 
annual values is $8.2 \mathrm{kWh}$ while the difference between PLPE average load and annual average load is $1.9 \mathrm{kWh}$.

Since the CCT considers one day of extreme condition, its load is very close to the maximum heating load required during the year $(2.4 \mathrm{kWh}$ lower) while the highest load in the PLPE sequence is $27.2 \mathrm{kWh}$ lower than the maximum annual heating load.

The two sequences do not identify days with space cooling load (not indicated in the figure) while during the year there are few days with cooling load. The cooling load is not relevant.
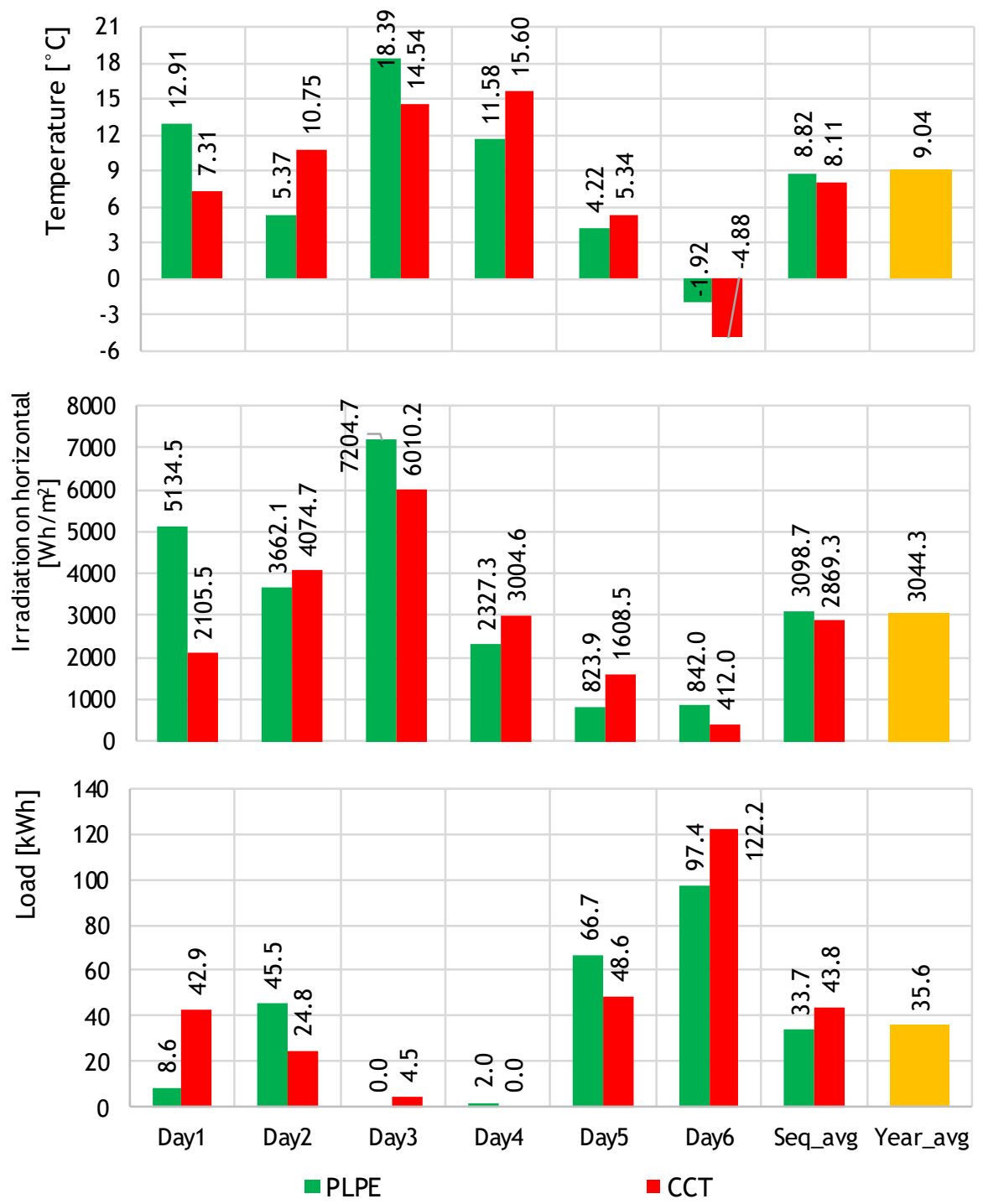

Fig. 4: Daily average temperatures and total irradiation on horizontal surface. Comparison of PLPE and CCT sequences.

In general, the PLPE sequence presents a profile closer to the annual average conditions. This outcome is a direct consequence of the clustering methodology. The CCT method presents the day with the extreme cold condition.

\subsection{Load}

As presented in the section 2.2, the CCT and PLPE follow two different approaches for the definition of load. In this way, the load resulting for the two test methods is different on the distribution of the load during the different days of the sequence. The motivation is given by the dynamics of the thermal load and the inertia of the building is accounted in different ways. For example, in the CCT the load of "day 6" is "preconditioned" by "day 5" and "day 4" while in the PLPE the load of "day 6" is preconditioned by the days that precede the "day 6" in the year.

As indicated in section 2.2, the CCT load could be called "six-day simulated load" while the PLPE called "load 
file from annual" and these two methods are compared in the Figure 5. Since the two methods have a different reference buildings, the load has been recalculated for the two methods with the two reference buildings. In addition, also the two test sequences are different and therefore the loads are defined considering the CCT sequence. That means that the load presented in the Figure 5 is not the one adopted in the PLPE method.

As a result, the daily loads are different and the maximum load can be reached only with the days taken from the annual load file ("load file from annual"), testing therefore the worst load condition. The average load of the "load file from annual" is higher than the "six-day simulated load" because the cold days are preconditioned by other cold days in the year. Since this comparison is made only on the approach of load definition (and not on the sequences), this does not mean that the extrapolated energy of the PLPE is higher. The PLPE method considers different days than the CCT.
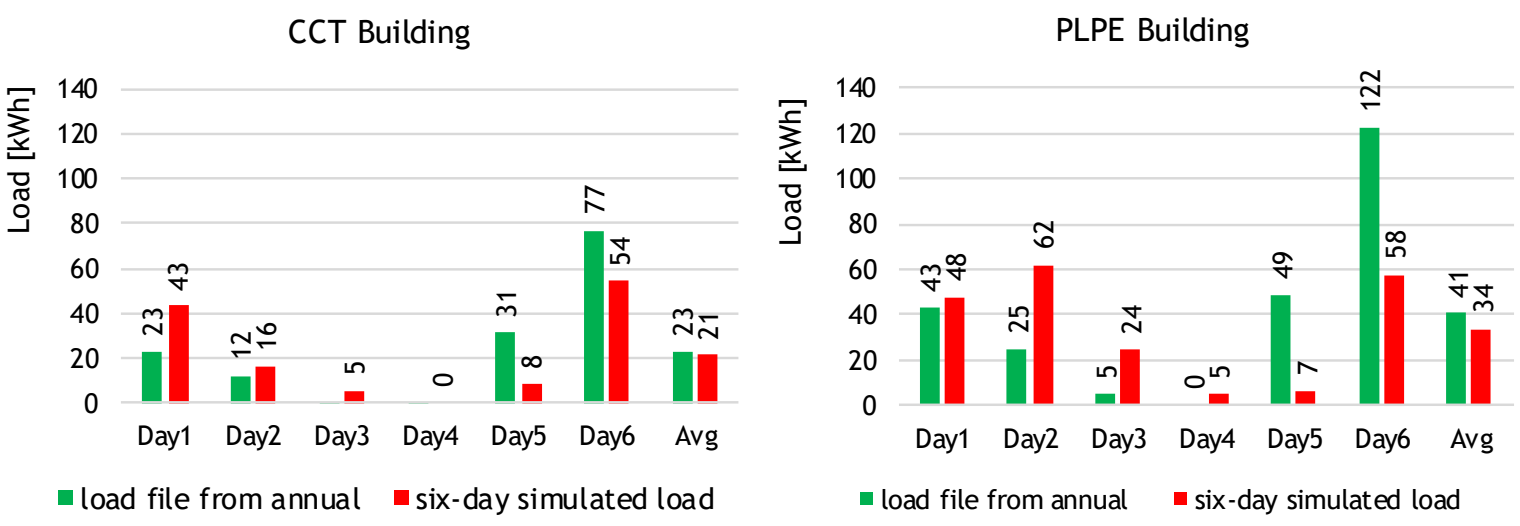

Fig. 5: Comparison of daily loads defined in the CCT and PLPE methods.

Note: the figure shows the average load instead of the sequence total load since it would have a different order of magnitude and the scale of graph would not be readable.

\subsection{Simulation of sequences and loads}

To understand the effect of applying the PLPE sequence and the CCT sequence, and the difference on the application of the two methods of load definition, the system indicated in the figure 1 has been simulated considering the "load file from annual" and the "six-day simulated load". In this case, one building should be considered to perform a coherent comparison. For this motivation the load has been defined with the PLPE reference building.

The table 3 presents the PLPE and CCT sequences simulated considering the two methods of load definition. In the first two rows the load has been defined according the PLPE method "load from annual file" while in the following two rows the load has been defined according the CCT method "six-day simulated load". The last row indicates the annual simulation that should be the objective function of the two test methods.

The table is combining the two sequences with the two methods of load definition that means that the row with "CCT sequence" and "load from annual file" is not coherent with the development of the CCT method and also the row with "PLPE sequence" and "six-day simulated row" is not coherent with the development of the PLPE method.

The table shows that the heating load required with the "CCT sequence" is higher than the heating load of the "PLPE sequence". That happens with the load definition with the "load from annual file" and with the "six-day simulated load". As we have seen in the previous section of selection of boundary conditions (3.1), the "CCT sequence" selects days colder than the PLPE method. From the table it is clear that is not possible to combine the PLPE sequence with the "six-day simulated load" and it is not possible to combine the CCT sequence with the "load from annual file". 
For every combination of sequence and load, the collector yield identified with the sequence is lower than the annual simulation.

Tab. 3: Comparison of simulation of sequences defined with PLPE and with CCT with the load file defined according to PLPE.

\begin{tabular}{|c|c|c|c|c|c|c|}
\hline Sequence & Load & $\begin{array}{c}\text { Qheat } \\
{[\mathbf{k W h}]}\end{array}$ & $\begin{array}{c}\text { Qdhw } \\
{[\mathbf{k W h}]}\end{array}$ & $\begin{array}{c}\text { Wheat } \\
{[\mathbf{k W h}]}\end{array}$ & $\begin{array}{c}\text { Wdhw } \\
{[\mathbf{k W h}]}\end{array}$ & $\begin{array}{c}\text { Qcoll } \\
{[\mathbf{k W h}]}\end{array}$ \\
\hline PLPE & $\begin{array}{c}\text { load from annual } \\
\text { file }\end{array}$ & 12250 & 2565 & 3241 & 343 & 7722 \\
\hline CCT & $\begin{array}{c}\text { load from annual } \\
\text { file }\end{array}$ & 15733 & 2456 & 4167 & 773 & 7710 \\
\hline PLPE & $\begin{array}{c}\text { Six-day simulated } \\
\text { load }\end{array}$ & 11450 & 2565 & 3015 & 399 & 7570 \\
\hline CCT & $\begin{array}{c}\text { Six-day simulated } \\
\text { load }\end{array}$ & 13595 & 2435 & 3376 & 546 & 7252 \\
\hline $\begin{array}{c}\text { Test Reference } \\
\text { Year }\end{array}$ & Annual load & 12996 & 2546 & 3646 & 428 & 10095 \\
\hline
\end{tabular}

Note: the energies indicated in this table are extrapolated according the (eq.1) and (eq.2)

\subsection{Simulation of CCT and PLPE}

As presented in the introduction, the PLPE defines the sequence with clustering and the load of each that is the same that occurs during the year, while the CCT considers the sequence defined with the optimization procedure and the load is simulated during the sequence. The results of CCT have been corrected with the correction factors defined in the procedure .

Table 4 presents the results of the seasonal performance evaluation calculated simulating the PLPE method, the CCT method and the annual profile. The CCT load has been scaled to reach the same level of the PLPE load.

Table 5 presents the deviation of the PLPE and the CCT method calculated in comparison with the annual simulation (eq. 3).

The results show to a similar deviation if compared to the annual simulation. The PLPE reaches a load 5\% lower than the annual value while the CCT reached a load 5\% higher than the annual value. Both results agree with the accuracy declared in the literature in the different test methods. In terms of SPF, the two sequences deviate about $1 \%$ one to each other and they deviate about $7 \%$ from the annual simulation.

The largest deviation is obtained in the calculation of DHW consumption.

Tab. 4: Comparison of simulations of PLPE and CCT methods. Performance figures

\begin{tabular}{|c|c|c|c|c|c|c|c|c|}
\hline & $\begin{array}{c}\text { Qheat } \\
{[\mathbf{k W h}]}\end{array}$ & $\begin{array}{c}\text { Qdhw } \\
{[\mathbf{k W h}]}\end{array}$ & $\begin{array}{c}\text { Qtot } \\
{[\mathbf{k W h}]}\end{array}$ & $\begin{array}{c}\text { Wheat } \\
{[\mathbf{k W h}]}\end{array}$ & $\begin{array}{c}\text { Wdhw } \\
{[\mathbf{k W h}]}\end{array}$ & $\begin{array}{c}\text { Wtot } \\
{[\mathbf{k W h}]}\end{array}$ & $\begin{array}{c}\text { Qcoll } \\
{[\mathbf{k W h}]}\end{array}$ & $\begin{array}{c}\text { SPFt } \\
{[-]}\end{array}$ \\
\hline PLPE & 12250 & 2565 & 14815 & 3241 & 343 & 3584 & 7722 & 4.13 \\
\hline CCT & 13595 & 2435 & 16029 & 3376 & 546 & 3922 & 7252 & 4.09 \\
\hline Annual & 12996 & 2546 & 15542 & 3646 & 428 & 4074 & 10095 & 3.82 \\
\hline
\end{tabular}

Tab. 5: Comparison of simulations of PLPE and CCT methods. Deviation with annual simulation

\begin{tabular}{|c|c|c|c|c|c|c|c|c|}
\hline & $\begin{array}{c}\text { Qheat } \\
{[\mathbf{k W h}]}\end{array}$ & $\begin{array}{c}\text { Qdhw } \\
{[\mathbf{k W h}]}\end{array}$ & $\begin{array}{c}\text { Qtot } \\
{[\mathbf{k W h}]}\end{array}$ & $\begin{array}{c}\text { Wheat } \\
{[\mathbf{k W h}]}\end{array}$ & $\begin{array}{c}\text { Wdhw } \\
{[\mathbf{k W h}]}\end{array}$ & $\begin{array}{c}\text { Wtot } \\
{[\mathbf{k W h}]}\end{array}$ & $\begin{array}{c}\text { Qcoll } \\
{[\mathbf{k W h}]}\end{array}$ & $\begin{array}{c}\text { SPFt } \\
{[-]}\end{array}$ \\
\hline PLPE & $-5.7 \%$ & $0.7 \%$ & $-4.7 \%$ & $-11.1 \%$ & $-19.9 \%$ & $-12.0 \%$ & $-23.5 \%$ & $7.6 \%$ \\
\hline CCT & $4.6 \%$ & $-4.4 \%$ & $3.1 \%$ & $-7.4 \%$ & $27.6 \%$ & $-3.7 \%$ & $-28.2 \%$ & $7.1 \%$ \\
\hline
\end{tabular}




\section{Conclusions}

The paper has presented the comparison of two whole system test methods: the CCT method and the PLPE. The aim is to understand the qualitative and quantitative differences of the two methods. The paper compares the different steps composing the test methods in order to understand the effect of those steps. In addition, the paper compares the two methods on one application study.

At first, the boundary conditions were compared. The two methods test the system under different boundary conditions. The CCT method reaches the lowest external temperature and the PLPE method reaches the highest temperature. In addition, the PLPE presents a test sequence closer to the annual average conditions.

As second comparison, the methods used to define the load has been compared. The PLPE method considers the load of each day as it is during the year while the CCT simulates the load during the sequence. As a consequence the load profiles that came out during the test are different. For this motivation, the PLPE requires a higher load than the CCT.

The two effects given by the different sequences and the different loads mitigate each other and therefore the CCT and PLPE method result in a similar load: the deviation between the short sequence and the annual load is about $5 \%$ in both cases.

Despite the different approaches on the test boundaries and the emulations, the two methods result in similar seasonal performance factors determined for the investigated system. The annual simulation of the system was taken as a reference and best estimation of the true value with a SPF of 3.82. From the direct extrapolation performed with the two methods, the CCT estimation is 4.09, while the PLPE yields 4.13.

\section{References}

Albaric, M., Nowag, J., Papillon, P, 2008. Thermal performance evaluation of solar combisystems using a global approach. In: EUROSUN 2008, Lisbon, Portugal.

Bales C., 2004. Combitest - a new test method for thermal stores used in solar combisystems. Doctoral Thesis Department of Building Technology, Chalmers university of Technology.

Chèze, D., Papillon, P., Leconte, A., Haller, M.Y., Haberl, R., Perrson, T., Bales, C., 2015. Towards an Harmonized Whole System Test Method for Combined Renewable Heating Systems for Houses, in: Eurosun 2014, International Solar Energy Society: pp. 1-10. doi:10.18086/eurosun.2014.03.06.

Chèze, D., Bales, C., Haberl, R., Haller, M., Matuska, T., Mojic, I., Persson, T., 2016. Report on improved whole system test method application experience, Deliverable 8.4 MacSheep. New Materials and Control for a next Generation of Compact Combined Solar and Heat Pump Systems with Boosted Energetic and Exergetic Performance.

Haberl, R., Frank, E., Vogelsanger, P., 2019. Holistic system testing-10 years of concise cycle testing. In: ISES 2009; p. 351-360.

Haberl, R., Haller, M.Y., Papillon, P., Chèze, D., Persson, T., Bales, C., 2015. "Testing of Combined Heating Systems for Small Houses: Improved Procedures for Whole System Test Methods.” Deliverable 2.3. MacSheep New Materials and Control for a next Generation of Compact Combined Solar and Heat Pump Systems with Boosted Energetic and Exergetic Performance. http://macsheep.spf.ch/fileadmin/user_upload/macsheep/dokumente/MacSheep_D2_3_Improved_Procedures_fo r_whole_system_testing_150211_final.pdf.

Haller, M.Y.,Perers, B., Bales, C., Paavilainen, J., Dalibard, A., Fischer, S., Bertram, E., 2012. TRNSYS Type 832 v5. 00 Dynamic Collector Model by Bengt Perers. Updated Input-Output Reference.

Haller, M.Y., Haberl, R., Persson, T., Bales, C., Kovacs, P., Chèze, D., Papillon, P., 2013. Dynamic Whole System 
Testing of Combined Renewable Heating Systems - The Current State of the Art. Energy and Buildings. 66, 667677. https://doi.org/10.1016/j.enbuild.2013.07.052.

Lazrak, A., Leconte, A., Chèze, D., Fraisse, G., Papillon, P. \& Souyri, B., 2015. Numerical and experimental results of a novel and generic methodology for energy performance evaluation of thermal systems using renewable energies. Applied Energy, 158, p.142-156.

Leconte, A., Chèze, D., Jobard, X., 2014. Proforma Type 5897 - Iso Building Model.

Menegon, D., 2016. Development of a Dynamic Test Procedure for the Laboratory Characterization of HVAC systems, PhD Thesis, University of Udine, pp. 125-126.

Menegon, D., Soppelsa, A., Fedrizzi, R., 2017a. Clustering Methodology for Defining a Short Test Sequence for Whole System Testing of Solar and Heat Pump Systems. In SWC 2017. Abu Dhabi, UAE: ISES.

Menegon, D., Soppelsa, A., Fedrizzi, R., 2017b. Development of a New Dynamic Test Procedure for the Laboratory Characterization of a Whole Heating and Cooling System. Applied Energy. 205, 976-990. https://doi.org/10.1016/j.apenergy.2017.08.120.

Klein, S. A., and et al., 2012. TRNSYS 17 Volume 4 Mathematical Reference. SEL (Solar Energy Laboratory, Univ. of Wisconsin-Madison), TRANSSOLAR Energietechnik GmbH, CSTB (Centre Scientifique et Techniquedu Bâtiment), TESS (Thermal Energy Systems Specialists).

Schicktanz, M.D., Schmidt, C., Fedrizzi, R., 2014. Classification of Rating Methods for Solar Heating and Cooling Systems, Energy Procedia. 48, 1676-1687. doi:10.1016/j.egypro.2014.02.189.

Wetter, M., Huber, A., 1997. Vertical Borehole Heat Exchanger EWS Model, Model description and implementing into TRNSYS. 


\title{
Analysis of Applicability of PLPE Method for the Test of a Solar Cooling System.
}

\author{
Diego Menegon ${ }^{1}$ \\ ${ }^{1}$ Eurac Research, Institute for Renewable Energy, Bolzano (Italy)
}

\begin{abstract}
Dynamic whole system testing methods are applied to evaluate the performance of heating system driven by renewable energy. The application of dynamic methods is needed to perform a reliable performance evaluation since these systems work under dynamic conditions. However, some procedures described in literature are defined for a specific application.

The PLPE procedure has been developed with the aims of simplification of its application and of having a general applicability. Nevertheless, the PLPE was validated only for a solar assisted heat pump system. The present paper wants to investigate the applicability of the PLPE procedure for the test of a solar cooling system.

The paper shows the representability of the emulations and the accuracy of estimating the seasonal performance for different climates in the case of solar cooling systems. The PLPE can estimate the thermal SPF with an accuracy of the $10 \%$.
\end{abstract}

Keywords: solar cooling; whole system testing; PLPE method.

\section{Introduction}

To evaluate the performance of a heating systems, different whole system testing methods (Haller et al. 2013) have been developed and are currently applied by different research institutes. The main motivation to apply a whole system testing method is that the system is studied under realistic working conditions since it is installed as a whole. In this way, it is possible to identify the different effects affecting the performance. Those testing methods allow system optimization, faults detection and resolution before the commercialization of the system or its installation in the final user site.

The procedures presented in literature are applied to some specific typology of heating system such as solar assisted heat pumps systems, solar and biomass system or hot water systems (Albaric et al., 2008, Bales, 2004, Haberl et al., 2009, Lazrak et al., 2015, Menegon et al., 2017b, Schicktanz et al., 2014).

The PLPE (Menegon et al., 2017b) has been developed with the aim of being applicable for different heating and cooling systems. However, this test method has been validated only for a solar assisted heat pumps system.

The present paper would verify the applicability of the PLPE method for the test of a solar cooling system. In the development of the PLPE, the authors have defined the sequence considering a generic heating and cooling system and therefore the boundary conditions are not depending from the system layout.

From the whole system testing method point of view, a solar cooling system is quite different from a solar heating system: when a short sequence is used for the test of a solar system, one of the causes of the deviation on the performance extrapolation is the error on the assessment of the solar contribution. Typically, in a solar heating system, a short sequence can overestimate the solar fraction since it can neglect the summer stagnation since there is a mismatching between load and availability of the source. On the other side, in a solar cooling system, during 
the summer, the solar energy corresponds to its use for the cooling production. It is not obvious that a procedure valid for the characterization of a solar heating system could be valid also for the characterization of a solar cooling system due to these different correspondences between the availability of the source and the requirement of load.

The paper presents the evaluation performed on a solar cooling system during the cooling season and with the use of numerical simulation. The study considers the climates of Bolzano and Palermo, different collector areas $\left(8 \mathrm{~m}^{2}\right.$, $12 \mathrm{~m}^{2}$ and $16 \mathrm{~m}^{2}$ ) and different sequence lengths (six-day, eight-day and ten-day).

The solar cooling system presented in this paper has been configured in the laboratory and the controls schemes were defined and improved with numerical simulations. The aim of this study it was not to develop a new system concept but to verify the applicability of the PLPE method for the test of solar cooling.

\section{Case study}

The systems presented in figure 1 has been used to verify the applicability of the PLPE. The system adopts an adsorption chiller of $8 \mathrm{~kW}$ (SorTech AG, 2009) fed with solar energy. The gas boiler is used as back-up for the domestic hot water preparation.

The numerical model has been developed in TRNSYS 17 (Klein and et al., 2012). The components' models have been validated with experimental data and monitoring data.

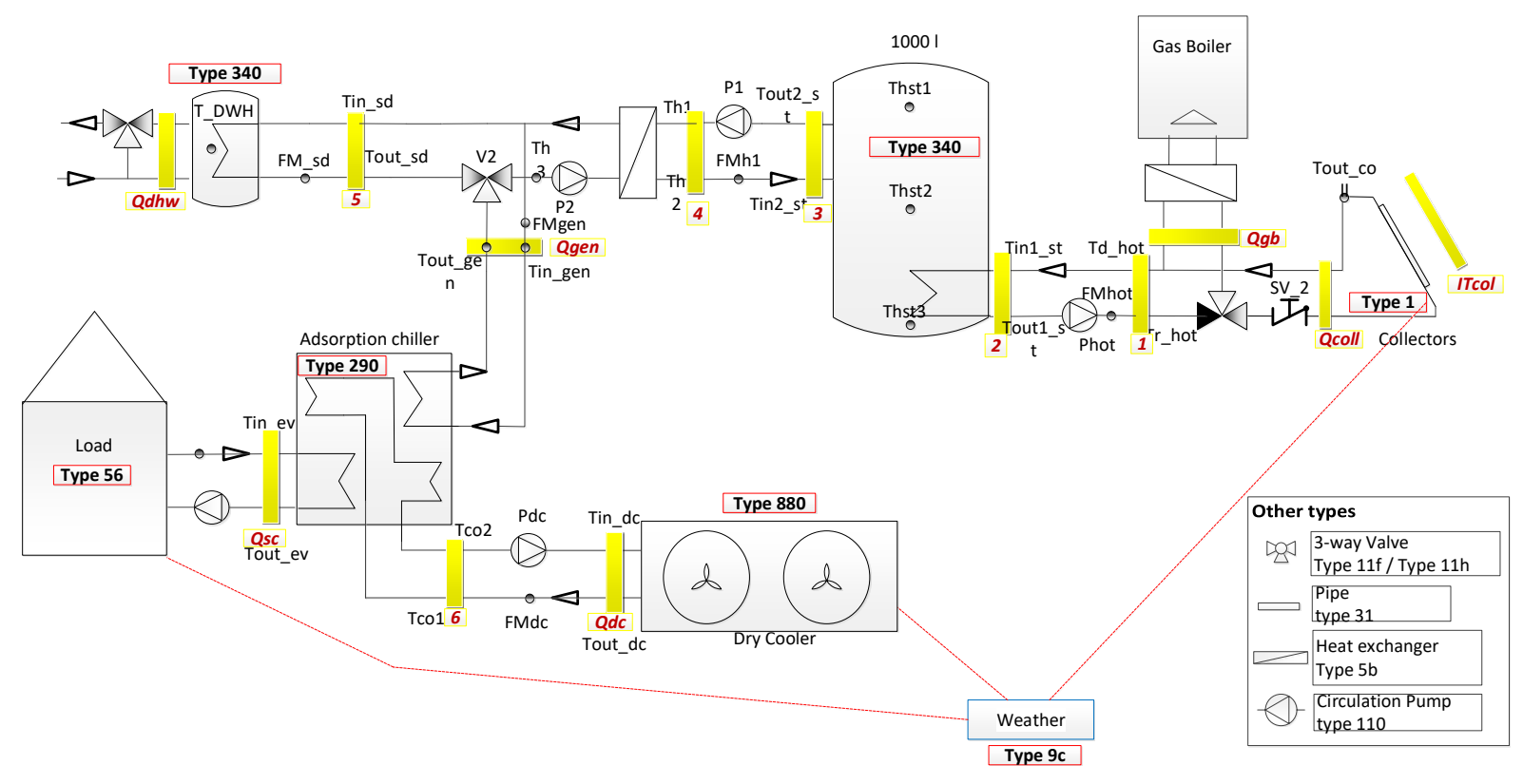

Fig. 1: Layout of the solar cooling system.

The system model uses the following types:

- Storage: Type 340 (Drück and Pauschinger, 2006); the geometry of the storage is defined for the model present in the laboratory. The validation has been performed with monitoring data.

- Adsorption chiller: the type 290 has been developed directly by the manufacturer (SorTech AG, 2009); the model is based on a performance map rated by the manufacturer. Since the DLL cannot be modified, a post-correction has been applied to validate the model according to the dynamic performance of the chiller rated in the laboratory (Menegon et al., 2014);

- Dry cooler: type 880 (Besana, 2009). The model is based on the $\varepsilon /$ NTU method and capacitance effects are considered. The validation of the model has been performed with monitoring data.

- Gas boiler: the performance of the gas boiler has been defined in laboratory under stationary condition. Since it was possible to define the heat as a linear regression of the inlet temperature, a calculator has been 
set up to calculate the output temperature from the performance map. This kind of calculation well fits with the laboratory test of this unit.

- Other components: standard TRNSYS types. The parameters of each component correspond to the commercial component composing the system (e.g. the electrical consumption has been measured in laboratory and so on).

From the simulation results, the load and source energy have been counted and used to calculate different performance factors. These are the electrical seasonal performance factor, the thermal seasonal performance factor, the solar fraction and the primary energy ratio.

The total electrical SPF $\left(\mathrm{SPF}_{\mathrm{el}}\right)$ is calculated as the ratio of total load to the total electric consumption. The total load is the sum of domestic hot water demand $\left(\mathrm{Q}_{\mathrm{dhw}}\right)$ and the space cooling demand $\left(\mathrm{Q}_{\mathrm{sc}}\right)$. For the electrical consumption $\left(\mathrm{W}_{\text {tot }}\right)$, it is accounted the contribution of all the auxiliaries (chiller, pumps and the fans of the dry cooler).

$$
S P F_{e l}=\frac{Q_{d h w}+Q_{s c}}{W_{t o t}}
$$

The total thermal SPF $\left(\mathrm{SPF}_{\mathrm{th}}\right)$ is calculated as the ratio of the total load with the total thermal energy in input. The thermal energy in input is the sum of the collector yield $\left(\mathrm{Q}_{\text {coll }}\right)$ with the gas boiler energy $\left(\mathrm{Q}_{\mathrm{gb}}\right)$.

$$
S P F_{t h}=\frac{Q_{d h w}+Q_{S c}}{Q_{c o l l}+Q_{g b}}
$$

In this study, the thermal and electrical SPF are considered as sum of total loads. There is not the distinction of cooling SPF and hot water SPF.

The solar fraction is defined as the ratio between the collector yield with the total input thermal energy.

$$
S F_{\text {tot }}=\frac{Q_{\text {coll }}}{Q_{\text {coll }}+Q_{g b}}
$$

As last performance factor, the primary energy ratio is defined as the ratio between the useful energy to the primary energy input. To define the primary energy a conversion factor of 0.41 for the electrical grid and 0.95 for the gas boiler.

$$
P E R=\left(Q_{d h w}+Q_{s c}\right) /\left(\frac{W_{e l}}{\eta_{e l}}+\frac{Q_{g b}}{\eta_{g b}}+Q_{c o l l}\right)
$$

\section{Method}

The flow chart of figure 2 shows the steps adopted to perform the analysis of applicability of the PLPE for the test of solar cooling systems. The first step is the selection of the weather conditions that are boundaries of the test sequence. Then, a short sequence is defined with a clustering classification (Menegon et al., 2017a). The main advantage is that different climates can be easily selected to define the test sequence. In this way, if the manufacturer need a specific climate, it can be set-up. Please note that the PLPE method at now is validated only for European climates.

The evaluation has been performed comparing a numerical simulation of the sequence with the annual simulation. The numerical model has been defined in the previous section. The system has been simulated considering sixday sequences defined for the climates of Bolzano and Palermo. A parametric simulation was done to investigate different collector areas $\left(8 \mathrm{~m}^{2}, 12 \mathrm{~m}^{2}\right.$ and $\left.16 \mathrm{~m}^{2}\right)$. In addition, the climate of Bolzano has been simulated to investigate different sequence lengths of six days, eight days and ten days.

In this study, the system is studied under the summer conditions. The seasonal energies indicated in the tables are referred from June to September. The test sequences were defined considering the annual file and then only the days between June and September have been simulated. 
The short sequence is also the boundary condition of the laboratory test. However, the results of the laboratory test are not present in this study.

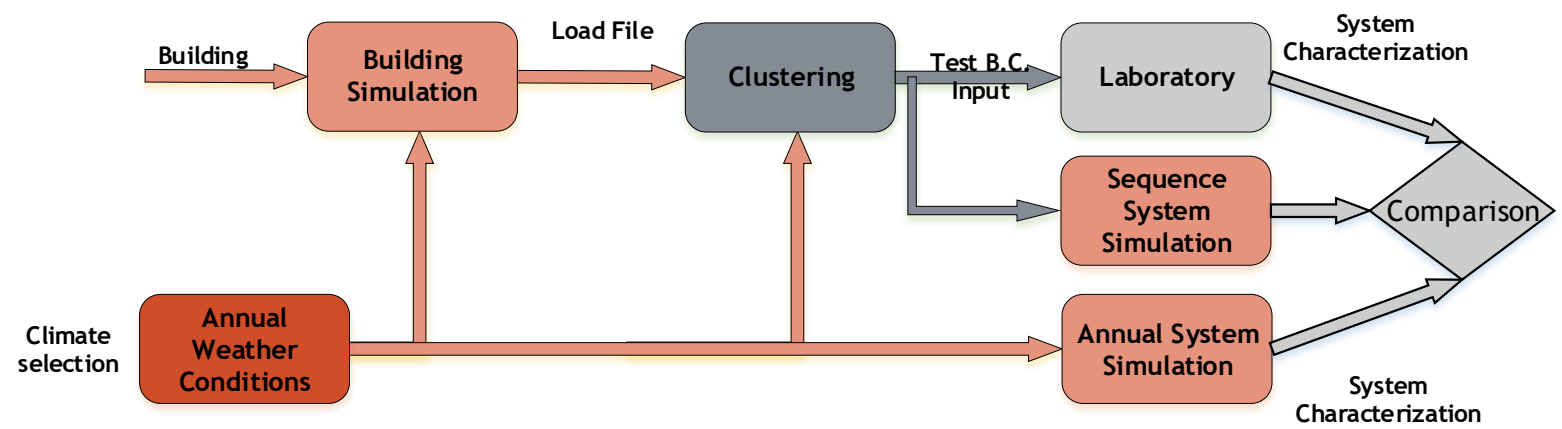

Fig. 2: Method for the evaluation of applicability of the PLPE for the test on a solar cooling system.

The seasonal performance is calculated from the short sequence according to the PLPE method. Specifically, the PLPE methods calculates the annual energies from the short sequence with the direct extrapolation indicated with (eq. 5). The daily energies of the sequence are weighted with the cluster size of each day $\left(\mathrm{N}_{\mathrm{i}}\right)$.

$$
Q_{a}=\sum_{i=1}^{N c} Q_{i} \cdot N_{i}
$$

In the (eq. 1), Q represents the energies of load (space heating, DHW, total), the energy of sources (e.g. solar collector) and the consumptions (e.g. electric, gas). The subscript "a" indicates the annual value (in this study referred as cooling season), "seq" the sequence, "i" the number of the day and Nc the number of clusters.

The deviation with the annual simulation of the values calculated with the eq. 1 is calculated as follows:

$$
\delta=\frac{Q_{a, s e q}-Q_{a}}{Q_{a}}
$$

Where the deviation $\delta$ is calculated for the different parameters calculated in this study: space-cooling load, DHW, total load, the collector yield, the electric consumption, the gas consumption, the electric and thermal SPF, the solar fraction and the primary energy ratio.

\section{Results}

This section presents the results of the parametric simulation performed for the solar cooling system during the summer season. The parametric simulations have considered different collector areas and different sequence lengths. The simulations were performed for the climates of Bolzano and Palermo.

\subsection{Evaluation for different sequence length}

Figure 4, figure 5 and table 1 present the simulation of the solar cooling system with $8 \mathrm{~m}^{2}$ of collector area. These results are referred to the simulation of the cooling season, the six-day sequence, the eight-day sequence and the ten-day sequence. As indicated in the section 3, the short sequences are defined for the entire year and only the days between June and September were simulated.

Figure 4 presents the space cooling load, the collector yield, the total radiation on collector surface and the gas boiler consumption. From the figure, it can be seen that the six-day sequence presents the higher deviation with the entire simulation while the deviation is reduced with the eight-day sequence and the ten-day sequence. The six-day sequence evaluates a lower cooling demand and a lower contribution of gas boiler while it overestimates the collector yield. The overestimation of the collector yield is a direct consequence of the higher irradiation on the collector. Since the irradiation is a known boundary condition, this deviation can be corrected by reducing the 
irradiation of the sequence in order to reach the level of the cooling season. However, in this study there is not any correction of boundary conditions since the procedure is the same presented for the SAHP system. (Menegon et al., 2017b). This consideration will be considered for any future development of the procedure.

The eight-day sequence and the ten-day sequence lead to a similar evaluation of seasonal performance. These two sequences overestimate the collector yield of about $10 \%$, the eight-day sequence presents a similar deviation on the gas boiler consumption while the ten-day sequence is more precise ( $2.9 \%$ of deviation).

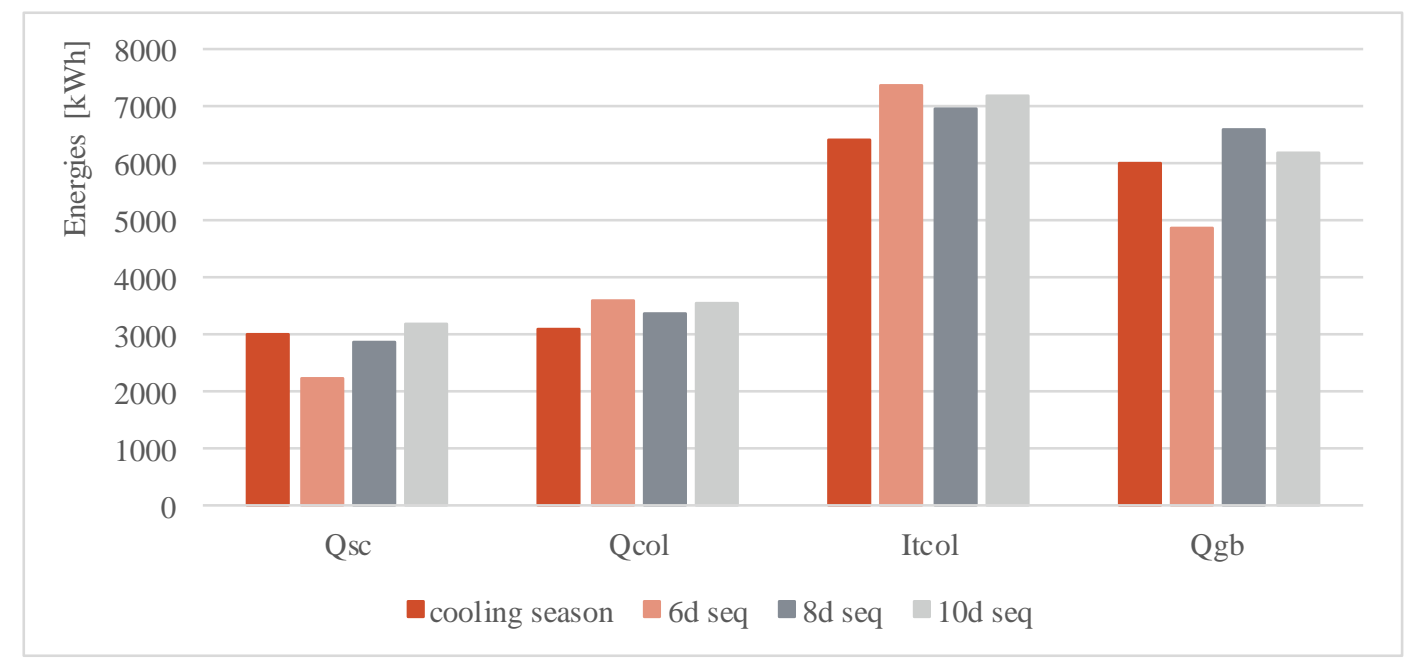

Fig. 4: Solar cooling system simulation. Energies calculated with summer simulation and short sequences. Collector area of $8 \mathbf{~ m}^{2}$.

Figure 5 presents the collector efficiency, the thermal SPF, the electrical SPF and the PER. The first outcome is that all the sequence identify correctly the collector efficiency.

As indicated the previous figure, the six-day sequence presents a higher deviation on the other performance factors. That is a consequence of the not correct assessment of the contribution of the solar collector and the gas boiler. Indeed, the higher collector yield previously presented lead to a higher solar fraction. With the higher solar contribution also the thermal losses increase and this can be noticed by the lower thermal SPF.

Again, the eight-day and ten-day sequence present similar results and these two sequence represent well the cooling season conditions.

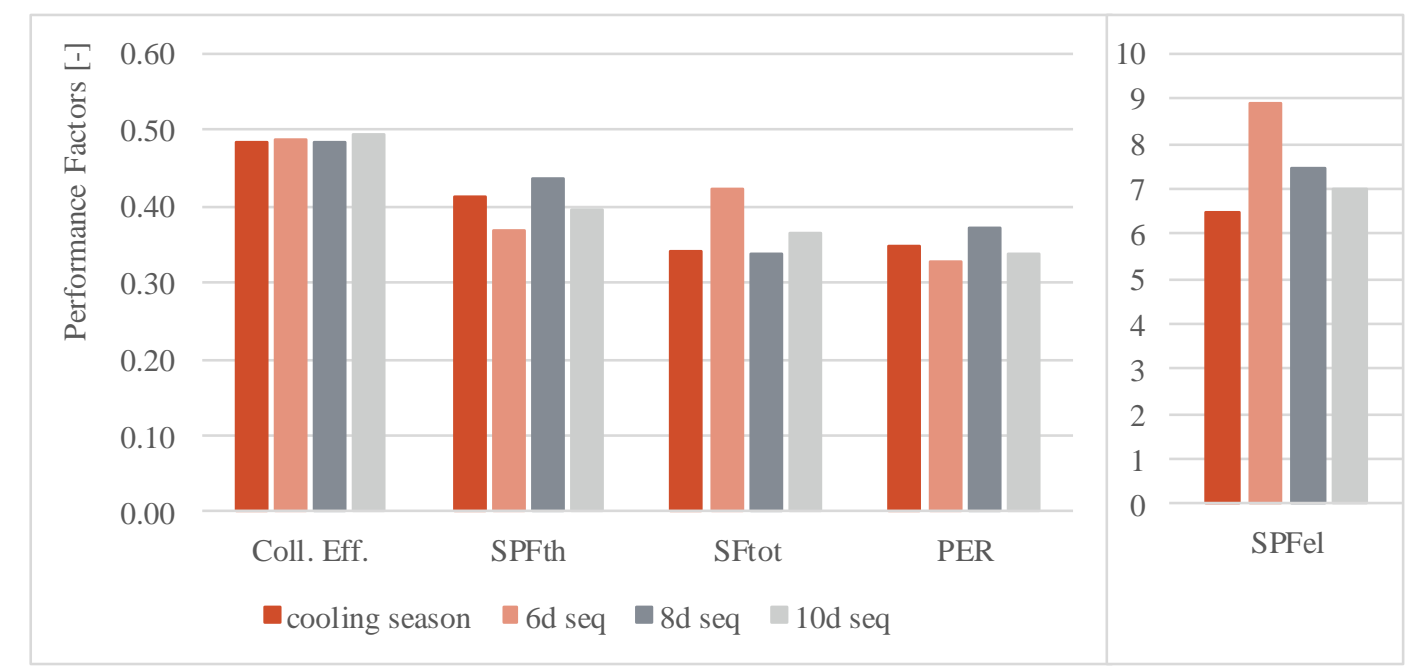

Fig. 5: Solar cooling system simulation. Performance factors calculated with summer simulation and short sequences. Collector area of $8 \mathbf{m}^{2}$.

Table 1 completes the information of previous figures and presents the deviation calculated between the short 
sequences and the summer simulation. It can be noticed that the deviations of the six-day sequence are too high while the deviation of the other two sequences are in line with other methods presented in literature.

Tab. 1: Solar cooling system simulation. Performance figures calculated with summer simulation and short sequences. Collector area of $8 \mathbf{~ m}^{2}$.

\begin{tabular}{|c|c|c|c|c|c|c|c|}
\hline & \multicolumn{4}{|c|}{ Performance figures } & \multicolumn{3}{c|}{ Deviation [\%] } \\
\hline & $\begin{array}{c}\text { cooling } \\
\text { season }\end{array}$ & six-day & eight-day & ten-day & six-day & eight-day & ten-day \\
\hline Qsc [kWh] & 3007.70 & 2241.87 & 2892.22 & 3182.55 & $-25.5 \%$ & $-3.8 \%$ & $5.8 \%$ \\
\hline Qcol [kWh] & 3116.17 & 3587.50 & 3375.43 & 3564.13 & $15.1 \%$ & $8.3 \%$ & $14.4 \%$ \\
\hline ITcol [kWh] & 6434.82 & 7375.50 & 6969.40 & 7211.70 & $14.6 \%$ & $8.3 \%$ & $12.1 \%$ \\
\hline Qgb [kWh] & 6020.77 & 4869.64 & 6612.66 & 6195.22 & $-19.1 \%$ & $9.8 \%$ & $2.9 \%$ \\
\hline Coll. Eff [-] & 0.48 & 0.49 & 0.48 & 0.49 & $0.4 \%$ & $0.0 \%$ & $2.1 \%$ \\
\hline SPFth [-] & 0.41 & 0.37 & 0.44 & 0.40 & $-10.6 \%$ & $5.6 \%$ & $-4.3 \%$ \\
\hline SPFel [-] & 6.48 & 8.90 & 7.40 & 7.00 & $37.3 \%$ & $15.2 \%$ & $8.0 \%$ \\
\hline SFtot [-] & 0.34 & 0.42 & 0.34 & 0.37 & $24.4 \%$ & $-0.9 \%$ & $7.1 \%$ \\
\hline PER [-] & 0.35 & 0.33 & 0.37 & 0.34 & $-5.7 \%$ & $6.8 \%$ & $-2.6 \%$ \\
\hline
\end{tabular}

The analysis has been repeated with the collector area of $12 \mathrm{~m}^{2}$ and $16 \mathrm{~m}^{2}$. The figure 6 presents the energies calculated for the $12 \mathrm{~m}^{2}$ of area while the figure 7 presents the energies calculated for the $16 \mathrm{~m}^{2}$ area. The figure 8 and figure 9 presents the performance factors respectively for the $12 \mathrm{~m}^{2}$ and $16 \mathrm{~m}^{2}$ cases.

When the collector area is increased, the contribution of solar collector increases and therefore the consumption of gas boiler decreases. Passing from $8 \mathrm{~m}^{2}$ to $12 \mathrm{~m}^{2}$, the collector yield increases about the $37 \%$ while the gas boiler consumption decreases about $15 \%$. By adding other $4 \mathrm{~m}^{2}$ to the collector area (passing from $12 \mathrm{~m}^{2}$ to $16 \mathrm{~m}^{2}$ ) the collector yield increases about $33 \%$ and the gas boiler consumption decreases about the $17 \%$. It can be noticed that the thermal losses increase since the sum of collector yield with the gas boiler is increasing from $9136 \mathrm{kWh}$ to $9416 \mathrm{kWh}$ (from 8 to $12 \mathrm{~m}^{2}$ ) and from $9417 \mathrm{kWh}$ to $10002 \mathrm{kWh}$ (from 12 to $16 \mathrm{~m}^{2}$ ).

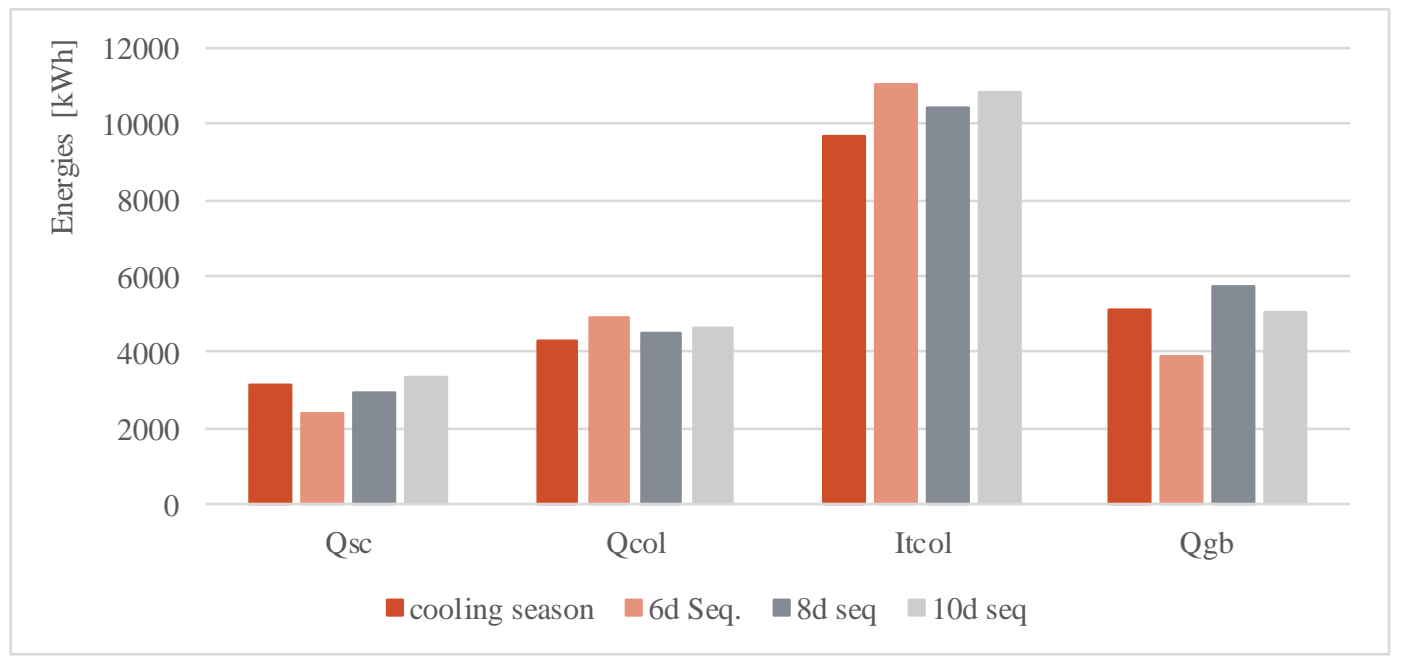

Fig. 6: Solar cooling system simulation. Energies calculated with summer simulation and short sequences. Collector area of $12 \mathbf{m}^{2}$. 


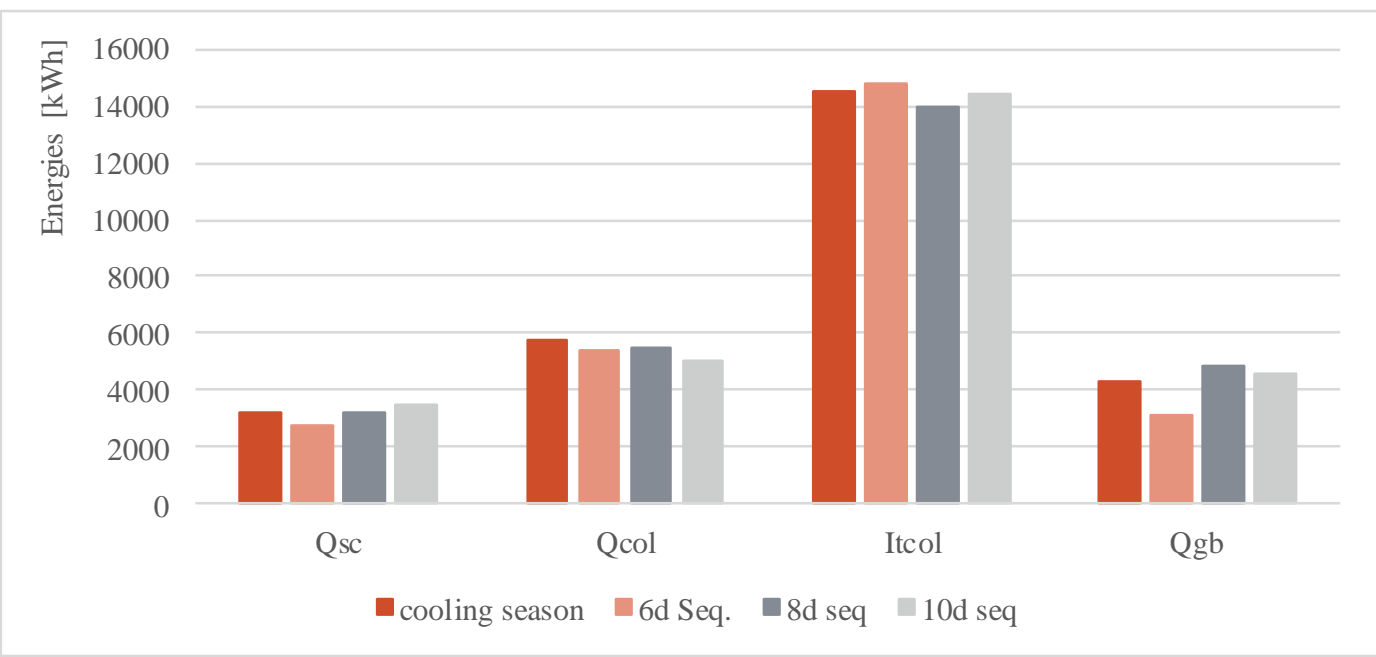

Fig. 7: Solar cooling system simulation. Energies calculated with summer simulation and short sequences. Collector area of $16 \mathbf{~ m}^{2}$.

The electrical SPF and the thermal SPF do not variate with the variation of collector area also if the denominator increase since the load slightly increases. Instead, the solar fraction increases with the collector area passing from $0.34\left(8 \mathrm{~m}^{2}\right)$ to $0.46\left(12 \mathrm{~m}^{2}\right)$ and finally to $0.57\left(16 \mathrm{~m}^{2}\right)$.

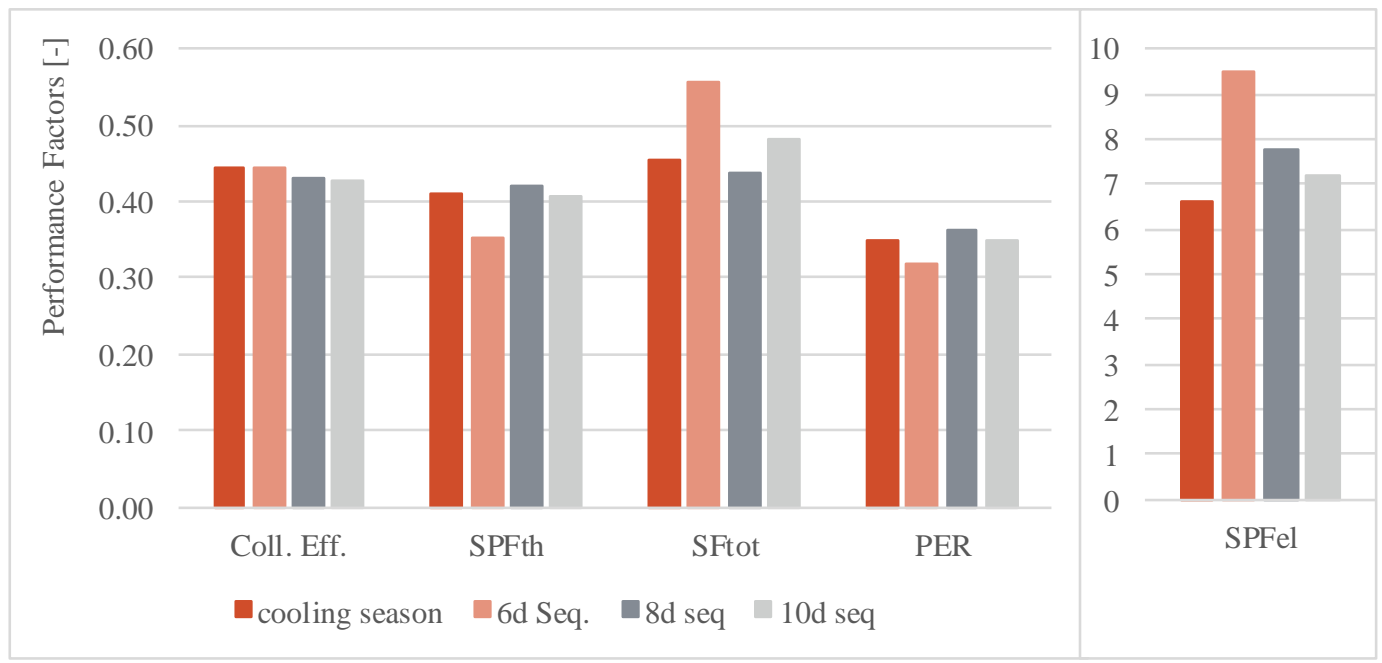

Fig. 8: Solar cooling system simulation. Performance factors calculated with summer simulation and short sequences. Collector area of $12 \mathrm{~m}^{2}$.

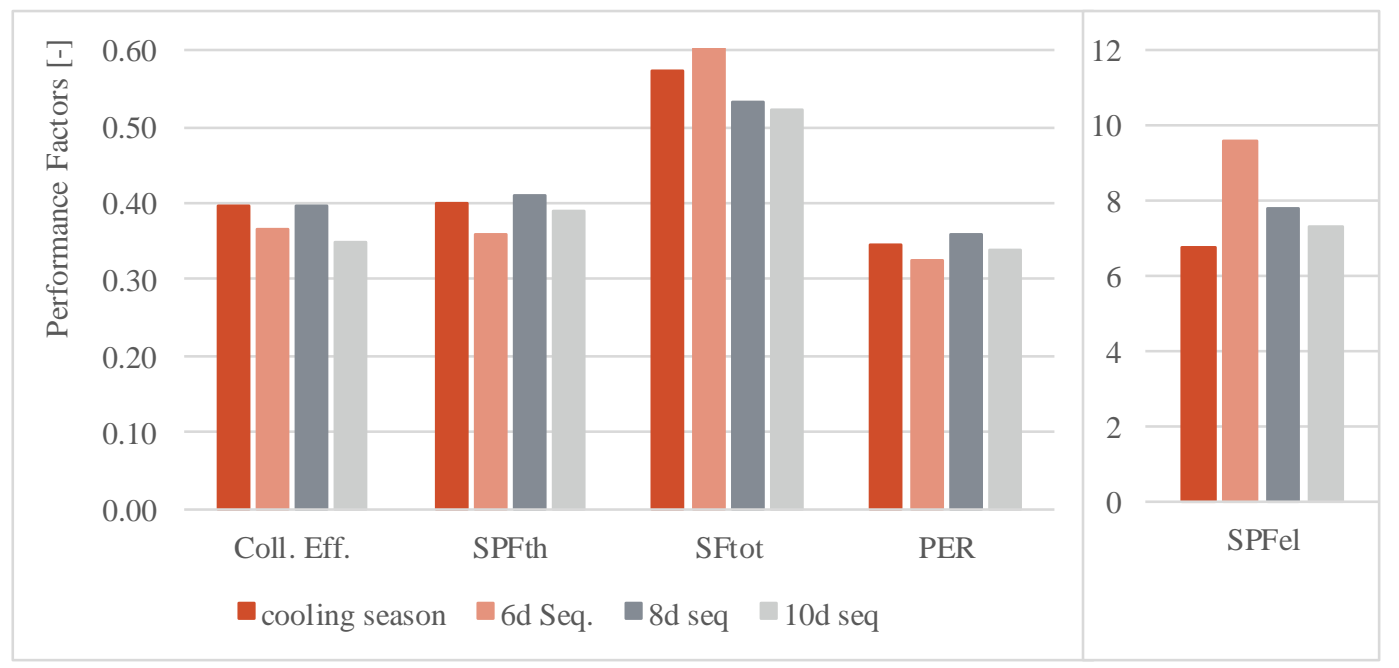

Fig. 9: Solar cooling system simulation. Performance factors calculated with summer simulation and short sequences. Collector area of $16 \mathrm{~m}^{2}$. 
Table 2 and table 3 present the values indicated in the previous figures and the deviation of the sequences with the entire cooling season.

The simulation performed for these two configurations of higher collector area confirm the lower accuracy of the six-day sequence as it was pointed out in the case of $8 \mathrm{~m}^{2}$ of collector area. Indeed, the deviations of the six-day sequence is included in a range of 8 to $25 \%$ (with one outliner that is the SPFel). Instead, the accuracy of the eightday sequence is closed to the accuracy of the ten-day sequence. Both sequences reach a deviation lower than $12 \%$ with the exception of the SPFel.

All the simulations have presented an higher deviation of SPFel. This can be explained in the following way: in the case of solar cooling system, the electric consumption is very low, and therefore a small variation of the absolute value of total consumption lead to a high variation in relative terms.

Tab. 2: Solar cooling system simulation. Performance figures calculated with summer simulation and short sequences. Collector area of $12 \mathrm{~m}^{2}$

\begin{tabular}{|c|c|c|c|c|c|c|c|}
\hline & \multicolumn{4}{|c|}{ Performance figures } & \multicolumn{3}{c|}{ Deviation [\%] } \\
\hline & $\begin{array}{c}\text { cooling } \\
\text { season }\end{array}$ & six-day & eight-day & ten-day & six-day & eight-day & ten-day \\
\hline Qsc [kWh] & 3098.79 & 2388.84 & 2910.30 & 3325.10 & $-22.9 \%$ & $-6.1 \%$ & $7.3 \%$ \\
\hline Qcol [kWh] & 4289.33 & 4915.62 & 4500.12 & 4634.03 & $14.6 \%$ & $4.9 \%$ & $8.0 \%$ \\
\hline ITcol [kWh] & 9652.22 & 11063.30 & 10454.10 & 10817.60 & $14.6 \%$ & $8.3 \%$ & $12.1 \%$ \\
\hline Qgb [kWh] & 5127.81 & 3896.13 & 5753.72 & 5016.42 & $-24.0 \%$ & $12.2 \%$ & $-2.2 \%$ \\
\hline Coll. Eff [-] & 0.44 & 0.44 & 0.43 & 0.43 & $0.0 \%$ & $-3.1 \%$ & $-3.6 \%$ \\
\hline SPFth [-] & 0.41 & 0.35 & 0.42 & 0.41 & $-13.8 \%$ & $2.7 \%$ & $-1.3 \%$ \\
\hline SPFel [-] & 6.63 & 9.48 & 7.75 & 7.19 & $43.0 \%$ & $16.9 \%$ & $8.4 \%$ \\
\hline SFtot [-] & 0.46 & 0.56 & 0.44 & 0.48 & $22.5 \%$ & $-3.6 \%$ & $5.4 \%$ \\
\hline PER [-] & 0.35 & 0.32 & 0.36 & 0.35 & $-8.5 \%$ & $4.4 \%$ & $0.2 \%$ \\
\hline
\end{tabular}

Tab. 3: Solar cooling system simulation. Performance figures calculated with summer simulation and short sequences. Collector area of $16 \mathrm{~m}^{2}$.

\begin{tabular}{|c|c|c|c|c|c|c|c|}
\hline & \multicolumn{4}{|c|}{ Performance figures } & \multicolumn{3}{c|}{ Deviation [\%] } \\
\hline & $\begin{array}{c}\text { cooling } \\
\text { season }\end{array}$ & six-day & eight-day & ten-day & six-day & eight-day & ten-day \\
\hline Qsc [kWh] & 3247.60 & 2751.08 & 3237.54 & 3473.65 & $-15.3 \%$ & $-0.3 \%$ & $7.0 \%$ \\
\hline Qcol [kWh] & 5729.52 & 5386.93 & 5530.74 & 5011.45 & $-6.0 \%$ & $-3.5 \%$ & $-12.5 \%$ \\
\hline ITcol [kWh] & 14478.34 & 14751.00 & 13938.80 & 14423.50 & $1.9 \%$ & $-3.7 \%$ & $-0.4 \%$ \\
\hline Qgb [kWh] & 4273.12 & 3161.03 & 4886.19 & 4581.28 & $-26.0 \%$ & $14.3 \%$ & $7.2 \%$ \\
\hline Coll. Eff [-] & 0.40 & 0.37 & 0.40 & 0.35 & $-7.7 \%$ & $0.3 \%$ & $-12.2 \%$ \\
\hline SPFth [-] & 0.40 & 0.36 & 0.41 & 0.39 & $-10.4 \%$ & $2.5 \%$ & $-2.6 \%$ \\
\hline SPFel [-] & 6.77 & 9.59 & 7.79 & 7.30 & $41.6 \%$ & $15.0 \%$ & $7.7 \%$ \\
\hline SFtot [-] & 0.57 & 0.63 & 0.53 & 0.52 & $10.0 \%$ & $-7.3 \%$ & $-8.8 \%$ \\
\hline PER [-] & 0.34 & 0.33 & 0.36 & 0.34 & $-5.5 \%$ & $4.0 \%$ & $-1.3 \%$ \\
\hline
\end{tabular}

\subsection{Evaluation for different climate}

The last analysis considers the climate of Palermo that has been simulated with a six-day sequence. Again, the system has been evaluated for different collector area of $8 \mathrm{~m}^{2}, 12 \mathrm{~m}^{2}$ and $16 \mathrm{~m}^{2}$.

In the case of the climate of Palermo, it can be seen that the six-day sequence is more accurate than the six-day 
sequence defined for the climate of Bolzano.

The results of this simulations confirm the trends noted for the climate of Bolzano with a different magnitude. The increase of collector area from $8 \mathrm{~m}^{2}$ to $12 \mathrm{~m}^{2}$ leads to an increase of collector yield of $45 \%$ and a decrease of gas boiler consumption of $19 \%$, while the increase from $12 \mathrm{~m}^{2}$ to $16 \mathrm{~m}^{2}$ leads to an increase of collector yield of $35 \%$ and a decrease of gas boiler consumption of $26 \%$. Again, the increase of the collector area is connected to the increase of the cooling load connected to the thermal losses. Therefore the thermal SPF is close to be constant while the solar fraction increases.

The six-day sequence presents the higher deviation on the gas boiler consumption (about $14 \%$ over the three simulations) and on the electrical SPF. This second deviation is due to the very low value of denominator of the electrical SPF and therefore a small variation leads to a higher deviation of the ratio. All the other performance figures are evaluated with a deviation lower than $10 \%$.

Tab. 4: Solar cooling system simulation. Performance figures calculated with summer simulation and short sequences. Climate of Palermo.

\begin{tabular}{|c|c|c|c|c|c|c|c|c|c|}
\hline & \multicolumn{3}{|c|}{ 8mq } & \multicolumn{3}{c|}{ 12mq } & \multicolumn{3}{c|}{ 16mq } \\
\hline & $\begin{array}{c}\text { cooling } \\
\text { season }\end{array}$ & six-day & $\boldsymbol{\delta}[\%]$ & $\begin{array}{c}\text { cooling } \\
\text { season }\end{array}$ & six-day & $\boldsymbol{\delta}[\%]$ & $\begin{array}{c}\text { cooling } \\
\text { season }\end{array}$ & six-day & $\boldsymbol{\delta}[\%]$ \\
\hline Qsc [kWh] & 4247.1 & 4556.4 & $6.8 \%$ & 4437.9 & 4654.6 & $4.7 \%$ & 4519.0 & 4593.0 & $1.6 \%$ \\
\hline Qcol [kWh] & 4088.9 & 4064.5 & $-0.6 \%$ & 5937.0 & 5743.2 & $-3.4 \%$ & 8034.1 & 7741.2 & $-3.8 \%$ \\
\hline ITcol [kWh] & 7823.0 & 7877.6 & $0.7 \%$ & 11734.5 & 11816.4 & $0.7 \%$ & 17601.7 & 17724.6 & $0.7 \%$ \\
\hline Qgb [kWh] & 7526.0 & 8813.9 & $14.6 \%$ & 6107.5 & 6825.5 & $10.5 \%$ & 4544.6 & 5505.6 & $17.5 \%$ \\
\hline Coll. Eff [-] & 0.523 & 0.516 & $-1.3 \%$ & 0.506 & 0.486 & $-4.1 \%$ & 0.456 & 0.437 & $-4.5 \%$ \\
\hline SPFth [-] & 0.432 & 0.435 & $0.7 \%$ & 0.432 & 0.454 & $4.7 \%$ & 0.420 & 0.426 & $1.3 \%$ \\
\hline SPFel [-] & 6.248 & 8.241 & $24.2 \%$ & 6.312 & 8.336 & $24.3 \%$ & 6.735 & 8.871 & $24.1 \%$ \\
\hline SFtot [-] & 0.352 & 0.316 & $-11.5 \%$ & 0.493 & 0.457 & $-7.9 \%$ & 0.639 & 0.584 & $-9.3 \%$ \\
\hline PER [-] & 0.360 & 0.376 & $4.3 \%$ & 0.363 & 0.394 & $7.9 \%$ & 0.360 & 0.378 & $4.8 \%$ \\
\hline
\end{tabular}

\section{Conclusions}

The PLPE method has been developed with the aim of being applicable for different typologies of heating and cooling systems. Since the method has been developed considering a reference system that is a solar assisted heat pump system, the aim of this paper was to further investigate on the applicability of the PLPE method. The case study presented in this paper is a solar cooling system that can provide also domestic hot water. The solar cooling system has been configured in laboratory with the aim to verify the test method and not to present a new concept of solar cooling.

The results have shown that the six-day sequence defined for the climate of Bolzano is not representing well the performance of the cooling season while the eight-day sequence and the ten-day sequence represent well the seasonal performance. The evaluation has been performed also variating the collector area of the system and the obtained deviation has investigated. The PLPE is not affected by the variation of the collector area and it is able to reach an accuracy of about $10 \%$.

The simulation has been performed also for the climate of Palermo where the system has been evaluated with only the six-day sequence. In this case, differently from the climate of Bolzano, the reached accuracy is good. The trends evaluated for the variation of collector area are confirmed.

In conclusion, with a proper sequence length, the PLPE method applied to a solar cooling system is able to reach an accuracy of about $10 \%$. 


\section{References}

Albaric, M., Nowag, J., Papillon, P, 2008. Thermal performance evaluation of solar combisystems using a global approach. In: EUROSUN 2008, Lisbon, Portugal.

Bales C., 2004. Combitest - a new test method for thermal stores used in solar combisystems. Doctoral Thesis Department of Building Technology, Chalmers university of Technology.

Besana, F., 2009. Heat rejection problematic in Solar Combi+ system. PhD Thesis, Universitá degli studi di Bergamo.

Drück, H., Pauschinger, D., 2006. MULTIPORT Store-Model, Type 340. Institut für Thermodynamik und Wärmetechnik (ITW), Universität Stuttgart. http://www.trnsys.de/download/en/ts_type_340_en.pdf.

Haberl, R., Frank, E., Vogelsanger, P., 2019. Holistic system testing-10 years of concise cycle testing. In: ISES 2009; p. 351-360.

Haller, M.Y., Haberl, R., Persson, T., Bales, C., Kovacs, P., Chèze, D., Papillon, P., 2013. Dynamic Whole System Testing of Combined Renewable Heating Systems - The Current State of the Art. Energy and Buildings. 66, 667677. https://doi.org/10.1016/j.enbuild.2013.07.052.

Lazrak, A., Leconte, A., Chèze, D., Fraisse, G., Papillon, P. \& Souyri, B., 2015. Numerical and experimental results of a novel and generic methodology for energy performance evaluation of thermal systems using renewable energies. Applied Energy, 158, p.142-156.

Menegon, D., Vittoriosi, A., Fedrizzi, R., 2014. A new test procedure for the dynamic laboratory characterization of thermal systems and their components, Energy Build. 84 (2014) 182-192. doi:10.1016/j.enbuild.2014.07.085.

Menegon, D., Soppelsa, A., Fedrizzi, R., 2017a. Clustering Methodology for Defining a Short Test Sequence for Whole System Testing of Solar and Heat Pump Systems. In SWC 2017. Abu Dhabi, UAE: ISES.

Menegon, D., Soppelsa, A., Fedrizzi, R., 2017b. Development of a New Dynamic Test Procedure for the Laboratory Characterization of a Whole Heating and Cooling System. Applied Energy. 205, 976-990. https://doi.org/10.1016/j.apenergy.2017.08.120.

Klein, S. A., and et al., 2012. TRNSYS 17 Volume 4 Mathematical Reference. SEL (Solar Energy Laboratory, Univ. of Wisconsin-Madison), TRANSSOLAR Energietechnik GmbH, CSTB (Centre Scientifique et Techniquedu Bâtiment), TESS (Thermal Energy Systems Specialists).

Schicktanz, M.D., Schmidt, C., Fedrizzi, R., 2014. Classification of Rating Methods for Solar Heating and Cooling Systems, Energy Procedia. 48, 1676-1687. doi:10.1016/j.egypro.2014.02.189.

SorTech AG, SorTech Adsorption Chiller ACS 08/ACS 15 - Design Manual, SorTech AG, Halle (Saale), Germany, 2009. 


\title{
OTSun: An Open Source Code for Optical Analysis of Solar Thermal Collectors and PV Cells
}

\author{
Pujol-Nadal, R. ${ }^{1}$, Bonnín-Ripoll, F. ${ }^{1}$, Julian, D., Hertel', Martínez-Moll, V. ${ }^{1}$, Cardona, G. ${ }^{2}$ \\ 1 Department of Physics, Universidad de las Islas Baleares, Cra. de Valldemossa km 7.5, Palma, \\ 07122, (Islas Baleares) España, ramon.pujol@uib.es \\ 2 Department of Mathematics and Computer Science, Universidad de las Islas Baleares, Cra. de \\ Valldemossa km 7.5, Palma, 07122, (Islas Baleares) España
}

\begin{abstract}
The OTSun project is a research project whose main objective is to develop an open-source software to simulate the optical behavior of solar collectors. In this Monte Carlo ray tracing program, the trajectory of light rays is determined by the Fresnel equations of electromagnetic optics. The geometry of the solar collector is generated using the free software FreeCAD, allowing the user to visualize the scene. OTSun determines the optical efficiency of solar thermal collectors and photovoltaic solar cells. Its library is hosted on GitHub and, to make it more userfriendly, a webtool has been developed. This paper describes the implemented algorithm as well as the types of materials available in the library. Two simple cases are presented, step by step, to allow for a correct simulation of solar thermal collectors and photovoltaic solar cells.
\end{abstract}

Keywords: ray-tracing, open-source, solar energy collector, solar cells

\section{Introduction}

The OTSun project is a research project financed by the Spanish Ministry of Economics and Competitiveness (MINECO) as well as the European Regional Development Fund (ERDF) (ENE2015-68339-R). The main objective is to develop an open-source software for the optical analysis of solar collectors (Pujol-Nadal et al., 2016.). The duration of the project is from 2016 to 2019. Physical equations that best describe the interaction between radiation and material were implemented to provide high precision results for optical simulations. These equations include the dependency on the wavelength, the polarization, and the incidence angle of the electromagnetic (EM) wave. The algorithm is based on the Monte Carlo ray tracing (MCRT) principle. Interference phenomena can also be taken into account for simulations by means of a pre-processing step using the transfer-matrix method (TMM). OTSun uses the open-source program FreeCAD as a graphical user interface, which allows the user to design and import the geometry of a collector in a user-friendly manner. The simulations further allow the user to determine the optical efficiency of both solar thermal collectors and photovoltaics.

\subsection{Graphical user interface: FreeCAD}

OTSun uses FreeCAD to model and visualize 3D objects of a scene. Since FreeCAD is an open-source code, the OTSun project can benefit directly from the contributions of programmers and users from all over the world. However, this also means that in order to begin a simulation with OTSun, it is crucial to have the collector geometry available in the FreeCAD-specific file format *.FCStd. In this geometry file, the optical properties are assigned to the different collector components that interact with the EM wave. The different components, in turn, consist of either surface or volume elements. Once the geometry is imported, the sun window is created, which is the region from where the rays are emitted. The sun window is rectangular in shape and its size is automatically adjusted to the collector dimensions to save CPU time. 


\subsection{The optical model}

The algorithm is based on an MCRT approach. Starting at the sun window, the trajectory of the rays is determined by the Fresnel equations for EM waves, taking into account wavelength, polarization, and incidence angle. The reflectance coefficient $R$ and the transmittance coefficient $T=1-R$ are given by Eqs. (1)-(2) (Macleod, 2010):

$$
\begin{gathered}
R=\left(\frac{\eta_{1}-\eta_{2}}{\eta_{1}+\eta_{2}}\right)\left(\frac{\eta_{1}-\eta_{2}}{\eta_{1}+\eta_{2}}\right)^{*} \\
\eta_{i}=\left\{\begin{array}{lc}
\frac{N_{i} \cos \vartheta_{i}}{Z_{0}}, & s-\text { polarized } \\
\frac{N_{i}}{Z_{0} \cos \vartheta_{i}}, & p-\text { polarized }
\end{array}\right.
\end{gathered}
$$

where $Z_{0}=\sqrt{\frac{\mu_{0}}{\epsilon_{0}}}$ is the optical impedance of free space and $N(\lambda)=n(\lambda)-i k(\lambda)$ the complex refraction index. The real part is the refraction index and the imaginary part represents the extinction coefficient. The complex refraction angle $\vartheta_{i}$ can be calculated by means of Snell's law, Eq. (3).

$$
N_{1} \sin \vartheta_{1}=N_{2} \sin \vartheta_{2}
$$

When a ray is refracted and passes through to the interior of a transparent material with an extinction coefficient, the energy of the ray is attenuated according to the Beer-Lambert law, Eq. (4).

$$
E(x, \lambda)=E_{0}(0, \lambda) e^{-\alpha(\lambda) x}
$$

where $\alpha(\lambda)=4 \pi k(\lambda) / \lambda$ is the absorption coefficient.

\subsection{The OTSun webtool}

The OTSun code, implemented in Python, is available on GitHub (Cardona and Pujol-Nadal, 2018). As the direct use of the OTSun library requires some Python programming skills, a webtool helps the user navigate through the simulation and easily input parameters. The user can choose from three different simulations, all of which take into account the Buie sun model (Buie et al., 2003).

- Single experiment with plot of rays: This simulation visualizes the scene. It produces a *.FCStd file that contains the collector geometry together with the trajectories of the emitted rays for a single sun position.

- Spectral analysis: This simulation obtains the optical efficiency for a single sun position with a user-defined range of wavelengths. The result are different *.txt files that contain the spectral efficiency.

- Total analysis: This simulation obtains the optical efficiency for different sun positions using the standard model for direct solar radiation ASTMG173. The result is stored in *.txt files.

The webtool can be accessed via http://otsun.uib.es/otsunwebapp/node/start. Fig. 1 shows a flow chart of the different tasks. The first step is to provide an email address for delivery of the results. The second step is to upload the *.FCStd file, which contains the geometry of the solar collector. In the third step, the material properties are specified. If all the material files are available, they can simply be uploaded together as a *.zip file. If this is not 
the case, a hyperlink redirects the user to the Creator of Materials page, where the OTSun-specific material files can be defined manually. The next step is to specify the type of simulation under Experiment to Run. The last step is to define the ray-tracing input parameters under Input Parameters. Once the simulation is running, the app redirects the user to a webpage where the progress is displayed.

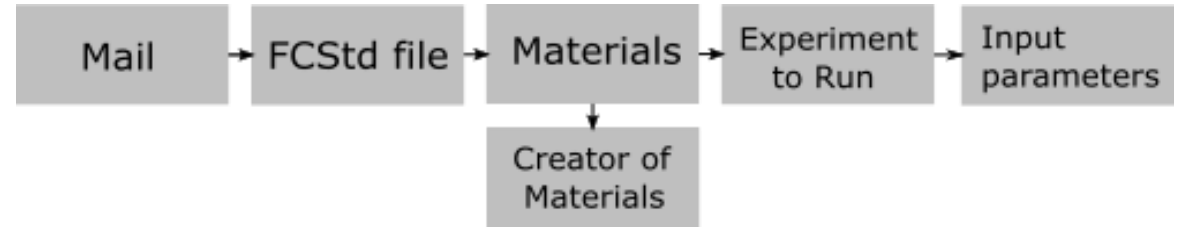

Fig. 1 Flowchart of the different stages of an OTSun webtool simulation.

\section{Material types}

When a ray is incident on a surface, it will be either reflected or transmitted depending on the Fresnel coefficients $R_{s / p}(\theta, \lambda)$ and $T_{s / p}(\theta, \lambda)$ (Eqs (1)-(2)) of the material. Both coefficients, which originate from the complex refractive index of the material, depend on the wavelength, the incidence angle $\theta$, and the polarization of the incident light (polarization $s / p$ ). OTSun distinguishes between two types of materials: volume and surface materials. For more details on the nomenclature and mathematical expressions, see (Hertel et al., 2016)

\subsection{Volume material}

- Constant Refractive Index: Material with a constant refraction index and absorption coefficient given by $n$ and $\alpha$. The absorption, which occurs in the material (Eq. (4)), leads to a loss of energy.

- Variable Refractive Index: Material with a refraction index that depends on the wavelength. It is necessary to provide the *.txt file that contains the following columns: $\lambda(\mathrm{nm}), n$, and $k$. The absorption, which occurs in the material (Eq. (4)), leads to a loss of energy.

- PV Material: Material used to simulate active materials in photovoltaic cells. This material has the same characteristics as the Variable Refractive Index, with the exception that the absorption in the material is the useful energy, which gives rise to the creation of electron/holes pairs and therefore conversion to electric energy.

- Thin-Film Material: Material whose coefficients $\mathrm{R}_{s / p}(\theta, \lambda)$ and $T_{s / p}(\theta, \lambda)$ are previously calculated using the TMM. It is necessary to provide a *.txt file with the following columns: $\lambda(\mathrm{nm}), \theta(\mathrm{deg}), R_{s}, R_{p}, T_{s}$, and $T_{p}$. Furthermore, the materials in contact with the TMM layer should be indicated (upper and lower surface). The refraction indices can be provided as a *.txt file, as with the Variable Refractive Index.

\subsection{Surface material}

- Opaque Simple Layer: Material with total absorption and without any contribution to useful energy gain.

- Transparent Simple Layer: Material with a constant transmittance $T$ and without absorption.

- Absorber Simple Layer: Material with constant absorption $\alpha$ and $T=0$. The absorbed rays contribute to the useful energy gain of the solar thermal collector.

- Absorber Lambertian Layer: Material with constant absorption $\alpha$, Lambertian (total diffuse) reflection, and $T$ $=0$. The absorbed rays contribute to the useful energy gain of the solar thermal collector.

- Absorber TW Model Layer: Material with $\alpha$ for normal incidence, together with $b$ and $c$ constants, which describe the incidence angle dependency of the model of (Tesfamichael and Wäckelgård, 2000). Reflection is Lambertian. Transmittance is $T=0$. The absorbed rays contribute to the useful energy gain of the solar thermal collector.

- Absorber Polarized Coating Layer: Material with $T=0$, where absorption $\alpha$ depends on the wavelength and incidence angle. A *.txt file should be provided with the following columns: $\lambda(\mathrm{nm}), \theta(\mathrm{deg}), R_{s}$, and $R_{p}$. 
- Reflector Specular Layer: Material with specular reflection, constant $R$, and $T=0$. It is also possible to define Gaussian or bi-Gaussian scattering (Pettit, 1977) with the parameters $\sigma_{1}(\mathrm{mrad}), \sigma_{2}(\mathrm{mrad})$, and the weighting factor $k_{\sigma l}$ for the Gaussian curve with variance $\sigma_{1}$.

- Reflector Lambertian Layer: Material with Lambertian reflection, constant parameter $R$, and $T=0$.

- Reflector Specular Metallic Layer: Metallic, specular material with a complex refractive index $N(\lambda)$. The refractive index should be provided as a *.txt file with the following columns: $\lambda(\mathrm{nm}), n$, and $k$. Gaussian or bi-Gaussian scattering can be defined the same as for the reflector specular layer. The reflectance will be calculated based on the Fresnel equations (1)-(2).

- Reflector Polarized Coating Layer: Material with $T=0$ and $R$ provided as a *.txt file with the following columns: $\lambda(\mathrm{nm}), \theta(\mathrm{deg}), R_{s}$, and $R_{p}$. Scattering can be defined in the same manner as in the reflector specular layer.

- Create Material From Two Layers: Surface material where different properties can be assigned to each side. The user can chose from any of the previously described surface models.

\section{Simulation of a parabolic trough collector}

This section describes how to conduct a simulation of a parabolic trough collector (PTC). The PTC under consideration consists of three basic elements: the parabolically shaped mirror, the absorber tube, and the glass envelope with anti-reflectance layer. The optical properties of the anti-reflectance layer, which is a thin layer where interference effects occur, have been calculated by means of a TMM algorithm (Steven Byrnes, 2018.). The tests folder on https://github.com/bielcardona/OTSun contains all files required for this simulation. One of these files is test_PTC.FCStd, which contains the geometry of the collector seen in Fig. 2. The figure also shows the different components of the collector with their respective optical property labels in parentheses.
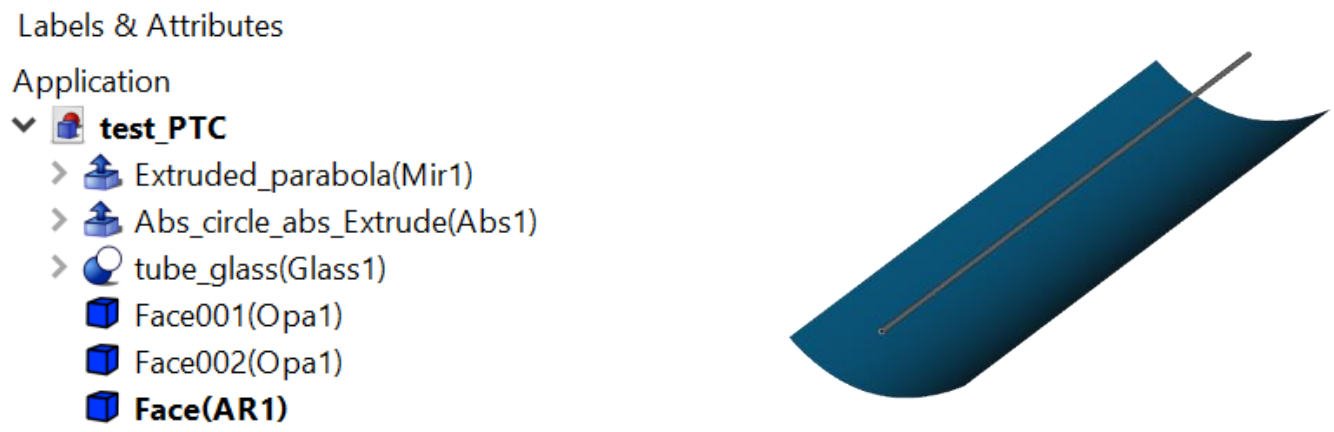

Fig. 2 Screenshot from the FreeCAD file test_PTC.FCStd. The optical property labels are clearly visible in parentheses.

After accessing the webtool, the user types in an email address and uploads the file test_PTC.FCStd. The next webpage, Materials, displays a list of all optical property labels that have been detected in the geometry file and are now expected to be provided by the user (Fig. 3).

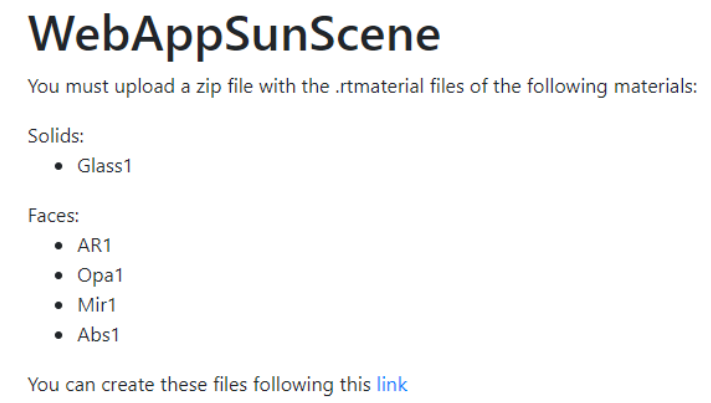

a)

Fig. 3 a) The labels of the optical properties defined in the *.FCStd file. b) Template to define optical properties.

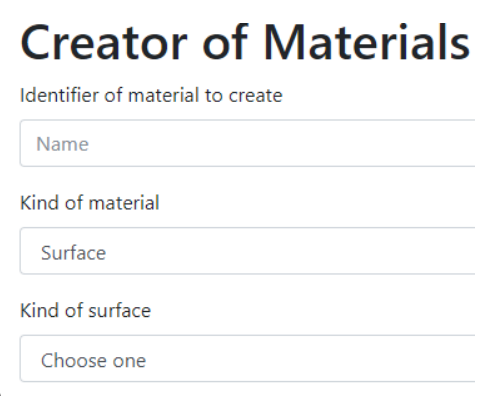

b)

To create material files manually, the user is redirected to the Creator of Materials webpage via the hyperlink http://otsun.uib.es/otsunwebapp/material. First, the user enters the material names, which must be identical to the 
optical property labels specified in the *.FCStd file in parenthesis. In the next step, the user specifies the material type, either surface or volume. As detailed in the previous chapter, the user provides all the different optical models and their respective parameters in the remaining fields. In this example, the materials are defined according to Table 1.

The webtool saves each material as an app-specific binary file *.otmaterial. Once all the material files have been created, they should be uploaded together in a zip folder. After defining the materials, the user chooses the desired simulation under Experiment to Run (Fig. 4). In this example, a total analysis was selected, which requires the following parameters: sun position $(\phi=0, \theta=0)$, number of rays for each sun position (100000), PTC aperture area $\left(19090215 \mathrm{~mm}^{2}\right)$, and creation of ray instances according to the Buie model $(C S R=0.05)$.

The results are sent to the provided email address, and they can also be accessed via the hyperlink on the last page of the webtool. In this example, the result is an optical efficiency of $82.5 \%$.

Table 1 Material types generated for the PTC.

\begin{tabular}{|c|c|c|}
\hline Name & Type of material & Source \\
\hline Glass1 & Volume - Variable Refractive Index & BK7_Schott.txt \\
\hline AR1 & Surface - Transparent Polarized Coating Layer & AR-J.txt: MgF2 (Hertel et al., 2018) \\
\hline Mir1 & Surface - Reflector Specular Layer & $\alpha=0.94$ \\
\hline Abs1 & Surface - Absorber Simple Layer & \\
\hline Opa1 & Surface - Opaque Simple Layer & \\
\hline
\end{tabular}

\section{WebAppSunScene}

Experiment to run:

Choose one
Choose one
Single experiment with plots of rays
Total analysis
Spectral analysis (single direction)

\section{WebAppSunScene}

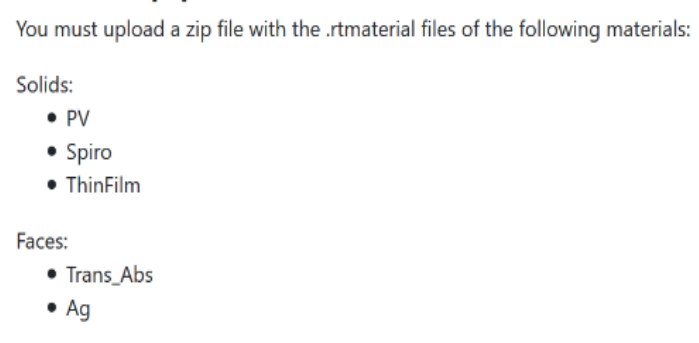

Fig. 4 a) Screenshot of the different simulations available. b) Materials which have been defined for the solar perovskite cell.

\section{Simulation of a photovoltaic cell}

This section explains the steps for conducting a simulation of a $200 \mathrm{~nm}$ perovskite photovoltaic cell. As with the PTC simulation, all files for this simulation can be found in the test folder on GitHub. This simulation is analagous to the PTC simulation, except the geometry is defined by Perovskite_Stack_200nm.FCStd. Examples of the different materials, which are specified in the *.FCStd file, are shown in Fig. 5. The configuration of the solar cell is shown in Fig. 5a and the different optical parameters are summarized in Table 2. The material thin film is an assembly of four layers that are in contact with the perovskite substrate. The optical properties of this multi-layer assembly were calculated using the TMM algorithm. 
Table 2 Geometry and material type available for solar cell simulations.

\begin{tabular}{|c|c|c|}
\hline Name & Type of material & Source \\
\hline Thin_Film & Volume - Thin Film Material & Fitxer_OTSun_Exp1a_theta0_90.txt \\
\hline PV & Volume - PV Material & Perovskite_Leguy.txt \\
\hline Spiro & Volume - Variable Refractive Index & Spiro_txt \\
\hline Ag & Surface - Reflector Specular Layer & Ag_Yang.txt \\
\hline
\end{tabular}

For this example, a spectral analysis (single direction) was conducted at normal incidence, with 1000 rays per wavelength in the range of 300 to $900 \mathrm{~nm}$, and a step size of $2 \mathrm{~nm}$. The aperture area of the photovoltaic collector is $10^{6} \mathrm{~mm}^{2}$. As with the previously discussed PTC simulation, the results are sent by email:

- PV_spectral_efficiency.txt: Spectral optical efficiency of the photovoltaic material (absorbed energy that generates electron/holes pairs)

- PV_paths_values.txt: Information about the ray trajectories inside the PV material

- source_wavelengths.txt: Information about the light source

Fig. 5b shows the spectral optical efficiency obtained by OTSun compared to the one obtained by the TMM algorithm. Since both curves are similar, the OTSun code is validated.

a)

\begin{tabular}{|l|}
\hline $\mathrm{MgF}_{2}$ (AR) \\
\hline $\mathrm{BK} 7$ (Glass) \\
\hline $\mathrm{ITO}$ (TCO) \\
\hline $\mathrm{TiO}_{2}$ (ETL) \\
\hline Perovskite (PV) \\
\hline Spiro-OMeTAD (HTL) \\
\hline $\mathrm{Ag}$ (BC) \\
\hline
\end{tabular}

Fig. 5 a) Thin-film assembly of the perovskite cell. b) Spectral, optical efficiency obtained by OTsun and the TMM algorithm respectively.

\section{Conclusions}

This study described the OTSun webtool for optical simulations, including the underlying mathematical principles of radiation-material interaction and the variety of materials available for testing. A step-by-step approach of how to use the OTSun webtool was presented using the examples of a PTC collector and a perovskite solar cell.

\section{Acknowledgment}

This work is partially supported by the MINECO and the ERDF [ENE2015-68339-R]. It has also been co-funded by the program of SOIB JOVE - Qualicats del Sector Public (Balearic Islands) and the European Social Fund by the Youth Guarantee Initiative. 


\section{References}

Buie, D., Dey, C.J., Bosi, S., 2003. The effective size of the solar cone for solar concentrating systems. Sol. Energy 74, 417-427. https://doi.org/http://dx.doi.org/10.1016/S0038-092X(03)00156-7

Cardona G. and Pujol-Nadal R., 2018. OTSunWebApp [WWW Document]. URL http://otsun.uib.es/otsunwebapp/node/start (accessed 3.8.18).

Hertel, J.D., Bonnín-Ripoll, F., Martínez-Moll, V., Pujol-Nadal, R., 2018. Incidence-angle- and wavelengthresolved ray-tracing simulations of a linear fresnel collector using the in-house software Otsun. J. Sol. Energy Eng. Trans. ASME 140. https://doi.org/10.1115/1.4039329

Hertel, J.D., Martínez-Moll, V., Pujol-Nadal, R., Bonnín, F., 2016. State of the Art of Radiation-Matter Interaction Models Applied for the Optical Characterization of Concentrating Solar Collectors, in: Proceedings of EuroSun2016. International Solar Energy Society, Freiburg, Germany, pp. 1-12. https://doi.org/10.18086/eurosun.2016.07.08

Macleod, H.A., 2010. Thin-Film Optical Filters, 4th ed. CRC Press.

Pettit, R.B., 1977. Characterization of the reflected beam profile of solar mirror materials. Sol. Energy 19, 733741. https://doi.org/10.1016/0038-092X(77)90036-6

Pujol-Nadal, R., Martínez-Moll, V., Moià-Pol, A., Cardona, G., Hertel, J.D., Bonnín, F., n.d. OTSun Project: Development of a Computational Tool for High- resolution Optical Analysis of Solar Collectors. https://doi.org/10.18086/eurosun.2016.06.04

Steven Byrnes, 2018. tmm 0.1.7 : Python Package Index [WWW Document]. URL https://pythonhosted.org/tmm/ (accessed 3.8.18)

Tesfamichael, T., Wäckelgård, E., 2000. Angular solar absorptance and incident angle modifier of selective absorbers for solar thermal collectors. Sol. Energy 68, 335-341. 


\title{
Decentralized DHW Production from Exhaust air in the Bathroom Prewall
}

\author{
Florian Ruesch ${ }^{1}$, Patrick Persdorf ${ }^{1}$, Duglas Hunziker ${ }^{2}$, Elias Büchel ${ }^{3}$ and Michel Haller ${ }^{1}$ \\ 1 SPF Institute for solar technology, HSR, Rapperswil (Switzerland) \\ 2 PV Laboratory, BFH, Burgdorf (Switzerland) \\ ${ }^{3}$ IES institute for energy systems, NTB, Buchs (Switzerland)
}

\begin{abstract}
In urban multifamily houses, decentralized DHW systems using gas or electric boilers are still widely used. Their replacement with renewable energy sources is difficult and generally needs centralized DHW systems with a circulation system that ensures comfort and hygiene at the price of elevated heat losses. A consortium of three academic and one industry partner developed a decentralized DHW system, which uses the residual heat from the exhaust air of a controlled ventilation unit as energy source for a micro heat pump. The entire system, including ventilation unit, heat pump, and storage tank fits into the bathroom prewall and produces hot water for one apartment. This contribution gives an overview of the system and focusses on the development of the flat storage tank that fits into the prewall space of less than $30 \mathrm{~cm}$ width.
\end{abstract}

Keywords: Decentralized DHW, micro heat pump, flat DHW tank

\section{Introduction}

In Switzerland, there are still about half a million decentralized electric domestic hot water (DHW) boilers in operation, of which a large share will be replaced in the next decade. In most of the cases of multifamily buildings a central DHW installation with circulation system has to be installed, which can be complicated and expensive and needs to be coordinated with all inhabitants. Especially for the case of individually owned apartments, a possibility to replace old DHW systems with renewable energy sources is desirable, but difficult to achieve.

DHW circulation systems in multifamily houses are subject to heat losses of 20-65\% (rel. to the consumed energy) when correctly designed and installed (Vetsch et al. 2012) and even higher numbers have been found in field measurements (Citherlet et al. 2011). Large DHW circulation systems also provide an elevated risk of legionella contamination and need to be operated at high temperatures.

Various heat pump boiler systems using the surrounding air as heat source are available on the market. Since the operation of a heat bump boiler cools down the surrounding room, an installation in the apartment is often not possible or causes additional use of space heat energy in winter (Von Euw et al. 2014).

A consortium of three universities and an industry partner developed a decentralized DHW preparation system with a small heat pump that uses exhaust air of a controlled ventilation unit. The developed system provides a possibility to replace decentral DHW systems and include modern ventilation in existing apartments when renovating the bathroom. The flat construction fits behind a bathroom prewall and therefore is invisible for the user and does not use any additional space. It includes (Fig 1):

1. A modern controlled ventilation system with heat and humidity recovery for the entire apartment (max. capacity of $180 \mathrm{~m}^{3} / \mathrm{h}$ ).

2. A small heat pump designed especially for the purpose of using exhaust air of a single apartment ventilation unit. It provides a power of $0.3-0.5 \mathrm{~kW}_{\text {th }}$, depending on the temperature conditions. A direct condenser is included in the storage volume. 
3. A cuboid unpressurized storage tank with a water volume of 831 and vacuum insulation. DHW is prepared with a stainless steel internal heat exchanger.

4. An electric flow through heater as a backup to ensure comfort also for long tappings.

5. A thermostatic tap for automatic compensation of temperature drops caused by the small volume of the storage tank.

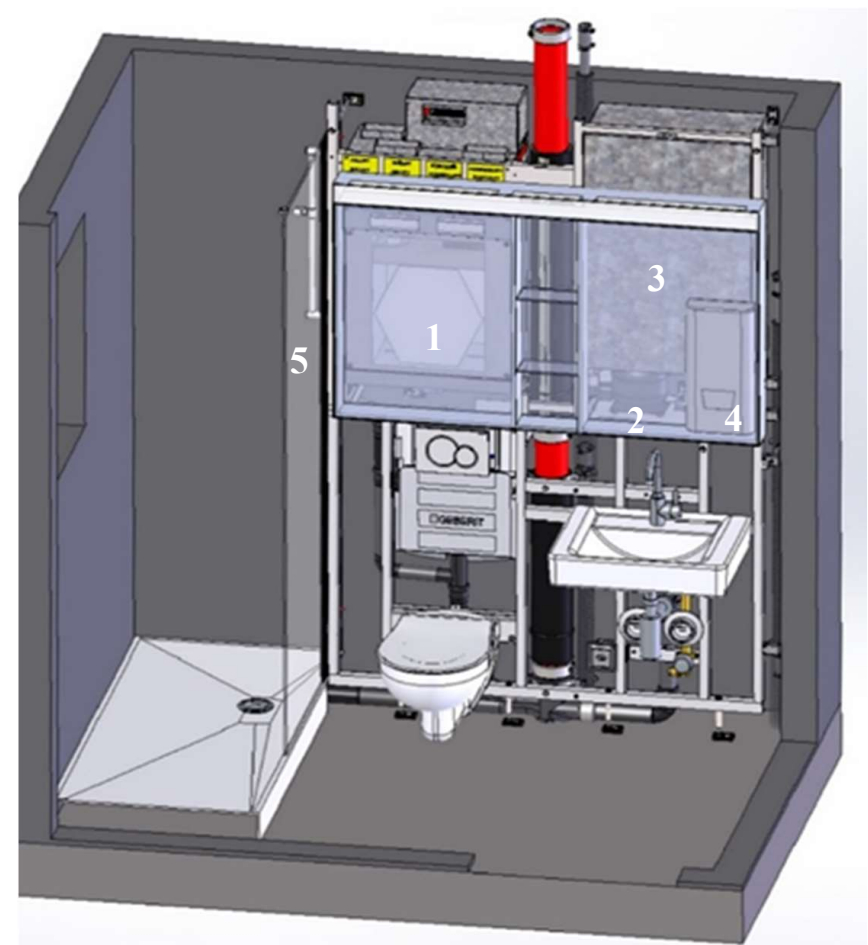

Figure 1: DHW system in the bathroom prewall.

The entire prewall (with the framing, the DHW system, the ventilation unit, all water and air piping and connections) is assembled in the factory and can be brought to the construction site in two parts. Therefore a high standardization and quality of the assembly can be achieved and the installation time is very short.

\section{Storage Tank}

The design of a storage tank that fits into the limited space behind a bathroom prewall with a spacing of only 30 $\mathrm{cm}$, but at the same time exhibits low thermal losses, was challenging. This challenge was tackled with the following approaches:

\subsection{Cuboid polypropylene container}

The cuboid form of the storage tank was given by the limited available space in the bathroom prewall. The DHW pressure would create elevated forces onto the flat walls which cannot be compensated with a construction of reasonable wall thickness. Therefore, an unpressurized but closed construction was chosen in combination with a stainless steel internal heat exchanger. Due to this construction, there are little requirements on the tank vessel and a cost effective solution based on polymers was possible. Out of an analysis of different materials and construction techniques, a roto-molded polypropylene construction was selected to be the most cost effective solution for small to middle sized production series. FEM simulations were carried out to optimize the design for minimal dilatations within a lifetime of 30 years at a temperature of $60^{\circ}$. Even though there is only the static pressure of the tank height $(<1 \mathrm{~m})$, three metal enforcements were needed to avoid dilatations greater than 2.5 $\mathrm{mm}$. Due to the higher coefficient of thermal expansion of polypropylene in comparison to water, a negative pressure is expected when heating the storage tank, which can be compensated with a small volume of air in the upper part of the vessel. This construction allows to close the vessel without inducing pressure changes due to 
temperature variations.

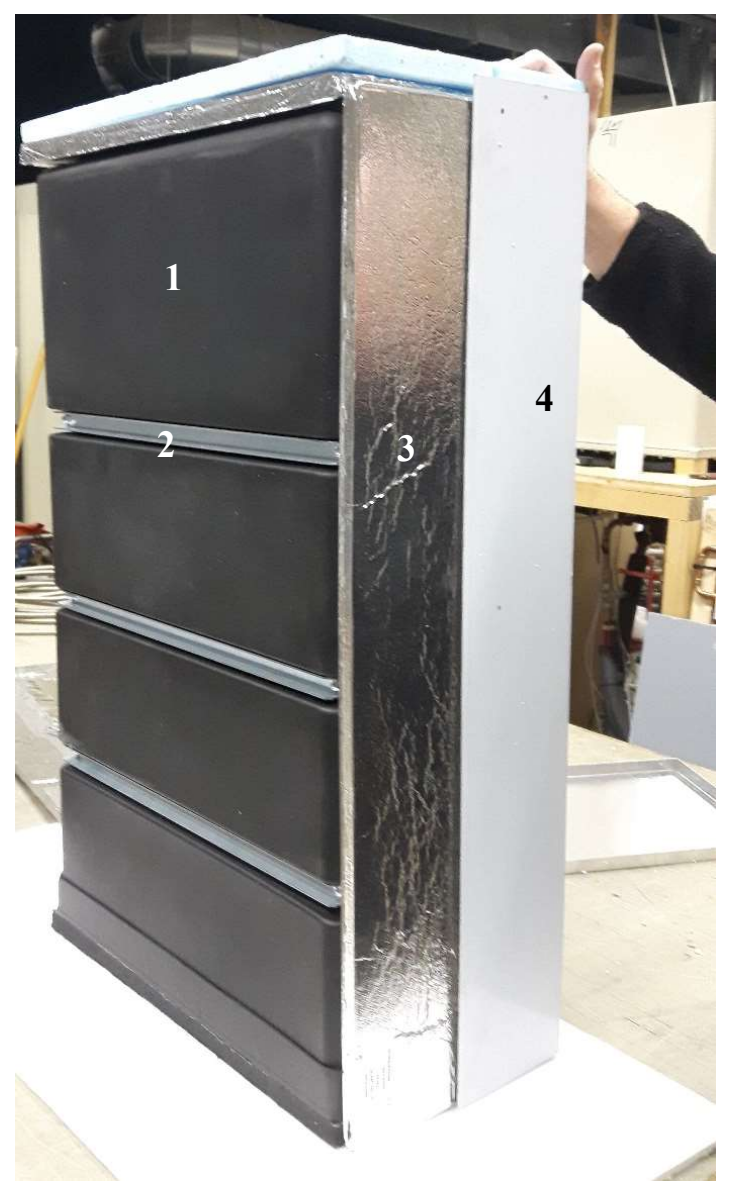

1 Polypropylene vessel manufactured with rotomolding

2 Metal reinforcement

3 Vacuum insulation panel (VIP)

4 Metal cover to protect VIP during transport and installation.

Figure 2: Photo of the storage tank vessel with metal reinforcement and VIP insulation.

\subsection{High performance vacuum insulation}

The flat cuboid form of the vessel is not favorable in terms of heat losses, due to the high ratio of surface to volume. Therefore, a good insulation is of particular importance. Different combinations of vacuum insulation panels (VIP), aerogel insulation and conventional insulation were simulated in 2D FEM. Material properties of the VIP were taken from the manufacturer's data sheet ("va-Q-vip" from the company va-Q-tec AG) and special attention was given to the joints of the VIP. Prototypes of the most promising solutions were constructed and heat losses were measured. As can be seen in Figure 3, the measured values of the overall heat loss coefficient was lower than the simulated ones for all tested configurations. This is due to a conservative value for the thermal conductivity in the data sheet $(<0.005 \mathrm{~W} / \mathrm{mK})$. The measurements show that the actual thermal conductivity, at least in an unaged state, is clearly lower than the declared limit. Furthermore, thermal bridges at the joints of the VIP (at the corners) can be minimized by the cuboid construction and don't lead to additional losses in the real prototype compared to the idealized simulation. 


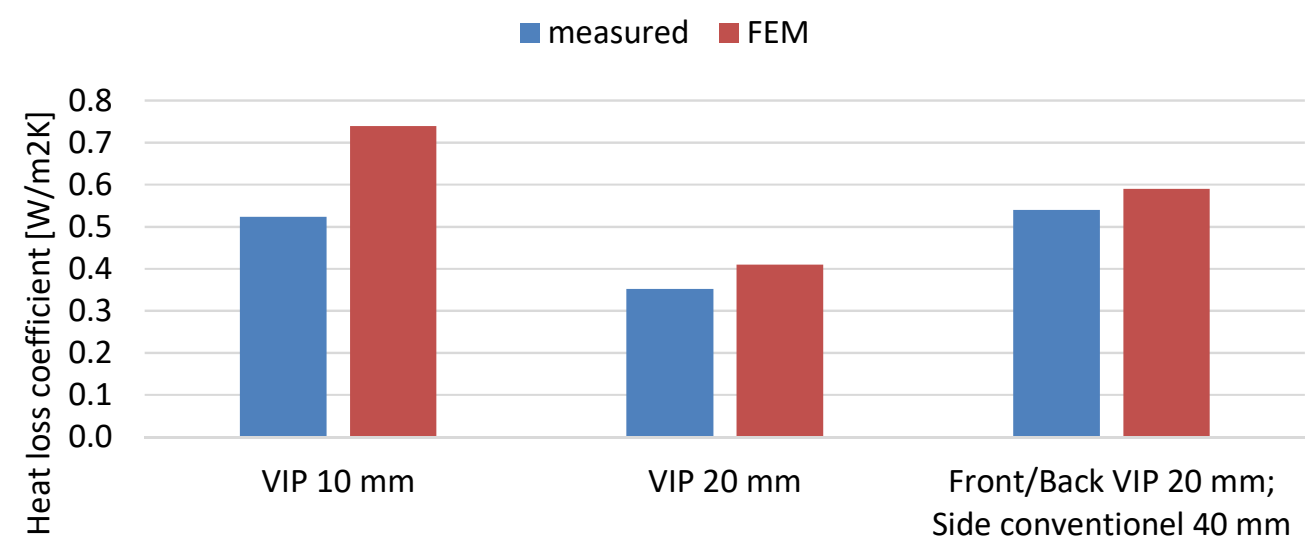

Figure 3: Measured heat loss coefficients vs. the predictions from FEM simulations.

\subsection{Connections only at the bottom}

In order to avoid heat losses and to simplify the construction of the tank all connections are integrated in a metal flange fixed to the bottom of the tank. This includes DHW heat exchanger, heat pump condenser and valves for filling and drain. The heat pump condenser consists of copper piping directly welded to the heat pump cycle. Conventional insulation is used at the bottom, which can be fitted around the connections.

\section{Other components}

More details on the development of the heat pump, including detailed performance measurement in the laboratory, is given by Büchel et al. 2016 and is therefore not explained in detail in this paper. Available standard products were used for the controlled ventilation (Zehnder, ComfoAir 180) unit and the electrical flow through backup heater (CLAGE, CEX ELECTRONIC MPS).

\section{Simulation}

Simulations were carried out with the simulation tool Polysun (Brönner et al. 2011) in order to characterize energy efficiency, the need of the electric backup heater and the possible direct consumption of PV electricity. The simulations were focused on the DHW system and the effect of the controlled ventilation was not considered.

- As there is no heat pump model with internal storage condenser available, an external heat pump was used. This heat pump was parametrized with measured data given by Büchel et al. 2016. A set point of $60^{\circ} \mathrm{C}$ was used for the heat pump control.

- Tapping profiles for 1-5 persons $\left(621 / \mathrm{p} @ 40^{\circ} \mathrm{C}\right)$ were generated with the DHWcalc tool from Jordan \& Vajen, 2003 and applied to different storage configurations. Special profiles with one second time steps during tapping were used to force the program to use small simulation time steps during these periods and to fit simulation parameters to measured data.

- Only cylindrical storage tanks can be implemented in the software. Therefore, insulation parameters were fit in order to match measured heat losses in four heights of the tank.

- Also the parameters of the internal heat exchangers were fit in order to match measured data rather than using the design geometries.

- Air flows and controlled ventilation units cannot be simulated in detail in the software polysun. As the heat pump only uses exhaust air it does not affect the operation of the unit and the simplified model with a constant recovery efficiency coefficient that is included in the building model can be used. On the other hand, the effect of the ventilation unit has to be considered when parametrizing the heat pump. 


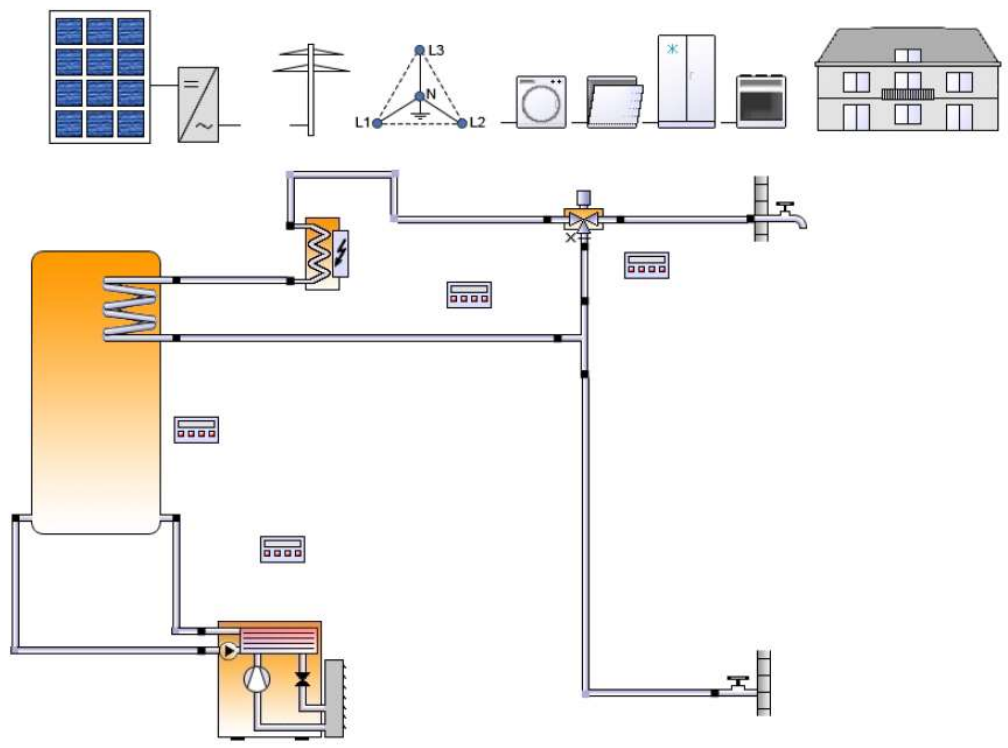

Figure 4: Simulation scheme in the software Polysun.

\section{Results of the simulations}

\subsection{Internal heat exchanger}

The size/surface of the internal storage heat exchanger affects the output temperature especially for longer tapping, which exceed the volume of the DHW stored inside the heat exchanger. High output temperatures are desired in order to keep the consumption of the additional electrical heater connected in series low. However, the consumption of the electrical backup heater also depends on the variable temperature/state of the storage tank and the tapping profile, which cannot be evaluated by a single measurement.

Figure 5 shows the influence of different tested internal heat exchangers on the annual consumption of the electric backup heater during dynamic operation with a stochastic tapping profile for three persons (186 1/day @ $40{ }^{\circ} \mathrm{C}$ ). A duplication of the length of the internal heat

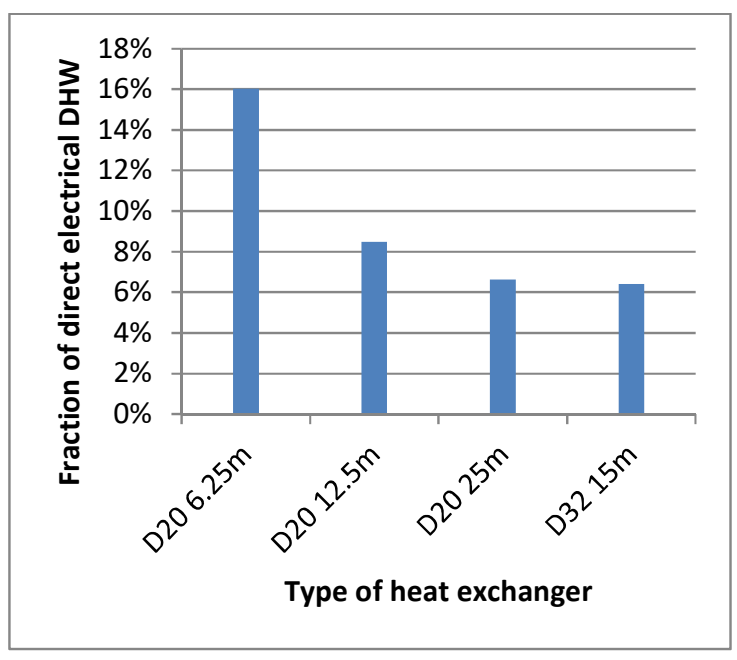

Figure 5: Annual fraction of direct electrical DHW heating with different internal heat exchangers.

exchanger from $6.25 \mathrm{~m}$ to $12.5 \mathrm{~m}$ cuts the use of the direct electricity use to half. The effect of a further duplication to $25 \mathrm{~m}$ is much less pronounced. In terms of a compromise between cost and efficiency a length of $12.5 \mathrm{~m}$ was used for the system prototype.

\subsection{System performance}

The main interest of the simulation was to gain knowledge about the performace of the system in different Situations. The most important parameter, is the amount of DHW consumption. Therefore, stochastic tapping profiles for one to five persons $\left(621 /\right.$ person $\left.@ 40^{\circ} \mathrm{C}\right)$ were used for the simulations. Figure 6 shows the electricity consumption of the heat pump as well as the direct electrical heater and the seasonal performance factor (SPF) of the heat pump and the entire system for different numbers of users. The electrical energy consumed by the heat 
pump increases nearly linearly from one to three persons. For more persons the possible runtime of the heat pump limits its contribution as it runs nearly continuously $(>8000 \mathrm{~h} / \mathrm{a})$ for five persons. This is compensated by a strong increase of the direct electricity consumption for more than three users. An increased DHW consumption leads to lower mean storage temperatures and therefore to less storage losses and increased SPF of the heat pump. A combination of all effects leads to the highest system performance (SPF 1.9) with 3-4 users.

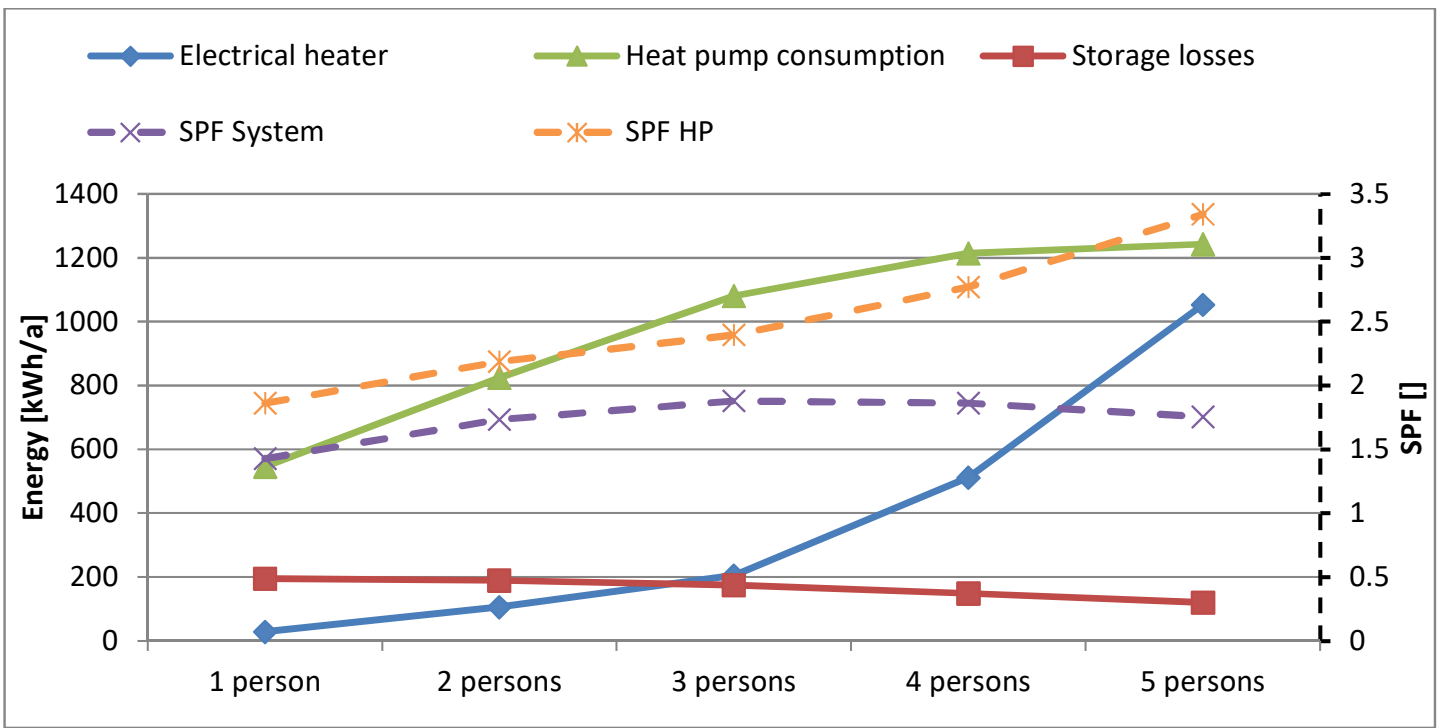

Figure 6: SPF and energy consumption of selected components for varying number of users.

The small size and therefore long runtimes of the heat pump limit the flexibility with respect to control and maximization of PV self-consumption. Simulations with different control strategies were carried out, but didn't result in great differences. However, as the heat pump generally runs during daytime, the system is suitable for the combination with PV-installations.

\section{Prototype testing}

A prototype of the system was constructed and installed in the lab. Different tapping profiles were automatically induced by a timer clock; two or three draw-offs of $100 \mathrm{l} / \mathrm{d}$ and a tapping profile similar to the EU tapping profile M (370 1/d, some small tapping were accumulated because the timer only handled 15 tapping per day). The different tapping profiles were run over various days, but with some interruptions and during different seasons. No systematic test was run was performed for an entire year.

In Figure 7, the temperature evolution in the tank and the tapping rates of the profile (similar to EU M) are given for an exemplary day. The fraction of direct electrical heater and the daily performance factor (DPF) of the heat pump is given in Figure 7 for all day operated with this profile (Sept. - Nov.). A clear dependence of the mean ambient temperature can be identified for the fraction of the direct electrical heater. On the other hand, there is no clear tendency for the DPF. This is due to the fact, that lower ambient temperatures result in lower output power of the heat pump and therefore in lower mean storage temperatures. The efficiency loss from cold ambient temperatures is therefore compensated by the efficiency gain caused by lower storage temperatures. This effect is especially pronounced when a lot of DHW is used (370 1 with this profile).

During the entire testing, which includes various profiles irregularly distributed over more than a year, a heat pump SPF of 2.8 and a system SPF of 2.0 was measured (temperature set point $60^{\circ} \mathrm{C}$ ). 


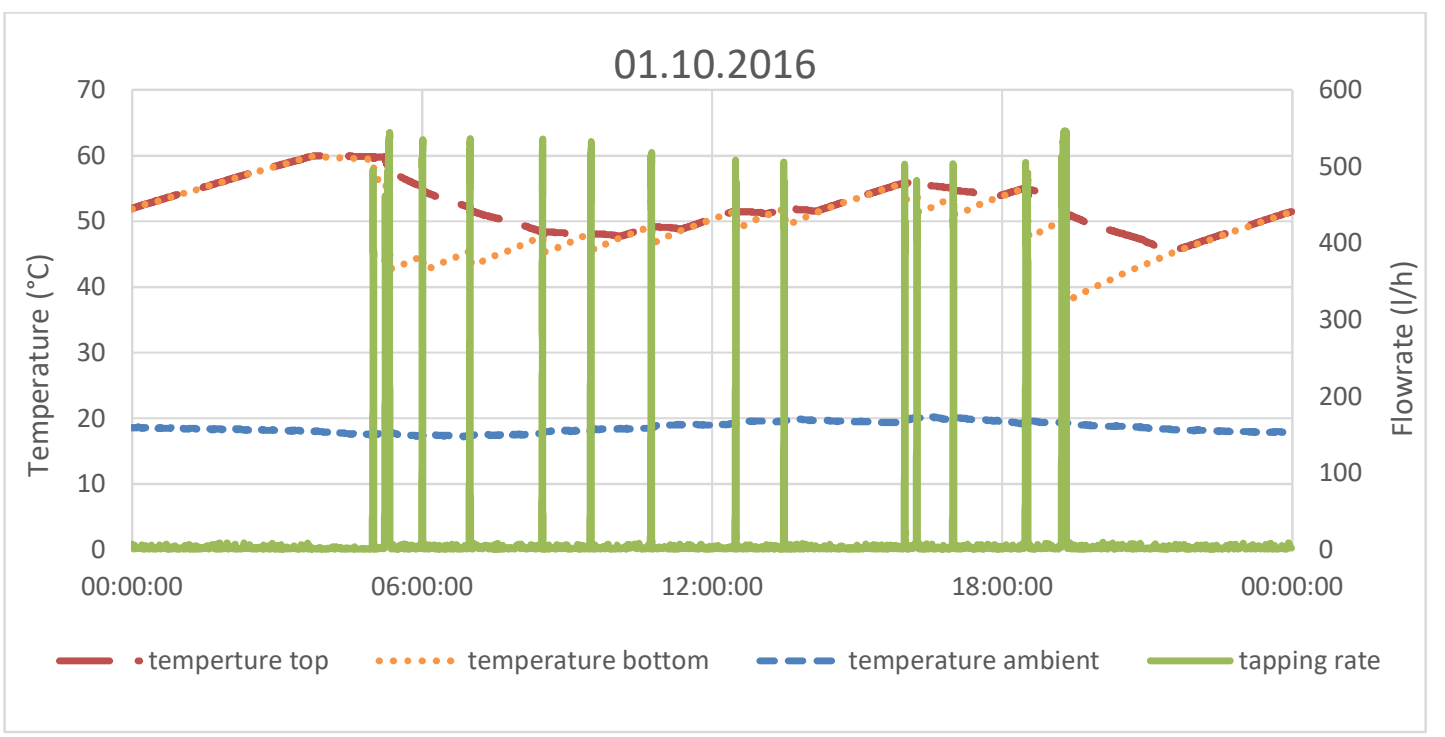

Figure 7: Temperature development at an exemplary day for a tapping profile similar to EU M.

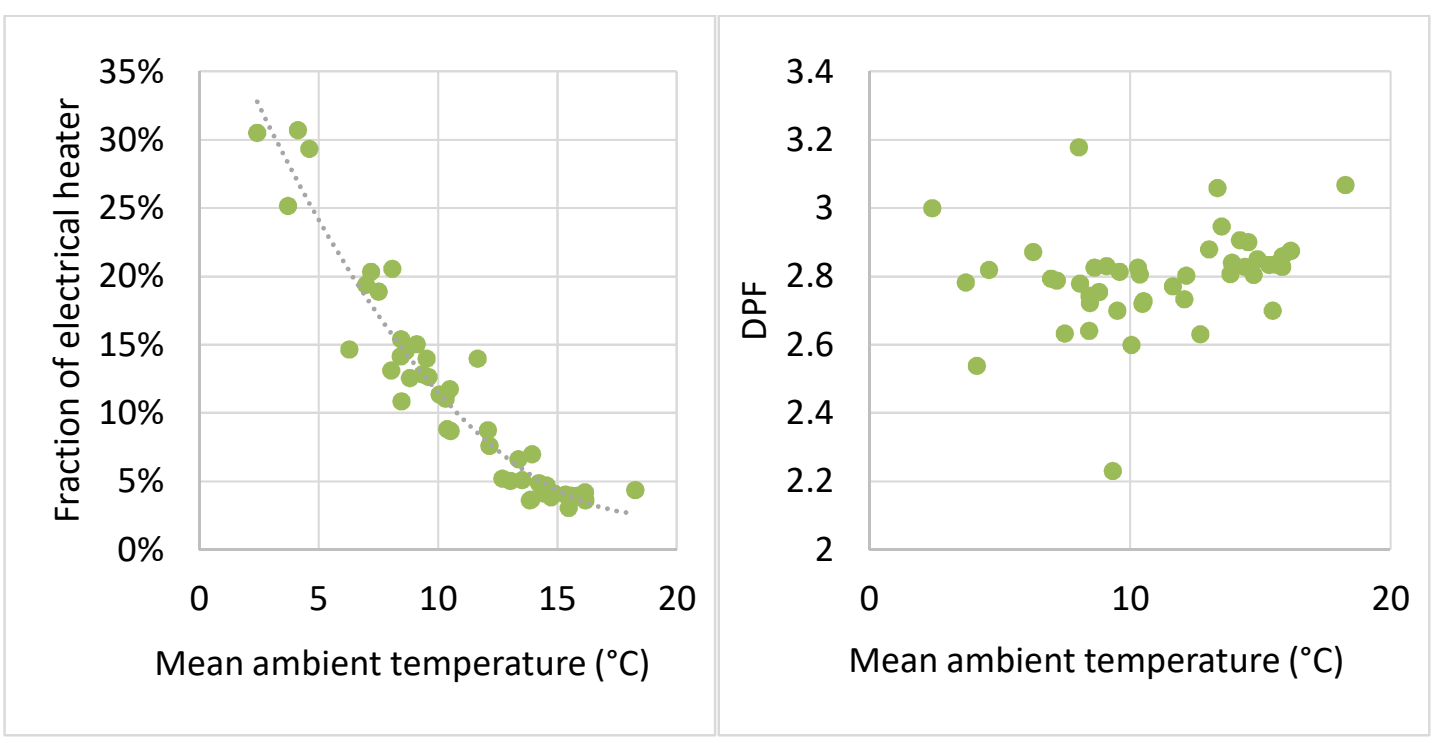

Figure 8: Fraction of the needed heat from the electrical heater (left) and corresponding DPF for all tested days with the profile EU $M$ as a function of the mean ambient temperature.

\section{Discussion and Conclusion}

- High performance VIP is well suited for the insulation of small cuboid storage tanks. In the contrary to initial concerns, the effect of thermal bridges at joints was low and good performance could be achieved despite the unfavorable surface/volume ratio. Manufacturer data on the heat conductivity were undermatched with the actual prototype set up and measured un-aged.

- A final test of the storage tank with an intermediate VIP thickness of $15 \mathrm{~mm}$ according to CDR (EU) No $812 / 2013$ resulted in a heat loss coefficient of $0.78 \mathrm{~W} / \mathrm{K}$ and an energy label "B" just at the limit to "A". The storage tank will be placed in the small space in the bathroom prewall, which will be heated up by thermal losses of the storage and the heat pump. This effect is expected to lower thermal losses in practice.

- The simulated system SPF of 1.9 (three persons) corresponds well to the measured value of 2.0, even though the values are not directly comparable because of interruptions and different tapping profiles in the measurements. 


\title{
CFD-based development, testing and optimization of flat plate collectors
}

\author{
Beate Vetter, Stephan Fischer, Harald Drück \\ University of Stuttgart, Institute for Building Energetics, Thermotechnology and \\ Energy Storage (IGTE) ${ }^{1}$, Stuttgart (Germany)
}

\begin{abstract}
Based on CFD (Computational Fluid Dynamics) simulations and virtual thermal performance tests, a development and optimization tool for flat plate collectors is presented. Using the example of a serial product flat plate collector, parametrized CAD data were generated. Dimensions like length, width and thickness of the transparent cover or the dimensions of the pipes, the aperture area and the welding lines are parametrized. Therewith geometrical changes can be executed quickly at a later stage for optimization. Essential for simulating solar collectors is the radiation spectrum model. The Multiband Thermal radiation model was chosen. It allows specifications of user-defined spectral bands, for which optical properties of the surfaces are defined. Thereby implementation of selective absorber coating is possible. Using a heat transfer coefficient, convection to the environment is taken into account by implementation as a boundary condition. Literature shows a wide range of convective heat transfer coefficients for forced air over flat surfaces, particularly flat plate collectors, which are based on empirical examinations and from boundary layer theory. Taking into account, that virtual dimensions of the collector are variable, selection of an equation from boundary layer theory is shown. Finally, results from a virtual thermal performance test are presented. Simulated component temperatures and peak collector efficiency from the virtual thermal performance test correspond well to measured values. With increasing mean fluid temperature, the difference between measured and simulated outlet temperature rises. Possible reasons are identified and presented.
\end{abstract}

Keywords: virtual thermal performance test, flat plate collector, CFD (Computational Fluid Dynamics)

\section{Introduction}

Knowledge of the thermal performance of the collector is required for the prediction of the energy output of a solar thermal system. Thermal performance test procedures are e.g. defined in DIN EN ISO 9806:2017. In phases of new and further development as well as for the optimization of flat plate collectors, the knowledge of the thermal performance as well as component temperatures such as the maximum temperature of the thermal insulation, are of interest before building and physically testing a prototype. To achieve this goal a CFD-based development and optimization tool, including a virtual thermal performance test procedure for flat plate collectors, is being developed in the VirtColl+ project. The paper presents the methodical approach and simulation results using the example of a serial product flat plate collector.

The CFD calculation is based upon modeling the physical processes in and around the flat plate collector. Therefore, in the first step, flat plate collectors are implemented in a CFD program and the outlet temperature as well as the component temperatures are calculated depending on the ambient and operating conditions (e.g. mass flow rate, inlet temperature, etc.) and the collector's construction (e.g. type of absorber coating, type and thickness of thermal insulation material, etc.). Due to specific ambient and operating conditions, the collector's performance can be virtually determined in a second step. On the basis of the virtually created measurement

\footnotetext{
${ }^{1}$ On July 1, 2018 the Institute for Building Energetics (IGE), the Institute of Thermodynamics and Thermal Engineering (ITW) with its Research and Testing Centre for Thermal Solar Systems (TZS) as well as the Institute of Energy Storage (IES) have been merged to the Institute for Building Energetics, Thermotechnology and Energy Storage (IGTE)
} 


\section{Beate Vetter}

data generated by means of CFD simulations, the conventional collector parameters are determined via parameter identification in an established way, compliant with standard. The paper shows the methodical approach from CAD data buildup to validation by means of a stationary thermal performance test of a serial product flat plate collector. During the thermal performance test, component temperatures were also measured.

The advantage of a CFD-based development, is the possibility to analyze a plurality of parameter alternatives in the forefront of prototyping. The CFD software used is STAR CCM+.

\section{Environment and operating conditions for stationary thermal performance tests according to DIN EN ISO 9806}

One collector was equipped with thermocouples on the absorber and the frame to validate the component temperatures resulting from the simulations. This collector was tested indoor in a solar simulator (collector C1375). In addition, another collector of the same type equipped with only a single thermocouple on the absorber was tested in- and outdoors (collector C1373). The efficiency curves are shown in Fig. 1. Instantaneous collector efficiency is calculated according to Eq. 1.

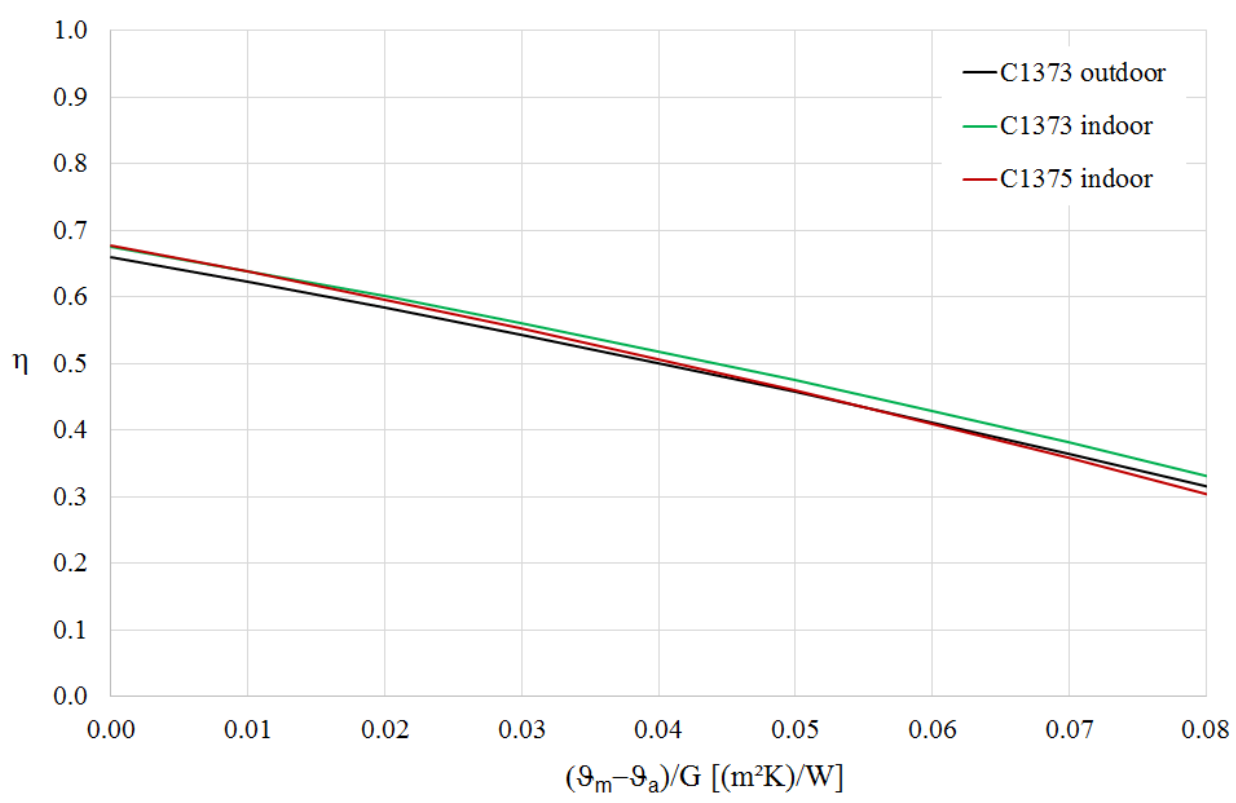

Fig. 1: Efficiency curves for stationary thermal performance test of collectors C1373 and C1375

$\eta=\frac{\dot{m} * c_{p} *\left(\vartheta_{\text {out }}-\vartheta_{\text {in }}\right)}{A * G}=\eta_{0}-a_{1} *\left(\frac{\vartheta_{m}-\vartheta_{a}}{G}\right)-a_{2} *\left(\frac{\left(\vartheta_{m}-\vartheta_{a}\right)^{2}}{G}\right)$

with:

$\eta \quad$ instantaneous collector efficiency

$[-]$

$\dot{m} \quad$ mass flow rate

$[\mathrm{kg} / \mathrm{s}]$

$c_{p} \quad$ specific heat capacity

$[\mathrm{J} /(\mathrm{kg} \mathrm{K})]$

$\vartheta_{\text {out }} \quad$ collector outlet temperature

$\left[{ }^{\circ} \mathrm{C}\right]$

$\vartheta_{\text {in }}$

collector inlet temperature

$\left[{ }^{\circ} \mathrm{C}\right]$

A

gross collector area

$\left[\mathrm{m}^{2}\right]$

G

hemispherical solar irradiation

$\left[\mathrm{W} / \mathrm{m}^{2}\right]$

peak collector efficiency

$[-]$

heat loss coefficient at $\left(\vartheta_{\mathrm{m}}-\vartheta_{\mathrm{a}}\right)=0$

$\left[\mathrm{W} /\left(\mathrm{m}^{2} \mathrm{~K}\right)\right]$

$a_{1}$

temperature dependence of the heat loss coefficient

$\left[\mathrm{W} /\left(\mathrm{m}^{2} \mathrm{~K}^{2}\right)\right]$

$\begin{array}{ll}a_{2} & \text { temperate } \\ \vartheta_{a} & \text { ambient temperature }\end{array}$

$\left[{ }^{\circ} \mathrm{C}\right]$

$\vartheta_{m}$

mean temperature of heat transfer fluid

$\left[{ }^{\circ} \mathrm{C}\right]$ 


\section{Beate Vetter}

Collector parameters $\eta_{0}, a_{1}$ and $a_{2}$ are identified from measurement results by parameter identification.

Comparing the indoor measurement results of C1373 and C1375 the following can be observed:

- The efficiency curve of C1375 shows a slightly larger gradient than the efficiency curve of C1373 which indicates higher thermal losses with increasing mean fluid temperature. Possible explanations are series scattering, minor defects due to the installation of the thermocouples and measurement uncertainties.

- The $\eta_{0}$ of the outdoor test (C1373) is lower compared to indoor test (C1375). This is not exceptional and in a range which is not uncommon as solar simulators usually do not match solar spectrum to $100 \%$.

Component temperatures of the CFD simulation are validated with the temperatures measured during the thermal performance test of C1375 in the solar simulator. Therefore, environment and operating conditions from this measurement were implemented as boundary conditions in the simulations, compare Tab. 1.

Tab. 1: Thermal performance test C1375, environment and operating conditions

\begin{tabular}{|l|l|}
\hline Mass flow rate & $0.042 \mathrm{~kg} / \mathrm{s}$ \\
\hline Inlet temperatures & $19.9^{\circ} \mathrm{C}, 40.8^{\circ} \mathrm{C}, 60.3^{\circ} \mathrm{C}, 79^{\circ} \mathrm{C}$ \\
\hline Wind velocity & $2 \mathrm{~m} / \mathrm{s} ;(3 \mathrm{~m} / \mathrm{s} \mathrm{C} 1373$ outdoor $)$ \\
\hline Ambient temperature & $22^{\circ} \mathrm{C}$ \\
\hline Hemispherical solar irradiation & $788 \mathrm{~W} / \mathrm{m}^{2}$ \\
\hline
\end{tabular}

\section{CAD buildup and meshing}

CFD-based development always starts with CAD (computer-aided design) data. Either available CAD data is imported in the CFD software or parameterized CAD data of the collector, more suitable for parameter studies, are prepared. Fig. 2 shows an isometric mapping of the collector in transparent mode. Fig. 3 illustrates a sectional drawing through a part of the collector geometry. The collector's gross area is $2.1 \mathrm{~m}^{2}$. The absorber is a selective coated aluminum sheet with copper pipes; the flow pattern is a harp with eight riser pipes. The bonding between the absorber sheet and piping is done by ultra-sonic welding. CAD data were prepared and parameterized using the 3D CAD tool included in STAR CCM+. Dimensions like length, width and thickness of the frame, transparent cover, absorber and the thermal insulation as well as the dimensions of the pipes, the aperture area and the welding line are parametrized and thereby can be changed quickly at a later stage for performance optimization. The advantage of preparing the CAD data in the same tool where the CFD calculations are done, is that the preparation and manipulation of the CAD data can be done without editing surface classifications after changing dimensions. The interface between transparent collector cover and ambient for example remains the same for all defined optical properties and boundary conditions after enlargement or reduction the aperture area in size.

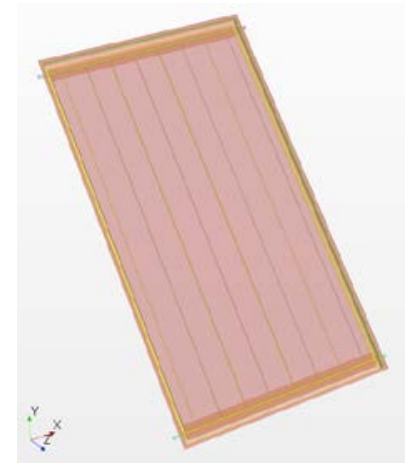

Fig. 2: Isometric collector mapping (transparent mode)

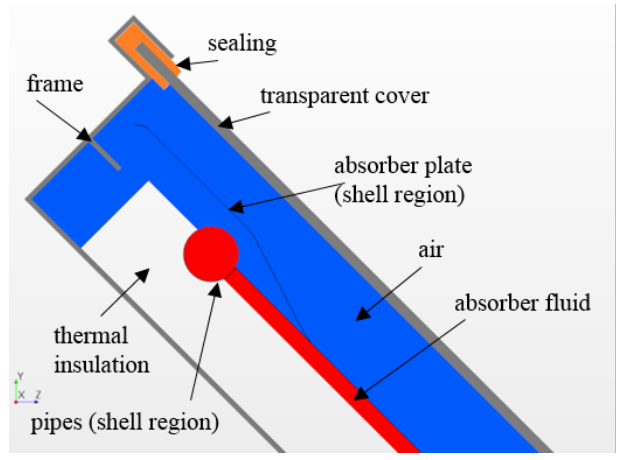

Fig. 3: Sectional drawing through part of the collector geometry 


\section{Beate Vetter}

One challenge in buildup and meshing a flat plate collector is, that the dimensions differ in the range of meters for horizontal dimensions (length and width of the transparent cover, the thermal insulation etc.) and in the range of some tenths of a millimeter for material thicknesses (absorber plate, pipes). Meshing such thin solids is not practical and leads to an enormously large number of cells. Therefore, the Shell Three-Dimensional model is used for the absorber plate and the absorber pipes. This model represents a volume in space whose thickness is so small that it can be adopted as a surface with a single-cell thickness in the normal direction. Instead of building the pipes as a volume for example, only the water in the pipes is created in the first step. A shell region, which represents the pipes, is stamped on the fluid afterwards. Wall thickness is applied as a parameter. The heat transfer by conduction is still represented in lateral directions.

For computation, the finite volume method is used. The conservation equations for mass, momentum and energy are adopted in integral form. For an efficient simulation strategy, the computation domain is divided in three mesh continua. The first mesh continuum contains the frame, sealing and transparent cover and is meshed with the "Thin Mesher". The "Thin Mesher" generates a prismatic type volume mesh for thin volumes. The second mesh continuum contains the riser pipes. The riser pipes are meshed with the "Direct Mesher". This method generates a high quality mesh and is flow-aligned in the present case. The third mesh continua includes the air volume, the thermal insulation and the collecting pipes and is meshed with the "Polyhedral Mesher". In fluid regions, prism layers are used to solve the boundary layer. The mesh consist of 7.8 Mio cells in total.

\section{Radiation}

To model energy transfer by means of radiation a radiation model as well as a radiation spectrum model is needed. The Surface-to-Surface (S2S) model is used as the radiation model. The S2S model considers radiation as an exclusive surface phenomenon. The surface properties are defined with the optical properties absorptance, reflectance and transmittance. Fluids that are present between surfaces are not include in the radiation heat transfer. Therefore, the air in the gap between the absorber and the transparent cover does not absorb, emit or scatter radiation. As dry air is transparent for radiation, this assumption is considered as permitted.

The base of the Surface-to-Surface model is a spatial discretization of the boundary surfaces into contiguous, non-overlapping patches. Then, a specified number of beams is emitted from each patch-center over the enclosing hemisphere with solid angles. Every beam is traced through the computational domain until it meets another patch. Between these pairs of patches, radiation energy is exchanged. The amount of radiation energy transferred is calculated from the boundary conditions and the radiation transport equation.

The optical properties absorption $(\alpha)$, reflection $(\rho)$ and transmission $(\tau)$ are spectral directional quantities. That means that they are dependent on wavelength $(\lambda)$ and the direction of incoming radiation. From Kirchhoff's law, the spectral directional emittance is, for the same wavelength, equal to the spectral directional absorptance. In STAR-CCM+, directional properties are not applied. Kirchhoff's law is implemented as Eq. 2 for the Multiband Thermal Radiation model and as Eq. 3 for the Gray Thermal Radiation model.

$\varepsilon_{\lambda}=\alpha_{\lambda}$

Eq. 2

$\varepsilon=\alpha$

Eq. 3

Essential components of a flat plate collector are the absorber and the transparent cover. Today absorber plates are usually selective coated. The coating leads to a high absorptance of up to $\alpha_{\text {sol }}=0.95$ for radiation with short wavelengths (solar irradiation) and low emittance down to $\varepsilon_{100^{\circ} \mathrm{C}}=0.05$ for radiation with long wavelengths (thermal radiation). High sensitivity on wavelength also occurs on optical properties for glass plates. Glass plates used for flat plate collectors have a transmittance of 0.9 and higher in the range of solar irradiation, whereas they are almost opaque in the range of infrared radiation. This reveals that a wavelength dependent radiation spectrum model is necessary. To accommodate the wavelength dependency of the optical properties of the surfaces, the Multiband Thermal Radiation model is implemented. Specifying numerous wavelength bands is possible. Optical properties of surfaces are then defined for each wavelength band. During the solution process, the governing radiation equations are solved for each band. The total radiation solution is obtained by summing up the solutions from each band. Because the governing equations are solved for each band, the computing time generally increases with the number of bands. Two spectral bands were defined, one for solar irradiation (short wavelength) and one for infrared radiation (long wavelength). For simulations, wavelength 


\section{Beate Vetter}

dependent optical properties were partly taken from literature and partly from measurements performed with an UV-VIS-NIR spectrometer for solar spectrum and an emission meter at $70^{\circ} \mathrm{C}$ sample temperature for infrared radiation. Tab. 2 displays the absorptance and accordingly emittance and transmittance for the components pictured in Fig. 3. The reflectivity of the materials was calculated using Eq. 4 for transparent materials and Eq. 5 for opaque materials.

Tab. 2: Optical properties of the different collector components

\begin{tabular}{|l|l|l|l|l|}
\hline- & \multicolumn{2}{|l|}{ absorptance / emittance } & \multicolumn{2}{l|}{ transmittance } \\
\hline Spectral band & short & long & short & long \\
\hline Absorber plate & 0.95 & 0.05 & - & - \\
\hline Transparent cover & 0.02 & 0.88 & 0.91 & 0.0 \\
\hline Frame & 0.2 & 0.01 & - & - \\
\hline Sealing & 0.95 & 0.91 & - & - \\
\hline Thermal insulation & 0.5 & 0.5 & - & - \\
\hline Absorber pipes & 0.3 & 0.3 & - & - \\
\hline
\end{tabular}

$\alpha+\rho+\tau=1$

Eq. 4

$\alpha+\rho=1$

Eq. 5

\section{Heat Conduction in thermal insulation material}

Thermal losses through heat conduction mainly take place through the thermal insulation on the backside of the absorber. Heat transfer through a porous material, as a thermal insulation, is a result from thermal radiation and thermal conduction as well as their interaction with mass transfer in humid materials. According to Krischer and Kast (1963), convection affects the heat transfer only when an air layer becomes $1 \mathrm{~cm}$ or thicker. Based on thermal conductivity and thermal radiation, Krischer and Kast introduced a model for mapping thermal conductivity as a function of temperature for porous materials. As for thermal radiation, temperature affects heat transfer with the power of 4, effective thermal conductivity of a thermal insulation increases exponentially with increasing temperature. However, in the range that is relevant for flat plate collectors, with average temperatures of about $150{ }^{\circ} \mathrm{C}$, the thermal conductivity can be modelled with a linear equation as a function of temperature (Vetter et al. 2015).

For the implementation in the CFD simulation, the linear equation for effective thermal conductivity of a sample thermal insulation was determined. Therefore, the thermal conductivity was measured at five average temperatures between $10^{\circ} \mathrm{C}$ and $90{ }^{\circ} \mathrm{C}$ by means of a Two-Plate-Apparatus. The values of Eq. 6 were then determined by linear regression from the measured data. Information about test method, modeling according to Krischer and Kast and simplified mapping is given in Vetter et al. (2015).

$k=0.032+0.0023 * \vartheta$

Eq. 6

with:

$\begin{array}{lll}k & \text { thermal conductivity } & {[\mathrm{W} /(\mathrm{m} \mathrm{K})]} \\ \vartheta & \text { temperature } & {\left[{ }^{\circ} \mathrm{C}\right]}\end{array}$

Fig. 4 shows the temperature distribution of the thermal insulation material at the surface towards the absorber at an averaged fluid temperature of $63^{\circ} \mathrm{C}$. Surface temperatures from approximately $40^{\circ} \mathrm{C}$ to $90^{\circ} \mathrm{C}$ occur. On the backside interface, between thermal insulation and frame, temperatures between $27^{\circ} \mathrm{C}$ and $34^{\circ} \mathrm{C}$ appear. In this temperature range the thermal conductivity is larger than the value stated in the manufacturer's data sheet, which is normally related to a mean temperature of $10^{\circ} \mathrm{C}$. In the present case, the thermal conductivity of the thermal insulation from the data sheet is $\lambda \leq 0.035 \mathrm{~W} /(\mathrm{m} \mathrm{K})$. Tab. 3 lists the minimum, maximum and volume averaged thermal conductivity relating to volume averaged fluid temperature. At an averaged fluid temperature of $81^{\circ} \mathrm{C}$, maximum thermal conductivity exceeds the value from the data sheet by more than $50 \%$. Even volume averaged thermal conductivity exceeds this value by more than $30 \%$. As thermal conductivity of 


\section{Beate Vetter}

thermal insulations is strongly dependent on temperature, values from the manufacturer data sheet at $10^{\circ} \mathrm{C}$ should neither be used for virtual collector testing nor for designing collectors.

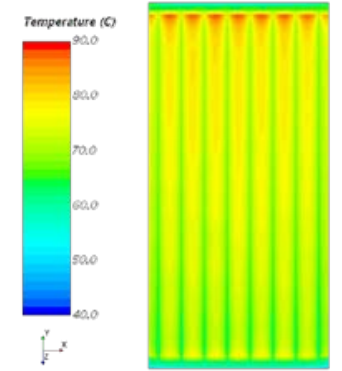

Fig. 4: Temperature distribution of the absorber oriented surface of the thermal insulation.
Tab. 3: Thermal conductivity of thermal insulation relating to volume averaged fluid temperature.

\begin{tabular}{|l|c|c|c|c|}
\hline $\begin{array}{l}\text { Volume averaged fluid } \\
\text { temperature }\left[{ }^{\circ} \mathbf{C}\right]\end{array}$ & $\mathbf{2 3 . 7}$ & $\mathbf{4 4 . 0}$ & $\mathbf{6 3 . 0}$ & $\mathbf{8 1 . 1}$ \\
\hline $\begin{array}{l}\text { Minimum thermal conductivity } \\
{\left[\mathrm{W} /\left(\mathrm{m}^{2} \mathrm{~K}\right)\right]}\end{array}$ & 0.037 & 0.038 & 0.039 & 0.039 \\
\hline $\begin{array}{l}\text { Maximum thermal conductivity } \\
{\left[\mathrm{W} /\left(\mathrm{m}^{2} \mathrm{~K}\right)\right]}\end{array}$ & 0.045 & 0.049 & 0.052 & 0.055 \\
\hline $\begin{array}{l}\text { Volume averaged thermal } \\
\text { conductivity }\left[\mathrm{W} /\left(\mathrm{m}^{2} \mathrm{~K}\right)\right]\end{array}$ & 0.039 & 0.042 & 0.044 & 0.046 \\
\hline
\end{tabular}

\section{Fluid flow in absorber pipes}

In compliance with DIN EN ISO 9806 virtual collector performance test is done with water as a heat transfer fluid in the absorber pipes. Fluid properties are temperature dependent and were implemented as equations, determined from property value tables from VDI Heat Atlas (2013). Temperature dependent equations for dynamic viscosity, density, specific heat and thermal conductivity were embedded.

An important dimensionless parameter for viscous flow is the Reynolds (Re) Number. Re Number is defined by Eq. 7. For pipes with circular cross-section Eq. 8 is also valid. If $\mathrm{Re}<2300$, flow is laminar, if $\mathrm{Re}>4000$ flow is turbulent. In between is a transition zone, flow can be either laminar or turbulent or a mixture of both.

$R e=\frac{\rho v D}{\mu}=\frac{v D}{v}$

$R e=\frac{4 \dot{V}}{\pi D v}=\frac{4 \dot{m}}{\pi D \mu}$

Where $\rho$ is the density $\left[\mathrm{kg} / \mathrm{m}^{3}\right], \mathrm{v}$ is the average fluid velocity $[\mathrm{m} / \mathrm{s}], \mathrm{D}$ is the pipe diameter $[\mathrm{m}], \mu$ is the dynamic viscosity $\left[\mathrm{m}^{2} / \mathrm{s}\right], v$ is the kinematic viscosity $[\mathrm{Pa} \mathrm{s}], \dot{V}$ is the volume flow rate $\left[\mathrm{m}^{3} / \mathrm{s}\right]$ and $\dot{m}$ is the mass flow rate $[\mathrm{kg} / \mathrm{s}]$.

It can be shown, that the flow pattern of a fully developed laminar flow in a pipe is parabolic. Averaged velocity is half of maximal velocity (= velocity in centerline). Depending on Re Number and diameter, laminar flow is fully developed after entrance length $\left(l_{e}\right)$. Entrance length is calculated according to Eq. 9.

$l_{e}=0.06 * \operatorname{Re} * D$

Eq. 9

Due to pressure drop, the mass flow rates in the different riser pipes are not exactly the same. Hereafter riser pipe 5 (from the left) is analyzed, Tab. 4. Other raising pipes show similar results.

Tab. 4: Volume averaged temperature, mass flow rate, Re Number and entrance length of riser pipe 5

\begin{tabular}{|c|c|c|c|c|}
\hline Volume averaged temperature $\left[{ }^{\circ} \mathrm{C}\right]$ & mass flow rate [kg/s] & Re (Eq. 7) & Re 3 (Eq. 8) & entrance length [m] \\
\hline 24.5 & 0.0052 & 1409 & 1412 & 0.44 \\
\hline 44.8 & 0.0052 & 2124 & 2129 & 0.67 \\
\hline 63.6 & 0.0053 & 2892 & 2899 & 0.91 \\
\hline 81.6 & 0.0053 & 3694 & 3702 & 1.16 \\
\hline
\end{tabular}

Re number according to Eq. 7 and Eq. 8 differ less than $0.3 \%$. As Re $<4000$ for all temperatures, flow was defined as laminar. The entrance length was verified by means of CFD simulations for both constant 


\section{Beate Vetter}

temperatures and during the virtual performance test. After entrance length, the requirement that average velocity is half of maximum velocity is fulfilled, with a deviation of less than $2 \%$.

\section{Convective heat loss to the environment}

According to DIN EN ISO 9806 air with a speed of $3 \pm 1 \mathrm{~m} / \mathrm{s}$ has to flow parallel to the collector outer surfaces during the performance test. In general, there are two possibilities to transfer this requirement to CFD simulations. The first is to establish an air volume around the collector with the enforced wind speed. The disadvantage is again that the mesh would contain a huge number of cells. To avoid the need of the air volume around the collector a convective heat transfer coefficient is implemented as boundary condition.

Literature shows a wide range of heat transfer coefficients for forced air flow over flat surfaces or particularly flat plate collectors. On the one hand are empirical equations and on the other hand equations from boundary layer theory. Sartori (2006) gives an overview. Following some equations are shown and compared.

Eq. 10 was implemented by Jurges (1924) for a vertical surface of $0.5 \mathrm{~m} \mathrm{x} 0.5 \mathrm{~m}$ and is widely used for flat plate collectors.

$h_{c}=5.7+3.8 * v$ with:

$\begin{array}{lll}h_{c} & \text { heat transfer coefficient } & {\left[\mathrm{W} /\left(\mathrm{m}^{2} \mathrm{~K}\right)\right]} \\ v & \text { wind velocity } & {[\mathrm{m} / \mathrm{s}]}\end{array}$

Watmuff et all. (1977) suggested that Eq. 10 presumably comprises radiative effects and recommended Eq. 11.

$h_{c}=2.8+3.0 * v$

Eq. 11

Lunde (1980) suggested Eq. 12.

$h_{c}=4.5+2.9 * v$

Eq. 12

Boundary layer theory leads to Eq. 13 for laminar flow and Eq. 14 for fully turbulent flow. Both, Eq. 13 and Eq. 14 were developed for flat surfaces and constant surface temperatures.

$N u=0.664 * \operatorname{Re}^{0.5} * \operatorname{Pr}^{\frac{1}{3}}$

$N u=0.0369 * \operatorname{Re}^{0.8} * \operatorname{Pr}^{\frac{1}{3}}$

Eq. 14

Incorpera and deWitt (1985) remark that it is fundamental for every convection problem to first determine, whether the boundary layer is laminar or turbulent. The heat loss strongly depends on which of these conditions occur. The empirical equations Eq. 10 to Eq. 12 do not comply with this requirement. Incorpera and deWitt (1985) also state, "it's well known that even small disturbance causes the flow to be turbulent." Francey and Papaioannou (1985) do confirm this when they say: "the finite thickness of the collector presents a blunt leading edge to the wind and presumably produce turbulent flow over the surface." Based on Rowley et al. (1930) who state that the effect resulting from differing reference temperatures on the convective heat transfer coefficient is not significant, Sartori (2006) developed Eq. 15 with a reference temperature of $\vartheta_{\text {ref }}=40{ }^{\circ} \mathrm{C}$ for fully turbulent flow over a flat surface. $L$ is the flat plate length in wind direction.

$h_{c}=5.74 * v^{0.8} * L^{-0.2}$

Eq. 15

Fig. 5 shows the convective heat transfer coefficient from Eq. 10 to Eq. 12 and Eq. 15 as a function of wind speed. As Eq. 10 presumably includes radiative effects, the convective heat transfer coefficient according to wind speed displays the highest values. Empirical Eq. 11 and Eq. 15 derived from boundary layer theory demonstrate a good match. Eq. 12 is in between.

According to boundary layer theory, the convective heat transfer is both, dependent on wind speed and the length of the flat plate in wind direction. The decay is proportional to $L^{-0.2}$ for turbulent flows, and to $L^{-0.5}$ for laminar flows. Experimental results from Parmelee and Huebscher (1947) and Test et al. (1981) found again, that the average convective heat transfer coefficient of a flat plate decreases with increasing length. Fig. 6 shows the convective heat transfer coefficient as a function of the surface length in wind direction, calculated from Eq. 


\section{Beate Vetter}

10 to Eq. 12 and Eq. 15. Compared to Eq. 15, empirical equations Eq. 10 to Eq. 12 do not consider the decay of the convective heat transfer coefficient with increasing surface length in wind direction.

As the objective of this work is a development and optimization tool for flat plate collectors, which could be a modification of the length in wind direction, Eq. 15 is implemented as a boundary condition for all outer surfaces of the collector. Technically speaking Eq. 15 is not valid for the front ends, but as the convective heat loss is small over the front ends, the error is marginal.

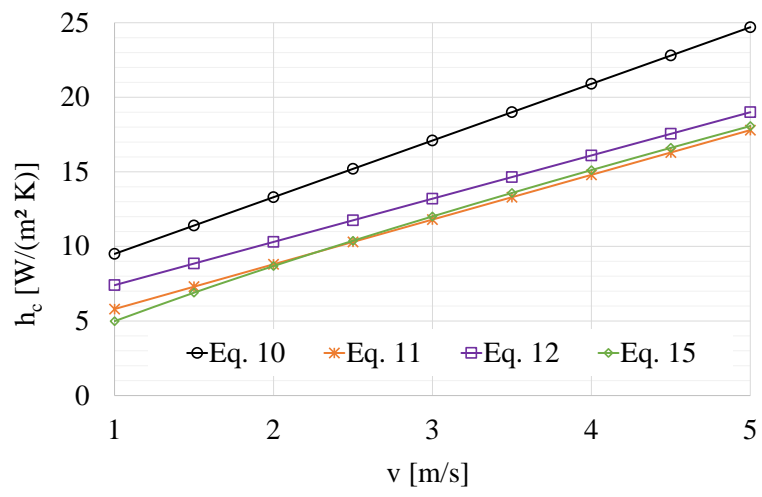

Fig. 5: Convective heat transfer coefficient as a function of wind speed

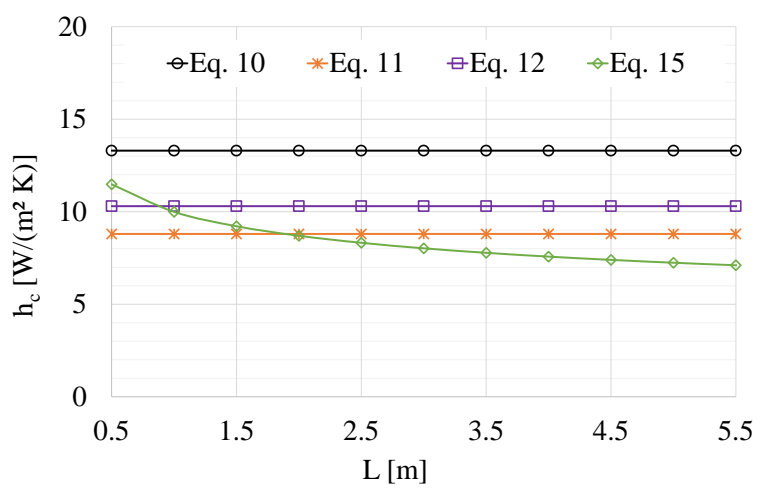

Fig. 6: Convective heat transfer coefficient as a function of surface length in wind direction

\section{Virtual collector performance test}

A virtual collector performance test was conducted. In order to validate the results determined by the virtual collector performance test, component temperatures were measured during a real physical performance test of collector C1375 in a solar simulator and the boundary conditions from this measurement were implemented in CFD simulations, compare Tab. 1 . Wind velocity is measured during the thermal performance test at a corner of the collector. The measurement of the wind velocity during the test is not representing to $100 \%$ the wind velocity on all outer surfaces of the collector. To study the influence of wind velocity, virtual thermal performance tests have been executed for $2 \mathrm{~m} / \mathrm{s}$ (measured at indoor test of collector C1375) and for $3 \mathrm{~m} / \mathrm{s}$ (measured at outdoor test of collector C1373), respectively $h_{c}=8.7 \mathrm{~W} /\left(\mathrm{m}^{2} \mathrm{~K}\right)$ and $\mathrm{h}_{\mathrm{c}}=12 \mathrm{~W} /(\mathrm{m} \mathrm{K})$, acc. Eq. 15 .

Fig. 7 and Fig. 8 show some of the points of temperature measurement. Temperature measurements have been executed using thermocouples. They were mounted on the backside of the absorber and on the inside of the frame.

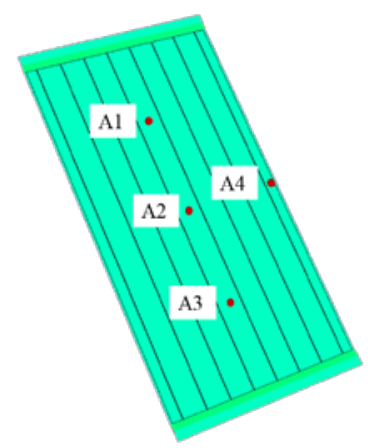

Fig. 7: Points of temperature measurement on the backside of the absorber

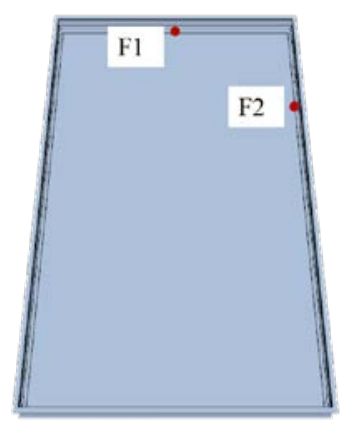

Fig. 8: Points of temperature measurement on the inside surface of the frame

Tab. 5 displays a comparison between measured and simulated outlet- and component temperatures for convective heat transfer coefficients at the outer collector surfaces of $h_{c}=8.7 \mathrm{~W} /\left(\mathrm{m}^{2} \mathrm{~K}\right)$ and $\mathrm{h}_{\mathrm{c}}=12 \mathrm{~W} /\left(\mathrm{m}^{2} \mathrm{~K}\right)$. The maximum deviation for component temperatures is $-3.7 \mathrm{~K}$ at point $\mathrm{A} 1$ for $\mathrm{h}_{\mathrm{c}}=8.7 \mathrm{~W} /\left(\mathrm{m}^{2} \mathrm{~K}\right)$ and $\vartheta_{\text {in }}=79{ }^{\circ} \mathrm{C}$ (simulated absorber temperature is $3.7 \mathrm{~K}$ higher than measured). The simulation for the same set of boundary conditions also shows the maximum deviation in the simulated outlet temperature. While temperature difference 


\section{Beate Vetter}

between in- and outlet measured accounts for $3.14 \mathrm{~K}$, the temperature difference resulting from the simulation is $3.79 \mathrm{~K}$. Therefore, the outlet temperature in simulation shows a $0.65 \mathrm{~K}$ higher temperature increase than measured. As also shown in chapter 2, measurement results between indoor measurement of C1373 and C1375 as well as outdoor measurement of C1373 show differences.

Tab. 5: Comparison between measurement and simulation results

\begin{tabular}{|c|c|c|c|c|c|}
\hline \multirow{2}{*}{$\vartheta_{\text {in }}=19.9^{\circ} \mathrm{C}$} & \multirow{2}{*}{$\frac{-}{\text { Measured }\left[{ }^{\circ} \mathrm{C}\right]}$} & \multicolumn{2}{|c|}{$\mathbf{h}_{\mathrm{c}}=8.7 \mathrm{~W} /\left(\mathrm{m}^{2} \mathrm{~K}\right)$} & \multicolumn{2}{|c|}{$h_{c}=12 \mathrm{~W} /\left(\mathrm{m}^{2} \mathrm{~K}\right)$} \\
\hline & & Simulated $\left[{ }^{\circ} \mathrm{C}\right]$ & Difference [K] & Simulated $\left[{ }^{\circ} \mathbf{C}\right]$ & Difference [K] \\
\hline$\vartheta_{\text {out }}-\vartheta_{\text {in }}[K]$ & 6.45 & 6.18 & 0.27 & 6.15 & 0.3 \\
\hline A1 & 43.8 & 43.9 & -0.1 & 43.8 & 0.0 \\
\hline A2 & 43.2 & 42.0 & 1.2 & 41.9 & 1.3 \\
\hline A3 & 41.3 & 39.5 & 1.8 & 39.5 & 1.8 \\
\hline A4 & 41.7 & 39.3 & 2.4 & 39.2 & 2.5 \\
\hline F1 & 27.5 & 26.6 & 0.9 & 25.6 & 1.9 \\
\hline $\mathrm{F} 2$ & 25.9 & 25.0 & 0.9 & 24.3 & 1.6 \\
\hline \multirow{2}{*}{$\vartheta_{\text {in }}=40.8^{\circ} \mathrm{C}$} & - & \multicolumn{2}{|c|}{$\mathbf{h}_{\mathrm{c}}=8.7 \mathrm{~W} /\left(\mathrm{m}^{2} \mathrm{~K}\right)$} & \multicolumn{2}{|c|}{$h_{c}=12 \mathrm{~W} /\left(\mathrm{m}^{2} \mathrm{~K}\right)$} \\
\hline & Measured $\left[{ }^{\circ} \mathrm{C}\right]$ & Simulated $\left[{ }^{\circ} \mathrm{C}\right]$ & Difference [K] & Simulated $\left[{ }^{\circ} \mathrm{C}\right]$ & Difference [K] \\
\hline$\vartheta_{\text {out }}-\vartheta_{\text {in }}[K]$ & 5.22 & 5.42 & -0.2 & 5.35 & -0.13 \\
\hline A1 & 60.6 & 61.9 & -1.3 & 61.6 & -1.0 \\
\hline A2 & 60.2 & 60.1 & 0.1 & 60.0 & 0.2 \\
\hline A3 & 58.8 & 57.7 & 1.1 & 57.5 & 1.3 \\
\hline A4 & 58.3 & 56.4 & 1.9 & 56.2 & 2.1 \\
\hline F1 & 29.1 & 29.5 & -0.4 & 27.9 & 1.2 \\
\hline $\mathrm{F} 2$ & 27.8 & 27.6 & 0.2 & 26.3 & 1.5 \\
\hline \multirow{2}{*}{$\vartheta_{\text {in }}=60.3^{\circ} \mathrm{C}$} & - & \multicolumn{2}{|c|}{$h_{c}=8.7 \mathrm{~W} /\left(\mathrm{m}^{2} \mathrm{~K}\right)$} & \multicolumn{2}{|c|}{$h_{c}=12 \mathrm{~W} /\left(\mathrm{m}^{2} \mathrm{~K}\right)$} \\
\hline & Measured $\left[{ }^{\circ} \mathrm{C}\right]$ & Simulated $\left[{ }^{\circ} \mathrm{C}\right]$ & Difference [K] & Simulated $\left[{ }^{\circ} \mathbf{C}\right]$ & Difference [K] \\
\hline $9_{\text {out }}-9_{\text {in }}[\mathrm{K}]$ & 4.26 & 4.61 & -0.35 & 4.52 & -0.26 \\
\hline A1 & 75.3 & 78.3 & -3.0 & 78.0 & -2.7 \\
\hline A2 & 74.7 & 77.1 & -2.4 & 76.6 & -1.9 \\
\hline A3 & 73.7 & 74.8 & -1.1 & 74.7 & -1.0 \\
\hline A4 & 71.9 & 72.2 & -0.3 & 71.8 & 0.1 \\
\hline F1 & 30.9 & 32.6 & -1.7 & 30.2 & 0.7 \\
\hline $\mathrm{F} 2$ & 29.9 & 30.5 & -0.6 & 28.4 & 1.5 \\
\hline \multirow{2}{*}{$\vartheta_{\text {in }}=79.0^{\circ} \mathrm{C}$} & - & \multicolumn{2}{|c|}{$h_{c}=8.7 \mathrm{~W} /\left(\mathrm{m}^{2} \mathrm{~K}\right)$} & \multicolumn{2}{|c|}{$h_{c}=12 \mathrm{~W} /\left(\mathrm{m}^{2} \mathrm{~K}\right)$} \\
\hline & Measured $\left[{ }^{\circ} \mathrm{C}\right]$ & Simulated $\left[{ }^{\circ} \mathrm{C}\right]$ & Difference [K] & Simulated $\left[{ }^{\circ} \mathrm{C}\right]$ & Difference [K] \\
\hline$\vartheta_{\text {out }}-\vartheta_{\text {in }}[K]$ & 3.14 & 3.79 & -0.65 & 3.64 & -0.5 \\
\hline A1 & 90.9 & 94.6 & -3.7 & 93.9 & -3.0 \\
\hline A2 & 90.5 & 93.1 & -2.6 & $\begin{array}{l}92.7 \\
\end{array}$ & -2.2 \\
\hline A3 & 89.7 & 91.4 & -1.7 & 90.9 & -1.2 \\
\hline A4 & 87.4 & 87.5 & -0.1 & 87.2 & 0.2 \\
\hline F1 & 32.5 & 35.6 & -3.1 & 32.5 & 0.0 \\
\hline F2 & 31.8 & 33.2 & -1.4 & 30.5 & 1.3 \\
\hline
\end{tabular}

Fig. 9 illustrates the efficiency curves. Both simulations match $\eta_{0}$ from the outdoor test very well. Because the solar simulator does not match the solar spectrum of the sun to $100 \%$, $\eta_{0}$ measurement from outdoor tests are 


\section{Beate Vetter}

favored. For higher temperature differences, simulations show an increasing deviation compared to experimental performance tests, whereby deviations are smaller for simulations with $\mathrm{h}_{\mathrm{c}}=12 \mathrm{~W} /\left(\mathrm{m}^{2} \mathrm{~K}\right)$.

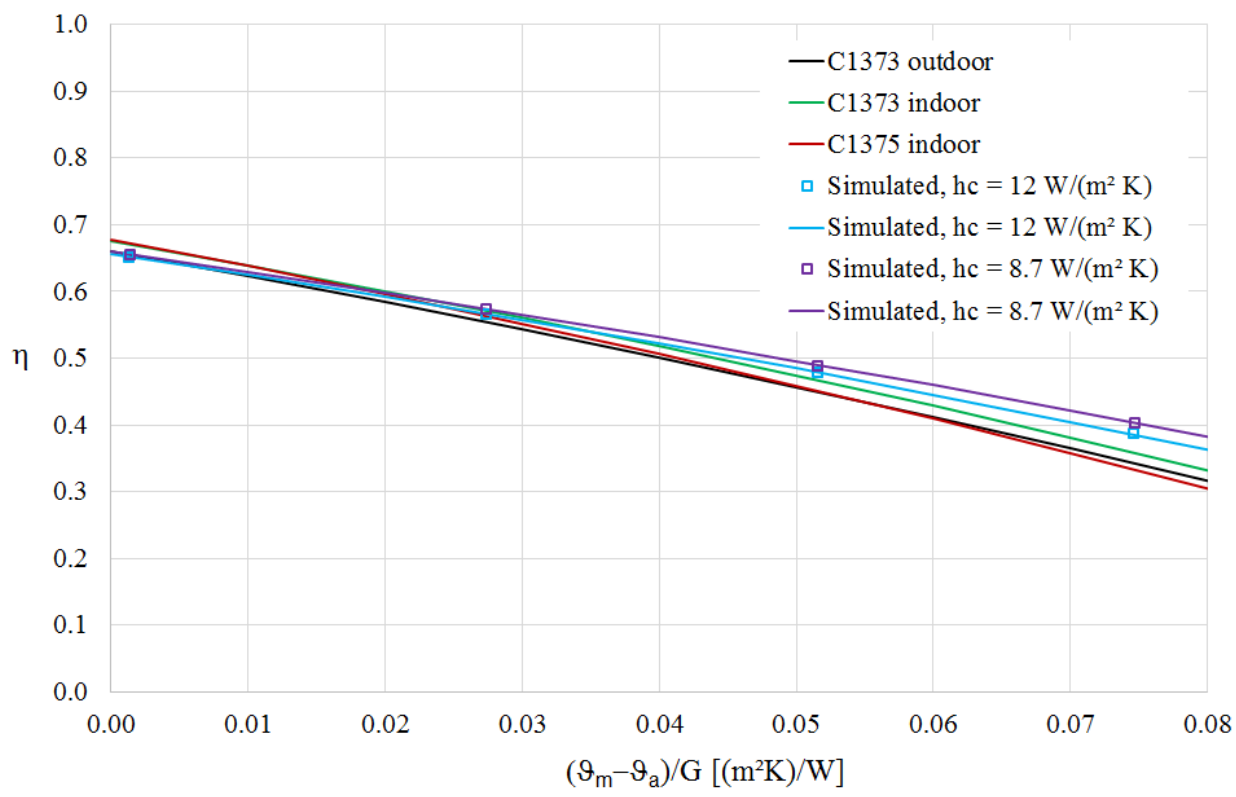

Fig. 9: Efficiency curves, based on experimental data and virtual thermal performance test results (indicated as simulated)

\subsection{Annual collector output calculation}

To compare the different results on the basis of the annual collector output the calculation tool ScenoCalc (Solar Collector Energy Output Calculator) was used. ScenoCalc is used for in the context of Solar Keymark certification. For all annual collector output calculations the incidence angle modifiers of the outdoor measurement of collector C1373 was used.

Tab. 6: Annual collector output for location Würzburg. Comparison between experimental performance test and simulation with $h_{c}=8.7 \mathrm{~W} /\left(\mathrm{m}^{2} \mathbf{K}\right)$

\begin{tabular}{|l|r|r|r|}
\hline 9 $_{\mathbf{m}}{ }^{\circ} \mathbf{C}$ ] & 25 & 50 & 75 \\
\hline $\mathbf{C 1 3 7 3}$ indoor [kWh/a] & 1329 & 825 & 465 \\
\hline Simulation [kWh/a] & 1334 & 894 & 564 \\
\hline Difference [kWh] & -5 & -69 & -99 \\
\hline C1375 indoor [kWh] & 1312 & 782 & 418 \\
\hline Simulation [kWh] & 1334 & 894 & 564 \\
\hline Difference [kWh] & -22 & -112 & -146 \\
\hline
\end{tabular}

Tab. 7: Annual collector output for location Würzburg. Comparison between experimental performance test and simulation with $h_{c}=12 \mathrm{~W} /\left(\mathrm{m}^{2} \mathrm{~K}\right)$

\begin{tabular}{|l|r|r|r|}
\hline $\mathbf{9}_{\mathbf{m}}\left[{ }^{\circ} \mathbf{C}\right]$ & 25 & 50 & 75 \\
\hline $\mathbf{C 1 3 7 3}$ indoor [kWh/a] & 1329 & 825 & 465 \\
\hline Simulation [kWh/a] & 1319 & 866 & 527 \\
\hline Difference [kWh] & 10 & -41 & -62 \\
\hline C1375 indoor [kWh] & 1312 & 782 & 418 \\
\hline Simulation [kWh] & 1319 & 866 & 527 \\
\hline Difference [kWh] & -7 & -84 & -109 \\
\hline
\end{tabular}

Tab. 6 presents the comparison between the annual collector output derived from experimental performance tests and simulations with $h_{c}=8.7 \mathrm{~W} /\left(\mathrm{m}^{2} \mathrm{~K}\right)$ for different mean fluid temperatures $\vartheta_{\mathrm{m}}$. Tab. 7 presents the comparison between the annual collector output derived from experimental performance tests and simulations with $h_{c}=12 \mathrm{~W} /\left(\mathrm{m}^{2} \mathrm{~K}\right)$, also for different mean fluid temperatures $\vartheta_{\mathrm{m}}$. Good agreement between annual collector output, calculated from experimental performance test results and from virtual performance test results, are shown for $\vartheta_{\mathrm{m}}=25^{\circ} \mathrm{C}$, for both simulations. For rising mean fluid temperatures, deviation increases, compare Tab. 7 and Tab. 6. 


\section{Beate Vetter}

\subsection{Influence of optical absorber properties}

In the manufacturer data sheet of the absorber coating, optical properties are given as follows:

$\alpha_{\mathrm{s}}=0.95 \pm 0.01[-]$

$\varepsilon_{100{ }^{\circ} \mathrm{C}}=0.05 \pm 0.02[-]$

To study the influence of the optical absorber properties, the tolerances given by the manufacturer data sheet were implemented in the CFD model and simulations for an inlet temperature of $79^{\circ} \mathrm{C}$ were performed. Tab. 8 presents the results. Maximal influence between $\alpha_{\text {sol }}=0.95 ; \varepsilon_{100}{ }^{\circ} \mathrm{C}=0.05$ and $\alpha_{\text {sol }}=0.94 ; \varepsilon_{100}{ }^{\circ} \mathrm{C}=0.07$ is $0.12 \mathrm{~K}$ for simulations with $h_{c}=8.7 \mathrm{~W} /\left(\mathrm{m}^{2} \mathrm{~K}\right)$, respectively $0.11 \mathrm{~K}$ for simulations with $\mathrm{h}_{\mathrm{c}}=12 \mathrm{~W} /\left(\mathrm{m}^{2} \mathrm{~K}\right)$. Therefore, tolerances do influence the result, but they do not explain the entire deviation between measurement and simulation at increasing mean temperatures.

Tab. 8: Edge case consideration for optical absorber properties at $\vartheta_{\text {in }}=79^{\circ} \mathrm{C}$

\begin{tabular}{|c|c|c|c|c|c|}
\hline \multicolumn{2}{|c|}{$h_{c}=8.7 \mathrm{~W} /\left(\mathrm{m}^{2} \mathrm{~K}\right)$} & \multirow{2}{*}{$\begin{array}{r}\boldsymbol{9}_{\text {out }}-\boldsymbol{9}_{\text {in }}[\mathbf{K}] \\
3.79\end{array}$} & \multicolumn{2}{|c|}{$h_{c}=12 \mathrm{~W} /\left(\mathrm{m}^{2} \mathrm{~K}\right)$} & \multirow{2}{*}{$\frac{\boldsymbol{9}_{\text {out }}-\boldsymbol{9}_{\text {in }}[\mathbf{K} \mathbf{]}}{3.64}$} \\
\hline S1 & $\alpha_{\text {sol }}=0.95 ; \varepsilon_{100{ }^{\circ} \mathrm{C}}=0.05$ & & S5 & $\alpha_{\text {sol }}=0.95 ; \varepsilon_{100{ }^{\circ} \mathrm{C}}=0.05$ & \\
\hline S2 & $\alpha_{\text {sol }}=0.95 ; \varepsilon_{100{ }^{\circ} \mathrm{C}}=0.07$ & 3.72 & S6 & $\alpha_{\text {sol }}=0.95 ; \varepsilon_{100^{\circ} \mathrm{C}}=0.07$ & 3.58 \\
\hline S3 & $\alpha_{\text {sol }}=0.94 ; \varepsilon_{100{ }^{\circ} \mathrm{C}}=0.05$ & 3.73 & S7 & $\alpha_{\text {sol }}=0.94 ; \varepsilon_{100{ }^{\circ} \mathrm{C}}=0.05$ & 3.60 \\
\hline S4 & $\alpha_{\text {sol }}=0.94 ; \varepsilon_{100{ }^{\circ} \mathrm{C}}=0.07$ & 3.67 & S8 & $\alpha_{\text {sol }}=0.94 ; \varepsilon_{100{ }^{\circ} \mathrm{C}}=0.07$ & 3.53 \\
\hline $\mathrm{S} 1-\mathrm{S} 4$ & Maximal deviation & 0.12 & S5 - S8 & Maximal deviation & 0.11 \\
\hline
\end{tabular}

\subsection{Thermal bridges}

CAD buildup contains some simplifications. At the absorber for example, is a temperature sensor socket mounted, which was not reproduced in CAD buildup. Furthermore, the exact position of the absorber in the frame while testing cannot be exactly determined. Due to extension because of temperature, absorber plate can corrugate and therefore contact a fillet which is part of the frame. Former simulations without the fillet have already demonstrated an influence on thermal performance even though no direct contact between absorber and frame persists in the presented simulations.

\subsection{Convection in the air gap between absorber and transparent cover}

Another factor that may falsify the simulation is the convection in the air gap between absorber and glass plate. However, a detailed analyses about the air flow in the collector is not performed up to now.

\section{Conclusion and outlook}

An effective simulation strategy was developed for a virtual, CFD based collector test. It was conducted for a serial product flat plate collector. Validation has been executed by comparison of component temperatures, collector efficiency and annual collector output determined based on real physical collector tests and on simulation data. Simulated component temperatures correspond well to measured values. The peak collector efficiency from the virtual thermal performance test fits the result from experimental thermal performance test very well. With increasing mean fluid temperature, the difference between measured and simulated outlet temperature rises. Possible reasons are identified, but need to be analyzed further. The next step is to analyze the air flow in the collector and therefore the convection in the air gap between absorber and glass plate. The authors are confident that appropriate modifications of the CFD simulation model will result in an even better match between the results derived from CFD based virtual collector tests and real physical tests, especially for high mean collector fluid temperatures. 


\section{Beate Vetter}

10.

\section{Acknowledgments}

The activities described in this contribution are being supported by the German Federal Ministry for Economic Affairs and Energy (BMWi) based on a decision of the German Bundestag by Projektträger Jülich (PtJ) under grant numbers 0325556 A, Project "VirtColl+ - Entwicklung eines neuartigen, auf CFD Simulationen und virtuellen Kollektorprüfungen basierenden Entwicklungs- und Optimierungswerkzeug für Flachkollektoren / development and optimization tool for flat plate collectors based on CFD simulations and virtual collector performance tests”. The authors gratefully acknowledge this support and carry the full responsibility for the content of this contribution.

11.

\section{References}

DIN EN ISO 9806:2014-06, Solar energy - Solar thermal collectors - Test methods.

Francey, J.L.A., Paraioannou, J.: Wind-related heat losses of a flat-plate collector. Solar Energy, Bd. 35, Nr. 1, S. 15-19, DOI 10.1016/0038-092X(85)90032-5, 1985.

Incropera, F. P., DeWitt, D. P.: Fundamentals of heat and mass transfer. 2. Aufl., XXIII, 802 S, ISBN 0-47188550-9, Wiley: New York NY u.a., 1985.

Jürges W. Gesundheitsingenieur, Reihe 1, Beiheft 19, 1924.

Krischer, O., Kast, W.: Die wissenschaftlichen Grundlagen der Trocknungstechnik. Trocknungstechnik, Band 1 ED. 3 REPRINT, XXI, 494 S ;, ISBN 3-540-08280-8, Springer: Berlin [etc.], op. 1992.

Lunde P. J.: Solar Thermal Engineering, Space Heating and Hot Watersystems. John Wiley \& Sons Ltd: New York (N.Y.), 1980.

Parmelee, G. V., Huebscher, R. G.: Forced convection heat transfer from flat surfaces, Part 1: smooth surfaces. American Society of Heating and Ventilating Engineers. Research Bulletin, vol. 53, no. 3, November, 1947, 47 S., American Society of Heating and Ventilating Engineers: New York (N.Y.), 1948.

Rowley, F.P., Algren, A.B. Blackshaw, J.L., 1930. Effects of air velocity on surface coefficients. ASHRAE 36, 123-136

Sartori, E.: Convection coefficient equations for forced air flow over flat surfaces. Solar Energy, Bd. 80, Nr. 9, S. 1063-1071, DOI 10.1016/j.solener.2005.11.001, 2006.

Test F.L., Lessmann R.C., Johary A.: Heat Transfer During Wind Flow over Rectangular Bodies in the Natural Environment. ASME J. Heat Transfer.

http://asmedigitalcollection.asme.org/solr/searchresults.aspx?q=heat\%20transfer\%20during\%20wind\%20flow\% 20over\%20rectangular\%20bodies\%20in\%20the\%20natural\%20environment\&allJournals=1\&f_ContentType=J ournals\&SearchSourceType $=3$

VDI-Wärmeatlas. VDI-Buch, 11. Aufl., 1650 Seiten, ISBN 978-3-642-19982-0, Springer Vieweg: Berlin, 2013.

Vetter B., Kofler P., Fischer S., Drück H.: Bestimmung der effektiven Wärmeleitfähigkeit von Wärmedämmmaterialien für Sonnenkollektoren, Tagungsband zum 25. Symposium Thermische Solarenergie, Bad Staffelstein, Kloster Banz, Deutschland, ISBN 978-3-3943891-51-5

Watmuff, J.H. and W.W.S. Proctor D.: Solar and wind conducted external coefficients for solar collectors. 1977. https://www.researchgate.net/publication/234355019_Solar_and_wind_induced_external_coefficients_-

_Solar_collectors 
System Simulation (2nd SIGES Conference on the Simulation of Building-Integrated Energy Systems) 


\title{
An Improved Model For Phase Change Material (PCM) Thermal Storage Tanks
}

\author{
Manuel Andrés Chicote ${ }^{1}$, Roberto Sanz Jimeno ${ }^{1}$ \\ ${ }^{1}$ CARTIF Technology Center, Energy Division. Boecillo, Valladolid (Spain)
}

\begin{abstract}
This work, performed in the context of the LowUP H2020 European project, presents a modelling approach for a PCM thermal storage tank. This model will allow estimating the potential of Latent Thermal Energy Storage technologies to support efficiency improvements in novel integrated heating and cooling solutions. Here, an existing modelling approach from literature is improved focusing on the mathematical representation of the PCM and its associated non-linear behavior. Main modelling assumptions are based on an energy balance for the PCM (assuming homogeneous temperature), the by-pass factor accounting for heat transfer inefficiencies and a simple representation of the phase change process through reasoned parametrization of the $\mathrm{h}-\mathrm{T}$ curve. Finally, the new proposed model is implemented into a custom TRNSYS Type and validated through satisfactory comparison between simulated and experimental values for several literature test cases.
\end{abstract}

Keywords: Thermal Energy Storage, Phase Change Materials (PCM), mathematical model, TRNSYS.

\section{Background}

Phase Change Materials (PCM) for heating and cooling applications in buildings have experienced an important growth in recent years. Particularly, numerous works investigating thermal energy storage solutions for low and medium temperature applications can be found in literature (da Cunha and Eames 2016). Scientific efforts have been recently centered on development of mathematical models to be applied in simulation analyses (Verma and Singal 2008), while several studies focused on experimental research related to this kind of systems, which constitute interesting data sources for validation of mathematical models (D'Avignon and Kummert 2016, Torregosa-Jaime et al. 2013). Special attention should be paid in this sense to the modelling research conducted by Belmonte et al. (2016). They presented a simple model for Thermal Energy Storages (TES) containing PCM. It is based on the traditional bypass factor method to obtain a simple representation of generic PCM storages that can be particularly suitable for application during preliminary design stages.

The purpose of this work is to develop and present an improved model for PCM thermal storage tanks based on a modified approach of the model from Belmonte et al. (2016). The proposed model will be validated with experimental data from literature and then implemented in a TRNSYS (Klein et al. 2009) .dll file to be available for use in future extended energy analyses.

\section{Modelling approach}

The simplified approach from literature is based on the application of an energy balance to a PCM-based TES system with homogeneous temperature taking into account the energy transferred from/to the heat transfer fluid (HTF) and the storage heat losses. The method considers the first term in any PCM-based storage system as though a portion of the HTF ideally transfers its entire heat content to the PCM, whereas the remainder by-passes the TES system unchanged. This bypass factor stream represents the heat transfer inefficiencies between the HTF and the PCM and through the PCM itself, which will occur during a real process in a TES system. This enables simple representation of the heat transfer phenomena using only a few parameters, which is an advantage for manufacturers and designers as well as for implementing the model into simulation or energy analysis tools. Further details can be found in the original paper, and are omitted here for the sake of simplicity.

The aforementioned main concept from the original model from Belmonte et al. (2016) also constitutes the basis of the approach here proposed. However, previous results from the original model and its prediction capabilities were analysed in more depth leading to the identification of potential improvements. In particular, this work addresses the following aspect: the original approach assumed that the PCM of the storage tank melts and freezes at a 
constant temperature, which is not strictly true for most of the existing PCMs being used in building conditioning applications. This leads to most of the observed differences between simulated and experimental data for Belmonte's work.

The new PCM storage modelling approach corrects this limitation though a more detailed representation of the PCM thermodynamic behaviour (enthalpy-temperature curve or h-T curve, see Fig.1), particularly in the phasechange temperature range.

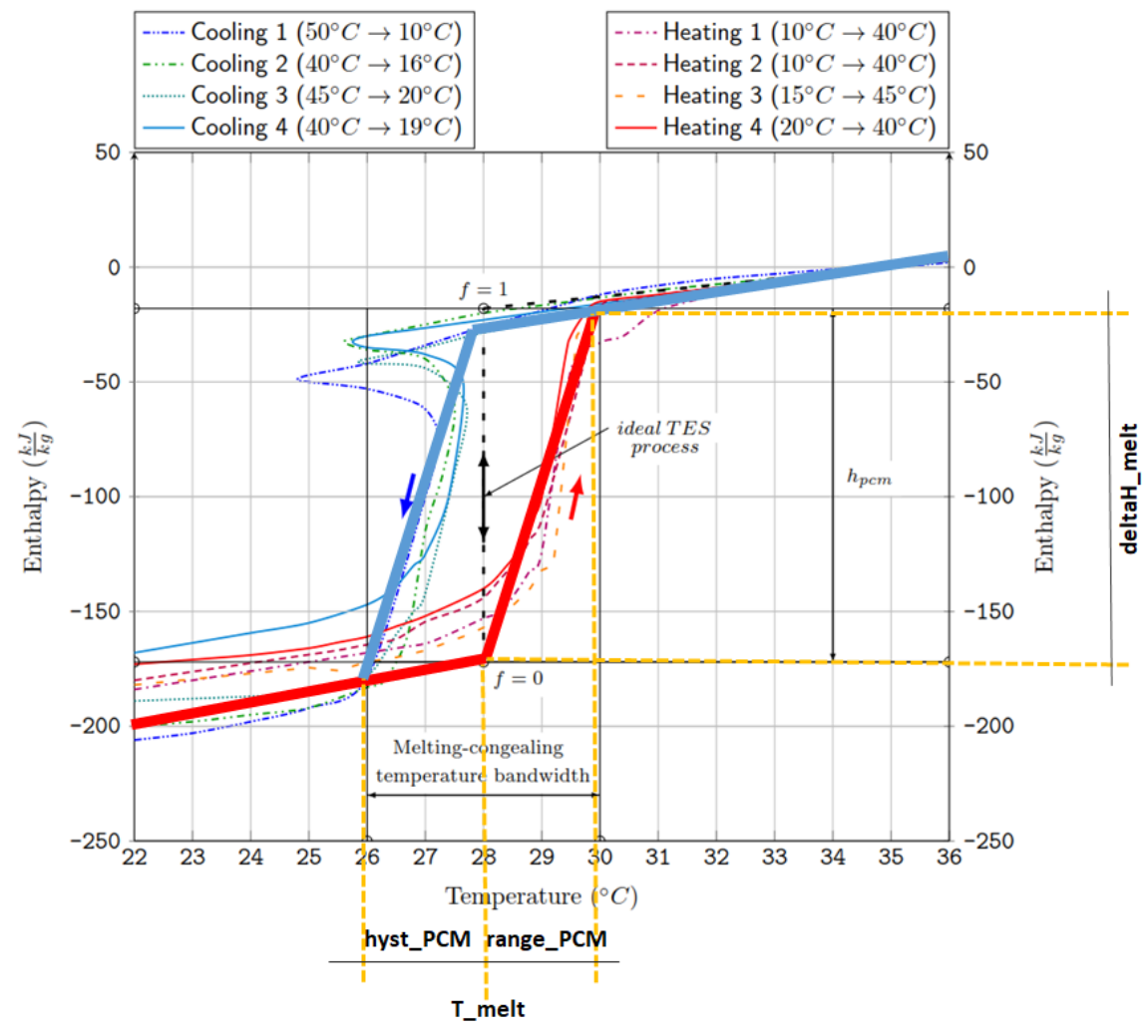

Fig.1: h-T behaviour of PCM and definition of related model parameters. Modified from Belmonte et al. (2016)

The actual behavior of PCMs often presents important deviations from the the simplified original assumption of constant melting temperature. These can be associated to the following three main different effects, which are also shown in the example h-T curves in Fig.1 representing real loading and unloading cycles of a given PCM:

- Variable temperature along the phase change process (temperature range)

- Different h-T curves (within the phase change range) for cooling and heating evolutions (i.e. hysteresis effects)

- Subcooling effects that makes the PCM requiring to achieve colder temperatures than the expected melting temperature range in order to start solidification (therefore, once the freezing process starts, the temperature increases slightly).

Depending on the level of detail applied to the modelling of the PCM thermo-physical behaviour, different approximations to represent the real $\mathrm{h}-\mathrm{T}$ curve could be used. This work proposes a PCM model based on the definition of 3 parameters to specify the h-T characteristic of the material, which allows accounting for most of common h-T behaviours with reasonable accuracy:

- The melting temperature (T_melt): it is here defined as the temperature at which the PCM starts melting during a heating cycle starting from completely solid state.

- The melting range (range_PCM): it is defined as the temperature range comprised between the melting temperature and that thermal level at which all the material in solid state disappears during a heating cycle starting from completely solid state (i.e. the temperature that indicates the completeness of the solid-to-liquid transformation)

- The melting hysteresis (hyst_PCM): it is defined as the temperature difference between the two limiting states at which the material is completely in solid phase during a heating cycle (starting from completely solid material) and a cooling cycle (starting from completely liquid material). In both cases, other states obviously 
correspond to completely solid material, however the referred two limiting states consider that any differential temperature increase would imply the co-existence of solid and liquid phases.

In addition, it should be noted that subcooling effects are neglected by this model. A clearer graphical definition of these parameters is also depicted in Fig.1.

Consequently, the main characteristics of the improved model are as follows:

- PCM storage volume treated as a thermal storage with homogeneous temperature.

- Improved parametrization of the enthalpy-temperature (h-T) behaviour of the Phase Change Material based on 3 parameters: melting temperature, melting range and melting hysteresis.

- Energy content of the PCM storage calculated through direct application of energy balance and according to the bypass concept to account for heat transfer inefficiencies.

The corresponding equations were programmed in MATLAB environment as a proof of concept and further implemented in a new dedicated TRNSYS Type.

Table 1 collects all the model inputs, outputs and internal variables required for the application of the proposed PCM storage model.

Table 1. Model inputs, outputs and internal parameters for the PCM storage model

\begin{tabular}{|c|c|}
\hline \multicolumn{2}{|l|}{ Model Inputs } \\
\hline T_ini_TES & Initial temperature of the PCM storage \\
\hline m_s & Source massflow rate \\
\hline m_l & Load massflow rate \\
\hline T_si & Inlet temprature of the source flow \\
\hline T_li & Inlet temperature of the load flow \\
\hline T_room & Room temperature (temperature of the PCM tank surroundings) \\
\hline V_PCM & Volume capacity of the PCM storage tank \\
\hline A_TES & Tank surface area in contact with surroundings temperature \\
\hline U_loss & Total tank heat loss coefficient \\
\hline phi & Fraction of total TES volume filled with PCM \\
\hline FB & Bypass factor \\
\hline \multicolumn{2}{|l|}{ Model Outputs } \\
\hline T_PCM & Temperature of the PCM storage \\
\hline E_PCM & Energy level of the PCM storage \\
\hline Q_loss & Heat transfer losses through PCM tank surface \\
\hline T_so & Outlet source temperature \\
\hline T_lo & Outlet load temperatue \\
\hline Q_S & Heat transfer to the source flow \\
\hline Q_1 & Heat transfer to the load flow \\
\hline f & Melted fraction of PCM ( 0 = completely solid; 1 = completely liquid $)$ \\
\hline \multicolumn{2}{|c|}{ Internal Parameters } \\
\hline U_loss & $\begin{array}{l}\text { Overall heat transfer coefficient from the PCM layer to the ambient temperature (including } \\
\text { insulation and convective/radiant external thermal resistance) }\end{array}$ \\
\hline Rho_PCM_liq & Density of the PCM liquid phase \\
\hline Rho_PCM_sol & Density of the PCM solid phase \\
\hline Cp_PCM_liq & Specific heat capacity of the PCM liquid phase \\
\hline Cp_PCM_sol & Specific heat capacity of the PCM solid phase \\
\hline deltaH_melt & Specific enthalpy \\
\hline Range_PCM & Characteristic temperature range for the phase change process \\
\hline Hyst_PCM & Characteristic temperature hysteresis for the phase change process \\
\hline
\end{tabular}




\section{Results and discussion}

The proposed model was validated based on 6 test cases extracted from literature that accounted for different loading and unloading conditions as well as two different PCM materials (organic/inorganic) with different thermal properties. This constitutes a considerably wide validation range that supports model results and makes the model very promising for future energy analyses.

Fig. 2 - Fig. 7 show the validation results for each one of the 6 test cases consisting of the comparison of different model output variables and corresponding experimental values. Experimental data can be found in literature (Belmonte et al. 2016) in graphical format. Numerical values enabling computation of the proposed model were extracted using an open application for plot digitalization (WebPlotDigitalizer, 2018).

In order to ease the comprehension and interpretation of these results, the following legend should be taken into account:

- Figures A (upper left corner): Temperatures in ${ }^{\circ} \mathrm{C}$ : Inlet fluid temperature (red), simulated outlet fluid temperature (green), real outlet fluid temperature (blue), ideal TES temperature (black)

- Figures B (upper right corner): Cooling power in $\mathrm{kW}$ : simulated value (green), real value (black)

- Figures C (lower left corner): Total cooling energy delivered along the test in kWh: simulated value (green), real value (black)

- Figures D (lower right corner): Percentage error in cooling energy delivered (blue)

It can be observed that, although outlet fluid temperature values do not match perfectly, the simulated values are able to capture quite satisfactorily the effect of the variable-temperature melting process revealed by the experimental measurements. As derived from Belmonte et al. (2016), this was not the case of the original approach, where the constant melting temperature showed clear deviations from real values.

In terms of outlet fluid temperature, the largest deviations are related to unloading tests (see Fig.4, Fig.5) probably due to the effect of subcooling phenomenon as well as of the non-linearity of the real $\mathrm{h}$-T curves. These errors are still considered as acceptable, although they allow identifying potential aspects to focus on within future research and model improvements.

In addition, it can be stated that deviations in cooling power values are in line with those referred in the temperature analysis, and simulated cooling charge and discharge profiles are represented satisfactorily by the model.

Finally, in terms of cumulated energy transferred to the TES system, the aforementioned deviations are even reduced when computed along a relevant period of time (in this case 12-14h). Cooling energy charged or discharged during the tests is calculated by the model with a very narrow deviation from real measurements. Evaluating the phase change process, percentage deviations on the delivered energy are in any case lower than $10 \%$. 
M. Andrés Chicote et. al. / EuroSun 2018 / ISES Conference Proceedings (2018)
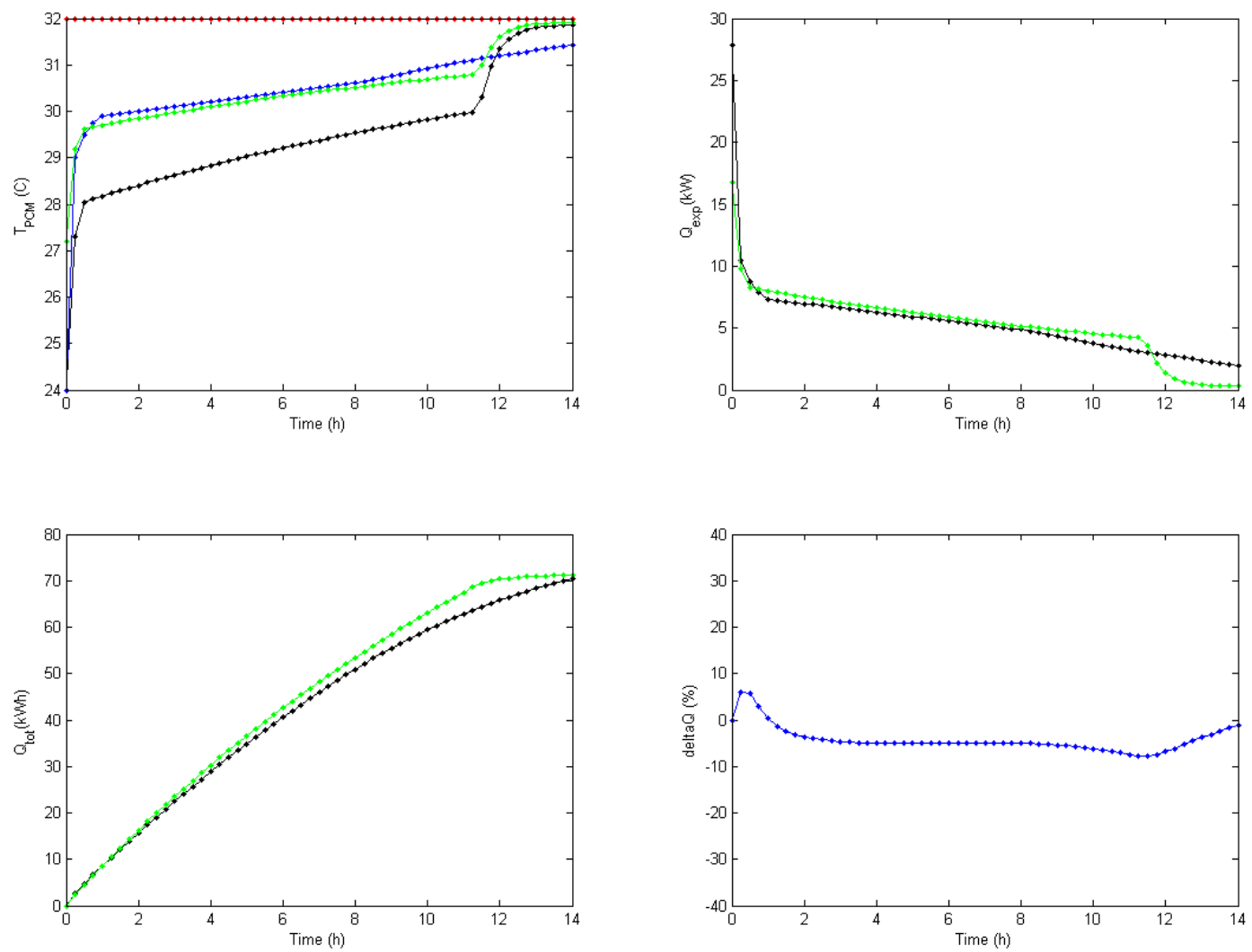

Fig.2: Comparison measured vs. simulated for the improved model validation: Inorganic PCM $/$ loading test $/$ initial temperature $=24$ $\mathrm{C} /$ setpoint temperature $=32 \mathrm{C}$
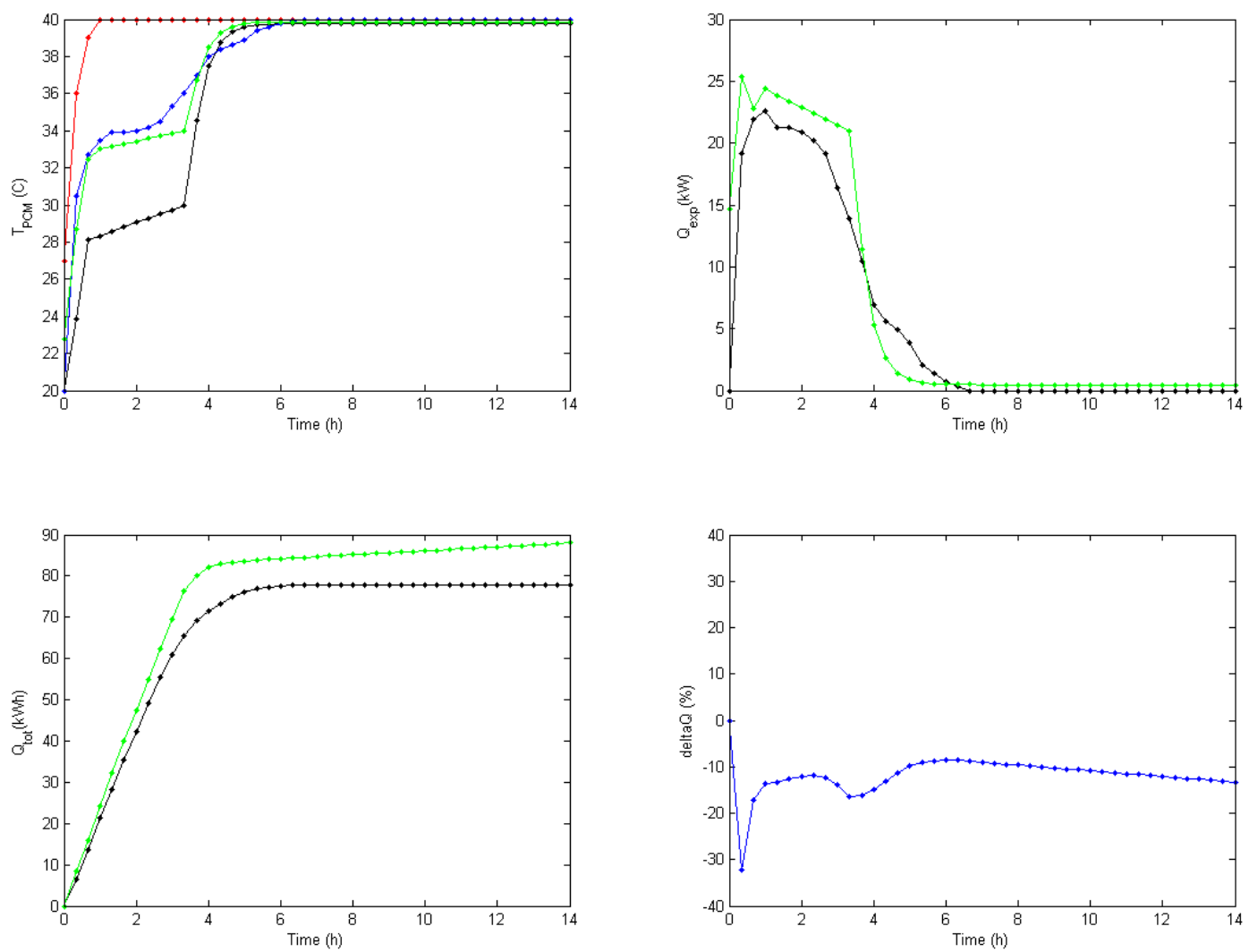

Fig.3: Comparison measured vs. simulated for the improved model validation: Inorganic PCM $/$ loading test $/$ initial temperature $=20$ $\mathrm{C} /$ setpoint temperature $=\mathbf{4 0} \mathrm{C}$ 
M. Andrés Chicote et. al. / EuroSun 2018 / ISES Conference Proceedings (2018)
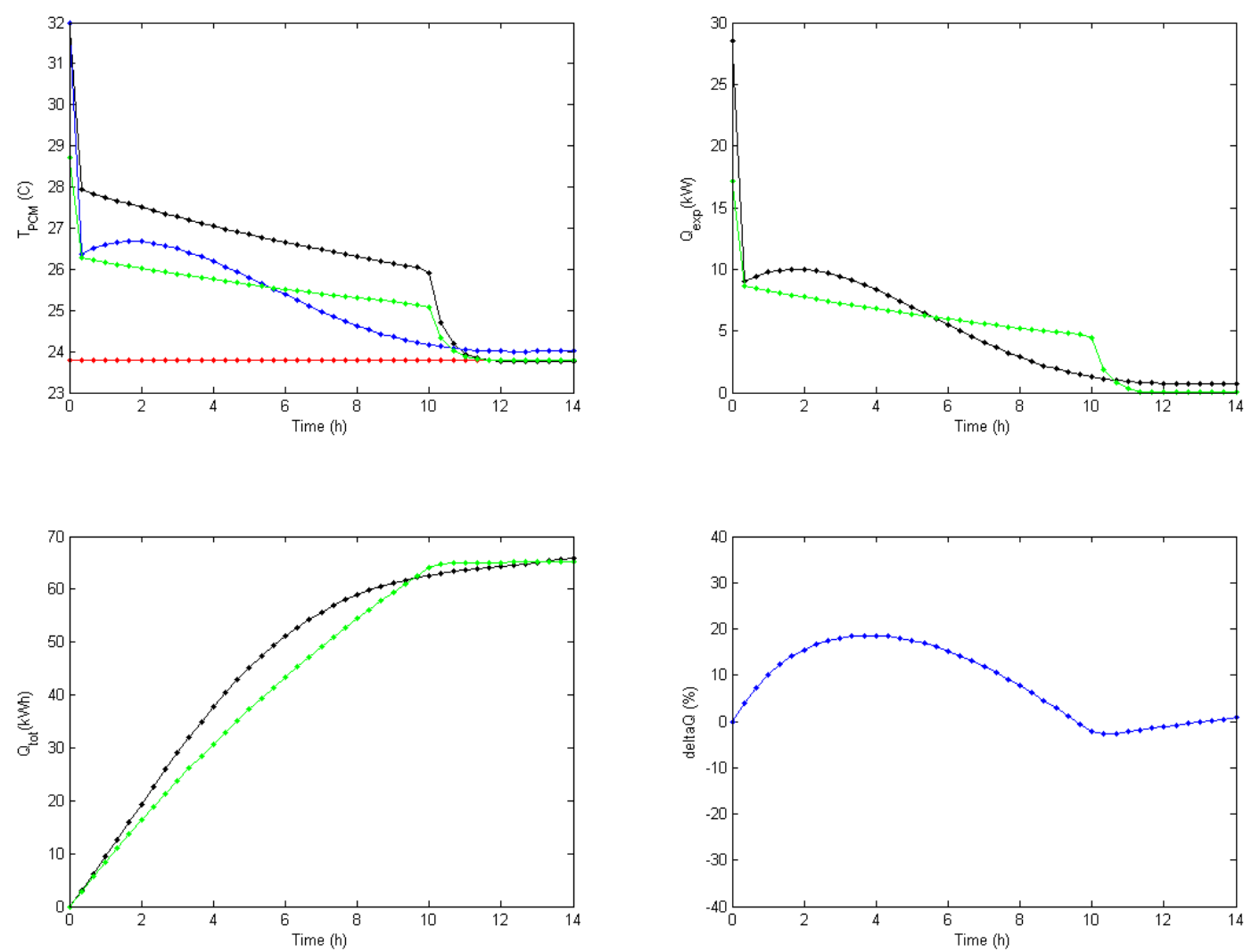

Fig.4: Comparison measured vs. simulated for the improved model validation: Inorganic PCM $/$ unloading test $/$ initial temperature = $32 \mathrm{C} /$ setpoint temperature $=24 \mathrm{C}$
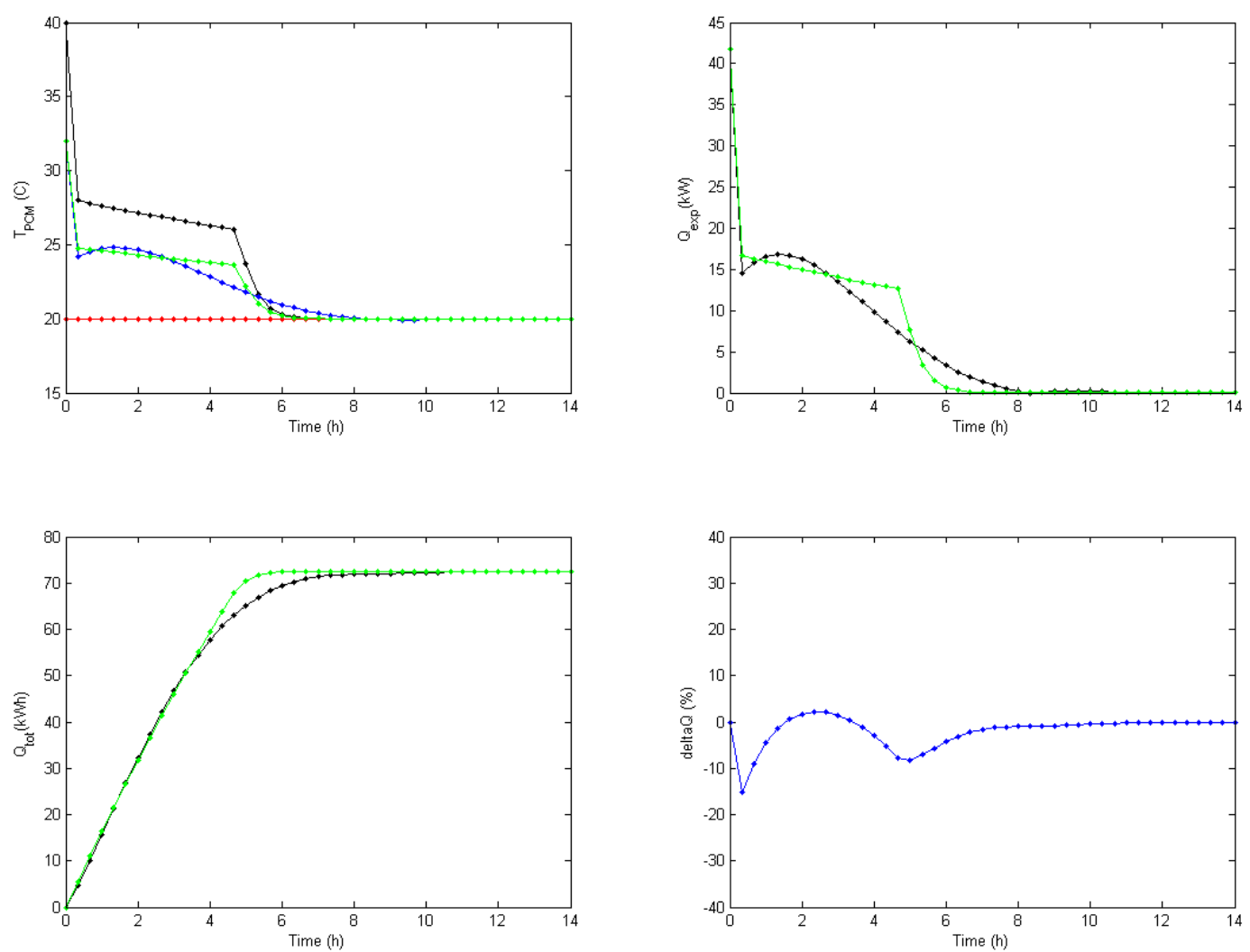

Fig.5: Comparison measured vs. simulated for the improved model validation: Inorganic PCM $/$ unloading test $/$ initial temperature $=$ $40 \mathrm{C} /$ setpoint temperature $=20 \mathrm{C}$ 

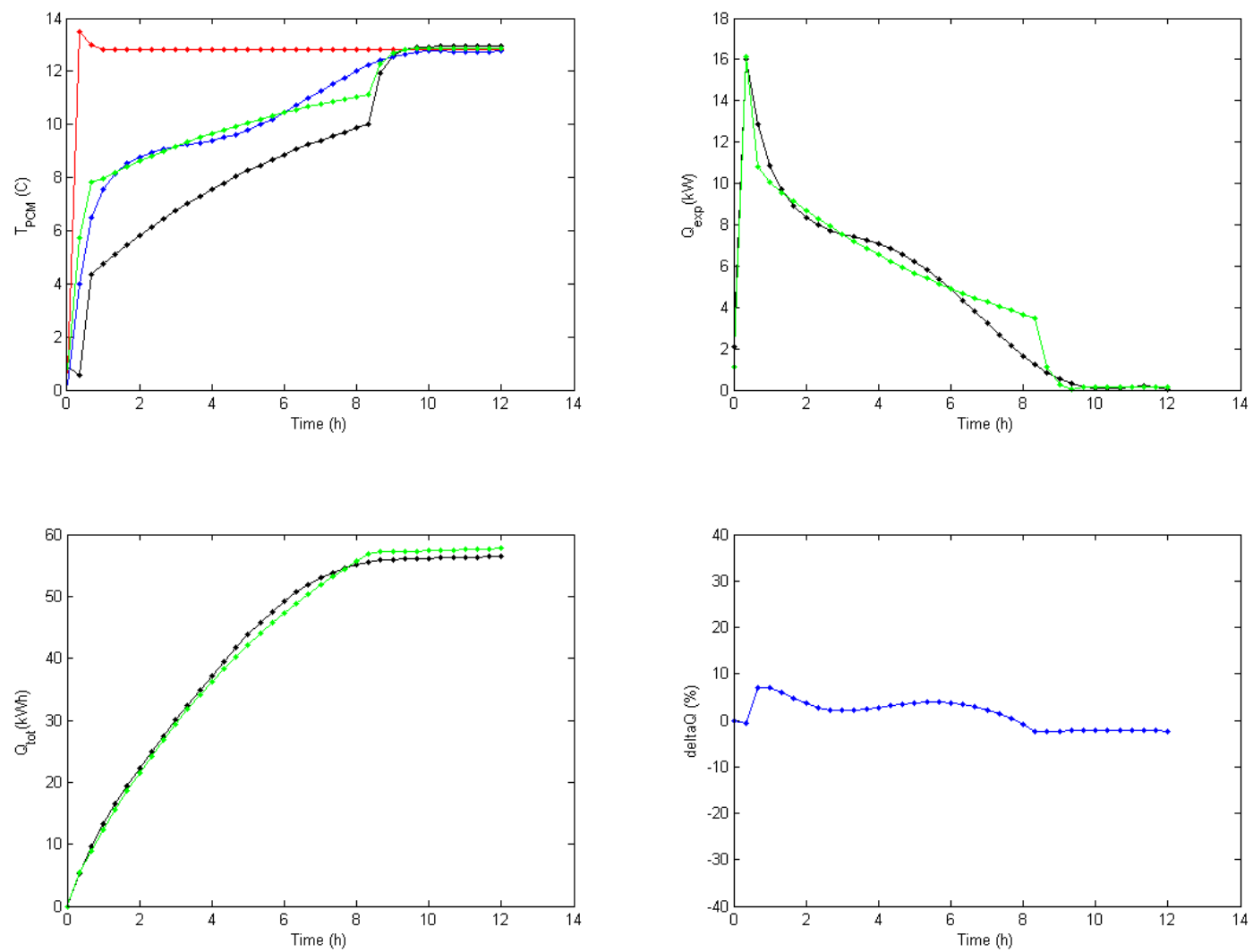

Fig.6: Comparison measured vs. simulated for the improved model validation: Organic PCM $/$ loading test $/$ initial temperature $=0.9$ $\mathrm{C} /$ setpoint temperature $=13 \mathrm{C}$
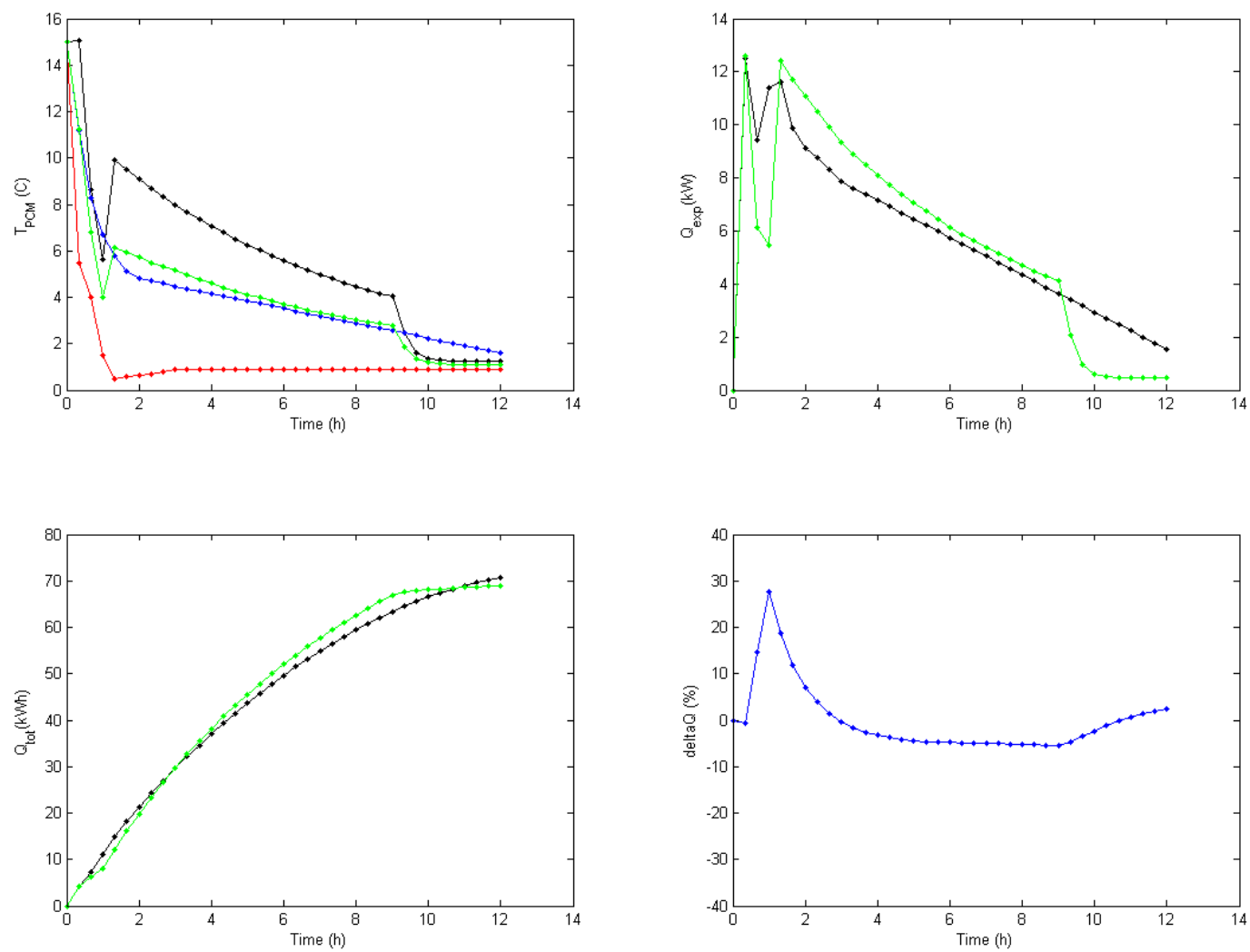

Fig.7: Comparison measured vs. simulated for the improved model validation: Organic PCM $/$ unloading test $/$ initial temperature $=$ $15 \mathrm{C} /$ setpoint temperature $=2 \mathrm{C}$

\section{Conclusion}

Comparison between experimental values and simulation results derived from the proposed PCM storage 
modelling approach proves highly satisfactory adjustment, being able to adequately capture the outlet fluid temperature profiles and leading to estimation errors lower than $10 \%$ in the cumulated energy transferred from/to the tank during the phase change process. Particularly, the improved representation of the PCM h-T curve reveals better behaviour than the original model presented in literature, while it does not add relevant complexity to the whole concept. This definition is only based on three very simple parameters that can be easily obtained from manufacturer PCM characterization, but provides noticeable improvements in outlet temperature and heat transfer estimations. The model has been implemented in MATLAB for validation, as well as embedded in a custom TRNSYS Type, so that it can be used in dynamic simulations to support design and analysis of sustainable energy concepts integrating PCM storage systems.

\section{Acknowledgements}

This work has been developed within the LowUP ('Low valued energy sources Upgrading for buildings and industry uses') project, which has received funding from the EU's Horizon 2020 Research and Innovation Programme under Grant Agreement n ${ }^{\circ} 723930$.

\section{References}

Belmonte, J.F., Eguía, P., Molina, A.E., Almendros-Ibáñez, J.A., Salgado, R. 2016. A simplified method for modelling the thermal performance of storage tanks containing PCMs. Applied Thermal Engineering, 95, 394-410.

da Cunha, J. P., Eames, P. (2016). Thermal energy storage for low and medium temperature applications using phase change materials-a review. Applied Energy, 177, 227-238

D'Avignon, K., \& Kummert, M. (2016). Experimental assessment of a phase change material storage tank. Applied Thermal Engineering, 99, 880-891.

Torregrosa-Jaime, B., López-Navarro, A., Corberán, J. M., Esteban-Matías, J. C., Klinkner, L., \& Payá, J. (2013). Experimental analysis of a paraffin-based cold storage tank. International Journal of Refrigeration, 36(6), 16321640.

Klein, S. A., Beckman, W. A., Mitchell, J. W., Duffie, J. A., Duffie, N. A., Freeman, T. L., Kummer, J. P. (2009). TRNSYS 17. A Transient System Simulation Program.

Verma, P., Singal, S. K. (2008). Review of mathematical modelling on latent heat thermal energy storage systems using phase-change material. Renewable and Sustainable Energy Reviews, 12(4), 999-1031.

WebPlotDigitilizer (2018) [web] https://apps.automeris.io/wpd/ Last access: 2018.09.06 


\title{
Model Predictive Control for Building Automation
}

\author{
Peter Bolt ${ }^{1}$, Christian Jaeger ${ }^{1}$, Volker Ziebart ${ }^{1}$, Remo Ritzmann ${ }^{2}$, \\ Olaf Meier ${ }^{2}$, Rudolf Marcel Füchslin ${ }^{1}$ \\ 1 ZHAW School of Engineering, Zurich University of Applied Science, 8401 Winterthur, Switzerland \\ 2 Rino Electronics AG, 8416 Flaach, Switzerland
}

\begin{abstract}
We propose a building HVAC system, integrating local energy production and storage, together with a model based controller. The heating system integrates several local heat production and storage devices and multiple fluid circuits at different temperatures to minimize entropy production through mixing. The controller uses a model of the system and predictive knowledge of demand and weather information to minimize electrical energy import, while maintaining thermal comfort by solving mixed integer optimization problems online. Time-varying and unknown system parameters are estimated and adapted online, using an unscented Kalman filter. The adaptation greatly reduces modeling effort and maintenance cost. The proposed setup is tested in a co-simulation, using a physical (modelica-) model of the building and energy system as well as realistic weather and demand data. Our system delivers nearly seven times more energy in the form of heat, than it needs to import (electrical) energy from external sources.
\end{abstract}

Keywords: PVT, MPC, Unscented Kalman Filter, Modelica.

\section{Introduction}

A HVAC system consists of the physical heating system and - equally important - an optimal control policy. The heating system proposed here integrates several local heat production and storage devices, operating on different time scales, including an ice storage. We use three separate fluid circuits at different temperatures to minimize the entropy arising from mixing temperature levels, and heat pumps to lift heat from one temperature level to another. For the control task, we use the framework of model predictive control (MPC). MPC offers a systematic framework to minimize the electrical import of energy while meeting heat demand. Its usage in building automation has been studied by e.g. (Fux, 2013), (Wimmer, 2004), (Bianchi, 2006), mostly focusing on the task of efficient generation of heat as well as (Sturzenegger, 2014), focusing on the consumer side i.e. reducing heat consumption, while maintaining comfort.

The rising share of electric power that comes from renewable and distributed energy sources fluctuates in a less predictable way, than energy from a "classical" power plant. Multiple demand response programs have been developed and implemented by grid operators during the past years (Ashouri et al., 2015). MPC is well suited to shift the load from a local energy management system towards low-tariff periods, due to the capability to include electrical cost and weather forecasts.

MPC requires a thermodynamic model of the heating system. The amount of work for tuning such a model can be prohibitive (Serale et al., 2018) to the application of MPC in practice. We integrate a framework for on-line estimation of states (Tab. 2) and unknown or time varying parameters (Tab. 4) of the energy supply model, based on an Unscented Kalman Filter (UKF), (Julier et al., 1995), leading to the Parameter-Adaptive Energy Supply Model. Adaptive MPC schemes for building control in which both the unknown parameters and unmeasured states are estimated using UKF or Extended Kalman Filters (EKF), (Peter S. Maybeck, 1979) and (Peter S. Maybeck, 1982), were investigated in (Fux, 2013), (Maasoumy et al., 2014) and (Radecki and Hencey, 2015). The two latter compared EKF and UKF and both concluded, that UKF is superior. A particularly beneficial feature of UKF is the fact that it can handle a nonlinear model, while the model must be linearized for EKF. Detailed investigations of UKF can be found in (Haykin, 2001).

The optimization problem itself is a mixed integer linear optimization problem (MILP), which must be solved once 
per time-step (cf. sec. 3.1). In our case we must handle a MILP with 36 integer and 112 continuous decision variables.

\section{The HVAC system}

The investigated system, integrates a small-scale, grid-connected photovoltaic-thermal collector (PV/T), two heat pumps (HP) charging two thermal storages and supplying energy for surface heating (low temperature), radiator heating (high temperature) and Domestic Hot Water (DHW). The consumers are two single family houses with a heating demand of $\sim 45 \mathrm{kWh} /\left(\mathrm{m}^{2}\right.$ a) and $\sim 100 \mathrm{kWh} /\left(\mathrm{m}^{2}\right.$ a) respectively, denoted SFH45 and SFH100. Fig. 1 shows a simplified schematic of the installation which integrates

- $\quad$ storage devices: ice storage (very long time constant, high capacity, low power, low temperature level) earth tubes, domestic hot water storage, room heating storage (short time constant, low capacity, high power, high temperature)

- local energy production: photovoltaic thermal hybrid (PV/T) collector

- $\quad$ fluid circuits operating at different temperatures levels with heat pumps to lift heat between temperature levels

Unlike geothermal probes, which could also be integrated into the system, the ice storage system does not require planning permission. It provides a reliable, economic and environmentally compatible heat supply to buildings of almost any size, from single-family homes to large residential or commercial buildings. The ice storage is also used for natural cooling in the summer months.

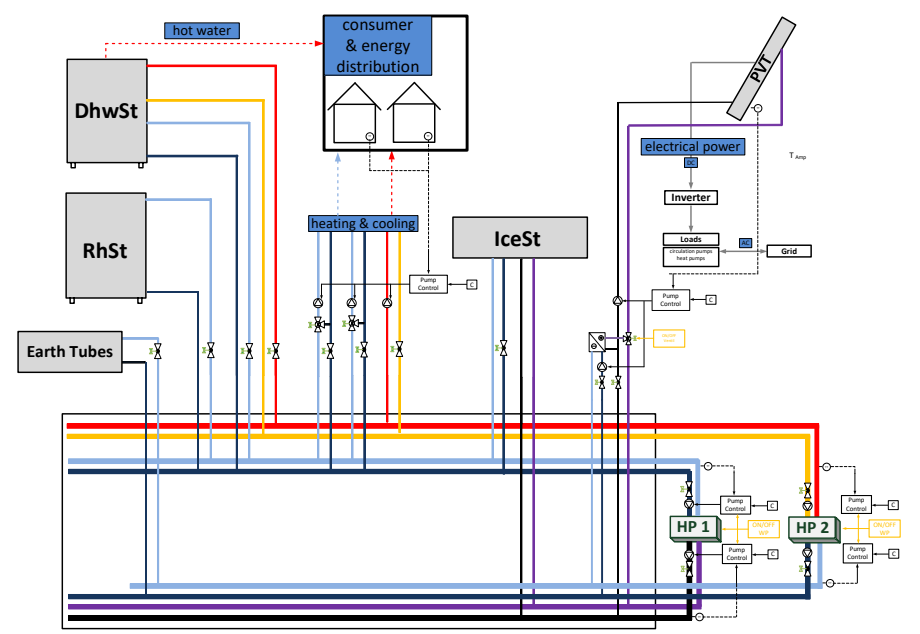

Fig. 1: Simplified schematic of the thermohydraulic system, consisting of fluid circuits, two heat-pumps (HP1, HP2), hot water storages (DhwSt, RhSt), Earth-Tubes, Ice Storage, PV/T collector and two single family homes as consumers.

The consumers, SFH45 and SFH100 along with general boundary conditions such as climate, domestic hot water load and properties of ground and boreholes for the simulation of ground heat exchangers are defined in (Ralf Dott, 2014) and (Haller et al., 2013). We use these definitions for the physical modeling of the energy plant and the building in Modelica. This ensures, that the results are directly comparable to other studies. The boundary conditions, as shown in Tab. 1, will - for the sake of comparability - not be changed, even if a change would further increase the efficiency of the MPC.

PV cell's electrical efficiency exhibits linear temperature dependency (Dubey et al., 2013), (Carigiet et al., 2014). (eq. 1) shows the electrical efficiency of a PV cell. $\eta_{\text {Tref }}$ is the module's electrical efficiency at the reference temperature $T_{\text {ref }}$ and at solar radiation of $1000 \frac{\mathrm{W}}{\mathrm{m}^{2}} \cdot \beta_{\text {ref }}=0.0043 \frac{1}{\mathrm{~K}}$ is the temperature coefficient and $T_{c}$ the actual temperature of the cell.

$$
\eta_{c}=\eta_{\text {Tref }}\left(1-\beta_{\text {ref }}\left(T_{c}-T_{\text {ref }}\right)\right)
$$

In the proposed integration the PV/T panel's main purpose is to regenerate the heat sources (ice storage and earth tubes) during the summer season. Because the thermal energy is led to the cold sources of the heat pumps, the temperature of the PV cells is kept below the reference temperature $T_{r e f}$, which increases electrical efficiency by about $3 \%$.

The main components and some chosen key figures of the heating plant are: 
- Brine to water HP with nominal heat output $3.93 \mathrm{~kW}$ at B0/W35 with a Coefficient of Performance (COP) of 4.65 .

- Brine to water HP with nominal heat output $7.07 \mathrm{~kW}$ at B0/W35 with a COP of 4.65.

- Room heating storage tank (RhSt) 3000 liter, domestic hot water tank (DhwSt) 2200 liter

- Ice storage (IceSt) $84 \mathrm{~m}^{3}$

- Two earth tubes length $60 \mathrm{~m}$

- Photovoltaic thermal hybrid solar collector (PV/T) $40 \cdot 1.641 \mathrm{~m}^{2}$, south facing

\section{Parameter Estimation and Control}

Fig. 2 shows the co-simulation setup. For the simulation environment, shown in the upper half, the open-source and free Modelica (Fritzson and Engelson, 1998) libraries and the Functional Mockup Interface (FMI) were used. Both are results from the IEA EBC project 60 New Generation Computational Tools for Building \& Community Energy Systems (Wetter and van Treeck, 2017). The parameter identification and online optimization scheme are implemented in MATLAB. The optimization problem (including the model) is formulated in MATLAB, using the YALMIP toolbox (Lofberg, 2004) and solved by the Gurobi solver (Gurobi Optimization, LLC, 2018).

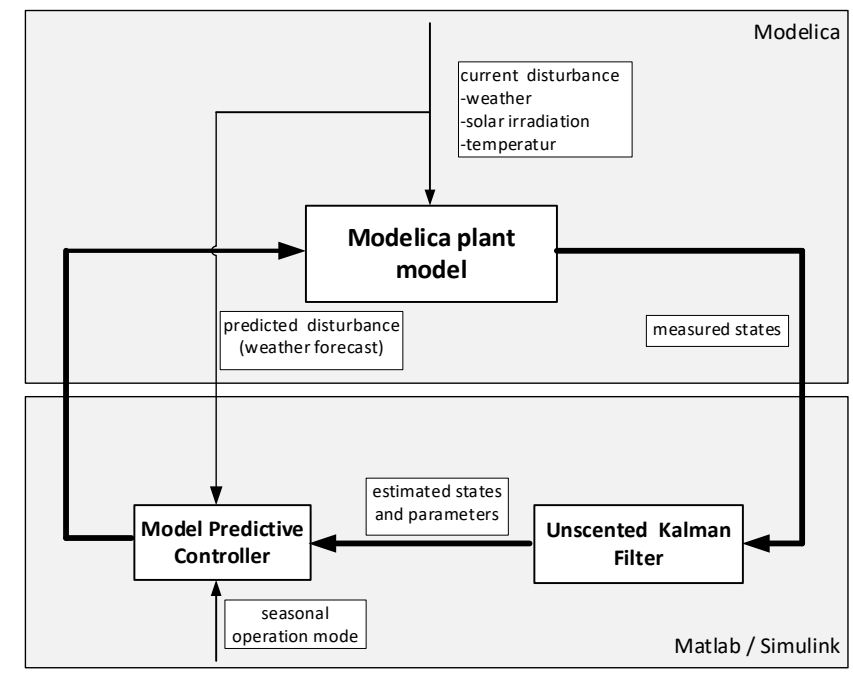

Fig. 2: Co-simulation setup. The upper half represents the simulated environment including heating system and consumers, the lower part represents the controller and state/parameter identification algorithms. The MPC contains a simplified plant model.

Tab. 1: Boundary conditions for simulation according to (Ralf Dott, 2014) and (Haller et al., 2013) for moderate climate of Strasbourg.

\begin{tabular}{llll} 
Parameter & Unit & SFH45 & SFH100 \\
\hline Space heating demand & $\mathrm{kWh} / \mathrm{a}$ & $6{ }^{\prime} 500$ & $14^{\prime} 000$ \\
DHW demand & $\mathrm{kWh} / \mathrm{a}$ & $2{ }^{\prime} 100$ & $2{ }^{\prime} 100$ \\
Heating demand at design conditions & $\mathrm{kW}$ & 4.1 & 7.4 \\
Design supply and return temperature of the heating system & ${ }^{\circ} \mathrm{C}$ & $35 / 30$ & $55 / 45$ \\
\hline
\end{tabular}

\subsection{Model Predictive Control}

(eq. 2) is the Mixed Integer Linear (MILP) Program formulation of the optimization problem

$$
\begin{aligned}
& J_{0 \rightarrow N}^{*}\left(x_{0}, U_{0 \rightarrow N}\right)=\max _{U_{0 \rightarrow N}} \sum_{k=0}^{N} q_{w}\left(x_{k}, u_{k}, b_{k}, d_{k}\right) \\
& \text { subject to } \quad x_{k+1}=F_{w}\left(x_{k}, u_{k}, b_{k}, d_{k}\right), \quad k=1, \ldots, N-1 \\
& h\left(x_{k}, u_{k}, b_{k}, d_{k}\right) \leq 0, \quad k=1, \ldots, N-1 \\
& x_{0}=x(0)
\end{aligned}
$$


with states $x_{k}$, control inputs $u_{k}$, input sequence $U_{0 \rightarrow N}=\left[u_{0}, \ldots, u_{N}\right]$, discrete variables $b_{k}$, disturbances $d_{k}$, such as weather and electricity costs, and the planning horizon $N$. The stage cost function $q_{w}$ (cost for one time step) and the possibly nonlinear system dynamics $F_{w}$, both depending on a set $w$ of system parameters. These parameters are identified with the UKF (see 3.2). The function $h$ encodes the system constraints.

The stage cost function $q_{w}$ (eq. 3) consists of two parts, the energy $E_{e l_{i}}=P_{e l_{i}} d t$ with the energy cost $c_{e}$ and the tracking term with the temperature set-points $T_{s e t_{i}}$ and weights $C_{i}$. The control objective is to keep the temperatures at the top of the storages above $35^{\circ} \mathrm{C}$ and $55^{\circ} \mathrm{C}$ respectively with as little imported electrical energy as possible. Electrical power used in the system, e.g. for operating heat pumps is counted positive, electric power which is produced by the PV/T has a negative sign. Only the positive part of $E_{e l_{i}}$ is considered in (eq. 3), i.e. exporting electricity is cost neutral.

Tab. 2: The MPC (high-level controller) has the following variables. States $x$, control inputs $u$, and disturbance.

\begin{tabular}{|c|c|c|}
\hline Variable & Description & Range/Unit \\
\hline$x_{1}, x_{2}, x_{3}, x_{4}$ & Temperature of the RhSt & ${ }^{\circ} \mathrm{C}$ \\
\hline$x_{5}, x_{6}, x_{7}, x_{8}$ & Temperature of the DwSt & ${ }^{\circ} \mathrm{C}$ \\
\hline$x_{9}$ & Temperature of the PV/T & ${ }^{\circ} \mathrm{C}$ \\
\hline$u_{H P I}$ & HP 1 On/Off & ${ }^{\circ} \mathrm{C}$ \\
\hline$u_{\text {HPITem }}$ & HP 1 supply temperature & $\{0,1\}$ \\
\hline$u_{H P I b}$ & Decision, loading RhSt or DwSt & ${ }^{\circ} \mathrm{C}$ \\
\hline$u_{H P 1}$ & HP 2 On/Off & $\{0,1\}$ \\
\hline$u_{\text {HP2Tem }}$ & HP 2 supply temperature & ${ }^{\circ} \mathrm{C}$ \\
\hline$d_{\text {dist }}$ & Internal gains (unkown) & $\mathrm{W} / \mathrm{m}^{2}$ \\
\hline$d_{T A m b}$ & Ambient temperature & \\
\hline$d_{\text {solar }}$ & Solar radiation & $\mathrm{W} / \mathrm{m}^{2}$ \\
\hline$\left.u_{k}, b_{k}, d_{k}\right)=c_{e} \cdot \max$ & $\left(\sum_{i} E_{e l_{i}}\left(x_{k}, u_{k}, b_{k}, d_{k}\right), 0\right)+$ & (eq. 3) \\
\hline
\end{tabular}

\subsection{State and parameter estimation with an Unscented Kalman Filter}

The accuracy of the model is fundamental for the performance of the MPC. Since each building and heating system is unique, a new model parameter set needs to be identified to represent its behavior. When retrofitting existing buildings, in most cases no Building Energy Model (BEM) will be available, and simulation based parameter tuning is therefore not possible.

Adaptive MPC schemes for building control in which both the unknown parameters and unmeasured states are estimated during operation, using EKF and UKF were proposed in (Fux, 2013), (Maasoumy et al., 2014) and (Radecki and Hencey, 2015). Simulations using these schemes the estimates of the unknown building parameters typically converge after a couple of weeks of operation. The initialization of a Kalman filter's parameters is still delicate and has an impact on the rate of convergence. In order to obtain the best initial parameter value, Maasoumy (Maasoumy et al., 2014) first performed an offline parameter identification based on historical data.

The convergence of EKF/UKF depends on careful choice of design matrices, in particular the initial covariance $P_{0}$, process noise covariance $R_{k}^{v}$ and measurement noise covariance $R_{k}^{n}$. These matrices are often chosen arbitrarily (Schneider and Georgakis, 2013). We propose to use a time-dependent covariance $R_{k}^{v}$ (eq. 5). This reduces the number of parameters to be initialized, since we may set $R_{0}^{v}=\left(\theta^{-1}-1\right) P_{0}$, where $R_{0}^{v}$ and $P_{0}$ are matrices and $\theta$ is a number (Haykin, 2001). For a consistent choice for the initial state covariance $P_{0}$ and initial state $\hat{x}_{0}$, we follow the procedure proposed in (Schneider and Georgakis, 2013).

The UKF was introduced in 1995 (Julier et al., 1995). A refinement for dual state/parameter estimation and for joint state/parameter estimation is given in (Wan and Merwe, 2000). We use the joint UKF framework to simultaneously identify states and parameters, where the signal-state $x_{k}$ and parameter $w_{k}$ vectors are concatenated into a single, joint state vector $\hat{x}_{k}=\left(x_{k} w_{k}\right)^{T}$ which is propagated according to (eq. 4) with control inputs $u_{k}$, process noise $v_{k}$, 
measurement noise $n_{k}$, lumped parameter model $F\left(x_{k}, u_{k}, w_{k}\right)$ and the measurement function $H\left(x_{k}\right)$, which is trivial in our case, since we can directly measure the temperatures.

$$
\begin{aligned}
& \hat{x}_{k+1}=\left(\begin{array}{l}
x_{k+1} \\
w_{k+1}
\end{array}\right)=\left(\begin{array}{c}
F\left(x_{k}, u_{k}, w_{k}\right) \\
w_{k}
\end{array}\right)+v_{k} \\
& y_{k}=H\left(x_{k}\right)+n_{k}=\left(x_{k}\right)+n_{k}
\end{aligned}
$$

Mean and standard deviation of the process noise $v_{k}$ and measurement noise $n_{k}$ can be time varying. The measurement noise covariance $R_{k}^{n}=E\left[n_{k} n_{k}^{T}\right]$ can be set to a constant diagonal matrix (e.g. $R_{k}^{n}=I$ ). The process noise covariance $R_{k}^{v}=E\left[v_{k} v_{k}^{T}\right]$ needs more attention, as it has a key influence in the tracking performance of the algorithm (Haykin, 2001). We set

$$
\begin{aligned}
& R_{k}^{v}=\left(\theta^{-1}-1\right) P_{k} \\
& P_{k}=E\left[\left\{\left(\begin{array}{c}
x_{k} \\
w_{k}
\end{array}\right)-\left(\begin{array}{c}
\hat{x}_{k} \\
\widehat{w}_{k}
\end{array}\right)\right\}\left\{\left(\begin{array}{c}
x_{k} \\
w_{k}
\end{array}\right)-\left(\begin{array}{c}
\hat{x}_{k} \\
\widehat{w}_{k}
\end{array}\right)\right\}^{T}\right]
\end{aligned}
$$

with $\left(\begin{array}{l}\hat{x}_{k} \\ \widehat{w}_{k}\end{array}\right)=E\left[\left(\begin{array}{l}x_{k} \\ w_{k}\end{array}\right)\right]$ and a forgetting factor $\theta \in[0,1]$. This provides an exponentially decaying weighting on past data (Haykin, 2001).

The function $F\left(x_{k}, u_{k}, w_{k}\right)$ can be nonlinear. The UKF propagates the probability distribution of $\hat{x}_{k}$ through $F\left(x_{k}, u_{k}, w_{k}\right)$. To do so, a set $\chi$ of $2 L+1$ sample points with $=\operatorname{dim}(\hat{x})$, called sigma points are chosen, propagated via $\chi_{k+1}=F\left(\chi_{k}, u_{k}\right)$ and the mean and covariance of $\hat{x}_{k+1}$ is calculated. (eq. 6) describes the calculation of sigma points. $\left(\sqrt{(L+\lambda) P_{\hat{x}}}\right)_{i}$ is the $i$ th column of the matrix square root.

\begin{tabular}{l}
\hline Sigma points calculation \\
$\begin{array}{l}\mathcal{X}_{0}=\hat{x} \\
\mathcal{X}_{i}=\hat{x}+\left(\sqrt{(L+\lambda) P_{\hat{x}}}\right)_{i} \quad i=1, \ldots, L \\
\mathcal{X}_{i}=\hat{x}-\left(\sqrt{(L+\lambda) P_{\hat{x}}}\right)_{i-L} \quad i=L+1, \ldots, 2 L\end{array}$
\end{tabular}

The setup for the Unscented Transformation (UT) (eq. 7) is shown below

$$
\begin{aligned}
\hline \text { UT Setup } & \text { (eq. 7) } \\
\lambda & =\alpha^{2}(L+\kappa)-L \\
W_{0}^{(m)} & =\frac{\lambda}{L+\lambda} \\
W_{0}^{(c)} & =\frac{\lambda}{L+\lambda}+1-\alpha^{2}+\beta \\
W_{i}^{(m)} & =W_{i}^{(c)}=\frac{\lambda}{2(L+\lambda)}, \quad i=1, \ldots, 2 L \\
\gamma & =\sqrt{L+\lambda}
\end{aligned}
$$

$\lambda$ is the scaling parameter, which depends on $\alpha, \kappa$ and $L$. The constant $\alpha$ determines the spread of sigma points about the mean $\hat{x}_{k}$. The constant $\kappa$ is a secondary scaling parameter, which we set to $3-L$. $\beta$ is used to incorporate prior knowledge of the distribution. $\beta=2$ is optimal for Gaussian distributions (Haykin, 2001).

Below the UKF Algorithm (eq. 8) is shown, which includes the following main steps:

- $\quad$ Prediction of the model outputs $\hat{y}_{k}^{-}$, based on the model with the current parameters.

- $\quad$ Obtain the measurements $y_{k}$ from sensors

- Update the prediction of the states, based on the errors (measurements-model prediction, $y_{k}-\hat{y}_{k}^{-}$) 


UKF Algorithm

Initialize with:

$$
\begin{aligned}
& \hat{x}_{0}=E\left[x_{0}\right] \\
& P_{0}=E\left[\left(x_{0}-\hat{x}_{0}\right)\left(x_{0}-\hat{x}_{0}\right)^{T}\right]
\end{aligned}
$$

calculate the sigma points:

$$
\mathcal{X}_{k-1}=\left[\begin{array}{lll}
\hat{x}_{k-1} & \hat{x}_{k-1}+\gamma \sqrt{P_{k-1}} & \hat{x}_{k-1}-\gamma \sqrt{P_{k-1}}
\end{array}\right]
$$

Prediction:

$$
\begin{aligned}
& \mathcal{X}_{i, k \mid k-1}^{*}=F\left(\mathcal{X}_{k-1}, u_{k-1}\right) \\
& \hat{x}_{k}^{-}=\sum_{i=0}^{2 L} W_{i}^{(m)} \mathcal{X}_{i, k \mid k-1}^{*} \\
& P_{k}^{-}=\sum_{i=0}^{2 L} W_{i}^{(c)}\left(\mathcal{X}_{i, k \mid k-1}^{*}-\hat{x}_{k}^{-}\right)\left(\mathcal{X}_{i, k \mid k-1}^{*}-\hat{x}_{k}^{-}\right)^{T}+R^{v} \\
& \mathcal{X}_{k \mid k-1}=\left[\begin{array}{lll}
\mathcal{X}_{k \mid k-1}^{*} & \mathcal{X}_{0, k \mid k-1}^{*}+\gamma \sqrt{R^{v}} & \mathcal{X}_{0, k \mid k-1}^{*}-\gamma \sqrt{R^{v}}
\end{array}\right] \\
& \mathcal{Y}_{k-1}=H\left(\mathcal{X}_{k-1}\right) \\
& \hat{y}_{k}^{-}=\sum_{i=0}^{2 L} W_{i}^{(m)} \mathcal{Y}_{i, k \mid k-1}^{*}
\end{aligned}
$$

Measurement-update:

$$
\begin{aligned}
P_{\tilde{y_{k}} \tilde{y_{k}}} & =\sum_{i=0}^{2 L} W_{i}^{(c)}\left(\mathcal{Y}_{i, k \mid k-1}-\hat{y}_{k}^{-}\right)\left(\mathcal{Y}_{i, k \mid k-1}-\hat{y}_{k}^{-}\right)^{T}+R^{n} \\
P_{x_{k} y_{k}} & =\sum_{i=0}^{2 L} W_{i}^{(c)}\left(\mathcal{X}_{i, k \mid k-1}-\hat{x}_{k}^{-}\right)\left(\mathcal{Y}_{i, k \mid k-1}-\hat{y}_{k}^{-}\right)^{T} \\
\mathcal{K}_{k} & =P_{x_{k} y_{k}} P_{\tilde{y_{k}} \tilde{y}_{k}}^{-1} \\
\hat{x}_{k} & =\hat{x}_{k}^{-}+\mathcal{K}_{k}\left(y_{k}-\hat{y}_{k}^{-}\right) \\
P_{k} & =P_{k}^{-}+\mathcal{K}_{k} P_{\tilde{y_{k}} \tilde{y_{k}}} \mathcal{K}_{k}^{T}
\end{aligned}
$$

\subsection{Simulation results for parameter estimation}

Tab. 4 lists the identified state variables and parameters. Parameter identification is done for RhSt, DhwSt, PV/T, and for the building model parameters of the SFH100. It is performed during the normal building operation.

Tab. 3: Simulations settings

\begin{tabular}{ll} 
Parameter & Value \\
\hline Measurement interval for identification & $0.5 \mathrm{~h}$ \\
Spread of sigma points $\alpha$ & $1 \mathrm{e}-3$ \\
Forgetting factor $\Theta$ & $1 \mathrm{e}-4 \ldots 1 \mathrm{e}-3$ \\
Optimization interval (MPC) & $1 \mathrm{~h}$ \\
Prediction horizon (MPC) & $8 \mathrm{~h}$ \\
Identification duration & $2 \ldots . .50$ days \\
\hline
\end{tabular}


P. Bolt et. al. / EuroSun 2018 / ISES Conference Proceedings (2018)

Tab. 4: Measurement $y$, identified parameters, disturbance $d$ and inputs u of the model.

\begin{tabular}{|c|c|c|}
\hline Variable & Description & Range/Unit \\
\hline $\mathrm{y}_{1}, \mathrm{y}_{2}, \mathrm{y}_{3}, \mathrm{y}_{4}$ & temperatures of the RhSt (4 layers) & ${ }^{\circ} \mathrm{C}$ \\
\hline $\mathrm{y}_{5}, \mathrm{y}_{6}, \mathrm{y}_{7}, \mathrm{y}_{8}$ & temperatures of the DwSt (4 layers) & ${ }^{\circ} \mathrm{C}$ \\
\hline $\mathrm{y}_{9}$ & temperature of the PVT & ${ }^{\circ} \mathrm{C}$ \\
\hline $\mathrm{y}_{\text {con }}$ & temperature of the concrete & ${ }^{\circ} \mathrm{C}$ \\
\hline yroom & temperature of the room & ${ }^{\circ} \mathrm{C}$ \\
\hline $\mathrm{Cm}_{1 \mathrm{SFH} 100}$ & thermal mass & $\mathrm{J} / \mathrm{K}$ \\
\hline $\mathrm{Cm}_{2} \mathrm{SFH} 100$ & thermal mass & $\mathrm{J} / \mathrm{K}$ \\
\hline $1 / \mathrm{R}_{1 \mathrm{SFH} 100}$ & thermal conduction to the ambient & $\mathrm{W} / \mathrm{K}$ \\
\hline $1 / \mathrm{R}_{2} \mathrm{SFH} 100$ & thermal conduction between thermal masses & $\mathrm{W} / \mathrm{K}$ \\
\hline $1 / \mathrm{R}_{3} \mathrm{SFH} 100$ & thermal conduction to soil & $\mathrm{W} / \mathrm{K}$ \\
\hline $\mathrm{K}_{1 \mathrm{SFH} 100}$ & solar factor & $\mathrm{m}^{2}$ \\
\hline $\mathrm{Cm}_{\mathrm{ST} 1}$ & thermal mass of the storage & $\mathrm{J} / \mathrm{K}$ \\
\hline $\mathrm{Cm}_{\mathrm{ST2} 2}$ & thermal mass of the storage & $\mathrm{J} / \mathrm{K}$ \\
\hline $1 / \mathrm{Cm}_{\mathrm{PVT}}$ & thermal mass (inverse) & $\mathrm{K} / \mathrm{J}$ \\
\hline $\mathrm{P}_{1}$ & lumped parameter & $\left(\mathrm{K} \mathrm{m}^{2}\right) / \mathrm{J}$ \\
\hline $\mathrm{P}_{2}$ & lumped parameter & $1 / \mathrm{s}$ \\
\hline $\mathrm{d}_{\text {dist }}$ & internal gains (unkown) & $\mathrm{W} / \mathrm{m}^{2}$ \\
\hline $\mathrm{d}_{\mathrm{TAmb}}$ & ambient temperature & ${ }^{\circ} \mathrm{C}$ \\
\hline$d_{\text {solar }}$ & solar radiation & $\mathrm{W} / \mathrm{m}^{2}$ \\
\hline $\mathrm{u}_{\text {pump HP1 }}, \mathrm{u}_{\text {pump HP2 }}$ & control input pumps & $\{0,1\}$ \\
\hline $\mathrm{u}_{\mathrm{T} \text { sup } \mathrm{ST} 1,} \mathrm{u}_{\mathrm{T} \text { ret } \mathrm{ST} 1,} \mathrm{u}_{\mathrm{T} \text { sup ST2},} \mathrm{u}_{\mathrm{T}}$ ret ST2 & supply and return temperature heat $\mathrm{ST}$ & ${ }^{\circ} \mathrm{C}$ \\
\hline $\mathrm{u}_{\mathrm{T} \text { sup } \mathrm{PVT}}, \mathrm{u}_{\mathrm{T} \text { ret } \mathrm{PVT}}$ & supply and return temperature PVT & ${ }^{\circ} \mathrm{C}$ \\
\hline $\mathrm{u}_{\mathrm{T} \text { sup SFH100, }}, \mathrm{u}_{\mathrm{T} \text { ret } \mathrm{SFH} 100}$ & supply and return temperature SFH & ${ }^{\circ} \mathrm{C}$ \\
\hline
\end{tabular}

For the identification of the building model, we presuppose very little knowledge of the actual parameter values. Twelve simulation runs are executed with randomly chosen initial values. Identification of the building model parameters (SFH 100) for randomly chosen initial conditions is shown in Fig. 4. Within ca. 20 days all parameter estimates - with one exception - converge. The estimated parameters are lumped parameters, thus only indirect verification of the estimation is possible. Fig. 3 shows the error for room and concrete temperatures for one of the runs.

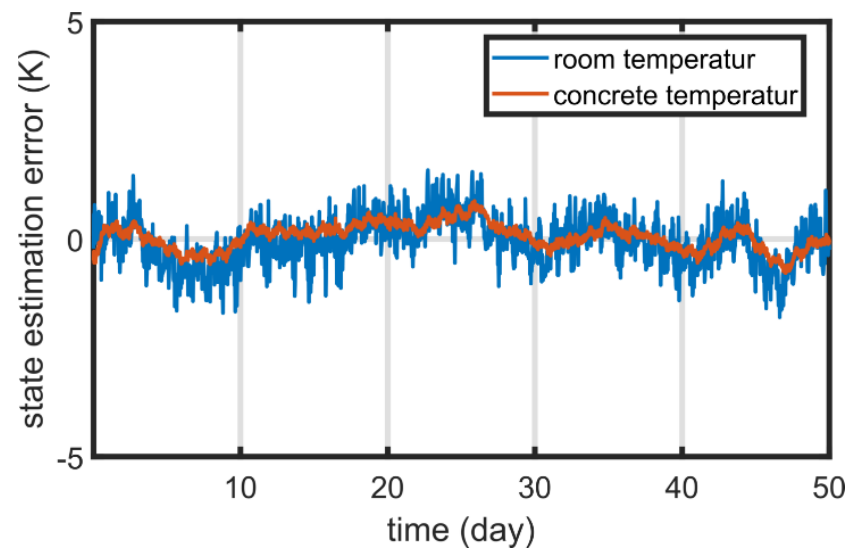

Fig. 3: Error between estimation and measured room and concrete temperature using UKF. The temperatures depend on the estimated parameters and can be measured directly. 

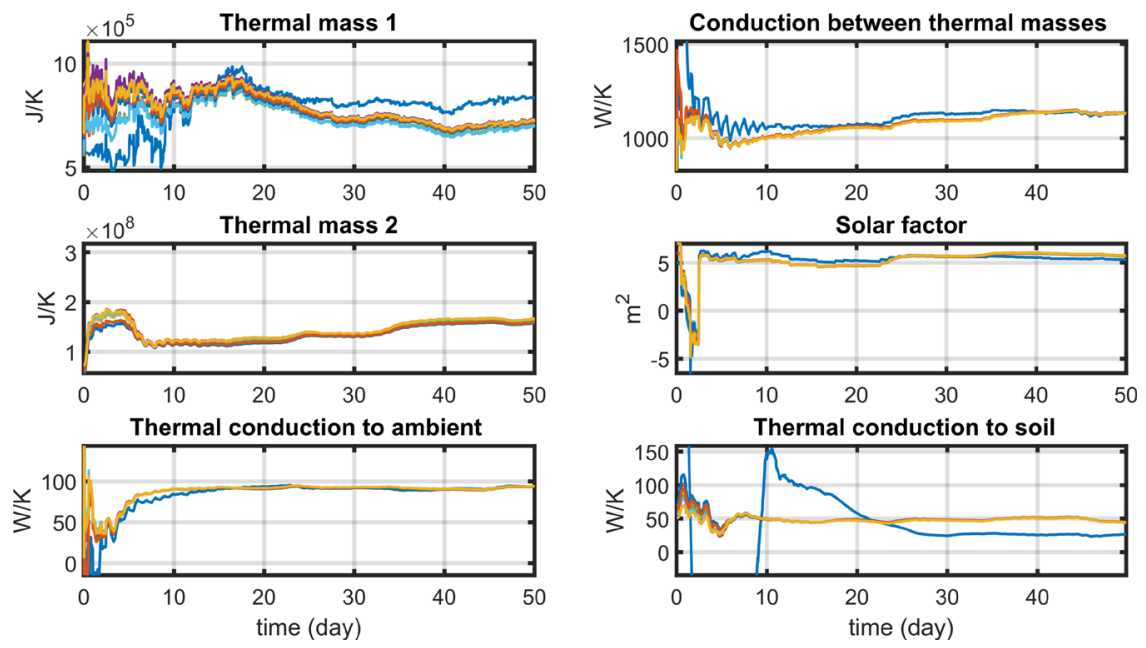

Fig. 4: Identification of the building model parameters (SFH 100) with different initial conditions during ordinary operation of the heating system. Several simulation runs with different initial guesses are shown. Within ca. 20 days all parameters converge, except in one of the runs (blue line) which failed to converge. The parameters are lumped parameters, thus they cannot be compared to "exact" values.

The identification of the heating system parameters (RhSt, DhwSt, PV/T) is shown in Fig. 5 and Fig. 6. Convergence is faster, than for the parameters in Fig. 4, because a good initial estimate is usually available.
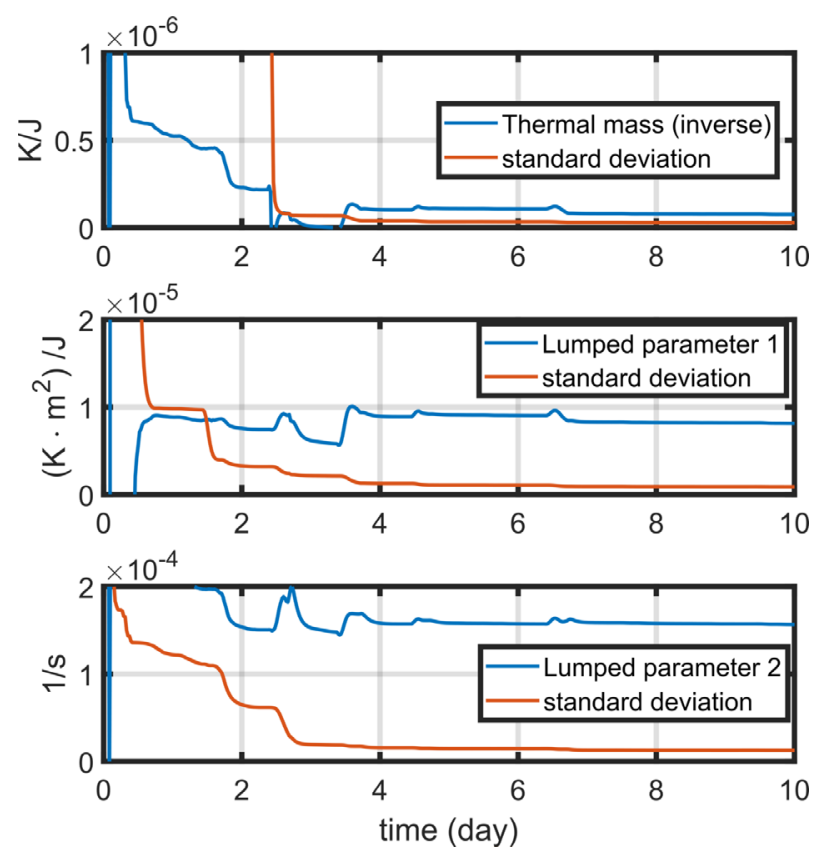

Fig. 5: Identification for the parameters. Compared to the identification of DhwSt and RhSt it takes a bit longer to reach a stable set of parameters. This is because the identification only can run when some excitation (irradiation sun) is active.
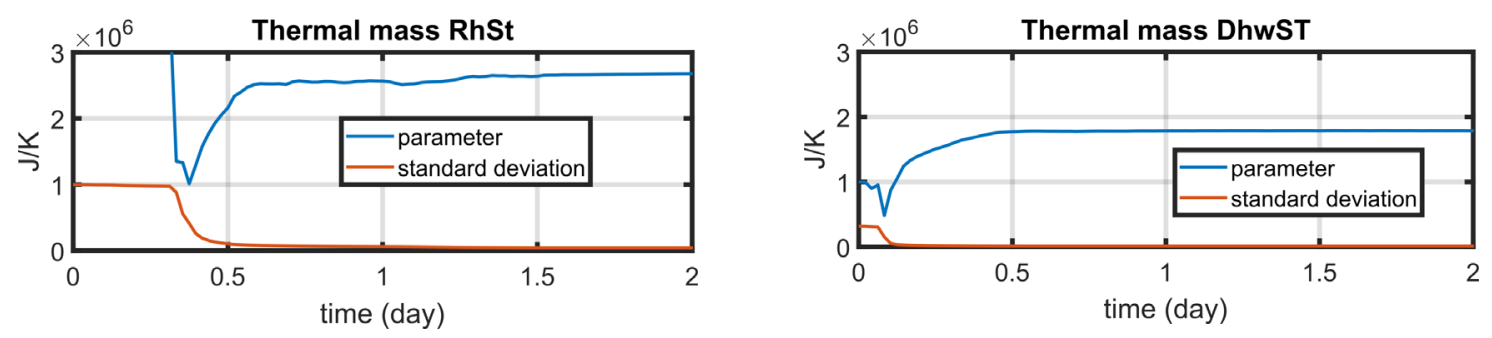

Fig. 6: Identification for the thermal mass of DhwSt and RhSt. Within ca. 0.5 days, the parameters converge with a relative error of 0.14 and 0.22 respectively. 


\section{Results for overall performance}

All presented results refer to annual simulation with synthetic weather data (averaged over several years) for Zurich, Switzerland, as provided by METEONORM 7 (Meteotest, 2013). We compare MPC to a Rule Based Controller (RBC) in terms of performance coefficient, self-consumption and self-sufficiency.

\subsection{Performance coefficient, self-consumption and self-sufficiency}

The performance coefficient is by definition

$$
J:=\int \frac{\dot{Q}_{t h}}{\dot{E}_{\text {ext }}} d t
$$

where $\dot{Q}_{t h}$ is the total useable thermal energy supplied for hot water supply and heating and $\dot{E}_{\text {ext }}$ is the imported electrical energy. We calculate the annual $J$ and monthly $J_{\text {monthly }}$ performance coefficient.

The system has a performance factor of $J=6.85$ for the MPC and $J=4.24$ for the RBC (Tab. 5). During the heating season the MPC achieves for the coldest months, January and December, a performance factor $J_{\text {monthly }}=4.9$ and 5 , while $\mathrm{RBC}$ reaches $J_{\text {monthly }}=3.8$ and 4.0 (Fig. 7).

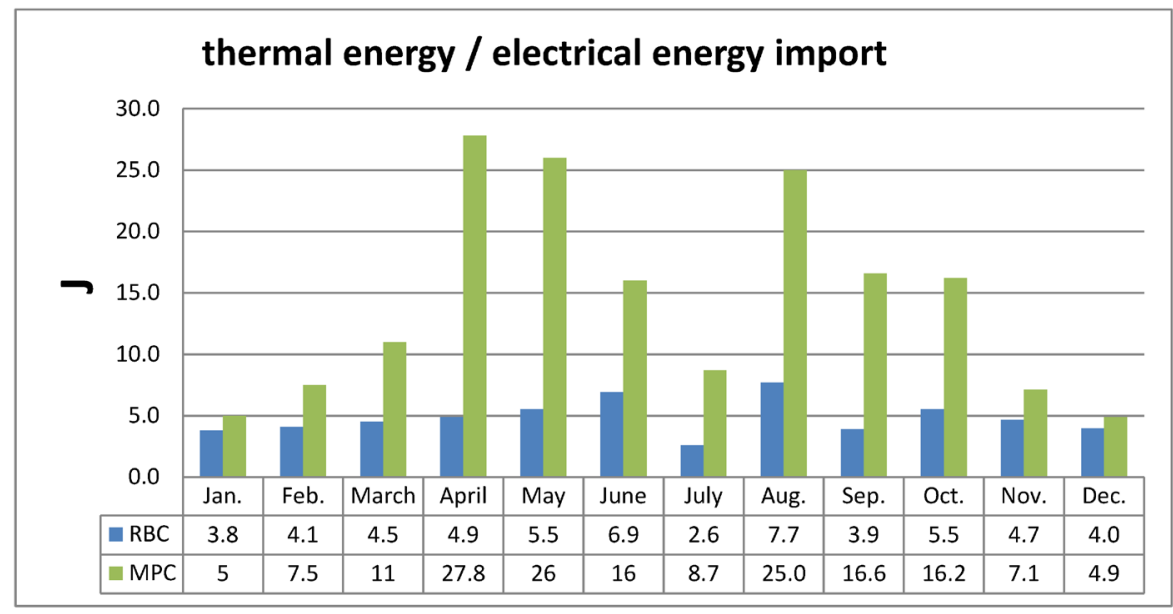

Fig. 7: Monthly performance factors $\mathrm{J}_{\text {monthly }}$ for $\mathrm{RBC}$ and MPC resulting from a realistic simulation with Zurich weather data.

Tab. 5: Result overview. RBC and MPC deliver roughly the same amount of heat and produce the same amount of energy, but MPC can use a much larger share of the produced energy on site.

\begin{tabular}{|c|c|c|c|}
\hline & Unit & $\mathrm{RBC}$ & MPC \\
\hline \multicolumn{4}{|l|}{ heating circuit } \\
\hline heating energy & $\mathrm{kWh}$ & 17119 & 17250 \\
\hline energy DHW & $\mathrm{kWh}$ & 2065 & 2065 \\
\hline thermal energy out (no cooling) & kWh & 19184 & 19316 \\
\hline cooling & $\mathrm{kWh}$ & 1371 & 1370 \\
\hline \multicolumn{4}{|l|}{ electricity } \\
\hline produced PV & $\mathrm{kWh}$ & 9508 & 9641 \\
\hline consumed WPs \& pumps & $\mathrm{kWh}$ & 5530 & 6466 \\
\hline exported & $\mathrm{kWh}$ & 8505 & 5994 \\
\hline imported & kWh & 4527 & 2819 \\
\hline Performance coefficient $\mathbf{J}$ & - & 4.24 & 6.85 \\
\hline
\end{tabular}

For self-consumption (eq. 10) and self-sufficiency (eq. 11) we use the terms as described by (Luthander et al., 2015). The meaning of the variables are self-consumption ratio $R_{\text {con }}(-)$, self-sufficiency ratio $R_{\text {suf }}(-)$, self-consumption of on-site PV electricity $E_{\text {self }}(\mathrm{kWh})$, electricity consumption $E_{\text {con }}(\mathrm{kWh})$, electricity import form the grid $E_{\text {grid }}(\mathrm{kWh})$ and on-site PV electricity produced $E_{\text {prod }}(\mathrm{kWh})$. 


$$
\begin{aligned}
& R_{\text {con }}=\frac{E_{\text {self }}}{E_{\text {prod }}}=\frac{E_{\text {con }}-E_{\text {grid }}}{E_{\text {prod }}} \\
& R_{\text {suf }}=\frac{E_{\text {self }}}{E_{\text {con }}}=\frac{E_{\text {con }}-E_{\text {grid }}}{E_{\text {con }}}=1-\frac{E_{\text {grid }}}{E_{\text {con }}}
\end{aligned}
$$

With MPC, the system consumes $R_{c o n}=56 \%$ of the generated PVT electrical energy in the course of one year and reaches a self sufficiency $R_{\text {suf }}=38 \%$ (Fig. 8, Fig. 9). With RBC, the self-consumption ratio is approximately $10 \%$ based only on coincidence and the self-sufficiency is $18 \%$. During the heating season from October to April the MPC achieves a PV self-consumption between $47 \%$ and $69 \%$. The worst month with respect to self-consumption is April and the best month is December.

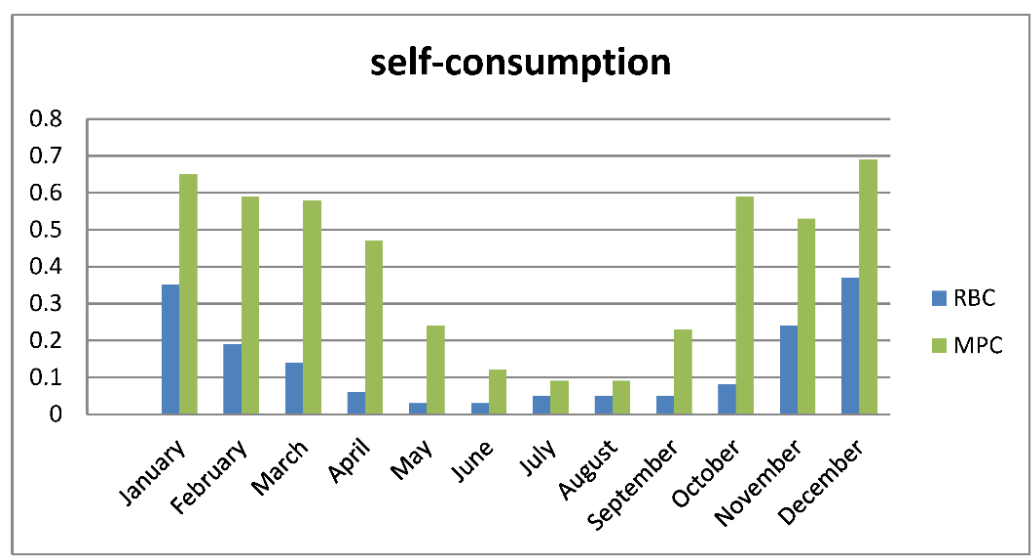

Fig. 8: Monthly self-consumption.

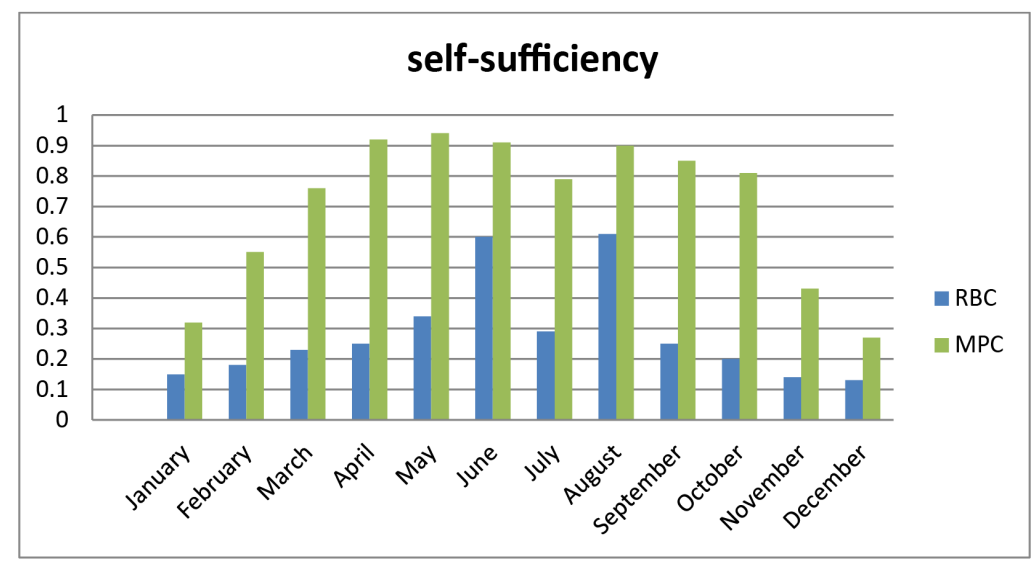

Fig. 9: Monthly self-sufficiency.

\subsection{Discussion}

There are two main reasons for optimizing the self-consumption. First, there is an economical reward for the consumer in case of low feed-in prices and high purchase prices. With variable electricity prices, the potential is even greater (Zogg et al., 2016). Second, grid-connected PV power plants may cause unwanted disturbances to the electricity grid.

Maximizing self-consumption and efficient operation of the HP are contradictory: maximizing the self-consumption implies heating up the storage while on-site PV electricity is available. The consequence are higher temperature lifts and thus a decreased efficiency of the HP. The HP still operates with maximum efficiency while there is no PV/T electricity generation.

Other common seasonal performance figures, such as the Seasonal Performance Factor ( $S P F+$ ) define the overall energy efficiency of the system as the quotient of overall useful energy output and the overall driving final energy input (Malenkovic et al., 2013) without distinction between imported and locally produced electrical energy. However if self-consumption should play a role in the optimization, this distinction is reasonable. 
In our setup, we find values of $\mathrm{SPF}+=3.2$ for $\mathrm{MPC}$ and $\mathrm{SPF}+=3.7$ for $\mathrm{RBC}$.

\section{Conclusion and Outlook}

In an annual simulation run with Zurich weather data, and two consumers (one SFH45 and one SFH100), a performance factor of $\mathrm{J}=6.85$ was reached. Economically this is a very competitive value (i.e. running costs are competitive). Similar systems like (Daniel Philippen, 2015) reach a ratio up to 7 for SFH45 and up to 3.5 for SFH100. Commissioning and maintenance costs are kept low by the continuous parameter identification, which ensures, that the model remains accurate over time, even in the presence of varying system parameters. Even with automatic adaptation of system parameters, the required modelling effort remains considerable. Model free, possibly heuristic or self-learning, optimal control concepts are therefore a very interesting future research objective.

\section{Acknowledgements}

The present work has been funded by the Swiss Commission for Technology and Innovation (KTI). The project is a collaboration between RINO Electronics AG, Jansen AG and the Zurich University of Applied Sciences (ZHAW).

\section{References}

Ashouri, A., Stadler, P., and Maréchal, F. (2015). Day-ahead promised load as alternative to real-time pricing. In 2015 IEEE International Conference on Smart Grid Communications (SmartGridComm), pp. 551-556.

Bianchi, M. (2006). Adaptive Modellbasierte Prädiktive Regelung einer Kleinwärmepumpenanlage. ETH Zürich.

Carigiet, F., Baumgartner, F., Sutterlueti, J., Allet, N., Pezzotti, M., and Haller, J. (2014). Energy rating based on thermal modelling of five different PV technologies. In Proceedings of the 29th European Photovoltaic Solar Energy Conference, Amsterdam, The Netherlands, pp. 22-26.

Daniel Philippen, D.C. (2015). High-Ice System development for high solar thermal gains with ice storage and heat pump.

Dubey, S., Sarvaiya, J.N., and Seshadri, B. (2013). Temperature Dependent Photovoltaic (PV) Efficiency and Its Effect on PV Production in the World - A Review. Energy Procedia 33, 311-321.

Fritzson, P., and Engelson, V. (1998). Modelica - A unified object-oriented language for system modeling and simulation. In ECOOP'98 — Object-Oriented Programming, (Springer, Berlin, Heidelberg), pp. 67-90.

Fux, S.F. (2013). Optimal energy management and component sizing of a stand-alone building energy system. ETH Zurich.

Gurobi Optimization, LLC (2018). Gurobi Optimizer Reference Manual.

Haller, M.Y., Dott, R., Ruschenburg, J., Ochs, F., and Bony, J. (2013). The Reference Framework for System Simulations of the IEA SHC Task 44/HPP Annex 38 Part A: General Simulation Boundary Conditions (Citeseer).

Haykin, S.S. (2001). Kalman Filtering and Neural Networks (New York, NY, USA: John Wiley \& Sons, Inc.).

Julier, S.J., Uhlmann, J.K., and Durrant-Whyte, H.F. (1995). A new approach for filtering nonlinear systems. In American Control Conference, Proceedings of the 1995, pp. 1628-1632 vol.3.

Lofberg, J. (2004). YALMIP: A toolbox for modeling and optimization in MATLAB. In Computer Aided Control Systems Design, 2004 IEEE International Symposium On, (IEEE), pp. 284-289.

Luthander, R., Widén, J., Nilsson, D., and Palm, J. (2015). Photovoltaic self-consumption in buildings: A review. Applied Energy 142, 80-94.

Maasoumy, M., Razmara, M., Shahbakhti, M., and Vincentelli, A.S. (2014). Handling model uncertainty in model predictive control for energy efficient buildings. Energy and Buildings 77, 377-392. 
P. Bolt et. al. / EuroSun 2018 / ISES Conference Proceedings (2018)

Malenkovic, I., Eicher, S., and Bony, J. (2013). Definition of main system boundaries and performance figures for reporting on SHP systems. Report Deliverable B 1 .

Meteotest (2013). Global Meteorological Database for Engineers, Planners and Education (Bern, Switzerland).

Peter S. Maybeck (1979). Stochastic Models Estimation And Control VOL 1.

Peter S. Maybeck (1982). Stochastic Models Estimation And Control VOL. 2.

Radecki, P., and Hencey, B. (2015). Online Model Estimation for Predictive Thermal Control of Buildings. ArXiv:1601.02947 [Cs].

Ralf Dott, M.Y.H. (2014). The Reference Framework for System Simulations of the IEA SHC Task 44 / HPP Annex 38 Part B: Buildings and Space Heat Load.

Schneider, R., and Georgakis, C. (2013). How To NOT Make the Extended Kalman Filter Fail. Industrial \& Engineering Chemistry Research 52, 3354-3362.

Serale, G., Fiorentini, M., Capozzoli, A., Bernardini, D., and Bemporad, A. (2018). Model Predictive Control (MPC) for Enhancing Building and HVAC System Energy Efficiency: Problem Formulation, Applications and Opportunities. Energies 11, 631.

Sturzenegger, D. (2014). Model predictive building climate control: Steps towards practice. Doctoral Thesis. ETH Zurich.

Wan, E.A., and Merwe, R.V.D. (2000). The unscented Kalman filter for nonlinear estimation. In Proceedings of the IEEE 2000 Adaptive Systems for Signal Processing, Communications, and Control Symposium (Cat. No.00EX373), pp. 153-158.

Wetter, M., and van Treeck, C. (2017). IEA EBC Annex 60: New Generation Computing Tools for Building and Community Energy Systems. The Regents of the University of California and RWTH Aachen University.

Wimmer, R. (2004). Regelung einer Wärmepumpenanlage mit Model Predictive Control. ETHZ. 


\title{
Techno-Economic Evaluation of Energy Self-Sufficiency for the Energy Supply of Single and Multifamily Buildings Johannes Bracke ${ }^{1}$ \\ 1 Baumann Consulting, Frankfurt am Main (Germany)
}

\begin{abstract}
Many consumers currently follow the idea of energy self-sufficiency and try to contribute to meet their energy needs to become independent and self-sufficient from the central energy network. In order to achieve load-related energy self-sufficiency, the energy supply must cover the energy demand at any time. Against this background, this study analyzes the costs and potential of load-related energy selfsufficiency of single and multi-family buildings. It is differentiated between electricity-, heat- and energy self-sufficiency. The modelling is carried out with the simulation environment „Polysun Designer“ which allows a high temporal, dynamic simulation of the annual energy demand and energy supply.

Keywords: Energy self-sufficiency, Energy supply systems, Whole Building Simulation, Evaluation
\end{abstract}

\section{Introduction}

The realization of extensive reduction targets of greenhouse gas emissions and the associated increased use of renewable energies in Europe and Germany lead to autonomy aspirations of consumers towards becoming more independent from the central energy supply network. As a result, consumers are turning from pure energy consumers to simultaneous energy producers, eventually becoming independent of the central energy supply network (Bardt et al., 2014). Within an interdisciplinary research network, the Institute of Energy Economics and Rational Energy Use (IER) investigated the energy self-sufficiency potential for different system boundaries as well as the required technologies (Tomaschek et al., 2015).

Interestingly, there is no clear definition of the term "energy self-sufficiency" in scientific literature. In this study, a distinction is made between energy self-sufficiency "on balance" and load-related energy self-sufficiency. For energy self-sufficiency on balance, the energy supply for a defined period of time (e.g. twelve months) must be at least equal to the energy demand (Deutschle et al. 2015). The overall balance of the energy exchange between the system and the environment must not be negative. However, energy can be imported from the environment into the system or exported from the system to make up the mismatch between energy supply Esupply and energy demand $E_{\text {Demand }}$ (see Fig. 1 a). The impact of energy self-sufficiency "on balance" for private households for different system boundaries is described in McKenna et al. (2016).

Load-related energy self-sufficiency is the more demanding of the two forms of energy self-sufficiency. It must always be ensured that the energy demand is met by the energy supply (see Fig. 1 b). Energy is never imported into the system at any time. Excluded is the entry of renewable energies such as solar energy, wind energy or hydroelectric power. However, it is allowed to export energy beyond the system boundaries (Deutschle et al., 2015).

$$
\begin{aligned}
& \int_{0}^{t} \dot{E}_{\text {Supply }} d t \geq \int_{0}^{t} \dot{E}_{\text {Demand }} d t \\
& \dot{E}_{\text {Supply }}(t) \geq \dot{E}_{\text {Demand }}(t)
\end{aligned}
$$


Against this background, this paper presents the costs and potential of a self-sufficient energy supply, of multiand single-family buildings, as the smallest system boundary. A distinction is made between electricity, heat and energy self-sufficiency.

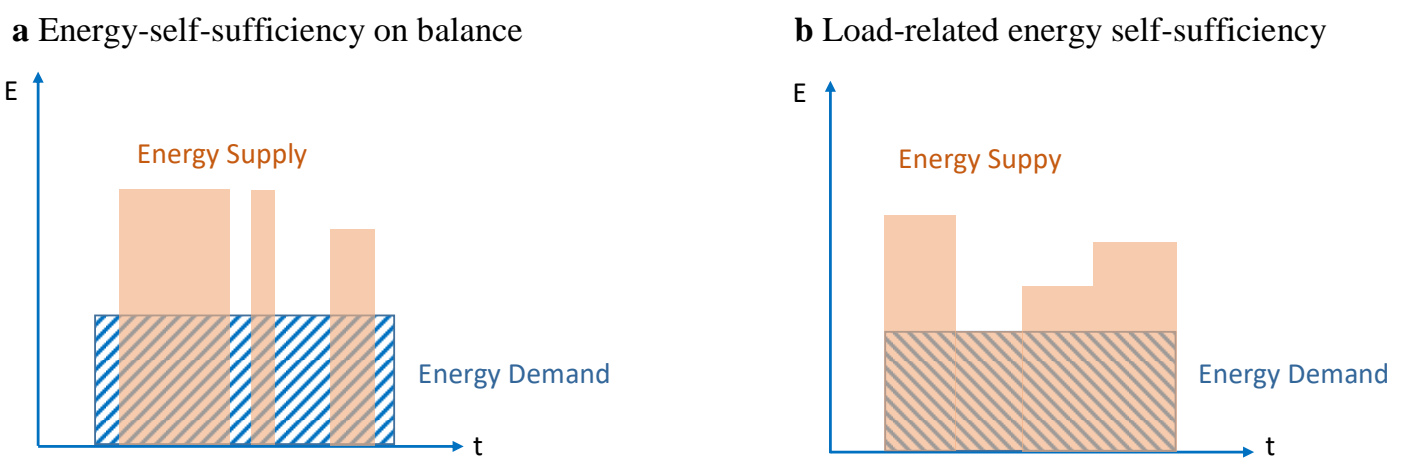

Fig. 1: Distinction between energy self-sufficiency on balance (a) and load-related energy self-sufficiency (b) (Deutschle et al. 2015)

\section{Methodology and Boundary Conditions}

The simulation environment "Polysun Designer" is used for the modeling of the energy systems (building model, energy supply system model and energy storage model). The software allows dynamic simulations of the annual energy demand and energy supply with a high temporal resolution. "Polysun Designer" is a software for the simulation of building energy systems developed and distributed by Vela Solaris. Polysun carries out dynamic annual simulations with a temporal resolution of up to one minute. The output parameters are, for example, the yield of the PV (Photovoltaic) system, the PV self- consumption factor or the annual performance factor of a heat pump.

Fig. 2 shows the basic process of a simulation with Polysun Designer. First, the input parameters are defined. These include the climate data, the building data (U-values, g-values, building dimensions) and the load profiles of the energy consumers (hot water, household electricity). The energy system is built on individual components (e.g. heat pump, PV system, battery storage system, building). The dimensioning of the system components is based on recommendations of the component manufacturers.

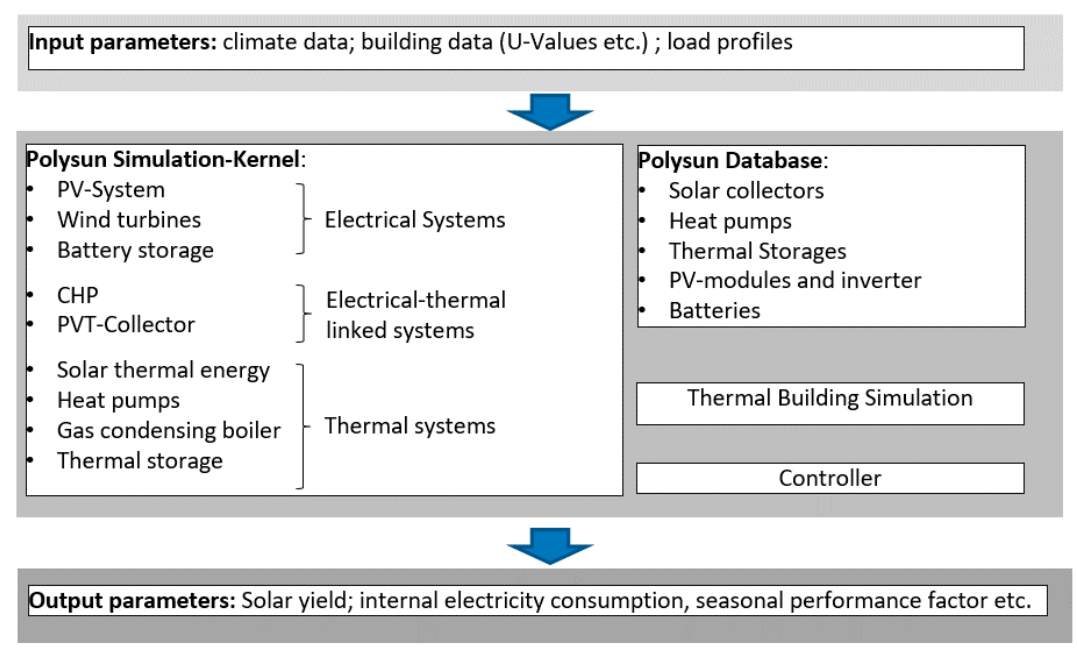

Fig. 2: Simulation process with "Polysun Designer"

To be able to assess the energy self-sufficiency potential for residential buildings, the definition of energy evaluation parameters is necessary. According to McKenna et al (2015b), the level of load-related energy selfsufficiency $a$ and the PV self-consumption factor $e$ can be used for this. The load-related energy self-sufficiency is defined as the ratio between energy production $E_{E}$ and energy consumption $V_{G}$ McKenna et al. (2015b). 


$$
\mathrm{a}=\frac{\mathrm{E}_{\mathrm{E}}}{\mathrm{V}_{\mathrm{G}}}=\frac{\int_{0}^{t} \dot{E}_{E} \cdot d t}{\int_{0}^{t} \dot{V}_{G} \cdot d t}
$$

The PV self-consumption factor $e$ is the share of electricity (i.e. considering storage losses) that is used in the building itself. $\mathrm{E}_{\mathrm{ES}}$ describes the amount of energy used for own electricity consumption:

$$
\mathrm{e}=\frac{\mathrm{E}_{\mathrm{ES}}}{E_{E}}=\frac{\int_{0}^{t} \dot{\mathrm{E}}_{\mathrm{ES}} \cdot d t}{\int_{0}^{t} \dot{E}_{E} \cdot d t}
$$

The paper considers two building energy standards to determine the influence of the heat demand on the energy self-sufficiency potential. For this purpose, a new building and an existing building are examined (cf. Table 1). The building energy standard of the new building is oriented towards the requirements of the passive house standard. The building energy standard of the existing is based on data of the German building stock and meets the requirements of the German Building Insulation Ordinance of 1995 (WSVO 95) (BUND 1994). The singlefamily building has a heated living area of $163 \mathrm{~m}^{2}$. The multifamily building has five apartment units with a total heated living area of $258 \mathrm{~m}^{2}$ (cf. Table 1).

The temporal resolution for this simulation is 15 minutes. The minimum level of energy self-sufficiency and the personal power consumption is determined for a one-year period. The investigated forms of self-sufficiency are load-related electricity self-sufficiency $\left(a_{\text {electricity }}\right)$, load-related heat self-sufficiency $\left(a_{\text {heat }}\right)$ and load-related energy self-sufficiency $\left(a_{\text {energy }}\right)$ which is the total of electricity and heat. In addition, the PV self-consumption factor $\left(e_{\text {Electricity }}\right)$ is calculated. The energy demand for mobility (fuels) and the energy use of raw materials / technologies (grey energy) are not included in the following analysis.

The "future" test reference year of region 6 (Germany) is the basis for the heat demand calculation as well as the yield calculation of the PV and the solar thermal systems. The climate data of the test reference years (TRY) of the German Weather Service (DWD) contain measurement data, such as the outdoor temperature and solar radiation, in hourly resolution for 15 representative regions in Germany (DWD 2011).

\begin{tabular}{|c|c|c|c|c|c|}
\hline & \multirow[b]{2}{*}{ Unit } & \multicolumn{2}{|c|}{ SFB } & \multicolumn{2}{|c|}{ MFB } \\
\hline & & $\begin{array}{l}\text { Existing } \\
\text { Building }\end{array}$ & $\begin{array}{c}\text { New } \\
\text { Construction }\end{array}$ & $\begin{array}{l}\text { Existing } \\
\text { Building }\end{array}$ & $\begin{array}{c}\text { New } \\
\text { Construction }\end{array}$ \\
\hline Specific heating demand & $\mathrm{kWh} / \mathrm{m}^{2}$ & 100 & 17 & 98 & 16 \\
\hline Specific domestic hot water demand & $\mathrm{kWh} / \mathrm{m}^{2}$ & 9.8 & & 20.5 & \\
\hline Household electricity demand & $\mathrm{kWh} / \mathrm{a}$ & 3500 & & 15000 & \\
\hline Air handling unit electricity demand & $\mathrm{kWh} / \mathrm{a}$ & - & 627 & & 1331 \\
\hline Solar thermal storage volume & $\begin{array}{l}1 / \mathrm{m}^{2} \text { (Solar thermal } \\
\text { module area) }\end{array}$ & 90 & & 90 & \\
\hline Number of residents & - & 3 & & 10 & \\
\hline Gross floor area $\left(\mathrm{A}_{(\text {Grosss }}\right)$ & $\mathrm{m}^{2}$ & 263 & & 419 & \\
\hline Living space $\left(\mathrm{A}_{\text {(living) }}\right)$ & $\mathrm{m}^{2}$ & 203 & & 323 & \\
\hline Heated living space ( $\left.A_{\text {(living,heated) }}\right)$ & $\mathrm{m}^{2}$ & 163 & & 258 & \\
\hline Households / living units & - & 1 & & 5 & \\
\hline Residents per unit & - & 3 & & 2 & \\
\hline Building floor area & $\mathrm{m}^{2}$ & 88 & & 105 & \\
\hline Roof slope & $\circ$ & 50 & & 35 & \\
\hline Roof orientation & - & North-South & & North-South & \\
\hline Surface-area to volume ratio & $\mathrm{m}^{2} / \mathrm{m}^{3}$ & 0.84 & & 0.7 & \\
\hline
\end{tabular}

Tab. 1: Summary of the system parameters for the single-family building (SFB) and multi-family building (MFB)

The temporal structure of the energy demand is determined using load profiles. The load profiles for electricity and hot water, with a temporal resolution of up to 1 minute, are taken from the VDI 4655 (VDI 4655 2008). The energy consumption of the building heating system is calculated for each hour of the year using Polysun Designer and consists of the power consumption of the heat distribution pumps and the power consumption of the heat pumps. The load profile for the building heat demand is calculated with the dynamic building energy model for 
each time step of the simulation. Transmission heat losses, heat losses through ventilation and infiltration, passive heat gains through solar radiation and internal gains are calculated. Thus, the influence of the effective heat storage capacity of the building is considered (Vela Solaris 2014).

For the economic evaluation, all costs related to the building energy supply are considered. The costs include the investment costs of the system components as well as the gas and electricity procurement costs. Revenue from feeding PV electricity into the public grid leads to a reduction in costs (feed-in tariff). Other funding programs in addition to the EEG (German Renewable Energy Law) are not considered for this study. The overall annual costs (annuity) are calculated from the expenditure and revenue according to VDI 2067. The assumptions listed in Table 2 are used for the economic valuation.

Tab. 2: Summary of the assumptions for the economic evaluation

\begin{tabular}{lll}
\hline & Unit & Assumption \\
\hline Reporting period & $\mathrm{a}$ & 20 \\
Imputed interest rate & $\%$ & 4 \\
Energy price alteration & $\%$ & 4 \\
Maintenance price alteration & $€ / \mathrm{kWh}$ & 2.5 \\
Energy price / feed-in remuneration & $€ / \mathrm{kWh}$ & 0.26 \\
Electricity price (incl. value added tax) & $€ / \mathrm{kWh}$ & 0.12 \\
Feed in remuneration & & $0.066-0.1$ \\
Gas price (incl. value added tax) depending on annual gas consumption & \\
Solar systems (incl. assembly without electrical/thermal energy storage) & $€ / \mathrm{kWp}^{2}$ & 1650 \\
Price PV-System (incl. value added tax) & $€ / \mathrm{m}^{2}$ & 302 \\
Price PV-System (incl. value added tax) & $€ / \mathrm{m}^{2}$ & $750-1030$ \\
Price solar-thermal system (incl. value added tax) & & \\
Electrical/thermal energy storage & $€ / \mathrm{kWh}$ \\
Battery storage price (incl. value added tax) & $€ / l$ & 1675 \\
Thermal storage price (incl. value added tax) & $€$ & 1.1 \\
Gas-fired condensing boiler & & 4168 \\
\hline
\end{tabular}

\section{Energy Supply Systems}

The energy supply systems are selected to cover the highest possible share of the buildings' energy demand with renewable energies. For the single-family building, the electricity- and heat supply are entirely based on electricity. The electricity supply is provided by a PV system and an AC-coupled battery storage system as well as a connection to the public grid. An electric heat pump is used for the heat supply of the building. The electric heat pump is connected to a vertical geothermal tubing system (see Fig. 4). The external energy source of the heat pump is either supplied by PV electricity, electricity from the battery storage, or electricity from the public grid. The heat pump is also connected to thermal storage. PU rigid foam with an insulation thickness of $150 \mathrm{~mm}$ is used as insulation material for the thermal storage. The HVAC control strategy is designed to achieve the highest possible degree of energy self-sufficiency. Priority is given to the energy supply of electricity consumers (household appliances + heat pump) with PV electricity. If excess PV electricity is available, the battery storage is charged. If the battery storage is fully charged and there is still excess electricity available from the PV system, the PV energy is thermally stored by extended heat pump operation (excess control). The requirement for this control is that the current PV output exceeds the required electrical load of the heat pump. The excess temperature control of the heat pump increases the temperature setpoint of the thermal storage from 50 to $60{ }^{\circ} \mathrm{C}$. Furthermore, the night-time room-temperature setback of three Kelvin leads to a shift of the heat pump operation into the hours of the day. This makes frequent operation of the heat pump with PV electricity possible. Another advantage of the night-time temperature-setback is that the heat pump won't discharge the battery storage overnight. As a result, the household electricity consumers can use the temporarily stored PV electricity. An air handling unit is available for the new construction building to ensure an adequate ventilation. 


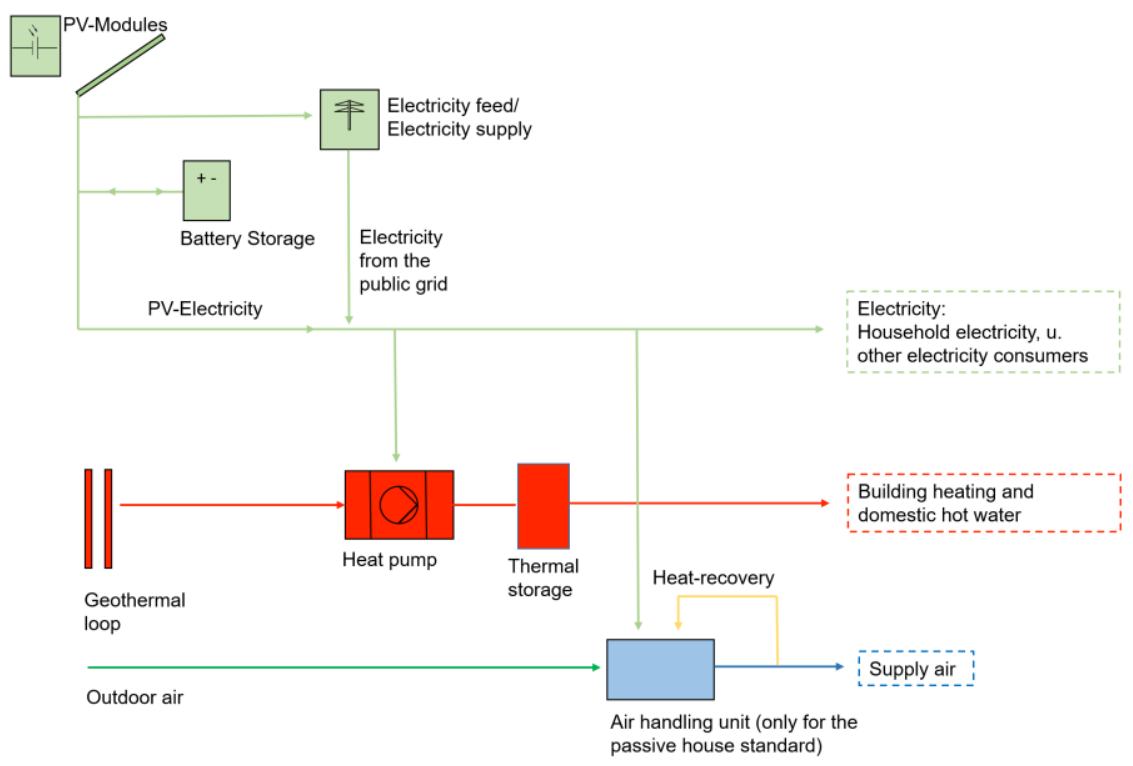

Fig. 4: Schematic of the heat and electricity supply of the single-family building

The electrical energy supply of the multi-family building is provided by a PV system, which is coupled to battery storage (see Fig. 5). In addition, a connection to the public power grid is available. According to the operating strategy, PV energy is first used for the direct supply of the electricity consumers. If excess PV electricity is available, it is used to charge the battery storage. Battery charging by the public grid electricity is not possible. Further excess electricity production of PV electricity is fed into the public grid. If the PV system is not able to meet the electricity loads, the battery will be discharged. If the battery is completely discharged, electricity is obtained form the public grid. The heating demand is met by a gas condensing boiler and a solar-thermal heating system. Both heat sources are connected to thermal storage, which is divided into two zones. The upper third of the thermal storage is used for DHW heating and has temperatures of $50-60{ }^{\circ} \mathrm{C}$. With a fresh water station, the cold water is heated to the set-point temperature using an external heat exchanger. The lower $2 / 3$ of the thermal storage are available for room heating purposes. A heat exchanger is integrated in the lower storage section, which enables the solar collectors to be integrated.

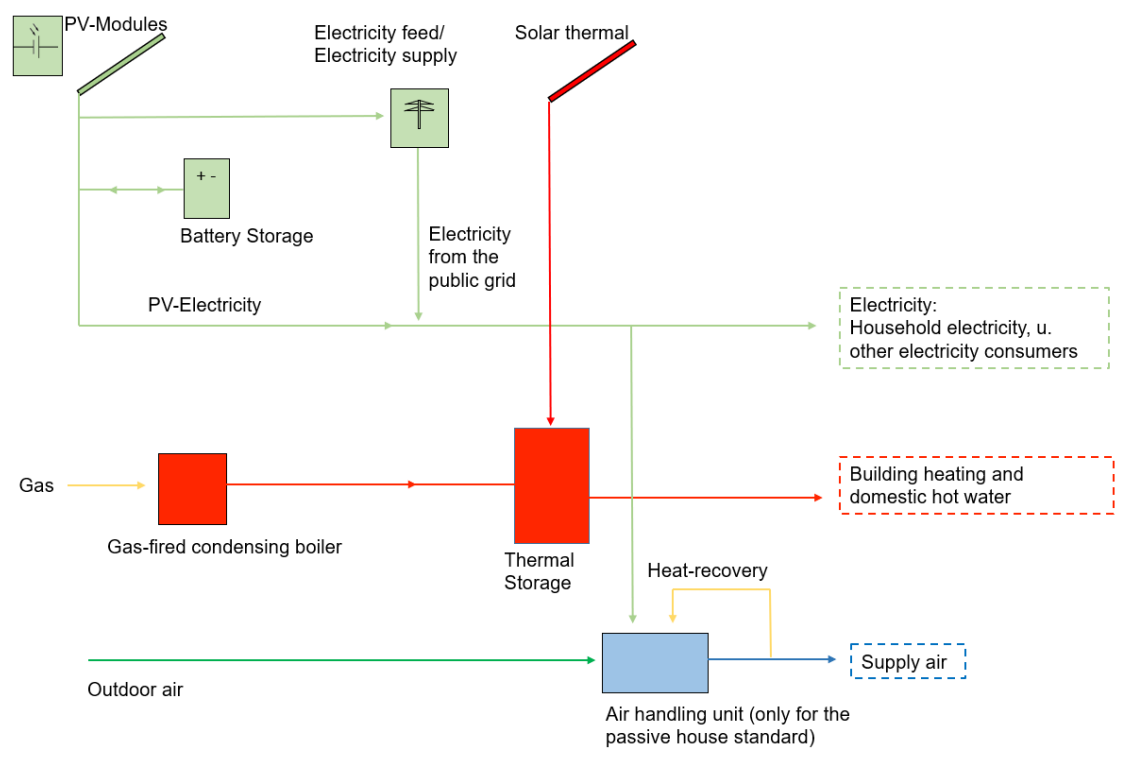

Fig. 5: Schematic of the heat and electricity supply of the multi-family building

Sensitivity analyses vary the roof area for PV and solar thermal systems from 0 to $100 \%$. The battery storage capacity varies between 0 and $20 \mathrm{kWh}$. The available roof area for energetic use is used completely for regenerative energy generation by PV modules or solar thermal collectors. Deductions due to roof installations etc. are considered. 


\section{Results for Energy Self Sufficiency}

To show the main influences on the load-related electricity self-sufficiency, the results for the single-family building (passive house standard) are presented first. The analysis of the load-related electricity self-sufficiency shows that a PV system with $20 \mathrm{kWh}$ battery storage can cover up to $82 \%$ of the household electricity demand (see Fig. 6a). With an increase in battery storage capacity, the largest increase in load-related electricity selfsufficiency and PV self-consumption can be achieved. Without a battery storage, the increase of PV roof area from 0 to $100 \%$ only leads to a slight increase of the load-related electricity self-sufficiency from 22 to $37 \%$ and also leads to a sharp reduction of the self-consumption factor from 65 to $19 \%$. The results for the new construction building shown in Fig. 6a can also be transferred to the existing building. For the existing building, the loadrelated electricity self-sufficiency levels are between 1-2 \% above those of the new construction building, as the electricity consumption of the ventilation system is eliminated. For the multifamily building, $44 \%$ of the consumer electricity consumption can be covered if the entire roof is utilized for PV modules and a $20-\mathrm{kWh}$ battery storage is used (see Fig. 6b). Without a battery storage, the maximum load-related electricity factor is $30 \%$. Compared to the single-family building, the multi-family building has significantly higher electricity self-consumption factors (cf. Fig. 6b). Due to the higher electricity demand compared to the single-family building, consumer electricity uses a significantly higher proportion of PV energy.
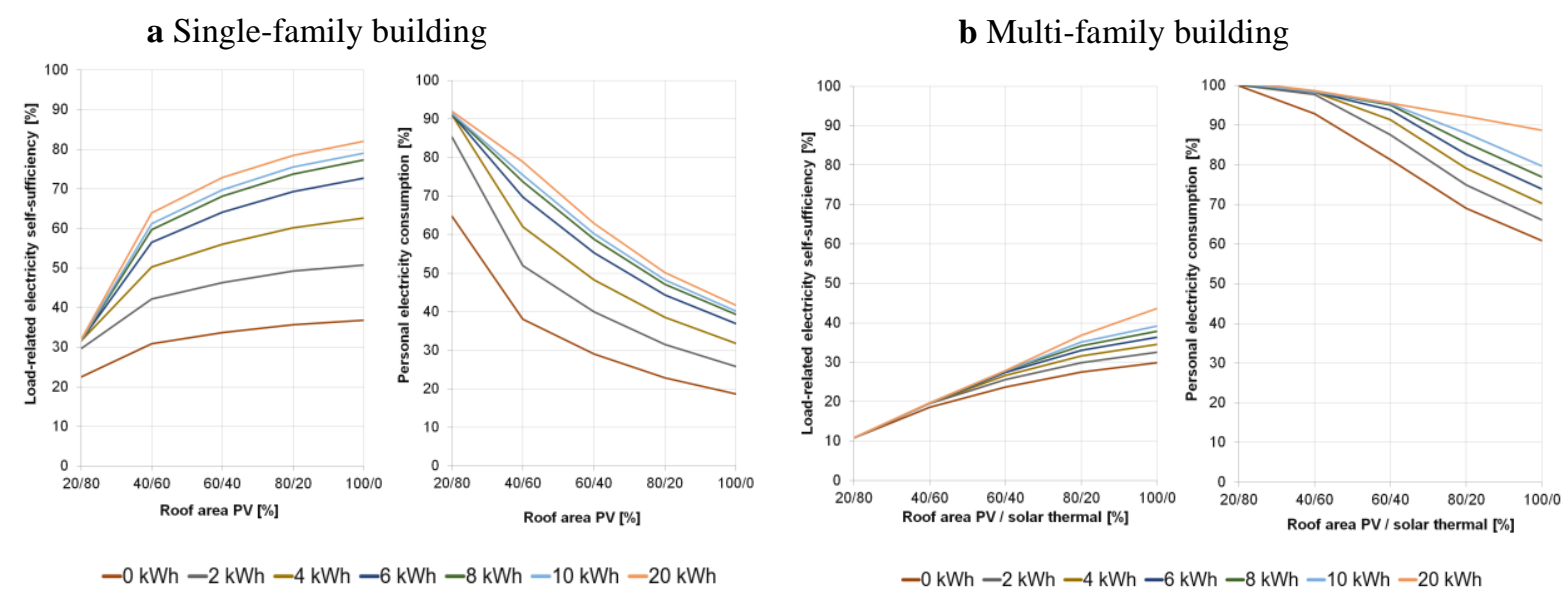

Fig 6: Influence of the PV roof area share and the battery capacity on electricity self-consumption and load-related electricity selfsufficiency for the single-family building (a) and multi-family building (b) both for new construction.

The maximum degrees of load-related heat self-sufficiency for the single-family building are between $55 \%$ (passive house standard) and $30 \%$ (existing building). The highest rates of load-related heat self-sufficiency are achieved if the entire roof surface of is covered with PV modules. For the multi-family building, the maximum load-related heat self-sufficiency is $57 \%$ for the new construction building and up to $24 \%$ for the existing building. The maximum degrees of heat self-sufficiency are achieved when the entire roof area is covered with solar thermal collectors.

A total load-related energy self-sufficiency is neither possible for the single-family building nor for the multifamily building. For the single-family building, a maximum of $45 \%$ (existing building) to $71 \%$ (new construction building) of the building's energy demand can be covered with renewable energies. The maximum load-related energy self-sufficiency levels are achieved with $100 \% \mathrm{PV}$ roof area and a battery capacity of $20 \mathrm{kWh}$. For both building standards, an increase in the degree of energy self-sufficiency can be seen for both building types with an increasing proportion of PV roof area and increasing battery storage capacity (see Fig. 7). 


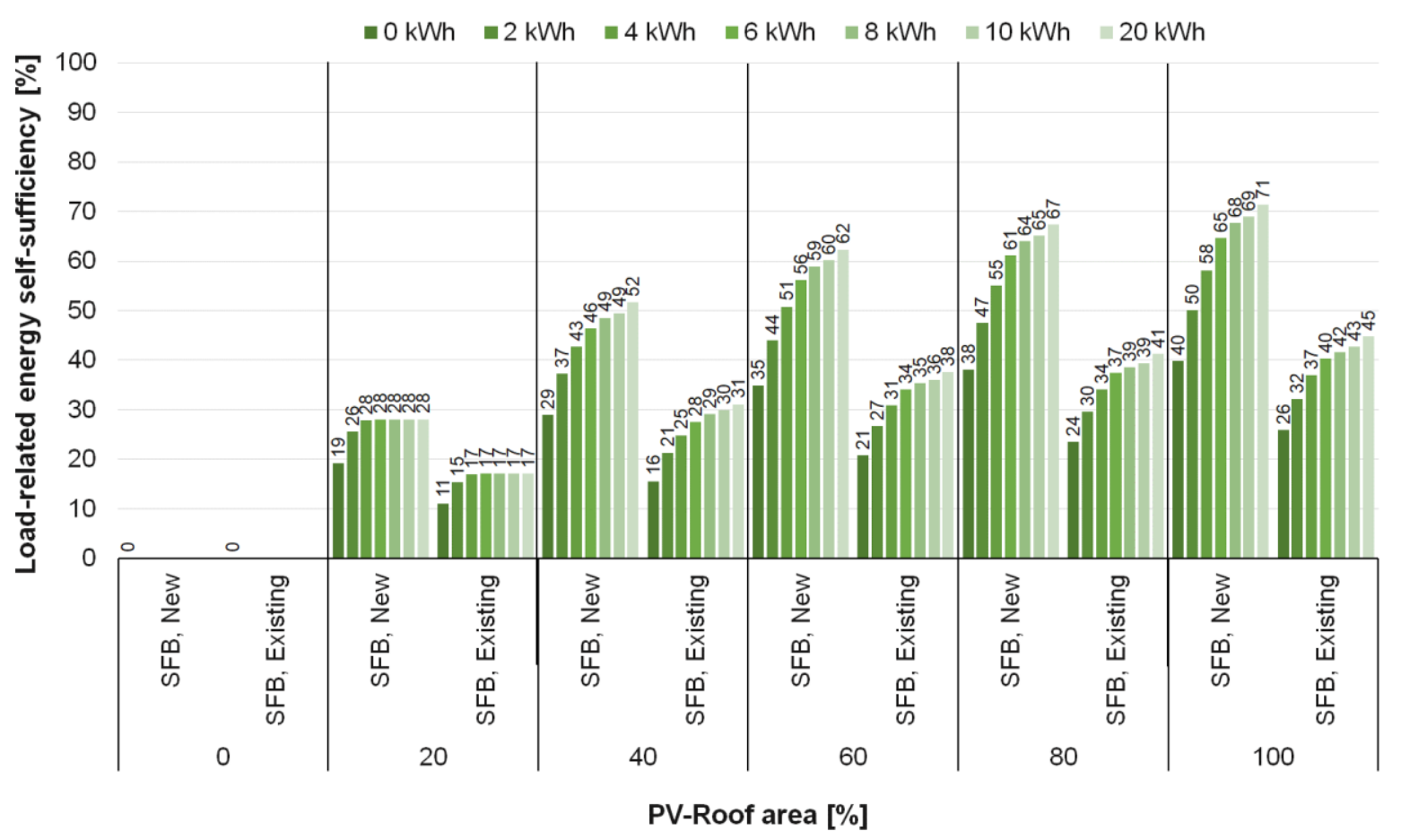

Fig. 7: Influence of PV roof area and battery capacity on the load-related energy self-sufficiency for the single-family building (SFB)

For the multi-family building the maximum load-related energy self-sufficiency is $20 \%$ for the existing building and $36 \%$ for the new construction. For both building types, an increase in load-oriented energy self-sufficiency up to a PV/Solar-thermal roof area of $60 \% / 40 \%$ and a battery capacity of $6 \mathrm{kWh}$ can be seen. A further increase in the PV area with a simultaneous reduction of solar thermal roof area leads to lower load-oriented energy selfsufficiency factors. This is due to the fact that the additional PV yield can only be stored to a limited extent in the battery and thus the grid feed-in increases.

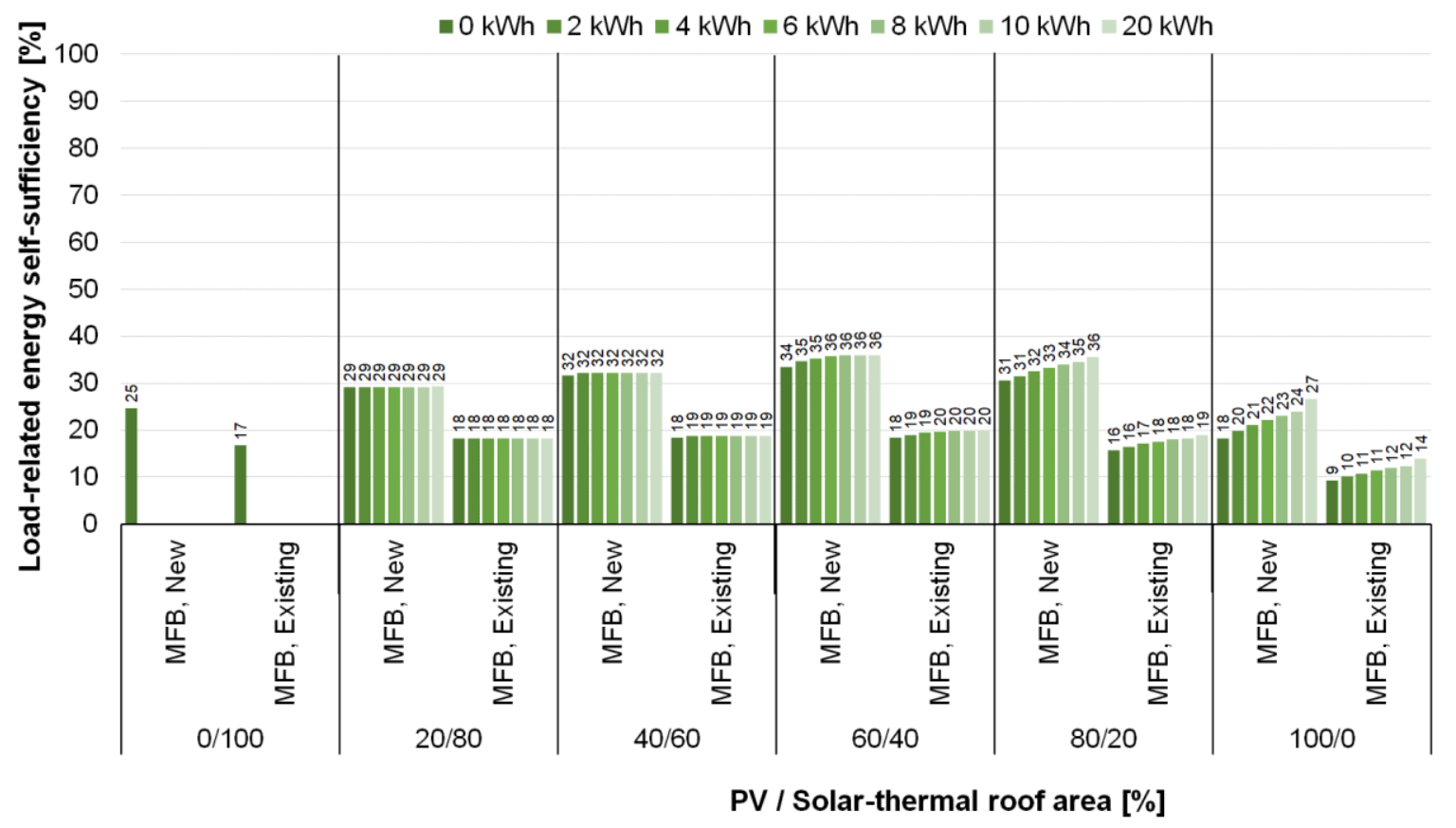

Fig. 8: Influence of PV/solar thermal roof area and battery capacity on the load-related energy self-sufficiency for the multi-family building (MFB) 


\section{Results for Cost-Effectiveness}

The economic evaluation consists of a cost comparison of the selected energy systems with a conventional energy supply system as a base case. The base case consists of a gas condensing boiler and an electricity connection to the public grid. The reference costs for the single-family building are 2,679 €/a for the new construction and 3,890 $€ / \mathrm{a}$ for the existing building. For the multifamily building the costs amount to $7,760 € / \mathrm{a}$ for the new construction and $9,250 € / \mathrm{a}$ for the existing building.

The combination of a heat pump with a PV system is not economical under current conditions compared to a conventional energy supply for the single-family building, since the annuities without battery storage are 32 to 59 $\%$ above those of the base case. With a battery storage, the annuities are even up to $163 \%$ higher than the base case (see Fig. 8). The annual payments for the maximum degree of load-related energy self-sufficiency are $140 \%$ (existing building) respectively $163 \%$ (new construction) above the base case. This shows that the advantage of the higher PV self-consumption due to the additional investment in a battery storage does not outweigh the cost disadvantage.

The selected energy system of the multi-family building is not economical compared to the base case for the maximum of load-related energy self-sufficiency (60/40\% PV/Solar-thermal roof area). For this PV/Solarthermal combination the annuities are $23 \%$ (new construction) and $21 \%$ (existing building) above the base case (see Fig. 9). With the maximum of battery storage capacity, the annuities are up to $31 \%$ higher compared to the base case. However, there are also economic advantages for certain system combinations. If the available roof area is fully utilized with PV modules in combination with $4 \mathrm{kWh}$ battery storage, the annuities are between 7,113 $€ / \mathrm{a}$ and 7,657 €/a for the new building and 8,710 €/a and 9,250 €/a for the existing building. Thus, the annuities are below the base case. The reason for the lower annuities compared to the base case is the high PV electricity self-consumption of the multi-family building. Due to the electricity price of $0.26 € / \mathrm{kWh}$, the savings in electricity costs have a greater impact on the annuity than the possible increase in income from the feed-in tariff of 0.12 $€ / \mathrm{kWh}$.

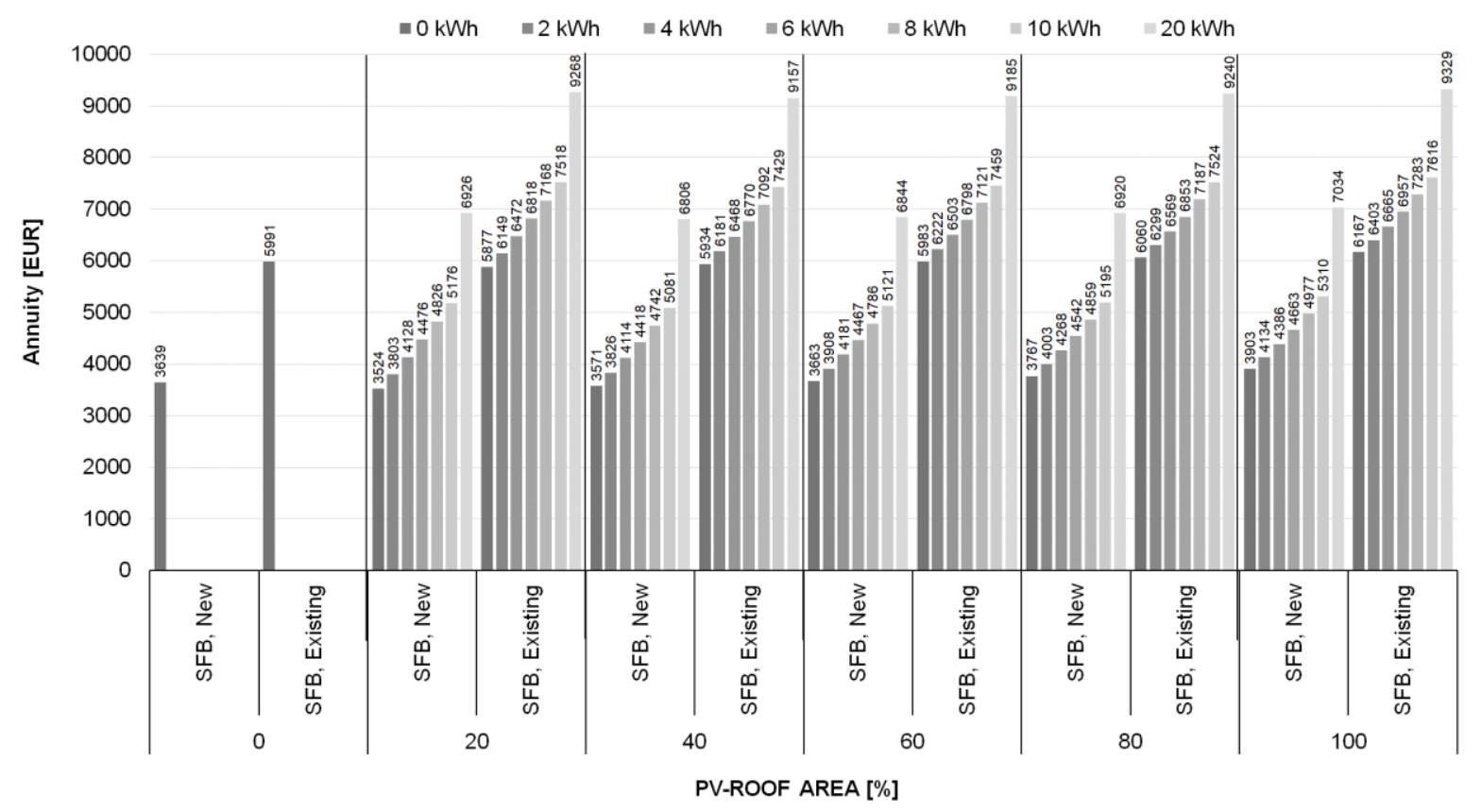

Fig. 8: Influence of PV/solar thermal roof area and battery capacity on annuity for the single-family building (SFB) 


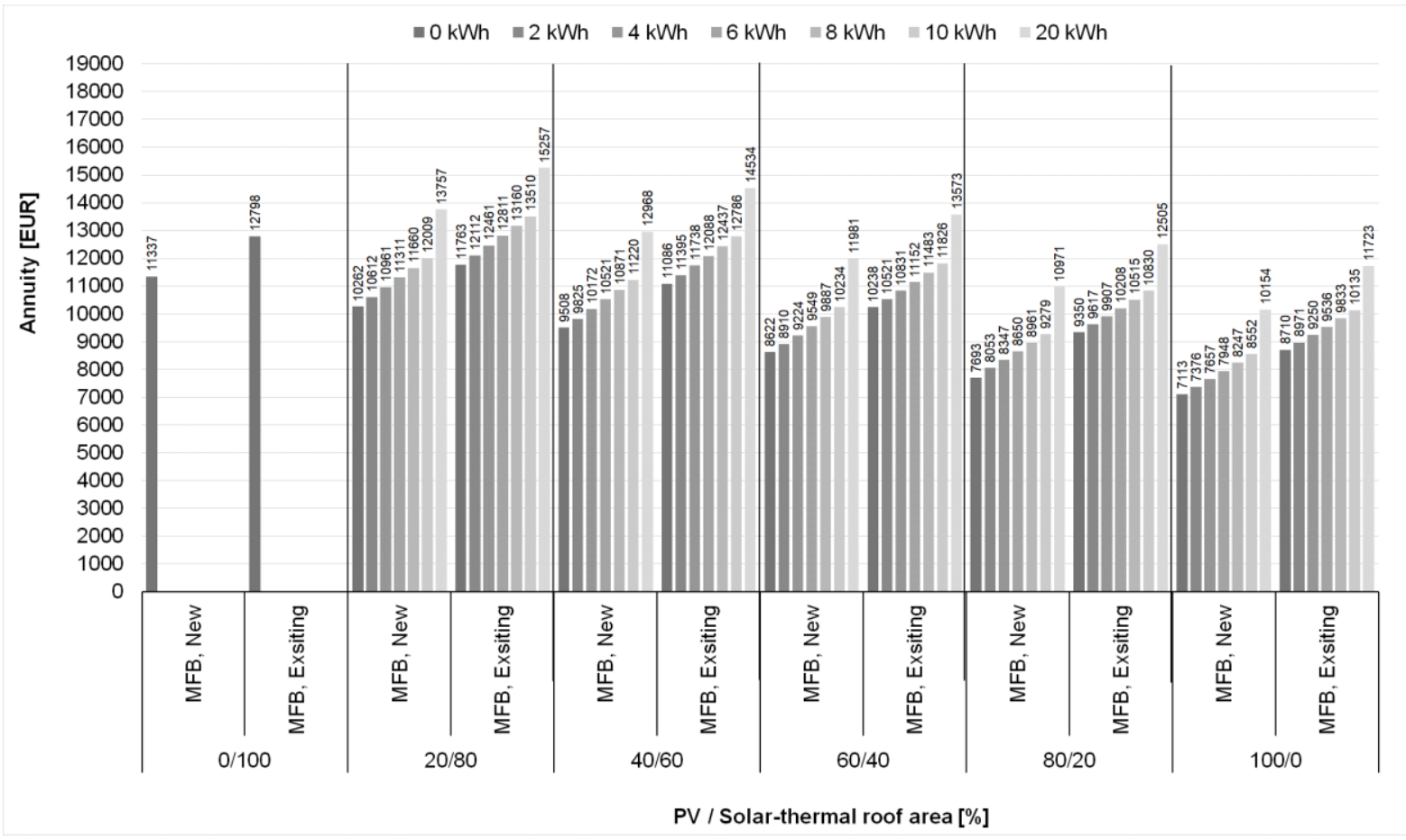

Fig. 9: Influence of PV/Solar-thermal roof area and battery capacity on annuity for the multi-family building (MFB)

\section{Conclusion}

Based on the reduction of greenhouse gas emissions and the associated increased use of renewable energies, this paper analyses the technical and economical potential of load-related energy self-sufficiency for the energy supply of single-family and multi-family buildings. To evaluate the effect of different heating requirements, the analysis distinguishes between a new construction and an existing building. The modeling of the energy systems (building model, heat supply systems, PV and battery storage technologies) was carried out with the simulation environment "Polysun-Designer", which enables a high-resolution and dynamic annual simulation of energy demand and energy supply.

The analysis of the load-related electricity self-sufficiency has shown that a PV system can cover up to $37 \%$ of the household electricity demand of a single-family building. By using a battery storage, the load-related electricity self-sufficiency can be increased up to $82 \%$. For the multi-family building, the maximum degree of load-related electricity self-sufficiency with a PV system is $30 \%$ and can be increased to $43 \%$ with a $20-\mathrm{kWh}$ battery storage. A full load-related electricity self-sufficiency is not possible and a connection to the public utility is necessary for all the analyzed buildings. The results of the load-related heat self-sufficiency indicate that, depending on the building energy standard, the maximum values are $30 \%$ (existing building) and $55 \%$ (new construction) for the single-family building and $24 \%$ (existing building) and $57 \%$ (new construction).

A full load-related energy self-sufficiency is not possible for any of the analyzed building types and energy standards. The highest degree of load-related energy self-sufficiency can be achieved with a PV system in combination with a heat pump and a battery storage. Depending on the building energy standard, a maximum of $45 \%$ (existing building) to $71 \%$ (new building) of the building energy demand can be covered by renewable energies for the single-family building. The highest degree of load-related energy self-sufficiency for the multifamily building can be achieved with a utilization of the roof area with $60 \% \mathrm{PV}$-modules and $40 \%$ solar thermal modules. The values range between $20 \%$ (existing building) and $36 \%$ (new construction) for the multi-family building.

The economic evaluation for the single-family building has shown that none of the investigated technologies can compete with a conventional energy supply (connection to the public grid + gas condensing boiler). For the multifamily building, some of the investigated energy system combinations show a cost benefit compared to a conventional energy supply. However, the maximum degrees of load-related energy self-sufficiency are not beneficial from an economic point of view. 
The paper has shown how partially load-related energy self-sufficiency for single-family and multi-family buildings can be achieved both for new and existing building energy standards. Therefore, the utilization of PVmodules and solar thermal systems, as well as thermal and battery storage technologies are necessary. The attainable degree of energy self-sufficiency depends to a large extent on the building heat demand. A partially load-related energy self-sufficiency can be realized for residential buildings but at very high costs for most of the cases.

This conclusion can only apply to the investigated buildings and the assumed economic conditions. Future price developments in the energy sector (e.g. feed-in rate, energy prices, battery storage and equipment costs, costs for $\mathrm{CO}_{2}$ emissions) may lead to a reassessment of the results.

The influence on the energy distribution network is negligible for this analysis. However, the increased use of renewable energies can lead to burdens on the energy system that need to be investigated in more detail. In addition, mobility and grey energy can be included in the evaluation of energy self-sufficiency in further studies.

\section{References}

Bardt H, Chrischilles E, Growitsch C, Hagspiel S, Schaupp L (2014) Eigenerzeugung und Selbstverbrauch von Strom - Stand, Potentiale und Trends. Z Energiewirtsch 38:83-99

Bundesregierung (1994) Verordnung über einen energiesparenden Wärmeschutz bei Gebäuden (Wärmeschutzverordnung - WärmeschutzV) vom 16. August 1994

Deutscher Wetterdienst (2011) Aktualisierte und erweiterte Testreferenzjahre von Deutschland für mittlere, extreme und zukünftige Witterungsverhältnisse. http://www.bbsr.bund.de/EnEVPortal/

DE/Regelungen/Testreferenzjahre/Testreferenzjahre/03_ergebnisse. html?nn=437706. Zugegriffen: 21. September 2015

Deutschle J, Hauser W, Sonnberger M, Tomaschek J, Brodecki L, Fahl U (2015) Energie-Autarkie und EnergieAutonomie in Theorie und Praxis. Z Energiewirtsch 39:151-162

McKenna R, Herbes C, FichtnerW(2015a) Energieautarkie: Vorschlag einer Arbeitsdefinition als Grundlage für die Bewertung konkreter Projekte. Z Energiewirtsch 39:235-252

McKenna R, Herbes C, FichtnerW(2015b) Energieautarkie: Definitionen, Für- bzw. Gegenargumente, und entstehende Forschungsbedarfe. KiT working paper series in production and energy, Karlsruhe

McKenna R, Merkel E, Fichtner W (2016) Energy autonomy in residential building: A techno-economic modelbased analysis of the scale effects. Appl Energy. doi:10.1016/j.apenergy.2016.03.062

Tomaschek J, Fahl U, Brodecki L (2015) Analyse des Energie-Autarkiegrades unterschiedlich großer Bilanzräume mittels integrierter Energiesystemmodellierung. http://fachdokumente.lubw.badenwuerttemberg.de/servlet/is/122354/bwe13033 bwe13034_final.pdf?command=downloadContent\&filename=bw e13033_bwe13034_final.pdf\&FIS=203 Zugegriffen: 5. November 2015

VDI 4655 (2008) Referenzlastprofile von Ein- und Mehrfamilienhäusern für den Einsatz von KWK-Anlagen, Verein Deutscher Ingenieure (VDI), Beuth Verlag, Düsseldorf

Vela Solaris (2014) Polysun Simulation Software. Benutzerdokumentation 


\section{Appendix:}

Table 1: Photovoltaic System Performance Figures

\begin{tabular}{|c|c|c|c|}
\hline Manufacturer & \multicolumn{3}{|c|}{ BenQ Solar } \\
\hline Typ & \multicolumn{3}{|c|}{ GreenTriplex PM060M02 } \\
\hline Rated Output & \multicolumn{3}{|c|}{$290 \mathrm{~W}$} \\
\hline Module Efficiency & \multicolumn{3}{|c|}{$18 \%$} \\
\hline Dimensions $(\mathrm{L} \times \mathrm{W} \times \mathrm{H})$ & \multicolumn{3}{|c|}{$1,639 \mathrm{~m} \times 0,983 \mathrm{~m} \times 0,04 \mathrm{~m}$} \\
\hline Gross Area & \multicolumn{3}{|c|}{$1,61 \mathrm{~m}^{2}$} \\
\hline Temperature coefficient & \multicolumn{3}{|c|}{$-0,42 \% / \mathrm{K}$} \\
\hline & & Unit & Value \\
\hline Reduction of PV yield due & ination & $\%$ & 2 \\
\hline Degradation per year & & $\%$ & 0,2 \\
\hline Wind Share & & $\%$ & 50 \\
\hline Rear Ventilation & & - & medium \\
\hline Cable Losses & & $\%$ & 2 \\
\hline
\end{tabular}

Table 2: Battery Performance Figures

\begin{tabular}{lcc} 
& Unit & Technical Details \\
\hline Nominal Capacity & $\mathrm{kWh}$ & $2 \mathrm{kWh}$ (expandable in 2 kWh steps) \\
Battery Technology & - & lithium iron phosphate \\
Battery Coupling & - & AC-Coupling \\
Max. Battery Efficiency & $\%$ & 98 \\
Max. Efficiency Battery Inverter & $\%$ & 96 \\
Battery Life & $\mathrm{a}$ & 20 \\
Charging Cycles & - & 10000 \\
Max. Discharge Depth & $\%$ & 100 \\
Warranty on the battery cells & $\mathrm{a}$ & 10 \\
\hline
\end{tabular}

Table 3: Solar Thermal System Performance Figures

\begin{tabular}{lcc} 
& Unit & Technical Details \\
\hline Gross Surface & $\mathrm{m}^{2}$ & 2,36 \\
Absorber Area & $\mathrm{m}^{2}$ & 1,6 \\
$\eta_{0}$ & - & 0,756 \\
$\alpha_{1}$ & - & 1,362 \\
$\alpha_{2}$ & - & 0,002 \\
$c_{\text {eff }}$ & $\mathrm{kJ} / \mathrm{K}$ & 19,6 \\
\hline
\end{tabular}

Table 4: Heat Pump Performance Figures

\begin{tabular}{lcc} 
& Heat Pump New Construction & Heat Pump Existing Building \\
\hline Manufacturer & Viessmann & Viessmann \\
Typ & Vitocal $300-G$ BWC.06 & Vitocal 300-G BWC. 10 \\
Heating Capacity & 5,69 & 10,36 \\
COP & 4,6 & 5,01 \\
Refrigerant & R410A & R410A \\
Max. Supply Water Temperature & $65^{\circ} \mathrm{C}$ & $65^{\circ} \mathrm{C}$
\end{tabular}




\title{
Pipe Network Analysis for Solar Thermal Plants \\ Ralph Eismann
}

\author{
University of Applied Science Northwestern Switzerland FHNW, Institute Energy in Buildings, \\ Muttenz (Switzerland)
}

\begin{abstract}
Efficiency, cost-effectiveness and operational safety of solar plants must be based on the knowledge of pressure loss as well as flow distribution and temperature distribution of branched collector arrays. Therefore, pipe network analysis is an essential step during the dimensioning process. This article presents an explicit, fast converging numerical scheme especially suited for collector fields. The effect of pipe dimensions and pipe routing on flow, temperature and pressure-distribution and collector field efficiency is demonstrated by application of a dedicated software tool, which is provided as an open source code.
\end{abstract}

Keywords: Pipe network analysis, flow distribution, pressure loss

\section{Introduction}

Circuits of large solar plants are branched networks of pipes. Pipe network analysis is needed to find the best solution among the many possible ways of pipe routing, the corresponding pipe diameters and the pump size. The optimum is characterized by the minimum of costs while each of the auxiliary conditions, e.g. pressure loss, limiting flow velocity, maximum variation of exit temperatures and thermal efficiency, are fulfilled. Several approaches for cost optimization of pipe networks can be found in literature. Murphy et al. (1993) developed an algorithm for water supply networks. Frank (2007) derived a numerical scheme for the optimization of pipe routing, pipe dimension and pump power of a large solar plant for district heating. Park et al. (2017) developed a model for the optimization of district heating networks.

A pipe network is characterized by the geometry of the pipes and the nodes where pipes are connected to other pipes. A node connecting two pipes is called junction. A node where two pipes with the same direction are connected and a third pipe is connected perpendicularly to the same node is called T-junction. A node is considered zero-dimensional. It can therefore store neither mass nor energy. A pipe or a series of pipes connecting two neighboring nodes defines a branch. A branch can also contain hydraulic elements such as valves, pumps or heat exchangers. A path consists of a series of branches. A closed path within a pipe network defines a loop. A loop is called elementary if the number of its nodes cannot be reduced by a shortcut. A pipe network is irregular if elementary loops of different size are arranged in an irregular pattern. A network is called periodical if it is dominated by a repeated arrangement of identical elementary loops. Periodical networks usually contain branches that dominate the pressure loss. These branches are named strings. Strings often consist of a series of identical hydraulic elements, e.g. serially connected solar collectors. In periodical networks, arrays of identical strings are connected in parallel by distribution and collection manifolds.

All methods for pipe network analysis are based on conservation equations for mass and momentum. Since fluid properties are temperature dependent, energy conservation must also be considered. The flow distribution within a pipe network is expressed by two sets of equations. The node-equations (1) define mass conservation in each node, $j$, where, $m$ is the number of pipes connected, $\rho_{k}$, is the density of the liquid entering or leaving the branch, $k$, and, $\dot{V}_{k}$, is the flow rate in the same branch.

$$
\sum_{k=1}^{m} \rho_{k j} \dot{V}_{k j}=0
$$


Ralph Eismann

The loop-equations (2) formulate momentum conservation. In steady state operation the sum of pressure losses, $\Delta p_{k}$, of the branches, $k$, of any closed loop is zero.

$$
\sum_{k=1}^{n} \Delta p_{k}=0
$$

In section 2 of this article, an equivalent formulation is used: The sum of pressure losses between two nodes, e.g. inlet and outlet of a collector field, is the same for all paths. Because of the non-linear relationship between flowrate and pressure loss these equations are solved by iterative methods. The choice of method depends primarily on the structure of the network, the number of nodes and the mode of operation. In the following, only methods for steady state flow are considered.

The probably oldest and still widely used method was developed by Cross (1936). The iterative procedure starts with initial values for the mass flow, which satisfy the node-equations. The evaluation of the loop-equation results in an error that is used to determine a correction of the flow rate, $\Delta V$, which is then added to the flow of all branches in the loop. The loop equation is subsequently applied to each elementary loop of the network. Derivation of Eq. (3) can be found in many textbooks, e.g. Massoud (2005), Horlacher and Lüdecke (2006) and Eismann (2017).

$$
\Delta \dot{V}_{k}=-\frac{\sum_{i=1}^{m} R_{k, i} \dot{V}_{k, i}\left|\dot{V}_{k, i}\right|}{2 \sum_{i=1}^{m} R_{k, i}\left|\dot{V}_{k, i}\right|}
$$

In Eq. (3) the elementary mesh, $k$, has $m$ branches. The term $R_{k, i}$ is the dimensional friction factor,

$$
R_{k, i}=\lambda_{k, i} \frac{8 l_{k, i} \rho_{k, i}}{d_{k, i}^{5} \pi^{2}},
$$

which is a function of a dimensionless friction factor, $\lambda$, the density, $\rho$, of the fluid and the pipe dimensions, $l$ and $d$. The procedure is repeated until the sum of relative changes of the flowrates is below a predefined margin. The method of Cross (1936) represents the class of explicit, sequential loop-methods. It is applicable for both irregular and periodical networks. Because of the sequential procedure, convergence is rather slow.

\section{Method for periodical networks with dominant strings}

Networks of solar thermal plants are essentially periodical. Figure 1 shows an array of $n$ strings connected in parallel by distribution and collection manifolds. The strings, $\mathrm{S}_{k}, k=1 . . n$, consist of one or more serially connected absorbers. The manifolds consist of a series of identical distribution pipes, $\mathrm{D}_{k}$, and collection pipes, $\mathrm{C}_{k}$. There are two ways of connecting arrays of strings. One-sided connection as shown in Figure 1 a) is figuratively called C-

a)
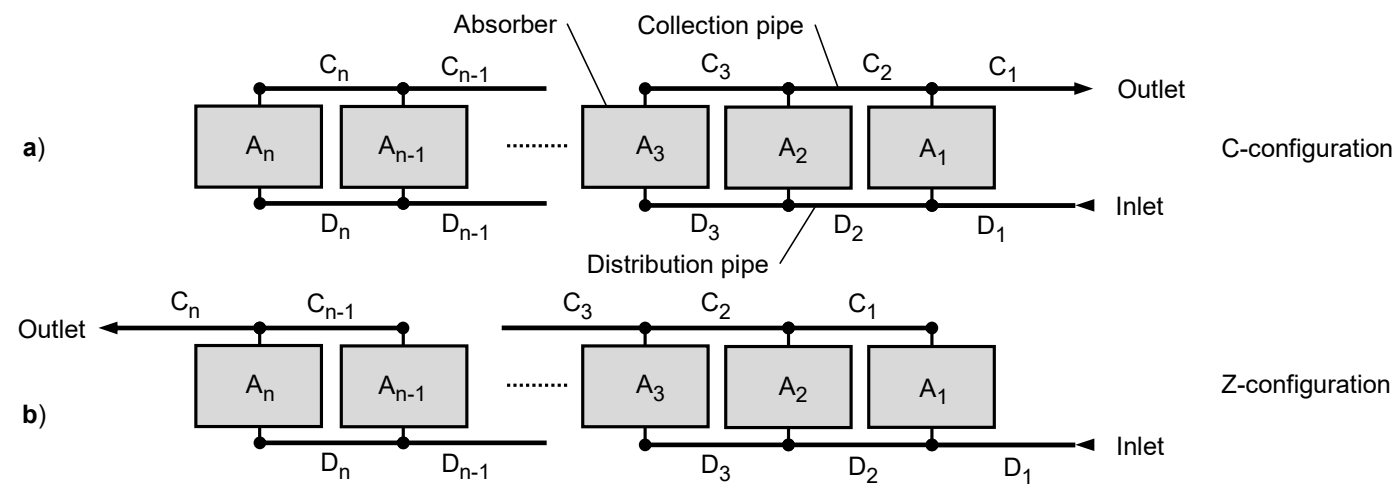

Z-configuration

Figure 1 Row of Absorbers connected in parallel a) C-configuration and b) Z-configuration. 
Ralph Eismann

configuration because the flow path between inlet and outlet through any of the strings resembles the letter C. Figure $1 \mathrm{~b}$ ) shows the alternative Z-configuration where all flow paths between inlet and outlet have the same length.

The primary goal of any method of pipe network analysis is to find the steady state mass flow distribution in an array of strings for a predetermined total mass flow, $\dot{m}$. Based on the corresponding chapter in Eismann (2017, p. 37) a fast converging method, well adapted for arrangements shown in Figure 1, is derived as follows.

The dominancy of the strings should be expressed by a dimensionless number valid for the whole array. The obvious choice is the ratio of pressure losses of the strings and the corresponding distribution and collection pipe expressed by the Darcy-Weisbach (Brown 2002) formula,

$$
\Delta p_{S, k}=\lambda_{k} \frac{l_{S}}{d_{S}} \frac{2}{\rho_{S, k}} w_{S, k}^{2} .
$$

It is therefore necessary to represent strings, which can have a rather complex internal hydraulic circuit, by an approximately equivalent pipe with a length, $l_{S}$, and a diameter, $d_{S}$. Setting friction factors and flow velocities to the same values results in an expression which can be interpreted as a dominancy ratio,

$$
R_{D}=\frac{l_{S} d_{D}}{2 d_{S} l_{D}}
$$

The iterative procedure is initiated by a uniform mass flow distribution.

$$
\dot{m}_{S, k}=\dot{m} / n
$$

In a first step, mass conservation is applied to each node to calculate the mass flows in the distribution and collection pipes. The mass flows for C-configuration are,

$$
\dot{m}_{D, k}=\dot{m}_{C, k}=\sum_{i=k}^{n} \dot{m}_{S, i},
$$

and for and Z-configuration,

$$
\dot{m}_{D, k}=\sum_{i=k}^{n} \dot{m}_{S, i} \quad ; \quad \dot{m}_{C, k}=\sum_{i=1}^{k} \dot{m}_{S, i} .
$$

In a second step, the flow velocities in all distribution pipes, collection pipes and strings, $w=4 \dot{m} / \pi d^{2} \rho$, and the pressure losses along each path between inlet and outlet are calculated. The pressure losses for $\mathrm{C}$ - configuration are,

$$
\Delta p_{k}=\sum_{i=1}^{k} \Delta p_{D, i}+\Delta p_{S, k}+\sum_{i=1}^{k} \Delta p_{C, i},
$$

and for Z-configuration,

$$
\Delta p_{k}=\sum_{i=1}^{k} \Delta p_{D, i}+\Delta p_{S, k}+\sum_{i=k}^{n} \Delta p_{C, i} .
$$

Furthermore, the average pressure loss of the paths between inlet and outlet is calculated.

$$
\langle\Delta p\rangle=\frac{1}{n} \sum_{k=1}^{n} \Delta p_{k}
$$

Pipe friction is usually, by far, the dominant contribution to the pressure loss. Each term can incorporate minor losses due to elbows, abrupt change of diameter and T-junctions. Momentum conservation requires the pressure losses calculated by Eq. (10) or Eq. (11), respectively, to be equal. With the initial uniform mass flow distribution, however, the pressure losses will differ significantly. 
Ralph Eismann

The following third step, which corrects the mass flow rates, is the key to the method. It is based on the following considerations. The friction factor for laminar flow in cylindrical tubes,

$$
\lambda_{\text {lam }}=\frac{64}{\operatorname{Re}} \text { with } \operatorname{Re}=\frac{w d}{v},
$$

results in a pressure loss proportional to the mass flow. The friction factor of Blasius (1913) for turbulent flow in hydraulically smooth pipes,

$$
\lambda_{\text {turb }}=0.3451 \cdot \mathrm{Re}^{-0.25},
$$

results in a pressure loss proportional to $\dot{m}^{1.75}$. The mass flow of each string is simultaneously corrected such that the pressure loss of the corresponding path equals the average pressure loss.

$$
\dot{m}_{S, k}^{\prime}=\dot{m}_{S, k}\left(\frac{\langle\Delta p\rangle}{\Delta p_{k}}\right)^{\frac{\gamma}{f}}
$$

The transition region where both laminar and turbulent flow can occur is defined as $2200<\operatorname{Re}<3000$. The denominator, $f$, of the exponent in Eq. (15) is,

$$
f=\begin{array}{ll}
1.75 \quad ; & \min \left(\operatorname{Re}_{S, k}\right)>2200 \\
1 \quad & ; \quad \max \left(\operatorname{Re}_{S, k}\right) \leq 2200
\end{array}
$$

Convergence can be enhanced by an over-relaxation factor, $\gamma>1$, whose optimum value depends on the dominance ratio. If the Reynolds number of any string is within the transition region, an over-relaxation factor of one is recommended.

Because of the nonlinear relationship between mass flow and pressure loss, the sum of the new mass flows is different from the predetermined total mass flow, $\dot{m}$. In a fourth and final step, each mass flow is correct by the ratio of the predetermined total mass flow and the iterative solution of the total mass flow. The new approximation for the mass flows are,

$$
\dot{m}_{S, k}^{\prime \prime}=\dot{m}_{S, k}^{\prime} \frac{\dot{m}}{\sum \dot{m}_{S, k}^{\prime}} .
$$

Steps 1 to 4 are repeated until the approximate solution is close enough to the theoretical limit. A suitable criterion is the relative standard deviation of the pressure losses, whose limit, $\sigma$, can be set according to the required accuracy, e.g. $\sigma=0.001$.

$$
\sigma>\frac{1}{\langle\Delta p\rangle} \sqrt{\sum \frac{\left(\Delta p_{k}-\langle\Delta p\rangle\right)^{2}}{n-1}}
$$

For dominancy ratios above $R_{D}=2.5$ the method converges faster than the method of Cross (1936). It is also applicable to hierarchically structured, periodical networks, where periodically arranged collector arrays are regarded as strings. However, requirement on periodicity can be alleviated considerably. The method is practical in cases where arrays have different numbers of strings and/or where the manifolds consist of a series of pipes with different diameters and length.

The following considerations are essential for any numerical method for pipe network analysis. Reynolds numbers in solar plants are quite low and often cover the regions of laminar-, transitional- and turbulent flow. Discontinuity at the transition between laminar and turbulent flow cause convergence problems. It is therefore mandatory to use friction factor correlations which are continuous functions of the Reynolds number covering laminar, transitional, and turbulent flow regions (Eismann and Adams 2018). In the following examples, the correlations (19) to (21) of Zanke (1993) are used, adapted for a transition region $2200<\mathrm{Re}<3000$. The probability for turbulent flow in the transition region is,

$$
P_{\text {turb }}=\exp [-\exp (10.45-0.0043 \mathrm{Re})]=1-P_{\text {lam }} .
$$




\section{Ralph Eismann}

The friction factor, Eq. (21), is defined as a linear combination of the laminar friction factor, Eq. (13), and the (explicit!) turbulent friction factor, Eq. (20),

$$
\lambda_{\text {turb }}=\left[-2 \log _{10}\left(\frac{2.7\left(\log _{10} \operatorname{Re}\right)^{1.2}}{\operatorname{Re}}+\frac{\varepsilon}{3.71 \cdot d}\right)\right]^{-2},
$$

weighted by their respective probabilities:

$$
\lambda=\left(1-P_{\text {turb }}\right) \lambda_{\text {lam }}+P_{\text {turb }} \lambda_{\text {turb }}
$$

\section{Examples}

\subsection{Convergence properties}

Convergence of the method is demonstrated using the example of an array of 10 strings. Each string consists of one flat plate collectors with $2.3 \mathrm{~m}^{2}$ aperture area and a meander-type absorber. The absorber tube is characterized by an equivalent pipe length of $18 \mathrm{~m}$ and $7 \mathrm{~mm}$ inner diameter. The strings are connected in C-configuration by distribution and collection pipes of $2.2 \mathrm{~m}$ length and $16 \mathrm{~mm}$ inner diameter. Minor losses in T-junctions are neglected. The flow is isothermal. Fluid properties of water at $20^{\circ} \mathrm{C}, v=1.044 \cdot 10^{-6} \mathrm{~m}^{2} / \mathrm{s}$ and $\rho=998 \mathrm{~kg} / \mathrm{m}^{3}$, are used. The dominance ratio is $R_{D}=10.3$. The accuracy limit was set to $\sigma=0.001$.

The total mass flow is $0.192 \mathrm{~kg} / \mathrm{s}$, which corresponds to an area specific volumetric flow rate of $30 \mathrm{l} / \mathrm{hm}^{2}$. The Reynolds number in all strings is above $\mathrm{Re}=3000$. According to Eq. (16), the appropriate C. Figure 2 shows iterative solutions of the flow distribution. Both the new method and the method of Cross (1936) converge towards the same final solution. With an over-relaxation factor of 1.1 the new method reaches the solution after three iterations, whereas the method of Cross (1936) requires 36 iterations.

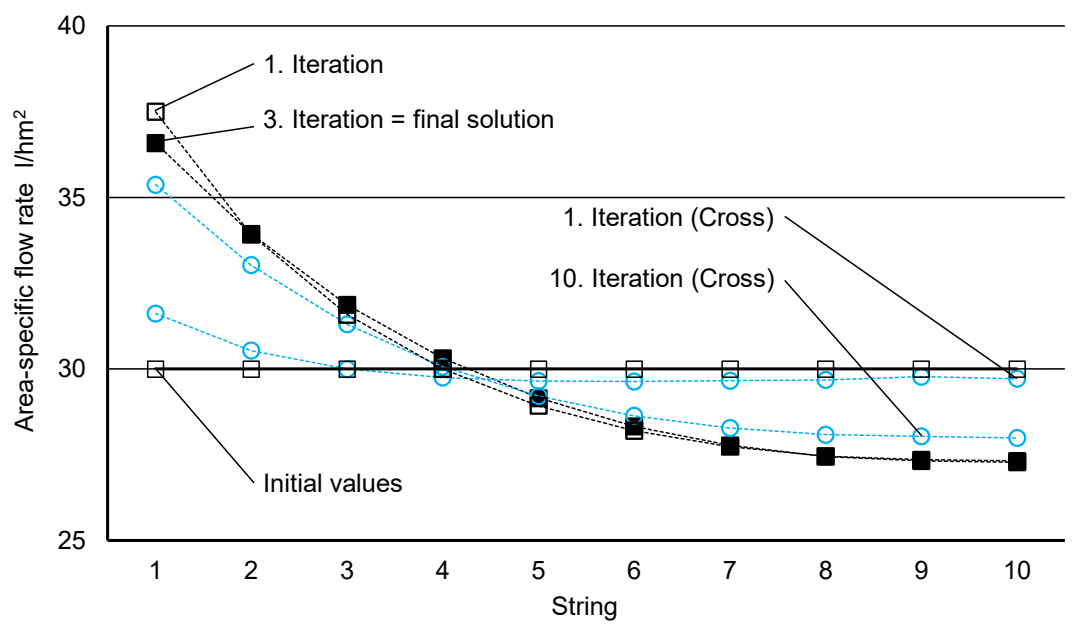

Figure 2 Convergence from initial uniform flow distribution of $30 \mathrm{I} / \mathrm{hm}^{2}$ to the final solution.

For an area specific volumetric flow rate of $101 / \mathrm{hm}^{2}$ the Reynolds number in all strings is below $\mathrm{Re}=2200$. With an over-relaxation factor of 1.2 the new method reaches the solution after four iterations, whereas the method of Cross (1936) requires 81 iterations. The reason for the fast convergence for purely laminar or turbulent flow lies in the denominator, $f$, which corresponds perfectly with the flow pattern of all strings.

Figure 3 shows the results for an average area specific volumetric flow rate of $20 \mathrm{l} / \mathrm{hm}^{2}$. The Reynolds numbers $1857 \leq \operatorname{Re} \leq 2830$ cover parts of the laminar and transition region. Because there is a probability for turbulent flow the denominator, $f$, must be set to the value 1.75. Application of Eq. (15) to strings with laminar flow results in slower convergence. The new method reaches the solution with 11 iterations compared to 46 iterations of the method of Cross. 
Ralph Eismann

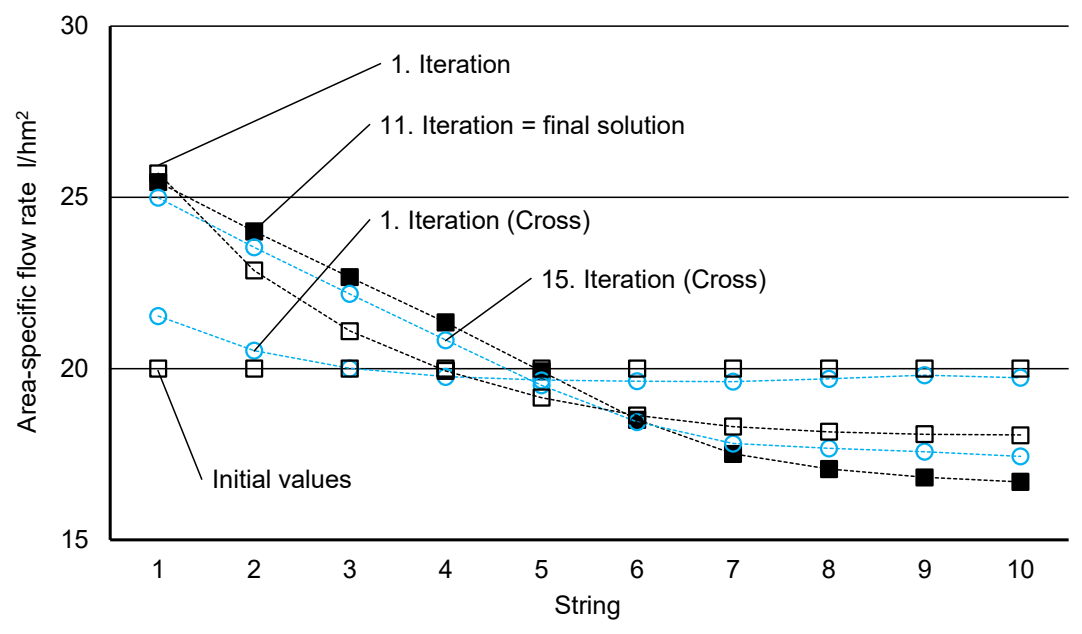

Figure 3 Convergence from initial uniform flow distribution of $20 \mathrm{l} / \mathrm{hm} 2$ to the final solution.

\subsection{Practical example}

A practical example in two versions is discussed using the EXCEL/VBA tool HYDRA dedicated to the dimensioning and thorough cost optimization of solar circuits. It is based on the above-described method for pipe network analysis and includes models for solar collectors, cylindrical pipes and corrugated metal hoses, pumps, check valves, fittings and heat exchangers. The following example illustrates some of the capabilities of the software.

A collector field consists of six arrays of glazed flat plate collectors with selective absorbers arranged in a row with a distance of $4 \mathrm{~m}$ between the leading edges of the arrays. Each collector has an absorber as specified in section 3.1. The conversion factor and the heat loss coefficients are, $\eta_{0}=0.8-, a_{1}=3.6 \mathrm{~W} / \mathrm{Km}^{2}$ and $a_{2}=0.01$ $\mathrm{W} / \mathrm{K}^{2} \mathrm{~m}^{2}$. Distribution and collection pipes have an inner diameter of $16 \mathrm{~mm}$ and a length of $2 \mathrm{~m}$. Solar gain is transferred to the liquid by the absorber tubes only. Metal bellows arranged between adjacent pipe ends compensate thermal expansion of the distribution and collection pipes. Metal bellows are characterized by a hydraulic diameter of $16 \mathrm{~mm}$, a length of $60 \mathrm{~mm}$ and a constant turbulent friction factor of $\lambda=0.095$. The arrays are connected in parallel by staged field pipes with an inner diameter of 25,32 and $39 \mathrm{~mm}$. For the pressure losses in T-junctions the correlations of Wagner (2001) are used. Fluid properties of the water-glycol mixture TYFOCOR ${ }^{\circledR} \mathrm{LS}^{\circledR}$ (TYFOROP 2015) are used. The area-specific flow rate is $30 \mathrm{l} / \mathrm{hm}^{2}$. Inlet temperature is $55^{\circ} \mathrm{C}$. Solar irradiation is $1000 \mathrm{~W} / \mathrm{m}^{2}$ and ambient temperature is $20^{\circ} \mathrm{C}$. Figure 4 shows an arrangement where both the collectors and the arrays are connected in Z-configuration.

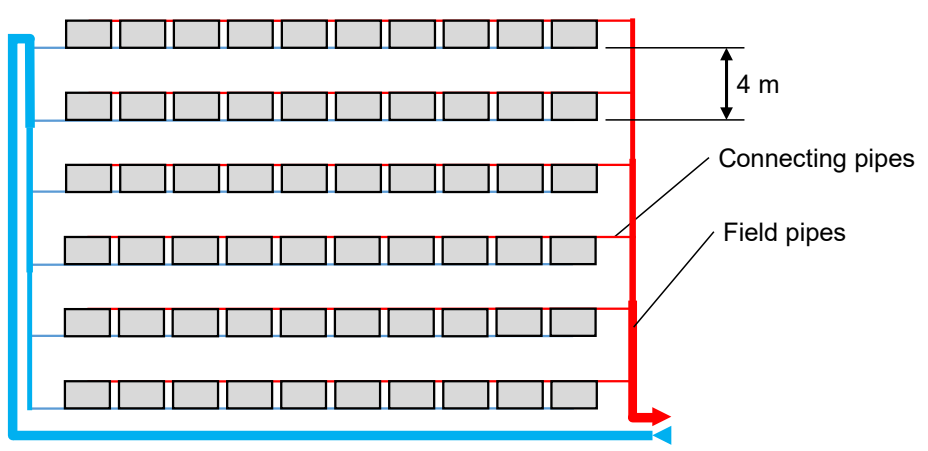

Figure 4 Flat-plate collector field. Collectors and arrays connected in Z-configuration.

Figure 5 shows the flow distribution of the collector field. As can be expected, the inhomogeneity of the flow distribution is nearly symmetrical and rather small. The temperature at the outlet is $74{ }^{\circ} \mathrm{C}$ and the useful gain is $84.4 \mathrm{~kW}$. The pressure loss between inlet and outlet is $37.5 \mathrm{kPa}$. 


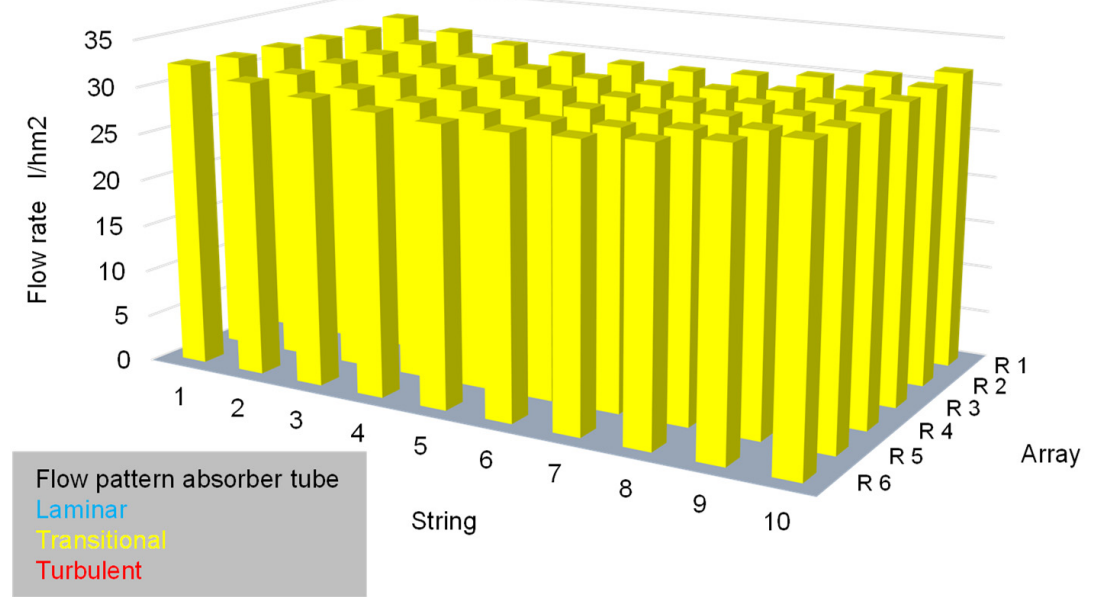

Figure 5 Flow distribution. Collectors and arrays connected in Z-configuration.

In the version shown in Figure 6, both the collectors and the arrays are connected in C-configuration. The flow distribution shown in Figure 7 is more inhomogeneous than with Z-configuration.

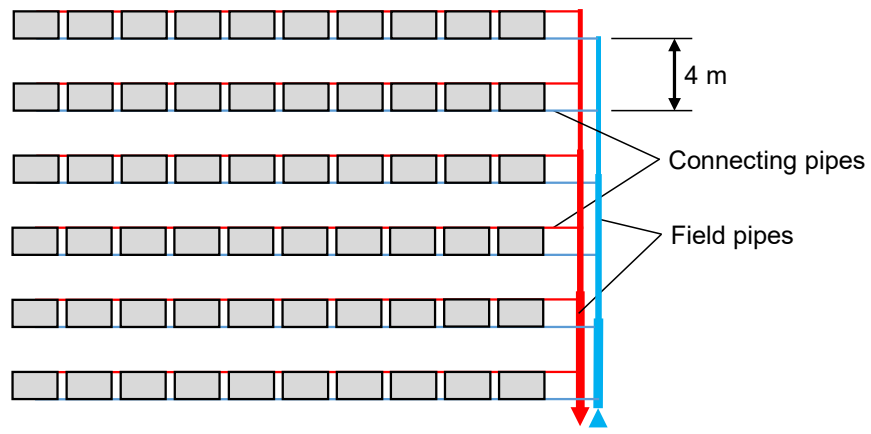

Figure 6 Flat-plate collector field. Collectors and arrays connected in C-configuration.

Expectedly, the highest flowrate occurs in the first string of the first array whereas the flow rate in the last string of the sixth array is smallest. The flow patterns cover the complete transitional region (yellow bars) and the adjacent regions of laminar (blue bars) and turbulent flow (red bars).

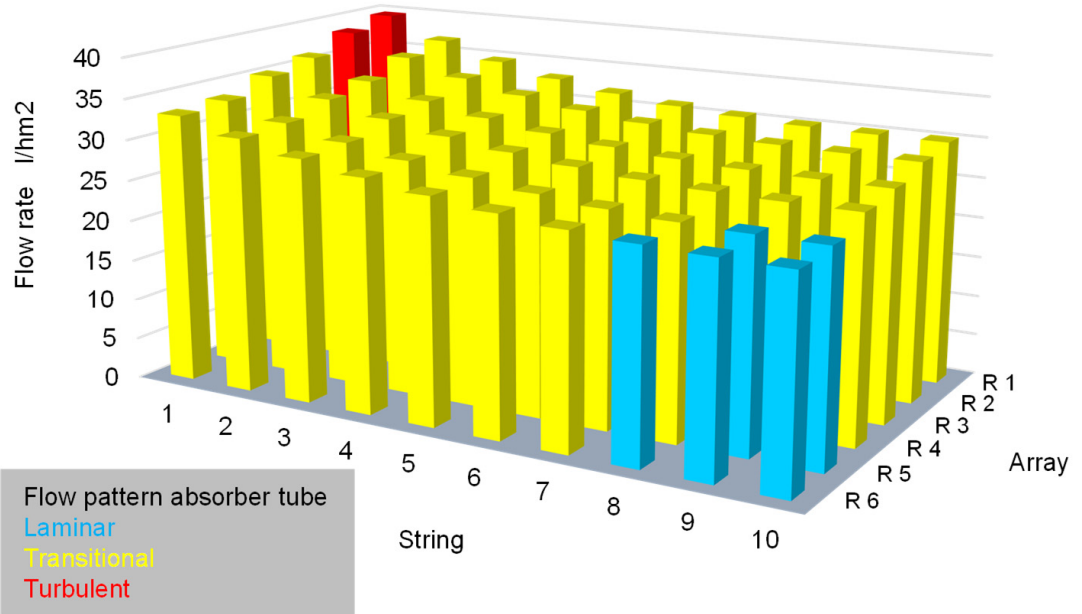

Figure 7 Flow distribution. Collectors and arrays connected in C-configuration.

C-configuration is much more economic than Z-configuration. The costs of about 40 meters of field pipes is saved. Because of the smaller pressure loss of only $30 \mathrm{kPa}$ the operational costs are also lower. Furthermore, less space for the pipe routing is needed. 
Ralph Eismann

In all operational states, the pressure must be well above atmospheric pressure and vapor pressure. Therefore, information about pressure and temperature distributions is needed. Figure 8 shows the pressure in the distribution and collection manifolds.

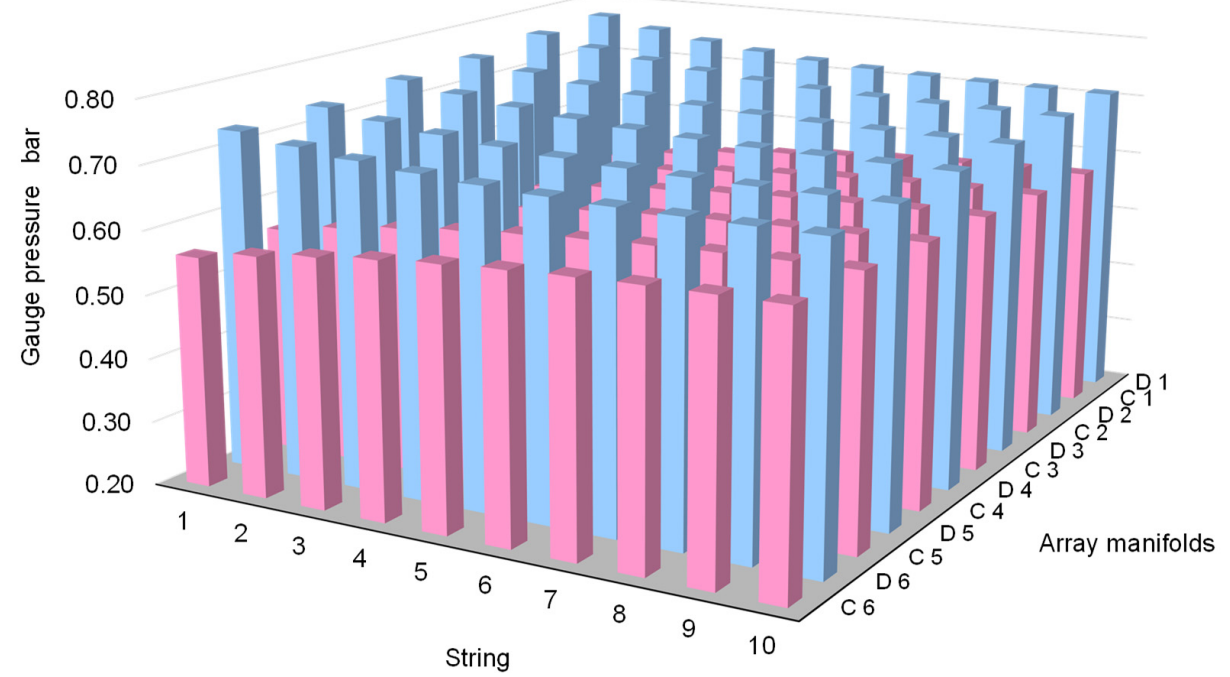

Figure 8 Pressure distribution. Collectors and arrays connected in Z-configuration.

The more pronounced inhomogeneity of the flow distribution causes a corresponding distribution of the exit temperature shown in Figure 9. However, the loss of collector efficiency compared to Z-configuration is below $0.2 \%$ and easily compensated by the avoided heat loss of $40 \mathrm{~m}$ field pipes. The arrays are arranged in reverse order for better visibility. The base plane of the diagram at $55^{\circ} \mathrm{C}$ indicates the temperature of the entering fluid.

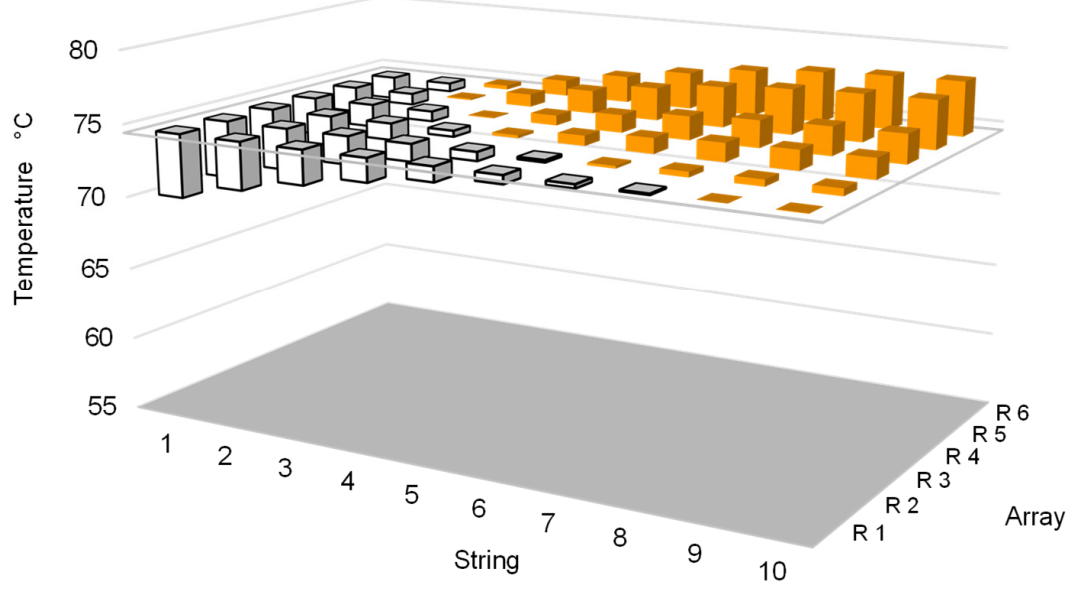

Figure 9 Exit temperature distribution. Collectors and arrays connected in C-configuration.

Figure 10 shows the temperature distribution in the header tubes. If the temperature sensor is placed in the collection pipe, the first collector of the third array should be chosen where the temperature differs only little from the temperature in the forward line.

In order to optimize venting capacity and to prevent partial stagnation, stagnant pipe sections must be avoided. Pipe routing is therefore predetermined by the collector hydraulics. Examples for flat plate collectors are shown in Figure 11. 


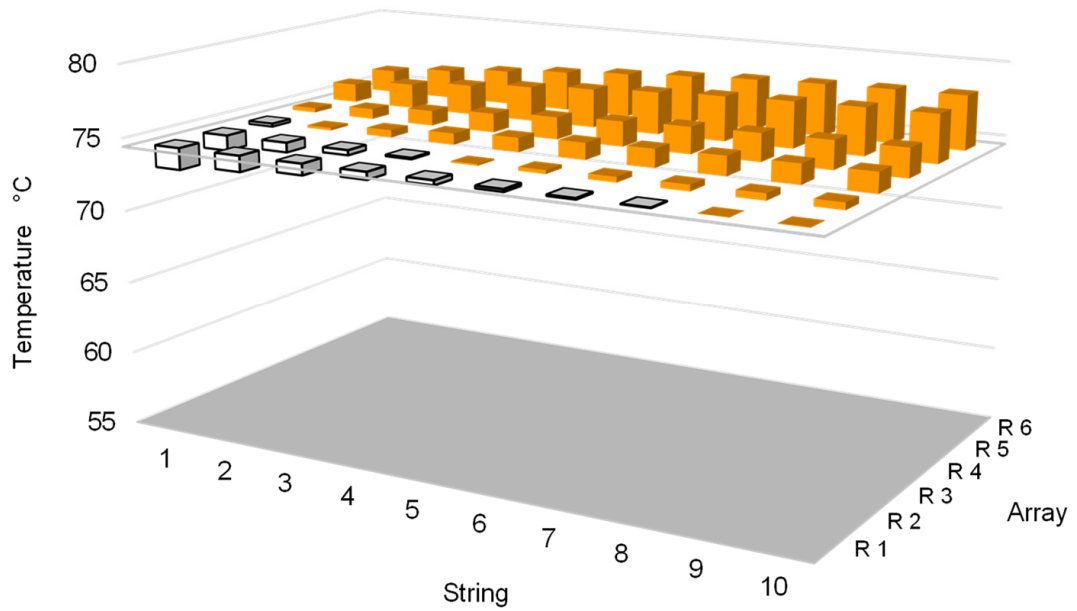

Figure 10 Temperature distribution in the collection manifolds. Collectors and arrays connected in C-configuration.

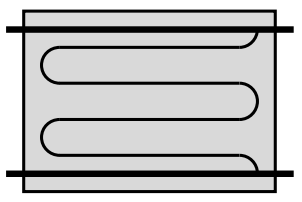

C-configuration

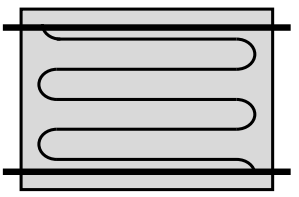

Z-configuration

Figure 11 Flat-plate collectors suited for C-and Z-configuration

\section{Conclusions}

A method for pipe network analysis was derived, suitable for periodical networks with dominant strings. The method is not only explicit and therefore easy to program but also simultaneous which accounts for the fast convergence. For dominance ratios $R_{D}>10$, which is a typical value for a flat plate collector with meander-type absorber, convergence is of the magnitude 10 times faster than the explicit, sequential method of Cross (1936).

The Excel/VBA tool HYDRA, dedicated to the dimensioning and thorough cost optimization of solar circuits, was used to demonstrate the application of the method. Comparison of $\mathrm{C}$ - and Z-configurations of a large collector field has shown that the influence of inhomogeneous flow distribution on the efficiency is negligible. In case of the example, one would choose the much cheaper C-configuration. However, it is not advisable to generalize this conclusion. Other aspects, like the internal collector hydraulics, venting capability and the flow velocity limit must also be considered. HYDRA is applicable to the design of solar thermal plants with glazed and unglazed flat plate collectors, vacuum tube collectors and PV/T collectors.

The author provides HYDRA as an open source code (Eismann 2018), with the objective of supporting the solar thermal market.

\section{Acknowledgements}

The Swiss Federal Office of Energy, SFOE, founded the project SI/501007-01, in whose framework the basis of the method was formulated. Refinement of the method presented in this article was supported in part by funds from the research program Future Energy Efficient Buildings and Districts (FEEB\&D) of the Swiss Competence Center for Energy Research (SCCER), (CTI.2014.0119). 


\section{Nomenclature}

$\begin{array}{llll}A & \text { Collector area } & w & \text { average flow velocity }[\mathrm{m} / \mathrm{s}] \\ a_{1} & \text { linear heat loss coefficient }\left[\mathrm{W} / \mathrm{Km}^{2}\right] & \text { Greek Symbols } \\ a_{2} & \text { quadratic heat loss coefficient }\left[\mathrm{W} / \mathrm{K}^{2} \mathrm{~m}^{2}\right] & \gamma & \\ d & \text { pipe diameter [m] } & \eta_{0} & \text { conversion factor [-] } \\ l & \text { pipe length [m] } & \lambda & \text { friction factor [-] } \\ \dot{m} & \text { mass flow rate }[\mathrm{kg} / \mathrm{s}] & v & \text { kinematic viscosity }\left[\mathrm{m}^{2} / \mathrm{s}\right] \\ P_{\text {lam }} & \text { probability for laminar flow [-] } & \rho & \text { density }\left[\mathrm{kg} / \mathrm{m}^{3}\right] \\ P_{\text {turb }} & \text { probability for turbulent flow [-] } & S u b s c r i p t s \\ \Delta p & \text { pressure loss [bar, Pa] } & C & \text { collection pipe } \\ R_{D} & \text { dominancy ratio [-] } & D & \text { distribution pipe } \\ \operatorname{Re} & \text { Reynolds number }[-] & S & \text { string } \\ \dot{V} & \text { volumetric flow rate }\left[\mathrm{m}^{3} / \mathrm{s}\right] & & \end{array}$

\section{References}

Blasius, H., 1913, "Das Aehnlichkeitsgesetz bei Reibungsvorgängen in Flüssigkeiten," In: Mitteilungen über Forschungsarbeiten auf dem Gebiete des Ingenieurwesens, 1-41, Springer-Verlag, Berlin, Heidelberg. http://dx.doi.org/10.1007/978-3-662-02239-9_1

Brown, G. O., 2002, "The History of the Darcy-Weisbach Equation for Pipe Flow Resistance," In: Environmental and Water Resources History, Washington, D.C., November 3-7 2002, 34-43, American Society of Civil Engineers. https://doi.org/10.1061/40650(2003)4

Cross, H., 1936, "Analysis of flow in networks of conduits or conductors," University of Illinois Engineering Experiment Station Bulletin; no 286,

Eismann, R., 2018, "HYDRA - VBA/EXCEL Program for Pipe Network Analysis of Solar Thermal Plants," University of Applied Science Northwestern Switzerland. https://sourceforge.net/projects/solar-pipe-networkanalysis/. Accessed 7. Aug. 2018

Eismann, R., 2017, "Thermohydraulische Dimensionierung von Solaranlagen : Theorie und Praxis der kostenoptimierenden Anlagenplanung", Springer Vieweg, Wiesbaden. ISBN: 978-3-658-07124-0. https://doi.org/10.1007/978-3-658-07125-7

Eismann, R., Adams, R., 2018, "An Explicit and Continuous Friction Factor Correlation for Helical Tubes with Arbitrary Roughness," Frontiers in Heat and Mass Transfer (FHMT), 11, 1-7. http://dx.doi.org/10.5098/hmt.11.4

Frank, E., 2007, "Modellierung und Auslegungsoptimierung unabgedeckter Solarkollektoren für die Vorerwärmung offener Fernwärmenetze", Kassel University Press GmbH, Kassel. ISBN: 3899583728.

Horlacher, H.-B., Lüdecke, H.-J., 2006, "Strömungsberechnung für Rohrsysteme", vol 9, 2. Aufl, expert-Verlag, Renningen.

Massoud, M., 2005, "Engineering Thermofluids", Springer-Verlag, Berlin, Heidelberg, New York.

Murphy, L. J., Simpson, A. R., Dandy, G. C., 1993, "Pipe network optimization using an improved genetic algorithm", Department of Civil and Environmental Engineering, University of Adelaide, Adelaide, Australia. 


\section{Ralph Eismann}

Park, B.-S., Imran, M., Hoon, I.-Y., Usman, M., 2017, "Thermo-economic optimization of secondary distribution network of low temperature district heating network under local conditions of South Korea," Applied Thermal Engineering, 126, 117-133.

TYFOROP, 2015, "Technical Information: TYFOCOR LS," TYFOROP CHEMIE GmbH. https://www.tyfo.de/uploads/TI/Ti TYFOCOR-LS gb.pdf.

Wagner, W., 2001, "Strömung und Druckverlust", Kamprath-Reihe, 5. Aufl, Vogel Buchverlag, Würzburg. 3802317203.

Zanke, U., 1993, "Zur Berechnung von Strömungswiderstandsbeiwerten," Wasser und Boden, 45 (1), 14-16. 


\title{
Dynamic Modelling of a Hybrid Solar Thermal/electric Energy Storage System for Application in Residential Buildings
}

\author{
Andrea Frazzica', Valeria Palomba', Francesco Sergi' ${ }^{1}$, Marco Ferraro', Luisa F. Cabeza ${ }^{2}$, Gabriel \\ Zsembinszki ${ }^{2}$, Eduard Oró ${ }^{2}$, Sotirios Karellas ${ }^{3}$, Stratis Varvagiannis ${ }^{3}$, Johann Emhofer ${ }^{4}$, Tilman \\ Barz $^{4}$ \\ ${ }^{1}$ Istituto di Tecnologie Avanzate per l'Energia CNR-ITAE, Messina (Italy) \\ 2 GREiA Research Group, INSPIRES Research Centre, Universitat de Lleida, Lleida (Spain) \\ ${ }^{3}$ Lab. of Steam Boilers and Thermal Plants, National Technical University of Athens, Athens (Greece) \\ ${ }^{4}$ Austrian Institute of Technology AIT, Energy Department, Vienna (Austria)
}

\begin{abstract}
The present paper presents the dynamic modelling of a hybrid thermal/electric energy storage for residential applications. Two systems are considered, which are suitable for application in Continental and Mediterranean climates. Both systems are suitable for the provision of heating, cooling and domestic hot water, but the Continental system is optimized for heating and domestic hot water production, whereas the Mediterranean system is optimized for the covering of cooling demands. The models are realized in Dymola/Modelica environment and are structured according to a modular approach, using only self-developed components or open source libraries. An adsorption module, used for thermal energy storage purposes, a battery pack, used for electrical storage, latent heat storages and heat pumps are the main components modelled. The integration in sub-system and the typical operation during one day under reference conditions are shown, which prove the successful integration of several sub-modules.
\end{abstract}

Keywords: Modelica, hybrid storage, heating and cooling, modelling

\section{Introduction}

One of the critical aspects related to the increasing share of renewables at the building scale is the management of surplus of electricity produced (Schwarz et al., 2018). Indeed, the European Commission (European Commission, 2016) is strongly promoting the self-consumption in order to further support the integration of renewables in buildings. In such a context, different approaches for the optimization of the self-consumption in distributed energy systems were reported in the literature. One of the most common approaches, widely analysed and tested, is the integration of electric storage to support the generation from PV (Camilo et al., 2017; Lorenzi and Silva, 2016; Schram et al., 2018). However, this solution entirely relies on electricity generation. Different solutions proposed include the exploitation of weather forecasts to improve the system control strategy (Petrollese et al., 2018), the development of power-to-heat systems to convert excess of electricity into heat for space heating and cooling applications (Battaglia et al., 2017), and the pooling of different heat pumps together to increase the flexibility of electricity market and grid (Spreitzhofer et al., 2018). Concerning the latter solution, based on the efficient conversion of electricity into heat, the integration of advanced technologies for thermal and electric storage is mandatory, in order to achieve high storage density as well as to guarantee the necessary flexibility in operation (Bloess et al., 2018).

A general classification of the available technologies is given in Bloess et al., 2018, the primary distinction being between centralized and decentralized solutions. Since in many European areas the centralized systems are limited to heating solutions, or do not cover large areas, the development of efficient decentralized systems is mandatory. Among the solutions available, a vast number focuses on the integration of gas-fired and electric heat pumps/boilers (Heinen et al., 2016). However, the application of thermal energy storage is still limited, even though it is considered a promising solution (Yilmaz et al., 2018). Moreover, the solutions tested and investment analysis are often centred on Central and Northern European countries only (Yilmaz et al., 2018), where heating demand represents the main contribution to the building energy consumption.

In this context, the H2020 project HYBUILD proposes the use of two innovative compact hybrid electrical/thermal energy storage systems for stand-alone and district connected buildings. The two concepts will be specifically developed for ensuring comfort condition in residential buildings located in two different climates: one for 
Mediterranean climate, where cooling season operation is particularly relevant, and another one for Continental climate, where the heating season operation is most important. Both systems will be able to efficiently cover also heating and cooling demand, respectively.

One of the main difficulties in the proper operation of the system is the integration of the core components and the development of a suitable management strategy. To this aim, it is mandatory to develop a reliable simulation tool, able to accurately describe the operation of the system. The present paper hence focuses on the dynamic simulation of the innovative hybrid thermal/electric storage solution proposed. The model was implemented in Dymola/Modelica environment using open source or self-developed components. A modular structure was followed, specifically focusing on an easy integration of the different components.

\section{The HYBUILD concept}

The proposed system will address two different concepts of hybrid energy storage: one mainly dedicated to the production of cooling energy, for Mediterranean countries (e.g. Spain, Italy, Greece, Cyprus, Portugal), and the other one, mainly dedicated to the delivering of heating energy, for the Continental countries (e.g. Austria, France, Germany, Switzerland, Denmark).

\subsection{Mediterranean system}

The proposed hybrid electric/thermal storage concept for Mediterranean climates aims at the integration of an electrically powered compression heat pump (HP) with a thermally driven sorption storage module and a battery pack. The HP will also be equipped with a latent heat thermal energy storage (LHTES) module. The proposed concept is reported in Figure 1a. The working principle is as follows: the electrical energy produced by the renewable source (PV panels) is directly connected, by means of a DC bus, to a DC powered vapour compression HP, which produces cooling energy for the building demand. On its evaporator side, a properly sized heat exchanger (HEX) and with a LHTES module is installed, in order to increase the storage capacity of the system, to stabilize the working boundary conditions of the compression HP, and to reduce the on/off period needed to follow the load evolution during the day. The condenser of the vapour compression chiller is coupled with the evaporator of the sorption storage, which produces DHW, exploiting solar thermal collectors as primary source to drive the desorption phase. In standard operation, the evaporator of the sorption storage module cools down the condenser of the compression HP, thus reducing its temperature lift between evaporator and condenser, resulting in enhanced efficiency in terms of electrical COP, that can even reach values above 6.0, which are about two times higher than the state-of-the-art HPs (Vasta et al., 2018). This will reflect in a reduced request of electrical energy to produce the cooling energy needed to cover the end-user's demand. Furthermore, solar thermal collectors and district heating network in case of districtconnected buildings, also allow covering the DHW demand, and an electric storage allows increasing the operating flexibility of the system. Thanks to the reversibility of the operating mode of both compression HP and sorption storage, the system can also operate in heating mode, increasing the share of renewable, both thermal and electrical, to provide space heating in winter season.

\subsection{Continental system}

The hybrid storage concept for Continental climate is based on a HP, a LHTES for DHW production and an electrical storage. Contrary to the Mediterranean solution, the prioritized operation is heating during winter and the production of domestic hot water, whereas cooling during summer plays a minor role compared to the other two. The system proposed is shown in Figure $1 \mathrm{~b}$.

In this case, the heat sources are the air-source DC-powered HP and the PV panels for energy production. The operation is as follows: the electrical energy produced by the PV panels is used to drive the HP, which produces the heating energy for provision to the building. In the HP, a LHTES is integrated, is charged by the hot gas at the compressor outlet that can be used for DHW production. This storage can be charged slowly during the day, increasing the energy efficiency compared to direct DHW heating. Furthermore, an innovative sensible water storage with a high heat exchanger surface will be used inside the building to provide enough hot water within a short time. During summer, the air-source heat pump operates in reverse mode, for moderate cooling of the building. 


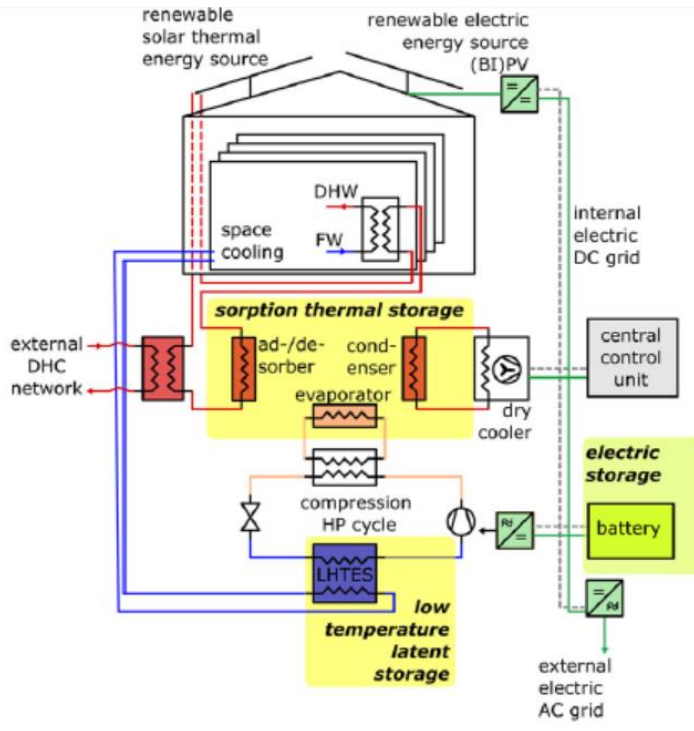

(a)

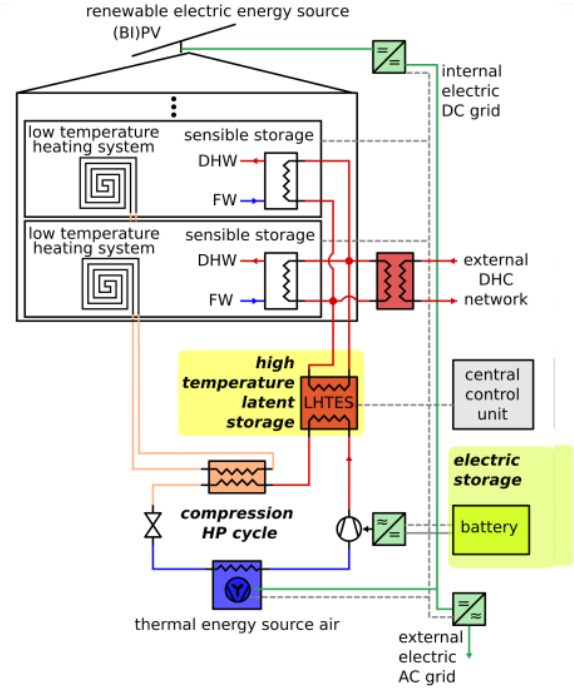

(b)

Figure 1. Schematic of the proposed system for hybrid thermal/electric storage, focusing on the provision of (a) cooling and (b) heating

\section{Modelling approach}

The target for the activity proposed is to describe both the Mediterranean and Continental hybrid sub-systems with models that are scalable, modular and easily integrated in different system configurations. The main features that the developed models possess are:

- utilization of open source libraries and components;

- $\quad$ easy connection to other components; and

- possibility to obtain useful results for the integration of the sub-system into the whole system.

The chosen modelling environment is Dymola, which represents a pre- and post-processing simulation platform for the open source language Modelica, which has already been proven to be suitable for the modelling of solar systems (Rodat et al., 2018). All the models were realised using self-developed components as well as components from Thermocycle (Quoilin et al., 2014) and CoolProp libraries (Bell et al., 2014).

\section{Models of the core components}

In the present section, important models for the core components of the sub-system will be described, whereas their integration into the whole sub-systems will be presented in the next section.

\subsection{Adsorption module}

The model structure is presented in Figure 2. It consists of four main components and an auxiliary valve that is used to continuously refill the refrigerant into the evaporator. The main components of the model are the adsorbers, the condenser and the evaporator, each of them consisting of two sub-components: an equilibrium model and a heat exchange model. The equilibrium model is the water/water vapour equilibrium for the condenser and the evaporator and the adsorption equilibrium model, defining the uptake as a function of pressure and temperature, in the adsorber. The approach followed is similar to that proposed for adsorption chillers by (Lanzerath et al., 2015; Schicktanz and Núñez, 2009), which proved to be reliable and suitable to describe, after a proper calibration, the operation of the systems considered. The model for the heat exchange on the heat transfer fluid (HTF) side is taken from Thermocycle library. It includes equations for mass, energy and momentum balance. 


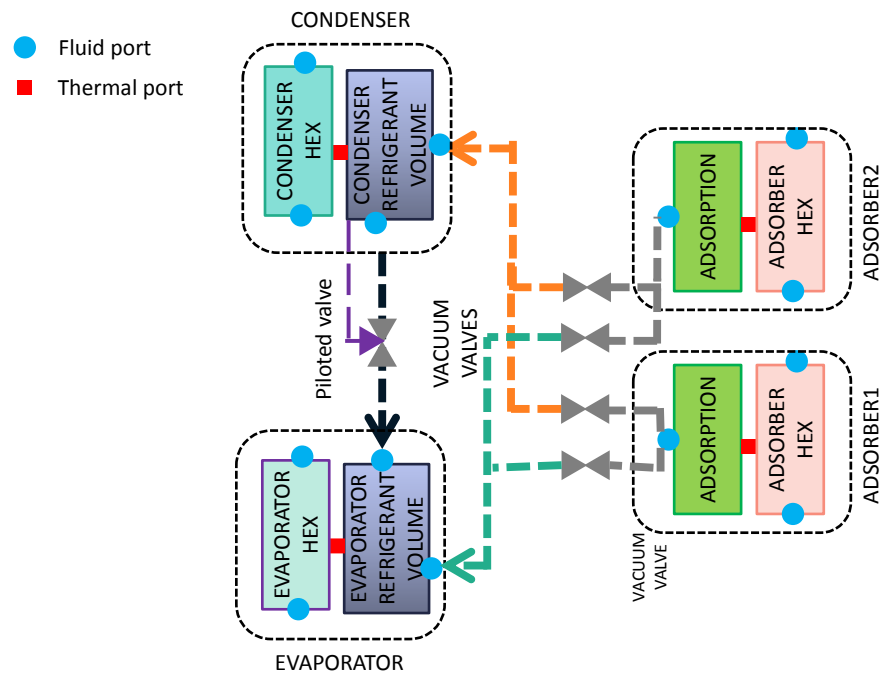

Figure 2. Layout of the model of the adsorption module

The model for the adsorption module results from the mass and energy conservation inside the adsorber. Energy conservation is expressed as:

$$
\left(m_{\text {sorb }} c_{p_{\text {sorb }}}+w \cdot m_{\text {sorb }} c_{p_{\text {ref }}}\right) \frac{d T_{\text {sorb }}}{d t}=\dot{Q}_{a d s}+\dot{m}_{r e f} h_{a d s}-m_{\text {sorb }} c_{p_{\text {sorb }}} T_{\text {sorb }} \frac{d w}{d t}
$$

The terms on the left-hand side represent the sensible heat stored in the adsorbent, whereas the terms on the righthand side represent the heat transferred through conduction and the mass exchange. For simplicity's sake, the heat of adsorption $\mathrm{h}_{\mathrm{ads}}$ was considered constant.

The equilibrium conditions for temperature $\mathrm{T}_{\text {sorb }}$, pressure $\mathrm{p}_{\text {ads }}$ and uptake $\mathrm{w}$ (the amount of refrigerant adsorbed onto the material) can be described by means of different equations according to the adsorbent chosen. For zeolite and zeotype materials, one common approach is to use Dubinin-Ashtakov (DA) correlation (Frazzica and Freni, 2017):

$$
w=w_{0} \exp \left[-\left(\frac{A}{E}\right)^{n}\right]
$$

where $w_{0}[\mathrm{~g} / \mathrm{g}]$ and $n[-]$ are empirical constants, and $A[\mathrm{~kJ} / \mathrm{mol}]$ is the adsorption potential:

$$
A=-R T_{\text {sorb }} \log \frac{p_{a d s}}{p_{\text {sat }}}
$$

The flow rate of refrigerant adsorbed is a function of the uptake variation in time:

$$
\dot{m}_{\text {ref }}=m_{\text {sorb }} \frac{d w}{d t}
$$

Adsorption kinetics is described by means of a Linear Driving Force (LDF) approach (El-Sharkawy, 2011):

$$
\frac{d w}{d t}=\beta\left(w_{e q}-w\right)
$$

where the constant $\beta\left[\mathrm{t}^{-1}\right]$ is calculated as (Lanzerath et al., 2015):

$$
\beta=\frac{15}{r^{2}{ }_{\text {sorb }}} D
$$

where $\mathrm{D}\left[\mathrm{m}^{2} \mathrm{~s}^{-1}\right]$ is a diffusion coefficient. Saturation properties of the refrigerant are calculated using CoolProp library.

The condenser and the evaporator of the adsorption module consist of a vacuum vessel with a heat exchanger partially immersed into the liquid refrigerant. Water/water vapour equilibrium is described by mass and energy balance equations:

$$
\frac{d m}{d t}=\dot{m}_{v}+\dot{m}_{l}
$$

In the case of the condenser, the incoming fluid is vapour at the temperature of the adsorber and the outlet fluid is 


$$
\frac{d U}{d t}=\dot{H}_{v}+\dot{H}_{l}+\dot{Q}
$$

liquid having saturation enthalpy. Conversely, in the case of the evaporator, the incoming fluid is liquid at the temperature of the condenser and the outlet fluid is vapour having saturation enthalpy. The term $\dot{Q}$ [W] represents the heat flow between the saturated refrigerant and the surface of the heat exchanger.

\subsection{Compression heat pump for the Mediterranean system}

The model of the heat pump is based on the acausal modelling technique and is mainly composed of four elements: the compressor, the heat exchangers for the evaporator and condenser, and the expansion valve.

The modelling approach followed for the heat exchangers is the Moving Boundaries technique. Moving boundaries models are generally faster compared to finite volume implementations, without loss in model's accuracy (Bendapudi et al., 2008). The moving boundary implementation used follows the equations described by Willatzen (Willatzen and Pettit, 1998). However, as an enhancement to the original equations proposed by Willatzen and similarly to the standard moving boundary implementation in ThermoCycle, the heat transfer between the primary and the secondary fluid is calculated by means of $\varepsilon$-NTU method, instead of calculating it using the temperature difference between the corresponding cells. A schematic representation of the model and heat contributions in each zone are shown in Figure 3 for the case of the condenser. The model for the evaporator is similar to that for the condenser, with the difference of having two zones instead of three (since the refrigerant enters the evaporator in two phase state).

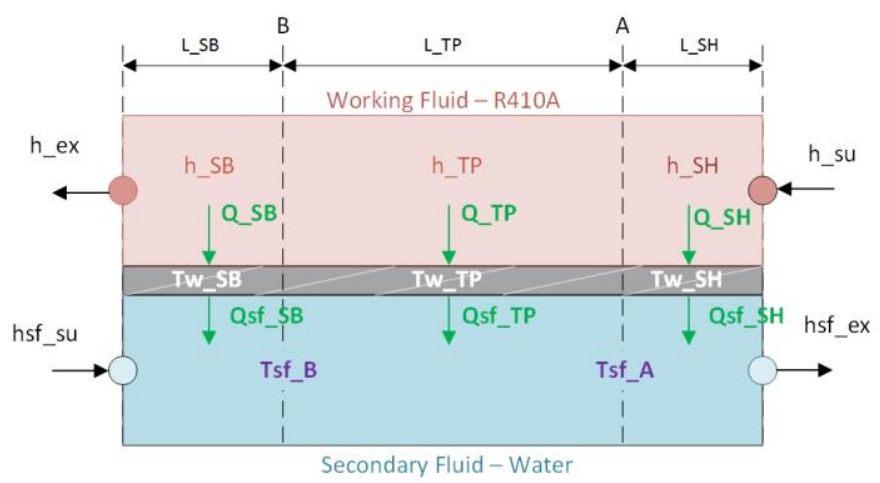

Figure 3. Schematic representation of the moving boundaries formulation in the condenser of the heat pump for the Mediterranean system

The model for the compressor is a steady state model, based on the volumetric and isentropic efficiency. This model is derived from the standard compressor model included in ThermoCycle library, while the volumetric and isentropic efficiencies are calculated as functions of the pressure ratio $r_{p}$ (Byrne et al., 2012):

$$
\begin{aligned}
e_{v o l} & =1-C\left(r_{p}^{\frac{1}{n}}-1\right) \\
e_{i s} & =K\left(1-e^{-b \cdot r_{p}}\right)
\end{aligned}
$$

In both equations, $\mathrm{C}, \mathrm{n}, \mathrm{K}$ and $\mathrm{b}$ are constants which must be calibrated to manufacturer efficiency curves.

The mass flow rate transferred by the compressor is calculated using the following equation:

$$
\dot{m}_{f}=e_{v o l} \frac{N_{r o t}(R P M) \cdot V_{s} \cdot \rho_{S U}}{60}
$$

where $V_{S}$ the swept volume of the compressor, which is the only parameter of the model and was given by the manufacturer as $V_{s}=102 \cdot 10^{-6} \mathrm{~m}^{3}$. The enthalpy at the outlet of the compressor using the definition of the isentropic efficiency:

$$
h_{e x}=h_{s u}+\frac{\left(h_{e x, i s}-h_{s u}\right)}{e_{i s}}
$$

The shaft power needed for the compression is calculated as:

$$
P_{\text {shaft }}=\dot{m}_{f}\left(h_{e x}-h_{\text {su }}\right)
$$

The thermostatic expansion valve model is based on the standard valve component of the ThermoCycle library, 
controlled by a PID controller which maintains the superheating at a desired value. While this implementation is actually an Electronic Expansion Valve (EEV) its operation is similar to the standard TEXV's operation. The expansion is assumed to be isenthalpic.

The mass flow rate through the valve is calculated from the pressure drop using the following expression:

$$
\dot{m}_{f}=A \cdot \sqrt{2 \cdot \rho_{S U} \cdot \Delta p}
$$

where $\mathrm{A}$ is the area of the orifice inside the valve, which changes linearly with the control signal.

The superheating of the fluid exiting the evaporator is calculated in real time by measuring its pressure and temperature. The degree of opening of the valve is controlled using a PID algorithm in order to achieve the desired superheating. The overall layout of the heat pump in Dymola environment is shown in Figure 4.

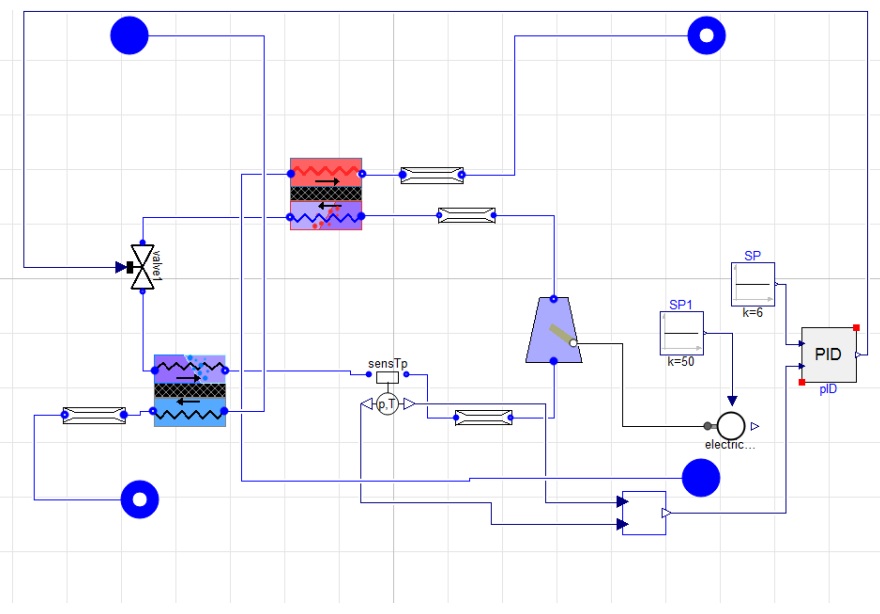

Figure 4. Schematics of the heat pump model in the Dymola environment

\subsection{Latent heat thermal energy storage module}

The LHTES module consists of a 3-fluid (refrigerant, PCM, and water) heat exchanger (RPW-HEX). The RPWHEX is a rectangular container. The internal design consists of a parallel arrangement of rectangular passages for water and refrigerant with rectangular layers of PCM in between. Fluid passages and PCM layers are arranged sequentially. In order to study the thermal behaviour of the RPW-HEX, a 2D numerical model was developed. Because of symmetry of the RPW-HEX design, the relatively abundance of passages and layers, and the thermal insulation of the storage container it is assumed that all parallel passages and PCM layers behave identically. Therefore, only the relevant section of the entire component was considered in the model, which considers solely one refrigerant + water + PCM layer, as schematically shown in Figure 5.

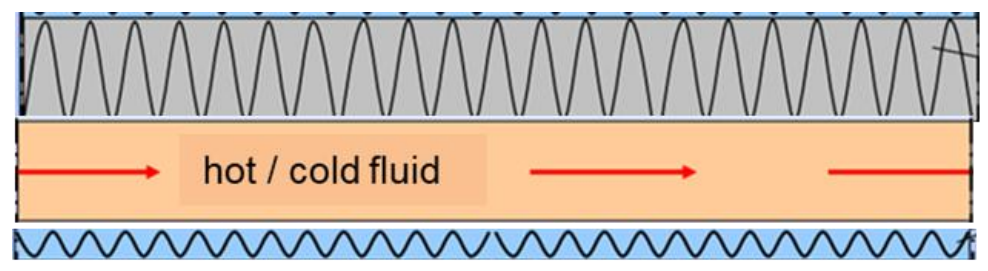

PCM

water

Refrigerant

Figure 5. Schematics of the control volume assumed for the RPW-HEX simulation

The discretization of each of the control volume is shown in Figure 6. Notice that there are three possible working conditions, depending on whether only one or both the refrigerant and water flows are moving within the RPWHEX:

- $\quad$ Refrigerant is charging the PCM (Figure 6-left). There is no water circulation.

- Water is discharging the PCM (Figure 6-center). There is no refrigerant circulation.

- Refrigerant is transferring heat/cold to the water (Figure 6-right). In this situation the PCM will be partially charged. 

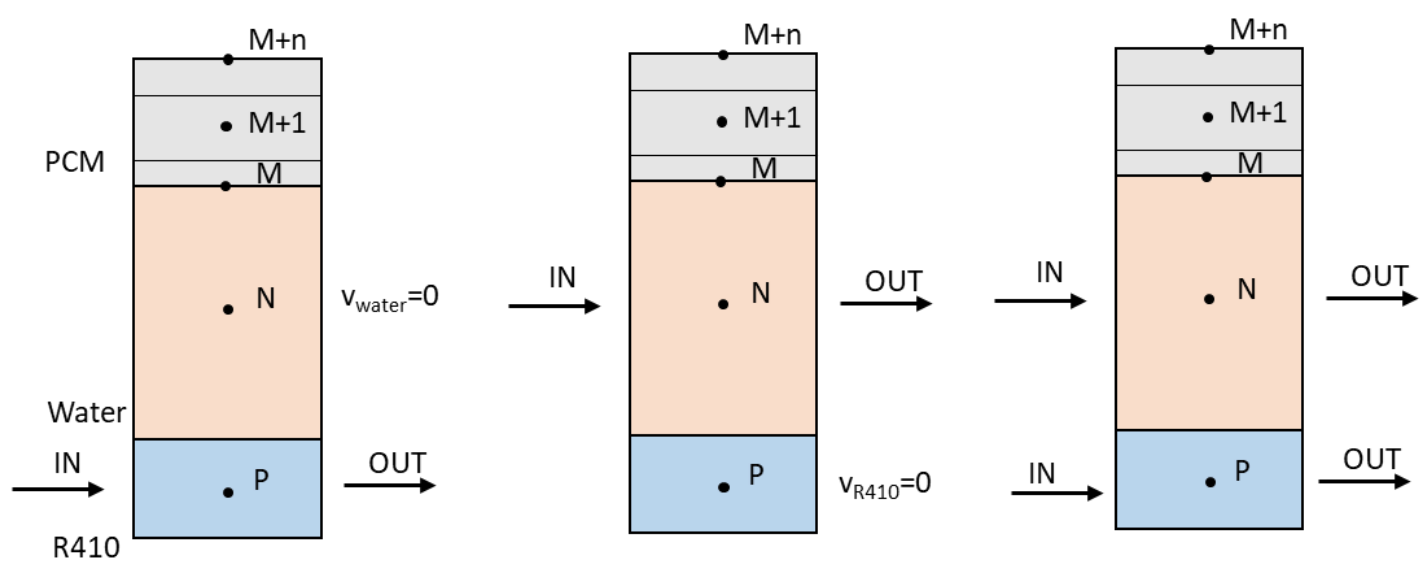

Figure 6. Schematics of the discretization of the control volume assumed for three different scenarios: left: PCM charging, centre: PCM discharging, right: standard working conditions

The two-dimensional heat transfer during charging/discharging is governed by the following equation:

$$
\sum \dot{Q}+\left(\dot{m}_{\text {in }} \cdot h_{\text {in }}\right)-\left(\dot{m}_{\text {out }} \cdot h_{\text {out }}\right)=\rho \cdot C_{p} \cdot \frac{\Delta T}{\Delta t} \cdot d V
$$

In the model, the number of nodes taken in the flow direction was 100, while in the vertical direction solely one node is used for the refrigerant and water, respectively, while 5 nodes were considered for PCM. The system of algebraic linear equations extracted from the finite volume method was solved using Gauss Seidel iterative method with a time step of 1 second. The solution was found to be mesh-independent based on the above nodes selection.

An important parameter of the RPW-HEX is its state of charge (SoC), which is used to indicate the extent to which a LHTES module is charged relative to storable latent heat (see definition of SoC (Barz et al., 2018)). The SoC, denoted by $\Xi$, is calculated as the geometric mean of local (liquid mass) phase fraction fields $\xi(\mathrm{x}, \mathrm{y}, \mathrm{z})$, where $\mathrm{x}, \mathrm{y}, \mathrm{z}$ represent spatial coordinates of the PCM contained in the LHTES module. The phase fraction fields $\xi(x, y, z)$ can be directly derived from the temperature fields $\mathrm{T}(\mathrm{x}, \mathrm{y}, \mathrm{z})$.

As stated above, a two dimensional geometry was considered, with a coordinate pointing in the water or refrigerant flow direction ( $\mathrm{x}$ on the domain $0 \leq \mathrm{x} \leq \mathrm{L}$ ), and one coordinate pointing into the PCM layer perpendicular to the first coordinate (y on the domain $0 \leq \mathrm{y} \leq \mathrm{d}$ ). For this two dimensional planar geometry of the PCM, the state of charge $\Xi$ is calculated as geometric mean as:

$$
\Xi=\frac{\int_{0}^{\mathrm{L}} \int_{0}^{d} \xi(x, y) d y d x}{L \cdot d}
$$

The integration of Eq. (16) needs to be carried out numerically.

For the Continental sub-system the RPW-HEX is used as hot storage, while for the Mediterranean sub-system it is used as cold storage. Accordingly, diff erent SoC are defined to account for the fact that the hot storage is fully charged if all PCM is in the liquid state, while the cold storage is fully charged when the PCM is in solid state:

$$
\begin{gathered}
\Xi^{\text {hot }}:=\Xi \\
\Xi^{\text {cold }}:=1-\Xi
\end{gathered}
$$

The numerical RPW-HEX model was implemented in Modelica/Dymola simulation software in order to facilitate sub-system simulations, and to develop and evaluate its design and basic control settings under diff erent operating scenarios. A minimal test example (no connection to other sub-system components) for the Mediterranean subsystem is shown in Figure 7. 


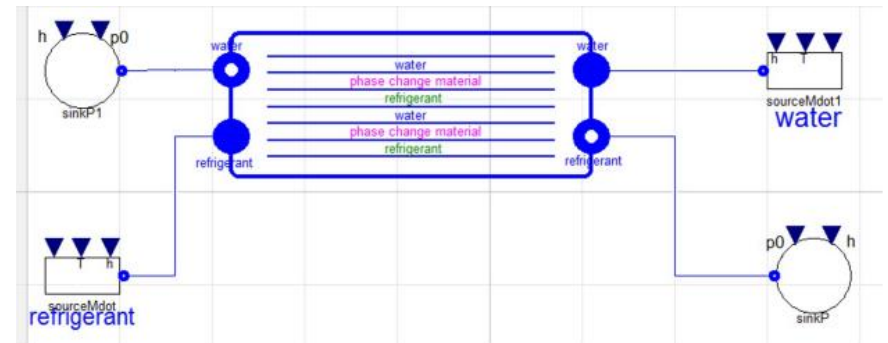

Figure 7. Dymola RPW-HEX model object of the MED system. This minimal test example uses fixed water and refrigerant inlet conditions

The implementation is based on the state-of-the-art ThermoCycle library model components (Quoilin et al., 2014). These model components are used to represent the water and refrigerant flow through the RPW-HEX internal parallel passages. Corresponding components are modifications of ThermoCycles so called "Flow1D" and "Cell1D" fluid flow components, see

Figure 12. Modifications concern the addition of a second heat port to account for: heat transfer between water (or refrigerant) passage and PCM, and heat transfer between water and refrigerant passage. The use of ThermoCycle standard fluid flow components, enables the user to select between different (available) options for state-of-the-art numerical discretization schemes and options for well-established heat transfer correlations.

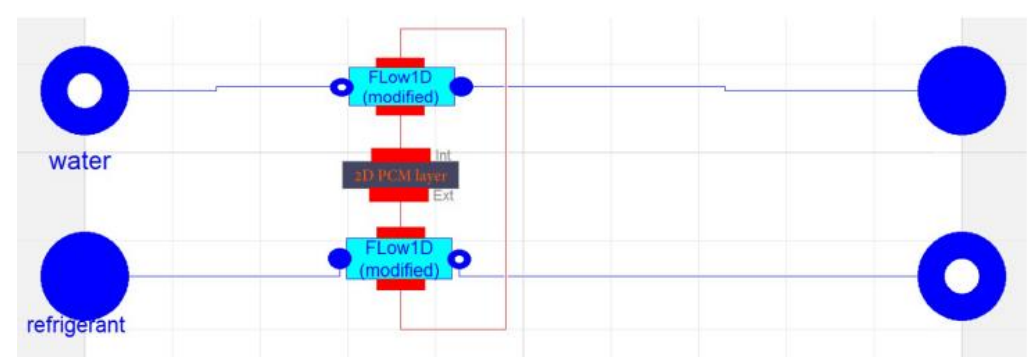

\begin{abstract}
Figure 8. Graphical representation of model classes used to define the Dymola RPW-HEX model of the Mediterranean sub-system. Heat ports and connectors between the balance envelops of the water passage, refrigerant passage and the PCM layer are shown in red.
\end{abstract}

The PCM layer is modelled using an ThermoCycle adapted heat flow component, namely a wall element. This component can be directly connected to the fluid flow elements using ThermoCycle thermal ports. According to the three-fluid RPW-HEX model, a two-dimensional PCM model is implemented and apparent (effective) PCM properties are used. The user can select between diff erent phase transition models, and the SoC is calculated as described above.

\title{
4.4 Electrical storage model
}

The model used for the electrical storage is based on Sheperd model, that describes the electrochemical behaviour of a battery in terms of voltage and current by excluding thermal and quantum phenomena (Hanlei Zhang and Mo-Yuen Chow, 2010; Shepherd, 1965). The model was improved by introducing the Peukert equation that quantifies the capacity reduction according to output current from the battery (Leksono et al., 2013). The reference equations of the model are the following:

$$
\begin{gathered}
V=E_{0}-J \frac{C_{\max }}{C_{\max }-C(t)} i+H \exp [-P \cdot C(t)]-R_{0} i \\
V=E-R_{0} i
\end{gathered}
$$

where: $\mathrm{V}$ is the cell voltage [V], $\mathrm{E}_{\mathrm{o}}$ the Open Circuit Voltage (OCV) [V], $\mathrm{J}$ the polarization factor $\left[\mathrm{Ah}^{-1}\right], \mathrm{C}_{\max }$ the maximum capacity of the battery $[\mathrm{Ah}], \mathrm{C}(\mathrm{t})$ the charged/discharged capacity at time $\mathrm{t}$, $\mathrm{i}$ the cell current $[\mathrm{A}], \mathrm{H}$ the exponential voltage component $[\mathrm{V}], \mathrm{P}$ the exponential capacity component $\left[\mathrm{Ah}^{-1}\right], \mathrm{R}_{0}$ the internal resistance $[\Omega]$.

The SOC is estimated as:

$$
S O C=\int \frac{i}{C_{\max }} d t
$$




\section{Models of the sub-systems}

\subsection{Mediterranean sub-system}

The Mediterranean hybrid sub-system comprises four main components: the sorption module, the compression heat pump, which includes the RPW-HEX module, and the electrical storage. Figure 9a shows Dymola diagram of the complete sub-system, including the sources and sinks that simulate the other components in the overall system and the electric parameters from the PV panels. The integration of the heat pump with the RPW-HEX is shown in detail in Figure 9b. What is clear is that the approach followed proved to be effective, since it was easily possible to connect all the components and realise a complete model of the sub-system.

(a)

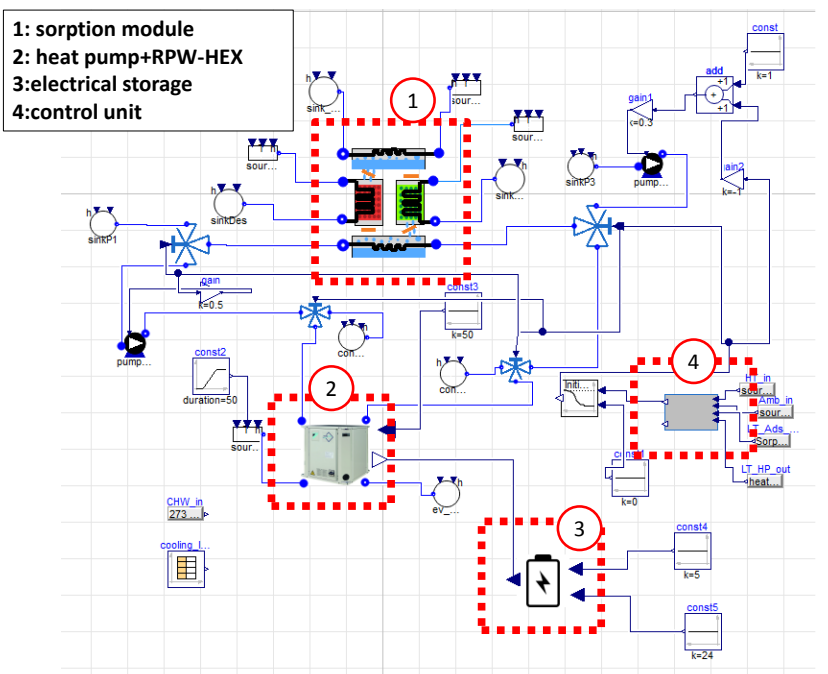

(b)

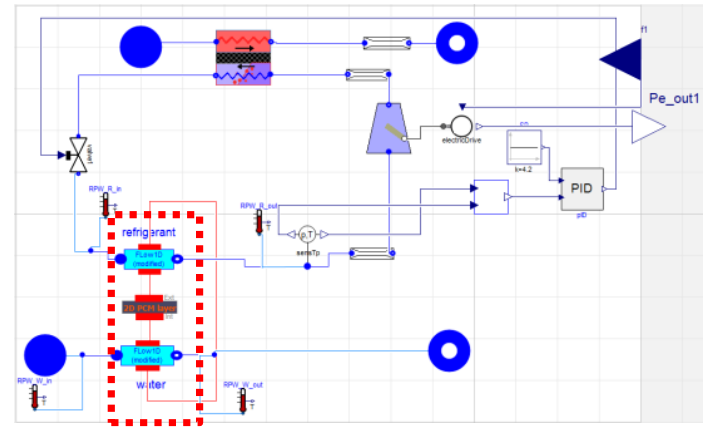

Figure 9. (a) Dymola diagram of the Mediterranean sub-system; (b) detail of the integration of the heat pump with the RPW-HEX.

\subsection{Continental sub-system}

The Continental hybrid sub-system consists of mainly three different types of storages: the latent storage (RPWHEX) integrated in the compression heat pump cycle, the decentralized sensible DHW storages, and the electric storage (see Figure $1 \mathrm{~b}$ and Figure 10). In the simulations (Figure 10) an option was investigated, where the process water to the decentralized DHW storage flows first through the condenser and afterwards through the latent storage. Furthermore, a simple building model working as a heat sink for the heating system, which considers a constant heat transfer coefficient, a representative mass of the building, and the ambient temperature was used.

During heating operation, solely the heat from the condenser is extracted with the aid of the process water flowing through the secondary side whereas in the case of DHW generation the process water flows also through the RPWHEX after leaving the condenser. With the aid of two three-way valves and three ramp-modules, operation can be switched between heating and DHW generation.

\section{Results}

\subsection{Mediterranean sub-system}

In order to test the model of the sub-system, operation on a typical day was considered. In particular, weather data for Aglantzia (CY), one of the locations chosen in the project for pilot installation were used, as well as the cooling demand for the building where the installation will take place. A reference day in August $\left(20^{\text {th }}\right)$ was chosen. For simplicity sake a constant heat source temperature of $90^{\circ} \mathrm{C}$ was considered, taking into account that the heat coming from Fresnel collectors in the installation for HYBUILD will be collected in a sensible storage.

Results from 9 am to 3 pm are shown in Figure 11. In particular, Figure 11a shows the temperatures in the circuits of the adsorption module and the heat pump. It is possible to notice that the cyclic operation of the adsorption module induces periodic rising in the temperature of the condenser of the heat pump, but the average inlet to the condenser of the heat pump is below $20^{\circ} \mathrm{C}$, thus reducing more than $10^{\circ} \mathrm{C}$ the temperature lift of the unit. Figure $11 \mathrm{~b}$ shows the powers in the different components of the adsorption module and the heat pump, calculated from the thermodynamic states of the fluids in each component. It is possible to notice that the power in the condenser of the heat pump corresponds to the average power from the evaporator of the adsorption module. Moreover, at each phase change 
there is a peak in the power absorbed/released from the adsorbers, due to the sensible heat and sorption heat of the material.

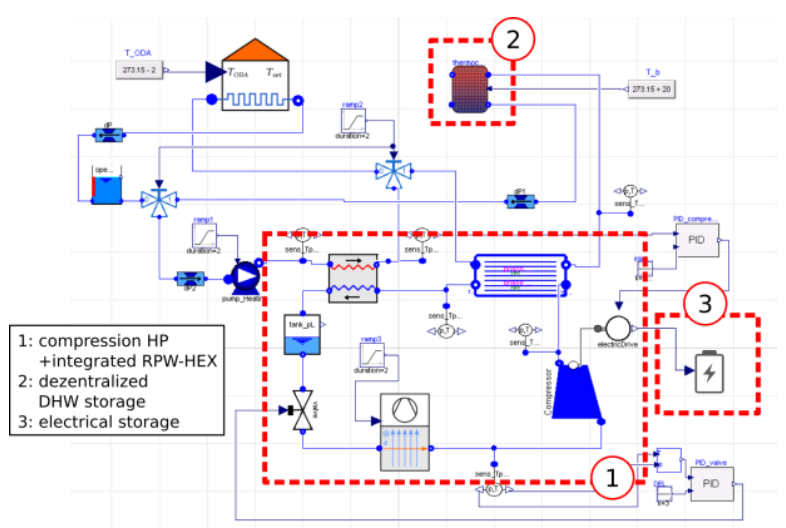

Figure 10. Dymola diagram of the Continental sub-system

(a)

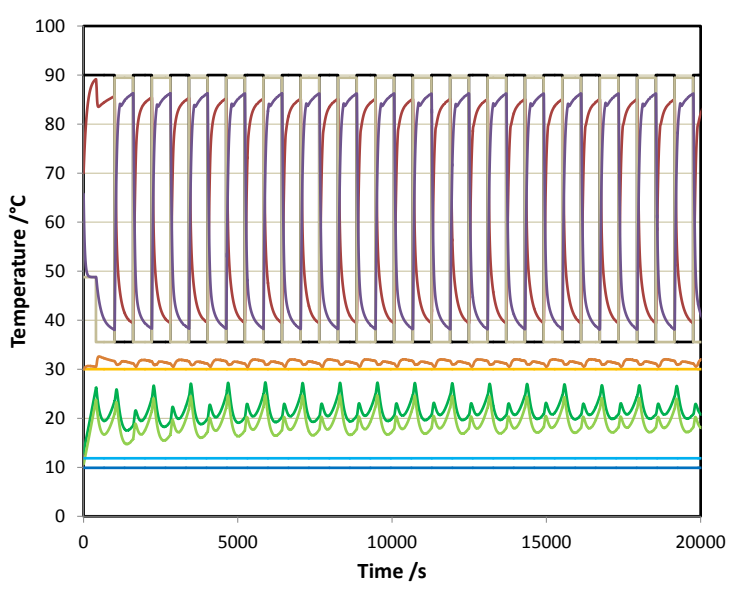

(b)

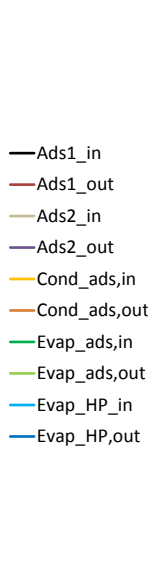

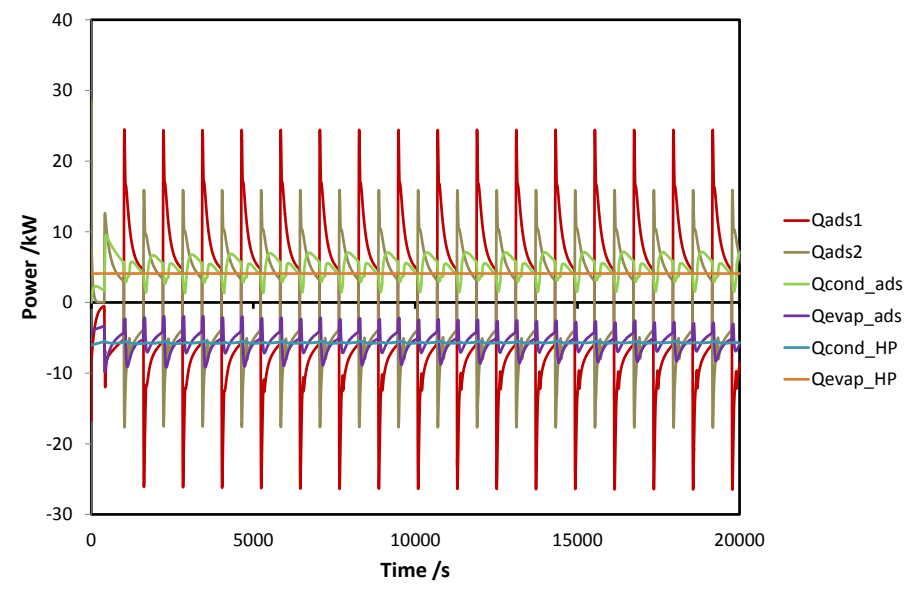

Figure 11. Temperatures (a) and thermal powers (b) in the circuits of the sorption module and heat pump for the reference conditions

\subsection{Continental sub-system}

In the following, the Continental sub-system will be discussed for a typical ambient condition in winter. The outdoor temperature was $2{ }^{\circ} \mathrm{C}$ in this scenario. The building itself is already heated to its steady-state temperature of $20.4{ }^{\circ} \mathrm{C}$ at $\mathrm{t}=0 \mathrm{~s}$. The DHW storage needs to be charged and had an initial temperature of $15^{\circ} \mathrm{C}$ at the bottom of the water tank and $35^{\circ} \mathrm{C}$ at the top (see

Figure 12a). The RPW-HEX is filled with a PCM that has a switching temperature at around $64{ }^{\circ} \mathrm{C}$. At $\mathrm{t}=0 \mathrm{~s}$ the RPW-HEX has a uniform temperature of $62{ }^{\circ} \mathrm{C}$, hence nearly no latent energy is stored at the beginning of the simulation $(\mathrm{SoC}=1.2 \%)$.

After starting the heat pump at $\mathrm{t}=0 \mathrm{~s}$ in heating mode (no mass flow to decentralized DHW storage), the system was switched after $4000 \mathrm{~s}$ to DHW generation mode. For a fair comparison we will observe solely the behaviour of the system after stabilization of the heat pump between SoCs of $5 \%$ or in other words between $\mathrm{t}=426 \mathrm{~s}$ and $\mathrm{t}=4714 \mathrm{~s}$ in our example. Hence, the building heating time will last for around 1 hour before the heat pump switches for 12 minutes into DHW generation mode. During heating operation, the RPW-HEX will be charged up to a maximum of $35 \%$ before the hydraulic valves are switched to DHW generation and slow down the process water. During DHW generation, the RPW-HEX will be discharged down to $5 \%$ again. Contrary to conventional systems, the condensing pressure/temperature controlled via the temperature of the process water outlet and the compressor rotational speed should stay nearly the same during heating and DHW generation operation. The extra thermal energy to heat up the process water to DHW-temperatures $\left(>60^{\circ} \mathrm{C}\right)$ will solely be extracted from the RPW-HEX in DHW generation mode. In Figure 12b (green, dashed line), one can see that the implemented PID-controller does not manage to limit the outlet condenser temperature $\vartheta_{w a, c o n}^{(o u t)}$ perfectly during DHW generation. This is actually a difficult task as the compressor speed (and therefore the power consumption) decreases and the inlet temperature to the secondary side 
of the condenser $\vartheta_{w a, c o n}^{(i n)}$ (blue solid line in Figure 12b) varies over the time. One can see clearly, that the stored energy in the RPW-HEX is sufficient to provide process water with a charging temperature of about $63^{\circ} \mathrm{C}$ (red dotted line in Figure 12b) for about 12 minutes which heats the top layer or the decentralized storage to about $50^{\circ} \mathrm{C}$.

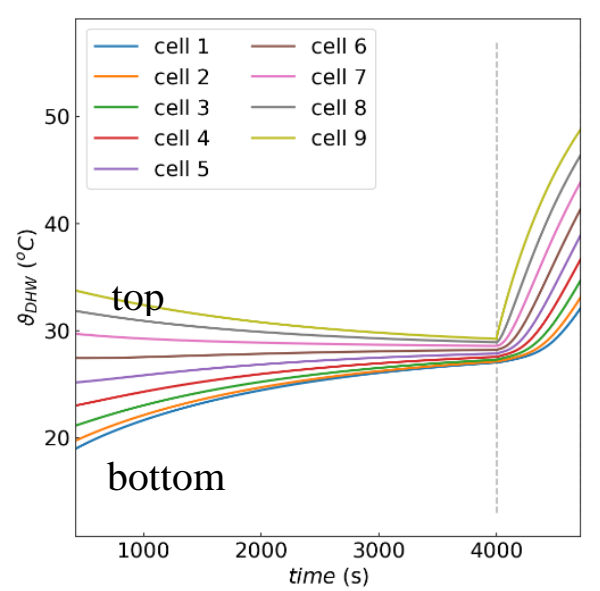

(a)

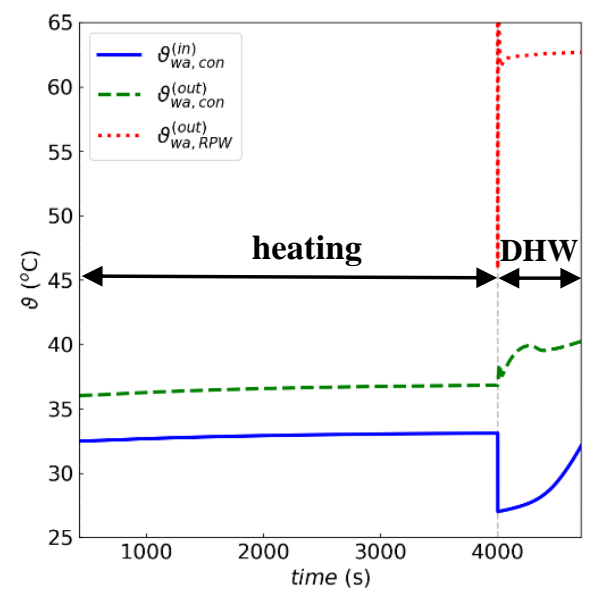

(b)

Figure 12. (a) Vertical temperature aistribution in the decentralized DHW-storage trom the top (cell 9) to the bottom (cell 1) and (b) temperatures on the process water side of the condenser and the RPW-HEX

\section{Conclusions and on-going activities}

The development of the models for two hybrid thermal/electrical storage systems for Continental and Mediterranean climates were presented. The models were realized in Dymola/Modelica environment, using a modular approach: the core components were modelled using open source libraries and self-developed components. Integration of the components and verification of the operation of the sub-systems under reference operating conditions were carried out. Current activities are aimed at the realization of prototypes of the core components and their laboratory testing, in order to validate and calibrate the realized models. The developed models will be subsequently used to test the management strategies and for techno-economic analysis.

\section{Acknowledgments}

This project has received funding from the European Union's Horizon 2020 research and innovation programme under grant agreement No 768824 (HYBUILD).

\section{References}

Barz, T., Seliger, D., Marx, K., Sommer, A., Walter, S.F., Bock, H.G., Korkel, S., 2018. State and state of charge estimation for a latent heat storage. Control Eng. Pract. 72, 151-166. doi:10.1016/J.CONENGPRAC.2017.11.006

Battaglia, M., Haberl, R., Bamberger, E., Haller, M., 2017. Increased self-consumption and grid flexibility of PV and heat pump systems with thermal and electrical storage. Energy Procedia 135, 358-366. doi:10.1016/J.EGYPRO.2017.09.527

Bell, I.H., Wronski, J., Quoilin, S., Lemort, V., 2014. Pure and Pseudo-pure Fluid Thermophysical Property Evaluation and the Open-Source Thermophysical Property Library CoolProp. Ind. Eng. Chem. Res. 53, 24982508. doi:10.1021/ie4033999

Bendapudi, S., Braun, J.E., Groll, E.A., 2008. A comparison of moving-boundary and finite-volume formulations for transients in centrifugal chillers Comparaison entre les formulations aux limites mobiles et ' gimes transitoires des aux volumes finis pour les re refroidisseurs centrifuges. Int. J. Refrig. 31, 1437-1452. doi:10.1016/j.ijrefrig.2008.03.006

Bloess, A., Schill, W.-P., Zerrahn, A., 2018. Power-to-heat for renewable energy integration: A review of technologies, modeling approaches, and flexibility potentials. Appl. Energy 212, 1611-1626. doi:10.1016/J.APENERGY.2017.12.073

Byrne, P., Miriel, J., Lénat, Y., 2012. Modelling and simulation of a heat pump for simultaneous heating and cooling. Build. Simul. 5, 219-232. doi:10.1007/s12273-012-0089-0

Camilo, F.M., Castro, R., Almeida, M.E., Pires, V.F., 2017. Economic assessment of residential PV systems with 
self-consumption and storage in Portugal. Sol. Energy 150, 353-362. doi:10.1016/J.SOLENER.2017.04.062

El-Sharkawy, I.I., 2011. On the linear driving force approximation for adsorption cooling applications. Int. J. Refrig. 34, 667-673. doi:10.1016/J.JJREFRIG.2010.12.006

European Commission, 2016. European Commission, 2016. Communication from the Commission to the European Parliament, the Council, the European Economic and Social Committee and the Committee of the Regions and the European Investment Bank, Brussels.

Frazzica, A., Freni, A., 2017. Adsorbent working pairs for solar thermal energy storage in buildings. Renew. Energy 110, 87-94. doi:10.1016/j.renene.2016.09.047

Hanlei Zhang, Mo-Yuen Chow, 2010. Comprehensive dynamic battery modeling for PHEV applications, in: IEEE PES General Meeting. IEEE, pp. 1-6. doi:10.1109/PES.2010.5590108

Heinen, S., Burke, D., O’Malley, M., 2016. Electricity, gas, heat integration via residential hybrid heating technologies - An investment model assessment. Energy 109, 906-919. doi:10.1016/J.ENERGY.2016.04.126

Lanzerath, F., Bau, U., Seiler, J., Bardow, A., Bardow, E., 2015. Optimal design of adsorption chillers based on a validated dynamic object-oriented model. Sci. Technol. Built Environ. 21, 248-257. doi:10.1080/10789669.2014.990337

Leksono, E., Haq, I.N., Iqbal, M., Soelami, F.X.N., Merthayasa, I.G.N., 2013. State of charge (SoC) estimation on LiFePO4 battery module using Coulomb counting methods with modified Peukert, in: 2013 Joint International Conference on Rural Information \& Communication Technology and Electric-Vehicle Technology (RICT \& ICeVT). IEEE, pp. 1-4. doi:10.1109/rICT-ICeVT.2013.6741545

Lorenzi, G., Silva, C.A.S., 2016. Comparing demand response and battery storage to optimize self-consumption in PV systems. Appl. Energy 180, 524-535. doi:10.1016/J.APENERGY.2016.07.103

Petrollese, M., Cau, G., Cocco, D., 2018. Use of weather forecast for increasing the self-consumption rate of home solar systems: An Italian case study. Appl. Energy 212, 746-758. doi:10.1016/J.APENERGY.2017.12.075

Quoilin, S., Desideri, A., Wronski, J., Bell, I., Lemort, V., 2014. ThermoCycle: A Modelica library for the simulation of thermodynamic systems, in: Proceedings of the 10th International Modelica Conference. Lund, Sweden. doi:10.3384/ECP14096683

Rodat, S., Baviere, R., Bruch, A., Camus, A., 2018. Dynamic simulation of a Fresnel solar power plant prototype with thermocline thermal energy storage. Appl. Therm. Eng. doi:10.1016/J.APPLTHERMALENG.2018.02.083

Schicktanz, M., Núñez, T., 2009. Modelling of an adsorption chiller for dynamic system simulation. Int. J. Refrig. 32, 588-595. doi:10.1016/J.JJREFRIG.2009.02.011

Schram, W.L., Lampropoulos, I., van Sark, W.G.J.H.M., 2018. Photovoltaic systems coupled with batteries that are optimally sized for household self-consumption: Assessment of peak shaving potential. Appl. Energy 223, 69-81. doi:10.1016/J.APENERGY.2018.04.023

Schwarz, H., Schermeyer, H., Bertsch, V., Fichtner, W., 2018. Self-consumption through power-to-heat and storage for enhanced PV integration in decentralised energy systems. Sol. Energy 163, 150-161. doi:10.1016/J.SOLENER.2018.01.076

Shepherd, C.M., 1965. Design of Primary and Secondary Cells. J. Electrochem. Soc. 112, 657. doi:10.1149/1.2423659

Spreitzhofer, J., Esterl, T., Schwalbe, R., Stifter, M., 2018. Pooling of smart heat pumps provides flexibility to the electricity market and grids. IEA HPT Mag.

Vasta, S., Palomba, V., La Rosa, D., Mittelbach, W., 2018. Adsorption-compression cascade cycles: An experimental study. Energy Convers. Manag. 156, 365-375. doi:10.1016/j.enconman.2017.11.061

Willatzen, M., Pettit, N.B.O.L., 1998. A general dynamic simulation model for evaporators and condensers in refrigeration. Part I : moving-boundary formulation of two-phase flows with heat exchange ' ne ' ral dynamique pour e' vaporateurs et Mode condenseurs frigorifiques . Partic I : Formul. Int. J. Refrig. 21, 398-403.

Yilmaz, H.Ü., Keles, D., Chiodi, A., Hartel, R., Mikulić, M., 2018. Analysis of the power-to-heat potential in the European energy system. Energy Strateg. Rev. 20, 6-19. doi:10.1016/J.ESR.2017.12.009 


\title{
Potential of direct solar thermal driven absorption heat pump in hybrid systems
}

\author{
Florian Gritzer ${ }^{1}$, Daniel Neyer ${ }^{1,2}$, Manuel Ostheimer ${ }^{1}$ and Alexander Thür ${ }^{1}$ \\ 1 University of Innsbruck, 6020 Innsbruck (Austria) \\ 2 daniel neyer brainworks, 6700 Bludenz (Austria)
}

\begin{abstract}
The energy requirement in buildings is currently changing, the heating demand is decreasing while the cooling demand can be expected to rise. Due to increase of global economics and thus living comfort as well as the need to minimize climate impact highly efficient and renewable solutions for heating and cooling are absolutely essential. Solar thermal and photovoltaic driven systems coupled to thermal/electrical driven heat pumps are promising technologies to satisfy these needs.

However, such systems show a wide range of efficiencies and economics caused by different system designs and control strategies. The research project "SolarHybrid" is systematically processing and optimizing the solar driven systems and their hybrid combinations thereby highly efficient and economic competitive solutions are accomplished.

A study on the hybrid combination of a solar-thermal direct driven absorption heat pump with a vapor compression heat pump for heating and cooling is highlighted here. Up to $80 \%$ non-renewable primary energy savings can be realized and despite increased initial investment costs this solution is economic. The results show that levelized energy costs at the same level or even lower as a reference system can be achieved.
\end{abstract}

Keywords: solar heating and cooling, hybrid systems, solar direct driven absorption chiller

Tab. 1: Nomenclature and Subscripts

\begin{tabular}{|c|c|c|c|c|c|}
\hline $\mathrm{ACM}$ & Absorption chiller & HiL & Hardware-in-the-loop & PV & Photovoltaic \\
\hline $\mathrm{C}$ & Cooling & HT & High temperature & Q & Energy $[\mathrm{kWh}]$ \\
\hline $\mathrm{CR}$ & Cost ratio (-) & HVAC & $\begin{array}{l}\text { Heating, ventilation and } \\
\text { air conditioning systems }\end{array}$ & ref & Reference system \\
\hline DHW & Domestic hot water & IEA & $\begin{array}{c}\text { International Energy } \\
\text { Agency }\end{array}$ & SE & Single effect \\
\hline$\varepsilon$ & $\begin{array}{l}\text { Primary Energy Factor } \\
\left(\mathrm{kWh} / \mathrm{kWh} \mathrm{h}_{\mathrm{PE}}\right)\end{array}$ & in & Input & $\mathrm{SH}$ & Space heating \\
\hline $\mathrm{EC}$ & Energy Carrier & KPI & $\begin{array}{l}\text { Key performance } \\
\text { Indicator }\end{array}$ & $\mathrm{SHC}$ & Solar heating and cooling \\
\hline el & Electrical & loss & Losses & SF & Solar Fraction \\
\hline equ & Equivalent & $\mathrm{LT}$ & Low temperature & SPF & $\begin{array}{c}\text { Seasonal Performance } \\
\text { Factor (-) }\end{array}$ \\
\hline$f_{\text {sav }}$ & Savings & NRE & Non-renewable & ST & Solar thermal \\
\hline$\eta$ & Efficiency & MT & Medium temperature & sys & System \\
\hline HB & Hot backup & out & Output & th & Thermal \\
\hline $\mathrm{HE}$ & Half effect & PER & Primary Energy Ratio & $\mathrm{VCC}$ & Vapour compression chiller \\
\hline
\end{tabular}




\section{Introduction}

Due to the expected development of the energy demand in the building sector and the global goal to reduce greenhouse gas emissions, the importance of energy-efficient and renewable (solar) heating and cooling systems is increasing. Especially the cooling demand is rising due to growth of global economy and thus increasing living standards (OECD 2018). The consumption of non-renewable primary energy in buildings can be minimized with the implementation of solar driven systems. However, in order to achieve the optimum utilization of nonrenewable energy sources the basic energy requirement of buildings must be reduced first. Following this demand optimization, the remaining energy can be covered by solar energy.

The two technologies that are available are solar thermal (ST) or solar-electric (photovoltaic - PV) supported systems. Depending on the boundary conditions, each of the solar technologies offers technical and/or economic advantages compared to standard reference system. However, these two technologies and their technical and economic benefits are still controversial, particularly in the field of heat and cold supply for buildings.

The Austrian "SolarHybrid" research project deals with the systematic processing and optimization of both technologies and their combination for different load profiles. In "SolarHybrid" energy efficient and economic (solar-) hybrid systems for heating and cooling (SHC) are developed. The project includes the development of a $\mathrm{NH}_{3} / \mathrm{H}_{2} \mathrm{O}$ single-/half effect absorption chiller (ACM), a $\mathrm{NH}_{3}$ vapor compression chiller (VCC), their detailed laboratory measurements and system integration as well as comprehensive modelling and system simulations. The systematic validation of the simulation approaches and the individual models including their partial load behavior is an essential basis for modeling. Further investigations are carried out with suitable dynamic simulation models, which are adapted to the laboratory measurements. The solar HVAC systems are adapted and evaluated for three different profiles (office building, hotel and a potential study).

The major barrier to introduce SHC systems in the market are the initial investment costs. To address this barrier, one focus of the project was the reduction of size and number of components. The approach to reduce the system components was (i) to define possible system configurations, (ii) to investigate them in software simulations, (iii) to test both main components (ACM/VCC) in Hardware-in-the-Loop (HiL) tests, (iv) to validate the simulations with the measured data and run annually simulation studies and (v) to assess the results from a technical and economical point of view. The systems are analyzed and evaluated with the standardized evaluation procedure, developed in IEA SHC Task 53 (T53E4-Tool) (Neyer et al., 2016). This tool is used to evaluate both the technical and the economic potential. The effect of changing technical and economic boundary conditions on key performance indicators (KPIs) are determined with comprehensive sensitivity analyses.

Two chillers/heat pumps were built for the project and optimized for hybrid operation: (i) a vapour compression chiller and (ii) an absorption chiller. The ammonia/water ACM developed in the DAKTris (2013) research project has been further optimized in the SolarHybrid research project and was operated in hybrid operation with the ammonia VCC in hardware-in-the-loop laboratory measurements.

A detailed examination of the components and systems, their modelling and the various load profiles was carried out. The systematic analysis of the simulation approaches and the individual models with their partial load behaviour and their limits of use were the main basis for the following modelling. Dynamic system simulation models are created by selecting and adapting the individual models. Further investigations on system level are carried out accordingly. The hybrid systems were optimized regarding non-renewable primary energy savings with respect to economic benefits. The economic and energetic optimization of solar thermal concepts is achieved by means of three strategies: (i) through adapted hydraulic design, (ii) radically reduced number of components and (iii) improved, more efficient control strategies.

The focus of this paper is on the results of the potential study of the hybrid ACM and VCC operation, which are developed on the basis of laboratory measurements and simulations. This study sought to assess both the technical and economic potential. The potential in maximum supply is evaluated in terms of various temperature levels and applications.

The potential study presented here is showing the potential in terms of minimized and reduced number of components (solar direct fired) and on the other hand the potential of the maximum deliverable energy for given temperature levels. 


\section{Evaluation}

Three methodologies were used to assess the potential of the hybrid ACM and VCC operation. The assessment follows the IEA SHC Task 53 approach and is based on Hardware- in-the-Loop measurements of the single components as well as the hybrid operation and TRNSYS simulations. In this chapter the key performance indicators, the steady state and dynamic laboratory measurements, and the simulation models are discussed. Fig. 1 shows the overall methodological approach of the project. The common nomenclature and subscripts are listed in Tab. 1.

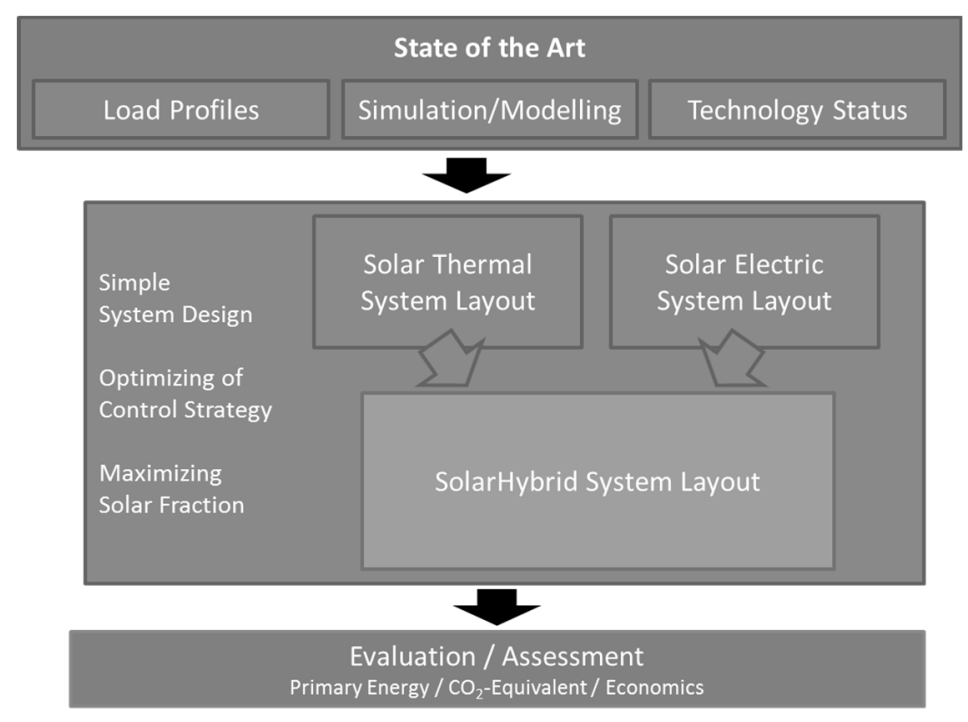

Fig. 1: Methodological approach and workflow of the project SolarHybrid

\subsection{Assessment - T53E4-Tool}

In general, the performance evaluation of SHC systems can be complex and the KPIs can be determined in different ways for different boundaries. Thus, the evaluation is carried on technical, economic and ecological aspects according to the methods developed in the IEA SHC Task 48 and 53. The method was implemented in a tool (T53E4 Tool) that contains a database with primary energy factors $(\varepsilon)$, efficiencies and economic data for all main SHC components. The evaluation is based on monthly energy balances and includes the calculation of different key performance indicators. The performance evaluation of the SHC system considers the energy distribution in different subsystems for different applications like space heating (SH), domestic hot water (DHW, water heating) and cooling (C).

The most important key figures are explained briefly below. The corresponding equations are shown in Tab. 2 . The key performance indicators are defined and discussed in detail by Neyer et al. (2016).

- Non-renewable Primary Energy Ratio (PER $\left.\mathrm{NRE}_{\mathrm{N}}\right)$

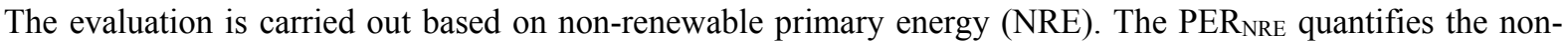
renewable primary energy efficiency of the system (eq. 1). The primary energy factors $(\varepsilon)$ required for the conversion are depending on type of energy, the location of the system and the season.

- Non-renewable primary energy savings $\left(\mathrm{f}_{\text {sav.NRE }}\right)$

The primary energy of the entire SHC system is compared to a reference system. The standardized Task 53 reference system is an air-cooled compression chiller (VCC) and a natural gas boiler and its primary energy ratio

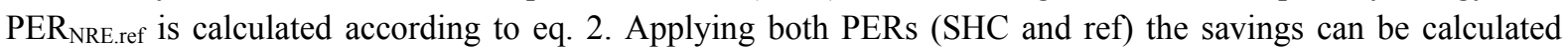
according to eq. 3 .

- Seasonal Performance Factor (SPF)

The SPF is the ratio of useful energy (out: energy supplied to satisfy the needs of the building) to consumed energy from external sources (eq. 4). It is distinguished between thermal and electrical performance. 
- $\quad$ Cost Ratio (CR)

The cost ratio is determined with the annualized costs for the SHC system $\left(\mathrm{C}_{\text {use.SHC}}\right)$ and the costs for the reference system $\left(\mathrm{C}_{\text {use.REF }}\right)$ according to the eq. 5 . The annualized costs include investment, replacement, maintenance, electricity, energy, water as well as feed-in tariffs for electricity of photovoltaic etc. The costs are discounted according to the annuity method and are summed up on a yearly basis. If the CR equals one cost parity is reached for the SHC system compared to the defined reference system.

Tab. 2: Overview technical and economic key performance figures defined in IEA SHC Task 53

\begin{tabular}{|c|c|c|}
\hline \multirow{2}{*}{$\begin{array}{l}\text { Non-renewable Primary } \\
\text { Energy Ratio }\end{array}$} & $P E R_{N R E}=\frac{\sum Q_{\text {out }}}{\sum\left(\frac{Q_{e l \text { lin }}}{\varepsilon_{\text {el }}}+\frac{Q_{\text {in }}}{\varepsilon_{\text {in }}}\right)}$ & (eq. 1) \\
\hline & $P E R_{\text {NRE.ref }}=\frac{\sum Q_{\text {out }}}{\sum\left(\frac{Q_{\text {out heat }}+Q_{\text {loss.ref }}}{\varepsilon_{\text {in }}{ }^{*} \eta_{H B . r e f}}+\frac{Q_{\text {out.cold }}}{\operatorname{SPF}_{\text {C.ref }}{ }^{*} \varepsilon_{\text {el }}}+\frac{Q_{\text {el,ref }}}{\varepsilon_{\text {el }}}\right)}$ & (eq. 2) \\
\hline $\begin{array}{l}\text { Non-renewable Primary } \\
\text { Energy Savings }\end{array}$ & $f_{\text {sav.NRE }}=1-\frac{P E R_{N R E . r e f}}{P E R_{N R E . s y s}}$ & (eq. 3) \\
\hline $\begin{array}{l}\text { Seasonal Performance } \\
\text { Factor }\end{array}$ & $S P F_{t h}=\frac{\sum Q_{\text {out }}}{\sum Q_{\text {in }}}, S P F_{\text {el }}=\frac{\sum Q_{\text {out }}}{\sum Q_{\text {elin }}}$ & (eq. 4) \\
\hline Cost Ratio & $C R=\frac{C_{\text {use }, S H C}}{C_{\text {use }, R E F}}$ & (eq. 5) \\
\hline
\end{tabular}

\subsection{Measurements \& Hardware-in-the-Loop}

Two tested components are built and optimized in the course of the project. The functional models of an ammonia/water (NH3/H2O) absorption chiller (ACM) and an ammonia vapour compression chiller (VCC) are investigated accordingly. The ACM was developed in the research project DAKTris (2013), it has a nominal cooling power of $20 \mathrm{~kW}$ and offers the possibility to switch from single- to half-effect (SE/HE). This enables the possibility of high heat rejection temperatures (up to $45^{\circ} \mathrm{C}$ ), the use of a dry cooling tower and the possibility of high useful temperatures in heat pump-mode. Within this project, the ACM is adapted and optimized concerning the findings in DAKTris and the requirements of SolarHybrid (for example automation of the solvent compensation). In consideration of the hybrid operation the cooling capacity of the VCC is also $20 \mathrm{~kW}$ (at nominal condition of evaporation temperature $4^{\circ} \mathrm{C}$ and condensing temperature $50^{\circ} \mathrm{C}$ ). The main components of the vapour compression chiller are a frequency-controlled piston compressor, a flooded evaporator and a hot gas bypass.

In a first step steady state performance of both machines is measured and characteristic curve diagrams are generated. The second step includes dynamic Hardware-in-the-loop (HiL) tests of the single components and the hybrid operation. The components in the laboratory are integrated in the simulated overall systems (HiL).

- Steady state measurements

Steady state measurements are used to identify the performance at constant operation points. The settings are adjusted accordingly considering the settling time and the measurement period to calculate a representative mean value and the corresponding deviation.

- Dynamic measurements

Based on the stationary results (limiting boundary conditions) and defined system configurations (c.f. next paragraph) a simulation model is set up in TRNSYS. Each configuration is measured under the boundary conditions of two significant days (one sunny, one cloudy) at the chosen location in different variations (temperatures, mass flows, control strategies, SE/HE mode, etc.).

- System configurations

As a consequence, to the idea of minimized and reduced number of components the measured configurations are defined accordingly as direct solar thermal driven systems (no hot water storage). The climatic conditions are simulated for different locations (Innsbruck, Seville, etc.). The solar collector field, the cooling tower and the other components are designed accordingly. The grid provides the required electrical energy. 
a) Chiller-mode ACM and VCC: The generator (HT) circuit of the ACM is directly connected to a solar collector field (ST), heat rejection (MT) circuits of both machines are connected in parallel with a dry cooling tower. The chilled water (LT) inlet of the VCC is connected in serial to the outlet of the ACM. Thus, the ACM is cooling the (LT) outlet further down to the required temperature for the cooling load if the power of the ACM is too low. The necessary electricity is drawn from the grid.

b) Heat pump-mode $\mathrm{ACM}$ (SE and HE): HT circuit of ACM is directly connected to the collector; MT mass flow is controlled to reach the desired temperature at the MT outlet (useful hot water temperature) of the ACM and the chilled water could be used optionally.

c) Combined chiller- and heat pump-mode ACM and VCC: HT circuit of ACM is directly connected to the collector field, MT and LT circuits of the VCC are connected in serial to the ACM, MT mass flow is controlled to deliver the defined temperature and VCC power is controlled to reach the set LT outlet temperature.

Fig. 2 shows the configuration for the configurations a) and c) on the left side and the configuration b) on the right side.
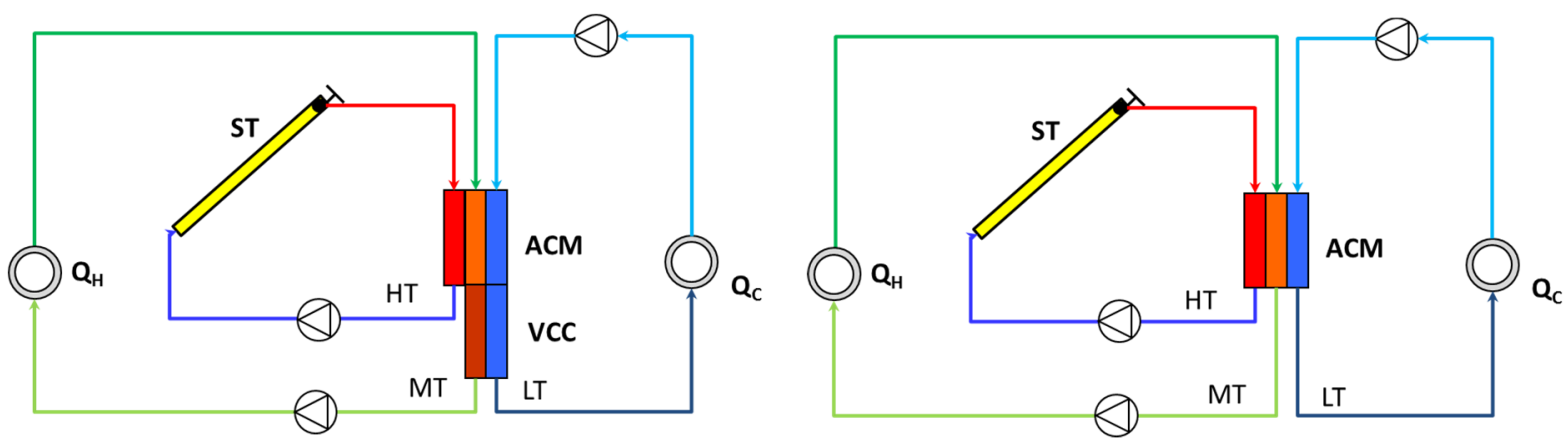

Fig. 2: heat pump and cooling-mode with ACM and VCC (left) and heat pump-mode with ACM only (right)

The main purpose of the combined chiller and heat pump-mode of ACM and VCC (configuration c) is the supply of heat and the simultaneous allocation of cooling energy. The defined temperature levels are $12 / 6^{\circ} \mathrm{C}$ for chilled water (LT) circuit, for useful heat of the rejection (MT) circuit $14 / 40^{\circ} \mathrm{C}$ and according to the direct coupled solar collector a variable generator (HT) input $\left(60 \sim 95^{\circ} \mathrm{C}\right)$. The ACM delivers as much as possible (depends on solar irradiation and the reached generator temperature) and the VCC is complementing to deliver the set LT and MT outlet temperature.

Subsequent to the measurements, the evaluated data and energy balances are used to fit the simulation model. Annual simulation studies are carried out for different systems and boundary conditions.

\subsection{Simulation studies}

The individual models (ACM, VCC, cooling tower, etc.) have been investigated and improved with respect to their partial load behaviour. The ACM and VCC are built up as characteristic curve models and are adjusted to the measured steady state and dynamic data.

The ACM model (Type 1005, Neyer et al., 2015) is based on semi-physical models of a single-effect (SE) ACM (Hannl et al., 2012) and a half-effect (HE) ACM (Zotter et al., 2015). The model can switch between the two operating modes (SE/HE) and its nominal capacity is scalable. A new characteristic curve model has been developed for the VCC. It's also based on a semi-physical simulation model (Luger 2017) that was fitted to the measurements accordingly. The deviation between the simulated and measured daily energy balances for each model is smaller than $3 \%$.

In general, two methods were used to deal with the entire load profiles (heating, cooling, domestic hot water and electricity requirements). The first approach (for a hotel and office building) is using building simulations of the load profiles, the HVAC system is designed according to these load profiles. The second approach used for the potential studies is a reversed way. The HVAC system is designed for a certain capacity (here $20 \mathrm{~kW}$ ) and is driven by solar only at certain useful temperature levels, thus delivering the maximum possible energy. The real 
application will either reduce the energy allocated and limiting the technical and economic performance or if the system is applied as base load the sub-system performance keeps the same but the total system performance indicators will change accordingly.

In this paper the results of the potential study are shown only, results of the combined building-HVAC simulations can be found in the final report of the project. The following variants are considered at different temperature levels, control strategies and climatic conditions.

The potentials of the solar directly driven absorption chiller (thermal) are investigated in HiL measurements as well as with simulation studies. The potential studies are carried out for three concepts for heating and cooling (c.f. Tab. 3) resulting in different solar fractions. If the ACM or AHP is operated only, the result is solar fraction $100 \%$. If the output of the $\mathrm{VCC} / \mathrm{HP}$ is controlled to a certain set outlet temperature via its compressor speed (55$100 \%$ ), values of approximately $50 \%$ are obtained. At maximum compressor speed of the $\mathrm{VCC} / \mathrm{HP}$ (thus maximum cooling generation) a SF of approximately $35 \%$ is achieved.

(i) exclusively solar thermal driven resulting in solar fraction of $100 \%$ (SF 100)

(ii) the hybrid concept, with a controlled operation of the vapor compression chiller (SF 50\%)

(iii) the hybrid concept, with maximum chiller/heat pump capacity (SF 37\%)

The absorption chiller is directly solar driven, no hot water storage is included. Due to the design of the system the collector can deliver sufficient generator power to run the ACM as soon as the solar irradiation is greater than $200 \mathrm{~W} / \mathrm{m}^{2}$. To determine the maximum potential of the system for heating, the chilled water circuit (LT circuit) is operated with constant inlet temperature and constant mass flow (simplified control, because there is no constant outlet temperature). The MT circuit is operated with a constant inlet temperature but with a variable mass flow so that a constant outlet temperature is achieved (energy for heating). The MT outlet temperature is controlled to reach $32^{\circ} \mathrm{C}, 40^{\circ} \mathrm{C}, 45^{\circ} \mathrm{C}$ or $60^{\circ} \mathrm{C}$ depending on the variation. The AHP is operated in single and half effect (SE/HE). If heating and cooling is investigated in parallel the LT circuit is also controlled to reach the entire setpoint.

Tab. 3: Evaluated variants of the potential study and their most important boundary conditions (operation of the ACM/AHP or $\mathrm{VCC} / \mathrm{HP})$

\begin{tabular}{|c|c|c|c|}
\hline Operating mode & SF 37\% & SF 50\% & SF 100\% \\
\hline Cooling & $\begin{array}{c}\text { ACM + ST direct } \\
\text { VCC maximum }\end{array}$ & $\begin{array}{c}\text { ACM + ST direct } \\
\text { VCC controlled }\end{array}$ & ACM + ST direct \\
\hline Heating & $\begin{array}{c}\text { AHP + ST direct } \\
\text { HP maximum }\end{array}$ & $\begin{array}{c}\text { AHP + ST direct } \\
\text { HP controlled }\end{array}$ & AHP + ST direct \\
\hline
\end{tabular}

Selected boundaries for this paper and configuration (c) are presented in Tab. 4. Three operation modes are analysed in order to reach different solar fractions: the ACM in single operation (without LT outlet temperature set point), the ACM with controlled VCC support (to reach the set LT temperature) and the ACM with maximum capacity VCC. The MT inlet temperature (returned to the chiller) is kept constant at $14^{\circ} \mathrm{C}$ and controlled to reach $40^{\circ} \mathrm{C}$ outlet (useful) temperature. The LT inlet is kept constant at $12^{\circ} \mathrm{C}$ The measurements/simulations are executed for the location of Innsbruck and Seville and are distinguished between the use of MT only and the simultaneous MT and LT usage.

Tab. 4: matrix of boundary conditions of the annual simulation for configuration (c)

\begin{tabular}{|c|c|c|c|c|c|}
\hline Use & Location & LT return & MT temp & LT set temp. & Operation mode \\
\hline MT & Innsbruck & \multirow{2}{*}{$12^{\circ} \mathrm{C}$} & \multirow{2}{*}{$14 / 40^{\circ} \mathrm{C}$} & Free floating & ACM only \\
\cline { 4 - 6 } & Seville & & $6^{\circ} \mathrm{C}$ & $\mathrm{ACM}+\mathrm{VCC}$ controlled \\
\cline { 4 - 6 } & & & Free floating & $\mathrm{ACM}+$ max VCC \\
\hline
\end{tabular}




\section{Results}

This paper only shows selected results, more details can be found in the final report of the project SolarHybrid (2014). The steady state results of both chillers as well as the annual simulation results of the above described boundaries are presented in the following paragraphs.

\subsection{Component results}

According to a defined measurement matrix, steady state measurements of ACM and VCC are executed. The performance maps of ACM (left) and VCC (right) are shown in Fig. 3.

The LT inlet temperature is held at $12^{\circ} \mathrm{C}$ for both cases (left ACM, right VCC). The MT volume flow rate is held constant at $6.5 \mathrm{~m}_{3} / \mathrm{h}$, LT volume flow is $3 \mathrm{~m}^{3} / \mathrm{h}$ for the ACM and $3.5 \mathrm{~m}^{3} / \mathrm{h}$ for the VCC measurements. The upper diagram of the ACM map shows the LT capacity over the MT inlet (MT $\mathrm{Min}_{\text {in }}$ temperature and the lower diagram the Energy Efficiency Ratio (EERth) in dependence on $\mathrm{MT}_{\text {in. }}$. The different lines represent different modes (SE/HE) and different $\mathrm{HT}$ inlet temperatures. In SE mode heat rejection temperatures up to $35^{\circ} \mathrm{C}$ are possible; $\mathrm{HE}$ modes enables heat rejection up to $45^{\circ} \mathrm{C}$, but at nearly half EER (caused by double generator power). In terms of maximum reachable capacity, switching from SE to HE could be reasonable at a MT inlet temperature higher $32^{\circ} \mathrm{C}$ (cf. Fig. 3 left, upper diagram).

The VCC map shows the relative performance at a certain part load ratio. The entire performance is compared to that at $100 \%$ capacity. The lines represent different MT inlet temperatures, the capacity is first reduced by controlling the compressor speed (100,75,50\% - right three points of each line) and second through opening a hot gas bypass (left three points of each line). Due to better heat transfer in condenser and evaporator, the maximum EER of the VCC is reached at minimal rpm with closed hot gas bypass.
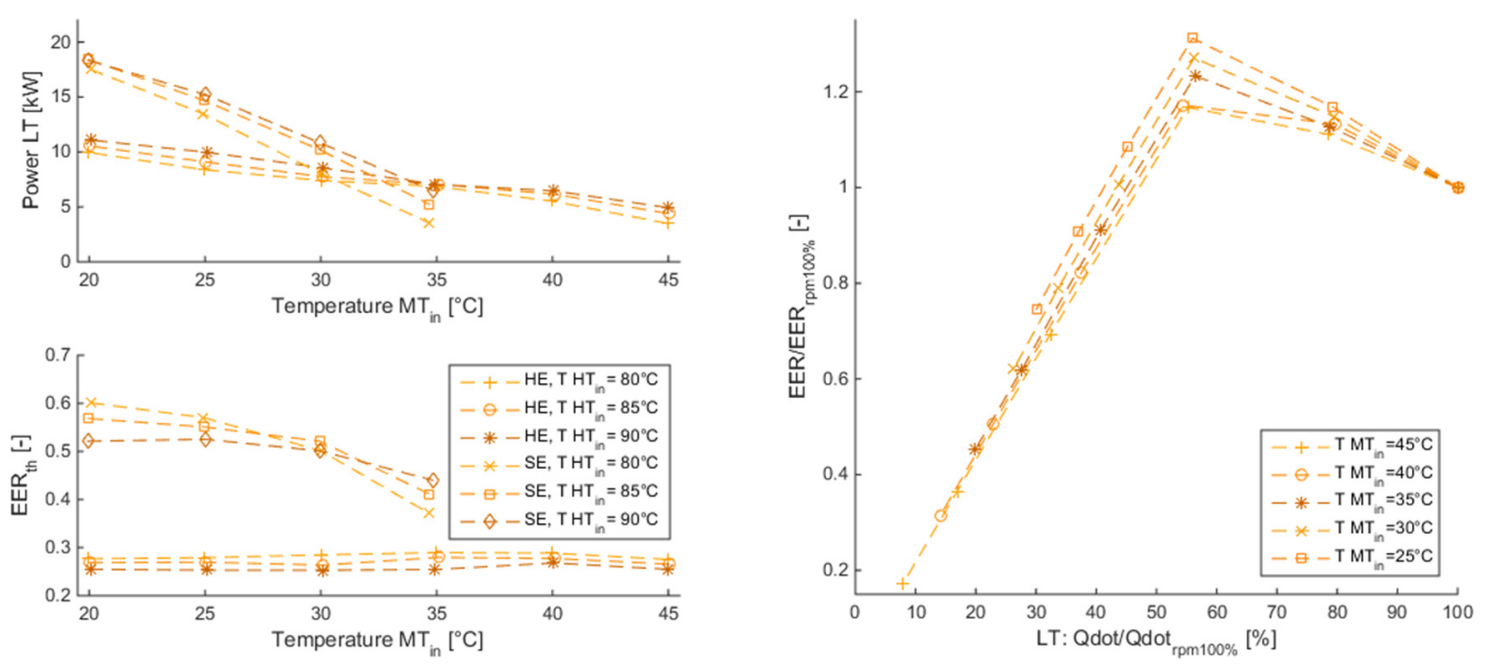

Fig. 3: Performance maps of ACM (left) and VCC (right), $\mathrm{LT}_{\text {in }}=12^{\circ} \mathrm{C}, \dot{\mathrm{V}}_{\mathrm{MT}}=6.5 \mathrm{~m}^{3} / \mathrm{h}, \dot{\mathrm{V}}_{\mathrm{LT} . A C M}=3 \mathrm{~m}^{3} / \mathrm{h}$ and $\dot{\mathrm{V}}_{\mathrm{LT} . \mathrm{VCC}}=3.5 \mathrm{~m}^{3} / \mathrm{h}$

Both chillers show a good performance, especially under consideration of their status as function models. The further development of the ACM show the expected impact and improve the performance significant. The VCC show EERs far above average (small-scaled chillers) and enables control strategies over a wide range of capacity.

Following the results of one dynamic HiL measurement of the described configuration (c) - combined chiller and heat pump mode of ACM and VCC - are discussed. The results are shown in diagrams, energies are summed up and characteristic performance indicators (e.g. electrical/thermal seasonal performance factor - SPF) are calculated.

Fig. 4 shows the course of a cloudy day (Innsbruck); upper diagram shows the capacities (HT, MT, LT, electrical) of ACM and VCC and the irradiation (multiplied with factor 10) on the collector field; lower diagram shows the corresponding temperatures (MT, LT in- and outlets; HT inlet temperatures multiplied with factor 0.1; ambient temperature) 

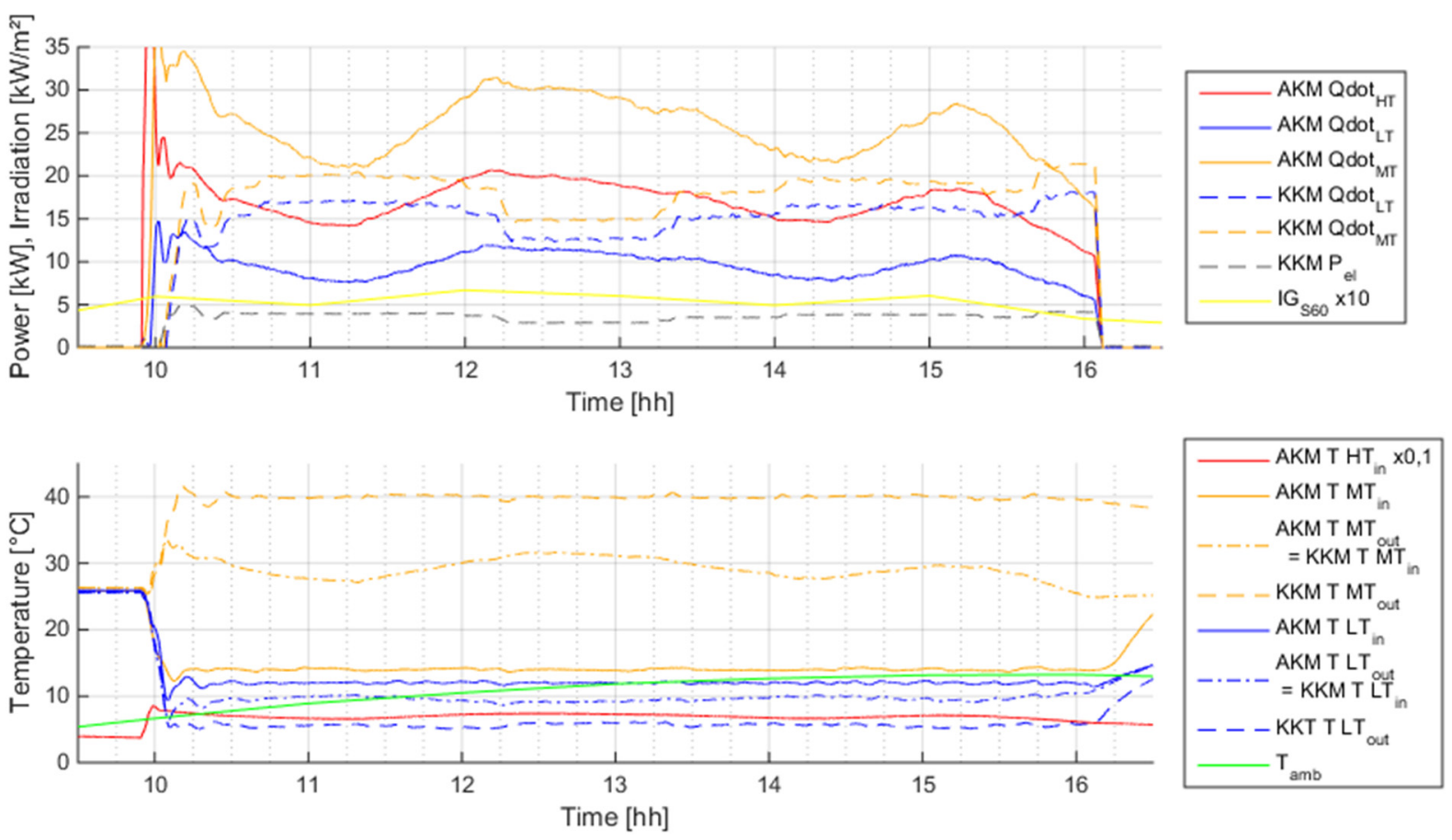

Fig. 4: Combined chiller and heat pump mode of ACM and VCC - course over a cloudy day for Innsbruck climate (upper diagram: power and irradiation; lower diagram: temperatures)

The curves of capacity evolution show the correlation between ACM and VCC, as soon as the ACM delivers less power the VCC raises the power to reach the set point. This results in a constant LT outlet temperature (cf. lower diagram), constant MT outlet temperature is reached by means of controlling MT mass flow.

Tab. 5 shows the energy balances and system SPFs over the daily courses (sunny and cloudy day). The SPFs are distinguished in used energy (MT or $\mathrm{MT}+\mathrm{LT})$; the thermal SPF $\left(\mathrm{SPF}_{\mathrm{th}}\right)$ represents the ratio of delivered energy (MT, MT $+\mathrm{LT}$ ) to used thermal energy $(\mathrm{HT}) ; \mathrm{SPF}_{\mathrm{el}}$ (electrical) shows the ratio of delivered energy to electrical energy (all circuit pumps, ACM solvent pump, VCC compressor; only compressor measure, pumps).

Tab. 5: Energy balances and SPFs of combined chiller and heat pump mode of ACM and VCC for Innsbruck climate

\begin{tabular}{|c|c|c|c|c|c|c|c|c|c|c|c|c|}
\hline & \multirow{2}{*}{\multicolumn{3}{|c|}{$\begin{array}{c}\text { Energies ACM } \\
{[\mathrm{kWh}]}\end{array}$}} & \multirow{2}{*}{\multicolumn{3}{|c|}{$\begin{array}{c}\text { Energies VCC } \\
{[\mathrm{kWh}]}\end{array}$}} & \multirow{2}{*}{\multicolumn{2}{|c|}{$\begin{array}{c}\mathbf{A C M}+\mathbf{V C C} \\
{[\mathrm{kWh}]}\end{array}$}} & \multicolumn{4}{|c|}{ System SPF [-] } \\
\hline & & & & & & & & & \multicolumn{2}{|c|}{ MT+LT } & \multicolumn{2}{|c|}{ MT } \\
\hline & $\mathrm{Q}_{\mathrm{HT}}$ & $\mathrm{Q}_{\mathrm{LT}}$ & $\mathrm{Q}_{\mathrm{MT}}$ & $\mathrm{Q}_{\mathrm{MT}}$ & $\mathrm{Q}_{\mathrm{LT}}$ & $\mathrm{Qel}_{\mathrm{el}}$ & $\mathrm{Q}_{\mathrm{MT}}$ & $\mathrm{Q}_{\mathrm{LT}}$ & $\mathrm{SPF}_{\text {th }}$ & $\mathrm{SPF}_{\mathrm{el}}$ & $\mathrm{SPF}_{\text {th }}$ & $\mathrm{SPF}_{\mathrm{el}}$ \\
\hline sunny day & 233 & 125 & 349 & 96 & 80 & 21 & 445 & 205 & 2,03 & 20,19 & 1,50 & 13,82 \\
\hline cloudy day & 102 & 57 & 152 & 102 & 86 & 21 & 254 & 143 & 2,04 & 12,33 & 1,49 & 7,89 \\
\hline
\end{tabular}

The configuration with the ACM and VCC used as heat pump reaches in all cases electrical efficiencies of $>8$. The difference between sunny and cloudy day get obvious but still provide optimization potential as the pumps are all calculated with constant power drawn, including further speed-controlled auxiliaries enables systems with electrical performance of SPF $>10$.

\subsection{Annual simulation results}

Fig. 5 and 6 are showing the annual simulation results of the cooling mode with ACM and VCC and the heat pump mode for this configuration. The three markers for each curve result from pure solar operation $(\mathrm{SF}=100 \%)$, the controlled combination (ACM+VCC) or the maximum operation of both components (c.f. Tab. $3 \& 4$ ) 
Both diagrams are comparing the non-renewable primary energy savings ( $\mathrm{f}_{\text {sav.NRE }}$ on $\mathrm{x}$-Axis) to the Cost Ratio ( $C R$ on $y$ - axis in reversed order). The less non-renewable primary energy is used the larger the $\mathrm{f}_{\text {sav.NRE }}$ and thus the results is displayed more on the right end of the diagram. If the annualized cost the solar driven system are lower than those of the reference system the CR results in values lower one and thus results are displayed on the upper end of the diagram.

- cooling-mode

Fig. 5 shows the results for the locations Innsbruck and Seville at two different LT inlet temperatures (the outlet depends on the operating mode). In the diagram, the locations are marked with the same symbols and the temperatures with the same color. In cooling-mode, only the ACM solar thermal direct operation or the hybrid operation of ACM + VCC is analyzed.

The selected system configuration results in maximum savings of non-renewable primary energy savings of 80 to $85 \%$. Although these variations represent $100 \%$ solar fraction the savings are lower as the electricity auxiliary demand of the system is considered accordingly. A further optimization of non-renewable primary energy savings could be feasible, but attention must be paid to the ratio of provided (usable) cooling to electrical system efficiency. The $\mathrm{f}_{\text {sav.NRE }}$ could be further increased at the expense of the CR by a larger design of the solar thermal system (here $3.5 \mathrm{~m}^{2} / \mathrm{kW}$ cooling) as well as a larger capacity of the ACM.

The variants with the $12^{\circ} \mathrm{C}$ LT-return temperatures give a wide spread picture with non-renewable primary energy savings (40 - 80\%) and higher CR than with the $22^{\circ} \mathrm{C}$ variants. The $22^{\circ} \mathrm{C}$ (LT-return) variants show a steeper and more compact course. This is mainly due to the performance of the $\mathrm{VCC}$, as it operates much more efficiently at higher LT temperatures (rising EER). This results in significantly increased non-renewable primary energy savings (approximately $+20 \% \mathrm{f}_{\text {sav.NRE}}$ ) and additional yield compared to the $12^{\circ} \mathrm{C}$ variant, which has a positive effect on the cost ratio $(\mathrm{CR}-0,1)$. The markers of the variants with $100 \%$ solar fraction (right) at the same location show that the influence of the LT temperature on the performance of the ACM is significantly lower than on the VCC.

The difference between Seville and Innsbruck is obvious. In Seville, higher solar fraction can be achieved due to the larger irradiation with the same configuration compared to Innsbruck. The cost ratio in Seville is correspondingly lower than in Innsbruck. The additional solar yield can be seen in the SF 100\% variants; the results for Seville are lower cost ratios (more energy delivered) at slightly lower savings (higher heat rejection temperatures). The results in hybrid operation present the same behavior. Due to the lower performance of the system due to higher heat rejection temperatures the non-renewable primary energy savings are smaller for Sevilla. Due to larger energy provided by the system the CostRatio is decreasing.
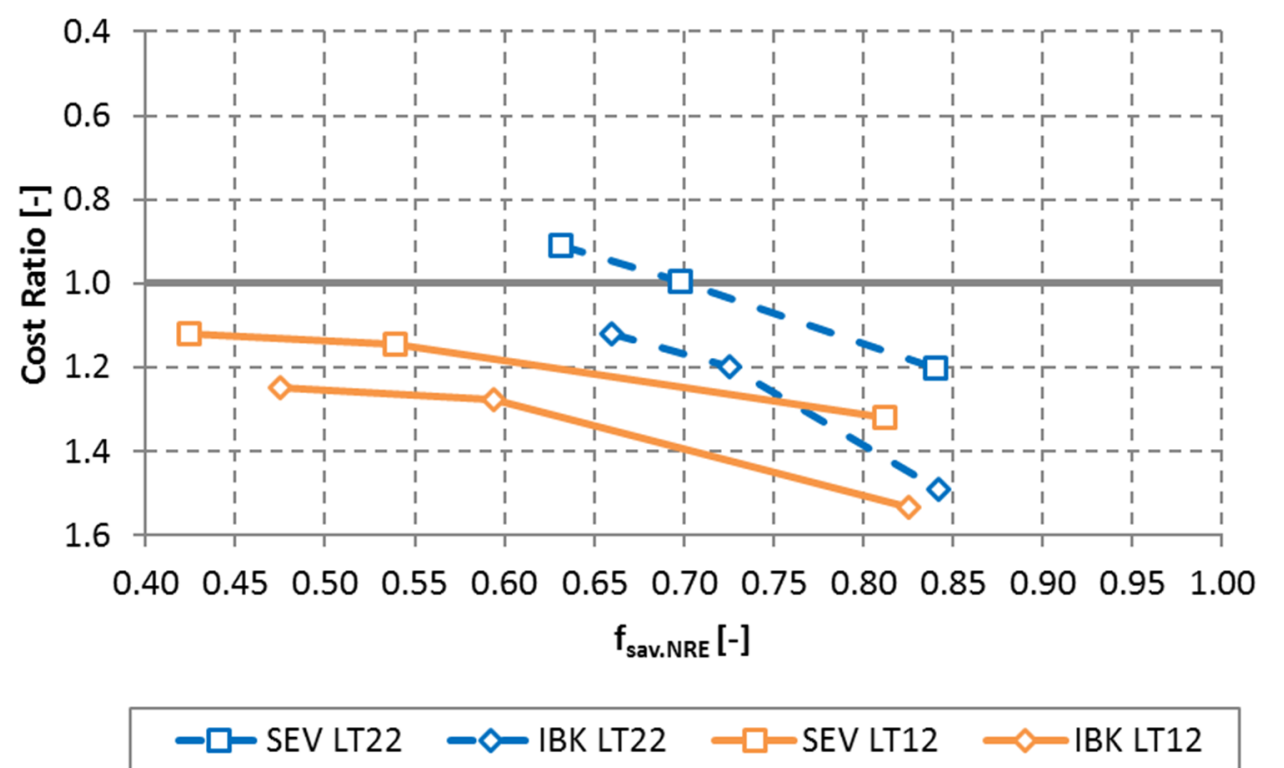

Fig. 5: Comparison of the simulation results for Seville (SEV) and Innsbruck (IBK) for the cooling-mode with $12 / 6^{\circ} \mathrm{C}$ and $22 / 6^{\circ} \mathrm{C}$ cold water (evaporator) and $14 / 40^{\circ} \mathrm{C}$ hot water (condenser) temperature; nomenclature: use(LT) Location LT return, MT in/out 
- Heat pump-mode

When switching from pure cooling operation to heat pump operation, the results shown in Fig. 6 are obtained. This figure shows the results for the two locations with pure heat pump operation (MT outlet at $40^{\circ} \mathrm{C}$ useful temperature) or combined operation with additional chilled water output (LT outlet $\left.6^{\circ} \mathrm{C}\right)$.

If both sides of the heat pump can be used, lower levelized costs of energy and CRs and higher non-renewable primary energy savings will result (see diagram on the left). The difference in CR is much more significant with

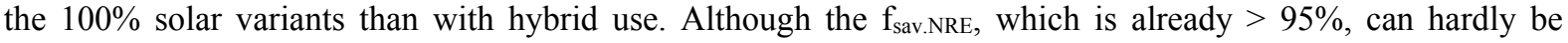
increased any more, the costs are considerably reduced due to the large proportion of MT energy. At the Innsbruck location the CR decreases from approximately 1.4 to 0.8 and in Seville from approximately 0.8 to 0.45 , which corresponds approximately (due to the energy balance of ACM) to a multiplication by the EER $(\sim 0,6)$. Also, for the hybrid variations, the $\mathrm{CR}$ is reduced by approximately 0.2 , with a simultaneous improvement of the $\mathrm{f}_{\text {Sav.NRE }}$ by approximately $5 \%$ points.

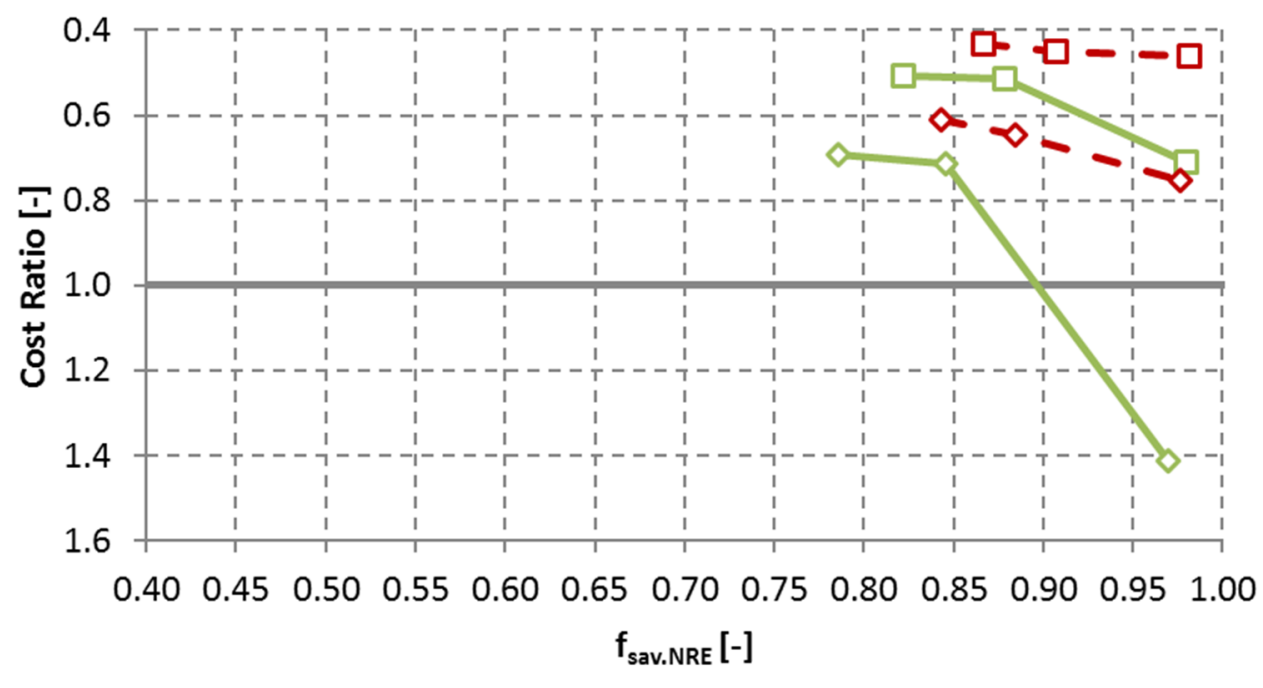

\section{$\because \square-S E V M T \quad \backsim$ IBK MT $\quad-\square-S E V M T+L T \quad \backsim-$ IBK MT+LT}

Fig. 6: Comparison of the simulation results for Seville (SEV) and Innsbruck (IBK) for the heat pump-mode with $12 / 6^{\circ} \mathrm{C}$ cold water (evaporator) and $14 / 40^{\circ} \mathrm{C}$ hot water (condenser) temperature; nomenclature: use(MT, MT+LT) Location LT return, MT in/out

Summing up the potential study illustrates that non-renewable primary energy savings $>80 \%$ and CostRatio's mostly below 0,8 and as far as 0,4 can be reached by a purely solar driven system. The economic performance is investment cost dominated, thus a sensitivity analysis on different parameters was performed in course of the project but is presented here.

The $\mathrm{f}_{\text {Sav.NRE }}$ are higher with $100 \%$ solar thermal systems and with heating operation higher savings can be achieved than with cooling-operation. If both sides of the heat pump can be used (MT\&LT) lower cost ratios and higher $\mathrm{f}_{\text {sav.NRE }}$ can be reached. If the vapour compression system is supporting less (SF 50, SF 100\%) the CRs are rising but higher non-renewable primary energy savings can be achieved.

Although the hybrid system with its two heat pumps (chillers) leads to roughly double of investment costs, the CR is lower than with the solar-only operated absorber. With hybrid systems CR lower than one can be achieved. This shows that hybrid systems can be economic viable in comparison with reference systems either for cooling or heating operation. 


\section{Summary \& Conclusion}

In SolarHybrid solar heating and cooling systems were investigated intensively by means of simulations, measurements of prototypes and the assessment \& benchmarking against conventional system and other solar solutions. All in all, this potential study shows a very interesting starting point for the development of highly efficient and economic solar driven HVAC systems.

- Solar heating and cooling can become cost competitive when systems are designed clever with simple HVAC layouts, advanced control strategies and high efficient components.

- If the load has a cooling requirement, the investigated hybrid cooling systems are cost competitive in regions with higher solar radiation and with $22^{\circ} \mathrm{C}$ LT temperature. They provide up to $70 \%$ non-renewable energy savings

- Non-renewable energy savings can be increased with a larger solar thermal system and more capacity of the absorber but leading to higher Cost Ratios. The focus should be on the reduction of investment costs.

\section{Acknowledgment}

The contents of this article refer to the SolarHybrid project, developed jointly by the University of Innsbruck, FH OÖ Forschungs und Entwicklungs GmbH, Engie Kältetechnik GmbH and Pink GmbH. The project is funded by the Austrian Climate and Energy Fund and is a part of the Energy Research Program 2013.

\section{References}

DAKTris, 2013: Dynamisches Betriebsverhalten von AKM im gebäudeübergreifenden TRI-Generation Betrieb (FFG Projekt Nr. 840650). Wien: Österreichische Förschungsförderungsgesellschaft - FFG.

Hannl, D., Rieberer, R., 2012. Analyse einer Ammoniak/Wasser Absorptionskälteanlage - Betriebserfahrungen okund Simulationsmodellbildung, DKV-Tagung 2012, Würzburg

Luger, Stefan: Giovanni, Aldo: (2017) Analyse einer Kompressionskältemaschine zur Kaltwassererzeugung mit kleiner Leistung im überfluteten Thermosiphonbetrieb mit Drehzahl- und Heißgasbypass- Leistungsregulierung mit dem natürlichen Kältemittel Ammoniak, Bachelorarbeit am MCI Innsbruck, Juli 2017

Neyer, D.; Thür, A.; Neyer, J.; Zotter, G.; Rieberer, R.; Pink, W.; Halmdienst, C., (2015) Operating Conditions of a NH3/H2O Chiller for Tri-Generation Systems - Chiller Adaption and First Results. SAC 2015, Rom

Neyer D., Neyer J., Stadler K., Thür A., (2016). Deliverable C3-1: TASK 53 - Energy-Economy-EcologyEvaluation Tool T53E4-Tool, Tool Description and introductory Manual, SHC Task 53

OECD/IEA (2018): The Future of Cooling. Opportunities for energy efficient air conditioning. Hg. v. IEA Publications, International Energy Agency.

SolarHybrid, 2014. Solare Hybridsysteme zum Heizen und Kühlen - Mit Optimierungen zu minimierten und kostengünstigen Systemkonzepten, Energy Mission Austra, e!Mission 2013, FFG Nr. 843855, Vienna, Austria

Zotter, G. et al.,(2015) Optimierung einer Ammoniak/Wasser-Absorptionskältemaschine für Kraft-WärmeKältekopplungen auf Basis von BHKWs kleiner Leistung, Dresden, Deutscher Kaelte- und Klimatechischer Verein (DKV) 


\title{
Dynamic Modeling and Optimization of Energy Use in Retrofitted Buildings at District Heating Level
}

\author{
Jon Iturralde ${ }^{1}$, Carol Pascual ${ }^{1}$, Iñigo Urra ${ }^{1}$, Ali Vasallo ${ }^{2}$, Manuel Andrés Chicote ${ }^{2}$, Javier Martín ${ }^{3}$ \\ and Enrique Martín ${ }^{3}$ \\ ${ }^{1}$ Tecnalia, San Sebastian (Spain) \\ ${ }^{2}$ Cartif, Valladolid (Spain) \\ ${ }^{3}$ Veolia, Valladolid (Spain)
}

\begin{abstract}
Buildings represent a significant share of global energy consumption in the European Union (EU). Heating and domestic hot water (DHW) needs account for an important part of that energy use. Considerable energy savings can be achieved by retrofitting buildings and improving heating systems. Such improvements are covered in this paper, as it presents a comprehensive retrofitting of 31 large residential buildings, within the European funded project CITyFiED. The retrofitting process consists of various measures (new renewable energy generation systems, façade retrofitting, etc.), but the focus of this paper is on district heating (DH) optimization measures, with the aim of increasing its overall system efficiency and sustainability. To that end, the actual system is modeled in a dynamic modeling software, TRNSYS, and modifications are tested. The results are a series of improvements that lead to better system performance, higher efficiency and sustainability.
\end{abstract}

Keywords: building retrofitting, district heating, dynamic modeling, efficiency, optimization, renewable energy

\section{Introduction}

According to European Commission data, buildings account for more than $40 \%$ of the global European Union (EU) energy use and for 36\% of global greenhouse gas (GHG) emissions (Lewis et al., 2013). Similarly, heating and DHW generation alone represent $79 \%$ of total energy use (European Commission, 2016). Additionally, it is worth mentioning that $84 \%$ of heating and cooling is still produced from fossil fuels, so only $16 \%$ of the generation comes from renewable energy sources (European Commission, 2016).

All those facts give an idea of how important it is to work on the improvement of energy efficiency and sustainability in buildings in order to fulfill EU's climate and energy goals and address crucial challenges, such as reduction of GHG emissions. Measures must be taken to achieve those goals, such as energy demand reduction via better insulation in new buildings or by retrofitting existing ones, optimization of heating and cooling system control strategies, switch from fossil fuels to renewable energy sources, etc. The scope of this paper is in line with this kind of improvements, as it covers the optimization of the heating system of a district consisting of several residential buildings. One of the tools used to that end are dynamic simulations conducted in TRNSYS modeling software, aiming at an increase in efficiency and renewable energy share. Simulations allow to identify the points of the system where a room for improvement exists, resulting in guidelines for an improved and better performing system.

This optimization work is framed within a EU funded project, CITyFiED (repliCable and InnovaTive Future Efficient Districts and cities), which aims at developing a replicable, systemic and integrated strategy to contribute to the transformation of European cities into future smart cities. For that purpose, the focus is on reducing the current energy demand and GHG emissions, as well as increasing the energy efficiency and use of renewable energy sources by, among others, developing and implementing innovative technologies and methodologies for building renovation, smart grid and district heating $(\mathrm{DH})$ networks.

In fact, the optimization work covered in this paper applies to a district of large retrofitted buildings which constitutes one of the three large demonstration sites of CITyFiED project. More specifically, the district, called 
Torrelago, consists of 31 residential 12-story buildings, constructed around 1980 and located in Laguna de Duero (Valladolid, Spain). All those buildings are individually analyzed and integrated into a new global control strategy. The retrofitting of the buildings and the rest of improvements made within the project have a considerable impact, on 1488 dwellings in total, corresponding to more than 4000 residents and accounting for a conditioned area of approximately $140000 \mathrm{~m}^{2}$.

Prior to the simulation works described in this paper, some previous steps were taken, implementing various measures which have contributed to a higher energy efficiency. For example, due to the construction date of the buildings, there was a substantial room for improvement regarding insulation. Therefore, one of the major changes was the façade renovation of all the buildings, resulting in a better insulation and a lower heat demand due to the reduction of energy losses. Another key modification was the installation of new biomass-fired boilers powering the DH network and resulting in a more sustainable system, as part of the fossil fuel consumption is replaced by renewable energy sources. The main goal of the work presented in this paper is to optimize the current DH system in such a way that biomass use is increased, leading to a more efficient and sustainable system.

\section{DH System and TRNSYS model description}

Originally, the buildings comprising the retrofitted district were divided into two different groups ("phase I" and "phase II"), each of which having its own and separate heating system. Both systems were powered by fossil fuels, specifically, gas boilers.

However, an important retrofitting work was carried out, unifying both systems into a joint DH network and installing biomass boilers (BB) in one of the phases, as a more sustainable alternative to the existing gas boilers. In order to boost the sustainability of the whole system, the use of biomass is fostered. To that end, the global control system of the newly joint biomass and gas fired district heating system was designed to promote the consumption of biomass. Thus, the use of biomass boilers is prioritized over gas boilers with the goal of meeting the demand preferably with renewable energy sources. Ideally most of that demand would be met by biomass boilers but, in reality, the capacity is often insufficient to feed the whole system. The overall yearly goal is to generate $80 \%$ of the energy by means of biomass boilers, reducing gas consumption to a great extent. The simulation and optimization work presented in this paper aim at finding measures to contribute to that increase in the share of biomass-fired thermal energy generation.

One important feature that must be addressed, is the fact that the façades of all the buildings were refurbished with the installation of external insulation. All those modifications entail substantial changes in important parameters (e.g. reduction in energy losses resulting in lower energy demand), affecting the whole system. However, not all the buildings were retrofitted simultaneously, the progress rate of the constructions works was different for each of the 31 buildings. Consequently, the energy demand was unevenly distributed throughout the system and constantly changing, posing a barrier to the optimum performance of the control. All those factors leave room for improvement on control strategy optimization, which is covered in this paper.

That optimization is achieved by means of modeling in TRNSYS (Version 17) a transient thermal energy software developed at the University of Winsconsin-Madison, used for dynamic simulation and offers great flexibility, which is very useful to test a wide range of configurations and control strategies.

The model consists of a comprehensive replication of the Torrelago DH network, including all the representative parts of the system: generation, distribution and consumption. The generation part is composed of the main biomass boilers (located in phase I, called "sector 1" in Fig. 1) and the auxiliary gas boilers (located in phase II); the distribution is made up of all the piping elements, pumps and valves; the consumption part consists of several substations, each of which corresponding to one or several buildings (up to 3) and globally split into the aforementioned two different phases. Fig. 1 shows the global hydraulic diagram of the actual system, which is then replicated in TRNSYS. 


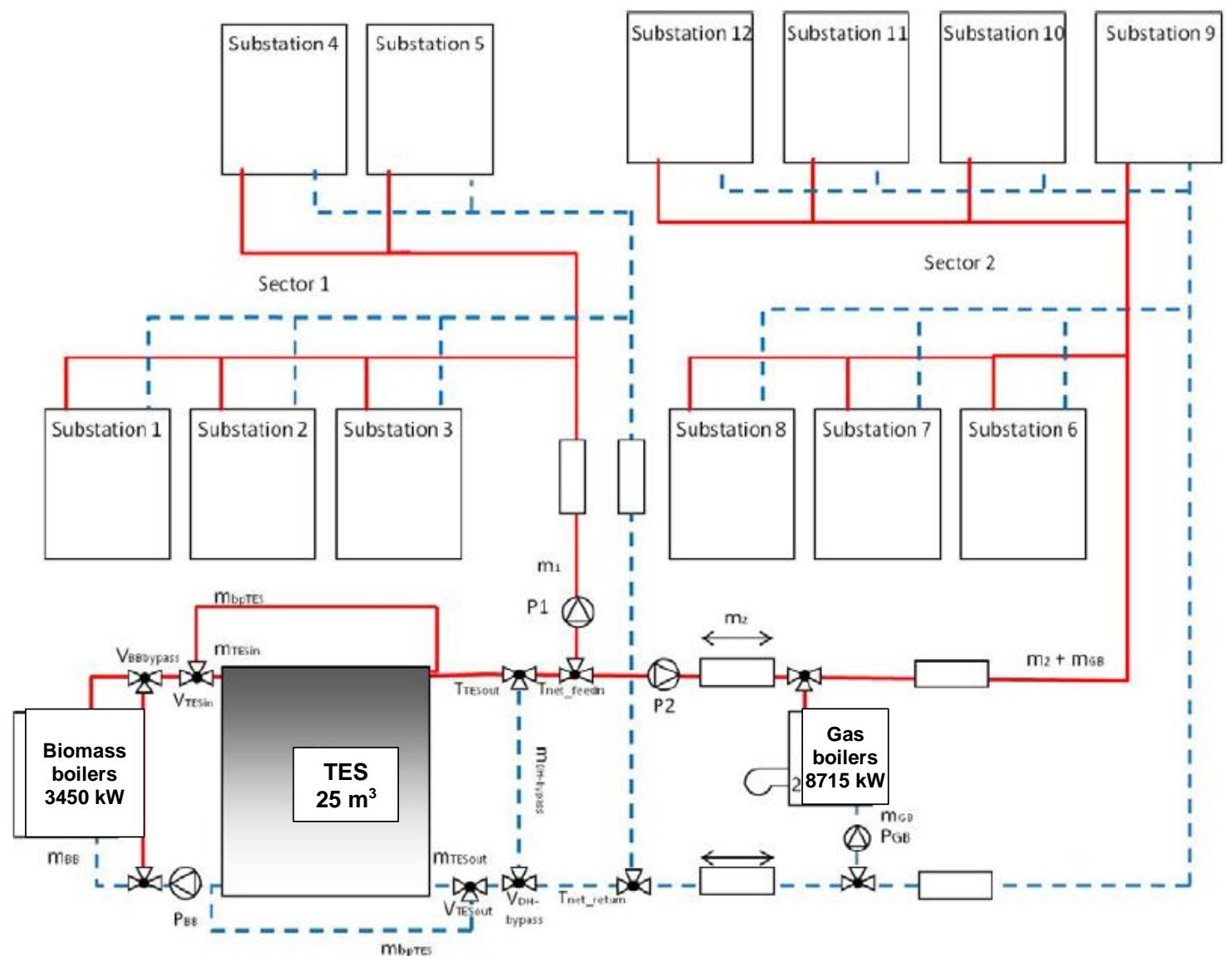

Fig. 1: Overall hydraulic schematic

It must be pointed out that the diagram in Fig. 1 represents the actual system schematically, including some simplifications. For example, in the real system there are 3 biomass boilers as well as 3 gas boilers, which are displayed as single boilers in this case (with a joint power including the addition of the single capacities). The same applies to the thermal energy storage, which in reality consists of two $12.5 \mathrm{~m}^{3}$ water tanks connected in series. It can be observed that gas boilers have a great capacity compared to biomass boilers. However, they are currently intended only as back-up boilers and thus, they would rarely operate close to full capacity. The high capacity value is due to the fact that gas boilers were upgraded prior to the start of CITyFiED project, when biomass boiler had not been installed yet.

Every single component of the real DH system has its corresponding representation in TRNSYS, called "type". Within each type, there are many options to define its performance characteristics in terms of physical properties (e.g. temperature, flow rate, etc.), operation modes, etc. Those can be seen in the corresponding TRNSYS model shown in Fig. 2. 


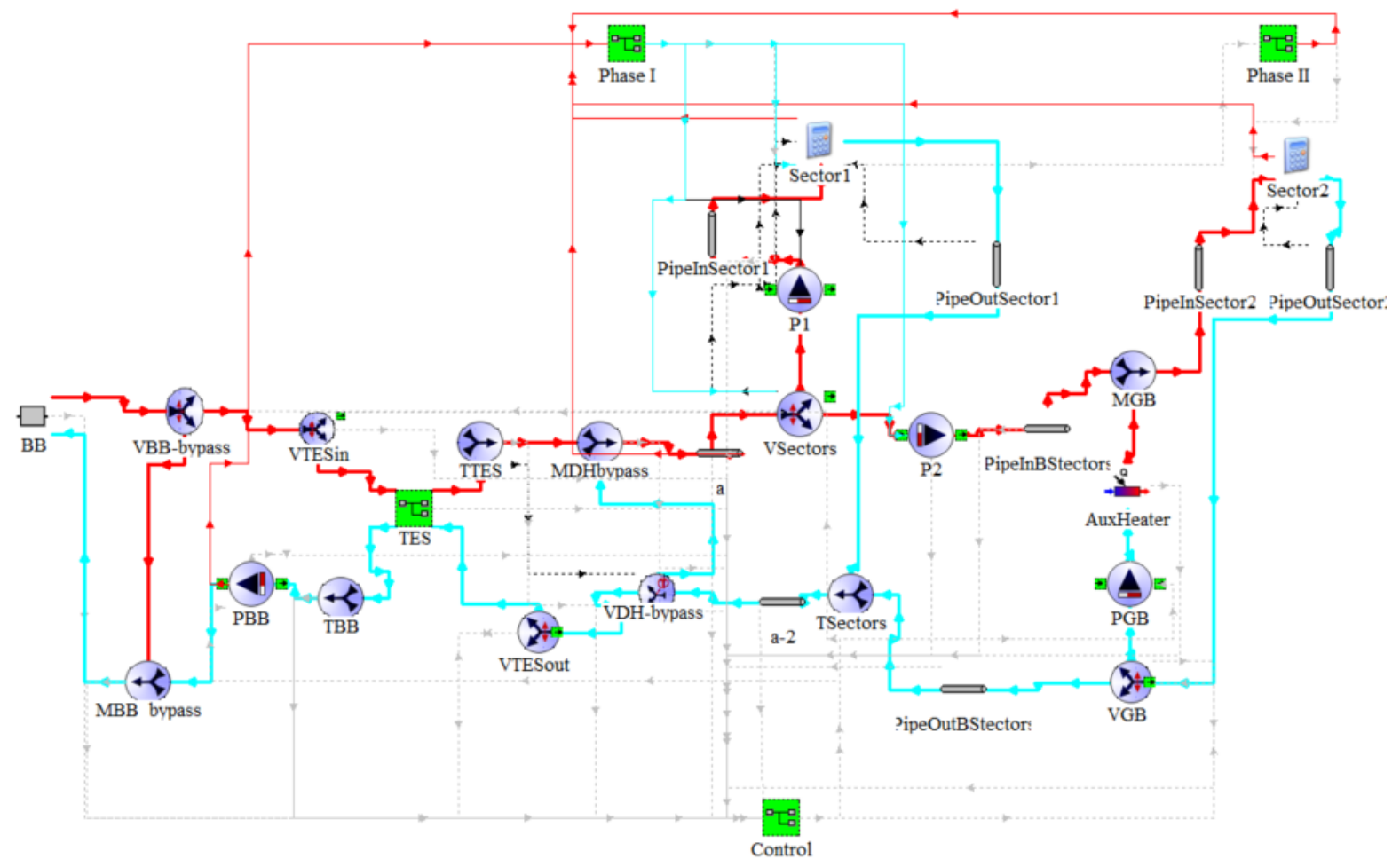

Fig. 2: Corresponding overall DH system representation in TRNSYS

The generation side consists of a heating plant with biomass boilers together with an auxiliary gas boiler supporting the main heating plant, each of which is represented by a specific type: "BB" and "AuxHeater", respectively. The main heating plant (biomass) is combined with a buffer consisting of two $12,5 \mathrm{~m}^{3}$ tanks which, in the model, are located inside a "macro" (a submodel containing some global inputs/outputs) called "TES" containing type 340 (Drück, 2006), a non-standard type representing a multi-port thermal energy storage model. Energy provided by BB is charged at the top part of the tank and return flow to the biomass boilers is taken from the bottom part. A temperature sensor from the bottom part of the storage is used as lower input value for the hysteresis controller of the primary circuit (BB on/off). The supply flow for the district heating network (Phase I and Phase II) is taken from the top of the tank and the return flow is connected to the bottom part.

The distribution part consists of all the piping, valves, pumps, etc. required to transfer the heat from the generation to the consumers. This part of the system implies the use of a considerable amount of types to model the actual distribution system accurately: type 31 for the supply and return pipe (taking into account losses), type 110 for variable speed pumps, type 11 for tee piece and temperature valve for mixing valves. Once again, the control system ruling those components is flexible and included in macro Control. As for the generation/distribution side, the control system allows different operation modes. In this sense, the set-point temperature for the biomass boiler was identified as a parameter with a great impact on the stability of the control.

Finally, a load module is developed to simulate the consumer side of the district heating network at building level. Consumers are represented by their corresponding substations, each of which has adjustable demand parameters. They are divided into two main sectors, replicating the distribution of the actual district heating network, which in the model is represented by two different macros: Phase I and Phase II. Consumer substation "submodels" are contained within those macros. The model is able to load a unique yearly heat demand file for each of the consumer substations or two different load profiles, one per phase.

\section{Simulation methodology}

Once the model is created it must be validated and properly adjusted, so that it replicates the real system in the best possible way. To that end, a comprehensive set of real performance data is needed. This data is then used to feed the model, leading to a more precise replication of the reality, as comparing the results obtained in the model with those measured in the actual system shows the existing deviation and allows adjusting the model. Once the 
model is adjusted and validated, simulations will be representative and meaningful. Thus, this section covers an important part of the optimization process.

First, a representative period of monitored data is selected in order to feed the models with meaningful real values. In this case, taking into account that the overall objective is the maximization of the biomass generation share, a worst-case scenario was selected: the third and fourth weeks of January, when the temperature is minimum and the thermal energy demand is maximum, posing a challenge for the limited heat supply capacity of biomass boilers. The whole DH network was comprehensively monitored during the selected period of time, registering any irregularities in the normal performance of the system.

Then, an exhaustive analysis of the registered data was carried out. First, a macro analysis was performed to identify the main trends and define the following actions. In the first place, the energy generation mix (by fuel type) was checked, giving $42 \%$ gas / $58 \%$ biomass as a result. The goal for the yearly biomass generation share is set to $80 \%$. It is normal that at the analyzed period the share was below that level, since the heat demand is much greater during winter time and the biomass boilers do not have enough capacity to meet such a high demand. Therefore, it is acceptable to have a lower share at that time, and the generation share goal for the winter season is set to around $70 \%$. Still, there was room for improvement, which is made in the next phase of the optimization work and presented in the results section.

This kind of data analysis provide valuable information on the state of many parts of the system. For example, it was observed that $96 \%$ of the energy generation arrived the substations in phase II, while only $89 \%$ did so in phase I. Hence, substantially higher energy losses were observed in phase II, finding room for improvement, e.g. via better thermal insulation. Another example is the identification of a measuring problem which was affecting several energy meters of a certain kind and resulting in highly inaccurate readings (noise, outliers for long periods, etc.). In fact, these reading problems were relatively frequent during the measured period and affected also other kind of sensors, such as thermocouples. All of these faulty readings made it necessary to undertake a heavy filtering and data correction process so as to be able to obtain a continuous series of meaningful and "usable" data.

One especially critical problem was related to the biomass boilers, which are the core of this study. They were supposed to operate in fully automatic mode, which means that they are most of the time either in load mode or in conservation mode. However, random shutdowns were registered throughout the whole registered period. For instance, biomass boiler 1 was off during 101 registered points and boiler 3 was off during 103 instants. Taking into account that timestep between measurements is $15 \mathrm{mins}$, that means that biomass boilers were off during a considerable amount of time while they were supposed to be in operation. As a consequence, not only the biomass generation dropped (going against the objective of increasing it) but the shutdowns affected the whole system, causing disturbances in many measured values. The problem with this is that TRNSYS is not able to replicate random events such as manual shutdowns, so the results of the simulations are only meaningful if the system is in full automatic mode during the registered period, otherwise the behavior of the system will not be successfully replicated. The solution was to select a period of 2 days where no random disturbances had an impact on the system, so it was a valid period representative of the normal performance of the system. The drawback was that the utilized period was short compared to the original aim of simulation 2 weeks.

Once the measured data was filtered with all necessary corrections, it was ready to be used as an input for the TRNSYS model. However, all the relevant components (types) in the model need to be properly adjusted so that the operation of the model replicates accurately the performance of the real system. The methodology for such adjustment is to validate and adjust each part of the model separately, following a logical order.

First, each biomass boiler was individually adjusted. The methodology is to adjust the parameters of the BB type so it replicates the operation of the actual boiler. Real monitored data is fed to the type (e.g. inlet temperature and mass flow rate), then the outputs of the type (e.g. outlet temperature) are read and compared to the real data monitored for those parameters. The deviation is the analyzed and corrected via type parameter adjustment, for instance, temperature set point and hysteresis. The process is repeated in an iterative manner until the output values of the type follow accurately the behavior of those of the real component.

The same process is done for other relevant types, such as thermal energy storage tanks. Then all the adjusted types are updated in the model and the behavior of the whole system is checked. Once its overall performance is equivalent to the real system, the model is ready for the optimization simulations. 
This optimization simulations consist in trying different modifications with the objective of improving the performance of the system and increasing the biomass generation share. That is, modification of parameters of existing components, inclusion of new components and other variations are tried and the effect of each modification is analyzed. Again, following an iterative process trends can be identified on how the system react to certain modifications. The modified parameters (i.e. manipulated variables) are the ones that have a considerable impact on the amount of biomass energy generation (i.e. target variable). After a series of tests, those modifications that have the greater impact are identified and the best improvements can be selected as a result of the optimization simulation campaign.

\section{Results}

The main expected result is the development of an optimized control strategy, improving the overall performance of the system and leading to reduced energy losses and a higher share of renewables. This is achieved through the aforementioned simulations by developing improvements that prioritize the use of biomass boilers over gas boilers, meeting the energy demand in a more sustainable way.

However, some interesting results were already obtained during the measured raw data analysis and filtering process, before any simulation run. These results are related to the identification of monitoring problems and the identification of opportunities for improving the data acquisition and control system, as explained in section 3 . Some of the most important findings were the following:

- $\quad$ Phase I has substantially higher energy losses than phase II (11\% vs 4\%). Therefore, some corrective actions could be taken, such as thermal insulation improvement.

- Random shutdowns were found in the biomass boilers, preventing them from operating normally in automatic mode.

- Several faulty measuring devices were pinpointed (i.e. some energy meters and thermocouples)

- Inconsistencies were observed in measured data, which could be pointing to a lack of accurate calibration.

The main results of the present work come from dynamic simulations of Torrelago district heating network, conducted under different conditions using TRNSYS software. Several modifications are analyzed with the purpose of increasing the renewable energy share (higher use of biomass boiler instead of gas-fired boilers). In order to determine which improvements, have a higher impact, results are compared to a baseline corresponding to the actual DH performance during the measured period, in terms of gas generation \% vs. biomass generation $\%$. The baseline corresponds to the integration of measured biomass boiler and gas boiler

Baseline: $37.8 \%$ gas generation $(\mathrm{G})$ vs. $\mathbf{6 2 . 2 \%}$ biomass generation (B)

Several cases are simulated, varying one or more property each time:

Case 1: increase of thermal energy storage (TES) capacity from $25 \mathrm{~m}^{3}$ to $500 \mathrm{~m}^{3}$. Obtained result:

- 1.1. $33,9 \%$ gas / 66,1\% biomass (noticeable improvement)

Case 2: Increase of the domestic hot water mode set point by $6^{\circ} \mathrm{C}$ (from $84^{\circ} \mathrm{C}$ to $90^{\circ} \mathrm{C}$ ). Obtained result:

- 2.1. $37,6 \%$ gas / $62,4 \%$ biomass (almost no improvement)

- 2.2. Same case but with $500 \mathrm{~m}^{3}$ TES: $31 \%$ gas / $69 \%$ biomass (substantial improvement)

Case 3: Extension of heating mode hours (both on demand and generation side).

- 3.1. + 2 hour extension (starting $2 \mathrm{~h}$ earlier): 36,3\% gas / 63,7\% biomass (minor improvement)

- 3.2. + 4 hour extension: $27,2 \%$ gas $/ 72,8 \%$ biomass ( $+10 \%$ in biomass use)

Case 4: Extension of heating mode hours (only in generation, same demand).

- 4.1. + 1 hour extension: $37,5 \%$ gas / 62,5\% biomass (almost no improvement)

- 4.2. + 1 hour extension and $500 \mathrm{~m}^{3}$ TES: $31,6 \%$ gas / 68,4\% biomass (higher improvement) 
- 4.3. +3 hour extension and $500 \mathrm{~m}^{3}$ TES: $26,8 \%$ gas / 73,2\% biomass (higher improvement)

Case 5: Increase of the biomass boiler power.

- $\quad 5.1 .+950 \mathrm{~kW}$ (total $4400 \mathrm{~kW}$ ): $25,8 \%$ gas / 74,2\% biomass (substantial improvement)

- $\quad 5.2 .+1250 \mathbf{~ k W}$ (total $4700 \mathrm{~kW}$ ): $21,2 \%$ gas / 78,8\% biomass (notable improvement)

\section{Case 6: Heat demand reduction (lower consumption).}

- 6.1. - 20\% demand: $25,5 \%$ gas / 74,5\% biomass (major improvement)

- 6.2. - 40\% demand: $13,3 \%$ gas / $86,7 \%$ biomass (great improvement)

All of the previous results are graphically displayed in Fig. 3 by biomass share in the thermal energy generation mix, which gives a better idea of the degree of possible improvement.

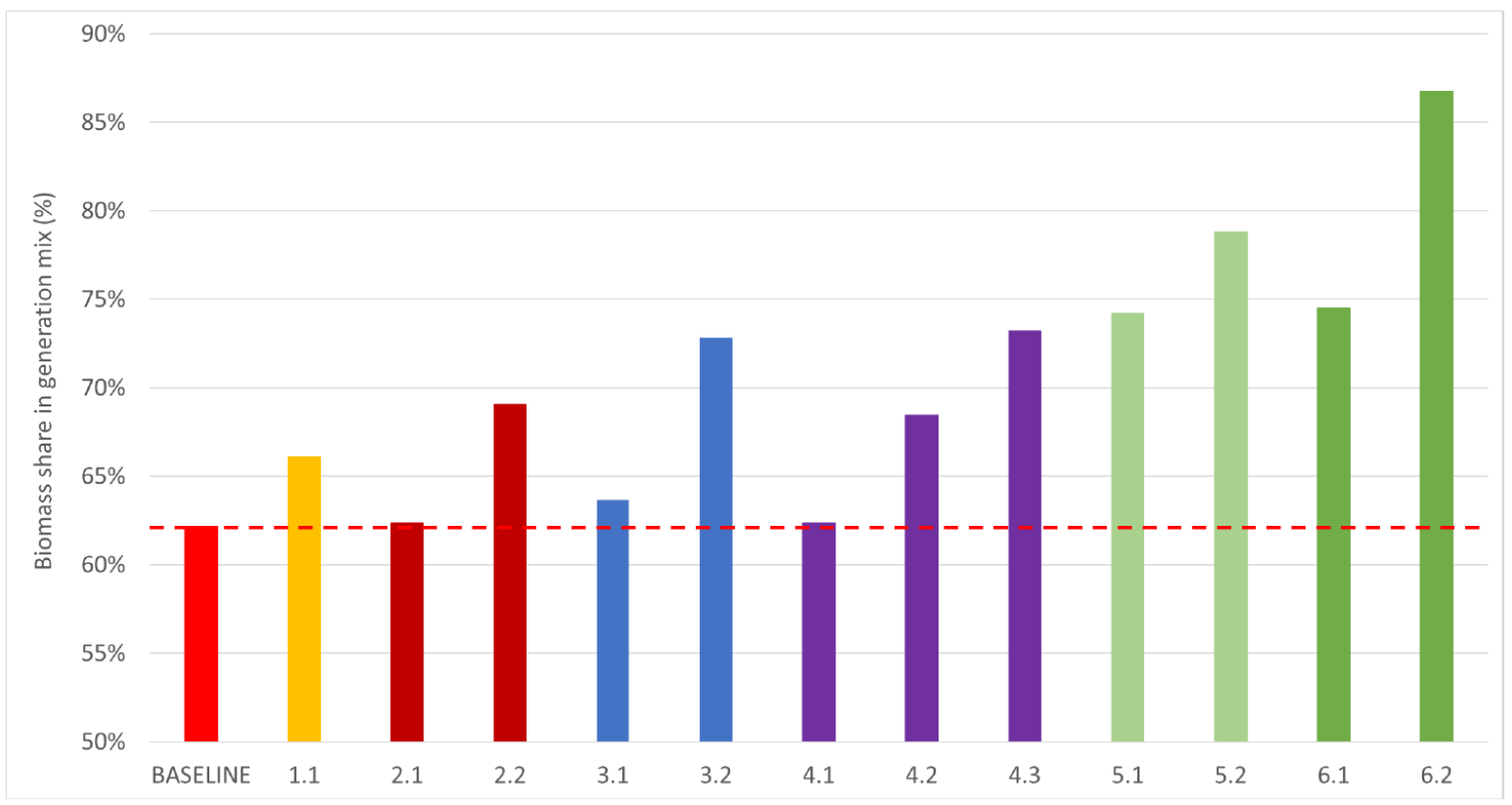

Fig. 3: Biomass generation share percentage achieved for several improvement cases

\section{Conclusions}

The following conclusions can be drawn from the results presented in section 4:

- Current thermal heat storage is too small to decouple the generation and demand and allow higher biomass boiler use, since the volume of hot water that can be stored represents a small buffer for such a big system.

- The two modifications that would entail greater increase in the biomass generation share, given the current circumstances, would be an increase of the biomass boiler power (i.e. by including an additional boiler) and reduction of the heat demand (not all the buildings were insulated when data was collected, thus lower demands are to be expected)

The optimization presented in this paper leads to an increase in the use of renewable energy sources which results in lower greenhouse gas emissions and thus in a more sustainable system. Additionally, economic benefits are also obtained as energy savings imply a reduction in operating costs.

Not only that, during the data analysis and filtering process undertaken prior to the actual simulations, several faults were identified, ranging from malfunctions in temperature sensors to poorly performing biomass boilers.

Therefore, this work gives as a result a series of guidelines on how to improve the district heating control strategy leading to more efficient performance, as well as various direct fixes regarding poorly performing devices. 


\section{References}

Drück, H., 2006. MULTIPORT Store-Model for TRNSYS, Type 340, Version 1.99F. Institut für Thermodynamik und Wärmetechnik (ITW), Universität Stuttgart, Stuttgart.

European Commission, 2016. Energy efficiency, Heating and cooling. Available online: https://ec.europa.eu/energy/en/topics/energy-efficiency/heating-and-cooling (Accessed on July 2018)

Lewis, J.O., Hógáin, S.N., Borghi, A., 2013. Building energy efficiency in European cities, Cities of Tomorrow Action Today. URBACT, Paris. 


\title{
BIM Use-Case: Model-Based Performance Optimization \\ Marc Jakobi ${ }^{1}$, Lars Kunath ${ }^{1}$ and Andreas Witzig ${ }^{2}$ \\ 1 Vela Solaris AG, Winterthur (Switzerland) \\ 2 Zurich University of Applied Sciences, ICP Institute of Computational Physics, Winterthur (Switzerland)
}

\begin{abstract}
This contribution demonstrates the application of two building information modeling (BIM) use cases including solar thermal collectors, photovoltaics (PV) and passive solar heating. It aims to close the performance gap that results from inconsistencies between the individual planning phases. Furthermore, it is shown how the pairing of the building project with a digital twin allows to set up predictive maintenance services and minimize the downtime of heating systems. Simulation software is used to create coupled models of the building and its facilities. For a case of PV combined with a heat pump and passive solar heating, this paper shows how the digital model is continuously and automatically updated as conditions change. With a focus on the building's energy demand, control parameters are optimized in alignment with the hardware. Thus, the energy demand is kept within the close range of the original estimation throughout the standard planning phases.
\end{abstract}

Keywords: PV, heat pump, building information modeling (BIM), digital twin, simulation, predictive maintenance, remote fault rectification

\section{Introduction}

Various standards (Bundesarchitektenkammer, 2013; SIA, 2015, 2014) provide a guideline for the planning, realization, and operation of building projects, categorized into different phases. While the individual tasks and responsibilities are clearly defined for each phase, the current state of the art lacks a way to ensure consistency throughout the entire project.

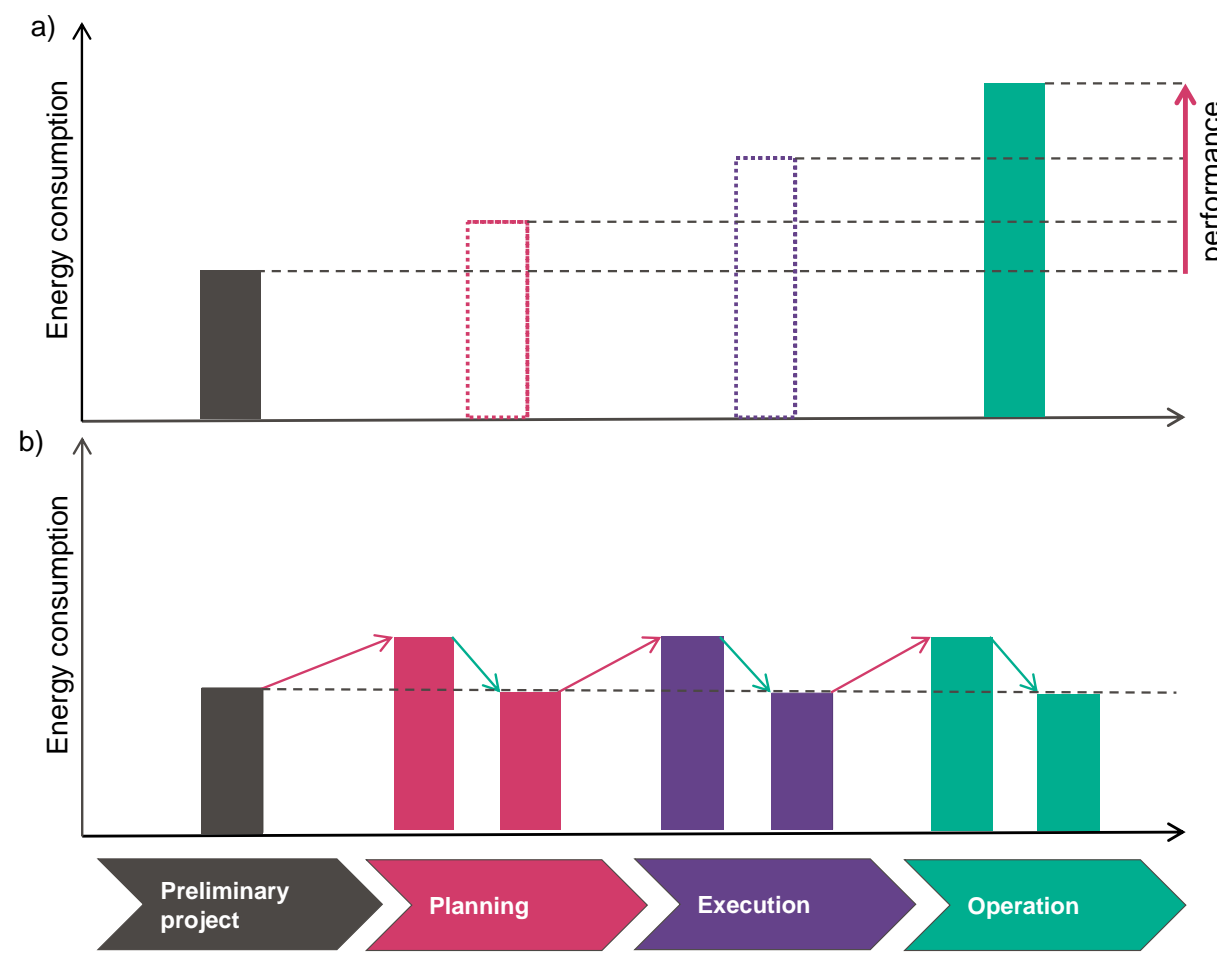

Fig. 1: Qualitative visualization of the performance gap that occurs throughout a project's phases (a) and the closing of the gap by pairing the project with a digital twin (b). 
Since responsibilities are passed on to persons of different professions, miscommunication is certain to occur. Adjustments that must be made in later stages are seldom reflected in the earlier phases' documentation. This results in a performance gap (Fig. 1a) and ultimately in unforeseen cost increases for many of the involved parties. In recent years, BIM has been gaining more and more popularity on a global scale thanks to its ability to keep track of changes and adjust models automatically. Its use, however, has mostly been limited to the minimization of material costs (Eastman, 2011), without regarding the energy consumption. This case study augments the use of BIM to include the building's energy facilities and their control parameters, making it possible to continually eliminate performance gaps, as shown in Fig. 1b.

\section{State of the Art and Challenges}

\subsection{Collaboration Guidelines}

In the German-speaking area (DACH region), there are currently three main standards that provide the state-of-the art guideline for the realization of building projects and the collaboration between involved parties:

- HOAI 2013 in Germany (Bundesarchitektenkammer, 2013)

- $\quad$ SIA 112 in Switzerland (SIA, 2014, p. 112)

- ÖNORM B 1801-1 in Austria (ASI, 2009)

They all provide similar guidelines, with differences regarding the exact division of the development process into various phases. Overall, the potential for performance gaps is the same for all three standards. This section examines SIA 112 more closely and describes some of the problems that may arise during its application. The standard divides a building project into six main phases, whereby each phase is subdivided into multiple smaller processes, resulting in a total of 63 sub-phases. Brief summaries of the six main phases are provided in Tab. 1. In the first phase, the commissioner defines the building's requirements such as the building standard and its use. At the same time, an information manager devises the specifications of the building service installations. Using these specifications, a building designer analyses the marginal conditions and devises a concept in phase 2 . It is here that the energy demand is estimated for the first time and in phase 3 that the central components (heat pump, buffer storage tank, etc.) are decided upon. Traditionally, the initial concept is documented on paper, i.e. in a functional specification document (SIA, 2014). Thus, any changes (e.g., in the architecture or use of the building) that occur later are not easily reflected in phase 2 and often ignored by phase 3 . This potential for a performance gap takes place two more times during this phase. Once, when the smaller components, such as pumps and valves, are defined - for the same reason as the first performance gap occurrence - and once when the initial control strategy and parameters are developed. A modern planning bureau may engineer the control strategy early on using simulation software. This can provide great benefits for the system's efficiency. However, there is currently no simulation tool for building facilities that enables a standardized definition of the control logic. If the building automation technician is not well-versed in the simulation software, the initial control strategy is likely to change and, in a worst-case scenario, to be revised completely. Even if the automation engineer implements the control logic without any changes, there is further potential for performance gaps when a communication protocol is decided upon and incompatible components are replaced without re-optimizing the control parameters accordingly in phase 5. Finally, unforeseen occupant behavior in phase 6 is a very common issue that can significantly impact the effectiveness of the control strategy (de Wilde, 2014).

Tab. 1: The main building project phases defined by SIA 112 .

\begin{tabular}{|c|c|c|}
\hline \# & Phase & Description/Goals \\
\hline 1 & Strategic planning & Definition of requirements and determination of solution strategies. \\
\hline 2 & Preliminary studies & $\begin{array}{l}\text { Definition of the building project; feasibility analysis; choice of project and } \\
\text { executors that best fit the requirements defined in Phase } 1 .\end{array}$ \\
\hline 3 & Project planning & $\begin{array}{l}\text { Optimization of concept and profitability; definition and verification of costs } \\
\text { and deadlines; approval. }\end{array}$ \\
\hline 4 & Tendering & The closing of purchase and work contracts. \\
\hline 5 & Execution & Implementation and commissioning of the project. \\
\hline 6 & Facility management & Operation, monitoring, inspection, maintenance. \\
\hline
\end{tabular}


a)

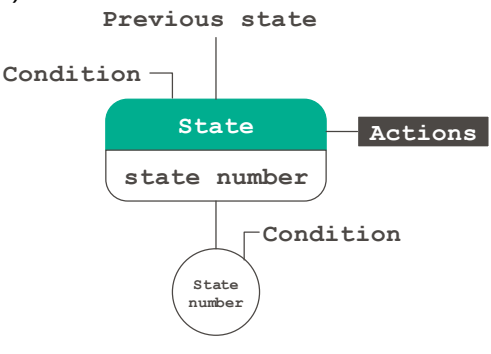

b)

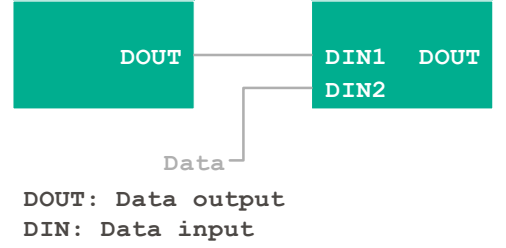

c)

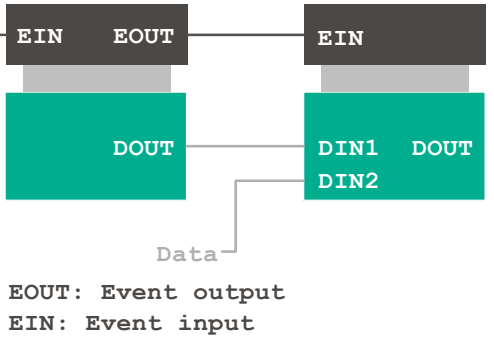

Fig. 2: Qualitative representations of the three standards commonly used in the automation industry: a) State machine (VDI 3812-14); b) FBD (IEC 61131-3); c) FB (IEC 61499).

\subsection{Control Standards}

Regarding the design of control logic using simulation tools, a common drawback is the fact that it rarely conforms with industry standards. The widely-used prototyping tool Matlab/Simulink, for example, utilizes a proprietary programming language. The simulation tool Polysun's programmable controller follows a state logic principle as it is well known from programmable logic controller implementations. Functional calculations and boolean operations are offered similar to spreadsheet applications such as Microsoft Excel. While these languages make control systems more accessible for designers and theoretical researchers, they also result in an additional potential for performance gaps, since the control logic must be ported to standardized languages by building automation technicians. To improve communication between designers and automation engineers, it is necessary to devise a method of linking simulation software with standardized automation logic. Common standards in the automation industry include VDI 3812-14, IEC 61313-3 and IEC 61499. The German VDI 3812-14 provides an easy to read, graphical description of control logic using UML (unified modeling language) state machine (or UML statechart), depicted in Fig. 2a. (VDI, 2018). IEC 61131-3, the most widely-adopted standard in the automation industry (Bolton, 2015), describes six graphical and textual programming languages (IEC, 1993), which are implemented by various integrated development environments (IDEs), such as CoDeSys or MKS Instruments. A relatively new standard, IEC 61499 builds upon IEC 61131-3's graphical "Function Block Diagram" (FBD) language, depicted in Fig. 2b, with the improved "Function Blocks" (FB) language (IEC, 2017), shown in Fig. 2c. Instead of relying on a procedural data transfer, function blocks' internal algorithms are activated by event inputs, and data transfer is triggered by event outputs. Thus, the algorithms and data flows are decoupled from one another. Though it is not as widely adopted as its predecessor, the standard provides an increased flexibility and the ability to develop far more complex control logic (Zoitl, 2014). Furthermore, IEC 61499 applications are mostly XML-based, which allows for cross-compatibility with various runtime environments and IDEs. Exemplary IDEs used for the development of IEC 61499 compliant control applications are 4diac-IDE, FBDK, ISaGRAF, and NxtONE.

\subsection{Current Research}

Some previous work has used predictive simulation tools used in the planning phase to facilitate the programming of heat pump controllers (Grosskopf, 2017). As an important result, this work lists the mapping between the control parameters used in the simulation and the possible settings in the controller hardware. Furthermore, the identification of heating systems based on log data and subsequent simulation-based optimization has been demonstrated by (Steiger and Shehu, 2018). It is a specific implementation of a digital twin, focusing on the energy facilities. While proposing a software interface to bridge the gap between the planning tool and the hardware and describing the processing of log data in the context of a digital twin, neither of the above-mentioned work reflect the information flow and the operational procedures in the real planning processes.

\section{Model-based performance optimization (MPO)}

\subsection{MPO Use Cases}

This case study involves two approaches (use cases), both focusing on the continuous use of simulation software to maintain a digital twin of the building project throughout all its stages. Their difference lies within the approach of eliminating the performance gap for the control logic: In the first use case, the simulation software used for designing the control logic and setting its parameters, exports the data to the VDI 3812-14 state machine format, described in section 2.3, to eliminate miscommunication between the designer and the automation engineer. 


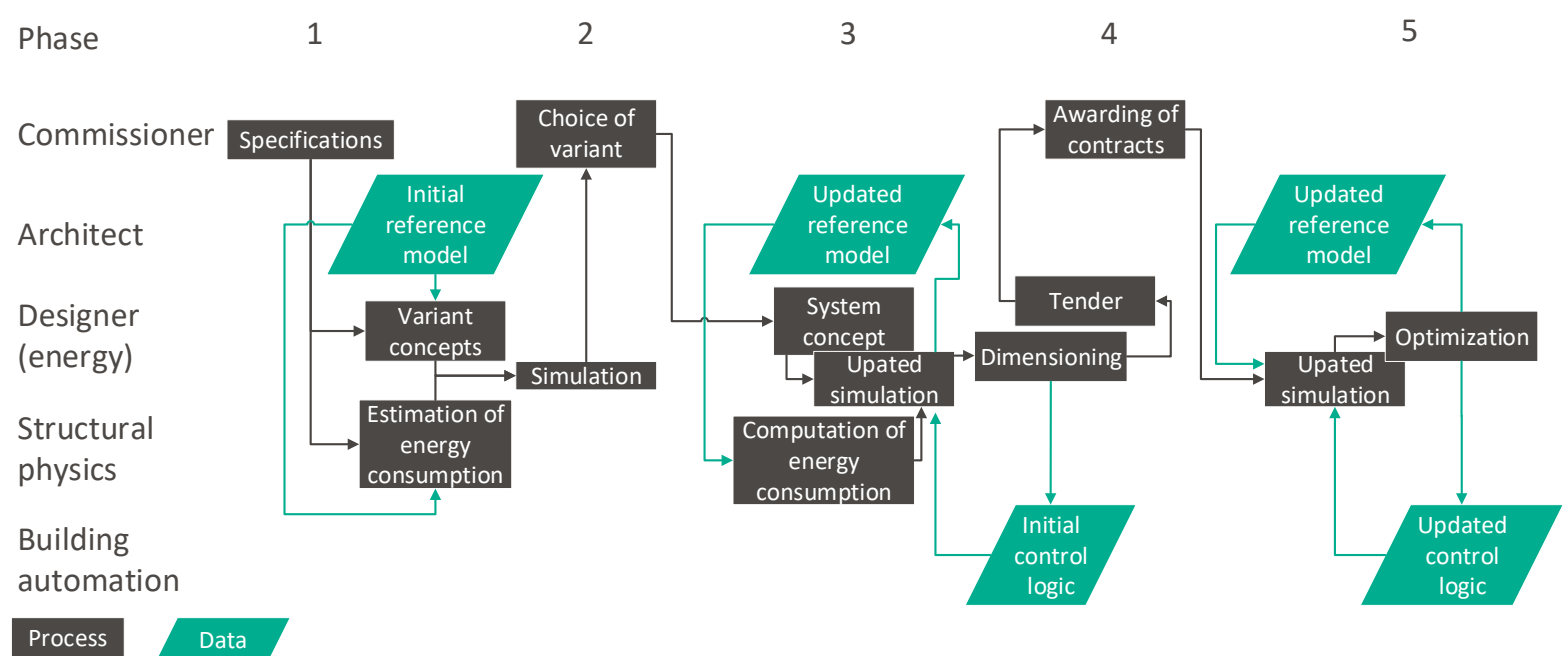

Fig. 3: BIM Use-Case. Simplified schematic representation of Operational Procedure (Meier, 2018).

The second use case is a manual simulation of a scenario in which the control logic is exported by the simulation software into a format that can directly be deployed to the control hardware. To simulate this use case, the control logic is implemented using the IEC 61499 compliant open-source IDE, 4diac and linked with the Simulation tool, Polysun, and MATLAB, via two plugins (Jakobi, 2017) that implement compatible communication protocols. It is envisaged that both use cases be combined to one in the future, with the state machine export of the former being used to aid the integration of the automatically exported IEC 61499 control logic into the system. For brevity, both use cases are described as if they were already combined from henceforth.

\subsection{Implementation}

During the implementation of the case study, the necessary steps and data flows were documented in a detailed process schematic (Meier, 2018). Fig. 3 provides a simplified representation of the resulting MPO operational procedure. After receiving the specifications from the project commissioner, the architect devises an initial reference model. Based on the reference model, two simulation models are linked via a BIM data platform: A building model (e.g., IDA-ICE or DOE-2) that represents the geometries and climatic parameters and performs simulations to estimate the thermal energy demand, and an energy systems model (e.g., Polysun or MATLAB Simulink with the CARNOT Toolbox) that uses the previously determined thermal demand as a basis for the simulation of the building facilities. The energy systems model combines the thermal technology simulations with electrical components and accounts for the dynamics of energy storage. In a first step, the most important components (PV, inverter, heat pump) are chosen based on weather data and dynamic simulations with a simple control logic applied. With the results, the designer can present the commissioner with multiple variants and a feasibility analysis.

The initial concept is then synchronized with the BIM data platform and a detailed building simulation is performed with the variant chosen by the commissioner. After specifying a detailed facility schematic and 3D model, the provided data are used for more detailed energy system simulations in a coupled setup. In our case study (Fig. 4), it is shown how initial optimizations of the energy consumption are achieved by utilizing Polysun's controller plugin to incorporate a control logic based on (Tjaden et al., 2017).

Implemented in 4diac, the control application is handed to an automation engineer in an XML format. The actual control logic can be used as is, without any changes. It is merely necessary to replace the communication interface so far used for co-simulations with one that can connect to the real components. A graphical description of the control system in the UML statechart format simplifies this process. Thanks to the ability to integrate the control application directly into the simulation software, refinements made can be integrated into the updated simulation model. This process occurs in a loop until no further optimizations are possible, and is repeated when the smaller components (pumps, valves, etc.) are defined. Furthermore, an update of the reference model triggers an additional repetition of both control optimization loops. 


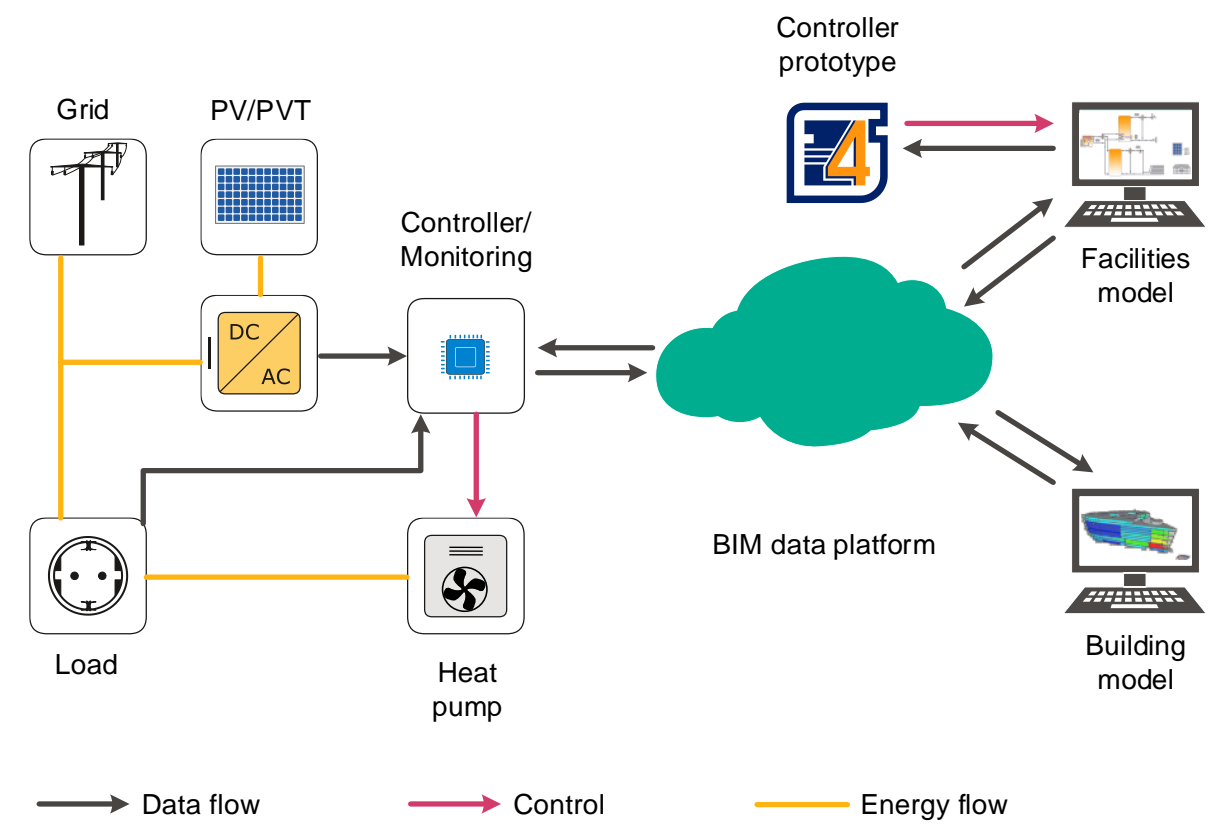

Fig. 4: Visualization of the case study.

After tendering, if the concept is changed due to the awarding of contracts, the simulation models are updated, and the optimization loops are repeated once again with the updated model. Apart from optimizing the heat pump's operation, the IEC 61499 application is designed in such a way that it supports periodical synchronization of control parameters with the BIM data platform, potentially allowing to optimize the control logic remotely without interrupting the running system. Once the controller is applied to the building, the energy production and consumption will be continuously monitored, and the data will be sent to the BIM platform, from where they will be used in the dynamic system simulation for the optimization of control parameters and system components.

Currently, the set-up presented in Fig. 4 must rely on serial co-simulations in which a load file is passed from the building model to the facility model. This is due to the lack of a communication interface between the two simulation tools. The development of an interface that allows timestep-based co-simulations can further improve the model's accuracy by allowing the building model to react to the facility model's energy output. However, it would also result in a significant increase in the duration of the simulations. Thus, the serial approach is more suitable for less detailed co-simulations in the early design stages and for set-ups in which the energy system has little influence on the building's thermal load.

\subsection{Implementation Levels}

The implementation levels of a step-by-step plan for the digital transition based on (Jost et al., 2018) is depicted in Fig. 5. Stage 0 describes the status quo of Switzerland - the currently most common case, in which all involved parties work without simulation models and all data transfer between the parties is analog. In stage 1, the analog data transfer is not eliminated yet, however, individual participants of the project perform their planning based on simulation models. This is the state-of-the-art that is implemented in modern planning bureaus. Our use cases are currently at stage 2 . The data is transferred between various digital models using standard protocols. Yet the data transfer does not occur automatically. While this stage requires an increased amount of dedication from all parties, it is an important step on the way to stage 3 (Jost et al., 2018).

In stage 3, all collaboration processes (i.e. data transfer) are fully automated for the digital models. This stage is the first milestone for the MPO process. Finally, stage 4 describes the link between physical systems and their digital twins. While it has not been reached, our use cases are designed with this stage in mind. 


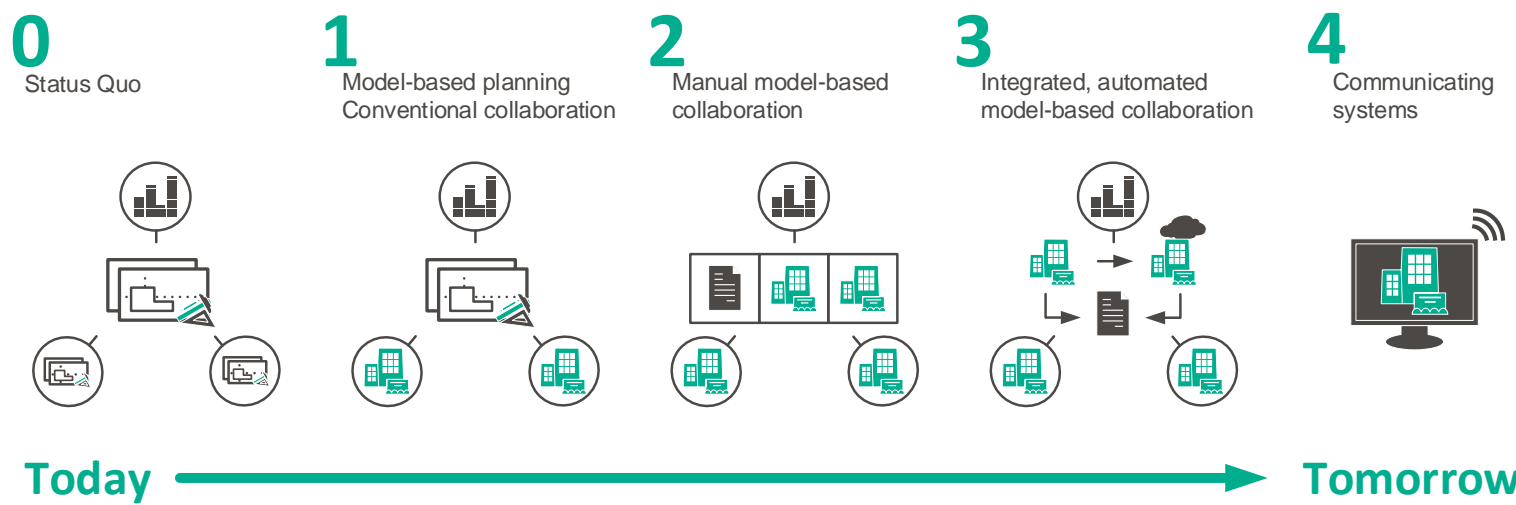

Fig. 5: Step-by-step-plan for the digital transition (Jost et al., 2018).

\subsection{Lessons Learned}

From previous scientific work, from experience in software engineering and from the support hotline of a commercial planning tool, some lessons learned can be summarized in order to support a successful implementation of supporting tools aiming to facilitate model-based performance optimization.

\section{Create an awareness of the project risks}

It is a challenge to motivate project owners to change from the traditional project management to a BIM process. In particular, the costs of the potential energy savings are often not the driver for MPO or for including energy simulation into the BIM process. However, recognizing the project risks as a potential cost hazard is often the basis for a decision to implement a digital twin and systematically avoid the performance gap by use of MPO. Legislation nowadays enforces good energy performance of buildings in the application phase. In a few years, periodical inspections will be required, revealing any performance gaps. High refurbishment costs may occur late in the project or even after closing the project as a consequence of a guarantee claim.

\section{Ensure consistency of data while avoiding the sharing of proprietary or protected data}

Many of the powerful players in the building industry try to push their own software solution to become a host for the project-wide BIM data platform. While one single master database in which all information regarding the building process is stored would be a good technical solution. However, nobody volunteers to give relevant proprietary data out of his hand and some information is by law prevented from being shared. In consequence, the BIM industry has to face the fact that in the future numerous databases exist in parallel, potentially with overlapping contents. Continuous consistency checks are a viable remedy for this situation. Software solutions have to support version information and a "consistency flag" indicating that data has been checked and fulfills the consistency criteria. Small pieces of software running in the background and comparing change logs and parameter entries in the various databases have to validate the data and potentially give the alert to the responsible people that conflicts have to be resolved. In the current state-of-the-art, manual interaction cannot be avoided in this process.

\section{Communication interfaces: Variety of hardware solutions \& slow convergence of standards}

Regarding the elimination of the performance gap by exporting control logic and parameters to a human-readable format to prevent miscommunication in our first use case (cf. section 3.1), it has been found that this alone does not suffice. When the building automation technician decides on a communication protocol, it is likely to turn out that one or more of the previously selected devices must be replaced, due to incompatibility. In this case, the performance gap cannot be fully eliminated if the control application is not integrated directly into the simulation model, as in our second use case. To prevent this miscommunication in the first place, the designer requires early information about the devices' compatibilities with communication protocols. This could be achieved by integrating a list of supported protocols in each device's catalog entry. The simulation tool could then issue a warning to the user if devices with incompatible protocols are placed in the same system. Furthermore, it could use the common compatibilities of the devices to provide the automation engineer with suggestions on which protocols to implement. Combined with the second use case, such a mechanism could even have the long-term potential to eliminate the manual addition of a communication interface to the exported IEC 61499 XML control logic. 


\section{Validation}

In the following section, the usefulness of MPO is assessed based on the experience with the above-mentioned use cases to date. Fig. 6 illustrates the evolution of the cost and energy consumption throughout the step-by-step digital transition plan (cf. section 3.3). The use of simulation software alone significantly reduces costs as well as energy consumption. These reductions can be attributed to the following benefits, among others:

- The ability to compare various components and project variations in a short amount of time.

- Support in decision-making (i.e. by suggesting contemporary components based on the set energy consumption goals).

- The ability to perform complex computations with little knowledge of the underlying models required.
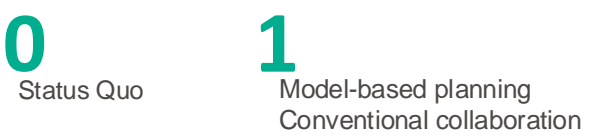

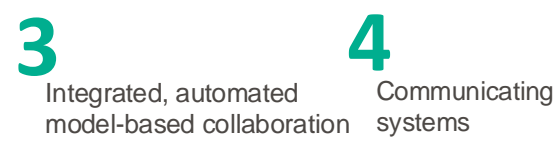

Manual model-based collaboration

systems

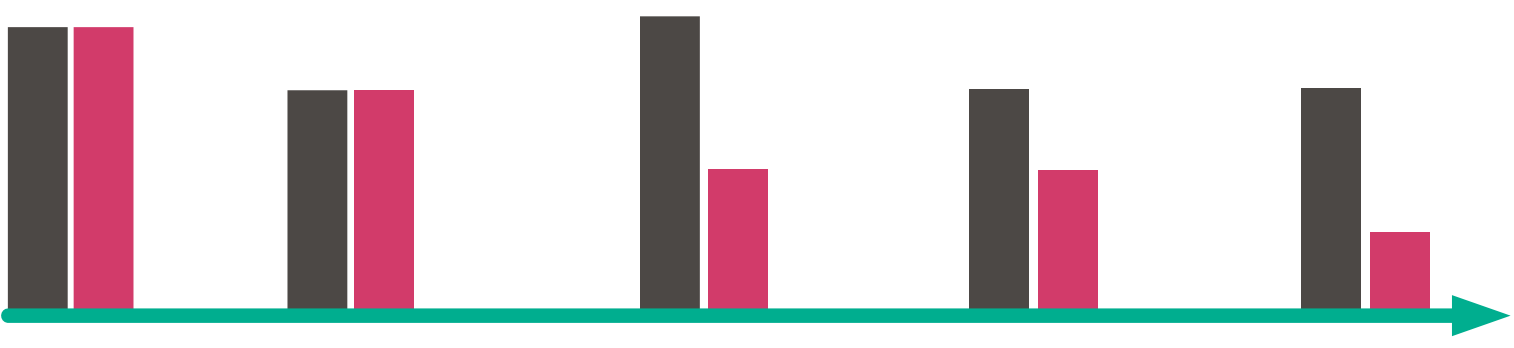

Costs Energy consumption

Fig. 6: Qualitative representation of the cost development and the reduction in energy consumption throughout the digital transition stages (Stages 0 - 2: Validated; stages 3-4: Projected).

The earlier in the pre-design stage model-based planning occurs, the higher the benefits. For example, (Raji et al., 2017) quantified that the general building design alone "can influence the energy use up to $32 \%$ ". With model-based collaboration, the energy consumption is reduced even further, since decision-making support is extended to all planning phases, and therefore helps to eliminate performance gaps. The manual process, however, currently results in a significant surcharge in costs, for the following reasons:

- A high technical expertise is required for the manual model-based collaboration.

- Participants must have proficiency not only in their own line of work but also in the fields they are collaborating with.

- A large amount of time must be invested to ensure a consistent workflow, and to ensure that the same energy consumption levels are achieved as would be expected from an integrated, automated model-based collaboration.

While significant reduction can be reached, another major drawback is the fact that the performance gap cannot be eliminated completely with today's state-of-the art technologies. There is still a long road ahead with the potential for many obstacles.

\section{Outlook}

All in all, the increased costs of the manual MPO process prevent it from being offered on the market today. If the contracting authority does not demand energy efficiency, there is no motivation for the designer. Another challenge is the need to redesign contracts so that they facilitate the early involvement of parties who would otherwise only contribute to the project after tendering. Nevertheless, the potential cost reductions due to the use of model-based planning tools in stage 2 can safely be projected to the integrated, automated model-based collaboration stage. An elimination of the manual processes and their drawbacks will at the very least bring the costs back down to the same level as they were in stage 2 .

Considering that the energy consumption achieved in stage 3 is unlikely to increase compared to its predecessor, an overall benefit can be anticipated. It is envisaged that the communication between running control applications and the digital models, and their continuous optimization (stage 4), will result in further performance gap 
reductions, and in due time, a complete elimination thereof. Though it is difficult to perform a detailed cost analysis to date, a significant change in costs compared to the previous stage is unlikely.

To conclude, the achievable welfare of the MPO process provides a high motivation to take the initial cost increase of the current, manual model-based collaboration stage into account.

\section{References}

ASI (Ed.), 2009. ÖNORM B 1801-1 Kosten im Hoch- und Tiefbau - Kostengliederung. Austrian Standards Institute (ASI), Vienna.

Bolton, W., 2015. Programmable logic controllers. Newnes, Kidlington, Oxford, UK; Waltham, MA.

Bundesarchitektenkammer, 2013. HOAI 2013 Honorarordnung für Architekten und Ingenieure. Wolters Kluwer Deutschland GmbH, Cologne.

de Wilde, P., 2014. The gap between predicted and measured energy performance of buildings: A framework for investigation. Autom. Constr. 41, 40-49. https://doi.org/10.1016/j.autcon.2014.02.009

Eastman, C.M. (Ed.), 2011. BIM handbook: a guide to building information modeling for owners, managers, designers, engineers and contractors, 2nd ed. ed. Wiley, Hoboken, NJ.

Grosskopf, R., 2017. Wärmepumpencontroller direkt angesteuert von Simulationssoftware (Bachelor's thesis). Zürich University of Applied Sciences, Zürich.

IEC, 2017. IEC 61499 - International Standard for Distributed Systems [WWW Document]. URL http://www.iec61499.com/ (accessed 4.27.17).

IEC (Ed.), 1993. IEC 61131 Programmable controllers. International Electrotechnical Commission (IEC), Geneva.

Jakobi, M., 2017. Development of model-based control applications compliant with IEC 61499 with a focus on PV (Master's thesis). HTW Berlin, Berlin.

Jost, A., Lukic, D., Scherer, P., 2018. Stufenplan Schweiz Digital Planen, Bauen und Betreiben. Bauen Digital Schweiz, Zurich.

Meier, M., 2018. Process Schematic MPO Planning (internal publication). Amstein + Walthert AG, Zurich.

Raji, B., Tenpierik, M., van den Dobbelsteen, A., 2017. Early-Stage Design Considerations for the EnergyEfficiency of High-Rise Office Buildings. Sustainability 9, 623. https://doi.org/10.3390/su9040623

SIA (Ed.), 2015. SIA 380 - Grundlagen für energetische Berechnungen von Gebäuden. Schweizerischer Ingenieur- und Architektenverein (SIA), Zürich.

SIA (Ed.), 2014. SIA 112 - Modell Bauplanung Verständigungsnorm. Schweizerischer Ingenieur- und Architektenverein (SIA), Zürich.

Steiger, S., Shehu, B., 2018. Optimierung innovativer Wärmepumpen-Anlagen anhand Analyse von Logdaten und Simulation (Bachelor's thesis). Zürich University of Applied Sciences, Zürich.

Tjaden, T., Weniger, J., Quaschning, V., 2017. Richtige Dimensionierung von Photovoltaik, Wärmepumpen und Pufferspeichern.

VDI, 2018. Richtlinienreihe VDI 3814 “Gebäudeautomation.” VDI, Düsseldorf.

Zoitl, A., 2014. Modelling control systems using iec 61499, 2nd edition. ed, IET control engineering series 95. The Institution of Engineering and Technology, Stevenage, Herts, United Kingdom 


\title{
From Simulation to Reality: IEC 61499 Compliant Control Applications for Solar Energy Systems
}

\author{
Marc Jakobi ${ }^{1}$, Urs Stöckli ${ }^{1}$, Luc Meier ${ }^{1}$, Tjarko Tjaden $^{2}$ and Volker Quaschning ${ }^{2}$ \\ 1 Vela Solaris AG, Winterthur (Switzerland) \\ 2 HTW Berlin (Germany)
}

\begin{abstract}
This contribution documents the development and validation of open source, model-based control applications for IEC 61499 compliant programmable logic controllers (PLCs) intended for the employment in solar energy systems, such as photovoltaic (PV) systems with a battery and/or heat pump (see Fig. 1). Communication interfaces were created between the simulation tools Polysun and Matlab and the PLC's runtime environment, 4diac RTE (FORTE). This allowed for the development and pre-validation of IEC 61499 control applications in co-simulations with established simulation models. The applications implement the PVprog algorithm, which uses locally sourced PV and load forecasts for charging optimized battery operation (Bergner, et al. 2016), combined with an optional PV curtailment and demand-side management (DSM) of SG Ready heat pumps. For validation, a control application was deployed to a Raspberry Pi 2 and employed in a field test.
\end{abstract}

Keywords: PV; IEC 61499; PLC; SG Ready; heat pump; battery; simulation; field test; forecasts; optimization

\section{Introduction}

Decreasing feed-in tariffs and the combination of declining PV energy costs and increasing grid electricity prices are driving the trend for PV systems further in the direction of self-consumption. More and more homeowners are incorporating batteries and heat pumps into their systems. However, political marginal conditions such as feed-in limitations have resulted in the need of more complex, intelligent operational strategies. Today, there is a wide range of "smart energy management" solutions available on the market. Their main tasks usually comprise of the shifting of the load to times of high PV production by means of forecast based battery operation and/or demand-side management (DSM).

The development of such control applications is often a long and tedious process. First, algorithms are prototyped and simulated using development environments such as Matlab/Simulink (Bundesverband Wärmepumpe e. V., 2014). Then, they must be ported to a programming language that can be compiled to the control hardware. Currently available proprietary applications are expensive and, in many cases, non-transparent for installers and end users, regarding the exact type of control that occurs. There exists an open source algorithm for the reduction of curtailment losses, which was devised by Bergner, et al. 2016 in Matlab (Bergner et al., 2016). To be usable in the field, however, it must be ported to other programming languages. The PV industry currently lacks generic, standards-based software for the management of multi-generator energy systems.

\section{Objectives}

This contribution has the objective to facilitate the development of intelligent control systems by means of open source libraries that enable co-simulations of IEC 61499 control applications and simulation tools. By minimizing the prototyping phase to a bare minimum, the need to port control software to other programming languages is eliminated. With these co-simulation tools, open source control applications that can readily be run on a large variety of programmable logic controller (PLC) hardware, are developed and validated. The applications are focused on grid-connected PV energy system configurations as illustrated in Figure 1. 


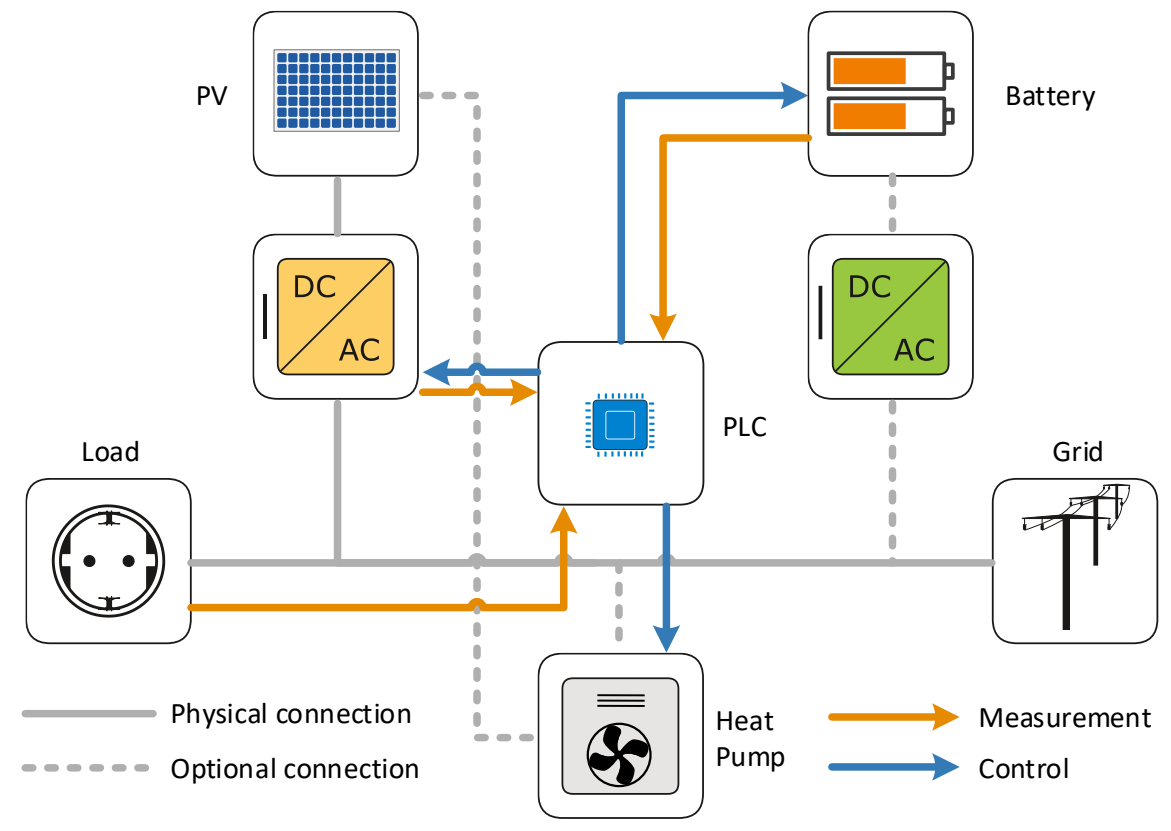

Fig. 1: System configurations and integration of the PLC.

Each system includes a PV generator, an electrical load, an optional battery and an optional heat pump. The controllers act upon the PV inverter, the battery, and the heat pump. Additionally, they take measurements from each of the components. Other household appliances that could potentially be used for DSM, such as washing machines or dishwashers, are not regarded within the scope of this contribution. However, a modular design is intended for the control applications, so that new components can be added later. The objectives can be summarized as follows:

- Facilitation of the development process of control applications by minimizing the prototyping phase.

- Elimination of the need to deploy prototypes into different programming languages.

- Design and validation of generic, standards-based, intelligent open-source control applications.

\section{Technology Selection}

The criteria for the control applications are discussed in the following subsections. Various technologies are compared and those that best fit the set criteria are selected.

\subsection{Criteria}

At the time of beginning this project, it was unclear whether deployment and field testing of a control application would be possible within the time constraints. Therefore, one of the main criteria is flexibility. The control applications need to be designed in such a way that their functionality can be validated using the tools at hand. Even with the possibility of field tests, one of the goals is to speed up the development process by reducing the prototyping phase. The control applications designed with simulation tools should be deployable to real systems with as few changes made to them as possible. As mentioned in section 2, the software should be generic and based on standards, in order to achieve a high portability and good comprehensibility for the end-user and developer. Finally, the project is intended to be fully open source. As such, the final products' usability should not be bound by any proprietary software or hardware limitations.

\subsection{Standard Selection}

Currently, two main standards are defined for PLC control applications: IEC 61131-3 (International Electrotechnical Commission (IEC), 1993) (published in 1993) and IEC 61499 (International Electrotechnical Commission (IEC), 2017) (defined in 2005, revised in 2012), whereby the former has been established in the automation industry (Bolton, 2015). IEC 61131-3 defines five programming languages: Function Block Diagram (FBD), Instruction List (IL), Ladder Diagram (LD), Sequential Function Chart (SFC) and Structured Text (ST). Compliant PLC applications can be programmed in integrated development environments (IDEs) such as CoDeSys, using combinations of these graphical and textual languages. 
Tab. 1: Advantages and disadvantages of the PLC standards.

\begin{tabular}{cc}
\hline IEC 61131-3 & IEC 61499 \\
\hline ++ Experience & - Not yet adopted by the industry \\
+ Large community & - Small community \\
+ Wide range of software/hardware & o Growing range of software/hardware \\
- - Low flexibility & ++ High flexibility \\
- - Platform dependent & ++ Platform independent \\
- - Little to no interoperability & ++ High interoperability \\
- - Little to no portability & ++ High portability \\
- Designed for centralized systems & + Distributed systems possible \\
- - Limited to simple control systems & ++ Complex control systems possible \\
- Low reliability & + High reliability
\end{tabular}

The fact that the standard has been established in the automation industry is the main argument for its use. There exists a large user community and a broad selection of software environments. In the long run, however, the procedural approach cannot live up to the rising requirements for PLCs (Zoitl and Strasser, 2016). Furthermore, IEC 61131-3 does not make any specifications about cross-compatibility between different platforms. As a result, a control application written for one piece of hardware may have to be rewritten from scratch for another controller.

To tackle these drawbacks, IEC 61499 was devised. The standard defines a graphical programming language that uses function blocks (FBs) similar to those defined in FBD. FBs and the control applications are saved in an Extensible Markup Language (XML) format and are not bound to any hardware, thanks to the "IEC 61499 compliance profile for feasibility demonstrations" (Holobloc Inc, 2017). Furthermore, rather than being procedural, the applications are object- and event-oriented. This results in a higher modularity and the possibility of complex, distributed control applications. The disadvantage of the standard lies in the fact that it has yet to be fully adopted by the automation industry (Zoitl and Strasser, 2016). Compared to IEC 61131-3, the standard has a small community and the range of IEC 61499 compliant software and hardware is still rather limited. It is, however, envisaged that IEC 61131-3 will be revised in the future and made compatible with IEC 61499 (Zoitl, 2014). The advantages and disadvantages of the two PLC standards are summarized in Table 1. Since the benefits of IEC 61499 far outweigh the drawbacks, it is chosen for the control applications developed within the scope of this contribution. As an IDE, the open source software 4diac is used.

\section{Software Libraries for the Co-Simulation of IEC 61499 control applications with Matlab and Polysun}

Because the chosen IEC 61499 compliant development- and runtime environment, 4diac, is still rather young, the available testing and validation utilities are very limited. To work around these limitations, and to enable the validation of IEC 61499 compliant control applications through simulations, two communication libraries were developed in Matlab and JAVA. Both libraries are based on (Holobloc Inc, 2017) and use the Transmission Control Protocol (TCP/IP) and/or the User Datagram Protocol (UDP/IP) to transfer data between the simulation programs and the control applications. The libraries convert IEC 61499 data types (e.g., LREAL, REAL, INT, ...) into corresponding Matlab- (double, single, int16, ...) or JAVA data types (double, float, int, ...), and vice versa. For the use of either of the two libraries, skills in the respective programming languages are required. To extend its usability to engineers without programming skills, the JAVA library was integrated into a Polysun controller plugin. The plugin contains controllers that can be set as actors and sensors for various simulated components (i.e. the battery or heat pump) and configured via a graphical user interface (GUI) to connect and communicate with the control application using one of the aforementioned protocols. For the connection of the control application with the plugin, a corresponding IEC 61499 function block library was developed. The co-simulation between the control logic and a Polysun model is visualized qualitatively in Figure 2. Due to the modular design of the communication interface, the only logic that must be replaced to use the application in a real system is the IEC 61499 communication logic that was previously used for the connection with Polysun. The source code of the Matlab and JAVA libraries, as well as the Polysun plugin, are available on the internet portal GitHub. 


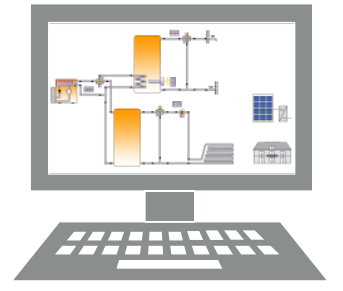

Polysun simulation model
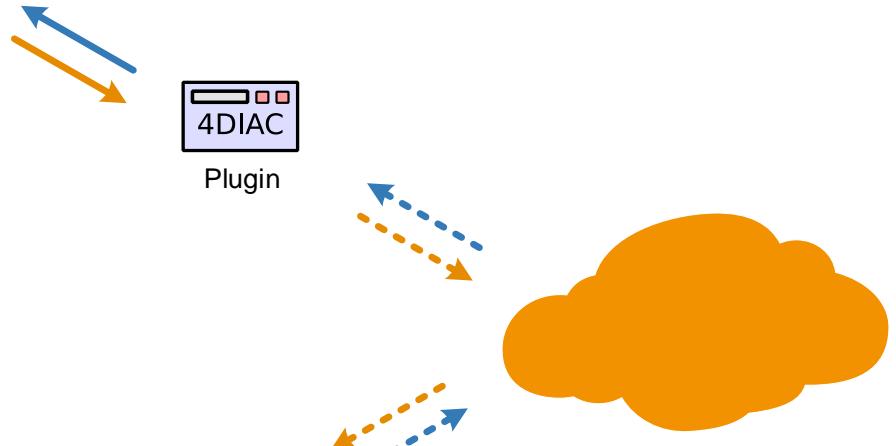

Network

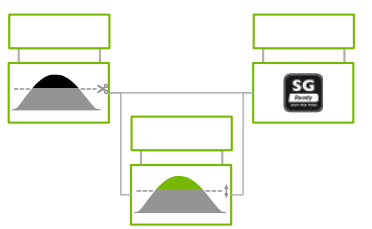

IEC 61499 control logic
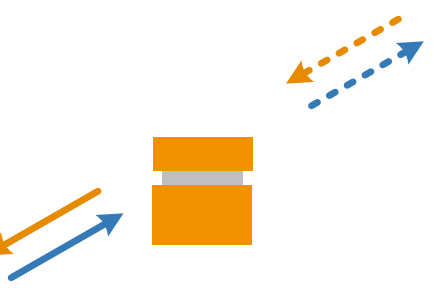

IEC 61499

communication logic

Fig. 2: Visualization of the communication interface between the simulation software Polysun and an IEC 61499 compliant control application (qualitative depiction).

\section{Implementation and Co-Simulation of the Control Applications}

Three IEC 61499 compliant control sub-applications were developed and pre-validated in co-simulations using the previously devised communication interfaces. The sub-applications can be used alone or connected with each other, respectively. They are described in the following subsections.

\subsection{Self-Sufficiency Optimization of SG Ready Heat Pumps}

With over 1000 heat pumps certified with the "SG Ready" label (Bundesverband Wärmepumpe e. V., 2014a), the specified control interface has established itself as a standard for heat pumps in Germany. The standard dictates that heat pumps carrying the label must make it possible to influence their operation using two switch contacts. Each contact can have the state "on" (1) or "off" (0). This results in four operation modes, which are listed and described in Table 2. Unfortunately, there is currently no fixed definition for the SG Ready modes 3 and 4. Normally, the heat pump's internal controller automatically switches back to mode 2 based on different set temperature limits for the storage tank and a hysteresis. From a user's perspective, it would be desirable to have clearly defined factory settings for the control modes, i.e. fixed set points for the storage tank temperature thresholds or increases thereof, in addition to clarifications on whether or not cartridge heaters are used. As part of this project, a control application was devised based on (Tjaden et al., 2017). It performs DSM on the heat pump to shift its use to times of high excess PV power, in order to optimize self-supply and minimize the amount of electricity purchased from the grid.

Tab. 2: The four states of SG Ready heat pumps. Source: (Bundesverband Wärmepumpe e. V., 2014b).

\begin{tabular}{|c|c|c|c|}
\hline$\#$ & Contact States & Short Description & Long Description \\
\hline 1 & $1: 0$ & Off & $\begin{array}{c}\text { The heat pump is turned off for a maximum of } 2 \\
\text { hours. }\end{array}$ \\
\hline 2 & $0: 0$ & Normal & $\begin{array}{l}\text { The heat pump runs in normal operation } \\
\text { (determined by an internal controller) }\end{array}$ \\
\hline 3 & $0: 1$ & Amplified I & $\begin{array}{l}\text { A recommendation for the heat pump to turn on. } \\
\text { Whether the heat pump is turned on or not, is } \\
\text { determined by an internal controller. }\end{array}$ \\
\hline 4 & $1: 1$ & Amplified II & $\begin{array}{l}\text { A definitive instruction to turn the heat pump on } \\
\text { as long as its internal controller deems it possible. }\end{array}$ \\
\hline
\end{tabular}




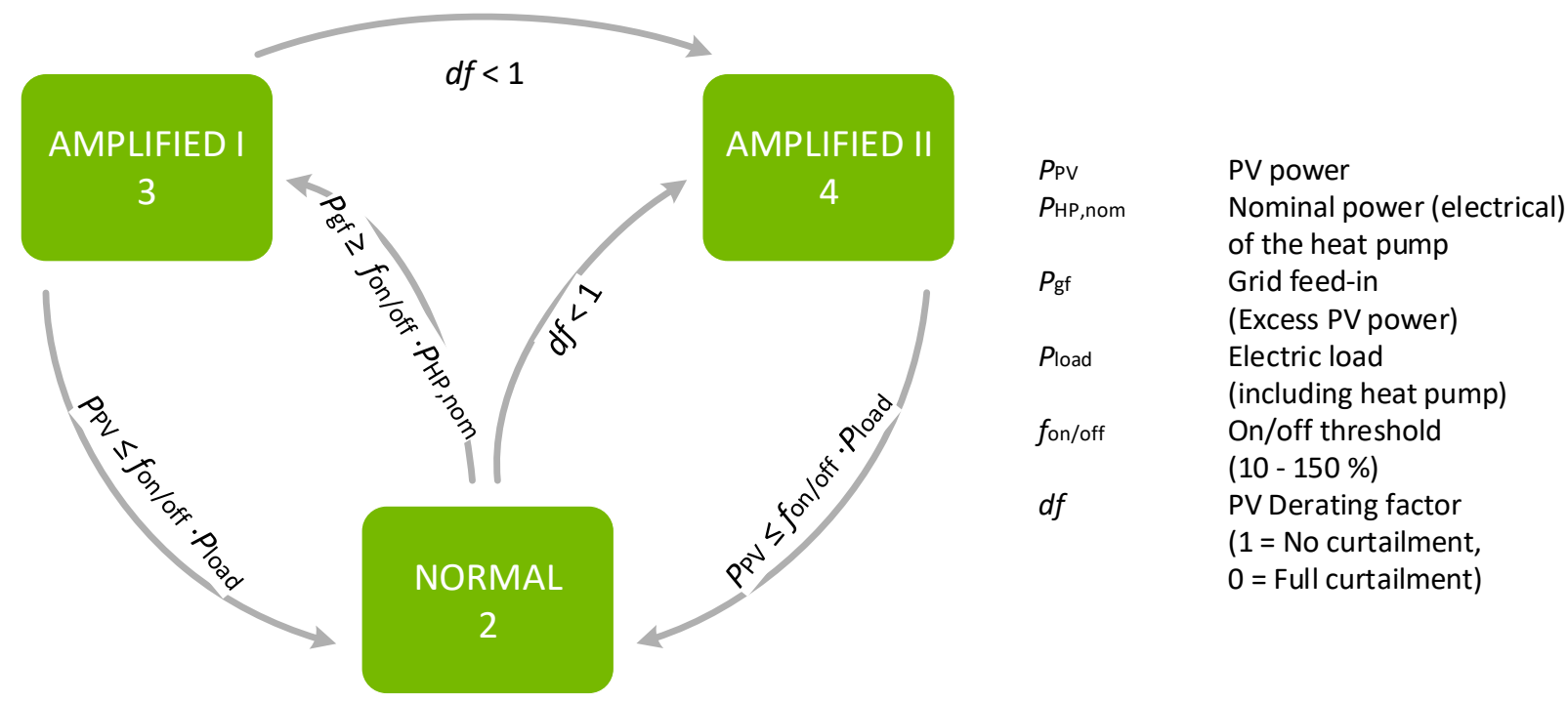

Fig. 3: Switching conditions of the SG Ready heat pump control logic.

The conditions for switching the heat pump from one operation mode to another is illustrated in Figure 3. Control mode 1 is not utilized by the control application. In the simulation model, it is assumed that the heat pump's internal control unit switches back to normal mode from mode 3 at a temperature threshold of $55^{\circ} \mathrm{C}$ in the third layer of the storage tank, with a hysteresis of $5 \mathrm{~K}$. For mode 4 , the threshold is set to $70{ }^{\circ} \mathrm{C}$. The IEC 61499 control application uses an on/off threshold of $100 \%$, as recommended by (Tjaden et al., 2017) for systems with a PV/heat pump nominal power ratio of $3: 1$. Figure 4 compares two PV systems with a heat pump used for heating and domestic hot water on a selected sunny day, simulated in Polysun.
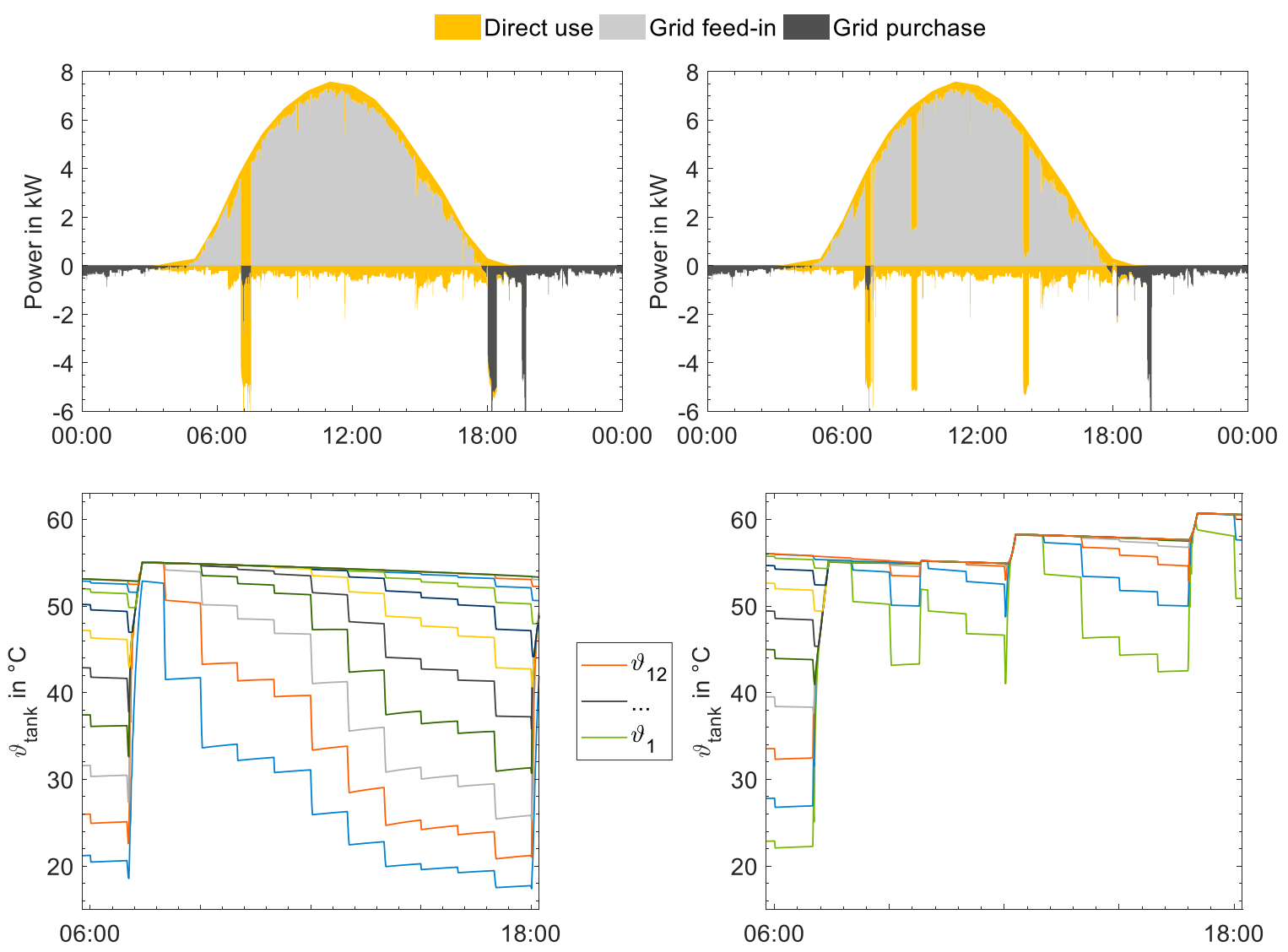

Fig. 4: Comparison of a PV system with a heat pump without (left) and with (right) an SG ready controller, simulated in Polysun. Above: Power flows on a sunny day. Below: Temperatures in the layers of the drinking water tank on the same day. Nominal PV power: $9.9 \mathrm{kWp}$; Nominal heat pump power: $3.3 \mathrm{~kW}$ (electrical), $10.1 \mathrm{~kW}$ (thermal); Household load profile: $5000 \mathrm{kWh} / \mathrm{a}$; Heat pump consumption: Approx. $5400 \mathrm{kWh} / \mathrm{a}$ (depending on the operation strategy). 
The system depicted on the left-hand side uses a regular heat pump and the system on the right is controlled using the SG Ready heat pump controller. The respective power flows are illustrated on top, with temperature levels in the various drinking water tank layers plotted below. Without the controller, the heat pump turns on once in the morning and heats up the tank. During the day, the temperatures in the individual tank layers decrease gradually, so that the stored energy is not enough to cover the demand in the evening. The controller adds two load peaks of the heat pump to the daytime, thus reducing its use at night and almost eliminating the large grid-supply peak at 6 PM. Instead of falling steadily during the day, the temperatures within the controlled system's buffer storage tank are kept at higher levels. By $6 \mathrm{PM}$, the second layer has a temperature above $50{ }^{\circ} \mathrm{C}$, which is more than enough to satisfy the hot water demand. In the one-year simulation, the degree of self-sufficiency is increased from $21.2 \%$ to $24.5 \%$, the own consumption ratio improves from $22.3 \%$ to $26 \%$ and the grid feed-in power and grid purchase are each reduced by $364 \mathrm{kWh}$ and $298 \mathrm{kWh}$, respectively. This load shift is approximately equal to the monthly electricity consumption of the heat pump without an SG Ready controller outside of the heating period. By fine-tuning the on/off threshold, adding a larger drinking water tank and with a more energy efficient building (Tjaden, 2015), the benefits of using the controller would increase even further.

\subsection{PV Curtailment}

The simplest way to limit PV feed-in power to a set value is curtailment. This is usually implemented by PV systems e.g., from SolarLog or SMA. Control applications that require the theoretical PV production before curtailment as an input, however, operate more effectively if they can communicate with the control unit performing curtailment to estimate the derated power (Jakobi, 2017). For this purpose, a subapplication for the curtailment of PV systems was developed as part of this project. It implements a simple proportional-integral-derivative (PID) controller. The set-point value is the running $10 \mathrm{~min}$ average of the grid feed-in power (as specified by the German KfW incentive programme, "Erneuerbare Energien, Speicher" (Forum Netztechnik/Netzbetrieb im VDE (FNN), 2014)). In a real system, curtailment can be determined by communicating with inverters that implement the "SunSpec open protocol for interoperability between devices in renewable energy systems".

\subsection{Forecast-Based Operation of PV Battery Systems}

It is possible to eliminate curtailment losses by intelligently operating a PV battery system. The simplest way to achieve this is to set a fixed feed-in limit, above which the battery is charged. The downside of this method is that it results in a lower use of the battery, compared to a feed-in limitation only through curtailment (Weniger, 2013). By using PV and load forecasts, a dynamic feed-in limitation that solves this problem can be realized. The research group "PV storage systems" at HTW Berlin developed "PVprog", a model-based control algorithm, in Matlab. It utilizes measurement-based PV and load forecasts to dynamically limit the PV feed-in power using a battery (Bergner et al., 2016). For this contribution, the algorithm was ported to an IEC 61499 sub-application (see Figure 5) and validated against a Matlab simulation model provided by HTW Berlin.

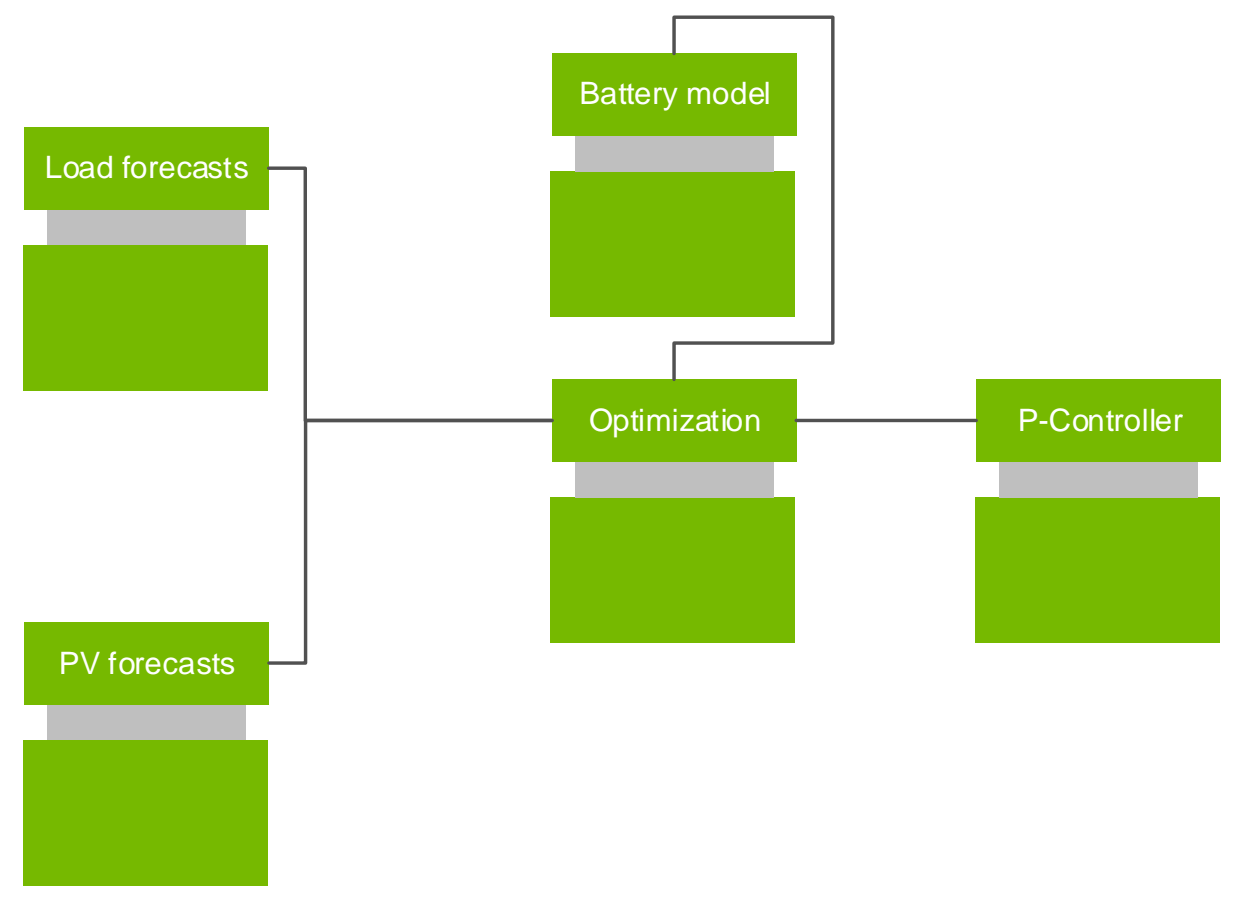

Fig. 5: Simplified depiction of the IEC 61499 implementation of the PVprog algorithm. 

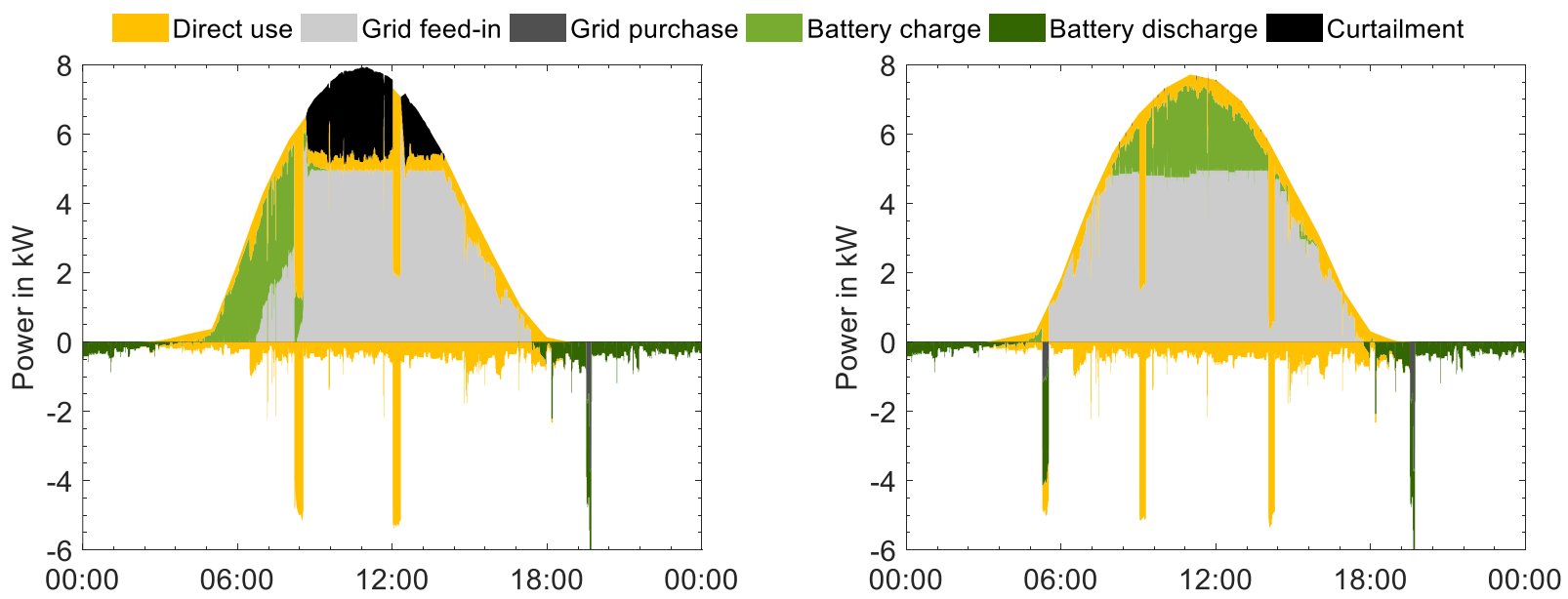

Fig. 6: Comparison of a PV system with an SG Ready heat pump and a battery (power flows on a sunny day). Left: The battery is charged as soon as a PV surplus occurs. Right: Forecast-based battery charging. Nominal PV power: $9.9 \mathrm{kWp}$; Usable battery capacity: $10 \mathrm{kWh}$; Nominal heat pump power: $3.3 \mathrm{~kW}$ (electrical), $10.1 \mathrm{~kW}$ (thermal); Household load profile: $5000 \mathrm{kWh} / \mathrm{a}$; Heat pump consumption: Approx. $5400 \mathrm{kWh} / \mathrm{a}$ (depending on the operation strategy); Feed-in limitation: $50 \%$.

For a higher modularity, the sub-application decouples the battery model from the optimization, which resulted in slight changes to the optimization algorithm. The original Matlab implementation iterates through feed-in limitations between $0 \%$ and $100 \%$ of the nominal PV power in equal intervals and pre-simulates the battery over the forecast horizon of $15 \mathrm{~h}$. An optimum is found when the limitation at which the used battery capacity can be kept as close as possible to the forecasted PV surplus energy while adhering to the maximum feed-in power. The IEC 61499 implementation, on the other hand, increases the dynamic feed-in limitation step-by-step, until the battery model cannot be charged any further or until the maximum allowed feed-in limit is reached. This results in a slightly higher resolution of the iteration steps, which in turn results in a slight change in the simulation results. The degree of self-sufficiency is increased by $0.1 \%$ and the curtailment losses are increased by $0.5 \%$. These deviations are most likely purely stochastic. After the first validation, the control application of the system simulated in Polysun in section 5.1 was extended with the PVprog sub-application and the curtailment sub-application described in section 5.2. Additionally, a battery with a capacity of $10 \mathrm{kWh}$ was added to the system and the feed-in limit was set to $50 \%$. Figure 6 compares the simulation results of a system with (right) and without (left) the PVprog sub-application. The use of the battery alone does not disturb the heat pump operation. However, it is not enough to prevent PV curtailment at noon. As long as the PVprog and SG Ready subapplications communicate with each other (Jakobi, 2017), the forecast-based operation of the battery can prevent almost all curtailment losses. In the co-simulated system, the degree of self-sufficiency is increased to $39.5 \%$ by adding the battery and again to $42 \%$ by using the PVprog sub-application (cf. section 5.1). The own consumption ratio increases to $44.7 \%$ and then to $45.1 \%$. Adding the battery reduces the grid feed-in power by another $2622 \mathrm{kWh}$ and incorporating the PVprog sub-application increases it again, by $281 \mathrm{kWh}$. The electricity purchased from the grid is reduced further by $1606 \mathrm{kWh}$ and by another $229 \mathrm{kWh}$, due to the forecast-based operation.

\section{Field Test}

Among other goals, objectives of this project include a high flexibility and the minimization of the prototyping phase by making it possible to directly use the developed control applications in real systems with as few as possible changes made to the control logic. To achieve this, the interfaces between the simulation software and the control logic was implemented in a modular manner, so that only the communication logic must be swapped out (see section 4). Today, commercial IEC 61499 IDEs like ISaGRAF and nxtSTUDIO can already automatically configure the communication logic. This is also planned for 4diac (Zoitl and Strasser, 2016). To validate that this project's goal has been achieved, the PVprog sub-application from section 5.3 was deployed to a Raspberry Pi 2 and tested in a real PV battery system.

\subsection{Set-Up}

The control application was integrated into the "Living Equia" house at HTW Berlin (HTW Berlin, 2017). The building has a PV system with a nominal capacity of $4.6 \mathrm{kWp}$ and a "Sonnenbatterie" battery system with a usable capacity of $5.3 \mathrm{kWp}$, as stated by the manufacturer. To be able to control the battery, a module for the 4diac runtime environment that implements the Hypertext Transfer Protocol (HTTP) had to be developed. 


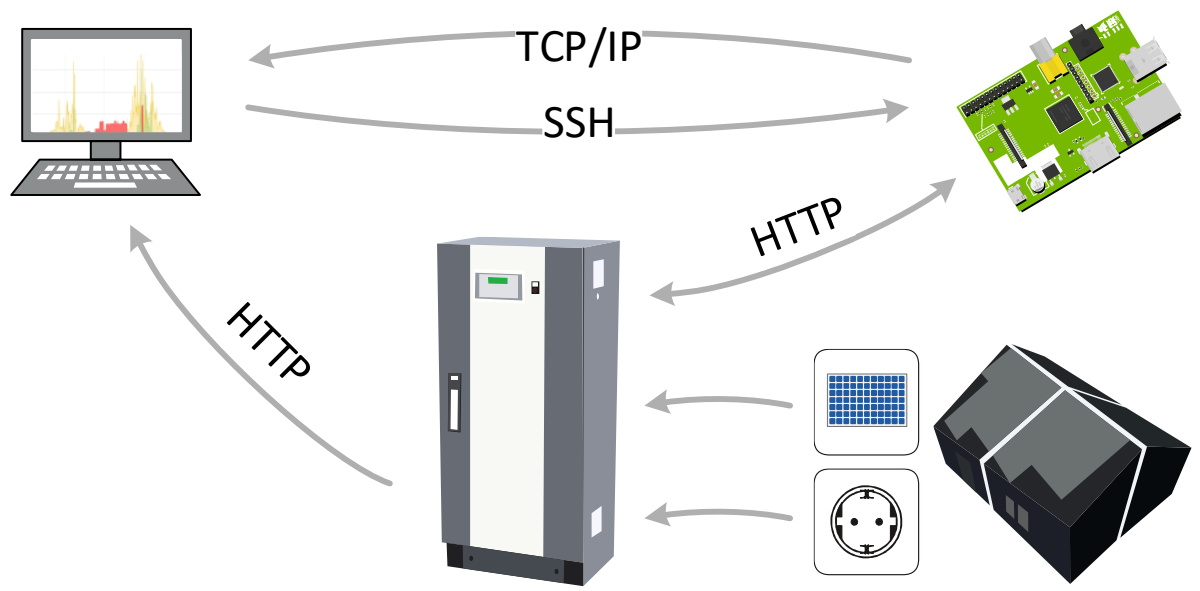

Fig. 7: Visualization of the field test set-up and the communication paths.

With this module, an IEC 61499 function block library for the Sonnenbatterie application programming interface (API) (Sonnen GmbH, 2013) was devised. The set-up of the field test is visualized in Figure 7. The control application on the Raspberry Pi obtains system measurements from a RESTful server, which is hosted on the Sonnenbatterie. On the one hand, the status and power flow measurements can be accessed by a web interface provided by the battery manufacturer. On the other hand, they can be obtained directly from the control application; together with information about its status. Access to the Raspberry Pi's operating system, on which the 4diac runtime environment is installed, can be achieved via Secure Shell (SSH).

\subsection{Results}

The power flows of the field test are depicted in Figure 8 for a selected sunny day. They prove that the IEC 61499 PVprog sub-application performs as envisaged in a real system. Early in the morning, the dynamic feed-in limit is set to a low value and adjusted for the high PV production during the day. The clouds in the late afternoon cause the limit to be lowered again. Reasons for the initially low feed-in limitation can include:

- High shadowing in the morning of the current day or evening of the previous day.

- The control application is still in an initializing state, which can take up to 10 days if every day is cloudy.

- The last 10 days were very cloudy, which can lead to an incomplete initialization of the PV forecasts.

- The useable battery capacity is lower than stated by the manufacturer (e.g., due to degradation).

In this case, the day before was completely sunny, which eliminates the second and third points as possible reasons. Apart from the last point, the first one could be a reason, because the test was performed in September.

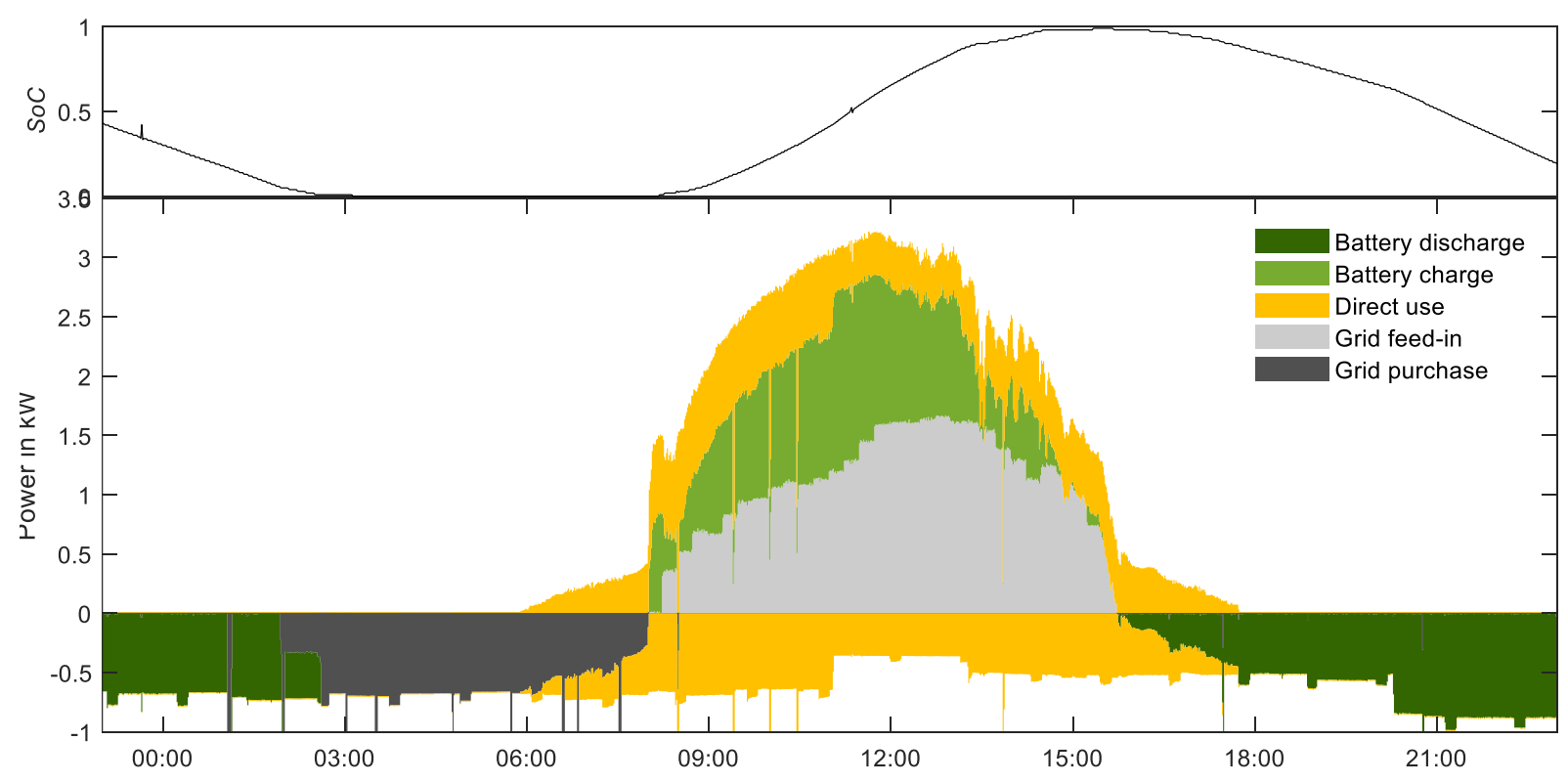

Fig. 8: Measured power flows (below) and battery state of charge (SoC) (above) on a selected sunny day during a field test of the IEC 61499 PVprog sub-application running on a Raspberry Pi 2. Nominal PV power: 4.6 kWp; useable battery capacity: 5.3 kWh. 
This is a time in which the PV power is reduced slightly every day, due to the Sun's declination; especially in the mornings and evenings, in which horizon shading is most prominent. The degraded useable battery capacity can be accounted for within the control application by implementing a sub-application that estimates the capacity according to how much energy is charged into and discharged from the battery.

\section{Conclusion}

The power flows of the field test in Figure 8 clearly show a shift of the battery charging to noon, which results in an elimination of PV curtailment losses. It can hence be concluded that the utilized simulation tools Polysun and Matlab have proven themselves to be reliable development aids for IEC 61499 control applications that can be implemented on a large variety of hardware. The need for standard-based control software has been met with a completely open source solution. Future work will include the implementation and development of additional communication protocols and robust standard control algorithms for multi-generator and multi-storage renewable energy systems.

\section{Source Code}

The source code of the projects described in this paper can be obtained via the following URLs:

- PVprog algorithm in Matlab:

www.pvspeicher.htw-berlin.de/veroeffentlichungen/daten/pvprog

- tcpip4diac: Matlab library for communication with IEC 61499 PLC applications: www.github.com/MrcJkb/tcpip4diac

- Polysun4diac: Polysun plugin and JAVA library for communication mit IEC 61499 PLC applications: www.github.com/MrcJkb/Polysun-4diac-ControllerPlugin

- IEC 61499 function block library and IEC 61499 PLC applications developed within the scope of this project:

www.github.com/MrcJkb/PVTControllerLib

- HTTP module for 4diac-RTE (discontinued, to be integrated into the official release of 4diac-RTE): www.github.com/MrcJkb/forte_http_com

\section{References}

Bergner, J., Weniger, J., Tjaden, T., 2016. PVprog-Algorithmus - Algorithmus zur Umsetzung der prognosebasierten Batterieladung für PV-Speichersysteme mit messwertbasierten PV- und Lastprognosen. Hochschule für Technik und Wirtschaft HTW Berlin, Berlin.

Bolton, W., 2015. Programmable logic controllers. Newnes, Kidlington, Oxford, UK; Waltham, MA.

Bundesverband Wärmepumpe e. V., 2014a. Modell-Liste "SG Ready"-Label für Smart-Grid-fähige Wärmepumpen [WWW Document]. SG Reagy-Label - Für Smartgrid Geeignete Wärmepumpen. URL http://www.waermepumpe.de/waermepumpe/qualitaetssicherung/sg-ready-label.html (accessed 12.16.14).

Bundesverband Wärmepumpe e. V., 2014b. Regularien des SG Ready-Labels [WWW Document]. SG Reagy-Label - Für Smartgrid Geeignete Wärmepumpen. URL http://www.waermepumpe.de/fileadmin/redakteurdaten/Waermepumpe/Qualitaet/SG_READY/2012-1101_SG_Ready_Regularien_Version1.1.pdf (accessed 12.16.14).

Forum Netztechnik/Netzbetrieb im VDE (FNN), 2014. Anschluss und Betrieb von Speichern am Niederspannungsnetz. Forum Netztechnik/Netzbetrieb im VDE (FNN), Berlin.

Holobloc Inc, 2017. IEC 61499 Compliance Profile for Feasibility Demonstrations [WWW Document]. URL http://www.holobloc.com/doc/ita/index.htm (accessed 4.26.17).

International Electrotechnical Commission (IEC), 2017. IEC 61499 - International Standard for Distributed Systems [WWW Document]. URL http://www.iec61499.com/ (accessed 4.27.17).

International Electrotechnical Commission (IEC) (Ed.), 1993. IEC 61131 Programmable controllers. International 
Electrotechnical Commission (IEC), Geneva.

Jakobi, M., 2017. Development of model-based control applications compliant with IEC 61499 with a focus on PV (Master's thesis). HTW Berlin, Berlin.

HTW Berlin, 2017. Solar Decathlon Europe 2010 - Living Equia - Teilprojekt HTW Berlin (ENOB) (SD Europe (BMWi-Energieoptimiertes Bauen Bundesförderung)) - Hochschule für Technik und Wirtschaft Berlin University of Applied Sciences - HTW Berlin [WWW Document]. URL http://www.htw-berlin.de/forschung/onlineforschungskatalog/projekte/projekt/?eid=1161 (accessed 9.21.17).

Sonnen GmbH, 2013. Sonnenbatterie API for battery systems operated in slave mode.

Tjaden, T., 2015. PV-Systeme mit Wärmepumpe ideal betreiben. Pv Mag. 106-108.

Tjaden, T., Weniger, J., Quaschning, V., 2017. Richtige Dimensionierung von Photovoltaik, Wärmepumpen und Pufferspeichern.

Weniger, J., 2013. Dimensionierung und Netzintegration von PV-Speichersystemen (Masterthesis). Hochschule für Technik und Wirtschaft Berlin, Berlin.

Zoitl, A., 2014. Modelling control systems using iec 61499, 2nd edition. ed, IET control engineering series 95 . The Institution of Engineering and Technology, Stevenage, Herts, United Kingdom.

Zoitl, A., Strasser, T., 2016. Distributed control applications: guidelines, design patterns, and application examples with the IEC 61499. 


\title{
Theoretical Analysis of Photovoltaic Panels Using a Spray Cooling System with a Shallow Geothermal Energy Heat Exchanger
}

\author{
Jyun-De Liang ${ }^{1}$, Li-Hao Yang ${ }^{1}$, Ching-Yi Tseng ${ }^{1}$, and Sih-Li Chen ${ }^{1}$ \\ ${ }^{1}$ Department of Mechanical Engineering, National Taiwan University, Taipei (Taiwan, ROC)
}

\begin{abstract}
In this study, a cooling system integrated with a U-shape borehole heat exchanger (UBHE) is utilized to cool the PV panel. This cooling system sprays water on back of the panel, and a tank is used to reclaim cooling water. To enhance the cooling capacity, the recycle water is poured into the U-shaped borehole heat exchangers (UBHE) and dissipates heat to soil and groundwater. A theoretical model is built for evaluating the panel temperature and the cooling water temperature. This is model including three control volumes: the PV panel, the water tank, and the UBHE. Energy equation is used for each control volume, and this study applies the Euler method to calculated differential equations. Theoretical values and experimental results has same tendency. This study also carries out the analysis of economic feasibility. For a plant factory powered by $10 \mathrm{PV}$ panels, for example, this cooling system can improve the efficiency of the panels about $14.3 \%$ compared with PV panels without cooling systems. Investment cost can be an be recovered in 8.7 years, meaning this cooling system is of great worth.
\end{abstract}

Keywords: PV panels, Spray Cooling System, Shallow Geothermal Energy, Borehole Heat Exchanger

\section{Introduction}

PV panels has been widely applied to generate electricity in the past decade, but the PV panel still has disadvantages, one of which is the high surface operating temperature causes the panel efficiency decline problem. Hence, there are many cooling systems has been developed to improve with this problem (Nižetić et al., 2018). The cooling systems can be mainly divided into active and passive forms. The active cooling systems are much effective than the passive cooling systems, but extra power is required to drive the fans or pumps. Consequently, the active cooling system must evaluate carefully economic feasibility. Among active cooling systems, water cooling methods, compared with air cooling methods, have better cooling capacity but require more power to drive pumps. Thus, water cooling methods are usually suitable for large area PV panels.

Shallow geothermal energy is a renewable resource, which is located at a depth of about $3-20 \mathrm{~m}$ and has a feature of stable temperature for the whole year (Soni, et al., 2015; Luo, et al., 2018). Thus, shallow geothermal energy is commonly applied to air-conditioning systems (Soni, 2015), which transfer excess heat to the soil. Similarly, it is also suitable for cooling PV panels. In Taiwan, the soil temperatures at $3 \mathrm{~m}$ in depth below the earth's surface are between $26{ }^{\circ} \mathrm{C}$ and $28{ }^{\circ} \mathrm{C}$ in summer and between $22{ }^{\circ} \mathrm{C}$ and $24{ }^{\circ} \mathrm{C}$ in winner. The soil temperature at $3 \mathrm{~m}$ in depth is lower than the atmosphere temperature in summer and higher than the atmosphere temperature in winter. In addition, the soil temperature is not easily influenced by regions and weather, which means it is stable.

According to above reasons, in this study, a spray cooling system integrated with a UBHE is utilized to cool the PV panel, as shown in Fig. 1. Water is sprayed on the back of the PV panel, and the waste heat is transferred to water. Then, the high temperature water is collected in the tank. Water in the tank is pumped into a UBHE, which is installed in a well, and thus the high temperature water rejects heat to groundwater through a UBHE. Finally, water is spray again to cool the PV panel. The entire process is continuous, and the PV panel could be maintained appropriate operating temperatures. 


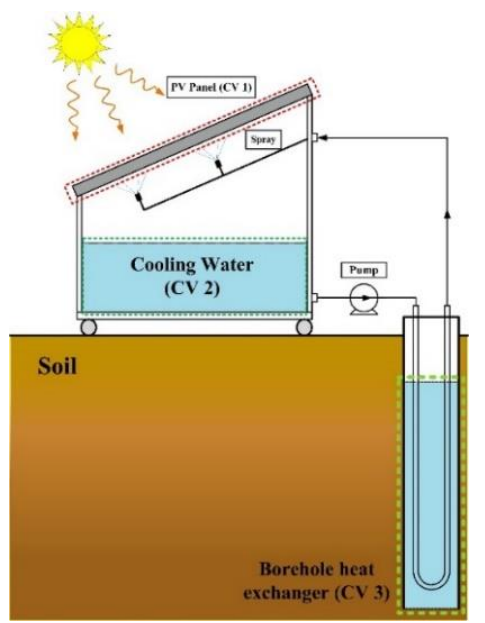

Fig. 1: The experimental setup of cooling system and the control volumes of theoretical model.

Jones and Underwood (2001) have used first-order differential equations to deduce the relationship between the panel temperature and the working time. In addition, a method for calculating the PV panel thermal capacity have been also proposed. Chen and Tsai (2011) further proved the correctness of the thermal model proposed by Jones and Underwood (2001). This model was used to analyze the panel temperature, and the model results were compared with experimental results. The results showed that this model has good agreement with experiment results. Moreover, Mihalakakou et al. (1997) has built a method based on energy conservation to predict the variation in the soil temperature. Ingersoll et al. (1951) has developed an infinite soil thermal model based on an infinitely long line heat source theory for calculating the temperature of soil. Furthermore, Pu et al. (2015) has applied simulation study to evaluate thermal performance of vertical U-tube heat exchangers for ground source heat pump system. The results showed that increasing the Reynolds number for laminar flow condition and enhancing the pipe diameter of UBHE can improve the cooling effect.

To the best of our knowledge, previous literatures only focus on the theoretical analysis of panel temperature or thermal performance of UBHEs. Consequently, this study aims to build a theoretical model for comprehensively evaluating the spray cooling system integrated with a UBHE. Moreover, investment costs and payback periods also be calculated and discussed.

\section{Experimental processes}

A 60-W PV panel (MSX-60) manufactured by SOLAREX is used in this study, and two nozzles installed in the tank are connected with pips and a diaphragm pump. The distance of nozzles from the panel is approximately $0.22 \mathrm{~m}$. The diaphragm pump has the maximum volume flow rate of 1.2 LPM. The total flow rate of spraying water is $0.57 \mathrm{LPM}$, corresponding to $5 \mathrm{~W}$. The total weight of cooling water in the tank is $60 \mathrm{~kg}$. The Solar Power Meter (Datalogging TES-132) has an operating range from 200 to $2000 \mathrm{~W} / \mathrm{m}^{2}$, and the accuracy is $\pm 10 \mathrm{~W} / \mathrm{m}^{2}$. The UBHE system includes pipes and a borehole wall. Between the pipe and the borehole wall is groundwater, and the groundwater level distance from the earth's surface is about $2 \mathrm{~m}$. The external and internal diameter of the well are $0.135 \mathrm{~m}$ and $0.125 \mathrm{~m}$, respectively. The pipe is made from stainless steel. It is located at a depth of $5 \mathrm{~m}$, its length, external diameter, and internal diameter are $10.3 \mathrm{~m}, 0.018 \mathrm{~m}, 0.016 \mathrm{~m}$. The working fluid is water.

In this study, the PV panel without the cooling system is used as the base model, and its power output and temperature variation are measured. Then, the cooling system combined with a UBHE for improving the panel efficiency is applied. To reduce the power consumption of the pump, pump is switched on once the panel temperature reaches $45^{\circ} \mathrm{C}$ and is switched off once the PV panel is cooled to $35^{\circ} \mathrm{C}$. Entire cooling processes are intermittent, which can maintain cooling water temperatures and can consume lower power. In Taiwan, the solar intensity is relatively stronger during summer (July) midday and relatively weaker during the afternoon. Thus, every experiment is carried out from 11:40 to 14:45. For each experiment, the power output and the temperature of the panel and cooling water are recorded through a data recorder (YOKOGAWA mv200). Apart from this, the solar radiation intensity, load voltage and load current are also measured. 


\section{Theoretical analysis}

This study builds a theoretical model, as shown in Fig. 1, which contains three control volumes: the PV panel, the water tank, and the UBHE. Energy equation is utilized to predict temperatures for each control volume. Because these control volume are connected wih each other, the calcualted results of one control volume are inlet boundary conditions of another control volume. The following assumption are applied in this theoretical model:

(1) The temperature of the PV panel is distributed equally.

(2) The heat generated by the internal resistance of the PV panel is ignored.

(3) The temperature of the cooling water of the tank is distributed equally.

(4) The thermal insulation is an ideal thermal insulation; thus, the walls of the tank and the pipe are adiabatic.

(5) The ambient temperature is constant.

(6) Natural convection inside the tank during operation of the cooling system is ignored.

(7) All of the cooling water is sprayed onto the panel equally.

(8) Ambient wind velocity is $1 \mathrm{~m} / \mathrm{s}$.

Based on the energy conservation equation of the PV panel, as shown in Fig 2. The energy equation is expressed as follows:

$$
C_{p v} \frac{d T_{p v}(t)}{d t}=A_{p v} \alpha \varphi-q_{o}-q_{r}-P_{p v}
$$

where $C_{p v}$ is the heat capacity of the PV panel, $\alpha$ is the absorption coefficient of the PV panel, $\varphi$ is the solar radiation intensity, $\mathrm{A}_{\mathrm{pv}}$ is the panel area, and $A_{p v} \alpha \varphi$ is the incoming solar radiation absorbed by the panel. Consulting the method by Jones and Underwood (2001), the thermal capacity $C_{p v}$ can be calculated.

The convection coefficient $q_{o}$ between the panel and fluid could be divided into two parts: $q_{c o}$ is the convection between the panel and outside air, and $q_{c i}$ is the convection between the panel and the tank.

$q_{c o}=A_{p v} \cdot h_{c o} \cdot\left[T_{p v}(t)-T_{a}\right]$

where $T_{p v}$ is the temperature of the PV panel, and $T_{a}$ is the temperature of air. The force convection coefficient proposed by Stultz and Wen (1977) is written below:

$$
h_{c o}=1.247\left[\left(T_{p v}-T_{a}\right) \cos \theta\right]^{1 / 3}+2.658 \mathrm{~V}, \mathrm{~V}=1 \mathrm{~m} / \mathrm{s}
$$

where $V$ is the wind velocity.

Further, $q_{c i}$ between the panel and the tank was predominantly based on natural convection of the air inside the tank before the cooling system initiated, and it could be expressed below:

$$
q_{c i}=A_{p v} \cdot h_{f} \cdot\left[T_{p v}(t)-T_{a}\right]
$$

According to Holman (1997), the natural convection coefficient $h_{f}$ of the air in the tank could be expressed as follows:

$$
h_{f}=\frac{k_{a} N u}{l}
$$

where $k_{a}$ is the thermal conductivity of air, $l$ is the length of the PV panel, $N u$ is the Nusselt number, and $G r$ is the Grashof number.

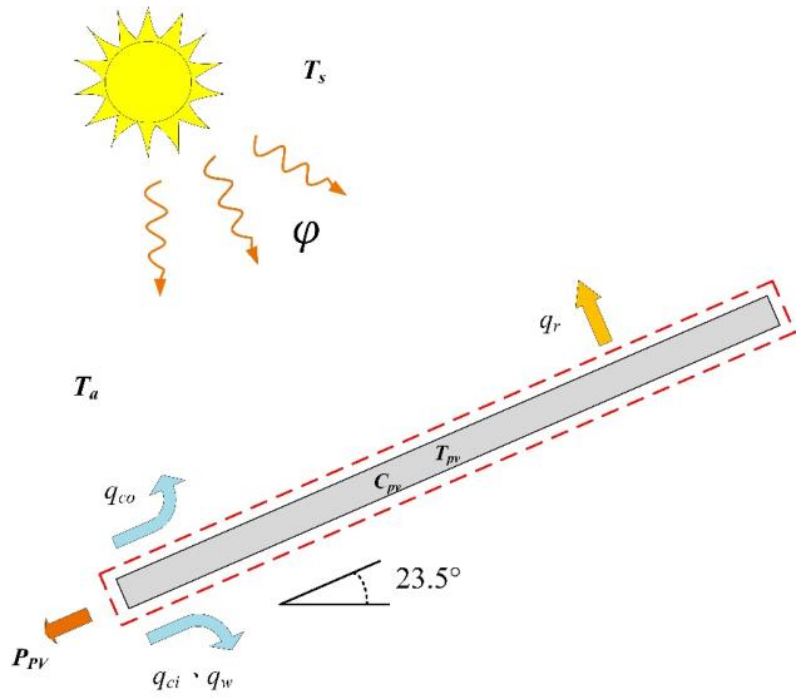

Fig. 2: The operation mechanism of the PV panel and the control volume of the PV panel. 


$$
\begin{aligned}
& N u=0.56\left[\operatorname{GrPr\operatorname {cos}}\left(90^{\circ}-\theta\right)\right]^{1 / 4}, \theta>2^{\circ} \\
& G r=\frac{g \beta\left(T_{p v}-T_{a}\right) l^{3}}{v_{a}^{2}}
\end{aligned}
$$

where $g$ is gravity, $\beta$ is the coefficient of thermal expansion, and $v_{a}$ is the kinematic viscosity of air.

After the cooling system is initiated, the force convection created by the spray is the main cooling mechanism, and internal natural convection could be ignored; thus, $q_{c i}$ could be expressed as $q_{w}$. According to the empirical formula reported by Oliphant et al. (1998), the fore convection coefficient created by the spray could be derived as follows:

$$
h_{s p}=\frac{k_{w} N u}{D}
$$

where $k_{w}$ is the thermal conductivity of water, and $D$ is the spray diameter of the nozzle.

$$
\begin{aligned}
& R e^{*}=\frac{G D}{\mu_{w}} \\
& G=\frac{\dot{m}}{A_{s p}} \\
& \mathrm{D}=2 \mathrm{H}_{\mathrm{sp}} \cdot \tan (0.5 \gamma)
\end{aligned}
$$

where $R e^{*}$ is the Reynold number, $G$ is the mass flux, $\dot{\mathrm{m}}$ is the mass flow rate, $H_{s p}$ is the distance between the nozzle and panel, and $\gamma$ is the spray angle.

Thus, $q_{w}$ could be derived as:

$$
h_{s p}=\frac{k_{w} N u}{D}
$$

where $A_{s p}$ is a spray area, $T_{n}(t)$ is the cooling water temperature $(\mathrm{K})$ at the outlet of the nozzles.

The heat radiation of the panel absorbed from the environment could be expressed as:

$$
q_{r}=A_{p v} \sigma\left[\varepsilon_{p v} \cdot T_{p v}(t)^{4}-S_{s} \varepsilon_{s} \cdot T_{s}^{4}\right]
$$

Consulting the formula by Liu and Jordan (1963), the shape factor between the sky and the panel could be expressed as:

$$
S_{s}=\frac{1+\cos \theta}{2}
$$

where $\varepsilon_{p v}=0.95, \varepsilon_{s}=0.95, T_{s}=T_{a}-20 \mathrm{~K}$ as demonstrated Schott (1985).

Based on Marion et al. (1999), the PV panel power output $P_{p v}$ could be expressed below:

$$
P_{p v}=\frac{\varphi_{\text {inc }}}{\varphi_{S R C}} \underset{S R C}{ }\left\{1+\gamma^{\prime}\left[T_{p v}(t)-298 K\right]\right\}
$$

where $\varphi_{S R C}$ is the solar intensity $\left(1000 \mathrm{~W} / \mathrm{m}^{2}\right.$, ambient temperature $\left.25^{\circ} \mathrm{C}\right)$ and $P_{S R C}$ is the maximum output power $(60 \mathrm{~W})$, both under standard reporting conditions (SRC); and $\gamma^{\prime}$ is the temperature correction factor $(-0.0057)$.

The cooling system combined with the UBHE is shown in Fig 3 . The heat from the panel is $\dot{E}_{i}$, and the heat that leaves from the tank is $\dot{E}_{e}$.

$$
\begin{aligned}
& \dot{E}_{i}=\dot{m}_{i} e_{w i} \\
& \dot{E}_{e}=\dot{m}_{e} e_{w}
\end{aligned}
$$

where $\dot{m}_{i}$ is the mass flowrate of the cooling water into the tank from the PV panel, $e_{w i}$ is the enthalpy of the cooling water into the tank from the PV panel, $\dot{m}_{e}$ is the mass flowrate that leaves from the tank, and $e_{w}$ is the enthalpy of the tank water.

The mass conversation of the tank and nozzles can be expressed as:

$$
\dot{m}_{i}=\dot{m}_{e}=2 \dot{m}
$$

where $\dot{m}$ is the mass flowrate of one nozzel.

The energy balance equation for the inside of the tank in this case could be expressed as:

$$
M c_{w} \frac{d T_{w}(t)}{d t}=\dot{E_{i}}-\dot{E_{e}}=2 \dot{m}\left(e_{w i}-e_{w}\right)
$$

where $M$ is the mass of the cooling water, $c_{w}$ is the specific capacity of the water, and $T_{\mathrm{w}}$ is the temperature of the cooling water.

Because the cooling system is combined with the UBHE, the cooling water temperature $T_{w}$ is equal to the UBHE inlet water temperature $T_{f i}$ and $T_{n}$ is equal to the UBHE outlet water temperature $T_{f o}$. Thus, $q_{w}$ could be expressed as follows:

$$
2 A_{s p} \cdot h_{s p} \cdot\left[T_{p v}(t)-T_{f o}(t)\right]=2 \dot{m} c^{\prime}\left[T_{w i}(t)-T_{f o}(t)\right]
$$




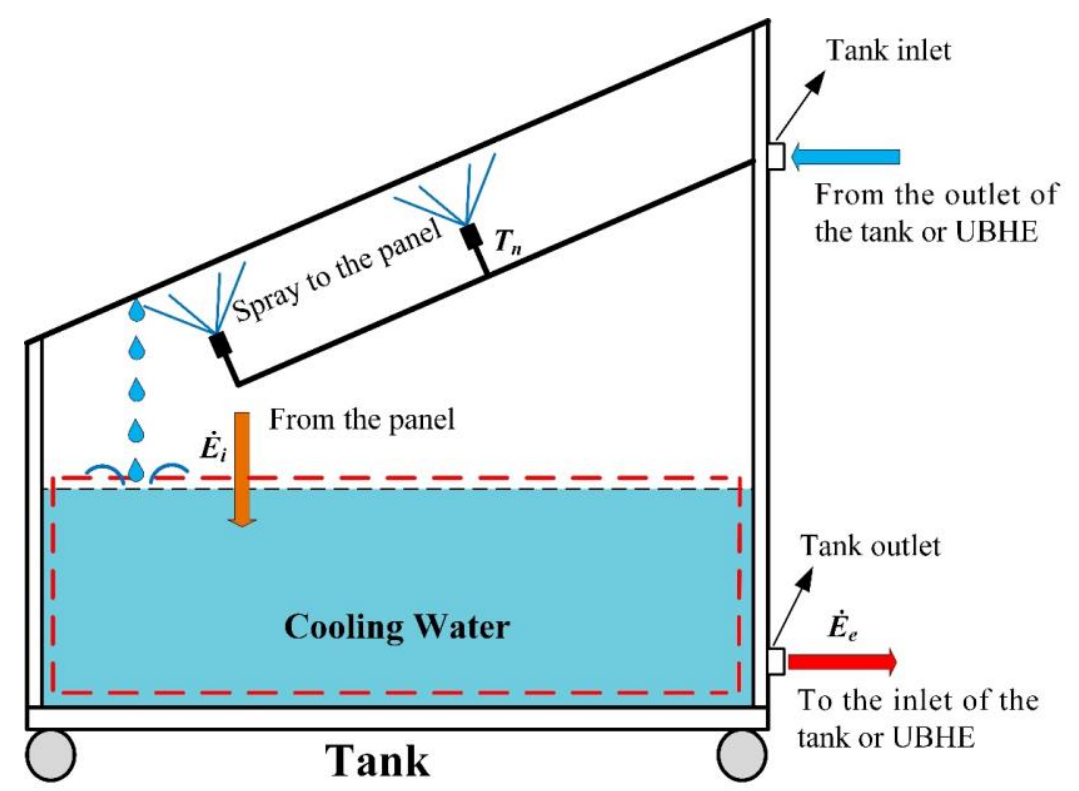

Fig. 3: The operation mechanism of the cooling system and the control volume of cooling water.

where $c^{\prime}$ is the specific heat of the tank water, $T_{w i}$ is the temperature of the cooling water after cooling the panel and flowing into the tank. In addition, $e_{w i}$ could be obtained from $T_{w i}$, which could be expressed as:

$$
T_{w i}(t)=\frac{A_{s p} \cdot h_{s p} \cdot\left[T_{p v}(t)-T_{f o}(t)\right]}{\dot{m} c^{\prime}}+T_{f o}(t)
$$

The mathematical models of the UBHE assume the soil is a thermal reservoir that can effectively absorb all waste heat as demonstrated Ball et al. (1983) and Soni et al. (2015), and thus, the soil temperature $T_{s o}$ can be set as a constant temperature. The cooling water stays in the UBHE and discharges its heat while the pump rests, so the discharge relationship between the cooling water and the UBHE could be expressed as follows:

$$
h_{b i} A_{p}\left[T_{p}(t)-T_{g w}(t)\right]=h_{b i} A_{b}\left[T_{g w}(t)-T_{s o}\right]
$$

where $h_{b i}$ is the convection coefficient of the water in the borehole, $A_{p}$ is the pipe area, $A_{b}$ is the borehole area, $T_{p}$ is the water temperature in the pipe, and $T_{g w}$ is the ground water temperature.

According to DeWitt and Lavine (2007), natural convection in the borehole of the U-tube could be derived as follows:

$$
\begin{aligned}
& h_{b i}=\frac{N u_{b i} k_{w}}{D^{\prime}} \\
& N u_{b i}=\frac{1}{24} R a_{b i}\left(\frac{D^{\prime}}{H_{b}}\right)\left\{1-\exp \left[\frac{-35}{R a_{b i}\left(\frac{D^{\prime}}{H_{b}}\right)}\right]\right\}^{3 / 4}, 10^{-1} \leq R a_{b i}\left(\frac{D^{\prime}}{H_{b}}\right) \leq 10^{5} \\
& R a_{b i}=\frac{g \beta\left(T_{f i}-T_{f o}\right) D^{\prime 3}}{a^{\prime} v}
\end{aligned}
$$

where $D^{\prime}$ is the distance between branch pipes, $k_{w}$ is the water conductivity, $N u_{b i}$ is the Nusselt number of the water in the borehole, $R a_{b i}$ is the Rayleigh number of the water in the borehole, $H_{b}$ is the borehole depth, $\beta$ is the coefficient of thermal expansion, $\alpha^{\prime}$ is Thermal diffusivity, and $v$ is kinematic viscosity.

Then, the ground water temperature could be expressed as:

$$
T_{g w}(t)=\frac{A_{p} T_{p}(t)+A_{b} T_{s o}}{A_{b}+A_{p}}
$$

Therefore, the energy balance equation between the UBHE and the ground water could be expressed as:

$$
\int_{t}^{t+\Delta t} h_{b i} A_{p}\left[T_{p}(t)-T_{g w}(t)\right] d t=M_{p} c_{w}\left[T_{p}(t)-T_{p}(t+\Delta t)\right]
$$

Thus, $h_{b i} A_{p}\left[\overline{T_{p}}(t)-T_{g w}\right] \Delta t=M_{p} c_{w}\left[T_{p}(t)-T_{p}(t+\Delta t)\right]$, and by means of estimate, average $\overline{T_{p}}(t)$ is $\frac{T_{p}(t)+T_{p}(t+\Delta t)}{2}$, and $M_{p}$ is the mass of the cooling water that in the pipe. eq. (27) could be reworded as follows:

$$
h_{b i} A_{p}\left[\frac{T_{p}(t)+T_{p}(t+\Delta t)}{2}-T_{g w}(t)\right] \Delta t=M_{p} c_{w}\left[T_{p}(t)-T_{p}(t+\Delta t)\right]
$$

where $T_{p}(t+\Delta t)$ is the temperature of the UBHE outlet water $T_{f o}$. From eq. (26) and eq. (28), $T_{f o}$ could be derived as follows:

$$
T_{f o}=\frac{-2}{2 M_{p} c_{w}+h_{b i} A_{p} \Delta t}\left\{h_{b i} A_{p} \Delta t\left[\frac{T_{p}(t)}{2}-\frac{A_{p} T_{p}(t)+A_{b} T_{s o}}{A_{b}+A_{p}}\right]-M_{p} c_{w} T_{p}(t)\right\}
$$


When the pump is working, the high-temperature cooling water in the tank will flow into the UBHE again, and it will affect the low-temperature cooling water in the UBHE. Thus, the mixed water temperature in the pipe could be expressed as $T_{p^{\prime}}$ :

$$
T_{p^{\prime}}=T_{f i} \frac{\sigma^{\prime} t_{\text {ope }}}{t_{\text {tot }}}+T_{p} \frac{t_{\text {tot }} \sigma^{\prime} t_{\text {ope }}}{t_{\text {tot }}}
$$

where $t_{t o t}$ is the total time for the cooling water to pass through the UBHE, $t_{\text {ope }}$ is the total operating time of the cooling system, and $\sigma^{\prime}$ is a correction factor that is considered an effective thermal ratio for the axial and radial parts of U-shape pipe.

From eq. (30) into eq. (29), $T_{f o}$ can be obtained; then, by substituting $T_{f o}$ into eq. (20), $q_{w}$ can be obtained; then, $q_{w}$ can be substituted into eq. (1). Finally, eq. (1), (19), (29), and eq. (30) represent a mathematical model for the cooling period of the PV panel system, which is cooled by the spray cooling system with UBHE. Governing equations of a cooling system combined with UBHE for PV panels are listed in Tab. 1. Then, the Euler method is applied to calculate the differential equations. In this study, theoretical analysis and experimental results are compared. In addition, the difference between them are also discussed.

Tab. 1: Governing equations of a cooling system combined with UBHE for PV panels.

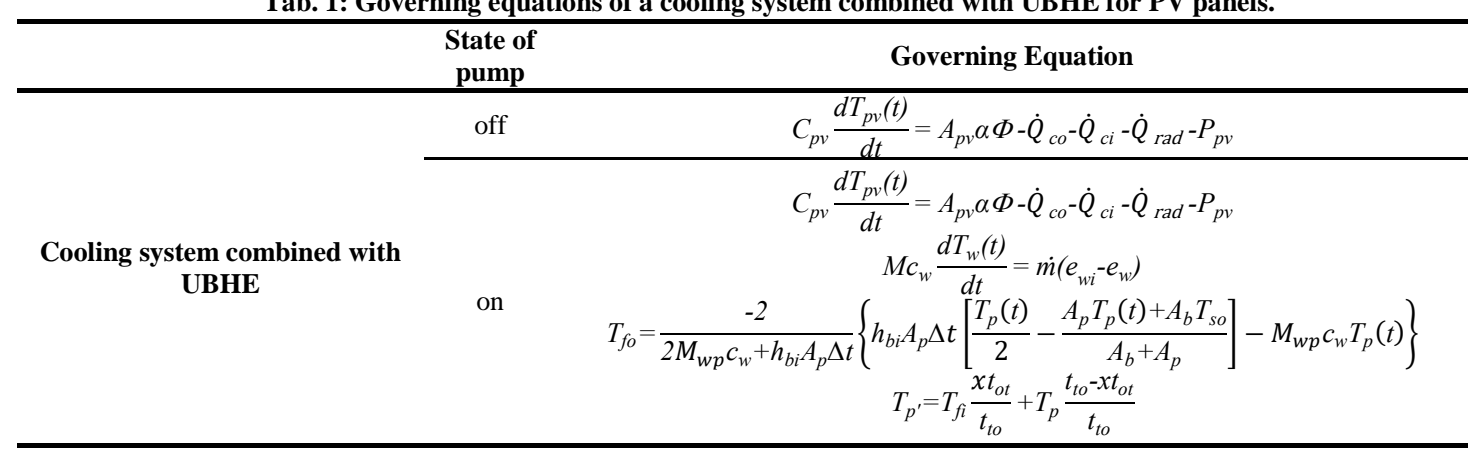

\section{Results and discussion}

First, this study investigated characteristics of the PV panel without the cooling system and discussed the effect of high PV panel temperatures on the PV efficiency. Experimental results were applied as the basic model for comparison. Fig. 4 shows the relationship of experimental and theoretical PV panel temperatures. The experiment was conducted from 11:40 to 14:45, and the theoretical PV temperature can be obtained through eq. (1). The initial temperature of the PV panel is $52{ }^{\circ} \mathrm{C}$, and the highest temperature in both the theoretical and experimental results are above $65^{\circ} \mathrm{C}$. Moreover, the average error between the theoretical and experimental result is about $1.49 \%$. Fig. 5 shows the relationship between the solar intensity and the power output. The average solar intensity and the average power output during experimental periods are $946.5 \mathrm{~W} / \mathrm{m}^{2}$ and $34.5 \mathrm{~W}$, respectively. The energy conversion efficiency of the PV panel is about $6.56 \%$. In accordance with Fig. 4 and Fig. 5, the solar intensity and panel temperature are main factors, which influence the power output. As shown in Fig. 5, the solar intensity at $\mathrm{t}=0 \mathrm{~min}$ is approximately the same as that at $\mathrm{t}=180 \mathrm{~min}$, i.e., about $850 \mathrm{~W} / \mathrm{m}^{2}$, but the temperatures of the panels are different. The temperature of the panel at $\mathrm{t}=180 \mathrm{~min}$ is higher than that at $\mathrm{t}=0 \mathrm{~min}$, thus the power output is lower at $\mathrm{t}=180 \mathrm{~min}$. The results show that the power output decreases as the PV panel temperature increases.

Second, to decrease PV panel temperatures, this study applies a spray cooling system combined with UBHEs. In addition, the spray cooling system is intermittent operating, which can reduce power consumption of a pump and maintain the cooling capacity. Pump is switched on once the panel temperature reaches $45^{\circ} \mathrm{C}$ and is switched off once the PV panel is cooled to $35^{\circ} \mathrm{C}$. The experimental results and theoretical predictions are shown in Fig. 6. The experiment was executed continuously for 3 hours 5 minutes. Theoretical results were calculated from eq. (1), (19), (29), and eq. (30). Because the tank could not be completely insulated in the experiment, the experimental tank water temperature was higher than the theoretical ones. The water temperature increase from the initial temperature in the experiment was about $3.5^{\circ} \mathrm{C}$ and, theoretically, was $2.4{ }^{\circ} \mathrm{C}$. Moreover, since soil cannot cool the cooling water completely in a short time, the increment of experimental cooling water temperature 


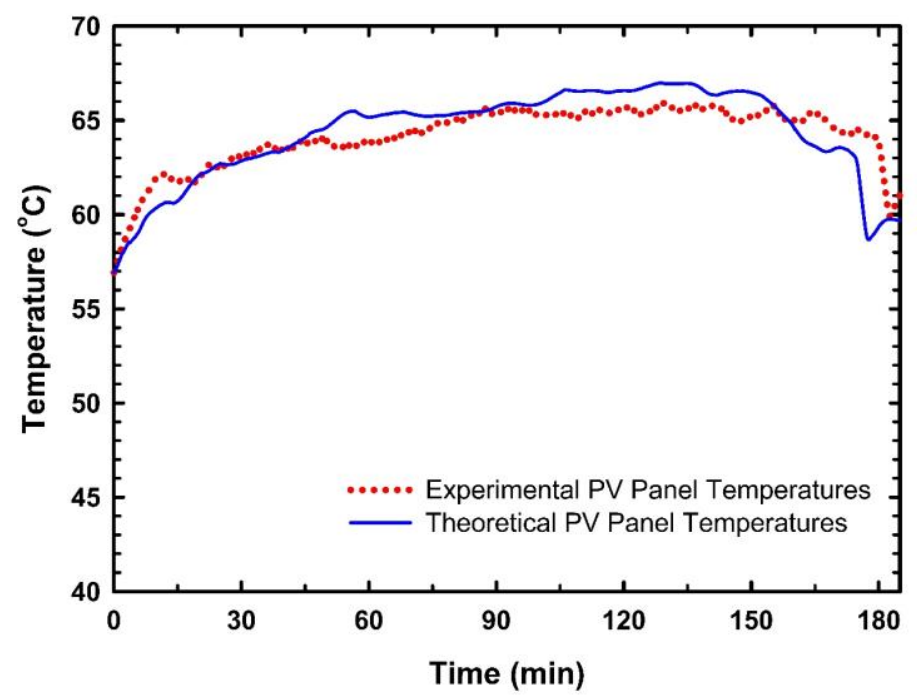

Fig. 4: Relationship between experimental and theoretical PV panel temperatures.

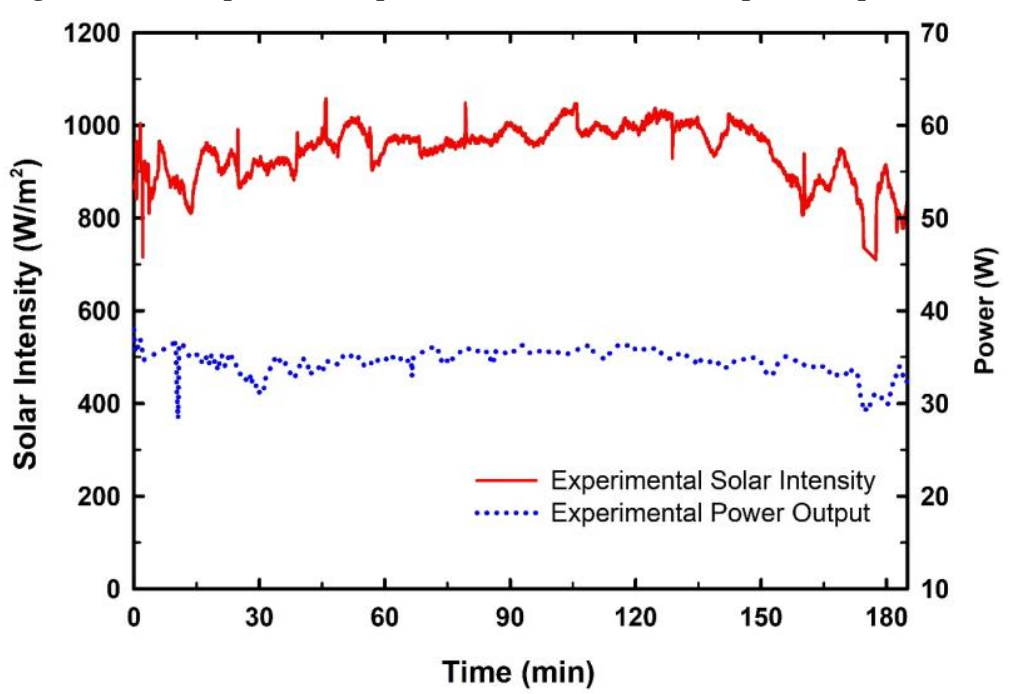

Fig. 5: Relationship between solar intensity and power output.

was higher than the theoretical temperature $\left(1.9^{\circ} \mathrm{C}\right)$. Thus, for the theoretical analysis, more cooling cycles than experimental results are observed because of the lower cooling water temperatures and the better cooling capacity. The number times of cooling cycles for theoretical predictions are 52, while the experimental results are 50. Fig. 7 shows the relationship between solar intensity and power output. The average solar intensity and the average power output are $777.1 \mathrm{~W} / \mathrm{m}^{2}$ and $30.7 \mathrm{~W}$, respectively. The energy conversion efficiency of the PV panel is about 7.5\%. However, the power consumption of a pump must be considered, so the actual energy conversion efficiency of the PV panel is $7.1 \%$. Fig. 7 shows the relationship between solar intensity and power output for the PV panel with the spray cooling system combined with UBHEs. Predictably, the power output is propotional to the solar intensity. At $\mathrm{t}=170 \mathrm{~min}$, because the solar intensity is lower, the output of the PV panel is also lower. The cooling water temperature increased during the working period; the temperature increased from 27 to $29{ }^{\circ} \mathrm{C}$ because of the increase in the groundwater temperature. The final temperature difference between the outlet and the inlet of the borehole was about $7^{\circ} \mathrm{C}$, and this result displayed that the UBHE had enough cooling capacity until the end of the experiment.

Based on above experimental results and theoretical analyses, the spray cooling system combined with a UBHE can improve the energy conversion efficiency of the PV panel. To analyze further economic feasibility, the theoretical model is utilized to calculated the power output under different solar intensity. The solar intensity adopted in the theoretical model is 800,900 , and $1,000 \mathrm{~W} / \mathrm{m}^{2}$, respectively. Moreover, this analysis fixes the ambient temperature at $32^{\circ} \mathrm{C}$ and the initial $\mathrm{PV}$ panel temperature at $45^{\circ} \mathrm{C}$. The results presented in Tab. 2 show that solar intensities are 800,900 , and $1,000 \mathrm{~W} / \mathrm{m}^{2}$, and the PV panels without any cooling systems have efficiencies of $8.72 \%, 8.41 \%$, and $8.31 \%$ respectively. With the increase of solar intensity and the increase of the 


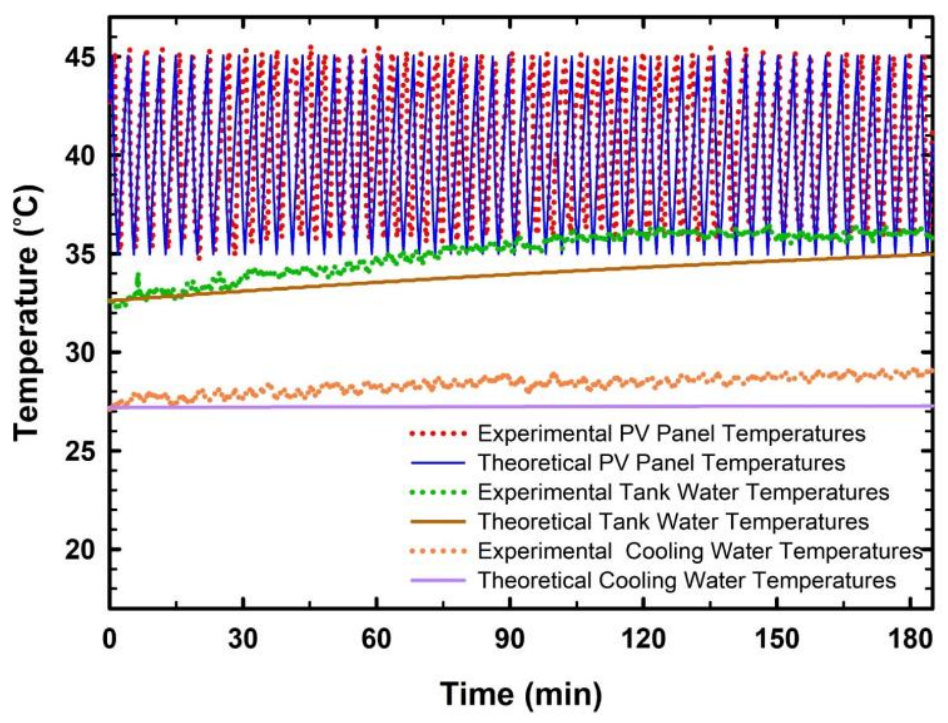

Fig. 6: Relationship between the PV panel temperatures, tank water temperatures and the cooling water temperatures in the experimental results and theoretical predictions.

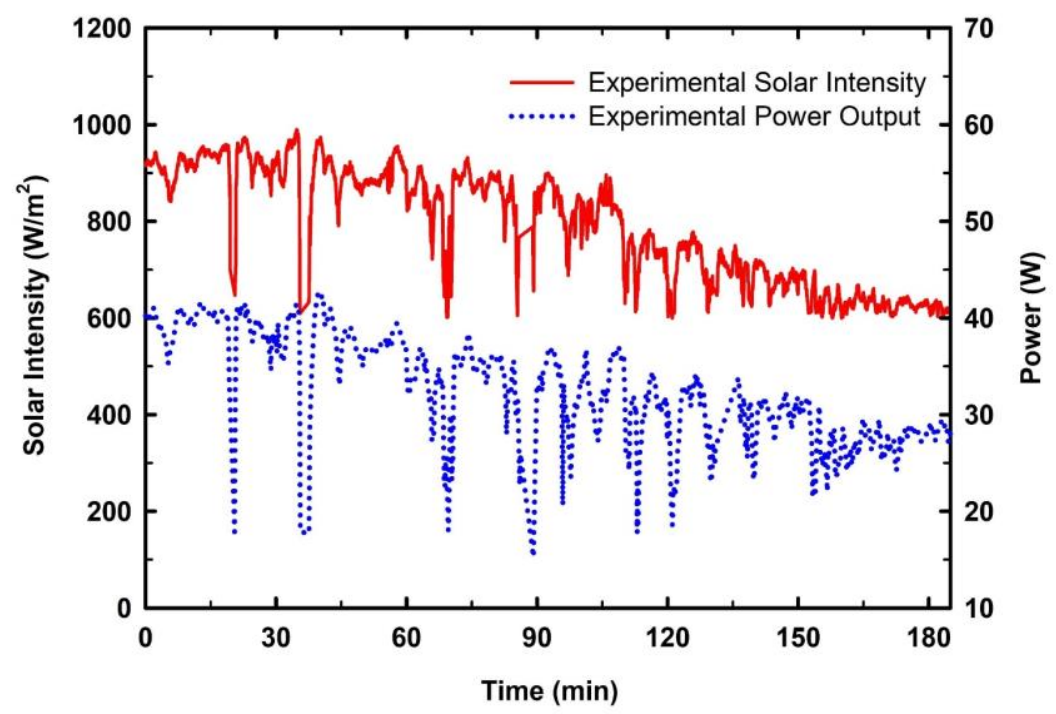

Fig. 7: Relationship between solar intensity and power output for the PV panel with the spray cooling system combined with UBHEs.

panel temperature, the efficiency declines. However, after this PV panel system utilized the UBHE system to cool its cooling water, the efficiency could be improved to $9.17 \%, 13.08 \%$, and $14.32 \%$, respectively. Those results indicate that the panel temperature or the solar intensity is higher, and the benefits of the UBHE system more obvious.

According to the calculated results in Tab. 2, because only a $60 \mathrm{~W}$ PV panel is used in this study, the increment of output power is slight. However, for a large-scale solar farm or plant factory utilizing solar electricity, the cooling system could effectively improve the efficiency of the PV panels. This study executes a further analysis by applying a theoretical model developed for the cooling system. Take a plant factory powered by 10 PV panels, for example; the UBHE cooling system can use the existing irrigation wells, so only investment in pumps and pipes is considered. Furthermore, the requirement of the cooling system applied in this example is an $85 \mathrm{~W}$ diaphragm pump (the head is $35 \mathrm{~m}$, and flow rate is 6LPM), and thus, an appropriately sized well is sufficient for the cooling demand, and its equipment costs can be recovered in 8.7 years in a sunny area (with an average solar intensity of $1,000 \mathrm{~W} / \mathrm{m}^{2}$ ). The economic analysis is presented in Tab. 3. This results shows that the spray cooling system combined with a UBHE has the economic feasibility and can be suitable for a large-scale solar farm or plant factory. 
Tab. 2: Theoretical power output for a fixed ambient temperature of $32^{\circ} \mathrm{C}$, with an initial panel temperature of $45^{\circ} \mathrm{C}$.

\begin{tabular}{|c|c|c|c|c|c|c|}
\hline $\begin{array}{c}\text { Solar } \\
\text { intensity } \\
\left(\mathrm{W} / \mathrm{m}^{2}\right)\end{array}$ & $\begin{array}{l}\text { Cooling } \\
\text { system }\end{array}$ & $\begin{array}{c}\text { Pump working } \\
\text { time (s) }\end{array}$ & $\begin{array}{l}\text { Average power } \\
\text { output (W) }\end{array}$ & $\begin{array}{c}\text { Average net power } \\
\text { output (W) }\end{array}$ & $\begin{array}{c}\text { Conversion } \\
\text { efficiency }(\%)\end{array}$ & $\begin{array}{c}\text { Increment } \\
(\%)\end{array}$ \\
\hline 800 & Yes & 3,750 & 44.0 & 42.4 & 9.52 & 9.17 \\
\hline \multirow{2}{*}{900} & No & - & 42.1 & 42.1 & 8.41 & - \\
\hline & Yes & 4,390 & 49.6 & 47.6 & 9.51 & 13.08 \\
\hline 1,000 & Yes & 5,110 & 55.2 & 52.9 & 9.50 & 14.32 \\
\hline
\end{tabular}

Tab. 3: Economic analysis for a plant factory powered by 10 PV panels; 1 USD = 30 NTD.

\begin{tabular}{|c|c|c|c|c|c|}
\hline Construction & Cost (NTD) & $\begin{array}{l}\text { Price per kWh } \\
(\mathrm{NTD} / \mathrm{kWh})\end{array}$ & $\begin{array}{l}\text { Solar intensity } \\
\left(\mathrm{W} / \mathrm{m}^{2}\right)\end{array}$ & $\begin{array}{c}\text { Net electricity generation } \\
(\mathrm{kWh} / \text { year })\end{array}$ & $\begin{array}{c}\text { Payback } \\
\text { period (year) }\end{array}$ \\
\hline Pump & 1,150 & & 800 & 28.32 & 18.5 \\
\hline Pipes and other & 2,000 & 6 & 900 & 49.30 & 10.7 \\
\hline Total & 3,150 & & 1,000 & 60.44 & 8.7 \\
\hline
\end{tabular}

\section{Conclusions}

This study used a cooling system integrated with a U-shape borehole heat exchanger (UBHE) to cool the PV panel. Moreover, a theoretical model for the cooling system was built. In addition, the theoretical model was utilized to evaluate the further economic feasibility. The results of the present research give the following conclusions:

(1) The spray cooling system combined with a UBHE can improve the energy conversion efficiency of the PV panel. The panel temperature or the solar intensity is higher, and the benefits of the UBHE cooling system more obvious.

(2) A theoretical model for estimation of the PV panel temperature and conversion efficiency under was developed, and the theoretical and experimental results had the same trend. This mathematical model is helpful for preliminary design and analysis of the PV panel systems with the UBHE.

(3) For a large-scale solar farm or plant factory utilizing solar electricity, the cooling system can effectively benefit the efficiency of the PV panels. Take a plant factory powered by 10 panels, for example, with a solar intensity of $1,000 \mathrm{~W} / \mathrm{m}^{2}$; this cooling system can improve the efficiency of the panels about $14.3 \%$, and its equipment costs can be recovered in 8.7 years. This results shows that the spray cooling system combined with a UBHE has the economic feasibility

\section{Reference}

Ball, D.A., Fischer, R.D., Hodgett, D.L., 1983. Design methods for ground-source heat pumps. ASHRAE Transactions. 89, 416-440.

Chen, P.J., Tsai, H.L., 2011. The Design and Experimental Verification of a Complete Photovoltaic Module Model Considering its Thermodynamics. Journal of Science and Engineering Technology. 7(2), 37-45.

DeWitt, I., Lavine, B., 2007. Fundamentals of Heat and mass transfer, Sixth ed. Wiley, New York.

Holman, J.P., 1997. Heat Transfer, Eighth ed. McGraw Hill, New York.

Ingersoll, L.R, Ingersoll, A.C, Adler, F.T., Plass, H.J., 1951. Theory of Earth Heat Exchangers for the Heat Pump. ASHVE Transactions. p.p. 167-188.

Jones, A.D., Underwood, C.P., 2001. A Thermal Model for Photovoltaic Systems. Solar Energy. 70, 349-359.

Liu, B.Y.H., Jordan, R.C., 1963. The Long-term Average Performance of Flat-plate Solar Energy Collerctors. Solar Energy. 7(2), 53-74.

Luo, J., Luo, Z., Xie, J., Xia, D., Huang, W., Shao, H., Rohn, J., 2018. Investigation of shallow geothermal potentials for different types of ground source heat pump systems (GSHP) of Wuhan city in China. Renewable Energy. 118, 230-244. 
Marion, B., Kroposki, B., Emery, K., Cueto, J., Myers, D., Osterwaid, C., 1999. Validation of a Photovoltaic Module Energy Ratings Procedure at NREL. Validation Results and Conclusions, National Renewable Energy Laboratory, Colorado. 43-47.

Mihalakakou, G., Santamouris, M., Lewis, J.O., Asimakopoulos, D.N., 1997. On the application of the energy balance equation to predict ground temperature profiles. Solar Energy. 60, 181-190.

Nižetić, S., Giama, E., Papadopoulos, A.M., 2018. Comprehensive analysis and general economic-environmental evaluation of cooling techniques for photovoltaic panels, Prat II: Active cooling techniques. Energy Conversion and Management 155, 301-323.

Oliphant, K., Webb, B.W., McQuay, M.Q., 1998. An experimental comparison of liquid jet array and spray impingement cooling in the non-boiling regime. Experimental Thermal and Fluid Science 18(1), 1-10.

Pu, L., Qi, D., Li, K., Tan, H., Li, Y., 2015. Simulation study on the thermal performance of vertical U-tube heat exchangers for ground source heat pump system. Applied Thermal Engineering. 79, 202-213.

Schott, T., 1985. Operational Temperature of PV Modules. 6 ${ }^{\text {th }}$ PV Solar Energy Conference. 392-396.

Soni, K.S., Mukesh, P., Bartaria, V.N., 2015. Ground coupled heat exchangers: A review and applications. Renewable and Sustainable Energy Reviews. 47, 83-92.

Stultz, J.W., Wen, L.C., 1977. Thermal Performance Testing and Analysis of Photovoltaic Module in Natural Sunlight. Jet Propulsion Laboratory, Pasadena, 5101-5131. 


\title{
BIM - A driver for Energy Transition and BIPV Adoption Van Khai Nguyen, Philippe Alamy ${ }^{1}$ \\ ${ }^{1}$ CADCAMation SA, Onex (Switzerland)
}

\begin{abstract}
In the framework of an increasingly demanding legislation related to energy performance in buildings, the integration of photovoltaic systems in the building skin offers many possibilities and has a key role to play towards bioclimatic buildings. Therefore, practically, the most important technological challenges toward energy-efficient buildings are twofold: (i)bioclimatic design, considering eco-friendly sources as well as renewable and durable material, and (ii)Building Information Modelling methodology for the whole architecture, engineering and construction (AEC) process to support the simulation, visualization and management of a building's performance throughout its lifecycle. This paper addresses the ambition put on merging high performance computing, scientific models and methodologies for energy modeling, user friendly software tools and web based services, together with collaborative processes supporting sustainable design towards positive energy buildings, active skins and the emerging Building Integrated Photo Voltaic materials.

The EU-funded PVSITES project focuses on these needs with the development of BIM-based software for the simulation of BIPV products and forecasting their impact on building energy performance. This project aims at contributing to the uptake of both BIPV implementation and its integration within a holistic BIM process.
\end{abstract}

Keywords: Building-integrated photovoltaics, BIPV, software, design, calculation, BIM

\section{Introduction}

Reducing energy consumption and carbon footprint of buildings has become a worldwide crucial issue in the construction sector, leading to increase energy performance requirements and to incorporate innovative green building concepts in architectural design towards Nearly Zero Energy Building (NZEB) [1]. To achieve this, bioclimatic design must be investigated to evaluate the potential of natural resources at the very early stage of the AEC process (Architecture/Engineering/Construction) and renewable energies incorporated as valuable assets within the building programmes.

Recently, Building Integrated Photovoltaics (BIPV) is promised to a bright future for commercial and residential buildings because of the limited Building-Added PV (BAPV) roofing possibilities. Integration into the building skins (e.g. facades) of these novel products and calculation of their performance against electrical, thermal and daylighting objectives are the major challenges for architects and engineers. Therefore, the assessment of solar energy potential at the conceptual stage of the BIM-based AEC process coupled with a dynamic simulation and planning program for the design and optimization of photovoltaic systems would undoubtedly support and facilitate BIPV (and also BAPV) deployment for both new and renovation buildings projects.

The simulation and planning software are relevant in designing green buildings because they provide projected qualitative and quantitative results of the building's performance. They can be used either to help making decisions (comparison of the advantages versus impacts of several technical scenarios), or to justify the choices based on relevant key indicators, at the end of the design process.

There is however a condition to optimize the green building design workflow: the extended AEC team must "begin with the end in mind" by collaborating from the very early conceptual stage towards the validation of the final product through successive design analysis and verification. Indeed, exchange between design team members (architects, engineers, energy consultants) might be complex and time consuming. BIM is a sum of processes and technologies that enables an integrated design and was consequently developed to facilitate exchange amongst the 
design team. The BIM model encompasses building geometry, spatial relationships, geographic information, and quantities and properties of building components.

In the context of energy-efficient and NZEB buildings, the EU-funded PVSITES project develops new generation digital solutions to be proposed within a Software as a Service (SaaS) strategy: linked to the main design and BIM software, it aims at being used by most of the designers and bridge the gap with manufacturers. Using interoperable formats and web based digital twins of BIPV products, securing and fostering data exchange within collaborative workflows, the solution intents to support NZEB building designers, from early decisional stages to pre-design,

\section{A building information management (BIM) framework for sustainability design}

\subsection{Holistic BIM: object-oriented modelling with the end in mind}

Historically, CAD software represented 2D geometry based on wireframe graphical elements. More complex information, such as the relationships between graphical elements, could not be added. The next generation of CAD, initially focused on 3D modeling for creating complex geometry in order to support their visualization, and thus enabling realistic rendering and light effects. More recently, object-oriented CAD systems replaced graphical symbols with building primitives or objects, capable of representing the characteristics of physical objects like mechanical components or building elements. These building elements can be parametrically calculated and displayed in multiple views, and non-graphic attributes can be assigned to them, thus enabling such elements or objects to become smart (parametric, contextual). This combination of parametric 3D geometry with assigned rules and dimensions represents therefore the "single source of truth" and allows the representation of complex geometric and functional relationships between building elements. BIM was initially conceived as the latest generation of object-oriented CAD systems, in which all of the intelligent building objects that constitute the design of a structure can co-exist in a single virtual structure that captures everything known about the structure.

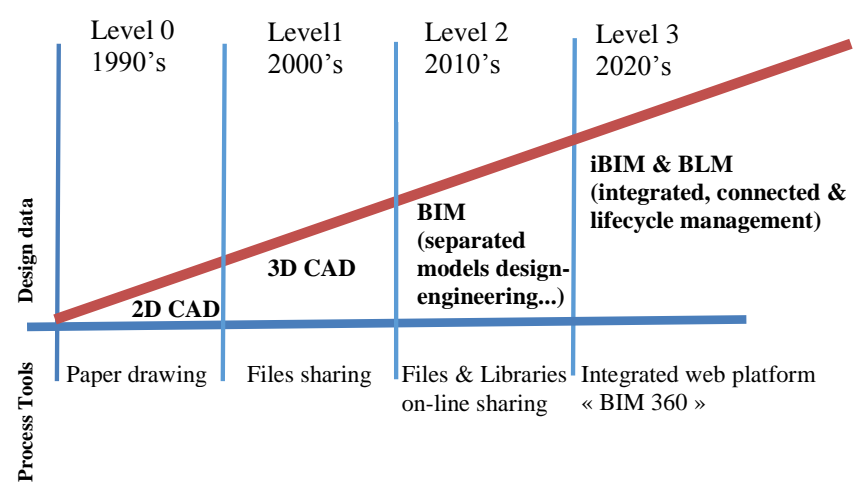

Fig. 1: BIM evolution

BIM success is all about a holistic approach towards understanding the whole AEC building process and streamlining the data- and workflow through the entire project lifespan in order to achieve efficient and quality projects that match with energy transition targets. Using BIM will allow to integrate and achieve holistic objectives about energy and environmental issues in building projects: BIM can drive towards life cycle operation information and data maintainability via communicating the future-proofing strategy from a whole life perspective and ensuring knowledge transfer across all stages. BIM models can be further used to support both Building Operations and Facilities Management through BIM workflows extension and Digital Twins on the web, anticipating platforms of O\&M services and information exchange regarding all aspects of building operational performance.

\subsection{Integrated and connected BIM towards digital twin for building performance simulations}

The major challenge of this forward-looking digital planning method is to provide comprehensive building performance analyses at the early stage of the building design process while implementing different computational technologies that exist across multiple domains into the conceptual BIM model. For instance, to perform solar building design, architects need to consider different technologies (e.g., building-integrated photovoltaic, solar 
thermal, and daylighting) into a combination of software and effectively simulate the impacts of the diverse natural resources to provide building performance analysis during the design phase. However, traditionally, architects and engineers have found it difficult to effectively perform building performance analysis mainly due to the following factors:

- Professional processes still based on 2D CAD drawings, rarely 3D/BIM driven;

- Current analysis software requires specific data that has to be derived from the CAD model or a discrete input model or must be created to fit each kind of simulation and calculation;

- Building design and technical studies are conducted separately, rarely in collaborative holistic approach;

- BIM adoption is low, due to the cost of equipment, software and lack of resources and time for training;

Seamless integration among the tools and between design models and building energy analysis models will be proposed based on an advanced BIM-based platform. This integrated approach towards sustainable design is expected to efficiently provide energy performance analyses based upon multiple simulations at the early design phase and readjusted throughout the whole lifespan of the building based on real-world captured data.

Integrated BIM with a consistent and structured data management is the key to generate such a digital twin model whose dynamic performance can be studied by building simulation tools for a variety of different boundary conditions (figure 2).

However, such an integrated building performance analysis would require a global and advanced calculation method based on multi-domain simulations. This method will enable the completion of a building performance analysis with a unified BIM model (figure 3) which can provide detailed physical and functional characteristics of buildings. In addition, it can be integrated with various environmental modeling and simulation approaches in order to achieve a holistic design and assessment of low carbon and energy-efficient buildings.

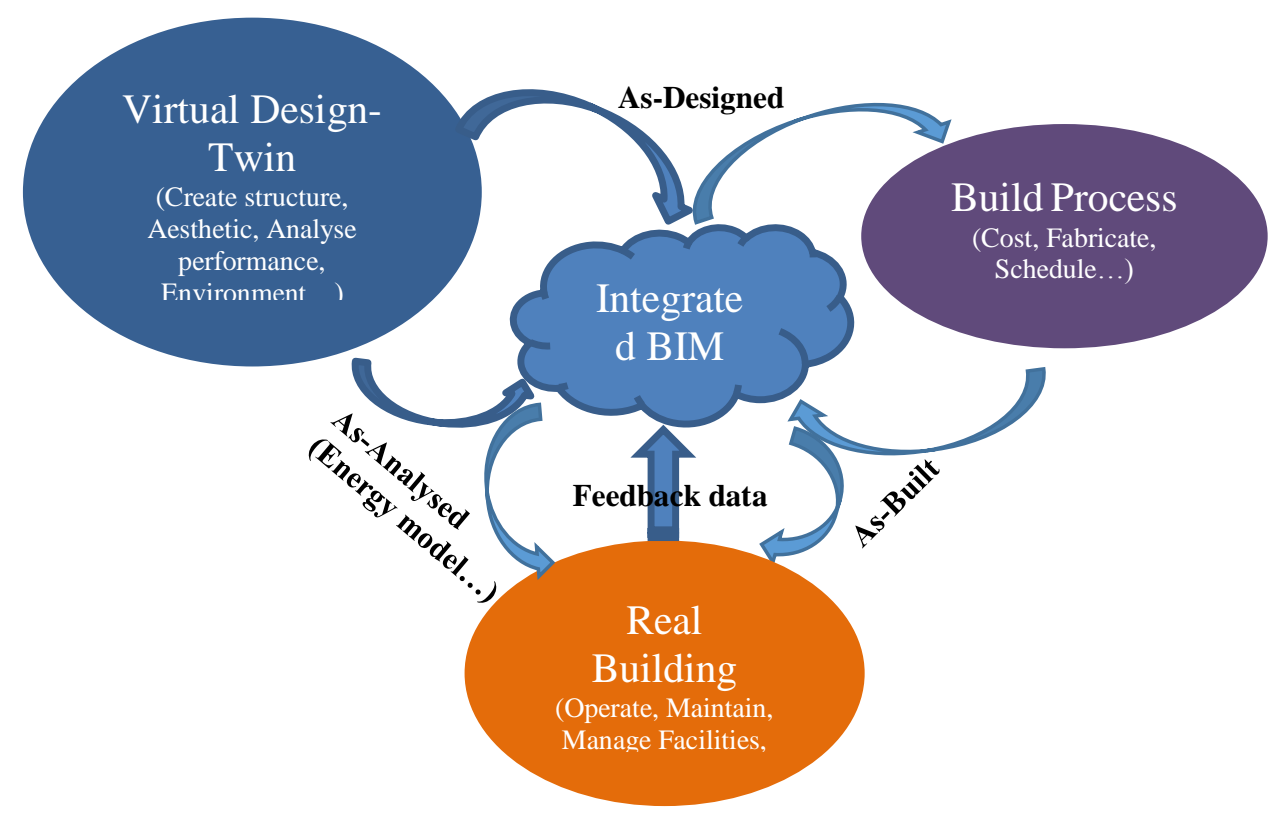

Figure 2: Integrated and connected BIM encompassing the three phases to allow enriched data and greater knowledge 
In the framework of the PVSITES project, a ray tracing algorithm has been developed to model solar radiation interaction with complex urban environments and its effects, including the total irradiance at pixel level in the 3D scene then the hourly to yearly photovoltaic production at module level. Lighting control integrated with daylighting is recognized as an important and useful strategy in terms of energy-efficient building design. It is believed that proper daylighting schemes can help reduce the energy demand and contribute to achieving environmentally sustainable building developments. Therefore, passive solar heating and lighting are important issues to be taken into consideration towards the reduction of energy consumption in new buildings and the design solar PV panels. This can be achieved at the very beginning of the conceptual design by advanced simulation methods and techniques allowing appropriate building design (bioclimatic architecture) and energy efficient systems and technologies, such as solar systems. BIM-based simulation tools allow for input of a single BIM model data to create energy models, this process can seamlessly insure the data workflow from design to analysis thus eliminating redundant operations such as re-entering the building's geometric information from the design model.

\section{BIM-based methodology for BIPV}

This section presents the BIPV simulation features available in PVSITES.
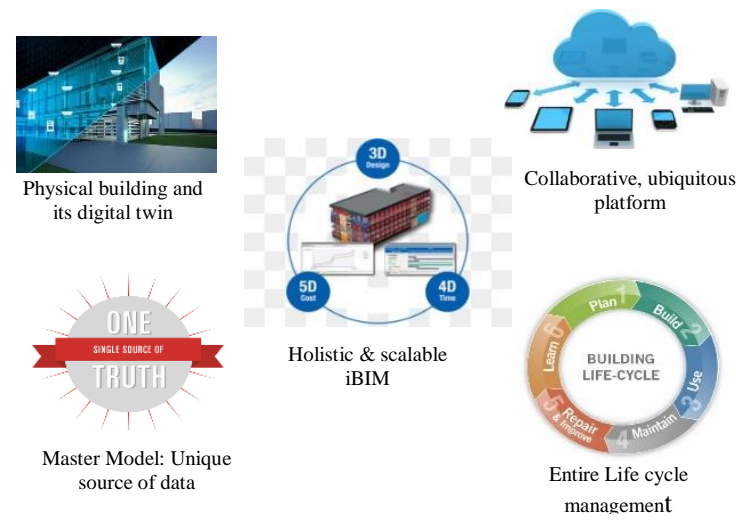

Figure 3: iBIM main features

The ambition is to provide the building project teams - and architects at first level - with a fast, reliable and easy to use digital solution, BIM-ready and connected to the master project virtual workspace (e.g. BIM - CAD solution).

\subsection{Global workflow}

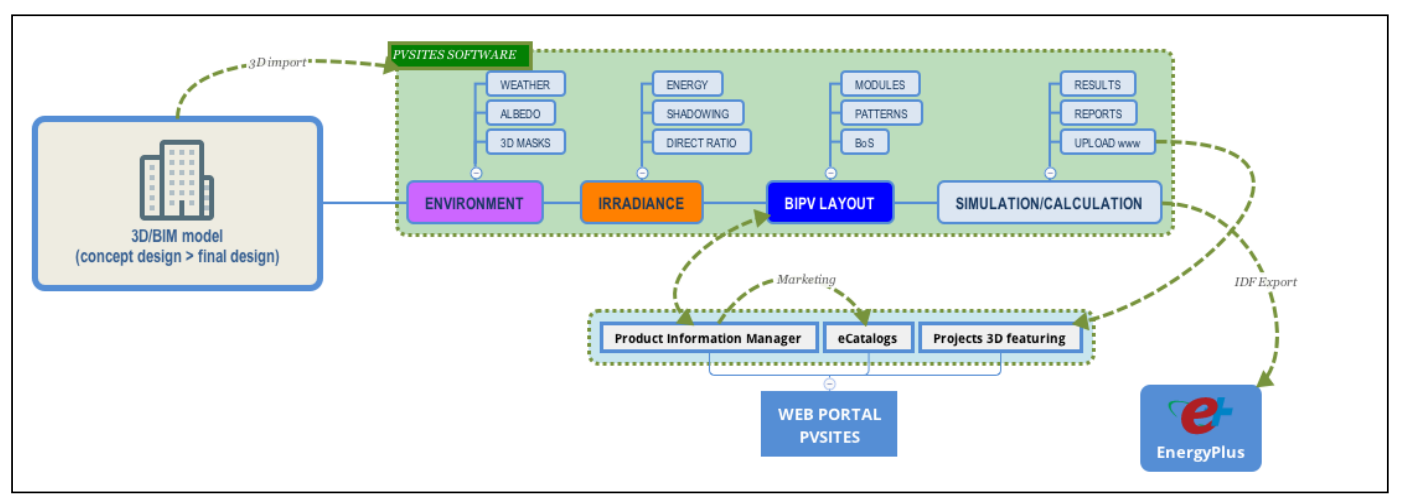

Figure 4: Global workflow for BIPV simulation

The PVSITES BIM solution, under development, is based on the BIMsolar® software [2], as a combination of two innovations:

- A standalone "BIMsolar ${ }^{\circledR}$ " software for high performance computing in solar simulation and calculation over imported 3D models, BIM-ready and user friendly;

- A connected web portal aimed at exchanging data (products features) and projects with standalone software, enabling manufacturers to disseminate innovations towards designers from element to building 
level, in a "web to 3D" design workflow. In return, designers can showcase their BIPV projects on the web portal.

The development followed AGILE methodologies and was as such continuously inspired by "user stories" from BIPV experts, architects, manufacturers and installers.

\section{STEP \#1: Importing a BIM model into a solar environment}

Importing a simple 3D model or a BIM model to simulate its solar and BIPV performance is made through a "classic" import (in other words, the "File>Open" function). Native BIM and software formats can be imported. A specific plugin is being developed for the Autodesk® REVIT® BIM solution.

The PVSITES algorithms then read the 3D geometry in its native format and reconstruct a model into the PVSITES workspace. The user gets a 3D digital twin model able to perform solar simulation and BIPV systems calculation.
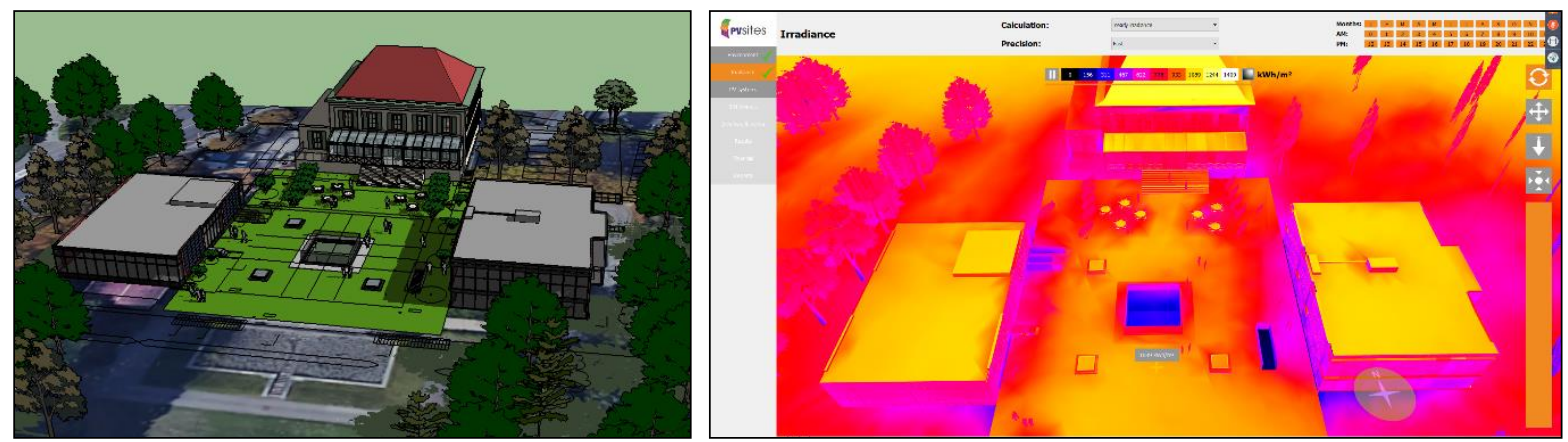

Figure 5: Twin models between architectural 3D model and PVSITES @ BEAR-iD Architecture

Once the import is done, the main virtual workspace becomes the PVSITES twin model. No update can be made if geometric changes occur; in this case the user has to import the updated model as a new project.

During the import process the geometry of the model is detected and the set of polygon mesh that forms the architectural envelope (walls, floors, roofs, windows), and the spatial relations between them, are analysed. This enables to import a model from almost any CAD and BIM format. To perform the import, some information such as textures and native BIM families of objects in Revit is recognized.

The surrounding environment (buildings, vegetation, even terrain modelling) has a considerable impact on a building solar performance because of shadings/masks effects on irradiance. It is thus essential to import it properly within the architectural project, albeit with the lowest possible level of details to prevent supernumerary mesh generation, in order not to exceed computer capacity.

The PVSITES solution is compatible with the leading 3D and BIM software, as shown in Table 1. Thus it can be used for almost any project.

Tab. 1: CAD and BIM compatibility with PVSITES

\begin{tabular}{|c|c|}
\hline \multicolumn{2}{|c|}{ Supported formats for 3D import } \\
\hline Open BIM (ISO) & .ifc \\
\hline GreenBuilding XML & .xml \\
\hline EnergyPlusTM format & .idf \\
\hline Trimble® SketchUp® & .skp \\
\hline AutoDesk® REVIT ${ }^{\circledR}$ & plugin \\
\hline
\end{tabular}

\section{STEP \#2: Environmental conditions}

Once a 3D model is imported into PVSITES, solar conditions must be set up for the whole project (building and environment) as they are crucial inputs for the BIPV performance. Parameters that can be set are:

- Geographic location and weather data import: a Google Maps popup window opens to select a weather 
data station; alternatively direct import of a weather file is possible (supported files formats: .epw and .tmy2).

- Albedo (e.g. irradiance reflectivity) for the surfaces within the 3D virtual workspace: mouse selection allows to set values for ground, walls, roofs and surroundings. Realistic values are to be chosen by the user; the contextual assistant proposes typical values from the literature.

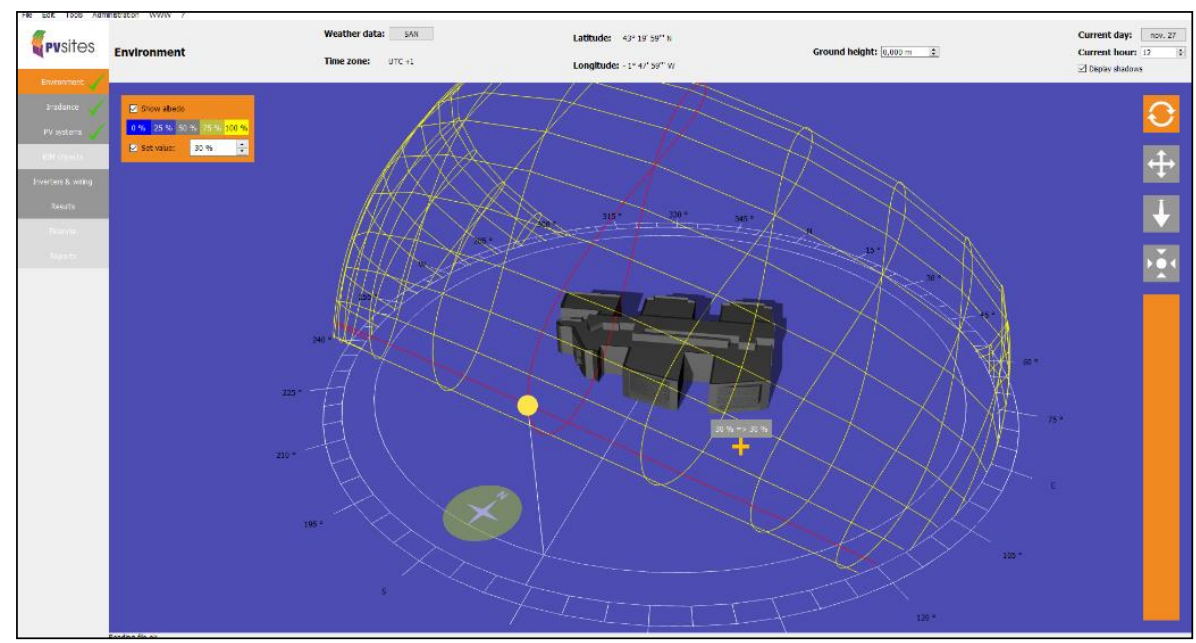

Figure 6: geo-location, weather data and albedo settings

The weather files (minute to hourly step values) feed the irradiance simulation algorithms with direct and diffuse irradiance values: Diffuse Horizontal Irradiance (DHI) and Direct Normal Irradiance (DNI). Weather data also provide dry bulb temperature used for module temperature calculation.

\section{STEP \#3: Irradiance simulation}

Tilted surfaces, such as BIPV glass walls and atriums, require high performance computing and accurate models to discretize the incoming solar energy at module or even cell level.

Irradiance value for each pixel of the 3D scene is calculated using EnerBIM's raytracing simulation core, also used in other software [3], at each step of the defined time range (based on the time resolution of the weather data).

Monte Carlo ray tracing is used to compute accurately the complex phenomenon of irradiance, taking into account direct and diffuse energy, as well as multiple reflections on the environment $[5,6]$.

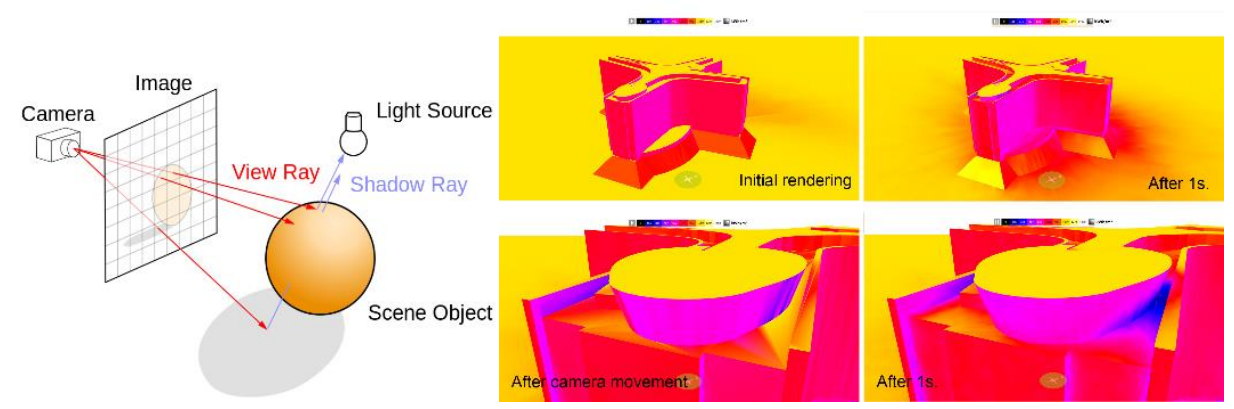

Figure 7: Raytracing principle - Irradiance rendering (sources: @Wikipedia - OENERBIM)

Irradiance display uses a view-dependant progressive refinement approach: irradiance is computed at key points on the image and stored in the 3D model. Zooming or changing point of view will re-use some of the key points already computed and will trigger the calculation of new points.

This results in a very fluid rendering of irradiance. After a couple of camera movements around the scene, delta calculations are few enough so that the user can navigate real time in his irradiance lit scene.

Users can alternatively select the "balance" and "accurate" calculation modes to get higher resolution in irradiance simulation, at the cost of a longer computation time. 
Indicators are derived from the irradiance simulation:

- The direct irradiance ratio indicates the proportion of Direct Irradiance received in the plane of each pixel on the 3D scene (pixel is the smallest unit to display in this "compute for is seen" strategy).

- The shadowing ratio indicates the proportion of total irradiance (direct, diffuse and reflected) received on each pixel of the scene.

\section{STEP \#4: BIPV layouts - Balance of System}

PVSITES BIPV products are diverse and different in complexity. To meet architectural integration requirements, as well as electrical, optical and thermal performance, a BIPV Product Information Manager (PIM) has been elaborated. The PIM aims at configuring virtual BIM objects with:

- Geometrical data: cell configurator, module configurator, pattern of cells configurator, module spacing, strings arrangement and inverter localization to generate 3D pathways for strings into the 3D model.

- Electrical data: I, V, Power values, diodes, busses.

- Thermal data: Nominal Operating Cell Temperature (NOCT), power losses coefficients, thermal conductivity, thermal transmittance, thermal emissivity.

- Optical data: solar and visible transmittance, solar and visible reflectance, colour.

- Layout features: horizontal/vertical cells and modules arrangement, mounting and fixing devices, framing.

The PIM works online as a web service, bridging manufacturers and users' databases of products with the virtual workspace for contextual issues. Once generated, the virtual PVSITES BIM objects (e.g. parametric dynamic components integrated into the BIM tools [7]) are dragged and dropped into the PVSITES workspace and applied in $3 \mathrm{D}$ onto the building surfaces. Becoming true BIPV components, they provide their embedded technical characteristics data to the simulation and calculation models (geometrical, electrical, thermal, optical).

The user drives a "What if Analysis" to fix some values, step-by-step, experiencing provisional results. Decision support is provided form real time contextual indicators such as peak power $(\mathrm{kWp})$, BIPV surfaces, number of modules, shadowing effects, primary production or array yield $(\mathrm{kWh} / \mathrm{kWp})$.

Example: The spacing and vertical/horizontal organization for PV cells integrated in a glass wall must fit with the existing structure. The PVSITES simulation tool enables user to handle the objects then calculates the PV production considering transparency and the thermal impact on the overall energy balance of the building.

Once fixed, the PVSITES objects should be transformed into specific BIM objects for the main BIM workspace, e.g. the CAD solution; this feature is under development for AutoDesk ${ }^{\circledR}$ REVIT $^{\circledast}$ families of BIPV objects.

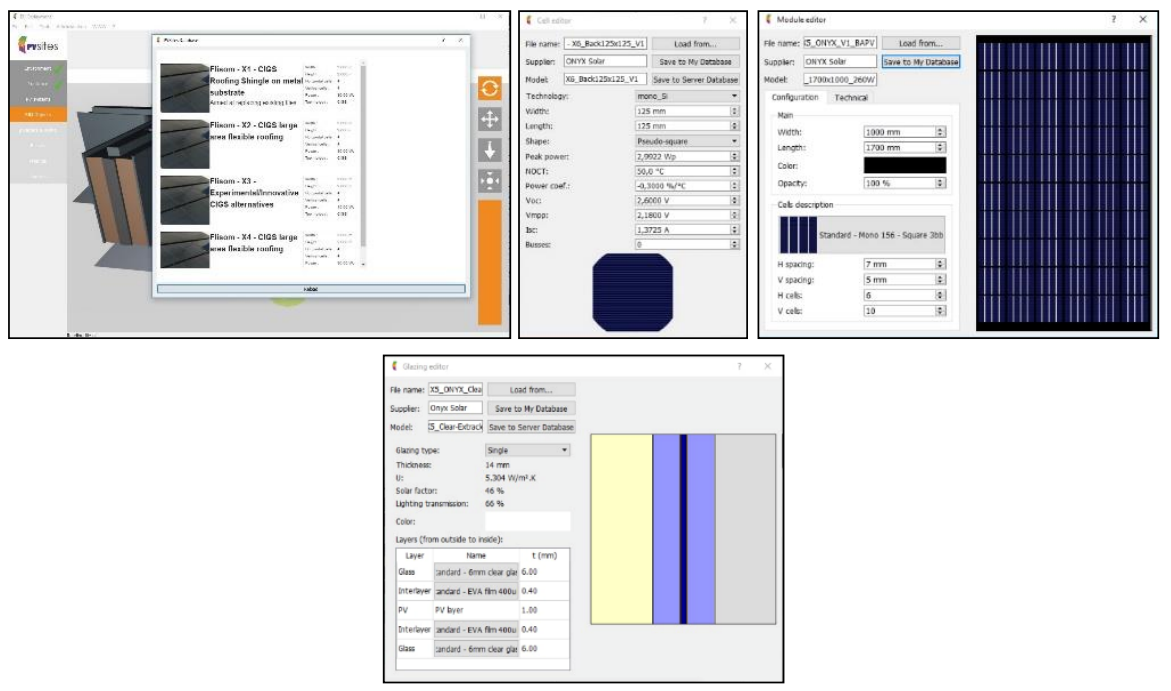

Figure 8: Product Information Manager; from cell editor to glazing editor 


\section{STEP \#5: BIPV calculation and outcomes}

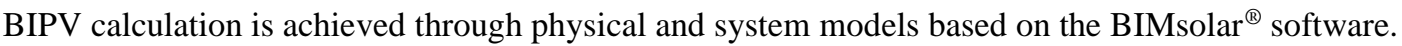

PVSITES objects feed those models with configured inputs from the PIM. The electrical, optical and thermal models have been developed for overall BIPV configurations and for tilted or curved (convex) surfaces:

- Electrical generation for various PV technologies: Crystalline-Si, CIGS, CdTe, Amorphous-Si, based on adapted models including diodes and resistors.

- Electrical selection for inverters, MPP trackers and strings regarding wiring, power and I/V specifications.

- Optical transmittance, reflectance for normal incidence reduced model,

- Thermal conductivity, thermal emissivity, resultant solar factor for cell and module level thermal calculation and impact on the energy balance at building level.

Energy balance at building level and impact on thermal comfort

EnergyPlus ${ }^{\mathrm{TM}}$ models have been chosen to provide general calculations on a building's energy balance.

The PVSITES software imports any idf file from the user and enriches it with thermal inputs related to BIPV systems: PV surfaces with their description and thermal data.

Thermal experts and energy consultants should be able to quantify the impact of BIPV adoption within their engineering process using coupled PVSITES and EnergyPlus ${ }^{\mathrm{TM}}$ software.

If no $i d f$ file is available, the PVSITES software will be able to generate it from its 3D geometry and BIPV features.

Outcomes

The following table summarizes the diverse outcomes provided through BIPV calculation:

Table 2: Outcomes from the PVSITES BIPV and EnergyPlus ${ }^{\mathrm{TM}}$ building energy calculations

\begin{tabular}{|c|c|c|c|c|}
\hline & Electrical & Thermal & Energetics & Daylighting \\
\hline \multirow{4}{*}{ Outcomes } & Production $\mathrm{kWh}$ & Module temp. & Irradiance (3D) & Light transmission \\
\hline & Array yield & U values & Heating needs & Daylight factor \\
\hline & Losses & Solar factor & Cooling needs & \\
\hline & Perform. Ratio & Givoni comfort & & \\
\hline
\end{tabular}

\section{Results}

Efforts have been made these recent years to unite BIM and energy in order to bridge the gap between energy modeling and architectural design. Main outcomes are already delivered to professionals:

- $\quad 3 \mathrm{D}$ modeling can generate energy modeling, for bioclimatic (passive) performance leading to positive energy modeling: geometry is interpreted via ray tracing technology; solar energy (irradiance) is distributed via probabilistic methodologies (Monte-Carlo [5, 6]).

- Models can be embedded into various forms of software; standalone software are able to exchange data with web-based platforms.

- Digital twins become operational, even for scientific purposes: products are virtualized, configurations are made versatile in contextual mode - element level adapted to building level and vice versa -; BIM objects are now replacing traditional tables of parameters.

BIPV designers using the PVSITES software can visualize and interact with the energy performance of their building. The software provides results through 3D graphical user interfaces, diagrams, and histograms. These results are updated in real-time after each data configuration modification or BIM object reconfiguration with the PIM (updated online and attached to the user). 
Amongst the relevant produced indicators, we can list:

- $\quad$ PV production figures and histograms (from array yield to Performance Ratio).

- The impact on energy needs of the building. Two indicators are affected by BIPV systems: Heating and Cooling demands.

- The impact on thermal occupant comfort (Givoni Comfort Zones [8]).

When more accurate results are needed, such as thermal calculation and comfort evaluation in each room, the Dynamic Thermal Simulation (EnergyPlus ${ }^{\mathrm{TM}}$ ) can be used. The EnergyPlus ${ }^{\mathrm{TM}}$ open source software is available for free download and "incorporated" in several design solutions.
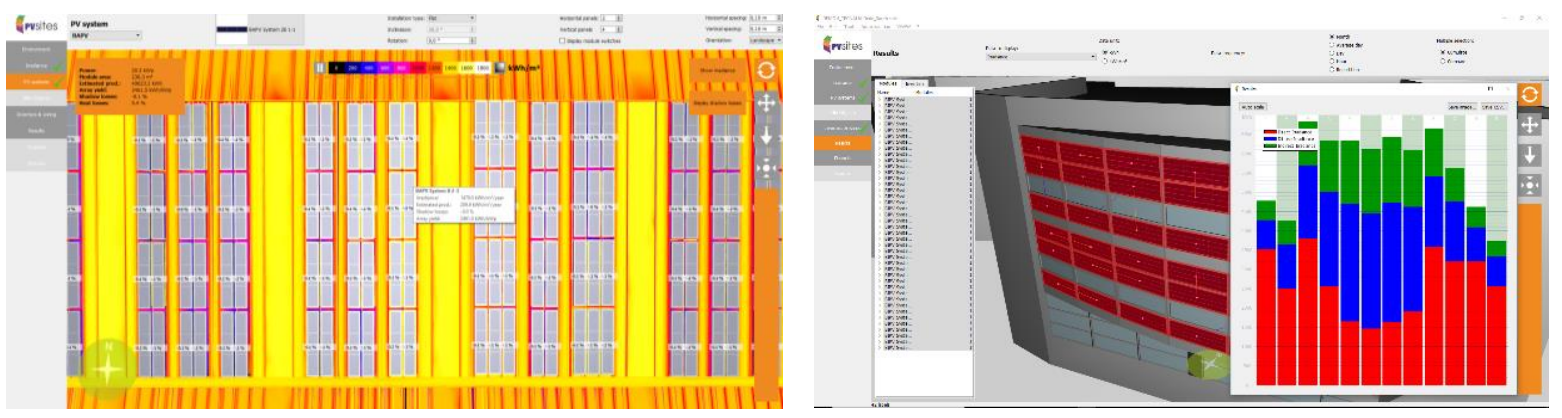

Figure 10: Results displayed to user in diverse graphical modes

\section{Conclusion}

BIPV performance can be simulated, calculated and visualized using the BIM-based software developed within the PVSITES project. Indeed, many decision-making criteria are available to help building designers optimize the electrical production (PV) but also the induced thermal comfort of the designed BIPV implementation, while minimizing the building energy needs, to achieve NZEB targets.

To optimize the design workflow, the PVSITES solution allows instant import of 3D models combined with intuitive and real-time results display. Strengths reside in that designers can easily evaluate the impact of any change of BIPV product configuration, or design option, in collaboration with manufacturers and end-users, as part of their normal workflow. Consequently, this solution helps minimizing the design risk. It allows to save time and money while optimizing bioclimatic characteristics and/or positive energy performance, for both new projects and the retrofit of the existing building stock.

The ability of this software to be used on existing buildings for refurbishment strategies with lower cost BIPV products offers strong opportunities, from evaluation to decision support, and considering energy savings coupled to improvements to thermal comfort, aesthetics and to the conjunction of performance and ecology.

\section{References}

[1] The Energy Performance of Buildings Directive (DIRECTIVE 2010/31/EU OF THE EUROPEAN PARLIAMENT AND OF THE COUNCIL of 19 May 2010 on the energy performance of buildings) requires all new buildings to be nearly zero-energy by the end of 2020. All new public buildings must be nearly zero-energy by 2018

[2] BIMsolar ${ }^{\circledR}$ : commercial version of the BIPV-Insight software solution developed by a European consortium (TECNALIA, ENERBIM, BEAR-iD, COMSA-TFM, i2M UNIVERSITY OF BORDEAUX) under EIT-InnoEnergy funding, 2014-2016

[3] Enhancing Bifacial PV modelling with Ray-tracing”, EDF 6th PV PMC Workshop, 25 of October 2016

[4] Kroese Dirk P., Brereton Tim, Taimre Thomas, Botev Zdravko I.. Why the Monte Carlo method is so important today. WIREs Comp Stat 2014, 6: 386-392. doi: 10.1002/wics.1314

[5] Monte Carlo Ray Tracing Siggraph 2003 Course 44 Tuesday, July 29, 2003

[6] [Bermes and al, 1999] S. Bermes, B. Lécussan, C. Coustet. MaRT: Lazy Evaluation for Parallel Ray tracing. High Performance Cluster Computing, Vol 2 Prentice Hall 1999 
[7] BIM for Building Owners and Developers: Making a Business Case for Using BIM - ㄷ K. Pramod Reddy, 2012

[8] GIVONI - Comfort, Climate Analysis and Building Design Guidelines; Baruch Givoni, 1991

https://www.slideshare.net/Be2campadmin/ibim-and-knowledge-management

\section{Acknowledgements}

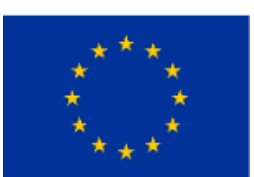

The work described in this publication has received funding from the European Union's Horizon 2020 research and innovation programme under grant agreement $\mathrm{N}^{\circ}$ 691768. Neither the European Commission nor any person acting on behalf of the Commission is responsible for the use that might be made of the presented information. The views expressed in this publication are the sole responsibility of the authors and do not necessarily reflect the views of the European Commission. 


\title{
A Comparison of Stratified Heat Storage with and without Modular PCM through Simulation
}

\author{
Valerie Pabst ${ }^{1}$, Prof. Dr.-Ing. Gerhard Mengedoht ${ }^{1}$ and Prof. Dr.-Ing. Peter Renze ${ }^{1}$ \\ 1 University of Applied Sciences Ulm, Ulm (Germany)
}

\begin{abstract}
In the scope of the current paper stratified heat storage tanks are analyzed by computational fluid dynamics (CFD) simulations and improvements regarding the capacity and flexibility of domestic storages are suggested. Therefore, a hybrid approach is investigated, where water is used both as the heat transfer fluid and storage medium and additionally a phase change material (PCM) is added to improve the storage capacity. The PCM is inserted into the tank as macro-encapsulated paraffin in a packed bed bulk. With the same boundary conditions, a comparison between the loading process of a simple stratified storage and a stratified latent heat storage is performed. Advantages are an enhanced capacity per volume with high loading power and an easy integration into state-of-the-art storage system. To model the phase change of the PCM the simulation is based on the volume of fluid (VOF) method. Further investigations will include long-term simulations as well as different PCM-zones in the packed bed bulk.
\end{abstract}

Keywords: Thermal Energy Storage, Simulation, Computational Fluid Dynamics, Stratified Storage, Latent Heat, Phase Change, Volume of Fluid (VOF)

\section{Introduction}

A further development of efficient technologies and a combination of energy systems is essential for renewable energies to scale up their share in the market. Their potential is by far not exploited yet. All those technologies already in use have one aspect in common: generation and consumption of energy are hardly simultaneously. Therefore, next to the improvement of smart, decentralized grids, investigation and development of energy storage plays a fundamental role for a successful energy revolution. Not just improving electrical energy storages is essential for a greater market share of renewable energies but especially to households a well-balanced thermal system plays a fundamental role. In these thermal systems, the storage tank is the heart of every application. Therefore, a stronger heart is an upgrade to the whole body of the thermal grid.

The current work has been done within the framework of InnoSüd, which is a research partnership between the University of Applied Sciences Biberach, Neu-Ulm and Ulm as well as the Ulm University. The goal of InnoSüd is the development of a regional dynamic innovation system. The research partnership is positioned as an active player in the public society that encourages a permanent exchange of ideas, knowledge and technology between companies and the academic world. It is a central driver of innovation in the region Donau-Iller.

\section{Thermal Energy Storage for Renewable Energies}

In the field of thermal energy storage (TES), there are generally three different types of applications. Most common, especially in domestic hot or cold water systems, is sensible heat storage (SHS) with water as storage material. Latent heat storage (LHS) includes all thermal energy stored through the change of state. The third process, thermo-chemical storage, is usually found in industrial applications. (Sarbu 2016) This paper shows a combination and comparison of TES with SHS and LHS. As future applications, especially renewable energies come to mind. With the right TES solar thermal energy for example can easily supply a whole household with hot water.

\subsection{Stratified Energy Storage}

Every domestic hot water system generally uses some form of TES, as they improve its thermal capacity and general conditions. They work as a buffer and backup of a system, but can also help optimize operating parameters of a thermal system such as providing base load capacity or cutting peak loads.

During charging, discharging and downtime energy or especially exergy, the usable amount of energy, can convert to anergy or transfer beyond the system boundaries. Different physical effects cause exergy or heat losses. Convection can occur within the storage tank; a temperature difference within the storage or to the boundary can lead to heat conduction or thermal blending and losses at the connection pipes show up negatively in energy balances. The goal is to avoid the irreversible entropy gain and heat losses. Exergy losses will not show up in an energy balance 
and are therefore hard to detect. Exact thermal blending, convection or vorticity at the connection pipes or other objects within the tank can hardly be determined through physical experiments. Numerical simulation of these experiments helps to find weaknesses in the system and improve them.

Stratification of water through temperature dependency of density minimizes exergy losses within the storage tank. There are many different methods of stratifying water in a tank but generally good thermal insulation, few installations in the tank and a small fluid momentum at charging and discharging lead to an improved stratification. The different methods of stratified sensible heat storage (SSHS) depend on the system parameters. They encounter diffusors that charge the system at one constant temperature, and swimming flexible tubes, lances charging from top or bottom or vertical pipes that can charge the system at a variable temperature. Fig. 1 shows the advantages of SSHS (on the left side) compared to SHS (on the right side) in the aspect of energy and exergy losses.

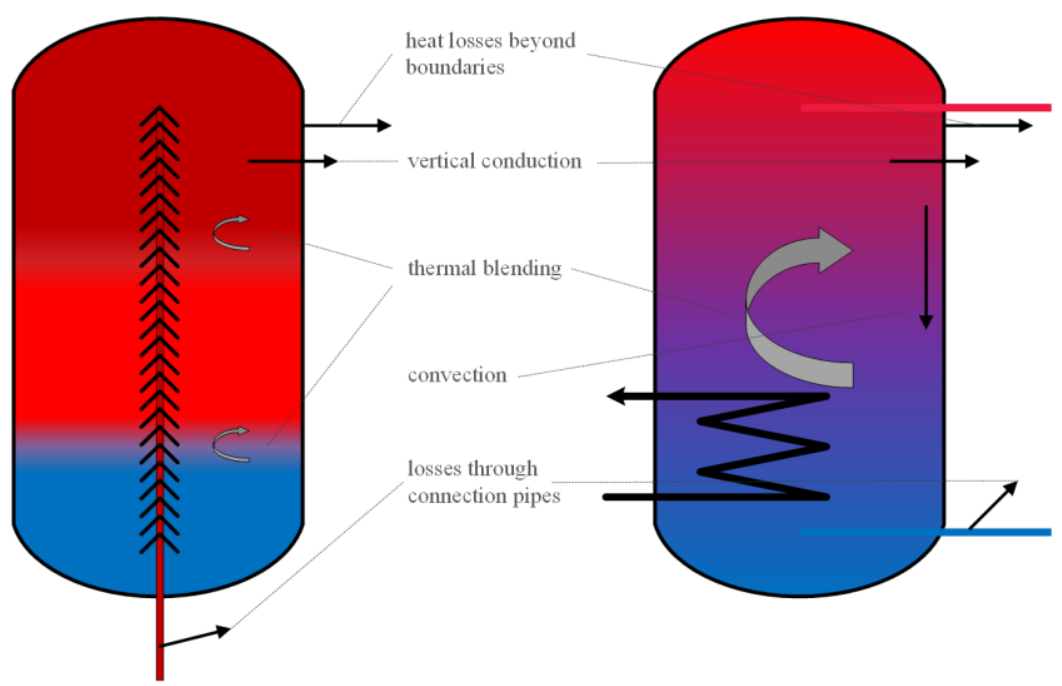

Fig. 1: Heat Losses of Stratified and Non-Stratified Heat Storage

For charging a system at one temperature, Findeisen et. al. have made various experiments towards radial diffusors in a three dimensional space with CFD. Based on these results a charging system of the storage tank with a small cone have been chosen for modelling the SSHS. (Findeisen et al. 2018a, 2018b)

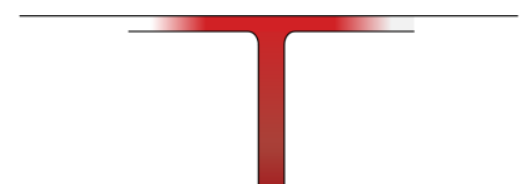

Fig. 2 Geometry Diffusor

As well as other sensible heat storages, the heat capacity of SSHS is given in respect of the amount of mass, material or volume. Therefore, the specific heat capacity, combined with the temperature difference and mass, provide insight to the ratio of heat stored in the tank.

$$
\Delta Q=c \cdot m \cdot \Delta T
$$

\subsection{Expanding Capacity per Volume through PCM}

When using water based TES the limit to an energetic reasonable use is usually the way its tank is designed. The more capacity a well-constructed SHS tank for domestic hot water has, the higher it is built. In order to expand the capacity per volume scientists research more and more about latent heat storages (LHS) with phase change materials (PCM). Energy here is not stored by the rise and drop of the temperature level but by changing a material's phase from usually solid to liquid and vice versa.

Most promising PCMs in domestic applications are paraffins and salt hydrates. Mehling and Cabeza (2008) released in their comparison of different energy storage densities a heat capacity of $200 \mathrm{~kJ} / \mathrm{kg}$ for salt hydrates as well as paraffins at phase change $\left(5^{\circ} \mathrm{C}\right.$ to $130^{\circ} \mathrm{C}$; depending on the type of specific PCM). New released PCMs from Rubitherm tend to have a higher capacity though. (Rubitherm Technologies $\mathrm{GmbH} 2018$ ) Salt hydrates are promised to reach higher heat capacities up to $250 \mathrm{~kJ} / \mathrm{kg}$ with a phase change temperature of $58^{\circ} \mathrm{C}$, but usually reach $150 \mathrm{~kJ} / \mathrm{kg}$ to $180 \mathrm{~kJ} / \mathrm{kg}$ between $0^{\circ} \mathrm{C}$ and $100^{\circ} \mathrm{C}$. The new Rubitherm paraffins reach maximal heat capacities during their phase change of $260 \mathrm{~kJ} / \mathrm{kg}$ at several phase change temperatures $\left(70^{\circ} \mathrm{C}\right.$ and $18^{\circ} \mathrm{C} ; 220-250 \mathrm{~kJ} / \mathrm{kg}$ at $80^{\circ} \mathrm{C}, 69^{\circ} \mathrm{C}, 64^{\circ} \mathrm{C}$, 
$62^{\circ} \mathrm{C}, 44^{\circ} \mathrm{C}, 35^{\circ} \mathrm{C}$ and $28^{\circ} \mathrm{C}$ ). According to the application, salt hydrates and paraffins come into use differently. (Zalba et al. 2003; Mehling and Cabeza 2008; Sarbu 2016) Some of their advantages and disadvantages can be seen in Tab. 1.

Tab. 1: Advantages and Disadvantages of Salt Hydrates and Paraffins

\begin{tabular}{|c|l|l|}
\hline & \multicolumn{1}{|c|}{ Advantages } & \multicolumn{1}{c|}{ Disadvantages } \\
\hline $\begin{array}{c}\text { Salt } \\
\text { Hydrates }\end{array}$ & $\begin{array}{l}\text { High storage density per volume or mass } \\
\text { Good thermal conductivity } \\
\text { Mostly chemically stable } \\
\text { Low costs (1-3€/kg) }\end{array}$ & $\begin{array}{l}\text { Cycling stability problems due to separation } \\
\text { Subcooling needed } \\
\text { Close to } 100^{\circ} \mathrm{C} \text { already vapour pressure } \\
\text { Corrosive to metals }\end{array}$ \\
\hline \multirow{5}{*}{ Paraffins } & $\begin{array}{l}\text { High storage density per mass } \\
\text { Little or no subcooling } \\
\text { Few safety constraints } \\
\text { Non corrosive and non-reactive with other } \\
\text { materials and water repellent }\end{array}$ & $\begin{array}{l}\text { Compared low thermal conductivity } \\
\text { Higher costs } \\
\text { (especially for pure paraffins; } ;-6 € / \mathrm{kg})\end{array}$ \\
\hline
\end{tabular}

In this paper, the focus lies on macro-encapsulated paraffin.

The main change from sensible heat to latent heat storage is when calculating its ratio of heat stored in the tank is that the enthalpy of the phase change is taken into consideration as well.

$$
Q_{s}=m\left[c_{s, p} \cdot\left(T_{m}-T_{i}\right)+a_{m} \Delta h_{m}+c_{f, p}\left(T_{f}-T_{m}\right)\right] \text { (eq. 2) }
$$

Designing a storage tank system with spheres in a packed bed bulk is possible without interfering with already existing components in the periphery. No adjustments to the system boundaries are therefore necessary. Calculating its capacity is done by taking the form factors and volume of the spheres into account with its fraction in the tank. The capacity will therefore be either provided by the sensible heat available through water or by convection and conduction around and in the PCM spheres (eq. 3). (Gesellschaft Verfahrenstechnik und Chemieingenieurwesen 2013)

$$
\dot{Q}_{i}=\dot{Q}_{i \text {;sensible }}=\dot{Q}_{i \text {;conduction }}+\dot{Q}_{i ; \text { convection }} \quad \text { (eq. 3) }
$$

The sensible heat capacity is calculated as usual but conduction and convection differ due to form factors of the spheres and the related flows around them. The calculations include the place $i$ and its change.

$$
\begin{aligned}
& \dot{Q}_{i, \text { conduction }}=A \cdot \lambda \cdot\left(\frac{T_{i+1, j}-T_{i, j}}{x_{i+1}-x_{i}}-\frac{T_{i, j}-T_{i-1, j}}{x_{i}-x_{i-1}}\right) \text { (eq. 4) } \\
& \dot{Q}_{i ; \text { convection }}=A_{P C M, \text { total }} \cdot \frac{A \cdot \Delta x}{V} \cdot \alpha \cdot \Delta T_{\mathrm{ln}}
\end{aligned}
$$

This capacity calculation has to be considered in correlation with equations (eq. 6) through (eq. 15):

$$
\begin{aligned}
& \Delta T_{\mathrm{ln}}=\frac{\left(T_{P C M}-T_{i-1}\right)-\left(T_{P C M}-T_{i}\right)}{\ln \frac{T_{P C M}-T_{i-1}}{T_{P C M}-T}} \\
& \alpha=\frac{\mathrm{Nu} \cdot \lambda}{R}
\end{aligned}
$$

The dimensionless numbers of Nusselt and Prandtl are calculated according to the geometry of the macroencapsulated material. Volume fractions and calculations for form factors are taken from calculations for spheres in a packed bed. (Gesellschaft Verfahrenstechnik und Chemieingenieurwesen 2013)

$$
\begin{aligned}
& \mathrm{Nu}=f_{a} \cdot \mathrm{Nu}_{S S P} \\
& \mathrm{Nu}_{S S P}=2+\sqrt{\mathrm{Nu}_{\text {la min } a r}^{2}+\mathrm{Nu}^{2}{ }_{\text {turbulent }}} \\
& \mathrm{Nu}_{\text {laminar }}^{2}=0,664 \cdot \sqrt{\mathrm{Re}_{\psi}} \cdot \sqrt[8]{\mathrm{Pr}}
\end{aligned}
$$




$$
\begin{aligned}
& \mathrm{Nu}_{\text {turbulent }}^{2}=\frac{0,037 \cdot\left(\operatorname{Re}_{\psi}\right)^{0,8} \operatorname{Pr}}{1+2,443 \cdot\left(\operatorname{Re}_{\psi}\right)^{-0,1} \cdot\left(\operatorname{Pr}^{\frac{2}{3}}-1\right)} \\
& \operatorname{Re}=\frac{w_{\text {flow }} \cdot R}{v \cdot \psi} \\
& \operatorname{Pr}=\frac{v}{\Delta x} \\
& f_{a}=1+(1,5 \cdot(1-\psi)) \\
& \psi=\frac{V_{\text {storage }}-V_{\text {spheres,total }}}{V_{\text {storage }}}
\end{aligned}
$$

The fraction of spheres in an ideal packed bed bulk cannot exceed 2/3 of the whole storage. A more realistic approach is rather a fraction just below $60 \%$. In the here used tank this realistic simulated fraction reached $56 \%$ of the storage tank, considering that some space was needed for the diffusor. In order to have a realistic comparison, the same tank was filled with the same volume fraction of paraffin plates.

\section{Research Approach}

\subsection{Thermodynamic Background}

To simulate phase change in CFD is still an intricate task and many different models are available, although none is generally applicable and the suitability has to be checked thoroughly for each application. A common approach is the use of the volume of fluid (VOF) approach to differentiate between the phases and apply a thermodynamic phase change model. Key point of this method is to calculate the interfacial heat flux on both the solid and the liquid side precisely. (Sun et al. 2012) The VOF method in the current paper accounts for incompressible flow and heat transfer between the two different phases. The model used here is an adapeted vapor-liquid phase change in the VOF method (Ding et al. 2017). Here $\varphi$ indicates the volume fraction of the solid phase $\left(\varphi_{\mathrm{s}}\right)$ and the liquid phase $\left(\varphi_{1}\right)$, meaning the solid volume fraction is 1 when the PCM is still fully solid and approaches 0 when liquefying.

$$
\varphi_{s}+\varphi_{l}=1
$$

Therefore, the volume fractions of the solid (eq. 17) and liquid phase (eq. 18) can be written with respect of the mass flux and density. It is

$$
\begin{aligned}
& \frac{\partial \varphi_{s}}{\partial t}+\nabla\left(\vec{u} \cdot \varphi_{s}\right)=\frac{\dot{m}_{s}}{\rho_{s}} \\
& \frac{\partial \varphi_{l}}{\partial t}+\nabla\left(\vec{u} \cdot \varphi_{l}\right)=\frac{\dot{m}_{l}}{\rho_{l}}
\end{aligned}
$$

Taking these volume fractions into account, the energy and momentum equation based on the Navier-Stokes Equations can be set up. The energy equation (eq. 19) for phase change reads

$$
\frac{\partial}{\partial t}(\rho h)+\nabla \cdot(\rho \vec{u} h)=\nabla \cdot(\lambda \nabla T)+S_{h}
$$

Including the enthalpy fraction of the solid and liquid phase (eq. 20) as well as the fractions of the heat transfer coefficient (eq. 21) and the source term(eq. 22) gives

$$
\begin{aligned}
h & =\frac{\varphi_{s} \rho_{s} h_{s}+\varphi_{l} \rho_{l} h_{l}}{\varphi_{s} \rho_{s}+\varphi_{l} \rho_{l}} \\
\lambda & =\lambda_{s} \varphi_{s}+\lambda_{l} \varphi_{l} \\
S_{h} & =-\dot{m}_{s} \cdot \Delta h_{m} \quad \text { (fully liquid phase) } \\
& =\dot{m}_{s} \cdot \Delta h_{m} \quad \text { (fully solid phase) }
\end{aligned}
$$

The momentum equations for phase change are based on the Navier-Stokes equations derived for the VOF model: 


$$
\frac{\partial}{\partial t}(\rho \vec{u})+\nabla \cdot(\rho \vec{u} \vec{u})=-\nabla p+\nabla \cdot(\mu(\nabla \vec{u}+\nabla \vec{u}))+\rho \vec{g}+\vec{F}_{C S F} \text { (eq. 23) }
$$

The momentum equation includes the continuum surface force (eq. 24) as well as the force coefficient. The dynamic viscosity of the PCM (eq. 25) and its density (eq. 26) is again calculated by its fractions of solid and liquid material:

$$
\begin{aligned}
& \vec{F}_{C S F}=2 \sigma \frac{\varphi_{s} \rho_{s} \kappa_{l} \nabla \varphi_{l}+\varphi_{l} \rho_{l} \kappa_{s} \nabla \varphi_{s}}{\rho_{s}+\rho_{l}} \\
& \mu=\mu_{s} \varphi_{s}+\mu_{l} \varphi_{l} \\
& \rho=\rho_{s} \varphi_{s}+\rho_{l} \varphi_{l}
\end{aligned}
$$

The continuum surface force considers the surface tension coefficient $\sigma$ as well as the interface curvature $\kappa$ of the surface between the solid and liquid volume fraction. The curvature is obtained from its deferential operation of the volume fraction relation.

$$
\kappa_{s}=-\kappa_{l}=-\nabla \cdot\left(\frac{\nabla \varphi_{s}}{\left|\nabla \varphi_{s}\right|}\right)
$$

\subsection{Simulation Approach}

The above-described VOF method is applied for detailed phase change simulations using the simulation program Star CCM+ (Siemens PLM Software 2017). For the simulations of the real scale tank a simplified approach neglecting the reconstruction of the interfacial surface has been implemented in OpenFOAM (The OpenFOAM Foundation 2018). The numerical resolution was set in an implicit unsteady time scheme with segregated flow, volume fraction and energy. As mentioned above, the comparison of the encapsulations is calculated in the Star $\mathrm{CCM}+$ simulation environment, where the grid is constructed using the Polyhedral Mesher, the Prism Layer Mesher and the Surface Remesher. The gravity model that is essential for the sinking of the solid phase is directed in $\mathrm{z}=-9.81$ $\mathrm{m} / \mathrm{s}^{2}$. (as shown in Fig. 3)
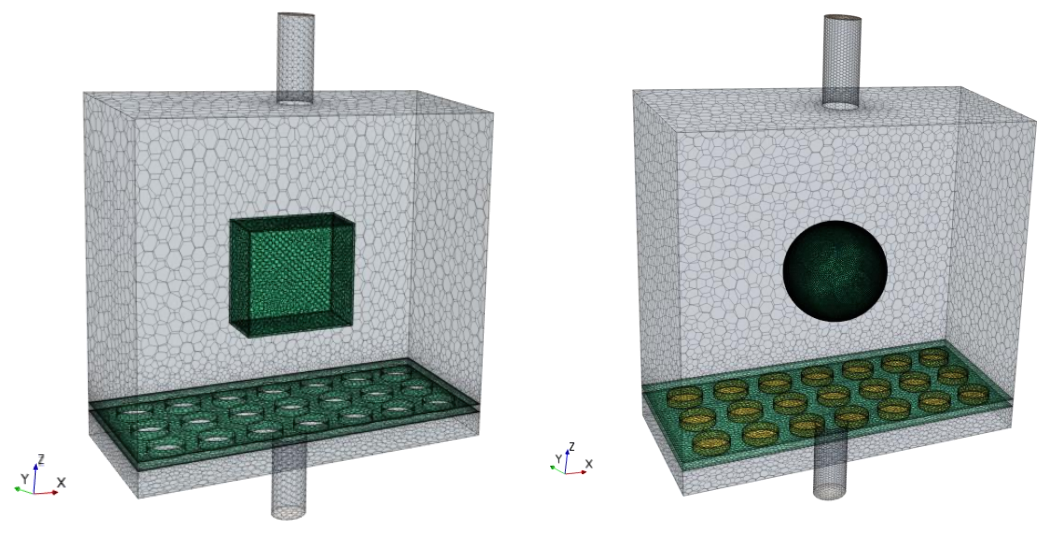

Fig. 3: Meshing models of sphere and cube

The simulations of the SSHS and the LHS have been set up in OpenFOAM. By pouring spheres into the tank beforehand with a particle simulation using blender (Partopour and Dixon 2017), a realistic packed bed bulk is created. Their share in the storage tank is $56 \%$ of the overall volume. The mesh generation starts after the PCM spheres are set in tank. The generated mesh at inlet, outlet and close to any components is denser than within the volume. Fig. 4 shows the mesh of the LHS with spheres. It becomes also clear that the spheres are randomly placed into the storage tank and are not designed by any geometric pattern, but just restricted by the boundaries of the tank. 


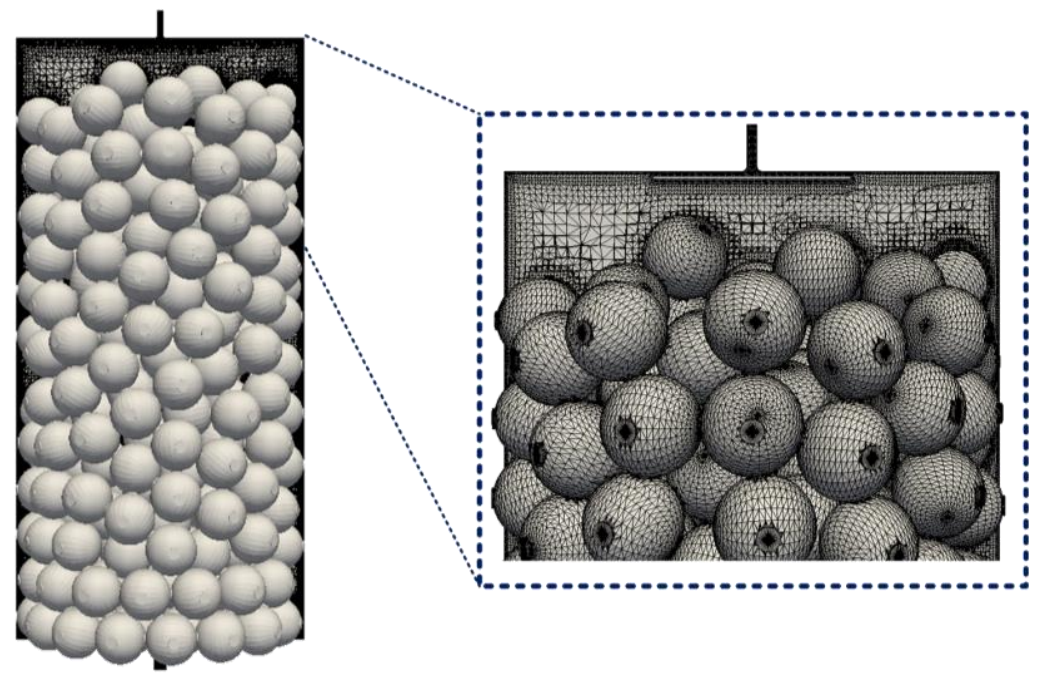

Fig. 4: Grid and Geometry of the LHS tank

The simulated radial diffusor plate is constructed close to the inlet. With a diameter of $0.4 \mathrm{~m}$ and $10 \mathrm{~mm}$ distance to the top wall of the storage tank, it is designed close enough to prevent the formation of vortices in the diffusor itself. The plate has a thickness of $5 \mathrm{~mm}$.

\section{Results}

\subsection{Encapsulation of PCM}

Simulations of different encapsulations have been made to analyze the reaction times and melting behavior of the possible structures. Generally, on the market available PCM often comes in form of plates. Therefore, the comparison of the sphere is made with a volumetric equal cube. The PCM used in the simulations is Rubitherms paraffin of the HC group RT44HC. As the name indicates, it stands for a high latent heat capacity around the melting temperature of $44^{\circ} \mathrm{C}$. The melting range is said to be between $313 \mathrm{~K}$ and $317 \mathrm{~K}$ with a heat capacity of $250 \mathrm{~kJ} / \mathrm{kg}$ in this melting range (including the sensible and latent heat).

The flow around the sphere is more even, so that the system starts to melt at an earlier time of the physical simulation time. The overall structure makes the whole process almost equal though. The graphs below show the solid volume fraction in two different encapsulations over time. It can be seen, that the temperature rises quickly up to the melting point. During the melting phase $(313 \mathrm{~K}$ until $317 \mathrm{~K})$ the temperature rise is linear and slow until all the PCM material is liquefied.

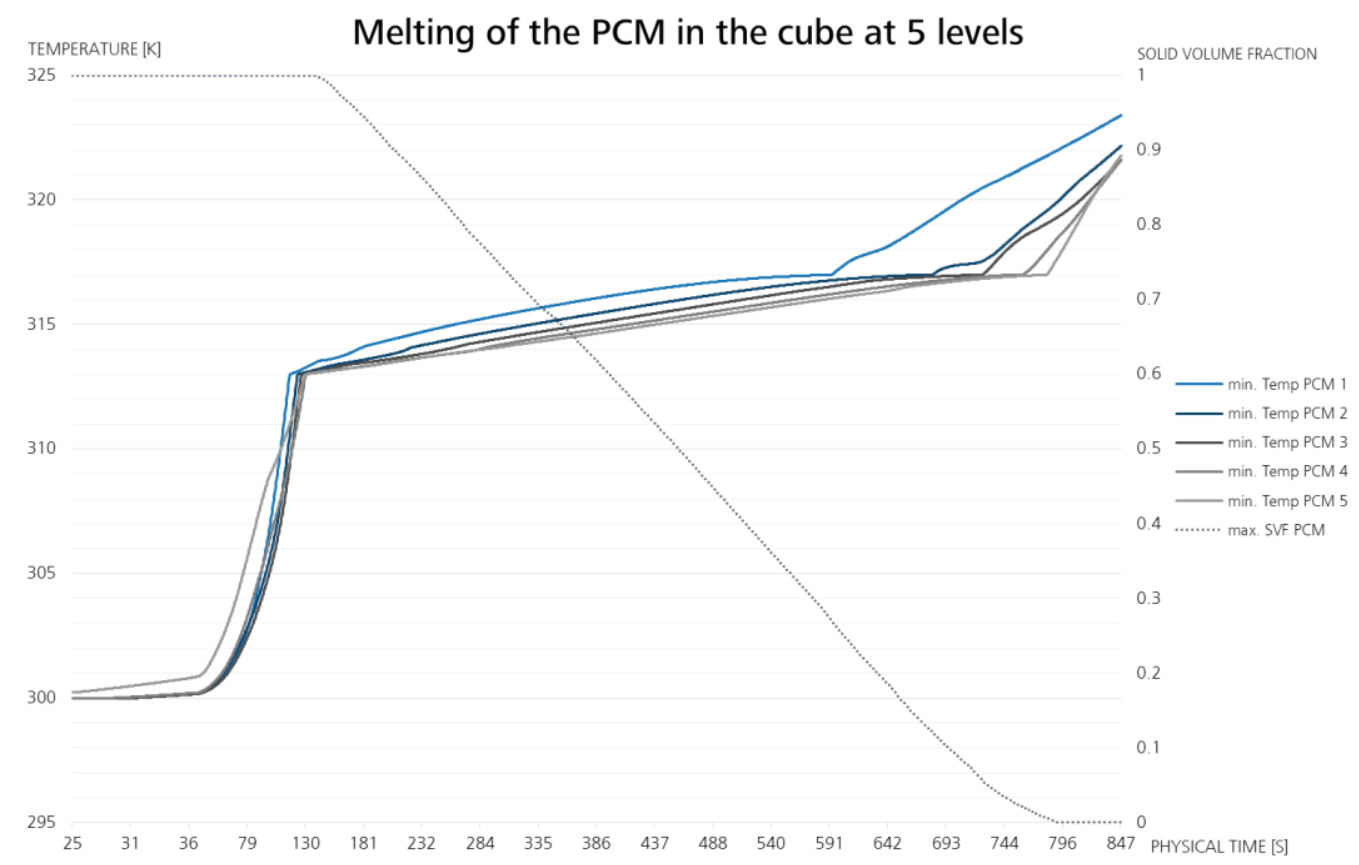

Fig. 5: Temperature profile and SVF during the PCM melting in the cube 
Measurement points in the cube were taken at five different levels averaged over 20 different points each. Level 1 has the highest $\mathrm{z}$-axes value and therefore shows the fastest melting curve. As level 5 has the lowest $\mathrm{z}$-value and gravitation lets the solid phase sink to the bottom of the encapsulation, it takes longest here for the paraffin to melt. The whole melting phase in the cube takes 10.8 minutes. This can seen by evaluating the solid volume fraction (SVF) curve in Fig. 5.

The measurement points of the sphere were chosen in the same amount. Therefore, the graph represents data from 5 different levels and 20 measurement points. Equally to the cube, in fastest melting curve is also the one with the highest z-value. Different here is that due to the structure the considered section planes have different volume. This leads to a faster melting phase in level 1 of the sphere compared to level 1 of the cube. The complete phase change of the sphere takes 10.3 minutes.

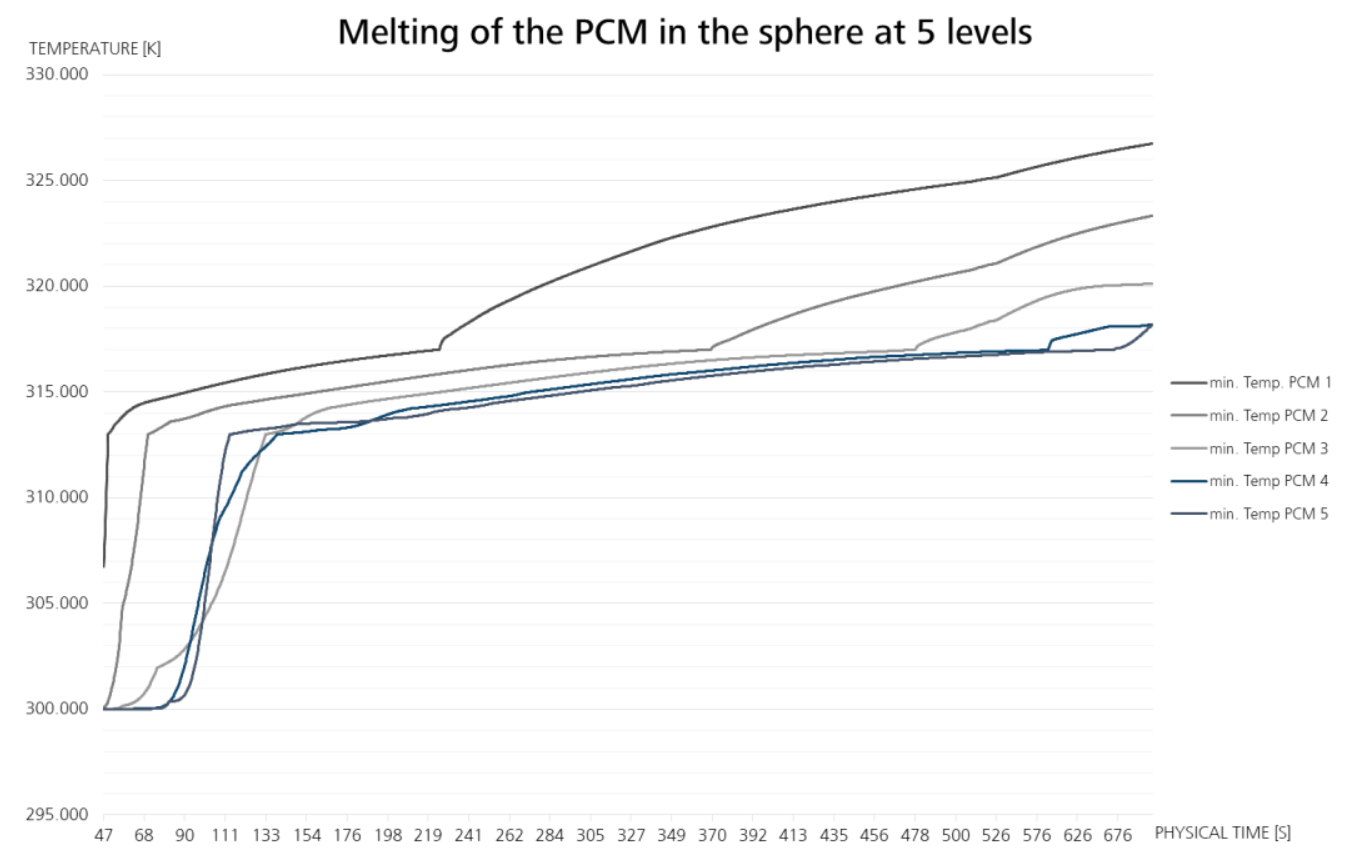

Fig. 6: Temperature profile during the PCM melting in the sphere

The graphic below (Fig. 7) also shows the solid volume fractions of the cube and sphere. It seems that the sphere melts quicker, as both the pictures are taken at the same time of physical simulation. However, it has to be considered that the sphere starts melting at an earlier time, but the overall melting process is almost equal to the cube's.

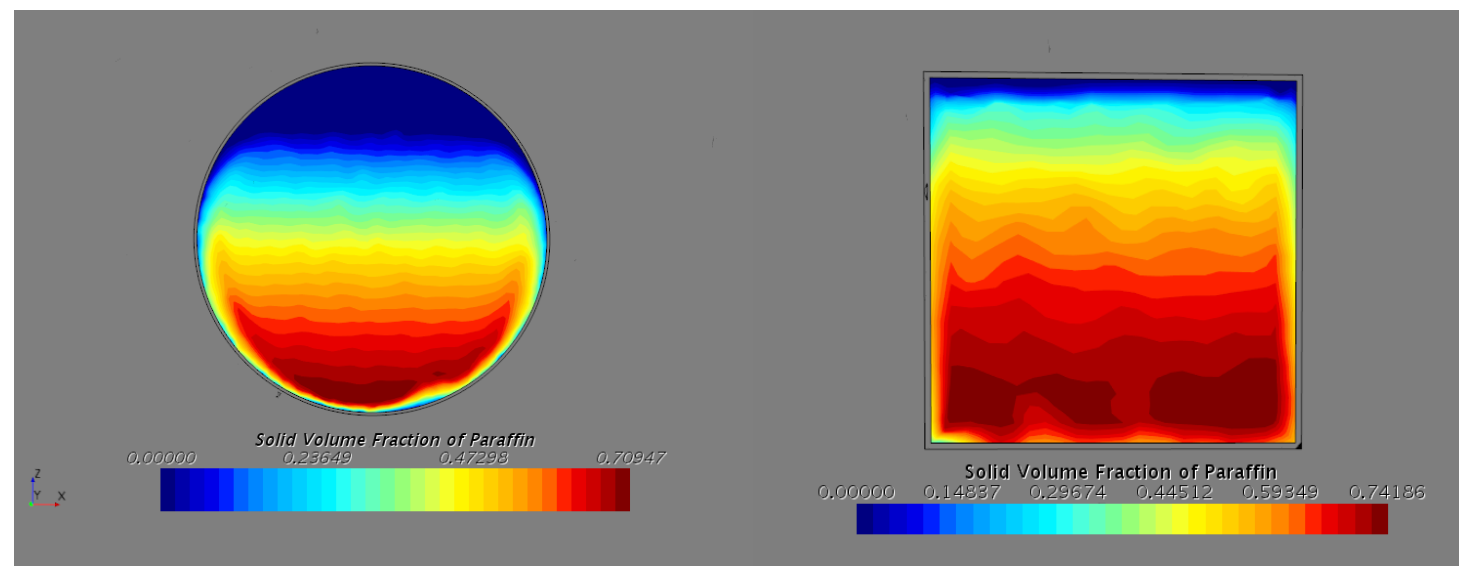

Fig. 7: Phase change in a sphere and a cube at 250s physical time simulated

Although the melting process of the sphere has no significant advantages, possible benefits can be long term down times and the solidification process might still favor this encapsulation method. The simple manufacturing process, high volumetric fraction in the tank and a higher resistance to volume expansion during the phase change speaks already for the sphere. Further simulations regarding these matters are planned. 


\subsection{Stratified Storage}

Research of Findeisen et al. (2018a, 2018b) shows that diffusor stratification for top loaded storage tanks works best with a dispersion at the inlet pipe. Together with a narrow diffusor, plate turbulences after the mass flow inlet are prevented. In order to avoid an uneven distribution of the flow, an additional guide cone at the stream separation is not added. Due to the same possible outcome, any curvature of the pipe before the tank inlet is neglected as well. (Findeisen et al. 2018a, 2018b)

Haller et al. (2014) studied the influences of mass flow rates and inlet geometries. In their results, low mass flow rates of $450 \mathrm{~kg} / \mathrm{h}$ show good stratification with the different geometries measured. As the mass flow rate increases to $900 \mathrm{~kg} / \mathrm{h}$ and $1800 \mathrm{~kg} / \mathrm{h}$, influences on the stratification occur at the different geometries simulated. A plate installed in front of the inlet gives the best results in stratification for any mass flow rate shown in their experiments and is comparable to the diffusor studies of Findeisen et. al. (2018a, 2018b). To still have a good possibility for stratification and have a higher input rate, the volume flow is set at $16 \mathrm{l} / \mathrm{min}$ (equivalent to $960 \mathrm{~kg} / \mathrm{h}$ ).

The inlet temperature of the simulation is set at $333.15 \mathrm{~K}$ with an initial storage tank temperature of $293.15 \mathrm{~K}$. As it can be seen in Fig. 8, the temperature descends even and parallel to top and bottom of the tank but also creates a zone of $0.2 \mathrm{~m}$ up to $0.4 \mathrm{~m}$ where a temperature blending occurs. The graphics show the calculated temperature values at various time steps from 5 s up to 2800 s, representing $40 \%$ loading of the tank.
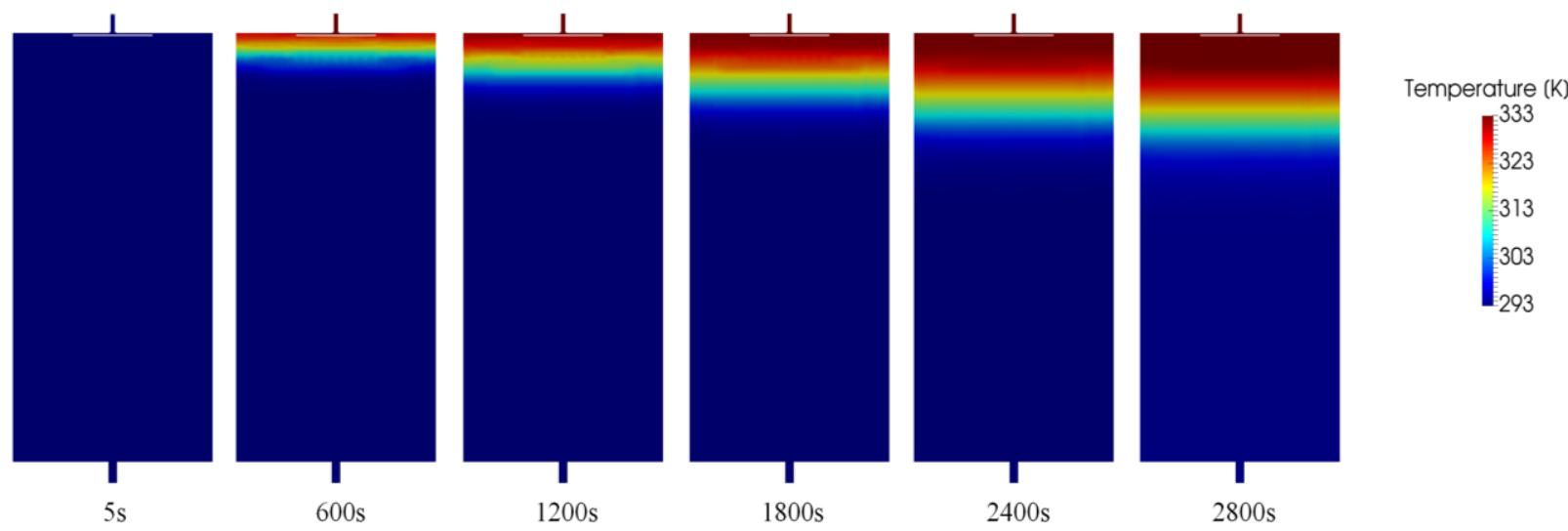

Fig. 8: Development of the temperature stratification

According to temperature contours in Fig. 8 the graph below shows the temperature over the height of the storage at the time steps 0s, 1000s, 1500s, 2000s, 2500s and 2800s. An additional line was added to show an ideal stratification at a storage height of $1.5 \mathrm{~m}$. For the inlet velocity cannot be reduced to a minimum, some thermal blending will always occur. As the simulation time increases, the expanding of the temperature profile increases as well. This can be explained by the still relatively high mass flow rate at the inlet. For a sharper interface between warm and cold layers, calculations of the stratification method are to be evaluated. Overall, this simulation shows a clear horizontal layering though, with a very symmetrical dispersion at the radial diffusor outlet. 


\section{Temperature Stratification in the SSHS Tank}

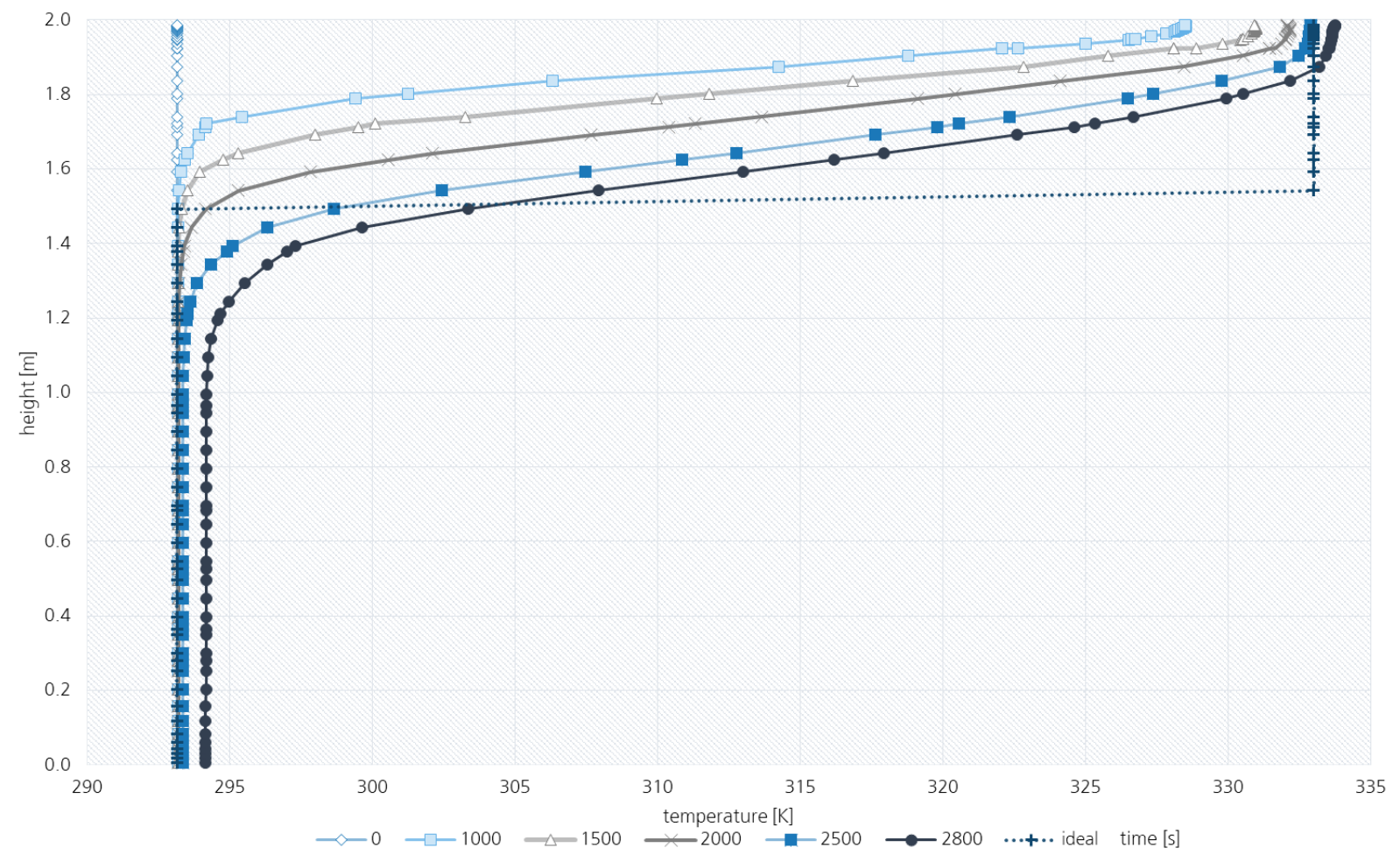

Fig. 9: Temperature profile of the SSHS over its height

The continuous stratification over 2800 s of simulation time can be seen in Fig. 10. The y-axes is the equivalent to the storage tank height from zero to two meters. In the storage 74 measurement points were evaluated over the height to give a detailed view of the stratification. Each vertical gridline represents a time step measured. At $\mathrm{t}=0$ the storage is fully initialized with $293 \mathrm{~K}$.

\section{Temperature stratification of the SSHS tank}

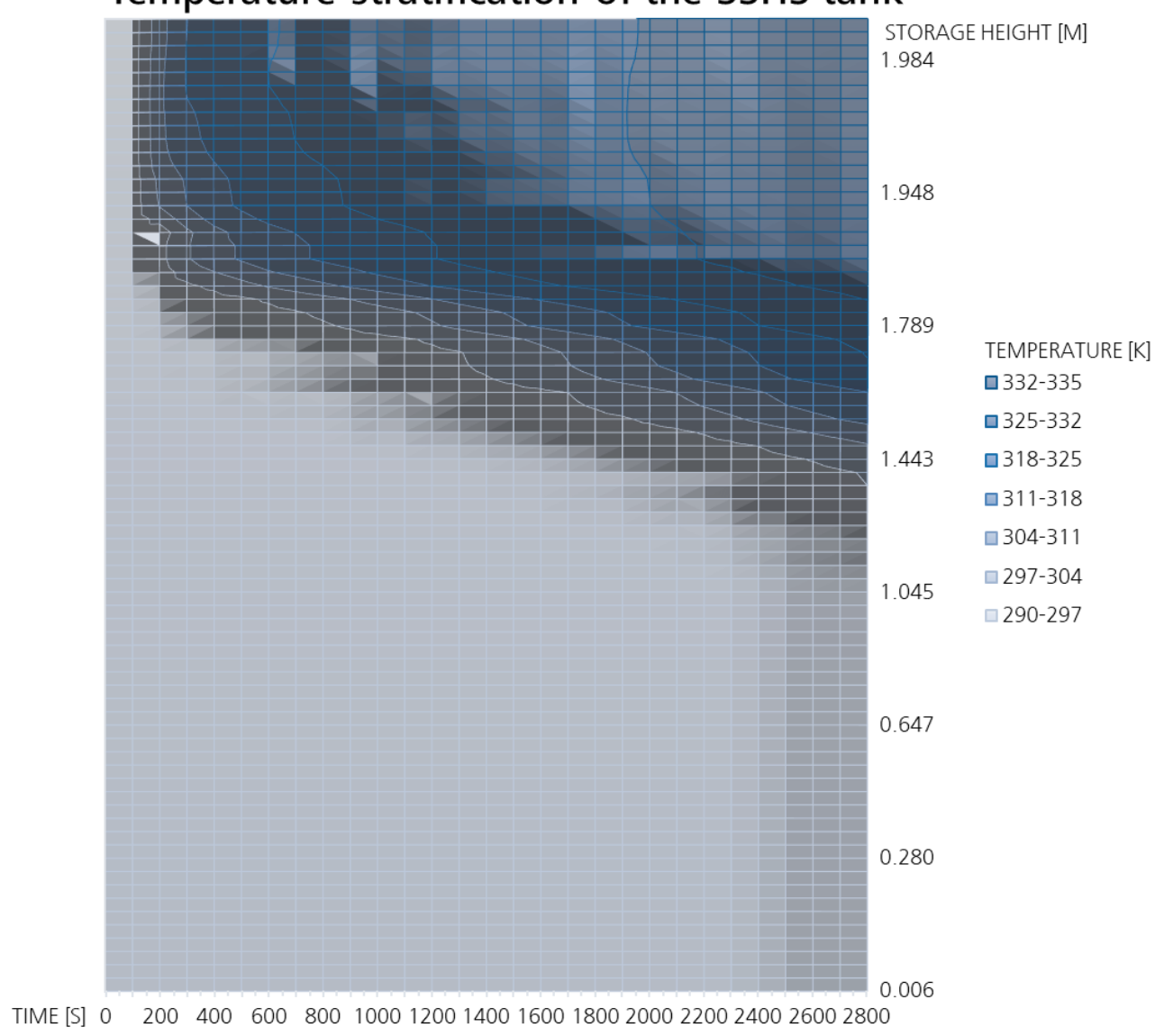

Fig. 10: Stratification of the SSHS tank up to $40 \%$ of loading 
The changing colors show the rise in temperature originating from the radial diffusor at the top of the tank. At the beginning of the simulation $(\mathrm{t}=600 \mathrm{~s})$ the temperature zone is still narrow with less than $0.2 \mathrm{~m}$. Further in the simulation time this range widens up to $0.3 \mathrm{~m}$ at $\mathrm{t}=1400 \mathrm{~s}$ up to $0.4 \mathrm{~m}$ at $\mathrm{t}=2800 \mathrm{~s}$. This zone seems to approach a steady state zone further in the calculation. At the end of the graph, about $40 \%$ of the storage tank is loaded.

In further research, simulations with different temperature differences will be made to indicate its influence on the stratification. This will be necessary to be able to make comparisons with different PCMs in the LHS.

\subsection{Stratified Latent Heat Storage}

With the same storage tank foundation, simulations of a stratified latent heat storage have been made. The model consists of the radial diffusor at the top of the storage that has the same dimensions as the SSHS (diameter: $0.4 \mathrm{~m}$; wall distance: $0.01 \mathrm{~m}$; thickness: $0.005 \mathrm{~m}$ ). The volume fraction of the spheres is $56 \%$ of the tank. The single sphere has a diameter of $0.06 \mathrm{~m}$.

Current simulations evaluated the velocity around the spheres in order to analyze, if a stratification is at all possible. As it can be seen in the graphic below Fig. 11 after the reaching the spheres, the velocity is mainly facing into the negative z-direction. A stratification in this part of the tank can therefore be possible. When analyzing the velocity direction just below the radial diffusor though, a backflow in the positive z-direction can be seen. This can be a result of the flow redirection at the sphere boundaries. Further simulations will show if this leads to a destruction, due to development of vortices, of a stratification from the beginning.
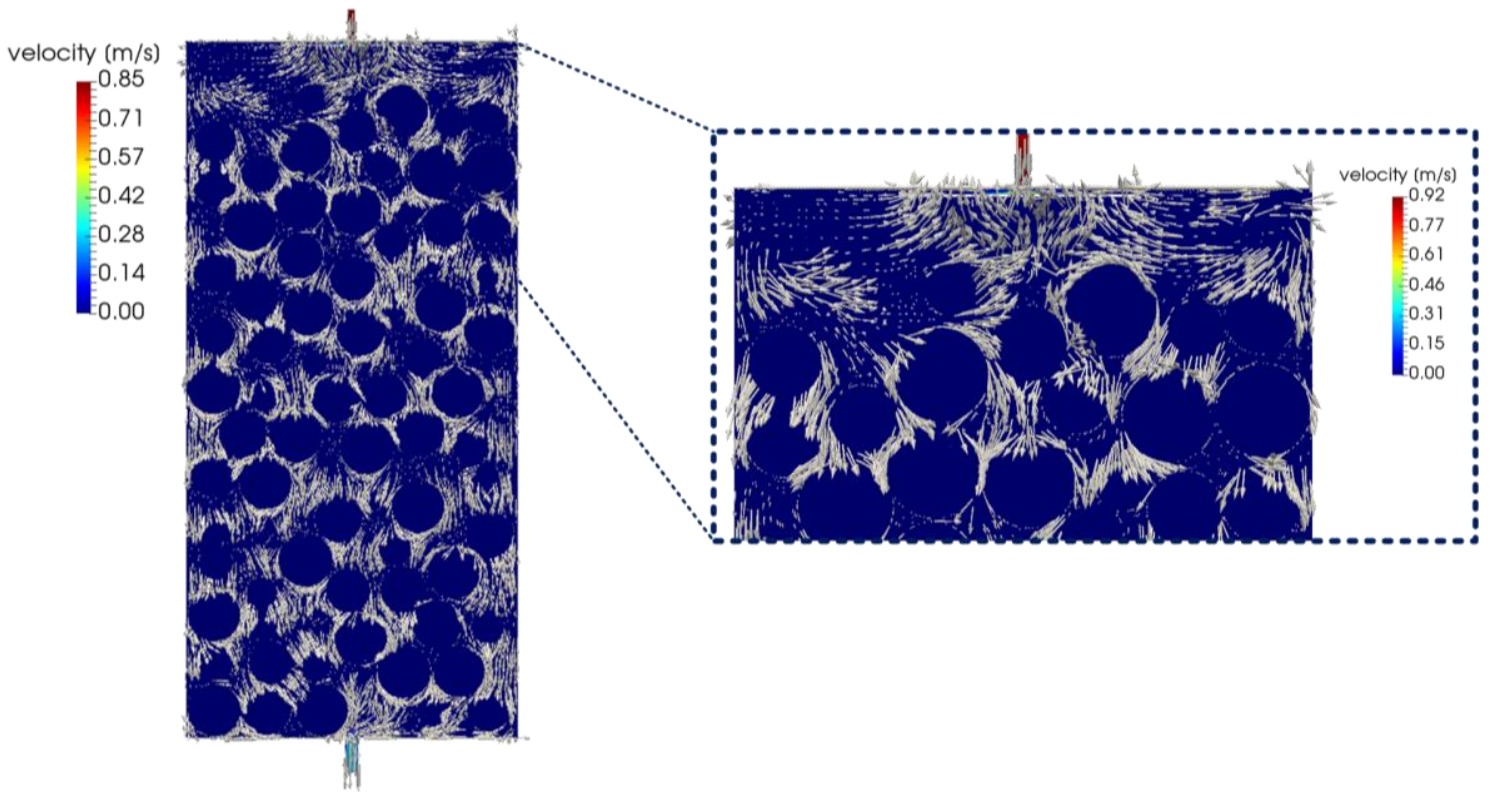

Fig. 11: Velocity around the spheres in the packed bed bulk in the LHS

\section{Outlook}

The here presented simulations of the encapsulation forms of the sphere and cube show that the PCM in the cube changes its phase faster than the paraffin in the sphere. One aspect that has not been taken into consideration yet, is essential for a well-balanced TES system, is its down time and discharging. Exactly this slightly longer melting time could be convenient at times where the storage is neither charged nor discharged. Therefore, the focus on further simulations for the encapsulations will also be their solidification cycles. In the main tank long-term loading and discharging simulations with PCMs are to evaluate as well to show heat losses in the encapsulated material as well as towards the system boundaries during downtimes.

For the overall goal to achieve a stratified LHS further optimization through CFD of different methods of stratification are necessary as well. The here presented method has its focus on charging with one single temperature at inlet. As there are some components available on the market where heat at different temperatures can be inserted into the tank at different levels of stratification, these methods will be taken into consideration in further simulations. These results can give additional information to improve the stratification of modular PCM via CFD.

To be able to evaluate the simulations made physical experiments will be necessary as well. Replicas of the encapsulation models can show the accuracy of the simulations. In further physical experiments, a direct comparison of a SSHS and the same model filled with modular PCM is planned as well. 


\section{Acknowledgements}

The authors acknowledge the financial support by the Federal Ministry of Education and Research of Germany in the framework program of InnoSüd.

\section{References}

Ding, Shui-Ting; Luo, Bin; Li, Guo (2017): A volume of fluid based method for vapor-liquid phase change simulation with numerical oscillation suppression. In International Journal of Heat and Mass Transfer 110, pp. 348359. DOI: 10.1016/j.ijheatmasstransfer.2017.03.015.

Findeisen, Fabian; Urbaneck, Thorsten; Platzer, Bernd (2018a): Radiale Diffusoren - Untersuchung des dreidimensionalen Strömungsverhaltens mittels CFD (Teil 1). In Chemie Ingenieur Technik 90 (7), pp. 956-968. DOI: $10.1002 /$ cite.201700023.

Findeisen, Fabian; Urbaneck, Thorsten; Platzer, Bernd (2018b): Radiale Diffusoren - Untersuchung des dreidimensionalen Strömungsverhaltens mittels CFD (Teil 2). In Chemie Ingenieur Technik 90 (7), pp. 969-978. DOI: $10.1002 /$ cite. 201700070.

Gesellschaft Verfahrenstechnik und Chemieingenieurwesen (2013): VDI-Wärmeatlas. Mit 320 Tabellen. 11., bearb. und erw. Aufl. Berlin: Springer Vieweg (VDI-Buch). Available online at http://dx.doi.org/10.1007/978-3-64219981-3.

Haller, Michel; Mojic, Igor; Kaufmann, Matthias; Huggenberger, Andreas; Podhradsky, Jason; Frank, Elimar et al. (2014 - 2014): Disturbance of Stratification Caused by Direct Horizontal Inlets into a Water Storage Tank. In Elimar Frank, Phillipe Papillon (Eds.): Proceedings of the EuroSun 2014 Conference. EuroSun 2014. Aix-les-Bains, France, 16.09.2014 - 19.09.2014. Freiburg, Germany: International Solar Energy Society, pp. 1-9.

Mehling, Harald; Cabeza, Luisa F. (2008): Heat and cold storage with PCM. An up to date introduction into basics and applications ; with 28 tables. Berlin, Heidelberg: Springer (Heat and mass transfer). Available online at http://www.springerlink.com/content/q46746, checked on 7/28/2017.

Partopour, Behnam; Dixon, Anthony G. (2017): An integrated workflow for resolved-particle packed bed models with complex particle shapes. In Powder Technology 322, pp. 258-272. DOI: 10.1016/j.powtec.2017.09.009.

Rubitherm Technologies GmbH (2018): Rubitherm - Produkte. Available online at https://www.rubitherm.eu/produktkategorien.html, checked on 8/31/2018.

Sarbu, Ioan (2016): Solar Heating and Cooling Systems. Fundamentals, Experiments and Applications. San Diego: Elsevier Science. Available online at http://gbv.eblib.com/patron/FullRecord.aspx?p=4721232.

Siemens PLM Software (2017): STAR-CCM+. Version 12.02.010.

Sun, Dong-Liang; Xu, Jin-Liang; Wang, Li (2012): Development of a vapor-liquid phase change model for volumeof-fluid method in FLUENT. In International Communications in Heat and Mass Transfer 39 (8), pp. 1101-1106. DOI: 10.1016/j.icheatmasstransfer.2012.07.020.

The OpenFOAM Foundation (2018): OpenFoam v6. Version Version 6. Available online at https://openfoam.org/version/6/.

Zalba, Belén; Marín, José Ma; Cabeza, Luisa F.; Mehling, Harald (2003): Review on thermal energy storage with phase change. Materials, heat transfer analysis and applications. In Applied Thermal Engineering 23 (3), pp. 251283. DOI: 10.1016/S1359-4311(02)00192-8. 


\section{Appendix}

Abbreviations, Subscripts and the nomenclature used in this paper are in order of appearance.

Abbreviations and Subscripts

\begin{tabular}{ll}
\hline Name & Abbreviation \\
\hline Computational fluid dynamics & CFD \\
Phase change material & PCM \\
Volume of fluid & VOF \\
Thermal energy storage & TES \\
Sensible heat storage & SHS \\
Latent heat storage & LHS \\
Stratified sensible heat storage & SSHS \\
Place & $\mathrm{j}$ \\
Time & $\mathrm{i}$ \\
Solid & $\mathrm{S}$ \\
Liquid & 1 \\
melting & $\mathrm{m}$ \\
Continuum surface force & CSF \\
Solid volume fraction & SVF \\
\hline
\end{tabular}

\section{Nomenclature}

\begin{tabular}{lll}
\hline Quantity & Symbol & Unit \\
\hline Ratio of storage heat & $\Delta \mathrm{Q}$ & $\mathrm{J}$ \\
Specific heat capacity & $\mathrm{c}$ & $\mathrm{J} / \mathrm{kgK}$ \\
Mass & $\mathrm{m}$ & $\mathrm{kg}$ \\
Temperature difference & $\Delta \mathrm{T}$ & $\mathrm{K}$ \\
Storage heat & $\mathrm{Q}_{\mathrm{s}}$ & $\mathrm{J}$ \\
Specific heat solid state & $\mathrm{c}_{\mathrm{s}, \mathrm{p}}$ & $\mathrm{J} / \mathrm{kgK}$ \\
Initial temperature & $\mathrm{T}_{\mathrm{i}}$ & $\mathrm{K}$ \\
Final temperature & $\mathrm{T}_{\mathrm{f}}$ & $\mathrm{K}$ \\
Share of melted material & $\mathrm{a}_{\mathrm{m}}$ & - \\
Melting enthalpy & $\Delta \mathrm{h}_{\mathrm{m}}$ & $\mathrm{J} / \mathrm{kg}$ \\
Capacity at time j and & $\dot{\mathrm{Q}}_{\mathrm{i}, \mathrm{j}}$ & $\mathrm{W}$ \\
place i & & \\
Sensible capacity (i,j) & $\dot{Q}_{i, j ; \text { sensible }}$ & $\mathrm{W}$ \\
Conduction capacity & $\dot{Q}_{i, j ; c \text { conduction }}$ & $\mathrm{W}$ \\
Convection capacity & $\dot{Q}_{i, j \text {;convection }}$ & $\mathrm{W}$ \\
Length & $\mathrm{x}$ & $\mathrm{m}$ \\
Time interval & $\Delta \mathrm{t}$ & $\mathrm{s}$ \\
Total PCM surface & APCM,total & $\mathrm{m}^{2}$ \\
Area & $\mathrm{A}$ & $\mathrm{m}{ }^{2}$ \\
Length between i and i-1 & $\Delta \mathrm{x}$ & $\mathrm{m}$ \\
Heat transfer coefficient & $\alpha$ & $\mathrm{W} / \mathrm{m}^{2} \mathrm{~K}$ \\
Logarithmic temperature & $\Delta \mathrm{T}_{\text {ln }}$ & $\mathrm{K}$ \\
Temperature PCM & $\mathrm{T}_{\mathrm{PCM}}$ & $\mathrm{K}$ \\
\hline & &
\end{tabular}

\begin{tabular}{lll}
\hline Quantity & Symbol & Unit \\
\hline Temperature before initial & $\mathrm{T}_{\mathrm{i}-1}$ & $\mathrm{~K}$ \\
Temperature after initial & $\mathrm{T}_{\mathrm{i}+1}$ & $\mathrm{~K}$ \\
Nusselt number & $\mathrm{Nu}$ & - \\
Nusselt nb. single sphere & $\mathrm{Nu}_{\mathrm{SSP}}$ & - \\
Thermal conductivity & $\lambda$ & $\mathrm{W} / \mathrm{mK}$ \\
Sphere diameter & $\mathrm{R}$ & $\mathrm{m}$ \\
Form factor & $\mathrm{fa}_{\mathrm{a}}$ & - \\
Prandtl number & $\mathrm{Pr}$ & - \\
Viscosity & $v$ & $\mathrm{~m} / \mathrm{s}$ \\
Reynolds number & $\mathrm{Re}$ & - \\
Velocity of flow & $\mathrm{W}_{\mathrm{flow}}$ & $\mathrm{m} / \mathrm{s}$ \\
Cavity proportion & $\psi$ & - \\
Volume & $\mathrm{V}$ & $\mathrm{m}{ }^{3}$ \\
Volume fraction & $\varphi$ & - \\
Volume fraction solid & $\varphi_{\mathrm{s}}$ & - \\
Volume fraction liquid & $\varphi \mathrm{l}$ & - \\
Velocity vector & $\vec{u}$ & $\mathrm{~m} / \mathrm{s}$ \\
Mass flow & $\dot{m}$ & $\mathrm{~kg} / \mathrm{s}$ \\
Density & $\rho$ & $\mathrm{kg} / \mathrm{m}^{3}$ \\
Surface tension volume force & $\vec{F}$ & $\mathrm{~N} / \mathrm{m}^{3}$ \\
Surface tension coefficient & $\sigma$ & $\mathrm{N} / \mathrm{m}$ \\
Interface curvature & $\kappa$ & - \\
Gravitation vector & $\vec{g}$ & $\mathrm{~m} / \mathrm{s}^{2}$ \\
\hline & &
\end{tabular}




\title{
Using Behavior Simulation to synthesize Electromobility Charging Profiles Noah Pflugradt and Urs Muntwyler \\ Berner Fachhochschule, Labor für Photovoltaiksysteme, Jlcoweg 1, 3400 Burgdorf \\ Tel.: +41344266927 \\ E-Mail: Noah.Pflugradt@bfh.ch \\ Internet: www.pv-test.ch
}

\begin{abstract}
In recent years a novel approach for the generation of residential load profiles was developed. It is based on an agent-simulation that models each person in a household as a separate software agent. For a new project this model has now been extended to also include transportation and travel times. This allows generating highly realistic mobility profiles. The model uses measurement data from real electric cars to generate charging profiles. Additionally, availability time profiles are generated, that describe when the car could have been charged. This is relevant in the context of PV system integration since electromobility will be one major driver of future electricity demand.
\end{abstract}

Keywords: load profiles, electromobility, agent simulation

\section{Introduction}

In the last years a novel approach for synthesizing load profiles was developed. The approach works by using an agent-based simulation approach that uses a psychological desire model to simulate the behavior of the residents. This approach has many advantages compared to a probabilistic approach especially for simulating single households. The model is implemented as a Windows program, called "LoadProfileGenerator (LPG)" and is freely available for download at (Pflugradt, 2017). The model is explained in detail in (Pflugradt, 2016).

Now the model has been extended to include electromobility. Due to the agent-based simulation the activity and the location for each resident in the household is always known. Based on this, it is possible to keep track of where the car of the residents is, how many kilometers it has driven and when it is available to get charged. This paper describes the extended simulation model, shows some of the performed measurements on the charging of the electric cars and the resulting synthetic load profiles.

\section{State of the art}

Currently data on electromobility charging profiles is rather sparse. (Wang et al., 2015) studied the energy consumption of vehicles based on driving data from Beijing. (Wolbertus et al., 2018) did large studies on the charging behavior of public charging stations but doesn't show individual charging events.

There are a number of approaches for synthesizing electric vehicle charging profiles, for example (Munkhammar et al., 2015), (García-Villalobos et al., 2014) or (Fischer et al., 2019). They all use a stochastic approach to model the driving behaviour. (Fischer et al., 2019) used statistical data to generate probability distributions over the day for driving events and for the driving distance. Based on those probability distributions they simulate the driving and calculate the state of charge (SOC) for each car. Then they simulate the driving behavior of the cars over the year and decide, depending on the current location of the vehicle, if it can be charged.

The novelty of the approach introduced in this paper is in three areas: First, the model will be publicly available to download for free. Second, the agent-based approach enables the simultaneous generation of load profiles for household electricity, warm water and charging electricity demand. This is very important for correctly modelling 
the impact of longer absences, such as vacations. Third, because detailed probability profiles are not needed for modelling, it is possible to model for example shift workers or part time employees, which make up a large percentage of the population and are not represented by the other approaches according to the published literature.

\section{Model}

The basic simulation works by modelling each resident of the household as an independent agent. This agent then decides based on the currently available activities and the current desires what to do next. For example, if the person comes home from work, the person might have a high desire for both relaxing and food and since food is a higher priority, the person will first eat and then maybe watch TV. This principle is shown in Figure 1.

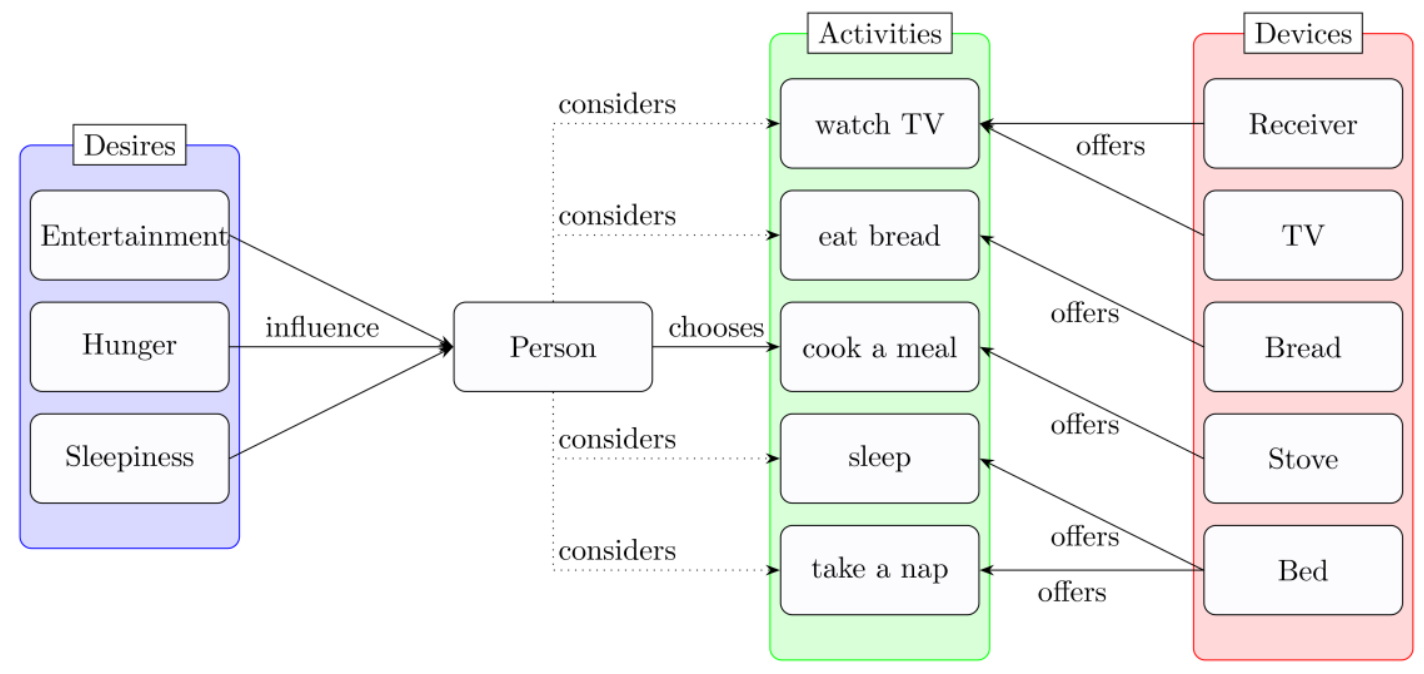

Figure 1: Basic Idea of the LoadProfileGenerator

\subsection{Requirements}

Due to this approach it is possible to generate realistic activity profiles for each person. From the activity profiles the load profiles can be generated.

The challenge was to extend the existing model to combine different households with different combinations of routes and transportation modes. Some examples of the different options are shown in Figure 2. For example, the same household could either have two cars and live far from any city or have no cars and very short travel distances to all points of interest.

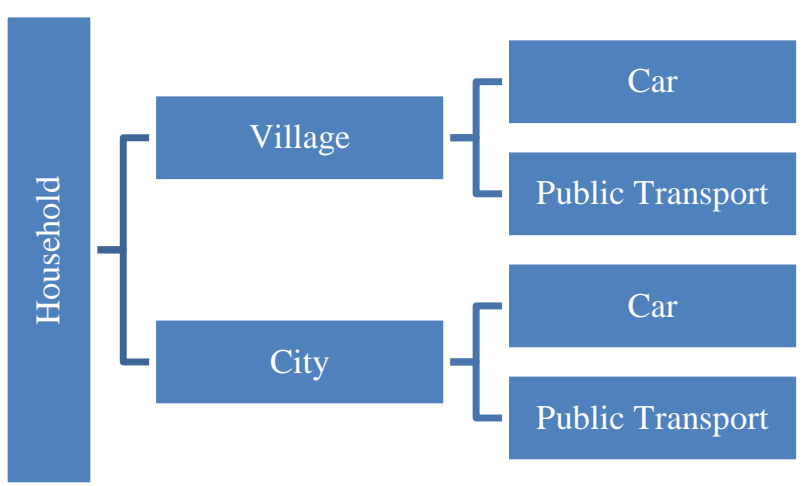

Figure 2: Different transportation scenarios that need to be combined with a household

An additional requirement was that travel routes can be multi-modal. That means one route can require the combination of different transportation devices, as shown in Figure 3. To get from home to work, a person might first have to take the elevator and then the car. 


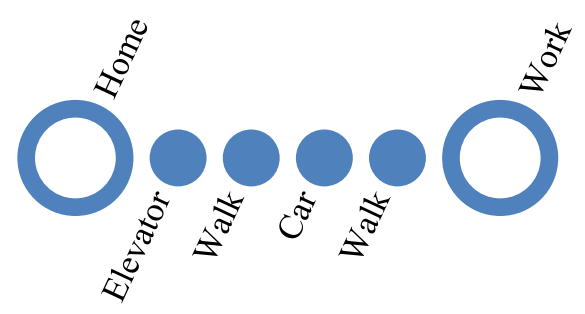

Figure 3: Travel steps for one example travel route

Quite frequently there are different travel options to reach the same goal. For example, a child might take a bus to go shopping, but a mother might take a car. So personal preferences and limitations on the use of transportation devices need to be integrated too.

There are different types of constraints to the transportation devices. Busses, for example, only run at certain times, but are always available, no matter when and by whom they were last used. Cars on the other hand are only available at a single location at a time and if the one person used the car to drive to work, the other person can't use the car at the same time to go shopping. Electric cars can only be charged at certain places and can't be used if the SOC is too low. Different transportation devices can go at different speeds. Electric cars have a state of charge that needs to be tracked.

\subsection{Model}

For modelling a relational database approach was used. The entities used in the LPG are written in italics in this section to aid in understanding.

The approach chosen for the model was to first define sites and transportation devices. Then the next step is defining transportation device categories for all transportation devices. For example, all cars are assigned to the category "car", while the different busses get assigned to the category "bus". This allows switching out internal combustion engine cars for electric cars without changing any of the travel routes. Every transportation device can consume resources that are logged, which makes it possible to keep track of, for example, the charging status of an electric car.

Then different locations in the LPG, such as rooms in a house, are assigned to the sites. Travel routes are defined between the sites. Each travel route has at least one travel route step. Each step has a distance and a transportation device category. Figure 3 shows an example for a travel route.

The travel routes are combined into a travel route set. The travel route set describes all travel options for a household. The LPG makes sure that it is possible to travel from every location in a household to every other location to avoid problems with people getting stuck in one location. If this rule wasn't enforced, it might be possible to create a situation where a person can travel from home to the office and from the office to the supermarket, but not from the supermarket home. This would theoretically be solvable with a path finding routine, but due to computational constraints it seemed more reasonable to instead enforce the rule that there needs to be a route between each site.

Then a transportation device set is defined which combines all the transportation devices for the household. The LPG again enforces that for every site there are devices for at least one travel route.

This model is visualized in Figure 4. By combing all these elements makes it possible to comprehensively model the traveling behavior of the residents in various configurations in a flexible and universal way. The model makes it possible to combine different transportation options with different routes for the same household. 


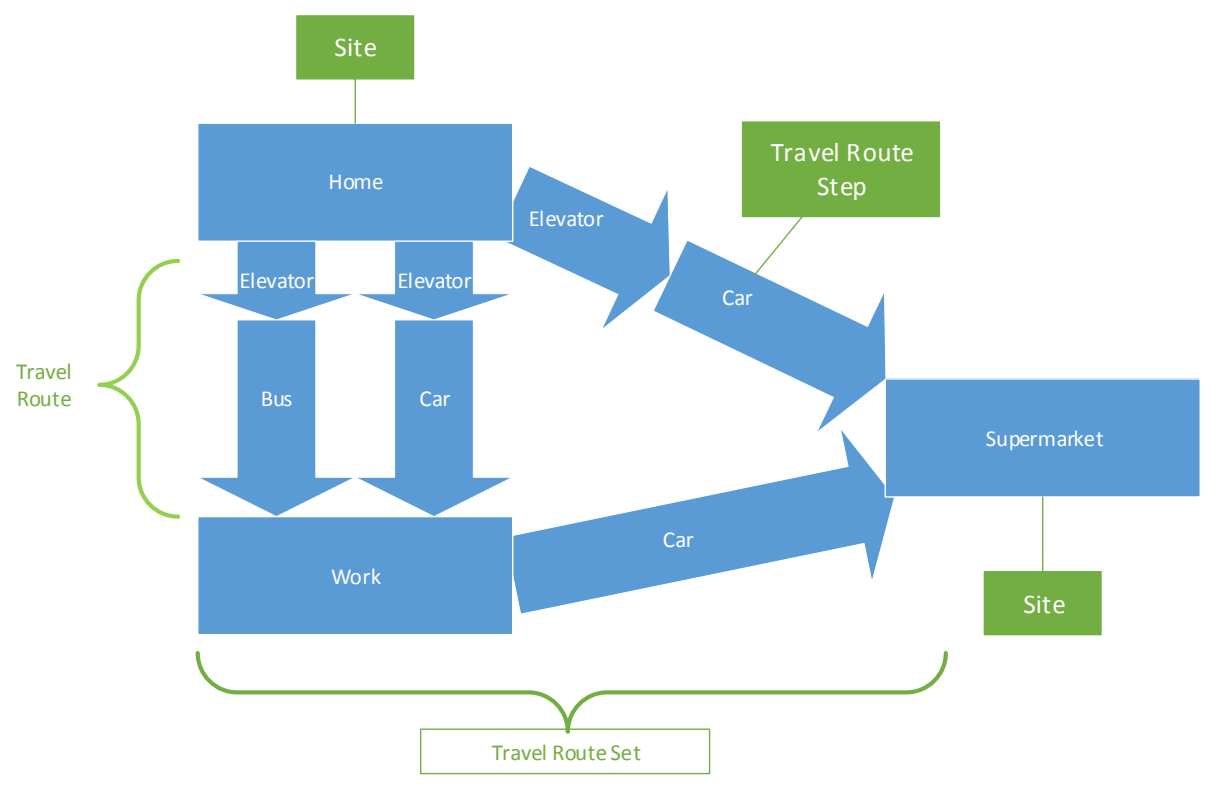

Figure 4: Data Model for the transportation module

\subsection{Simulation}

During the decision-making process of choosing the next activity, the software agent first checks the available activities and the reachability of each activity. For example, it checks if an electric car is available and sufficiently charged for a two-way trip. Then it picks the activity that satisfies its current desires best.

To model the charging process, the software includes a database of measured high-resolution charging profiles which are then truncated as needed to recharge the battery from the taken trips. For this purpose charging points are defined and if, for example, the car is at home, it will be charged. Intelligent charging control with peak shaving is currently still under development though.

\section{Measurements}

Of particular interest are the diverse charging profiles of the different cars. Probably largely due to the still early stage of the entire development of electric cars, the charging patterns differ significantly between manufacturers and models. Figure 5 shows an optimal charging behavior.

Other cars show curious aspects such as:

- the poor power stability in the later phase of the charging of the Nissan Leaf, where the power varies by more than $1000 \mathrm{~W}$, see Figure 6. This only happens when charging with $3.7 \mathrm{~kW}$. When charging the same car with $10 \mathrm{~kW}$, no such fluctuations occur.

- The charging behavior for two different Renault Zoe Models are shown in Figure 7 and Figure 9. They show a very strong decrease in charging power as the SOC increases. The behavior improved considerably already though from 2014 to 2017.

- The Renault Zoe has the worst charging profile regarding the production of reactive power, as shown in Figure 8 and Figure 10. It is visible that Renault improved this significantly from the 2014 model to the 2017 model.

- The Citroen C-Zero performs frequent brief measurements that cause power dips for unknown reasons. 


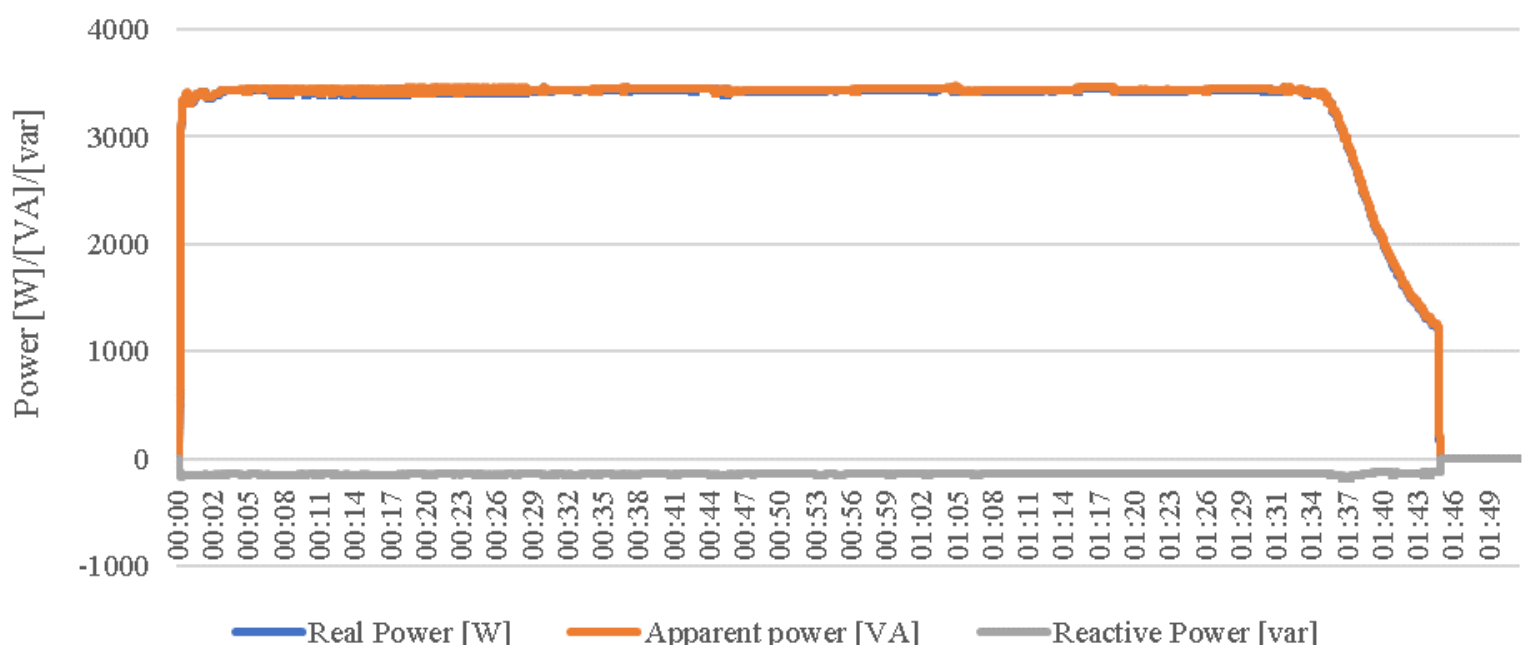

Figure 5: Charging measurement for an Opel Ampere from 2013

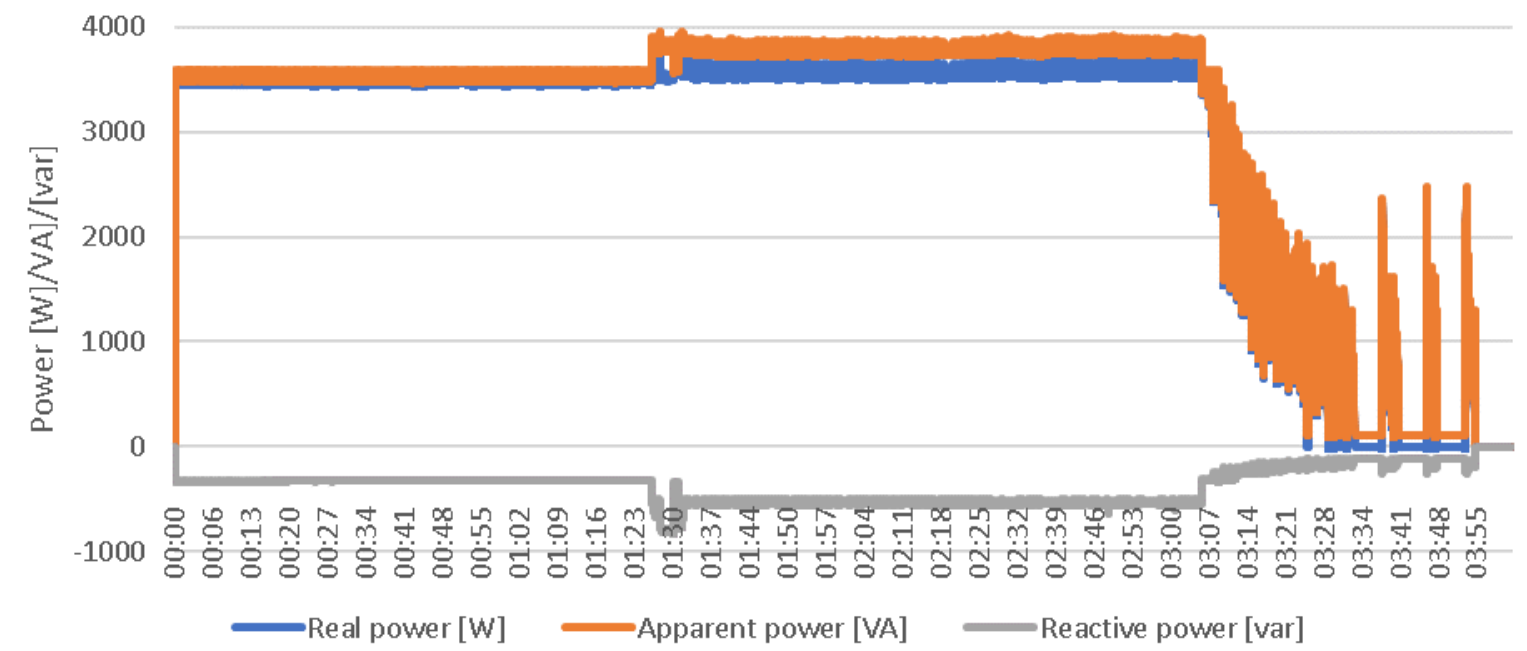

Figure 6: Charging behavior of a Nissan Leaf from 2015

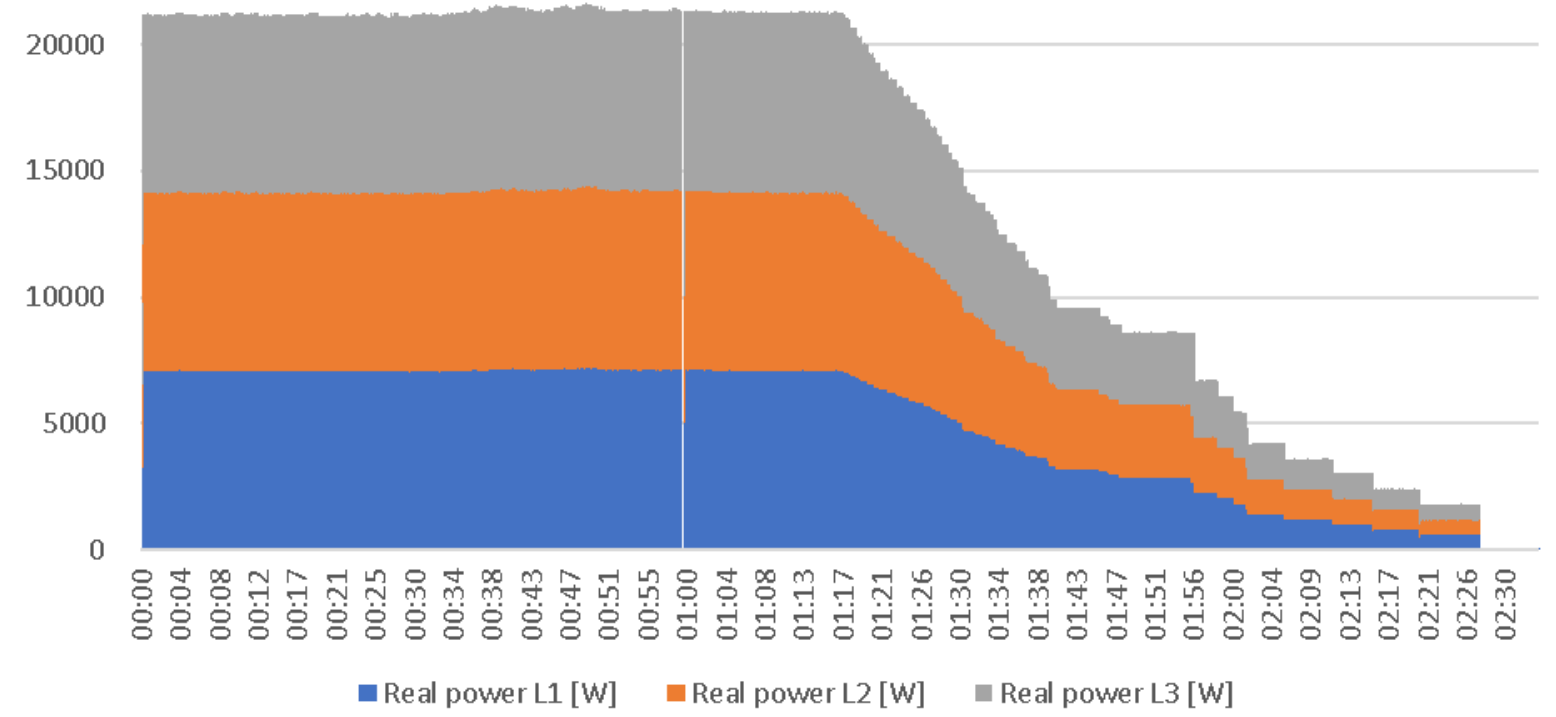

Figure 7: Charging behavior for a Renault Zoe from 2017 that uses three phases 


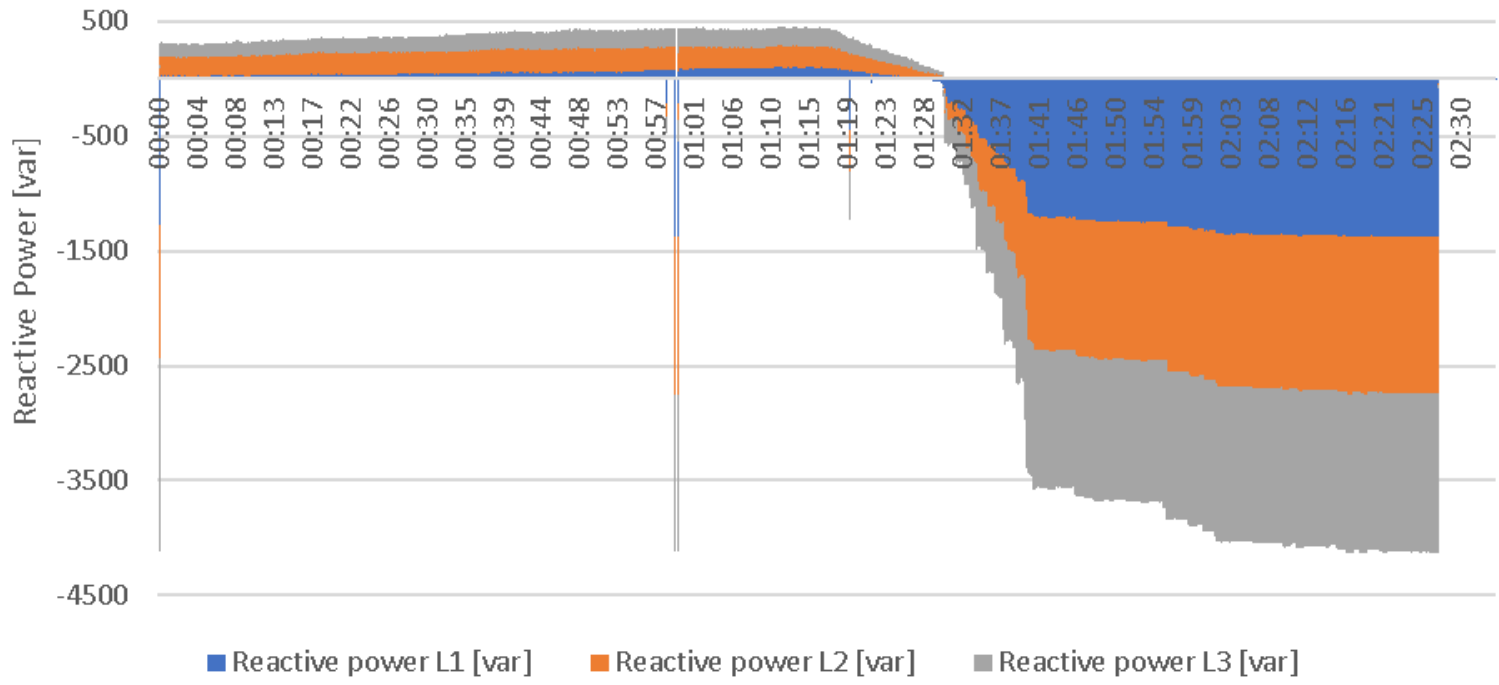

Figure 8: Reactive Power of the charging process for a Renault Zoe from 2017

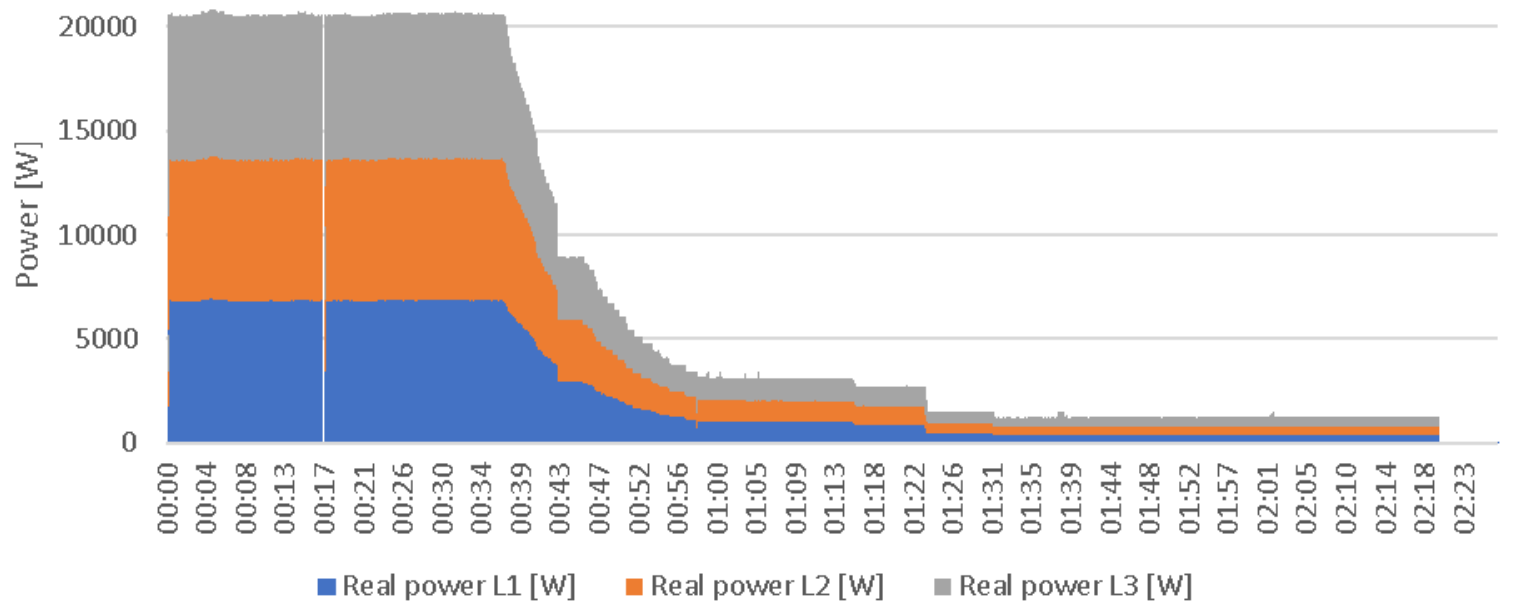

Figure 9 : Real power from the charging process of a Renault Zoe from 2014

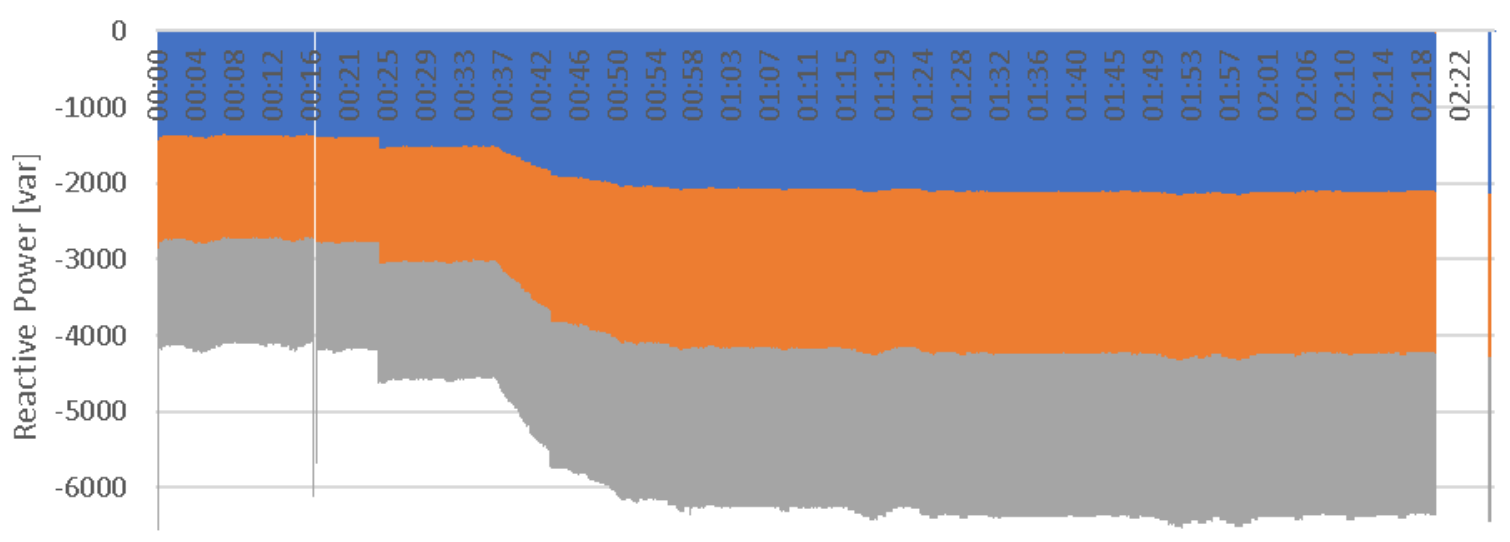

$-7000$

- Reactive power L1 [var] $\quad$ Reactive power L2 [var] $\quad$ Reactive power L3 [var]

Figure 10: Reactive power from the charging process of a Renault Zoe from 2014 


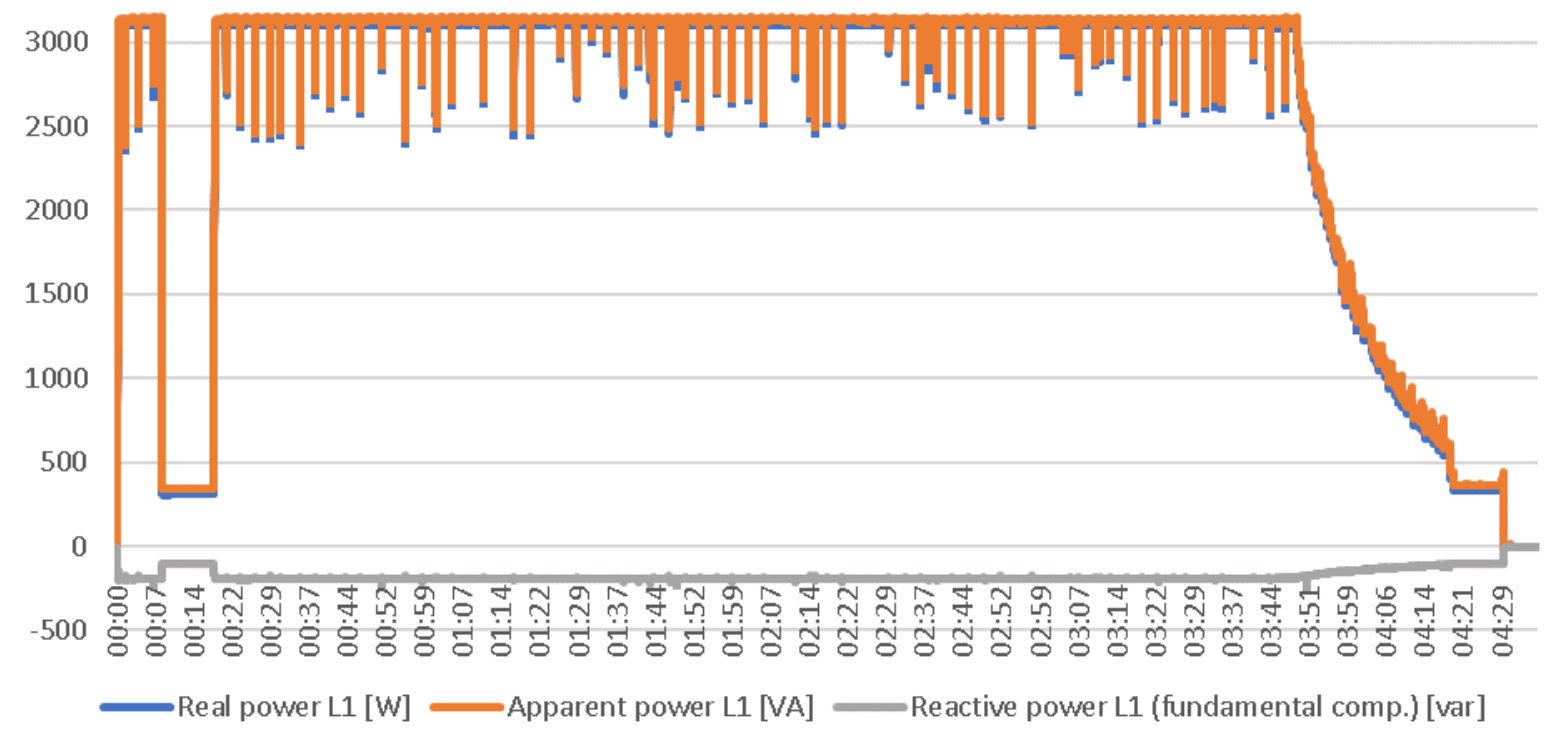

Figure 11: Charging behavior of a Citroen C-Zero from 2016

\section{Results}

Due to the increasing sector coupling, the interaction between PV-Systems, electric cars and battery systems become increasingly relevant. In many cases, smart grid algorithms are not validated with good availability and demand profiles of electric cars though. This research provides an easy and convenient method to generate realistic and highly detailed profiles, which include details such as vacations, sickness, rotating shift workers and many more details.

Figure 12 and Figure 13 show two different examples of charging availability profiles. Figure 12 shows the profile of a simplified single office worker with a very regular lifestyle, a single trip in the evening each week to the fitness studio and a shopping trip each Saturday. Also visible are the vacations around Christmas/New Year and the summer vacation. As charging algorithm, a simple "plug in as soon as home" is used. A daily distance of about $50 \mathrm{~km}$ and a charging power of $3.7 \mathrm{~kW}$ is assumed. The diagram shows that the charging is mostly done in the early afternoon and the car would be available for $\mathrm{V} 2 \mathrm{G}$-applications most of the night.

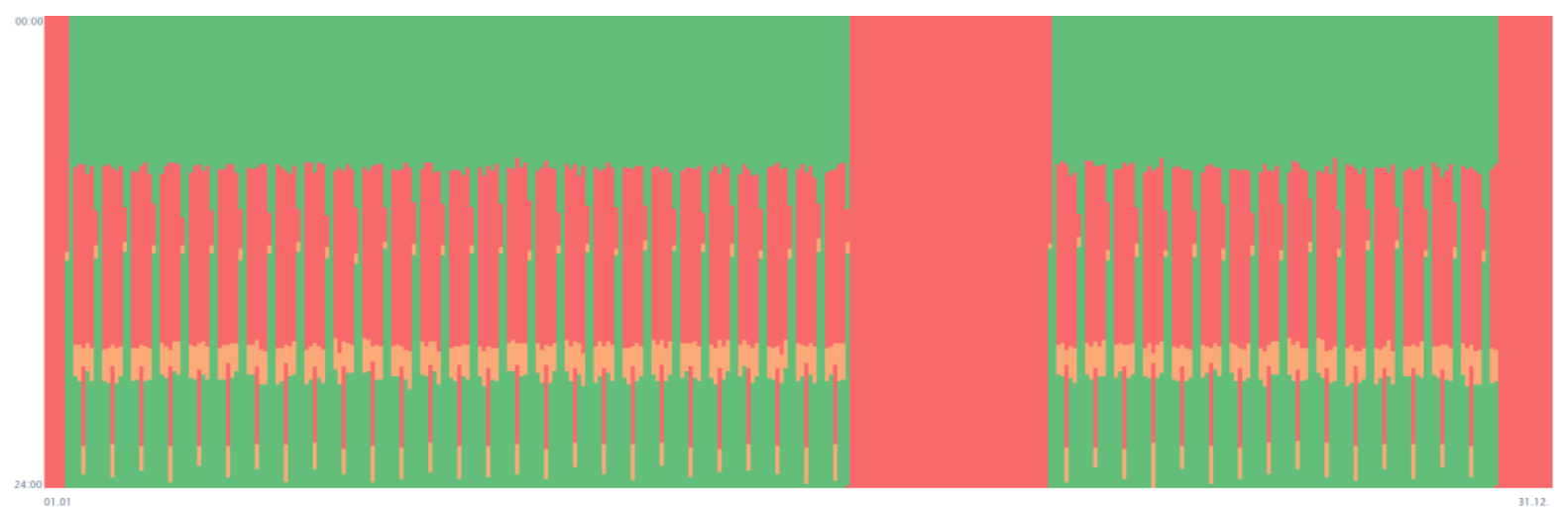

Figure 12: Charging state of the car of a simplifed office worker profile. Red is defined as "away from home", orange means "the car is charging", and green means "the car is available for charging but the battery is full". 


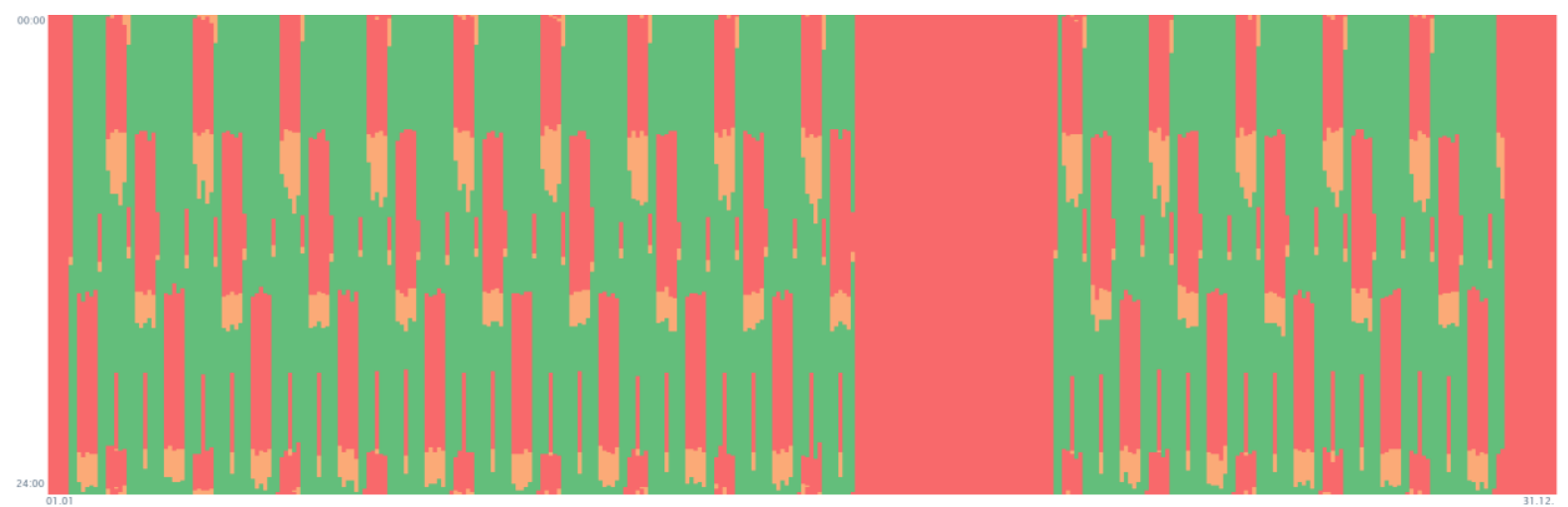

Figure 13: Charging state of the car of a simplified three shift worker profile. Red means away from home, orange means that the car is charging, and green means the car is available for charging but the battery is full.

Figure 13 shows the charging availability for a simplified single shift worker. The same parameters as before were used. It is visible that here the car is also mostly at home and available for V2G-services for example. The averaged yearly charging profiles for both cases are shown in Figure 14. It is visible that the charging behavior varies strongly between the two cars and the charging times of the shift worker match much better with a photovoltaic charging profile.
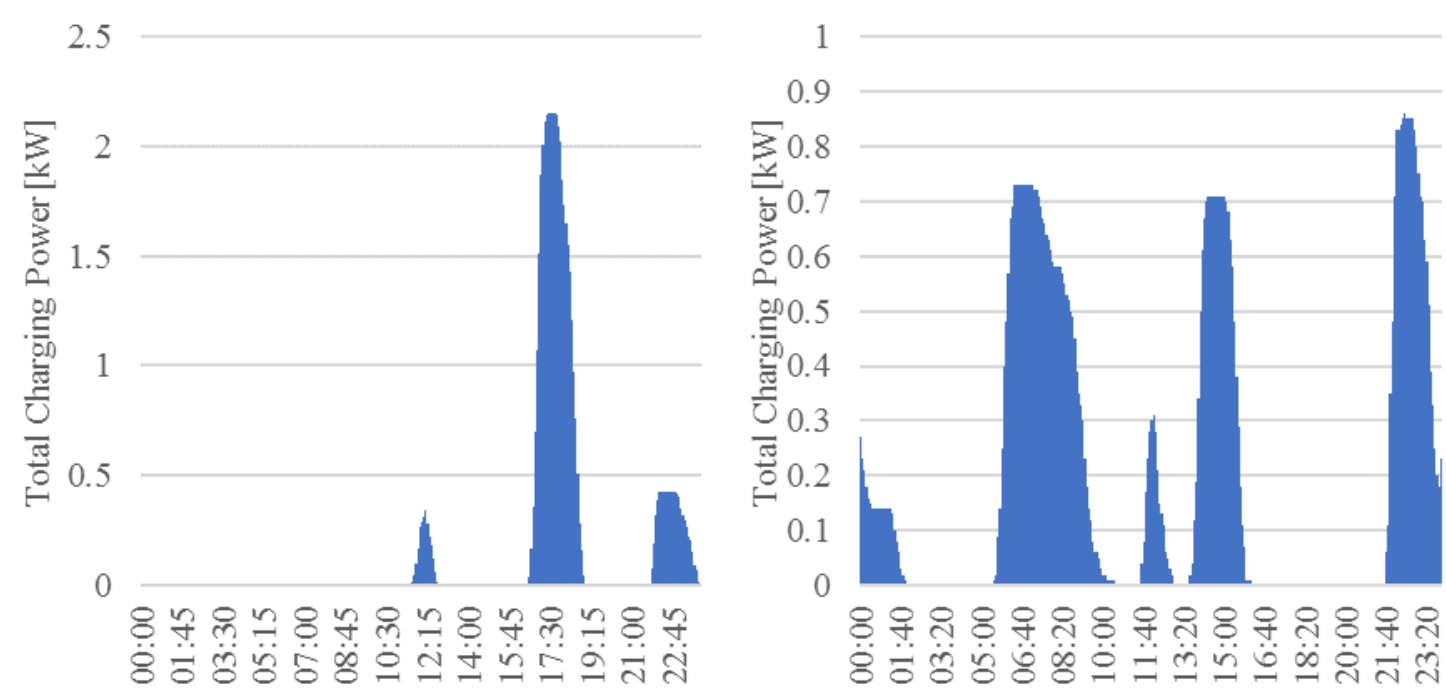

Figure 14: Averaged charging profiles of the two cases for one year. On the left the office worker is shown and on the right the shift worker.

One important conclusion is that the availability of the car für charging depends very strongly on the lifestyle of the car owner. In general, the car of employees tends to be at home around 70-80\% of the time, but especially for office workers, the car is rarely home at the time when the most photovoltaic energy is available, which makes charging from the residential PV-System very difficult. For shift workers, the situation is much better. Thus, for minimizing buffer energy storage needs, workplace charging is essential to any future energy system with high PV and high electromobility penetration.

\section{Acknowledgement}

This research project is financed by the Swiss Federal Office for Energy (SFOE). We also thank the Swiss Centre for Competence in Energy Research on the Future Swiss Electrical Infrastructure (SCCER-FURIES), which is financially supported by the Swiss Innovation Agency (Innosuisse - SCCER program). We also gratefully acknowledge funding from Bern University of Applied Sciences BFH, Burgdorf, Switzerland. 


\section{References}

Fischer, D., Hambrecht, A., Surmann, A., McKenna, R., 2019. Electric vehicles' impacts on residential electric local profiles-A stochastic modelling approach considering socio-economic, behavioural and spatial factors. Applied Energy 233, 644-658.

García-Villalobos, J., Zamora, I., P. Eguia, J. I. San Martín, F. J. Asensio, 2014. Modelling social patterns of plugin electric vehicles drivers for dynamic simulations, in: 2014 IEEE International Electric Vehicle Conference (IEVC), pp. 1-7.

Munkhammar, J., Widén, J., Rydén, J., 2015. On a probability distribution model combining household power consumption, electric vehicle home-charging and photovoltaic power production. Applied Energy 142, $135-143$.

Pflugradt, N., 2016. Modellierung von Wasser und Energieverbräuchen in Haushalten.

Pflugradt, N., 2017. LoadProfileGenerator. http://www.loadprofilegenerator.de.

Wang, H., Zhang, X., Ouyang, M., 2015. Energy consumption of electric vehicles based on real-world driving patterns: A case study of Beijing. Applied Energy 157, 710-719.

Wolbertus, R., Kroesen, M., van den Hoed, R., Chorus, C., 2018. Fully charged. An empirical study into the factors that influence connection times at EV-charging stations. Energy Policy 123, 1-7. 


\title{
Multiobjective Synthesis of a Polygeneration System for a Residential Building Integrating Renewable Energy and Electrical and Thermal Energy Storage
}

\author{
Edwin S. Pinto, Luis M. Serra \\ GITSE I3A, Department of mechanical engineering, University of Zaragoza, Spain
}

\begin{abstract}
The residential sector plays an important role in the action to combat climate change and its impacts. Recent studies show that the integration of thermal and electrical systems allows to increase the share of renewable energy, and the reduction of $\mathrm{CO}_{2}$ emissions. Polygeneration systems lead to a reduction of economic costs and $\mathrm{CO}_{2}$ emissions with respect to the separate production of energy services, thanks to an adequate systems integration. Achieving such benefits requires an appropiate design procedure bearing in mind that the minimization of the economic costs is often opposite to the minimization of the environmental impact. The aim of this paper is to carry out the synthesis of a polygeneration system for a residential building located in Zaragoza (Spain) encompassing renewable energy, thermal energy storage and batteries, considering economic and environmental aspects. A mixed integer linear programming (MILP) model has been developed to obtain tradeoff solutions through the multiobjective optimization in two cases: grid connected and standalone systems. In both cases, five configurations of commercially available equipment were obtained, finding interesting solutions where significant $\mathrm{CO}_{2}$ emissions reduction were achieved with a small increasing in the economic cost.
\end{abstract}

Keywords: Representative days, multiobejective optimization, polygeneration systems, MILP.

\section{Introduction}

A suitable energy process integration in polygeneration systems allows an effective way to achieve a lower consumption of natural resources, a reduction of $\mathrm{CO}_{2}$ emissions and pollutant emissions as well as economic savings relative to conventional separate production (Mancarella, 2014). To achieve it, two fundamental issues must be addressed in the design of polygeneration systems (Pina et al., 2017; Wakui and Yokoyama, 2015): the synthesis of the plant configuration (installed technologies and capacities, etc.) and the operational planning (strategy concerning the operational state of the equipment, energy flow rates, purchase/selling of electricity, etc.). However, finding the optimal configuration of polygeneration systems in building applications is a complex task, given the wide variety of technology options available and great diurnal and annual fluctuations in energy demands and energy prices (Tapia-Ahumada et al., 2013). Additional factors that increase the complexity are: (i) the incorporation of renewable energy technologies, such as wind turbines, photovoltaic panels and solar thermal collectors, which are characterized by intermittent behavior and non-simultaneity between production and consumption; (ii) the incorporation of energy storage, either electrical and/or thermal, which allow to decouple production from consumption; and (iii) conflicting objectives, as the minimization of environmental and economic costs. Therefore, a MILP has been developed to tackle such issues focused in the multiobjective synthesis of a polygeneration system for a residential building located in Zaragoza (Spain) integrating electrical and thermal systems, driven by conventional and renewable energies for two cases: Grid connected and standalone systems. To do this, firstly, a set of representative days, in order to reduce the computational effort, is selected considering the energy demands, renewable energy production and $\mathrm{CO}_{2}$ emissions, then the superstructure is defined considering the candidate technologies to cover the energy demands. Afterwards, the MILP model developed to carry out the multiobjective optimization is presented and finally, the trade-off solutions through the Pareto curve for both cases are analyzed.

\section{Description of the system}

A multifamily building composed of 12 dwellings, each one with $102.4 \mathrm{~m}^{2}$ of surface area and an average occupancy of 3 people per dwelling located in Zaragoza-Spain is studied. The annual space heating $S H_{d}$, and 
cooling $R_{d}$ demands are respectively $49,889 \mathrm{kWh}$ and $14,008 \mathrm{kWh}$, corresponding to 41 and $11 \mathrm{kWh} / \mathrm{m}^{2}$ respectively according to IDAE (2009). Their hourly distribution is calculated by applying the degree days method and an hourly function distribution (Ramos, 2012). Heating degree days (HDD) and cooling degree days $(C D D)$ are calculated with base temperatures $T_{b h}=15^{\circ} \mathrm{C}$, for space heating and $T_{b c}=21{ }^{\circ} \mathrm{C}$, for cooling. These values were selected as being suitable for Spain (Valor, E., Meneu, V., Caselles, 2001). Ambient temperature data $\left(T_{a m b}\right)$, and the required climatic data, are obtained from the meteonorm database (Meteotest, 2017). In the case of domestic hot water (DHW), the total annual consumption of $367.9 \mathrm{~m}^{3}$ (IDAE, 2017), which is monthly distributed by applying a distribution factor (Viti, 1996). The energy required to heat the monthly volume of water is calculated considering the water network supply temperature (AENOR, 2005) and the required DHW temperature of $60^{\circ} \mathrm{C}$ established in the Spanish regulation (IDAE, 2017). Monthly energy is divided by days of the month and distributed by means of an hourly distribution function (Ramos, 2012). This procedure assumes that the hourly DHW energy demand $Q_{D H W}$ is the same for every day of the month. In the case of electricity demand, the annual electricity demand for appliances and lighting is $35,267 \mathrm{kWh}$ according to IDAE (2011a) which is monthly distributed by applying a distribution factor, which is divided by the days of the month and distributed by an hourly distribution function (Marín-Giménez, 2004), that considers different hourly consumption for each season, thus providing the hourly electricity demand $E_{d}$. The procedures briefly described above, provide the hourly demand data series of heating $\left(Q_{d}\right)$, cooling $\left(R_{d}\right)$ and electricity $\left(E_{d}\right)$, where heating demand consists of space heating $\left(S_{d}\right)$ and DHW $\left(Q_{D H W}\right)$.

Available renewable energy resources are calculated beforehand. Hourly energy production per square meter of photovoltaic, $\mathrm{E}_{\mathrm{PV}}$, and solar thermal, $\mathrm{E}_{\mathrm{ST}}$, are calculated using data manufacturers, according to the procedures described in (Duffie and Beckman, 2013). For photovoltaic technology PV, it has been considered polycrystalline modules of $255 \mathrm{Wp}$ with the maximum point power efficiency $\eta_{m p}=0.1566$ and the temperature coefficient of open-circuit voltage $\mu_{V o c}=-0.32 \% /{ }^{\circ} \mathrm{C}$ (Atersa, 2017). In the case of solar thermal ST, collectors with optical efficiency $\eta_{o}=0.801$, and $1^{\text {st }}$ and $2^{\text {nd }}$ order heat loss coefficients of $a_{1}=3.188 \mathrm{~W} / \mathrm{m}^{2} \cdot \mathrm{K}, a_{2}=0.011 \mathrm{~W} / \mathrm{m}^{2} \cdot \mathrm{K}^{2}$ (Salvador Escoda S.A, 2017). For both PV and ST, the production has been calculated as a function of the solar radiation $G_{T}$ over a tilted surface at $36^{\circ}$ and azimuth angle of $0^{\circ}$ (Meteotest, 2017). Restriction due to shading is considered by applying the procedure described in (IDAE, 2011b). The area required to install PV and ST collectors is limited by the total area available in the multifamily building $400 \mathrm{~m}^{2}$. For wind energy technology PW, the production $\mathrm{E}_{\mathrm{PW}}$ has been calculated as a function of wind speed obtained from (Meteotest, 2017) and the production curve of a wind turbine of $3 \mathrm{~kW}$ of nominal capacity (Bornay, 2017) according to the procedure described in Manwell et al. (2009).

\subsection{Selection of representative days}

The timeframe of this case of study is one year, nevertheless, carrying out the optimization of dynamic energy systems by using hourly data for a whole year can become a computational demanding task, mainly when integer variables are involved. To tackle this issue, some strategies have been developed to define representative days (Domínguez-Muñoz et al., 2011; Poncelet et al., 2017), which allow to reproduce in a reasonable way the original data series of a whole year. To do this, every data series of energy demands and renewable energy production have to be considered simultaneously as well as $\mathrm{CO}_{2}$ emissions data series (in particular for the hourly $\mathrm{CO}_{2}$ emissions associated to the electricity consumed in the case of grid connected system) in order to match every hourly data considered in the optimization process. Hourly $\mathrm{CO}_{2}$ emissions from the grid were collected from Red Electrica de España (2017) where are available in a time scale of 10 minutes; however, as the analysis is carried out hourly, it has been taken the average hourly to this study. Besides, year 2016 had 366 days so the 29 February data have not been considered. In the standalone system, data collection of $\mathrm{CO}_{2}$ emissions is not required because these are only caused by the conventional equipment operation. In this study, we applied the $k$-medoid method (Domínguez-Muñoz et al., 2011) to select a set of twelve representative days $\left(N_{\text {rep }}=12\right)$ to carry out the multiobjective optimization. Tab. 1 presents the representative days $d$ along with their respective weights $\omega$, which represents the number of times that has to be repeated $d$ to approach to the original data series.

Tab. 1. Representative days

\begin{tabular}{|c|c|c||c|c|c||c|c|c|}
\hline Month & $\boldsymbol{d}$ & $\boldsymbol{\omega}$ & Month & $\boldsymbol{d}$ & $\boldsymbol{\omega}$ & Month & $\boldsymbol{d}$ & $\boldsymbol{\omega}$ \\
\hline January & 5 & 21 & May & 150 & 36 & October & 299 & 31 \\
\hline February & 38 & 35 & July & 186 & 54 & November & 329 & 27 \\
\hline April & 116 & 40 & July & 191 & 26 & December & 344 & 24 \\
\hline May & 147 & 31 & July & 208 & 19 & December & 351 & 21 \\
\hline
\end{tabular}


Scale factors were calculated and applied to the representative data to preserve the total energy demands, renewable energy production and $\mathrm{CO}_{2}$ emissions from the original data series without exceeding the extreme values. In addition, normalized root-mean-square error (NRMSE) which represents the distribution of values and their frequency of occurrence for every duration curve were calculated in order to verify the accuracy of the representative data. The NRMSE has been calculated for each data series and it has been verified to be below 5\%, which are considered appropriated in accordance with similar works such as Poncelet et al., (2017). On the other hand, two additional days corresponding to heating and cooling extreme demands are taken into account with weight zero in order to assure the coverage of the energy services in all circumstances, with the corresponding impact on the annual fixed cost, but not on the annual operation cost.

\subsection{Superstructure definition including technical, economic and environmental data}

The superstructure depicted in the Fig. 1, considers the candidate technologies and the feasible connections between them in the polygeneration system for both cases: grid connected and standalone. The system is composed of an electrical and thermal part. The electrical part consists of photovoltaic modules PV whose electrical production $W_{P V}$ is a function of the modules area APv; wind turbines WT whose electrical production $W_{W}$ is the result of the unit production $\mathrm{E}_{\mathrm{PW}}$ multiplied by the number of turbines; inverter Inv which converts the direct current produced from renewable energy to alternating current, batteries Bat which can store electric energy and inverter-charger InvC which converts alternating current to direct current and conversely. The thermal part consists of conventional boiler GB that consumes fossil fuel $F_{b}$ to produce heat; solar thermal collectors ST whose heat production $Q_{S T}$ is a function of the area $\mathrm{A}_{\mathrm{ST}}$; a single-effect absorption chiller ACH that uses heat and a small quantity of electricity to produce cooling; and finally thermal energy storage for heating TSQ and cooling TSR, which can charge/discharge thermal energy. Components such as cogeneration module CM, converting the energy of fossil fuels $F_{c}$ into electricity $W_{c}$ and heat $Q_{c}$, and reversible heat pumps HP, converting the electrical energy $E_{H P}$ into thermal energy either heating $Q_{H P}$ or cooling $R_{H P}$, allow the integration of electric and thermal parts.

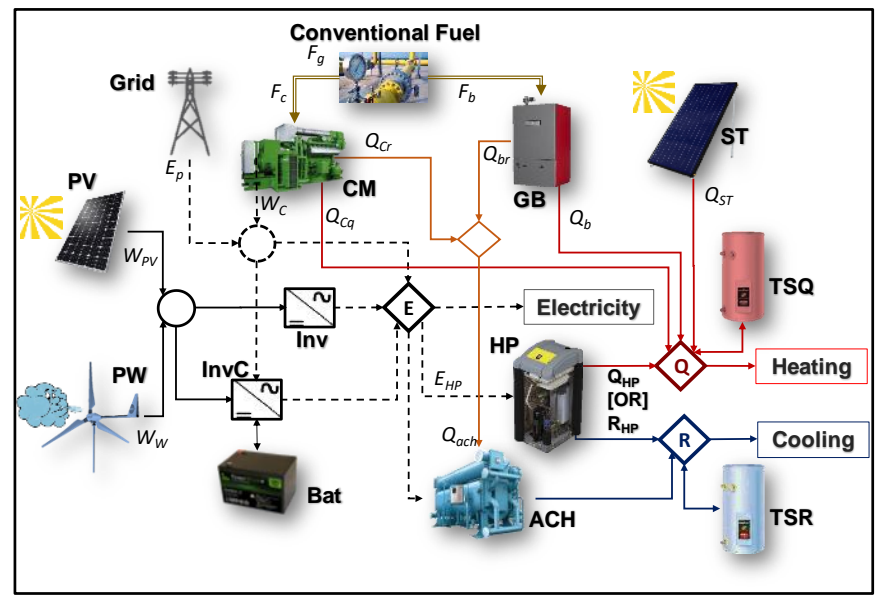

Fig. 1. Superstructure

From the point of view of operation, the electrical part considers a three-phase alternating current bus (ac-bus) with an operating voltage $V_{a c}$ of $230 \mathrm{~V}$ and a direct current bus (dc-bus) with an operating voltage $V_{d c}$ of $96 \mathrm{~V}$ with a maximum operating current $I_{m a x-d c}$ of $120 \mathrm{~A}$. For the thermal part, a low temperature radiant heating indoor end system was considered, with operation temperatures about of $45^{\circ} \mathrm{C}$, in addition, temperatures about $60{ }^{\circ} \mathrm{C}$ are required for DHW. The required thermal energy for space heating and DHW can be provided by the heat pumps, solar thermal collectors, cogeneration module and boiler. In the case of cooling demands, temperatures of about $7-12{ }^{\circ} \mathrm{C}$ are considered, and the required energy can be provided by the reversible heat pumps and the absorption chiller. The activation temperature for the absorption chiller is about $88^{\circ} \mathrm{C}$, which thermal energy is produced in the boiler and/or the cogeneration module. Reversible heat pumps can operate in heating or cooling mode, but it is not allowed their operation simultaneously in both modes. The operation ranges of temperature and voltage are verified for all the components in the system according to manufacturers' catalogues.

\section{Technical data}

All technologies considered in the superstructure are commercially available. Main technical parameters obtained from the manufacturers' catalogues are shown in Tab. 2. The equipment can modulate up to nominal load, except 
for the non-manageable ones (PV, ST and PW), cogeneration module CM and batteries. Heat pump operates in heating mode assuming a constant coefficient of performance COP, or in cooling mode assuming a constant Energy Efficiency Ratio EER with a constant cooling/heating capacity ratio $\beta$. Both COP and EER have been estimated considering the operational temperature of the reservoirs expected for Zaragoza (Spain). In the case of the $\mathrm{CM}$, reciprocating engines are not allowed to work below $30 \%$ of the nominal capacity, and the electrical and thermal productions are proportional to $\alpha_{\mathrm{w}}$ and $\alpha_{\mathrm{q}}$ factors respectively. For the inverter and inverter-charger, an oversizing factor $F_{i n v}$ is applied to size their capacity, and efficiency $\eta$ is applied to consider their performance. Single effect absorption chiller operates with a constant $\mathrm{COP}_{\mathrm{ACH}}$. The performance $\eta_{\mathrm{GB}}$ of conventional boiler is assumed constant. Regarding thermal energy storage tanks, the energy stored $S_{q}$ and $S_{r}$ for heating and cooling respectively, are calculated in each time step taking into account the energy losses by applying a $\lambda$ factor. In the case of batteries, the round trip efficiency $\eta_{r t}$, determines the energy losses during the charging and discharging process in each time step. Charging and discharging processes are not allowed simultaneously either in thermal energy storage tanks or in batteries. Further, maximum deep of discharge $D O D$ is defined for batteries to avoid premature failures. During the batteries lifetime operation, the number of charge-discharge cycles has to be lower than the maximum number of cycles that provoke the failure $N_{c, \text { failure }}$, indicated by the manufacturer. This is verified by applying the equivalent full cycle to failure ageing method described by Dufo-López et al. (2014). There are two technologies for batteries proposed for this study, ion lithium and lead acid, but in the optimal configuration, only one of them is selected. Models of capacity $q$, are applied to calculate their dynamic behaviour in the equipment. Ion lithium batteries capacity $q_{i o n}$, are modelled according to DiOrio et al., (2015), taking into account both, the maximum charge current $I_{m a x, c}$ stablished by manufacturer and the charge ratio $\alpha_{c}$ in A/Ah described by Homer Energy (2016). For lead acid batteries, the technology used for this study is the OPz batteries applying the KiBaM model (Manwell and McGowan, 1993), which requires three parameters, calculated on the basis of manufacturers' data catalogues: $k$, the rate constant; $c$, the fraction of the capacity that may hold available charge; and the maximum capacity of the battery $q_{\max }$, as a function of $k$ and $c$. Taking into account that this study is based on representative days, for both, thermal and electrical storage, the energy stored at the beginning of each representative day must be equal to the energy stored at the end of each representative day.

\section{Economic data}

The investment cost of every component is calculated from the unit cost $C u$ and the installed capacity. Installation and maintenance costs are considered by applying the factor $F_{m}$. In order to calculate the fixed annual cost, a Capital Recovery Factor $C R F=0.082 \mathrm{yr}^{-1}$ is applied based on a lifetime of the installation of 20 years and an interest rate $r=5 \%$. However, some components have different lifetime $n_{r}$, hence, a net present value factor FNPV is calculated for every component to consider the total repositions carried out during the lifetime of the installation. The indirect costs are considered by applying a factor $F_{\text {ind }}$ of 0.2 . For all investments, the ValueAdded Tax VAT, is applied, whose value for Spain case is 0.21. All economic data are shown in Tab. 2.

In grid connected case, the polygeneration system has the possibility of selecting the required contracted power from the grid Pct below $15 \mathrm{~kW}$, with a cost of cPct of $44.76 € / \mathrm{kW}$. A time-of-use tariff has been applied with three time periods with different cost of electricity purchased $\mathrm{cp}_{i}$ : i) $0.195302 € / \mathrm{kWh}$ from 14 to 23 hours; ii) 0.123573 $€ / \mathrm{kWh}$ at 1 hour, 24 hour and from 8 to 13 hours; and iii) $0.0091957 € / \mathrm{kWh}$ from 2 to 7 hours. These tariffs apply for both winter and summer (Endesa, 2017). Also it has been considered a meter equipment rental cost $C_{a l q}$ of $16.32 € /$ yr and the electricity tax of $\operatorname{Tax}_{e}=0.05113$.

The natural gas $N G$ contract depends on annual gas consumption. For our study, the tariff 3.2, which annual consumption must be below 50,000 kWh/yr has been considered. This has a fixed cost $C_{f g}$ of $101.4 € / \mathrm{yr}$ and a constant price $c p_{N G}$ of $0.04328 € / \mathrm{kWh}$ (Endesa, 2017). Further, a meter equipment rental cost $C_{a l q-g}$ of $15 € / \mathrm{yr}$ is considered. In the case of standalone system only gasoil for heating $G H$ with fixed price $c p_{G H}$ of $0.0613 € / \mathrm{kWh}$ (Eurostat, 2017) has been considered.

\section{Environmental data}

In order to evaluate the environmental impact of the polygeneration system, it has been considered the unit $\mathrm{CO}_{2} \mathrm{eq}$ emissions embodied $\mathrm{CO}_{2} \mathrm{U}$ in every component of the superstructure based on the life cycle assessment $L C A$ of every component (see Tab. 2), the $\mathrm{CO}_{2}$ emissions released due to the natural gas combustion considering a constant value of $0.252 \mathrm{kgCO}_{2} \mathrm{eq} / \mathrm{kWh}$ (IDAE, 2016) and the hourly $\mathrm{CO}_{2}$ emissions due to electricity consumption from the grid (Red Electrica de España, 2017). In the case of standalone system, $\mathrm{CO}_{2}$ emissions released due to the gasoil combustion were calculated considering a constant value of $0.311 \mathrm{kgCO}_{2} \mathrm{eq} / \mathrm{kWh}$ (IDAE, 2016). 
Tab. 2. Technical, economic and environmental data

\begin{tabular}{|c|c|c|c|c|c|c|}
\hline \multirow{2}{*}{$\underset{j}{\text { Component }}$} & \multirow[b]{2}{*}{ Technical data } & \multicolumn{3}{|c|}{ Economic data } & \multirow{2}{*}{$\begin{array}{l}\text { Environmental data } \\
\mathrm{CO}_{2} \mathrm{U}\left[\mathrm{kgCO}_{2} \mathrm{eq} /{ }^{*}\right]\end{array}$} & \multirow[b]{2}{*}{ References } \\
\hline & & $\mathrm{Cu}[€ / *]$ & Fm & $\begin{array}{l}\mathbf{n}_{\mathbf{r}} \\
\text { [Years] }\end{array}$ & & \\
\hline PV & $\begin{aligned} \eta_{m p} & =15.66 \% \\
\mu_{V o c} & =-0.32 \% /{ }^{\circ} \mathrm{C}\end{aligned}$ & $113.4 € / \mathrm{m}^{2}$ & 0.5 & 20 & $161 \mathrm{kgCO}_{2} \mathrm{eq} / \mathrm{m}^{2}$ & $\begin{array}{l}\text { (Ardani et al., 2016; Atersa, 2017; } \\
\text { Frischknecht et al., 2015; Fthenakis and } \\
\text { Raugei, 2017; JUDELSA, 2017) }\end{array}$ \\
\hline PW & Manufacturer curve & $6404 € /$ ud & 2 & 20 & $2160 \mathrm{kgCO}_{2} \mathrm{eq} / \mathrm{ud}$ & $\begin{array}{l}\text { (Bornay, 2017; Orrell and Poehlman, } \\
\text { 2017; Tremeac and Meunier, 2009) }\end{array}$ \\
\hline ST & $\begin{array}{c}\eta_{o}=0.801 \\
a_{1}=3.188 \mathrm{~W} / \mathrm{m}^{2} \mathrm{~K} \\
a_{2}=0.011 \mathrm{~W} / \mathrm{m}^{2} \mathrm{~K}^{2}\end{array}$ & $254 € / \mathrm{m}^{2}$ & 1.5 & 20 & $95 \mathrm{kgCO}_{2} \mathrm{eq} / \mathrm{m}^{2}$ & $\begin{array}{l}\text { (Guadalfajara, 2016; IDAE, 2011c; } \\
\text { SALVADOR ESCODA S.A, 2017) }\end{array}$ \\
\hline GB & $\eta_{\mathrm{b}}: 0.96$ & $80 € / \mathrm{kWt}$ & 0.5 & 15 & $10 \mathrm{kgCO}_{2} \mathrm{eq} / \mathrm{kWt}$ & (BAXI, 2017; Pina et al., 2017) \\
\hline HP & $\begin{array}{c}\mathrm{COP}=3.0, \mathrm{EER}=4.0 \\
\beta=0.9\end{array}$ & $500 € / \mathrm{kW}$ & 0.5 & 20 & $160 \mathrm{kgCO}_{2} \mathrm{eq} / \mathrm{kWt}$ & $\begin{array}{l}\text { (Beccali et al., 2016; ENERTRES, 2017; } \\
\text { Pina et al., 2017) }\end{array}$ \\
\hline $\mathrm{ACH}$ & $\mathrm{COP}_{\mathrm{ACH}}=0.7$ & $485 € / \mathrm{kWt}$ & 1.5 & 20 & $165 \mathrm{kgCO}_{2} \mathrm{eq} / \mathrm{kWt}$ & $\begin{array}{l}\text { (Beccali et al., 2016; Pina et al., 2017; } \\
\text { U.S. Department of Energy, 2017) }\end{array}$ \\
\hline $\mathrm{CM}$ & $\alpha_{w}=0.28, \alpha_{q}=0.56$ & $1150 € / \mathrm{kW}$ & 0.7 & 10 & $65 \mathrm{kgCO}_{2} \mathrm{eq} / \mathrm{kWe}$ & (Darrow et al., 2017; Pina et al., 2017) \\
\hline TSQ & $\lambda=1 \%$ & $376 € / \mathrm{kWh}$ & \multirow{2}{*}{0.1} & \multirow{2}{*}{15} & $31 \mathrm{kgCO}_{2} \mathrm{eq} / \mathrm{kWht}$ & \multirow{2}{*}{$\begin{array}{c}\text { (BAXI, 2017; Beccali et al., 2016; ISSF, } \\
\text { 2015) }\end{array}$} \\
\hline TSR & $\lambda=3 \%$ & $752 € / \mathrm{kWh}$ & & & $62 \mathrm{kgCO}_{2} \mathrm{eq} / \mathrm{kWht}$ & \\
\hline Bat Ion-Li & $\begin{array}{l}\eta_{\mathrm{rt}}=90 \% ; D O D=80 \% \\
N_{c, \text { failure }}=8000 ; \alpha_{\mathrm{c}}=0.4\end{array}$ & $500 € / \mathrm{kWh}$ & 0.25 & 15 & $160 \mathrm{kgCO}_{2} \mathrm{eq} / \mathrm{kWh}$ & $\begin{array}{c}\text { (Cho et al., 2015; Parra et al., 2017; Peters } \\
\text { et al., 2017) }\end{array}$ \\
\hline $\begin{array}{l}\text { Bat Lead } \\
\text { Acid }\end{array}$ & $\begin{array}{c}\eta_{\mathrm{rt}}=70 \% ; D O D=60 \% ; \\
N_{c, \text { failure }}=2000 ; k=0.11, \\
\quad c=0.53\end{array}$ & $220 € / \mathrm{kWh}$ & 0.25 & 7 & $60 \mathrm{kgCO}_{2} \mathrm{eq} / \mathrm{kWh}$ & $\begin{array}{c}\text { (Cho et al., 2015; Hiremath, Mitavachan \& } \\
\text { Derendorf, Karen \& Vogt, 2015; } \\
\text { McManus, 2012; Parra et al., 2017) }\end{array}$ \\
\hline Inv & \multirow{2}{*}{$\begin{array}{c}\eta_{\text {inv }}=96 \%, \eta_{\text {invc }}=94 \% \\
F_{\text {inv }}=1.2\end{array}$} & $400 € / \mathrm{kW}$ & 0.5 & 15 & $191 \mathrm{kgCO}_{2} \mathrm{eq} / \mathrm{kW}$ & \multirow{2}{*}{$\begin{array}{l}\text { (Ardani et al., 2016; Frischknecht et al., } \\
\text { 2015; Fthenakis and Raugei, 2017; Fu et } \\
\text { al., 2017; JUDELSA, 2017) }\end{array}$} \\
\hline InvC & & $774 € / \mathrm{kW}$ & 0.25 & 15 & $191 \mathrm{kgCO}_{2} \mathrm{eq} / \mathrm{kW}$ & \\
\hline
\end{tabular}

\section{Optimization model}

A MILP model is developed using the software LINGO (LINDO Systems Inc, 2013) to carry out the multiobjective optimization. The two objective functions are: economic and environmental cost. In the case of the economic cost the objective is to minimize the total annual cost (eq. 1), consisting of the investment annual cost $C I A$, and operational costs $C_{o p}$.

$M I N=C I A+C_{o p}$

$C I A=(1+V A T) \cdot\left(1+F_{\text {ind }}\right) \cdot C R F \cdot \sum_{j=\text { component }} C u_{j} \cdot \operatorname{Cap}_{j} \cdot\left(1+F N P V_{j}\right)\left(1+F_{m_{j}}\right)$

$C_{o p}=C_{E}+C_{g}$

In the grid connected system the operational cost is composed of the annual electricity purchased $\operatorname{cost} C_{E}$ (eq. 4) (sell to the grid is not allowed) and the annual natural gas purchased cost $C_{g}$. The first term $C_{E}$, has a fixed cost $C_{f}$ (eq. 5) as a function of the contracted power from the grid $P c t$, which must be greater than the electricity purchased $E_{p}$ in any time $t$ (eq. 6) and a variable $\operatorname{cost} C_{v}$ calculated by (eq. 7) according to time-of-use tariff and the weight of each representative day $\omega_{d}$.

$C_{E}=\left(\left(C_{f}+C_{v}\right) \cdot\left(1+\operatorname{Tax}_{e}\right)+C_{a l q}\right) \cdot(1+V A T)$

$C_{f}=c P c t \cdot P c t$

$P c t(t) \geq E p(t)$

$C_{v}=\sum_{d=1}^{N_{r e p}} \omega_{d} \cdot\left(\sum_{t=1}^{24} c p_{i}(t) \cdot E p(t)\right)_{d}$

The annual gas purchased cost is calculated by (eq. 8). This is composed of two fixed costs namely, $C_{f g}$ and $C_{a l q-g}$, and a variable cost $C_{v g}$ (eq. 9 ) which is proportional to the natural gas consumption $F_{N G}$. In the case of standalone system there is not electricity consumption from the grid and $C_{g}$ refers only to the annual gasoil consumption in which there is not fixed cost associated, but variable cost $C_{v g}$ which is proportional to the gasoil consumption $F_{G H}$.

$C_{g}=\left(C_{f g}+C_{a l q-g}+C_{v g}\right)(1+V A T)$

$C_{v g}=\sum_{d=1}^{N_{r e p}} \omega_{d} \cdot\left(\sum_{t=1}^{24} c p_{N G / G H} \cdot F_{N G / G H}(t)\right)_{d}$ 
In the case of the environmental cost, the objective is to minimize the $\mathrm{CO}_{2}$ emissions (eq. 10). The environmental objective function is composed of a fixed part $\mathrm{CO}_{\text {fix }}$ corresponding to the $\mathrm{CO}_{2}$ emissions embodied in the components (eq. 11) and a variable part $\mathrm{CO}_{2}$ ope corresponding to the $\mathrm{CO}_{2}$ emissions due to the conventional fuel consumption and/or electricity consumption from the grid during the operation system (eq. 12).

$M I N=C O 2_{f i x}+C O 2_{\text {ope }}$

$C O 2_{f i x}=\sum_{j} C O_{2} U(j) \cdot C A P(j) \cdot\left(1+\operatorname{Repl}_{j}\right) / n y r$

$C O 2_{\text {ope }}=\sum_{d=1}^{N_{\text {rep }}} \omega_{d} \cdot\left(\sum_{t=1}^{24}\left(C O 2_{N G / G H} \cdot F_{N G / G H}(t)+C O 2_{\text {grid }}(t) \cdot E p(t)\right)\right)_{d}$

Repl is the number of replacements carried out during the lifetime of the installation for every component, $C O 2_{N G / G H}$ is the $\mathrm{CO}_{2}$ emissions associated to the combustion of the natural gas (grid connected system) or gasoil (standalone system) in $\mathrm{kgCO}_{2} \mathrm{eq} / \mathrm{kWh}$, and $\mathrm{CO}_{\text {grid }}(t)$ are the $\mathrm{CO}_{2}$ emissions associated to the electricity from the grid in each hour, in $\mathrm{kgCO}_{2} \mathrm{eq} / \mathrm{kWh}$.

Both, economic and environmental cost functions are minimized subject to:

Balance equations:

An energy balance is carried out in each node $m$ of the superstructure:

$\sum_{m}\left(E_{\text {in }}^{m}-E_{\text {out }}^{m}\right)=0$

Equipment efficiency:

GB: $\eta_{G B} \cdot F_{b}-Q_{b}=0$

HP: $Q_{H P}-E_{H P} \cdot C O P=0$

HP: $R_{H P}-E_{H P} \cdot E E R=0$

$\mathrm{CM}: \alpha_{w} \cdot F_{c}-W_{c}=0$

$\mathrm{CM}: \alpha_{q} \cdot F_{c}-Q_{c}=0$

$\mathrm{ACH}: R_{a c h}=C O P_{a c h} \cdot Q_{a c h}$

For each energy in-out through the inverter or inverter-charger $j$ :

$E_{\text {out }}-\eta_{j} \cdot E_{\text {in }_{j}}=0$

For thermal energy storages for heating ${ }_{q}$ and cooling $r$ :

$S_{q, r}(t)=S_{q, r}(t-1) \cdot \lambda_{q, r}+E_{\text {in }_{q, r}}-E_{\text {out }} q, r$

For batteries the charge efficiency $\eta_{c h}$, and discharge efficiency $\eta_{d i s}$ are considered for the charge $I_{c h}$ and discharge $I_{d i s}$ currents, and the charge $E_{b_{\text {in }}}$ and discharge $E_{b_{\text {out }}}$ energies:

$\eta_{r t}=\eta_{c h} \cdot \eta_{\text {dis }}$

$E_{b_{\text {in }}}(t) \cdot \eta_{c h}-I_{c h}(t) \cdot V_{d c} \cdot t=0$

$E_{b_{\text {out }}}(t)-\eta_{\text {dis }} \cdot I_{d i s}(t) \cdot V_{d c} \cdot t=0$

Equipment's capacities:

For renewable energy production components:

$\mathrm{PV}: W_{P V}=E_{P V} \cdot A_{P V}$

ST: $Q_{S T}=E_{S T} \cdot A_{S T}$

$\mathrm{PW}: W_{W}=E_{P W} \cdot N_{a e r}$

For each component $j$, the energy production is equal or lower than its nominal capacity. Thus, for heating $Q$, cooling $R$ or electricity $W$ production: 
$Q_{j} \leq \operatorname{Cap}_{j}$

$R_{j} \leq \operatorname{Cap}_{j}$

$W_{j} \leq \operatorname{Cap}_{j}$

For thermal energy storage for heating and cooling:

$S_{q, r} \leq \operatorname{Cap}_{T S Q, T S R}$

The capacity in $\mathrm{kWh}$ for batteries, is the product of the capacity $q$ in kAh multiplying by $V_{d c}$ :

$q_{b a t} \cdot V_{d c} \leq \operatorname{Cap}_{b a t}$

The capacity of the inverter and inverter-charger must be greater than the sum of all energy fluxes into the devices in any time $t$. As aforementioned, an oversizing factor $F_{i n v}$ is applied:

$F_{i n v} \cdot\left(\sum_{j=I n v, I n v C} E_{i n_{j}}(t)\right) \leq \operatorname{Cap}_{j}$

\section{Results and discussion}

The multiobjective optimization is carried out for the two systems aforementioned: grid connected and standalone. For both systems, the two objective functions (economic and environmental) were evaluated separately as a first step. Reference systems based on conventional equipment were considered to evaluate the advantage of the use of polygeneration systems. In these reference systems, heat pump HP is used only for cooling. Afterwards, multiobjective optimization is carried out based on $\varepsilon$-constraint procedure to construct the Pareto curve.

\subsection{Single Objective optimization}

In the grid connected system, electricity from the grid and natural gas are available for the system. The reference scenario does not consider renewable energy, cogeneration module, absorption chiller and energy storage systems. Energy from the grid $E_{p}$ covers the electricity demand $E_{d}$ and can be used to run the heat pump only for cooling. Natural gas is available to be used in the boiler to cover heating demands. In the polygeneration system, only ionlithium technology has been considered in the optimization of the superstructure.

Tab. 3 Grid connected system. Single optimization results

\begin{tabular}{|c|c|c|c|}
\hline System & \multicolumn{2}{|c|}{ Polygeneration system } & \multirow{2}{*}{ Reference system } \\
\hline Equipment & Economic optimum & Environmental optimum & \\
\hline Grid contracted power $[\mathrm{kW}]$ & 13.856 & 13.856 & $17.321 / 24.249 / 17.321$ \\
\hline Cogeneration module CM $[\mathrm{kW}]$ & 1.6 & 0.0 & 0.0 \\
\hline Photovoltaic modules PV $\left[\mathrm{m}^{2}\right]$ & 68.7 & 75.0 & 0.0 \\
\hline Wind turbine PW [kW] & 0.0 & 16.3 & 0.0 \\
\hline Solar thermal collectors ST $\left[\mathrm{m}^{2}\right]$ & 0.0 & 85.9 & 0.0 \\
\hline Heat pump HP [kWt] & 77.7 & 48.3 & 78.1 \\
\hline Gas boiler GB [kWt] & 23.0 & 5.1 & 65.2 \\
\hline Absorption chiller $\mathrm{ACH}[\mathrm{kWt}]$ & 0.3 & 0.3 & 0.0 \\
\hline Heat thermal storage TSQ [kWht] & 0.0 & 46.6 & 0.0 \\
\hline Cooling thermal storage TSR [kWht] & 0.0 & 54.5 & 0.0 \\
\hline Batteries BAT [kWh] & 0.0 & 13.1 & 0.0 \\
\hline Electricity consumption [kWh] & 24518 & 18444 & 38770 \\
\hline Gas consumption [kWh] & 50000 & 122 & 72901 \\
\hline Annual cost $[€ / y r]$ & 18444 & 45480 & 22565 \\
\hline Annual $\mathrm{CO}_{2}$ emissions $\left[\mathrm{kgCO} \mathrm{CO}_{2} \mathrm{eq} / \mathrm{yr}\right]$ & 18307 & 6328 & 25658 \\
\hline
\end{tabular}

According to the values shown in Tab. 3, comparing the polygeneration system with respect to the reference systems, we observe that it could be achieved a reduction of about $18 \%$ and $29 \%$ in the annual cost and $\mathrm{CO}_{2}$ emissions respectively from the economic optimum or it would be needed double the annual cost to achieve a reduction of about $75 \%$ in the annual $\mathrm{CO}_{2}$ emissions from the environmental optimum. On the other hand, by using polygeneration systems, it is possible reduce the contracted power from the grid and natural gas, achieving a significant reduction in electricity and natural gas consumption.

In the standalone system, electricity from the grid and natural gas are not available. Therefore, gasoil for heating is used as a conventional fuel to run the boiler GB and the cogeneration module CM. This last, produce electricity 
to cover the demand $\mathrm{E}_{\mathrm{d}}$ and for running the heat pump HP as well. A reference system in which energy demands are attended only by cogeneration module, heat pump (only for cooling) and boiler is considered. In both systems, reference and polygeneration systems the thermal energy storage (TSQ and TSR) and batteries are considered to tackle the restriction of reciprocating engines to work above $30 \%$ of partial load. Both systems are optimized with lead acid (OPz) and ion-lithium (Ion-Li) batteries separately. Tab. 4 and Tab. 5 present the main results for both cases.

Tab. 4. Standalone system with ion lithium batteries. Single optimization results

\begin{tabular}{|c|c|c|c|c|}
\hline Ion Lithium System & Standalone polygeneration system & \multicolumn{2}{c|}{ Standalone reference system } \\
\hline Equipment & $\begin{array}{c}\text { Economic } \\
\text { optimum }\end{array}$ & $\begin{array}{c}\text { Environmental } \\
\text { optimum }\end{array}$ & $\begin{array}{c}\text { Economic } \\
\text { optimum }\end{array}$ & 14.9 \\
optimum
\end{tabular}

Tab. 5. Standalone system with Lead Acid batteries. Single optimization results

\begin{tabular}{|c|c|c|c|c|}
\hline Lead Acid System & \multicolumn{2}{|c|}{ Standalone polygeneration system } & \multicolumn{2}{|c|}{ Standalone reference system } \\
\hline Equipment & $\begin{array}{l}\text { Economic } \\
\text { optimum }\end{array}$ & $\begin{array}{c}\text { Environmental } \\
\text { optimum }\end{array}$ & $\begin{array}{l}\text { Economic } \\
\text { optimum }\end{array}$ & $\begin{array}{c}\text { Environmental } \\
\text { optimum }\end{array}$ \\
\hline Cogeneration module CM [kW] & 6.9 & 7.5 & 14.7 & 9.3 \\
\hline Photovoltaic modules PV $\left[\mathrm{m}^{2}\right]$ & 93.0 & 148.0 & 0.0 & 0.0 \\
\hline Wind turbine $\mathrm{PW}[\mathrm{kW}]$ & 0.0 & 45.0 & 0.0 & 0.0 \\
\hline Solar thermal collectors ST $\left[\mathrm{m}^{2}\right]$ & 0.0 & 12.8 & 0.0 & 0.0 \\
\hline Heat pump HP $[\mathrm{kWt}]$ & 47.8 & 65.1 & 77.0 & 26.6 \\
\hline Gas boiler GB $[\mathrm{kWt}]$ & 37.2 & 0.0 & 46.1 & 41.9 \\
\hline Absorption chiller ACH [kWt] & 27.2 & 10.5 & 0.0 & 0.0 \\
\hline Heat thermal storage TSQ [kWht] & 0.0 & 83.9 & 0.0 & 53.2 \\
\hline Cooling thermal storage TSR [kWht] & 0.0 & 1.3 & 1.0 & 126.6 \\
\hline Batteries BAT $[\mathrm{kWh}]$ & 1.0 & 78.3 & 24.0 & 9.3 \\
\hline Annual Fuel consumption [kWh] & 106364 & 23527 & 173442 & 163693 \\
\hline Annual cost $[€ / y r]$ & 23040 & 70639 & 29215 & 41573 \\
\hline Annual $\mathrm{CO}_{2}$ emissions [kgCO $\left.2 \mathrm{eq} / \mathrm{yr}\right]$ & 34871 & 13528 & 55083 & 52291 \\
\hline
\end{tabular}

From the comparison between the polygeneration systems with respect to the reference system, we can observe a reduction of about $20 \%$ and $35 \%$ in the annual cost and $\mathrm{CO}_{2}$ emissions respectively from the economic optimum, and an increasing of about $70 \%$ in the annual cost to achieve a reduction of about $75 \%$ in the annual $\mathrm{CO}_{2}$ emissions from the environmental optimum.

\subsection{Multiobjective optimization}

In order to carry out a multiobjective optimization, a Pareto solution's set are found by means the $\varepsilon$-constraint method (Haimes et al., 1971). This means that we can obtain different solutions by optimizing one of the objective functions whereas the value of the other objective function is fixed. This procedure can be carried out as many times as required to create the Pareto curve. The solutions in between the single-objective optimization solutions are known as trade-off solutions or non-dominated solutions. For both systems, five different configurations through the Pareto curves were defined according to the minimum capacities commercially available.

Fig. 2a shows the Pareto curve of the grid connected system. Along the curve different solutions are obtained with different configurations and capacities. Each symbol corresponds to a specific configuration (with different pieces of equipment and capacities). 

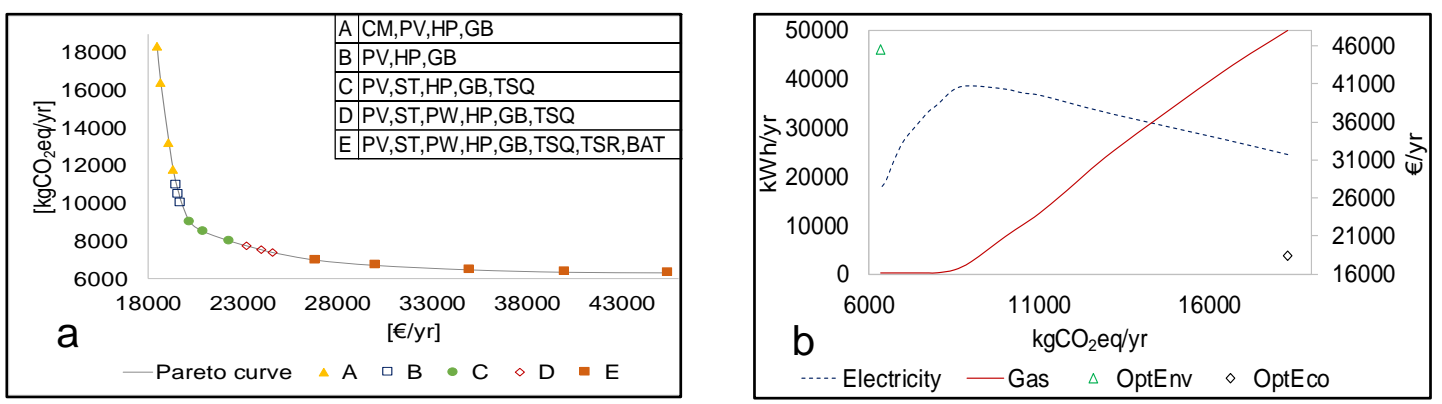

Fig. 2. a) Grid connected system Pareto curve. b) Electricity and gas consumption vs $\mathrm{CO}_{2}$ emissions

There is not an absolute "best solution", because it depends on the decision maker. The set of Pareto solution's must be evaluated to take the "best solution" according to the weights of different objectives considered for the decision maker. For the authors, configurations $\mathrm{B}$ and $\mathrm{C}$ seem to be interesting trade-off solutions considering the great reduction of $\mathrm{CO}_{2}$ emissions about $43 \%$ and $54 \%$, with only an increasing of about $7 \%$ and $15 \%$ in the total annual cost respectively, with respect to the economic optimum. Configuration $\mathrm{B}$ is simpler than $\mathrm{C}$, in fact is the simplest configuration among the Pareto curve configurations, therefore, could be considered the best trade-off solution considering its simplicity and their achievements in terms of the relation annual cost $/ \mathrm{CO}_{2}$ emissions.

On the other hand, Fig. $2 \mathrm{~b}$ shows the electricity and natural gas consumption with respect to the $\mathrm{CO}_{2}$ emissions. From the economic optimum (OptEco) to the environmental optimum (OptEnv) gas consumption always decrease whereas electricity consumption increases up to reach the maximum point at $9000 \mathrm{kgCO}_{2} \mathrm{eq} / \mathrm{yr}$, then it decreases rapidly, due to the PV and PW increasing capacity. The electricity is mainly use to run the heat pump to produce heating/cooling, which shows the advantage of using this technology to reduce the environmental impact.

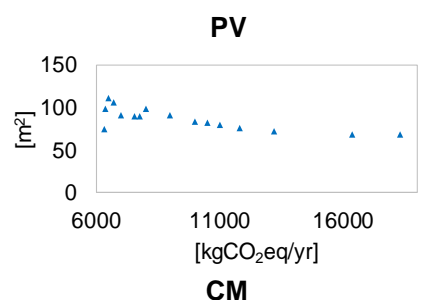

PW

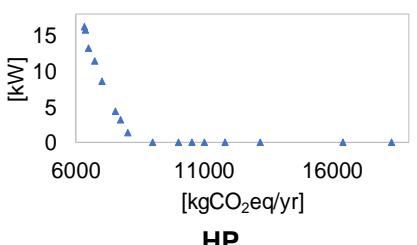

HP
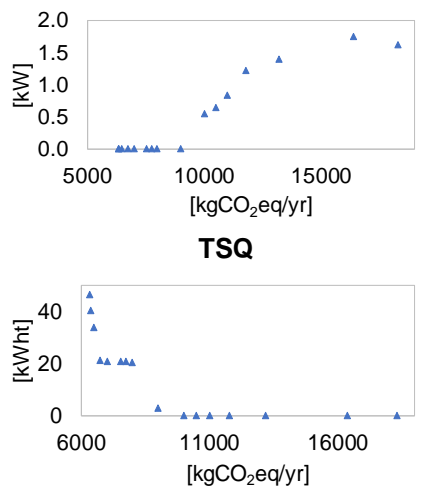
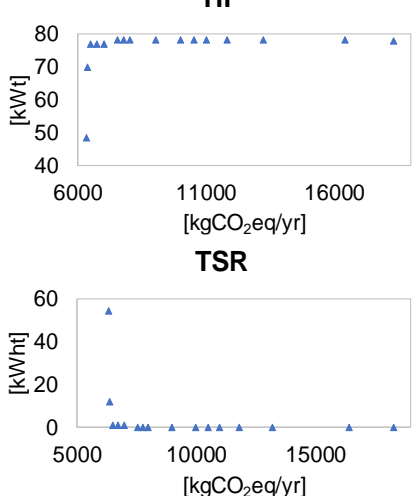

ST

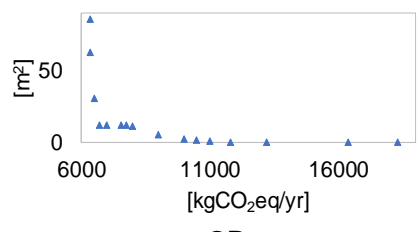

GB
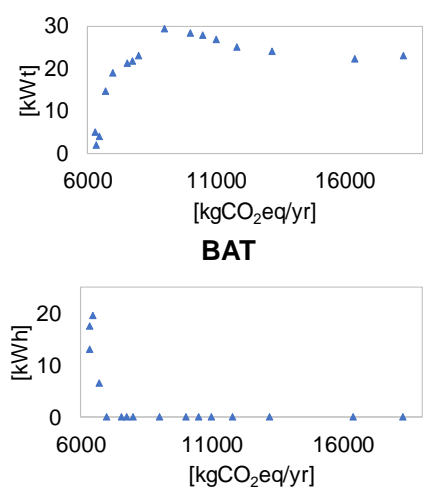

Fig. 3. Installed capacity along the Pareto curve for the grid connected system

Fig. 3 presents the technologies capacity with respect to the $\mathrm{CO}_{2}$ emissions. ACH technology does not appear since it is not part of any configuration. As we can see PV, HP and GB technologies are feasible in every configuration. ST and PW technologies are only attractive when it is required a $\mathrm{CO}_{2}$ emissions reduction higher than $55 \%$ with respect to the economic optimum. $\mathrm{CM}$ is viable above $12000 \mathrm{kgCO}_{2} \mathrm{eq} / \mathrm{yr}$, in which capacities above $1 \mathrm{~kW}$ is required. Although there is $\mathrm{CM}$ of $1 \mathrm{~kW}$ available in the market, this capacity is still very low, so it can be neglected in the trade off solutions. TSQ is viable below $9000 \mathrm{kgCO}_{2} \mathrm{eq} / \mathrm{yr}$ whereas TSR and BAT are feasible only close to the environmental optimum.

Fig. 4 shows the Pareto curve of the standalone system. Along the Pareto curve different solutions are obtained with different configurations and capacities. Each symbol corresponds to specific configuration (with different components and capacities). In this case, two Pareto curves are depicted corresponding to both battery technologies evaluated. As we can see the Pareto curves for both technologies are practically the same, however, the configurations do not coincide in every point necessarily. 


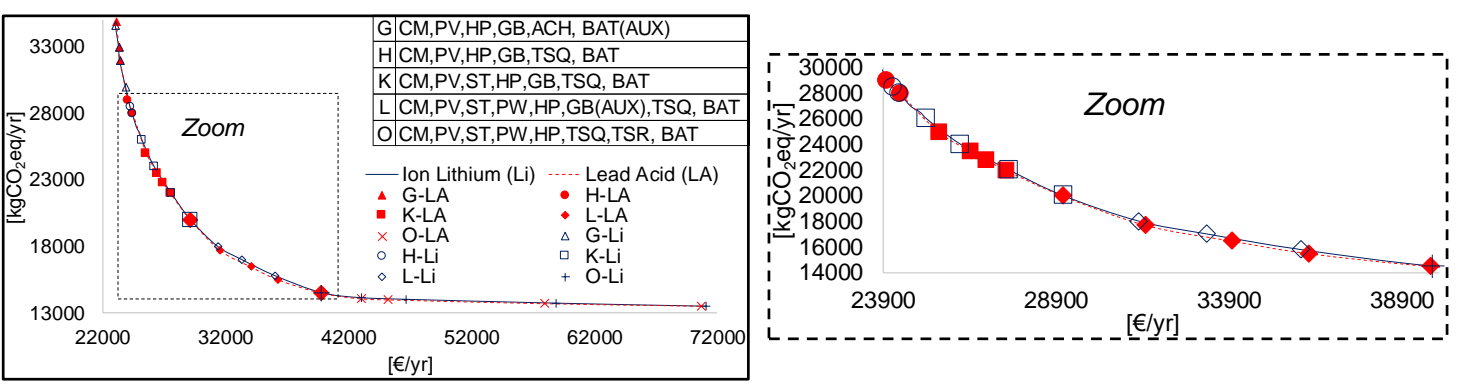

Fig. 4. Standalone system Pareto curve. Ion lithium (Blue-continuous) and Lead acid (Red-dashed) batteries

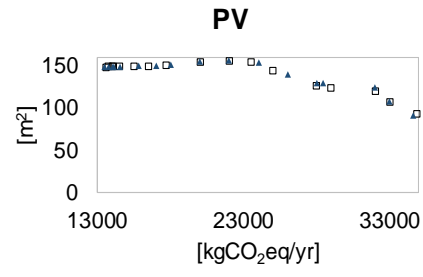

CM

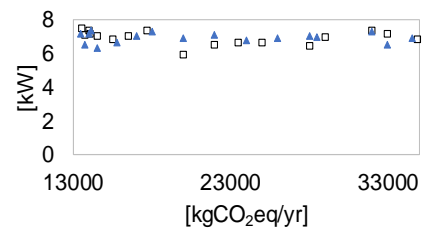

TSQ

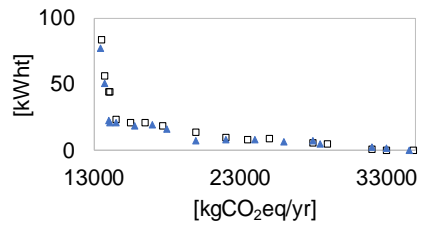

PW

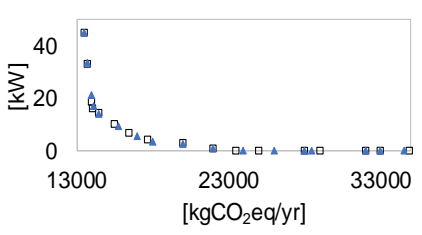

HP

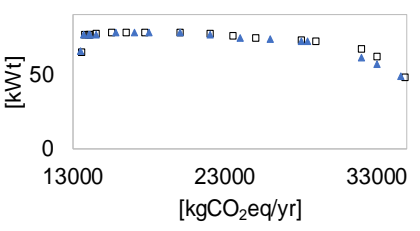

TSR

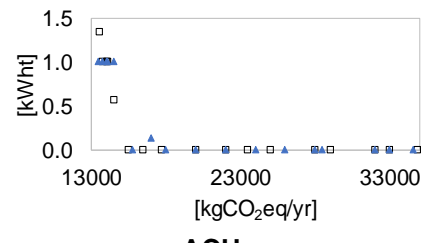

$\mathrm{ACH}$

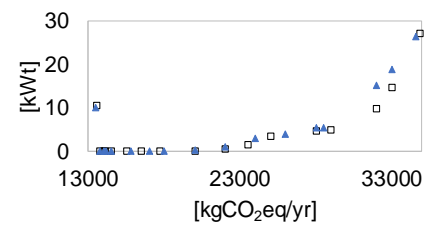

ST

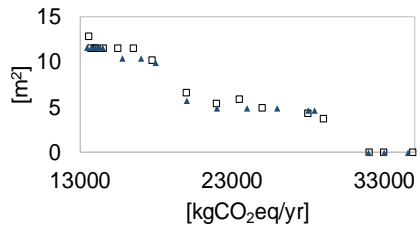

GB

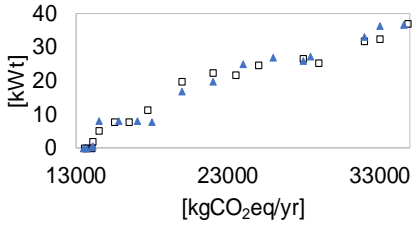

BAT

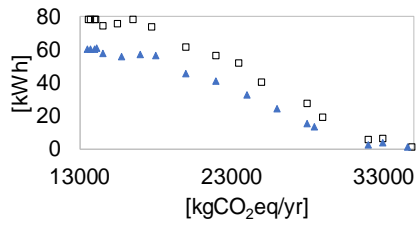

$\square$ Lead Acid (LA)

Ion Lithium (Li)

Fig. 5. Installed capacity along the Pareto curve for the standalone system

In this case, authors suggest the configurations $\mathrm{H}$ and $\mathrm{K}$ as interesting trade-off solutions. The difference between them lies only in the presence of ST in the $\mathrm{K}$ configuration. In $\mathrm{H}$ configuration it is possible to achieve a $\mathrm{CO}_{2}$ emissions reduction of about $18 \%$ by increasing the annual cost in about $6 \%$, whereas, through $\mathrm{K}$ configuration it is possible to achieve a $\mathrm{CO}_{2}$ emissions reduction of about $25 \%$ up to $40 \%$ by increasing the annual cost in about $10 \%$ up to $20 \%$, with respect to the economic optimum.

In the standalone system CM is the prime mover, therefore it is present in every configuration. From the Fig. 5 we can see that PV and HP technologies are feasible in every configuration. ST and PW technologies are present below about 26000 and $18000 \mathrm{kgCO}_{2} \mathrm{eq} / \mathrm{yr}$ respectively. $\mathrm{ACH}$ is part only in the configuration $\mathrm{G}$ which is above $32000 \mathrm{kgCO}_{2} \mathrm{eq} / \mathrm{yr}$. GB is present in G, $\mathrm{H}, \mathrm{K}$ and L configurations, however, in this last could be considered as an auxiliary component (AUX) because its capacity decreases below the minimal commercial capacity up to disappearing in the configuration $\mathrm{O}$. Regarding the electrical energy storage, we can see the difference in capacity between Ion Lithium and Lead acid batteries. Remark that smaller capacities are required for ion lithium technology to achieve the same relation $€ / \mathrm{kgCO}_{2} \mathrm{eq}$ through the Pareto curve. In the economic optimum a small capacity is required in both cases, hence, it is considered that in the configuration $\mathrm{G}$ batteries are required as backup or auxiliary component (AUX) in the system. In the case of thermal storage, it is observed that TSQ is considered every configuration except in G configuration, whereas TSR is only considered in the O configuration close to the environmental optimum. 


\section{Conclusions}

A multiobjective optimization was carried out to tackle the issue of conflicting objectives in the synthesis of polygeneration systems including renewable energy namely PV, ST and PW technologies, thermal energy storage and batteries. To this propose, a MILP model was developed and applied to a residential building located in Zaragoza (Spain) in two cases: Grid connected and Standalone. At first, representative days were selected to reproduce in a reasonable way the whole year data, reducing the computational effort during the optimization of the polygeneration system. Then, single optimizations were compared with respect to the reference systems, which show the advantages of using polygeneration systems with respect to the conventional systems from the economic and environmental point of view. The $\varepsilon$-constraint method was applied to obtain the Pareto curve or trade off solutions. Five different configurations were defined through the Pareto curve according to the minimum commercial capacities available in the market which allow different $€ / \mathrm{kgCO}_{2}$ eq ratios. Interesting solutions show that a $\mathrm{CO}_{2}$ emissions reduction of about $43 \%$ with only an increasing of about $7 \%$ in the total annual cost could be achieved in the grid connected system, whereas in the standalone system a $\mathrm{CO}_{2}$ emissions reduction of about $18 \%$ could be achieved by increasing the annual cost in about $6 \%$. In every case PV and HP technologies are feasible from the economic and environmental point of view for both systems. Regarding energy storage, in the grid connected system, TSQ become important only from about $50 \%$ of $\mathrm{CO}_{2}$ emissions reduction, whereas TSR and batteries are considered only close to the environmental optimum. On the other hand, in the standalone system, TSQ and batteries become important from about $12 \%$ of $\mathrm{CO}_{2}$ emissions reduction, whereas TSR is considered only close to the environmental optimum.

\section{Acknowledgements}

This work was developed in the frame of the research projects ENE2014-57262-R and ENE2017-87711-R, partially funded by the Spanish Government (Energy Program), the Government of Aragon (Spain) and the EU Social Fund (FEDER Program). The authors also want to acknowledge the mobility program for Latin-Americans offered by Unizar-Santander Universities.

\section{References}

AENOR, 2005. Instalaciones solares térmicas para producción de agua caliente sanitaria-UNE 94.002.

Ardani, K., O’Shaughnessy, E., Fu, R., McClurg, C., Huneycutt, J., Margolis, R., 2016. Installed Cost Benchmarks and Deployment Barriers for Residential Solar Photovoltaics with Energy Storage: Q1 2016.

Atersa, 2017. Specifications of photovoltaic module A-255P [WWW Document]. URL http://www.atersa.com/Common/pdf/atersa/manuales-usuario/modulos-fotovoltaicos/Ficha_Tecnica_A255P-A-265P_Ultra.pdf (accessed 1.6.18).

BAXI, 2017. Catálogo tarifa [WWW Document]. URL https://www.baxi.es//media/websites/baxies/files/catalogo-2017-bajaress.pdf (accessed 1.6.18).

Beccali, M., Cellura, M., Longo, S., Mugnier, D., 2016. A Simplified LCA Tool for Solar Heating and Cooling Systems. Energy Procedia 91, 317-324. https://doi.org/10.1016/J.EGYPRO.2016.06.226

Bornay, 2017. Wind turbine specifications [WWW Document]. URL https://www.bornay.com/es/productos/aerogeneradores/bornay (accessed 1.6.18).

Cho, J., Jeong, S., Kim, Y., 2015. Commercial and research battery technologies for electrical energy storage applications. Prog. Energy Combust. Sci. 48, 84-101. https://doi.org/10.1016/j.pecs.2015.01.002

Darrow, K., Tidball, R., Wang, J., Hampson, A., 2017. Catalog of CHP technologies.

DiOrio, N., Dobos, A., Janzou, S., Nelson, A., Lundstrom, B., 2015. Technoeconomic Modeling of Battery Energy Storage in SAM.

Domínguez-Muñoz, F., Cejudo-López, J.M., Carrillo-Andrés, A., Gallardo-Salazar, M., 2011. Selection of typical demand days for CHP optimization. Energy Build. 43, 3036-3043. Duffie, J.A., Beckman, W.A., 2013. Solar Engineering of Thermal Processes, 4th ed. John Wiley \& Sons.

Dufo-López, R., Lujano-Rojas, J.M., Bernal-Agustín, J.L., 2014. Comparison of different lead-acid battery lifetime prediction models for use in simulation of stand-alone photovoltaic systems. Appl. Energy 115, 242-253. https://doi.org/10.1016/j.apenergy.2013.11.021

Endesa, 2017. Tarifas de energía Endesa [WWW Document]. URL https://www.endesaclientes.com/empresas.html (accessed 1.6.18).

ENERTRES, 2017. Catálogo tarifa 10E [WWW Document]. URL http://www.enertres.com/uploads/[1485867548]Tarifa-bomba-de-calor-2017-web.pdf (accessed 1.6.18).

Eurostat, 2017. Gas prices for household consumers [WWW Document]. URL http://appsso.eurostat.ec.europa.eu/nui/show.do?dataset=nrg_pc_202\&lang=en

Frischknecht, R., Itten, R., Sinha, P., Wild-Scholten, M. de, Zhang, J., 2015. Life Cycle Inventories and Life 
Cycle Assessments of Photovoltaic Systems.

Fthenakis, V., Raugei, M., 2017. 7 - Environmental life-cycle assessment of photovoltaic systems. Perform. Photovolt. Syst. 209-232. https://doi.org/10.1016/B978-1-78242-336-2.00007-0

Fu, R., Feldman, D., Margolis, R., Woodhouse, M., Ardani, K., 2017. U.S. Solar Photovoltaic System Cost Benchmark: Q1 2017.

Guadalfajara, M., 2016. Economic and environmental analysis of central solar heating plants with seasonal storage for the residential sector. Universidad de Zaragoza.

Haimes, Y.Y., Lasdon, L.S., Wismer, D.A., 1971. On a bicriterion formation of the problems of integrated system identification and system optimization. IEEE Trans. Syst. Man. Cybern. 3, 296-297.

Hiremath, Mitavachan \& Derendorf, Karen \& Vogt, T., 2015. Comparative Life Cycle Assessment of Battery Storage Systems for Stationary Applications. Environ. Sci. Technol. https://doi.org/10.1021/es504572q

Homer Energy, 2016. HOMER® Pro Version 3.7 User Manual.

IDAE, 2017. Código Técnico de la Edificación-Ahorro de energía.

IDAE, 2016. Factores de emisión de CO2 y coeficientes de paso de energía primaria de diferentes fuentes de energía final consumidas en el sector de edificios en España.

IDAE, 2011a. Consumos del Sector Residencial en España - Resumen de Información Básica.

IDAE, 2011b. Pliego de Condiciones Técnicas de Instalaciones Conectadas a Red.

IDAE, 2011c. Plan de Energías Renovables (PER) 2011-2020.

IDAE, 2009. Escala de calificación energética para edificios de nueva construcción.

ISSF, 2015. Stainless Steel and CO2 : Facts and Scientific Observations.

JUDELSA, 2017. Energética futura-Tarifa de productos [WWW Document]. URL https://energeticafutura.com/recursos/documentos/tarifa.pdf (accessed 1.6.18).

LINDO Systems Inc, 2013. Lingo-Optimization Modeling Software for Linear, Nonlinear, and Integer Programming.

Mancarella, P., 2014. MES (multi-energy systems): An overview of concepts and evaluation models. Energy 65, 1-17. https://doi.org/10.1016/J.ENERGY.2013.10.041

Manwell, J.F., McGowan, J.G., 1993. Lead acid battery storage model for hybrid energy systems. Sol. Energy 50, 399-405. https://doi.org/10.1016/0038-092X(93)90060-2

Manwell, J.F., McGowan, J.G., Rogers, A.L., 2009. Wind Energy Explained, 2nd ed. WILEY.

Marín-Giménez, J.M., 2004. Evaluación de alternativas para el abastecimiento energético de una urbanización residencial en Zaragoza.

McManus, M.C., 2012. Environmental consequences of the use of batteries in low carbon systems: The impact of battery production. Appl. Energy 93, 288-295. https://doi.org/10.1016/J.APENERGY.2011.12.062

Meteotest, 2017. Meteonorm Software.

Orrell, A., Poehlman, E., 2017. Benchmarking U.S. Small Wind Costs With the Distributed Wind Taxonomy.

Parra, D., Swierczynski, M., Stroe, D.I., Norman, S.A., Abdon, A., Worlitschek, J., O’Doherty, T., Rodrigues, L., Gillott, M., Zhang, X., Bauer, C., Patel, M.K., 2017. An interdisciplinary review of energy storage for communities: Challenges and perspectives. Renew. Sustain. Energy Rev. 79, 730-749.

Peters, J.F., Baumann, M., Zimmermann, B., Braun, J., Weil, M., 2017. The environmental impact of Li-Ion batteries and the role of key parameters - A review. Renew. Sustain. Energy Rev. 67, 491-506.

Pina, E.A., Lozano, M.A., Serra, L.M., 2017. A Multicriteria Approach for the Integration of Renewable Energy Technologies and Thermal Energy Storage to Support Building Trigeneration Systems, in: International Confenerence on Solar Heating and Cooling for Buildings and Industry.

Poncelet, K., H. H oschle, Delarue, E., Virag, A., W.D'haeseleer, 2017. Selecting representative days for capturing the implications of integrating intermittent renewables in generation expansion planning problems. IEEE Trans. POWER Syst. 32. https://doi.org/10.1109/TPWRS.2016.2596803

Ramos, J., 2012. Optimización del diseño y operación de sistemas de cogeneración para el sector residencial comercial. Universidad de Zaragoza.

Red Electrica de España, 2017. Demanda y producción en tiempo real [WWW Document]. URL http://www.ree.es/es/actividades/demanda-y-produccion-en-tiempo-real

Salvador Escoda S.A, 2017. Tarifa de precios [WWW Document]. URL http://www.salvadorescoda.com/tarifas/index.htm (accessed 1.6.18).

Tapia-Ahumada, K., Pérez-Arriaga, I.J., Moniz, E.J., 2013. A methodology for understanding the impacts of large-scale penetration of micro-combined heat and power. Energy Policy 61, 496-512.

Tremeac, B., Meunier, F., 2009. Life cycle analysis of 4.5 MW and 250 W wind turbines. Renew. Sustain. Energy Rev. 13, 2104-2110. https://doi.org/10.1016/J.RSER.2009.01.001

U.S. Department of Energy, 2017. Absorption Chillers for CHP Systems.

Valor, E., Meneu, V., Caselles, V., 2001. Daily air temperature and electricity load in Spain. J. Appl. Meteorol. 40, 1413-1421.

Viti, A., 1996. Preparación de agua caliente para usos sanitarios.

Wakui, T., Yokoyama, R., 2015. Optimal structural design of residential cogeneration systems with battery based on improved solution method for mixed-integer linear programming. Energy 84, 106-120. 


\title{
Quantifying the potential of smart heat pump control to increase the self consumption of photovoltaic electricity in buildings Yves Stauffer ${ }^{1}$, Nelson Koch ${ }^{1}$, Andreas Hutter ${ }^{1}$, Noah D. Pflugradt ${ }^{2}$ \\ ${ }^{1}$ CSEM, Neuchâtel (Switzerland) \\ ${ }^{2}$ BFH, Biel (Switzerland)
}

\begin{abstract}
Energy management systems that efficiently use self-produced renewable energy are becoming popular. However, quantifying their benefits in terms of self-consumption increase and associated financial benefits, is difficult in real life conditions. In that context, the Prosumer-Lab project was launched. In the latter, a building, grid and photovoltaic installation are emulated and real energy management systems can be connected for evaluation. In this article, we describe various control strategies for energy management systems and benchmark their yearly performance in simulation in order to quantify the potential of the different approaches. This works is the first step towards the identification of possible improvements.
\end{abstract}

Keywords: Self consumption, energy managements systems, photovoltaic, rule based control

\section{Introduction}

In ProsumerLab we aim at testing energy management systems (EMS) in a controlled environment. For that purpose, a test bench was developed by the Berner Fachhochshule (BFH), that is composed of grid and photovoltaic (PV) emulators, real batteries as well as a load emulator to mimic the electric consumption of a building. The latter is simulated using Polysun. The Centre Suisse d'Electronique et de Microtechnique (CSEM), is in charge of evaluating various EMSs and implement novel control strategies. The work presented in this paper focuses on following aspects:

- Impact of various EMS control strategies on self consumption ratio (SCR) improvement and comparison with the maximal theoretical SCR. SCR is defined as the ratio between the locally used PV energy and produced PV energy.

- Impact of SCR increase on the electricity bill.

It will be shown that SCR can be increased by $8 \%$ by using rule based control acting on storage tanks or building overall heating (i.e. storage in the building envelope), by up to $37 \%$ by adding batteries combined to the rule based controller mentioned before. It is also shown, that the SCR increase obtained by rule based controllers, is far from the theoretical maximum that could be reached by implementing model predictive control (MPC).

For the impact on the electricity bill, it is shown that depending on the electricity tariffs, high SCR might not have the desired results on the electricity bill. Indeed, if electricity buying and selling tariffs are equal (or the difference between these tariffs is small), high SCR penalize the electricity bill and can lead to a yearly increase of $263 \mathrm{chf}$ in the considered scenarios. Whereas if the difference between buying and selling is high, in the same simulation scenario savings of $540 \mathrm{chf}$ can be achieved.

\section{Scenarios and simulation setup}

In the frame of this work, the Polysun (Velasolaris, 2018) simulation environment was used. In order to assess the impact of the various EMS control concepts two types of buildings and two type of inhabitants were selected, as summarized in Table 1. These correspond to the $S x$ simulation scenarios, where $x$ denotes the simulation scenario number. 
Tab. 1: simulation scenario summary

\begin{tabular}{|l|l|l|r|r|r|}
\hline & House type & Inhabitant type $^{\mathbf{1}}$ & $\begin{array}{l}\text { PV } \\
\left(\mathbf{k W p}^{\mathbf{2}}\right)\end{array}$ & $\begin{array}{l}\text { Battery } \\
(\mathbf{k W h})\end{array}$ & $\begin{array}{l}\text { Yearly thermal } \\
\text { load (kWh) }\end{array}$ \\
\hline S1 & Well insulated & Family (2 adults, 2 kids) & 7.4 & 7.4 & $8^{\prime} 170$ \\
\hline S2 & Well insulated & Working couple (2 adults) & 5.5 & 5.7 & $7^{\prime} 642$ \\
\hline S5 & Poorly insulated & Family (2 adults, 2 kids) & 11.1 & 11.7 & $21^{\prime} 332$ \\
\hline S6 & Poorly insulated & Working couple (2 adults) & 9 & 9.2 & $21^{\prime} 141$ \\
\hline
\end{tabular}

Further details about the house configuration:

- Surface: $150 \mathrm{~m}^{2}$

- Building u-value $e^{3}: 0.19 \mathrm{~W} / \mathrm{K} / \mathrm{m}^{2}$ for the well insulated and $0.5 \mathrm{~W} / \mathrm{K} / \mathrm{m}^{2}$ for the poorly insulated

- Location: Koppigen in the canton of Bern (Switzerland)

- PV: sized according to the "1:1" rule ( $1 \mathrm{~kW}$ p PV for $1 \mathrm{MWh}$ of electricity consumption)

- Batteries: the in house battery was sized according to the "1:1" rule $(1 \mathrm{kWh}$ of battery for $1 \mathrm{MWh}$ of electricity consumption). The car battery was set to $100 \mathrm{kWh}$.

For each scenario, different control strategies were tested, as summarized in Table 2. It is worth pointing out that the batteries are always controlled by the Polysun default battery controller. The latter stores excess PV energy in the battery and uses the battery power to minimize the energy drawn from the grid. Regarding the heat pump (HP) control, in the "ref" scenario the HP and 3-way mixing valve is controlled by the standard Polysun controller. The latter aims at maintaining the domestic hot water tank and space heating tank temperatures between desired temperatures. This is done without any considerations regarding PV production. Note that domestic hot water has priority over space heating. Whereas in the C1,2,5-8 control strategies, the HP as well as the 3-way valve are controlled by the Matlab based controller as illustrated in Figure 1. The latter is described in further details below.

Tab. 2: control strategies summary

\begin{tabular}{|l|l|}
\hline $\begin{array}{l}\text { Strategy } \\
(\#)\end{array}$ & Description \\
\hline ref & reference controller (from Polysun) \\
\hline C1 & storage of excess PV energy in water tank \\
\hline C2 & storage of excess PV energy in building envelope \\
\hline C3 & storage of excess PV energy in in-house battery ("small capacity") \\
\hline C4 & storage of excess PV energy in car battery ("large capacity") \\
\hline C5 & C1 and C3 (battery controlled by Polysun) \\
\hline C6 & C1 and C4 (battery controlled by Polysun) \\
\hline C7 & C1, C2 and C3 \\
\hline C8 & C1, C2 and C4 \\
\hline
\end{tabular}

\footnotetext{
${ }^{1}$ The space heating demand is adapted as a function of the number of inhabitants.

${ }^{2} \mathrm{~kW}$ peak

${ }^{3}$ The space heating demand is computed based on this value, coupled to other parameters such as window area, orientation, floor surface, number of floors etc. these parameters are set equal for the two buildings.
} 


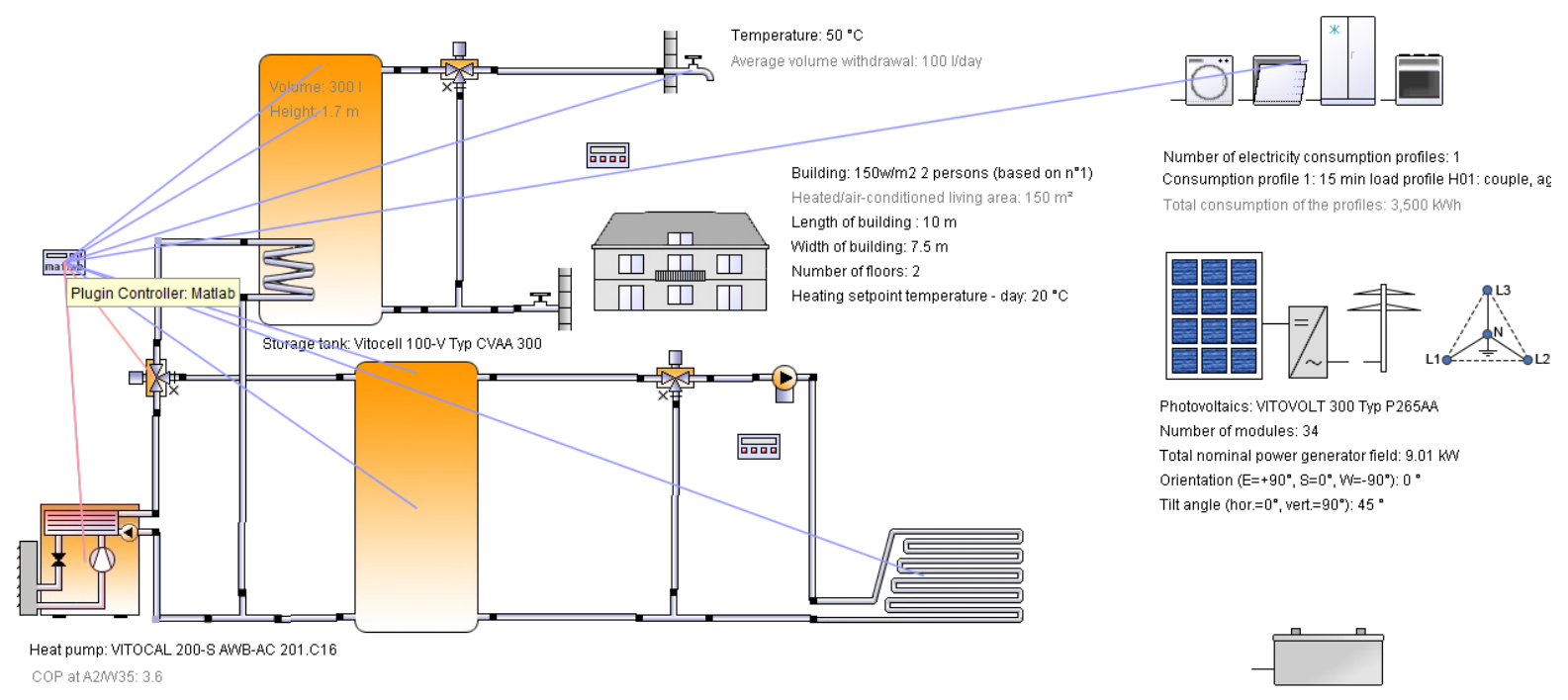

Fig. 1: Simulation layout in Polysun

The Matlab rule based heating controller used in $\mathrm{C} 1$ aims at reducing the electric energy injected into the grid, by increasing the domestic hot water (DHW) tank set-point (SP) temperature and/or the space heating (SH) tank setpoint temperature. To do that the following steps are followed:

1) Check if there is PV overproduction, if yes, is it bigger than the HP nominal (electric) power?

2) If so, increase the DHW tank SP by $5^{\circ} \mathrm{C}$ and the $\mathrm{SH}$ tank SP by $10^{\circ} \mathrm{C}$

3) Let the classical HP controller activate the HP and 2-way valve as needed (with priority to DHW and no SH if the average exterior temperature is above a given threshold)

It is worth noting that commercial EMSs (Smartfox, 2018, Sloarlog, 2918, Solarwatt, 2018) operate in a similar way, regarding PV overproduction.

For the case C2, as there is no direct way in Polysun to dynamically increase the building (indoor) temperature SP, an additional buffer tank, that mimics the storage in the envelop was added. The sizing of the latter was done based on the house surface and assuming a thickness of about $20 \mathrm{~cm}$. This tank is coupled to a "virtual" heating circuit. This additional heating circuit controller is configured so as to take energy from the buffer tank and allow over heating of the rooms. Naturally, the main controller has an upper temperature boundary to prevent excessive over heating. The developed Matlab rule based controller for this case is similar to the one of $\mathrm{C} 1$ except that if there is still overproduction and both the SH and DHW tanks are already fully heated up, the third water tank temperature is increased.

\section{Theoretical SCR boundaries}

In order to fully assess the potential of SCR increase for each scenario, the following key performance indicators (KPI) are computed. This self-consumption could be optimally unlocked by MPC as in (Candanedo and Athienitis, 2011) and/or usage of optimally sized batteries. The two additional KPI are $S C R_{\max }^{E M S}$ and $S C R_{\max }^{\text {battery }}$, which respectively represent the maximum theoretical SCR achieved with the use of an EMS and a battery.

To illustrate how these indexes are computed, the simplified power profiles presented in Figure 2 are used.

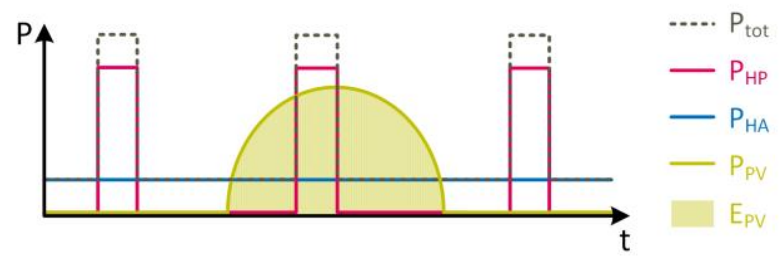

Fig. 2: Basic power profile to illustrate the computation of $S R C_{\max }^{E M S}$ and $S R C_{\max }^{\text {battery }}$

In the simplified case illustrated above one can observe: a constant consumption of the home appliances $\left(P_{H A}\right)$, a pulsed consumption of the heat pump $\left(P_{H P}\right)$, the total power consumption $\left(P_{t o t}\right)$ and the photovoltaic production 
$\left(P_{P V}\right)$. Moreover, the surface below $P_{P V}$ which represent the produced PV energy $\left(E_{P V}\right)$ is highlighted. In this example, the HP consumption is considered controllable and the consumption of the home appliances is fixed.

The $S C R_{\text {max }}^{E M S}$ is defined as the maximum achievable SCR by shifting and modulating $P_{H P}$ without any constraints. Visually, the maximum self-consumable energy using an EMS $\left(E_{s c}^{E M S}\right)$ is represented in Figure 3.

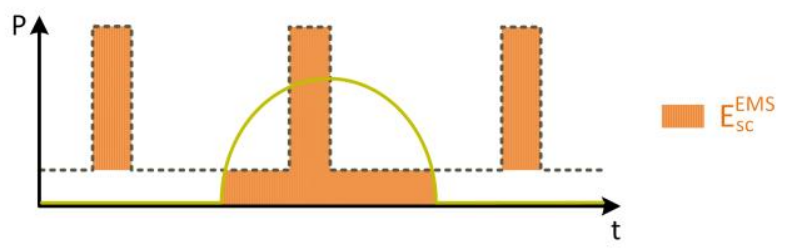

Fig. 3: Illustration of the maximum self-consumable energy using an EMS $\left(E_{s c}^{E M S}\right)$

It is the sum of the total HP consumption and the self-consumed home appliances consumption. The $S C R_{\max }^{E M S}$ is then defined with the following equation:

$$
S C R_{\max }^{E M S}=\min \left\{\frac{E_{S C}^{E M S}}{E_{P V}}, 100 \%\right\}
$$

The $S C R_{\max }^{\text {battery }}$ is defined as the maximum achievable SCR when using a battery big enough to store the total PV production to use it for self-consumption. The maximum self-consumable energy using a suitable battery $\left(E_{s c}^{b a t}\right)$ is simply the total load consumption, as depicted in Figure 4.

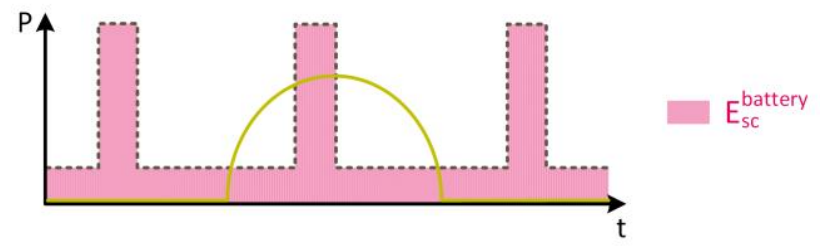

Fig. 4: Illustration of the maximum self-consumable energy using suitable battery $\left(E_{s c}^{b a t}\right)$

The $S C R_{\max }^{\text {battery }}$ is then computed with the following equation:

$$
S C R_{\max }^{\text {battery }}=\min \left\{\frac{E_{s c}^{\text {battery }}}{E_{P V}}, 100 \%\right\}
$$

\section{Controller evaluation results}

Several key performance indicators (KPI) are investigated:

- $\quad$ self consumption (Table 3) and self-sufficiency (Table A.1). Self sufficiency is the ratio of locally used PV production and total electric consumption.

- exchanges with the electric grid (Tables A.2 and A.3). Figure 5 shows for $S 1$ the interplay between controller, grid exchanges and self-consumption.

- financial aspects (yearly costs are available in Tables A.4 to A.6, the cost difference with respect to the reference controller is provided in Tables 5 to 7). Given the scope of the work, only operational expenses linked to electricity purchasing and selling are considered. The used tariffs are highlighted in Table 4 were obtained through (ElCom, 2018) and (PVtarif, 2018). It is to be noted that these three locations were chosen to illustrate the impact of difference between the electricity buying and selling price.

Tab. 3: self consumption

\begin{tabular}{|l|r|r|r|r|r|r|r|r|l|}
\hline Case & Ref & C1 & C2 & C3 & C4 & C5 & C6 & C7 & C8 \\
\hline S1 & $25 \%$ & $28 \%$ & $35 \%$ & $47 \%$ & $62 \%$ & $49 \%$ & $63 \%$ & $55 \%$ & $66 \%$ \\
\hline S2 & $24 \%$ & $29 \%$ & $34 \%$ & $47 \%$ & $63 \%$ & $50 \%$ & $63 \%$ & $55 \%$ & $66 \%$ \\
\hline S5 & $22 \%$ & $23 \%$ & $27 \%$ & $43 \%$ & $51 \%$ & $44 \%$ & $52 \%$ & $47 \%$ & $54 \%$ \\
\hline S6 & $21 \%$ & $22 \%$ & $24 \%$ & $39 \%$ & $51 \%$ & $39 \%$ & $51 \%$ & $42 \%$ & $53 \%$ \\
\hline
\end{tabular}


Tab. 4: used electricity tariffs

\begin{tabular}{|l|r|r|l|}
\hline \multirow{2}{*}{ Koppigen } & \multicolumn{2}{|c|}{ End user tariff for: } & Difference between buying and selling \\
\cline { 2 - 4 } & Buying $(\mathbf{C H F} / \mathbf{k W h})$ & Selling $(\mathbf{C H F} / \mathbf{k W h})$ & - \\
\hline Bern & 0.155 & 0.155 & Zero \\
\hline Eggiwil & 0.1869 & 0.1009 & Low \\
\hline
\end{tabular}

Tab. 5: yearly cost difference of $\mathrm{Cx}$ with respect to reference (electricty only, negative: gain, positive: losses) for tariffs from Koppigen

\begin{tabular}{|l|r|r|r|r|r|r|r|r|}
\hline Case & \multicolumn{1}{l|l|l|l|l}{ C1 } & \multicolumn{1}{l|}{ C2 } & \multicolumn{1}{l|}{ C3 } & \multicolumn{1}{l|}{ C4 } & \multicolumn{1}{l|}{ C5 } & \multicolumn{1}{l|}{ C6 } & \multicolumn{1}{l|}{ C7 } \\
\hline S1 & 10.4 & 113.9 & 139.3 & 173.4 & 142.4 & 168.6 & 211.9 & 215.9 \\
\hline S2 & 4.0 & 84.9 & 72.7 & 135.5 & 71.0 & 131.0 & 123.8 & 165.5 \\
\hline S5 & 0.9 & 81.7 & 136.1 & 205.1 & 132.2 & 198.2 & 201.5 & 263.0 \\
\hline S6 & 0.0 & 47.3 & 93.9 & 168.8 & 91.3 & 164.5 & 130.2 & 199.8 \\
\hline
\end{tabular}

Tab. 6: yearly cost difference of $\mathrm{Cx}$ with respect to reference (electricty only, negative: gain, positive: losses) for tariffs from Bern

\begin{tabular}{|l|r|r|r|r|r|r|r|r|}
\hline Case & \multicolumn{1}{l|l}{ C1 } & \multicolumn{1}{l|}{ C2 } & \multicolumn{1}{l|}{ C3 } & \multicolumn{1}{l|}{ C4 } & \multicolumn{1}{l|}{ C5 } & \multicolumn{1}{l|}{ C6 } & \multicolumn{1}{l|}{ C7 } & \multicolumn{1}{l|}{ C8 } \\
\hline S1 & -12.6 & 66.1 & -61.0 & -139.2 & -69.9 & -143.6 & -25.8 & -109.7 \\
\hline S2 & -20.7 & 50.0 & -67.1 & -108.3 & -81.8 & -111.2 & -46.5 & -86.2 \\
\hline S5 & -8.4 & 40.1 & -126.2 & -164.8 & -135.3 & -171.9 & -90.5 & -124.3 \\
\hline S6 & -12.7 & 29.2 & -87.1 & -135.4 & -93.3 & -138.3 & -67.4 & -110.9 \\
\hline
\end{tabular}

Tab. 7: yearly cost difference of $\mathrm{Cx}$ with respect to reference (electricty only, negative: gain, positive: losses) for tariffs from Eggiwil

\begin{tabular}{|l|l|r|r|r|r|r|r|r|}
\hline Case & \multicolumn{1}{l|}{ C1 } & \multicolumn{1}{l|}{ C2 } & \multicolumn{1}{l}{ C3 } & \multicolumn{1}{l|}{ C4 } & \multicolumn{1}{l|}{ C5 } & \multicolumn{1}{l|}{ C6 } & \multicolumn{1}{l|}{ C7 } & \multicolumn{1}{l|}{ C8 } \\
\hline S1 & -37.8 & 12.5 & -281.0 & -481.9 & -303.1 & -485.9 & -287.5 & -467.2 \\
\hline S2 & -47.7 & 10.8 & -220.4 & -375.7 & -249.1 & -376.8 & -233.6 & -362.5 \\
\hline S5 & -18.6 & -6.2 & -413.6 & -570.5 & -428.4 & -577.6 & -411.1 & -549.6 \\
\hline S6 & -26.6 & 9.0 & -285.6 & -468.9 & -295.6 & -470.2 & -284.3 & -452.0 \\
\hline
\end{tabular}

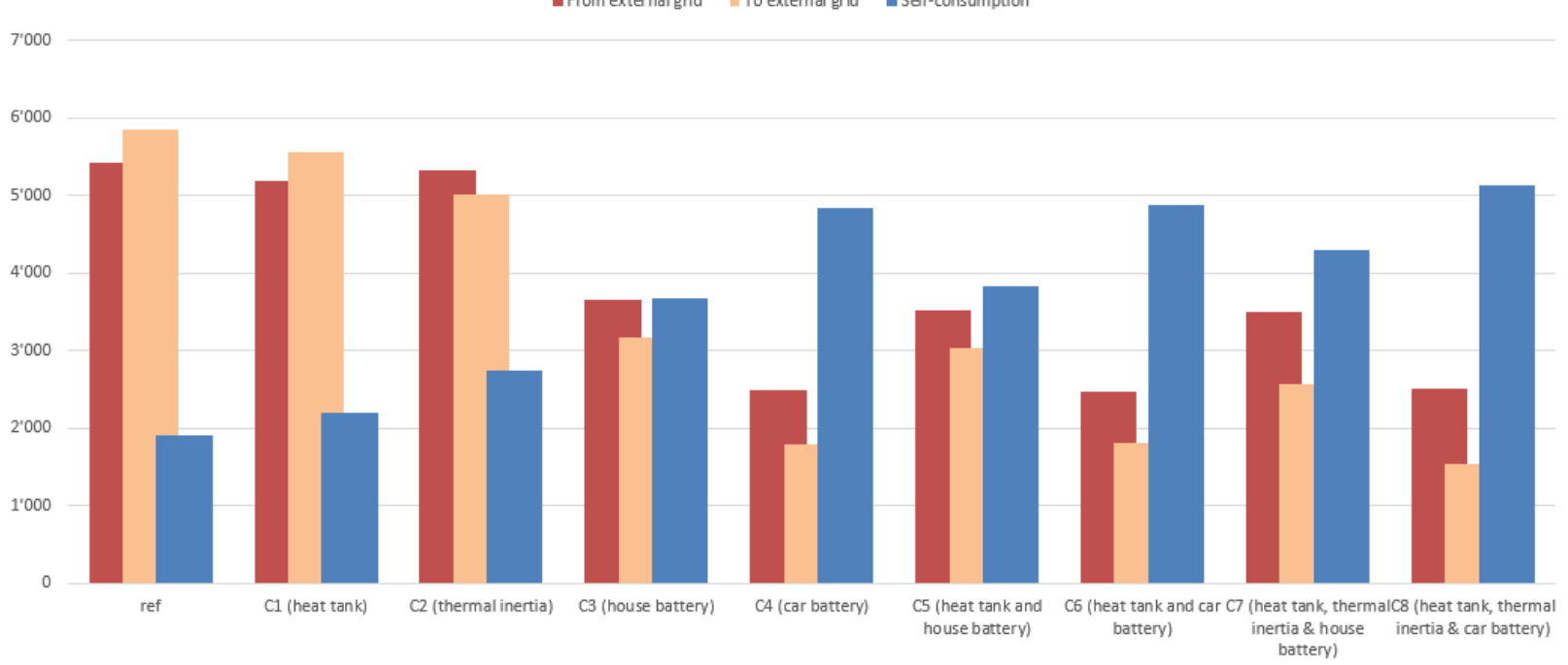

Fig. 5: grid exchanges and self-consumption (kWh over the year) for scenario S1 and different controllers 


\section{Analysis}

The analysis will first focus on SCR increase as a function of the control strategies. Table 8 summarizes the SCR increase with respect to the reference controller and provides also an average SCR increase by controller. It can be observed that:

- Storage of excess PV production in the storage tanks $(\mathrm{C} 1)$ or in the building envelope (C2) leads to an SCR increase of 3\%, respectively $8 \%$. These results are in line with (Vandhoudt et al., 2014).

- $\quad$ Storing electric energy overproduction in house sized batteries (C3) or in a large car battery (C4) increases the SCR by $21 \%$, respectively $34 \%$.

- $\quad$ By combining tank storage and batteries $(\mathrm{C} 5=\mathrm{C} 1+\mathrm{C} 3, \mathrm{C} 6=\mathrm{C} 1+\mathrm{C} 4)$ and by adding thermal storage in the building envelope $(\mathrm{C} 7=\mathrm{C} 5+\mathrm{C} 2, \mathrm{C} 8=\mathrm{C} 6+\mathrm{C} 2)$, the SCRs increase as expected.

Tab. 8: SCR increase with respect to reference case and average SCR increase by control strategy

\begin{tabular}{|l|r|r|r|r|r|r|r|r|}
\hline Case & \multicolumn{1}{|l|}{ C1 } & \multicolumn{1}{l|}{ C2 } & \multicolumn{1}{l|}{ C3 } & \multicolumn{1}{l|}{ C4 } & \multicolumn{1}{l|}{ C5 } & \multicolumn{1}{l|}{ C6 } & \multicolumn{1}{l|}{ C7 } & C8 \\
\hline S1 & $4 \%$ & $11 \%$ & $23 \%$ & $38 \%$ & $25 \%$ & $38 \%$ & $31 \%$ & $41 \%$ \\
\hline S2 & $5 \%$ & $10 \%$ & $23 \%$ & $39 \%$ & $26 \%$ & $39 \%$ & $31 \%$ & $43 \%$ \\
\hline S5 & $1 \%$ & $6 \%$ & $21 \%$ & $30 \%$ & $22 \%$ & $30 \%$ & $26 \%$ & $33 \%$ \\
\hline S6 & $2 \%$ & $3 \%$ & $18 \%$ & $30 \%$ & $19 \%$ & $30 \%$ & $21 \%$ & $32 \%$ \\
\hline Average & $\mathbf{3 \%}$ & $\mathbf{8 \%}$ & $\mathbf{2 1 \%}$ & $\mathbf{3 4 \%}$ & $\mathbf{2 3 \%}$ & $\mathbf{3 4 \%}$ & $\mathbf{2 7 \%}$ & $\mathbf{3 7 \%}$ \\
\hline
\end{tabular}

In addition, an investigation of the financial benefits is done. As mentioned before, only the costs linked to energy buying and selling are considered. The link with electricity tariffs, SCR and control strategies is highlighted in Figure 6. It can clearly be observed that if the buying and selling tariffs are equal, as it is the case in Koppigen, high SCR lead to higher electricity bills. In other terms, increasing SCR in such cases is not desirable. On the other hand, if the incentive of selling electricity to the grid is low, as in Eggiwil, increasing the SCR to lower the electricity bill is desirable.
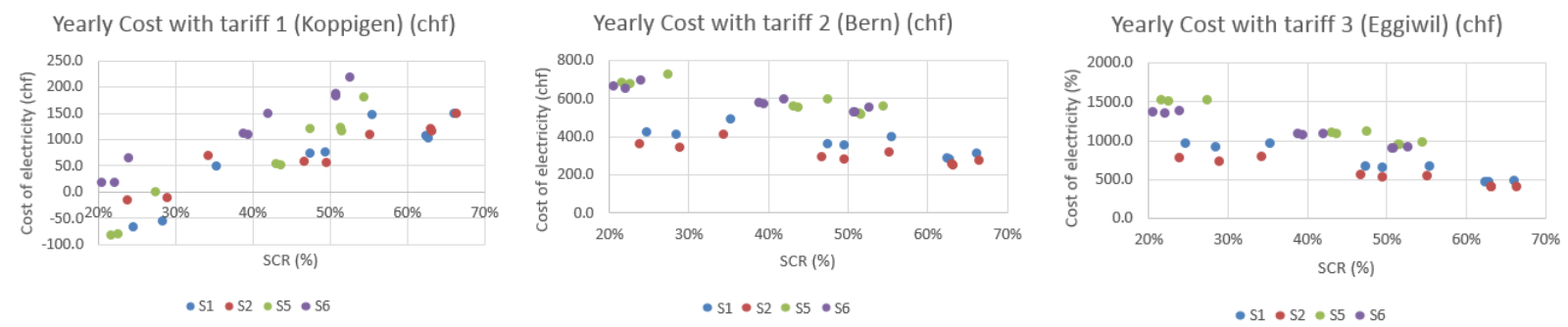

Fig. 6: yearly electricity costs for 3 different electricity tariffs and different control strategies for the four scenarios

In terms of theoretical maximal SCR. The values of these yearly KPIs for the four systems previously defined are gathered in Table 9.

Tab. 9: Current yearly SCR and SCR maximal values (with EMS or batteries)

\begin{tabular}{|c|c|c|c|}
\hline Case & $\begin{array}{l}\text { Current SCR } \\
\text { (controller: C1) }\end{array}$ & SCR EMS max & SCR bat. max \\
\hline S1 ref & $25 \%$ & $46 \%$ & $93 \%$ \\
\hline S2 ref & $24 \%$ & $54 \%$ & $97 \%$ \\
\hline S5 ref & $22 \%$ & $64 \%$ & $94 \%$ \\
\hline S6 ref & $21 \%$ & $75 \%$ & $100 \%$ \\
\hline
\end{tabular}

Theoretically, the use of an EMS can more than double the SCR for the studied cases. It can be observed that this theoretical maximum increases for increasing system reference number. Note that in badly isolated systems $(5$ and 6), the energy consumed by the HP represents a higher share of the total energy consumption than for well isolated ones (1 and 2). The amount of energy which can be shifted to better fit with the PV production is thus higher in such cases. 
When implementing a battery in the system, the SCR could theoretically increases up to $100 \%$. This is explained by the fact that the system is designed to have a yearly consumption matching the yearly PV production. In that case, and with a hypothetically big enough battery, all the produced energy can then be stored for a latter local use.

Even though these results are highly promising, it important to emphasize the fact that these are theoretical maximum which do not take into account the constraints of the system, especially the comfort temperature for space heating and domestic hot water and the battery capacity. The purpose of these KPI is only to provide an upper bound to the achievable performances.

Another interesting assessment is the evolution of these KPI over the year. As example, Figure 7 depicts the evolution of the daily SCR over the year for the case S1 ref, in the upper graph. In the lower one, is represented the heat pump daily operating rate $\left(O R_{H P}\right)$. It is defined as the percentage of the time during which the HP is in operation during the day. In order to improve the reading, a 7-term moving average trend line is superposed for each parameters.
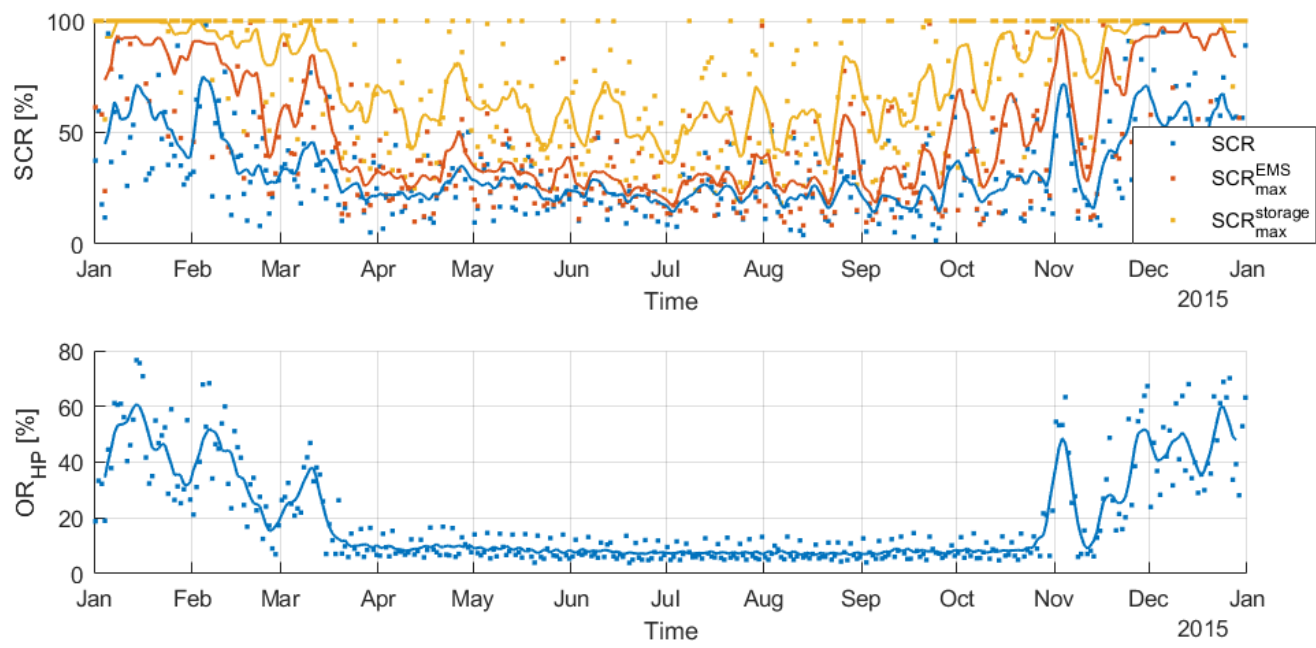

Fig. 7: Yearly evolution of the different SCR and the HP operating rate for case S1 ref

This figure allows to highlight the fact that the theoretical maximum benefit of an EMS is not constant over the year. Indeed, the SCR improvement which can be provided by the use of an EMS is higher in winter than for the rest of the year. This is explained by a higher amount of controllable energy consumed by the HP during this period, as it can be observed in the lower graph.

During this same period, the additional SCR increase with the use of a storage system compared to an EMS is relatively low. Since the PV production is low in winter and the consumption is higher (due to space heating), a high SCR can already be achieved with the use of an EMS only. However, the use of a storage system during the hot seasons is way more beneficial than an EMS.

\section{Conclusion and outlook}

In this article 8 control strategies that are aimed at increasing SCR were presented and tested against standard controllers using different scenarios.

The first objective was to find what control strategy or combination of strategies would lead to the highest SCR and assess how far this value is with respect to the theoretical maximal SCR. It was shown that the SCR increase ranges on average from 3\% to 37\% depending on the used control strategy (or combination of strategy), however, this SCR is far from the maximal SCR. There is room for improvement that can be achieved for instance by employing smarter control, such as MPC or larger batteries.

The second objective, was to investigate the impact of SCR increase on the electricity bill. It was shown that depending on the local electricity tariffs (for buying and selling), SCR increase is not always desirable. Indeed, if both tariffs are equal, increasing SCR leads to higher overall costs. Whereas if the tariff for selling PV energy to the grid is significantly lower than the buying tariff, higher SCR leads to savings. In the considered scenarios the yearly losses can go up to $263 \mathrm{chf}$ and the savings up to $540 \mathrm{chf}$, when compared to the reference controller.

Future work will be carried out to refine the financial analysis by taking into account capital expenditure and component ageing, development of smarter controllers (typically MPC based) and exploring the potential of optimal component sizing rules. 


\section{Acknowledgement}

This research is funded by the Bundesamt für Energie under the grant SI/501434-01.

\section{References}

Candanedo J. A. and Athienitis A. K., Predictive control of radiant floor heating and solar-source heat pump operation in a solar house, HVAC\&R Research , Volume 17, 2011 - Issue 3: Modeling high-performance buildings

ElCom, https://www.prix-electricite.elcom.admin.ch/BaseDataSelection.aspx, accessed: January 2018

PVtarif, http://www.vese.ch/pvtarif-apps/, accessed: January 2018

Smartfox, https://www.smartfox.at/, accessed: June 2018

Solarlog, https://www.solar-log.com/, accessed: June 2018

Solarwatt, https://www.solarwatt.fr/gerer-lenergie/, accessed: June 2018

Vandhoudt D. et al., An actively controlled residential heat pump: Potential on peak shaving and maximization of self-consumption of renewable energy, Renewable Energy Volume 63, March 2014, Pages 531-543

Velasolaris, http://www.velasolaris.com/, accessed : September 2018

\section{Appendix}

Tab. A.1: self sufficiency

\begin{tabular}{|l|l|l|l|l|l|l|l|l|l|}
\hline Case & Ref & C1 & C2 & C3 & C4 & C5 & C6 & C7 & C8 \\
\hline S1 & $26 \%$ & $30 \%$ & $34 \%$ & $50 \%$ & $66 \%$ & $52 \%$ & $66 \%$ & $55 \%$ & $67 \%$ \\
\hline S2 & $24 \%$ & $29 \%$ & $32 \%$ & $48 \%$ & $64 \%$ & $50 \%$ & $64 \%$ & $53 \%$ & $65 \%$ \\
\hline S5 & $23 \%$ & $24 \%$ & $27 \%$ & $45 \%$ & $54 \%$ & $46 \%$ & $54 \%$ & $48 \%$ & $55 \%$ \\
\hline S6 & $20 \%$ & $22 \%$ & $23 \%$ & $38 \%$ & $50 \%$ & $39 \%$ & $50 \%$ & $40 \%$ & $51 \%$ \\
\hline
\end{tabular}

Tab. A.2: energy to the grid (i.e. sold to the grid)

\begin{tabular}{|l|l|l|l|l|l|l|l|l|l|}
\hline Case & Ref & C1 & C2 & C3 & C4 & C5 & C6 & C7 & C8 \\
\hline S1 & $5^{\prime} 843$ & $5^{\prime} 551$ & $5^{\prime} 014$ & $3^{\prime} 180$ & $1^{\prime} 793$ & $3^{\prime} 033$ & $1^{\prime} 809$ & $2^{\prime} 572$ & $1^{\prime} 540$ \\
\hline S2 & $4^{\prime} 432$ & $4^{\prime} 135$ & $3^{\prime} 822$ & $2^{\prime} 632$ & $1^{\prime} 273$ & $2^{\prime} 486$ & $1^{\prime} 302$ & $2^{\prime} 155$ & $1^{\prime} 109$ \\
\hline S5 & $9^{\prime} 116$ & $9^{\prime} 005$ & $8^{\prime} 437$ & $5^{\prime} 741$ & $4^{\prime} 324$ & $5^{\prime} 689$ & $4^{\prime} 338$ & $5^{\prime} 239$ & $3^{\prime} 983$ \\
\hline S6 & $7^{\prime} 487$ & $7^{\prime} 339$ & $7^{\prime} 164$ & $5^{\prime} 157$ & $3^{\prime} 546$ & $5^{\prime} 122$ & $3^{\prime} 573$ & $4^{\prime} 878$ & $3^{\prime} 396$ \\
\hline
\end{tabular}

Tab. A.3: energy from the grid (i.e. purchased from the grid)

\begin{tabular}{|l|c|c|c|c|c|c|c|c|c|}
\hline Case & Ref & C1 & C2 & C3 & C4 & C5 & C6 & C7 & C8 \\
\hline S1 & $5^{\prime} 416$ & $5^{\prime} 191$ & $5^{\prime} 322$ & $3^{\prime} 652$ & $2^{\prime} 485$ & $3^{\prime} 525$ & $2^{\prime} 470$ & $3^{\prime} 512$ & $2^{\prime} 506$ \\
\hline S2 & $4^{\prime} 330$ & $4^{\prime} 059$ & $4^{\prime} 268$ & $2^{\prime} 999$ & $2^{\prime} 045$ & $2^{\prime} 842$ & $2^{\prime} 045$ & $2^{\prime} 852$ & $2^{\prime} 075$ \\
\hline S5 & $8^{\prime} 587$ & $8^{\prime} 482$ & $8^{\prime} 435$ & $6^{\prime} 090$ & $5^{\prime} 118$ & $6^{\prime} 013$ & $5^{\prime} 088$ & $6^{\prime} 010$ & $5^{\prime} 151$ \\
\hline S6 & $7^{\prime} 604$ & $7^{\prime} 456$ & $7^{\prime} 586$ & $5^{\prime} 880$ & $4^{\prime} 752$ & $5^{\prime} 828$ & $4^{\prime} 751$ & $5^{\prime} 835$ & $4^{\prime} 802$ \\
\hline
\end{tabular}


Y. Stauffer et. al. / EuroSun 2018 / ISES Conference Proceedings (2018)

Tab. A.4: yearly cost (electricity only, negative: gain, positive: losses) for tariffs from Koppigen

\begin{tabular}{|l|r|r|r|r|r|r|r|r|l|}
\hline Case & \multicolumn{1}{l|}{ Ref } & \multicolumn{1}{l|}{ C1 } & \multicolumn{1}{l|}{ C2 } & \multicolumn{1}{l|}{ C3 } & \multicolumn{1}{l|}{ C4 } & \multicolumn{1}{l|}{ C5 } & \multicolumn{1}{l|}{ C6 } & \multicolumn{1}{l|}{ C7 } & C8 \\
\hline S1 & -66.2 & -55.8 & 47.7 & 73.2 & 107.3 & 76.3 & 102.5 & 145.7 & 149.7 \\
\hline S2 & -15.8 & -11.8 & 69.1 & 56.9 & 119.7 & 55.2 & 115.2 & 108.0 & 149.7 \\
\hline S5 & -82.0 & -81.1 & -0.3 & 54.1 & 123.1 & 50.2 & 116.3 & 119.5 & 181.0 \\
\hline S6 & 18.1 & 18.1 & 65.4 & 112.1 & 186.9 & 109.4 & 182.6 & 148.3 & 217.9 \\
\hline
\end{tabular}

Tab. A.5: yearly cost (electricity only, negative: gain, positive: losses) for tariffs from Bern

\begin{tabular}{|l|l|l|l|l|l|l|l|l|l|}
\hline Case & Ref & C1 & C2 & C3 & C4 & C5 & C6 & C7 & C8 \\
\hline S1 & 422.7 & 410.1 & 488.8 & 361.7 & 283.5 & 352.8 & 279.1 & 396.9 & 313.0 \\
\hline S2 & 362.1 & 341.4 & 412.0 & 294.9 & 253.8 & 280.3 & 250.8 & 315.6 & 275.9 \\
\hline S5 & 685.1 & 676.7 & 725.2 & 559.0 & 520.3 & 549.8 & 513.2 & 594.7 & 560.8 \\
\hline S6 & 665.7 & 653.0 & 695.0 & 578.6 & 530.4 & 572.4 & 527.4 & 598.4 & 554.8 \\
\hline
\end{tabular}

Tab. A.6: yearly cost (electricity only, negative: gain, positive: losses) for tariffs from Eggiwil

\begin{tabular}{|l|r|r|r|r|l|r|r|r|r|}
\hline Case & \multicolumn{1}{|c|}{ Ref } & \multicolumn{1}{c|}{ C1 } & \multicolumn{1}{c|}{ C2 } & \multicolumn{1}{l|}{ C3 } & \multicolumn{1}{l|}{ C4 } & \multicolumn{1}{l|}{ C5 } & \multicolumn{1}{l|}{ C6 } & \multicolumn{1}{l|}{ C7 } & \multicolumn{1}{l|}{ C8 } \\
\hline S1 & 956.2 & 918.4 & 968.7 & 675.1 & 474.2 & 653.1 & 470.3 & 668.7 & 489.0 \\
\hline S2 & 774.0 & 726.4 & 784.8 & 553.6 & 398.4 & 524.9 & 397.2 & 540.4 & 411.5 \\
\hline S5 & 1521.9 & 1503.3 & 1515.7 & 1108.3 & 951.5 & 1093.5 & 944.3 & 1110.8 & 972.4 \\
\hline S6 & 1371.1 & 1344.5 & 1380.1 & 1085.6 & 902.2 & 1075.5 & 900.9 & 1086.8 & 919.2 \\
\hline
\end{tabular}




\title{
Integrating Polysun into a Test Bench for Prosumer Hardware
}

\author{
Steffen Wienands ${ }^{1}$, Noah Pflugradt ${ }^{1}$ and Andrea Vezzini' ${ }^{1}$ \\ ${ }^{1}$ Bern University of Applied Sciences, Quellgasse 21, 2501 Biel (Switzerland)
}

\begin{abstract}
New hardware such as batteries, energy management systems and inverters need to be tested and the correct function needs to be verified before companies install the hardware in the consumer homes. For this the Prosumer-Lab test bench was created. It contains a wide range of emulation hardware enabling Hardware in the Loop (HIL) testing and development of system components for prosumer-households. System components used in smart buildings can be compared regarding increase in self-consumption, economic efficiency or influence on grid stability. The integration of the simulation software Polysun expands the Prosumer-Lab portfolio by including sophisticated simulation models as well as weather and temperature profiles for systems with renewable energies. Polysun is integrated into the Prosumer-Lab test bench via a custom controller programmed in Java and is used to simulate the building and the building infrastructure such as heat pumps.
\end{abstract}

Keywords: Prosumer, energy management system (EMS), Polysun, self-consumption, HIL, smart building

\section{Introduction}

The expansion of renewable energies, in particular photovoltaics, is increasingly driven by private households. The next step will be so called Prosumers, which actively participate in the energy market. As a result, new operational concepts for household devices controlled by smart algorithms are emerging.

The Prosumer-Lab test bench aims to enable testing of solutions for a better integration of renewable energies into smart homes, while simultaneously maintaining stability and power quality of the domestic and distribution grid. Therefor it emulates a prosumer-household.

These tests are done with the hardware in the loop (HIL) method. That means that the object under test is physically present and real current flows, but other components of the house are simulated. This combination of emulation hardware and simulation enables testing, optimization and development of system components. Currently, the Prosumer-Lab is mainly used to test and compare different energy management systems (EMS), namely the SolarLog (Solare Datensysteme GmbH), the SolarWatt (SOLARWATT GmbH) and the SmartFox (DAfi GmbH) EMS.

Within the Prosumer-Lab a wide range of different devices and emulators are available to enable testing of smart control algorithms in distinct household setups. Thereby different states or situations of a household, which would otherwise be difficult to reproduce, can be realistically simulated with previously created profiles (consumption, weather, temperature profiles, etc.). The test bench uses a combination of emulation and simulation to recreate the electrical energy flows of a household with photovoltaics, heat pump and battery storage to the grid connection point with real voltages and currents. Furthermore, real system components such as batteries, inverters and MPPTs are integrated into the test bench. This setup enables development, comparison and testing of system components such as energy management systems, inverters or battery storage under controlled conditions. For this, the systems can be confronted reproducible testing scenarios, grid instabilities or with different error states. Thanks to its modular design, the test platform is suitable for testing all types of energy management systems and system components for private households such as batteries, inverters, etc.

\section{Method}

\subsection{Overview}

To simulate a prosumer household as realistically as possible, emulations, simulations and system components available on the market are combined in the test bench. The power grid and the accumulated household consumption are each mapped on an emulation device with an output of up to $50 \mathrm{kVA}$. Several photovoltaic emulators can model 
different roof orientations of the system with up to eight times $5 \mathrm{kWp}$.

For the operation of this physical emulation of the system, realistic profiles are required, which are generated partly by long-term measured values, partly by simulations. In addition, simulations are used within the test bench to depict components or profiles that are difficult to integrate. Validity and accuracy of HIL-simulations for private households depends upon the integration of highly realistic simulations of thermal and electrical profiles.

For that, Polysun (Vela Solaris AG) is used in the Prosumer-Lab as simulation software. It offers a wide range of sophisticated simulation models for systems regarding renewable energies that are commercially available - such as heat pump systems, photovoltaics or solar thermal systems.

The integration of Polysun extends the test bench with a complex building simulation, which considers thermal mass, insulation and heat losses of the building. In addition, heat pumps or battery storage systems can be simulated via Polysun. Calculation models for hot water storage tanks and hot water load profiles are also integrated.

The top-level control of the Prosumer-Lab is called the scenario manager, which is programmed in Java. Fig. 1 presents the integration of different applications required within the test bench by the scenario manager. Through a web interface it provides access to the Prosumer-Lab test bench for different research groups. This way different test scenarios can be implemented or started on the test bench. The scenario manger provides basically a hub for different smaller applications that each deal with individual tasks. They communicate with a REST-Interface. For example, the communication with Polysun, the integration of CSV-profiles or the communication with the energy readers are all realized as individual applications. The hardware-connector programmed in java and python connects to the test bench via the dSPACE MicroLabBox. The scenario manager also deals with logging all measurement values to a database. It was decided to use SQLite as format for all logging, since it is very performant and enables the logging of all kinds of data into a single file. In this way all the results including the test configuration from a test can be stored in a single file, which makes it very easy to archive the results.

scenario data

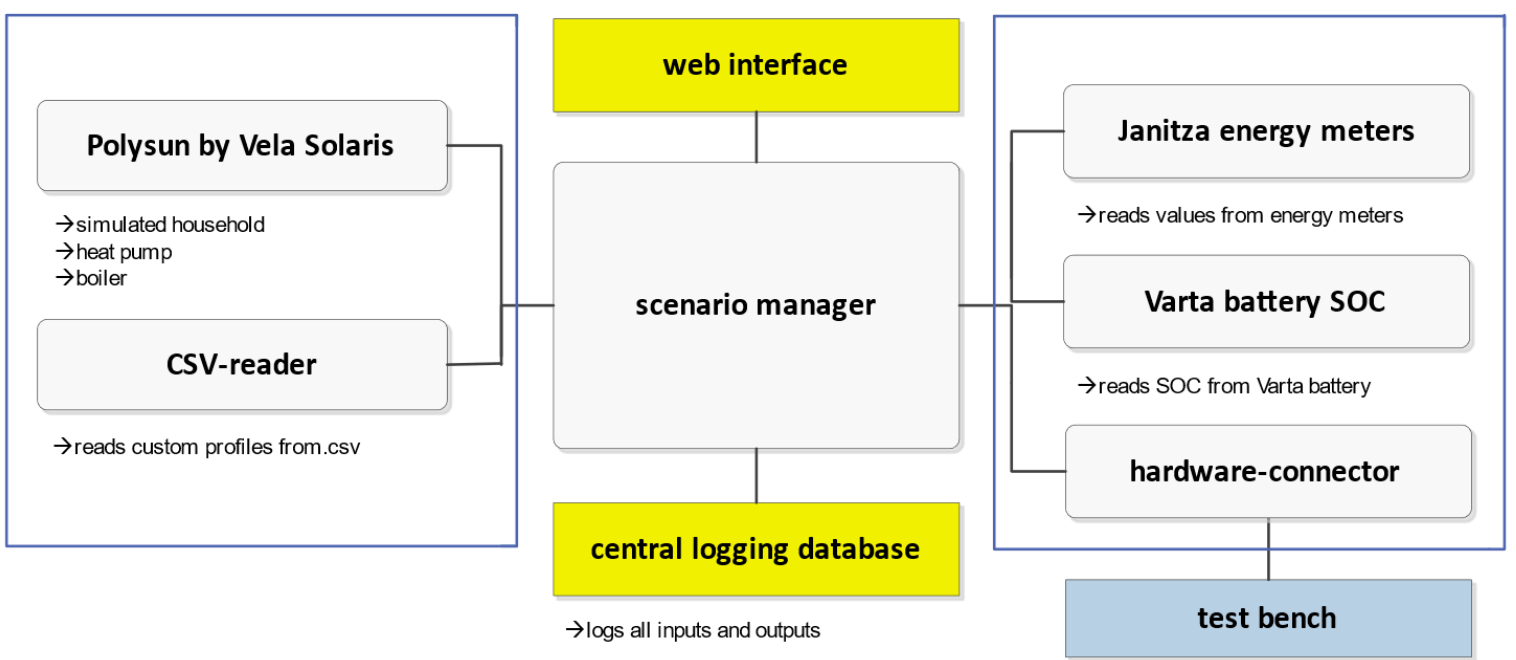

Fig. 1: The scenario manager as the top-level control integrates various applications into the Prosumer-Lab test bench.

\subsection{Control of the simulated heat pump through the EMS}

The connection from the scenario manager to Polysun is done with a custom controller in Polysun, which connects to the scenario manager with the mentioned REST interface. It replaces the built-in heat pump controller in Polysun with a custom controller. Polysun starts the simulation at the beginning of the year and then runs in accelerated mode, where days are simulated in seconds, until the day that should be tested in the ProsumerLab. Then the custom controller switches Polysun to real time mode where one simulated second is one real second. The custom controller starts talking to the scenario manager and acquires for example the current state of the EMS signal from the scenario manager every second and then controls the target temperature for the two DHW storages and subsequently the switching of the simulated heat pump based on that target value. The simulated heat pump then generates a simulated power consumption, which is fed into the load emulator and leads to real current flowing.

The plugin which integrates Polysun into the Prosumer-Lab can have as many input and output channels as needed. 
It can be easily extended to different controller strategies. New input channels can be defined in the configuration file so that any needed value can be extracted from Polysun and be sent to the scenario manager.

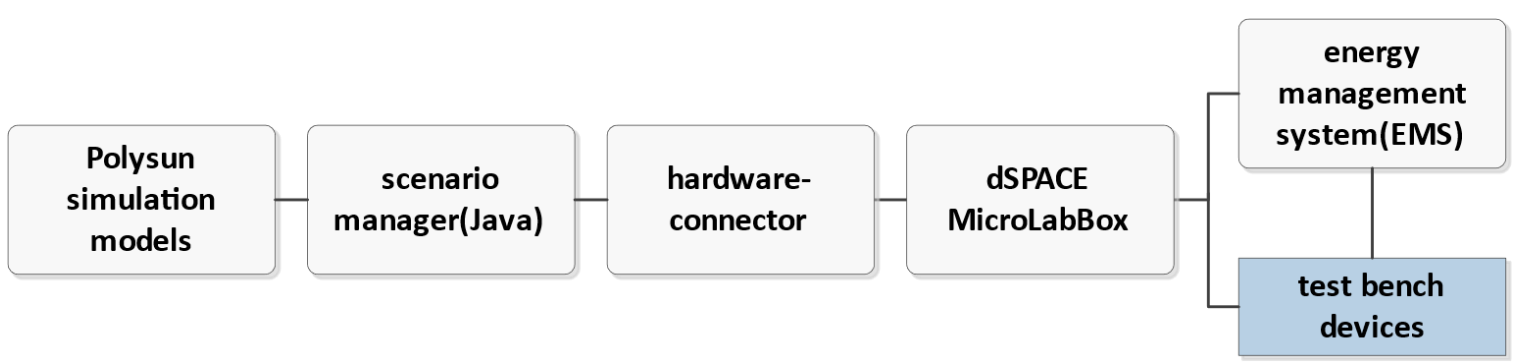

Fig. 2: Integration of Polysun to the Prosumer-Lab HIL test bench. The device under test is an energy management system which communicates with other test bench devices and the scenario manager.

As shown in Fig. 2 the scenario manager connects to the internal control unit of the test bench - a dSPACE MicroLabBox - and supplies it with target values to be set for the different devices.

The MicroLabBox is a programmable real-time system with various interfaces, such as analogue and digital I/O, RS232/RS485 and Ethernet. It is therefore very well suited as a central control unit for the test bench hardware. Control algorithms are programmed on the MicroLabBox in Matlab Simulink. It has an ASAM XIL API model access port (MAPort) through which the scenario manager can access the MicroLabBox application using a Python script. This allows the system to be started and stopped remotely. During operation, the scenario manager transfers setpoints for the various devices of the test bench via the access port and reads out actual values. The Prosumer-Lab operates with an update frequency of $1 \mathrm{~Hz}$. The control and regulation of the test bench devices via the MicroLabBox, however, operates at a much higher resolution of up to $10 \mathrm{kHz}$ to generate for example the wave forms of the grid emulator in real-time. This makes it possible to emulate all kinds of grid conditions and evaluate how the devices deal with them.

The device under test (DUT), in this case an EMS, receives all the required inputs - either directly from the test bench devices or through a simulation - and feeds back its operating commands for the devices available in the prosumer-household.

To integrate one of the EMS into the test bench a separate heat pump consumption measurement was required. This could be solved by programming an S0-signal on the MLB and emulating it via optocouplers.

\subsection{Representative testing scenarios}

The profiles, calculation and target values required for a test are predefined in scenarios. A scenario defines all load and production profiles and lasts, for example, 24 hours for a typical test day. This information comes directly from applications, simulations, measurements and calculations to obtain realistic test conditions. The development and comparison of systems are based on identical profiles or conditions over an entire test series.

Four main scenarios were developed for testing and comparing EMS, each of which corresponds to a representative day of one of the four seasons. Each of these scenarios is tested with a different hardware setup of the test bench, testing either control of single or a combination of multiple devices by the EMS.

Table 1: General description for the scenarios used for comparing control of the simulated Polysun heat pump with and without EMS.

\begin{tabular}{ll}
\hline PV installed & Parameters \\
\hline PV inverter & PM-emulators, $5.4 \mathrm{kWp}$, orientation: south, $45^{\circ}$ elevation \\
\hline Heat pump & Polysun: air-fluid HP $(10 \mathrm{~kW}$, COP at A2/W35: 3.1) \\
\hline Boiler & Polysun: $3.5 \mathrm{~kW}$ \\
\hline Thermal loads & Polysun: indoor temperature development with given min/max-values \\
\hline Household & Polysun: 200 liters/day warm water at $50^{\circ} \mathrm{C}$ \\
\hline Irradiance data & Bern; single-family house; family, 4 persons \\
\hline Outside temp. data & MeteoSwiss, Koppingen, Switzerland, 2015 \\
\hline
\end{tabular}


Table 1 shows the general description of the main scenarios for one specific kind of household. It lists the components which will be simulated through Polysun. The irradiance data used for the PV-emulators is based on MeteoSwiss measurement data in a resolution of 10 minutes. A software called LoadProfileGenerator (Pflugradt, 2015) creates target values for emulating the consumption of the household based on behavior simulation. The target values for the PV-emulators as well as the ones extracted from the LoadProfileGenerator are read into the scenario manager via the CSV-reader.

Project PROSUMERLAB V1 - System diagram VITOCAL 200-S: with electric heater and standard HP/heater controller (Reference)

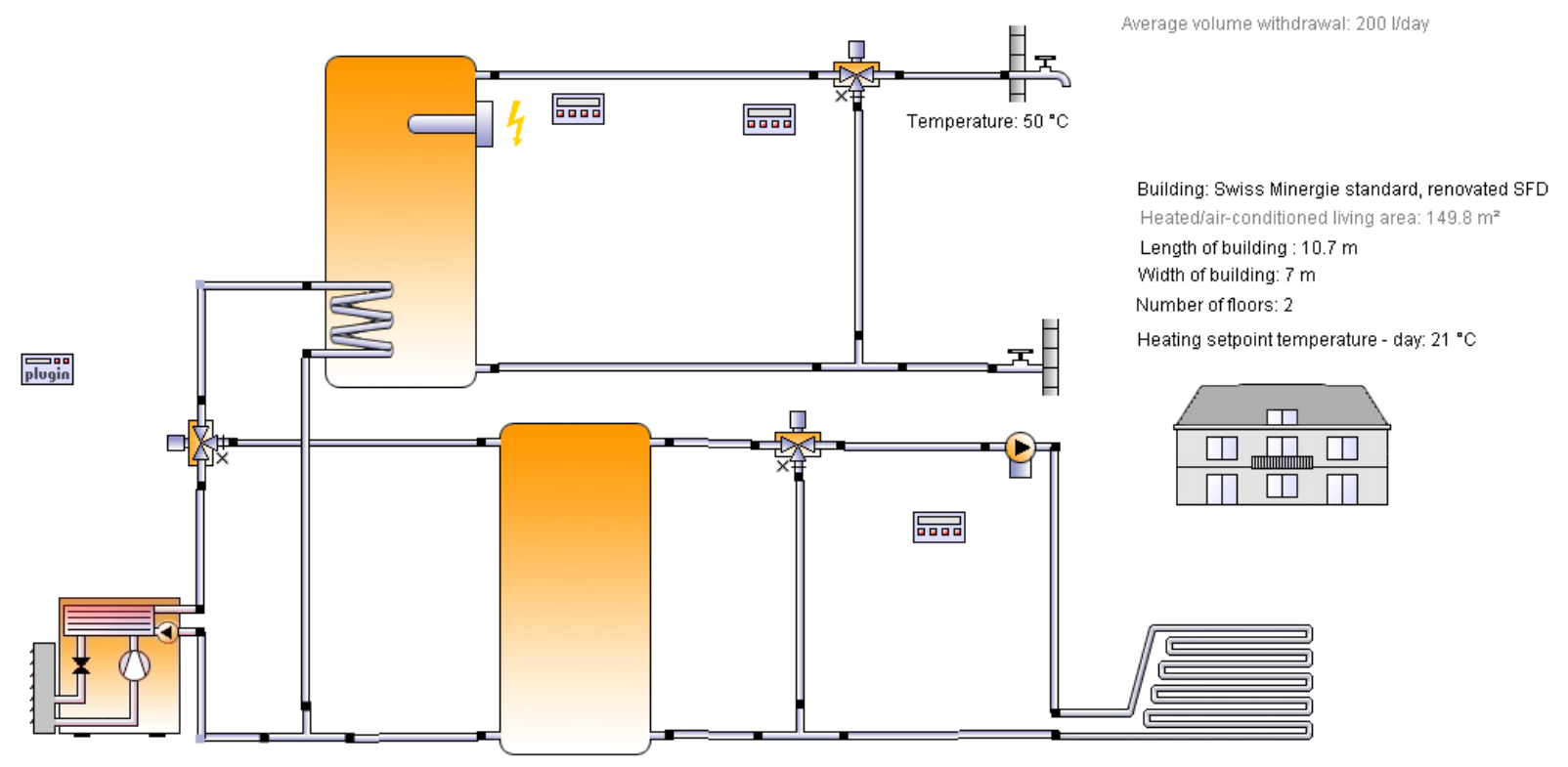

Heat pump: Modulating heat pump $10 \mathrm{~kW}$
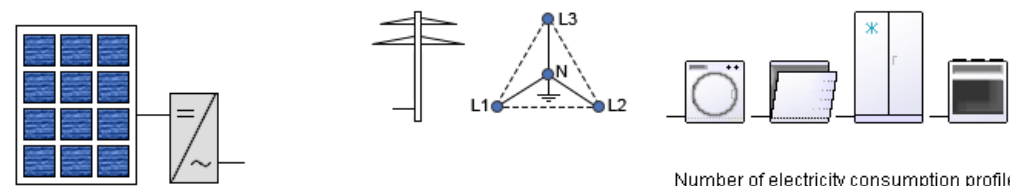

Number of electricity consumption profiles: 1

Consumption profile 1: Prosumerlab Scenario 10

Total consumption of the profiles: 4,99 ? $\mathrm{kWh}$

Fig. 3: Configuration of Polysun used for in the Prosumer-Lab test bench for the main scenarios.

Fig. 3 shows the configuration done in Polysun which is used in the main scenarios, corresponding to the description in Table 1.

\section{Results}

To compare the increase in own consumption of the various energy management systems, the same main test scenario with data from a typical day of the year was carried out for all EMS. A representative day was selected for each season to highlight the clear seasonal differences - for example, 20 October 2015 with the corresponding power flows, i.e. the production of the photovoltaic system and the consumption of the household (Fig. 4). This scenario can be used any number of times to test different EMS. 


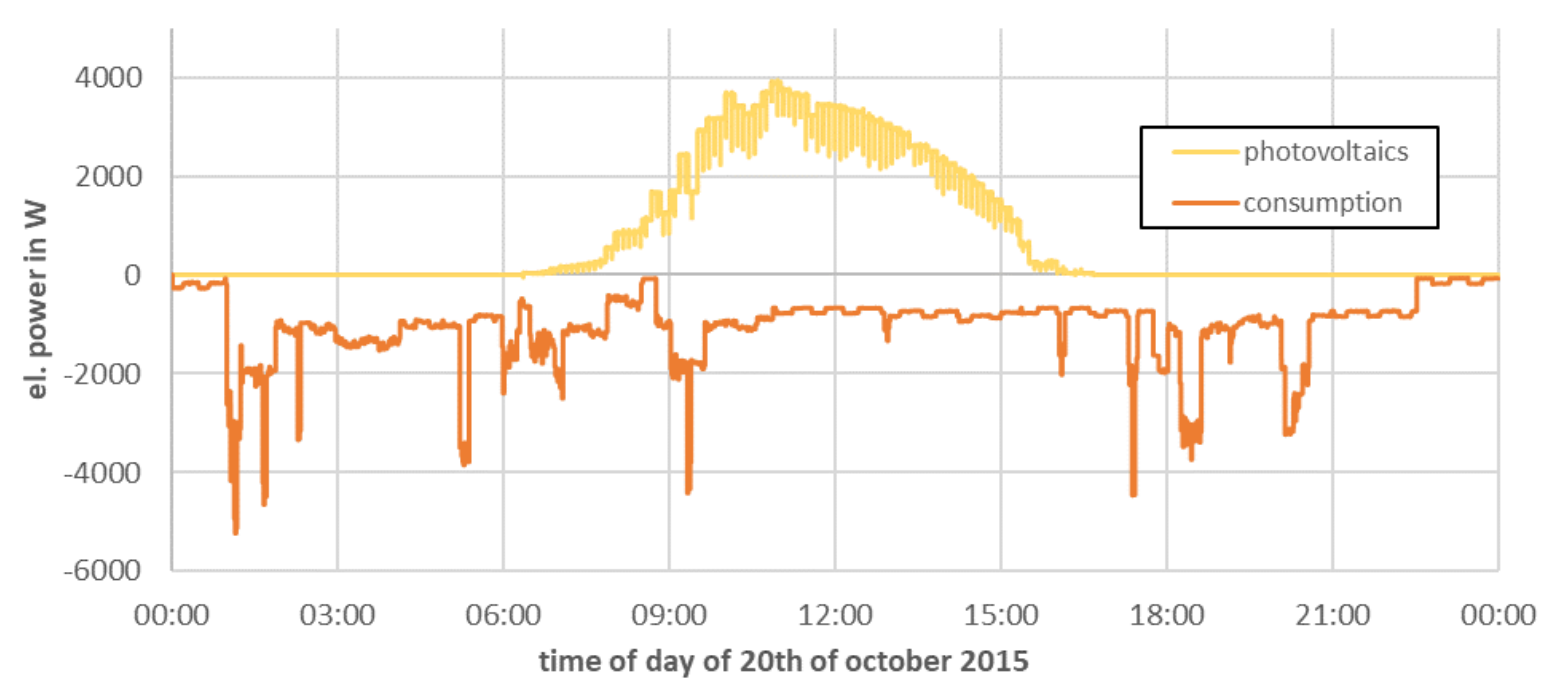

Fig. 4: Power flows of a representative 4-person household in Switzerland on 20 October 2015, divided into production by photovoltaics and accumulated consumption.

As a reference for quantifying the EMS performance, the scenario is run through once without an EMS connected. Subsequently, the control of the heat pump simulated in Polysun can be examined. In this test scenario no battery was used.

Fig. 5 shows the power consumption of the heat pump with different operating characteristics. The operation of the heat pump without control and with control by two different EMS is compared. The EMS tested in the ProsumerLab basically use rule-based controllers. Thresholds for surplus power, minimum and maximum turn on or turn off times and other parameters can be set in the configuration interfaces of the EMS.

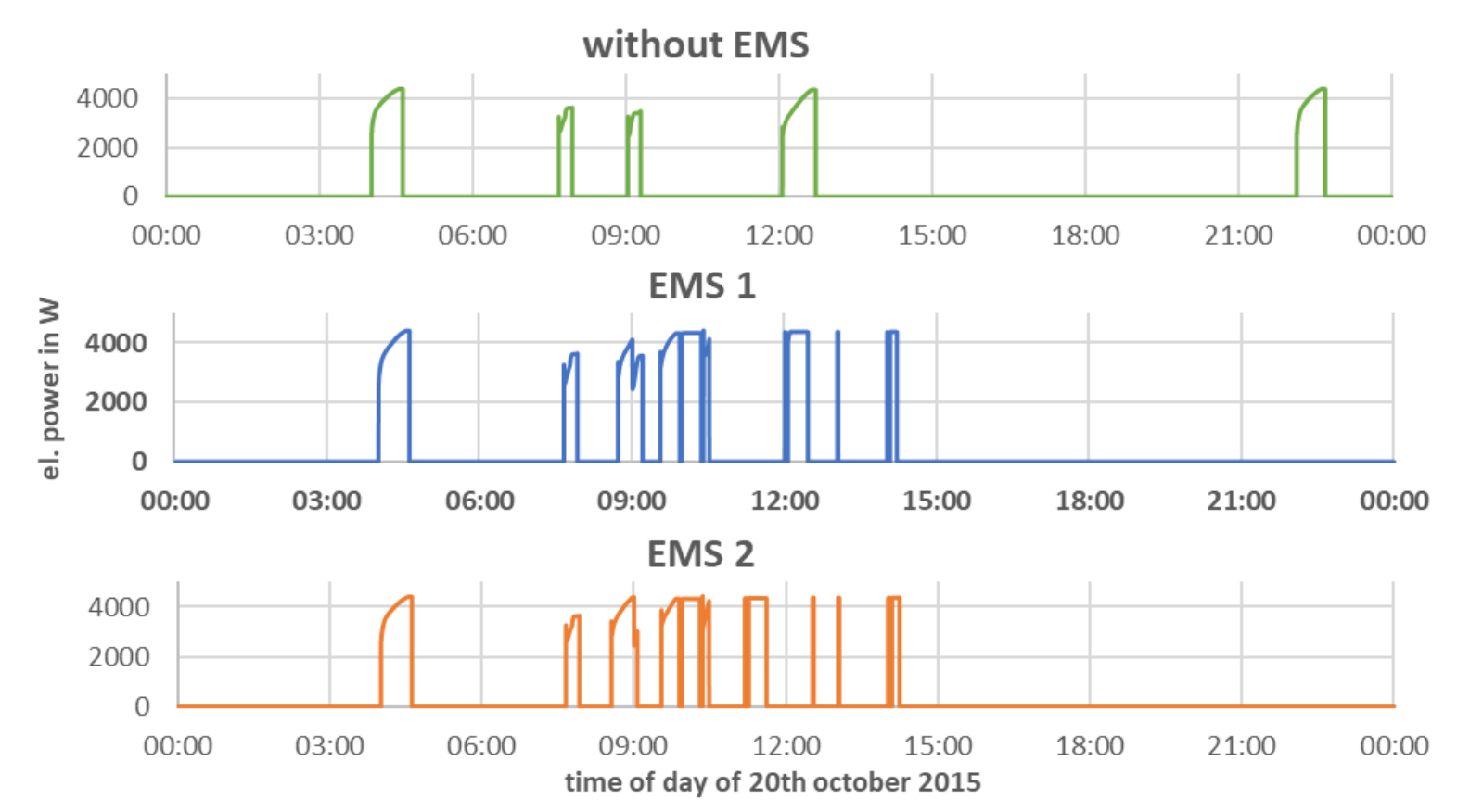

Fig. 5: Comparison of power consumption of the heat pump during operation without control and when controlled by two different anonymized EMS.

Without the EMS, the main parameter influencing the switching behavior of the heat pump is the internal temperature of the water storage tank. When controlling the heat pump with an EMS, the excess power of the household due to a high production of photovoltaics as well as setting of the configuration parameters for the EMS are further factors. The control signal of the EMS can switch between a default and a raised target temperature for the DHW cylinders. Based on the actual temperature and its target value the heat pump can switch on or off. This means the EMS does not control the heat pump directly but controls it via setting the desired temperature value of the DHW cylinders.

As can be seen in Fig. 5, the energy management systems increase the use of the excess power produced during the day by photovoltaics for the operation of the heat pump. Since the temperature of the DHW cylinder cools down 
only slowly, there is no need to switch on the heat pump again at night. This increases the amount of own consumption of electricity by the user. The target temperature in the DHW cylinder is also raised temporarily.

The EMS examined have a very similar switching behavior of the heat pump to increase own consumption. However, they have several configuration parameters that can be set by the user which can greatly affect their behavior. This example shows the importance of a systematic investigation of the EMS for understanding the functionalities. The results of this research project will be published in a final report in mid-2019.

\section{Conclusion}

Testing system components for Prosumer-households such as energy management systems (EMS) requires realistic and reproducible electrical and thermal testing conditions. The setup of a complete thermal system in the test bench could be avoided by integrating thermal simulations. The application of a custom controller successfully integrated Polysun into the Prosumer-Lab test bench, whereby a significant development effort for specially developed simulations could be saved. Electrical profiles for the emulation devices of the test bench are based on measurements and behavior simulation and are integrated into the top-level control as well. During testing, Polysun simulations run in real-time and influence setting of the target values for the test bench devices. First EMS test results indicate similar switching behavior of the heat pump to increase own consumption. Therefore, a systematic investigation of the EMS is necessary to understanding functionalities.

\section{References}

DAfi GmbH. Energy management system SMARTFOX REG. Last accessed 06.09.2018. URL: http://smartfox.at/en/smartfox-reg.html.

Noah Pflugradt. LoadProfileGenerator. Last accessed 06.09.2018. URL: https://www.loadprofilegenerator.ch/.

Solare Datensysteme GmbH. Energy management system Solar-Log 1200. Last accessed 06.09.2018. URL: https://www.solar-log.com/en/products-components/monitoring-hardware/solar-log-1200/.

SOLARWATT GmbH. SOLARWATT EnergyManager. Last accessed 06.09.2018. URL: https://www.solarwatt.de/energie-management/energymanager.

Vela Solaris AG. Polysun Simulation Software. Last accessed 06.09.2018. URL: http://www.velasolaris.com/. 


\section{Solar Resource and Energy Meteorology}




\title{
A first approach of the influence of the forecasting horizon in the electricity generation simulation of a solar tower plant
}

\author{
Joaquín Alonso-Montesinos ${ }^{1,2}$, Jesús Polo ${ }^{3}$, Jesús Ballestrín' ${ }^{4}$, Javier Barbero, Gabriel López ${ }^{5}$, \\ Aitor Marzo ${ }^{6,7}$ and Francisco Javier Batlles ${ }^{1,2}$ \\ 1 Department of Chemistry and Physics, University of Almería, 04120 Almería, Spain \\ ${ }^{2}$ CIESOL, Joint Centre University of Almería-CIEMAT, 04120 Almería, Spain \\ ${ }^{3}$ Photovoltaic Solar Energy Unit (Renewable Energy Division, CIEMAT), 28040 Madrid, Spain \\ ${ }^{4}$ Concentrating Solar System Unit (Plataforma Solar de Almería, CIEMAT), 04200 Almería, Spain \\ ${ }^{5}$ Department of Electrical and Thermal Engineering, Design and Projects, University of Huelva, \\ 21004, Huelva, Spain \\ ${ }^{6} \mathrm{CDEA}$, University of Antofagasta, 02800 Antofagasta, Chile \\ ${ }^{7}$ Solar Energy Research Center (SERC-Chile), Santiago (Chile)
}

\begin{abstract}
Solar power plants are very interested in the prediction of power net generation and the instabilities that can affect the production of the plant. System Advisor Model (SAM) is widely used to simulate the behavior of concentration solar power plants, where different inputs parameters can be considered for simulations. Reliable short-term forecasting of the solar resource has significant positive consequences since it helps the planning of power plant operators for power dispatch and assess the plant reliability and the market trends. In this work, we quantify the accuracy of the electricity predictions of a solar power plant at different hour-scale, by using the solar irradiance forecasting obtained from Meteosat satellite images. For that, we have simulated the power generation of a solar power plant taking as input the solar irradiance forecasting with the purpose to determine the best forecast horizon time. The main novelty in this work is the analysis on the impact of short-term forecasting of DNI in the plant energy output at different forecasting horizons in solar tower plants with large thermal storage systems.
\end{abstract}

Keywords: Solar power plant, power net generation, SAM, satellite images, forecasting,

\section{Introduction}

The growing human population is causing an ever-increasing demand for conventional energy resources, which results in environmental negative effects. Renewable energies offer a viable and potent solution to counter the effects of this problem since they are pollution free, inexhaustible and affordable. In this context, solar energy technologies are growing in the last two decades being an alternative of conventional ways to produce electricity. Before constructing a solar power plant, several simulations are carried out to determine the best emplacements where technology can optimize the final production. System Advisor Model (SAM) is a software, which allows to determine a complete list of features to consider a plant in a concrete region. Developed and delivered at no cost by NREL (National Renewable Energy Lab), it has become the standard model for calculating the performance of solar thermal and photovoltaic plants since it has proven high reliability and performance compared to TRNSYS libraries designed for modeling CSP plants (Dobos et al., 2014; Wagner, 2008; Wagner and Gilman, 2011). Once that the solar plant has been built, the operation mode plays an important role. Decisions can increase the optimization of the plant and, subsequently, the electricity production and grid-power integration. Solar irradiance predictions are one of the best techniques to introduce in the operator systems for determining the future episodes that can affect the plant working. Concretely, Meteosat Second Generation (MSG) images are commonly used in the meteorological field, providing images every 15 mins, serving as relevant data for many researchers, for predicting the atmospheric conditions in short and large temporal scales (Alonso-Montesinos and Batlles, 2015; Boulifa et al, 2015).

In this work, we present a first approximation of the electricity generation simulation, where satellite predictions are used as input of the SAM simulation software. The aim is to obtain some deterministic characteristics for the choosing of the best forecasting horizon time, which would be very useful in the management and optimization of a solar power plant. 


\section{Data acquisition and solar plant design}

Radiation data are obtained from a radiometric station placed at the CIESOL building at the University of Almería, Spain $\left(36.8^{\circ} \mathrm{N}, 2.4^{\circ} \mathrm{W}\right.$, at sea level). The meteorological station has a two-axes solar tracker (2AP Kipp\&Zonen) above which direct, diffuse and global radiation sensors are installed. Furthermore, we collect images from a Meteosat Second Generation (MSG) satellite station, also placed on the roof of the CIESOL building. Radiation data are collected every minute. For the forecasting radiation, MSG satellite channels are collected every 15 minutes for 2013 and 2014 years.

The solar tower plant performance has been modeled with the System Advisor Model (SAM). SAM is a free and open source tool developed and distributed by the National Renewable Energy Laboratory (NREL) for estimating the energy production of different renewable energy systems (Dobos et al., 2014). In this work, the specific module for molten salt power tower systems is used (Neises and Wagner, 2012; Wagner, 2008). For the simulation of the solar power plant, one molten salt solar tower plant is selected as reference: Gemasolar, which is as a small plant with a very large thermal storage system. According to the case studies reported by NREL, the uncertainty in the annual production of Gemasolar plant computed with SAM is around 2.4\%. Gemasolar has a total solar field area of $305401 \mathrm{~m}^{2}$, the tower height is 140 meters with a total of 2650 heliostats. The technology is based on central receiver, using $\mathrm{NaNO}_{3}-\mathrm{KNO}_{3}$ as heat transfer fluid. The power block has $19.9 \mathrm{MWe}$ and the total capacity for storage is 15 hours.

\section{Methodology}

This section introduces the methodology for power gross output of a central tower plant, combining remote sensing techniques SAM simulations.

\subsection{Intra-hour DNI forecasting}

For power gross output, it is necessary to carry out a solar radiation forecasting to know the radiation level available in the near future. For that, three consecutive images are processed to determine the vectors that identifies the pixel motion along the time based on cloud detection. Figure 1 shows a MSG satellite image, where the raw image (upper image) represents the Iberian Peninsula, focusing the interest in the CIESOL area (marked in red and presented in the bottom-left image), and the final image represents the identification of clouds in this area. 

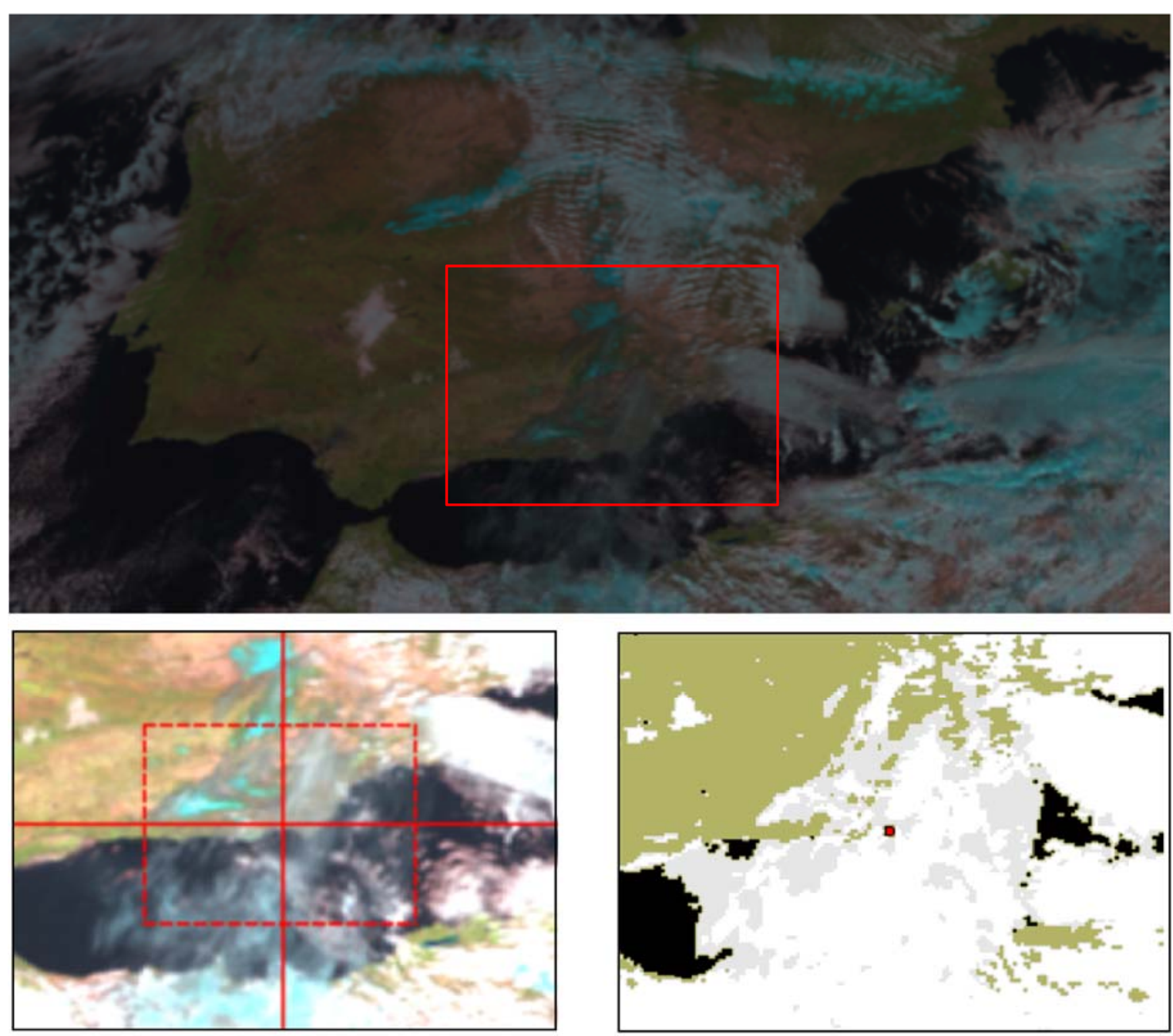

Fig. 1: MSG satellite image obtained on 10th February 2018 at 12:00 hours.

For each image collected every 15 minutes, 5 channels are used from the total 11 spectral channels. These channels are VIS 0.6, VIS 0.8, IR 3.9, IR 10.8 and IR 12.0. The images received are reduced, taking a $121 \times 161$ pixel raster image is taken, centred on the University of Almería. After that, an algorithm for detecting the presence of any clouds is applied in the various atmospheric layers of the raster map, considering full raster image (Escrig et al. 2013). With the cloud detection carried out in the three consecutive images, it is determined the cloud motion vectors. When vectors are calculated, the estimation of solar irradiance is obtained from the last image applying the Heliosat-2 method (Rigollier et al. 2000). Basically, this method considers the DNI estimation under cloudless skies for next applying an attenuation factor determined by presence of clouds. The expression which represents this approach can be defined as follows:

$$
D N I=D N I_{\text {clear sky }} K_{c s}
$$

where $D N I_{\text {clear sky }}$ is the DNI predicted for a clear sky condition using the ESRA model and $K_{c S}$ is the attenuation factor considering the presence of clouds.

In order to determine the value of $D N I_{\text {clear sky, }}$, eq. 2 defines the expression to obtain the aforementioned value.

$$
D N I_{\text {clear sky }}=I_{0} \varepsilon \sin (\alpha) T_{r b}(\alpha)
$$


where $I_{0}$ is the solar extraterrestrial radiation, $\varepsilon$ is the correction used for the variation in the sun-earth distance from its mean value, $\alpha$ is the solar altitude angle and $T_{r b}(\alpha)$ is an expression which related the Linke Turbidity factor and the Rayleigh optical thickness, as a function of the $\alpha$ angle.

When $D N I_{\text {clear sky }}$ is obtained for cloudless skies, the last step for estimating the DNI value is to obtain the $K_{c s}$ value through Heliosat 2 method which employs satellite images to calculate atmospheric attenuation (Rigollier et al. 2004; Alonso-Montesinos et al. 2015). The next expression shows the process to determine this attenuation factor at the pixel level:

$$
\begin{aligned}
& n<-0.2, K_{c s}=1.2 \\
& -0.2<n<0.8, K_{c s}=1-n \\
& 0.8<n<1.1, K_{c s}=2.0677-3.667 n+1.667 n^{2} \\
& n>1.1, K_{c S}=0.05
\end{aligned}
$$

where $\mathrm{n}$ is the cloud index, obtained using the albedo retrieved from satellite image.

After that, there are two matrices, each with $121 \times 161$ pixels: one matrix corresponds to the $D N I_{\text {clear }}$ sky estimations whereas the other one represents/corresponds to the $K_{C S}$ factor, both of them at pixel level. Therefore, the next step consists of determining the future DNI values. As one motion represents a 15-minute prediction, 12 motions are practiced to obtain a forecast from 15 to 180 minutes. Consequently, we have applied cloud motion vectors to each pixel of the raster image.

Therefore, for having a final DNI forecasting, when the $K_{c s}$ pixels are moved, the $D N I_{\text {clear sky }}$ is estimated for the future moments and for a cloudless sky in all the pixels of the satellite raster image (Alonso-Montesinos et al. 2015), ending with the product between the $D N I_{c l e a r ~ s k y}$, estimated in a pixel, and the $K_{c s}$, in the same pixel, generating the final DNI forecast.

\subsection{Power plant simulation}

After obtaining the DNI forecasting from 15 minutes to three hours, we simulate the power net production of a central tower solar power plant including the predictions obtained from satellite images. The aim is to compare the output gross production using each DNI prediction and the real DNI value to compare the differences, due to we simulate that Gemasolar plant is located in the CIESOL emplacement. Due that, we can use measured data from CIESOL's radiometric station.

The simulations are undertaken by means of the SAM software. The results obtained are then used to determine the best forecasting horizon by analyzing the impact of meteorological input compared to the experimental irradiance. For this work, the extinction model was used by default according to $25 \mathrm{~km}$ of visibility, not considering atmospheric attenuation measurements. This impact can be included in the operation and decisional way of a solar power plant management control system. The first results show that the predicted and real scenarios follow an interesting trend that can be deterministic in the choosing of the best forecasting time-scale applied in a solar power plant. 


\section{Results}

Before to present the graphs for the two different plants, the trend between DNI experimental values and DNI forecasting values is analyzed. This result is the first parameter considered for determining the accuracy of the prediction model. Fig. 2 represents the total DNI for one year using experimental data against the DNI for the same year using the 12 predictions each one for 15 minutes, in an interval that goes from 15 to 180 minutes.

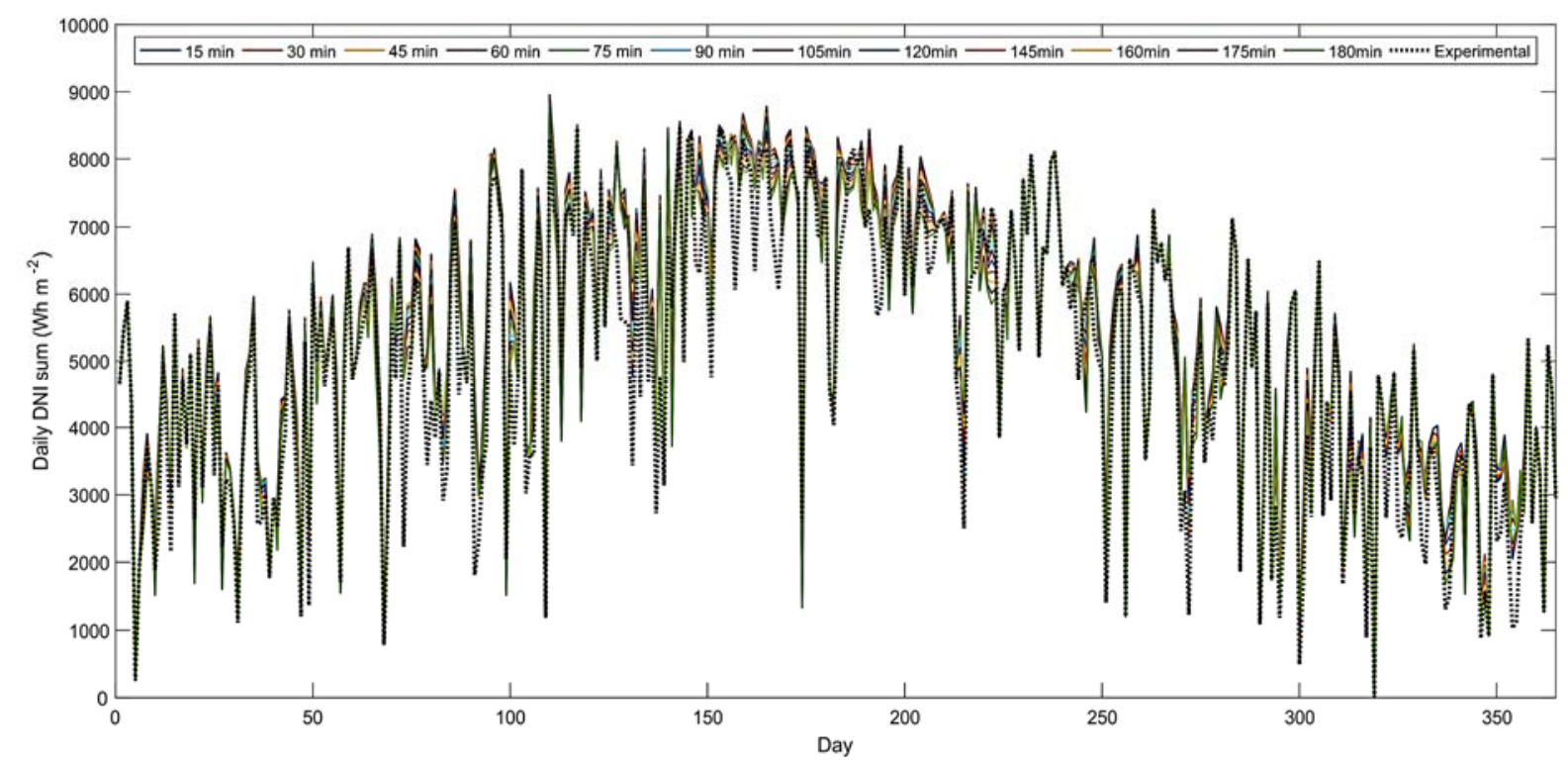

Fig. 2: Daily DNI for UAL emplacement.

In general, the main and important characteristic is the similitude between experimental and predicted data. This fact indicates the good concordance obtained from predictions using MSG images regarding to the measured DNI values. The trend goes from lower values (first and last part of the graph) that corresponds with winter days, reaching an average daily DNI value of $3000 \mathrm{Wm}^{-2}$, whereas for central days in the year (corresponding to summer days) this value is centered in $7000 \mathrm{Wm}^{-2}$. Obviously, there are important oscillations occasioned by clouds covering the surface of study, but they are well represented by the satellite predictions.

Considering the forecast method suitable according the results observed, the next consideration is to analyze the impact of the forecast interval in CSP plants. To represent the degree of concordance between the energy output obtained from simulation using real DNI values and obtained from simulation using DNI predictions, it has been developed one graph for the CSP plant. 


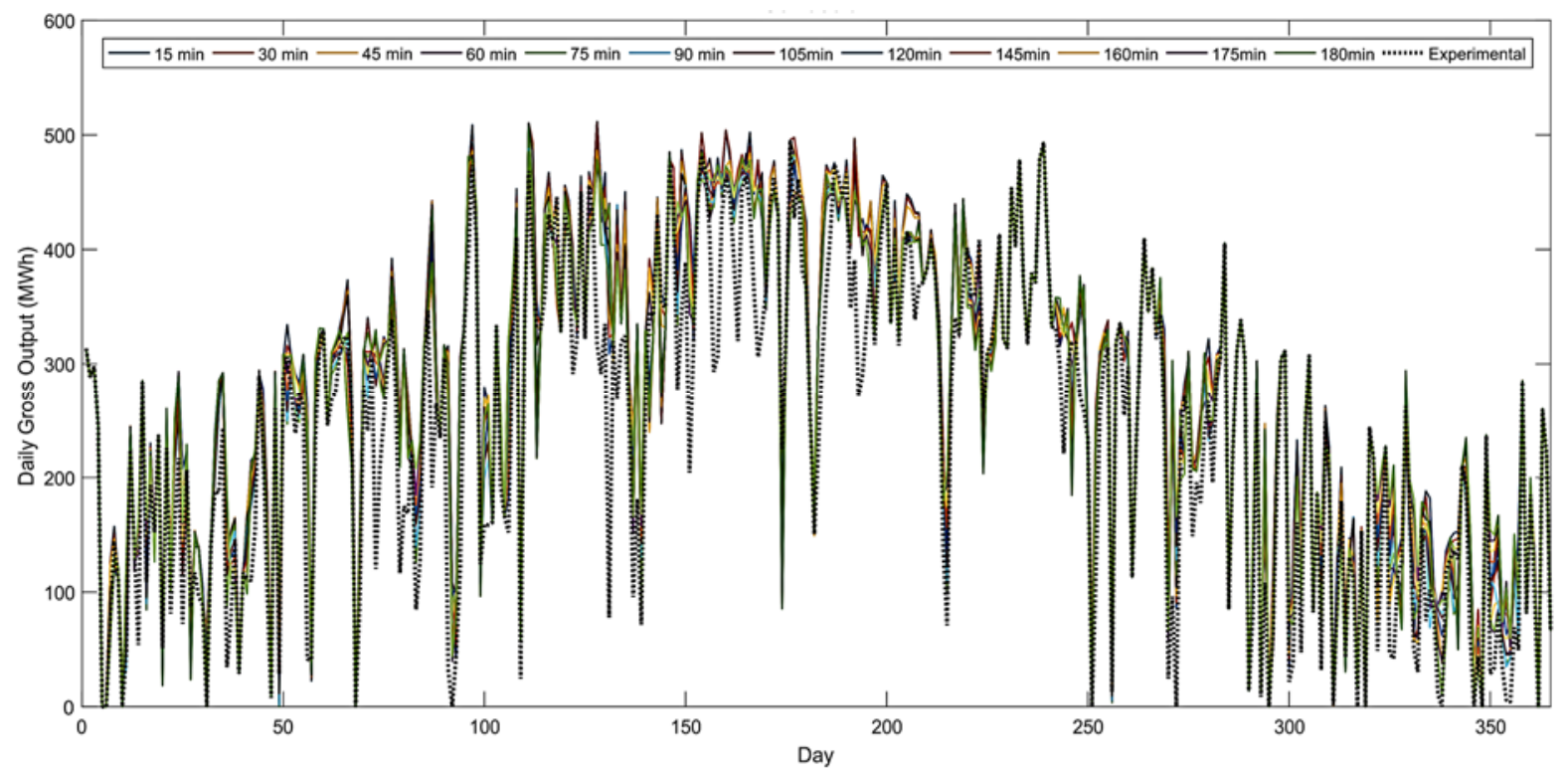

Fig. 3: Forecasted and simulated daily gross output for the UAL emplacement.

The daily gross energy output for Gemasolar plant follows a similar pattern than daily DNI, however, the oscillations present a lower amplitude, thanks to the plant's capability for producing energy using the heat stored in the molten salt tanks. The peak energy output values appear in summer where there are more hours of sunshine, reaching values near to $500 \mathrm{MWh}$. Moreover, the results show that the forecasting energy is in general agreement with the experimental in terms of the dynamics along the year. However, the forecasted energy has a trend to overestimate the energy. More detailed, green line is the more visible along the year, so, the other predictions present better approximations.

The accuracy of the predictions is analyzed in terms of both the root mean square error (RMSE) and mean bias error (MBE) between the predicted values $Y_{\text {est }}$ and the measured ones, $Y_{\text {mea. }}$. They are expressed as a percentage of the mean value of the latter, $\bar{Y}_{\text {mea }}$. The RMSE gives information about how concentrated the data are around the line of best fit and the MBE shows the tendency of the model to provide over- or under- estimation predictions. They are calculated according to Eqs. 4 and 5:

$$
\begin{aligned}
& \operatorname{RMSE}(\%)=\frac{100}{\bar{Y}_{\text {mea }}} \sqrt{\frac{1}{N} \sum_{i=1}^{N}\left(Y_{\text {est }}-Y_{\text {mea }}\right)^{2}} \quad \text { (eq. 4), } \\
& M B E=100 \frac{\frac{1}{N} \sum_{i=1}^{N}\left(Y_{\text {est }}-Y_{\text {mea }}\right)}{\bar{Y}_{\text {mea }}}
\end{aligned}
$$


Figure 4 shows the relative metrics for the performance in daily basis, the MBE and the RMSE for Gemasolar plant.

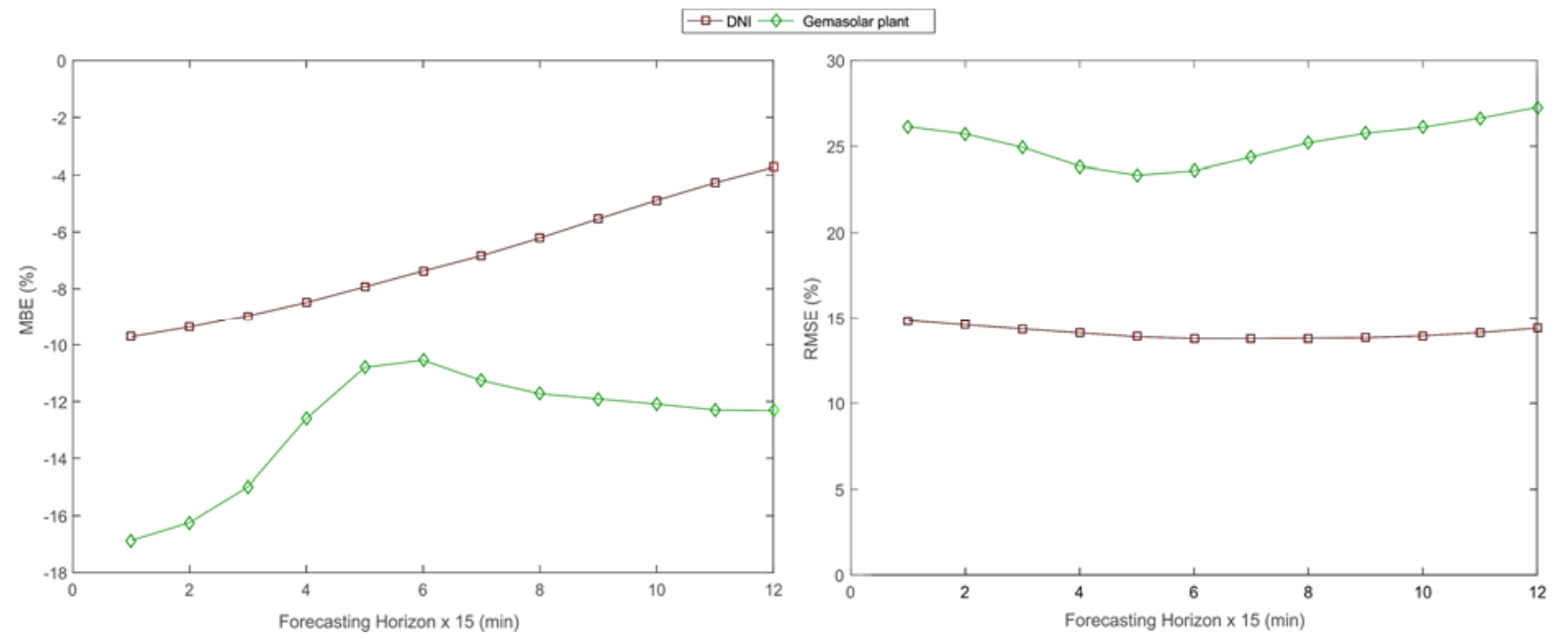

Fig. 4: MBE and RMSE results for the predictions from 15 minutes to 2 hours in Gemasolar plant.

The bias of the forecasted DNI presents a monotonically increase trend with the forecasting horizon while the RMSE exhibits an almost constant value of around $15 \%$ for daily values and for any forecasting horizon The bias clearly shows the overestimation tendency of all the forecasting horizons corresponding to the daily power output predictions. However a minimum bias and RMSE can be observed at around 75 and 90 minutes of forecasting horizon. Similarly, the RMSE decreases with the forecasting horizon till 90 minutes where it is placed around $24 \%$ in daily basis for both plants. Beyond 90 minutes, the RMSE (\%) turns to an increase trend with the forecasting horizon. These results would suggest an optimum forecasting horizon for this type of solar tower plants with large thermal storage systems.

Moreover, it is important to focus the attention in one particular because of the influence of the prediction can play a deterministic role for adapting the CSP plant management.

\section{Conclusions}

In this work, a novel CSP power output forecasting has been presented, where satellite images along with the SAM simulation software are used to predict DNI values from 15 minutes to three hours.

A prototype of central tower power plant based on the Gemasolar plant and located at the University of Almería (Spain), where measured and predicted DNI are available, is used to undertake the simulations

The results obtained analyzing the full year of DNI prediction show a good concordance between measured and predicted values. In general terms, the DNI is overestimated along with RMSE values lower than $15 \%$ for all forecast horizons.

The power output is overestimated about a 10-17\%. Furthermore, the results manifest a best approximation at 90min horizon, with a MBE value of $12 \%$ and a RMSE value of $23 \%$. In this respect, the molten salt thermal storage can modify the behavior of the DNI forecasting error, presenting better results within this specific horizon interval.

Therefore, this work has left in evidence that forecasting horizon plays an important role in the power output forecasting that can be decisive in the study of viability and management of a CPS plant. 


\section{Acknowledgements}

This project has been financed by Projects (ENE2017-83790-C3-1, 2 and 3, and ENE2014-59454-C3-1, 2 and 3), which were funded by the Ministerio de Economía y Competitividad and co-financed by the European Regional Development Fund. The authors also acknowledge the financial support provided by Chilean Economic Development Agency, CORFO, with the contract no. 17PTECES-75830 under the framework of the project AtaMoS TeC, the Innova Chile - CORFO, project code: 17BPE3-83761, as well as CONICYT/ FONDAP/15110019 "Solar Energy Research Center" SERC-Chile.

\section{References}

Alonso-Montesinos, J., Batlles, F. J., Bosch, J. L., 2015. J. Beam, diffuse and global solar irradiance estimation with satellite imagery, Energy Conversion and Management 105, 1205-1212. https://doi.org/10.1016/j.enconman.2015.08.037

Alonso-Montesinos, J., Batlles, F. J., 2015. Solar radiation forecasting in the short- and medium-term under all sky conditions, Energy 83, 387-393. https://doi.org/10.1016/j.energy.2015.02.036

Boulifa, M., Adane, A., Rezagui, A., Ameur, E.Z., 2015. Estimate of the Global Solar Radiation by Cloudy Sky Using HRV Images. Energy Procedia 74, 1079-1089. https://doi.org/10.1016/j.egypro.2015.07.747

Dobos, A., Neises, T., Wagner, M., 2014. Advances in CSP simulation technology in the system advisor model. Energy Procedia 49, 2482-2489. http://dx.doi.org/10.1016/j.egypro.2014.03.263. https://doi.org/10.1016/j.egypro.2014.03.263

Escrig, H., Batlles, F. J., Alonso, J., Baena, F. M., Bosch, J. L., Salbidegoitia, I. B., Burgaleta, J. I., 2013. Cloud detection, classification and motion estimation using geostationary satellite imagery for cloud cover forecast. Energy 55, 853-859. https://doi.org/10.1016/j.energy.2013.01.054

Neises, T., Wagner, M. J., 2012. Simulation of Direct Steam Power Tower Concentrated Solar Plant. ASME 2012 6th International Conference on Energy Sustainability, Parts A and B, 499. https:// doi:10.1115/ES2012-91364

Rigollier C, Bauer O, Wald L., 2000. On the clear sky model of the ESRA e European Solar Radiation Atlas with respect to the Heliosat method. Solar Energy 68, 33-48. https://doi.org/10.1016/S0038-092X(99)00055-9

Rigollier C, Lefvre, M., Wald L., 2004. The method Heliosat-2 for deriving shortwave solar radiation from satellite images. Solar Energy 77, 159-169. https://doi.org/10.1016/j.solener.2004.04.017

Wagner, M.J., 2008. Simulation and Predictive Performance Modeling of Utility-Scale Central Receiver System Power Plants. Thesis at the University of Wisconsin-Madison, Thesis at the University of Wisconsin-Madison.

Wagner, M.J., Gilman, P., 2011. Technical manual for the SAM physical trough model, Contract. NREL Report No. NREL/TP-5500-51825. 


\title{
Climatic and Global Validation of Daily MODIS Precipitable Water Data at AERONET Sites for Clear-sky Irradiance Modelling
}

\author{
Jamie M. Bright ${ }^{1}$, Christian A. Gueymard ${ }^{2}$, Sven Killinger ${ }^{3}$, David Lingfors ${ }^{4}$, Xixi Sun ${ }^{5}$, Peng \\ Wang $^{5,6}$, Nicholas A. Engerer ${ }^{1}$. \\ 1 Fenner School of Environment and Society, Australian National University, Canberra (Australia) \\ 2 Solar Consulting Services, Colebrook, NH (USA) \\ 3 Fraunhofer Institute for Solar Energy Systems ISE, 79100 Freiburg (Germany) \\ 4 Department of Engineering Sciences, Uppsala University, Uppsala (Sweden) \\ 5 Department of Mathematics and System Sciences, Beihang University, Beijing (China) \\ 6 Beijing Advanced Innovation Center for Big Data, Beihang University, Beijing (China)
}

\begin{abstract}
Precipitable water (PW) is an influential variable in regards to clear-sky radiation modelling and solar resource assessment. Thus, the accuracy of solar energy estimates depends on the accuracy of PW measurements. Gridded satellite information is commonly used for solar modelling because of its benefit of a broad geographical coverage, thus a global validation of commonly utilised PW products is imperative. Here, all Level-3 Moderate Resolution Imaging Spectroradiometer (MODIS) daily PW products from the Aqua and Terra satellites (at $1^{\circ} \times 1^{\circ}$ spatial resolution) from 01/2000 to 02/2018 are compared and validated against all of NASA's ground-sensing Aerosol Robotic NETwork (AERONET) V3 Level-2 PW daily averages from sites that have at least one year of observations during 2000-2018 (452 sites representing 675,158 observations). Furthermore, sub-categorisation by Köppen-Geiger climate regions enables climate specific validation to ascertain any distinct climatic influence. The results demonstrate significant climatological influences that impact the derived PW products. It is found that the Terra PW is more accurate than the Aqua PW, and that blending these two products yields a higher accuracy of daily PW estimates. The MODIS PW product also suffers from overestimation at larger magnitudes $(>3 \mathrm{~cm})$. The absolute errors do not reduce linearly with the PW magnitude, so that relative errors are far worse in areas of low $\mathrm{PW}$, such as the polar climate. The equatorial climate, with the highest PW records, behaves best. Finally, a simple sensitivity test using the REST2 clear-sky radiation model shows that the global PW RMSE $(0.511 \mathrm{~cm})$ of the combined MODIS data would result in a $1.5-2.5 \%$ under- or overestimate on direct normal irradiance (DNI) depending on latitude relative to using the AERONET mean PW of $1.8971 \mathrm{~cm}$. It is thus concluded that the daily MODIS PW product is not ideal for clear-sky radiation modelling, at least whenever accurate DNI predictions are necessary on a global scale.
\end{abstract}

Keywords: MODIS, AERONET, clear-sky model, precipitable water, aerosol optical depth, global validation.

\section{Introduction}

Precipitable water (PW) is the atmospheric variable that quantifies the depth (typically expressed in $\mathrm{cm}$ ) of water vapour present within a column of atmosphere, should all the water vapour be precipitated as liquid water. Water vapour is the most important gaseous element of infrared opacity in the atmosphere and leads to significant attenuation of radiation (Gueymard, 2014a). In turn, PW is a convenient way to quantify the water vapour amount within the atmosphere at any instant (Pérez-Ramírez et al., 2014). Clear-sky radiation modelling is fundamental to all solar forecasting estimates and historical database production (Engerer et al., 2017). Many different clear-sky radiation models have been validated around the world in various studies (Sun et al., 2018; Ineichen, 2016; Engerer and Mills, 2015; Gueymard, 1993, 2012a). In such studies, the most successful models were those that use a specific representation of PW within their derivation. Some simpler radiation models consider the PW attenuation only indirectly through the Linke turbidity factor, which combines the PW effect with those of aerosols and air mass. Of the 57 clear-sky models analysed by Sun et al. (2018), for instance, 52 models have specific consideration for PW. The 5 models that do not consider PW are at least 30-year old and tend to underperform. Global coverage of PW is of significant importance in solar applications such as satellite-based forecasting and historical reconstructions of solar irradiance time series. It is now possible to use reanalysis data, such as NASA's MERRA2, ECMWF's CAMS, or NOAA's NCEP, whereby global high-resolution derivations of PW are offered. However, these reanalyses are also more or less strongly dependent on the raw estimates from satellite sensors that are assimilated into the atmospheric model to constrain the boundary conditions. It is, therefore, imperative to have a fundamental 
understanding of how accurate the original satellite-based estimates are, and to ascertain whether specific climatological biases might exist.

The satellite observations/retrievals from the two MODIS (Moderate Resolution Imaging Spectroradiometer) sensors across the two satellite platforms of Aqua (launched 2002) and Terra (launched 1999) are of particular interest because they were specifically designed to monitor various atmospheric constituents of Earth. Furthermore, the MODIS products offer gridded access at $10 \mathrm{~km} \times 10 \mathrm{~km}$ spatial resolution globally, of which a quality-controlled product is available at a daily temporal scale. This type of gridded data is particularly useful for applications such as solar forecasting and worldwide irradiance estimates (Engerer et al., 2017). The PW products from the two MODIS platforms have been validated in a few studies at various spatial or temporal scales. The spatial scale, in particular, can be as small as one or more specific ground sites (Gui et al., 2017; Li et al., 2003; Lu et al., 2011), a region (Kang et al., 2016; Kumar et al., 2013; Liu et al., 2006; Wang et al., 2017), or as large as a country or subcontinent (Bennouna et al., 2013; Prasad et al., 2009; Roman et al., 2014; Shi et al., 2018; Vaquero-Martinez et al., 2018; Wong et al., 2014). The results of these studies generally showed good agreement between the PW data from MODIS and from other experimental sources. There are only a few known studies whereby the MODIS PW data sources are used as input to solar radiation models to test the effect of any potential error propagation on modelled surface irradiance. While observing a strong agreement between reanalysis data and other PW determinations (although not from MODIS) in a case study, Gueymard (2014a) observed that errors in PW did not result in significant errors in modelled clear-sky direct or global irradiance. In a more detailed study, Roman et al. (2014) evaluated the uncertainty of MODIS PW data against observations from six ground-based stations located in Spain, and the resulting uncertainty on modelled global irradiance. This was found reasonable, but not negligible (less than $4 \%$ for solar zenith angles below $75^{\circ}$ ).

Based on this literature review, there is considerable scope to offer deeper insight into the accuracy assessment of MODIS PW in terms of its performance at the largest (global) scale, possible geographic variations of this performance, and the resulting impact on modelled solar irradiance at the surface. The geographic influence of PW is explored here using climate categorisation. In parallel, it is worthwhile to compare the MODIS PW products from the two platforms, Aqua and Terra. Certain products from these platforms have been compared to each other and to ground truth previously, noting distinct discrepancies between them, in part caused by a more rapid degradation of the MODIS-Terra instrument (Levy et al., 2018).

The Aerosol Robotic Network (AERONET; http://aeronet.gsfc.nasa.gov/) offers ground truth of PW, as measured with an automatic sunphotometer in the 940-nm absorption band. AERONET PW is measured at sites in various kinds of climate and environment around the world. There are many research studies whereby a MODIS product (most usually AOD) is compared to its AERONET counterpart for analysis of a distinct climatic zone (Shi et al., 2018; Zhong et al., 2015), often accompanied by a correction factor that is specific to those individual sites analysed. There are only a few research studies focusing on comparing Level-3 MODIS AOD against ground AERONET stations. One such study by Ruiz-Arias et al. (2013) evaluated the performance of the Level-3 MODIS AOD both globally and by geographic region (e.g., Australia, Southern Africa, and Northwest America); they demonstrated distinct errors by region and suitability for solar radiation calculations in numerical weather modelling. This level of analysis previously performed on AOD can be extended to the PW product, which is the major objective of the present investigation. In that respect, the global validation of the latest version (Collection 6.1) of MODIS Aqua and Terra Level-3 satellite-derived PW is performed by comparing its daily values to daily-mean measurements from AERONET. One goal here is to assess performance of such data similarly to the regional analysis of Ruiz-Arias et al. (2013). One important new feature developed here, however, is the subcategorisation of the AERONET sites into different statistically distinguishable climatic regions. This is achieved following the Köppen-Geiger climate classification (Kottek et al., 2006), as explained further in Section 2. Additional goals are (i) to ascertain whether blending the datasets from the two MODIS platforms can improve the PW retrievals; and (ii) to establish whether or not the accuracy of the MODIS PW data is sufficient to guarantee solar irradiance predictions with the low uncertainty required by demanding solar resource assessments.

\section{Data}

PW is retrieved from the MODIS instrument aboard the Terra (EOS AM; MOD08_D3 product) and Aqua (EOS PM; MYD08_D3 product) satellites. Only the Level-3 daily products at $1 \times 1^{\circ}$ spatial resolution are considered here. All MODIS data records from 01/2000 to 02/2018 are used here, as offered by the Collection 6.1 database. This is available from NASA's Level-3 and Atmosphere Archive \& Distribution System (LAADS) Distributed Active Archive Center (DAAC) (https://ladsweb.nascom.nasa.gov). 
PW is independently measured by multiple AERONET sites around the world with extensive global coverage (Dubovik et al. 2002; Eck et al. 2003; Holben et al. 1998; Sinyuk et al. 2012). The daily averages are obtained from the V3 collection that has Level-2 quality assurance, which means that both pre- and post-field calibration are already applied, that the data time series is manually inspected for consistency, and that it is screened to remove cloud interference. Only sites with more than a combined 365 daily values during 01/2000 to 02/2018 with coincident MODIS data are considered, totalling 452 AERONET sites. The total number of validation data points available for PW comparison is 675,158 daily observations.

The Köppen-Geiger classification has five main classes that are denoted A, B, C, D and E, respectively representing equatorial, arid, warm temperate, snow, and polar climates (Fig. 1). Further complexity exists with up to 29 variations derived from the five main classifiers. This more detailed classification is not considered here because it would significantly reduce the sample size within each class. The latitude and longitude boundaries of each climate class are provided in lookup tables (Kottek et al., 2006).

Gueymard and Thevenard (2009) expressed the general need for altitude corrections to gridded data due to the natural decrease of PW with increasing altitude (due to its impact on temperature and pressure profiles). This is particularly significant when the satellite pixel's mean elevation differs from the ground validation site's elevation, for example over mountainous areas. Fig. 2 illustrates the differences of the reported altitude at station height to the gridded digital surface elevations from MODIS. The proposed correction is based on a scale-height approximation:

$$
P W(h)=P W\left(h_{0}\right) \times \exp \left[\frac{h_{0}-h}{H_{W}}\right], \quad \text { (eq. 1) }
$$

where $h_{0}$ is the reference site's satellite pixel elevation above mean sea level (amsl), and $h$ is the AERONETdefined elevation of the site. The water vapour scale height $H_{w}$ is experimentally derived (Hayasaka et al., 2007) and varies both spatially and temporarily. Because there has been little global study to estimate the scale height and its variability, Gueymard and Thevenard (2009) proposed a mean value of $H_{w}=2100 \mathrm{~m}$, which is assumed satisfactory for general global purpose. Using all possible pairs of MODIS pixels and AERONET sites, the correction factor $f=\exp \left[\left(h_{0}-h\right) / H_{w}\right]=P W(h) / P W\left(h_{0}\right)$ is found to vary between a minimum of 0.303 and a maximum of 2.177, with a mean of 1.13. All sites' $f$ values are reasonably well represented by a Burr distribution $B(\alpha, c, k)$, where $\alpha, c$ and $k$ are the scale, first shape and second shape parameters with values of $\approx 0.988,32.3$, and 0.672 , respectively. A scatter plot of this correction value versus the RMSE of MODIS combined PW to AERONET PW is presented later in Fig. 5 (bottom right).

\section{Methodology}

AERONET sites are first subcategorised into the five climate classes mentioned above and shown in Fig. 1. The global performance of the MODIS products is simply calculated as an equally-weighted mean of the error metrics derived for each climate class. This way, a climate class having a large number of sites (the majority of AERONET sites are warm temperate) has the same weight than a class with fewer sites. Hence, a highly populated class cannot overwhelm the overall results. MODIS L3 daily PW values are extracted from the appropriate gridded location that correspond to each AERONET site and for all days with valid data. MODIS PW is corrected for natural variations in water vapour caused by height differences, according to Eq. 1 .

Error metrics are then derived for each of the five climate classifications. The error metrics used here are the root mean square error (RMSE), the mean bias error (MBE), the mean absolute error (MAE), and the Pearson correlation coefficient $(R)$. Relative metrics (rRMSE and rMBE) are also evaluated, after normalisation by their respective mean. Absolute metrics are possibly important because the impact of PW on the modelled surface irradiance is larger when PW is small (Gueymard, 2014a). The interest of also using relative metrics in this case is to help compare different climate regions on a relatively equal footing. Because PW in equatorial regions is typically higher than in polar climates, it is important to have a normalised approach to make the metrics comparable. The effectiveness of this principle is demonstrated in Section 4. It is useful to have an established target of performance in order to ascertain whether or not the MODIS PW retrievals perform satisfactorily. Further complexity could be added, such as the statistical performance indicators suggested by Gueymard (2014b), but this is deemed unnecessary at this stage. 


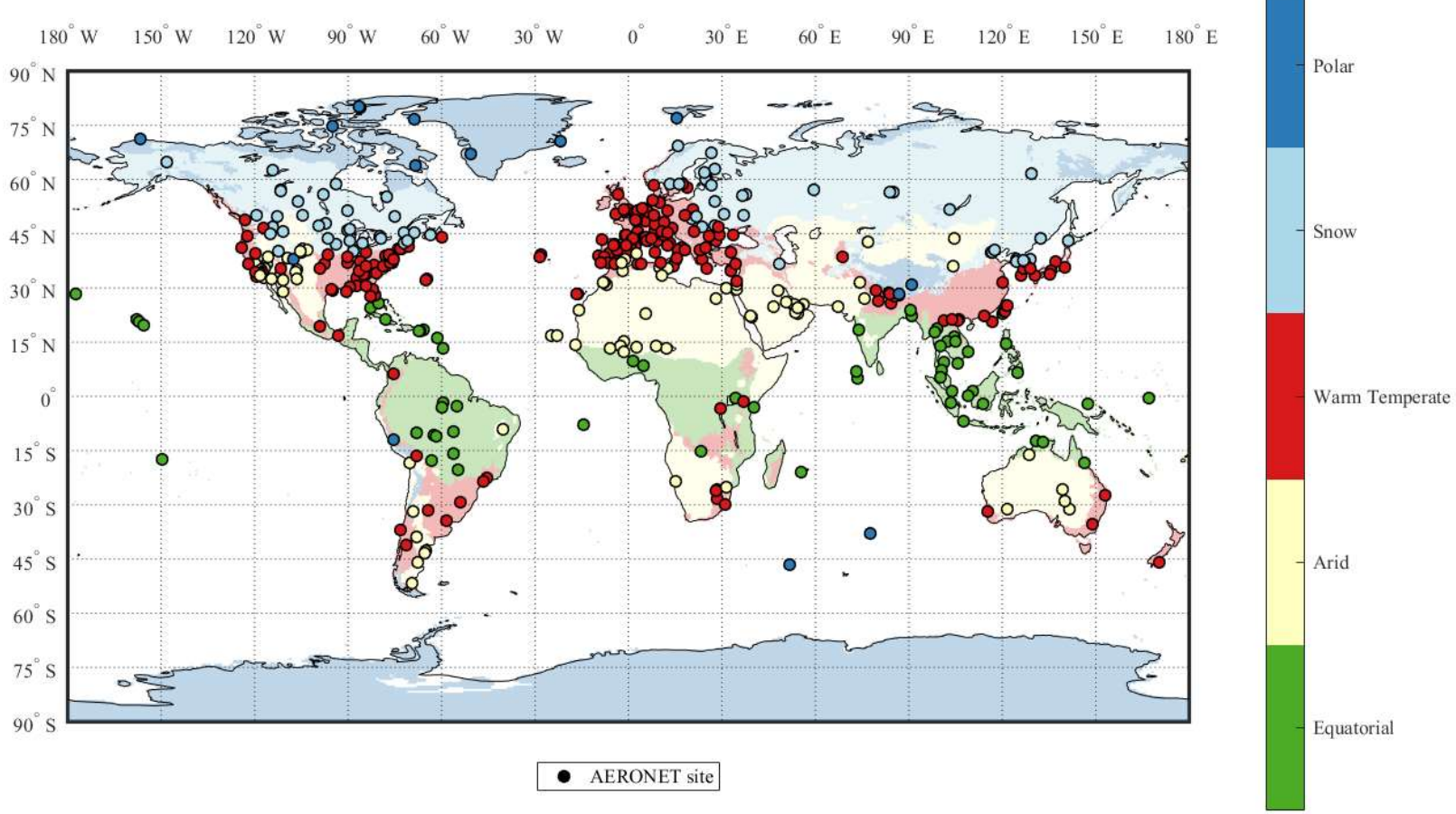

Fig. 1: Equidistant cylindrical projected world map indicating the location of the 452 AERONET sites considered within this study. Each AERONET site is coloured according to its associated Köppen-Geiger climate classification, as indicated by the colour bar.

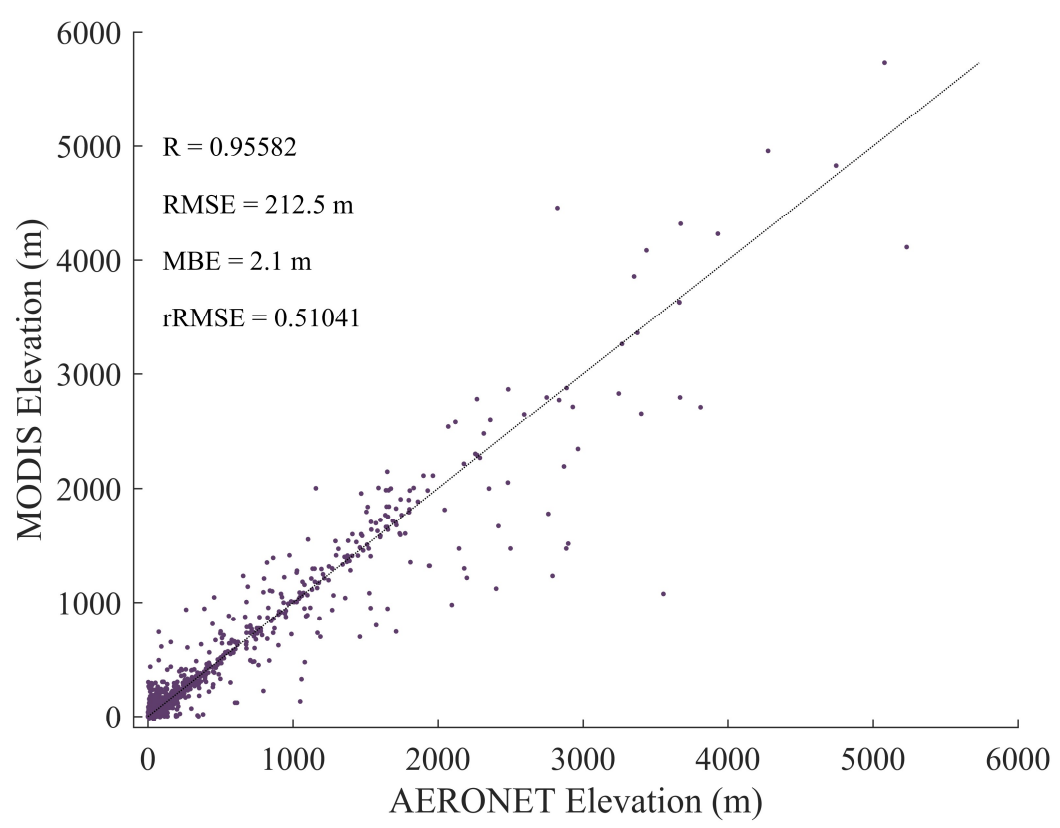

Fig. 2: Observed differences between reported AERONET station heights $(h)$ used within the study and the gridded surface elevation from the MODIS platform data $\left(h_{0}\right)$. These discrepancies are attributed to terrain changes within the $10 \mathrm{~km}^{2}$ MODIS pixels.

In order to test the influence of PW on clear-sky radiation modelling, a top-performing model-REST2v5, as detailed by Gueymard (2008) — is selected based on the thorough study from Sun et al. (2018). REST2v5 was shown to perform excellently across all Köppen-Geiger climate classifications and is therefore considered a suitable test bed to explore the influence of PW on irradiance. A simple test is done here in a pseudo-random way by selecting the mean annual irradiance outputs from REST2v5 obtained at midday for 10 locations of constant $0^{\circ}$ longitude and latitudes increasing from $0^{\circ}$ to $90^{\circ}$ with $10^{\circ}$ increments. All input variables are fixed except PW, which is explored across its full range. The REST2 model requires a number of input variables besides PW; here they are imposed the following default values: pressure $=1013.25 \mathrm{mb}$, total column ozone $=0.35 \mathrm{~atm}-\mathrm{cm}$, total column nitrogen dioxide $=0.0002 \mathrm{~atm}-\mathrm{cm}$, Ångström exponent $=1.3$, Ångström turbidity $=0.2$ and surface albedo $=0.3$. PW is varied parametrically from 0 to $10 \mathrm{~cm}$ in $0.05-\mathrm{cm}$ increments to observe the effect of varying PW on the mean annual midday irradiance at different points on the surface of the Earth, and subsequently estimate the impact of the MODIS PW errors on the modelled irradiance uncertainty. 


\section{Results and discussion}

In addition to the normal PW products from MODIS Aqua and Terra, a third product (referred to here as "combined platform") is obtained as an equal blend, using the mean value when both Aqua and Terra data are available. The performance of these three products is obtained by comparison with the AERONET PW ground data, all within each of the five climate classes defined above. A "global climate" category, which encompasses all five classes and thus all AERONET stations, is also considered. Performance metrics are thus evaluated for three MODIS platforms (Aqua, Terra and Combined), each across six climate regions (5 Koppen classes + global), i.e., 18 cases total. To conform with the goals of this study, the discussion will revolve around observable differences between climate regions for each of the MODIS PW platforms, as well as comparisons between the Aqua and Terra platforms to detect any systematic bias or climate-induced differences between them.

All the error metrics for each climate region and variable are presented in Tab. 1. The table is colour coded for better legibility, considering the disaggregation by climate region. Furthermore, boldface is used to indicate the best performing platform for each of the presented metrics. For example, $R$ is found to be highest in all cases when the Aqua and Terra data are averaged to create the combined data source, which is why the combined value for $R$ is in boldface.

It is remarkable that the lowest RMSE, rRMSE and MAE, as well as the highest $R$ is nearly always best for the "MODIS combination" data source. The combined rRMSE is outperformed by the Terra platform in only one specific case-the equatorial climate class. These results are in stark contrast to those for MBE and rMBE, where Terra always outperforms the other data sources. It is evident that the Aqua platform has the worst bias, overestimating consistently in all climates. Because of this significant Aqua bias, the combination of Aqua and Terra cannot outperform the less biased Terra platform. Interestingly, both Aqua and Terra platforms (and therefore also their combination) overestimate in every climate.

Tab. 1: Error metrics of climate-specific and global performance of PW from MODIS Aqua, MODIS Terra and their combination (mean of Aqua and Terra). Climate regions are highlighted by colour. The best performing platforms are highlighted in boldface.

\begin{tabular}{|c|c|c|c|c|c|c|c|}
\hline Platform & RMSE $(\mathrm{cm})$ & rRMSE & $\operatorname{MBE}(\mathrm{cm})$ & rMBE & $\operatorname{MAE}(\mathrm{cm})$ & $\mathrm{R}$ & Climate \\
\hline Aqua & 0.922 & 0.272 & -0.587 & -0.172 & 0.748 & 0.794 & \multirow{3}{*}{ 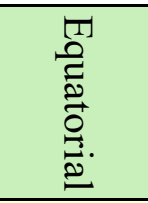 } \\
\hline Terra & 0.681 & 0.205 & -0.199 & -0.066 & 0.545 & 0.774 & \\
\hline Combined & 0.709 & 0.216 & -0.376 & -0.116 & 0.576 & 0.817 & \\
\hline Aqua & 0.576 & 0.392 & -0.269 & -0.197 & 0.441 & 0.832 & \multirow{3}{*}{ : } \\
\hline Terra & 0.577 & 0.398 & -0.234 & -0.175 & 0.442 & 0.813 & \\
\hline Combined & 0.536 & 0.373 & -0.244 & -0.186 & 0.418 & 0.845 & \\
\hline Aqua & 0.608 & 0.403 & -0.302 & -0.232 & 0.471 & 0.846 & \multirow{3}{*}{ 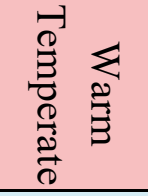 } \\
\hline Terra & 0.517 & 0.357 & -0.092 & -0.117 & 0.399 & 0.840 & \\
\hline Combined & 0.504 & 0.349 & -0.186 & -0.170 & 0.394 & 0.864 & \\
\hline Aqua & 0.495 & 0.393 & -0.250 & -0.203 & 0.362 & 0.884 & \multirow{3}{*}{$\underset{z}{\tilde{z}}$} \\
\hline Terra & 0.406 & 0.335 & -0.107 & -0.100 & 0.298 & 0.881 & \\
\hline Combined & 0.401 & 0.329 & -0.171 & -0.147 & 0.297 & 0.903 & \\
\hline Aqua & 0.436 & 0.955 & -0.245 & -0.648 & 0.336 & 0.823 & \multirow{3}{*}{$\begin{array}{l}\stackrel{0}{\circ} \\
\stackrel{7}{\Rightarrow}\end{array}$} \\
\hline Terra & 0.424 & 0.947 & -0.220 & -0.629 & 0.326 & 0.833 & \\
\hline Combined & 0.404 & 0.903 & -0.233 & -0.635 & 0.319 & 0.857 & \\
\hline Aqua & 0.607 & 0.483 & -0.331 & -0.290 & 0.471 & 0.836 & \multirow{3}{*}{$\begin{array}{l}\Omega \\
\stackrel{Q}{O} \\
\stackrel{0}{0}\end{array}$} \\
\hline Terra & 0.521 & 0.448 & -0.170 & -0.218 & 0.402 & 0.828 & \\
\hline Combined & 0.511 & 0.434 & -0.242 & -0.251 & 0.401 & 0.857 & \\
\hline
\end{tabular}




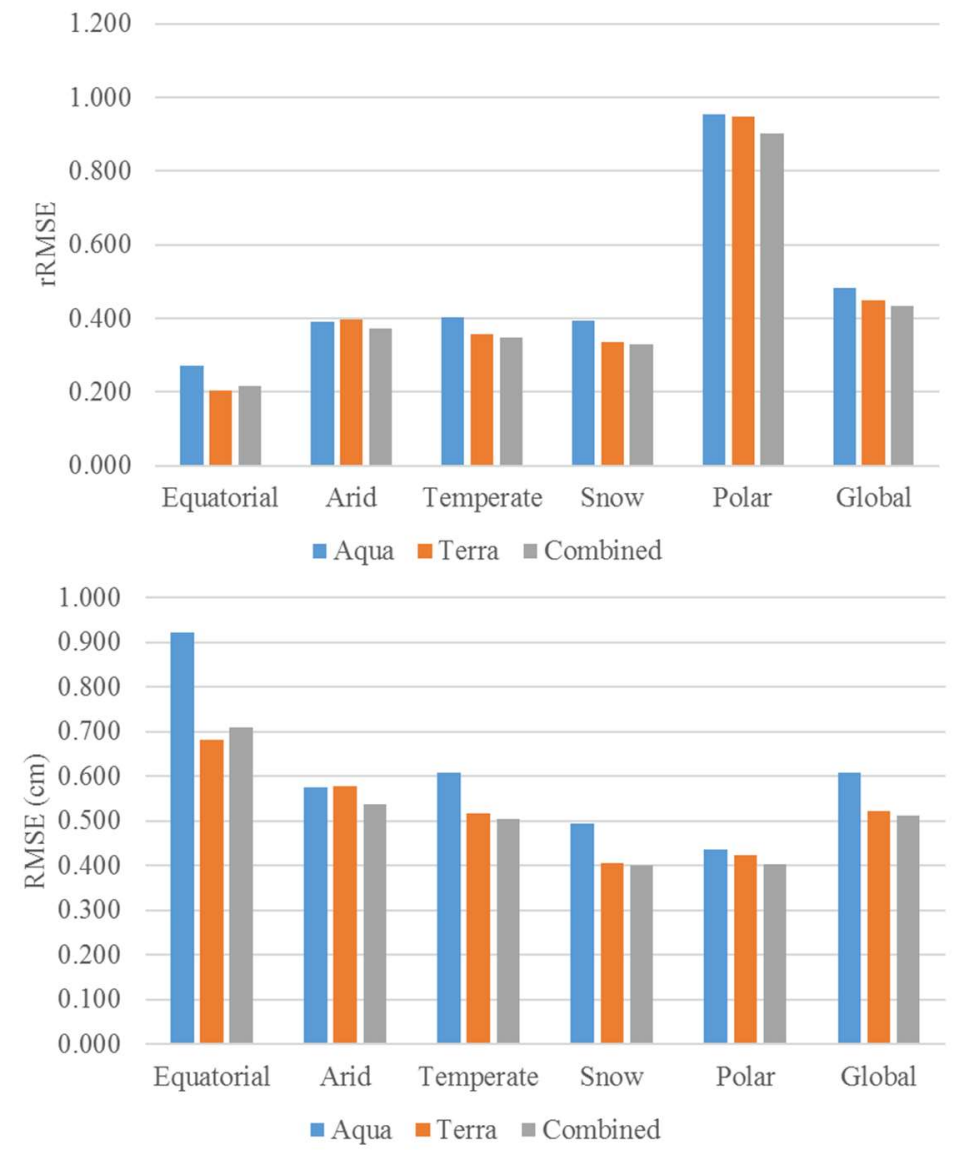

Fig. 3: Bar graph representation of the PW (top) relative RMSE, and (bottom) absolute RMSE (cm). The coloured series represent the three different platforms of MODIS Aqua, MODIS Terra and MODIS combination.

This lends weight to previous arguments (e.g. Shi et al., 2018) that a flat bias correction could be applied, whether on a climate specific scale or globally. The polar PW bias is particularly strong, suggesting the necessity of some bias correction there. These conclusions, however, are based on the assumption that the AERONET PW is itself unbiased in any climate region, and represents "ground truth" for satellite data, exactly as the AERONET AOD product.

RMSEs from Tab. 1 are graphically represented as bar plots in Fig. 3, relative to both the relative (top) and absolute (bottom) definitions. These two metrics (RMSE and rRMSE) are selected to provide a good indication of overall performance of each platform. PW displays the largest relative errors under polar conditions, where it is low. Naturally, the global-climate performance cannot exceed the performance of PW under any climate class since it is obtained as the mean performance of all climates. Conversely, the equatorial climate (where PW is high) performs best for all platforms. For a better understanding of how these metrics relate to the data, scatter plots of PW in each climate are plotted for the combined Aqua and Terra platforms in Fig. 4. The combined data source is selected here because it offers the best results. The scatter plots corroborate the poor polar rRMSE results shown in Fig. 3 (top).

Fig. 3 (bottom) displays the absolute RMSE and shows a different behaviour than rRMSE. Whilst relative metrics are useful to compare how good the performance of MODIS is relatively to each climate, they do not truly illustrate the actual capability of the MODIS methodology itself. The relative performance of $\mathrm{PW}$ is found best in equatorial regions, but simultaneously, and counterintuitively, the absolute error in those regions is the worst in almost all cases. The climatic regions generally follow a latitudinal relationship (albeit with altitude exceptions) that can be observed in Fig. 1; from Fig. 3 (bottom) it is clear that the PW RMSE decreases with latitude. A possible explanation is that satellite parallax corrections influence the quality of the retrievals.

The RMSE is almost always improved by combining Aqua and Terra, with the notable exception of the equatorial climate where Terra performs best. The "global" classification can be considered as the overall performance of combined MODIS Aqua and Terra as it is the mean of all other climates. In terms of absolute RMSE, the global performance of their combination is $0.511 \mathrm{~cm}$, compared to a mean AERONET value from all 452 sites of 1.897 $\mathrm{cm}$. Typically, relative errors are larger at sites where typical PW values are low, since the MODIS retrieval algorithms are then closer to their detection limit (Ruiz-Arias et al., 2013). 

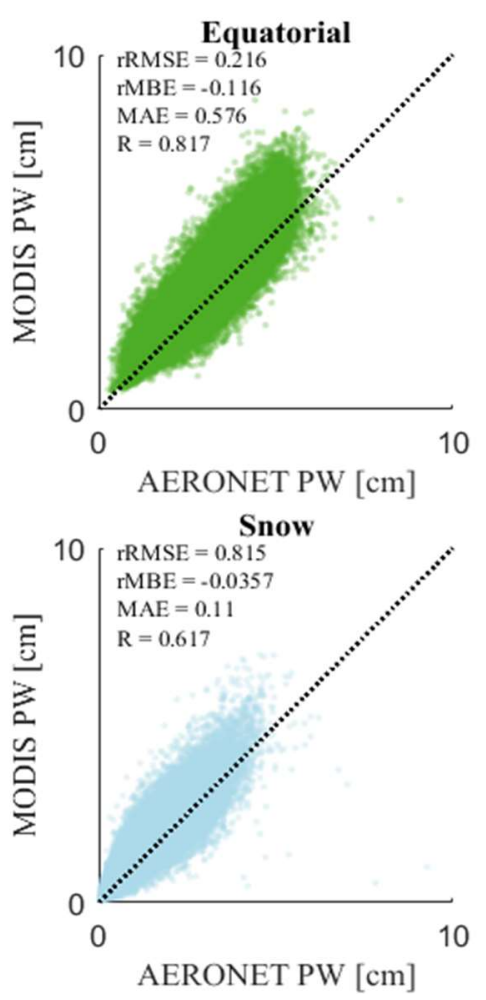
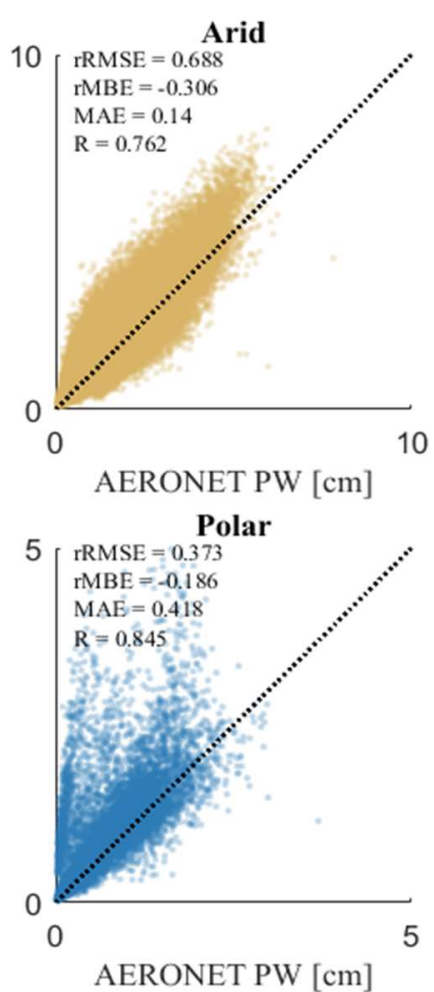

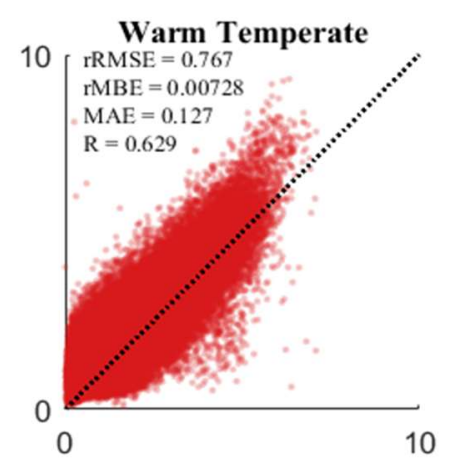

AERONET PW $[\mathrm{cm}]$

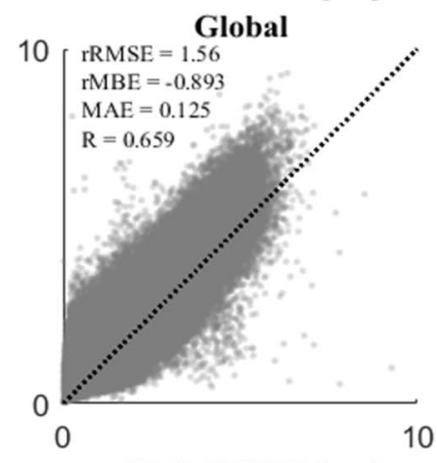

AERONET PW $[\mathrm{cm}]$

Fig. 4: Scatter plots of the combined MODIS Aqua and Terra PW product against AERONET ground measurements in each climate zone, as well as the global climate zone. A diagonal is plotted to indicate perfect performance. The polar climate has different axes limits, for legibility. The rRMSE, rMBE, MAE and $R$ metrics are stated in each panel. Scatter point transparency is in place so that darker regions represent a greater density of data.

Fig. 5 analyses all the daily PW data from Aqua and Terra against AERONET ground stations, as well as against each other. A distinctive overestimation occurs when $\mathrm{PW}$ increases above $\approx 3 \mathrm{~cm}$, particularly in the case of Aqua. However, the linear correlation is high for Aqua and Terra $(R=0.836$ and 0.828 , respectively). Some sites do not match the linear fit, even after scale-height correction, which was not expected. For instance, consider the two red circles highlighting significant overestimations made by MODIS. From Fig. 4, most of these sites appear to be in the polar climate, although some warm temperate regions demonstrate similar behaviour. The bottom-left plot in Fig. 5 displays a good agreement between Aqua and Terra platforms with, however, significant scatter and larger Aqua values in general. Both platforms are seemingly in agreement for the potentially "erroneous" data circled in the two upper plots. These features highlighted in the circles do not appear when directly comparing Aqua to Terra directly because they are then closer to the diagonal. This suggests that both Aqua and Terra significantly underestimate at the same locations. The bottom-right plot tests the potential for introducing error from scale height correction, since the proposed correction was only previously tested on monthly data. We observe no correlation for both Aqua and Terra scale height correction to the observed, site-specific RMSE. We do observe that the second largest RMSE does coincide with the largest correction factor, perhaps suggesting an error in station height reporting. From data exploration, we observed no globally applicable rule that elevation is the cause of error for PW despite the fact that 8 of the 10 worst performing sites are situated at high $(>2 \mathrm{~km})$ elevation.

To evaluate the influence of PW on clear-sky surface irradiance, a simple test is performed using the REST2 clearsky radiation model (Gueymard, 2008), as described in Section 3. Multiple latitudes of the north hemisphere are tested at a fixed longitude of $0^{\circ}$. Fig. 6 illustrates the change in mean annual midday clear-sky irradiances of the global horizontal irradiance (GHI), direct normal irradiance (DNI) and diffuse horizontal irradiance (DHI) when fixing all input variables while varying PW. As expected, DNI is the most impacted by PW. The sensitivity of DNI to PW is stronger for PW between 0 and $5 \mathrm{~cm}$, and less in the range $5-10 \mathrm{~cm}$, thus corroborating previous results (Gueymard, 2014a). In comparison with Figs. 4 and 5, it is clear that the vast majority of PW daily values are within the range of $0-5 \mathrm{~cm}$, hence any error in that interval may result in significant deviations in the modelled irradiances. The irradiance reduction with increasing $\mathrm{PW}$ with reference to the ideal case when $\mathrm{PW}=0$ is illustrated in Fig. 7. 

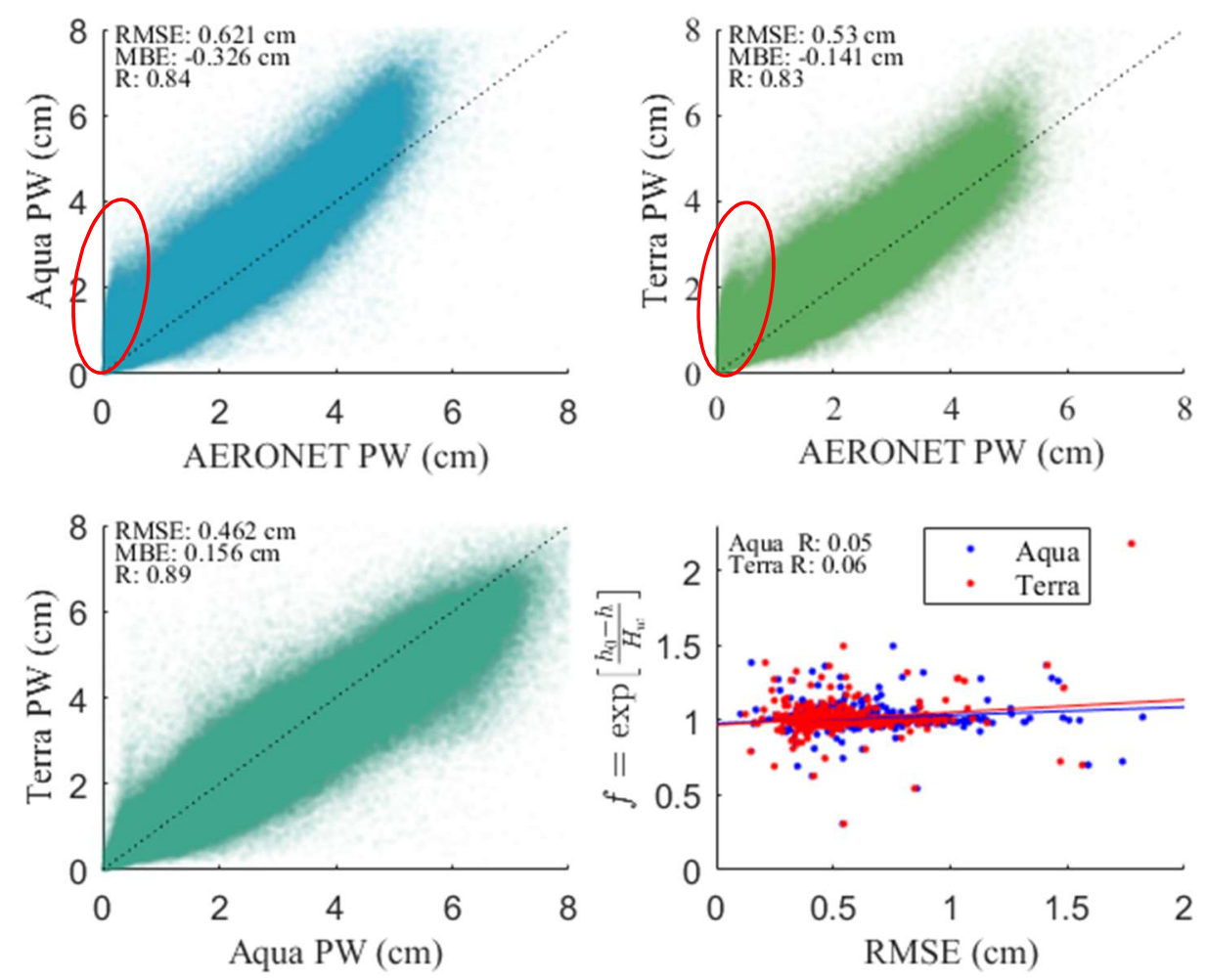

Fig. 5. (Top left) Aqua PW product plotted against AERONET PW for all 452 sites with rRMSE, rMBE and $R$ indicated. (Top right) As before but for Terra. (Bottom left) Terra PW plotted against Aqua PW with error metrics. (Bottom right) Aqua and Terra PW RMSE against site elevation. A linear fit is applied and the corresponding Pearson correlation indicated for both Aqua and Terra.

The gradient is illustrative of the sensitivity of the modelled irradiance to errors in the PW input. Were we to set PW to the mean AERONET value of $1.897 \mathrm{~cm}$, and apply a $0.511 \mathrm{~cm}$ underestimate and overestimate, the increase and decrease in GHI, DHI and DNI can be significant. These are presented in Fig. 8 where we observe typical variance of $14 \mathrm{Wm}^{-2}$ overestimation in GHI when $\mathrm{PW}$ is underestimated by $0.511 \mathrm{~cm}$, and $12 \mathrm{Wm}^{-2}$ underestimation in GHI when PW is overestimated by $0.511 \mathrm{~cm}$ at a latitude of 0 degrees. The relative error impact on GHI increases with latitude from 1.25 to $1.75 \%$ of GHI. The DNI is more sensitive to changes in PW than the DHI. One must remember that these are distinct cases represented by the global RMSE versus the global average PW. The impact on GHI can be considerably worse with the persistence of larger errors. Looking back to the top row in Fig. 5 , we observe many instances where the estimated MODIS PW are regularly $3 \mathrm{~cm}$ over estimated, which could result in a reduction in DNI by up to $100 \mathrm{Wm}^{-2}$, this does of course depend on the actual magnitude of the PW at the time.

What is most significant about Figs. 6 and 7 is that the extreme latitudes (towards $\pm 90^{\circ}$ ), despite having reduced absolute magnitude of irradiance, have the most significant relative variability in $\mathrm{PW}$. This is primarily due to the preponderance of large air masses (low sun), and therefore increased interaction of sunlight with water vapour.

Since Fig. 3 showed that the relative error in PW is the highest over polar regions, it can be inferred that small absolute errors around the typical polar PW values $(\approx 1.5 \mathrm{~cm}$ or less) will result in significant impact on the modelled clear-sky irradiance. Hence, the global RMSE of $0.5 \mathrm{~cm}$ appears inadequate for accurate clear-sky irradiance modelling, particularly in climates of reduced PW (e.g., polar regions). Over warmer regions, such as at temperate or equatorial latitudes, the MODIS PW data sources appear more satisfactory in general, thus yielding reasonable accuracy in modelled irradiance and confirming previous results (Gueymard, 2014a; Roman et al., 2014). 
J.M. Bright et. al. / EuroSun 2018 / ISES Conference Proceedings (2018)

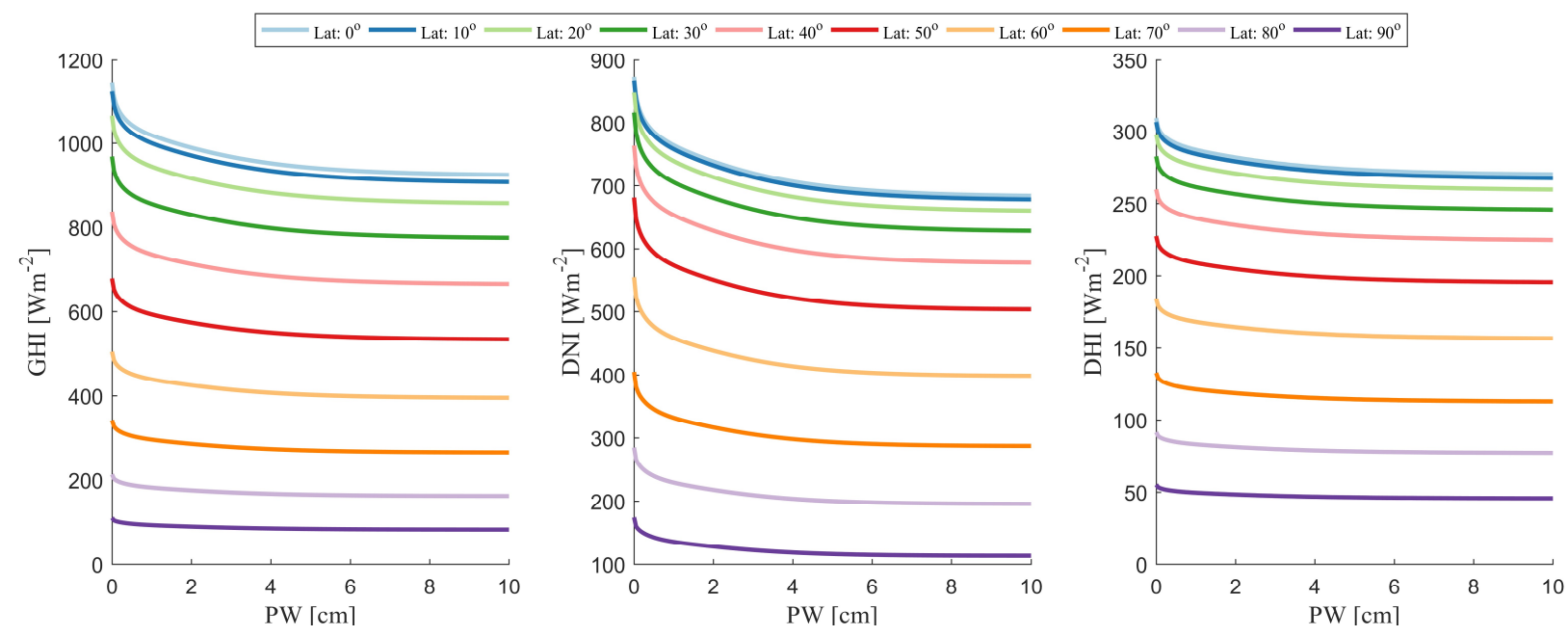

Fig. 6: Mean annual midday clear-sky global horizontal, direct normal and diffuse horizontal irradiance at latitudes ranging from $0^{\circ}$ to $90^{\circ}$ with $10^{\circ}$ increments and fixed longitude of $0^{\circ}$ as calculated from the REST2 clear-sky model (Gueymard, 2008) using constants of pressure $=1013.25 \mathrm{mb}$, total column ozone $=0.35 \mathrm{~atm}-\mathrm{cm}$, total column nitrogen dioxide $=0.0002 \mathrm{~atm}-\mathrm{cm}$, Ångström exponent $=$ 1.3, Ångström turbidity $=0.2$ and surface albedo $=0.3$. The $\mathrm{PW}$ is varied from 0 to $10 \mathrm{~atm}-\mathrm{cm}$ with 0.05 increments. Note the difference in scales on the $y$-axes.

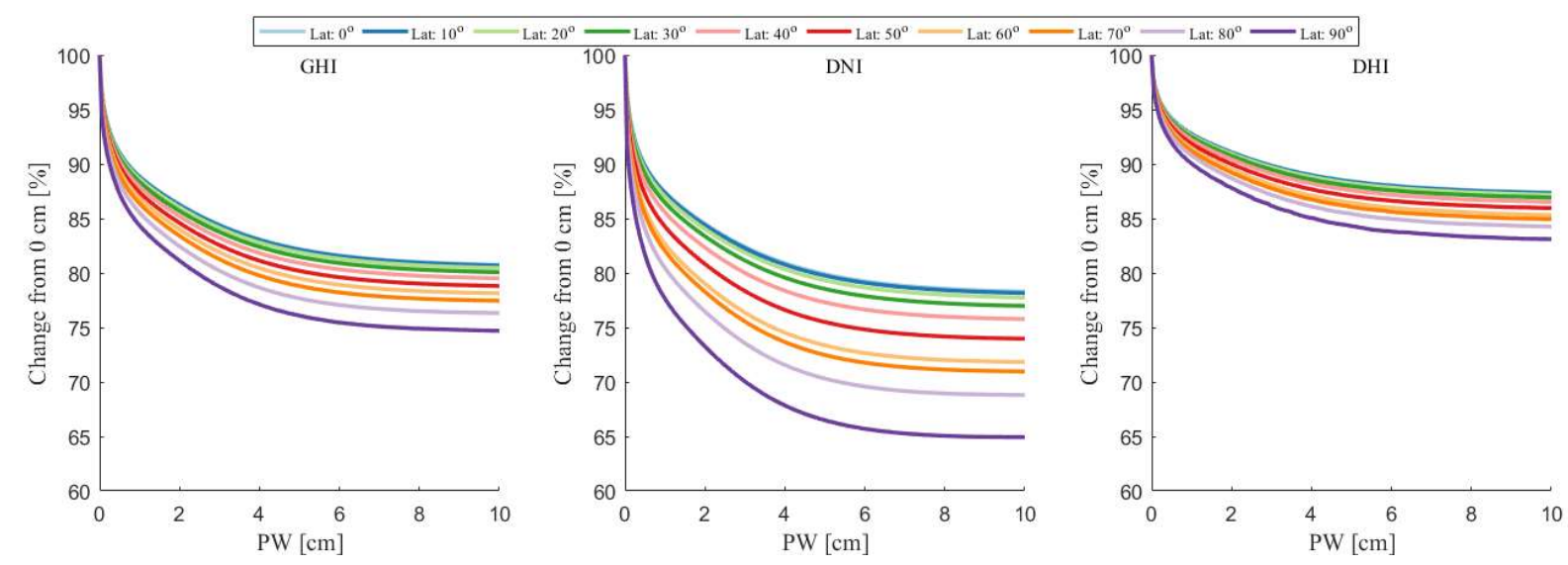

Fig. 7: Percentage reduction of mean annual midday global clear-sky global horizontal, direct normal and diffuse horizontal irradiance expressed in relation to the irradiance at $\mathrm{PW}=0 \mathrm{~cm}$ at latitudes ranging from $0^{\circ}$ to $90^{\circ}$ with $10^{\circ}$ increments and fixed longitude of $0^{\circ}$ as calculated from the REST2 clear-sky model (Gueymard, 2008) using constants of pressure $=1013.25 \mathrm{mb}$, total column ozone $=$ $0.35 \mathrm{~atm}-\mathrm{cm}$, total column nitrogen dioxide $=0.0002$ atm-cm, Ångström exponent $=1.3$, Ångström turbidity $=0.2$ and surface albedo $=0.3$.
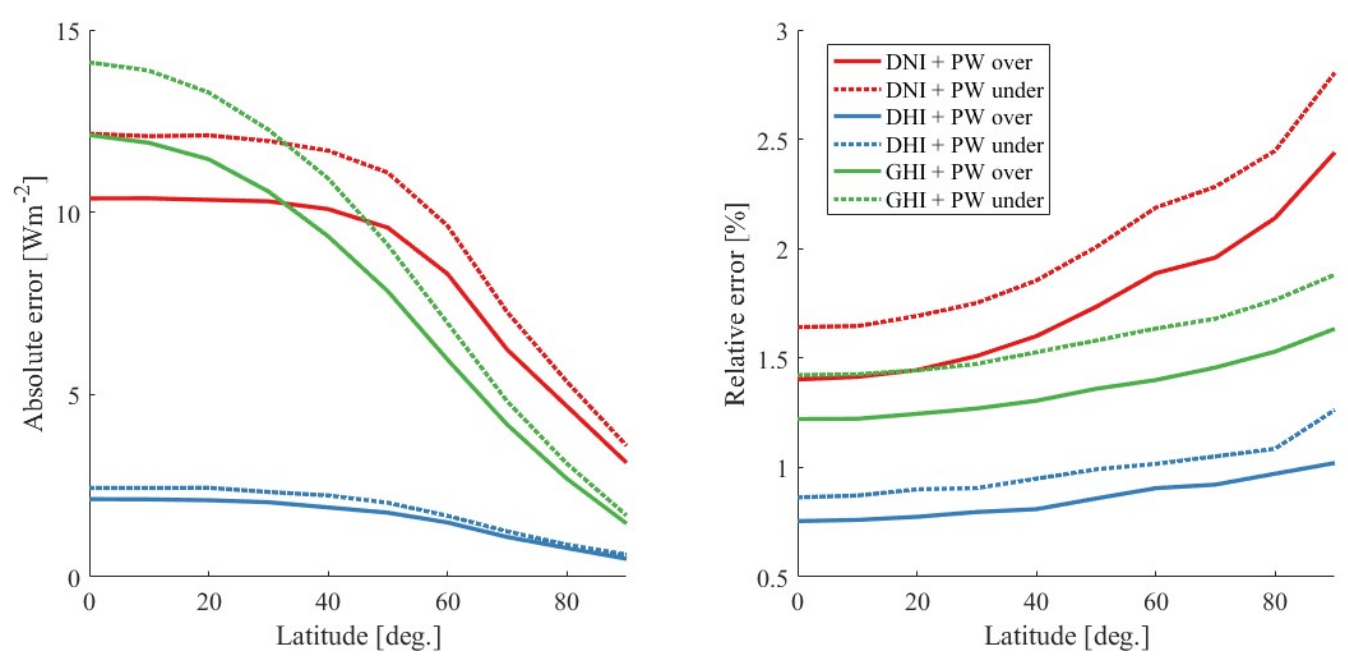

Fig. 8: The absolute difference (left) and relative (right) difference in irradiance at different latitudes when compared to the irradiance derived with the mean AERONET PW of $1.8971 \mathrm{~cm}$. PW over and under represents overestimate and underestimate by 0.511 cm, which is the global PW RMSE. 


\section{Conclusions}

Precipitable Water (PW) is an important atmospheric variable that directly impacts the accuracy of clear-sky irradiance modelled estimates around the world. Access to gridded PW is only available from reanalysis databases or from satellites such as the MODIS (Moderate Resolution Imaging Spectroradiometer) instrument on board the polar orbiting pair of the Aqua and Terra platforms. As the reanalysis generally depend on satellite measurements, it is important that the accuracy of satellite PW products be validated against high-quality ground data, such as those from the worldwide AERONET network. In this study, all AERONET sites with at least 365 days of data (452 sites) were considered to validate the MODIS products.

This paper analysed all data from the MODIS Aqua and Terra PW products from the beginning of operations (2002 for Aqua and 2000 for Terra) to 02/2018. These daily datasets were validated against the ground truth from 452 AERONET sites. The total number of PW validation data points available was 675,158 . An added complexity was introduced by categorising each AERONET site into its associated Köppen-Geiger climate classification, defined as equatorial, arid, warm temperate, snow and polar. A global climate classification was also established by taking an equal average of the results from all five root climates. The MODIS Aqua and Terra platforms were validated, as well as an equal blend of both Aqua and Terra measurements called the "combined platform".

This combined platform offered the most consistently low errors across all climates and globally in terms of both relative and absolute RMSE, MAE and best performing R. It is, therefore, concluded that the most appropriate values of daily MODIS PW is from this equal blend of Aqua and Terra data. Estimations of PW were found to perform the worst in the polar climate, despite having a low RMSE when compared to other climates. Because typical polar values of PW are much smaller than elsewhere, while the retrieval error is not negligible, the relative performance is considerably weaker. This is perhaps due to the adverse conditions in polar areas with considerable and regular cloud cover periods that may interfere with observation measurements, or to the adverse impact of a high surface albedo, whose large signal can overwhelm the relatively small signal of the MODIS scanner. The Aqua platform overestimates PW more so than the Terra platform, which also overestimates PW. The Terra PW generally performs better than Aqua, though never as good as the combined platform. This may be caused by the different flight path timings of the two platforms, and any morning/afternoon asymmetry in the natural daily PW patterns, which is perhaps offset through blending.

The REST2 clear-sky irradiance model was tested for its sensitivity to PW. Low PW values are most sensitive to errors. Hence, the high rRMSE and generally poor RMSE of the PW daily MODIS products are poorly suited to clear-sky modelling in overall low PW areas, at least without local or global bias correction. We present the impact of typical sensitivity to the global RMSE of combined MODIS PW and see typical and persistent over- and underestimates of between 1-2\% in GHI, though observe individual instances of up to $15 \%$ underestimation in DNI. Subsequent studies are needed to evaluate whether alternative gridded databases, from other satellites or reanalysis products, would be more appropriate.

\section{Acknowledgements}

The authors would like to thank the Australian Renewable Energy Agency (ARENA) for partially supporting this work (Research and Development Programme Funding: G00854 — Real-time Operational Distributed PV Simulations for Distribution Network Service Providers).

The Principal Investigator and staff of each of the 452 AERONET sites used in this investigation are warmly thanked for establishing and maintaining this invaluable source of data.

\section{References}

Bennouna, Y.S., Torres, B., Cachorro, V.E., Ortiz de Galisteoa, J.P., Toledanoa, C. 2013. The evaluation of the integrated water vapour annual cycle over the Iberian Peninsula from EOS-MODIS against different ground-based techniques. Q. J. R. Meteorol. Soc. 139. 1935-1956.

Chu, D.A. et al. 2002. Validation of MODIS aerosol optical depth retrieval over land. Geophys. Res. Lett. 29.

Chung, C.E. et al. 2005, Global anthropogenic aerosol direct forcing derived from satellite and ground-based observations. J. Geophys Res. 110D. doi:10/1029/2005JD006356.

Dubovik, O., Holben, B.N., Eck, T.F., Smirnov, A., Kaufman, Y.J., King, M.D., Tanre, D., Slutsker, I., 2002. Vari- 
ability of absorption and optical properties of key aerosol types observed in worldwide locations. J.Atm.Sci., 59, 590-608.

Eck, T.F., Holben, B.N., Reid, J.S., O'Neill, N.T., Schafer, J.S., Dubovik, O., Smirnov, A., Yamasoe, M.A., Artaxo, P., 2003. High aerosol optical depth biomass burning events: A comparison of optical properties for different source regions. Geophys. Res. Lett., 30, 2035, doi:10.1029/2003GL017861, 2003.

Engerer, N.A., Bright, J.M., Killinger, S. 2017. Himawari-8 enabled real-time distributed PV simulations for distribution networks. IEEE-PVSC44 Washington 25th June 2017.

Engerer, N.A., Mills, F.P. 2015. Validating nine clear sky radiation models in Australia. Solar Energy. 120, 9-24.

Gueymard, C.A. 1993. Critical analysis and performance assessment of clear sky solar irradiance models using theoretical and measured data. Solar Energy. 51, 121-138.

Gueymard, C.A. 2008. REST2: High-performance solar radiation model for cloudless-sky irradiance, illuminance, and photosynthetically active radiation - Validation with a benchmark dataset. Solar Energy. 82, 272-285.

Gueymard, C.A., Thevenard, D. 2009. Monthly average clear-sky broadband irradiance database for worldwide solar heat gain and building cooling load calculations. Solar Energy. 83, 1998-2018.

Gueymard, C.A. 2012a. Clear-sky irradiance predictions for solar resource mapping and large-scale applications: improved validation methodology and detailed performance analysis of 18 broadband radiative models. Solar Energy. 86, 2145-2169.

Gueymard, C.A. 2012b. Temporal variability in direct and global irradiance at various time scales as affected by aerosols. Solar Energy. 86, 3544-3553.

Gueymard, C.A. 2014a. Impact of on-site atmospheric water vapor estimation methods on the accuracy of local solar irradiance predictions. Solar Energy. 101, 74-82.

Gueymard, C.A. 2014b. A review of validation methodologies and statistical performance indicators for modeled solar radiation data: Towards a better bankability of solar projects. Renewable and Sustainable Energy Reviews. 39, 1024-1034.

Guia, K., Chea, H., Chenc, Q., Zengd, Z., Liue, H., Wanga, Y., Zhenga, Y., Suna, T., Liaoc, T., Wanga, H., Zhanga, H. 2017. Evaluation of radiosonde, MODIS-NIR-Clear, and AERONET precipitable water vapor using IGS ground-based GPS measurements over China. Atmospheric Research. 197. 461-473.

Hayasaka, T., Satake, S., Shimizu, A., Sugimoto, N., Matsui, I., Aoki, K., Muraji, M. 2007. Vertical distribution and optical properties of aerosols observed over Japan during the Atmospheric Brown Clouds-East Asia Regional Experiment 2005. J. Geophys. Res. 112D. doi:10.1029/2006JD008086.

Holben B.N., Eck, T.F., Slutsker, I., Tanre, D., Buis, J.P., Setzer, A., Vermote, E., Reagan, J.A., Kaufman, Y., Nakajima, T., Lavenu, F., Jankowiak, I., Smirnov, A. 1998. AERONET - A federated instrument network and data archive for aerosol characterization, Rem. Sens. Environ. 66, 1-16.

Ineichen, P. 2016. Validation of models that estimate the clear sky global and beam solar irradiance. Solar Energy. 132, 332-344.

Kang, K., Kumar, R., Hu, K., Yu, X., Yin, Y. 2016. Long-term (2002-2014) evolution and trend in Collection 5.1 Level-2 aerosol products derived from the MODIS and MISR sensors over the Chinese Yangtze River Delta. Atmospheric Research. 181. 29-43.

Kaufman, Y.J., Tanré, D., Remer, L., Vermote, E., Chu, A., Holben, B. 1997. Operational remote sensing of tropospheric aerosols over the land from EOS-MODIS. J. Geophys. Res. 102D, 17051-17061.

Kinne, S. et al. 2003. Monthly averages of aerosol properties: a global comparison among models, satellite data, and AERONET ground data. J. Geophys. Res. 108D. doi:10.1029/2001/JD001253.

Kinne, S. et al. 2006. An AeroCom initial assessment - optical properties in aerosol component modules of global models. Atmos. Chem. Phys. 6, 1815-1834.

Kumar, S., Singh, A.K., Prasad, A.K., Singh, R.P. 2014. Variability of GPS derived water vapor and comparison with MODIS data over the Indo-Gangetic plains. Physics and Chemistry of the Earth 55-57, 11-18.

Kottek, M., Grieser, J., Beck, C., Rudolf, B., Rubel, F., 2006. World map of the Köppen-Geiger climate classifica- 
tion updated. Meteorologische Zeitschrift 15, 259-263.

Levy, R.C., Mattoo, S., Sawyer, V., Shi, Y., Colarco, P.R., Lyapustin, A.I., Wang, Y., Remer, L.A. 2018. Exploring systematic offsets between aerosol products from the two MODIS sensors. Atmos. Meas. Tech. 11, 4073-4092.

Liu, J., Liang, H., Sun, Z., Zhoul, X. 2006. Validation of the Moderate-Resolution Imaging Spectroradiometer precipitable water vapor product using measurements from GPS on the Tibetan Plateau. Journal of Geophysical Research. 111. D14103. doi:10.1029/2005JD007028.

Lu, N., Qin, J., Yang, K., Gao, Y., Xu, X., Koike, T. 2011. On the use of GPS measurements for Moderate Resolution Imaging Spectrometer precipitable water vapor evaluation over southern Tibet. Journal of Geophysical Research. 116, D23117, doi:10.1029/2011JD016160.

Pérez-Ramírez, D., Whiteman, D.N., Smirnov, A., Lyamani, H., Holben, B.N., Pinker, R., Andrade, M. and Alados-Arboledas, L. 2014. Evaluation of AERONET precipitable water vapor versus microwave radiometry, GPS, and radiosondes at ARM sites. Journal of Geophysical Research: Atmospheres. 119, 9596-9613.

Prasad, A.K., Singh, R.P. 2009. Validation of MODIS Terra, AIRS, NCEP/DOE AMIP-II Reanalysis-2, and AERONET Sun photometer derived integrated precipitable water vapor using ground-based GPS receivers over India. Journal of Geophysical Research. 114, D05107, doi:10.1029/2008JD011230.

Román, R., Bilbao, J., de Miguel, A. 2014. Uncertainty and variability in satellite-based water vapor column, aerosol optical depth and Angström exponent, and its effect on radiative transfer simulations in the Iberian Peninsula. Atmospheric Environment. 89. 556-569.

Ruiz-Arias, J.A., Dudhia, J., Gueymard, C.A., Pozo-Vázquez, D. 2013. Assessment of the Level-3 MODIS daily aerosol optical depth in the context of surface solar radiation and numerical weather modeling. Atmos. Chem. Phys. 13, 675-692.

Schaap, M. et al. 2008. Evaluation of MODIS aerosol optical thickness over using sun photometer observations. Atmos. Environ. 42, 2187-2197.

Shi, F., Xin, J., Yang, L., Cong, Z., Liu, Z., Ma, Y., Wang, Y., Lu, X., Zhao, L. 2018. The first validation of the precipitable water vapour of multisensory satellites over the typical regions in China. Remote Sensing of Environment. 206, 107-122.

Sinyuk, A., Holben, B.N., Smirnov, A., Eck, T. F., Slutsker, I., Schafer, J.S., Giles, D.M., Sorokin, M. 2012, Assessment of error in aerosol optical depth measured by AERONET due to aerosol forward scattering. Geophys. Res. Lett. 39, L23806, doi:10.1029/2012GL053894.

Sun, X., Wang, P., Gueymard, C.A., Acord, B., Engerer, N.A., Bright, J.M. 2018. Worldwide performance assessment of 57 global clear-sky irradiance models. Solar Energy. In Review.

Vaquero-Martíneza, J., Antón, M., de Galisteo, J.P.O., Cachorro, V.E., Álvarez-Zapatero, P., Román, R., Loyola, D., Costa, M.J., Wang, H., Abad, G.G., Noël, S. 2018. Inter-comparison of integrated water vapor from satellite instruments using reference GPS data at the Iberian Peninsula. Remote Sensing of Environment. 204. 729-740.

Wang, Y., Yang, K., Pan, Z., Qin, J., Chen, D., Lin, C., Chen, Y., Lazhu, Tang, W., Han, M., Lu, N., Wu, H. 2017. Evaluation of Precipitable Water Vapor from Four Satellite Products and Four Reanalysis Datasets against GPS Measurements on the Southern Tibetan Plateau, J. Clim., doi: 10.1175/JCLI-D-16-0630.1.

Wong, M.S., Jin, X., Liu, Z., Nichola, J., Chan, P.W. 2014. Multi-sensors study of precipitable water vapour over mainland China. Int. J. Climatol. doi: 10.1002/joc.4199.

Zhenhong, L., Muller, J.-P., Cross, P. 2003. Comparison of precipitable water vapor derived from radiosonde, GPS, and Moderate-Resolution Imaging Spectroradiometer measurements, Journal of Geophysical Research. 108, D20, 4651. doi:10.1029/2003JD003372.

Zhong, X. and Kleissl, J. 2015. Clear sky irradiances using REST2 and MODIS. Solar Energy. 116. 144-164. 


\title{
Brazilian Photovoltaic Potential
}

\author{
Enio Bueno Pereira1, Fernando Ramos Martins ${ }^{2}$ André Rodrigues Gonçalves ${ }^{1}$, Rodrigo Santos Costa ${ }^{1}$ \\ ${ }^{1}$ National Institute for Space Research, São José dos Campos (Brazil) \\ ${ }^{2}$ Federal University of São Paulo, Santos (Brazil)
}

\begin{abstract}
The expansion of the Brazilian energy matrix foresees the sharing of renewable sources with $48 \%$ of the internal energy supply in the next 10 years, in accordance with the Brazilian commitments to the United Nations Paris agreement on climate change (NDC). Among the various alternatives for renewable sources stands out the solar, which experienced a national growth at more than $250 \%$ in the last two years. In order to support this robust growth and to provide a reliable source of solar data, the mapping of the Brazilian solar potential was carried out using a radiative transfer model adjusted for the tropical climate in Brazil and employing 17 years of satellite data.
\end{abstract}

Keywords: Solar Energy, Photovoltaic Energy, Renewable Energy, Brazil,

\section{Introduction}

The Brazilian electrical system is primarily hydrothermal with a strong predominance of hydropower plants. The total capacity of power generation in Brazil reached the approximate mark of $624 \mathrm{TWh}$ with the hydropower generation contributing with $65 \%$ (EPE/BEN, 2018). The Brazilian electrical system is all connected through the National Interconnected System (SIN) presenting size and characteristics considered unique worldwide. Isolated systems, located mainly in the Amazon region, serve only $1.7 \%$ of the total electricity demand in Brazil.

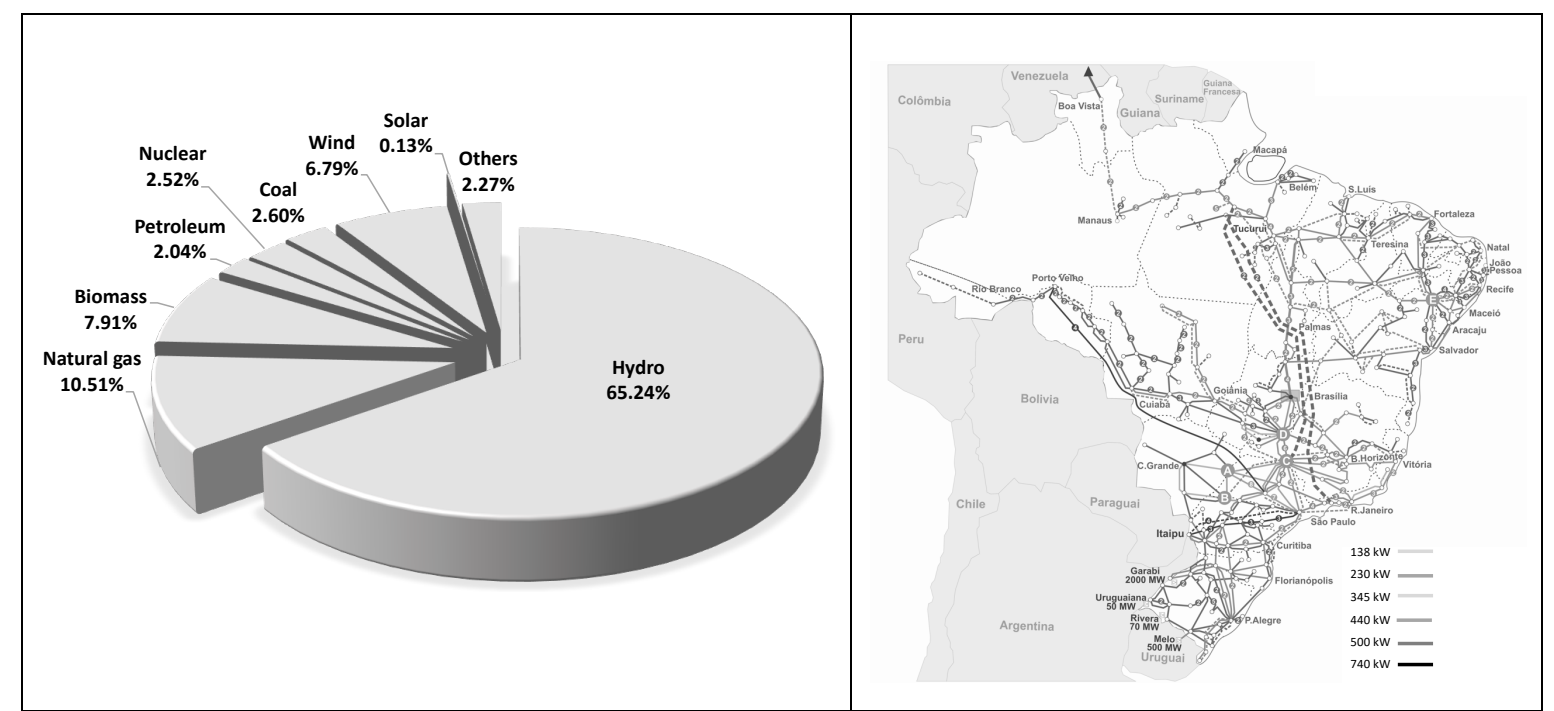

Fig. 1: Brazilian electric matrix (left) and the national interconnect electricity distribution grid - SIN (right) source: EPE/BEN, 2018

Conflicts related to the multiple use of water and the climatic conditions that lead to rationing bring constant concerns about the vulnerability of hydroelectric plants. In addition, the country is approaching the exhaustion of its main hydrographic basins, which has led to the expansion of the sector to areas of great environmental and social concerns, such as the Amazon region. Water demand for power generation competes with water demand for agriculture, public urban supply, maintenance of biocapacity, and other purposes. This brings us to the intricate issue of the water-energy-food security nexus approach. In addition, the 10-Year Brazilian Energy Expansion Plan (PDE2026, 2018) anticipates increasing electricity consumption at an annual average rate of $3.7 \%$, adding an additional demand of about $225 \mathrm{TWh}$ by 2026 .

Besides the need to meet the growing energy demand and to diversify energy sources, there are the Brazilian commitments to reduce emissions of greenhouse gases. Brazil should reduce $43 \%$ of the greenhouse gas 
emissions by 2030 in relation to 2005 and achieve $45 \%$ renewable energy share in its energy matrix, including solar.

Brazil receives high levels of solar irradiation with low temporal and geographical variability. The annual average of global irradiation is between $1300 \mathrm{kWh} / \mathrm{m}^{2}$ and $2200 \mathrm{kWh} / \mathrm{m}^{2}$ throughout the Brazilian territory (Pereira, et al., 2017). Although the solar energy accounts for only $0.83 \%$ of the current national power supply (ANNEL, 2018), the solar technologies industries for power generation are growing fast in the country, at more than $250 \%$ increase in the last two years. The distributed microgeneration systems add up to $300 \mathrm{MW}$ of installed power capacity with predominance of residential consumers $(26,5 \%)$. The installed capacity in large photovoltaic power plants connected to the SIN, in turn, have recently exceeded the 1.5 GW. The country is expected to reach $2.4 \mathrm{GW}$ at the end of 2018, accounting for the contribution of solar photovoltaic plants from the national reserve power auctions of 2014 and 2015 (EPE, 2018). Figure 2 depicts the annual growth of the installed PV capacity for distributed PV systems and large centralized PV plants.

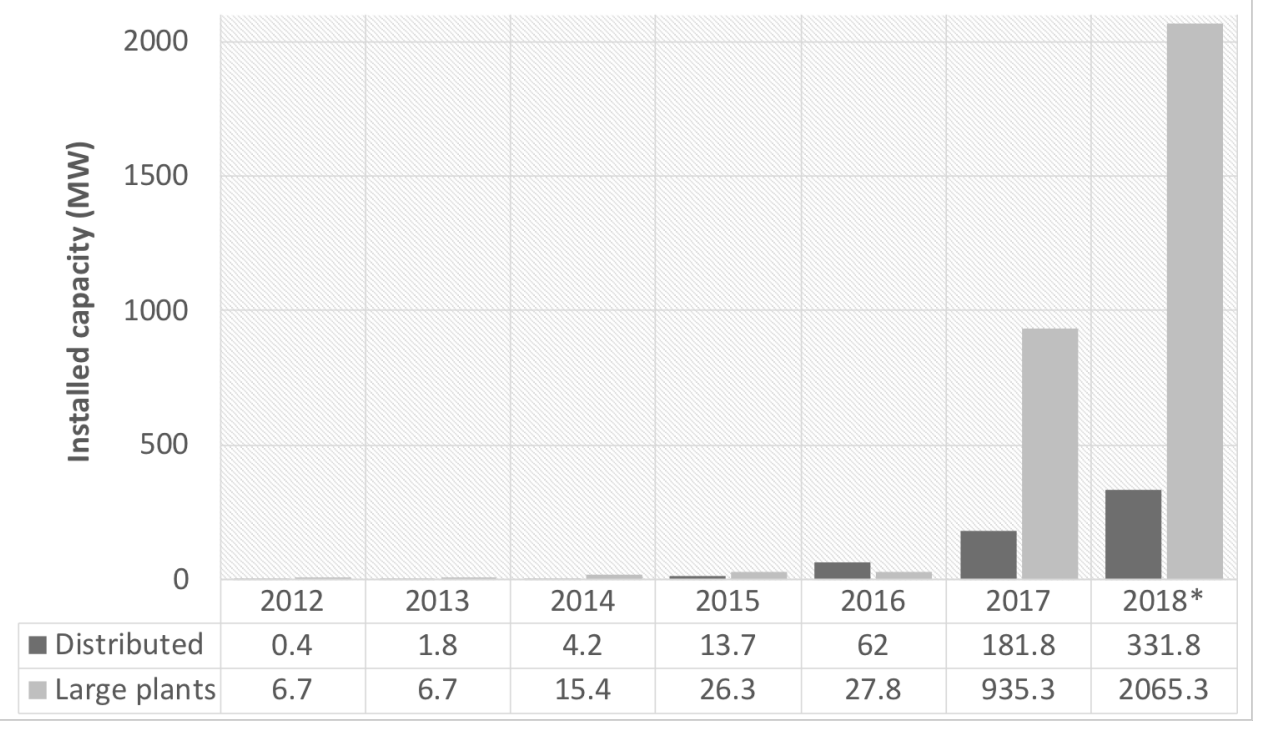

Fig. 2: Brazilian PV cumulative installed capacity source: ABSOLAR, 2018

The investment in large-scale intensive applications of solar technologies in Brazil is inhibited by insufficient or inadequate information on solar energy resource. Without reliable data, the potential investors tend to avoid the risk of solar project development activities. Barriers of knowledge and perception, once removed, are unlikely to return.

\section{The Solar Energy Resource Assessment Model}

In order to remove this information barrier, INPE/LABREN launched the Brazilian Atlas of Solar Energy (Pereira, et al., 2017). This work comprises 17 years of satellite data and a physical spectral model for solving the radiative transfer equation in the atmosphere, called BRASIL-SR (Martins \& Pereira, 2006). This work has provided stakeholders and investors with good estimates of the various components of solar irradiation needed for solar energy projects. The model BRASIL-SR estimates the incoming solar irradiation based on the assumption that the solar radiation flux measured at the top of the atmosphere is linearly distributed between two extreme conditions of solar light transmittances: the clear sky $\left(\tau_{\text {clear }}\right)$ and totally cloudy sky $\left(\tau_{\text {cloud }}\right)$. These extreme transmittances are calculated by using a "two-stream" approximation scheme (Meador and Weaver,1980), for solving the radiative transfer equation. The model uses as input a normalized pixel-by-pixel digital data $\left(l^{i}\right)$ provided by the geostationary satellite images, to evaluate the effective cloud coverage $\left(C_{e f f}^{i}\right.$ defined by Equation 1 :

$$
C_{e f f}^{i}=\frac{l^{i}-l_{\text {clear }}^{i}}{l_{\text {cloud }}^{i}-l_{\text {clear }}^{i}}
$$


The spatial resolution of the satellite images is $0.125^{\circ}$ in latitude and $0.155^{\circ}$ in longitude, corresponding to $12.5 \mathrm{~km} \times 15.5 \mathrm{~km}$ at the lowest point until 2003. Thereafter, the resolution passes to $0.05^{\circ}$ in latitude and $0.03^{\circ}$ in longitude $(3 \mathrm{~km} \times 5 \mathrm{~km})$, which also corresponds to the spatial resolution of the model output.The clear sky $\left(l_{\text {clear }}^{i}\right)$ and cloudy sky $\left(l_{\text {cloud }}^{i}\right)$ satellite readings are obtained from a monthly statistic for each satellite image timeframe.

The transmitance coefficients are obtained from the parameterization of the physical processes in the atmosphere. The atmospheric optical properties are parameterized from the meteorological variables of surface air temperature, relative humidity, atmospheric visibility and surface albedo. The temperature and relative humidity database were produced from the average values measured by automatic meteorological stations distributed all over Brazil and operated by the National Institute of Meteorology (INMET). Surface albedo values were obtained from DAAC-Langley products. The topography data was re-sampled from the GTOPO products, produced by EROS Data Center, with same horizontal resolution of the image of the GOES satellite used to obtain effective cloud cover $\left(\boldsymbol{C}_{\boldsymbol{e} f \boldsymbol{f}}^{\boldsymbol{i}}\right)$. The horizontal visibility data $(\mathrm{Costa}, 2012)$ and the aerosol optical thickness data at $550 \mu \mathrm{m}$ from MACC / ECMWF reanalysis was used to parametrize the aerosol transmitance (Costa et. al, 2015).

It is known that numerical models present limitations, which cause uncertainties that vary from region to region throughout the year. In order to evaluate such model uncertainties, the outputs were validated against surface data collected by pyranometers. This procedure employed more than 400 radiometric stations from the SONDA network $<$ http://sonda.ccst.inpe.br/ $>$ and from the INMET automatic weather stations network $<$ http://www.inmet.gov.br/portal/index.php?r=estacoes/estacoesautomaticas $>$, distributed throughout the nation.

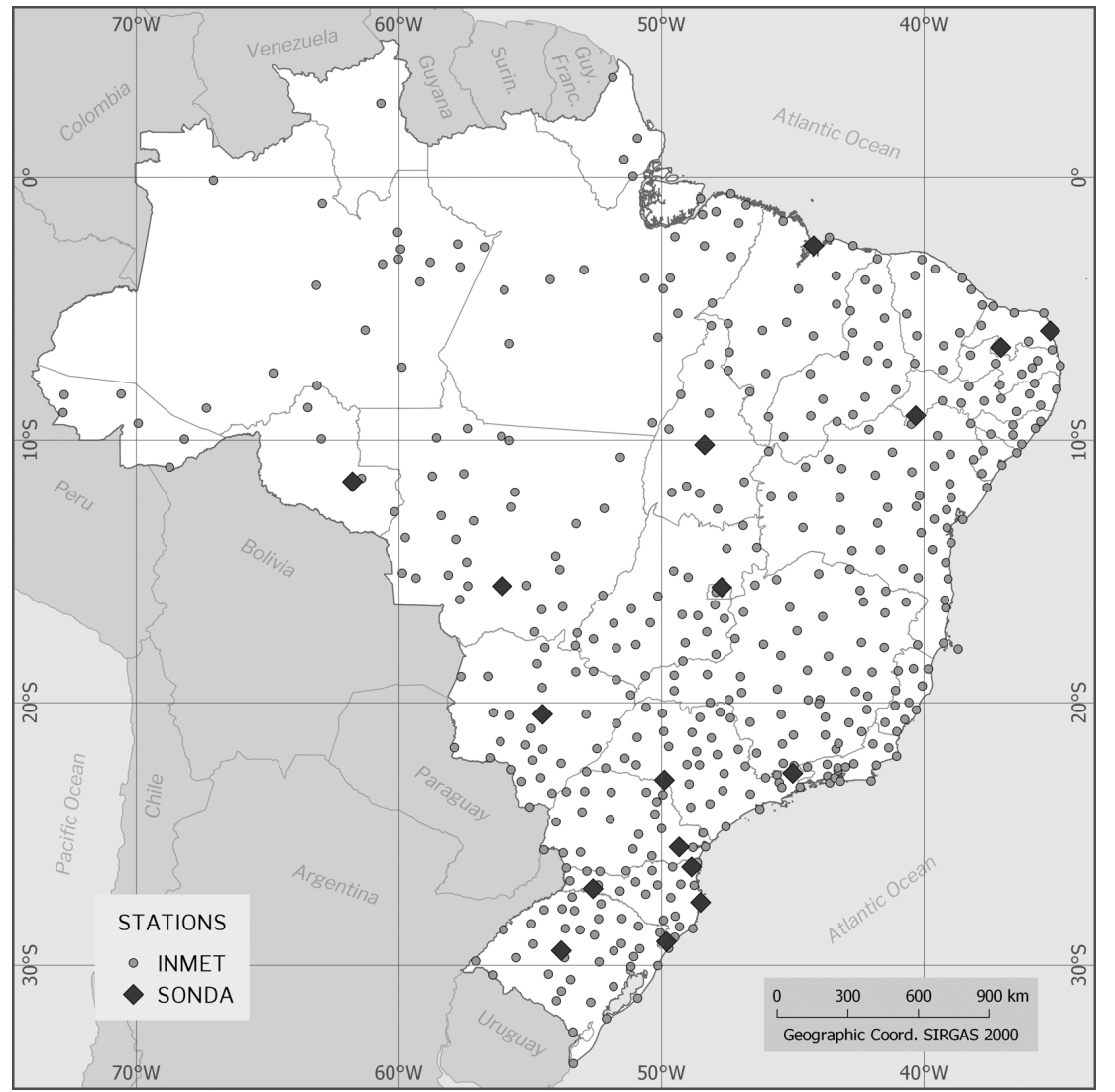

Fig. 3: Spatial distribution of ground data for global solar irradiation used to validate the model outputs - dots are INMET weather stations, and squares, are ground sites of the SONDA network.

This dense radiometric database also allowed us not only to spatially evaluate the accuracy of the numerical model in the estimates of daily irradiation on Brazil for each pixel/month of the year but also to minimize the 
model uncertainty through a post-processing procedure. To do this, a regionalized bias removal methodology was applied. This post-processing methodology consisted in adjusting the daily irradiation data, where the mean error (Bias) patterns for each month were statistically modeled using local spatial regression techniques, generating corrections that were applied to the modeled irradiation data. Figure 4 shows the relative systematic deviations between the untreated model outputs and the adjusted surface of bias. This surfaces of bias were obtained by a judicious procedure of bias interpolation, using as validation metrics independent samples (control) containing the best quality data from the SONDA network. This stage allowed a reduction of around $50 \%$ in the uncertainties of the numerical model outputs. From this figure it is possible to see that the North region presented the maximum positive bias during the austral summer (January) while the Northeast presented the maximum negative bias during winter (Junho). The large number of convective clouds in the Amazon region can explain this pattern during the austral summer when the ITCZ is shifted to the southern hemisphere. This condition causes a persistent overcast sky throughout the month, which precludes the correct determination of $l_{\text {clear }}^{i}$. On the other hand, during the winter, there is a persistence of clear days in the Brazilian Northeastern region, which results in a opposite situation, in which $\boldsymbol{C}_{\boldsymbol{e f f}}^{\boldsymbol{i}}$ is also distorted by the difficulty of determining $l_{\text {cloud }}^{i}$. Both situations lead to inaccurate values of $\boldsymbol{C}_{\boldsymbol{e f f}}^{\boldsymbol{i}}$ and as consequence, systematic deviations on the model outputs.
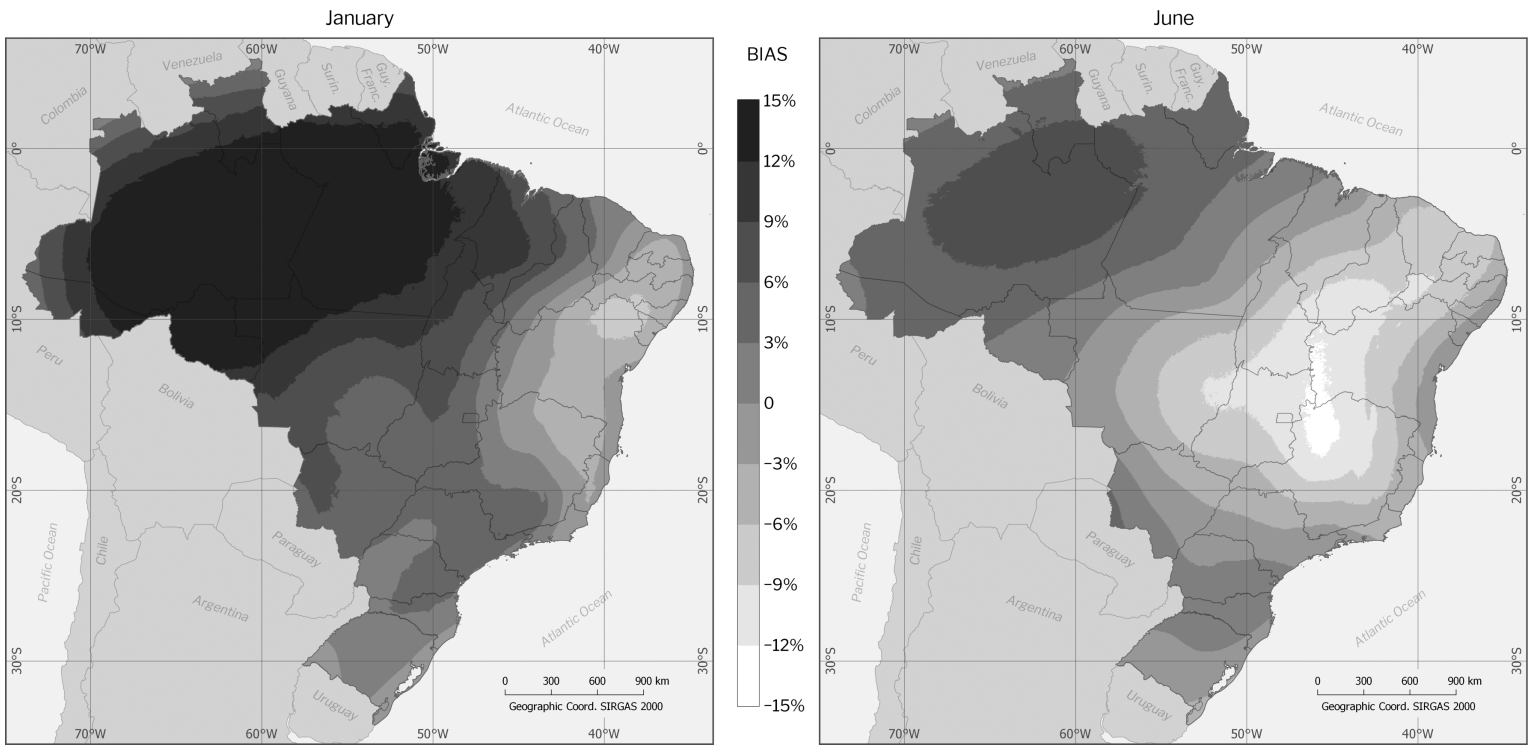

Fig. 4: Maps of the relative systematic deviations (Bias) of the raw output provided by the model BRASIL-SR, left: January and right: June.

From the final database, the Brazilian Southern and Southeastern regions presented the lowest relative bias deviation compared to the other regions, $0.1 \%$ of the annual solar irradiation average, while the Northeastern and the Midwestern regions exhibited the lowest relative root mean square error (RMSE) of 8,3\%. The Northern region has shown the largest deviations, 9.7\% for the relative RMSE and 0,6\% for the relative bias deviation. Table 1 shows the benchmark result of the validation procedure.

Table 1: Benchmark parameters of Global horizontal irradiation for the model for each of the major geographic regions in Brazil:

\begin{tabular}{|ccccccc|}
\hline $\begin{array}{c}\text { Geographic } \\
\text { Region }\end{array}$ & $\mathbf{r}$ & $\begin{array}{c}\text { Bias } \\
\left(\mathbf{k W h} / \mathbf{m}^{\mathbf{2}} \mathbf{a}\right)\end{array}$ & $\begin{array}{c}\text { Relative Bias } \\
\mathbf{( \% )}\end{array}$ & $\begin{array}{c}\text { RMSE } \\
\left(\mathbf{k W h} / \mathbf{m}^{\mathbf{2}} \mathbf{a}\right)\end{array}$ & $\begin{array}{c}\text { Relative RMSE } \\
(\mathbf{\%})\end{array}$ & $\begin{array}{c}\text { Annual Mean } \\
\left(\mathbf{k W h} / \mathbf{m}^{\mathbf{2}} \mathbf{a}\right)\end{array}$ \\
\hline North & 0.81 & 11 & 0.6 & 170 & 9.7 & 1761 \\
\hline Northeast & 0.87 & 4.4 & 0.2 & 166 & 8.3 & 2001 \\
\hline Midwest & 0.86 & 8.4 & 0.5 & 154 & 8.3 & 1855 \\
\hline Southeast & 0.91 & 1.5 & 0.1 & 152 & 8.4 & 1807 \\
\hline South & 0.98 & -1.5 & -0.1 & 144 & 8.9 & 1622 \\
\hline
\end{tabular}




\section{Solar irradiation mapping}

Figure 5 shows the month-by-month global solar irradiation in $\mathrm{Wh} / \mathrm{m} 2$.day, calculated for a tilted plan with an angle equal to de local latitude facing the North. Regarding the geographic distribution, the highest values of the surface solar irradiation occur mostly along a wide northeast-southwest band. The maximum values of solar irradiation occur mostly during winter time with monthly averages of about $6.9 \mathrm{kWh} / \mathrm{m}^{2}$.day in the Northeastern region while the monthly minimum averages occur in the southern region, also in the southern winter of about $3.0 \mathrm{kWh} / \mathrm{m}^{2}$. day.
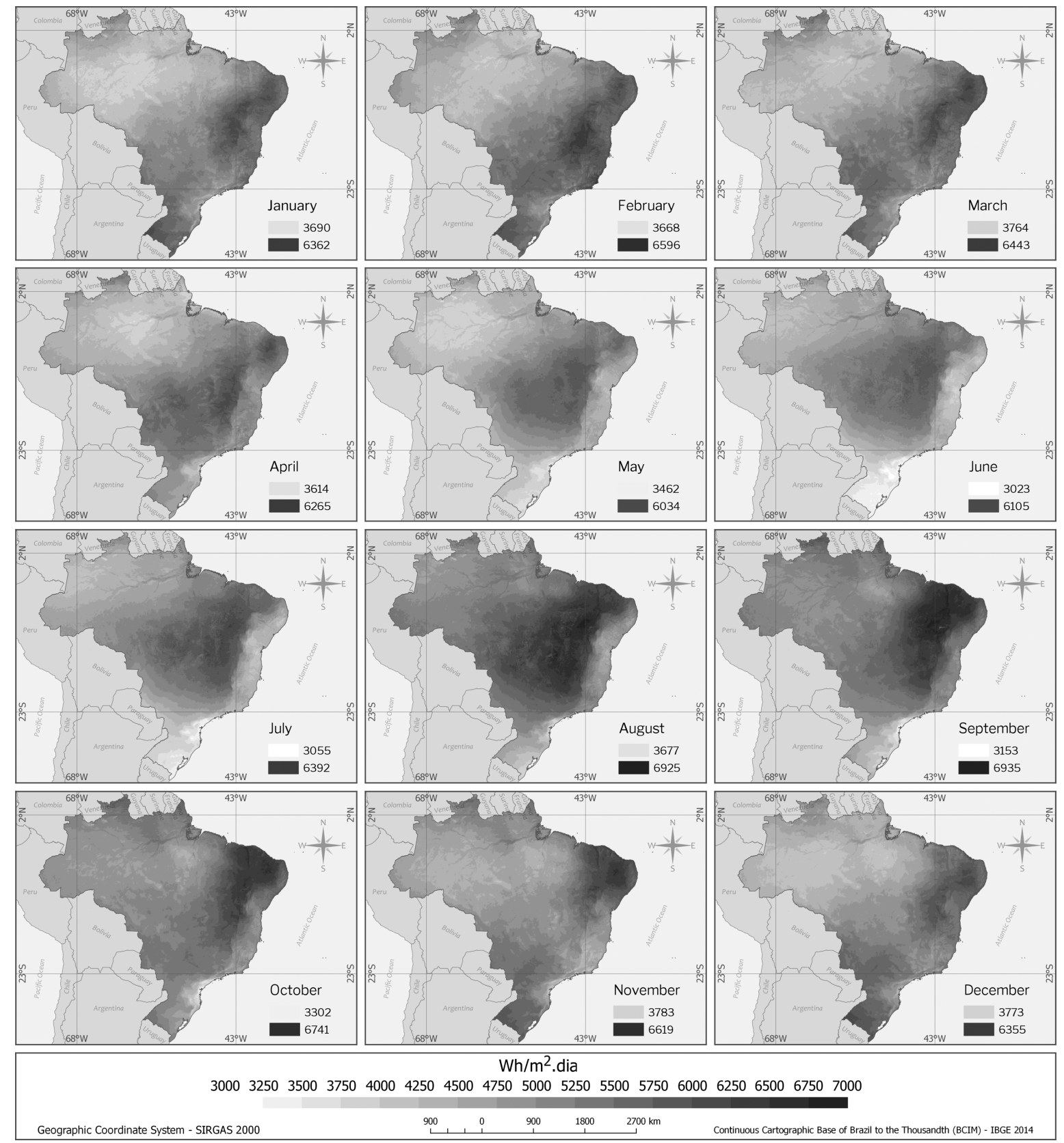

Fig. 5: Monthly maps for the mean surface solar global irradiation $(\mathrm{Wh} / \mathrm{m} 2$. day) at the tilted plan equal to the local latitude angle.

Figure 6 shows the boxplot for the interannual variability of the surface solar irradiation for all Brazilian regions. The Northeastern region presents the lowest interannual variability, with extreme values between 5.39 and $5.59 \mathrm{kWh} / \mathrm{m}^{2}$, and $50 \%$ of the annual averages are in the range between 5.43 and $5.50 \mathrm{kWh} / \mathrm{m}^{2}$. In the South, $50 \%$ of the annual averages present values between 4.53 and $4.61 \mathrm{kWh} / \mathrm{m}^{2}$, while in the Northern region the average annual values range between 4.61 and $4.69 \mathrm{kWh} / \mathrm{m}^{2}$. The Southeastern region presented 
the highest interannual variability, with annual mean values between 4.97 and $5.11 \mathrm{~kW} / \mathrm{m}^{2}$ in $50 \%$ of the years between 2005 and 2015, although the extremes ( 4.95 and $5.23 \mathrm{kWh} / \mathrm{m}^{2}$ ) present amplitude lower than that of the Southern Region.

Figure 7 shows the maximum annual energy yield (measured in kWh of energy generated per year for each $\mathrm{kWp}$ of installed photovoltaic power) throughout the country, both for large centralized plants and for distributed photovoltaic generation, integrated in roofs of households and commercial buildings. The annual average performance ratio of $80 \%$ was adopted to simplify the analysis and represents the performance of a well-designed and installed photovoltaic power generator and good quality equipment. The major cities and urban metropolitan regions are represented by dots which sizes are proportional to the population.

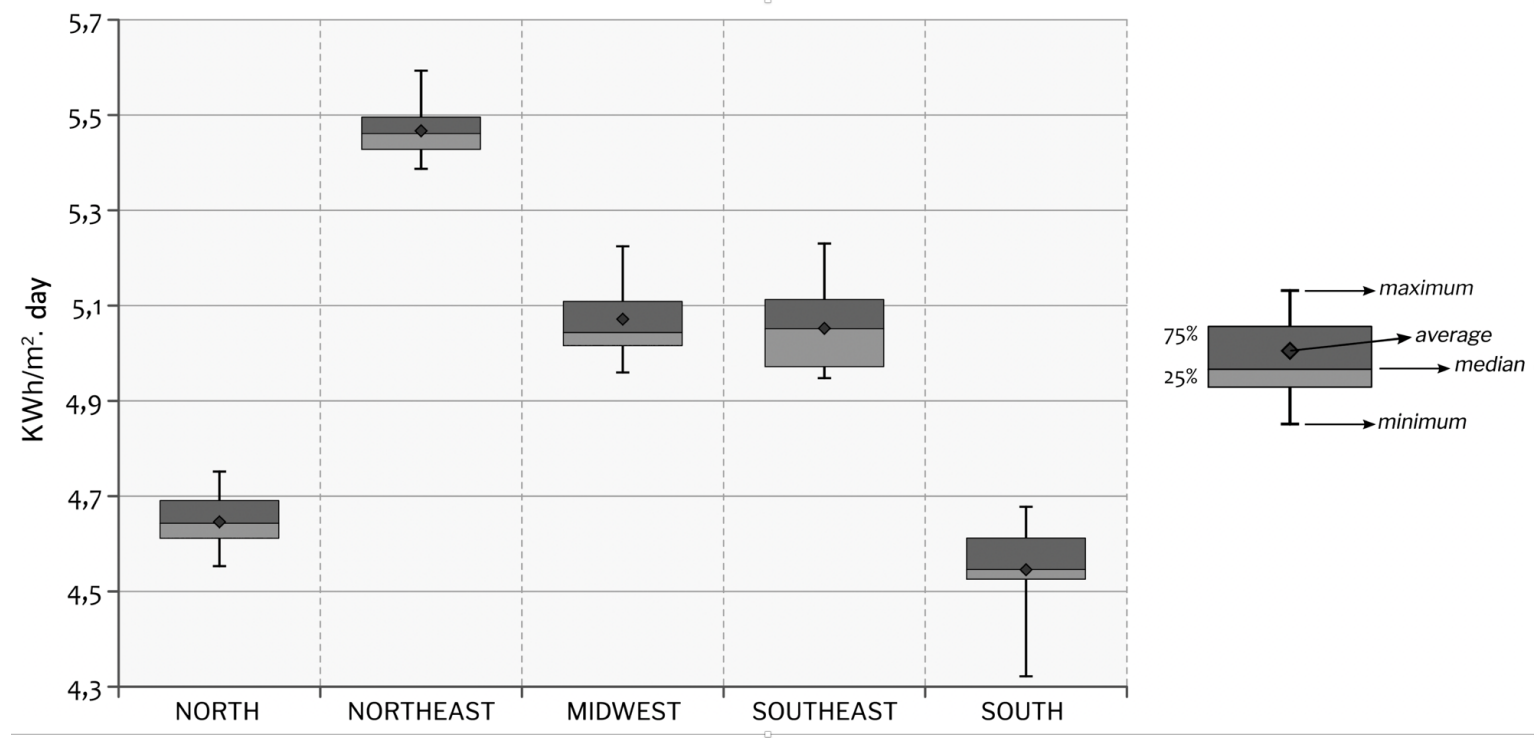

Fig. 6: Interannual variability of the annual mean of the surface solar irradiation for all Brazilian regions. 


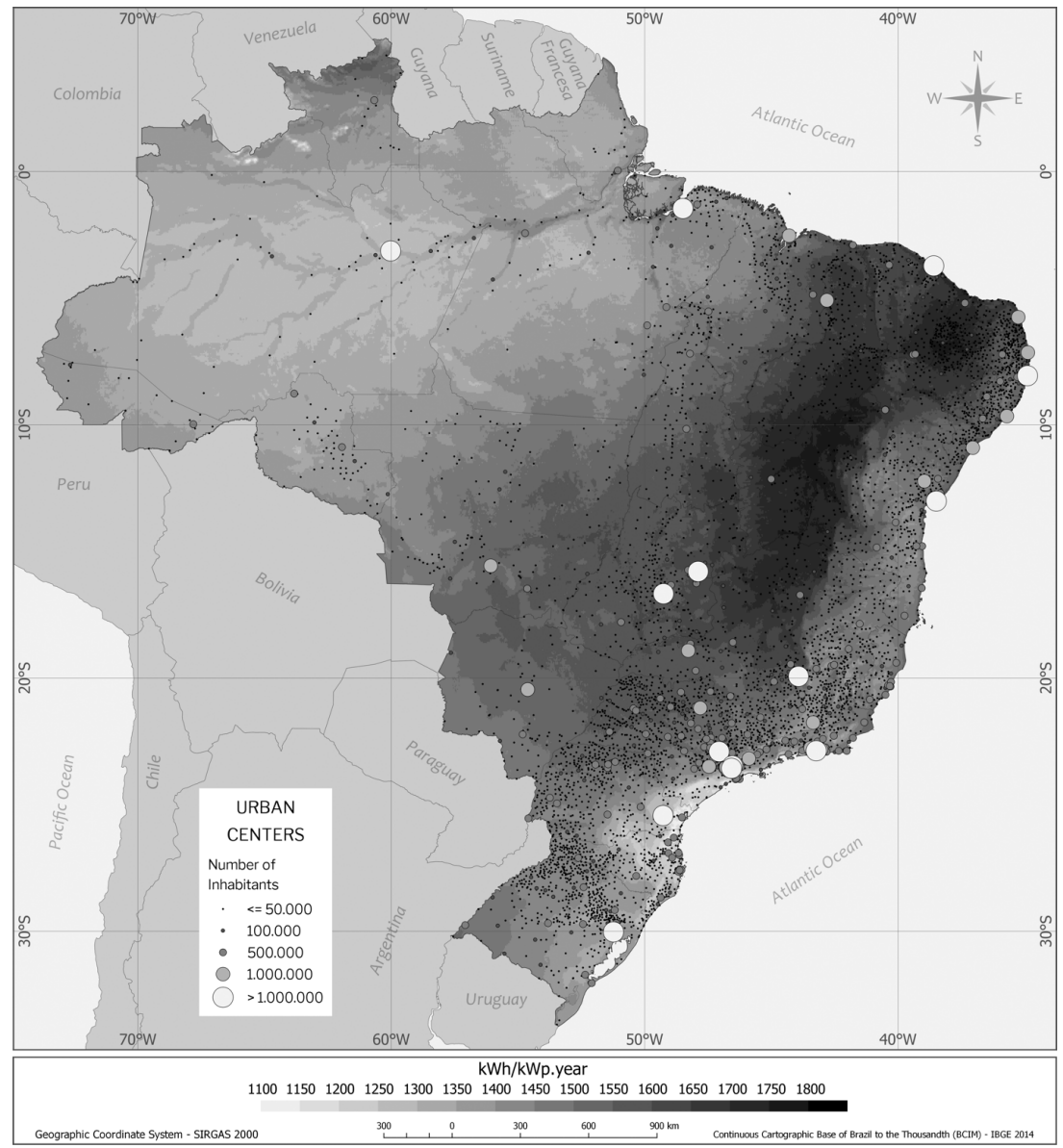

Fig. 7: Map of the $\mathrm{PV}$ yield in $\mathrm{kWh} / \mathrm{kWp}$. The round dots are the location of the major urban areas and their size is proportional to the number of inhabitants.

Figure 8 compares the variability of the monthly mean global horizontal irradiance in Brazil and some European countries. The comparison is made by box-plot diagram for monthly averages of daily solar irradiation. The height of the boxes is representative of the variability for the monthly average of the surface solar irradiation. The plot highlights the relatively high levels and the low variability of the surface solar irradiation in the Brazilian territory compared to some EU countries where PV technology is already settled. The Brazilian Northeastern region surpasses even countries of the Iberian Peninsula with much lower variability. The Southern region presents similar surface solar irradiation to these European countries, particularly in terms of the monthly variability. This is due to the higher latitudes of these countries and, therefore, greater differences in the duration of the day between seasons. 


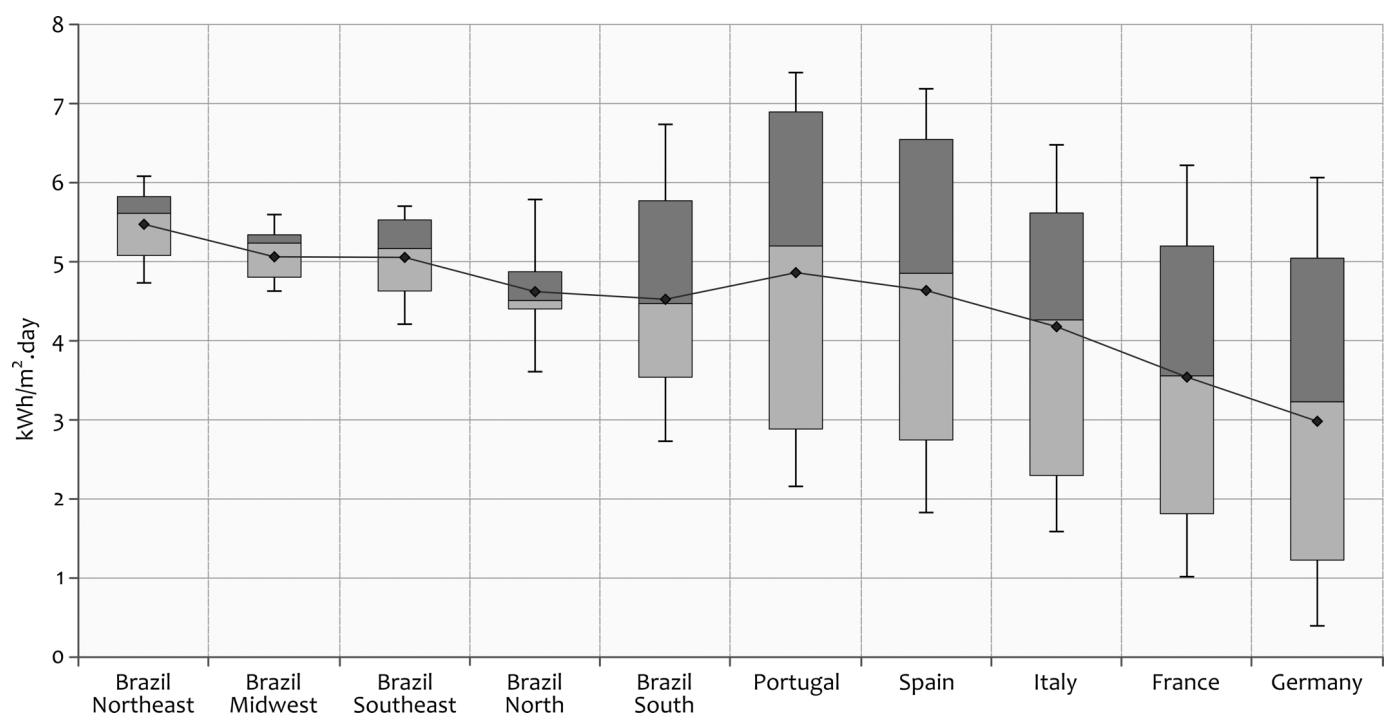

Fig. 8: Box-plot diagram for the PV potential in the all Brazilian macro-regions and some European countries where the solar energy market is well consolidated. Source: Pereira, 2017 and Súri et al., 2007.

\section{Conclusions}

The Brazilian Northeastern region has the highest PV potential, presenting an average value of the global horizontal solar irradiation of $5.49 \mathrm{kWh} / \mathrm{m}^{2}$.day and the direct normal component of $5.05 \mathrm{kWh} / \mathrm{m}^{2}$.day. It is the region with the lowest interannual and intra-annual variability of the surface solar irradiation. The Southeastern and Midwestern regions present daily totals of the global horizontal irradiation close to 5.07 $\mathrm{kWh} / \mathrm{m}^{2}$.day. The mean global irradiance for latitude tilted plane in the in the Southeast of Brazil is of 5.26 $\mathrm{kWh} / \mathrm{m}^{2}$.day, while the Midwestern region is $5.20 \mathrm{kWh} / \mathrm{m}^{2}$.day.

The relatively lower surface solar irradiation in the Northern region are justified by the typical climate characteristics of the region presenting frequent cloudiness, mainly during the austral summer when the ITCZ is shifted toward the South hemisphere. Thus, the average global irradiance in the horizontal and tilted planes has values close to those obtained for the Southern region and the direct normal irradiation is lower than all other regions of the country due to large diffuse solar irradiation.

Large-scale plants, typically installed on fixed-sloping metal structures or following the apparent trajectory of the Sun on one axis, have been mainly located in the Northeast, Midwest and some in the Southeast of Brazil. These regions have the highest average annual yields, as shown in Figure 7. To the extent that these areas and their energy transmission systems tend to saturate or require larger investments to accommodate increasing installed capacity, other regions of Brazil will be competitive, notably the Southern regions. Smaller distances to the key energy consumption centers and the large load of the National Interconnected System (SIN) favor the displacement of target areas for solar power projects. Furthermore, the greater availability of connection points to the SIN minimizes the need for new transmission lines. There are excellent annual levels of irradiation in the western areas of the states of São Paulo, Paraná, Santa Catarina and Rio Grande do Sul during the summer months, and in some areas the values may be similar to the monthly averages of several locations where large photovoltaic are being installed.

This work highlighted the high level and low variability of solar irradiation in the Brazilian territory compared to countries where PV technology is well established. In addition to the abundance of radiant energy from the Sun, the country has an enormous extension of degraded areas, or of low economic value, for the deployment of power generation projects using solar technology, enhanced by an electric energy distribution system that covers practically the entire national territory connected to several large hydroelectric plants. It brings the possibility of connecting PV power plants to the energy distribution system practically all over the country, with the exception of the North region. Notwithstanding these advantages, another great differential is based on the possibility of socioeconomic transformation of the low-income population of the Northeastern semi-arid region. Micro and mini distributed PV power generation, solar water desalination and water pumping, can become reality through new public policies, promoting regional 
economic development and social inclusion.

Acknowledgements: This work is a contribution of the National Institute of Science and Technology for Climate Change (INCT-MC) financed by FAPESP 2014/50848-9, CNPq 465501/2014-1, and CAPES / FAPS No. 16/2014 and of project 1042118005 - CENPES/NUBI. Thanks are due to CNPq for financial supporting of the authors through research scholarships.

\section{References}

ANEEL, 2018 - http://www2.aneel.gov.br/aplicacoes/capacidadebrasil/capacidadebrasil.cfm, latest access, Aug. 2018.

EPE-BEN, 2018. National Energy Balance. Rio de Janeiro: Brazilian Energy Research Company-Ministry of Mines and Energy.

EPE 2018 http://www.epe.gov.br/pt/leiloes-de-energia/leiloes, latest access, 20 Aug. 2018.

Martins, F. R. and Pereira, E. B., 2006. Parameterization of aerosols from burning biomass in the Brazil-SR radiative transfer model, Solar, 80 (3), 231-239, doi.org/10.1016/j.solener.2005.03.008

Meador, W.E and Weaver, W. R., Two stream approximations to radiative transfer in planetary atmospheres: A unified description of existing methods and a new improvement. Journal Atmospheric Science, New York, v.37, p. 630-643, 1980.

PDE2026, 2018. 10-Year Brazilian Energy Expansion Plan. Brazilian Energy Research Company, EPE/MME.

Pereira, E. B.; Martins, F. R.; Gonçalves, A. R.; Costa, R. S.; et al, 2017. Atlas Brasileiro de Energia Solar. São José dos Campos: INPE, $2^{\text {nd }}$ edition, 84 pp. ISBN 978-85-17-000900.4.

Costa, R.S.; Goncalves, A. R. ; Souza, J. G. ; Martins, F. R. ; Pereira, E. B. Assimilation of aerosols from biomass burning by the radiative transfer model Brasil-SR. In: AGU Fall Meeting 2015. Proceedings, San Francisco. 2015

Súri M., Huld T.A., Dunlop E.D. Ossenbrink H.A., 2007. Potential of solar electricity generation in the European Union member states and candidate countries. Solar Energy, 81, 1295-1305. 


\title{
Assessing Solar Electricity Potential and Prospective Present Day Costs for a Low Latitude Caribbean Island: Trinidad
}

\author{
Nalini Dookie ${ }^{1}$, Xsitaaz T. Chadee ${ }^{1}$ and Ricardo M. Clarke ${ }^{1}$ \\ ${ }^{1}$ Department of Physics, Faculty of Science and Technology, The University of the West Indies, St. \\ Augustine (Trinidad and Tobago). Email: nalini.dookie@my.uwi.edu
}

\begin{abstract}
Presently, Trinidad and Tobago and many other Caribbean islands are faced with a challenge of integrating renewable energy into their energy sector. A key factor towards successful integration of any renewable energy resource in the electricity sector is through good economic prospects. In this study, the levelized cost of that energy (LCOE) output was determined by modeling utility scale solar photovoltaic systems in the absence of operational PV system data. An existing model of a utility scale solar system is adapted by considering energy loss factors at each stage of the electricity generation process. A range of LCOEs were determined by considering the ranges of the different losses in a PV system. The daily total in-plane insolation at Piarco for 2003 was used as input into an adapted model. The estimated energy was then applied to an economic model to calculate the LCOEs. For Piarco, the estimated annual performance ratios of PV systems were found to range between $56.6 \%$ for maximum losses and $80.2 \%$ for minimum losses and a performance ratio of $69.8 \%$ for standard losses. The standard loss model with a $3 \%$ discount rate leads to LCOEs in the range US $\$ 0.07$ - US $\$ 0.09$ per $\mathrm{kWh}$. These are promising results when considering incorporating solar energy into the energy mix of Trinidad and Tobago for electricity generation.
\end{abstract}

Keywords: solar energy, Trinidad and Tobago, PV system

\section{Introduction}

The Government of Trinidad and Tobago aims to ensure that by 2021, $10 \%$ of power generation should come from renewable energy. However, currently, power generation is still $100 \%$ fossil-fuel based. Trinidad and Tobago's economy is based on natural gas and crude oil production and they are the Caribbean's largest oil and natural gas producer (Ministry of Energy and Energy Industries of Trinidad and Tobago, 2017). In recent years, falling natural gas and crude oil production has resulted in a drop in revenue of TT $\$ 17.6$ billion dollars, or $92 \%$ in annual revenue (Government of the Republic of Trinidad and Tobago, 2016).

Solar energy is a clean source of energy which could contribute to electricity generation if implemented on a large scale basis and therefore, reduce the country's dependence on its fossil fuel resources. The first step in determining the feasibility of solar energy for electricity generation is the conduct of a national solar resource assessment. Such a complete solar resource assessment is currently unavailable for Trinidad and Tobago. To date, solar resource assessments have been limited mostly to the climatological assessment of solar radiation data, the development of models to predict monthly solar radiation (Smith, 1960; Stone, 1999; De Souza and Andrews, 2015; De Souza, 2018) and an assessment of "A unique approach for sustainable energy in Trinidad and Tobago" (Marzolf et al., 2015). A solar resource assessment provides reasonable and accurate projections of annual energy solar production at a prospective energy production site and therefore the performance of utility photovoltaics systems under varying climatic conditions (Makrides et al., 2010). It also considers the levelized costs of electricity (LCOE) generation as the financial aspects of a renewable energy project is key for further analyses and implementation.

To date, one study which has considered LCOEs for solar energy for Trinidad and Tobago evaluated the LCOE for solar generated electricity to be US\$ 0.140 to US $\$ 0.288$ per $\mathrm{kWh}$ at 2012 prices (Marzolf et al., 2015). They used meteorological software to determine the total solar irradiance and assumed a performance ratio (PR) more 


\section{Nalini Dookie}

than $81.5 \%$. Performance ratios of photovoltaic systems range between 60 and $90 \%$ (Dierauf et al., 2013). As such, in order to consider the economic feasibility of implementing utility scale PV systems in Trinidad and Tobago, the evaluation of the cost of electricity generation using a site specific performance ratio is of significance.

In the absence of operational utility PV systems, we are required to model the energy output of PV systems in order to estimate the LCOEs. This energy output is influenced by the PR of the PV system. The aim of this study is therefore to estimate the range of LCOEs for a site in Trinidad and Tobago using a range of possible losses and on site solar radiation data for the 2003 year. Nearby Caribbean islands are subjected to similar environmental constraints applied in this model and as such the approach applied here can also be used to supplement studies in those nearby islands.

\section{PV System Model}

Typical photovoltaic grid utility systems are made up of photovoltaic modules, inverters, mounting systems, transformers and grid connection (International Finance Corporation, 2015; Solargis, 2016).

In order to accurately estimate electricity that can be produced by a photovoltaic power plant, information on the solar resource, temperature conditions of the site, the layout and technical specifications of the power plant are required.

The performance ratio of the PV system, PR, as defined in the standard IEC 61724, is the quotient obtained by dividing the final yield of the PV system by the reference yield of the PV system and it represents the overall effect of the plant's losses on the rated array output (Khalid et al., 2016). $E_{P V}$, the net AC energy output of the system is found by:

$E_{P V}=\frac{(P R)\left(P_{r}\right)\left(H_{T}\right)}{E_{\mathrm{R}}}($ Kymakis et al., 2009)

where $P_{r}$ is the peak power of the installed system under standard test conditions (STC) of $1000 \mathrm{~W} / \mathrm{m}^{2}$ solar irradiance and $25{ }^{\circ} \mathrm{C}$ cell temperature, $H_{T}$ is the total in-plane solar irradiation and $E_{R}$ is the array reference irradiance $\left(1 \mathrm{~kW} / \mathrm{m}^{2}\right)$.

Kymakis et al. (2009) defined the PR as the product of various losses:

$P R=\frac{Y_{F}}{Y_{R}}=\eta_{\text {deg }} \eta_{\text {temp }} \eta_{\text {soil }} \eta_{\text {net }} \eta_{\text {inv }} \eta_{\text {tran }} \eta_{\text {ppc }}$ (Kymakis et al., 2009)

where $Y_{F}$ is the final yield, $Y_{R}$ is the reference yield, $\eta_{\text {deg }}, \eta_{\text {temp }}, \eta_{\text {soil }}, \eta_{n e t}, \eta_{\text {inv }}, \eta_{\text {tran }}$ and $\eta_{p p c}$ are the efficiencies due to module degradation, module temperature, module soiling, internal network losses, inverter losses, transformer losses and availability and grid connection losses respectively.

Similar to the definition used by Kymakis et al., (2009), the PR of the PV system is adapted to be representative of losses due to air mass $\left(\mathrm{n}_{M}\right)$, tilt $\left(\mathrm{\eta}_{\text {tilt }}\right)$, shading $\left(\mathrm{\eta}_{\text {shad }}\right)$, angular reflectivity $\left(\mathrm{\eta}_{A R}\right)$, soiling $\left(\mathrm{n}_{\text {soil }}\right)$, temperature $\left(\mathrm{\eta}_{\text {temp }}\right)$, inverter $\left(\mathrm{\eta}_{\text {inv }}\right)$, internal network (DC wiring and interconnection losses) $\left(\mathrm{\eta}_{\text {net }}\right)$, transformer $\left(\mathrm{\eta}_{\text {tran }}\right)$ and availability and grid connection $\left(\eta_{\mathrm{ppc}}\right)$. In this study, the PR is estimated using equation 3 and is then substituted in equation 1 to determine the net energy output $E_{P V}$.

$P R=\eta_{M} \eta_{\text {tilt }} \eta_{\text {shad }} \eta_{\text {AR }} \eta_{\text {soil }} \eta_{\text {temp }} \eta_{\text {inv }} \eta_{\text {net }} \eta_{\text {tran }} \eta_{\text {ppc }}$

The monthly capacity factor (CF) of the PV system is found by:

$C F=\frac{E_{P V}}{P_{r} \times \text { No. of hours per month }}$

We account for losses in the various components such as the PV array, connecting wires, the inverter and the transformer. However, we modify the values of the loss factors to be representative for low-latitude regions, in particular, soiling, angular reflectivity, air mass and temperature characteristics.

Estimates of the potential losses due to specific factors such as air mass (Chegaar and Mialhe, 2008; Duffie and Beckman, 2006), shading (Duffie and Beckman, 2006; Sathyanarayana et al., 2015), angular reflectivity (Martı'n and Ruiz, 2005), soiling (Field et al., 2015; Mohammed and Hasan, 2012) and temperature on the module 


\section{Nalini Dookie}

(Skoplaki and Palyvos, 2009; Huld and Amillo, 2015) were made using site photovoltaic studies which considered losses specific to that location's latitude and climate. The performance loss due to inefficiencies in the internal network resistances (Kymakis et al., 2009; Kumar and Sudhakar, 2015), the inverter (Kymakis et al., 2009; Rehman et al., 2007; Kumar and Sudhakar, 2015), and the transformer (Kymakis et al., 2009, Kumar and Sudhakar, 2015) as well as losses incurred due to technical availability (Kymakis et al., 2009; Kumar and Sudhakar, 2015) were made using overall power system studies.

In this model, several loss factors are represented by a range of values rather than a single value where the model considers maximum, standard and minimum losses. The standard model will consider the normal or average expected losses.

The factors considered in the model for assessing the solar electricity potential are the efficiency of the module, air mass, tilt, shading, angular reflectivity, soiling, temperature, internal network efficiency, inverter efficiency, transformer efficiency and availability and grid connection losses. The suitable range of losses/ efficiency values was determined for each factor based on practical studies and experiences for low latitudes (Table 1).

Tab. 1: Range of derate factors considered

\begin{tabular}{|c|c|c|c|c|}
\hline \multirow[t]{2}{*}{ Derate Factors } & \multicolumn{3}{|c|}{$\begin{array}{c}\text { Partial losses due to individual } \\
\text { factors }(\%)\end{array}$} & \multirow[t]{2}{*}{ References } \\
\hline & Min & Max & Standard & \\
\hline Efficiency of PV module & 80.00 & 88.00 & 84.00 & $\begin{array}{l}\text { International Renewable Energy } \\
\text { Agency (2012), } \\
\text { International Finance Corporation } \\
\text { World Bank Group (2012), } \\
\text { Smets et al. (2015) }\end{array}$ \\
\hline Effect of air mass & 0.00 & 1.00 & 1.00 & $\begin{array}{l}\text { The air mass for Trinidad was } \\
\text { calculated. } \\
\text { Chegaar and Mialhe (2008) }\end{array}$ \\
\hline Effect of tilt angle of module & 0.00 & 0.00 & 0.00 & $\begin{array}{l}\text { The model considers a horizontal } \\
\text { module. }\end{array}$ \\
\hline Effect of shading & 1.00 & 6.00 & 2.50 & $\begin{array}{l}\text { Duffie and Beckman (2006) } \\
\text { Sathyanarayana et al. (2015) }\end{array}$ \\
\hline Effect of angular reflectivity & 3.00 & 4.00 & 3.50 & Martı'n and Ruiz (2005) \\
\hline Effect of soiling & 1.00 & 7.00 & 1.50 & $\begin{array}{l}\text { Trinidad has exposure to Sahara dust. } \\
\text { Duffie and Beckman (2006) } \\
\text { Mohammed and Hasan (2012) } \\
\text { Kimber et al. (2006) } \\
\text { Kymakis et al. (2009) }\end{array}$ \\
\hline Effect of temperature & 8.50 & 15.00 & 10.00 & $\begin{array}{l}\text { Huld and Amillo (2015) } \\
\text { Ariza Taba et al. (2016) } \\
\text { Parretta et al. (1998) } \\
\text { Vasisht et al. (2016) }\end{array}$ \\
\hline $\begin{array}{l}\text { Effect of internal network } \\
\text { losses }\end{array}$ & 3.00 & 6.00 & 5.00 & $\begin{array}{c}\text { Kymakis et al. (2009) } \\
\text { Kumar and Sudhakar (2015) }\end{array}$ \\
\hline Effect of inverter losses & 2.00 & 8.00 & 5.00 & $\begin{array}{l}\text { Kymakis et al. (2009) } \\
\text { Rehman et al. (2007) }\end{array}$ \\
\hline
\end{tabular}


Nalini Dookie

\begin{tabular}{|c|c|c|c|c|}
\hline & & & & Kumar and Sudhakar (2015) \\
\hline Effect of transformer losses & 1.00 & 2.50 & 2.00 & $\begin{array}{c}\text { Kymakis et al. (2009) } \\
\text { Shukla et al. (2016) } \\
\text { Kumar and Sudhakar (2015) }\end{array}$ \\
\hline $\begin{array}{c}\text { Effect of availability and grid } \\
\text { connection losses }\end{array}$ & 2.00 & 5.00 & 4.50 & $\begin{array}{c}\text { Kymakis et al. (2009) } \\
\text { Kumar and Sudhakar (2015) }\end{array}$ \\
\hline
\end{tabular}

\subsection{Description of the PV System}

This study focused on crystalline photovoltaic systems as crystalline systems are today the most widely used (Buchla et al., 2015). The model considers a horizontal module and therefore the effect due to tilt is not considered. It was further assumed that the photovoltaic system in this energy model is to be set up in flat terrain, isolated from the shading of large vegetation and buildings.

\section{Study Area and Data}

\subsection{Study Area}

Trinidad and Tobago are the most southern islands of the Caribbean archipelago (Gov.tt 2017). The global solar radiation data for this study were obtained for Piarco, Trinidad, for the period 2000 to 2010 from the Trinidad and Tobago Meteorological Office. This station is a World Meteorological Organization (WMO) station.

Trinidad and Tobago has a dry and a wet season. The dry season spans the months of January to May while the wet season extends from June to December. The climate experienced during the dry season is a tropical maritime climate while the wet season experiences a modified moist equatorial climate. The mean maximum and minimum temperatures (1971-2000) in Trinidad are $31.3^{\circ} \mathrm{C}$ and $22.7^{\circ} \mathrm{C}$ respectively (Trinidad and Tobago Meteorological Service 2017). Piarco has an average annual wind speed of $2.88 \mathrm{~m} / \mathrm{s}$ at the $10 \mathrm{~m}$ height (Chadee, 2015). The annual average of daily solar radiation for Piarco was calculated to be $4.41 \mathrm{kWh} / \mathrm{m}^{2}$.

\subsection{Data Quality Control}

The daily global radiation data for Piarco, Trinidad were obtained for the period 2000 to 2010. Each data value in the daily data set was checked for instances of missing days, negative values and zero values. No missing daily totals are permitted in calculating the monthly global radiation. Also, no missing monthly normals are permitted if an annual normal is to be calculated. Checks for thresholds were also conducted. Daily data values were checked against the upper limit of each month and below the lower limit for each month as defined by WMO (1987). In low latitude regions throughout the year, the minimum daily values average was about 0.3 to $0.4 \mathrm{MJ} / \mathrm{m}^{2}$ (WMO 1987). All daily averages were checked against a lower threshold of $0.4 \mathrm{MJ} / \mathrm{m}^{2}$. After subjecting the data to all the quality control steps outlined, only one valid year of data (2003) was obtained.

\subsection{Site Specific Solar Insolation Characteristics}

The dataset consisted of the daily total in-plane insolation for 2003 at Piarco, Trinidad. In 2003, the daily total in plane insolation range was $0.85-6.15 \mathrm{kWh} / \mathrm{m}^{2}$ with a daily average of $4.41 \mathrm{kWh} / \mathrm{m}^{2}$. The monthly total in-plane insolation ranged from a minimum value of $109.48 \mathrm{kWh} / \mathrm{m}^{2}$ in November 2003 to a maximum value of 158.64 $\mathrm{kWh} / \mathrm{m}^{2}$ in March 2003 (Figure 1). The dry season had a higher monthly average total in-plane insolation for 2003 of $145.94 \mathrm{kWh} / \mathrm{m}^{2}$ as compared to the wet season with $125.80 \mathrm{kWh} / \mathrm{m}^{2}$.

The annual total in plane insolation for 2003 was found to be $1610.27 \mathrm{kWh} / \mathrm{m}^{2}$. This value was measured at Piarco and is used as a representative value for Trinidad. This observed value is smaller than the value of the total insolation $1761 \mathrm{kWh} / \mathrm{m}^{2}$ used by Marzolf et al. (2015) who used meteorological software to estimate the total inplane insolation at $15 \%$ tilted surface at Crown Point, Tobago. 
Nalini Dookie

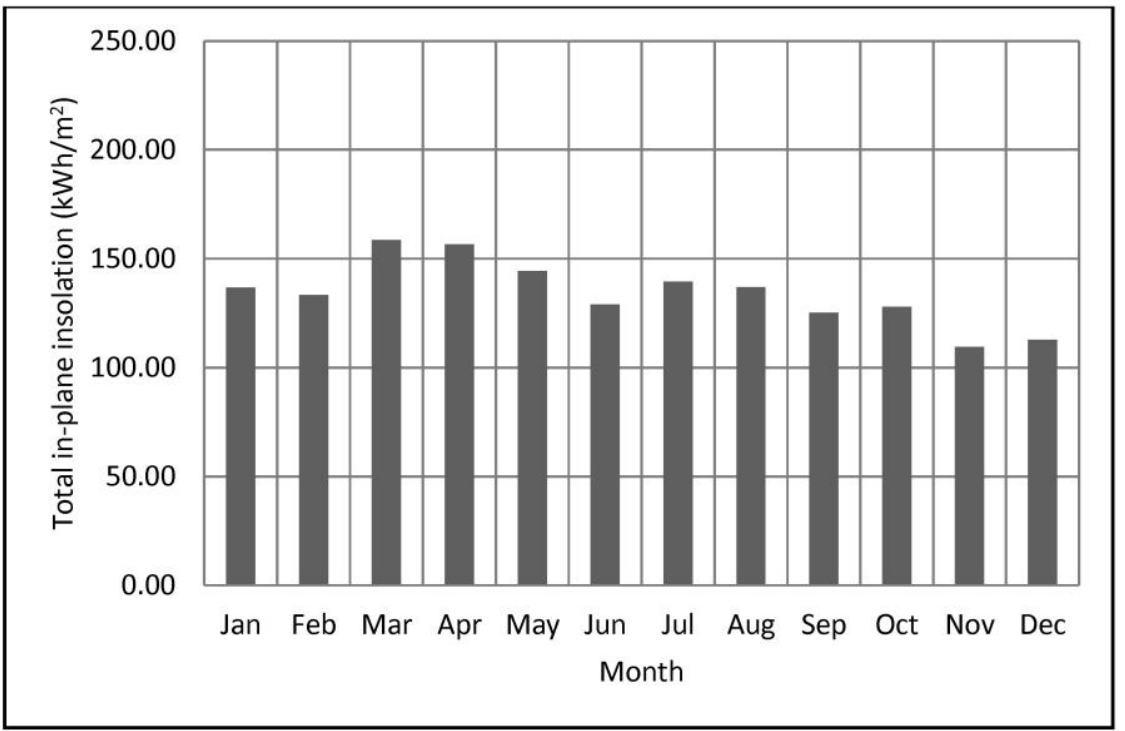

Fig. 1: Monthly total in-plane insolation for 2003

\section{Energy Analysis}

\subsection{Annual Energy Analysis}

The model resulted in a range of annual performance ratios between $56.6 \%$ and $80.2 \%$ with a standard modelled value of $69.8 \%$ and capacity ratios between $10.4 \%$ and $14.8 \%$ with a standard modelled value with $12.8 \%$. This resulted in annual electricity generating capacities of $4555 \mathrm{MWh}$ to $6459 \mathrm{MWh}$ for a $5 \mathrm{MW}$ system, $9109 \mathrm{MWh}$ to $12920 \mathrm{MWh}$ for a $10 \mathrm{MW}$ system, $45550 \mathrm{MWh}$ to $64590 \mathrm{MWh}$ for a $50 \mathrm{MW}$ system and $91090 \mathrm{MWh}$ to $129200 \mathrm{MWh}$, in their first year of operation.

\subsection{Estimated Monthly Capacity Factors}

For the PV systems considered, the monthly capacity factors were estimated to range from $10.6 \%$ to $15.2 \%$. Overall, all systems produce the maximum amount of electricity during March to May as these months have the highest total in-plane insolation. The minimum electricity generating months are November and December as they have the lowest total in-plane insolation of the year.

\subsection{Annual Energy Sensitivity Analysis}

Table 2 shows how the performance ratio and capacity factor may be influenced by the variation in estimated losses of individual factors considered in the model.

Tab. 2: Properties of the photovoltaic system within the considered range of losses

\begin{tabular}{|c|c|c|c|c|}
\hline $\begin{array}{c}\text { Overall Model } \\
\text { Losses }\end{array}$ & $\begin{array}{c}\text { Performance Ratio } \\
(\mathbf{\%})\end{array}$ & $\begin{array}{c}\text { PR - standard PR } \\
(\mathbf{\%})\end{array}$ & $\begin{array}{c}\text { Capacity Factor } \\
(\mathbf{\%})\end{array}$ & $\begin{array}{c}\text { CF }- \text { standard CF } \\
(\mathbf{\%})\end{array}$ \\
\hline Minimum & 80.2 & 10.5 & 14.8 & 1.9 \\
\hline Standard & 69.8 & 0.00 & 12.8 & 0.00 \\
\hline Maximum & 56.6 & -13.2 & 10.4 & -2.4 \\
\hline
\end{tabular}

\section{Economic Analysis}

An accurate valuation of the cost of solar energy generation is required for the development and integration of photovoltaic technologies. The levelized cost of electricity (LCOE) is a standard technique used in energy generation projections and technology assessments (Foster et al., 2014) and is frequently used when comparing electricity generation technologies or considering grid parities for emerging technologies (Hernández-Moro and Martínez-Duart, 2013; Branker et al., 2011; IRENA, 2012). The LCOE is the net present value of the total life 


\section{Nalini Dookie}

cycle cost of the project per quantity of energy produced over the system life (Cambell, 2008).

In this study a constant dollar, no-tax, LCOE (Short et al., 1995) is considered. It is defined by the following equations:

$$
\begin{aligned}
& L C O E=\frac{T L C C}{\sum_{n=1}^{N} \frac{Q n}{(1+d)^{n}}} \\
& T L C C=I+P V O M \\
& P V O M=\sum_{N=1}^{n} \frac{O \& M_{n}}{(1+d)^{n}}
\end{aligned}
$$

where $L C O E$ is the levelized cost of electricity, TLCC is the total life cycle cost, $Q_{n}$ is the energy output or energy saved in year n, $d$ is the discount rate, $N$ is the analysis period, $I$ is the initial investment, PVOM is the present value operating, maintenance and fuel expenses and $O \& M$ is the annual operating, maintenance and fuel expenses.

This model considers the application of no taxes and is applied to non-profit and Government ventures (Short et al., 1995). The model is simplistic given that this is a baseline study. It is widely used as a first order measure to compare power generating technologies (IRENA, 2017). In addition, it is transparent and easy to understand (IRENA, 2017).

Generic cost data (Fu et al., 2017), shown in Table 3, was used to model the total life cycle cost of the photovoltaic systems at different discount rates and lifetime/analysis periods. Good quality photovoltaic modules have a degradation rate of $0.75 \%$ per year (Fu et al., 2017) and as such this study will be done for a 25 -year lifetime with a degradation rate of $0.75 \%$.

Tab. 3: The Input Cost Data (Fu et al., 2017)

\begin{tabular}{|c|c|c|}
\hline Capacity (MW) & $\begin{array}{c}\text { Installed Cost } \\
\text { (USD/ kW) }\end{array}$ & $\begin{array}{c}\text { Operations and Maintenance Cost per Annum } \\
\text { (USD/ kW annum) }\end{array}$ \\
\hline 5 & 1381.52 & 15.40 \\
\hline 10 & 1264.02 & 15.40 \\
\hline 50 & 1119.38 & 15.40 \\
\hline 100 & 1029.21 & 15.40 \\
\hline
\end{tabular}

The LCOE was determined at different discount rates; $3 \%, 4.75 \%, 5 \%, 7 \% 10 \%, 15 \%$. Marzolf et al. (2015) used $4.75 \%$ in that study as given by the Central Bank of Trinidad and Tobago on December 6th, 2012.

IRENA (2015) and IRENA (2017) recommends that a $10 \%$ discount rate be applied to non-OECD countries such as Trinidad and Tobago. Wittenstein and Rothwell (2015) states that a real discount rate of $3 \%$ should be used by government-owned utilities in countries with good bond ratings or ones with stable rate-of-return regulation and fuel price increase allowances while it is recommended that countries with government-owned utilities with poor bond ratings use a higher discount rate. As such, a minimum $3 \%$ discount rate is considered in this analysis. Wittenstein and Rothwell (2015) recommends that a $7 \%$ real discount rate can be considered as the rate available to an investor with a low risk of default in a stable environment or to private investors in a low-risk technological option in a favourable market environment. The $10 \%$ real discount rate is recommended for investments with considerably larger financial, technological and price risks (Wittenstein and Rothwell, 2015). A maximum $15 \%$ discount rate is considered for an extreme case of high technological and price risks.

The variation is the LCOE is shown in Table 4. It was found that the LCOE may range between USD 0.06 to 0.26 depending on the size of the system and the discount rate considered. The LCOE for the standard loss energy model ranged from USD 0.07 to 0.21 . The variation in cost according to system size was small, as all systems showed a minimum LCOE of USD 0.06 to 0.08 (at a $3 \%$ discount rate) and a maximum LCOE of USD 0.20 to 0.26 (at a $15 \%$ discount rate). The LCOE for the minimum loss model and the maximum loss model are $87 \%$ and $123 \%$ compared to the standard model respectively. 
Nalini Dookie

Tab. 4: LCOE of standard model considering the overall modelled losses (maximum, standard and minimum) at different discount rates

\begin{tabular}{|c|c|c|c|c|c|c|c|c|c|c|c|c|}
\hline \multirow{2}{*}{$\begin{array}{l}\text { Discount } \\
\text { Rate (\%) }\end{array}$} & \multicolumn{4}{|c|}{ LCOEMinimum Losses (USD) } & \multicolumn{4}{|c|}{ LCOESTANDARD LOSSES (USD) } & \multicolumn{4}{|c|}{ LCOEMAXimum Losses (USD) } \\
\hline & $\begin{array}{c}5 \\
\text { MW }\end{array}$ & $\begin{array}{c}10 \\
\text { MW }\end{array}$ & $\begin{array}{c}\mathbf{5 0} \\
\text { MW }\end{array}$ & $\begin{array}{l}100 \\
\text { MW }\end{array}$ & $\begin{array}{c}5 \\
\text { MW }\end{array}$ & $\begin{array}{c}10 \\
\text { MW }\end{array}$ & $\begin{array}{c}\mathbf{5 0} \\
\text { MW }\end{array}$ & $\begin{array}{l}100 \\
\text { MW }\end{array}$ & $\begin{array}{c}5 \\
\text { MW }\end{array}$ & $\begin{array}{c}10 \\
\text { MW }\end{array}$ & $\begin{array}{c}\mathbf{5 0} \\
\text { MW }\end{array}$ & $\begin{array}{l}100 \\
\text { MW }\end{array}$ \\
\hline 3 & 0.08 & 0.07 & 0.07 & 0.06 & 0.09 & 0.08 & 0.08 & 0.07 & 0.11 & 0.10 & 0.09 & 0.09 \\
\hline 4.75 & 0.09 & 0.08 & 0.08 & 0.07 & 0.10 & 0.10 & 0.09 & 0.08 & 0.13 & 0.12 & 0.11 & 0.10 \\
\hline 5 & 0.09 & 0.09 & 0.08 & 0.07 & 0.11 & 0.10 & 0.09 & 0.08 & 0.13 & 0.12 & 0.11 & 0.10 \\
\hline 7 & 0.11 & 0.10 & 0.09 & 0.09 & 0.13 & 0.12 & 0.11 & 0.10 & 0.16 & 0.14 & 0.13 & 0.12 \\
\hline 10 & 0.14 & 0.13 & 0.11 & 0.11 & 0.16 & 0.15 & 0.13 & 0.12 & 0.19 & 0.18 & 0.16 & 0.15 \\
\hline 15 & 0.19 & 0.17 & 0.15 & 0.14 & 0.21 & 0.20 & 0.18 & 0.16 & 0.26 & 0.24 & 0.22 & 0.20 \\
\hline
\end{tabular}

\section{Discussion}

Utility sized PV systems were modelled for one site in Trinidad and Tobago using system losses and existing onsite global solar radiation data collected in 2003. Annual performance ratios were found to range between $56.6 \%$ for minimal losses and $80.2 \%$ for maximum losses and a performance ratio of $69.8 \%$ for standard losses. Only one previous study, Marzolf et al. (2015), assumed a performance ratio for a photovoltaic system in Trinidad and Tobago to be $81.5 \%$. They assumed that typical systems have performance ratios between 80 and $90 \%$. This value is larger than the $69.8 \%$ performance ratio found in this study by using standard losses. The estimated performance ratio of $69.8 \%$ is within the typical range of performance ratios of photovoltaic systems, $60 \%$ to 90 $\%$, as assessed by NREL (Dierauf et al., 2013). The average performance ratio found is smaller than those found for operating PV systems in various countries such as Malaysia (70.88 \% and $77.28 \%$ ) (Humada et al., 2017; Farhoodnea et al., 2015), India (85 \% - 86.12 \%) (Vasisht et al., 2016; Kumar and Sudhakar, 2013) and South Africa (84\%) (Okello et al., 2015).

The standard loss model leads to LCOEs in the range US $\$ 0.08$ - US $\$ 0.10$ per $\mathrm{kWh}$ at $4.75 \%$ discount rate. Marzolf et al. (2015) used the same discount rate and estimated LCOEs to be US $\$ 0.14-$ US $\$ 0.29$ per $\mathrm{kWh}$. The lower LCOEs of this study may be attributed to the global reduction in capital costs of solar PV plants. Marzolf et al. (2015) had used costs in 2012 while we used 2017 costs in this study.

Lower discount rates could make solar PV plants in Trinidad and Tobago competitive with current electricity tariffs. At $3 \%$ discount rate and maximum losses, LCOEs range from US $\$ 0.06$ - US $\$ 0.11$ per $\mathrm{kWh}$. The upper end of the range is approximately twice the subsidized electricity tariff in Trinidad and Tobago (US\$0.040 US\$0.054 per kWh) (T\&TEC, 2018; Central Bank of Trinidad and Tobago, 2018). Given the economic climate in Trinidad and Tobago, it is expected that electricity rates are due for an increase. This could make solar PV comparable with new electricity tariffs. LCOEs of US $\$ 0.11$ per $\mathrm{kWh}$ for solar PV in Trinidad is also less than the residential electricity tariffs in other Caribbean islands who import most of their energy and contain a renewable energy component. Jamaica, Barbados and St Kitts and Nevis had residential electricity rates of US\$0.32, $\$ 0.28$ and $\$ 0.23$ to $\$ 0.26$ respectively in 2013 (US Department of Energy, 2017).

Based on the analyses of this study, we find that solar PV in Trinidad could be cost competitive for electricity generation under low discount rates. This pre-feasibility analysis provides a foundation for proceeding with more detailed solar PV analyses in Trinidad and Tobago via assessing actual PV system performance and validating the estimated LCOEs. 


\section{References}

\section{Nalini Dookie}

Ahmad, S., Kahir, M., and Shafie, S. 2011. Current perspective of the renewable energy development in Malaysia. Renewable and Sustainable Energy Reviews. 15, 897- 904. doi: 10.1016/j.rser.2010.11.009

Ariza Taba, M. F., Mwanza, M., Çetin N. S. and Ülgen, K. 2016. Assessment of the energy generation potential of photovoltaic systems in Caribbean region of Colombia. 3rd International Symposium on Environment and Morality (ISEM2016), 791-802. doi: 10.21533/pen.v5i1.76

Branker, K., Pathak, M.J.M. and Pearce, J.M. 2011. A review of solar photovoltaic levelized cost of electricity. Renewable and Sustainable Energy Reviews. 15 (9), 4470-4482. doi: https://doi.org/10.1016/j.rser.2011.07.104.

Buchla, David, Thomas Kissell and Thomas Floyd. 2015. "Renewable Energy Systems. United States of America: Pearson.

Cambell, M. 2008. The Drivers of the Levelized Cost of Electricity for Utility-Scale Photovoltaics. In, ed SunPower. https://us.sunpower.com/sites/sunpower/files/media-library/white-papers/wp-levelized-cost-driverselectricity-utility-scale-photovoltaics.pdf. Accessed September 20, 2016.

Central Bank of Trinidad and Tobago. 2018. Exchange Rates. https://www.central-bank.org.tt/. Accessed May 3, 2018.

Chadee, Xsitaaz. 2015. Mapping the wind resources of Trinidad and Tobago. PhD thesis. The University of the West Indies, St. Augustine, Trinidad and Tobago.

Chegaar, M. and Mialhe, P. 2008. Effect of atmospheric parameters on the silicon solar cells performance. Journal of Electron Devices, 173-176. http://citeseerx.ist.psu.edu/viewdoc/download?doi=10.1.1.665.2318\&rep=rep1\&type=pdf. Accessed January 20, 2018.

De Souza, K. 2018. Temperature-based model for monthly average hourly global solar radiation for the Caribbean island of Trinidad. Journal of Renewable and Sustainable Energy 10. doi: https://doi.org/10.1063/1.5000817.

De Souza, K., and R. Andrews. 2015. Models for daily global solar radiation for the Caribbean island of Trinidad, Journal of Renewable and Sustainable Energy. doi: https://doi.org/10.1063/1.4909539.

Dierauf, T, Growitz, A., Kurtz, S., Cruz, J. L. B., Riley E. and Hansen, C. 2013. Weather-Corrected Performance Ratio. http://www.nrel.gov/docs/fy13osti/57991.pdf. Accessed on August 8, 2017.

Duffie, J. A., and Beckman, W. A. 2006. Solar engineering of thermal processes. New Jersey: John Wiley \& Sons.

Farhoodnea, M., Mohamed, A., Khatib, T. and Wilfried Elmenreich. 2015. Performance evaluation and characterization of a 3-kWp grid-connected photovoltaic system based on tropical field experimental results: new results and comparative study."Renewable and Sustainable Energy Reviews. 42, 1047-1054. doi: https://doi.org/10.1016/j.rser.2014.10.090.

Field, D., T. Rogers and A. Sealy. 2015. The effect of Saharan dust on PV system yields in the tropical environment of Barbados. IEEE 42nd Photovoltaic Specialist Conference (PVSC). 1-4. doi: 10.1109/PVSC.2015.7355980

Foster, J, Wanger, L. and Bratanova A. 2014. LCOE models: A comparision of the theoretical frameworks and key assumptions. In: The Commonwealth Scientific and Industrial Research Organisation http://eemg.uq.edu.au/filething/get/137/2014-4.pdf. Accessed September 20, 2016.

Fu, R., Feldman, D., Margolis, R., Woodhouse, M. and Ardani K. 2017. U.S. Solar Photovoltaic System Cost Benchmark: Q1 2017. https://www.nrel.gov/docs/fy17osti/68925.pdf. Accessed March 26, 2018.

Government of the Republic of Trinidad and Tobago. 2016. Budget Statement 2017. http://www.finance.gov.tt/wp-content/uploads/2016/09/Budget-Statement-2017-for-web.pdf. Accessed July 19, 2018)

Gov.tt. General Information. Government of the Republic of Trinidad and Tobago. https://www.ttconnect.gov.tt/gortt/portal/ttconnect/!ut/p/a1/jdBNC4JAEAbgX- 
Nalini Dookie

PVGRUju3kwU4PQqHQvobCtxrYrumk_P_Mm9jW3GZ4XXgYIpEBE31UsV5UUOX_tZHGOYhPtwLFwF6O DZhIYHtqR5SfGALIJSPz1ADzb2ERHCxH_y-

OHcX_m91TACchXFuIMzGuO4EuPEAjjshh_krmisJYMSEMvtKGNfm-

Gc6lU3a401LDve51JyTjVldLwXaKUrYJ0AqG-

HdJHcLV5t3WfKioerw!!/d15/d5/L2dBISEvZ0FBIS9nQSEh/?WCM_GLOBAL_CONTEXT=/gortt/wcm/conne $\mathrm{ct} /$ GorTT\%20Web\%20Content/ttconnect/home/about+t+and+t/general+information/geography. Accessed April 27th 2017.

Hernández-Moro, J., Martínez-Duart, J.M. 2013. Analytical model for solar PV and CSP electricity costs: Present LCOE values and their future evolution. Renewable and Sustainable Energy Reviews. 20, 119-132. doi: https://doi.org/10.1016/j.rser.2012.11.082.

Huld, T. and Gracia Amillo A.M. 2015. Estimating PV Module Performance over Large Geographical Regions: The Role of Irradiance, Air Temperature, Wind Speed and Solar Spectrum. Energies. : 5159-5181. doi:10.3390/en8065159

Humada, A. M., Aaref, A. M., Hamada, H. M., Sulaiman, M. H., Amin, N., \& Mekhilef, S. 2017. Modeling and characterization of a grid-connected photovoltaic system under tropical climate conditions. Renewable and Sustainable Energy Reviews. DOI: 10.1016/j.rser.2017.08.053

International Finance Corporation. 2015. Utility-Scale Solar Photovoltaic Power Plants. https://www.ifc.org/wps/wcm/connect/f05d3e00498e0841bb6fbbe54d141794/IFC+Solar+Report_Web+_08+05 .pdf?MOD=AJPERES. Accessed April 24, 2017.

International Finance Corporation World Bank Group. 2012. Utility Scale Solar Power Plants. https://www.ifc.org/wps/wcm/connect/04b38b804a178f13b377ffdd29332b51/SOLAR\%2BGUIDE\%2BBOOK. pdf?MOD=AJPERES. Accessed January 24, 2017.

International Renewable Energy Agency (IRENA). 2017. Renewable Power Generation Costs in 2017. https://www.irena.org/-

/media/Files/IRENA/Agency/Publication/2018/Jan/IRENA_2017_Power_Costs_2018.pdf. Accessed August 8th 2018.

International Renewable Energy Agency (IRENA). 2015. Renewable Power Generation Costs in 2014. https://www.irena.org/documentdownloads/publications/irena_re_power_costs_2014_report.pdf. Accessed April 24, 2017.

International Renewable Energy Agency (IRENA). 2012. Renewable Energy Technologies: Cost Series Analysis. In Solar Photovoltaics. https://www.irena.org/DocumentDownloads/Publications/RE_Technologies_Cost_Analysis-SOLAR_PV.pdf. Accessed October 10, 2016

Khalid, A.M., Mitra, I., Warmuth, W. and Schacht V. 2016. Performance ratio- Crucial parameter for grid connected PV plants. Renewable and Sustainable Energy Reviews. 65, 1139-1158. doi: http://dx.doi.org/10.1016/j.rser.2016.07.066

Kimber, A, L. Mitchell, S. Nogradi and H. Wenger. 2006. The Effect of Soiling on Large Grid-Connected Photovoltaic Systems in California and the Southwest Region of the United States. IEEEXplore. 2391-2395.. http://ieeexplore.ieee.org/stamp/stamp.jsp?arnumber=4060159. Accessed on August 8, 2017

Kumar, S. B., and Sudhakar, K. 2015. Performance evaluation of 10 MW grid connected solar photovoltaic power plant in India. Energy Reports. 184-192. https://doi.org/10.1016/j.egyr.2015.10.001. Accessed August 8, 2017.

Kymakis, E, Kalykakis S. and Papazoglou T. M.. 2009. Performance analysis of a grid connected photovoltaic park on the island of Crete. Energy Conversion and Management. 433-438. doi: 10.1016/j.enconman.2008.12.009

Makrides, G., Zinsser, B., Norton, M., Georghiou, G.E., Schubert, M., Werner, J.H. 2010. Potential of photovoltaic systems in countries with high solar radiation. Renewable Sustainable Energy Reviews. 14, 754-762. doi: https://doi.org/10.1016/j.rser.2009.07.021.

Martín, N. and J. M. Ruiz. 2005. Annual angular reflection losses in PV modules. Progress in Photovoltaics.: 75- 
84. doi:10.1002/pip.585

\section{Nalini Dookie}

Marzolf, N. C., Cañeque F. C., Klein, J. and Loy, D. 2015. A Unique Approach for Sustainable Energy in Trinidad and Tobago. In. 1300 New York Avenue, N.W. Washington, D.C. 20577: Inter-American Development Bank. http://www.energy.gov.tt/wp-content/uploads/2016/08/A-Unique-Approach-for-Sustainable-Energy-inTrinidad-and-Tobago.pdf. Accessed August 23, 2016.

Ministry of Energy and Energy Industries. 2017. Our Business. http://www.energy.gov.tt/ourbusiness/alternative-energy/inter-american-development-bank-idb-sustainable-energy-program/. Accessed September 21, 2017.

Mohamed, A. O., and Hasan, A. 2012. Effect of Dust Accumulation on Performance of Photovoltaic Solar Modules in Sahara Environment. Journal of Basic and Applied Scientific Research. :11030-11036. http://rollingwash.net/docs/Effect\%20of\%20Dust\%20Accumulation\%20on\%20PV\%20Solar\%20Modules\%20in \%20Sahara\%20Environment.pdf. Accessed on August 8, 2017.

Okello, D., van Dyk, E.E. and F.J. Vorster. 2015. Analysis of measured and simulated performance data of a 3.2 kWp grid-connected PV system in Port Elizabeth, South Africa. Energy Conversion and Management. 100, 1015. doi: https://doi.org/10.1016/j.enconman.2015.04.064

Parretta, A, Sarno A. and Vicari, L. R. M. 1998. Effects of solar irradiation conditions on the outdoor performance of photovoltaic modules. Optics Communications. 153-163. doi: 10.1016/S0030-4018(98)00192-8

Rehman, S, Bader, M. and Al-Moallem, S. A. 2007. Cost of solar energy generated using PV panels. Renewable and Sustainable Energy Reviews.:1843-1857. doi:10.1016/j.rser.2006.03.005.

Sathyanarayana, P., Ballal, R., Sagar P. S. L. and Kumar, G. 2015. Effect of Shading on the Performance of Solar PV Panel. Energy and Power. 1-4. doi: 10.5923/c.ep.2015

Short, W., Packey D. and Holt, T. 1995. A Manual for the Economic Evaluation of Energy Efficiency and Renewable Energy Technologies. National Renewable Energy Laboratory. http://www.nrel.gov/docs/legosti/old/5173.pdf. Accessed April 24, 2017.

Shukla, A.K., Sudhakar, K. and Baredar, P. 2016. Design, simulation and economic analysis of standalone roof top solar PV system in India. Solar Energy. 136, 437-449. https://doi.org/10.1016/j.solener.2016.07.009.

Skoplaki, E. and Palyvos, J. 2009. On the temperature dependence of photovoltaic module electrical performance: A review of efficiency/power correlations. Solar Energy. 614-624. doi:10.1016/j.solener.2008.10.008

Smets, A., Jäger, K., Isabella, O., Van Swaaij, R. and Zeman, M. Solar energy: the physics and engineering of photovoltaic conversion, technologies and systems. Cambridge, England: UIT Cambridge, 2016.

Smith, G. W. 1960. Solar radiation and the duration of sunshine in Trinidad. West Indies. Q.J.R. Meteorol. Soc., 86, 415-415. doi:10.1002/qj.49708636916

Solargis. 2016. Solargis pvPlanner. https://solargis2-web-assets.s3.eu-west1.amazonaws.com/public/doc/c4b3fa896f/Solargis-pvPlanner-Manual-2016-12-14.pdf. Accessed January 30, 2017.

Stone. R.J. 1999. A New Sunshine-based Global Solar Radiation Estimation Model for Trinidad. West Indian Journal of Engineering. 22, $42-48$.

Trinidad and Tobago Electricity Commission (T\&TEC). 2018. "Summary of Electricity Rates." https://ttec.co.tt/default/tariffs-2. Accessed May 3, 2018.

Trinidad and Tobago Meteorological Office. 2017. https://www.metoffice.gov.tt/Climate. Accessed August 8, 2017.

US Department of Energy. 2017. Island Energy Snapshots. https://energy.gov/eere/island-energy-snapshots. Accessed September 16, 2017.

Vasisht, M. Srinivasan, S. J. and Ramasesha. S. K. 2016. Performance of solar photovoltaic installations: Effect of seasonal variations. Solar Energy. 39-46. doi:10.1016/j.solener.2016.02.013 
N. Dookie et. al. / EuroSun 2018 / ISES Conference Proceedings (2018)

Nalini Dookie

Wittenstein, M and Rothwell G. 2015. Projected Costs of Generating Electricity. https://www.oecdnea.org/ndd/pubs/2015/7057-proj-costs-electricity-2015.pdf. Accessed August 20, 2017.

The World Meteorological Organization (WMO). 1987. Guidelines on the quality control of data from the world radiometric network. https://library.wmo.int/pmb_ged/wmo-td_258_en.pdf. Accessed July 6, 2017. 


\title{
Accuracy of Solar Resource Assessments on the Basis of Publicly Available GHI Databases
}

\author{
Matthias Egler \\ e $4 r$ - engineers for renewables $\mathrm{GmbH}$, Berlin (Germany)
}

\begin{abstract}
The "true" long-term Global Horizontal Irradiation (GHI) for a given location is normally unknown. Thus, the selection of the most appropriate, publicly or commercially available dataset or the application of a corresponding data handling approach is a key challenge and task when assessing the site-specific GHI solar resource.

Based on reference data obtained from Baseline Surface Radiation Network (BSRN) as well as the German and Dutch national weather services, a database and approach benchmarking including 63 locations in Europe mainly Germany and the Netherlands - and 1 location in North Africa has been conducted.

For publicly available databases and various arithmetic means, a typical relative Root Mean Square Error (RMSE) of the long-term annual GHI of $\pm 1.8 \%$ to $\pm 7.2 \%$ has been found. Regarding inter-annual variability, the corresponding range is $\pm 0.4 \%$ to $\pm 4.0 \%$. In both cases, the arithmetic means typically achieve smaller relative RMSE, thus suggesting a greater reliability for Solar Resource Assessment purposes.
\end{abstract}

Keywords: Solar Resource Assessment, Global Horizontal Irradiation, Photovoltaic

\section{Introduction}

Accurate Solar Resource Assessments are essential for the success of both a single solar photovoltaic (PV) project and the energy transition towards renewable energies in general. For PV applications, the most important energy meteorological parameter is the Global Horizontal Irradiation (GHI).

There are several databases available that provide site-specific GHI from either ground observations and/or satellite information. The long-term average values obtained from these sources typically differ by a few percent. In addition, spatially-distributed, high-quality and high-accuracy long-term measurements are sparse, i.e. the "true" value of the GHI solar resource is normally unknown. The selection or application of the most appropriate dataset or approach is therefore one of the most important challenges and tasks when assessing the site specific solar resource.

A method that combines various datasets for site-specific GHI solar resource assessment was first published by Pagola et al. (2010). It includes database-related weights that account for the number of years of data, the quality of the information and the spatial resolution. Validation of the approach at five Spanish locations showed that the included five different databases individually exhibited a worse performance than the values obtained by the new methodology. The annual value bias of the combined datasets ranged from $0.42 \%$ to $3.16 \%$, which results in an overall relative RMSE of $\pm 1.7 \%$.

Similarly, in a global benchmarking effort that compared single database information as well as weighted means against 38 high-quality GHI reference datasets, Egler et al. (2017) found smaller overall relative RMSE for the combined datasets as well. The database-related weights utilized in this study were limited to the technical features, i.e. number of years of data and spatial resolution. Globally, the relative RMSE of the annual values for the weighted mean method was $\pm 2.2 \%$, while the seven different, single databases achieved between $\pm 2.6 \%$ and $\pm 5.3 \%$. Overall, it was concluded that combining different datasets for GHI solar resource assessment results in a more stable accuracy.

Comparably, for solar power forecasting it has been found that combination of discrete forecasts reduces the 
forecasting error. For day-ahead purposes, this has been shown, for example, by Bührer et al. (2018).

For PV Solar Resource Assessment, adequate averaging period is of relevance. Müller et al. (2014) concluded that applying the average of the last 10 years of historic data best meets the criteria of being an expedient predictor for the next 20 years. Accordingly, the commonly available recent period of 2007-2016 has been selected in the present benchmarking of various, publicly accessible GHI databases. In addition, arithmetic means, formed by the different datasets, have been included in the evaluation as well. The study area of the benchmarking is Europe and North Africa, with a reference data focus on Germany and the Netherlands. The aim of this work is to determine the accuracy of each single database and potential arithmetic means and to provide recommendations for accurate PV Solar Resource Assessments.

\section{Database and approach benchmarking}

\subsection{Reference data and locations}

Baseline Surface Radiation Network (BSRN) data are an ideal reference for GHI benchmarking, since its objective is to provide the best possible quality of solar irradiation data. However, for the considered study area and period, measurements of only eight BSRN locations are available. Therefore, datasets considered reliable - mainly, that is records being made utilizing Secondary Standard pyranometer - and obtained from the German and Dutch national weather services, Deutscher Wetterdienst (DWD) and Koninklijk Nederlands Meteorologisch Instituut (KNMI), at 24 locations in Germany and 32 in the Netherlands, have been included in the reference database as well. The data retrieval via the URLs presented in Tab. 1 mainly took place in June 2017 and August 2017.

Fig. 1 gives a geographical overview of the reference locations included in this study.

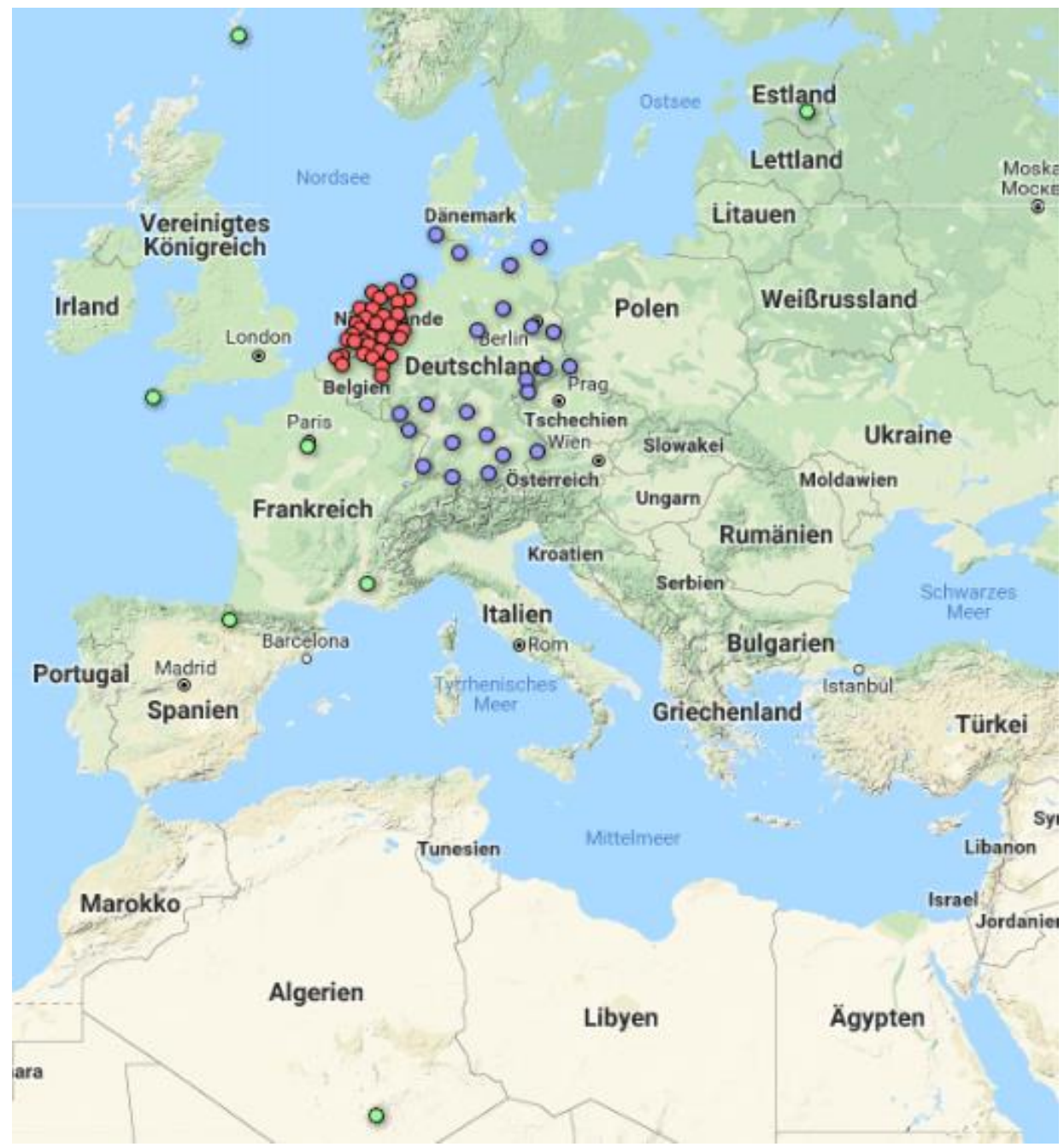

Fig. 1: Map of reference locations with BSRN sites indicated by green, DWD by blue and KNMI by red dots. 
Tab. 1: BSRN, DWD and KNMI reference data URLs

\begin{tabular}{|l|l|}
\hline Network / Weather service & URL \\
\hline BSRN & https://dataportals.pangaea.de/bsrn/?q=LR0100 \\
\hline DWD & ftp://ftp-cdc.dwd.de/pub/CDC/observations_germany/climate/hourly/solar/ \\
\hline KNMI & http://projects.knmi.nl/klimatologie/uurgegevens/selectie.cgi \\
\hline
\end{tabular}

Reference data density is greatest for Dutch territory, with approximately one reference site per $1,300 \mathrm{~km}^{2}$. For Germany, the corresponding value is about $14,300 \mathrm{~km}^{2}$.

The reference data are available in $1 \mathrm{~min}$ - BSRN - and hourly - DWD and KNMI - resolution. For the preparation of the long-term monthly and annual averages, each dataset is reviewed, and monthly daytime data availability calculated. Months featuring less than $95 \%$ availability are excluded and all remaining are corrected for missing information. Correction is made on the assumption that the maximum $5 \%$ lacking feature the same GHI per percent as the available data. This means the GHI sum of the corrected months include a fraction that is based on an extrapolation using the recorded GHI sum multiplied with the missing percent. Based on the reviewed dataset, long-term averages are calculated afterwards. Following this process, about half of the reference locations provide a complete dataset for the examined averaging period. For the remainder, the resulting data availability is displayed in Tab. 2 .

Tab. 2: Reference locations featuring less than $100 \%$ data availability in 2007-2016 period

\begin{tabular}{|c|c|c|c|}
\hline Location name & Country & Database & Data Availability \\
\hline Carpentras & FR & BSRN & $81.7 \%$ \\
\hline Palaiseau & FR & BSRN & $87.5 \%$ \\
\hline Tamanrasset & DZ & BSRN & $98.3 \%$ \\
\hline Cabauw & NL & BSRN & $93.3 \%$ \\
\hline Toravere & $\mathrm{EE}$ & BSRN & $97.5 \%$ \\
\hline Camborne & GB & BSRN & $86.7 \%$ \\
\hline Cener & ES & BSRN & $73.3 \%$ \\
\hline Lerwick & GB & BSRN & $76.7 \%$ \\
\hline Arkona & $\mathrm{DE}$ & DWD & $88.3 \%$ \\
\hline Braunschweig & $\mathrm{DE}$ & DWD & $98.3 \%$ \\
\hline Dresden-Klotzsche & $\mathrm{DE}$ & DWD & $96.7 \%$ \\
\hline Fichtelberg & $\mathrm{DE}$ & DWD & $96.7 \%$ \\
\hline Freiburg & $\mathrm{DE}$ & DWD & $57.5 \%$ \\
\hline Geisenheim & $\mathrm{DE}$ & DWD & $60.0 \%$ \\
\hline Görlitz & $\mathrm{DE}$ & DWD & $96.7 \%$ \\
\hline Hohenpeißenberg & $\mathrm{DE}$ & DWD & $88.3 \%$ \\
\hline List auf Sylt & $\mathrm{DE}$ & DWD & $76.7 \%$ \\
\hline Norderney & $\mathrm{DE}$ & DWD & $97.5 \%$ \\
\hline Potsdam & $\mathrm{DE}$ & DWD & $99.2 \%$ \\
\hline Rostock-Warnemünde & $\mathrm{DE}$ & DWD & $98.3 \%$ \\
\hline Saarbrücken-Ensheim & $\mathrm{DE}$ & DWD & $99.2 \%$ \\
\hline Schleswig & $\mathrm{DE}$ & DWD & $99.2 \%$ \\
\hline Stuttgart (Schnarrenberg) & $\mathrm{DE}$ & DWD & $96.7 \%$ \\
\hline Trier-Petrisberg & $\mathrm{DE}$ & DWD & $87.5 \%$ \\
\hline Weihenstephan-Dürnast & $\mathrm{DE}$ & DWD & $80.0 \%$ \\
\hline Weißenburg-Emetzheim & $\mathrm{DE}$ & DWD & $75.8 \%$ \\
\hline Würzburg & $\mathrm{DE}$ & DWD & $98.3 \%$ \\
\hline Fürstenzell & $\mathrm{DE}$ & DWD & $98.3 \%$ \\
\hline Valkenburg & NL & KNMI & $94.2 \%$ \\
\hline Wilhelminadorp & NL & KNMI & $70.0 \%$ \\
\hline
\end{tabular}


To account for the data unavailability at these reference locations, the benchmarking is performed in a like-to-like way, i.e. only data points available in both the reference dataset and the databases are included.

A simple way to assess the quality or consistency of the DWD and KNMI reference datasets is cross-comparison. For this, the GHI of each reference location is estimated using the data of the surrounding reference locations, with the site of interest being excluded from the estimation but used as reference. By applying the 3-D inverse distance model introduced by Zelenka et al. (1992), with the additions of Lefèvre and Wald (2001), a relative RMSE for the long-term annual values of $\pm 2.7 \%$ for the German reference locations and $\pm 2.2 \%$ for the Dutch reference locations has been determined. According to Lorenz (2009) the BSRN target accuracy for GHI ground measurements is $\pm 2 \%$, which means that the DWD and KNMI information can be considered as of comparable quality.

\subsection{Databases and means}

The databases considered in the benchmarking are all publicly available and provide data for the considered reference period as well as for all but two locations of the study area - PVGIS-CMSAF information for Toravere / EE and Lerwick / UK are unavailable.

Site-specific GHI data have been retrieved from PVGIS-CMSAF, PVGIS-SARAH, CAMS-RAD and NASA POWER via the URLs presented in Tab. 3. Data was mainly accessed between July and September 2017 as well as February 2018.

Tab. 3: URLs of the databases included in the work

\begin{tabular}{|l|l|}
\hline Database & URL \\
\hline PVGIS-CMSAF/-SARAH & http://re.jrc.ec.europa.eu/pvg_tools/en/tools.html\#MR \\
\hline CAMS-RAD & http://www.soda-pro.com/en_GB/web-services/radiation/cams-radiation-service \\
\hline NASA POWER & https://power.larc.nasa.gov/data-access-viewer/ \\
\hline
\end{tabular}

The arithmetic means included in the benchmarking are labelled as follows: Mean-PVGIS, formed by both PVGIS databases; Mean-HighRe, formed by the high-resolution databases of PVGIS-CMSAF, PVGIS-SARAH and CAMS-RAD; Mean-All, which includes all databases; and Mean-All-2, which is a combination of PVGISSARAH, CAMS-RAD and NASA POWER.

In case of GHI benchmarking, first monthly average values are calculated using the corresponding long-term data provided by each database, before the annual sum of the respective arithmetic mean is determined. For interannual variability, the arithmetic mean values correspond to the average of the included database information.

\subsection{Accuracy metrics and benchmarking}

The site-specific monthly and annual long-term averages and inter-annual variabilities of each database and arithmetic mean are compared against the corresponding reference data. The comparison is made in a like-to-like way, i.e. only data points available in both reference and the databases are included in each respective long-term value or year-on-year variability figure. Finally, depending on the investigated parameter, various common accuracy metrics are calculated, with relative Root Mean Square Error (RMSE) being considered the most important in the context of the study.

Relative monthly and annual deviations (dev) between the database or arithmetic mean values and the reference information at each reference location (r) are determined. Subsequently resulting relative RMSE, relative Mean Bias Error (MBE) and relative Mean Absolute Error (MAE) over the full number of reference locations (N) are calculated as follows:

$$
\begin{aligned}
& R M S E=\sqrt{\frac{1}{N}} \sum_{r=1}^{N} d e v_{r}^{2} \\
& M B E=\sum_{r=1}^{N} d e v_{r} \\
& M A E=\sum_{r=1}^{N}\left|d e v_{r}\right|
\end{aligned}
$$




\section{Results}

\subsection{Long-term annual GHI}

For the different databases and arithmetic means, the relative RMSE differentiated by reference sub-dataset, i.e. for BSRN, DWD and KNMI reference locations separately, is presented in Fig. 2.
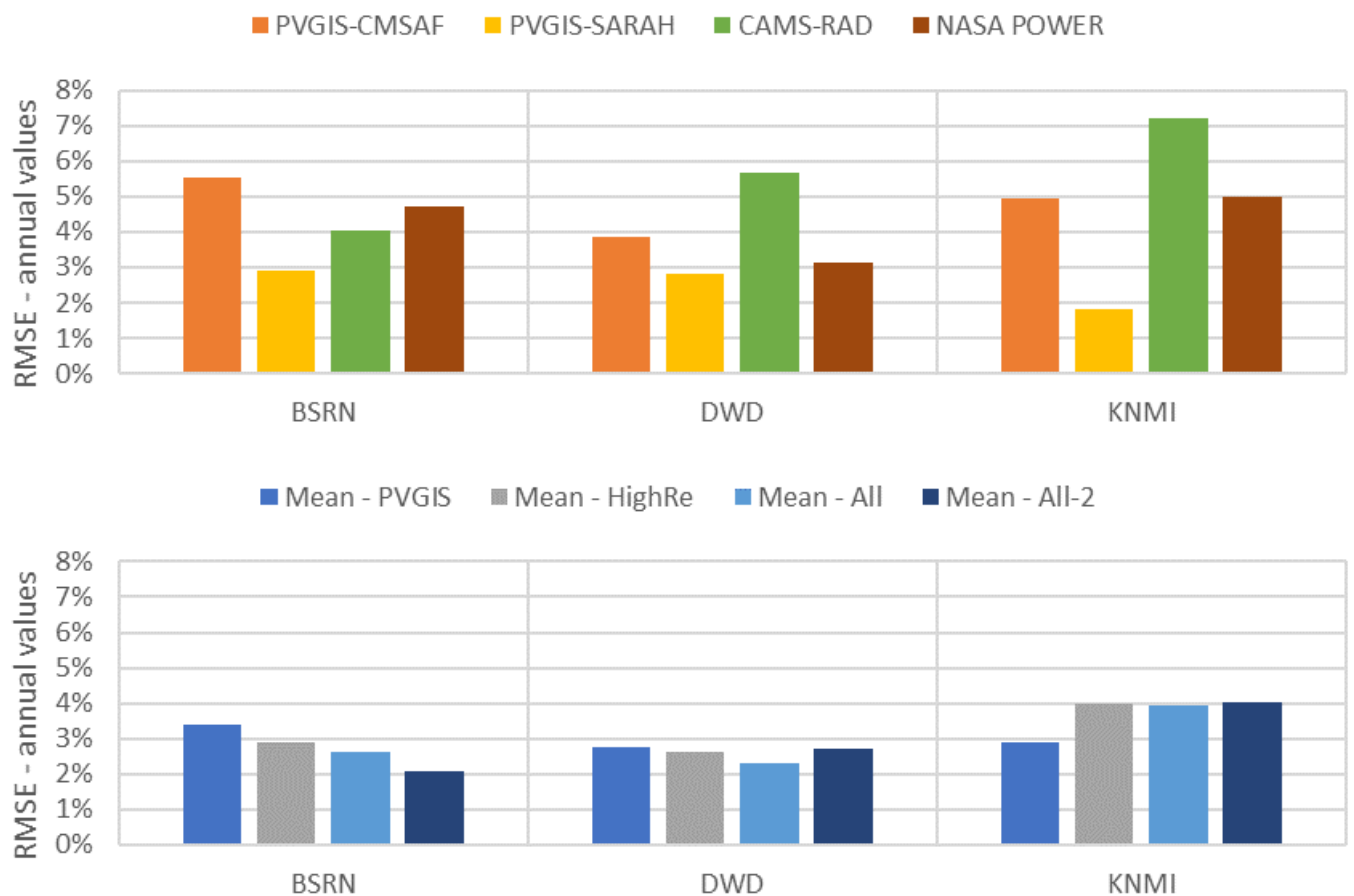

Fig. 2: Relative RMSE of annual values of different databases and arithmetic means as a function of reference sub-dataset

The range of relative RMSE of the publicly accessible databases is $\pm 1.8 \%$ to $\pm 7.2 \%$, and the corresponding values of the arithmetic means are $\pm 2.1 \%$ to $\pm 4.0 \%$.

Fig. 3 provides the long-term annual relative MBE results over each reference sub-dataset.

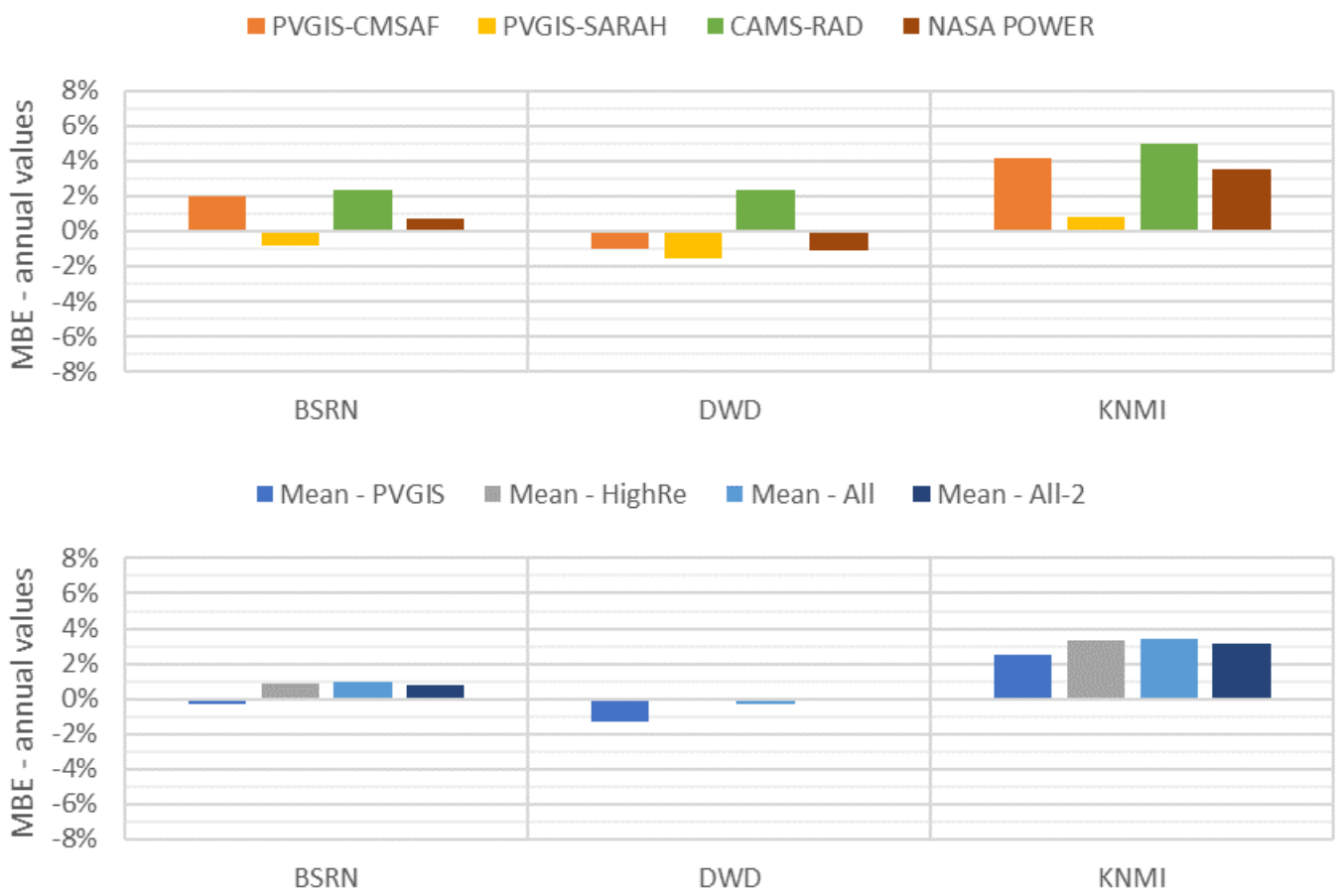

Fig. 3: Relative MBE of annual values of different databases and arithmetic means as a function of reference sub-dataset 
The publicly available databases exhibit a relative MBE range of $-1.6 \%$ to $+5.0 \%$, the arithmetic means of $-1.3 \%$ to $3.4 \%$. Of note, while for BSRN and DWD both negative and positive numbers occur, this is not the case when looking at KNMI reference sub-dataset. For KNMI, only positive relative MBE are determined.

Overall, both accuracy metric results indicate that typically arithmetic means show less deviation and thus provide more reliable, site-specific GHI estimates than selecting a single database. The scatter plots presented in Fig. 4 further visualize this finding by showing the respective MAE determined for each individual reference location.
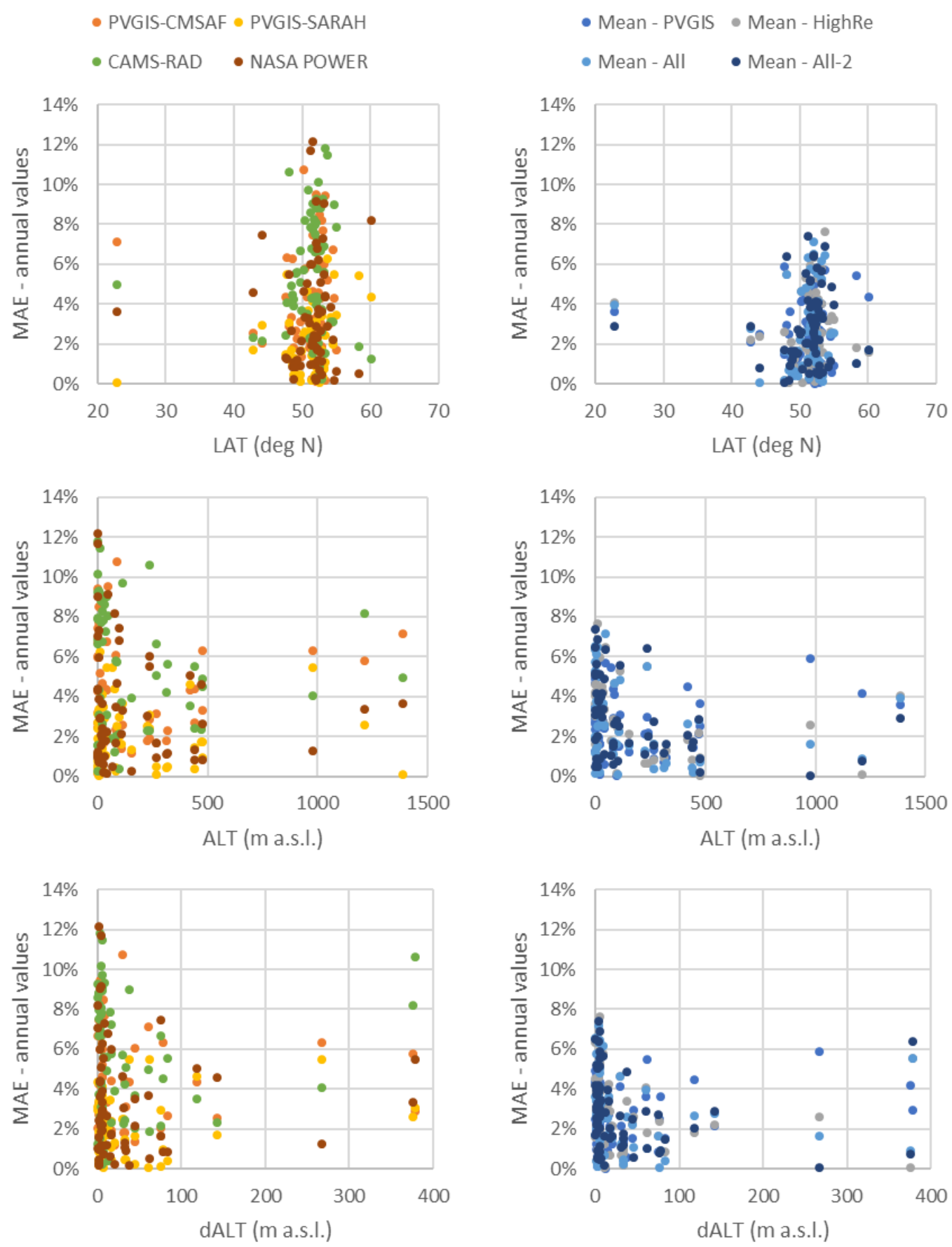

Fig. 4: Scatter plots of relative MAE of annual values for each database and arithmetic mean

In addition to this general observation, the most stable performance over the DWD, KNMI and BSRN reference sub-dataset has been found for PVGIS-SARAH database.

Fig. 5 and Fig. 6 show the resulting relative RMSE and relative MBE numbers when sorting the reference locations by geographic characteristics. There, location class Coastal / Island includes locations on small islands and less 
than approximately $20 \mathrm{~km}$ from the sea, while Flat, Hilly and Mountainous is differentiated by altitude variability of the spatial resolved information - less than $30 \mathrm{~m}$, between $30 \mathrm{~m}$ to $100 \mathrm{~m}$ and more than $100 \mathrm{~m}-$ of the surrounding terrain, as provided by SoDa's "altitude of a point" service (http://www.soda-pro.com/en_GB/webservices/altitude/altitude-of-a-point).

- PVGIS-CMSAF IPVGIS-SARAH —CAMS-RAD —NASA POWER
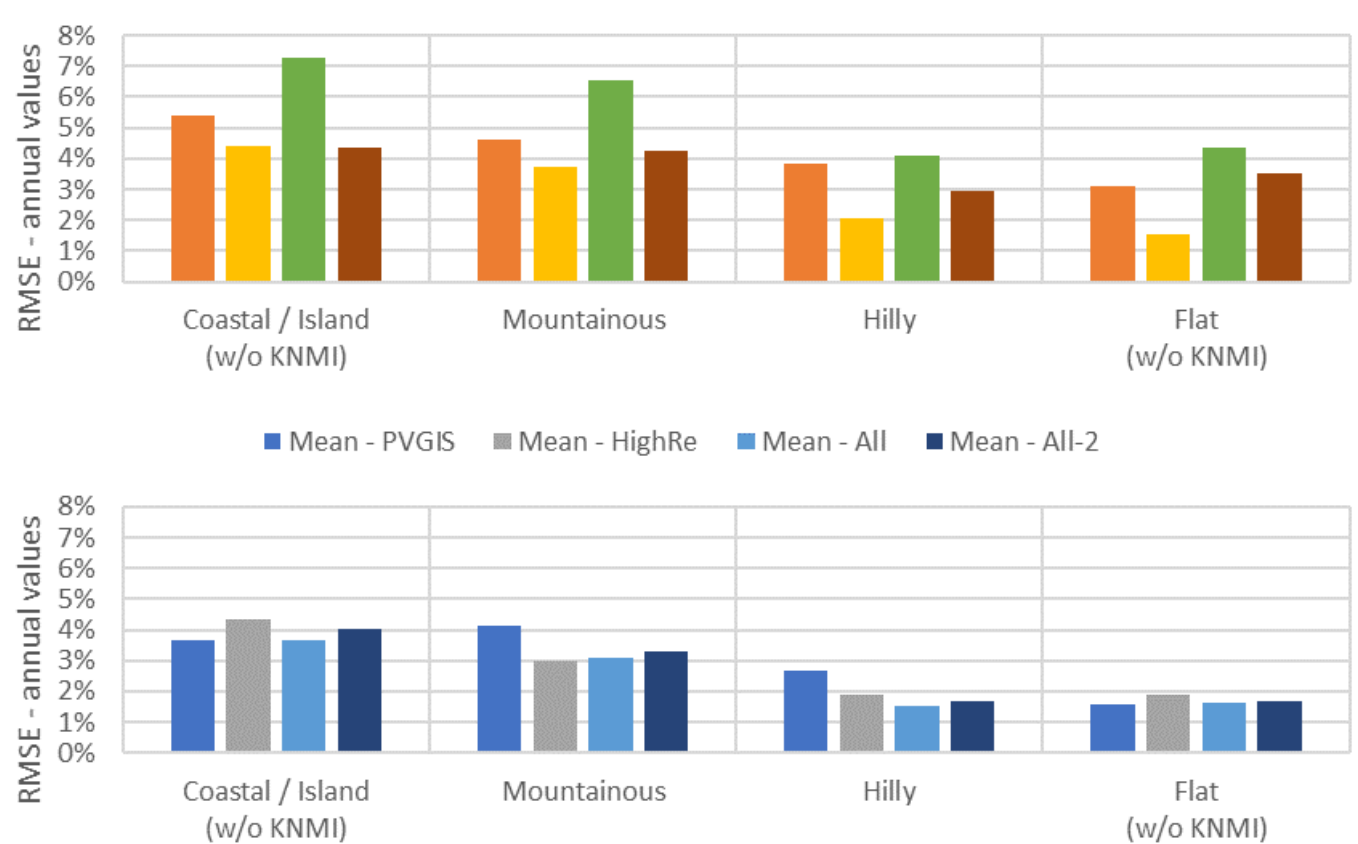

Fig. 5: Relative RMSE of annual values of different databases and arithmetic means as a function of location class
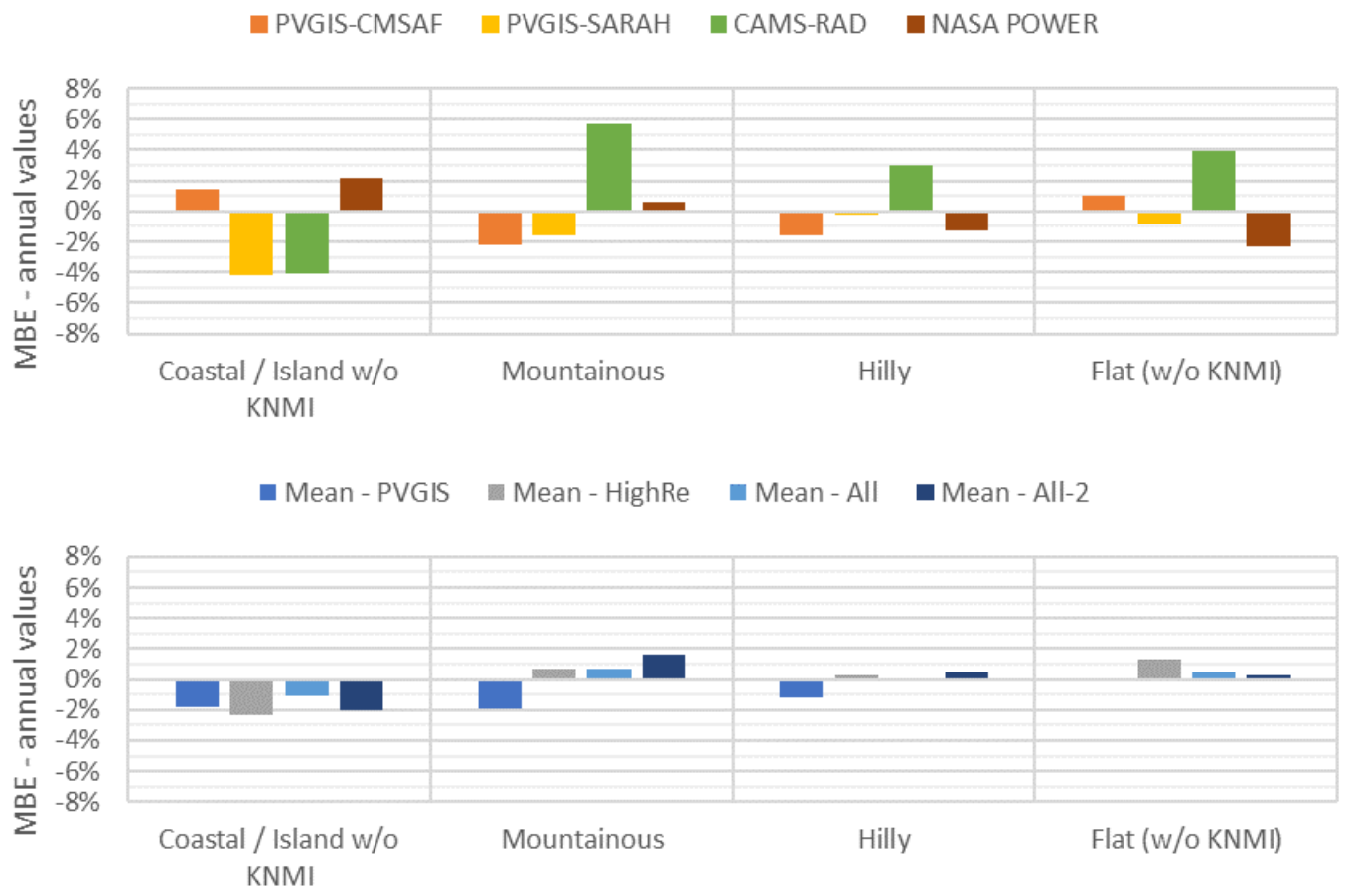

Fig. 6: Relative MBE of annual values of different databases and arithmetic means as a function of location class

Because the accuracy metric results obtained for KNMI reference sub-dataset differs from both BSRN and DWD and to achieve relatively equal numbers of reference locations in each class, all KNMI locations have been excluded in above analysis. If included, relative RMSE values change by up to $\pm 1.5 \%$ for Coastal / Island and up to $\pm 3 \%$ for Flat. 
Considering the different situations of the locations, varying performances can be observed. This is in line with expectations, which say that for more complex geographic environment greater deviations likely occur.

\subsection{Long-term monthly GHI}

For the benchmarking of long-term monthly GHI database or arithmetic mean performance, the respective monthly deviations at each reference location is used to calculate relative RMSE before an average over each reference sub-dataset is determined. Fig. 7 presents the resulting numbers.

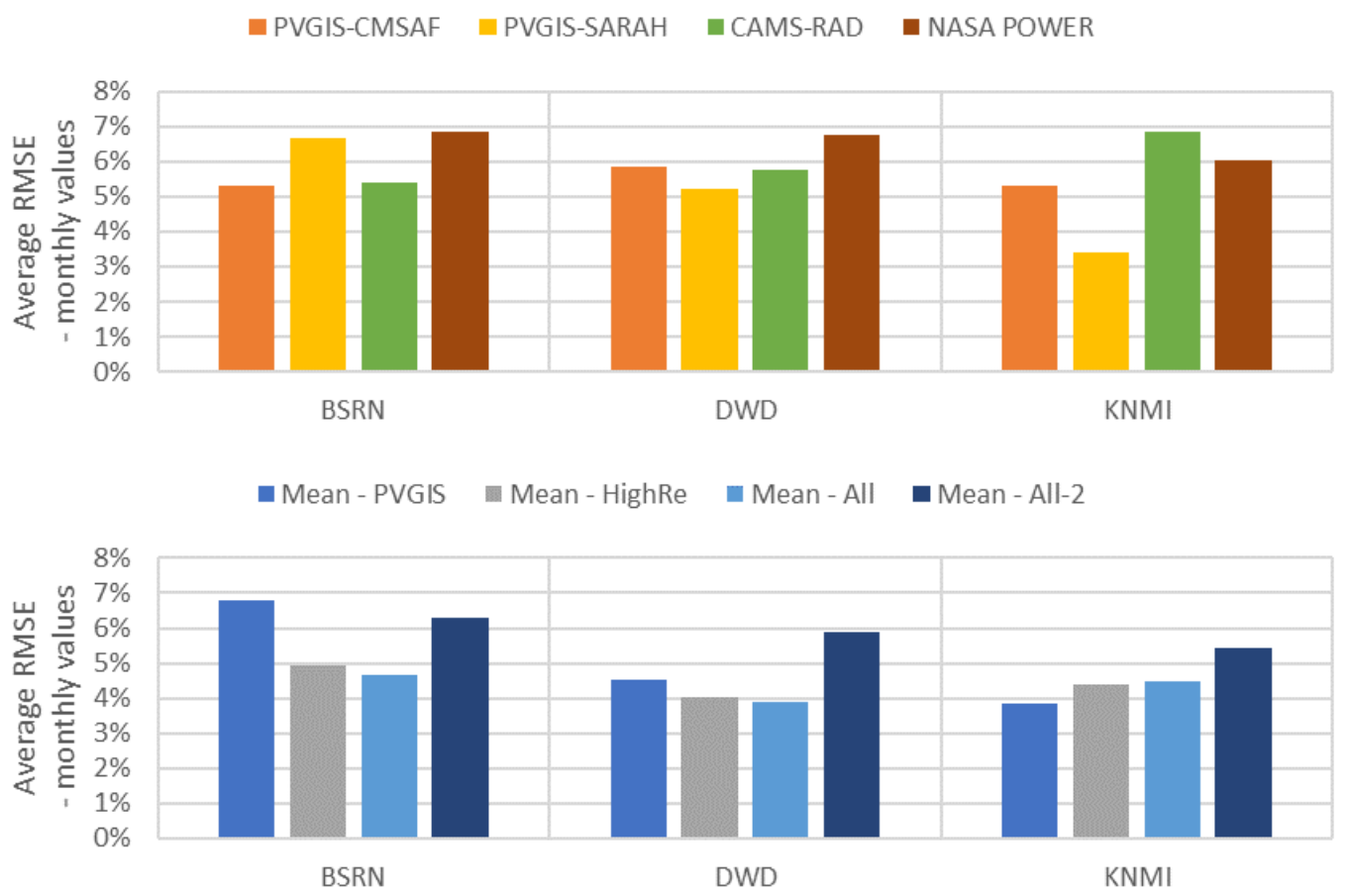

Fig. 7: Average of relative RMSE of monthly values of different databases and arithmetic means as a function of reference subdataset

The average relative RMSE for monthly values of the individual databases ranges from $\pm 3.4 \%$ to $\pm 6.9 \%$, the corresponding values for the arithmetic means are $\pm 3.9 \%$ to $\pm 6.8 \%$. Except for the greater numbers and some changes in the ranking relative to each other, the results are similar to the ones obtained for long-term annual values, as the combined datasets typically give more accurate estimates.

\subsection{Inter-annual GHI variability}

Overleaf Fig. 8 and Fig. 9 show the relative RMSE and relative MBE with regard to inter-annual variability, differentiated by reference sub-datasets.

In contrast to the GHI benchmarking of both long-term monthly and annual values, performance of NASA POWER database is significantly worse than those of the other three databases and the arithmetic means when considering year-on-year variations. Even for the combination of datasets a negative influence can be observed. The strong deviation of NASA POWER against the reference datasets is likely caused by multiple changes affecting this database during the 2007-2016 period.

Considering inter-annual GHI variability, the differences between individual database and arithmetic mean performances are smaller than within the long-term data benchmarking, but still combined datasets provide more reliable estimates. Overall, the relative RMSE ranges from $\pm 0.6 \%$ to $\pm 1.9 \%$ for arithmetic means and from $\pm 0.4 \%$ to $\pm 4.0 \%$ for the databases. Excluding NASA POWER, the results are $\pm 0.6 \%$ to $\pm 1.1 \%$ and $\pm 0.4 \%$ to $\pm 1.6 \%$. In terms of relative MBE, all but one number - PVGIS-CMSAF with $0.2 \%$ - are negative. For the databases the MBE results are between $+0.2 \%$ and $-3.9 \%$, or between $+0.2 \%$ and $-1.2 \%$ if NASA POWER is excluded. The arithmetic means achieve relative MBE ranging from $-0.2 \%$ to $-1.8 \%$ including NASA POWER or $-0.2 \%$ to $-0.8 \%$ excluding NASA POWER dataset. 


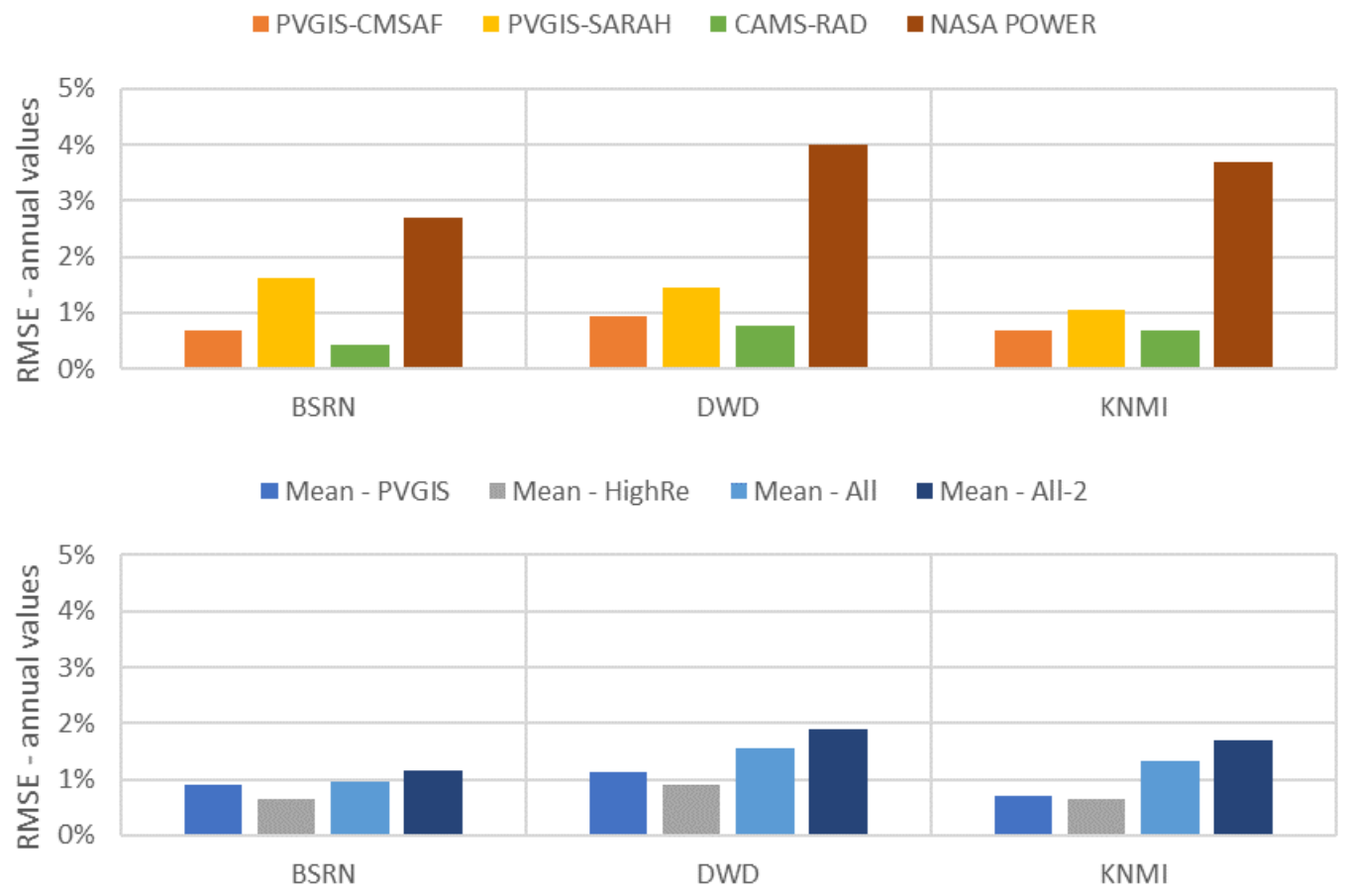

Fig. 8: Relative RMSE of annual values of different databases and arithmetic means as a function of reference sub-dataset
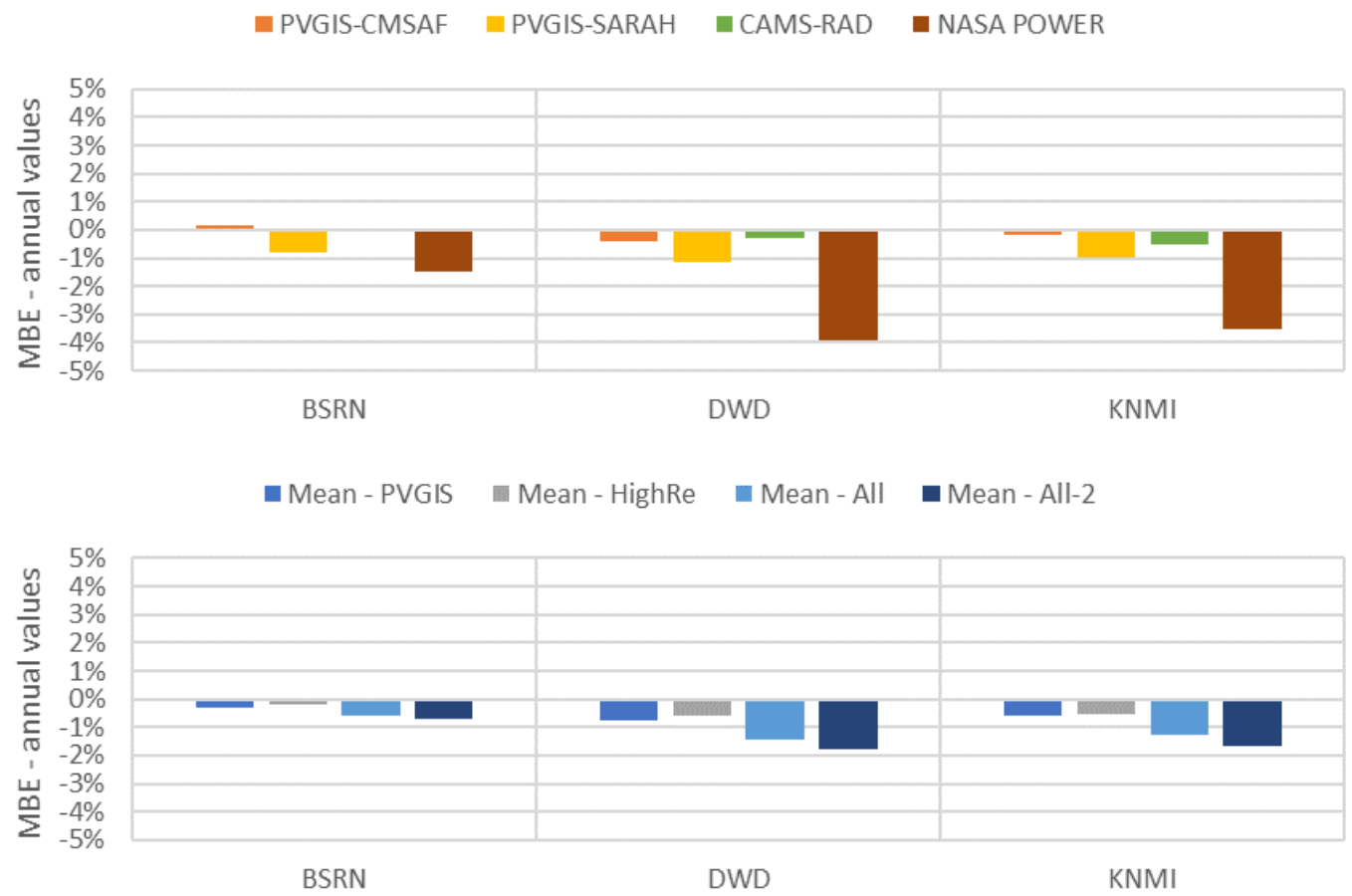

Fig. 9: Relative MBE of annual values of different databases and arithmetic means as a function of reference sub-dataset

\section{Conclusion}

The performance in terms of relative RMSE and relative MBE of individual databases and different combinations or arithmetic means formed using this information has been analysed. The values obtained have been benchmarked against reliable reference information. The results indicate that for both long-term GHI averages and their inter-annual variability, arithmetic means typically provide more accurate estimates than single databases. Thus, it is concluded that an approach which combines database information is more reliable than selection of an individual dataset for Solar Resource Assessment purposes. However, the actual performance of 
the arithmetic means depends on the selection of the databases included in the combining and therefore requires a continuous benchmarking, particularly when entering new markets. Finally, individual information is not generally outperformed and might be equal or slightly better choice in specific regions.

\section{References}

Egler, M.; Rusbridge, S.; Santos, C.: Solar Resource Databases vs Weighted Means - Results of a Global Benchmarking Effort; 4th International Conference Energy Meteorology 2017, Bari / Italy; DOI: 10.13140/RG.2.2.36161.76646

Bührer, M.; Gutbrod, K. G.; Kanefeldt, T.; Beinert, D.; Fritz, R.: Vergleich der Einstrahlungsdaten aus verschiedenen numerischen Wettermodellen und deren Kombination in Multimodell Prognosen; 5. Fachtagung Energiemeteorologie, Goslar / Germany; 2018

Wald, L.; M. Lefèvre: Interpolation schemes - Profile Method (a process-based distance for interpolation schemes); SoDa Deliverable D5-1-1 (internal document)

Lorenz, E.: MESoR Training Seminar Part 2: Overview on Solar Resource Products; Munich / Germany; 2009

Müller, B.; Wild, M.; Driesse, A.; Behrens, K.: Rethinking solar resource assessments in the context of global dimming and brightening; Solar Energy 99 (2014) 272-282; http://dx.doi.org/10.1016/j.solener.2013.11.013

Pagola, I.; Gastón, M.; Fernández-Peruchena, C.; Moreno, S.; Ramirez, L.: New methodology of solar radiation evaluation using free access databases in specific locations; Renewable Energy 35 (2010) 2792-2798; DOI: 10.1016/j.renene.2010.04.034

Zelenka, A.; Czeplak, G.; D'Agostino, V.; Weine, J.; Maxwell, E.; Perez, R.; Noia, M.; Ratto, C.; Festa, R.: Techniques for supplementing solar radiation network data, Volume 1-3; IEA Report No. IEA-SHCP-9D-1 


\title{
Solar Irradiation over a Flat Surface with Different Tracking Strategies
}

\author{
Adriana E. Gonzalez-Cabrera', David Riveros-Rosas ${ }^{1}$, Héctor Estevez ${ }^{1}$, Anayeli Ramirez, Mauro \\ G. Valdes ${ }^{1}$, Camilo A. Arancibia-Bulnes ${ }^{2}$ and Luis F. Zarzalejo ${ }^{3}$ \\ ${ }^{1}$ Universidad Nacional Autónoma de México, Instituto de Geofísica, Circuito de la investigación \\ científica s/n, Ciudad Universitaria, Ciudad de México, CP 04510, (México) \\ 2 Universidad Nacional Autónoma de México, Instituto de Energías Renovables, Temixco, Mor. CP \\ 62580, (México) \\ ${ }^{3}$ Centro de Investigaciones Energéticas Medio Ambientales y Tecnológicas, Avda. Complutense 40, \\ 25040 Madrid, España.
}

\begin{abstract}
The importance of solar tracking systems lies in the need to optimize the amount of solar radiation on solar collectors of different types. In this work, the monthly mean daily irradiation was analyzed on a flat surface of unitary area, under different tracking schemes of the Sun, by means of the use of a numerical model. For this purpose, solarimetric data was obtained from some stations of the new Mexican Solarimetric Network, the solar irradiance incident on a flat horizontal plate was calculated. Also, the movement of some tracking systems was carried out in steps with different time intervals in order to compare it with their respective continuous movement. It was found that stepped movements report yearly incident solar irradiation values above $98 \%$ respect to continuous movement in the widest interval.
\end{abstract}

Keywords: Solar resource assessment, solar tracking strategies, PV collectors, solar collectors

\section{Introduction}

The importance of solar tracking systems lies in the need to optimize the amount of solar radiation on solar collectors of different types (Yang, 2016). In particular, PV systems present significant variations in their performance depending on the optical configuration and tracking strategies used (Sumathi et al, 2017; Joshi and Arora, 2017;Fernandez-Ahumada et al, 2017; Mehleri et al, 2010; Li and Lam, 2007). The cost of tracking schemes can significantly impact overall costs depending on the complexity and precision of the mechanisms.

There are several works in literature (Sumathi et al, 2017; Yang, 2016) for the optimization of the solar energy intercepted for the different configurations of one and two axes devices. However, most of the works are focused on the continuous solar tracking systems and the optimization of photovoltaic panel operation, either with open or closed loop control systems. In this work results are presented for different solar tracking schemes and for different geographical conditions. The same schemes were applied to solar radiation data obtained from the new solarimetric network of México (González-Cabrera et al, 2017). These stations are maintained by the Mexican Solarimetric Service in the Institute of Geophysics at the Universidad Nacional Autónoma de México (UNAM), and there is part of the project Mexican Centre of Innovation in Solar Energy (CEMIESol, by its Spanish acronym). This project involves 67 academic institutions and 21 private companies, 50 individual projects with the main goals in the academic-industry linkage, the promotion of technology transfer and the technological development of capacities for companies in the solar energy area.

CEMIESol includes a specific subproject to create the National Inventory of Solar Resource in México and contemplates the creation of a national network of solarimetric reference stations. The solar radiation irradiances were measured in their principal components: global, DNI and diffuse. These data are the basis to calculate the daily irradiation over a flat plate collector at different solar tracking strategies that includes steeping tracking 
with different time intervals. This information is useful to determine the need of accuracy for a solar tracking system and determines the energy that is not collected depending on the step-time for on solar tracking.

Tab. 1: Nomenclature

\begin{tabular}{|c|l|c|l|}
\hline Symbol & \multicolumn{1}{|c|}{ Meaning } & Symbol & \multicolumn{1}{|c|}{ Meaning } \\
\hline $\mathrm{H}_{\mathrm{fc}}$ & Global solar irradiation over flat collector & $\mathrm{G}_{\mathrm{b}}$ & Direct normal solar irradiance \\
\hline $\mathrm{G}_{\mathrm{fc}}$ & Global solar irradiance over flat collector & $\mathrm{G}_{\mathrm{D}}$ & Diffuse solar irradiance \\
\hline$\Delta \mathrm{t}$ & Time interval for solar measurements & $\mathrm{N}$ & Number of available days for a month \\
\hline $\mathrm{H}_{\mathrm{m}}$ & Monthly mean daily irradiation & $\mathrm{z}_{0}$ & Angle of incidence over the collector \\
\hline $\mathrm{G}_{\beta \mathrm{b}}$ & Direct tilted irradiance & $\mathrm{a}_{\mathrm{z}}$ & Solar azimuthal angle \\
\hline $\mathrm{G}_{\beta \mathrm{D}}$ & Diffuse tilted irradiance & $\mathrm{z}_{\mathrm{e}}$ & Solar zenithal angle \\
\hline $\mathrm{G}_{\beta \mathrm{R}}$ & Reflected tilted irradiance & $\gamma$ & Collector azimuthal angle \\
\hline & & $\beta$ & Tilt angle of flat collector \\
\hline
\end{tabular}

\section{Methodology}

To numerically quantify the radiative power incident on a flat plate, a computer routine was written that allows calculating the daily irradiation in Watts-hour (Wh) according to equation 1 (eq.1). Once the daily irradiation is obtained, the monthly mean daily irradiation is calculated with the available complete days of solar radiation irradiances (N) (eq. 2).

$$
\begin{aligned}
& \mathrm{H}_{\mathrm{fc}}=\sum_{\text {day }} \mathrm{G}_{\mathrm{fc}} \Delta t \\
& \mathrm{H}_{\mathrm{m}}=\frac{1}{N} \sum_{\text {month }} \mathrm{H}_{\mathrm{fc}}
\end{aligned}
$$

The irradiance over the flat collector is determined by equation 3, using direct, diffuse and reflected irradiance and the incidence angle over the collector. The albedo was considered the same for all stations with a value of 0.2. The total irradiance over the collector is calculated with the sum of the three mentioned components in equation 3. In equations 4, 5 and 6 are the expressions to calculate each solar component.

$$
\mathrm{G}_{\mathrm{fc}}=\mathrm{G}_{\beta \mathrm{D}}+\mathrm{G}_{\beta \mathrm{R}}+\mathrm{G}_{\beta \mathrm{b}}
$$

Where

$$
\begin{aligned}
& \mathrm{G}_{\beta \mathrm{b}}=\mathrm{G}_{\mathrm{b}} \cos \left(\mathrm{z}_{0}\right) \\
& \mathrm{G}_{\beta \mathrm{D}}=\mathrm{G}_{\mathrm{D}} \mathrm{T}_{\mathrm{D}} \\
& \mathrm{G}_{\beta \mathrm{R}}=\rho\left[\mathrm{G}_{\mathrm{D}}+\mathrm{G}_{\mathrm{b}} \cos \left(\mathrm{z}_{\mathrm{e}}\right)\right] \mathrm{T}_{\mathrm{R}}
\end{aligned}
$$

The factors for diffuse $\left(T_{D}\right)$ and reflected $\left(T_{R}\right)$ irradiances are calculated, for simplicity in this work, with the isotropic model of Liu-Jordan (1961), and the expressions are shown in equation 7. The incidence angle $\left(\mathrm{z}_{0}\right)$ over the collector is obtained with equation 8 . 


$$
\begin{aligned}
& \mathrm{T}_{\mathrm{R}}=\frac{1}{2}[1-\cos (\beta)] \\
& \mathrm{T}_{\mathrm{D}}=\frac{1}{2}[1+\cos (\beta)] \\
& \cos \left(\mathrm{z}_{0}\right)=\cos \left(\mathrm{z}_{\mathrm{e}}\right) \cos (\beta)+\left[\sin \left(\mathrm{z}_{\mathrm{e}}\right) \sin (\beta)\right] \cos \left(\mathrm{a}_{\mathrm{z}}-\gamma\right)
\end{aligned}
$$

The selected tracking strategies include fixed, continuous and steeped movement with different time intervals, as is described in the following bullets

Fixed

- Horizontal, the flat collector is positioned horizontally

- Fixed latitude, the flat collector is tilted by latitude facing to the South

Continuous movement

- Heliotrope, continuous movement where the normal to flat collector is pointing to the sun at any moment

- Azimuthal tracking, continuous movement with the flat collector tilted by latitude. The tracker turns with the solar azimuthal angle.

Stepped movement

- Stepped azimuthal tracking, the flat collector is tilted by latitude and the tracker turns every defined time interval in order to keep the azimuthal angle for collector in the middle of the azimuthal solar angle interval. The step-time intervals are 10, 30, 60 and 120 minutes.

The solar position is determined every minute by the Campbell Scientific $\AA$ acquisition system, using the Solar Position Algorithm (Reda \& Andreas, 2003) and it is reported next to the Solar radiation measurements for each station. The solarimetric data was obtained from 4 stations belonging to the Mexican Solarimetric Reference Network. The name and geographical coordinates of selected stations are reported in table 2. All stations contain the main solar parameters: global, diffuse and normal direct irradiance recorded every minute. The years selected were from 2016 to 2018.

Tab. 2: Geographical coordinates of solarimetric stations for the study

\begin{tabular}{|c|c|c|c|c|}
\hline Site Name & Latitude & Longitude & $\begin{array}{c}\text { Altitude MAMSL } \\
\text { [meters] }\end{array}$ & $\begin{array}{c}\text { Starting date } \\
\text { [DD/MM/YYYY] }\end{array}$ \\
\hline Mexico City & $19.3260^{\circ} \mathrm{N}$ & $99.1760^{\circ} \mathrm{W}$ & 2281 & $01 / 011984$ \\
\hline Coeneo, Mich & $19.8136^{\circ} \mathrm{N}$ & $101.6947^{\circ} \mathrm{W}$ & 1989 & $10 / 28 / 2015$ \\
\hline Zacatecas, Zac & $22.7725^{\circ} \mathrm{N}$ & $102.6436^{\circ} \mathrm{W}$ & 2317 & $11 / 17 / 2015$ \\
\hline Gomez Palacio, Dgo & $23.9568^{\circ} \mathrm{N}$ & $104.5704^{\circ} \mathrm{W}$ & 1877 & $11 / 19 / 2015$ \\
\hline
\end{tabular}

For stepped azimuthal angle from collector, was chosen to the middle of the solar azimuthal angle interval, corresponding to an interval time (fig. 1). As an example, figure 2 shows the graph for continuous azimuthal angle from the Sun compared with the stepped azimuthal angle from collector, for 60 minutes. 


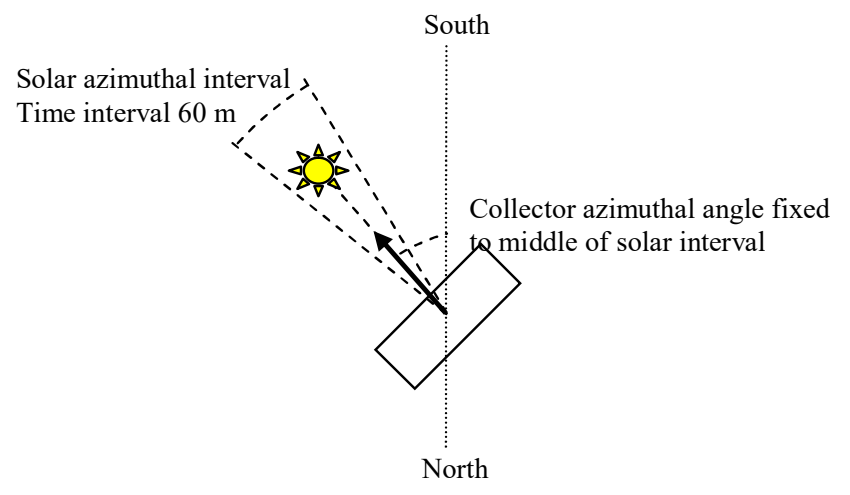

Fig. 1: Diagram of collector azimuthal angle respect the Solar azimuthal angle interval

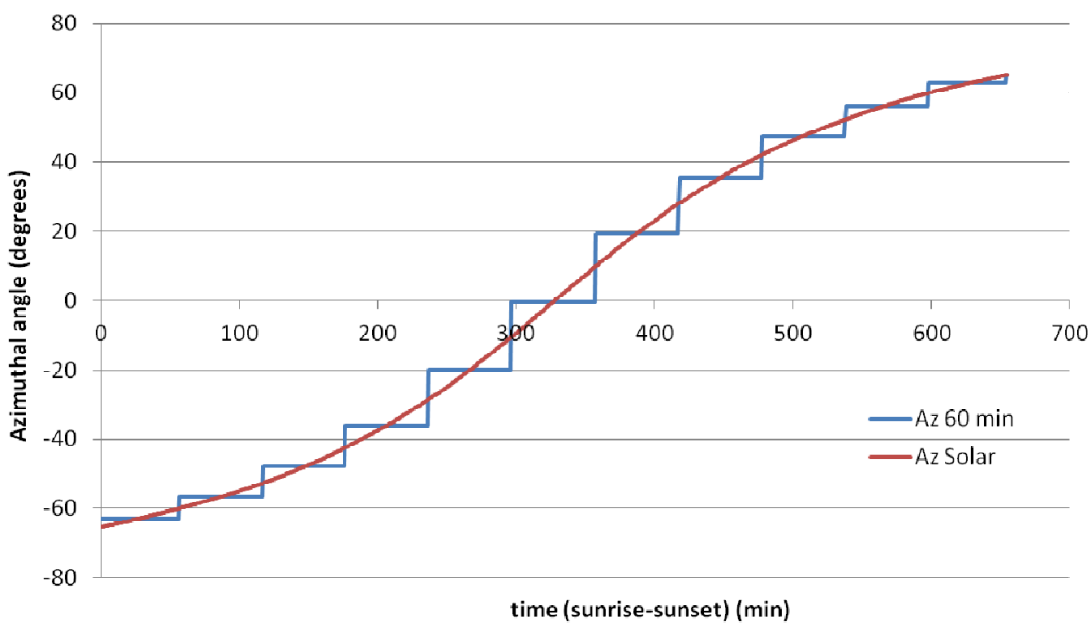

Fig. 2: Graph of continuous azimuthal angle compared with the 60 minutes stepped azimuthal angle from collector at spring equinox

\section{Results}

\subsection{Mean monthly daily irradiation}

The monthly mean daily irradiations for selected stations are shown in figure 3. This figure includes fixed and continuous tracking cases. As could be expected, cases with continuous tracking have larger amount of irradiation collected respect the fixed cases, and the heliotropes case has the best energy collection. For fixed cases the flat collector tilted with latitude have a better daily irradiation respect the Horizontal case, mainly in the autumn and winter months. This behavior is due to the solar geometry along the year, in autumn and winter months, the solar position is founded completely ant the south and the cosine factor reduces the irradiation over a horizontal collector. Otherwise, in spring and summer months the horizontal collector have a better irradiation respect the latitude tilted case, due in these months the solar position is very close to the local zenith point at noon.

Another issue, observed in figure 3, is in July and September, for Ciudad de México and Coeneo, the difference between the irradiation collected is reduced respect other months. This could be explained due this month corresponds to a rainy season, therefore the direct irradiance contribution is also reduced and the effect of the tracking is less significant. 
a) Zacatecas, Zac.

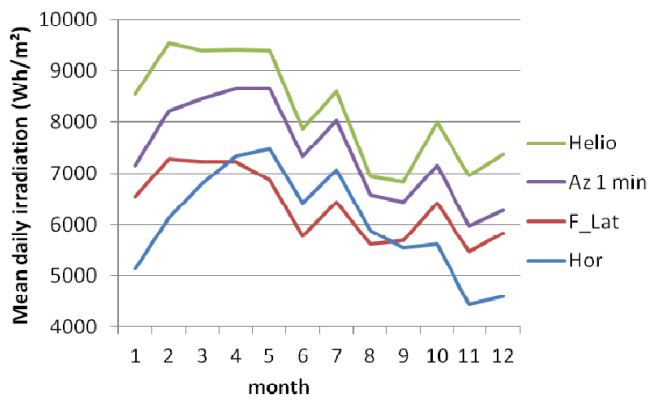

c) Ciudad de México, CDMX

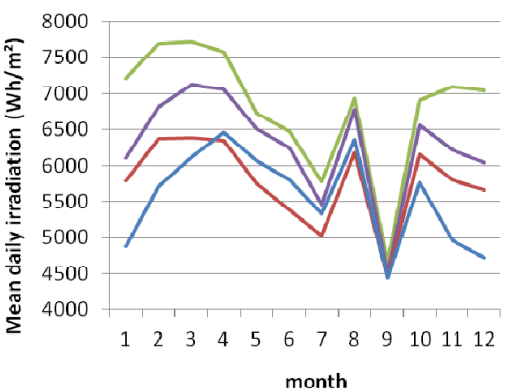

Fig. 3: Graph of monthly mean daily irradiation for fixed and continuous tracking in selected stations

a) Zacatecas, Zac.

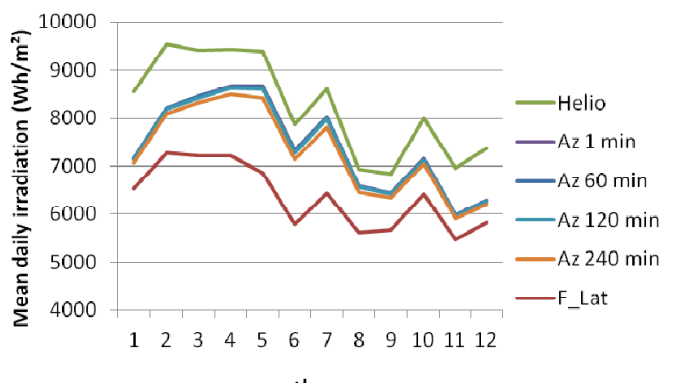

c) Ciudad de México, CDMX

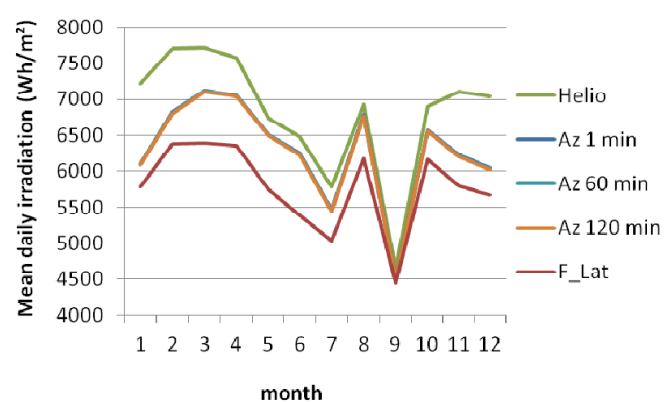

b) Gómez Palacio, Dgo.

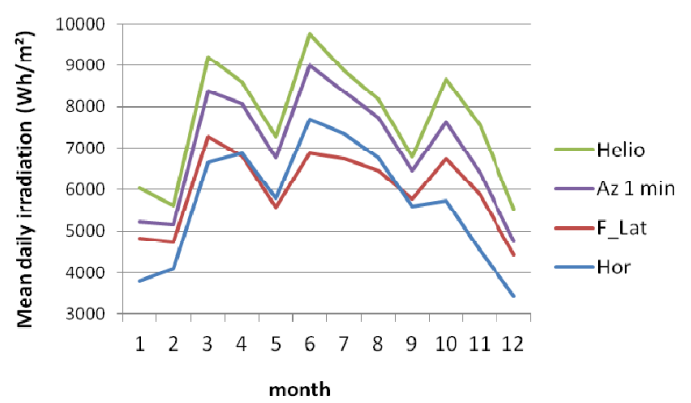

d) Coeneo, Mich.

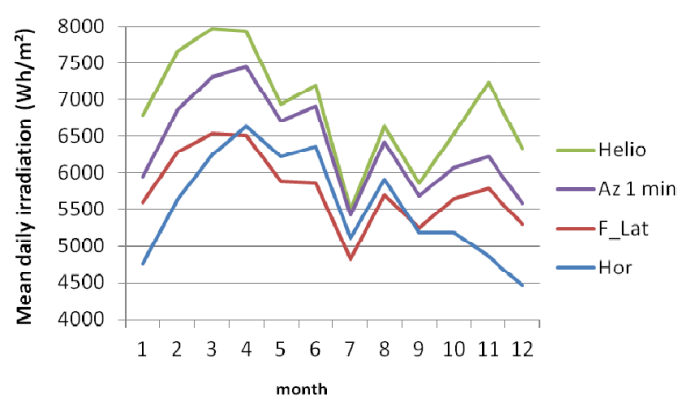

b) Gómez Palacio, Dgo.

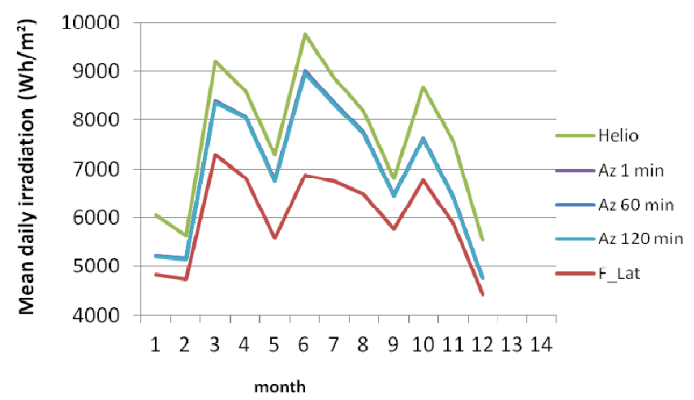

d) Coeneo, Mich.

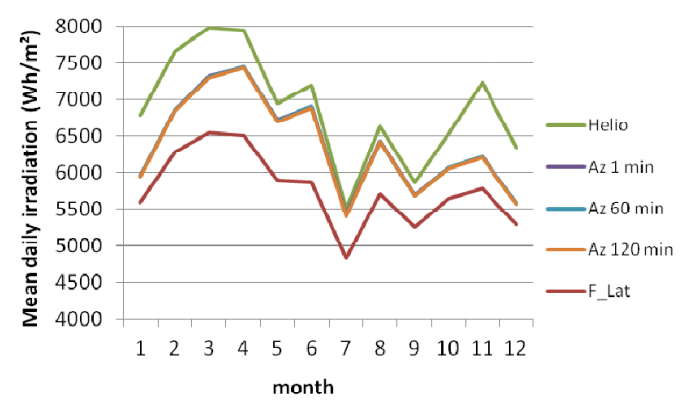

Fig. 4: Graph of monthly mean daily irradiation for azimuthal steeped tracking in selected stations 
In figure 4, the steeped tracking cases are shown. As it could be expected, these cases collect less irradiation than the heliotrope case and more than the fixed collector tilted by latitude. However, it must be noted that the difference of collected irradiation is not significant for steep time intervals less than 120 minutes. The major differences respect the continuous tracking are less than $2 \%$. The reason can be found with an analysis of angular differences.

\subsection{Angular differences}

It can be observed, in figure 5, the angular differences, over the collector, between the incident angles for steeped tracking, respect the continuous tracking. The differences are determined in the relation of the continuous solar azimuthal angle for the steep time intervals of 10,60 and 120 minutes. The differences were obtained for specific days: summer and winter solstice, and spring equinox. The major angular difference corresponds to the summer solstice with values less than 15 degrees (for 120 min steep time) near to the noon. In fact, the average difference for all day is less than $1^{\circ}$ for the case of 120 minutes steep time. This angular behavior can be observed in figure 6 , for Jun-21, where the differences of azimuthal angle between steeped and continuous cases are almost not significant for most of the day.

a) Winter solstice

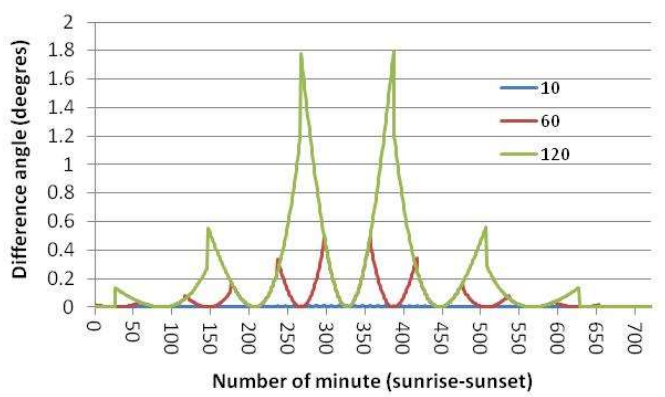

b) Spring equinox

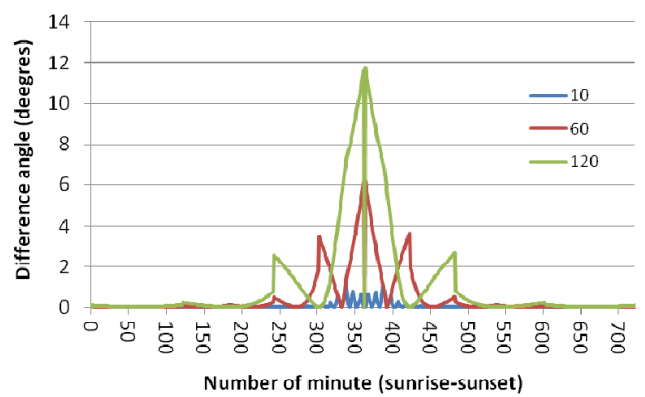

c) Summer solstice

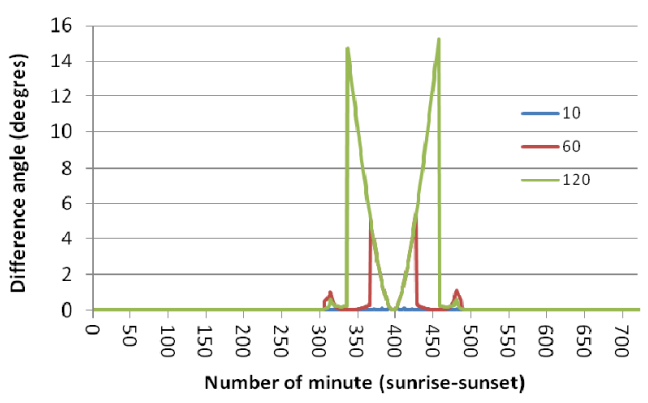

Fig. 5: Graph of continuous azimuthal angle compared with the 60 minutes stepped azimuthal angle from collector at summer solstice

If these small angular differences are taking in account with the corresponding cosine factor, the difference of calculated irradiation is even lower. For example, the percentage difference applying the cosine factor, at the summer solstice with a steep time of 120 minutes, is less than $6 \%$, and for all day, the average difference is less than $0.5 \%$. 


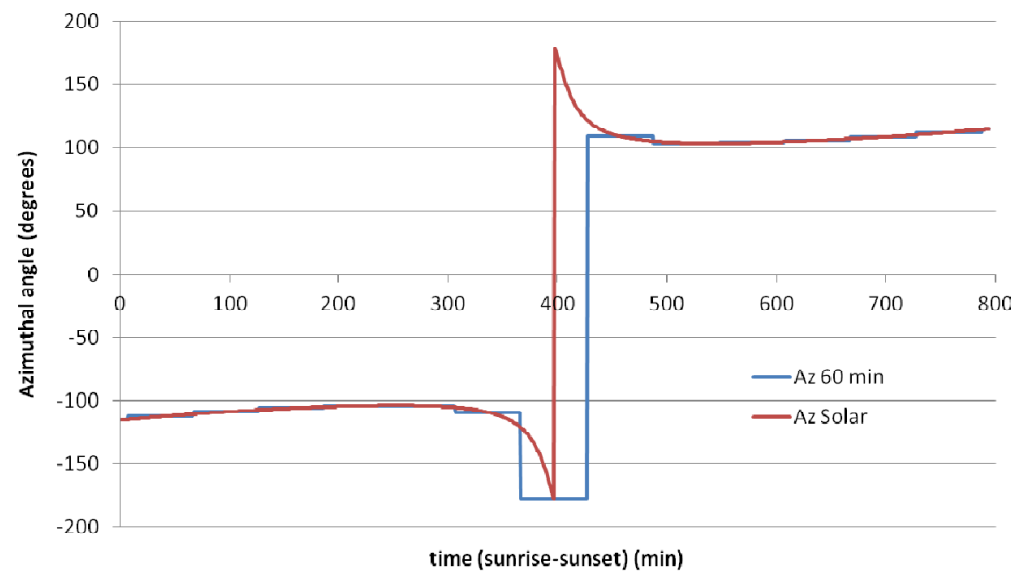

Fig. 6: Graph of continuous azimuthal angle compared with the 60 minutes stepped azimuthal angle from collector at summer solstice

Table 3 reports the annual energy captured by stepped tracking compared to that obtained by azimuthal continuous movement. All cases the difference is not significant according to the observed behavior of angular differences discussed previously. Table 4 reports the annual energy captured for the rest of cases compared with the Heliotrope tracking. It must be noted that Zacatecas have the major losses compared with the heliotrope movement due to latitude and this site have more clear days along the year. For all cases the azimuthal tracking capture near of $90 \%$ compared with Heliotrope case.

Tab. 3: Annual energy captured respect continuous tracking

\begin{tabular}{|c|c|c|c|c|c|}
\hline Site & $\begin{array}{c}\text { Azimuthal } \\
\text { continuous }\end{array}$ & $\begin{array}{c}\text { Steep } \\
\mathbf{3 0} \mathbf{~ m i n}\end{array}$ & $\begin{array}{c}\text { Steep } \\
\mathbf{6 0} \mathbf{~ m i n}\end{array}$ & $\begin{array}{c}\text { Steep } \\
\mathbf{1 2 0} \mathbf{m i n}\end{array}$ \\
\hline Mexico City & $100 \%$ & $99.99 \%$ & $99.92 \%$ & $99.74 \%$ & - \\
\hline Zacatecas & $100 \%$ & $99.98 \%$ & $99.91 \%$ & $99.63 \%$ & $99.18 \%$ \\
\hline Coeneo & $100 \%$ & $99.99 \%$ & $99.92 \%$ & $99.73 \%$ & - \\
\hline Gomez Palacio & $100 \%$ & $99.98 \%$ & $99.92 \%$ & $99.61 \%$ & - \\
\hline
\end{tabular}

Tab. 4: Annual energy captured for continuous tracking and fixed collectors respect Heliotrope Tracking

\begin{tabular}{|c|c|c|c|c|}
\hline Site & $\begin{array}{c}\text { Heliotrope } \\
\text { Tracking }\end{array}$ & $\begin{array}{c}\text { Azimuthal } \\
\text { Tracking }\end{array}$ & $\begin{array}{c}\text { Fixed by } \\
\text { latitude }\end{array}$ & $\begin{array}{c}\text { Fixed } \\
\text { Horizontal }\end{array}$ \\
\hline Mexico City & $100 \%$ & $92.20 \%$ & $84.71 \%$ & $81.41 \%$ \\
\hline Zacatecas & $100 \%$ & $89.96 \%$ & $77.24 \%$ & $73.24 \%$ \\
\hline Coeneo & $100 \%$ & $92.76 \%$ & $83.76 \%$ & $80.63 \%$ \\
\hline Gomez Palacio & $100 \%$ & $91.20 \%$ & $78.38 \%$ & $74.21 \%$ \\
\hline
\end{tabular}




\section{Conclusions}

The Monthly mean daily irradiation collected by a flat collector with different tracking strategies were obtained from solarimetric data for some stations of the Mexican Solarimetric Network. The results confirm that the heliotropes cases have the best energy collection, annually azimuthal tracking loses approximately $10 \%$ of the energy and the fixed collector tilted by latitude loses between 16 to $23 \%$ of the daily irradiation. For azimuthal stepped tracking the differences respect the continuous tracking are not significant. In the worst case for a steep time of 240 minutes, in Zacatecas city, the annual loss was less than $1 \%$.

\section{References}

L.M. Fernández-Ahumada, F.J. Casares, J. Ramírez-Faz, R. López-Luque, 2017. Mathematical study of the movement of solar tracking systems based on rational models. Solar Energy 150, 20-29

A.E. González-Cabrera, D. Riveros-Rosas, M.G. Valdes-Barrón, R. Bonifaz-Alfonzo, V.M. Velasco-Herrera, H.R. Estévez-Pérez and G. Carabali, 2017. New Reference Solarimetric Network for Mexico. SolarPACES congress 2017. Santiago de Chile, Chile.

Puneet Joshi, Sudha Arora, 2017. Maximum power point tracking methodologies for solar PV systems - A review. Renewable and Sustainable Energy Reviews 70, 1154-1177

Danny H. W. Li, Tony N. T. Lam, 2007. Determining the optimum tilt angle and orientation for solar energy collection based on measured solar radiance data, City University of Hong Kong. International Journal of Photoenergy 2007

B.Y.H. Liu and R.C. Jordan, 1961. Daily insolation on surfaces tilted towards the equator. ASHRAE Journal, Vol. 3, No. 0, pp. 53-59.

E.D. Mehleri, P.L. Zervas, H. Sarimveis, J.A. Palyvos, N.C. Markatos, 2010. Determination of the optimal tilt angle and orientation for photovoltaic arrays, Solar Energy, 35, 2468-2475

Ibrahim Reda and Afshin Andreas, 2003. Solar Position Algorithm for solar Radiation Applications. NREL Technical Report NREL/TP-560-34302

Vijayan Sumathi, R. Jayapragash, Abhinav Bakshi, Praveen Kumar Akella, 2017. Solar tracking methods to maximize PV system output - A review of the methods adopted in recent decade. Renewable and Sustainable Energy Reviews 74, 130-138

Dazhi Yang, 2016. Solar radiation on inclined surfaces: Corrections and benchmarks. Solar Energy 136, 288302 


\title{
Validation of Real-Time Solar Irradiance Simulations over Kuwait Using WRF-Solar
}

\author{
Christian A. Gueymard ${ }^{1}$ and Pedro A. Jimenez ${ }^{2}$ \\ 1 Solar Consulting Services, Colebrook, NH (USA) \\ ${ }^{2}$ National Center for Atmospheric Research, Boulder, CO (USA)
}

\begin{abstract}
The performance of the WRF-Solar ${ }^{\circ}$ mesoscale model is evaluated in the desert environment of Kuwait's Shagaya Park, where various solar technologies are being deployed. WRF-Solar is configured with one large domain (D1) covering the Arabian Peninsula and a nested domain (D2) centered on Kuwait. The daily simulations focus on the day-ahead forecast, and span the whole year of 2017. The initial and boundary conditions are provided by the GFS analysis, and the aerosol information is imported from NASA's GEOS-5 analysis. WRF-Solar predicts an absence of cloudiness $80 \%$ of the time. During such periods, the aerosol optical depth (AOD) predicted by GEOS-5 is found biased compared to local AERONET observations, which negatively impacts the performance of irradiance predictions, particularly for direct irradiance and under high-AOD situations. The impact of the horizontal grid spacing is evaluated. During cloudless conditions, the forecasts obtained for D1 and D2 are found practically identical. During cloudy conditions, however, mixed results are obtained. D2's results do offer improvement over those from D1 in some cases (depending on type of cloudiness), but not in general. By comparison with high-quality local irradiance observations, it is found that many situations evaluated as cloudless by WRF-Solar are actually cloudy, or vice versa. The performance of the Fast All-sky Radiation model for Solar applications (FARMS), now incorporated into WRF-Solar, is evaluated here in a desert environment for the first time and compared to that of the more established Rapid Radiative Transfer Model for GCMs (RRTMG). The two models satisfactorily agree under cloudless conditions, but not always under cloudy conditions. Depending on cloud conditions, one or the other might be closer to observations. In general, neither model is able to forecast the variations of direct irradiance with acceptable accuracy under clouds, which can be a concern for concentrating solar applications.
\end{abstract}

Keywords: WRF-Solar, aerosols, solar irradiance, Kuwait, forecast, GEOS-5, AERONET

\section{Introduction}

The Kuwait Institute for Scientific Research (KISR) oversees the development of various sources of renewable energy in Shagaya, Kuwait, a remote desert site. This is part of a national initiative to develop alternative energy sources and limit the internal consumption of oil for electricity production. Current installations in service or in construction at Shagaya amount to $70 \mathrm{MW}$, including solar photovoltaics (PV), concentrating solar power (CSP), and wind turbines. More installations $(1.5 \mathrm{GW})$ are scheduled in the near future, so that a significant fraction of the electricity production in Kuwait will soon be provided by variable sources. To avoid problems due to grid instability or brownouts, KISR is now cooperating with the National Center for Atmospheric Research (NCAR) and Solar Consulting Services (SCS) to develop the necessary capabilities to obtain forecasts of the power production. For that purpose, NCAR is developing new forecasting tools based on previous experience (Haupt and Kosovic, 2016; Haupt et al., 2018). These forecasting tools incorporate a number of components to efficiently forecast the resource (solar or wind) itself, and the power production. The forecast horizon is typically 15 min to 7 days.

In the case of solar applications, the main components are a mesoscale numerical weather prediction (NWP) model, an advanced machine-learning toolkit, and a powerful blending integrator, with external information about the power plant's physical characteristics (Haupt et al., 2018). The present contribution proposes a preliminary investigation into the accuracy of irradiance predictions using a solar-enhanced version of the Weather Research and Forecasting (WRF-Solar ${ }^{\circ}$ ) mesoscale model (Jimenez et al., 2016a, 2016b; Powers et al., 2017) over Kuwait. WRF, and more recently WRF-Solar, have been used in a considerable number of studies related to the solar (or wind) forecasts in the context of renewable energy applications (Diagne et al., 2014; Eissa et al., 2018; LaraFanego et al., 2012a; Lee et al. 2017; Liu et al., 2016; Mukkavilli et al., 2018; Pierro et al., 2015), and to the as- 
sessment of the solar resource (Almeida et al., 2015; Fountoukis et al., 2018; Ruiz-Arias et al., 2013; 2015). Here, some new features of WRF-Solar are investigated. Additionally, the performance of the model is assessed by comparing its predictions to actual high-quality irradiance measurements, while testing the role of the spatial resolution assigned to the study domain. The latter issue is important in general because NWP simulations require a lot of computer resources, which increase as an inverse quadratic function of the grid cell size. Hence, one objective of this study is to investigate whether a fine spatial resolution (such as $3 \mathrm{~km}$ ) is necessary to improve irradiance forecasts, compared to a cruder resolution (such as $9 \mathrm{~km}$ ).

In the particular case of Kuwait, cloudy periods are irregular and somewhat seasonal, but hazy situations caused by episodes of high dust aerosol loads are frequent. Such situations result in significant attenuation of the solar resource, and ultimately on soiling of all solar systems, which decreases their efficiency. An objective of this study is to investigate the impact of external sources of aerosol forecasts on the prediction of the irradiance incident on solar systems. The related soiling issue is beyond the scope of this contribution, however.

\section{Mesoscale modeling with WRF-Solar}

Irradiance predictions for a whole year (2017) are performed with the WRF-Solar mesoscale model, version 3.9.1.1 (Jimenez et al., 2016a). The Fast All-sky Radiation model for Solar applications (FARMS) model (Xie et al., 2016) was recently added to WRF-Solar as a new option. After a large number of tests, various issues (which will be described in a separate report) were found with its implementation. Version 3.9.1.1 introduced appropriate fixes to these issues, although a few small additional fixes can be expected in the near future, based on the results of the present study in particular.

For solar forecasting using any version of WRF, it is usual to consider a number of nested domains. For instance, Lara-Fanego et al. (2012b) and Kim et al. (2017) used four nested domains to simulate direct normal irradiance (DNI) over southern Spain and South Korea, respectively. Similarly, Lara-Fanego et al. (2012a) used three nested domains to simulate DNI and global horizontal irradiance (GHI) over the Andalusia region of Spain. Interestingly, the results of Lara-Fanego et al. (2012b) showed that the forecasting performance improved only imperceptibly between the third domain at $3-\mathrm{km}$ resolution and the fourth (and innermost) domain at $1-\mathrm{km}$ resolution. Partially based on these results, the experiment conducted here has been simplified to the point of using only two domains: An outer domain (D1) with 9-km spatial resolution, and an inner domain (D2) at 3-km resolution. Both domains use 45 layers in the vertical with the model lid at $100 \mathrm{hPa}$.

A number of processes are parameterized. Cloud microphysics is based on Thompson et al. (2008), whereas the cumulus parameterization (only active in D1) follows Grell and Freitas (2014). The Mellor-Yamada-NakanishiNiino (MYNN) planetary boundary layer parameterization (Nakanishi and Niino, 2006) and the revised FifthGeneration Mesoscale Model (MM5) surface layer formulation (Jimenez et al., 2012) are used in the two domains. The unified National Centers for Environmental Prediction-Oregon State University-Air Force-Hydrologic Research Laboratory (NOAH) land surface model is adopted (Tewari et al., 2004). The parameterization of the aerosol interactions with radiation follows Ruiz-Arias et al. (2014), whereas the longwave radiation is parameterized using RRTM (Mlawer et al., 1997). Two shortwave radiation parameterizations, RRTMG and FARMS, are evaluated and more details are provided below.

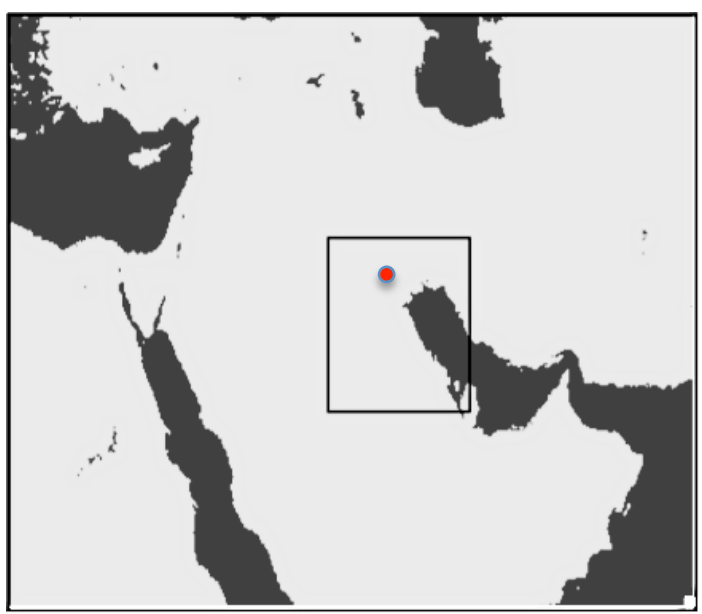

Fig. 1: Land mask of the region covered by the two domains. The inner domain, at 3-km resolution, covers Kuwait. The red dot indicates the Shagaya Park. 
For the present investigation, separate forecasts are obtained over two separate domains. One large outer domain (D1) covers the Arabian Peninsula with a 9-km resolution and a nested inner 3-km-resolution domain (D2) is centered on Kuwait (Fig. 1). Each day, the model is initialized at 00 UTC and is run for 48 hours to focus on the dayahead forecast. Hence, 365 daily simulations are performed here with WRF-Solar. Each domain provides independent irradiance simulations, which are helpful to quantify sensitivities of the predictions to the grid spacing. One important question being addressed here is how the 9-km and 3-km simulations compare over Kuwait. The importance of this question stems from the fact that WRF simulations over an inner (high-resolution) domain are computationally intensive. If this additional computational load were found not to yield significant performance improvements in the forecasts, a faster, low-resolution single-domain simulation might become sufficient.

Solar irradiance predictions are known to be sensitive to the radiative transfer model being used. This is true in the case of predictions related to the past (Fouquart et al., 1991), even when restricted to clear-sky situations (Gueymard and Ruiz-Arias, 2015). This is also true for DNI or GHI forecasts from NWP simulations (Montornès et al., 2015; Ronzio et al., 2013; Zhong et al., 2016). For the present contribution, the performance of two radiative transfer algorithms is examined. The first one is the Rapid Radiative Transfer Model for GCMs, better known as RRTMG (Iacono et al., 2008; Mlawer et al., 2016), which is well established and has been a standard radiative transfer parameterization in WRF and other NWP systems for many years. Its parameterization is computationally demanding, however, and thus is not typically called every time step of the model. In the present WRF-Solar simulations, RRTMG is called every 5 minutes. In between these calls, the irradiance is kept constant at all atmospheric levels. The second radiative transfer algorithm is the Fast All-sky Radiation model for Solar applications (FARMS; Xie et al., 2016). Contrary to RRTMG, FARMS only provides surface irradiances, which allows for their fast calculation, and makes it possible to call FARMS at each time step of the WRF-Solar model. The time step is $30 \mathrm{~s}$ in the 9-km domain (i.e., 10 times during a 5-min interval), and 3 times finer in the 3-km domain. This rapid cycle is attractive for solar irradiance applications that demand high temporal resolution, such as short-term forecasting. The performance of FARMS coupled with the WRF-Solar model has not been investigated before, and hence constitutes one important goal here.

\section{Sources of data}

WRF-Solar being a regional NWP model, it requires the specification of initial and boundary conditions representing the atmospheric state. In the present case, these conditions are imposed from the Global Forecast System (GFS) analyses run by NOAA. These are available every six hours at $0.25^{\circ} \times 0.25^{\circ}$ spatial resolution. In addition, the aerosol optical depth (AOD) at $550 \mathrm{~nm}$ is imposed every hour from the aerosol analysis performed with NASA's Goddard Earth Observing System version 5 (GEOS-5) model, initially at $\approx 25$-km resolution. GEOS-5 assimilates a number of actual aerosol observations, from either satellite platforms (e.g., NASA's Moderate Resolution Imaging Spectroradiometer, MODIS, or Multi-angle Imaging SpectroRadiometer, MISR) or surface measurements from NASA's Aerosol Robotic Network (AERONET). To the authors' knowledge, however, this assimilation does not use data from the two AERONET sites that exist in Kuwait. Since the latter type of observations has much lower uncertainty than those from satellites, it is possible that the aerosol information generated by GEOS-5 is biased over Kuwait. This is investigated further in Section 4.

WRF-Solar's predictions are compared here to irradiance measurements carried out at the Shagaya Park station in Kuwait (lat. $29.21^{\circ} \mathrm{N}$, long. $47.06^{\circ} \mathrm{E}$, elev. $242 \mathrm{~m}$ ), which is part of the KISR radiometric network (Al-Rasheedi et al., 2014). Solar irradiance observations are done with a time resolution of 1 minute, and include separate measurements of direct normal irradiance (DNI), global horizontal irradiance (GHI), and diffuse horizontal irradiance (DIF) made with individual thermopile radiometers. Helpful redundancy is provided by a rotating shadowband irradiometer (RSI). A stringent maintenance program, including daily cleaning of all instruments, results in a very high quality of the whole dataset. In particular, the RSI and thermopile observations have been found in close agreement (Al-Rasheedi et al., 2018). A time series of the best possible values of DNI, GHI and DIF has been assembled since 2012, and is used here for validation purposes. Measurement uncertainty is estimated to be $\approx 2 \%$ for DNI and $\approx 4 \%$ for GHI under normal conditions, and somewhat higher during dust storm conditions due to rapid soiling (Gueymard and Myers, 2008). A sunphotometer has been added to the station in 2015, and has joined the AERONET network since then. This instrument provides the aerosol optical depth (AOD) at seven wavelengths, the Ångström exponent (AEX), and precipitable water (PW) approximately every 15 min whenever the sun is unobscured by clouds. If AOD, AEX and PW are known precisely (as with AERONET data), it is possible to evaluate the clear-sky irradiances with good accuracy for that moment, even under the very hazy conditions that can occur in Kuwait (Gueymard et al., 2017). Under cloudless conditions, AOD is the main atmospheric driver for 
DNI, and has a lesser, but still significant, impact on GHI (Gueymard, 2012). To forecast these two quantities correctly, it is thus necessary to use appropriate AOD estimates. Three potential avenues are possible, but none is biasfree: (i) Use an AOD climatology (i.e., a fixed pre-calculated monthly value representative of the long-term mean aerosol conditions over the area); (ii) Use the AOD from the previous hour or day (assumed persistence); or (iii) Use an AOD forecast for the appropriate time horizon. The latter option is used here, as provided by GEOS- 5 on an hourly basis.

\section{Aerosol data accuracy}

Considering the high frequency of cloudless conditions over Kuwait and the high impact of AOD on DNI and GHI, it is important to quantify the error propagation effects from AOD to the predicted surface irradiance, which can directly affect all forecasts. Figure 2 compares AOD values obtained from different sources during four clear or essentially clear days with (i) exceptionally low AOD (2017-12-11); (ii) low AOD (017-03-07 and 2017-03-17); and (iii) high AOD (2017-04-29). The AOD forecasts from GEOS-5 (which are used here as inputs to WRF-Solar) are compared to modeled data from NASA's MERRA-2 - the reanalysis derived from GEOS-5 - and to local ground observations from the Shagaya AERONET station. The significant and systematic difference between these results suggests that neither GEOS-5 nor MERRA-2 assimilates the observations from this AERONET station specifically. The present results corroborate a previous analysis (Gueymard et al., 2017), which indicated significant differences in AOD data between MERRA-2 predictions and the observations from two AERONET stations in Kuwait. At Shagaya, the absolute difference, $\triangle$ AOD, between the GEOS-5 forecasts and the AERONET ground truth is highly variable over time, but is rarely below 0.05 . This bias can temporarily reach values larger than 1 when a dust event does reach the site but is not forecasted by GEOS-5, as in the 2017-04-29 case (Fig. 2, bottom right). The induced error in DNI can be evaluated from $\triangle \mathrm{AOD}$ and the tabulated results provided by Gueymard (2012). For instance, for an air mass of $\approx 1.5$ (or a sun zenith angle of $\approx 48^{\circ}$ ), it is found that the relative error in $\mathrm{DNI}$ is $\approx 10 \%$ for $\triangle \mathrm{AOD}=0.1$. It is thus expected that systematic errors in DNI forecasts will result from the inadequacies in the AOD input that are documented here. The impact on GHI, however, can be expected to be 3-4 times less (Gueymard, 2012), due to compensation effects between the direct and diffuse components.
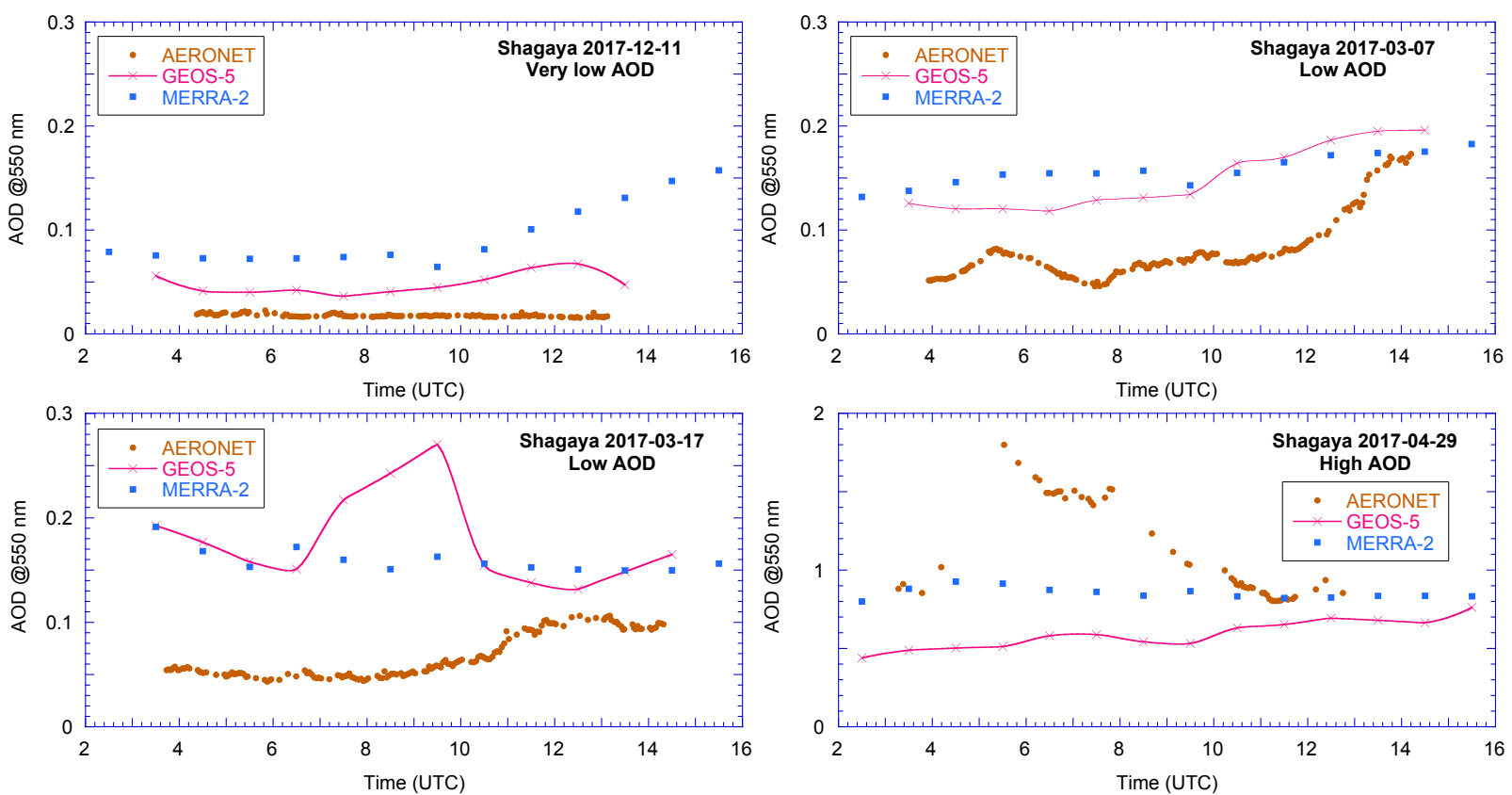

Fig. 2: Temporal variation of AOD at $550 \mathrm{~nm}$ at Shagaya during four cloudless (or nearly cloudless) days, as obtained from three sources: local AERONET observations, GEOS-5 forecasts, and MERRA-2 reanalysis. Note the different scale of the Y-axis in the high-AOD case (bottom right plot).

\section{Simulation results}

\subsection{Cloudless conditions}

Under cloudless conditions, the accuracy of WRF-Solar simulations is expected to depend mostly on that of the AOD inputs, per the discussion above. In this section, "cloudless conditions" are defined from the standpoint of WRF-Solar, i.e., whenever the forecasted total cloud liquid water path (CLW) is zero. During the daytime periods 
of 2017 , such conditions occurred $80.2 \%$ of the time. It is found that the irradiance forecasts for domains D1 and D2 are almost identical (the relative deviations in either DNI or GHI are within 1\% on average), as could be expected considering that the footprint of either domain is much smaller than the spatial resolution of the AOD data from GEOS-5, and that the terrain is flat and homogenous around Shagaya.
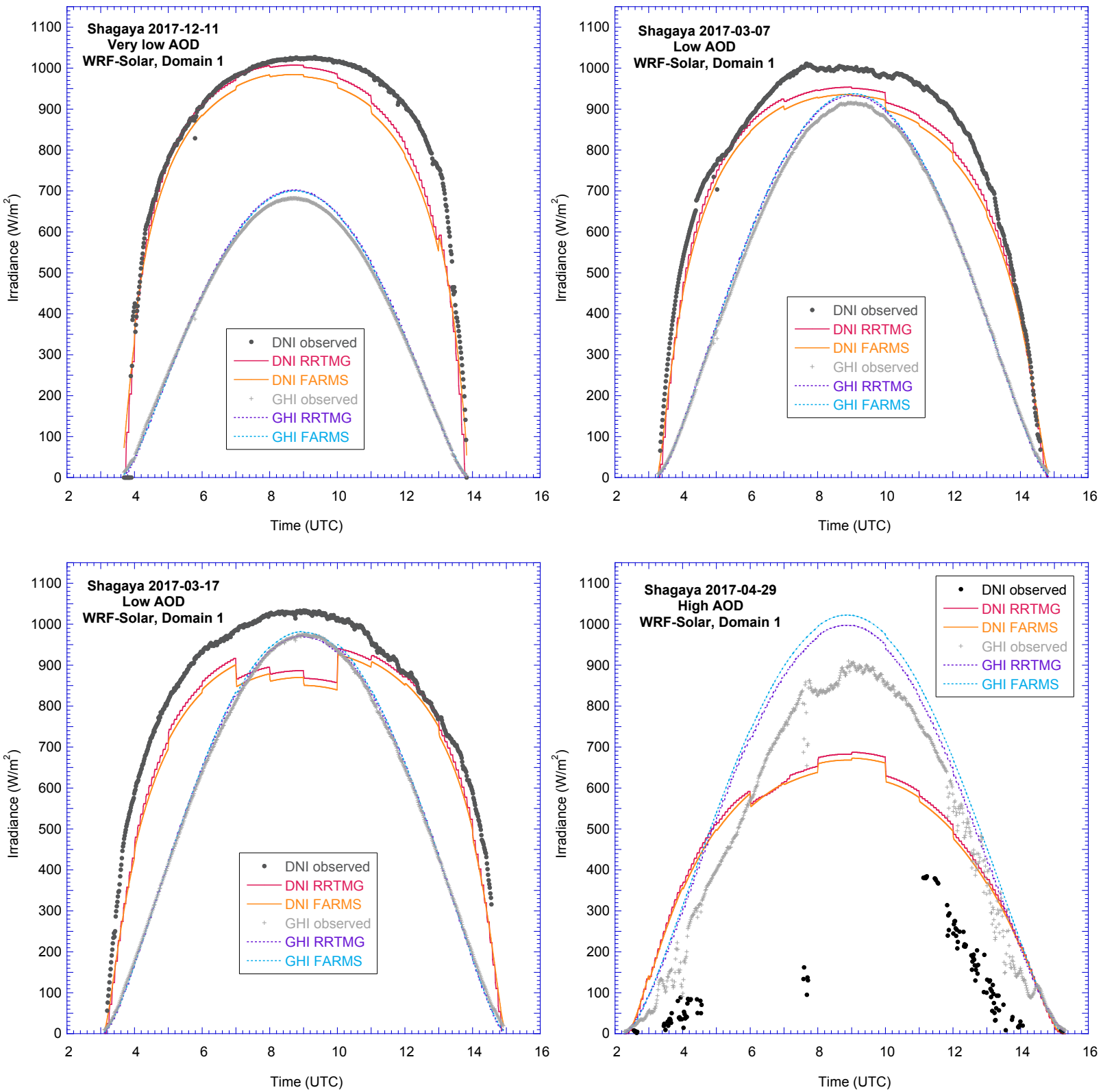

Fig. 3: Temporal variation of direct normal (DNI) and global horizontal (GHI) irradiance at Shagaya during the four cloudless (or nearly cloudless) days depicted in Fig. 2, as obtained from two radiative transfer models in WRF-Solar: RRTMG and FARMS, comparatively to local observations. The DNI observations that have been flagged during the quality control step are not shown. Most deviations between the modeled and measured values are caused by biased AOD inputs to the models.

Figure 3 shows the WRF-Solar forecasts for the same four days as in Fig. 2, based on the results from D1 at 9-km resolution. It can be observed that:

- DNI's predictions from RRTMG and FARMS quite systematically differ by $\approx 2 \%$ - a difference comparable to the experimental uncertainty in magnitude, and apparently caused by algorithmic variations-whereas their GHI predictions are almost identical, except under high-AOD circumstances.

- The DNI predictions tend to be too low compared to observations, as a direct consequence of GEOS-5's AOD being too high (Fig. 2).

- There are distinct discontinuities, or "steps", in the DNI results, which are caused by abrupt change in AOD data from one hour to the next (since no temporal interpolation is used).

- During the high-AOD event (2017-04-29), both DNI and GHI are considerably overestimated during most of the day. 
- GHI predictions are only slightly higher than observations during the very low AOD event (top left) and the first low AOD event (top right), but are in good agreement with the observations during the second low AOD event (bottom left).

Based on these examples, it can be concluded that the slight DNI prediction difference between RRTMG and FARMS is usually small in comparison to the systematic misprediction caused by the imperfect AOD inputs. Scatterplots comparing DNI and GHI forecasts from RRTMG simulations over D1 are compared to their measured counterpart in Fig. 4. The plots are clearly not symmetric, with many points scattered on the left side of the diagonal. Those data points of lower-than-expected irradiance actually correspond to real-world cloudy situations that are misdiagnosed as "cloudless" by WRF-Solar. This issue translates into a tendency to overestimate DNI and GHI when the CLW forecast is zero. How this noise affects the relative performance of RRTMG and FARMS under truly cloudless conditions is still unclear. Considering all points shown in Fig. 4 and the usual statistics (mean bias deviation, MBD, and root mean square deviation, RMSD), the overall performance of FARMS appears slightly better than that of RRTMG for DNI: MBD is $3.1 \%$ and $0.7 \%$ for RRTMG and FARMS, whereas RMSD is $19.4 \%$ and $19.1 \%$, respectively. For GHI, the opposite situation is found. MBD and RMSD are then $5.6 \%$ and $13.1 \%$ for RRTMG, and $7.7 \%$ and $14.6 \%$ for FARMS, respectively. Almost identical results are found over D2.
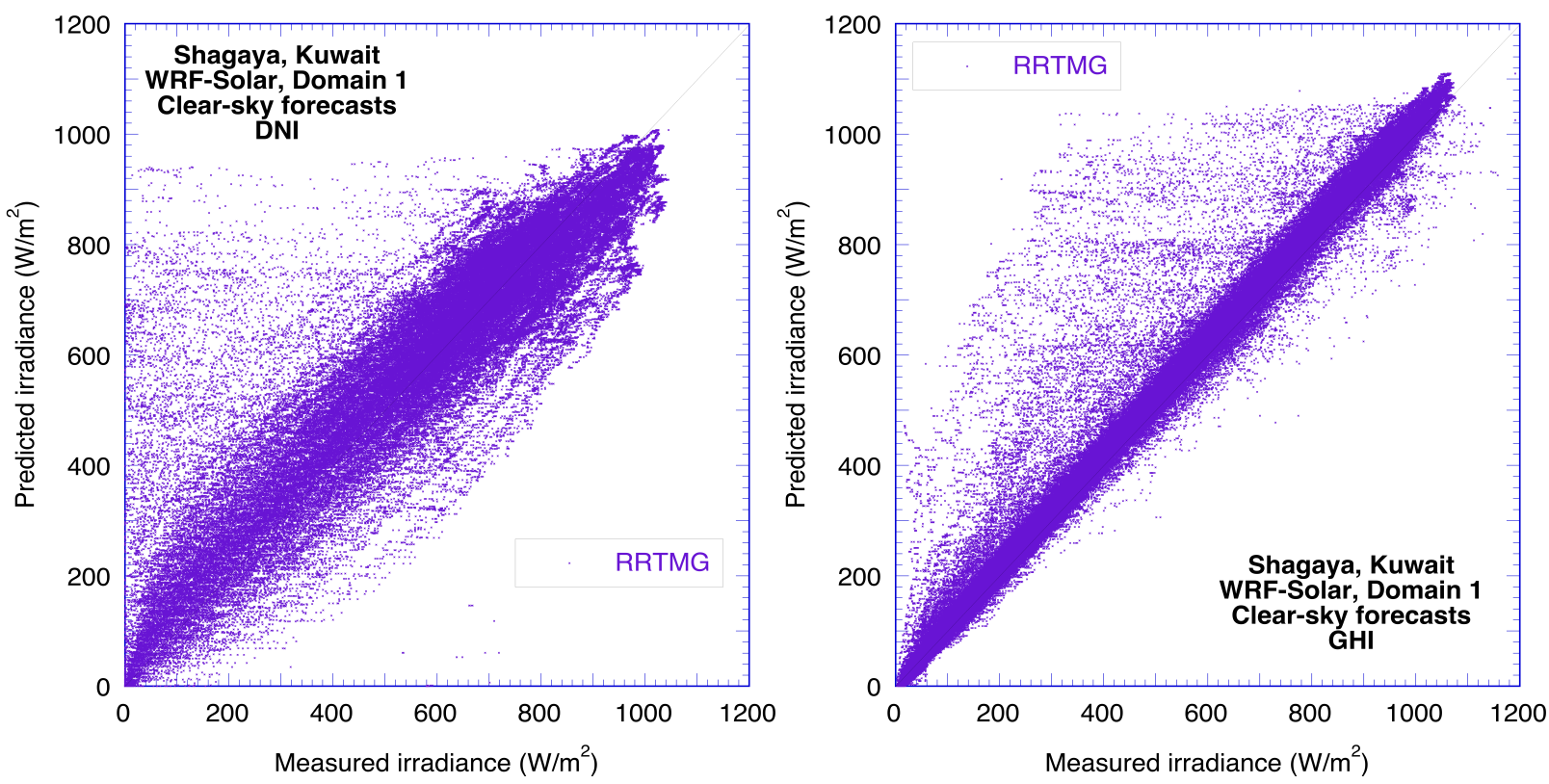

Fig. 4: Scatterplots of direct normal (DNI, left) and global horizontal (GHI, right) irradiance at Shagaya during 2017 as obtained with RRTMG over D1 during periods diagnosed as cloudless by WRF-Solar, comparatively to local observations.
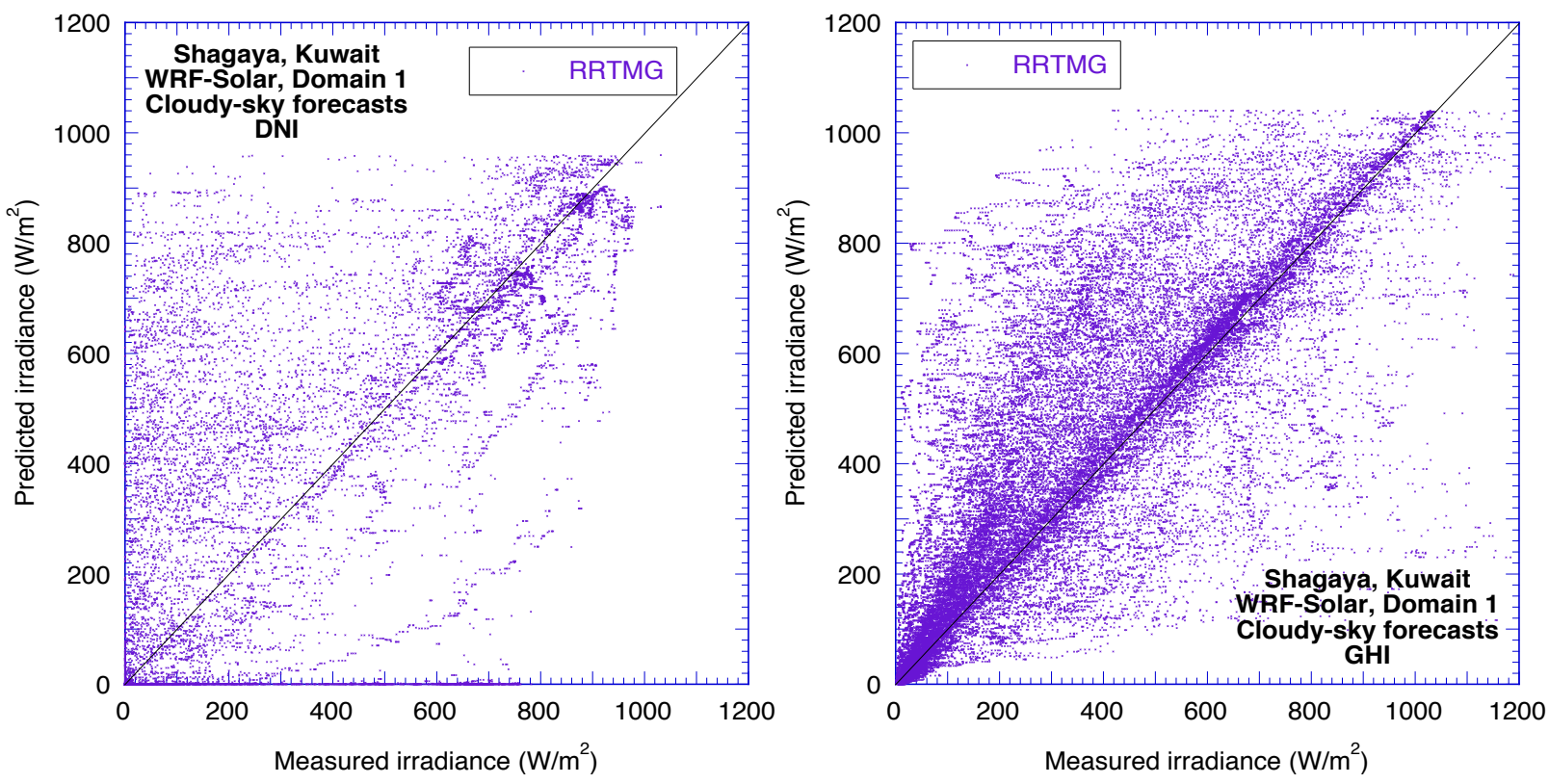

Fig. 5: Scatterplots of direct normal (DNI, left) and global horizontal (GHI, right) irradiance at Shagaya during 2017 as obtained with RRTMG over D1 during periods diagnosed as cloudy in either D1 or D2 by WRF-Solar, comparatively to local observations. 


\subsection{Cloudy conditions}

When WRF-Solar does forecast cloudy periods (CLW > 0), the predictions of GHI and DNI differ more or less significantly from observations, depending on conditions and radiative model. Figure 5 shows scatterplots similar to those in Fig. 4, but for those periods diagnosed as cloudy by WRF-Solar in either D1 or D2, which represent $19.8 \%$ of the whole dataset. Note that, in about one seventh of these cases, the conditions are diagnosed cloudless by the D1 simulations and cloudy by D2, or vice versa. Compared to Fig. 4, the scatter is considerable here, particularly for DNI, as could be expected.

The large noise displayed in Fig. 5 can be explained by the misprediction of various characteristics of the cloud field. Even more noise is generated by FARMS, which however is less biased than RRTMG overall. To gain insight into the possible triggers of these circumstances, it is important to look into a number of cases with more scrutiny. For this analysis, four days are selected, during which the forecasts by RRTMG and FARMS differ substantially, and/or the simulations for D1 and D2 are remarkably different.

Figure 6a represents the GHI forecasts for a slightly cloudy day (2017-11-04), considering both radiative models and both domains. FARMS overestimates more than RRTMG until $\approx 10: 30$ UTC, then underestimates until 12:00 UTC. Between those two times, the average between RRTMG and FARMS would have provided the best estimate. For this specific day, the response from the two domains is similar with each model.
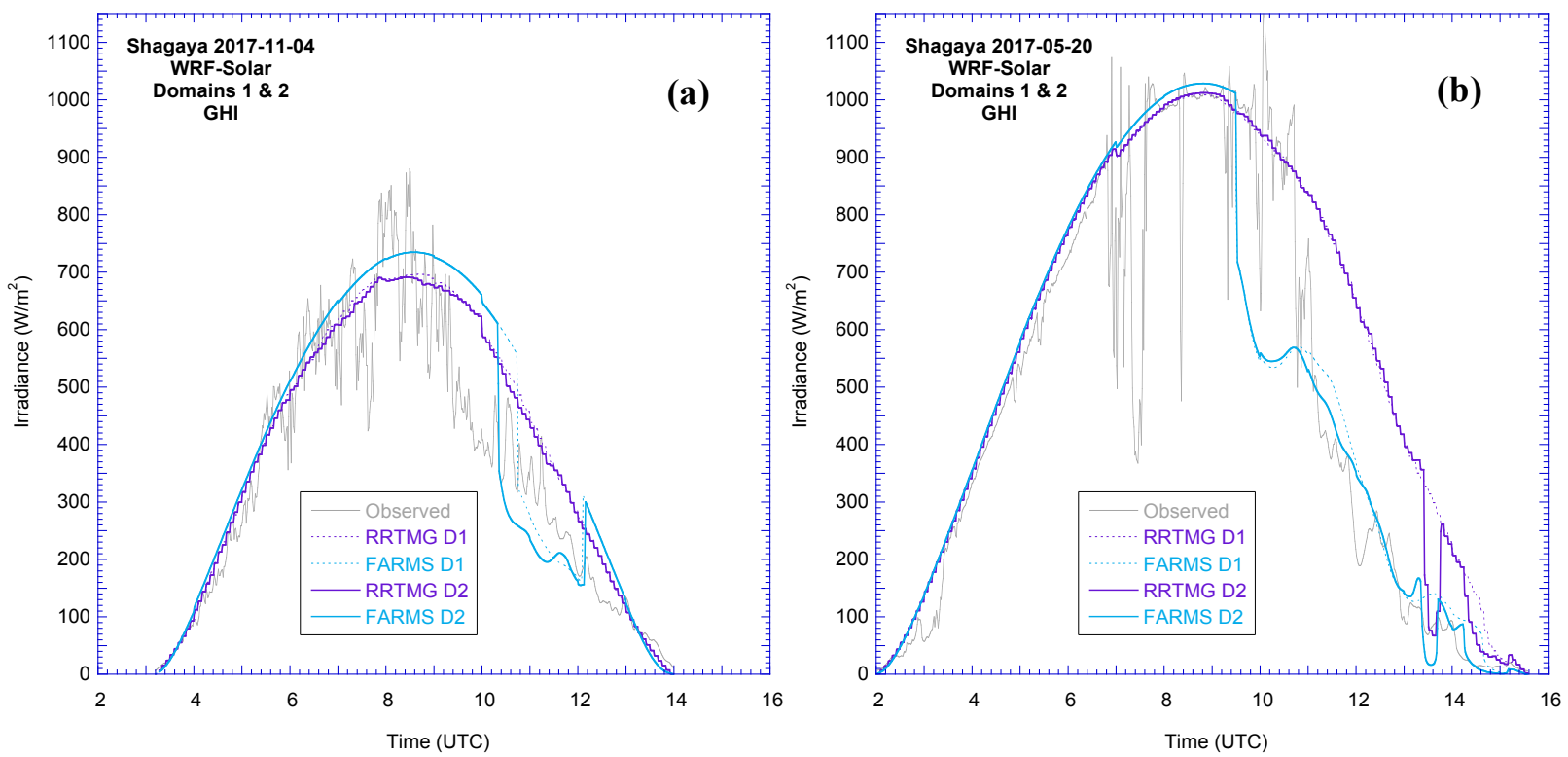

Fig. 6: Simulation of global horizontal irradiance at Shagaya during 2017-11-04 (a) and 2017-05-20 (b) as obtained with RRTMG and FARMS over both D1 and D2, comparatively to local observations.

Figure 6b is similar to Fig. 6a, but for 2017-05-20. In this case, cloudiness is more pronounced after 11:00 UTC. As before, the difference is small between the D1 and D2 results. Nevertheless, whereas RRTMG is closer to observations until 11:00 UTC, FARMS performs exceptionally well after that while RRTMG strongly overestimates.

In contrast with Fig. 6b, Fig. 7a shows results for D2 during 2017-04-16, during which scattered cloudiness conditions prevailed. The GHI predictions from FARMS then become unrealistically low, practically zero at times. The same kind of extreme FARMS underprediction occurs on 2017-05-05, for instance. The results for that day are shown in Fig, 7b, but only for RRTMG, which behaves much better. The contrast between the D1 and D2 simulations is obvious here, with the latter having a much more dynamic response to rapidly changing cloudiness. Note also the frequent cloud enhancement situations, which cannot currently be modeled by WRF-Solar. In particular, the observed GHI reached $1333 \mathrm{~W} / \mathrm{m}^{2}$ at $08: 44$ UTC, representing a $33 \%$ enhancement compared to the corresponding clear-sky value and $2 \%$ enhancement compared to the extraterrestrial value. Such circumstances are not unusual, and would be important to forecast because of the induced large ramps in power production and risks for the power electronics, such as inverters. More details on this issue are described in, e.g., Gueymard (2017). Although WRF-Solar may not be able to forecast the exact moments when these ramps occur, the fact that a highly variable GHI can be predicted using the D2 forecasts is in itself very valuable because it represents a clear alert of the risk of such ramps and/or cloud enhancement situations, based on which the solar system operator grid regulator can take appropriate decisions. 

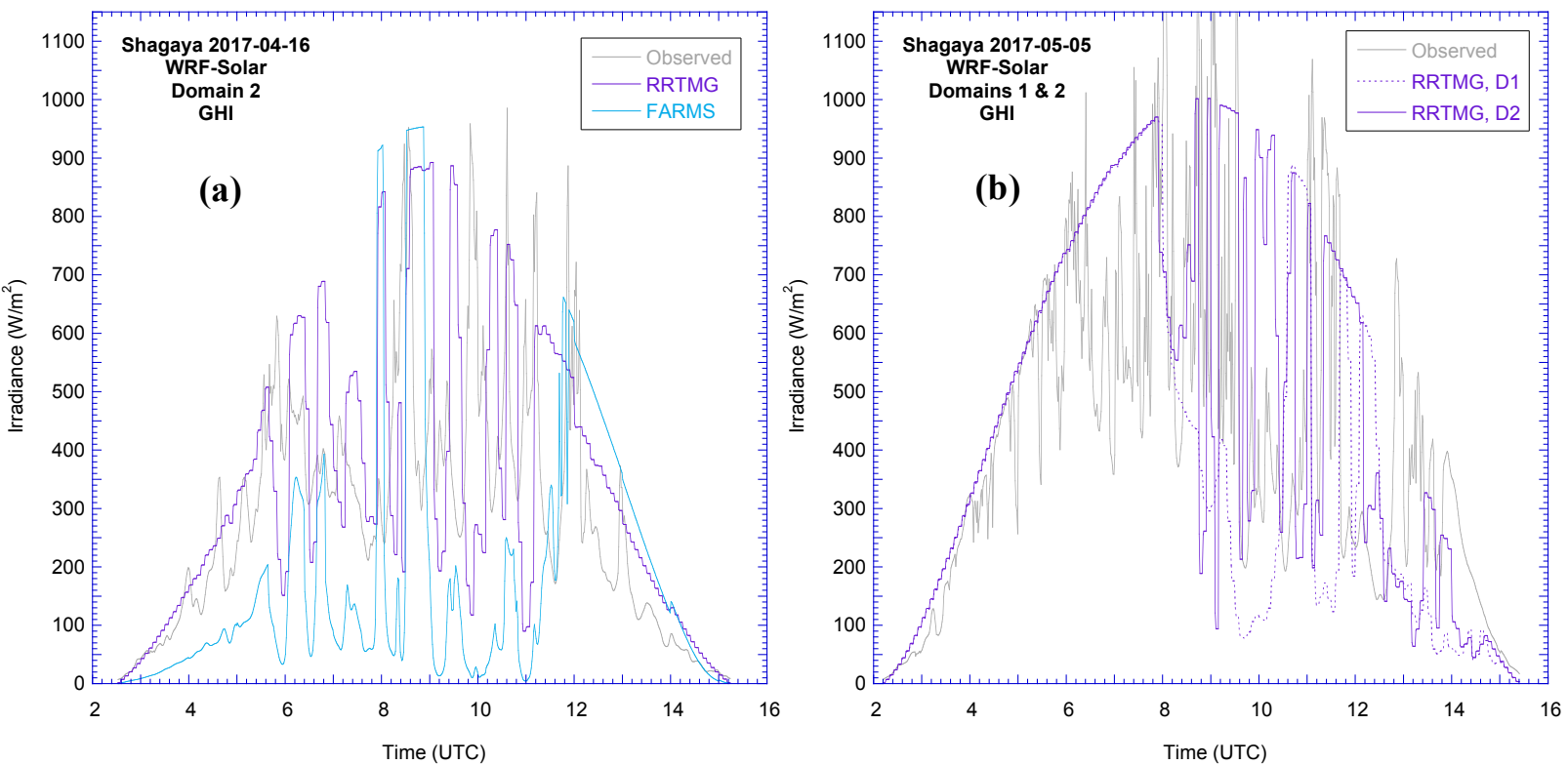

Fig. 7: Simulation of global horizontal irradiance at Shagaya during 2017-04-16 (a) and 2017-05-20 (b) as obtained with RRTMG and FARMS over both D1 and D2, comparatively to local observations.

\subsection{Discussion}

It is clear from the present results that RRTMG and FARMS tend to produce widely different predictions under various types of cloud conditions. It is anticipated that, in the near future, this can be exploited favorably through optimal combination of their results, thus leading to improved forecasts. Before this can be done, however, the FARMS implementation would first have to be corrected to eliminate its current shortcomings of, e.g. forecasting excessively low GHI under specific cloud conditions.

Tab. 1: Overall irradiance performance statistics for WRF-Solar forecasts at Shagaya, 2017 for domains D1 and D2, evaluated against observations (Obs.) of DNI and GHI. Clear conditions are selected based on WRF-Solar's diagnostic.

\begin{tabular}{|c|c|c|c|c|c|c|c|c|c|c|}
\hline \multirow[b]{2}{*}{ Statistic } & \multicolumn{5}{|c|}{ DNI } & \multicolumn{5}{|c|}{ GHI } \\
\hline & Obs. & RRTMG-D1 & FARMS-D1 & RRTMG-D2 & FARMS-D2 & Obs. & RRTMG-D1 & FARMS-D1 & RRTMG-D2 & FARMS-D2 \\
\hline \multicolumn{11}{|l|}{ CLEAR } \\
\hline Mean $\left(\mathrm{W} / \mathrm{m}^{2}\right)$ & 593.8 & 612.1 & 597.8 & 613.5 & 597.7 & 510.9 & 539.5 & 550.1 & 541.2 & 549.9 \\
\hline $\operatorname{MBD}\left(\mathrm{W} / \mathrm{m}^{2}\right)$ & & 18.3 & 4.0 & 19.7 & 4.0 & & 28.6 & 39.2 & 30.3 & 39.0 \\
\hline $\operatorname{RMSD}\left(\mathrm{W} / \mathrm{m}^{2}\right)$ & & 115.4 & 113.7 & 115.5 & 113.8 & & 67.1 & 74.4 & 68.1 & 74.4 \\
\hline MBD (\%) & & 3.1 & 0.7 & 3.3 & 0.7 & & 5.6 & 7.7 & 5.9 & 7.6 \\
\hline RMSD (\%) & & 19.4 & 19.1 & 19.5 & 19.2 & & 13.1 & 14.6 & 13.3 & 14.6 \\
\hline \multicolumn{11}{|l|}{ CLOUDY } \\
\hline Mean $\left(\mathrm{W} / \mathrm{m}^{2}\right)$ & 395.0 & 428.7 & 456.7 & 448.9 & 473.9 & 357.1 & 418.6 & 361.6 & 425.8 & 370.8 \\
\hline MBD (W/m²) & & 33.7 & 61.7 & 53.9 & 78.9 & & 61.5 & 4.5 & 68.7 & 13.8 \\
\hline $\mathrm{RMSD}\left(\mathrm{W} / \mathrm{m}^{2}\right)$ & & 273.0 & 284.0 & 259.2 & 272.4 & & 187.0 & 207.0 & 189.4 & 204.0 \\
\hline MBD (\%) & & 8.5 & 15.6 & 13.6 & 20.0 & & 17.2 & 1.3 & 19.2 & 3.9 \\
\hline RMSD (\%) & & 69.1 & 71.9 & 65.6 & 69.0 & & 52.4 & 58.0 & 53.0 & 57.1 \\
\hline \multicolumn{11}{|l|}{ ALL } \\
\hline Mean $\left(\mathrm{W} / \mathrm{m}^{2}\right)$ & 576.0 & 595.7 & 585.2 & 598.8 & 586.7 & 481.5 & 516.3 & 514.0 & 519.1 & 515.7 \\
\hline $\operatorname{MBD}\left(\mathrm{W} / \mathrm{m}^{2}\right)$ & & 19.7 & 9.2 & 22.7 & 10.7 & & 34.9 & 32.5 & 37.7 & 34.2 \\
\hline $\operatorname{RMSD}\left(\mathrm{W} / \mathrm{m}^{2}\right)$ & & 137.1 & 137.7 & 134.7 & 135.7 & & 101.6 & 112.6 & 103.0 & 111.5 \\
\hline $\operatorname{MBD}(\%)$ & & 3.4 & 1.6 & 3.9 & 1.8 & & 7.2 & 6.8 & 7.8 & 7.1 \\
\hline RMSD (\%) & & 23.8 & 23.9 & 23.4 & 23.6 & & 21.1 & 23.4 & 21.4 & 23.2 \\
\hline
\end{tabular}

Overall performance statistics are presented in Table 1, separately for the two irradiance components (DNI and GHI), the two domains (D1 and D2), the two radiative models (RRTMG and FARMS), and the three sky conditions as diagnosed by WRF-Solar (cloudless, cloudy in either D1 or D2, and all-sky conditions). Based on these simple statistics, and for the mostly cloudless conditions of Shagaya, the additional complexity of considering a high-resolution inner domain (D2) does not appear justified. This appears to be related to the "double penalty" issue, whereby the combination of observed-but-not-forecast and forecast-but-not-observed cases is more prevalent at high resolution than at low resolution (Ebert, 2008). Under clear (or nearly clear) conditions, the results for D2 
are similar (but not better) than those for D1, since they are partly driven by inaccuracies in large-scale AOD data. Under cloudy situations, either the bias or variability (or both) in DNI and GHI tends to increase when considering D2 rather than D1, which seems counterproductive. Still, as mentioned in the previous section, a potentially useful (but currently unaccounted for) value of the D2 simulations might be the additional information about the expected rate of change of GHI and DNI. Further studies will look into a way to translate this qualitative information into a tangible performance indicator from a system operation perspective.

\section{Conclusion}

In this contribution, the WRF-Solar mesoscale model has been used to forecast the day-ahead surface solar irradiance at Shagaya, Kuwait. In this arid environment, cloudless conditions are predominant, while the aerosol optical depth (AOD) is highly variable and modulates the direct normal irradiance (DNI) and, to a lesser extent, the global horizontal irradiance (GHI).

To obtain simulations for the whole year 2017 with WRF-Solar, two nested domains are defined: An outer domain (D1) at 9-km resolution and an inner domain (D2) at 3-km resolution. The latter covers Kuwait entirely. The boundary conditions are provided by 6-hourly GFS forecasts. The aerosol field in D1 and D2 is determined by the hourly AOD analysis from NASA's GEOS-5 global model. By comparison with high-quality ground observations of AOD at the Shagaya AERONET station, it is found that the GEOS-5 AOD is most often biased, severely at times. A specific assessment of the forecasts obtained during those periods diagnosed as "cloudless" by WRF-Solar (representing $\approx 80 \%$ of all daytime periods) showed that the impact on the DNI forecasts is significant overall, and less significant on GHI. It can be inferred that the error propagation from the AOD inputs to the irradiance forecasts will affect concentrating solar thermal technologies more significantly than fixed-flat-plate photovoltaic (PV) generators, with intermediate effects on tracking PV systems. In parallel, it was found that a small, albeit sizeable, fraction of those periods that are found "cloudless" by WRF-Solar are actually cloudy, which tends to bias the performance results.

Under cloudless or nearly cloudless conditions, the performance of the D1 and D2 forecasts is very similar. For periods diagnosed as "cloudy" (representing $\approx 20 \%$ of all daytime situations overall), the D2 performance appears to degrade in comparison with that for D1. This counterintuitive result may have various causes, which are still being explored, but appear directly related to the "double penalty" issue. One apparent and possibly major cause is that, under rapidly changing scattered cloudiness, the D2 forecasts do correctly predict more temporal variability than the D1 forecasts - but with imprecise timing, which tends to increase the error in the forecast. Although the (costly) D2 forecasts for both DNI and GHI might appear unnecessary because of their lower performance, their main value might reside in the day-ahead prediction of rapidly variable irradiance. This ultimately could help system operators to prepare for strong ramps, cloud-enhancement effects, need for storage, or additional generation to avoid grid instability, etc.

The two radiative transfer, RRTMG vs. FARMS, used in parallel to evaluate the surface irradiance components returned similar predictions under cloudless conditions. Their $\approx 2 \%$ difference in DNI predictions is comparable to the experimental uncertainty. Under cloudy conditions, RRTMG performed somewhat better overall. Under some types of cloudiness situations, FARMS predicted unrealistically low GHI. This might be related to the current set of acceptable limits in cloud optical depth imposed on FARMS, which would need to be corrected in a future release of WRF-Solar. Under other cloud situations, though, FARMS performed better than RRTMG. Provided that any FARMS shortcoming in the model itself or its implementation can be addressed, it appears desirable to explore the development of an optimal combination of the two models' predictions. It is also anticipated that further postprocessing, using soft-computing techniques applied to both RRTMG and FARMS results, will help improve forecasting accuracy for both GHI and DNI. Additionally, more research is needed to improve or appropriately correct the gridded AOD analyses that are required to obtain accurate DNI forecasts.

\section{Acknowledgments}

The authors thank Alaa Ismail, P.I. of the Shagaya Park station of AERONET and their staff. This work was funded by a research grant from the Kuwait Institute for Scientific Research. We particularly thank Dr. Majed AlRasheedi who oversees this project. The National Center for Atmospheric Research is sponsored by the U.S. National Science Foundation. 


\section{References}

Almeida, M.P., Perpiñán, O., Narvarte, L., 2015. PV power forecast using a nonparametric PV model. Solar Energy $115,354-368$.

Al-Rasheedi, M., Gueymard, C.A., Ismail, A., Al-Hajraf, S., 2014. Solar resource assessment over Kuwait: validation of satellite-derived data and reanalysis modeling. Proc. ISES EuroSun 2014 Conf., Aix-les-Bains.

Al-Rasheedi, M., Gueymard, C.A., Ismail, A., Hussain, T., 2018. Comparison of two sensor technologies for solar irradiance measurement in a desert environment. Solar Energy 161, 194-206.

Diagne, M., David, M., Boland, J., Schmutz, N., Lauret, P., 2014. Post-processing of solar irradiance forecasts from WRF model at Reunion Island. Solar Energy 105, 99-108.

Ebert, E.E., 2008. Fuzzy verification of high-resolution gridded forecasts: a review and proposed framework. Meteorol. Appl. 15, 51-64.

Eissa, Y., Beegum, N.S., Gherboudj, I., Chaouch, N., Al Sudairi, J., Jones, R.K., Al Dobayan, N., Ghedira, H., 2018. Prediction of the day-ahead clear-sky downwelling surface solar irradiances using the REST2 model and WRF-CHIMERE simulations over the Arabian Peninsula. Solar Energy 162, 36-44.

Fountoukis, C., Martín-Pomares, L., Perez-Astudillo, D., Bachour, D., Gladich, I., 2018. Simulating global horizontal irradiance in the Arabian Peninsula: Sensitivity to explicit treatment of aerosols. Solar Energy 163, $347-355$.

Fouquart, Y., Bonnel, B., Ramaswamy, V., 1991. Intercomparing shortwave radiation codes for climate studies. J. Geophys. Res. 96D, 8955-8968.

Grell, G.A., Freitas, S.R., 2014. A scale and aerosol aware stochastic convective parameterization for weather and air quality modeling, Atmos. Chem. Phys. 14, 5233-5250.

Gueymard, C.A., 2012. Temporal variability in direct and global irradiance at various time scales as affected by aerosols. Solar Energy 86, 3544-3553.

Gueymard, C.A., 2017. Cloud and albedo enhancement impacts on solar irradiance using high-frequency measurements from thermopile and photodiode radiometers. Part 1: Impacts on global horizontal irradiance. Solar Energy $153,755-765$.

Gueymard, C.A., Al-Rasheedi, M., Ismail, A., Hussain, T., 2017. Long-term variability of aerosol optical depth, dust episodes, and direct normal irradiance over Kuwait for CSP applications. Proc. ISES Solar World Congress, Abu Dhabi, UAE.

Gueymard, C.A., Myers, D.R., 2008. Solar radiation measurement: progress in radiometry for improved modeling. In: Badescu, V. (Ed.), Modeling Solar Radiation at the Earth Surface. Springer, pp. 1-27.

Gueymard, C.A., Ruiz-Arias, J.A., 2015. Validation of direct normal irradiance predictions under arid conditions: A review of radiative models and their turbidity-dependent performance. Renewable and Sustainable Energy Reviews 45, 379-396.

Haupt, S.E., Kosovic, B., 2016. Variable generation power forecasting as a big data problem. IEEE Transactions on Sustainable Energy 8, 725-732.

Haupt, S.E., Kosovic, B., Jensen, T., Lazo, J.K., Lee, J.A., Jimenez, P.A., Cowie, J., Wiener, G., McCandless, T.C., Rogers, M., Miller, S., Sengupta, M., Xie, Y., Hinkelman, L., Kalb, P., Heiser, J., 2018. Building the Sun4Cast system: Improvements in solar power forecasting. Bull. Amer Met. Soc. 99, 121-135.

Iacono, M.J., Delamere, J.S., Mlawer, E.J., Shephard, M.W., Clough, S.A., Collins, W.D., 2008. Radiative forcing by long-lived greenhouse gases: Calculations with the AER radiative transfer models. J. Geophys. Res. 113, D13103.

Jimenez, P.A., Dudhia, J., Gonzalez-Rouco, J.F., Navarro, J., Montavez, J.P., and Garcia-Bustamante, E., 2012. A revised scheme for the WRF surface layer formulation. Mon. Wea. Rev. 140, 898-918.

Jimenez, P.A., Hacker, J.P., Dudhia, J., Haupt, S.E., Ruiz-Arias, J.A., Gueymard, C.A., Thompson, G., Eidhammer, T., Deng, A., 2016a. WRF-Solar: description and clear-sky assessment of an augmented NWP model for solar power prediction. Bull. Am. Meteorol. Soc. 97, 1249-1264.

Jimenez, P.A., Alessandrini, S., Haupt, S.E., Deng. A., Kosovic, B., Lee, J.A., Delle Monache, L., 2016b. The role 
of unresolved clouds on short-range global horizontal irradiance predictability. Mon. Wea. Rev. 144, 3099-3107.

Kim, J-Y., Yun, C-Y., Kim, C.K., Kang, Y-H., Kim, H-G, Lee, S-N., Kim, S-Y., 2017. Evaluation of WRF modelderived direct irradiance for solar thermal resource assessment over South Korea. AIP Conf. Proc. 1850, 140013; doi: $10.1063 / 1.4984521$.

Lara-Fanego, V., Ruiz-Arias, J.A., Pozo-Vázquez, D., Santos-Alamillos, F.J., Tovar-Pescador, J., 2012a. Evaluation of the WRF model solar irradiance forecasts in Andalusia (southern Spain). Solar Energy 86, 2200-2217.

Lara-Fanego, V., Ruiz-Arias, J.A., Pozo-Vázquez, D., Gueymard, C.A., Tovar-Pescador, J., 2012b. Evaluation of DNI forecast based on the WRF mesoscale atmospheric model for CPV applications. AIP Conf. Proc. 1477, 317, doi: $10.1063 / 1.4753895$.

Lee, J.A., Haupt, S.E., Jimenez, P.A., Rogers, M.A., Miller, S.D., McCandles, T., 2017. Solar irradiance nowcasting case studies near Sacramento. J. Appl. Meteorol. Climatol. 56, 85-108.

Liu, Y., Shimada, S., Yoshino, J., Kobayashi, T., Miwa, Y., Furuta, K., 2016. Ensemble forecasting of solar irradiance by applying a mesoscale meteorological model. Solar Energy 136, 597-605.

Mlawer, E.J., Iacono, M.J., Pincus, R., Barker, H.W., Oreopoulos, L., Mitchell, D.L., 2016. Contributions of the ARM Program to radiative transfer modeling for climate and weather applications. AMS Meteorological Monographs 57, 15.1-15.19.

Mlawer, E. J., Taubman, S.J., Brown, P.D., Iacono, M.J., Clough, S.A., 1997. Radiative transfer for inhomogeneous atmospheres: RRTM, a validated correlated-k model for the longwave. J. Geophys. Res. 102D, $16663-16682$.

Montornès, A., Codina, B., Zack, J.W., 2015. A discussion about the role of shortwave schemes on real WRFARW simulations. Two case studies: cloudless and cloudy sky. Tethys 12, 13-31.

Mukkavilli, S.K., Prasad, A.A., Taylor, R.A. Troccoli, A., Kay, M.J., 2018. Mesoscale simulations of Australian direct normal irradiance, featuring an extreme dust event. J. Appl. Meteorol. Climatol. 57, 493-515.

Nakanishi, M., Niino, H., 2006. An improved Mellor-Yamada level 3 model: its numerical stability and application to a regional prediction of advecting fog. Bound. Layer Meteor. 119, 397-407.

Pierro, M., Bucci, F., Cornaro, C., Maggioni, E., Perotto, A., Pravettoni, M., Spada, F., 2015. Model output statistics cascade to improve day ahead solar irradiance forecast. Solar Energy 117, 99-113.

Powers, J.G., et al., 2017. The Weather Research and Forecasting model: overview, system efforts, and future directions. Bull. Amer. Meteor. Soc. 98, 1717-1737.

Ronzio, D.A., Collino, E., Bonelli, P., 2013. A survey on different radiative and cloud schemes for the solar radiation modeling. Solar Energy 98, 153-166.

Ruiz-Arias, J.A., Dudhia, J., Santos-Alamillos, F.J., Pozo-Vázquez1, D., 2013. Surface clear-sky shortwave radiative closure intercomparisons in the Weather Research and Forecasting model. J. Geophys. Res. 118D, 9901-9913.

Ruiz-Arias, J.A., Dudhia, J., Gueymard, C.A., 2014. A simple parameterization of the short-wave aerosol optical properties for surface direct and diffuse irradiances assessment in a numerical weather prediction model. Geosci. Model. Dev. 7, 1159-1174.

Ruiz-Arias, J.A., Quesada-Ruiz, S., Fernández, E.F., Gueymard, C.A., 2015. Optimal combination of gridded and ground-observed solar radiation data for regional solar resource assessment, Solar Energy 112, 411-424.

Tewari, M., Chen, F., Wang, W., Dudhia, J., LeMone, M.A., Mitchell, K., Ek, M., Gayno, G., Wegiel, J., Cuenca, R.H., 2004. Implementation and verification of the unified NOAH land surface model in the WRF model. 20th conference on weather analysis and forecasting/16th conference on numerical weather prediction, pp. 11-15.

Thompson, G., Field, P.R., Rasmussen, R.M., Hall, W.D., 2008. Explicit forecasts of winter precipitation using an improved bulk microphysics scheme. Part II: Implementation of a new snow parameterization. Mon. Wea. Rev. $136,5095-5115$.

Xie, Y., Sengupta, M., Dudhia, J., 2016. A Fast All-sky Radiation Model for Solar applications (FARMS): Algorithm and performance evaluation. Solar Energy 135, 435-445.

Zhong, X., Ruiz-Arias, J.A., Kleissl. J., Dissecting surface clear sky irradiance bias in numerical weather prediction: Application and corrections to the New Goddard Shortwave Scheme. Solar Energy 132, 103-113. 


\title{
Progress in Sky Radiance and Luminance Modeling Using Circumsolar Radiation and Sky View Factors
}

\author{
Christian A. Gueymard ${ }^{1}$ and Stoyanka Ivanova ${ }^{2}$ \\ ${ }^{1}$ Solar Consulting Services, Colebrook, NH (USA) \\ ${ }^{2}$ University of Architecture, Civil Engineering and Geodesy, Sofia (Bulgaria)
}

\begin{abstract}
The main applications of radiance/luminance models are reviewed here, with an emphasis on empirical models based on experimental data, typically provided by sky scanners. Such measurements, and the derived models, are subject to various limitations. Nevertheless, the Igawa radiance model is validated under the highelevation and low-turbidity conditions of Colorado, and found reasonably accurate under both clear and cloudy conditions. Here, the Igawa model is enhanced by combining it with a new parameterization of the clear-sky circumsolar radiance to improve the overall radiance prediction within the aureole region. This results in the turbidity-dependent IGI model. Based on this new anisotropic radiance model, a real sky view factor (RSVF) for partially obstructed skies can be used as a basis for realistic calculations. It can be calculated with the SOLARES software, which is designed to accept irradiance inputs from, e.g., a typical meteorological year (TMY), and thus can be used to provide hourly results at any location where a TMY or an irradiance time series is available. A simulation is performed for an ideal solar system with or without sky obstruction and compared to the classic SVF approach, resulting in significant differences. The proposed approach can be advantageously used in lieu of the conventional isotropic SVF method in many types of shading geometry in the built environment.
\end{abstract}

Keywords: Sky radiance; Luminance; Shading; Radiative transfer; Aerosols; Circumsolar radiation; Sky view factor

\section{Introduction}

The main goal of a radiance model is to describe the radiant energy emitted from any point of the sky. Luminance is similar to radiance, but after adaptation to the spectral range of human vision. A radiance/luminance model has two purposes: (i) to assist the understanding of the directional properties of solar irradiance or illuminance at the earth surface, and their bearing on various atmospheric constituents, most importantly aerosols and clouds; and (ii) to serve various applications in many fields, such as engineering, architecture, forestry, photobiology or climatology. The literature on these topics is quite abundant. In particular, the determination of the sky diffuse radiance under cloudless conditions has been at the center of many developments in atmospheric scattering theory and radiative transfer for decades. Bullrich (1964) offered one early review of such developments. More recently, it is worthwhile to underline the theoretical work that allows a precise determination of the sky radiance distribution from the aerosol optical properties (Burley et al., 2017; Kocifaj, 2009, 2012, 2015; Liang and Lewis, 1996; Zibordi and Voss, 1989). Conversely, the measurement of sky radiance is at the core of inversion methods that aim at deriving some essential aerosol properties (Dubovik and King, 2000; Nakajima et al., 1996; Oliveros et al., 1998; Qin et al., 2002).

All the models just mentioned are of a spectral nature, which entails a high level of complexity (including the need for specialized inputs) that makes them typically incompatible with most applications in solar engineering or architecture, for instance. For such applications, many simpler models of a broadband nature have been developed over the years. Both radiance and luminance models of this type can be classified into either clear-sky models (e.g., Gueymard, 1986; Harrison and Coombes, 1988; Vida et al., 1999) or all-sky models (e.g., Brunger and Hooper, 1993; Igawa, 2014; Kocifaj, 2011; Kocifaj and Gueymard, 2017; Perez et al., 1993; Rosen et al., 1989). A partial review of such models was proposed by Torres and Torres (2008). 
Like irradiance, radiance has two different components - direct (beam) and diffuse. For simplification, the direct component is usually considered as emanating from a simple point source at the center of the sun disk. The diffuse radiance distribution over the whole sky hemisphere is not trivial and has been the topic of many experimental or theoretical investigations, as reviewed above. From a solar engineering standpoint, the integrated diffuse radiance from the visible sky parts leads to the estimation of the diffuse irradiance under a partly obstructed sky. Related tasks are the determination of the diffuse irradiance on tilted planes or of the optimal tilt and azimuth of solar systems (Li and Lam, 2007; Smith et al., 2016), particularly in the presence of obstructions (Lou et al., 2016). A convenient way to solve diffuse shading calculations is to rely on the sky view factor (SVF) concept. Whereas, in general, this assumes that the sky radiance is isotropic, it is now possible to take into account the actual anisotropy of the radiance/luminance (Ivanova and Gueymard, 2018). In parallel, sky luminance models are important for architectural and daylighting applications since they condition the illuminance (or daylight availability) inside buildings (Acosta et al., 2015; Darula et al., 2015).

In the engineering or architectural practice, all radiance/luminance models in current use are based on an empirical representation of experimental data, typically provided by sky scanners (Brunger and Hooper, 1991; Harrison and Coombes, 1988; Igawa, 2014; Wittkopf and Soon, 2007). Such measurements-and the derived models - are subject to various limitations, particularly in the circumsolar region (or "aureole"). That region is particularly bright when the sun and its immediate proximity are either unobscured (clear sky) or obscured with a thin layer of cirrus cloud (Blanc et al., 2014). The present investigation is aimed at exploring improvement possibilities on these limitations, and at developing a radiance/luminance model amenable to the precise calculation of anisotropic sky view factors.

\section{Experimental and modeling limitations}

Most sky scanners implement the Tregenza (1987) method of mapping the sky into elements, or "patches", of roughly equal angular size $(\approx 0.2 \mathrm{rad})$. Although Tregenza's original design called for 151 such patches, in later experimental implementation this number was reduced to 145, for reasons explained elsewhere (Subramaniam and Mistrick, 2017). This low number of elements entails a coarse spatial resolution. Moreover, a complete sky scan takes a few minutes to complete, which indicates a coarse temporal resolution as well, and a likely risk of errors under rapidly changing sky conditions. Furthermore, due to stray-light contamination, no accurate measurement can be made within $15-20^{\circ}$ from sun center. This limitation means that the bright aureole surrounding the sun cannot be modeled correctly from such data. Similarly, the radiance near the horizon cannot be measured precisely due to contamination from surface reflections. Hence, the radiance/luminance model developed by Igawa (2014), for instance, is based on measured datasets that exclude all radiance observations that are within $18^{\circ}$ of sun center or within $6^{\circ}$ of the horizon. Consequently, the radiance/luminance models empirically derived from such data cannot predict the circumsolar radiance reliably, and tend to underestimate it since it is much brighter there than elsewhere under clear conditions, in particular. A method to alleviate this issue is investigated in what follows.

Aerosol particles scatter intensely in the forward direction, which explains the brightness of the sun aureole region. The angular intensity of this scattering is described by a phase function that is specific to each type of aerosol, and thus varies over time and space. (Alternatively, this quantity is referred to as "indicatrix" in the luminance literature (Kittler, 1994).) For simplification, the empirical radiance/luminance models of the literature do not use any specific information on aerosol type, or even turbidity, which prevents a correct modeling of the radiance in the aureole. This is exemplified in Fig. 1, which compares the clear-sky diffuse radiance in the principal plane (i.e., the vertical plane containing the sun and the zenith), as predicted by four models of the literature that are representative of two distinct groups: Turbidity-independent models (Brunger and Hooper, 1993; Igawa, 2014) vs. turbidity-dependent models (Gueymard, 1986; Vida et al., 1999). The radiance is normalized by the diffuse horizontal irradiance, evaluated here for winter conditions (sun elevation, $h=30^{\circ}$ or zenith angle, $Z=60^{\circ}$ ) in Sofia, Bulgaria under clean conditions (characterized by an aerosol optical depth at $1 \mu \mathrm{m}, \beta$, of 0.025). The turbidity-independent models by Brunger and Hooper (1993) and Igawa (2014) agree relatively well, whereas the turbidity-dependent models of Vida et al. (1999) and Gueymard (1986) predict widely different circumsolar radiance. Similar comparisons, involving another set of four models, have been described by Gracia et al. (2011). A method to correctly evaluate the circumsolar radiance components is discussed in Section 4, and an application for the built environment is proposed in Section 5. 
Despite its expected lack of accuracy in the solar aureole or close to the horizon, the Igawa (2014) model appears an interesting option for general modeling of both radiance and luminance — considering that basically all other models are rather exclusive, i.e., designed to represent either radiance or luminance distributions. Moreover, Igawa's model is based on a long series of carefully conducted radiance and luminance measurements, and also benefits from a variety of ancillary meteorological observations. All this is conducive to prediction results of potentially good accuracy, at least over areas of similar climate to the urban environments where the measurements were conducted (in Osaka and Tokyo, Japan). To receive general acceptance, the model still needs to be validated in a broader sense. To that effect, a limited validation is conducted at a site with a widely different climate, as discussed in the next Section.

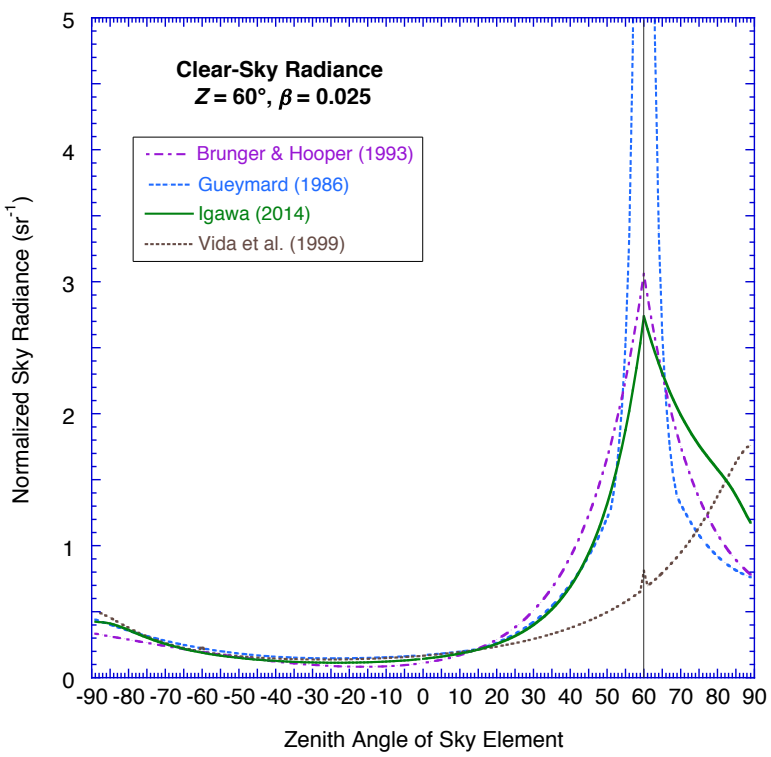

Fig. 1. Sky radiance (normalized by the diffuse horizontal irradiance) in the principal plane obtained by four different models under typical (low-turbidity) conditions for winter in Sofia. The vertical line indicates the sun's position (zenith angle: $\left.60^{\circ}\right)$.

\section{Igawa's model performance in Colorado}

The National Renewable Energy Laboratory (NREL) conducted three years of measurements (from June 14, 2000 to October 28, 2002) of sky radiance and luminance distribution at 145 sky points with an EKO MS300LR Sky Scanner. Scans (lasting 3.5 minutes each) were acquired every 15 minutes during the whole day at the Solar Radiation Research Laboratory (SRRL; https://midcdmz.nrel.gov/srrl_bms/) in Golden, Colorado (lat. $39.742^{\circ}$, long. $-105.18^{\circ}$, elev. $1828.8 \mathrm{~m} \mathrm{AMSL}$ ). Additionally, the same website offers detailed 1-min global and diffuse solar irradiance data, among many other radiometric or meteorological observations. These two irradiance quantities are the normal input data for Igawa's all-sky luminance and radiance model. Owing to its high elevation, that station experiences a much cleaner atmosphere (lower turbidity) than most urban areas, such as those where Igawa's model was developed.

A preliminary analysis of the measured radiance is required for quality-control purposes. It is found that the scanner reported anomalous null values of radiance much too frequently, signaling either very low radiance values (under the instrument's detection threshold) or possible malfunction in hardware of software. Another problem is that the scanner was apparently not correctly calibrated, as revealed when comparing the horizontally integrated sky radiance with the measured diffuse horizontal irradiance. The ratio between the measured irradiance and the spatially integrated radiance is found equal to 1.53 . This correction factor is thus applied as a pseudo calibration coefficient for the validation exercise described below.

Figure 2 illustrates the horizontal projections of sky diffuse radiance, as measured with NREL's sky scanner (left column) and modeled with Igawa's model (right column) during two moments (one per row) of a single cloudy day (2000-06-15). The occasional sky patches with reported null values are displayed in magenta. Visual inspection of a large number of such images proves how precise the Igawa's model reflects the anisotropic nature of sky diffuse radiance. 

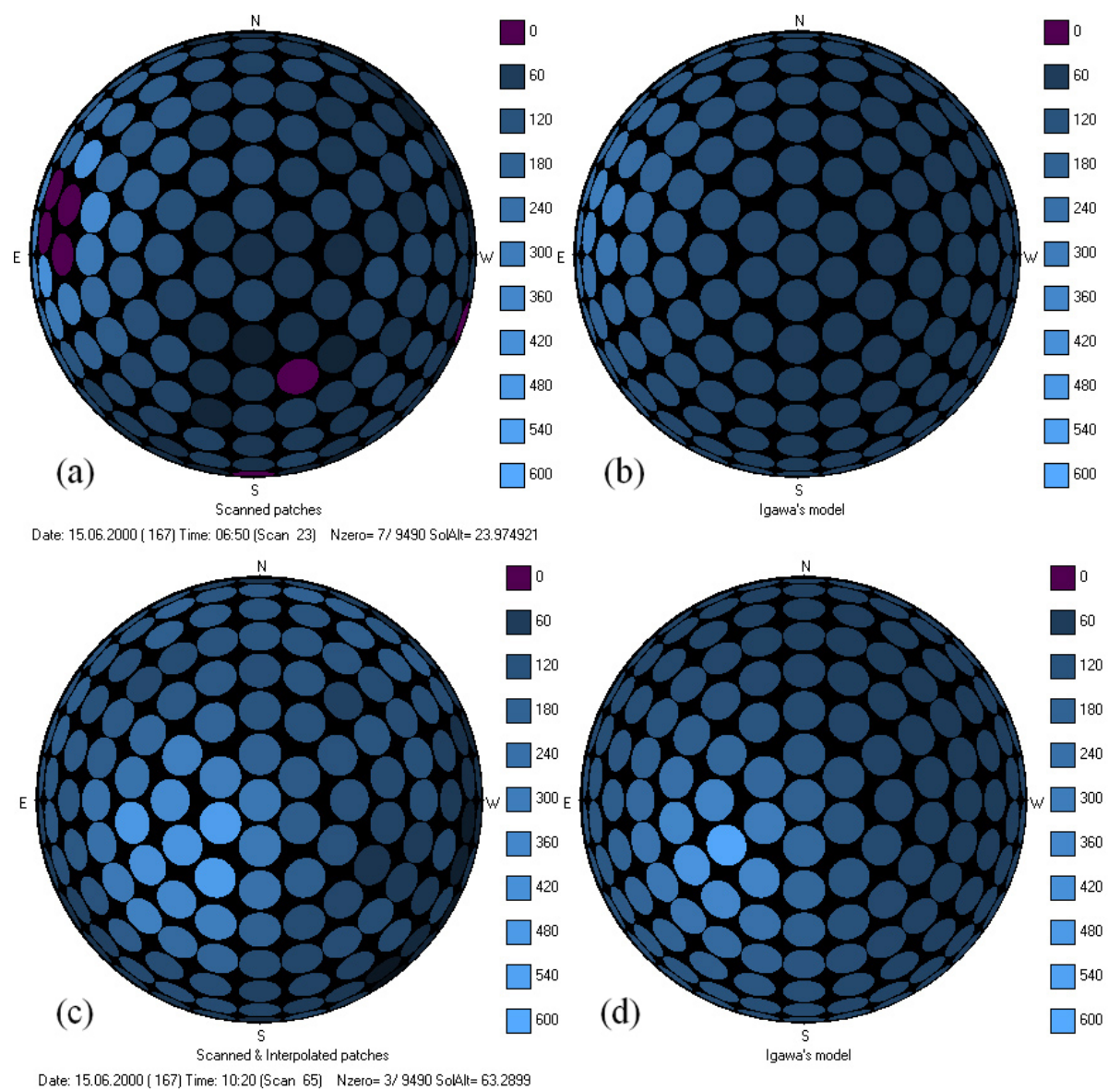

Fig. 2. Horizontal projections of sky diffuse radiance for 145 patches during two moments of a cloudy day, 2000-06-15: (a) Scanned radiance at 06:50 local standard time (magenta circles are for anomalous zero radiance in seven patches);

(b) Igawa-modeled radiance at 06:50 for the same 145 patches; (c) Scanned radiance at 10:20 (the radiance in three anomalous null patches is interpolated from their neighbors); (d) Igawa-modeled radiance at 10:20 for the same 145 patches. The solar altitude (SolAlt or $h$ ) is indicated in each case.
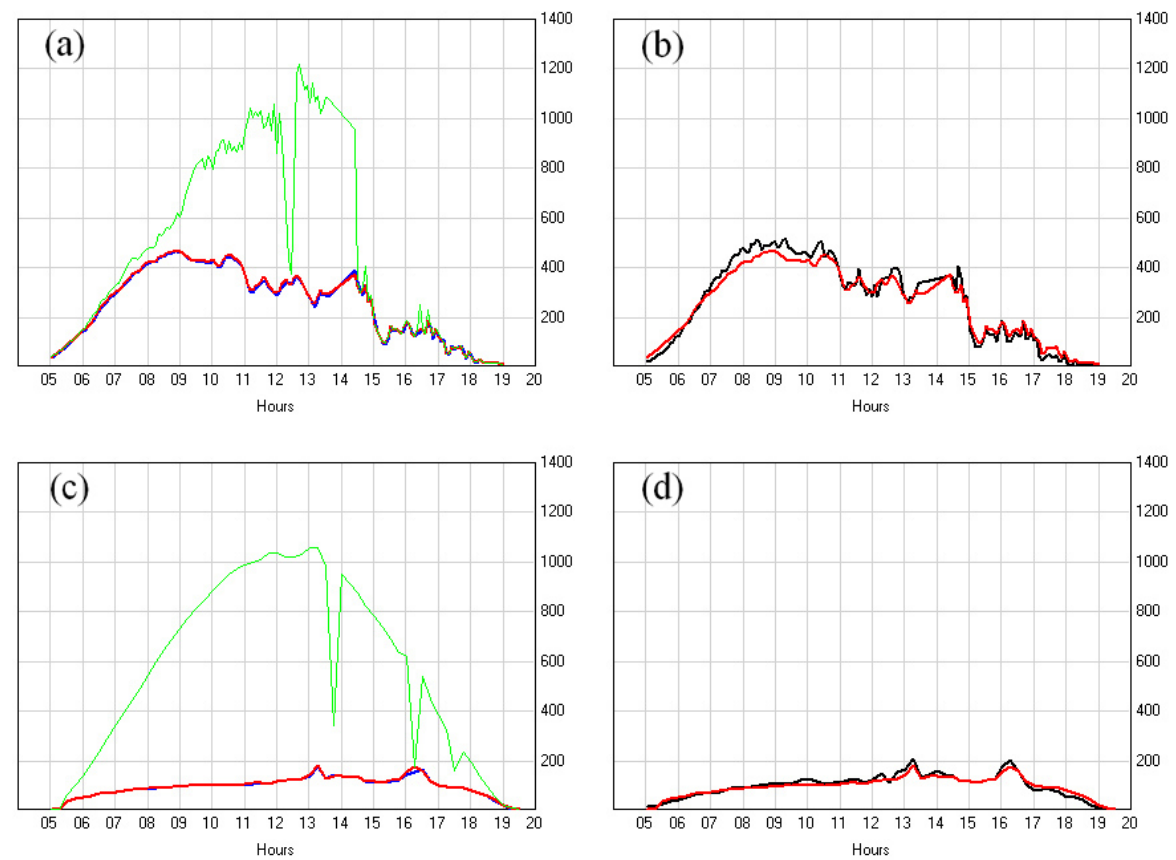

Fig. 3. Components of irradiance measured or modeled at NREL's station in Colorado. Green line is for measured global horizontal irradiance, red line is for measured diffuse horizontal irradiance, blue line is for predicted irradiance using modeled radiance (Igawa, 2014), and black line is for integrated diffuse irradiance from experimental radiance measurements after interpolation of anomalous null patches. (a, b) predominantly cloudy sky, 2000-06-15; (c, d) clear sky, 2000-07-22. 
For the same cloudy test day as in Fig. 2, the top row of Fig. 3 indicates the close agreement between the diffuse horizontal irradiance measured with a pyranometer (in red), the predicted diffuse irradiance derived from Igawa's model (in blue), and the spatially integrated measured radiance based on the interpolated scanned values (in black). Similarly, the bottom row of Fig. 3 is for a mostly clear day (2000-07-22). The red and blue lines almost coincide in both cases, which indicates a good performance of the model under varied sky clearness conditions. For the cloudy day, however, the black line of integrated experimental diffuse radiance exceeds the measured diffuse irradiance. This can be caused in part by inadequacies caused by the rapidly changing sky conditions, or by shortcomings in the model under some specific types of clouds.

A more systematic comparison is performed between the diffuse irradiance measured with a pyranometer and that obtained by spatially integrating Igawa's radiance, under favorable conditions $\left(h>10^{\circ}\right.$ and scans with less than 30 null patches). All null patches with zero radiance are substituted with interpolated values, calculated from the radiance of neighboring patches with valid and non-null data. Sky patches considered valid here are those whose center's altitude is more than $6^{\circ}$ and that are at a minimum distance of $18^{\circ}$ from sun center. Using the estimated values of the modeled diffuse radiance and their deviations in comparison with the scanned values, statistical indicators such as MBD (Mean Bias Deviation), rMBD (relative Mean Bias Deviation, in percent), MAB (Mean of Absolute Bias), and RMSD (Root Mean Square Deviation), are calculated. The results for June and July 2000 are given in Table 1 . The daily level of cloudiness is indicated by the diffuse ratio, $K$, defined as $H_{d} / H$, the ratio of the daily diffuse and global horizontal irradiations. $K$ varied between 0.16 and 0.93 during the two months, thus allowing the validation of Igawa's model for very clear to very cloudy sky conditions. Overall, the model is found to behave adequately at the SRRL station, despite its widely different climate than the low-elevation urban climates pertaining to Igawa's model. Due to the experimental limitations encountered here, more validation is desirable at sites using high-resolution sky cameras and emerging processing techniques (e.g., Chauvin et al., 2015), for instance.

Tab. 1: Results from the analysis of radiance and irradiance data for June and July 2000 in Colorado.

\begin{tabular}{|c|c|c|c|c|c|c|c|c|}
\hline Date & $\begin{array}{l}\text { Number of } \\
\text { scan cycles }\end{array}$ & $K$ & $\begin{array}{c}\text { MBD } \\
\left(\mathrm{W} / \mathrm{m}^{2} \mathrm{sr}\right)\end{array}$ & $\begin{array}{l}\mathrm{rMBD} \\
(\%)\end{array}$ & $\begin{array}{c}\mathrm{MAB} \\
\left(\mathrm{W} / \mathrm{m}^{2} \mathrm{sr}\right)\end{array}$ & $\begin{array}{c}\text { RMSD } \\
\left(\mathrm{W} / \mathrm{m}^{2} \mathrm{sr}\right)\end{array}$ & $\begin{array}{c}\text { Modeled/Observed } \\
H_{d}\end{array}$ & $\begin{array}{c}\text { \# Analyzed } \\
\text { patches }\end{array}$ \\
\hline 2000-06-14 & 110 & 0.232 & -8.4 & -11.1 & 32.4 & 42.2 & 0.991 & 5167 \\
\hline $2000-06-17$ & 169 & 0.565 & -4.9 & -5.0 & 42.0 & 55.5 & 1.079 & 9924 \\
\hline 2000-06-18 & 169 & 0.474 & -13.0 & -13.6 & 42.5 & 55.8 & 0.950 & 11218 \\
\hline 2000-06-19 & 81 & 0.518 & -2.4 & -2.8 & 44.1 & 57.0 & 1.064 & 2587 \\
\hline $2000-06-24$ & 59 & 0.440 & -5.5 & -6.2 & 50.4 & 63.6 & 1.032 & 3341 \\
\hline $2000-06-25$ & 59 & 0.697 & -7.0 & -7.3 & 45.6 & 58.9 & 1.057 & 2584 \\
\hline $2000-06-26$ & 59 & 0.927 & -6.3 & -10.3 & 21.0 & 26.6 & 1.067 & 1724 \\
\hline $2000-06-28$ & 50 & 0.707 & -5.6 & -6.7 & 30.5 & 40.1 & 1.056 & 2051 \\
\hline $2000-07-01$ & 59 & 0.570 & -7.4 & -7.6 & 50.6 & 64.1 & 1.059 & 2800 \\
\hline $2000-07-05$ & 59 & 0.198 & -1.4 & -2.6 & 28.7 & 42.2 & 1.104 & 1724 \\
\hline $2000-07-16$ & 59 & 0.725 & -15.6 & -12.1 & 48.6 & 63.2 & 1.025 & 2802 \\
\hline $2000-07-17$ & 59 & 0.467 & -8.3 & -10.4 & 38.7 & 51.3 & 1.012 & 2700 \\
\hline $2000-07-18$ & 59 & 0.202 & 2.6 & 3.9 & 37.8 & 47.3 & 1.098 & 754 \\
\hline $2000-07-20$ & 59 & 0.189 & -9.9 & -16.0 & 36.0 & 50.4 & 1.005 & 1942 \\
\hline $2000-07-21$ & 59 & 0.184 & -7.0 & -13.6 & 30.3 & 44.1 & 0.996 & 2372 \\
\hline $2000-07-22$ & 59 & 0.161 & -0.9 & -2.6 & 19.3 & 29.6 & 1.018 & 1509 \\
\hline
\end{tabular}

\section{Circumsolar radiance}

Based on the discussion in Section 2, it is argued here that Igawa's model (as well as essentially all empirical radiance models based on similar sky scanner measurements) cannot be accurate in the circumsolar (CS) region. That region extends from the edge of the sun's disk to a few degrees around it. Although there is no accepted definition of its precise extent, it is important to note that the innermost area within $2.5^{\circ}$ of sun center is considered as direct irradiance in field radiometry (Blanc et al., 2014). For the present purpose, the CS area is defined as the sky annulus between the edge of the sun's disk (at $\approx 0.26^{\circ}$ from its center) up to $\approx 6^{\circ}$.

Thick clouds do not transmit direct irradiance and do not generate CS radiance either. In contrast, thin clouds (like cirrus) do transmit direct irradiance and actually generate high levels of CS radiance (Blanc et al., 2014). 
Because of the complexity of modeling such situations, they are not considered in what follows. Rather, a pure clear-sky CS circumsolar radiance model is developed using parameterized results from SMARTS v2.9.8 (Gueymard, 2001). A rural aerosol model is assumed, along with a wide range of zenith angles $\left(0-85^{\circ}\right)$ and of turbidity ( $\beta$ from 0 to 0.6 ). Denoting $\xi$ (in degrees) as the scattering angle (i.e., the angular distance between sun center and a sky element), the simulated broadband CS radiance can be accurately modeled as

$$
L_{C S} / E_{d}=\left(A_{0}+A_{1} \xi\right) /\left(1+A_{2} \xi\right) \quad \text { (eq. 1) }
$$

where $E_{d}$ is the clear-sky diffuse horizontal irradiance, and $A_{i}(i=0-2)$ are intricate functions of both $\beta$ and relative air mass, $m$ (a pure function of $Z$ ); see Appendix. Figure 4 shows two examples of the normalized radiance thus obtained for high-sun $\left(h=60^{\circ}\right.$ or $\left.Z=30^{\circ}\right)$ and low-sun $\left(h=30^{\circ}\right.$ or $\left.Z=60^{\circ}\right)$ conditions and variable turbidity. Note the strong effect of turbidity, and that the maximum normalized radiance is reached for $\beta \approx 0.15$. It is verified that Eq. (1) can be extrapolated to at least $\xi=10^{\circ}$. Because this CS radiance decreases steeply with $\xi$, it becomes lower than Igawa's clear-sky radiance within typically $2-6^{\circ}$ from sun center. Assuming cloudless conditions in the CS area, the CS-corrected radiance model takes the form

$$
L_{c}=\operatorname{Max}\left(L_{C S}, L_{I c}\right)
$$

where $L_{I c}$ is Igawa's clear-sky radiance model mentioned above. Examples of results obtained with Eq. (2) are shown in Fig. 5, which is similar to Fig. 1. For the same zenith angle of $60^{\circ}$, the impact of $\beta$ is obvious. It appears, however, that Eq. (2) translates into a radiance distribution that lacks the expected smoothness at the seams, due to the simplicity of this preliminary version of the overall radiance model described by Eq. (2).
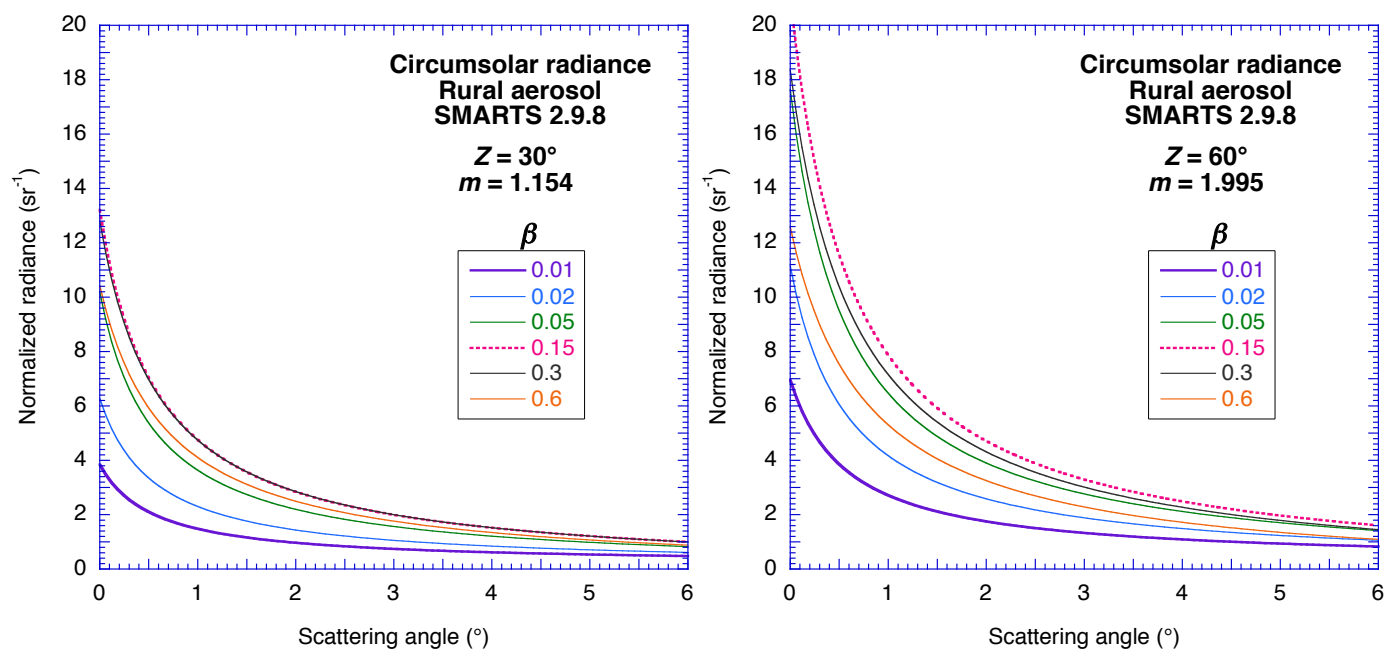

Fig. 4. SMARTS-derived circumsolar radiance for two zenith angles and various turbidity conditions
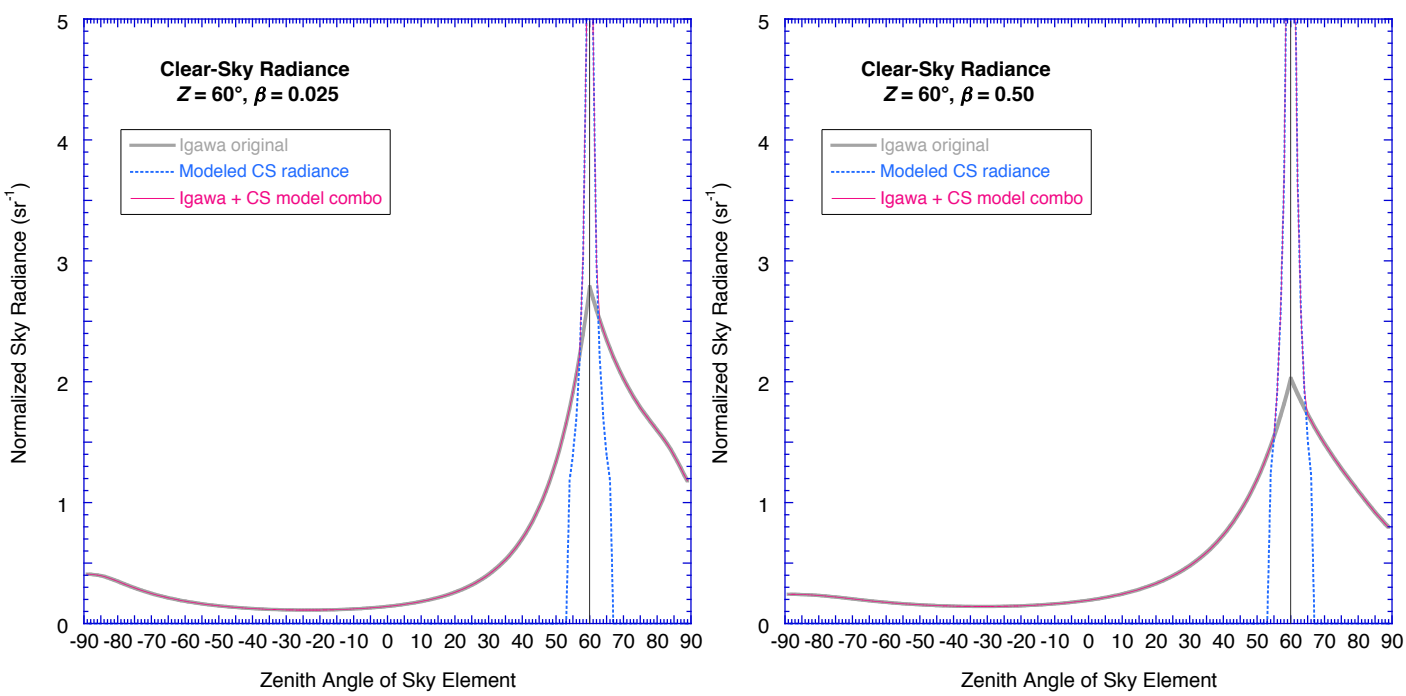

Fig. 5. Clear-sky radiance along the principal plane for very clean conditions (left) and hazy conditions (right), showing the components of Eq. (2) 


\section{Sky radiance anisotropy and sky view factors}

The concept of "Sky View Factor" (SVF) is widely used in many applications. It denotes the ratio between the radiation received by a planar surface and that from the entire radiating (i.e., unshaded) sky hemisphere. For simplification, the "classic" approach is to calculate SVF as the fraction of sky visible from the ground. This implies a simple isotropic diffuse approximation, which states that the radiance (or luminance) is uniform over the whole sky hemisphere. In the general case (e.g., Figs. 1 or 5) this assumption is not realistic, and thus leads to significant errors. In what follows, an example of anisotropic SVF for partially obstructed skies, generated with the help of the improved version of an orthographic urban radiance model (Ivanova, 2015), illustrates the gain of accuracy that can be expected in practice by following a more physical method than that based on the conventional isotropic assumption.

For this demonstration, a complete annual set of daily cumulative radiance patterns is prepared with the highresolution SOLARES model (Ivanova and Gueymard, 2018) for the particular location of Sofia during a single year, 2014. The input dataset consists of the hourly SARAH satellite-derived irradiance values obtained from PVGIS (http://re.jrc.ec.europa.eu/pvg_tools/en/tools.html). In the control experiment, the sky diffuse radiance and tilted irradiance values are calculated with the naïve assumption of an isotropic radiance. This is compared to two slightly different anisotropic approaches: (i) the Igawa model, as published (Igawa, 2014); and (ii) a more involved model obtained by combining that model with the simple circumsolar model described in Section 4 , for solar altitudes more than $5^{\circ}$ and for sky patches within $6^{\circ}$ of sun center. The input data are values of $\beta$ and clear-sky determinations for the three irradiance components, obtained with hourly atmospheric data from NASA's MERRA-2 reanalysis and the REST2 model (Gueymard, 2008a). In particular, the clear-sky determination of the direct normal irradiance, DNI, is denoted $\mathrm{DNI}_{\mathrm{clr}}$. Using these values, the clear-sky diffuse radiance is estimated with Igawa's specific model for clear-sky conditions, $L_{I c}$. That radiance is compared with the diffuse radiance estimated with the CS model, again for clear conditions in the aureole. For each hour, the effective whole-sky radiance is obtained as a weighted average of the clear-sky radiance including circumsolar effects and all-sky Igawa radiance:

$$
L=F L_{c}+(1-F) L_{I}
$$

where $F$ is the direct clear-sky index (i.e., DNI/DNI $I_{c l r}$ ), $L_{c}$ is the clear-sky radiance from Eq. (2), and $L_{I}$ is the all-sky Igawa radiance. $F$ is a proxy for the fractional time during which the aureole can be assumed cloudless. The resulting radiance is compared again with Igawa's all-sky radiance and the larger of the two values is stored as the effective diffuse radiance of the corresponding patch, without any temporal interpolation (although this is technically possible). This development uses the same beam radiance as with the pure Igawa model or the control experiment. The new sky radiance model is referred to here as IGI (Igawa-GueymardIvanova).

The usefulness of anisotropic SVF modeling is demonstrated below with two simple examples, one involving an unobstructed sky and the other involving obstructions and partial shading. In both examples, two very long photovoltaic (PV) panel rows are to be located in Sofia, facing south. The optimum angle to maximize its annual sky irradiation is to be determined using the radiance models described above. For this purpose, the global tilted irradiation is estimated for tilts from $0^{\circ}$ to $90^{\circ}$ using a constant step of $1^{\circ}$. The calculation procedure includes the estimation of the annual diffuse $\left(H_{d}\right)$ and beam $\left(H_{b}\right)$ irradiations on the tilted surface, as well as their sum, $H_{t}$. The reflected irradiance is assumed low and is simply ignored.

One appropriate tool to undertake the numerous calculation steps that are necessary to handle the examples above is the SOLARES software (Ivanova and Gueymard, 2018). Typical inputs are time series of the usual hourly irradiation components that can be found in, e.g., Typical Meteorological Year (TMY) files. A preprocessor creates an annual database with daily cumulative beam and diffuse sky radiance patterns, taking into account anisotropic effects into consideration. This information is stored using a sky division scheme with a selectable number of sky patches. In the results discussed below, a high-resolution scheme with 147,457 patches, referred to as "Reinhart MF:32", is used (Fig. 6b). It is considerably more detailed than the conventional 145-patch Tregenza's scheme (Fig. 6a), and thus allows better modeling of the sky radiance. The cumulative database is then used to calculate the direct and diffuse irradiations incident on any tilted plane, with or without shading, with the help of fisheye orthographic projections of the sky hemisphere and shading objects (Ivanova, 2015). 
The SOLARES software also provides visualization of the results. For instance, Fig. 7 shows inclined projections of annual sky radiance patterns onto rows of PV panels with different tilts. The sky and the ground (in green) are partially shaded by the closest row of panels. The sky's black shade looks fuzzy because it is averaged over 20 segments, which are positioned at regular intervals along the central panel's height ( $1 \mathrm{~m}$ assumed), and have a different viewpoint to the shading surface. The cumulative beam and diffuse radiances are displayed with different color scales for clarity.
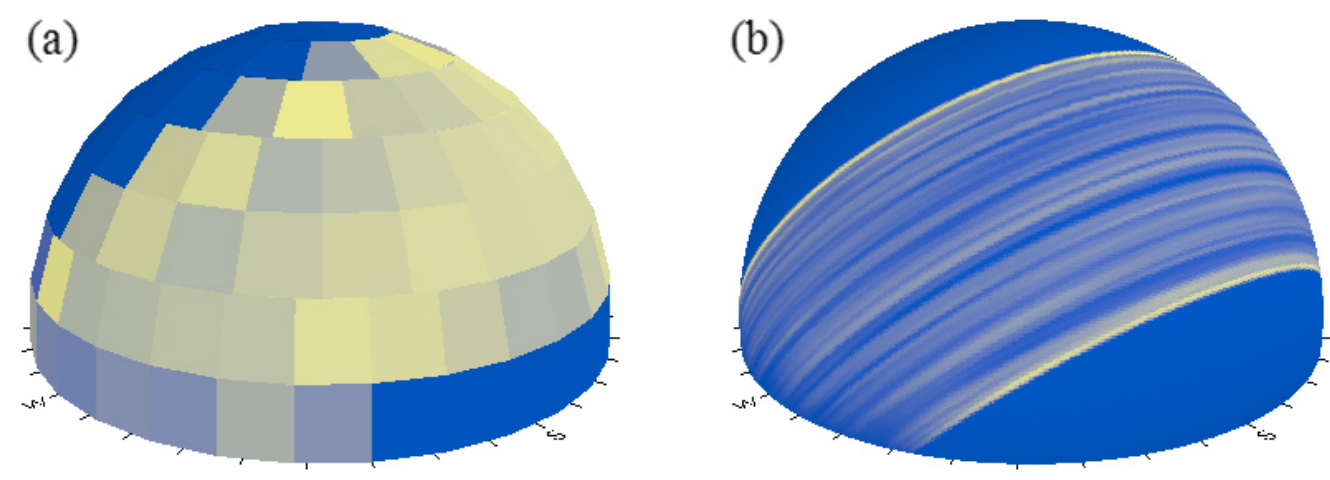

Fig. 6 Continuous sky model of cumulative annual sky radiance pattern, illustrated with different sky division schemes: (a) Tregenza (145 patches); (b) Reinhart-MF:32 (147,457 patches).
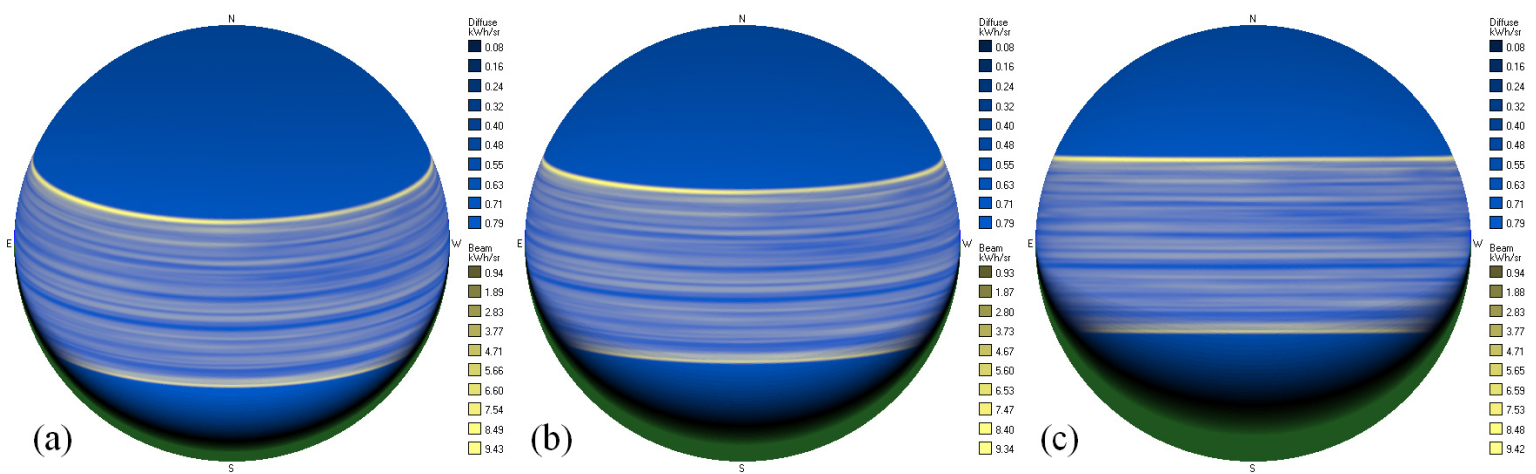

Fig. 7 Fisheye orthographic sky projections for Sofia, as seen from a row of PV panels: (a) on a $25^{\circ}$-tilted surface facing south; (b) on a $32^{\circ}$-tilted surface facing south; (c) on a latitude-tilt surface facing south for Sofia's latitude, $42.698^{\circ}$.

The green and black colors represent the foreground and the sky shaded areas, respectively.

Using SOLARES to undertake all calculations for both the unobstructed and partially-obstructed sky cases, the results are illustrated in Fig. 8a for the latter case. With an angular resolution of $1^{\circ}$, the maximum beam tilted irradiation, $H_{b}=710.8 \mathrm{kWh} / \mathrm{m}^{2}$, occurs at a tilt angle of $33^{\circ}$ for both annual radiance databases. In the control experiment (with isotropic SVF), the maximum diffuse tilted irradiation $\left(672.4 \mathrm{kWh} / \mathrm{m}^{2}\right)$ occurs for a tilt angle of $0^{\circ}$ because the circumsolar radiance is ignored. This increases to $688.0 \mathrm{kWh} / \mathrm{m}^{2}$ for a tilt angle of $13^{\circ}$ with Igawa's model and $689.2 \mathrm{kWh} / \mathrm{m}^{2}$ with the IGI model, again for a $13^{\circ}$ tilt angle. The global tilted irradiance, $H_{t}=H_{b}+H_{d}$, reaches an annual maximum of $1318.2 \mathrm{kWh} / \mathrm{m}^{2}$ for a tilt angle of $20^{\circ}$ in the control experiment with isotropic SVF (Fig. 7a), $1373.7 \mathrm{kWh} / \mathrm{m}^{2}$ for a tilt angle of $25^{\circ}$ with Igawa's model, and $1374.8 \mathrm{kWh} / \mathrm{m}^{2}$ for the same tilt angle of $25^{\circ}$ with the IGI model. This angle is less than the local optimum angle under non-obstructed sky $\left(32^{\circ}\right.$, see Fig. $\left.7 \mathrm{~b}\right)$ or than the local latitude $\left(42.698^{\circ}\right.$, Fig. $\left.7 \mathrm{c}\right)$. All results are summarized in Tables 2 and 3 for the unobstructed and partially obstructed sky cases, respectively.

Tab. 2: Maximum annual diffuse and global irradiation and optimum tilt for control experiment with SVF, Igawa's model and IGI model; unobstructed sky case

\begin{tabular}{lccc}
\hline \multicolumn{1}{c}{ Irradiation } & $\begin{array}{c}\text { Control experiment } \\
\text { (isotropic SVF) }\end{array}$ & Igawa's model & IGI model \\
\hline Max. diffuse irradiation $\left(\mathrm{kWh} / \mathrm{m}^{2}\right)$ & 672.4 at tilt $0^{\circ}$ & 704.2 at tilt $22^{\circ}$ & 705.4 at tilt $22^{\circ}$ \\
Max. global irradiation $\left(\mathrm{kWh} / \mathrm{m}^{2}\right)$ & 1347.3 at tilt $26^{\circ}$ & 1418.3 at tilt $32^{\circ}$ & 1419.5 at tilt $32^{\circ}$ \\
\hline
\end{tabular}


Tab. 3: Maximum annual diffuse and global irradiation and optimum tilt for control experiment with SVF, Igawa's model and IGI model; partially obstructed sky case

\begin{tabular}{lccc}
\hline \multicolumn{1}{c}{ Irradiation } & $\begin{array}{c}\text { Control experiment } \\
\text { (isotropic SVF) }\end{array}$ & Igawa's model & IGI model \\
\hline Max. diffuse irradiation $\left(\mathrm{kWh} / \mathrm{m}^{2}\right)$ & 672.4 at tilt $0^{\circ}$ & 688.0 at tilt $13^{\circ}$ & 689.2 at tilt $13^{\circ}$ \\
Max. global irradiation $\left(\mathrm{kWh} / \mathrm{m}^{2}\right)$ & 1318.2 at tilt $20^{\circ}$ & 1373.7 at tilt $25^{\circ}$ & 1374.8 at tilt $25^{\circ}$ \\
\hline
\end{tabular}

The difference in annual diffuse tilted irradiation between the two models ( $H_{d I}$ for Igawa's model, and $H_{d C S}$ with CS improvement) varies almost linearly from $0.15 \%$ for a tilt of $0^{\circ}$ to $0.24 \%$ for $90^{\circ}$. This translates into smaller differences (up to $0.1 \%$ ) when rather considering the global tilted irradiance, as shown in Fig. 8a. It can be expected that significantly larger differences would be obtained in a sunnier climate.

In the literature, as used in many applications, SVF is estimated as the ratio between the non-obstructed part of the sky and the entire sky's circular projection. The underlying assumption is that the sky radiance is isotropic, which is only a crude approximation. A more accurate definition, referred to here as the Real Sky View Factor (RSVF), consists in taking the ratio between the radiation received by a planar surface under a partially obstructed sky of realistic (anisotropic) radiance and that received from the entire radiating sky hemisphere in the absence of shading.

The blue line in Fig. $8 \mathrm{~b}$ represents RSVF as a function of tilt; the red line is the conventional SVF under the obstructions caused by the PV panel row to the south, denoted SVF_obstructed, and the green line is the SVF under an unobstructed sky. The difference between RSVF and SVF_obstructed varies from $0 \%$ for a horizontal surface to a maximum of $30 \%$ (relative to RSVF) for a tilt of $60^{\circ}$. These results confirm that the conventional SVF, based on the isotropic sky model, is a very imperfect tool. Even though this has been pointed out long ago (Johnson and Watson, 1984), the isotropic SVF paradigm is still used in the vast majority of applications.
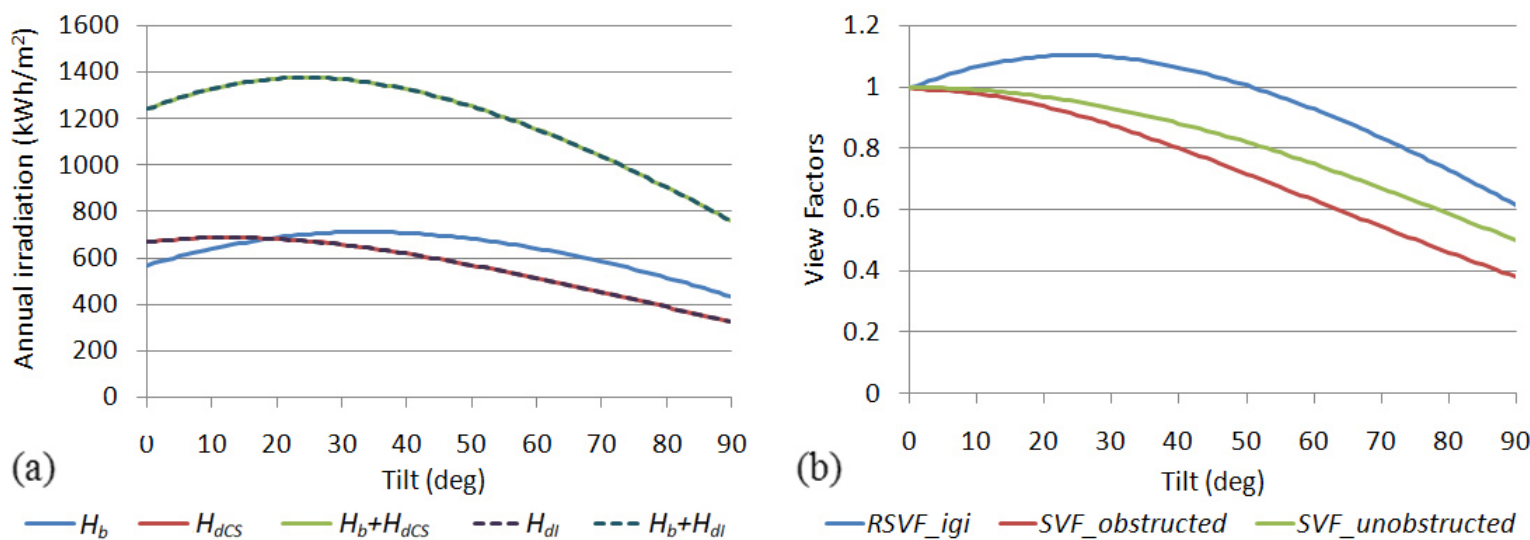

-RSVF_igi —SVF_obstructed —SVF_unobstructed

Fig. 8 Annual irradiation under partially obstructed sky for different tilt angles from $0^{\circ}$ to $90^{\circ}$ in Sofia:

(a) Beam and diffuse irradiations and their sum; (b) Real SVF (with IGI model) and SVF for different tilts.
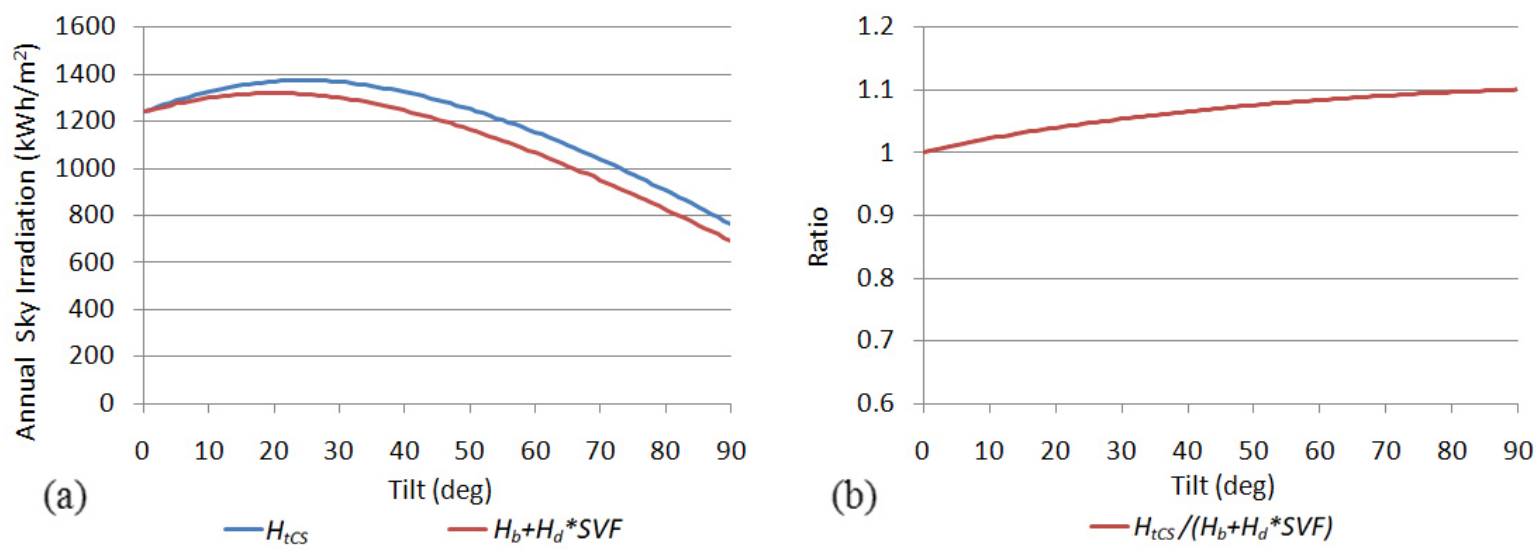

Fig. 9 Anisotropic vs. isotropic SVF approaches to estimate the tilted sky irradiation under a partially obstructed sky in 2014:

(a) Annual sums of the total irradiation on various tilts; (b) Ratio between the anisotropic and isotropic results. 
Figure 9 illustrates the results obtained with the approaches described above to estimate the sky diffuse tilted irradiation under a partially obstructed sky. The lower red line in Fig. 9a is for the control experiment, i.e., a naïve calculation based on the isotropic assumption, hence estimating the diffuse tilted irradiation as the product $\mathrm{SVF} \cdot H_{d}$. This conventional approach was followed by, e.g., Appelbaum (2018) to evaluate a catalog of SVFs applicable to various configurations of PV collector geometries. (Based on the results obtained here, this catalog would need to be revised to take anisotropic effects into account.) The blue line illustrates the more realistic result obtained with SOLARES and the IGI model. In particular, the annual optimal tilt is $25^{\circ}$ for the anisotropic RSVF compared to $20^{\circ}$ for the isotropic SVF.

Finally, Fig. 9b shows the relative improvement produced by the anisotropic radiance treatment (as calculated with the IGI model in SOLARES) in the partly obstructed sky case, compared to the control experiment. The IGI approach results in up to $10 \%$ higher global irradiance than the SVF approach, depending on tilt. Because the sky anisotropy is normally more pronounced under cloudless conditions, it can be expected that the difference just noted would increase when the diffuse ratio, $K$, decreases. For 2014 in Sofia, $K$ is 0.54 on average, meaning that diffuse irradiation outweighs the direct beam component overall. It can be inferred that this difference would be significantly larger at sunnier sites, where the mean annual $K$ can reach values lower than 0.25 (Gueymard, 2008b). Since sun elevation also plays a role, their interaction needs to be better understood.

\section{Conclusion}

Considering the paucity and current limitations of broadband measurements of the sky radiance or luminance with sky scanners, applications in engineering or architecture (among other fields) typically rely on simplified models. Despite being unrealistic, the isotropic model — simplest radiance distribution - is still commonly used in many applications, including the calculation of sky view factors (SVF) in the presence of sky shading.

In this contribution, the Igawa radiance/luminance model has been validated under the conditions of Colorado, whose low-turbidity climate at high elevation is in sharp contrast with that of the urban areas where this empirical model had been originally developed. Because of this model's lack of proper treatment of the circumsolar radiance within $\approx 6^{\circ}$ from sun center, a specific circumsolar model has been proposed, using turbidity-dependent parameterizations based on SMARTS simulations. The combination of the original Igawa model and this circumsolar extension specific to the sun's aureole (if unobstructed by clouds) defines the newly proposed IGI model.

An application illustrating the improvement made possible by the consideration of anisotropic sky view factors in the case of either unobstructed or partly obstructed sky scenes has been demonstrated. It involves the calculation of annual tilted irradiations on tilted surfaces, using the SOLARES software (with the IGI model) and hourly irradiance time series from, e.g., TMY data. Significant differences are found between results obtained with the conventional approach (isotropic SVF) and its more realistic anisotropic replacement proposed here. This new IGI-based approach would be most beneficial at sunny sites. Further research is needed to (i) smooth the transition of radiance between the aureole and the rest of the sky hemisphere; (ii) better understand the intricate interactions between aerosol type, turbidity, cloudiness, and sun position; and (iii) validate the new radiance model with modern experimental equipment, such as high-resolution sky imagers.

\section{References}

Acosta, I., Munoz, C., Esquivias, P., Moreno, D., Navarro, J., 2015. Analysis of the accuracy of the sky component calculation in daylighting simulation programs. Sol. Energy 119, 54-67.

Appelbaum, J., 2018. The role of view factors in solar photovoltaic fields. Renew. Sust. Energ. Rev. 81, $161-171$.

Blanc, P., Espinar, B., Geuder, N., Gueymard, C., Meyer, R., Pitz-Paal, R., Reinhardt, B., Renné, D., Sengupta, M., Wald, L., Wilbert, S., 2014. Direct normal irradiance related definitions and applications: The circumsolar issue. Sol. Energy 110, 561-577.

Brunger, A.P., Hooper, F.C., 1991. Measured shortwave radiance in an urban atmosphere. Sol. Energy 47, $137-142$. 
Brunger, A.P, Hooper F.C., 1993. Anisotropic sky radiance model based on narrow field of view measurements of shortwave radiance. Sol. Energy 51, 53-64.

Bullrich, K., 1964. Scattered radiation in the atmosphere and the natural aerosol. Adv. Geophys. 10, 99-200.

Burley, J.L., Fiorino, S.T., Elmore, B.J., Schmidt, J.E., 2017. A fast two-stream-like multiple-scattering method for atmospheric characterization and radiative transfer. J. Appl. Meteorol. Clim. 56, 3049-3063.

Chauvin, R., Nou, N., Thil, S., Grieu, S., 2015. Modelling the clear-sky intensity distribution using a sky imager. Sol. Energy 119, 1-17.

Darula, S., Kittler, R., Komar, L., 2015. Simulation of luminance sky patterns predetermining daylight illuminance on vertical house fronts with windows. Sol. Energy 120, 195-207.

Dubovik, O., King, M.D., 2000. A flexible inversion algorithm for retrieval of aerosol optical properties from Sun and sky radiance measurements. J. Geophys. Res. 105D, 20673-20696.

Gueymard, C.A., 1986. Une paramétrisation de la luminance énergétique du ciel clair en fonction de la turbidité. Atmosphere-Ocean 24, 1-15.

Gueymard, C.A., 2001. Parameterized transmittance model for direct beam and circumsolar spectral irradiance. Sol. Energy 71, 325-346.

Gueymard, C.A., 2008a. REST2: High-performance solar radiation model for cloudless-sky irradiance, illuminance, and photosynthetically active radiation - Validation with a benchmark dataset. Sol. Energy 82, 272 285.

Gueymard, C.A., 2008b. Fixed or tracking solar collectors? Helping the decision process with the Solar Resource Enhancement Factor. Proc. SPIE Conf. Vol. 7046, Optical Modeling and Measurements for Solar Energy Systems II, San Diego, CA.

Harrison, A.W., Coombes, C.A., 1988. Angular distribution of clear sky short wavelength radiance. Sol. Energy 40, 57-63.

Igawa, N., 2014. Improving the All Sky Model for the luminance and radiance distributions of the sky. Sol. Energy 105, 354-372.

Ivanova, S., 2015. Using of fisheye orthographic projection for cumulative estimation of direct and diffuse radiation on building surfaces in an urban environment. Proc. WREC XIV Conf., Bucharest, Romania.

Ivanova, S., Gueymard, C.A., 2018. Simulation and applications of cumulative anisotropic sky radiance patterns. Sol. Energy (in review).

Johnson, G.T., Watson, I.D., 1984. The determination of view-factors in urban canyons. J. Appl. Meteorol. Clim. 23, 329-335.

Kittler, R., 1994. Some qualities of scattering functions defining sky radiance distributions. Sol. Energy 53, $511-516$.

Kocifaj, M., 2009. Sky luminance/radiance model with multiple scattering effect. Sol. Energy 83, 1914-1922.

Kocifaj, M., 2011. CIE standard sky model with reduced number of scaling parameters. Sol. Energy 85, $553-$ 559.

Kocifaj, M., 2012. Angular distribution of scattered radiation under broken cloud arrays: An approximation of successive orders of scattering. Sol. Energy 86, 3575-3586.

Kocifaj, M., 2015. Unified model of radiance patterns under arbitrary sky conditions. Sol. Energy 115, 40-51.

Kocifaj, M., Gueymard, C.A., 2017. High-resolution tilted surface illuminance/irradiance spectral model applicable to arbitrary sky conditions. Proc. Lux Europa Conf., Ljubljana, Slovenia.

Li, D.H.W., Lam, T.N.T., 2007. Determining the optimum tilt angle and orientation for solar energy collection based on measured solar radiance data. Int. J. Photoenergy 2007, 85402.

Liang, S., Lewis, P., 1996. A parametric radiative transfer model for sky radiance distribution. J. Quant. Spec- 
trosc. Radiat. Transfer 55, 181-189.

Lou, S., Li, D.H.W., Lam, J.C., Lee, E.W.M., 2016. Estimation of obstructed vertical solar irradiation under the 15 CIE Standard Skies. Build. Environ. 103, 123-133.

Nakajima, T., Tonna, G., Rao, R., Boi, P., Kaufman, Y., Holben, B., 1996. Use of sky brightness measurements from ground for remote sensing of particulate polydispersions. Appl. Opt. 35, 2672-2686.

Oliveros, C.S., Reyes, F.J.O., Alados-Arboledas, L., 1998. Determination of aerosol optical thickness from measurements of spectral sky radiance. J. Aerosol. Sci. 29, 1199-1211.

Perez, R., Seals, R., Michalsky, J., Steward, R., 1993. All-weather model for sky luminance distributionpreliminary configuration and validation. Sol. Energy 50, 235-245.

Qin, Y., Box, M.A., Jupp, D.L.B., 2002. Inversion of multiangle sky radiance measurements for the retrieval of atmospheric optical properties_-1. Algorithm. J. Geophys. Res. 107D, doi:10.1029/2001JD00094.

Rosen, M.A., Hooper, F.C., Brunger, A.P., 1989. The characterization and modelling of the diffuse radiance distribution under partly cloudy skies. Sol. Energy 43, 281-290.

Smith, C.J., Forster, P.M., Crook, R., 2016. An all-sky radiative transfer method to predict optimal tilt and azimuth angle of a solar collector. Sol. Energy 123, 88-101.

Torres, J.L., Torres, L.M., 2008. Angular distribution of sky diffuse radiance and luminance. In: Badescu, V. (Ed.), Modeling Solar Radiation at the Earth Surface. Springer, pp. 427-448.

Tregenza, P.R., 1987. Subdivision of the sky hemisphere for luminance measurements. Light. Res. Technol. $19,13-14$.

Vida, J., Foyo-Moreno, I., Alados-Arboledas, L., 1999. Performance validation of MURAC, a cloudless sky radiance model proposal. Energy 25, 705-721.

Wittkopf, S.K., Soon, L.K., 2007. Analysing sky luminance scans and predicting frequent sky patterns in Singapore. Lighting Res. Technol. 39, 31-51.

Zibordi, G., Voss, K.J., 1989. Geometrical and spectral distribution of sky radiance: comparison between simulations and field measurements. Remote Sens. Environ. 27, 343-358.

\section{Appendix}

Coefficients $A_{i}$ in Eq. (1) are provided by the equations below, valid for $\beta$ strictly $>0$.

$$
\begin{aligned}
& A_{0}=\left\{b_{2} /\left(b_{0} \beta\right)\right\} \exp \left\{-0.5\left[\left(\ln \beta-b_{1}\right) / b_{0}\right]^{2}\right\} \\
& A_{1}=\left(c_{0}+c_{1} \beta\right) /\left(1+c_{2} \beta+c_{3} \beta^{2}\right) \\
& A_{2}=\left(d_{0}+d_{1} \beta\right) /\left(1+d_{2} \beta\right)
\end{aligned}
$$

where

$$
\begin{aligned}
& b_{0}=\left(2.4413+0.77346 m+0.0066318 m^{2}\right) /(1+0.71507 m) \\
& b_{1}=\left(5.4847-1.7750 m-0.028094 m^{2}\right) /(1+0.94430 m) \\
& b_{2}=\left(98.386+21.399 m-0.48309 m^{2}\right) /(1+3.6764 m) \\
& c_{0}=m(0.50144+0.071324 m) /\left(1+0.15932 m+0.059551 m^{2}\right) \\
& c_{1}=m(4.4497-29.822 m) /\left(1+1.1167 m+0.046374 m^{2}\right) \\
& c_{2}=m(77.474-4.2505 m) /\left(1+1.9922 m+0.19715 m^{2}\right) \\
& c_{3}=\left(2171.9-2352.3 m+1696.0 m^{2}\right) /\left(1+41.4 m-0.99879 m^{2}\right) \\
& d_{0}=\left(2.1308+17.274 m+1.2349 m^{2}+0.017568 m^{3}\right) /\left(1+9.0143 m+1.3056 m^{2}\right) \\
& d_{1}=\left(-0.28158+0.18907 m-0.067057 m^{2}+0.0030898 m^{3}\right) /\left(1-0.17939 m+0.03345 m^{2}\right) \\
& d_{2}=\left(-0.14376+0.43815 m-0.10685 m^{2}+0.0094731 m^{3}\right) /\left(1-0.1235 m+0.025835 m^{2}\right)
\end{aligned}
$$




\title{
Most Probable Operating Conditions and Performance Assessment of Four PV Technologies at 10 Locations in India
}

\author{
N C Gupta ${ }^{1}$, P K Dash ${ }^{1 *}$, Prasun Kumar Das ${ }^{2}$ and G Giridhar ${ }^{2}$ \\ ${ }^{1}$ University School of Environment Management, GGSIPU, Dwarka, New Delhi (India) \\ ${ }^{2}$ National Institute of Wind Energy, Valachery, Chennai (India) \\ * Corresponding Author
}

\begin{abstract}
The revised target of $100 \mathrm{GW}$ of solar energy by 2022, under National Solar Mission has opened up new challenges in resource assessment, grid balancing, geographical distribution of these solar power plants and power forecasting for solar grid integration in India. The performance of fixed photovoltaic (PV) modules is site specific and largely depends on the climatic parameters, such as, solar radiation, temperature and other meteorological conditions. The present study is aimed to have a comparison of prevalent conditions, in terms of distribution of solar radiation and ambient temperature based on actual ground measurement data at 10 locations representing the different climatic zones in India. Consequently, in this study performance of four commercially available PV technologies are also assessed and compared with respect to annual energy generation and levelized cost of energy (LCOE) in the selected 10 locations. The study will be helpful to project developers and policy planners for better deployment of solar energy in India and to promote solar energy in total energy mix in India.
\end{abstract}

Keywords: Photovoltaics, Insolation, Irradiance, Annual energy generation, Temperature

\section{Introduction}

Photovoltaics constitute a major chunk of the India's proposed target of $100 \mathrm{GW}$ of solar energy by 2022. Considerable amount of research work has already been carried out to know the behavior of different PV technologies in various climatic conditions. The study of site specific performance of various commercially available PV technologies is gaining importance as large scale deployments of PV power plants have become a reality because of lower cost of energy generation (Rawat et al., 2016). A novel climate classification criteria based on performance of four PV technologies was proposed along with technology selection criteria for a particular location (Dash et al., 2017). Solar radiation and temperature are two important climatic parameters that significantly affect the output of PV module. When the temperature increases, the electrical efficiency of the photovoltaic modules reduces irrespective of PV module technology. However, the extent of decrease is dependent on PV technology. The output current is directly proportional to the incident irradiance on the plane of the module and hence the power output. Some literature related to the effect of climate on PV modules performance is discussed below.

Most of the solar installations are located in the western regions of India due to the availability of higher solar radiation resources (Carr and Pryor, 2004; Guenounou et al., 2016; Tossa et al., 2016; Ferrada et al., 2015; Rawat et al., 2016; Makrides et al., 2014 and Huld et al. (2010). The electrical energy generation from on-grid PV solar systems of $1 \mathrm{~kW}$ capacity in the republic of Srpska, climate conditions and energy potential of the renewable sources has been studied by Pavlovic et al (2013). The performance of $1 \mathrm{~kW}$ solar plants of different types of PV technology such as mono-crystalline silicon, CdTe and CIS solar modules at 13 cities in the republic of Srpska has been evaluated by using PVGIS and the annual energy generation is compared. Characteristics of a $6150 \mathrm{Wp}$ roof mounted grid-connected photovoltaic system at Mexico City studied by Santana-Rodŕiguez et al (2013). The study results compare the performance of four PV technologies such as mono-crystalline silicon, polycrystalline silicon, amorphous silicon and $\mathrm{CdS} / \mathrm{CdTe}$ under the climatic conditions 
of Mexico City. The study concluded that, amorphous silicon PV technology performs better under temperature variations typical of Mexico City's environmental conditions. Swift (2013) compared the cost and financial returns for solar photovoltaic systems installed in different locations across the United States and results have demonstrated that, costs and financial returns of solar PV systems vary much depending on the location, where they are installed. This study confirmed that, detailed, site specific information about incentives, grid produced electricity rates, and levels of solar insolation is needed to determine whether the installation of a solar PV system makes economic sense in a particular location. Variation of PV efficiency on irradiance level for nine different commercially available PV module technologies are studied by Reindl et al. (2012). They have also analysed the irradiance distribution in tropical Singapore. Outdoor module testing data in Singapore for an entire year showed that, two energy peaks are observed at irradiance levels of one at around $400 \mathrm{~W} / \mathrm{m}^{2}$ and $850 \mathrm{~W} / \mathrm{m}^{2}$. The advantage of the peak performance at $850 \mathrm{~W} / \mathrm{m}^{2}$ irradiance level not fully convertible to power as high light intensities in Singapore are always associated with higher module temperatures, which decreases the module efficiencies. Cucchiella and Dadamo (2012) estimated the energetic and environmental impacts of roof-mounted building-integrated photovoltaic systems located in Italy. The module efficiency, the embodied energy and the annual solar irradiance are variables that played a strong role in their analysis. Huld et al. (2008 and 2010) geographically assessed the performance of crystalline silicon photovoltaic (PV) modules over Europe. They developed a method that is based on a material specific analytical expression of the PV conversion efficiency, relative to nominal efficiency, as a function of module temperature and irradiance. Lim et al (2013) showed that, the power output of PV module decreases $0.469 \% /{ }^{\circ} \mathrm{C}$ with respect to temperature keeping all other parameters controlled. Actual Operating temperature is very important for photovoltaic energy conversion as observed by Skoplaki and Palyvos (2009) as the electrical efficiency and power output of a PV device varies linearly with operating temperature. The present study aims comparison of solar radiation and temperature based on actual ground measurement data at 10 geographically distributed locations in India, representing the different climatic zones. Consequently the performance of four different commercially available PV technologies also assessed and compared with respect to annual energy generation and leveized cost of energy generation (LCOE) in the selected 10 locations.

\section{Methodology}

National Institute of Wind Energy (NIWE), Chennai has set up the world's largest network of Solar Radiation Resource Assessment (SRRA) stations across the country to develop investor grade, ground measured solar radiation data crucial for planning and implementation of solar power projects. The data has been obtained for the period of five years (2012-2016) for selected locations except Neemuch and Tura for which the data was available only for three years (2012-2014). One hour averaged data for Global Horizontal Irradiance (GHI), Direct Normal Irradiance (DNI), Diffuse Horizontal Irradiance (DHI), ambient temperature, wind speed, relative humidity and precipitation for the aforesaid ten locations was analyzed. The available hourly average data is first filtered for day time radiation and temperature. Solar Radiation and temperature data is segregated in three separate bins having irradiance distribution $<400 \mathrm{~W} / \mathrm{m}^{2}, 400-800 \mathrm{~W} / \mathrm{m}^{2}$ and $>800 \mathrm{~W} / \mathrm{m}^{2}$ and $<20^{\circ} \mathrm{C}, 20-30^{\circ} \mathrm{C}$ and $>30^{\circ} \mathrm{C}$ respectively in order to assess the favorable conditions. Further, performance of four commercially available PV technologies, namely Heterogeneous intrinsic thin film (HIT), Multi crystalline silicon (mC-Si), amorphous silicon (a-Si) and Cadmium Telluride (CdTe) are assessed at these 10 locations. Based on the environmental data, the annual energy generations for aforesaid four PV technologies have been estimated and levelised cost of energy (LCOE) calculated in order to have the techno-economic comparison of four PV technologies for the ten locations. Details of the locations selected for this study are exhibited in table-1 and figure-1. The locations are selected based on preliminary data assessment from the solar map, to cover maximum locations in the sunny and various climatic zones of India.

Tab.1: Details of the Locations Selected for the Study

\begin{tabular}{|c|c|c|c|c|}
\hline Sr.No & Location & Latitude $\left[{ }^{\mathbf{0}} \mathbf{N}\right]$ & Longitude $\left[{ }^{\mathbf{0}} \mathbf{E}\right]$ & Altitude[m] \\
\hline 1 & Bilaspur & 22.08 & 82.18 & 267 \\
\hline 2 & Leh & 34.14 & 77.48 & 3252 \\
\hline 3 & Chitradurga & 14.22 & 76.43 & 760 \\
\hline 4 & Gandhinagar & 23.15 & 72.67 & 65 \\
\hline
\end{tabular}




\begin{tabular}{|c|c|c|c|c|}
\hline 5 & Jodhpur & 26.27 & 73.03 & 233 \\
\hline 6 & Karaikudi & 10.09 & 78.80 & 101 \\
\hline 7 & Neemuch & 24.48 & 74.87 & 501 \\
\hline 8 & Rajhmundry & 17.06 & 81.87 & 93 \\
\hline 9 & Shegaon & 20.78 & 76.68 & 288 \\
\hline 10 & Tura & 25.53 & 90.21 & 397 \\
\hline
\end{tabular}

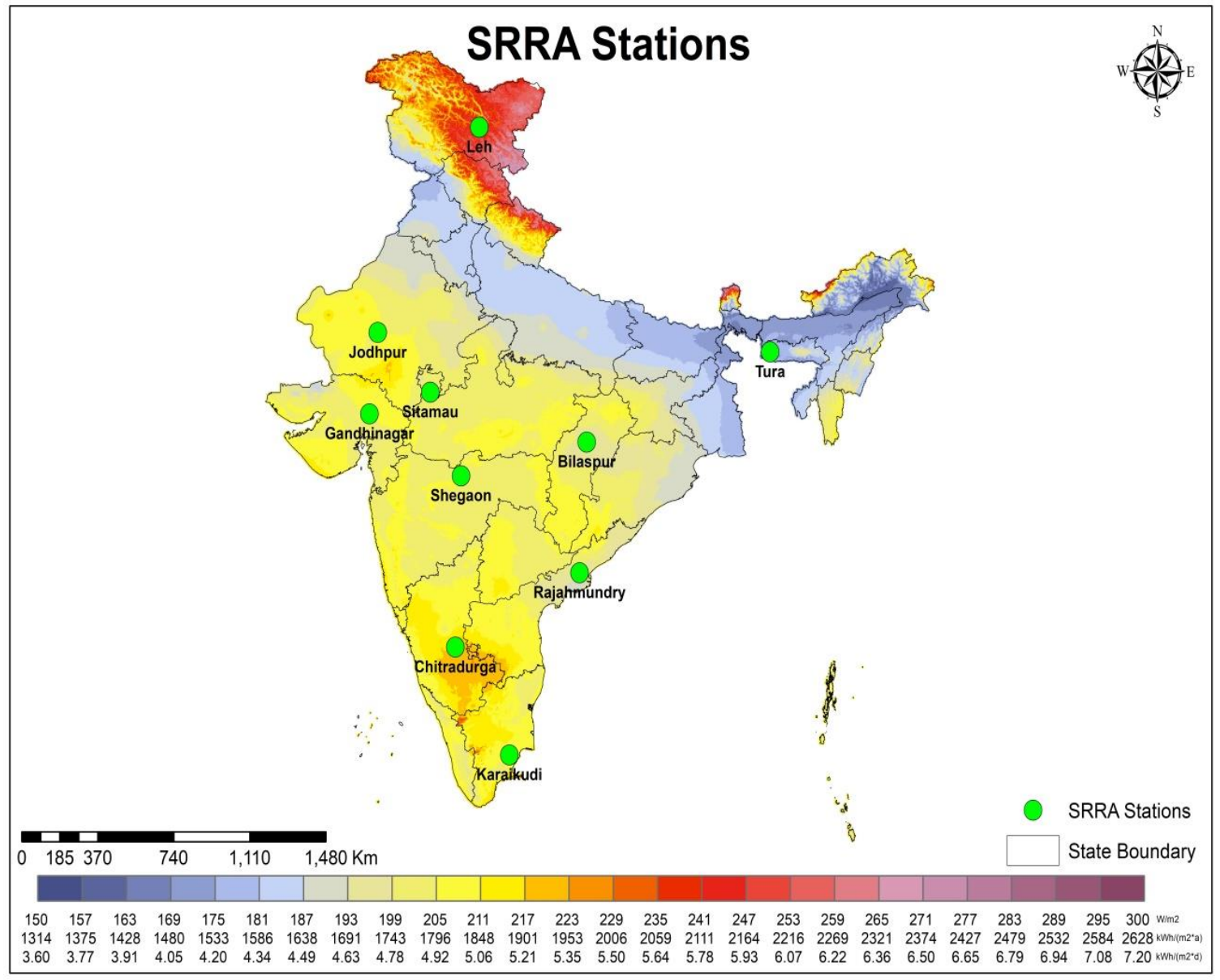

Fig. 1: Locations Selected for the Study

The annual energy generation has been computed using equations 1 and 2 given below.

$$
\begin{aligned}
& \mathrm{M}_{\mathrm{T}}=\mathrm{A}_{\mathrm{T}}+(\mathrm{NOCT}-20) * \frac{\mathrm{GHI}}{800} \\
& \mathrm{AEG}=\sum\left(\mathrm{GHI} * \eta-\mathrm{GHI} * \eta * \mathrm{TC} *\left(\mathrm{M}_{\mathrm{T}}-\mathrm{A}_{\mathrm{T}}\right)\right)
\end{aligned}
$$

where, AEG is the annual energy generation, $\mathrm{M}_{\mathrm{T}}$ is the Module Temperature, $\mathrm{A}_{\mathrm{T}}$ is the Ambient temperature, GHI is the Global Horizontal Irradiance, NOCT is the Nominal Operating Cell Temperature and $\eta$ is the efficiency of the PV technology. The value of NOCT and TC which has been measured and used in the equation is given in Table-2 below;

Tab.2: Measured TC and NOCT of the Selected PV Modules

\begin{tabular}{|c|c|c|c|c|}
\hline Type of Modules & HIT & Multi C-Si & a-Si & CdTe \\
\hline TC $\left(\% /{ }^{\circ} \mathrm{C}\right)$ & 0.36 & 0.42 & 0.27 & 0.21 \\
\hline NOCT $\left({ }^{\circ} \mathrm{C}\right)$ & 44 & 41 & 49.2 & 45 \\
\hline
\end{tabular}


The assumptions made towards calculation of levelised cost of energy from different technology PV power plant of $1 \mathrm{MW}$ are given in table-3. The capital cost of the solar PV modules of different technology is assumed based on the latest price available in the business to business e-commerce website Alibaba.com. Other costs are assumed to be same for all the locations selected for the study. This assumption was based on the fact that, the supply chain and logistics cost will come down and remain same in all the locations when large scale deployment of solar PV power plants will take place throughout the country.

Tab. 3: Assumptions for Calculation of LCOE

\begin{tabular}{|c|c|c|c|c|}
\hline Parameter/Technology & HIT & mC-Si & a-Si & CdTe \\
\hline Capital Cost /MW & Rs.700 lakh & Rs. 330 Lakh & Rs. 350 lakh & Rs. 400 Lakh \\
\hline Debt: Equity & $70: 30$ & $70: 30$ & $70: 30$ & $70: 30$ \\
\hline Interest on debt & $8.00 \%$ & $8.00 \%$ & $8.00 \%$ & $8.00 \%$ \\
\hline Return on equity & $14.00 \%$ & $14.00 \%$ & $14.00 \%$ & $14.00 \%$ \\
\hline O \& M cost & \multicolumn{2}{|c|}{ Rs. 7.00 lakh /MW with 5.72\% escalation every year } \\
\hline Degradation rate & $.50 \% / y r$ & $.50 \% / y r$ & $1.00 \% / y r$ & $1.02 \% / y r$ \\
\hline Discount Rate (d) & $7.86 \%$ & $7.86 \%$ & $7.86 \%$ & $7.86 \%$ \\
\hline Depreciation & \multicolumn{5}{|c|}{$5.83 \%$ for first 12 yrs then $1.54 \%$ up to $25^{\text {th }}$ year } \\
\hline
\end{tabular}

The method of calculation used for determining the generation potential and unit cost of energy from four PV technologies in the ten selected locations is given as under.

$$
\begin{aligned}
& U C E=\frac{A C}{A E G} \\
& A C=I_{d}+D+R+O M+I_{w c}
\end{aligned}
$$

Where, UCE is the Unit Cost of Energy in Rs./kWh, AC is the Annualized Cost, $\mathrm{I}_{\mathrm{d}}$ is the Interest on debt, D is the Depreciation, $\mathrm{R}$ is the Return on equity, $\mathrm{OM}$ is the operation and maintenance cost and $\mathrm{I}_{\mathrm{wc}}$ is the Interest on working capital.

The Working Capital requirement in respect of solar PV Power projects is computed in accordance with the following procedure laid down by Central Electricity Regulatory Commission (CERC) with (a) Operation \& Maintenance expenses for one month (b) Receivables equivalent to two months of energy charges for sale of electricity and (c) Maintenance spare at the rate of $15 \%$ of operation and maintenance expenses. Similarly, the discount rate has been computed to the post tax weighted average cost of capital on the basis of normative debt: equity ratio of 70:30 as proposed in the CERC Regulations (2017). Interest Rate considered for the loan component of $70 \%$ of capital cost is $8.00 \%$. For equity component of $30 \%$, rate of Return on Equity (ROE) is considered at post tax rate of $14 \%$. The discount factor derived by this method for all technologies is given as under (Income tax rate is considered at $34.61 \%$ with $30 \%$ IT rate $+12 \%$ surcharge $+3 \%$ Education cess):

$$
\begin{aligned}
& d=\left(0.7 * I_{d}\left(1-\frac{34.61}{100}\right)\right)+0.3 * R \\
& d f=(1+d)^{n} \\
& L C O E=\frac{\sum U C E / d f}{C R F} \\
& C R F=\frac{d(1+d)^{n}}{(1+d)^{n-1}}
\end{aligned}
$$

Where, 'df' is the discounted factor, $\mathrm{n}$ is the number of year, and CRF is the Capital Recovery Factor.

\section{Results and Discussion}

The characteristics of solar radiation and annual temperature distribution for the 10 selected locations are analysed and discussed as under: 


\subsection{Annual Irradiance Distribution at Various Temperatures at Bilaspur}

The place Bilaspur, Chhattisgarh receives nearly $1521 \mathrm{kWh} / \mathrm{m}^{2}$ of annual solar irradiance out of which major portion is received in the lower and medium irradiance range. 58.6\% of the solar insolation is received in the irradiance level of less than $600 \mathrm{~W} / \mathrm{m}^{2}$ and nearly $93 \%$ of energy in the irradiance level of less than $800 \mathrm{~W} / \mathrm{m}^{2}$. Similarly, nearly $68 \%$ of the annual day time temperature is in the range of $25^{\circ} \mathrm{C}$ to $35^{\circ} \mathrm{C}$. The most frequent operating condition lies in temperature range $25-30^{\circ} \mathrm{C}$ and irradiance range of up to $200 \mathrm{~W} / \mathrm{m}^{2}$. The annual irradiance distribution at various temperature ranges is given in figure- 2 .

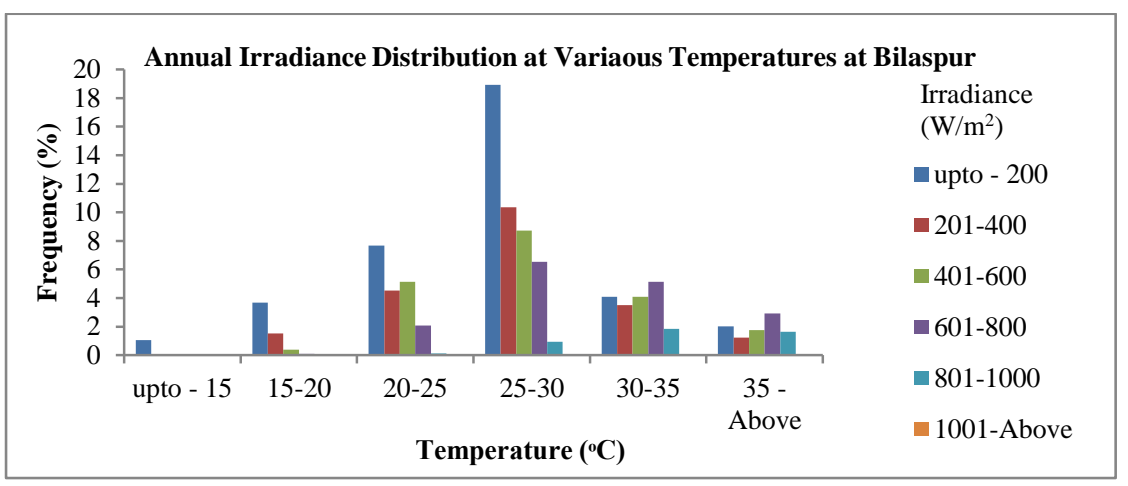

Fig. 2: Annual Irradiance Distributions at Bilaspur, Chhattisgarh

\subsection{Annual Irradiance Distribution at Various Temperatures at Leh}

Leh, located in the Indian State of Jammu and Kashmir, receives total annual solar irradiance of 1730 $\mathrm{kWh} / \mathrm{m}^{2} .47 \%$ of the solar insolation is received in the irradiance level of less than $600 \mathrm{~W} / \mathrm{m}^{2}$ and nearly $73 \%$ of energy in the irradiance level of less than $800 \mathrm{~W} / \mathrm{m}^{2}$. Similarly, nearly $94 \%$ of the annual day time temperature is in the range of $25^{\circ} \mathrm{C}$ and below. The annual irradiance distribution at various temperatures is shown in figure-3. The most frequent condition is in the temperature of below $15^{\circ} \mathrm{C}$ and irradiance up to $200 \mathrm{~W} / \mathrm{m}^{2}$.

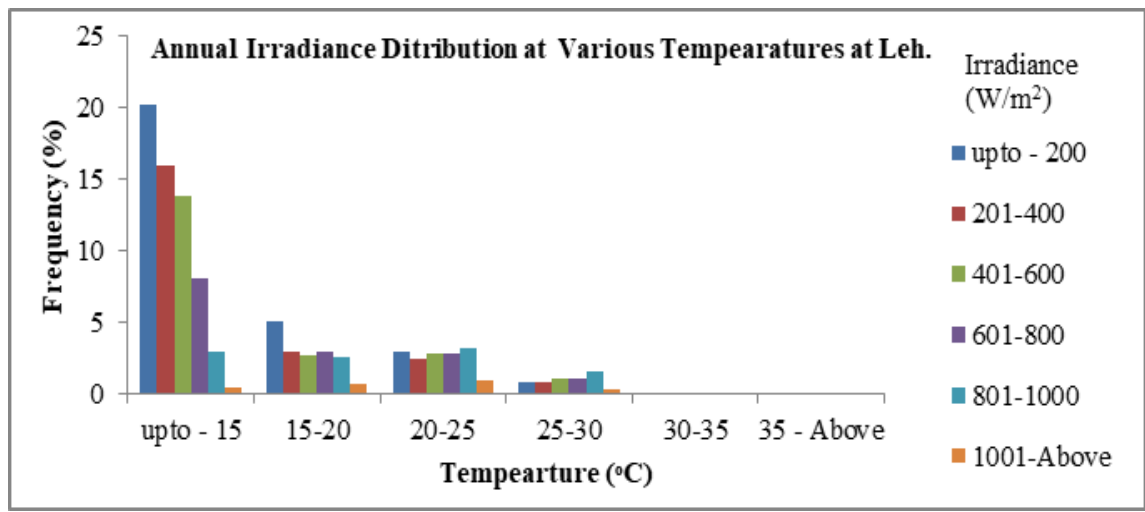

Fig. 3: Annual Irradiance Distributions at Leh, Jammu and Kashmir

\subsection{Annual Irradiance Distribution at Various Temperatures at Chitradurga}

Chitradurga in the Indian State of Karnataka, receives a total annual insolation of $1757 \mathrm{kWh} / \mathrm{m}^{2}$ out of which substantial amount of its annual solar radiation in the medium and high irradiance ranges. $56 \%$ of the solar insolation is received in the irradiance level of more than $600 \mathrm{~W} / \mathrm{m}^{2}$ and nearly $33 \%$ of energy in the irradiance level of more than $800 \mathrm{~W} / \mathrm{m}^{2}$. Similarly, nearly $58 \%$ of the annual day time temperature is in the range of $25^{\circ} \mathrm{C}$ to $35^{\circ} \mathrm{C}$. The annual irradiance distribution at various temperatures is shown in figure-4. The most frequent operating condition lies in temperature range between $20^{\circ} \mathrm{C}$ to $25^{\circ} \mathrm{C}$ and up to $200 \mathrm{~W} / \mathrm{m}^{2}$. 


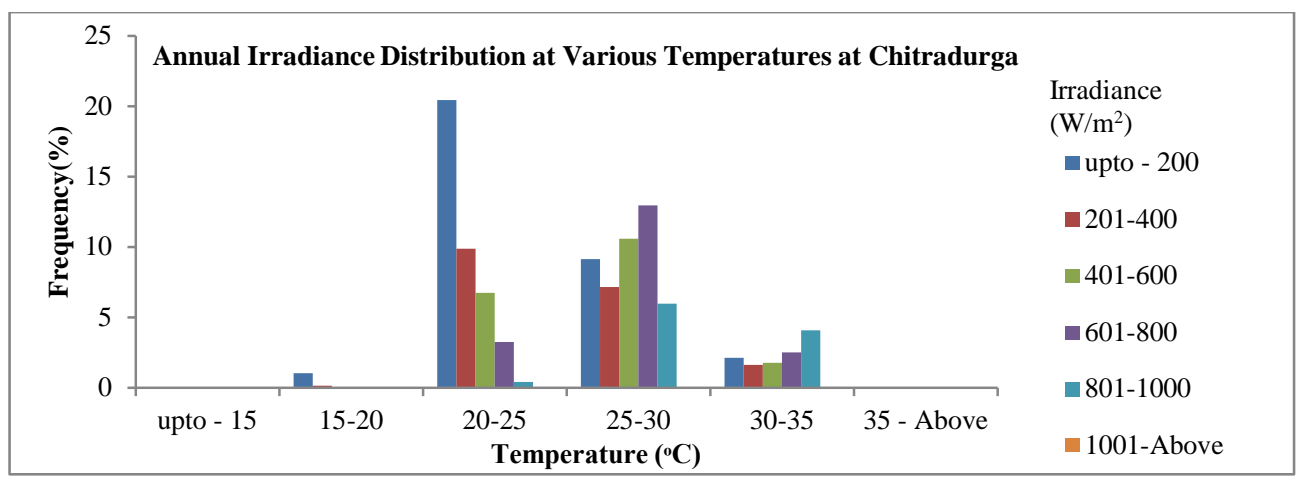

Fig. 4: Annual Irradiance Distributions at Chitradurga, Karnataka

\subsection{Annual Irradiance Distribution at Various Temperatures at Gandhinagar}

Gandhinagar located in the Indian State of Gujarat, receives total annual insolation of $1715 \mathrm{kWh} / \mathrm{m}^{2}$ out of which substantial amount of its annual solar radiation in the medium and high irradiance ranges. Nearly $50 \%$ of the solar insolation is received in the irradiance level of more than $600 \mathrm{~W} / \mathrm{m}^{2}$ and nearly $15 \%$ of energy in the irradiance level of more than $800 \mathrm{~W} / \mathrm{m}^{2}$. Similarly, nearly $69 \%$ of the annual day time temperature is in the range of $25^{\circ} \mathrm{C}$ to $35^{\circ} \mathrm{C}$. The most frequent condition is in the temperature range of $25^{\circ} \mathrm{C}$ to $30^{\circ} \mathrm{C}$. The annual irradiance distribution at various temperatures is shown in figure-5.

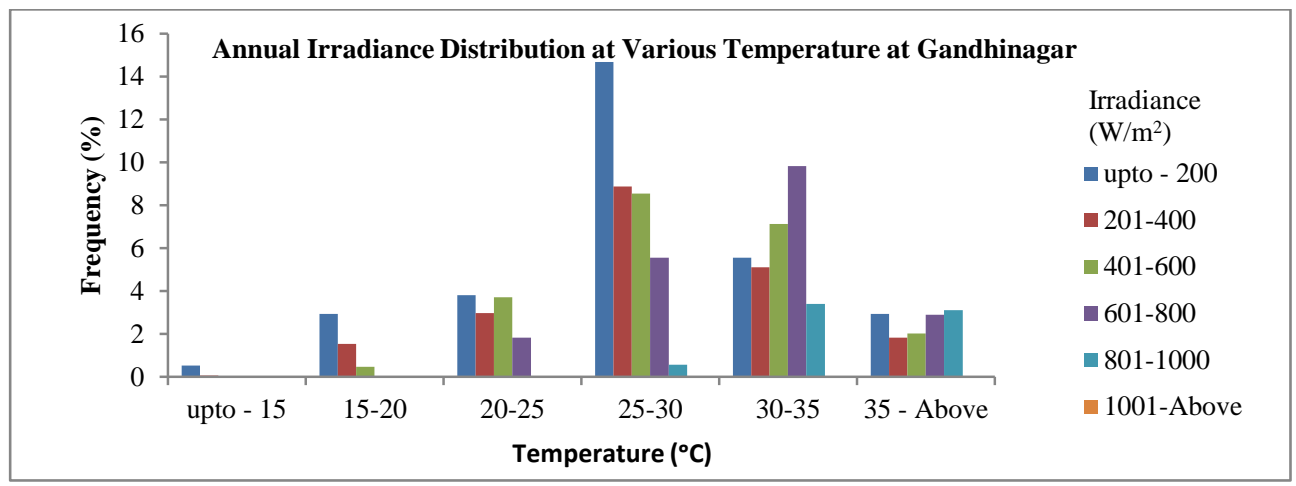

Fig. 5: Annual Irradiance Distributions at Gandhinagar, Gujarat

\subsection{Annual Irradiance Distribution at Various Temperatures at Jodhpur}

Jodhpur located in the Indian state of Rajasthan, receives total annual global horizontal irradiance of $1712 \mathrm{kWh} / \mathrm{m}^{2}$ out of which substantial amount of its annual solar radiation in the medium and high irradiance ranges. Nearly $50 \%$ of the solar insolation is received in the irradiance level of more than $600 \mathrm{~W} / \mathrm{m}^{2}$ and nearly $20 \%$ of energy in the Irradiance level of more than $800 \mathrm{~W} / \mathrm{m}^{2}$. Similarly, nearly $60 \%$ of the annual day time temperature is in the range of $25^{\circ} \mathrm{C}$ to $35^{\circ} \mathrm{C}$. The most frequent condition lies within the temperature range of $30^{\circ} \mathrm{C}$ to $35^{\circ} \mathrm{C}$ and irradiance range of $600 \mathrm{~W} / \mathrm{m}^{2}$ to $800 \mathrm{~W} / \mathrm{m}^{2}$. The annual irradiance distributions at various temperatures are shown in figure-6.

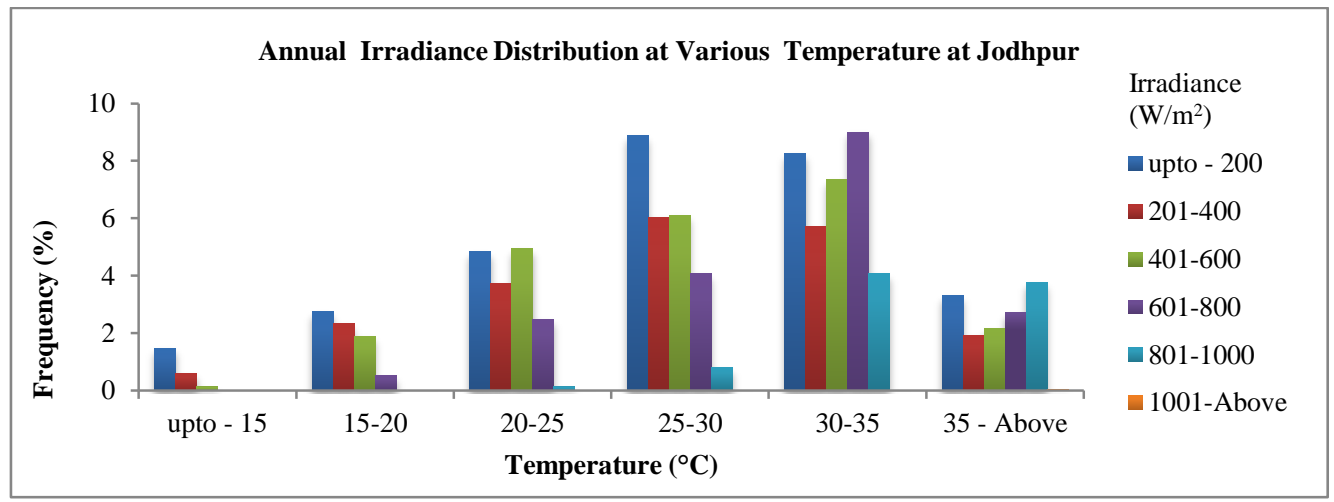

Fig. 6: Annual Irradiance Distribution at Jodhpur, Rajasthan 


\subsection{Annual Irradiance distribution at Various Temperatures at Karaikudi}

Karaikudi is located in the Indian state of Tamil Nadu receives total annual horizontal irradiance of 1744 $\mathrm{kWh} / \mathrm{m}^{2}$ out of which substantial amount of its annual solar radiation in the medium and high irradiance ranges. Nearly $55 \%$ of the solar insolation is received in the irradiance level of more than $600 \mathrm{~W} / \mathrm{m}^{2}$ and nearly $22 \%$ of energy in the irradiance level of more than $800 \mathrm{~W} / \mathrm{m}^{2}$. Similarly, nearly $91 \%$ of the annual day time temperature is in the range of $25^{\circ} \mathrm{C}$ to $35^{\circ} \mathrm{C}$. The annual irradiance distribution at various temperatures is shown in figure-7. The most frequent condition lies within the temperature range of $25^{\circ} \mathrm{C}$ to $30^{\circ} \mathrm{C}$ and irradiance up to $200 \mathrm{~W} / \mathrm{m}^{2}$.

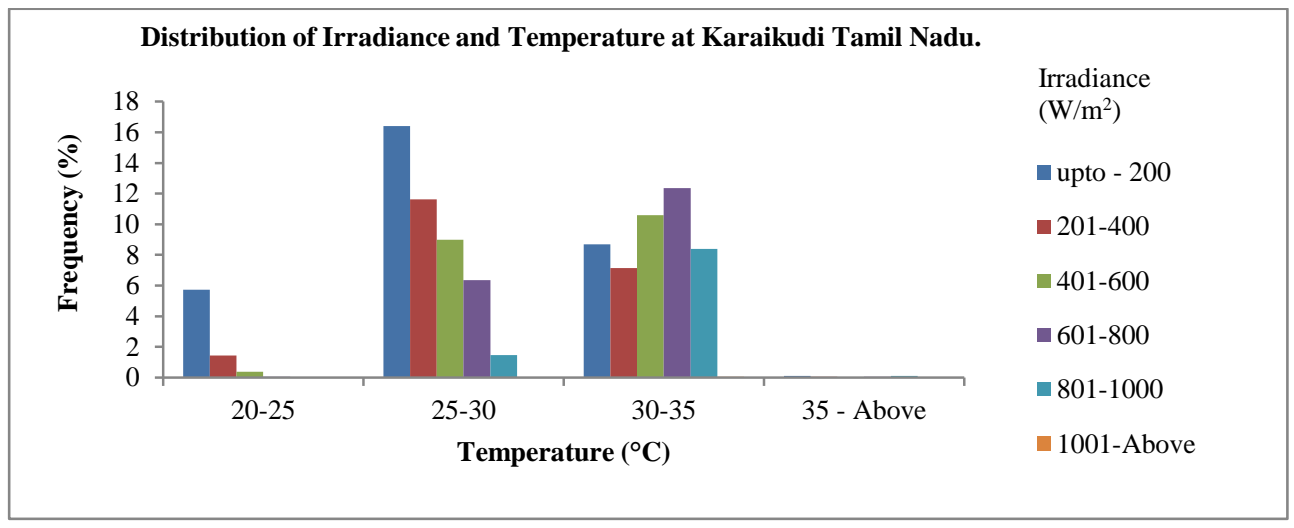

Fig.7: Annual Irradiance Distribution at Karaikudi, Tamil Nadu

\subsection{Annual Irradiance Distribution at Various Temperatures at Neemuch}

Neemuch located in the Indian state of Rajasthan, receives total annual global horizontal irradiance of $1635 \mathrm{kWh} / \mathrm{m}^{2}$ out of which substantial amount of its annual solar radiation in the low and medium irradiance ranges. Nearly $53 \%$ of the solar insolation is received in the irradiance level of less than $600 \mathrm{~W} / \mathrm{m}^{2}$ and nearly $87.8 \%$ of energy in the irradiance level of less than $800 \mathrm{~W} / \mathrm{m}^{2}$. Similarly, nearly $58 \%$ of the annual day time temperature is in the range of $25^{\circ} \mathrm{C}$ to $35^{\circ} \mathrm{C}$. The annual irradiance distribution at various temperatures is shown in figure-8. The most frequent condition lies within the temperature range of $25^{\circ} \mathrm{C}$ to $30^{\circ} \mathrm{C}$ and irradiance level up to $200 \mathrm{~W} / \mathrm{m}^{2}$.

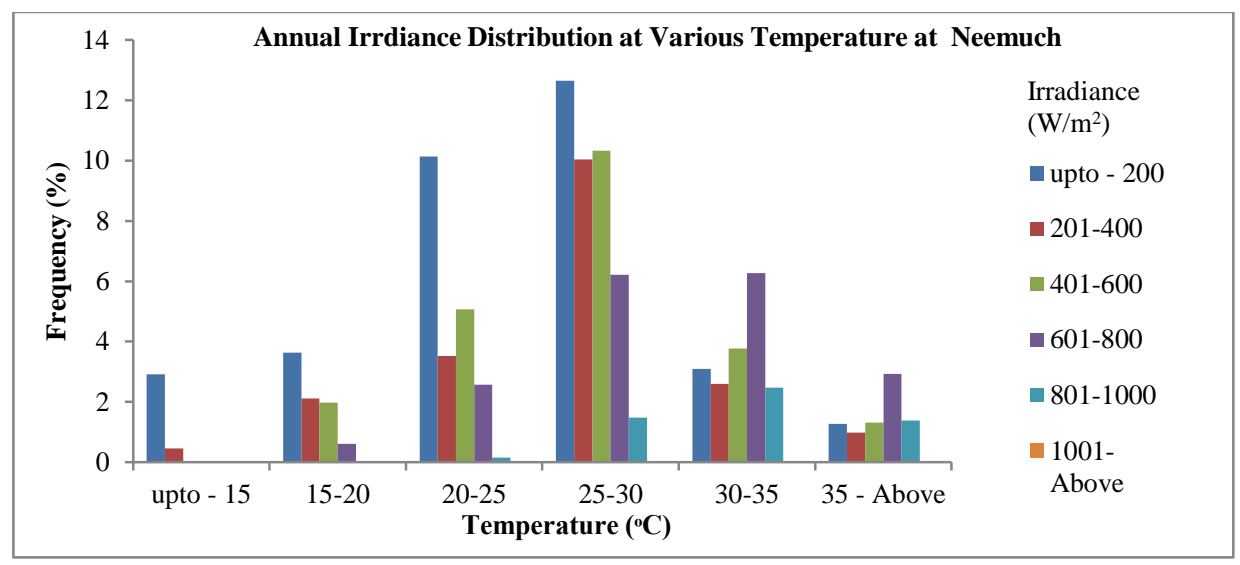

Fig. 8: Annual Irradiance Distribution at Neemuch, Madhya Pradesh

\subsection{Annual Irradiance Distribution at Various Temperatures at Rajahmundry}

Rajahmundry located in the Indian State of Andhra Pradesh, receives total annual global horizontal irradiance of $1595 \mathrm{kWh} / \mathrm{m}^{2}$ out of which substantial amount of its annual solar radiation in the low and medium irradiance ranges. More than $50 \%$ of the solar insolation is received in the irradiance level of less than $600 \mathrm{~W} / \mathrm{m}^{2}$ and nearly $84 \%$ of energy in the irradiance level of less than $800 \mathrm{~W} / \mathrm{m}^{2}$. Similarly, nearly $75 \%$ of the annual day time temperature is in the range of $25^{\circ} \mathrm{C}$ to $35^{\circ} \mathrm{C}$. The annual irradiance distribution at various temperatures is shown in figure-9. The most frequent condition lies within the temperature range of $25^{\circ} \mathrm{C}$ to $30^{\circ} \mathrm{C}$ and irradiance range of up to $200 \mathrm{~W} / \mathrm{m}^{2}$ level. 


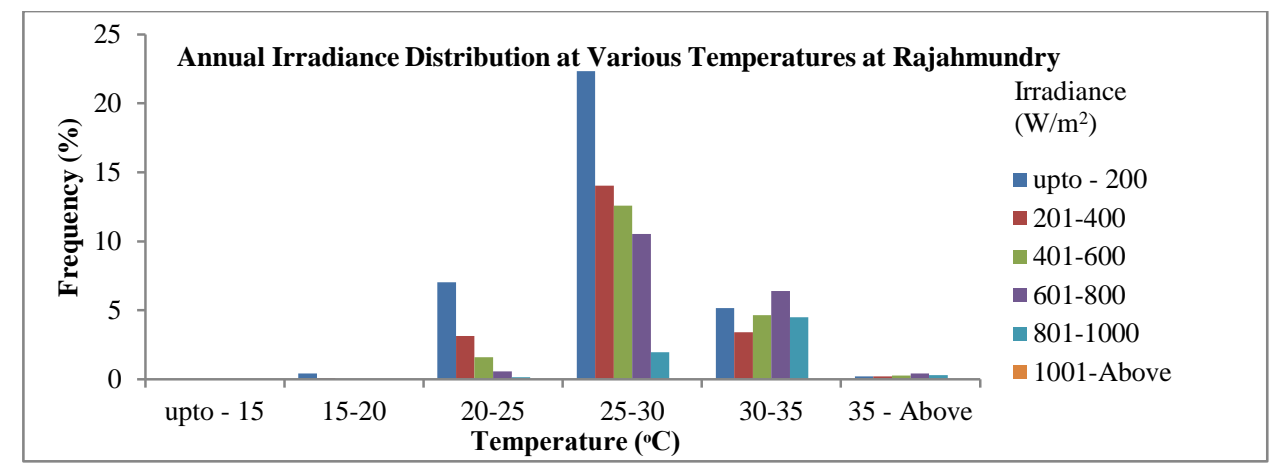

Fig. 9: Annual Irradiance Distributions at Rajahmundry, Andhra Pradesh

\subsection{Annual Irradiance Distribution at Various Temperatures at Shegaon}

Shegaon located in the Indian state of Maharashtra, receives total annual global horizontal irradiance of $1690 \mathrm{kWh} / \mathrm{m}^{2}$ out of which substantial amount of its annual solar radiation in the medium and high irradiance ranges. More than $53 \%$ of the solar insolation is received in the irradiance level of more than $600 \mathrm{~W} / \mathrm{m}^{2}$ and nearly $20 \%$ of energy in the irradiance level of more than $800 \mathrm{~W} / \mathrm{m}^{2}$. Similarly, nearly $77 \%$ of the annual day time temperature is in the range of $25^{\circ} \mathrm{C}$ to $35^{\circ} \mathrm{C}$. The annual irradiance distribution at various temperatures is shown in figure-10. The most frequent condition lies within temperature range of $25^{\circ} \mathrm{C}$ to $30^{\circ} \mathrm{C}$ and irradiance level up to $200 \mathrm{~W} / \mathrm{m}^{2}$.

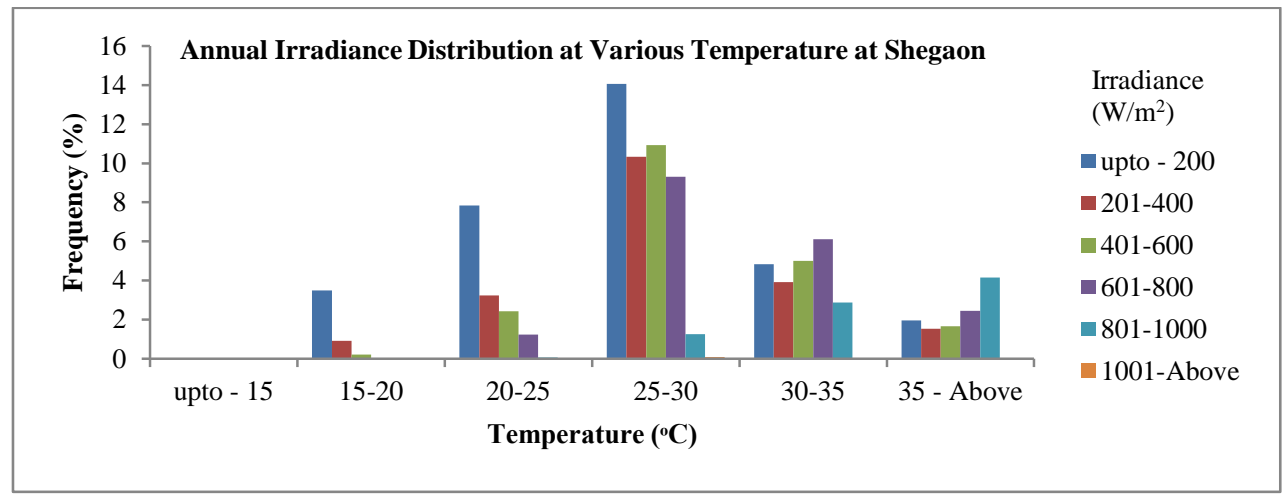

Fig. 10: Annual Irradiance Distributions at Shegaon, Maharashtra

\subsection{Annual Irradiance Distribution at Various Temperatures at Tura}

Tura located in the Indian state of Meghalaya situating in north east part, receives total global horizontal irradiance of $1472 \mathrm{Kwh} / \mathrm{m}^{2}$ out of which substantial amount is in the low and medium irradiance ranges. More than $65 \%$ of the solar insolation is received in the irradiance level of less than $600 \mathrm{~W} / \mathrm{m}^{2}$ and nearly $90 \%$ of energy in the irradiance level of less than $800 \mathrm{~W} / \mathrm{m}^{2}$. Similarly, nearly $62 \%$ of the annual day time temperature is in the range of $25^{\circ} \mathrm{C}$ to $35^{\circ} \mathrm{C}$. The annual irradiance distribution at various temperatures is shown in figure- 11 . The most frequent condition lies in the temperature range of $25^{\circ} \mathrm{C}$ to $30^{\circ} \mathrm{C}$ and irradiance range up to $200 \mathrm{~W} / \mathrm{m}^{2}$.

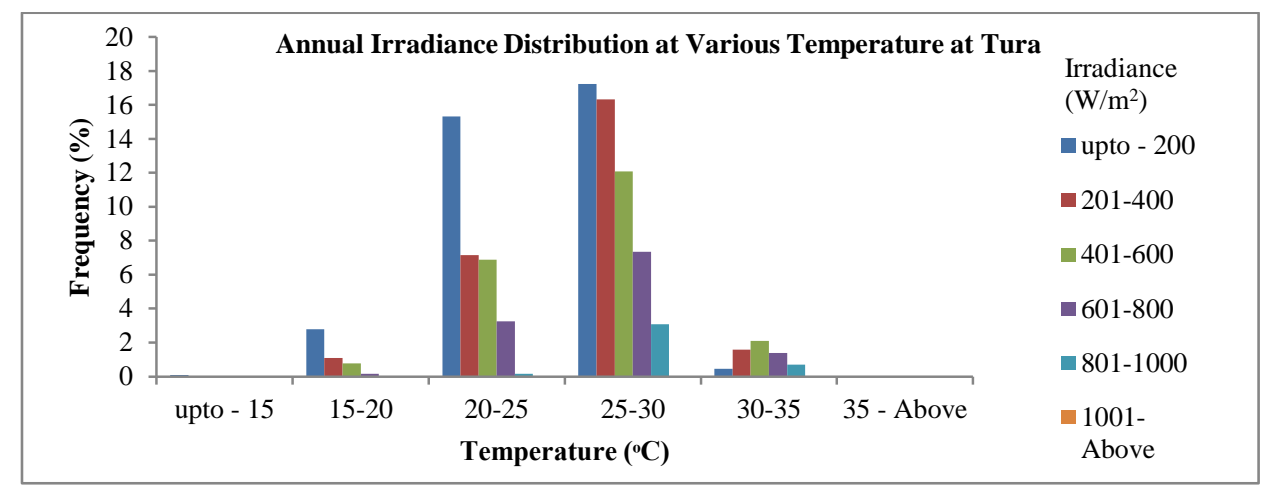

Fig.11: Annual Irradiance Distributions at Tura, Meghalaya 


\subsection{Comparison of Annual Irradiance Distribution and Annual Temperature Distribution for the Selected Locations}

Based on the analysis of the actual ground measured data of selected 10 locations, it has been observed that, the maximum annual sunlight hour (total duration having GHI more than $50 \mathrm{~W} / \mathrm{m}^{2}$ in a year) is received at Chitradurga followed by Tura and Bilaspur. Similarly, the locations receiving maximum radiation at low irradiance level $(<400 \mathrm{~W} / \mathrm{m} 2)$ is Tura followed by Bilaspur and Rajahmundry The irradiance distribution is given at figure-12 and the temperature distribution is given at figure-13.

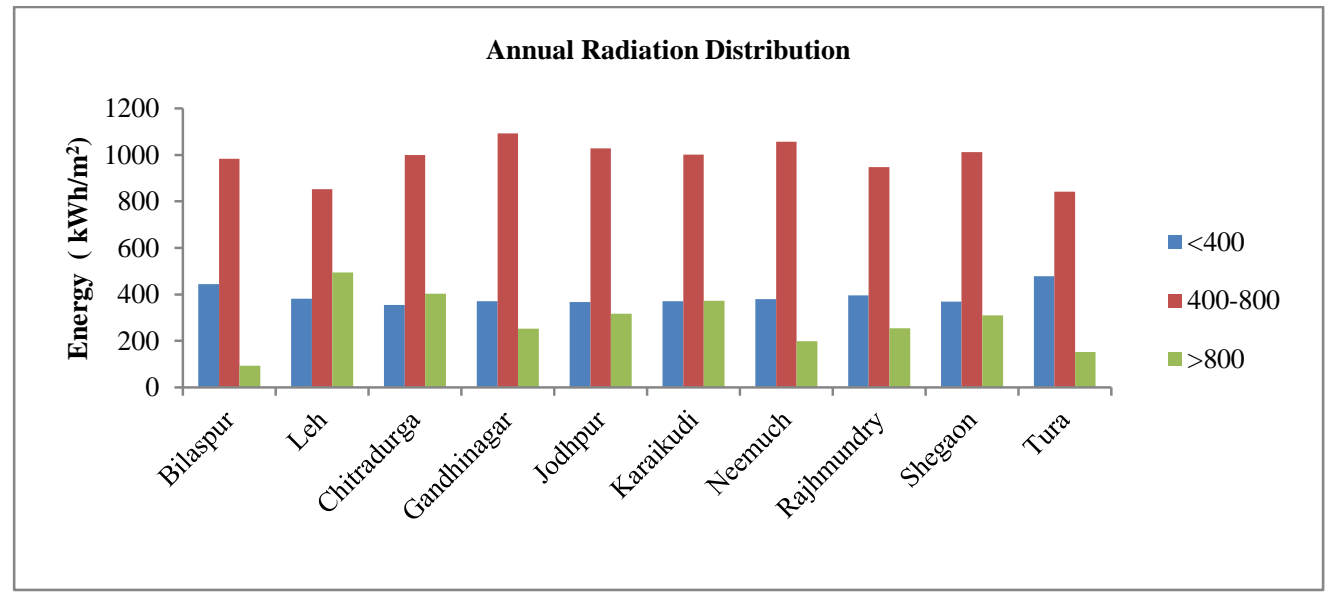

Fig. 12: Annual Distribution of Radiation at Various Irradiance Levels

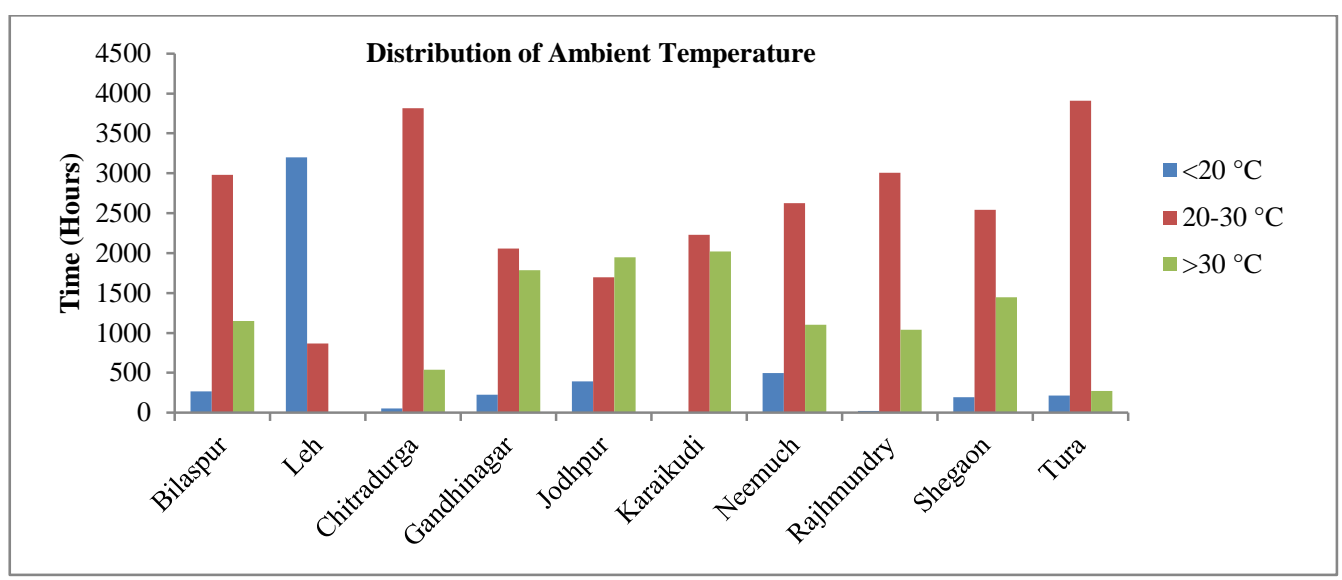

Fig. 13: Annual Day Time Temperature Distribution

\subsection{Comparison of Annual Energy Generation from Various PV Technologies for the Selected Locations}

The annual energy yield of four commercially available PV technologies is studied and compared at ten different geographical location in India, which are depicted in figure-14.The CdTe PV technology is estimated to have highest annual energy generation in all the places in comparison to other technologies in terms of unit installation capacity due to its better response to low irradiance and low temperature coefficient of power. The PV technology HIT is estimated to have highest annual energy generation in terms of unit collector area of the collector due to its highest efficiency among the four PV technologies selected. However keeping in mind the recent development in the efficiency of crystalline silicon technology it can be concluded that, $\mathrm{mC}-\mathrm{Si}$ can also be a promising technology in Indian climate condition in order to get maximum energy output from unit area of installation. 
The estimated levelised cost of energy is presented in figure-15. In terms of levelised cost of energy the technology $\mathrm{mC}$-Si estimated to be having the lowest among the four selected technologies mainly due to its lowest capital cost coupled with better generation in all climatic conditions. The annual average generation from $1.0 \mathrm{~kW}$ installation capacity in case of $\mathrm{mC}-\mathrm{Si}$ varies from $1378 \mathrm{kWh}$ to $1698 \mathrm{kWh}$ from the lowest to the highest solar potential location. Similarly in case of CdTe it varies from $1417 \mathrm{kWh}$ to $1702 \mathrm{kWh}$, for a-Si it varies from $1392 \mathrm{kWh}$ to $1680 \mathrm{kWh}$ and for the highest efficiency technology HIT taken for this study it varies from 1383 $\mathrm{kWh}$ to $1698 \mathrm{kWh}$. In the present scenario it seems $\mathrm{mC}-\mathrm{Si}$ is the sole winner in terms of economic benefits. Accordingly, the prospect for market penetration of other technologies can happen only when there is a technology evolution in terms of low cost.

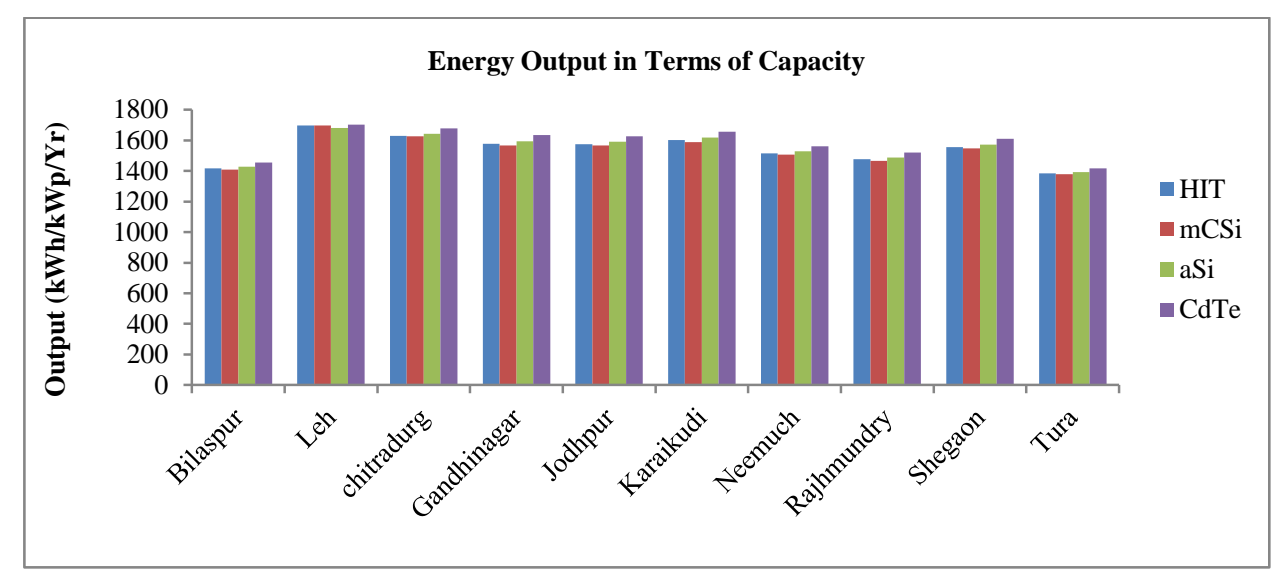

Fig.14: Energy Yield From Four PV Technologies

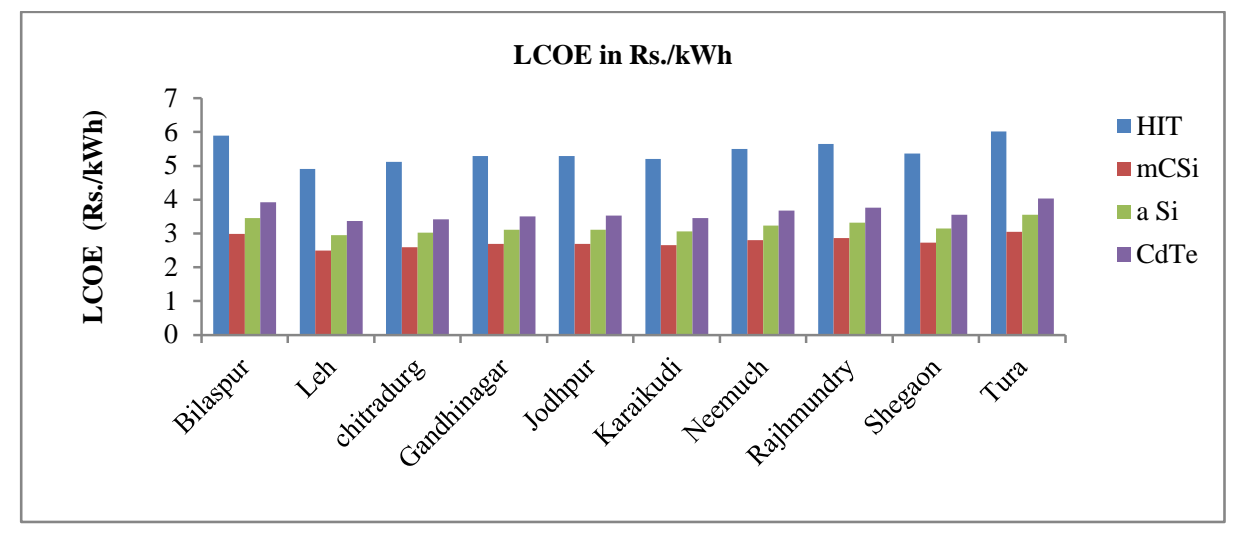

Fig.15 LCOE for Four PV Technologies

\section{Conclusion}

The ground measured solar resource analysis gives a broad picture of the kind of solar resource available in ten selected locations of India representing different climatic conditions prevalent in the country. The irradiance and temperature distribution throughout the year is analysed to indicate the most frequent condition in each location. Further, the annual energy generation and LCOE is estimated for four PV technologies available commercially in the market for the above ten locations. From the above study, it is concluded that, the annual energy generation from $\mathrm{CdTe}$ has been observed to be highest for all locations because of its low temperature coefficient and better response at low irradiance, at Leh the energy generation from HIT is almost same as from CdTe. For places like Tura and Bilaspur, where the amount of radiation received at low irradiance level, thin film technologies are looking promising in terms of energy generation compared to $\mathrm{mC}$-Si Technologies. It is also observed that HIT technology shows highest LCOE in all ten geographical locations in India and $\mathrm{mC}-\mathrm{Si}$ shows lowest LCOE in ten different climatic zones in India due lowest installation cost. 
Based on the already available solar resource map of India, which suggests that, most of the solar potential exists in the western and southern part of India and accordingly most of the present solar installations are located in these regions. The energy generated from these solar plants is consumed in various parts of the country. Although, the interstate transmission charges are presently not applicable for energy generated from solar power plants, this is certainly a cost to the country which has been socialized. Geographically distributed solar installations will certainly have the advantage of minimizing the transmission loss. This study will provide important information for all the stakeholders of PV industry to take an informed decision on selection of a PV technology for a particular location.

\section{Acknowledgements}

The SRRA data was collected by NIWE, as part of the Government of India's National Solar Mission, which was sponsored by MNRE (Ministry of New and Renewable Energy). The involvement of the NIWE (National Institute of Wind Energy) is acknowledged.

\section{Reference}

Carr, A.J., Pryor, T.L., 2004. A comparison of the performance of different PV module types in temperate climates. Solar Energy 76 (1-3), 285-294. https://doi.org/10.1016/j.solener.2003.07.026.

CERC (Terms and Conditions for Tariff determination from Renewable Energy Sources) Regulations, 2017. http://www.cercind.gov.in/2017/regulation/Noti131.pdf.

Chakraborty, S., Sadhu, P., 2015. Technical mapping of solar photovoltaic for the Coal City of India. Renewables: Wind, Water, and Solar, 2(1). doi:10.1186/s40807-015-0013-1.

Cucchiella, F., D'Adamo, I., 2012. Estimation of the energetic and environmental impacts of a roof mounted Building- integrated Photovoltaic system. Renewable and Sustainable Energy Reviews 16, 5245-5259. https://doi.org/10.1016/j.rser.2012.04.034.

Dash, P.K., Gupta, N. C., Rawat, R., Pant, P.C., 2017. A novel climate classification criterion based on the performance of solar photovoltaic technologies. Solar Energy 144, 392-398. https://doi.org/10.1016/j.solener.2017.01.046.

Dash, P.K., Gupta, N.C., 2015. Effect of temperature on power output from different commercially available photovoltaic modules. Int. J. of Engineering Research and Applications 5(1), 148-151.

Huld, T., Suri, M., Dunlop, E. D., 2008. Geographical variation of the conversion efficiency of crystalline silicone photovoltaics modules in Europe. Progress in Photovoltaics: Research and application 16 (7), 595-607. https://doi.org/10.1002/pip.846.

Huld, T., Gottschalg, R., Beyer, H.G., Topič, M., 2010. Mapping the performance of PV modules, effects of module type and data averaging. Solar Energy 84 (2), 324-338. https://doi.org/10.1016/j.solener.2009.12.002.

https://www.alibaba.com (accessed on January, 2018)

Lim, J. L., Woo, S. C., Jung, T. H., Min, Y. K., Won, C. S., Ahn, H. K., 2013. Analysis of factor on the temperature effect on the output of PV module. Transactions of the Korean Institute of Electrical Engineers 62 (3), 365-370. DoI: 10.5370/KIEE.2013.62.3.365. 
Makrides, G., Zinsser, B., Schubert, M., Georghiou, G.E., 2014. Performance loss rate of twelve photovoltaic technologies under field conditions using statistical techniques. Solar Energy 103, $28-42$. https://doi.org/10.1016/j.solener.2014.02.011.

Ministry of New and Renewable Energy. http://www.mnre.gov.in (assessed on June, 2018).

National Institute of Wind Energy. http://niwe.res.in (assessed on June, 2018).

Pavlovic, T. M., Milosavljevic, D. D., Mirjanic, D., Pantic, L. S., Radonjic, I. S., Pirsl, D., 2013. Assessments and perspectives of PV solar power engineering in the Republic of Srpska (Bosnia and Herzegovina). Renewable and Sustainable Energy Reviews 18, 119-133. https://doi.org/10.1016/j.rser.2012.10.007.

Rawat, R., Kaushik, S.C., Sastry, O.S., Singh, Y.K., Bora, B., 2016. Energetic and exergetic performance analysis of $\mathrm{CdS} / \mathrm{CdTe}$ based photovoltaic technology in real operating conditions of composite climate. Energy Convers. Manage. 110, 42-50. https://doi.org/10.1016/j.enconman.2015.11.069.

Reindl, T., Ouyang, J., Khaing, A. M., Ding, K., Khoo, Y. S., Walsh, T. M., Aberle, A.G., 2012. Investigation of the Performance of Commercial Photovoltaic Modules under Tropical Conditions. Japan Journal of Applied Physics 51, 10NF11. https://doi.org/10.1143/JJAP.51.10NF11.

Santana-Rodŕiguez, G., Vigil-Galan, O., Jimenez-Olarte, D., Contreras-Puente, G., Monroy, B.M., EscamillaEsquivel, A., 2013. Evaluation of a grid-connected photovoltaic system and in-situ characterization of photovoltaic modules under the environmental conditions of Mexico City. Revista Mexicana de Fisica 59(2), 88-94.

Skoplaki, E., Palyvos, J.A., 2009. On the temperature dependence of photovoltaic module electrical performance; A review of efficiency/power correlations. Solar Energy 83 (5), 614-624. https://doi.org/10.1016/j.solener.2008.10.008.

Swift, K. D., 2013. A comparison of the cost and financial returns for solar photovoltaic systems installed by businesses in different locations across the United States. Renewable Energy 57, 137-143. https://doi.org/10.1016/j.renene.2013.01.011.

Tossa, A.K., Soro, Y.M., Thiaw, L., Azoumah, Y., Sicot, L., Yamegueu, D., Lishou, C., Coulibaly, Y., Razongles, G., 2016. Energy performance of different silicon photovoltaic technologies under hot and harsh climate. Energy 103, 261-270. https://doi.org/10.1016/j.energy.2016.02.133 


\title{
Short Term PV Forecasting Using Satellite Data for Austria Dominik Kortschak ${ }^{1}$, Marianne Feichtinger-Hofer ${ }^{1}$ and Michael Kernitzkyi ${ }^{1}$ \\ ${ }^{1}$ JOANNEUM RESEARCH, Graz (Austria)
}

\begin{abstract}
For the grid integration as well as for the integration into smart grids of renewable energies accurate forecasting methods for renewal energies are important. In this paper we consider intraday forecasting of photovoltaic (PV) power production and focus on methods which can be used with satellite data. After a literature review we tested the methods cross correlation (CC), the Bayes method (BM), Variational optical flow (VOF) and persistence (PER) in more detail. With these methods we predict the PV- output for approximately $1500 \mathrm{PV}$ systems in Austria. Finally we present some ideas how the existing methods can be improved and provide first results.
\end{abstract}

Keywords: global radiation, forecast, satellite data, photovoltaic

\section{Introduction}

For the grid integration as well as for the integration into smart grids of renewable energies accurate forecasting methods for renewal energies are of key importance (Kaur et al. 2016; Nonnenmacher et. al 2016). In this paper we concentrate on short term forecasts of photovoltaic (PV) systems. Power forecasts for PV systems can be classified into 3 main methods depending on the data used, i.e. on-site online measurements of PV power, offsite satellite-based or ground-based measurements of global horizontal irradiance (GLO), and NWP-based forecasts. While satellite-based PV prediction uses satellite images to determine the cloud motions field and subsequently possible shadowing of the panel as well as decrease in global horizontal irradiance (GLO) (e.g. Hammer et al., 1999, 2003, Lorenz et al., 2004), ground-based PV prediction uses images from sky imagers (e.g. Chow et al., 2011, 2015, Quesada-Ruiz et al., 2014), fish eye cameras (Chu et al., 2014, 2015b) and sometimes also other data like irradiance measurements from pyranometers and cloud height/distribution from ceilometers as input (Schmidt et al., 2016). The forecast horizon should cover a range of a few minutes to few hours, i.e. nowcasting, to take actions in balancing out the solar power volatility in energy management (Huang et al., 2013). Other forecast methods with larger horizons up to days derive information from NWPs as input and apply post processing methods (e.g. , Larson et al., 2016; Lorenz et al., 2007, 2009, 2011), like sometimes neural networks (e.g. Lauret et al., 2014), since the use of NWPs provide more accuracy in the medium range (Perez et al., 2010).

In this paper we will concentrate on methods that use satellite data. Methods used for satellite-based PV prediction and methods using sky imagers for PV prediction, both depend on motion detection in consecutive images. Hence methods of both branches of the literature are considered in this paper. Popular methods to determine the cloud motion vector field are for example Cross Correlation (e.g. Chow et al., 2011) between two consecutive images, the Bayes method consisting in applying probability functions to different motion fields for determining the most probable vector field (Hammer et al., 2003, Lorenz et al., 2004), Variational Optical Flow by minimization of the energy function of the optical flow field (Chow et al., 2015), sector method by averaging the motion fields over sectors (Quesada-Ruiz et al., 2014) and the use of other motion detection algorithm from the field of computational imaging (Schmidt et al. 2016; West et al. 2014). Most papers use persistence as benchmark and not all used methods are shown to improve over the persistence method.

Whereas determining cloud motion vectors via Cross Correlation (Chow et al., 2011) using sky imager data shows only improvements for very short forecast horizons $<5 \mathrm{~min}$ with respect to persistence, Chow et al. (2015) could derive better forecast results (21-19\%) via the Variational Optical Flow method with a fixed smoothness parameter.

Hammer et al. $(1999,2003)$ and Lorenz et al. (2004) used the HELIOSAT method to derive the ground 
irradiance from satellite-based imagery by correcting the measured irradiance for cloud transmission. Prior to this the satellite images are smoothed and the displacement fields between two consecutive images are determined via probability functions (Bayes method). The one with the maximum probability constitutes the actual cloud motion vector field used for the forecast. Hammer et al. (2003) could show that for point as well as region forecasts this method outperforms persistence and that the optimum size for the smoothing mask applied to the images increases with forecast horizon. Furthermore according to Lorenz et al. (2004), with increasing forecast horizon smoothing becomes even more important for decreasing the forecast error than the methods used, i.e. motion vector estimation (Bayes method) or persistence.

Considering the results for different forecast methods in the literature we choose to concentrate on four existing algorithms namely cross correlation (CC), the Bayes method (BM), Variational optical flow (VOF) and persistence (PER), where from the literature especially (BM) and (VOF) are chosen for their good performance stated in the literature. Besides the algorithms from the literature we also developed a new idea and show first results for this new Algorithm compared to existing ones.

The rest of the paper is organized as follows: In section 2 we describe the used data. In section 3 we describe the used methods from the literature. In section 3 we define a new method for cloud motion forecasts based on affine transformations. In section 5 we provide the used method do calculate power forecasts from global radiation forecasts. In section 6 we provide some information for the implementation of the methods. In section 7 we provide the results of numerical evaluation and finally we add some conclusions in section 8 .

\section{Data}

In this paper we use three types of data. We use satellite images, data from NWP and data on feed-in power to the grid.

\section{Satellite data}

To test the different state-of-the-art methods for cloud motion estimation we use the global irradiation, cloud height and cloud mask data from the Spinning Enhanced Visible and Infrared Imager (SEVIRI) of the Meteosat Second Generation (MSG, http://msgcpp.knmi.nl/) satellite provided by the Royal Netherlands Meteorological Institute (KNMI). The data covering the period January 2015 to December 2016 has a spatial horizontal resolution of approximately $5 \times 5-\mathrm{km}$ and a temporal resolution of 15 minutes. The cloud mask ("cloud area fraction") distinguishes pixels in cloud free, cloud contaminated and cloud filled. The calculation of global horizontal irradiation (GLO; "surface downwelling shortwave flux in air") is based on the Cloud Physical Properties (CPP) algorithm from KNMI.

\section{NWP data}

We use the output of the AROME (Application of Research to Operations at MEsoscale) forecast model that is implemented by the ZAMG (Zentralanstalt für Meteorologie und Geodynamik). The model has a special resolution of approximately $2.5 \mathrm{~km}$. For this paper we use global radiation forecasts for the time horizon between January 2015 and December 2016. The forecast are calculated on a daily basis and are available for the next 48 hours with a temporal resolution of 1 hour. This represents a state of the art NWP for Austria.

\section{Data on feed-in power}

In this paper we use the feed-in power data of approximately load profile meters of 1497 PV systems all over Austria. The feed-in power data was provided by the APG (Austrian Power Grid) and belongs to the OeMAG Abwicklungsstelle für Ökostrom AG. The feed-in power covers the years 2015 and 2016 and has a temporal resolution of 15 minutes. We have to remark that for each solar power system we have information on the location and on the installed capacity but we don't have information on the orientation of the solar power panels. Finally we should mention that some of the PV systems only feed-in a part of the produced power. In Fig. 1 we provide a smoothed version of the distribution of the installed kilowatt-peak in Austria we can observe that PV systems usually occur in clusters but are distributed all over Austria. 


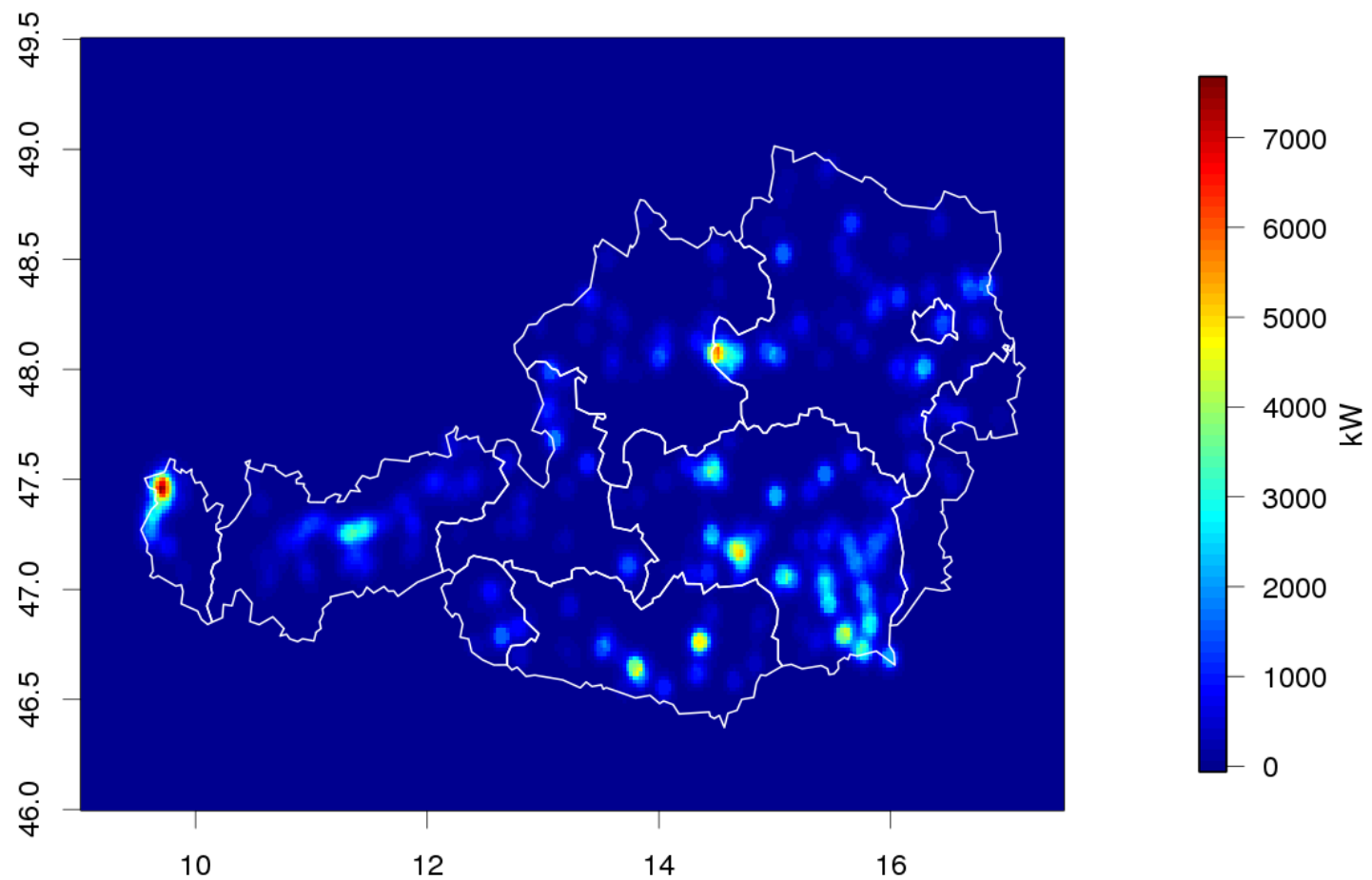

Fig. 1 Spatial distribution of used PV systems in Austria

\section{Description of used state of the art methods for satellite images}

We consider cloud motion forecasts from satellite images to generate intraday forecasts of global radiation and feed-in solar power. We decided to implement 4 Methods from the literature: Persistence (PER), Cross Correlation (CC), Variational Optical flow (VOF), and Baysian Method (BM).

Persistence is the simplest method and assumes that cloud cover stays constant at the last observed state. This method is used as benchmark method in most papers.

Cross Correlation: Following (Chow et al. 2011) the cloud motion vector of a sky image can be determined via the cross correlation method (CC) between two consecutive images. We decided to apply the method for blocks with sizes of $41 \times 41$ pixels. The reason for this is twofold. First the use of blocks makes the resulting motion field smoother and second reduces the computational load. For every block cross correlation is carried out between a field spanning 41x41 pixels around the block centre of the first image with a shifted pixel field of the same size in the previous image. The maximum displacement is chosen with 9 pixels in each direction corresponding to a maximum wind speed of approximately $180 \mathrm{~km} / \mathrm{h}$.

Variational Optical flow: As was stated in Chow et al. (2015) cross correlation does not always improve over the persistence method hence an alternative method was considered in Chow et al. (2015). Chow et al. (2015) use the variational optical flow (VOF) algorithm form (Liu 2009). The principle idea of the algorithm is that the value of a pixel does not change over time but changes location. The VOF method assumes that the pixel intensity remains constant between two consecutive images and only shifts position. The algorithm finds the motion vector that minimizes the difference between the two consecutive satellite images with an additional smoothness constraint on the resulting motion vector. For the estimation we further use a coarse-to-fine warping technique using Gaussian pyramids, meaning that the motion vectors are first calculated at lower resolutions and the motion vector for the lower resolution images is used as starting solution for higher resolution (Liu 2009). In some numerical experiments (not included in this paper) we found that the size of the satellite image can have a significant impact on the performance of the VOF method, meaning that it works better for bigger satellite images.

Bayesian method: The Bayes method described in (Hammer et al. 1999, 2003, 2015; Lorenz et al. 2004; Perez et 
al. 2010). The idea of the method is to find the motion vector that maximizes probability given the two consecutive satellite images. Where the probability of a motion vector depends on the difference of the pixel values, the difference in the gradient in the pixels and some smoothness conditions. We applied this method to image fields of $11 \times 11$ pixels corresponding to 5 neighbors in each direction

We should highlight the similarity between the BM and VOF method. The principle idea is to find the motion vector of an area that minimizes the difference between the first images and the moved second image. In both methods smoothness of the resulting motion field is also part of the optimization which is the main difference to cross correlation method.

Finally for the implementation we used the programming language R. The methods are implemented according to the cited papers and the references therein.

To make forecasts we first normalize the global radiation from the satellite data with the clear sky index and then apply the motion field repetitively to the normalized global radiation. The clear sky index is finally used to calculate the forecast of the global radiation at a new time point.

\section{A method using affine transformation}

In this section we describe a new method for cloud motion tracking. The principle idea of the method is to track individual cloud systems separately. We will assume that we have two consecutive satellite images image 1 and image 2. The first step is to split the image 1 into areas with similar cloud cover. We will later discuss different possibilities of how the satellite image can be split into different areas. The area basically consists of a set of pixels that can be described by a set of coordinates $I=\left\{\left(I_{x, 1}, I_{y, 1}\right), \cdots,\left(I_{x, n}, I_{y, n}\right)\right\}$. The idea of the method is to find a transformation of the set $I$ to a set $\bar{I}$ such that the difference between the image 1 at set $I$ is close to the values in image 2 of set $\bar{I}$. As possible transformations we will use affine transformations i.e.

$\bar{I}=A I+s$

Where $s=\left(s_{x}, s_{y}\right)$ is a vector for shifts and $A$ is a $2 \times 2$-Matrix. The calculation of the error and the parameters of the transform are calculated similar as in the VOF algorithm. Meaning at first the image 1 is blurred with a Gaussian filter and evaluated at the index set $I$ the resulting set of values is denoted with $P_{I}$. The image 2 is evaluated with the help of Gaussian interpolation at the index set $\bar{I}$, we denote the resulting values with $\bar{P}_{\bar{I}}$. As in the VOF algorithm the goal is to minimize

$\varphi\left(\left(P_{I}-\bar{P}_{\bar{I}}\right)^{2}\right) \quad($ eq. 2$)$

where $\varphi(x)=\sqrt{x+0.001^{2}}$ is a robust function. As in the VOF algorithm the optimizations is done with the help of a Taylor expansion i.e. For a given start solution of the affine transformation $\overline{I_{0}}$, we denote with $d \bar{P}_{\bar{I}_{0}}^{x}, d \bar{P}_{\bar{I}_{0}}^{y}$ the derivative of $\bar{P}_{\bar{I}_{0}}$ in $x$ respectively $y$ direction further for a new solution leading to an image set $\overline{I_{n}}$ we denote with $d I_{n}^{x}, d I_{n}^{y}$ the difference between $\overline{I_{0}}$ and $\overline{I_{n}}$ in the direction of the $x$ respectively $y$ coordinate. The new affine transformation with leading to the index set $\overline{I_{1}}$ is than the transformation that minimizes the approximation

$\varphi\left(\left(P_{I}-\bar{P}_{\bar{I}}+d I_{n}^{x} \cdot d \bar{P}_{\bar{I}_{0}}^{x}+d I_{n}^{y} \cdot d \bar{P}_{I_{0}}^{y}\right)^{2}\right)$

This procedure is iterated until the solution converges or a maximal number of iterations are exceeded.

With the above described method we can calculate for every chosen area a motion vector in direction of the coordinates $\mathrm{x}$ and $\mathrm{y}$. The next step is to generate the motion vector for the complete index. In a first step we assigned every pixel the average motion from the different areas in which it is located. For pixels that are in no area a speed of 0 is assumed. Finally a Gaussian filter is used to smooth the wind speeds. If the used areas are not covering the whole satellite image it can be favorable to interpolate the data for pixels outside the chosen areas depending on the distance to other pixel (this can be done with standard methods from spatial kriging). This provides us with motion vectors for the complete satellite image. To get forecasts the methods described in Lorenz (2004) can be used. But we implemented an alternative method where we first calculated for every 
chosen area the average motion and translated the complete area by this motion. We then get with the above described method a new motion vector for the complete wind field.

At last we want to describe the method of how to select the areas for the motion vectors. In the first method we normalized the global radiation with the clear sky radiation. This data is then rounded to 4 different values and areas with the same value that are connected together with a buffer are chosen further we discard areas with to view pixels. This method will be referred as AFFINE in the rest of the text. The second method uses the cloud top high for the satellite data determine the areas. As connected areas the connected areas with clouds above $2000 \mathrm{~m}$ respectively below $2000 \mathrm{~m}$ are used for the calculations. In this example we get 2 motion fields one for low clouds and one for high clouds. This method will be referred as CloudHigh in the rest of the text.

\section{From solar forecast to prediction of feed-in power}

In section 3 and 4 we have described methods to forecast the global radiation at a given location using satellite images. In this chapter we describe the model that was used to estimate the feed-in power from the global radiation forecasts. We assumed a rather simple model that calculates the infeed data. The main reason for using a simple model is that we are mainly interested in the different performances of the global radiation forecasts and not finding an optimal model for the calculation of feed-in power data from global radiation. Since the main source of error for the feed-in power is usually the error of the global radiation forecast a more sophisticated model would most probably not lead to different results. The model is defined as

$\frac{P_{\text {out }}}{K W_{p}}=a_{1}(A, Z) \frac{G L O}{1000}+a_{2}(A, Z) a_{3}(C S)+I \quad($ eq. 4$)$

where $P_{\text {out }}$ is the measured feed-in power in $\mathrm{kW}, k W_{p}$ is the kilowatt peak of the considered PV system, GLO denotes the global radiation, $A$ denotes the azimuth, $Z$ the solar Zenith angle and $C S$ the clear sky radiation. The $a_{i}$ are continuous functions of the arguments and $I$ is the intercept. We calculated the parameters for each of the 1497 PV systems individually. For the calibration we used the data of the satellite images and we used least squares for the parameters where we additionally added an error term that adds a penalty on the roughness of the functions $a_{i}$ to avoid overfitting.

\section{Applications of data}

We provide a little more details for the applications of the methods for global radiation forecasts. The implemented methods for global radiation forecasts where applied to satellite images with a spatial extend between $6^{\circ}$ and $22^{\circ}$ eastern longitude and $43.8^{\circ}$ and $51^{\circ}$ of northern latitude. We applied the models for the Satellite images with at most $10 \%$ of missing data (images are only provided at daylight). With the generated motion vectors we calculate forecasts until the time of the image which has at last less than $50 \%$ of missing values. From each forecasts we only used the values for the pixels that correspond to the considered PV systems. We additional added the forecasts of a NWP where we used the average over 30 pixel in each direction instead of the single pixel of the forecast. For the error evaluation we will use the weighted average of the forecasted global radiation. As weights we use the installed kilowatt peak of the PV system.

After calculating the forecasts for the global radiation for the individual PV systems we use the models from section 5 to estimate the feed-in power forecast of the data. The models in section 5 are calibrated with the global radiation data from the satellite images and only the year 2015 is used for the estimation of parameters. For the error calculations we again aggregated the individual PV systems.

With the considered method we have two disadvantages. First satellite images as used in forecasts only exist during daylight. Second we estimated models for individual PV systems, with the aggregation of the model there might be systematic errors in the prediction. To solve the second disadvantage we use generalized additive models with formula $\mathrm{SP} \sim \mathrm{s}(\mathrm{PSP})+\mathrm{s}(\mathrm{DT})$, where $S P$ is the total measured feed-in power, $P S P$ is the predicted feed-in power and $D T$ denotes the time of the day $(s(\cdot)$ means that we consider a smooth function of the variable). To solve the first disadvantage we use the forecast from the NWP meaning that we use the forecast from the NWP whenever no satellite forecast exists. We also used combination of the different models using generalized additive models (COMB). Finally we also tried to incorporate the last known feed-in power. This is again done with generalized additive models and similar to WPPT. This means, that we added a term with the 
error of the last known forecast in the generalized additive model. The values are provided for the (COMB) and (NWP) method and are denoted with COMP.C and NWP.C.

\section{Numerical examples}

At first we consider the results for the approximation of the global radiation. In Fig. 2 we provide the normalized mean squared errors (nRMSE). As normalization we use the maximal observed global irradiation. We can observe that the methods using satellite data work better for 2015 than 2016. A possible explanation for this might be different weather conditions in the two years. Interestingly the method using NWP performs better in 2016 than 2015. If we compare the different methods, we can observe that all methods outperform the NWP method for a time horizon of up to 3 hours. Considering the methods based on satellite images, we can observe that the AFFINE method works best followed by the methods CloudHigh, CC, and Bayes, which all work comparable. The methods with the highest nRMSE are the persistence method and the VOF method.

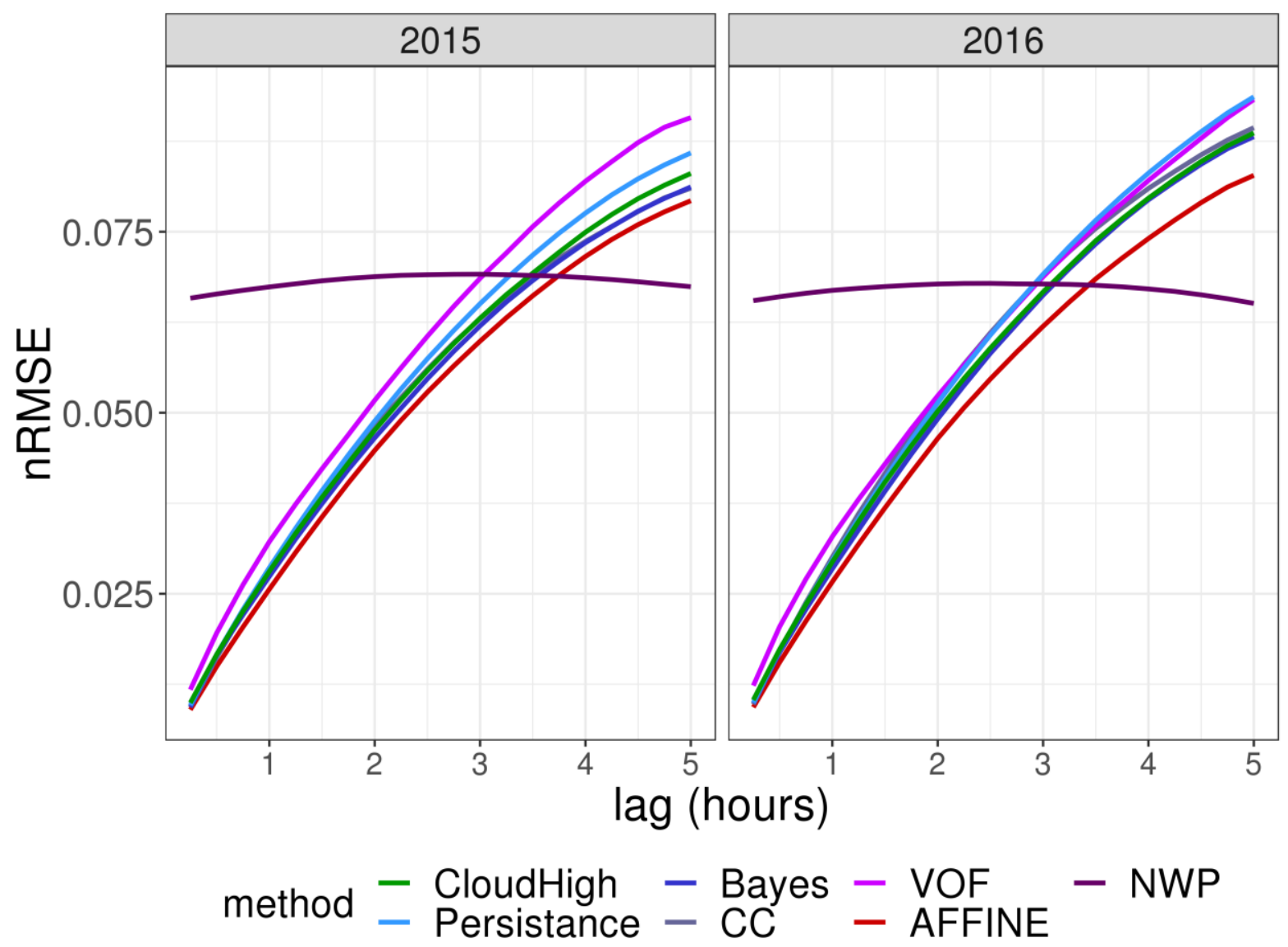

Fig. 2 Normalized mean squared error (nRMSE) for the prediction of the global radiation

Next we consider the results for the approximation of the feed-in power in Fig. 3. As normalization we use the installed $k W_{p}$. We only used time points when forecasts with satellite images where available. In Fig. 3 we added forecasts using the observed satellite data as benchmark (satellite). We can observe that the nRMSE using the satellite decreases for higher lags. The reason for the decreasing of nRMSE is that with increasing lag there are fewer times at which all methods provide forecasts. If we compare the different forecast methods, we can observe that all methods outperform the NWP method for a time horizon of up to 5 hours. Considering the nRMSE of the forecasts methods based on satellite images we can observe a similar order then in Fig. 2 only that especially for 2016 the CloudHigh method outperforms the methods CC, and Bayes. The difference in the ordering of the Fig. 2 and Fig. 3 can be explained by a different weighting of the errors on different times of the 
day and that also the satellite measurements are not completely accurate for a considered PV system.

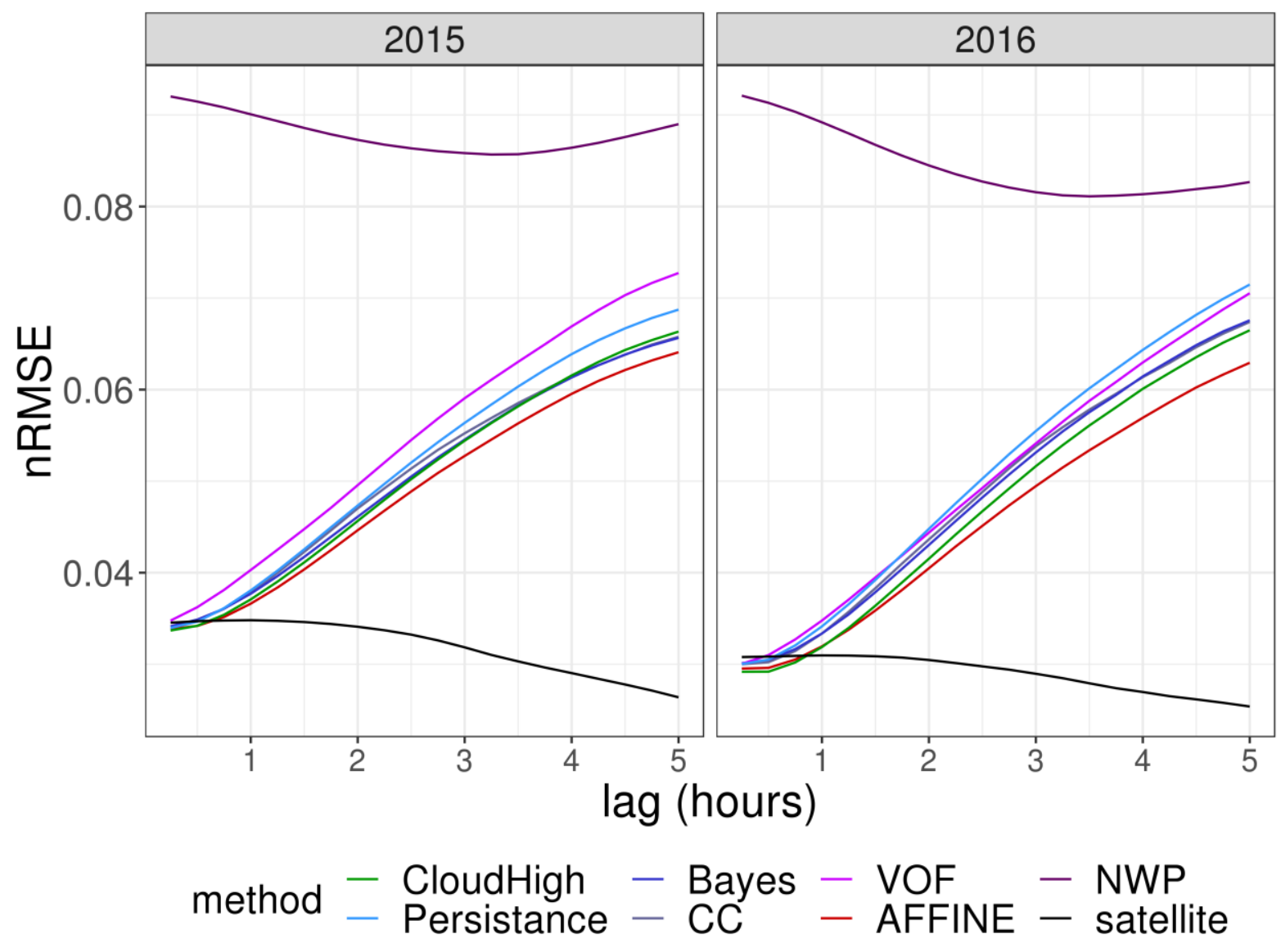

Fig. 3 Normalized mean squared error (nRMSE) for the prediction of the feed in power

Finally in Fig. 4 we provide the results for the feed-in power when linear models are applied to the forecasts and for times without data the NWP method is used as well as the combined methods and the methods that are corrected with observed infeed-power. At first we can observe that combining different methods can improve the forecast this especially true for higher lags. Second if we combine forecast with measured feed-in power we can observe that the method can even improve over the measured global radiation from satellite data. The ordering of the other methods is similar as for the results in Fig. 2 and Fig. 3. 

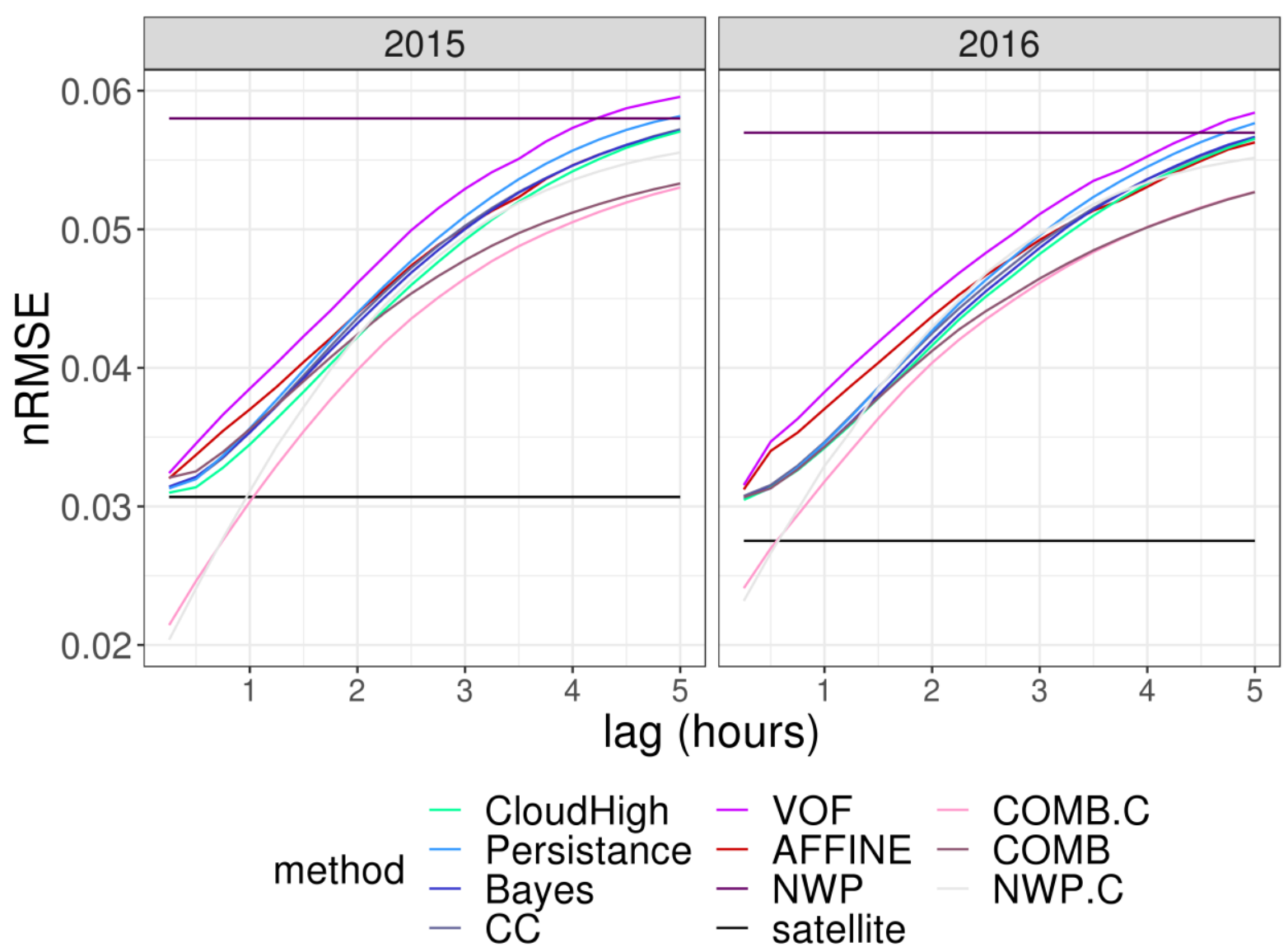

Fig. 4 Normalized mean squared error (nRMSE) for the prediction of the feed in power

\section{Conclusion}

In this paper we have considered satellite based PV-forecasts for Austria. We considered the error of the forecasts for the global radiation and for the feed-in power for approximately $1500 \mathrm{PV}$-systems. We compared the results to a state of the art NWP and tested also the combination of different methods. We have shown that the new method using affine transformation can improve over the other methods that are used in the paper. We can observe that satellite based methods improve over NWP for at least lag of 3 hours. Finally we have seen that combing different methods with linear models and especially adding online measurements can improve the forecasts of individual models (compare Heinemann et al. 2006)

\section{Acknowledgements}

The results are part from the project RESOLW - Renewable Energy Forecast by new Solarradiation- and Windnowcastingsystems which was funded by the Federal Ministry Republic of Austria Transport, Innovation and Technology (BMVIT).

\section{References}

Chow, C.W., Belongie, S., Kleissl, J., 2015. Cloud motion and stability estimation for intra-hour solar forecasting. Solar Energy 115, 645-655. doi: 10.1016/j.solener.2015.03.030

Chow, C.W., Urquhart, B., Lave, M., Dominguez, A., Kleissl, J., Shields, J., Washom, B., 2011. Intra-hour forecasting with a total sky imager at the UC San Diego solar energy testbed. Solar Energy 85(11), 2881-2893. doi: 10.1016/j.solener.2011.08.025 
Chu, Y., Pedro, H.T.C., Nonnenmacher, L., Inman, R.H., Liao, Z., Coimbra, C.F.M., 2014. A Smart ImageBased Cloud Detection System for Intrahour Solar Irradiance Forecasts. Journal of Atmospheric and Oceanic Technology 31, 1995-2007. doi: 10.1175/JTECH-D-13-00209.1

Chu, Y., Urquhart, B., Gohari, S.M.I., Pedro, H.T.C., Kleissl, J., Coimbra, C.F.M., 2015. Short-term reforecasting of power output from a 48 MWe solar PV plant. Solar Energy 112, 68-77. doi: 10.1016/j.solener.2014.11.017

Hammer, A., Heinemann, D., Hoyer, C., Kuhlemann, R., Lorenz, E., Müller, R., Beyer, H. G., 2003. Solar energy assessment using remote sensing technologies. Remote Sensing of Environment, 86(3), 423-432. doi: $10.1016 / \mathrm{S} 0034-4257(03) 00083-\mathrm{X}$

Hammer, A., Heinemann, D., Lorenz, E., Lückehe, B., 1999. Short-term forecasting of solar radiation: a statistical approach using satellite data. Solar Energy 67(1), 139-150. doi: 10.1016/S0038-092X(00)00038-4

Hammer, A., Kühnert, J., Weinreich, K., Lorenz, E., 2016. Short-term forecasting of surface solar irradiance based on Meteosat-SEVIRI data using a nighttime cloud index. Remote Sensing 7(7), 9070-9090. doi: $10.3390 /$ rs 70709070

Heinemann, D., Lorenz, E., Girodo, M., 2006. Forecasting of solar radiation, in: Dunlop, E.D., Wald, L., Suri, M. (Eds.), Solar energy resource management for electricity generation from local level to global scale. Nova Science Publishers, New York, pp. 83-94.

Huang, H., Xu, J., Peng, Z., Yoo, S., Yu, D., Huang, D., Qin, H., 2013. Cloud motion estimation for short term solar irradiation prediction. IEEE Smart Grid Communications (SmartGridComm) 2013, Symposium, Vancouver, BC, 696-701. doi: 10.1109/SmartGridComm.2013.6688040

Kaur, A., Nonnenmacher, L., Coimbra, C.F., 2016. Net load forecasting for high renewable energy penetration grids. Energy 114, 1073-1084. doi: 10.1016/j.energy.2016.08.067

Liu, C., 2009. Beyond pixels: exploring new representations and applications for motion analysis. doctoral theses, MIT. URL: http://hdl.handle.net/1721.1/53293, last accessed: 13.01.2017

Larson, D.P., Nonnenmacher, L., Coimbra, C.F., 2016. Day-ahead forecasting of solar power output from photovoltaic plants in the American Southwest. Renewable Energy 91, 11-20. doi: 10.1016/j.renene.2016.01.039

Lauret, P., Diagne, M., David, M., 2014. A neural network post-processing approach to improving NWP solar radiation forecasts. Energy Procedia 57, 1044-1052. doi: 10.1016/j.egypro.2014.10.089

Lorenz, E., Hammer, A., Heinemann, D., 2004. Short term forecasting of solar radiation based on satellite data. In proceedings of EuroSun 2004 Congress, Freiburg, Germany, 841-848. URL: https://www.researchgate.net/ profile/Annette_Hammer/publication/267971482_Short_term_forecasting_of_solar_radiation_based_on_satellit e_data/links/5583ecb708ae4738295bb661.pdf, last accessed: 25.11.2016

Lorenz, E., Heinemann, D., Wichramarathne, H., Beyer, H.G., Bofinger, S., 2007. Forecast of ensemble power production by grid-connected PV systems. In proceedings of 20th European PV Conference, 2007, Milano, Italy URL: $\quad$ https://uol.de/fileadmin/user_upload/physik/ag/ehf/enmet/publications/solar/conference/2007/ eupv_milano/forecast_of_ensemble_power_production_by_grid_connected_pv_systems.pdf last accessed: 24.11.2016

Lorenz, E., Scheidsteger, Th., Hurka, J., Heinemann, D., Kurz, C., 2011. Regional PV power prediction for improved grid integration. Prog. Photovolt: Res. Appl. 19, 757-771. doi: 10.1002/pip.1033

Lorenz, E., Remund, J., Müller, S.C., Traunmüller, W., Steinmaurer, G., Pozo, D., Ruiz-Arias, J.A., Faneo, V.L., Ramirez, M.G., Kurz, C., Pomares, L.M., Guerrero, C., 2009. Benchmarking of Different Approaches to Forecast Solar Radiation. 24th European Photovoltaic Solar Energy Conference, 2009, Hamburg, Germany. URL: http://task3.iea-shc.org/data/sites/1/publications/24th_EU_PVSEC_5BV.2.50_lorenz_final.pdf, last accessed: 25.11.2016

Nonnenmacher, L., Kaur, A., Coimbra, C. F., 2016. Day-ahead resource forecasting for concentrated solar power integration. Renewable energy 86, 866-876. doi: 10.1016/j.renene.2015.08.068 
Perez, R., Kivalov, S., Schlemmer, J., Hemker, K., Renné, D., Hoff, T.E., 2010. Validation of short and medium term operational solar radiation forecasts in the US. Solar Energy 84, 2161-2172. doi: 10.1016/ j.solener.2010.08.014

Quesada-Ruiz, S., Chu, Y., Tovar-Pescador, J., Pedro, H.T.C., Coimbra, C.F.M., 2014. Cloud-tracking methodology for intra-hour DNI forecasting. Solar Energy 102, 267-275. doi: 10.1016/j.solener.2014.01.030

Schmidt, T., Kalisch, J., Lorenz, E., Heinemann, D., 2016. Evaluating the spatio-temporal performance of skyimager-based solar irradiance analysis and forecasts. Atmospheric Chemistry and Physics 16(5), 3399-3412. doi: $10.5194 /$ acp-16-3399-2016

West, S.R., Rowe, D., Sayeef, S., Berry, A., 2014. Short-term irradiance forecasting using skycams: motivation and development. Solar Energy 110, 188-207. doi: 10.1016/j.solener.2014.08.038 


\title{
The Spatial and Temporal Patterns of the Surface Solar Irradiation in Northeastern Region of Brazil
}

\author{
Francisco José Lopes de Lima ${ }^{1,2 *}$, Fernando Ramos Martins ${ }^{1}$, Rodrigo Santos Costa ${ }^{2}$, André \\ Rodrigues Gonçalves ${ }^{2}$, Ana Paula Paes dos Santos ${ }^{2}$, Enio Bueno Pereira ${ }^{2}$ \\ 1 Federal University of São Paulo, Santos-SP (Brazil) \\ 2 Brazilian Institute for Space Research, São José dos Campos (Brazil)
}

\begin{abstract}
Earlier studies have demonstrated that the Northeastern region (NEB) receives the largest surface solar irradiance of the Brazilian territory due to its location in the tropical area and its climate and environment characteristics. The work aimed at investigating the surface solar irradiation variability and trends and relates it with regional climate and environmental characteristics. The statistical analysis was based on ground data acquired in automated weather stations operated by INMET. A quality control procedure was accomplished according to WMO criteria to avoid suspicious data. The results pointed out a significant variability in seasonal and annual scales. The cluster analysis methodology was performed and provided five regional patterns concerning the incoming solar irradiation. There are quite interesting temporal complementary regimes in the region. From December to February, the surface solar irradiation average achieves simultaneously its maximum in the southeastern area and its minimum in the western area of NEB. The Mann-Kendall method and the Sen technique were used to evaluate the annual and seasonal trends of the surface solar irradiation averages. The surface solar irradiation in the southeastern area of NEB is decreasing by $50 \mathrm{Wh} / \mathrm{m}^{2} /$ year since 2008 . On the other hand, it is increasing around $40 \mathrm{Wh} / \mathrm{m}^{2} /$ year in the semi-arid area along the same timeframe.
\end{abstract}

Keywords: Solar Irradiation, Analysis of Clustering, Seasonal and Interannual.

\section{Introduction}

The study of the incoming solar radiation has direct implications on the meteorology, especially on the climate variability (Lohmann et al., 2016). The solar radiation is the energy resource for every physical and biological process regulating the life in Earth including the diurnal and seasonal cycles of temperature and the photosynthesis (Lima et al., 2007). The evapotranspiration is intrinsically related to the Earth's energy balance, and the solar energy data allows to quantify the energy allocated to heat soil and atmosphere (Silva et al., 2005). The surface solar radiation also plays an important role in carbon assimilation by canopies and, consequently, in the productivity of the ecosystems (Cohen et al., 2002; Gu, 2003; Roderick et al., 2001; V. de P. R. da Silva et al., 2010; R. A. E. Silva et al., 2010).

In addition, the solar radiation has also an important role in several human activities with important environmental and socioeconomic consequences like agriculture, engineering, architecture, energy generation and consumption and other sectors (Wild, 2009).

Currently, the world's primary energy demand relies largely on fossil fuels. The consumption of fossil fuels releases a large quantity of greenhouse gases into the atmosphere, especially carbon oxides. The Brazilian energy matrix is already an exemplary case of renewable energy usage presenting a large share of hydro, wind and biomass power generation. However, taking into consideration the resumption of economic growth, there will be an increasing energy demand in Brazil (Goldemberg and Lucon, 2008). The renewable energy sources, especially solar and wind power, are an important alternative not only because of the inherent advantages related to energy matrix diversification but also there will be great worldwide pressure to stabilize carbon emissions rate in the atmosphere through reducing the consumption of fossil fuels.

Nowadays, the solar energy is already considered an alternative to complement the Brazilian energy matrix based on mostly hydroelectric and thermoelectric power plants (Pereira et al., 2006). The conversion of solar radiation 
into electricity or thermal energy reduces the environmental impacts and emission of pollutants during the operation of the power plants. However, in addition to the unsolved technological difficulties related to the temporal intermittency and dependence on weather conditions, the investments to install and operate solar power plants are still larger than the required for the conventional hydropower and thermal power plants (Pereira et al. 2017).

Thus, the solar energy will not replace the fossil fuels or hydroelectric power in the current scenario, but it will be gradually added to complement the current sources through hybrid and distributed generation systems (Goldemberg and Lucon, 2008). The current limitations on solar energy exploitation tend to be reduced or even eliminated, mainly in response to technological development and to the growth of world energy demand in developing countries.

Brazil is a country located mostly in the intertropical region and, consequently, it has a large solar energy potential throughout its territory. Despite of that, reliable database on surface solar irradiance are still scarce in the country. Several studies faced many limitations due to the low density of radiometric stations in the Brazilian territory (Echer et al., 2006; Lima et al., 2016; Martins et al., 2007; Martins and Pereira, 2011). However, reliable solar energy assessments are an important tool to understand the uncertainties associated with the spatial and temporal variabilities of solar energy resource. In addition to that, the methodologies to provide reliable short-term forecasts of solar energy are gaining great importance to support the energy sector for both planning and operation of the solar generation plants and country's electricity grid system (F. R. Martins et al., 2008; F.R. Martins et al., 2008; Martins and Pereira, 2006).

In this context, the present work provides information and knowledge on the spatial variability of the surface solar irradiation in the Northeastern region of Brazil (NEB). The study aimed at identifying consistent time series of surface solar irradiation data acquired by the National Institute of Meteorology (INMET) using reliable ground data acquired by the automated weather stations operating in NEB territory from 2008 to 2015 . It also aimed at investigating the climatological trends presented by surface solar radiation data. The results can provide information for several issues of great relevance: better understanding and knowledge on the solar energy availability and variability; providing the energy sector with reliable solar radiation data and specialized meteorological services to support the solar energy deployment in the Brazilian Northeastern region.

\section{Material and Methods}

This chapter is segmented in the following topics to facilitate comprehension of the work development: the study area; the data qualification procedure; the cluster analysis; the evaluation of inter-annual variability and trend analysis.

\subsection{Study area: Brazilian Northeastern region (NEB)}

The Northeastern region of Brazil presents a wide variety of climate and anthropic features affecting the incoming solar irradiation. This topic briefly describes the main issues, but the authors recommend reading Cavalcanti et al. (2009) for more detailed description.

The NEB has an area around of 1.56 million $\mathrm{km}^{2}$ corresponding to $18 \%$ of the Brazilian territory. According to Kayano and Andreoli (2009), the region is usually described as presenting three major climates (see Figure 1). The humid coastal climate is the typical climate from the coast of Bahia till Rio Grande do Norte. The tropical climate covers the continental area of the states of Bahia, Ceará, Maranhão and Piauí. The semi-arid tropical climate comprises the central area of the region.

The precipitation presents an uneven distribution throughout the year, between 300 and $2000 \mathrm{~mm}$, and great spatial-temporal variability. The precipitation variability is basically associated with regional atmospheric systems such as the Subtropical Anticyclones over the South Atlantic and North Atlantic and the Equatorial Trough (Kayano and Andreoli, 2009). The rainfall regime in the NEB is quite complex presenting three distinct precipitation patterns illustrated at the Figure 1. The rain occurs from February to April in the North of the NEB (States of Ceará, Rio Grande do Norte, interior of Paraíba and Pernambuco) linked to the displacement of the Intertropical Convergence Zone (ITCZ) to the south (Kousky, 1979; Molion and Bernardo, 2002). The precipitation over Eastern coast occurs from May to June (from Rio Grande do Norte to Bahia) and it is related to the influence of the tropical air masses and easterly waves disturbances (EWD). It is also important to mention 
that sea breeze also has an important contribution to precipitation rates in the coastal areas. Finally, the precipitation in the continental area (including Bahia, Pernambuco and southern areas of Maranhão, Piauí) occurs from November to December due to the influence of frontal systems, local convection, and cyclonic vortices.

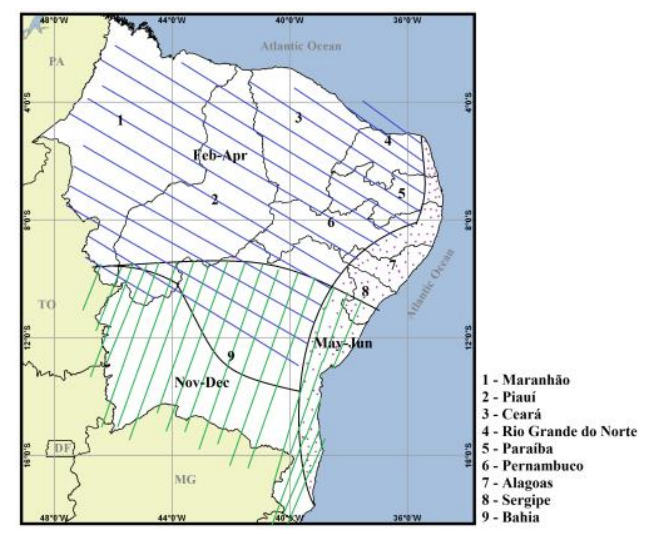

Figure 1. Spatial and temporal distribution of precipitation in NEB territory. The months in which the average monthly precipitation reaches the maximum of rainfall regimes are describe over each area. Source: adapted by (Kousky, 1979).

The air temperature presents high annual averages in the NEB reaching values between $20^{\circ}$ and $28^{\circ} \mathrm{C}$. The temperature averages between $24^{\circ}$ to $26^{\circ} \mathrm{C}$ in the areas under $200 \mathrm{~m}$ high and in the eastern seaboard. However, in high altitude areas (see Figure 2), like Chapada Diamantina and the Borborema Plateau, the annual mean temperature reaches values below $20^{\circ} \mathrm{C}$ (Kayano and Andreoli, 2009; Pereira et al., 2006). The incidence of solar radiation is large all year round presenting annual average around $5.5 \mathrm{kWh} / \mathrm{m}^{2}$.dia for global solar irradiation. The NEB is the area presenting the largest solar energy potential according to the Brazilian Atlas of Solar Energy (F.R. Martins et al., 2008; Pereira et al., 2017).

\subsection{Observational Data}

The solar radiation data used in this work were acquired from January/2005 to December/2015 in 129 automated weather stations (AWS) operated by the National Institute of Meteorology (INMET). The automatic surface weather station includes a data logger unit to store data acquired by several sensors for the following meteorological parameters (atmospheric pressure, air temperature and relative humidity, precipitation, solar radiation, direction and wind speed, etc.). The data acquisition system operates at one-minute frequency but data is stored with one-hour time step. Figure 2 shows the location of the AWS used for this study.

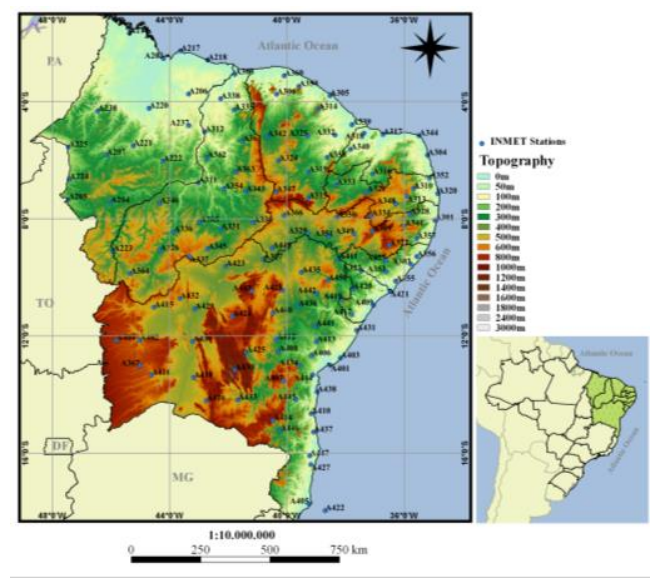

Figure 2. The orography map shows the spatial distribution of the automatic weather stations operated by Brazilian Institute for Meteorology (INMET) in the NEB region.

\subsection{Data qualification procedure}

Some factors can affect the reliability of the ground observations. Power outage, electrical discharges, environment changes in the site neighborhood and equipment substitution are some of them.

The major quality issue in the AWS's databases was the occurrence of failure acquisition gaps extending for days, months and years. Such gaps are associated with a variety of reasons including low maintenance. All 
measurements sites presenting long failure gaps in solar data acquisition were discarded. In addition, a computational script was developed to check if data was physically feasible or extremely rare using threshold criteria established by WMO for BSRN (Baseline Surface Radiation Network) measurement sites (Roesch et al., 2011). We discarded all solar radiation data flagged as suspicious in order to ensure the reliability of solar and meteorological data used in this study.

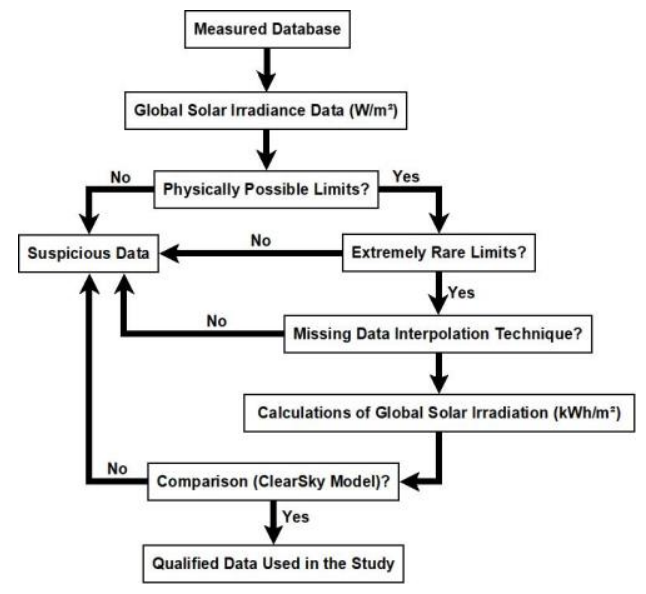

Figure 3. Flowchart of the computational procedure used for quality control of the solar radiation data acquired at the measurement sites in the NEB.

In addition, the authors established a criterion to ensure the database is representative of the typical variability of solar irradiation over the annual cycle. All measuring sites presenting less than $70 \%$ of the expected data records for one year-round cycle were discarded. Then the annual, monthly and daily descriptive statistical analyses were performed for the entire timeframe in each of the INMET meteorological stations.

\subsection{Interpolation Mapping and Cluster Analysis (CA)}

The maps of the surface solar irradiation were prepared using the kriging interpolation of the reliable ground data. Such maps provided information to evaluate the climatology of the incoming solar radiation in NEB and its inherent variability (Dobesch et al., 2010, 2007; Journée and Bertrand, 2010; Mello et al., 2003; Mueller et al., 2004).

The Cluster Analysis (CA) was the statistical approach used to identify homogenous regions based on the similarity of the surface solar irradiation. The CA procedure used a data array containing the monthly average values of the surface solar irradiation and the geographical coordinates assigned to each AWS. The agglomerative hierarchical method based on (Ward, 1963) was used. The hierarchical cluster analysis follows three steps: calculate the Euclidean distances between AWS data arrays, bond the AWS clusters in a dendrogram, and then find the best similarity threshold to establish the homogeneous regions (Corrar et al., 2007; Lima et al., 2010, 2016; Paixao et al., 2011; A. P. P. dos Santos et al., 2016b; Tennant and Hewitson, 2002). Both the number of similar regions and the number of members (AWS) in each of them were obtained subjectively by establishing a threshold in the dendrogram (Hair Jr. et al., 2005).

\subsection{Seasonal and Inter-annual Variability and Trend Analysis}

The statistical boxplot technique, described by Wilks (2006), was used to evaluate the surface solar irradiation data variability on each homogeneous region. The boxplot provides a complete statistical description: the average and/or median values, the interquartile range and the asymmetry (the difference between quartile and median).

Several studies used the Mann-Kendall method to investigate the climate trends based on historical datasets of meteorological parameters and it is the most appropriate method for climate change studies (dos Santos et al., 2018; Goossens and Beerger, 1986). In summary, the Mann-Kendall method is a non-parametric test to evaluate whether the null hypothesis that each record data is independent and equally distributed, i.e., there is no trend in the dataset. The null hypothesis is rejected if $|Z|>Z_{a / 2}$ for significance level equals $\square$. The equations (1) and (2) show the mathematical expression to evaluate $Z$. In this case, the upward trend occurs for $Z>0$ and, a downward trend for $Z<0$. 
$Z=\left\{\begin{array}{ccc}\frac{S-1}{\sqrt{\operatorname{VAR}(S)}} & \text { if } & S>0 \\ 0 & \text { if } & S=0 \\ \frac{S+1}{\operatorname{VAR}(S)} & \text { if } & S<0\end{array}\right.$

where:

$S=\sum_{k=1}^{n-1} \sum_{j=k+1}^{n} \operatorname{sign}\left(x_{j}-x_{k}\right)$

where $x_{j}$ and $x_{k}$ are two successive data records; $j$ and $k(j>k)$ stands for their position in the dataset; and $n$ is the database size. The function sign provides three possible outputs: it is 1 (one) if $x_{j}-x_{k}>0$; it is null (0) when the successive data records are equal; and it is $(-1)$ when $x_{j}-x_{k}<0$. The $\operatorname{VAR}(S)$ is obtained from equation (3):

$\operatorname{VAR}(S)=\frac{1}{18}\left[n(n-1)(2 n+5)-\sum_{p=1}^{g}\left(t_{p}-1\right)\left(2 t_{p}+5\right)\right]$

where $g$ is the number of groups with data repetitions and $t_{p}$ is the number of data in the $p$-th group. (Hisdal et al. 2001; Wu et al. 2008)

We also evaluated the slope and scale of the data trend using the non-parametric method described by Sen according to equation (4) (Sen, 1968; Sneyers, 1990). The method is indifferent to the presence of outliers, providing a more realistic measure of trends in a time series than the typical linear regression (Fan and Wang, n.d.; Pereira et al., 2017; A. P. P. Santos et al., 2016; A. P. P. dos Santos et al., 2016a; Silva and Dereczynski, 2014)

$$
f(t)=Q t-B
$$

where $Q$ is the linear coefficient of the trend line and $B$ is a constant. In order to estimate the slope $Q$, the first step is to calculate the slopes of all data pairs as follows:

$Q_{i}=\frac{x_{j}-x_{k}}{j-k} \quad$ for $j>k$

Assuming $n$ is the number of records in the time series, there will be $N=n(n-1) / 2$ estimates for Qi. So, the method Sen assumes $\boldsymbol{Q}$ as the average of all values of $Q i$ :

$Q=Q_{[(N+1) / 2]}$, if $N$ be odd, and

$Q=\frac{1}{2}\left(Q_{[N / 2]}+Q_{[(N+2) / 2]}\right)$, if $N$ be pair.

Similar procedure is adopted to get the constant $B$ using the $N$ values for the difference $\left(x_{i}-Q_{t i}\right)$.

The seasonal timeframes were defined as follows: the summer is from December to February (DJF); the fall season is from March to May (MAM); the winter is from June to August (JJA); and spring occurs from September to November (SON).

\section{Results}

\subsection{Results from the data quality control procedure and Kriging interpolation}

The INMET provided the ground observations in 129 automated weather stations (AWS) operating in from 20052015 in the Brazilian Northeastern region (NEB). The number of AWS presenting reliable data was different from year to year as consequence of the operation and maintenance difficulties along the 10-years period. The kriging interpolation method requires at least 30 AWS providing surface solar radiation data for fitting the semivariogram function. Less than 30 AWS provided reliable data during the 2005-2007 period, and those years were not considered for the spatial interpolation. The Figure 4 shows all AWS providing solar radiation data in 2008-2015. So, the data acquired during this period were employed for the spatial interpolation and the following steps of this study. 


\subsection{Spatial interpolation}

Figure 4 also presents a map for the annual average obtained from the kriging interpolation technique of daily total of global solar irradiation (Ig). The surface solar irradiance in the NEB is spatially heterogeneous either due to the regional topography or to the diverse meteorological systems reaching the region along the year.

The low cloud cover, especially in the backlands, explains the largest solar irradiance values. The maximum Ig occurs in an area encompassing part of the Bahia and Maranhão states where rainfall and the annual average of cloud cover are the lowest in the Brazilian territory. Figure 4 demonstrates that the coastal area in the North of the NEB, especially in the state of Rio Grande do Norte, receives the largest Ig values.

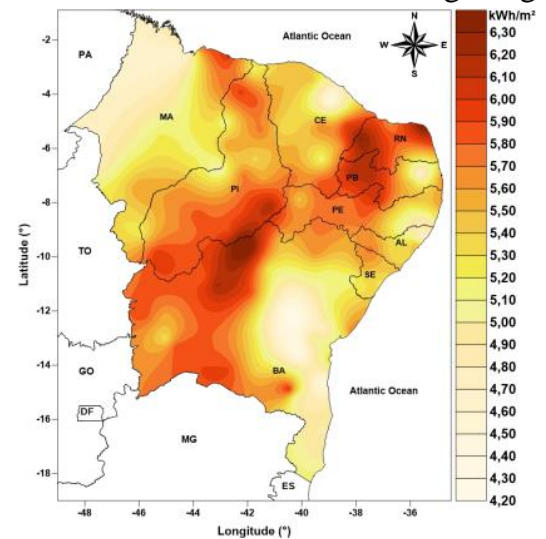

Figure 4. Map $\left(\mathrm{kWh} / \mathrm{m}^{2}\right)$ obtained by kriging interpolation of annual average of daily global solar irradiation data acquired at the 127 AWS operating in the Northeastern region of Brazil.

The lowest Ig values were observed in the Northwestern area of Maranhão, and in the Eastern coast area including Bahia, Sergipe and Alagoas states. This distribution pattern occurs as consequence of different meteorological phenomena like the Intertropical Convergence Zone (ITCZ), the frontal systems, the upper-tropospheric Cyclonic Vortices (UTCV), the easterly waves disturbances (EWD), the sea breezes and the trade winds.

The climate phenomena and their combination in different time and spatial scales may cause significant variations in the solar energy resource. Figure 5 presents the seasonal maps for global solar irradiation at the surface and the strong influence from the typical climate-specific mechanisms in each area can be identified in the spatial distribution patterns. The solar irradiation variability is intrinsically associated with the ITCZ movement during the year and change of the descending branch position of the Walker cell. Figure $5 \mathrm{~d}$ demonstrates that the largest solar irradiation occurs during the dry season in the NEB (from September to November - Spring in the southern hemisphere). The season MAM (Figure 5b) depicts for the period with the lowest surface solar irradiation associated with the highest convective activity in the region linked to the ITCZ displacement to the north hemisphere (Nobre and Shukla, 1996).
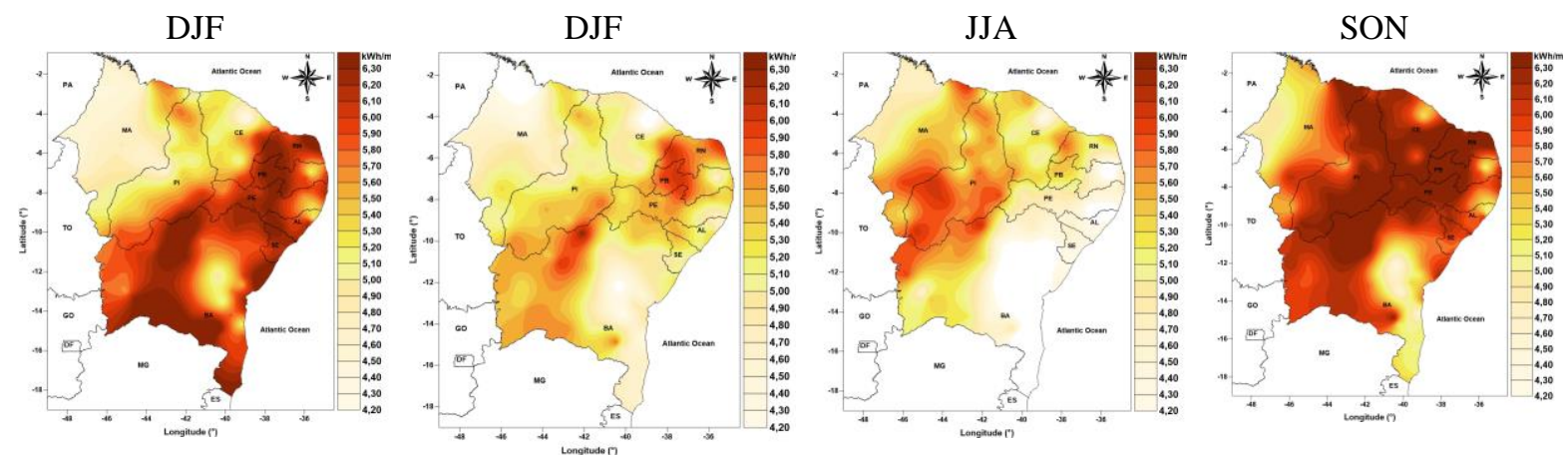

Figure 5. Seasonal maps for daily total of global solar irradiation $\left(\mathrm{kWh} / \mathrm{m}^{2}\right)$ : (a) DJF (summer), (b) MAM (fall), (c) JJA (winter) and (d) SON (spring).

The low incidence of solar irradiation in the eastern area of the NEB during the seasons MAM and JJA can be described by the influence of the easterly waves disturbances and the frontal systems reaching the Equatorial latitudes, especially during winter (JJA) in the southern hemisphere. As mentioned earlier, the season MAM is the rainy season in the eastern coastal area and the solar irradiation achieves seasonal averages ranging between 
4.30 and $5.80 \mathrm{kWh} / \mathrm{m}^{2}$. The solar irradiation averages from 4.90 till $6.30 \mathrm{kWh} / \mathrm{m}^{2}$ in the seasons JJA and SON. Such large solar irradiation values happen generally in the driest period of the year in the eastern coastal area of the NEB as indicated in Figures $6 \mathrm{c}$ and $6 \mathrm{~d}$. At this time of the year, the cloudiness associated with the ITCZ is located further north over the Atlantic Ocean (Molion and Bernardo, 2002). The lowest solar irradiation in the Southern area of the NEB, occurs during JJA and SON periods due to the influence of the frontal systems interacting with the local convection and precipitation.

\subsection{Cluster Analysis (CA)}

The CA analysis was performed using the geographical coordinates and the monthly average of the daily total solar irradiation as input data. The number of homogeneous regions was established taking into consideration the dendrogram presented in Figure 6. The dendrogram was obtained using the Ward method. The 127 stations are displayed on the horizontal axis, referenced by their ID's, and the vertical scale shows the similarity distance (or similarity level) between similar groups. The larger the similarity level, the more heterogeneous are the individuals inside a group of weather stations. The CA analysis provided five regions homogeneous using a subjective cutoff value for similarity level. The Figure 6 shows the homogeneous regions in different colors obtained using the Cutoff line in dendrogram. The cutoff threshold was chosen to provide homogeneous regions with a significant number of AWS in each one.

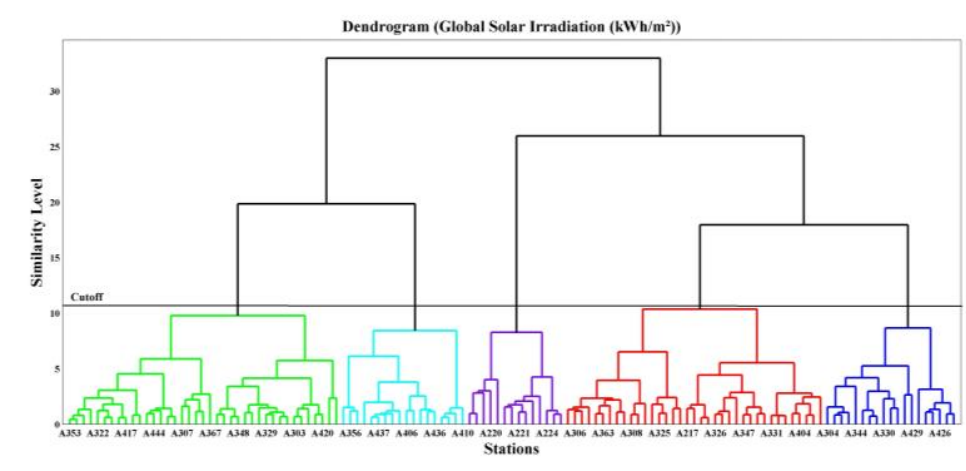

Figure 6. Dendrogram resulting from Ward method applied to the 127 AWS operating in NEB.

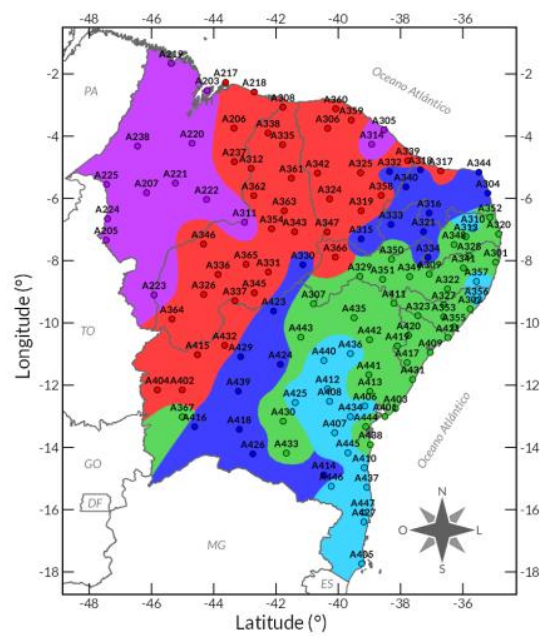

Figure 7. The five homogeneous areas (HR) regarding the surface solar irradiation in NEB. The colors are the same used in dendrogram shown in Figure 6: HR1, cyan; HR2, purple; HR3, green; HR4, Red; HR5, blue. The dots are the AWS's locations used in the cluster analysis.

The map in Figure 7 shows the geographical location of the homogeneous regions in NEB represented by the same colors used in Figure 6. There are some homogeneous regions divided into different areas of the NEB. Figure 7 also shows a strong spatial matching between the geographical location of the homogeneous regions and the spatial patterns observed in the interpolation map presented in Figure 4.

The geographical distribution of solar irradiation in NEB reflects the influence of the seasonal meteorological systems and environment features. The homogeneous regions 4 and 5 (HR4 and HR5) are the ones presenting the largest annual averages of surface solar irradiation. The lowest averages are observed in the regions HR1 and HR2 as indicated in Figure 8.

The HR4 and HR5 have a large territorial extension over the Northeastern backlands where climate dynamics and topography do not sustain the development of convective clouds. By contrast, the HR2 has a lower incidence of solar radiation due to the influence of heat and moisture from the Amazon region supporting a more convection activity than any other HR in NEB.

Figure 8 also provides information on the distinct seasonal cycles in each HR. Three of the HR areas (HR1, HR3, and HR5) present seasonal cycles in phase with the maximum (minimum) of the monthly average of the daily surface solar irradiation occurring in October/November (June). The other two regions, HR2 and HR4, also get 
the highest monthly average values in September. However, both regions present very low variability along the first six months of the years $\left(5 \mathrm{kWh} / \mathrm{m}^{2}\right)$ due to the intense convection systems in the Center-North of the NEB. The HR1 and HR2 have very close annual averages and a very low interannual variability, but the annual cycles are very different. The geographical distance among them is large and they have very distinct climatic characteristics. Similar behavior can explain the differences among HR3 e HR4. The HR5 receives the largest solar irradiance all year long.
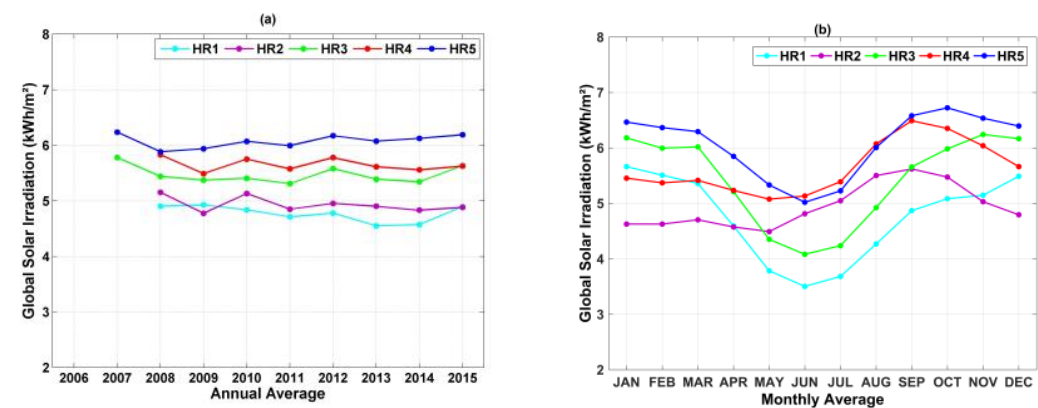

Figure 8. The annual and monthly averages of solar irradiation in the five homogeneous areas in NEB.

Figure 9 presents the boxplot analysis for incoming global solar irradiation in each homogeneous region of the NEB. The boxplot allows evaluating the inter-annual variability. The dot and line inside the rectangles represent the mean and the median values, respectively. The rectangles and vertical bars demonstrate the spreading of the annual average taking into consideration one-standard deviation and two-standard deviation interval, respectively. For the time-period under investigation, the HR2 and HR4 showed the lowest inter-annual variability. The HR3 has the largest variability with annual averages ranging between 3.7 and $6.7 \mathrm{~kW} / \mathrm{m}^{2}$, followed by the HR1 region (between 3.2 and $6.1 \mathrm{kWh} / \mathrm{m}^{2}$ ). The highest annual mean values occurred in HR4 and HR5, up to 7.1 and 6.8 $\mathrm{kWh} / \mathrm{m}^{2}$, respectively. The lowest annual mean global solar irradiation was in region HR1 (around $3.2 \mathrm{kWh} / \mathrm{m}^{2}$ ).

The inter-annual variability on a seasonal scale is presented in Figures 9b to 9e. The seasons MAM (fall) and JJA (austral winter) show the largest inter-annual amplitudes for seasonal averages in every homogeneous region. The seasonal averages for HR4 and HR5 are larger in season SON (spring). For other three regions, the seasonal averages are larger in summer (season DJF). This behavior is quite consistent with regional climatology for the spring season - low nebulosity in most of the Northeastern region.
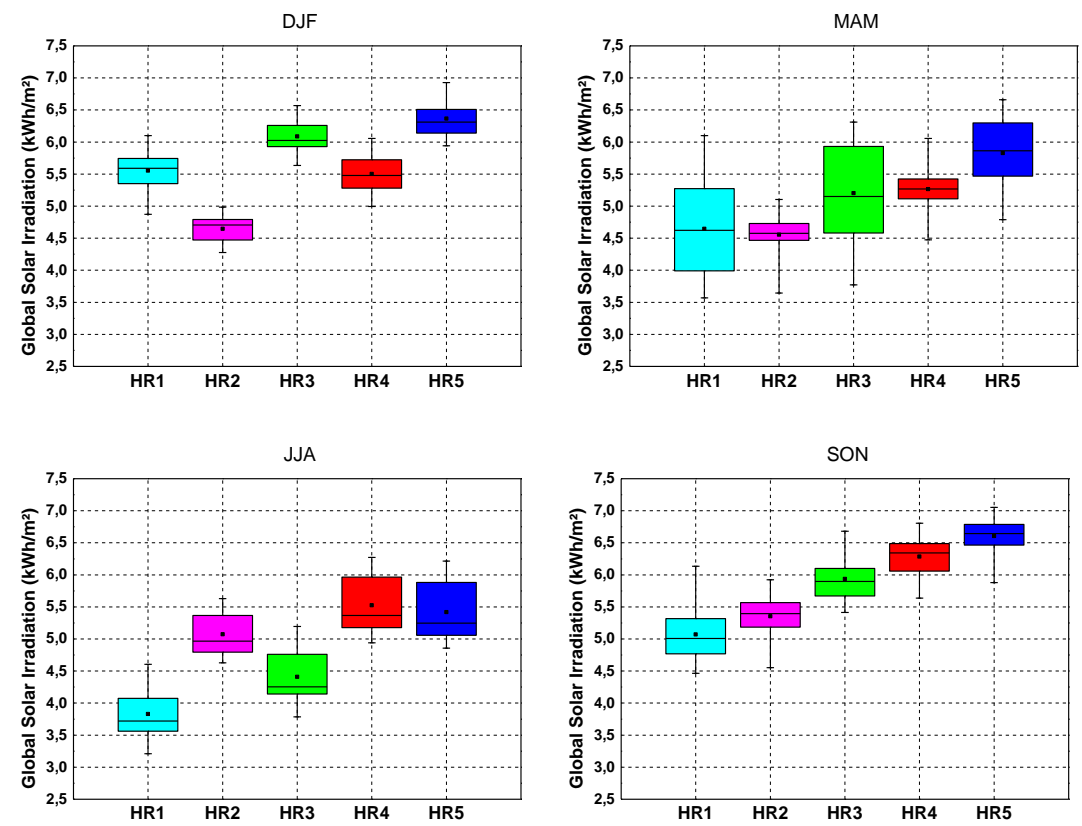


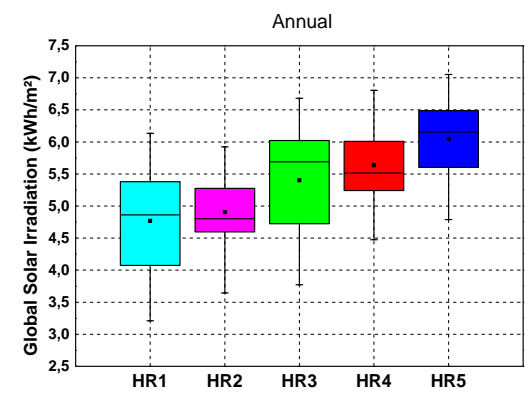

Figure 9. The inter-annual variability on seasonal scale are presented in (a) DJF (austral summer), (b) MAM (fall), (c) JJA (austral winter) and (d) SON (spring).

Figure 10 presents the trend analysis for the annual and seasonal averages of the surface solar radiation using the Mann-Kendall and Sen methods. The daily surface solar irradiation in HR5 showed an increasing trend with a magnitude of $+0.04 \mathrm{kWh} / \mathrm{m}^{2} /$ year and statistical significance of $90 \%$. On the contrary, the surface solar irradiation in HR1 showed a decreasing trend around $-0.05 \mathrm{kWh} / \mathrm{m}^{2} /$ year with the statistical significance of $90 \%$.

In seasonal scale, the surface global solar irradiation in HR1 presented a decreasing trend (around -0.05 $\mathrm{kWh} / \mathrm{m}^{2} /$ year) with the statistical significance of $95 \%$ during the seasons MAM and JJA. In RH5, the surface solar irradiation presented a trend around $+0.04 \mathrm{kWh} / \mathrm{m}^{2} /$ year in the season DJF and $+0.07 \mathrm{kWh} / \mathrm{m}^{2} / \mathrm{year}$ in the season MMA. Other trends were identified but none of them presented statistical significance.
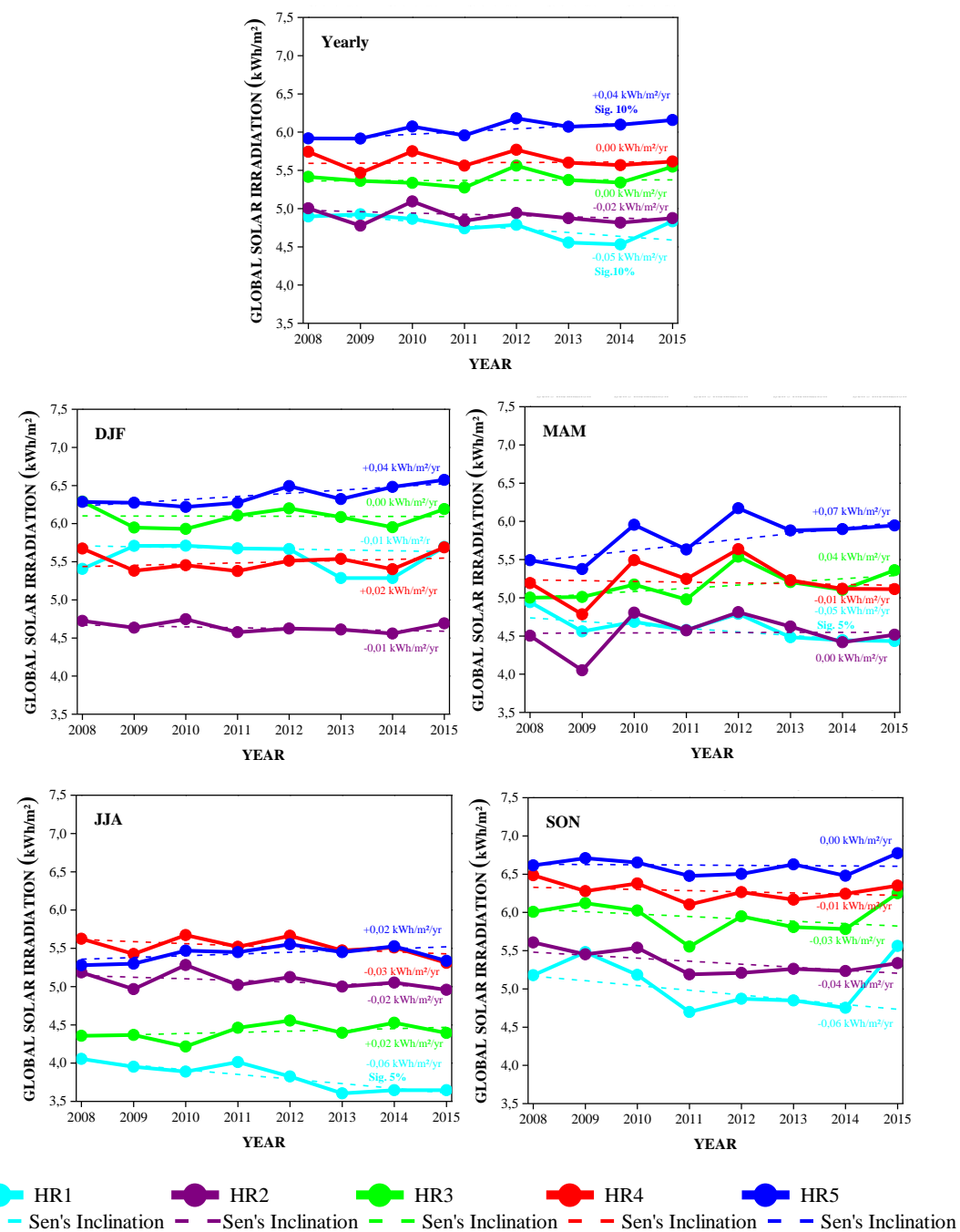

Figure 10. The temporal evolution of the annual and seasonal averages of daily total surface global solar irradiation $\left(\mathrm{kWh} / \mathrm{m}^{2}\right):(a)$ annual, (b) DJF season (summer), (c) MAM season (fall), (d) JJA (winter) and (e) SON season (spring). The graphs also shows the slope and magnitude of the trend obtained by using the Sen method and the Mann-Kendall test. 


\section{Conclusions}

This work aimed at characterizing the surface global solar irradiation in the Northeastern region of Brazil based on statistical analysis of ground data acquired during the 2008-2015 timeframe. The cluster analysis pointed out five regions (HR) presenting distinct patterns regarding the incoming global solar irradiation in NEB territory. These five patterns (HRs) have a geographical distribution quite consistent with the climate features and typical meteorological systems operating in the NEB. The HR5 is the driest area, and it has the largest daily average of global solar irradiation. The southeastern area of NEB (HR1) has the lowest daily solar irradiation. The interannual variability is larger in the eastern and central area (HR3) of NEB due to the influence of several mechanisms to generate cloudiness. On the other hand, the smallest interannual variability occurs in the western area of NEB (HR2). The HR2 is the area presenting the largest nebulosity in NEB due to the influence of heat and moisture from the Amazonia region.

The austral summer season, from December to February, presents the smallest inter-annual variability of daily global solar irradiation, but not the largest averages in all homogenous regions. It is worthy to mention two opposite situations. First, the largest seasonal average of daily solar incidence in HR1 and HR3 occurs in the season DJF (summer). On the other hand, the smallest lowest seasonal average of daily solar irradiation in HR2 occurs in the same season (DJF).

The trend analysis demonstrates that the daily surface solar irradiation in the southeastern of NEB is decreasing by $50 \mathrm{Wh} / \mathrm{m}^{2} /$ year since 2008 . On the other hand, the daily surface solar irradiation in HR5 (the semi-arid area) is increasing around $40 \mathrm{Wh} / \mathrm{m}^{2} /$ year along the same timeframe. It is worth noting that increasing frequency of climate events, such as ENOS, can influence these results.

Although there is a large solar energy resource in NEB, there are some particular issues related to the geographical distribution and the influence of typical regional climate features, which needs to be better known to support solar energy deployment. The results can help to understand the seasonal and inter-annual variability of the surface solar irradiation in NEB to meet the information demand from the energy sector. Besides that, these results are important to help in methodology development for short-term forecasts of solar irradiation taking into account the regional features and typical variability of the solar resource in NEB

\section{References}

Cavalcanti, I.F.A., Ferreira, N.J., Dias, M.A.F. da S., Justi, M.G.A., 2009. Tempo e Clima no Brasil, 1st ed. São Paulo.

Cohen, S., Ianetz, A., Stanhill, G., 2002. Evaporative climate changes at Bet Dagan, Israel, 1964-1998. Agric. For. Meteorol. https://doi.org/10.1016/S0168-1923(02)00016-3

Corrar, L., Paulo, E., Dias, J., 2007. Análise multivariada: para os cursos de administração, ciências contábeis e economia, São Paulo: Atlas.

Dobesch, H.., Dumolard, P.., Dyras, I.., 2010. Spatial Interpolation for Climate Data: The Use of GIS in Climatology and Meteorology, Spatial Interpolation for Climate Data: The Use of GIS in Climatology and Meteorology. https://doi.org/10.1002/9780470612262

Dobesch, H.., Dumolard, P.., Dyras, I.., 2007. Spatial Interpolation for Climate Data, Spatial Interpolation for Climate Data: The Use of GIS in Climatology and Meteorology. ISTE, London, UK.

https://doi.org/10.1002/9780470612262

dos Santos, A.P.P., Coelho, C.A.S., Pinto Júnior, O., dos Santos, S.R.Q., de Lima, F.J.L., de Souza, E.B., 2018. Climatic diagnostics associated with anomalous lightning incidence during the summer 2012/2013 in Southeast Brazil. Int. J. Climatol. 38, 996-1009. https://doi.org/10.1002/joc.5227

Echer, M.P.D.S., Martins, F.R., Pereira, E.B., 2006. A importância dos dados de cobertura de nuvens e de sua variabilidade: metodologias para aquisição de dados. Rev. Bras. Ensino Física. https://doi.org/10.1590/S180611172006000300011

Fan, X.-H., Wang, M.-B., n.d. Change trends of air temperature and precipitation over Shanxi Province, China. https://doi.org/10.1007/s00704-010-0319-2 
Goldemberg, J., Lucon, O., 2008. Energia, meio ambiente e desenvolvimento. Editora da Universidade de São Paulo.

Goossens, C., Beerger, A., 1986. Annual and Seasonal Climatic Variations over the Northern Hemisphere and Europe during the Last Century. Ann. Geophys.

Gu, L., 2003. Response of a Deciduous Forest to the Mount Pinatubo Eruption: Enhanced Photosynthesis. Science (80-. ). https://doi.org/10.1126/science.1078366

Hair Jr., J.F., Anderson, R.E., Tatham, R.L., Black, W.C., 2005. Análise Fatorial. Análise Multivariada de Dados.

Journée, M., Bertrand, C., 2010. Improving the spatio-temporal distribution of surface solar radiation data by merging ground and satellite measurements. Remote Sens. Environ. 114, 2692-2704.

https://doi.org/10.1016/j.rse.2010.06.010

Kayano, M.T., Andreoli, R. V., 2009. Clima da região Nordeste do Brasil, in: Off (Ed.), Tempo e Clima No Brasil. Oficina de Texto, São Paulo, p. 464.

Kousky, V.E., 1979. Frontal Influences on Northeast Brazil. Mon. Weather Rev. https://doi.org/10.1175/15200493(1979)107<1140:FIONB>2.0.CO;2

Lima, E. de A., Molion, L.C.B., Gomes Filho, M.F., Firmino, J.L. da N., Silva, A.O. da, 2007. Variabilidade interanual da profundidade óptica da atmosfera sobre Maceió, AL. Rev. Bras. Eng. Agrícola e Ambient. 11, 509-514. https://doi.org/10.1590/S1415-43662007000500010

Lima, F.J. de L., Castro Amanajás, J., Valter De Souza Guedes, R., Mariano, E., Silva, D., 2010. Análises de Componente Principal e de Agrupamento para estudo de ventos para a geração de energia eólica na região do Ceará, Paraíba, Pernambuco e Rio Grande do Norte, Brasil. Rev. Ambient. Água -An Interdiscip. J. Appl. Sci. 5. https://doi.org/10.4136/1980-993X

Lima, F.J.L., Martins, F.R., Pereira, E.B., Lorenz, E., Heinemann, D., 2016. Forecast for surface solar irradiance at the Brazilian Northeastern region using NWP model and artificial neural networks. Renew. Energy 87, 807818. https://doi.org/10.1016/j.renene.2015.11.005

Lohmann, G.M., Monahan, A.H., Heinemann, D., 2016. Local short-term variability in solar irradiance. Atmos. Chem. Phys. 16, 6365-6379. https://doi.org/10.5194/acp-16-6365-2016

Martins, F.R., Pereira, E.B., 2011. Enhancing information for solar and wind energy technology deployment in Brazil. Energy Policy 39, 4378-4390. https://doi.org/10.1016/j.enpol.2011.04.058

Martins, F.R., Pereira, E.B., 2006. Parameterization of aerosols from burning biomass in the Brazil-SR radiative transfer model. Sol. Energy. https://doi.org/10.1016/j.solener.2005.03.008

Martins, F.R., Pereira, E.B., Abreu, S.L., 2007. Satellite-derived solar resource maps for Brazil under SWERA project. Sol. Energy. https://doi.org/10.1016/j.solener.2006.07.009

Martins, F.R., Pereira, E.B., Silva, S. a. B., Abreu, S.L., Colle, S., 2008. Solar energy scenarios in Brazil, Part one: Resource assessment. Energy Policy. https://doi.org/10.1016/j.enpol.2008.02.014

Martins, F.R., Rüther, R., Pereira, E.B., Abreu, S.L., 2008. Solar energy scenarios in Brazil. Part two: Photovoltaics applications. Energy Policy 36, 2855-2867. https://doi.org/10.1016/j.enpol.2008.04.001

Mello, C.R., Lima, J.M., Silva, A.M., Mello, J.M., Oliveira, M.S., 2003. Kriging and inverse-square-distance for the interpolation of rainfall equation parameters. Rev. Bras. Cienc. Do Solo.

Molion, L.C.B., Bernardo, S. de O., 2002. Uma Revisão da Dinâmica das Chuvas no Nordeste Brasileiro. Rev. Bras. Meteorol.

Mueller, T.G., Pusuluri, N.B., Mathias, K.K., Cornelius, P.L., Barnhisel, R.I., Shearer, S.A., 2004. Map Quality for Ordinary Kriging and Inverse Distance Weighted Interpolation. Soil Sci. Soc. Am. J.

https://doi.org/10.2136/sssaj2004.2042

Nobre, P., Shukla, J., 1996. Variations of sea surface temperature, wind stress, and rainfall over the tropical 
Atlantic and South America. J. Clim. https://doi.org/10.1175/1520-0442(1996)009<2464:VOSSTW>2.0.CO;2

Paixao, E., Auld, H., Mirza, M.M.Q., Klaassen, J., Shephard, M.W., 2011. Regionalization of heavy rainfall to improve climatic design values for infrastructure: case study in Southern Ontario, Canada. Hydrol. Sci. J. 56, 1067-1089. https://doi.org/10.1080/02626667.2011.608069

Pereira, E.B., Martins, F.R., Abreu, S.L. de, Rüther, R., 2006. Atlas Brasileiro de energia Solar, 1st ed. São José dos Campos.

Pereira, E.B., Martins, F.R., Gonçalves, A.R., Costa, R.S., Lima, F.J.L. de, Rüther, R., Abreu, S.L. de, Tiepolo, G.M., Pereira, S.V., Souza, J.G. de, 2017. Atlas Brasileiro de Energia Solar, 2nd ed. São José dos Campos.

Roderick, M.L., Farquhar, G.D., Berry, S.L., Noble, I.R., 2001. On the direct effect of clouds and atmospheric particles on the productivity and structure of vegetation. Oecologia. https://doi.org/10.1007/s004420100760

Roesch, A., Wild, M., Ohmura, A., Dutton, E.G., Long, C.N., Zhang, T., 2011. Assessment of BSRN radiation records for the computation of monthly means. Atmos. Meas. Tech. https://doi.org/10.5194/amt-4-339-2011

Santos, A.P.P., Júnior, P., Souza, O., Santos, R., Paes, A.P., Santos ${ }^{1}$, D., Júnior ${ }^{2}$, O.P., Barreiros De Souza ${ }^{3}$, E., Azambuja, R., Quadro, S.R., Santos, D., 2016. Revista Brasileira de Geografia Física Variabilidade espaçotemporal e identificação de Eventos Extremos de Descargas Atmosféricas no Estado de São Paulo durante o Verão. Rev. Bras. Geogr. Física V. 09 N 02, 346-352.

Santos, A.P.P. dos, Aragão, M.R. da S., Correia, M. de F., Santos, S.R.Q. dos, Silva, F.D. dos S., Araújo, H.A. de, Santos, A.P.P. dos, Aragão, M.R. da S., Correia, M. de F., Santos, S.R.Q. dos, Silva, F.D. dos S., Araújo, H.A. de, 2016a. Precipitação na Cidade de Salvador: Variabilidade Temporal e Classificação em Quantis. Rev. Bras. Meteorol. 31, 454-467. https://doi.org/10.1590/0102-778631231420150048

Santos, A.P.P. dos, Lima, F.J.L. de, Souza, E.B. de, Pinto Júnior, O., Santos, S.R.Q. dos, 2016b. Application of cluster analysis in the identification of homogeneous regions for the cloud-to-ground lightning incidence in the state of São Paulo, Southeastern Brazil. Rev. Bras. Geogr. Física 9. https://doi.org/10.5935/19842295.20160155

Sen, P.K., 1968. Estimates of the Regression Coefficient Based on Kendall's Tau. J. Am. Stat. Assoc. https://doi.org/10.1080/01621459.1968.10480934

Silva, B.B. Da, Lopes, G.M., Azevedo, P.V. De, 2005. Balanço de radiação em áreas irrigadas utilizando imagens LANDSAT 5 - TM. Rev. Bras. Meteorol. 20, 243-252.

Silva, V. de P.R. da, Silva, R.A. e, Cavalcanti, E.P., Braga, C.C., Azevedo, P.V. de, Singh, V.P., Pereira, E.R.R., 2010. Trends in solar radiation in NCEP/NCAR database and measurements in northeastern Brazil. Sol. Energy. https://doi.org/10.1016/j.solener.2010.07.011

Silva, R.A.E., De, V., Da Silva, P.R., Cavalcanti, E.P., Dos Santos, D.N., 2010. Study of the variability of solar radiation in northeast Brazil. Rev. Bras. Eng. Agrícola e Ambient. 14, 501-509.

Silva, W.L., Dereczynski, C.P., 2014. Caracterização Climatológica e Tendências observadas em extremos climáticos no Estado do Rio de Janeiro. Anu. do Inst. Geociencias. https://doi.org/10.11137/2014_2_123_138

Sneyers, R., 1990. On the statistical analysis of series of observations. Secretariat of the World Meteorological Organization.

Tennant, W.J., Hewitson, B.C., 2002. Intra-seasonal rainfall characteristics and their importance to the seasonal prediction problem. Int. J. Climatol. https://doi.org/10.1002/joc.778

Ward, J.H., 1963. Hierarchical Grouping to Oprimize an Objective Function. J. Am. Stat. Assoc.

Wild, M., 2009. Global dimming and brightening: A review. J. Geophys. Res. 114, D00D16. https://doi.org/10.1029/2008JD011470

Wilks, D.S., 2006. Statistical methods in the atmospheric sciences, Statistical Methods in the Atmospheric Sciences.2nd ed. 


\title{
Regression by Integration applied to Ångström-Prescott-type relations
}

\author{
Heinrich Morf \\ Senior Member ISES, Buechraiweg 47, 5452 Oberrohrdorf (Switzerland)
}

\begin{abstract}
We present a novel approach for the determination of the relationship between two random variables, which we call Regression by Integration. The resulting curve is a least absolute error estimate. Compared to other regression methods, it has the advantage that, instead of a sample of simultaneously taken pairs of the two random variables, only a separate sample of each of the random variables is required. We demonstrate the practicability of the method on Ångström-Prescott-type relations and compare the results with those obtained by least square error fits.
\end{abstract}

Keywords: Ångström-Prescott relation, curve fit, Regression by Integration, random variable

\section{Introduction}

Representing the relationship between two random variables $-X$ and $Y$ by a curve is established engineering practice. Solar energy engineering routinely employs many such relations.

A well-established procedure is the least square error regression, where a curve $y(x)$ is fitted to a sample of pairs of values $(x, y)$ that minimizes the sum of the error squares in either the direction of $x$ or $y$. (See for example Kreiszig (2006), pp. 860-863.) While the objective of the fit is clear, the result is somewhat ambiguous as it depends on the choice of the variable ( $x$ or $y$ ) whose least square error was minimized.

We present an alternative method that treats the two random variables equally, which we call Regression by Integration. It has the advantage that - instead of a sample of pairs of values $(x, y)$ - only separate samples of $x$ and $y$ need to be known. It is a least absolute error estimate; the probability for an outcome of $(x, y)$ to be on either side of the regression curve is the same. As a least absolute error estimate, it is less susceptible to outliers than a least square error fit.

This paper is organized as follows. First, the basic mathematical model leading to Regression by Integration is described. Then, we introduce to the properties of the model that are important when applying the method. A stepby-step application procedure follows. Its practicability is demonstrated on examples of Ångström-Prescott-type relations.

\section{Introduction into Regression by Integration}

We give a succinct introduction into Regression by Integration. We present the basic model behind the method. Then, we introduce to the properties of the model that are important when applying the method.

\subsection{Regression by Integration - the idea}

The method of Regression by Integration builds on the expression of the relationship between two strictly dependent random variables $-Y(X)$ as an ordinary differential equation (See for example Brandt, 1968, pp. 2729.):

$$
f_{2}(y) \cdot d y=f_{1}(x) \cdot d x
$$

with the initial condition

$$
y\left(x=x_{\min }\right)=y_{\min }
$$

$f_{1}(x)$ and $f_{2}(y)$ are the probability density functions (pdfs) of $X$ and $Y$. 
The objective is to find the function $y(x)$.

We assume that $y(x)$ will be a non-decreasing function. (Situations resulting in a decreasing function can be transformed into the non-decreasing case by a variable transformation.) Therefore, eq. (1) can be solved by equalizing the distribution functions of $X-F_{1}(x)$ and $Y-F_{2}(y)$, and state

$$
F_{1}(x)=F_{2}(y)=F^{*},
$$

whereby $F^{*}$ may be any value within its range of validity $0 \leq F^{*} \leq 1$.

$$
F_{1}(x)=\int_{x=x_{\min }}^{x} f_{1}(x) \cdot d x=P(X \leq x)
$$

and

$$
F_{2}(y)=\int_{y=y_{\min }}^{y} f_{2}(y) \cdot d y=P(Y \leq y)
$$

The solution is then

$$
y(x) \mid F^{*}=\left(x\left(F^{*}\right), y\left(F^{*}\right)\right)
$$

eq. (6) states that $x$ and $y$ at ${ }^{F^{*}}$ are a pair of values that obey $y(x)$.

We will also employ eq. (1) to find an estimate for $y(x)$ when there is a bivariate distribution of the two random variables $-(X, Y)$ where the data points $(x, y)$ form rather a data cloud than a curve in the $x, y$ plane. Our estimate is then the relationship between the two random variables under the assumption of strict interdependence.

\subsection{Key features of Regression by Integration}

We point to some properties of the method and its results. In first place we do so, because their understanding is essential for its successful application. In second place we would like to substantiate the advantages of Regression by Integration in comparison to other methods. For the sake of clarity, we restrict our exposition to the minimum necessary for the application of the method. Justifying details and theoretical proofs may be found in Morf (2018).

- The fit is a least absolute error estimate for the random variable $(X, Y)$. The probability for an outcome $(x, y)$ to be on either side of the regression curve is the same.

- Instead of a sample of $(x, y)$, only separate samples of $x$ and $y$ need to be known. This increases the number for prospective sample choices, because samples of $X$ and $Y$ taken over different time periods and even at different locations may be considered.

- When the standardized distributions of $X$ and $Y$ are the same, the fit leads to a linear relation of the form $y=a+b \cdot x$.

- Often, the result deviates little from a least square error fit. However, this is not necessarily so. For example, applying Regression by Integration to two random variables $X$ with $0<x \leq 1$ and $Y$ with $0<y \leq 1$ expanding a uniform bivariate distribution, the result would be $y=x$, whereas for a linear least square error regression it would be $y=0.5$.

- As a least absolute error estimate the result is less susceptible to outliers than a least square error estimate.

\section{Application of the method}

We present a step-by-step application procedure for Regression by Integration. The practicability of the procedure is demonstrated on examples of Ångström-Prescott-type regressions over various time periods.

\subsection{A procedure for the generation of $y(x)$}

We devised the following step-by-step procedure for the generation of pairs of values $(x, y)$ of $y(x)$ :

- $\quad$ Take samples of $X$ and $Y$ in the real world. 
- Generate discrete probability functions of the samples $-f_{l}\left(x_{i}\right)$, respectively $f_{2}\left(y_{j}\right)$ - by sorting the outcomes into classes of appropriate width delimited by $x_{1}, x_{2}, \ldots x_{i}, \ldots x_{m}$, respectively $y_{1}, y_{2}, \ldots y_{j}, \ldots y_{n}$.

- Generate discrete distribution functions of $X$ and $Y$ :

$$
\begin{aligned}
& F_{1}\left(x_{i}\right)=P\left(X \leq x_{i}\right)=\sum_{x_{i} \leq x} f\left(x_{i}\right), \text { and } \\
& F_{2}\left(y_{j}\right)=P\left(Y \leq y_{j}\right)=\sum_{y_{j} \leq y} f\left(y_{j}\right)
\end{aligned}
$$

- Estimate the continuous inverse functions $x\left(F_{1}\right)$ and $y\left(F_{2}\right)$ using polynomial least square error regression, or any other method that suits the data sets at hand.

- $\quad$ Set $F_{1}(x)=F_{2}(y)=F^{*}$. Then $\left(x\left(F^{*}\right), y\left(F^{*}\right)\right)=(x, y)$.

From many values $(x, y)$ generated in the last step above, one may then generate a continuous fit for $y(x)$, if required. (Least square error, least absolute error, cubic spline, or any other fit suiting a specific problem at hand.)

\subsection{Applications on Ångström-Prescott-type relations}

We present applications of Regression by Integration on Ångström-Prescott-type relations over various time periods. They relate the clearness index to the relative sunshine duration over the given time period. We refer to the nomenclature for definitions of these two random variables.

In the presented graphs results of Regression by Integration are marked with triangles tagged with the corresponding common value of the marginal distributions $-F^{*}$. For comparison, the results of linear and quadratic least square error fits are also shown.

\subsubsection{Monthly fits for daily values}

Fig. 1 depicts the results of Regression by Integration on the relation between the daily clearness index $-K$ and daily relative sunshine duration - $S$, for Payerne, Switzerland and Perth, Australia in January, April, July, and October, based on ten-year datasets.
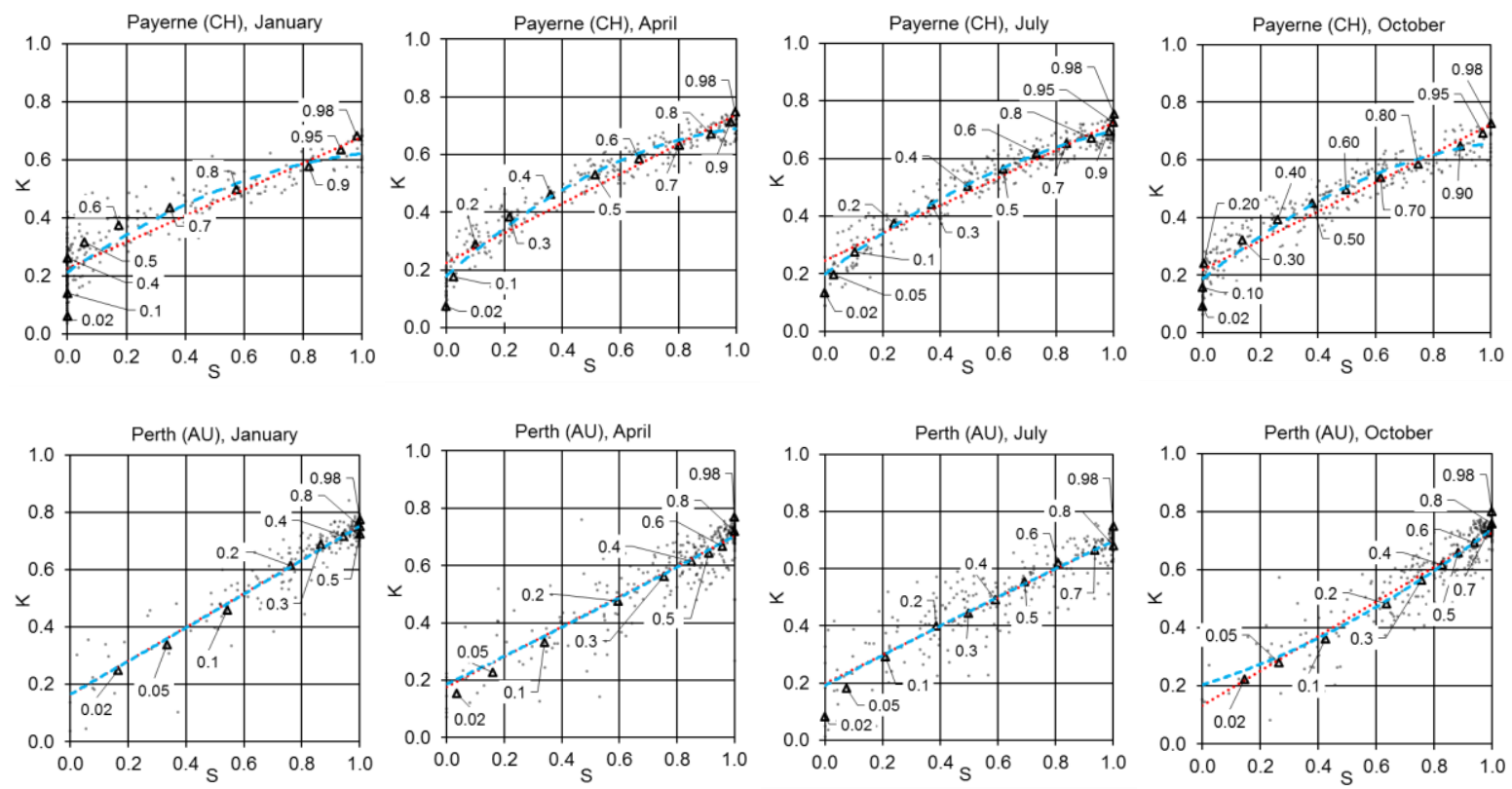

\begin{tabular}{|ccll|}
\hline$\cdot \quad$ observations & $\Delta$ & Regression by Integration \\
$\ldots . .$. & linear least square error regression & - & - quadratic least square error regression \\
\hline
\end{tabular}

Fig. 1: Regression by Integration for the daily clearness index $-K$ as a function of daily relative sunshine duration $-S$, for Payerne and Perth in January, April, July, and October, based on ten-year data-sets.

The points for Regression by Integration were determined following the procedure outlined in Section 3.1. The fits rise from $(K=0, S=0)$, bend over to $S=1$ where they continue to rise to $K=1$. Due to the inaccuracy of the results we refrain from presenting fitted data points for the lower and upper two percent of $F^{*}$. Nevertheless, the point for $F^{*}=0$ must be located at $(K=0, S=0)$, because $K$ and $S$ cannot be negative. Also on physical grounds, we place $F^{*}=1$ at $(K=1, S=1)$. 
Fitting a curve through the results of Regression by Integration, will hardly ever result in a linear fit for daily values. Scrutiny at $S=0$ reveals that the attenuation of solar irradiation by clouds is variable. Having a closer look at $S=1$, one concludes that also clear sky irradiation is of varying intensity.

\subsubsection{Monthly fits for monthly means}

Fig. 2 depicts the result of Regression by Integration on the relation between monthly means of daily clearness index $-\bar{K}$ and monthly means of daily relative sunshine duration $-\bar{S}$, for Payerne, Switzerland and Perth, Australia in January, April, July, and October, based on ten-year datasets.
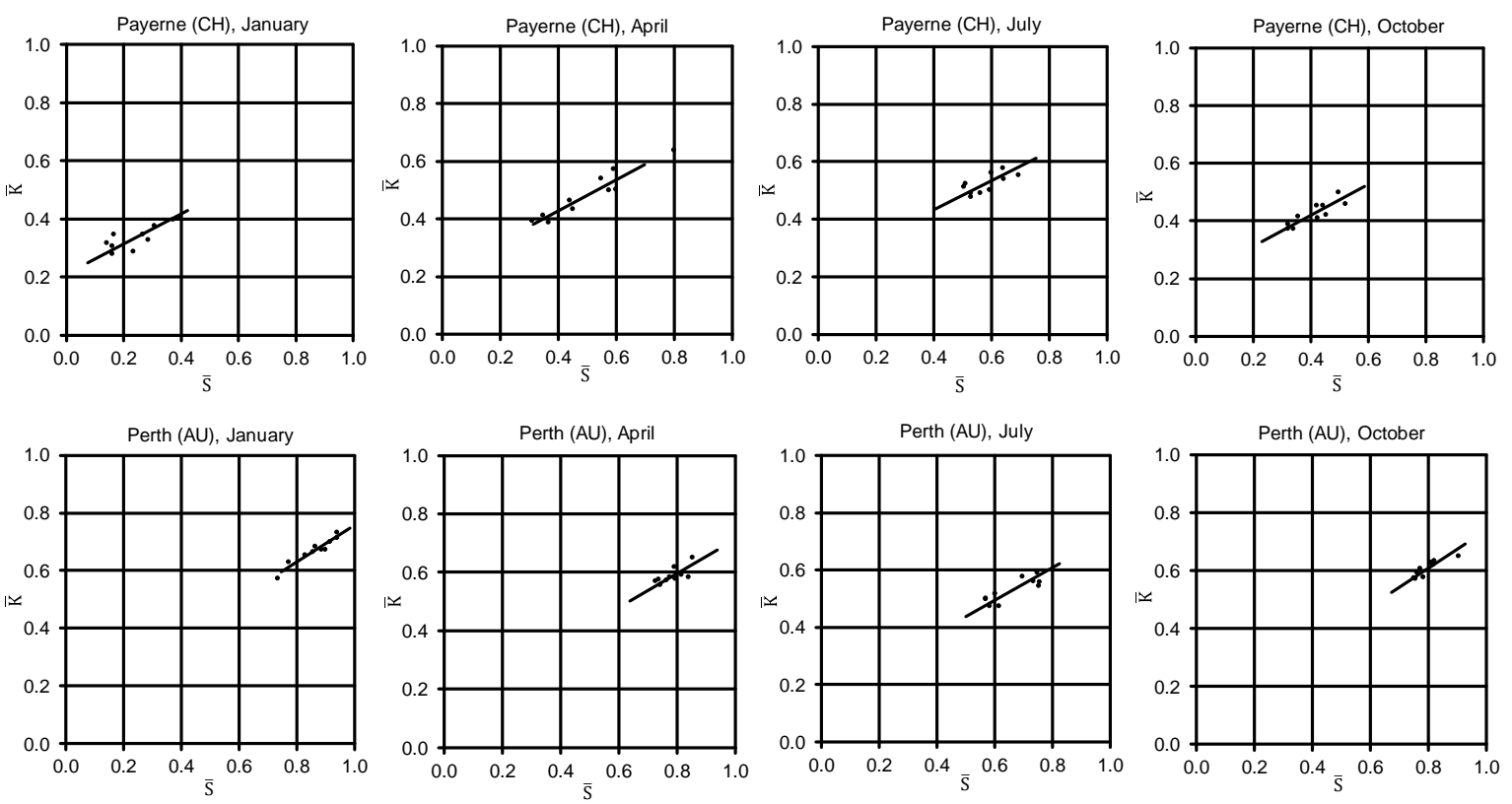

- observed monthly means - linear regression by integration

Fig. 2: Regression by Integration for the monthly means of the daily clearness index $-\bar{K}$ as a function of the monthly means of daily relative sunshine duration $-\bar{S}$, for Payerne and Perth in January, April, July, and October, based on ten-year data-sets. The line is the Regression by Integration calculated under the assumption that the relation be linear. It expands over the range of $\mu \pm 3 \sigma$ of the distributions of $\bar{K}$ and $\bar{S} .99 .7 \%$ of the outcomes of a normal variable would be within this range

Being the mean of roughly 30 daily values, monthly means present a probing ground for linear fits of Regression by Integration. Based on the Central Limit Theorem (See for example Kreiszig, 1998, pp. 200-202.) one concludes that - under ideal conditions - means of the daily clearness index and means of daily relative sunshine duration are asymptotically normal. Consequently, the standardized distributions of $\bar{K}$ and $\bar{S}$ will be equal, as required for a linear outcome of Regression by Integration.

One obtains for the linear fit of Regression by Integration

$$
\bar{K}=a+b \cdot \bar{S}
$$

with intercept

$$
a=\mu_{2}-\frac{\sigma_{2}}{\sigma_{1}} \cdot \mu_{1}
$$

and slope

$$
b=\frac{\sigma_{2}}{\sigma_{1}}
$$

$\mu_{1}$ and $\sigma_{1}$ are mean and standard deviation of daily relative sunshine duration $-S . \mu_{2}$ and $\sigma_{2}$ are mean and standard deviation of daily clearness index $-K$. 
Working with monthly means is not an ideal situation to obtain linear fits. Contiguous daily values of $K$ and $S$ are not completely independent. The number of values $-n$ to form the means is limited to about 30 . In statistical data analysis, a value of $n=30$ is considered to be sufficiently large to obtain reliable results for the mean, whereas for the variance a value of $n=100$ is deemed to be necessary (Kreiszig, 1998, pp. 201-202). Nevertheless, a special Kolmogorov-Smirnov test (Lilliefors, 1967) applied to test whether the standardized distributions of $\bar{K}$ and $\bar{S}$ were normal seldom failed, and the standard two sample Kolmogorov-Smirnov test (Kreiszig, 1998, pp. 234-237) applied to test the equality of the standardized distributions of $\bar{K}$ and $\bar{S}$ always passed. The test results are listed in Table 1.

Table 1. Kolmogorov-Smirnov tests on monthly means of the daily clearness index $-\bar{K}$ and monthly means of daily relative sunshine duration - $\bar{S}$, for Payerne and Perth in January, April, July, and October, based on ten-year data-sets. The standardized distributions were tested for normality (KS-1) and equality of the corresponding standardized distributions of $\bar{K}$ and $\bar{S}$ (KS-2). A significance level of 0.01 was used for the Kolmogorov-Smirnov tests. Sample size: 10 for the monthly tests, and 120 for the yearly tests. Also mean and variance of the data sets are given. The regression parameters for the linear Regression by Integration were

\begin{tabular}{|c|c|c|c|c|c|c|c|c|c|}
\hline \multirow[b]{2}{*}{ Period } & \multicolumn{6}{|c|}{ calculated from these values. } & \multirow[b]{2}{*}{$\bar{K} \& \bar{S}$} & \multirow{2}{*}{\multicolumn{2}{|c|}{ Regression }} \\
\hline & & $\bar{S}$ & & & $\bar{K}$ & & & & \\
\hline & Mean & Variance & KS-1 & Mean & Variance & KS-1 & KS-2 & $a$ & $b$ \\
\hline \multicolumn{10}{|l|}{ PAYERNE } \\
\hline Jan & $2.480 \mathrm{E}-01$ & $3.410 \mathrm{E}-03$ & fail & 3.385E-01 & 8.390E-04 & pass & pass & 0.2122 & 0.5091 \\
\hline Apr & $5.047 \mathrm{E}-01$ & $4.116 \mathrm{E}-03$ & pass & $4.851 \mathrm{E}-01$ & 1.203E-03 & fail & pass & 0.2122 & 0.5407 \\
\hline Jul & $5.802 \mathrm{E}-01$ & $3.361 \mathrm{E}-03$ & pass & $5.236 \mathrm{E}-01$ & 8.484E-04 & pass & pass & 0.2311 & 0.5024 \\
\hline Oct & $4.088 \mathrm{E}-01$ & 3.523E-04 & pass & 4.242E-01 & 1.013E-03 & pass & pass & 0.2050 & 0.5362 \\
\hline Year & $4.305 \mathrm{E}-01$ & $2.568 \mathrm{E}-02$ & pass & 4.414E-01 & 7.928E-03 & pass & pass & 0.2022 & 0.5556 \\
\hline \multicolumn{10}{|l|}{ PERTH } \\
\hline Jan & 8.664E-01 & $1.590 \mathrm{E}-03$ & pass & $6.721 \mathrm{E}-01$ & 6.323E-04 & pass & pass & 0.1258 & 0.6305 \\
\hline Apr & 7.887E-01 & $2.507 \mathrm{E}-03$ & pass & $5.899 \mathrm{E}-01$ & 8.533E-04 & pass & pass & 0.1297 & 0.5835 \\
\hline Jul & $6.625 \mathrm{E}-01$ & $2.961 \mathrm{E}-03$ & fail & 5.297E-01 & 9.323E-04 & pass & pass & 0.1580 & 0.5611 \\
\hline Oct & 7.999E-01 & $1.806 \mathrm{E}-03$ & pass & $6.084 \mathrm{E}-01$ & 7.710E-04 & pass & pass & 0.0858 & 0.6533 \\
\hline Year & 7.741E-01 & $1.144 \mathrm{E}-02$ & pass & 5.973E-01 & 4.979E-04 & pass & pass & 0.0868 & 0.6596 \\
\hline
\end{tabular}

\subsubsection{Yearly fits for monthly means}

Fig. 3 depicts the result of Regression by Integration on the relation between the monthly average daily clearness index $-\bar{K}$ and monthly average daily relative sunshine duration $-\bar{S}$, for Payerne, Switzerland and Perth, Australia over the entire year based on ten year datasets.
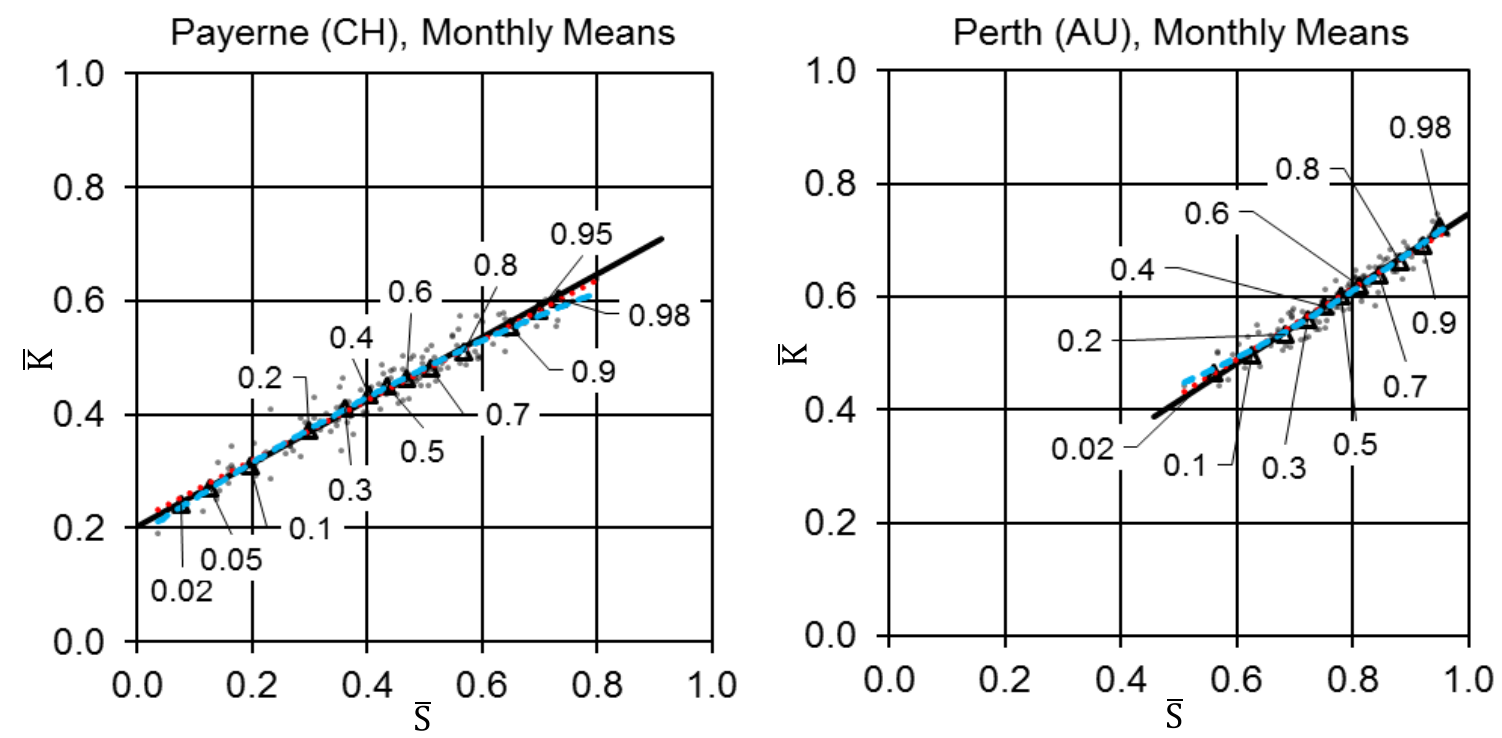

\begin{tabular}{|ccl|}
\hline $\begin{array}{c}\text { observations } \\
\text { linear regression by integration }\end{array}$ & $\Delta$ & Regression by Integration \\
\hline$-\infty$ & $\ldots$ & linear least square error regression \\
$-\infty$ quadratic least square error regression & & \\
\hline
\end{tabular}

Fig. 3: Regression by Integration for the monthly means of the daily clearness index $-\bar{K}$ as a function of the monthly means of daily relative sunshine duration $-\bar{S}$, for Payerne and Perth taken over the entire year, based on ten-year data sets. The full line is the Regression by Integration calculated under the assumption that the relation be linear. It expands over the range of $\mu \pm 3 \sigma$ of the distributions of $\bar{K}$ and $\bar{S} .99 .7 \%$ of the outcomes of a normal variable would be within this range. 
The data points were determined by Regression by Integration as outlined in Section 3.1. The linear fits of Regression by Integration were calculated under the assumption that the relation be linear. The linear least square error fit, the quadratic least square error fit, and the linear fit by Regression by Integration can hardly be distinguished on the graphs.

Kolmogorov-Smirnov tests to verify whether the standardized distributions of $\bar{K}$ and $\bar{S}$ were normal and equal always passed. Results are listed in Table 1. As may be seen, monthly fits (Fig. 2) and fits over the entire year (Fig. 3) deviate little.

\section{Multivariate distributions}

Expanding the method of Regression by Integration to multivariate distributions is a natural next step in pursuit of the perfect fit. For a multivariate distribution one expands eq. (3) to

$$
F_{1}(1)=F_{2}(2)=F_{3}(3) \ldots=F_{n}(n)=F^{*}
$$

(For flexibility, we substituted the alphabetic mnemonics for the dimension in eq. (3) by their corresponding numbers.)

Fig. 4 depicts trivariate distributions of daily clearness index $-K$, daily relative sunshine duration $-S$, and daily mean cloud cover $-C$. One observes the curves of the bivariate distributions $K(S), K(C)$, and $C(S)$. The intercept of the projection of points with equal $F^{*}$ value of the three two-dimensinal curves (marked with bullets) leads to the corresponding point of the three-dimensional curve (marked with a triangle and tagged with the corresponding value of $F^{*}$ ).

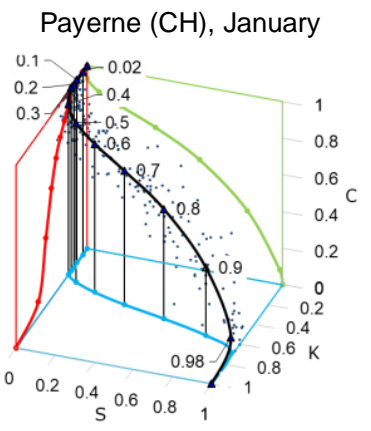

Payerne (CH), April

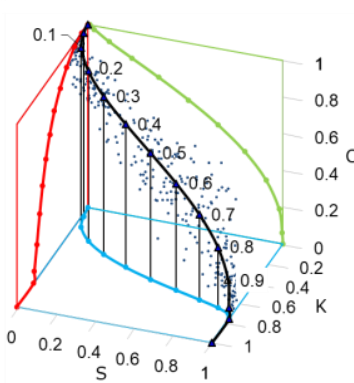

Payerne $(\mathrm{CH})$, July

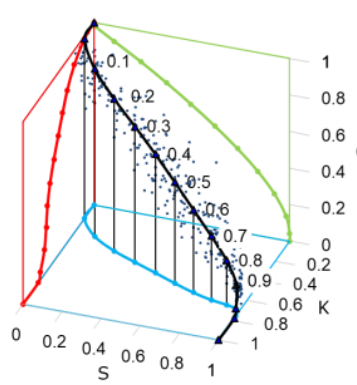

Perth $(A U)$, January

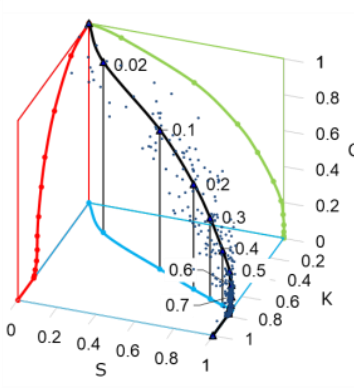

Pert (AU), April

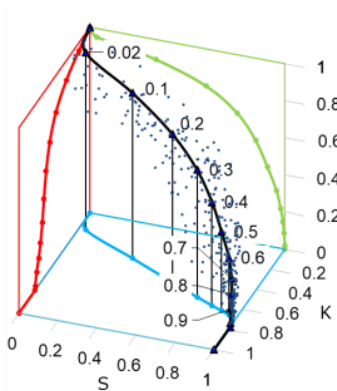

Perth (AU), July

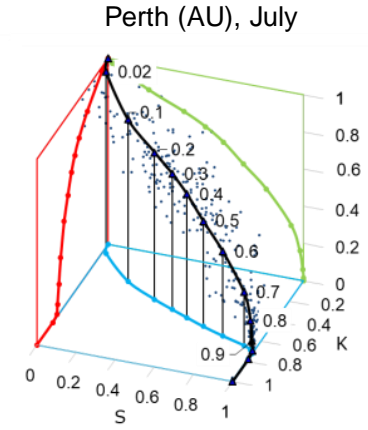

Payerne $(\mathrm{CH})$, October

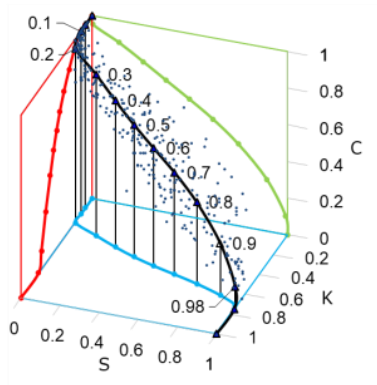

Perth (AU), Oczober

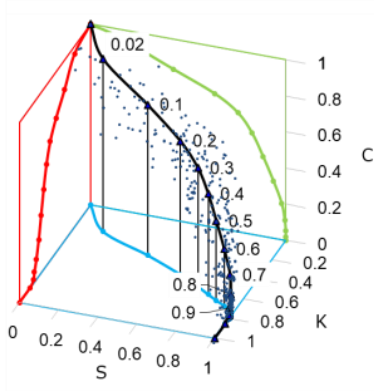

observations $\rightarrow-2 \mathrm{~d}$ regressions $\rightarrow-3 \mathrm{~d}$ regression

Fig. 4: Regression by Integration applied to the trivariate distribution of daily clearness index $-K$, daily relative sunshine duration $-S$, and daily mean cloud cover $-C$ for Payerne and Perth in January, April, July, and October, based on ten-year data-sets. 


\section{Concluding remarks and outlook}

In this paper we present a novel method for the determination of the relationship between two random variables, which we call Regression by Integration. We demonstrate its practicability on Ångström-Prescott-type relations and compare the results with those obtained by least square error fits.

The method treats the two random variables equally. As to be expected for the dependence of two strictly dependent stochastic variables, the result will always be a monotonic function. Compared to other regression methods, it has the advantage that - instead of a sample of simultaneously taken pairs of the two random variables - only a separate sample of each of the random variables is required. This increases the number of prospective sample choices, because samples of the two random variables may be taken over different time periods, and even at different locations.

Morf (2018) presents justifying details and proofs for many of the properties of Regression by Integration based on copulas. Among others, he demonstrates that

- Regression by Integration is a least absolute error estimate: the probability for an outcome to be on either side of the regression curve is the same. As a least absolute error estimate, it is less susceptible to outliers than a least square error fit.

- Regression by Integraton leads to the curve $y(x)$ of strict interdependence beween the two stochastic variables $X$ and $Y$; Spearman's rho is eaqual to one.

The method is universally applicable. Treating the two random variables equally, and being a least absolute error estimate, it will be the best choice for many applications.

\section{Data}

Publicly available data of the following locations have been used:

- Payerne, Switzerland, $46.80^{\circ} \mathrm{N} / 6.93^{\circ} \mathrm{E}$, for the years 2001-2010.

- Perth Airport, Australia, $31.93^{\circ} \mathrm{S} / 115.98^{\circ} \mathrm{E}$, for the years 1998-2007.

From both stations records of daily clearness index, daily relative sunshine duration, and 3-hourly synoptic cloud cover observations were used. Daily mean cloud cover was calculated as the mean of the synoptic cloud cover observations from sunrise to sunset, using linear interpolation. The rare days with unreliable or missing data were removed.

\section{Acknowledgements}

The author wishes to thank the Western Australian Climate Service Centre for the supply of a ten year data set of Perth Airport, containing daily clearness index, daily relative sunshine duration, and 3-hourly synoptic total cloud cover observations.

The author wishes to thank the Swiss Federal Office of Meteorology and Climatology - Meteo Swiss for the supply of a ten year data set of Payerne, containing daily clearness index, daily relative sunshine duration, and 3hourly synoptic total cloud cover observations.

\section{References}

Brandt, S., 1968. Statistische Methoden der Datenanalyse. Bibliographisches Institut, Mannheim.

Kreiszig, E., 1998. Statistische Methoden und ihre Anwendungen. 7th Edition. Vandenhoek und Ruprecht, Göttingen.

Kreiszig, E., 2006. Advanced Engineering Mathematics. Ninth Edition. Wiley and Sons, Hoboken, NJ.

Lilliefors, H.W., 1967. On the Kolmogorov-Smirnov test for normality with mean and variance unknown. Journal of the American Statistical Association 62, 399-402.

Morf, H., 2018. Regression by Integration demonstrated on Ångström-Prescott-type of relations. Renewable Energy 127, 713-723. https://doi.org/10.1016/j.renene.2018.05.004 


\section{Nomenclature}

\section{Capital Letters}

C daily mean cloud cover The mean of cloud cover over the period between sunrise and sunset.

$F \quad$ probability distribution (function)

$K \quad$ daily clearness index

Ratio between daily solar irradiation $\left[\mathrm{W} \mathrm{s} \mathrm{m}^{-1}\right]$ on a horizontal surface and daily extraterrestrial irradiation on a horizontal surface $\left[\mathrm{W} \mathrm{s} \mathrm{m}{ }^{-1}\right]$.

$P \quad$ probability

$S \quad$ daily relative sunshine duration

Ratio between daily sunshine duration [s] and the time between sunrise and sunset [s].

$X \quad$ independent random variable

$Y \quad$ dependent random variable

\section{Small Letters}

a intercept of a linear regression

$b \quad$ slope of a linear regression

$f \quad$ probability function of a discrete random variable

$f \quad$ probability density function of a continuous random variable

$n \quad$ number of days in a calendar month, sample size

$x \quad$ independent variable

$y \quad$ dependent variable

\section{Greek Letters}

$\mu \quad$ mean, expectation

$\rho \quad$ Spearman's rho

$\sigma \quad$ standard deviation

$\sigma^{2} \quad$ variance

\section{Special Characters}

| Condition

- monthly mean

* $\quad$ equal value of two marginal probability distribution (function)

\section{Indices}

1 of the independent random variable (mostly of $\mathrm{X}$ )

2 of the dependent random variable (mostly of Y)

$i \quad$ generic index

$j \quad$ generic index

$\min$ minimum

$\max$ maximum 


\title{
Effect of Solar Position Calculations on Filtering and Analysis of Solar Radiation Measurements
}

\author{
Daniel Perez-Astudillo', Dunia Bachour ${ }^{1}$ and Luis Martin-Pomares ${ }^{1}$ \\ ${ }^{1}$ Qatar Environment and Energy Research Institute (QEERI), HBKU, Qatar Foundation, Doha (Qatar)
}

\begin{abstract}
An important step in the analysis and aggregation of solar radiation measurements is quality filtering of the measured values, and most of these tests rely on calculations of the solar position. Such calculations can be performed at different degrees of precision by using algorithms of various complexities. In this work, two solar position calculation methods are used to process one-minute measurements of direct, global and diffuse irradiances from two different locations, and the resulting aggregated and derived quantities at various time scales are compared in order to look for variations in the final products. The differences are found to be mostly irrelevant, except for clearness indices, which are useful in models deriving solar data from satellite observations, so the higher precision calculations are still recommended for such applications. In any case, the differences against non-filtered data can be quite large, stressing the importance of quality checks.
\end{abstract}

Keywords: solar position, data quality, solar resources

\section{Introduction}

For the determination and characterisation of available solar resources, the highest accuracies can be achieved by direct on-site measurements, usually collected at one-minute resolution. These measurements are then aggregated temporally to obtain averaged values at diverse time scales, such as 5-, 10-, 15-, 30-minute, or hourly, daily, monthly and up to yearly totals or averages, depending on the application. Given the difficulties involved in the measurement of solar radiation (Panday and Katiyar, 2013), from sensor uncertainties to instrument operation and maintenance, one should not simply average all available data within the desired intervals with the assumption that all measured values are correct; even in well-maintained stations some method of data quality assurance should be used in order to filter out values that are questionable or clearly wrong. The Baseline Surface Radiation Network's (BSRN) recommended checks (Long and Dutton, 2002) are some of the most commonly applied, being an international standard, but other methods can be found (Journee and Bertrand, 2011; Kendrick et al., 1994; Long and Shi, 2009; Moradi, 2009; NREL, 1993; Pashiardis and Kalogirou, 2016; Schwandt, 2014; Younes et al., 2005), some of them even custom-made for a specific project or user. In any case, the most basic quality checks are based on the maximum solar radiation available at any given time.

Solar radiation availability is driven mainly by the sun's position with respect to the observer. Before reaching the surface of the earth, the radiation emitted by the sun must traverse the earth's atmosphere, and this process results in an attenuation of the original energy. Therefore, incoming solar radiation is studied in two steps: first, the so-called extraterrestrial radiation, which is the solar energy arriving at the top of the earth's atmosphere, unaffected along its path from the sun; and second, the radiation arriving at the surface, after atmospheric absorption and scattering.

Due to the eccentricity of the earth's orbit around the sun, the sun-earth distance changes through the year by around $+/-1.7 \%$. This is reflected in a slow cyclic change of around $+/-3.3 \%$ in the extraterrestrial beam radiation, $\mathrm{I}_{\mathrm{ob}}$, measured on a plane perpendicular to the direction of the sun rays, and at any given time is the same for all locations on earth (or zero for places on the night-side). However, the extraterrestrial horizontal radiation, $\mathrm{I}_{0}$, which is $\mathrm{I}_{0 \mathrm{~b}}$ projected on a horizontal surface at the top of the atmosphere, depends both on the time of the day and the location on earth (apart from the time of the year, which determines $\mathrm{I}_{0 \mathrm{~b}}$ ).

Atmospheric attenuation of solar radiation depends fundamentally on the amount of air that light must traverse from the top of the atmosphere to reach a given location, and is furthermore affected by clouds, aerosols and other phenomena. Thus, under clean skies, locations at sea level see decreased levels of radiation as compared to places at high altitudes. However, latitude plays a larger role. At any particular site, variations in solar radiation are determined 


\section{Perez-Astudillo et. al. / EuroSun 2018 Fis Astudillo}

by the continuous changes in the apparent height of the sun above the local horizontal; indeed, attenuation increases rapidly as sun elevations decrease, for and locations at higher latitudes the sun does not always reach high elevations, especially in winter. Moreover, and also for any given location, the sun does not follow the same diurnal path in the sky through the year as the planet revolves around the sun, because the earth's axis of rotation is not perpendicular to the plane of its orbit, but has a $23.5^{\circ}$ tilt.

The geometry-related points described above must be considered and quantified when computing the solar position for the site of interest at all times. As geographical and astronomical knowledge has improved through the years, algorithms and their inputs have improved, reaching accuracies of the order of 1/1000 of a degree in the solar position, at the cost, however, of more complex equations. Different methods exist and can be used, from ones comprising few equations to others even requiring current measurements of some parameters; usually, the simpler methods can be applied for any year (within reasonable limits, as the sun-earth geometry changes at the scale of millenia), although with lower accuracies; more advanced methods specify the range of time within which they keep their high accuracy, some covering a few years, and some covering centuries.

Solar resource applications often need data on real or near real time, with quality checks applied at the same time. Even with ever-faster computer processing available, higher speeds are always desirable, so faster algorithms are an advantage. Alternatively, look-up tables of the solar position can be prepared in advance, so that the positions need not be calculated on-the-fly. In all cases, when developing a framework for solar resource assessment, one of the decision points is which solar algorithm to adopt, and currently there is no standard or recommended practice on this regard. With the different options available, the question arises of whether using one or another will result in noticeably different results at the level of the variables useful for solar resource assessment and applications such as solar plant operations, forecasting, etc. This work presents an investigation of possible differences in quality-filtered, aggregated solar data using measurements from three years, taken at two locations; two years are taken from one site, one year from the other.

\section{Methodology}

As mentioned above, the objective in this work is to compare whether the use of different "solar calculators" (short for solar position calculation methods), when assessing the quality of solar radiation measurements, results in different conclusions in the characterisation of solar resources. This section describes the measured data analysed here, the solar calculators used, the quality checks applied on the data, and the comparison metrics.

\subsection{Solar Radiation Data}

Measurements from two locations equipped with high-precision monitoring stations were used here. Both stations collected data with Kipp and Zonen instrumentation, comprising thermoelectric sensors and a sun tracker to measure separately the direct normal (Gb), global horizontal (G), and diffuse horizontal (Gd) irradiances, at one-minute resolution.

One station is located in Doha, Qatar, $25.33^{\circ} \mathrm{N}, 51.43^{\circ} \mathrm{E}, 20 \mathrm{~m}$ AMSL, and is operated by the Qatar Environment and Energy Research Institute (QEERI) (Perez-Astudillo and Bachour, 2014); from this station, two full years were studied, 2014 and 2015, identified from here on as DOH14 and DOH15. The second station is located at Dar Es Salam University, Tanzania, $6.78^{\circ} \mathrm{S}, 39.20^{\circ} \mathrm{E}, 96 \mathrm{~m}$ AMSL (ESMAP, 2016), and one year of data was used, from 1/June/2015 to 31/May/2016, denoted here as DES15.

Data of varying quality is represented by these datasets. In general, the QEERI station provides measurements of higher quality, with the lowest amount of 'bad' data in the DOH14 dataset. The DES15 set shows some long periods of bad data, most likely due to tracking or shading issues. These datasets provide thus the opportunity to test whether the differences in solar calculations have different effect on data that deviates at varying degrees from the limits of the tests (note also that these limits depend on the calculated solar positions).

The BSRN quality checks were applied on the one-minute data, and entries that fail the tests were discarded and considered as missing. The remaining entries, hereby called "valid", were then used to calculate irradiance averages at time scales of 15, 30 and 60 minutes, daily, monthly, and yearly. Table 1 shows the input data ('source') used to derive each averaged value. Missing source entries, either because there is no measured/averaged value or because the (one-minute) value failed QC (quality checks), were not counted in the calculation of averages, i.e., the averages are the sum of valid irradiances divided by the total number of valid source entries in the interval.

To avoid unrepresentative averages when many source entries are missing, minimum numbers of valid data were 


\section{Perez-Astudillo et. al. / EuroSun 2018 Fisistudillo Conference Proceedings (2018)}

imposed on each average. The 15-, 30- and 60-minute averages were only calculated if 50\% or more of the minutes (at least 7,15, and 30, respectively) within the interval were valid; otherwise, the average was reported as missing. For daily averages, the minimum acceptable was $80 \%$ of the daytime hours in that day, a number that varies with day length through the year. For monthly and yearly averages, $75 \%$ of the days within that month or year, respectively, must have a valid average.

Tab. 1: Data used for calculation of different aggregated values, after quality filtering is done on the one-minute data.

\begin{tabular}{|c|c|}
\hline Averaged interval & Source data \\
\hline $15 \mathrm{~min}$ & $1-\mathrm{min}$ \\
\hline $30 \mathrm{~min}$ & $1-\mathrm{min}$ \\
\hline 60 min (hourly) & 1 -min \\
\hline Daily & hourly averages \\
\hline Monthly & daily averages \\
\hline Yearly & daily averages \\
\hline
\end{tabular}

\subsection{Solar Position}

Two different algorithms were used for this study. The first one, identified here as 'NO' (NOAA, 2018), is from NOAA, the USA's National Oceanic and Atmospheric Administration. The second, called here 'SP' is the MIDC SolPos v2.0 algorithm (SolPos, 2001) from NREL, the USA's National Renewable Energy Laboratory.

For both algorithms, the solar position was calculated for every second of each year (in the case of SP, since NO is year-independent) at each of the sites and from these values, one-minute averages were calculated. This was done because the base solar measurements used are also one-minute averages. Then, 15-, 30- and 60-minute averages were calculated from the one-minute values, also similarly to the solar averages; note, however, that for solar position averages all the minutes within each interval were included.

\subsection{Data Quality Checks}

The BSRN set of tests were applied to the one-minute measurements. The BSRN tests check whether the values are: within physically possible limits, within extremely rare but physically possible limits, under a maximum diffuse ratio $(\mathrm{Gd} / \mathrm{G})$, and consistent among each other (measured $\mathrm{G}$ is not very different from a $\mathrm{G}$ calculated from $\mathrm{Gb}$ and $\mathrm{Gd}$ ), see (Long and Dutton, 2002). Using the calculated zenith angle and extraterrestrial radiation from each method, SP and NO, the QC equations and limits for each test were obtained and the checks were applied to all daytime entries, which were then flagged according to whether they passed or failed each test from each claculation method, separately. Note that day and night are defined by the sun crossing the local horizon and in this case a zenith angle of 90 degrees was used for both locations; therefore, daytime length depends on the calculated solar position; for NO and SP this meant differences of at most two minutes in daytime length (from sunrise to sunset) in some days of the year. Entries that failed the physically possible, diffuse ratio and consistency checks were removed from the averaging calculations to obtain the aggregated values listed in Table 1. All nighttime entries were considered as 'good quality' and included in the averagings with an irradiance value of zero.

\subsection{Comparison Parameters}

Comparisons between the methods were quantified through the mean bias error (MBE), mean absolute error (MAE), root-mean-square error (RMSE) and their corresponding relative quantities rMBE, rMAE, rRMSE (in \%). Error in this context means the difference between the values derived using the NO method with respect to the ones derived using the SP method, that is, quantities derived from SP calculations were taken as 'reference', since SP provides higher precision.

\section{Results and Discussion}

\subsection{Solar Position Variables}

Table 2 presents the differences in the calculated solar variables studied, for all daytime minutes of the year; as previously stated, daytime entries are defined here as those with solar zenith angle $(\Theta z)$ less than 90 degrees. Since sunrise and sunset may occur at slightly different minutes for each solar calculator, the results in this table only include minutes in which $\Theta z$ is less than 90 degrees in both sets at the same time. The zenith and azimuth angles are in degrees; $\mathrm{I}_{0}$ and $\mathrm{I}_{0 \mathrm{~b}}$ in $\mathrm{W} / \mathrm{m}^{2}$; the air mass (AM) and fpr (factor used to obtain the modified clearness index proposed 


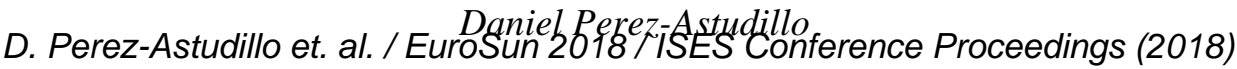

by R. Perez) are dimensionless. In general, differences appear smaller than $1 \%$ in most cases, but some larger values can be observed. The largest differences are seen for air mass and happen, as shown in Figure 1, at the lowest solar elevations, that is, near sunrise and sunset, when the zenith angle approaches 90 degrees, and the same is found for the fpr factor, which has behaviour similar to that of air mass; this is mainly attributed to the fact that SP includes a correction for atmospheric refraction, which was not included in the NO calculator, and this correction is larger at low solar elevations; however, since solar radiation is low at these elevations, these differences may not have a big effect.

Tab. 2: Comparison of solar calculations for all daytime minutes in each year; 'errors' refer to the difference in NO values with respect to the SP values

\begin{tabular}{|c|c|c|c|c|c|c|}
\hline & MBE & rMBE(\%) & MAE & rMAE $(\%)$ & RMSE & rRMSE $(\%)$ \\
\hline \multicolumn{7}{|l|}{ DOH14 } \\
\hline$\Theta z$ & 0.043 & 0.082 & 0.156 & 0.295 & 0.190 & 0.359 \\
\hline azimuth & 0.004 & 0.002 & 0.277 & 0.154 & 0.352 & 0.196 \\
\hline $\mathrm{I}_{0}$ & -0.957 & -0.126 & 3.669 & 0.482 & 4.440 & 0.583 \\
\hline $\mathrm{I}_{0 \mathrm{~b}}$ & -0.072 & -0.005 & 1.913 & 0.140 & 2.222 & 0.163 \\
\hline $\mathrm{AM}$ & 0.111 & 3.367 & 0.117 & 3.559 & 0.570 & 17.339 \\
\hline fpr & 0.003 & 0.276 & 0.004 & 0.324 & 0.013 & 1.078 \\
\hline \multicolumn{7}{|l|}{ DOH15 } \\
\hline$\Theta z$ & 0.043 & 0.082 & 0.123 & 0.233 & 0.153 & 0.289 \\
\hline azimuth & 0.006 & 0.003 & 0.208 & 0.116 & 0.271 & 0.151 \\
\hline $\mathrm{I}_{0}$ & -0.955 & -0.125 & 3.137 & 0.412 & 3.824 & 0.502 \\
\hline $\mathrm{I}_{0 \mathrm{~b}}$ & -0.072 & -0.005 & 1.913 & 0.140 & 2.222 & 0.163 \\
\hline $\mathrm{AM}$ & 0.111 & 3.381 & 0.115 & 3.498 & 0.563 & 17.109 \\
\hline fpr & 0.003 & 0.276 & 0.004 & 0.307 & 0.012 & 1.046 \\
\hline \multicolumn{7}{|l|}{ DES15 } \\
\hline$\Theta z$ & 0.031 & 0.065 & 0.092 & 0.189 & 0.118 & 0.241 \\
\hline azimuth & 0.005 & 0.003 & 0.298 & 0.166 & 2.786 & 1.548 \\
\hline $\mathrm{I}_{0}$ & -0.802 & -0.097 & 2.001 & 0.241 & 2.664 & 0.321 \\
\hline $\mathrm{I}_{0 \mathrm{~b}}$ & -0.065 & -0.005 & 1.977 & 0.145 & 2.303 & 0.168 \\
\hline $\mathrm{AM}$ & 0.101 & 3.313 & 0.103 & 3.385 & 0.533 & 17.472 \\
\hline fpr & 0.003 & 0.252 & 0.003 & 0.270 & 0.012 & 0.988 \\
\hline
\end{tabular}
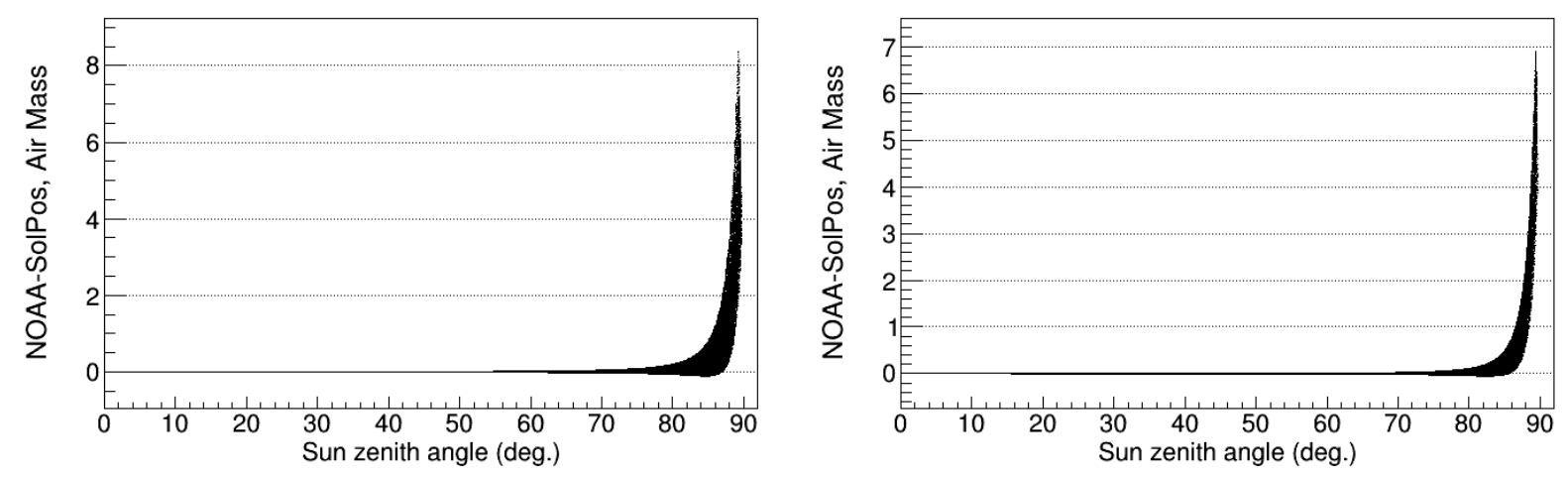

Fig. 1: Difference in air mass as calculated with NO with respect to SP, as function of solar zenith angle, for DOH14 (left) and DES15 (right).

\subsection{Quality Check Filtering}

The percentages of daytime entries, per dataset (year), that failed to pass the quality checks using the NO and SP methods are listed in Table 3, together with the total number of daytime minutes (only excluding non-available entries) according to each method. 


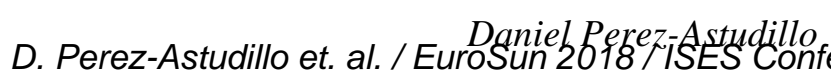

Tab. 3: Percentages of one-minute daytime entries that failed QC in each year, from the SP and NO methods. NSP and $N_{N O}$ are the total number of daytime minutes, according to each method; unavailable entries are not counted.

\begin{tabular}{|c|c|c|c|c|}
\hline & \%SP & \%NO & NsP & $\mathbf{N}_{\text {No }}$ \\
\hline DOH14 & & & & \\
\hline $\mathrm{Gb}$ & 0.072 & 0.095 & 265389 & 263880 \\
\hline $\mathrm{G}$ & 0.237 & 0.158 & 265389 & 263880 \\
\hline $\mathrm{Gd}$ & 0.595 & 0.338 & 265389 & 263880 \\
\hline DOH15 & & & & \\
\hline $\mathrm{Gb}$ & 3.051 & 3.033 & 265717 & 264218 \\
\hline $\mathrm{G}$ & 3.247 & 3.117 & 265717 & 264218 \\
\hline $\mathrm{Gd}$ & 3.555 & 3.283 & 265717 & 264218 \\
\hline $\mathrm{DES15}$ & & & & \\
\hline $\mathrm{Gb}$ & 15.365 & 14.814 & 265435 & 264082 \\
\hline $\mathrm{G}$ & 15.382 & 14.830 & 265435 & 264082 \\
\hline $\mathrm{Gd}$ & 15.389 & 14.837 & 265435 & 264082 \\
\hline
\end{tabular}

To identify where the QC are producing the highest differences, Figure 2 presents the difference (NO with respect to SP) in percentage of failed entries within each hour and day of the year, for the three datasets. Most differences are negative, indicating that the NO-based checks find lower amounts of bad entries. No seasonal trends can be seen, but it is noted that the quality evaluation of $\mathrm{G}$ and $\mathrm{Gb}$ data from the $\mathrm{DOH}$ station presents higher differences at the lowest elevations, mainly during summer, and all through days with large amounts of bad quality data (e.g., around day 280 in DES15, as mentioned in Section 2.1).
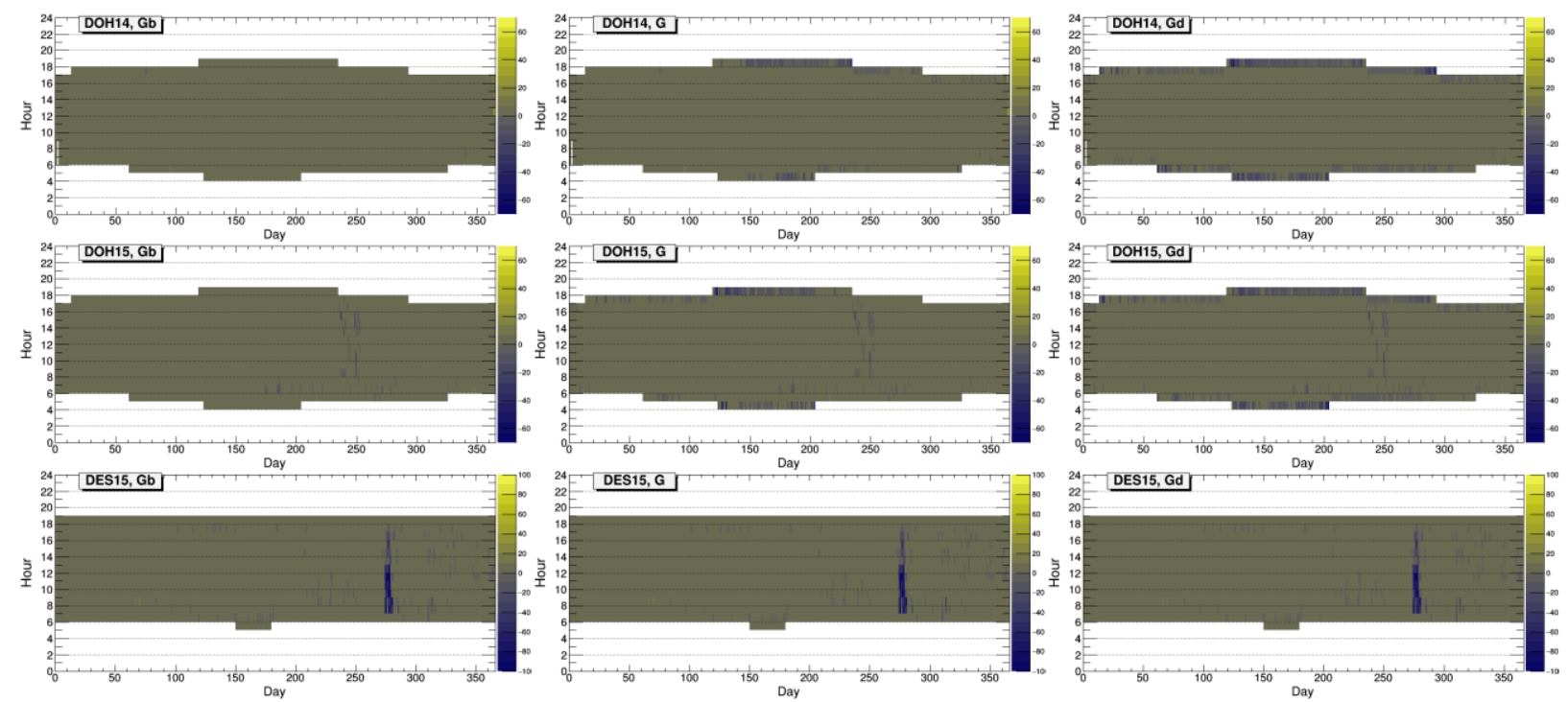

Fig. 2: Differences in the percentage of daytime entries that failed QC for each solar irradiance component, within each hour of each day. The colour scales represent the differences of NO with respect to SP. Note that for DES15 the scales go up to +/-100\%.

Looking from another perspective, the percentages of failure, from each method separately, are depicted in Figure 3 as a function of irradiance, in bins of $100 \mathrm{~W} / \mathrm{m}^{2}$. The graphs show that the lowest $\mathrm{G}$ and $\mathrm{Gd}$ values have failure rates around 2-3\% at the DOH station, with the NO-based tests finding less bad-quality entries than SP. Otherwise, the difference between both methods does not indicate a noticeable dependency on irradiance. Notice also that for DES15 the large Gd values, which are clearly erroneous, are always identified in the most extreme cases $\left(\sim 1000 \mathrm{~W} / \mathrm{m}^{2}\right.$ and above), but between 500 and $1000 \mathrm{~W} / \mathrm{m}^{2}$ the tests are less likely to find all the (possibly) wrong data. 
D. Perez-Astudillo et. al. / Eurosuniel Perez-Astudillo

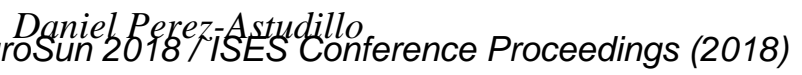
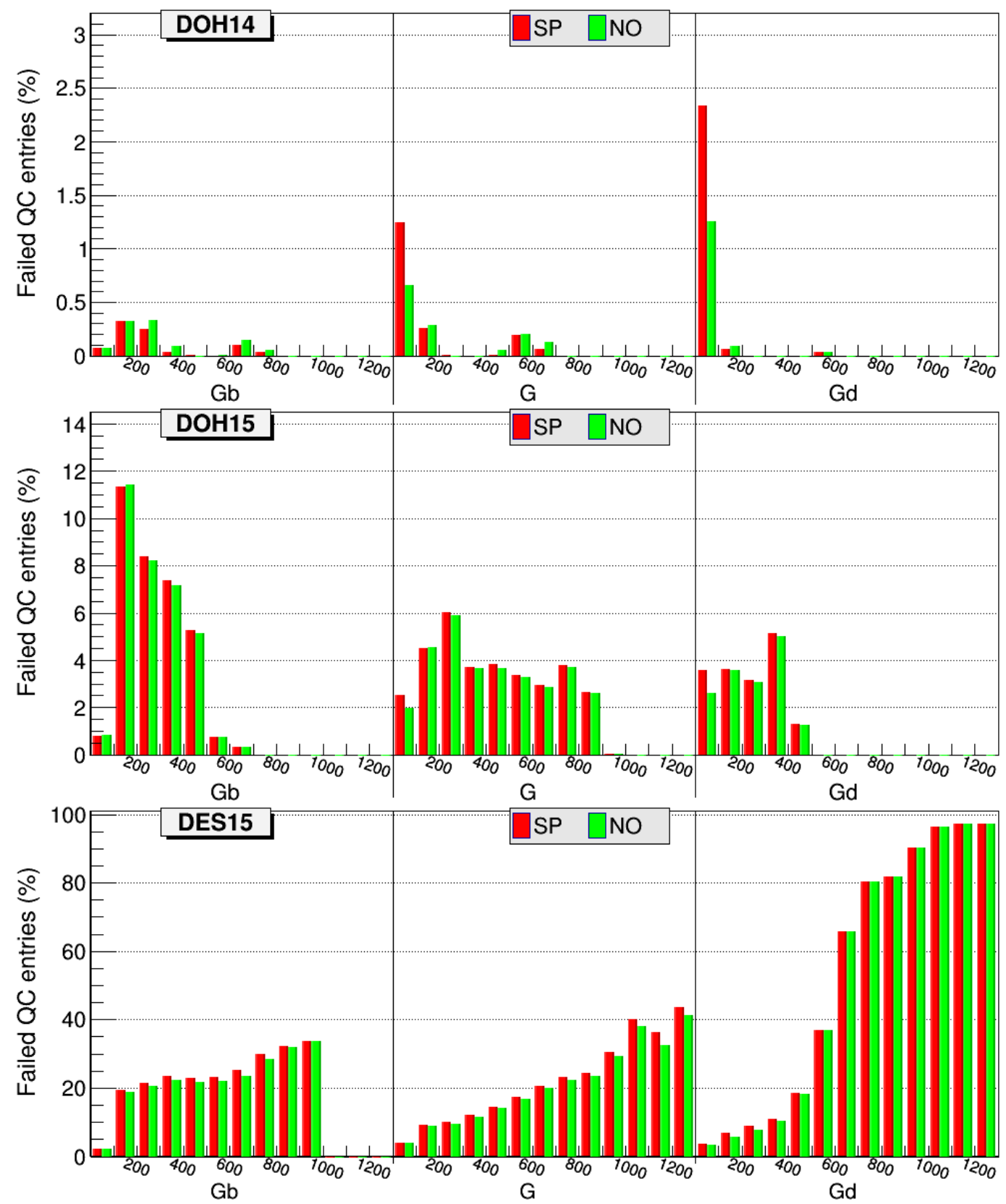

Fig. 3: Percentage of entries that failed QC for each solar irradiance component, as a function of irradiance.

\subsection{Aggregated Solar Radiation}

After removing the entries that fail QC, different averages were calculated. As general overview, the total annual irradiations (in $\mathrm{kWh} / \mathrm{m}^{2}$ ) are given in Table 4. For reference, the table also includes the annual totals obtained without any quality filtering, that is, by including all the available measurements. For DES15 the required the number of days with valid data had to be reduced in order to obtain a yearly value. It is evident that at this level the solar calculation method does not make any difference.

Tab. 4 :Total annual irradiations (in $\mathrm{kWh} / \mathrm{m}^{\wedge} 2$ ) for the three datasets by using all available data (RAW columns), and after QC filtering based on SP and NO calculations.

\begin{tabular}{|c|c|c|c|c|c|c|c|c|c|}
\hline & & Gb & & & G & & & Gd & \\
\hline & RAW & SP & NO & RAW & SP & NO & RAW & SP & NO \\
\hline DOH14 & 2073 & 2068 & 2069 & 2203 & 2205 & 2206 & 777 & 778 & 778 \\
\hline DOH15 & 1785 & 1800 & 1799 & 2130 & 2134 & 2133 & 879 & 876 & 875 \\
\hline DES15 & 1389 & 1266 & 1266 & 1910 & 1798 & 1798 & 1159 & 902 & 902 \\
\hline
\end{tabular}

Also at the level of monthly and daily irradiations (not shown) both solar calculation methods produce the same 


\section{Perez-Astudillo et. al. / EurosunielPerezi-Astudillo 20 Conference Proceedings (2018)}

results. At higher temporal resolution, but looking for possible temporal dependencies, Figure 4 illustrates the monthly averages of the differences in hourly irradiance, for each daytime hour of the day. No seasonal dependences are seen, but it is noted that, in general, the differences are slightly larger in two cases: the more common is in the hours that include sunrise and sunset, mainly due to the smaller values of measurements and calculations, which result in comparatively larger sensitivities in the tests; and relatively larger differences (although still small, under $+/-4 \mathrm{~W} / \mathrm{m}^{2}$ ) are found in periods with large percentages of low-quality data, as seen in August-September for DOH15 and February-March for DES15.
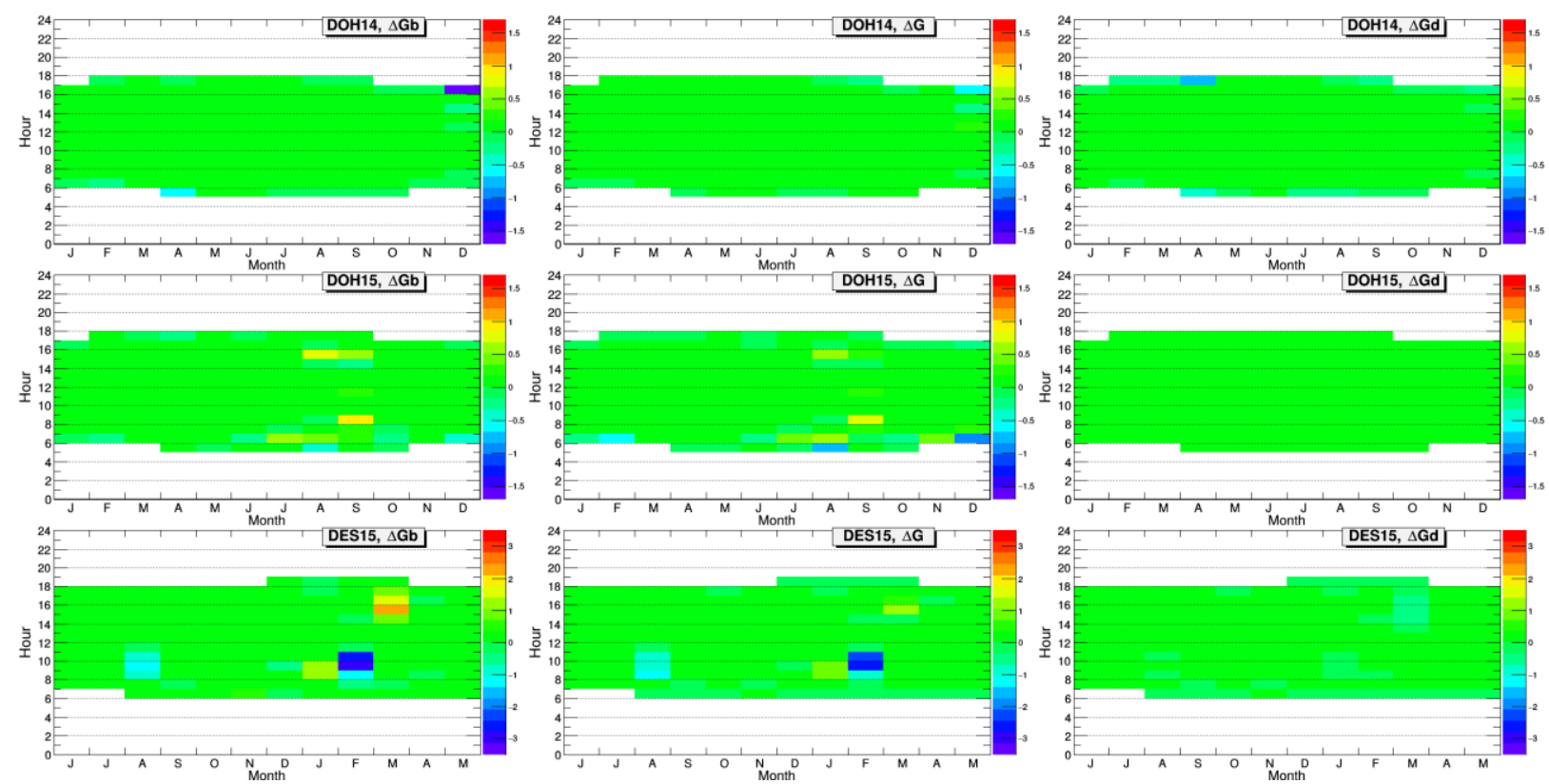

Fig. 4: Monthly averages of the difference $(\mathrm{NO}-\mathrm{SP})$ in hourly irradiances are shown in colour scales, in W/m^2.

\subsection{Clearness Indices}

The atmospheric clearness indices are normalised forms of the irradiances that remove the seasonal changes in Iob and $\mathrm{I}_{0}$, and are commonly used in many applications, from charaterising solar climate to modelling and forecasting solar radiation. Given their widespread use, two indices were also studied here: the beam clearness index $\mathrm{Kn}=\mathrm{Gb} /$ $\mathrm{I}_{0 \mathrm{~b}}$, and the global clearness index $\mathrm{Kt}=\mathrm{G} / \mathrm{I}_{0}$; their values range from 0 to 1 , but in some cases can be slightly above 1 due to reflections from clouds. Figure 5 shows the relative differences, in $\%$, between the hourly clearness indices, averaged over each month in the periods under study; as before, the SP-based values were taken as reference. The hourly $\mathrm{Kt}$ and $\mathrm{Kn}$ were obtained using the corresponding hourly averages of the measured and extraterrestrial irradiances. As in the previous cases, no clear seasonal dependencies can be seen (the change in shade of green from June to July corresponds to a change of less than $0.2 \%$ ), and the larger differences are seen in the sunrise/sunset hours, reaching as much as $8 \%$, but the rest of the time the differences are well within $+/-2 \%$. 
D. Perez-Astudillo et al. I EurosuielPerez-Astudillo
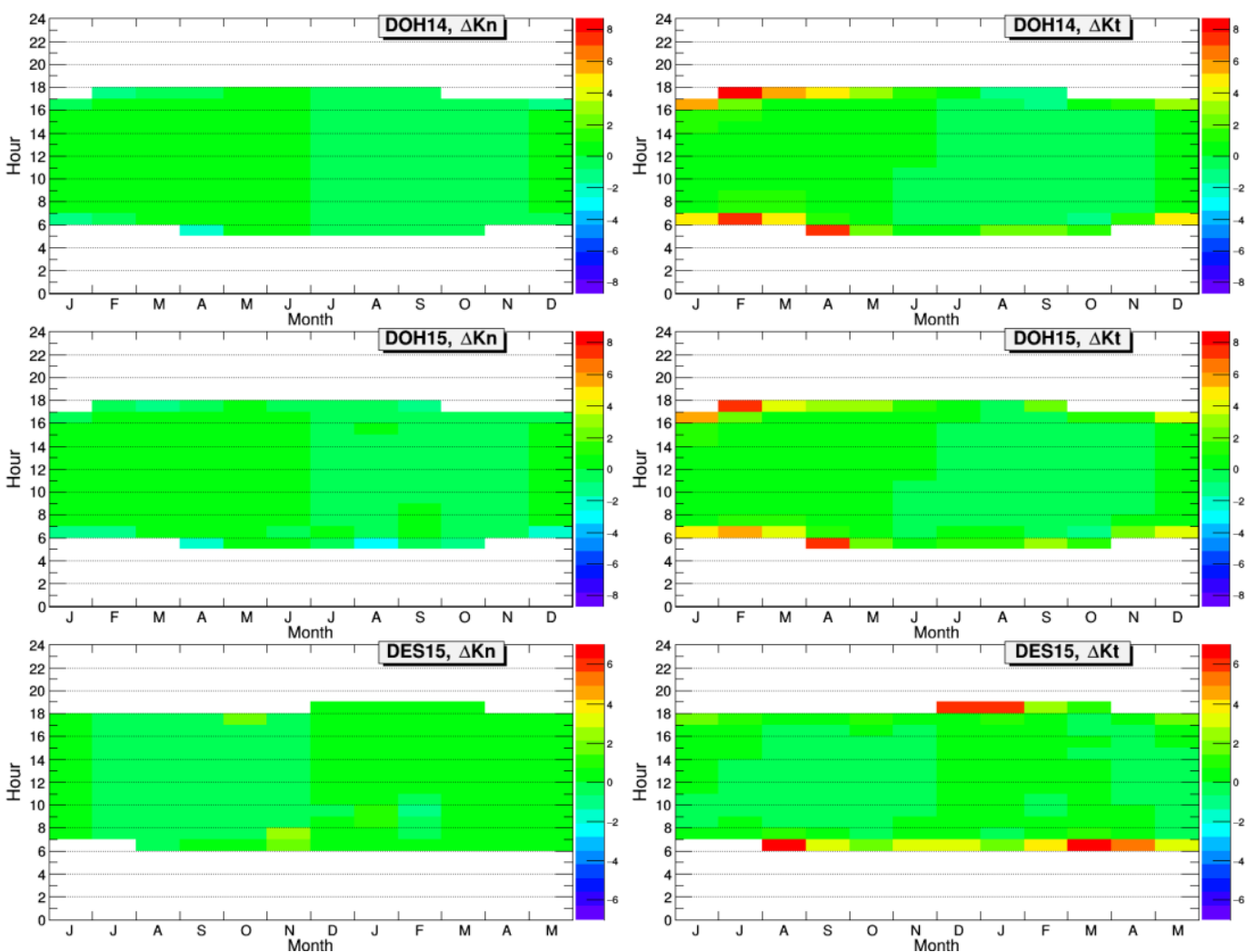

Fig. 5: Monthly averages of the relative difference (No - SP) in the hourly values of the beam and global clearness indices, Kn and Kt respectively, shown in the colour scales in \%.

\section{Conclusion}

To assess the quality of measured solar radiation, a number of tests are applied in order to flag data so that erroneous measurements can be excluded from the analysis. Many commonly used tests are based on the position of the sun in the local sky at the time of each measurement, and since it is not practical to measure this position continuously, it is normally determined through calculations, for which a wide spectrum of choice exists. Calculation methods differ in precision and temporal coverage, varying in complexity, with some of them even requiring external (measured) inputs. For solar applications, currently there is no recommended standard methodology for the calculation of solar position, so the selection is in each case a matter of convenience, chance, or speed, although the highest precisions are frequently sought for, without knowing whether the highest accuracies are really necessary for studying solar resources, that is, whether they actually make a difference in a practical sense. The study presented here used two different solar calculation methods to derive the BSRN quality checks applied to a total of three years of data from two different locations. After filtering the measured data at one minute resolution, averages of the direct, global and diffuse irradiances were made at different time scales, namely, 15, 30 and 60 minutes, daily, monthly and annual, and results from both methods were compared to look for differences. The results indicate that through the year there is no noticeable change in derived quantities by using either of the two solar position calculation methods, although some (yet still small) differences can be noticed at low solar elevations and during periods with large amounts of bad-quality data.

\section{References}

ESMAP, 2016. https://www.esmap.org/re_mapping_TNZ Last accessed 28/Aug/2018.

Journee, M., Bertrand, C., 2011. Quality control of solar radiation data within the RMIB solar measurements network. Solar Energy 85, 72-86. doi:10.1016/j.solener.2010.10.021.

Kendrick, D. et al., 1994. Guide to recommended practice of daylight measurement. Report no. CIE 108-1994. Wien, Austria: International Commission on Illumination (CIE). ISBN 9783900734503.

Long, C.N., Dutton, E.G., 2002. BSRN Global Network recommended QC tests, V2.0. Available online at http://epic.awi.de/30083/1/BSRN_recommended_QC_tests_V2.pdf Last accessed 28/Aug/2018.

Long, C.N., Shi, Y., 2009. An Automated Quality Assessment and Control Algorithm for Surface Radiation 


\section{Perez-Astudillo et. al. / EuroSunielPerreziAstudillo}

Measurements. The Open Atmospheric Science Journal 2, 23-37.

Moradi, I., 2009. Quality control of global solar radiation using sunshine duration hours. Energy 34, 1-6. doi:10.1016/j.energy.2008.09.006.

NOAA, 2018. http://www.esrl.noaa.gov/gmd/grad/solcalc/solareqns.PDF Last accessed 28/Aug/2018.

NREL, 1993. User's Manual for SERI_QC Software - Assessing the Quality of Solar Radiation Data. NREL/TP-

463-5608. Golden, CO: National Renewable Energy Laboratory. Available online at http://www.nrel.gov/docs/legosti/old/5608.pdf Last accessed 28/Aug/2018.

Pandey, C. K., Katiyar, A. K., 2013. Solar Radiation: Models and Measurement Techniques. Journal of Energy, 2013, ID 305207. doi:10.1155/2013/305207

Pashiardis, S., Kalogirou, S.A., 2016. Quality control of solar shortwave and terrestrial longwave radiation for surface radiation measurements at two sites in Cyprus. Renewable Energy 96, 1015-1033. doi:10.1016/j.renene.2016.04.001

Perez-Astudillo, D., Bachour, D., 2014. DNI, GHI and DHI Ground Measurements in Doha, Qatar. Proceedings of the 2013 SolarPACES Conference, Energy Procedia 49, 2398-2404. doi:10.1016/j.egypro.2014.03.254

Schwandt, M., Chhatbar, K., Meyer, R, Mitra, I., Vashistha, R., Giridhar, G., Gomathinayagam, S., Kumar, A., 2014. Quality check procedures and statistics for the Indian SRRA solar radiation measurement network. Proceedings of the 2013 ISES SWC. Energy Procedia 57, 1227-1236. doi:10.1016/j.egypro.2014.10.112

SolPos, 2001. http://rredc.nrel.gov/solar/codesandalgorithms/solpos/ Last accessed 28/Aug/2018.

Younes, S., Claywell, R., Muneer, T., 2005. Quality control of solar radiation data: Present status and proposed new approaches. Energy 30, 1533-1549. doi:10.1016/j.energy.2004.04.031 


\title{
Urban climate - Impact on energy consumption and thermal comfort of buildings Jan Remund ${ }^{1}$ and Urs Grossenbacher ${ }^{2}$ \\ ${ }^{1}$ Meteotest AG, Bern (Switzerland) \\ ${ }^{2}$ INES GmbH, Bern (Switzerland)
}

\begin{abstract}
Climate change and the urban heat effect is expected to have a large influence on the energy consumption and thermal comfort of buildings. However, using meteorological data which incorporates effects of climate change and characteristics of cities is not currently a standard practice in building simulation.

By default, Typical Meteorological Years (TMY) based on 20-year meteorological statistics from nearby meteorological stations often outside cities are used. This may lead to important discrepancies between simulation results and actual energy consumption and/or indoor climate data for buildings in urban areas.

These effects are analyzed within Building energy part of H2020 climate-fit.city project. First, adapted urban and future meteorological data modelled using the VITO UrbClim model and standard meteorological data were compared. Second, these data were included within the Meteonorm software. In a first phase, this was carried out for the cities of Bern and Vienna. In the future, this data will be included for other urban areas in Europe.

In a third step the urbanized TMY data sets generated by Meteonorm were used to simulate energy consumption and indoor climate conditions with models of three typical buildings. The whole-year simulation runs were made in series for several urban locations and - as a reference scenario - with the standard TMY.

First results show that meteorological data are modelled generally well; however at some sites differences are statistically significant. In some locations Meteonorm based data show lower discrepancies, in some the ERAInterim / Urbclim model based. The differences regarding building energy needs are relatively low. Heating energy consumption is $6 \%$ lower within cities and cooling energy $15 \%$ higher. The hours outside comfort levels within cities are higher, however only to a small extent. Currently, only results from Bern and Vienna have been analysed. For other cities in other climate regions, the results and conclusions may be different.
\end{abstract}

Climate-fit.city is a EU project within the framework of Horizon 2020

Key-words: climate change, urban heat, building energy simulation, thermal comfort

\section{Introduction}

Climate change, and in particular the urban heat effect, is expected to have a large influence on the energy consumption and thermal comfort of buildings. However, using meteorological data which incorporates effects of climate change and characteristics of cities (e.g. susceptibility to the 'urban heat island' phenomenon) is not currently a standard practice in building simulation.

By default, Typical Meteorological Years (TMY) based on 20-year meteorological statistics with time lags of several years and from nearby meteorological stations are used. These stations are often located outside the city centers (e.g. at airports). From this, it follows that neither climate change nor urban effects are taken into account in building performance simulation. This may lead to important discrepancies between simulation results and actual energy consumption and/or indoor climate data for buildings in urban areas.

These effects are analyzed within Building energy part of H2020 climate-fit.city project. In a first step, adapted urban and future meteorological data, modelled using the VITO's UrbClim model (De Ridder et al., 2015) and standard (non-adapted) meteorological data were compared. In a second step, these data were compressed and included within the Meteonorm software. This will enable the software to model the urban and climate change effects for any location within the urban areas. In a first application, this was carried out for the cities of Bern and Vienna. In the future, this data will be included for other urban areas in Europe. In a third step the urbanized TMY data sets generated by Meteonorm (www.meteonorm.com) were used to simulate energy consumption (heating, cooling) and indoor climate conditions (operative temperature) with models of three typical buildings. 
The whole-year simulation runs were made in series for several urban locations and - as a reference scenario with the standard TMY. The "urban" results where then compared with the reference scenario.

\section{Objectives}

The purpose of the project is to develop services to provide building design engineers more accurate and adequate meteorological data for the simulation of buildings located in cities. The objective is to construct/refurbish buildings with better indoor quality and lower energy demand.

For the Building Energy service, Meteotest enhances its Meteonorm software to account for urban climate conditions, in particular the urban heat island effect, using UrbClim output files. Concretely, this enables the stochastic generation of time series of a so-called Typical Meteorological Year (TMY), as well as extreme (hot/cold) years, both for the current situation and under future climate conditions.

The first phase is equal to the test phase of urbanized Meteonorm (a.k.a. Meteonorm Version 7.3 / MN 7.3). INES will employ urbanized Meteonorm data for Bern and Vienna to simulate building cooling and heating loads and thermal comfort levels using the IDA-ICE (https://www.equa.se/en/ida-ice) building simulation software. The results will be compared to simulation based on standard TMYs.

The objective of the first phase is to show low deviations at sites with meteorological stations used to produce standard TMY (the data used historically for building design) and to prove the working hypothesis that for sites within cities significant deviations are seen when compared to the standard meteo stations (and therefore urban adaptation is needed).

In the second phase of the H2020 project (2019), more cities in Meteonorm will be upgraded with urbanized data. The final target is to include urbanized Meteonorm data for all larger urban areas in Europe and on other continents and thus enable more accurate building performance simulations for urban areas.

\section{Data \& Methods used}

\section{1: Generation of urban climate data}

VITO delivered ERA5 (2010-16) and ERA-Interim (1987-2016) based UrbClim NetCDF files for Bern and Vienna in hourly time resolution. Parameters used were temperature, wind speed, relative humidity, global radiation (directly from ERA5/Interim) and precipitation (directly from ERA5/Interim - and not used for modelling).

Based on the input values, Meteotest calculated TMY based on Sandia method (Wilcox and Marion, 2008).and condensed the temperature information into Meteonorm (urbanized Meteonorm; see section 3.3.1). The results of Meteonorm were TMY datasets in hourly input format of IDA-ICE. This includes the parameters air temperature, relative humidity, wind speed, wind direction, direct horizontal radiation and diffuse horizontal radiation.

\section{2: Condensing UrbClim output into "urbanized Meteonorm"}

Starting point for condensing UrbClim output into "urbanized" Meteonorm are ERA/UrbClim high resolution fields calculated by VITO. To produce TMY datasets as well as input data for urbanized Meteonorm, 30 years of hourly data are needed. The spatial resolution of the Urbclim data is $100 \mathrm{~m}$.

In a preliminary step, ERA5 and ERA-Interim based datasets were bias corrected. This was done by defining the difference of the yearly average temperature and the factors of wind speed and global radiation at the site of the official meteo station (Bern/Zollikofen and Wien/Hohe Warte) for the period 2010-16. The correction values were then applied to the whole modelled grid (Table 1). 
Tab. 1: Bias corrections for Bern and Vienna for ERA-Interim

\begin{tabular}{|c|c|c|c|c|}
\hline Site & Temperature $\left[{ }^{\circ} \mathbf{C}\right.$ ] & Wind speed [-] & Precipitation [-] & Global rad. [-] \\
\hline Bern/Zollikofen & $1.4^{\circ} \mathrm{C}$ & 1.00 & 1.0 & 1.076 \\
\hline Vienna/Hohe Warte & $0.0^{\circ} \mathrm{C}$ & 0.75 & 0.9 & 1.000 \\
\hline
\end{tabular}

Meteotest condensed the bias corrected fields on a regular grid $(1.6 \mathrm{~km}$ at the outer areas of the cities, $0.8 \mathrm{~km}$ in the surrounding of the center and $400 \mathrm{~m}$ within the city centers) to TMY and input data for the Meteonorm stochastic temperature model. At this stage higher resolutions (e.g. $100 \mathrm{~m}$ ) have not been included as the data volume and calculation time would have been too high.

A total of approximately 400 locations were saved for Bern and 950 for Vienna each. For Bern 9 additional test locations were modelled and 5 for Vienna (see Figure 1 and Figure 2). These were used for comparing the building simulation results. As shown, the topography in Bern and Vienna is rather complex; both are located next to a river (Aare and Danube) and are located at the foothills of the Alps.

TMY generation, directly based on ERA/UrbClim data, was used as an intermediate step. The resulting datasets have also been benchmarked along the urbanized Meteonorm data. TMY were calculated based on Sandia method described by NREL (Wilcox and Marion 2008). Preliminary tests with other methods have clearly shown, that lower accuracies were therefore not used (prEN ISO 15927-4:2005; https://www.iso.org/ standard/41371.html ).
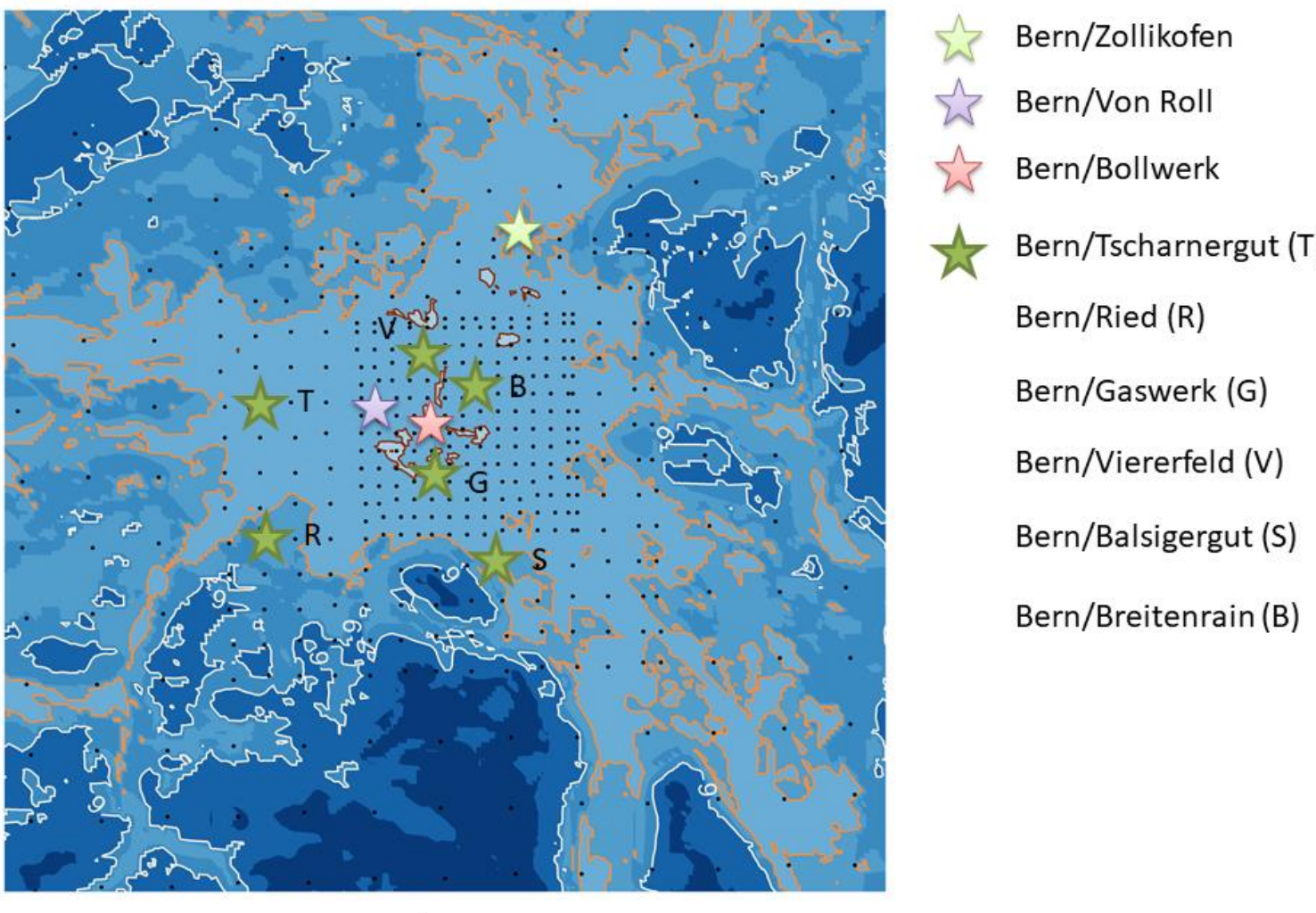

$20 \mathrm{~km}$

Fig. 1: Yearly average temperature in the Bern area $(20 \times 20 \mathrm{~km})$ based on uncorrected ERA5/UrbClim model (red line: $\left.11^{\circ} \mathrm{C}\right)$; black points: sites, where TMY and input data of the Meteonorm stochastic model have been used (1.6/0.8/0.4 km grid) 


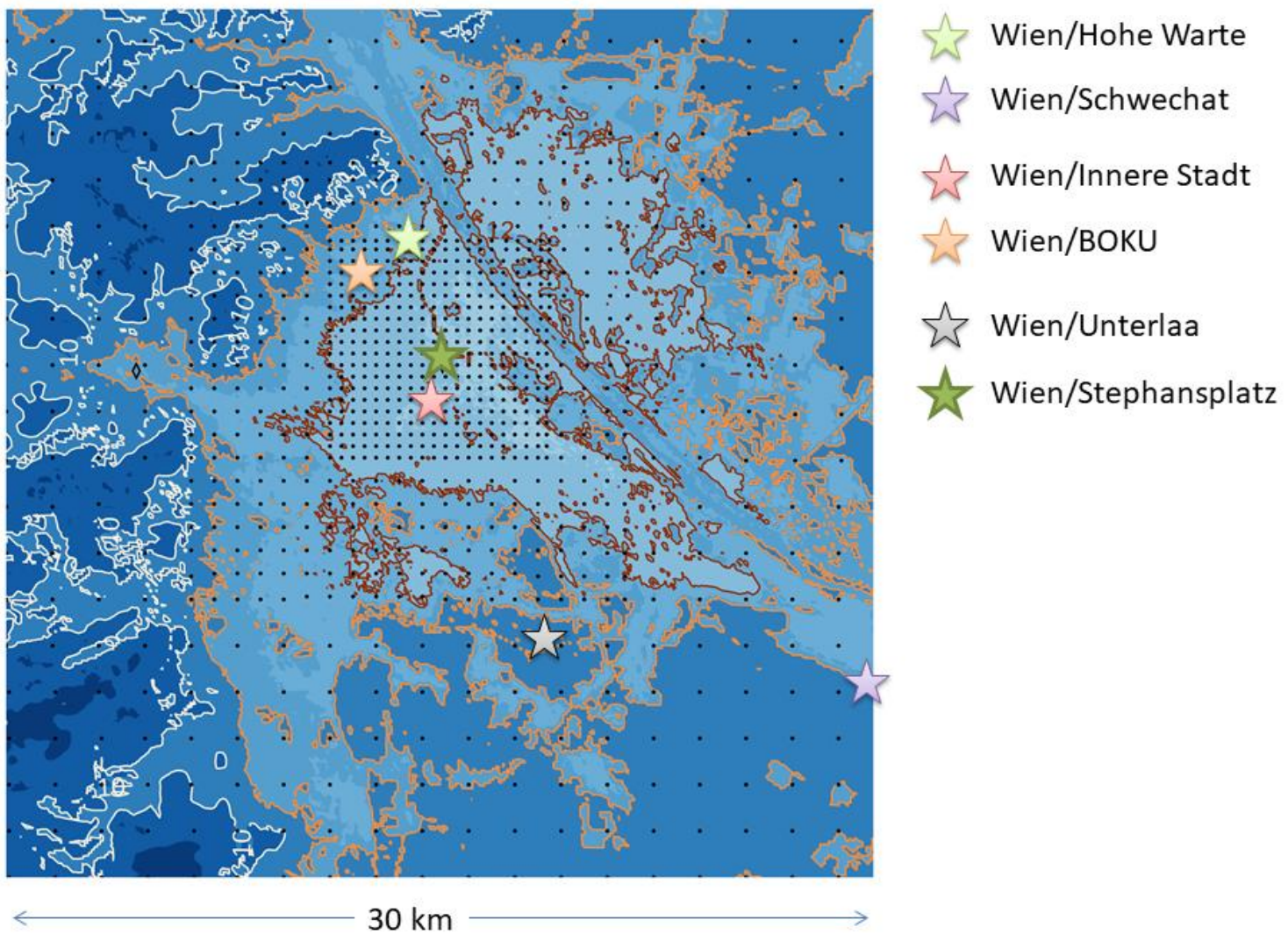

Fig. 2: Yearly average temperature in the Vienna area $(30 \times 30 \mathrm{~km})$ based on uncorrected ERA5/UrbClim model $\left(\right.$ red line: $\left.11^{\circ} \mathrm{C}\right)$; black points: sites, where TMY and input data of the Meteonorm stochastic model have been used (1.6/0.8/0.4 km grid)

In Meteonorm a Markov chain model (Remund et al. 2018) is used to generate daily temperature values. This model is based on temperature distributions from meteo stations (approximately 6000 stations). To get urbanized Meteonorm temperatures, distributions of approx. 400 input sites for Berne and 950 for Vienna were added from ERA/UrbClim models (at the points in the Figures 1 and 2 above). The following temperature parameters are used as statistical values for the model:

1. Monthly distribution of the daily temperature (7 points of the monthly distribution are stored: $1 / 31,3 / 31$, $6 / 31,15 / 31,25 / 31,28 / 31,30 / 31$ quantiles)

2. Monthly mean temperature

3. Monthly mean of daily minimum and maximum hourly temperatures

4. Mean monthly minimum and maximum hourly temperatures

5. Mean standard deviation and difference of day to day variation, separated for days below and above the average daily difference between maximum and minimum temperatures. This approximately corresponds to a separation into clear and overcast days or days with high and low radiation

6. Mean minimum daily temperature per year

7. Mean 4-day minimum temperature per year

8. Mean maximum daily temperature per year

9. Minimum and maximum hourly value per month of all 10 years

10. Monthly deviation of average temperature in relation to meteo station (e.g. Zollikofen for Bern area); values are adapted for altitude differences

For sites within a city a general urban heat effect value of $1^{\circ} \mathrm{C}$ is assumed in Meteonorm. The last bullet point (10) is new and is used to correct the standard yearly urban heat effect value. At the new data points the urban heat effect is corrected to the local level. 


\section{3: Comparing meteorological data}

At Bern and Vienna the following parameters have been tested:

- yearly average temperature

- average yearly maximum temperature

- $\quad$ number of tropical nights (daily minimum $>20^{\circ}$ )

- $\quad$ number of hot days (daily maximum $>30^{\circ} \mathrm{C}$ )

- visual comparison of daily temperature profiles and daily temperature profiles between city and outside

- distribution tests (Kolmogorov-Smirnoff Index, Espinar et al., 2009)

\section{Results}

\section{1: Meteorological data}

A test based on urbanized Meteonorm (MN 7.3) was done by comparing the meteo datasets with measurements at meteo stations. TMY directly made from ERA/UrbClim time series (ERA5 / ERA-Interim), Meteonorm 7.2 (last version), Meteonorm 7.3 and measurements are listed in the tables. The table for Bern (Table 2) additionally includes SIA 2028 (1984-2003), the default TMY in Switzerland for building design (https://www.energytools.ch/index.php/de/downloads/grundlagenberichte/download/5-grundlagenberichte/47klimadaten-sia-2028-de), whereas for Vienna (Table 3) additionally the official TMY (1993-2017) provided by Austria's national meteorological service (ZAMG) is listed.

In the case of Bern, all datasets aside SIA 2028 have been adapted to Zollikofen (this is why all show low deviations for Zollikofen). SIA 2028 shows somewhat lower temperature values due to the older period (19842003).

For Bern the urban effect between Bollwerk, Von Roll and Zollikofen is about $1^{\circ} \mathrm{C}$ (measured as well as modelled). ERA5 and ERA-Interim underestimate the urban heat effect, whereas Meteonorm shows the same magnitude. For Vienna ERA-Interim shows correct levels of the urban effect $\left(0.9^{\circ} \mathrm{C}\right)$, whereas Meteonorm overestimates the effect slightly.

Tab. 2: Yearly average temperature in ${ }^{\circ} \mathrm{C}$ for 3 sites with measurements in Bern

\begin{tabular}{|c|c|c|c|}
\hline Model combination & Bollwerk & Zollikofen & Von Roll \\
\hline ERA-Interim/urbclim TMY & 9.9 & 9.7 & 9.7 \\
\hline SIA 2028 (1984-2003) & & 9.3 & \\
\hline MN 7.2 & 10.5 & 9.6 & 10.4 \\
\hline MN 7.3 & 10.5 & 9.6 & 10.4 \\
\hline Measured (2010-15/16) & 10.6 & 9.6 & 10.7 \\
\hline
\end{tabular}

Tab. 3: Yearly average temperature in ${ }^{\circ} \mathrm{C}$ for 3 sites with measurements in Vienna

\begin{tabular}{|c|c|c|c|}
\hline Model combination & $\begin{array}{c}\text { Wien/ } \\
\text { City }\end{array}$ & $\begin{array}{c}\text { Wien/ } \\
\text { Hohe Warte }\end{array}$ & $\begin{array}{c}\text { Wien/ } \\
\text { Unterlaa }\end{array}$ \\
\hline ERA-Interim/urbclim TMY & 12.2 & 10.5 & 11.6 \\
\hline ZAMG (1993-2017) & & 11.1 & \\
\hline MN 7.2 & 12.9 & 11.1 & 12.3 \\
\hline MN 7.3 & 12.4 & 11.3 & 11.2 \\
\hline Measured (2010-15/16) & & 11.1 & \\
\hline
\end{tabular}

In Tables 4 and 5 the numbers of hot days (daily maximum above $30^{\circ} \mathrm{C}$ ) are listed as an example of temperature threshold values. 
Tab. 4: Number of hot days 3 sites with measurements in Bern

\begin{tabular}{|c|c|c|c|}
\hline Model & $\begin{array}{c}\text { Bern/ } \\
\text { Bollwerk }\end{array}$ & $\begin{array}{c}\text { Bern/ } \\
\text { Zollikofen }\end{array}$ & $\begin{array}{c}\text { Bern/ } \\
\text { Von Roll }\end{array}$ \\
\hline $\begin{array}{c}\text { ERA-Interim/urbclim } \\
\text { TMY }\end{array}$ & 3 & 1 & 5 \\
\hline SIA 2028 (TMY) & & 0 & 3 \\
\hline MN 7.2 & 4 & 3 & 3 \\
\hline MN 7.3 & 3 & 3 & 14 \\
\hline Measured & 12 & 9 & \\
\hline
\end{tabular}

Tab. 5: Number of hot days for 3 sites with measurements in Vienna

\begin{tabular}{|c|c|c|c|}
\hline Model & $\begin{array}{c}\text { Wien/ } \\
\text { City }\end{array}$ & $\begin{array}{c}\text { Wien/ } \\
\text { Hohe Warte }\end{array}$ & $\begin{array}{c}\text { Wien/ } \\
\text { Unterlaa }\end{array}$ \\
\hline $\begin{array}{c}\text { ERA-Interim/urbclim } \\
\text { TMY }\end{array}$ & 16 & 11 & 12 \\
\hline TMY ZAMG TMY & 13 & 7 & 9 \\
\hline MN 7.2 & 19 & 12 & 10 \\
\hline MN 7.3 & 30 & 24 & 23 \\
\hline Measured & & & \\
\hline
\end{tabular}

The number of hot days is underestimated by both ERA and MN datasets, but also by TMY at both sites. Urban effects are visible also in the modelled data. MN 7.3 gives more accurate results as MN 7.2 especially for Vienna. Official TMY's (sia and ZAMG) are showing also too low numbers of hot days (lower than Meteonorm based).

\section{Daily profiles}

Average daily profiles during summer half year (April-September) have been also compared graphically. Those profiles give a good impression of the urban heat effect. On one side the profiles at the three sites and on the other side the differences of the profiles from stations compared to the main meteo station are shown (here only the profiles are shown) (Figure 3).
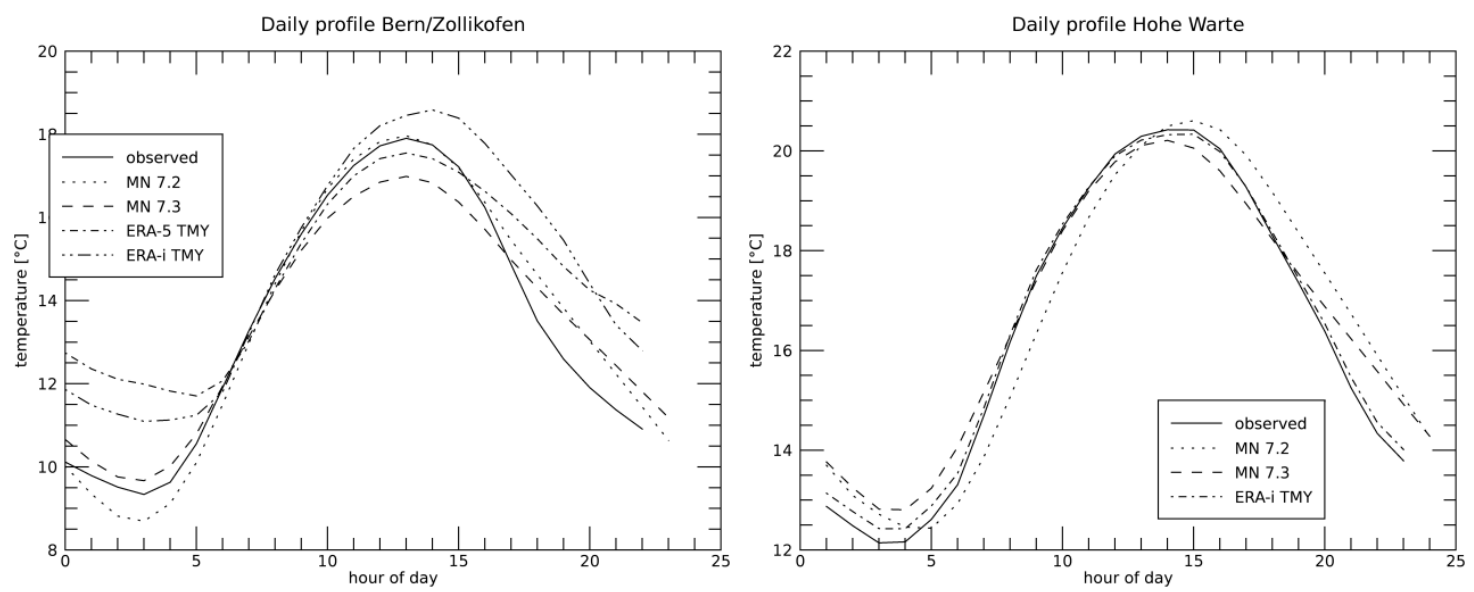

Fig. 3: Daily temperature profiles during summer at Bern/Zollikofen (left) and Vienna/Hohe Warte (right).

Meteonorm based profiles show a good agreement regarding profiles at Bern/Zollikofen; ERA based data show too high night time values. Meteonorm and ERA based profiles show a good agreement regarding profiles at Wien/Hohe Warte. Overall there is a diverse result: for Bern MN based date are closer to the measured values, whereas in Vienna the ERA based TMY are showing less difference to the measurements. 


\section{$\underline{\text { Distribution tests }}$}

Distribution tests were used to compare the different values (as TMY can't be compared hour by hour). Tables 6 and 7 contain the Kolmogorov-Smirnoff test index (KSI) over values (Espinar et al., 2009).

Tab. 6: KSI over (\%) values for three sites in Bern

\begin{tabular}{|c|c|c|c|}
\hline Model & $\begin{array}{c}\text { Bern/ } \\
\text { Bollwerk }\end{array}$ & $\begin{array}{c}\text { Bern/ } \\
\text { Zollikofen }\end{array}$ & $\begin{array}{c}\text { Bern/ } \\
\text { Von Roll }\end{array}$ \\
\hline ERA-Interim/urbclim TMY & 468 & 118 & 1216 \\
\hline SIA 2028 TMY & - & 175 & - \\
\hline MN 7.2 & 0 & 0 & 65 \\
\hline MN 7.3 & 0 & 1.0 & 17 \\
\hline
\end{tabular}

Tab. 7: KSI over (\%) values for three sites in Vienna

\begin{tabular}{|c|c|c|c|}
\hline Model & $\begin{array}{c}\text { Wien/ } \\
\text { City }\end{array}$ & $\begin{array}{c}\text { Wien/ } \\
\text { Hohe Warte }\end{array}$ & $\begin{array}{c}\text { Wien/ } \\
\text { Unterlaa }\end{array}$ \\
\hline ERA-Interim/urbclim TMY & 6 & 5 & 35 \\
\hline SIA 2028 TMY & & 508 & \\
\hline MN 7.2 & 564 & 336 & 685 \\
\hline MN 7.3 & 301 & 164 & 456 \\
\hline
\end{tabular}

KSI values below $100 \%$ mean, that statistically no difference between the distributions exists. In Bern Meteonorm TMY have clearly lower KSI values than directly constructed TMY based on ERA/urbclim. However in Vienna ERA-Interim based TMY show clearly lower differences. MN 7.3 (urbanized Meteonorm) shows slightly lower differences than MN 7.2.

Figure 4 shows the cumulative distributions of modelled vs. measured temperature values at site Bern/Zollikofen and Wien/City. Whereas for Bern ERA based TMY show differences around $4{ }^{\circ} \mathrm{C}$, Meteonorm files are mostly below the threshold of $95 \%$ uncertainty (horizontal line at approx. 0.02). For Vienna/City ERA based TMY show smaller deviations than $\mathrm{MN}$ based (biggest deviations are also at $4{ }^{\circ} \mathrm{C}$ ).

Regarding distributions official TMY (sia 2028 / ZAMG) show larger discrepancies than ERA and MN based TMY's as they do for extreme values even for the station they have been made for.
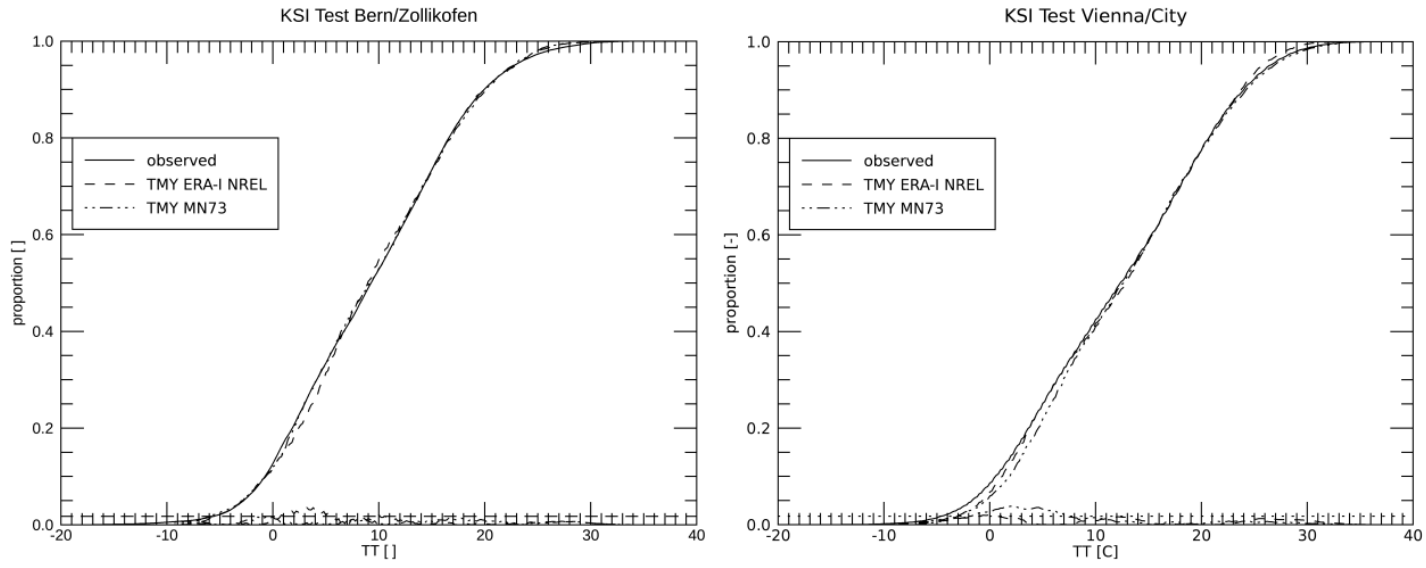

Fig. 4: Cumulative distributions of hourly temperature values at Bern/Zollikofen (left) and Vienna/City (right) 


\section{2: Building simulation}

INES defined three types of buildings (apartment building from the 70's, current apartment building, current office building). They compared the energy consumption (heating and cooling) and the indoor climate (EN15251: typical hours per year in four comfort classes) for the different buildings and climate files.

Figure 5 exemplarily shows the definition for a current Office building. The photograph in the top right corner gives a visual impression and the 3D-view below shows the model in the IDA-ICE-editor. The highlighted zone represents the selected room for analyzing the thermal comfort criteria. In this case, an open space office on the top floor has been chosen. The table below the pictures gives an overview on the quality of the typical thermal insulation for buildings like this, in comparison with actual requirements for new constructions in Switzerland.

\begin{tabular}{|c|c|c|c|}
\hline \multicolumn{3}{|l|}{ Building } & \\
\hline Country / City: & \multicolumn{2}{|c|}{ Switzerland / Berne } & \\
\hline Project name & \multicolumn{2}{|c|}{$\mathrm{CH}$-Office New } & \\
\hline Year of constructic & \multicolumn{2}{|c|}{2012} & 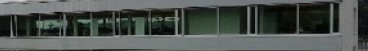 \\
\hline Building category: & \multicolumn{2}{|c|}{ Office building } & 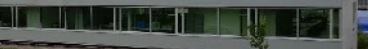 \\
\hline Area: & \multicolumn{2}{|c|}{$3^{\prime} 198 \mathrm{~m}^{2}$} & \\
\hline No. of workplaces: & \multicolumn{2}{|l|}{70} & \\
\hline \multicolumn{4}{|l|}{ Building specification } \\
\hline \multicolumn{3}{|l|}{ HVAC-System } & \\
\hline Heating system & \multicolumn{2}{|c|}{ Heating / Cooling slabs (concrete) } & \\
\hline Cooling system & \multicolumn{2}{|c|}{ Chiller with dry cooler } & $\underline{2=5}$ \\
\hline Mechanical ventilation & \multicolumn{2}{|c|}{ Ventilation with heat recovery } & 11 \\
\hline Solar protection & \multicolumn{2}{|c|}{ External textile blinds } & \\
\hline Control system & \multicolumn{2}{|c|}{ Building control system } & \\
\hline $\mathrm{DHW}$ & \multicolumn{2}{|c|}{ Heat recovery from chiller / Gas boiler } & \\
\hline \multicolumn{4}{|l|}{ Thermal envelope } \\
\hline \multirow{2}{*}{\multicolumn{2}{|c|}{ Element }} & \multicolumn{2}{|c|}{ U-Values $\mathrm{W} / \mathrm{m}^{2 *} \mathrm{~K}$} \\
\hline & & Current va & Requirement new constr. \\
\hline \multicolumn{2}{|l|}{ External walls and floors } & 0.15 & 0.17 \\
\hline \multicolumn{2}{|c|}{ Roofs } & 0.15 & 0.17 \\
\hline \multicolumn{2}{|c|}{ Walls, slabs to ground or basement } & 0.20 & 0.25 \\
\hline \multicolumn{2}{|c|}{ Windows } & 1.10 & 1.00 \\
\hline
\end{tabular}

Fig. 5: Characteristics of a current Swiss office building

After testing and validating the model by comparing the simulations results with real energy consumption data and other criteria, a series of simulation runs where performed, where the results using the standard TMY meteo data are considered as a reference scenario.

Figure 6 shows the simulation results using standard TMY meteo data:

- Energy consumption for space heating, domestic hot water, auxiliaries (Ventilation) and cooling

- Classification into energy efficiency categories by comparison with the national requirements for new constructions.

- Operative indoor temperature (in the highlighted zone) and the classification according EN-15251 


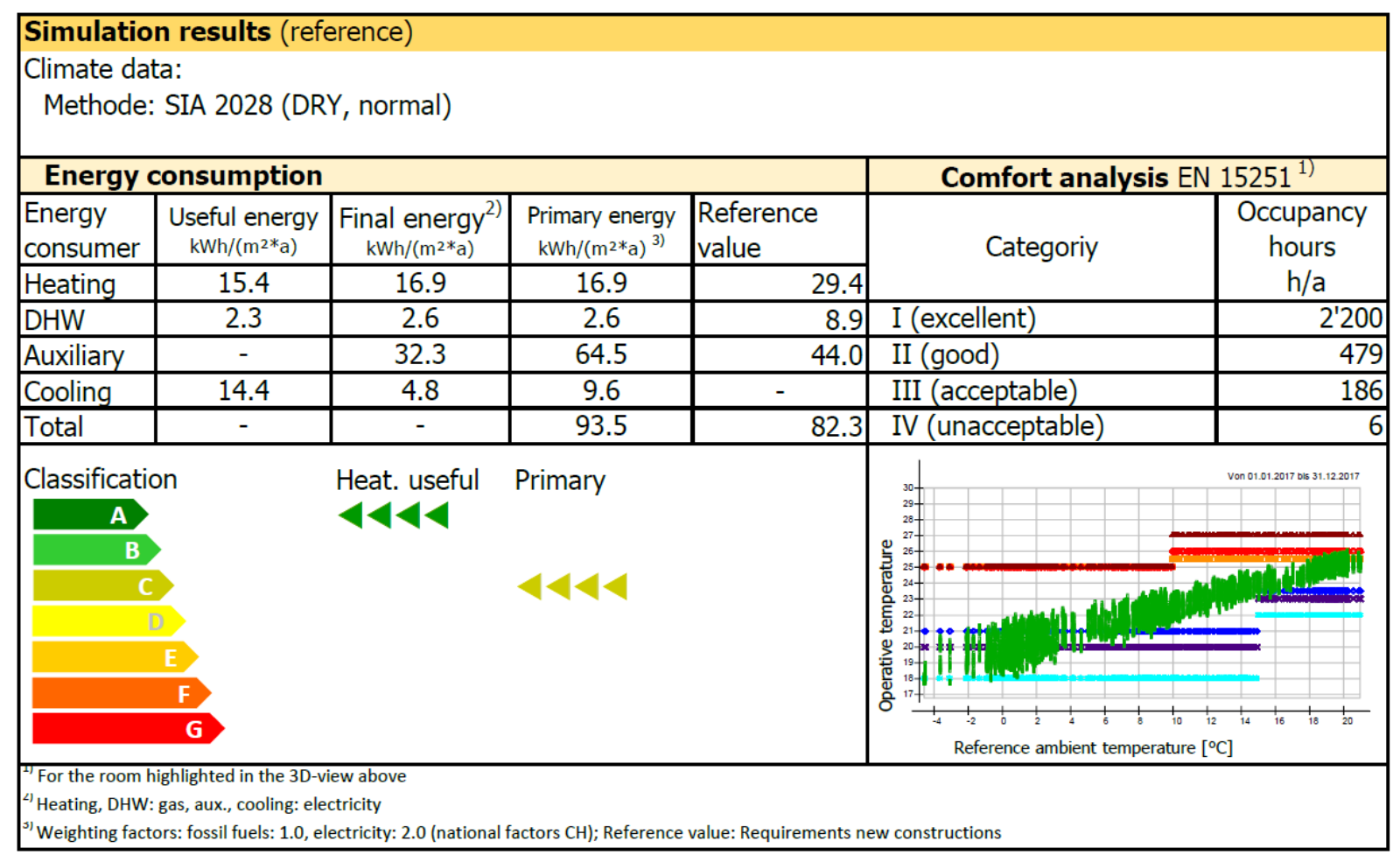

Fig. 6: Simulation results for a typical Swiss office building with standard TMY meteo data.

The results from all the other simulation runs where then compared to the reference scenario. (Table 8)

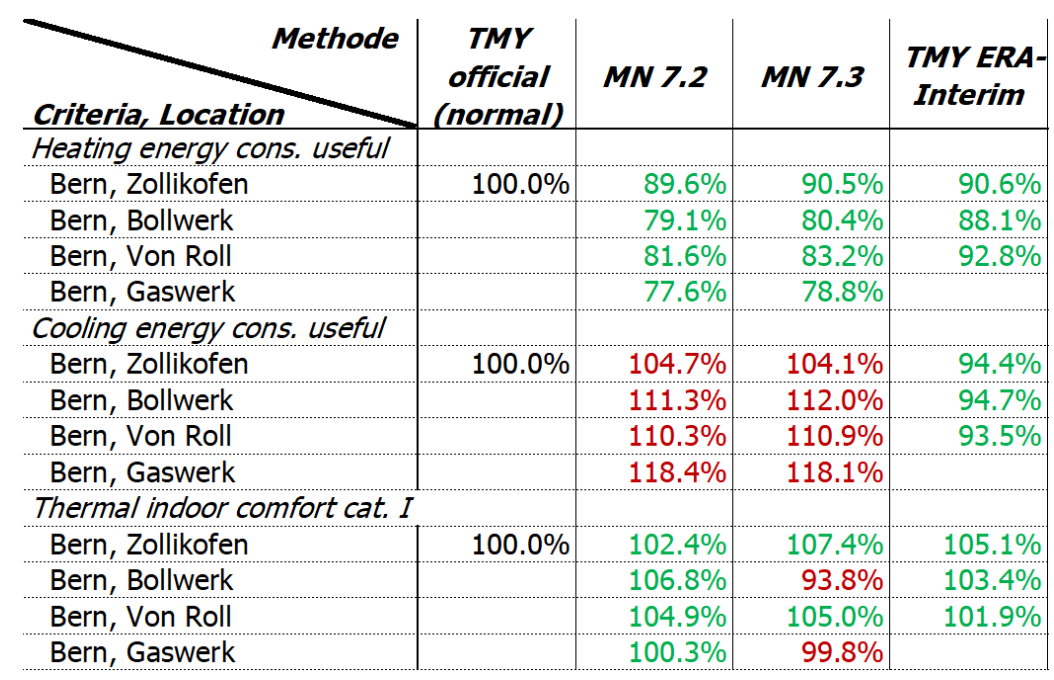

Tab. 8: Summary of a series of simulation results with relative difference to the reference scenario: Green figures: lower energy consumption / more occupancy hours in best comfort category, Red figures: higher energy consumption / less occupancy hours in best comfort category

Based on these results the following conclusions can be drawn:

- The use of urban climate data has a measurable impact on energy consumption and thermal indoor comfort.

- Currently, only results from Bern and Vienna have been analysed. For other cities in other climate regions, the results and conclusions can be very different.

- The differences in heating / cooling demand are up to $~ 15 \%$ in comparison to official TMY

- The differences within various urban locations are low: below $10 \%$

- The differences are surprisingly low for buildings without air conditioning and cooling system. For the shown example of the office building it's obvious, because it's equipped with a cooling system 
Relevance of urban climate effect on the Swiss building portfolio

Based on the simulation results obtained for different building models and statistical data concerning energy consumption and the Swiss building portfolio, the overall relevance of the urban climate effect can be estimated:

Due to urban climate, ...

- the energy consumption for space heating is $6 \mathrm{TWh} / \mathrm{a}$ lower than (hypothetical case) when all buildings would be exposed on rural climate conditions. (6.4\% of overall consumption for space heating),

- the additional energy consumption for cooling is $480 \mathrm{GWh} / \mathrm{a}$ in comparison to a (hypothetical) case, where all buildings would be exposed on rural climate conditions. (6.0\% of overall consumption for space cooling).

In the balance, the lower energy consumption for heating is much more important than the higher consumption for cooling. For Switzerland about 5.5 TWh are "saved" or 1.4 Mio tons of greenhouse gas emissions are not emitted. Of course, the GHG-figures are strongly influenced by the low carbon based Swiss energy mix (around $\left.250 \mathrm{~g} \mathrm{CO}^{2} / \mathrm{kWh}^{2}\right)$.

\section{Conclusions}

This project showed that the use of urban meteo data has measurable impact on climate and therefore also on energy consumption and thermal indoor comfort. This simple fact might not be very surprisingly, but it is probably the first time that this aspect has been studied in a way to quantify the effect in high time and space resolution.

We understand this work also as a contribution to the actual discussion about the performance gap (difference between planned and real building performance). As long as the construction regulations requires the use of nonurban meteo data for the design process for buildings in urban areas, it is obvious, that there occurs a difference between planned and real energy consumption or/and indoor climate. Therefore, regulations should be modified at this point, where they define which meteo data must to be used for which location. For instance, this becomes relevant, when the planed yearly electricity consumption for air-conditioning has to be generated on-site (which is the already the case in some Swiss Cantons). The dimension of the PV-plant depends directly on the chosen meteo data for the simulation.

Up to now effects of future climate change hasn't been tested yet. This will be done during the next phase of the H2020 project.

\section{References}

Espinar, B., Ramírez, L., Drews, A., Beyer, H. G., Zarzalejo, L. F., Polo, J., \& Martín, L., 2009. Analysis of different comparison parameters applied to solar radiation data from satellite and German radiometric stations. Solar Energy 83(1), 118-125. http://doi.org/10.1016/j.solener.2008.07.009

Remund, J., Müller, S.C., Kunz, S., Huguenin-Landl, B., Studer, C., Cattin, R., 2018. Meteonorm handbook. https://meteonorm.com/assets/downloads/mn73_software.pdf (last visited: November 27th 2018)

Wilcox, S, and Marion, W., 2008. "Users Manual for TMY3 Data Sets.” Technical Report. doi: NREL/TP-58143156, https://www.nrel.gov/docs/fy08osti/43156.pdf (last visited: May 9th 2018)

\section{Acknowledgements}

Climate-fit.city is developed as part of the PUCS project, which has received funding from the European Union's H2020 Research and Innovation Programme under Grant Agreement No. 73004. 


\title{
Evaluation of Solar Radiation from MERRA, MERRA-2, ERA-Interim and CFSR Reanalysis Datasets Against Surface Observations for Multan, Pakistan
}

\author{
Zia ul Rehman Tahir, Muhammad Junaid Ali, Syed Uzair Ahmad, Muhammad Asim, Nasir \\ Hayat, Muhammad Azhar and Afkar Hussain
}

Mechanical Engineering Department, University of Engineering and Technology Lahore, Pakistan

Abstract

The solar radiation data measured by ESMAP for Multan in South Punjab, Pakistan is compared with four reanalysis datasets (MERRA, MERRA-2, ERA-Interim, and CFSR). The validation of reanalysis estimates of solar radiation against surface measured data is performed on the basis of monthly mean time series, clearness index and statistical analysis based on MBE, RMSE and correlation coefficient (R). All reanalysis datasets overestimate the solar radiation except ERA-Interim shows both underestimation and overestimation. The MBE for four datasets ranges from $18.82 \mathrm{~W} / \mathrm{m}^{2}$ to $34.05 \mathrm{~W} / \mathrm{m}^{2}$. The monthly time series shows that the estimations of solar radiations by reanalysis datasets are relatively better in clear sky months but in cloudy months results are poor. The cloud fraction is one of the main reason for the overestimation and underestimation of solar radiation by reanalysis datasets. The bias in clearness index ranges from 0.05 to 0.11 for four reanalysis datasets. All reanalysis datasets overestimate the daily clearness index except ERA-Interim, ERA-Interim both overestimates and underestimates the clearness index. The estimates from MERRA are less accurate among all datasets whereas ERA-Interim has most accurate hence, ERA-Interim can be used for initial solar resource assessment of Multan. NCEP-CSFR also shows good results with a constant bias, which indicates that it can be used for solar forecasting for Multan.

Keywords: Solar Radiation, NCEP-NCAR, ERA-Interim, MERRA, MERRA-2, NCEP-DOE, NCEP-CFSR Pakistan

\section{Introduction}

Solar energy is an important renewable energy source and fortunately, Pakistan is very rich in solar energy. Pakistan has enormous potential for solar photovoltaic and solar thermal projects. This signifies the need for reliable solar resource assessment both for commercial and non-commercial solar energy projects. The surface measured data for Pakistan is limited and long-term measured data is not available. In the absence of measured GHI (Global Horizontal Irradiance), long-term time series from reanalysis dataset is an option which can be used as an initial site assessment (Tahir and Asim, 2018).

Different long-term global reanalysis datasets have been developed by organizations in the world that are used to estimate the surface irradiance. Reanalysis use estimations from a Numerical Weather Prediction model with ground observations and reanalysis data. The reanalysis model uses the assimilation model, which uses past records to limit and guide the predictions of the Weather Prediction model. This enables the extrapolation of the variables in space and time (Zhang et al., 2016). There are an increasing number of research studies and industrial applications that incorporate reanalysis products (Juruš et al., 2013; You et al., 2013) (Pfenninger and Staffell, 2016). Slater (Slater, 2016) compared MERRA and MERRA-2 reanalysis with the ground measured data. (Pfenninger and Staffell, 2016) compared MERRA, ERA-Interim and NCEP-CSFR with the ground measured data and calculated the clearness index.

Researchers have found that reanalysis datasets show a large bias in global horizontal irradiance. All these studies found large biases in global horizontal irradiance estimations from MERRA, MERRA-2 and ERA-Interim when the datasets were compared against ground measured data of solar radiation. Mostly reanalyses showed average positive bias for MERRA and ERA-Interim (Decker et al., 2012) (Zhang et al., 2016), and strong overestimations in solar radiation were observed in regions such as Europe, Asia and North America. This positive bias was found due to an underestimation of the cloud fraction (Zhang et al., 2016; Zhao et al., 2013), although the opposite effects were also observed under clear-skies (Boilley and Wald, 2015). Cloud variables in the model of the reanalysis are one of the major limitations and bias depends on sky clearness (Alexandri et al., 2017; Yi et al., 2011). The clearness indices are also calculated for the atmospheric condition and solar radiation estimation (Boilley and Wald, 2015; Urraca et al., 2018). Zhang studied over 674 stations from 2001 to 2009, the world was 
divided into nine sub-regions which included North American, South American, Asia, Europe, Africa, Australia, Oceania, Antarctic, and the oceans. A positive bias was observed in the results obtained from the NCEP-CFSR dataset (Khaled, 2014; Zhang et al., 2016) and (El Afandi, 2014) also evaluated NCEP-CFSR dataset over the Middle East \& North Africa (MENA) region and clear positive bias was observed.

\section{Datasets}

The measured GHI by the Energy Sector Management Assistance Program (ESMAP) of the Word Bank for Multan from January 2015 to December 2015 was used in this study. The surface solar radiation data (GHI) was measured by ESMAP of the World Bank (Stokler and Schillings, 2015). The Modern Era Retrospective Analysis for Research and Applications (MERRA) product is a second reanalysis project from National Aeronautics and Space Administration (NASA) that uses an updated new version of the Goddard Earth Observing System Data Assimilation System, it provides several different variables including global horizontal irradiance. Data ranges from 1979 to the present. Its temporal resolution for 2D diagnostics dataset is 1 hourly and its spatial resolution is $0.5^{\circ} \times 0.667^{\circ}$ (Rienecker and Takacs, 2011). The MERRA-2 dataset is an updated version of MERRA with the same temporal resolution of 1 hour but spatial resolution of $0.5^{\circ} \times 0.625^{\circ}$ which is better than MERRA. MERRA2 is the first long-term global reanalysis to assimilate space-based observations of aerosols and represent their interactions with other physical processes in the climate system (Rienecker et al., 2011). The ERA-Interim dataset is a product of ECMWF (European Centre for Medium-Range Weather Forecasts) having a temporal resolution of three hours and spatial resolution of $0.125^{\circ} \times 0.125^{\circ}$ for solar radiation. ERA-Interim shows an overestimation of $2 \mathrm{~W} / \mathrm{m}^{2}$ of the incoming shortwave radiation at the top of the atmosphere (Dee, 2011). The radiative transfer model uses water vapour and cloud variables from the meteorological model and climatologic values for aerosols, carbon dioxide, other gases and ozone. The Climate Forecast System Reanalysis (CFSR) dataset by NCEP has spatial resolution $0.204^{\circ} \times 0.204^{\circ}($ NCAR UCAR, 2017). Its first version started in 1979 which covered a period of 31 years (1979-2009) in 2010. Its second version started from March 2011 known as NCEP-CFSR v2. NCEPCFSR second version creates many more products for forecasting with an extensive set of retrospective forecasts for users to calibrate their forecast products. CFSR second version is designed to improve consistency between the model states and the initial states produced by the data assimilation system and it includes a fully coupled ocean model, the Geophysical Fluid Dynamics Laboratory Modular Ocean Model (GFDL MOM) version 4 (Decker et al., 2012).

\section{Methodology}

The reanalysis datasets provide data in different variables of solar radiation, the variable generally used to represent GHI is named as shortwave radiation. The surface measured data was available with a temporal resolution of ten minutes that was converted into hourly, three hourly and six hourly datasets for comparison with the reanalysis datasets with respective temporal resolutions. The comparison is done by between solar radiation data from the reanalysis datasets and the ground measured data by plotting graphs between these two datasets and then the overestimation and underestimation are evaluated. Environmental models and climatic conditions of the station were studied to find the reasons of overestimation and underestimation of solar radiations. For quantitative evaluation of these datasets, different statistical parameters are used in previous studies. To quantify the performance of reanalysis datasets statistical analysis was performed based on mean bias error (MBE), mean absolute error (MAE), root mean square error (RMSE) and correlation coefficient (R). Scatter plots were generated to understand the overestimation and underestimation of solar radiation from the ground measurement.

Daily Clearness Indices $\left(K_{T}\right)$ for each reanalysis dataset was calculated to compute the clear sky conditions and the variation of the quality of each product with the cloudiness. The clearness index is a function of solar radiation at the top of the atmosphere and the ground level and it indicates the optical state of the atmosphere. The comparison was carried out using ground measured data and reanalysis datasets clearness index $\left(K_{T}\right)$. If $E$ denotes the daily GHI and $E_{o}$ denotes the daily irradiation received on a horizontal surface at the top of the atmosphere, $K_{T}$ is defined as Eq. (1).

$$
K_{T}=E / E_{o}
$$

The changes in solar radiation at the top of the atmosphere due to changes in geometry, namely the daily course of the sun and seasonal effects, are usually well reproduced by models and lead to a de facto correlation between 
observations and estimates hiding the potential weakness of a model. $E_{o}$ is a function of the solar constant that is different for different reanalysis datasets. The solar constant is the mean yearly value of the solar radiation incident on a plane normal to the sun rays located at the top of the atmosphere. The solar constant used to calculate the $K_{T}$ for ground measured data is $1367 \mathrm{~W} / \mathrm{m}^{2}$ which is equal to that used in HelioClim-1, solar constants used for MERRA and ERA-Interim is $1365 \mathrm{~W} / \mathrm{m}^{2}$ and $1370 \mathrm{~W} / \mathrm{m}^{2}$ respectively (Boilley and Wald, 2015; Urraca et al., 2018). The values of $K_{T}$ greater than 0.7 indicate clear sky conditions while the values less than 0.7 indicate less clear or cloudy sky conditions.

\section{Results and Discussion}

The monthly mean time series of solar radiation is shown in Fig 1 which shows a variation of GHI for the year 2015 and its comparison with reanalysis datasets. There is a sudden drop in the value of solar radiations in the months of July and August due to Monsoon. The Monsoon starts from June and lasts till September. Violent storms also occur during Monsoon in July and August. Solar radiations drop due to cloudy sky condition and increase in water content in the atmosphere after rainfall.

All reanalysis datasets overestimate the surface measured data except ERA-Interim that underestimates the surface measurements during the months of June, July and August. Overall results vary for each reanalysis dataset, but the results for ERA-Interim and MERRA 2 are better with respect to the ground measured data. June, July and August are the months of Monsoon in Multan that's why the results of reanalysis datasets are relatively less accurate for these months. For MERRA the trend of solar radiations throughout the year is like the measured data but the overall overestimation is more compared to others. The time series of NCEP-CSFR is same as that of measured data but the variation is more as compared to others. In the month of July, there is a sudden drop in solar radiation according to NCEP-CFSR which indicates that NCEP-CFSR considers more cloud friction in its radiative transfer model.

For the months of February, March, April, October, November and December, all reanalysis datasets show smooth time series closer to measured data monthly mean time series. This is since these months are relatively dry due to less precipitation and fewer weather changes. Reanalyses datasets overestimate the solar radiations in these months reason being the improper consideration of dust particles and water vapours in their radiative transfer models.

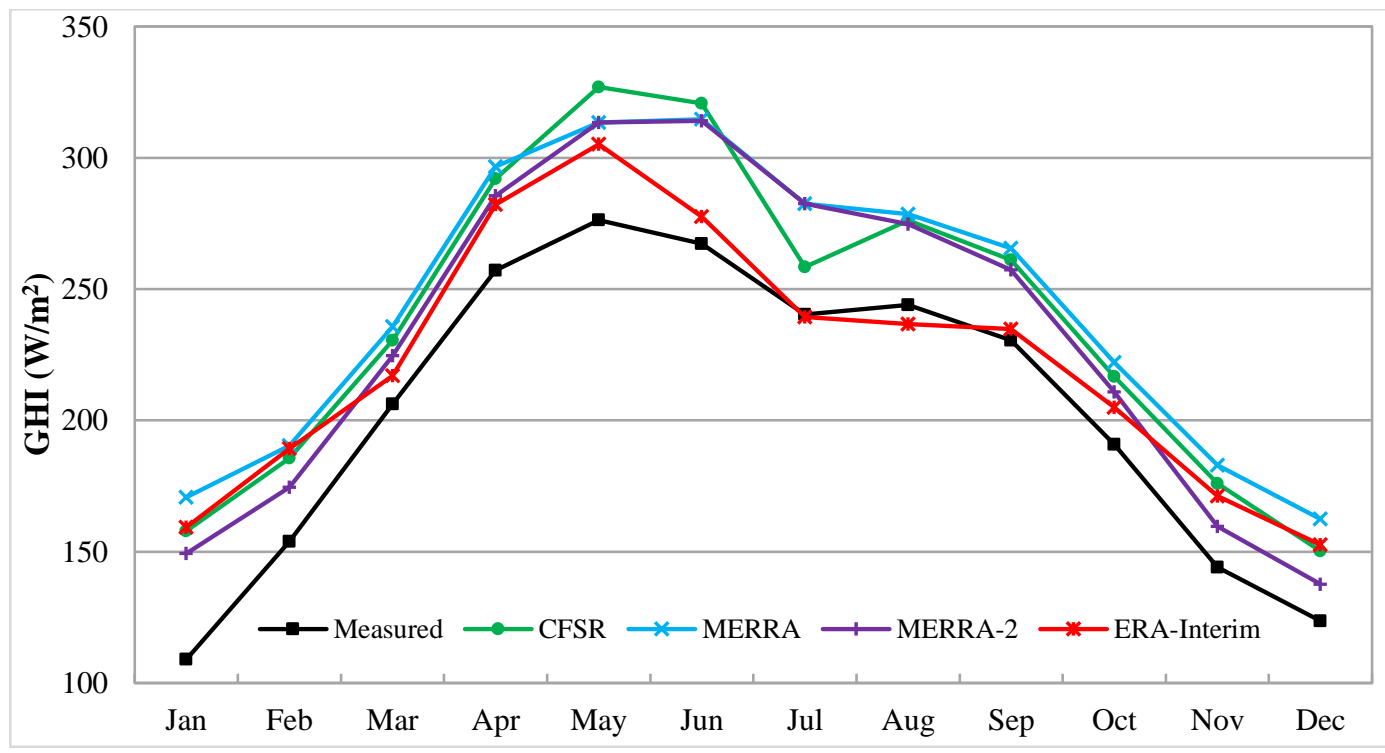

Figure 1: Comparison of Monthly Mean Time Series of GHI for the Year 2015

The statistical parameters MBE, MAE, RMSE and R have been calculated are given in Tab 1. The MBE and RMSE values are lowest for ERA-Interim while MAE is lowest for MERRA 2. MERRA differs the most in magnitude from the surface values. The values of MBE, MAE and RMSE range from 18.82 to $39.39 \mathrm{~W} / \mathrm{m}^{2}, 28.55$ to $41.02 \mathrm{~W} / \mathrm{m}^{2}$ and 38.10 to $51.29 \mathrm{~W} / \mathrm{m}^{2}$ respectively. 
MERRA has worse results among all, the MBE, MAE and RMSE values are $39.39 \mathrm{~W} / \mathrm{m}^{2}, 46.21 \mathrm{~W} / \mathrm{m}^{2}$ and 94.43 $\mathrm{W} / \mathrm{m}^{2}$ which are highest among all datasets. The correlation coefficient is 0.881 which represents that how much points are scattered along 1:1 Line, most of the points are above the 1:1 Line which shows that MERRA overestimates the GHI. The value of the slope is 0.77 which indicates that the smaller values are more overestimated than the larger ones. The value of intercept (c) is 85.7 which indicates the poor results.

The results of NCEP-CFSR are better than MERRA, the MBE, MAE and RMSE values are $34.05 \mathrm{~W} / \mathrm{m}^{2}, 40.92$ $\mathrm{W} / \mathrm{m}^{2}$ and $50.81 \mathrm{~W} / \mathrm{m}^{2}$ respectively. The correlation coefficient is 0.864 which represents that how much points are scattered along 1:1 Line, most of the points are above the 1:1 Line which shows that NCEP-CFSR overestimates the surface solar radiation. The value of the slope is 0.92 , the trend line is parallel to $1: 1$ Line, the value of intercept (c) is 49.89 that is smallest among all.

Table 1: Statistical analysis of global horizontal irradiance (GHI) for Multan, Pakistan

\begin{tabular}{|l|l|l|l|l|l|l|l|l|l|}
\hline Dataset & MBE & MAE & RMSE & rMBE & rMAE & rRMSE & m & c & R \\
\hline NCEP-CFSR & 34.05 & 40.92 & 50.81 & 16.71 & 20.08 & 24.93 & 0.92 & 49.89 & 0.864 \\
\hline ERA-Interim & 18.82 & 28.55 & 38.10 & 9.24 & 14.01 & 18.70 & 0.74 & 72.70 & 0.879 \\
\hline MERRA & 39.39 & 41.02 & 51.29 & 19.33 & 20.13 & 25.17 & 0.77 & 85.70 & 0.881 \\
\hline MERRA2 & 28.46 & 31 & 43.32 & 13.97 & 15.21 & 21.26 & 0.87 & 55.49 & 0.887 \\
\hline
\end{tabular}
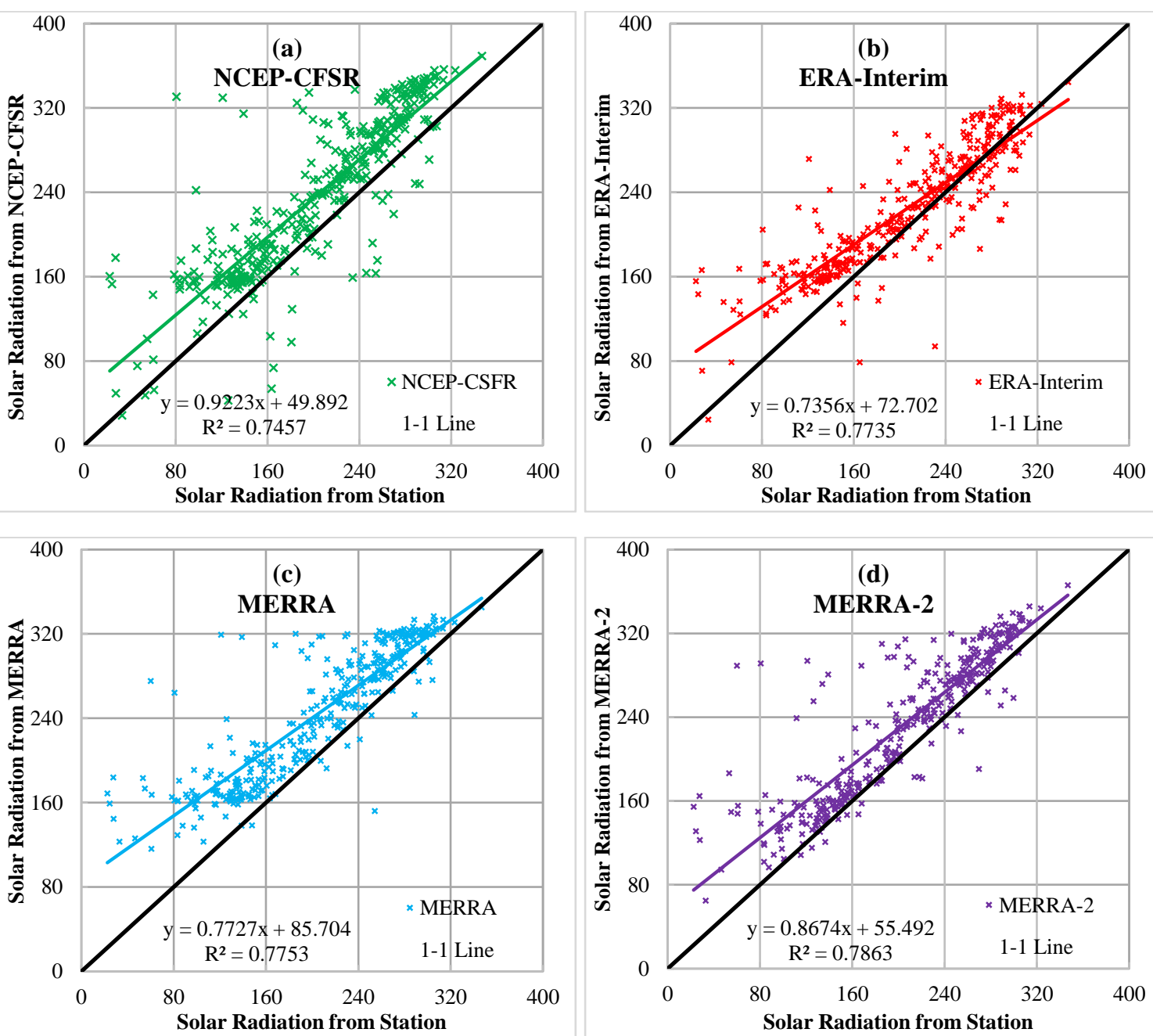

Figure 2: Scatter Plots of Daily Solar Radiation from Station and Reanalysis

The results of MERRA-2 are better than both CFSR and MERRA, the MBE, MAE and RMSE values are 28.46 $\mathrm{W} / \mathrm{m}^{2}, 31 \mathrm{~W} / \mathrm{m}^{2}$ and $43.32 \mathrm{~W} / \mathrm{m}^{2}$. The correlation coefficient is 0.887 which represents that how much points are scattered along 1:1 Line, most of the points are above the 1:1 Line which shows that MERRA-2 overestimate the 
GHI. The value of the slope is 0.87 , the value of intercept $(c)$ is 55.49 that is smaller than MERRA and EraInterim.

The results show that ERA-Interim has MBE, MAE and RMSE values of $18.82 \mathrm{~W} / \mathrm{m}^{2}, 28.55 \mathrm{~W} / \mathrm{m}^{2}$ and 38.10 $\mathrm{W} / \mathrm{m}^{2}$ respectively which are lowest among all. The correlation coefficient is 0.879 which represents that how much points are scattered along 1:1 Line, most of the points are above the 1:1 Line which shows that ERA-Interim overestimates the GHI, the higher values of solar radiation have been underestimated by ERA-Interim. The value of the slope is 0.74 , the value of intercept $(c)$ is 72.7 that is value is smaller than MERRA. The MAE is more than MBE which means ERA-Interim data is not consistent with respect to ground data. ERA-Interim shows both overestimation and underestimation as given in Fig. 1. Based on statistical parameters, ERA-Interim gave the better results than others.

Scatter plots of daily solar radiation between station and reanalysis datasets are shown in Fig 2. For MERRA the slope of the regression line is closer to 1 and the regression coefficient is 0.881 . MERRA shows low values are more overestimated. For NCEP-CFSR the slope of the regression line is closer to 1 and the regression coefficient is 0.864 which indicates the better model performance of NCEP-CFSR. For MERRA-2 the slope of the regression line is 0.887 and intercept is 13.16 which shows that the estimation of MERRA-2 is close to the measured solar radiation values. The MERRA, MERRA-2 shows more bias for lower values of solar radiation. For ERA-Interim the slop of the regression line is 0.74 which shows that ERA-Interim both underestimates and overestimates the GHI. The value of intercept is 72.7 , it is due to underestimation and overestimation due to seasonal variation. The values of the bias are low because of overestimation is compensated by underestimation.

The statistical analysis of clearness index is given in Tab 2 and comparison of clearness index for all the reanalysis datasets is shown in Fig 3. The daily clearness index for MERRA shows worse results among all, there is a large discrepancy between the measurements and MERRA data. From the scatter plot of daily clearness index, it is evident that the cloud of points does not follow the 1:1 Line. All the points are above the 1:1 Line means MERRA largely overestimates the ground measured daily clearness index. The correlation coefficient is 0.278 , the cloud of points ranging between 0.5 to 0.7 are closer to line $1: 1$ which indicates that the estimations of MERRA are better during clear sky conditions.

Table 2 Statistical analysis of daily clearness index for Multan, Pakistan

\begin{tabular}{|l|l|l|l|l|l|l|l|l|l|}
\hline Dataset & MBE & MAE & RMSE & rMBE & rMAE & rRMSE & m & c \\
\hline NCEP-CFSR & 0.10 & 0.12 & 0.14 & 18.01 & 21.61 & 25.22 & 0.62 & 0.31 & 0.619 \\
\hline ERA-Interim & 0.05 & 0.08 & 0.11 & 9.01 & 14.41 & 19.81 & 0.45 & 0.36 & 0.579 \\
\hline MERRA & 0.11 & 0.12 & 0.15 & 19.81 & 21.61 & 27.02 & 0.33 & 0.49 & 0.527 \\
\hline MERRA2 & 0.08 & 0.08 & 0.12 & 14.41 & 14.41 & 21.61 & 0.43 & 0.39 & 0.659 \\
\hline
\end{tabular}

For MERRA the MBE, MAE and RMSE values are $0.11,0.12$ and 0.15 respectively. MERRA overestimates $K_{T}$ overall while the slope of the regression line is 0.33 which means it underestimates the higher values. The rMBE, rMAE and rRMSE are 19.81, 21.61 and 27.02 respectively. It is evident from Fig 2 that the MERRA predicts the clear sky conditions while the actual conditions are less clear or cloudy.

The daily clearness results for NCEP-CFSR are better than MERRA, most of the values are between 0.5 to 0.7. The values of the clearness index between 0.5 to 0.7 are closer to the $1: 1$ Line. The points are above the 1:1 Line which indicates that NCEP-CFSR overestimates the clear sky conditions. The MBE, MAE and RSME values are $0.1,0.12$ and 0.14 respectively. The coefficient of regression and slope 0.619 and 0.62 respectively. The rMBE, rMAE and rRMSE are $18.01 \%, 21.61 \%$ and $25.22 \%$ respectively. The value of intercept is 0.31 which is best among all datasets. From Fig 2, NCEP-CSFR predicts the clear sky conditions when actual conditions are cloudy or less clear.

The daily clearness index for MERRA-2 shows better results than MERRA, most of the points are between 0.5 to 0.7 and the points are close to the 1:1 Line. MERRA-2 overestimates the daily clearness index, the $K_{T}$ values lesser than 0.5 are away from line 1:1, the points larger than 0.5 is close to the $1: 1$ Line. The coefficient of regression and slop are 0.659 and 0.43 respectively, the MERRA-2 underestimates the values of daily clearness index higher than 0.7. The MBE, MAE and RMSE values are 0.08, 0.08 and 0.12 respectively, the errors are lesser 
than MERRA and NCEP-CFSR. The rMBE, rMAE and rRMSE values are $14.41 \%, 14.41 \%$ and $21.61 \%$ respectively. MERRA-2 predicts the clear sky conditions when the actual conditions are less clear or cloudy and vice versa.

The daily clearness index results for Era-interim are best among all, the points in between 0.5 and 0.7 are closer to 1:1 Line while the points less than 0.5 are away from 1:1 Line. Era-interim shows an underestimation of daily clearness index. The coefficient of regression is 0.579 , the points are more scattered as it both underestimates and overestimate the daily clearness index. The slope of the line is 0.45 which shows that the high values of $K_{t}$ are below the 1:1 Line. The MBE, MAE and RMSE values are 0.05, 0.8 and 0.11 respectively. The rMBE, rMAE and rRMSE values are $9.01 \%, 14.4 \%$ and 19.81\%. Boilley and Wald in their study (Boilley and Wald, 2015) pointed out that ERA-Interim predicts clear sky conditions while actual conditions are cloudy. The opposite is also true though less pronounced: actual clear sky conditions are predicted as cloudy by ERA-Interim. This overestimation in cloudy conditions compensates the underestimation in clear sky conditions which results in a small bias overall. ERA-Interim predicts cloudy sky conditions while the actual conditions are clear. The error in prediction is greater than MERRA and less than NCEP-CFSR. The overestimation of clear sky conditions leads to an overestimation of the surface solar radiation and KT. Zhang et al. (Zhang et al., 2016) and Wael M. Khaled (Khaled, 2014) also compared these reanalysis datasets with surface observations for other stations around the globe and results were in accordance with our result.

Boilley and Wald (Boilley and Wald, 2015) found that MERRA and ERA-Interim that both predict clear sky conditions while actual conditions are cloudy and actual clear sky conditions are predicted as cloudy by both. A similar trend was observed in our study where MERRA predicted cloudy conditions as clear sky conditions. Urraca et al. (Urraca et al., 2018) found that the reanalysis overestimates solar radiation under cloudy and intermediate conditions, while they underestimate under clear-sky.
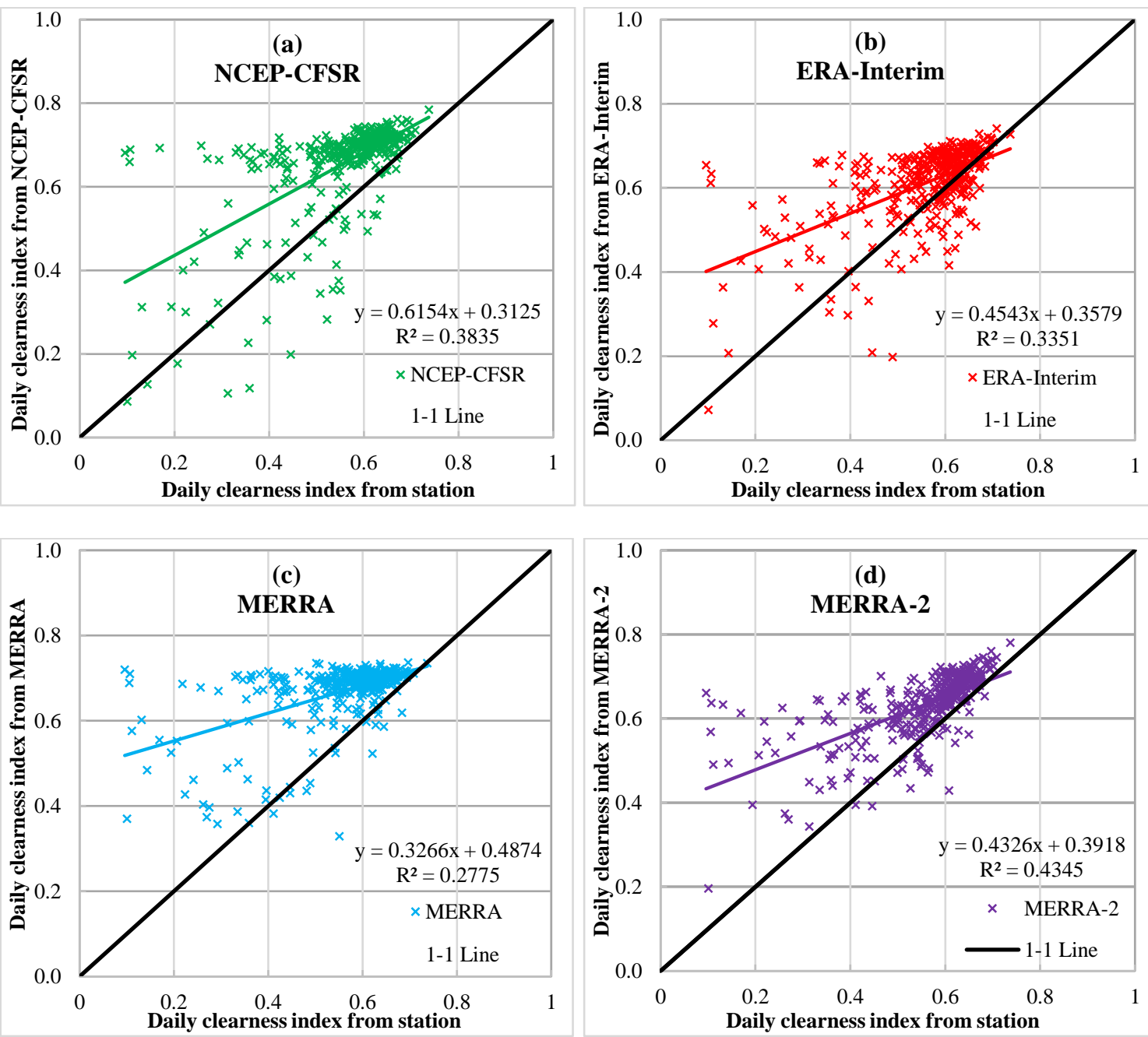

Figure 3: Scatter Plots of Clearness Index from Station and Reanalysis 


\section{Conclusion}

The MBE for solar radiation estimation ranges from $18.82 \mathrm{~W} / \mathrm{m}^{2}$ to $34.05 \mathrm{~W} / \mathrm{m}^{2}$, all the reanalyses overestimate the GHI except ERA-Interim that underestimates. The most accurate results are for ERA-Interim while the least accurate results are shown by MERRA. The MBE values for $K_{T}$ range from 0.05 to 0.11 . The scatter plots of $K_{T}$ show that all reanalysis datasets predict the clear sky conditions while the actual conditions are cloudy and vice versa, the overestimations and underestimations are less in clear sky conditions. Era-Interim only underestimates the daily clearness index. The maximum MBE in clearness index is shown by MERRA 0.11 and minimum MBE is shown by ERA-Interim 0.05. ERA-Interim predicts clear sky conditions while actual conditions are cloudy, the opposite is also true though not much prominent. Overall Era-interim gives the best estimation of surface solar radiations for Multan region.

\section{References}

Alexandri, G., Georgoulias, A.K., Meleti, C., Balis, D., Kourtidis, K.A., Sanchez-Lorenzo, A., Trentmann, J., Zanis, P., 2017. A high resolution satellite view of surface solar radiation over the climatically sensitive region of Eastern Mediterranean. Atmospheric Research 188, 107-121.

Boilley, A., Wald, L., 2015. Comparison between meteorological re-analyses from ERA-Interim and MERRA and measurements of daily solar irradiation at surface. Renewable Energy 75(Supplement C), 135-143.

Decker, M., Brunke, M.A., Wang, Z., Sakaguchi, K., Zeng, X., Bosilovich, M.G., 2012. Evaluation of the reanalysis products from GSFC, NCEP, and ECMWF using flux tower observations. Journal of Climate 25(6), 1916-1944.

Dee, D.P., and Coauthors, 2011. The ERA-Interim reanalysis: Configuration and performance of the data assimilation system.

El Afandi, G., 2014. Evaluation of NCEP climate forecast system reanalysis (CFSR) against surface observations over Egypt. Am. J. Sci. Technol 1(4), 157-167.

Juruš, P., Eben, K., Resler, J., Krč, P., Kasanický, I., Pelikán, E., Brabec, M., Hošek, J., 2013. Estimating climatological variability of solar energy production. Solar Energy 98, 255-264.

Khaled, W.M., 2014. Evaluation of NCEP-CFSR solar data against ground observation over MENA.

NCAR UCAR, 2017. NCEP Climate Forecast System Version 2 (CFSv2) 6-hourly Products. https://rda.ucar.edu/datasets/ds094.0/. (Accessed 25-12-2017 2017).

Pfenninger, S., Staffell, I., 2016. Long-term patterns of European PV output using 30 years of validated hourly reanalysis and satellite data. Energy 114, 1251-1265.

Rienecker, M.M., Suarez, M.J., Gelaro, R., Todling, R., Julio Bacmeister, Liu, E., Bosilovich, M.G., Schubert, S.D., Takacs, L., Kim, G.-K., Bloom, S., Chen, J., Collins, D., Conaty, A., Silva, A.d., Gu, W., Joiner, J., Koster, R.D., Lucchesi, R., Molod, A., Owens, T., Pawson, S., Pegion, P., Redder, C.R., Reichle, R., Robertson, F.R., Ruddick, A.G., Sienkiewicz, M., Woollen, J., 2011. MERRA: NASA's Modern-Era Retrospective Analysis for Research and Applications. Journal of Climate 24(14), 3624-3648.

Rienecker, M.M.S., M.J.; Gelaro, R.; Todling, R.; Bacmeister, J.; Liu, E.; Bosilovich, M.G.; Schubert, S.D.; Takacs, L.K., G.-K, 2011. Merra: NASA's Modern-Era Retrospective analysis for Research and Applications.

Slater, A.G., 2016. Surface Solar Radiation in North America: A Comparison of Observations, Reanalyses, Satellite, and Derived Products. Journal of Hydrometeorology 17(1), 401-420.

Stokler, S., Schillings, C., 2015. ESMAP - Renewable Energy Resource Mapping Initiative - Solar Resource Mapping for Pakistan - Solar Modeling Report. Energy Sector Management Assistance Program, The World Bank. Tahir, Z.R., Asim, M., 2018. Surface measured solar radiation data and solar energy resource assessment of Pakistan: A review. Renewable and Sustainable Energy Reviews 81, 2839-2861.

Urraca, R., Huld, T., Gracia-Amillo, A., Martinez-de-Pison, F.J., Kaspar, F., Sanz-Garcia, A., 2018. Evaluation of global horizontal irradiance estimates from ERA5 and COSMO-REA6 reanalyses using ground and satellite-based data. Solar Energy 164, 339-354.

Yi, Y., Kimball, J.S., Jones, L.A., Reichle, R.H., McDonald, K.C., 2011. Evaluation of MERRA Land Surface Estimates in Preparation for the Soil Moisture Active Passive Mission. Journal of Climate 24(15), 3797-3816.

You, Q., Sanchez-Lorenzo, A., Wild, M., Folini, D., Fraedrich, K., Ren, G., Kang, S., 2013. Decadal variation of surface solar radiation in the Tibetan Plateau from observations, reanalysis and model simulations. Climate Dynamics 40(7), 2073-2086.

Zhang, X., Liang, S., Wang, G., Yao, Y., Jiang, B., Cheng, J., 2016. Evaluation of the Reanalysis Surface Incident Shortwave Radiation Products from NCEP, ECMWF, GSFC, and JMA Using Satellite and Surface Observations. Remote Sensing 8(3), 225.

Zhao, L., Lee, X., Liu, S., 2013. Correcting surface solar radiation of two data assimilation systems against FLUXNET observations in North America. Journal of Geophysical Research: Atmospheres 118(17), 9552-9564. 


\title{
Evaluation of NCEP Products (NCEP-NCAR, NCEP-DOE, NCEP- FNL, NCEP-GFS) of Solar Radiation for Karachi, Pakistan
}

\author{
Zia ul Rehman Tahir, Muhammad Azhar, Muhammad Asim, Nasir Hayat, Hamza Shahid, and \\ Hasnain Ali
}

Mechanical Engineering Department, University of Engineering and Technology Lahore, Pakistan

Abstract

The solar radiation data measured by ESMAP for Karachi, Pakistan is compared with four NCEP products (NCEPNCAR, NCEP-DOE, NCEP FNL, NCEP-GFS). The evaluation of satellite estimates of solar radiation against surface measured data is performed on the basis of statistical analysis and daily mean time series. The statistical analysis shows that the mean bias error (MBE), root mean square error (RMSE) and correlation coefficient (R) for four datasets range from -4.48 to $63.24 \mathrm{~W} / \mathrm{m}^{2}, 55.70$ to $108.77 \mathrm{~W} / \mathrm{m}^{2}$ and 0.966 to 0.976 respectively. The monthly analysis of solar radiation is performed on the basis of daily mean time series to assess the impact of season on their accuracy. Cloud fraction is the main reason for less accuracy of solar radiation products for July and August because of Monsoon in Pakistan. Three-months evaluation of NCEP-FNL is also performed on the basis of monthly mean time series and scatter plots to assess the model performance of dataset in different seasons. The estimates from NCEP-NCAR are least accurate among all datasets whereas the performance of NCEP-FNL is most accurate for initial assessment of solar for Karachi. The results of NCEP-GFS are closer to NCEP-FNL, hence NCEP-GFS can be used to forecast solar energy for Karachi.

Keywords: Solar Radiation, NCEP-NCAR, NCEP-DOE, NCEP FNL, NCEP-GFS

\section{Introduction}

Energy sector is considered as the backbone for the economic development of a country. Pakistan spent more than 10 Billion USD on imports of fossil fuel in the year 2017 (Wasti, 2018). The solution to avoid or decrease the impact on the country's economy is to use local energy resources. Oil, gas and coal reserves of Pakistan are limited that may last in a few years if we completely utilize these with current reserve to production ratio. The other natural resources are hydroelectric, wind and solar energy. The hydroelectric resources are suitable for the largescale projects; Indus water treaty, earthquake danger areas and the internal political rift are the key barriers to utilize these resources. Wind is located in the coastal areas and the capacity factor is also low (0.2-0.25).

Pakistan's geographic location and climate offer a very high potential for solar energy applications. Accurate and precise solar resource assessment of the potential site is a prerequisite for the successful deployment of any solar energy system. The high-quality surface measured data for solar radiations is not usually available on the potential site, to ensure proper solar assessment and thus to secure the final acceptance of the project. The long-term time series of solar radiation data are required for the success of the solar projects which might not available for the potential project site. The long-term time series estimates are available in the form of satellite reanalysis and analysis datasets.

The organizations all over the world provide long-term solar radiation datasets: The United States National Centers for Environmental Prediction (NCEP), The European Centre for Medium-Range Weather Forecasts (ECMWF) and The Japan Meteorological Agency (JMA). The National Centers for Environmental Prediction (NCEP) and the National Center for Atmospheric Research (NCAR) collaborated to produce a record of global reanalysis of atmospheric fields and named this project as NCEP-NCAR. The NCEP worked with Department of Energy USA on a project named as NCEP-DOE. The NCEP-FNL was recently launched as the final product of the Global Data Assimilation System (GDAS) used by NCEP Global Forecast Systems (GFS) model, it includes observations in its model.

The evaluation of these datasets is performed to study the model performance of these datasets, the evaluation is carried out on the basis of statistical analysis which includes the parameters: Mean Bias Error (MBE), Root Mean Square Error (RMSE), Relative Errors (rMBE, rMAE, rRMSE) and Correlation Coefficient (R). The statistical analysis of these datasets indicates the errors in the estimation of solar radiation by these datasets. Da Silva et al. (Da Silva et al., 2010) in their study for North Eastern Brazil pointed out errors in the estimation of solar radiation by NCEP-NCAR. Zhang et al. (Zhang et al., 2016) in their study for six products (ERA-Interim, MERRA, NCEPNCAR, NCEP-DOE, CFSR, and JRA-55) indicated bias in estimation of solar radiation ranging between -2.98 to 
$49.80 \mathrm{~W} / \mathrm{m}^{2}$. A study of surface solar radiation for different regions of China by Xia et al. (Xia et al., 2006) revealed that the NCEP-DOE overestimated solar radiations ranging from 55.01 to $80.86 \mathrm{~W} / \mathrm{m}^{2}$.

The datasets like NCEP-NCAR and NCEP-DOE have been widely studied by researchers, the datasets like NCEPFNL and NCEP-GFS have not been reported much in literature being the recent products of NCEP. This study is first of its own type for Pakistan, the evaluation of these datasets has not been performed for the South Asia region. The aim of this study is to compare surface measured data with four NCEP solar radiation data sets. The surface measured data from Karachi was used for evaluation of NCEP data. The current study will help researchers and project planners to evaluate the initial assessment of a potential site in Pakistan.

\section{Datasets}

The surface measured data (GHI) for Karachi for the year 2016 was used. The solar surface radiation measurement system for Karachi is installed at NED University of Engineering and Technology (UET) and coordinates of stations are $24.933^{\circ} \mathrm{N}, 67.112^{\circ} \mathrm{E}$. The surface data was measured by The Energy Sector Management Assistance Program (ESMAP) of the World Bank. Four globally available NCEP products for solar fluxes were used for the study; NCEP-NCAR, NCEP-DOE, NCEP-FNL, GFS. These datasets have different spatial resolution and radiative transfer model. NCEP-NCAR provides global data of solar radiations from 1948 with spatial resolution is $1.905^{\circ} \times 1.875^{\circ}$ (Kalnay et al., 1996). NCEP-NCAR uses Lacis and Hansen (Lacis and Hansen, 1974) parameterization method and does not consider aerosol in its model. NCEP in collaboration with the Department of Energy, USA (DOE) gave a new reanalysis dataset known as NCEP-DOE which has a spatial resolution of $1.905^{\circ} \times 1.875^{\circ}$ (Kanamitsu et al., 2002). The parameterization method of Lacis and Hansen (Lacis and Hansen, 1974) was replaced by Chou (Chou, 1992) and Chou and Li (Chou and Lee, 1996) model in NCEP-DOE. NCEPFNL commonly known as NCEP final is the product of the Global Data Assimilation System (GDAS), the spatial resolution used for this study is $0.117^{\circ} \times 0.117^{\circ}$. The NCEP operational Global Forecast System (NCEP-GFS) analysis and forecast grids are on a spatial resolution of $0.25^{\circ} \times 0.25^{\circ}$. NCEP-FNL and NCEP-GFS use the same model while NCEP-GFS model runs earlier, also NCEP-FNL has an aerosol component called as NOAA Environment Modeling System GFS Aerosol component (NGAC), that makes it better to predict surface solar radiations. All above four reanalysis or model forecast datasets have a temporal resolution of six hours and runs occur at 00, 06, 12, and 18 UTC daily.

\section{Methodology}

The evaluation of solar radiation datasets has been performed on the basis of statistical analysis and daily mean time series. To quantify the performance of solar radiation from various NCEP datasets in comparison with surface measured data, mean bias error (MBE), mean absolute error (MAE), root mean square error (RMSE), relative mean bias error (rMBE), relative mean absolute error (rMAE), relative root mean square error (rRMSE), and correlation coefficient $(\mathrm{R})$ have been calculated. These parameters were used in other similar studies (Espinar et al., 2009). MBE is the average difference between estimated solar radiations from NCEP products and surface measured solar radiations, the values of MBE closer to zero are desirable. RMSE is calculated by squaring the difference estimated and measured solar radiations, the smaller values of RMSE are acceptable. Correlation coefficient explains the linear relationship between estimated and measured solar radiations, the value closer to 1 indicates the 1:1 relation between estimated and measured solar radiations. The NCEP products provide different variables of solar fluxes but the downward shortwave radiations generally represent global horizontal irradiance (GHI). The surface measured data has a temporal resolution of ten minutes, which was converted to the temporal resolution of 6 hours at UTC for comparison with NCEP datasets, the NCEP products used in the study have a temporal resolution of 6 hours. The satellite datasets were downloaded in netCDF format and MATLAB program was used to get time series for a specific location. The satellite data for the specific location was calculated from four nearby grid points using bilinear interpolation.

\section{Results and Discussion}

To quantify the relationship between solar radiation datasets and surface solar measurements, the statistical parameters: MBE, MAE, RMSE, rMAE, rMBE, rRMSE and R were calculated, the statistical analysis is presented in Table 1. The MBE values can be positive and negative representing overestimation and underestimation of 
solar radiations on the surface respectively. The RMSE values are always positive and values closer to zero indicate lesser errors. NCEP-NCAR data overestimates solar radiation, the MBE and RMSE values for Karachi are $63.24 \mathrm{~W} / \mathrm{m}^{2}$ and $108.77 \mathrm{~W} / \mathrm{m}^{2}$ respectively, which are close to the results derived in a study by Zhang et al. (Zhang et al., 2016). This overestimation has also been reported by multiple studies (Hicke, 2005). The relative errors: rMBE, rMAE, rRMSE are $29.13 \%, 30.12 \%$ and $50.11 \%$ respectively for NCEP-NCAR. The smaller values of relative errors are acceptable, the rRMSE is largest of all the relative errors for NCEP-NCAR which indicates the inefficiency of the solar model to incorporate the larger errors. The slope for NCEP-NCAR is 1.15 which represents the overestimation of large values. The intercept for NCEP-NCAR is 29.83 which represents the relation between solar radiations estimated by NCEP-NCAR and measured solar radiations. The aerosols were not considered in the NCEP-NCAR model which is the potential reason of larger errors and inaccurate estimation of solar radiation to the Earth's surface. The fit for NCEP-NCAR came out to be 0.966 , the value is close to 1 hence the points are more scattered along 1:1 Line.

The NCEP-DOE also overestimates the solar radiations on the surface. The MBE and RMSE values are 39.28 $\mathrm{W} / \mathrm{m}^{2}$ and $92.27 \mathrm{~W} / \mathrm{m}^{2}$, the results are in accordance with the study of Jia et al. (Jia et al., 2013) where the reanalysis overestimated the solar radiations. Zhang et al. (Zhang et al., 2016) in their study also indicated similar overestimation of surface solar radiation by NCEP-DOE, the MBE and RMSE values were reported as 30.83 $\mathrm{W} / \mathrm{m}^{2}$ and $46.82 \mathrm{~W} / \mathrm{m}^{2}$ respectively The radiative transfer model of Lacis and Hansen (Lacis and Hansen, 1974) in NCEP-NCAR was replaced by Chou (Chou, 1992) and Chou and Lee (Chou and Lee, 1996) in NCEP-DOE which resulted in better estimation of solar radiations compared to NCEP-NCAR. The NCEP-DOE considers aerosol in its radiative transfer model, also the cloud fraction for NCEP-DOE was improved hence the results are better than NCEP-NCAR. The relative errors rMBE, rMAE, rRMSE are $18.10 \%, 22.75 \%$ and $42.51 \%$ respectively for NCEP-DOE. The relative errors are less than NCEP-NCAR, the rRMSE value is $7.6 \%$ lesser which indicates the better model performance of NCEP-DOE to incorporate larger errors compared to NCEPNCAR. The slope for NCEP-DOE is 1.09 which represents the overestimation of larger values, the slope of NCEPDOE is comparatively less than NCEP-NCAR. The intercept for NCEP-DOE is 19.70, the smaller values of intercept are acceptable and intercept for NCEP-DOE is smaller than NCEP-NCAR. The fit for NCEP-DOE is 0.961, the points are less scattered along 1:1 Line compared to NCEP-NCAR.

The results for NCEP-FNL are far better than the previous two datasets because its model includes the latest aerosol component known as NGAC, it overestimates solar radiations by $3.13 \mathrm{~W} / \mathrm{m}^{2}$. The RMSE value is 56.57 $\mathrm{W} / \mathrm{m}^{2}$ which is again less than NCEP-NCAR and NCEP-DOE. The relative errors rMBE, rMAE, rRMSE are 1.44 $\%, 11.98 \%$ and $26.06 \%$ respectively for NCEP-FNL, the relative errors of NCEP-FNL are less than both NCEPNCAR and NCEP-DOE. The slope for NCEP-FNL is 0.98 which represents the underestimation of larger values. The intercept for NCEP-FNL is 8.06, for NCEP-FNL is smaller than both NCEP-NCAR and NCEP-DOE. The fit for NCEP-FNL is 0.976 which indicates that most of the points are scattered along 1:1 Line, the correlation of NCEP-FNL is better than both NCEP-NCAR and NCEP-DOE. The aerosol component incorporated in NCEPFNL resulted in a better estimation of solar radiation for the Industrial city of Karachi, the surface solar radiations are reduced because of the air pollution.

The NCEP-GFS has the same trend as NCEP-FNL, there is an overall underestimation of solar radiations by NCEP-GFS and MBE value is $-4.48 \mathrm{~W} / \mathrm{m}^{2}$. The MAE value for NCEP-FNL and NCEP-GFS are quite close which indicates that the overall error for both the datasets is same. The RMSE value for NCEP-GFS is $55.70 \mathrm{~W} / \mathrm{m}^{2}$ that is better than NCEP-FNL, the NCEP-GFS has incorporated larger errors and outliers slightly better than NCEPFNL. The relative errors for NCEP-FNL are less than that of NCEP-GFS. The relative errors rMBE, rMAE, rRMSE are $-2.06 \%, 12.81 \%$ and $25.66 \%$ respectively for NCEP-GFS, the relative errors of NCEP-GFS are close to NCEP-FNL, the possible reason is similar data assimilation technique. The slope for NCEP-GFS is 0.94 which represents the underestimation of larger values. The intercept for NCEP-DOE is 8.26, the intercept for NCEPGFS is close to the intercept for NCEP-FNL. The fit for NCEP-GFS is 0.976 which indicates that most of the points are scattered along 1:1 Line, the correlation of NCEP-GFS is same as that of NCEP-FNL. The overall results indicate that the NCEP-FNL has predicted surface solar radiations better for Karachi. The forecast results of NCEP-GFS are also close to NCEP-FNL, the reason being the same solar model except for the new aerosol component.

The daily mean time series of solar radiations for all the four datasets for the year 2016 indicates the variation of solar radiation throughout the year. The time series of solar radiation form NCEP products tended to follow the 
surface measurements. The NCEP datasets could not predict the exact trends but they followed the solar energy variations in different months. The results for the datasets vary from January to December depending upon the season and seasonal anomalies. The Karachi like rest of Pakistan has four seasons winter, spring, summer and autumn. The spring and autumn are indistinguishable because of no drastic changes of temperature, the summer and winter are the prevalent seasons of the city.

Tab. 1: Comparison between surface measured data and satellite data

\begin{tabular}{|c|c|c|c|c|c|c|c|c|c|}
\hline Dataset & MBE & MAE & RMSE & rMBE & rMAE & rRMSE & $\boldsymbol{m}$ & $\boldsymbol{c}$ & $\mathbf{R}$ \\
\hline NCEP-NCAR & 63.24 & 65.39 & 108.77 & 29.13 & 30.12 & 50.11 & 1.15 & 29.83 & 0.966 \\
\hline NCEP-DOE & 39.28 & 49.39 & 92.27 & 18.10 & 22.75 & 42.51 & 1.09 & 19.70 & 0.961 \\
\hline NCEP-FNL & $\mathbf{3 . 1 3}$ & $\mathbf{2 6 . 0 1}$ & 56.57 & $\mathbf{1 . 4 4}$ & $\mathbf{1 1 . 9 8}$ & 26.06 & 0.98 & 8.06 & $\mathbf{0 . 9 7 6}$ \\
\hline NCEP-GFS & -4.48 & 27.81 & $\mathbf{5 5 . 7 0}$ & -2.06 & 12.81 & $\mathbf{2 5 . 6 6}$ & 0.94 & 8.26 & $\mathbf{0 . 9 7 6}$ \\
\hline
\end{tabular}

The January is the coolest month of the city with mostly clear skies and dry Siberian winds called Quetta waves hit the city, the western disturbances coming from the Persian Gulf bring light rain with them. The measured solar radiations in January range from 89.12 to $193.06 \mathrm{~W} / \mathrm{m}^{2}$. The MBE values in January for NCEP-NCAR, NCEPDOE, NCEP-GFS and NCEP-FNL are $39.32 \mathrm{~W} / \mathrm{m}^{2}, 29.19 \mathrm{~W} / \mathrm{m}^{2},-1.59 \mathrm{~W} / \mathrm{m}^{2}$ and $4.30 \mathrm{~W} / \mathrm{m}^{2}$ respectively. The time series for NCEP-NCAR overestimates the solar radiations in this month. The maximum and minimum values of solar radiation for NCEP-NCAR in January are $240.65 \mathrm{~W} / \mathrm{m}^{2}$ and $147.95 \mathrm{~W} / \mathrm{m}^{2}$ respectively. The NCEP-DOE also overestimates the solar radiations and estimations are better than NCEP-NCAR. The maximum and minimum values of solar radiations by NCEP-DOE for January are $216.74 \mathrm{~W} / \mathrm{m}^{2}$ and $148.95 \mathrm{~W} / \mathrm{m}^{2}$ respectively. The NCEPFNL slightly overestimates the solar radiations and estimations are better than both NCEP-NCAR and NCEPDOE. The maximum and minimum values of solar radiations by NCEP-FNL for January are $185.75 \mathrm{~W} / \mathrm{m}^{2}$ and $91.76 \mathrm{~W} / \mathrm{m}^{2}$ respectively. The NCEP-GFS underestimates the solar radiations and estimations are closer to the results of NCEP-FNL. The maximum and minimum values of solar radiations by NCEP-GFS for January are $178.04 \mathrm{~W} / \mathrm{m}^{2}$ and $105.47 \mathrm{~W} / \mathrm{m}^{2}$ respectively.

From February the warming trend begins in the city, the skies are overcast because of the western disturbances, the intensity of rain is more compared to the preceding month. The measured solar radiations in February range from 174.94 to $238.70 \mathrm{~W} / \mathrm{m}^{2}$. The MBE values in February for NCEP-NCAR, NCEP-DOE, NCEP-GFS and NCEP-FNL are $55.62 \mathrm{~W} / \mathrm{m}^{2}, 32.05 \mathrm{~W} / \mathrm{m}^{2},-11.25 \mathrm{~W} / \mathrm{m}^{2}$ and $-2.13 \mathrm{~W} / \mathrm{m}^{2}$ respectively. The time series for NCEPNCAR overestimates the solar radiations in this month. The maximum and minimum values of solar radiation for NCEP-NCAR in January are $290.85 \mathrm{~W} / \mathrm{m}^{2}$ and $235.25 \mathrm{~W} / \mathrm{m}^{2}$ respectively. The NCEP-DOE also overestimates the solar radiations and estimations are better than NCEP-NCAR. The maximum and minimum values of solar radiations by NCEP-DOE for February are $269.88 \mathrm{~W} / \mathrm{m}^{2}$ and $202.16 \mathrm{~W} / \mathrm{m}^{2}$ respectively. The NCEP-FNL slightly underestimates the solar radiations and estimations are better than both NCEP-NCAR and NCEP-DOE. The maximum and minimum values of solar radiations by NCEP-FNL for February are $232.96 \mathrm{~W} / \mathrm{m}^{2}$ and $190.59 \mathrm{~W} / \mathrm{m}^{2}$ respectively. The NCEP-GFS also underestimates the solar radiations for the month of February. The maximum and minimum values of solar radiations by NCEP-GFS for February are $223.41 \mathrm{~W} / \mathrm{m}^{2}$ and $181.34 \mathrm{~W} / \mathrm{m}^{2}$ respectively.

The March is springtime in the city with clear blue skies, the western depressions can bring moderate rainfall in this month. The measured solar radiation in March ranges from 155.25 to $288.33 \mathrm{~W} / \mathrm{m}^{2}$. The MBE values for March by NCEP-NCAR, NCEP-DOE, NCEP-GFS and NCEP-FNL are $37.22 \mathrm{~W} / \mathrm{m}^{2}, 2.44 \mathrm{~W} / \mathrm{m}^{2},-18.27 \mathrm{~W} / \mathrm{m}^{2}$ and $-8.05 \mathrm{~W} / \mathrm{m}^{2}$ respectively. The time series for NCEP-NCAR overestimates the solar radiations in this month, the maximum and minimum values of solar radiation for NCEP-NCAR in March are $339.63 \mathrm{~W} / \mathrm{m}^{2}$ and 118.50 $\mathrm{W} / \mathrm{m}^{2}$ respectively. The NCEP-DOE also overestimates the solar radiations and estimations are better than NCEPNCAR. The maximum and minimum values of solar radiations by NCEP-DOE for March are $314.65 \mathrm{~W} / \mathrm{m}^{2}$ and $99.64 \mathrm{~W} / \mathrm{m}^{2}$ respectively. The estimations of NCEP-DOE for March are better than the preceding month. The NCEP-FNL underestimates the solar radiations and estimations are better than both NCEP-NCAR and NCEPDOE. The maximum and minimum values of solar radiations by NCEP-FNL for March are $272.20 \mathrm{~W} / \mathrm{m}^{2}$ and $142.84 \mathrm{~W} / \mathrm{m}^{2}$ respectively. The NCEP-GFS underestimates the solar radiations and estimations are somehow closer to the results of NCEP-FNL. The maximum and minimum values of solar radiations by NCEP-GFS for March are $261.46 \mathrm{~W} / \mathrm{m}^{2}$ and $139.37 \mathrm{~W} / \mathrm{m}^{2}$ respectively. 
The April is a relatively hot month of the city with humidity increasing, the western depressions from the Persian Gulf may bring heavy rain with them. The measured solar radiation in April ranges from 190.36 to $315.89 \mathrm{~W} / \mathrm{m}^{2}$. The MBE values for March by NCEP-NCAR, NCEP-DOE, NCEP-GFS and NCEP-FNL are $54.24 \mathrm{~W} / \mathrm{m}^{2}, 35.26$ $\mathrm{W} / \mathrm{m}^{2},-20.95 \mathrm{~W} / \mathrm{m}^{2}$ and $-9.51 \mathrm{~W} / \mathrm{m}^{2}$ respectively. The time series for NCEP-NCAR overestimates the solar radiations in this month, the maximum and minimum values of solar radiation for NCEP-NCAR in April are 374.3 $\mathrm{W} / \mathrm{m}^{2}$ and $212.73 \mathrm{~W} / \mathrm{m}^{2}$ respectively. The NCEP-DOE also overestimates the solar radiations and estimations are better than NCEP-NCAR. The maximum and minimum values of solar radiations by NCEP-DOE for April are $345.68 \mathrm{~W} / \mathrm{m}^{2}$ and $237.99 \mathrm{~W} / \mathrm{m}^{2}$ respectively. The NCEP-FNL slightly underestimates the solar radiations and estimations are better than both NCEP-NCAR and NCEP-DOE. The maximum and minimum values of solar radiations by NCEP-FNL for April are $295.52 \mathrm{~W} / \mathrm{m}^{2}$ and $174.36 \mathrm{~W} / \mathrm{m}^{2}$ respectively. The NCEP-GFS underestimates the solar radiations, the maximum and minimum values of solar radiations by NCEP-GFS for January are $283.78 \mathrm{~W} / \mathrm{m}^{2}$ and $165.38 \mathrm{~W} / \mathrm{m}^{2}$ respectively.

The May is the hottest month of the city with rare rainfall, the cyclones can hit the city causing overcast. The measured solar radiation in May ranges from 139.16 to $310.75 \mathrm{~W} / \mathrm{m}^{2}$. The MBE values for May by NCEP-NCAR, NCEP-DOE, NCEP-GFS and NCEP-FNL are $64.40 \mathrm{~W} / \mathrm{m}^{2}, 43.10 \mathrm{~W} / \mathrm{m}^{2},-9.36 \mathrm{~W} / \mathrm{m}^{2}$ and $2.74 \mathrm{~W} / \mathrm{m}^{2}$ respectively. The time series for NCEP-NCAR overestimates the solar radiations in this month, the maximum and minimum values of solar radiation for NCEP-NCAR in May are $375.59 \mathrm{~W} / \mathrm{m}^{2}$ and $293.31 \mathrm{~W} / \mathrm{m}^{2}$ respectively. The NCEPDOE also overestimates the solar radiations and estimations are better than NCEP-NCAR. The maximum and minimum values of solar radiations by NCEP-DOE for May are $349.67 \mathrm{~W} / \mathrm{m}^{2}$ and $251.83 \mathrm{~W} / \mathrm{m}^{2}$ respectively. The NCEP-FNL slightly overestimates the solar radiations and estimations are better than both NCEP-NCAR and NCEP-DOE. The maximum and minimum values of solar radiations by NCEP-FNL for May are $298.60 \mathrm{~W} / \mathrm{m}^{2}$ and $273.07 \mathrm{~W} / \mathrm{m}^{2}$ respectively. The NCEP-GFS underestimates the solar radiations and overall estimations are closer to the results of NCEP-FNL. The maximum and minimum values of solar radiations by NCEP-GFS for May are $285.10 \mathrm{~W} / \mathrm{m}^{2}$ and $262.31 \mathrm{~W} / \mathrm{m}^{2}$ respectively.

The climatic conditions of June are similar to precedent month, the effect of cyclones as tropical depressions along the coast of Karachi can cause rainfalls and overcast. The measured solar radiation in June ranges from 175.18 to 328.27 W/m². The MBE values for June by NCEP-NCAR, NCEP-DOE, NCEP-GFS and NCEP-FNL are 71.05 $\mathrm{W} / \mathrm{m}^{2}, 37.70 \mathrm{~W} / \mathrm{m}^{2},-12.76 \mathrm{~W} / \mathrm{m}^{2}$ and $-1.87 \mathrm{~W} / \mathrm{m}^{2}$ respectively. The time series for NCEP-NCAR overestimates the solar radiations in this month, the maximum and minimum values of solar radiation for NCEP-NCAR in June are $379.24 \mathrm{~W} / \mathrm{m}^{2}$ and $283.74 \mathrm{~W} / \mathrm{m}^{2}$ respectively. The NCEP-DOE also overestimates the solar radiations and estimations are better than NCEP-NCAR. The maximum and minimum values of solar radiations by NCEP-DOE for June are $351.03 \mathrm{~W} / \mathrm{m}^{2}$ and $247.59 \mathrm{~W} / \mathrm{m}^{2}$ respectively. The NCEP-FNL slightly underestimates the solar radiations and estimations are better than both NCEP-NCAR and NCEP-DOE. The maximum and minimum values of solar radiations by NCEP-FNL for June are $302.23 \mathrm{~W} / \mathrm{m}^{2}$ and $93.58 \mathrm{~W} / \mathrm{m}^{2}$ respectively. The NCEP-GFS underestimates the solar radiations and estimations are closer to the results of NCEP-FNL. The maximum and minimum values of solar radiations by NCEP-GFS for June are $288.71 \mathrm{~W} / \mathrm{m}^{2}$ and $115.26 \mathrm{~W} / \mathrm{m}^{2}$ respectively.

The July is the month when monsoon starts in the city, the low-level layers cover the sky for the most part of the day. The measured solar radiation in July ranges from 43.43 to $287.50 \mathrm{~W} / \mathrm{m}^{2}$. The MBE values for July by NCEPNCAR, NCEP-DOE, NCEP-GFS and NCEP-FNL are $121.91 \mathrm{~W} / \mathrm{m}^{2}, 105.67 \mathrm{~W} / \mathrm{m}^{2}, 20.15 \mathrm{~W} / \mathrm{m}^{2}$ and $19.45 \mathrm{~W} / \mathrm{m}^{2}$ respectively. The time series for NCEP-NCAR highly overestimates the solar radiations in this month, the maximum and minimum values of solar radiation for NCEP-NCAR in July are $341.71 \mathrm{~W} / \mathrm{m}^{2}$ and $248.51 \mathrm{~W} / \mathrm{m}^{2}$ respectively. The NCEP-DOE also overestimates the solar radiations and estimations are better than NCEPNCAR. The maximum and minimum values of solar radiations by NCEP-DOE for July are $328.49 \mathrm{~W} / \mathrm{m}^{2}$ and $136.13 \mathrm{~W} / \mathrm{m}^{2}$ respectively. The NCEP-FNL slightly overestimates the solar radiations and estimations are better than both NCEP-NCAR and NCEP-DOE. The maximum and minimum values of solar radiations by NCEP-FNL for July are $279.59 \mathrm{~W} / \mathrm{m}^{2}$ and $62.99 \mathrm{~W} / \mathrm{m}^{2}$ respectively. The NCEP-GFS overestimates the solar radiations and estimations are closer to the results of NCEP-FNL. The maximum and minimum values of solar radiations by NCEP-GFS for July are $266.44 \mathrm{~W} / \mathrm{m}^{2}$ and $83.17 \mathrm{~W} / \mathrm{m}^{2}$ respectively.

The climatic conditions of August are similar to precedent month, the monsoon weakens in last week of August. The measured solar radiation in August ranges from 89.12 to $280.52 \mathrm{~W} / \mathrm{m}^{2}$. The MBE values for August by NCEPNCAR, NCEP-DOE, NCEP-GFS and NCEP-FNL are $116.14 \mathrm{~W} / \mathrm{m}^{2}, 73.98 \mathrm{~W} / \mathrm{m}^{2}, 31 \mathrm{~W} / \mathrm{m}^{2}$ and $34.02 \mathrm{~W} / \mathrm{m}^{2}$ respectively. The time series for NCEP-NCAR overestimates the solar radiations in this month, the maximum and 
minimum values of solar radiation for NCEP-NCAR in August are $350.04 \mathrm{~W} / \mathrm{m}^{2}$ and $235.41 \mathrm{~W} / \mathrm{m}^{2}$ respectively. The NCEP-DOE also overestimates the solar radiations and estimations are better than NCEP-NCAR. The maximum and minimum values of solar radiations by NCEP-DOE for August are $324.16 \mathrm{~W} / \mathrm{m}^{2}$ and $147.32 \mathrm{~W} / \mathrm{m}^{2}$ respectively. The NCEP-FNL slightly overestimates the solar radiations and estimations are better than both NCEP-NCAR and NCEP-DOE. The maximum and minimum values of solar radiations by NCEP-FNL for August are $274.85 \mathrm{~W} / \mathrm{m}^{2}$ and $25.86 \mathrm{~W} / \mathrm{m}^{2}$ respectively. The NCEP-GFS overestimates the solar radiations and estimations are closer to the results of NCEP-FNL. The maximum and minimum values of solar radiations by NCEP-GFS for August are $262.07 \mathrm{~W} / \mathrm{m}^{2}$ and $31.41 \mathrm{~W} / \mathrm{m}^{2}$ respectively.

The September has light rainfall for the first two weeks, the monsoon completely withdraws from the city. The measured solar radiation in September ranges from 75.13 to $276.03 \mathrm{~W} / \mathrm{m}^{2}$. The MBE values for September by NCEP-NCAR, NCEP-DOE, NCEP-GFS and NCEP-FNL are $50.13 \mathrm{~W} / \mathrm{m}^{2}, 31.31 \mathrm{~W} / \mathrm{m}^{2},-8.00 \mathrm{~W} / \mathrm{m}^{2}$ and -1.43 $\mathrm{W} / \mathrm{m}^{2}$ respectively. The time series for NCEP-NCAR overestimates the solar radiations in this month, the maximum and minimum values of solar radiation for NCEP-NCAR in September are $318 \mathrm{~W} / \mathrm{m}^{2}$ and $217.81 \mathrm{~W} / \mathrm{m}^{2}$ respectively. The NCEP-DOE also overestimates the solar radiations and estimations are better than NCEPNCAR. The maximum and minimum values of solar radiations by NCEP-DOE for September are $294.49 \mathrm{~W} / \mathrm{m}^{2}$ and $172.61 \mathrm{~W} / \mathrm{m}^{2}$ respectively. The NCEP-FNL slightly underestimates the solar radiations and estimations are better than both NCEP-NCAR and NCEP-DOE. The maximum and minimum values of solar radiations by NCEPFNL for September are $267.43 \mathrm{~W} / \mathrm{m}^{2}$ and $48.42 \mathrm{~W} / \mathrm{m}^{2}$ respectively. The NCEP-GFS underestimates the solar radiations and estimations are closer to the results of NCEP-FNL. The maximum and minimum values of solar radiations by NCEP-GFS for September are $255.70 \mathrm{~W} / \mathrm{m}^{2}$ and $72.23 \mathrm{~W} / \mathrm{m}^{2}$ respectively.

The October is the driest month of the city with clear skies, October is the second hottest month of the city after May due to Post-Monsoon summer. The measured solar radiation in October ranges from 196.01 to $246.91 \mathrm{~W} / \mathrm{m}^{2}$. The MBE values for October by NCEP-NCAR, NCEP-DOE, NCEP-GFS and NCEP-FNL are 55.31 W/m², 25.64 $\mathrm{W} / \mathrm{m}^{2},-11.16 \mathrm{~W} / \mathrm{m}^{2}$ and $-2.88 \mathrm{~W} / \mathrm{m}^{2}$ respectively. The time series for NCEP-NCAR overestimates the solar radiations in this month, the maximum and minimum values of solar radiation for NCEP-NCAR in October are $304.53 \mathrm{~W} / \mathrm{m}^{2}$ and $245.72 \mathrm{~W} / \mathrm{m}^{2}$ respectively. The NCEP-DOE also overestimates the solar radiations and estimations are better than NCEP-NCAR. The maximum and minimum values of solar radiations by NCEP-DOE for October are $282.07 \mathrm{~W} / \mathrm{m}^{2}$ and $128.42 \mathrm{~W} / \mathrm{m}^{2}$ respectively. The NCEP-FNL slightly underestimates the solar radiations and estimations are better than both NCEP-NCAR and NCEP-DOE. The maximum and minimum values of solar radiations by NCEP-FNL for October are $239.78 \mathrm{~W} / \mathrm{m}^{2}$ and $179.56 \mathrm{~W} / \mathrm{m}^{2}$ respectively. The NCEPGFS underestimates the solar radiations and estimations are closer to the results of NCEP-FNL. The maximum and minimum values of solar radiations by NCEP-GFS for October are $229.42 \mathrm{~W} / \mathrm{m}^{2}$ and $177.90 \mathrm{~W} / \mathrm{m}^{2}$ respectively.

The November has warm days and conditions are similar to October. The measured solar radiation in November ranges from 165.47 to $207.55 \mathrm{~W} / \mathrm{m}^{2}$. The time series for NCEP-NCAR overestimates the solar radiations in this month but the estimations are comparatively close to the measured solar radiations. The MBE values for September by NCEP-NCAR, NCEP-DOE, NCEP-GFS and NCEP-FNL are $45.28 \mathrm{~W} / \mathrm{m}^{2}, 27.23 \mathrm{~W} / \mathrm{m}^{2},-9.21 \mathrm{~W} / \mathrm{m}^{2}$ and $-1.25 \mathrm{~W} / \mathrm{m}^{2}$ respectively. The maximum and minimum values of solar radiation for NCEP-NCAR in November are $254.18 \mathrm{~W} / \mathrm{m}^{2}$ and $201.90 \mathrm{~W} / \mathrm{m}^{2}$ respectively. The NCEP-DOE also overestimates the solar radiations and estimations are better than NCEP-NCAR. The maximum and minimum values of solar radiations by NCEP-DOE for November are $233.49 \mathrm{~W} / \mathrm{m}^{2}$ and $194.35 \mathrm{~W} / \mathrm{m}^{2}$ respectively. The NCEP-FNL slightly underestimates the solar radiations and estimations are better than both NCEP-NCAR and NCEP-DOE. The maximum and minimum values of solar radiations by NCEP-FNL for November are $202.322 \mathrm{~W} / \mathrm{m}^{2}$ and 164.97 $\mathrm{W} / \mathrm{m}^{2}$ respectively. The NCEP-GFS underestimates the solar radiations and estimations are closer to the results of NCEP-FNL. The maximum and minimum values of solar radiations by NCEP-GFS for November are 194.01 $\mathrm{W} / \mathrm{m}^{2}$ and $157.82 \mathrm{~W} / \mathrm{m}^{2}$ respectively.

The December is the start of winter in the city, the sky remains overcast for part of the month. The measured solar radiation in December ranges from 137.39 to $179.45 \mathrm{~W} / \mathrm{m}^{2}$. The MBE values for December by NCEP-NCAR, NCEP-DOE, NCEP-GFS and NCEP-FNL are $46.70 \mathrm{~W} / \mathrm{m}^{2}, 26.48 \mathrm{~W} / \mathrm{m}^{2},-3.75 \mathrm{~W} / \mathrm{m}^{2}$ and $2.98 \mathrm{~W} / \mathrm{m}^{2}$ respectively. The time series for NCEP-NCAR overestimates the solar radiations, the maximum and minimum values of solar radiation for NCEP-NCAR in December are $221.15 \mathrm{~W} / \mathrm{m}^{2}$ and $175.581 \mathrm{~W} / \mathrm{m}^{2}$ respectively. The NCEP-DOE also overestimates the solar radiations and estimations are better than NCEP-NCAR. The maximum and minimum 
values of solar radiations by NCEP-DOE for December are $197.102 \mathrm{~W} / \mathrm{m}^{2}$ and $168.67 \mathrm{~W} / \mathrm{m}^{2}$ respectively. The NCEP-FNL slightly overestimates the solar radiations and estimations are better than both NCEP-NCAR and NCEP-DOE. The maximum and minimum values of solar radiations by NCEP-FNL for December are 173.78 $\mathrm{W} / \mathrm{m}^{2}$ and $158.47 \mathrm{~W} / \mathrm{m}^{2}$ respectively. The NCEP-GFS underestimates the solar radiations and estimations are closer to the results of NCEP-FNL. The maximum and minimum values of solar radiations by NCEP-GFS for December are $167.16 \mathrm{~W} / \mathrm{m}^{2}$ and $149.80 \mathrm{~W} / \mathrm{m}^{2}$ respectively.

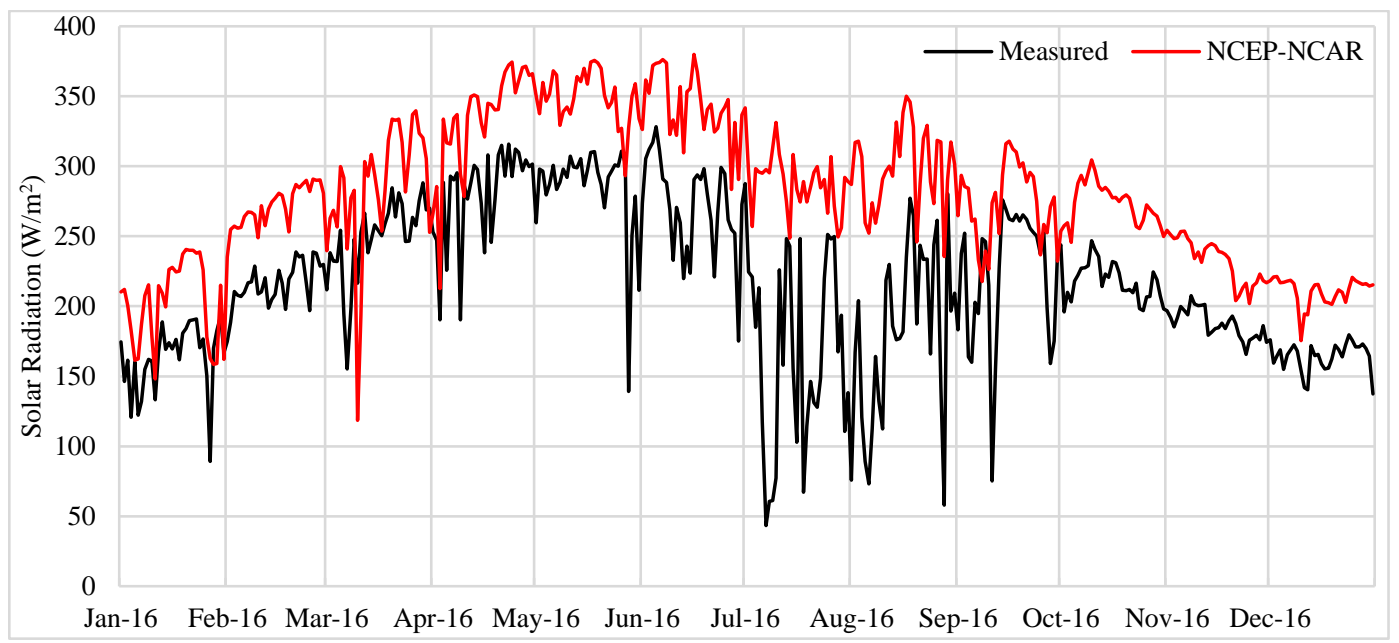

Fig. 1: Comparison of daily mean time series of solar radiation from NCEP-NCAR and measurements

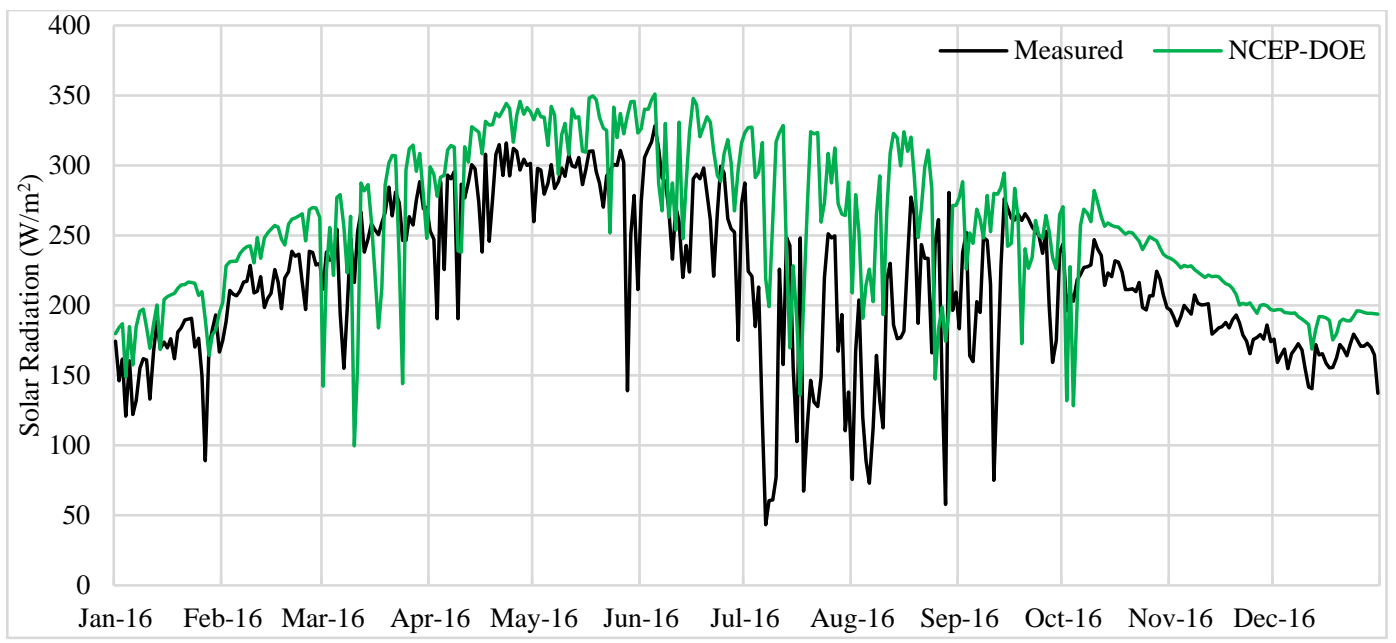

Fig. 2: Comparison of daily mean time series of solar radiation from NCEP-DOE and measurements

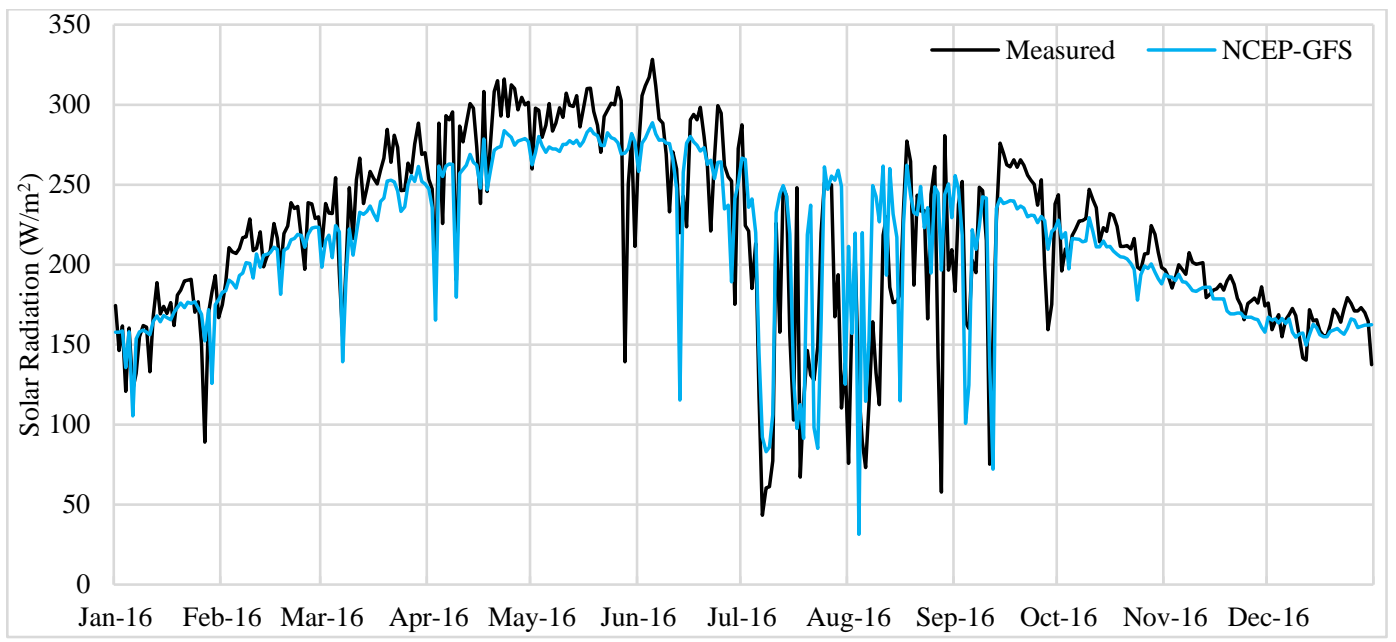

Fig. 3: Comparison of daily mean time series of solar radiation from NCEP-GFS and measurements 


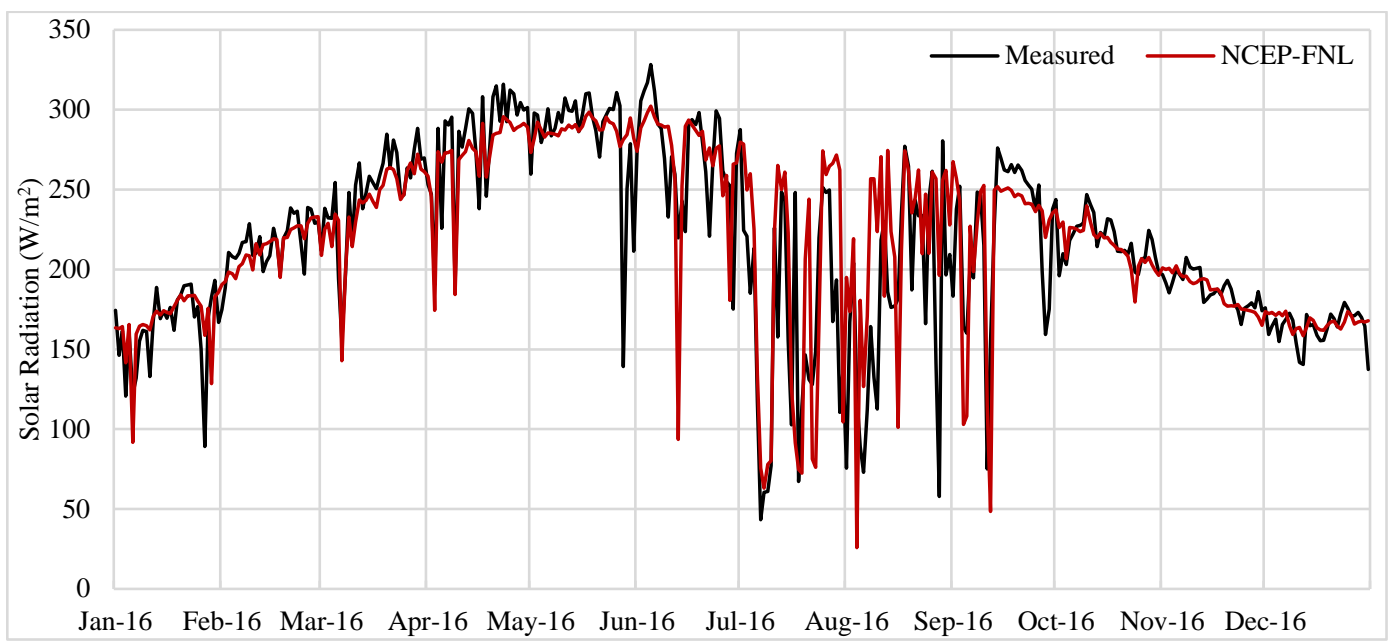

Fig. 4: Comparison of daily mean time series of solar radiation from NCEP-FNL and measurements

The NCEP-NCAR and NCEP-DOE mostly overestimated the solar radiations on the surface except for some days in March and October. The difference between NCEP-NCAR and surface measurements is more compared to the difference between NCEP-DOE and surface measurement. The NCEP-DOE detected the trend of surface solar radiations relatively better compared to NCEP-NCAR, the reason is updated radiative transfer model of NCEPDOE. The Karachi has more aerosol factor being the industrial city, the pollution causes errors in the estimation of solar radiations. The similar reason has also been reported in a study by Xia et al. (Xia et al., 2006)for China. The optical thickness of aerosol may exceed 2.0 because of heavy pollution (Xiang-Ao et al., 2005), hence the heavy aerosol under cloud layer can cause up to $20-30 \mathrm{~W} / \mathrm{m}^{2}$ overestimation if not properly treated in the solar model (T. Hayasaka et al., 2004). The monthly analysis from daily time series indicates that results are most distorted for the months of June, July and August. This is the time of Monsoon in the city and cloudiness increases which suggests that the errors in the estimation of solar radiation increase with an increase in cloudiness. The cloud cover amount varies from one season to another, the winter season is mostly clear and in summers the sky remains overcast. El-Metwally (El-Metwally, 2005) after analyzing the solar radiation estimation in Egypt pointed out that the cloudiness is the reason for the increase in errors. He explained that the cloudiness increases because of the winter extra-tropical systems crossing over the Mediterranean due to which errors also increase in solar estimation. The daily time series analysis indicates that the predictions of solar radiation datasets are better for less cloudy months. Yang et al. (Yang et al., 2001) in their study have also indicated that the cloudy sky conditions are the potential reason for larger errors.

The NCEP-FNL is most updated dataset of NCEP, the results of NCEP-FNL are better than NCEP-NCAR and NCEP-DOE. The MBE and RMSE values for NCEP-FNL are $3.13 \mathrm{~W} / \mathrm{m}^{2}$ and $26.01 \mathrm{~W} / \mathrm{m}^{2}$ respectively, which indicates a better estimation of solar radiation by NCEP-FNL radiative transfer model. The NCEP-FNL includes oxides of carbon, Sulphur and quick-fire emissions in its model that play an important role in the better prediction of solar radiations for an Industrial city like Karachi. The pollution of Karachi is the potential reason for poor predictions, the atmospheric aerosol component used in NCEP-FNL incorporated most of air pollution components hence the overall results of NCEP-FNL are better. For understanding the seasonal dependency of radiative transfer model of NCEP-FNL three-month variation of estimation has been studied on the basis of daily mean time series and scatter plots.

January and March are relatively clear months and there is no issue of cloud fractions, the sky remains overcast for some days of February. The estimated solar radiation by NCEP-FNL follows the trend of measured solar radiation, the bias for these months is comparatively lower. The solar radiations have an overall increasing trend from January to March, the average bias for these months is $-1.96 \mathrm{~W} / \mathrm{m}^{2}$. The regression analysis of measured and NCEP-FNL solar radiation for January, February and March is presented in Fig. 5. The $\mathrm{R}^{2}$ value for these three months is 0.987 which indicates that the scatter of points is close to 1:1 Line, the higher values of solar radiation are underestimated. The slope is 0.97 which indicates that the trend of best-fit is close to 1:1 Line. 


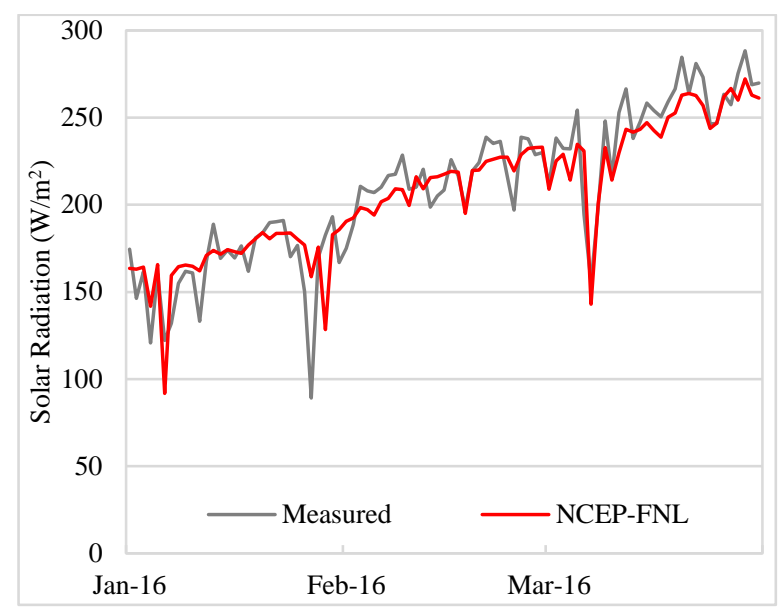

(a)

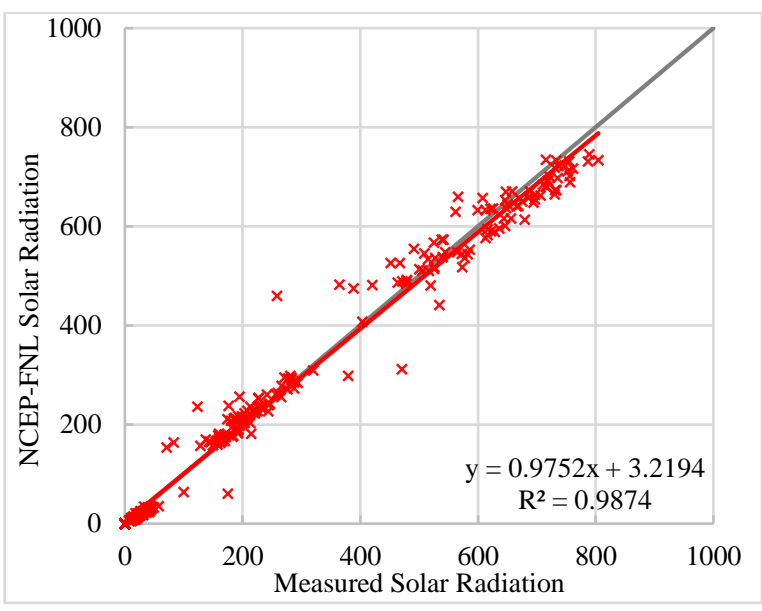

(b)

Fig. 5: NCEP-FNL versus measured solar radiation for January to March 2016 (a) Daily mean time series (b) Scatter plot

April has the effect of western depressions which causes unclear sky conditions; May and June have similar climatic conditions the effect of cyclones can cause sky overcast in these months. The estimated solar radiation by NCEP-FNL follows the trend of measured solar radiation except for some days of these three months, the bias for these months is higher compared to precedent three months. The average bias for April, May and June is -2.82 $\mathrm{W} / \mathrm{m}^{2}$. The regression analysis of measured and NCEP-FNL solar radiation for April, May and June is presented in Fig. 6. The $\mathrm{R}^{2}$ value for these three months is 0.968 which indicates that scatter of points is close to 1:1 Line, the higher values of solar radiation are underestimated. The scatter for April, May and June is more compared to January, February and March. The slope is 0.96 which indicates that the trend of best-fit is close to 1:1 Line.

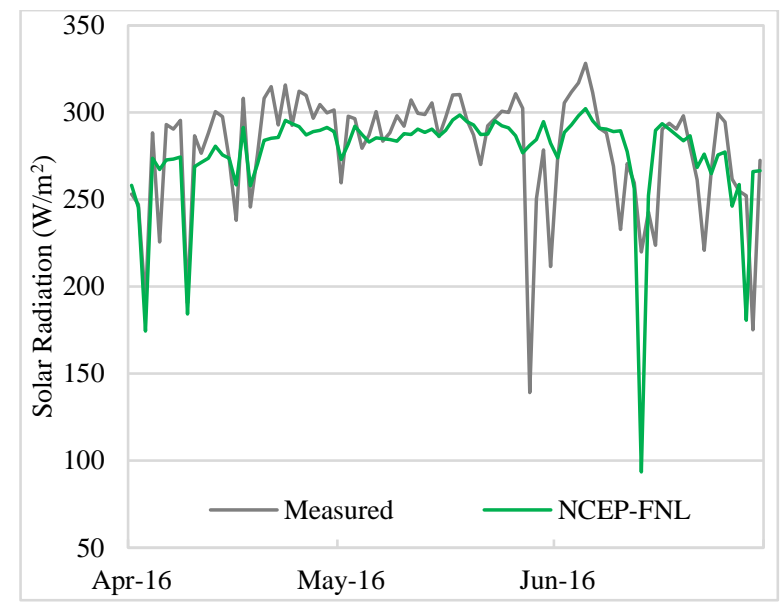

(a)

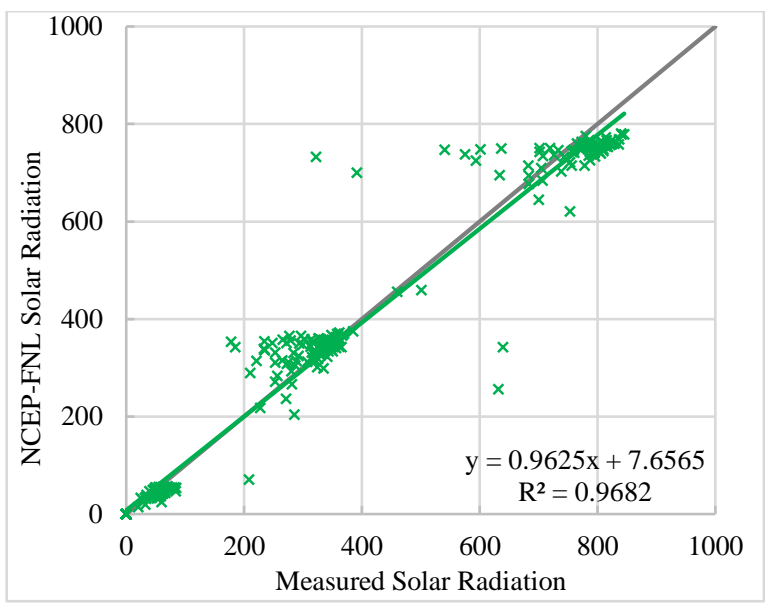

(b)

Fig. 6: NCEP-FNL versus measured solar radiation for April to June 2016 (a) Daily mean time series (b) Scatter plot

July, August and September are months of Monsoon in the city; the sky remains cloudy during Monsoon. The estimated solar radiation by NCEP-FNL tended to follow the trend of measured solar radiation whereas the predictions are poor due to the unpredictability of Monsoon, the bias for these months is highest for these three months compared to the rest of year. The solar radiations continuously variate from July to September, the average bias for these months is $-2.82 \mathrm{~W} / \mathrm{m}^{2}$. The regression analysis of measured and NCEP-FNL solar radiation for July, August and September is presented in Fig. 7. The $\mathrm{R}^{2}$ value for these three months is 0.867 which indicates more scatter for these months, the values of solar radiation are overestimated. The scatter for July, August and September is more due to Monsoon and cloud fraction considered in the solar model. The slope is 1.01 which indicates that the trend of best-fit is close to 1:1 Line although overestimating. 


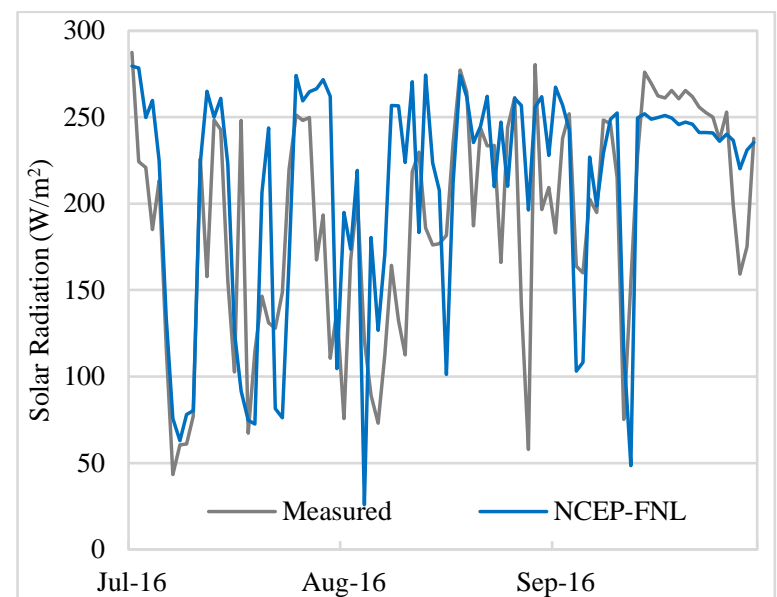

(a)

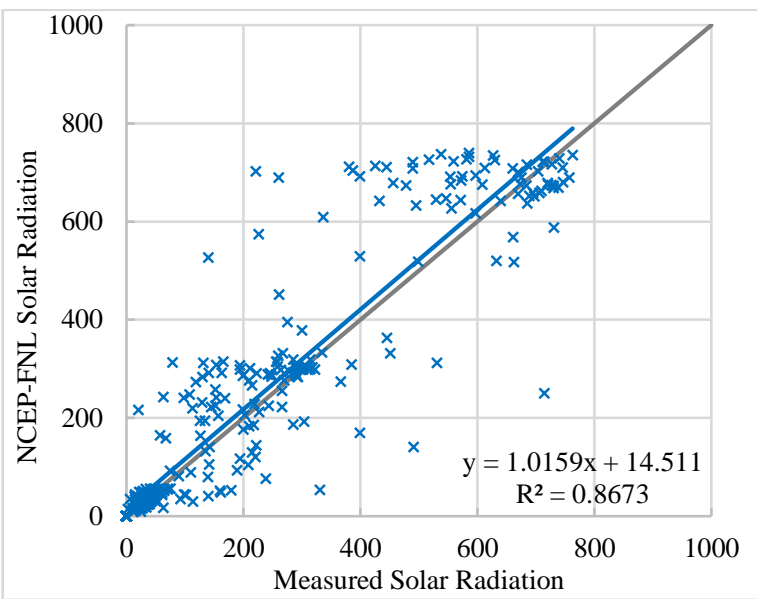

(b)

Fig. 7: NCEP-FNL versus measured solar radiation for July to September 2016 (a) Daily mean time series (b) Scatter plot

October and November are dry months of the city due to post-Monsoon Summer, December is winter month and the sky remains overcast for part of the month. The estimated solar radiation by NCEP-FNL follows the trend of measured solar radiation except for some days of these three months. The solar radiations have an overall increasing trend from October December, the average bias for these months is $-0.37 \mathrm{~W} / \mathrm{m}^{2}$. The regression analysis of measured and NCEP-FNL solar radiation for July, August and September is presented in Fig. 8 . The $\mathrm{R}^{2}$ value for these three months is 0.992 which indicates that the scatter is around 1:1 Line, the values of solar radiation are underestimated. The scatter for October, November and December is less due to clear sky conditions. The slope is 0.97 which indicates that the trend of best-fit is close to $1: 1$ Line.

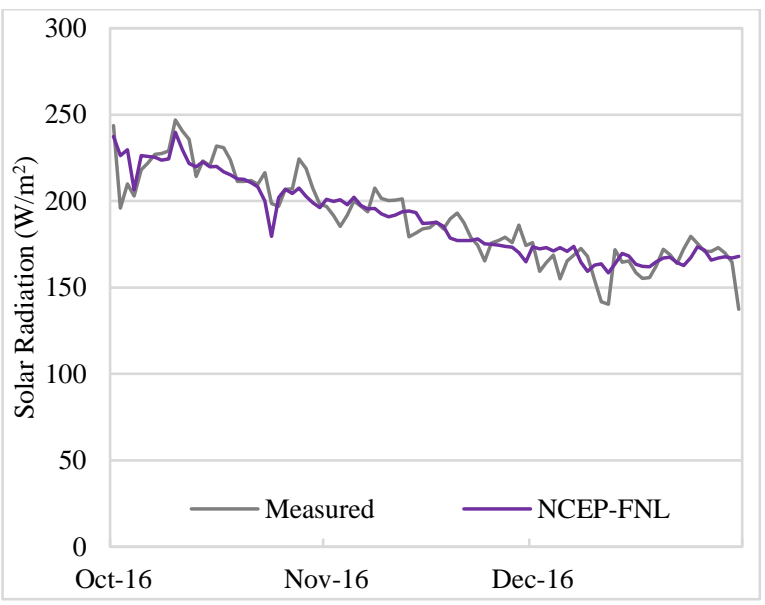

(a)

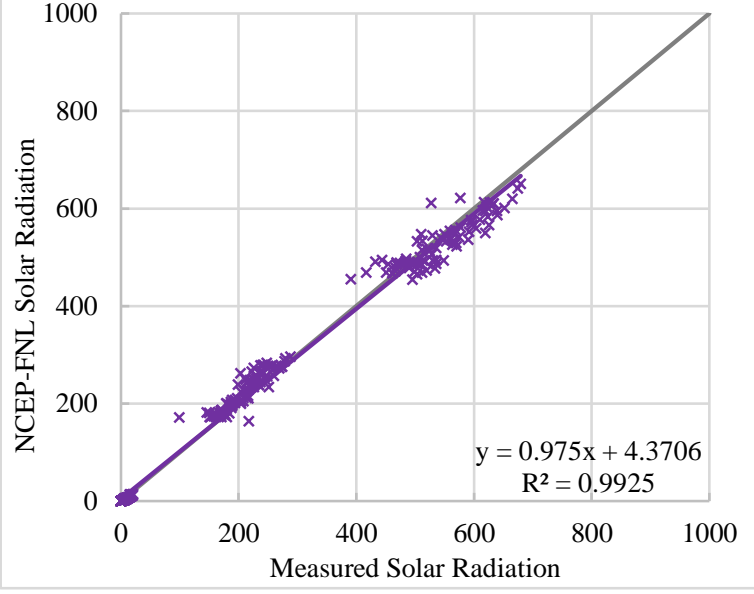

(b)

Fig. 8: NCEP-FNL versus measured solar radiation for October to December 2016 (a) Daily mean time series (b) Scatter plot

The overall results show that the NCEP-NCAR and NCEP-DOE both overestimate solar radiations, the reduction in solar radiation is due to the burning of fossil fuel in power stations and transport, and other atmospheric pollutants. These pollutants reflect solar energy back out to space. The NCEP-NCAR does not consider aerosol in its model hence the reduction in solar radiation was not predicted by NCEP-NCAR. The NCEP-DOE considers aerosol in its model, the results are better than NCEP-NCAR but still, there is an overestimation. The NCEP-FNL has the latest aerosol component in its model that helps it to better predict the solar radiations according to the atmospheric conditions of Karachi. The reason for higher errors in the summer season is because of inaccurate consideration of cloud fraction in solar models.

The NCEP-GFS underestimates the solar radiation throughout the year, except for some months of summer season. The differences between NCEP-GFS and measured values are comparatively less. The overall trend of solar radiations of NCEP-GFS for Karachi is similar to that of NCEP-FNL, the results of NCEP-FNL are better. The NCEP-GFS model runs earlier and provides the forecast of solar radiations for coming 16 days. The relative errors of NCEP-GFS are round about $10 \%$, the NCEP-GFS can prove to be a useful tool for solar radiation forecast of Karachi. 


\section{Conclusion}

The RMSE and MBE values for Karachi range from 55.70 to $108.77 \mathrm{~W} / \mathrm{m}^{2}$ depending upon the radiative transfer model of NCEP datasets. The results of NCEP-NCAR are least accurate among all datasets because the aerosol component was not considered in its model, the MBE and RMSE values are $63.24 \mathrm{~W} / \mathrm{m}^{2}$ and $108.77 \mathrm{~W} / \mathrm{m}^{2}$ respectively. The results of NCEP-FNL are most accurate among all datasets accurate due to the improved model and better incorporation of aerosol components, the MBE and RMSE values are $3.13 \mathrm{~W} / \mathrm{m}^{2}$ and $56.57 \mathrm{~W} / \mathrm{m}^{2}$ respectively.

These NCEP datasets both overestimate and underestimate solar radiation for Karachi due to seasonal variation. The best correction coefficient for Karachi is 0.976 for NCEP-GFS. The best estimation of solar radiations by datasets is in the months with clear sky, the worst predictions are for July and August due to Monsoon in Pakistan as the sky conditions are cloudy for these months. The improvements in the satellite estimates of solar radiation can be done by refining cloud covers and aerosols in the physical models. Based on the statistical analysis and daily time series analysis the NCEP-FNL is the most suitable dataset for Karachi for initial solar assessment. The results of NCEP-GFS are closer to NCEP-FNL hence NCEP-GFS is suitable to forecast solar energy for Karachi.

\section{References}

Chou, M.-D., 1992. A solar radiation model for use in climate studies. Journal of the Atmospheric Sciences 49(9), 762-772.

Chou, M.-D., Lee, K.-T., 1996. Parameterizations for the absorption of solar radiation by water vapor and ozone. Journal of the atmospheric sciences 53(8), 1203-1208.

Da Silva, V.d.P.R., e Silva, R.A., Cavalcanti, E.P., Braga, C.C., de Azevedo, P.V., Singh, V.P., Pereira, E.R.R., 2010. Trends in solar radiation in NCEP/NCAR database and measurements in northeastern Brazil. Solar Energy 84(10), 1852-1862.

El-Metwally, M., 2005. Sunshine and global solar radiation estimation at different sites in Egypt. Journal of Atmospheric and Solar-Terrestrial Physics 67(14), 1331-1342.

Espinar, B., Ramírez, L., Drews, A., Beyer, H.G., Zarzalejo, L.F., Polo, J., Martín, L., 2009. Analysis of different comparison parameters applied to solar radiation data from satellite and German radiometric stations. Solar Energy 83(1), 118-125.

Hicke, J.A., 2005. NCEP and GISS solar radiation data sets available for ecosystem modeling: Description, differences, and impacts on net primary production. Global Biogeochemical Cycles 19(2).

Jia, B., Xie, Z., Dai, A., Shi, C., Chen, F., 2013. Evaluation of satellite and reanalysis products of downward surface solar radiation over East Asia: Spatial and seasonal variations. Journal of Geophysical Research: Atmospheres 118(9), 3431-3446.

Kalnay, E., Kanamitsu, M., Kistler, R., Collins, W., Deaven, D., Gandin, L., Iredell, M., Saha, S., White, G., Woollen, J., 1996. The NCEP/NCAR 40-year reanalysis project. Bulletin of the American meteorological Society 77(3), 437471.

Kanamitsu, M., Ebisuzaki, W., Woollen, J., Yang, S.-K., Hnilo, J., Fiorino, M., Potter, G., 2002. NCEP-DOE AMIPII Reanalysis (R-2). Bulletin of the American Meteorological Society 83(11), 1631-1643.

Lacis, A.A., Hansen, J., 1974. A parameterization for the absorption of solar radiation in the earth's atmosphere. Journal of the atmospheric sciences 31(1), 118-133.

T. Hayasaka, K. Kawatomo, J. Q. Xu, G. Y. Shi, 2004. Longterm trend of surface shortwave radiation over China, International Radiation Symposium. Busan, Korea.

Wasti, S.E., 2018. Pakistan Economic Survey 2017-2018, in: Pakistan, F.D.G.o. (Ed.). Pakistan.

Xia, X.A., Wang, P.C., Chen, H.B., Liang, F., 2006. Analysis of downwelling surface solar radiation in China from National Centers for Environmental Prediction reanalysis, satellite estimates, and surface observations. Journal of Geophysical Research: Atmospheres 111(D9).

Xiang-Ao, X., Hong-Bin, C., Pu-Cai, W., Xue-Mei, Z., Jin-Huan, Q., Gouloub, P., 2005. Aerosol properties and their spatial and temporal variations over North China in spring 2001. Tellus B: Chemical and Physical Meteorology 57(1), 28-39.

Yang, K., Huang, G., Tamai, N., 2001. A hybrid model for estimating global solar radiation. Solar energy 70(1), 1322.

Zhang, X., Liang, S., Wang, G., Yao, Y., Jiang, B., Cheng, J., 2016. Evaluation of the Reanalysis Surface Incident Shortwave Radiation Products from NCEP, ECMWF, GSFC, and JMA Using Satellite and Surface Observations. Remote Sensing 8(3), 225. 


\title{
Evaluation of the solar irradiance variability in Brazil using satellite-based Variability Score
}

\author{
Eduardo Weide Luiz', Fernando Ramos Martins², André Rodrigues Gonçalves', Rodrigo \\ Santos Costa ${ }^{1}$, Jefferson Gonçalves de Souza ${ }^{1}$, Francisco J. Lopes de Lima ${ }^{1}$, Marcelo Pizzuti \\ Pes $^{1}$ and Enio Bueno Pereira ${ }^{1}$ \\ ${ }^{1}$ Center for Earth System Science/National Institute for Space Research, São José dos Campos, SP \\ (Brazil) \\ ${ }^{2}$ Brazilian Federal University of São Paulo, Santos, SP (Brazil)
}

\begin{abstract}
One of the main barriers to increase the solar energy share is its intermittency. In this work, we compared ground observations in different timescales (1-, 5- and 30-minutes) with satellite effective cloud cover coefficient variability, with 30-minutes time resolution. The smallest discrepancies happen when analyzing the same timescale (30-minutes), where the Pearson correlation for all sites was up 0.94. However, when the frequency of the solar irradiance measurements increased, the correlation decreased. A solution may be the use of downscaling methods, which may be a topic for future work. The most important result achieved in this study was the development of a simple methodology for evaluating the surface solar irradiance variability using only the cloud cover obtained from visible satellite imagery. The results denoted that the proposed methodology is an interesting alternative to evaluate the solar irradiance variability over large areas with satisfactory accuracy, where no ground data is available.
\end{abstract}

Keywords: Solar variability, cloud cover, satellite data

\section{Introduction}

Solar energy presents a high variability in different timescales driven mostly by the natural cycles and local typical weather conditions. The first one is precisely estimated by calculating the apparent motion of the Sun in the sky. On the other hand, the variability caused by weather and atmospheric conditions is mostly governed by clouds motion and weather systems, and it is much less predictable (Perez et al., 2016; Watanabe et al., 2016). The solar variability produces transients incompatible with the required power security standards expected for the electricity grid, e. g., voltage variability, imbalance between power generation and energy demand, and thermal stress of the devices (Ari and Baghzouz, 2011; Kazantzidis et al., 2012; Kleissl, 2013).

The different solar power technologies require data on different physical variables: global horizontal irradiance is relevant for PV technologies while the direct normal irradiance is relevant for concentrating technologies. To evaluate the incoming solar irradiance variability, it is important to use normalization parameters to avoid the influence of issues linked to the Sun-Earth position. For PV technologies, the clearness index, Kt (ratio between surface and the extraterrestrial global irradiances) and the clear sky index, $\mathrm{Kt} *$ (ratio of the measured solar data and the global irradiance in clear sky condition) are good parameters for meeting this criterion (Lave et al., 2017; Perez et al., 2016; Watanabe et al., 2016).

Furthermore, it is important to analyze the solar power variability in the correct context. Different timescales are relevant for different technologies and power plant sizes (footprint). For example, when we increase the footprint from a single location to a resource dispersed over a large region, the intermittency is reduced considerably. In this context, fluctuations below 30 minutes are not relevant for grid balancing of distribution system, while for single distribution systems and large centralized plants, one-minute fluctuations are important due to voltage control issues (Perez et al., 2016). Moreover, for concentrating technologies, one-hour data provides simplistic results about the prediction of a plant performance (Meybodi et al., 2017).

For this reason, it is important to quantify and investigate the solar variability in the correct spatial and temporal 
context. Watanabe et al. (2016) used the mean, standard deviation and sample entropy to evaluate the solar irradiance variability over Japan. Lave et al. (2015) proposed the Variability Score of solar irradiance ramp rates (RR) as a metric to quantify the local high-frequency variability based on their cumulative distribution functions. Perez et al. )2016) used used the RR, defined as the change in magnitude of the solar irradiance during a specific time-step as a metric to study the solar power variability.

Additionally, it is important to emphasize that ground-based measurements are useful only to understand the solar irradiance variability in small areas. Such limitation makes difficult to evaluate the impact of cloud variability in power plants located far away from the measurement sites. Satellite observations can help and provide useful data to analyze surface solar variability over large areas, however with coarser temporal and spatial resolutions (Lave et al., 2017; Luiz et al., 2018; Watanabe et al., 2016).

In this study we compare the monthly ground-based irradiance variability in different timescales (1- to 30-minutes) at three locations in Brazil with the satellite cloud cover variability obtained from 30-minutes time resolution satellite imagery. The study analyzes locations with different climate regimes in order to understand how the typical local climate can influence the temporal variability of the surface solar variability.

\section{Methodology}

\subsection{Study Area}

Brazil has several distinct climate regimes mostly because of its large territorial extension. This study uses data acquired in three measurement sites located in different climate regions. The Cachoeira Paulista (CPA) site has an annual rainfall around $1500 \mathrm{~mm}$ and the region presents two distinct climate seasons - a wet season, from October to March ( $190 \mathrm{~mm} / \mathrm{month})$ and a dry season, from April to September ( $\sim 55 \mathrm{~mm} / \mathrm{month})$ (Climatempo, 2017). During the winter (dry season) is very common the occurrence of cold fronts, in summer (wet season) the region is affected by the South Atlantic Convergence Zone (ZCAS) and natural convection (Nunes et al., 2009). The São Martinho da Serra (SMS) site has annual rainfall around $1600 \mathrm{~mm}$ presenting monthly averages ranging from $120 \mathrm{~mm}$ to $160 \mathrm{~mm}$, with low seasonal variability (Climatempo 2017b). The occurrence of different systems like cold fronts in winter and convective systems in summer explain the low rainfall variability during the year (Pereira et al., 2017). The Petrolina (PTR) site, a much dryer place, has annual rainfall around $580 \mathrm{~mm}$ with a wet season, from November to April ( $\sim 87 \mathrm{~mm} / \mathrm{month})$ and a dry season, from May to October $(\sim 9 \mathrm{~mm} / \mathrm{month})$ (Climatempo 2017c). The main reason to the dry climate is the influence of the Walker's circulation, which is only broken from February to April because the Intertropical Convergence Zone (ITCZ) is in its southernmost position (Cavalcanti et al., 2009; Strang, 1972). Figure 1 presents the main climate regimes in Brazil and the location of the measurement sites.

\subsection{Data}

In this work, we calculated the clearness index Kt at the three measurement sites using global irradiance data with one-minute global solar irradiance. Additionally, we used the empirical correction, proposed by Perez et al. (1990), to remove the effects of the air mass at large zenith angles. Equation 1 presents the corrected value (Kt') where 'am' is the relative air mass.

$K t^{\prime}=K t /(1.031 \exp (-1.4 /(0.9+9.4 / \mathrm{am}))+0.1) \quad$ (eq. 1$)$

Additionally, we used the moving average proposed by Kleissl (2013) as a definition to ramp rates in order to estimate the solar variability. The ramp rates of $\mathrm{Kt}^{\prime}$, designated from now on as $R R_{\Delta t}^{K t \prime}$ are defined in Equation 2, where $\Delta \mathrm{t}$ is the timescale of interest

$R R_{\Delta t}^{K t \prime}=\frac{1}{\Delta t}\left(\sum_{t}^{t+\Delta t} K t^{\prime}-\sum_{t-\Delta t}^{t} K t^{\prime}\right)$ 


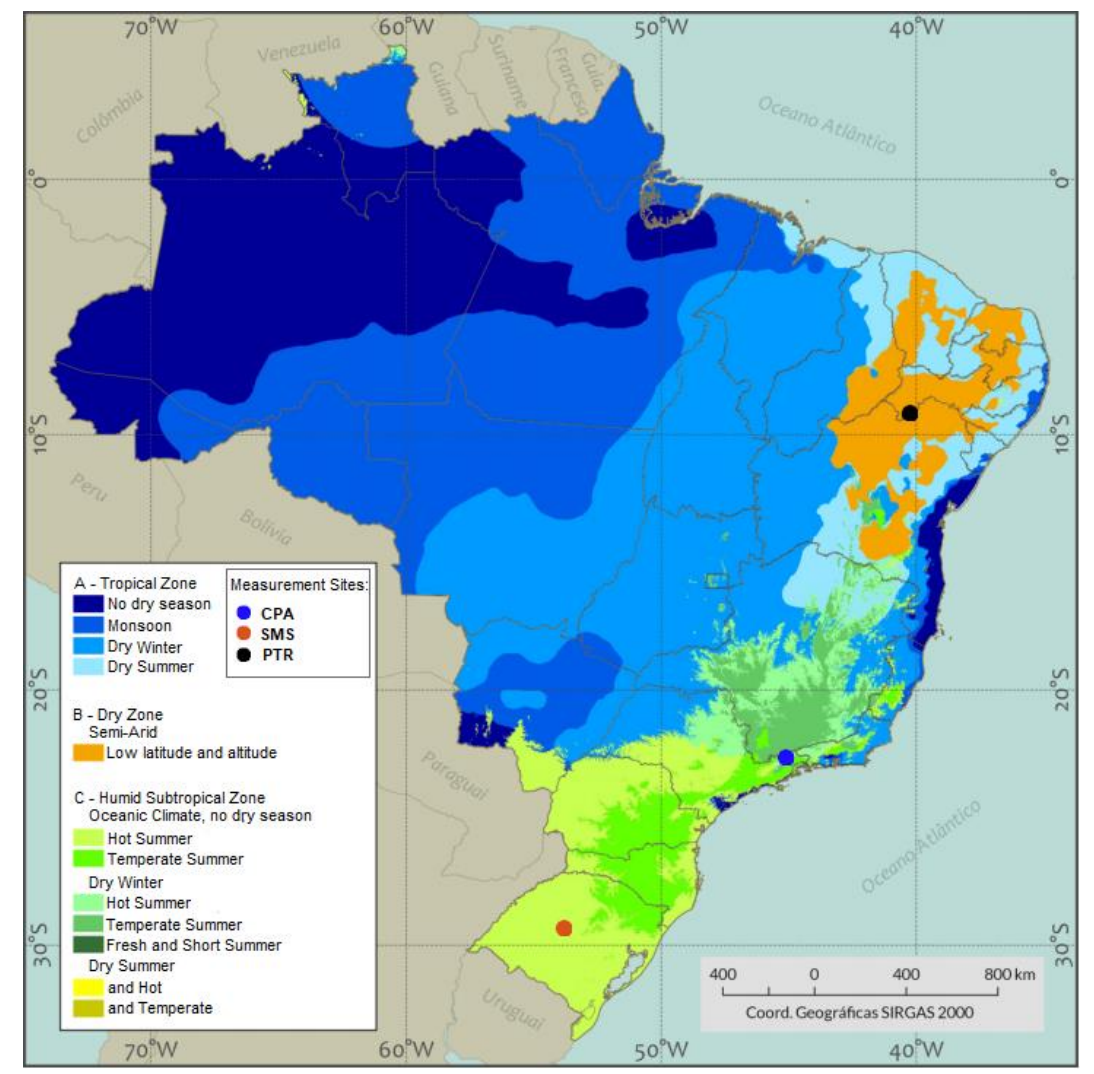

Fig 1. The typical climate zones in Brazil and the location of measurement sites used in this study. Adapted from Alvares et al. (2013).

In South America, the Geostationary Operational Environmental Satellite, GOES-13, managed by NOAA, provided images with a 30-minutes time interval during the study period. Equation 3 defines the effective cloud cover coefficient $\left(\mathrm{C}_{\text {eff }}\right)$ for each pixel of the satellite image in terms of the radiance $\left(\mathrm{L}_{\mathrm{r}}\right)$ measured by the satellite in the visible channel. The clear-sky radiance $\left(\mathrm{L}_{\mathrm{clr}}\right)$ and the radiance for overcast conditions $\left(\mathrm{L}_{\mathrm{cld}}\right)$. The $\mathrm{L}_{\mathrm{clr}}$ and $\mathrm{L}_{\text {cld }}$ values were obtained by composing clear and overcast images from satellite images acquired during a onemonth period. In this step, we divided the reflectance by the cosine of the sun's zenith angle to avoid the influence of illuminance geometry in the radiance data observed by the satellite. According to Martins et al. (2008), $\mathrm{C}_{\text {eff }}$ is a dimensionless coefficient related to the cloud optical depth in each image pixel. The $\mathrm{C}_{\text {eff }}$ ranges in the 0 to 1 interval corresponding from the clear sky condition to a completely overcast sky with no direct solar irradiance reaching the Earth's surface.

$\mathrm{C}_{\text {eff }}=\left(L_{r}-L_{c l r}\right) /\left(L_{c l d}-L_{c l r}\right)$

In this study, we used the $\mathrm{C}_{\text {eff }}$ ramp rates as the difference between $\mathrm{C}_{\text {eff }}$ values in two consecutive satellite images at each pixel, as proposed by Luiz et al., 2018, as a metric using satellite data. The $\mathrm{C}_{\mathrm{eff}}$ ramp rates are designated from now on as $R R_{30}^{\text {Ceff }}$ where the index 30 refers to the 30-minutes temporal resolution of the satellite images.

\subsection{Variability Score}

As a metric to study variability, we used the Variability Score (VS) proposed by Lave et al. (2015), which is based on the cumulative distribution functions of the $\mathrm{RR}$ values (Eq. 4), where $R R_{0}$ is the ramp rates magnitudes ranging from the minimum to the maximum value.

$V S(\Delta t)=100 . \max \left[R R_{0} \cdot P\left(\left|R R_{\Delta t}^{s m}\right|>R R_{0}\right)\right]$

The VS is generally well correlated to the number of tap changes at a solar electric plant, however variables like the tracking setup, cloud velocity and geographic smoothing may lead to some erroneous evaluations and need to be better analyzed (Lave et al., 2015). The VS( $\Delta \mathrm{t}$ ) value ranges from 0 (no variability) to 100 (all ramp rates presenting the maximum value). Larger VS $(\Delta t)$ indicates more variability. 


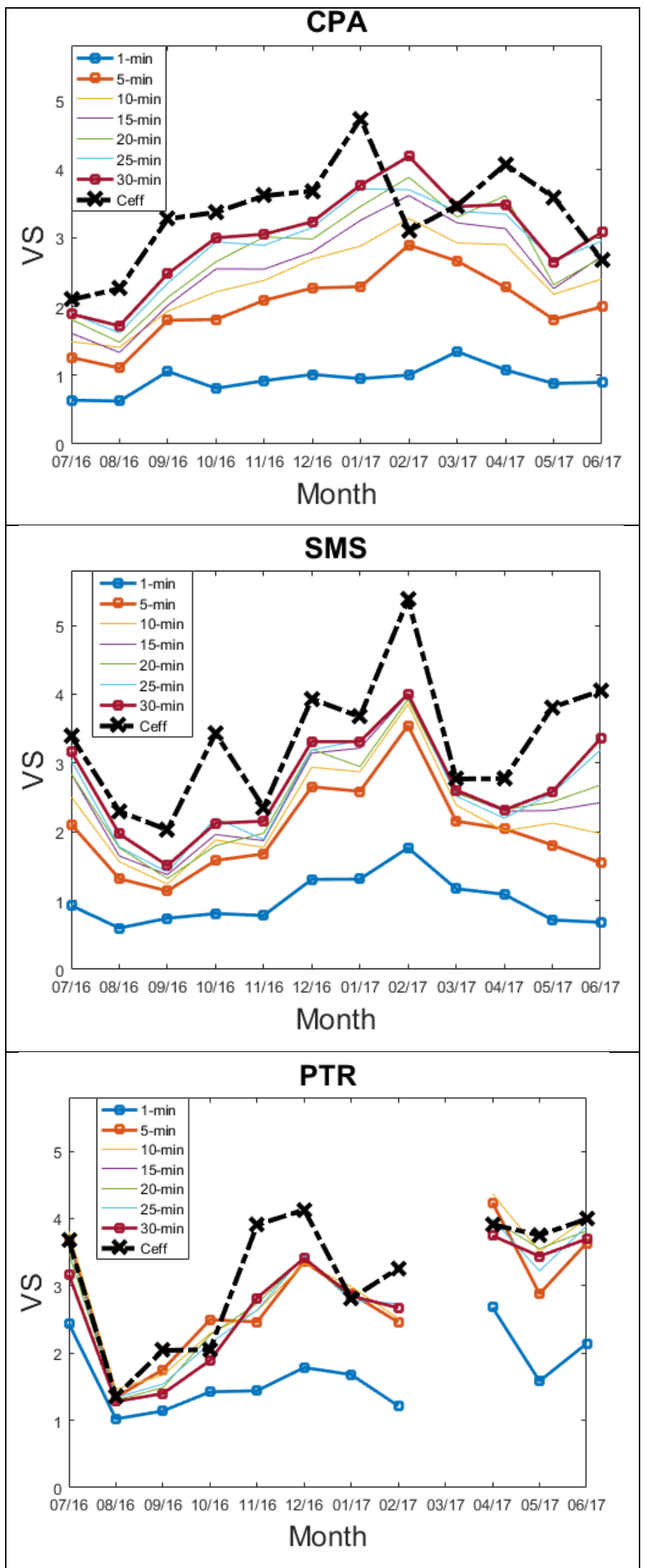

Fig. 2: Annual cycle of the monthly average of variability scores for $\mathrm{Kt}^{\prime}$ in timescales from 1 to 30 minutes, and for Ceff in 30 minutes timestep for all 3 measurement sites: CPA, SMS and PTR. 


\section{Results}

The Pearson correlation between the monthly VS(30) from the $\mathrm{C}_{\text {eff }}$ and the $\mathrm{Kt}$ ' data were found as $0.94,0.88$ and 0.71 for PTR, SMS and CPA respectively. Fig. 2 presents how the monthly VS changes in different timescales during the year at the three sites. As we can see in the three graphs, the monthly average of the Kt' VS $(\Delta \mathrm{T})$ changes gradually, and its highest variability occurs in months with large precipitation (i.e., large nebulosity). Furthermore, regarding the comparison between the $\mathrm{Kt}^{\prime} \mathrm{VS}(\Delta \mathrm{T})$ and Ceff $\mathrm{VS}(30)$, we can see that the smallest difference happens for the same timescale (30-minutes).

In most cases, the annual cycle of $\mathrm{Kt}^{\prime} \mathrm{VS}(\Delta \mathrm{T})$ is well represented by the Ceff VS(30). Exceptions occur in October/2016 at SMS and in February/2017 at CPA. In the second case, the $\mathrm{C}_{\text {eff }}$ VS varies in opposite direction of the Kt' VS variation. This odd condition may be the reason to the lower CPA correlation, and it will be a subject for further investigation.

\section{Conclusion}

The incoming solar irradiance variability on three climate regions of Brazil was investigated using the Variability Score (VS). The determination of the VS values used one-year of the effective cloud cover (Ceff) estimated from satellite visible images. The local ground-irradiance data for the same period was the reference information to evaluate the uncertainties and the reliability of the method.

The results pointed out that the Variability Score (VS) using only visible satellite information can be an interesting alternative to study the solar irradiance variability over large areas with no ground data available. Besides that, we proved to be possible to get reliable information on solar irradiance variability without using radiative transfer models that demand larger computational resources than the proposed methodology. The Ceff values, obtained only using the visible geostationary satellite imagery, proved itself to be enough to characterize the solar resource variability on surface with the required accuracy.

The major limitation of the methodology is the temporal resolution of 30-minutes of satellite images. Even though, the information in 30-minutes timescale is useful for grid balancing of the PV power systems in the distribution grids, it cannot deliver the required accuracy to deal with the voltage control issues by operators of large solar PV power plants.

The future work will focus on the improvement of the methodology to evaluate the relationship between the high frequency variability (1-min or 5-min) of the incoming solar irradiance, with the cloud cover variability observed by geostationary satellites.

\section{References}

Ari, G.K., Baghzouz, Y., 2011. Impact of high PV penetration on voltage regulation in electrical distribution systems, in: 2011 International Conference on Clean Electrical Power (ICCEP). IEEE, pp. 744-748.

https://doi.org/10.1109/ICCEP.2011.6036386

Cavalcanti, I.F. de A., Ferreira, N.J., Silva, M.G.A.J. da, Dias, M.A.F. da, 2009. Tempo e Clima no Brasil, 1st ed. Oficina de Textos, São Paulo (SP), Brazil.

Climatempo, 2017a. Climatologia Cachoeira Paulista - SP [WWW Document]. URL

https://www.climatempo.com.br/climatologia/415/cachoeirapaulista-sp (accessed 11.10.17).

Climatempo, 2017b. Climatologia Santa Maria - RS [WWW Document]. URL

https://www.climatempo.com.br/climatologia/366/santamaria-rs (accessed 11.10.17). 
Climatempo, 2017c. Climatologia Petrolina - PE [WWW Document]. URL

https://www.climatempo.com.br/climatologia/258/petrolina-pe (accessed 11.10.17).

Kazantzidis, A., Tzoumanikas, P., Bais, A.F., Fotopoulos, S., Economou, G., 2012. Cloud detection and classification with the use of whole-sky ground-based images. Atmos. Res. 113, 80-88.

Kleissl, J., 2013. Solar Energy Forecasting and Resource Assessment, 1st ed. Elsevier Ltd.

Lave, M., Broderick, R.J., Reno, M.J., 2017. Solar variability zones: Satellite-derived zones that represent highfrequency ground variability. Sol. Energy 151, 119-128. https://doi.org/10.1016/j.solener.2017.05.005

Lave, M., Reno, M.J., Broderick, R.J., 2015. Characterizing local high-frequency solar variability and its impact to distribution studies. Sol. Energy 118, 327-337. https://doi.org/10.1016/j.solener.2015.05.028

Luiz, E.W., Martins, F.R., Gonçalves, A.R., Pereira, E.B., 2018. Analysis of intra-day solar irradiance variability in different Brazilian climate zones. Sol. Energy 167, 210-219.

https://doi.org/10.1016/j.solener.2018.04.005

Martins, F.R., Silva, S.A.B., Pereira, E.B., Abreu, S.L., 2008. The influence of cloud cover index on the accuracy of solar irradiance model estimates. Meteorol. Atmos. Phys. 99, 169-180.

https://doi.org/10.1007/s00703-007-0272-5

Meybodi, M.A., Ramirez Santigosa, L., Beath, A.C., 2017. A study on the impact of time resolution in solar data on the performance modelling of CSP plants. Renew. Energy 109, 551-563.

https://doi.org/10.1016/j.renene.2017.03.024

Nunes, L.H., Vicente, A.K., Candido, D.H., 2009. Clima da Região Sudeste do Brasil, in: Cavalcanti, I.F.A., Ferreira, N.J., Silva, M.G.A.J., Dias, M.A.F.S. (Eds.), Tempo e Clima No Brasil. Officina de Textos, pp. 243258.

Pereira, E.B., Martins, F.R., Gonçalves, A.R., Costa, R.S., Lima, F.J.L. de, Rüther, R., Abreu, S.L., Tiepolo, G.M., Pereira, S.V., Souza, J.G. de, 2017. Brazilian Atlas of Solar Energy, 2nd ed. São José dos Campos (SP), Brazil.

Perez, R., David, M., Hoff, T.E., Jamaly, M., Kivalov, S., Kleissl, J., Lauret, P., Perez, M., 2016. Spatial and Temporal Variability of Solar Energy. Found. Trends® Renew. Energy 1, 1-44.

https://doi.org/10.1561/2700000006

Strang, D.M.G.D., 1972. Análise climatológica das normais pluviométricas do Nordeste brasileiro. CTA/IAE, São José dos Campos (SP), Brazil.

Watanabe, T., Oishi, Y., Nakajima, T.Y., 2016. Characterization of surface solar-irradiance variability using cloud properties based on satellite observations. Sol. Energy 140, 83-92.

https://doi.org/10.1016/j.solener.2016.10.049 


\section{Solar Education}




\title{
On the Importance of Education When Implementing Renewable Energy
}

Lars Broman*, Tara C Kandpal, Aadu Ott

Strömstad Academy, SE-45280 Strömstad, Sweden

*lars.broman@stromstadakademi.se

\begin{abstract}
The twelfth International Symposium on Renewable Energy Education ISREE was held in Strömstad, Sweden on 19-22 June 2017, twelve years after the eleventh ISREE. The re-started series of ISREE symposiums marks a renewed understanding that education is a vital part of implementation of renewable energy. Renewable energy education could gain by including aspects of revolution, evolution, enrichment and provocation of established educational approaches. It is important to identify important target groups regarding renewable energy education. This is discussed in the present paper. Furthermore, good methods are presented. It is important to understand that implementation of renewable energy is more than pure technology. We therefore suggest that it would be fruitful to make a "quantum jump" in renewable energy education: from "hard" discourses as science, technology and mathematics to more "soft" discourses like sociology of science, psychology and educational neuroscience.
\end{abstract}

Keywords: Renewable energy, renewable energy education, renewable energy implementation.

\section{Introduction: ISREE 2017}

Presently it has finally been internationally accepted, through the important work of IPCC scientists and the UN COP conferences including COP-21 in Paris in December 2015 that fossil fuels have to be terminated and replaced by renewable sources of energy in order to keep the planet's atmospheric temperature below $1.5^{\circ} \mathrm{C}$ above the pre-industrial era temperature. Of major importance to achieve this goal is intense and world-wide education of a number of target groups. This has been understood by renewable energy educators and scientists for several decades, and a recent review article, Renewable energy education: A global status review (Kandpal and Broman 2014) lists no less than 376 publications on the subject.

"Progress to a truly sustainable renewable energy world requires a strong workforce of renewable energy professionals and practitioners, and an informed public supportive of the energy transformation" (Middleton 2018a).

In 1989 International Association of Solar Energy Education IASEE was formed and in 1990 it became ISES Working Group for Education (Broman 1990). During the years 1991 - 2005, eleven International Symposiums on Renewable Energy Education ISREE were held in six different countries: Dalarna University in Borlänge, Sweden, 19-20 June 1991. Carl von Ossietzky University in Oldenburg, Germany, 10-11 June 1992. Borlänge, 14-16 June 1993. Asian Institute of Technology in Bangkok, Thailand, 12-14 December 1994. Oldenburg, September 1996. Tata Energy Research Institute TERI in New Delhi, India 26-28, November 1998. University of Oslo in Oslo, Norway, 15-18 June 2000. In Orlando, Florida, 4-8 August 2002. Chalmers University of Technology in Göteborg, Sweden, 14-15 June 2003. In Perth, Australia, 28 November - 1 December 2004. Orlando, Florida, 6-7 August 2005.

Then the series of topical symposiums took a long pause, even if educational papers were presented regularly at ISES Solar World Congresses. Last year, it was however felt that it was time to re-start the series of educational symposia. Thus, the 12th ISREE was hosted by Strömstad Academy 19-22 June in Strömstad, Sweden. The close to 40 participants came from over a dozen countries in six continents and 29 papers were given as keynote, oral, and poster presentations. 18 of them were written up as papers in the symposium proceedings (Broman 2017). Several of them have since been extended to full-length articles, and accepted for publication in Solar Energy, Volume 173, published in October 2018:

Sustainable Living Education: Techniques to Help Advance the Renewable Energy Transformation by Paulette Middleton (2018b) 
From Experiential To Research-based Learning: The Renewable Energy Online (REO) Master's Program by Christiane Stroth et al. (2018)

Development of a Holistic Method for Assessing Success of Renewable Energy Study Programs by Hans Holtorf et al. (2018)

Influence of Diversity in Lectures on the Students' Learning Process and on Their Perspectives About Renewable Energies in an International Context - the Students' View by Mónica Gutiérrez et al. (2018)

A Pedagogical Approach to Solar Energy Education by Aadu Ott et al. (2018)

Dealing With Victor's History in Renewable Energy Education for Transportation Applications by Ari Lampinen. (2018)

On the Alumni Networking of the Postgraduate Programme Renewable Energy at the University of Oldenburg by Evelyn Brudler and Hans Holtorf. (2018)

Education and Training Gaps in the Renewable Energy Sector by Hugo Lucas et al. (2018)

It seems like ISREE 2017 has marked the beginning of a new era where more interest is being given to renewable energy education issues. Thus, when ISES Board meets on 10 March this year, the (re-)formation of an ISES Working Group on Education was on the agenda. A thirteenth ISREE supported by ISES is being planned to be held together with ISES Solar World Congress in Santiago, Chile, in November 2019.

\section{Renewable Energy Education: Target Groups and Methods}

In recent years, the renewable energy sector has been growing at a rapid rate with investments in the sector being more than that in the fossil fuel sector for past couple of years. As a consequence, a variety of employment avenues including those of researchers, engineers/technicians/mechanics for design, fabrication/manufacture, installation, operation and maintenance of renewable energy technologies, sales and marketing professionals, project appraisal and financing specialists, policy makers as well as professionals to engage in capacity building at all levels. One of the barriers to large scale development and deployment of renewable energy technologies is the unavailability of qualified human resource with the shortage being more acute in developing countries (Ciriminna et al. 2016, Lucas et al. 2018). For example, in case of photovoltaics industry it has been reported that, in several countries, the training of required technicians within approved and accredited training centers has not kept pace with industry requirements within the specific training framework of the country (Stapleton and Collins, 2017).

It is also important to educate politicians, media professionals and potential entrepreneurs and project developers so that they are able to appreciate and assess the strength as well as limitations of the renewable energy options in an objective manner (Oliphant, 2017). Science communication workshops were developed by the ESConet group with members from some 20 European universities and research institutions (Miller et al. 2009); the major target group was young post-docs and renewable energy was one of several topics included. Similarly, education and training of school teachers in the field of renewable energy is also important so as to ensure that relevant inputs could be introduced in the school curricula (Ocetkiewicz, 2017). Above all, there is a critical need for improving awareness and understanding of the common public about various renewable energy options and their direct relevance for long term sustainability of the planet earth (Broman and Kandpal, 2010).

Some target groups have been approached quite strongly during the decades through the establishments of master programs in renewable energy engineering; as an example the European Solar Engineering School that started in Borlänge, Sweden (Broman et al. 1998) and since then has created a yearly group of Masters from all over the world. However, other target groups have to be approached by other means. It is also quite important to ensure the relevance of the knowledge and skills imparted through the renewable energy education programs. For example, in the case of developing countries, a disconnect has been reported between the education system and the expertise required by the industry (Lucas et al. 2018). In order to ensure that latest in the field is provided to the students, the need to involve industry professionals in renewable energy education has also been highlighted (Goswami, 2017). Moreover, there is a strong case for including social, sociological and pedagogical aspects in renewable energy education (Ott et al. 2018). 
In 2010 (Broman and Kandpal 2010) we wrote: "Public understanding of science PUS is a central concept among science communicators. Public understanding of renewable energy PURE is proposed as an important sub-concept of PUS. Four separate important questions for a PURE research project can be identified: (A) Is PURE important? (B) Which issues of PURE are the most important ones, according to renewable energy scientists? (C) What understanding of renewable energy has the general public today, worldwide? (D) How to achieve PURE? These question marks have to be straightened."

\section{A New View on Renewable Energy Education}

10th grader "Johanna" (alias): "It's a pity that I'm not so interested in physics. For example, I am interested in religion. One meets people with different religious faith all the time. But physics is only with you two hours per week." (Gustafsson et al 2001). Obviously science has to be taught in a very different way - not only in schools but everywhere.

The research question: Could it be fruitful to introduce and merge, in a tentative way, in contemporary time and with contemporary knowledge scientific know why and technological know-how with insights in pedagogical, social, societal, humanistic and cultural aspects on transfer and acquisition of knowledge about utilization of renewable energy sources on a personal and/or societal level?

Pedagogical traditions. A part of an answer could be found in some of the common educational theories: The pragmatic or progressive theory, founded by the American philosopher and educationalist John Dewey (18591952). This theory (Dewey, 1966) is connected to the well-known expression "Learning by doing", or in the individual constructive theory for learning founded by the Swiss biologist and researcher Jean Piaget (1896 1980). Piaget regarded children as mini scientists. In contemporary time a lot of interest has been focused on a combination of the sociocultural theory for learning founded by the Russian psychologist Lew Vygotsky (1896 - 1934). Known for his merging of pedagogy with cultural and historical aspects (Vygotsky, 1978). In recent years neuroscience and OECD's publications about the interaction between research and practice (Dumont et al. 2010, The Ille Handbook, 2016) contain valuable insight and inspiration, as well as a "road map" for pedagogical implementation of cultural and societal aspects in the field of education.

Four key aspects: This could also, tentatively, be gained by application of a perspective including aspects of revolution, evolution, enrichment and provocation of established approaches to utilizing energy for our society from different sources in nature.

To many people a transition from fossil to renewable energy sources may seem to imply a revolution. At the same time even utilization of energy sources have an inherent evolution. Many times it is possible to just enrich standard energy sources with renewables. Some people may even find that using renewable energy involve a provocation. These four aspects implied by energy transition have to be carefully explained by pedagogical methods.

STEMM to HACD. The American scientist Robert Root-Bernstein proposes in an article in Science (Bernstein, 2018) that the key concept "STEMM" (Science, Technology, Engineering, Mathematics and Medicine) in education should be changed to "HACD" (Humanities, Arts, Crafts and Design). This means the incorporation of humanities, arts, crafts and design into curricula in order to educate scientists to be more insightsful and this paradigmatic change of mindsets should also affect their scientific results.

Robert Root-Bernstein proposes also in his book "Sparks of Genius" (Bernstein et.al. 1999) a number of "mental tool" for thinking. These are: observing (using any or all senses); abstracting; pattern recognition; pattern forming; dimensional thinking; analogizing; proprioceptive (or body) thinking; empathizing or play acting; modeling; playing; transforming between these various ways of thinking and synthesizing.

These mental tools could be utilized within the sociocultural theory of learning in order to function as "mediating artifacts" for the learner in her exploration of phenomena in the surrounding world.

MIT. Charles M. West, president emeritus of MIT, is cited by Root Bernstein (ibid): “(Engineering) systems cannot be wisely envisioned, designed, or deployed without an understanding of society, culture, politics, economics, and communications - in other words - the very stuff of the liberal arts, and also of the social sciences." 
Climate Change. Changes in society, culture, politics economics and most of all in Climate Change suggests strongly introduction of renewable sources of energy and thus implies a need of education in this field in order to provide acceptance in our society for this kind of technology.

Mind Change. The English neuroscientist Susan Greenfield points in her book "Mind Change" (Greenfield, 2014) out that human mind change is as important as the more well-known Climate Change. This aspect stresses the need for utilization of renewable sources of energy but also the need for education about these options in order to promote the needed transition from fossil to renewable sources of energy.

MegaMind. In the beginning of the decade 2010 work started on a new basic exhibition at the National Museum for Science and Technology in Stockholm. The name of the project became MegaMind.

The aim of the exhibition was to present a pedagogical and educational neuroscientific overview of our learning brain. The project has as its key concept the acronym STEAM (Science Technology, Engineering, Art and Mathematics). This exhibition is presented extensively Online with pictures which show how "hard" technological discourses could be "softened" with an early application of the one key concept $H A C D$ in order to fit expectations of general public.

ILE. In summary it could be concluded that these aspects which demonstrate the need for a pedagogical approach to solar energy education including that a transformation from STEMM to HACD or from STEM to STEAM would be favorable in creating an Innovative Learning Environment, ILE as suggested by OECD in five publications. (The ILE Handbook -Preliminary Draft Online 2017.

\section{Acknowledgements}

The International Symposium on Renewable Energy Education ISREE 2017 was organized by Strömstad Academy in collaboration with Strömstad's municipality and University West, supported by International Solar Energy Society ISES, Solar Energy Association of Sweden, and Chalmers University of Technology, and granted by the Swedish Research Council.

\section{References}

Van der Geer, J., Hanraads, J.A.J., Lupton, R.A., 2000. The art of writing a scientific article. J. Sci. Commun. $163,51-59$.

Broman, L., 1990. International Association for Solar Energy Education. Proc.1st Renewable Energy Congress, Reading, U.K. 23-28 September 1990.

Broman, L., 2004. Solar Energy Studies and Extramural Learning. Proc. ISES Solar World Congress, https://shop.ises.org/bookshop/pages/displayBook.xsp?id=16

Broman, L., Editor, 2017. Proc. 12th International Symposium on Renewable Energy Education. http://www.stromstadakademi.se/sa_pdf/AAS-33.pdf

Broman L., Blum K., Garofoli V., Kristoferson L., Kusoffsky U., Hidemark B., 1998. Creating a European Solar Engineering School. In Anil Misra, Ed., Renewable Energy Education - Current Scenario and Future Projections - Proc. Sixth International Symposium on Renewable Energy Education 26-28 Nov. 1998, 42-47. Tata Energy Research Institute, New Delhi, India.

Broman, L., Gustavsson, K., 1991. An educational travelling exhibition on solar energy. Proc. ISES Solar World Congress, Denver, Colorado, 3849-3852. Pergamon Press.

Broman, L., Kandpal, T.C., 2010. Public Understanding of Renewable Energy PURE. Proc. 11th International Conference on Public Communication of Science \& Technology, New Delhi, India 6-1 Dec. 2010.

Brudler, E., Holtorf, H., 2018. On the Alumni Networking of the Postgraduate Programme Renewable Energy at the University of Oldenburg. Solar Energy Vol. 173, 691-695.

Ciriminna, R., Meneguzzob, F., Pecorainoc, M., Pagliaroa M., 2016. Reshaping the education of energy managers, Energy Research and Social Science. 21, 44-48. 
Dewey, J. C., 1966. Democracy and Education. Free Press. N. Y.

Dumont, H., Istance, D., Benavides, F., editors, 2010. The Nature of Learning: Using Research to Inspire Practice. OECD Press.

Goswami D. Y., 2017. Preparing Next Generation Professionals For the 21st Century Solar Energy Industry. Paper presented at 12th International Symposium on Renewable Energy Education- ISREE 2017, Strömstad, Sweden 19-21 June, 2017. http://www.stromstadakademi.se/sa_pdf/AAS-33.pdf

Greenfield, S., 2014. Mind Change, How Digital Technologies Are Leaving Their Mark on Our Brains. Random House.

Gustafsson, R., Nilsson, J., Snabb, E., 2001. How Some Pupils in Grade 10 Apprehend the Teacher's Goals With Education in Mechanics and Electronics. BA Exam paper at Dalarna University supervised by L. Broman (unpublished).

Gutiérrez, M., Ghotge, R., Siemens, A., Blake-Rath, R., Pätz, C., 2018. Influence of Diversity in Lectures on the Students' Learning Process and on Their Perspectives About Renewable Energies in an International Context - the Students' View. Solar Energy Vol. 173, 268-271.

Holtorf, H., Brudler, E., Torío, H., 2018. Development of a Holistic Method for Assessing Success of Renewable Energy Study Programs. Solar Energy Vol. 173, 209-214.

Lucas, H., Pinnington, S. and Cabeza, L. F., 2018. Education and Training Gaps in Renewable Energy Sector. Solar Energy 173, 449-455.

The ILE Handbook - Preliminary Draft, Online, 2017. http://www.oecd.org/education/the-oecd-handbook-forinnovative-learning-environments-9789264277274-en.htm

Kandpal, T.C., Broman, L., 2014. Renewable Energy Education: A Global Status Review. Renewable and Sustainable Energy Reviews 34, 300-324.

Lampinen, A., 2018. Dealing With Victor's History in Renewable Energy Education for Transportation Applications. Solar Energy Vol. 173, 272-276

Lucas, H., Pinnington, S., Cabeza, L.F., 2018. Education and Training Gaps in the Renewable Energy Sector. Solar Energy Vol. 173, 449-455

Middleton, P., 2018a. Private communication.

Middleton, P., 2018b. Sustainable Living Education: Techniques to Help Advance the Renewable Energy Transformation. Solar Energy Vol. 173, 1016-1018

Miller, S., Fahy, D., The ESConet Team, 2009. Can Science Communication Workshops Train Scientists for Reflexive Public Engagement? Science Communication Vol. 31, 116-126. Members of the Team were Steve Miller, Declan Fahy, Elsa Poupardin, Blanka Jergovic, Vasilis Koulaidis, Brian Trench, Lars Broman, Massimiano Bucchi, Darja Cot, Baudouin Jurdant, Vladimir de Semir, Lida Arnellou, Sofia Araújo, Silvia Coll, Kostas Dimopoulos, Todor Galev, Ana Godinho, Nina Kuryata-Stasiv, Andrea Lorenzet, Mary Mulvihill, Juanita Zorrilla Pujana, Aleksandar Višnjevac, Mónica Bettencourt Dias, Mark Brake, Maria Teresa Escalas, Stefano Fantoni, Steve Harris, Neil Hook, Mladen Juracic, Monika Kallfass, Edvard Kobal, Bertrand Labasse, Nico Pitrelli, Kristina Petkova, Hans Peter Peters, Giancarlo Sturloni, and Oleg Yordanov.

Ocetkiewicz, I., Tomaszewska, B. Mroz, A., 2017. Renewable Energy in Education for Sustainable Development: The Polish Experience. Renewable and Sustainable Energy Reviews 80, 92-97.

Oliphant M., 2017. Importance of Renewable Energy Education to Counter Growing Media Disinformation in Some Countries as Renewable Penetrations Increase. Paper presented at 12th International Symposium on Renewable Energy Education - ISREE 2017, Strömstad, Sweden 19-21 June, 2017. http://www.stromstadakademi.se/sa_pdf/AAS-33.pdf

Ott, A., Broman, L., Blum, K., 2018. A Pedagogical Approach to Solar Energy Education, Solar Energy Vol. 173, 740-743.

Root-Bernstein R., 2018. STEMM Education Should Get “HACD”. Science July 2018, Vol. 361, ISSUE 6397

Root-Bernstein, R., Root-Bernstein, M., 1999. Sparks of Genius. Houghton Mifflin, N. Y. 
Stapleton G., Collins R., 2017. Quality Renewable Energy Training Programmes For Technicians. Paper presented at 12th International Symposium on Renewable Energy Education - ISREE 2017, Strömstad, Sweden 19-21 June, 2017. http://www.stromstadakademi.se/sa_pdf/AAS-33.pdf

Stroth, C., Knecht, R., Günther, A., Behrendt, T., Golba, M., 2018. From Experiential To Research-based Learning: The Renewable Energy Online (REO) Master's Program. Solar Energy Vol. 173, 425-428.

Vygotsky, L. S., 1978. Mind in Society. The Development of Higher Psychological Processes. Cambridge MA. Harvard University Press. 


\title{
A Simple Tool for Assessing Solar and Daylight Access in Urban Canyons
}

\author{
Raphaël Compagnon, Christina Chatzipoulka \\ Haute école d'ingénierie et d'architecture de Fribourg (HEIA-FR) \\ HES-SO // University of Applied Sciences of Western Switzerland
}

\begin{abstract}
A new online tool to assess solar and daylight access over the surfaces enclosing an urban canyon (i.e. building façades and street) is presented. From a limited series of parameters, users can easily describe the orientation and geometry of an urban canyon and precisely define an area of interest for which the calculations have to be performed. By implementing an original calculation method based on stereographic pictures, this tool aims both to demonstrate its capabilities and to serve for architectural and urban planning educational purposes. Its main advantage is that, beside providing numerical indicators (e.g. solar exposure, solar irradiation, sky view factor, daylight sky component) that can take inter-reflections into account, it also allows to visually interpret the results in a rather intuitive manner. The calculation method is available as an open source software package. It can serve to assess solar and daylight access in more complex urban forms.
\end{abstract}

Keywords: urban canyon, solar exposure, solar irradiation, sky view factor, daylight sky component, inter-reflections

\section{Introduction}

In the framework of a recently completed research project, we developed a simple method to quantify solar and daylight access over building envelopes or open spaces located in urban areas (Compagnon et al. 2015, Chatzipoulka et al., 2018). It is based on special types of images that retain only the geometrical information required to compute the incoming solar irradiance or daylight illuminance on the surfaces forming an entire urban masterplan or a subpart of it (e.g. buildings' façades, roofs, streets). These special images, the so-called "multishading masks" and "effective envelope area pictures", are formed as stereographic projections showing the visibility between the surfaces considered and the sky vault. They can be visual interpreted as well as processed to compute solar and daylight quantities on the considered surfaces. The method has been embedded in INDALUX, an open-source, RADIANCEbased software package [RAD, IDLX].

Previously, in order to demonstrate the method and its capabilities, we developed (Compagnon, 2014) an interactive web interface [IBIC] that allows the application of the method for building surfaces in a series of typical settings (e.g. unobstructed vertical façades or tilted planes, and urban canyon's façades and streets) for a dozen of different locations/climates. In this paper, we present a second interactive web tool devoted to urban canyons [UBC] that also incorporates the latest developments of the method, namely its extension to account for inter-reflections. From its home page, the user can specify the dimensions and orientation of the studied urban canyon, and define the precise part of the façade on which the analysis has to be performed. Next, the tool will automatically generate a proper 3D model and apply the programs from the INDALUX package installed on the server. Since this process does not last but few seconds before the results are displayed on a web page, the tool can be easily used repeatedly to observe how the results are affected by varying one or several parameters. Hence, it is well suited for being applied in the teaching context, for instance in architecture or urban studies.

The paper is organised as follows: Section 2 presents the input parameters (required and optional) using a particular urban canyon as a case study example. Section 3 presents the outputs/indicators derived from processing "multishading masks", while Section 4 focuses on those obtained by processing "effective envelope area pictures". 


\section{Defining an urban canyon}

Our tool assumes an infinitely long symmetrical urban canyon (i.e. both façades have the same height). Figure 1 shows the adjustable parameters defining the canyon's orientation and dimensions that can be specified in any unit at any scale.

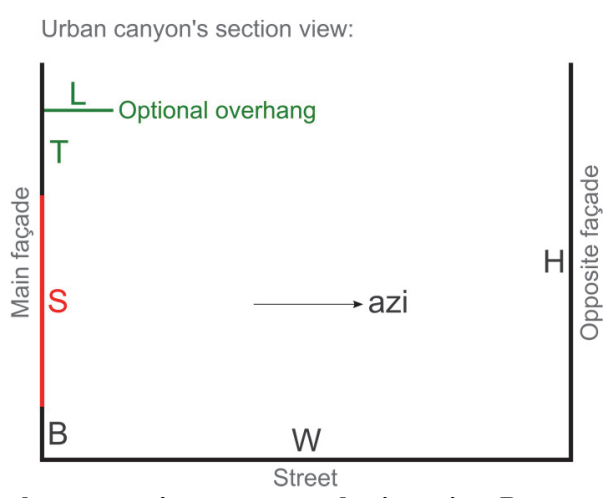

Fig.1: Adjustable parameters defining urban canyon's geometry and orientation. By properly setting parameters B and S, the user can specify on which part of the façade the results have to be computed. Azimuth is counted clockwise from North.

We have chosen a $\sim 100$ meters long street located in the city of Biel in Switzerland. To serve as a case study example throughout this paper, two parts of the main façade are selected for analysis: the façade of the $3^{\text {rd }}$ floor and the shop's vitrine at ground floor (Fig. 2). An optional overhang located above the façade area of interest can also be specified with two additional parameters as shown here for the shop's vitrine.

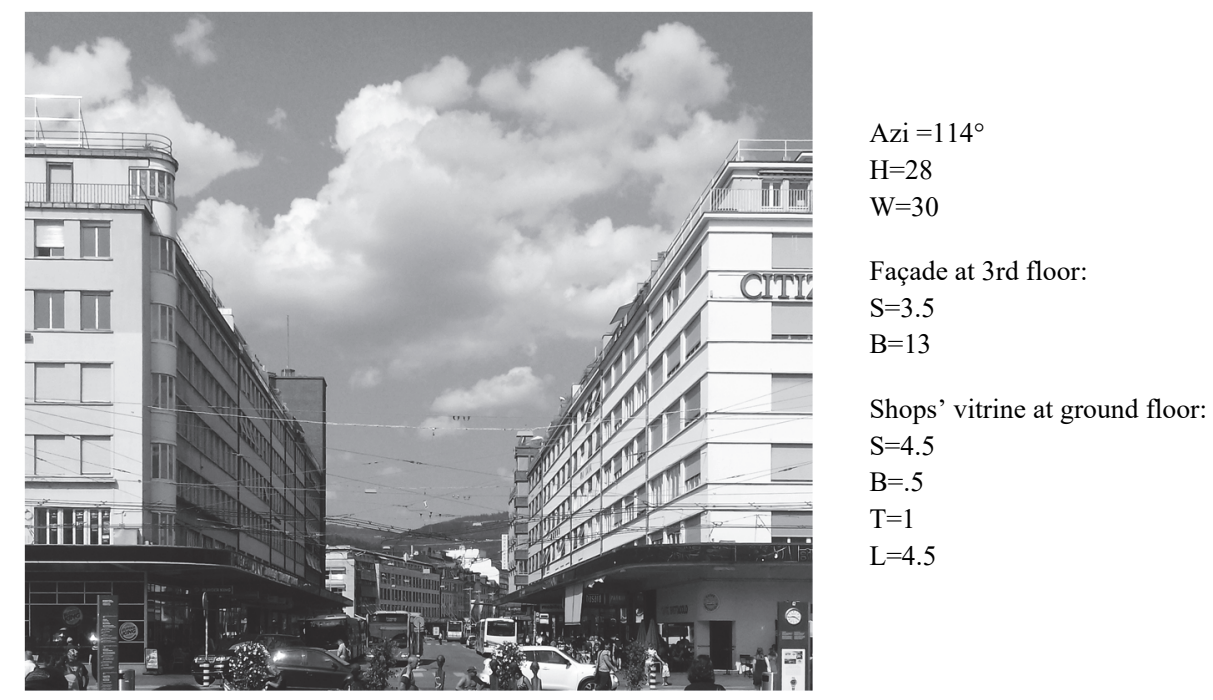

Fig. 2: The urban canyon serving as a case study is located in front of the railway station in Biel, Switzerland. Dimensions shown on the right have been estimated directly from this picture.

Façade and street reflectance values can also be specified to take into account inter-reflections between these surfaces. By default, reflectance values are set to 0.2 . This relatively low value is plausible for two reasons: surface finishes in urban areas are inevitably covered with dust and windows usually occupying large façade fractions behave almost as light traps relatively to the exterior. The calculations are performed assuming purely diffuse reflections with constant reflectance values over the full solar spectrum.

Finally, a location has to be specified. Two options are available to specify a location: either by a latitude or by selecting a specific site from a list of sites for which annual and monthly sky models are available. The sky models have been created based on hourly climatic data obtained from METEONORM software [MET]. More sites will be progressively added to the list in the future.

Figure 3 shows the tool's input page where users specify all these parameters. As seen, by ticking the relevant box, the tool can also produce results on the street level. 


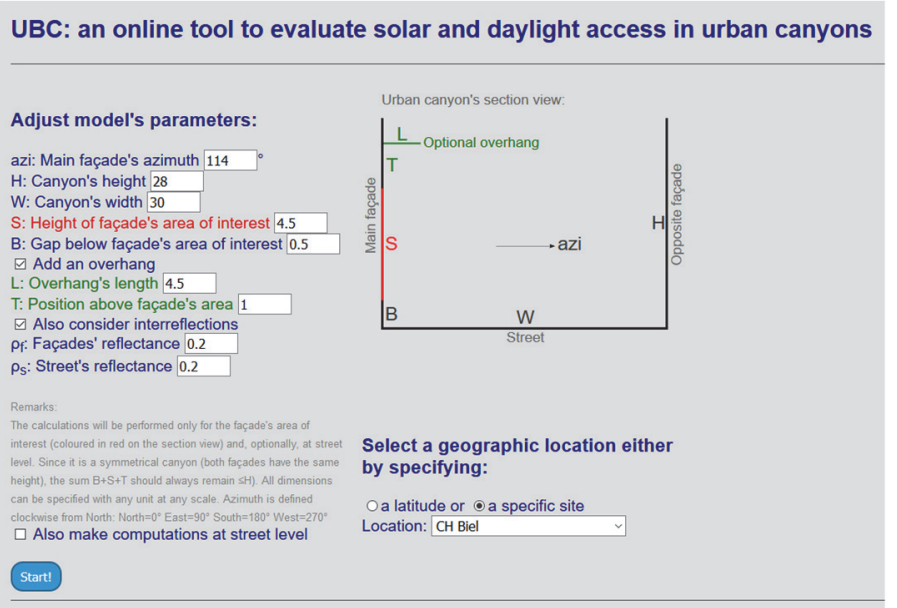

Fig. 3: UBC input page. The parameter values shown here describe the shop's vitrine of our example.

\section{Analyzing sunlight exposure from multi-shading masks}

The sunlight exposure of an area is assessed through its "multi-shading mask". The "multishading mask" is a stereographical projection of the sky vault where the grey level value of each pixel (i.e. from $0=$ black to $1=$ white) indicates the fraction of the considered area (in our case the façade area of interest defined as explained in the preceding section) that has an unobstructed view to the sky in the corresponding direction.

This picture type serves to assess the provision of sunlight through exposure indicators, i..e. WSE and AWSE (Compagnon et al. 2015). Only those hours for which the direct normal irradiance exceeds a threshold of 120 [W/m2] are considered for computing these indicators. This is in line with the "sunshine duration" parameter as defined by (WMO, 2008). In case the location is defined by a latitude only, the potential sunlight exposure WSE is calculated whereas, if a site is selected, the actual sunlight exposure AWSE instead. Since only the latter takes into account the actual climatic conditions it is not surprising that AWSE is much lower than WSE that is computed assuming permanently clear sky conditions. Figure 4 shows the results as presented by the tool.

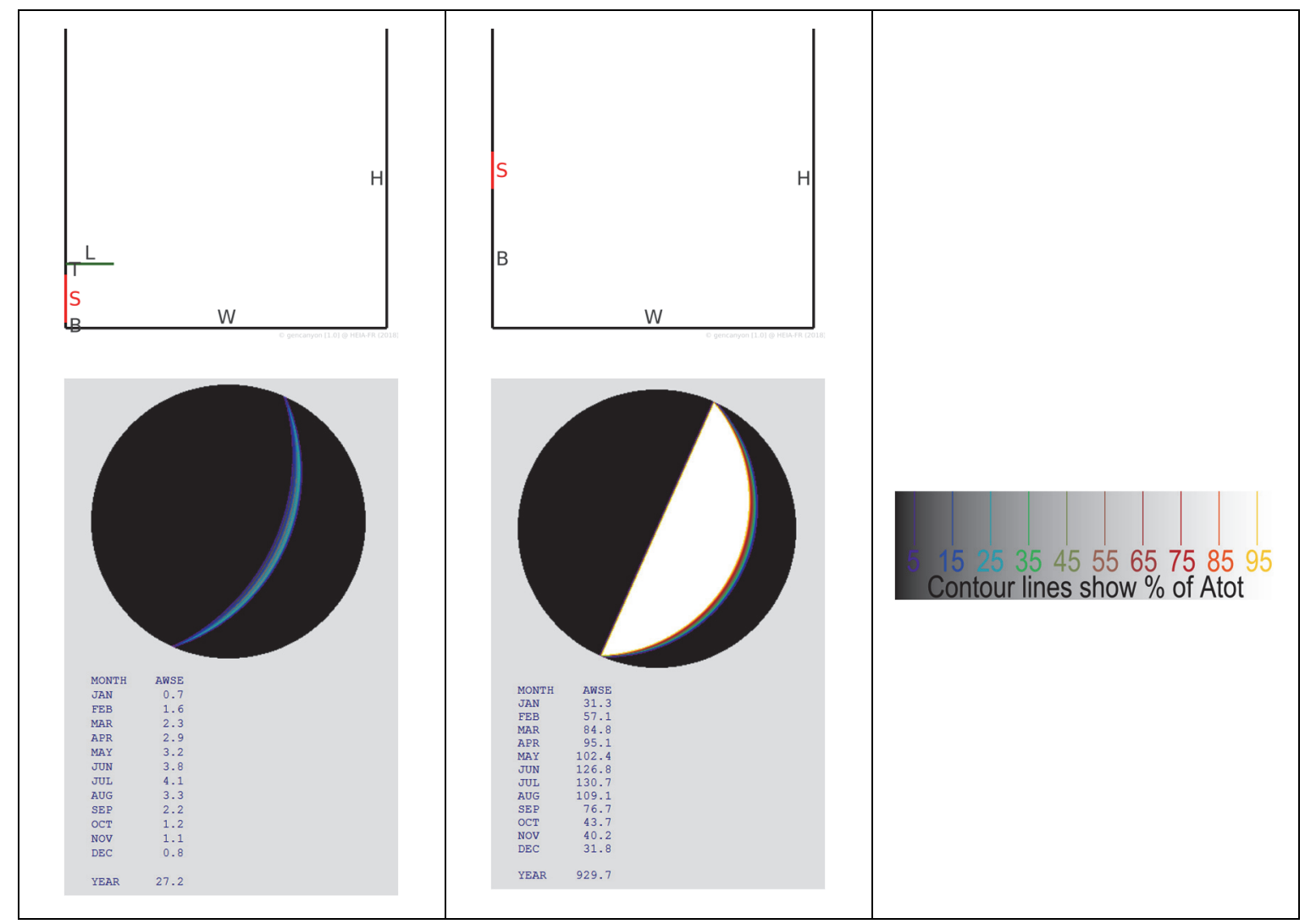

Fig. 4: Sunlight exposure analysis for the shop's vitrine (left) and for the $3^{\text {rd }}$ floor façade (middle). To help visually comparing the multishading masks, coloured iso-contour lines are superimposed (right). 
It is not surprising that, due to the large overhang, the shop's vitrine is almost entirely shaded during the whole year. However, it remains to check to what degree this overhang also decreases vitrine's access to daylight. This aspect is evaluated in the next section.

Even if users are not familiar or even interested in the calculated indicators, they can visually compare the multishading masks with either the sunpath diagram or a representation of the annual sky model for a location. The latter is provided as a stereographic picture of the sky vault showing how the sun and sky radiances are distributed over it (Fig. 5)
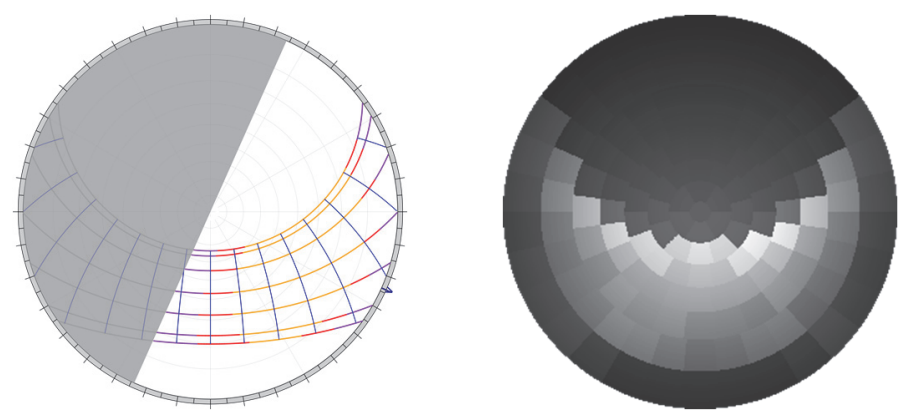

Fig. 5: Left: sunpath diagram for the latitude of Biel. The colours indicate approximate direct irradiance that could potentially reach the considered façade (purple: low $<\sim 200 \mathrm{~W} / \mathrm{m}^{2}$, red: middle $\sim 200$ to $\sim 400 \mathrm{~W} / \mathrm{m}^{2}$, yellow: high $>\sim 400 \mathrm{~W} / \mathrm{m}^{2}$ ). Right: relative distribution of the sky radiance over the sky vault computed from climatic data.

At street level, the multishading mask can serve to check if sunlit and shaded areas are simultaneously provided in adequate fractions. The following indicators are computed (Compagnon et al., 2015): AHOL: number of hours for which the open space (here the street) is overlit (lack of shaded parts); AHOK: number of hours where at least $20 \%$ of shaded or sunlit parts are available (assumed to be benefical for outdoor comfort) and AHOS: number of hours for which the open space is overshaded (lack of sunlit parts). In addition, by superimposing a sunpath diagram, overlit and overshaded periods can be traced in the year (Fig. 6).
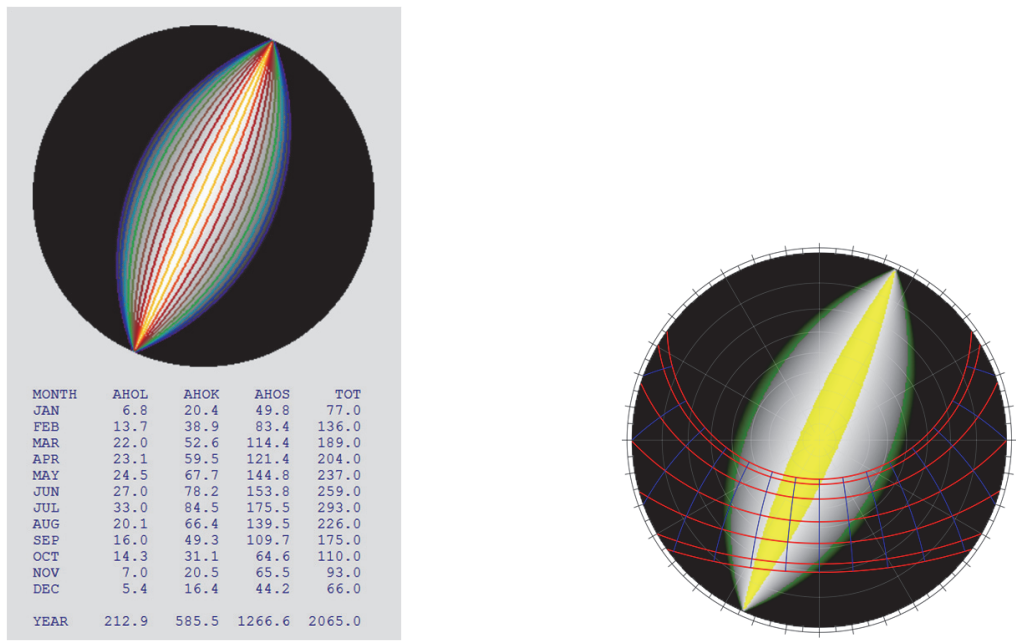

Fig. 6 : Left: multishading mask computed at street level (without any overhang along both façades) and the resulting analysis in term of adequate provision of sunlit and shaded areas. Right: sunpath diagram superimposed on the multishading (overlit hours appear in the yellow coloured region while overshaded hours appear in the green coloured region).

\section{Analyzing irradiation and daylight illuminance from effective envelope area pictures}

An "effective envelope area picture" is again a stereographical projection of the sky vault but where each pixel indicates the total amount (in $\mathrm{m}^{2}$ ) of the considered area that has unobstructed view to the sky in the corresponding direction. More precisely, the amounts stored in each pixel represent projected areas (i.e. the actual façade area is «scaled down» by the cosines between the façade's perpendicular direction and the directions in the sky vault). If this definition may seem complicated, this type of picture can be intuitively interpreted as a representation of how the various directions on the sky vault are visible from an element (e.g. a façade, a street). Furthermore, the Sky View Factor (SVF) and the Average Sky Component (ASC) can be computed from effective envelope area pictures (Fig. 7). 


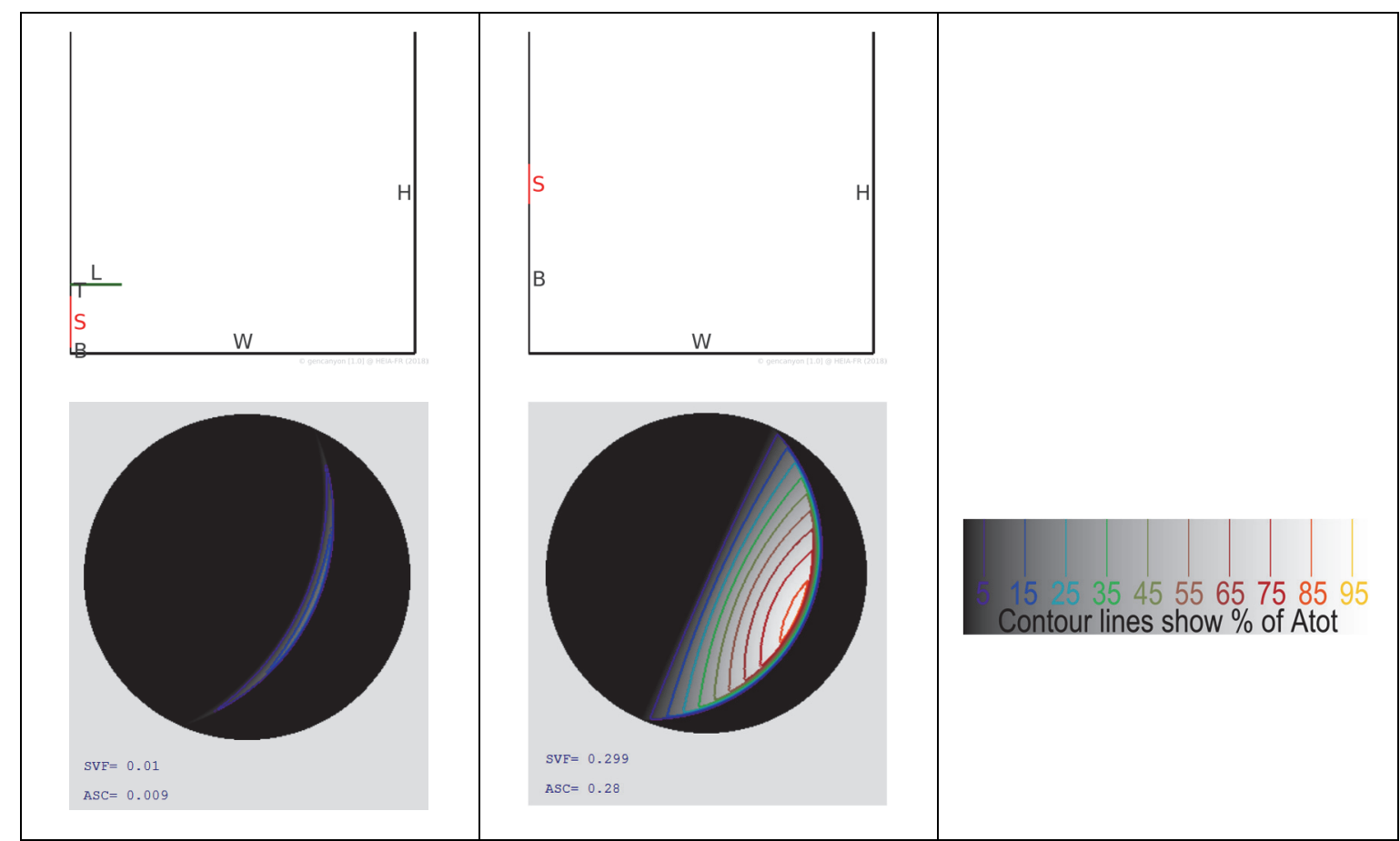

Fig. 7: SVF and ASC calculated for the shop's vitrine (left) and for the $3^{\text {rd }}$ floor façade (middle). To help visually comparing the effective envelope area pictures, coloured iso-contour lines are superimposed (right).

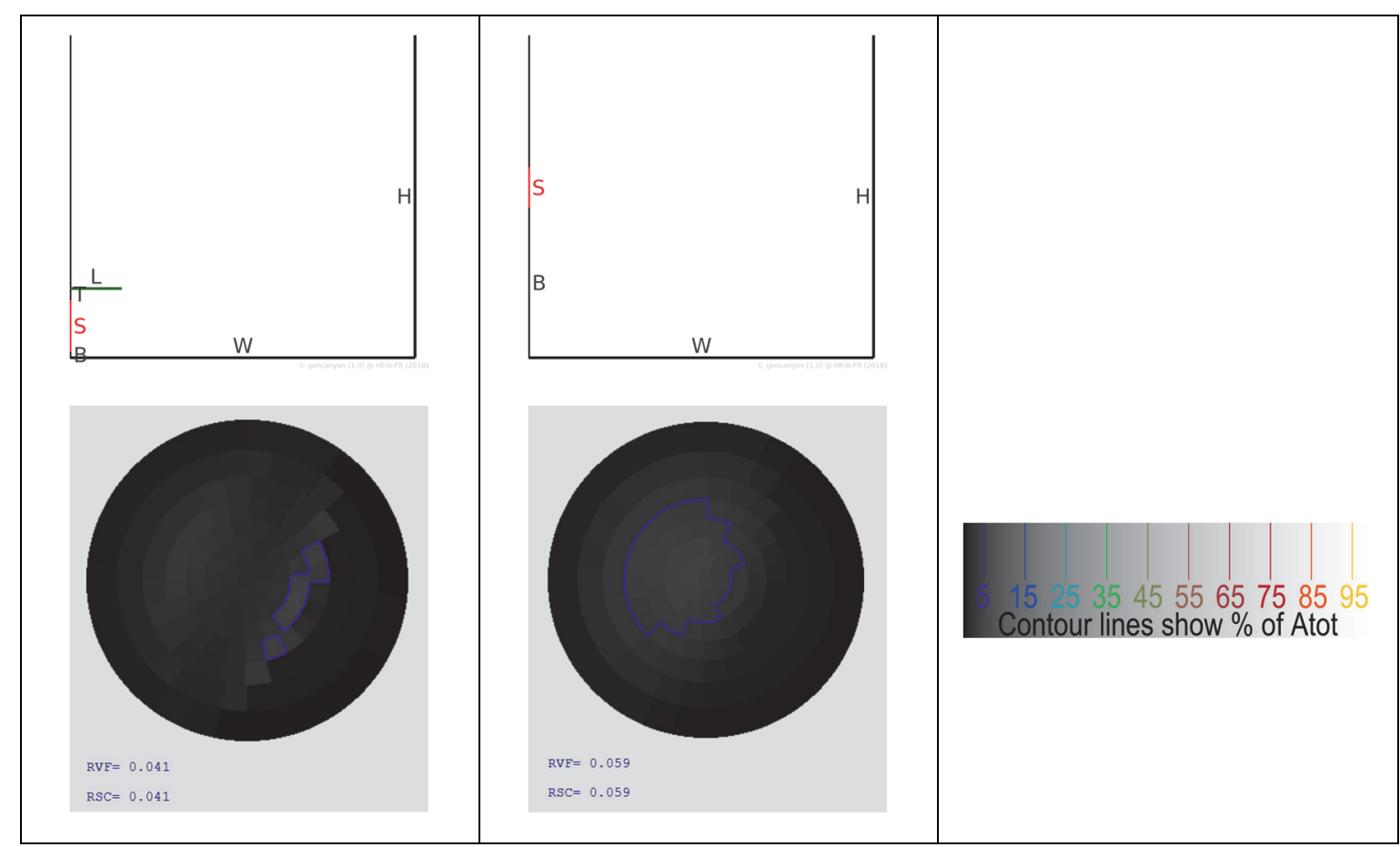

Fig. 8: RVF and RSC calculated for the shop's vitrine (left) and for the $3^{\text {rd }}$ floor façade (middle). To help visually comparing the effective envelope area pictures due to inter-reflections, coloured iso-contour lines are superimposed (right). These results showing that $\mathrm{RVF}=\mathrm{RSC}$ are a pure coincidence.

Here it appears that the shop's vitrine has an ASC value which does not comply with the minimal value of 0.05 recommended by (Littlefair, 2011). After repeating the calculations a few times by altering parameters $\mathrm{L}$ or $\mathrm{T}$, it appears that an ASC value of 0.05 can be reached, for instance, with a shorter overhang (i.e. decreasing length $\mathrm{L}$ to 2.75 ) or by elevating its position (i.e. increasing length $\mathrm{T}$ to 3.1 ).

The inter-reflections occurring between canyon's surfaces can also be taken into account in an effective envelope area picture. In this case, each picture pixel value is calculated differently: for each direction on the sky vault the 
considered area is weighted by a dimensionless factor that accounts for all inter-reflections that contribute to its irradiance. Technically this factor is computed using a particular Radiance program named rtcontrib (Ward, 2010) with the sky vault divided into 145 zones only. The resulting effective envelope area picture can again be intuitively interpreted as a representation of how the various directions on the sky vault are visible from an element. Interestingly, such a picture clearly shows that the whole sky vault contributes to the irradiance of a façade through inter-reflections.

In order to estimate the contribution of inter-reflections to the irradiance or illuminance, two new dimensionless indicators are defined: the Reflected View Factor (RVF) and the Reflected Sky Component (RSC). As shown below, they are both computed very similarly as SVF and ASC respectively:

The global irradiance $\mathrm{G}$ and the illuminance $\mathrm{E}$ of an element are first split into components as:

$$
\begin{aligned}
& \mathrm{G}=\mathrm{G}_{\mathrm{b}}+\mathrm{G}_{\mathrm{d}}+\mathrm{G}_{\mathrm{r}} \\
& \mathrm{E}=\mathrm{E}_{\mathrm{b}}+\mathrm{E}_{\mathrm{d}}+\mathrm{E}_{\mathrm{r}}
\end{aligned}
$$

with $\mathrm{G}_{\mathrm{b}} \mathrm{G}_{\mathrm{d}}$ and $\mathrm{G}_{\mathrm{r}}$ the direct, diffuse from sky and diffuse from inter-reflections irradiance respectively, and $E_{b} E_{d}$ and $E_{r}$ the direct, diffuse from sky and diffuse from inter-reflections illuminance respectively (for convenience, these components will be respectively named in short: direct, diffuse and reflected)

SVF and ASC can be computed as irradiance and illuminance ratios respectively:

$$
\begin{aligned}
& \mathrm{SVF}=\mathrm{G}_{\mathrm{d}} / \mathrm{G}_{\mathrm{dh}} \\
& \mathrm{ASC}=\mathrm{E}_{\mathrm{d}} / \mathrm{E}_{\mathrm{dh}}
\end{aligned}
$$

with $\mathrm{G}_{\mathrm{dh}}$ the diffuse irradiance computed on an unobstructed horizontal plane and $E_{\mathrm{dh}}$ the diffuse illuminance computed on an unobstructed horizontal plane.

Now RVF and RSC can be defined similarly:

$$
\begin{aligned}
& \mathrm{RVF}=\mathrm{G}_{\mathrm{r}} / \mathrm{G}_{\mathrm{dh}} \\
& \mathrm{RSC}=\mathrm{E}_{\mathrm{r}} / \mathrm{E}_{\mathrm{dh}}
\end{aligned}
$$

It is important to note that SVF and RVF are computed under a uniform sky (eq. 3 and 5) while ASC and RSC are computed under a standard CIE overcast sky (eq. 4 and 6).

Figure 8 shows how large the reflected component contribute to the irradiance and daylight illuminance in an urban canyon even with rather low reflectance values (0.2). By comparing Fig. 7 and 8 , it appears that for the shop's vitrine, the reflected component contribute four times more than the sky component!

Finally, effective envelope area pictures can also be combined with sky model pictures in order to compute solar irradiance or irradiation. These figures can be separated into their direct, diffuse and reflected components. The calculation requires three steps: First, a so-called "product picture" is obtained by making a pixel by pixel multiplication between the effective envelope area picture and the sky model picture. Second, the irradiance is computed by summing the values of all pixels contained in the product picture. Last, irradiation is obtained by multiplying the result with the number of hours accounted within the sky model picture. Figure 9 shows how a product picture is produced and how it appears. Note that on this figure, both effective envelope area pictures shown in Figures 7 and 8 have been merged together into a "total effective envelope area picture" that embed the relative contributions of the whole sky vault. The computed irradiations are shown on Figure 10.

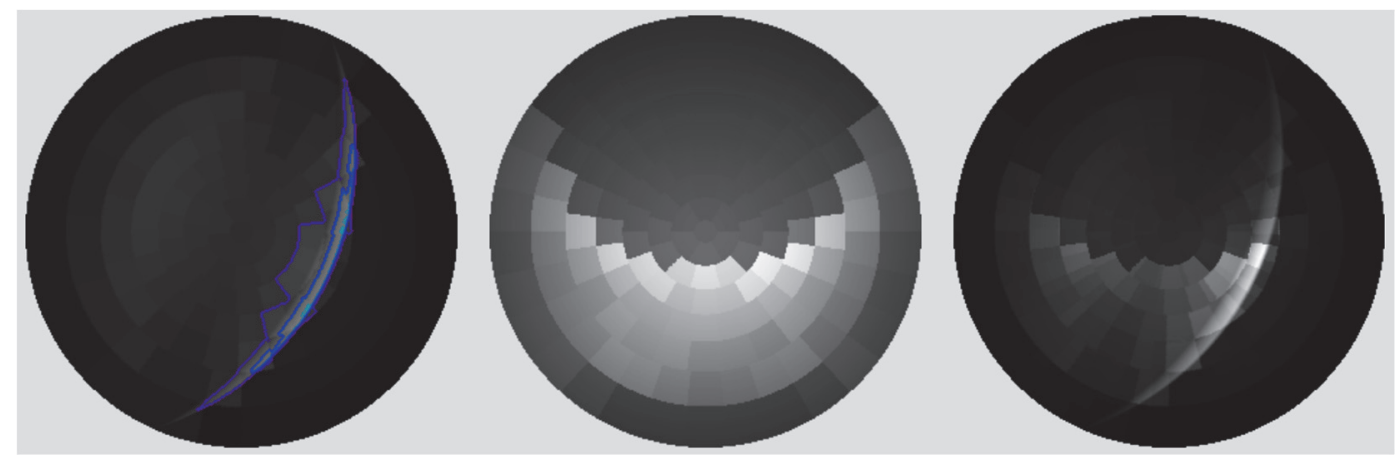

Fig. 9: Left: total effective envelope area picture computed for the shop's vitrine. Middle: annual sky model picture for Biel. Right: product picture from which annual irradiance or irradiation can be computed. 


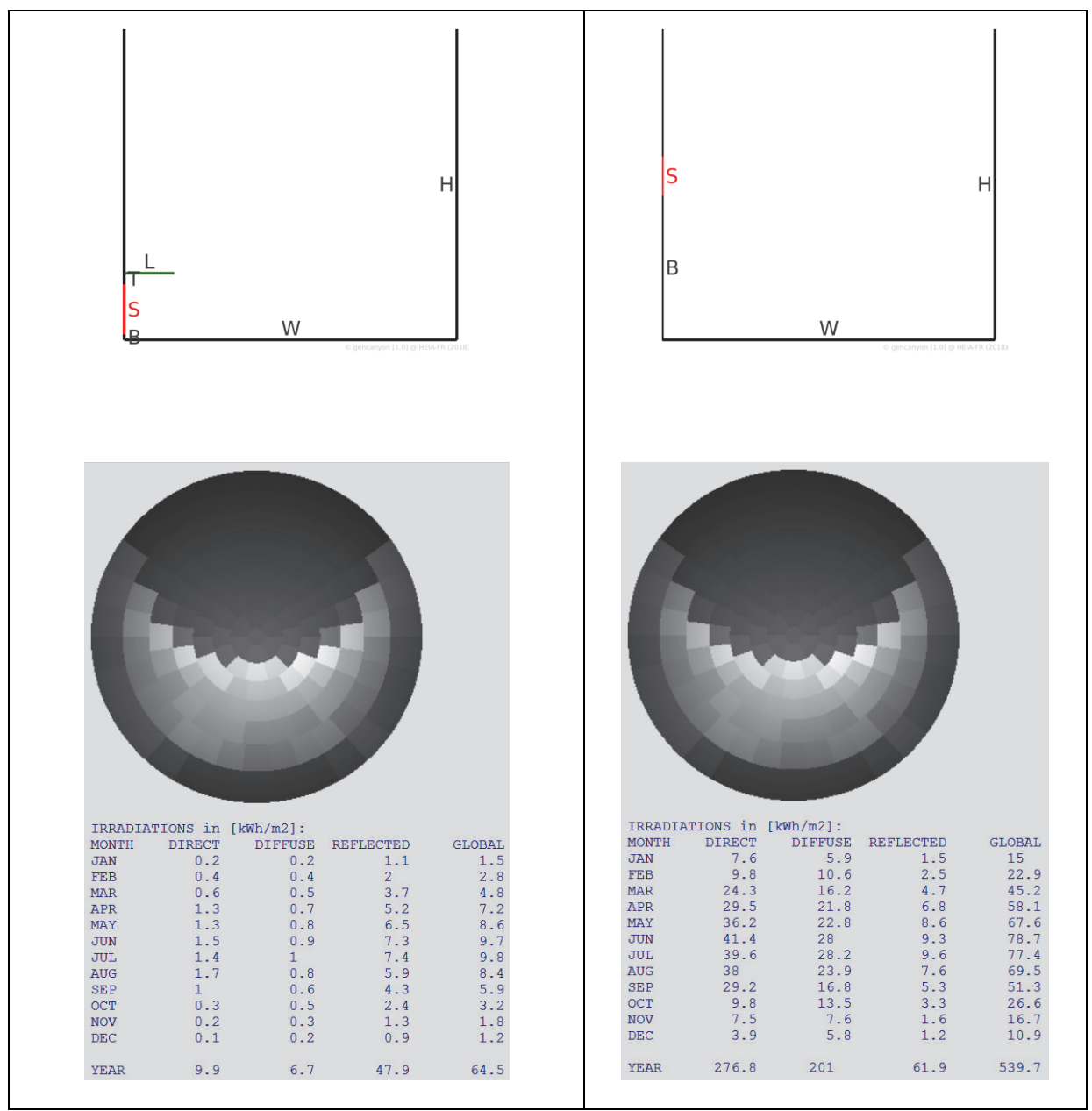

Fig. 10: Irradiations computed for the shop's vitrine (left) and for the $3^{\text {rd }}$ floor façade (right). The annual sky picture for Biel is displayed above the results.

\section{Conclusions}

The [UBC] tool offers a fast way to compute several indicators characterizing solar and daylight access in urban canyons. It uses a calculation method which is based around different types of images facilitating greatly the interpretation of the numerical results. In short, the solar and daylight access of an urban canyon is studied by separating the problem in two parts: a representation of the visibility of the considered surface (part of a façade or the street) from the sky vault (through a multishading mask and an effective envelope area picture) and representations of the climatic context (through a sunpath diagram or sky model pictures). By visually comparing these two representations, the user can understand why some canyon configurations perform better or worse than others do. Since the calculations are performed in just few seconds, the user is encouraged to explore how varying the adjustable parameters can affect the results.

This tool is mainly intended to serve for architectural and urban planning educational purposes. For instance, some of the questions that can be addressed using it are the following:

- Which urban canyon orientation is preferable for a specific location in order to increase the buildings' façades irradiation and enhance active or passive solar applications?

- In a warm climate, which urban canyon orientation offers the maximum shading on façades or on the street level?

- For a façade adjacent to a deep urban canyon, is the shading effect of the opposite façade sufficient to justify not equipping its windows with their own solar shading system? If so, up to which storey level is this valid?

- By how much varies the irradiation when the canyon's façades reflectance is modified?

Beyond the interactive web tool [UBC], the INDALUX open source software package [IDLX] is also available to perform calculations on more complex urban forms. 


\section{Acknowledgements}

The present study was conducted at the smart living lab [SLL] as part of the research project INDALUX funded by the Haute école d'ingénierie et d'architecture de Fribourg [HEIA] and a grant from the ARUP company. The authors would also like to thank the industry partners of the project namely, Paola Longato and Giulio Antonutto from ARUP, Julie Riedo from URBASOL and Céline Girard from CSD ingénieurs.

\section{References}

Chatzipoulka, Ch., Compagnon, R., Kaempf, J., 2018. An Image-Based Method to Evaluate Solar and Daylight Potential in Urban Areas. In: 2018 Proceedings of the Symposium for Architecture and Urban Design, pp. 337-344. Available at: http://simaud.org/proceedings/ [Accessed 27 August 2018]

Compagnon, R., Antonutto, G., Longato, P., Rotsch, A., 2015. Assessing daylight and sunlight access in the built environment: A new tool for planners and designers. In: Proceedings PLEA2015 - 31st Conference on Passive and Low Energy Architecture. Available at: https://multidoc.heia-fr.ch/record/2120 [Accessed 28 August 2018]

Compagnon, R., 2014. Evaluating solar irradiance on urban sites by superimposing Radiance pictures. In: $13^{\text {th }}$ International Radiance workshop. Available at: https://www.radiance-online.org/community/workshops/2014london [Accessed 5 September 2018]

WMO, 2008. Guide to Meteorological Instruments and Methods of Observation, 7th edition, World Meteorological Organization, Geneva, Switzerland.

Littlefair, P., 2011. Site layout planning for daylight and sunlight, a guide to good practice, BR 209 2nd edition. Building Research Establishment, Garston, UK.

Ward, G., 2010. The Radiance rtcontrib program. In: $9^{\text {th }}$ International Radiance workshop. Available at: https://www.radiance-online.org/community/workshops/2010-freiburg [Accessed 7 September 2018]

\section{Web references}

[HEIA] Haute école d'ingénierie et d'architecture de Fribourg: https://heia-fr.ch [Accessed 29 August 2018]

[IBIC] Image based irradiation \& irradiance calculations: https://phybat.heia-fr.ch/ibic/ [Accessed 28 August 2018] [IDLX] INDALUX software package: https://phybat.heia-fr.ch/idlx/ [Accessed 6 September 2018]

[MET] Meteonorm; Irradiation data for every place on Earth: http://www.meteonorm.com/ [Accessed 6 September 2018]

[RAD] Radsite: https://www.radiance-online.org/ [Accessed 5 September 2018]

[SLL] smart living lab: a research and development center for the built environment of the future: http://smartlivinglab.ch [Accessed 29 August 2018]

[UBC] UBC: an online tool to evaluate solar and daylight access in urban canyons: https://phybat.heia-fr.ch/ubc/ [Accessed 29 August 2018] 


\title{
Development of a compact and didactic solar energy kit using Arduino
}

\author{
João Costeira ${ }^{1}$, Manuel Vieira' ${ }^{1}$, Abolfazl Hayati ${ }^{2}$, João Gomes ${ }^{2}$, and Diogo Cabral ${ }^{2}$ \\ 1 University of Minho, Portugal \\ 2 University of Gävle, Sweden
}

\begin{abstract}
When the sun rises, so does the key element that will shape the future of the world energy landscape. It is not an understatement to say that the solar energy industry is beginning to lead the path towards a sustainable future for all of us. However, the awareness of the potential of this amazing source of energy must begin from the most basic levels of education all the way to university. The scope of this paper is to display a new compact and didactic solar energy kit with the potential to replace current high cost and complex solar energy kits. These solutions are often too expensive and therefore unavailable for most of Europe's public schools. As such, an equipment was developed using an open-source platform called Arduino that will enable students to conduct practical experiments in a fast, effective and simple manner and thus allow students to acquire the proper expertise in areas like energy, electronics, and programming.
\end{abstract}

Keywords: Photovoltaic (PV) cells; Solar energy; Teaching kit; Active learning; Arduino

\section{Introduction}

The education of science and engineering plays a significant role in modern society, serving as a base for the current technological developments. Moreover, the increased demand for sustainable sources of energy, like solar or wind, must be side by side with a sustained educational policy that provides trustworthy tools and conditions for young students to develop their technical skills in such areas as well as increase their awareness of the existing green technologies. Integrating labs with lectures can also increase the so called-active learning with students via learning by doing experience (Sanders et al., 2017). Renewable energy technologies are experiencing a rapid growth, like solar photovoltaic with the recent reaching of the $300 \mathrm{GW}$ milestone, and this is leading to a larger scale production and price reduction. Nonetheless, this rapid growth has exacerbated the problem of a serious shortage of skilled professionals, with experience in renewables (Jennings, 2009). Among the most important needs of the renewable energy industry are the initial training of scientists and engineers to design and develop new renewable energy systems (Jennings, 2009). Additionally, studies have identified the lack of undergraduate studies in renewable energy technologies, the unsatisfactory, encyclopedic rather than a systematic approach to teaching renewable energy sources at engineering faculties (Keramitsoglou and Kiriaki, 2016). As such, the improvement of the current solar energy equipment used in schools and universities is particularly sought after, especially if this improvement culminates with an increased technical skill obtained.

One of the main objectives for the construction of the photovoltaic (PV) solar energy teaching kit, the so-called CompactSun (Costeira, 2017), is to allow students to perform quality experiments in reduced space and in a faster manner. In fact, schools often do not have laboratory spaces and small classrooms by nature, are used as test benches. Compact systems can be built by reducing the number of components and materials used in the experiments and by improving their portability. In this context, and given that this kit was developed to be used mainly by secondary school students in a classroom context, it is crucial that the kit can be easily used without jeopardizing the learning objectives.

Taking into consideration that the main purpose of the development of this equipment is to provide students with learning by doing experience, we chose to use a hardware and software tool called "Arduino" (Arduino, 2018). Arduino is an electronic open-source platform and is widely used for various projects in the areas of electronics and robotics. 
Among the several advantages of Arduino are the following:

- $\quad$ Reduced price of its components;

- Transversally of your software, operating in the various operating systems;

- Simple programming environment;

- Open-Source Software;

- Open-Source Hardware.

The development of the CompactSun was driven by the increasing need to raise awareness near the next generations of students for the environmental challenges and provide the initial tools to the future solar energy engineers and scientists. The most advanced solar energy kits are often too expensive for most of the public schools, which are often obligated to rely on lower quality and cheaper didactic kits that aren't capable of helping students to meet their learning needs and don't stimulate the students to pursue a solar engineering career.

The main aim is to conduct practical experiments in a fast, effective and simple manner and thus allow students to acquire the proper expertise in areas like energy, electronics and programming. Moreover, such product should be affordable for the wide range of secondary schools throughout the world. As such, a reliable and innovative solar learning equipment was designed to help students to develop not only their energy skills but also their programming and engineering capabilities.

\section{Methods}

In order to verify the full functionality of the CompactSun prototype, two experiments were conducted. For both experiments, a 50W halogen lamp was used as a light source.

\section{Experiment 1: Association of series connected photovoltaic}

A photovoltaic system can be installed on the roof of a house in order to convert solar energy into electricity and help meet the energy needs of a particular family. The power of a cell, module or photovoltaic panel is measured in Watts (W), is calculated by the product between the voltage (V) and the current (I) it produces. In order to ensure that the system functions properly, it is necessary to find the correct balance between voltage and current. For this purpose, the PV cells or modules can be connected in series, in parallel or with a mixed configuration depending on the needs of the system to be fed. Students should discover through this experiment the effect on the voltage and current of the system of the connection of connected cells in series.

The solar cells used in these experiments each had $0.8 \mathrm{~W}$ power with $5 \mathrm{~V}$ Open Circuit Voltage (V $\left.\mathrm{V}_{\text {OC }}\right)$ and 160 $\mathrm{mA}$ Short Circuit Current $\left(\mathrm{I}_{\mathrm{SC}}\right)$. The dimension of each cell was $80 \times 80 \times 3 \mathrm{~mm}$. Using the photovoltaic solar photovoltaic prototype kit, students are asked to measure open circuit voltages and short-circuit currents for each of the three $0.8 \mathrm{~W}$ cells individually and record the values. They should then be series connected, the first cell to the second cell and then associate the third cell in series with the previous cells, see figure 1.

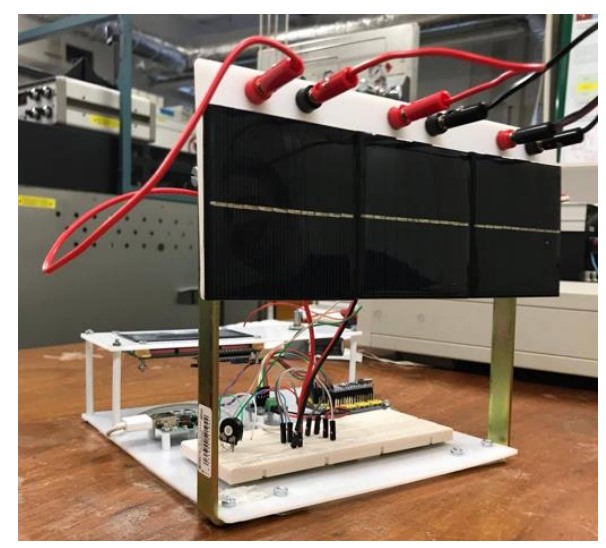

Fig. 1: Set up for experiment 1 - Association of series connected photovoltaic cells 


\section{Experiment 2: Current-Voltage (IV) characteristic curve of a photovoltaic cell.}

If no load (for example an electric resistance) is connected to the photovoltaic cell under illumination, an open circuit voltage will be obtained but no current flow will occur. If the terminals of the photovoltaic solar cell are connected to one another (short-circuit condition) a very high current, the so-called short-circuit will be produced, but with a zero voltage. In either case, no power is produced. However, if a load with variable resistance is added it is possible to produce the characteristic curve of the PV cell. The objective of this experiment is to understand the influence of the variation of the load resistance on the voltage and current values of the photovoltaic cell.

In this experiment the photovoltaic solar energy teaching kit integrates only one cell, having $4.5 \mathrm{~W}$ power with 6 V Open Circuit Voltage $\left(\mathrm{V}_{\mathrm{OC}}\right)$ and $750 \mathrm{~mA}$ Short Circuit Current $\left(\mathrm{I}_{\mathrm{SC}}\right)$. The dimension of the cell was $165 \times 165 \times 3$ $\mathrm{mm}$. The photovoltaic cell was exposed to the action of a light source emitted by a $50 \mathrm{~W}$ halogen lamp. Figure 2 shows the prototype of the photovoltaic solar energy teaching kit with cell a) integrated into the system. Furthermore, a load (100 $\Omega$ potentiometer) was added to the system. In order to obtain the characteristic IV curve, the student must vary the load resistance of the system by using a potentiometer.

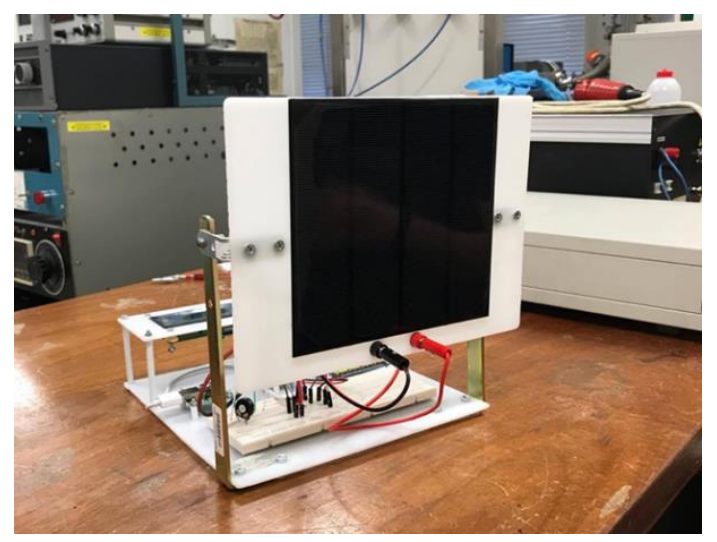

Fig. 2: Set up for experiment 2 - Current-Voltage (IV) characteristic curve of a photovoltaic cell

\section{Results and discussion}

The first task was to measure Voltage (V) and the Current (I) of each of the 3 solar cells individually. The results are presented in Tab. 1. Next, each cell was gradually connected to the other and the same parameters measured. Cell 1 individually, cell $1+$ cell 2 and finally cell $1+$ cell $2+$ cell 3 . The results are presented in table 2 .

Tab. 1: Voltage and Current of the three $0.8 \mathrm{~W}$ solar cells individually

\begin{tabular}{|c|c|c|c|}
\cline { 2 - 4 } \multicolumn{1}{c|}{} & Cell 1 & Cell 2 & Cell 3 \\
\hline $\begin{array}{c}\text { Voltage } \\
(\mathbf{V})\end{array}$ & 5.28 & 5.32 & 5.26 \\
\hline $\begin{array}{c}\text { Current } \\
(\mathbf{m A})\end{array}$ & 152.1 & 155.2 & 153.6 \\
\hline
\end{tabular}

Tab. 2: Series connection of the three solar cells

\begin{tabular}{|c|c|c|c|}
\cline { 2 - 4 } \multicolumn{1}{c|}{} & Cell 1 & Cell 1 + Cell 2 & Cell 1 + Cell 2+ Cell 3 \\
\hline Voltage (V) & 5.28 & 10.58 & 15.84 \\
\hline Current(mA) & 152.1 & 154.7 & 153.4 \\
\hline
\end{tabular}

After analyzing the experimental results, one can realize that the open circuit voltages of the individual cells correspond approximately to the open circuit voltage value supplied by the manufacturer $(5 \mathrm{~V})$. By associating the electrically coupled cells in series, it would be expected that the open circuit voltage of the system would be equal to the sum of the individual voltages of each cell. This assumption was successfully tested, as can be seen from the analysis of table 2 . 
Regarding the short-circuit current of the individual cells; it was also found that the values obtained are very close to the values reported by the manufacturer $(160 \mathrm{~mA})$. On the other hand, it is also observed that after the series connection has been made, the short-circuit current of the system practically remains unchanged. However, it should be noted that the small differences recorded in the short-circuit current values occur because they are located at slightly different distances from the light source. In fact, the central cell is slightly closer to the light source than the remaining two that are located at the end of the system, as can be seen in figure 1 . This behaviour asserts that the distance and the angle of incidence of the light on a collecting surface are directly related to the number of photons that impinge on that surface and, consequently, capable of transmitting the sufficient energy differently to the electrons to generate electric current

In the second experiment, the photovoltaic solar energy teaching kit included only one cell. The photovoltaic cell was exposed to the action of a light source emitted by a $50 \mathrm{~W}$ halogen lamp, see figure 2 . The resistance of the load was varied from the minimum to the maximum resistance and the values of voltage, current and resistance of the system displayed by the Liquid Crystal Display (LCD) were registered, see table 3. The values obtained were used to create the characteristic current-voltage (IV) curve of the cell, see Fig 3.

Tab. 3: Voltage, current and resistance registered in the experiment 2 set-up

\begin{tabular}{|c|c|c|c|}
\hline $\begin{array}{c}\text { Turns } \\
\text { (in the } \\
\text { potentiometer) }\end{array}$ & Voltage (V) & Current (mA) & Resistance $(\boldsymbol{\Omega})$ \\
\hline Minimum load & 0.08 & 66.7 & 1.2 \\
\hline 1 & 0.72 & 66.2 & 10.9 \\
\hline 2 & 1.55 & 65.7 & 23.6 \\
\hline 3 & 2.09 & 65.3 & 32.0 \\
\hline 4 & 2.59 & 61.5 & 42.1 \\
\hline 5 & 3.06 & 59.8 & 51.2 \\
\hline 6 & 3.57 & 57.4 & 62.2 \\
\hline 7 & 4.06 & 56.4 & 72.0 \\
\hline 8 & 4.49 & 55.3 & 83.5 \\
\hline 9 & 4.87 & 53.8 & 90.5 \\
\hline 10 & 4.93 & 48.7 & 101.2 \\
\hline
\end{tabular}

According to figure 3, the IV curve produced with the experimental results is similar to the conventional IV curve of a solar cell thereby proving the functionality of the system. Plus, this practical experiment can easily be performed by untrained students with minimal guidance within 15-30 min. This is possible because the setup is already made and the results appear in the LCD automatically thus allowing a significant reduction in time. The IV curve experience is one of the most important tasks for those who want to learn the basics of electronics within the solar energy context. To reap the benefits of this task, one must keep the duration of the experiment below 30 min and avoid distracting deviations such as wiring. The IV curve experiment requires minimum wiring from the student, if the setup is previously prepared by the teacher, and therefore it can be completed faster.

It should be emphasized that the final price of the developed product was only around 75 Euros. For information about each component, please refer to (Costeira, 2017). This aspect is extremely important as it makes this system extremely competitive against similar products on the market and therefore endowing it with a high commercial potential as it can be widely purchased and used by hundreds of national and foreign high schools. 


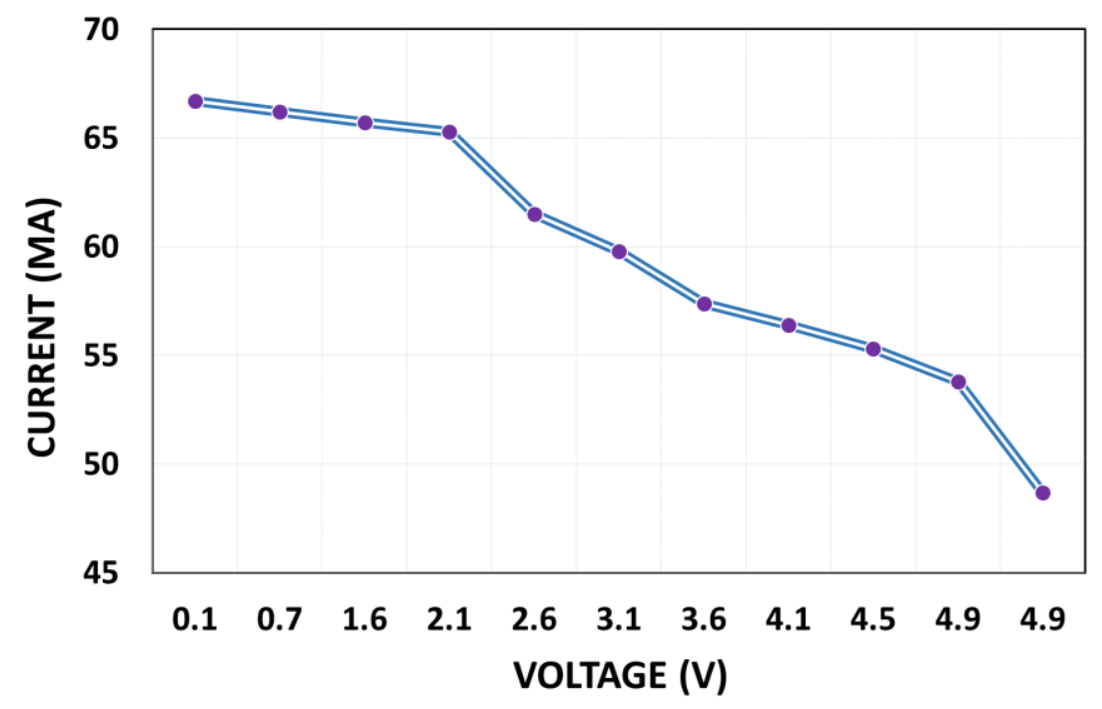

Fig. 3: IV characteristic curve of a $4.5 \mathrm{~W}$ solar cell

\section{Conclusions}

The results obtained from the practical experiments conducted to certify the functionality of the kit and its potential to significantly increase the quality of solar energy education throughout the various levels of education all over the world. Furthermore, given the fact it is a low-cost equipment it can be purchased even by schools in the socalled "developing countries" and thus provide valuable conditions for students to develop their engineering acumen. In addition, the setup of the experiments allows a significant reduction in time required to perform them, when compared to experiments undertaken with conventional products. The CompactSun displays great versatility and allows students to perform distinct experiments with varying degrees of difficulty. As such, it is possible and recommends for maximum learning that the setup is built completely by the student, including programming and connections. This option, however, comes with the caveat that the duration of the experiment will increase with the rising difficulty. Notwithstanding, great benefits are obtained by the students who perform the experiments such as the ones described in this paper.

The time has come to provide the future generation of scientists and engineers with proper tools that fit their increasing potential. Additional improvements in design and robustness of the CompactSun are required to guarantee its durability and ensure reliable interest by the students.

\section{References}

Arduino. (2018, September 2). What is Arduino? Available at: https://www.arduino.cc/en/Guide/Introduction\#.

Costeira, J. (2017). Desenvolvimento de um kit didático de energia solar fotovoltaica. [Development of a photovoltaic solar energy teaching kit], Master thesis (In Portuguese), University of Minho, Portugal. http://hdl.handle.net/1822/54825

Jennings, P., (2009). New directions in renewable energy education. Renewable Energy, 34(2), 435-439. https://doi.org/10.1016/j.renene.2008.05.005.

Keramitsoglou, Kiriaki, M., (2016). Exploring adolescents' knowledge, perceptions and attitudes towards Renewable Energy Sources: A colour choice approach. Renewable and Sustainable Energy Reviews, 59, 11591169. https://doi.org/10.1016/j.rser.2015.12.047.

Sanders, K., Boustedt, J., Eckerdal, A., McCartney, R., \& Zander, C. (2017, August). Folk pedagogy: Nobody doesn't like active learning. In Proceedings of the 2017 ACM Conference on International Computing Education Research (pp. 145-154). ACM. DOI: 10.1145/3105726.3106192. 


\title{
Using Heliodon for Solar Building Design Education in the Age of Computer Simulations
}

\author{
Luka Pajek, Jaka Potočnik, Mateja Dovjak, David Božiček, Nika Šubic, Roman Kunič \\ and Mitja Košir \\ University of Ljubljana, Faculty of Civil and Geodetic Engineering, Ljubljana (Slovenia)
}

\begin{abstract}
Nowadays, engineering students tend to focus on computer simulations for the study of real-world phenomena, although in many cases they do not understand the basic principles behind the specific software. Therefore, in the time of computers, using a heliodon (physical device for solar analysis) for educational purposes might be an encouragement. The presented paper discusses the differences between analogue (heliodon) and digital (computer simulation) methods for determining insolation through educational work with students at bachelor level. Through the comparison of insolation results obtained by computer software and those obtained by heliodon, the potential accuracy error of the heliodon was evaluated. The results showed that the highest achieved accuracy of the analysed heliodon was at scale 1:400 (average error 7\% on the equinox and 20\% on the winter solstice). Furthermore, a questionnaire was handed to the students during the Bioclimatic design course at the University of Ljubljana. The students evaluated the user-friendliness of heliodon as sufficient (mean SUS score was 83.3).
\end{abstract}

Keywords: solar geometry, insolation, teaching tools, System Usability Scale (SUS), heliodon

\section{Introduction}

The knowledge about (energy) performance of buildings is becoming an increasingly important subject for architects, architectural, civil and environmental engineers. Consequently, the curricula of architecture and engineering schools are giving the field ever greater attention resulting in introduction of new courses as well as whole study programs dedicated to the field of architectural engineering (DTU, 2018; KTH, 2018; TU Berlin, 2018; UL, 2018; UMONS, 2018; University of Leeds, 2018). Due to the complexity of the subject, characterized by the need for holistic treatment of buildings (e.g. energy performance, passive design, daylighting, renewable energy integration, indoor comfort, environmental impacts, etc.), sophisticated and complex simulation tools are often used during the educational process. Such approach assists students to address the problems at hand with great detail and complexity. However, from the educational point of view, the sole reliance on complex simulation tools such as EnergyPlus can obscure the basic principles governing the performance of buildings, resulting in poor understanding by students. It can be argued that for the purpose of education of engineers the understanding of basic principles is crucial, as it establishes solid foundations on which advanced knowledge can be built. In the context of energy performance of buildings and daylighting, one of such basic principles is understanding of solar geometry and its impacts (e.g. solar gains, shading, etc.) on the design of building elements and components.

The teacher is faced with the dilemma of how to present the subject of solar geometry to the students enrolled into engineering courses. The two most common approaches are the use of sun charts or diagrams (either in physical or digital form) and the use of computer models (Muneer et al., 2004; Prinsloo and Dobson, 2015). However, both methods lack in plastic representation of the problem, as they are disassociated from the real world phenomena and, therefore, demand an abstract and conceptualized understanding from the students. This in particular was identified as a problem through our educational work with students in junior years of Civil Engineering and Sanitary Engineering (i.e. Public and Environmental Health Professionals) at the University of Ljubljana (UL), Faculty of Civil and Geodetic Engineering (UL FGG) and Faculty of Health Sciences (UL ZF), respectively. Through practical work with the students, we recognised that some students have problems with the interpretation and relation between the abstract results gained from sun charts and/or computer simulations and the real world case of the studied building. As an alternative, a more intuitive approach using solar emulators can be implemented, where students use physical models of buildings under an artificial sky or a heliodon device (Lechner, 2018, 2015; Shaviv, 1999) to perform solar analysis. The main benefit of such approach is that the relation between building shading and the apparent position of the sun in the sky is more evident in spatial as well 
as in temporal context. This also provides a more plastic representation of the studied problem as well as a gradual translation between the real world phenomena and the abstract engineering tools used for its representation. However, the use of heliodon and especially artificial sky can present its own set of problems, mainly connected to the physical size, cost of construction and maintenance of such devices as well as to the accuracy of results.

This paper presents a heliodon emulator constructed at UL FGG (Fig. 1). Further on, its accuracy was tested and compared to computer simulation. Because the primary function of the UL FGG heliodon is to be used in the context of educational process, the feedback from students regarding the use of the device was acquired through a simple survey conducted within the course Bioclimatic design run at both faculties (i.e. UL FGG and UL ZF). Finally, the pros and cons of using heliodon as a teaching instrument in the digital age, when engineers are predominantly dependent of the use of computer simulations, is debated.

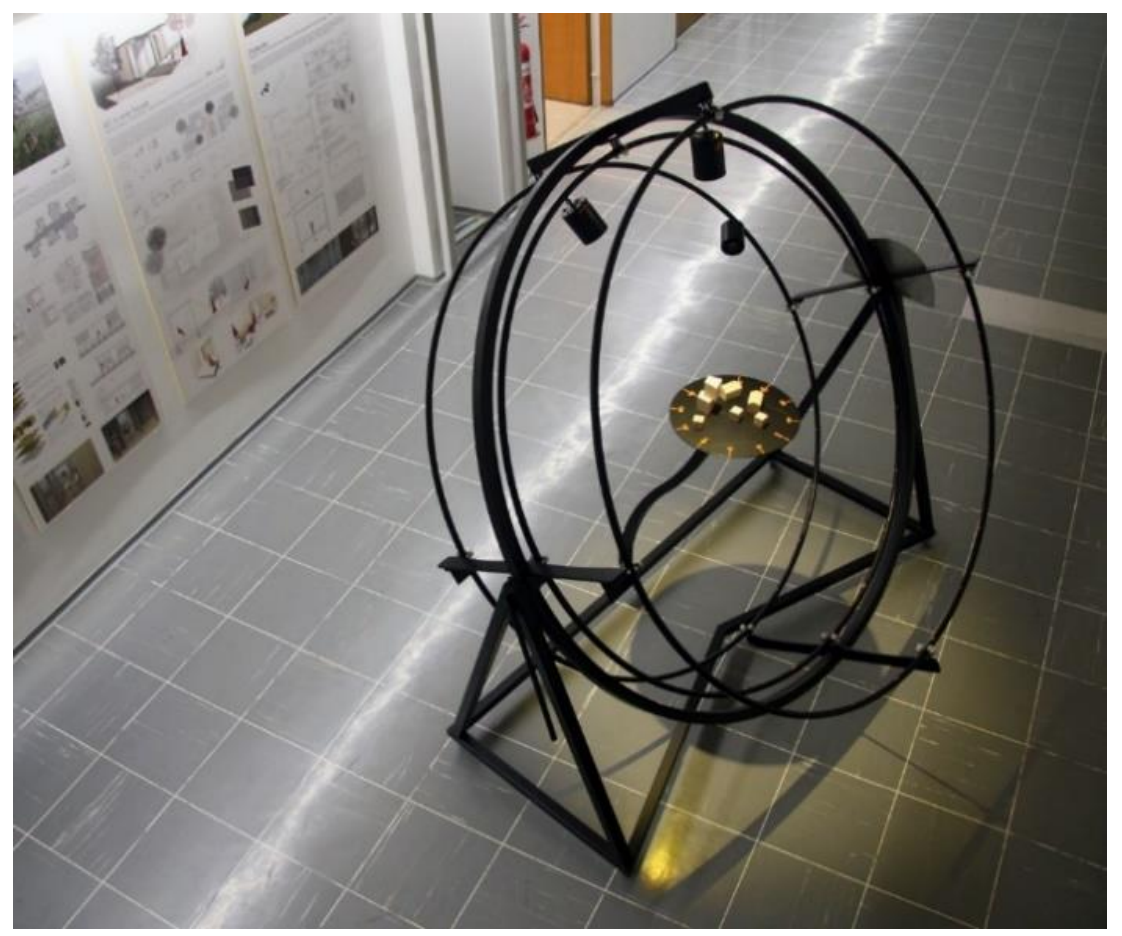

Fig. 1: Heliodon used for the educational purposes within the Bioclimatic design course held at UL FGG and UL ZF.

\section{About heliodon}

Broadly speaking, heliodon is any device that enables to physically (i.e. using models) simulate the effects of yearly and daily movement of the Earth around the Sun. All such devices, irrespective of theirs construction and design, represent the Sun-Earth geometric relationship through a lococentric view (Szokolay, 2014, 2007), where it is assumed that the observed location is fixed and the Sun moves around it. Because of this assumption, they are in fact emulators and not simulators, because they represent the effect of the Sun-Earth geometric relationship and not the physical process behind it. The main objective of heliodons in architectural applications is to determine the insolation of building surfaces (e.g. walls, windows, roofs, etc.), which has a direct impact on the energy performance as well as daylighting of buildings. All heliodon devices can be classified into one of the two categories (Cheung et al., 2012):

- Heliodons with fixed or movable light source representing the Sun and a movable and/or rotatable surface representing the Earth surface onto which the model of a building is placed. The tilting of the surface with the model defines the geographical location (i.e. latitude), the movement of the light source defines the change in seasons (i.e. months) (Cheung et al., 2012; Lechner, 2015), while the rotation of the model defines the hours in a day. Such devices are compact and easy to use. However, they are conceptually unclear, as the apparent movement of the Sun across the sky, observable in reality, is not presented (Lechner, 2015).

- The second group is comprised of heliodons with fixed horizontal surface representing the surface of the Earth and the location of the model (Figs. 1 and 2). The light source representing the Sun is rotated around the analysed fixed model using a ring representing the Sun trajectory in a specific month (Cheung et al., 2012; Doberneck and Knechtel, 2013; Lechner, 2018, 2015; Olgyay and Olgyay, 1957). The rotation of the ring with 
the light source emulates the daily movement of the Sun (i.e. hours), while the tilting of the ring with respect to the observed surface defines the geographical location of the analysed model. Individual rings represent monthly Sun trajectories. Such devices are conceptually clear, because they faithfully (although transformed) represent the observable Sun-Earth relationship perceived from the surface of the Earth. A drawback of this type of heliodons is their size, as they need to be large in order to facilitate the analysis of larger models; their accuracy is strongly related to the distance between the light source and the observed model (Lechner, 2015).

Because the presented UL FGG heliodon prime intention was to use it in the educational process, the type with fixed horizontal surface was chosen, because it is conceptually clear and therefore easier to understand by the students. The basic scheme of the UL FGG heliodon was taken from the heliodons presented by Lechner (Lechner, 2018, 2015) and by Doberneck and Knechtel (Doberneck and Knechtel, 2013) and adapted to suit the needs of the educational process and physical limitations of the classrooms. Therefore, the main limitation in the design of the heliodon was its final physical size, which was limited by the $900 \mathrm{~mm}$ wide and $2300 \mathrm{~mm}$ high door of classrooms at the UL FGG building. As a result, all other dimensions were derived from this limitation, thus also defining the maximum sizes or scales of models that can be tested with sufficient accuracy. The UL FGG heliodon consists of a horizontal surface placed in the centre of the heliodon with a diameter of $400 \mathrm{~mm}$, onto which a model of building can be placed. Surrounding it, there are the three rings with light sources depicting the Sun trajectories at equinoxes as well as summer and winter solstices (Fig. 2), effectively defining the extremes of the apparent Sun movement across the sky. These rings can be rotated in order to move the light source to the correct hour of a day (i.e. $15^{\circ}$ rotation $=1 \mathrm{~h}$ ). They are also fixed into a fourth larger ring that can be rotated around the longitudinal axis of the heliodon (Fig. 2). Tilting the external main ring defines the geographical location of the analysed model by setting the latitude from $0^{\circ}$ (i.e. equator - rings are vertical) to $90^{\circ}$ (i.e. pole - rings are horizontal). The rotation of the inner ring as well as of the tilting of the main ring are manual. The light sources used to depict the Sun are remotely controlled battery powered LED lights with maximum luminosity of $900 \mathrm{~lm}$.

The main limitation influencing the accuracy of the UL FGG heliodon is the use of non-parallel light source, meaning that the LED lights will also cast non-parallel shadows, which is not the case with the real Sun. This limitation could be addressed by placing the lights farther away from the centre of the heliodon. However, this would increase its size, which was limited by the above mentioned width of the classroom doors. Alternatively, a quasi-parallel light source using Fresnel lenses could be used (Cheung et al., 2012). Nevertheless, we opted not to implement such a design due to its bulkiness and complexity and rather opted for simplicity while sacrificing some accuracy.

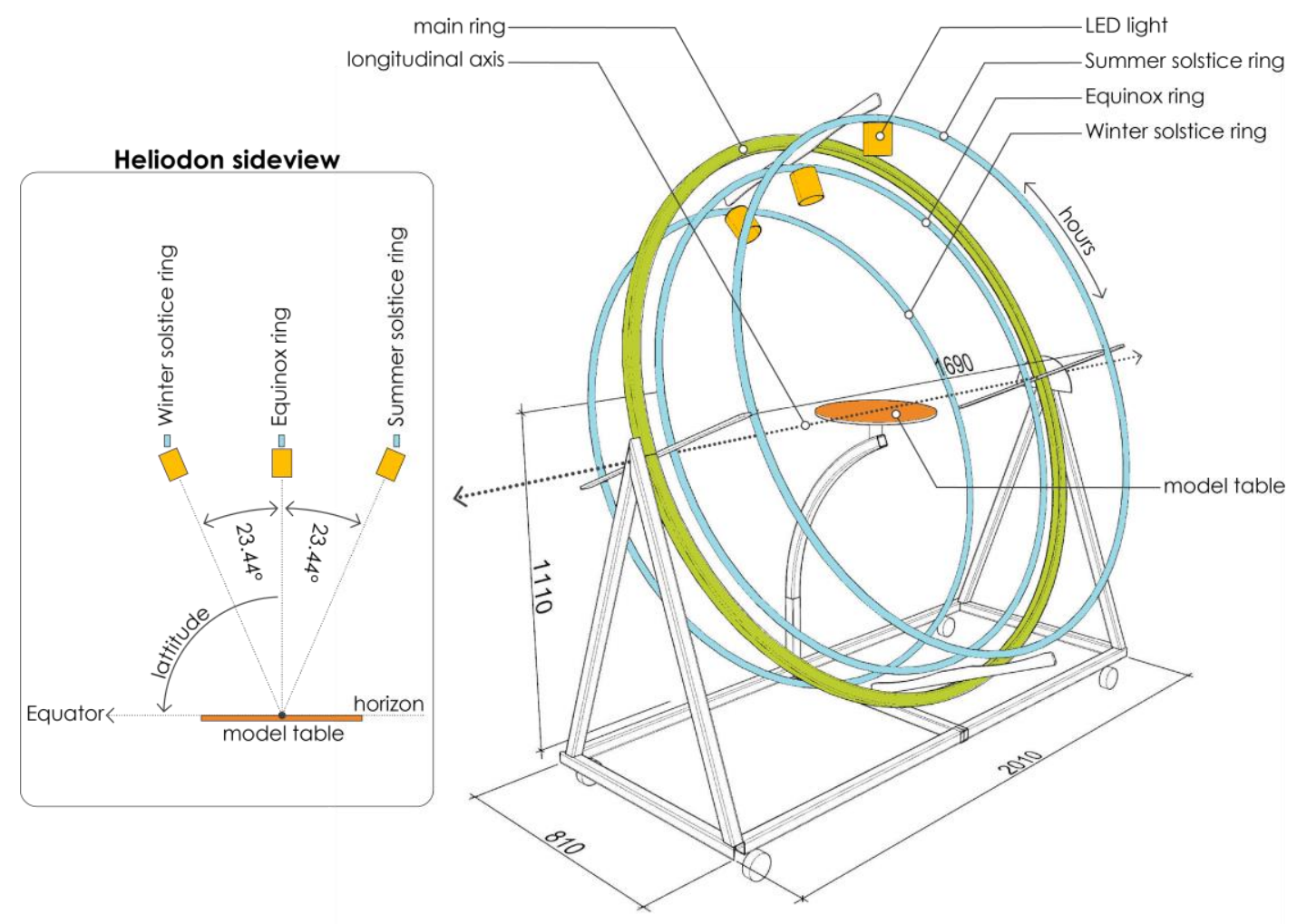

Fig. 2: Perspective drawing of the UL FGG heliodon with main dimensions given in mm. 


\section{Methodology}

The study included an experimental and an experiential evaluation of the UL FGG heliodon emulator. For the purpose of the experimental evaluation, a comparison between the attained results using analogue (i.e. heliodon) and digital (i.e. computer simulation) methods for determining insolation was executed. Thus, the potential error in the accuracy of the heliodon was easier to evaluate. The results of both methods were used to identify the difference between the results obtained by computer and by the heliodon. Secondly, for the experiential part of the study, a comparison between the methods was evaluated using questionnaires handed out to the students during the spring semester of the 2017/18 academic year at the UL FGG and UL ZF. The focus of the questionnaires was to evaluate the students' opinion about the use of heliodon during the executed practical exercises. Additionally, they were asked about their preference at studying insolation - using the heliodon or, rather, computer simulations. Both experimental and experiential results were used to assess the usefulness of the heliodon as a teaching tool.

\subsection{Experimental evaluation of heliodon}

A simplified parallelepiped shaped building model with sides ratio of 1:1:2 (i.e. L:D:H) was tested at the geographical location of Ljubljana, Slovenia $\left(46^{\circ} 3^{\prime} \mathrm{N}, 14^{\circ} 30^{\prime} \mathrm{E}\right)$. Both, digital model for computer simulations and equivalent physical models used for the heliodon analysis were made at various scales corresponding to realistic building size of $6 \mathrm{~m} \times 6 \mathrm{~m} \times 12 \mathrm{~m}$. For the analysis, we selected three different sizes of models, namely small (scale of 1:400, corresponding model dimensions of $15 \mathrm{~mm} \times 15 \mathrm{~mm} \times 30 \mathrm{~mm}$ ), medium (scale of 1:200, corresponding model dimensions of $30 \mathrm{~mm}$ x $30 \mathrm{~mm}$ x $60 \mathrm{~mm}$ ) and large (scale of 1:100, corresponding model dimensions of $60 \mathrm{~mm} \times 60 \mathrm{~mm} \times 120 \mathrm{~mm}$ ). The shadows cast by the described models placed under the heliodon were drawn on a standard ISO A3 format (i.e. $420 \mathrm{~mm}$ x $297 \mathrm{~mm}$ ) paper and later scanned into a digital form. The results of computer simulations were also generated in such a manner as to correspond to the sizes acquired by the heliodon analysis. For the digital simulations, a plug-in software for Rhinoceros named DIVA (Solemma LLC, 2018) was used. An hourly shadow analysis was conducted by both the heliodon and computer simulations for each hour from 7.00 until 17.00, solar time, for selected critical days of the year when the shadows are more prominent (i.e. winter solstice and equinox). The evaluation of the acquired results was done by overlaying the simulated and emulated results and calculating the respective areas of shadows for each plotted hour. The simulated results were used as a reference for error (ERR) calculation and were considered to be $100 \%$ accurate. Therefore, heliodon ERR was determined using equation 1.

$E R R=100-\left(\frac{A_{\text {hel }}}{A_{\text {sim }}} \times 100\right)$

Where ERR is error of the heliodon shadows in \%; Asim is area of simulated shadows and Ahel is area of the heliodon shadows. ERR was determined for each scale (i.e. 1:100, 1:200 and 1:400) and for both analysed dates (i.e. winter solstice and equinox). However, only shadows that were entirely cast inside the projection area (i.e. $420 \mathrm{~mm} \times 297 \mathrm{~mm}$ ) were considered as relevant for calculating the average heliodon error. In particular, incomplete shadows were omitted from the average ERR evaluation. The expected heliodon error due to the nonparallel light source will be accentuated at the selected critical days as well as during early morning and late afternoon hours due to longer shadows caused by the low incident angles of emulated sunlight. Analogously, error will increase with larger scale or by moving the observed object from the centre of the heliodon.

\subsection{Experiential evaluation of heliodon}

One of the aspects of the experiential evaluation of a product or a tool is the usability testing. Performing usability testing greatly benefits users by minimizing or eliminating their frustration, because it exposes design issues, which can be improved (Rubin and Chisnell, 2008). An example of a questionnaire used to determine user satisfaction with a product they used is SUS, or System Usability Scale, which is also part of the ISO standard 9241 (Rubin and Chisnell, 2008). According to Brooke (Brooke, 1996), SUS is a quick, reliable, low-cost usability ten-item scale that can be used for global assessments of usability. The SUS is used immediately after the respondent had an opportunity to use the product and has to be filled before any debriefing or discussion takes place (Brooke, 1996). Each statement of the SUS has a five-point scale that ranges from "strongly disagree" to "strongly agree". The SUS scores have a range of 0 (negative) to 100 (positive), where scores under 50 would be found as not acceptable, scores between 50 and 70 as marginal and scores above 70 as acceptable (Bangor et al., 2009). 
For the purpose of experiential evaluation of the UL FGG heliodon the described commonly practiced SUS questionnaire was used. In addition, an $11^{\text {th }}$ question was added in order to asses user-friendliness according to the recommendation given by Bangor et al. (Bangor et al., 2009). The $11^{\text {th }}$ question has seven point Likert scale that ranges from worst imaginable to best imaginable and is used as an adjective scale/rating. The questionnaire was divided into two sections.

\section{USABILITY ASSESSMENT OF HELIODON TOOL}

Please check the box that reflects your immediate response to each statement. Don't think too long about each statement. If you don't know how to respond, simply check box " 3 ". Make sure you respond to every statement.

Strongly $\quad$ Strongly

disagree agree

1. I think that I would like to use heliodon frequently.

\begin{tabular}{|c|c|c|c|c|}
\hline 1 & 2 & 3 & 4 & 5 \\
\hline 1 & 2 & 3 & 4 & 5 \\
\hline 1 & 2 & 3 & 4 & 5 \\
\hline 1 & 2 & 3 & 4 & 5 \\
\hline
\end{tabular}

4. I think that I would need the support of a technical person to be able to use heliodon tool.

5. I found the various functions in heliodon tool were well integrated.

6. I thought there was too much inconsistency in heliodon tool.

7. I imagine that most people would learn to use heliodon tool very quickly.

8. I found heliodon tool very awkward to use.

9. I felt very confident using heliodon tool.

10. I needed to learn a lot of things before I could get going with heliodon tool.

\begin{tabular}{|l|l|l|l|l|}
\hline 1 & 2 & 3 & 4 & 5 \\
\hline
\end{tabular}
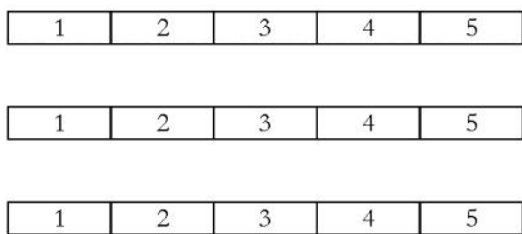

\begin{tabular}{|l|l|l|l|l|}
\hline 1 & 2 & 3 & 4 & 5 \\
\hline 1 & 2 & 3 & 4 & 5 \\
\hline
\end{tabular}

11. Overall, I would rate the user-friendliness of heliodon tool as:
\begin{tabular}{|c|c|c|c|c|c|c|}
\hline $\begin{array}{c}\square \\
\text { worst } \\
\text { imaginable }\end{array}$ & $\begin{array}{c}\square \\
\text { awful }\end{array}$ & $\begin{array}{c}\square \\
\text { poor }\end{array}$ & $\begin{array}{c}\square \\
\text { neutral }\end{array}$ & $\begin{array}{c}\square \\
\text { good }\end{array}$ & $\begin{array}{c}\square \\
\text { excellent }\end{array}$ & $\begin{array}{c}\square \\
\text { best } \\
\text { imaginable }\end{array}$ \\
\hline
\end{tabular}

1. In general I prefer using computer tools (simulation tools, CAD tools, etc.) rather than physical tools (models, sketching, physical plans, manual calculations, etc.).

\begin{tabular}{|c|c|c|c|c|c|c|}
\hline $\begin{array}{c}\text { I strongly } \\
\text { disagree }\end{array}$ & $\begin{array}{c}\square \\
\text { I disagree }\end{array}$ & $\begin{array}{c}\square \\
\text { I partly } \\
\text { disagree }\end{array}$ & $\begin{array}{c}\text { I neither agree } \\
\text { nor disagree }\end{array}$ & $\begin{array}{c}\square \\
\text { I partly } \\
\text { agree }\end{array}$ & $\begin{array}{c}\square \\
\text { I agree }\end{array}$ & $\begin{array}{c}\text { I strongly } \\
\text { agree }\end{array}$ \\
\hline
\end{tabular}

2. In the case of insolation analysis at course Bioclimatic design I found using heliodon tool favourable over the computer simulation (SketchU $\mathrm{p}$ ).

\begin{tabular}{|c|c|c|c|c|c|c|}
\hline $\begin{array}{c}\text { I strongly } \\
\text { disagree }\end{array}$ & $\begin{array}{c}\square \\
\text { I disagree }\end{array}$ & $\begin{array}{c}\text { I partly } \\
\text { disagree }\end{array}$ & $\begin{array}{c}\square \\
\text { I neither agree } \\
\text { nor disagree }\end{array}$ & $\begin{array}{c}\text { I partly } \\
\text { agree }\end{array}$ & $\begin{array}{c}\square \\
\text { I agree }\end{array}$ & $\begin{array}{c}\text { I strongly } \\
\text { agree }\end{array}$ \\
\hline
\end{tabular}

3. Please mark the most appropriate approach to achieving a sufficient understanding of insolation theory.

\begin{tabular}{|c|c|c|c|c|}
\hline $\begin{array}{c}\square \\
\text { using solely } \\
\text { computer tools }\end{array}$ & \begin{tabular}{|c|}
$\square$ \\
mostly using \\
computer tools and \\
only partly heliodon \\
tool
\end{tabular} & $\begin{array}{c}\square \\
\text { an equivalent } \\
\text { combination of both }\end{array}$ & \begin{tabular}{|c|} 
\\
mostly using \\
heliodon tool and \\
only partly computer \\
tools
\end{tabular} & $\begin{array}{l}\square \\
\text { using solely } \\
\text { heliodon tool }\end{array}$ \\
\hline
\end{tabular}

4. Which approach do you find more practical (circle the appropriate answer):
To carry out exercises (learning process):
HELIODON TOOL
COMP. TOOLS
To work in practice:
HELIODON TOOL
COMP. TOOLS

Fig. 3: Questionnaire on the usability assessment of heliodon tool (modified Brooke`s and Bangor's instrument). 
The first section consists of 11 statements about usability of the heliodon. The second section consists of 4 additional questions about the comparison between the heliodon and computer simulations, where students stated their opinion and preference of using computer or physical tools (e.g. would they choose to use the heliodon over the use of computer (e.g. SketchUp) and which approach they find the most appropriate to achieve sufficient understanding of insolation, etc.). In the end, they were asked, which tool they would prefer using during learning process or when working in practice. The modified Brook`s and Bangor`s instrument is presented in Fig. 3.

A questionnaire-based study was conducted in order to qualitatively and quantitatively assess the usability of the UL FGG heliodon tool. The above described SUS was used for the measurement and evaluation of effectiveness and users`subjective reactions to using the tool (Bangor et al., 2009; Brooke, 1996). The unit of observation was an individual student at the UL FGG $(\mathrm{N}=15)$ and UL ZF $(\mathrm{N}=23)$, who participated at practical exercises (i.e. Bioclimatic design course, $3^{\text {rd }}$ study year). The study period was April-May, 2018. All questionnaires were filled anonymously. Response rate was $100 \%$.

\section{Results}

The results of the study are shown in the following two subsections. The first subsection represents the results of the heliodon accuracy evaluation conducted by comparing the differences between the insolation results obtained by computer simulation (DIVA) and those acquired by using the UL FGG heliodon tool. The second subsection contains the results of the heliodon usability assessment made by handing out questionnaires to the students after using the UL FGG heliodon during the educational process.

\subsection{Experimental evaluation: Computer simulated insolation vs. heliodon acquired insulation}

Experimental evaluation of the heliodon accuracy was conducted by estimating its accuracy by comparison of the simulated and the emulated results at selected hours for selected critical days at various scales. The error determination of the results is shown in Table 1. Shaded cells represent relevant error results (i.e. hour with full shadows in the projected area), which were used to determine the average error of the heliodon tool at various scales and at specific studied dates.

Table 1. Results of heliodon accuracy evaluation. Errors $(E R R)$ presented in bold text were considered in the determination of average error, while shaded values were determined as useful.

\begin{tabular}{|c|c|c|c|c|c|c|c|c|c|c|c|c|c|}
\hline & \multicolumn{11}{|c|}{ Hours (solar time) } & \multirow[b]{2}{*}{ AVG } \\
\hline & & 7.00 & 8.00 & 9.00 & 10.00 & 11.00 & 12.00 & 13.00 & 14.00 & 15.00 & 16.00 & 17.00 & \\
\hline & Scale & \multicolumn{12}{|c|}{$\operatorname{ERR}[\%]$} \\
\hline \multirow{3}{*}{ 蒫 } & $1: 400$ & 48 & 16 & 6 & 1 & 2 & 3 & 9 & 8 & 8 & 12 & 31 & 7 \\
\hline & $1: 200$ & 23 & 52 & 27 & 17 & 13 & 22 & 28 & 28 & 34 & 49 & 17 & 24 \\
\hline & 1:100 & 2 & 20 & 28 & 52 & 41 & 38 & 52 & 58 & 36 & 12 & 15 & 48 \\
\hline \multirow{3}{*}{ 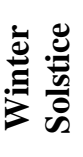 } & 1:400 & / & 21 & 52 & 18 & 9 & 11 & 8 & 9 & 32 & 11 & / & 20 \\
\hline & $1: 200$ & / & 16 & 17 & 26 & 28 & 34 & 67 & 38 & 14 & 10 & / & 43 \\
\hline & 1:100 & / & 18 & 22 & 15 & 17 & 20 & 14 & 13 & 17 & I & I & I \\
\hline
\end{tabular}

The hourly error analysis showed that the most accurate insolation results acquired with the heliodon are around midday (i.e. 10.00 - 14.00), when the incidence angles of solar rays are relatively large (i.e. the Sun is high in the sky). Such conditions do not cause large inaccuracies of the emulated results, due the light source non-parallel rays. Analogously, error of the heliodon at winter solstice is almost double of that at equinox (Table 1 and Fig. 4), since shadows are longer and the error is magnified due to non-parallel light source. Figure 4 shows that some shadows at the model scale of 1:200 fall out of the projection area during the intervals from 7.00 to 10.00 and from 15.00 to 18.00 , while at the 1:400 scale the intervals are shorter (Table 1). Thus, the calculated errors presented in Table 1 are inaccurate because $\mathrm{A}_{\text {sim }}$ and $\mathrm{A}_{\text {hel }}$ do not represent the total area of shadows during these intervals.

According to the conducted analysis it was found that the highest accuracy of the heliodon was at the scale of 1:400 for both analysed dates. The error at this scale was in the range between $1 \%$ and $16 \%$ (average: $7 \%$ ) at equinox and 9\% and 52\% (average: 20\%) at winter solstice. Error ranges for the former are between 8.00 and 
16.00 and for the latter between 9.00 and 15.00. Expectedly, the least accurate results were acquired in the case of the model at the 1:100 scale at equinox, where the error inside the selected hours ranged from $38 \%$ to $58 \%$ (average: $48 \%$ ). Overall accuracy of emulated shadows tends to decrease in relationship to larger scale of the model, to a point where the attained results are completely unreliable. Such case is the winter solstice with model at the scale of 1:100 (Table 1), where major portions of shadows fell outside the projection area. Therefore, the stated error of the heliodon (Table 1) is not realistic, because the largest differences occur at the end of the shadows, which are not recorded due to long shadows. The main reason for the decrease in accuracy of the heliodon with the increase of the model size lies in the non-parallel light source, the effect of which is accentuated at smaller scales. Moreover, the error also originates from the fact that the rotatable rings are not ideal circles, which are impossible to manufacture, nor can they be ideally mounted. Therefore, the distance between the LED light and the model table varies by $\pm 3-5 \mathrm{~mm}$.
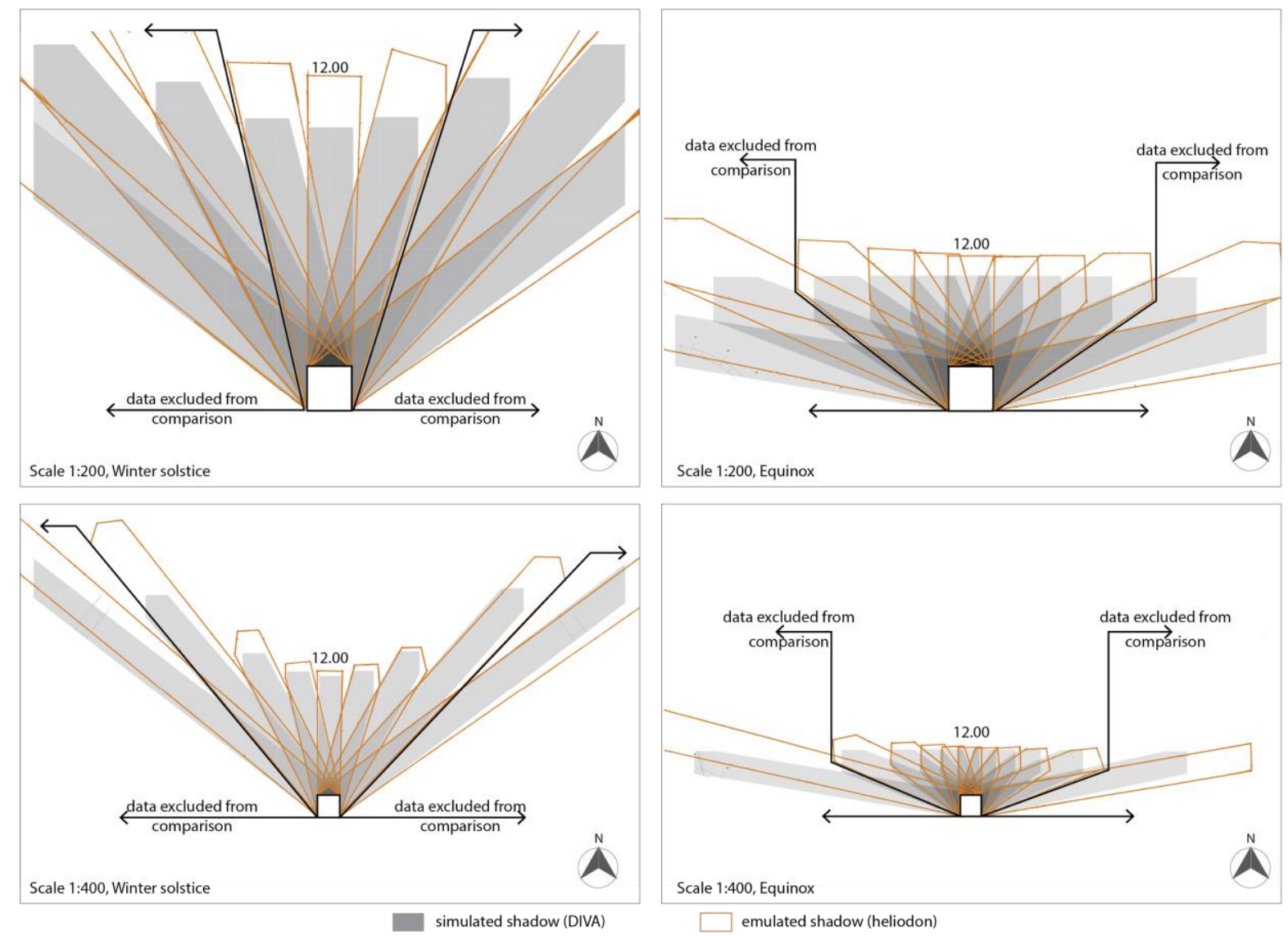

Fig. 4: Example of shadows acquired by heliodon and by computer simulations for winter solstice (left) and equinox (right) at 1:200 (top) and 1:400 (bottom) model scale.

The directionality of the shadows cast by the heliodon has been found to be satisfactory, since general directions of shadows at the observed hours are coincident with those of the simulations. Error in the direction of shadows tends to increase for early and late hours and is accentuated at winter solstice, again due to the non-parallel light source.

It was found that the UL FGG heliodon is most suitable for the use at smaller scales (i.e. 1:200 or smaller), because its accuracy is enhanced with the decrease of the model size. Furthermore, models at larger scales cast substantially longer shadows, meaning that they fall out of the projection area, reducing the practical applicability and usefulness of the heliodon analysis.

\subsection{Experiential evaluation: Students' evaluation of heliodon as an educational tool}

38 respondents (students) completed the survey. The majority of students $(60.5 \%)$ were the UL ZF students and $39.5 \%$ of them the UL FGG students. Table 2 lists mean, median and SD scores. The SUS scores were in the range from 57.5 to 100. Mean SUS scores were higher for students from UL ZF (85.1) than for students from UL FGG (80.5). The quartile breakdown of study mean scores is shown in Table 3. 


\section{Pajek et. al. / EuroSun 2018 L\% Pajék Conference Proceedings (2018)}

Table 2. Summary of SUS Scores.

\begin{tabular}{|c|c|c|c|c|}
\hline Respondent & MEAN & MED & SD & Range \\
\hline UL ZF & 85.1 & 85.0 & 7.2 & $72.5-100$ \\
\hline UL FGG & 80.5 & 82.5 & 9.3 & $57.5-92.5$ \\
\hline Total & 83.3 & 83.8 & 8.4 & $57.5-100$ \\
\hline
\end{tabular}

In reply to the $11^{\text {th }}$ question (adjective rating) "Overall, I would rate the user-friendliness of heliodon tool as:", the majority of respondents $(68.4 \%)$ evaluated the usability of the heliodon tool as "excellent". That corresponds to mean SUS score of 83.3 (Table 4). 18.4\% respondents of the total sample of users evaluated the usability of the tool as "best imaginable". This corresponds to mean SUS score of 86.1 (Table 4). Only 13.2\% of respondents evaluated the usability of the tool as "good", corresponding to mean SUS score of 79.5. None of the users assessed the UL FGG heliodon tool worse than good.

Table 3. Quartiles for SUS Study Means Scores.

\begin{tabular}{|c|c|c|}
\hline Quartile & Lower Bound & Upper Bound \\
\hline 1 & 57.5 & 77.5 \\
\hline 2 & 77.5 & 83.8 \\
\hline 3 & 83.8 & 90.0 \\
\hline 4 & 90.0 & 100.0 \\
\hline
\end{tabular}

If the adjective rating scores (i.e. the $11^{\text {th }}$ question) are translated into $0-100$ scale, the average score is 84.2 . It is evident that the results of adjective rating very closely match the total mean SUS score (Table 2). Figure 3 presents individual SUS scores based on students of both faculties.

Table 4. Descriptive Statistics of SUS Scores for Adjective Ratings.

\begin{tabular}{|l|c|c|c|}
\hline \multicolumn{1}{|c|}{ Adjective } & Count & Mean SUS Score & Standard Deviation \\
\hline Worst Imaginable & 0 & $/$ & $/$ \\
\hline Awful & 0 & $/$ & $/$ \\
\hline Poor & 0 & $/$ & $/$ \\
\hline OK & 0 & 79.5 & 11.6 \\
\hline Good & 5 & 83.3 & 7.6 \\
\hline Excellent & 26 & 86.1 & 8.0 \\
\hline Best Imaginable & 7 & & $/$ \\
\hline
\end{tabular}

On average, students partly disagree (i.e. -0.7 on the scale from -3 to +3 ) with the stated fact "I prefer using computer tools (simulation tools, CAD tools, etc.) rather than physical tools (models, sketching, physical plans, manual calculations, etc.)", which was surprising, because it was expected that they would prefer the use of computer tools. The disagreement was more significant for the UL ZF students (-1.2) and less for the UL FGG students $(-0.1)$. In the sample, the majority of the students replied that in order to achieve a sufficient understanding of the insolation theory, an equivalent use of both, heliodon and computer simulations, is necessary. In reply to the question "Which approach do you find more practical to carry out learning process", $86.8 \%$ of students thought that heliodon tool was more practical for learning the process and only $13.2 \%$ thought computer simulation tools were better. At this question, there is no statistically significant difference between the two student populations. In reply to the question "Which approach do you find more practical when working in practice", the received total answers were $32.0 \%$ in favour of the heliodon and $68.0 \%$ in favour of computer software. Interestingly, there exists a substantial difference between the two populations. $56.5 \%$ of students from the UL ZF found computer tools more useful for work in practice, while the remaining $43.5 \%$ of students opted for the heliodon. Opposite to the respondents from the UL ZF, the majority of students from the UL FGG (86.7\%) found computer tools handier for work in practice and the minority of students (13.3\%) stated that the heliodon is more useful for work in practice. 


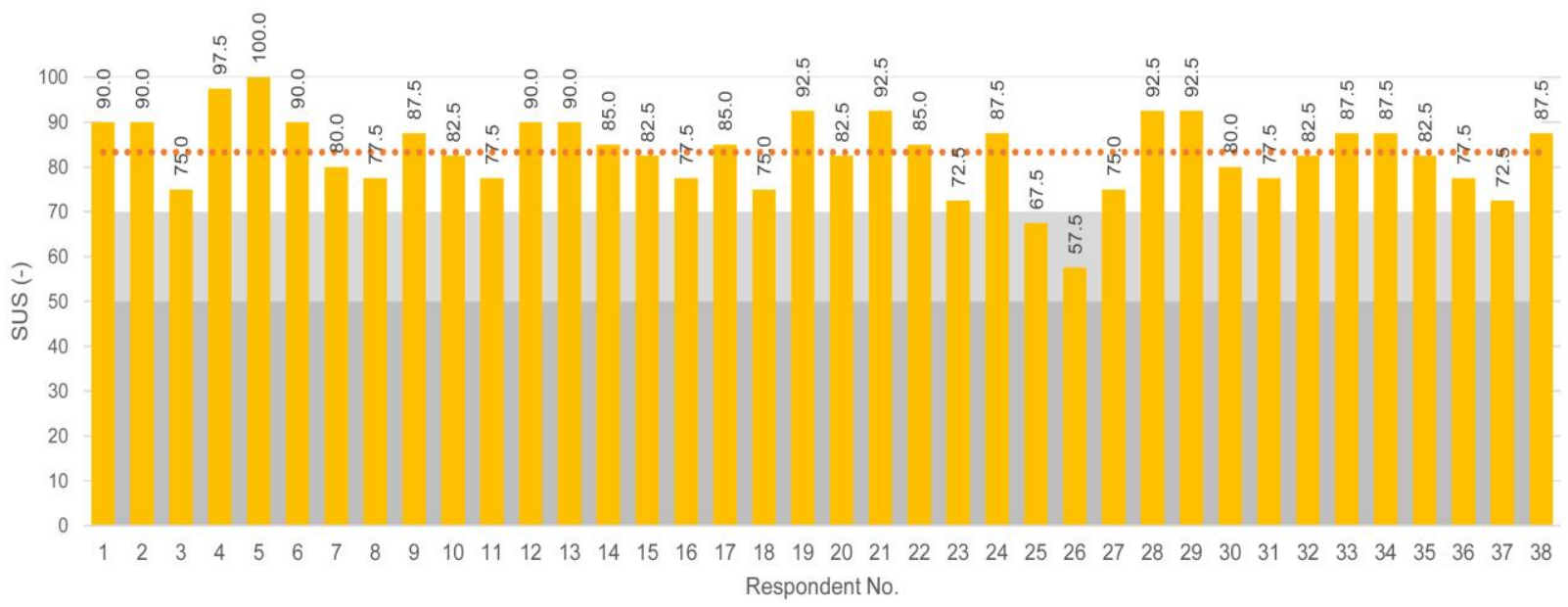

Fig.4: SUS scores for UL ZF students ( $N=23$; $x$ axis no. 1-23) and UL FGG students ( $N=15 ; x$ axis no. 24-38). Red line: Mean SUS score; white zone area: acceptable; light grey zone area: marginal, dark grey zone area: not acceptable.

\section{Discussion and Conclusions}

Student evaluation of the UL FGG heliodon gives evidence that it is a very useful educational tool, having no significant drawbacks, as relatively high average SUS score was achieved. The obtained objective SUS score is also in line with the scores of adjective ratings, where students assessed the heliodon user-friendliness mostly as "excellent". The attained SUS scores of the UL FGG heliodon can be compared to the SUS scores of a heliodon used at MIT (Osser, 2007), which was also a subject of a SUS survey among students $(\mathrm{N}=7)$. Their results ranged between 75 and 98, with an average of 84.6 and standard deviation of 8.6, indicating fairly favourable response. Osser's results are in line with the results of this study, with the difference in average SUS value being only 1.3 points. The results of our survey have also shown that students of both faculties (i.e. UL FGG and UL ZF) prefer a combination of both, heliodon and computer simulations, in order to achieve sufficient understanding of the insolation theory. The stated is in line with the results shown by Dubois et al. (Dubois et al., 2015), which highlighted that students value the opportunity to handle several types of tools rather than just one. Such use of combination of several tools is more likely to improve the knowledge and skills of students on issues such as climate change adaptation, where the understanding of solar geometry is important (Pajek and Košir, 2017). However, within the study made by Dubois et al. (Dubois et al., 2015) students stated that using the heliodon tool was less helpful due to the time required to build scale model necessary for the use of the heliodon. Additionally, they noted that the invested time was not justified in the light of lower precision of the results. The same issue was exposed by the experimental evaluation of the UL FGG heliodon in the present study, where concerns about the accuracy of the obtained results were exposed as substantial, especially with larger scale models. Therefore, the future of heliodon tools may lay in the development of advanced augmented reality tools, such as one presented by Sheng et al. (Sheng et al., 2011). However, it could be argued that for the use as an educational tool, the absolute accuracy of the heliodon is irrelevant for the presentation of the principle, where the accuracy of the obtained results is less important.

\section{Acknowledgements}

The authors acknowledge the financial support from the Slovenian Research Agency (research core funding No. P2 - 0158). Additionally, we would like to thank the engineer Marko Tratar and the manufacturing company Miks kovinarstvo d.o.o., who partially supported and assisted the construction of the UL FGG heliodon.

\section{References}

Bangor, A., Kortum, P., Miller, J., 2009. Determining What Individual SUS Scores Mean: Adding an Adjective Rating Scale. Journal of Usability Studies 4, 114-123.

Brooke, J., 1996. SUS-A quick and dirty usability scale, in: Jordan, P.W., Thomas, B., Weerdmeester, B.A., McClelland, I.L. (Eds.), Usability Evaluation in Industry. Taylor \& Francis, London, pp. 189-194. 
Cheung, K.P., Chung, S.L., Leung, M.F., Chu, P., 2012. A discussion on some assemblies of fresnel lens and quartz lamps in simulating quasi-parallel light for testing building models in heliodon studies. International Journal on Architectural Science 9, 18-35.

Doberneck, D., Knechtel, K., 2013. Heliodon: A hands-on daylighting educational tool. Presented at the 42nd ASES National Solar Conference 2013 (SOLAR 2013), ASES, Baltimore, Maryland, USA, pp. 342-348.

DTU, 2018. Architectural Engineering (MSc) [WWW Document]. http://www.dtu.dk. URL http://www.dtu.dk/english/education/msc/programmes/architectural_engineering (accessed 2.20.18).

Dubois, C., Cloutier, G., Potvin, A., Adolphe, L., Joerin, F., 2015. Design support tools to sustain climate change adaptation at the local level: A review and reflection on their suitability. Frontiers of Architectural Research 4, 1-11. https://doi.org/10.1016/j.foar.2014.12.002

KTH, 2018. KTH Royal Institute of Technology Stockholm, Master's programme in Civil and Architectural Engineering [WWW Document]. URL https://www.kth.se/en/studies/master/civil-and-architecturalengineering/description-1.198454 (accessed 2.20.18).

Lechner, N., 2018. Heliodons - helping create a more sustainable future [WWW Document]. URL http://www.heliodons.org/index.html (accessed 2.20.18).

Lechner, N., 2015. Heating, cooling, lighting: sustainable design methods for architects, Fourth edition. ed. John Wiley \& Sons, Inc, Hoboken, New Jersey.

Muneer, T., Gueymard, C., Kambezidis, H., Muneer, T., 2004. Solar radiation and daylight models: with software available from companion web site, 2nd ed. ed. Elsevier Butterworth Heinemann, Oxford ; Burlington, MA.

Olgyay, A., Olgyay, V., 1957. Solar control and shading devices. Quarterly Journal of the Royal Meteorological Society 86, 201.

Osser, R.E., 2007. Development of Two Heliodon Systems at MIT and Recommendations for their Use (Master Thesis). Massachusetts Institute of Technology, Boston, Massachusetts, USA.

Pajek, L., Košir, M., 2017. Can building energy performance be predicted by a bioclimatic potential analysis? Case study of the Alpine-Adriatic region. Energy and Buildings 139, 160-173.

https://doi.org/10.1016/j.enbuild.2017.01.035

Prinsloo, G.J., Dobson, R.T., 2015. Solar Tracking. Stellenbosch University: SolarBooks, Stellenbosch.

Rubin, J., Chisnell, D., 2008. Handbook of usability testing: how to plan, design, and conduct effective tests, 2nd ed. ed. Wiley Pub, Indianapolis, IN.

Shaviv, E., 1999. Design tools for bio-climatic and passive solar buildings. Solar Energy 67, 189-204. https://doi.org/10.1016/S0038-092X(00)00067-0

Sheng, Y., Yapo, T.C., Young, C., Cutler, B., 2011. A spatially augmented reality sketching interface for architectural daylighting design. IEEE Trans Vis Comput Graph 17, 38-50.

https://doi.org/10.1109/TVCG.2009.209

Solemma LLC, 2018. DIVA [WWW Document]. URL https://www.solemma.com/ (accessed 7.18.18).

Szokolay, S.V., 2014. Introduction to architectural science: the basis of sustainable design, Third edition. ed. Routledge, London; New York, NY.

Szokolay, S.V., 2007. Solar geometry. PLEA: Passive and Low Energy Architecture International, London.

TU Berlin, 2018. Technische Universität Berlin, Building Sustainability MBA [WWW Document]. Energy Studies in Berlin. URL https://master-in-energy.com/courses/building-sustainability/ (accessed 2.20.18).

UL, 2018. University of Ljubljana, Faculty of civil and geodetic engineering, 2nd Cycle Study: Buildings (MA) [WWW Document]. URL https://www.en.fgg.uni-lj.si/study/2nd-cycle-study-programmes/buildings-ma/ (accessed 2.20.18).

UMONS, 2018. University of Mons, Architectural Engineering [WWW Document]. Faculté / FPMS. URL https://web.umons.ac.be/fpms/en/etudes/examen-dadmission/ingenieur-civil-architecte/ (accessed 2.20.18).

University of Leeds, 2018. University of Leeds, , School of Civil Engineering, Architectural Engineering MEng, BEng [WWW Document]. URL https://engineering.leeds.ac.uk/courses/UG/F416/architectural-engineeringmeng-beng (accessed 2.20.18). 


\title{
Dialogue between Research Solar Practices and Training Activities: Interactive Webinar by Integration of ICT in Education Cristina S. Polo López ${ }^{1}$ and Francesco Frontini ${ }^{1}$ \\ ${ }^{1}$ ISAAC/SUPSI, Campus Trevano, CH 6952, Canobbio, Lugano (Switzerland)
}

\begin{abstract}
An educational Webinar targeted to students, architects and professionals, has been organized in the context of the European research project ConstructPV and the bachelor course of Architecture of SUPSI to stimulate a discussion on the role of solar energy in buildings. The main feature of innovation of our Webinar has been to combine the traditional method of live conference with computer-mediated to allow the interaction with all participants of other institutions and other learning environments. This has greatly encouraged the participation and generated a wealth of feedback for ConstructPV by making a direct survey on several key-topics thus increasing effectiveness in knowledge transfer
\end{abstract}

Keywords: solar education, building integrated photovoltaics BIPV, ICT technologies, blended e-learning

\section{Introduction}

Building-integrated photovoltaic (BIPV) systems are the main elements of the architecture, delivering solar generated electrical power that replace conventional building materials as part of the building envelope. BIPV uses in construction have been increased slowly in recent years and are still considered a niche product trying to grow towards a wide mass market (Delponte et al. 2015). In new building developments and in renovations, BIPV are the most effective installation delivering renewable energy since the cost of customized product that improved the overall aesthetic have been reduced (Bonomo et al., 2017 and Zanetti et al., 2017). When compared to nonintegrated systems, BIPV initial cost can be offset by reducing the materials and labour cost of the building elements. It is noted that general cultural resistance still exists in the use of BIPV among building industry professionals, including architects, planners, engineers, builders, clients and end-users. Thus education and effective knowledge transfer solutions are needed to improve BIPV adoption. As recently remarked (Tabakovic, et al., 2017), activities in the technical, legal, and, not least, in the educational areas will be necessary to foster the adoption from architects, professional operators and students, dedicated to the needs of each target audience.

\section{Knowledge transfer for BIPV exploring the pedagogic use of ICTs}

Nowadays, Internet and the Word Wide Web support collaborative work and e-learning environments almost everywhere, without time and location restrictions. Use of computing platform is widespread and moved from "central computing" to more distributed "networked computers". Given the excellence diffusion of internet and connectivity, e-learning environments are well position to provide a student-centric service at high level education (Gomes and García-Zubía, 2007).

Solar energy education is a topic covered only in few international programs (e.g. IEA SHC task 51, IEA SHC task 41) and research projects. But today many international associations such as International Solar Energy Society, offer already free online courses and webinars related the renewable energy sector trough a Renewable Energy Platform (https://www.ises.org/webinars/439). CHEETAH PVirtual Academy has also launched in January 2018 the Knowledge exchange Platform (KEP) that has become EERA Knowledge Exchange Platform for PV Technology (KEPT-PV) since May 2018 (CHEETAH project FP7-Energy-2013, http://www.cheetah-project.eu). The PV Knowledge Exchange Portal of CHEETAH and EERA-PV offers day-by-day lecturers and short "virtual" on-line courses focused on the best practice utilization of infrastructures, equipment, experiments and test procedures or technical-scientific aspects. In addition, webinars, conferences, workshops, or technical meetings are organized and reported with the aim to introduce scientists/students/experts/stakeholders concerning strategy in PV RTD, market and interaction with industries, as key action in Science and technology dissemination. An innovative approach is used in the European research project Dem4BiPV (http://www.dem4bipv.eu/project/, Figure 1) with 
the aim to develop innovative and multidisciplinary courses on BIPV to train professionals utilizing ICT platforms (van Sark, 2016, 2017). Within the project major knowledge gaps and target audiences from stakeholder perspectives has been identified to define specific courses.

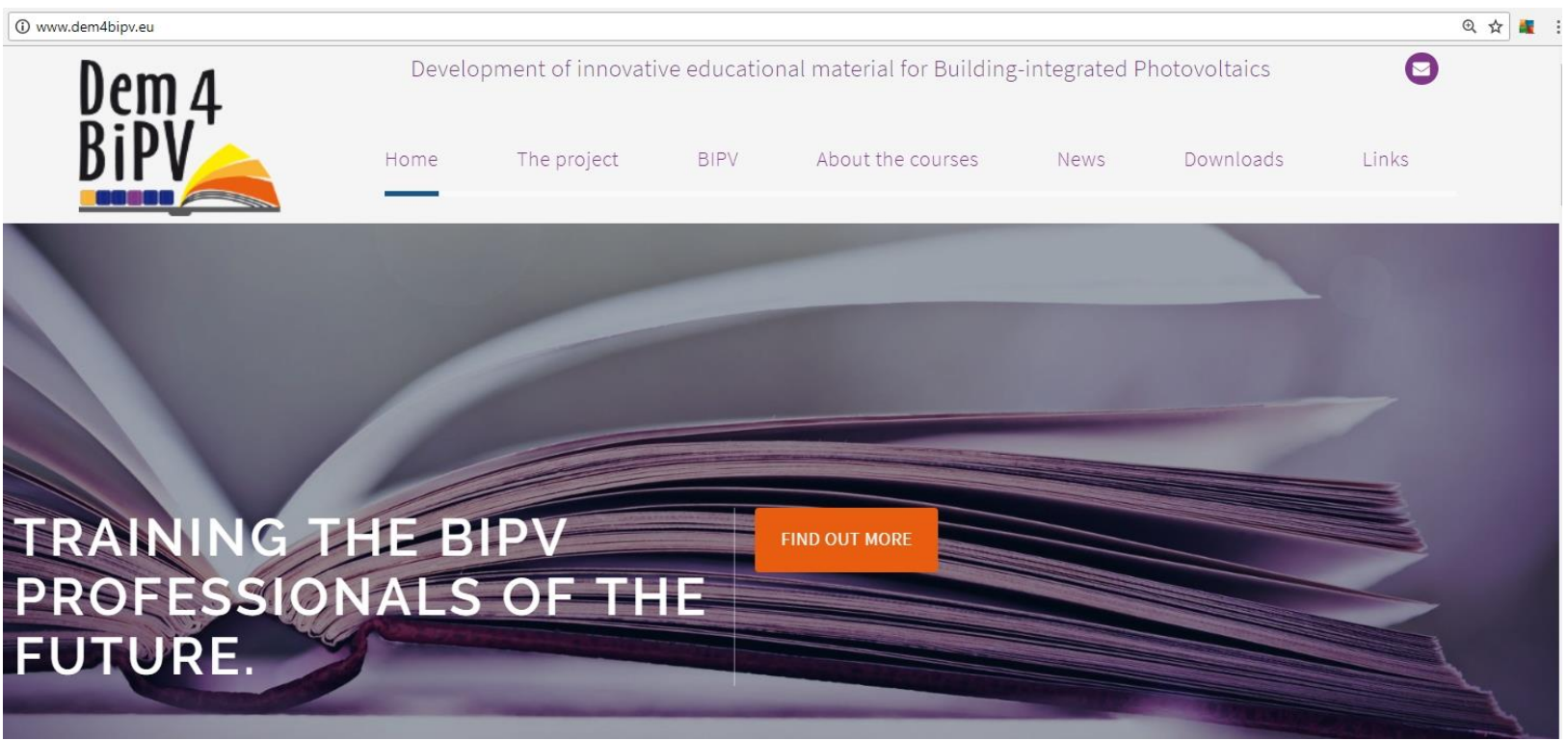

Fig. 1: e-learning environment of Dem4BiPV Web Platform (source: http://www.dem4bipv.eu/)

As BIPV may bring significant contribution to reach EU energy challenges and benchmarks for 2020 and beyond, education and training should play an important role to enhance the skills of the professionals, but also for high quality employment in the BIPV industry by increasing the efficiency of higher education on sustainable energy. In this field, the combination of innovations that explore the pedagogic use of ICTs( as for example, smartlabs, elearning experiences, WebLabs or Virtual Learning Environments (VLE)), is as important as the need to enhance the partnership between research higher education institutions, industry and other stakeholders. It is possible to perform an interdisciplinary training scheme with the technical knowledge and competencies to deliver specialised workforce required for the successful implementation of BIPV projects.

ICT alone does not ensure effective teaching, but nevertheless in the 21 st-century teachers and educational trainers need to be equipped with Technological Pedagogic Knowledge, TPK (Mishra and Koehler, 2006) to know how to proper use the available ICT tools making profitable use of specific educational contents. The same authors (Koehler et al. 2013) considers that the teacher knowledge for technology integration (i.e. technological pedagogical content knowledge TPACK) enables teachers to relate creative ideas using ICT tools in the educational process to improve competences and learning outcomes. The role of experimentation is key concept.

\section{Research practices vs. training and dissemination activities, an experience of interactive Webinar}

This paper presents an example of successful collaboration among scientists and teachers to create greater links between research and education, strengthening the knowledge and competence of relevant stakeholders in solar energy also in order to obtain a useful feedback to improve some contents/process of the research. The European project Construct-PV (FP7-ENERGY-2011-2, http://www.constructpv.eu/) developed and demonstrated customizable, efficient and cost-effective Building Integrated Photovoltaics (BIPV) for the opaque building envelope. The demonstrative target of the project makes tangible the results and the potential transfer of PV technology in the built environment developing new promising technologies with an advanced design. To be attractive to both the building and PV market, Construct-PV systems are multifunctional, integrating the most promising PV technologies.

With the aim to present the main achievements on solar BIPV technologies reached within the project, a conference was hosted at SUPSI Campus, in Lugano, Switzerland (see, Figure 2). About 50 people attended the event in classroom and on the web platform. Architecture students of the last-year bachelor program together with professors, architects, engineers and other members of companies working on PV field (80\%) attended the conference in site while the other participants $(20 \%)$ attended the conference by Internet through the interactive Webinar platform, specifically created for this event. 

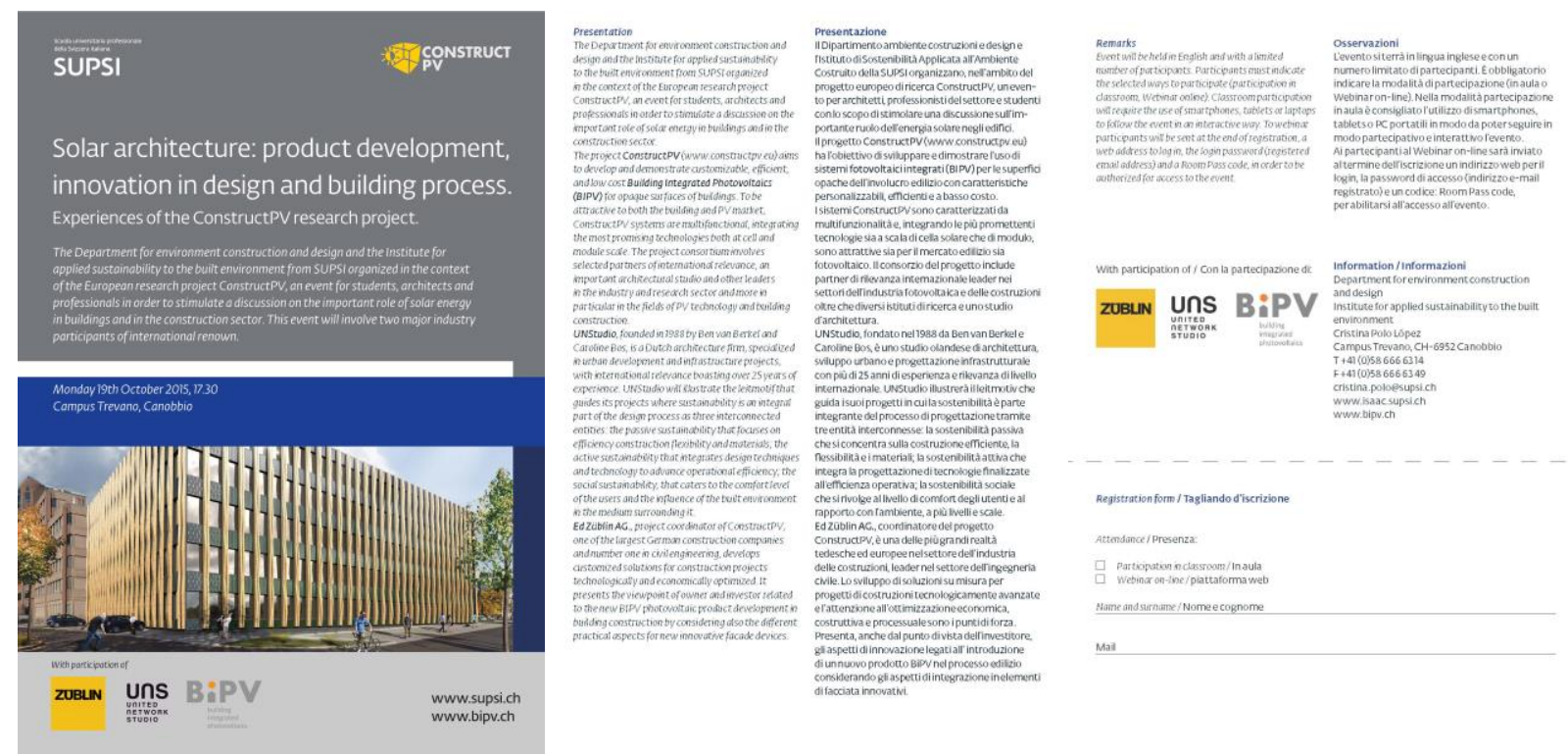

Fig. 2: Promotional flyer developed for this special event (source: SUPSI)

The purpose and main innovation of this interactive Webinar has been to combine the traditional method of a frontal live conference with computer-mediated activities in blended learning allowing the interaction with remote participants in other institutions or in other learning environments: e learning, video conferencing, for example. Some authors describes blended learning as the fusion or convergence of face-to-face and online learning experiences (Graham 2006 and Vaughan, 2008) but also other combinations of technologies, locations or pedagogical approaches (Mason and Rennie, 2006). However, and despite the fact that online learning, e-learning or flexible learning concepts are associated with an electronic environment, the term blended learning, intended as combination of virtual and physical environments, recognizes the potential of a positive relationship between online and face-to-face environments for both learners and their teachers (Stacey and Gerbic, 2008).

The in-site live conference was specifically design to introduce the process of blending (the online and face-to-face environments) but also has been the basis for an interactive and participatory Webinar with the aim of involving, with the IT e media support, other university bodies, researches or professionals at local level and abroad in a questionnaire on research findings. During the event has been shown real case studies and the main outputs on solar BIPV product development research results has been presented to students, professionals and members of the industry. The blend of technologies with face-to-face interaction using webinars/workshops, also in a professional context where personal relationships can be established, with an online community encourage critical reflection and discussion of practice setting the basis of much effective professional development (Garrison and Vaughan, 2008).

\subsection{Interactive survey: two-way exchange of knowledge}

Currently, there is not an all-in-one tool or resource containing all of the information to consider when determining an appropriate participatory approach for a specific educational workplace. This event was organized through the platform Swiss E-Learning Community, with the SWITCHinteract Adobe Connect tool specifically custom redesigned to reach the blended e-learning outcomes pursued and organizational needs.

In this case the instructor/lecturer guides the learning process delivering content on research results which is at the same time guided by a master conference manager taking charge of the overall organization of the tool. Participants to the interactive Webinar access the content also via the network (Internet) and the management system engage learners and track informally the learning activities through the in-live survey regarding the contents of the conference acting as a Learning Management System (LMS). This e-model scheme follows the delivery model for blended e-learning suggested by Al-Huwail et al. (2018) which play a key role in creating a successful collaborative environment by avoiding substantial cross-cultural differences in interaction and communication (see Figure 3). 
a)

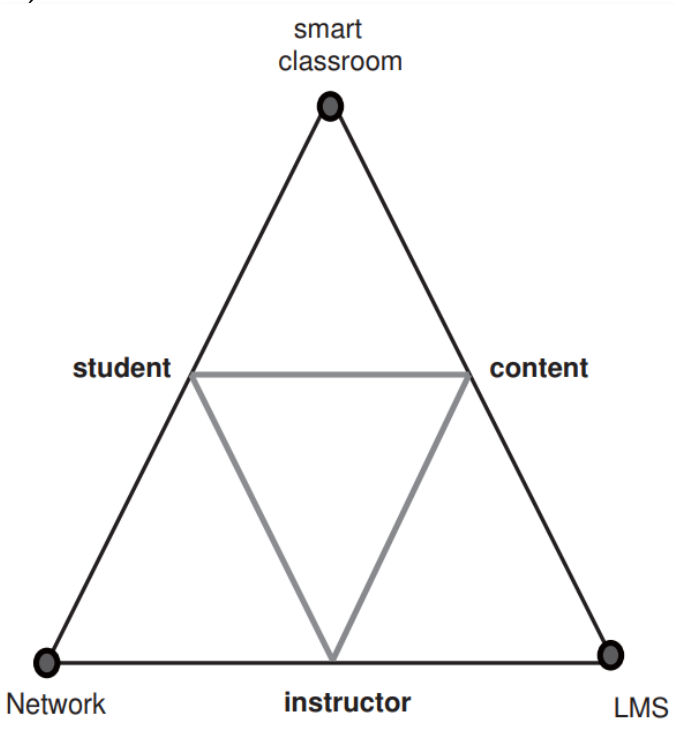

b) face-to-face settings combined with on-line interactive IT e media support

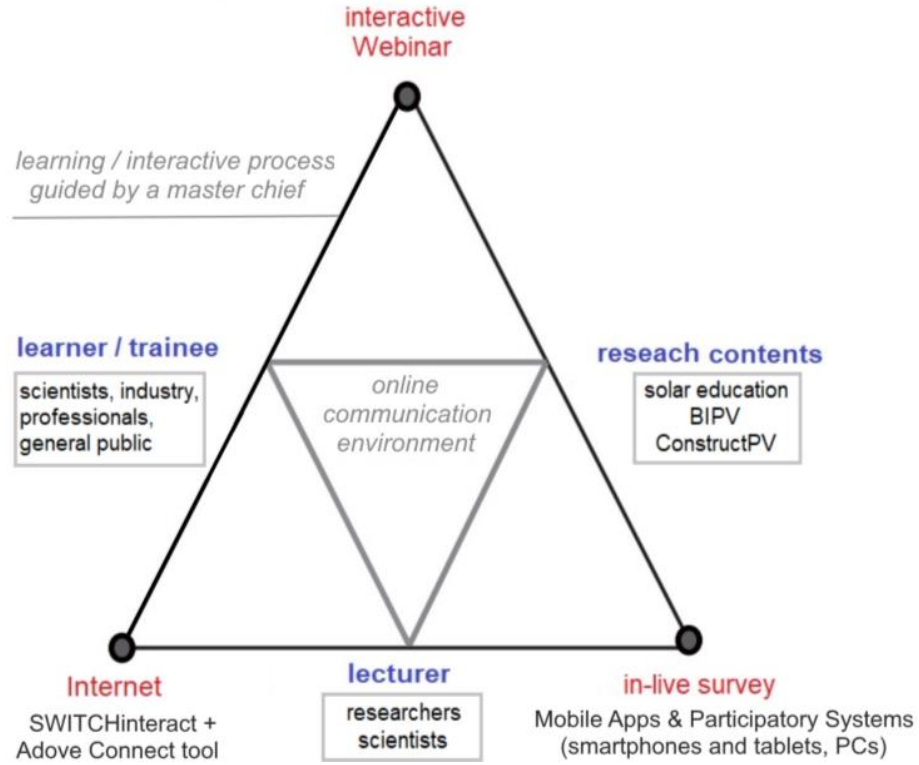

Fig. 3: e-model scheme: a) Delivery Model for Blended E-Learning (source: Al-Huwail et al., 2018); b) Adapted e-learning Environment Framework (source: authors)

A focal point of this Webinar has been to include and to use a participatory systems, driven by mobile systems (such as smartphones and tablets, $\mathrm{PCs}$ ), in live via $\mathrm{Wi}$-Fi among the people attending conference and also remotely on the web platform to enable the participation of a large external public (Figure 4). This approach had the intention to foster the integration of ICT (information and communications technology) into learning activities concerning solar buildings in an efficient and fruitful way.

As defined by Bousset et al. (2005), "participatory methods are methods to structure group processes in which participants play an active role and articulate their knowledge, values and preferences for different goals". In are suggested as key factor for innovations success favouring dissemination process the users relevant point of view, citing "The assessment of defect and advantage of innovation is wholly in the users' hands : it depends on their waiting, their interests, the problem they are taking" (Akrich, et al., 1988a; 1988b). These studies suggest that an innovative object or innovative features of a product are not only the result of technical decisions, but also from the interaction with involved social groups and stakeholders, some as allies (forces in favor), others as opponents or sceptics (forces against). In this way, the social environment where this object will move and where it will impact can be assessed.

In our case, a participatory and interactive approach was used to test end-users commitment and interest with research findings, and to check learning skills acquired during the conference. A shift of written or visual elements (scrolling titles, slideshows or flash elements) together with a live survey appeared at time of the speakers' presentations to track the answers for specific questions and to achieve results for the survey simultaneously to presentations. In this way, it has been possible to see the direct response of the public, encouraging participation of students and different stakeholders thus stimulating the fair competition among the participants in order to obtain a greater response in the survey (for example by displaying the a minimum threshold of participants and the total number of people responding to each possible answer). It was also possible to integrate in real-time the direct visualization of the flow of participants and the answers to the online questionnaire on the project. It was also available the use of blogs to post comments that interface directly with the lecturers (Figure 5). 


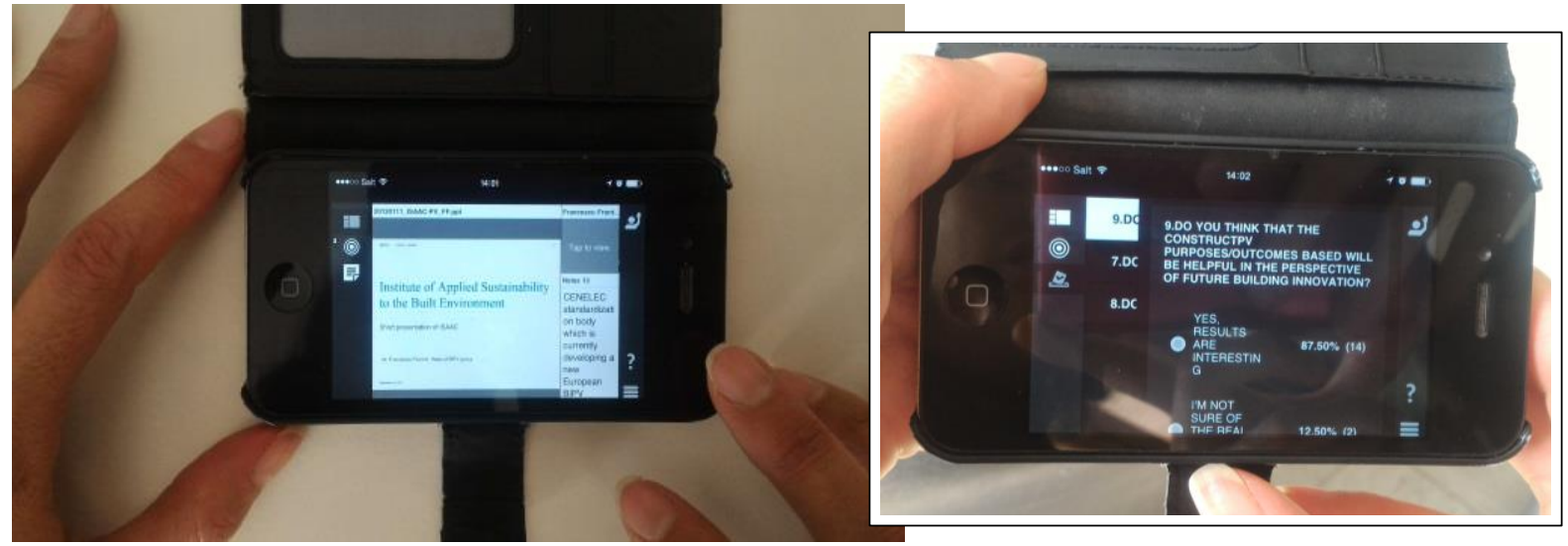

Fig. 4 - Adove Connect Mobile App have been used in this interactive Webinar. This Mobile Apps can be used to host or attend online meetings, webinars and virtual classes anytime (source: SUPSI)
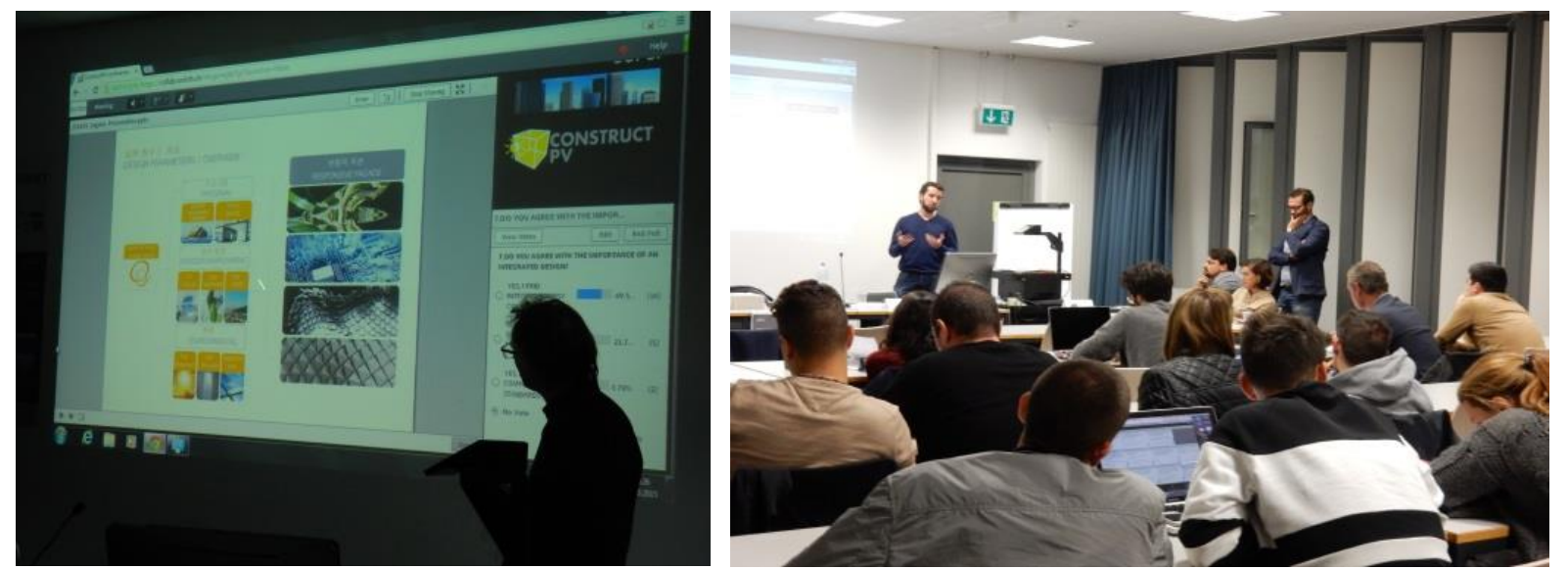

Fig. 5: Lecture session during the interactive frontal live conference and Webinar (source: SUPSI)

\subsection{Results}

The e-learning platform has allowed collecting all useful data from the interactive survey divided by different aspects (i.e. by attendees, by sessions, by questions) for the synthesis of the information obtained based in the most important indicators and filters for the research project, according to the main topics scheduled (see Figure 6 and Figure 7). An open discussion with a survey results analysis of the poll questions was performed at the end of the lecture session among the in-site participants while the chat allow interaction the with the webinar participants by reaching a greater audience (beyond SUPSI students). In this way, professionals could follow the lecturer sessions directly from their own workstation saving time and limiting unnecessary commuting with a good interaction with the audience in the classroom and the lecturers through chats, blogs or video conferencing features.

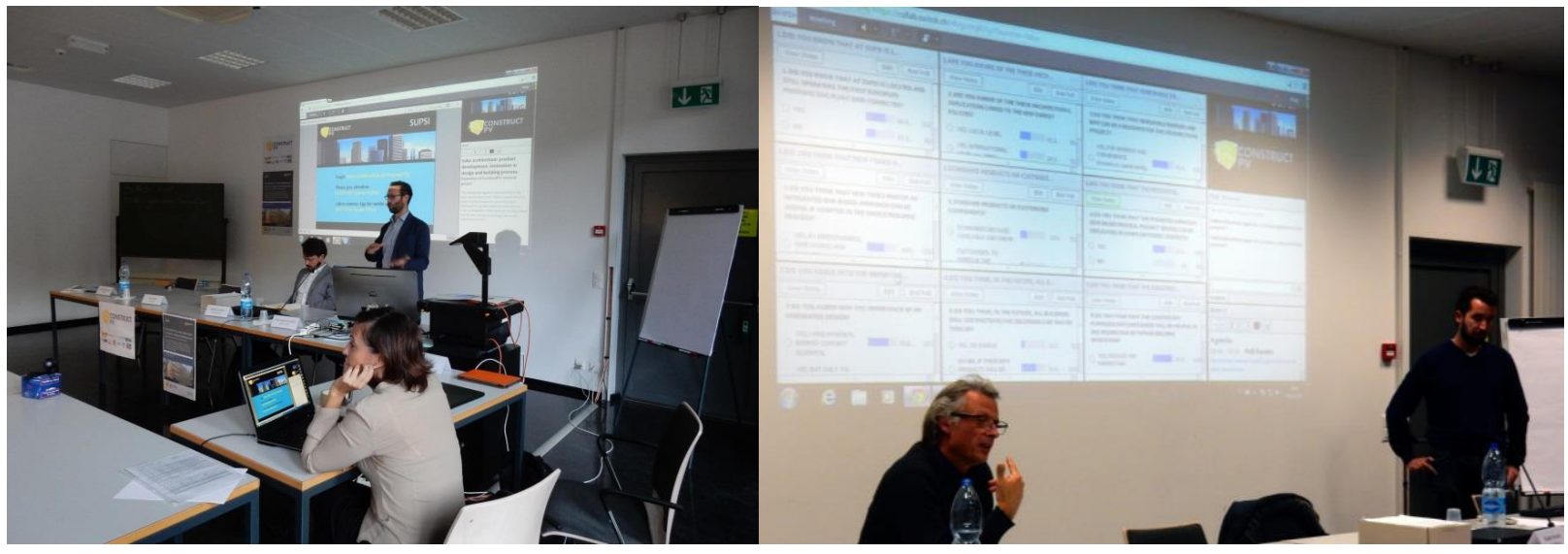

Fig. 6: Open discussion and survey results analysis at the end of the lecture session. 


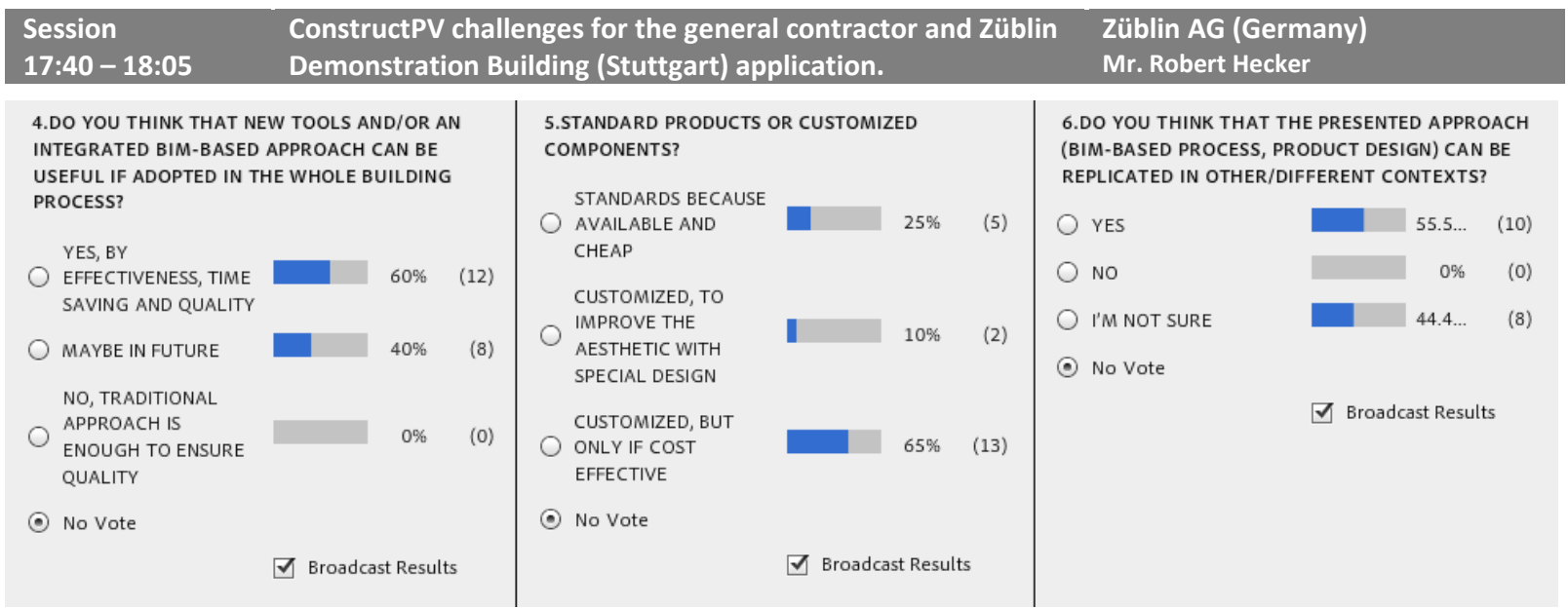
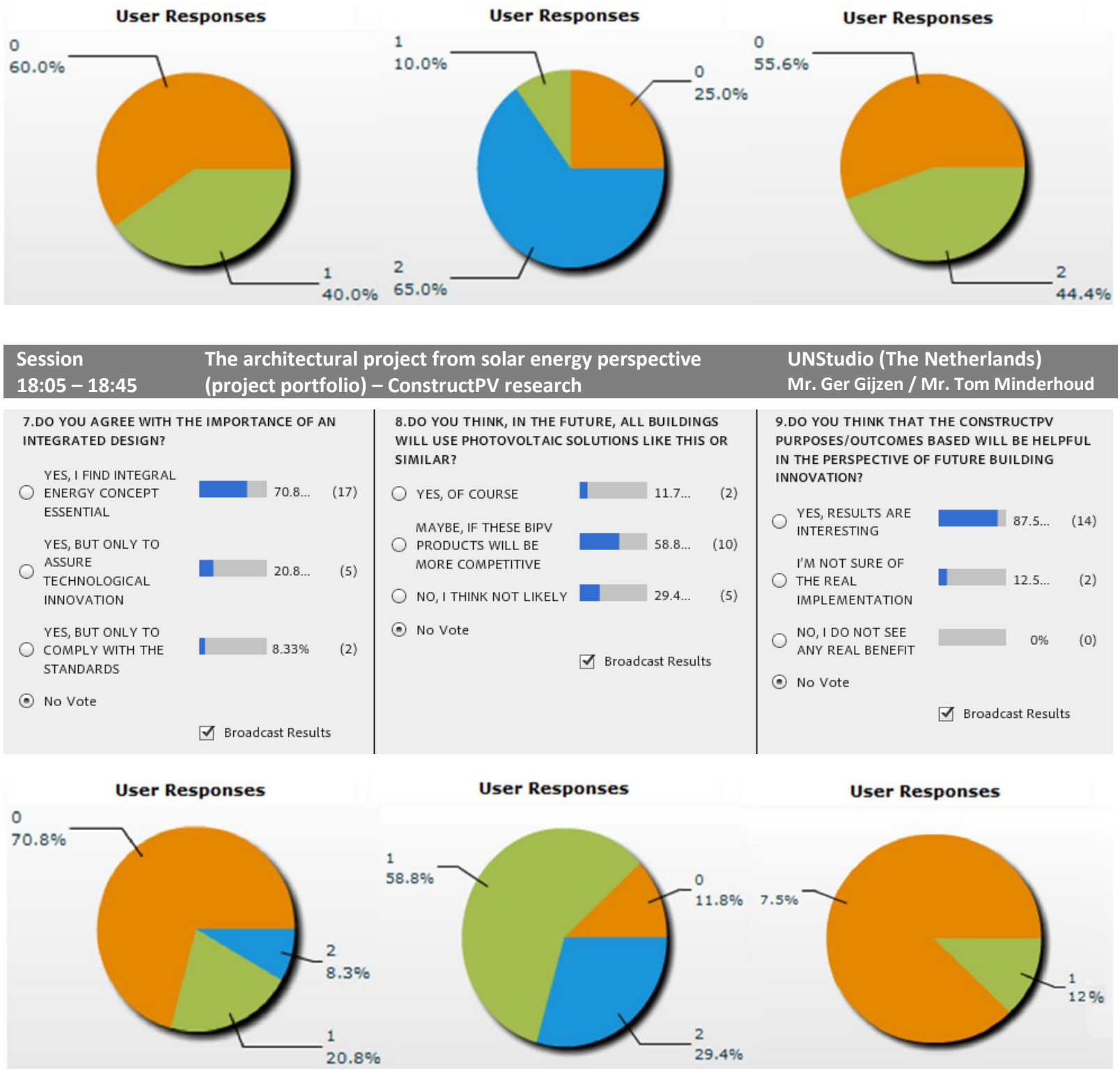

Fig.7: Example of live- survey questionnaire held during the interactive Webinar.

The event tracking feature allows knowing the most interesting information gathered during the session, by custom dimensions: class of participants and users, answers to specific questions, traffic flow visualization, etc. Furthermore, to facilitate the creation of reports in the perspective of dissemination activities borne by SUPSI in WP7 of ConstructPV research project, all the information have been gathered to develop a brief summary report of the interactive webinar. The whole event was recorded and monitored thanks to the Adobe Connect SWITCHinteract web platform. 


\section{Conclusions}

Truly successfully e-learning environments need a blend of both the new technology and traditional learning, by means of using its successful learning principles. Profiting from networking and communication technologies advances, multimedia applications (audio/video conferencing, interactive elements, live video streaming) reshape the learning and educational system (Al-Huwail et al., 2018). However, new learning technologies including also social networking as blogs or wikis, pod/vodcasting as internet based audio and video communication tools, synchronous and asynchronous communication, are contributing in create new blending potentials for web-based instruction.

The experience carried out in SUPSI within the activities of ConstructPV research project has demonstrate the validity on using blended e-learning environments in solar education. The use of ICT web-based computer systems to better transfer research contents on new solar BIPV systems has allowed to reach in a more effective way a wider audience, with different levels of expertise, promoting an open dialogue and two-directional exchange of knowledge, for mutually beneficial collaboration among researchers, students and the public, by using an interactive process and implementing new methods of teaching, promotion and dissemination of research. This kind of interactive ICT approach, particularly significant in this multidisciplinary BIPV field, encouraged the participation /attention of the public (students, professionals and business sector) to achieve more direct results with also an immediate impact on research activities thanks live polls as inputs for the project. The use of new ICT blended instruction methods as a mix of different learning environments is possible also to communicate and disseminate the research results in a fruitful way by directly to test public opinion and interested stakeholders profiting from the research results.

The main results and findings were:

- $\quad$ ITCs and interactive participatory methods can be used to transfer knowledge from research to public changing relationships between people as technology mediates interaction and learning between the virtual and the physical environment and creating a new landscape of educational technology;

- The active e-learning method used, based on blended learning approaches and ITCs, has allowed good communication and feedback channels with students, researchers and professionals. The network and ITCs technologies have been used for delivery educational contents on solar BIPV, facilitating access to the information on cutting edge research worldwide and to create multi-directional interaction and exchange of knowledge among different stakeholders.

- The in-live survey test based on a set of poll questions served as a way of sounding out public opinion, to get an audience interacting with the webinar presenter and their content, as well as, to generate and to stimulate the dialogue and to gather useful information on the matter.

- The adaption of educational and training innovative methods to research field in photovoltaics (BIPV) by using computer-mediated communication (CMC) tools to build online communication environments, as well as at the same time, using a blended approach with appropriate face-to-face meetings with researchers seems to be more relevant to create attraction, allowing discussion for bi-directional exchange of knowledge and experiences from research to public and vice versa with a possible uninterrupted and iterative application again to reach findings.

- This kind of co-learning method built around an e-learning situation have favored the information exchange (electronic meeting systems) to reinforce the influence of informed stakeholders to follow the changing definition of knowledge from scientific-oriented to consensus oriented (Geurts and Joldersma, 2001) where social interaction facilitate participation of non-scientific experts, citizens, users, and other policy actors in the research process.

- This e-learning activity allows creating a flexible learning environment based on the concept of concept of network management. This concept is based on the assumption of the model of "co-production of knowledge" (Callon, 1999): by means of identifying the key actors or stakeholders in the system, and assessing their respective interests to be even more and more present in the process of research and development activities. Theories that see in the exchange of information and the collaboration between specialists, researchers, and stakeholders involved as fundamental actors in this collective process of production and circulation of knowledge to be considered as a source of experiences and ideas.

- Such event represents a good experience of successful model on publicizing and effective communicating of research results to a wide public, contributing to solar education not only for bachelor ongoing students (architects or engineers) but also for continuing professional development (scientists, professionals, BIPV industry members). 


\section{Acknowledge}

In this case, the use of ICT has improved the teaching and learning process. However, it would be necessary to making use of the in-service training on the tools organized by the school (e-Lab service of USI/SUPSI). We thank the eLab eLearning Lab members, in particular, Mr. Stefano Tardini and Mr. Christian Milani which have given a very important contribution and technical support for the Webinar preparation to achieve the goals of this interactive event. For the same reason we want to remember Mr. Pierluigi Bonomo and Ms. Erika Saretta for their contribution in the organization phases. We also make an special mention to the partners of ConstructPV EU research project (Grant Agreement no.: 295981), Mr. Tom Minderhoud and Mr. Ger Gijzen (UNS UNStudio Architects, NL) and Mr. Robert Hecker (Ed. Züblin AG, GE) for their valuable contribution to this event.

\section{References}

Delponte E., Marchi F., Frontini F., Polo-López C., Fath K., Batey M., 2015. BIPV in EU28, from Niche to Mass Market: An Assessment of Current Projects and the Potential for Growth through Product Innovation. 31st European Photovoltaic Solar Energy Conference and Exhibition (EUPVSEC 2015), Hamburg, Germany, 3046 3050. ISBN 3-936338-39-6. ISSN 2196-0992. Paper DOI: 10.4229/EUPVSEC20152015-7DO.15.4

Tabakovic M., Fechner H., van Sark W., Louwen A., Georghiou G., Makrides G., Loucaidou E., Ioannidou M., Weiss I., Arancon S., Betz S., 2017. Status and Outlook for Building Integrated Photovoltaics (BIPV) in Relation to Educational needs in the BIPV Sector. Energy Procedia, Volume 111, 2017, 993-999. ISSN 1876-6102. Paper DOI: <https://doi.org/10.1016/j.egypro.2017.03.262> (accessed in July 18th, 2018)

Bonomo P., Zanetti I., Frontini F., van den Donker M.N., Vossen F., Folkerts W., 2017. BIPV Products Overview for Solar Building Skin. 34th EU PVSEC 2017 Proceedings, Amsterdam. The Netherlands, 2093 - 2098. ISBN:3936338-47-7, Paper DOI:10.4229/EUPVSEC20172017-6DO.10.1.

Zanetti I., Bonomo P., Frontini F., Saretta E., van den Donker M., Vossen F., Folkerts W., 2017. Building Integrated Photovoltaics: Product overview for solar building skins. Status Report 2017 SUPSI-SEAC, SUPSI, University of Applied Sciences and Arts of Southern Switzerland, Lugano, Switzerland, Pages 71, available at <http://www.bipv.ch/images/Report\%202017_SUPSI_SEAC_BIPV.pdf> (accessed in July 18th, 2018)

IEA SHC Task 51: Solar Energy in Urban Planning (May 2013 - April 2017). IEA Task 51/Report D1 Part 1. State-of-the-Art of Education on Solar Energy in Urban Planning. Editors: Tanja Siems (University of Wuppertal) Katharina Simon (University of Wuppertal) Maria Wall (Lund University). DOI: 10.18777/ieashc-task51-20170001 Publication Date 05/2017. Publisher: IEA SHC Task 51. Pages: 125. Document Number: Task 51/Report D1 Part 1 <http://task51.iea-shc.org/publications> (accessed in July 18th, 2018)

IEA SHC Task 41: Solar Energy and Architecture (May 2009 — April 2012). Report T.41.B.1 State-of-the-art of digital tools used by architects for solar design. Subtask B - Methods and Tools for Solar Design. September 2010 Editors: Marie-Claude Dubois (Université Laval), Miljana Horvat (Ryerson University), Pages: 121.

Dem4BiPV project, Development of innovative educational material for Building-Integrated Photovoltaics. Cofunded by the Erasmus + Programme of the European Union. Project duration: September 2015 to August 2018.

van Sark W.G.J.H.M., Arancón S., Weiss I., Tabakovic M., Fechner H., Louwen A., Georghiou G., Makrides G., Hadjipanayi M., Loucaidou E., Ioannidou M., 2017. Development of BIPV Courseware for Students and Professionals on the Need for Education in the BIPV Sector: The Dem4BIPV Project. 33rd EU PVSEC 2017 Proceedings, Amsterdam. The Netherlands, 2895 - 2899. ISBN: 3-936338-47-7, Paper DOI: 10.4229/EUPVSEC20172017-7DV.1.32.

van Sark W., Louwen A., Georghiou G., Makrides G., Loucaidou E., Ioannidou M., Fechner H., Tabakovic M., Weiss I., Arancón S. \& Betz S., 2016. Development of Innovative Educational Material for Building Integrated Photovoltaics - Dem4BiPV. 32nd EU PVSEC 2016 Proceedings, Munich, Germany.

Gomes L., García-Zubía J. (eds.), 2007. Advances on remote laboratories and e-learning experiences, Engineering, no. 6, University of Deusto, Bilbao. ISBN: 978-84-9830-662-0

CHEETAH project: Cost-reduction through material optimisation and Higher EnErgy outpuT of solAr pHotovoltaic modules - joining Europe's Research and Development efforts in support of its PV industry. FP7Energy-2013 Integrated Research Project (IRP). Duration of the project: 01/01/2014 -01/01/2018.

<http://www.cheetah-project.eu/> (accessed in July 18th, 2018) 
Mishra, P., and Koehler, M. J., 2006. Technological Pedagogical Content Knowledge: A new framework for teacher knowledge. Teachers College Record 108 (6), 1017-1054.

Koehler M. J., Mishra P., Kereluik K., Seob Shin T., and. Graham C. R, 2014. The Technological Pedagogical Content Knowledge Framework. Handbook of Research on Educational Communications and Technology, Springer Science+Business Media New York, pages: .101-111. Paper DOI 10.1007/978-1-4614-3185-5_9,

Construct PV project: Constructing building with a customizable size PV modules integrated in the opaque part of the building skin. FP7-ENERGY-2011-2. Duration of the project: 01/02/2013 - 31/01/2017

<http://www.constructpv.eu/ > (accessed in July 18th, 2018)

Graham, C., 2006. Blended learning systems. Definitions, current trends and future directions. In C. Bonk \& C. Graham (Eds.), The handbook of blended learning: Global perspectives, local designs. San Francisco: John Wiley and Sons.

Vaughan, N., 2007. Perspectives on blended learning in higher education. International Journal on ELearning, 6(1), 81-94.

Mason, R., Rennie, F., 2006. Elearning: The key concepts. London: Routledge Key Guides, 1st Edition. Pages: 200. ISBN-13: 978-0415373074. ISBN-10: 0415373077

Stacey, E., Gerbic, P., 2008. Success factors for blended learning. In Hello! Where are you in the landscape of educational technology? Proceedings ascilite Melbourne 2008, 964-968.

<http://www.ascilite.org/conferences/melbourne08/procs/stacey.pdf> (accessed in July 19th, 2018)

Garrison, R., Vaughan, H., 2008. Blended learning in higher education: Framework, principles and guidelines. San Francisco: Jossey-Bass

Bousset, J.P., Macombe, C., Taverne, M., 2005. Participatory methods, guidelines and good practice guidance to be applied throughout the project to enhance problem definition, co-learning, synthesis and dissemination, SEAMLESS Report No.10, SEAMLESS integrated project, EU 6th Framework Programme, contract no. 0100362, www.SEAMLESS-IP.org, 248 pp, ISBN no. 90-8585-038-X.: 90-8585-038-X.

Akrich M., Callon M., Latour B., 1988a. A quoi tient le succès des innovations. Premier épisode: l'art del'intéressement, Annales des Mines, June volume 1988, 4-17

Akrich M., Callon M., Latour B., 1988b. A quoi tient le succès des innovations. Deuxième épisode : l'art de choisir les bons porte-parole, Annales des Mines, September volume 1988, 1988, 14-29.

Al-Huwail N., Al-Sharhan S., Al-Hunaiyyan A., 2018. Learning design for a successful blended e-learning environment: Cultural dimensions. Journal of Computer Science. 6. 60-69.

Geurts J.L.A., Joldersma C., 2001. Methodology for participatory policy analysis. European Journal of Operational Research, Volume 128, Issue 2, Pages 300-310, ISSN 0377-2217, <https://doi.org/10.1016/S0377-2217(00)00073$\underline{4}>$ (accessed in Augustt 6th, 2018)

Callon M., The role of lay people in the production and dissemination of scientific knowledge, Science, Technology and Society, vol.4, no 1, 1999, p 81-94. 


\title{
Understanding the Dynamics of Solar Energy Systems by Using Simulation Narratives
}

\author{
Andreas Witzig, Joachim Borth, Serena Danesi
}

ZHAW Zurich University of Applied Sciences, School of Engineering, Winterthur (Switzerland)

\begin{abstract}
In this paper, we discuss the application of modern didactic approaches to solar energy education. We focus on the dynamics of decentralized energy systems and solar thermal applications. In order to bridge the gap between theory and practice, students are engaged in investigating solar systems in numerical analysis combined with hands-on laboratory exercises. Our learning material includes simulation software and state-of-the-art analysis tools for the post-processing of log data. We recognize similarities in the students' cognitive processes when they do simulations in one part of their practical work and hardware experiments in the other part. In both cases, the narrative nature of the processes are a key to a fundamental understanding of the underlying physics. For both the simulation approach as well as the hardware experiments, students train to explain the physical processes in words: Simulation software and hardware laboratory equipment are the "story worlds" and a specific simulation run or a measurement experiment is the "story" (Fuchs 2015). Consequently, students at the same time practice clearly phrasing their observations and extend their expertise in solar energy. They also train abilities like system modeling, parameter validation, and practical skills like the handling of large data amounts typically produced by logging devices. We conclude that a narrative approach helps to thoroughly understand the controller strategies in solar systems with all its consequences and at the same time enables solar engineers for successful communication with the various players.
\end{abstract}

Keywords: Solar education, seamless learning, simulation narratives

\section{Introduction}

The various types of usage of solar energy all require dealing with the stochastic nature of both solar energy production as well as consumption. Firstly, one needs to understand the key figures of solar energy systems, such as system efficiency and self-consumption. They are the basis for all financial considerations such as the calculation of payback time or net present value. Secondly, understanding the dynamics of such systems is important for the proper dimensioning of system components (thermal or electrical storage, selection of heat pump size, dimensioning of heat exchanger). Thirdly, optimizing modern energy systems, or in many cases simply meeting the future regulatory requirements, involves analyzing their dynamic behavior and working out scenarios. Consequently, teaching the dynamics of decentralized energy systems is relevant for both technical colleges and the training of specialists (see also Carberry, 2014). To some degree, this is also relevant for decision-makers in regulatory bodies, funding agencies and utility companies. In particular, we believe that the knowledge of the dynamics of thermal systems is of very high importance for the renewable energy engineers despite the fact that low cost photovoltaic systems dominate the renewable energy market today.

At Zurich University of Applied Sciences in the bachelor's degree Energy and Environmental Engineering, solar thermal systems are treated in the last year, employing a combination of a classroom teaching in classical lecture format with simulation exercises and hands-on experience in the laboratory. Simulations are done with Polysun (Vela Solaris, 2017). In this work, we compare the learning processes in simulation and laboratory experiments. Simulation experiments lately receive a lot of attention due to the digitalization of the engineering disciplines. We are convinced that a combination with hardware experiments remains important both in order to strengthen the technical understanding as well as in supporting the cognitive learning process.

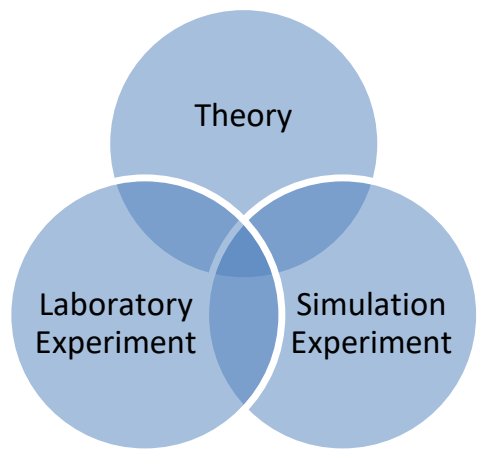

Fig. 1: Interplay between theory and experiment 


\section{Seamless learning and the narrative approach in science education}

The paradigm of seamless learning is relevant for the teaching of engineering sciences because it recognizes the importance of paying attention to rifts, breaks, or divides, i.e., seams, in learning biographies and accounts for the impact of modern mobile devices and recent results in learning sciences relevant for the teaching process. We are concerned with such rifts in life-long learning where differences in form and level of technical education need to be bridged. In continuing education as well as universities of applied sciences, it is an advantage that students previously acquired practical knowledge as practitioners in an industrial work environment. It is equally an opportunity as a challenge to tie new theoretical contents to the individual experience of every student - in the seamless learning context, the relevant dimension is the learning across time and the "knowledge synthesys", i.e. the conjunction of prior and new knowledge (Wong 2012). Likewise, the gap between theoretical and practical knowledge can be a major obstacle for graduates from technical universities to be successful in their first years as engineers in industry.

Furthermore, and with a specific relevance to dynamic energy systems, we recognize the three links between theory, the laboratory experiment and the simulation as major divides. As an example, it is a danger that theoretical knowledge cannot be transferred to the laboratory setting or that it students do not see the direct relation between a hardware experiment and the results of a computer simulation.

Being aware of the seams as described above, it can be one strategy to reduce the gap and design learning material in a way that the student clearly sees the similarities between the two worlds. As an example, the laboratory experiment and the simulation setup shown in Fig. 1 have a clear correspondence in topology. The student exercise is chosen to measure and simulate exactly the same period of time and the resulting curves can be directly compared.

Alternatively, we believe that the seamless learning paradigm helps to empower students to recognize and overcome divides that will inevitably exist in his professional career; the simulation-measurement divide being a classical challenge in the modern engineering world. Good learning results have been observed in a two-stage process where an initial phase was used to familiarize oneself with computer simulations and in a second phase students work out optimization problems with computer simulations and in hands-on laboratory exercises make measurements in the laboratory with an obvious rift between the two worlds.

The narrative approach as a common methodology bridges the gap: in both worlds, the students have to express their findings in words and describe the fundamental physical relationships. The time-domain nature of the dynamical processes give a good guidance in developing the "story" that needs to be told. Students identify the "actors" and describe how they influence what happens in the system. As an example, a controller has the temperature sensor at the solar collector $\vartheta_{c}$ and at the bottom of the storage tank $\vartheta_{s}$ as input parameters. Depending on a given set of rules, in this case if $\vartheta_{s}<\vartheta_{c}$, the controller activates the pump in the fluid starts to circulate in the solar loop. Students identify the mass transport, the energy transport and the flow of information as separate flow phenomena and gains a deeper understanding of physical principles. 

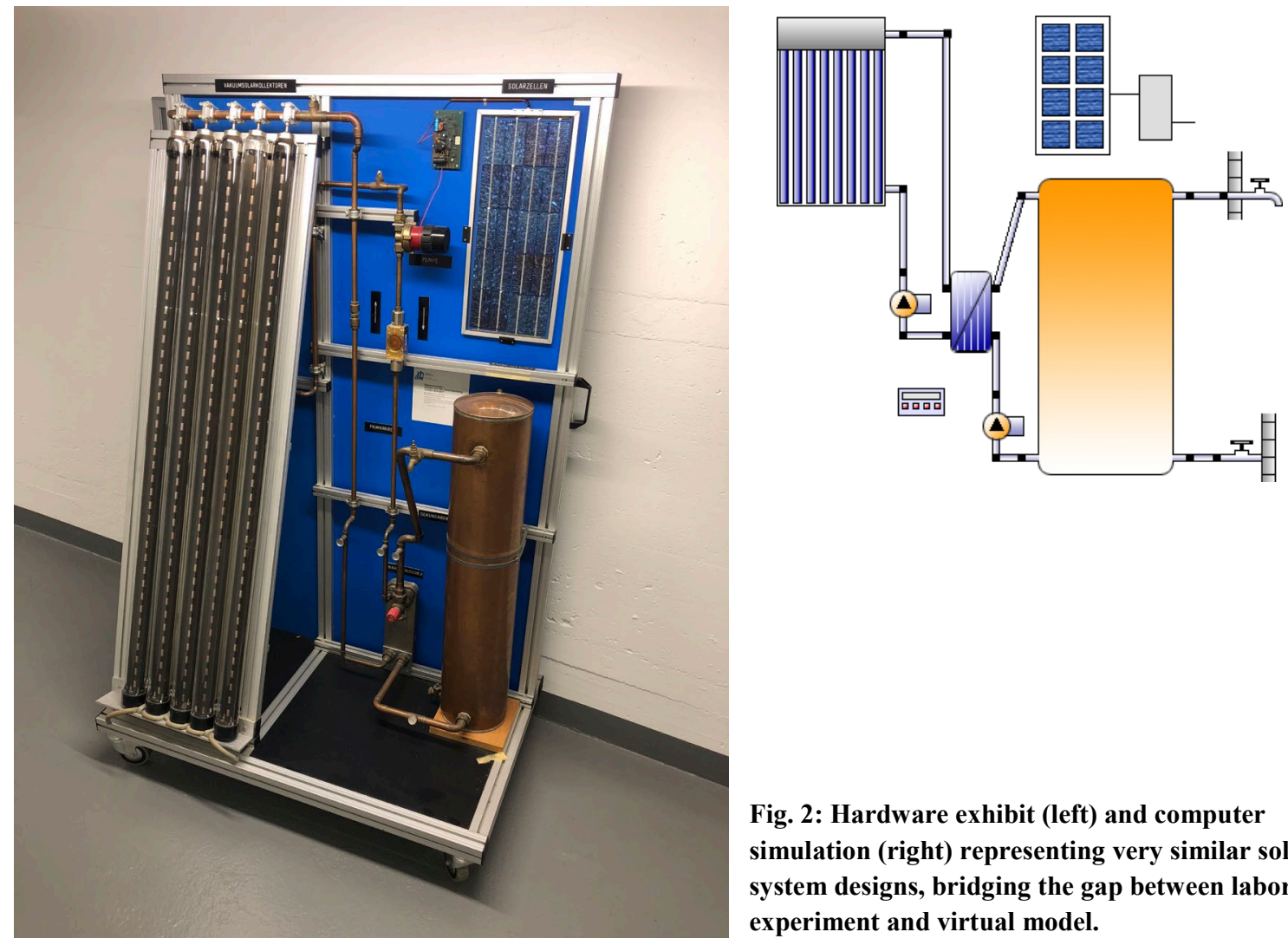

Fig. 2: Hardware exhibit (left) and computer simulation (right) representing very similar solar system designs, bridging the gap between laboratory experiment and virtual model.

\section{Practical work with experimental solar installation}

The practical work experiences are fundamental in the engineering syllabus and is repeatedly trained during the course of studies. The solar thermal laboratory of the Institute of Energy Systems and Fluid Engineering at Zurich University of Applied Sciences is used during the practical exercises in the above mentioned course in solar thermal technologies. The goal is that students gain a general understanding of the behavior fo different types of collectors under real conditions. Six types of collectors are installed in parallel on the roof of the machine laboratory building: one unglazed, one hybrid PVT collector, three glased collectors, but with different reflection coating and absorber material, and one vacuum collector. The collectors are south facing with adjustable tilt angle (Fig. 4).

In the exercise, students use their own computers for the analyzation of measurement results. In particular, they learn to handle large amounts of data and sharpen their engineering perception in interpreting simulation results and discussing the behavior and performance of the system under test and the different collectors.

The system can be operated in two different modes (Fig. 3):

- Storage mode: this mode help to get familiar with a solar system as normally is built. The collectors are connected to a stratified thermal water storage. Water is fed from the storage to external heat exchangers to simulated warm water users and space heating. The temperatures are monitored in the storage at different heights, so the students can have a picture of the temperature profile inside the storage and understand better the operation mode of the system (Fig. 3). More temperature sensors and flowmeters are installed along the circuit allowing a complete energy balance and the computation of the thermal losses in the circuit and in the storage itself (for example during the night).

- Yield mode: the scope is to determine the yield curves of the collector at different absorber temperatures. The temperature at collector inlet can be maintained constant at the required value by a cooling/heating system. That allows comparing the performances of different collectors under the same boundary conditions. 


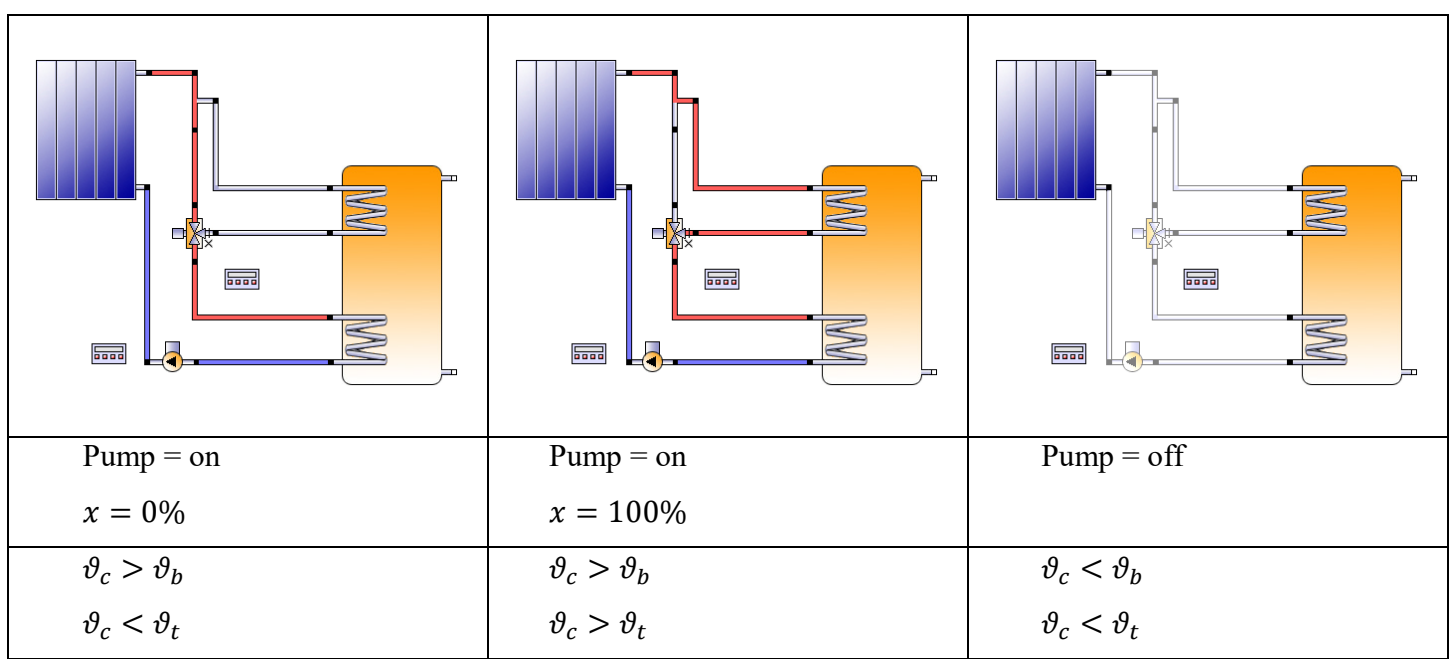

Fig. 3: operation of the stratified thermal water storage. $\vartheta_{c}$ : collector temperature; $\vartheta_{t}$ : top temperature of storage; $\vartheta_{b}$ : bottom temperature of storage. Depending of the collector temperature, the three-way valve is controlled in a way that the collector fluid is fed to the bottom or upper part of the storage, $x$ being the percentage of the flow as indicated in the schematic. In case the collector temperature is lower than the storage temperature, the circulation pump is turned off.

Another important aspect is the thermal inertia of the systems. The temperature sensors shown a time delay between a suddenly shading and the decrease in the collector yields as well as between temperature change at collector outlet and storage inlet. These aspects shall be analyzed carefully during the result validation in order to get correct results during transient conditions and to integrate these into the simulation tools.

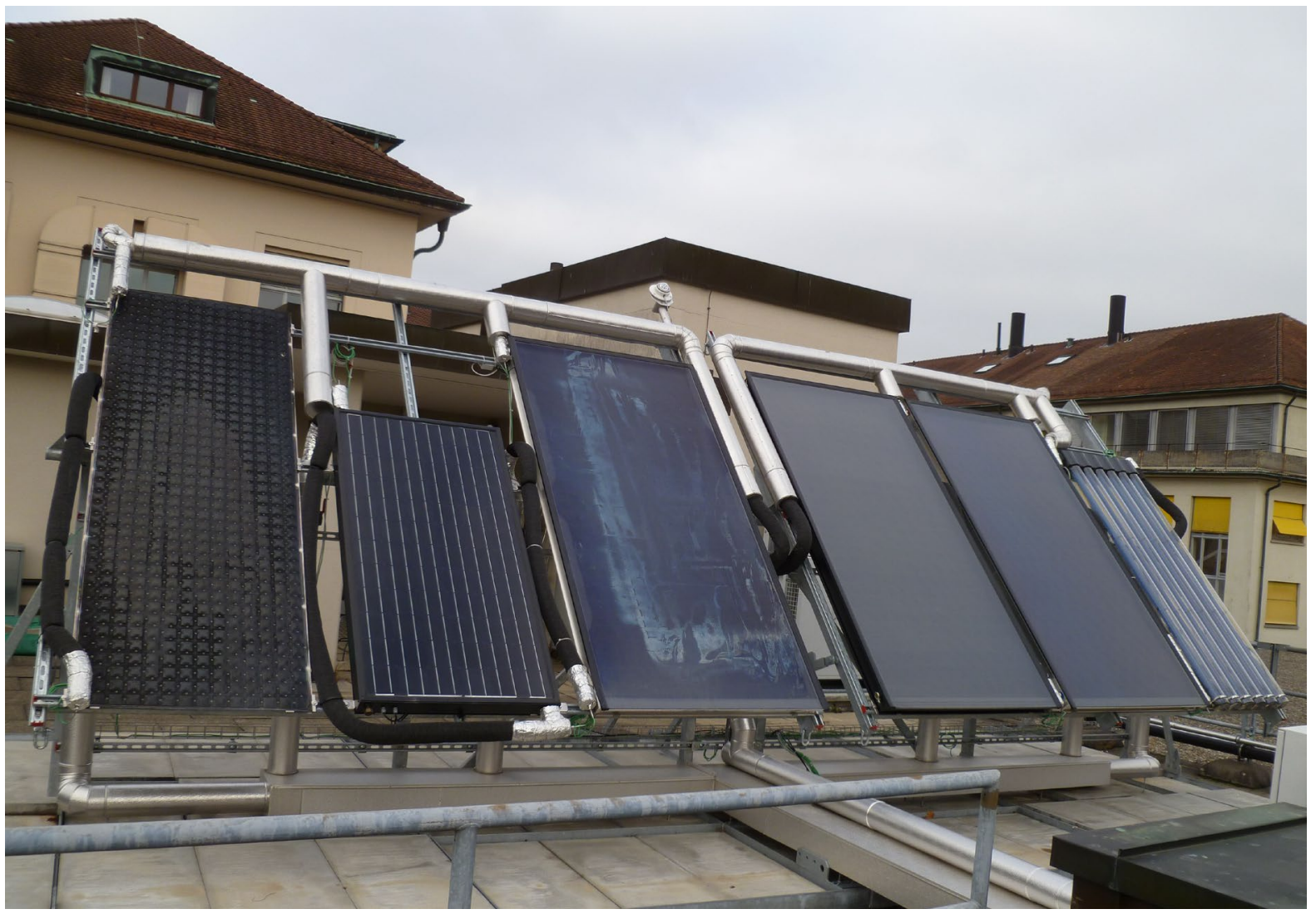

Fig. 4: Collector test field for lab experiments and student projects 


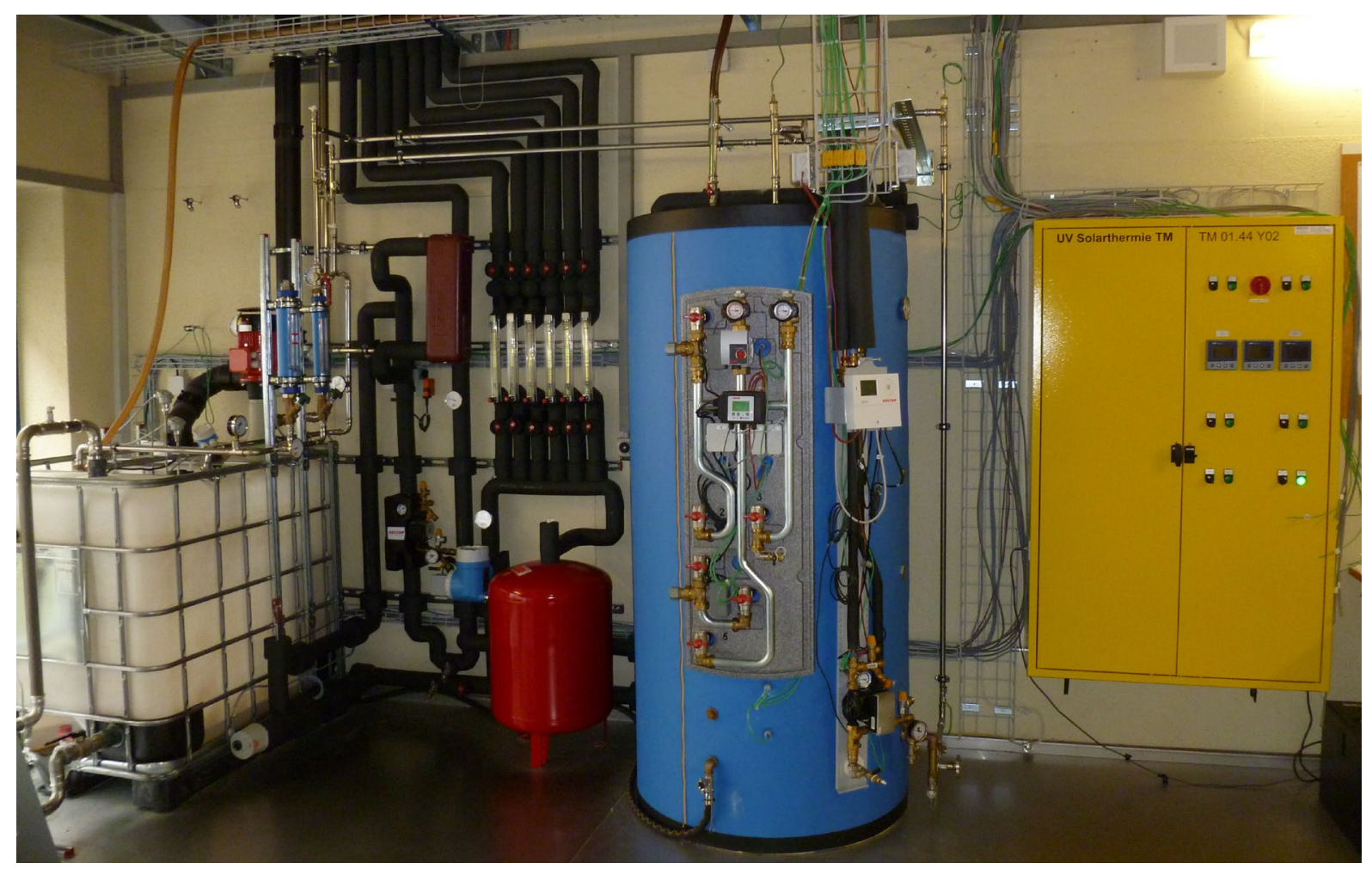

Fig. 5: Solar thermal Laboratory of the Institute of Energy Systems and Fluid Engineering (IEFE). Solar energy storage tank (blue), large reservoir as a reference for short term measurements (white)

\section{Results}

Research on cognitive skills suggests that simulation narratives obtain a more central role in explaining how dynamic systems operate (Fuchs 2015). Students learn how to model the real world by creating a story world in their mind. Our approach trains them to talk in a colloquial but precise language about physical phenomena. They recognize the different flow quantities such as information, thermal energy, electrical energy, mass transport. The approach is particularly suitable in time domain simulations and in experiments with controllers that are equally have an inherent time sequence.

We expect the narrative embedding has a positive effect upon a widespread practice-theory divide, to lead to improvements in lifelong learning and in this way help alleviate the shortage of qualified technical specialists. In order to take into consideration breaks and rifts in individual learning biographies, we make use of the paradigm of seamless learning (Wong, 2015).

As scientists or engineers, we are not commonly acquainted with the idea of narrative aspects of our formal and practical work. Still, it has become apparent in fields as diverse as economics and physics that modeling and simulation are a form of narrative practice. Economists tell themselves stories about events from which they distill models (Morgan, 2001). In computational science, a simulation takes us through a series of events, a process that is rather unlike the results of a formal derivation based upon some laws of nature (Wise, 2011). Inspired by these observations, and by work in narratology that has pointed to the importance of the distinction between stories and story-worlds, we suggest that simulations resemble stories whereas models represent story-worlds (Fuchs, 2015). This suggests interesting avenues for education in fields that require computation. It points at simulations as sources of experience of the action of characters such as heat or electricity in natural and technical worlds in the same way that novels can be the origin of understanding of (human) characters acting in social and psychological worlds. Being exposed to such experience and learning to "retell" what is "seen" in these "stories" is expected to help create story-worlds, i.e., mental models, that allow a practitioner to better understand, and even criticize and extend, the models that underlie his or her simulations. 


\section{Conclusion and Outlook}

We have followed the seamless learning paradigm in the design of teaching material starting with theory and subsequently deepening the knowledge both with use of simulation software and laboratory measurement. In a first step, exercises have been design in a simplifying way, reducing the gap between simulation and measurement. In a second step, the differences between a virtual system (numerical model) and a hardware experiment (laboratory measurement) have been emphasized, letting students develop their skills in switching between the two worlds.

Progress in a deep understanding of physical phenomena is observed during our courses. However, exam questions are not yet set up in a way that allows to measure the learning effect properly.

\section{References}

Vela Solaris (2017). Polysun 10.1: Systeme vergleichen und übersichtlich darstellen. Polysun release notes. Winterthur

Wong, L.-H. (2012). A learner-centric view of mobile seamless learning. British Journal of Educational Technology, vol. 43, no. 1, pp. $19-23$.

Wong, L.-H., Milrad, M., \& Specht, M. (2015). Seamless learning in the age of mobile connectivity. Singapore: Springer.

Carberry, A. R., McKenna, A. F. (2014). Exploring Student Conceptions of Modeling and Modeling Uses in Engineering Design, Journal of Engineering Education, Wiley Online Library, vol. 103, issue 1, pp 77-91

Fuchs, H. U. (2015). From Stories to Scientific Models and Back: Narrative framing in modern macroscopic physics, International Journal of Science Education, Pages 934-957 


\section{Renewable Energy Strategies and Policies}




\title{
Indoor Climate Agreements in Energy-Efficiency and Renovation
}

\author{
Projects - A Question of Justice?
}

\author{
Annette Henning \\ Dalarna University SE-791 88 Falun, Sweden
}

\begin{abstract}
One of the global dilemmas of our time is the urgent need to reduce energy demand in some parts of the world and at the same time manage to increase and improve energy services in others. This paper calls attention to the importance of also recognizing local energy dilemmas and pockets of more vulnerable groups in energy efficiency and building renovation projects. Interviews with tenants in a Swedish 'million-program' housing area are used to illustrate the arguments in the paper. Results show essential variations in male and female thermal sensation. They also show little compatibility between the tenants' wishes for a comfortable home and the housing company's energy saving ambitions. The paper argues that the use of generalized indoor climate agreements needs to be taken less for granted and complemented with qualitative investigations of all main actors in a specific local context. Only then can possible disparities become evident, and alternative, more just, solutions be worked out.
\end{abstract}

Keywords: Thermal comfort, energy renovation, climate justice

\section{Introduction}

Some authors have used the term 'climate justice' to describe the state of the world, although this primarily refers to the uneven impacts of climate change, such as rising sea levels, pollution etc. It may also include the fact that future generations will bear the cost of our current actions or that the norms of minimum standards are escalating in a time when we need to save energy (Simcock and Mullen 2016, Sovacool and Dworking 2015, Walker et al. 2016). However, more specifically relevant for the purpose of this paper is the term 'energy dilemma', which has been put forward by Wilhite (2012) to describe the asymmetrical global development of the past century, a development which has, as he says, led to a striking global gap in per capita energy use and, consequently, a situation with huge challenges.

The aim of this article is to contribute to such discussions, but to do so by raising, in particular, the question of how we may handle specific cases of energy dilemma. As Day et al. (2016) have argued, there may seem to be an in-built conflict between the needs of much of the Global South to extend access to energy services, and the global objectives to reduce energy consumption. However, similar energy dilemmas may occur when the levels of energy consumption are raised among certain groups in the richer parts of the world, in spite of this global need to reduce carbon emissions. Walker and Day (2012), in particular, have been clear about the necessity of addressing such issues in an interconnected way.

Results from ongoing research indicate that the aim of saving thermal energy may be incongruent with a just treatment of a vulnerable group of immigrant women. This dilemma has evoked some ideas and questions, and is used to exemplify further arguments and discussions in the paper. 


\section{Case-study: Thermal comfort in energy-efficient renovation}

In the 1960s and 70s, the Swedish 'million-program' housing policy gave rise to a boom of growing suburban areas and a fast construction of new residential blocks. Today, most of these housing areas are in considerable need of renovation, and various attempts are being made to render the buildings more energy-efficient. In our case-study, a multi-disciplinary research team is testing cautious ways of renovating three-storey buildings in a mid-Swedish town. An important purpose of the project as a whole is to be able to suggest easy ways of making million-program area buildings more energy-efficient. One of the aspects that was investigated in a test building was the thermal comfort before renovation.

\subsection{Combining technical and social scientific methods}

Two methods were used to study thermal comfort, one technical and one social scientific. The technical method consisted of indoor climate measurements and evaluations of predicted indoor comfort in accordance with thermal comfort standards, the social scientific methods included qualitative interviewing. Since we were interested in the subjective thermal experiences of these specific tenants, interview methods were preferred to surveys or laboratory studies, which otherwise tend to be more commonly used within the thermal comfort field (Engvall et al. 2009, Leijonhufvud and Henning 2014, Nicol et al. 2012). Men and women in six of the ten interviewed households were immigrants with Somali backgrounds, while householders in the remaining four had Kurdish backgrounds.

\subsection{Differing results}

Results emanating from these two quite different methodological approaches turned out to be similar concerning certain aspects, such as variations of thermal comfort throughout the day. Thus, interviews showed that all occupants perceive their flats to be coldest in the morning, in the evening, and/or at night-time, while measurements indicated similar results; that the largest number of dissatisfied occupants should be found before eight o'clock in the morning and after four o'clock in the evening.

The results where occupants express thermal discomfort are much less in accord with results where they are merely assumed to experience and complain about this. Consequently, we found that all the interviewed occupants described their flats as either "cold" or "very cold", and that at least eighty percent of them complained about this. Measurements, on the hand, showed a "predicted percentage of dissatisfied occupants" (PPD) of only twelve to thirty-one percent.

\subsection{Gender variation}

Even more essential for the discussion here, however, is the fact that interview results indicate that the female occupants tend to suffer much more from thermal discomfort than their male counterparts. A clear majority of the interviewees either stated such a gender difference explicitly, or the women would be the only ones who emphatically expressed how bad the cold made them feel. For example, one of the women stated firmly, and with strong emotion in her voice, that "It is very cold!! I am freezing all the time!" Another woman complained about her aching feet and how she did not feel well because of the cold. A third example is the woman who described how the cold floor makes her toes go numb, and that, whenever she gets the opportunity, she has to lie down under the bedroom quilt in order to endure it.

Most important to note here, is the fact that the interview results clearly indicate a gendered variation of thermal comfort, while such results are absent altogether in results from the standardized measurements. 


\section{Are women a 'vulnerable group'?}

The stronger sense of discomfort, which we found among our female occupants, fits well into the bigger picture drawn by Karjalainen in his thorough literature review on indoor thermal comfort (Karjalainen 2012). Karjalainen shows that when a large number of laboratory and questionnaire studies are put together, a clear pattern arises. It turns out that, irrespective of outdoor climates, women tend to be less satisfied with indoor climates than men, particularly in cooler conditions. Women are also more sensitive to deviations from an optimal thermal environment and tend to express more dissatisfaction than men in the same indoor thermal environment. All this is clearly in line with our interview results.

\subsection{Pockets of vulnerability}

According to Bouzarovski (2014), The Scandinavian countries have the lowest degree of domestic energy poverty in Europe, while Southern Europe has the highest degree, due to poorly insulated homes and more income poverty. The Scandinavian countries also have the lowest number of people who are unable to keep their homes adequately warm. Still, we may find pockets of more vulnerable groups everywhere, which is one of the points made in this article. In the case study referred to here, a group of female immigrant tenants emerge as one such pocket of vulnerability.

Until recently, research in the field of 'energy poverty' or 'fuel poverty' has mainly been focusing on certain groups, whose health and well-being is considered to be particularly precarious due to cold and draughty indoor climates. So far, these groups have largely consisted of old or disabled people, of the chronically ill, and, to some degree, also children (Bouzarovski 2014, Day et al. 2016, O'Sullivan et al. 2016, Walker and Day 2012). However, if we should also include all women in these more vulnerable groups and, perhaps, all immigrant families too (Bouzarovski 2014, Fraser 1999 in Jenkins et al. 2016), there would not be many others left, apart from the reasonably well-to-do young and native born men! Women as a whole could hardly be categorized as a 'vulnerable group', despite the differences between men and women in terms of sensitivity to thermal variation.

\subsection{Energy justice}

Even though the terms energy poverty and fuel poverty overlap to a great extent with the 'energy justice' concept, the increasing use of the latter mirrors a growing emphasis on a just and fair treatment of those who are deprived of certain energy services. In particular, the 'justice recognition approach' seems useful for the arguments of the current article. Articles by Walker and Day (2012) and Jenkins et al. (2016) refer back to the work of Frazer, who at an early stage defined and formulated some categories of misrecognition. Walker and Day (2012) argue that, an alternative to the distributional approach to social justice is to emphasise relationships, and to look upon social injustice as a failure to show certain human beings the same respect as others and to allow them equal rights. "Where there is a lack of recognition", they say (2012:71), "groups may be over-looked or stigmatised". They refer also to an article by Day, who states that certain groups may sometimes have special needs. Older people may, for example, require more home heating than others for physiological reasons, or because they may spend more time at home than those who are working.

Another important point that Walker and Day make, is that not only must special needs be recognised, but they must also be seen in their context, "defined with reference to the society that they operate in" (2012:74). When relating this argument to the empirical example of the current paper, it becomes clear that our concern here does not merely relate to the fact that women in general tend to be more vulnerable than men when it comes to a lack of thermal comfort. The ongoing research among immigrant families also sheds light on a vulnerable group, which may need to be more clearly recognised as such. These are the female tenants with refugee backgrounds, low-income earners or house-wives who tend to spend large parts of their days in draughty, poorly insulated dwellings. This focus should have bearing on many European contexts today. Still, since there may also be a 
high risk for immigrant women to be generalised and stereotyped, it seems particularly important to base such studies on context-specific investigations which take native perceptions and experiences seriously.

\section{The local energy dilemma}

The most recurrent and dominant focus of research on fuel poverty, energy poverty and energy justice has been on problems for those who have difficulty in affording a certain energy service, or who lack access to such service (Bickerstaff et al. 2013, Day and Walker 2013, Walker et al. 2016).

Since the beginning of this research tradition, the larger part of the studies has concerned the many older people, particularly in the UK, who cannot afford to keep their homes warm (Bickerstaff et al. 2013, Day et al 2016). Bickerstaff et al. (2013) have added to this concern a serious dilemma more directly concerned with the global climate threat. In referring to other authors, they state that climate policies in UK are largely funded through electricity and gas bills, which have to be paid by the households. This, in turn, puts an extra heavy burden on the lower-income households.

The local energy dilemma in our case is, however, different. The occupants of this study have heating costs included in the rent. This means that, even though they are not able to influence the temperature and thermal comfort in the flat to any great extent, their discomfort does not have such a direct link to which bills they can afford to pay. The dilemma is still one between energy justice and climate change mitigation. It may be described as an imbalance and state of tension between the occupants' well-being on the one hand, and the housing company's endeavour to save energy and reduce the consumption of thermal heating, on the other.

\subsection{Company strategies to save energy}

The housing company has two main strategies for saving energy. One is to insulate the buildings and provide them with new roofs and energy-efficient heating systems. The other strategy is to inform the householders about the renovation process and the new heating system, but also to try and regulate their energy consumption through technical means. One such means is to limit the use of hot water through the installation of low-flow devices in kitchens and bathrooms. Another way is to install thermostats where the temperature adjustment can be locked, which means they are able to prevent tenants from increasing indoor temperatures too much.

\subsection{Tenant perspectives on a comfortable home - example clothes}

While the company strategies mainly concern the energy performance of the building, the tenants themselves struggle to cope with thermal discomfort on an every-day basis and to find ways of making the flat feel less cold.

It was, however, a bit surprising to find most of the interviewees barefooted at the time of the interview. This was even the case with women who emphatically described how their feet would ache or go numb. When one of these women was asked why she did not wear socks as protection from the cold floor, her answer was simply 'I need to be able to feel at home'. The woman made an expressive gesture, letting her hands fall from her shoulders, following the sides of her thin ankle-length dress towards her feet, where her left foot made a light stamp, emphasizing her need to feel connected to the floor. "Besides", she added with slight disgust in her voice, "my feet get sweaty when I wear socks". In the continued conversation with the woman, the interviewer described to her, how previous Scandinavian studies have shown that some can feel it is cosy and pleasant to huddle under a blanket when it feels cold (Henning 2003). This woman was of a completely different opinion. On the contrary, she said, she feels unwell when she has to use a blanket to keep warm. This is something she normally only does when she is ill.

The gesture this woman made to emphasize her wish to wear a thin dress and be bare-footed bears a strong resemblance to results from a study of home-feeling in contemporary Japan (Daniels 2015). Daniels suggests there, that the Japanese habit of removing shoes and sitting or sleeping on the floor, is linked to an experience of 
comfort created through this direct bodily contact with the ground. Still, most of all the conversation with this particular woman illustrates how the habit of using socks and blankets to endure a chilly environment may be perceived very differently. The way people dress, as well as whether they wear socks or use blankets had, of course, an effect on how cold they feel in a cooler environment (Amrit 2007). The example points at something else, however, namely the importance of being able to dress in a way that makes one feel relaxed, comfortable, and at home.

The connection between warmth and comfort is obvious in our interviews. Less obvious though, is the degree to which the experience of cold or warm indoor temperatures may be connected to their perceptions of home in more general terms. We know from previous studies in Norway and Sweden that a pleasant home in the Scandinavian area tends to be described as 'warm' in both a literal and figurative sense (Gullestad 1992, Henning 2003). Unless a home in this part of the world is warm enough, the cosy, homelike feeling will generally not emerge, no matter how much effort has been put into home decoration (Gullestad 1992, Henning 2006). Still, most of these studies have been conducted among natively born Swedes or Norwegians, whilst the interviewees in the current study all grew up in Somalia or some part of Kurdistan. It remains to find out more about what these differences in childhood experiences may mean for the link between perceptions of the home and indoor thermal comfort. What we do know, however, is that variations in how a warm or cool indoor environment is perceived and handled not just varies with each individual. It is also culture-specific, as well as adjusted with time and context (Andamon 2005, Daniels 2015, Henning 2003, Wilhite et al. 1996, Wilhite 2008).

\section{Discussion}

The two main actors in this local energy story have very different ways of relating to the indoor climate of the building. While the housing company management has more of an outsider's theoretical view on the thermal performance of the building, the relationship of the occupants to their respective flats is more personal, emotional and practical. Their ability to keep their privacy and dress as they like, affects whether they perceive their homes as comfortable or not. Since many of the tenants spend a major part of their days in these flats, thermal comfort becomes an important part of their perception of their homes and influences whether they are able to feel at home or not. As with the housekeepers and guides in Leijonhufvud and Henning's article on decision-making among professionals in a historic house museum (2014), the chilly temperature has become an embodied experience.

\subsection{Unequal power balance}

Another parallel to the Leijonhufvud \& Henning article is the reverse relationship between the amount of time each of the main actors spend in the building and how much each of them has to say in terms of determining the temperature of the rooms. Both case studies involve this imbalance, where those who have the least options for making decisions concerning the indoor climate are the ones most affected by a cold environment.

One of the most concrete ways by which this unequal power balance manifests itself in the current case-study, is through the limited possibilities for tenants to regulate indoor temperatures. Some researchers have argued that thermal comfort for all can only be achieved when occupants have effective control over their own thermal environment (Karjalainen 2012, van Hoof 2008). Others argue that the way one experiences thermal comfort in one's home tends to be affected by the extent to which one's free will is being circumscribed (Engvall et al 1997 , Henning 2006, Stoops 2001). Both these arguments speak in favour of better opportunities for the householders to adjust the temperature as they like. This is not a problem-free solution, however. The experience among those who work at the housing company is that many tenants in this area have difficulty in handling the thermostat correctly. The occupants also tend to wish for a much warmer indoor climate than the housing company managers consider feasible, and that which is generally recommended. This is the reason why they now install thermostats that can be locked and are as simple and sturdy as possible.

\subsection{Thermal comfort agreements}


The ambition of the company management is to combine energy-efficiency with cost-effectiveness. They aim at keeping $20,5^{\circ} \mathrm{C}$ in the building during day-time and $19^{\circ} \mathrm{C}$ during night, although the actual temperatures vary somewhat throughout the year, tending to be lower in spring and autumn. The experienced temperature ("operative temperature") among occupants is most probably a few degrees lower than that because of the severe draught from windows and doors. The company is supported in these decisions by the national building regulations. Even though it is more common in Sweden today to keep $22^{\circ} \mathrm{C}$ in flats, the regulations of the National Board of Housing, Building and Planning (2016) do not prescribe more than $18^{\circ} \mathrm{C}$ in the "occupant zone" of houses and residential blocks, while $20^{\circ} \mathrm{C}$ should be kept in care centres, in spaces for children in preschools and for old people in service homes.

There is also strong agreement between these national guidelines and international thermal comfort standards. Furthermore, the energy saving ambitions of the housing company are well in line with those of the Swedish Government and the European Union (EU 2012, Hautijärvi \& Landfors 2013, SOU 2017, Swedish National Audit Office 2013). Due to this congruity between national guidelines, thermal comfort standards, the national and EU programmes for climate mitigation, as well as the company's own energy strategies, there is strong legitimacy for the company decisions, and little reason to question them.

\subsection{Risks with the taken-for-granted}

There are some risks with such strong and taken-for-granted indoor climate agreements, however. One of them is the risk of missing particularly vulnerable individuals. The fact that certain categories, such as children, the elderly, or those in poor health, can be more vulnerable to heat or cold than others, may seem obvious (The Public Health Agency of Sweden 2014). Attention has also been paid to the fact that those who do not have a physically strenuous job need a warmer working environment (Swedish Work Environment Authority 2015). It may be more difficult to detect and recognise those who are unused to cold thermal conditions, those who become vulnerable due to a worrying life situation, or those who simply spend long hours in a chilly home and have little opportunity to do anything about their situation.

Another risk with the 'near doxa' ideas of suitable thermal comfort is that it becomes natural to turn to normative solutions, where only those who are affected by cold conditions and complain about them, need to change. Jenkins (2016) has, for instance, described how Government-sponsored programmes in the UK typically have treated the energy poor as suffering from a "knowledge deficit", which has to be fixed. Also Swedish recommendations to and strategies regarding occupants tend to be limited to information campaigns and the installation of individual metres (e.g. Hautajärvi \& Landfors 2013). There is a parallel between such strategies and the current case, where technical devices are used to make the occupants change their ways and stay within accepted temperature limits. However, the question is whether it could be considered a fair treatment when only the energy receivers (just one of the main actors) are supposed to alter their ways. To put it bluntly; how much do those who spend their days in the building have to feel cold in order to save energy? This is actually what this particular energy dilemma is about.

\subsection{Recognizing occupant experiences}

If, as Jenkins and Fraser recommend (Jenkins 2016), the thermal experiences among these occupants were recognised, and their needs for higher-than-average room temperatures respected, it might be possible to find a better balance in which both the receivers and providers of energy would have to try to contribute. With respect to the fact that many of these women, in particular, spend a large part of their day in the flat and with curiosity as to their specific needs and wishes, habits, experiences and modes of thinking; perhaps it would be possible to save energy and mitigate global climate change without creating energy injustice. Would it, for instance, be possible to allow a few degrees higher temperature and provide the tools to adjust temperatures within certain limits? It may be reasonable to expect the tenants to wear cardigans, but perhaps that should be sufficient. Furthermore, if the possibility of being bare-footed at home is so essential for the well-being of some tenants, perhaps floor heating or better floor covering could be provided? Yet another idea for negotiation could be to provide tenants with more efficient, well-functioning and aesthetic blinds if they, in turn, agree to let the sun in certain hours in the middle of the day in order to help in heating the flat. 
These suggestions are merely tentative examples of such a give and take. The important point here is that those who suffer from cold indoor climates should be recognised and respected for what they feel and experience. With too much focus on taken-for-granted thermal climate agreements, it is, as Jenkins says (2016), a risk to miss out on valuable knowledge and insights about marginalized groups.

\section{Conclusion}

More generalised, generic and quantitative methods and models for investigating energy-efficiency and renovation projects needs to be complemented with models that take into account specific situations and contexts.

Due to the few born Swedes among the studied tenants, we were not able to make any thorough comparison of the impact that background and life situation might have had on their ways of perceiving and handling thermal comfort (or discomfort). However, the interviewees of this research differ from, for example, those of a previous study of thermal comfort, where born Swedes had replaced old heating systems in their single-family houses (Henning 2003). Their way of interacting differed, as did their respective habits and ways of experiencing and handling indoor thermal comfort.

Still, similar for both these two studies was the fact that the women proved more sensitive than the men to temperature fluctuations and cool indoor thermal conditions. There may very well be explanations to such differences related to psychological, situational or culture-specific aspects (see references in Karjalainen 2012: 106f). Or there may be physiological explanation, such as gender variations in body mass, surface area, core temperature, blood flow, sweating etc. The important point, however, is that, irrespective of the reasons for variations in male and female thermal sensation, this gender issue needs to be taken seriously.

The basic goal behind thermal comfort standards - to achieve as few unhappy occupants as possible - is commendable in many ways. The 'Fanger's model of thermal comfort', on which most standards are built, is increasingly criticized, though, and various suggestions for adjustments and complements have been put forward (Leijonhufvud and Henning 2014, Nicol et al. 2012, van Hoof 2008). Most relevant for this article is Karjalainen's criticism (2012), in which he argues that women have more need for individual temperature control than men, and that thermal comfort standards should be more based on female requirements. If females are satisfied with their thermal comfort, he says, it is highly probable that males can also accept it.

Still, if the aim is to detect differences between categories such as gender or age and understand the meaning of these, it is not sufficient to alter the basis for current comfort standards. The use of generalized predictions and estimations also needs to be complemented with investigations of specific local contexts, including the interaction between some of the main actors and their respective ways of relating to a certain situation (Henning 2015). Only then will it be possible to detect local energy dilemmas, consider the well-being of more vulnerable groups, and avoid energy injustice. In the case-study, the occupants were able to describe their experiences of the indoor climate during interviews. Their wishes for a comfortable home may not fit so easily into the energy saving ambitions of the housing company. Still, their main focus and ways of perceiving and handling the thermal conditions of their flats were, for the first time, fully recognised.

The case also illustrates the importance of being alert to possible imbalances in the ability of different actors to make their voices heard. It was only when focus was shifted away from how the tenants could be made to fit into the frame of dominant, taken-for-granted indoor climate agreements that the energy dilemma came into view. To sum up, it is not until all the main actors of a local energy dilemma are recognised and treated with the same respect, that their respective ways of relating to a particular situation can be compared on an equal basis. Possible disparities can then become evident, and alternative, more just, solutions be worked out. 


\section{Acknowledgements}

The research has been funded by the Swedish Energy Agency.

\section{References}

Amrit, U.R. 2007. 'Bedding textiles and their influence on thermal comfort and sleep'. In AUTEX Research Journal, Vol 8, No 4, December 2007.

Andamon, M.M. 2005. Building Climatology and Thermal Comfort. Thermal Environment and Occupant (Comfort) Responses in Philippine Office Buildings. Thesis. School of Architecture, Landscape Architecture and Urban Design. University of Adelaide, Australia.

Bickerstaff, K., Walker, G., Bulkely, H. (2013). 'Introduction: making sense of energy justice'. In K. Bickerstaff, G. Walker and H. Bulkely (eds): Energy Justice in a Changing Climate. Social equity and low-carbon energy. London, New York: Zed Books.

Bouzarovski, S. 2014. 'Energy poverty in the European Union: landscapes of vulnerability'. WIREs Energy Environment 2014, 3: 276-289, doi: 10.1002/wene.89

Daniels, I. 2015. 'Feeling at home in contemporary Japan: Space, atmosphere and intimacy', in Emotion, Space and Society 15 (2015) 47-55.

Day, R. and Walker, G. 2013. 'Household energy vulnerability as assemblage'. In K. Bickerstaff, G. Walker and H. Bulkeley (eds): Energy Justice in a Changing Climate. Social equity and low-carbon energy. London, New York: Zed Books.

Day, R., Walker, G., Simcock, N. 2016. 'Conceptualising energy use and energy poverty using a capabilities framework'. In Energy Policy 93 (2016) 255-264.

Engvall, K. 1997. Upplevt inneklimat $i$ sex energisnåla hus - en jämförande studie mellan år 1 och år 5. Stockholmsprojektets boendeundersökning. Utredningsrapport nr 1997:2. Stockholm: Utrednings- och statistikkontoret.

Engvall, K., Corner, R., Emenius, G., Hult, M. 2009. Upplevd inomhusmiljö och hälsa i Stockholms flerbostadshus 2005. Report from Uppsala University, Miljöförvaltningen, Karolinska Institute and White Architects.

EU. 2012. 'Directive 2012/27/EU of the European Parliament and of the Council. 14.11.2012'. In Official Journal of the European Union.

Gullestad, M. 1992. The Art of Social Relations. Essays on Culture, Social Action and Everyday Life in Modern Norway. Scandinavian University Press, Kristiansand.

Hautajärvi, H., Landfors, K. 2013. Så når offentliga fastighetsägare 2050-målen. En studie av framgångsfaktorer. Stockholm: UFO (Utveckling av fastighetsföretagande i offentlig förvaltning). www.offentligafastigheter.se.

Henning, A. 2003. Tio hushåll om elkonvertering - Hem och härd, del II. SERC-report, DU-SERC-82-SE, Solar Energy Research Center SERC, Dalarna University, Borlänge. 
Henning, A. 2006. Can qualitative methods support the development of more flexible and energy saving thermal comfort? In conference proceedings (CD) for the international NCEUB-conference 'Comfort and Energy Use in Buildings: Getting them right', 27-30 April 2006, Windsor, England.

Henning, A. 2015. 'Making Energy Interventions more Effective: Situation, Interaction, and Precondition.' In International Journal of Humanities and Social Science. Vol. 5, No. 9; September 2015.

Jenkins. K., McCauley, D, Heffron, R. et al. 2016. 'Energy justice : A conceptual review'. In Energy Research \& Social Science 11 . 2016.( 174-182).

Karjalainen, S. 2012. 'Thermal comfort and gender: a literature review'. In Indoor Air 2012; 22: 96 - 102.

Leijonhufvud, G., Henning, A. 2014. 'Rethinking indoor climate control in historic buildings: The importance of negotiated priorities and discursive hegemony at a Swedish museum'. In Energy Research \& Social Science 4 (0): 117-23.

Nicol, F., Humphreys, M. and Roaf, S. 2012. Adaptive Thermal Comfort. Principles and Practice. London and New York: Routledge.

O’Sullivan, K., Barnard, L. T., Viggers, H. and Howden-Chapman, P. 2016. 'Child and youth fuel poverty: assessing the known and unknown". In People, Place and Policy .2016: 10/1, pp. 77-87. DOI: 10.3351/ppp.0010.0001.0006

Simcock, N., Mullen, C. 2016. 'Energy demand for everyday mobility and domestic life: Exploring the justice implications'. In Energy Research \& Social Science 18. 2016. 1-6.

SOU. 2017. Kraftsamling för framtidens energi, SOU 2017:02. Betänkande av Energikommissionen. Stockholm: Statens offentliga utredningar.

Sovacool, B., Dworking, M. 2015. 'Energy justice: conceptual insights and practical applications'. In Applied Energy 142. 2015. 435-444.

Stoops, J.L. 2001. The Physical Environment and Occupant Thermal Perceptions in Office Buildings. An Evaluation of Sampled Data from Five European Countries. Department of Building Services Engineering, Chalmers University of Technology, Göteborg.

Swedish National Audit Office. 2013. 'Bilaga 3: EU:s och Sveriges klimat- och energimål'. I Granskningar inom klimatområdet 2009 - 2013. Slutrapport: hållbar utveckling - klimat (RiR 2013:19). Stockholm: riksdagens interntryckeri.

Swedish Work Environment Authority /https://www.av.se/inomhusmiljo/temperatur-och-klimat/. Last updated 2015-07-01. From Arbetsplatsens utformning, föreskrifter (AFS 2009:2 and AFS 2013:3).

The Public Health Agency of Sweden 2014. Folkhälsomyndighetens allmänna råd om temperatur inomhus. FoHMFS 2014:17. Stockholm: Folkhälsomyndighetens författningssamling.

Walker, G., Day, R. 2012. 'Fuel poverty as injustice: Integrating distribution, recognition and procedure in the struggle for affordable warmth'. In Energy Policy 49. 2012 .69-75.

Walker, G., Simcock, N., Day, R. 2016. 'Necessary energy uses and a minimum standard of living in the United Kingdom: Energy justice or escalating expectations?’ In Energy Research \& Social Science 18. 2016. 129-138.

Van Hoof, J. 2008. 'Forty years of Fanger's model of thermal comfort: comfort for all?' In Indoor Air 2008; 18 : 182-201. 
Wilhite, H., Nakagami et al. 1996. 'A cross-cultural analysis of household energy use behaviour in Japan and in Norway’. In Energy Policy 24 (9), 795-803.

Wilhite, H. 2008. 'New thinking on the agentive relationship between end-use technologies and energy-using practices'. In Energy Efficiency 2008, 1:121-130.

Wilhite, H. 2012. 'The Energy Dilemma'. In Bjørkdahl, K. and K. B. Nielsen (eds): Development and Environment. Practices, theories, policies. Oslo: Akademika Publishing. 


\section{Photovoltaics or Solar Thermal? The Winner Takes It All!}

Urs Muntwyler, PV LAB, Bern University of Applied Sciences BFH, Dept. Engineering and Information Technology, Jlcoweg 1, 3400 Burgdorf; E-mail: urs.muntwyler@bfh.ch; www.pvtest.ch

Eva Schüpbach, PV LAB, Bern University of Applied Sciences BFH, Dept. Engineering and Information Technology, Jlcoweg 1, 3400 Burgdorf; E-mail: eva.schuepbach@bfh.ch; www.pvtest.ch

\section{Introduction}

Of all renewable energy sources, solar energy has by far the most comprehensive potential. Solar energy can be used for heating, cooling and the production of electricity. In the past, the solar thermal applications have had a significant share of the portfolio. However, the market for PV has gone up in the last years, while the solar thermal market has declined. Several factors are responsible for this shift, among them being the low price for PV modules, PV components and PV electricity. Based on the market in Switzerland, the most important factors underlying this shift are presented. An outlook to the worldwide market complements the analysis.

Keywords: Photovoltaics (PV), solar thermal (ST), solar air, solar passive

\section{Development of the Solar Market in Switzerland}

In Switzerland, the solar thermal market started in the 1980es. It has declined since 2009 (Fig. 1) and now has the same size as about 10 years ago, i.e., below > 50\% of its peak in 2009 .

\section{Solarwärmemarkt Schweiz}

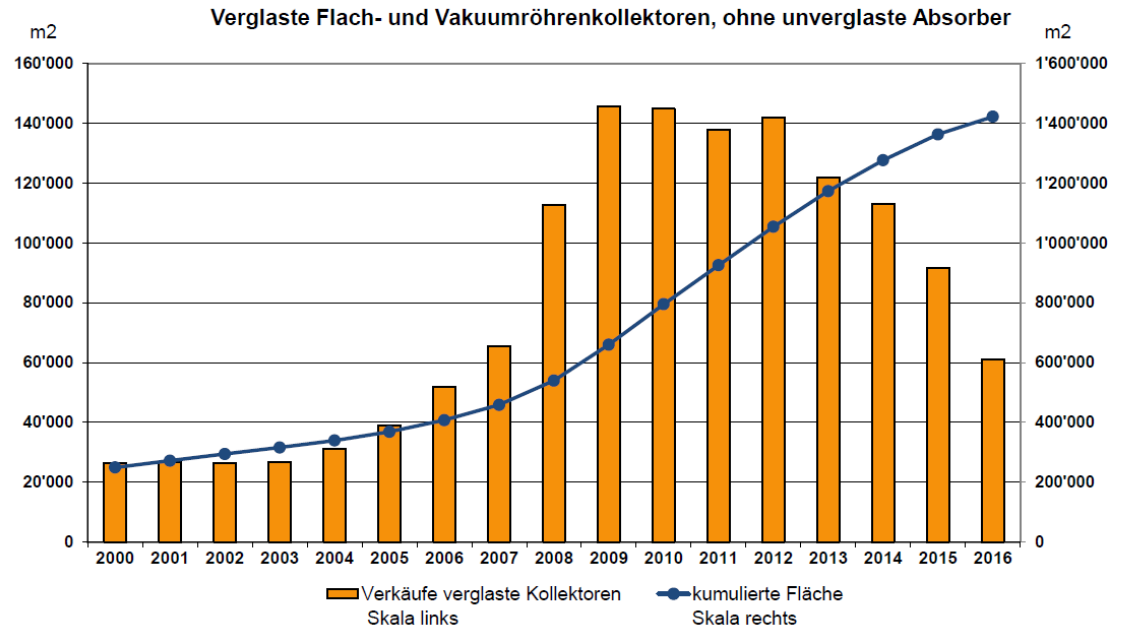

Fig. 1: Solar thermal market development in Switzerland from 2000 to 2016. Source: Swissolar.

The PV market in Switzerland (Fig. 2) played a minor role from 1975 to 1985 and was mainly an off-grid market. After 1986, grid-connection allowed bigger PV installations and the market started to grow from a very low level. When the "feed-in-tariff" was introduced in Switzerland in 2008, the PV market increased from 10MWp (2008) to 250 - 300MWp per year.

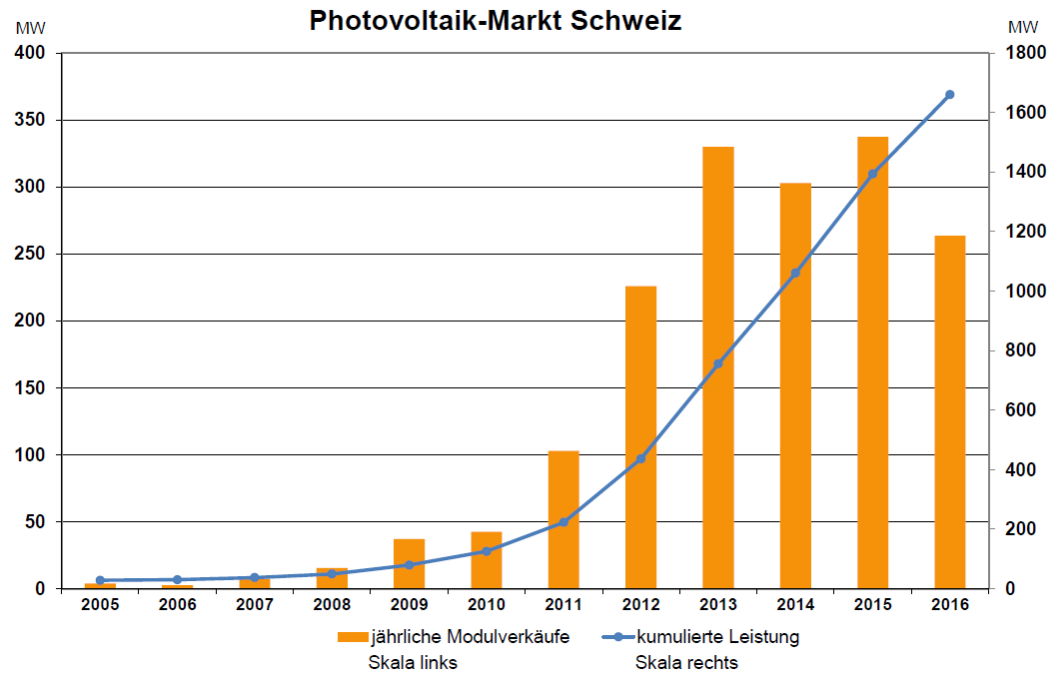

Fig. 2: Development of the PV market in Switzerland (2005-2016). Source: Swissolar. 


\section{User Needs for Solar Thermal Energy and Photovoltaic Electricity}

Based on the user needs, we develop a customer value that can be turned into a sales process and a project. Regarding the user needs, we state that the basic electricity / energy needs of humans these days are:

a) Electricity for light, mobile phones, entertainment systems, cooling of nutrition, power for several purposes

b) Hot water as an important hygienic and comfort factor

c) Heating and cooling according to the climate zone

d) Energy for mobility

The need for heating and cooling purposes varies with the ambient temperature (climate zone). Global warming lowers the need for heating and puts the cooling application as a priority in the agenda. New house construction techniques lower the need for heating energy by a factor of 7 and more. With its electric energy production, photovoltaics (PV) serves all four needs (a)-(d). Specifically, combined with heat pumps, PV is very effective for cooling and heating devices, too. Solar thermal and passive solar systems are well suited for the needs (b) and (c).

\section{Technology Development}

Solar thermal (ST) applications have been known for decades and have improved over time. Yet, they still look very much the same as 30 years ago. The possibility to reach temperatures above 200 degrees Celsius even with flat plat collectors created new problems. Prevention against overheating needs special attention. In cold regions with pumped anti-freezing liquids, the control and service of these systems is a challenge, expensive and adds to the complexity of the system. In financial terms, solar thermal installations with flat plate collectors haven't improved very much past the last 20 years in industrialized countries. Some producers of solar thermal collectors disappeared from the market. More severely, the knowhow of the hot water industry is also gradually receding. Therefore, some professional investors have turned away from solar hot water applications and towards PV installations. Solar thermal installations with cheap vacuum tubes from, e.g., China could - in theory - lower the total costs but have, until now, not been very popular. On the positive side of solar thermal installations are the high rate of subsidies and the possibility to lower the income tax if such a system is installed in an existing building.

Hot air collectors are an interesting device, still a market niche and only few producers such as GRAMMER (D), Solar Venti Ltd. and home-built constructions. The big market in Switzerland was in the 1990s for hay-drying purposes for farmers but has completely disappeared because of new hay storage techniques.

Passive solar energy systems are less important as the heating needs of modern houses has continuously dropped. Low energy houses today are totally different than 30 years ago.

On the other hand, PV has improved the efficiency by a factor of 2 and lowered the price by a factor of more than 200 in the last 40 years. Together with an increase in size and lifetime of the PV modules, the overall efficiency increase has been more than 4’000 since 1975!

\section{Prices are Influenced by the Market Development and Material}

The market development of ST and PV have been different since 2010 (Fig. 3). In 2016 (Fig. 4), ST still had more installed power than PV. But the growth rate of PV is much higher what leads to the assumption that PV will still be cheaper in the future even if the growth rate will continue rising.

30 years ago, a PV module with $64 \mathrm{Wp}$ (Solarex MSX 64) and a surface of about $0,5 \mathrm{~m}^{2}$ had a price of about 500 sFr. (US\$) or $900 \mathrm{sFr} . / \mathrm{m}^{2}$ (quantity of about 100 modules). A ST collector (Solahart Kf) with a surface of $1,8 \mathrm{~m}^{2}$ had a price of about $900 \mathrm{sFr}$. or $500 \mathrm{sFr}$. $/ \mathrm{m}^{2}$. Today, a PV module with $1,6 \mathrm{~m}^{2}$ and $300 \mathrm{Wp}$ costs about $150 \mathrm{sFr}$. and below sFr. $100 / \mathrm{m}^{2}$. The price of the solar collector is still similar. A PV module earns about $200 \mathrm{kWh} / \mathrm{m}^{2}$ in mid-Europe and costs about 100s FR. $/ \mathrm{m}^{2}$. The ST flat plate collector earns up to $500 \mathrm{kWh} / \mathrm{m}^{2}$ for costs of about $500 \mathrm{sFr}$. Per $100 \mathrm{kWh}$ annual yield, PV is half the price of a flat plate solar thermal collector. The product is on one hand electric energy which costs $25 \mathrm{Rp}$. / $\mathrm{kWh}$ (cent/US\$) and on the other hand thermal energy, which costs about $10 \mathrm{Rp}$. / kWh. The difference is now a factor of 5 . 


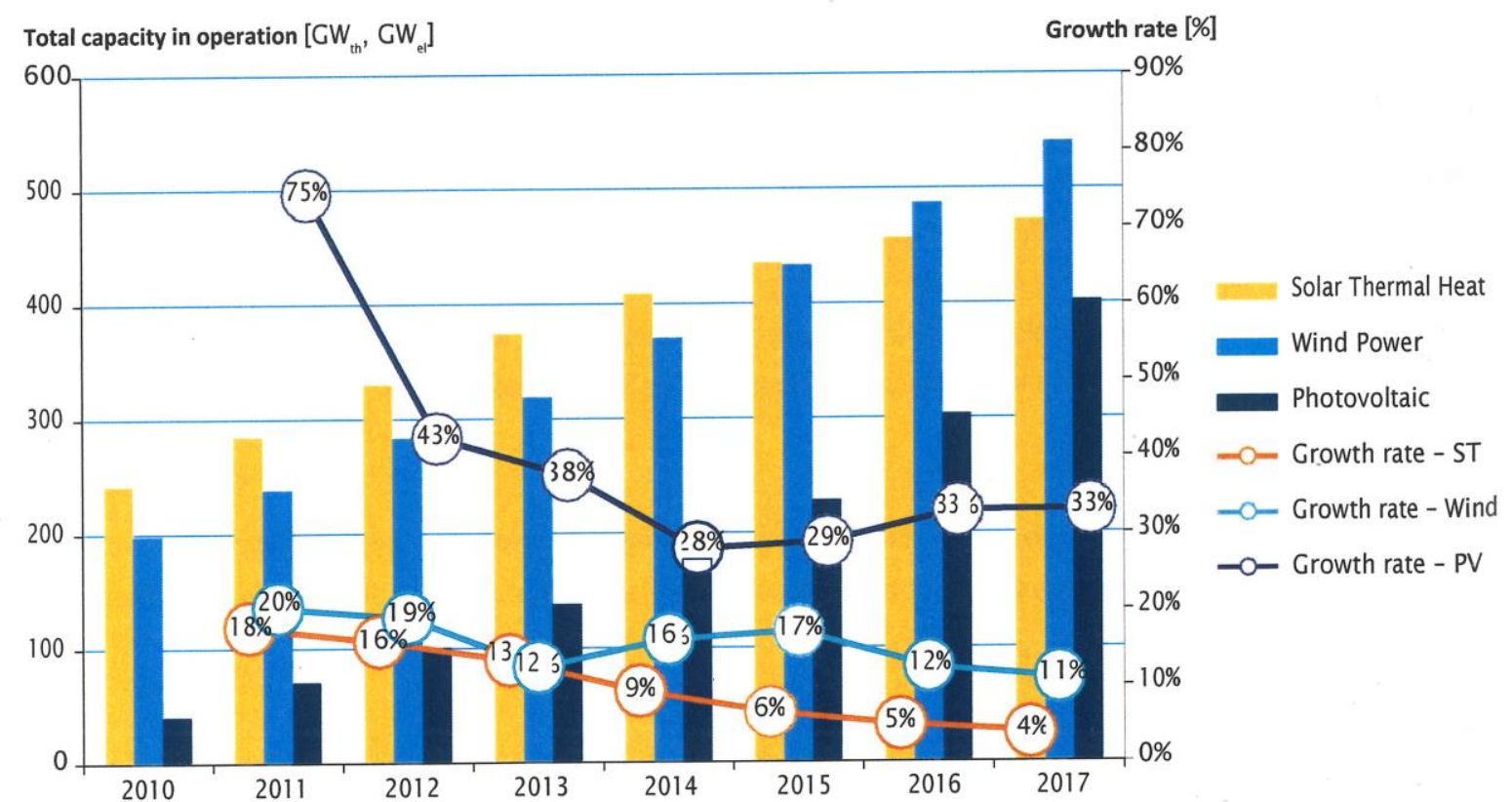

Global capacity in operation and market growth rates between 2010 and 2017 (Sources: AEE INTEC, Global Wind Energy Council

(GWEC), SolarPower Europe, REN21 - Global Status Reports 2011-2018)

Fig. 3: Market growth rate of ST and PV between 2010-2017 and projections. Sources see Figure.

ST technology utilizes relatively expensive material such as copper for the absorbers of the flat plat collectors. Copper is a relatively rare material. If the production volume goes up, the price follows. In comparison, solar modules are mainly composed of silicon, a cheap material with sizable global resources (no. 2 of all the elements on earth). If more silicon material is used, the mass production drives the price further down. This and the massive production volumes in China pushed the price of PV up in some regions on the globe, what now disrupts the energy industry. These developments might suggest that the ST technology should shift to cheaper material such as, for example, vacuum tube collectors from China. Nevertheless, it is expected that the price gap between PV and ST will continue to grow in future.

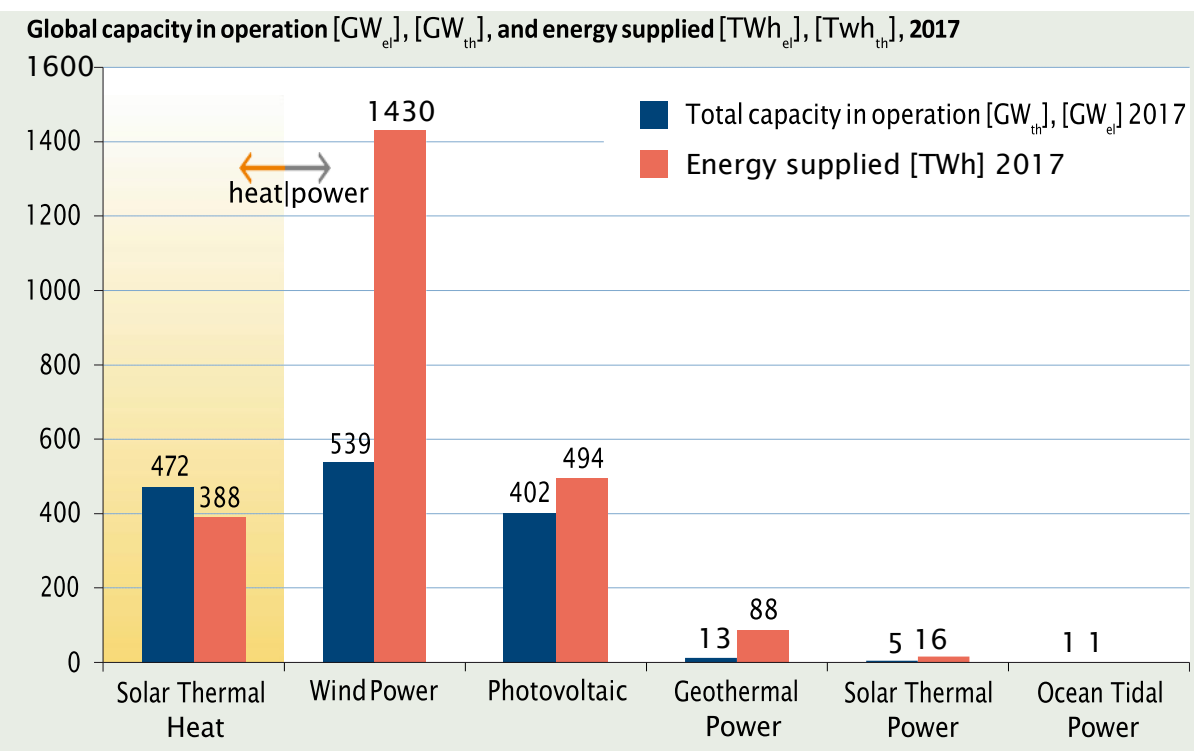

Global capacity in operation [GW ${ }_{\mathrm{el}}$, [GW $\mathrm{th}_{\mathrm{th}} 2017$ and annual energy yields [TWh $\left.{ }_{\mathrm{el}}\right],\left[T W h_{\mathrm{th}}\right]$. (Sources: AEE INTEC, Global Wind Energy Council (GWEC), SolarPower Europe, REN21 - Global Status Report 2018)

Fig. 4: Total global capacity in operation of new renewable energy, ST and PV in 2017. Source see Figure. 
In 2015 , the market for ST was $40.2 \mathrm{GW}$, i.e., a decline of $14 \%$. PV was at $50.9 \mathrm{GWp}$ with a growth of $29 \%$; in 2016, PV sold 76,8GWp (+32\%) with a total of 306,5 GWp. In 2017, PV sold over $100 \mathrm{GWp}$, reaching over 400GWp installed power. The produced energy of PV exceeds the ST energy for the first time (Fig. 4). In 2018, the installed PV power is expected to equal the ST power.

The dependency of the PV market from China is strong (2016: 45\%; 2017: <60\%) but not so strong as compared to the ST market (China: $75 \%$ market share). There are over 20 countries with a PV market over 1 GWp annually. For 2018, a market decline is expected in China. This will drive the price of the PV panels further down and will stimulate the other markets again.

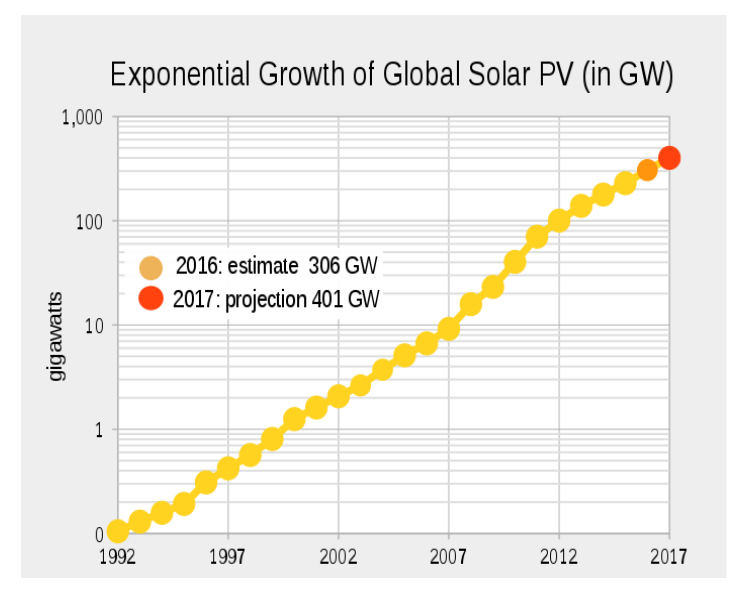

Fig. 5: Strong growth rate of the global PV market.

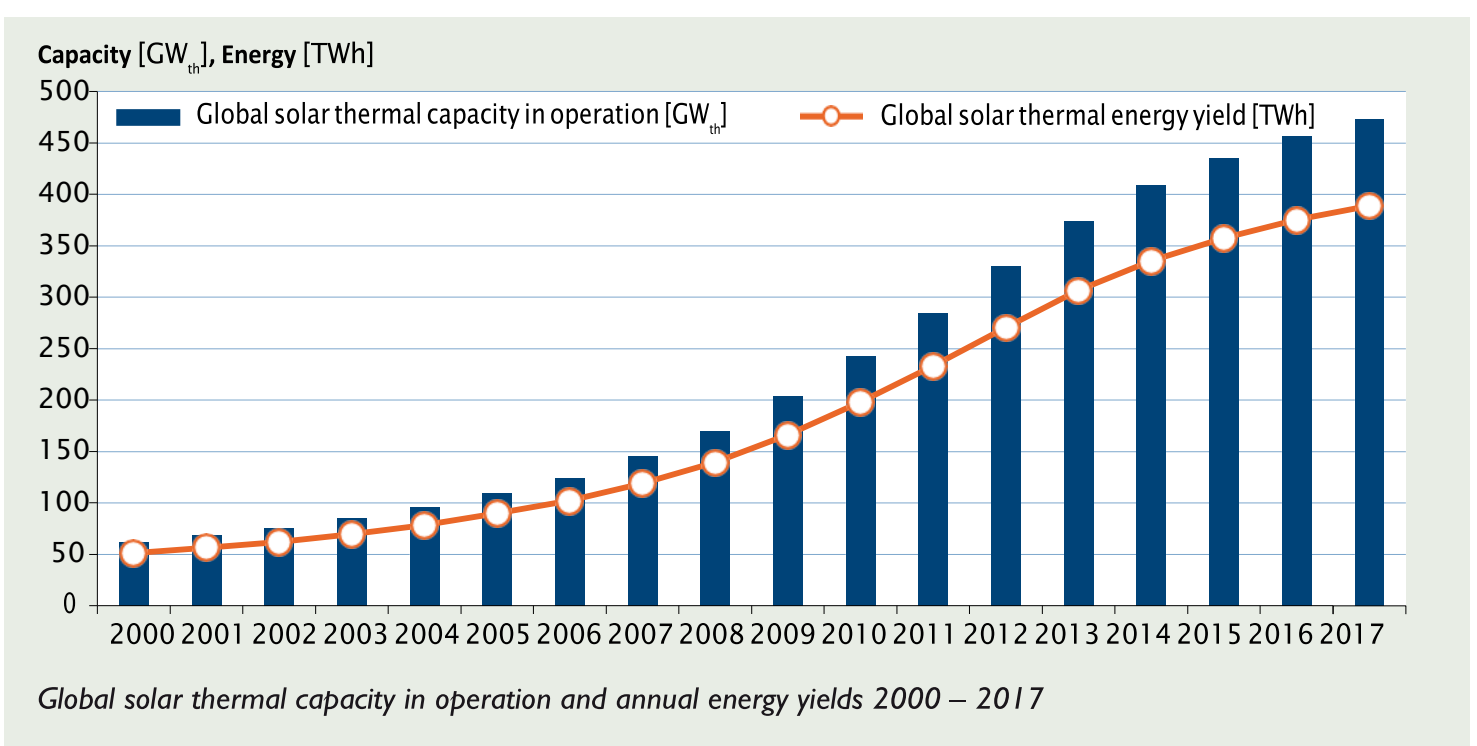

Fig. 6: Stagnation in the solar thermal market.

ST installations are normally small. The biggest plant, a district heating system in Denmark, has an installed power of $110 \mathrm{MW}$. In comparison, PV systems have reached the $1 \mathrm{GWp}$ size and there are now more than 40 plants over 200 MWP on the globe. PV has a strong market for big utility-size installations. This gives PV a further advantage over ST to drive the "economy of scale" and lower the price of PV installations. For costoptimized PV plants, prices below 2 cent/US\$/ kWh are realistic.

\section{Synergies in the Swiss market of PV and ST in the Past}

In the past, there has been a significant synergy for solar thermal and PV in the Swiss market. Customers tended to restrict the size (and costs) of the expensive PV installations and added solar thermal installation for hot water and the heating support (Fig. 6). Heating in these houses was / is predominantly with oil, gas or wood and so, a solar thermal installation was an interesting and relative cheap start into the "solar technology". 

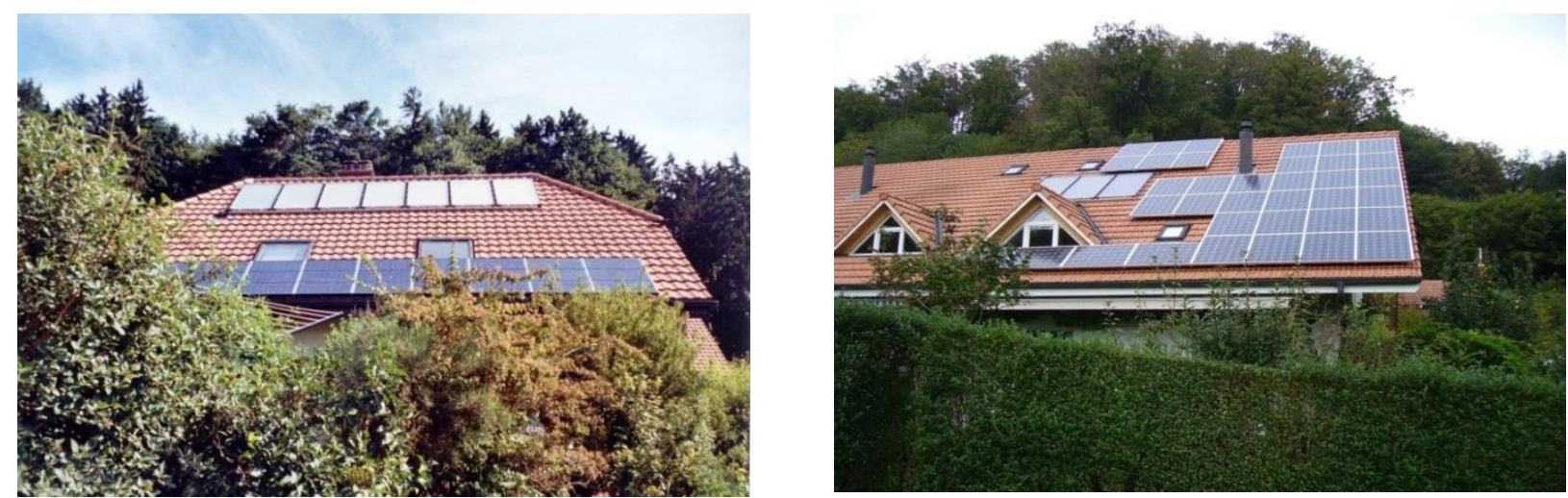

Fig. 6: Typical houses of a solar energy consumer around the year 2005. The hot water solar thermal device (left picture) cost about 15'000 sFr. (or US\$). The 6 kWp PV plant (right picture) was about 50-60’0000sFr. (Photos: Muntwyler).

\section{The Energy Consumption in the Last 40 Years}

In the last 40 years, the energy consumption in a single-family house went down and/ or has been covered with electricity (see Table 1).

Table 1: Comparison of electricity and energy consumption in 1975 and 2018 in Switzerland. Own calculations.

\begin{tabular}{|l|l|l|l|}
\hline Application & $\mathbf{1 9 7 5}$ & $\mathbf{2 0 1 8}$ & Due to... \\
\hline Electricity & Ca. $6,5 \mathrm{kWh} /$ person & $6,96 \mathrm{kWh} /$ person & $\begin{array}{l}\text { Stable due to more but } \\
\text { efficient consumers }\end{array}$ \\
\hline Hot water & About $501 /$ person & Similar & Trend to smaller families \\
\hline Heating and cooling & $220 \mathrm{kWh} / \mathrm{m}^{2}$ & $30 \mathrm{kWh} / \mathrm{m}^{2}$ & $\begin{array}{l}\text { Massive reduction: } \mathrm{new} \\
\text { construction codes }\end{array}$ \\
\hline Energy for displacement & $\begin{array}{l}9001 \text { gasoline / } \\
9 \text { '000kWh }\end{array}$ & $2250 \mathrm{kWh} /$ year & $\begin{array}{l}\text { Massive reduction: } \\
15 \text { '000km / year }\end{array}$ \\
\hline
\end{tabular}

Energy savings in houses led to dramatic decreases in energy consumption for the heating system; with a heat pump by a factor of seven or much more! The figure reflects the new energy guidelines in the energy law for Swiss cantons (MuKen 2014) compared with the standard from 1975. For a $100 \mathrm{~m}^{2}$ house with a heat pump, 1 '000 kWh electricity or less is needed today instead of 22'000 kWh thermal energy in 1975. The installation of heat pumps has declined the need for thermal energy dramatically, even more so as the heat pump for heating and hot water has been the leading technology for thermal energy in Switzerland past the last 40 years. Today, with a PV system of about 8-10 kWp and a heat pump, a "Plushouse" (i.e., a house producing more energy than can be consumed by itself), can be achieved, including the electricity for an EV. This also saves a massive amount of money for the user. The energy need for the car went down at a factor of 4 due to the electric drive train and is electric too.

The electric consumption is stable, but only usable for PV. Only the hot water consumption is the same or went up due to comfort behavior of the consumers in the last 40 years. But the hot water consumption in a singlefamily house is not stable. Often, these systems are installed in existing houses with elderly people. If the children leave the house, the hot water consumption goes down and the economy of the solar hot water system is gone forever.

The profile of the two technologies (PV and ST) shows strong advantages for PV:

\begin{tabular}{|l|l|l|l|l|l|l|l|}
\hline \multicolumn{1}{|c|}{ Strong } & $\mathbf{6}$ & $\mathbf{5}$ & $\mathbf{4}$ & $\mathbf{3}$ & $\mathbf{2}$ & $\mathbf{1}$ & Weak \\
\hline Price/ $\mathrm{kWp}$ & & PV & & & ST & & \\
\hline Price/ $\mathrm{m}^{2}$ & PV & & & ST & & & \\
\hline Price/ $\mathrm{kWh}$ & & PV & & ST & & & \\
\hline Efficiency & & ST & & & PV & & PV without heat pump \\
\hline Efficiency with heat pump & PV & ST & & & & & \\
\hline Technical complexity & & & PV & & ST & & \\
\hline Life time & & PV & & ST & & & \\
\hline Flexible in size & & PV & & ST & & & \\
\hline Service + maintenance & & PV & & & ST & & \\
\hline Technical problems in use & & ST & & & PV & & Overheating in the system. \\
\hline Optical appearance & & PV & & ST & & & \\
\hline Subsidize & & ST & PV & & & & \\
\hline
\end{tabular}


It can be expected that PV costs further decline in the future while, at the same time, the lifetime goes up to 40 years. New PV modules with different colors and sizes also fit the requirements of the architects.

A further disadvantage of the ST is the need for a storage tank. Some niche market applications such as swimming pool heating have no tank. ST systems have normally a storage tank. The tank is an expensive, but necessary method to store the heat energy. In contrast, the PV has the philosophy to use the electricity on time. The grid is the "storage". This is very efficient but not for free. Only in recent times are battery storage systems widely used in certain markets such as Germany. This is the result of a low feed-in tariff for surplus injected electricity and another way to slow down the growth of the PV.

\section{Nearly no Synergies between PV and ST in the Future}

In the previous Sections, it has been discussed that the synergy between PV and ST has now disappeared. Today, PV is so cheap that it makes sense to mount a PV installation covering the entire roof. In Switzerland roof-integrated PV installations have a market share of about $20 \%$. This leads to an overproduction of PV electricity. If the electricity can be fed into the grid under a "feed-in-tariff (FIT)" scheme, the maximum economic benefits can be reached. The user then makes profit of the "economy of scale" and can sell each kilowatt-hour electricity to the grid. However, in Switzerland, the "feed-in-tariff" system for PV is closed for new projects and all electricity produced has primarily to be used by the producer itself. The surplus electricity may be sold to the local electricity company at often a very low price (in Switzerland 5-10 cents $\mathrm{sFr}$. / kWh). This has the effect of a "virtual storage" tank and the producer and consumer (= Prosumer) hence look for smart electric consumer. All energy converters such as hot water device, heating system and later an electric car will be turned into an electric consumer to reach a high "own consumption" and to find additional consumers for his "cheap" electricity. This is first the hot water supply, the heating systems and an electric vehicle. They all have a storage system that improves the "own consumption". A solar hot water system will downgrade this situation. In certain markets, battery storage systems also enhance the "own consumption rate". In the future, bi-directional EVs can optimize this function. Another important factor is the complexity of solar thermal systems being one of the reasons underlying the disappearance of experienced solar thermal companies from the market in the past. It is hard to find the needed specialists for planning, installation and maintenance. PV on the other hand improved the situation very much. Under such a regime, ST lowers the financial performance of the PV system and ST is pushed out of the market. The argument of the high efficiency and low use of surface is also gone. A PV system with a heat pump can easily reach efficiencies over 50\%. In such an efficient "energy world", ST systems will disappear and only appear in niche markets any more.

\section{What are the Niche Markets for Solar Thermal?}

There are still niche markets for solar thermal:

- Very cheap small solar hot water systems in sunny regions (thermosiphon)

Swimming pool heating - not only in sunny regions

Big district heating systems (example Denmark)

Solar thermal electricity plants with night storage

Solar air collectors for heating and ventilation

Solar houses with a solar thermal concept (example Jenni Energietechnik AG in Burgdorf, Switzerland)

To remain in or enter these market niches, marketing is crucial. The desire to have hot water available is a strong driver for every human and has an increasingly growing buying power. This opens a huge market for solar hot water systems in developing countries that are often located in sunny climate regions. As more and more electric systems are in use, PV get a higher penetration. For sunny regions, this can be the air conditioning system. Such a house can have an electricity consumption that is almost the same as in a Europe house with a heat pump heating system.

For industrialized countries, ST can be placed in market niches with clever marketing and system concepts. The Swiss ST company Jenni Energietechnik AG sells multi-family houses with huge hot water tanks suitable for a seasonal storage of the heat energy. The product is therefore a $100 \%$ heated solar house.

\section{PV or ST - the Winner takes it all - or is there still a Market for Solar Thermal?}

The future will see a further growth of PV. This depends on many factors but the worldwide trend for PV is still a growing market. In industrialized countries with heating systems and air conditioning, PV will push ST out of the main markets outside the niches described above. There are several markets for solar thermal. One is for very cheap compact solar hot water systems in the sunbelt-regions. As many regions still don't have a (reliable) grid, PV is more concentrated on small solar home systems (SHS) and micro-grids. On the other hand, in cold alpine climates with high sunshine, solar thermal is still interesting. Solar air systems could find their place in such systems. In the range of big system, the district heating is a market for solar thermal systems, too.

Switzerland currently needs about 60 TWh of electricity, which are mainly produced by hydro- and nuclear power. PV contributes about 3\%. In the "Swiss Energy Strategy 2050" of the government, the five nuclear power 
plants will be phased out in the future. The replacement is mainly PV, wind, geothermal and other renewable sources such as small hydro, waste combustion etc. PV is expected to produce about $12 \mathrm{TWh}(1,5 \mathrm{kWp}$ or $8-12$ $\mathrm{m}^{2}$ per person). Considering the low possibility for geothermal, the problems with the construction of wind power sites in Switzerland and new consumers such as EVs, up to $24 \mathrm{GWp}$ PV production are possible ( $3 \mathrm{kWp}$ or $15-20 \mathrm{~m}^{2}$ per person). As Swiss utilities own more than 6TWh wind energy outside Switzerland, wind is expected to fill the electricity gap in the winter.

The Swiss PV market needs to grow from 300 MWp to 600 - 1'000 MWp each year to fulfill the targets of the Swiss "Energy Strategy 2050" and to cover the needs of 5 million electric vehicles. The worldwide PV market needs to grow from $100 \mathrm{GWp}$ to 1 '000 GWp and more.

The solar thermal market will still be under pressure as the demand for heating is going down. Clever marketing strategies for $100 \%$ multi-level houses could open a very small market niche in Switzerland. Small hot water systems will increasingly be replaced by PV and heat pumps. Unfortunately, the market of district heating has never been tackled in Switzerland so far. In the big picture, PV will be the dominant technology in the active solar applications in Switzerland. Here, it's the winner that takes it all!

\section{Acknowledgements}

This research is part of the activities of the Swiss Centre for Competence in Energy Research on the Future Swiss Electrical Infrastructure (SCCER-FURIES), which is financially supported by the Swiss Innovation Agency (Innosuisse - SCCER program). We also gratefully acknowledge funding from the Swiss Federal Office of Energy (SFOE) and Bern University of Applied Sciences BFH, Burgdorf, Switzerland. 


\title{
Preliminary Economic Evaluation of the First Grid-connected Photovoltaic System in the Aysén Region Under the Current Law of Distributed Generation in Chile
}

\author{
Juan Carlos Osorio-Aravena' ${ }^{1}$ and Emilio Muñoz-Cerón ${ }^{2}$ \\ ${ }^{1}$ Campus Patagonia, Universidad Austral de Chile, Coyhaique (Chile) \\ 2 Projects Engineering Area, IDEA Research Group (Research and Development in Solar Energy), \\ Center for Advanced Studies in Energy and Environment, University of Jaén, Jaén (Spain)
}

\begin{abstract}
Chile has a law of distributed generation that came into effect in October 2014. Nevertheless, in the Aysén Region, which has solar resources similar to other areas with higher installation ratios, the first grid-connected photovoltaic system under this law was installed two years after it was enacted. In order to analyse the existing barriers to the implementation of photovoltaic technology in this area, a preliminary economic evaluation was conducted for this study after the first system installed in the region had been in operation for one year. In economic terms, the results reveal an unfavourable situation for the large-scale installation of these types of systems intended for home consumption compared to other areas of the country with similar radiation levels. We therefore suggest analysing options that consider multiple interrelated factors to be able to model scenarios with high penetration of local distribution grid-connected photovoltaic technology on a residential scale.
\end{abstract}

Keywords: Economic Evaluation, Grid-connected PV, Local Distribution Grid, PV costs, PV for Buildings

\section{Introduction}

Photovoltaic (PV) technology is key to the sustainable energy transition (Child and Breyer, 2017). In 2016, PV systems of residential prosumers reached a share of $25-30 \%$ of the PV solar energy installed globally (REN21, 2017). According to Breyer et al. (2017), in one scenario of energy demand in the global power sector, the primary generation of PV electricity in 2050 may reach $69 \%, 31 \%$ of this contribution coming from PV prosumers.

The high penetration of photovoltaic systems in power grids has therefore been identified as essential to the transition towards sustainable energy systems (IEA-PVPS, 2014). Still, under some circumstances, impediments have been detected that hinder their integration into local distribution grids, even varying within the same country. In the case of Chile, Law 20571 -known as "Citizen Generation" and whose aim is to promote the selfconsumption of electricity- was passed in 2012 and came into effect in October 2014 under a net-billing scheme. Thanks to this Law, a total of 2059 grid-connected PV systems were installed by the end of 2017; only four of them in the Aysén Region (CNE, 2018), located in the south of the country. The first grid-connected PV system installed in this region $-1.56 \mathrm{kWp}$ and a total investment of $5774.9 \mathrm{USD}_{2016}$ (VAT included)-, was financed with public funds and began operating in October 2016 in the city of Coyhaique, the capital of the region undergoing study.

In 2016, the project "Elaboración de un Índice de Precios de sistemas FV conectados a la red de distribución comercializados en Chile" ("Development of a Price Index of Grid-Connected Photovoltaic Systems Marketed in Chile") (ME and GIZ, 2016) was conducted. It did not include the Aysén Region as, at that time, there were no systems installed under Law 20571. In addition, considering that this region has areas with average solar radiation levels of up to $4.50 \mathrm{kWh} \mathrm{m}^{-2}$ per day, similar to those of the centre-south of Chile (ME, 2018), it follows that the main barrier to the large-scale penetration of residential PV systems in the region has to do with factors associated with its initial investment; affecting the time of recovery.

In order to elucidate some of the causes that have hindered the implementation of grid-connected PV systems in 


\section{Juan Carlos Osorio-Aravena}

the territory in question, this study presents a preliminary economic assessment based on the first PV system under Law 20571. The initial investment in the system is compared to the price index (PI) of the country's PV systems; the prices of the residential tariff and the feed-in tariff in the territory under consideration are compared to the prices of the tariffs in areas with similar solar resources, and; the time for return on investment in the system is calculated for different ranges of self-consumption and energy injected into the grid. The results indicate that the Aysén Region exhibits disadvantages, in economic terms, for the implementation of grid-connected PV systems.

In short, in addition to revealing the unfavourable situation of the area under consideration to expand access to grid-connected PV systems, this study contributes with the detection of factors and aspects to consider for the development of models of scenarios with high penetration of PV technology on a residential scale, also serving as a reference for other similar studies.

\section{Method}

First, considering the total investment costs of the PV system installed -turnkey-, the Wp price in USD without VAT was calculated and compared to the PI of grid-connected PV systems with a range of installed capacity of 1-5 kWp, according to information from ME and GIZ (2016). Subsequently, based on the data published by electricity supply companies in cities with solar radiation levels similar to those of Coyhaique (Temuco and Osorno), a comparison was conducted of the average prices of tariffs in 2017. These included both those corresponding to energy consumption for residential customers - due to the fact that it is the price of the $\mathrm{kWh}$ saved through energy self-consumption -, as well as those of valuation of feed-in tariff. Then, with the real electricity production data of the $1.56 \mathrm{kWp} \mathrm{PV}$ system, recorded in 2017, the times for return on investment were calculated using eq. 1 with different self-consumption $\left(\boldsymbol{F}_{\boldsymbol{S C}}\right)$ and grid injection $\left(\boldsymbol{F}_{\boldsymbol{G I}}\right)$ factors -both of them simultaneously varying between 1.00 and 0.00 -, under different scenarios. In the equation, $\boldsymbol{P} \boldsymbol{t}$ is the payback time, $\boldsymbol{I}$ is the initial investment, $\boldsymbol{E}$ is the monthly energy production of the PV system, $\boldsymbol{T}_{\boldsymbol{S C}}$ is the price of the selfconsumption savings tariff and $\boldsymbol{T}_{\boldsymbol{G} I}$ is the feed-in tariff, the latter varying monthly.

$$
P t=\frac{I}{\sum_{i=1}^{n=12}\left[E_{i}\left(T_{S C, i} \cdot F_{S C}+T_{G I, i} \cdot F_{G I}\right)\right]}
$$

\section{Results and Discussion}

\subsection{Price index comparison}

According to ME and GIZ (2016), grid-connected PV systems in Chile with an installed capacity in the range of $1-5 \mathrm{kWp}$ have average and median prices of $2.76 \mathrm{USD} \mathrm{Wp}^{-1}$ and $2.56 \mathrm{USD} \mathrm{Wp}^{-1}$, respectively. The installation price of the PV system in the Aysén Region had a value of $3.11 \mathrm{USD} \mathrm{Wp}^{-1}$. This suggests that the system under consideration is $11.3 \%$ more expensive than the national average and $17.7 \%$ more expensive than the national median.

As the lowest prices have been shown to be in the Metropolitan region -the centre of Chile- (ME and GIZ, 2016), it is possible that one of the causes that the price per installed $\mathrm{Wp}$ is higher in the area under consideration is the fact that the Aysén Region is isolated from the rest of the country. This may cause the investment cost to increase due to factors related to the transport of equipment and in a range higher than that of other regions. It is therefore suggested to analyse the budgetary breakdown of investment in systems with the same installed capacity for a more objective comparison and, in turn, to detect items for cost reduction and/or subsidy options since the latter, at the residential level, do not exist in Chile.

\subsection{Tariff comparison}

As can be seen in Tab. 1, the average price of self-consumption savings tariffs among the cities compared to the one under consideration is insignificant. This would not entail a large difference in the recovery of investment in a setting of $100 \%$ self-consumption of the energy produced if the total cost of PV systems were the same for each territory. However, as explained in section 3.1, the initial investment in the city of Coyhaique is above the national 


\section{Juan Carlos Osorio-Aravena}

average. Nevertheless, with the enactment of the Tariff Equity Law -at the end of 2017-, the price of tariffs changed for residential customers across Chile, thus leading to a variation in the times for return on investment. This last point will be necessary to consider in future studies.

Tab. 1: Comparison of annual average tariffs, 2017

\begin{tabular}{|c|c|c|}
\hline City [latitude] & $\boldsymbol{T}_{\boldsymbol{S C}}\left(\mathbf{U S D}_{\mathbf{2 0 1 7}} \mathbf{\mathbf { K W h } ^ { - 1 }}\right)$ & $\boldsymbol{T}_{\boldsymbol{G I}}\left(\mathbf{U S D}_{\mathbf{2 0 1 7}} \mathbf{k W h}^{\mathbf{- 1}}\right)$ \\
\hline Temuco $\left[-38.74^{\circ}\right]$ & 0.239 & 0.109 \\
\hline Osorno $\left[-40.57^{\circ}\right]$ & 0.239 & 0.127 \\
\hline Coyhaique $\left[-45.57^{\circ}\right]$ & 0.237 & 0.100 \\
\hline
\end{tabular}

In addition, if follows from Tab. 1 that in the city of Coyhaique $8.3 \%$ and $21.3 \%$ less per $\mathrm{kWh}$ injected into the grid is appraised than in Temuco and Osorno, respectively. These differences have significant effects on the time for recovery of investment, depending on the amount of energy injected into the grid. It is likely that the differences in feed-tariff are due to the fact that the electricity systems in the Aysén Region, on the one hand, are isolated from the interconnected systems of the rest of the country and, on the other, are classified as mediumsized electricity systems (below $200 \mathrm{MW}$ ). It is therefore suggested in future studies to analyse tariff regulation under the Law of distributed generation.

\subsection{Estimation of time for investment recovery}

Tab. 2 shows a summary of the results obtained with eq. 1. In 2017, the PV system in question produced a total of $1951.7 \mathrm{kWh} ; 1509.7 \mathrm{kWh}$ was self-consumed and $442 \mathrm{kWh}$ was injected into the grid. Considering these data as $\boldsymbol{F}_{\boldsymbol{S C}}=0.77$ and $\boldsymbol{F}_{\boldsymbol{G I}}=0.23$ for the calculation of annual return, it was found that the recovery of the investment would be completed in 14.4 years. This would be 13.0 and 12.8 years for the cases of Temuco and Osorno, respectively.

Tab. 2: Time for investment recovery with different factors

\begin{tabular}{|c|c|c|c|c|}
\hline City [latitude] & $\begin{array}{c}\boldsymbol{F}_{S C}=\mathbf{0 . 7 7} \\
\boldsymbol{F}_{G I}=\mathbf{0 . 2 3} \\
\text { (years) }\end{array}$ & $\begin{array}{c}\boldsymbol{F}_{S C}=\mathbf{1 . 0 0} \\
\boldsymbol{F}_{G I}=\mathbf{0 . 0 0} \\
\text { (years) }\end{array}$ & $\begin{array}{c}\boldsymbol{F}_{S C}=\mathbf{0 . 1 5} \\
\boldsymbol{F}_{G I}=\mathbf{0 . 8 5} \\
\text { (years) }\end{array}$ & $\begin{array}{c}\boldsymbol{F}_{S C}=\mathbf{0 . 0 0} \\
\boldsymbol{F}_{G I}=\mathbf{1 . 0 0} \\
\text { (years) }\end{array}$ \\
\hline Temuco $\left[-38.74^{\circ}\right]$ & 13.0 & 12.7 & 22.6 & 27.4 \\
\hline Osorno $\left[-40.57^{\circ}\right]$ & 12.8 & 12.7 & 20.3 & 23.6 \\
\hline Coyhaique $\left[-45.57^{\circ}\right]$ & 14.4 & 12.7 & 25.0 & 30.0 \\
\hline
\end{tabular}

In one scenario of residential self-consumption in the area under consideration, it was found that the most favourable situation is produced with $\boldsymbol{F}_{\boldsymbol{S C}}=1.00$ and $\boldsymbol{F}_{\boldsymbol{G} \boldsymbol{I}}=0.00$, where the investment would be recovered in 12.7 years. It was also found that the more generated energy is injected into the grid, the greater the time for return on investment. For the PV system in Coyhaique, its maximum limit is with $\boldsymbol{F}_{\boldsymbol{S C}}=0.15$ and $\boldsymbol{F}_{\boldsymbol{G I}}=0.85$, since, in this situation, the investment would be recovered in 25 years. In other words, it becomes unviable. Using these same self-consumption and injection values, the investment in Temuco and Osorno would be recovered in 22.6 and 20.3 years, respectively.

\subsection{Final Considerations}

In summary, grid-connected PV systems in the Aysén Region have higher investment costs than the rest of the country and the feed-in tariff is lower than in other areas with similar solar radiation. The investment therefore takes longer to recover, causing the implementation of this type of system to be less attractive in the area under consideration. This may explain why it took two years for the first grid-connected PV systems to be installed and may be the main reason it is the region of Chile with the least amount of this type of system in operation. 


\section{Juan Carlos Osorio-Aravena}

Even so, along with analysing the budgetary breakdown of the initial investment, it is necessary to perform a deeper economic assessment. To do so, it is proposed to consider real profiles of residential consumption, as well as the calculation of parameters including: Levelized Cost of Energy, to compare it to the price of the tariff for residential customer energy consumption; and socket parity. In addition, bank financing and state subsidy options may also be assessed.

It will also be necessary in future studies to review and analyse techno-regulatory factors that influence the implementation of decentralised PV systems. Furthermore, it is suggested to consider aspects such as the socioeconomic benefits and environmental externalities associated with this type of system, all with a view to model scenarios with high penetration of PV technology on a residential scale in local distribution grids.

\section{Conclusion}

From the results obtained in the preliminary economic assessment conducted of the first grid-connected PV system in the Aysén Region, it has been concluded that the territory has disadvantages in economic and probably regulatory terms compared to other areas of the country, thus impeding the widespread use of grid-connected PV systems. Furthermore, with the enactment of the Tariff Equity Law, it will be necessary to reassess the economic viability of grid-connected PV systems, not only in the Aysén Region but throughout the country. In turn, it proves necessary to analyse PV energy production data and compare them to profiles of residential consumption in order to foresee the real viability of the systems. In addition, it is also necessary to consider public incentives or subsidies for residential customers - until now non-existent in Chile-. Finally, for future analyses of high penetration gridconnected PV systems, along with conducting a broader economic assessment, it is suggested to consider factors such as technical and regulatory limitations of the local distribution grids as well as social and environmental externalities in order to envision options that contribute to the decentralisation and democratisation of energy through PV technology.

\section{References}

Breyer C., Bogdanov D., Aghahosseini A., Gulagi A., Child M., Oyewo A.S., Farfan J., Sadovskaia K. and Vainikka P., 2017. Solar photovoltaics demand for the global energy transition in the power sector. Prog. Photovolt: Res. Appl. 1-19. https://doi.org/10.1002/pip.2950

Child M. and Breyer C., 2017. Transition and transformation: a review of the concept of change in the progress towards future sustainable energy systems. Energy Policy. 107, 11-26. https://doi.org/10.1016/j.enpol.2017.04.022

Comisión Nacional de Energía (CNE), 2018. Reporte mensual ERNC. Volumen N ${ }^{\circ}$ 17. Gobierno de Chile. Available at: https://www.cne.cl/wp-content/uploads/2015/06/RMensual_ERNC_v201801.pdf [accessed: 26/01/2018]

International Energy Agency (IEA-PVPS), 2014. High Penetration of PV in Local Distribution Grids. Report IEA PVPS T14-02:2014. ISBN: 978-3-906042-23-7. Available at: http://www.iea-pvps.org/index.php?id=295 [accessed: 26/01/2018]

Ministerio de Energía (ME), 2018. Política Energética Región de Aysén del General Carlos Ibáñez del Campo. Gobierno de Chile. Available at: http://www.energia2050.cl/wp-content/uploads/2018/02/POLITICAENERGETICA-AYSEN-2050.pdf [accessed: 09/02/2018]

Ministerio de Energía y Deutsche Gesellschaft für Internationale Zusammenarbeit (ME and GIZ), 2016. Elaboración de un Índice de Precios de sistemas fotovoltaicos (FV) conectados a la red de distribución comercializados en Chile. Available at: https://energypedia.info/images/temp/7/7b/20170221223219!phpWJQihw.pdf [accessed: 09/02/2018]

Renewable Energy Policy Network for the 21st Century (REN21), 2017. Renewables 2017 Global Status Report. Paris, Francia. Available at: http://www.ren21.net/wp-content/uploads/2017/06/178399_GSR_2017_Full_Report_0621_Opt.pdf [accessed: 09/02/2018] 
J.C. Osorio-Aravena et. al. / EuroSun 2018 / ISES Conference Proceedings (2018)

Juan Carlos Osorio-Aravena

\section{Appendix}

\subsection{Abbreviations}

PV Photovoltaic

USD United States Dollar

VAT Value Added Tax

PI Price Index

\subsection{Variables}

Pt Payback time

I Initial investment

$\boldsymbol{E} \quad$ Monthly Energy Production

$\boldsymbol{T}_{\boldsymbol{S C}} \quad$ Price of the self-consumption savings tariff

$\boldsymbol{F}_{S C} \quad$ Self-consumption factor

$\boldsymbol{T}_{\boldsymbol{G}} \quad$ Feed-in tariff

$\boldsymbol{F}_{\boldsymbol{G I}} \quad$ Grid injection factor 


\title{
Accompanying Project Owners and Professionals All the Way to Secure Solar Thermal Plants
}

\author{
Edwige Porcheyre ${ }^{1}$ and Daniel Mugnier ${ }^{2}$ \\ ${ }^{1}$ Enerplan, La Ciotat (France) \\ 2 Tecsol, Perpignan (France)
}

\begin{abstract}
SOCOL is a collaborative platform gathering specialists, professionals and institutions operating within the solar thermal market in France. Dedicated to promoting multi-family and commercial solar thermal systems, SOCOL is fully representative of the industry. Operationally, SOCOL consists of working groups manned by solar thermal specialists, who regularly produce documents and other tools (such as software) and make them freely available online.

For nine years, French experts working with SOCOL have been providing free access to technical and pedagogical tools, addressing ST experts and project-owners alike, targeting medium to large solar thermal installations in the residential sector. These tools now cover every step in solar thermal projects, from conception to daily maintenance, ensuring peace of mind for project-owners and performance in the long run for solar thermal systems.
\end{abstract}

Key words: solar thermal, secure projects, performance, free tools

\section{What Is SOCOL?}

SOCOL stands for «_SOlar (thermal) and COLlective (distributed) »: initiated by ENERPLAN (French Trade Association of Solar Professionals) in 2009, it remains a unique service desk for the solar thermal community to this day.

The SOCOL community gathers almost 3,000 members and addresses ST experts (manufacturers, engineers, installers, maintainers...) and project-owners as well as institutional actors: it is therefore fully representative of the industry. Solar thermal specialists within SOCOL initiate working groups, who meet and speak together regularly to work on documents and other tools (such as software) to fit the needs of the solar thermal industry.

SOCOL's set of actions can be summarized as follows:

- National tasks: technical and communication actions

- Regional tasks

All the tools produced are freely available online. Some leaflets also exist as printed documents and can be sent free of charge.

The SOCOL team within Enerplan are also dedicated to disseminating good practice guidelines and tools for «zero default» installations, as widely as possible and collaborating with numerous partners both nationally and in each French region. Market data is gathered at national level to provide all relevant information and advice, including financial aspects: not only is it possible to download material on eligible grants and subsidies, but SOCOL also offers free use of a dedicated software named OUTISOL.

Project owners and professionals involved within the French speaking solar thermal market can become SOCOL members free of charge, and therefore receive regular information; however, non-members also full have access to the public website.

SOCOL acts as a group working on developing good practice and on promoting reliable, durable solar systems: it is not considered as a lobby. Some SOCOL actions have helped the industry by raising specific points such as errors in the calculation tool in buildings regulation, which were the corrected; however political actions are not carried out by SOCOL. 


\section{The SOCOL Toolkit}

Over the years, SOCOL experts have developed a whole set of tools that now cover every step in solar thermal projects, from conception to daily maintenance and monitoring, ensuring peace of mind for project-owners and performance in the long run for solar thermal systems.

Along with these tools, relevant data on the solar thermal market and solar heat technologies can be found on the SOCOL website, such as information on specific training and qualification, but also answers to the following questions: what is solar thermal, which various technologies are available and how to choose between them, could solar thermal be an appropriate solution for a particular project, what is provided on the website to help with a successful solar thermal project...

The tabs at the top of the home page enable access to information on how SOCOL works, on solar heat and its uses to provide hot water for multi-family housing and in the industrial and tertiary sectors, as well as its integration in district heating and industrial applications. Users can also use the top tabs to find out more on different technologies (drain-back systems, solar cooling...), technical data sheets and videos detailing the design and monitored performance of active solar heat systems (housing, hotel industry, factories, medical sector...) as well as SOCOL publications (leaflets, brochures, flyers...).

Browsers interested in the solar thermal market will also find current information in the news section to keep up to date with national and international matters relating to the industry.

Besides, specific data and advice relevant to each French region can be accessed by clicking on the desired area on the map:

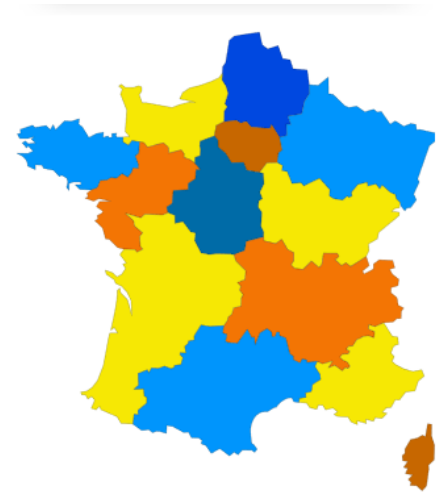

Fig. 1: Information on each specific region can be accessed by clicking on the map

As well as this general market and technological information, SOCOL offers a specific project toolkit, to accompany professionals and project-owners all the way. To ease navigation on the website, the SOCOL toolkit can be accessed via dedicated buttons, depending on which step of the project is being considered : before the actual project is decided on ("before you start"), during the design and engineering phase, while implementing the project, as works are being completed or handed over, as well as during the system's lifetime (monitoring, maintenance).

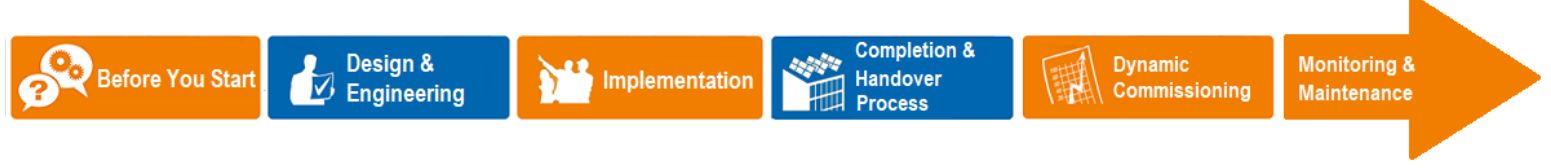

Fig. 2: SOCOL tools cover every step in solar thermal projects

Each button leads to the set of tools relevant to the chosen section.

In 2018 so far, 4,263 downloads by 22,786 different users (ca.2,000 users a month) can be counted and the pages most visited are the home page, the design \& engineering section. This represents a $74 \%$ increase compared to the same period in 2017 as far as the number of visitors is concerned and a 14\% increase for the number of visits.

\subsection{Before You Start}

SOCOL experts have developed a tailor-made software named OUTISOL, aiming at giving project-owners and 
technical advisers / prescribing engineers, indications on the technical and financial implications of their projects. No prior knowledge of the solar thermal technology is required to get quick results from this user-friendly software as far as sizing, budget, grants available, return on investment are concerned.

The user starts with choosing the location of the project and will then be led through the actual specifications (building's typology and features, users...) before accessing the detailed result page,

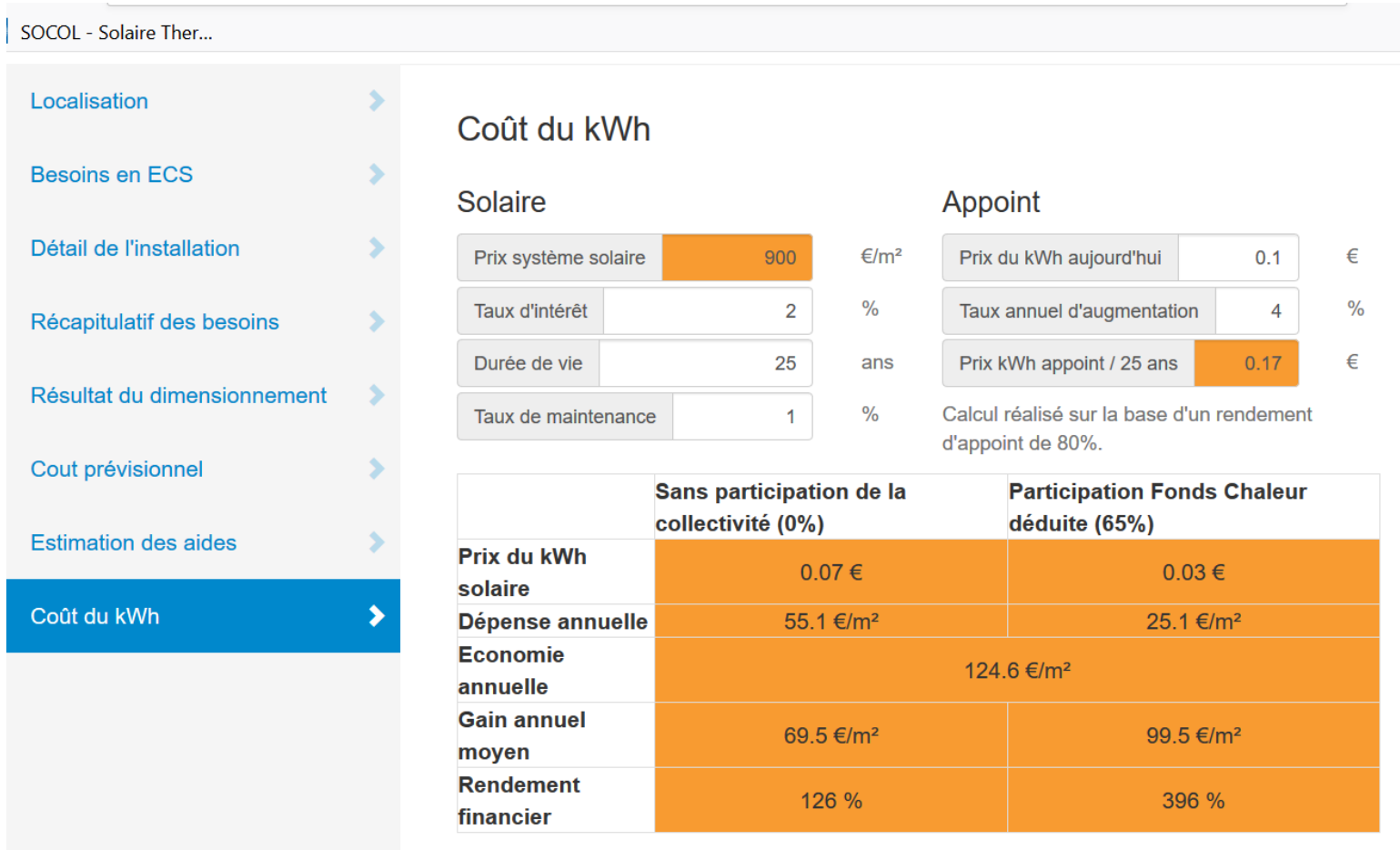

Fig. 3: Simulation results from the OUTISOL software calculations on the SOCOL website

Also to be found on the "Before You Start" page is a set of documents advising on commissioning (a pedagogical document as well as four technical booklets, complete with checklists to take all professionals through the various stages of the projects).

Information provided in this section includes data on the financing of the solar thermal systems as well as advice and technical tools to help with the current buildings regulation in France.

\subsection{Design and Engineering}

Designers and engineers working on a medium to large solar thermal project can refer to all SOCOL guidelines and technical information online.

SOCOL schematic diagrams, first published in 2013 and regularly updated, have now become a reference in France. Six of the diagrams have been selected by the ADEME (French Environment and Energy Management Agency) as mandatory: solar thermal projects have to comply with these in order to be eligible to the Fonds Chaleur (Heat Fund) subsidies.

Dedicated ratios for a proper evaluation of hot domestic water requirements are also available online: these ratios indicate the correct amount of sanitary water needed for a correct sizing of solar thermal installations. The figures are based on monitoring and also aim at avoiding an oversizing of the systems.

The SOCOL website also access to free dimensioning software. The SOLO sizing software has just been updated and is now available in its SOLO2018 version, offering new features such as calculation options for hot water recirculation loops and utility water storages. The SCHEFF software is dedicated to sizing medium and large solar thermal systems for multi-family buildings equipped with individual water heaters.

A technical sheet advising on specific sizing of expansion vessels in solar thermal systems was also updated in 2018 to offer two different sizing methods.

Another add-on this year was the creation of a technical document explaining how to take into account the hot water 
recirculation loop when sizing a solar thermal system.

SOCOL advises to choose the right monitoring level and system very early on, at the start of the project. Indeed, this point is essential to ensure cost effectiveness as well as long term performance of solar systems. For this reason, data regarding the questions of monitoring is also to be found in the "Design and Engineering" section. A recent database produced by SOCOL provides a listing of tele-monitoring services available in France. This database sorts monitoring products and services according to the requested level requirements (alert, simple monitoring, detailed monitoring), thus helping owners to choose the right monitoring for their personal needs. A user guide can also be downloaded to help choosing the right level of monitoring to suit each particular project according to its size and the project-owner's preferences.

\subsection{Implementation}

Technical data and guides as well as information on required training, qualification and insurance are to be found in this section, aimed at accompanying solar thermal installers in their medium and large size projects.

For example, a set of tools regarding the specific technology of drain-back systems can be found on this page.

\subsection{Completion and Handover Process}

This section aims at explaining what happens during the handover process and at stressing the importance of starting a dynamic commissioning procedure after this stage and as soon as there is enough hot water usage to justify starting placing the installation in service.

\subsection{Dynamic Commissioning}

The SOCOL Dynamic Commissioning toolkit includes a complete (technical and legal) set of guidelines regarding the specific requirements for solar thermal installations running after the placed-in-service date and how to ascertain their performance before the maintainer takes over.

This method has been developed by SOCOL and can be referred to as Dynamic Commissioning ("Mise en Service Dynamique" in French). It aims at providing an accurate definition and a precise log of all technical steps along the project, from design and engineering to the start of maintenance. It includes checking the installation has been made according to requirements, and a surveyed period of three to six months after the initial system run, thus ensuring performance levels match the expected forecasts.

During the dynamic commissioning process of the installation (Fig 4), all the actors must remain implicated in order to check the conformity of the installation according to the specifications, as well as a smooth run of the operation.

The operator who has been designated to provide maintenance services will therefore receive all the necessary elements to take immediate charge of the solar installation. The implementation of a monitoring will be done simultaneously at the start of operation.

To target this goal, the SOCOL process recommends formalizing and documenting dynamic commissioning through the following set of documents managed by the project owner and consisting of a logbook of the installation:

1) the acceptance report (static), which marks the beginning of the guarantee of perfect completion, with a reservation concerning the attainment of optimal performance that can be lifted with the dynamic commissioning, and other reserves as appropriate. Upon reception of the installation, it may be anticipated that the dynamic commissioning procedure cannot be completed before the end of the guarantee period (perfect completion guarantee). In this case, it is possible to consider a temporary technical procedure (filling / emptying the primary) to verify that the installation works, without prejudicing the actual performance.

2) the elements relating to dynamic commissioning i.e. the elements included in the technical study (sizing ratios, schematic diagram, reminder of the main adjustment elements, measurement points, calculation of the theoretical performance...), the list of control and measurement points during dynamic commissioning, the actual performance data (useful solar energy compared to a performance calculated according to the parameters of sunshine and withdrawal), and description of any tasks implemented to achieve the nominal 
performance where appropriate.

3) technical documents (installation and maintenance leaflets) from the relevant manufacturers regarding at least panels, sensors, solar water $\operatorname{tank}(\mathrm{s})$ and regulation.

4) the contractual elements relating to the monitoring of performance over time, including the "guarantee of proper functioning "or the "solar result guarantee" where appropriate, as well as operational backlog.

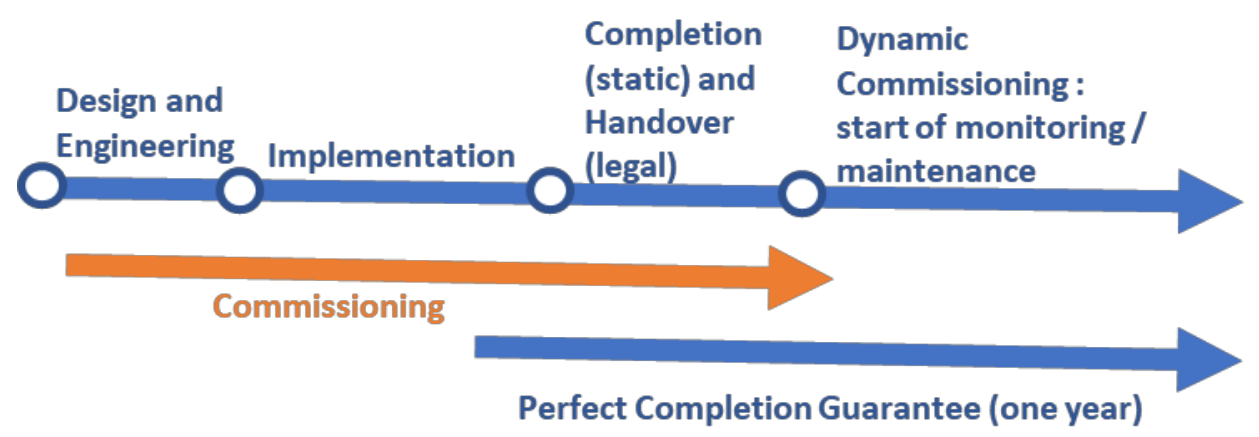

Fig. 4: Complete process diagram of Dynamic Commissioning according SOCOL

The dynamic commissioning procedure marks the beginning of the installation's operation and monitoring.

It is interesting to point out that this procedure will soon have to be implemented by project-owners wishing to benefit from the state subsidies granted via the French "Heat Fund" system (Fonds Chaleur): this official requirement represents a major recognition of the important added value provided by the SOCOL method, to ensure quality all the way through the project

\subsection{Monitoring and Maintenance}

A well designed and dimensioned installation, implemented by a qualified professional with a documented dynamic commissioning procedure, is set to produce efficient and sustainable collective solar heat for decades, if it is maintained by a competent professional.

However, to mitigate the unforeseen hazards during the life of the installation (failure of a pump, inappropriate intervention on the control, etc ...) which will not alter the comfort, but will affect the performance (less economy, more $\mathrm{CO}_{2}$ emission), it is imperative to set up a solar heat production monitoring system and the relevant associated service, for each installation.

This investment in monitoring enables a long term, high performance. It makes it possible to choose a mainly curative maintenance contract and therfore reduce operating costs.

Production monitoring is essential to ensure the effective operation of a solar DHW installation in the long run and to optimize maintenance services.

Several types of devices and associated services are available according to the size of the installation and the expectations of the owner. It can be entrusted to an external service provider, or performed internally by the client as the case may be. SOCOL provides information on a set of available solutions and services for France, to be downloaded on the website.

Although many plants are equipped with a useful energy meter, it is acknowledged that the meter is seldom used to monitor the installation (real-time malfunction, alert and curative maintenance). Only the proper production monitoring can ensure correct operation and reduce hazards.

SOCOL therefore recommends the implementation of an operational follow-up service, which offers a $100 \%$ reliable and optimal productive capacity and enables to produce an annual performance report and send it to the ADEME agency as required when receiving subsidies via the Heat Fund.

Also to be found on this section of the SOCOL website are a set of technical sheets helping with maintenance procedures and legal models for monitoring and maintenance contracts.

\section{Ground Action}


The SOCOL team work close to all involved in solar thermal activities and promotion: council housing associations, professional trade associations (installers, maintainers...), state-financed local agencies dedicated to promoting renewable energy, French regional authorities, and all partners working on developing cleaner energy systems.

Actions include technical and informative meetings locally to present professionals and project-owners with all positive impacts and advantages of using and developing the solar thermal technology and how SOCOL can help with the fluidity and secure unfolding of the projects, for durable performance of the systems. SOCOL actions and tools are therefore the subject of regular presentations at conferences both at national and regional levels. These conferences can be organized by or with SOCOL and can be dedicated to solar thermal subjects or address a wider scope such as renewable energies or sustainable building. These conferences can also take place as side-events during trade fairs.

SOCOL is also involved in the annual conference dedicated to solar thermal in France: les Etats Généraux de la Chaleur Solaire. This event gathers around 150 part-takers, involved in the French solar thermal industry.

To complete this set of actions, SOCOL webinars are widely and regularly offered to gather a larger audience and communicate on specific items concerning technical, legal or pedagogical aspects impacting the solar thermal industry. The webinars are free to all participants. Some of the webinars are developed jointly with other partners and target relevant topics such as the dynamic commissioning procedure, monitoring, positioning of solar thermal technologies in the frame of building regulations and so on. Some of the webinars can be replayed on the SOCOL website.

\section{What Next?}

In the coming years, SOCOL are committed to continue their actions to secure, promote and develop solar thermal technologies on the French market.

The technical working groups are still gathering regularly to initiate proper actions, tools and guidelines to further accompany professionals and project-owners, collaborating with other associations to identify appropriate needs and disseminate information widely.

One of the current tasks is dedicated to pinpointing the main subjects to be addressed when advising installers on good practices regarding implementation. This work will also point out which common mistakes are to be avoided when replacing existing solar thermal material. As a result, some of the existing SOCOL tools and guideline will updated and some more sheets will be created if necessary.

However, the most important set of actions will certainly lie within the communication scope: improving community management, using social networks and media more efficiently, informing in a timely manner... SOCOL is evolving to target all potentially interested in energy efficiency, aiming at making solar thermal an option to always have in mind when renovating or conceiving a building, a plant or a district.

SOCOL is a French-speaking website however, it would also be a reward for all the team's work if foreign entities were to use some of the free online data to also help promote solar thermal on an international level. 


\title{
Research for Compiling a Mandatory National Standard 《Technical Code for Energy Efficiency in Buildings and Renewable Energy Application 》
}

\author{
Ruicheng Zheng, Tao He, Bojia Li, Min Wang and Xinyu Zhang \\ China Academy of Building Research, Beijing (China)
}

\begin{abstract}
It is introduced a China's research item from the Ministry of Housing and Urban-Rural Development of PRC in this paper. The title of the item is Research for Compiling a Mandatory National Standard 《Technical Code for Energy Efficiency in Buildings and Renewable Energy Application》. The main contents of the paper are background introduction for reformation of China's national engineering standard system and research results of the item in the field of renewable energy application which mainly are compiling principles for this mandatory national standard and key technical stipulation of the standard for renewable energy application including solar thermal systems, solar PV systems, ground and air heat pump systems etc. On the base of this research item, a compiling work for Mandatory National Standard 《Technical Code for Energy Efficiency in Buildings and Renewable Energy Application》 will start in near future.
\end{abstract}

Keywords: Mandatory national standard, energy efficiency in buildings, renewable energy application, solar thermal systems, solar PV systems, ground-source heat pump systems, air heat pump systems

\section{National engineering standard system in China}

There are two kinds of national engineering standards now in China, one is mandatory standard and another is voluntary standard. Compiling and publishing for national standards, professional standards and local standards were all managed by governments, but the association standards which are in common use in many developed countries had not key status in the past. So this situation has not been suitable to the requirement of market economy development in China.

Therefore a reformation for this national engineering standard system has been started since 2015. Only the mandatory standards are National Standards and their compiling are still organized by governments, but voluntary standards compiling will be changed to organizing by associations or companies etc. gradually. To strengthen the management for mandatory standards and ensure basic supply for voluntary standards of public welfare, a new standard system will be set up in the future.

\section{Research for reformation of compiling principle}

\subsection{Background}

For making sure a successful reformation several research items have been issued by the Ministry of Housing and Urban-Rural Development of PRC. So the item "Research for Compiling a Mandatory National Standard 《Technical Code for Energy Efficiency in Buildings and Renewable Energy Application》 was started in 2016 and it will be completed in 2018. The chief research unit of this item is China Academy of Building Research (CABR). After completing research of this item a compiling task for 《Technical Code for Energy Efficiency in Buildings and Renewable Energy Application》will be started formally.

National mandatory engineering standards are divided into two types, engineering projects standards and common technologies standards. A common technology standard is aimed at a special technical profession and its content should cover the general performance demands and key technical measures for planning, 
reconnaissance, survey, design, construction, pilot run and inspection etc. The mandatory technical demand to be entered in a common technology standard can be quoted by engineering projects standards which need not repeat providing. 《Technical Code for Energy Efficiency in Buildings and Renewable Energy Application》 belongs to common technology standard.

\subsection{Research for reformation of compiling principle}

At the present situation if having even one compulsory provision in a standard, this standard is a mandatory standard, but in the future an important reformation is that all contents should be compulsory provisions in a mandatory standard. The mandatory national engineering standards (technical code) are technical bottom lines to guarantee safety, healthy, engineering quality, ecological environment, public interests etc. and technical stipulations to promote energy and natural resources saving and to manage community economy.

In the past the compulsory provisions of mandatory national standards are only concerned personal security, person's physical health, engineering safety, ecological condition safety and public interests etc. But in the future some contents related to promoting resources conservation and energy saving will also be put in compulsory provisions and it is a reformation for compiling principle.

The main research tasks include following aspects: to collect and refer all concerned requirements such as public security, environment protection and energy efficiency etc. in China's national laws and regulations, to investigate the compiling inscapes, contents and technical indexes etc. in concerned laws, codes and standards of foreign countries such as EU, US, UK, Japan etc., to analysis the practicability and operability of compulsory provisions in present concerned mandatory standards. Undergoing about one year's work, a research report was completed in the end of 2017 and some useful research results were gotten.

\section{Main research results for key technical stipulation}

The research results of this item include all provisions which will be entered in 《Technical Code for Energy Efficiency in Buildings and Renewable Energy Application 》 and mainly they are some technical stipulations in different technology application fields. These provisions of different technology application will be introduced briefly in the next.

\subsection{General regulation}

The total energy consumption for heating and air conditioning of new-built residential buildings, for HVAC and lighting of new-built public buildings shall decrease $30 \%$ and $20 \%$ respectively compare with energy efficiency index of the present design standards for energy efficiency of residential buildings/public buildings in 2016. The energy consumption limits to various types of buildings in different climate areas are given. The design indexes for energy consumption of various typical public buildings in different climate zones at standard working condition are shown in Tab.1.

Tab. 1: Design indexes for energy consumption of various public buildings in different climate zones $\left(\mathrm{kWh} / \mathrm{m}^{2} \mathrm{a}\right)$

\begin{tabular}{|c|c|c|c|c|c|}
\hline Type & $\begin{array}{c}\text { Severe cold } \\
\text { zone }\end{array}$ & $\begin{array}{c}\text { Cold } \\
\text { zone }\end{array}$ & $\begin{array}{c}\text { Hot summer and } \\
\text { cold winter zone }\end{array}$ & $\begin{array}{c}\text { Hot summer and } \\
\text { warm winter zone }\end{array}$ & $\begin{array}{c}\text { Moderate } \\
\text { climate zone }\end{array}$ \\
\hline $\begin{array}{c}\text { Common office buildings } \\
\text { Area <20000m² }\end{array}$ & $\leq 50$ & $\leq 45$ & $\leq 55$ & $\leq 55$ & $\leq 40$ \\
\hline $\begin{array}{c}\text { Large office buildings } \\
\text { Area } \geq 20000 m^{2}\end{array}$ & $\leq 55$ & $\leq 50$ & $\leq 60$ & $\leq 65$ & $\leq 50$ \\
\hline $\begin{array}{c}\text { Common hotel buildings } \\
\text { Area <20000m }\end{array}$ & $\leq 40$ & $\leq 40$ & $\leq 50$ & $\leq 70$ & $\leq 40$ \\
\hline Large hotel buildings & $\leq 45$ & $\leq 45$ & $\leq 60$ & & $\leq 75$ \\
Area $\geq 20000 m^{2}$ & & & & & \\
\hline
\end{tabular}




\begin{tabular}{|c|c|c|c|c|c|}
\hline Market buildings & $\leq 70$ & $\leq 65$ & $\leq 70$ & $\leq 80$ & $\leq 40$ \\
\hline Hospital buildings & $\leq 75$ & $\leq 70$ & $\leq 70$ & $\leq 85$ & $\leq 40$ \\
\hline School buildings & $\leq 35$ & $\leq 30$ & $\leq 35$ & $\leq 40$ & $\leq 30$ \\
\hline
\end{tabular}

Investigation and evaluation for renewable energy application in buildings shall be taken during the stage of planning design, to decide rational application patterns and to confirm application effects according to local solar energy resource etc. and suitable conditions. The design documents should include special articles for renewable application in scheme and preliminary design period. The technical requirements of construction and operation concerned with renewable energy application should be noted in detail design documents.

\subsection{Solar thermal systems}

A solar thermal system should be comprehensive utilization in all year, has the capacity to supply hot water, heating or cooling for building according to user's requirements, local climate and suitable condition.

The performance of solar collectors shall meet related stipulation in concerned National Standards and collector's working life shall not lower than 15 years. The average efficiency of solar collector systems for solar thermal application in buildings shall meet the requirement in Tab.2.

Tab. 2: Requirement for average efficiency of solar collector systems $\eta(\%)$

\begin{tabular}{|c|c|c|}
\hline Solar water heating system & Solar heating combisystem & Solar cooling system \\
\hline$\eta \geq 42$ & $\eta \geq 35$ & $\eta \geq 30$ \\
\hline
\end{tabular}

Note: for solar water heating system $\eta$ is average value in one year, for solar heating combisystem $\eta$ is average value in one heating season, for solar cooling system $\eta$ is average value in one summer.

Solar thermal systems shall have related technical measures for freeze-proofing, frosty-proofing, overheatingproofing, hot water leakage proofing, lightning protection, hail preventing, wind resistance, anti-seismic and electric safety etc. according to different areas and using conditions.

The relief valves in the systems shall be mounted at a place where discharge steam or high-temperature hot water could not endanger surrounding persons and related facilities shall be allocated. All electrical instruments used in solar thermal systems shall have safety measures for earth potential, residual current protection and interruption of power supply etc.

\subsection{Solar PV systems}

Solar PV grid-connected systems shall have related protection capacity, install switch cabinet for special use of grid-connected system and necessary metering apparatus. Gap device shall be set up between a solar PV gridconnected system and a public power grid.

"Electric Shock Risk" warning label shall be put at the grid-connected place and where installed PV systems of buildings. The PV systems installed in buildings shall have related protection measures for electric safety and lightning protection.

\subsection{Solar systems integrated in buildings}

Design of integrated in buildings should be adopted in the design for solar systems (solar thermal systems and solar PV systems) used in buildings.

The brackets of solar collectors/solar PV panels shall be firmly connected to superstructures of the buildings through embedded parts which shall meet the demands of anchoring bearing capacity.

The safety protection measures for system operation/maintenance and broken components falling down shall be set in buildings which are installed solar systems. 
A solar system installed on roof of the building shall not create sunlight shelter to adjacent buildings and decrease the sunshine level of adjacent buildings.

When using solar collectors instead of balcony breast boards, the total performance such as rigidity and strength etc. shall meet the requirement for protection capacity of the balcony.

In the case of fire poisonousness grade for burning smoke of solar collectors/solar PV panels shall not be lower than the second security level $\mathrm{AQ}_{2}$.

Checking for structure security must be passed before additionally to build solar systems in existing buildings.

\subsection{Ground heat pump systems}

Before scheme design for a ground heat exchanger system the investigation and survey to construction field and geothermal resource shall be taken. The feasibility and economy analysis to practice ground heat exchanger system shall be carried out.

A thermal response test shall be done when building area for application ground heat exchanger system is larger than $5000 \mathrm{~m}^{2}$.

Dynamic load calculation of one year at least for ground heat exchanger system shall be taken. The total quantity for heat storage and heat supply of the ground shall be balanced during calculation period.

Design for a groundwater system shall be taken according to survey data of hydrology and geology. The reliable recharge measure must be taken and groundwater shall be recharged to same aquifer. The situation of groundwater waste and pollution is not permitted and groundwater quality shall be monitored regularly.

Evaluation to water resource and environment influenced by surface water (rivers and lakes etc.) systems shall be carried out and the item construction shall be approved by local departments in charge of shipping and water resource.

The devices and pipes of sea water heat pump system shall be provided with anti-corrosion performance. The measures to prevent sea living beings adhering shall be installed.

Freeze-proofing measures shall be set for ground heat exchanger system, close circle heat exchanger system of surface water and sea water in the areas where freeze will be happened in winter.

\subsection{Air heat pump systems}

The effective heating capacity of a unit of air heat pump shall be corrected in accordance with outside temperature, humidity, operating mode of frost and defrost. The correction shall be also in accordance with connective pipe length and height difference between inside unit and outside unit for a multi-connected split unit of air heat pump.

Auxiliary heat resource shall be set when design indoor temperature is lower than temperature of balance point of a unit of air heat pump.

During continuous heating operation for an air heat pump unit the total defrosting time shall not exceed $20 \%$ of one continuous heating period.

The necessary freeze-proofing measures shall be taken when an air heat pump system is used in severe cold and cols zones.

The winter heating COP of an air heat pump system operated in severe cold zones, cold zones, hot summer and cold winter zones shall not be lower than 1.6, 1.8 and 2.1 respectively.

\subsection{System installation and acceptance}

The main components and materials related to safety, energy efficiency and environment protection used in systems shall be retested through witness random sampling on construction site. The retested contents include: safety and thermal performance of solar collectors, generation power and efficiency of solar PV panel.

Orientation and tilt angle for installation of solar collectors and solar PV panels shall meet the design requirements and deviation shall not be more than $\pm 3^{0}$. 
During installation for solar systems structure such as roof and anti-water layer etc. in existing buildings shall not be damaged.

The testing items for thermal performance of a solar thermal system shall include heat gain and efficiency of solar collector system, total energy consumption and solar fraction of solar thermal system. The efficiency of solar collector system shall meet design requirement.

The test of drawing water from a heat resource well and recharge water to same heat resource well for a groundsource heat pump system shall be done and accepted alone. The sustained water output and recharge quantities shall be checked with design drawing and be stable.

The testing of water quality and sediment concentration for a ground-source heat pump system shall be done. The water quality and sediment concentration shall meet the using requirement of equipment in system.

Before the final acceptance for a ground-source heat pump system operation testing during winter and summer shall be carried out. The testing results of system performance shall be compared with design requirement and evaluation shall be given.

\subsection{System operation and management}

The energy efficiency management system and directive rules for energy efficiency operation of equipment shall be made.

The detail operation plan for a combination system of common energy with renewable energy shall guarantee to give priority to using renewable energy.

The obvious sign of season exchange in winter and summer for a ground-source heat pump system shall be set and operation for valve exchange shall be completed before season exchange.

The surfaces of solar collectors and PV panels in solar systems shall be cleaned at regular intervals.

During operation of a solar collector system, checking and maintaining for system shall meet following stipulations:

1) The integral checking up for solar collectors shall be done every one year.

2) The safety of lighting protection measures of solar collector systems shall be checked at regular intervals.

3) Freeze-proofing measures of solar collector systems shall be checked before winter operation.

4) The exposure and stagnation of solar collector shall be avoided during operation of a solar collector system.

5) There shall be effective measures to avoid overheating of a solar collector system when operation stops for a solar cooling system after summer.

\subsection{System metering and building energy labelling}

Metering parameters for a solar heating or cooling system shall include outside temperature, temperatures in typical rooms, input and output water temperature of solar collector system, circle water flow of solar collector system and total solar irradiation.

Metering parameters for a solar PV system shall include outside temperature, surface temperature on back side of solar panels, total solar irradiation and generating capacity.

During operation of a ground-source heat pump system, metering and analysis for temperature in the side of ground source shall be taken.

The statistic period for energy consumption in buildings shall be whole one calendar year. The renewable energy system shall be metered solely.

The building owners or operation units shall record original data for energy consumption accurately and set statistic standing books. The metering instruments shall be calibrated at demand regular intervals.

The statistic for energy consumption in buildings shall include power consumption, coal gas or oil consumption, heating consumption, cooling consumption and renewable energy consumption. 
The energy using efficiency of buildings shall be tested, evaluated and labelled before final acceptance. The testing and evaluation for energy using efficiency of buildings by the third part shall be done after building using one year and occupancy rate of a residential building is more than $30 \%$. The building owners shall open the evaluation results.

The building energy labelling shall be directed against one single building. The labelling contents include basic building information, energy efficiency grade and relative fractional energy saving, case of new technology application, testing and evaluation results for building energy efficiency.

The information of building energy labelling shall be given in agreement, quality guarantee and using instructions which shall supply to purchaser when selling a commercial residential building.

The owners of public buildings shall give publicity to energy consumption of real operation in buildings at the notable location of the buildings.

In management contracts of EPC items the quantifiable targets for energy consumption and environment characters which can be tested and verified shall be given.

\section{Conclusion}

The results of item "Research for Compiling a Mandatory National Standard 《Technical Code for Energy Efficiency in Buildings and Renewable Energy Application》 will ask advice openly in the next months of 2018. The formal compiling for Mandatory National Standard 《Technical Code for Energy Efficiency in Buildings and Renewable Energy Application》 will start and complete in 2019.

All study work provides a better basis for compiling Mandatory National Standard 《Technical Code for Energy Efficiency in Buildings and Renewable Energy Application》. Through the study technical level, engineering quality and real effects for Energy Efficiency in Buildings and Renewable Energy Application will be also raised in the future in China.

\section{References}

1. China Academy of Building Research, 2017. the Report for Research of 《Technical Code for Energy Efficiency in Buildings and Renewable Energy Application 》.

2. China National Standard, GB 50364-2018. 《Technical code for solar water heating system of civil buildings》.

3. China National Standard, GB 50496-2009. 《Technical code for solar heating system》.

4. China National Standard, GB 50366-2005. 《Technical code for ground-source heat pump system》,Version 2009.

5. China National Standard, GB/T 50801-2013, 《Evaluation standard for application of renewable energy in buildings》.

6. China Professional Standard, JGJ 203-2010. 《Technical code for solar PV system of civil buildings》 . 
Author Index 


\section{A}

\section{Abdurafikov, R.}

Control Strategies for a Residential Property with Solar Building, Thermal and Electricity...

\section{Abrecht, S.}

Annual Efficiency - Easy Understanding of Collector Performance.

Adam, M.

Efficient Design of Solar Assisted Heating Systems for Multi-Family Houses. .

\section{Agalit, $\mathbf{H}$.}

Solar Heat Integration in Rotational Molding Process: Case Study. .

Ahmad, S.U.

Evaluation of Solar Radiation from MERRA, MERRA-2, ERA-Interim and CFSR Reanalysis...

Alet, $\mathbf{P}$.

Quantifying the Potential of Smart Heat-Pump Control to Increase the Self-Consumption... .

Ali, $\mathbf{H}$.

Evaluation of NCEP-Products (NCEP-NCAR, NCEP-DOE, NCEP-FNL, NCEP-GFS) of Solar Radiation...

Ali, M.J.

Evaluation of Solar Radiation from MERRA, MERRA-2, ERA-Interim and CFSR Reanalysis... ...

Alonso Alvarez, D.

Development and Field Testing of a Novel Hybrid PV-Thermal Solar Collector.

Alonso-Montesinos, J.

A First Approach of the Influence of the Forecasting Horizon in the Electricity Generation... . . . . . . . . . . 1482

PV Power Production Estimation by Using Radiometric and Meteorological Data. ...

Al-Riyami, $\mathbf{S}$.

Simulations of Solar Thermal Cooling System for a Building at Innovation Park Muscat . .

Altamirano Cundapí, A.

Selection of High-Performance Working Fluid for a Solar-Geothermal Absorption Cooling..

\section{André, $\mathbf{P}$.}

Experimental Study of a 600 w Seasonal Solar Heat Storage Reactor for the Heating...

\section{Andrés Chicote, $\mathbf{M}$.}

An Improved Model for Phase Change Material (PCM) Thermal Storage Tanks.

\section{Arancibia-Bulnes, C.}

Solar Irradiation Over a Flat Surface with Different Tracking Strategies

Asim, M.

Evaluation of NCEP-Products (NCEP-NCAR, NCEP-DOE, NCEP-FNL, NCEP-GFS) of Solar Radiation...

Evaluation of Solar Radiation from MERRA, MERRA-2, ERA-Interim and CFSR Reanalysis. .

\section{Athienitis, A.}

Design and Performance Assessment of a Prefabricated BIPV/T Roof System Coupled with... . . . . . . . . . 859

Early Design Stage Consideration of Building Form and BIPVT Energy Performance . . . . . . . . . . . . . 140

Modular Rooftop Building-Integrated Photovoltaic/Thermal Systems for Low-Rise Buildings... . . 


\section{Azhar, M.}

Evaluation of NCEP-Products (NCEP-NCAR, NCEP-DOE, NCEP-FNL, NCEP-GFS) of Solar Radiation...

\section{B}

\section{Bachour, D.}

Effect of Solar Position Calculations on Filtering and Analysis of Solar Radiation...

\section{Backes, $\mathrm{K}$.}

Efficient Design of Solar Assisted Heating Systems for Multi-Family Houses. .

\section{Bagchi, A.}

\section{Baiwir, R.}

Experimental Study of a 600 w Seasonal Solar Heat Storage Reactor for the Heating...

\section{Baldini, L.}

High Temperature Seasonal BTES for Effective Load Shifting and CO2 Emission Reduction.

\section{Balsells, M.}

Experimental Investigation on the Dynamic Performance of a Thermally-Driven Adsorption...

\section{Bamberger, E.}

Hardware-In-The-Loop Tests on Complete Systems with Heat Pumps and PV for the Supply..

bannenberg, J.

RESSSPI: The Network of Simulated Solar Systems for Industrial Processes.

\section{Barz, T.}

Dynamic Modelling of a Hybrid Solar Thermal/Electric Storage System for Application...

\section{Batlles, F.J.}

\section{Battaglia, M.}

Extended Hottel-Whillier Models for uncovered PVT-Collectors. . . . . . . . . . . . . . . . . . . . . . . . . . 941

Stratification in Large Thermal Storage Tanks. . . . . . . . . . . . . . . . . . . . . . . . . . . . . . . . . . . . . . 1097

Validation of an Ice Storage Model and Its Integration Into a Solar-Ice System. . . . . . . . . . . . . . . . . . . . . 1162

\section{Bauer, G.}

Experimental Comparison of Scroll and Swash-Plate Compressors for PV Driven Compression...

Baup, 0.

Development of a Photovoltaic Driven Thermodynamic Chiller - Application to Solar...

\section{Beausoleil-Morrison, I.}

Preliminary Results for the First Year of Operation of a Seasonal Storage Solar Combisystem...

Beccali, M.

Life Cycle Assessment Experiences for Solar Heating and Cooling Systems. . . . . . . . . . . . . . . . . . 493

Monitoring and Energy Performance Assessment of the Compact DEC HVAC System "Freescoo... ...

\section{Beck, A.}

Evacuated Glazing with Silica Aerogel Spacers.

Becke, W.

High Solar Fraction By Thermally Activated Components. 


\section{Bellanco, I.}

Experimental Investigation on the Dynamic Performance of a Thermally-Driven Adsorption.

Ben Cheikh, R.

Testing and Modeling of Direct Steam Generating Parabolic Trough Collectors. .

\section{Bennacer, R.}

Field Test Results of an Innovative PV/T Collector for an Outdoor Swimming Pool

Bennouna, E.G.

Solar Heat Integration in Rotational Molding Process: Case Study. .

\section{Bergmann, T.}

Thermo-Chemical District Networks.

Best, I.

Comparison of Solar District Heating Concepts at Various Land Prices.

Bianchini, A.

Performance Analysis of a Small Scale Solar Cooling Plant Based on Experimental Measurements. ..

Bohren, A.

Optical Properties of Solar Absorbers - Results on Round Robin and Guidelines...

Bolt, $\mathbf{P}$.

Model Predictive Control for Building Automation.

Bonato, P.

Definition of a Reference Office Building for Simulation Based Evaluation of Solar...

Bonnín-Ripoll, $\mathrm{F}$.

OTSun: An Open Source Code for Optical Analysis of Solar Thermal Collectors and PV...

\section{Bony, J.}

Drainback Solar Thermal Systems in Switzerland - Market Overview and Main Barriers.

Borth, J.

Understanding the Dynamics of Solar Energy Systems by Using Simulation Narratives.

\section{Bottse, J.}

An Overview of PVT Modules on the European Market and the Barriers and Opportunities..

Bouden, C.

Testing and Modeling of Direct Steam Generating Parabolic Trough Collectors. .

994

Božiek, D.

Using Heliodon for Solar Building Design Education in the Age of Computer Simulations. .

Bright, J.M.

Climatic and Global Validation of Daily MODIS Precipitable Water Data at AERONET... ...

Broman, L.

On the Importance of Education when Implementing Renewable Energy. . .

Brottier, L.

Field Test Results of an Innovative PV/T Collector for an Outdoor Swimming Pool. .

Broum, M.

Simulation and Monitoring of PV Heat Pump System with Seasonal Storage. . . 409

\section{Brüggemann, D.}


Brun, G.

Experimental Investigation of PVT Collectors with Phase Change Material. . .

Brunold, S.

Ageing Performance of New Solar Cover Materials After Outdoor Exposure.

\section{Büchel, E.}

Decentralized DHW Production from Exhaust Air in the Bathroom Prewall. . .

Buck, D.

Evacuated Glazing with Silica Aerogel Spacers.

Bueno Pereira, E.

Brazilian Photovoltaic Potential.

Monthly Solar Irradiance Variability in Brazilian Climate Zones.

\section{Bunea, M.}

Drainback Solar Thermal Systems in Switzerland - Market Overview and Main Barriers

Bunea, M.S.

Solar Heat in Industrial Processes in Switzerland - Theoretical Potential and Promising...

Büttner, B.

Evacuated Glazing with Silica Aerogel Spacers.

\section{C}

\section{Cabeza, L.F.}

Dynamic Modelling of a Hybrid Solar Thermal/Electric Storage System for Application...

Cabral, D.

Development of a Compact and Didactic Solar Energy Kit Using Arduino. .

Electrical and Thermal Performance Evaluation of a District Heating System Composed..

Caflisch, M.

Solar Heat in Industrial Processes in Switzerland - Theoretical Potential and Promising...

\section{Calabrese, T.}

Potential of Covering Electricity Needs of a Flat of a MFH with Decentral Compact...

Carbajo Jiménez, $P$.

Energetic Behaviour of a Solar Thermal System Producing Domestic Hot Water and Preheating... . .

Carbonell, D.

Validation of an Ice Storage Model and Its Integration Into a Solar-Ice System.

Cardona, G.

OTSun: An Open Source Code for Optical Analysis of Solar Thermal Collectors and PV...

Carrobé, A.

Radiative Cooling to Cover Cooling Demands of an Earthbag Building in a Training...

Thermal Monitoring on an Earthbag Building in Mediterranean Continental Climate. .

\section{Carvalho, M.J.}

Accelerated Aging Tests for Solar Absorber Coatings...

Assessment of Durability of Solar Absorbers - Performance Criterion.

Optical Properties of Solar Absorbers - Results on Round Robin and Guidelines. 
Castell, A.

Radiative Cooling to Cover Cooling Demands of an Earthbag Building in a Training... . . . . . . . . . . . . . . . 13

Castro, J.

Testing and Modeling of Direct Steam Generating Parabolic Trough Collectors. ... 994

Celik, S.B.

Modelling of an Absorption Cycle With a Direct Ammonia Vapor Generator Inside a Concentrating... 513

Cellura, M.

Life Cycle Assessment Experiences for Solar Heating and Cooling Systems. 493

Thermal Collection and Seasonal Storage Potential of a Mixed-Use Neighborhood . . 1108

Cerneckiene, J.

Review of Combined Solar Thermal and Heat Pump Systems Installations in Lithuanian... 444

Solar Thermal Systems VS. Photovoltaic Systems. Case Study: Single Family Building... 449

Chadee, X.T.

Assessing Solar Electricity Potential and Prospective Present Day Costs For A Low...

\section{Chambino, T.}

Accelerated Aging Tests for Solar Absorber Coatings.

Chatzipoulka, C.

A Simple Tool for Assessing Solar and Daylight Access in Urban Canyons.

Chávez, A.F.

Surface Modification of AISI 316 Stainless Steel by Oxynitrocarburizing for Solar..

Chen, S.

Improvements on the Efficiency of the Photovoltaic Panel by Integrating a Spray Cooling... . . . . . . . . . . . . 930

Performance Investigation of Liquid Desiccant Dehumidification System Integrated... . . . . . . . . . . . . . . 716

Theoretical Analysis of Photovoltaic Panels Using a Spray Cooling System with a Shallow... . . . . . . . . . . . 1413

\section{Cheong, K.W.D.}

Levelised Cost of Thermal Energy Storage and Battery Storage to Store Solar PV Energy...

Chèze, $\mathbf{D}$.

Comparative Dynamic Performance Tests of Two Real Technology Packages for Buildings.

Chicote, M.A.

Dynamic Modeling and Optimization of Energy Use in Retrofitted Buildings at District... . .

Christodoulaki, R.

Optical Analysis of an Evacuated Tube Collector with Built-In Semicircular Concentrator.

Citherlet, S.

Drainback Solar Thermal Systems in Switzerland - Market Overview and Main Barriers. 334

Clarke, R.M.

Assessing Solar Electricity Potential and Prospective Present Day Costs For A Low..

Coca-Ortegón, A.

Modelling and Simulation of a PV Driven Refrigerator with Phase-Change Materials...

Collard, L.

Experimental Study of a 600 w Seasonal Solar Heat Storage Reactor for the Heating...

Compagnon, $\mathbf{R}$.

A Simple Tool for Assessing Solar and Daylight Access in Urban Canyons. 


\section{Cordes, T.}

Simulations of Solar Thermal Cooling System for a Building at Innovation Park Muscat.

\section{Coronas, A.}

Modelling and Simulation of a PV Driven Refrigerator with Phase-Change Materials. .

\section{Correa-Jullian, C.}

Simulation of a Solar Fired Absorption System for a Case Study in the Dairy Industry. . .

\section{Cortés, F.}

Simulation of a Solar Fired Absorption System for a Case Study in the Dairy Industry. . 544

\section{Cortés, M.}

PV Power Production Estimation by Using Radiometric and Meteorological Data

Corti, P.

bFAST: A Methodology for Assessing the Solar Potential of Façades in Existing Building..

Costa, $\mathbf{R}$.

The Spatial and Temporal Patterns of the Surface Solar Irradiation in Northeastern...

Costeira, J.

Development of a Compact and Didactic Solar Energy Kit Using Arduino.

Electrical and Thermal Performance Evaluation of a District Heating System Composed..

Crema, L.

Solar Flux Map Distribution of a Parabolic-Spheric Dish Based on Photographic Method.

Crespo, A.

Simulation of a Solar Fired Absorption System for a Case Study in the Dairy Industry. .

Cusenza, M.A.

Life Cycle Assessment Experiences for Solar Heating and Cooling Systems. .

D

\section{D'Antoni, M.}

Definition of a Reference Office Building for Simulation Based Evaluation of Solar... . . . . . . . . . . . . . . 19

Energetic and Economic Analysis of a Solar-Assisted Trigeneration System . . . . . . . . . . . . . . . . . . . . . 168

\section{Daguenet-Frick, $\mathbf{X}$.}

Design and Construction of a 10 KW Sorption Heat Pump Prototype. .

\section{Danesi, S.}

Thermo-Chemical District Networks. . . . . . . . . . . . . . . . . . . . . . . . . . . . . . . . . 178

Understanding the Dynamics of Solar Energy Systems by Using Simulation Narratives . . . . . . . . . . . . . 1687

\section{Das, P.K.}

Most Probable Operating Conditions and Performance Assessment of Four PV Technologies.

\section{Davin, E.}

Experimental Study of a 600 w Seasonal Solar Heat Storage Reactor for the Heating...

\section{de Beijer, $\mathbf{H}$.}

The Development of the Sunridge, an Orientation Independent Thermal Solar System ...

de Geus, A.

The Development of the Sunridge, an Orientation Independent Thermal Solar System. 


\section{de Jong, M.}

An Aesthetic Energy Producing Roof with Integration of PV Modules and Solar Thermal...

An Overview of PVT Modules on the European Market and the Barriers and Opportunities.. .

de Keizer, C.

An Aesthetic Energy Producing Roof with Integration of PV Modules and Solar Thermal...

Delgado, 0.

Ray Tracing Method for the Evaluation of Yearly Performance of a Solar Thermal Concentrator.

Del Medico, F.

Cleaning Strategies for Fresnel Linear Concentrator Mirrors in Solar Heating Plants.

Dermentzis, $\mathbf{G}$.

Potential of Covering Electricity Needs of a Flat of a MFH with Decentral Compact...

\section{Descy, A.}

Semi Continuous Thermochemical Reactor for Thermal Storage.

Descy, G.

Semi Continuous Thermochemical Reactor for Thermal Storage.

\section{de Vries, $\mathbf{S}$.}

Definition of a Reference Office Building for Simulation Based Evaluation of Solar...

\section{Diamantino, $\mathrm{T}$.}

Accelerated Aging Tests for Solar Absorber Coatings. ...

Assessment of Durability of Solar Absorbers - Performance Criterion. . .

Di Palo, M.

Cleaning Strategies for Fresnel Linear Concentrator Mirrors in Solar Heating Plants. .

\section{Di Pietra, B.}

Monitoring and Energy Performance Assessment of the Compact DEC HVAC System "Freescoo...

Dookie, N.

Assessing Solar Electricity Potential and Prospective Present Day Costs For A Low..

Dovjak, M.

Application of PCM in Building's Envelope of Lightweight Prefabricated Houses as...

Using Heliodon for Solar Building Design Education in the Age of Computer Simulations. .

\section{Drosou, V.}

Optical Analysis of an Evacuated Tube Collector with Built-In Semicircular Concentrator.

\section{Drïck, $\mathbf{H}$.}

CFD-Based Development, Testing and Optimization of Flat Plate Collectors.

\section{Dumoulin, $\mathbf{R}$.}

Design and Performance Assessment of a Prefabricated BIPV/T Roof System Coupled with...

Duta, A.

Tailoring Alumina Matrix Optical Properties for Colored Solar Thermal Absorber Coatings. . 


\section{E}

\section{Eckert, T.}

Design and Practical Validation of a Hybrid Absorption/Compression Chiller Driven...

Eggert, D.

Efficient Design of Solar Assisted Heating Systems for Multi-Family Houses. . .

301

Egler, M.

Accuracy of Solar Resource Assessments on the Basis of Publicly Available GHI Databases.

1522

Eicher, $\mathbf{S}$.

Drainback Solar Thermal Systems in Switzerland - Market Overview and Main Barriers. ..

Eismann, $\mathbf{R}$.

PIPE Network Analysis for Solar Thermal Plants. .

Ekins-Daukes, $\mathbf{N}$.

Development and Field Testing of a Novel Hybrid PV-Thermal Solar Collector.

Emhofer, J.

Dynamic Modelling of a Hybrid Solar Thermal/Electric Storage System for Application...

Engerer, N.A.

Climatic and Global Validation of Daily MODIS Precipitable Water Data at AERONET...

Esparcieux, P.

Development of a Photovoltaic Driven Thermodynamic Chiller - Application to Solar...

Estevez, H.

Solar Irradiation Over a Flat Surface with Different Tracking Strategies.

F

Fahr, S.

In Situ Characterization of Thermal Collectors in Field Installations. ..

Famiglietti, A.

Modelling of an Absorption Cycle With a Direct Ammonia Vapor Generator Inside a Concentrating...

Farchado, M.

Abrasion and Cleaning Tests on Antireflective and Antireflective/Antisoiling Coatings..

Influence of Using Different SiO2 Antireflective Coatings and Sintering Conditions. .

Fedrizzi, $\mathbf{R}$.

Definition of a Reference Office Building for Simulation Based Evaluation of Solar... . . . . . . . . . . . . . 19

Energetic and Economic Analysis of a Solar-Assisted Trigeneration System . . . . . . . . . . . . . . . . . . 168

Feichtinger-Hofer, M.

Short Term PV Forecasting Using Satellite Data for Austria.

Feierl, L.

Measurement Results and Operating Experience of Large-Scale Solar Air Conditioning...

574

Ferchichi, S.

Testing and Modeling of Direct Steam Generating Parabolic Trough Collectors. .

994

Ferrada, $\mathbf{P}$.

PV Power Production Estimation by Using Radiometric and Meteorological Data. 
Ferraro, M.

Dynamic Modelling of a Hybrid Solar Thermal/Electric Storage System for Application...

Ferreira, C.

Accelerated Aging Tests for Solar Absorber Coatings.

Fink, C.

High Solar Fraction By Thermally Activated Components

Finocchiaro, $\mathbf{P}$.

Monitoring and Energy Performance Assessment of the Compact DEC HVAC System "Freescoo... 505

Fischer, S.

CFD-Based Development, Testing and Optimization of Flat Plate Collectors. . . . . . . . . . . . . . . . . . 1309

Modelling the Relative Humidity Inside Flat Plate Collectors. . . . . . . . . . . . . . . . . . . . . . . . . . . . . . . 1241

Optical Properties of Solar Absorbers - Results on Round Robin and Guidelines. . . . . . . . . . . . . . . . . . 1223

Fleig, D.

Comparison of Modeled and Measured Heat and Mass Transfer in a Liquid Desiccant Air-Conditioning... ... 648

\section{Fokaides, P.}

Environmental Assessment of Industrial Solar Thermal Systems.

Solar Thermal Systems VS. Photovoltaic Systems. Case Study: Single Family Building... . .

Folkerts, W.

An Overview of PVT Modules on the European Market and the Barriers and Opportunities.

Fraisse, $\mathbf{G}$.

Energetic Behaviour of a Solar Thermal System Producing Domestic Hot Water and Preheating...

Frasquet, M.

RESSSPI: The Network of Simulated Solar Systems for Industrial Processes. .

Frazzica, A.

Dynamic Modelling of a Hybrid Solar Thermal/Electric Storage System for Application..

1364

Experimentally Validated Dynamic Model for a Hybrid Cascade System for Solar Heating... . .

Frey, G.

Implementation and Experimental Validation of a Photovoltaic-Thermal (PVT) Collector... ... 798

Frey, $\mathbf{H}$.

Development of a Software System for Optimal Operation of Heating Networks with Central...

Frontini, $\mathbf{F}$.

DFAST: A Methodology for Assessing the Solar Potential of Façades in Existing Building..

Dialogue Between Research Solar Practices and Training Activities: Interactive Webinar...

Füchslin, $\mathbf{R}$.

Model Predictive Control for Building Automation.

Fuente Dacal, $\mathbf{R}$.

Solar Hybrid PVT Coupled Heat Pump Systems Towards Cost-Competitive NZEB.

Fuentes, E.

Experimental Investigation on the Dynamic Performance of a Thermally-Driven Adsorption...

Fujisawa, T.

Basic Study on Flow Stabilization of Top-Heat-Type Thermosiphon

Study on Distributed MPPT System in Solar EV. 
Fuligni, $\mathbf{F}$.

Comparative Dynamic Performance Tests of Two Real Technology Packages for Buildings..

G

\section{Gabbrielli, R.}

Cleaning Strategies for Fresnel Linear Concentrator Mirrors in Solar Heating Plants.

Gadhia, D.

Using the Heat of Sun to Cool: A Case Study of 100 TR (350kWth) Solar Air-Conditioning..

665

Gandhi, 0.

Levelised Cost of Thermal Energy Storage and Battery Storage to Store Solar PV Energy...

638

Gantenbein, P.

Design and Construction of a $10 \mathrm{KW}$ Sorption Heat Pump Prototype.

García, H.

Ray Tracing Method for the Evaluation of Yearly Performance of a Solar Thermal Concentrator

Ge, $\mathrm{H}$.

Modular Rooftop Building-Integrated Photovoltaic/Thermal Systems for Low-Rise Buildings...

Geisler-Moroder, D.

Definition of a Reference Office Building for Simulation Based Evaluation of Solar.

Georgii, M.

Towards Automated Continuous Performance Benchmarking of DHW and Combi Systems.

Germán, N.

Abrasion and Cleaning Tests on Antireflective and Antireflective/Antisoiling Coatings... . . . . . . . . . . 1063

Influence of Using Different SiO2 Antireflective Coatings and Sintering Conditions... ...

Giovannetti, F.

Experimental Investigations on the Stagnation Behavior of Thermochromic Flat Plate...

Giridhar, G.

Most Probable Operating Conditions and Performance Assessment of Four PV Technologies. .

Giroux-Julien, S.

Building Integrated Photovoltaic Systems - Energy Production Modelling in Urban Environment. . .

Glazar, V.

Experimental Analysis of Air-Water Heat Exchanger with Microchannel Coil Exposed..

Goldsworthy, M.

PV Driven Dew-Point Cooling for Australia.

\section{Gomes, J.}

Development of a Compact and Didactic Solar Energy Kit Using Arduino.

Electrical and Thermal Performance Evaluation of a District Heating System Composed...

Numerical Simulation of the Thermal Performance of Four Prototypes of CPC Collectors.

Quasi-Dynamic Testing of a Novel Concentrating Solar Collector According to ISO 9806:2013. . . .

\section{Gonçalves, A.}

The Spatial and Temporal Patterns of the Surface Solar Irradiation in Northeastern...

\section{Gonçalves, $\mathbf{R}$.}

Accelerated Aging Tests for Solar Absorber Coatings. 


\section{Gonçalves de Souza, J.}

Monthly Solar Irradiance Variability in Brazilian Climate Zones.

Gonzalez-Cabrera, A.E.

Solar Irradiation Over a Flat Surface with Different Tracking Strategies

Göschel, T.

Development of a Software System for Optimal Operation of Heating Networks with Central...

Götzelmann, D.

Efficient Design of Solar Assisted Heating Systems for Multi-Family Houses. .

Govehovitch, B.

Building Integrated Photovoltaic Systems - Energy Production Modelling in Urban Environment.

\section{Gritzer, F.}

Potential of Direct Solar Thermal Driven Absorption Heat Pump in Hybrid Systems.

Große, A.

Experimentally Validated Dynamic Model for a Hybrid Cascade System for Solar Heating... ...

Grossenbacher, U.

Urban Climate - Impact on Energy Consumption an Thermal Comfort of Buildings.

Guarirno, F.

Thermal Collection and Seasonal Storage Potential of a Mixed-Use Neighborhood ...

Guedea, I.

Experimental Investigation of PVT Collectors with Phase Change Material. . .

Gueymard, C.

Climatic and Global Validation of Daily MODIS Precipitable Water Data at AERONET... ...

Progress in Sky Radiance and Luminance Modeling Using Circumsolar Radiation and Sky... . .

Validation of Real-Time Solar Irradiance Simulations Over Kuwait Using WRF-Solar. . .

\section{Guillaume, M.}

Drainback Solar Thermal Systems in Switzerland - Market Overview and Main Barriers.

Solar Heat in Industrial Processes in Switzerland - Theoretical Potential and Promising...

\section{Gulino, G.}

Cleaning Strategies for Fresnel Linear Concentrator Mirrors in Solar Heating Plants. ..

Gumbel, U.

In Situ Characterization of Thermal Collectors in Field Installations.

\section{Gupta, N.C.}

Most Probable Operating Conditions and Performance Assessment of Four PV Technologies...

Gutierrez, A.

Ray Tracing Method for the Evaluation of Yearly Performance of a Solar Thermal Concentrator.

Guzzini, A.

Performance Analysis of a Small Scale Solar Cooling Plant Based on Experimental Measurements. 


\section{Haberl, $\mathbf{R}$.}

Comparison of Two Whole System Test Methods: CCT and PLPE. . . . . . . . . . . . . . . . . . . . . . . . . . 1274

Hardware-In-The-Loop Tests on Complete Systems with Heat Pumps and PV for the Supply... . . . . . . . . . . 357

\section{Häberle, A}

Editorial to the Proceedings of EuroSun 2018.

\section{Hachem-Vermette, C.}

Thermal Collection and Seasonal Storage Potential of a Mixed-Use Neighborhood. . .

Hadzich, M.

Thermal Analysis and Validation of a Geodesic Dome Dryer for Capsicum Baccatum.

\section{Hadzich Marin, M.A.}

Design and Evaluation of a Compact Thermal Storage System Using River Stones for...

Haeberle, A.

Design and Construction of a $10 \mathrm{KW}$ Sorption Heat Pump Prototype. .

Hafner, B.

Experimental Investigations on the Stagnation Behavior of Thermochromic Flat Plate...

\section{Haghighi, $\mathbf{Z}$.}

Assessment of the Suitability of Different Photovoltaic Cell Technologies for Product... . .

\section{Haller, M.}

Comparison of Two Whole System Test Methods: CCT and PLPE.

Decentralized DHW Production from Exhaust Air in the Bathroom Prewall. . . . . . . . . . . . . . . . . . . . . . . 1174

Hardware-In-The-Loop Tests on Complete Systems with Heat Pumps and PV for the Supply... . . . . . . . . . . 357

Stratification in Large Thermal Storage Tanks. . . . . . . . . . . . . . . . . . . . . . . . . . . . . . . . . . . . . . . . . . 1097

\section{Hassabou, A.}

Energy Efficient \& Sustainable Buildings in Qatar \& Integration of Solar Assisted..

\section{Hauer, $\mathbf{N}$.}

Polymer Collectors with Temperature Control - Thermosyphon Valve Development and... . .

\section{Hayat, $\mathbf{N}$.}

Evaluation of NCEP-Products (NCEP-NCAR, NCEP-DOE, NCEP-FNL, NCEP-GFS) of Solar Radiation... . . . . . 1631

Evaluation of Solar Radiation from MERRA, MERRA-2, ERA-Interim and CFSR Reanalysis... . . . . . . . . . . . 1624

\section{Hayati, A.}

Development of a Compact and Didactic Solar Energy Kit Using Arduino . . . . . . . . . . . . . . . . . . . . . . . 1663

Numerical Simulation of the Thermal Performance of Four Prototypes of CPC Collectors... . . . . . . . . . . . $8 \mathbf{8 1 0}$

\section{He, T.}

Research for Compiling a Mandatory National StandardTechnical Code for Energy Efficiency...

\section{Heimrath, R.}

High Solar Fraction By Thermally Activated Components. .

\section{Heinemann, U.}

Evacuated Glazing with Silica Aerogel Spacers.

Heinrich, I.

Development of a Software System for Optimal Operation of Heating Networks with Central... 


\section{Heithorst, B.}

Energy Efficient \& Sustainable Buildings in Qatar \& Integration of Solar Assisted... . . . . . . . . . . . . . . . 61

Experimental Comparison of Scroll and Swash-Plate Compressors for PV Driven Compression... . . . . . . . . 609

Helbig, S.

Efficient Design of Solar Assisted Heating Systems for Multi-Family Houses. . . . . . . . . . . . . . . . . . . . . 301

Helm, M.

Design and Practical Validation of a Hybrid Absorption/Compression Chiller Driven... . . . . . . . . . . . . . . 621

\section{Hendel, S.}

The SOLAR DECATHLON Knowledge Platform - Concept and Initial Application. ..

\section{Hennaut, $\mathbf{S}$.}

Experimental Study of a 600 w Seasonal Solar Heat Storage Reactor for the Heating...

\section{Henning, A.}

Indoor Climate Agreements in Energy-Efficiency and Renovation Projects - A Question.

Hernandez Gonzalez, $\mathrm{H}$.

Organic PVT - A Novel Hybrid Collector Combining Organic Photovoltaics and Polymer..

\section{Herrera, E.}

Design and Evaluation of a Compact Thermal Storage System Using River Stones for

\section{Hertel, J.D.}

OTSun: An Open Source Code for Optical Analysis of Solar Thermal Collectors and PV...

Holter, C.

Measurement Results and Operating Experience of Large-Scale Solar Air Conditioning...

Hsu, P.C.

Economic Feasibility of Solar PV System for Buildings.

Huang, B.

Economic Feasibility of Solar PV System for Buildings.

Modified Solar-Assisted Ejector Cooling System ...

Hussain, A.

Evaluation of Solar Radiation from MERRA, MERRA-2, ERA-Interim and CFSR Reanalysis...

Hussain, M.I.

Comparative Economic Analysis of Single and Dual-Fluid Based Photovoltaic Thermal...

Hutter, A.

Quantifying the Potential of Smart Heat-Pump Control to Increase the Self-Consumption...

\section{|}

\section{Ibarra, M.}

Simulation of a Solar Fired Absorption System for a Case Study in the Dairy Industry. .

\section{Impala, V.}

Experimental Investigation on the Dynamic Performance of a Thermally-Driven Adsorption...

\section{loannides, A.}


Ioannidis, $\mathbf{Z}$.

Design and Performance Assessment of a Prefabricated BIPV/T Roof System Coupled with...

Irrgang, L.

Experimental Comparison of Scroll and Swash-Plate Compressors for PV Driven Compression. 609

Isabella, 0.

Assessment of the Suitability of Different Photovoltaic Cell Technologies for Product.. 774

\section{Isac, L.}

Tailoring Alumina Matrix Optical Properties for Colored Solar Thermal Absorber Coatings. .

\section{Iturralde, J.}

Dynamic Modeling and Optimization of Energy Use in Retrofitted Buildings at District...

Ivanova, $\mathbf{S}$.

Progress in Sky Radiance and Luminance Modeling Using Circumsolar Radiation and Sky...

\section{Iwata, T.}

Difference in Evaluation of Discomfort Glare from Windows between Middle-Eastern...

$J$

\section{J. Lopes de Lima, F.}

Monthly Solar Irradiance Variability in Brazilian Climate Zones. .

Jaeger, C.

Model Predictive Control for Building Automation.

Jakobi, M.

BIM Use Case: Model-Based Performance Optimization. . . . . . . . . . . . . . . . . . . . . . . . . . 1395

From Simulation to Reality: IEC 61499 Compliant Control Applications for Solar Energy... . . . . . . . . . . . . . 1403

Jesper, M.

Standardisation of Solar Process Heat Applications to Increase Market Penetration. . .

Jimenez, $\mathbf{P}$.

Validation of Real-Time Solar Irradiance Simulations Over Kuwait Using WRF-Solar. . .

Jirka, V.

Glazed PVT Collector Integrated Into Façade Module. .

Jonas, $\mathbf{D}$.

Implementation and Experimental Validation of a Photovoltaic-Thermal (PVT) Collector.. . .

Jordan, U.

Comparison of Modeled and Measured Heat and Mass Transfer in a Liquid Desiccant Air-Conditioning...

648

Jurelionis, A.

Environmental Assessment of Industrial Solar Thermal Systems.

Solar Thermal Systems VS. Photovoltaic Systems. Case Study: Single Family Building... 


\section{Kalogirou, S.}

Environmental Assessment of Industrial Solar Thermal Systems.

Kandpal, T.C.

On the Importance of Education when Implementing Renewable Energy.

Karellas, $\mathbf{S}$.

Dynamic Modelling of a Hybrid Solar Thermal/Electric Storage System for Application...

Kastner, $\mathbf{R}$.

Comparative Analysis of Life-Cycle Assessment Tools (LCA) Using the Example of Different...

Kawaguchi, T.

Basic Study on Flow Stabilization of Top-Heat-Type Thermosiphon.

Kernitzkyi, M.

Short Term PV Forecasting Using Satellite Data for Austria. .

Kessentini, $\mathbf{H}$.

Testing and Modeling of Direct Steam Generating Parabolic Trough Collectors.

Khan, M.

Energy Efficient \& Sustainable Buildings in Qatar \& Integration of Solar Assisted..

Kicker, $\mathbf{H}$.

Sustainability Assessment of Most Relevant Solar Thermal Heat Systems. . .

\section{Killinger, $\mathbf{S}$.}

Climatic and Global Validation of Daily MODIS Precipitable Water Data at AERONET... ...

\section{Kim, M.}

Energy Performance Investigation of Energy-Plus Solar House Integrated Renewable...

Kirini, M.

Experimental Analysis of Air-Water Heat Exchanger with Microchannel Coil Exposed..

Ko, $\mathbf{H}$.

Modified Solar-Assisted Ejector Cooling System

Kocak, B.

Sensible Thermal Energy Storage in Packed Bed for Industrial Solar Applications.

Koch, N.

Quantifying the Potential of Smart Heat-Pump Control to Increase the Self-Consumption...

Köll, R.

Technical and Economic Performance of Best Practice SHC Plants - A Compilation of...

Koller, C.

Thermo-Chemical District Networks.

Konstantinou, T.

Assessment of the Suitability of Different Photovoltaic Cell Technologies for Product.. 774

Kortschak, D.

Short Term PV Forecasting Using Satellite Data for Austria.

Korvola, T.

Control Strategies for a Residential Property with Solar Building, Thermal and Electricity.. 
Košir, M.

Using Heliodon for Solar Building Design Education in the Age of Computer Simulations

Krajnc, A.

New Water Adsorbent for Adsorption Driven Chillers. .

Kramer, $\mathbf{K}$.

In Situ Characterization of Thermal Collectors in Field Installations.

Kramer, W.

Artificial Intelligence for the Efficient Control of Solar Heating Systems.

Kratz, P.

Direct Solar Thermal Systems with Thermosiphon Frost Protection and Innovative Control...

474

Kruglov, 0.

Design and Performance Assessment of a Prefabricated BIPV/T Roof System Coupled with. 859

Modular Rooftop Building-Integrated Photovoltaic/Thermal Systems for Low-Rise Buildings...

\section{Kühnert, S.}

Experimentally Validated Dynamic Model for a Hybrid Cascade System for Solar Heating...

684

Kunath, L.

Validation of an Ice Storage Model and Its Integration Into a Solar-Ice System.

Kuni, R.

Using Heliodon for Solar Building Design Education in the Age of Computer Simulations...

Kurdia, A.

Quasi-Dynamic Testing of a Novel Concentrating Solar Collector According to ISO 9806:2013.

\section{Kusyy, 0.}

Simulation-Based Optimization of Solar Combisystem. Sensitivity Analysis at Optimum.

Towards Automated Continuous Performance Benchmarking of DHW and Combi Systems.

Kylili, A.

Environmental Assessment of Industrial Solar Thermal Systems. .

L

\section{Laadel, N.E.}

Solar Heat Integration in Rotational Molding Process: Case Study. .

Lämmle, M.

Organic PVT - A Novel Hybrid Collector Combining Organic Photovoltaics and Polymer...

\section{Lança, M.}

Numerical Simulation of the Thermal Performance of Four Prototypes of CPC Collectors.

Lang, R.W.

Sustainability Assessment of Most Relevant Solar Thermal Heat Systems. . .

Leconte, $A$.

Energetic Behaviour of a Solar Thermal System Producing Domestic Hot Water and Preheating...

Semi-Virtual Tests of a System Using Exhaust Air, Grey Water and Solar Heat for Domestic..

Lecuona Neuman, A.

Modelling of an Absorption Cycle With a Direct Ammonia Vapor Generator Inside a Concentrating... 


\section{Lee, $B$.}

Early Design Stage Consideration of Building Form and BIPVT Energy Performance . . . . . . . . . . . . . . 140

Modular Rooftop Building-Integrated Photovoltaic/Thermal Systems for Low-Rise Buildings... . . . . . . . . . . 89

Leni, $\mathbf{K}$.

Experimental Analysis of Air-Water Heat Exchanger with Microchannel Coil Exposed..

\section{Le Pierrès, $\mathbf{N}$.}

Selection of High-Performance Working Fluid for a Solar-Geothermal Absorption Cooling...

\section{Lerch, W.}

High Solar Fraction By Thermally Activated Components

Li, B.

Research for Compiling a Mandatory National StandardTechnical Code for Energy Efficiency... ...

Li, C.

Organic PVT - A Novel Hybrid Collector Combining Organic Photovoltaics and Polymer...

\section{Liang, J.}

Improvements on the Efficiency of the Photovoltaic Panel by Integrating a Spray Cooling... . . . . . . . . . . . 930

Performance Investigation of Liquid Desiccant Dehumidification System Integrated... . . . . . . . . . . . . . . . 716

Theoretical Analysis of Photovoltaic Panels Using a Spray Cooling System with a Shallow... . . . . . . . . . . 1413

\section{Lima, $\mathbf{F}$.}

The Spatial and Temporal Patterns of the Surface Solar Irradiation in Northeastern...

\section{Lingfors, D.}

Climatic and Global Validation of Daily MODIS Precipitable Water Data at AERONET...

\section{Longo, $\mathbf{S}$.}

Life Cycle Assessment Experiences for Solar Heating and Cooling Systems.

Loonen, R.C.G.M.

Definition of a Reference Office Building for Simulation Based Evaluation of Solar...

\section{López, L.}

Surface Modification of AISI 316 Stainless Steel by Oxynitrocarburizing for Solar...

\section{Lopez Vasquez, E.}

Design and Evaluation of a Compact Thermal Storage System Using River Stones for...

Thermal Analysis and Validation of a Geodesic Dome Dryer for Capsicum Baccatum.

\section{Loren, A.}

Optical Properties of Solar Absorbers - Results on Round Robin and Guidelines

\section{Louvet, Y.}

Measurement Evaluation and Simulation of an Innovative Drainback Solar Combi-System. ...

\section{Lowenstein, A.}

Comparison of Modeled and Measured Heat and Mass Transfer in a Liquid Desiccant Air-Conditioning..

\section{Lozano, M.A.}

Opportunities for the Integration of Solar Thermal Heat, Photovoltaics and Biomass..

\section{Lucio, B.}

Encapsulation of Inorganic Phase Change Materials by Sol-Gel Method for Thermal Energy...

\section{Luerssen, C.}

Levelised Cost of Thermal Energy Storage and Battery Storage to Store Solar PV Energy... 


\section{Mach, T.}

High Solar Fraction By Thermally Activated Components

\section{Machado, M.}

BIM a Driver for Energy Transition and BIVP Adoption.

Madani, $\mathbf{H}$.

A Techno-Economic Comparison Between PV and PVT Integrated Ground Source Heat Pumps.

Magni, M.

Definition of a Reference Office Building for Simulation Based Evaluation of Solar...

Maier, 0.

Model Predictive Control for Building Automation.

Mandow, W.

Comparison of Modeled and Measured Heat and Mass Transfer in a Liquid Desiccant Air-Conditioning...

Manzolini, G.

Experimental Performance Evaluation of PV/T Panels at Negative Reduced Temperatures.

Marquez, $\mathrm{F}$.

Modelling the Relative Humidity Inside Flat Plate Collectors.

Martín, E.

Dynamic Modeling and Optimization of Energy Use in Retrofitted Buildings at District..

Martin, J.

Solar Heat in Industrial Processes in Switzerland - Theoretical Potential and Promising...

Martín, J.

Dynamic Modeling and Optimization of Energy Use in Retrofitted Buildings at District...

Martinez-Durbán, M.

PV Power Production Estimation by Using Radiometric and Meteorological Data.

\section{Martínez-Moll, V.}

OTSun: An Open Source Code for Optical Analysis of Solar Thermal Collectors and PV...

Martín Miranda, A.J.

Solar Hybrid PVT Coupled Heat Pump Systems Towards Cost-Competitive NZEB. 869

\section{Martin-Pomares, L.}

Effect of Solar Position Calculations on Filtering and Analysis of Solar Radiation...

\section{Martins, F.}

The Spatial and Temporal Patterns of the Surface Solar Irradiation in Northeastern.

\section{Martorell, I.}

Radiative Cooling to Cover Cooling Demands of an Earthbag Building in a Training..

Thermal Monitoring on an Earthbag Building in Mediterranean Continental Climate. .

\section{Marvillet, C.}

Development of a Photovoltaic Driven Thermodynamic Chiller - Application to Solar...

\section{Marzo, A.}




\section{Matuska, T.}

Development of Solar Assisted Sorption Unit for Extraction of Water from Ambient... . . . . . . . . . . . . . 659

Glazed PVT Collector Integrated Into Façade Module . . . . . . . . . . . . . . . . . . . . . . . . . . . . . . . . . . 850

Simulation and Monitoring of PV Heat Pump System with Seasonal Storage . . . . . . . . . . . . . . . . . . 409

Theoretical Analysis of Combined Solar System Based on Dual Purpose Solar Collector . . . . . . . . . . . . . . . 1043

\section{Medrano, M.}

Radiative Collector and Emitter: Experimental Results............................... 1071

Radiative Cooling to Cover Cooling Demands of an Earthbag Building in a Training... . . . . . . . . . . . 13

Thermal Monitoring on an Earthbag Building in Mediterranean Continental Climate . . . . . . . . . . . . . . . . 109

Mehta, K.

Using the Heat of Sun to Cool: A Case Study of 100 TR (350kWth) Solar Air-Conditioning... . . . . . . . . . . 665

Meier, L.

From Simulation to Reality: IEC 61499 Compliant Control Applications for Solar Energy... . . . . . . . . . . . . 1403

Meir, M.

Organic PVT - A Novel Hybrid Collector Combining Organic Photovoltaics and Polymer... . . . . . . . . . . 822

Meister, C.

Preliminary Results for the First Year of Operation of a Seasonal Storage Solar Combisystem... . . . . . . . . . 1144

Mellor, A.

Development and Field Testing of a Novel Hybrid PV-Thermal Solar Collector ...

Menegon, D.

Analysis of Applicability of PLPE Method for the Test of a Solar Cooling System . . . . . . . . . . . . . . 1285

Comparison of Two Whole System Test Methods: CCT and PLPE. . . . . . . . . . . . . . . . . . . . . . . 1274

Ménézo, C.

Building Integrated Photovoltaic Systems - Energy Production Modelling in Urban Environment. . . . . . . . 29

Mengedoht, G.

A Comparison of Stratified Heat Storage With and Without Modular PCM Storage Through...

Menna, F.

Solar Flux Map Distribution of a Parabolic-Spheric Dish Based on Photographic Method

Mogro, 0.

Experimental Investigation on the Dynamic Performance of a Thermally-Driven Adsorption... . .

\section{Moià-Pol, A.}

Distributed vs Centralized Solar District Systems. Study Case in Balearic Islands... . . . . . . . . . . . . . . . 187

Solar Seminar Room in the University of Balearic Islands with a New Advanced Radiant... . . . . . . . . . . 116

Molinaroli, L.

Experimental Performance Evaluation of PV/T Panels at Negative Reduced Temperatures. . . . . . . . . . . . . . 881

\section{Morales, Á.}

Abrasion and Cleaning Tests on Antireflective and Antireflective/Antisoiling Coatings... . . . . . . . . . . . 1063

Influence of Using Different SiO2 Antireflective Coatings and Sintering Conditions... . . . . . . . . . . . . . 983

\section{Morales, $\mathbf{S}$.}

Testing and Modeling of Direct Steam Generating Parabolic Trough Collectors. . . . . . . . . . . . . . . . . . . . 994

Morf, $\mathbf{H}$.

Regression by Integration applied to Angström-Prescott-type Relations. 


\section{Mossegård, J.}

Electroplating of Selective Surfaces for Concentrating Solar Collectors.

Motta, M.

Monitoring and Energy Performance Assessment of the Compact DEC HVAC System "Freescoo... 505

\section{Mouaky, A.}

Solar Heat Integration in Rotational Molding Process: Case Study. .

\section{Moureaux, S.}

Semi-Virtual Tests of a System Using Exhaust Air, Grey Water and Solar Heat for Domestic...

\section{Mugnier, D.}

Accompanying Project Owners and Professionals All the Way to Secure Solar Thermal... . . . . . . . . . . . . . 1716

Development of a Photovoltaic Driven Thermodynamic Chiller - Application to Solar... . . . . . . . . . . . . . . . 562

Life Cycle Assessment Experiences for Solar Heating and Cooling Systems. . . . . . . . . . . . . . . . . . . . . . 493

Technical and Economic Performance of Best Practice SHC Plants - A Compilation of... . . . . . . . . . . . . . 673

\section{Müller, J.}

Modelling and Simulation of a PV Driven Refrigerator with Phase-Change Materials... ... 524

Müller, S.

Experimental Investigations on the Stagnation Behavior of Thermochromic Flat Plate...

\section{Muñoz-Cerón, E.}

Preliminary Economic Evaluation of the First Grid-Connected Photovoltaic System in ... .

\section{Muntwyler, U.}

Degradation of photovoltaic systems based on long-term measurements and laboratory... . . . . . . . . . . 828

Photovoltaics or Solar Thermal -The Winner Takes it All? . . . . . . . . . . . . . . . . . . . . . . . . . . . . . . . . . 1704

Using Behavior Simulation to Synthesize Electromobility Charging Profiles. . . . . . . . . . . . . . . . . . . . . . . 1445

\section{Murrell, A.}

Development and Field Testing of a Novel Hybrid PV-Thermal Solar Collector. ...

Mützel, M.

\section{N}

\section{Nascimento, I.}

Accelerated Aging Tests for Solar Absorber Coatings.

\section{Nauschütz, J.}

Evacuated Glazing with Silica Aerogel Spacers.

Nel, Y.

RESSSPI: The Network of Simulated Solar Systems for Industrial Processes.

\section{Nemoto, Y.}

Study on Distributed MPPT System in Solar EV. . .

\section{Neyer, $\mathbf{D}$.}

Potential of Direct Solar Thermal Driven Absorption Heat Pump in Hybrid Systems.

\section{Nguyen, V.K.}

BIM a Driver for Energy Transition and BIVP Adoption. . 
Nicolas, L.

Comparative Dynamic Performance Tests of Two Real Technology Packages for Buildings... . .

Nielsen, J.E.

Optical Properties of Solar Absorbers - Results on Round Robin and Guidelines.

Nordenström, A.

Electroplating of Selective Surfaces for Concentrating Solar Collectors

0

\section{Ochs, F.E.}

Definition of a Reference Office Building for Simulation Based Evaluation of Solar...

Oliveira, A.

Testing and Modeling of Direct Steam Generating Parabolic Trough Collectors

Ollas, $\mathbf{P}$.

Quasi-Dynamic Testing of a Novel Concentrating Solar Collector According to ISO 9806:2013. . . .

Olsson, 0.

Quasi-Dynamic Testing of a Novel Concentrating Solar Collector According to ISO 9806:2013.

Oppelt, T.

Development of a Software System for Optimal Operation of Heating Networks with Central...

Orò, $\mathrm{E}$.

Dynamic Modelling of a Hybrid Solar Thermal/Electric Storage System for Application...

Orozaliev, J.

Comparison of Solar District Heating Concepts at Various Land Prices. ...

Measurement Evaluation and Simulation of an Innovative Drainback Solar Combi-System. .

Towards Automated Continuous Performance Benchmarking of DHW and Combi Systems.

Ortiz Lizcano, J.C.

Assessment of the Suitability of Different Photovoltaic Cell Technologies for Product...

Osorio-Aravena, J.C.

Preliminary Economic Evaluation of the First Grid-Connected Photovoltaic System in...

Ostheimer, M.

Potential of Direct Solar Thermal Driven Absorption Heat Pump in Hybrid Systems.

Ott, A.

On the Importance of Education when Implementing Renewable Energy.

Otto, S.

Development of a Software System for Optimal Operation of Heating Networks with Central...

Ouvrier Bonnaz, 0.

Energetic Behaviour of a Solar Thermal System Producing Domestic Hot Water and Preheating... 


\section{Pabst, V.}

A Comparison of Stratified Heat Storage With and Without Modular PCM Storage Through...

\section{Pag, F.}

Standardisation of Solar Process Heat Applications to Increase Market Penetration.

Pajek, L.

Using Heliodon for Solar Building Design Education in the Age of Computer Simulations

Paksoy, H.O.

Sensible Thermal Energy Storage in Packed Bed for Industrial Solar Applications. .

Palomba, V.

Dynamic Modelling of a Hybrid Solar Thermal/Electric Storage System for Application... . . . . . . . . . . . . 1364

Experimentally Validated Dynamic Model for a Hybrid Cascade System for Solar Heating... . .

\section{Páscoa, S.}

Accelerated Aging Tests for Solar Absorber Coatings . . . . . . . . . . . . . . . . . . . . . . . . . . . . . . . . . 973

Assessment of Durability of Solar Absorbers - Performance Criterion . . . . . . . . . . . . . . . . . . . . . . . . . . 964

Optical Properties of Solar Absorbers - Results on Round Robin and Guidelines. . . . . . . . . . . . . . . . . . 1223

\section{Pascual, C.}

Dynamic Modeling and Optimization of Energy Use in Retrofitted Buildings at District.. . .

Patric, B.

Comparative Dynamic Performance Tests of Two Real Technology Packages for Buildings.

Paulini, S.

Modeling and Validation of Different Heat Exchanger Geometries for Solar Ice Storage...

Pellegrini, M.

Performance Analysis of a Small Scale Solar Cooling Plant Based on Experimental Measurements.

Pereira, E.

The Spatial and Temporal Patterns of the Surface Solar Irradiation in Northeastern...

Perez, J.

Thermal Analysis and Validation of a Geodesic Dome Dryer for Capsicum Baccatum.

Perez-Astudillo, D.

Effect of Solar Position Calculations on Filtering and Analysis of Solar Radiation...

Perniu, D.

Tailoring Alumina Matrix Optical Properties for Colored Solar Thermal Absorber Coatings.

\section{Persdorf, $\mathbf{P}$.}

Decentralized DHW Production from Exhaust Air in the Bathroom Prewall. . . . . . . . . . . . . . . . . . . 1174

Design and Construction of a $10 \mathrm{KW}$ Sorption Heat Pump Prototype.

Peyrol, E.

Building Integrated Photovoltaic Systems - Energy Production Modelling in Urban Environment. . .

Pflugradt, N.

Quantifying the Potential of Smart Heat-Pump Control to Increase the Self-Consumption... . . . . . . . . . . . . 1466

Using Behavior Simulation to Synthesize Electromobility Charging Profiles.

Pflugradt, N.D.

Integrating Polysun into a Test Bench for Prosumer Hardware. 


\section{Philippen, D.}

Validation of an Ice Storage Model and Its Integration Into a Solar-Ice System.

Piekarczyk, A.

Organic PVT - A Novel Hybrid Collector Combining Organic Photovoltaics and Polymer... . .

Pina, E.A.

Opportunities for the Integration of Solar Thermal Heat, Photovoltaics and Biomass.. . .

Pinto, E.S.

Multiobjective Synthesis of a Polygeneration System for a Residential Building Integrating...

Pita Bauermann, L.

Organic PVT - A Novel Hybrid Collector Combining Organic Photovoltaics and Polymer... . .

Pius, G.

Quasi-Dynamic Testing of a Novel Concentrating Solar Collector According to ISO 9806:2013.

Pizzuti Pes, M.

Monthly Solar Irradiance Variability in Brazilian Climate Zones.

Plessing, T.

Modeling and Validation of Different Heat Exchanger Geometries for Solar Ice Storage...

Poier, $\mathbf{H}$.

Measurement Results and Operating Experience of Large-Scale Solar Air Conditioning...

Poirier, M.

Multi-Objective Optimization of a Solar Heat Pump System Using PVT and Ice-Based... . .

Pokorny, N.

Glazed PVT Collector Integrated Into Façade Module . . . . . . . . . . . . . . . . . . . . . . . . . . 850

Theoretical Analysis of Combined Solar System Based on Dual Purpose Solar Collector.

Polo Lopez, C.S.

bFAST: A Methodology for Assessing the Solar Potential of Façades in Existing Building..

Polo López, C.S.

bFAST: A Methodology for Assessing the Solar Potential of Façades in Existing Building...

Dialogue Between Research Solar Practices and Training Activities: Interactive Webinar...

Porcheyre, E.

Accompanying Project Owners and Professionals All the Way to Secure Solar Thermal...

Portillo, C.

PV Power Production Estimation by Using Radiometric and Meteorological Data. .

Potonik, J.

Using Heliodon for Solar Building Design Education in the Age of Computer Simulations.

Povall, S.

Development and Field Testing of a Novel Hybrid PV-Thermal Solar Collector. ...

Pujol-Nadal, R.

OTSun: An Open Source Code for Optical Analysis of Solar Thermal Collectors and PV...

1295 


\section{Quaschning, V.}

R

\section{Ramirez, C.}

Ray Tracing Method for the Evaluation of Yearly Performance of a Solar Thermal Concentrator

\section{Ramirez-Ramirez, A.}

Solar Irradiation Over a Flat Surface with Different Tracking Strategies. . .

\section{Ramos Martins, F.}

Brazilian Photovoltaic Potential. . . . . . . . . . . . . . . . . . . . . . . . . . . . . . . . . . . . . . . . . . . . . . . . . . . 1502

Monthly Solar Irradiance Variability in Brazilian Climate Zones. . . . . . . . . . . . . . . . . . . . . . . . . . . . . . . . 1642

\section{Ramschak, T.}

High Solar Fraction By Thermally Activated Components. .

\section{Rauscher, B.}

Experimental Comparison of Scroll and Swash-Plate Compressors for PV Driven Compression...

\section{Reber, $\mathbf{A}$.}

Hardware-In-The-Loop Tests on Complete Systems with Heat Pumps and PV for the Supply...

Reda, F.

Control Strategies for a Residential Property with Solar Building, Thermal and Electricity... ...

\section{Reichenauer, $\mathbf{G}$.}

Evacuated Glazing with Silica Aerogel Spacers.

\section{Reim, M.}

Comparative Analysis of Life-Cycle Assessment Tools (LCA) Using the Example of Different.

\section{Reindl, T.}

Levelised Cost of Thermal Energy Storage and Battery Storage to Store Solar PV Energy...

\section{Reineke-Koch, R.}

Experimental Investigations on the Stagnation Behavior of Thermochromic Flat Plate...

\section{Rekstad, J.}

Organic PVT - A Novel Hybrid Collector Combining Organic Photovoltaics and Polymer..

\section{Remondino, F.}

Solar Flux Map Distribution of a Parabolic-Spheric Dish Based on Photographic Method. .

\section{Remund, J.}

Urban Climate - Impact on Energy Consumption an Thermal Comfort of Buildings.

Renne, D.

Editorial to the Proceedings of EuroSun 2018.

Renze, $\mathbf{P}$.

A Comparison of Stratified Heat Storage With and Without Modular PCM Storage Through..

\section{Rincón, L.}

Radiative Cooling to Cover Cooling Demands of an Earthbag Building in a Training... 
Rindt, C.

An Aesthetic Energy Producing Roof with Integration of PV Modules and Solar Thermal...

Risti, A.

New Water Adsorbent for Adsorption Driven Chillers.

Ritter, D.

Standardisation of Solar Process Heat Applications to Increase Market Penetration.

Rittmann-Frank, M.H.

Solar Heat in Industrial Processes in Switzerland - Theoretical Potential and Promising...

Ritzmann, R.

Model Predictive Control for Building Automation

Roccabruna, M.

Solar Flux Map Distribution of a Parabolic-Spheric Dish Based on Photographic Method.

Rodrigues Aumente, P.A.

Modelling of an Absorption Cycle With a Direct Ammonia Vapor Generator Inside a Concentrating...

Rodrigues Gonçalves, A.

Brazilian Photovoltaic Potential.

Monthly Solar Irradiance Variability in Brazilian Climate Zones.

Romero, M.

Encapsulation of Inorganic Phase Change Materials by Sol-Gel Method for Thermal Energy...

Rongchai, K.

Development of a Solar Paddy Dryer by Fluidization Technique Using Heat from a Solar.. . .

Rosiek, S.

PV Power Production Estimation by Using Radiometric and Meteorological Data. ...

Rounis, E.

Modular Rooftop Building-Integrated Photovoltaic/Thermal Systems for Low-Rise Buildings..

Rounis, E.D.

Design and Performance Assessment of a Prefabricated BIPV/T Roof System Coupled with.. 859

Ruesch, F.

Ageing Performance of New Solar Cover Materials After Outdoor Exposure. ...

Decentralized DHW Production from Exhaust Air in the Bathroom Prewall. . .

S

\section{Sabater, $\mathbf{P}$.}

Distributed vs Centralized Solar District Systems. Study Case in Balearic Islands..

Saccani, C.

Performance Analysis of a Small Scale Solar Cooling Plant Based on Experimental Measurements.

\section{Sallaberry, F.}

Optical Properties of Solar Absorbers - Results on Round Robin and Guidelines.

Salom, J.

Experimental Investigation on the Dynamic Performance of a Thermally-Driven Adsorption...

SanJoaquín, S.

Experimental Investigation on the Dynamic Performance of a Thermally-Driven Adsorption... 
Santos, A.P.

The Spatial and Temporal Patterns of the Surface Solar Irradiation in Northeastern..

Santos Costa, $\mathbf{R}$.

Brazilian Photovoltaic Potential. . . . . . . . . . . . . . . . . . . . . . . . . . . . . . . . . . . . . . . . . . . . . . . 1502

Monthly Solar Irradiance Variability in Brazilian Climate Zones . . . . . . . . . . . . . . . . . . . . . . . . . . . . . 1642

San Vicente, G.

Abrasion and Cleaning Tests on Antireflective and Antireflective/Antisoiling Coatings... . . . . . . . . . . . . 1063

Influence of Using Different SiO2 Antireflective Coatings and Sintering Conditions... . . . . . . . . . . . . . . . . 983

Sanz Jimeno, $\mathbf{R}$.

An Improved Model for Phase Change Material (PCM) Thermal Storage Tanks. . . . . . . . . . . . . . . . . . . . . 1322

Sanz Martinez, A.

Solar Hybrid PVT Coupled Heat Pump Systems Towards Cost-Competitive NZEB . . . . . . . . . . . . . . . . . . 869

Saretta, E.

DFAST: A Methodology for Assessing the Solar Potential of Façades in Existing Building... . . . . . . . . . . . . 122

Sattelmayer, T.

Experimental Comparison of Scroll and Swash-Plate Compressors for PV Driven Compression...

609

Sayans, A.

Experimental Investigation on the Dynamic Performance of a Thermally-Driven Adsorption...

585

Schäfer, A.

Single Source "solar Thermal" Heat Pump for Residential Heat Supply: Performance... ...

426

Schäfer, K.

Experimental Plant for Analyzing the Technical Feasibility of Decentralized Solar... .

212

Scherdel, C.

Evacuated Glazing with Silica Aerogel Spacers. . . . . . . . . . . . . . . . . . . . . . . . . . . . . . . . . . . 5

Scheuren, J.

Simulations of Solar Thermal Cooling System for a Building at Innovation Park Muscat. . .

Schlatmann, R.

Simulations of Solar Thermal Cooling System for a Building at Innovation Park Muscat ...

Schmelzer, C.

Towards Automated Continuous Performance Benchmarking of DHW and Combi Systems.

Schmidt, A.

Development of a Software System for Optimal Operation of Heating Networks with Central..

Schmidt, C.

Single Source "solar Thermal" Heat Pump for Residential Heat Supply: Performance.

Schmitt, B.

Standardisation of Solar Process Heat Applications to Increase Market Penetration.

Schott, T.

Degradation of photovoltaic systems based on long-term measurements and laboratory...

Schroll, J.

Polymer Collectors with Temperature Control - Thermosyphon Valve Development and.. 438

Schuepbach, E.

Photovoltaics or Solar Thermal -The Winner Takes it All?. 
Schwarz, $\mathbf{R}$.

Space Cooling Application with Unglazed Solar Absorber.

Sekhar, C.

Levelised Cost of Thermal Energy Storage and Battery Storage to Store Solar PV Energy....

638

Selke, T.

Life Cycle Assessment Experiences for Solar Heating and Cooling Systems. ...

Sergi, F.

Dynamic Modelling of a Hybrid Solar Thermal/Electric Storage System for Application...

Serra, L.M.

Multiobjective Synthesis of a Polygeneration System for a Residential Building Integrating...

1454

Opportunities for the Integration of Solar Thermal Heat, Photovoltaics and Biomass...

\section{Sethuvenkatraman, S.}

PV Driven Dew-Point Cooling for Australia.

Shahid, H.

Evaluation of NCEP-Products (NCEP-NCAR, NCEP-DOE, NCEP-FNL, NCEP-GFS) of Solar Radiation...

\section{Shemelin, V.}

Theoretical Analysis of Combined Solar System Based on Dual Purpose Solar Collector. ...

Siegele, D.

Potential of Covering Electricity Needs of a Flat of a MFH with Decentral Compact... . .

Silva, M.

RESSSPI: The Network of Simulated Solar Systems for Industrial Processes. .

Simón, R.

Experimental Investigation of PVT Collectors with Phase Change Material . .

Simonetti, R.

Experimental Performance Evaluation of PV/T Panels at Negative Reduced Temperatures.

Singh, R.M.

Review of Combined Solar Thermal and Heat Pump Systems Installations in Lithuanian... ...

\section{Soares, J.}

Testing and Modeling of Direct Steam Generating Parabolic Trough Collectors.

Solé, C.

Radiative Collector and Emitter: Experimental Results.

Thermal Monitoring on an Earthbag Building in Mediterranean Continental Climate. .

Sommerfeldt, $\mathbf{N}$.

A Techno-Economic Comparison Between PV and PVT Integrated Ground Source Heat Pumps.

Souliotis, M.

Environmental Assessment of Industrial Solar Thermal Systems. . .

\section{Sourek, B.}

Development of Solar Assisted Sorption Unit for Extraction of Water from Ambient...

Glazed PVT Collector Integrated Into Façade Module.

Simulation and Monitoring of PV Heat Pump System with Seasonal Storage. .

Theoretical Analysis of Combined Solar System Based on Dual Purpose Solar Collector. 


\section{Spinnler, M.}

Energy Efficient \& Sustainable Buildings in Qatar \& Integration of Solar Assisted... . . . . . . . . . . . . . . . . . 61

Experimental Comparison of Scroll and Swash-Plate Compressors for PV Driven Compression... . . . . . . . . 609

Stathopoulos, T.

Design and Performance Assessment of a Prefabricated BIPV/T Roof System Coupled with..

Modular Rooftop Building-Integrated Photovoltaic/Thermal Systems for Low-Rise Buildings...

Stauffer, $\mathbf{Y}$.

Quantifying the Potential of Smart Heat-Pump Control to Increase the Self-Consumption... ...

1466

\section{Stickelberger, D.}

Editorial to the Proceedings of EuroSun 2018.

Stöckli, U.

BIM Use Case: Model-Based Performance Optimization.

From Simulation to Reality: IEC 61499 Compliant Control Applications for Solar Energy...

\section{Streicher, W.}

Editorial to the Proceedings of EuroSun 2018.

Stritih, U.

Application of PCM in Building's Envelope of Lightweight Prefabricated Houses as... 728

Stutz, B.

Selection of High-Performance Working Fluid for a Solar-Geothermal Absorption Cooling.. 481

Šubic, N.

Using Heliodon for Solar Building Design Education in the Age of Computer Simulations.

\section{Sun, $X$.}

Climatic and Global Validation of Daily MODIS Precipitable Water Data at AERONET...

\section{T}

\section{Tahir, Z.u.R.}

Evaluation of NCEP-Products (NCEP-NCAR, NCEP-DOE, NCEP-FNL, NCEP-GFS) of Solar Radiation... . . . . . 1631 Evaluation of Solar Radiation from MERRA, MERRA-2, ERA-Interim and CFSR Reanalysis... . . . . . . . . . . . 1624

\section{Tamainot-Telto, Z.}

Efficient Solar Driven Air Conditioning System for Hot Climates: Case Study of Doha. .

Tamasauskas, J.

Multi-Objective Optimization of a Solar Heat Pump System Using PVT and Ice-Based...

Theis, D.

Implementation and Experimental Validation of a Photovoltaic-Thermal (PVT) Collector... . .

Thissen, B.

Validation of an Ice Storage Model and Its Integration Into a Solar-Ice System. ..

\section{Thür, A.}

Polymer Collectors with Temperature Control - Thermosyphon Valve Development and...

Potential of Direct Solar Thermal Driven Absorption Heat Pump in Hybrid Systems.

\section{Tipula, $\mathbf{R}$.}

Thermal Analysis and Validation of a Geodesic Dome Dryer for Capsicum Baccatum. 


\section{Tipula Ramos, R.R.}

Design and Evaluation of a Compact Thermal Storage System Using River Stones for...

\section{Tjaden, $\mathrm{T}$.}

From Simulation to Reality: IEC 61499 Compliant Control Applications for Solar Energy...

\section{Torres, $\mathbf{V}$.}

Modelling and Simulation of a PV Driven Refrigerator with Phase-Change Materials...

\section{Trigo, M.}

PV Power Production Estimation by Using Radiometric and Meteorological Data ...

Trp, A.

Experimental Analysis of Air-Water Heat Exchanger with Microchannel Coil Exposed.

\section{Tsekouras, $\mathbf{P}$.}

Optical Analysis of an Evacuated Tube Collector with Built-In Semicircular Concentrator...

\section{Tseng, C.}

Improvements on the Efficiency of the Photovoltaic Panel by Integrating a Spray Cooling... . . . . . . . . . . . 930

Performance Investigation of Liquid Desiccant Dehumidification System Integrated... . . . . . . . . . . . . . . . 716

Theoretical Analysis of Photovoltaic Panels Using a Spray Cooling System with a Shallow... . . . . . . . . . . . 1413

\section{Tundee, $\mathbf{S}$.}

\section{Uhlig, U.}

Development of a Software System for Optimal Operation of Heating Networks with Central...

Urbaneck, T.

Development of a Software System for Optimal Operation of Heating Networks with Central.

Urena, D.

Decentralized DHW Production from Exhaust Air in the Bathroom Prewall. . .

Urra, I.

Dynamic Modeling and Optimization of Energy Use in Retrofitted Buildings at District... . .

\section{V}

\section{Vaiciunas, J.}

Solar Thermal Systems VS. Photovoltaic Systems. Case Study: Single Family Building... . .

\section{Vajen, $\mathrm{K}$.}

Comparison of Modeled and Measured Heat and Mass Transfer in a Liquid Desiccant Air-Conditioning... . . . 648

Comparison of Solar District Heating Concepts at Various Land Prices. . . . . . . . . . . . . . . . . . . . . . 156

Measurement Evaluation and Simulation of an Innovative Drainback Solar Combi-System . . . . . . . . . . . . . 397

Simulation-Based Optimization of Solar Combisystem. Sensitivity Analysis at Optimum . . . . . . . . . . . . 385

Standardisation of Solar Process Heat Applications to Increase Market Penetration . . . . . . . . . . . . . . . . . . 279

Towards Automated Continuous Performance Benchmarking of DHW and Combi Systems . . . . . . . . . . . . 418

\section{Valancius, $\mathbf{R}$.}

Environmental Assessment of Industrial Solar Thermal Systems. . . . . . . . . . . . . . . . . . . . . . . . . 229

Review of Combined Solar Thermal and Heat Pump Systems Installations in Lithuanian... . . . . . . . . . . . . . . 444

Solar Thermal Systems VS. Photovoltaic Systems. Case Study: Single Family Building... . . . . . . . . . . . . . 449 


\section{Valdes-Barron, M.}

Solar Irradiation Over a Flat Surface with Different Tracking Strategies

Vall, S.

Radiative Collector and Emitter: Experimental Results.

Radiative Cooling to Cover Cooling Demands of an Earthbag Building in a Training..

van den Dobbelsteen, $A$.

Assessment of the Suitability of Different Photovoltaic Cell Technologies for Product... 774

van de Voort, $\mathbf{R}$.

An Aesthetic Energy Producing Roof with Integration of PV Modules and Solar Thermal. 149

van Diemen, $\mathbf{R}$.

An Aesthetic Energy Producing Roof with Integration of PV Modules and Solar Thermal...

\section{van Paassen, M.}

An Aesthetic Energy Producing Roof with Integration of PV Modules and Solar Thermal.. .

van Ruth, $\mathbf{N}$.

Direct Solar Thermal Systems with Thermosiphon Frost Protection and Innovative Control...

Vargas, G.

Surface Modification of AISI 316 Stainless Steel by Oxynitrocarburizing for Solar...

\section{Varvagiannis, $\mathbf{S}$.}

Dynamic Modelling of a Hybrid Solar Thermal/Electric Storage System for Application...

Vasallo, A.

Dynamic Modeling and Optimization of Energy Use in Retrofitted Buildings at District..

Vergara, $\mathbf{S}$.

Thermal Analysis and Validation of a Geodesic Dome Dryer for Capsicum Baccatum.

\section{Vergara Dávila, S.G.}

Design and Evaluation of a Compact Thermal Storage System Using River Stones for...

\section{Vetter, B.}

CFD-Based Development, Testing and Optimization of Flat Plate Collectors.

\section{Vezzini, A.}

Integrating Polysun into a Test Bench for Prosumer Hardware.

\section{Vicente Quiles, P.G.}

Life Cycle Assessment Experiences for Solar Heating and Cooling Systems.

Vieira, M.

Development of a Compact and Didactic Solar Energy Kit Using Arduino.

\section{Villén, $\mathbf{R}$.}

Experimental Investigation of PVT Collectors with Phase Change Material. . .

W

\section{Wågberg, $\mathrm{T}$.}

Electroplating of Selective Surfaces for Concentrating Solar Collectors.

Wallner, G.M.

Sustainability Assessment of Most Relevant Solar Thermal Heat Systems. 
Wang, M.

Research for Compiling a Mandatory National StandardTechnical Code for Energy Efficiency...

Wang, $\mathbf{P}$.

Climatic and Global Validation of Daily MODIS Precipitable Water Data at AERONET...

Weber, C.

Development of a Photovoltaic Driven Thermodynamic Chiller - Application to Solar... 562

Weber, $\mathbf{R}$.

High Temperature Seasonal BTES for Effective Load Shifting and CO2 Emission Reduction.

\section{Weide Luiz, E.}

Monthly Solar Irradiance Variability in Brazilian Climate Zones.

\section{Weinläder, H.}

Evacuated Glazing with Silica Aerogel Spacers.

\section{Weismann, S.}

Comparative Analysis of Life-Cycle Assessment Tools (LCA) Using the Example of Different...

Evacuated Glazing with Silica Aerogel Spacers. . .

Wemhoener, C.

Space Cooling Application with Unglazed Solar Absorber. 455

\section{Wienands, $\mathbf{S}$.}

Integrating Polysun into a Test Bench for Prosumer Hardware.

\section{Williams, C.}

Development and Field Testing of a Novel Hybrid PV-Thermal Solar Collector.

\section{Willwerth, L.}

Testing and Modeling of Direct Steam Generating Parabolic Trough Collectors ...

\section{Wilson, H.R.}

Optical Properties of Solar Absorbers - Results on Round Robin and Guidelines

\section{Wimmer, L.}

Standardisation of Solar Process Heat Applications to Increase Market Penetration.

\section{Wirth, H.P.}

Efficient Design of Solar Assisted Heating Systems for Multi-Family Houses. .

\section{Witzig, A.}

BIM Use Case: Model-Based Performance Optimization.

Understanding the Dynamics of Solar Energy Systems by Using Simulation Narratives. .

\section{Wurtz, E.}

Energetic Behaviour of a Solar Thermal System Producing Domestic Hot Water and Preheating

Wyttenbach, J. 


\section{Yang, L.}

Improvements on the Efficiency of the Photovoltaic Panel by Integrating a Spray Cooling... . . . . . . . . . . . . 930

Performance Investigation of Liquid Desiccant Dehumidification System Integrated... . . . . . . . . . . . . . . . 716

Theoretical Analysis of Photovoltaic Panels Using a Spray Cooling System with a Shallow... . . . . . . . . . . . 1413

Yip, S.

Early Design Stage Consideration of Building Form and BIPVT Energy Performance. ...

Yu, Y.

Comparative Analysis of Life-Cycle Assessment Tools (LCA) Using the Example of Different... ...

Z

\section{Zabukovec Logar, N.}

New Water Adsorbent for Adsorption Driven Chillers.

704

Zäll, E.

Electroplating of Selective Surfaces for Concentrating Solar Collectors

1086

Zarzalejo, F.

Solar Irradiation Over a Flat Surface with Different Tracking Strategies. . .

Zavrl, E.

Application of PCM in Building's Envelope of Lightweight Prefabricated Houses as..

Zeman, M.

Assessment of the Suitability of Different Photovoltaic Cell Technologies for Product...

774

Zenhäusern, D.

Extended Hottel-Whillier Models for uncovered PVT-Collectors. .

Zhang, $\mathbf{X}$.

Research for Compiling a Mandatory National StandardTechnical Code for Energy Efficiency...

Zheng, $\mathbf{R}$.

Research for Compiling a Mandatory National StandardTechnical Code for Energy Efficiency...

Zierbart, $\mathbf{V}$.

Model Predictive Control for Building Automation.

Zirkel-Hofer, A.

In Situ Characterization of Thermal Collectors in Field Installations.

Zmeureanu, R.

Multi-Objective Optimization of a Solar Heat Pump System Using PVT and Ice-Based... . .

Zmrhal, V.

Development of Solar Assisted Sorption Unit for Extraction of Water from Ambient..

Zsembinszki, G.

Dynamic Modelling of a Hybrid Solar Thermal/Electric Storage System for Application...

Zupanc, G.

Application of PCM in Building's Envelope of Lightweight Prefabricated Houses as... 
